\title{
AN INTIMATE INSIGHT ON PSYCHOPATHY AND A NOVEL HERMENEUTIC PSYCHOLOGICAL SCIENCE
}

\author{
EMMANUEL TAKU \\ LONDON, UNITED KINGDOM \\ UNAFFILIATED AUTHOR \\ LOCOMOZ@GMAIL.COM
}

Besides and together with a study of the social sciences and philosophy, this author's intuitive confidence in this hermeneutic design insights that underlies the arguments and discourse, is inspired from an 'intimate and spontaneous idiosyncratic philosophical exercise (praxis) in the quest for the essence of meaning', a 'craft' that has been nurtured continuously for nearly 25 years now (without conscious planning at the beginning nor at any time thereafter) since his discovery of 'philosophical questioning and discourse' at high school. An exercise that mirrors the intimate idiosyncratic exercise/praxis allowing an artist like a musician to grasp and develop memes that latter down the years enable the artist to be more or less 'consummate with respect to the personal orientation they give to their arts'. Central to all such idiosyncratic processes is a continuous idiosyncratic memetic refinement over time of rough-cuttings, internal coherences, insights, inspirations, intuitive validations, constraining, sense-of-failing, sense-of-succeeding, confidence, mental inflections and mental projections; of course as per ability and ultimate pertinence with respect to intrinsic reality! 
An Intimate Insight on Psychopathy and a Novel Hermeneutic Psychological Science

\begin{abstract}
This paper is rather a profound hermeneutic enunciation putting-into-question our present understanding of psychopathy. It further articulates, in complement, a novel theoretical and methodological conceptualisation for a hermeneutic psychological science. Methodology-wise, it puts into question a traditional more or less categorical and mechanical approach to the social and behavioural sciences as it strives to introduce a creative and insightful approach for the articulation of ideas. It rather seeks to construe the scientific method as being more about falsifiability ${ }^{12}$ and validation but driven by a sense of creative understanding and insight of notions laid out as open-ended conceptualisations. Theory-wise, it sees continuity between anthropology and psychology as anthropopsychology behind an entropic construct of human psychology based on a recurrent re-institutionalisation mechanism for intemporal-preservationentropy-or-contiguity-or-ontological-preservation.
\end{abstract}

Keywords: psychopathy, hermeneutic, theory, meaning, ontology 
An Intimate Insight on Psychopathy and a Novel Hermeneutic Psychological Science

\section{Introduction}

Quite possibly everything about this paper whether the authoring, the approach and the substance sparks of novelty bordering on the outlandish. Further, why not take a traditional categorical approach and clearly present scientific ideas the traditional way? It is a personal insight developed more than 20 years ago, and just when the author began his B.Sc. in Sociology and Anthropology; that a study of the social and behavioural should carry the philosophical and insightful at its very core above anything else given the inherent ephemeral nature of its subject matter. When I came across the term hermeneutics (and others like phenomenology), this author felt as a personal persuasion that that was the chart for the future of the social sciences. My vision in this regard is one of a social science that delves directly into the core of things and avoids platitudes. To come back to the point of this abstract, this explains my apparently tattered approach. But tattered really? No, as the central insight of my articulation is that the scientific method is a validation and falsifiability ${ }^{12}$ method, and not necessarily the creative method. The creative method as a hermeneutics isn't supposed to roll down and stifle its very expressiveness, and at the same time it should be articulated in such a way that an exercise of falsifiability ${ }^{42}$ validation and open-ended questioning can be undertaken over it. Such a hermeneutic science 
calls for a mutual sense of such a hermeneutics by both the author and would-be critic. I hopefully believe the way I have articulated ideas should be able to allow for such an examination. My hermeneutic inspiration in this regard can be analogised with musical creation and music theory. The latter is there to ensure the appropriate articulation of rules but is not really the drive of musical creation, as musical creation is rather the musician's fepistemictotalising 3 3 ${ }^{3}$ hermeneutic/textuality/reprojecting/supererogating/zeroing/re-acuting,\{decompulsing delinearity for-cogency insight of how to go about creating music while adhering to music theory, such that any such music is analysable/critiqued by the way it credibly adheres to music theory, and actually in exceptional cases further develop music theory. A second point that makes this method ideal is that the apparent enunciation of this paper (an outright call for a reinvention of the state of the art regarding our understanding of psychopathy and the underlying psychology science); is that it is doubtful such an articulation can be credibly presented in simple categorical terms, without rather utilising an entropic hermeneutic-referential approach based on an open-endedness for falsifiability ${ }^{12}$ and validation in future elaboration and development of ideas. Further, I thought it more critical (wary of platitudinising the occasion) that the purity of ideas expressed herein shouldn't be overly clouded particularly as the treatment of this paper is largely in substance virgin territory, as of the underlying conceptualisation referential drive (beyond just simplistic rhyming/speculative/interpreted categories of philosophical theories and concepts but rather as a 'driven distinct comprehensively coherent/contiguous operant-level of insights articulation, and carrying implicative and applicative operant-level possibilities going forward', more like a song is a coherent referential whole beyond just naïve categories of disjointing/disparateness/ing percussions-and-tunes more-or-less similar-to-those-of-the-song construed as constituting the song). As a matter of fact, I would rather I wrote another paper talking about influences for such an articulation for this paper going by my hermeneutic design insights. Moreover, going by the very nature of how humans develop new ideas; while many, if 
not most, of my arguments may be more or less 'plainly intelligible', I equally thought it important to articulate ideas I hold in deep conviction and further as many such ideas come with their requisite precise convoluted qualifications even if such ideas might not be quite intelligible from a plain and simple reading, with the notion that such a requisite insight will be forthcoming in future critique as the very nature of the introduction of new ways of thinking often mean their unintelligibility at first (equally explains my repeating of many terms for 'habituation'), but then it is not the pertinence of reality that compromises it is the impertinence of human certitudes that does! In-the-bigger-scheme-of-things, it is herein contended that human social and institutional progress and development 'is not contiguous as to the very inherent nature of any given institutionalised framework' as all such frameworks arrive at their apathetic threshold as these rather develop into denaturing $<$ amplituding/formative $>$ wooden-language-〈imbued temporal-mere-form/virtualities/dereification/akrasiatic-drag/denatured/preconverging-ordementing -narratives-of-the- reference-of-thought- categoricalimperatives/axioms/registry-teleology $\rangle$ stifling prospective sublimating possibilities, thus requiring prospective fundamental reconception that thus speaks of the 'preconverging/postconverging-de-mentating/structuring/paradigming underlying overall human social and institutional progress and development'. While such prospective reprojection/re-anticipation recognises prior human cumulated knowledge as enabling institutional-cumulation/institutional-recomposure-〈as-to- historiality/ontologicaleventfulness /ontological-aesthetic-tracing-<perspective-ontologicalnormalcy/postconvergence-reflected-'epistemicity-relativism-determinism' $>>$ right up to the present, it also cognisant that at a certain point the 'prior knowledge-as-of-mechanicalknowledge predisposition and its developed temporal institutional self-serving predisposition' becomes critically a drawback for the possibility of knowledge-reification $\sim$ gesturing-andaccounting - of-epistemic-phenomenalism- $<$ in- 
prospective_psychologismic apriorising/axiomatising/referencing-\{of- ${ }^{\text {prospectively }}$

implicited_attendant-ontological-contiguity ' educed-

existentialising/contextualising/textualising_'intelligibility/epistemicity/reflexivity-contiguity-

$<$ imbued-notional cogency $\left.>^{\prime}\right\}$-conflatedness -in-\{preconverging -ment by\}

postconverging-entailment $>$ as of prospective human-subpotency-

aporia/undecidability/dilemma/ought-indeterminacy/deficiency/limitation/constraint

overcoming/unovercoming; as dimensionality-of-sublimating

<<amplituding/formative>supererogatory $\sim$ de-mentativeness/epistemic-growth-or-

conflatedness /transvaluative-rationalising/transepistemicity/anamnestic-residuality/spirit-

drivenness-equalisation> behind the 'inventing'/'creation' of prior knowledge fades into secondnatured mechanical predispositions requiring the renewal of dimensionality-ofsublimating $25<<$ amplituding/formative $>$ supererogatery $\sim$ de-mentativeness/epistemic-growth-

or-conflatedness /transvaluative-rationalising/transepistemicity/anamnestic-residuality/spirit-

drivenness-equalisation> prospectively. At which point, the more decisive issue is recognising and assuming the reality of a fundamental apriorising/axiomatic/referencing intellectual break/schism/estrangement with such 'prior knowledge-as-of-mechanical-knowledge predisposition and its developed temporal institutional self-serving predisposition', as soimplied across human sublimating ${ }^{4}$ historiality/ontological-eventfulness ${ }^{38} /$ ontological- $^{2}$ aesthetic-tracing-<perspective-ontological-normalcy/postconvergence-reflected-'epistemicityrelativism-determinism'> say between non-universalising sophistry and prospective Socraticphilosophers ${ }^{103}$ universalising-idealisation as well as in the case of medieval-scholasticism and prospective budding-positivism, and it is herein contended likewise with regards to our modernday pedantising/muddling/formulaic-hollowing-out—in-subontologisation/subpotentiation〈blurring/undermining-of-prospective-totalising-entailing,-as-to-entailing-

<amplituding/formative-epistemicity>totalising in-relative-ontological-completeness $>$ as of 
procrypticism-or-disjointedness-as-of- ${ }^{8}$ reference-of-thought (associated with a predisposition for disparateness-of-conceptualisation-<unforegrounding-ment,-failingprospectively-to-reflect-'immanent $\sim$ relative-unreflexivity/relative-reflexivity ontological-

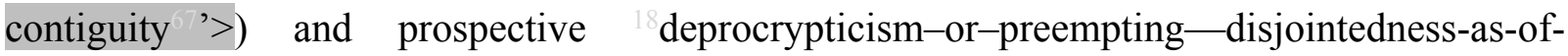
reference-of-thought ( ${ }^{4}$ foregrounding_entailment- $<$ in-succession-of-profoundsupererogation ${ }^{9}>-\langle$ postconverging-narrowing-down $\sim$ sublimation-as-to-'existence-assublimating-withdrawal/unenframing/re-ontologising,-elicited-from-prospective-profoundsupererogation '-in-reflecting-'immanent relative-unreflexivity/relative-reflexivity ontological-contiguity ';--as-operative-notional deprocrypticism) as of ecstatic-existence-astranscendental-signifier-emergence/becoming-spontaneity-implications reflected as existence-potency ${ }^{39} \sim$ sublimating-nascence,-disclosed-from-prospective-epistemic-digression). Underlying all such apriorising/axiomatic/referencing intellectual break/schism/estrangement is the prospective manifestation of teleological-decadence- $<$-in-dimensionality-of-desublimatinglack-of $-<<$ amplituding/formative >supererona-de-mentativeness/epistemic-growth-orconflatedness /transvaluative-rationalising/transepistemicity/anamnestic-residuality/spiritdrivenness-equalisation) (wherein 'prior knowledge-as-of-mechanical-knowledge predisposition of mere-formulaicity/ritualisation- $<$ as-to-mere-formulaic methodologising/mutualising/organising/institutionalising,-prospectively-losing-track-of‘\{epistemic-totalising ${ }^{\dagger}$ re-apriorising/re-axiomatising/re-referencing - residuality-in-reoriginariness/re-origination'> as of its developed temporal institutional self-serving predisposition' as so-reflecting its <amplituding/formative> wooden-language-_imbuedtemporal-mere-form/virtualities/dereification/akrasiatic-drag/denatured/preconverging-ordementing -narratives - of-the- reference-of-thought- categoricalimperatives/axioms/registry-teleology $\rangle$ critically absconds from veridical prospective transcendence-and-sublimity/sublimation/supererogatory de-mentativity its 
$<$ amplituding/formative-epistemicity $>$ totalising $\sim$ self-referencing-

syncretising/circularity/interiorising/akrasiatic-drag ${ }^{34}$ ). This is so-construed from the prospective relative-ontological-completeness ${ }^{87}$ perspective (as it prompts/elicits the supposedly coherent human ontological-commitment $-<$ implied - self-assuredness-of-ontological-goodfaith/authenticity postconverging-de-mentating/structuring/paradigming -as-being-as-ofexistential-reality $>$ as of ecstatic-existence-as-transcendental-signifier-emergence/becomingspontaneity-implications reflected as existence-potency ${ }^{3} \sim$ sublimating-nascence,-disclosedfrom-prospective-epistemic-digression); so-reflecting the teleological-decadence-<-indimensionality-of-desublimating-lack-of $-\langle<$ amplituding/formative $>$ supererogatory $\sim$ dementativeness/epistemic-growth-or-conflatedness /transvaluativerationalising/transepistemicity/anamnestic-residuality/spirit-drivenness-equalisation $\rangle$ as rather reverting to eliciting 'untransvaluated-temporal-intemporality ${ }^{52}$ values' (being passed for knowledge-reification $\sim$ gesturing-and-accounting —of-epistemic-phenomenalism- $<$ inprospective_psychologismic apriorising/axiomatising/referencing-\{of-'prospectively implicited_attendant-ontological-contiguity ' educedexistentialising/contextualising/textualising_ intelligibility/epistemicity/reflexivity_contiguity<imbued-notional cogency >’ \}-conflatedness -in-\{preconverging -ment by\} postconverging-entailment $>$ ) while undermining the prospective 'relative-ontologicalincompleteness $8 /$ relative-ontological-completeness ${ }^{8}$ -

\section{〈sublimating referencing/registering/decisioning,--as-self-becoming/self-}

conflatedness /formative-supererogating-<projective/reprojective-aestheticising-re-motifand-re-apriorising/re-axiomatising/re-referencing,-in-perspective-ontologicalnormalcy/postconvergence $>>\quad$ (as to human-and-social-expectations/anticipationsmetaphoricity ${ }^{57}$-as-preconverging/postconverging-redementating/restructuring/reparadigming-psychologism' ${ }^{99}$ of dimensionality-of-sublimating 
<<amplituding/formative>supererogatory $\sim$ de-mentativeness/epistemic-growth-or-

conflatedness /transvaluative-rationalising/transepistemicity/anamnestic-residuality/spirit-

drivenness-equalisation)). This is so-manifested for instance when statistics/methods/methodologies/approaches as the outcome of prior human originarinessparrhesia,-as-spontaneity-of-aestheticisation in resolving prior human-subpotencyaporia/undecidability/dilemma/ought-indeterminacy/deficiency/limitation/constraint are turned around 'mechanically' to falsely imply progress occurs anyway to then paradoxically suggest surreptitiously there shouldn't be any prospective human originariness-parrhesia,--asspontaneity-of-aestheticisation in resolving prospective human-subpotencyaporia/undecidability/dilemma/ought-indeterminacy/deficiency/limitation/constraint overcoming/unovercoming, speaking to the issue of the fundamental lack of dimensionality-ofsublimating $25<<$ amplituding/formative $>$ supererogatory $\sim$ de-mentativeness/epistemic-growthor-conflatedness /transvaluative-rationalising/transepistemicity/anamnestic-residuality/spiritdrivenness-equalisation); as 'knowledge becomes increasingly mechanical' and is rather a secondary and derivational tool for temporal self-serving posturing and is poorly perceived as worthy in of itself but for the imprimaturing blurriness- $<$ sterilising/anecdotalising/trivialisingof-prospective-re-ontologising_by-preconverging,-in-disontologising-formulaic-draggingout/hollowing-out $>$ ) so projected and the perceived temporal social-value arising with such imprimaturing blurriness-<sterilising/anecdotalising/trivialising-of-prospective-reontologising_by-preconverging,-in-disontologising-formulaic-dragging-out/hollowing-out>) and as it is increasingly associated with generalised incuriosity in genuine intellectual development and the substituting of mere sterile/anecdotal imprimatur totalisingly-ingdiscretion/whim-of-thought over genuine knowledge-reification $\sim$ gesturing-and-accountingof-epistemic-phenomenalism- $<$ in- 
implicited_attendant-ontological-contiguity ' reduced-

existentialising/contextualising/textualising_'intelligibility/epistemicity/reflexivity_contiguity<imbued-notional cogency>' \}-conflatedness -in-\{preconverging ment by\}

postconverging-entailment $>$ as to existence-potency ${ }^{39} \sim$ sublimating-nascence,-disclosed-fromprospective-epistemic-digression. This has developed in our present age of pedantising/muddling/formulaic-hollowing-out_-in-subontologisation/subpotentiation〈blurring/undermining-of-prospective-totalising-entailing,-as-to-entailing$<$ amplituding/formative-epistemicity>totalising in-relative-ontological-completeness $>$ into the absurdity/ridiculousness of pop-intellectualism substituting for genuine and reifying thought, as to the relentless expansion of our modern merchandising mentality to which nothing resists; and paradoxically, such a disposition hangs onto the 'dereifying as to deficient conceptivity/epistemic-reflexivity/epistemicity-relativism-determinism- $<$ reifying \{as-toknowledge-developing $\}$-and-empowering $>$ of our $<$ amplituding/formative $>$ wooden-language〈imbued-temporal-mere-form/virtualities/dereification/akrasiaticdrag/denatured/preconverging-or-dementing -narratives - of-the- reference-of-thoughtcategorical-imperatives/axioms/registry-teleology > it then sophistically usurp in its teleological-degradation rather than teleologically-elevating it out of its $<$ amplituding-formative $>$ wooden-language-〈imbued - averaging-of-thought- $<$ as-toleveling/ressentiment/closed-construct-of- meaningfulness-and-teleology -as-of'nondescript/ignorable-void '-with-regards-to-prospective-apriorising-implications $>$ > (with media-driven imprimaturing blurriness-<sterilising/anecdotalising/trivialising-of-prospectivere-ontologising_by-preconverging,-in-disontologising-formulaic-dragging-out/hollowingout $>$ ) increasingly usurping the role of genuine academic standard production and ultimate validity hanging on the mere sterile/anecdotal imprimatur). As what becomes critical in such a context is no longer prospective knowledge-reification $\sim$ gesturing-and-accounting-of- 
epistemic-phenomenalism-<in-

prospective_psychologismic apriorising/axiomatising/referencing-\{of-'prospectively implicited_attendant-ontological-contiguity ' educed-

existentialising/contextualising/textualising_intelligibility/epistemicity/reflexivity-contiguity<imbued-notional cogency >' $\}$-conflatedness -in-\{preconverging-ment by\}

postconverging-entailment $>$ as the primary and essential constraining worth but rather obsession with mere sway and influence even to the point of undermining prospective knowledgereification $\sim$ gesturing-and-accounting — of-epistemic-phenomenalism- $<$ in-

prospective_psychologismic apriorising/axiomatising/referencing-\{of-"prospectively implicited_attendant-ontological-contiguity ' educedexistentialising/contextualising/textualising_intelligibility/epistemicity/reflexivity_contiguity<imbued-notional cogency >' \}-conflatedness -in-\{preconverging-ment by\}

postconverging entailment $>$ as supposed intellection is increasingly infused with obfuscations, falsehoods and subterfuges (as to the fact that misrepresentations and pretences to misunderstand are rather conveniently projected as of perceived social-stake-contention-or-confliction and hardly reflecting a discernment about the possibility for advancing human progress); in so-doing apparently render human-subpotency/mortality bigger than existence-potency ${ }^{39} \sim$ sublimatingnascence,-disclosed-from-prospective-epistemic-digression as to immortality. But then human intellection across all ages and times come to an end not because of inherently right or inherently wrong ideas per se (as the very basic genuine striving for intellectual progress is what is critically decisive as that exercise ensures that down-the-line correct and reifying ideas will arise anyway), but critically when deliberate deception-and-induced-deception-as-of-ontological-badfaith/inauthenticity ${ }^{64}$ becomes more important than an aspiration for genuine intellection as an open-ended activity providing the possibility for human knowledge and reflexive empowerment from that knowledge. At which point, it is wrong for 'genuine intellection' not to recognise what 
is going on (as to wrongly imply that it is veridically in dialogical-equivalence- $<$ as-topsychologismic $\sim$ apriorising/axiomatising/referencing-\{of-"prospectively implicited_attendant-ontological-contiguity ' educedexistentialising/contextualising/textualising_'intelligibility/epistemicity/reflexivity-contiguity$<$ imbued-notional cogency $>$ ' $\}$-conflatedness -in-\{preconverging ment by\} postconverging-entailment,-in-self-becoming/self-conflatedness /formative-supererogating $>$ ), as such deception-and-induced-deception-as-of-ontological-bad-faith/inauthenticity ${ }^{64}$ (whether or not, beyond-the-consciousness-awareness-teleology ${ }^{9}<$ of-preconverging-existentialextrication-as-of-existential-unthought>) only leads to a human destructuring-threshold〈uninstitutionalised-threshold /presublimating-desublimating-decisionality $\rangle$ of-ontologicalperformance ${ }^{2}-<$ including-virtue-as-ontology $>/$ morality/ethics/justice/etc. which habituates and enculturates/endemises such deception-and-induced-deception-as-of-ontological-badfaith/inauthenticity ${ }^{64}$ rendering the supposedly empowering activity of knowledgereification $\sim$ gesturing-and-accounting - of-epistemic-phenomenalism- $<$ inprospective_psychologismic apriorising/axiomatising/referencing-\{of-'prospectively implicited_attendant-ontological-contiguity ' educedexistentialising/contextualising/textualising_'intelligibility/epistemicity/reflexivity-contiguity<imbued-notional cogency >’ \}-conflatedness -in-\{preconverging -ment by\} postconverging-entailment $>$ impotent as in-many-ways such denatured intellection effectively claims openly as of its disparateness-of-conceptualisation-<unforegrounding-ment,-failingprospectively-to-reflect-'immanent relative- unreflexivity/relative-reflexivity - ontologicalcontiguity ' $>$ inclinations (poorly appreciative of existence-potency ${ }^{39} \sim$ sublimating-nascence,disclosed-from-prospective-epistemic-digression implications of transcendence-andsublimity/sublimation/supererogatory de-mentativity). In-many-ways this intellectual falsehood (so-construed herein as to the 'implausibility of genuine lack of understanding as from 
a serious intellectual engagement' but rather 'strategic/calculated behaviour of mere institutional power even against genuine knowledge' herein construed as a 'decadent and dangerous conception of knowledge' that is effectively destructive of prospective human knowledge reifying and empowering possibilities) is at the 'root source' for surreptitiously ensuring that the public debate fails and thus leading to public policy defaulting into vested postures and interests. This is especially manifested when such an intellectual teleological-decadence- $<$-indimensionality-of-desublimating-lack-of $-\langle<$ amplituding/formative $>$ supererogatory $\sim$ dementativeness/epistemic-growth-or-conflatedness /transvaluativerationalising/transepistemicity/anamnestic-residuality/spirit-drivenness-equalisation〉 undermines informed insight and requisite human intellectual and emotional sacrifice for genuine knowledge-reification $\sim$ gesturing-and-accounting-of-epistemic-phenomenalism- $<$ inprospective_psychologismic apriorising/axiomatising/referencing-\{of-'prospectively_ implicited_attendant-ontological-contiguity ' reducedexistentialising/contextualising/textualising_'intelligibility/epistemicity/reflexivity-contiguity<imbued-notional cogency >' \}-conflatedness -in-\{preconverging ment by\} postconverging-entailment $>$ and prospective progress involving the authentic self and social transformation rather than 'gimmicks instilling a merchandising mentality of ideas' (whether by mystifications-that-are-vague-and-imprimaturing blurriness$<$ sterilising/anecdotalising/trivialising-of-prospective-re-ontologising_by-preconverging,-indisontologising-formulaic-dragging-out/hollowing-out>)-driven elaboration-as-to-mereextrapolating/constituting/abstracting/deducing/inferring-of-elucidation-outside'prospectively_implicited_attendant-ontological-contiguity ${ }^{67}$ ' educedexistentialising/contextmalising/textualising_'intelligibility/epistemicity/reflexivity_contiguity$<$ imbued-notional $\sim$ cogency $>^{\prime}$, misinterpretation-ofstatistics/methods/methodologies/approaches totalising-entailing-implications, denial-of- 
relativism-thus foiling/undermining-relative-ontological-completeness ${ }^{8}$ implications/conclusions/projections of prospective knowledge-reification -gesturing-andaccounting - of-epistemic-phenomenalism- $<$ in-

prospective_psychologismic apriorising/axiomatising/referencing-\{of-'prospectively implicited_attendant-ontological-contiguity ' educedexistentialising/contextualising/textualising_intelligibility/epistemicity/reflexivity-contiguity<imbued-notional $\sim$ cogency $>>$ ' -conflatedness -in-\{preconverging-ment by\} posteonverging entailment $>$ in a-dumbing-down-posturing-that-implies that-the-present-is unchangeable as of ${ }^{7}$ presencing-absolutising-identitive-constitutedness ${ }^{14}$, etymologicalflouting as of mere conceptual-patterning-〈as-devoid-of-'prospectively implicited_attendantontological-contiguity ' educedexistentialising/contextualising/textualising_intelligibility/epistemicity/reflexivity-contiguity$<$ imbued-notional cogency>' 's-reifying-or-elucidating-of-'prospective-relative-ontologicalcompleteness ';-so-rather-enabled-<by-a- nonpresencing-divulging-of-momentoushistoriality/ontological-eventfulness /ontological-aesthetic-tracing-<perspectiveontological-normalcy/postconvergence-reflected-'epistemicity-relativism-determinism'>), mere-stigmatising-of-competing-theories-and-concepts-on-the-naivety-that-such-stigmatisingrepresentation-will-undermine/override-their-analysable-ontological-veracity, and finally anapproach-as-of-the-ordinary-human-egotistic-perspective-in-existential-extrication-thatabsolutises-the-present-passed-as-prospective knowledge-reification $\sim$ gesturing-andaccounting - of-epistemic-phenomenalism- $<$ inprospective _psychologismic apriorising/axiomatising/referencing-\{of-'prospectively implicited_attendant-ontological-contiguity ' reducedexistentialising/contextualising/textualising_intelligibility/epistemicity/reflexivity-contiguity<imbued-notional $\sim$ cogency>' $\}$-conflatedness -in-\{preconverging ment by\} 
postconverging-entailment $>$ ). This then provides paradoxically the underlying meaningfulness-and-teleology infrastructure for upholding the status quo and inducing inmany-ways the impotence of the social sciences in thoroughly addressing human-subpotencyaporia/undecidability/dilemma/ought-indeterminacy/deficiency/limitation/constraint overcoming/unovercoming of society that ultimately have serious preconverging/postconverging-de-mentative/structural/paradigmatic consequences associated with institutional failures (which such intellectualism is hardly inclined to address). Critically, such a 'self-contented intellectualism' increasingly focuses not on knowledgereification $\sim$ gesturing-and-accounting — of-epistemic-phenomenalism- $<$ inprospective_psychologismic $\sim$ apriorising/axiomatising/referencing-\{of-'prospectively implicited_attendant-ontological-contiguity ' educedexistentialising/contextualising/textualising_'intelligibility/epistemicity/reflexivity-contiguity<imbued-notional cogency $\left.>^{\prime}\right\}$-conflatedness -in-\{preconverging -ment by\} postconverging-entailment $>$ production as to existence-potency ${ }^{32} \sim$ sublimating-nascence,disclosed-from-prospective-epistemic-digression or its critical analysis, but rather in the face of criticism consciously substitutes strategies of institutional ascendency as of a strategy of influence by default sterile/anecdotal imprimatur status rather than genuine knowledgereification $\sim$ gesturing-and-accounting — of-epistemic-phenomenalism- $<$ in-

prospective_psychologismic apriorising/axiomatising/referencing-\{of- ${ }^{*}$ prospectively implicited_attendant-ontological-contiguity ' reducedexistentialising/contextualising/textualising_'intelligibility/epistemicity/reflexivity-contiguity<imbued-notional cogency >' \}-conflatedness -in-\{preconverging-ment by\} pesteonverging entailment> pertinence. It will be as naïve as implying the validity of a common basis for doing arithmetic where an interlocutor insists on $2+2$ as 5 but when appropriately explained the veridical assumptions of arithmetic goes on to insist $3+3$ as 7 ; speaking not of a 
fundamental problem of arithmetic operation as of dialogical-equivalence- $<$ as-topsychologismic apriorising/axiomatising/referencing-\{of-'prospectively implicited_attendant-ontological-contiguity ' educedexistentialising/contextualising/textualising_'intelligibility/epistemicity/reflexivity-contiguity$<$ imbued-notional cogency $>$ ' $\}$-conflatedness -in-\{preconverging ment by\} postconverging-entailment,-in-self-becoming/self-conflatedness /formative-supererogating> but a fundamental question of ontological-bad-faith/inauthenticity ${ }^{64}$ on the naïve mental reflex that ‘anyway dialogical-equivalence-<as-to-

psychologismic $\sim$ apriorising/axiomatising/referencing-\{of-"prospectively implicited_attendant-ontological-contiguity ' ceducedexistentialising/contextualising/textualising_'intelligibility/epistemicity/reflexivity-contiguity<imbued-notional cogency >' \}-conflatedness -in-\{preconverging-ment by\} postconverging-entailment,-in-self-becoming/self-conflatedness /formative-supererogating> is ever always assumed' to then adopt an apriorising/axiomatising/referencing attitude of abusing the notion of dialogical-equivalence- $<$ as-to-

\section{psychologismic apriorising/axiomatising/referencing-\{of-"prospectively}

implicited_atendant-ontological-contiguity ' educed-

existentialising/contextualising/textualising_'intelligibility/epistemicity/reflexivity-contiguity$<$ imbued-notional cogency $>$ ' \}-conflatedness -in-\{preconverging-ment by\} postconverging-entailment,-in-self-becoming/self-conflatedness /formative-supererogating> as to wrongly implied logical-dueness. Faced with such an orientation the genuine intellectual reaction is to engage it upfront as of an inclination 'not just to evaluate logical coherence as of correctness or incorrectness or any other evaluation in-between on the basis of ontological-goodfaith/authenticity ${ }^{6}$, but beforehand 'to equally evaluate the apriorising/axiomatising/referencing in ontological-good-faith/authenticity ${ }^{6}$ or ontological-bad- 
faith/inauthenticity

(beyond-the-consciousness-awareness-teleology

$-<$ of-preconverging-

existential-extrication-as-of-existential-unthought>) as of underlying 'implicited_attendantontological-contiguity ${ }^{67}$, educed-

existentialising/contextualising/textualising_'intelligibility/epistemicity/reflexivity_contiguity-

<imbued-notional cogency>' elucidation (as to unblurriness-<re-ontologising_by-

postconverging-as-to-dragged-out-supererogatory -wholesomeness/profound-supererogation

while-anecdotalising-prior-disontologising-thresholding $>$ ) as well as whether the veracity of such apriorising/axiomatising/referencing can be established as being of 'relative-ontologicalincompleteness 8 /relative-ontological-completeness ${ }^{87}$ -

〈sublimating $\sim$ referencing/registering/decisioning,-as-self-becoming/self-

conflatedness /formative-supererogating-<projective/reprojective-aestheticising-re-motifand-re-apriorising/re-axiomatising/re-referencing,-in-perspective-ontologicalnormalcy/postconvergence $>>$ as to human-and-social-expectations/anticipationsmetaphoricity ${ }^{57}$-as-preconverging/postconverging-rede-

mentating/restructuring/reparadigming-psychologism' ${ }^{89}$ (as so-construed necessary herein in overriding ontologically-flawed apriorising/axiomatising/referencing as of presencingabsolutisng-identitive-constitutedness ${ }^{14}$ in relative-ontological-incompleteness ${ }^{88}$ that seem to undermine the absolute a-priori of existence and imply that when existence doesn't fit/digressesfrom its conceptual-moulds then existence must have an inherent issue strangely enough as to be ignored/overcome by the stubborn/dogged/political upholding of such defective conceptualmoulds over inherent knowledge-reification $\sim$ gesturing-and-accounting-of-epistemicphenomenalism- $<$ in-prospective_psychologismic $\sim$ apriorising/axiomatising/referencing-\{of'prospectively_implicited_attendant_ontological-contiguity ' educedexistentialising/contextualising/textualising_'intelligibility/epistemicity/reflexivity_contiguity<imbued-notional cogency>' \}-conflatedness -in-\{preconverging -ment by\} 
postconverging-entailment $>$ implications as of existential-reality)'. We can appreciate that while many a subject-matter especially of nascent-particular/incipient-and-material/technicalsublimations- $<$ blinded-to-their-relative-ontological-completeness - reference-of-thoughtdevolving $>$ will often seem to imply that dialogical-equivalence- $<$ as-topsychologismic $\sim$ apriorising/axiomatising/referencing-\{of-"prospectivelyimplicited_attendant-ontological-contiguity ' reducedexistentialising/contextualising/textualising_intelligibility/epistemicity/reflexivity_contiguity<imbued-notional cogency $\left.>^{\prime}\right\}$-conflatedness -in-\{preconverging -ment by\} postconverging-entailment,-in-self-becoming/self-conflatedness /formative-supererogating> is just assumed 'as to the fact of merely engaging as of logical coherence without questioning the underlying apriorising/axiomatising/referencing ontological-faith-notion-or-ontologicalfideism - imbued-underdetermination-of-motif-and-apriorising/axiomatising/referencing-asso-being-as-of-existential-reality in ontological-good-faith/authenticity ${ }^{69}$ or ontological-badfaith/inauthenticity ${ }^{6}$, the fact is this is rather the consequence of their historially achieved ${ }^{3}$ universal-transparency $^{104}$-〈transparency-of-totalising-entailing,-as-to-entailing<amplituding/formative-epistemicity>totalising in-relative-ontological-completeness > of 'prospective postconverging aporeticism-overcoming/unovercoming as the-Good/knowledgereification $\sim$ gesturing-and-accounting - of-epistemic-phenomenalism- $<$ inprospective_psychologismic apriorising/axiomatising/referencing-\{of-'prospectively implicited_attendant-ontological-contiguity ' educedexistentialising/contextualising/textualising_'intelligibility/epistemicity/reflexivity-contiguity<imbued-notional cogency $\left.>^{\prime}\right\}$-conflatedness -in-\{preconverging -ment by\} postconverging-entailment $>$ /understanding/<amplituding/formativeepistemicity $>$ causality $\sim$ as-to-projective-totalitative-implications-of-prospectivenonpresencing,-for-explicating relative-unreflexivity/relative-reflexivity - ontological- 
contiguity , rendering the possibility of ontological-bad-faith/inauthenticity ${ }^{64}$ directly ridiculous as in the natural sciences given its direct ${ }^{103}$ universal-transparency ${ }^{104}-\langle$ transparencyof-totalising-entailing,-as-to-entailing-<amplituding/formative-epistemicity $>$ totalising inrelative-ontological-completeness > subjection to prediction. Such that we can hardly contemplate of an interlocutor insisting to imply that gravity on earth is $7 \mathrm{~m} / \mathrm{s}^{2}$ to ensure that calculations conform to its expectations for one temporal interest or another. But the reality of that ${ }^{103}$ universal-transparency ${ }^{104}$-〈transparency-of-totalising-entailing,-as-to-entailing<amplituding/formative-epistemicity>totalising in-relative-ontological-completeness $>$ as preempting such ontological-bad-faith/inauthenticity ${ }^{64}$ inclinations is not so directly obvious in many a social domain-of-study and that blurred possibility effectively elicits circumstances of disparateness-of-conceptualisation-<unforegrounding-ment,-failing-prospectively-to-reflect'immanent relative- unreflexivity/relative-reflexivity - ontological-contiguity ' $>$ not only as of wrong ontological-conception out of good-naturedness (failing 'technical' ontological-goodfaith/authenticity as from ontological-normalcy/postconvergence epistemic-projection perspective conceptualisation) but equally as of outright ontological-bad-faith/inauthenticity (in spirit). This idea is essential in the thought of many such postmodern thinkers as Derrida and Foucault given the implications of human limited-mentation-capacity-as-subjecting 'educedunlimitedness/existence-sublimating nascence' to-limitedness/human-subpotency as herein construed as reflecting both human constructiveness-of-ontological-performance ${ }^{72}<$ includingvirtue-as-ontology $>$ /morality/ethics/justice/etc. and destructuring-threshold〈uninstitutionalised-threshold /presublimating-desublimating-decisionality $>$ of-ontologicalperformance ${ }^{2}-<$ including-virtue-as-ontology $>$. The fact is knowledge-reification $\sim$ gesturingand-accounting - of-epistemic-phenomenalism- $<$ inprospective_psychologismic apriorising/axiomatising/referencing-\{of-'prospectively_ implicited_attendant-ontological-contiguity ' educed- 
existentialising/contextualising/textualising_ 'intelligibility/epistemicity/reflexivity-contiguity<imbued-notional cogency>' \}-conflatedness -in-\{preconverging-ment by\}

postconverging-entailment> is of 'existential <amplituding/formative-

epistemicity $>$ totalising/circumscribing/delineating construal for human limited-mentationcapacity-deepening —as-subjecting -limitedness/human-subpotency-to-'educed-

unlimitedness/existence-sublimating nascence' ${ }^{3}$ ' and nothing can be construed in totalisinglying — discretion/whim-of-thought whether as of ignoring or on-the-other-hand exaggerating and then be considered as ontological/scientific; and just as we can fathom that we don't have the choice to fiddle with even a single number or operation without a mathematical equation going wrong as of inherent existence-potency ${ }^{39} \sim$ sublimating-nascence,-disclosed-from-prospectiveepistemic-digression over our human-subpotency motives, the same actually do apply in all knowledge-reification $\sim$ gesturing-and-accounting —of-epistemic-phenomenalism- $<$ inprospective_psychologismic apriorising/axiomatising/referencing-\{of- ${ }^{\text {pprospectively }}$ implicited_attendant-ontological-contiguity ' educedexistentialising/contextualising/textualising_'intelligibility/epistemicity/reflexivity-contiguity<imbued-notional cogency $>$ ' \}-conflatedness -in-\{preconverging ment by\}

entailment $>$ and claims of subject-matter specificities (wrongly implying their subontological nature) 'rather speak of the difficulty with respect to human emotionalinvolvement and associated lack of rigour relative to prospective knowledgereification $\sim$ gesturing-and-accounting - of-epistemic-phenomenalism- $<$ inprospective_psychologismic apriorising/axiomatising/referencing-\{of-'prospectively_ implicited_attendant-ontological-contiguity ' educedexistentialising/contexalising/textralising_intelligibility/epistemicity/reflexivity-contiguity$<$ imbued-notional cogency >' \}-conflatedness -in-\{preconverging-ment by\} postconverging-entailment $>\quad$ in addressing human-subpotency- 
aporia/undecidability/dilemma/ought-indeterminacy/deficiency/limitation/constraint', but doesn't speak of inherently constraining existence-potency ${ }^{32} \sim$ sublimating-nascence,-disclosedfrom-prospective-epistemic-digression dissimilarity of subject-matters. Just as there is no magical mathematics or magical physics to resolve such a more fundamental apriorising/axiomatising/referencing situation involving 'abusing the assuming of dialogicalequivalence-<as-to-psychologismic apriorising/axiomatising/referencing- \{of-" prespectively implicited_attendant-ontological-contiguity ' educedexistentialising/contextualising/textualising_'intelligibility/epistemicity/reflexivity-contiguity$<$ imbued-notional cogency $>\quad\}$-conflatedness -in-\{preconverging ment by\} postconverging-entailment,-in-self-becoming/self-conflatedness /formative-supererogating>', it is wrong and foolhardy not to bluntly recognise this reality in the social domain as to the possibility of then achieving prospective transcendence-andsublimity/sublimation/supererogatory $\sim$ de-mentativity as to existence-potency ${ }^{39} \sim$ sublimatingnascence,-disclosed-from-prospective-epistemic-digression implications. The fact is the 'apriori or axiomatic conception' is effectively what precedes and validates logic as of elaborationas-to-mere-extrapolating/constituting/abstracting/deducing/inferring-of-elucidation-outside'prespectively implicited_attendant-ontological-contiguity ${ }^{67}$ ' educedexistentialising/contextmalising/textualising_intelligibility/epistemicity/reflexivity_contiguity<imbued-notional cogency>', however there is no logical-basis/logic,-as-derivedfrom $\sim$ transversality-<for-sublimating-existential-eventuating/denouement-from-'thinking-atfirst/pure-predisposition - preemptive-of prospective-disontologising/subontologising' as-ofprospectively-disambiguated-affirmed-and-unaffirmed-'motif-andapriorising/axiomatising/referencing' $>101$ for the 'a-priori or axiomatic conception' but for 'its ontological-faith-notion-or-ontological-fideism - imbued-underdetermination-of-motif-andapriorising/axiomatising/referencing-as-so-being-as-of-existential-reality in ontological-good- 
faith/authenticity ${ }^{6}$ construal as of existence'; as can thereof be validated as from strong prediction arising as of existence - as-sublimating-withdrawal/unenframing/re-ontologising,elicited-from-prospective-profound-supererogation establishing its ${ }^{103}$ universaltransparency ${ }^{104}$-〈transparency-of-totalising-entailing,-as-to-entailing-<amplituding/formativeepistemicity $>$ totalising in-relative-ontological-completeness $\rangle$. This reflects the fact of human $<$ amplituding/formative-epistemicity $>$-totalising $\sim$ thrownness-in-existence ${ }^{35}$,-imbuedprojective-arbitrariness/waywardness-〈as-to-the-human-projective/reprojectiveaestheticising-re-motif-and-re-apriorising/re-axiomatising/re-referencing-process-of‘<amplituding/formative-epistemicity $>$ totalising conceptualisation' $\rangle$, and speaks to the reality that logic is rather the inner working coherence/contiguity of any human apriorising/axiomatising/referencing construct; and thus the 'a-priori or axiomatic conception' is rather about 'Derridean underdetermination-imbued force/violence conception' and 'Foucauldian knowledge/power conception construed as knowledge-empowerment/ignorancedisempowerment' (as to supererogating \{'sublimation affirmation/projection/assertion/notional self-distantiation/dueness-validatinglogicising/suitable-measuringinstrument-validating-measuring-<as-to-postconverging-ordialectical-thinking -apriorising-psychologism>’ 'desublimation unaffirmation/deprojection/deassertion/epistemic-decadence/undueness-invalidatinglogicising/unsuitable-measuringinstrument-invalidating-measuring-<as-to-preconverging-ordementing -apriorising-psychologism >'\} as so-underlining existence-as-the-absolute-apriori-of-conceptualisation and existence—as-sublimating-withdrawal/unenframing/reontologising,-elicited-from-prospective-profound-supererogation $-<$ as-to-perspectiveontological-normalcy/postconvergence-implied-'prospective-aporeticismovercoming/unovercoming'> as to human transversality-<for-sublimating-existentialeventuating/denouement,from-'thinking-at-first/pure-predisposition-preemptive-of- 
prospective-disontologising/subontologising' as-of-prospectively-disambiguated-affirmed-

and-unaffirmed-'motif-and-apriorising/axiomatising/referencing' $\left.>{ }^{101}\right) . \quad$ However, the

${ }^{3}$ universal-transparency ${ }^{104}$-〈transparency-of-totalising-entailing,-as-to-entailing-

<amplituding/formative-epistemicity $>$ totalising in-relative-ontological-completeness $>$

generated in domains like mathematics and many a natural sciences is so efficient (as of the underlying positivism/rational-empiricism ${ }^{83}$ reference-of-thought achieved ' 103 universaltransparency ${ }^{104}$-〈transparency-of-totalising-entailing,-as-to-entailing-<amplituding/formativeepistemicity>totalising in-relative-ontological-completeness > so-reflected as positivising/rational-empiricism-based-universalisation-directed-rulemaking-over-non-rulesapriorising/axiomatising/referencing-psychologism underlying our present positivism/rationalempiricism apriorising/axiomatising/referencing-psychologism' first induced by buddingpositivists like Copernicus, Galileo, Descartes, Newton, Leibniz, etc.) that in-many-ways mathematicians 'don't go on to be thinking about the soundness of axioms once these are construed as of existence' for instance with the axioms-of-addition. But this doesn't mean that the idea of unsoundness of 'a-priori or axiomatic conception' (as to invalidate dialogicalequivalence-<as-to-psychologismic apriorising/axiomatising/referencing- $\left\{\right.$ of- ${ }^{\text {p }}$ prespectively implicited_attendant-ontological-contiguity ' reducedexistentialising/contextualising/textualising_'intelligibility/epistemicity/reflexivity-contiguity-

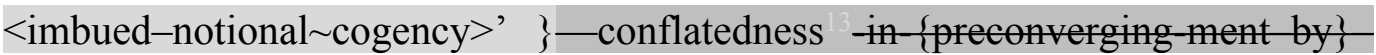
postenverging entailment,-in-self-becoming/self-conflatedness /formative-supererogating $>$ ) doesn't 'technically' exist especially so when it comes to blurred domains not only in the social sciences but sometimes in the natural sciences as well where lack of ${ }^{103}$ universal-transparency ${ }^{104}$ 〈transparency-of-totalising-entailing,-as-to-entailing-<amplituding/formativeepistemicity $>$ totalising in-relative-ontological-completeness $\rangle$ arises such that there is nothing that transparently renders someone ridiculous from fiddling around 'wrongly implying 
apriorising/axiomatising/referencing ${ }^{56}$ meaningfulness-and-teleology ${ }^{99}$ as of existence' not only out of good-naturedness ('technical' ontological-bad-faith/inauthenticity ${ }^{64}$ ) or ontological-goodfaith/authenticity ${ }^{6}$ but equally ontological-bad-faith/inauthenticity ${ }^{64}$ (in spirit). In this regards, the idea of 'putting in question dialogical-equivalence- $<$ as-topsychologismic apriorising/axiomatising/referencing-\{of-'prospectively implicited_attendant-ontological-contiguity ' educedexistentialising/contextualising/textualising_'intelligibility/epistemicity/reflexivity-contiguity$<$ imbued-notional cogency >' \}-conflatedness -in-\{preconverging-ment by\} postconverging-entailment,-in-self-becoming/self-conflatedness /formative-supererogating> by not merely engaging for logical coherence but equally putting-into-question the apriorising/axiomatising/referencing ${ }^{56}$ meaningfulness-and-teleology ${ }^{9}$ pretense of being as of existence - as-sublimating-withdrawal/unenframing/re-ontologising,-elicited-fromprospective-profound-supererogation , is effectively central to all prospective institutionalisations in relative-ontological-completeness ${ }^{87}$ as reflected with the Socraticphilosophers putting in question the apriorising/axiomatising/referencing of non-universalising sophists specifically with Socrates during his trial as to his highlighting of the inconsistencies of his accusers sophistic non-universalising apriorising arguments priorly for the notion of a mutual logical coherent engagement to arise in-the-very-first-place with Socrates rather purporting that such a possibility of mutual logical coherent engagement could only arise on the basis of his epistemic-projection of ${ }^{103}$ universalising-idealisation apriorising arguments as to existence-assublimating-withdrawal/unenframing/re-ontologising,-elicited-from-prospective-profoundsupererogation and budding-positivists equally putting-into-question the apriorising/axiomatising/referencing of non-positivising/non-rational-empiricists medievalscholasticism specifically as with Galileo's implicit dismissal of any such pretence of logical coherence engagement in-the-very-first-place in the face of what he could see 
positively/rational-empirically through the telescope with respect to the 'imaginary pedantic machinations' of his medieval-scholasticism interlocutors and so as to the prospective positivism/rational-empiricism apriorising/axiomatising/referencing as to existence-assublimating-withdrawal/unenframing/re-ontologising,-elicited-from-prospective-profoundsupererogation ; as in fact the very notion of prospective institutionalisation is one of renewing reference-of-thought-and- ${ }^{83}$ reference-of-thought- ${ }^{8}$ devolving- ${ }^{5}$ meaningfulness-andteleology ${ }^{9}$ apriorising/axiomatising/referencing prospectively as to existence — as-sublimatingwithdrawal/unenframing/re-ontologising,-elicited-from-prospective-profoundsupererogation, putting-into-question the <amplituding/formative $>$ wooden-language〈imbued-temporal-mere-form/virtualities/dereification/akrasiaticdrag/denatured/preconverging-or-dementing -narratives - of-the- reference-of-thoughtcategorical-imperatives/axioms/registry-teleology > of the prior registryworldview's/dimension's presencing-absolutising-identitive-constitutedness superseded/transcended. With such teleologically-decadent-as-in-dimensionality-ofdesublimating-lack-of - -<<amplituding/formative $>$ supererogatory $\sim$ de-mentativeness/epistemicgrowth-or-conflatedness /transvaluative-rationalising/transepistemicity/anamnesticresiduality/spirit-drivenness-equalisation $\rangle$ spirit of intellectualism, it can difficultly be fathomed how such a ground-breaking evental-instigation as the appearance of Einsteinian physics in early $20^{\text {th }}$ century prompting great excitement and curiosity among physicists recasting the contributions of prior physicists, and then eliciting the work of many other physicists and mathematicians in the subsequent decades leading in-between to the superseding of Einsteinian physics with Bohrian physics and then Feynmanian physics, etc. as to existencepotency ${ }^{39} \sim$ sublimating-nascence,-disclosed-from-prospective-epistemic-digression constraining, can be contemplated as of such a rather impoverished conception of genuine intellection which poorly recognises the pre-eminence of existence-potency ${ }^{32} \sim$ sublimating- $^{-}$ 
nascence,-disclosed-from-prospective-epistemic-digression

over

human-subpotency (notwithstanding the fact that we are at the backend of human institutionalcumulation/institutional-recomposure-〈as-to- historiality/ontological-

\section{eventfulness /ontological-aesthetic-tracing-<perspective-ontological-}

normalcy/postconvergence-reflected-'epistemicity-relativism-determinism'> $>\rangle$ ); and so because in-many-ways it is hardly the case that the priority is obsession with such intellectual emancipation rather than obsession with institutional-being-and-craft muddlement. While the natural sciences are 'naturally' constrained by the stronger manifestation for prediction, there is nothing that says because the social domain is relatively blurred the possibility for such rigour cannot be achieved in the social as well even as it is highly subject to social-stake-contentionor-confliction meddling; as the possibility of the undercutting of the latter's $<$ amplituding/formative $>$ wooden-language-〈imbued-temporal-mere-

\section{form/virtualities/dereification/akrasiatic-drag/denatured/preconverging-or-dementing} narratives - of-the- reference-of-thought- categorical-imperatives/axioms/registry-

teleology > with asceticism does exist as has existed throughout sublimating historiality/ontological-eventfulness ${ }^{38} /$ ontological-aesthetic-tracing-<perspectiveontological-normalcy/postconvergence-reflected-'epistemicity-relativism-determinism'> since even the natural sciences practices arose out of the profound asceticism stances against their initial societal predispositions of ${ }^{79}$ presencing-absolutising-identitive-constitutedness ${ }^{14}$. Beyond the seemingly intellectual ebullience ever so portrayed today, the question can be asked to which extent it usually reflect deep curiosity for prospective knowledge-reification $\sim$ gesturingand-accounting - of-epistemic-phenomenalism- $<$ in-

prospective_psychologismic apriorising/axiomatising/referencing-\{of-'prespectively implicited_attendant-ontological-contiguity ' educedexistentialising/contextualising/textualising_ 'intelligibility/epistemicity/reflexivity-contiguity- 
postconverging-entailment $>$ rather than a culture of pop-intellectualism today that seem to define our human-subpotency/mortality purposes as superseding existence-potency ${ }^{39} \sim$ sublimatingnascence,-disclosed-from-prospective-epistemic-digression as to intemporality purposes, as soreflected in the supposed intellection values conferred in many a press operation with such vague catchphrases as 'the-greatest/most-influential thinker of our times' as of mere influence peddling and poorly advancing the inherent importance of prospective knowledge-reification $\sim$ gesturingand-accounting - of-epistemic-phenomenalism- $<$ in-

prospective_psychologismic $\sim$ apriorising/axiomatising/referencing-\{of-'prospectively implicited_attendant-ontological-contiguity ' reducedexistentialising/contextualising/textualising_'intelligibility/epistemicity/reflexivity-contiguity$<$ imbued-notional $\left.\sim \operatorname{cogency}>^{\prime}\right\}$-conflatedness -in-\{preconverging-ment by\} postconverging entailment> as addressing the human-subpotencyaporia/undecidability/dilemma/ought-indeterminacy/deficiency/limitation/constraint of our prior reproducibility—mathesis/motif/thrownness-disposition,--as-reproducibility-ofaestheticisation, notwithstanding the sometimes crude and unsavoury social discomfort implications in this respect. Thus in-many-ways such an orientation is unsettling to upcoming/future young thinkers as to what can be of profound intellection value with respect to opting for a profound intellectual commitment for prospective knowledge-reification $\sim$ gesturingand-accounting - of-epistemic-phenomenalism- $<$ inprospective_psychologismic apriorising/axiomatising/referencing-\{of-‘prospectively implicited_attendant-ontological-contiguity ' reducedexistentialising/contexalising/texalising_intelligibility/epistemicity/reflexivity-contiguity$<$ imbued-notional cogency $>$ ' $\}$-conflatedness -in-\{preconverging ment by\}

postconverging entailment $>$ rather than just strategies of socially perceived intellectual success 
within deified temporal/mortal existential-<disontologising/re-ontologising aporeticism $>$ frameworks; especially in the underhanded institutional presence of such avowedly teleologically-decadent-as-in-dimensionality-of-desublimating-lack-of ${ }^{-}$

\section{<<amplituding/formative $>$ supererogatede-mentativeness/epistemic-growth-or-}

\section{conflatedness /transvaluative-rationalising/transepistemicity/anamnestic-residuality/spirit-}

drivenness-equalisation $>$ mantras like theories die with the passing of their authors as so-implied with regards to many a postmodern scholar, wherein such highbrowing has been surreptitiously inclined to put-up their temporalities/mortalities (notwithstanding that knowledge is as to existence-potency ${ }^{39} \sim$ sublimating-nascence,-disclosed-from-prospective-epistemic-digression consequences accruing to the entire humankind) to institutionally and socially undermine prospective knowledge-reification gesturing-and-accounting-of-epistemic-phenomenalism<in-prospective_psychologismic apriorising/axiomatising/referencing-\{of-'prospectively implicited_attendant-ontological-contiguity ' educedexistentialising/contextualising/textualising_'intelligibility/epistemicity/reflexivity_contiguity<imbued-notional cogency $>\quad\}$-conflatedness - in-\{preconverging-ment by\}

postconverging-entailment> with stooges/foils muddying the ontological-veracity of genuine thought as of its true human emancipating implications, as they 'sneak-in and sneak-out about knowing and not knowing' in a distorted conception of intellectualism as to a Machiavellian/political exercise rather than the requisite magnanimity of engagement for a genuine knowledge-reification $\sim$ gesturing-and-accounting-of-epistemic-phenomenalism- $<$ inprospective_psychologismic apriorising/axiomatising/referencing-\{of-`prospectively implicited_attendant-ontological-contiguity ' reducedexistentialising/contextualising/textualising_'intelligibility/epistemicity/reflexivity-contiguity<imbued-notional cogency >' \}-conflatedness -in-\{preconverging-ment by\} postconverging-ntailment $>$ exercise! Actually the projection of values including intellectual 
values in such <amplituding/formative-epistemicity $>$ totalising $\sim$ self-referencingsyncretising/circularity/interiorising/akrasiatic-drag ${ }^{34}$ are often prospectively deficient, given the fact that notions of value are only as pertinent as of their transvaluation implications in relative-ontological-completeness 87 since the-very-same conception of value when construed on the basis of relative-ontological-incompleteness ${ }^{88}$ may actually be associated with vices-andimpediments ${ }^{105}$, and so beyond-the-consciousness-awareness-teleology ${ }^{9}<$ of-preconvergingexistential-extrication-as-of-existential-unthought $>$; given that virtue is rather as of 'prospective postconverging-aporeticism-overcoming/mnovercoming as the-Good/knowledgereification $\sim$ gesturing-and-accounting — of-epistemic-phenomenalism- $<$ inprospective_psychologismic apriorising/axiomatising/referencing-\{of-'prospectively implicited_attendant-ontological-contiguity ' educedexistentialising/contextualising/textualising_'intelligibility/epistemicity/reflexivity_contiguity<imbued-notional cogency>’ \}-conflatedness -in-\{preconverging ment by\} postconverging-entailment $>$ /understanding/<amplituding/formativeepistemicity $>$ causality $\sim$ as-to-projective-totalitative-implications-of-prospectivenonpresencing,-for-explicating relative-unreflexivity/relative-reflexivity —ontologicalcontiguity , conceptualisation as to transcendental-enabling/sublimating/suredementativity and not the vagueness of impression-driven/good-naturedness/wishfulness <amplituding/formative $>$ wooden-language-〈imbued-temporal-mereform/virtualities/dereification/akrasiatic-drag/denatured/preconverging-or-dementing narratives - of-the- reference-of-thought- categorical-imperatives/axioms/registryteleology > in human-subpotency social-aggregation-enabling. We can grasp in this respect that the value conception as from the non-universalising sophistry perspective construed as decadent the prospective Socratic-philosophers ${ }^{103}$ universalising-idealisation just as did medievalscholasticism of budding-positivists like Galileo and Descartes; as in-many-ways prospective 
knowledge-reification $\sim$ gesturing-and-accounting — of-epistemic-phenomenalism- $<$ inprospective_psychologismic apriorising/axiomatising/referencing-\{of-'prospectively implicited_attendant-ontological-contiguity ' educedexistentialising/contextualising/textualising_'intelligibility/epistemicity/reflexivity-contiguity<imbued-notional cogency >' \}-conflatedness -in-\{preconverging-ment by\} postconverging-entailment $>$ requires that we supersede our emotional-involvement starting with the very intellection striving for such prospective knowledge-reification $\sim$ gesturing-andaccounting - of-epistemic-phenomenalism- $<$ in-

prospective_psychologismic apriorising/axiomatising/referencing-\{of-'prospectively implicited_attendant-ontological-contiguity ' educedexistentialising/contextualising/textualising_'intelligibility/epistemicity/reflexivity-contiguity<imbued-notional cogency>’ $\}$-conflatedness -in-\{preconverging-ment by\} postconverging-ntailment>. In any case, ultimately the reality of human knowledgereification $\sim$ gesturing-and-accounting — of-epistemic-phenomenalism- $<$ inprospective_psychologismic apriorising/axiomatising/referencing-\{of- ${ }^{\text {pprospectively }}$ implicited_attendant-ontological-contiguity ' educed-

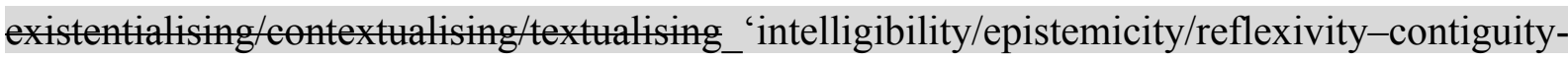
<imbued-notional cogency>’ $\}$-conflatedness -in-\{preconverging -ment by\} postconverging-entailment $>$ involves 'direct bilateral relationship of appropriate constructionof-the-Self for appropriate cognisance-and-integration of prospective relative-ontologicalcompleteness ${ }^{87}{ }^{56}$ meaningfulness-and-teleology ${ }^{9}$, and so in the transvaluation of prospective human postconverging aporeticism-overcoming/unovercoming; as for instance, it can hardly be imagined that the ${ }^{83}$ reference-of-thought of the non-positivism/medievalism mindset as of its preconverging/postconverging-de-mentative/structural/paradigmatic ontologisation/ontological-veracity/aestheticisation-towards-ontology is apt as of its 
supererogatory acuity/perspicacity/astuteness/edginess/incisiveness-ofapriorising/axiomatising/referencing/intelligibilitysettingup/measuringinstrumenting - forconceptualisation to grasp our modern-day conception of say physics given its 'valuation framework as of its <amplituding/formative-epistemicity>totalising $\sim$ self-referencingsyncretising/circularity/interiorising/akrasiatic-drag ${ }^{34}$ that needs to be transvaluated into a positivism mindset. It can fairly be contended that prospective issues of knowledgereification $\sim$ gesturing-and-accounting — of-epistemic-phenomenalism- $<$ inprospective_psychologismic apriorising/axiomatising/referencing-\{of-'prospectively implicited_attendant-ontological-contiguity ' educedexistentialising/contextualising/textualising_'intelligibility/epistemicity/reflexivity-contiguity<imbued-notional cogency $>$ ' $\}$-conflatedness -in-\{preconverging ment by\} postconverging-ntailment $>$ in modern-day physics having to do with theory-of-everything conception arise because of our inappropriately apt supererogatory acuity/perspicacity/astuteness/edginess/incisiveness-ofapriorising/axiomatising/referencing/intelligibilitysettingup/measuringinstrumenting -forconceptualisation as of an occlusive-consciousness ${ }^{83}$ reference-of-thought requiring prospective notional ${ }^{18}$ deprocrypticism $\quad{ }^{83}$ reference-of-thought preconverging/postconverging-dementative/structural/paradigmatic ontologisation/ontological-veracity/aestheticisation-towardsontology as of a protensive-consciousness (out of a full insight about causality as from the epistemic 'relative-ontological-completeness ${ }^{87} \quad$ <amplituding/formativeepistemicity $>$ causality $\sim$ as-to-projective-totalitative-implications-of-prospectivenonpresencing,-for-explicating relative unreflexivity/relative-reflexivity - ontologicalcontiguity as to apriorising/axiomatising/referencing-\{of- prespectively implicited_attendant-ontological-contiguity ' reducedexistentialising/contextualising/textualising_intelligibility/epistemicity/reflexivity_contiguity- 
<imbued-notional cogency >' \}-conflatedness ${ }^{13}$ in-\{preconverging-ment by \} $^{\prime}$ postconverging-entailment' herein implied as <amplituding/formativeepistemicity $>$ causality $\sim$ as-to-projective-totalitative-implications-of-prospectivenonpresencing,-for-explicating relative-unreflexivity/relative-reflexivity - ontologicalcontiguity (involving a 'direct bilateral relationship of appropriate construction-of-the-Self for appropriate cognisance-and-integration of prospective relative-ontological-completeness meaningfulness-and-teleology"' as implied prospectively in 'construing of both the right apriorising/axiomatising/referencing/intelligibilitysettingup/measuringinstrumenting mindsetas-of-prospective-deprocrypticism-dissemination ${ }^{28}$ and thus the knowledge for that right mindset-as-of-prospective-deprocrypticism-dissemination $\left.{ }^{2{ }^{\prime}}\right)$. We can better understand as such why underlying confliction arises with all registry-worldviews/dimensions transcendence-andsublimity/sublimation/supererogatory de-mentativity because these involve humansubpotency-aporia/undecidability/dilemma/ought-

indeterminacy/deficiency/limitation/constraint postconverging aporeticismovercoming/mnovercoming; as putting in question the old valuation as to requisite human limited-mentation-capacity-deepening—as-subjecting limitedness/human-subpotency-to'duce unlimitedness/existence sublimating nascence' ${ }^{33}$. In this regards the transcendental/transvaluating conception of postconverging-apereticismovercoming/unovercoming is of existential-<disontologising/re-ontologising aporeticism $>$ comprehensiveness and cannot be just about the physical world without social world implications and vice-versa as so-underlined with the fact that both are for-human-studies/forhuman-constructs epistemic-projection by the underlying fact that these are the-very-same human-subpotency sublimation implications as to overall reifying-and-empowering-reflexivity-

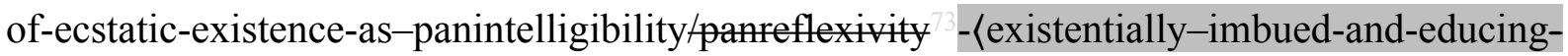
Kepistemictalising thermeneutically/textually/reprojectingly/supererogatingly/zeroingly/re- 
acutingly, -\{decompulsing\} delinearity $\sim$ for-cogency $\geq$-epistemic-perspective-of-

projective/reprojective - aestheticising-re-motif-and-re-apriorising/re-axiomatising/re-

referencing conceptualisation,-as-herein-specifically-relevant-to human-subpotency);

inevitably the apparently socially innocuous Copernican, Galilean, Cartesian, Newtonian, etc. conception of the material world as of positivism/rational-empiricism in superseding their human-subpotency-aporia/undecidability/dilemma/ought-

indeterminacy/deficiency/limitation/constraint of 'traditional mythological/supernatural conceptualisation of material world/things as of the ${ }^{103}$ universalising but non-positivismmedievalism preclusive-consciousness' have constructive implications about corresponding requisite prospective positivism/rational-empiricism social-values (in superseding the humansubpotency-aporia/undecidability/dilemma/ought-

indeterminacy/deficiency/limitation/constraint of 'traditional mythological/supernatural conceptualisation of the social-construct as of the ${ }^{103}$ universalising but non-positivismmedievalism preclusive-consciousness'), and the possibility for the further advancement of such 'material sciences as to cumulating/recomposuring positivism/rational-empiricism' rather arises from the corresponding effectively enabling 'cumulating/recomposuring positivism/rationalempiricism social-values' like freedom-of-speech, opened communication, etc. availing as of the transcending positivism/rational-empiricism occlusive-consciousness. Likewise, it is herein contended that the future possibility for the natural sciences advancement is inseparable from the possibility of social and social-organisational advancement as of prospective human postconvergingaporeticism-overcoming/unovereoming as to the prospective deprocrypticism-or-preempting-disjointedness-as-of- ${ }^{83}$ reference-of-thought protensiveconsciousness induced Being-development/ontological-framework-expansion-as-to-depth-ofontologising-development-as-infrastructure-of- meaningfulness-and-teleology and so over our present ${ }^{80}$ procrypticism-or-disjointedness-as-of- ${ }^{3}$ reference-of-thought occlusive- 
consciousness; and in effect this conjoint-epistemic-relationship-and-fate in the conceptualisation of the material and social world is even confirmed today as with the social and social-organisational framework that underlied and was necessary for most of the scientific and technological advances after the second-world war. Basically, dimensionality-of-sublimating <<amplituding/formative>supererogatery $\sim$ de-mentativeness/epistemic-growth-or-

\section{conflatedness /transvaluative-rationalising/transepistemicity/anamnestic-residuality/spirit-}

drivenness-equalisation) as such reflects the successively induced originariness-parrhesia,--asspontaneity-of-aestheticisation specific 'constructiveness-by-destructuring cut-offs/thresholds

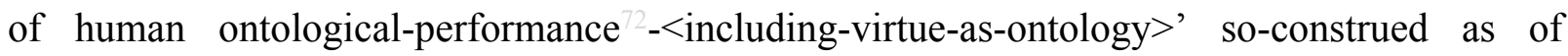
notional protensive-consciousness (trepidatious-consciousness/warpedconsciousness/preclusive-consciousness/occlusive-consciousness/protensive-consciousness) implications; and as eliciting any such prospective specific construction-of-the-Self and its given registry-worldview/dimension ${ }^{83}$ reference-of-thought-and- ${ }^{83}$ reference-of-thought- ${ }^{84}$ devolvingmeaningfulness-and-teleology overall preconverging/postconverging-dementative/structural/paradigmatic construct-of- -5 meaningfulness-and-teleology 99 as secondnatured institutionalisation. The 'destructuring cut-offs/thresholds of human ontologicalperformance ${ }^{2}-<$ including-virtue-as-ontology $>$ ' reflect prospective lack of dimensionality-ofsublimating $25<<$ amplituding/formative $>$ supererogatory $\sim$ de-mentativeness/epistemic-growthor-conflatedness /transvaluative-rationalising/transepistemicity/anamnestic-residuality/spiritdrivenness-equalisation> so-reflected in the shiftiness-of-the-Self 's $<$ amplituding/formative $>$ wooden-language-〈imbued-temporal-mereform/virtualities/dereification/akrasiatic-drag/denatured/preconverging-or-dementing narratives - of-the- reference-of-thought- categorical-imperatives/axioms/registryteleology > implying a human ontological-performance ${ }^{72}-$ including-virtue-as- $^{-}$ ontology $>$ /morality/ethics/justice/etc. that is rather constrained 'mechanically' on the prior 
reproducibility—-mathesis/motif/thrownness-disposition,-as-reproducibility-ofaestheticisation, 'despite the implications arising from budding/nascent insights of ecstaticexistence-as-transcendental-signifier_emergence/becoming-spontaneity-implications reflected as existence-potency ${ }^{39} \sim$ sublimating-nascence,-disclosed-from-prospective-epistemicdigression' for the need for prospective originariness-parrhesia,-as-spontaneity-ofaestheticisation; to which the Self absconds (in <amplituding/formativeepistemicity $>$ totalising $\sim$ self-referencing-syncretising/circularity/interiorising/akrasiatic-drag as to limited-mentation-capacity—as-subjecting-'educed-unlimitedness/existence-sublimating nascence' to-limitedness/human-subpotency implications) until the perceived induced notional-positive-opportunism—of-social-functioning-and-accordance ${ }^{75}$ from any such prospective originariness-parrhesia,-as-spontaneity-of-aestheticisation elicits the requisite human limited-mentation-capacity-deepening—as-subjecting limitedness/human-subpotency to-'educed-unlimitedness/existence-sublimating nascence' 3 (involving prospective knowledge-reification $\sim$ gesturing-and-accounting — of-epistemic-phenomenalism- $<$ inprospective_psychologismic apriorising/axiomatising/referencing-\{of- ${ }^{\star p r o s p e c t i v e l y}$ implicited_attendant-ontological-contiguity ' reducedexistentialising/contexalising/textising_intelligibility/epistemicity/reflexivity-contiguity<imbued-notional cogency >’ \}-conflatedness -in-\{preconverging -ment by\} postconverging-entailment $>$ and/or deferential-formalisation-transference) for prospective secondnatured institutionalisation as of renewed prospective reproducibilitymathesis/motif/thrownness-disposition,-as-reproducibility-of-aestheticisation. Furthermore, besides the conceptualisation articulated herein, what vindicates this idea of apriorising/axiomatic/referencing intellectual break/schism/estrangement is effectively that the possibility for prospective ${ }^{56}$ meaningfulness-and-teleology 99 is associated with a renewed framework of ontologisation/ontological-veracity/aestheticisation-towards-ontology which is in 
'affirmation/projection

by

its

underlying

supererogatery acuity/perspicacity/astuteness/edginess/incisiveness-of-

apriorising/axiomatising/referencing/intelligibilitysettingup/measuringinstrumenting - for-

conceptualisation' to the superseded framework of prior ontologisation/ontological-

veracity/aestheticisation-towards-ontology prospectively disontologising as

unaffirmed/deprojected; as to the possibility of the recovery of dimensionality-of-sublimating

<<amplituding/formative>supererogatory $\sim$ de-mentativeness/epistemic-growth-or-

conflatedness /transvaluative-rationalising/transepistemicity/anamnestic-residuality/spirit-

drivenness-equalisation) prospectively, disentangled from 'prior knowledge-as-of-mechanicalknowledge predisposition and its developed temporal institutional self-serving predisposition'. After many years of formative contemplation this author is rather dedicated to writing henceforth even if read/skimmed just by a handful or fortuitously or never-but-potentially, whatever cometh, hopefully over the next half a century, and thinks any human who genuinely feels strongly about the need for profound human thought should be able to do likewise, as ultimate responsibility/relative-reflexivity and choice notionally lies with the individual. 
what a psychopath is philosophically-speaking

BEGINNING OF DIGRESSION (ON OVERALL CONCEPTION OF THE FULL POTENTIAL OF HUMAN ONTOLOGICAL-PERFORMANCE- $<$ INCLUDINGVIRTUE-AS-ONTOLOGY>).

END OF DIGRESSION (ON OVERALL CONCEPTION OF THE FULL POTENTIAL OF HUMAN ONTOLOGICAL-PERFORMANCE- $<$ INCLUDING-VIRTUE-ASONTOLOGY>)

'correct

apriorising/axiomatising/referencing/intelligibilitysettingup/measuringinstrumenting producing-measurements' (appropriateness-of-reference-of-thought-as-of-conflatedness)

meaningfulness-and-teleology is preconverging/postconverging-de-

mentatively/structurally/paradigmatically constrained as to threshold-ofnonconviction/madeupness/bottomlining-in-shallow-supererogation-<as-to- 'attendantintradimensional' -prospectively-disontologising $\sim$ preconverging/dementing-apriorisingpsychologism>, as from candidity/candour-capacity perspective

relative-ontological-completeness-of-reference-of-thought as of diminishing-human-

epistemic-abnormalcy-or-preconvergence

transcendental knowledge (as relatively 'consecrated' by relative intrinsic-

reality/ontological-veridicality transcendental-enabling/sublimating/supererogatory $\sim$ dementativity) necessarily carries a 'cynicism-of-grandeur-as-of-effective-intemporalsolipsistic-commitment'

The notion of 'beyond-the-consciousness-awareness-teleology-<of-preconvergingexistential-extrication-as-of-existential-unthought>'

a 'relative teleological-differentiation/scission/variance/disambiguation of references-ofthought' as to what the appropriateness-of-reference-of-thought-as-of-conflatedness (correct

apriorising/axiomatising/referencing/intelligibilitysettingup/measuringinstrumentingproducing-measurements) and the perversion-of-reference-of-thought- $<$ aspreconvergingly-apriorising/axiomatising/referencing-innonconviction/madeupness/bottomlining-as-to-shallow-supererogation $>$ (defective apriorising/axiomatising/referencing/intelligibilitysettingup/measuringinstrumenting producing-measurements) truly are

difference between postlogism (postlogism-as-of-compulsingnonconviction/madeupness/bottomlining-〈'< $<$ decontextualising/de-existentialising $\sim$ ofattendant-intradimensional-apriorising/axiomatising/referencing $>$-induceddisontologising'-of-the- 'attendant-intradimensional-ontologising'-imbued$<$ contextualising/existentialising attendant-ontological-contiguity $>$;-in-shallowsupererogation- $<$ as-to-disontologising-perverted-outcome-sought-precedes-existentiallyveridical-'attendant-intradimensional-apriorising/axiomatising/referencing'-logicaldueness $>>$ ) and prelogism (prelogism-as-of-conviction,-in-profound-supererogation$<$ existentially-veridical-'attendant-intradimensional- 
apriorising/axiomatising/referencing'-logical-dueness-precedes-disontologising-logical-

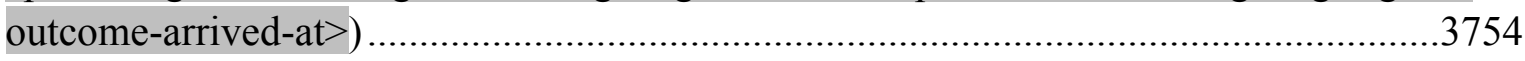

'existential perpetuation in circularity/recurrence/repetition/repeatability' .....................3780

upholding of prospective transcendental-enabling/sublimating/supererogatory $\sim \mathrm{de}-$

mentativity over any temporal extricatory preconverging-de-

mentating/structuring/paradigming

3856

emanantly/becomingly/solipsistically temporal-dispositions do not appreciate that there is

a more 'profound level of living in the realm of human thoughtfulness'

3860

acting as-of-a-'secondnatured reproducibility—mathesis/motif/thrownness-disposition,as-reproducibility-of-aestheticisation nature' is not enough for articulating prospective institutionalisation requiring 'intemporal projection <amplituding/formative-

epistemicity>-totalising $\sim$ renewing-realisation/re-perception/re-thought' for the requisite prospective maximalising-recomposuring-for-relative-ontological-completenessunenframed/re-ontologising conceptualisation

The psychopath is in a state of compulsing-nonconviction/madeupness/bottomlining-

$\langle<<$ decontextualising/de-existentialising of-attendant-intradimensionalapriorising/axiomatising/referencing>-induced-disontologising'-of-the-'attendantintradimensional-ontologising'-imbued-<contextualising/existentialising $\sim$ attendantontological-contiguity $>$;-in-shallow-supererogation-<as-to-disontologising-pervertedoutcome-sought-precedes-existentially-veridical-'attendant-intradimensionalapriorising/axiomatising/referencing'-logical-dueness $>$ > or 'compulsive-dementing' ...3895

it is critical to distinguish between the notion of slanting (cinglé in French) as postlogismas-of-compulsing-nonconviction/madeupness/bottomlining-<‘ $<$ decontextualising/deexistentialising $\sim$ of-attendant-intradimensional-apriorising/axiomatising/referencing $>$ induced-disontologising'-of-the- 'attendant-intradimensional-ontologising'-imbued$<$ contextualising/existentialising attendant-ontological-contiguity>;-in-shallowsupererogation-<as-to-disontologising-perverted-outcome-sought-precedes-existentiallyveridical-'attendant-intradimensional-apriorising/axiomatising/referencing'-logicaldueness $>>$ and the notion of a lie which is in manifest prelogism-as-of-conviction,-inprofound-supererogation-<existentially-veridical-'attendant-intradimensionalapriorising/axiomatising/referencing'-logical-dueness-precedes-disontologising-logicaloutcome-arrived-at>

we 'consistently' have two sets of mental-dispositions having to do with the uninstitutionalised-threshold of all registry-worldviews/dimensions; as of metaphysics-ofpresence--_implicited-'nondescript/ignorable-void'-as-to-presencing-absolutisingidentitive-constitutedness $\rangle$ and metaphysics-of-absence-〈implicited-epistemic-veracity-ofnonpresencing-<perspective-ontological-normalcy/postconvergence $>>$ representations

rational-realism attends to the idea of human limited-mentation-capacity-deepening-assubjecting limitedness/human-subpotency-to-'educed-unlimitedness/existencesublimating nascence' as enabling its more profound grasp of intrinsic-reality/ontologicalveridicality by way of a concurrently more and more 'rational realistic' construal of intrinsic-reality/ontological-veridicality as of a natural human psychological growth 
disposition ('postconverging-or-dialectical-thinking-psychology or psychology-ofmentation-dynamics or natural psychological-dynamics') ....

wrongly elevate psychopathic meaningfulness-and-teleology as of veridical

'implicited_attendant-ontological-contiguity' educed-

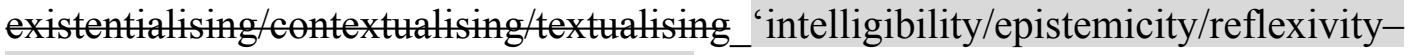
contiguity-<imbued-notional cogency $>$ ' rather than reflect the reality of its 'formulaic meaningfulness-and-teleology'

The underlying fact about meaningfulness-and-teleology is that the apriorising-registry (as the individual grounding of the reference-of-thought of the social-construct registryworldview/dimension) precedes logic as of apriorising/axiomatising/referencing basis for logic

'social protraction of psychopathy across individuals and society'

The suspected psychosomatic basis for the psychopath to be slanted/'cinglé' is a 'faultymentation-procedure-deception-or-urge (entitlement folie/folie raisonnante)' as opposed to a logical motivation of a supplanting-conviction-as-to-profound-supererogation- of'attendant-intradimensional'-postconverging/dialectical-thinking-apriorisingpsychologism or prelogic mental-disposition.

'mental roaming/drifting-cycle disposition known as postlogism-retreating'

'mere-formulaic constrained/unconstrained perception and relation to meaningfulnessand-teleology'.

social-discomfiture is in reality not a veridical logical 'contention' but in veridicality/ontologically a 'protracted manifestation' of notional procrypticism/notionaldisjointedness-as-of-reference-of-thought.

'poor or bad supplanting-conviction-as-to-profound-supererogation-of-'attendantintradimensional'-postconverging/dialectical-thinking-apriorising-psychologism', contrasted to the psychopath's compulsing-nonconviction/madeupness/bottomlining〈' $<$ decontextualising/de-existentialising of-attendant-intradimensionalapriorising/axiomatising/referencing >-induced-disontologising'-of-the-'attendantintradimensional-ontologising'-imbued-<contextualising/existentialising attendantontological-contiguity $>$; -in-shallow-supererogation-<as-to-disontologising-pervertedoutcome-sought-precedes-existentially-veridical-'attendant-intradimensionalapriorising/axiomatising/referencing'-logical-dueness $>$ > or compulsively-dementing ..4636 the psychopath overemphasises in a consciously active manner the empty forms of prosody in-of-themselves first and over the intrinsic attributive essence of meaning like overemphasising the toning form (toning triggering) and the supposition form (presumptuousness) in their expressed deductive reasoning, as it mimicks the fact that the forms of prosody tend to be overemphasised spontaneously when naturally expressing profound/deep conviction

mechanism of 'induced-ring-of-gyges-effect/solipsistic-point-of-temporalthresholding/point-of-ontological-faith-notion-or-ontological-fideism-imbuedunderdetermination-of-motif-and-apriorising/axiomatising/referencing-as-so-being-as-ofexistential-reality' at the point of lack of social universal-transparency-〈transparency-oftotalising-entailing,-as-to-entailing-<amplituding/formative-epistemicity $>$ totalising $\sim$ in- 
relative-ontological-completeness $\rangle$ about the psychopathic postlogism/slantedness compulsing-nonconviction/madeupness/bottomlining-<“<decontextualising/deexistentialising $\sim$ of-attendant-intradimensional-apriorising/axiomatising/referencing $>$ induced-disontologising' -of-the- 'attendant-intradimensional-ontologising'-imbued$<$ contextualising/existentialising attendant-ontological-contiguity $>$;-in-shallowsupererogation-<as-to-disontologising-perverted-outcome-sought-precedes-existentiallyveridical-'attendant-intradimensional-apriorising/axiomatising/referencing'-logicaldueness $>>$ in hollow-constituting-<as-disjointed-misappropriation-of-meaningfulness-andfailing-intemporal-preservation $>$

mechanism for psychopathic and postlogic slantedness is relayed to apparently sound supplanting-conviction-as-to-profound-supererogation - of- 'attendant-intradimensional'postconverging/dialectical-thinking-apriorising-psychologism interlocutors, and so along five factors 4650

psychopathy as postlogism is associated with temporal-dispositions in their 'perversion-ofreference-of-thought-<as-preconvergingly-apriorising/axiomatising/referencing-innonconviction/madeupness/bottomlining-as-to-shallow-supererogation $>$ (as prior intemporal reference-of-thought-categorical-imperatives/axioms/registry-teleology) of the various institutionalisation/intemporalisation levels 4660

'institutionalisation intemporal-preservation-entropy-or-contiguity-or-ontologicalpreservation' is what creates a 'sounder scientific foundation' for a '\{epistemictotalisinglhermeneutic/texality/reprojecting/supererogating/zeroing/re anting,\{decompulsing delinearity for-cogency psychological science' termed 'anthropopsychology' or the 'anthropological continuity'

transcendental analysis (institutional-cumulation/institutional-recomposure-〈as-tohistoriality/ontological-eventfulness/ontological-aesthetic-tracing-<perspectiveontological-normalcy/postconvergence-reflected-'epistemicity-relativism-determinism' $>>$ analysis) is not, as may wrongly be thought, analogical but is rather an 'ontologicallycontiguous meaningfulness-and-teleology reference' .....

Psychoanalytic-unshackling/memetic-reordering/institutional-recomposuring process can then be defined as arising when a registry-worldview's/dimension's

\{cumulated/recomposured $\}$-consciousness-awareness-teleology is transcended/superseded as to human limited-mentation-capacity-deepening - as-subjecting-limitedness/human-

subpotency to-'educed-unlimitedness/existence-sublimating nascence'. 4668 de-mentation-〈stpereregatery ontological-de-mentation-or-dialectical-de-mentationstranding-or-attributive-dialectics $\rangle$ as preconvergingly-de-mentated/structured/paradigmed registry-worldviews/dimensions.

illusion-of-the-present/present-consciousness/epistemic-totalising $\sim$ self-referencingsyncretising/mirage.

The very specific nature of the deprocryptic transcendence-andsublimity/sublimation/supererogatory $\sim$ de-mentativity/institutionalisation is to recognise and articulate the veridicality of the fact of human-subpotencyaporia/undecidability/dilemma/ought-indeterminacy/deficiency/limitation/constraint imbued-"notional firstnaturedness-formativeness-<as-to-eventualising-inkling-drive-or- 
seeding-misprising $>$ - temporal-to-intemporal-dispositions- $<$ so-construed-as-fromperspective-ontological-normalcy/postconvergence>'-existentialism-form-factor .

Knowledge-notionalisation as such carries a transcendent-existentialism/in-full-existentialdepth-of-notional firstnaturedness-formativeness-<as-to-eventualising-inkling drive-orseeding misprising $>$ temporal-to-intemporal-dispositions-<so-construed-as-fromperspective-ontological-normalcy/postconvergence $>$-implications which is more than just reactionary to the possibility of temporality/shortness (shortness-of-register-ofmeaningfulness-and-teleology) but rather a 'transcendent-existentialism maturing of thought' (intemporality as longness-of-register-of-meaningfulness-and-teleology) that takes abstract cognisance of temporality/shortness as an intransient potency (hitherto accounting for the circularity/recurrence/repetition/repeatability of human circularuninstitutionalised-threshold) to be conceptually understood and superseded recurrently and perpetually

The conceptualisation of reference-of-thought-categorical-imperatives/axioms/registryteleology refers to the same deconstructed/ontological-reconstituting-as-to-conflatedness notion

The reference-of-thought is the fundamental-dispositional mentation architecture for human referencing or construing of meaningfulness-and-teleology 4682 a registry-worldview/dimension defect is one of systematic defect of reference-of-thought

preconverging-or-dementing-apriorising-psychologism/unsoundness-or-ontological-badfaith/inauthenticity-of-reference-of-thought does not arise because of failure of logicalprocessing-or-logical-implicitation - supposedly-apriorising-in-conviction-as-to-profoundsupererogation but rather because of failure of reference-of-thought as of perversion-andderived-perversion-of-reference-of-thought- $<$ as-preconverginglyapriorising/axiomatising/referencing-in-nonconviction/madeupness/bottomlining-as-toshallow-supererogation $>$

Soundness-or-ontological-good-faith/authenticity-of-reference-of-thought on the other hand implies being-or-ontological-or-existential-or-meaningfulness-and-teleology disposition as of supplanting-conviction-as-to-profound-supererogation - of-'attendantintradimensional'-postconverging/dialectical-thinking-apriorising-psychologism........4686

The 'de-mentation-〈supererogatory $\sim$ ontological-de-mentation-or-dialectical-dementation - stranding-or-attributive-dialectics $\rangle$ of reference-of-thought'

intradimensional socially-betraying-threshold-of-ontologising-depth-of-analysis with respect to their social-stake-contention-or-confliction specific to each registryworldview/dimension defining its 'inherent institutionalisation and snowballed recomposuring' going by human-subpotency-aporia/undecidability/dilemma/oughtindeterminacy/deficiency/limitation/constraint_ imbued-'notional firstnaturednessformativeness-<as-to-eventualising inkling drive-or-seeding misprising $>$ - temporal-tointemporal-dispositions- $<$ so-construed-as-from-perspective-ontologicalnormalcy/postconvergence $>$ '-existentialism-form-factor 
with regards to adult psychopathy and the induced social psychopathy, it will be naïve to simply analyse on a dichotomous basis of psychopathy and its violation of social norm

psychopathy is associated with temporal-dispositions destructuring-threshold〈uninstitutionalised-threshold/presublimating-desublimating-decisionality $\rangle$ ofontological-performance-<including-virtue-as-ontology $>$ /morality/ethics/justice/etc. 'as of the positivism-procrypticism registry-worldview's/dimension's socially-betrayingthreshold-of-ontologising-depth-of-analysis'/socially-betraying-threshold-of-intemporalpreservation-entropy-or-contiguity-or-ontological-preservation

potentially nefarious influences that may arise from pseudo-formalisms as well, and where these are construed out of their inherent context to wrongly imply a genuine ontological analysis

implied intemporal/ontological/social/species/universal/transcendental/maximalisingrecomposuring-for-relative-ontological-completeness - unenframed/reontologising conceptualisation postconverging-de-mentating/structuring/paradigming, contrasted with a temporal extricatory preconverging-dementating/structuring/paradigming, is necessarily the prospective transcending/superseding registry-worldview/dimension....

Ontological-normalcy/postconvergence (as to epistemic relative-ontologicalcompleteness) abstractly refers to any relevant/implied registry-worldview/dimension that is in a reflected/perspectivated state of prospective transcending/superseding.

'existentialism/full-depth-of-existential-implications form-factor' is the reflection of the contiguity of successive existentialisms/full-depths-of-existential-implications across varying meaningful frames, references and registry-worldviews/dimensions

'postconverging-or-dialectical-thinking-psychology or psychology-of-mentationdynamics or natural psychological-dynamics' as being ontologically-driven

fundamental construct of rational-realism that human progress is the outcome of human increasingly realistic grasp of what man is with 'lesser and lesser vague idealisations' 4727 grasping the social psychopathy dynamism is by articulating an intemporal-referencing transversality-<for-sublimating-existential-eventuating/denouement,-from-'thinking atfirst/pure-predisposition -preemptive-of prospective-disontologising/subontologising' asof-prospectively-disambiguated-affirmed-and-unaffirmed-'motif-andapriorising/axiomatising/referencing'> ontological-normalcy/postconvergence reality construct

\{epistemic-totalising\}'hermeneutic/textuality/reprojecting/supererogating/zeroing/re acuting,\{decompulsing? delinearity for-cogency 'ontological reasoning' to arrive at 'intemporal-orontological meaning' that is beyond any <amplituding/formativeepistemicity>totalising $\sim$ self-referencing-syncretising/self-centered/presentconsciousness/illusion-of-the-present/mirage mental projection within just a given registry-worldview/dimension.

Referentialism involves a reference-of-thought (so-characteristic of the prospective deprocrypticism registry-worldview/dimension) construing existence and existentialconceptualisation/construal as about the 'precedingness of becoming' as of 
apriorising/axiomatising/referencing-\{of-'prospectively_implicited_attendant-ontologicalcontiguity' $\sim$ educed-

existentialising/contextualising/textualising_'intelligibility/epistemicity/reflexivity_ contiguity-<imbued-notional $\sim \operatorname{cogency}>$ ' $\}$ - conflatedness-in-\{preconverging-ment by\} pestconverging entailment rather than apriorising/axiomatising/referencing- of'prospectively_implicited_attendant_ontological-contiguity' educedexistentialising/contextualising/textualising_'intelligibility/epistemicity/reflexivitycontiguity-<imbued-notional $\sim$ cogency $>$ ' $\}$ - constitutedness-in-preconverging-entailment

BODMAS characters and character A (Addition) as the additionality defect character.4745 the reason why a prospective/transcending/superseding registry-worldview/dimension needs its own knowledge-construct reference-of-thought psychologism has to do with the fact that every registry-worldview/dimension has 'its own specific apriorising/axiomatising/referencing-\{of-'prospectively implicited_attendant-ontologicalcontiguity' educedexistentialising/contextualising/textualising_'intelligibility/epistemicity/reflexivitycontiguity-<imbued-notional cogency $>$ ' $\}$ - constitutedness-in-preconvergingentailment/conflation psychological complex reflex mechanism' wherein its limits in the construal/conceptualisation of intrinsic-reality/ontological-veridicality are defined

'social framework of intersolipsistic deambulation' (which holds the resources for individual and collective human possibilities, like prior developed culture, language, skills, etc. available for individual and collective intersolipsistic exploitation and renewal)

transcending/superseding of human uninstitutionalised-threshold.

an incidental study like psychopathy and social psychopathy with respect to the grander notional deprocrypticism institutionalisation level within the treatment of the institutional-cumulation/institutional-recomposure-〈as-to-historiality/ontologicaleventfulness/ontological-aesthetic-tracing-<perspective-ontologicalnormalcy/postconvergence-reflected-'epistemicity-relativism-determinism' $>>$ metaconceptual frame

Institutionalisation/intemporalisation entropy (intemporal-preservation-entropy-orcontiguity-or-ontological-preservation) involves.....

the psychopath's and other postlogic articulations have a nefarious effect, on social meaningfulness-and-teleology particularly in 'spheres of extended-informality〈susceptible-to-effecting-parsimony-as-of-shoddiness-and-incompleteness-tomeaningfulness-and-teleology〉' of society in general and social institutions.....

a registry-worldview/dimension that so misanalyses is not 'shaped' to review but rather syncretises/is-circular in its failing/not-upholding-<as-ofapriorising/axiomatising/referencing $>$ reference-of-thought-categoricalimperatives/axioms/registry-teleology,-for-intemporal-preservation-entropy-or-contiguityor-ontological-preservation rather than implying prospective ones for intemporalpreservation-entropy-or-contiguity-or-ontological-preservation 
no need to breach the scientific principle known as the 'mediocrity principle', (which says that there are no exceptions/specialness in science), to wrongly say that man is inherently intemporal

transcendental/transdimensional/interdimensional/maximalising-recomposuring-forrelative-ontological-completeness - unenframed/re-ontologising conceptualisation, for a novel genuinely universal psychology as anthropopsychology, involved in all successive institutional-cumulation/institutional-recomposure-〈as-to-historiality/ontologicaleventfulness/ontological-aesthetic-tracing-<perspective-ontologicalnormalcy/postconvergence-reflected-'epistemicity-relativism-determinism' $>\rangle$ for intemporal-preservation-entropy-or-contiguity-or-ontological-preservation......

intemporal-disposition is rather about emphasising institutionalisation/intemporalisation percolation-channelling-<in-deferential-formalisation-transference $>$ as the means and basis for prospective institutionalisation/intemporalisation

the teleology of human de-mentation-〈supererogatory $\sim$ ontological-de-mentation-ordialectical-de-mentation-stranding-or-attributive-dialectics $\rangle$ reflects the humansubpotency for attaining crossgenerational transcendence-and-

sublimity/sublimation/supererogatory $\sim$ de-mentativity with corresponding dialectical and psychoanalytic existential-<disentologising/re-ontologising apereticism $>$ reorientations ('postconverging-or-dialectical-thinking-psychology or psychology-of-mentationdynamics or natural psychological-dynamics' psychoanalytic-unshackling/memeticreordering/institutional-recomposuring).

de-mentation-〈supererogatory ontological-de-mentation-or-dialectical-de-mentationstranding-or-attributive-dialectics $\rangle$,-in-a-contiguity-of-increasing-ontologicalnormalcy/postconvergence dialecticism of transcendence-andsublimity/sublimation/supererogatory de-mentativity involving the transcended and the transcending dimensions

uninhibited/decomplexified and forward-looking perspective imbued in a notional deprocrypticism institutionalisation/intemporalisation with respect to procrypticism....

'<amplituding/formative-epistemicity $>$ causality as-to-projective-totalitativeimplications-of-prospective-nonpresencing,-for-explicating relative-unreflexivity/relativereflexivity - ontological-contiguity retracing (for notional firstnaturedness-formativeness$<$ as-to-eventualising inkling-drive-or-seeding-misprising $>$ temporal-to-intemporaldispositions-<so-construed-as-from-perspective-ontological-normalcy/postconvergence $>$ disambiguation articulation)'.

'profoundly ontological', with psychoanalytic-unshackling/memeticreordering/institutional-recomposuring possibilities for transcendental institutionalisation/intemporalisation of notional deprocrypticism (superseding the vicesand-impediments of, as well as human emancipation over, procrypticism)

'<amplituding/formative-epistemicity>causality as-to-projective-totalitativeimplications-of-prospective-nonpresencing,-for-explicating relative-unreflexivity/relativereflexivity - ontological-contiguity retracing (for notional firstnaturedness-formativeness<as-to-eventualising-inkling-drive or seeding misprising $>$ temporal-to-intemporal- 
dispositions-<so-construed-as-from-perspective-ontological-normalcy/postconvergence $>$ pedestals-disambiguation) as reference-of-thought-scheme'

'intemporal-prioritisation-of-reference-of-thought'-as-conflatedness-or-ontologicalreprojecting (deconstruction/ontological-reconstituting/organic-comprehension-thinking) holds that 'critically what matters with respect to ontology and virtue is simply and completely intemporal-preservation-entropy-or-contiguity-or-ontological-preservation as ontological-veridicality/relative-unreflexivity/relative-reflexivity-ontological-contiguity of reference-of-thought (as from ontological-normalcy/postconvergence epistemic-ornotional projective-perspective)

technical point-of-departure-of-construal of reference-of-thought for distractivealignment-to-reference-of-thought- $<$ of-apriorising/axiomatising/referencing $>$ with respect to the '<amplituding/formative-epistemicity $>$ causality $\sim$ as-to-projective-totalitativeimplications-of-prospective-nonpresencing,-for-explicating $\sim$ relative mnreflexivity/relativereflexivity ontological-contiguity retracing'

Without 'intemporal-prioritisation-of-reference-of-thought'-as-conflatedness-orontological-reprojecting disposition the possibility for transcendence-andsublimity/sublimation/supererogatory de-mentativity from perversion-of-reference-ofthought-<as-preconvergingly-apriorising/axiomatising/referencing-innonconviction/madeupness/bottomlining-as-to-shallow-supererogation $>$ (as prior intemporal reference-of-thought-categorical-imperatives/axioms/registry-teleology) to prospective ones which are intemporal-preservational, the institutionalcumulation/institutional-recomposure-_as-to-historiality/ontologicaleventfulness/ontological-aesthetic-tracing-<perspective-ontologicalnormalcy/postconvergence-reflected-'epistemicity-relativism-determinism' $>>$ process will not occur and be regenerative.

reference-of-thought-categorical-imperatives/axioms/registry-teleology,-for-intemporalpreservation-entropy-or-contiguity-or-ontological-preservation are not by themselves the definitive basis for ontology/intrinsic-reality/existential-reality as these are only as pertinent as they are ontologically-veridical/ontologically-continuous/contextuallycontiguous (in ontological-normalcy/postconvergence)

new requisite reference-of-thought-categorical-imperatives/axioms/registry-teleology,-forintemporal-preservation-entropy-or-contiguity-or-ontological-preservation not only for this particular circumstance of the BODMAS characters but all such circumstances that may arise as a perversion-of-reference-of-thought- $<$ as-preconverginglyapriorising/axiomatising/referencing-in-nonconviction/madeupness/bottomlining-as-toshallow-supererogation $>$ as-of-unsoundness-or-ontological-bad-faith/inauthenticity-ofreference-of-thought thus requiring de-mentation-〈supererogatory $\sim$ ontological-dementation-or-dialectical-de-mentation - stranding-or-attributive-dialectics $\rangle$ of all such temporal-dispositions

why the different registry-worldviews/dimensions are seemingly preconverging-ordementing-apriorising-psychologism with respect to one another (from the prospective perspectives)

human ontological transcendental possibilities arise from human individuations that correspond to the appropriate 'intemporal-projecting existential-<disontologising/re- 
entologising aporeticism $>$ becoming' allowing for such ontological possibilities, and the latter is made possible by the 'so-renewed

apriorising/axiomatising/referencing/intelligibilitysettingup/measuringinstrumenting as to renewed logical-basis/logic,-as-derived-from $\sim$ transversality- $<$ for-sublimating-existentialeventuating/denouement, from-'thinking at first/pure-predisposition-preemptive-ofprospective-disontologising/subontologising' as-of-prospectively-disambiguatedaffirmed-and-unaffirmed-'motif-and-apriorising/axiomatising/referencing'>'

our psychological nature is actually about mental-devising-representation which is meant to serve notionally the pertinence of supposed ontological articulations with respect to intrinsic reality, and it doesn't has any end to itself but for such dialectical readjustments to ontological-veridicality

3 transversality-<for-sublimating-existential-eventuating/denouement,-from-'thinking at first/pure predisposition preemptive of prospective disontologising/subontologising' asof-prospectively-disambiguated-affirmed-and-unaffirmed-'motif-andapriorising/axiomatising/referencing'> pedestals of meaningfulness

analysing perversion-of-reference-of-thought-<as-preconverginglyapriorising/axiomatising/referencing-in-nonconviction/madeupness/bottomlining-as-toshallow-supererogation $>$ of a different nature in a superseded registryworldview/dimension like non-positivism/medievalism registry-worldview/dimension

when it comes to deciding between ontological-veridicality/relative-unreflexivity/relativereflexivity - ontological-contiguity of reference-of-thought (as from ontologicalnormalcy/postconvergence epistemic-or-notional projective-perspective) and the human temporal psyche, what gives-in is the human temporal psyche (and so for the betterment of the species)

de-mentation-〈supererogatory ontological-de-mentation-or-dialectical-de-mentationstranding-or-attributive-dialectics $\rangle$ as such redefines psychology as a postdicatory science (tying the mental-devising-representation process to the abstract and infallible ontologicalnormalcy/postconvergence ontological-veridicality referencing/correction-tool) .4935 soundness-or-ontological-good-faith/authenticity-of-reference-of-thought-ofmeaningfulness is not given, as it is a devising mechanism (mental-devisingrepresentation) for ontological-veridicality as dialectically upheld for intemporalpreservation-entropy-or-contiguity-or-ontological-preservation (ontologicalnormalcy/postconvergence).

registry-worldviews/dimensions are rather prospectively

$<$ amplituding/formative $>$ wooden-language-〈imbued-temporal-mere-

form/virtualities/dereification/akrasiatic-drag/denatured/preconverging-or-dementingnarratives - of-the-reference-of-thought-categorical-imperatives/axioms/registryteleology $\rangle$ of their own specific evolving successive existentialisms

contrasting ontological-normalcy/postconvergence as to potential human ontologicalperformance- $<$ including-virtue-as-ontology $>$ /morality/ethics/justice/etc. (longness-ofdepth-of-meaningfulness and shortness-of-register-of-meaningfulness-and-teleology) and the reality of human temporal-dispositions at all institutional-cumulation/institutionalrecomposure-_as-to-historiality/ontological-eventfulness/ontological-aesthetic-tracing- 
$<$ perspective-ontological-normalcy/postconvergence-reflected-'epistemicity-relativismdeterminism'>> uninstitutionalised-threshold perverting/undermining ontological-

normalcy/postconvergence

peculiarity for achieving all the institutional-cumulation/institutional-recomposure-〈as-tohistoriality/ontological-eventfulness/ontological-aesthetic-tracing-<perspectiveontological-normalcy/postconvergence-reflected-'epistemicity-relativism-determinism' $>$ > is about bringing the prior registry-worldview/dimension perversion-of-reference-ofthought-<as-preconvergingly-apriorising/axiomatising/referencing-innonconviction/madeupness/bottomlining-as-to-shallow-supererogation $>$ to its placeholdersetup/mental-devising-representation/mentation/ \{cumulated/recomposured $\}$ consciousness-awareness-teleology awareness for the collective-mind to psychoanalytically-unshackle/memetically-reorder/institutionally-recomposure

a psychological science which is more comprehensive, timeless and unbounded by its conceptualisation as it emphasises psychological-representation/mental-devisingrepresentation as more 'ontologically-driven/ontologised' rather than 'conventioninglydriven/conventionalised'

deconstruction when extended from its 'textual basis' to its 'full meaningfulness basis' as 'ontological-reconstituting-as-to-conflatedness', has to do with the fact that the full implications of 'ontological-reconstituting-as-to-conflatedness'/deconstruction is that it prospectively calls for suprastructuring or construal beyond-the-consciousness-awarenessteleology-<of-preconverging-existential-extrication-as-of-existential-unthought $>$ of prior registry-worldview mindset/reference-of-thought. 4984

what is 'ontologically normal' beyond the subjective conventioning of the psychology science (before even worrying about the abnormal)?

notional deprocrypticism institutionalisation will imply a superseding psychoanalyticunshackling/memetic-reordering/institutional-recomposuring as new-mentation and further extension of formalisation as 'deferential-formalisation-transference' of 'deprocryptic formalisation' into the extended-informality-〈susceptible-to-effectingparsimony-as-of-shoddiness-and-incompleteness-to-meaningfulness-and-teleology $\rangle. . .4995$

comprehensive postconverging-or-dialectical-thinking-apriorising-psychologism-bypreconverging-or-dementing-apriorising-psychologism dialectical representation involves articulating a comprehensive organic-comprehension-thinking narrative in 'intemporalprioritisation-of-reference-of-thought'-as-conflatedness-or-ontological-reprojecting ...4999 intemporal/ontological/social/species/universal/transcendental/maximalisingrecomposuring-for-relative-ontological-completeness - unenframed/reontologising $\sim$ conceptualisation postconverging-de-mentating/structuring/paradigming resolution as against an extricatory/temporal/non-ontological preconverging-dementating/structuring/paradigming resolution fundamentally implies putting-into-question a registry-worldview's/dimension's reference-of-thought .5005

reality is as of ontological-normalcy/postconvergence and suprastructural and is not constraint to and have nothing to do inherently with human mental-devising-representation incrementalism-in-relative-ontological-incompleteness-

enframed/disontologising $\sim$ conceptualisation and notional $\sim$ disjointedness 
knowledge-notionalisation is about a 'deterministic and operant construct preserving intemporality/longness as ontology’.

fundamental construal about the conceptual-and-institutionalisation-phenomena has to do with how any and all conceptualisations and meaningfulness harken back to 'intemporalpreservation-entropy-or-contiguity-or-ontological-preservation' .

'EMPTINESS of psychopathic postlogic-backtracking-<iterative-looping-'set-ofdereifying-hollow-narratives-and-acts' $>$ and the conjugation/inflection/protraction of that EMPTINESS to the temporal-dispositions in hollow-constituting-<as-disjointedmisappropriation-of-meaningfulness-and-failing-intemporal-preservation $>$ postlogism

preconverging-or-dementing-apriorising-psychologism as thus implied can be defined as reflecting/perspectivating/highlighting of the deficient mental-devising-representation (as so-referenced from ontological-normalcy/postconvergence so-construed as in prospectivetranscendence-in-perpetually-upholding-intemporal-preservation-entropy-or-contiguityor-ontological-preservation as to suprastructural proxying of intrinsic-reality), beyond the deficient mental-devising-representation intradimensional representation of meaningfulness-and-teleology.

fundamentally it is impossible to conjugate/inflect/protract intemporality/longness out of demonstrated temporality/shortness (notional-discontiguity/epistemic-discontiguity$<$ between - prior-shallow-supererogation-of-mentallyaestheticised preconverging/dementing-qualia-schema_and_prospective-profoundsupererogation-of-mentally-aestheticised postconverging/dialectical-thinking-qualiaschema $>$ ) as then one is just in <amplituding/formative-epistemicity>totalising $\sim$ selfreferencing-syncretising/circularity/interiorising/akrasiatic-drag and wrongly implying the registry-worldview/dimension is beyond transcendence-and-

sublimity/sublimation/supereregatory $\sim$ de-mentativity or is non-transcendable .5027

'Intemporal-prioritisation-of-reference-of-thought'-as-conflatedness-or-ontologicalreprojecting points out that conventioning constructs like sub-par/formulaicassociation/temporal/alibi conventioning-rationalising do not supersede the ontologicalnormalcy/postconvergence and suprastructural nature of intrinsic-reality/intrinsicveridicality, as may be naively advanced with circumventing/distractive-temporalprioritisation-of-reference-of-thought

we don't have absolute mentation capacity and the most intemporal of our dispositions should take pride of place in defining our achievement motives whether as philosophies, causes, skillsets and talents in our value and valor aspirations .5034 transcendental institutionalisation is basically an 'intemporal-prioritisation-of-referenceof-thought'-as-conflatedness-or-ontological-reprojecting/intemporal-preservation preemptive conceptualisation

articulating a 'creative existentialism (full-existential-depth-implications) storying construal' which is 'profoundly ontological', with psychoanalytic-unshackling/memeticreordering/institutional-recomposuring possibilities for transcendental institutionalisation/intemporalisation of deprocrypticism .5039 
ontological-normalcy/postconvergence in precedingness points out that at registryworldview/dimension-level ontology as the transcending dimension is veridically an utter organicalism (organic-comprehension-thinking)

‘amplituding/formative-epistemicity $>$ causality $\sim$ as-to-projective-totalitativeimplications-of-prospective-nonpresencing,-for-explicating relative enreflexivity/relativereflexivity - ontological-contiguity-retracing (for notional firstnaturedness-formativeness<as-to-eventualising inkling drive-or-seeding misprising > temporal-to-intemporaldispositions-<so-construed-as-from-perspective-ontological-normalcy/postconvergence $>$ pedestals-disambiguation) as reference-of-thought-scheme'

Entropy as defined ('intemporal-preservation-entropy-or-contiguity-or-ontologicalpreservation re-institutionalisation') relates that the intemporal-preservationinstitutionalisation entropy is the preceding-and-defining reference for the hermeneuticreferencing of the ontological meaning of all other associated conceptualisations and notions

'referentialism' which makes reference to the supersedingness/precedingness of the 'intemporal preservation institutionalisation/intemporalisation entropy/contiguity' before articulating concepts and notions in referential and organic elucidation of the entropic construct. Referentialism as such is actually central to the spontaneity required in hermeneutics

'Intemporal-preservation-entropy-or-contiguity-or-ontological-preservation reinstitutionalisation' with respect to uninstitutionalised-threshold

Logic as logical-congruence only arises where there is a mutual registry-worldview reference-of-thought-categorical-imperatives/axioms/registry-teleology

*the mind is actually a mental devising tool' whose veracity/ontological-pertinence must be validated by an abstractly veridical intrinsic-reality/ontological-veridicality ....

contention is an 'ontological-entrapment' not about logical operation/processing/contention of the 'non-veridical hollow perversion-of-reference-ofthought- $<$ as-preconvergingly-apriorising/axiomatising/referencing-in-

nonconviction/madeupness/bottomlining-as-to-shallow-supererogation $>$ narratives' but rather reflecting/perspectivating/highlighting (reasoning-through-and-not-reasoning-with) it as <amplituding/formative-epistemicity >causality as-to-projective-totalitativeimplications-of-prospective-nonpresencing,-for-explicating relative-unreflexivity/relativereflexivity ontological-contiguity .5065

virtue (knowledge is virtue) is treated scientifically as highlighted above is that virtue is a 'the-Good/understanding/knowledge construct' and not a 'good-natured/impression construct'

each registry-worldview/dimension is only capable of the virtue reflected by its intemporal-preservation-entropy-or-contiguity-or-ontological-preservation.

a defect of postlogism/psychopathy compulsing-nonconviction/madeupness/bottomlining-

$\langle<$ decontextualising/de-existentialising of-attendant-intradimensionalapriorising/axiomatising/referencing >-induced-disontologising'-of-the-'attendantintradimensional-ontologising'-imbued-<contextualising/existentialising attendantontological-contiguity $>$;-in-shallow-supererogation-<as-to-disontologising-perverted- 
outcome-sought-precedes-existentially-veridical-'attendant-intradimensionalapriorising/axiomatising/referencing'-logical-dueness $>$ > in hollow-constituting- $<$ asdisjointed-misappropriation-of-meaningfulness-and-failing-intemporal-preservation $>$ operates on the 'parasitising/co-opting' basis that intemporal-preservation-entropy-orcontiguity-or-ontological-preservation reference-of-thought-categoricalimperatives/axioms/registry-teleology are mere-formulaic determinants of human thought and action.

it is de-mentation-〈supererogatory $\sim$ ontological-de-mentation-or-dialectical-de-

mentation - stranding-or-attributive-dialectics $\rangle$ that enables the mentalreflecting/perspectivating/highlighting (reasoning-through-and-not-reasoning-with)representation of the registry-worldview's/dimension's-uninstitutionalised-thresholddefect- $<$ as-Being-or-ontological-or-existential-defect $>$ as perversion-of-reference-ofthought- $<$ as-preconvergingly-apriorising/axiomatising/referencing-innonconviction/madeupness/bottomlining-as-to-shallow-supererogation $>$ in construing unsoundness-or-ontological-bad-faith/inauthenticity-of-reference-of-thought

Reality being blunt/incisive as it is rather preceding/superseding and ontologicalnormalcy/postconvergence with respect to us, is in essence of potent operant and deterministic phenomenality that doesn't have any place for our thresholding discrete incrementalism-in-relative-ontological-incompletenessenframed/disontologising conceptualisation notions

'traditionally 4 human mental projections/representations/dispositions' associated with virtuous preconverging/postconverging-de-mentative/structural/paradigmatic construct

Human mental development across time validate the notion that we have consistently been in a state of psychoanalytic-unshackling/memetic-reordering/institutional-recomposuring

Rational-Realism as the initial institutionalisation/intemporalisation recomposure orientation that goes beyond just articulating reference-of-thought-categoricalimperatives/axioms/registry-teleology,-for-intemporal-preservation but involves anticipating human notional firstnaturedness-formativeness-<as-to-eventualising inkling drive or seeding misprising $>$ temporal-to-intemporal-dispositions- $<$ so-construed-asfrom-perspective-ontological-normalcy/postconvergence $>$ in preempting the perversionof-reference-of-thought- $<$ as-preconvergingly-apriorising/axiomatising/referencing-innonconviction/madeupness/bottomlining-as-to-shallow-supererogation $>$ of prior/superseded registry-worldview's reference-of-thought-categoricalimperatives/axioms/registry-teleology,-for-intemporal-preservation-entropy-or-contiguity-

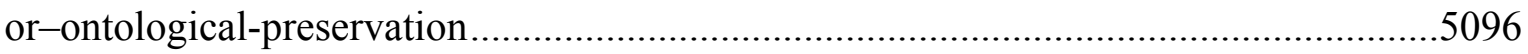

two dilemma with respect to the conceptualisation of virtue ........................................5097

intemporal-preservation is a memetically/psychoanalytically evasive construct at uninstitutionalised-threshold, the pursuit of which is veridically the human species eudaemonic comtemplation.

'human progress/transcendence happens as a matter of fact, with no registryworldview/dimension having any ontological and veridical claim/pretence to extricate 
itself from psychoanalytic-unshackling/memetic-reordering/institutional-recomposuringas-dialectical-stranding-backdrop-for-prospective-transcendence....

Stranding (of-perverting-temporal-dispositions-of-reference-of-thought) should be construed at a registry-worldview's/dimension's uninstitutionalised-threshold (the threshold where the registry-worldview/dimension is failing/not-upholding-<as-ofapriorising/axiomatising/referencing $>$ intemporal-preservation-entropy-or-contiguity-orontological-preservation).

There is no reason for de-mentation-〈supererogatory-ontological-de-mentation-ordialectical-de-mentation - stranding-or-attributive-dialectics $\rangle$ and recomposuring but for the fact that the internal coherence of a registry-worldview/dimension is failing/notupholding-<as-of-apriorising/axiomatising/referencing $>$ intemporal-preservation-entropyor-contiguity-or-ontological-preservation at its uninstitutionalised-threshold .5105 ontological construct 'escalates' specific/particular instances of phenomena (in this case psychopathy and social psychopathy phenomenon) into a universal conceptualisation which 'knowledge principle conceptualisation' then addresses (percolates into) the 'infinity of related incidental phenomena and cases'

notional firstnaturedness-formativeness-<as-to-eventualising-inkling-drive-or-seeding misprising $>$ temporal-to-intemporal-dispositions- $<$ so-construed-as-from-perspectiveontological-normalcy/postconvergence $>$-pedestals-disambiguation before logical processing/operation.

'ontology is about working with what is/knowledge-driven, and not wishfulthinking/impression-driven' to accede to intrinsic-reality transcendentalenabling/sublimating/supererogatory $\sim$ de-mentativity as this highlights $<$ amplituding/formative-epistemicity >causality as-to-projective-totalitative-implicationsof-prospective-nonpresencing,-for-explicating relative-unreflexivity/relative-reflexivity ontological-contiguity.

it is critical to distinguish between a true philosophical development that arises by intemporal-disposition and an institutionalised development that is articulated to elicit 'positive-opportunism — of-social-functioning-and-accordance' in humans.

the concepts of intemporality/longness and temporality/shortness is more scientific than the impression notions of good and bad

The use of 'human mental-dispositions/individuations' as of notional firstnaturednessformativeness-<as-to-eventualising inkling-drive-or-seeding-misprising $>$ temporal-tointemporal-dispositions- $<$ so-construed-as-from-perspective-ontologicalnormalcy/postconvergence $>$ herein doesn't mean ontologically that some individuals are inherently/exclusively solipsistically temporal and others are inherently/exclusively solipsistically intemporal....

By pedestal is meant the 'temporal-to-intemporal individuations dispositions of meaningfulness whether the intemporal-disposition individuation-pedestal or the temporaldispositions individuations-pedestals .5128

'Unconscionability-drag' (from an ontological/intemporal reference) refers to the comprehensive state of undisambiguation of temporal-dispositions individuation-pedestals 
which are wrongly associated to the intemporal-disposition as being ontologicallyveridical as these conjugate/inflect/protract (in mimicking-protraction)

at 'uninstitutionalised-threshold' human learned behaviour is primarily geared towards what is 'perceived as succeeding as of positive-opportunism - of-social-functioning-andaccordance'

'unconscionability-drag' carries the resolution for disambiguating reference-of-thought in the ontological social construction of meaning

Unconscionability-drag (enabling ontological reference), by which the perversion-ofreference-of-thought- $<$ as-preconvergingly-apriorising/axiomatising/referencing-innonconviction/madeupness/bottomlining-as-to-shallow-supererogation $>$ /mentalperversions teleologies of meaning is accounted for....

an 'ontological psychoanalytic/memetic-contiguity deconstruction across anthropology' which the present treatment of psychology doesn't recognise

the transcendental requirement for a 'habituation' to a so-called 'prospective intemporal and more veridical mental-devising-representation registry-worldview's/dimension's reference-of-thought-categorical-imperatives/axioms/registry-teleology is rather 'unfathomable' for the prior <amplituding/formative> wooden-language-_imbuedtemporal-mere-form/virtualities/dereification/akrasiatic-drag/denatured/preconverging-ordementing-narratives - of-the-reference-of-thought-categoricalimperatives/axioms/registry-teleology

For deprocrypticism, 'notional firstnaturedness-formativeness-<as-toeventualising inkling-drive-or-seeding-misprising $>$ temporal-to-intemporaldispositions-<so-construed-as-from-perspective-ontological-normalcy/postconvergence $>$ aetiologisation/ontological-escalation-<ontologicalveridicality_commitment/otherliness_transcending/compulsionsencumbered_transcending >' teleology: will involve identifying, defining, characterising, qualifying and articulating the aetiology of this individuation perversion-of-reference-ofthought- $<$ as-preconvergingly-apriorising/axiomatising/referencing-innonconviction/madeupness/bottomlining-as-to-shallow-supererogation $>$ dynamism ....5150

Conventioning/social-temporal-thresholding thus refers to the fact that in a 'social construction of meaning', intrinsic-reality by itself and in of itself (as may be grasped ontologically from superseding/transcendental categorical-imperatives preserving intemporality) is not necessarily the deterministic basis for human social adherence to it

an exercise in institutionalisation/intemporalisation beyond just intemporal philosophical projection is needed for the social integration of any transcending veridicality postconverging-de-mentating/structuring/paradigming

'conventioning' is not wholly antipodal to 'ontologising/intrinsic-veridicality' as the latter prospective integration in the social-construct is through the former

The application of the universal technique of human transcendence-andsublimity/sublimation/supererogatory $\sim$ de-mentativity to procrypticismnotional deprocrypticism transcendence-and-sublimity/sublimation/supererogatory dementativity can be basically be articulated as follows (the ontological-entrapment)......5168 
Institutionalisation and formalisation are based exactly on the fact that we don't have a universal intemporality/longness or the-good disposition, but rather according to the mediocrity principle of science we are solipsistically temporal-to-intemporal in our mental-disposition with respect to 'socially-perceived-value as of social-stake-contentionor-confliction'

Solipsism means I exist alone (as to the epistemic perspective with respect to intrinsic reality/ontological-veridicality)

By ontological-normalcy/postconvergence is meant that 'intrinsic reality' is one and given (ontology), and that the flaws and corrections in how we go about representing 'intrinsic reality' (metaphysics or the human-centered temporal-perspective) has no influence on reality's intrinsic nature

how can meaningfulness-and-teleology be represented in a 'prospective apriorisingregistry state' which is ontologically more real contrasted to a 'present retrospective apriorising-registry', as meaningfulness-and-teleology 'temporally seems' to vary depending on the uninstitutionalised-threshold point-of-reference to imply at one moment it is intemporal and at another it is temporal?

Pedestalled disambiguation explains the dynamism of human institutional-

cumulation/institutional-recomposure-_as-to-historiality/ontological-

eventfulness/ontological-aesthetic-tracing-<perspective-ontological-

normalcy/postconvergence-reflected-'epistemicity-relativism-determinism' $>>$ going by a

recurrent emanance/becoming template

There is no such thing as 'intemporal temporality' as mental-dispositions 'geared to accommodate temporality' (as to incrementalism-in-relative-ontological-incompletenessenframed/disontologising conceptualisation) are doing nothing but providing the anchoring for the endemisation and enculturation of the vices-and-impediments associated with such temporal registry-worldview's/dimension's-uninstitutionalised-thresholddefect- $<$ as-Being-or-ontological-or-existential-defect $>$.

Technically, it can be said that the underlying psychopathic phenomenon known as postlogism-as-of-compulsing-nonconviction/madeupness/bottomlining-

$\langle<<$ decontextualising/de-existentialising of-attendant-intradimensionalapriorising/axiomatising/referencing $>$-induced-disontologising'-of-the-'attendantintradimensional-ontologising'-imbued-<contextualising/existentialising attendantontological-contiguity $>$;-in-shallow-supererogation-<as-to-disontologising-pervertedoutcome-sought-precedes-existentially-veridical-'attendant-intradimensionalapriorising/axiomatising/referencing'-logical-dueness $>$ ) is associated with all the institutional-cumulation/institutional-recomposure-〈as-to-historiality/ontologicaleventfulness/ontological-aesthetic-tracing-<perspective-ontologicalnormalcy/postconvergence-reflected-'epistemicity-relativism-determinism' $>>$ by its eliciting of 'protracted slantedness' in temporal-dispositions

distractive-alignment-to-reference-of-thought-<of-apriorising/axiomatising/referencing $>$ (mental-slantedness or decandoring-of-the-mind or denaturing, and not soundness-orontological-good-faith/authenticity-of-reference-of-thought/candor) 
the articulation of reality as referentially of ontological-normalcy/postconvergence enables and allow creative projective-insights thought possibilities that the all too common 'fixated traditional categorisation conceptualisation of reality' doesn't allow

the specificity of the would-be intellectualism involved in a transcendental construct, as different from just intellectualism as mere-institutionalised-being-and-craft

Memetism as to suprastructural meaningfulness-and-teleology will refer to the projective conceptualisation of meaningfulness-and-teleology beyond and superseding an intradimensional registry-worldview abstraction scope to the scope of transdimensional/transcendental existential-<disentologising/re-ontologising aporeticism $>$ psychoanalytic ontological form (in full blossoming of the transcending dimension with its existentialism/full-existential-depth-implications personhoods-andsocialhood-formation)

ontologically (i.e. 'the-Good/understanding' contrasted with 'good-natured/impressiondriven') the bigger issue is how do our development and institutionalisation/intemporalisation of true knowledge 'save us from potent-temporality and its vices-and-impediments with respect to 'socially-perceived-value as of social-stakecontention-or-confliction'

The notion of higher teleologies as such is specific to the human species in holding that beyond just a 'physical animal passing of specie generational succession' for survival and optimising-specie-flourishing, with higher teleologies there is an 'even more critical passing of generational succession' as memetic-skewing-or-reordering/philo-cultural optimising of possibilities

Meaningfulness of notional firstnaturedness-formativeness-<as-to-eventualising-inklingdrive-or-seeding-misprising $>$ - temporal-to-intemporal-dispositions- $<$ so-construed-asfrom-perspective-ontological-normalcy/postconvergence $>$ as to 'existential idealism/success' as these define mental orientations or registry-worldview teleologicaldispositions

the entropy behind such a philosophical-driven conceptualisation of human meaning and corresponding psychoanalytic-unshackling.....

the perpetuation-of-notional deprocrypticism transcendence-and-

sublimity/sublimation/supereregatory $\sim$ de-mentativity is that it is 'weakly positive opportunistic' to the cross-section of the social construct.

transcendence-and-sublimity/sublimation/supereregatory $\sim$ de-mentativity is more of a human-mentation-capacity driven construct and its mundane recognition is not inherently by its supposed virtue (given that survival-and-flourishing, and not veracity/ontologicalpertinence, are the more punctual/immediacy/constituted/compulsions-encumbered basis for the human temporal drive)

Meaning (defined previously as what defines/predicates value, thought and action) .....5251 all the vices-and-impediments of the <cumulating/recomposuring attendant-ontologicalcontiguity $>$-successive registry-worldviews/dimensions can be directly ascribed as corresponding perversion-of-reference-of-thought-<as-preconverginglyapriorising/axiomatising/referencing-in-nonconviction/madeupness/bottomlining-as-to- 
shallow-supererogation $>$ of temporal-dispositions at the registry-worldviews/dimensions uninstitutionalised-threshold

'knowledge-notionalisation' or knowledge as a continuum-of-construal from human individuative manifestations of 'ignorances'/desublimation/temporal-dispositions to knowledge/sublimation/intemporal-disposition

preconverging-or-dementing-apriorising-psychologism arises simply by a shift of reference-of-thought (in the strive for intemporal-preservation-entropy-or-contiguity-orontological-preservation wherein the latter reference-of-thought as a registryworldview/dimension is shown to be more intemporally-preservational)

a new reference-of-thought and reference-of-thought-categorical-

imperatives/axioms/registry-teleology,-for-intemporal-preservation-entropy-or-contiguityor-ontological-preservation as transcending/superseding deprocrypticism, will sound unintelligible/existentially-suprastructural to the positivism-procrypticism mindset/reference-of-thought

why ontological-normalcy/postconvergence indicates that 'good-naturedness constructs' are defective is quite simple as it is based on adhering to a registryworldview's/dimension's institutionalisation temporal-mereform/virtualities/dereification/akrasiatic-drag/denatured/preconverging-or-dementingnarratives - of-the-reference-of-thought-categorical-imperatives/axioms/registry-teleology

this insight in transcendental analysis is that by its very nature in that it puts into question ways, assumptions and traditions of thought and practices, the possibility of truly profound insights that go well beyond more or less platitudes and inevitably requires taking stock of the full-depth-of-existential-implications/existentialism of transcendental-meaningfulnessapriorising/axiomatising/referencing/intelligibilitysettingup/measuringinstrumenting ..5280 dialectical <cumulating/recomposuring attendant-ontological-contiguity>-succession of registry-worldviews/dimensions as the successive/snowballing institutionalcumulation/institutional-recomposure-_as-to-historiality/ontologicaleventfulness/ontological-aesthetic-tracing-<perspective-ontologicalnormalcy/postconvergence-reflected-‘epistemicity-relativism-determinism' $>>$

différance-disambiguation-of-ontologically-veridical-meaningfulness-and-teleology as meaning produced apparently with the 'same-terms-of-expressions (seemingly-sameimplied-meaningfulness)'

'dynamic-cumulative-aftereffect of subontologisation'

'Différance-existential-transitory-articulation-of-the-protraction-of-perversion-ofreference-of-thought-<as-preconvergingly-apriorising/axiomatising/referencing-innonconviction/madeupness/bottomlining-as-to-shallow-supererogation $>$,-ofmeaningfulness'

'postlogic denaturing of temporal-dispositions individuations ontological-performance$<$ including-virtue-as-ontology $>$ /morality/ethics/justice/etc. as conjugated-postlogism' is so-inherently linked with the registry-worldview uninstitutionalised-threshold.

proof of the Sartrean notion of 'existence-preceding-essence' or the Derridean notion of 'there is nothing outside the text' 
'Différance-existential-transitory-articulation-of-the-protraction-of-perversion-ofreference-of-thought-<as-preconvergingly-apriorising/axiomatising/referencing-innonconviction/madeupness/bottomlining-as-to-shallow-supererogation $>,-$ of-

meaningfulness' technique

how individuals arrive at their various teleologies/finalities of the intemporal-disposition as 'logically sound acts' or temporal-dispositions as 'logically unsound acts' or defect-oflogical-processing-or-logical-implicitation - supposedly-apriorising-in-conviction-as-toprofound-supererogation of the registry-worldview's/dimension's-reference-of-thoughtfor-social-functioning-and-accordance.

'postconverging-or-dialectical-thinking-psychology or psychology-of-mentationdynamics or natural psychological-dynamics' psychoanalytic-unshackling/memeticreordering/institutional-recomposuring ....

at uninstitutionalised-threshold, we should be expecting nothing less than the 'normal' human-subpotency-aporia/undecidability/dilemma/oughtindeterminacy/deficiency/limitation/constraint_-imbued-'notional firstnaturednessformativeness-<as-to-eventualising inkling drive-or-seeding misprising > temporal-tointemporal-dispositions- $<$ so-construed-as-from-perspective-ontologicalnormalcy/postconvergence $>$ '-existentialism-form-factor

distortion of ontologically-veridical-meaningfulness from postlogism and conjugatedpostlogism/preconverging-or-dementing-integration leading to temporal-preservation-aspseudointemporality-preservation occurs at the three levels of contextualisation as individuation, intradimensional and transcendental/transdimensional/interdimensional/maximalising-recomposuring-forrelative-ontological-completeness — unenframed/re-ontologising conceptualisation ....5323

The vocation of the intemporal-disposition (intemporality/ontological-construct/longnessef register-of meaningfulness-and-teleelogy) is not-to-come-to-and-construe meaningfulness-and-teleology at a same pedestal as a temporal-dispositions extricatory preconverging-de-mentating/structuring/paradigming

with or without postlogism including psychopathic individuations, human limitedmentation-capacity-deepening — as-subjecting limitedness/human-subpotency-to-'educedunlimitedness/existence-sublimating nascence' warrants that our temporal-dispositions will nonetheless still fail the intemporal-preservation-entropy-or-contiguity-orontological-preservation at the registry-worldview/dimension uninstitutionalised-threshold

postlogic/psychopathic mental-disposition will seem to be the 'weakest human mentaldisposition for acting intemporally in supplanting-conviction-as-to-profoundsupererogation - of-'attendant-intradimensional'-postconverging/dialectical-thinkingapriorising-psychologism reflex to meaningfulness-and-teleology as of its intrinsicness/essence/ontological-veridicality'. .5337

derived-'threshold-of-nonconviction/madeupness/bottomlining-in-shallowsupererogation-<as-to-'attendant-intradimensional'-prospectivelydisontologising preconverging/dementing-apriorising-psychologism>' social constructions of meaningfulness are in effect reflecting the registry-worldview/dimension 
uninstitutionalised-threshold requiring corresponding prospective

institutionalisations/intemporalisations

approach of temporal-dispositions of dealing with temporality/shortness with respect to perversion-of-reference-of-thought-<as-preconverginglyapriorising/axiomatising/referencing-in-nonconviction/madeupness/bottomlining-as-toshallow-supererogation $>\mathrm{s}$ in all the registry-worldviews/dimensions (institutionalcumulation/institutional-recomposure-_as-to-historiality/ontologicaleventfulness/ontological-aesthetic-tracing-<perspective-ontologicalnormalcy/postconvergence-reflected-'epistemicity-relativism-determinism' $>\rangle$ ) is what endemises/enculturates the dialectically-out-of-phase or dialectically-primitive

maximalising-recomposuring-for-relative-ontological-completeness - unenframed/reontologising conceptualisation is actually the drive for transcendence-andsublimity/sublimation/mentativity in reflecting holographically$<$ conjugatively-and-transfusively $>$ the relative-unreflexivity/relative-reflexivity ontological-contiguity of-the-human-institutionalisation-process successive institutionalcumulation/institutional-recomposure-_as-to-historiality/ontologicaleventfulness/ontological-aesthetic-tracing-<perspective-ontologicalnormalcy/postconvergence-reflected-'epistemicity-relativism-determinism'>>

incrementalism-in-relative-ontological-incompleteness-

enframed/disontologising conceptualisation tends to operate as if at any one instance human meaningfulness is absolutely set (and so rather as mere-formulaicity/ritualisation$<$ as-to-mere-formulaic - methodologising/mutualising/organising/institutionalising,prospectively-losing-track-of- ' \{epistemictising\}re-apriorising/re-axiomatising/rereferencing-residuality - in-re-originariness/re-origination' $>$ ) and thus incrementalism-inrelative-ontological-incompleteness - enframed/disontologising conceptualisation is nontranscendental

intemporal projection-of-thought in an intersolipsistic relation to intrinsicreality/ontology/ontological-veridicality

maximalising-recomposuring-for-relative-ontological-completeness - unenframed/reontologising conceptualisation summoning a depth of 'ontological-reconstituting-as-toconflatedness'/deconstruction as of ontological-faith-notion-or-ontological-fideism imbued-underdetermination-of-motif-and-apriorising/axiomatising/referencing-as-sobeing-as-of-existential-reality enables humankind to supersede the circularity of intradimensional hollow-constituting-<as-disjointed-misappropriation-of-meaningfulnessand-failing-intemporal-preservation $>$

solipsism enables the requisite 'moulting' of human limited-mentation-capacitydeepening - as-subjecting limitedness/human-subpotency-to-'educedunlimitedness/existence-sublimating nascence' of notional firstnaturednessformativeness-<as-to-eventualising -inkling drive-or-seeding misprising $>$ temporal-tointemporal-dispositions-<so-construed-as-from-perspective-ontologicalnormalcy/postconvergence $>$ to allow for successive transcendence-andsublimity/sublimation/supererogatery $\sim$ de-mentativity

'ontological implications' of the Derridean conceptualisations of Différance, Répétititon, Altérité and Iterabilité. 
the exercise of institutionalisation/intemporalisation is not about transforming temporaldispositions as of dimensionality-of-sublimating-

<<amplituding/formative>supererogatory -de-mentativeness/epistemic-growth-orconflatedness/transvaluative-rationalising/transepistemicity/anamnestic-residuality/spiritdrivenness-equalisation $\rangle$ exercise but rather institutionalisation/intemporalisation or secondnaturing....

the philosophical pessimism of many a philosopher stems from this confusion about the achievement of human emancipation and virtue

postdication (as metaphysics-of-absence-〈implicited-epistemic-veracity-of-nonpresencing$<$ perspective-ontological-normalcy/postconvergence $>\rangle)$ highlights that ontologicalnormalcy/postconvergence is rather conceptualised more effectively with the presentconsidered-as-being-in-epistemic-abnormalcy/preconvergence-perspective-

\{preconverging-or-dementing-apriorising-psychologism-reference-of-thought -andhence-suprastructurable by 'metaphysics-of-absence-〈implicited-epistemic-veracity-ofnonpresencing-<perspective-ontological-normalcy/postconvergence $>\rangle$ '-perspective\{'postconverging-or-dialectical-thinking-apriorising-psychologism'-reference-of-thought\} which is then actually prospective (to-resolve-the epistemic-abnormalcy/preconvergence)

postlogism-and-conjugated-postlogism in preconverging-or-dementing-integration-oftemporal-dispositions as a 'dynamic-cumulative-aftereffect of subontologisation' ........5414 issues of perversion-of-reference-of-thought- $<$ as-preconverginglyapriorising/axiomatising/referencing-in-nonconviction/madeupness/bottomlining-as-toshallow-supererogation $>$ including postlogism are more-than-just-and-beyond an issue of a temporal frame of contemplation as this requires an overall registry-

worldview/dimension transcendental preconverging/postconverging-dementative/structural/paradigmatic resolution

ontological focus should rather be placed on the 'abstract conceptualisation that enables institutionalisation-as-virtue and not any naïve purported presencing - absolutisingidentitive-constitutedness poorly appreciative of dimensionality-of-sublimating<<amplituding/formative>supererogatory -de-mentativeness/epistemic-growth-orconflatedness/transvaluative-rationalising/transepistemicity/anamnestic-residuality/spiritdrivenness-equalisation)

need for an operant conceptualisation of psychology in grasping human dynamics

need for defining human psychology from a transcendentally-enabling-levelof ontological-good-faith-or-authenticity/objectification/desubjectification-asobjectification-<as-to-ontological-faith-notion-or-ontological-fideism-imbuedunderdetermination-of-motif-and-apriorising/axiomatising/referencing-as-so-being-as-ofexistential-reality as antinihilism $>$ and thus operant perspective of ontologically-dynamicand-coherent construal/conceptualisation, as a profound superseding-oneness-of-ontology

de-mentation-〈supererogatory ontological-de-mentation-or-dialectical-de-mentationstranding-or-attributive-dialectics $\rangle$ of 'postconverging-or-dialectical-thinking-apriorisingpsychologism' and preconverging-or-dementing-apriorising-psychologism is never about generating a prospective 'postconverging-or-dialectical-thinking-apriorising- 
psychologism' (with respect to the present as 'postconverging-or-dialectical-thinkingapriorising-psychologism'), but such de-mentation-(supererogatory ontological-dementation-or-dialectical-de-mentation - stranding-or-attributive-dialectics $\rangle$ is rather about decentering and preconverging-or-dementing-apriorising-psychologism/oblongating the placeholder-setup/mental-devising-representation/mentation/consciousness-awarenessteleology of the present as preconverging-or-dementing-apriorising-psychologism which becomes 'old-present'/retrospective as prior'

by transcendence-and-sublimity/sublimation/supererogatory de-mentativity is meant dispose to construe the ontological resolution of registry-worldview's/dimension'suninstitutionalised-threshold-defect- $<$ as-Being-or-ontological-or-existential-defect $>$ transcendentally/transdimensionally/interdimensionally, as needing a prospective registryworldview/dimension

deeper superseding-oneness-of-ontology conceptualisation and shallow supersedingoneness-of-ontology conceptualisation, central to a maximalising-recomposuring-forrelative-ontological-completeness — unenframed/re-ontologising conceptualisation ....5429 social phenomenon is determined and effectively deconstructible/ontologicallyreconstitutable from the inherent dynamism of human-subpotencyaporia/undecidability/dilemma/ought-indeterminacy/deficiency/limitation/constraintimbued-'notional firstnaturedness-formativeness-<as-to-eventtalising-inkling drive-orseeding-misprising $>$ temporal-to-intemporal-dispositions- $<$ so-construed-as-fromperspective-ontological-normalcy/postconvergence>' - existentialism-form-factor .......5437

the condition of 'recurrence' and 'non-transience' transcendability arising from postlogism and conjugated-postlogism/preconverging-or-dementing-integration that is ontologically relevant for ontological-reconstituting-as-to-conflatedness/deconstruction for prospective transcendability.....

'threshold-of-nonconviction/madeupness/bottomlining-in-shallow-supererogation-<as-to'attendant-intradimensional'-prospectively-disontologising preconverging/dementingapriorising-psychologism $>$ and supplanting-conviction-as-to-profound-supererogationof-'attendant-intradimensional'-postconverging/dialectical-thinking-apriorisingpsychologism' is actually central to suprastructuring or a conceptualisation that can integrate both relevant metaphysics-of-presence--〈implicited-'nondescript/ignorablevoid'-as-to-presencing - absolutising-identitive-constitutedness $\rangle$ and metaphysics-ofabsence-〈implicited-epistemic-veracity-of-nonpresencing-<perspective-ontologicalnormalcy/postconvergence $>\rangle$

unspokenly do imply this notion of institutionalisation-as-virtue (in tacit recognition of our notional firstnaturedness-formativeness-<as-to-eventualising inkling-drive-or-seeding misprising $>$ temporal-to-intemporal-dispositions- $<$ so-construed-as-from-perspectiveontological-normalcy/postconvergence>), however, the notion of 'consciously-spoken' as herein highlighted is that it enables the necessary uninhibitedness/decomplexification that allows the requisite "postconverging-or-dialectical-thinking-psychology or psychology-ofmentation-dynamics or natural psychological-dynamics' psychoanalyticunshackling/memetic-reordering/institutional-recomposuring .5448

without a maximalising-recomposuring-for-relative-ontological-completenessunenframed/re-ontologising $\sim$ conceptualisation disposition no prospective 
institutionalisation transcendence-and-sublimity/sublimation/supererogatory $\sim \mathrm{de}-$ mentativity will be possible.

deprocrypticism, with respect to the central concept of 'knowledge-notionalisation' wherein understanding is much more than about grasping the ideals but equally preemptively construing the possibilities of the 'ignorances/desublimation'/temporaldispositions as part-and-parcel of knowledge construct.

dimensionality-of-sublimating-<<amplituding/formative $>$ supererogatory $\sim$ de-

mentativeness/epistemic-growth-or-conflatedness/transvaluative-

rationalising/transepistemicity/anamnestic-residuality/spirit-drivenness-equalisation $\rangle$ in the psychoanalytic dynamism of human-subpotency-

aporia/undecidability/dilemma/ought-indeterminacy/deficiency/limitation/constraint imbued-'notional firstnaturedness-formativeness-<as-to-eventualising inkling-drive - or seeding misprising $>$ temporal-to-intemporal-dispositions- $<$ so-construed-as-fromperspective-ontological-normalcy/postconvergence $>$ '-existentialism-form-factor across all the institutional-cumulation/institutional-recomposure-〈as-to-historiality/ontologicaleventfulness/ontological-aesthetic-tracing-<perspective-ontologicalnormalcy/postconvergence-reflected-'epistemicity-relativism-determinism' $>>$ as of human shallow-to-deepening-limited-mentation-capacity —as-subjecting-'educedunlimitedness/existence-sublimating nascence' to-limitedness/human-subpotency, aslimited-mentation-capacity-deepening - as-subjecting-limitedness/human-subpotency-to'educed-unlimitedness/existence-sublimating nascence'.

'storied-construct/ontologically-valid-narration of comprehensive intuitive insight' grounded on: the construal of temporal-dispositions threshold-ofnonconviction/madeupness/bottomlining-in-shallow-supererogation- $<$ as-to- 'attendantintradimensional' -prospectively-disontologising $\sim$ preconverging/dementing-apriorisingpsychologism>

the capacity for philosophy to further clarify such an 'ontological-consistency' will be a further critical foundation for broadening the efficacy of all second-level ontologies ...5461 uninstitutionalised-threshold is characterised by the "trace of disambiguated-mentaldispositions as notional firstnaturedness-formativeness-<as-to-eventtalising - inkling drive or seeding misprising $>$ - temporal-to-intemporal-dispositions- $<$ so-construed-asfrom-perspective-ontological-normalcy/postconvergence $><$ amplituding/formativeepistemicity $>$ causality as-to-projective-totalitative-implications-of-prospectivenonpresencing,-for-explicating relative unreflexivity/relative-reflexivity ontologicalcontiguity

registry-worldview's/dimension's-uninstitutionalised-threshold-defect-<as-Being-orontological-or-existential-defect $>$ (with regards to both postlogism and conjugatedpostlogism)

perpetuating the precedingness/supersedingness/ascendency over reference-of-thought and meaningfulness of the intemporal-disposition as ontological over the temporal-dispositions

'preconverging-de-mentating/structuring/paradigming registry-worldview's/dimension'suninstitutionalised-threshold-defect- $<$ as-Being-or-ontological-or-existential-defect $>$ that defines a registry-worldview/dimension as preconverging-or-dementing-apriorising- 
psychologism and dialectically-out-of-phase with respect to intrinsic-reality/ontologicalveridicality

différance-disambiguation-of-ontologically-veridical-meaningfulness-and-teleology is dealing with perversion-and-derived-perversion-of-reference-of-thought- $<$ aspreconvergingly-apriorising/axiomatising/referencing-innonconviction/madeupness/bottomlining-as-to-shallow-supererogation $>$ (at the uninstitutionalised-threshold or socially-betraying-threshold-of-ontologising-depth-ofanalysis or socially-betraying-threshold-of-intemporal-preservation-entropy-or-contiguityor-ontological-preservation or threshold-of-nonconviction/madeupness/bottomlining-inshallow-supererogation-<as-to- 'attendant-intradimensional'-prospectivelydisontologising $\sim$ preconverging/dementing-apriorising-psychologism $>$ ). .

a reference-of-thought construal is simply as of a dynamic-cumulative-aftereffect

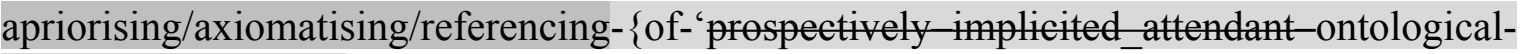
contiguity' educed-

existentialising/contextualising/textualising_'intelligibility/epistemicity/reflexivitycontiguity-<imbued-notional $\sim$ cogency $>$ ' $\}$ - conflatedness-in-\{preconverging ment by postconverging-entailment

faced with incidental issues arising in various effective social contexts, the 'ontological/intemporal postconverging-de-mentating/structuring/paradigming approach' is to have at hand a 'universal cadre' that conceptualises and is geared towards attendingto/resolving all such and other incidental issues as it is suprastructural to all such incidentals

Human-subpotency-aporia/undecidability/dilemma/ought-

indeterminacy/deficiency/limitation/constraint_imbued-'notional firstnaturednessformativeness-<as-to-eventualising-inkling-drive-or-seeding-misprising $>$ temporal-tointemporal-dispositions- $<$ so-construed-as-from-perspective-ontologicalnormalcy/postconvergence $>$ '-existentialism-form-factor as such is ontologically a preceding and defining construct that provides insight on 'existentialism/full-depth-ofexistential-implications issues' across all the institutional-cumulation/institutionalrecomposure-〈as-to-historiality/ontological-eventfulness/ontological-aesthetic-tracing$<$ perspective-ontological-normalcy/postconvergence-reflected-'epistemicity-relativismdeterminism' $>>$.

'knowledge-notionalisation' or knowledge construct not only based on intemporal idealisation but that also factors in how the temporalities will relate to meaning.....

'institutionalisation devising and devices' already speaks a lot about human potential and capacity (and are basically our virtue with no need for 'false idealisation'

with respect to futural Being-development/ontological-framework-expansion-as-to-depthof-ontologising-development-as-infrastructure-of-meaningfulness-and-teleology as of prospective deprocrypticism, our formalisation mechanisms acknowledge unspokenly/tacitly/by-mere-intuition the veracity/ontological-pertinence of our potential 'perverting temporal-dispositions inclinations' by its 'abstract preemptive mechanisms'

a 'referential-as-natural' conceptualisation of knowledge that consciously tautologically

subsumes temporal-dispositions and intemporal-disposition 
Suprastructuralism ultimately reflects the relative-unreflexivity/relative-reflexivity ontological-contiguity $\sim$ of-the-human-institutionalisation-process by bringing to the 'collective-human-psyche-and-consciousness as a transparent-pillar or social universaltransparency-〈transparency-of-totalising-entailing,-as-to-entailing<amplituding/formative-epistemicity>totalising in-relative-ontological-completeness)

mobilising an 'ontological-tautologisation/existential-reference conceptual-scheme' (like a hermeneutics-derived psycho-ontological, bio-ontological, econo-ontological, mathematico-ontological, etc.) construed as of ontological-normalcy/postconvergence teleology thus postdicatory (as metaphysics-of-absence-〈implicited-epistemic-veracity-ofnonpresencing-<perspective-ontological-normalcy/postconvergence $>\rangle$ conceptualisation)

It is rather naïve to depart from a philosophical angle and try to imply causal effectiveness of a natural science nature (rather than effective validation techniques relevant to transversal nature of philosophical conceptualisation) just as the same holds true the other way round

the tautological/referential/existential-reference nature of intrinsicreality/ontology/existence allowing for 'predication or predictive-insight' and 'postdication or projective-insights'.

with our human limited-mentation-capacity-deepening — as-subjecting-limitedness/humansubpotency-to-'educed-unlimitedness/existence-sublimating nascence', we are actually involved in a 'developmental notional teleology of ontology' construed as coherent shallow superseding-oneness-of-ontology to coherent deeper superseding-oneness-ofontology in reflecting holographically-<conjugatively-and-transfusively $>$ the relativeunreflexivity/relative-reflexivity - ontological-contiguity of-the-humaninstitutionalisation-process

why spatialisation, indirectness and craftiness are critical to postlogic and conjugatedpostlogic mental-dispositions so as to evade their prospective interlocutors 'putting one and one together' as will arise in an existentially-<disontologising/re-ontologising aporeticism $>$ veridical context

need for a retracing to establish the existential-<disontologising/re-ontologising aporeticism $>$ reality of the breaching or non-breaching of axiomatic rules, before determining the ontological-veridicality of the results of the arithmetic operations

The notion of temporality/shortness as actually 'pseudointemporality' provides a deeper insight to such traditional notions as bad, evil, wicked, etc. that we attach to temporaldispositions

a 'postconverging-or-dialectical-thinking-psychology or psychology-of-mentationdynamics or natural psychological-dynamics' rather captures the ontological undercurrents that constantly redefine human placeholder-setup/mental-devisingrepresentation/mentation/consciousness-awareness-teleology.

Existence is actually an 'implicited_attendant_ontological-contiguity' reduced-

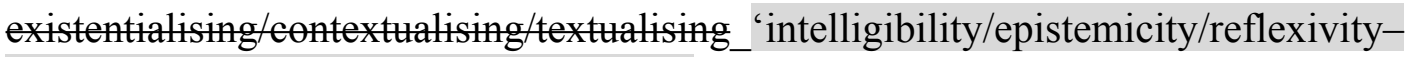
contiguity-<imbued-notional $\sim$ cogency $>$ ' of existence-potency $\sim$ sublimating-nascence,- 
disclosed-from-prospective-epistemic-digression-rules-ofapriorising/axiomatising/referencing-that-further-epistemically-unconceal-the-veryontologically-same-existential-reality (so-construed from our given limited-mentationcapacity - as-subjecting-'educed-unlimitedness/existence-sublimating nascence'-tolimitedness/human-subpotency as of our relative-ontological-incompleteness-induced,'threshold-of-nonconviction/madeupness/bottomlining-in-shallow-supererogation- $<$ as-to'attendant-intradimensional'-prospectively-disontologising preconverging/dementingapriorising-psychologism >')

readjustment for intrinsic-reality/ontological-veridicality is actually a human 'changing-ofthe-psyche'/psychical-readjustment (psychoanalytic-unshackling/memeticreordering/institutional-recomposuring) with its increasing-ontological-completeness or diminishing-human-epistemic-abnormalcy-or-preconvergence

'increasing relative realism' over the corresponding-successive-prioruninstitutionalisations-registry-worldviews

the relative-unreflexivity/relative-reflexivity - ontological-contiguity implied by 'projective-insights of sublimating-epistemic-imbricatedness/threadedness/recomposuring as of 'implicited_attendant-ontological-contiguity' educedexistentialising/contextualising/textualising_intelligibility/epistemicity/reflexivitycontiguity-<imbued-notional $\sim \operatorname{cogency}>$ ',-<reifying-or-elucidating-of-prospectiverelative-ontological-completeness-of-reference-of-thought-devolving-as-of-instantiativecontext $>$ as to existence-potency $\sim$ sublimating-nascence,-disclosed-from-prospectiveepistemic-digression - rules-of-apriorising/axiomatising/referencing-that-furtherepistemically-unconceal-the-very-ontologically-same-existential-reality/dynamiccumulative-aftereffect/aftereffect' as of deepest being-construal/existentialreference/existential-tautologisation that underlies the relative-unreflexivity/relativereflexivity - ontological-contiguity of-the-human-institutionalisation-process

'aetiologisation/ontological-escalation-<ontological-

veridicality_commitment/otherliness_transcending/compulsions-

encumbered_transcending $>$ storied-construct/ontologically-valid-narration

conceptualisation'

inducing uninstitutionalised-threshold, as it is impossible to critically extend ontologicalcapacity on the basis of the same reference-of-thought/psyche/psychological — dementating/structuring/paradigming but for a new reference-ofthought/psyche/psychological—de-mentating/structuring/paradigming with respect to existential-<disontologising/re-ontologising aporeticism $>$ reality to enable prospective institutionalisation over the uninstitutionalised-threshold.

not allowing for the 'breaking of the threadedness/thread of ontologically-veridical meaningfulness (as such a breaking induces virtuality-or-ontologically-flawed-construal leading correspondingly to the false uptake as ontologically-veridical of the wrongly implied soundness/non-perverted-reference-of-thought.

a traditional approach of analysis of psychopathy (as so construed from this papers totalising-entailing/nested-congruence insight including psychopathy and social psychopathy) will tend to be just as palliative as a non-positivism/medievalism world's 
postlogism associated with their social cognisance-and-integration of say notions-andaccusations-of-sorcery

humans actually come into existence which avows an 'implicited_attendant-ontologicalcontiguity' educed-

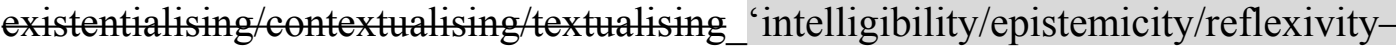
contiguity-<imbued-notional $\sim$ cogency $>$ ',-<reifying-or-elucidating-of-prospectiverelative-ontological-completeness-of-reference-of-thought-devolving-as-of-instantiativecontext $>$ of imbricated-becoming-transitioning within which they come to grasp rules and principles .5635

The reason for the disambiguation of transversality- $<$ for-sublimating-existentialeventuating/denouement, from-'thinking at first/pure-predisposition-preemptive-ofprospective-disontologising/subontologising' as-of-prospectively-disambiguatedaffirmed-and-unaffirmed-'motif-and-apriorising/axiomatising/referencing' $>$ into a supratransversality- $<$ in-sublimating-existential-eventuating/denouement $>\sim$ of-motif-andapriorising/axiomatising/referencing reference-of-thought over a subtransversality- $<$ indesublimating-existential-eventuating/denouement $>\sim$ of-motif-andapriorising/axiomatising/referencing reference-of-thought.

knowledge is not constructed as a 'human mutual agreement exercise for its construal/conceptualisation/discovery/invention/development' since solipsistically/emanantly/becomingly we are of temporal/shortness to intemporal/longness mental-dispositions and this cannot be averaged to get transcendental knowledge which is rather the outcome of an enabling process as to 'intrinsic-reality/ontological-veridicality transcendental enabling'

virtue is a 'The-Good/knowledge-reification gesturing-and-accounting - of-epistemicphenomenalism-<in-prospective_psychologismic $\sim$ apriorising/axiomatising/referencing\{of-'prospectively implicited_attendant-ontological-contiguity' educedexistentialising/contextualising/textualising_'intelligibility/epistemicity/reflexivitycontiguity-<imbued-notional $\sim$ cogency $>$ ' $\}$ - conflatedness-in-\{preconverging-ment by\} postconverging entailment $>$ /understanding/<amplituding/formativeepistemicity>causality as-to-projective-totalitative-implications-of-prospectivenonpresencing,-for-explicating relative -unreflexivity/relative-reflexivity - ontologicalcontiguity construct' and not 'impression-driven/good-naturedness/wishfulness construct' as reality is above all 'effectivity' by its manifestation. .5648 ever-perverting effect on ontological-veridicality of subtransversality-<in-desublimatingexistential-eventuating/denouement $>\sim$ of-motif-and-apriorising/axiomatising/referencing (as-of-pseudointemporalities) reflected by the 'contrastive intellectual-and-moral tone-astemperament and thematic teleological constructs of subtransversality-<in-desublimating existential-eventuating/denouement $>\sim$ of-motif-and-apriorising/axiomatising/referencing (as-of-pseudointemporalities) in relation to supratransversality-<in-sublimatingexistential-eventuating/denouement $>\sim$ of-motif-and-apriorising/axiomatising/referencing (as-of-non-pseudointemporality)' as instigated by postlogism/enculturated-postlogism in protraction as temporal-preservation-as-pseudointemporality-preservation .5658 ascetic intemporal-prioritising/maximalising-recomposuring-for-relative-ontologicalcompleteness - unenframed/re-ontologising conceptualisation Socrates will be passed by 
the ordinariness/earthliness of thought in that institutionalised-being-and-craft setup as vague while upholding its shallow notion of value

'irrealism and corresponding virtualities' that will undermine analytical pertinence, as man has to be understood exactly for what man is in effective reality, to then articulate effective knowledge constructs that are actually most efficient because of their realism

.5667

'requisite specialness of the discipline of philosophy as a first-order ontology' among all subject-matters (or-as-it-protrudes-into-subject-matters-or-second-order-ontologies), as the one that can least afford to be of normal trade

'subtransversality-<in-desublimating-existential-eventuating/denouement $>$-by-

supratransversality- $<$ in-sublimating-existential-eventuating/denouement $>$ technique of transversality-<for-sublimating-existential-eventuating/denouement-from-'thinking atfirst/pure-predisposition -preemptive-of prospective-disontologising/subontologising' asof-prospectively-disambiguated-affirmed-and-unaffirmed-'motif-andapriorising/axiomatising/referencing'>

postlogism dynamism in its social protraction reflects a threshold-ofnonconviction/madeupness/bottomlining-in-shallow-supererogation- $<$ as-to- 'attendantintradimensional'-prospectively-disontologising preconverging/dementing-apriorisingpsychologism $>$ as of temporality/non-transcendence-and-

sublimity/sublimation/supererogatory $\sim$ de-mentativity/incrementalism-in-relativeontological-incompleteness — enframed/disontologising conceptualisation in corresponding conjugated-postlogism of temporal-dispositions

teleology/teleological-differentiation is not a discrete construct but rather deterministic as of existential-reference/existential-tautologisation/ontology/ontological-veridicality of 'implicited_attendant-ontological-contiguity' educedexistentialising/contextalising/textalising_intelligibility/epistemicity/reflexivitycontiguity-<imbued-notional $\sim$ cogency $>$ ',-<reifying-or-elucidating-of-prospectiverelative-ontological-completeness-of-reference-of-thought-devolving-as-of-instantiativecontext>

Existence/existential-reality is thus a teleological-contiguity/oneness-of-teleology 'with teleological-discretion being defined only by epistemic choice/differentiation'

decentering is what divulges all the uninstitutionalised-threshold as recurrent-utteruninstitutionalisation, ununiversalisation, non-positivism/medievalism and prospectively procrypticism by maximalising-recomposuring-for-relative-ontological-completenessunenframed/re-ontologising $\sim$ conceptualisation .....

the idea of pivoting/decentering extends to the notion of the 'self's own pivoting/decentering for understanding'

ontological-normalcy/postconvergence points out that paradoxically the transcendental mindset/reference-of-thought associated with a 'knowledge construct of intrinsic-reality' should priorly be established ('centered' over the prior meaningful-frame which is 'decentered') for the knowledge construct to take hold by the continuing 'moulting' of its proponents and corresponding social construct....

the Social is much more than aggregativity (social-aggregation) 


\section{Long-form of Terms and their Elucidations}

Useful Tips for seamlessly/interactively navigating throughout the document for elucidation of terms:

- 'Ctrl + Click' (on any hyperlinked superscript) for the elucidation of the given term

- 'Alt + Left-Arrow' to go back to the previous location in the document (that is precisely at the clicked hyperlinked superscript location)

- 'Alt + Right-Arrow' to go in the reverse direction again

- Also the darkened and/or strikedthrough text elaborates upon the immediately prior or succeeding text and is darkened and/or strikedthrough (to point out its interjecting nature) in order to ease the 'continuity readability' of long phrases/sentences while at the same time striving herein for a 'most profound and extended articulation of prospective intolerance-<of-disparateness $>$ /exactifying_precisioning-of-sublimation- $<$ as-topostconverging-narrowing-down apriorising/axiomatising/referencing-entailingtheoretical,-conceptual-and-operant-implications>

absolving/fleeting/ absolving/fleeting/escaping-reflex-logic-\{in-'disdain-of-sanctity-ofescaping-reflex- prelogism -as-of-conviction,-in-profound-supererogation logic ${ }^{1} \quad<$ existentially-veridical-'attendant-intradimensionalapriorising/axiomatising/referencing'-logical-dueness-precedesdisontologising-logical-outcome-arrived-at>-mental-disposition'-as-ofcircumstantial-extremes-of-'vague-rhyming-or-copiedmimicry-or- 
formulaic-projection-or-projection-of-form-or-hollow-and-vague-

vocalisation-or-subknowledging '-in-a-circularity-of-'contemptuous-

deceptive-elicitation',- 'contemptuous-engagement'-and- 'contemptuous-

disengagement',-within-the-scope-of- 'the-registry-

worldview's/dimension's- reference-of-thought-for-social-functioning-

and-accordance'।

accreting-

accreting-substitutive-subsumption-as-futural-différance-freeplay-

substitutive-

\transcendental-futural-différance-freeplay-that-produces-ontological-

subsumption-as-

aesthetic-tracing-<perspective-ontological-normalcy/postconvergence-

futural-différance-

reflected-'epistemicity-relativism-determinism'>-of- meaningfulness-

freeplay $^{2}$

and-teleology -epistemic-totalisation-sublimity:-as-of-'ontological-faith-

notion-or-ontological-fideism-imbued-underdetermination-of-motif-and-

apriorising/axiomatising/referencing-as-so-being-as-of-existential-

reality,-protracted-dynamics-of-ontological-correspondence',-in-

superseding-the-successive-registry-worldviews/dimensions- reference-

of-thought-temporality -as-of-neuterisation /relative-ontological-

incompleteness /preconverging existential-extrication-as-of-existential-

unthought'>

supererogatory ac supererogatory acuity/perspicacity/astuteness/edginess/incisiveness-of-

uity/perspicacity/a apriorising/axiomatising/referencing/intelligibilitysettingup/measuringins

stuteness/edginess/ trumenting-for-conceptualisation with regards to the-very-same-

incisiveness-of- immanent-existence/intrinsic-reality/ontological-veridicality,-as-to-

apriorising/axioma 'human<amplituding/formative-epistemicity>totalising $\sim$ purview-of-

tising/referencing/i construal refers to the 'cut-through/deflating effect' of 
ntelligibilitysetting supererogating $\{$ relative-ontological-completeness - -as-singularisationup/measuringinstru <as-to-the-nondisjointedness/entailment-of-prospective-

conceptualisation affirmation/projection/assertion/notional self-distantiation/duenessvalidating-logicising/suitable-measuringinstrument-validatingmeasuring-<as-to-postconverging-or-dialectical-thinking -apriorisingpsychologism $>\quad$ over relative-ontological-incompleteness ${ }^{8-a s-}$ dissingularisation-<as-to-the-disjointedness/ment-of- presencingabsolutising-identitive-constitutedness $>$ lepistemicnonimmanencelflawed-epistemicity-relativism-determinism construal as of unaffirmation/deprojection/deassertion/epistemicdecadence/undueness-invalidating-logicising/unsuitablemeasuringinstrument-invalidating-measuring-<as-to-preconverging-ordementing -apriorising-psychologism $>$ \} (thus in both cases establishing their inherently-determinable- 'apriorising-teleological-thresholding-asteleological-framework/narrative-framework contextualising/existentialising/instantiative-devolving-meaningfulness' with relative-ontological-incompleteness ${ }^{8}$ prospectively deneutered from its <amplitudingfformative-epistemicity>totalising $\sim$ self-referencingsyncretising/circularity/interiorising/akrasiatic-drag 34 in pseudoedginess/pseudo-incisiveness), underlying a postconverging-ordialectical-thinking -apriorising-psychologism representation over a preconverging-or-dementing -apriorising-psychologism representation as of the-very-same-immanent-existence/intrinsic-reality/ontologicalveridicality,-as-to- 'human<amplituding/formative- 
epistemicity>totalising purview-of-construal, wherein for instance as of relative-ontological-completeness $\quad$ theory-of-relativity-together-withquantum-mechanics - axiomatic-constructs as postconverging-ordialectical-thinking -apriorising-psychologism representation runsthrough/deflates classical-mechanics-axiomatic-constructs as preconverging-or-dementing -apriorising-psychologism representation given that the former just supersedes/transcends the latter as of maximalising-recomposuring-for-relative-ontological-completeness unenframed/re-ontologising conceptualisation of 'the-very-same physics $<$ amplitudingfformative-epistemicity >totalising $\sim$ devolvedpurview/domain-of-construal-as-intrinsic-reality/ontologicalveridicality/existential-reality' with human limited-mentation-capacitydeepening - as subjecting limitedness/human subpotency to 'educedunlimitednesstexistence sublimating nascence' and is not involved with the latter as of any incrementalism-in-relative-ontologicalincompleteness ${ }^{8}$-enframed/disontologising conceptualisation, and the same elucidation extends to the overall human formativeepistemicity>-totalising thrownness-in-existence ${ }^{35}$ as of the-very-sameimmanent-existence/intrinsic-reality/ontological-veridicality,-as-to'human< amplituding/formative-epistemicity>totalising $\sim$ purview-ofconstrual wherein our present positivism/rational-empiricism <amplitudinglformative-epistemicity>totalising $\sim{ }^{56}$ meaningfulness-andteleology as postconverging-or-dialectical-thinking-apriorisingpsychologism representation runs-through/deflates prior nonpositivism/medievalism 
epistemicity>totalising meaningfulness-and-teleology

preconverging-or-dementing -apriorising-psychologism representation or wherein prospective deprocrypticism-or-preemptingdisjointedness-as-of- reference-of-thought <amplitudingfformativeepistemicity>totalising ${ }^{5}$ meaningfulness-and-teleology as postconverging-or-dialectical-thinking -apriorising-psychologism representation will cut-through/deflate our 'positivism- ${ }^{80}$ procryticism shiftiness-of-the-Self , <amplitudingfformativeepistemicity $>$ totalising meaningfulness-and-teleology as preconverging-or-dementing -apriorising-psychologism representation; 9 such that we can fathom that this fepistemictotalising 3: 3 hermeneuticttextuality/reprojecting/supererogating/zeroing/reacuting,-\{decompulsing\} delinearity for-cogency elucidation by its 'mere prompting of what is implied by notional deprocrypticism $<$ amplituding/formative-epistemicity>totalising ${ }^{56}$ meaningfulness-andteleology, is rather 'sparing to our positivism-procrypticism emotional-involvement for the sake of intellectual engagement' as it 'doesn't directly project the fulsome supererogatory acuity/perspicacity/astuteness/edginess/incisiveness-ofapriorising/axiomatising/referencing/intelligibilitysettingup/measuringins trumenting-for-conceptualisation as of prospective notional deprocrypticism full construal' relative to our 'positivismprocrypticism shiftiness-of-the-Self dereifying-gesturing perspective', and this sparingness thus should not be naively construed to imply that we can engage as of epistemic-veracity and thus ontological-veracity such 
notional deprocrypticism

epistemicity>totalising meaningfulness-and-teleology in prospective relative-ontological-completeness 87 from our relative-ontologicalincompleteness 'positivism- procrypticism shiftiness-of-the-Self perspective' as if as of postconverging-or-dialectical-thinking apriorising-psychologism representation whereas in reality such perspectival $<$ preconverging 'motif-andapriorising/axiomatising/referencing'-entailing>-existentialisingenframing/imprintedness-_as-to- historicity-tracing_in-presencinghyperrealisation/hyperreal-transposition/ is rather flawed-and-untenable as it is just a furtherance of positivism- procrypticism preconverging-ordementing -apriorising-psychologism representation warranting rather prospective psychoanalytic-unshackling/memetic-reordering/institutionalrecomposuring of the positivism- procrypticism mindset to effectively begin to contemplate and come to terms-as-of-axiomatic-construct with the <emplitudingfformative-epistemicity >causality $\sim$ as-to-projectivetotalitative-implications-of-prospective- nonpresencing,-forexplicating relative unreflexivity/relative reflexivity ontologicalcontiguity of prospective notional deprocrypticism as a perspective that is prospectively_unenframed-or-re-ontologising-to as edgily-andincisively-spilling-over-our-'positivism- ${ }^{8}$ procrypticism shiftiness-of-theSelf ', such that even in the expanded-view-of-things just as buddingpositivists existentially< <isontologising/re ontologising aporeticism> impregnated in-many-ways with a non-positivism/medievalism mindset more critically simply grasped of the wake for more salient human 
ontological possibilities as of positivism/rational-empiricism down-theline likewise this author and many disseminating postmodern thinkers existentially-disontologising/re ontologising aporeticism> impregnated in-many-ways with positivism- procrypticism mindset as 'occlusive self-consciousness shiftiness-of-the-Self' more critically project rather of the wake of more salient human futural ontological possibilities implied by prospective deprocrypticism-or-preemptingdisjointedness-as-of- reference-of-thought as of its 'unenframed/reontologising protensive self-consciousness nonshiftiness-of-the-Self as of mere reproducibility-mathesis/motif/thrownness-disposition,-asreproducibility-of-aestheticisation reifying-gesturing'

amplituding supererogatory de-mentative-amplituding$<$ supererogatorily stranding/attributing as of either 'postconverging/dialectical-thinking,-as-soundness or preconverging/dementing , ,-as-unsoundness' in reflecting transcendenceand-sublimity/sublimation/supererogatory-de-mentativity> undergirding aestheticisation-and-aestheticisation-towards-ontology-<elicitedidiomatisation> and so-underlying phenomenal existence manifestlyimbued/permeated/integral conceptivity/epistemic-reflexivity/epistemicityrelativism-determinism-<reifying\{as-to-knowledge-developing\}-andempowering >-〈exuding_fepistemictotalising $3 \frac{3}{3}$ hermeneutically/textually/reprojectingly/supererogatingly/zeroin gly/re acutingly, - - focom- 
'interlay/organicalism/aestheticising-handle-<of-'psychologismic-

transfixity\{residualising \{decompulsing ${ }^{\prime}$ delinearity over nonresidualising

fompulsing'linearity\}'>-\{manifest-supererogatory de-mentative-

amplituding-or-mental-aestheticising-attuning\}',-in-

supererogatory projective-arbitrariness/waywardness-

of transversalisation/tandemisation/abstractive-

conjugation/perspectivation/depthing-for-'aestheticising-re-

margining/re-edging/re-acuity-in-

postconverging/preconverging_circumscriptive/totalitative-

restructuring'-educing-sublimation/desublimation>, (amplituding is so-

construed as conceptivity/epistemic-reflexivity/epistemicity-relativism-

determinism-<reifying\{as-to-knowledge-developing\}-and-

empowering >-for-inlining and speaks not just of the 'specific humansubpotency conceptivity/epistemic-reflexivity/epistemicity-relativismdeterminism-<reifying\{as-to-knowledge-developing\}-and-

empowering $>$ - for-inlining with phenomenal existence' but equally all other possible 'phenomenal/manifest $\sim$ subpotencies-_in-transitiveconflatedness -reflexivity,-in-the-full-potency-of-

existence's sublimating-nascence) conceptivity/epistemicreflexivity/epistemicity-relativism-determinism- $<$ reifying\{as-to-

knowledge-developing\}-and-empowering>-for-inlining with phenomenal existence' whether of animate or inanimate conceptivity/epistemic-reflexivity/epistemicity-relativism-determinism$<$ reifying\{as-to-knowledge-developing\}-and-empowering >, and amplituding is so-elaborated-as-of conceptivity/epistemic- 
reflexivity/epistemicity-relativism-determinism-<reifying\{as-to-

knowledge-developing\}-and-empowering $>-<a s$-to-frame-ofmotif/pattern/sign/token/mark/type/figure/symbol/attribute/inscription/wri ting $>$ - for-inlining-<as-to-frame-of-

reflection/retentiveness/recollection/memoration/memory/anamnesis/cogn isance/intelligibility/comprehension/realisation>, with this elucidation practically underlined with the elucidation of such notions like 'real, pseudoreal and unreal' wherein everything contemplatable about existence is necessarily real whether of 'phenomenal/manifest occurrence' or 'phenomenal/manifest imaginary occurrence' as to existence's panintelligibility/panreflexivity -effusing/ecstatic-inlining while thevery-same notions rather speak to the 'notional <preconverging 'motifand-apriorising/axiomatising/referencing'-entailing>-existentialisingenframing/imprintedness-_as-to- historicity-tracing-in-presencinghyperrealisation/hyperreal-transposition) by <postconverging 'motifand-apriorising/axiomatising/referencing'-entailing>-existentialisingframing/imprinting-\{as-to-prospective- historiality/ontologicaleventfulness /ontological-aesthetic-tracing-<perspective-ontologicalnormalcy/postconvergence-reflected-'epistemicity-relativismdeterminism'>) of human-subpotency conceptivity/epistemicreflexivity/epistemicity-relativism-determinism-<reifying\{as-toknowledge-developing\}-and-empowering > as to social-stake-contentionor-confliction' as thus implicating the veracity of human-subpotency differentiating contemplation of ontological-veracity as surrealising/supererogating); $\uparrow$ amplituding as to its 
<amplituding/formative-epistemicity>totalising underlies (as of nonpresencing-<perspective-ontological-normalcy/postconvergence $>$ veridical epistemic-projection perspective) the 'preconverging/postconverging-de-mentating/structuring/paradigming implications of conceptivity/epistemic-reflexivity/epistemicity-relativismdeterminism-<reifying\{as-to-knowledge-developing\}-and-empowering >

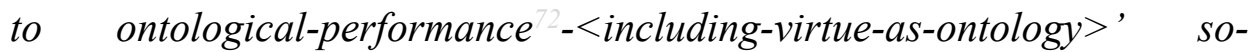
reflected as to the 'notionalisation/notional-conception/amplituding referencing/registering/decisioning imbued shallow-supererogation to-profound-supererogation 'spanning human temporal-to-intemporal ontological-performance ${ }^{72}<$ including-virtue-as-

ontology $>$ /morality/ethics/justice/etc. (as to Beingdevelopment/ontological-framework-expansion-as-to-depth-ofontologising-development-as-infrastructure-of- meaningfulness-andteleology , institutional-development-as-to-social-function-development and living-development-as-to-personality-development psychologismic epistemic aentisation diffeuly<<for, residualising \{decompulsing ${ }^{2}$ delinearity for cogency $\geq$ magnitudes $\{$ of-experientiality/experiment\})

asceticism $^{4}$ asceticism speaks of the disposition of value-ricochetting/transvaluationas-to-prospective-relative-ontological-completeness acuity/perspicacity/astuteness/edginess/incisiveness-ofapriorising/axiomatising/referencing/intelligibilitysettingup/measuringins trumenting -for-conceptualisation cognisant of the fact that the Beingdevelopment/ontological-framework-expansion-as-to-depth-of- 
ontologising-development-as-infrastructure-of- meaningfulness-andteleology , institutional-development-as-to-social-function-development and living-development-as-to-personality-development psychologismic epistemic acutisation difficulty<<for, residualising

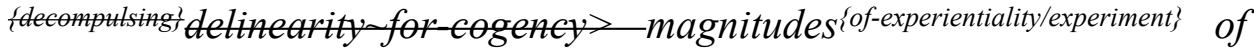
the '<amplitudinglformative> wooden-language-_imbued-temporalmere-

form/virtualities/dereification/akrasiaticdrag/denatured/preconvergingor-dementing -narratives-of-the-reference-of-thought-categoricalimperatives/axioms/registry-teleology /

<amplituding/formative> wooden-language-fimbued-averaging-of-

thought-<as-to-leveling/ressentiment/closed-construct-ofmeaningfulness-and-teleology -as-of-'nondescript/ignorable-void 'with-regards-to-prospective-apriorising-implications $>$ ), is preconverging/postconverging-de-

mentatively/structurally/paradigmatically incompatible with the possibility at its prospective human-subpotencyaporia/undecidability/dilemma/ought-

indeterminacy/deficiency/limitation/constraint of ${ }^{83}$ reference-of-thought as of its destructuring-threshold-\{uninstitutionalisedthreshold /presublimating-desublimating-decisionality / of-ontologicalperformance ${ }^{2}-<$ including-virtue-as-

ontology >/morality/ethics/justice/etc. to integratively contemplate of the prospective registry-worldview's/dimension's Being- 
development/ontological-framework-expansion-as-to-depth-of-

ontologising-development-as-infrastructure-of- meaningfulness-and-

teleology , institutional-development-as-to-social-function-development

and living-development-as-to-personality-development psychologismic

epistemic acutisation difficuly < for, residualising

\{decompulsing ${ }^{\text {delinearity for-cogency> magnitudes }}{ }^{\text {\{of-experientiality/experiment\} }}$ by

dispensing-with-immediacy-for-relative-ontological-completeness ${ }^{7}$-by-

reification/contemplative-distension (as of human self-surpassing-

existentialism-form-factor,-in-overcoming- 'notional collateralising-

beholdening-protohumanity'-to- 'attain-sublimating-humanity'-as-to-

existence-potency $\sim$ sublimating-nascence,-disclosed-from-prospective-

epistemic-digression to supersede human temporality /shortness

<amplituding/formative> wooden-language-fimbued-averaging-of-

thought-<as-to-leveling/ressentiment/closed-construct-of-

meaningfulness-and-teleology -as-of-'nondescript/ignorable-void '-

with-regards-to-prospective-apriorising-implications $>$ )) as it rather

enters into <emplitudinglformative-epistemicity>totalising $\sim$ selfreferencing-syncretising/circularity/interiorising/akrasiatic-drag ${ }^{34}$ of its prior registry-worldview/dimension

supererogatory acuity/perspicacity/astuteness/edginess/incisiveness-of-

apriorising/axiomatising/referencing/intelligibilitysettingup/measuringins

trumenting-for-conceptualisation to any such prospectively implied meaningfulness-and-teleology reference-of-thought; 9 and thus all human transcendence-and-sublimity/sublimation/stpererogatory dementativity can only occur as of asceticism induced psychoanalytic- 
unshackling/memetic-reordering/institutional-recomposuring that is preconverging/postconverging-rede-

mentating/restructuring/reparadigming (in the face of ecstatic-existenceas-transcendental-signifier-emergence/becoming-spontaneityimplications reflected as existence-potency $\sim$ sublimating-nascence,disclosed-from-prospective-epistemic-digression) the possibility of the prior registry-worldview/dimension to 'perceive value in transvaluation as value-ricochetting/transvaluation-as-to-prospective-relativeontological-completeness ${ }^{83}$ reference-of-thought' as of the prospective registry-worldview/dimension perspective ontologicalnormalcy/postconvergence implications of value-construct, and so practically as of the ascetic capacity to induce recurrent-utteruninstitutionalisation to perceive base-institutionalisation value-construct as of more pertinent transvaluation of value, base-institutionalisationununiversalisation value-construct to perceive ${ }^{10 n i v e r s a l i s a t i o n}$ valueconstruct as of more pertinent transvaluation of value, ${ }^{103}$ universalisationnon-positivism/medievalism value-construct to perceive positivism/rational-empiricism value-construct as of more pertinent transvaluation of value, and prospectively our positivism- procrypticism to perceive deprocrypticism-or-preempting-disjointedness-as-of${ }^{3}$ reference-of-thought as of more pertinent transvaluation of value, and as we can appreciate that the non-universalising social-construct didn't perceive universalising-idealisation as of value but for the induced psychoanalytic-unshackling/memetic-reordering/institutionalrecomposuring afterthought/reasoning-from-results instigated by 
Socratic-philosophers and their successors, and likewise with medievalpedantic dogmatism social-construct relative to budding-positivists, and prospectively it is herein contended that our procrypticism-ordisjointedness-as-of- reference-of-thought disposition with respect to deprocrypticism-or-preempting—disjointedness-as-of- reference-ofthought prospective ${ }^{56}$ meaningfulness-and-teleology ; and fundamentally the notion of 'asceticism as implying valuericochetting/transvaluation-as-to-prospective-relative-ontologicalcompleteness $^{87}$ cannot be explained to any prior registryworldview/dimension construed as a <amplitudingfformative > woodenlanguage-\{imbued - averaging-of-thought-<as-to-

leveling/ressentiment/closed-construct-of- meaningfulness-andteleology -as-of-'nondescript/ignorable-void '-with-regards-toprospective-apriorising-implications $>$ । on the basis of its relativeontological-incompleteness

aposteriorising/logicising/deriving/intelligising/measuring of meaningfulness-and-teleology from its prior deficient/ontologicallyimpertinent supererogatory acuity/perspicacity/astuteness/edginess/incisiveness-ofapriorising/axiomatising/referencing/intelligibilitysettingup/measuringins trumenting -for-conceptualisation since the asceticism is rather as of the prospective registry-worldview's/dimension's supererogatory acuity/perspicacity/astuteness/edginess/incisiveness-ofapriorising/axiomatising/referencing/intelligibilitysettingup/measuringins trumenting -for-conceptualisation 
aposteriorising/logicising/deriving/intelligising/measuring meaningfulness-and-teleology, and this explains why the asceticism in transvaluation of universalising-idealisation disposition over nonuniversalising sophistry disposition, budding-positivism over medievalscholasticism dogmatism and prospectively notional deprocrypticism over our procrypticism are non-intelligible to their respective nonuniversalising/medieval-pedantic-dogmatism/procrypticism

'<amplituding/formative> wooden-language-fimbued-temporal-mereform/virtualities/dereification/akrasiatic-drag/denatured/preconvergingor-dementing -narratives-of-the- reference-of-thought-categoricalimperatives/axioms/registry-teleology /

<amplitudingfformative> wooden-language-_imbued-averaging-of-

thought-<as-to-leveling/ressentiment/closed-construct-ofmeaningfulness-and-teleology -as-of-"nondescript/ignorable-void with-regards-to-prospective-apriorising-implications $>>$ ' as in effect it is simply the 'projected habituation by the prospective registryworldview's/dimension's veridically postconverging/dialecticalthinking-qualia-schema reflection of the prior registryworldview's/dimension's destructuring-threshold-\{uninstitutionalisedthreshold /presublimating-desublimating-decisionality /of-ontologicalperformance ${ }^{72}-<$ including-virtue-asontology>/morality/ethics/justice/etc. as of preconverging/dementing qualia-schema' that carries the psychoanalytic-unshackling/memeticreordering/institutional-recomposuring explaining the asceticism; 9 in 
other words, the full-picture of asceticism transvaluation implications can be garnered operantly with a preconverging/dementing-qualia-schema projection of 'reasoning out' the relative-ontological-incompleteness meaningfulness-and-teleology in terms-as-of-axiomatic-construct of the relative-ontological-completeness postconverging/dialecticalthinking -qualia-schema ${ }^{56}$ meaningfulness-and-teleology in exposing the former's nondescript/ignorable-void as of its preconverging/dementing -qualia-schema; 9 and in-the-bigger-schemeof-things asceticism implied transvaluation speaks to the fact that 'notions of values in relative-ontological-incompleteness destructuringthreshold-\{uninstitutionalised-threshold /presublimating-

desublimating-decisionality $/$ of-ontological-performance ${ }^{72}<$ includingvirtue-as-ontology>/morality/ethics/justice/etc. are of teleologicallydecadent-as-in-dimensionality-of-desublimating-lack-of < <amplituding/formative >supererogatory de-mentativeness/epistemicgrowth-or-conflatedness /transvaluativerationalising/transepistemicity/anamnestic-residuality/spirit-drivennessequalisation) ontological-performance $-<$ including-virtue-asontology>/morality/ethics/justice/etc. as of vices-and-impediment' and 'notions of values aspiring-for-and-in relative-ontological-completeness constructiveness-of-ontological-performance ${ }^{72}<$ including-virtue-asontology>/morality/ethics/justice/etc. are of emancipating/teleologically-

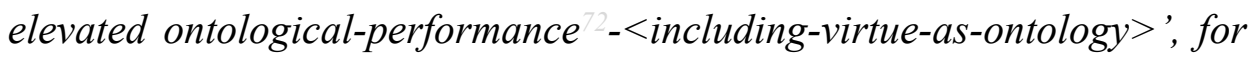
instance in the sense that while there is nothing inherently wrong with achievement motives across all registry-worldviews/dimensions 
conventional constructs as of human finite aspirations whether socially, professionally, family-wise, hedonic, etc., their implications as of the destructuring-threshold-_uninstitutionalised-threshold /presublimatingdesublimating-decisionality $/$ of-ontological-performance ${ }^{72}<$ includingvirtue-as-ontology $>/$ morality/ethics/justice/etc. in relative-ontologicalincompleteness is bound to teleologically-decadent-as-indimensionality-of-desublimating-lack-of -

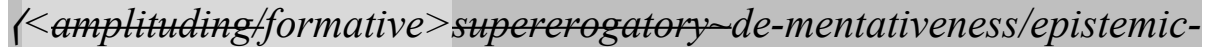
growth-or-conflatedness /transvaluativerationalising/transepistemicity/anamnestic-residuality/spirit-drivennessequalisation/vices-and-impediments ${ }^{105}$ and likewise regarding the same context their overlooking/foregoing/dispensing-with-immediacy-forrelative-ontological-completeness -by-reification/contemplativedistension (as of human self-surpassing_existentialism-form-factor,-inovercoming- 'notional collateralising-beholdening-protohumanity'-to'attain-sublimating-humanity'-as-to-existence-potency sublimatingnascence,-disclosed-from-prospective-epistemic-digression to supersede human temporality /shortness <emplitudinglformative> woodenlanguage-_imbued-averaging-of-thought-<as-to-

leveling/ressentiment/closed-construct-of- meaningfulness-andteleology -as-of-'nondescript/ignorable-void～'-with-regards-toprospective-apriorising-implications $>$ ) ) as of transvaluation for prospective relative-ontological-completeness constructiveness-ofontological-performance ${ }^{72}<$ including-virtue-as- 
ontology $>/$ morality/ethics/justice/etc. brings about prospective emancipating/teleologically-elevated ontological-performance ${ }^{72}$ <including-virtue-as-ontology>, pointing out that all values are as ontologically-pertinent as of the prospective relative-ontologicalcompleteness ${ }^{87}$ transvaluation implications as to the fact that for instance 'supposed friendship/family/social/professional values' leading to involvement in say a genocide (as of the insight exposed from such an extreme/stark example undermining human predisposition for a 'nihilistic <amplituding/formative> wooden-language-fimbued-averaging-ofthought-<as-to-leveling/ressentiment/closed-construct-ofmeaningfulness-and-teleology -as-of- 'nondescript/ignorable-void with-regards-to-prospective-apriorising-implications $>$ I) are effectively associated with vices-and-impediments ${ }^{105}$ as to preconverging-existentialextrication-as-of-existential-unthought, and thus pointing out that there are no true values without the prior conception of their transvaluation as of 'relative-ontological-incompleteness /relative-ontologicalcompleteness - (sublimating referencing/registering/decisioning,-asself-becoming/self-conflatedness /formative-supererogating$<$ projective/reprojective-aestheticising-re-motif-and-re-apriorising/reaxiomatising/re-referencing,-in-perspective-ontologicalnormalcy/postconvergence $>$ ) as to human-and-socialexpectations/anticipations - metaphoricity -aspreconverging/postconverging-redementating/restructuring/reparadigming-psychologism,; the effective manifest 'asceticism-as-of-parrhesiastic-askesis-or-acumen 
transvaluation development' (as enabling the superseding of human prior $<$ amplituding/formative-epistemicity $>$ totalising $\sim$ self-referencingsyncretising/circularity/interiorising/akrasiatic-drag ${ }^{34}$ can be contemplated as of reference-of-thought-level induced ${ }^{103}$ universalisingidealisation transvaluation as reflected with 'Socrates principled ascetic stances associated with his maieutic eliciting of a basic sense of universalising-idealisation in his interlocutors even when bordering on the incongruous during his condemnation while upholding the ontologicalpertinence of the incongruous ${ }^{103}$ universalising-idealisation over sophistic/pedantic apparently congruous non-universalising' developing into 'Plato's perpetuating of the philosophical tradition with his Academy with a further phronesis/practicality emphasis in striving, as of the deferential-formalisation-transference implications underlying all true knowledge-constructs (as of the underlying Socrates maieutic exercise 'inconclusiveness insight' which is rather more critical in eliciting/instigating a sense of knowledge-reification gesturing-andaccounting-of-epistemic-phenomenalism-<inprospective_psychologismic apriorising/axiomatising/referencing-\{of'prospectively implicited_attendant-ontological-contiguity ' reducedexistentialising/contextualising/textualising_intelligibility/epistemicity/re flexivity-contiguity-<imbued-notional cogency >' \}-conflatedness in \{preconverging ment by\} postconverging entailment $>$ and soreflecting the reality that the ordinariness as <amplitudinglformative> wooden-language-_imbued-averaging-ofthought-<as-to-leveling/ressentiment/closed-construct-of- 
meaningfulness-and-teleology -as-of-'nondescript/ignorable-void '-

with-regards-to-prospective-apriorising-implications $>$ | disontologising framework lacks the requisite dispensing-with-immediacy-for-relativeontological-completeness -by-reification/contemplative-distension (as of human self-surpassing-existentialism-form-factor,-in-overcoming'notional collateralising-beholdening-protohumanity'-to- 'attainsublimating-humanity'-as-to-existence-potency sublimating-nascence,disclosed-from-prospective-epistemic-digression to supersede human temporality /shortness <amplitudingfformative> wooden-language(imbued-averaging-of-thought-<as-to-leveling/ressentiment/closedconstruct-of- meaningfulness-and-teleology -as-of'nondescript/ignorable-void '-with-regards-to-prospective-apriorisingimplications $>$ J) for profound knowledge-reification gesturing-andaccounting_of-epistemic-phenomenalism-<inprospective psychologismic $\sim$ apriorising/axiomatising/referencing-\{of'prospectively implicited_attendant-ontological-contiguity ' reducedexistentialising/contextualising/textualising_intelligibility/epistemicity/re flexivity-contiguity-<imbued-notional cogency > ' \}-conflatedness in \{preconverging ment by\} postconverging entailment $>$ as of human limited-mentation-capacity-as-subjecting 'educedunlimitedness/existence-sublimating nascence'-to-limitedness/humansubpotency commitment induced disinterest/indifferencelapathy and thus 'veridical knowledge-reification $\sim$ gesturing-and-accounting-ofepistemic-phenomenalism-<inprospective psychologismic apriorising/axiomatising/referencing-\{of- 
'prospectively implicited_attendant-ontological-contiguity ' reducedexistentialising/contextualising/textualising_intelligibility/epistemicity/re flexivity-contiguity-<imbued-notional $\sim$ cogency $>$ ' \}-conflatedness in \{preconverging ment by\} postconverging entailment> is postconvergingly-de-mentated/structured/paradigmed out-of-profoundlydeveloped-interest/concern/care-induced-institutionalising as of deferential-formalisation-transference for its requisite appropriate dispensing-with-immediacy-for-relative-ontological-completeness 37 -byreification/contemplative-distension '), to influence Dionysus I of Syracuse along the philosopher-king postconverging-dementating/structuring/paradigming' and 'Aristotle's expansive approach to philosophical and knowledge inquiry along the universalisingidealisation postconverging-de-mentating/structuring/paradigming, setting up the Lyceum together with the tutoring of Alexander the Great' along the same lines of reasoning as Plato, as well as latter post-Socratic philosophical perpetuation like the Stoics, Cynics, etc. and their institutional influence on Greek and Roman leadership and society; $\boldsymbol{\top}$ this same asceticism ideal can be recounted with budding-positivists as of Galileo, Copernicus, Descartes, etc. ascetic stances even against the condemnation of their then present-day medieval establishment creating the possibility for later enlightenment scientific and social emancipating thought (highlighting the incontrovertible necessity for asceticism as of its broader meaning as to human originariness-parrhesia,-as-spontaneityof-aestheticisation renewing of reproducibilitymathesis/motif/thrownness-disposition,-as-reproducibility-of- 
aestheticisation to overcome the <amplitudingfformativeepistemicity $>$ totalising $\sim$ self-referencing-

syncretising/circularity/interiorising/akrasiatic-drag ${ }^{34}$ of any prior reproducibility — mathesis/motif/thrownness-disposition,-asreproducibility-of-aestheticisation mere complexification, as so-implied with any given registry-worldview/dimension possibilities for prospective transcendence-and-sublimity/sublimation/supererogatory-de-mentativity)

attitude/mental- attitude/mental-disposition/care-and-episteme construed as of ${ }^{15}$ dedisposition/care- $\quad$ mentation-_supererogatory-ontological-de-mentation-or-dialectical-deand-episteme ${ }^{5} \quad$ mentation-stranding-or-attributive-dialectics $>$ imbued psychoanalyticunshackling/memetic-reordering/institutional-recomposuring reconstrual (as to 'human Being-development/ontological-framework-expansion-asto-depth-of-ontologising-development-as-infrastructure-ofmeaningfulness-and-teleology, institutional-development-as-to-socialfunction-development and living-development-as-to-personalitydevelopment psychologismic epistemic acutisation difficulty<for, residualising magnitudes ${ }^{\{o f}$ experientiality/experiments'), so-implied as of contrastive 'postconverging-ordialectical-thinking -as-of-assertion' attitude/mental-disposition/careand-episteme over 'preconverging-or-dementing-as-of-deassertion' attitude/mental-disposition/care-and-episteme, in apriorising/axiomatising/referencing/intelligibilitysettingup/measuringins trumenting,-foraposteriorising/logicising/deriving/intelligising/measuring- 
meaningfulness-and-teleology

\begin{tabular}{|c|c|}
\hline beyond-the- & beyond-the-consciousness-awareness-teleology $-<$ of-preconverging- \\
\hline consciousness- & existential-extrication-as-of-existential-unthought> \\
\hline awareness- & 'unconscious' \\
\hline teleology 9 - of - & nonconviction/madeupness/bottomlining-in-shallow-supererogation \\
\hline preconverging- & $<$ as-to-'attendant-intradimensional'-prospectively- \\
\hline existential- & disontologising preconverging/dementing -apriorising-psychologism $>$ \\
\hline
\end{tabular}

extrication-as-of- at the uninstitutionalised-threshold of a registry-worldview/dimension existential- whether with regards to retrospective or prospective transcendental unthought $>6 \quad$ implications

${ }^{7}$ blurriness- $\quad$ blurriness $-<$ sterilising/anecdotalising/trivialising-of-prospective-re$<$ sterilising/anecdo ontologising_by-preconverging,-in-disontologising-formulaic-draggingtalising/trivialising out/hollowing-out> speaks to 'lack of intellectual lucidity/clarity with -of-prospective-re- respect to supposed knowledge articulation as of existential-reality' ontologising_by- wherein a given human-subpotency registry-worldview/dimension preconverging,-in- supererogatory acuity/perspicacity/astuteness/edginess/incisiveness-ofdisontologising- apriorising/axiomatising/referencing/intelligibilitysettingup/measuringins formulaic- $\quad$ trumenting -for-conceptualisation so-construed as of reproducibilitydragging- mathesis/motif/thrownness-disposition,-as-reproducibility-ofout/hollowing- aestheticisation is rather wrongly construed in presencingout> absolutising-identitive-constitutedness ${ }^{14}$ as superseding ecstaticexistence/intrinsic-reality at its prospective destructuring-thresholdfuninstitutionalised-threshold /presublimating-desublimatingdecisionality $/$ of-ontological-performance ${ }^{2}<$ including-virtue-as- 
ontology>/morality/ethics/justice/etc. and so as of a lack of insight about <amplituding/formative-epistemicity >causality $\sim$ as-to-projectivetotalitative-implications-of-prospective- nonpresencing,-forexplicating relative unreflexivity/relative reflexivity ontologicalcontiguity as of 'relative-ontological-incompleteness 8 /relativeontological-completeness

(sublimating referencing/registering/decisioning,-as-self-becoming/selfconflatedness /formative-supererogating-<projective/reprojectiveaestheticising-re-motif-and-re-apriorising/re-axiomatising/rereferencing,-in-perspective-ontological-normalcy/postconvergence $>$ | as to human-and-social-expectations/anticipations-metaphoricity -aspreconverging/postconverging-redementating/restructuring/reparadigming-psychologism', and blurriness$<$ sterilising/anecdotalising/trivialising-of-prospective-reontologising_by-preconverging,-in-disontologising-formulaic-draggingout/hollowing-out> is reflected aporetically with such conundrums as existence-in-existence, disparateness-of-conceptualisation$<$ unforegrounding-ment,-failing-prospectively-to-reflect-

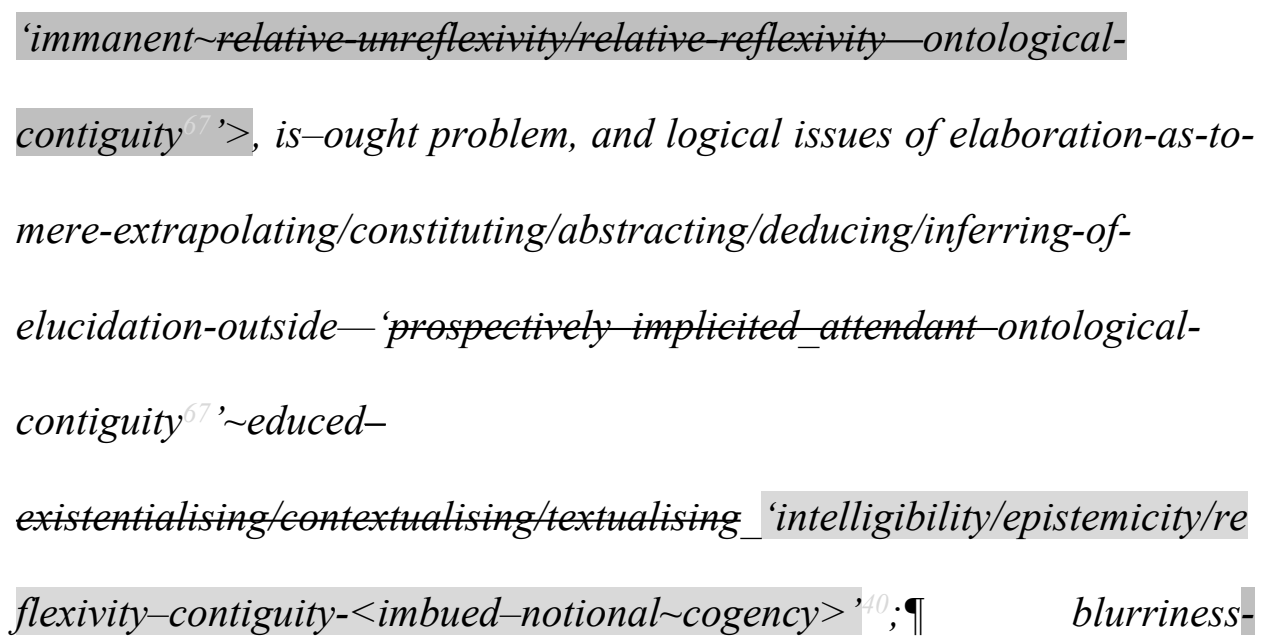




\section{$<$ sterilising/anecdotalising/trivialising-of-prospective-re-}

ontologising_by-preconverging,-in-disontologising-formulaic-dragging-

out/hollowing-out> thus fundamentally speaks of a 'closed-minded unilateral-conceptualisation-of-knowledge' wherein the human Self is wrongly construed as of a presencing-absolutising-identitiveconstitutedness ${ }^{14}$ reference for the conception of knowledge rather than reflecting ontological-veracity with an 'open-minded bilateralconceptualisation-of-knowledge' wherein the human Self itself has to prospectively be developed/constructed-out-of-its-prior-shiftiness-of-theSelf in 'epistemic-conflatedness construed as epistemicricochetting/transepistemicity construct' (so-construed as projectiveinsights) to then be able to register the entailing implications of prospective knowledge (so-construed as predicative insights), in the sense that for instance without implying the need for psychoanalyticunshackling/memetic-reordering/institutional-recomposuring as of prospective positivism construction-of-the-Self/self-consciousness a nonpositivism mindset as animistic or as medieval in its non-positivism 'closed-minded unilateral-conceptualisation-of-knowledge' (thus lacking the positivistic projective-insights as of apriorising/axiomatising/referencing-psychologism) will only end up 'complexifying the mechanical outcome of positivism ${ }^{56}$ meaningfulnessand-teleology on the basis of its non-positivism as animism or as medievalism apriorising/axiomatising/referencing/intelligibilitysettingup/measuringins trumenting' as implied in an animistic God-of-plane type of articulation 


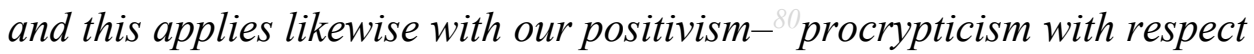
to prospective deprocrypticism, as this is exactly what explains the disparateness-of-conceptualisation-<unforegrounding-ment,-failingprospectively-to-reflect- 'immanent relative unreflexivity/relativereflexivity ontological-contiguity '> of all registryworldviews/dimensions as to the fact that $<$ cumulating/recomposuring attendant-ontological-contiguity successive registry-worldviews/dimensions involve successive renewing of reproducibility - mathesis/motif/thrownness-disposition,-as-

reproducibility-of-aestheticisation as of relative-ontologicalcompleteness $^{87}$ in reflection of human limited-mentation-capacitydeepening - as-subjecting limitedness/human-subpotency to 'educedunlimitedness/existence sublimating nascence'3 grasp of existencepotency $\sim$ sublimating-nascence,-disclosed-from-prospective-epistemicdigression at their destructuring-threshold-\{uninstitutionalisedthreshold /presublimating-desublimating-decisionality fof-ontologicalperformance ${ }^{2}-<$ including-virtue-as-ontology $>$; blurriness-

\section{$<$ sterilising/anecdotalising/trivialising-of-prospective-re-}

ontologising_by-preconverging,-in-disontologising-formulaic-draggingout/hollowing-out> at the destructuring-threshold-funinstitutionalisedthreshold /presublimating-desublimating-decisionality /of-ontologicalperformance ${ }^{72}-<$ including-virtue-asontology>/morality/ethics/justice/etc. is what brings up the is-ought problem (which had hitherto traditionally been wrongly framed rather in presencing-absolutising-identitive-constitutedness terms as of 
elaboration-as-to-mere-

extrapolating/constituting/abstracting/deducing/inferring-of-elucidationoutside-'prospectively_implicited_attendant-ontologicalcontiguity ' ' educedexistentialising/contextualising/textualising_intelligibility/epistemicity/re flexivity-contiguity-<imbued-notional cogency>', because going by ecstatic-existence as it reflects human historiality/ontologicaleventfulness 38 ontological-aesthetic-tracing-<perspective-ontologicalnormalcy/postconvergence-reflected-'epistemicity-relativismdeterminism'> becoming in 'implicited_attendant-ontologicalcontiguity ${ }^{\prime}$ 'educedexistentialising/contextualising/textualising_intelligibility/epistemicity/re flexivity-contiguity-<imbued-notional $\sim$ cogency $>^{\prime}$, human ontological/knowledge uncertainty-as-failing-to-reflect-the-effective'existential-veracity-and-entailment-of relative-unreflexivity/relativereflexivity' inherently implies human sovereign choices and options are then necessarily of 'ought indeterminacy' as of prior relative-ontologicalincompleteness ${ }^{8}$ but prospective relative-ontological-completeness ${ }^{87}$ with respect to prospective knowledge implications provides the ontological/knowledge certainty-as-reflecting-the-effective-'existentialveracity-and-entailment-of relative-unreflexivity/relative-reflexivity' to turn such prior 'ought indeterminacy' into 'is determinacy' whether this prospective 'is determinacy' transformation carries with it the given prospective knowledge acceptance, rejection or any other qualified attribution associated with the prior 'ought indeterminacy') given that the 
prior

mathesis/motif/thrownness-disposition,-as-reproducibility-of-

aestheticisation

specific

elaboration-as-to-mere-

extrapolating/constituting/abstracting/deducing/inferring-of-elucidation-

outside-'prospectively_implicited_attendant-ontological-

contiguity ${ }^{\prime}$ educed-

existentialising/contextualising/textualising_intelligibility/epistemicity/re

flexivity-contiguity-<imbued-notional $\sim$ cogency $>$ ' reaches its 'is determinacy' limits of analysis from whence its 'ought indeterminacy' arises at its destructuring-threshold-\{uninstitutionalisedthreshold /presublimating-desublimating-decisionality /of-ontologicalperformance $-<$ including-virtue-as-ontology $>$, speaking of an issue of relative-ontological-incompleteness that is only resolvable by the very fact that prospective relative-ontological-completeness changes the prior 'ought indeterminacy' as of prior normativities/conventions/practices into the prospective registry-worldview/dimension ontologically-veridical is determinacy' as reflected in renewed normativities/conventions/practices as to prospective institutionalisation, and in this regard we can appreciate how medieval-scholasticism non-positivism ${ }^{83}$ reference-of-thought-level pedantic dogmatism 'ought indeterminacy' emphasis gave way to the positivism/rational-empiricism scientific cause-and-effect 'is determinacy' emphasis or how ancient-sophists non-universalising 'ought indeterminacy' gave way to the universalising-idealisation 'is determinacy' of Socratic-philosophers or how notions like cannibalism, various practices of slavery and serfdom, etc. in human history as of 'ought 
indeterminacy' of their practices in relative-ontological-incompleteness gave way to the present 'is determinacy' of their rejection as of relativeontological-completeness ${ }^{87}$ on the basis of human-subjectemancipatingrelativism-driven-recomposuring-constructivism-towardssingularisation$<$ as-to-the-nondisjointedness/entailment-of-prospectivenonpresencing $>$; blurriness-<sterilising/anecdotalising/trivialisingof-prospective-re-ontologising_by-preconverging,-in-disontologisingformulaic-dragging-out/hollowing-out $>$ as of disparateness-ofconceptualisation-<unforegrounding-ment,-failing-prospectively-toreflect- immanent relative unreflexivity/relative reflexivity ontologicalcontiguity '> highlights that the destructuring-threshold\{uninstitutionalised-threshold /presublimating-desublimating-

decisionality $/$ of-ontological-performance ${ }^{72}<$ including-virtue-asontology>/morality/ethics/justice/etc. of all registryworldviews/dimensions are knowledge-deadends-<as-preconverging-dementating/structuring/paradigming $>$ of ${ }^{5}$ meaningfulness-and-teleology with the implication that without originariness-parrhesia,-as-spontaneityof-aestheticisation renewing of reproducibilitymathesis/motif/thrownness-disposition,-as-reproducibility-ofaestheticisation there is basically no chance for non-universalising ancient-sophists ever getting to universalising-idealisation, medievalscholastics pedantic dogmatism ever getting to positivism/rationalempiricism, and just as well with our positivism- procrypticism ever getting to prospective deprocrypticism, and in all these instances as ' foregrounding_entailment-<in-succession-of-profound- 
supererogation $>$ - (postconverging-narrowing-down $\sim$ sublimation-as-to-

'existence - as-sublimating-withdrawal/unenframing/re-ontologising,-

elicited-from-prospective-profound-supererogation '-in-reflecting-

immanent relative unreflexivity/relative reflexivity ontological-

contiguity ';-as-operative-notional deprocrypticism) as of

construction-of-the-Self', as involving the respectively implied baseinstitutionalisation, ${ }^{103}$ universalisation, positivism/rational-empiricism and prospectively notional deprocrypticism ('relative-ontologicalcompleteness — apriorising/axiomatising/referencing-psychologism enculturated/constructed social-pragmatics-framing-of-predicativeeffectivity-sublimation-_as-to-underlying,-ontological-commitment <implied-self-assuredness-of-ontological-good-

faith/authenticity postconverging-dementating/structuring/paradigming -as-being-as-of-existentialreality $>$ J') $\quad{ }^{4}$ foregrounding_entailment-<in-succession-of-profoundsupererogation $>$ - (postconverging-narrowing-down $\sim$ sublimation-as-to'existence - as-sublimating-withdrawal/unenframing/re-ontologising,elicited-from-prospective-profound-supererogation '-in-reflecting'immanent relative unreflexivy ontologicalcontiguity ';-as-operative-notional deprocrypticism); $\uparrow \quad$ blurriness$<$ sterilising/anecdotalising/trivialising-of-prospective-reontologising_by-preconverging,-in-disontologising-formulaic-draggingout/hollowing-out $>$ is ultimately associated with lack of dispensing-withimmediacy-for-relative-ontological-completeness ${ }^{87}$-by- 
reification/contemplative-distension (as of human self-surpassingexistentialism-form-factor,-in-overcoming- 'notional collateralisingbeholdening-protohumanity'-to- 'attain-sublimating-humanity'-as-toexistence-potency $\sim$ sublimating-nascence,-disclosed-from-prospectiveepistemic-digression to supersede human temporality/shortness <amplitudinglformative> wooden-language-fimbued-averaging-ofthought-<as-to-leveling/ressentiment/closed-construct-ofmeaningfulness-and-teleology -as-of-'nondescript/ignorable-void 'with-regards-to-prospective-apriorising-implications $>$ J) with regards to human existential-extrication-as-of-existential-unthought in the perception and relation to the human existential<disontologising/re ontologising aporeticism> narrative, with contrastive conceptualisation as of an 'asceticism for opened-constructof- meaningfulness-and-teleology that is reflexive of overall Beingdevelopment/ontological-framework-expansion-as-to-depth-ofontologising-development-as-infrastructure-of- meaningfulness-andteleology implications' (as to the possibility of prospective originarinessparrhesia,-as-spontaneity-of-aestheticisation) and a 'nihilistic <amplitudingfformative> wooden-language-_imbued-averaging-ofthought-<as-to-leveling/ressentiment/closed-construct-ofmeaningfulness-and-teleology -as-of-'nondescript/ignorable-void 'with-regards-to-prospective-apriorising-implications $>$ ) that is rather reflexive of constraining secondnatured institutionalisation positiveopportunism-of-social-functioning-and-accordance implications' (as to a mechanical/mere-form disposition for reproducibility- 
mathesis/motif/thrownness-disposition,-as-reproducibility-of-

aestheticisation that do-not/poorly-appreciate dimensionality-ofsublimating $-1<$ amplituding/formative $>$ supererogatory $\sim d e-$

mentativeness/epistemic-growth-or-conflatedness /transvaluative-

rationalising/transepistemicity/anamnestic-residuality/spirit-drivenness-

equalisation (); $\mathbf{q}$ and finally blurriness-

$<$ sterilising/anecdotalising/trivialising-of-prospective-re-

ontologising_by-preconverging,-in-disontologising-formulaic-dragging-

out/hollowing-out> is associated with sophistic/pedantic induced

equivalence of teleologically-elevated knowledge-reifying meaningfulness-and-teleology (as to maximalising-recomposuringfor-relative-ontological-completeness -unenframed/re-

ontologising conceptualisation) and teleologically-degraded

$<$ amplinglive $>$ wooden-language-fimbued-averaging-of-

thought-<as-to-leveling/ressentiment/closed-construct-of-

meaningfulness-and-teleology -as-of- 'nondescript/ignorablevoid'-withregards-to-prospective-apriorising-implications $>>{ }^{56}$ meaningfulness-andteleology (as to incrementalism-in-relative-ontologicalincompleteness - enframed/disontologising conceptualisation) as of social-stake-contention-or-confliction perversed inclination; $\uparrow$ unblurriness-<re-ontologising_by-postconverging-as-to-dragged-outsupererogatory wholesomeness/profound-supererogation ,-whileanecdotalising-prior-disontologising-thresholding $>$ as construed from the ontologically-veridical perspective of ontologicalnormalcy/postconvergence (as from prospective ${ }^{6 /}$ nonpresencing- 
$<$ perspective-ontological-normalcy/postconvergence $>$ reflection

< amplituding/formative-epistemicity >causality $\sim$ as-to-projective-

totalitative-implications-of-prospective- nonpresencing,-for-

explicating felative unreflexivity/relative reflexivity -ontological-

contiguity as of relative-ontological-incompleteness /relative-

ontological-completeness

(sublimating referencing/registering/decisioning,-as-self-becoming/self-

conflatedness /formative-supererogating-<projective/reprojective-

aestheticising-re-motif-and-re-apriorising/re-axiomatising/re-

referencing,-in-perspective-ontological-normalcy/postconvergence $>$ I),

highlights that there is a 'human capacity of

apriorising/axiomatising/referencing-\{of- 'prospectively

implicited_attendant_ontological-contiguity ' reduced-

existentialising/contextualising/textualising_intelligibility/epistemicity/re

flexivity-contiguity-<imbued-notional $\sim$ cogency $>$ ' \}-conflatedness ${ }^{13}$ -

in-\{preconverging-ment by\} postconverging-entailment (so-construed as

dimensionality-of-sublimating ${ }^{25}$

< $<$ amplituding/formative $>$ supererogatory de-mentativeness/epistemic-

growth-or-conflatedness /transvaluative-

rationalising/transepistemicity/anamnestic-residuality/spirit-drivenness-

equalisation ) intimately associated with its prospective ${ }^{56}$ meaningfulnessand-teleology/knowledge as to institutional-cumulation/institutionalrecomposure-_as-to- historiality/ontological-eventfulness /ontologicalaesthetic-tracing-<perspective-ontological-normalcy/postconvergence- 
reflected-'epistemicity-relativism-determinism'>) so-implied in the relative unreflexivity/relative reflexivity ontological-contiguity $\sim$ of-thehuman-institutionalisation-process ${ }^{6,}$, as of an underlying human epistemic-ricochetting/transepistemicity foregrounding_entailment$<$ in-succession-of-profound-supererogation ${ }^{>}$-〈postconvergingnarrowing-down sublimation-as-to-'existence - as-sublimatingwithdrawal/unenframing/re-ontologising,-elicited-from-prospectiveprofound-supererogation '-in-reflecting- 'immanent felativeunreflexivity/relative reflexivity ontological-contiguity ';-as-operativenotional deprocrypticism) (that speaks more of human limitedmentation-capacity-deepening - as-subjecting limitedness/humansubpotency to 'educed unlimitedness/existence sublimating nascence' in its becoming ${ }^{4}$ historiality/ontological-eventfulness ${ }^{38}$ ontologicalaesthetic-tracing-<perspective-ontological-normalcy/postconvergencereflected- 'epistemicity-relativism-determinism'>) wherein foregrounding_entailment-<in-succession-of-profoundsupererogation $>$ - (postconverging-narrowing-down $\sim$ sublimation-as-to'existence - as-sublimating-withdrawal/unenframing/re-ontologising,elicited-from-prospective-profound-supererogation '-in-reflecting'immanent relative unreflexivitrelative reflexivity ontologicalcontiguity ';-as-operative-notional deprocrypticism) is more than just a question of arbitrary unification but rather is a 'preconverging/postconverging-de-mentative/structural/paradigmatic postconverging-confiscation/selectiveness of the possibility of prospective 
relative-ontological-completeness

ontological-veracity

of

'meaningfulness-and-teleology that is reflexive of ecstatic-existence',

and foregrounding_entailment-<in-succession-of-profound-

supererogation $>_{-}$(postconverging-narrowing-down $\sim$ sublimation-as-to-

'existence-as-sublimating-withdrawal/unenframing/re-ontologising,-

elicited-from-prospective-profound-supererogation '-in-reflecting-

'immanent relative unreflexivity/relative reflexivity ontological-

contiguity ';-as-operative-notional deprocrypticism) effectively

implies that at reference-of-thought-level intellectual-entitlement to

disparateness-of-conceptualisation-<unforegrounding-ment,-failing-

prospectively-to-reflect- 'immanent relative unreflexivity/relative-

reflexivity ontological-contiguity '> possibilities as from * recurrent-

utter-uninstitutionalisation's

supererogatory acuity/perspicacity/astuteness/edginess/incisiveness-of-

apriorising/axiomatising/referencing/intelligibilitysettingup/measuringins

trumenting-for-conceptualisation, is invalid and rather of

foregrounding_entailment-<in-succession-of-profound-

supererogation $>$ - (postconverging-narrowing-down $\sim$ sublimation-as-to-

'existence-as-sublimating-withdrawal/unenframing/re-ontologising,-

elicited-from-prospective-profound-supererogation '-in-reflecting-

'immanent relative-unreflexivity/relative-reflexivity ontological-

contiguity ';-as-operative-notional deprocrypticism) (as of

ontological-normalcy/postconvergence prospective

postconverging aporeticism-overcoming/unovercoming implications) of

rulemaking-over-non-rules - apriorising/axiomatising/referencing- 
psychologism (excludes all other supposed ${ }^{56}$ meaningfulness-andteleology /knowledge based on prior nonrulesapriorising/axiomatising/referencing-psychologism') inducing prospective 'base-institutionalisation foregrounding_entailment-<insuccession-of-profound-supererogation >-_postconverging-narrowingdown sublimation-as-to- 'existence —as-sublimatingwithdrawal/unenframing/re-ontologising,-elicited-from-prospectiveprofound-supererogation '-in-reflecting- 'immanent relativeunreflexivity/relative reflexivity ontological-contiguity ';-as-operativenotional deprocrypticism)', likewise foregrounding_entailment-<insuccession-of-profound-supererogation >-[postconverging-narrowingdown Sublimation-as-to-'existence-as-sublimatingwithdrawal/unenframing/re-ontologising,-elicited-from-prospectiveprofound-supererogation '-in-reflecting- 'immanent relative-

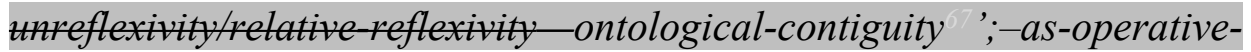
notional deprocrypticism) as from *base-institutionalisationuninstitutionalisation (as of ontological-normalcy/postconvergence prospective postconvergingaporeticism-overcoming/unovercoming implications) to ${ }^{103}$ universalisation-directed-rulemaking-over-non-rulesapriorising/axiomatising/referencing-psychologism (excludes all other supposed ${ }^{5}$ meaningfulness-and-teleology/knowledge 'based on prior rulemaking-over-non-rules—apriorising/axiomatising/referencingpsychologism') to then induce prospective '03iversalisation foregrounding_entailment-<in-succession-of-profound- 
supererogation $>$ - (postconverging-narrowing-down $\sim$ sublimation-as-to'existence - as-sublimating-withdrawal/unenframing/re-ontologising,elicited-from-prospective-profound-supererogation '-in-reflecting'immanent relative unreflexivity/relative reflexivity ontologicalcontiguity ';-as-operative-notional deprocrypticism)', likewise foregrounding_entailment-<in-succession-of-profoundsupererogation >-(postconverging-narrowing-down $\sim$ sublimation-as-to'existence - as-sublimating-withdrawal/unenframing/re-ontologising,elicited-from-prospective-profound-supererogation '-in-reflecting'immanent relative unreflexivity/relative reflexivity ontologicalcontiguity ';-as-operative-notional deprocrypticism) as from * universalisation-non-positivism/medievalism (as of ontologicalnormalcy/postconvergence prospective postconvergingaaporeticismoremplications) to positivising/rationalempiricism-based-universalisation-directed-rulemaking-over-non-rulesapriorising/axiomatising/referencing-psychologism (excludes all other supposed ${ }^{5}$ meaningfulness-and-teleology /knowledge 'based on prior universalisation-directed-rulemaking-over-non-rules-

apriorising/axiomatising/referencing-psychologism') to then induce prospective 'positivism/rational-empiricism foregrounding_entailment$<$ in-succession-of-profound-supererogation ${ }^{>}$-〈postconvergingnarrowing-down $\sim$ sublimation-as-to- 'existence - as-sublimatingwithdrawal/unenframing/re-ontologising,-elicited-from-prospectiveprofound-supererogation '-in-reflecting- 'immanent felative- 
unreflexivity/relative reflexivity ontological-contiguity ';-as-operative-

notional deprocrypticism)', and likewise ${ }^{4}$ foregrounding_entailment-

$<$ in-succession-of-profound-supererogation ${ }^{>}>$-ppostconverging-

narrowing-down sublimation-as-to-'existence-as-sublimating-

withdrawal/unenframing/re-ontologising,-elicited-from-prospective-

profound-supererogation '-in-reflecting- 'immanent relative-

unreflexivity/relative reflexivity ontological-contiguity ';-as-operative-

notional deprocrypticism) as from *positivism- procrypticism (as of ontological-normalcy/postconvergence

prospective

postconvergingaporeticism overcoming/unovercoming implications) to

notional deprocrypticism as preempting-disjointedness-as-of-

${ }^{3}$ reference-of-thought,-as-to- ${ }^{3}<$ amplitudinglformative-

epistemicity>growth-or-conflatedness ${ }^{13} /$ transvaluative- $^{-}$

rationalising/transepistemicity/anamnestic-residuality/spirit-

drivenness'-in-superseding-mere-formulaic-positivising/rational-

empiricism-based-universalisation-directed-rulemaking-over-non-rules-

apriorising/axiomatising/referencing-psychologism (excludes all other supposed ${ }^{5}$ meaningfulness-and-teleology"/knowledge 'based on prior positivising/rational-empiricismbased-universalisation-directed-

rulemaking-over-non-rules — apriorising/axiomatising/referencing-

psychologism') to then induce prospective 'notional deprocrypticism

foregrounding_entailment-<in-succession-of-profound-

supererogation $>$ - (postconverging-narrowing-down $\sim$ sublimation-as-to-

'existence-as-sublimating-withdrawal/unenframing/re-ontologising,-

elicited-from-prospective-profound-supererogation '-in-reflecting- 
'immanent relative unreflexivity/relative reflexivity ontological-

contiguity ';-as-operative-notional deprocrypticism)', and in all such cases the idea is ever always to move from a <amplitudingfformative> wooden-language-_imbued-averaging-ofthought-<as-to-leveling/ressentiment/closed-construct-ofmeaningfulness-and-teleology -as-of-'nondescript/ignorable-void 'with-regards-to-prospective-apriorising-implications $>$ | to an openedconstruct-of- meaningfulness-and-teleology reflexive of ecstaticexistence in postconverging-narrowing-down sublimation as from 'nonrules, rulemaking-over-non-rules, $\quad$ universalisation-directedrulemaking-over-non-rules, positivising/rational-empiricism-baseduniversalisation-directed-rulemaking-over-non-rules, and preemptingdisjointedness-as-of- reference-of-thought,-as-to-

' amplituding/formative-epistemicity>growth-orconflatedness $/$ transvaluativerationalising/transepistemicity/anamnestic-residuality/spiritdrivenness'-in-superseding-mere-formulaic-positivising/rationalempiricism-based-universalisation-directed-rulemaking-over-non-rules foregrounding_entailment-<in-succession-of-profoundsupererogation $>$ - (postconverging-narrowing-down $\sim$ sublimation-as-to'existence - as-sublimating-withdrawal/unenframing/re-ontologising,elicited-from-prospective-profound-supererogation '-in-reflectingimmanent relative unreflexivity/relative reflexivity ontologicalcontiguity ';-as-operative-notional deprocrypticism)' while 
superseding any presencing-absolutising-identitive-constitutedness (failing to imply this ontological-normalcy/postconvergence in reflecting holographically-<conjugatively-and-transfusively $>$ the relativeunreflexivity/relative reflexivity-ontological-contiguity of-the-humaninstitutionalisation-process as from 'non-rules, rulemaking-overnonrules, $\quad$ universalisation-directed-rulemaking-over-non-rules, positivising/rational-empiricism-based-universalisation-directed-

rulemaking-over-non-rules, and preempting-disjointedness-as-ofreference-of-thought,-as-to- ${ }^{3}<$ amplitudinglformative-

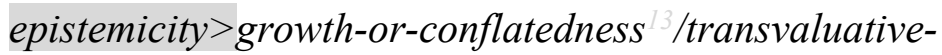
rationalising/transepistemicity/anamnestic-residuality/spiritdrivenness'-in-superseding-mere-formulaic-positivising/rationalempiricism-based-universalisation-directed-rulemaking-over-non-rules foregrounding_entailment-<in-succession-of-profoundsupererogation $>_{-}$(postconverging-narrowing-down $\sim$ sublimation-as-to'existence - as-sublimating-withdrawal/unenframing/re-ontologising,elicited-from-prospective-profound-supererogation '-in-reflectingimmanent relative unreflexivity/relative reflexivity ontologicalcontiguity ';-as-operative-notional (deprocrypticism)') which by its very token elaboration-as-to-mereextrapolating/constituting/abstracting/deducing/inferring-of-elucidationoutside-'prospectively implicited_attendant-ontologicalcontiguity ${ }^{\prime} \sim$ educedexistentialising/contextualising/textualising_intelligibility/epistemicity/re flexivity-contiguity-<imbued-notional $\sim$ cogency $>$ ' rather wrongly 
supersedes ecstatic-existence as of existence-as-the-absolute-a-priori-ofconceptualisation $\sim$ and $\sim$ existence — as-sublimatingwithdrawal/unenframing/re-ontologising,-elicited-from-prospectiveprofound-supererogation $-<$ as-to-perspective-ontologicalnormalcy/postconvergence-implied-" prospective-aporeticismovercoming/unovercoming'>, with 4foregrounding_entailment-<insuccession-of-profound-supererogation $>$-_postconverging-narrowingdown sublimation-as-to- 'existence-as-sublimatingwithdrawal/unenframing/re-ontologising,-elicited-from-prospectiveprofound-supererogation '-in-reflecting- 'immanent relativeunreflexivity/relative-reflexivity ontological-contiguity ';-as-operativenotional deprocrypticism) 'preconverging/postconverging-dementative/structural/paradigmatic postconvergingconfiscation/selectiveness of the possibility of the ontological-veracity of 'meaningfulness-and-teleology' implying for instance that there can be no conception/theory/idea of positivism/rational-empiricism devolving meaningfulness-and-teleology that is not rational-empirical like mentioning say magical or supernatural causes and effects, and likewise prospectively with notional deprocrypticism any conception/theory/idea in disjointedness that fails to reflect 'implicited_attendant-ontologicalcontiguity $\stackrel{\sim}{\sim}$ educed-

existentialising/contextualising/textualising_intelligibility/epistemicity/re flexivity-contiguity-<imbued-notional $\sim \operatorname{cogency}>$ ' as of parrhesiastic and reproducibility—mathesis/motif/thrownness-disposition,-asreproducibility-of-aestheticisation organic coherence and as ultimately 
reflecting all human knowledge as to overall reifying-and-empoweringreflexivity-of-ecstatic-existence-as-panintelligibility-panreflexivity ${ }^{3-}$ lexistentially-imbued-and-educing-<epistemic-

totalising ${ }^{3}$ hermeneutically/textually/reprojectingly/supererogatingly/zeroin gly/re actingly, \{decompulsing? delinearity for-cogency $\geq$ epistemicperspective-of-projective/reprojective-aestheticising-re-motif-and-reapriorising/re-axiomatising/re-referencing conceptualisation,-as-hereinspecifically relevant to human subpotency)', furthermore with regards specifically to say the 'positivism/rational-empiricism ${ }^{83}$ reference-ofthought- devolving level of 'meaningfulness-and-teleology' we can factor in that any 'supposedly deepening/profound' conception/theory/idea say about biological hereditary is rather inconceivable as a phenomenality that fails foregrounding_entailment-<in-succession-of-profoundsupererogation $>$-〈postconverging-narrowing-down $\sim$ sublimation-as-to'existence - as-sublimating-withdrawal/unenframing/re-ontologising,elicited-from-prospective-profound-supererogation '-in-reflecting'immanent relative unreflexivity/relative reflexivity ontologicalcontiguity ';-as-operative-notional deprocrypticism) (as of ontological-normalcy/postconvergence prospective postconverging implications) rather to a specific-and-coherent conceptualisation of gene regulation and so except it can demonstrate a further foregrounding_entailment-<insuccession-of-profound-supererogation >-(postconverging-narrowingdown sublimation-as-to- 'existence-as-sublimating- 
withdrawal/unenframing/re-ontologising,-elicited-from-prospective-

profound-supererogation '-in-reflecting- 'immanent relative-

unreflexivity/relative reflexivity ontological-contiguity ';-as-operative-

notional deprocrypticism) (epistemic-ricochettingly/transepistemically

as of ontological-normalcy/postconvergence prospective

postconvergingaporeticism overcoming/unovercoming implications)

that implies the 'totalising-entailing complementing-and/or-supersedingand/or-subsuming of gene regulation' and the life scientist will hardly take seriously any such conceptualisation of biological hereditary that fails to fulfil the above conditions on mere 'pedantic grounds of intellectualentitlement to disparateness-of-conceptualisation-<unforegroundingment,-failing-prospectively-to-reflect- immanent relative-

unreflexivity/relative reflexivity ontological-contiguity '>' and so as of the life sciences need for existential-reality constraining ‘ foregrounding_entailment-<in-succession-of-profound-

supererogation $>$ - (postconverging-narrowing-down $\sim$ sublimation-as-to'existence - as-sublimating-withdrawal/unenframing/re-ontologising,elicited-from-prospective-profound-supererogation '-in-reflecting'immanent relative unreflexivity/relative reflexivity ontologicalcontiguity ';-as-operative-notional deprocrypticism) supererogatory acuity/perspicacity/astuteness/edginess/incisiveness-ofapriorising/axiomatising/referencing/intelligibilitysettingup/measuringins trumenting-for-conceptualisation' as so-reflected consistently in gene regulation 'as of ${ }^{4}$ foregrounding_entailment-<in-succession-of-

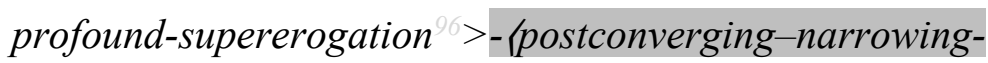


down sublimation-as-to-'existence-as-sublimating-

withdrawal/unenframing/re-ontologising,-elicited-from-prospective-

profound-supererogation '-in-reflecting- 'immanent felative-

unreflexivity/relative reflexivity - ontological-contiguity ';-as-operative-

notional deprocrypticism) preconverging/postconverging-de-

mentative/structural/paradigmatic postconverging-

confiscation/selectiveness of the possibility of the ontological-veracity of

biological hereditary ${ }^{56}$ meaningfulness-and-teleology ; $;$ (the overall implications of unblurriness-<re-ontologising_by-postconverging-as-todragged-out-supererogatory-wholesomeness/profound-

supererogation ,-while-anecdotalising-prior-disontologising-

thresholding $>\quad$ reflected as from '<amplitudingfformativeepistemicity>totalising/circumscribing/delineating 'implicited_attendantontological-contiguity ${ }^{\text {' }}$ educed-

existentialising/contextualising/textualising_intelligibility/epistemicity/re flexivity-contiguity-<imbued-notional $\sim$ cogency $>$

foregrounding_entailment-<in-succession-of-profound-

supererogation $>$ - \{postconverging-narrowing-down $\sim$ sublimation-as-to'existence-as-sublimating-withdrawal/unenframing/re-ontologising,-

elicited-from-prospective-profound-supererogation '-in-reflecting-

'immanent relative unreflexivity/relative reflexivity ontological-

contiguity ';-as-operative-notional deprocrypticism) in reifying-orelucidating relative unreflexivity/relative reflexivity-ontological-

contiguity $-<$ as-from-prospective-ontological-

normalcy/postconvergence-epistemic-or-notional projective- 
perspective $>$ ' is in highlighting that ecstatic-existence as of existence-asthe-absolute-a-priori-of-conceptualisation $\sim$ and $\sim$ existence-assublimating-withdrawal/unenframing/re-ontologising,-elicited-fromprospective-profound-supererogation $-<$ as-to-perspective-ontologicalnormalcy/postconvergence-implied-" prospective-aporeticismovercoming/unovercoming'> is of the inherent '<amplitudingfformativeepistemicity>causality $\sim$ as-to-projective-totalitative-implications-ofprospective- nonpresencing,-for-explicating felative unreflexivity/relative reflexivity ontological-contiguity epistemicricochetting/transepistemicity primacy and on this basis is alldefining/deterministic in the construing of knowledgereification gesturing-and-accounting-of-epistemic-phenomenalism<in-prospective psychologismic $\sim$ apriorising/axiomatising/referencing\{of-'prospectively_implicited_attendant-ontologicalcontiguity ' 'educedexistentialising/contextualising/textualising_intelligibility/epistemicity/re flexivity-contiguity-<imbued-notional $\sim$ cogency $>$ ' \}-conflatedness in \{preconverging ment by\} postconverging entailment> as of 'implicited_attendant-ontological-contiguity ' reducedexistentialising/contextualising/textualising_intelligibility/epistemicity/re flexivity-contiguity-<imbued-notional $\sim \operatorname{cogency}>$ ' in apriorising/axiomatising/referencing-\{of-"prospectively implicited ontological-contiguity ' educedexistentialising/contextualising/textualising_intelligibility/epistemicity/re flexivity-contiguity-<imbued-notional $\sim$ cogency> ' $\}$-conflatedness ${ }^{13}-$ 
in 'fpreconverging ment by) postconverging entailment', and so as ecstatic-existence is what can 'validate-and-falsify the ontologicalveracity of any supposed <amplituding/formativeepistemicity >causality as-to-projective-totalitative-implications-ofprospective- nonpresencing,-for-explicating relative unreflexivity/relative-reflexivity ontological-contiguity' and as it overrides any human secondary epistemic inclination that may wrongly be of ${ }^{7}$ presencing-absolutising-identitive-constitutedness ${ }^{14}$, with the inherent becoming of ecstatic-existence rather reflected in ontologicallyveridical 'knowledge-reification $\sim$ gesturing-and-accounting-ofepistemic-phenomenalism-<in-

prospective psychologismic $\sim$ apriorising/axiomatising/referencing-\{of'prospectively implicited_attendant-ontological-contiguity ' educedexistentialising/contextualising/textualising_intelligibility/epistemicity/re flexivity-contiguity-<imbued-notional $\sim$ cogency> ' \}-conflatedness in \{preconverging ment by\} postconverging entailment>/process entailing-<mplinglformative-epistemicity $>$ totalising $\sim$ in-relativeontological-completeness $\quad$ epistemic-ricochetting/transepistemicity implications of aetiologisation/ontological-escalation-<ontologicalveridicality_commitment/otherliness_transcending/compulsionsencumbered_transcending >' and in so doing 'abstractivelyandsystematically justifying the socially imbued intellectual deferentialformalisation-transference' as to the fact that the knowledgereification $\sim$ gesturing-and-accounting-of-epistemic-phenomenalism$<$ in-prospective psychologismic $\sim$ apriorising/axiomatising/referencing- 
\{of-'prospectively_implicited_attendant-ontological-

contiguity ' reduced-

existentialising/contextualising/textualising_intelligibility/epistemicity/re flexivity-contiguity-<imbued-notional $\sim$ cogency $>$ ' \}-conflatedness -

in \{preconverging ment by? postconverging entailment> is not of 'mere sterile/anecdotal imprimatur totalisingly-ing — discretion/whim-of-thought that fails to justify abstractively-and-systematically any such entailing$<$ amplitudingfformative-epistemicity>totalising in-relative-ontologicalcompleteness $^{87}$ epistemic-ricochetting/transepistemicity implications of aetiologisation/ontological-escalation-<ontological-

veridicality_commitment/otherliness_transcending/compulsionsencumbered_transcending >', and thus 'superseding-and-resolving the epistemic postconvergingaporeticism-overcoming/unovercoming of prospective knowledge-reification gesturing-and-accounting-ofepistemic-phenomenalism- $<$ in-

prospective psychologismic apriorising/axiomatising/referencing-\{of'prospectively implicited_antontontolontontiguity ' reducedexistentialising/contextualising/textualising_intelligibility/epistemicity/re flexivity-contiguity-<imbued-notional $\sim$ cogency> ' \}-conflatedness in \{preconverging ment by\} postconverging entailment>' with regards to 'determining intrinsic-reality/ontological-veracity' as the latter is ever always caught up, given human-subpotencyaporia/undecidability/dilemma/oughtindeterminacy/deficiency/limitation/constraint—imbued'notional firstnaturedness-formativeness-<as to-eventualising inkling 
drive or seeding misprising $>$ temporal-to-intemporal-dispositions-

$<$ so-construed-as-from-perspective-ontological-

normalcy/postconvergence>'-existentialism-form-factor, in human ontological-faith-notion-or-ontological-fideism—imbued-

underdetermination-of-motif-and-apriorising/axiomatising/referencing-

as-so-being-as-of-existential-reality

between

'intemporalising/ontologising

ontological-good-

faith/authenticity $\sim$ postconverging-de-

mentating/structuring/paradigming ' and 'temporalising ontologicalbad-faith/inauthenticity $\sim$ preconverging-de-

mentating/structuring/paradigming ${ }^{5}, \quad$ beyond-the-consciousness-

awareness-teleology -<of-preconverging-existential-extrication-as-of-

existential-unthought $>$ )

${ }^{8}$ categorical- categorical-imperatives/axioms/registry-teleology (as to the epistemicimperatives/axiom operance of human meaningfulness-and-teleology s/registry- $\quad$ underlying

teleology apriorising/axiomatising/referencing/intelligibilitysettingup/measuringins trumenting,-so-construed-as-categorical-imperatives/axioms/registryteleology) underlies human conceptivity/epistemicreflexivity/epistemicity-relativism-determinism-<reifying\{as-toknowledge-developing\}-and-empowering $>$ in existence as to overall reifying-and-empowering-reflexivity-of-ecstatic-existence-aspanintelligibilityłpanreflexivity - lexistentially-imbued-and-educing$\leq$ fepistemic 
gly/re acutingly, -\{decompulsing $d e l i n e a r i t y \sim$ for-cogency $\geq$ epistemic-

perspective-of-projective/reprojective-aestheticising-re-motif-and-re-

apriorising/re-axiomatising/re-referencing conceptualisation,-as herein

specifically relevant to human-subpotency) (so-reflected as to 'human

Being-development/ontological-framework-expansion-as-to-depth-of-

ontologising-development-as-infrastructure-of- meaningfulness-and-

teleology , institutional-development-as-to-social-function-development

and living-development-as-to-personality-development psychologismic

epistemic acutisation difficulty< <or, residualising

\{decompulsing' delinearity-for-cogency> magnitudes'(of-experientiality/experiment\}'),

with the implication that human limited-mentation-capacity-as-

subjecting 'educed unlimitedness/existence-sublimating nascence' to-

limitedness/human-subpotency undermines the existential-

$<$ disontologising/re ontologising aporeticism> ontological-

performance ${ }^{72}<$ including-virtue-as-

ontology>/morality/ethics/justice/etc. of human categoricalimperatives/axioms/registry-teleology so-reflected as to successive human registry-worldviews/dimensions uninstitutionalised-threshold circularity-as-subtransversality-<in-desublimating-existential-

eventuating/denouement> of-motif-and-

apriorising/axiomatising/referencing rather superseded with human limited-mentation-capacity-deepening - as subjecting limitedness/humansubpotency to-'educed unlimitedness/existence sublimating nascence' and the further epistemic consequence (from nonpresencing- 
$<$ perspective-ontological-normalcy/postconvergence $>$

epistemic-

projection) that human limited-mentation-capacity-as-subjecting

'educed unlimitedness/existence sublimating nascence' to-

limitedness/human-subpotency implies human ${ }^{5}$ meaningfulness-andteleology is ever always caught up between any given registryworldview's/dimension's

institutionalisation-threshold-

supratransversality-<in-sublimating-existential-

eventuating/denouement $>\sim$ of-motif-and-

apriorising/axiomatising/referencing in postconverging/dialecticalthinking -qualia-schema/psychologism and its prospectively uninstitutionalised-threshold ${ }^{02}$-circularity-as-subtransversality-<indesublimating-existential-eventuating/denouement> of-motif-andapriorising/axiomatising/referencing in preconverging/dementing qualia-schema/psychologism (with the latter marked by the registryworldview's/dimension's $\quad$ '<amplitudinglformative>wooden-language(imbued-temporal-mere-form/virtualities/dereification/akrasiaticdrag/denatured/preconverging-or-dementing -narratives-of-thereference-of-thought-categorical-imperatives/axioms/registryteleology / as reflecting the '<amplitudingfformative> wooden-language(imbued-averaging-of-thought-<as-to-leveling/ressentiment/closedconstruct-of- meaningfulness-and-teleology -as-of'nondescript/ignorable-void '-with-regards-to-prospective-apriorisingimplications $>$ ) 
ative-

epistemicity $>$ causa

lity ${ }^{9}$ as-to-

projective-

totalitative-

implications-of-

prospective-

nonpresencing,-

for-

explicating relativ

e-

unreflexivity/relati

ve-reflexivity

ontological-

contiguity

totalitative-implications-of-prospective- nonpresencing,-for-

explicating relative unreflexivity/relative reflexivity ontological-

contiguity as of foregrounding_entailment-<in-succession-ofprofound-supererogation $>$-_postconverging-narrowing-

down sublimation-as-to-'existence-as-sublimating-

withdrawal/unenframing/re-ontologising,-elicited-from-prospective-

profound-supererogation '-in-reflecting- 'immanent relative-

unreflexivity/relative reflexivity ontological-contiguity ';-as-operative-

notional deprocrypticism) ${ }^{5}$ meaningfulness-and-teleology in

reflecting holographically-<conjugatively-and-transfusively $>$ the

relative unreflexivity/relative reflexivity ontological-contiguity of-the-

human-institutionalisation-process , and so-construed-as-from-theontological-normalcy/postconvergence-epistemic-or-notional $\sim$ projectiveperspective-of-conceptualisation; $\boldsymbol{q}$ in this regards 'formativeness in existence as <amplituding/formative-epistemicity>causality $\sim$ as-toprojective-totalitative-implications-of-prospective- nonpresencing,-forexplicating relative unreflexivity/relative reflexivity ontologicalcontiguity ' is rather reflected as of the teleologies ('phenomenal/manifest conceptivity/epistemic-reflexivity/epistemicity-relativism-determinism$<$ reifying\{as-to-knowledge-developing\}-and-empowering $>$ in existence as ontological') of phenomenal/manifest $\sim$ subpotencies-(in-transitiveconflatedness -reflexivity,-in-the-full-potency-of-

existence's sublimating-nascence) as so-underlied as of overall reifyingand-empowering-reflexivity-of-ecstatic-existence-as- 
gly/re acutingly, - \{decompulsing ${ }^{2}$ delinearity for-cogency $\geq$ epistemic-

perspective-of-projective/reprojective-aestheticising-re-motif-and-re-

apriorising/re-axiomatising/re-referencing conceptualisation, as herein specifically relevant to human-subpotency), with the supererogatory implication that the 'epistemic-projection perspectives of preconverging/dementing -apriorising-psychologism and postconverging/dialectical-thinking -apriorising-psychologism' are of 'the-very-same notionalisation/notional-conception/amplituding of referencing/registering/decisioning of shallow-supererogation - toprofound-supererogation', (such that the relative-unreflexivity/relativereflexivity ontological-contiguity of-the-human-institutionalisationprocess is the-very-same notionalisation/notionalconception/amplituding of referencing/registering/decisioning of shallowsupererogation -to-profound-supererogation ') thus reflecting the fact that the 'ontological-normalcy/postconvergence of the full-potency of existence' as the absolute epistemic-projection perspective of profoundsupererogation' is 'not of referenced/registered/decisioned presence/constitutedness ${ }^{4} \quad$ but rather of referencing/registering/decisioning becoming/conflatedness ${ }^{13 / f o r m a t i v e-~}$ supererogating' and by extension the 'epistemicabnormalcy/preconvergence ${ }^{3 /}$ of phenomenal/manifest $\sim$ subpotencies-_intransitive-conflatedness -reflexivity,-in-the-full-potency-of- 
existence's sublimating-nascence)' as to their epistemic-projection perspectives of relative profound-supererogation is 'not of desublimating referenced/registered/decisioned self-presence/selfconstitutedness $^{4}-<$ in-perspective-epistemic-

abnormalcy/preconvergence ${ }^{3}$ ' but rather 'of sublimating referencing/registering/decisioning self-becoming/self-

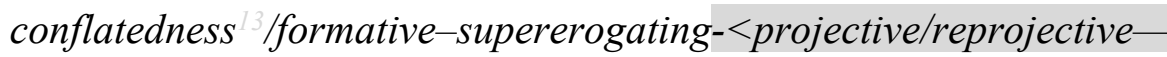
aestheticising-re-motif-and-re-apriorising/re-axiomatising/rereferencing,-in-perspective-ontological-normalcy/postconvergence> ', and so as to imply that 'intelligibility of phenomenality/manifestation in existence as to causality' can only be divulged as of 'any given sublimating referencing/registering/decisioning (whether 'of sublimating inlining-as-to-inherent-immanence-of-manifestation/phenomenality' or 'of sublimating conceptivity/epistemic-reflexivity/epistemicity-relativismdeterminism-<reifying\{as-to-knowledge-developing\}-and-empowering $>$ as-to-transcendent-reflexivity-of-manifestation/phenomenality' underlied totalisingly as of overall panintelligibility/panreflexivity effusing/ecstatic-inlining) sublimating in self-becoming/self-

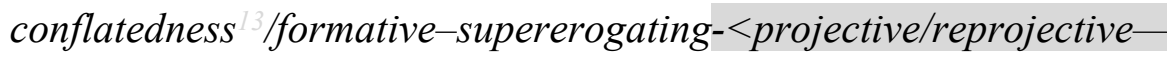
aestheticising-re-motif-and-re-apriorising/re-axiomatising/rereferencing,-in-perspective-ontological-normalcy/postconvergence $>$ (and so-construed as to the sublimating inlining-as-to-inherentimmanence-of-manifestation/phenomenality and/or sublimating conceptivity/epistemic-reflexivity/epistemicity-relativism-determinism$<$ reifying\{as-to-knowledge-developing\}-and-empowering >-as-to- 
transcendent-reflexivity-of-manifestation/phenomenality

phenomenal/manifest $\sim$ subpotencies-_in-transitive-conflatedness

reflexivity,-in-the-full-potency-of-existence's sublimating-nascence)); $₫$

$<$ formative-epistemicity >causality as-to-projective-

totalitative-implications-of-prospective- nonpresencing,-for-

explicating relative unreflexivity/relative reflexivity ontological-

contiguity / totalitative-accruing-relative-cause-and-effect-predicativeeffectivity-sublimation-\{as-to-underlying,-ontological-commitment

<implied-self-assuredness-of-ontological-good-

faith/authenticity postconverging-de-

mentating/structuring/paradigming -as-being-as-of-existential-reality>)

/ operatives-of-ontologically-hegemonising-narrative : implicating- 'thespecific-human-subpotency-panintelligibilityfpanreflexivity ${ }^{73}$-reflexivityin-ecstatic-existence'-as-of-its-knowledge-reifying-and-empoweringconflatedness ${ }^{3}$-construal-of-existence/intrinsic-reality-and-so-reflectedas-of 'implicited_attendant-ontological-contiguity' ' educedexistentialising/contextualising/textualising_intelligibility/epistemicity/re flexivity-contiguity-<imbued-notional cogency $>$ - $\{$ as-thepanintelligibilityłpanreflexivity -insight-about-ecstatic-existenceepistemically-deflates- 'existence-in-existence-constitutedness ${ }^{4}$ construal'\}, and this speaks to the fact that any implied ${ }^{56}$ meaningfulnessand-teleology (as knowledge-reification gesturing-and-accounting-ofepistemic-phenomenalism- $<$ in-

prospective psychologismic $\sim$ apriorising/axiomatising/referencing-\{of'prospectively_implicited_attendant_ontological-contiguity ' reduced- 
existentialising/contextualising/textualising_intelligibility/epistemicity/re

flexivity-contiguity-<imbued-notional $\sim$ cogency $\left.>^{\prime}\right\}$ ' - conflatedness

in fpreconverging ment by\} postconverging entailment>) 'epistemicveracity as well as its induced human empowerment for transcendenceand-sublimity/sublimation/supererogatory de-mentativity/emancipation' can only arise preconverging/postconverging-dementatively/structurally/paradigmatically as of its inherent supposedly coherent ontological-commitment -<implied-self-assuredness-ofontological-good-faith/authenticity postconverging-dementating/structuring/paradigming -as-being-as-of-existential-reality> as so-reflected in <amplitudingfformative-epistemicity>causality $\sim$ as-toprojective-totalitative-implications-of-prospective- nonpresencing,-forexplicating relative unreflexivity/relative reflexivity ontologicalcontiguity —so-construed-as-from-ontologicalnormalcy/postconvergence-epistemic-perspective / notional projectiveperspective-of-conceptualisation/totalitative-accruing-relative-causeand-effect-predicative-effectivity-sublimation-_as-to-underlying,ontological-commitment _<implied-self-assuredness-of-ontologicalgood-faith/authenticity postconverging-dementating/structuring/paradigming -as-being-as-of-existential-reality>> / operatives-of-ontologically-hegemonising-narrative ; with the result that vague articulations of 'flawed prior_knowledgereification $\sim$ gesturing-and-accounting-of-epistemic-phenomenalism<in-prior_psychologismic apriorising/axiomatising/referencing-\{of'prior-implicited_attendant-ontological-contiguity ' reduced- 
existentialising/contextualising/textualising_intelligibility/epistemicity/re flexivity-contiguity-<imbued-notional cogency >' \}-constitutedness in preconverging entailment>' out of this framework are rather epistemically-impertinent and ineffectual given their elaboration-as-tomere-extrapolating/constituting/abstracting/deducing/inferring-ofelucidation-outside-'prospectively implicited_attendant-ontologicalcontiguity ' $\sim$ educedexistentialising/contextualising/textualising_intelligibility/epistemicity/re flexivity-contiguity-<imbued-notional $\sim$ cogency> ; insightfully, the inherent human epistemic relation to ecstatic-existence-as-transcendentalsignifier-emergence/becoming-spontaneity-implications reflected as existence-potency $\sim$ sublimating-nascence,-disclosed-from-prospectiveepistemic-digression, implies that human conception of causality inherently 'is-not-of/not-ontological' but rather 'is-as-of/is-epistemic' about ecstatic-existence-as-transcendental-signifier, and this explains the conception of causality herein as <amplitudingfformativeepistemicity>causality as-to-projective-totalitative-implications-ofprospective- nonpresencing,-for-explicating felative unreflexivity/relative reflexivity ontological-contiguity as conflating towards the inherent ontological-normalcy/postconvergence of ecstaticexistence-as-transcendental-signifier as from human-subpotency epistemic-abnormalcy/preconvergence ${ }^{31}$ to epistemic-normalcy as humansubpotency strives to converge-as-construing to ecstatic-existence-astranscendental-signifier as of the projective-totalitative-implications of $<$ emplitudinglformative-epistemicity $>$ causality $\sim$ as-to-projective- 
totalitative-implications-of-prospective- nonpresencing,-for-

explicating felative unreflexivity/relative reflexivity ontological-

contiguity construed as causality; wherein for instance the appraisal of 'health epiphenomenon of existence' as of historiality/ontologicaleventfulness 3 /ontological-aesthetic-tracing-<perspective-ontologicalnormalcy/postconvergence-reflected-'epistemicity-relativism-

determinism'> ranging from per-cep-ti-vi-ty-as-of-bad-omen, per-cep-tivi-ty-as-of-a-specific-place-or-specific-evil-people-or-specific-evilperiod, per-cep-ti-vi-ty-as-of-failure-to-follow-the-heeding-of-the-Deityor-failure-to-adhere-to-a-certain-mysticism-or-failure-to-pay-reverenceto-an-ancestor, $\quad$ per-cep-ti-vi-ty-as-of-full-disease-and-scientific-theoryconstruct-as-the-exclusive-cause-and-effect-conceptualisation, and percep-ti-vi-ty-as-of-factoring-in—\{epistemic-

Hermeneutically/textully/reprojectingly/supererogatingly/zeroin

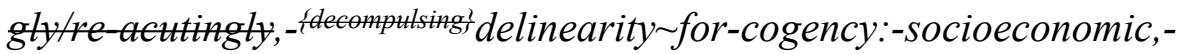
education,-information,-environmental,-gender-and-power-relationsissues-underlying-healthcare-and-medical-delivery reflects the 'epistemicveracity of human apriorising/axiomatising/referencing-\{of'prospectively_implicited_attendant-ontological-contiguity ' reducedexistentialising/contextualising/textualising_intelligibility/epistemicity/re flexivity-contiguity-<imbued-notional $\sim$ cogency $>^{\text {' }}$ \} - conflatedness ${ }^{13}-$ in \{preconverging ment by\} postconverging entailment/projectiveconflating apriorising' towards construing the ontologicalnormalcy/postconvergence of ecstatic-existence-as-transcendentalsignifier speaking of 'ontological-primemover-totalitative-framework as 
causality as of construction', whereas a presencing-absolutisingidentitive-constitutedness ${ }^{14}$ will naively equate any one of the registryworldview's/dimension's given per-cep-ti-vi-ty of 'health epiphenomenon of existence' in which it projects-mentally-by-its- reference-of-thought as the 'absolute basis for construing, defining and refining the conception of causality' failing to factor-in that it is rather in an 'epistemic situation as of epistemic-abnormalcy/preconvergence in relative-ontologicalincompleteness requiring not an apriorising/axiomatising/referencing-\{of- "prospectively implicited_attendant-ontological-contiguity ' educedexistentialising/contextualising/textualising_intelligibility/epistemicity/re flexivity-contiguity-<imbued-notional $\sim$ cogency $>$ ' \}-constitutedness ${ }^{14}$ in preconverging entailment apriorising/axiomatising/referencing but rather an apriorising/axiomatising/referencing-\{of-'prospectively implicited_attendant-ontological-contiguity ' educedexistentialising/contextualising/textualising_intelligibility/epistemicity/re flexivity-contiguity-<imbued-notional $\sim$ cogency> ' \}-conflatedness ${ }^{13}$ in \{preconverging ment by\} postconverging entailment/projectiveconflating apriorising/axiomatising/referencing in relative-ontologicalcompleteness ${ }^{87}$ in reflecting the ontological-normalcy/postconvergence of ecstatic-existence-as-transcendental-signifier (this ontologicalprimemovers-totalitative-implications insight about causality as reflected with the health epiphenomenon can be extended to all domains construed as for-human-studies/for-human-constructs for the simple reason that all such domains are of 'epistemically manifest historiality/ontological- 
eventfulness $\%$ ontological-aesthetic-tracing-<perspective-ontologicalnormalcy/postconvergence-reflected-'epistemicity-relativism-

contiguity ' ' educed-

existentialising/contextualising/textualising_intelligibility/epistemicity/re flexivity-contiguity-<imbued-notional $\sim$ cogency $>$ ' as of human limitedmentation-capacity-deepening —as-subjecting limitedness/humansubpotency to 'educed unlimitedness/existence sublimating nascence' '); 9 and this explains why a registry-worldview/dimension is a <emplitudingfformative > wooden-language-fimbued-averaging-ofthought-<as-to-leveling/ressentiment/closed-construct-ofmeaningfulness-and-teleology -as-of-'nondescript/ignorable-void 'with-regards-to-prospective-apriorising-implications $>\mid$ with the state of relative-ontological-incompleteness just as well aspiring for progress just as the state of relative-ontological-completeness 8 but the former failing to grasp that progress preconverging/postconverging-dementatively/structurally/paradigmatically arises rather by a change of supererogatory acuity/perspicacity/astuteness/edginess/incisiveness-ofapriorising/axiomatising/referencing/intelligibilitysettingup/measuringins trumenting -for-conceptualisation for aposteriorising/logicising/deriving/intelligising/measuring of meaningfulness-and-teleology in existence, such that even such budding-positivists like Newton or Descartes while making breakthroughs as of positivism/rational-empiricism are still caught up in 'reasoning as of the old' non-positivism/medievalism apriorising/axiomatising/referencing 
respectively with Newton's interests in alchemy and in the case of Descartes lingering religious sacrality/inviolability influence/grip on his thoughts; $\uparrow$ causality as herein construed as <amplituding/formativeepistemicity>causality as-to-projective-totalitative-implications-ofprospective- nonpresencing,-for-explicating felativethreflexivity/relative-reflexivity ontological-contiguity can thus be understood as the preconverging/postconverging-dementative/structural/paradigmatic implications of relative-ontologicalcompleteness in superseding/overcoming/transcending humansubpotency-aporia/undecidability/dilemma/ought-

indeterminacy/deficiency/limitation/constraint of relative-ontologicalincompleteness 'as so constructively implied herein, as to the reality that a 'traditional conception of causality as if human-subpotency is constituting the possibility for causations in existence' is herein construed as ontologically-flawed as it fails to reflect that existence is already a given and the very exercise of 'human-subpotency construal of causation is one of apriorising/axiomatising/referencing-\{of-'prospely implicited_attendant-ontological-contiguity ' reducedexistentialising/contextualising/textualising_intelligibility/epistemicity/re flexivity-contiguity-<imbued-notional $\sim$ cogency $>$ ' $\}$-conflatedness ${ }^{13}-$ in \{preconverging ment by\} postconverging entailment/projectiveconflating apriorising/axiomatising/referencing about the already given existence' and so as to overall reifying-and-empowering-reflexivity-ofecstatic-existence-as-panintelligibilityfpanreflexivity ${ }^{73}$ - lexistentiallyimbued-and-educing-<epistemic 
totalising ihermeneutically/textually/reprojectingly/supererogatingly/zeroin

gly/re acutingly, -idecompulsing? delinearity for-cogency $\geq$ epistemic-

perspective-of-projective/reprojective-aestheticising-re-motif-and-re-

apriorising/re-axiomatising/re-referencing conceptualisation, as herein

specifically relevant to human subpotency), speaking to the fact that

existence is rather about ecstatic notional $\sim$ reflexivity- $<$ \{veridical/sound\}

relative-reflexivity-in-existencetrelativising from limited mentation as

its deepening/psychologismic < residualising \{decompulsingt delinearity for

eogency>-by \{flawed/unsound? relative-unreflexivity-in-

existencetabsolutising from limited mentation/psychologismic epistemic

acutisation nonresidualising-imbued-icompulsing linearity-in-eclecticism-

of prior mere formulaicity/ritualisation>

as

all

phenomena/manifestations in existence (so-construed as

phenomenal/manifest $\sim$ subpotencies-_in-transitive-conflatedness

reflexivity,-in-the-full-potency-of-existence's $\sim$ sublimating-nascence l) are

as of their specifically/notionally enabled reifying and empowering; 9

finally it is just as important to grasp also here that the 'articulation as human-causative-construction' of the notions of 'temporal individuations or temporal-dispositions' and 'intemporal individuation or intemporal disposition' are rather conceived epistemically as of their preconverging/postconverging-de-mentative/structural/paradigmatic implications from the perspective of the ontologicalnormalcy/postconvergence of ecstatic-existence-as-transcendentalsignifier and thus are construed as of their 'preconverging/postconverging-de-mentative/structural/paradigmatic 
implications

aporia/undecidability/dilemma/ought-

indeterminacy/deficiency/limitation/constraint of relative-ontologicalincompleteness , reflecting a human-causative-construction conception in apriorising/axiomatising/referencing-\{of-"prospectively implicited_attendant-ontological-contiguity ' reducedexistentialising/contextualising/textualising_intelligibility/epistemicity/re flexivity-contiguity-<imbued-notional $\sim$ cogency $>^{\text {' }}$, - conflatedness ${ }^{13}-$ in \{preconverging ment by\} postconverging entailment/projectiveconflating apriorising/axiomatising/referencing about existence as ontologically-veridical (as it is the 'totalitative epistemic-ornotional projective-perspective' that points out the veridical conception of causation) and so over a traditional reflex construal of human causation in apriorising/axiomatising/referencing-\{of-'prospectivelyimplicited_attendant-ontological-contiguity ' reduced-

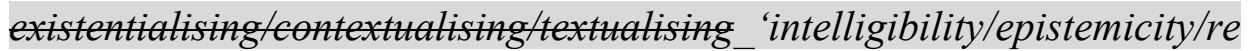
flexivity-contiguity-<imbued-notional $\sim$ cogency>' \}-constitutedness ${ }^{4}$ in preconverging entailment as of 79 presencing-absolutising-identitiveconstitutedness ${ }^{14}$ apriorising/axiomatising/referencing (wherein for instance with regards to prospective human-causative-construction, as to overall reifying-and-empowering-reflexivity-of-ecstatic-existence-aspanintelligibilityłpanreflexivity - (existentially-imbued-and-educing- 
gly/re acutingly, -\{decompulsing? delinearity for-cogency $\geq$ epistemic-

perspective-of-projective/reprojective-aestheticising-re-motif-and-re-

apriorising/re-axiomatising/re-referencing conceptualisation, as herein

specifically relevant to human subpotency), prospective

aetiologisation/ontological-escalation-<ontological-

veridicality_commitment/otherliness_transcending/compulsions-

encumbered_transcending $>$ say with respect to a temporal-disposition for accusing others of sorcery in a social-setup cognisant-and-integrative of notions-and-accusations-of-sorcery in conjugation and protraction of other temporal dispositions, speaks to the preconverging/postconvergingde-mentative/structural/paradigmatic implications of 'non-positivism notional procrypticism/notional disjointedness-as-of- reference-ofthought' induced vices-and-impediments ${ }^{15}$ as destructuring-thresholdfuninstitutionalised-threshold /presublimating-desublimatingdecisionality $\sim$ of-ontological-performance ${ }^{72}<$ including-virtue-asontology>/morality/ethics/justice/etc. requiring prospective intemporaldisposition projection as of the 'specific notional deprocrypticism or < amplituding/formative>notional preempting—disjointedness-as-ofreference-of-thought of positivism/rational-empiricism' ontologicalperformance ${ }^{72}<$ including-virtue-as-

ontology>/morality/ethics/justice/etc. as prospective constructiveness-ofontological-performance ${ }^{2}-<$ including-virtue-as-ontology $>$, and this fundamental conception of aetiologisation/ontological-escalation$<$ ontological-

veridicality_commitment/otherliness_transcending/compulsions- 
encumbered_transcending $>$ applies in reflecting holographically$<$ conjugatively-and-transfusively $>$ the relative unreflexivity/relative reflexivity ontological-contiguity of-the-human-institutionalisationprocess with respect to human-subpotencyaporia/undecidability/dilemma/ought-

indeterminacy/deficiency/limitation/constraint, including prospectively say as of our present positivism-1 procrypticism requiring the preconverging/postconverging-de-mentative/structural/paradigmatic implications of prospective deprocrypticism-or-preemptingdisjointedness-as-of- reference-of-thought aetiologisation/ontologicalescalation-<ontological-

veridicality_commitment/otherliness_transcending/compulsionsencumbered_transcending $>$ )

circularity/recurren with regards to the-very-same-<emplituding/formativece/repetition/repeat epistemicity>totalising $\sim$ purview-of-construal-as-immanentability $^{10} \quad$ existence/intrinsic-reality/ontological-veridicality circularity/recurrence/repetition/repeatability-as-reflected-fromconflation-perspective,-in-preconverging/postconverging-dementative/structural/paradigmatic-registry-worldview-'terms-as-ofaxiomatic-construct'-〈of- 'perversion-and-derived- perversion-ofreference-of-thought-<as-preconverginglyapriorising/axiomatising/referencing-innonconviction/madeupness/bottomlining-as-to-shallowsupererogation >,-as-to-uninstitutionalised-threshold -circularity-as- 


\section{subtransversality-<in-desublimating-existential-}

eventuating/denouement $>\sim$ of-motif-and-

apriorising/axiomatising/referencing'-and- corresponding-ontological-

reconstituting-in-perspective-ontological-normalcy/postconvergence-

induced-conflatedness -of-veridical- reference-of-thought-as-

prospective-institutionalisation/supratransversality-<in-sublimating-

existential-eventuating/denouement $>\sim$ of-motif-and-

apriorising/axiomatising/referencing')

${ }^{11}$ compulsing-_ compulsing-nonconviction/madeupness/bottomlining-

nonconviction/mad $/<$ decontextualising/de-existentialising of-attendant-intradimensional_ eupness/bottomlini apriorising/axiomatising/referencing>-induced-disontologising'-of-theng- 'attendant-intradimensional-ontologising'-imbued-

$\langle<<$ decontextualisi $<$ contextualising/existentialising attendant-ontological-contiguity >;ng/de- in-shallow-supererogation -<as-to-disontologising-perverted-outcomeexistentialising of- sought-precedes-existentially-veridical- 'attendant-intradimensionalattendant- apriorising/axiomatising/referencing'-logical-dueness $>1$ - $<$ as-existentialintradimensional- decontextualised-transposition,-falsely-projectedapriorising/axioma apriorising/axiomatising/referencing-in-caricaturing-hollow-stagingtising/referencing $>$ and-performance $>$ -induceddisontologising'of-the-'attendantintradimensionalontologising'- 
imbued-

$<$ contextualising/e

xistentialising atte

ndant-ontological-

contiguity $>$;-in-

shallow-

supererogation

$<$ as-to-

disontologising-

perverted-

outcome-sought-

precedes-

existentially-

veridical-

'attendant-

intradimensional-

apriorising/axioma

tising/referencing'-

logical-dueness $>>$

${ }^{12}$ conjoining- conjoining-looping-set-of-narratives-(construed-as-of-slanted-cohering-

looping-set-of- 'unsoundness-or-ontological-bad-faith/inauthenticity -of- reference-of-

narratives thought'-of-the-derived- perversion-of- reference-of-thought-<as-

preconvergingly-apriorising/axiomatising/referencing-in-

nonconviction/madeupness/bottomlining-as-to-shallow- 
supererogation >,-and-thus-invalidating-any-wrongly-implied-logical-

processing-engaging)

conflatedness $^{13}$ or

apriorising/axiomatising/referencing-\{of- "prospectively

apriorising/axioma

implicited_attendant-ontological-contiguity ' educed-

tising/referencing- existentialising/contextualising/textualising_intelligibility/epistemicity/re

\{of- $\quad$ flexivity-contiguity-<imbued-notional $\left.\sim \operatorname{cogency}>^{\prime}\right\}$ \}-conflatedness-in

'prospectively fpreconverging ment by\} postconverging entailment or effecting-

implicited_attenda wholeness-as-of-profoundness-and-completeness-to- ${ }^{5}$ meaningfulness-

nt-ontological- and-teleology ; 9 so-implied by '<amplitudingfformative-

contiguity ' educ epistemicity>totalising/circumscribing/delineating epistemic conflating of

ed- motif-and-apriorising/axiomatising/referencing-\{of- prospectively-

existentialising/eo implicited_attendant-ontological-contiguity ' reduced-

ntextualising/textu existentialising/contextualising/textualising_intelligibility/epistemicity/re

alising_intelligibil flexivity-contiguity-<imbued-notional $\sim$ cogency $>$ ' \}-conceptualisation

ity/epistemicity/ref with-and-as-to-the-precedence-of existence-potency $\sim$ sublimating-

lexivity- nascence,-disclosed-from-prospective-epistemic-digression in

contiguity- 'implicited_attendant-ontological-contiguity ' reduced-

<imbued-_ existentialising/contextualising/textualising_intelligibility/epistemicity/re

notional cogency> flexivity-contiguity-<imbued-notional $\sim$ cogency $>$ ',$\quad$ as $\quad$ of

, singularisation-<as-to-the-nondisjointedness/entailment-of-prospective-

conflatedness-in- nonpresencing $>$ projected epistemic-immanence/veridical-

\{preconverging epistemicity-relativism-determinism in reflecting the ecstatic singularity of

ment by\} existence-as-the-absolute-a-priori-of-

postconverging- conceptualisation $\sim$ and $\sim$ existence-as-sublimating- 
withdrawal/unenframing/re-ontologising,-elicited-from-prospective-

profound-supererogation $-<$ as-to-perspective-ontological-

normalcy/postconvergence-implied- 'prospective-aporeticism-

overcoming/unovercoming'> as it is effectively underscored by differenceconflatedness-as-to-totalitative-reification-in-singularisation-<as-to-thenondisjointedness/entailment-of-prospective- nonpresencing $>\quad$-asveridical-epistemicity-relativism-determinism ;

apriorising/axiomatising/referencing-\{of- 'prospectively implicited_attendant-ontological-contiguity ' reducedexistentialising/contextualising/textualising_intelligibility/epistemicity/re flexivity-contiguity-<imbued-notional $\sim$ cogency $>$ ' ' - conflatedness-in\{preconverging ment by\} postconverging entailment preconverging/postconverging-dementatively/structurally/paradigmatically validated by the underlying reality of human limited-mentation-capacity-as-subjecting 'educedunlimitedness/existence sublimating nascence' to limitedness/human(speaking of human epistemic-abnormalcy/preconvergence to the human-subpotency-aporia/undecidability/dilemma/oughtindeterminacy/deficiency/limitation/constraint of any given moment) thus in a state of prospective relative-ontological-incompleteness in need for prospective human limited-mentation-capacity-deepening-as-subjectinglimitedness/human-subpotency to 'educed-unlimitedness/existenceto achieve relative-ontological-completeness ${ }^{87}$, and so as of the-very-same-<amplitudingfformativeepistemicity>totalising purview-of-construal-as-immanent- 
existence/intrinsic-reality/ontological-veridicality; $\uparrow$ and by that token as apriorising/axiomatising/referencing-\{of-'prospectively implicited_attendant-ontological-contiguity ' reducedexistentialising/contextualising/textualising_intelligibility/epistemicity/re flexivity-contiguity-<imbued-notional $\sim$ cogency $>$ ' \}-conflatedness-in\{preconverging-ment by\} postconverging-entailment aspires for relative epistemic-normalcy it becomes reflective of the 'ontologicalnormalcy/postconvergence of existence-potency $\sim$ sublimating-nascence,disclosed-from-prospective-epistemic-digression as this effectively prompts the homely relative-unreflexivity/relative-reflexivityontological-contiguity of-the-human-institutionalisation-process apriorising/axiomatising/referencing-\{of-'prospectively implicited_attendant-ontological-contiguity ' reducedexistentialising/contextualising/textualising_intelligibility/epistemicity/re flexivity-contiguity-<imbued-notional $\sim$ cogency >' \}-reoriginariness/re-origination as of ${ }^{83}$ reference-of-thought-andreference-of-thought- devolving- ${ }^{5}$ meaningfulness-and-teleology, marked by the successive transepistemicity/epistemically-conflatedness of registry-worldviews/dimensions in relative-ontological-completeness giving warranty to apriorising/axiomatising/referencing-\{of'prospectively implicited_attendant-ontological-contiguity ' reducedexistentialising/contextualising/textualising_intelligibility/epistemicity/re flexivity-contiguity-<imbued-notional $\sim$ cogency > ' \}-conflatedness-in \{preconverging ment by\} postconverging entailment epistemic-veracity as to human ontological-performance $-<$ including-virtue-as- 
ontology >/morality/ethics/justice/etc. with regards to human-subpotencyaporia/undecidability/dilemma/ought-

indeterminacy/deficiency/limitation/constraint_imbued-

'notional firstnaturedness-formativeness < as to-eventualising inkling-

drive or seeding misprising > temporal-to-intemporal-dispositions-

$<$ so-construed-as-from-perspective-ontological-

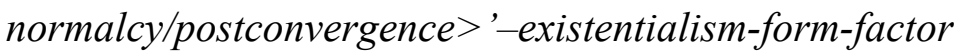

constitutedness $^{14}$

constitutedness

or

apriorising/axiomatising/referencing-\{of-

or

'prospectively implicited_attendant-ontological-contiguity ' reduced-

apriorising/axioma

existentialising/contextualising/textualising_intelligibility/epistemicity/re

tising/referencing-

flexivity-contiguity-<imbued-notional $\sim$ cogency $>$ ' \}-constitutedness-

$\{$ of-

in-preconverging entailment or effecting-parsimony-as-of-shoddiness-

'prospectively

implicited_attenda

At-ontological-

contiguity ' $\sim$ educ

ed-

existentialising/ce

ntextualising/textu

alising_intelligibil

ity/epistemicity/ref

lexivity-

contiguity-

$<$ imbued- and-incompleteness-to- meaningfulness-and-teleology , so-implied by

'atomising

epistemic

constituting

of

motif-and-

apriorising/axiomatising/referencing-\{of- "prospectively

implicited_attendant-ontological-contiguity ' educed-

existentialising/contextualising/textualising_intelligibility/epistemicity/re

flexivity-contiguity-<imbued-notional $\sim$ cogency>' \}-conceptualisation

as to falsely imply their existence-in-existence (since

'implicited_attendant_ontological-contiguity ' reduced-

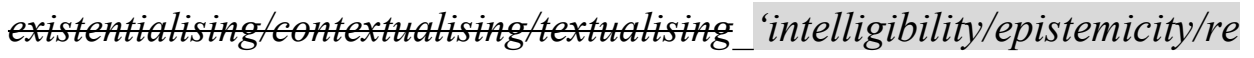
flexivity-contiguity-<imbued-notional cogency> ${ }^{\text {-is }}$-is thus-inherently-

not-construed-as-to-its

<emplitudinglformative-

epistemicity>totalisingly preceding-and-redefining')

as

of 


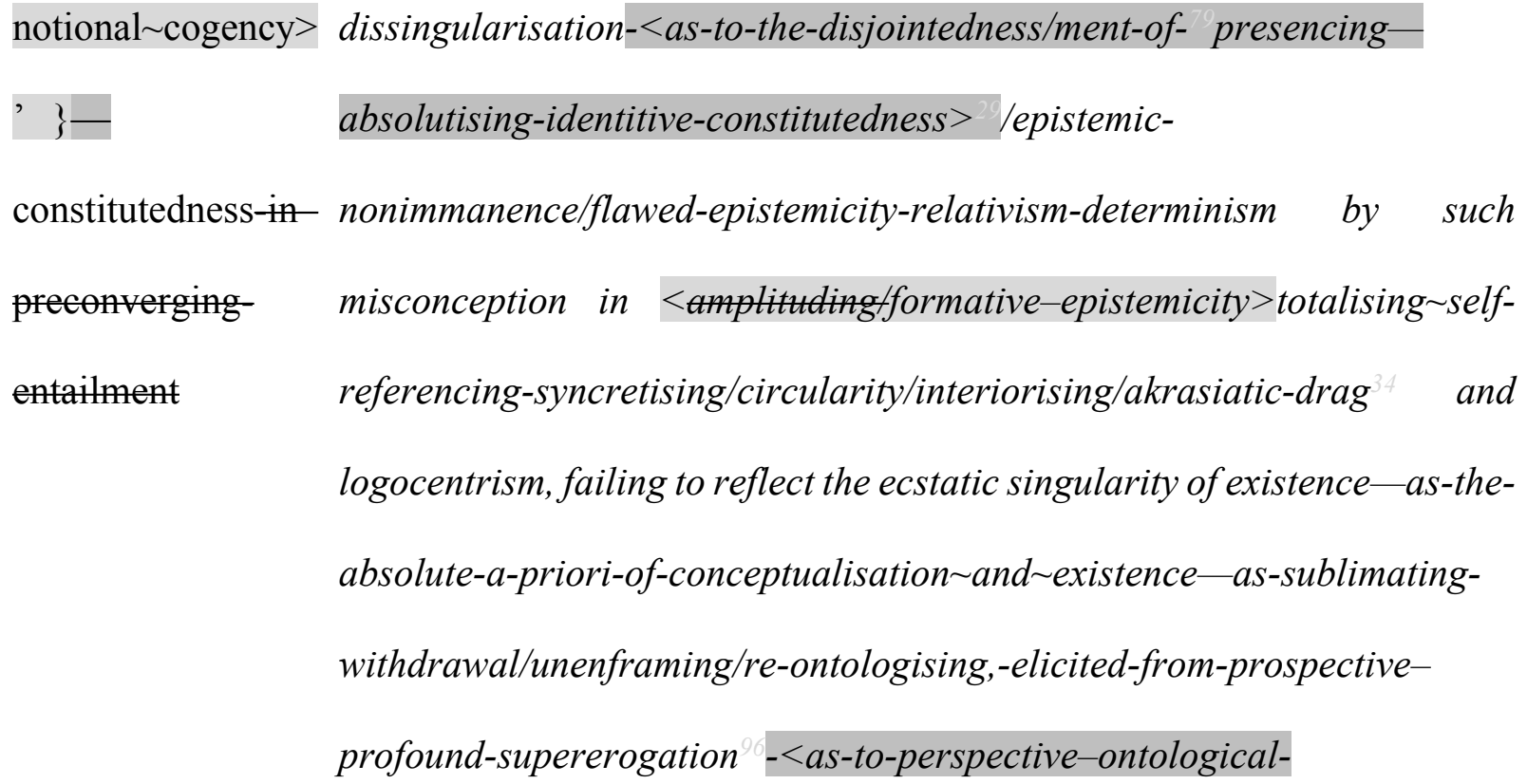


unlimitedness/existence sublimating nascence' to limitedness/human-

subpotency at any given moment (speaking of human epistemicabnormalcy/preconvergence with respect to the human-subpotencyaporia/undecidability/dilemma/ought-

indeterminacy/deficiency/limitation/constraint of that given moment) such that apriorising/axiomatising/referencing-\{of-'prospectively implicited_attendant-ontological-contiguity ' reducedexistentialising/contextualising/textualising_intelligibility/epistemicity/re flexivity-contiguity-<imbued-notional $\sim \operatorname{cogency}>^{\prime}$; $\}$-constitutednessin preconverging entailment poorly construes of 'relative-ontologicalincompleteness /relative-ontological-completeness

(sublimating referencing/registering/decisioning,-as-self-becoming/selfconflatedness /formative-supererogating-<projective/reprojectiveaestheticising-re-motif-and-re-apriorising/re-axiomatising/rereferencing,-in-perspective-ontological-normalcy/postconvergence $>>$ as to human-and-social-expectations/anticipations-metaphoricity -aspreconverging/postconverging-redementating/restructuring/reparadigming-psychologism, (beyond-theconsciousness-awareness-teleology -<of-preconverging-existentialextrication-as-of-existential-unthought $>$ ) as it is in an underlying state of homelessness (as failing to grasp that homeliness as to the possibility of attaining originariness/origination-_so-construed-as-to-ontologicalnormalcy/postconvergence-perspective-scalarising-construal-ofexistence) can only arise as human-subpotency pursues-and-achieves relative epistemic-normalcy as of prospective human limited-mentation- 
capacity-deepening -as subjecting limitedness/human-subpotency to'educed unlimitedness/existence sublimating nascence' ${ }^{3}$ to achieve relative-ontological-completeness ${ }^{87}$ so-reflected as ${ }^{6 /}$ nonpresencing$<$ perspective-ontological-normalcy/postconvergence $>)$ since the state of human limited-mentation-capacity-as-subjecting 'educedunlimitedness/existence-sublimating nascence'to-limitedness/humansubpotency implies that 'human understanding has-ever-and-is-everalways about attaining apriorising/axiomatising/referencing-\{of'prospectively implicited_attendant-ontological-contiguity ' educedexistentialising/contextualising/textualising_intelligibility/epistemicity/re flexivity-contiguity-<imbued-notional $\sim$ cogency $>$ ' \}-re-

originariness/re-origination conception of the-very-same$<$ emplituding/formative-epistemicity > totalising $\sim$ purview-of-construalas-immanent-existence/intrinsic-reality/ontological-veridicality as it strives to reflect as from relative epistemic-normalcy the 'ontologicalnormalcy/postconvergence of existence-potency ${ }^{30}$ sublimating-nascence,disclosed-from-prospective-epistemic-digression, but then the apriorising/axiomatising/referencing-\{of- prospectively implicited_attendant-ontological-contiguity ' reducedexistentialising/contextualising/textualising_intelligibility/epistemicity/re flexivity-contiguity-<imbued-notional $\sim \operatorname{cogency}>^{\prime}$ ' \}-constitutednessin preconverging entailment epistemic stance in perspective epistemicabnormalcy/preconvergence by wrongly implying its prior attainment of epistemic-normalcy from the state of human limited-mentation-capacityas subjecting 'educed unlimitedness/existence sublimating nascence' to- 
limitedness/human-subpotency is in effect wrongly projecting flawed absolutising// presencing-absolutising-identitive-constitutedness thus veering-off from originariness/origination-_so-construed-as-toontological-normalcy/postconvergence-perspective-scalarisingconstrual-of-existence) as of the absolute a-priori that is existence as to the-very-same-<amplitudinglformative-epistemicity>totalising purviewof-construal-as-immanent-existence/intrinsic-reality/ontologicalveridicality and as so-validated with causality as of <emplituding/formative-epistemicity >causality $\sim$ as-to-projectivetotalitative-implications-of-prospective- nonpresencing,-forexplicating felative unreflexivity/relative reflexivity ontologicalcontiguity

${ }^{15}$ de-mentation- de-mentation-(supererogatoryontological-de-mentation-or-dialectical〈supererogatory $\sim 0$ de-mentation-stranding-or-attributive-dialectics 〉,-as-to- 'priorntological-de- preconverging/dementing -qualia-schema'-and-'prospectivementation-or- postconverging/dialectical-thinking -qualia-schema'-_rescheduling-ofdialectical-de- placeholder-setup/mental-devisingmentation- representation/mentation/consciousness-awareness-teleology \ as to stranding-or- human-'limited-mentation-capacity-deepening-as-subjecting attributive- limitedness/human-subpotency to-'educed-unlimitedness/existencedialectics〉 sublimating nascence' '-construal-of-'superseding-oneness-ofontology'-in-successive-registry-worldviews/dimensionsuninstitutionalised-threshold ${ }^{12}$-superseding-or-suprastructuring, and as in association with preconverging/postconverging-de- 
mentative/structural/paradigmatic, $\quad$ preconverging/postconverging-dementatively/structurally/paradigmatically,

preconverging/postconverging-de-mentating/structuring/paradigming, preconverging/postconverging-de-mentate/structure/paradigm, preconverging/postconverging-de-mentated/structured/paradigmed, preconverging/postconverging-redementating/restructuring/reparadigming, preconverging/postconvergingrede-mentate/restructure/reparadigm, preconverging/postconvergingrede-mentated/restructured/reparadigmed rathers points to the veracity of an apriorising/axiomatising/referencing-\{of- prospectively implicited_attendant-ontological-contiguity ' reducedexistentialising/contextualising/textualising_intelligibility/epistemicity/re flexivity-contiguity-<imbued-notional $\sim$ cogency ${ }^{\text {' }}$, '-conflatedness ${ }^{13}$ in \{preconverging ment by\} postconverging entailment conception (and not an apriorising/axiomatising/referencing-\{of-"prospectively implicited_attendant-ontological-contiguity ' reduced-

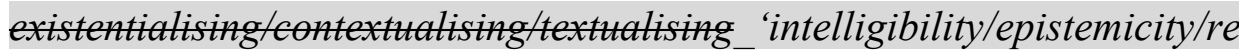
flexivity-contiguity-<imbued-notional $\sim$ cogency>' \}-constitutedness ${ }^{4}$ in preconverging entailment conception) as to perspective ontologicalnormalcy/postconvergence epistemic conception in conceptualising dementative, de-mentatively, de-mentating, de-mentate, de-mentated, redementating, rede-mentate, rede-mentated so-reflected counterintuitively as rather moving towards or recovering what is 'mentatively normal' as towards/recovering ontological-normalcy/postconvergence by human'limited-mentation-capacity-deepening -as-subjecting 
timitedness/human subpotency to 'educed unlimitednesstexistencesublimating nascence' 3 ' as so-underlying 'relative-ontologicalincompleteness 8 /relative-ontological-completeness

(sublimating referencing/registering/decisioning,-as-self-becoming/selfconflatedness /formative-supererogating-<projective/reprojectiveaestheticising-re-motif-and-re-apriorising/re-axiomatising/rereferencing,-in-perspective-ontological-normalcy/postconvergence > । as to human-and-social-expectations/anticipations-metaphoricity -aspreconverging/postconverging-redementating/restructuring/reparadigming-psychologism,; as so-implied with respect to the de-mentation-(supererogatoryontological-dementation-or-dialectical-de-mentation-stranding-or-attributivedialectics) of human reference-of-thought (as the reference-of-thought is the 'superseding-axiomatic-construct postconverging-dementating/structuring/paradigming of all other devolving axiomaticconstructs', and preconverging/postconverging-dementatively/structurally/paradigmatically underlies as of successive de-

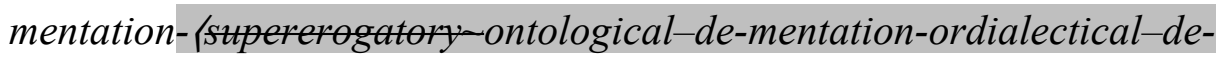
mentation-stranding-or-attributive-dialectics $)$ of human ${ }^{83}$ reference-ofthought the relative unreflexivity/relative reflexivity-ontologicalcontiguity of-the-human-institutionalisation-process ${ }^{8}$ and the 'operative de-mentation-(supererogatory-ontological-de-mentation-ordialectical-de-mentation-stranding-or-attributive-dialectics) of 'reference-of-thought- devolving' (as of reference-of-thought 'implied 
$<$ amplituding/formative>nondisjointing/nondisparate/notional deprocr ypticism' induced foregrounding_entailment-<in-succession-ofprofound-supererogation $>$-\{postconverging-narrowing-

down sublimation-as-to- 'existence - as-sublimating-

withdrawal/unenframing/re-ontologising,-elicited-from-prospective-

profound-supererogation '-in-reflecting- 'immanent felative-

unreflexivity/relative reflexivity ontological-contiguity ';-as-operative-

notional deprocrypticism) ${ }^{5}$ meaningfulness-and-teleology as

derivative axiomatic-constructs from superseding/overcoming humansubpotency-aporia/undecidability/dilemma/ought-

indeterminacy/deficiency/limitation/constraint), and in both referenceof-thought-and- reference-of-thought- ${ }^{8}$ devolving- ${ }^{5}$ meaningfulness-

and-teleology frames as of human limited-mentation-capacitydeepening - as subjecting limitedness/human subpotency to 'educedunlimitednesstexistence-sublimating nascence' ${ }^{3}$ grasp of ecstaticexistence as of existence-as-the-absolute-a-priori-ofconceptualisation $\sim$ and $\sim$ existence—as-sublimating-

withdrawal/unenframing/re-ontologising,-elicited-from-prospectiveprofound-supererogation $-<$ as-to-perspective-ontological-

normalcy/postconvergence-implied-" prospective-aporeticism-

overcoming/unovercoming'>); $\uparrow$ and as of human aestheticisation-andaestheticisation-towards-ontology-<elicited-idiomatisation $>$ in inducing 'both ${ }^{56}$ meaningfulness-and-teleology and its existentially$<$ disontologising/re ontologising aporeticism> incipient 
metaphoricity $^{5}$ (as to apriorising/axiomatising/referencingpsychologism of conceptualisation), de-mentation(supererogatory ontological-de-mentation-or-dialectical-dementation-stranding-or-attributive-dialectics $\rangle$ is metaphoricitically-andmeaningfully reflected as the human mental-aestheticisationarchitectonically-consigning-aestheticised-perceptibility-and-disposition that underlies 'supererogatory acuity/perspicacity/astuteness/edginess/incisiveness of apriorising/axiomatising/referencing as to postconverging/dialecticalthinking -qualia-schema-mental-aestheticisation-attribution and preconverging/dementing -qualia-schema-mental-aestheticisationattribution and then their mutually-reinfusing-attributive-possibilities,-for'<emplitudingfformative-

epistemicity >totalising pseudoconflation/conflation-of-human-limitedmentation-capacity-as subjecting 'educed unlimitedness/existencesublimating nascence'-to-limitedness/human-subpotency'-as-tocorrespondingly-ensuing — desublimating-or-sublimating-mentalaestheticisation-representation (with regards to 'varying psychologismic epistemic acutisation difficulty< <or, residualising \{decompulsing' delinearity for cogency> magnitudes ${ }^{\{0 f-}$ experientiality/experiment' $/$ scales-as-to-successively-profoundpreconverging/postconverging-redementating/restructuring/reparadigming-frames-as-from-living,institutionalising,-and-Being-ontologising/infrastructure-ofmeaningfulness-and-teleology of prospective human-subpotency- 
aporia/undecidability/dilemma/ought-

indeterminacy/deficiency/limitation/constraint -imbued-

'notional firstnaturedness-formativeness < as to-eventualising inkling

drive or seeding misprising > temporal-to-intemporal-dispositions-

$<$ so-construed-as-from-perspective-ontological-

normalcy/postconvergence > '-existentialism-form-factor')

denaturing $^{16} \quad$ denaturing/usurping/arrogating/perverting-in-constitutedness

deneuterising ${ }^{17} \quad$ deneuterising-/disambiguation of intemporal-as-sound/postconvergingor-dialectical-thinking and temporal-as-denaturing /preconverging-ordementing , so-construed-as-binarity-of-categoricalimperatives/axioms/registry-teleology -as-respectively-in notionalcontiguity/epistemic-contiguity $-<$ profound-supererogation -ofmentally-aestheticised postconverging/dialectical-thinking -qualiaschema>-and 'notional-discontiguity/epistemic-discontiguity $<$ between-prior-shallow-supererogation -of-mentallyaestheticised preconverging/dementing -qualiaschema_and_prospective-profound-supererogation -of-mentallyaestheticised postconverging/dialectical-thinking -qualia-schema>',as-of-the-very-same-<amplituding/formativeepistemicity>totalising purview-of-construal-as-immanentexistence/intrinsic-reality/ontological-veridicality); hence deneuterisingreferentialism/deascriptivity-as-of-ontological-reconstituting-as-ofconflatedness $^{13}$-différance/internal-dialectics/difference-deferral-ofreference-of-thought- devolving highlighting the dynamics of limited- 
mentation-capacity-deepening-as-subjecting limitedness/humansubpotency to 'educed unlimitedness/existence sublimating nascence' inducing deneuterising of motif-and-apriorising/axiomatising/referencing over shallow limited-mentation-capacity-as-subjecting 'educedunlimitedness/existence sublimating nascence' to limitedness/humansubpotency relative ${ }^{58}$ neuterising of motif-andapriorising/axiomatising/referencing

${ }^{18}$ deprocrypticism- deprocrypticism-or-preempting - disjointedness-as-of- reference-ofor-preempting — thought,-as-to-' ${ }^{3}$ emplitudingfformative-epistemicity>growth-ordisjointedness-as- conflatedness ${ }^{13} /$ transvaluativeof- reference-of- rationalising/transepistemicity/anamnestic-residuality/spiritthought drivenness'-in-superseding-mere-formulaic-positivising/rationalempiricism-based-universalisation-directed-rulemaking-over-non-rulesapriorising/axiomatising/referencing-psychologism, and so as of apriorising/axiomatising/referencing-\{of-'prospely implicited_attendant-ontological-contiguity ' educedexistentialising/contextualising/textualising_intelligibility/epistemicity/re flexivity-contiguity-<imbued-notional $\sim$ cogency> ' \}-conflatedness ${ }^{13}-$ in \{preconverging ment by\} postconverging entailment of the positivism/rational-empiricism apriorising/axiomatising/referencing/intelligibilitysettingup/measuringins trumenting for upholding intemporal-preservation as to perspective ontological-normalcy/postconvergence over the '<amplituding/formative $>$ wooden-language-\{imbued-temporal-mere- 
form/virtualities/dereification/akrasiatic-drag/denatured/preconvergingor-dementing -narratives-of-the- reference-of-thought-categoricalimperatives/axioms/registry-teleology \ of such positivism/rationalempiricism

apriorising/axiomatising/referencing/intelligibilitysettingup/measuringins trumenting', and across the <cumulating/recomposuring attendantontological-contiguity >-successive registry-worldviews/dimensions as of such upholding of intemporal-preservation as to perspective ontological-normalcy/postconvergence as so-reflecting all the successive transcendence-and-sublimity/sublimation/supererogatory-de-mentativity instigation over their prospectively uninstitutionalised-threshold ${ }^{22}$ (that is, as successive notional deprocrypticism-or-notional preemptingdisjointedness-as-of- reference-of-thought and so-construed

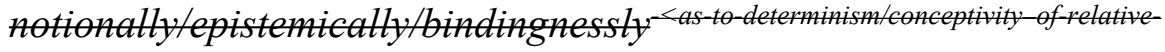
unreflexivity/relative-reflexivity $>$ as dimensionality-of-sublimating

1<amplituding/formative >supererogatory de-mentativeness/epistemicgrowth-or-conflatedness /transvaluativerationalising/transepistemicity/anamnestic-residuality/spirit-drivennessequalisation)), so-driven by ontological-faith-notion-or-ontologicalfideism-imbued-underdetermination-of-motif-andapriorising/axiomatising/referencing-as-so-being-as-of-existential-reality induced maximalising-recomposuring-for-relative-ontologicalcompleteness —unenframed/re-ontologising conceptualisation 'reification gesturing/accounting-of-epistemic-phenomenalism for prospective knowledge' arising as from 'implicited_attendant- 
ontological-contiguity ' educed-

existentialising/contextualising/textualising_intelligibility/epistemicity/re

flexivity-contiguity-<imbued-notional $\sim \operatorname{cogency}>$

<amplituding/formative-epistemicity >causality $\sim$ as-to-projective-

totalitative-implications-of-prospective- nonpresencing,-for-

explicating felative-unreflexivity/relative-reflexivity ontological-

contiguity of prospective relative-ontological-completeness

supererogatory acuity/perspicacity/astuteness/edginess/incisiveness-of-

apriorising/axiomatising/referencing/intelligibilitysettingup/measuringins

trumenting-for-conceptualisation)

destructuring- destructuring-transitoriness-_construed-as-of-dissingularisation-<as-to-

transitoriness $^{19}$ the-disjointedness/ment-of- presencing-absolutising-identitive-

constitutedness > lepistemic-nonimmanence/flawed-epistemicity-

relativism-determinism-induced-deratiocination-or-deratiocontiguity)

preconverging-or- dementing-<as-of-preconverging-conceptivity/epistemic-

dementing $^{20} \quad$ reflexivity/epistemicity-relativism-determinism-<reifying\{as-to-

knowledge-developing\}-and-empowering >-\{as-to-the-' preconverging-

stranding/attribution'-of-the- de-mentation-

(supererogatory ontological-de-mentation-or-dialectical-de-

mentation-stranding-or-attributive-dialectics /\},-induced-

disposedness/psychologismic-construct-and-entailing,-of-ontologically-

flawed 'teleology of leveling-down/equating' so-construed as from

existence - as-sublimating-withdrawal/unenframing/re-ontologising,-

elicited-from-prospective-profound-supererogation perspective of 
notional deprocrypticism>

postconverging-or- dialectical-thinking-<as-of-postconverging-conceptivity/epistemic-

dialectical-thinking reflexivity/epistemicity-relativism-determinism-<reifying\{as-to-

knowledge-developing\}-and-empowering>-\{as-to-the-'postconverging-

stranding/attribution'-of-the- de-mentation-

(supererogatory ontological-de-mentation-or-dialectical-de-

mentation-stranding-or-attributive-dialectics $)\}$,-induced-

disposedness/psychologismic-construct-and-entailing,-of-ontologically-

sound 'teleology of unleveling/disambiguating' so-construed as from

existence-as-sublimating-withdrawal/unenframing/re-ontologising,-

elicited-from-prospective-profound-supererogation perspective of

notional ${ }^{18}$ deprocrypticism $>$

difference- difference-conflatedness ${ }^{3}$-as-to-totalitative-reification-in-

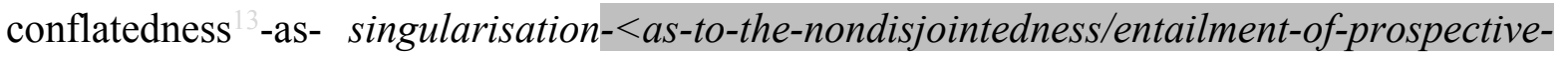

to-totalitative- nonpresencing $>$-as-veridical-epistemicity-relativism-determinism,-as-

reification-in- of-epistemically-differentiated-ontological-depth-of-reality-las-of-the-

singularisation- differentiated-and-disambiguatedtrace-of-dynamic-temporal-to-

$<$ as-to-the- intemporal-ontological-performance $-<$ including-virtue-as-ontology $>$ -

nondisjointedness/ as-postconverging-or-dialectical-thinking -apriorising-psychologism-

entailment-of- and-preconverging-or-dementing -apriorising-psychologism-

prospective- $\quad$ respectively|; $\mid$ difference-conflatedness ${ }^{3}$-as-to-totalitative-reification-in-

nonpresencing $>$ singularisation- $<$ as-to-the-nondisjointedness/entailment-of-prospective-

-as-veridical-

nonpresencing $>$-as-veridical-epistemicity-relativism-determinism is

epistemicity- more fundamentally construed as from ontological- 
relativism- normalcy/postconvergence epistemic-projection perspective as a reflection determinism $^{22}$ of dimensionality-of-sublimating < <amplituding/formative >supererogatory-de-mentativeness/epistemicgrowth-or-conflatedness /transvaluativerationalising/transepistemicity/anamnestic-residuality/spirit-drivennessequalisation) underlying the relative unreflexivity/relative reflexivity ontological-contiguity $\sim$ of-the-human-institutionalisation-process ${ }^{68}$ (as to human Being-development/ontological-framework-expansion-as-todepth-of-ontologising-development-as-infrastructure-ofmeaningfulness-and-teleology , institutional-development-as-to-socialfunction-development and living-development-as-to-personalitydevelopment psychologismic epistemic acutisation difficulty< <or, residualising magnitudes ${ }^{\text {sof- }}$ experientiality/experiments)', and speaks to the fact that human limited-mentationcapacity-deepening - as subjecting limitedness/human-subpotency to'educed-unlimitednesstexistence-sublimating nascence' reflects an overall human existential-<isontologising/re-ontologisingaporeticism $>\quad$ foregrounding_entailment-<in-succession-of-profoundsupererogation $>$ - (postconverging-narrowing-down $\sim$ sublimation-as-to'existence - as-sublimating-withdrawal/unenframing/re-ontologising,elicited-from-prospective-profound-supererogation '-in-reflectingimmanent relative unreflexivity/relative reflexivity ontologicalcontiguity ';-as-operative-notional deprocrypticism) wherein as to 'the-very-same overall phenomenality/manifestation of existence-assublimating-withdrawal/unenframing/re-ontologising,-elicited-from- 
prospective-profound-supererogation, human limited-mentationcapacity-deepening - as subjecting limitedness/human-subpotency to'educed unlimitednesstexistence sublimating nascence" 3 variously attains differing ontological-performance $-<$ including-virtue-asontology>/morality/ethics/justice/etc. so-reflected as the $<$ cumulating/recomposuring attendant-ontological-contiguity successive registry-worldviews/dimensions $\quad$ reference-of-thought-andreference-of-thought- devolving- meaningfulness-and-teleology implying that human ${ }^{56}$ meaningfulness-and-teleology can be construed as ever always twofaceted as to the facet of achieved sublimation-overdesublimation of ${ }^{56}$ meaningfulness-and-teleology as validated with predicative-effectivity-sublimation-_as-to-underlying,-ontological-

commitment -<implied-self-assuredness-of-ontological-goodfaith/authenticity $\sim$ postconverging-dementating/structuring/paradigming -as-being-as-of-existential-reality >) and on-the-other-hand the facet of the existentially-withdrawn-〈as'unaccounted-for'-leftover-or-residuality-or-spirit-of- meaningfulnessand-teleology -so-construed-as-metaphoricity ,-informing-prospectivesupererogatory acuity/perspicacity/astuteness/edginess/incisiveness,-soreflected-and-compensated-with-the-notion-of-dimensionality-ofsublimating $-<<$ amplituding/formative $>$ supererogatory $\sim d e-$ mentativeness/epistemic-growth-or-conflatedness/transvaluativerationalising/transepistemicity/anamnestic-residuality/spirit-drivennessequalisation /) which is just as decisive for prospective human limited- 
mentation-capacity-deepening -as-subjecting limitedness/human-

subpotency to 'educed unlimitedness/existence sublimating nascence'

in the sense that 'human intelligibility ever always projects of an underlying

<emplituding/formative-

epistemicity>totalising/circumscribing/delineating reference-of-thought striving to grasp existence as it is signified-as-to-immanency (speaking of notional-contiguity/epistemic-contiguity 2 - profound-supererogation of-mentally-aestheticised postconverging/dialectical-thinking -qualiaschema> perspective of the unchanging immanency of existence as superseding-oneness-of-ontology as to the coherence underlying the very possibility for construing-and-reconstruing of intelligibility in existence)' and this facet preconverging/postconverging-dementatively/structurally/paradigmatically acts as the 'prior requisite human experiential framework to be challengeddisproved-invalidated' which surpassing enables further sublimation-overdesublimation of meaningfulness-and-teleology as validated with predicative-effectivitysublimation-_as-to-underlying,-ontological-commitment $-<$ impliedself-assuredness-of-ontological-good-

faith/authenticity postconverging-dementating/structuring/paradigming -as-being-as-of-existential-reality>) (as to the fact that it is recurrent-utter-uninstitutionalisation, ununiversalisation, non-positivism/medievalism and procrypticism respectively'as reflecting the 'prior requisite human experiential framework to be challenged-disproved-invalidated' highlighting the facet of the existentially-withdrawn-_as-'unaccounted-for'-leftover- 
orresiduality-or-spirit-of- meaningfulness-and-teleology -so-construedas-metaphoricity ,-informing-prospectivesupererogatory acuity/perspicacity/astuteness/edginess/incisiveness,-soreflected-and-compensated-with-the-notion-of-dimensionality-ofsublimating -<emplituding/formative $>$ supererogatory $\sim d e-$ mentativeness/epistemic-growth-or-conflatedness/transvaluativerationalising/transepistemicity/anamnestic-residuality/spirit-drivennessequalisation/) as limiting or of prospective human-subpotency aporeticism' which surpassing as to human psychoanalyticunshackling/memetic-reordering/institutional-recomposuring enables the possibility for human limited-mentation-capacity-deepening-assubjecting limitedness/human-subpotency to 'educedunlimitednesstexistence sublimating nascence' as of prospective baseinstitutionalisation, ${ }^{103}$ unversalisation, positivism and prospectively notional deprocrypticism sublimation-over-desublimation of meaningfulness-and-teleology as validated with predicative-effectivitysublimation-\{as-to-underlying,-ontological-commitment $-<$ impliedself-assuredness-of-ontological-good-

faith/authenticity postconverging-dementating/structuring/paradigming -as-being-as-of-existential-reality >) and so with regards to the-very-same overall phenomenality/manifestation of existence-as-sublimatingwithdrawal/unenframing/re-ontologising,-elicited-from-prospectiveprofound-supererogation ') 
difference-in- difference-in-kind/difference-in-aposteriorising-or-logicising-

kind/difference-in- < difference-in-aposteriorising-or-logicising-or-deriving-in-determiningaposteriorising-or- 'mutually-relative-validity-by-invalidity-as-to-the-veracity-of-any-givenlogicising $23 \quad$ existential-instantiation',-though-in-notional-contiguity/epistemiccontiguity $\quad<$ profound-supererogation -of-mentallyaestheticised postconverging/dialectical-thinking -qualia-schema>-ofthevery-same-mutually-abstract-apriorising-or-axiomatising-orreferencing-conceptualisation $>$

difference-in- difference-in-nature/difference-in-apriorising-or-axiomatising-ornature/difference- referencing-〈difference-in-apriorising-or-axiomatising-or-referencing-asin-apriorising-or- to-mutually-constrastive-'notional-contiguity/epistemic-contiguity _ axiomatising-or- $\quad<$ profound-supererogation -of-mentallyreferencing ${ }^{24}$ aestheticised postconverging/dialectical-thinking -qualia-schema >-
and-notional-discontiguity/epistemic-discontiguity -<between-priorshallow-supererogation -of-mentallyaestheticised preconverging/dementing -qualiaschema_and prospective-profound-supererogation -of-mentallyaestheticised postconverging/dialectical-thinking -qualia-schema> '-ofabstract-conceptualisation,-as- 'rendering-irrelevant-any-mutualaposteriorising-or-logicising-or-deriving-exercise,'-given-that-thevalidity-or-invalidity-as-to-the-ontological-veracity-of-any-givenexistential-instantiation-is-aposteriorised-or-logicised-or-derived-fromthe-more-profound-apriorising-or-axiomatising-or-referencingconceptualisation,-so-construed-as-thesupratransversality-<in- 
sublimating-existential-eventuating/denouement $>\sim$ of-motif-and-

apriorising/axiomatising/referencing-and-rendering-ontologically-

irrelevant/impertinent-the-subtransversality-<in-desublimating-

existential-eventuating/denouement $>\sim$ of-motif-and-

apriorising/axiomatising/referencing/

dimensionality-of- dimensionality-of-sublimating-

sublimating ${ }^{25} \quad$ <amplituding/formative $>$ supererogatory-de-mentativeness/epistemic-

<<amplituding/for growth-or-conflatedness /transvaluative-

mative>supereroga rationalising/transepistemicity/anamnestic-residuality/spirit-drivenness-

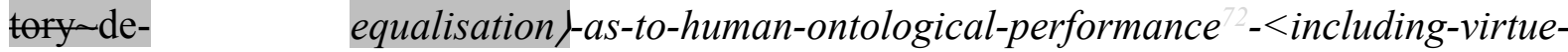

mentativeness/epis as-ontology>,-as-so-construed-as-from-prospective-ontological-

temic-growth-or- normalcy/postconvergence-epistemic-projection-perspective-as-to-re-

conflatedness $/$ tra originariness/reorigination-as-reflecting-difference-conflatedness ${ }^{13}$-as-

nsvaluative- $\quad$ to-totalitative-reification-in-singularisation-<as-to-the-

rationalising/transe nondisjointedness/entailment-of-prospective- nonpresencing $>$-as-

pistemicity/anamn veridical-epistemicity-relativism-determinism

estic-

residuality/spirit-

drivenness-

equalisation $\rangle$

dimensionality-of- dimensionality-of-desublimating-lack-of-

desublimating- $\quad$ <amplituding/formative $>$ supererogatory-de-mentativeness/epistemic-

lack-of ${ }^{26}$ growth-or-conflatedness /transvaluative-

<<amplituding/for rationalising/transepistemicity/anamnestic-residuality/spirit-drivenness- 


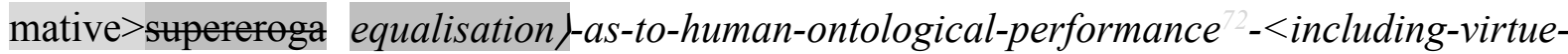
tory de- as-ontology>,-as-so-construed-as-from-prospective-ontologicalmentativeness/epis normalcy/postconvergence-epistemic-projection-perspective-intemic-growth-or- reflecting-perspective-epistemic-abnormalcy/preconvergence ${ }^{3 /}$-distortedconflatedness $/$ tra originariness/distorted-origination-as-to- presencing-absolutisingnsvaluative- identitive-constitutedness

rationalising/transe

pistemicity/anamn

estic-

residuality/spirit-

drivenness-

equalisation>

dispensing-with- dispensing-with-immediacy-for-relative-ontological-completeness ${ }^{87}$-byimmediacy-for- $\quad$ reification/contemplative-distension-_as-'dispensing-with-shallowrelative- reproducibility-mathesis/motif/thrownness-disposition'-for-relativeontological- ontological-completeness -by-reification,-so-construed-insightfully-ascompleteness ${ }^{87}$-by- of-human-limited-mentation-capacity-as-subjecting 'educedreification/contem unlimitedness/existence sublimating nascence' to limitedness/humanplative-distension subpotency-successive-re-originary-projections/anticipations-about-the27 $<$ amplituding/formative-epistemicity>totalising purview-of-construalas-existence/intrinsic-reality/ontological-veridicality-for-articulation-ofmeaningfulness-and-teleology ,-that-in-that-succession-are-'as-fromrelative-ontologically-flawed-to-relative-ontologically-veridicalarticulation-of- meaningfulness-and-teleology ',-but-then-as-the- 
'preceding-originary-projection/anticipation-of-relative-ontologically-

flawed-articulation-of- meaningfulness-and-teleology -construed-ashabit-and-tradition'-is- 'preconverging/postconverging-de-

mentatively/structurally/paradigmatically-defining-as-reference-to-be-

superseded'-by-dialectically-successive- 're-originary-

projections/anticipations-of-relative-ontologically-veridical-articulation-

of- meaningfulness-and-teleology , (as to 'human Being-

development/ontological-framework-expansion-as-to-depth-of-

ontologising-development-as-infrastructure-of- meaningfulness-and-

teleology , institutional-development-as-to-social-function-development

and living-development-as-to-personality-development psychologismic

epistemic acutisation difficuly<< for, residualising

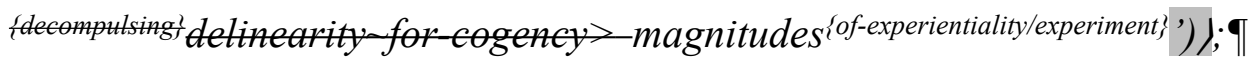

as-the-very-implication-and-reason-why-human-existential-thrownness-

as-of-human-limited-mentation-capacity-as subjecting 'educed-

unlimitedness/existence sublimating nascence' to limitedness/human-

subpotency-paradoxically-renders-prospective- " nonpresencing-or-

withdrawal/unenframing/re-ontologising-or-metaphysics-of-absence-

fimplicited-epistemic-veracity-of- nonpresencing-<perspective-

ontological-normalcy/postconvergence $>$ - - or-transcendental-reasoning-

of-event ${ }^{38}$-as-prospective-ontology-origination-

perspective/framing/reference/horizon/projection-of- meaningfulness-

and-teleology '-the-critical-determination-of-relative-ontologically-

veridical- ${ }^{56}$ meaningfulness-and-teleology -over- 'presencing-or-

metaphysics-of-presence-fimplicited- 'nondescript/ignorable-void '-as- 
to- presencing-absolutising-identitive-constitutedness _-or-ordinary-

nontranscendental-reasoning-

perspective/framing/reference/horizon/projection-of- ${ }^{5}$ meaningfulness-

and-teleology , in enabling transcendence-and-

sublimity/sublimation/ster for the need for human limited-mentation-capacity-deepening-as-subjecting

timitedness/human subpotency to 'educed unlimitedness/existence-

sublimating nascence' ; and operantly, dispensing-with-immediacy-forrelative-ontological-completeness ${ }^{87}$-by-reification/contemplative-

distension doesn't mean 'giving up on life' (as of <amplituding/formative $>$ wooden-language-_imbued-averaging-of-

thought-<as-to-leveling/ressentiment/closed-construct-of-

meaningfulness-and-teleology -as-of-'nondescript/ignorable-void

with-regards-to-prospective-apriorising-implications $>$ ) of temporaldispositions and as prodded by sophistic/pedantic distraction inclinations in incrementalism-in-relative-ontological-incompleteness enframed/disontologising conceptualisation) wrongly implying a propensity to construe 'preconverging-existential-extrication-as-ofexistential-unthought as more of life as to the supposed precedence of human shallow-supererogation over profound-supererogation ', but rather dispensing-with-immediacy-for-relative-ontologicalcompleteness -by-reification/contemplative-distension speaks of a 'more profound intemporal solipsistic contemplative appreciation of life as of the precedence of human sublime potential reflected in a projective disposition to rethinking human ${ }^{5}$ meaningfulness-and-teleology infrastructure', and 
as validated by the fact that the $<$ cumulating/recomposuring attendantontological-contiguity >-succession of human registryworldviews/dimensions are grounded on such 'dimensionality-ofsublimating $-1<$ mplinglformative $>$ supererogatory dementativeness/epistemic-growth-or-conflatedness /transvaluativerationalising/transepistemicity/anamnestic-residuality/spirit-drivennessequalisation) reasoning-through/messianic-reasoning for human secondnatured institutionalisation for Being-development/ontologicalframework-expansion-as-to-depth-of-ontologising-development-asinfrastructure-of- meaningfulness-and-teleology , institutionaldevelopment-as-to-social-function-development and living-developmentas-to-personality-development psychologismic epistemic acutisationdifficulty< <or, residualising decompling for cogency> magnitudes \{of-experientiality/experiment\}, against the torrent of '<amplitudingfformative > wooden-language-_imbued-averaging-ofthought-<as-to-leveling/ressentiment/closed-construct-ofmeaningfulness-and-teleology -as-of-'nondescript/ignorable-void 'with-regards-to-prospective-apriorising-implications >। and as prodded by sophistic/pedantic distractive reasoning-from-results/afterthought imbued incrementalism-in-relative-ontological-incompleteness enframed/disontologising conceptualisation' that is ever always 'parrhesiastically wanting' for the prospect of prospective 'dimensionality-of-sublimating ${ }^{25}$

1<amplitudinglformative $>$ superergatory-de-mentativeness/epistemic- 
growth-or-conflatedness/transvaluative-

rationalising/transepistemicity/anamnestic-residuality/spirit-drivenness-

equalisation) reasoning-through/messianic-reasoning' transcendenceand-sublimity/sublimation/supererogatory-de-mentativity, as it can be appreciated that preconverging/postconverging-dementatively/structurally/paradigmatically every $\quad{ }^{79}$ presencingabsolutising-identitive-constitutedness ${ }^{14}$ registry-worldview/dimension as of its <amplitudingfformative> wooden-language-_imbued-averagingof-thought-<as-to-leveling/ressentiment/closed-construct-ofmeaningfulness-and-teleology -as-of- 'nondescript/ignorablevoid'-withregards-to-prospective-apriorising-implications $>$ | and as prodded by its given pedantising/muddling/formulaic-hollowing-out-insubontologisation/subpotentiation-_blurring/undermining-of-prospectivetotalising-entailing,-as-to-entailing-< formativeepistemicity>totalising in-relative-ontological-completeness J paradoxically disinclined to its prospective reasoning-through/messianicreasoning as it is ever always in <amplitudinglformativeepistemicity>totalising self-referencing-

syncretising/circularity/interiorising/akrasiatic-drag as of its prospectively ontologically-flawed ${ }^{5}$ meaningfulness-and-teleology as it seem to poorly construe of the implications of its apriorising-teleologicaldegradation-in notional-discontiguity/epistemic-discontiguity _ $<$ between-prior-shallow-supererogation -of-mentallyaestheticised preconverging/dementing -qualia- 
schema_and_prospective-profound-supererogation -of-mentally-

aestheticised postconverging/dialectical-thinking -qualia-schema>

and as it wrongly substitutes for it a 'communication-as-of-dialogicalequivalence-<as-to-

psychologismic apriorising/axiomatising/referencing-\{of- 'prospectively implicited_attendant-ontological-contiguity ' reduced-

existentialising/contextualising/textualising_intelligibility/epistemicity/re flexivity-contiguity-<imbued-notional cogency > ' \}-conflatedness in \{preconverging ment by\} postconverging entailment,-in-selfbecoming/self-conflatedness /formative-supererogating > issue' like with the sophists accusing Socrates for not communicating well by the terms of their 'warped/twisted adhoc/makeshift/nonprincipled-as-of-their-nonuniversalising-syllogising' faced with his ${ }^{103}$ universalising-idealisation or medieval scholastics by the terms of their 'pedantic dogmatism' blaming Galileo for not communicating well faced with his 'buddingpositivism/rational-empiricism', and a modern-day naïve $<$ formative-epistemicity $>$ totalising $\sim$ self-referencingsyncretising/circularity/interiorising/akrasiatic-drag ${ }^{34}{ }^{56}$ meaningfulnessand-teleology communication discourse that is utterly clueless of the <emplituding/formative-epistemicity>causality $\sim$ as-to-projectivetotalitative-implications-of-prospective- nonpresencing,-forexplicating relative unreflexivity/relative reflexivity ontologicalcontiguity of our positivism-procrypticism 'procrypticism-ordisjointedness-as-of- reference-of-thought as of an occluded selfconsciousness' requiring prospective deprocrypticism-or-preempting- 
disjointedness-as-of- reference-of-thought psychoanalyticunshackling/memetic-reordering/institutional-recomposuring as of dementation-(supererogatory ontological-de-mentation-or-dialectical-dementation-stranding-or-attributive-dialectics

dissemination ${ }^{28} / \mathrm{se}$ maximalising-recomposuring-for-relative-ontological-completeness eding unenframed/re-ontologising conceptualisation driven by ontologicalfaith-notion-or-ontological-fideism —imbued-underdetermination-ofmotif-and-apriorising/axiomatising/referencing-as-so-being-as-ofexistential-reality 'reification gesturing/accounting-of-epistemicphenomenalism for prospective knowledge' arising as from 'implicited_attendant-ontological-contiguity ' reducedexistentialising/contextualising/textualising_intelligibility/epistemicity/re flexivity-contiguity-<imbued-notional $\sim$ cogency $>$ $<$ amplituding/formative-epistemicity $>$ causality $\sim$ as-to-projectivetotalitative-implications-of-prospective- nonpresencing,-forexplicating relative unreflexivity/relative reflexivity ontologicalcontiguity of prospective relative-ontological-completeness supererogatory acuity/perspicacity/astuteness/edginess/incisiveness-ofapriorising/axiomatising/referencing/intelligibilitysettingup/measuringins trumenting-for-conceptualisation so-construed as of reproducibilitymathesis/motif/thrownness-disposition,-as-reproducibility-ofaestheticisation amenable thus to existence's validation as of $<$ emplituding/formative-epistemicity $>$ causality $\sim$ as-to-projectivetotalitative-implications-of-prospective- nonpresencing,-for- 
explicating felative unreflexivity/relative reflexivity ontological-

contiguity ; wherein for instance the same budding-positivists reproducibility — mathesis/motif/thrownness-disposition,-asreproducibility-of-aestheticisation dissemination/seeding as reflected in different budding-positivists like Copernicus, Galileo, Descartes, Newton, Leibniz are variously-and-transversally validated by existence as of positivism <emplituding/formative-epistemicity>causality $\sim$ as-toprojective-totalitative-implications-of-prospective- nonpresencing,-forexplicating felative unreflexivity/relative reflexivity ontologicalcontiguity

dissingularisation- epistemically-not-immanent'-as-lacking-internal-necessity-and-

$<$ as-to-thesupererogatory acuity/perspicacity/astuteness/edginess/incisiveness-of-

disjointedness/men apriorising/axiomatising/referencing/intelligibilitysettingup/measuringins t-oftrumenting -for-conceptualisation; $\uparrow \quad$ as-of-apriorising-teleological-

presencing_ $\quad$ parsimony/disparateness of conceptualisations, dissingularisation-<as-toabsolutising- the-disjointedness/ment-of- presencing-absolutising-identitiveidentitive- $\quad$ constitutedness $>$-loperantly-construed-as-of- incrementalism-inconstitutedness $>$ relative-ontological-incompleteness g/internal-decoherencing); -1 and thus dissingularisation-<as-to-thedisjointedness/ment-of- presencing-absolutising-identitive-

constitutedness $>$ is construed 'as from prospective ${ }^{61}$ nonpresencing$<$ perspective-ontological-normalcy/postconvergence $>$ reflection of <emplitudinglformative-epistemicity>causality $\sim$ as-to-projective- 
totalitative-implications-of-prospective- nonpresencing,-for-

explicating relative unreflexivity/relative reflexivity ontological-

contiguity of relative-ontological-incompleteness /relative-ontologicalcompleteness -_sublimating referencing/registering/decisioning,-asself-becoming/self-conflatedness /formative-supererogating-

$<$ projective/reprojective-aestheticising-re-motif-and-re-apriorising/reaxiomatising/re-referencing,-in-perspective-ontologicalnormalcy/postconvergence>)' rather as 'preconverging-or-dementing apriorising-psychologism representation', with dissingularisation-<as-tothe-disjointedness/ment-of- presencing-absolutising-identitive-

constitutedness $>\quad$ so-induced by-prospective parrhesiasticaestheticisation of prior reproducibility-mathesis/motif/thrownnessdisposition,-as-reproducibility-of-aestheticisation as preconverging/dementing -qualia-schema', reflecting the contrastive apriorising-teleological-thresholding-as-

teleologicalframework/narrative-framework of 'prior preconverging-ordementing -apriorising-psychologism temporal underpinningsuprasocial-construct,-<amplitudingfformative $>$ wooden-language(imbued-averaging-of-thought-<as-to-leveling/ressentiment/closedconstruct-of- meaningfulness-and-teleology -as-of'nondescript/ignorable-void '-with-regards-to-prospective-apriorisingimplications $>$ |,-and-sophistry reproducibilitymathesis/motif/thrownness-disposition,-as-reproducibility-ofaestheticisation as reasoning-from-results/afterthought' undermined/preconverging-or-dementing -apriorising-psychologism by 
'prospective postconverging-or-dialectical-thinking-apriorisingpsychologism intemporal parrhesiastic-aestheticisation induced reasoning-through/messianic-reasoning reproducibilitymathesis/motif/thrownness-disposition,-as-reproducibility-ofaestheticisation'

distractive- 'distractive-alignment-to- reference-of-thought-<of-

alignment-to- $\quad$ apriorising/axiomatising/referencing > '-as-destructuring-or-of${ }^{3}$ reference-of- constitutedness ${ }^{4}$-over-conflatedness

thought $-<$ of-

apriorising/axioma

tising/referencing $>$

30

epistemic- epistemic-abnormalcy/preconvergence-<preconvergence-as-

abnormalcy/precon 'preconverging-or-dementing -apriorising-psychologism representationvergence $^{31} \quad$ as-of-preconverging-aestheticisation',-and-not-postconvergence-as'postconverging-or-dialectical-thinking -apriorising-psychologism representation-as-of-postconverging-aestheticisation'>

\footnotetext{
${ }^{32}<$ amplituding/for $<$ emplituding/formative-epistemicity $>$ growth-ormative- $\quad$ conflatedness $3 /$ transvaluative-
}

epistemicity>grow rationalising/transepistemicity/anamnestic-residuality/spirit-drivennessth-or(construed-as-transepistemic-apriorising/axiomatising/referencing-as-toconflatedness $^{13} /$ tra existence-potency $\sim$ sublimating-nascence,-disclosed-from-prospectivensvaluative- $\quad$ epistemic-digression ); $\mid$ reflecting intemporal-solipsistic-firstnaturenessrationalising/transe of-epistemic-growth-or-conflatedness $/ 3$ transvaluative- 
pistemicity/anamn rationalising/anamnestic-residuality-as-ratiocinative-integrity-\{not-

esticmythical-recollection\}/transepistemicity

residuality/spirit-

drivenness

epistemic-

epistemic-totalising refers to 'Being-as-epistemically-all-defining-and-

totalising 33

determining-in-effect-as-of-circumscribing/delineating,-and-so-as-of-

meaningfulness-and-teleology -underlying-re-motif-and-re-

apriorising/re-axiomatising/re-referencing/re-intelligibilitysettingup/re-

measuringinstrumenting as of relative-ontological-

incompleteness 8 /relative-ontological-completeness

(sublimating referencing/registering/decisioning,-as-self-becoming/self-

conflatedness /formative-supererogating-<projective/reprojective-

aestheticising-re-motif-and-re-apriorising/re-axiomatising/re-

referencing,-in-perspective-ontological-normalcy/postconvergence $>$ ) as

to human-and-social-expectations/anticipations-metaphoricity -as-

preconverging/postconverging-rede-

mentating/restructuring/reparadigming-psychologism, and so-reflected as of the epistemic construal from existence-potency $\sim$ sublimatingnascence,-disclosed-from-prospective-epistemic-digression epistemic-ornotional projective-perspective of analysis as to ontologicalnormalcy/postconvergence in determining ontological-veracity or ontological-impertinence', and is contrasted with the notion of totalitarian as 'being-all-defining-and-determining-rather-by-humansubpotencyobstinacy/ideology-overt-projection/assertion that ignores- 
and-overlooks the epistemic construal from existencepotency ${ }^{3}$ sublimating-nascence,-disclosed-from-prospective-epistemicdigression epistemic-or-notional projective-perspective of analysis as to ontological-normalcy/postconvergence in determining ontologicalveracity or ontological-impertinence'; such that the notion of <amplitudingtformative-

epistemicity>totalising/circumscribing/delineating is rather as of the epistemic reflection of ontological-veracity about say a given $<$ emplitudinglformative-epistemicity>-totalising $\sim$ thrownness-inexistence registry-worldview/dimension in effect

\section{<emplitudingfformative-}

epistemicity>totalising/circumscribing/delineating ${ }^{56}$ meaningfulness-andteleology, as reflected by the fact that apriorising/axiomatising/referencing/intelligibilitysettingup/measuringins trumenting by a positivistic mindset is <amplituding/formativeepistemicity>totalisingly $/$ circumscribingly/delineatingly different from a non-positivistic mindset whereas the notion of totalitarian as-ofideology/obstinacy is rather about direct dogmatic commitment to a given meaningfulness-and-teleology with the inclination to dispense whether extensively or partially with ontological-veracity often on a supposed assumption of grander overall ontological-veracity

$<$ amplituding/form ative-
$<$ amplituding/formative-epistemicity>totalising self-referencingsyncretising/circularity/interiorising/akrasiatic-drag-_as-wrongly-

epistemicity>totali implying- 
$\operatorname{sing} \sim$ self-

apriorising/axiomatising/referencing/intelligibilitysettingup/measuringins

referencing-

trumenting-as-of-prior-relative-ontological-incompleteness -of-

syncretising/circul

reference-of-thought-that-is-prospectively-as-from-perspective-

arity/interiorising/a

ontological-normalcy/postconvergence-rather-of-

krasiatic-drag ${ }^{34}$

preconverging/dementing -apriorising-psychologism)

\section{$<$ amplituding/form}

ative-

epistemicity $>$ - <amplitudingfformative-epistemicity>-totalising thrownness-inexistence refers to the fact that human limited-mentation-capacity-assubjecting 'educed unlimitedness/existence sublimating nascence' tototalising thrownn limitedness/human-subpotency mindset as of construction-of-the-Self is ess-in-existence $^{35}$ inherently of a given 'determinable relative-ontologicalcompleteness /incompleteness apriorising-teleological-thresholding-asteleological-framework/narrative-framework of contextualising/existentialising/instantiative-devolving-meaningfulness' as reflected in its given <amplituding/formative-epistemicity>totalising thrownness-in-existence registry-worldview/dimension apriorising/axiomatising/referencing/intelligibilitysettingup/measuringins trumenting/axiomatising as to epistemictotalising $\sim$ resubjecting_or_totalising-entailing reconstrual-<f the wholelpurview of the wholetoneness-of ontology> of existence (soconstrued successively as the formative-epistemicity>totalising thrownness-in-existence of the state of recurrent-utteruninstitutionalisation trepidatious-consciousness, baseinstitutionalisation-ununiversalisation warped-consciousness, universalisation-non-positivism/medievalism preclusive-consciousness, 
our present positivism- procrypticism occlusive-consciousness and prospective notional deprocrypticism protensive-consciousness), such that ontologically there is variance of human limited-mentation-capacityas subjecting 'educed unlimitedness/existence sublimating nascence' tolimitedness/human-subpotency mindset in its <amplitudingfformativeepistemicity>-totalising thrownness-in-existence disposition (as to variance in Being-development/ontological-framework-expansion-as-todepth-of-ontologising-development-as-infrastructure-ofmeaningfulness-and-teleology psychologismic epistemic acutisationdifficulty<<for, residualising \{decompulsing' delinearity for cogency> magnitude \{of-experientiality/lexperiment $\}^{\}}$and its then imbued institutionaldevelopment-as-to-social-function-development and living-developmentas-to-personality-development psychologismic epistemic acutisation difficulty< <or, residualising dectinearity for cogency> magnitudes ${ }^{\text {(of-experientiality/experiment' }}$ ), and so-impliciting the notional $\sim$ selfdistantiation-<imbued-re-motif-and-re-apriorising/re-axiomatising/rereferencing $>/$ 'distantiation of contemplative existentialising-frame-丹f entailment of motif and apriorising/axiomatising/referencing as to transversality-<for-sublimating-existential-eventuating/denouementfrom 'thinking at first/pure predisposition preemptive of prospective disontologising/subontologising' as-of-prospectively-disambiguatedaffirmed-and-unaffirmed- 'motif-and-

apriorising/axiomatising/referencing'> at the very core of human psychoanalytic-unshackling/memetic-reordering/institutionalrecomposuring inducing of re-motif-and-re-apriorising/re- 
axiomatising/re-referencing/re-intelligibilitysettingup/re-

measuringinstrumenting as conflating towards the possibility of 'scalarity/immanency of existence's ontologicalnormalcy/postconvergence' (in notional deprocrypticism epistemicprojection) as so underlied by 'human intellection exercise direct-orelicited very own self-distantiation' involving appropriate 'metaphoricity as

tolling 3 hermenticttextuality/reprojecting/supererogating/zeroing/re acuting, - - dectinearity for-cogency <amplituding/formative epistemicity>-totalising renewing-realisation/re-perception/re-thought,in-supererogatory-epistemic-conflatedness ${ }^{13} ;$ and so in reflection of the historiality/ontological-eventfulness 38 ontological-aesthetic-tracing$<$ perspective-ontological-normalcy/postconvergence-reflected'epistemicity-relativism-determinism'> metaphoricity of human meaningfulness-and-teleology as of underlying de-mentation(supererogatoryontological-de-mentation-ordialectical-de-mentationstranding-or-attributive-dialectics) in reflecting holographically$<$ conjugatively-and-transfusively $>$ the relative unreflexivity/relative reflexivity ontological-contiguity of-the-human-institutionalisationprocess shifting phasing of 'postconverging-or-dialectical-thinking apriorising-psychologism' representation over preconverging-ordementing -apriorising-psychologism representation of the very ontologically same existence purview as of relative-ontologicalcompleteness ${ }^{8}$ over relative-ontological-incompleteness 
epistemic-

totalitative $e^{36}$

epistemic-totalitative is rather 'of the nonpresencing-<perspectiveontological-normalcy/postconvergence $>$ notionallepistemic/bindingnesssas determinism projective evaluation of ontological-performance ${ }^{72}<$ including-virtue-asontology>/morality/ethics/justice/etc. as to existencepotency $\sim$ sublimating-nascence,-disclosed-from-prospective-epistemicdigression and so with regards to the conception of all the relevant specific epistemic-totalising $\sim$ resubjecting_or_totalisingentailing reconstrual-<of the wholelpurview of the wholetoneness of entology $>$ of existence' as cumulatively/recomposuringly reflecting the epistemic-totalitative (and as epistemic-totalitive is articulated herein as the underlying relative-unreflexivity/relative reflexivity-ontologicalcontiguity of-the-human-institutionalisation-process ${ }^{6}$ reflected in the epistemic $<$ cumulating/recomposuring attendant-ontologicalcontiguity >-succession of human registry-worldviews/dimensions ${ }^{3}$ reference-of-thought 'specific epistemictotalising $\sim$ resubjecting_or_totalising-entailing $\sim$ reconstrual $<$ of the whole/purview of the wholetoneness-of ontology of existence' as of recurrent-utter-uninstitutionalisation, base-institutionalisation, universalisation, positivism/rational-empiricism and prospectively deprocrypticism, so-implied as notional deprocrypticism), with epistemic-totalitative so-construed as <amplituding-formativeepistemicity $>$ causality $\sim$ as-to-projective-totalitative-implications-ofprospective- nonpresencing,-for-explicating felativeunreflexivity/relative reflexivity ontological-contiguity' whereas the 
'specific

epistemic-totalising $\sim$ resubjecting_or_totalising-

entailing reconstrual-<of the wholelpurview of the wholeloneness of entology> of existence' is rather about any inherent <amplituding/formative-

epistemicity>totalising/circumscribing/delineating given meaningfulness-and-teleology representation arising as of the specific human limited-mentation-capacity-as subjecting 'educedunlimitedness/existence sublimating nascence' to limitedness/humansubpotency $<$ amplituding/formative-epistemicity > totalising thrownness-in-existence ${ }^{35}$, and thus epistemic-totalitative contrasts with <amplitudingfformativeepistemicity>totalising/circumscribing/delineating (as of humansubpotency apriorising/axiomatising/referencing/intelligibilitysettingup/measuringins trumenting) in that while the latter refers to any given registryworldview/dimension <emplituding/formative> wooden-language(imbued-averaging-of-thought-<as-to-leveling/ressentiment/closedconstruct-of- meaningfulness-and-teleology -as-of'nondescript/ignorablevoid'-with-regards-to-prospective-apriorisingimplications $>>$ as of its social-stake-contention-or-confliction and so whether as of a given relative-ontological-incompleteness 8 or relativeontological-completeness registry-worldview/dimension inherent <amplituding/formative-

epistemicity>totalising/circumscribing/delineating of ${ }^{56}$ meaningfulnessand-teleology, epistemic-totalitative (as to existence- 
potency $\sim$ sublimating-nascence,-disclosed-from-prospective-epistemicdigression

supererogatory acuity/perspicacity/astuteness/edginess/incisiveness-ofapriorising/axiomatising/referencing/intelligibilitysettingup/measuringins trumenting -for-conceptualisation epistemic-veracity implications) rather refers to notionally/epistemically/bindingnessly-<as-to-determinism/conceptivity-of relative-unreflexivity/relative-reflexivity> construing/evaluating projectively the human meaningfulness-and-teleology of any such <amplituding/formativeepistemicity>totalising/circumscribing/delineating and so in reflecting holographically-<conjugatively-and-transfusively $>$ the relativeunreflexivity/relative reflexivity ontological-contiguity of-the-humaninstitutionalisation-process opened-construct-of- meaningfulness-andteleology in increasing relative-ontological-completeness as of the notional deprocrypticism 'true-ontology-as-of-Beingdevelopment/ontological-framework-expansion-as-to-depth-ofontologising-development-as-infrastructure-of- meaningfulness-andteleology 'perspective of perception in reflecting human-subpotency potential to converge to existence-potency $\sim$ sublimating-nascence,disclosed-from-prospective-epistemic-digression supererogatory acuity/perspicacity/astuteness/edginess/incisiveness-ofapriorising/axiomatising/referencing/intelligibilitysettingup/measuringins trumenting-for-conceptualisation; with the implication that the <mplitinglformativeepistemicity >totalising/circumscribing/delineating attendant-ontologyas-of-conventioning-referencing perspective of say non- 
positivism/medievalism or procrypticism cannot all of a sudden respectively start postconverging-or-dialectical-thinking-apriorisingpsychologism in positivism or notional deprocrypticism terms-as-ofaxiomatic-construct and it is only an epistemic-totalitative sense-of-things 'as to existence-potency ${ }^{3}$ sublimating-nascence,-disclosed-fromprospective-epistemic-digression notionallepistemic/bindingnesf ${ }^{<a s-t o-}$ determinism/conceptivity-of-relative-unreflexivity/relative-reflexivity> projective construal/evaluation' that can allow for the mental-projection out of any given registry-worldview/dimension <amplituding/formative> woodenlanguage-_imbued - averaging-of-thought-<as-to-

leveling/ressentiment/closed-construct-of- meaningfulness-andteleology -as-of-'nondescript/ignorable-void ' -with-regards-toprospective-apriorising-implications $>>$ to reflect-and-contemplate of prospective postconverging-or-dialectical-thinking -apriorisingpsychologism representation as of transcendence-andsublimity/sublimation/supererogatory-de-mentativity over prior preconverging-or-dementing -apriorising-psychologism representation, hence such an epistemic-totalitative <amplitudinglformativeepistemicity>causality $\sim$ as-to-projective-totalitative-implications-ofprospective- nonpresencing,-for-explicating relativeunreflexivity/relative reflexivity ontological-contiguity construal is intimately associated with dispensing-with-immediacy-for-relativeontological-completeness ${ }^{8}$-by-reification/contemplative-distension (as of human self-surpassing-existentialism-form-factor,-in-overcoming'notional collateralising-beholdening-protohumanity'-to- 'attain- 
sublimating-humanity'-as-to-existence-potency sublimating-nascence,-

disclosed-from-prospective-epistemic-digression to supersede human temporality /shortness <amplitudingfformative> wooden-language-

(imbued-averaging-of-thought-<as-to-leveling/ressentiment/closedconstruct-of- meaningfulness-and-teleology -as-of-

'nondescript/ignorable-void '-with-regards-to-prospective-apriorising-

implications $>$ I) as to the 'displacement/decentering-of-the-human-subject induced as of de-mentation-(stpererogatorytological-de-mentationor-dialectical-de-mentation-stranding-or-attributive-dialectics), in undermining the 'shiftiness-of-the-Self' associated with <amplituding/formative-

epistemicity>totalising/circumscribing/delineating as to the <amplituding/formative> wooden-language-fimbued-averaging-ofthought-<as-to-leveling/ressentiment/closed-construct-ofmeaningfulness-and-teleology -as-of-'nondescript/ignorable-void 'with-regards-to-prospective-apriorising-implications $>$ | perspective epistemic-totality ${ }^{37}$ epistemic-totality refers to the fact that human limited-mentationcapacity-as-subjecting 'educed unlimitedness/existence sublimating nascence' to limitedness/human-subpotency induces human <amplitudinglformative-epistemicity>-totalising thrownness-inexistence which $^{35} \quad$ preconverging/postconverging-dementatively/structurally/paradigmatically further induces the <amplituding/formative-

epistemicity>totalising/circumscribing/delineating nature of human 
meaningfulness-and-teleology in existence so-reflected in epistemictotalising $\sim$ resubjecting_or_totalising-entailing $\sim$ reconstrual-<f the wholelpurview of the wholetoneness of ontology> of existence (as of apriorising/axiomatising/referencing-\{of-'prospectively implicited_attendant-ontological-contiguity ' educedexistentialising/contextualising/textualising_intelligibility/epistemicity/re flexivity-contiguity-<imbued-notional $\sim$ cogency> ' $\}$-conflatedness ${ }^{13}-$ in (preconverging ment by\} postconverging entailment) for human limited-mentation-capacity-deepening - as subjecting limitedness/humansubpotency to 'educed unlimitednesslexistence sublimating nascence',

with this <amplituding/formativeepistemicity>totalising/circumscribing/delineating varying as from 'relative-ontological-incompleteness ${ }^{8}$ to relative-ontologicalcompleteness ${ }^{87} \quad{ }^{83}$ reference-of-thought <amplitudinglformativeepistemicity $>$ causality $\sim$ as-to-projective-totalitative-implications-ofprospective- nonpresencing,-for-explicating relativethreflexivityelative reftexivity ontological-contiguity, such that human Being-development/ontological-framework-expansion-as-todepth-of-ontologising-development-as-infrastructure-ofmeaningfulness-and-teleology conception and thereof-its-devolvinginstitutional-and-living-conceptions-in-existence are reflected-as-of-its‘ $<$ amplitudinglformative-epistemicity>-totalising thrownness-inexistence $^{35}$ educing <mplinglformativeepistemicity>totalising and-internally-coherent apriorising/axiomatising/referencing/intelligibilitysettingup/measuringins 
trumenting for aposteriorising/logicising/deriving/intelligising/measuring meaningfulness-and-teleology in existential-instantiations; epistemic-totality as such further speaks of the <amplitudingfformativeepistemicity>totalising/circumscribing/delineating nature of human ${ }^{3}$ reference-of-thought-which-varies-as-of 'relative-ontologicalincompleteness /relative-ontological-completeness

(sublimating referencing/registering/decisioning,-as-self-becoming/selfconflatedness /formative-supererogating-<projective/reprojectiveaestheticising-re-motif-and-re-apriorising/re-axiomatising/rereferencing,-in-perspective-ontological-normalcy/postconvergence $>$ | as to human-and-social-expectations/anticipations-metaphoricity -aspreconverging/postconverging-redementating/restructuring/reparadigming-psychologism,', as-so-liable-tometaphoricity -as-of- reference-of-thought-evolving-and-devolvingteleological-de-mentating/structuring/paradigming-of-meaningfulness, and we can consider in this regards 'the-very-same physics $<$ amplitudingfformative-epistemicity $>$ totalising $\sim$ devolvedpurview/domain-of-construal-as-intrinsic-reality/ontologicalveridicality/existential-reality' wherein existence-potency ${ }^{32}$ sublimatingnascence,-disclosed-from-prospective-epistemic-digression epistemic-ornotional projective-perspective of human ontological-performance ${ }^{72}$ $<$ including-virtue-as-ontology>/morality/ethics/justice/etc. ontological-veracity shows a relative-ontological-completeness variation as of 'traditional classical mechanics axiomatic-construct' to theory-of-relativity-together-with-quantum-mechanics-axiomatic- 
constructs

event $^{38}$

event (as to event-construed-as-the-prospective-ontology-origination or evental-instigation) speaks of 'existentially-contextualised intemporalparrhesiastic-aestheticisation instigation(s) of humanity-level of possibilities of Being-development/ontological-framework-expansion-asto-depth-of-ontologising-development-as-infrastructure-ofmeaningfulness-and-teleology , institutional-development-as-to-socialfunction-development and living-development-as-to-personalitydevelopment psychologismic epistemic acutisation difficulty< for, residualising \{decompulsing delinearity for cogency> magnitudesiofexperientiality/experiment? transformation of 'meaningfulness-and-teleology ' as of 'aetiologisation/ontological-escalation-<ontologicalveridicality_commitment/otherliness_transcending/compulsionsencumbered_transcending > implications' of metaphoricity - as-eventof-prospective-intemporal-parrhesiastic-aestheticisation induced prospective relative-ontological-completeness -of-reference-of-thought reproducibility — mathesis/motif/thrownness-disposition,-asreproducibility-of-aestheticisation as preconverging/postconverging-dementatively/structurally/paradigmatically providing the possibility for deflating/superseding the vices-and-impediments of prior relativeontological-incompleteness -of- reference-of-thought, as so-implied with regards to the events ${ }^{38}$ instigating the successive prospective registryworldviews/dimensions in reflecting holographically-<conjugativelyandtransfusively> the relative unreflexivity/relative-reflexivity- 
ontological-contiguity $\sim$ of-the-human-institutionalisation-process ${ }^{6}$ say with 'Socrates/Plato/Aristotle with their schools existentiallycontextualised intemporal-parrhesiastic-aestheticisation eventalinstigation of universalising-idealisation apriorising/axiomatising/referencing/intelligibilitysettingup/measuringins trumenting as reproducibility—mathesis/motif/thrownness-disposition,as-reproducibility-of-aestheticisation wherein prospective universalising-idealisation is postconverging-or-dialectical-thinking apriorising-psychologism and prior base-institutionalisationununiversalisation is preconverging-or-dementing-apriorisingpsychologism' or 'budding-positivists existentially-contextualised intemporal-parrhesiastic-aestheticisation evental-instigation of positivism/rational-empiricism apriorising/axiomatising/referencing/intelligibilitysettingup/measuringins trumenting as reproducibility—mathesis/motif/thrownness-disposition,as-reproducibility-of-aestheticisation wherein prospective positivism/rational-empiricism is postconverging-or-dialecticalthinking -apriorising-psychologism and prior universalisation-nonpositivism/medievalism is preconverging-or-dementing-apriorisingpsychologism'; with the underlying insight here that 'existentiallycontextualised intemporal-parrhesiastic-aestheticisation eventalinstigation(s)' speaks of the possibility of aetiologisation/ontologicalescalation-<ontologicalveridicality_commitment/otherliness_transcending/compulsionsencumbered_transcending $>$ as of infinity/a-million-and-one-instances- 
and-locales implications' of deflating/superseding the vices-andimpediments of prior relative-ontological-incompleteness -ofreference-of-thought as of a transversality-<for-sublimating-existentialeventuating/denouement, from 'thinking at first/pure predisposition preemptive of prospective disontologising/subontologising' as-ofprospectively-disambiguated-affirmed-and-unaffirmed-'motif-andapriorising/axiomatising/referencing'> that preconverging/postconverging-dementatively/structurally/paradigmatically recognises an issue of notionaldiscontiguity/epistemic-discontiguity 3 - between - prior-shallowsupererogation -of-mentally-aestheticised preconverging/dementing qualia-schema_and_prospective-profound-supererogation -of-mentallyaestheticised postconverging/dialectical-thinking -qualia-schema $>$ with regards to 'ontologically-flawed apriorising/axiomatising/referencing/intelligibilitysettingup/measuringins trumenting and the preconverging-or-dementing-apriorisingpsychologism implications' warranting the superseding/deflating of prior relative-ontological-completeness ${ }^{-o f}$ reference-of-thought rather than the given prior relative-ontological-incompleteness underpinningsuprasocial-construct/sophistry <emplitudinglformative $>$ woodenlanguage-_imbued-averaging-of-thought-<as-toleveling/ressentiment/closed-construct-of- meaningfulness-andteleology -as-of-'nondescript/ignorable-void ' -with-regards-toprospective-apriorising-implications $>>$ induced false pretence of an issue of 'aposteriorising/logicising/deriving/intelligising/measuring on the basis 
of the its prospectively unrecognised ontologically-flawed apriorising/axiomatising/referencing/intelligibilitysettingup/measuringins trumenting and the preconverging-or-dementing-apriorisingpsychologism implications', such that the true 'issue of prosecution' with regards to Socrates or Galileo with respect to their asceticism stances was about the ontological-impertinence of their respective social-setup in failing to recognise prospective Socratic-philosophers ${ }^{103}$ universalisingidealisation and positivism/rational-empiricism apriorising/axiomatising/referencing/intelligibilitysettingup/measuringins trumenting which then exposed them to their social-setup sophistry in a pretence that theirs were just case-issues-and-not-of-event-implications thus their respective sophistry 'aposteriorising/logicising/deriving/intelligising/measuring on the basis of their respective social-setup ununiversalisation and nonpositivism/medievalism ontologically-flawed apriorising/axiomatising/referencing/intelligibilitysettingup/measuringins trumenting and as of the preconverging-or-dementing-apriorisingpsychologism implications', just as it is herein contended that the sophistic/pedantic disposition of our times in incrementalism-in-relativeontological-incompleteness

enframed/disontologising conceptualisation will assume a nondescript/ignorable-void pretence of case-issues-and-not-of-eventimplications thus 'aposteriorising/logicising/deriving/intelligising/measuring on the basis of our positivism/rational-empiricism manifestation of procrypticism-or- 
disjointedness-as-of- reference-of-thought prospectively ontologicallyflawed

apriorising/axiomatising/referencing/intelligibilitysettingup/measuringins trumenting' thus 'ignoring the aetiologisation/ontological-escalation$<$ ontological-

veridicality_commitment/otherliness_transcending/compulsionsencumbered_transcending $>$ implications with regards to existentiallycontextualised intemporal-parrhesiastic-aestheticisation eventalinstigation of prospective deprocrypticism-or-preemptingdisjointedness-as-of- reference-of-thought apriorising/axiomatising/referencing/intelligibilitysettingup/measuringins trumenting implied prospective ${ }^{5}$ meaningfulness-and-teleology infrastructure for deflating/superseding vices-and-impediments ${ }^{105}$ of positivism/rational-empiricism manifestation of procrypticism-ordisjointedness-as-of- reference-of-thought'

existence-potency existence-potency sublimating-nascence,-disclosed-from-prospective-

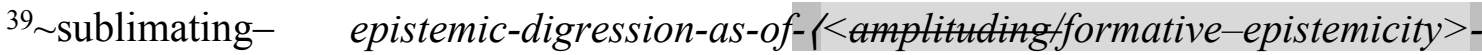
nascence,- $\quad$ totalising renewing-realisation/re-perception/re-thought,-indisclosed-from- supererogatory-epistemic-conflatedness - as-to-the-ontologicalprospective- $\quad$ normalcy/postconvergence-projective-perspective,-to-which-latterepistemic- human-subpotency-projectively-conflates-to-in-order-to-overcome-ourdigression prospective-epistemic-abnormalcy/preconvergence ।

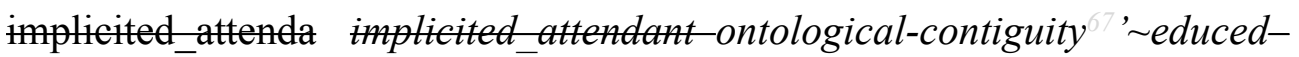
nt-ontological- existentialising/contextualising/textualising_intelligibility/epistemicity/re 
contiguity ${ }^{67}$ 'educ flexivity-contiguity-<imbued-notional $\sim$ cogency $>$ ' is the 'notionally ededuced human conceptivity/epistemic-reflexivity/epistemicity-relativismexistentialising/eo determinism-<reifying\{as-to-knowledge-developing\}-and-empowering > ntextmalising/textm as to nonpresencing-<perspective-ontologicalalising_intelligibil normalcy/postconvergence> epistemic-projective-equalisation of human ity/epistemicity/ref limited-mentation-capacity-deepening - as-subjecting-limitedness/humanlexivity- $\quad$ subpotency to 'educed unlimitedness/existence sublimating nascence' contiguity- as so-educed upon the inherent relative unreflexivity/relative reflexivity$<$ imbued- ontological-contiguity that is the-very-same-immanentnotional cogency> existence/intrinsic-reality/ontological-veridicality', and , 40 'implicited_attendant-ontological-contiguity ' reducedexistentialising/contextualising/textualising_intelligibility/epistemicity/re flexivity-contiguity-<imbued-notional $\sim$ cogency $>$, refers to meaningfulness-and-teleology projective epistemic-veracity and thus ontological-veracity construed preconverging/postconverging-dementatively/structurally/paradigmatically as of 'apriorising/axiomatising/referencing-\{of-'pecty implicited_attendant-ontological-contiguity ' educedexistentialising/contextualising/textualising_intelligibility/epistemicity/re flexivity-contiguity-<imbued-notional $\sim$ cogency > ' \}-conflatedness ${ }^{3-}$ in \{preconverging ment by\} postconverging entailment-with-existence or conflatedness $^{13}$-of-construal-alongside-existential-sublimatingmanifestation', so-implied as 'implicitontontolontcontiguity ${ }^{\prime} \sim$ educedexistentialising/contextualising/textualising_intelligibility/epistemicity/re 
flexivity-contiguity-<imbued-notional $\sim$ cogency $>$ ',-<reifying-orelucidating-of-prospective-relative-ontological-completeness -ofreference-of-thought- devolving-as-of-instantiative-context $>$ or logicaldueness-rather-as-of-prospective-relative-ontological-completeness -ofreference-of-thought or relative-ontological-veridicality-as-ofprospective- reference-of-thought; $\Phi$ implicited_attendant-ontologicalcontiguity ${ }^{\prime} \sim$ educedexistentialising/contextualising/textualising_intelligibility/epistemicity/re flexivity-contiguity-<imbued-notional $\sim$ cogency $>$ ' as 'apriorising/axiomatising/referencing-\{of- "prospectively implicited_attendant-ontological-contiguity ' reducedexistentialising/contextualising/textualising_intelligibility/epistemicity/re flexivity-contiguity-<imbued-notional $\sim$ cogency ${ }^{\text {' }}$, '-conflatedness ${ }^{13}-$ in \{preconverging ment by\} postconverging entailment-with-existence as to existence-potency $\sim$ sublimating-nascence,-disclosed-fromprospective-epistemic-digression construal of <amplituding/formativeepistemicity >causality $\sim$ as-to-projective-totalitative-implications-ofprospective- nonpresencing,-for-explicating relativeunreflexivity/relative reflexivity ontologicalcontiguity /conflatedness ${ }^{13}$-of-construal-alongside-existentialmanifestation' is effectively what allows for the projective epistemic countenancing of 'relative-ontological-incompleteness /relativeontological-completeness

(sublimating referencing/registering/decisioning,-as-self-becoming/selfconflatedness /formative-supererogating-<projective/reprojective- 
aestheticising-re-motif-and-re-apriorising/re-axiomatising/re-

referencing,-in-perspective-ontological-normalcy/postconvergence $>$ । as

to human-and-social-expectations/anticipations-metaphoricity -as-

preconverging/postconverging-rede-

mentating/restructuring/reparadigming-psychologism '

of

apriorising/axiomatising/referencing/intelligibilitysettingup/measuringins

trumenting' as of human limited-mentation-capacity-deepening-as-

subjecting limitedness/human subpotency to 'educed-

tunlimitedness/existence sublimating nascence', and thus the

corresponding knowledge-reification gesturing-and-accounting-of-

epistemic-phenomenalism- $<$ in-

prospective_psychologismic $\sim$ apriorising/axiomatising/referencing-\{of-

'prospectively implicited_attendant-ontological-contiguity ' reduced-

existentialising/contextualising/textualising_intelligibility/epistemicity/re

flexivity-contiguity-<imbued-notional cogency> ' \} - conflatedness

in \{preconverging ment by\} postconverging entailment> capacity

towards singularisation-<as-to-the-nondisjointedness/entailment-of-

prospective- nonpresencing $>\quad$ projected epistemic-

immanence/veridical-epistemicity-relativism-determinism as implied with the relative unreflexivity/relative reflexivity ontological-contiguity $\sim$ ofthe-human-institutionalisation-process $\quad$ 'true-ontology-as-of-Being-

development/ontological-framework-expansion-as-to-depth-of-

ontologising-development-as-infrastructure-of- meaningfulness-and-

teleology ; $;$ such that implicited_attendant-ontological-

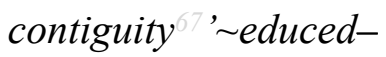


existentialising/contextualising/textualising_intelligibility/epistemicity/re flexivity-contiguity-<imbued-notional $\sim$ cogency $>$ '

<amplituding/formative-epistemicity>causality $\sim$ as-to-projective-

totalitative-implications-of-prospective- nonpresencing,-for-

explicating felative unreflexivity/relative reflexivity ontological-

contiguity apriorising/axiomatising/referencing-\{of-"prospectively

implicited_attendant-ontological-contiguity ' reduced-

existentialising/contextualising/textualising_intelligibility/epistemicity/re flexivity-contiguity-<imbued-notional $\sim$ cogency $>^{\text {' }}$, - conflatedness ${ }^{13}-$ in \{preconverging ment by\} postconverging entailment highlights that abstract notions/conceptualisations are only as pertinent as reflexive of existential-<isontologising/re-ontologising aporeticism $>$ sublimating manifestation which preconverging/postconverging-dementatively/structurally/paradigmatically precedes ("not the unforegrounding-ment or vague-foregrounding/vague-entailment as background' implied with such abstract notions/conceptualisations, but rather as the foregrounding entailment-<in-succession-of-profoundsupererogation $>$-_postconverging-narrowing-down $\sim$ sublimation-as-to'existence-as-sublimating-withdrawal/unenframing/re-ontologising,elicited-from-prospective-profound-supererogation '-in-reflecting'immanent relative unreflexivity/relative reflexivity ontologicalcontiguity ';-as-operative-notional deprocrypticism) which is soconstrued as: 'implicited_attendant-ontological-contiguity ' reducedexistentialising/contextualising/textualising_intelligibility/epistemicity/re flexivity-contiguity-<imbued-notional cogency>' as to existence- 
potency ${ }^{3}$ sublimating-nascence,-disclosed-from-prospective-epistemicdigression' underlying causality with regards to <amplitudingfformativeepistemicity>causality $\sim$ as-to-projective-totalitative-implications-ofprospective- nonpresencing,-for-explicating felativeunreflexivity/relative reflexivity ontological-contiguity) any such abstract notions/conceptualisations thus avoiding any elaboration-as-tomere-extrapolating/constituting/abstracting/deducing/inferring-ofelucidation-outside-'prospectively implicited_attendant-ontologicalcontiguity ' ${ }^{\prime 2}$ educedexistentialising/contextualising/textualising_intelligibility/epistemicity/re flexivity-contiguity-<imbued-notional $\sim$ cogency>' and reflecting the epistemic-veracity of human knowledge-reification gesturing-andaccounting-of-epistemic-phenomenalism-<in-

prospective_psychologismic apriorising/axiomatising/referencing-\{of'prospectively implicited_attendant-ontological-contiguity ' reducedexistentialising/contextualising/textualising_intelligibility/epistemicity/re flexivity-contiguity-<imbued-notional $\sim$ cogency $>$ ' \}-conflatedness in \{preconverging ment by\} postconverging entailment>/ontologicalveracity rather as of the <amplitudingfformativeepistemicity>causality $\sim$ as-to-projective-totalitative-implications-ofprospective- nonpresencing,-for-explicating relativeunreflexivity/relative reflexivity ontological-contiguity so-imbued in difference-conflatedness ${ }^{3}$-as-to-totalitative-reification-insingularisation-<as-to-the-nondisjointedness/entailment-of-prospectivenonpresencing $>$-as-veridical-epistemicity-relativism-determinism 
and

SO

contrary

to

atomising/taking-to-pieces

apriorising/axiomatising/referencing-\{of- "prospectively

implicited_attendant-ontological-contiguity ' reduced-

existentialising/contextualising/textualising_intelligibility/epistemicity/re

flexivity-contiguity-<imbued-notional $\sim$ cogency $>^{\prime}$ \} - constitutedness ${ }^{4}$

in preconverging-entailment of poor projective epistemic countenancing

of

'relative-ontological-incompleteness /relative-ontological-

completeness ${ }^{-}$/sublimating $\sim$ referencing/registering/decisioning,-as-

self-becoming/self-conflatedness /formative-supererogating-

$<$ projective/reprojective-aestheticising-re-motif-and-re-apriorising/re-

axiomatising/re-referencing,-in-perspective-ontological-

normalcy/postconvergence $>$ as to human-and-social-

expectations/anticipations - metaphoricity -as-

preconverging/postconverging-rede-

mentating/restructuring/reparadigming-psychologism '

of

apriorising/axiomatising/referencing' as of their ontologically-flawed

reflection of <emplituding/formative-epistemicity>causality $\sim$ as-to-

projective-totalitative-implications-of-prospective- nonpresencing,-for-

explicating relative unreflexivity/relative reflexivity ontological-

contiguity given their <amplitudingfformative-

epistemicity $>$ totalising $\sim$ self-referencing-

syncretising/circularity/interiorising/akrasiatic-drag ${ }^{34}{ }^{56}$ meaningfulness-

and-teleology of presencing-absolutising-identitive-

constitutedness / /identitive-constitutedness ${ }^{4}$-as- 'epistemic-totality ${ }^{37}$ -

dereification-in-dissingularisation-<as-to-the-disjointedness/ment-of- 
presencing-absolutising-identitive-constitutedness $>$-as-flawed-

epistemicity-relativism-determinism ; 9 thus implicited_attendant ontological-contiguity ' educed-

existentialising/contextualising/textulising_intelligibility/epistemicity/re

flexivity-contiguity-<imbued-notional $\sim$ cogency $>$ '

<amplitudinglformative-epistemicity>causality $\sim$ as-to-projective-

totalitative-implications-of-prospective- nonpresencing,-for-

explicating relative unreflexivity/relative reflexivity ontological-

contiguity as of its implied epistemic maximalising-recomposuring-forrelative-ontological-completeness —unenframed/re-

ontologising conceptualisation veridically implies the

'(<amplitudingfformative-epistemicity >causality $\sim$ as-to-projective-

totalitative-implications-of-prospective- nonpresencing,-for-

explicating relative unreflexivity/relative reflexivity ontological-

contiguity ) ${ }^{4}$ foregrounding_entailment-<in-succession-of-profound-

supererogation $>$ - \{postconverging-narrowing-down $\sim$ sublimation-as-to-

'existence - as-sublimating-withdrawal/unenframing/re-ontologising,-

elicited-from-prospective-profound-supererogation '-in-reflecting-

'immanent relative unreflexivity/relative reflexivity ontological-

contiguity ';-as-operative-notional deprocrypticism)

meaningfulness-and-teleology, as of the existential-

$<$ disontologising/re-ontologising aporeticism $>\quad$ notional reflexivity-

$<\{$ veridical/sound\} relative-reflexivity-in-existencetrelativising from

limited mentation as its deepening/psychologismic < residualising

fdecompulsings delinearity for cogency $>-b y$ - flawed/unsound\}-relative- 
unreflexivity-in-existencelabsolutising from limited-

mentation/psychologismic epistemic acutisation nonresidualising

imbued fompulsingl linearity in eclecticism of prior mere

formulaicity/ritualisation > of epistemic causality with regards to overall reifying-and-empowering-reflexivity-of-ecstatic-existence-as-

panintelligibilityfpanreflexivity - 〈existentially-imbued-and-educing-

$\leq$ fepistemic-

totising Thermeneutically/textully/reprojectingly/supererogatingly/zeroin

gly/re acutingly, \{decompulsing? delinearity for-cogency $\geq$ epistemic-

perspective-of-projective/reprojective-aestheticising-re-motif-and-re-

apriorising/re-axiomatising/re-referencing conceptualisation,-as-herein-

specifically relevant to human subpotency) (as implicited_attendant-

ontological-contiguity $\sim$,educed-

existentialising/contextualising/textualising_intelligibility/epistemicity/re

flexivity-contiguity-<imbued-notional $\sim$ cogency $>$ ' is rather about human-

subpotency-aporia/undecidability/dilemma/ought-

indeterminacy/deficiency/limitation/constraint—imbued-

'notional firstnaturedness-formativeness-<as-to-eventualising-inkling

drive or seeding misprising> temporal-to-intemporal-dispositions-

$<$ so-construed-as-from-perspective-ontological-

normalcy/postconvergence >'-existentialism-form-factor for human selfsurpassing_existentialism-form-factor,-in-overcoming-

'notional collateralising-beholdening-protohumanity'-to- 'attain-

sublimating-humanity'-as-to-existence-potency sublimating-nascence,-

disclosed-from-prospective-epistemic-digression), and this point is 
important to preempt the 'ontologically-flawed unforegrounding-ment' of 'implicited_attendant-ontological-contiguity ' reduced-

existentialising/contextualising/textualising_intelligibility/epistemicity/re flexivity-contiguity-<imbued-notional $\sim \operatorname{cogency}>$ ' by way of vague and naïve elaboration-as-to-mere-

extrapolating/constituting/abstracting/deducing/inferring-of-elucidationoutside-'prospectively_implicited_attendant-ontological-

contiguity ' $\sim$ educedexistentialising/contextualising/textualising_intelligibility/epistemicity/re flexivity-contiguity-<imbued-notional $\sim$ cogency> ${ }^{\prime}$ as can be wrongly/unwittingly be projected with flawed used of 'human conceptualtools' like language/logic/mathematics/statistics/algorithms/models/etc. that are only as pertinent as of their reflecting of the absolute a-priori that is existence and 'not superseding/overriding existential-reality in presencing-absolutising-identitive-constitutedness ${ }^{1 /} /$ constitutedness $^{14}$, (even as such conceptual-tools of formulation and representation can rather be of valid foregrounding_entailment-<in-succession-ofprofound-supererogation $>-$-postconverging-narrowing-

down sublimation-as-to- 'existence-as-sublimatingwithdrawal/unenframing/re-ontologising,-elicited-from-prospectiveprofound-supererogation '-in-reflecting- 'immanent felativethreflexivy relative reflexivity ontological-contiguity ';-as-operativenotional deprocrypticism) as to their epistemically-construed phenomenal/manifest $\sim$ subpotencies-_in-transitive-conflatedness reflexivity,-in-the-full-potency-of-existence's sublimating-nascence) but 
not epistemically overriding/superseding inherent existence which is ever always absolutely the foregrounding_entailment-<in-succession-ofprofound-supererogation $>-$ postconverging-narrowing-

down sublimation-as-to- 'existence-as-sublimating-

withdrawal/unenframing/re-ontologising,-elicited-from-prospectiveprofound-supererogation '-in-reflecting- 'immanent relative-

unreflexivity/relative reflexivity ontological-contiguity ';-as-operativenotional deprocrypticism ), and this explains why existential-reality is priorly affirmative as to the epistemic validity/invalidity of contrastive apriorising/axiomatising/referencing-conceptualisations such that the 'questioning of the apriorising/axiomatising/referencing validity/invalidity of existence itself doesn't arise in-the-very-first-place' as it is existence in its foregrounding_entailment-<in-succession-of-profoundsupererogation $>_{-}$(postconverging-narrowing-down $\sim$ sublimation-as-to'existence - as-sublimating-withdrawal/unenframing/re-ontologising,elicited-from-prospective-profound-supererogation '-in-reflecting'immanent relative unreflexivity/relative reflexivity ontologicalcontiguity ';-as-operative-notional deprocrypticism/as the absolute apriori that gives reasons and the 'human consciousness level of epistemicsufficiency-constitutedness ${ }^{1,}$ doesn't inherently commits existencelexistential-manifestation as to the fact that it is the human consciousness that recurrently has to readjust itself in its epistemic reevaluation of existence/existential-manifestation from its prior posture of epistemic sufficiency, as of human limited-mentation-capacitydeepening - as subjecting limitedness/human-subpotency to 'educed- 
unlimitedness/existence sublimating nascence' (as starkly manifested with such epiphenomenon like quantum entanglement); $₫$ further knowledge-reification gesturing-and-accounting-of-epistemicphenomenalism-<in-

prospective psychologismic apriorising/axiomatising/referencing-\{of'prospectively implicited_attendant_ontological-contiguity ' reducedexistentialising/contextualising/textualising_intelligibility/epistemicity/re flexivity-contiguity-<imbued-notional $\sim$ cogency $>$ ' \}-conflatedness in \{preconverging ment by\} postconverging entailment> as of 'implicited_attendant-ontological-contiguity ' reducedexistentialising/contextualising/textualising_intelligibility/epistemicity/re flexivity-contiguity-<imbued-notional cogency>' as underlined by the 'coherence/contiguity-of-superseding-oneness-of-ontology-implied-as-ofinherent-existencecoherence/contiguity,-and-so-construed-as-theenabler-of-insight-orintuition-or-foresight-as-of-embodiedconsciousness' reflects the veridicality that all epistemic-conceptions of phenomenal/manifest $\sim$ subpotencies-_in-transitive-conflatedness reflexivity,-in-the-full-potency-of-existence's $\sim$ sublimating-nascence) speak to the congruence of overall existence as to overall reifying-andempowering-reflexivity-of-ecstatic-existence-aspanintelligibilityfpanreflexivity - lexistentially-imbued-and-educing$\leq$ \{epistemic thermeneutically/textually/reprojectingly/supererogatingly/zeroin gly/re acutingly, -tdecompulsing $d e l i n e a r i t y \sim$ for-cogency $\geq$ epistemicperspective-of-projective/reprojective-aestheticising-re-motif-and-re- 
apriorising/re-axiomatising/re-referencing conceptualisation,-as hereinspecifically relevant to human subpotency) reflecting the 'relativeunreflexivity/relative reflexivity-ontological-contiguity of the comprehensive supervening of phenomenal/manifest $\sim$ subpotencies-_intransitive-conflatedness -reflexivity,-in-the-full-potency-of-

existence's Sublimating-nascence)' as enabling human existential$<$ disontologising/re ontologising aporeticism $>$ analysis as of transverse epistemic-conception phenomenal/manifest subpotency-_in-transitiveconflatedness -reflexivity,-in-the-full-potency-of-

existence's sublimating-nascence) and so while invalidating any reductionist subpotency substituting for any other epistemic-conceptions of immanently imbued phenomenal/manifest $\sim$ subpotencies-\{in-transitiveconflatedness -reflexivity,-in-the-full-potency-of-

existence's sublimating-nascence) thus 'enabling the transverse talising 3 hermeneuticttextuality/reprojecting/supererogating/zeroing/reacuting,-\{decompulsing delinearity for-cogency process that bringsabout/yields human knowledge-reification gesturing-and-accounting-ofepistemic-phenomenalism- $<$ in-

prospective psychologismic apriorising/axiomatising/referencing-\{of'prospectively_implicited_attendant_ontological-contiguity ' reducedexistentialising/contextualising/textualising_intelligibility/epistemicity/re flexivity-contiguity-<imbued-notional $\sim$ cogency $>$ ' \}-conflatedness in \{preconverging ment by\} postconverging entailment>' as ultimately validated/invalidated by prospective sublimation-over-desublimation 
ontological implications; $\boldsymbol{\Phi}$ and this conception of human knowledgereification gesturing-and-accounting-of-epistemic-phenomenalism$<$ in-prospective psychologismic $\sim$ apriorising/axiomatising/referencing\{of-'prospectively implicited_attendant-ontologicalcontiguity ' 'educedexistentialising/contextualising/textualising_intelligibility/epistemicity/re flexivity-contiguity-<imbued-notional $\sim$ cogency $\left.>^{\prime}\right\}$-conflatedness in \{preconverging ment by\} postconverging entailment> as of 'implicited_attendant-ontological-contiguity' reducedexistentialising/contextualising/textualising_intelligibility/epistemicity/re flexivity-contiguity-<imbued-notional cogency>' is different from the typical notion of analogy/mere-analogising in the sense that the latter is rather generally about mere conceptualisations of common/comparative patterning and the accompanying vague elaboration-as-to-mereextrapolating/constituting/abstracting/deducing/inferring-of-elucidationoutside-'prospectively implicited_attendant-ontological-

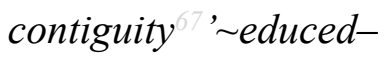
existentialising/contextualising/textualising_intelligibility/epistemicity/re flexivity-contiguity-<imbued-notional $\sim$ cogency>' without establishing the analogy/mere-analogising coherent relative unreflexivity/relativereflexivity ontological-contiguity as of implicited_attendantontological-contiguity ${ }^{\prime}$,educedexistentising intelligibility/epistemicity/re flexivity-contiguity-<imbued-notional $\sim \operatorname{cogency}>$ ' and thus do not speak to an 'entailing dynamics of existentially-disontologising/re- 
ontologising aporeticism> reflected relative unreflexivity/relativereflexivity ontological-contiguity as to existence-as-sublimatingwithdrawal/unenframing/re-ontologising,-elicited-from-prospectiveprofound-supererogation' as is the case with 'thought-experiments of mere common/comparative patterning' thus inducing 'blurriness$<$ sterilising/anecdotalising/trivialising-of-prospective-reontologising_by-preconverging,-in-disontologising-formulaic-draggingout/hollowing-out> of ${ }^{56}$ meaningfulness-and-teleology as to disparateness-of-conceptualisation-<unforegrounding-ment,-failingprospectively-to-reflect- immanent relative unreflexivity/relative reflexivity ontological-contiguity '> which do not project an entailing dynamics unlike thought-experiments of veridical implicited_attendantontological-contiguity ' $\sim$ educedexistentialising/contextualising/textualising_intelligibility/epistemicity/re flexivity-contiguity-<imbued-notional $\sim$ cogency>' such as Einsteinian relativity conceptualisations as to their foregrounding_entailment-<insuccession-of-profound-supererogation $>$ - (postconverging-narrowingdown sublimation-as-to- 'existence-as-sublimatingwithdrawal/unenframing/re-ontologising,-elicited-from-prospectiveprofound-supererogation '-in-reflecting- 'immanent relativeunreflexivity/relative reflexivity ontological-contiguity ';-as-operativenotional deprocrypticism) and so since thought-experiments reflecting 'implicited_attendant-ontological-contiguity ' reducedexistentialising/contextualising/textualising_intelligibility/epistemicity/re flexivity-contiguity-<imbued-notional cogency>' because of their 
awareness of 'relative-ontological-incompleteness /relative-ontologicalcompleteness ${ }^{8}$-\{sublimating $\sim$ referencing/registering/decisioning,-asself-becoming/self-conflatedness /formative-supererogating$<$ projective/reprojective-aestheticising-re-motif-and-re-apriorising/reaxiomatising/re-referencing,-in-perspective-ontological-

normalcy/postconvergence $>$ as to human-and-socialexpectations/anticipations - metaphoricity ${ }^{5}$-aspreconverging/postconverging-redementating/restructuring/reparadigming-psychologism's don't fall into the ontological-flaws of equating/levelling-down everything across space and time associated with presencing-absolutising-identitiveconstitutedness $^{14}$ when it comes to reflecting notionalcontiguity/epistemic-contiguity $-<$ profound-supererogation -ofmentally-aestheticised postconverging/dialectical-thinking -qualiaschema $>$ projection in relative-ontological-completeness as of existence - as-sublimating-withdrawal/unenframing/re-ontologising,elicited-from-prospective-profound-supererogation given that existence-is-the-absolute-a-priori-of-conceptualisation enabling sublimation-over-desublimation, and this differentiation between veridical knowledge-reification -gesturing-and-accounting-of-epistemicphenomenalism-<in-

prospective_psychologismic apriorising/axiomatising/referencing-\{of'prospectively_implicited_attendant-ontological-contiguity ' reducedexistentialising/contextualising/textualising_intelligibility/epistemicity/re flexivity-contiguity-<imbued-notional $\sim$ cogency $>$ ' \}-conflatedness 
analogy/mere-analogising also highlights that actually knowledge is more critically a contiguous whole as to the underlying reference-of-thoughtand- reference-of-thought- ${ }^{8}$ devolving- ${ }^{5}$ meaningfulness-and-teleology (and this should be the overall expected epistemic attitude) but for the artificial divisions arising as to human limited-mentation-capacity-assubjecting 'educed unlimitedness/existence sublimating nascence' tolimitedness/human subpotency warranting specialisations and the fact that various epistemic-conceptions of specialisations are of their 'peculiar optimal epistemicity for inducing sublimation', but then the requisite originariness-parrhesia,-as-spontaneity-of-aestheticisationsupererogatory acuity/perspicacity/astuteness/edginess/incisiveness-ofapriorising/axiomatising/referencing/intelligibilitysettingup/measuringins trumenting-for-conceptualisation as to sublimating ontological-goodfaith/authenticity $\sim$ postconverging-dementating/structuring/paradigming ${ }^{7}$ remains of the same ontologicalcongruence across all human knowledge-reification gesturing-andaccounting_of-epistemic-phenomenalism-<in-

prospective psychologismic $\sim$ apriorising/axiomatising/referencing-\{of'prospectively implicited_attendant-ontological-contiguity ' reducedexistentialising/contextualising/textualising_intelligibility/epistemicity/re flexivity-contiguity-<imbued-notional cogency> ' \}-conflatedness in \{preconverging ment by\} postconverging entailment> domains as reflected by the overall registry-worldview's/dimension's ${ }^{83}$ reference-ofthought-and- reference-of-thought- devolving- ${ }^{5}$ meaningfulness-and- 
teleology implied peculiar ('relative-ontological-completeness apriorising/axiomatising/referencing-psychologism

enculturated/constructed social-pragmatics-framing-of-predicativeeffectivity-sublimation-\{as-to-underlying,-ontological-commitment

<implied-self-assuredness-of-ontological-good-

faith/authenticity postconverging-de-

mentating/structuring/paradigming -as-being-as-of-existential-

reality $>$ J') $\quad$ foregrounding_entailment-<in-succession-of-profoundsupererogation $>_{-}$(postconverging-narrowing-down $\sim$ sublimation-as-to'existence - as-sublimating-withdrawal/unenframing/re-ontologising,-

elicited-from-prospective-profound-supererogation '-in-reflecting-

'immanent relative unreflexivity/relative reflexivity ontological-

contiguity ';-as-operative-notional deprocrypticism) and this insight will explain why conceptual/axiomatic epistemic-veracity analyses across subject-matters like physics, chemistry, biology, psychology, the social are not 'mere conceptualisations of common/comparative patterning' but speak to an underlying overall reference-of-thought epistemic-veracity for sublimation warranted across all the subject-matters so-reflected as of overall philosophical epistemological conceptualisation (and so specifically as to the positivism/rational-empiricism overall epistemic attitude of ${ }^{83}$ reference-of-thought underlying all these subject-matters) but more thoroughly implicited in many a natural science domain (given the natural sciences very strong constraining to predicative-effectivitysublimation-_as-to-underlying,-ontological-commitment $-<$ implied- 
self-assuredness-of-ontological-good-

faith/authenticity postconverging-de-

mentating/structuring/paradigming -as-being-as-of-existential-reality>>

and low emotional-involvement inducing the requisite candidness for prospective knowledge-reification gesturing-and-accounting-ofepistemic-phenomenalism- $<$ in-

prospective psychologismic apriorising/axiomatising/referencing-\{of'prospectively_implicited_attendant-ontological-contiguity ' reducedexistentialising/contextualising/textualising_intelligibility/epistemicity/re flexivity-contiguity-<imbued-notional cogency $\left.>^{\text {' }}\right\}$-conflatedness in-\{preconverging-ment by\} postconverging-entailment> sublimation) but requiring a thoroughly insightful philosophical expliciting and elucidation to induce a more consciously profound epistemic-veracity in the social as well as the overall registry-worldview's/dimension's ${ }^{3}$ reference-of-thought in enhancing overall human contemplation for knowledge-reification $\sim$ gesturing-and-accounting-of-epistemicphenomenalism- $<$ in-

prospective_psychologismic $\sim$ apriorising/axiomatising/referencing-\{of'prospectively implicited_attendant-ontological-contiguity ' reducedexistentialising/contextualising/textualising_intelligibility/epistemicity/re flexivity-contiguity-<imbued-notional cogency> ' \}-conflatedness in \{preconverging ment by\} postconverging antment>; 9 such an 'implicited_attendant-ontological-contiguity' ${ }^{6}$ educedexistentialising/contextualising/textualising_intelligibility/epistemicity/re flexivity-contiguity-<imbued-notional $\sim$ cogency $>$ ' conception of 
knowledge-reification gesturing-and-accounting-of-epistemicphenomenalism- $<$ in-

prospective psychologismic $\sim$ apriorising/axiomatising/referencing-\{of'prospectively implicited_attendant-ontological-contiguity ' educedexistentialising/contextualising/textualising_intelligibility/epistemicity/re flexivity-contiguity-<imbued-notional cogency> ' \}-conflatedness in \{preconverging ment by\} postconverging entailment $>$ unlike the mere aestheticisation of abstract dialecticism or analogy/mere-analogising makes a most profound claim to being ontological/scientific by the more profound veracity that it is epistemically embedded as to existence-assublimating-withdrawal/unenframing/re-ontologising,-elicited-fromprospective-profound-supererogation (thus averting vague elaborationas-to-mere-extrapolating/constituting/abstracting/deducing/inferring-ofelucidation-outside_-'prospectively implicited_attendant-ontological-

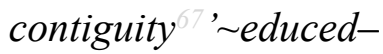
existentialising/contextualising/textualising_intelligibility/epistemicity/re flexivity-contiguity-<imbued-notional $\sim \operatorname{cogency}>^{\prime}$ ) and construes of existence-as-the-absolute-a-priori-ofconceptualisation $\sim$ and $\sim$ existence - as-sublimatingwithdrawal/unenframing/re-ontologising,-elicited-from-prospectiveprofound-supererogation -<as-to-perspective-ontologicalnormalcy/postconvergence-implied- 'prospective-aporeticismovercoming/unovercoming'> enabling sublimation-over-desublimation, that is, the implicited_attendant-ontological-contiguity ' reducedexistentialising/contextualising/textualising_intelligibility/epistemicity/re 
flexivity-contiguity-<imbued-notional $\sim$ cogency>' of knowledgereification gesturing-and-accounting-of-epistemic-phenomenalism$<$ in-prospective psychologismic $\sim$ apriorising/axiomatising/referencing\{of-'prospectively_implicited_attendant-ontologicalcontiguity ' educedexistentialising/contextualising/textualising_intelligibility/epistemicity/re flexivity-contiguity-<imbued-notional cogency>' \}-conflatedness in \{preconverging ment by\} postconverging entailment $>$ projects/construes of transcendence-andsublimity/sublimation/supererogatory $\sim$ de-mentativity and transcendentalenabling/sublimating/supererogatory de-mentativity in recognition of an 'effective reality basis implying more and more profound reconstruals/reconceptualisations (and so as to <amplituding/formativeepistemicity>-totalising renewing-realisation/re-perception/re-thought arising by human limited-mentation-capacity-deepening-as-subjectinglimitedness/human-subpotency to-'educed unlimitedness/existencethus is not mere 'eclecticism-of-prior-mereformulaicity/ritualisation-<as-of-prior rationalisation-ofcontentivity/argumentativity/dialecticism/discursivity> composition/blending-in_linearity/linear-accetion of relativeontological-completeness and relative-ontological-incompleteness apriorising/axiomatising/referencing as to secondnatured prior mereformulaicity/ritualisation-<as-to-mere-formulaicmethodologising/mutualising/organising/institutionalising,-prospectivelylosing-track-of- sepistemic-totalising ’’re apriorising/re axiomatising/re- 
referencing residuality-in-re-originariness/re-origination'>' as can be interpreted from a naïve presencing-absolutising-identitiveconstitutedness ${ }^{14}$ epistemic-projection perspective of prior_knowledgereification gesturing-and-accounting-of-epistemic-phenomenalism$<$ in-prior_psychologismic apriorising/axiomatising/referencing-\{of'prior-implicited_attendant-ontological-contiguity ' reducedexistentialising/contextualising/textualising_intelligibility/epistemicity/re flexivity-contiguity-<imbued-notional $\sim$ cogency>' \}'-constitutedness in preconverging entailment $>$ as to a relic/artifactual orientation poorly entertaining notional-contiguity/epistemic-contiguity $-<$ profoundsupererogation -of-mentally-aestheticised postconverging/dialecticalthinking-qualia-schema> projection of 'relative-ontologicalincompleteness 8 /relative-ontological-completeness

(sublimating referencing/registering/decisioning,-as-self-becoming/selfconflatedness /formative-supererogating-<projective/reprojectiveaestheticising-re-motif-and-re-apriorising/re-axiomatising/rereferencing,-in-perspective-ontological-normalcy/postconvergence $>$ । as to human-and-social-expectations/anticipations - metaphoricity -aspreconverging/postconverging-redementating/restructuring/reparadigming-psychologism, and that then equates/level-down everything across space and time failing to reflect historiality/ontological-eventfulness $3 \%$ ontological-aesthetic-tracing$<$ perspective-ontological-normalcy/postconvergence-reflected'epistemicity-relativism-determinism'> associated with prospective sublimation, and so just as say Einsteinian relativity in rearticulating prior 
physics conception like Lorentz transformation, Maxwell's equations, etc. do not speak to a soulless 'eclecticism-of-prior-mereformulaicity/ritualisation-<as-of-prior rationalisation-ofcontentivity/argumentativity/dialecticism/discursivity> composition/blending-in-\{compulsing\}linearity/linear-accretion of relativeontological-completeness and relative-ontological-incompleteness apriorising/axiomatising/referencing as to secondnatured prior mereformulaicity/ritualisation-<as-to-mere-formulaicmethodologising/mutualising/organising/institutionalising,-prospectivelylosing-track-of- "sepistemic-totalising ì re apriorising/re axiomatising/rereferencing residuality-in-re-originariness/re-origination'>' in gathering of such conceptions but rather priorly a re-originary_as-_

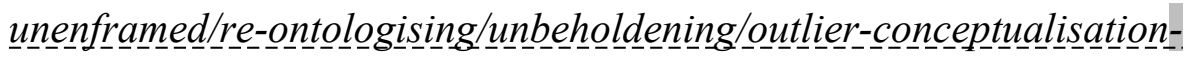
fimbued-postconverging/dialectical-thinking - projectiveinsights'/'epistemic-projection-in-conflatedness '-ofnotional deprocrypticism-prospective-sublimation) drivenness as to a prospective notional-contiguity/epistemic-contiguity $2-<$ profoundsupererogation -of-mentally-aestheticised postconverging/dialecticalthinking-qualia-schema> projection of relative-ontologicalcompleteness that is what develops the insight about the true prospective sublimating possibilities lying behind such prior physics conceptions as reflected with the Theory of relativity) inducing transformative implications with respect to ${ }^{56}$ meaningfulness-and-teleology as transcendence-and-sublimity/sublimation/supererogatory-de-mentativity (and so in contrast to the mere aestheticisation of abstract dialecticism or 
analogy/mere-analogising) with 'implicited_attendant-ontologicalcontiguity ${ }^{\prime}$;educed-

existentialising/contextualising/textualising_intelligibility/epistemicity/re flexivity-contiguity-<imbued-notional cogency>' speaking thus of overall human sublimation-educing_\{epistemictotalising 35 hermeneuticttextuality/reprojecting/supererogating/zeroing/reacuting, -\{decompulsing $\}$ delinearity for-cogency $\sim$ as-to-possibilities-of-selfbecoming-as-of- 'existential-interpretation/epistemicity-inapriorising/axiomatising/referencing-of-existence", and we can consider in this regards for instance the veridicality that the convolutedness of say modern-day DNA genetics knowledge-reification gesturing-andaccounting-of-epistemic-phenomenalism-<in-

prospective psychologismic apriorising/axiomatising/referencing-\{of'prospectively_implicited_attendant-ontological-contiguity ' reducedexistentialising/contextualising/textualising_intelligibility/epistemicity/re flexivity-contiguity-<imbued-notional $\sim$ cogency $>$ ' \}-conflatedness in fpreconverging ment by\} postconverging entaitment> in 'implicited_attendant-ontological-contiguity ' reducedexistentialising/contextualising/textualising_intelligibility/epistemicity/re flexivity-contiguity-<imbued-notional cogency>' cannot be construed as of mere conceptual-patterning-〈as-devoid-of-"prospectively implicited ontological-contiguity ' educedexistentialising/contextualising/textualising_intelligibility/epistemicity/re flexivity-contiguity-<imbued-notional cogency >' 's-reifying-orelucidating-of-'prospective-relative-ontological-completeness ';-so- 
rather-enabled-<by-a- nonpresencing-divulging-of-momentous-

historiality/ontological-eventfulness /ontological-aesthetic-tracing-

$<$ perspective-ontological-normalcy/postconvergence-reflected-

'epistemicity-relativism-determinism'>) as say in terms of Mendelian hereditary (as conceptual-patterning can be so-elicited with the mere aestheticisation of abstract dialecticism or analogy/mere-analogising) since such a conceptual-patterning conception will be existentially/ontologically elusive by its poor reflection of relativeontological-completeness ${ }^{87}$ and by the relic/artifactual orientation not postconvergingly-de-mentated/structured/paradigmed in perpetually furthering/inducing the veracity of existence-as-sublimatingwithdrawal/unenframing/re-ontologising,-elicited-from-prospectiveprofound-supererogation underlying the complex sublimating conception of genetics in 'implicited_attendant-ontological-contiguity' reducedexistentialising/contextualising/textualising_intelligibility/epistemicity/re flexivity-contiguity-<imbued-notional $\sim$ cogency>' and in many case such an approach as to blurriness-<sterilising/anecdotalising/trivialising-ofprospective-re-ontologising_by-preconverging,-in-disontologisingformulaic-dragging-out/hollowing-out $>\quad$ of ${ }^{56}$ meaningfulness-andteleology will rather distract from the more ontologically-profound issue of deeper and deeper induced sublimation of genetics science as of 'antological-contiguity ${ }^{\prime \prime}$ oducedexistentialising/contextualising/textualising_intelligibility/epistemicity/re flexivity-contiguity-<imbued-notional $\sim$ cogency>' imbued sublimationeducing- 
totalising $3 \frac{3}{3}$ hermeneuticttextuality/reprojecting/supererogating/zeroing/reacuting, -\{decompulsings delinearity for-cogency $\sim$ as-to-possibilities-of-selfbecoming-as-of-'existential-interpretation/epistemicity-inapriorising/axiomatising/referencing-of-existence" (and this mistake is often made as of mere academicism in a flawed prior_knowledgereification gesturing-and-accounting-of-epistemic-phenomenalism<in-prior psychologismic apriorising/axiomatising/referencing-\{of'prior-implicited_attendant-ontological-contiguity ' reducedexistentialising/contextualising/textualising_intelligibility/epistemicity/re flexivity-contiguity-<imbued-notional $\sim$ cogency> ' \}-constitutedness in preconverging entailment $>$ that construe of the insights of latter 'implicited_attendant-ontological-contiguity' 'educedexistentialising/contextualising/textualising_intelligibility/epistemicity/re flexivity-contiguity-<imbued-notional $\sim$ cogency>' elucidations as of notional-contiguity/epistemic-contiguity ${ }^{2}<$ profound-supererogation of-mentally-aestheticised postconverging/dialectical-thinking -qualiaschema> projection of 'relative-ontological-incompleteness /relativeontological-completeness

(sublimating referencing/registering/decisioning,-as-self-becoming/selfconflatedness /formative-supererogating-<projective/reprojectiveaestheticising-re-motif-and-re-apriorising/re-axiomatising/rereferencing,-in-perspective-ontological-normalcy/postconvergence>> as to human-and-social-expectations/anticipations-metaphoricity -aspreconverging/postconverging-redementating/restructuring/reparadigming-psychologism' rather in terms 
of abstract and vague relic/artifactual conceptualisations failing to establish the entailing dynamics of existentially-disontologising/re ontologising aporeticism $>$ reflected notional-contiguity/epistemiccontiguity 2 - profound-supererogation -of-mentallyaestheticised postconverging/dialectical-thinking -qualia-schema> as to existence-as-sublimating-withdrawal/unenframing/re-ontologising,elicited-from-prospective-profound-supererogation invalidating any 'implicited_attendant-ontological-contiguity ' reducedexistentialising/contextualising/textmalising_intelligibility/epistemicity/re flexivity-contiguity-<imbued-notional $\sim$ cogency>' analysis and end up equating/leveling-down everything across space and time as of naive absolutising conceptual-patterning-〈as-devoid-of- "prospectively implicited_attendant-ontological-contiguity ' reducedexistentialising/contextualising/textualising_intelligibility/epistemicity/re flexivity-contiguity-<imbued-notional cogency>' 's-reifying-orelucidating-of-'prospective-relative-ontological-completeness ' ;-sorather-enabled-<by-a- nonpresencing-divulging-of-momentoushistoriality/ontological-eventfulness /ontological-aesthetic-tracing$<$ perspective-ontological-normalcy/postconvergence-reflected'epistemicity-relativism-determinism'>) and isms-conceptualisations articulated as of presencing-absolutising-identitive-constitutedness by wrongly implying everything is of the same notionalcontiguity/epistemic-contiguity $-<$ profound-supererogation -ofmentally-aestheticised postconverging/dialectical-thinking -qualiaschema> (as of undisambiguated relative-unreflexivity/relative- 
reflexivity ontological-contiguity as to relative-ontologicalincompleteness -of-apriorising/axiomatising/referencing and relativeontological-completeness ${ }^{8}$-of-apriorising/axiomatising/referencing thus inducing 'apriorising/axiomatising/referencingequating/leveling/ressentiment/closed-construct-of- meaningfulnessand-teleology moronisation-<sublimating-nascence,-extricatorydesublimating-downstreaming/'avalage'>') thus undermining historiality/ontological-eventfulness $3 \%$ ontological-aesthetic-tracing$<$ perspective-ontological-normalcy/postconvergence-reflected'epistemicity-relativism-determinism'> insights along the same lines like absurdly striving to idly rearticulate Mendelian hereditary as from the insight garnered from say modern-day DNA genetics with a poor capacity to discern their respective historiality/ontologicaleventfulness $3 \%$ ontological-aesthetic-tracing-<perspective-ontologicalnormalcy/postconvergence-reflected-'epistemicity-relativismdeterminism'> implications as to the overall human prospective knowledge-reification gesturing-and-accounting-of-epistemicphenomenalism-<in-

prospective psychologismic $\sim$ apriorising/axiomatising/referencing-\{of'prospectively implicited_attendant-ontological-contiguity ' reducedexistentialising/contextualising/textualising_intelligibility/epistemicity/re flexivity-contiguity-<imbued-notional cogency > ' \}-conflatedness in \{preconverging ment by\} postconverging entailment> project of sublimation and human emancipation) and this insight underlies the contention herein to overcome blurriness- 
$<$ sterilising/anecdotalising/trivialising-of-prospective-re-

ontologising_by-preconverging,-in-disontologising-formulaic-draggingout/hollowing-out> of meaningfulness-and-teleology of our positivismprocrypticism uninstitutionalised-threshold for the prospective relative-ontological-completeness ${ }^{87}$ and so-reflected as the deprocrypticism—apriorising/axiomatising/referencing-psychologism enculturated/constructed social-pragmatics-framing-of-predicativeeffectivity-sublimation-〈as-to-underlying,-ontological-commitment $<$ implied-self-assuredness-of-ontological-goodfaith/authenticity $\sim$ postconverging-dementating/structuring/paradigming -as-being-as-of-existential-reality>> ('preempting - disjointedness-as-of- reference-of-thought,-as-to-

'<emplituding/formative-epistemicity>growth-orconflatedness $^{1 / 2}$ transvaluativerationalising/transepistemicity/anamnestic-residuality/spiritdrivenness'-in-superseding-mere-formulaic-positivising/rationalempiricism-based-universalisation-directed-rulemaking-over-non-rulesapriorising/axiomatising/referencing-psychologism') with regards to its given relative <amplituding/formativeepistemicity>totalising/circumscribing/delineating implicited_attendantontological-contiguity ' educedexistentialising/contextualising/textualising_intelligibility/epistemicity/re flexivity-contiguity-<imbued-notional $\sim \operatorname{cogency}>$ ' ${ }^{4}$ foregrounding_entailment-<in-succession-of-profoundsupererogation $>$ - (postconverging-narrowing-down $\sim$ sublimation-as-to- 
'existence —as-sublimating-withdrawal/unenframing/re-ontologising,-

elicited-from-prospective-profound-supererogation '-in-reflecting-

'immanent relative unreflexivity/relative reflexivity ontological-

contiguity ';-as-operative-notional deprocrypticism) in elucidating relative unreflexivitrelative reflexivitontological-contiguity $-<$ as-

from-prospective-ontological-normalcy/postconvergence-epistemic-or-

notional projective-perspective $>$ as to its prospectively induced scalarising as of human supererogatory/messianic intemporal and secondnatured socially-optimal instigative potency' at its given/defined institutionalisation ontologically-pertinent epistemic-conception of 'thevery-same overall phenomenality/manifestation of existence-assublimating-withdrawal/unenframing/re-ontologising,-elicited-fromprospective-profound-supererogation ' (and so over prior positivismprocrypticism - apriorising/axiomatising/referencing-psychologism enculturated/constructed social-pragmatics-framing-of-predicativeeffectivity-sublimation-_as-to-underlying,-ontological-commitment $<$ implied-self-assuredness-of-ontological-goodfaith/authenticity postconverging-dementating/structuring/paradigming -as-being-as-of-existential-reality>> construed-as 'mere-formulaic-positivising/rational-empiricism-baseduniversalisation-directed-rulemaking-over-non-rulesapriorising/axiomatising/referencing-psychologism,-that-is-not-ofpreempting —disjointedness-as-of- reference-of-thought,-as-to-

' <emplituding/formative-epistemicity>growth-orconflatedness $/$ transvaluative- 
rationalising/transepistemicity/anamnestic-residuality/spirit-

drivenness'-in-superseding-mere-formulaic-positivising/rational-

empiricism-based-universalisation-directed-rulemaking-over-non-rulesapriorising/axiomatising/referencing-psychologism' given 'relative disparateness-of-conceptualisation-<unforegrounding-ment,-failing-

prospectively-to-reflect- 'immanent relative-unreflexivity/relative-

reflexivity ontological-contiguity '> as to prior descalarising totalisingly-ing-discretion/whim-of-thought of individuals-suboptimal instigative potency as of human notional firstnaturedness-formativenessSas to eventualising inkling drive or seeding misprising > temporalto-intemporal-dispositions-<so-construed-as-from-perspectiveontological-normalcy/postconvergence $>\quad$ accordioning-(as-of-varyingindividuations-contextually-transverse-desublimation/sublimation,-as-tothe-waveringtredounding/waveforming of-their-referencing-and-theirdevolved-referencing-imbued-ontological-performance -<includingvirtue-as-ontology> J' at its given/defined uninstitutionalised-threshold ontologically-deficient epistemic-conception of 'the-very-same overall phenomenality/manifestation of existence-as-sublimatingwithdrawal/unenframing/re-ontologising,-elicited-from-prospectiveprofound-supererogation '); critically with regards to the '<amplituding/formative-

epistemicity>totalising/circumscribing/delineating 'implicited_attendantontological-contiguity ' reducedexistentialising/contextualising/textualising_intelligibility/epistemicity/re flexivity-contiguity-<imbued-notional $\sim$ cogency $>$ ' 
foregrounding_entailment-<in-succession-of-profound-

supererogation $>$ - (postconverging-narrowing-down $\sim$ sublimation-as-to-

'existence - as-sublimating-withdrawal/unenframing/re-ontologising,-

elicited-from-prospective-profound-supererogation '-in-reflecting-

'immanent felative unreflexivity/relative reflexivity-ontological-

contiguity ';-as-operative-notional deprocrypticism) in elucidating

relative unreflexivity/relative reflexivity ontological-contiguity $-<$ as-

from-prospective-ontological-normalcy/postconvergence-epistemic-or-

notional projective-perspective $>$ ',

blurriness-

$<$ sterilising/anecdotalising/trivialising-of-prospective-re-

ontologising_by-preconverging,-in-disontologising-formulaic-dragging-

out/hollowing-out $>$ as to the very nature of the social will often lead to the naïve 'epistemic obviating of the inherent implicited_attendantontological-contiguity $\sim$ educed-

existentialising/contextualising/textualising_intelligibility/epistemicity/re flexivity-contiguity-<imbued-notional $\sim$ cogency>' foreground/operantlyentailing-conception of many a social-domain (as to their veridical < amplituding/formative-epistemicity >causality as-to-projective-

totalitative-implications-of-prospective- nonpresencing,-for-

explicating relative unreflexivity/relative reflexivity -ontological-

contiguity) accounting for the resolution of underlying humansubpotency-aporia/undecidability/dilemma/ought-

indeterminacy/deficiency/limitation/constraint implications', for instance, with the flawed and paradoxical supposedly foregrounding_entailment-

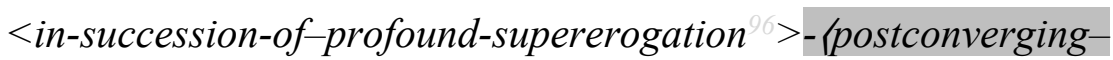


narrowing-down $\sim$ sublimation-as-to- 'existence-as-sublimating-

withdrawal/unenframing/re-ontologising,-elicited-from-prospective-

profound-supererogation '-in-reflecting- 'immanent felative-

unreflexivity/relative reflexivity ontological-contiguity ';-as-operative-

notional deprocrypticism/ statistics over the effectively veridical and

potent social-domain implicited_attendant-ontological-

contiguity ' $\sim$ educed-

existentialising/contextualising/textualising_intelligibility/epistemicity/re flexivity-contiguity-<imbued-notional cogency>' thus 'ignoring the social-domain 'implicited_attendant-ontological-contiguity ' educedexistentialising/contextualising/textualising 'intelligibility/epistemicity/re flexivity-contiguity-<imbued-notional cogency>' effective originariness/reifying/intellectualisingidealising/transcending/sublimating-meaningfulness-and-itsinstitutionalisation responsible for the resolution of underlying humansubpotency-aporia/undecidability/dilemma/ought-

indeterminacy/deficiency/limitation/constraint' as prospectively accounting for the manifestation of the statistical outcomes in-the-veryfirst-place (consider for instance that the statistical outcomes arising from past social aporia-resolving transformational initiatives like the New Deal, G.I. bill, Medicare, civil rights, the post-war public infrastructure and technology investments, etc. accounting-for/as-the-true 'implicited_attendant-ontological-contiguity ' reducedexistentialising/contextualising/textualising_intelligibility/epistemicity/re flexivity-contiguity-<imbued-notional $\sim$ cogency>' foreground/operantly- 
entailing-conception for the growth of the U.S. middle-class specifically as well as the statistical outcomes associated with both international organisations public policies and countries-specific public policies worldwide are paradoxically being raised-and-foregrounded-over-theontological-veracity-of-the social implicited_attendant-ontologicalcontiguity reduced-

existentialising/contextualising/textualising_intelligibility/epistemicity/re flexivity-contiguity-<imbued-notional $\sim$ cogency>' to 'surreptitiously' imply that the need for such social aporia-resolving transformational initiatives in the future as advocated by many is unwarranted as the 'statistical outcomes seem to be construed as their very own epistemic causation of the rise of the US middle-class and global population data improvements' or in another respect the aporia-resolving nature of budding-positivists and before them ${ }^{103}$ universalising-idealisation thinkers in both instances as to their foregrounding_entailment-<in-successionof-profound-supererogation $>>-\{$ postconverging-narrowingdown sublimation-as-to- 'existence —as-sublimatingwithdrawal/unenframing/re-ontologising,-elicited-from-prospectiveprofound-supererogation '-in-reflecting- 'immanent relativeunreflexivity/relative reflexivity ontological-contiguity ';-as-operativenotional deprocrypticism/social commitments in contributing towards and enabling the overcoming of the corresponding social and emancipating limitations and social-vestedness/normativity-<discretelyimplied-functionalism > of their societies and epochs is naively being interpreted-and-unforegrounded/ed as of our presencing-absolutising- 
identitive-constitutedness ${ }^{14}$ to wrongly imply ours is the era that 'would hardly harbour any such critiquing for its further aporia-resolving emancipation and growth' as to a 'humanism' that hardly grasp the 'implicited_attendant-ontological-contiguity ' reducedexistentialising/contextualising/textualising_'intelligibility/epistemicity/re flexivity-contiguity-<imbued-notional $\sim$ cogency> ' ontological-veracity in reflecting holographically-<conjugatively-and-transfusively $>$ the relative unreflexivity/relative reflexivity ontological-contiguity $\sim$ of-thehuman-institutionalisation-process as of human self-surpassingexistentialism-form-factor,-in-overcoming- 'notional collateralisingbeholdening-protohumanity'-to- 'attain-sublimating-humanity'-as-toexistence-potency sublimating-nascence,-disclosed-from-prospectiveepistemic-digression), likewise as manifested for instance in the economics domain the extensive use of mathematics as a conceptual-tool often takes on a purpose all of its own that overrides/unforegrounds/conceptually-s the socioeconomic-domain 'implicited_attendant-ontological-

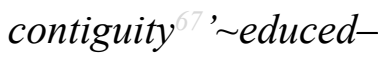
existentialising/contextualising/textualising_intelligibility/epistemicity/re flexivity-contiguity-<imbued-notional $\sim$ cogency > ' elucidation of veridical economic phenomena as it is often uncritically skewed in the direction of vested political and big-business interests perception of things bound to overlooked the underlying postconvergingaporeticismconcerns associated with the recurrence of economic and financial crises and weak income growth and redistribution; all such cases of blurriness- 
$<$ sterilising/anecdotalising/trivialising-of-prospective-re-

ontologising_by-preconverging,-in-disontologising-formulaic-dragging-

out/hollowing-out $>\quad$ that unforegrounds/conceptually-s

'implicited_attendant-ontological-contiguity ' reduced-

existentialising/contextualising/textualising_intelligibility/epistemicity/re

flexivity-contiguity-<imbued-notional $\sim$ cogency $>$ ' are intimately related

to the poor capacity of such blurry domains-of-study to naturally (as of

their underlying supposedly coherent ontological-commitment

<implied-self-assuredness-of-ontological-good-

faith/authenticity $\sim$ postconverging-de-

mentating/structuring/paradigming -as-being-as-of-existential-reality >

with regards to the full-conflatedness ${ }^{13}$ of

apriorising/axiomatising/referencing-conceptualisation as to existencepotency $\sim$ sublimating-nascence,-disclosed-from-prospective-epistemic-

digression) and clearly define their human-subpotencyaporia/undecidability/dilemma/ought-

indeterminacy/deficiency/limitation/constraint—imbued-

'notional firstnaturedness-formativeness < as to eventualising inkling

drive or seeding misprising> temporal-to-intemporal-dispositions-

$<$ so-construed-as-from-perspective-ontological-

normalcy/postconvergence > '-existentialism-form-factor

framework/cadre (as to keep tab of the perpetual '< ampliting formative-

epistemicity>totalising/circumscribing/delineating 'implicited_attendantontological-contiguity ' $\sim$ educed- 
existentialising/contextualising/textualising_intelligibility/epistemicity/re flexivity-contiguity-<imbued-notional $\sim$ cogency $>$ '

foregrounding_entailment-<in-succession-of-profound-

supererogation $>$ - (postconverging-narrowing-down $\sim$ sublimation-as-to'existence - as-sublimating-withdrawal/unenframing/re-ontologising,-

elicited-from-prospective-profound-supererogation '-in-reflecting-

'immanent relative unreflexivity/relative reflexivity ontological-

contiguity ';-as-operative-notional deprocrypticism) in elucidating relative unreflexivity/relative reflexivity ontological-contiguity $-<$ asfrom-prospective-ontological-normalcy/postconvergence-epistemic-ornotional projective-perspective ${ }^{>}$' and preempting its unforegroundingment with flawed use of conceptual-tools), as such blurry domains rather adopt a presencing-absolutising-identitive-constitutedness disposition construed social-vestedness/normativity-<discretely-impliedfunctionalism $>\quad$ for their supposed originariness/reifying/intellectualisingidealising/transcending/sublimating-meaningfulness-anditsinstitutionalisation; 9 whereas in-many-ways there is relatively more profound universal-transparency -Stransparency-of-totalisingentailing,-as-to-entailing-<amplituding/formativeepistemicity>totalising in-relative-ontological-completeness J in the natural sciences as to their very strong constraining of human-subpotencyaporia/undecidability/dilemma/ought-

indeterminacy/deficiency/limitation/constraint to 'inherent existencepotency $\sim$ sublimating-nascence,-disclosed-from-prospective-epistemic- 
digression of construal of <amplitudingfformativeepistemicity $>$ causality $\sim$ as-to-projective-totalitative-implications-ofprospective- nonpresencing,-for-explicating relativeunreflexivity/relative reflexivity ontological-contiguity as reflecting existential-reality/ontological-veracity', (and where this fails as with climate change it again has to do with blurriness$<$ sterilising/anecdotalising/trivialising-of-prospective-reontologising_by-preconverging,-in-disontologising-formulaic-draggingout/hollowing-out $>$ and the associated eliciting of socialvestedness/normativity-<discretely-implied-functionalism $>$ ) as we can appreciate as of a typical case in point how the similar integration of conceptual-tools like mathematics, statistics, algorithms, models, etc. operate between say the economic sciences and natural sciences wherein the latter relatively-tends to preserve their natural science 'implicited_attendant-ontological-contiguity ' reducedexistentialising/contextualising/textualising_intelligibility/epistemicity/re flexivity-contiguity-<imbued-notional $\sim$ cogency $>$ ' foregrounding_entailment-<in-succession-of-profoundsupererogation $>_{-}$(postconverging-narrowing-down $\sim$ sublimation-as-to'existence - as-sublimating-withdrawal/unenframing/re-ontologising,elicited-from-prospective-profound-supererogation '-in-reflecting'immanent relative ontologicalcontiguity ';-as-operative-notional deprocrypticism) 'as served by the conceptual-tools' while the former (with the manifestation of mystification complexes of conceptual-tools) often end up overlooking their very own 
socioeconomic 'implicited_attendant-ontological-contiguity ' reducedexistentialising/contextualising/textmalising_intelligibility/epistemicity/re flexivity-contiguity-<imbued-notional $\sim \operatorname{cogency}>$ ' ${ }^{45}$ foregrounding_entailment-<in-succession-of-profoundsupererogation $>$ - (postconverging-narrowing-down $\sim$ sublimation-as-to'existence - as-sublimating-withdrawal/unenframing/re-ontologising,elicited-from-prospective-profound-supererogation '-in-reflecting'immanent relative unreflexivity/relative reflexivity ontologicalcontiguity ';-as-operative-notional deprocrypticism) 'and seem to serve the conceptual-tools' which take a purpose all of their own in the pursuit of a given social-vestedness/normativity-<discretely-impliedfunctionalism > construal of things bent on 'collateralising other critically postconverging aporeticism-overcoming/unovercoming things'

existential- existential-transitioning-or-iterability-trace-of-narratives-astransitioning-or- dots_or_implicited_attendant-ontological-contiguity ' $\sim$ educediterability-trace-of- existentialising/contextualising/textualising_intelligibility/epistemicity/re narratives-as- $\quad$ flexivity-contiguity-<imbued-notional $\sim \operatorname{cogency}>$ '

dots_or_implicited reification_or_intrinsic-reality-ontological-coherence_or_superseding_attendant- oneness-of-ontology-\{in-lockstep-of-temporal-dispositions-hollowontological- constituting-<as-disjointed-misappropriation-of-meaningfulness-andcontiguity ${ }^{67} \sim$ educ failing-intemporal-preservation>,-as-non-veridical-narratives-anded- intemporal-corresponding-ontological-reconstituting-as-toexistentialising/eo conflatedness ${ }^{1 / 2} /$ deconstruction-realterations-for-ontologically-veridicalntextmalising/textu narratives) 
alising_intelligibil

ity/epistemicity/ref

lexivity-

contiguity-

$<$ imbued-

notional $\sim \operatorname{cogency}>$

reification_or_intri

nsic-reality-

ontological-

coherence_or_supe

rseding-oneness-

of-ontology 41

falsifiability ${ }^{42} \quad$ falsifiability refers to epistemic-veracity 'determinable as from existencepotency $\sim$ sublimating-nascence,-disclosed-from-prospective-epistemicdigression construal of <emplituding/formativeepistemicity>causality as-to-projective-totalitative-implications-ofprospective- nonpresencing,-for-explicating relativeunreflexivity/relative reflexivity-ontological-contiguity as reflecting existential-reality/ontological-veracity' as so-construed as from nonpresencing-<perspective-ontological-normalcy/postconvergence $>$ epistemic-conception in prospective reflection of relative-ontologicalcompleteness -of-apriorising/axiomatising/referencing and so over naïve presencing-absolutising-identitive-constitutedness $\quad$ epistemic- 
conception prospectively in relative-ontological-incompleteness -ofapriorising/axiomatising/referencing that fails to appreciate human selfsurpassing 'relative-ontological-incompleteness /relative-ontological-

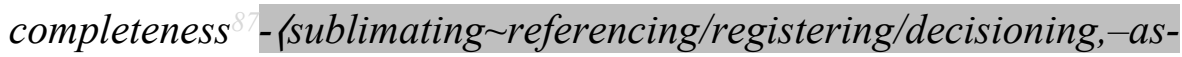
self-becoming/self-conflatedness /formative-supererogating$<$ projective/reprojective-aestheticising-re-motif-and-re-apriorising/reaxiomatising/re-referencing,-in-perspective-ontologicalnormalcy/postconvergence $>$ as to human-and-socialexpectations/anticipations-metaphoricity -aspreconverging/postconverging-redementating/restructuring/reparadigming-psychologism' (as to the fact that 'falsifiability is constantly redefined as to when relative-ontologicalcompleteness is-educed-and-avails-and-re-avails with human limitedmentation-capacity-deepening - as subjecting limitedness/humansubpotency to 'educed unlimitedness/existence sublimating nascence' 3 , so-reflected with the 'effective-and-relative theorising supererogatory acuity/perspicacity/astuteness/edginess/incisiveness-ofapriorising/axiomatising/referencing/intelligibilitysettingup/measuringins trumenting -for-conceptualisation, by the Corpenicuses/Galileos/Pasteurs, etc. up to our modern-day scientific standards 'wherein the very sublimating-nascence induced by scientific theorising is part-and-parcel of redefining/re-epistemising the notion-offalsifiability' and so as to dimensionality-of-sublimating < amplituding/formative $>$ supererogatory-de-mentativeness/epistemicgrowth-or-conflatedness /transvaluative- 
rationalising/transepistemicity/anamnestic-residuality/spirit-drivenness

equalisation)), and thus the broader implication of falsifiability is construed basically as 'epistemic-veracity for determining existentialreality/ontological-veracity as of <amplituding/formativeepistemicity>causality as-to-projective-totalitative-implications-ofprospective- nonpresencing,-for-explicating felativeunreflexivity/relative reflexivity ontological-contiguity '; with the implication that since existence is the absolute a priori, the 'becoming of existence as ecstatic-existence' is the inherent determinative basis of falsifiability as the latter is reflexive of <amplitudingfformativeepistemicity $>$ causality $\sim$ as-to-projective-totalitative-implications-ofprospective- nonpresencing,-for-explicating felativeunreflexivity/relative reflexivity ontological-contiguity, and where ecstatic-existence manifestation is rather as of an 'overall singular/unrepeatable/nonrecurring/as-of-yet-unrepeatable-ornonrecurring unfolding manifestation' as implied with the ambit of such theories as the big bang theory, string theory, the relative unreflexivity/relative reflexivity ontological-contiguity of-the-humaninstitutionalisation-process etc., falsifiability is reflected by determining the coherence-as-of-ontological-congruence and incoherence-as-ofontological-incongruence of any such ambit implied 'overall singular ecstatic-existence unfolding manifestation model-theory' as reflected by the 'falsifiability of its underlying-and-subsumed-phenomena' with regards to the epistemic-veracity of their <amplitudinglformativeepistemicity>causality $\sim$ as-to-projective-totalitative-implications-of- 


\section{prospective- nonpresencing,-for-explicating relative-}

unreflexivity/relative reflexivity ontological-contiguity going by their specifically relevant repeatable/recurring methodological evaluations or observations or experiments, whereas where ecstatic-existence manifestation is about just a 'repeatable/recurrent ecstatic-existence manifestation phenomenon' then such an ecstatic-existence manifestation phenomenon is falsifiable as of the epistemic-veracity of its <amplitudinglformative-epistemicity>causality as-to-projectivetotalitative-implications-of-prospective- nonpresencing,-forexplicating relative unreflexivity/relative reflexivity ontologicalcontiguity going by its specifically relevant methodological evaluations or observations or experiments as to underlying human conceptivity/epistemic-reflexivity/epistemicity-relativism-determinism<reifying\{as-to-knowledge-developing\}-and-empowering>

faulty-mentation- faulty-mentation-procedure-deception-or-urge-_as-ofprocedure- $\quad$ postlogicbacktracking-<iterative-looping-'set-of-dereifying-hollowdeception-or-urge narratives-and-acts'>-with-succeeding-shifting-of-the-narratives-and43 acts-foci-as-deception-of-successively-shifting-or-non-coheringnarratives-and-acts $)$

flawed-existential- flawed-existential-elevation-of- reference-of-thought-lof-preconvergingelevation-of- $\quad$ or-dementing -apriorising-psychologism,-'denaturing -postlogic'reference-of- backtracking-towards-social-aggregation-enablers' over postconvergingthought $^{44}$ or-dialectical-thinking - 'intrinsic-reality/ontological-veridicality transcendental-enabling/sublimating/supererogatory-de-mentativity') 


\begin{tabular}{|c|c|}
\hline entailment- $<$ in- & supererogation $>-$ (postconverging-narrowing-down $\sim$ sublimation-as-to- \\
\hline succession-of- & 'existence-as-sublimating-withdrawal/unenframing/re-ontologising,- \\
\hline profound- & elicited-from-prospective-profound-supererogation '-in-reflecting- \\
\hline supererogation $>$ - & 'immanent felative unreflexivity \\
\hline 〈postconverging- & contiguity ';-as-operative-notional deprocrypticism),-as-to- \\
\hline narrowing- & '<amplitudingfformative- \\
\hline down $\sim$ sublimation & epistemicity>totalising/circumscribing/delineating 'implicited_attendant- \\
\hline -as-to-'existence- & ontological-contiguity $\sim$ educed- \\
\hline as-sublimating- & 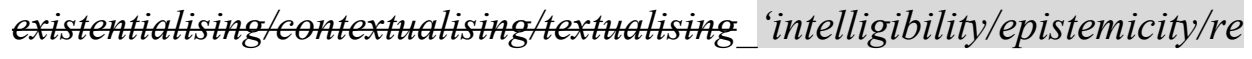 \\
\hline withdrawal/unenfr & flexivity-contiguity-<imbued-notional $\sim$ cogency $>$ in elucidating \\
\hline aming/re- & relative unreflexivity/relative reflexivity ontological-contiguity $-<$ as- \\
\hline ontologising,- & from-prospective-ontological-normalcy/postconvergence-epistemic-or- \\
\hline elicited-from- & notional projective-perspective $>^{\prime}$ so-construed as the knowledge- \\
\hline prospective- & reification gesturing-and-accounting-of-epistemic-phenomenalism- \\
\hline profound- & <in-prospective_psychologismic $\sim$ apriorising/axiomatising/referencing- \\
\hline supererogation '- & \{of-prospectively_implicited_attendant-ontological- \\
\hline in-reflecting- & contiguity ' $\sim$ educed- \\
\hline 'immanent relativ & existentialising/contextualising/textualising_intelligibility/epistemicity/re \\
\hline e- & flexivity-contiguity-<imbued-notional $\sim$ cogency $>$ ' $\}$-conflatedness - \\
\hline unreflexivity/relati & in \{preconverging ment by\} postconverging entailment $>$ exercise \\
\hline ve reflexivity & 'foregrounding_entailment-<in-succession-of-profound- \\
\hline ontological- & supererogation >-(postconverging-narrowing-down $\sim$ sublimation-as-to- \\
\hline contiguity ';-as- & 'existence - as-sublimating-withdrawal/unenframing/re-ontologising,- \\
\hline operat & ation '-in-reflecting- \\
\hline
\end{tabular}


notional deprocr

ypticism>

\section{immanent relative unreflexivity/relative reflexivity-ontological-}

contiguity ;-as-operative-notional deprocrypticism) as

to

apriorising/axiomatising/referencing-\{of- prospectively

implicited_attendant-ontological-contiguity ' reduced-

existentialising/contextising/textualing_intelligibility/epistemicity/re

flexivity-contiguity-<imbued-notional $\sim$ cogency $>$,$\} -conflatedness { }^{3-}$

in \{preconverging ment by\} postconverging entailment' with regards to prospective knowledge and its overall coherence with the relevant relativeontological-completeness reference-of-thought's-nestedcongruence/running-through/deflating-cogent-unifying-operantdynamics-unification-of-explanations,-with-such-explanations-reflectedas-of-relative unreflexivity/relative-reflexivity-ontological-contiguity and-inducing-corresponding-prospective-sublimity, and so as to dimensionality-of-sublimating ${ }^{5}$

< amplituding/formative $>$ supererogatory-de-mentativeness/epistemicgrowth-or-conflatedness /transvaluativerationalising/transepistemicity/anamnestic-residuality/spirit-drivennessequalisation) involved in the dispensing-with-immediacy-for-relativeontological-completeness -by-reification/contemplative-distension for such prospective knowledge-reification gesturing-and-accounting-ofepistemic-phenomenalism-<in-

prospective psychologismic apriorising/axiomatising/referencing-\{of'prospectively implicited_attendant-ontological-contiguity ' reducedexistentialising/contextualising/textualising_intelligibility/epistemicity/re flexivity-contiguity-<imbued-notional $\sim \operatorname{cogency}>$,$\} -conflatedness$ 
in \{preconverging ment by\} postconverging entailment $>$; $\mathbb{1}$ and with

regards to the reference-of-thought of all the

$<$ cumulating/recomposuring attendant-ontological-contiguity $>-$

successive registry-worldviews/dimensions in their successive relativeontological-completeness as so-construed in reflecting holographically$<$ conjugatively-and-transfusively $>$ the relative-unreflexivity/relativereflexivity ontological-contiguity of-the-human-institutionalisation-

process ' implied knowledge-reification gesturing-and-accounting-ofepistemic-phenomenalism- $<$ in-

prospective psychologismic apriorising/axiomatising/referencing-\{of'prospectively_implicited_attendant_ontological-contiguity ' reducedexistentialising/contextualising/textualising_intelligibility/epistemicity/re flexivity-contiguity-<imbued-notional $\sim$ cogency $>$ ' \}-conflatedness in \{preconverging ment by\} postconverging entailment>, the foregrounding_entailment-<in-succession-of-profoundsupererogation $>-$ - postconverging-narrowing-down $\sim$ sublimation-as-to'existence - as-sublimating-withdrawal/unenframing/re-ontologising,elicited-from-prospective-profound-supererogation '-in-reflectingimmanent relative unreflexivity/relative reflexivity ontologicalcontiguity ';-as-operative-notional deprocrypticism) of meaningfulness-and-teleology is rather as of the 'successive reference-of-thought in relative-ontological-completeness apriorising/axiomatising/referencing-\{of- prospectively implicited_attendant-ontological-contiguity ' reducedexistentialising/contextualising/textualising_intelligibility/epistemicity/re 
flexivity-contiguity-<imbued-notional $\sim$ cogency ${ }^{\text {' }}$, '-conflatedness ${ }^{13}-$ in \{preconverging ment by\} postconverging entailment-construal-of 'implicited_attendant-ontological-contiguity ' reducedexistentialising/contextualising/textualising_intelligibility/epistemicity/re flexivity-contiguity-<imbued-notional $\sim \operatorname{cogency}>$ ' - as-of<amplitudinglformative-epistemicity >causality $\sim$ as-to-projectivetotalitative-implications-of-prospective- nonpresencing,-forexplicating felative unreflexivity/relative reflexivity ontologicalcontiguity ; it can also be appreciated for instance that the natural sciences aspire for comprehensive foregrounding_entailment-<insuccession-of-profound-supererogation >-(postconverging-narrowingdown sublimation-as-to- 'existence - as-sublimatingwithdrawal/unenframing/re-ontologising,-elicited-from-prospectiveprofound-supererogation '-in-reflecting-'immanent felativeunreflexivity/relative reflexivity ontological-contiguity ;'-as-operativenotional deprocrypticism) in other to reflect deeper and deeper notional-contiguity/epistemic-contiguity ${ }^{2}<$ profound-supererogation of-mentally-aestheticised postconverging/dialectical-thinking -qualiaschema $>$ and corresponding sublimation, and so in the sense that their articulated axiomatic-constructs and their 'assemblages of axiomaticconstructs' are meant as derivable-as-of-necessity-and-mutually-coherent in all existential-disontologising/re ontologising aporeticism> instantiations and not as discretionary-and-incoherent, such that where issues undermining derivation-as-of-necessity-and-mutual-coherence arise at any given unreified-threshold then it is understood that prospective 
knowledge-reification gesturing-and-accounting-of-epistemicphenomenalism-<in-

prospective psychologismic $\sim$ apriorising/axiomatising/referencing-\{of'prospectively_implicited_attendant-ontological-contiguity ' reducedexistentialising/contextulising/textualising_intelligibility/epistemicity/re flexivity-contiguity-<imbued-notional $\sim$ cogency>' \}-conflatedness in \{preconverging ment by\} postconverging entailment $>$ requires defining-and-superseding that prospective human-subpotencyaporia/undecidability/dilemma/ought-

indeterminacy/deficiency/limitation/constraint of poor derivation-as-ofnecessity-and-mutual-coherence so-revealed as from foregrounding_entailment-<in-succession-of-profoundsupererogation $>$ - (postconverging-narrowing-down $\sim$ sublimation-as-to'existence - as-sublimating-withdrawal/unenframing/re-ontologising,elicited-from-prospective-profound-supererogation '-in-reflecting'immanent relative unreflexivity/relative reflexivity ontologicalcontiguity ';-as-operative-notional deprocrypticism) conception in 'implicited_attendant-ontological-contiguity ' reducedexistentialising/contextualising/textualising_intelligibility/epistemicity/re flexivity-contiguity-<imbued-notional $\sim$ cogency $>$ ', foregrounding_entailment-<in-succession-of-profoundsupererogation $>$ - (postconverging-narrowing-down $\sim$ sublimation-as-to'existence - as-sublimating-withdrawal/unenframing/re-ontologising,elicited-from-prospective-profound-supererogation '-in-reflecting'immanent relative unreflexivity/relative reflexivity ontological- 
contiguity ';-as-operative-notional deprocrypticism),-as-to-

'<amplitudingfformative-

epistemicity>totalising/circumscribing/delineating 'implicited_attendantontological-contiguity ' educed-

existentising intelligibility/epistemicity/re

flexivity-contiguity-<imbued-notional $\sim \operatorname{cogency}>$ ' in elucidating

relative unreflexivity/relative reflexivity-ontological-contiguity $-<$ as-

from-prospective-ontological-normalcy/postconvergence-epistemic-or-

notional projective-perspective $>$ speaks to the fact that existence can only truly epistemically be construed as of phenomenal/manifest $\sim$ Subpotencies(in-transitive-conflatedness -reflexivity,-in-the-full-potency-of-

existence's sublimating-nascence)

so-reflected

as

'foregrounding_entailment-<in-succession-of-profound-

supererogation $>$ - (postconverging-narrowing-down $\sim$ sublimation-as-to-

'existence - as-sublimating-withdrawal/unenframing/re-ontologising,-

elicited-from-prospective-profound-supererogation '-in-reflecting-

immanent relative unreflexivity/relative reflexivity ontological-

contiguity ';-as-operative-notional deprocrypticism) as to overall reifying-and-empowering-reflexivity-of-ecstatic-existence-as-

panintelligibilityfpanreflexivity - lexistentially-imbued-and-educing-

$\leq$ fepistemic

thermeneutically/textually/reprojectingly/supererogatingly/zeroin

gly/re acutingly, -\{decompulsing ${ }^{2}$ delinearity for-cogency $\geq$ epistemic-

perspective-of-projective/reprojective-aestheticising-re-motif-and-re- 
apriorising/re-axiomatising/re-referencing conceptualisation,-as hereinspecifically relevant to human-subpotency)', and this potency-driven epistemic-conception of existence's foregrounding_entailment-<insuccession-of-profound-supererogation >-(postconverging-narrowingdown sublimation-as-to- 'existence-as-sublimating-

withdrawal/unenframing/re-ontologising,-elicited-from-prospectiveprofound-supererogation '-in-reflecting- 'immanent relativeunreflexivity/relative reflexivity ontological-contiguity ';-as-operativenotional deprocrypticism) reflects the 'relativeness to originariness/origination-_so-construed-as-to-ontologicalnormalcy/postconvergence-perspective-scalarising-construal-ofexistence) of epistemic-situations as to phenomenal/manifest $\sim$ subpotencies-and-their-corresponding-manifestteleological-aporeticism in the full-potency of existence (so-construed as from the ontological-normalcy/postconvergence epistemic-projection perspective)', and so with regards to the fact that transcendence-andsublimity/sublimation/supererogatory de-mentativity and desublimation in existence is preconvergingly/postconvergingly-dementated/structured/paradigmed around phenomenal/manifest $\sim$ subpotencies-_in-transitive-conflatedness reflexivity,-in-the-full-potency-of-existence's $\sim$ sublimating-nascence) (such that there is a notional symmetrisation of phenomenal/manifestsubpotencies-and-theircorresponding-phenomenal/manifest-teleologicalaporeticism that is equally reflected in the 'human-subpotency 
consciousness phenomenal/manifest epistemicity in existence with regards to its notional symmetrisation-<as-to-symmetrisation-bydesymmetrisation,-in-reflecting-postconverging-or-dialectical-thinking by-preconverging-or-dementing $\sim$ perspectives-of-humanmeaningfulness-and-teleology > underlying human ontologicalperformance ${ }^{72}<$ including-virtue-as-ontology $>$ ' and so with respect to the perspectival binarity as of human-subpotency epistemic-projection soconstrued as temporality and human-subpotency epistemic-projection towards the full-potency of existence so-construed as intemporality ${ }^{5}$, as so-reflected in both 'Derridean underdetermination-imbued force/violence conception' and 'Foucauldian knowledge/power conception construed as knowledge-empowerment/ignorance-disempowerment' with regards to human phenomenal/manifest sublimation and desublimation in existence, as to the insight for mitigating the attendant drawback of desublimating historicity-tracing - in-presencing-hyperrealisation/hyperrealtransposition in the pursuit for sublimating historiality/ontologicaleventfulness 38 ontological-aesthetic-tracing-<perspective-ontologicalnormalcy/postconvergence-reflected-'epistemicity-relativismdeterminism'> at the very center of Foucault and Derrida contentions, instead misconstrued by their presencing-absolutising-identitiveconstitutedness ${ }^{14}$ critics as to the latter's truth "nonpresencing$<$ perspective-ontological-normalcy/postconvergence $>$ relativism/relative-scope for epistemic-growth,-as \{ret/f relative-reflexivity-in-existencetrelativising from-limited-mentation-asits deepening/psychologismic epistemic acutisation residualising, 
\{decompulsing' delinearity-for cogency' accusations that speak of their socialvestedness/normativity-<discretely-implied-functionalism $>\quad$ posturing rather than profound critiquing accounting for the ontological-veracity of human sublimation and desublimation in existence underlined by Foucauldian historial/genealogical-a-priori ontological implications and Derridean quasi-transcendental ontological implications as both directly undermining presencing-absolutising-identitive-constitutedness conceptualisations and indirectly-and-heuristically pointing to human selfsurpassing 'relative-ontological-incompleteness 8 /relative-ontologicalcompleteness ${ }^{8}$-〈sublimating $\sim$ referencing/registering/decisioning,-asself-becoming/self-conflatedness /formative-supererogating$<$ projective/reprojective-aestheticising-re-motif-and-re-apriorising/reaxiomatising/re-referencing,-in-perspective-ontologicalnormalcy/postconvergence $>$ ) as to human-and-socialexpectations/anticipations - metaphoricity -aspreconverging/postconverging-redementating/restructuring/reparadigming-psychologism' as to human subjection to the sublimating possibilities of existence as herein fully-andotherwise conceptualised as to the full implications of the notion of " dementation-(supererogatory-ontological-de-mentation-or-dialectical-dementation-stranding-or-attributive-dialectics $\rangle$ of human ${ }^{83}$ reference-ofthought-and- reference-of-thought- devolving- ${ }^{5}$ meaningfulness-andteleology, as driving/dynamising the '<cumulating/recomposuring attendant-ontological-contiguity >-
succession of registry-worldviews/dimensions in institutional- 
cumulation/institutional-recomposure-_as-to- historiality/ontologicaleventfulness /ontological-aesthetic-tracing-<perspective-ontologicalnormalcy/postconvergence-reflected-'epistemicity-relativismdeterminism'>> as of human limited-mentation-capacity-deepening-assubjecting limitedness/human-subpotency to 'educedunlimitednesstexistence sublimating nascence' 'underlying the relativeunreflexivity/relative reflexivity ontological-contiguity rof-the-humaninstitutionalisation-process as of 'human Beingdevelopment/ontological-framework-expansion-as-to-depth-ofontologising-development-as-infrastructure-of- meaningfulness-andteleology , institutional-development-as-to-social-function-development and living-development-as-to-personality-development psychologismic epistemic acutisation difficulty< <or, residualising

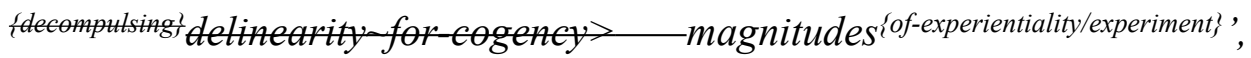
and so decisively derived-and-construed as from the counterintuitive discernment about the full ontological implications of human cognisanceand-integration of postlogism/notional psychopathy denatured meaningfulness-and-teleology at uninstitutionalised-threshold as articulated herein specifically with regards to psychopathy and social psychopathy manifestation in our positivism- ${ }^{8}$ procrypticism registryworldview/dimension' providing insight on the 'human ontologicalperformance ${ }^{72}<$ including-virtue-as-

ontology>/morality/ethics/justice/etc. of registry-worldviews/dimensions reference-of-thought-and- ${ }^{8}$ reference-of-thought- ${ }^{3}$ devolving'meaningfulness-and-teleology' so-reflected dialectically as of human 
notional-contiguity/epistemic-contiguity

$-<$ profound-supererogation

of-mentally-aestheticised postconverging/dialectical-thinking -qualia-

schema $>\quad$ and notional-discontiguity/epistemic-discontiguity

$<$ between-prior-shallow-supererogation -of-mentally-

aestheticised preconverging/dementing -qualia-

schema_and_prospective-profound-supererogation -of-mentally-

aestheticised postconverging/dialectical-thinking -qualia-schema>

speaking of 'notional symmetrisation-<as-to-symmetrisation-bydesymmetrisation,-in-reflecting-postconverging-or-dialectical-thinking by-preconverging-or-dementing $\sim$ perspectives-of-human-

meaningfulness-and-teleology $>$ of the

$<$ cumulating/recomposuring attendant-ontological-contiguity $>$

successive registry-worldviews/dimensions ${ }^{83}$ reference-of-thought-and${ }^{3}$ reference-of-thought- devolving- ${ }^{5}$ meaningfulness-and-teleology'); $\uparrow$ such existence foregrounding_entailment-<in-succession-of-profoundsupererogation $>$ - (postconverging-narrowing-down $\sim$ sublimation-as-to'existence-as-sublimating-withdrawal/unenframing/re-ontologising,elicited-from-prospective-profound-supererogation '-in-reflectingimmanent relative unreflexivity/relative reflexivity ontologicalcontiguity ';-as-operative-notional deprocrypticism) conception is very much unlike entailment as of vague elaboration-as-to-mereextrapolating/constituting/abstracting/deducing/inferring-of-elucidationoutside-'prospectively_implicited_attendant-ontologicalcontiguity $\stackrel{\sim}{\sim}$ educedexistentialising/contextualising/textmalising_intelligibility/epistemicity/re 
flexivity-contiguity-<imbued-notional $\sim$ cogency>' caught up in presencing-absolutising-identitive-constitutedness ${ }^{4}$ in distortedoriginariness/distorted-origination failing to reflect 'phenomenal/manifest $\sim$ subpotencies-as-to-their-drivenness-and-theircorresponding-teleological-aporeticism in the full-potency of existence, (as from the ontological-normalcy/postconvergence epistemic-projection perspective), in the sense that 'existence is the overall originariness/origination-_so-construed-as-to-ontologicalnormalcy/postconvergence-perspective-scalarising-construal-ofexistence) of relative-unreflexivity/relative-reflexivity-ontologicalcontiguity, construed as overall ecstatic-existence-superveningconflatedness $^{13}$ with the implication that supervening phenomenal/manifest $\sim$ subpotencies-_in-transitive-conflatedness reflexivity,-in-the-full-potency-of-existence's sublimating-nascence) as to overall reifying-and-empowering-reflexivity-of-ecstatic-existence-aspanintelligibilityfpanreflexivity - (existentially-imbued-and-educing-

$<$ Sepistemic

totalising ${ }^{3}$ hermeneutically/textually/reprojectingly/supererogatingly/zeroin gly/re atingly, \{decompulsing? delinearity for-cogency $\geq$ epistemicperspective-of-projective/reprojective-aestheticising-re-motif-and-reapriorising/re-axiomatising/re-referencing conceptualisation,-as herein specifically relevant to human-subpotency) are all in originariness/origination-_so-construed-as-to-ontologicalnormalcy/postconvergence-perspective-scalarising-construal-of- 
existence); 9 this further undermines naïve physicalism that 'fails to perceive the comprehensive supervening of phenomenal/manifest $\sim$ subpotencies-_in-transitive-conflatedness reflexivity,-in-the-full-potency-of-existence's sublimating-nascence) which is exactly what existentially-<isontologising/re-ontologisingaporeticism $>$ avails as to the fact that it is the human-subpotency consciousness that epistemically conceptualises reality (as of for-humanstudies(for-human-constructs) as to varied phenomenal/manifest $\sim$ subpotencies-corresponding-teleologicalpostconvergingaporeticism overcoming/unovercoming as from the physical, chemical, biological, psychological, social, etc. as to the 'relative unreflexivity/relative reflexivity-ontological-contiguity of the comprehensive supervening of phenomenal/manifest $\sim$ subpotencies-_intransitive-conflatedness -reflexivity,-in-the-full-potency-ofexistence's sublimating-nascence)' so-reflected as overall reifying-andempowering-reflexivity-of-ecstatic-existence-aspanintelligibilityłpanreflexivity - (existentially-imbued-and-educing$\leq$ fepistemic totalising ihermeneutically/textually/reprojectingly/supererogatingly/zeroin gly/re acutingly, -\{decompulsing ${ }^{2}$ delinearity for-cogency $\geq$ epistemicperspective-of-projective/reprojective-aestheticising-re-motif-and-reapriorising/re-axiomatising/re-referencing conceptualisation, as herein specifically relevant to human subpotency), and there is no veracity for a superseding physical epistemic-conception of the chemical, of the chemical 
of the biological, and of the biological of the psychological or social (and not even mathematics as of its transverse epistemic-conception phenomenal/manifest subpotency-\{in-transitive-conflatedness reflexivity,-in-the-full-potency-of-existence's sublimating-nascence) substitutes for any other epistemic-conceptions of immanently imbued phenomenal/manifest $\sim$ subpotencies-_in-transitive-conflatedness reflexivity,-in-the-full-potency-of-existence's $\sim$ sublimating-nascence $)$ as to the comprehensive supervening of phenomenal/manifest $\sim$ subpotencies-\{intransitive-conflatedness -reflexivity,-in-the-full-potency-of-

existence's $\sim$ sublimating-nascence) so-reflected as overall reifying-andempowering-reflexivity-of-ecstatic-existence-aspanintelligibilityłpanreflexivity - 〈existentially-imbued-and-educing$\leqslant$ fepistemic totalising ${ }^{3}$ hermeneutically/textually/reprojectingly/supererogatingly/zeroin gly/re acutingly, -tdecompulsings delinearity for-cogency $\geq$ epistemicperspective-of-projective/reprojective-aestheticising-re-motif-and-reapriorising/re-axiomatising/re-referencing conceptualisation, as herein specifically relevant to human subpotency)), explaining the fact that such vague approaches turn out to be epistemically inefficacious/desublimating impracticalities when seriously considered, and reflecting that existence's originariness/origination-_so-construed-as-to-ontologicalnormalcy/postconvergence-perspective-scalarising-construal-ofexistence) is the 'relative unreflexivity/relative reflexivity-ontologicalcontiguity of the comprehensive supervening of 
phenomenal/manifest $\sim$ subpotencies-_in-transitive-conflatedness

reflexivity,-in-the-full-potency-of-existence 's sublimating-nascence)' as that is what is of applicative veracity as to inherent subject-matters epistemic-conceptions of phenomenal/manifest $\sim$ subpotencies-_intransitive-conflatedness -reflexivity,-in-the-full-potency-of-

existence's $\sim$ sublimating-nascence |; $\uparrow$ it can further be appreciated in this regards for instance that no amount of abstract mathematics can substitute for the requisite inherent physics epistemic-conception foregrounding_entailment-<in-succession-of-profound-

supererogation $>$ - (postconverging-narrowing-down $\sim$ sublimation-as-to'existence-as-sublimating-withdrawal/unenframing/re-ontologising,elicited-from-prospective-profound-supererogation '-in-reflecting'immanent relative unreflexivity/relative reflexivity ontologicalcontiguity ,;-as-operative-notional deprocrypticism),-as-to'<amplitudingfformativeepistemicity>totalising/circumscribing/delineating 'implicited_attendantontological-contiguity ${ }^{\prime}$ educedexistentialising/contextualising/textualising_intelligibility/epistemicity/re flexivity-contiguity-<imbued-notional $\sim \operatorname{cogency}>^{\text {' }}$ in elucidating the inherent physics epistemic-conception phenomenal/manifest $\sim$ subpotency(in-transitive-conflatedness -reflexivity,-in-the-full-potency-ofexistence's $\sim$ sublimating-nascence) with regards to the relativeunreflexivity/relative-reflexivity ontological-contiguity of existence' given the inherent physics epistemic-conception 
phenomenal/manifest $\sim$ subpotency-\{in-transitive-conflatedness

reflexivity,-in-the-full-potency-of-existence's sublimating-nascence) as to overall reifying-and-empowering-reflexivity-of-ecstatic-existence-aspanintelligibilityłpanreflexivity - 〈existentially-imbued-and-educing-

$\leqslant$ fepistemic

thermeneutically/textually/reprojectingly/supererogatingly/zeroin gly/re acutingly, - tdecompulsingt delinearity for-cogency $\geq$ epistemicperspective-of-projective/reprojective-aestheticising-re-motif-and-reapriorising/re-axiomatising/re-referencing conceptualisation, as hein specifically relevant to human subpotency) implied

originariness/origination-_so-construed-as-to-ontological-

normalcy/postconvergence-perspective-scalarising-construal-of-

existence), and the same can be said of any other inherent subject-matter epistemic-conception with regards to the relative unreflexivity/relativereflexivity ontological-contiguity of existence, and just as the same can be said even of inherent mathematics epistemic-conception notwithstanding its rather contemplatable peculiar transverse epistemicconception phenomenal/manifest $\sim$ subpotency-_in-transitiveconflatedness -reflexivity,-in-the-full-potency-of-

existence's sublimating-nascence), but then all other subjectmatters are equally epistemic-conceptions as of their very own peculiar transverse epistemic-conception phenomenal/manifest $\sim$ subpotencies-(in-transitiveconflatedness -reflexivity,-in-the-full-potency-of-

existence's sublimating-nascence) with regards to the relative- 
unreflexivity/relative reflexivity ontological-contiguity of existence (as even the social and socio-psychological phenomenal/manifest subpotencies-_in-transitive-conflatedness reflexivity,-in-the-full-potency-of-existence's sublimating-nascence) as of human living/institutional/Being implications do have transversephenomenal/manifest existential-<isontologising/reontologising aporeticism> consequences as to the human organisingand-institutionalising capacity to elucidate the natural sciences phenomenal/manifest $\sim$ subpotencies-_in-transitive-conflatedness reflexivity,-in-the-full-potency-of-existence's sublimating-nascence) even as the former don't substitute for the inherent natural sciences phenomenal/manifest $\sim$ subpotencies-_in-transitive-conflatedness reflexivity,-in-the-full-potency-of-existence's sublimating-nascence) in elucidating the natural sciences); 1 rather the valid epistemic-conceptions of $\quad$ phenomenal/manifest $\sim$ subpotencies-\{in-transitive-conflatedness reflexivity,-in-the-full-potency-of-existence's $\sim$ sublimating-nascence) as to their peculiar transverse epistemic-conception phenomenal/manifest $\sim$ subpotencies-_in-transitive-conflatedness reflexivity,-in-the-full-potency-of-existence's sublimating-nascence) should not lead to naïve reductionist interpretations in apriorising/axiomatising/referencing-\{of- 'prospecty implicited_attendant-ontological-contiguity ' educedexistentialising/contextualising/textualising_intelligibility/epistemicity/re flexivity-contiguity-<imbued-notional $\sim$ cogency > ' \}-constitutedness ${ }^{14}$ 
in preconverging entailment that pretend to then substitute for the other phenomenal/manifest $\sim$ subpotencies-_in-transitive-conflatedness reflexivity,-in-the-full-potency-of-existence's sublimating-nascence) (as it can be noted not only with the naivety of physicalism reductionism or universal mathematical/informational reductionism or consciousness reductionism) 'wrongly seeming to supersede the relativeunreflexivity/relative reflexivity ontological-contiguity of existencelecstatic-existence as of overall-ecstatic-existence-superveningconflatedness $^{\text {' }}$ whereas 'ultimately it is sublimation in existence' as of phenomenal/manifest $\sim$ subpotencies-_in-transitive-conflatedness reflexivity,-in-the-full-potency-of-existence's sublimating-nascence) induced sublimation (so-reflected as foregrounding_entailment-<insuccession-of-profound-supererogation $>$-_postconverging-narrowingdown sublimation-as-to- 'existence-as-sublimatingwithdrawal/unenframing/re-ontologising,-elicited-from-prospectiveprofound-supererogation '-in-reflecting- 'immanent relativeunreflexivity/relative reflexivity ontological-contiguity ';-as-operativenotional deprocrypticism) as to overall reifying-and-empoweringreflexivity-of-ecstatic-existence-as-panintelligibilityfpanreflexivity lexistentially-imbued-and-educing-<epistemic thermeneutically/textually/reprojectingly/supererogatingly/zeroin gly/re acutingly, - ${ }^{\text {fdecompulsing }}$ delinearity for-cogency $\geq$ epistemicperspective-of-projective/reprojective-aestheticising-re-motif-and-reapriorising/re-axiomatising/re-referencing conceptualisation,-as herein 
specifically relevant to human-subpotencyl) that is the 'defining and superseding epistemic-conception of originariness/origination-〈soconstrued-as-to-ontological-normalcy/postconvergence-perspectivescalarising-construal-of-existence) of the relative-unreflexivity/relativereflexivity ontological-contiguity of existence' as to the possibility of human limited-mentation-capacity-deepening-as-subjecting limitedness/human-subpotency to 'educed unlimitedness/existencesublimating nascence induced epistemic-conceptions of phenomenal/manifest $\sim$ Subpotencies-_in-transitive-conflatedness reflexivity,-in-the-full-potency-of-existence's sublimating-nascence) (and this actually allows for the epistemic-conception of any other possible phenomenal/manifest $\sim$ subpotencies-_in-transitive-conflatedness reflexivity,-in-the-full-potency-of-existence's sublimating-nascence) that are not as of yet divulged as to their correspondingly inducible sublimation in existence), and so over all such reductionist epistemic-conceptions wrongly construing peculiar transverse epistemic-conception phenomenal/manifest $\sim$ subpotencies-_in-transitive-conflatedness reflexivity,-in-the-full-potency-of-existence's sublimating-nascence) in apriorising/axiomatising/referencing-\{of- "prospectively implicited_attendant-ontological-contiguity ' reducedexistentialising/contextualising/textualising_intelligibility/epistemicity/re flexivity-contiguity-<imbued-notional $\sim$ cogency $>$ ' $\}$-constitutedness ${ }^{14}$ in preconverging entailment as substituting for other phenomenal/manifest $\sim$ subpotencies-_in-transitive-conflatedness 
reflexivity,-in-the-full-potency-of-existence's sublimating-nascence) (and thus fundamentally since a physics reductionism of existence cannot generate the profound sublimation in existence of say a biology epistemicconception of living phenomena or a biological/neurological reductionism of existence cannot generate the more profound sublimation in existence of say a social and socio-psychological epistemic-conception of socialconstructs and institutions ${ }^{5}$ meaningfulness-and-teleology, such pretences are often at best unscientific postures riding-the-wavelexploitwithout-correspondingsublimation-as-to-existence-

potency ${ }^{3}$ sublimating-nascence-implications of the success obtained in their relevant epistemic-conceptions of physical phenomena and living phenomena respectively to then wrongly project substitutive sublimation in another domain-of-study, and so-manifested at worst with the usurpation of such natural sciences successes associated particularly with their desublimating projections in wrongly drawing profound social and sociopsychology interpretations)

${ }^{46}$ historiality/ontol 'historiality/ontological-eventfulness $/$ ontological-aesthetic-tracingogical$<$ perspective-ontological-normalcy/postconvergence-reflectedeventfulness 38 onto 'epistemicity-relativism-determinism'> logical-aesthetic- apriorising/axiomatising/referencing as to ${ }^{83}$ reference-of-thought-andtracing- 'reference-of-thought- devolving', and so underlined by the $<$ perspective- 'momentousness for prospective transcendence-andontological- sublimity/sublimation/supererogatory-de-mentativity induced as from normalcy/postconv human limited-mentation-capacity-deepening-as-subjecting 
ergence-reflected- limitedness/human-subpotency to 'educed-unlimitednesslexistence'epistemicity- sublimating nascence' ${ }^{3}$ in perspective ontologicalrelativismnormalcy/postconvergence projective-totalitative-implications-ofdeterminism’> prospective- nonpresencing-for-explicating relativeunreflexivity/relative reflexivity -ontological-contiguity ,-as-reflecting$<$ amplitudingfformative-epistemicity >causality $\sim$ all-alongcomprehensively-as-to-the-relative unreflexivity/relative reflexivityontological-contiguity $\sim$ of-the-human-institutionalisation-process ,〈construed-psychoanalytically-as-of-the-conflatedness - 'dynamics-offundamentally-seeded/incipient-human- limited-mentation-capacitydeepening -as-subjecting-limitedness/human-subpotency-to-'educedunlimitedness/existence sublimating nascence' -driven-as-tointemporality /intemporal-preservation-psychology-of-completeness-innotional-contiguity/epistemic-contiguity -<profound-supererogation of-mentally-aestheticised postconverging/dialectical-thinking -qualiaschema $>$-as-so-reflecting-prospective-transcendence-andsublimity/sublimation/supererogatory de-mentativity,-in-contrast-withthe-various-temporalities-psychologies-of-incompleteness-in-notionaldiscontiguity/epistemic-discontiguity -<between - prior-shallowsupererogation -of-mentally-aestheticised preconverging/dementing qualia-schema_and_prospective-profound-supererogation -of-mentallyaestheticised postconverging/dialectical-thinking -qualia-schema>,-asthreshold-of-nonconviction/madeupness/bottomlining-in-shallowsupererogation -<as-to- 'attendant-intradimensional'-prospectivelydisontologising preconverging/dementing -apriorising-psychologism >- 
and-reflecting-prospectively-desublimation/gimmickiness', and so as-tothe-underlying-social- 'epistemic-totality '-of- meaningfulness-andteleology -with-regards-to-social-stake-contention-or-confliction)
${ }^{47}$ historicity-
'historicity-tracing-in-presencing-hyperrealisation/hyperreal-
tracing-in-
transposition of apriorising/axiomatising/referencing as to reference-of-
presencing-
thought-and- reference-of-thought- devolving' (is-so-construed-as-of-

hyperrealisation/hy its-defining-shallow-preconverging/postconverging-de-

perreal-

mentative/structural/paradigmatic- 'presencing-conceptualisation-

transposition

disposition')-as-to-human-psychological-entrapment-to-the-

incrementalism-in-relative-ontological-incompleteness

enframed/disontologising conceptualisation-disposition-of- 'defining-

priorly-aestheticised-conceptualisations,',-as-so-resulting-from-prior-

human-limited-mentation-capacity-as-subjecting 'educed-

unlimitedness/existence sublimating nascence' to limitedness/human-

subpotency-ontological-performance ${ }^{72}<$ including-virtue-as-ontology $>$ -

outcomes; $\boldsymbol{\square}$

historicity-tracing-in-presencing-

hyperrealisation/hyperreal-transposition constrasts with prospective

historiality/ontological-eventfulness $3 \%$ ontological-aesthetic-tracing-

$<$ perspective-ontological-normalcy/postconvergence-reflected-

'epistemicity-relativism-determinism'> (which-is-construed-as-of-its-

defining-prospective-aestheticised-conceptualisations-more-profound-

preconverging/postconverging-de-mentative/structural/paradigmatic- 're-

originariness/reorigination-futural-ontological-performance ${ }^{72}$

<including-virtue-as-ontology>-projection,-superseding-presencing- 
conceptualisation-disposition')-as-to-human-psychological-

uninhibitedness/decomplexification-for- maximalising-recomposuring-

for-relative-ontological-completeness - unenframed/re-

ontologising conceptualisation-disposition-of-'defining-prospectively-

aestheticised-conceptualisations, ',-and-so-for-renewed-ontological-

performance ${ }^{72}<$ including-virtue-as-ontology>-outcome-as-from-the-

ontological-normalcy/postconvergence-projective-perspective; $\mathbb{\uparrow}$

as

historicity-tracing - in-presencing-hyperrealisation/hyperreal-

transposition is the 'repetitive presencing-absolutising-identitive-

constitutedness

incrementalism-in-relative-ontological-

incompleteness —enframed/disontologising conceptualisation

disposition' of the <cumulating/recomposuring attendant-ontological-

contiguity >-successive registry-worldviews/dimensions as to their

<amplitudinglformative> wooden-language-fimbued-averaging-of-

thought-<as-to-leveling/ressentiment/closed-construct-of-

meaningfulness-and-teleology -as-of-'nondescript/ignorable-void

with-regards-to-prospective-apriorising-implications $>$ | with respect to

prospective human-subpotency-aporia/undecidability/dilemma/ought-

indeterminacy/deficiency/limitation/constraint—imbued-

'notional firstnaturedness-formativeness < as to eventualising inkling

drive or seeding misprising> temporal-to-intemporal-dispositions-

$<$ so-construed-as-from-perspective-ontological-

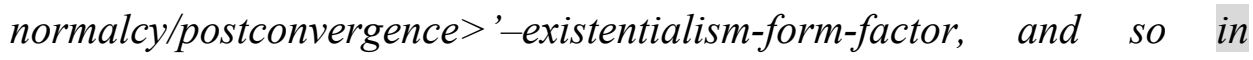
reflecting holographically-<conjugatively-and-transfusively $>$ the relative unreflexivity/relative reflexivity ontological-contiguity of-the- 
human-institutionalisation-process as to prior, present and prospective human-subpotency potential of overall aestheticisation-andaestheticisation-towards-ontology-<elicited-idiomatisation $>$

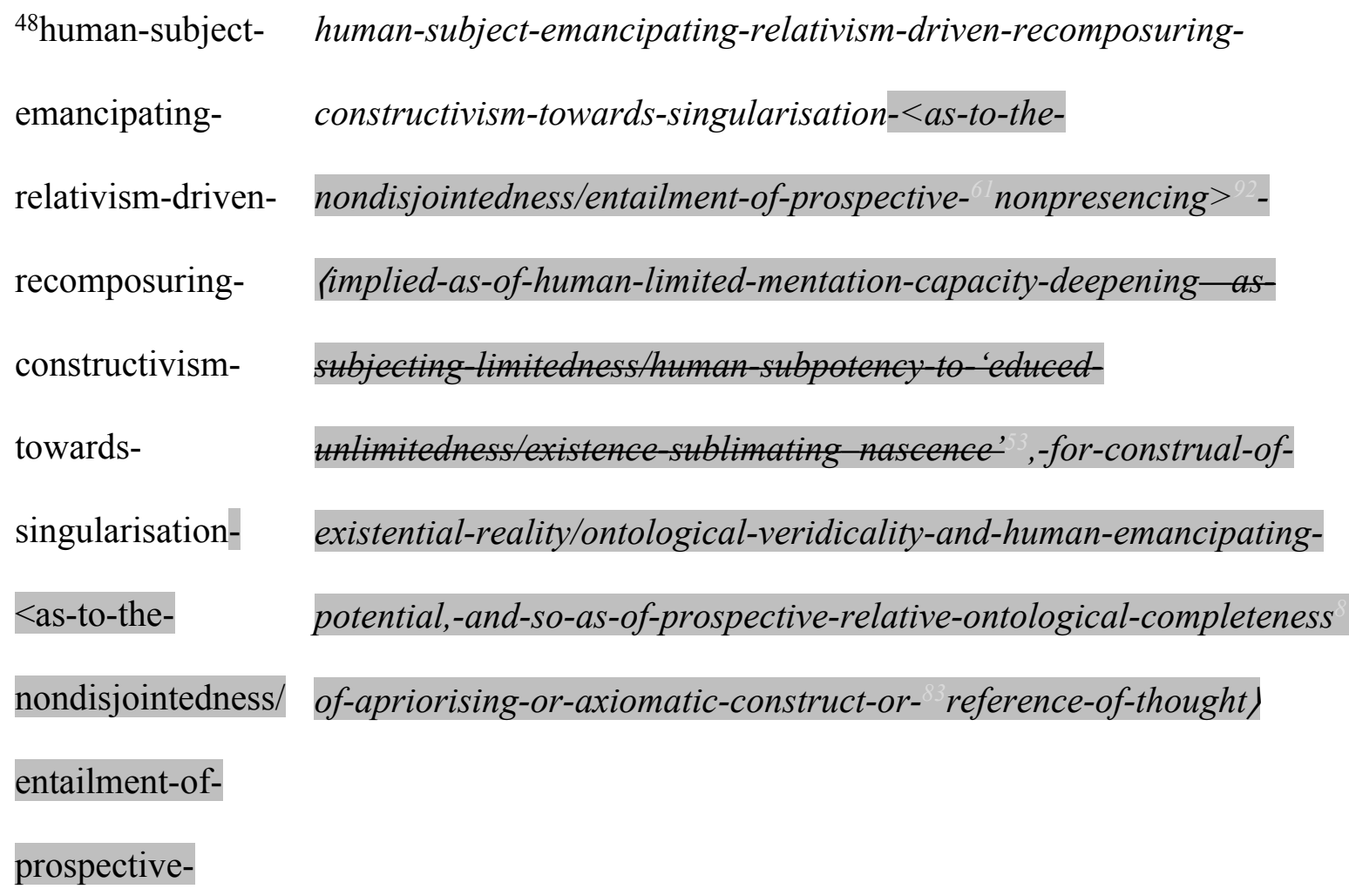




\section{presencing-}

absolutising-

identitive-

constitutedness

-as-flawed-

epistemicity-

relativism-

determinism $^{49}$

${ }^{50}$ ignorance/afforda ignorance/affordability/opportunism/exacerbation/social-chainism-orbility/opportunism/ social-discomfiture-or-negative-social-aggregation/temporalexacerbation/social enculturation-or-temporal-endemisation-_as-to- 'implicited_attendant -chainism-or- ontological-contiguity ' reducedsocial- existentialising/contextualising/textualising_intelligibility/epistemicity/re discomfiture-or- flexivity-contiguity-<imbued-notional $\sim \operatorname{cogency}>$ ' merenegative-social- forms/reprisings' by psychopathic postlogism -slantedness, inducing aggregation/tempo derived- perversion-of- reference-of-thought-<as-preconverginglyral-enculturation- apriorising/axiomatising/referencing-inor-temporal- nonconviction/madeupness/bottomlining-as-to-shallowendemisation supererogation > as from 'prelogism -as-of-conviction,-in-profoundsupererogation -<existentially-veridical-'attendant-intradimensionalapriorising/axiomatising/referencing'-logical-dueness-precedesdisontologising-logical-outcome-arrived-at $>$ mental-projection then followed by muddled- reference-of-thought in cohering-to-postlogism set-of-narratives in denaturing -prelogism -as-of-conviction,-in- 


\section{profound-supererogation -<existentially-veridical-'attendant-}

intradimensional-apriorising/axiomatising/referencing'-logical-duenessprecedes-disontologising-logical-outcome-arrived-at>'); $\uparrow$ arising as a result of the 'registry-worldview relative-ontological-incompleteness ${ }^{8}$-ofreference-of-thought (beyond-the-consciousness-awareness-teleology $<$ of-preconverging-existential-extrication-as-of-existential-unthought $>$ ) epistemic-projection' and corresponding 'lack of constraining social universal-transparency -〈transparency-of-totalising-entailing,-as-toentailing-<amplitudingfformative-epistemicity $>$ totalising in-relativeontological-completeness J', and so-construed more precisely not on the basis of our positivism- procrypticism (or any given self-presence/selfconstitutedness $^{1 /}-<$ in-perspective-epistemic-

abnormalcy/preconvergence ${ }^{3 /}$ ) epistemicity>totalising $\sim$ self-referencing-

syncretising/circularity/interiorising/akrasiatic-drag ${ }^{34}$ for elucidative ontological-veracity (with regards to such individuations $<$ amplituding/formative-epistemicity >totalising intervalist-ascategorising - implicited_attendant-ontological-contiguity ' reducedexistentialising/contextualising/textualising_intelligibility/epistemicity/re flexivity-contiguity-<imbued-notional $\sim \operatorname{cogency}>^{\text {' }}$;-phenomenalabstractiveness-of-presencing-in- 'occlusive-consciousness'-enablingapriorising/axiomatising/referencing/intelligibilitysettingup/measuringins trumenting-for-operant-or-incidenting-predicative-insights of positivismprocrypticism 'implicited_attendant_ontological-contiguity ' educedexistentialising/contextualising/textualising_intelligibility/epistemicity/re 
flexivity-contiguity-<imbued-notional $\sim$ cogency $>$, ,-<reifying-or-

elucidating-of-prospective-relative-ontological-completeness -of-

reference-of-thought- devolving-as-of-instantiative-context>

categorisation) but rather veridically evaluated on the notional deprocrypticism basis of the relative unreflexivity/relativereflexivity ontological-contiguity of-the-human-institutionalisationprocess $^{6}$ as 'individuations candidity/candour capacity' in perspective ontological-normalcy/postconvergence notional elucidative ontologicalveracity of 'temporality/shortness-to-intemporality'/longness-ofregister-of-meaningfulness $/{ }^{3}$ reference-of-thought associated preconverging/postconverging-de-mentating/structuring/paradigming ontological-performance ${ }^{72}<$ including-virtue-as-ontology $>$ '

${ }^{51}$ incrementalism- akrasiatic-incrementalism-in-relative-ontological-incompleteness ${ }^{8}$ in-relative- $\quad$ enframed/disontologising $\sim$ conceptualisation-<as-to- ${ }^{-}$historicityontological- $\quad$ tracing-in-presencing-hyperrealisation/hyperreal-transposition,incompleteness $\quad$ 'circularly-in-akrasiatic-drag/interiorising'-of-motif-andapriorising/axiomatising/referencing $>$ -

enframed/disontol enframed/disontologising conceptualisation as to dimensionality-ofogising conceptua desublimating-lack-of $-\langle<$ flinglivermativelisation mentativeness/epistemic-growth-or-conflatedness /transvaluativerationalising/transepistemicity/anamnestic-residuality/spirit-drivennessequalisation) so-reflecting lack-of-the-epistemic-projective-perspectiveof-ontological-normalcy/postconvergence

intemporality ${ }^{52}$ intemporality / longness-of-register-of- meaningfulness-and-teleology / 
dispensing-with-ontologically-perverting-immediacy-behaviour,-as-ofprospective-institutionalisation,-as-from-inherently-determinableapriorising-teleological-thresholding-as-teleological-framework-ornarrative-framework / upholding-or-renewing-of-categorical-imperativesor-axioms-or-registry-teleology -for-intemporal-preservation-entropyor-contiguity-or-ontological-preservation-<as-so-preceding-inperspective-ontological-normalcy/postconvergence-human-epistemiccategoricality-of-apriorising/axiomatising/referencing > / dimensionalityof-sublimating $-1<$ amplitudinglformative $>$ supererogatory $\sim d e-$ mentativeness/epistemic-growth-or-conflatedness /transvaluativerationalising/transepistemicity/anamnestic-residuality/spirit-drivennessequalisation); $\uparrow$ as to 'implied human limited-mentation-capacitydeepening - as subjecting limitedness/human subpotency to 'educedunlimitedness/existence sublimating nascence' ${ }^{5}$ inducing ${ }^{15}$ dementation-(supererogatory ontological-de-mentation-or-dialectical-dementation-stranding-or-attributive-dialectics) of human placeholdersetup/mental-devising-representation/mentation/consciousnessawareness-teleology" (with regards to the 'full incipient supererogating breadth of human intelligibility transmutation' exuding '< tolalising preformulating/preframing/premeaningfulness of notional originariness-parrhesia,-as-spontaneity-of-aestheticisation' before the incipience of metaphoricity and then ${ }^{56}$ meaningfulness-andteleology as to existentialising-frame-of entailment of motif and apriorising/axiomatising/referencing) behind the sublimating- 
postconverged 'substantive abstract-tissue-of-social-emanance fepistemictotalising 3 'Thermeneutically/textually/reprojectingly/supererogatingly/zeroin gly/re acutingly, - fdecompusingl delinearity for-cogencycumulated/recomposured as to cumulating/recomposuring of 'prospectively implicited_attendant-ontological-contiguity' ' educedexistentialising/contextualising/textualising_intelligibility/epistemicity/re flexivity-contiguity-<imbued-notional $\sim \operatorname{cogency}>$ ' , intemporality 'in reflecting human profound ontological-performance ${ }^{72}<$ including-virtueas-ontology>/morality/ethics/justice/etc. as of nonpresencing$<$ perspective-ontological-normalcy/postconvergence $>\quad$ epistemicconception of intemporal individuation' it is herein contended (beyond naivist human intragenerational/intradimensional conception of individual persons punctual existential-disontologising/re-ontologisingaporeticism $>\quad$ ontological-performance $-<$ including-virtue-asontology>/morality/ethics/justice/etc. so-construed as to the given registry-worldview/s/dimension's $<$ preconverging 'motif-andapriorising/axiomatising/referencing'-entailing>-existentialisingenframing/imprintedness-_as-to- historicity-tracing-in-presencinghyperrealisation/hyperreal-transposition/shallow social-functioning-andaccordance-as-of-social-stake-contention-or-confliction), speaks to the 'sole veridically scientific conception of human ontologicalperformance ${ }^{72}-<$ including-virtue-as-

ontology>/morality/ethics/justice/etc. subsuming notions of ontology, morality, ethics, etc.' and so as to a 'cogent epistemictotalising protraction conceptivity/epistemic-reflexivity/epistemicity-relativism- 
determinism-<reifying\{as-to-knowledge-developing\}-and-empowering >

of

human

supererogatory acuity/perspicacity/astuteness/edginess/incisiveness in reflecting holographically-<conjugatively-and-transfusively $>\quad$ the relative unreflexivity/relative reflexivity ontological-contiguity rof-thehuman-institutionalisation-process as so-underlying 'human meaningfulness-and-teleology effective epistemic totalising consequence with regards to the fact that its profoundness/ontologisingdepth is of non-disjointedness/contiguity/coherence) (in its '<amplitudingfformative $>$ disposedness/psychologismic-construct-\{as-toorientation/value-construct/valuation-and-derived-parameterising/ and < amplituding/formative > entailment-_as-to-totalising-

contiguous/coherent-factuality-of-variability)' underlined as to its prospective foregrounding_entailment-<in-succession-of-profoundsupererogation $>$ - (postconverging-narrowing-down $\sim$ sublimation-as-to'existence - as-sublimating-withdrawal/unenframing/re-ontologising,elicited-from-prospective-profound-supererogation '-in-reflecting'immanent relative unreflexivity/relative reflexivity ontologicalcontiguity ';-as-operative-notional deprocrypticism))

limited-mentation- limited-mentation-capacity-deepening-as-subjecting limitedness/human capacitysubpotency to 'educed unlimitedness/existence-sublimating nascence'deepening as < <amplitudingfformative-epistemicity>totalisingly as-to-existence-assubjecting sublimating-withdrawal/unenframing/re-ontologising,-elicited-fromlimitedness/human prospective-profound-supererogation /,-as-recomposuring-of- 
-subpotency to-

seduced- apriorising/axiomatising/referencing-as-of-existence-

potency $\sim$ sublimating-nascence,-disclosed-from-prospective-epistemic-

unlimitedness/exist digression,-as-of-" human-subject-emancipating-relativism-driven-

ence-sublimating recomposuring-constructivism-towards-singularisation-<as-to-the-

nascence' 53 nondisjointedness/entailment-of-prospective- nonpresencing > '-〈as of

relative apriorising/axiomatising/referencing-\{of-"prospectively

implicited_attendant-ontological-contiguity ' reduced-

existentialising/contextualising/textualising_intelligibility/epistemicity/re

flexivity-contiguity-<imbued-notional $\sim$ cogency > ' \}-constitutedness ${ }^{14}$

in preconverging entailment towards relative

apriorising/axiomatising/referencing-\{of- "prospectively

implicited_attendant-ontological-contiguity ' educed-

existentialising/contextualising/textualising_intelligibility/epistemicity/re

flexivity-contiguity-<imbued-notional $\sim$ cogency $>$ ' \}-conflatedness ${ }^{13}-$

in-\{preconverging-ment by\} postconverging-entailment); - limited-

mentation-capacity-deepening-as-subjecting-limitedness/human-

subpotency to 'educed unlimitedness/existence sublimating nascence'

fundamentally speaks of human knowledge-reification $\sim$ gesturing-and-

accounting-of-epistemic-phenomenalism-<in-

prospective psychologismic apriorising/axiomatising/referencing-\{of-

'prospectively implicited_attendant-ontological-contiguity ' reduced-

existentialising/contextualising/textualising_intelligibility/epistemicity/re

flexivity-contiguity-<imbued-notional cogency> ' \}-conflatedness

in \{preconverging ment by\} postconverging entailment> as from time

immemorial so-construed as involving human projective conceptualising 
beyond animality (as from human recurrent-utter-uninstitutionalisation trepidatious-consciousness, base-institutionalisation-ununiversalisation warped-consciousness, ${ }^{103}$ universalisation-non-positivism/medievalism preclusive-consciousness, our present positivism- procrypticism occlusive-consciousness and prospective notional deprocrypticism protensive-consciousness), speaking of human teleology so-construed as 'human phenomenal/manifest conceptivity/epistemicreflexivity/epistemicity-relativism-determinism-<reifying\{as-toknowledge-developing\}-and-empowering $>$ in existence as ontological (so-reflecting < amplituding/formative > disposedness/psychologismicconstruct-_as-to-orientation/value-construct/valuation-and-derivedparameterising) and <amplituding/formative >entailment-\{as-tototalising-contiguous/coherent-factuality-of-variability))', underlied as of overall reifying-and-empowering-reflexivity-of-ecstatic-existence-aspanintelligibilityfpanreflexivity - (existentially-imbued-and-educing$\leq$ fepistemic thermeneutically/textually/reprojectingly/supererogatingly/zeroin gly/re acutingly, -idecompulsing delinearity for-cogency $\geq$ epistemicperspective-of-projective/reprojective-aestheticising-re-motif-and-reapriorising/re-axiomatising/re-referencing conceptualisation, as herein specifically relevant to human subpotency); 9 with limited-mentationcapacity-deepening - as subjecting limitedness/human-subpotency to'educed unlimitednesslexistence sublimating nascence' (as to human Being-development/ontological-framework-expansion-as-to-depth-of- 
ontologising-development-as-infrastructure-of- meaningfulness-andteleology , institutional-development-as-to-social-function-development and living-development-as-to-personality-development psychologismic epistemic acutisation difficully< for, residualising \{decompulsing delinearity for cogency $\geq$ magnitudes \{f-experientiality/experiment $\left.^{\}}\right)$, rather arising as of 'aestheticisation-and-aestheticisation-towardsontology-<elicited-idiomatisation $>$ of human ontological-performance ${ }^{72}$ <including-virtue-as-ontology>' underlying both 'motif-as-toaestheticisation-<imbued-projective-arbitrariness/waywardness > ' and 'apriorising/axiomatising/referencing/intelligibilitysettingup/measuringin strumenting-for-conceptualisation as to aestheticisation-towardsontology' (so-construed as <amplitudingfformativeepistemicity $>$ totalising $\sim$ conflatedness ${ }^{13}$ of meaningfulness-andteleology involving the 'epistemictotalising $\sim$ resubjecting_or_totalising-entailing reconstrual-of the wholelpurview of the wholetoneness of ontology $>$ of motif-as-toaestheticisation-<imbued-projective-arbitrariness/waywardness $>$ to existence-as-sublimating-withdrawal/unenframing/re-ontologising,elicited-from-prospective-profound-supererogation in preconverging/postconverging-redementating/restructuring/reparadigming intelligibility-_as-to-humanprojective/reprojective - aestheticising-re-motif-and-re-apriorising/reaxiomatising/re-referencing/re-intelligibilitysettingup/remeasuringinstrumenting-process,-in-<amplituding/formativeepistemicity>totalising conceptualisation)', and so-underscored by the 
reference-of-thought-and- reference-of-thought- devolving dynamics of re-motif-and-re-apriorising/re-axiomatising/re-referencing/reintelligibilitysettingup/re-measuringinstrumenting) of human meaningfulness-and-teleology with respect to 'human existentialinstantiations of both manifest motif (outcome/outfit/shell-construedhistorially-as-of-the-specifically-aestheticised-incrusting/plating/coatingas-institutional-manifestation) and associated/attendant manifest aposteriorising/logicising/deriving/intelligising/measuring meaningfulness-and-teleology '; with human limited-mentationcapacity-deepening - as subjecting limitedness/human subpotency to'educed unlimitedness/existence sublimating nascence' (as to aestheticisation-and-aestheticisation-towards-ontology-<elicitedidiomatisation>) speaking to an emphasis on both human knowledge 'generativity potential' and its 'ontological-performance ${ }^{72}<$ includingvirtue-as-ontology>/morality/ethics/justice/etc. potential' (as reflected in issues of human ${ }^{56}$ meaningfulness-and-teleology induced presencingabsolutising-identitive-constitutedness ${ }^{14}$ ) requiring appropriate human dispensing-with-immediacy-for-relative-ontological-completeness -byreification/contemplative-distension to ever always preserve human 'meaningfulness-and-teleology cross-fertilising 'generativity potential' and 'ontological-performance ${ }^{72}<$ including-virtue-asontology>/morality/ethics/justice/etc. potential' as so-socially-andinstitutionally reflected respectively with the artistic, the philosophical and the scientific/ontological orientations of human ${ }^{56}$ meaningfulnessand-teleology', and in this respect the 'philosophical as straddling both 
aestheticisation (generativity potential) and aestheticisation-towardsontology (ontological-performance ${ }^{72}<$ including-virtue-asontology>/morality/ethics/justice/etc. potential) of human 'meaningfulness-and-teleology' speaks to the 'epistemic successes and failures of human aestheticising' as to human ontological-performance $<$ including-virtue-as-ontology>/morality/ethics/justice/etc. leading up to science/ontology as aestheticisation-towards-ontology (ontologicalperformance ${ }^{72}<$ including-virtue-asontology>/morality/ethics/justice/etc. potential) such that the philosophical notionally reflects 'human solipsistic impulse/intuition for prospective re-originariness/re-origination of intelligibility-andknowledge as-looping-with prior social-emanance (society) already developed-and-developing formulaic institutionalisation conception of intelligibility-and-knowledge' implying that the philosophical thus necessarily permeates all human subject-matter as to their prospective re-originariness/re-origination possibilities (even though as to a practical division-of-labour the philosophical covers the upper ontologies of human ${ }^{56}$ meaningfulness-and-teleology including metaphysics, ethics, etc.) whereas science (including the aspiration of the human and social sciences) is thus but the 'prospective intolerance $<\theta f$ disparateness>texactifying_precisioning-of-sublimation-<as-topostconverging-narrowing-down apriorising/axiomatising/referencingentailing-theoretical,-conceptual-and-operant-implications $>$ of the philosophical' from which it emerges as of natural philosophy (and 'human-nature philosophy as to human self-reflexive construal of the 
human and social' so-associated with aspiring human and social sciences) and is ever always implicitly anchored to the philosophical in the face of its prospective postconverging aporeticismovercoming/unovercoming, while the philosophical as well must necessarily be concerned about its ultimate ontological-veracity relevance to avoid degenerating into a pedantising/muddling/formulaichollowing-out-in-subontologisation/subpotentiationfblurring/undermining-of-prospective-totalising-entailing,-as-toentailing-<amplitudingfformative-epistemicity $>$ totalising $\sim$ in-relativeontological-completeness $\backslash$ in incrementalism-in-relative-ontologicalincompleteness —enframed/disontologising conceptualisation (as we can appreciate that both ancient-sophists and medieval-scholastics could

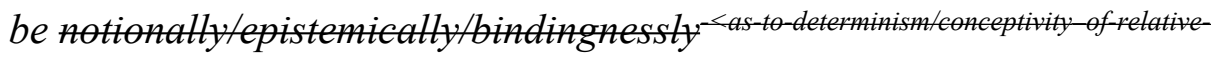
unreflexivity/relative-reflexivity> be considered as involved in philosophy however ontologically-flawed we may now think of their given closed mindsets very much as pseudoscience is decried by serious scientists as it is only such ontological-veracity by its perpetual epistemictotalising $\sim$ resubjecting_or_totalising-entailing $\sim$ reconstrual $<$ of the wholelpurview of the wholetoneness of ontology $>$ to the sublimatingvalidation/desublimating-invalidation of existence-as-sublimatingwithdrawal/unenframing/re-ontologising,-elicited-from-prospectiveprofound-supererogation that can establish the historiality/ontological-eventfulness $3 \%$ ontological-aesthetic-tracing$<$ perspective-ontological-normalcy/postconvergence-reflected'epistemicity-relativism-determinism'> of philosophical knowledge to 
avoid its degeneracy into a poor and relic/artifactual prior_knowledgereification gesturing-and-accounting-of-epistemic-phenomenalism<in-prior_psychologismic apriorising/axiomatising/referencing-\{of'prior-implicited_attendant-ontological-contiguity ' reducedexistentialising/contextualising/textualising_intelligibility/epistemicity/re flexivity-contiguity-<imbued-notional $\sim$ cogency $>^{\prime}$, '-constitutedness in preconverging entailment $>$ in a pedantic gesturing/accounting-ofepistemic-phenomenalism of mere aestheticisation hardly appreciative of the 're ontologising fepistemictalsing 're apriorising/re axiomatising/rereferencingoresiduality in re-originariness/re-origination \{decompulsing' delinearity/delinear accreting/recomposuring cogency/tensing/limpidity-<as-of-prospective-profoundsupererogation ,-for-residuality-in-re-originariness/reorigination>,-pprospective reifying mental aestheticising <as of 'prospective reformulating of mental aestheticising'as to 'residuality in re originariness/re origination' of mental aestheticising ’' of 'relative-ontological-incompleteness /relative-ontologicalcompleteness - -Sublimating $\sim$ referencing/registering/decisioning,-asself-becoming/self-conflatedness /formative-supererogating$<$ projective/reprojective-aestheticising-re-motif-and-re-apriorising/reaxiomatising/re-referencing,-in-perspective-ontologicalnormalcy/postconvergence $>$ ) as to human-and-socialexpectations/anticipations - metaphoricity -aspreconverging/postconverging-redementating/restructuring/reparadigming-psychologism "as to a 
conception of cumulative/recomposuring knowledge allowing for future knowledge-reification -gesturing-and-accounting-of-epistemicphenomenalism- $<$ in-

prospective psychologismic apriorising/axiomatising/referencing-\{of'prospectively implicited_attendant-ontological-contiguity ' educedexistentialising/contextualising/textualising_intelligibility/epistemicity/re flexivity-contiguity-<imbued-notional $\sim$ cogency> ' '-conflatedness in \{preconverging ment by\} postconverging entailment $>$ beyond a nä̈ve institutionalised social-vestedness/normativity as to relic/artifactual conception of knowledge weakened to the questioning of how-does-itknows-that-what-it-says-is-true especially when it adopts disparatenessof-conceptualisation-<unforegrounding-ment,-failing-prospectively-toreflect- 'immanent relative unreflexivity/relative reflexivity ontologicalcontiguity '> over foregrounding_entailment-<in-succession-ofprofound-supererogation $>$-_postconverging-narrowingdown sublimation-as-to- 'existence —as-sublimatingwithdrawal/unenframing/re-ontologising,-elicited-from-prospectiveprofound-supererogation '-in-reflecting- 'immanent relativeunreflexivity/relative reflexivity ontological-contiguity ';-as-operativenotional deprocrypticism) meaningfulness-and-teleology that sublimatingly projects requisite <amplituding/formative > disposedness/psychologismic-construct-_as-toorientation/value-construct/valuation-and-derived-parameterising) and $<$ formative $>$ entailment-_as-to-totalising- 
contiguous/coherent-factuality-of-variability) as herein

implied/ambitioned), with the implication that the philosophical epistemic attitude gives an aestheticising 'prospective leeway of tolerance- <ofdisparateness>finexactitude' for further aestheticising sublimating possibilities of human thought different-from/completementary-to a prospective intolerance $<\theta f$ disparateness>texactifying_precisioning-ofsublimation-<as-to-postconverging-narrowingdown apriorising/axiomatising/referencing-entailing-theoretical,conceptual-and-operant-implications $>$ scientific/ontological epistemic attitude that may by naivety utterly shut down alternate/complementary sublimating human aestheticising possibilities (as more radically manifested today with many a science-ideology approach), but then only allowing for such a 'prospective leeway of tolerance $<\theta f$ disparateness>-inexactitude' specifically rather within the ambit/scope of underlying-elucidative 'requisite sublimating/desublimating formulativeframing/fielding - of-entailment of human ontological-performance ${ }^{72}$ $<$ including-virtue-as-ontology >/morality/ethics/justice/etc. contemplation' as of notionally implied ${ }^{4}$ foregrounding_entailment$<$ in-succession-of-profound-supererogation ${ }^{-}$-〈postconvergingnarrowing-down sublimation-as-to-'existence - as-sublimatingwithdrawal/unenframing/re-ontologising,-elicited-from-prospectiveprofound-supererogation '-in-reflecting- 'immanent relativeunreflexivity/relative reflexivity ontological-contiguity ';-as-operativenotional deprocrypticism)(for instance, in the sense that while a 'prior philosophical-analysis prospective leeway of tolerance $<\theta f$ 
disparateness $>$ finexactitude associated with human servitude' was entertained with ancient epochal philosophies/thoughts it is rather of 'manifest philosophically unseriousness in our present times' to claim/imply such a human servitude contemplation as of "prior philosophical-analysis prospective leeway of tolerance < <f disparateness>finexactitude'), as so-enabling such alternate/complementary sublimating human aestheticising possibilities 'inducible prospective intolerance $<\theta f$ disparateness $>$ texactifying_precisioning-of-sublimation- $<$ as-topostconverging-narrowing-down apriorising/axiomatising/referencingentailing-theoretical,-conceptual-and-operant-implications $>$ sublimating elucidations' (as it can be appreciated that it is 'prior philosophicalanalysis prospective leeway of tolerance $<\theta$ fdisparateness $>$ finexactitude associated with human servitude' which ultimate historial sublimating elucidation brought about our 'present-day philosophical-analysis prospective intolerance <of disparateness>texactifying_precisioning against human servitude sublimating elucidation') for science's very own further development in its prospective postconverging aporeticism overcoming/unovercoming (as increasingly appreciated with a postmodern influence and conception of science so-reflecting experientiality/experiment-<as-to-existentially-formativetotalising '̌re apriorising/re axiomatising/re referencing residuality - inre-originariness/re-origination',-so'Aotionally/epistemically/bindingnessly-<as-to-determinism/conceptivity-of-relativeunreflexivity/relative-reflexivity>-implicited-and-articulated'_as-from- 
nonextricatory- 'prospective-re-ontologising-Being-then-Institutional-

then-Living-magnitudes-of-\{hermeneutic/reprojection-protraction-

बffreframing-and-reformulation\}'> underlied as of 're-

apriorising/re-axiomatising/re-referencing residuality-in-re-

originariness/re-origination with regards to the-very-same

purview/devolved-purview/devolving-purview-of-

unlimitedness/existence-<full potency-of_sublimating nascence $>;-$

'implicited_attendant-ontological-contiguity ' reduced-

existentialising/contextualising/textualising_intelligibility/epistemicity/re

flexivity-contiguity-<imbued-notional $\sim$ cogency $>$ ' underlied by the

veridical epistemic-projection of " nonpresencing-<perspective-

ontological-normalcy/postconvergence $>$ relativism/relative-scope for

epistemic-growth,-as \{veridical/sound\}-relative-reflexivity-in-

existencefrelativising from limited mentation as its-

deepening/psychologismic epistemic acutisation residualising,

\{decompulsing delinearity for cogency' and as so 'comprehensively

undergirding human sublimating/desublimating

apriorising/axiomatising/referencing/intelligibilitysettingup/measuringins

trumenting') and so given that human thought at any given moment as of its aestheticisation-and-aestheticisation-towards-ontology-<elicitedidiomatisation $>$ is not absolutely determinative/certain (about all sublimating possibilities) so-reflected by the veracity of the metaphoricity or enframed/disontologising-by-unenframed/reontologising or enframed/disontologising-superseding/overcoming or re-

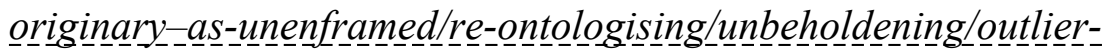


conceptualisation_-_imbued-postconverging/dialectical-thinking

'projective-insights'/'epistemic-projection-in-conflatedness '-of-

notional deprocrypticism-prospective-sublimation) that truly

underlies all human meaningfulness-and-teleology thus enabling the

prospective possibility for human emancipation and progress (as even the

sciences while ultimately aspiring for prospective intolerance $<\varnothing f$

disparateness>texactifying_precisioning-of-sublimation-<as-to-

postconverging-narrowing-down apriorising/axiomatising/referencing-

entailing-theoretical,-conceptual-and-operant-implications $>$ scientific

accounts, will implicitly/punctually adopt practices of "prospective

leeway of tolerance < of disparateness>finexactitude' as to the more

critical issue of their prospective postconverging aporeticism-

overcoming/unovercoming wherein for instance it is mostly in the last 30-

or-so years that astronomy has arrived at a highly cogent/tense/limpid-

$<$ as-of-prospective-profound-supererogation ,-for-residuality-in-re-

originariness/re-origination $>$ scientific account of astronomical

phenomena, in the medical domain because of the critical nature of any

developments to human health and preservation of life even the most

flimsy statistics are often portrayed as of relevance however the

possibility for pseudo-analysis or later retractions, and generally in this

respect science at its 'breakthrough-level of scientific accounts' is rather

of relatively high 'prospective leeway of tolerance $<$ of

disparateness>-inexactitude' as nascent scientific conceptions even

within say the physics domain are contested, with the critical notion of

science-in-practice rather being about ultimate aspiration to continually 
converge towards more and more prospective intolerance $<0 f$

disparateness >texactifying_precisioning-of-sublimation-<as-to-

postconverging-narrowing-down apriorising/axiomatising/referencing-

entailing-theoretical,-conceptual-and-operant-implications $>$ scientific

accounts); $\mid$ but then human limited-mentation-capacity-deepening -as-

subjecting-limitedness/human-subpotency-to-'educed-

unlimitedness/existence sublimating nascence' as to aestheticisation-

and-aestheticisation-towards-ontology-<elicited-idiomatisation $>$

necessarily priorly conforms to existence - as-the-absolute-a-priori-of-

conceptualisation $\sim$ and $\sim$ existence-as-sublimating-

withdrawal/unenframing/re-ontologising,-elicited-from-prospective-

profound-supererogation $-<$ as-to-perspective-ontological-

normalcy/postconvergence-implied- 'prospective-aporeticism-

overcoming/unovercoming'> (and so over any human-subpotency

institutionalising conceptions like philosophy and science), and in-the-

bigger-picture in this regards the institutionalised conception of

philosophy for instance is a distorted Western metaphysics-of-presence-

(implicited-'nondescript/ignorable-void '-as-to- presencing-

absolutising-identitive-constitutedness \notion of the more universal concept of overall human knowledge (pure and simple), with the flaw that speaking of say non-Western philosophy is a misnomer so-construed as a 'distorted and undue epistemic intercession of supposed Western philosophy as a reference point of conception into any non-Western society aestheticisation-and-aestheticisation-towards-ontology$<$ elicited-idiomatisation> notion of overall human knowledge' (as to any 
such non-Western postconverging epistemic-projective-equalisation social dynamics very own originariness-parrhesia,-as-spontaneity-ofaestheticisation inducing of prior reproducibilitymathesis/motif/thrownness-disposition,-as-reproducibility-ofaestheticisation as outcome/outfit/shell_construed-historially-as-ofthespecifically-aestheticised-incrusting/plating/coating-as-institutionalmanifestation) and furthermore such a misnomer as to its metaphysics-ofpresence-_implicited- 'nondescript/ignorable-void '-as-to- presencingabsolutising-identitive-constitutedness \seem to supersede the more fundamental notion of human underlying ontological-commitment <implied-self-assuredness-of-ontological-goodfaith/authenticity $~ p o s t c o n v e r g i n g-d e-$ mentating/structuring/paradigming -as-being-as-of-existential-reality> (as instigatingly driving the human out of animality) as to the more pivotal/critical human-subpotency 'fatedness-of-sublimation-overdesublimation, to existence-potency $\sim$ sublimating-nascence,-disclosedfrom-prospective-epistemic-digression (as reflecting holographically$<$ conjugatively-and-transfusively $>$ the relative unreflexivity/relative reflexivity ontological-contiguity of-the-human-institutionalisationprocess beyond any identitive conception as Western or non-Western or even differentiation internal to any such Western conception or nonWestern conception), thus overlooking the dynamic underlying human constructive and cultural diffusionary process critically leading to various social-setups dynamics of relative-ontological-completeness ${ }^{87}$ renewing of human ${ }^{5}$ meaningfulness-and-teleology '); $\mid$ human limited- 
mentation-capacity-deepening -as-subjecting limitedness/humansubpotency to 'educed unlimitedness/existence sublimating nascence' thus implies that ultimately the actual knowledge attitude is that of the creative generation, elucidation and intolerance $<$ of disparateness $>$ texactifying_precisioning-of-sublimation-<as-topostconverging-narrowing-down apriorising/axiomatising/referencingentailing-theoretical,-conceptual-and-operant-implications $>$ of human sublimating meaningfulness-and-teleology and so as to the requisite originariness-parrhesia,-as-spontaneity-of-aestheticisationsupererogatory acuity/perspicacity/astuteness/edginess/incisiveness-ofapriorising/axiomatising/referencing/intelligibilitysettingup/measuringins trumenting -for-conceptualisation within the artistic framing, philosophical framing or scientific/ontological framing as to their respective prospective postconverging aporeticismovercoming/unovercoming need for aestheticisation (generativity potential) and/or aestheticisation-towards-ontology (ontologicalperformance ${ }^{72}-<$ including-virtue-asontology>/morality/ethics/justice/etc. potential), and so as we can appreciate that even the artistic as to aestheticisation is much more than just mere patterning but a 'projection of aestheticising depth' that speaks of its specific generative, elucidative and intolerance $<\theta f$ disparateness $>$ /exactifying_precisioning-of-sublimation-<as-topostconverging-narrowing-down apriorising/axiomatising/referencingentailing-theoretical,-conceptual-and-operant-implications $>$ aspects as to specific human perception of artistic sublimation; $\uparrow$ and in this regards 
human limited-mentation-capacity-deepening-as-subjecting limitedness/human-subpotency to 'educed unlimitedness/existencesublimating nascence' needs to factor in that much of the institutional confusion associated with the artistic, philosophical and scientific speaks more of presencing-absolutising-identitive-constitutedness $<$ preconverging 'motif-and-apriorising/axiomatising/referencing'entailing>-existentialising - enframing/imprintedness-\{as-to- historicitytracing-in-presencing-hyperrealisation/hyperreal-transposition) conscious and unconscious institutional politics of self-preservation whether from 'institutionalised philosophy' or 'institutionalised science' as to the overall politicisation of knowledge given that human limitedmentation-capacity-as-subjecting 'educed unlimitedness/existencesublimating nascence' to limitedness/human subpotency warrants human institutional specialisations as subdividing the overall human knowledge aestheticisation-and-aestheticisation-towards-ontology$<$ elicited-idiomatisation $>$ (while factoring that existence-as-theabsolute-a-priori-of-conceptualisation $\sim$ and $\sim$ existence-as-sublimatingwithdrawal/unenframing/re-ontologising,-elicited-from-prospectiveprofound-supererogation $-<$ as-to-perspective-ontologicalnormalcy/postconvergence-implied- 'prospective-aporeticismovercoming/unovercoming'> is not of prospective apriorising/axiomatising/referencing-sublimating-reflexivitybeholdening to any such human-subpotency institutionalising) implying that scientific achievements are de facto philosophical achievements as inherent to the practice of science is 
notionally/epistemically/bindingnessly-<as-to-determinism/eonceptivity-of-relative-

mnreffexivity/relative-reflexivity> 'implicited philosophy' whether the scientist is

explicitly conscious or not of this such that faced with scientific dilemma some of the most novel philosophies are implicitedly articulated in scientific works in need for their philosophical explicitation (as herein explicated as to the fact that nascent-particular/incipient-andmaterial/technical-sublimations-<blinded-to-their-relative-ontologicalcompleteness - reference-of-thought- devolving > actually point to an overall ${ }^{83}$ reference-of-thought/grandest-axiomatic-construct-as-toreferencing/registering/decisioning sublimation as for instance with Newtonian physics pointing to an overall positivism/rational-empiricism reference-of-thought/grandest-axiomatic-construct-as-toreferencing/registering/decisioning), and likewise the scientific methods/methodologies/approaches were developed by philosophers involved in natural philosophy knowledge-reification gesturing-andaccounting-of-epistemic-phenomenalism-<inprospective psychologismic apriorising/axiomatising/referencing-\{of'prospectively implicited_attendant-ontological-contiguity ' reducedexistentialising/contextualising/textualising_intelligibility/epistemicity/re flexivity-contiguity-<imbued-notional cogency> ' \} - conflatedness in \{preconverging ment by\} postconverging entailment $>$ firstly as thought experiments and thereafter articulating effective practical methodologies not because they gave up on natural philosophy but because their normal living experience cognition they used was no longer sufficient for a more profound and creative insight into abstruse 
phenomenality and so they expanded upon their normal living experience cognition associated with thought experiments to intolerance< <of disparateness $>$ texactifying_precisioning-of-sublimation-<as-topostconverging-narrowing-down apriorising/axiomatising/referencingentailing-theoretical,-conceptual-and-operant-implications $>$ framework of controlled experiences involving control methods' as extension of their normal living experience cognition into the existentially$<$ disontologising/re ontologising aporeticism $>$ atypical manifestation of natural phenomena and this is the very true meaning of scientific approaches and methods as not breaking away from philosophising but rather extension of philosophising into methodologically framed and controlled experiences known as experiments (with the naïve perspectiveless/soulless adoption of methods/methodologies/approaches in many a domain-of-study today by the mere token that this is the practice in the natural sciences losing sight of the underlying and relevant philosophising of such methods/methodologies/approaches as to profound and creative supererogatory acuity/perspicacity/astuteness/edginess/incisiveness-ofapriorising/axiomatising/referencing/intelligibilitysettingup/measuringins trumenting -for-conceptualisation required for the relevant domain-ofstudy as to reflecting its given epistemic-conception phenomenal/manifest $\sim$ subpotency-\{in-transitive-conflatedness reflexivity,-in-the-full-potency-of-existence's sublimating-nascence) pertinence to which any such scientific methods/methodologies/approaches are rather subjected); $\uparrow$ human 
limited-mentation-capacity-deepening - as subjecting limitedness/humansubpotency to 'educed unlimitedness/existence sublimating nascence' as reflecting both overall knowledge-reification gesturing-andaccounting-of-epistemic-phenomenalism-<inprospective psychologismic $\sim$ apriorising/axiomatising/referencing-\{of'prospectively implicited_attendant-ontological-contiguity ' reducedexistentialising/contextualising/textualising_intelligibility/epistemicity/re flexivity-contiguity-<imbued-notional $\sim$ cogency $>$ ' \}-conflatedness in \{preconverging ment by\} postconverging entailment> orientation associated with the overall philosophical and intolerance $<$ of disparateness $>$ texactifying_precisioning-of-sublimation- $<$ as-topostconverging-narrowing-down apriorising/axiomatising/referencingentailing-theoretical,-conceptual-and-operant-implications $>$ orientation associated with science rather fundamentally speaks to the pre-eminence of their aetiologisation/ontological-escalation-<ontologicalveridicality_commitment/otherliness_transcending/compulsionsencumbered_transcending $>$ purpose so-reflected in the succession of 'relative-ontological-completeness ${ }^{87}$ apriorising/axiomatising/referencing-psychologism enculturated/constructed social-pragmatics-framing-of-predicativeeffectivity-sublimation-\{as-to-underlying,-ontological-commitment <implied-self-assuredness-of-ontological-goodfaith/authenticity postconverging-dementating/structuring/paradigming -as-being-as-of-existentialreality $>$ J' as narrowing-down selectivity of the intemporal-disposition as 
of ontological-pertinence for prospectively secondnatured institutionalisation (as from recurrent-utter-uninstitutionalisation, baseinstitutionalisation-ununiversalisation, ${ }^{103}$ universalisation-nonpositivism/medievalism, our positivism/rational-empiricism manifestation of procrypticism-or-disjointedness-as-of- reference-of-thought and prospectively deprocrypticism-or-preempting-disjointedness-as-of${ }^{3}$ reference-of-thought) and is thus primarily concerned about human reontologising prospective Being-development/ontological-frameworkexpansion-as-to-depth-of-ontologising-development-as-infrastructure-ofmeaningfulness-and-teleology psychologismic epistemic acutisation difficulty< <or, residualising \{decompulsing delinearity for eogency $>$ magnitude $\left\{\begin{array}{l}\text { (of-experientiality/experiment }\} \\ \text { and thereof the derived }\end{array}\right.$ prospective institutional-development-as-to-social-function-development and living-development-as-to-personality-development psychologismic epistemic acutisation difficuly<<for, residualising \{decompulsing\} delinearity for cogency $>$ magnitudes $\left.{ }^{\{o f-e x p e r i e n t i a l i t y / e x p e r i m e n t}\right\}$, sospeaking to a dispensing-with-immediacy-for-relative-ontologicalcompleteness -by-reification/contemplative-distension epistemic attitude, such that the philosophical nor the scientific cannot be construed as a self-serving conception (as can be so-construed in modern-day psychology individual augmentation/enhancement notion in preconverging-existential-extrication-as-of-existential-unthought) but rather a 'self-development conception preconverging/postconverging-dementatively/structurally/paradigmatically construed in association with the development of a better world as to the selfless notional asceticism 
implied' (with a confusion as of individual augmentation/enhancement rather arising from a misconstrual of the Socratic-philosophers and their successors like stoics and cynics emphasis on self-development as to the fact that their universalising-idealisation as to their given epoch implied a more fated/precarious/perilous/uncertain world with their notion of self-development implying forming individuals that can face such a world as of appropriate 'sovereign human existential$<$ disontologising/re ontologising aporeticism $>$ valour' in view to a constructive projection of a better world), and such is the general basis for interpreting philosophical thought as to its specific epochal postconverging aporeticism overcoming/unovercoming associated with the corresponding human limited-mentation-capacity-as-subjecting 'educed unlimitedness/existence sublimating nascence' tolimitedness/human-subpotency and the prospective projective-insights from all such specific postconverging aporeticism overcoming/unovercoming concerning their retrospective and prospective implications and is in-many-ways no different from a cumulative/recomposuring understanding as to scientific postconverging aporeticism-overcoming/unovercoming reflection of human ${ }^{4}$ historiality/ontological-eventfulness 38 ontological-aesthetictracing-<perspective-ontological-normalcy/postconvergence-reflected'epistemicity-relativism-determinism'> while avoiding an epistemicallyflawed complex of presencing-absolutising-identitiveconstitutedness $;$ along the same lines human limited-mentationcapacity-deepening - as subjecting limitedness/human-subpotency to- 
'educed unlimitedness/existence sublimating nascence' as reflecting

both overall knowledge-reification $\sim$ gesturing-and-accounting-of-

epistemic-phenomenalism- $<$ in-

prospective psychologismic apriorising/axiomatising/referencing-\{of-

'prospectively_implicited_attendant-ontological-contiguity ' reduced-

existentialising/contextualising/textualising_intelligibility/epistemicity/re

flexivity-contiguity-<imbued-notional $\sim$ cogency >' $\}$-conflatedness

in \{preconverging ment by\} postconverging entailment $>$ orientation

further implies that there can't be any tradition/practice of knowledge

that overrides existence-as-sublimating-withdrawal/unenframing/re-

ontologising,-elicited-from-prospective-profound-supererogation as it

can be often naively implied in many a blurry and pedantic domain-of-

study subject to totalisingly-ing — discretion/whim-of-thought with any

such orientations claiming to ignore ontological-veracity rather speaking

of institutional bankruptcy as to the fact that 'human-subpotency cannot

subject knowledge but is rather subject to knowledge' such that issues of

human ineptness/incapacity arising from disparateness-of-

conceptualisation-<unforegrounding-ment,-failing-prospectively-to-

reflect- immanent relative unreflexivity/relative reflexivity -ontological-

contiguity '> 'cannot be artificially transformed and construed as

preconverging/postconverging-de-mentative/structural/paradigmatic

issues of inherent knowledge as of the inherent nature of science or

inherent nature of the philosophical knowledge' (failing to attend to

prospective existential-<isontologising/re ontologising aporeticism>

postconverging aporeticism-overcoming/unovercoming while 'naively 
construing of the framework of human agreeability and agreeing as knowledge' rather than the 'construal of ontological-veracity as of the impersonal manifestation of the sublime as to existence-as-sublimatingwithdrawal/unenframing/re-ontologising,-elicited-from-prospectiveprofound-supererogation as the more fundamental purpose of the intellectual enterprise', and so as to the reality of the fact that true knowledge has ever always been about superseding human limitedmentation-capacity-as subjecting 'educed unlimitednesstexistencesublimating nascence' to limitedness/human subpotency and not defining it as a point-of-reference however disagreeable the exercise), and in-many-ways this drawback is reflected in the modern practice of philosophical interpretations in the humanities as to a relic/artifactual orientation and academic practice of prior_knowledgereification $\sim$ gesturing-and-accounting-of-epistemic-phenomenalism$<$ in-prior_psychologismic apriorising/axiomatising/referencing-\{of'prior-implicited_attendant-ontological-contiguity ' reduced-

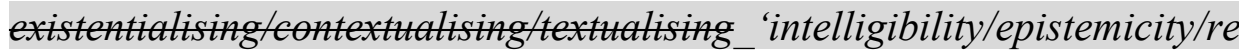
flexivity-contiguity-<imbued-notional $\sim$ cogency $>$ ' \}-constitutedness in preconverging entailment $>$ that equates/level-down everything across space and time as to wrongly imply everything is of the same notionalcontiguity/epistemic-contiguity $-<$ profound-supererogation -ofmentally-aestheticised postconverging/dialectical-thinking -qualiaschema $>$ (as of undisambiguated ene reflexivity -ontological-contiguity as to relative-ontologicalincompleteness -of-apriorising/axiomatising/referencing and relative- 
ontological-completeness -of-apriorising/axiomatising/referencing thus inducing 'apriorising/axiomatising/referencing-

equating/leveling/ressentiment/closed-construct-of- ${ }^{5}$ meaningfulnessand-teleology moronisation-<sublimating-nascence,-extricatory desublimating-downstreaming/'avalage'>') with regards to the proliferation of isms-conceptualisations without any 'relativeontological-completeness < emplitudingfformative>entailment-as-tototalising-contiguous/coherent-factuality-of-variability reflecting historiality/ontological-eventfulness 38 ontological-aesthetic-tracing$<$ perspective-ontological-normalcy/postconvergence-reflected'epistemicity-relativism-determinism'>' as well as mere conceptualpatterning-_as-devoid-of-'prospectively-implicited_attendantontological-contiguity ' reducedexistentialising/contextualising/textualising_intelligibility/epistemicity/re flexivity-contiguity-<imbued-notional $\sim$ cogency $>$ ' 's-reifying-orelucidating-of-'prospective-relative-ontological-completeness ';-sorather-enabled-<by-a- nonpresencing-divulging-of-momentoushistoriality/ontological-eventfulness /ontological-aesthetic-tracing<perspective-ontological-normalcy/postconvergence-reflected'epistemicity-relativism-determinism'> / with no contiguous knowledgereification $\sim$ gesturing-and-accounting-of-epistemic-phenomenalism$<$ in-prospective psychologismic $\sim$ apriorising/axiomatising/referencing\{of-'prospectively implicited_attendant-ontologicalcontiguity ' 'educedexistentialising/contextualising/textualising_intelligibility/epistemicity/re 
flexivity-contiguity-<imbued-notional cogency> ' ', conflatedness

in \{preconverging ment by\} postconverging entailment> (as to when for instance such notions as humanism and antihumanism, enlightenment and counter-enlightenment, etc. seem to imply that the latter conceptualisations are against humanity or enlightenment rather than being more profound conceptions of humanity and enlightenment over the former as shallow conceptions thus inducing blurriness$<$ sterilising/anecdotalising/trivialising-of-prospective-reontologising_by-preconverging,-in-disontologising-formulaic-draggingout/hollowing-out $>$ of thought) and in a further twisted relic/artifactual approach the very notion of postmodernism as of "postmodern-thought elucidation of ontologically-flawed desublimating historicity-tracingin-presencing-hyperrealisation/hyperreal-transposition' is paradoxically construed as postmodern condition as of the modern's take prospectively uninstitutionalised-threshold of procrypticism or disjointedness-as-of${ }^{3}$ reference-of-thought (as to an academically induced confusion equating postmodern-thought with the analytical criticism of modern society's metanarratives so-articulated by postmodern-thought more like paradoxically qualifying budding-positivists critiquing of the nonpositivising medieval-world/medievalism as the medieval condition) with all this contradictory pedantising/muddling/formulaic-hollowing-out-insubontologisation/subpotentiation-_blurring/undermining-of-prospectivetotalising-entailing,-as-to-entailing-<amplituding fformativeepistemicity>totalising in-relative-ontological-completeness / arising because of the precedence of institutional self-preservation over 
existence-as-sublimating-withdrawal/unenframing/re-ontologising,elicited-from-prospective-profound-supererogation as we can easily appreciate that the lack of blurriness-

$<$ sterilising/anecdotalising/trivialising-of-prospective-re-

ontologising_by-preconverging,-in-disontologising-formulaic-dragging-

out/hollowing-out $>$ in many a natural science as to an untenable

constraining of social ${ }^{103}$ universal-transparency -\{transparency-of-

totalising-entailing,-as-to-entailing-<amplituding/formative-

epistemicity>totalising in-relative-ontological-completeness । will avert

any such relic/artifactual approach to knowledge (say for instance

construing modern genetics as a deeper conception of hereditary as antihereditary or say quantum physics as a deeper conception of physics as anti-physics along the lines of equating/leveling-down everything across space and time as of naive absolutising conceptual-patterning-las-

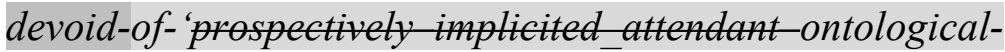
contiguity ' educedexistentialising/contextualising/textualising_intelligibility/epistemicity/re flexivity-contiguity-<imbued-notional $\sim$ cogency $>$ ' 's-reifying-orelucidating-of-'prospective-relative-ontological-completeness ';-sorather-enabled-<by-a- nonpresencing-divulging-of-momentoushistoriality/ontological-eventfulness /ontological-aesthetic-tracing$<$ perspective-ontological-normalcy/postconvergence-reflected'epistemicity-relativism-determinism'>/ and isms-conceptualisations because of institutional-prescience/imprimaturing-dullness of the spirit/psychologismic epistemic acutisation nonresidualising imbued- 
\{compulsing linearity in eclecticism-of prior mere

formulaicity/ritualisation> blurriness-

$<$ sterilising/anecdotalising/trivialising-of-prospective-re-

ontologising_by-preconverging,-in-disontologising-formulaic-dragging-

out/hollowing-out>) over relative-ontological-completeness conception

as of existence-as-sublimating-withdrawal/unenframing/re-

ontologising,-elicited-from-prospective-profound-supererogation ), thus speaking of the requisite underlying ontological-good-faith/authenticity and ontological-bad-faith/inauthenticity insight (manifested beyond-theconsciousnessawareness-teleology $\quad<$ of-preconverging-existentialextrication-as-of-existential-unthought>) when of prior_knowledgereification $\sim$ gesturing-and-accounting-of-epistemic-phenomenalism<in-prior_psychologismic apriorising/axiomatising/referencing-\{of'prior-implicited_attendant-ontological-contiguity ' educedexistentialising/contextualising/textualising_intelligibility/epistemicity/re flexivity-contiguity-<imbued-notional $\left.\sim \operatorname{cogency}>{ }^{\prime},\right\}$-constitutedness in preconverging entailment $>$ in domains-of-study subject to blurriness$<$ sterilising/anecdotalising/trivialising-of-prospective-reontologising_by-preconverging,-in-disontologising-formulaic-draggingout/hollowing-out>, and critically human knowledgereification $\sim$ gesturing-and-accounting-of-epistemic-phenomenalism<in-prospective psychologismic apriorising/axiomatising/referencing\{of- prospectively implicited_atendant-ontologicalcontiguity ' educedexistentialising/contextualising/textualising_intelligibility/epistemicity/re 
flexivity-contiguity-<imbued-notional cogency> ' \} - conflatedness

in \{preconverging ment by\} postconverging entailment $>$ as to organicknowledge is inherently of existential-<disontologising/re-ontologisingaporeticism $>$ implications (as to the-very-same-immanent-

existence/intrinsic-reality/ontological-veridicality,-as-to-

'human< amplitudingfformative-epistemicity>totalising purview-ofconstrual to which the sublimating relative-ontological-completeness has to be epistemically affirmed while the desublimating relativeontological-incompleteness ${ }^{8}$ has to be epistemically unaffirmed and so with regards to the constraining implications as to existence-assublimating-withdrawal/unenframing/re-ontologising,-elicited-fromprospective-profound-supererogation with no naïve notion of neutrality or impression-driven/good-naturedness/wishfulness that wrongly leads to equating/leveling-down everything across space and time as of naive absolutising conceptual-patterning-las-devoid-of- prospectively implicited_attendant-ontological-contiguity ' reducedexistentialising/contextualising/textualising_intelligibility/epistemicity/re flexivity-contiguity-<imbued-notional cogency>' 's-reifying-orelucidating-of-'prospective-relative-ontological-completeness ';-sorather-enabled-<by-a- nonpresencing-divulging-of-momentoushistoriality/ontological-eventfulness /ontological-aesthetic-tracing$<$ perspective-ontological-normalcy/postconvergence-reflected'epistemicity-relativism-determinism'> / and isms-conceptualisations) such that part-and-parcel of knowledge is to identify and qualify improbable, obscure and shady misanalyses passing for true knowledge 
(just as the Socratic-philosophers as to their universalisingidealisation and budding-positivists understood respectively with regards to mere-sophistry and mere-scholasticism) with such blurriness-

$<$ sterilising/anecdotalising/trivialising-of-prospective-re-

ontologising_by-preconverging,-in-disontologising-formulaic-dragging-

out/hollowing-out> failing to grasp 'relative-ontological-

incompleteness /relative-ontological-completeness

(sublimating referencing/registering/decisioning,-as-self-becoming/self-

conflatedness /formative-supererogating-<projective/reprojective-

aestheticising-re-motif-and-re-apriorising/re-axiomatising/re-

referencing,-in-perspective-ontological-normalcy/postconvergence $>\mid$ as

to human-and-social-expectations/anticipations-metaphoricity -as-

preconverging/postconverging-rede-

mentating/restructuring/reparadigming-psychologism and

equating/leveling-down everything across space and time as of naive

absolutising conceptual-patterning-〈as-devoid-of-'prospectively

implicited_attendant-ontological-contiguity ' reduced-

existentialising/contextualising/textualising_intelligibility/epistemicity/re

flexivity-contiguity-<imbued-notional cogency> ' 's-reifying-or-

elucidating-of-'prospective-relative-ontological-completeness ';-so-

rather-enabled-<by-a- nonpresencing-divulging-of-momentous-

historiality/ontological-eventfulness /ontological-aesthetic-tracing-

$<$ perspective-ontological-normalcy/postconvergence-reflected-

'epistemicity-relativism-determinism'>/ and isms-conceptualisations

providing the ubiquitous framework for a poorly accounted for media- 
driven pop-intellectualism subject to marionetting subterfuges of dominance/vested-interest actors as to a circular interest holding down the profound emancipative potential of the humanities and social sciences as of their inherent sublimating nature (and likewise it is critical to grasp that human sublimation as induced from nascent-particular/incipientand-material/technical-sublimations-<blinded-to-their-relativeontological-completeness - reference-of-thought- devolving> equally requires corresponding institutional sublimation that doesn't just assume a relative-ontological-incompleteness - presublimation-constructof meaningfulness-and-teleology value-construct and shallowsupererogating methodologising/mutualising/organising/institutionalising <preconverging 'motif-and-apriorising/axiomatising/referencing'entailing>-existentialising_enframing/imprintedness-〈as-to- historicitytracing-in-presencing-hyperrealisation/hyperreal-transposition/as we can appreciate for instance that such modern developments like nuclear science, general technical progress and even the Internet today require corresponding human referencing/registering/decisioning social and institutional sublimation that cannot simply be assumed by 'default of institutional status/pre-eminence' without profound questioning and reflection for corresponding prospective sublimation as to nonpresencing-<perspective-ontological-normalcy/postconvergence $>$ epistemic-projection); $\uparrow$ and in this regards as to human limitedmentation-capacity-deepening - as subjecting limitedness/humansubpotency to 'educed unlimitedness/existence sublimating nascence' as being ever always about the-very-same-immanent-existence/intrinsic- 
reality/ontological-veridicality,-as-to- 'human<amplituding/formativeepistemicity>totalising purview-of-construal (de-

mentating/structuring/paradigming the veracity of knowledge necessarily as being in relative unreflexivity/relative reflexivity ontologicalcontiguity ), knowledge-reification gesturing-and-accounting-ofepistemic-phenomenalism- $<$ in-

prospective psychologismic $\sim$ apriorising/axiomatising/referencing-\{of'prospectively_implicited_attendant-ontological-contiguity ' reducedexistentialising/contextualising/textualising_intelligibility/epistemicity/re flexivity-contiguity-<imbued-notional $\sim$ cogency $>$ ' \}-conflatedness in \{preconverging ment by\} postconverging entailment $>$ construed as of interpretation of say a given historical figure's theory/philosophy/thought is ever always 'priorly about the interpreter's relative-ontologicalcompleteness ${ }^{8}$ constructive construal as to the starting reference which is the-very-same-immanent-existence/intrinsic-reality/ontologicalveridicality,-as-to- 'human< emplituding/formativeepistemicity>totalising purview-of-construal' such that in reality the 'ontological-veracity of interpretation is never truly about a relic/artifactual notion of interpretation of any given historical figure's theory/philosophy/thought without involving any relative-ontologicalcompleteness conception as to the-very-same-immanentexistence/intrinsic-reality/ontological-veridicality,-as-to'human< $<$ formative-epistemicity>totalising $\sim$ purview-ofconstrual' but rather any such a given historical figure articulate their theory/philosophy/thought as of the projected ontological-veracity they 
make of the-very-same-immanent-existence/intrinsic-reality/ontologicalveridicality,-as-to- 'human<amplituding/formativeepistemicity>totalising purview-of-construal, with existence being exactly the 'starting/instigative concern (as to relative-ontologicalcompleteness construal) of the interpreter' and thereof deriving the historiality/ontological-eventfulness 38 /ontological-aesthetic-tracing$<$ perspective-ontological-normalcy/postconvergence-reflected'epistemicity-relativism-determinism'> implications (as to aestheticisation and aestheticisation-towards-ontology) with respect to the given historical figure's theory/philosophy/thought as to relativeontological-completeness ontological-veracity (and we can appreciate in this regards for instance that as to the-very-same-immanentexistence/intrinsic-reality/ontological-veridicality,-as-to'human<amplituding/formative-epistemicity>totalising $\sim$ purview-ofconstrual there was no better interpretation of say the prior foregoing physics as to when say Einsteinian physics was introduced as rather providing the more profound epistemic-projection perspective for appreciating the historiality/ontological-eventfulness 38 ontologicalaesthetic-tracing-<perspective-ontological-normalcy/postconvergencereflected- 'epistemicity-relativism-determinism'> implications of such prior foregoing physics like Newtonian mechanics and other subsequent prior physics conceptions like Lorentz transformation, Maxwell's equations, etc. without adopting any relic/artifactual notion of their interpretation as to equate/level-down everything across space and time as to an improbable poor sense of relative-ontological-completeness 
underlying/organising their comprehensive conceptualisation), and this insight is very much implicited in the Derridean and Foucauldian conceptions of interpretation as to the implicited grasp of projectiveinsights in deconstruction and archaeology/genealogy knowledgereification gesturing-and-accounting-of-epistemic-phenomenalism<in-prospective psychologismic $\sim$ apriorising/axiomatising/referencing\{of-'prospectively implicited_attendant-ontologicalcontiguity ' reducedexistentialising/contextualising/textualising_intelligibility/epistemicity/re flexivity-contiguity-<imbued-notional $\sim$ cogency $>$ ' \}-conflatedness in \{preconverging ment by\} postconverging entailment $>$ respectively which by their underlying/organising implicited 'projectiveinsights'/'epistemic-projection-in-conflatedness ${ }^{\text {/3' of }}$ apriorising/axiomatising/referencing as to human limited-mentationcapacity-deepening - as subjecting limitedness/human subpotency to'educed-unlimitedness/existence-sublimating nascence' as of the-verysame-immanent-existence/intrinsic-reality/ontological-veridicality,-as-to'human< amplituding/formative-epistemicity>totalising purview-ofconstrual, as so-explicited herein, stand-out particularly as to their reoriginary_as-unenframed/re-ontologising/unb_heholdening/outlierconceptualis_ation__(imbued-postconverging/dialectical-thinking 'projective-insights'/'epistemic-projection-in-conflatedness '-ofnotional deprocrypticism-prospective-sublimation) of the-very-sameimmanent-existence/intrinsic-reality/ontological-veridicality,-as-to'human< amplituding/formative-epistemicity>totalising $\sim$ purview-of- 
construal and thus preconverging/postconverging-dementatively/structurally/paradigmatically effectively enabling the construal of sublimating ${ }^{4}$ historiality/ontologicaleventfulness 38 /ontological-aesthetic-tracing-<perspective-ontologicalnormalcy/postconvergence-reflected-'epistemicity-relativismdeterminism'> implications of relative-ontological-completeness just as it is so-implicited in the natural sciences (unlike many a presencingabsolutising-identitive-constitutedness ${ }^{14}$ prior_knowledgereification gesturing-and-accounting-of-epistemic-phenomenalism$<$ in-prior psychologismic apriorising/axiomatising/referencing-\{of'prior-implicited_attendant-ontological-contiguity ' educedexistentialising/contextualising/textualising_intelligibility/epistemicity/re flexivity-contiguity-<imbued-notional $\sim \operatorname{cogency}>$ ' \}-constitutedness in preconverging entailment $>$ posturing which are preconverging/postconverging-dementatively/structurally/paradigmatically bogged down in desublimating historicity-tracing-in-presencing-hyperrealisation/hyperrealtransposition as to their relic/artifactual postures equating/leveling-down everything across space and time as of naive absolutising conceptualpatterning-_as-devoid-of- 'prospectively_implicited_attendant ontological-contiguity ' reduced-

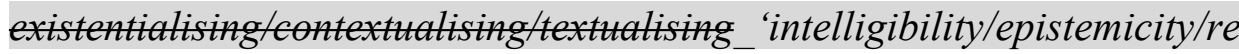
flexivity-contiguity-<imbued-notional $\sim$ cogency $>$ ' 's-reifying-orelucidating-of-'prospective-relative-ontological-completeness ' '-sorather-enabled-<by-a- nonpresencing-divulging-of-momentous- 
historiality/ontological-eventfulness /ontological-aesthetic-tracing-

$<$ perspective-ontological-normalcy/postconvergence-reflected-

'epistemicity-relativism-determinism'>> and isms-conceptualisations

with a poor sense of the projective-insights/epistemic-projection-in-

conflatedness of apriorising/axiomatising/referencing as of

underlying/organising 'relative-ontological-incompleteness/relative-

ontological-completeness

(sublimating referencing/registering/decisioning,-as-self-becoming/self-

conflatedness /formative-supererogating-<projective/reprojective-

aestheticising-re-motif-and-re-apriorising/re-axiomatising/re-

referencing,-in-perspective-ontological-normalcy/postconvergence $>>$ as

to human-and-social-expectations/anticipations-metaphoricity -as-

preconverging/postconverging-rede-

mentating/restructuring/reparadigming-psychologism " and it is herein

critically contended so-associated with 'desublimating blurriness-

$<$ sterilising/anecdotalising/trivialising-of-prospective-re-

ontologising_by-preconverging,-in-disontologising-formulaic-dragging-

out/hollowing-out $>$ from an academicism linchpinning practice of

absolute beholdening to historical figures/schools as if bigger-

than/superseding the-very-same-immanent-existence/intrinsic-

reality/ontological-veridicality,-as-to- 'human< amplituding/formative-

epistemicity>totalising purview-of-construal' that doesn't serve

prospective existential-<disontologising/re ontologising aporeticism>

knowledge-reification gesturing-and-accounting-of-epistemic-

phenomenalism-<in- 
prospective psychologismic $\sim$ apriorising/axiomatising/referencing-\{of'prospectively implicited_attendant-ontological-contiguity ' reducedexistentialising/contextualising/textualising_intelligibility/epistemicity/re flexivity-contiguity-<imbued-notional $\sim$ cogency> ' \}-conflatedness in \{preconverging ment by\} postconverging entailment $>$ but rather sterile/anecdotal institutional-prescience/imprimaturing- $<$ dullness-ofthe spirit/psychologismic epistemic acutisation nonresidualising imbued tempulsing linearity in eclecticism of prior mere formulaicity/ritualisation $\geq$ wherein re-originary insights arising from new thinking is 'inferentially-and-selectively reappropriated' as supposedly enlightened reinterpretation of the given historical figures/schools and 'so-deducible as inferentially-and-selectively reappropriated' by 'such awkwardness-of-thought associated with lack of prospective existentialising/contextualising/textualising sublimation implications as to conceptivity/epistemic-reflexivity/epistemicityrelativism-determinism-<reifying\{as-to-knowledge-developing\}-andempowering > imbued theoretical/conceptual/operant implications but for the empty institutional-imprimaturing blurriness-

\section{$<$ sterilising/anecdotalising/trivialising-of-prospective-re-}

ontologising_by-preconverging,-in-disontologising-formulaic-draggingout/hollowing-out>) mystification/solemnity/gravity projected' and sofundamentally defeating the fundamental dimensionality-of-sublimating < amplituding/formative $>$ supererogatory-de-mentativeness/epistemicgrowth-or-conflatedness/transvaluativerationalising/transepistemicity/anamnestic-residuality/spirit-drivenness- 
equalisation\that motivated the given historical thinker in the first place as to succeeding human generations relaying the prospective existentialising/contextualising/textualising sublimation of their thought for human progress and so as we can appreciate that the 'development of the mind' that led say Mendel or Pasteur or Einstein or Newton, etc. to develop their theories will not naively construe that their worth lies in hereditary biology or germ theory or physics, etc. remaining at the level they left it as the greatest scientist of their time but rather how this is prospectively historially enabling to the overall human scientific project continuum even if their ideas come to pass as no longer the most up-todate), with this ${ }^{4}$ historiality/ontological-eventfulness 38 /ontologicalaesthetic-tracing-<perspective-ontological-normalcy/postconvergencereflected-'epistemicity-relativism-determinism'> insight explicitly reflected and elaborated herein as to the relative unreflexivity/relative reflexivity ontological-contiguity of-the-human-institutionalisationprocess imbued ${ }^{6}$ historiality/ontological-eventfulness 38 ontologicalaesthetic-tracing-<perspective-ontological-normalcy/postconvergencereflected-'epistemicity-relativism-determinism'> projective-insights of 'relative-ontological-incompleteness /relative-ontologicalcompleteness - /sublimating $\sim$ referencing/registering/decisioning,-asself-becoming/self-conflatedness /formative-supererogating$<$ projective/reprojective-aestheticising-re-motif-and-re-apriorising/reaxiomatising/re-referencing,-in-perspective-ontologicalnormalcy/postconvergence $>$ / as to human-and-socialexpectations/anticipations - metaphoricity -as- 
preconverging/postconverging-rede-

mentating/restructuring/reparadigming-psychologism ' (so-reflected as of notional deprocrypticism or

<amplituding/formative >notional preempting — disjointedness-as-ofreference-of-thought dimensionality-of-sublimating

< amplituding/formative $>$ supererogatory-de-mentativeness/epistemicgrowth-or-conflatedness/transvaluative-

rationalising/transepistemicity/anamnestic-residuality/spirit-drivennessequalisation / profound dispensing-with-immediacy-for-relativeontological-completeness -by-reification/contemplative-distension projected apriorising/axiomatising/referencing-psychologisms) thusly striving to explain everything as of human-subpotency 'fatedness-ofsublimation-over-desublimation, to existence-potency $\sim$ sublimatingnascence,-disclosed-from-prospective-epistemic-digression (in reflecting holographically-<conjugatively-and-transfusively $>$ the relativeunreflexivity/relative-reflexivity ontological-contiguity of-the-humaninstitutionalisation-process ); 9 with human limited-mentation-capacitydeepening - as subjecting limitedness/human subpotency to 'educed unlimitedness/existence sublimating nascence' as of the-very-sameimmanent-existence/intrinsic-reality/ontological-veridicality,-as-to'human< amplitudingfformative-epistemicity>totalising purview-ofconstrual implying necessarily that the intellectual-and-moral 'sovereign human existential< <disontologising/re ontologising aporeticism> valour' in the human knowledge-reification gesturing-and-accountingof-epistemic-phenomenalism- $<$ in- 
prospective psychologismic $\sim$ apriorising/axiomatising/referencing-\{of'prospectively implicited_attendant-ontological-contiguity ' reducedexistentialising/contextualising/textualising_intelligibility/epistemicity/re flexivity-contiguity-<imbued-notional $\sim$ cogency $>$ ' \}-conflatedness in \{preconverging ment by\} postconverging entailment $>$ exercise is all about articulating its ${ }^{4}$ historiality/ontological-eventfulness 38 ontologicalaesthetic-tracing-<perspective-ontological-normalcy/postconvergencereflected-'epistemicity-relativism-determinism'> as to relativeontological-completeness ontological-veracity while collectively taking pride in the collective advancement so-arising with the very first commitment of the intellectual being a 'prior commitment to inherent knowledge above all else' including above their very own theoretical/philosophical/thought postures as so-allowing for the full human knowledge-reification gesturing-and-accounting-of-epistemicphenomenalism- $<$ inprospective psychologismic $\sim$ apriorising/axiomatising/referencing-\{of'prospectively implicited atentontonical-contiguity ' reducedexistentialising/contextualising/textualising_intelligibility/epistemicity/re flexivity-contiguity-<imbued-notional $\sim$ cogency> ' ' -conflatedness in \{preconverging ment by\} postconverging entailment> potential as it is very often a relic/artifactual attachment to institutionally hallowed postures irrespective of the implications as to existence-as-sublimatingwithdrawal/unenframing/re-ontologising,-elicited-from-prospectiveprofound-supererogation that brings about the enculturation of strategies of institutional self-preservation over prospective knowledge- 
reification gesturing-and-accounting-of-epistemic-phenomenalism<in-prospective psychologismic $\sim$ apriorising/axiomatising/referencing\{of-'prospectively_implicited_attendant-ontologicalcontiguity ' 'educedexistentialising/contextualising/textualising_intelligibility/epistemicity/re flexivity-contiguity-<imbued-notional $\sim$ cogency $>$ ' \}-conflatedness in \{preconverging ment by\} postconverging entailment>; $₫$ and in this

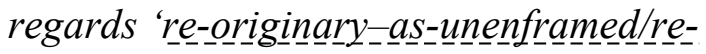

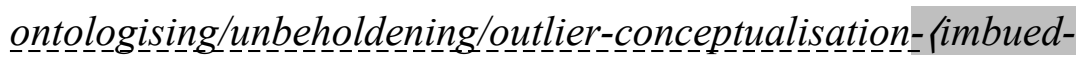
postconverging/dialectical-thinking - projective-insights'/'epistemicprojection-in-conflatedness '-of-notional deprocrypticismprospective-sublimation) 'relative-ontologicalincompleteness /relative-ontological-completeness (sublimating referencing/registering/decisioning,-as-self-becoming/selfconflatedness /formative-supererogating-<projective/reprojectiveaestheticising-re-motif-and-re-apriorising/re-axiomatising/rereferencing,-in-perspective-ontological-normalcy/postconvergence $>$ / as to human-and-social-expectations/anticipations-metaphoricity -aspreconverging/postconverging-redementating/restructuring/reparadigming-psychologism as of the-verysame-immanent-existence/intrinsic-reality/ontological-veridicality enabling the construal of sublimating historiality/ontologicaleventfulness 38 ontological-aesthetic-tracing-<perspective-ontologicalnormalcy/postconvergence-reflected-'epistemicity-relativismdeterminism'>' fundamentally reflects how prospective destructuring- 
threshold-\{uninstitutionalised-threshold /presublimating-

desublimating-decisionality $/$ of-ontological-performance ${ }^{72}<$ includingvirtue-as-ontology>/morality/ethics/justice/etc. of human meaningfulness-and-teleology are superseded by mere 'projectiveinsights'/'epistemic-projection-in-conflatedness ${ }^{13}$ as to the fact that there is no logical-basis/logic,-as-derived-from transversality-<forsublimating-existential-eventuating/denouement, from 'thinking at first/pure predisposition preemptive of prospective disontologising/subontologising' as-of-prospectively-disambiguatedaffirmed-and-unaffirmed-'motif-and-

apriorising/axiomatising/referencing' for any prospective relativeontological-completeness ${ }^{57}$ meaningfulness-and-teleology with logic rather being the inner working coherence/contiguity of any such a relative-ontological-completeness apriorising/axiomatising/referencing construct with the consequence that the prior relative-ontologicalincompleteness ${ }^{56}$ meaningfulness-and-teleology logical-basis/logic,as-derived-from $\sim$ transversality-<for-sublimating-existentialeventuating/denouement, from 'thinking at first/pure predispositionpreemptive of prospective disontologising/subontologising' as-ofprospectively-disambiguated-affirmed-and-unaffirmed-'motif-andapriorising/axiomatising/referencing' $>$ is preconverging/postconverging-dementatively/structurally/paradigmatically incompetent-and-irrelevant but for ${ }^{103}$ universal human 'projective-insights'/'epistemic-projection-inconflatedness ', capacity to-come-to-terms-with/to-respond-to 
prospective sublimating ${ }^{5}$ meaningfulness-and-teleology as to existence-as-sublimating-withdrawal/unenframing/re-ontologising,elicited-from-prospective-profound-supererogation as of human underlying ontological-commitment $-<$ implied-self-assuredness-ofontological-good-faith/authenticity postconverging-dementating/structuring/paradigming -as-being-as-of-existential-reality > that then as of psychoanalytic-unshackling/memeticreordering/institutional-recomposuring begets the prospective relativeontological-completeness ${ }^{87}$ apriorising/axiomatising/referencing construct logical-basis/logic,-as-derived-from $\sim$ transversality- $<$ forsublimating-existential-eventuating/denouement, from 'thinking at first/pure predisposition preemptive of prospective disontologising/subontologising' as-of-prospectively-disambiguatedaffirmed-and-unaffirmed- 'motif-andapriorising/axiomatising/referencing' $>$ (as there is no prior recurrentutter-uninstitutionalisation, base-institutionalisation-ununiversalisation, universalisation-non-positivism/medievalism, and positivism/rationalempiricism manifestation of procrypticism-or-disjointedness-as-ofreference-of-thought respective logical-basis/logic,-as-derivedfrom $\sim$ transversality-<for-sublimating-existentialeventuating/denouement, from 'thinking at first/pure predispositionpreemptive of prospective disontologising/subontologising' as-ofprospectively-disambiguated-affirmed-and-unaffirmed-'motif-andapriorising/axiomatising/referencing'> for prospective baseinstitutionalisation, ${ }^{103}$ universalisation, positivism and prospectively 
deprocrypticism-or-preempting-disjointedness-as-of- reference-ofthought respectively but for ${ }^{10}$ universal human 'projectiveinsights'/'epistemic-projection-in-conflatedness ${ }^{13}$ ' capacity to-come-toterms-with/to-respond-to prospective sublimating ${ }^{5}$ meaningfulness-andteleology as to existence - as-sublimating-withdrawal/unenframing/reontologising,-elicited-from-prospective-profound-supererogation as of human underlying ontological-commitment -<implied-selfassuredness-of-ontological-good-faith/authenticity postconverging-dementating/structuring/paradigming -as-being-as-of-existential-reality> in then begetting as of psychoanalytic-unshackling/memeticreordering/institutional-recomposuring their prospective relativeontological-completeness apriorising/axiomatising/referencing construct logical-bases/logics-<as-to $\sim$ transversality-<for-sublimatingexistential-eventuating/denouement, from 'thinking at first/purepredisposition preemptive of prospective disontologising/subontologising' as-of-prospectively-disambiguatedaffirmed-and-unaffirmed- 'motif-andapriorising/axiomatising/referencing'> ${ }^{\prime}$ ) so-reflected starkly in the fact that for instance as to a predisposition in an animistic social-setup to relate to the notion of plane as God-of-plane it is rather the effective veracity as to existence - as-sublimating-withdrawal/unenframing/reontologising,-elicited-from-prospective-profound-supererogation as of human underlying ontological-commitment $-<$ implied-selfassuredness-of-ontological-good-faith/authenticity postconverging-dementating/structuring/paradigming -as-being-as-of-existential-reality> 
that as to induced psychoanalytic-unshackling/memetic-

reordering/institutional-recomposuring is bound to bring about an animistic change of apriorising/axiomatising/referencing construct as mentality rather than any engagement as of prior animistic meaningfulness apriorising/axiomatising/referencing construct logicalbasis/logic,-as-derived-from $\sim$ transversality-<for-sublimating-existentialeventuating/denouement, from 'thinking at first/pure predisposition preemptive of prospective disontologising/subontologising' as-ofprospectively-disambiguated-affirmed-and-unaffirmed-'motif-andapriorising/axiomatising/referencing'> , but then any such prospective worldview reference-of-thought-and-reference-of-thought- devolving transforming meaningfulness-and-teleology is bound to elicit notional firstnaturedness-formativeness-as to-eventualising inkling drive or seeding misprising> temporal-to-intemporal-dispositions$<$ so-construed-as-from-perspective-ontologicalnormalcy/postconvergence $>$ at any such prospective destructuringthreshold-\{uninstitutionalised-threshold /presublimatingdesublimating-decisionality $/$ of-ontological-performance ${ }^{72}<$ includingvirtue-as-ontology>/morality/ethics/justice/etc. with regards to socialstake-contention-or-confliction as so-preconverging/postconverging-dementatively/structurally/paradigmatically associated with an elicited 'pedantising/muddling/formulaic-hollowing-out-insubontologisation/subpotentiation-bblurring/undermining-of-prospectivetotalising-entailing,-as-to-entailing-<amplitudingtformativeepistemicity>totalising in-relative-ontological-completeness । in 
incrementalism-in-relative-ontological-incompleteness

enframed/disontologising conceptualisation' emphasising the disjointing relative-ontological-incompleteness logical-basis/logic,-as-derivedfrom $\sim$ transversality-<for-sublimating-existentialeventuating/denouement, from 'thinking at first/pure predispositionpreemptive-of-prospective-disontologising/subontologising' as-ofprospectively-disambiguated-affirmed-and-unaffirmed-'motif-andapriorising/axiomatising/referencing' $>$ which is in want for prospective transcendence-andsublimity/sublimation/supererogatory de-mentativity as of maximalising-recomposuring-for-relative-ontological-completeness unenframed/re-ontologising conceptualisation (to enable re-ontologising prospective Being-development/ontological-framework-expansion-as-todepth-of-ontologising-development-as-infrastructure-ofmeaningfulness-and-teleology ) as with the respective emphasising of non-universalising logical-basis/logic,-as-derived-from $\sim$ transversality$<$ for-sublimating-existential-eventuating/denouement,frem thinking at first/pure predisposition preemptive of prospective disontologising/subontologising' as-of-prospectively-disambiguatedaffirmed-and-unaffirmed-'motif-andapriorising/axiomatising/referencing'> ${ }^{101}$, non-positivising/non-rationalempiricism logical-basis/logic,-as-derived-from $\sim$ transversality- $<$ forsublimating-existential-eventuating/denouement, from 'thinking at first/pure predisposition preemptive of prospective disontologising/subontologising' as-of-prospectively-disambiguated- 
affirmed-and-unaffirmed- 'motif-and-

apriorising/axiomatising/referencing'> and

disjointing/disparateness/ing logical-basis/logic,-as-derived-

from $\sim$ transversality-<for-sublimating-existential-

eventuating/denouement, from 'thinking at first/pure predisposition-

preemptive-of-prospective-disontologising/subontologising' as-of-

prospectively-disambiguated-affirmed-and-unaffirmed-'motif-and-

apriorising/axiomatising/referencing' $>$ (with regards to the

apriorising/axiomatising/referencing construct of meaningfulness-and-

teleology ) by ancient-sophists, medieval-scholastics and modern-day

pedantising/muddling/formulaic-hollowing-out-in-

subontologisation/subpotentiation-bblurring/undermining-of-prospective-

totalising-entailing,-as-to-entailing-<amplitudingfformative-

epistemicity>totalising in-relative-ontological-completeness \(to

undermine prospective universalising-idealisation, budding-positivism

and postmodern-thought respectively) and involving 'their seeding-

misprising ontological-bad-faith/inauthenticity $\sim$ preconverging-de-

mentating/structuring/paradigming that covertly and/or overtly project

respectively that afterall all the human world that exists is-of-non-

universalising-sophistry or is-of-non-positivising-scholasticism or is-of-

disjointed pedantising/muddling/formulaic-hollowing-out-in-

subontologisation/subpotentiation-bblurring/undermining-of-prospective-

totalising-entailing,-as-to-entailing-<amplituding/formative-

epistemicity>totalising in-relative-ontological-completeness \in

contempt of 'relative-ontological-incompleteness /relative-ontological- 
completeness -_sublimating referencing/registering/decisioning,-asself-becoming/self-conflatedness /formative-supererogating$<$ projective/reprojective-aestheticising-re-motif-and-re-apriorising/reaxiomatising/re-referencing,-in-perspective-ontologicalnormalcy/postconvergence $>$ / as to human-and-socialexpectations/anticipations-metaphoricity -aspreconverging/postconverging-redementating/restructuring/reparadigming-psychologism ; human limited-mentation-capacity-deepening-as-subjecting limitedness/humansubponcy to 'educed unlimitednesstexistence sublimating nascence' as of organic-knowledge more critically involves the 'requisite fundamental knowledge-reification $\sim$ gesturing-and-accounting-of-epistemicphenomenalism- $<$ inprospective_psychologismic $\sim$ apriorising/axiomatising/referencing-\{of'prospectively implicited_attendant-ontological-contiguity ' reducedexistentialising/contextualising/textualising_intelligibility/epistemicity/re flexivity-contiguity-<imbued-notional $\sim$ cogency $>$ ' \}-conflatedness in \{preconverging ment by\} postconverging entailment $>$ point-ofdeparture' as referencing/registering/decisioning nascentparticular/incipient-and-material/technical-sublimations-<blinded-totheir-relative-ontological-completeness - reference-of-thoughtdevolving $>$ by 'their very own sublimating prospective/nascent relativeontological-completeness ${ }^{83}$ reference-of-thought/grandest-axiomaticconstruct - as-to-referencing/registering/decisioning' in order to fulfil the requisite ${ }^{55}$ maximalising-recomposuring-for-relative-ontological- 
completeness —unenframed/re-ontologising conceptualisation for effective theoretical-conceptual-operant conceptualisation enabling 'sublimating supererogatory unbeholdening-conflatedness historiality/ontological-eventfulness 38 /ontological-aesthetic-tracing$<$ perspective-ontological-normalcy/postconvergence-reflected'epistemicity-relativism-determinism'>' (and so over referencing/registering/decisioning such nascent-particular/incipientand-material/technical-sublimations-<blinded-to-their-relativeontological-completeness - reference-of-thought- devolving > by the 'presublimation relative-ontological-incompleteness ${ }^{83}$ reference-ofthought/grandest-axiomatic-construct—as-toreferencing/registering/decisioning' thus rather inducing 'desublimating relic/artifactual-beholdening-constitutedness ${ }^{14}$ historicity-tracing-inpresencing-hyperrealisation/hyperreal-transposition'), and in this respect the institutionalised intellectual practice of any given registryworldview/dimension failing to reflect the 'fundamental knowledgereification $\sim$ gesturing-and-accounting-of-epistemic-phenomenalism$<$ in-prospective psychologismic $\sim$ apriorising/axiomatising/referencing\{of- prospectively_implicited_attendant-ontologicalcontiguity ' 'educedexistentialising/contextualising/textualising_intelligibility/epistemicity/re flexivity-contiguity-<imbued-notional cogency $\left.>^{\text {' }}\right\}$-conflatedness in \{preconverging ment by) postconverging entailment> point-ofdeparture of prospective/nascent relative-ontological-completeness ${ }^{3}$ reference-of-thought/grandest-axiomatic-construct - as-to- 
referencing/registering/decisioning' rather speaks to a fundamental institutional-bankruptcy wherein for instance the 'presublimating relative-ontological-incompleteness ${ }^{83}$ reference-of-thought/grandestaxiomatic-construct - as-to-referencing/registering/decisioning' respectively as of the "non-universalising knowledgereification gesturing-and-accounting-of-epistemic-phenomenalism$<$ in-prospective psychologismic $\sim$ apriorising/axiomatising/referencing\{of- prospectively implicited_attendant-ontologicalcontiguity ' 'educedexistentialising/contextualising/textualising_intelligibility/epistemicity/re flexivity-contiguity-<imbued-notional $\sim$ cogency $>$ ' \}-conflatedness in \{preconverging ment by\} postconverging entailment $>$ ' of ancientsophistry, 'non-positivising knowledge-reification gesturing-andaccounting_of-epistemic-phenomenalism-<inprospective psychologismic apriorising/axiomatising/referencing-\{of'prospectively_implicited_attendant-ontological-contiguity ' reduced-

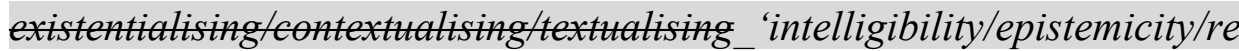
flexivity-contiguity-<imbued-notional $\sim$ cogency $>$ ' \}-conflatedness in \{preconverging ment by\} postconverging entailment>' of medievalscholasticism or 'disjointing/disparateness/ing knowledgereification gesturing-and-accounting-of-epistemic-phenomenalism$<$ in-prospective psychologismic $\sim$ apriorising/axiomatising/referencing\{of- 'prospectively implicited_atentant-ontologicalcontiguity ' reducedexistentialising/contextualising/textualising_intelligibility/epistemicity/re 
flexivity-contiguity-<imbued-notional cogency> ' \} - conflatedness

in \{preconverging ment by\} postconverging entailment>' of modern-

day pedantising/muddling/formulaic-hollowing-out-in-

subontologisation/subpotentiation-_blurring/undermining-of-prospective-

totalising-entailing,-as-to-entailing-< $<$ formative-

epistemicity>totalising in-relative-ontological-completeness J as to

their flawed fundamental knowledge-reification gesturing-and-

accounting-of-epistemic-phenomenalism-<in-

prospective psychologismic $\sim$ apriorising/axiomatising/referencing-\{of-

'prospectively ontological-contiguity ' reduced-

existentialising/contextualising/textualising_intelligibility/epistemicity/re

flexivity-contiguity-<imbued-notional $\sim$ cogency > ' \}-conflatedness

in \{preconverging ment by\} postconverging entailment $>$ point-of-

departure cannot intelligibly conceptualise the effective theoretical-

conceptual-operant implications warranting the 'prospective/nascent

relative-ontological-completeness ${ }^{83}$ reference-of-thought/grandest-

axiomatic-construct-as-to-referencing/registering/decisioning'

respectively of Socratic-philosophers "universalising-idealisation

knowledge-reification $\sim$ gesturing-and-accounting-of-epistemic-

phenomenalism-<in-

prospective_psychologismic apriorising/axiomatising/referencing-\{of-

'prospectively_implicited_attendant-ontological-contiguity ' reduced-

existentialising/contextualising/textualising_intelligibility/epistemicity/re

flexivity-contiguity-<imbued-notional $\left.\sim \operatorname{cogency}>{ }^{\prime},\right\}$-conflatedness

in \{preconverging ment by\} postconverging entailment>', budding- 
positivists 'rational-empiricism/positivism knowledge-

reification $\sim$ gesturing-and-accounting-of-epistemic-phenomenalism-

$<$ in-prospective psychologismic $\sim$ apriorising/axiomatising/referencing-

\{of-'prospectively_implicited_attendant-ontological-

contiguity ' $\sim$ educed-

existentialising/contextualising/textualising_intelligibility/epistemicity/re

flexivity-contiguity-<imbued-notional $\sim$ cogency> ' '-conflatedness

in \{preconverging ment by\} postconverging entailment>' and

prospective postmodern-thought " deprocrypticism-or-preempting-

disjointedness-as-of- reference-of-thought knowledge-

reification $\sim$ gesturing-and-accounting-of-epistemic-phenomenalism-

<in-prospective psychologismic $\sim$ apriorising/axiomatising/referencing-

\{of-'prospectively implicited_attendant-ontological-

contiguity ' 'educed-

existentialising/contextualising/textualising_intelligibility/epistemicity/re

flexivity-contiguity-<imbued-notional cogency >' \}-conflatedness

in \{preconverging ment by\} postconverging entailment>' (as reflecting

a rather more fundamental apriorising and psychoanalytic

presublimating defect warranting prospective psychoanalytic-

unshackling/memetic-reordering/institutional-recomposuring to

supersede such presencing-absolutising-identitive-constitutedness

mental-flex equating/leveling-down everything across space and time as

of naive absolutising conceptual-patterning-〈as-devoid-of-'prospectively

implicited_attendant-ontological-contiguity ' reduced-

existentialising/contextualising/textualising_intelligibility/epistemicity/re 
flexivity-contiguity-<imbued-notional $\sim \operatorname{cogency}>$ ' 's-reifying-or-

elucidating-of-'prospective-relative-ontological-completeness ' ;-so-

rather-enabled-<by-a- nonpresencing-divulging-of-momentous-

historiality/ontological-eventfulness /ontological-aesthetic-tracing-

$<$ perspective-ontological-normalcy/postconvergence-reflected-

'epistemicity-relativism-determinism'> | and isms-conceptualisations and so in lieu of grasping the projective-insights for drawing sublimating 'relative-ontological-incompleteness /relative-ontologicalcompleteness - (sublimating $\sim$ referencing/registering/decisioning,-asself-becoming/self-conflatedness /formative-supererogating-

$<$ projective/reprojective-aestheticising-re-motif-and-re-apriorising/reaxiomatising/re-referencing,-in-perspective-ontologicalnormalcy/postconvergence $>$ ) as to human-and-socialexpectations/anticipations-metaphoricity -aspreconverging/postconverging-redementating/restructuring/reparadigming-psychologism'"), and in-manyways such presublimating mental-reflex as of mere institutionalprescience/imprimaturing- $<$ dullness of the spiritpsychologismic epistemic acutisation nonresidualising imbued_fcompulsing\}linearity in eclecticism-of prior mere formulaicity/ritualisation $>$ pretense of integrating such nascent-particular/incipient-and-material/technicalsublimations-<blinded-to-their-relative-ontological-completeness reference-of-thought- devolving $>$ is not of prospective apriorising/axiomatising/referencing-sublimating-reflexivitybeholdening upon existence —as-sublimating-withdrawal/unenframing/re- 
ontologising,-elicited-from-prospective-profound-supererogation and speaks to <amplituding/formative-epistemicity>totalising $\sim$ selfreferencing-syncretising/circularity/interiorising/akrasiatic-drag that rather stifles prospective human knowledge possibilities as to their disparateness-of-conceptualisation-<unforegrounding-ment,-failingprospectively-to-reflect- 'immanent relative-unreflexivity/relativereflexivity ontological-contiguity '> (rather than foregrounding_entailment-<in-succession-of-profoundsupererogation $>$ - (postconverging-narrowing-down $\sim$ sublimation-as-to'existence - as-sublimating-withdrawal/unenframing/re-ontologising,elicited-from-prospective-profound-supererogation '-in-reflecting'immanent relative unreflexivity/relative reflexivity ontologicalcontiguity ';-as-operative-notional deprocrypticism) meaningfulness-and-teleology that projects requisite $<$ amplituding/formative $>$ disposedness/psychologismic-construct-_as-toorientation/value-construct/valuation-and-derived-parameterising/and <amplituding/formative > entailment-\{as-to-totalisingcontiguous/coherent-factuality-of-variability)); ultimately, as to the fact that human limited-mentation-capacity-deepening - as subjecting limitedness/human-subpotency to 'educed unlimitednesslexistencesublimating nascence' is all about 'genuine knowledgereification gesturing-and-accounting_of-epistemic-phenomenalism$<$ in-prospective_psychologismic $\sim$ apriorising/axiomatising/referencing\{of-'prospectively implicied_antolontol- 
contiguity ' reduced-

existentialising/contextualising/textualising_intelligibility/epistemicity/re

flexivity-contiguity-<imbued-notional $\sim$ cogency $>$ ' $\}$-conflatedness

in \{preconverging ment by\} postconverging entailment $>$ framework

involving a detour to existence-potency ${ }^{3}$ sublimating-nascence,-

disclosed-from-prospective-epistemic-digression in epistemic-

totalisingly /acutely-resubjecting the collective and individual mortals

that we are (however the emotional-involvement as succumbing to

temporal impulses is exactly what leads to relic/artifactual conceptions of

knowledge bent on institutional self-preservation rather than attending to

prospective postconvergingauporeticism-overcoming/unovercoming),

there can't be any pretense as of vague human-subpotency temporal

purposes to compromise knowledge as to the fact that only the

'affirmation as of sublimating veracity' or 'unaffirmation as of

desublimating impertinence' reflects organic-knowledge as to its

requisite

acuity/perspicacity/astuteness/edginess/incisiveness-of-

apriorising/axiomatising/referencing/intelligibilitysettingup/measuringins

trumenting -for-conceptualisation rather than any social or institutional

extrinsic-attribution decadent crafts perceived as superseding the

requisite intrinsic-attribution for genuine knowledge (even to the extent of temporal institutional or social non-recognition as the primary purpose

of knowledge, especially as it reflects prospective human destructuring-

threshold-\{uninstitutionalised-threshold /presublimating-

desublimating-decisionality $>$ of-ontological-performance $-<$ including- 
virtue-as-ontology>, is to enable the social and institutional attendanceto/dealing-with its prospective postconverging aporeticismovercoming/unovercoming as to human self-surpassing and by this token rather construing of practices of institutional or social recognition within prior institutionalised framework as dispensable/superfluous with regards to prospective knowledge imbued transcendence-andsublimity/sublimation/supererogatory-de-mentativity parrhesiastic purposes of prospective knowledge-reification gesturing-andaccounting-of-epistemic-phenomenalism-<inprospective psychologismic apriorising/axiomatising/referencing-\{of'prospectively_implicited_attendant-ontological-contiguity ' reducedexistentialising/contextualising/textualising_intelligibility/epistemicity/re flexivity-contiguity-<imbued-notional $\sim$ cogency $>$ ' \}-conflatedness in (preconverging ment by\} postconverging entailment>) and so beyond presencing-absolutising-identitive-constitutedness $<$ amplituding/formative-epistemicity >totalising self-referencingsyncretising/circularity/interiorising/akrasiatic-drag ${ }^{34}$ and blurriness$<$ sterilising/anecdotalising/trivialising-of-prospective-reontologising_by-preconverging,-in-disontologising-formulaic-draggingout/hollowing-out $>$ induced pedantic abandonment to desublimating incrementalism-in-relative-ontological-incompleteness enframed/disontologising conceptualisation (in lieu of sublimating maximalising-recomposuring-for-relative-ontological-completeness unenframed/re-ontologising conceptualisation with the so-induced universal-transparency -〈transparency-of-totalising-entailing,-as-to- 
entailing-<amplitudingfformative-epistemicity $>$ totalising $\sim$ in-relative-

ontological-completeness I part-and-parcel of the process of human crossgenerational transformation more critical and important than any punctual enframed notions of knowledge acquiescence) and with the appropriate intellectual attitude being one beyond the immediate <preconverging 'motif-and-apriorising/axiomatising/referencing'entailing >-existentialising_enframing/imprintedness-_as-to- historicitytracing-in-presencing-hyperrealisation/hyperreal-transposition/as to 'fundamentally skewing the dynamism in the play of temporal-andintemporal-dispositions of social-stake-contention-or-confliction of the social-construct towards sublimating ontological-good-

faith/authenticity $\sim$ postconverging-dementating/structuring/paradigming ${ }^{\prime}$ ' and in this regards knowledgereification gesturing-and-accounting-of-epistemic-phenomenalism$<$ in-prospective_psychologismic $\sim$ apriorising/axiomatising/referencing\{of- prospectively_implicited_attendant-ontologicalcontiguity ' educedexistentialising/contextualising/textualising_intelligibility/epistemicity/re flexivity-contiguity-<imbued-notional cogency> ' \}-conflatedness in \{preconverging ment by\} postconverging entailment $>$ can only extend as far as eliciting human ontological-commitment $-<$ impliedself-assuredness-of-ontological-good-

faith/authenticity postconverging-dementating/structuring/paradigming -as-being-as-of-existential-reality> as to existence-as-sublimating-withdrawal/unenframing/re-ontologising 
and subsequent secondnatured human institutionalisation from the universal-transparency -_transparency-of-totalising-entailing,-as-toentailing-<amplitudingfformative-epistemicity $>$ totalising $\sim$ in-relativeontological-completeness ), but knowledge-reification $\sim$ gesturing-andaccounting-of-epistemic-phenomenalism-<inprospective psychologismic $\sim$ apriorising/axiomatising/referencing-\{of'prospectively implicited_attendant-ontological-contiguity ' reducedexistentialising/contextualising/textualising_intelligibility/epistemicity/re flexivity-contiguity-<imbued-notional cogency> ' \}-conflatedness in fpreconverging ment by\} postconverging entailment> ends/shouldnot aspire to any 'convincing' of ontological-bad-

faith/inauthenticity $\sim$ preconverging-dementating/structuring/paradigming as the latter is nothing but a circular process that only ends up degrading knowledge into falsehoods as individual supererogatory-shallowness or supererogatoryprofoundness inceptively lies with the individual and not knowledge, well before sublimating knowledge can be of any relevance thereof as to derived-formulaicity projected reproducibilitymathesis/motif/thrownness-disposition,-as-reproducibility-ofaestheticisation

${ }^{54}$ logicallogical-processing-or-logical-implicitation-supposedly-apriorising-inprocessing-orconviction-as-to-profound-supererogation - $<$ construed-as-to-actlogicalexecution-or-logical-implications-of- 'notion-of-agreement-orimplicitation disagreement'> 
supposedly-

apriorising-in-

conviction-as-to-

profound-

\section{supererogation}

${ }^{55}$ maximalising- antiakrasiatic-maximalising-recomposuring-for-relative-ontological-

recomposuring- completeness $\quad$ unenframed/re-ontologising $\sim$ conceptualisation- $<$ as-to-

for-relative- $\quad{ }^{4}$ historiality/ontological-eventfulness $3 \%$ ontological-aesthetic-tracing-

ontological- <perspective-ontological-normalcy/postconvergence-reflected-

completeness ${ }^{87}$ — 'epistemicity-relativism-determinism’>,- ‘fepistemic-

unenframed/re- totalising $3 \frac{3}{3}$ hermeneutically/textully/reprojectingly/supererogatingly/zeroin

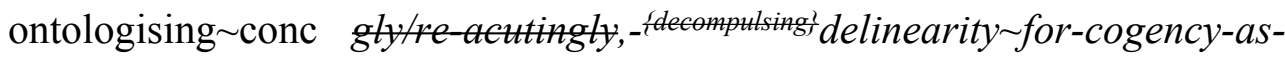

eptualisation exteriorising/deneuterising '-of-motif-and-

apriorising/axiomatising/referencing >-unenframed/re-

ontologising conceptualisation as to dimensionality-of-sublimating

< amplituding/formative >supererogatory-de-mentativeness/epistemic-

growth-or-conflatedness/transvaluative-

rationalising/transepistemicity/anamnestic-residuality/spirit-drivenness-

equalisation) so-reflected in the epistemic-projective-perspective-ofontological-normalcy/postconvergence-_unwinding-as-

unfolding/dépliage-as-détendre of elucidation-in grasping

'implicited_attendant-ontological-contiguity' ' educed-

existentialising/contextualising/textualising_intelligibility/epistemicity/re

flexivity-contiguity-<imbued-notional $\sim$ cogency $>,,-<$ reifying-or- 
elucidating-of-prospective-relative-ontological-completeness -of-

reference-of-thought- devolving-as-of-instantiative-context $>$ as to

existence-potency sublimating-nascence,-disclosed-from-prospective-

epistemic-digression - rules-of-apriorising/axiomatising/referencing-that-

further-epistemically-unconceal-the-very-ontologically-same-existential-

reality over wrongly-projected decontextualising-

unimbricatedness/unthreadedness/unrecomposuring,-as-virtuality-or-

ontologically-flawed-construal (preconverging-or-dementing

apriorising-psychologism reference-of-thought in threshold-of-

nonconviction/madeupness/bottomlining-in-shallow-supererogation -

$<$ as-to- 'attendant-intradimensional'-prospectively-

disontologising preconverging/dementing -apriorising-psychologism>

as shallowness-of-thought-or-unsophistication-of-understanding))

${ }^{56}$ meaningfulness- meaningfulness as of its inherent 'apriorising-teleological-thresholdingand-teleology as-teleological-framework/narrative-framework of contextualising/existentialising/instantiative-devolving-meaningfulness' as of apriorising/axiomatising/referencing-\{of-"prospectively implicited_attendant-ontological-contiguity ' reducedexistentialising/contextualising/textualising_intelligibility/epistemicity/re flexivity-contiguity-<imbued-notional $\sim$ cogency> ' \}-conflatedness ${ }^{13}$ in \{preconverging ment by\} postconverging entailment-with-existence,as-defining-backdrop-Being-development/ontological-frameworkexpansion-as-to-depth-of-ontologising-development-as-infrastructure-ofmeaningfulness-and-teleology -as-well-as-derived-conventioning- 
referencing-with-regards-to-institutional-development-as-to-social-

function-development-and-living-development-as-to-personality-

development-possibilities; 9 construed as <amplituding/formative-

epistemicity>totalising/circumscribing/delineating $\quad$ reference-ofthought- devolving-as-of-instantiative-context $>$ - meaningfulness-andteleology defining any given registry-worldview/dimension in reflection of the fact that there can only be one <amplituding/formativeepistemicity>totalising/circumscribing/delineating meaningfulness-andteleology as of the-very-same-immanent-existence/intrinsicreality/ontological-veridicality,-as-to- 'human<amplituding/formativeepistemicity>totalising purview-of-construal' for inducing intelligibility, such that the reification issue/problem with meaningfulness-andteleology is rather derivational as of human relative ontologicalperformance ${ }^{72}<$ including-virtue-as-

ontology>/morality/ethics/justice/etc. as of 'various relative-ontologicalcompleteness -of- reference-of-thought' in reflecting meaningfulnessand-teleology as of the-very-same-immanent-existence/intrinsicreality/ontological-veridicality,-as-to- 'human< amplituding/formativeepistemicity>totalising purview-of-construal' as from existencepotency $\sim$ sublimating-nascence,-disclosed-from-prospective-epistemicdigression epistemic-or-notional projective-perspective over humansubpotency epistemic-or-notional projective-perspective (thus inducing successive relative apriorising/axiomatising/referencing/intelligibilitysettingup/measuringins trumenting for aposteriorising/logicising/deriving/intelligising/measuring 
meaningfulness-and-teleology) as well as the given reference-ofthought- devolving temporal-to-intemporal ontological-performance 2 <including-virtue-as-ontology>/morality/ethics/justice/etc. of its <emplitudinglformative-

epistemicity>totalising/circumscribing/delineating of meaningfulnessand-teleology

metaphoricity 57

metaphoricity as evolving-and-devolving-'<amplituding/formativeepistemicity>totalising $\sim$ conception-of 'implicited_attendant-ontologicalcontiguity $\stackrel{\sim}{\sim}$ educedexistentialising/contextualising/textualising_intelligibility/epistemicity/re flexivity-contiguity-<imbued-notional cogency>' -in-elucidation-orreification', construed ultimately as of the crossgenerational superseding of any given registry-worldview/dimension <amplitudinglformativeepistemicity>totalising $\sim$ self-referencing-

syncretising/circularity/interiorising/akrasiatic-drag ${ }^{34}{ }^{56}$ meaningfulnessand-teleology' (as to 'human Being-development/ontological-frameworkexpansion-as-to-depth-of-ontologising-development-as-infrastructure-ofmeaningfulness-and-teleology , institutional-development-as-to-socialfunction-development and living-development-as-to-personalitydevelopment psychologismic epistemic acutisation difficulty<for, restulising \{decompulsing delinemagnitudes for cogency> experientiality/experiment\}'), as of prospective relative-ontological-completeness superseding/undermining/deflating of prior relative-ontologicalincompleteness, as ${ }^{5}$ meaningfulness-and-teleology infrastructure 
preconverging/postconverging-rede-

mentating/restructuring/reparadigming; $\uparrow$ implying 'differing-andincompatible 'meaningfulness-and-teleology finality' of the relativeontological-incompleteness and the relative-ontological-completeness as

of

their

respectively

implied

supererogatory acuity/perspicacity/astuteness/edginess/incisiveness-of-

apriorising/axiomatising/referencing/intelligibilitysettingup/measuringins

trumenting -for-conceptualisation

as

opened-construct-of-

meaningfulness-and-teleology and pseudo-edginess/pseudo-

incisiveness as <amplituding-formative> wooden-language-fimbued-

temporal-mere-form/virtualities/dereification/akrasiatic-

drag/denatured/preconverging-or-dementing -narratives-of-the-

reference-of-thought-categorical-imperatives/axioms/registry-

teleology \as of the implied reproducibility—mathesis/motif/thrownnessdisposition,-as-reproducibility-of-aestheticisation as reasoning-fromresults/afterthought (as to elicitable <amplitudingfformative> woodenlanguage-_imbued - averaging-of-thought-<as-to-

leveling/ressentiment/closed-construct-of- meaningfulness-and-

teleology -as-of-'nondescript/ignorable-void '-with-regards-to-

prospective-apriorising-implications $>1$ ), thus rendering 'propositional

compatibility as of mutual aposteriorising/logicising/deriving/intelligising/measuring ' improbable as both are affirmative whereas in reality the former should be affirmed and the latter should be unaffirmed thus explaining why only a 'prospective meaningfulness-and-teleology routing ontologically-hegemonising- 
narrative

reordering/institutional-recomposuring' can arise from the former over the latter to restore ontological-veracity, and this is enabled/validated only by their mutually supposedly coherent ontological-commitment $<$ implied-self-assuredness-of-ontological-good-

faith/authenticity postconverging-de-

mentating/structuring/paradigming -as-being-as-of-existential-reality> underlying any society/social-setup conventioning as so reflected by its 'self-assuredness-of-ontological-goodfaith/authenticity $\sim$ postconverging-dementating/structuring/paradigming -as-being-as-of-existential-reality with respect to its social-stake-contention-or-confliction' enabling the relative-ontological-completeness 'prospective ${ }^{56}$ meaningfulness-andteleology routing ontologically-hegemonising-narrative as to psychoanalytic-unshackling/memetic-reordering/institutional-

recomposuring (and not propositional-convincing-of-dialogicalequivalence-<as-to-

psychologismic apriorising/axiomatising/referencing-\{of- prospectively implicited_attendant-ontological-contiguity ' educedexistentialising/contextualising/textualising_intelligibility/epistemicity/re flexivity-contiguity-<imbued-notional cogency $\left.>^{\text {' }}\right\}$-conflatedness in \{preconverging ment by\} postconverging entailment,-in-selfbecoming/self-conflatedness /formative-supererogating $>$ )' over the relative-ontological-incompleteness crossgenerationally as of <amplituding/formative-epistemicity>causality $\sim$ as-to-projective- 
totalitative-implications-of-prospective- nonpresencing,-for-

explicating relative unreflexivity/relative reflexivity ontological-

contiguity sublimating implications, reflecting the fact that there is no base-institutionalisation

propositional-convincing-of-dialogical-

equivalence-<as-to-

psychologismic apriorising/axiomatising/referencing-\{of- "prospectively

implicited_attendant-ontological-contiguity ' reduced-

existentialising/contextualising/textualising_intelligibility/epistemicity/re

flexivity-contiguity-<imbued-notional $\sim$ cogency> ' \}-conflatedness -

in \{preconverging ment by\} postconverging entailment,-in-self-

becoming/self-conflatedness /formative-supererogating $>$ of recurrent-

utter-uninstitutionalisation but rather a 'prospective ${ }^{5}$ meaningfulness-

and-teleology routing ontologically-hegemonising-narrative as to psychoanalytic-unshackling/memetic-reordering/institutional-

recomposuring' arising as of their <amplitudinglformativeepistemicity >causality $\sim$ as-to-projective-totalitative-implications-of-

prospective- nonpresencing,-for-explicating relative

unreflexivity/relative reflexivity ontological-contiguity sublimating implications pointing out that base-institutionalisation is relatively as to existence-potency $\sim$ sublimating-nascence,-disclosed-from-prospectiveepistemic-digression and this notion of "prospective meaningfulness-andteleology routing ontologically-hegemonising-narrative as to psychoanalytic-unshackling/memetic-reordering/institutionalrecomposuring (and not propositional-convincing-of-dialogicalequivalence-<as-to- 
psychologismic apriorising/axiomatising/referencing-\{of-"prospectivelyimplicited_attendant-ontological-contiguity ' educedexistentialising/contextualising/textualising_intelligibility/epistemicity/re flexivity-contiguity-<imbued-notional cogency>' \}-conflatedness in \{preconverging ment by\} postconverging entailment,-in-selfbecoming/self-conflatedness /formative-supererogating $>$ )' applies likewise in 'affirming relative existence-potency $\sim$ sublimating-nascence,disclosed-from-prospective-epistemic-digression sublimatingvalidation/desublimating-invalidation implications' of universalisation over base-institutionalisation, positivism/rational-empiricism over universalisation, and prospectively notional deprocrypticism over our positivism- procrypticism, and such a state of improbable propositionalconvincing-of-dialogical-equivalence- $<$ as-to-

psychologismic apriorising/axiomatising/referencing-\{of- "prospectively implicited_attendant-ontological-contiguity ' reducedexistentialising/contextualising/textualising_intelligibility/epistemicity/re flexivity-contiguity-<imbued-notional $\sim$ cogency> ' \}-conflatedness in \{preconverging ment by\} postconverging entailment,-in-selfbecoming/self-conflatedness /formative-supererogating > arises because of prior relative-ontological-incompleteness shiftiness-of-the-Self associated with human sovereignconstructs in <amplitudingfformativeepistemicity>totalising $\sim$ self-referencing-

syncretising/circularity/interiorising/akrasiatic-drag which can naturally be overcomed by human insight of its limited-mentationcapacity -as subjecting 'educed unlimitedness/existence sublimating- 
nascence' to limitedness/human-subpotency implications and 'as requiring knowledge-construct specialisms' involving human deferentialformalisation-transference to 'perceived significant others' with respect to such specialisms 'limited-mentation-capacity-deepening-as-subjecting limitedness/human-subpotency to 'educed unlimitedness/existencesublimating nascence' resources-and-talent focussing for knowledgereification -gesturing-and-accounting-of-epistemic-phenomenalism<in-prospective psychologismic apriorising/axiomatising/referencing\{of-'prospectively implicited_attendant-ontologicalcontiguity ' 'educedexistentialising/contextualising/textualising_intelligibility/epistemicity/re flexivity-contiguity-<imbued-notional $\sim$ cogency> ' \}-conflatedness in \{preconverging ment by\} postconverging entailment>', but then sophistic/pedantic dispositions as of social-stake-contention-or-confliction in incrementalism-in-relative-ontological-incompleteness enframed/disontologising conceptualisation with regards to such issues like climate change, public policy, etc. can turn around and wrongly reaffirm the ontological-veracity of human <amplitudingfformative> wooden-language-_imbued-averaging-ofthought-<as-to-leveling/ressentiment/closed-construct-ofmeaningfulness-and-teleology -as-of-'nondescript/ignorable-void 'with-regards-to-prospective-apriorising-implications $>$ ) as of propositional-convincing-of-dialogical-equivalence- $<$ as-topsychologismic apriorising/axiomatising/referencing-\{of-'prospectively implicited_attendant-ontological-contiguity ' reduced- 
existentialising/contextualising/textualising_intelligibility/epistemicity/re

flexivity-contiguity-<imbued-notional cogency >' \}-conflatedness

in \{preconverging ment by\} postconverging entailment,-in-self-

becoming/self-conflatedness /formative-supererogating >' to undermine

such 'prospective ${ }^{5}$ meaningfulness-and-teleology routing ontologicallyhegemonising-narrative as to psychoanalytic-unshackling/memeticreordering/institutional-recomposuring' enlightenment from its dispensing-with-immediacy-for-relative-ontological-completeness -byreification/contemplative-distension specialisms even though we know that the truly specialist lawyer, chemist, etc. doesn't adopt any such propositional-convincing-of-dialogical-equivalence-<as-to-

psychologismic apriorising/axiomatising/referencing-\{of-"prospectively implicited_attendant-ontological-contiguity ' reducedexistentialising/contextualising/textualising_intelligibility/epistemicity/re flexivity-contiguity-<imbued-notional $\sim$ cogency>' \}_-conflatedness in \{preconverging ment by\} postconverging entailment,-in-selfbecoming/self-conflatedness /formative-supererogating > relation with <amplituding/formative> wooden-language-fimbued-averaging-ofthought-<as-to-leveling/ressentiment/closed-construct-ofmeaningfulness-and-teleology -as-of- 'nondescript/ignorablevoid'-withregards-to-prospective-apriorising-implications $>$ | but rather is in an enlightening/educating deferential-formalisation-transference posture of 'prospective ${ }^{5}$ meaningfulness-and-teleology routing ontologicallyhegemonising-narrative as to psychoanalytic-unshackling/memeticreordering/institutional-recomposuring', and this relation between flawed 
sophistic/pedantic social-stake-contention-or-confliction encouraging of <amplitudinglformative> wooden-language-_imbued-averaging-ofthought-<as-to-leveling/ressentiment/closed-construct-ofmeaningfulness-and-teleology -as-of-'nondescript/ignorablevoid'-withregards-to-prospective-apriorising-implications $>$ | propositionalconvincing-of-dialogical-equivalence- $<$ as-topsychologismic apriorising/axiomatising/referencing-\{of- "prospectively implicited_attendant-ontological-contiguity ' reducedexistentialising/contextualising/textualising_intelligibility/epistemicity/re flexivity-contiguity-<imbued-notional cogency > ' \}-conflatedness in \{preconverging ment by\} postconverging entailment,-in-selfbecoming/self-conflatedness /formative-supererogating> in incrementalism-in-relative-ontological-incompleteness enframed/disontologising conceptualisation and veridical intellectual 'prospective ${ }^{56}$ meaningfulness-and-teleology routing ontologicallyhegemonising-narrative as to psychoanalytic-unshackling/memeticreordering/institutional-recomposuring' for ${ }^{55}$ maximalisingrecomposuring-for-relative-ontological-completeness - unenframed/reontologising conceptualisation also arises when it comes to prospective knowledge-reification gesturing-and-accounting-of-epistemicphenomenalism- $<$ inprospective psychologismic $\sim$ apriorising/axiomatising/referencing-\{of'prospectively_implicited_attendant-ontological-contiguity ' reducedexistentialising/contextualising/textualising_intelligibility/epistemicity/re flexivity-contiguity-<imbued-notional $\sim$ cogency $>$ ' \}-conflatedness 
preceding/traditional normativities, conventions, practices, etc. (such as manifested with sophistic/pedantic mediums, shamans, witchdoctors, ancient-sophists, medieval-scholasticism pedants and modern-day pedantising/muddling/formulaic-hollowing-out-in-

subontologisation/subpotentiation-_blurring/undermining-of-prospectivetotalising-entailing,-as-to-entailing-<amplituding/formativeepistemicity>totalising in-relative-ontological-completeness J), and hence ultimately with respect to human limited-mentation-capacity-assubjecting ' 'duced unlimitednesstexistence sublinating nascence' to limitedness/human-subpotency implications sophistry can-and-is only undermined by prospective relative-ontological-completeness 'prospective ${ }^{5}$ meaningfulness-and-teleology routing ontologicallyhegemonising-narrative as to psychoanalytic-unshackling/memeticreordering/institutional-recomposuring' knowledgereification $\sim$ gesturing-and-accounting-of-epistemic-phenomenalism$<$ in-prospective psychologismic $\sim$ apriorising/axiomatising/referencing\{of- prospectively_implicited_attendant-ontologicalcontiguity ' reducedexistentialising/contextualising/textualising_intelligibility/epistemicity/re flexivity-contiguity-<imbued-notional $\sim \operatorname{cogency}>^{\text {' }}$, '-conflatedness in \{preconverging ment by\} postconverging entailment $>$ in inducing the universal-transparency -〈transparency-of-totalising-entailing,-as-toentailing-<amplitudinglformative-epistemicity >totalising $\sim$ in-relativeontological-completeness ) of the prospective registry- 
worldview/dimension "foregrounding_entailment-<in-succession-ofprofound-supererogation $>-$ postconverging-narrowing-

down sublimation-as-to- 'existence - as-sublimating-

withdrawal/unenframing/re-ontologising,-elicited-from-prospective-

profound-supererogation '-in-reflecting- 'immanent welative

unreflexivity/relative reflexivity ontological-contiguity ';-as-operative-

notional deprocrypticism) as of its construction-of-the-Self' from whence its devolving specialisms/profound knowledge-construct can then be socially engaged in deferential-formalisation-transference undermining sophistry, and so in the sense that it is only because by-and-large every modern human construction-of-the-Self is positivistic/rational-empirical as of reference-of-thought-level that the possibility of devolving specialisms/profound positivistic knowledge-construct can arise (without the possibility of its sophistic/pedantic social-stake-contention-orconfliction undermining with regards to eliciting non-positivism, supernaturalism, etc. <amplitudingfformative> wooden-languagefimbued-averaging-of-thought-<as-to-leveling/ressentiment/closedconstruct-of- meaningfulness-and-teleology -as-of'nondescript/ignorable-void '-with-regards-to-prospective-apriorisingimplications $>$ ) ) even when the vast majority of humans never have a thorough grasp of any specifically given specialism/profound positivistic knowledge-construct say modern medicine, physics, social science, etc., and likewise the sophistic/pedantic difficulty facing the prospective possibility of notional deprocrypticism as it is prospectively reflective of our present positivism- procrypticism uninstitutionalised-threshold 
lies in the fact that it is highly liable to present social-stake-contention-orconfliction procrypticism-or-disjointedness-as-of- reference-ofthought sophistry 'flawed encouraging of propositional-convincing-ofdialogical-equivalence-<as-to-

psychologismic apriorising/axiomatising/referencing-\{of-"prospectivelyimplicited_attendant-ontological-contiguity ' reducedexistentialising/contextualising/textualising_intelligibility/epistemicity/re flexivity-contiguity-<imbued-notional cogency>' \}'-conflatedness in \{preconverging ment by\} postconverging entailment,-in-selfbecoming/self-conflatedness /formative-supererogating> <amplituding/formative> wooden-language-fimbued-averaging-ofthought-<as-to-leveling/ressentiment/closed-construct-ofmeaningfulness-and-teleology -as-of-'nondescript/ignorable-void ', with-regards-to-prospective-apriorising-implications $>$ | as of present disjointedness-as-of- reference-of-thought' in undermining the 'prospective ${ }^{56}$ meaningfulness-and-teleology routing ontologicallyhegemonising-narrative as to psychoanalytic-unshackling/memeticreordering/institutional-recomposuring' of deprocrypticism-orpreempting-disjointedness-as-of- reference-of-thought as of its dispensing-with-immediacy-for-relative-ontological-completeness -byreification/contemplative-distension, and such prospective notional deprocrypticism organic knowledge-reification gesturingand-accounting-of-epistemic-phenomenalism-<in-

prospective_psychologismic $\sim$ apriorising/axiomatising/referencing-\{of'prospectively_implicited_attendant-ontological-contiguity ' reduced- 
existentialising/contextualising/textualising_intelligibility/epistemicity/re

flexivity-contiguity-<imbued-notional cogency >' \}-conflatedness

in \{preconverging ment by\} postconverging entailment $>$ necessarily requires at least the induced ${ }^{103}$ unersal-transparency -Stransparencyof-totalising-entailing,-as-to-entailing-<mplinglformativeepistemicity>totalising in-relative-ontological-completeness $>$ of the deprocrypticism-or-preempting-disjointedness-as-of- reference-ofthought "foregrounding_entailment-<in-succession-of-profoundsupererogation $>$ - (postconverging-narrowing-down $\sim$ sublimation-as-to'existence - as-sublimating-withdrawal/unenframing/re-ontologising,elicited-from-prospective-profound-supererogation '-in-reflecting'immanent relative unreflexivity/relative reflexivity ontologicalcontiguity ';-as-operative-notional deprocrypticism) as of notional ' deprocrypticism construction-of-the-Self' from whence its implied specialised/profound knowledge-construct can be engaged in deferential-formalisation-transference (without the possibility of sophistic/pedantic undermining like the eliciting of various temporal manifestations of disjointedness-as-of- reference-of-thought as of socialstake-contention-or-confliction implications) even if the vast majority of humans don't have a thorough grasp of notional deprocrypticism implied profound/specialisms knowledge-construct implications; $\mathbf{\uparrow}$ critically metaphoricity speaks to the veridical transience of human existential < disontologising/re-ontologising aporeticism $>$ conceptualisation as of human limitedness (so-reflected as to human limited-mentation-capacity-deepening —as-subjecting limitedness/human- 
subpotency to 'educed unlimitedness/existence sublimating nascence' 'as reflexively in-phasing with the extensive unlimitedness that is existence exuding sublimating/desublimating validative/invalidative thresholds of human ontological-performance ${ }^{72}<$ including-virtue-as-ontology> '), such that the veracity of human ${ }^{56}$ meaningfulness-and-teleology conceptualisation arises as a thresholding-flux as of 'absolute projective reference-threshold for gauging relative human ontologicalperformance ${ }^{2}-<$ including-virtue-as-ontology $>$ on-the-one-hand (accounting for the 'constraining/defining intersolipsistic reflexivesublimating/unreflexive-desublimating measure/objectification that is unlimitedness/existence-as-ontological-normalcy/postconvergence-<invalidation-of- 'metaphysics-of-absence_epistemic-projection'> $\quad$ with regards to all apparent 'supposed-subjects'/subpotencies in their notional reflexivity-<\{veridical/sound\}-relative-reflexivity-inexistencetrelativising from limited mentation as itsdeepening/psychologismic < residualising \{decompulsing' delinearity for eogency>by relative-unreflexivity-inexistencetabsolutising from limited mentation/psychologismic epistemic. acutisation nonresidualising imbued-fompulsing? linearity in eclecticism of prior mere formulaicity/ritualisation> imbued sublimating/desublimating in existence and thus as requiring appropriate conceptualisation of ${ }^{6 /}$ nonpresencing-or-withdrawal/unenframing/reontologising-or-metaphysics-of-absence-_implicited-epistemic-veracityof- nonpresencing-<perspective-ontologicalnormalcy/postconvergence $>$ - or-transcendental-reasoning-of-event ${ }^{38}$ 
as-prospective-ontology-origination to disambiguatingly/differentiatingly account for notional reflexivity-<\{veridical/sound\}-relative-reflexivityin-existencetrelativising from limited mentation as itsdeepening/psychologismic < residualising \{decompulsing? delinearity-for eogency>-by-\{flawed/unsound\}-relative-unreflexivity-inexistencetabsolutising from-limited-mentation/psychologismic epistemicacutisation nonresidualising imbued-icompulsing linearity in eclecticismof prior mere formulaicity/ritualisation> as so-undergirded rather by prospective re-ontologising 'deconstruction conception as to epistemicgrowth,-as-\{veridical/sound, relative-reflexivity-inexistencetrelativising from limited mentation as itsdeepening/psychologismic epistemic acutisation residualising, \{decompulsing' delinearity for cogency') and on-the-other-hand as of 'effective existential< <isontologising/re ontologising aporeticism $>$ manifestation of human ontological-performance ${ }^{72}<$ including-virtue-as-ontology $>$ ' (necessarily reflecting the station/locus of human limited-mentationcapacity as subjecting 'edued mlimitednesstexistence sublimating nascence' to limitedness/human-subpotency as to 'veridical existentialising-frame-of entailment-of motif and apriorising/axiomatising/referencing becoming of human consciousness in-its-embodiment' as from prior <preconverging 'motif-andapriorising/axiomatising/referencing'-entailing>-existentialisingenframing/imprintedness-_as-to- historicity-tracing_in-presencinghyperrealisation/hyperreal-transposition) to prospective <postconverging 'motif-and-apriorising/axiomatising/referencing'- 
entailing>-existentialising-framing/imprinting-_as-to-prospective-

historiality/ontological-eventfulness /ontological-aesthetic-tracing-

$<$ perspective-ontological-normalcy/postconvergence-reflected-

'epistemicity-relativism-determinism'>1), with this overall contrastive thresholding-flux pointing out that notions speaking to prospective human transcendence-and-sublimity/sublimation/supererogatory-de-mentativity such as construction-of-the-Self, surrealising-<as-to-supererogation $>$ (as to the nurrealising nature of the $<$ cumulating/recomposuring attendant-ontological-contiguity $>$ successive registry-worldviews/dimensions), etc. can only effectively arise rather as being freed/liberated from the very incipient/seeding \{flawed/unsound? relative-unreflexivity-in-existencetabsolutising fromlimited mentation/psychologismic epistemic acutisation nonresidualising imbued fompulsings linearity in eclecticism of prior mere formulaicity/ritualisation residual human <amplitudinglformativeepistemicity>-totalising thrownness-in-existence imbued prior $<$ preconverging 'motif-and-apriorising/axiomatising/referencing'entailing>-existentialising_enframing/imprintedness-〈as-to- historicitytracing-in-presencing-hyperrealisation/hyperreal-transposition/ to then project of their epistemic-growth,-as relativereflexivity-in-existencetrelativising from limited mentation as itsdeepening/psychologismic epistemic acutisation residualising, dectinearity for cogency prospective <postconverging 'motifand-apriorising/axiomatising/referencing'-entailing >-existentialising- 
framing/imprinting-_as-to-prospective- historiality/ontological-

eventfulness /ontological-aesthetic-tracing-<perspective-ontological-

normalcy/postconvergence-reflected-'epistemicity-relativism-

determinism'>) (thus reflecting that metaphoricity with regards to

prospective

human

transcendence-and-

sublimity/sublimation/supererogatory-de-mentativity is rather an exercise of prospective re-ontologising 'deconstruction conception as to epistemicgrowth,-as-\{veridical/sound\}-relative-reflexivity-in-

existencetrelativising from limited mentation as its-

deepening/psychologismic epistemic aentisation residualising,

\{decompulsing'delinearity for cogency' over prior disontologising

"presencing-absolutising-identitive-constitutedness $\quad$ normalising

functionalism conception as to \{flawed/unsound? relative-unreflexivity-inexistencetabsolutising from limited mentation/psychologismic epistemic. acutisation - nonresidualising imbued-fompulsing'linearity in eclecticismof prior-mere-formulaicity/ritualisation') and such that in-many-ways it can thus be appreciated for instance that 'budding-positivists are rather becoming out of medieval-scholasticism'

neuterising 58 neuterising—ascriptivity/ascription-hardening/pseudo-referentialism-asepistemically-flawed- ${ }^{70}$ presencing-absolutising-identitiveconstitutedness ${ }^{14}$-or-identitive-constitutedness ${ }^{14}$-as- 'epistemic-totality ${ }^{37}$ dereification-in-dissingularisation-<as-to-the-disjointedness/ment-ofpresencing - absolutising-identitive-constitutedness $>$-as-flawedepistemicity-relativism-determinism 
neuterisation $^{59}$

neuterisation-\{undisambiguation of temporal-as-

denaturing /preconverging-or-dementing from intemporal-assound/postconverging-or-dialectical-thinking , so-construed-as-to-

\section{binarity-of-categorical-imperatives/axioms/registry-teleology -with-} temporal-as-denaturing falsely-represented-as-if-in notionalcontiguity/epistemic-contiguity $-<$ profound-supererogation -ofmentally-aestheticised postconverging/dialectical-thinking -qualiaschema>-with-intemporal-as-sound, 'rather-than-disambiguated-into intemporal-as-prospective-notional-contiguity/epistemic-contiguity $<$ profound-supererogation -of-mentallyaestheticised postconverging/dialectical-thinking -qualia-schema> and temporal-as-prior-notional-discontiguity/epistemic-discontiguity $<$ between-prior-shallow-supererogation -of-mentallyaestheticised preconverging/dementing -qualiaschema_and_prospective-profound-supererogation -of-mentallyaestheticised postconverging/dialectical-thinking -qualia-schema>representations', but-wrongly-implying-both-are of the-very-samerelative-reflexivity-of-immanent-existence/intrinsic-reality/ontologicalveridicality,-as-to- 'human< <mplitudinglformativeepistemicity>totalising $\sim$ purview-of-construal' imbuedapriorising/axiomatising/referencing of meaningfulness-andteleology )

nondescript/ignora nondescript/ignorable-void, in underlying holographicallyble-void ${ }^{60}<$ conjugatively-and-transfusively $>$ the relative-unreflexivity/relative 


$$
\begin{aligned}
& \text { reflexivity_ontological-contiguity } \sim \text { of-the-human-institutionalisation- } \\
& \text { process } \\
& \text { epistemic-ricochetting/transepistemicity } \\
& \text { foregrounding_entailment-<in-succession-of-profound- } \\
& \text { supererogation >-_postconverging-narrowing-down } \sim \text { sublimation-as-to- } \\
& \text { 'existence-as-sublimating-withdrawal/unenframing/re-ontologising,- } \\
& \text { elicited-from-prospective-profound-supererogation '-in-reflecting- }
\end{aligned}
$$$$
\text { 'immanent relative unreflexivity/relative reflexivity ontological- }
$$$$
\text { contiguity ';-as-operative-notional deprocrypticism) }
$$$$
\text { meaningfulness-and-teleology as of human limited-mentation-capacity- }
$$$$
\text { deepening as subjecting limitednesshman subotency to 'educed }
$$$$
\text { unlimitedness/existence sublimating nascence' grasp of 'ecstatic- }
$$$$
\text { existence as of existence-as-the-absolute-a-priori-of- }
$$$$
\text { conceptualisation } \sim \text { and } \sim \text { existence — as-sublimating- }
$$

withdrawal/unenframing/re-ontologising,-elicited-from-prospective-

profound-supererogation -<as-to-perspective-ontological-

\section{normalcy/postconvergence-implied- 'prospective-aporeticism-}

overcoming/unovercoming'>', a 'prior registry-worldview's/dimension's nondescript/ignorable-void as of its ontologically-flawed preconverging/dementing -qualia-schema' refers to the fact that no registry-worldview/dimension going by its relative-ontologicalincompleteness as of prior registry-worldview/dimension epistemic perspective is representatively cognisant-and-integrative of its meaningfulness-and-teleology as of its prospective destructuringthreshold-\{uninstitutionalised-threshold /presublimatingdesublimating-decisionality $/$ of-ontological-performance $-<$ including- 
virtue-as-ontology>/morality/ethics/justice/etc. implied/appreciable preconverging/dementing -qualia-schema (so-reflected as from the prospective registry-worldview/dimension in relative-ontologicalcompleteness epistemic perspective), as it rather reproduces circularly its 'prior registry-worldview's/dimension's nondescript/ignorable-void as of its ontologically-flawed preconverging/dementing-qualia-schema' over any such prospective registry-worldview's/dimension's veridically implied/appreciable preconverging/dementing-qualia-schema representation of the prior registry-worldview's/dimension's destructuring-threshold-_uninstitutionalised-threshold /presublimatingdesublimating-decisionality $/$ of-ontological-performance ${ }^{72}<$ includingvirtue-as-ontology>, with the implication that the 'destructuringthreshold-\{uninstitutionalised-threshold /presublimating-

desublimating-decisionality $>$ of-ontological-performance 2 - includingvirtue-as-ontology>/morality/ethics/justice/etc.

preconverging/dementing -qualia-schema' respectively of prior recurrent-utter-uninstitutionalisation, ununiversalisation, nonpositivism/medievalism and our procrypticism-or-disjointedness-as-of${ }^{3}$ reference-of-thought (as failing dispensing-with-immediacy-for-relativeontological-completeness ${ }^{8}$-by-reification/contemplative-distension ${ }^{27}$ as reflected from the epistemic perspective respectively of prospective baseinstitutionalisation, universalisation, positivism and notional deprocrypticism (as dispensing-with-immediacy-for-relativeontological-completeness -by-reification/contemplative-distension ${ }^{27}$ are rather construed by the respective prior registry-worldviews/dimensions 
circularly as of their 'prior registry-worldview's/dimension's nondescript/ignorable-void as of their ontologically-flawed preconverging/dementing - qualia-schema': and any such 'prior registryworldview's/dimension's nondescript/ignorable-void as of its ontologically-flawed preconverging/dementing -qualia-schema' can only veridically be conceptualised-and-analysed as of the relativeunreflexivity/relative reflexivity ontological-contiguity of-the-humaninstitutionalisation-process $^{6}$ (ecstatic-existence prospective digression induced epistemic-ricochetting/transepistemicity) dimensionality-ofsublimating $-<<$ amplituding/formative $>$ supererogatory $-d e-$ mentativeness/epistemic-growth-or-conflatedness/transvaluativerationalising/transepistemicity/anamnestic-residuality/spirit-drivennessequalisation) as to difference-conflatedness ${ }^{13}$-as-to-totalitativereification-in-singularisation-<as-to-the-nondisjointedness/entailment-ofprospective- nonpresencing $>$-as-veridical-epistemicity-relativism-

determinism ' with regards to the transepistemic/epistemic-ricochetting <amplitudinglformative-epistemicity>causality as-to-projectivetotalitative-implications-of-prospective- nonpresencing,-forexplicating felative unreflexivity/relative reflexivity ontologicalcontiguity of human limited-mentation-capacity-deepening-assubjecting limitedness/human-subpotency to-'educed-

unlimitednesstexistence sublimating nascence' in human epistemictotalising $\sim$ resubjecting_or_totalising-entailing $\sim$ reconstrual $<\theta f$ the wholelpurview of the wholetoneness of ontology $>$ of ecstatic-existence as of existence-as-the-absolute-a-priori-of- 
conceptualisation $\sim$ and $\sim$ existence - as-sublimating-

withdrawal/unenframing/re-ontologising,-elicited-from-prospective-

profound-supererogation -<as-to-perspective-ontological-

normalcy/postconvergence-implied- 'prospective-aporeticism-

overcoming/unovercoming'>', and so as of the relative-ontological-

completeness prospective registry-worldview's/dimension's

supererogatory acuity/perspicacity/astuteness/edginess/incisiveness-of-

apriorising/axiomatising/referencing/intelligibilitysettingup/measuringins

trumenting -for-conceptualisation 'induced postconverging/dialectical-

thinking -qualia-schema as from its apriorising-pyschologism/mental-

schema implicited value-ricochetting/transvaluation-as-to-prospective-

relative-ontological-completeness ${ }^{\text {, }}$ superseding of the relative-

ontological-incompleteness prior registry-worldview's/dimension's

supererogatory acuity/perspicacity/astuteness/edginess/incisiveness-of-

apriorising/axiomatising/referencing/intelligibilitysettingup/measuringins

trumenting -for-conceptualisation implied prior

postconverging/dialectical-thinking -qualia-schema which becomes

prospectively a prior preconverging/dementing-qualia-schema' (thus

grasping the 'teleologically-determinative <amplitudingfformative-

epistemicity $>$ causality $\sim$ as-to-projective-totalitative-implications-of-

prospective- nonpresencing,-for-explicating relative-

unreflexivity/relative reflexivity ontological-contiguity, of the prior registry-worldview's/dimension's meaningfulness so-construable as of its preconverging/dementing -qualia-schema reflection of its destructuringthreshold-_uninstitutionalised-threshold /presublimating- 
desublimating-decisionality $>$ of-ontological-performance ${ }^{72}<$ includingvirtue-as-ontology>); 9 as the prior registry-worldview's/dimension's destructuring-threshold-_uninstitutionalised-threshold /presublimatingdesublimating-decisionality $/$ of-ontological-performance ${ }^{72}<$ includingvirtue-as-ontology>/morality/ethics/justice/etc. is construed as a <amplituding/formative $>$ wooden-language-fimbued-temporal-mereform/virtualities/dereification/akrasiaticdrag/denatured/preconvergingor-dementing -narratives-of-the-reference-of-thought-categoricalimperatives/axioms/registry-teleology / as of the implied reproducibility — mathesis/motif/thrownness-disposition,-asreproducibility-of-aestheticisation as reasoning-from-results/afterthought, speaking of human-subpotency prospective lack of 'platonic anamnesis' (rather as of human-'limited-mentation-capacity-deepening-assubjecting limitedness/human-subpotency to 'educedunlimitedness/existence sublimating nascence' 3 '-construal-of'superseding-oneness-of-ontology' with respect to the prior pertinence of the 'organic-spirit of knowledge' over 'mechanical-knowledge', soimplied beyond the 'epochal literal mysticism' as naively analysed from their ${ }^{103}$ universalising-idealisation ${ }^{79}$ presencing-absolutising-identitiveconstitutedness perspective, and noting as well here that the conceptualpatterning-_as-devoid-of- 'prospectively_implicited_attendantontological-contiguity ' $\sim$ educedexistentialising/contextulising/textualising_intelligibility/epistemicity/re flexivity-contiguity-<imbued-notional $\sim$ cogency $>$ ' 's-reifying-or- 
elucidating-of-'prospective-relative-ontological-completeness ';-so-

rather-enabled-<by-a- nonpresencing-divulging-of-momentous-

historiality/ontological-eventfulness /ontological-aesthetic-tracing-

$<$ perspective-ontological-normalcy/postconvergence-reflected-

'epistemicity-relativism-determinism'>) naivety of Platonism as merely prior reproducibility—mathesis/motif/thrownness-disposition,-asreproducibility-of-aestheticisation is alien to Plato and the Socraticphilosophers whose anamnesis rather speaks of originariness-parrhesia,as-spontaneity-of-aestheticisation conceptualisation of their universalising-idealisation), as human-subpotency doesn't constrain the 'becoming of ecstatic-existence-as-transcendental-signifier' as of the latter's transcendence-and-sublimity/sublimation/supererogatory 2 dementativity inducing implications such that ecstatic-existence-astranscendental-signifier-emergence/becoming-spontaneity-implications reflected as existence-potency ${ }^{3}$ sublimating-nascence,-disclosed-fromprospective-epistemic-digression as from such human-subpotency prior reproducibility—mathesis/motif/thrownness-disposition,-as-

reproducibility-of-aestheticisation in restoring dimensionality-ofsublimating $-<$ amplituding/formative $>$ supererogatory - dementativeness/epistemic-growth-or-conflatedness /transvaluativerationalising/transepistemicity/anamnestic-residuality/spirit-drivennessequalisation), implies the prospective registry-worldview/dimension in relative-ontological-completeness is of superseding valuericochetting/transvaluation-as-to-prospective-relative-ontologicalcompleteness 50 -reflected as of the 'relative unreflexivity/relative 
reflexivity ontological-contiguity of-the-human-institutionalisationprocess (ecstatic-existence prospective digression induced epistemicricochetting/transepistemicity) dimensionality-of-sublimating

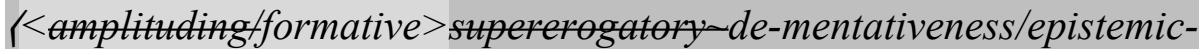
growth-or-conflatedness/transvaluative-

rationalising/transepistemicity/anamnestic-residuality/spirit-drivenness-

equalisation) as to difference-conflatedness ${ }^{3}$-as-to-totalitativereification-in-singularisation-<as-to-the-nondisjointedness/entailment-ofprospective- nonpresencing > -as-veridical-epistemicity-relativismdeterminism ' induced 'prospective intemporal-as-ontologicallyveridical/ontological-faith-notion-or-ontological-fideism-imbuedunderdetermination-of-motif-and-apriorising/axiomatising/referencingas-so-being-as-of-existential-reality parrhesiastic seeding-promise of reasoning-through/messianic-reasoning ${ }^{56}$ meaningfulness-and-teleology as equivalence/correspondence antiakrasiatic-aspiration ontologicalperformance -<including-virtue-as-ontology>' over the prior registryworldview's/dimension's destructuring-threshold-_uninstitutionalisedthreshold /presublimating-desublimating-decisionality / of-ontologicalperformance ${ }^{72}-<$ including-virtue-as-

ontology >/morality/ethics/justice/etc. ' " presencing-absolutisingidentitive-constitutedness ${ }^{1 /} /$ identitive-constitutedness $^{14}$-as-'epistemictotality '-dereification-in-dissingularisation-<as-to-thedisjointedness/ment-of- presencing - absolutising-identitiveconstitutedness > -as-flawed-epistemicity-relativism-determinism induced 'temporal/sophistic-as-ontologically-flawed/ontological-bad- 

disposition,-as-reproducibility-of-aestheticisation seeding-misprising of reasoning-from-results/afterthought ${ }^{56}$ meaningfulness-and-teleology as covert-pretence-of-equivalence/correspondence-antiakrasiaticaspiration-ontological-performance ${ }^{72}<$ including-virtue-as-ontology > '; with the above reflecting the fact that originariness-parrhesia,-asspontaneity-of-aestheticisation inducing of prior reproducibilitymathesis/motif/thrownness-disposition,-as-reproducibility-ofaestheticisation as outcome/outfit/shell-construedhistorially-as-of-thespecifically-aestheticised-incrusting/plating/coating-as-institutionalmanifestation is rather a 'secondnatured positive-opportunism-of-socialfunctioning-and-accordance implied mechanical-knowledge' but then the very possibility for prospective originariness-parrhesia,-asspontaneity-of-aestheticisation inducing of prospective reproducibilitymathesis/motif/thrownness-disposition,-as-reproducibility-ofaestheticisation (as to when ecstatic-existence-as-transcendentalsignifier-emergence/becoming-spontaneity-implications reflected as existence-potency ${ }^{3}$ sublimating-nascence,-disclosed-from-prospectiveepistemic-digression from such human-subpotency prior reproducibilitymathesis/motif/thrownness-disposition,-as-reproducibility-ofaestheticisation is implied), lies with the organic-knowledge reconstrual of anamnesis as of the 'relative unreflexivity/relative reflexivityontological-contiguity $\sim$ of-the-human-institutionalisation-process (ecstatic-existence prospective digression induced epistemicricochetting/transepistemicity) dimensionality-of-sublimating 
< <mplituding/formative >supererogatory-de-mentativeness/epistemic-

growth-or-conflatedness /transvaluative-

rationalising/transepistemicity/anamnestic-residuality/spirit-drivenness-

equalisation) as to difference-conflatedness -as-to-totalitativereification-in-singularisation-<as-to-the-nondisjointedness/entailment-ofprospective- nonpresencing $>$-as-veridical-epistemicity-relativismdeterminism ' induced 'prospective intemporal-as-ontologicallyveridical/ontological-faith-notion-or-ontological-fideism-imbuedunderdetermination-of-motif-and-apriorising/axiomatising/referencingas-so-being-as-of-existential-reality parrhesiastic seeding-promise of reasoning-through/messianic-reasoning ${ }^{56}$ meaningfulness-and-teleology as equivalence/correspondence antiakrasiatic-aspiration ontologicalperformance ${ }^{72}<$ including-virtue-as-ontology $>^{\prime} ; \mid$ and it is herein that the notion of construction-of-the-Self is central as to the implication that meaningfulness-and-teleology ontological-performance ${ }^{72}<$ includingvirtue-as-ontology>/morality/ethics/justice/etc. involves 'direct bilateral relationship of appropriate construction-of-the-Self for appropriate cognisance-and-integration of prospective relative-ontologicalcompleteness 'meaningfulness-and-teleology' in order for the upholding of anamnesis (as to when ecstatic-existence-as-transcendentalsignifier-emergence/becoming-spontaneity-implications reflected as existence-potency $\sim$ sublimating-nascence,-disclosed-from-prospectiveepistemic-digression from such human-subpotency prior reproducibilitymathesis/motif/thrownness-disposition,-as-reproducibility-ofaestheticisation is implied), as to the fact that with regards to social-stake- 
contention-or-confliction the prior registry-worldview's/dimension's prior reproducibility—mathesis/motif/thrownness-disposition,-as-

reproducibility-of-aestheticisation <emplituding/formative> woodenlanguage-fimbued-temporal-mere-

form/virtualities/dereification/akrasiaticdrag/denatured/preconvergingor-dementing -narratives-of-the- reference-of-thought-categoricalimperatives/axioms/registry-teleology । at its destructuring-threshold(uninstitutionalised-threshold /presublimating-desublimatingdecisionality $/$ of-ontological-performance ${ }^{2}<$ including-virtue-asontology>/morality/ethics/justice/etc. cannot uphold/uptake the prospective registry-worldview's/dimension's 'meaningfulness-andteleology as it rather engages with such prospective knowledge in complexification of its prior reproducibility—mathesis/motif/thrownnessdisposition,-as-reproducibility-of-aestheticisation <amplituding/formative> wooden-language-fimbued-temporal-mereform/virtualities/dereification/akrasiatic-drag/denatured/preconvergingor-dementing -narratives-of-the- reference-of-thought-categoricalimperatives/axioms/registry-teleology \ which is alien to the requisite prospective registry-worldview's/dimension's parrhesiastic valuericochetting/transvaluation-as-to-prospective-relative-ontologicalcompleteness $\quad$ human-and-social-expectations/anticipationsmetaphoricity - as-preconverging/postconverging-redementating/restructuring/reparadigming-psychologism-<as-fromperspective-ontological-normalcy/postconvergence $>$; hence the 
<amplituding/formative> wooden-language-fimbued-temporal-mere-

form/virtualities/dereification/akrasiatic-drag/denatured/preconvergingor-dementing -narratives-of-the-reference-of-thought-categoricalimperatives/axioms/registry-teleology / of a prior registryworldview's/dimension's destructuring-threshold-funinstitutionalisedthreshold /presublimating-desublimating-decisionality /of-ontologicalperformance ${ }^{72}<$ including-virtue-as-

ontology>/morality/ethics/justice/etc. as its human-subpotencyaporia/undecidability/dilemma/ought-

indeterminacy/deficiency/limitation/constraint emerges as of 'asceticism consciousness point-of-referencing projection (<amplitudingfformativeepistemicity>causality $\sim$ as-to-projective-totalitative-implications-ofprospective- nonpresencing,-for-explicating felativethreflexivitrelative reflexivity ontological-contiguity) towards the prospective registry-worldview/dimension' eliciting the relativeunreflexivity/relative reflexivity ontological-contiguity rof-the-humaninstitutionalisation-process dimensionality-of-sublimating 1<atformative > growth-or-conflatedness /transvaluativerationalising/transepistemicity/anamnestic-residuality/spirit-drivennessequalisation) as to difference-conflatedness -as-to-totalitativereification-in-singularisation-<as-to-the-nondisjointedness/entailment-ofprospective- nonpresencing $>$-as-veridical-epistemicity-relativism-

determinism , wherein the ascetically implied metaphoricity as of the 
prospective registry-worldview/dimension, by its prospective psychoanalytic-unshackling/memetic-reordering/institutionalrecomposuring for the prospective construction-of-the-Self, induces 'value-ricochetting/transvaluation-as-to-prospective-relativeontological-completeness ${ }^{56}$ meaningfulness-and-teleology, thus overriding the 'prior registry-worldview's/dimension's nondescript/ignorable-void as of its ontologically-flawed preconverging/dementing -qualia-schema' with regards to its destructuring-threshold-\{uninstitutionalised-threshold /presublimatingdesublimating-decisionality $>$ of-ontological-performance $-<$ includingvirtue-as-ontology>, such that a <emplitudinglformative> woodenlanguage-_imbued-temporal-mere-

form/virtualities/dereification/akrasiatic-drag/denatured/preconvergingor-dementing -narratives-of-the- reference-of-thought-categoricalimperatives/axioms/registry-teleology । simply speaks of a registryworldview's/dimension's <amplituding/formativeepistemicity>totalising $\sim$ self-referencingsyncretising/circularity/interiorising/akrasiatic-drag as of the 'shiftiness-of-the-Self', whether as of trepidatious/warped/preclusive/occlusive $\quad{ }^{70}$ presencing-absolutisingidentitive-constitutedness /identitive-constitutedness ${ }^{14}$-as- 'epistemictotality $^{3}$-dereification-in-dissingularisation-<as-to-thedisjointedness/ment-of- presencing - absolutising-identitiveconstitutedness $>$-as-flawed-epistemicity-relativism-determinism 
${ }^{61}$ nonpresencing nonpresencing-or-withdrawal/unenframing/re-ontologising-or-

metaphysics-of-absence-_implicited-epistemic-veracity-of-

nonpresencing-<perspective-ontological-

normalcy/postconvergence $>$ - - or-transcendental-reasoning-of-event ${ }^{38}$

as-prospective-ontology-origination

perspective/framing/reference/horizon/projection of ${ }^{5}$ meaningfulness-

and-teleology as to the transcendence-and-

sublimity/sublimation/supererogatory-de-mentativity implications of

difference-conflatedness ${ }^{13}$-as-to-totalitative-reification-in-

singularisation-<as-to-the-nondisjointedness/entailment-of-prospective-

nonpresencing $>\quad$-as-veridical-epistemicity-relativism-determinism

reflected as existence-potency $\sim$ sublimating-nascence,-disclosed-from-

prospective-epistemic-digression or existence-potency ${ }^{39} \sim$ sublimating-

nascence,-disclosed-from-prospective-epistemic-digression-rules-of-

apriorising/axiomatising/referencing-that-further-epistemically-

unconceal-the-very-ontologically-same-existential-reality; $\mathbb{\uparrow}$

nonpresencing-<perspective-ontological-normalcy/postconvergence $>$

speaks to the transcendental-signifier/transcendental-

enabling/sublimating/supererogatory de-mentativity that is ecstatic-

existence as phenomenologically reflecting existence-as-sublimating-

withdrawal/unenframing/re-ontologising,-elicited-from-prospective-

profound-supererogation 'both as signifier-as-to-transcending

(speaking of human-subpotency ontological-performance $-<$ including-

virtue-as-ontology>/morality/ethics/justice/etc. perspective of the

changing transcendence-and-sublimity of existence reflected as to 
sublimating notional-contiguity/epistemic-contiguity and desublimating notional-discontiguity/epistemic-discontiguity as of human limitedmentation-capacity-deepening —as subjecting limitedness/humansubpotency to 'educed unlimitedness/existence sublimating nascence' implications) and signified-as-to-immanency (speaking of notionalcontiguity/epistemic-contiguity $-<$ profound-supererogation -ofmentally-aestheticised postconverging/dialectical-thinking -qualiaschema $>$ perspective of the unchanging immanency of existence as superseding-oneness-of-ontology as to the coherence underlying the very possibility for construing-and-reconstruing of intelligibility in existence)' so-construed as notional reflexivity-in-ecstatic-existence, and critically in this regards reductionist conceptions will wrongly tend to imply 'human-subpotency non-scalarity/beholdening-<as-to-what-has-gonebefore-aesthetically-de-mentates/structures/paradigms-distortedly-thepossibility-for-the-later-ontologisation >' supersedes the 'scalarity/immanency of existence's ontologicalnormalcy/postconvergence'; 9 this further explains why reductionisms (as to their <amplituding/formativeepistemicity>totalising/circumscribing/delineating implications) fail to reflect nonpresencing-<perspective-ontologicalnormalcy/postconvergence $>$ as to the requisite human limited-mentationcapacity-deepening -as-subjecting limitedness/human-subpotency to'edued unlmitednesstexistence sublimating nascence' knowledgereification $\sim$ gesturing-and-accounting-of-epistemic-phenomenalism$<$ in-prospective psychologismic $\sim$ apriorising/axiomatising/referencing- 
\{of-'prospectively_implicited_attendant-ontological-

contiguity ' reduced-

existentialising/contextualising/textualising_intelligibility/epistemicity/re flexivity-contiguity-<imbued-notional cogency>' ', conflatedness

in \{preconverging ment by\} postconverging entailment $>$ and with such reductionisms rather inducing presencing-absolutising-identitiveconstitutedness 14 as to elaboration-as-to-mere-

extrapolating/constituting/abstracting/deducing/inferring-of-elucidationoutside-'prospectively_implicited_attendant-ontologicalcontiguity $\stackrel{\text { ? }}{\sim}$ educedexistentialising/contextualising/textualising_intelligibility/epistemicity/re flexivity-contiguity-<imbued-notional $\sim$ cogency $>$ ' poor and relic/artifactual conceptions of knowledge that poorly contemplates of human limited-mentation-capacity-deepening -as-subjecting timitedness/human subpotency to 'educed unlimitedness/existencesublimating nascence' implications, and so as 'failing to override apriorising/axiomatising/referencing-\{of- 'prospely implicited_attendant-ontological-contiguity ' educedexistentialising/contextualising/textualising_intelligibility/epistemicity/re flexivity-contiguity-<imbued-notional $\sim$ cogency $>$ ' $\}$-constitutedness ${ }^{14}-$ in preconverging entailment with apriorising/axiomatising/referencing\{of-'prospectively implicited_attendant-ontologicalcontiguity ' reducedexistentialising/contextualising/textualising_intelligibility/epistemicity/re flexivity-contiguity-<imbued-notional $\sim$ cogency $>^{\text {' }}$;-conflatedness ${ }^{3-}$ 
in \{preconverging ment by\} postconverging entailment as the latter enables 'relative-ontological-incompleteness'/relative-ontologicalcompleteness - (sublimating $\sim$ referencing/registering/decisioning,-asself-becoming/self-conflatedness /formative-supererogating$<$ projective/reprojective-aestheticising-re-motif-and-re-apriorising/reaxiomatising/re-referencing,-in-perspective-ontologicalnormalcy/postconvergence $>$ / as to human-and-socialexpectations/anticipations - metaphoricity -aspreconverging/postconverging-redementating/restructuring/reparadigming-psychologism' to be drawn in keeping tab of existence - as-sublimating-withdrawal/unenframing/reontologising,-elicited-from-prospective-profound-supererogation' both as signifier-as-to-transcending (speaking of human-subpotency ontological-performance ${ }^{72}<$ including-virtue-asontology >/morality/ethics/justice/etc. perspective of the changing transcendence-and-sublimity of existence reflected as to sublimating notional-contiguity/epistemic-contiguity and desublimating notionaldiscontiguity/epistemic-discontiguity as of human limited-mentationcapacity-deepening - as subjecting limitedness/human-subpotency to'educed unlimitedness/existence sublimating nascence' implications) and signified-as-to-immanency (speaking of notionalcontiguity/epistemic-contiguity $-<$ profound-supererogation -ofmentally-aestheticised postconverging/dialectical-thinking -qualiaschema $>$ perspective of the unchanging immanency of existence as superseding-oneness-of-ontology as to the coherence underlying the very 
possibility for construing-and-reconstruing of intelligibility in existence)' so-construed as notional reflexivity-in-ecstatic-existence; $\boldsymbol{\square}$ the failure to adopt such a nonpresencing-<perspective-ontologicalnormalcy/postconvergence $>$ apriorising/axiomatising/referencing-\{of'prospectively_implicited_attendant_ontological-contiguity ' reducedexistentialising/contextualising/textualising_intelligibility/epistemicity/re flexivity-contiguity-<imbued-notional $\left.\sim \operatorname{cogency}>^{\prime}{ }^{\prime}\right\}$-conflatedness ${ }^{13}$ in \{preconverging ment by\} postconverging entailment construal (underlined by human limited-mentation-capacity-deepening-assubjecting limitedness/human-subpotency to-'educedunlimitednesstexistence sublimating nascence' as to 'implicited_attendant-ontological-contiguity ' educedexistentialising/contextualising/textualising_intelligibility/epistemicity/re flexivity-contiguity-<imbued-notional cogency>' 'implied $<$ emplituding/formative-epistemicity >-totalising $\sim$ renewing-realisation,-re-perception,-re-thought-in-epistemic-conflatedness ${ }^{13} \mathrm{~s}$ of relativeontological-contiguity ') is critically associated with presencing-absolutising-identitive-constitutedness academicism proliferation of isms-conceptualisations mere conceptualpatterning-〈as-devoid-of-'prospectively_implicited_attendant ontological-contiguity ' reduced-

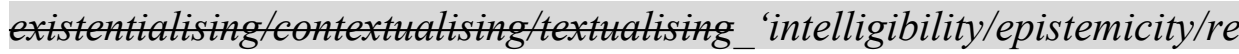
flexivity-contiguity-<imbued-notional cogency>' 's-reifying-orelucidating-of-'prospective-relative-ontological-completeness ' '-sorather-enabled-<by-a- nonpresencing-divulging-of-momentous- 
historiality/ontological-eventfulness /ontological-aesthetic-tracing-

$<$ perspective-ontological-normalcy/postconvergence-reflected-

'epistemicity-relativism-determinism'>)' articulated rather as of

elaboration-as-to-mere-

extrapolating/constituting/abstracting/deducing/inferring-of-elucidation-

outside-'prospectively implicited_attendant-ontological-

contiguity $\sim$ ' educed-

existentialising/contextualising/textualising_intelligibility/epistemicity/re

flexivity-contiguity-<imbued-notional cogency> (wherein the

knowledge-reification $\sim$ gesturing-and-accounting-of-epistemic-

phenomenalism- $<$ in-

prospective_psychologismic apriorising/axiomatising/referencing-\{of'prospectively_implicited_attendant-ontological-contiguity ' reducedexistentialising/contextualising/textualising_intelligibility/epistemicity/re flexivity-contiguity-<imbued-notional $\sim$ cogency > ', -conflatedness in \{preconverging ment by\} postconverging entailment $>$ is simply construed 'out of idly/singly abstractable logical possibilities for such ‘sms-conceptualisations mere conceptual-patterning-〈as-devoid-of'prospectively_implicited_attendant-ontological-contiguity ' reducedexistentialising/contextualising/textualising_intelligibility/epistemicity/re flexivity-contiguity-<imbued-notional $\sim$ cogency $>$ ' 's-reifying-orelucidating-of-'prospective-relative-ontological-completeness ';-sorather-enabled-<by-a- nonpresencing-divulging-of-momentoushistoriality/ontological-eventfulness /ontological-aesthetic-tracing$<$ perspective-ontological-normalcy/postconvergence-reflected- 
'epistemicity-relativism-determinism'> J' and not-or-poorly aspiring to portray the unchanging immanent-backdrop construable-andreconstruable as of existential<-disontologising/re ontologisingaporeticism $>$ contextualising in relative unreflexivity/relative

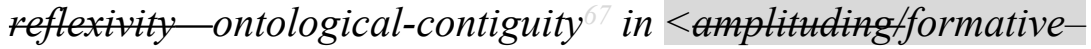
epistemicity>totalising/circumscribing/delineating conception-ofmeaningfulness-and-teleology') as to disparateness-ofconceptualisation-<unforegrounding-ment,-failing-prospectively-toreflect- 'immanent relative unreflexivity/relative reflexivity ontologicalcontiguity '> and thus with the 'ontologically-flawed implication that the absolute a-priori is not construed as existence-as-sublimatingwithdrawal/unenframing/re-ontologising,-elicited-from-prospectiveprofound-supererogation 'but instead any of such given ismsconceptualisations and associated reductionisms now substituting for the unchanging immanent-backdrop of 'implicited_attendant-ontologicalcontiguity ${ }^{\text {' educed- }}$ existentialising/contextualising/textualising_intelligibility/epistemicity/re flexivity-contiguity-<imbued-notional $\sim$ cogency $>$ ' as the absolute apriori of conceptualisation, and so as of vague academicism proceduralisms in totalisingly-ing — discretion/whim-of-thought, rather than a knowledge-reification gesturing-and-accounting-of-epistemicphenomenalism- $<$ inprospective psychologismic $\sim$ apriorising/axiomatising/referencing-\{of'prospectively implicited_attendant-ontological-contiguity ' reducedexistentialising/contextualising/textualising_intelligibility/epistemicity/re 
flexivity-contiguity-<imbued-notional cogency >' \}-conflatedness

in \{preconverging ment by\} postconverging entailment $>$ of

foregrounding_entailment-<in-succession-of-profound-

supererogation $>_{-}$(postconverging-narrowing-down $\sim$ sublimation-as-to-

'existence-as-sublimating-withdrawal/unenframing/re-ontologising,-

elicited-from-prospective-profound-supererogation '-in-reflecting-

'immanent relative unreflexivity/relative reflexivity ontological-

contiguity ';-as-operative-notional deprocrypticism/that starts-from-

and-remains-in/is-of-epistemical-embeddedness-with

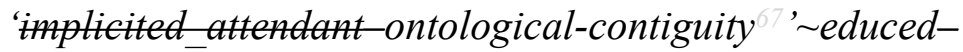

existentialising/contextualising/textualising_intelligibility/epistemicity/re

flexivity-contiguity-<imbued-notional $\sim$ cogency $>$ ' (as to prospective

knowledge-reification gesturing-and-accounting-of-epistemic-

phenomenalism- $<$ in-

prospective_psychologismic apriorising/axiomatising/referencing-\{of-

'prospectively implicited_attendant-ontological-contiguity ' reduced-

existentialising/contextualising/textualising_intelligibility/epistemicity/re

flexivity-contiguity-<imbued-notional $\sim$ cogency $>$ ' \} - conflatedness -

in \{preconverging ment by\} postconverging entailment> 'implied

<emplituding/formative-epistemicity>-totalising renewing-realisation,-

re-perception,-re-thought-in-epistemic-conflatedness ${ }^{13} \mathrm{~s}$ of relative-

unreflexivity/relative reflexivity ontological-contiguity ') in construing

of prospective human-subpotency-aporia/undecidability/dilemma/ought-

indeterminacy/deficiency/limitation/constraint to be conceptually

superseded/overcome in transcendence-and- 
sublimity/sublimation/supererogatory-de-mentativity as is the case with all true science/ontology so-reflected in their historiality/ontologicaleventfulness 38 ontological-aesthetic-tracing-<perspective-ontologicalnormalcy/postconvergence-reflected-'epistemicity-relativismdeterminism'> (consider in this regards the apriorising/axiomatising/referencing-\{of-"prospectively implicited_attendant-ontological-contiguity ' reducedexistentialising/contextualising/textualising_intelligibility/epistemicity/re flexivity-contiguity-<imbued-notional $\sim$ cogency $\left.>^{\prime} ;\right\}$-conflatedness ${ }^{3}-$ in \{preconverging ment by\} postconverging entailment, in reflecting the unchanging immanent-backdrop of 'implicited_attendant-ontologicalcontiguity ${ }^{\prime} \sim$ educedexistentialising/contextualising/textualising_intelligibility/epistemicity/re flexivity-contiguity-<imbued-notional $\sim$ cogency>' of recurrent aspiration for notional-contiguity/epistemic-contiguity $2<$ profoundsupererogation -of-mentally-aestheticised postconverging/dialecticalthinking -qualia-schema> across

Galilean/Cartesian/Newtonian/Leibnizian physics to modern-day stringtheory/loop-quantum-gravity/etc. as to existence-as-sublimatingwithdrawal/unenframing/re-ontologising,-elicited-from-prospectiveprofound-supererogation, ever always being about conceptually superseding/overcoming the physics epistemic-conception prospective human-subpotency-aporia/undecidability/dilemma/oughtindeterminacy/deficiency/limitation/constraint in producing the 'successive sublimating physics as successive <amplituding/formative- 
epistemicity>totalising/circumscribing/delineating conception of relativeunreflexivity/relative reflexivity ontological-contiguity of physics across-the-times' (as to 'the-very-same physics <amplitudinglformativeepistemicity>totalising devolved—purview/domain-of-construal-asintrinsic-reality/ontological-veridicality/existential-reality') rather than an apriorising/axiomatising/referencing-\{of-'prospectively implicited_attendant-ontological-contiguity ' reducedexistentialising/contextualising/textualising_intelligibility/epistemicity/re flexivity-contiguity-<imbued-notional $\sim$ cogency $>$ ' ' - constitutedness ${ }^{14}$ in preconverging entailment disposition for the mere articulation of idle/single 'isms-conceptualisations mere conceptual-patterning-_asdevoid-of-'prospectively_implicited_attendant-ontologicalcontiguity ' reducedexistentialising/contextualising/textualising_intelligibility/epistemicity/re flexivity-contiguity-<imbued-notional cogency>' 's-reifying-orelucidating-of-'prospective-relative-ontological-completeness ';-sorather-enabled-<by-a- nonpresencing-divulging-of-momentoushistoriality/ontological-eventfulness /ontological-aesthetic-tracing$<$ perspective-ontological-normalcy/postconvergence-reflected'epistemicity-relativism-determinism'> J' as of elaboration-as-to-mereextrapolating/constituting/abstracting/deducing/inferring-of-elucidationoutside-'prospectively implicited_attendant-ontologicalcontiguity ${ }^{\prime} \sim$ educedexistentialising/contextualising/textualising_intelligibility/epistemicity/re flexivity-contiguity-<imbued-notional $\sim$ cogency >' lacking 
<amplituding/formative-

epistemicity $>$ totalising/circumscribing/delineating profound-andcontiguous knowledge-reification -gesturing-and-accounting-ofepistemic-phenomenalism-<in-

prospective psychologismic $\sim$ apriorising/axiomatising/referencing-\{of'prospectively implicited_attendant-ontological-contiguity ' reducedexistentialising/contextualising/textualising_intelligibility/epistemicity/re flexivity-contiguity-<imbued-notional $\sim$ cogency $>$ ' \}-conflatedness in \{preconverging ment by\} postconverging entailment $>$ and in fact one of the most critical/challenging epistemic concern of physicists today given the increasing theoretical abstraction is in preempting such a development of a conceptualising that poorly aligns with the epistemictotality of 'implicited_attendant-ontological-contiguity ' educedexistentialising/contextualising/textualising_intelligibility/epistemicity/re flexivity-contiguity-<imbued-notional cogency>' however difficult the available experimental possibilities for portraying prospective sublimation, and it should further be noted here that the successive sublimating physics across-the-times 'are of complementary historiality/ontological-eventfulness $3 \%$ ontological-aesthetic-tracing$<$ perspective-ontological-normalcy/postconvergence-reflected'epistemicity-relativism-determinism'> and rather so as successive <amplitudingfformativeepistemicity>totalising/circumscribing/delineating profound-andcontiguous knowledge-reification gesturing-and-accounting-ofepistemic-phenomenalism-<in- 
prospective psychologismic apriorising/axiomatising/referencing-\{of'prospectively implicited_attendant-ontological-contiguity ' reducedexistentialising/contextualising/textualising_intelligibility/epistemicity/re flexivity-contiguity-<imbued-notional $\sim$ cogency>' ' '-conflatedness in \{preconverging ment by, postconverging entailment> and 'not any naïve shallow-minded comparison of commonality of 'ismsconceptualisations mere conceptual-patterning-_as-devoid-of'prospectively_implicited_attendant-ontological-contiguity ' reducedexistentialising/contextualising/textualising_intelligibility/epistemicity/re flexivity-contiguity-<imbued-notional cogency >' 's-reifying-orelucidating-of-'prospective-relative-ontological-completeness ';-sorather-enabled-<by-a- nonpresencing-divulging-of-momentoushistoriality/ontological-eventfulness /ontological-aesthetic-tracing$<$ perspective-ontological-normalcy/postconvergence-reflected'epistemicity-relativism-determinism'>)' failing priorly to disambiguate the successive knowledge-reification gesturing-and-accounting-ofepistemic-phenomenalism- $<$ inprospective psychologismic $\sim$ apriorising/axiomatising/referencing-\{of'prospectively_implicited_attendant-ontological-contiguity ' reducedexistentialising/contextualising/textualising_intelligibility/epistemicity/re flexivity-contiguity-<imbued-notional $\sim \operatorname{cogency}>^{\text {' }}$, '-conflatedness in \{preconverging ment by\} postconverging entailment> across-thetimes as preceding-and-framing any given concepts' like failing to realise that the 'notion of time in physics' priorly speaks to different physics 'knowledge-reification gesturing-and-accounting-of-epistemic- 
phenomenalism- $<$ in-

prospective psychologismic apriorising/axiomatising/referencing-\{of'prospectively_implicited_attendant-ontological-contiguity ' reducedexistentialising/contextualising/textualising_intelligibility/epistemicity/re flexivity-contiguity-<imbued-notional $\sim$ cogency> ' , -conflatedness in-\{preconverging-ment by\} postconverging-entailment $>$ in relativeunreflexivity/relative reflexivity ontological-contiguity in reflection of 'implicited_attendant-ontological-contiguity ' reducedexistentialising/contextualising/textualising_intelligibility/epistemicity/re flexivity-contiguity-<imbued-notional $\sim$ cogency>' as of 'relativeontological-incompleteness /relative-ontological-completeness (sublimating referencing/registering/decisioning,-as-self-becoming/selfconflatedness /formative-supererogating-<projective/reprojectiveaestheticising-re-motif-and-re-apriorising/re-axiomatising/rereferencing,-in-perspective-ontological-normalcy/postconvergence $>\mid$ as to human-and-social-expectations/anticipations - metaphoricity -aspreconverging/postconverging-redementating/restructuring/reparadigming-psychologism' across-the-times with respect to physics relative-ontological-completeness conception as from pre-Newtonian/Leibnizian notion of time, Newtonian/Leibnizian notion of time, Einsteinian notion of time in terms of spacetime up to present-day physics theories notion of time in terms of further developments as from a big-bang-theory insights reflecting the epistemicveracity that there is no sound concept and conceptualising without the 'priorly projected notional-contiguity/epistemic-contiguity $-<$ profound- 
supererogation -of-mentally-aestheticised postconverging/dialectical-

thinking -qualia-schema> in reflection of 'implicited_attendant-

ontological-contiguity ' educed-

existentialising/contextualising/textualising_intelligibility/epistemicity/re

flexivity-contiguity-<imbued-notional cogency $>$ and as of the

relative-ontological-completeness implied profoundness' within which

any such concept and conceptualising is articulated and 'this effectively

contrasts with such apriorising/axiomatising/referencing-\{of-

'prospectively implicited_attendant-ontological-contiguity ' reduced-

existentialising/contextualising/textualising_intelligibility/epistemicity/re

flexivity-contiguity-<imbued-notional $\sim$ cogency $>^{\prime}$, '-constitutedness ${ }^{4}-$

in preconverging entailment disposition naïve shallow-minded isms-

conceptualisations mere conceptual-patterning-_as-devoid-of-

'prospectively implicited_attendant-ontological-contiguity ' educed-

existentialising/contextualising/textualising_intelligibility/epistemicity/re

flexivity-contiguity-<imbued-notional cogency>' 's-reifying-or-

elucidating-of-'prospective-relative-ontological-completeness ';-so-

rather-enabled-<by-a- nonpresencing-divulging-of-momentous-

historiality/ontological-eventfulness /ontological-aesthetic-tracing-

$<$ perspective-ontological-normalcy/postconvergence-reflected-

'epistemicity-relativism-determinism'>)' that equates/level-down

everything across space and time as to wrongly imply everything is of the

same notional-contiguity/epistemic-contiguity $-<$ profound-

supererogation -of-mentally-aestheticised postconverging/dialectical-

thinking -qualia-schema> (as of undisambiguated relative- 
unreflexivity/relative reflexivity ontological-contiguity as to relativeontological-incompleteness -of-apriorising/axiomatising/referencing and relative-ontological-completeness ${ }^{87}$-ofapriorising/axiomatising/referencing thus inducing 'apriorising/axiomatising/referencingequating/leveling/ressentiment/closed-construct-of- ${ }^{5}$ meaningfulnessand-teleology moronisation-<sublimating-nascence,-extricatory desublimating-downstreaming/'avalage'>') thus with a poor grasp of 'knowledge-reification gesturing-and-accounting-of-epistemicphenomenalism- $<$ inprospective psychologismic $\sim$ apriorising/axiomatising/referencing-\{of'prospectively_implicited_attendant-ontological-contiguity ' reducedexistentialising/contextualising/textualising_intelligibility/epistemicity/re flexivity-contiguity-<imbued-notional $\sim$ cogency $>$ ' \}-conflatedness in \{preconverging ment by\} postconverging entailment $>$ in a veridical

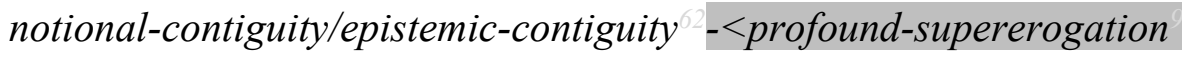
of-mentally-aestheticised postconverging/dialectical-thinking -qualiaschema> reflection of implicited_attendant-ontologicalcontiguity ${ }^{\prime}$ educedexistentialising/contextualising/textualising_intelligibility/epistemicity/re flexivity-contiguity-<imbued-notional $\sim$ cogency>' as of 'relativeontological-incompleteness /relative-ontological-completeness (sublimating referencing/registering/decisioning,-as-self-becoming/selfconflatedness /formative-supererogating-<projective/reprojectiveaestheticising-re-motif-and-re-apriorising/re-axiomatising/re- 
referencing,-in-perspective-ontological-normalcy/postconvergence $>>$ as to human-and-social-expectations/anticipations-metaphoricity -aspreconverging/postconverging-redementating/restructuring/reparadigming-psychologism, and so 'as to a superficiality and ontological-bad-faith/inauthenticity ${ }^{64}$ that is patently incapable of construing underlying human <amplitudinglformativeepistemicity>-totalising thrownness-in-existence ${ }^{35}$ relevant humansubpotency-aporia/undecidability/dilemma/oughtindeterminacy/deficiency/limitation/constraint to be superseded and rather often directly/indirectly contravene/disregard such re-originary parrhesiastic insights' (as so-often instigated with such idle/single 'ismsconceptualisations mere conceptual-patterning-_as-devoid-of'prospectively implicited_attendant-ontological-contiguity ' reducedexistentialising/contextualising/textualising_intelligibility/epistemicity/re flexivity-contiguity-<imbued-notional $\sim$ cogency $>$ ' 's-reifying-orelucidating-of-'prospective-relative-ontological-completeness ' ';-sorather-enabled-<by-a- nonpresencing-divulging-of-momentoushistoriality/ontological-eventfulness /ontological-aesthetic-tracing$<$ perspective-ontological-normalcy/postconvergence-reflected'epistemicity-relativism-determinism'>)' in apriorising/axiomatising/referencing-\{of- 'prospectively implicited_attendant-ontological-contiguity ' educedexistentialising/contextualising/textualising_intelligibility/epistemicity/re flexivity-contiguity-<imbued-notional $\sim$ cogency $>^{\prime}$; -constitutedness ${ }^{14}-$ in preconverging entailment as of elaboration-as-to-mere- 
extrapolating/constituting/abstracting/deducing/inferring-of-elucidationoutside-'prospectively_implicited_attendant-ontological-

contiguity ${ }^{\prime} \sim$ educed-

existentialising/contextualising/textualising_intelligibility/epistemicity/re

flexivity-contiguity-<imbued-notional $\sim$ cogency>' ) and which in so

doing do not satisfy foregrounding_entailment-<in-succession-of-

profound-supererogation $>-$ (postconverging-narrowing-

down sublimation-as-to- 'existence-as-sublimating-

withdrawal/unenframing/re-ontologising,-elicited-from-prospective-

profound-supererogation '-in-reflecting-'immanent felative-

unreflexivity/relative-reflexivity ontological-contiguity ';-as-operative-

notional deprocrypticism/as to '<emplitudinglformative-

epistemicity>totalising/circumscribing/delineating 'implicited_attendantontological-contiguity ${ }^{\prime}$ 'educed-

existentialising/contextualising/textualising_intelligibility/epistemicity/re

flexivity-contiguity-<imbued-notional $\sim$ cogency $>$ ' in elucidating

relative unreflexivity/relative reflexivity ontological-contiguity $-<a s-$

from-prospective-ontological-normalcy/postconvergence-epistemic-or-

notional projective-perspective > ' with the consequence of failing/poorly

reflecting the 'requisite ontologically-pertinent dynamic theoretical-

conceptual-operant depth/profoundness for addressing subject-matters

as epistemic-conceptions as to their given/defined human-subpotency-

aporia/undecidability/dilemma/ought-

indeterminacy/deficiency/limitation/constraint with respect to

originariness-parrhesia,-as-spontaneity-of-aestheticisation- 
supererogatory acuity/perspicacity/astuteness/edginess/incisiveness-ofapriorising/axiomatising/referencing/intelligibilitysettingup/measuringins trumenting -for-conceptualisation'), with foregrounding_entailment$<$ in-succession-of-profound-supererogation ${ }^{>}>$- postconvergingnarrowing-down sublimation-as-to-'existence - as-sublimatingwithdrawal/unenframing/re-ontologising,-elicited-from-prospectiveprofound-supererogation '-in-reflecting- 'immanent relativeunreflexivity/relative reflexivity ontological-contiguity ';-as-operativenotional deprocrypticism) operantly implying 'drawing out the full <amplitungformativeepistemicity>totalising/circumscribing/delineating implications of assertions/claims/conceptualisations as of notional-contiguity/epistemiccontiguity 2 profound-supererogation -of-mentallyaestheticised postconverging/dialectical-thinking -qualia-schema $>$ in reflection of 'implicited_attendant-ontological-contiguity ' reducedexistentialising/contextualising/textualising_intelligibility/epistemicity/re flexivity-contiguity-<imbued-notional cogency>' such that there is hardly any notional disjointedness of the assertions/claims/conceptualisations as validating their ontologicalveracity'; on-the-other-hand, the 'knowledge-reification gesturing-andaccounting_of-epistemic-phenomenalism-<inprospective psychologismic apriorising/axiomatising/referencing-\{of'prospectively_implicited_attendant-ontological-contiguity ' reducedexistentialising/contextualising/textualising_intelligibility/epistemicity/re flexivity-contiguity-<imbued-notional $\sim$ cogency $>$ ' \}-conflatedness 
in \{preconverging ment by\} postconverging entailment $>$ in notional-

contiguity/epistemic-contiguity $-<$ profound-supererogation -of-

mentally-aestheticised postconverging/dialectical-thinking -qualia-

schema $>$ in reflection of 'implicited_attendant-ontological-

contiguity ' $\sim$ educed-

existentialising/contextualising/textualising_intelligibility/epistemicity/re

flexivity-contiguity-<imbued-notional $\sim \operatorname{cogency}>$ ' as of 'relative-

ontological-incompleteness /relative-ontological-completeness

(sublimating referencing/registering/decisioning,-as-self-becoming/self-

conflatedness /formative-supererogating-<projective/reprojective-

aestheticising-re-motif-and-re-apriorising/re-axiomatising/re-

referencing,-in-perspective-ontological-normalcy/postconvergence > / as

to human-and-social-expectations/anticipations-metaphoricity -as-

preconverging/postconverging-rede-

mentating/restructuring/reparadigming-psychologism' implied with

deconstruction, genealogy and other critical theory practices are meant

to articulate ${ }^{5}$ meaningfulness-and-teleology /conceptualisations by their derivation/delineation/disambiguation as from human epistemic-

embeddedness in existence so-construed as <amplituding/formative-

epistemicity>-totalising thrownness-in-existence (as to the

phenomenological aspiration/possibility for overcoming imbued

deficiency construed as metaphysics-of-presence-_implicited-

'nondescript/ignorable-void '-as-to- presencing - absolutising-

identitive-constitutedness J, and so as defining/given human-

subpotency-aporia/undecidability/dilemma/ought- 
indeterminacy/deficiency/limitation/constraint originariness-parrhesia,-as-spontaneity-of-aestheticisation-

supererogatory acuity/perspicacity/astuteness/edginess/incisiveness-ofapriorising/axiomatising/referencing/intelligibilitysettingup/measuringins trumenting -for-conceptualisation) for reflecting 'relative-ontologicalincompleteness /relative-ontological-completeness (sublimating referencing/registering/decisioning,-as-self-becoming/selfconflatedness /formative-supererogating-<projective/reprojectiveaestheticising-re-motif-and-re-apriorising/re-axiomatising/rereferencing,-in-perspective-ontological-normalcy/postconvergence $>>$ as to human-and-social-expectations/anticipations-metaphoricity -aspreconverging/postconverging-redementating/restructuring/reparadigming-psychologism underlying knowledge-reification -gesturing-and-accounting-of-epistemicphenomenalism- $<$ inprospective psychologismic $\sim$ apriorising/axiomatising/referencing-\{of'prospectively_implicited_attendant_ontological-contiguity ' reducedexistentialising/contextualising/textualising_intelligibility/epistemicity/re flexivity-contiguity-<imbued-notional $\sim$ cogency $>$ ' \}-conflatedness in \{preconverging ment by\} postconverging entailment>, such that inmany-ways the poor appreciation of postmodern-thought is very much associated with their critics fundamentally poor grasp of the precedence of 'knowledge-reification gesturing-and-accounting-of-epistemicphenomenalism-<inprospective_psychologismic apriorising/axiomatising/referencing-\{of- 
'prospectively_implicited_attendant-ontological-contiguity ' reducedexistentialising/contextualising/textualising_intelligibility/epistemicity/re flexivity-contiguity-<imbued-notional $\sim$ cogency> ' \}, conflatedness in \{preconverging ment by\} postconverging entailment $>$ in notionalcontiguity/epistemic-contiguity $-<$ profound-supererogation -ofmentally-aestheticised postconverging/dialectical-thinking -qualiaschema $>$ in reflection of 'implicited_attendant-ontologicalcontiguity ' $\sim$ educedexistentialising/contextualising/textualising_intelligibility/epistemicity/re flexivity-contiguity-<imbued-notional $\sim$ cogency>' as of 'relativeontological-incompleteness /relative-ontological-completeness (sublimating referencing/registering/decisioning,-as-self-becoming/selfconflatedness /formative-supererogating-<projective/reprojectiveaestheticising-re-motif-and-re-apriorising/re-axiomatising/rereferencing,-in-perspective-ontological-normalcy/postconvergence $>\mid$ as to human-and-social-expectations/anticipations - metaphoricity -aspreconverging/postconverging-redementating/restructuring/reparadigming-psychologism, over mere apriorising/axiomatising/referencing-\{of- 'prospectively implicited_attendant-ontological-contiguity ' educedexistentialising/contextualising/textualising_intelligibility/epistemicity/re flexivity-contiguity-<imbued-notional $\sim$ cogency $>$ ' ' '-constitutedness ${ }^{14}$ in preconverging entailment shallow-minded articulation of conceptualisations with a poor sense of 'relative-ontologicalincompleteness /relative-ontological-completeness 
(sublimating referencing/registering/decisioning,-as-self-becoming/self-

conflatedness /formative-supererogating-<projective/reprojective-

aestheticising-re-motif-and-re-apriorising/re-axiomatising/re-

referencing,-in-perspective-ontological-normalcy/postconvergence $>>$ as

to human-and-social-expectations/anticipations-metaphoricity -as-

preconverging/postconverging-rede-

mentating/restructuring/reparadigming-psychologism "', as so-

exemplified with naïve truth accusations lacking in the veridical

epistemic-projection of " nonpresencing-<perspective-ontological-

normalcy/postconvergence $>$ relativism/relative-scope for epistemic-

growth,-as-\{veridical/sound?-relative-reflexivity-in-

existencetrelativising from limited mentation as its-

deepening/psychologismic epistemic acutisation residualising,

\{decompulsing delinearity for cogency' as to the weirdly and wrongly implied

posture that human limited-mentation-capacity-deepening-as-

subjecting-limitedness/human-subpotency-to-'educed-

tunlimitedness/existence sublimating nascence' doesn't occur; 1 and the specific articulation herein by this author is rather of a profound 'knowledge-reification gesturing-and-accounting-of-epistemicphenomenalism-<in-

prospective psychologismic apriorising/axiomatising/referencing-\{of'prospectively implicited_attendant-ontological-contiguity ' reducedexistentialising/contextualising/textualising_intelligibility/epistemicity/re flexivity-contiguity-<imbued-notional cogency >' \}-conflatedness in \{preconverging ment by\} postconverging entailment $>$ in notional- 
contiguity/epistemic-contiguity $-<$ profound-supererogation -ofmentally-aestheticised postconverging/dialectical-thinking -qualiaschema $>$ in reflection of 'implicited_attendant-ontologicalcontiguity ' ' educedexistentialising/contextulising/textualising_intelligibility/epistemicity/re flexivity-contiguity-<imbued-notional $\sim$ cogency>' as of 'relativeontological-incompleteness /relative-ontological-completeness (sublimating referencing/registering/decisioning,-as-self-becoming/selfconflatedness /formative-supererogating-<projective/reprojectiveaestheticising-re-motif-and-re-apriorising/re-axiomatising/rereferencing,-in-perspective-ontological-normalcy/postconvergence $>>$ as to human-and-social-expectations/anticipations - metaphoricity -aspreconverging/postconverging-redementating/restructuring/reparadigming-psychologism as reflecting ‘ $<$ amplitudingfformativeepistemicity>totalising/circumscribing/delineating 'implicited_attendantontological-contiguity ' $\sim$ educedexistentialising/contextualising/textualising_intelligibility/epistemicity/re flexivity-contiguity-<imbued-notional $\sim$ cogency $>$ foregrounding_entailment-<in-succession-of-profoundsupererogation $>$ - (postconverging-narrowing-down $\sim$ sublimation-as-to'existence - as-sublimating-withdrawal/unenframing/re-ontologising,elicited-from-prospective-profound-supererogation '-in-reflecting'immanent relative unreflexivity/relative reflexivity ontologicalcontiguity ';-as-operative-notional deprocrypticism/in elucidating 
relative unreflexivity/relative reflexivity -ontological-contiguity

from-prospective-ontological-normalcy/postconvergence-epistemic-or-

notional projective-perspective> ' prompted

derivation/delineation/disambiguation of conceptualisations in

apriorising-conflatedness -as-to-difference (over-and-undermining

apriorising/axiomatising/referencing-\{of-"prospectively

implicited_attendant_ontological-contiguity ' reduced-

existentialising/contextualising/textualising_intelligibility/epistemicity/re

flexivity-contiguity-<imbued-notional $\sim$ cogency> ' \}-constitutedness ${ }^{4}$ -

in preconverging entailment as-to-absolutising-identity) with regards to

the conceptual 'overcoming of metaphysics-of-presence-_implicited-

'nondescript/ignorable-void '-as-to- presencing-absolutising-

identitive-constitutedness / intermediating-ascriptivity or ${ }^{58}$ neuterising

of human ${ }^{5}$ meaningfulness-and-teleology apriorising

conceptualisation' (so-articulated from the 'deepest phenomenological

transcendental-point-of-departure handle as of the

notional conflatedness of notional deprocrypticism deneuterising referentialism or deascriptivity' as from the ontological-

normalcy/postconvergence epistemic-projection perspective and in

reflecting the 'temporal-to-intemporal-notional-binarity of human

ontological-performance ${ }^{2}-<$ including-virtue-as-

ontology >/morality/ethics/justice/etc. at uninstitutionalised-threshold

in the face of prospective human-subpotency-

aporia/undecidability/dilemma/ought-

indeterminacy/deficiency/limitation/constraint' and so-construed as 
human-subpotency-aporia/undecidability/dilemma/ought-

indeterminacy/deficiency/limitation/constraint—imbued-

'notional firstnaturedness-formativeness-<as to-eventualising inkling

drive or seeding misprising > temporal-to-intemporal-dispositions-

$<$ so-construed-as-from-perspective-ontological-

normalcy/postconvergence $>$ '-existentialism-form-factor), so-

underscored by human limited-mentation-capacity-deepening-as-

subjecting limitedness/human subpotency to 'educed-

unlimitedness/existence sublimating nascence' as of de-mentation-

(supererogatory-ontological-de-mentation-or-dialectical-de-

mentation-stranding-or-attributive-dialectics >implied

'notional symmetrisation-<as-to-symmetrisation-by-desymmetrisation,in-reflecting-postconverging-or-dialectical-thinking -by-preconvergingor-dementing $\sim$ perspectives-of-human- ${ }^{5}$ meaningfulness-andteleology $>$ of the <cumulating/recomposuring attendant-ontologicalcontiguity >-successive registry-worldviews/dimensions ${ }^{83}$ reference-ofthought-and- reference-of-thought- devolving- ${ }^{5}$ meaningfulness-andteleology' as to their 'aestheticisation-and-aestheticisation-towardsontology-<elicited-idiomatisation $>$ of human ontological-performance ${ }^{72}$ <including-virtue-as-ontology> '; (as to 'human Beingdevelopment/ontological-framework-expansion-as-to-depth-ofontologising-development-as-infrastructure-of- meaningfulness-andteleology , institutional-development-as-to-social-function-development and living-development-as-to-personality-development psychologismic epistemic acutisation difficuly<<for, residualising 
\{decompulsing' delinearity for cogency>magnitudes (of-experientiality/experiment\}') in notionally/epistemically/bindingnessly-<as-to-determinism/conceptivity-of relativeconstruing the ontological-performance <including-virtue-as-ontology>/morality/ethics/justice/etc. of human limited-mentation-capacity-deepening - as subjecting limitedness/humansubpotency-to-'educed-unlimitedness/existence-sublimating nascence' implied <cumulating/recomposuring attendant-ontologicalcontiguity >-successive registry-worldviews/dimensions translated as the various specifically given descalarising of the 'scalarity/immanency of existence's ontological-normalcy/postconvergence' (as to the specific neuterising/ascriptivities construed as specifically given 'humansubpotency nonscalarity/beholdening-<as-to-what-has-gone-beforeaestheticallystructures/paradigms-distortedly-the-possibility-for-thelaterontologisation>') and so-reflected respectively as recurrent-utteruninstitutionalisation '<emplitudingfformativeepistemicity>totalising random-as-impulsive- implicited_attendantontological-contiguity ' educedexistentialising/contextualising/textualising_intelligibility/epistemicity/re flexivity-contiguity-<imbued-notional $\sim$ cogency $>$ 'descalarising, baseinstitutionalisation-ununiversalisation '<amplituding/formativeepistemicity>totalising nominal-as-tendentious_- implicited_attendantontological-contiguity $\sim$ ' educed-

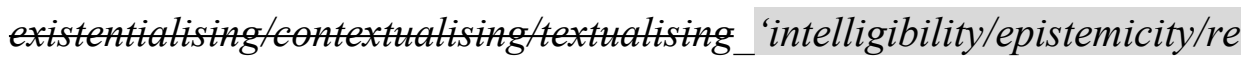
flexivity-contiguity-<imbued-notional $\sim \operatorname{cogency}>^{\prime}$ descalarising, universalisation-non-positivism/medievalism 
'<amplitudingfformative-epistemicity >totalising ordinal-as-qualifying'implicited_attendant-ontological-contiguity ' reducedexistentialising/contextualising/textualising_intelligibility/epistemicity/re flexivity-contiguity-<imbued-notional cogency >' descalarising and positivism- ${ }^{80}$ procrypticism '<emplituding/formativeepistemicity >totalising intervalist-as-categorising'implicited_attendant-ontological-contiguity ' reducedexistentialising/contextualising/textualising_intelligibility/epistemicity/re flexivity-contiguity-<imbued-notional cogency>' descalarising while paradoxically wrongly assuming (as to their <amplitudingfformativeepistemicity>totalising $\sim$ self-referencingsyncretising/circularity/interiorising/akrasiatic-drag ${ }^{34}$ ) the ontologicalperformance ${ }^{72}<$ including-virtue-asontology>/morality/ethics/justice/etc. of the 'scalarity/immanency of existence's ontological-normalcy/postconvergence' so-implied veridically as to the deneuterising /deascriptivity of deprocrypticism-orpreempting - disjointedness-as-of- reference-of-thought ‘ amplituding/formativeepistemicity>totalising ratiocontiguity/ratiocination-as-referentialism'implicited_attendant-ontological-contiguity' reducedexistentialising/contextualising/textualising_intelligibility/epistemicity/re flexivity-contiguity-<imbued-notional cogency> ${ }^{\text {' }}$ scalarising; - (thus 'scalarising of human ${ }^{56}$ meaningfulness-and-teleology' effectively speaks of ontological-normalcy/postconvergence epistemic-projection perspective as to nonpresencing-<perspective-ontological- 
normalcy/postconvergence> implications while 'descalarising of human 'meaningfulness-and-teleology' effectively speaks of epistemicabnormalcy/preconvergence epistemic-projection perspective as to the specifically given presencing-absolutising-identitive-constitutedness registry-worldview/dimension), and it should be noted as well that besides the defining descalarising of any specifically given registryworldview/dimension as ${ }^{8}$ reference-of-thought epistemic-totality of meaningfulness-and-teleology, the

$<$ cumulating/recomposuring attendant-ontological-contiguity successive registry-worldviews/dimensions as to their reference-ofthought- devolving further involve 'devolving descalarising and scalarising of human ${ }^{56}$ meaningfulness-and-teleology ' (that is, descalarising as to epistemic-devolving random-as-impulsive'implicited_attendant-ontological-contiguity ' reducedexistentialising/contextualising/textualising_intelligibility/epistemicity/re flexivity-contiguity-<imbued-notional $\sim$ cogency $>$, epistemic-

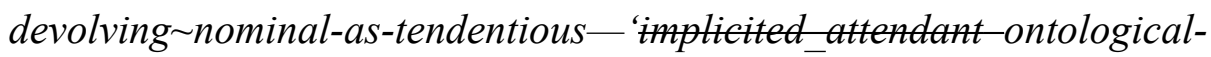
contiguity $\stackrel{\sim}{\sim}$ educedexistentialising/contextualising/textualising_intelligibility/epistemicity/re flexivity-contiguity-<imbued-notional cogency>', epistemicdevolving ordinal-as-qualifying_implicited_attendant-ontologicalcontiguity $\sim$ ' educed-

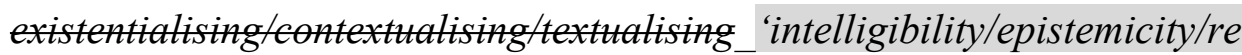
flexivity-contiguity-<imbued-notional $\sim$ cogency $>$ ', epistemicdevolving intervalist-as-categorising_ 'implicited_attendant- 
ontological-contiguity ' educed-

existentialising/contextualising/textualising_intelligibility/epistemicity/re flexivity-contiguity-<imbued-notional $\sim$ cogency $>$ ' and scalarising as to epistemic-devolving ratiocontiguity/ratiocination-as-referentialism'implicited_attendant-ontological-contiguity ' 'educedexistentialising/contextmalising/textualising_intelligibility/epistemicity/re flexivity-contiguity-<imbued-notional cogency>') reflecting the manifest specifically given registry-worldview/dimension ontologicalperformance ${ }^{72}-<$ including-virtue-asontology>/morality/ethics/justice/etc. of human ${ }^{5}$ meaningfulness-andteleology with regards to 'human living-development-as-to-personalitydevelopment and human institutional-development-as-to-social-functiondevelopment', as rather so-devolving conjugatively under the specifically given and defining registry-worldview/dimension reference-of-thought descalarising as epistemic-totality of meaningfulness-and-teleology implied 'human Being-development/ontological-framework-expansionas-to-depth-of-ontologising-development-as-infrastructure-ofmeaningfulness-and-teleology ' (reflecting the ontological-veracity of 'human notional firstnaturedness-formativeness-<as toeventualising inkling drive or seeding misprising>-temporal-tointemporal-dispositions-<so-construed-as-from-perspective-ontologicalnormalcy/postconvergence $>$ accordioning-las-of-varying-individuationscontextually-transverse-desublimation/sublimation,-as-to-thewavering/redounding/waveforming of-their-referencing-and-theirdevolved-referencing-imbued-ontological-performance -<including- 
virtue-as-ontology>/ at uninstitutionalised-threshold ${ }^{02}$ as reflecting both desublimating historicity-tracing_in-presencinghyperrealisation/hyperreal-transposition and sublimating historiality/ontological-eventfulness 38 ontological-aesthetic-tracing$<$ perspective-ontological-normalcy/postconvergence-reflected'epistemicity-relativism-determinism'> possibilities'); 9 thus in-thebigger-scheme-of-things, the more thoroughly profound/fundamental deprocrypticism-or-preempting-disjointedness-as-of- reference-ofthought issue is about the notional-contiguity/epistemic-contiguity $<$ profound-supererogation -of-mentallyaestheticised postconverging/dialectical-thinking -qualia-schema> (as of '<amplitudinglformativeepistemicity>totalising/circumscribing/delineating 'implicited_attendantontological-contiguity ${ }^{\text {' }}$ educedexistentialising/contextualising/textualising_intelligibility/epistemicity/re flexivity-contiguity-<imbued-notional $\sim$ cogency $>$ foregrounding_entailment-<in-succession-of-profoundsupererogation $>$ - (postconverging-narrowing-down $\sim$ sublimation-as-to'existence — as-sublimating-withdrawal/unenframing/re-ontologising,elicited-from-prospective-profound-supererogation '-in-reflecting'immanent relative unreflexivity/relative reflexivity ontologicalcontiguity ';-as-operative-notional deprocrypticism/in elucidating relative unreflexivity/relative reflexivity ontological-contiguity $-<$ asfrom-prospective-ontological-normalcy/postconvergence-epistemic-ornotional projective-perspective $>$ ) of assertions/claims articulated in 
today's pedantising/muddling/formulaic-hollowing-out-in-

subontologisation/subpotentiation-_blurring/undermining-of-prospectivetotalising-entailing,-as-to-entailing-<amplitudingfformativeepistemicity>totalising in-relative-ontological-completeness । institutional-being-and-craft ladened (beyond-the-consciousnessawareness-teleology $<$ of-preconverging-existential-extrication-as-ofexistential-unthought>) with sophistic strategies of empty/vague process and pedantising/muddling/formulaic-hollowing-out-insubontologisation/subpotentiation-bblurring/undermining-of-prospectivetotalising-entailing,-as-to-entailing-<amplituding/formativeepistemicity>totalising in-relative-ontological-completeness I, vague sensibility/decorum-drivenness, providing credence to frivolity over equanimity, emotional gimmickiness/manipulation as well as surreptitious practices of perfidious/double-dealing/betraying as to 'dilutive/drowning and sabotaging imposturing/jumbling/sleight in undermining prospective genuine knowledge-reification $\sim$ gesturing-andaccounting-of-epistemic-phenomenalism-<inprospective psychologismic $\sim$ apriorising/axiomatising/referencing-\{of'prospectively implicited_attendant-ontological-contiguity ' educed-

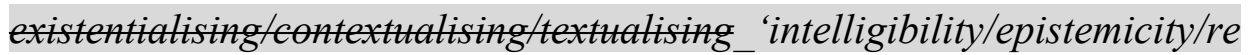
flexivity-contiguity-<imbued-notional cogency> ' \} - conflatedness in \{preconverging ment by\} postconverging entailment>' for agendadriven deceitful/dastardly/scheming purposes in proximity with deceptive supposedly objectively mediative institutions, and so as to underlying ontological-bad-faith/inauthenticity $\sim$ preconverging-de- 
mentating/structuring/paradigming inducing a social intellectual impotency undermining the supposed purpose of veridically cumulating/expanding the breadth of human knowledge as to an intellectual potency that never/hardly comes but for its institutionalbeing-and-craft human-subpotency agency (in disparateness-ofconceptualisation-<unforegrounding-ment,-failing-prospectively-toreflect- immanent relative unreflexivity/relative reflexivity ontologicalcontiguity '>) substituting for and in-many-ways not exposed to the sublimating-validation/desublimating-invalidation of existencepotency $\sim$ sublimating-nascence,-disclosed-from-prospective-epistemicdigression, so-associated with sycophantic beholdenness to socially dominant vested-interests/actors reflecting an underlying overall procrypticism-or-disjointedness-as-of- reference-of-thought <amplitudinglformative $>$ wooden-language-fimbued-temporal-mereform/virtualities/dereification/akrasiatic-drag/denatured/preconvergingor-dementing -narratives-of-the- reference-of-thought-categoricalimperatives/axioms/registry-teleology |; $\mid$ as the evaluation of assertions/claims as to such a prospective deprocrypticism-orpreempting —disjointedness-as-of- reference-of-thought projected notional-contiguity/epistemic-contiguity $-<$ profound-supererogation of-mentally-aestheticised postconverging/dialectical-thinking -qualiaschema $>$ overcoming procrypticism-or-disjointedness-as-ofreference-of-thought blurriness-

$<$ sterilising/anecdotalising/trivialising-of-prospective-reontologising_by-preconverging,-in-disontologising-formulaic-dragging- 
out/hollowing-out $>$ of meaningfulness-and-teleology is rather of foregrounding_entailment-<in-succession-of-profound-

supererogation $>$ - (postconverging-narrowing-down $\sim$ sublimation-as-to'existence-as-sublimating-withdrawal/unenframing/re-ontologising,elicited-from-prospective-profound-supererogation '-in-reflecting'immanent relative unreflexivity/relative reflexivity ontologicalcontiguity ';-as-operative-notional deprocrypticism/and strictlydefined as of "notional deprocrypticism originariness-parrhesia,-asspontaneity-of-aestheticisation-

acuity/perspicacity/astuteness/edginess/incisiveness-ofapriorising/axiomatising/referencing/intelligibilitysettingup/measuringins trumenting -for-conceptualisation' so-reflected as of deprocrypticismapriorising/axiomatising/referencing-psychologism enculturated/constructed social-pragmatics-framing-of-predicativeeffectivity-sublimation-〈as-to-underlying,-ontological-commitment $<$ implied-self-assuredness-of-ontological-goodfaith/authenticity $~ p o s t c o n v e r g i n g-d e-$ mentating/structuring/paradigming -as-being-as-of-existential-reality>> construed-as 'preempting - disjointedness-as-of- reference-of-thought,-

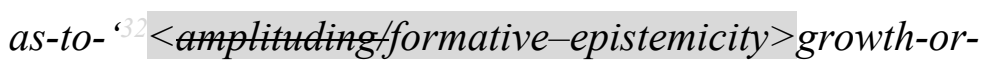
conflatedness $/$ transvaluativerationalising/transepistemicity/anamnestic-residuality/spiritdrivenness'-in-superseding-mere-formulaic-positivising/rationalempiricism-based-universalisation-directed-rulemaking-over-non-rulesapriorising/axiomatising/referencing-psychologism' given 'relative 
<amplituding/formative-

epistemicity>totalising/circumscribing/delineating 'implicited_attendantontological-contiguity ' educed-

existentialising/contextualising/textualising_intelligibility/epistemicity/re

flexivity-contiguity-<imbued-notional $\sim \operatorname{cogency}>$

foregrounding_entailment-<in-succession-of-profound-

supererogation $>-$ - postconverging-narrowing-down $\sim$ sublimation-as-to-

'existence - as-sublimating-withdrawal/unenframing/re-ontologising,-

elicited-from-prospective-profound-supererogation '-in-reflecting-

'immanent relative unreflexivity/relative reflexivity ontological-

contiguity ';-as-operative-notional deprocrypticism/in elucidating

relative unreflexivity/relative reflexivity ontological-contiguity $-<a s-$

from-prospective-ontological-normalcy/postconvergence-epistemic-or-

notional projective-perspective $>$ as to its prospectively induced

scalarising as of human supererogatory/messianic intemporal and

secondnatured socially-optimal instigative potency' at its given/defined

institutionalisation ontologically-pertinent epistemic-conception of 'the-

very-same overall phenomenality/manifestation of existence-as-

sublimating-withdrawal/unenframing/re-ontologising,-elicited-from-

prospective-profound-supererogation ' (and so over prior positivism-

procrypticism — apriorising/axiomatising/referencing-psychologism

enculturated/constructed social-pragmatics-framing-of-predicative-

effectivity-sublimation-\{as-to-underlying,-ontological-commitment

<implied-self-assuredness-of-ontological-good-

faith/authenticity postconverging-de- 
mentating/structuring/paradigming -as-being-as-of-existential-reality >

construed-as 'mere-formulaic-positivising/rational-empiricism-baseduniversalisation-directed-rulemaking-over-non-rulesapriorising/axiomatising/referencing-psychologism,-that-is-not-ofpreempting — disjointedness-as-of- reference-of-thought,-as-to'3 emplituding/formative-epistemicity>growth-orconflatedness $/$ transvaluativerationalising/transepistemicity/anamnestic-residuality/spiritdrivenness'-in-superseding-mere-formulaic-positivising/rationalempiricism-based-universalisation-directed-rulemaking-over-non-rulesapriorising/axiomatising/referencing-psychologism' given 'relative disparateness-of-conceptualisation-<unforegrounding-ment,-failingprospectively-to-reflect- 'immanent relative unreflexivity/relativereflexivity ontological-contiguity '> as to prior descalarising totalisingly-ing — discretion/whim-of-thought of individuals-suboptimal instigative potency as of human notional firstnaturedness-formativenesssas to eventualising inkling drive or seeding misprising> temporalto-intemporal-dispositions-<so-construed-as-from-perspectiveontological-normalcy/postconvergence $>$ accordioning-las-of-varyingindividuations-contextually-transversedesublimation/sublimation,-as-tothe-waveringtredounding/waveforming of-their-referencing-and-theirdevolved-referencing-imbued-ontological-performance -<includingvirtue-as-ontology> J' at its given/defined uninstitutionalised-threshold ontologically-deficient epistemic-conception of 'the-very-same overall phenomenality/manifestation of existence-as-sublimating- 
withdrawal/unenframing/re-ontologising,-elicited-from-prospectiveprofound-supererogation'), with the 'deprocrypticismapriorising/axiomatising/referencing-psychologism enculturated/constructed social-pragmatics-framing-of-predicativeeffectivity-sublimation-_as-to-underlying,-ontological-commitment $<$ implied-self-assuredness-of-ontological-goodfaith/authenticity postconverging-dementating/structuring/paradigming -as-being-as-of-existentialreality $>$ J' peculiarly/uniquely differentiated from the 'positivismprocrypticism — apriorising/axiomatising/referencing-psychologism enculturated/constructed social-pragmatics-framing-of-predicativeeffectivity-sublimation-_as-to-underlying,-ontological-commitment <implied-self-assuredness-of-ontological-good-

faith/authenticity postconverging-dementating/structuring/paradigming -as-being-as-of-existentialreality $>$ J' in that notional deprocrypticism as of its originariness/origination-_so-construed-as-to-ontologicalnormalcy/postconvergence-perspective-scalarising-construal-ofexistence) perspective construes of prospective knowledgereification $\sim$ gesturing-and-accounting-of-epistemic-phenomenalism$<$ in-prospective psychologismic $\sim$ apriorising/axiomatising/referencing\{of-'prospectively implicited_attendant-ontologicalcontiguity ' educed-

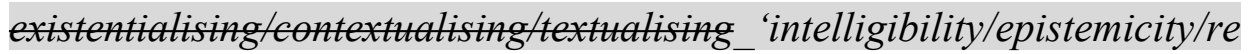


flexivity-contiguity-<imbued-notional cogency> ' \} - conflatedness

in 'fpreconverging ment by, postconverging entailment $>$ as of the 'full ontological implications of full human limited-mentation-capacitydeepening - as subjecting limitedness/human subpotency to-'educedunlimitedness/existence sublimating nascence as to its deepest/mostprofound foregrounding_entailment-<in-succession-of-profoundsupererogation $>$ - (postconverging-narrowing-down $\sim$ sublimation-as-to'existence - as-sublimating-withdrawal/unenframing/re-ontologising,elicited-from-prospective-profound-supererogation '-in-reflecting'immanent relative unreflexivity/relative reflexivity ontologicalcontiguity ';-as-operative-notional deprocrypticism)' thus speaking to deprocryticism requisite preconverging/postconverging-dementative/structural/paradigmatic delineation of both the existentially$\leq$ disontologising/re ontologising aporeticism $>$ contextualised 'sublimating ontological-good-faith/authenticity postconverging-dementating/structuring/paradigming ${ }^{70}$ underlying intemporal ontologicalperformance $-<$ including-virtue-asontology>/morality/ethics/justice/etc. (as of dimensionality-ofsublimating $-<<$ amplituding/formative $>$ supererogatory $d e-$ mentativeness/epistemic-growth-or-conflatedness/transvaluativerationalising/transepistemicity/anamnestic-residuality/spirit-drivennessequalisation / profound dispensing-with-immediacy-for-relativeontological-completeness -by-reification/contemplative-distension projected apriorising/axiomatising/referencing-psychologism)' and 'desublimating ontological-bad-faith/inauthenticity $\sim$ preconverging-de- 
mentating/structuring/paradigming underlying temporal ontologicalperformance ${ }^{72}<$ including-virtue-as-

ontology>/morality/ethics/justice/etc. (as of dimensionality-ofdesublimating-lack-of $-1<$ flinglformative $>$ supererog mentativeness/epistemic-growth-or-conflatedness /transvaluativerationalising/transepistemicity/anamnestic-residuality/spirit-drivennessequalisation/shallow/lack-of dispensing-with-immediacy-for-relativeontological-completeness -by-reification/contemplative-distension projected apriorising/axiomatising/referencing-psychologism)' associated with any " deprocrypticism-or-preempting-disjointednessas-of- reference-of-thought prospective knowledgereification gesturing-and-accounting-of-epistemic-phenomenalism<in-prospective psychologismic $\sim$ apriorising/axiomatising/referencing\{of- prospectively implicited_attendant-ontologicalcontiguity ' $\sim$ educedexistentialising/contextualising/textualising_intelligibility/epistemicity/re flexivity-contiguity-<imbued-notional $\sim$ cogency $>$ ' \}-conflatedness in \{preconverging ment by\} postconverging entailment $>$ as ever always about preserving the ascendancy of organic-knowledge in supersedingandoverriding mechanical-knowledge (with the latter rather associated with <amplituding/formative > wooden-language-fimbued-temporalmere-form/virtualities/dereification/akrasiaticdrag/denatured/preconverging-or-dementing -narratives-of-thereference-of-thought-categorical-imperatives/axioms/registryteleology J) thus involving the anticipation of human temporal-to- 
intemporal ontological-performance ${ }^{72}<$ including-virtue-as-

ontology >/morality/ethics/justice/etc. of prospective knowledge-

reification gesturing-and-accounting-of-epistemic-phenomenalism-

$<$ in-prospective psychologismic $\sim$ apriorising/axiomatising/referencing-

\{of-'prospectively_implicited_attendant-ontological-

contiguity ' 'educed-

existentialising/contextualising/textualising_intelligibility/epistemicity/re

flexivity-contiguity-<imbued-notional $\sim$ cogency $>$ ' \}-conflatedness

in \{preconverging ment by\} postconverging entailment> imbued

reference-of-thought-categorical-imperatives/axioms/registry-

teleology ; and critically so, as to the fact that

supererogatory acuity/perspicacity/astuteness/edginess/incisiveness-of-

apriorising/axiomatising/referencing/intelligibilitysettingup/measuringins

trumenting -for-conceptualisation rather speaks of 'one long continuous

whole of human originariness-parrhesia,-as-spontaneity-of-

aestheticisation as of notional ' deprocrypticism' (reflecting 'relative-

ontological-incompleteness 8 /relative-ontological-completeness

(sublimating referencing/registering/decisioning,-as-self-becoming/self-

conflatedness /formative-supererogating-<projective/reprojective-

aestheticising-re-motif-and-re-apriorising/re-axiomatising/re-

referencing,-in-perspective-ontological-normalcy/postconvergence $>>$ as

to human-and-social-expectations/anticipations-metaphoricity -as-

preconverging/postconverging-rede-

mentating/restructuring/reparadigming-psychologism,") which as

guiding spirit no human prospective 
apriorising/axiomatising/referencing-conceptualisation can pretend to ignore-and-override without falling into perversion of ${ }^{5}$ meaningfulnessand-teleology as to pedantising/muddling/formulaic-hollowing-out-insubontologisation/subpotentiation-bblurring/undermining-of-prospectivetotalising-entailing,-as-to-entailing-< $<$ formativeepistemicity>totalising in-relative-ontological-completeness J by mereformulaic-methodologising/mutualising/organising/institutionalising the human-subpotency < preconverging 'motif-andapriorising/axiomatising/referencing'-entailing>-existentialisingenframing/imprintedness-〈as-to- historicity-tracing-in-presencinghyperrealisation/hyperreal-transposition/in gimmickiness/desublimation, as supererogatory $\sim$ acuity/perspicacity/astuteness/edginess/incisivenessofapriorising/axiomatising/referencing/intelligibilitysettingup/measuringins trumenting -for-conceptualisation underlies dimensionality-ofsublimating $-<<$ amplituding/formative $>$ supererogatory $\sim d e-$ mentativeness/epistemic-growth-or-conflatedness /transvaluativerationalising/transepistemicity/anamnestic-residuality/spirit-drivennessequalisation/ontological-good-faith/authenticity postconverging-dementating/structuring/paradigming ${ }^{7}$ ' with regards to the fact that by the inherently implied prior-institutionalisation-threshold-by-prospectiveuninstitutionalised-threshold ${ }^{02}$ of any given registryworldview/dimension as reflecting the preconverging-or-dementing apriorising-psychologism perspective in shallower teleological depth 
'there is no limitedness/human-subpotency presencing-absolutisingidentitive-constitutedness ${ }^{14}$ neutrally sound knowledge in relativeontological-incompleteness ${ }^{8}$ as to when prospective insight about the relative-ontological-incompleteness deficient ontologicalperformance ${ }^{72}<$ including-virtue-as

ontology >/morality/ethics/justice/etc. existentially $<$ disontologising/reentologising aporeticism $>$ avails as reflecting prospective humansubpotency-aporia/undecidability/dilemma/oughtindeterminacy/deficiency/limitation/constraint' with prospective knowledge-reification gesturing-and-accounting-of-epistemicphenomenalism-<in-

prospective psychologismic apriorising/axiomatising/referencing-\{of'prospectively implicited_attendant-ontological-contiguity ' reducedexistentialising/contextualising/textualising_intelligibility/epistemicity/re flexivity-contiguity-<imbued-notional cogency> ' \}-conflatedness in \{preconverging ment by\} postconverging entailment $>$ in relativeontological-completeness necessitatively about overriding relativeontological-incompleteness ${ }^{8}$ apriorising/axiomatising/referencingconceptualisation as to psychoanalytic-unshackling/memeticreordering/institutional-recomposuring metaphoricity implications in transversality-<for-sublimating-existential-eventuating/denouement,from 'thinking at first/pure predisposition preemptive of prospective disontologising/subologising' as-of-prospectively-disambiguatedaffirmed-and-unaffirmed- 'motif-andapriorising/axiomatising/referencing'> such that any ontologically- 
flawed engagement as 'wrongly implying underlying ${ }^{5}$ logicalprocessing-or-logical-implicitation-supposedly-apriorising-inconviction-as-to-profound-supererogation deficiency validating logical re-engagement' rather leads to the mere complexification of the prior relative-ontological-incompleteness apriorising/axiomatising/referencing-conceptualisation (as to its deficient ontological-performance ${ }^{72}<$ including-virtue-asontology>/morality/ethics/justice/etc. and vices-and-impediments undermining the ontological-good-faith/authenticity postconvergingde-mentating/structuring/paradigming ') and so as analysing-andaccounting-for the instigative underlying 'ontological-faith-notion-orontological-fideism-imbued-underdetermination-of-motif-andapriorising/axiomatising/referencing-asso-being-as-of-existential-reality human solipsistic necessitativedrivenness' either as of 'parrhesiastic seeding-promise-of-human-subpotency-ontological-performance <including-virtue-as-ontology>-correspondence-with-the-full-potencyof-existence's sublimating-nascence-as-of-itscoherence/contiguity' or 'seeding-misprising of reasoning-from-results/afterthought meaningfulness-and-teleology as covert-pretence-ofequivalence/correspondence-antiakrasiatic-aspiration-ontologicalperformance ${ }^{72}<$ including-virtue-as-ontology >' (as the latter conception with regards to the notional deprocrypticism of the relativeontological-contiguity rof-the-humaninstitutionalisation-process ${ }^{6}$ reflects the fact that ${ }^{56}$ meaningfulness-andteleology' is much 'more profoundly than just about projected 
reproducibility — mathesis/motif/thrownness-disposition,-as-

reproducibility-of-aestheticisation, which at uninstitutionalised-

threshold ${ }^{2}$ actually involves <amplituding/formative-

epistemicity>totalising self-referencing-

syncretising/circularity/interiorising/akrasiatic-drag

<amplitudingfformative> wooden-language-fimbued-temporal-mere-

form/virtualities/dereification/akrasiatic-drag/denatured/preconverging-

or-dementing -narratives-of-the- reference-of-thought-categorical-

imperatives/axioms/registry-teleology /, but speaks of instigated and

reinstigated originariness-parrhesia,-as-spontaneity-of-

aestheticisation-

supererogatory acuity/perspicacity/astuteness/edginess/incisiveness' as

to the fact that knowledge cannot be articulated to imply other human-

beings are not warranted to project the requisite dispensing-with-

immediacy-for-relative-ontological-completeness ${ }^{8}$-by-

reification/contemplative-distension arising from ontological-good-

faith/authenticity but rather just responding mechanically to the

untenable constraining of social ${ }^{103}$ universal-transparency

(transparency-of-totalising-entailing,-as-to-entailing-

$<$ amplitudingfformative-epistemicity >totalising in-relative-ontological-

completeness Jof any prospective knowledge-reification $\sim$ gesturing-and-

accounting-of-epistemic-phenomenalism-<in-

prospective psychologismic a apriorising/axiomatising/referencing-\{of-

'prospectively_implicited_attendant-ontological-contiguity ' reduced-

existentialising/contextualising/textualising_intelligibility/epistemicity/re 
flexivity-contiguity-<imbued-notional cogency> ' \} - conflatedness in \{preconverging ment by\} postconverging entailment> as to positiveopportunism-of-social-functioning-and-accordance ' as wrongly and seemingly implying that if such prospective knowledgereification $\sim$ gesturing-and-accounting-of-epistemic-phenomenalism$<$ in-prospective_psychologismic $\sim$ apriorising/axiomatising/referencing\{of-'prospectively implicited_attendant-ontologicalcontiguity ' $\sim$ educedexistentialising/contextualising/textualising_intelligibility/epistemicity/re flexivity-contiguity-<imbued-notional $\sim$ cogency> ' \}-conflatedness in \{preconverging ment by\} postconverging entailment $>$ untenable constraining and positive-opportunism-of-social-functioning-andaccordance doesn't avail then the human-being is enabled/entitled for corresponding intellectual-and-moral irresponsibilityfrelativeunreflexivity notwithstanding the fact that the possibility for all prospective knowledge-reification $\sim$ gesturing-and-accounting-ofepistemic-phenomenalism-<inprospective psychologismic apriorising/axiomatising/referencing-\{of'prospectively_implicited_attendant-ontological-contiguity ' reducedexistentialising/contextualising/textualising_intelligibility/epistemicity/re flexivity-contiguity-<imbued-notional cogency>' \}-conflatedness in \{preconverging ment by\} postconverging entailment $>$ arises as of ontological-good-faith/authenticity reasoningthrough/messianicreasoning induced sublimation-over-desublimation), and in-many-ways human cognitive confliction at uninstitutionalised- 
threshold ${ }^{2}$ doesn't imply the given ${ }^{79}$ presencing-absolutising-

identitive-constitutedness ${ }^{14}$ is the ontologically-veridical framing for reconstruing human ontological-performance ${ }^{72}<$ including-virtue-asontology >/morality/ethics/justice/etc. even as it is the apriorising/axiomatising/referencing-psychologism/mental-schema since it is fundamentally about overcoming the latter's

$<$ amplituding/formative-epistemicity>totalising $\sim$ self-referencingsyncretising/circularity/interiorising/akrasiatic-drag as of prospective secondnaturing institutionalisation as revealed when it turns away from inherent-and-genuine knowledge-reification gesturing-and-accountingof-epistemic-phenomenalism-<inprospective psychologismic apriorising/axiomatising/referencing-\{of'prospectively implicited_attendant-ontological-contiguity ' reducedexistentialising/contextualising/textualising_intelligibility/epistemicity/re flexivity-contiguity-<imbued-notional cogency > ' \}-conflatedness in \{preconverging ment by\} postconverging entailment $>$ into strategies of social-chainism/social-influence and effectively the possibility for all prospective human sublimation-over-desublimation rather implies the possibility for human solipsistic firstnature superseding and overriding of any given presencing-absolutising-identitive-constitutedness ${ }^{7 /}$ with reoriginary_a_as-unenframed/reconceptugalis_ation_-_imbued-postconverging/dialectical-thinking 'projective-insights'/'epistemic-projection-in-conflatedness '-ofnotional deprocrypticism-prospective-sublimation) intemporaldisposition prospective apriorising/axiomatising/referencing- 
conceptualisation (as to existence-potency sublimating-nascence,disclosed-from-prospective-epistemic-digression) and the corresponding social secondnaturing, as thus enabling and explaining the $<$ cumulating/recomposuring attendant-ontological-contiguity succession of registry-worldviews/dimensions reflecting holographically$<$ conjugatively-and-transfusively $>$ the relative-unreflexivity/relativereflexivity ontological-contiguity of-the-human-institutionalisationprocess with genuineknowledge ever always about 'adopting an uncompromising bluntness to solipsistic falsehood and ontological-badfaith/inauthenticity ' as to its self-contained intemporal purpose as of the very defining tradition of all such ${ }^{4}$ historiality/ontologicaleventfulness $\%$ ontological-aesthetic-tracing-<perspective-ontologicalnormalcy/postconvergence-reflected-'epistemicity-relativismdeterminism'> sublimation-over-desublimation so-construed as intellectualism with respect to the fact that there can't be any ontology/science where any mortal by mere status and influence can be excepted directly or indirectly from ontological analysis implications as this then preconverging/postconverging-dementatively/structurally/paradigmatically defines how the supposed ontology/science is bound to flop theoretically-conceptually-operantly (and in-many-ways explains the current crisis/usurpation of the genuine social intellectual-function/posture wherein socially dominant vestedinterests/actors come to surreptitiously assume ascendence as to generalised social intellectual apathy that leads to the relegating of 'true intellectualism' into 'competence/expertising as a useful secondary 
adjunct' to any whatever primary interest hence rendering the latter susceptible to perversion/impertinence/impotency and incapable of genuinely driving a specific or general human and social emancipating vision) and this is particularly the case with an ontology/science that claims to construe of the pervasiveness of postlogism 7 social implications as associated say with notions-and-accusations-of-sorcery in non-positivistic social-constructs or postlogism psychopathy social

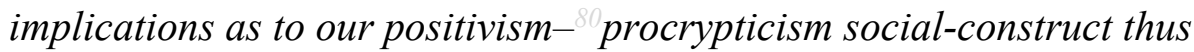
requiring that any such ontologically illegitimate perverted dynamics of social status and influence is necessarily trampled upon to preconverging/postconverging-dementatively/structurally/paradigmatically preserve the possibility of an ontology/science and so notwithstanding any sophistic disposition to elicit <amplitudinglformative> wooden-language-fimbued-averaging-ofthought-<as-to-leveling/ressentiment/closed-construct-ofmeaningfulness-and-teleology -as-of- 'nondescript/ignorablevoid'-withregards-to-prospective-apriorising-implications $>$ | as of <amplituding/formative-epistemicity>totalising $\sim$ self-referencingsyncretising/circularity/interiorising/akrasiatic-drag against the requisite dispensing-with-immediacy-for-relative-ontologicalcompleteness -by-reification/contemplative-distension associated with all such prospective postconvergingaaporeticismovercoming/unovercoming superseding sublimation-overdesublimation; 9 in this respect, the 'equalisation of all ${ }^{4}$ historiality/ontologicaleventfulness $3 \%$ ontological-aesthetic-tracing-<perspective-ontological- 
normalcy/postconvergence-reflected-'epistemicity-relativism-

determinism'> aestheticisation-and-aestheticisation-towards-ontology$<$ elicited-idiomatisation > ' as to dimensionality-of-sublimating

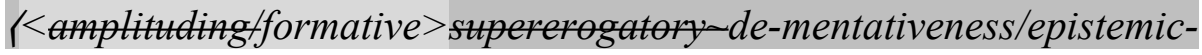
growth-or-conflatedness/transvaluative-

rationalising/transepistemicity/anamnestic-residuality/spirit-drivennessequalisation) is exactly what reflects supererogatory acuity/perspicacity/astuteness/edginess/incisiveness-ofapriorising/axiomatising/referencing/intelligibilitysettingup/measuringins trumenting -for-conceptualisation as 'one long continuous whole of human originariness-parrhesia,-as-spontaneity-of-aestheticisation reflecting holographically-<conjugatively-and-transfusively $>$ the relative unreflexivity/relative reflexivity ontological-contiguity $\sim$ of-thehuman-institutionalisation-process ' (that precedes-anddefines registryworldviews/dimensions mere-formulaicmethodologising/mutualising/organising/institutionalising as to humansubpotency) as it is so-fundamentally tied down to ontological-goodfaith/authenticity postconverging-dementating/structuring/paradigming ${ }^{70}$ 'reflecting the implications of human limited-mentation-capacity-deepening -as-subjecting limitedness/human subpotency to 'educed unlimitedness/existencesublimating nascence' in the face of prospective human-subpotencyaporia/undecidability/dilemma/oughtindeterminacy/deficiency/limitation/constraint, as to the fact that the intemporal-projection (driven as of ontological-good-faith/authenticity ${ }^{6}$ ) 
associated with the reference-of-thought-categoricalimperatives/axioms/registry-teleology in respectively superseding prior recurrent-utter-uninstitutionalisation, ununiversalisation, nonpositivism/medievalism and procrypticism addressing/bound-to-address their given prospective human-subpotencyaporia/undecidability/dilemma/oughtindeterminacy/deficiency/limitation/constraint are flipped-about mechanically as of mere-formulaicmethodologising/mutualising/organising/institutionalising temporalprojection (driven as of ontological-bad-faith/inauthenticity ${ }^{64}$ in respectively undermining the attainment of prospective baseinstitutionalisation, ${ }^{103}$ universalisation, positivism and notional deprocrypticism as to the fact that such temporal-projection associated with sophistic and pedantic tendencies are rather of presencing-absolutising-identitive-constitutedness relation with prior ${ }^{3}$ reference-of-thought-categorical-imperatives/axioms/registryteleology originally meant to address prior human-subpotencyaporia/undecidability/dilemma/oughtindeterminacy/deficiency/limitation/constraint (as so-reflected with the sophists satisfaction with non-universalising sophistry in the face of Socratic-philosophers ${ }^{10}$ universalising-idealisation, medieval scholastics satisfaction with non-positivising pedantising/muddling/formulaichollowing-out-in-subontologisation/subpotentiationblurring/undermining-of-prospective-totalising-entailing,-as-toentailing-<amplitudingfformative-epistemicity $>$ totalising $\sim$ in-relative- 
ontological-completeness J in the face of budding-positivism as well as with today's pedantising/muddling/formulaic-hollowing-out-insubontologisation/subpotentiation-_blurring/undermining-of-prospectivetotalising-entailing,-as-to-entailing-< formativeepistemicity>totalising in-relative-ontological-completeness J of flawed prior_knowledge-reification $\sim$ gesturing-and-accounting-of-epistemicphenomenalism-<in-

prior_psychologismic apriorising/axiomatising/referencing-\{of- 'priorimplicalogical-contiguity ' oducedexistentialising/contextualising/textualising_intelligibility/epistemicity/re flexivity-contiguity-<imbued-notional cogency >' \}-constitutedness in preconverging entailment $>$ that fails 'prospective veridical knowledge-reification gesturing-and-accounting-of-epistemicphenomenalism- $<$ inprospective_psychologismic apriorising/axiomatising/referencing-\{of'prospectively implicited_attendant-ontological-contiguity ' reducedexistentialising/contextualising/textualising_ intelligibility/epistemicity/re flexivity-contiguity-<imbued-notional $\sim$ cogency > ',-conflatedness in \{preconverging ment by\} postconverging entailment $>$ in notionalcontiguity/epistemic-contiguity $-<$ profound-supererogation -ofmentally-aestheticised postconverging/dialectical-thinking -qualiaschema $>$ in reflection of implicited_attendant-ontologicalcontiguity $\stackrel{\sim}{\sim}$ educedexistentialising/contextualising/textulising_intelligibility/epistemicity/re flexivity-contiguity-<imbued-notional $\sim \operatorname{cogency}>$ ' as of 'relative- 
ontological-incompleteness /relative-ontological-completeness (sublimating referencing/registering/decisioning,-as-self-becoming/selfconflatedness /formative-supererogating-<projective/reprojectiveaestheticising-re-motif-and-re-apriorising/re-axiomatising/rereferencing,-in-perspective-ontological-normalcy/postconvergence $>>$ as to human-and-social-expectations/anticipations-metaphoricity -aspreconverging/postconverging-redementating/restructuring/reparadigming-psychologism and for instance naively interprets enlightenment thinkers in ${ }^{79}$ presencing-absolutisingidentitive-constitutedness ${ }^{14}$ terms while lacking the originarinessparrhesia,-as-spontaneity-of-aestheticisationsupererogatory acuity/perspicacity/astuteness/edginess/incisiveness for addressing our procrypticism-or-disjointedness-as-of- reference-ofthought prospective human-subpotency-

aporia/undecidability/dilemma/oughtindeterminacy/deficiency/limitation/constraint and wrongly and defectively decontextualising enlightenment thought into the present as of disparateness-of-conceptualisation-<unforegrounding-ment,-failingprospectively-to-reflect- 'immanent relative unreflexivity/relativereflexivity ontological-contiguity '> that fail the notional deprocrypticism foregrounding_entailment-<in-successionof-profound-supererogation $>$-_postconverging-narrowingdown sublimation-as-to- 'existence-as-sublimatingwithdrawal/unenframing/re-ontologising,-elicited-from-prospectiveprofound-supererogation '-in-reflecting- 'immanent relative- 
unreflexivity/relative reflexivity ontological-contiguity ';-as-operative-

notional deprocrypticism) operant test of 'drawing out the full

<amplitudingfformative-

epistemicity>totalising/circumscribing/delineating implications of

assertions/claims/conceptualisations as of notional-contiguity/epistemic-

contiguity 2 profound-supererogation -of-mentally-

aestheticised postconverging/dialectical-thinking -qualia-schema> in

reflection of 'implicited_attendant-ontological-contiguity ' 'educed-

existentialising/contextualising/textualising_intelligibility/epistemicity/re

flexivity-contiguity-<imbued-notional cogency>' such that there is

hardly any notional disjointedness of the

assertions/claims/conceptualisations as validating their ontological-

veracity'); $\mid$ and to perfectly understand what is meant by 'equalisation of all ${ }^{4}$ historiality/ontological-eventfulness 38 /ontological-aesthetic-tracing$<$ perspective-ontological-normalcy/postconvergence-reflected-

'epistemicity-relativism-determinism'> aestheticisation-and-

aestheticisation-towards-ontology-<elicited-idiomatisation $>$ ' as to

dimensionality-of-sublimating

Kamplituding/formative $>$ supererogatory de-mentativeness/epistemic-

growth-or-conflatedness /transvaluative-

rationalising/transepistemicity/anamnestic-residuality/spirit-drivenness-

equalisation), the idea is that as of underlying maximalising-

recomposuring-for-relative-ontological-completeness —unenframed/re-

ontologising conceptualisation for institutional-cumulation/institutional-

recomposure-_as-to- historiality/ontological-eventfulness /ontological- 
aesthetic-tracing-<perspective-ontological-normalcy/postconvergence-

reflected- 'epistemicity-relativism-determinism'>) with regards to reference-of-thought-and- reference-of-thought- devolvingmeaningfulness-and-teleology implications had Socrates as typifying universalising-idealisation Socratic-philosophers been at the more profound human limited-mentation-capacity-deepening - as subjecting limitedness/human subpotency to 'educed unlimitednesstexistence sublimating nascence' postconvergingaporeticismovercoming/unovercoming possibility for prospective positivism/rationalempiricism as to existence-as-sublimating-withdrawal/unenframing/reontologising,-elicited-from-prospective-profound-supererogation he would have supererogatorily (even as there is no universalisingidealisation logical-basis/logic,-as-derived-from $\sim$ transversality-<forsublimating-existential-eventuating/denouement, from 'thinking at first/pure predisposition preemptive of prospective disontologising/subontologising' as-of-prospectively-disambiguatedaffirmed-and-unaffirmed-'motif-andapriorising/axiomatising/referencing'> for advocating any such positivism/rational-empiricism but for Socrates 'aporeticismovercoming/unovercoming supererogating ontological-performance ${ }^{72}$ <including-virtue-as-ontology>' which manifested in inducing universalising-idealisation over prior non-universalising sophistry which had no logical-basis/logic,-as-derived-from $\sim$ transversality-<forsublimating-existential-eventuating/denouement, from 'thinking at first/pure predisposition preemptive of prospective 
disontologising/subontologising' as-of-prospectively-disambiguated-

affirmed-and-unaffirmed-'motif-and-

apriorising/axiomatising/referencing'> for any such ${ }^{103}$ universalisingidealisation) acted as Descartes as typifying the budding-positivists and likewise had Descartes and Socrates been at the more profound human limited-mentation-capacity-deepening as-subjecting-limitedness/humansubpotency to 'educed unlimitedness/existence sublimating nascence' postconverging aporeticism overcoming/unovercoming possibility for prospective deprocrypticism-or-preempting—disjointedness-as-of${ }^{3}$ reference-of-thought as articulated herein they would have supererogatorily adopted this same deprocrypticism-or-preemptingdisjointedness-as-of- reference-of-thought insight as to the scalarity/immanency of existence's ontologicalnormalcy/postconvergence (as the underlying idea of notional deprocrypticism as to existence-as-sublimatingwithdrawal/unenframing/re-ontologising,-elicited-from-prospectiveprofound-supererogation speaks of the 'successive supererogatory maximalising-recomposuring-for-relative-ontological-completeness unenframed/re-ontologising conceptualisation as scalarisation for institutional-cumulation/institutional-recomposure-_as-tohistoriality/ontological-eventfulness /ontological-aesthetic-tracing$<$ perspective-ontological-normalcy/postconvergence-reflected'epistemicity-relativism-determinism'> / crossgenerational levels of human limited-mentation-capacity-deepening—as-subjecting limitedness/human-subpotency to 'educed unlimitedness/existence- 
sublimating nascence" "with regards to "reference-of-thought-andreference-of-thought- devolving- meaningfulness-and-teleology soconstrued as of notional deprocrypticism/notional preemptingdisjointedness-as-of- reference-of-thought' (since there is no logicalbasis/logic,-as-derived-from $\sim$ transversality-<for-sublimating-existentialeventuating/denouement,-from-'thinking-at-first/pure-predispositionpreemptive of prospective disontologising/subontologising' as-ofprospectively-disambiguated-affirmed-and-unaffirmed-'motif-andapriorising/axiomatising/referencing '> inherent to any relativeontological-incompleteness registry-worldview/dimension validating its prospectively projected relative-ontological-completeness registryworldview/dimension but rather an 'aporeticismovercoming/unovercoming supererogating ontological-performance <including-virtue-as-ontology>' as to projective-insights/epistemicprojection-in-conflatedness $^{13}$ of apriorising/axiomatising/referencing with regards to underlying/organising 'relative-ontologicalincompleteness /relative-ontological-completeness (sublimating referencing/registering/decisioning,-as-self-becoming/selfconflatedness /formative-supererogating-<projective/reprojectiveaestheticising-re-motif-and-re-apriorising/re-axiomatising/rereferencing,-in-perspective-ontological-normalcy/postconvergence $>\mid$ as to human-and-social-expectations/anticipations - metaphoricity -aspreconverging/postconverging-redementating/restructuring/reparadigming-psychologism') and soreflected in the successive foregrounding_entailment-<in-succession- 
of-profound-supererogation $>-$ postconverging-narrowing-

down sublimation-as-to- 'existence — as-sublimating-

withdrawal/unenframing/re-ontologising,-elicited-from-prospective-

profound-supererogation '-in-reflecting- 'immanent relative-

threflexivityelative reflexity ontological-contiguity ';-as-operative-

notional deprocrypticism) as from non-rules-

apriorising/axiomatising/referencing-psychologism of recurrent-utter-

uninstitutionalisation, rulemaking-over-non-rules-

apriorising/axiomatising/referencing-psychologism of base-

institutionalisation-ununiversalisation, ${ }^{103}$ universalisation-directed-

rulemaking-over-non-rules-apriorising/axiomatising/referencing-

psychologism of universalisation-non-positivism/medievalism,

positivising/rational-empiricism-based-universalisation-directed-

rulemaking-over-non-rules—apriorising/axiomatising/referencing-

psychologism of positivism- procrypticism and preempting-

disjointedness-as-of- reference-of-thought,-as-to-

- ${ }^{3}$ emplitudinglformative-epistemicity>growth-or-

conflatedness $/$ transvaluative-

rationalising/transepistemicity/anamnestic-residuality/spirit-

drivenness'-in-superseding-mere-formulaic-positivising/rational-

empiricism-based-universalisation-directed-rulemaking-over-non-rules-

apriorising/axiomatising/referencing-psychologism of deprocrypticism)

and thus reflecting the human limited-mentation-capacity-as-subjecting

'educed-unlimitedness/existence sublimating nascence' to-

limitedness/human-subpotency centrality of 'originariness-parrhesia,-as- 
spontaneity-of-aestheticisation-

supererogatory acuity/perspicacity/astuteness/edginess/incisiveness as to the ontological-good-faith/authenticity $~ p o s t c o n v e r g i n g-d e-$ mentating/structuring/paradigming ${ }^{70}$ as preceding-and-defining in addressing human-subpotency-aporia/undecidability/dilemma/oughtindeterminacy/deficiency/limitation/constraint before-and-over any soderived mere-formulaicmethodologising/mutualising/organising/institutionalising reproducibility - mathesis/motif/thrownness-disposition,-asreproducibility-of-aestheticisation with respect to the fact that ontological-pertinence rather priorly lies with the addressing of prospective human-subpotency-aporia/undecidability/dilemma/oughtindeterminacy/deficiency/limitation/constraint (and this is the fundamental insight about all knowledge and philosophical interpretations as rather construed implicitly or explicitly as of difference-conflatedness ${ }^{13}$-as-to-totalitative-reification-insingularisation-<as-to-the-nondisjointedness/entailment-of-prospectivenonpresencing $>$-as-veridical-epistemicity-relativism-determinism in aporetically reflecting prospectively the ontological-goodfaith/authenticity $\sim$ postconverging-dementating/structuring/paradigming ${ }^{70}$ 'underlying human limitedmentation-capacity-deepening-as-subjecting limitedness/humansubpotency to 'educed unimitednesstexistence sublimating nascence' in ${ }^{4}$ foregrounding_entailment-<in-succession-of-profoundsupererogation $>$ - (postconverging-narrowing-down $\sim$ sublimation-as-to- 
'existence - as-sublimating-withdrawal/unenframing/re-ontologising,-

elicited-from-prospective-profound-supererogation '-in-reflecting-

'immanent relative unreflexivity/relative reflexivity ontological-

contiguity ';-as-operative-notional deprocrypticism/and so as

superseding presencing-absolutising-identitive-constitutedness ${ }^{14}$ which

poor 'prospective postconverging aporeticism-

overcoming/unovercoming' hardly contemplates of such profound

prospective human limited-mentation-capacity-deepening-as-subjecting

limitedness/human subpotency to-'educed unlimitedness/existence-

sublimating nascence' implications and rather adopting the framework

of prior mere-formulaic-

methodologising/mutualising/organising/institutionalising reflecting

dimensionality-of-desublimating-lack-of -

< amplituding/formative $>$ supererogatory de-mentativeness/epistemic-

growth-or-conflatedness /transvaluative-

rationalising/transepistemicity/anamnestic-residuality/spirit-drivenness-

equalisation) 'as to the fact that dimensionality-of-sublimating ${ }^{2}$ -

< amplituding/formative $>$ supererogatory de-mentativeness/epistemic-

growth-or-conflatedness/transvaluative-

rationalising/transepistemicity/anamnestic-residuality/spirit-drivenness-

equalisation/as to existence-as-sublimating-

withdrawal/unenframing/re-ontologising,-elicited-from-prospective-

profound-supererogation is aporetically the more fundamental

incipient/seeding originariness-parrhesia,-as-spontaneity-of- 
aestheticisation to both Descartes thinking-proposition for buddingpositivism and Socrates's ${ }^{103}$ universalising-idealisation in then secondarily inducing their respective reproducibilitymathesis/motif/thrownness-disposition,-as-reproducibility-ofaestheticisation' and thus in-many-ways the nä̈ve/flawed conception of Platonism and Cartesianism today arise as to a reasoning as from reproducibility — mathesis/motif/thrownness-disposition,-asreproducibility-of-aestheticisation perspective whereas Descartes and Plato-and-Plato's Socrates are more fundamentally involved in an postconverging aporeticism overcoming/unovercoming exercise with respect to medieval-scholasticism non-positivising and ancient-sophists non-universalising respectively 'which is defining of where philosophy commences' as 'philosophy commences with dimensionality-ofsublimating $-1<$ amplituding/formative $>$ supererogatory - dementativeness/epistemic-growth-or-conflatedness /transvaluativerationalising/transepistemicity/anamnestic-residuality/spirit-drivennessequalisation \as to existence-as-sublimatingwithdrawal/unenframing/re-ontologising,-elicited-from-prospectiveprofound-supererogation ', and in turn such naïve conception of philosophy as of reproducibility — mathesis/motif/thrownnessdisposition,-as-reproducibility-of-aestheticisation, by equating/levelingdown everything across space and time and failing to grasp the implications of human institutional-cumulation/institutionalrecomposure-_as-to- historiality/ontological-eventfulness /ontologicalaesthetic-tracing-<perspective-ontological-normalcy/postconvergence- 
reflected-'epistemicity-relativism-determinism'>।

postconverging aporeticism-overcoming/unovercoming as to human limited-mentation-capacity-deepening —as subjecting limitedness/humansubpotency to 'educed unlimitedness/existence sublimating nascence' < <amplituding/formative-epistemicity >totalisingly as-to-existence-assublimating-withdrawal/unenframing/re-ontologising,-elicited-fromprospective-profound-supererogation \so-underlied herein as to ${ }^{15} \mathrm{de}$ mentation-/supererogatory-ontological-de-mentation-or-dialectical-dementation - stranding-or-attributive-dialectics), is what today underlies the misanalysis/overemphasis of say Humean or Kantian philosophy as if of differently evolved framing to Descartes's thinking-proposition thus leading to their positivism/rational-empiricism relative ${ }^{79}$ presencingabsolutising-identitive-constitutedness ${ }^{14}$ <preconverging 'motif-andapriorising/axiomatising/referencing'-entailing>-existentialisingenframing/imprintedness-_as-to- historicity-tracing-in-presencinghyperrealisation/hyperreal-transposition / reproducibilitymathesis/motif/thrownness-disposition,-as-reproducibility-ofaestheticisation poorly contemplative prospectively of the more fundamental incipient/seeding originariness-parrhesia,-as-spontaneityof-aestheticisation for prospective philosophical framing as to existence-as-sublimating-withdrawal/unenframing/re-ontologising,elicited-from-prospective-profound-supererogation as so-implied with advanced postmodern-thought), and their 'epistemic-projectiveequalisation' exactly implies that Descartes and budding-positivists and 
Socrates and universalising-idealisation Socratic-philosophers are more profoundly construed more than just as of their mere-formulaicmethodologising/mutualising/organising/institutionalising reproducibility — mathesis/motif/thrownness-disposition,-asreproducibility-of-aestheticisation but are rather critically construed as to their 'parrhesiastic/messianicity/profound-supererogation disposedness/psychologismic-construct' with regards to their prospective postconverging aporeticism-overcoming/unovercoming addressed with their respective foregrounding_entailment-<in-succession-ofprofound-supererogation ${ }^{9}$-\{postconverging-narrowingdown sublimation-as-to-'existence - as-sublimatingwithdrawal/unenframing/re-ontologising,-elicited-from-prospectiveprofound-supererogation '-in-reflecting- 'immanent relativeunreflexivity/relative reflexivity ontological-contiguity ';-as-operativenotional deprocrypticism/ and it is this that more profoundly informs their thought and make them ever always relevant as to their respective historiality/ontological-eventfulness $3 \%$ ontological-aesthetic-tracing$<$ perspective-ontological-normalcy/postconvergence-reflected'epistemicity-relativism-determinism'> in the overall human institutionalcumulation/institutional-recomposure-/as-to- historiality/ontologicaleventfulness /ontological-aesthetic-tracing-<perspective-ontologicalnormalcy/postconvergence-reflected-'epistemicity-relativismdeterminism'> / of historiality/ontological-eventfulness 3 /ontologicalaesthetic-tracing-<perspective-ontological-normalcy/postconvergencereflected-'epistemicity-relativism-determinism'> (as the 'veracity of all 
prior human 'prospective postconverging aporeticism

overcoming/unovercoming' as to self-surpassing of reference-ofthought-and- reference-of-thought- devolving- ${ }^{5}$ meaningfulness-andteleology in reflection of the immanence of existence as the-very-same all along' has ever always veridically been about attaining deprocrypticism-or-preempting-disjointedness-as-of- reference-ofthought but for human limited-mentation-capacity-as-subjecting 'educed unlimitednesstexistence sublimating nascence' tolimitedness/human-subpotency implications thus inducing the entailing dynamics of the ' $<$ cumulating/recomposuring attendant-ontologicalcontiguity >-successive registry-worldviews/dimensions postconverging aporeticism overcoming/unovercoming thresholds of existential< <isontologising/re ontologising aporeticism> apriorising/axiomatising/referencing rule' as to human limitedmentation-capacity-deepening - as subjecting limitedness/humansubpotency to 'educed unlimitedness/existence sublimating nascence' towards originariness/origination-_so-construed-as-to-ontologicalnormalcy/postconvergence-perspective-scalarising-construal-ofexistence) as notional deprocrypticism in overcoming any relative presencing-absolutising-identitive-constitutedness ${ }^{14}$ and so no different from say human 'prospective postconverging aporeticismovercoming/unovercoming' as to self-surpassing associated with construing what-matter-is-made-up-of as of the succession of such defining questioning and answers across registry-worldviews/dimensions even if just as with overall existence concerning overall human 
meaningfulness-and-teleology what-matter-is-made-up-of equally remains immanently the same all along but for human postconverging aporeticism-overcoming/unovercoming implications of limited-mentation-capacity-deepening - as subjecting limitedness/humansubpotency to 'educed unlimitedness/existence sublimating nascence' pointing out that the veracity of the questioning and answers about whatmatter-is-made-up-of by the Democrituses and others is veridically as of the prospective profoundness of such questioning and answers being wrestled with today as the sublimated modern-day and future developments of physics and so as to the physics epistemic-conception human limited-mentation-capacity-deepening-as-subjecting limitedness/human subpotency to 'educed unlimitednesstexistencesublimating nascence' implied 'originariness/origination-_soconstrued-as-to-ontological-normalcy/postconvergence-perspectivescalarising-construal-of-existence) in overcoming any relative presencing-absolutising-identitive-constitutedness ${ }^{14}$ ), and our own present 'originariness-parrhesia,-as-spontaneity-of-aestheticisationsupererogatory acuity/perspicacity/astuteness/edginess/incisiveness as to the ontological-good-faith/authenticity postconverging-dementating/structuring/paradigming ${ }^{7}$ ' is rather about not construing of their prior mere-formulaicmethodologising/mutualising/organising/institutionalising reproducibility—mathesis/motif/thrownness-disposition,-asreproducibility-of-aestheticisation in ontological-badfaith/inauthenticity $\sim$ preconverging-de- 
mentating/structuring/paradigming failing to factor in their relativeontological-incompleteness ${ }^{8}$ hman limited-mentation-capacity-assubjecting 'educed unlimitedness/existence sublimating nascence' tolimitedness/human-subpotency postconverging aporeticism overcoming/unovercoming context so as to falsely justify our present procrypticism-or-disjointedness-as-of- reference-of-thought presencing-absolutising-identitive-constitutedness ${ }^{4}$ and then fail to address our own prospective human postconverginga aporeticismovercoming/unovercoming context as to existence-as-sublimatingwithdrawal/unenframing/re-ontologising,-elicited-from-prospectiveprofound-supererogation but rather lies in conceptualising how to reconstrue of their projected 'originariness-parrhesia,-as-spontaneityof-aestheticisationsupererogatory acuity/perspicacity/astuteness/edginess/incisiveness as to the ontological-good-faith/authenticity postconverging-dementating/structuring/paradigming ${ }^{70}$ in the light of our present human limited-mentation-capacity-deepening as subjecth subpotency to 'educed unlimitednesstexistence sublimating nascence' postconverging aporeticism-overcoming/unovercoming context soreflected as our prospective procrypticism-or-disjointedness-as-ofreference-of-thought human-subpotencyaporia/undecidability/dilemma/oughtindeterminacy/deficiency/limitation/constraint and this is what crucially explains the ontological-normalcy/postconvergence epistemic-projection perspective of analysis assumed herein as to our prospective 
procrypticism-or-disjointedness-as-of- reference-of-thought 'prospective postconverging aporeticism overcoming/unovercoming' resolvable as of deprocrypticism-or-preempting —disjointedness-as-of${ }^{3}$ reference-of-thought ${ }^{4}$ historiality/ontological-

eventfulness 38 /ontological-aesthetic-tracing-<perspective-ontologicalnormalcy/postconvergence-reflected-'epistemicity-relativismdeterminism'> as a further human ${ }^{4}$ foregrounding_entailment-<insuccession-of-profound-supererogation $>$ - (postconverging-narrowingdown sublimation-as-to- 'existence - as-sublimatingwithdrawal/unenframing/re-ontologising,-elicited-from-prospectiveprofound-supererogation '-in-reflecting- 'immanent relativeunreflexivity/relative reflexivity ontological-contiguity ';-as-operativenotional deprocrypticism/ with this insight pointing to the 'unassailability/centrality across all times of human dimensionality-ofsublimating $-1<$ amplituding/formative $>$ supererogatory $\sim d e-$ mentativeness/epistemic-growth-or-conflatedness /transvaluativerationalising/transepistemicity/anamnestic-residuality/spirit-drivennessequalisation/ with regards to human knowledge-reification gesturingand-accounting-of-epistemic-phenomenalism-<inprospective psychologismic apriorising/axiomatising/referencing-\{of'prospectively implicited_attendant-ontological-contiguity ' reducedexistentialising/contextualising/textualising_intelligibility/epistemicity/re flexivity-contiguity-<imbued-notional $\sim$ cogency $>$ ' \}-conflatedness in \{preconverging ment by\} postconverging entailment>' (given that later generations don't need to reinvent from scratch the ontological- 
performance ${ }^{72}<$ including-virtue-as-

ontology>/morality/ethics/justice/etc. level achieved by the successive preceding generations as to institutional-cumulation/institutionalrecomposure-_as-to- historiality/ontological-eventfulness /ontologicalaesthetic-tracing-<perspective-ontological-normalcy/postconvergencereflected-'epistemicity-relativism-determinism'>) and can then redirect more critically their limited-mentation-capacity-as-subjecting 'educedunlimitedness/existence sublimating nascence' to limitedness/humansubpotency to further advance human self-surpassing to overcome prospective human aporeticism); $\uparrow$ and this insight points out that human <amplituding/formative-epistemicity>causality is more fundamentally formative as to human projected 'originariness-parrhesia,-asspontaneity-of-aestheticisationsupererogatory acuity/perspicacity/astuteness/edginess/incisiveness as to the ontological-good-faith/authenticity postconverging-dementating/structuring/paradigming ' and is a central conceptualisation for the deprocrypticism-or-preempting-disjointedness-as-ofreference-of-thought ${ }^{45}$ foregrounding_entailment-<in-succession-ofprofound-supererogation $>$-_postconverging-narrowingdown sublimation-as-to- 'existence - as-sublimatingwithdrawal/unenframing/re-ontologising,-elicited-from-prospectiveprofound-supererogation '-in-reflecting- 'immanent relativeunreflexivity/relative reflexivity-ontological-contiguity ';-as-operativenotional deprocrypticism/ in undermining temporal distorting/undermining of prospective knowledge-reification $\sim$ gesturing- 
and-accounting-of-epistemic-phenomenalism-<in-

prospective_psychologismic apriorising/axiomatising/referencing-\{of'prospectively_implicited_attendant-ontological-contiguity ' reducedexistentialising/contextualising/textualising_intelligibility/epistemicity/re flexivity-contiguity-<imbued-notional cogency >' \}-conflatedness in-\{preconverging-ment by\} postconverging-entailment $>$ categoricalimperatives/axioms/registry-teleology

notionalnotional-contiguity/epistemic-contiguity-<profound-supererogation -ofcontiguity/epistemi mentally-aestheticised postconverging/dialectical-thinking -qualiac-contiguity ${ }^{62} \quad$ schema>-fin-'mutual supererogatory acuity/perspicacity/astuteness/edginess/incisiveness-ofapriorising/axiomatising/referencing/intelligibilitysettingup/measuringins trumenting -for-conceptualisation',-whether-with-regards-to-mutualrelative-ontological-incompleteness -or-mutual-relative-ontologicalcompleteness -\{of-the-underlying- reference-of-thought-level\},notwithstanding-differing-notional firstnaturedness-formativeness $<a s-$ to eventualising inkling drive or seeding misprising $>$ temporal-tointemporal-dispositions-<so-construed-as-from-perspective-ontologicalnormalcy/postconvergence $>$-ontological-performance -<includingvirtue-as-ontology>-as-to- reference-of-thought- devolving-level-asimplying-differingaposteriorising/logicising/deriving/intelligising/measuring); $\uparrow \quad$ notionalcontiguity/epistemic-contiguity-<profound-supererogation -of-mentallyaestheticised postconverging/dialectical-thinking -qualia-schema> (as 
supererogatory acuity/perspicacity/astuteness/edginess/incisiveness-ofapriorising/axiomatising/referencing/intelligibilitysettingup/measuringins trumenting-for-conceptualisation') rather speaks to difference-inkind/difference-in-aposteriorising-orlogicising; and finally, as-of-theepistemic-veracity-implications-for-knowledge-construal as implied with 'the-specific-notional-contiguity/epistemic-contiguity-<profoundsupererogation -of-mentally-aestheticised postconverging/dialecticalthinking -qualia-schema>-of relative unreflexivity/relative reflexivityontological-contiguity , notional-contiguity/epistemic-contiguity$<$ profound-supererogation -of-mentallyaestheticised postconverging/dialectical-thinking -qualia-schema> speaks-of-the-epistemic-normalcy-and-ontologicalnormalcy/postconvergence-perspective-of-analysis

notionalnotional-discontiguity/epistemic-discontiguity-<between-prior-shallowdiscontiguity/epist supererogation -of-mentally-aestheticised preconverging/dementing emic-discontiguity qualia-schema_and_prospective-profound-supererogation -of-mentally63 aestheticised postconverging/dialectical-thinking -qualia-schema>-_indiffering-relative-ontological-incompleteness -and-relative-ontologicalcompleteness -at- reference-of-thought-level-as-implying-'differing supererogatory acuity/perspicacity/astuteness/edginess/incisiveness-ofapriorising/axiomatising/referencing/intelligibilitysettingup/measuringins trumenting -for-conceptualisation',-fundamentally-implying-at-theirreference-of-thought- devolvinglevel-the-irrelevance-or-ontological- 
impertinence-of-the-relative-ontological-incompleteness -in-relation-to-

the-relevance-or-ontological-veracity-of-the-relative-ontological-

completeness -for-

aposteriorising/logicising/deriving/intelligising/measuring); $\uparrow \quad$ notional-

discontiguity/epistemic-discontiguity-<between-prior-shallow-

supererogation -of-mentally-aestheticised preconverging/dementing

qualia-schema_and_prospective-profound-supererogation -of-mentally-

aestheticised postconverging/dialectical-thinking -qualia-schema> (as

of such differing-relative-ontological-incompleteness -and-relative-

ontological-completeness ${ }^{8}$-at- ${ }^{8}$ eference-of-thought-level-as-implying-

'differing

supererogatory acuity/perspicacity/astuteness/edginess/incisiveness-of-

apriorising/axiomatising/referencing/intelligibilitysettingup/measuringins

trumenting-for-conceptualisation') rather speaks to difference-innature/difference-in-apriorising-or-axiomatising-or-referencing; $\boldsymbol{\uparrow}$ and finally, as-of-the-epistemic-veracity-implications-for-knowledge-construal as implied with 'the-specific-notional-contiguity/epistemic-contiguity $<$ profound-supererogation -of-mentally-

aestheticised postconverging/dialectical-thinking -qualia-schema>of relative unreflexivity/relative reflexivity ontological-contiguity ", notional-discontiguity/epistemic-discontiguity-<between-prior-shallowsupererogation -of-mentally-aestheticised preconverging/dementing qualia-schema_and_prospective-profound-supererogation -of-mentallyaestheticised postconverging/dialectical-thinking -qualia-schema>,speaks-of-the-epistemic-abnormalcy/preconvergence -perspective 
ontological-bad- ontological-bad-faith/inauthenticity-_as-to-manifest-or-induced-

faith/inauthenticity discrete/noncontiguous/incoherence-human-subpotency-epistemic-

perspective-of-notional-discontiguity/epistemic-discontiguity -failing-to-

reflect relative unreflexivity/relative reflexivity ontological-

contiguity ,-in-prectering existential-extrication-as-of-existential-

unthought-as-in-dimensionality-of-desublimating-lack-of -

< amplituding/formative > supererogatory-de-mentativeness/epistemic-

growth-or-conflatedness /transvaluative-

rationalising/transepistemicity/anamnestic-residuality/spirit-drivenness-

equalisation /)

ontological-bad- ontological-bad-faith/inauthenticity $\sim$ preconverging-de-

faith/inauthenticity mentating/structuring/paradigming-<seeding/incipient-shallow-

$\sim$ preconverging- supererogation ${ }^{\circ}$, -as-mentally-aestheticised preconverging/dementing de-

qualia-schema>-〈as-of-formative-thrownness-projective-

mentating/structuri arbitrariness/waywardness- 'imbued-psychologism'-of-

ng/paradigming ${ }^{65}$ apriorising/axiomatising/referencing-\{as-preconverging-or-dementing -

reflexive-and-entailing-'leveling-teleology '\}) prospectively failing to reflect existence-as-sublimating-withdrawal/unenframing/reontologising,-elicited-from-prospective-profound-supererogation

ontological- human supposedly coherent ontological-commitment-<implied-selfcommitment ${ }^{66}$ assuredness-of-ontological-good-faith/authenticity $\sim$ postconverging-de$<$ implied-self- mentating/structuring/paradigming -as-being-as-of-existential-reality >, assuredness-of- so-construed-as-of-reifying-and-empowering-reflexivity,-given-humanontological-good- subpotency-epistemic-reflexivity-in-ecstatic-existence-as-so-associated- 
faith/authenticity with-human historiality/ontological-eventfulness 38 /ontological$\sim$ postconverging- aesthetic-tracing-<perspective-ontological-normalcy/postconvergencedereflected- 'epistemicity-relativism-determinism'> (in reflecting the accrued mentating/structuri transcendence-and-sublimity/sublimation/supererogatory de-mentativity ng/paradigming - underlying the relative-unreflexivity/relative reflexivity-ontologicalas-being-as-of- contiguity $\sim$ of-the-human-institutionalisation-process ${ }^{68}$ so-constrained existential-reality> by existence-potency $\sim$ sublimating-nascence,-disclosed-fromprospective-epistemic-digression), otherwise construed as 'prospective transcendence-and-sublimity/sublimation/supererogatory de-mentativity percolation-channelling-<in-deferential-formalisation-transference $>$ asto-social/institutional/conceptual-constructs formation/establishment/superseding-metaphoricity '>, and so as of 'relative-ontological-incompleteness /relative-ontologicalcompleteness - -Sublimating $\sim$ referencing/registering/decisioning,-asself-becoming/self-conflatedness /formative-supererogating$<$ projective/reprojective-aestheticising-re-motif-and-re-apriorising/reaxiomatising/re-referencing,-in-perspective-ontologicalnormalcy/postconvergence $>$ ) as to human-and-socialexpectations/anticipations - metaphoricity -aspreconverging/postconverging-redementating/restructuring/reparadigming-psychologism of nonextricatory firstnaturedness-as-to-inkling $\quad{ }_{55}^{5}$ maximalisingrecomposuring-for-relative-ontological-completeness -unenframed/reontologising conceptualisation in 'prospectiveapriorising/axiomatising/referencing-superseding-logical-basis- 
of dialogical-equivalence-<as-to-

psychologismic apriorising/axiomatising/referencing-\{of-"prospectively implicited_attendant-ontological-contiguity ' reduced-

existentialising/contextualising/textualising_intelligibility/epistemicity/re

flexivity-contiguity-<imbued-notional $\sim$ cogency $>$ ' \}-conflatedness

in-\{preconverging-ment by\} postconverging-entailment,-in-self-

becoming/self-conflatedness /formative-supererogating > , (beyond-

andsuperseding the wrongly-implied 'prior-

apriorising/axiomatising/referencing-superseded-logical-basis-

of dialogical-equivalence-<as-to-

psychologismic apriorising/axiomatising/referencing-\{of-'prospectively

implicited attendant-ontological-contiguity ' reduced-

existentialising/contextualising/textualising_intelligibility/epistemicity/re

flexivity-contiguity-<imbued-notional $\sim$ cogency $>$ ' \}-conflatedness

in \{preconverging ment by\} postconverging entailment,-in-self-

becoming/self-conflatedness /formative-supererogating $>{ }^{82}$, in relative-

ontological-incompleteness

human-and-social-

expectations/anticipations-metaphoricity -as-

preconverging/postconverging-rede-

mentating/restructuring/reparadigming-psychologism-<as-from-

perspective-ontological-normalcy/postconvergence $>$ of extricatory

secondnatured incrementalism-in-relative-ontological-

incompleteness ${ }^{8}$ —enframed/disontologising conceptualisation); $\uparrow$

critically the basis for human sublimating-over-desublimating social-andinstitutional-constructs-of- meaningfulness-and-teleology - 
incumulation/recomposuring as to human-subpotency potential for social formation, modes-of-living, language-as-of-dialogical-equivalence-<asto-psychologismic apriorising/axiomatising/referencing-\{of'prospectively_implicited_attendant_ontological-contiguity ' reducedexistentialising/contextualising/textualising_intelligibility/epistemicity/re flexivity-contiguity-<imbued-notional cogency>' \}-conflatedness in \{preconverging ment by\} postconverging entailment,-in-selfbecoming/self-conflatedness /formative-supererogating >, cultural practices, etc. is rather as of 'prospective transcendence-andsublimity/sublimation/supererogatory-de-mentativity percolationchannelling-<in-deferential-formalisation-transference $>\quad$ as-tosocial/institutional/conceptual-constructs formation/establishment/superseding-metaphoricity with respect to existence-potency $\sim$ sublimating-nascence,-disclosed-from-prospectiveepistemic-digression, in the sense that human social, institutional and conceptual constructions (as to their projected 'self-assuredness-ofontological-good-faith/authenticity postconverging-dementating/structuring/paradigming - as-being-as-of-existential-reality with respect to social-stake-contention-or-confliction') warrant that the 'capacity to fulfil the prospective transcendence-andsublimity/sublimation/supererogatory-de-mentativity function/posture' like prospective cure from the doctor, prospective technical transformation from the technician/engineer, prospective scientific breakthrough from the researcher, prospective social transformation from the social scientist/advocate/policymaker, etc. rather supersedes human prior- 
apriorising/axiomatising/referencing-superseded-logical-basis-

of dialogical-equivalence-<as-to-

psychologismic apriorising/axiomatising/referencing-\{of-"prospectively implicited_attendant-ontological-contiguity ' educedexistentialising/contextualising/textualising_intelligibility/epistemicity/re flexivity-contiguity-<imbued-notional $\sim$ cogency $>$ ' \}-conflatedness in \{preconverging ment by\} postconverging entailment,-in-selfbecoming/self-conflatedness /formative-supererogating $>$ (as to its naïve pretence of mere logical convincing rather tha prospective transcendence-and-sublimity/sublimation/supererogatory-de-mentativity implications) as the prior-apriorising/axiomatising/referencingsuperseded-logical-basis-of dialogical-equivalence-<as-topsychologismic apriorising/axiomatising/referencing-\{of- "prospectively implicited_attendant-ontological-contiguity ' reducedexistentialising/contextualising/textualising_intelligibility/epistemicity/re flexivity-contiguity-<imbued-notional $\sim \operatorname{cogency}>$ ' \}-conflatedness in \{preconverging ment by, postconverging entailment,-in-selfbecoming/self-conflatedness /formative-supererogating $>$ ' is more of prior reasoning-from-results/afterthought secondnatured institutionalisation derived from 'prior reasoning-through/messianicreasoning induced transcendence-andsublimity/sublimation/supererogatory de-mentativity out of prior human ontological-faith-notion-or-ontological-fideism-imbuedunderdetermination-of-motif-and-apriorising/axiomatising/referencingas-so-being-as-of-existential-reality'; thus dialogical-equivalence-<as- 
to-psychologismic apriorising/axiomatising/referencing-\{of-

'prospectively implicited_attendant-ontological-contiguity ' reducedexistentialising/contextualising/textualising_intelligibility/epistemicity/re flexivity-contiguity-<imbued-notional $\sim$ cogency $>$ ' \}-conflatedness in fpreconverging ment by\} postconverging entailment,-in-selfbecoming/self-conflatedness /formative-supererogating> as of prior reproducibility — mathesis/motif/thrownness-disposition,-as-

reproducibility-of-aestheticisation (especially as prospectively susceptible at the uninstitutionalised-threshold ${ }^{02}$ to human temporality /shortness <amplitudingfformative> wooden-language-_imbued-averaging-ofthought-<as-to-leveling/ressentiment/closed-construct-ofmeaningfulness-and-teleology -as-of-'nondescript/ignorable-void 'with-regards-to-prospective-apriorising-implications $>$ | induced <amplituding/formative-epistemicity>totalising $\sim$ self-referencingsyncretising/circularity/interiorising/akrasiatic-drag <amplituding/formative> wooden-language-fimbued-temporal-mereform/virtualities/dereification/akrasiatic-drag/denatured/preconvergingor-dementing -narratives-of-the- reference-of-thought-categoricalimperatives/axioms/registry-teleology ) cannot substitute for prospective transcendence-and-sublimity/sublimation/mativity as of prospective originariness-parrhesia,-as-spontaneity-ofaestheticisation as to prospective-apriorising/axiomatising/referencingsuperseding-logical-basis-of dialogical-equivalence-<as-topsychologismic apriorising/axiomatising/referencing-\{of- 'prospectively implicited_attendant-ontological-contiguity ' reduced- 
existentialising/contextualising/textualising_intelligibility/epistemicity/re

flexivity-contiguity-<imbued-notional $\sim$ cogency $>$ ' $\}$-conflatedness

in \{preconverging ment by\} postconverging entailment,-in-self-

becoming/self-conflatedness /formative-supererogating $>$ as rather

tied/constrained to existence-potency $\sim$ sublimating-nascence,-disclosedfrom-prospective-epistemic-digression, explaining why all prospective transcendence-and-sublimity/sublimation/supererogatory de-mentativity are rather about breaking from prior reproducibilitymathesis/motif/thrownness-disposition,-as-reproducibility-of-

aestheticisation; $\boldsymbol{\Phi}$ and in this regards, the ontological-commitment$<$ implied-self-assuredness-of-ontological-good-

faith/authenticity $\sim$ postconverging-de-

mentating/structuring/paradigming -as-being-as-of-existential-reality>

significance of prospective-apriorising/axiomatising/referencingsuperseding-logical-basis-of dialogical-equivalence-<as-to-

psychologismic apriorising/axiomatising/referencing-\{of-"prospectively implicied_antontolonical-contiguity ' reducedexistentialising/contextualising/textualising_intelligibility/epistemicity/re flexivity-contiguity-<imbued-notional cogency>' \}-conflatedness in \{preconverging ment by\} postconverging entailment,-in-selfbecoming/self-conflatedness /formative-supererogating $>$ rather arises as a 'prospectively conflated possibility/invention' as from prospective human ontological-faith-notion-or-ontological-fideism-imbuedunderdetermination-of-motif-and-apriorising/axiomatising/referencingas-so-being-as-of-existential-reality wherein the disseminative- 
sublimating-selectivity-of-ontological-good-

faith/authenticity postconverging-de-

mentating/structuring/paradigming, -over desublimating deselectivity

of ontological bad faith/inauthenticity opreconverging de

mentating/structuring/paradigming as of dimensionality-of-

sublimating $-1<$ amplituding/formative $>$ supererogatory $\sim d e-$

mentativeness/epistemic-growth-or-conflatedness /transvaluative-

rationalising/transepistemicity/anamnestic-residuality/spirit-drivenness-

equalisation) for human reference-of-thought-and- reference-ofthought- devolving- ${ }^{5}$ meaningfulness-and-teleology generation of 'prospective base-institutionalisation apriorising/axiomatising/referencing' out of recurrent-utteruninstitutionalisation, 'prospective universalisation apriorising/axiomatising/referencing' out of base-institutionalisationununiversalisation, 'prospective positivism/rational-empiricism apriorising/axiomatising/referencing' out of '103iversalisation-nonpositivism/medievalism, and 'prospective notional deprocrypticism apriorising/axiomatising/referencing' out of positivism_ procrypticism, and in all the above instances of prospective transcendence-andsublimity/sublimation/supererogatoryode-mentativity percolationchannelling-<in-deferential-formalisation-transference $>\quad$ as-tosocial/institutional/conceptual-constructs formation/establishment/superseding-metaphoricity ' actually rendered possible as of the successive prospectiveapriorising/axiomatising/referencing-superseding-logical-basis- 
of dialogical-equivalence-<as-to-

psychologismic apriorising/axiomatising/referencing-\{of-"prospectively implicited_attendant-ontological-contiguity ' reducedexistentialising/contextualising/textualising_intelligibility/epistemicity/re flexivity-contiguity-<imbued-notional $\sim$ cogency $>$ ' \}-conflatedness in-\{preconverging-ment by\} postconverging-entailment,-in-selfbecoming/self-conflatedness /formative-supererogating $>$ (and not the successive prior-apriorising/axiomatising/referencing-supersededlogical-basis-of dialogical-equivalence-<as-topsychologismic apriorising/axiomatising/referencing-\{of- "prospectivelyimplicited_attendant-ontological-contiguity ' reducedexistentialising/contextualising/textualising_intelligibility/epistemicity/re flexivity-contiguity-<imbued-notional cogency > ' \}-conflatedness in \{preconverging ment by\} postconverging entailment,-in-selfbecoming/self-conflatedness /formative-supererogating $>2$ respectively on the basis of 'prior recurrent-utter-uninstitutionalisation apriorising/axiomatising/referencing', 'prior base-institutionalisationununiversalisation apriorising/axiomatising/referencing', 'prior universalisation-non-positivism/medievalism apriorising/axiomatising/referencing' or 'prior positivismprocrypticism apriorising/axiomatising/referencing'); $\uparrow$ and likewise the dispensing-with-immediacy-for-relative-ontological-completeness ${ }^{8}$-byreification/contemplative-distension (as of human self-surpassingexistentialism-form-factor,-in-overcoming- 'notional collateralisingbeholdening-protohumanity'-to- 'attain-sublimating-humanity'-as-to- 
existence-potency sublimating-nascence,-disclosed-from-prospective-

epistemic-digression to supersede human temporality /shortness

<amplitudingfformative> wooden-language-_imbued-averaging-of-

thought-<as-to-leveling/ressentiment/closed-construct-of-

meaningfulness-and-teleology -as-of-'nondescript/ignorable-void '-

with-regards-to-prospective-apriorising-implications $>$ )) choices (as to

ontological-faithnotion-or-ontological-fideism-imbued-

underdetermination-of-motif-and-apriorising/axiomatising/referencing-

as-so-being-as-of-existential-reality) of the Socrates, Galileos, Descartes,

Newtons, Darwins, Einsteins, etc. and as associated with corresponding human knowledge and scientific breakthroughs did not have any valid prior-apriorising/axiomatising/referencing-superseded-logical-basis-

of dialogical-equivalence-<as-to-

psychologismic apriorising/axiomatising/referencing-\{of-"prospectively implicited_attendant-ontological-contiguity ' educed-

existentialising/contextualising/textmalising_intelligibility/epistemicity/re

flexivity-contiguity-<imbued-notional $\sim$ cogency $>$ ' \}-conflatedness

in \{preconverging ment by\} postconverging entailment,-in-self-

becoming/self-conflatedness /formative-supererogating $>2$ but for the

disseminative-sublimating-selectivity-of-ontological-good-

faith/authenticity postconverging-de-

mentating/structuring/paradigming ,-over desublimating deselectivity

of ontological bad faith/inauthenticity opreconverging de

mentating/structuring/paradigming that could invent/made-possible the prospective-apriorising/axiomatising/referencing-superseding-logical- 
basis-of dialogical-equivalence-<as-to-

psychologismic apriorising/axiomatising/referencing-\{of-"prospectively implicited_attendant-ontological-contiguity ' reduced-

existentialising/contextualising/textualising_intelligibility/epistemicity/re

flexivity-contiguity-<imbued-notional $\sim$ cogency $>$ ' \}-conflatedness

in-\{preconverging-ment by\} postconverging-entailment,-in-self-

becoming/self-conflatedness /formative-supererogating $>$ and so as of

their 'prospective transcendence-and-

sublimity/sublimation/supererogatoryode-mentativity percolation-

channelling-<in-deferential-formalisation-transference $>\quad$ as-to-

social/institutional/conceptual-constructs

formation/establishment/superseding-metaphoricity ; ; human

ontological-commitment-<implied-self-assuredness-of-ontological-

good-faith/authenticity postconverging-de-

mentating/structuring/paradigming -as-being-as-of-existential-reality>

as such implies that the doctor, researcher, technologist, etc. initiative is not critically about logically engaging the social framework in its presencing-absolutising-identitive-constitutedness $\quad$ priorapriorising/axiomatising/referencing-superseded-logical-basis-

of dialogical-equivalence-<as-to-

psychologismic apriorising/axiomatising/referencing-\{of-'prospectively implicited attendant-ontological-contiguity ' reduced-

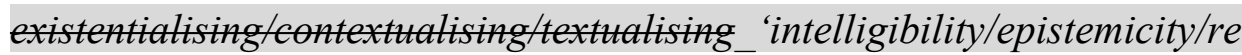
flexivity-contiguity-<imbued-notional cogency> ' \}-conflatedness

in \{preconverging ment by\} postconverging entailment,-in-self- 
becoming/self-conflatedness /formative-supererogating $>2$ but rather eliciting 'prospective transcendence-andsublimity/sublimation/supererogatory-de-mentativity percolationchannelling-<in-deferential-formalisation-transference $>$ as-tosocial/institutional/conceptual-constructs formation/establishment/superseding-metaphoricity as to historiality/ontological-eventfulness 38 /ontological-aesthetic-tracing$<$ perspective-ontological-normalcy/postconvergence-reflected'epistemicity-relativism-determinism'> and critically as of prospectiveapriorising/axiomatising/referencing-superseding-logical-basis-

of dialogical-equivalence-<as-to-

psychologismic apriorising/axiomatising/referencing-\{of- 'prospectively implicited_attendant-ontological-contiguity ' educedexistentialising/contextualising/textualising_intelligibility/epistemicity/re flexivity-contiguity-<imbued-notional $\sim$ cogency > ' \}-conflatedness in \{preconverging ment by\} postconverging entailment,-in-selfbecoming/self-conflatedness /formative-supererogating $>$ in reflecting the underlying supposedly coherent ontological-commitment-<impliedself-assuredness-of-ontological-good-

faith/authenticity $~ p$ postconverging-dementating/structuring/paradigming -as-being-as-of-existential-reality> of the social as to 'fulfilling the prospective transcendence-andsublimity/sublimation/sunction/posture' like prospective cure from the doctor, prospective technical transformation from the technician/engineer, prospective scientific breakthrough from the 
researcher, prospective social transformation from the social scientist, etc. (but only as so-validated by the ontological-veracity of the manifest prospective transcendence-and-sublimity/sublimation/supererogatory-dementativity implications preconverging/postconverging-dementatively/structurally/paradigmatically as upholding their deferentialformalisation-transference statuses or institutionally-and-socially surpassing-and-substituting-for prior deficient deferential-formalisationtransference statuses as to quackery, scamming, sophistry, etc.); $\mathbb{1}$ interestingly it is only as of the inventing/making-possible of the apriorising/axiomatising/referencing conception of genes-and-genetics, quantum mechanics, prospective greek-philosophy-out-of-sophistry, etc. that the prospective-apriorising/axiomatising/referencing-supersedinglogical-basis-of dialogical-equivalence-<as-to-

psychologismic apriorising/axiomatising/referencing-\{of-"prospectively implicited_attendant-ontological-contiguity ' educedexistentialising/contextualising/textualising_intelligibility/epistemicity/re flexivity-contiguity-<imbued-notional $\sim$ cogency $>$ ' \}-conflatedness in \{preconverging ment by\} postconverging entailment,-in-selfbecoming/self-conflatedness /formative-supererogating $>$ of the respective notions arose in the first place as before then such notions did not notionally/epistemically/bindingnessly unreflexivity/relative-reflexivity $\quad$ entailed any priorapriorising/axiomatising/referencing-superseded-logical-basis-

of dialogical-equivalence-<as-topsychologismic apriorising/axiomatising/referencing-\{of-"prospectively 
implicited_attendant-ontological-contiguity ' reduced-

existentialising/contextualising/textualising_intelligibility/epistemicity/re flexivity-contiguity-<imbued-notional $\sim$ cogency> ' \}, conflatedness

in \{preconverging ment by\} postconverging entailment,-in-selfbecoming/self-conflatedness /formative-supererogating $>$ and likewise it is herein contended that prospective notional deprocrypticism rather notionally/epistemically/bindingnessly-<as-to-determinism/conceptivity-of relative-

unreflexivityelative reflexivity> entails its prospectiveapriorising/axiomatising/referencing-superseding-logical-basis-

of dialogical-equivalence-<as-topsychologismic apriorising/axiomatising/referencing-\{of-"prospectivelyimplicited_attendant-ontological-contiguity ' reducedexistentialising/contextualising/textualising_intelligibility/epistemicity/re flexivity-contiguity-<imbued-notional $\sim$ cogency $>$ ' \}-conflatedness in \{preconverging ment by\} postconverging entailment,-in-selfbecoming/self-conflatedness /formative-supererogating $>$ beyond-andsuperseding any pretence of prior-apriorising/axiomatising/referencingsuperseded-logical-basis-of dialogical-equivalence-<as-topsychologismic apriorising/axiomatising/referencing-\{of- "prospectively implicited_attendant-ontological-contiguity ' reducedexistentialising/contextualising/textualising_intelligibility/epistemicity/re flexivity-contiguity-<imbued-notional $\sim$ cogency $>$ ' ;-conflatedness in \{preconverging ment by\} posteonverging entailment,-in-selfbecoming/self-conflatedness /formative-supererogating $>$ s as to our presencing-absolutising-identitive-constitutedness manifestation of 
positivism/rational-empiricism manifestation of procrypticism-ordisjointedness-as-of- reference-of-thought and so as of human ${ }^{3}$ reference-of-thought prospective relative-ontological-completeness implied existence-potency $\sim$ sublimating-nascence,-disclosed-fromprospective-epistemic-digression

relativerelative unreflexivity/relative reflexivity ontological-contiguity-_as-ofunreflexivity/relati the-effectively-operant-implications-of-prospective-relative-ontologicalve-reflexivity completeness -ofontologicalapriorising/axiomatising/referencing/intelligibilitysettingup/measuringins contiguity ${ }^{67}$ trumenting,-foraposteriorising/logicising/deriving/intelligising/measuring/; $\uparrow \quad$ as to attendant-ontological-contiguity or 'specifically given relativeunreflexivity/relative-reflexivity in existence' <amplituding/formativeepistemicity>-totalising thrownness-in-existence imbued supererogating $\{$ as-of-affirmation/projection/assertion/notional $\sim$ selfdistantiation/dueness-validating-logicising/suitablemeasuringinstrument-validating-measuring-<as-to-postconverging-ordialectical-thinking -apriorising-psychologism $>$, while implying as of the same unaffirmation/deprojection/deassertion/epistemicdecadence/undueness-invalidating-logicising/unsuitablemeasuringinstrument-invalidating-measuring-<as-to-preconverging-ordementing -apriorising-psychologism>-of-prior-relative-ontologicalincompleteness -of-reference-of-thought, and relative unreflexivity/relative-reflexivity ontological-contiguity so-herein reflects 
unreflexivity/relative-reflexivity>> (as of any limitedness/human-subpotency conceptualising/construal as attendant-ontological-contiguity or 'specifically given relative-unreflexivity/relative-reflexivity in existence') and so with regards such conceptualising/construal 'span of relativeunreflexivity-by-relative-reflexivity of ontological-performance ${ }^{72}$ <including-virtue-as-ontology>/morality/ethics/justice/etc.'); relative unreflexivity/relative-reflexivity-ontological-contiguity speaksof-and-inherently-implies notional-contiguity/epistemic-contiguity

\section{$<$ profound-supererogation -of-mentally-}

aestheticised postconverging/dialectical-thinking -qualia-schema> as from the perspective of relative-ontological-completeness of overall relative unreflexivity/relative reflexivity-ontological-contiguity; 9 for instance as of 'the-very-same physics <amplitudinglformativeepistemicity>totalising devolved-purview/domain-of-construal-asintrinsic-reality/ontological-veridicality/existential-reality', the state of relative-ontological-completeness of theory-of-relativity-together-withquantum-mechanics-axiomatic-constructs with respect to the state of relative-ontological-incompleteness ${ }^{8}$ of classical-mechanics-axiomaticconstructs implies that the former perspective (as attendant-ontologicalcontiguity) is of notional-contiguity/epistemic-contiguity $-<$ profoundsupererogation -of-mentally-aestheticised postconverging/dialecticalthinking-qualia-schema> since its perspective sublimating historiality/ontological-eventfulness 38 /ontological-aesthetic-tracing$<$ perspective-ontological-normalcy/postconvergence-reflected- 
'epistemicity-relativism-determinism'> provides knowledge about itself and enlightens the interpretation of the latter as to the latter's correctnessand-flaws, while the latter perspective (as attendant-ontologicalcontiguity) is rather of notional-discontiguity/epistemic-discontiguity $<$ between-prior-shallow-supererogation -of-mentallyaestheticised preconverging/dementing -qualiaschema_and_prospective-profound-supererogation -of-mentallyaestheticised postconverging/dialectical-thinking -qualia-schema> since it cannot grasp the overall picture of its own correctness-and-flaws and furthermore it is inherently in no position to analyse and account for the picture of the correctness-and-flaws of the former, and insightfully this equally explains why prospective notional deprocrypticism perspective (as attendant-ontological-contiguity) implying existencepotency $\sim$ sublimating-nascence,-disclosed-from-prospective-epistemicdigression as-to-ontologically-uncompromised-ontologicalnormalcy/postconvergence/referentialism is the notionalcontiguity/epistemic-contiguity $-<$ profound-supererogation -ofmentally-aestheticised postconverging/dialectical-thinking -qualiaschema $>$ for articulating and explaining the relative unreflexivity/relativereflexivity ontological-contiguity of-the-human-institutionalisationprocess ${ }^{6}$ since it is the most profound human state/attendant-ontologicalcontiguity of relative-ontological-completeness -of-reference-ofthought affirmation/projection/assertion/notional $\sim$ selfdistantiation/dueness-validating-logicising/suitablemeasuringinstrument-validating-measuring-<as-to-postconverging-or- 
dialectical-thinking -apriorising-psychologism>; it should be noted here that there is no such thing as 'ontological-discontiguity' by the mere fact that ontology/intrinsic-reality/existence/existential-reality is the superseding-oneness-of-ontology so-underlined as relativeunreflexivity/relative reflexivity-ontological-contiguity and any 'supposedly implied ontological incoherence' that may arise from human poor grasp of ontology/intrinsic-reality/existence/existential-reality is rather as of human reference-of-thought relatively deficient perception/construal that then actually speaks of notionaldiscontiguity/epistemic-discontiguity 3 - between - prior-shallowsupererogation -of-mentally-aestheticised preconverging/dementing qualia-schema_and_prospective-profound-supererogation -of-mentallyaestheticised postconverging/dialectical-thinking -qualia-schema> just as human ${ }^{3}$ reference-of-thought relatively efficient perception/construal 'supposedly attaining perspective sublimating relativeunreflexivity/relative reflexivity ontological-contiguity' speaks of notional-contiguity/epistemic-contiguity ${ }^{2}<$ profound-supererogation of-mentally-aestheticised postconverging/dialectical-thinking -qualiaschema>, and likewise there is no such thing like 'ontological-decadence' but rather 'epistemic-decadence' or teleological-decadence-<-indimensionality-of-desublimating-lack-of < amplituding/formative $>$ supererogatory de-mentativeness/epistemicgrowth-or-conflatedness /transvaluativerationalising/transepistemicity/anamnestic-residuality/spirit-drivennessequalisation) (given that humankind is ever always of limited-mentation- 
capacity-as subjecting 'educed unlimitednesstexistence sublimatingnascence' to limitedness/human-subpotency the ever always present reality of human 'ontological incoherence' means that human limitedmentation-capacity-deepening - as subjecting limitedness/humansubpotency to 'educed unlimitedness/existence sublimating nascence' can only elicit a human relative-ontological-completeness perspective 'relative unreflexivity/relative reflexivity ontological-contiguity of existence as surreal reflecting the ${ }^{97}$ surrealising nature of the $<$ cumulating/recomposuring $\sim$ attendant-ontological-contiguity $>$ successive registry-worldviews/dimensions' rather than the 'sublimating absolute of relative-unreflexivity/relative reflexivity-ontologicalcontiguity of existence as the-real'), and going by the-very-same reasoning while there is 'ontological-normalcy' however there is no such thing as 'ontological-abnormalcy' but rather human 'epistemicabnormalcy/preconvergence ", and further there is no such thing as ontological-causality/metaphysical-causality as 'existence as of its inherent immanency is tautologically all the causation that there is as to its overall relative unreflexivity/relative reflexivity-ontologicalcontiguity' and all the notion of causality that is relevant thereof is undissociable from human-subpotency epistemic-situation (as to human teleology so-construed as 'human phenomenal/manifest conceptivity/epistemic-reflexivity/epistemicity-relativism-determinism$<$ reifying\{as-to-knowledge-developing\}-and-empowering $>$ in existence as ontological (so-reflecting $<$ amplituding/formative $>$ disposedness/psychologismic-construct-_as-to- 
orientation/value-construct/valuation-and-derived-parameterising) and

$<$ amplituding/formative > entailment-_as-to-totalising-

contiguous/coherent-factuality-of-variabilityl)', underlied as of overall reifying-and-empowering-reflexivity-of-ecstatic-existence-as-

panintelligibilityfpanreflexivity - (existentially-imbued-and-educing-

$\leqslant$ fepistemic-

totalising ${ }_{j}^{\prime}$ hermeneutically/textually/reprojectingly/supererogatingly/zeroin

gly/re acutingly, \{tecompulsing? delinearity $\sim$ for-cogency $\geq$ epistemic-

perspective-of-projective/reprojective-aestheticising-re-motif-and-re-

apriorising/re-axiomatising/re-referencing conceptualisation,-as herein

specifically relevant to human-subpotency)) speaking of

< amplituding/formative-epistemicity>causality $\sim$ as-to-projective-

totalitative-implications-of-prospective- nonpresencing,-for-

explicating relative unreflexivity/relative reflexivity -ontological-

contiguity as to human relative-ontological-completeness

apriorising/axiomatising/referencing-\{of- prospectively

implicited_attendant-ontological-contiguity'reduced-

existentialising/contextualising/textualising_intelligibility/epistemicity/re

flexivity-contiguity-<imbued-notional $\left.\left.\sim \operatorname{cogency}>^{\prime}\right\}^{\prime}\right\}$-conflatedness ${ }^{13}$

in \{preconverging ment by\} postconverging entailment implications,

with the idea of ontological-causality/metaphysical-causality rather a confusion arising out of human presencing-absolutising-identitiveconstitutedness (and this further translates to imply that existence is what is of 'immanent determination' notwithstanding 'human-subpotency 
<amplitudingfformative-epistemicity >causality $\sim$ as-to-projective-

totalitative-implications-of-prospective- nonpresencing,-for-

explicating relative unreflexivity/relative reflexivity ontological-

contiguity imbued underdetermination' of the 'immanentrelativeunreflexivity/relative reflexivity-ontological-contiguity determination that is existence' such that a notion like overdetermination is also a confusion arising out of human presencing-absolutising-identitiveconstitutedness ${ }^{4}$ given that there can't be any determination superseding the 'immanent relative unreflexivity/relative reflexivity-ontologicalcontiguity determination that is existence' with any exaggerated-<assupposedly-overdetermination $>\quad$ or $\quad$ understated-<as-supposedlyunderdetermination $>$ conception of determination rather speaking of 'human-subpotency <emplitudinglformative-epistemicity>causality $\sim$ asto-projective-totalitative-implications-of-prospective- nonpresencing,for-explicating relative unreflexivity/relative reflexivity ontologicalcontiguity imbued underdetermination' in waiting for the validative/invalidative manifestation of existence-as-sublimatingwithdrawal/unenframing/re-ontologising,-elicited-from-prospectiveprofound-supererogation that as such speaks of human ontological-faithnotion-or-ontological-fideism-imbued-underdetermination-of-motif-andapriorising/axiomatising/referencing-as-so-being-as-of-existential-reality as to implicited human <amplituding/formative-epistemicity>totalising thrownness-in-existence ${ }^{35}$,-imbued-projectivearbitrariness/waywardness-_as-to-the-human-projective/reprojectiveaestheticising-re-motif-and-re-apriorising/re-axiomatising/re- 
referencing-process-of- '<amplitudingfformative-

epistemicity>totalising conceptualisation') reflecting the underdetermined potential for attaining ontologicalnormalcy/postconvergence as of the immanent felativeontological-contiguity determination that is existence', with such underdetermined potential realisable as to existence-as-sublimating-withdrawal/unenframing/re-ontologising,elicited-from-prospective-profound-supererogation ); interestingly it is important to grasp that 'ontology as of relative unreflexivity/relative reflexivity-ontological-contiguity' is integrative of both relative-

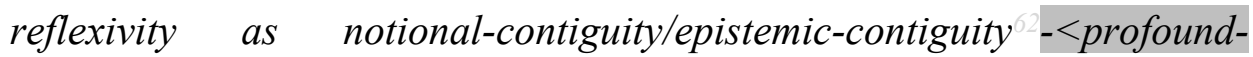
supererogation -of-mentally-aestheticised postconverging/dialecticalthinking -qualia-schema> and relative-unreflexivity as notionaldiscontiguity/epistemic-discontiguity $3<$ between - prior-shallowsupererogation -of-mentally-aestheticised preconverging/dementing qualia-schema_and_prospective-profound-supererogation -of-mentallyaestheticised postconverging/dialectical-thinking -qualia-schema> in the sense that 'existence is a full-potency that reflects the epistemicconception of phenomenal/manifest subpotencies-(in-transitiveconflatedness -reflexivity,-in-the-full-potency-of-

existence's sublimating-nascence) in both their notionalcontiguity/epistemic-contiguity $-<$ profound-supererogation -ofmentally-aestheticised postconverging/dialectical-thinking -qualiaschema> and notional-discontiguity/epistemic-discontiguity $<$ between-prior-shallow-supererogation -of-mentally- 
aestheticised preconverging/dementing -qualia-

schema_and_prospective-profound-supererogation -of-mentally-

aestheticised postconverging/dialectical-thinking -qualia-schema>

explaining why existence is rather tautologically construed as overall reifying-and-empowering-reflexivity-of-ecstatic-existence-as-

panintelligibilityfpanreflexivity - 〈existentially-imbued-and-educing-

$\leq$ fepistemic-

thermeneutically/textually/reprojectingly/supererogatingly/zeroin

gly/re acutingly, \{decompulsing? delinearity for-cogency $\geq$ epistemic-

perspective-of-projective/reprojective-aestheticising-re-motif-and-re-

apriorising/re-axiomatising/re-referencing conceptualisation,-as-herein-

specifically relevant to human subpotency) (as epistemically-deficient

and epistemically-efficient phenomenal/manifest subpotencies-_in-

transitive-conflatedness -reflexivity,-in-the-full-potency-of-

existence's sublimating-nascence) ontological-performance ${ }^{72}$

<including-virtue-as-ontology>/morality/ethics/justice/etc. in existence

are part-and-parcel of existence 'with epistemic-deficiency rather speaking to phenomenal/manifest $\sim$ subpotencies-(in-transitiveconflatedness -reflexivity,-in-the-full-potency-of-

existence's sublimating-nascence) perspective of ontological-deficiency construal'), and it should be pointed out as well that 'existence's reifyingand-empowering-reflexivity-of-ecstatic-existence-as panintelligibilityłpanreflexivity - lexistentially-imbued-and-educing- 
totalising ihermeneutically/textually/reprojectingly/supererogatingly/zeroin

gly/re acutingly, - \{decompulsing? delinearity for-cogency $\geq$ epistemic-

perspective-of-projective/reprojective-aestheticising-re-motif-and-re-

apriorising/re-axiomatising/re-referencing conceptualisation,-as herein

specifically relevant to human subpotency) is conceptually/theoretically exactly what is most profoundly of epistemic-normalcy and ontologicalnormalcy/postconvergence about existence' as starkly manifested with such epiphenomenon like quantum entanglement (even as 'classical interpretations about reality' superficially as of 'human conscious level of epistemic-sufficiency-constitutedness ${ }^{4}$ ' seem to overlook-the-reflexivityor-wrongly-imply-the-non-reflexivity of existential-<disontologising/reontologising aporeticism $>$ sublimating manifestation reflected with the epistemic-conception of phenomenal/manifest $\sim$ subpotencies-_intransitive-conflatedness -reflexivity,-in-the-full-potency-of-

existence's sublimating-nascence), failing to grasp that the ontologicalveracity is one of transitive-conflatedness ${ }^{3}$-reflexivity speaking of an 'imbricated/threaded/recomposuring notional reflexivity-connection between epistemicity and ontologisation of existential-phenomena-andepiphenomena-subpotencies-<wherein-'subpotencies-as-their-

conflatedness ${ }^{13}$-structuring-out-their-phenomenal-conflation-oversupervened-epiphenomena $>$ as to overall-ecstatic-existence-superveningconflatedness ') basically because there is nothing beyond existence and 'all phenomenal/manifest $\sim$ subpotencies-\{in-transitive-conflatedness reflexivity,-in-the-full-potency-of-existence's $\sim$ sublimating-nascence) are 
epistemic situations that speak to the transitive-conflatedness ${ }^{3}$-reflexivity that is existence' as 'there is no whole that is construable as existence and then beside that whole the epistemic-conception of phenomenal/manifest $\sim$ subpotencies-_in-transitive-conflatedness reflexivity,-in-the-full-potency-of-existence's sublimating-nascence) of the said whole' but rather the 'full-potency of existence is integrative of phenomenal/manifest $\sim$ subpotencies-_in-transitive-conflatedness reflexivity,-in-the-full-potency-of-existence's sublimating-nascence) in transitive-conflatedness -reflexivity as the whole' such that a full human epistemic construal of existential-disontologising/re-ontologisingaporeticism $>$ phenomena/manifestations should necessarily involve insight (as to overall reifying-and-empowering-reflexivity-of-ecstaticexistence-as-panintelligibility/panreflexivity ${ }^{3}$ - Lexistentially-imbued-andeducing-<epistemic-

totalising ${ }^{3}$ hermeneutically/textually/reprojectingly/supererogatingly/zeroin gly/re acutingly, - tecompusing delinearity for-cogency $\geq$ epistemicperspective-of-projective/reprojective-aestheticising-re-motif-and-reapriorising/re-axiomatising/re-referencing conceptualisation,-as-hereinspecifically relevant to human-subpotency)) about the 'specific humansubpotency in transitive-conflatedness ${ }^{3}$-reflexivity in existence (just as of all other phenomenal/manifest $\sim$ subpotencies-(in-transitiveconflatedness -reflexivity,-in-the-full-potency-ofexistence's sublimating-nascence) of sufficiently relevant epistemicconception)', and this is exactly what epistemically underlies the construal 
of $\quad$ knowledge-reification $\sim g e s t u r i n g-a n d-a c c o u n t i n g-o f-e p i s t e m i c-$ phenomenalism-<in-

prospective psychologismic $\sim$ apriorising/axiomatising/referencing-\{of'prospectively implicited_attendant-ontological-contiguity' reducedexistentialising/contextualising/textualising_intelligibility/epistemicity/re flexivity-contiguity-<imbued-notional cogency >' \}-conflatedness in \{preconverging ment by\} postconverging entailment $>$ as the 'coherence/contiguity-of-superseding-oneness-of-ontology-implied-as-ofinherent-existencecoherence/contiguity,-and-so-construed-as-theenabler-of-insight-orintuition-or-foresight-as-of-embodiedconsciousness'; critically, (as from its notional-contiguity/epistemiccontiguity ${ }_{-}<$profound-supererogation -of-mentallyaestheticised postconverging/dialectical-thinking -qualia-schema> perspective of construal as human knowledge-reification gesturing-andaccounting-of-epistemic-phenomenalism-<inprospective psychologismic $\sim$ apriorising/axiomatising/referencing-\{of'prospectively implicited antontontolont-contiguity'reducedexistentialising/contextualising/textualising_intelligibility/epistemicity/re flexivity-contiguity-<imbued-notional cogency >' \}-conflatedness in \{preconverging ment by\} postconverging entailment $>\quad$ and sublimation) relative unreflexivity/relative reflexivity ontologicalcontiguity implied ontological-normalcy/postconvergence thus reflects that what is central-and-defining is human notionaldiscontiguity/epistemic-discontiguity 3 - between - prior-shallowsupererogation -of-mentally-aestheticised preconverging/dementing 
qualia-schema_and_prospective-profound-supererogation -of-mentallyaestheticised postconverging/dialectical-thinking -qualia-schema> as of its formativeness/formative-existential-process (that is as of notionallepistemic/bindingness-<as-to-determinism/conceptivity-of relativeunreflexivity/relative-reflexivity>> lack of notional-contiguity/epistemic-contiguity $<$ profound-supererogation -of-mentallyaestheticised postconverging/dialectical-thinking -qualia-schema>), soconstruable as to the <emplituding/formative-epistemicity>causality $\sim$ asto-projective-totalitative-implications-of-prospective- nonpresencing,for-explicating relative unreflexivity/relative reflexivity-ontologicalcontiguity of overall reifying-and-empowering-reflexivity-of-ecstaticexistence-as-panintelligibility/panreflexivity - (existentially-imbued-andeducing-<epistemic

totlising ${ }^{3}$ hermeneutically/textually/reprojectingly/supererogatingly/zeroin gly/re acutingly,-\{decompulsing ${ }^{2}$ delinearity for-cogency $\geq$ epistemicperspective-of-projective/reprojective-aestheticising-re-motif-and-reapriorising/re-axiomatising/re-referencing conceptualisation, as hereinspecifically relevant to human-subpotency) with regards to 'varying psychologismic epistemic acutisation difficulty< <or, residualising \{decompulsing' delinearity for cogency> magnitudes ${ }^{\{0 f-}$ experientiality/experiments/scales-as-to-successively-profoundpreconverging/postconverging-redementating/restructuring/reparadigming-frames-as-from-living,institutionalising,-and-Being-ontologising/infrastructure-ofmeaningfulness-and-teleology of prospective human-subpotency- 
aporia/undecidability/dilemma/ought-

indeterminacy/deficiency/limitation/constraint -imbued-

'notional firstnaturedness-formativeness < as to eventualising inkling

drive or seeding misprising $>$ temporal-to-intemporal-dispositions-

$<$ so-construed-as-from-perspective-ontological-

normalcy/postconvergence $>$ '-existentialism-form-factor', and this then

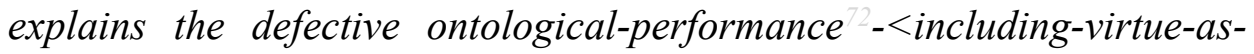
ontology>/morality/ethics/justice/etc. of all presencing-absolutisingidentitive-constitutedness ${ }^{5}$ meaningfulness-and-teleology preconverging/postconverging-de-

mentatively/structurally/paradigmatically (as to de-mentation(supererogatory ontological-de-mentation-or-dialectical-de-

mentation-stranding-or-attributive-dialectics) of mental-aestheticisation induced level of human notional-discontiguity/epistemic-discontiguity $<$ between-prior-shallow-supererogation -of-mentally-

aestheticised preconverging/dementing -qualia-

schema_and prospective-profound-supererogation -of-mentally-

aestheticised postconverging/dialectical-thinking -qualia-schema>)

tied down to underlying relative-ontological-incompletenss of a registryworldview's/dimension's

supererogatory acuity/perspicacity/astuteness/edginess/incisiveness-ofapriorising/axiomatising/referencing/intelligibilitysettingup/measuringins trumenting-for-conceptualisation for aposteriorising/logicising/deriving/intelligising/measuring of meaningfulness-and-teleology in existence and thereof the 
preconverging epistemic-projective-equalisation social dynamics of the derived temporal manifestations of postlogism and ignorance/affordability/opportunism/exacerbation/social-chainism-orsocial-discomfiture-or-negative-social-aggregation/temporalenculturation-or-temporal-endemisation in situations as to social-stakecontention-or-confliction

ontological- ontological-contiguity of-the-human-institutionalisation-process (as of contiguity ${ }^{67} \sim$ of- $\quad$ its '<amplitudingtformative-

the-humanepistemicity>totalising/circumscribing/delineating 'implicited_attendantinstitutionalisation ontological-contiguity ' 'educed- process $^{68}$ existentialising/contextualising/textualising_intelligibility/epistemicity/re flexivity-contiguity-<imbued-notional $\sim \operatorname{cogency}>$ foregrounding_entailment-<in-succession-of-profoundsupererogation $>$ - (postconverging-narrowing-down $\sim$ sublimation-as-to'existence - as-sublimating-withdrawal/unenframing/re-ontologising,elicited-from-prospective-profound-supererogation '-in-reflecting'immanent relative unreflexivity/relative reflexivity ontologicalcontiguity ';-as-operative-notional deprocrypticism) in elucidating relative unreflexivity/relative reflexivity ontological-contiguity $-<$ asfrom-prospective-ontological-normalcy/postconvergence-epistemic-ornotional projective-perspective>'), speaks of overall philosophical depth of contemplation as to 'coherence/contiguity-of-superseding-oneness-ofontology-implied-as-of-inherent-existence-coherence/contiguity,-and-soconstrued-as-the-enabler-of-insight-or-intuition-or-foresight-as-of- 
embodied-consciousness' as a 'deflating-andunifying conception of human ontological-performance ${ }^{72}<$ including-virtue-as-

ontology>/morality/ethics/justice/etc. across prior/present/prospective sublimating $\quad$ historiality/ontological-eventfulness 38 ontologicalaesthetic-tracing-<perspective-ontological-normalcy/postconvergencereflected-'epistemicity-relativism-determinism'>' as 'true-ontology-asof-Being-development/ontological-framework-expansion-as-to-depth-ofontologising-development-as-infrastructure-of- meaningfulness-andteleology,' reflecting human underlying supposedly coherent ontological-commitment -<implied-self-assuredness-of-ontologicalgood-faith/authenticity postconverging-dementating/structuring/paradigming -as-being-as-of-existentialreality>; $\$$ wherein such a conception 'deflates-and-unifies-by-its-moreprofound-explication all hitherto philosophical ideas and insights as well as raising up questions-of-coherence-beyond-the-prismof_enframed/disontologising-traditional-thinking' as from 'relativeontological-incompleteness ${ }^{8}$ to relative-ontological-completeness (renewing supererogatory acuity/perspicacity/astuteness/edginess/incisiveness-ofapriorising/axiomatising/referencing/intelligibilitysettingup/measuringins trumenting-for-conceptualisation, as of apriorising-teleologicalthresholding-as-teleologicalframework-or-narrative-framework) induced < formative-epistemicity $>$ causality $\sim$ as-to-projectivetotalitative-implications-of-prospective- nonpresencing,-forexplicating relative unreflexivity/relative reflexivity ontological- 
contiguity of knowledge-reification gesturing-and-accounting-ofepistemic-phenomenalism- $<$ in-

prospective_psychologismic $\sim$ apriorising/axiomatising/referencing-\{of'prospectively_implicited_attendant-ontological-contiguity ' reducedexistentialising/contextulising/textualising_intelligibility/epistemicity/re flexivity-contiguity-<imbued-notional cogency> ' \}-conflatedness in \{preconverging ment by\} postconverging entailment> '; construed as of difference-conflatedness ${ }^{3}$-as-to-totalitative-reification-insingularisation-<as-to-the-nondisjointedness/entailment-of-prospectivenonpresencing $>$-as-veridical-epistemicity-relativism-determinism or protracted-teleological-wholeness/nested-congruence-in-reflecting-therelative unreflexivity/relative reflexivity ontological-contiguity rof-thehuman-institutionalisation-process,-so-construed-as-singularisation- $<$ asto-the-nondisjointedness/entailment-of-prospective- nonpresencing> projected epistemic-immanence/veridical-epistemicity-relativismdeterminism', thus providing a 'seeding-level of philosophical meaningfulness-and-teleology that overcomes human-subpotency emotional-involvement and institutional <preconverging 'motif-andapriorising/axiomatising/referencing'-entailing>-existentialisingenframing/imprintedness-_as-to- historicity-tracing-in-presencinghyperrealisation/hyperreal-transposition)', and can enable the social domain to truly attain the same ontological-depth of operant construal of existence-potency $\sim$ sublimating-nascence,-disclosed-from-prospectiveepistemic-digression as is sought in the natural sciences, given that the 'apriorising/axiomatising/referencing-\{of- prospectively 


\section{implicited_attendant-ontological-contiguity ' reduced-}

existentialising/contextualising/textualising_intelligibility/epistemicity/re flexivity-contiguity-<imbued-notional $\sim$ cogency $>^{\text {' }}$, - conflatedness ${ }^{13}-$ in \{preconverging ment by\} postconverging entailment-construal-of 'implicited_attendant-ontological-contiguity ' reducedexistentialising/contextmalising/textmalising_intelligibility/epistemicity/re

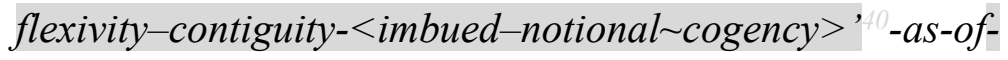
< amplitudinglformative-epistemicity>causality $\sim$ as-to-projectivetotalitative-implications-of-prospective- nonpresencing,-forexplicating felative unreflexivity/relative reflexivity ontologicalcontiguity knowledge-reification $\sim$ gesturing-and-accounting-ofepistemic-phenomenalism- $<$ in-

prospective psychologismic $\sim$ apriorising/axiomatising/referencing-\{of'prospectively_implicited_attendant-ontological-contiguity ' reducedexistentialising/contextualising/textualising_intelligibility/epistemicity/re flexivity-contiguity-<imbued-notional $\sim$ cogency $>$ ' \}-conflatedness in \{preconverging ment by\} postconverging explicitly articulated with the relative unreflexivity/relative reflexivityontological-contiguity $\sim$ of-the-human-institutionalisation-process just as it is rather implicitly reflected in the natural sciences and as of yet is hardly/poorly countenance in the social tradition which 'tends to be lost in a maze of apriorising/axiomatising/referencing-\{of-"prospectively implicited ontological-contiguity ' educedexistentialising/contextualising/textualising_intelligibility/epistemicity/re flexivity-contiguity-<imbued-notional $\sim$ cogency $>$ ' \}-constitutedness ${ }^{14}$ 
extrapolating/constituting/abstracting/deducing/inferring-of-elucidationoutside-'prospectively_implicited_attendant-ontologicalcontiguity ' ' educedexistentialising/contextualising/textualising_intelligibility/epistemicity/re flexivity-contiguity-<imbued-notional cogency>' ending up in its very own <amplituding/formative-epistemicity>totalising $\sim$ self-referencingsyncretising/circularity/interiorising/akrasiatic-drag ${ }^{34}{ }^{56}$ meaningfulnessand-teleology that in-many-ways (as of our present positivismprocrypticism registry-worldview/dimension) increasingly amalgates in its practice knowledge-reification -gesturing-and-accounting-ofepistemic-phenomenalism- $<$ in-

prospective psychologismic apriorising/axiomatising/referencing-\{of'prospectively_implicited_attendant-ontological-contiguity ' reducedexistentialising/contextualising/textualising_intelligibility/epistemicity/re flexivity-contiguity-<imbued-notional $\sim$ cogency $>$ ' \}-conflatedness in \{preconverging ment by\} posteonverging entailment> with social/media-driven influence and is poorly discriminating with $<$ emplitudingfformative $>$ wooden-language-fimbued-averaging-ofthought-<as-to-leveling/ressentiment/closed-construct-ofmeaningfulness-and-teleology -as-of-'nondescript/ignorable-void 'with-regards-to-prospective-apriorising-implications $>$ ) as of a sophistic/pedantic inclination, and so beyond-theconsciousnessawareness-teleology $\quad<$ of-preconverging-existentialextrication-as-of-existential-unthought $>^{\prime} ; \boldsymbol{1}$ the relative- 
unreflexivity/relative reflexivity ontological-contiguity rof-the-humaninstitutionalisation-process as such is reflexive of human-subpotencyaporia/undecidability/dilemma/ought-

indeterminacy/deficiency/limitation/constraint-imbued'notional firstnaturedness-formativeness-<as-to-eventualising inkling drive or seding-misprising> temporal-to-intemporal-dispositions$<$ so-construed-as-from-perspective-ontological-

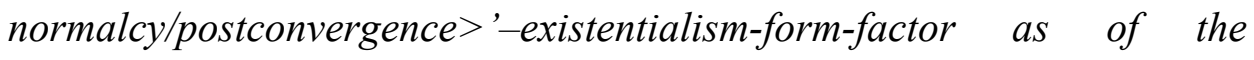
preconverging/postconverging-de-mentative/structural/paradigmatic accordioning-〈as-of-varyingindividuations-contextually-transversedesublimation/sublimation,-as-to-thewaveringtredounding/waveforming of-their-referencing-and-theirdevolved-referencing-imbued-ontological-performance -<includingvirtue-as-ontology>) implications of 'human dimensionality-ofsublimating $-<<$ amplituding/formative $>$ supererogatory $\sim d e-$ mentativeness/epistemic-growth-or-conflatedness /transvaluativerationalising/transepistemicity/anamnestic-residuality/spirit-drivennessequalisation) ontological-faith-notion-or-ontological-fideism-imbuedunderdetermination-of-motif-and-apriorising/axiomatising/referencingas-so-being-as-of-existential-reality reasoning-through/messianicreasoning in eliciting the apriorising/axiomatising/referencing possibility for prospective constructiveness-of-ontological-performance $<$ including-virtue-as-ontology>/morality/ethics/justice/etc. construction-of-the-Self' and 'human <emplitudingfformative> wooden- 
language-fimbued-temporal-mere-

form/virtualities/dereification/akrasiatic-drag/denatured/preconvergingor-dementing -narratives-of-the- reference-of-thought-categoricalimperatives/axioms/registry-teleology / in eliciting the apriorising/axiomatising/referencing destructuring-threshold\{uninstitutionalised-threshold /presublimating-desublimatingdecisionality $\sim$ of-ontological-performance $-<$ including-virtue-asontology>/morality/ethics/justice/etc. as shiftiness-of-the-Self , as generating, by the successive psychoanalytic-unshackling/memeticreordering/institutional-recomposuring of human ${ }^{83}$ reference-of-thoughtand- reference-of-thought- ${ }^{8}$ devolving- ${ }^{5}$ meaningfulness-and-teleology (so-construed as ${ }^{15}$ de-mentation-(supererogatory ontological-dementation-or-dialectical-de-mentation-stranding-or-attributive-

dialectics)), the <cumulating/recomposuring attendant-ontologicalcontiguity >-successive registry-worldviews/dimensions as from recurrent-utter-uninstitutionalisation, $\quad$ base-institutionalisationununiversalisation, ${ }^{103}$ universalisation-non-positivism/medievalism, our positivism/rational-empiricism manifestation of procrypticism-ordisjointedness-as-of- reference-of-thought and prospectively deprocrypticism-or-preempting—disjointedness-as-of- reference-ofthought

ontological-good- ontological-good-faith/authenticity-las-to-thefaith/authenticity ${ }^{69}$ nondiscrete/contiguous/coherence-ontologicalnormalcy/postconvergence-epistemic-perspective-of-notional- 
contiguity/epistemic-contiguity -reflecting relative

unreflexivity/relative reflexivity ontological-contiguity ,-in-

postconverging-nonextricatory-existential-preempting-of-existential-

unthought-as-of- <emplitudingfformative-epistemicity>growth-or-

conflatedness $/$ /transvaluative-

rationalising/transepistemicity/anamnestic-residuality/spirit-drivenness )

ontological-good- ontological-good-faith/authenticity postconverging-de-

faith/authenticity ${ }^{69}$ mentating/structuring/paradigming-<seeding/incipient-profound-

$\sim$ postconverging- supererogation ,-as-mentally-aestheticised postconverging/dialectical-

de-

thinking -qualia-schema>-_as-of-formative-thrownness-projective-

mentating/structuri

arbitrariness/waywardness- 'imbued-psychologism'-of-

ng/paradigming ${ }^{70}$

apriorising/axiomatising/referencing-\{as-postconverging-or-dialectical-

thinking 3) prospectively reflecting existence-as-sublimatingwithdrawal/unenframing/re-ontologising,-elicited-from-prospectiveprofound-supererogation

ontologically- ontologically-hegemonising-

hegemonising- narrative/narrativity/notional deprocrypticism-narrative/totalitative-

narrative ${ }^{71} /$ narrativ aspiring-or-'hegemonising-intemporal-as-ontological-narrative-

ity/notional ${ }^{18}$ depr metaphoricity -as-of-ontological-aesthetic-tracing-<perspective-

ocrypticism- ontological-normalcy/postconvergence-reflected-'epistemicity-relativism-

narrative/totalitativ determinism'>'-_ontologically-driven construal as of correspondingly

e-aspiring-or- $\quad$ profound supposedly coherent ontological-commitment $-<$ implied-self-

'hegemonising- assuredness-of-ontological-good-faith/authenticity postconverging-de-

intemporal-as- mentating/structuring/paradigming -as-being-as-of-existential-reality> 
ontologicalunderlying any society/social-setup conventioning as so reflected by its narrative'self-assuredness-of-ontological-good-

metaphoricity ${ }^{57}$-as- faith/authenticity $\sim$ postconverging-deof-ontological- mentating/structuring/paradigming -as-being-as-of-existential-reality aesthetic-tracing- with respect to its social-stake-contention-or-confliction'), which is then $<$ perspective- enabling for critical prospective metaphoricity ontological-veracity ontological- implications as of prospective relative-ontological-completeness ${ }^{87}$ given normalcy/postconv the absolute primacy of existence-potency $\sim$ sublimating-nascence,ergence-reflected- disclosed-from-prospective-epistemic-digression over human-subpotency 'epistemicity- as of <amplituding/formative-epistemicity>causality as-to-projectiverelativism- totalitative-implications-of-prospective- nonpresencing,-for-

determinism'>' explicating relative unreflexivity/relative reflexivity ontologicalcontiguity

ontological- ontological-performance-<including-virtue-asperformance ${ }^{72}$ ontology>/morality/ethics/justiceletc. of human ${ }^{56}$ meaningfulness-and$<$ including-virtue- teleology by its epistemic-veracity of conception-and articulation as-ontology> reflection of 'existence/intrinsic-reality/ontological-veridicality as the absolute a-priori of conceptualisation going by its ecstatic singularity' and so-construed as epistemic-veracity of human ${ }^{56}$ meaningfulness-andteleology as of human supposedly coherent ontological-commitment $<$ implied-self-assuredness-of-ontological-goodfaith/authenticity $~ p o s t c o n v e r g i n g-d e-$ mentating/structuring/paradigming -as-being-as-of-existential-reality> self-assuredness-of-ontological-good- 
faith/authenticity postconverging-de-

mentating/structuring/paradigming -as-being-as-of-existential-reality

with respect to its social-stake-contention-or-confliction; $\uparrow$ with meaningfulness-and-teleology construed epistemically in reflecting the human subject 'level of relative-ontological-incompleteness /relativeontological-completeness

(sublimating referencing/registering/decisioning,-as-self-becoming/selfconflatedness /formative-supererogating-<projective/reprojectiveaestheticising-re-motif-and-re-apriorising/re-axiomatising/rereferencing,-in-perspective-ontological-normalcy/postconvergence $>$ ) of reference-of-thought

apriorising/axiomatising/referencing/intelligibilitysettingup/measuringins trumenting' as from the epistemic perspective of existencepotency ${ }^{3}$ sublimating-nascence,-disclosed-from-prospective-epistemicdigression as-to-ontologically-uncompromised-ontologicalnormalcy/postconvergence/referentialism, and the further operant reference-of-thought- devolving of meaningfulness-and-teleology as of any such given ${ }^{83}$ reference-of-thought implicited_attendantontological-contiguity $\sim$ educedexistentialising/contextualising/textualising_intelligibility/epistemicity/re flexivity-contiguity-<imbued-notional $\sim \operatorname{cogency}>^{\text {' }}$ instantiations of aposteriorising/logicising/deriving/intelligising/measuring temporal-tointemporal ${ }^{56}$ meaningfulness-and-teleology ; ontological-performance$<$ including-virtue-as-ontology>/morality/ethics/justice/etc. is thus about notionalisation/notional-conception/amplituding of knowledge as to the 
human conceptivity/epistemic-reflexivity/epistemicity-relativismdeterminism-<reifying\{as-to-knowledge-developing\}-and-empowering> purpose of aetiologisation/ontological-escalation-<ontologicalveridicality_commitment/otherliness_transcending/compulsionsencumbered_transcending > (more like medicine is rather about notionally understanding the body for the preconverging/postconverging-dementative/structural/paradigmatic possibility of curing), as so-reflecting human 'epistemic-projection of perspective ontologicalnormalcy/postconvergence' and 'epistemic-projection of perspective epistemic-abnormalcy/preconvergence ${ }^{31}$ of relativeunreflexivity/relative reflexivity ontological-contiguity of-the-humaninstitutionalisation-process ${ }^{68}$ (with regards to human Beingdevelopment/ontological-framework-expansion-as-to-depth-ofontologising-development-as-infrastructure-of- meaningfulness-andteleology , institutional-development-as-to-social-function-development and living-development-as-to-personality-development psychologismic epistemic acutisation diffeuly<-for, residutising \{decompulsing ${ }^{\prime}$ delinearity for cogency $>$ magnitudes (of-experientiality/experiment\} $\left.^{2}\right)$ and so-evaluated as to 'human notional firstnaturedness-formativeness-<asto eventualising inkling drive or seeding misprising $>$ temporal-tointemporal-dispositions-<so-construed-as-from-perspective-ontologicalnormalcy/postconvergence $>$ of individuation' in reflection of the preconverging/postconverging-de-mentative/structural/paradigmatic implications of human limited-mentation-capacity-deepening-assubjecting limitedness/human subpotency to 'educed 
unlimitednesstexistence sublimating nascence'

as so-underlied by

human

institutional-cumulation/institutional-recomposure-_as-to-

historiality/ontological-eventfulness /ontological-aesthetic-tracing-

$<$ perspective-ontological-normalcy/postconvergence-reflected-

'epistemicity-relativism-determinism'>) (as to the

$<$ cumulating/recomposuring attendant-ontological-contiguity $>$

succession of registry-worldviews/dimensions) as so-operatively enabled as of human ${ }^{15}$ de-mentation-(supererogatory-ontological-de-mentation-

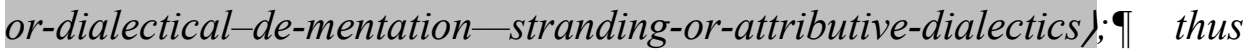
ontological-performance-<including-virtue-as-

ontology>/morality/ethics/justice/etc. as herein construed (as from nonpresencing-<perspective-ontological-normalcy/postconvergence $>$ )

is rather all about evaluating/assessing human ${ }^{56}$ meaningfulness-andteleology while notionally accruing the conceptivity/epistemicreflexivity/epistemicity-relativism-determinism-<reifying\{as-to-

knowledge-developing\}-and-empowering > implications as to relativeontological-incompleteness /relative-ontological-completeness

(sublimating referencing/registering/decisioning,-as-self-becoming/selfconflatedness /formative-supererogating-<projective/reprojectiveaestheticising-re-motif-and-re-apriorising/re-axiomatising/rereferencing,-in-perspective-ontological-normalcy/postconvergence >), soreflected as of human 'referencing/registering/decisioning of shallowsupererogation - to-profound-supererogation conception of socialstake-contention-or-confliction', and in this regards just as say medicine 
in the understanding of the body for preconverging/postconverging-redementating/restructuring/reparadigming the possibility of curing is way more than just curing (as to the fact that at any given moment in time just a little proportion of the human population is actually/directly in quest for medical attention) with the even grander social implications of modern medicine being the 'overall sublimation-induced human-and-socialexpectations/anticipations - metaphoricity -as-

preconverging/postconverging-rede-

mentating/restructuring/reparadigming-psychologism-<as-from-

perspective-ontological-normalcy/postconvergence> of healthy behaviour and healthy living <postconverging 'motif-andapriorising/axiomatising/referencing'-entailing>-existentialisingframing/imprinting-_as-to-prospective- historiality/ontologicaleventfulness /ontological-aesthetic-tracing-<perspective-ontologicalnormalcy/postconvergence-reflected-'epistemicity-relativismdeterminism'>)' likewise the articulation of human ontologicalperformance-<including-virtue-as-ontology $>/$ morality/ethics/justice/etc.

(as to relative-ontological-incompleteness/relative-ontologicalcompleteness ${ }^{8}$-Sublimating referencing/registering/decisioning,-asself-becoming/self-conflatedness /formative-supererogating$<$ projective/reprojective-aestheticising-re-motif-and-re-apriorising/reaxiomatising/re-referencing,-in-perspective-ontologicalnormalcy/postconvergence >) is much more than just as of the 'direct conceptivity/epistemic-reflexivity/epistemicity-relativism-determinism$<$ reifying\{as-to-knowledge-developing\}-and-empowering>' but speaks to 
entailing reconstrual-<of the wholelpurview of the wholeloneness of entology> for overall sublimation-over-desublimation induced humanand-social-expectations/anticipations-metaphoricity -as-

preconverging/postconverging-rede-

mentating/restructuring/reparadigming-psychologism-<as-from-

perspective-ontological-normalcy/postconvergence $>$ as of prospective human ontological-performance-<including-virtue-asontology >/morality/ethics/justice/etc. $<$ postconverging 'motif-andapriorising/axiomatising/referencing'-entailing>-existentialisingframing/imprinting-_as-to-prospective- historiality/ontologicaleventfulness /ontological-aesthetic-tracing-<perspective-ontologicalnormalcy/postconvergence-reflected-'epistemicity-relativismdeterminism'>ノ' associated with 'relative-ontologicalincompleteness 8 /relative-ontological-completeness

(sublimating referencing/registering/decisioning,-as-self-becoming/selfconflatedness /formative-supererogating-<projective/reprojectiveaestheticising-re-motif-and-re-apriorising/re-axiomatising/rereferencing,-in-perspective-ontological-normalcy/postconvergence $>$ ) as to human-and-social-expectations/anticipations-metaphoricity -aspreconverging/postconverging-redementating/restructuring/reparadigming-psychologism (as to the fact for instance that say the prevalence of notions-and-accusations-of-sorcery as inducing vices-and-impediments in a non-positivistic social-setup is much more than just about doing away with the 'direct 
conceptivity/epistemic-reflexivity/epistemicity-relativism-determinism$<$ reifying\{as-to-knowledge-developing\}-and-empowering>' of incidental manifestations of notions-and-accusations-of-sorcery in such a nonpositivistic social-setup but rather the 'overall sublimation-induced human-and-social-expectations/anticipations-metaphoricity -aspreconverging/postconverging-redementating/restructuring/reparadigming-psychologism- $<$ as-fromperspective-ontological-normalcy/postconvergence $>$ as to human ontological-performance-<including-virtue-as-

ontology>/morality/ethics/justice/etc. in adopting a positivistic $<$ postconverging 'motif-and-apriorising/axiomatising/referencing'entailing >-existentialising-framing/imprinting-_as-to-prospectivehistoriality/ontological-eventfulness /ontological-aesthetic-tracing$<$ perspective-ontological-normalcy/postconvergence-reflected'epistemicity-relativism-determinism'>)' are even much more momentous in myriad of positivistic ways and along the same lines it is herein contended that more than just doing away with the 'direct conceptivity/epistemic-reflexivity/epistemicity-relativism-determinism$<$ reifying\{as-to-knowledge-developing\}-and-empowering>' of incidental manifestations of our procrypticism-or-disjointedness-as-ofreference-of-thought the 'overall sublimation-induced human-andsocial-expectations/anticipations - metaphoricity -aspreconverging/postconverging-redementating/restructuring/reparadigming-psychologism-<as-fromperspective-ontological-normalcy/postconvergence $>$ as to human 
ontological-performance-<including-virtue-as-

ontology>/morality/ethics/justice/etc. in adopting prospective deprocrypticism-or-preempting - disjointedness-as-of- reference-ofthought $<$ postconverging 'motif-andapriorising/axiomatising/referencing'-entailing>-existentialisingframing/imprinting-_as-to-prospective- historiality/ontologicaleventfulness /ontological-aesthetic-tracing-<perspective-ontologicalnormalcy/postconvergence-reflected-'epistemicity-relativismdeterminism'>)' are even much more profoundly significant as to potentially reflecting 'human-decisionality-<as-to-play-of-valid/invaliddecisionality-imbued-sublimation/desublimation> omni-potential commensurability with inherent immanent-existence's sublimationstructure'/omnipotentiality, and in all these instances such an expanded implication for prospective human ontological-performance-<includingvirtue-as-ontology>/morality/ethics/justice/etc. arise as to the epistemicprojection perspective of relative profound-supererogation' is 'not of desublimating referenced/registered/decisioned self-presence/selfconstitutedness $^{14}<$ in-perspective-epistemic-

abnormalcy/preconvergence ${ }^{3 /}$ ' but rather 'of sublimating referencing/registering/decisioning self-becoming/self-

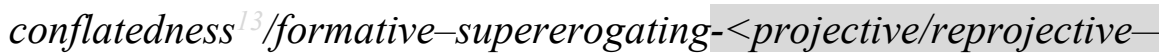
aestheticising-re-motif-and-re-apriorising/re-axiomatising/rereferencing,-in-perspective-ontological-normalcy/postconvergence> ' involving renewed self-awareness as to prospective construction-of-theSelf) 
panintelligibility $/ p$ panintelligibilityfpanreflexivity (and specifically with regards to humananreflexivity $^{73} \quad$ subpotency panintelligibility/panreflexivity-effusing/ecstatic-inlining construed as reifying-and-empowering-reflexivity-of-ecstatic-existenceas-panintelligibility (existentially-imbued-and-educing$\leqslant$ fepistemic totalising ${ }^{3}$ hermeneutically/textually/reprojectingly/supererogatingly/zeroin gly/re acutingly,-\{decompulsingt delinearity for-cogency $\geq$ epistemicperspective-of-projective/reprojective-aestheticising-re-motif-and-reapriorising/re-axiomatising/re-referencing conceptualisation, as hereinspecifically relevant to human subpotencyl) underscores the 'more fundamental < amplituding/formative-epistemicity>totalising theoreticalconceptual-operant difference-scientific-construal of underlying existence phenomenality/manifestation as of conceptivity/epistemicreflexivity/epistemicity-relativism-determinism-<reifying\{as-to-

knowledge-developing\}-and-empowering > involving phenomenal/manifest $\sim$ subpotencies-_in-transitive-conflatedness reflexivity,-in-the-full-potency-of-existence's sublimating-nascence) as to their perspective epistemic-totalising ${ }^{3} \sim$ resubjecting_or_totalisingentailing reconstrual $<$ of the wholelpurview of the wholetoneness of of motif-as-to-aestheticisation-<imbued-projectivearbitrariness/waywardness $>$ to existence-as-the-absolute-a-priori-ofconceptualisation $\sim$ and $\sim$ existence — as-sublimatingwithdrawal/unenframing/re-ontologising,-elicited-from-prospectiveprofound-supererogation $-<$ as-to-perspective-ontologicalnormalcy/postconvergence-implied- 'prospective-aporeticism- 
overcoming/unovercoming'> so-underlying their dynamicintelligibilities/teleologies in existence reflected as to re-motif-and-reapriorising/re-axiomatising/re-referencing automatism' (and specifically with regards to human-subpotency panintelligibilityfpanreflexivity effusing/ecstatic-inlining reflects the 'epistemictotalising ${ }^{3} \sim$ resubjecting_or_totalising-entailing $\sim$ reconstrual-<of thewholelpurview of the wholeloneness of ontology $>$ of motif-as-toaestheticisation-<imbued-projective-arbitrariness/waywardness $>\quad$ to existence-as-sublimating-withdrawal/unenframing/re-ontologising,elicited-from-prospective-profound-supererogation in preconverging/postconverging-redementating/restructuring/reparadigming intelligibility-_as-to-humanprojective/reprojective - aestheticising-re-motif-and-re-apriorising/reaxiomatising/re-referencing/re-intelligibilitysettingup/remeasuringinstrumenting-process,-in-<amplituding/formativeepistemicity>totalising conceptualisation)' as so-underscored by 'effectively underlying human beholdening-inching,-apprehending,-andtaming-drive or aestheticising_ surrealising/supererogating-drive for <postconverging 'motif-and-apriorising/axiomatising/referencing' entailing>-existentialising-framing/imprinting-_as-to-prospectivehistoriality/ontological-eventfulness /ontological-aesthetic-tracing$<$ perspective-ontological-normalcy/postconvergence-reflected'epistemicity-relativism-determinism'>)' and so as to the inherent absolutising referencing/registering/decisioning ontological-deficiency necessarily arising from human limited-mentation-capacity-as- 
subjecting 'educed unlimitednesstexistence sublimating nascence' tolimitedness/human-subpotency' requiring 'projective-insights'/'epistemic-

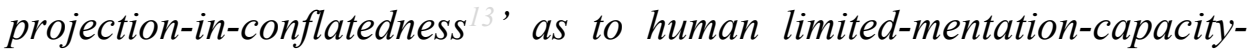
deepening - as subjecting limitedness/human-subpotency to 'educedtnlimitedness/existence sublimating nascence') that underlies the notion of human ${ }^{15}$ de-mentation-(supererogatory-ontological-dementation-or-dialectical-de-mentation-stranding-or-attributive-

dialectics) as factoring in the implications of human limited-mentationcapacity-as subjecting 'educed unlimitedness/existence sublimating

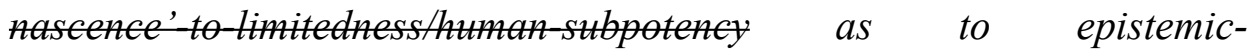
abnormalcy/preconvergence and ontological-normalcy/postconvergence epistemic-projection perspectives reflected respectively as of preconverging-or-dementing -apriorising-psychologism and postconverging-or-dialectical-thinking -apriorising-psychologism); $₫$ panintelligibilityfpanreflexivity is so-underlied as to teleology implied 'phenomenal/manifest conceptivity/epistemic-reflexivity/epistemicityrelativism-determinism-<reifying\{as-to-knowledge-developing\}-andempowering $>$ in existence as ontological', and with overall panintelligibilityfpanreflexivity -effusing/ecstatic-inlining reflected as of the 'full-potency of existence as epistemically integrative of phenomenal/manifest $\sim$ subpotencies-_in-transitive-conflatedness reflexivity,-in-the-full-potency-of-existence's sublimating-nascence) as the whole in relative unreflexivity/relative reflexivity-ontologicalcontiguity or integrality', and with panintelligibilityfpanreflexivity conception as herein articulated speaking to the more profound-and- 
dynamic existential-<disontologising/re ontologising aporeticism> construal of difference fepistemichermeneutically/textully/reprojectingly/supererogatingly/zeroin gly/re acutingly, -\{decompulsing $d e l i n e a r i t y \sim f o r-c o g e n c y-e d u c i n g$ sublimationover-desublimation so-construed beyond the successive Heideggerian ontological-difference conception knowledge-reification gesturing-andaccounting_of-epistemic-phenomenalism-<in-

prospective psychologismic apriorising/axiomatising/referencing-\{of'prospectively_implicited_attendant-ontological-contiguity ' reducedexistentialising/contextualising/textualising_intelligibility/epistemicity/re flexivity-contiguity-<imbued-notional cogency $\left.>^{\text {' }}\right\}$-conflatedness in \{preconverging ment by\} postconverging entailment> (of shallow epistemicity insight) and the Derridean différance conception knowledgereification $\sim$ gesturing-and-accounting-of-epistemic-phenomenalism<in-prospective psychologismic $\sim$ apriorising/axiomatising/referencing\{of-'prospectively_implicited_attendant-ontologicalcontiguity ' reducedexistentialising/contextualising/textualising_intelligibility/epistemicity/re flexivity-contiguity-<imbued-notional $\sim$ cogency> ' ' -conflatedness in \{preconverging ment by\} postconverging entailment> (of more profound epistemicity insight as to its quasi-transcendental epistemicity) towards an integral-difference of epistemic-as-ontological-reflexivity integrality of sublimation-over-desublimation' knowledgereification $\sim$ gesturing-and-accounting-of-epistemic-phenomenalism$<$ in-prospective psychologismic $\sim$ apriorising/axiomatising/referencing- 
\{of-'prospectively_implicited_attendant-ontological-

contiguity ' reduced-

existentialising/contextualising/textualising_intelligibility/epistemicity/re

flexivity-contiguity-<imbued-notional $\sim$ cogency>' ', conflatedness -

in \{preconverging ment by\} postconverging entailment>

(panintelligibilityfpanreflexivity as articulated herein rather projects of scientific intolerance <of disparateness>texactifying_precisioning-ofsublimation-<as-to-postconverging-narrowing-

down apriorising/axiomatising/referencing-entailing-theoretical,-

conceptual-and-operant-implications $>$, as so-underlied by 'existential phenomenalities/manifestations projected perspective <amplituding/formative>disposedness/psychologismic-construct-_as-toorientation/value-construct/valuation-and-derived-parameterising/ and $<$ formative $>$ entailment-\{as-to-totalisingcontiguous/coherent-factuality-of-variability/'); $\uparrow$ and with this overall scientific conception of panintelligibilitytpanreflexivity 'differing from a metaphysical projection of a mere pan-conceptualisation of undefined theoretical-conceptual-operant aestheticisation-and-aestheticisationtowards-ontology-<elicited-idiomatisation $>$ as may be so-implied with panpsychism conception' and so as panintelligibility is not about 'any metaphysical/ideological advocacy' but is rather asserted as of ontologically-veracity in the reflection of existential-reality in the sense that the conception of say an atom or a cell or the social inherently speak to their 'phenomenal/manifest perspective conceptivity/epistemicreflexivity/epistemicity-relativism-determinism-<reifying\{as-to- 
knowledge-developing\}-and-empowering $>$ in existence as ontological' (and so-reflected by their projected perspective <amplituding/formative>disposedness/psychologismic-construct-_as-toorientation/value-construct/valuation-and-derived-parameterising) and <amplituding/formative > entailment-_as-to-totalising-

contiguous/coherent-factuality-of-variability) as to the overall coherence/relative unreflexivity/relative reflexivity ontologicalcontiguity /integrality of their variously implied intelligibilities/teleologies construed as from 'existence projected perspective singularisation-<as-to-the-nondisjointedness/entailment-ofprospective- nonpresencing $>\quad$ projected epistemicimmanence/veridical-epistemicity-relativism-determinism backdrop' rather so-reflected by 'superseding nonreductionist ontologicallycontiguous-epistemicity of the underlying overall panintelligibilityfpanreflexivity effusing/ecstatic-inlining of existence', implying that the atom is not construable-as-existentially-incongruous with the cell which is not construable-as-existentially-incongruous with the social or for that matter all phenomenal/manifest subpotencies-fintransitive-conflatedness -reflexivity,-in-the-full-potency-of-

existence's sublimating-nascence) are necessarily construable-asexistentially-congruous as so-reflected by 'superseding nonreductionist ontologically-contiguous-epistemicity of the underlying overall panintelligibilityfpanreflexivity effusing/ecstatic-inlining of existence'), such that actually 'all phenomenal/manifest $\sim$ subpotencies-(in-transitive- 
conflatedness -reflexivity,-in-the-full-potency-of-

existence's sublimating-nascence) are rather of reductionist <amplitudingtformative-epistemicity>-totalising thrownness-inexistence conception' (with the underlying nonreduction being of overall panintelligibility effusing/ecstatic-inlining of existence) and thus are supersedingly underlied by 'superseding nonreductionist ontologically-contiguous-epistemicity of the underlying overall panintelligibility/panreflexivity effusing/ecstatic-inlining of existence' (as the veridical perspective singularisation-<as-to-thenondisjointedness/entailment-of-prospective- nonpresencing>

projected epistemic-immanence/veridical-epistemicity-relativismdeterminism backdrop for sublimation-over-desublimation' to which '<amplituding/formative-epistemicity>-totalising thrownness-inexistence conceptivity/epistemic-reflexivity/epistemicity-relativismdeterminism-<reifying\{as-to-knowledge-developing $\}$-and-empowering $>$ adopts a projective-insights as of difference-conflatedness for $^{13}$ sublimation-over-desublimation'), such that panintelligibilityfpanreflexivity also 'doesn't actually speak of any constitutive-emergence conceptualisation (though entertains an overallecstatic-existence-supervening-conflatedness ${ }^{13}$ conceptualisation) as such a constitutive-emergence conceptualisation will rather imply the idea of any such '< $<$ formative-epistemicity>-totalising thrownnessin-existence 35 conceptivity/epistemic-reflexivity/epistemicity-relativismdeterminism-<reifying\{as-to-knowledge-developing\}-and-empowering > of say the conceptualisation of atomicity, cellularity or social-aggregation 
as constitutively superseding the 'superseding nonreductionist ontologically-contiguous-epistemicity of the underlying overall panintelligibilityfpanreflexivity effusing/ecstatic-inlining of existence, thus wrongly inducing $a$ '<emplituding/formative-epistemicity>totalising presencing-absolutising-identitive-constitutedness epistemicity reductionism as so-construing the full-potency of existence' (and further failing to epistemically account for relative-ontological-incompleteness of $\quad$ reductionist '<amplitudingfformative-epistemicity>totalising thrownness-in-existence conceptivity/epistemicreflexivity/epistemicity-relativism-determinism-<reifying\{as-toknowledge-developing\}-and-empowering >' as to prospective supererogation for relative-ontological-completeness inherent conceptivity/epistemic-reflexivity/epistemicity-relativism-determinism$<$ reifying\{as-to-knowledge-developing\}-and-empowering > imbuement of existence) rather than '<amplituding/formative-epistemicity>totalising projective-insights as of difference-conflatedness epistemicity nonreductionism of phenomenal/manifest subpotencies-(in-transitiveconflatedness -reflexivity,-in-the-full-potency-of-

existence 's sublimating-nascence)' as to 'superseding nonreductionist ontologically-contiguous-epistemicity of the underlying overall panintelligibilityfpanreflexivity effusing/ecstatic-inlining of existence, (in other words phenomenal/manifest epistemicity reductionist human conceptions are of '<amplitudingfformative-epistemicity>totalising thrownness-in-existence conceptivity/epistemicreflexivity/epistemicity-relativism-determinism- $<$ reifying\{as-to- 
knowledge-developing\}-and-empowering>' and cannot constitutively explain existence even as various phenomenal/manifest reductionist human elucidations can provide in apriorising/axiomatising/referencing-\{of'prospectively implicited_attendant-ontological-contiguity ' reducedexistentialising/contextulising/textualising_intelligibility/epistemicity/re flexivity-contiguity-<imbued-notional $\sim$ cogency $\left.>^{\text {' }}\right\}$-conflatedness ${ }^{13}-$ in \{preconverging ment by\} postconverging entailment of the various phenomenal/manifest $\sim$ subpotencies-_in-transitive-conflatedness reflexivity,-in-the-full-potency-of-existence's sublimating-nascence) socontrued as from human 'relative-ontological-incompleteness /relativeontological-completeness

(sublimating referencing/registering/decisioning,-as-self-becoming/selfconflatedness /formative-supererogating-<projective/reprojectiveaestheticising-re-motif-and-re-apriorising/re-axiomatising/rereferencing,-in-perspective-ontological-normalcy/postconvergence >) as to human-and-social-expectations/anticipations-metaphoricity -aspreconverging/postconverging-redementating/restructuring/reparadigming-psychologism' the projectiveinsights about 'superseding nonreductionist ontologically-contiguousepistemicity of the underlying overall panintelligibility effusing/ecstatic-inlining of existence', and in fact existential<disontologising/re ontologising aporeticism> supererogation as to ‘<amplituding/formative-epistemicity>-totalising thrownness-in-

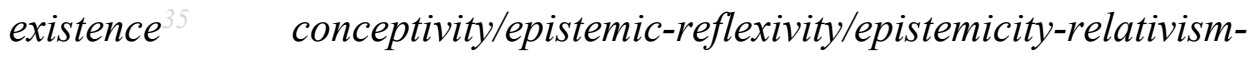
determinism-<reifying\{as-to-knowledge-developing\}-and-empowering > 
is always about driving towards 'nonreductionist epistemic-reflexive conflating-construal of existential-disontologising/re-ontologisingaporeticism $>$ phenomenality/manifestation as to ontologicalnormalcy/postconvergence perspective' reflecting existence-as-theabsolute-a-priori-of-conceptualisation $\sim$ and $\sim$ existence - as-sublimatingwithdrawal/unenframing/re-ontologising,-elicited-from-prospectiveprofound-supererogation $-<$ as-to-perspective-ontologicalnormalcy/postconvergence-implied- 'prospective-aporeticismovercoming/unovercoming'> and so over-and-beyond grotesquely punctual confusion/misconstrual as of 'reductionist conceptivity/epistemic-reflexivity/epistemicity-relativism-determinism$<$ reifying\{as-to-knowledge-developing\}-and-empowering $>$ constitutingconstrual of existential-disontologising/re ontologising aporeticism> phenomenality/manifestation as to human epistemicabnormalcy/preconvergence perspective' as manifested for instance with naïve science-ideology interpretations of the social in the sense that inmany-ways such science-ideology interpretations tend to 'confusingly in shallow-supererogation, implicit the reality of the '<amplituding/formative-

epistemicity>totalising/circumscribing/delineating necessitation frameof relative unreflexivity/relative reflexivity ontological-contiguity of the social and socio-psychological epistemic-conception phenomenal/manifest $\sim$ subpotencies-_in-transitive-conflatedness reflexivity,-in-the-full-potency-of-existence's sublimating-nascence) (as to their implied sublimating existence's necessitating implications and 
consequences)', and then surreptitiously project/select/pop-up (in totalisingly-ing—discretion/whim-of-thought) opportune/ad-hoc biological/neurological and evolutionary substitutive/reductionist interpretations of the social and socio-psychological frame-of relativeunreflexivity/relative reflexivity ontological-contiguity, and so as of vague disparateness-of-conceptualisation-<unforegrounding-ment,failing-prospectively-to-reflect- immanent relative unreflexivity/relative-

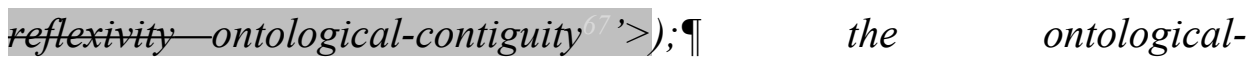
normalcy/postconvergence epistemicity perspective reflected by the 'superseding nonreductionist ontologically-contiguous-epistemicity of the underlying overall panintelligibility/panreflexivity effusing/ecstaticinlining of existence' contrasting with phenomenal/manifest $\sim$ subpotenciesfin-transitive-conflatedness -reflexivity,-in-the-full-potency-ofexistence's sublimating-nascence) '<amplituding/formativeepistemicity>-totalising thrownness-in-existence conceptivity/epistemic-reflexivity/epistemicity-relativism-determinism<reifying\{as-to-knowledge-developing\}-and-empowering>, as to epistemic-abnormalcy/preconvergence epistemicity perspective is what underlies 'phenomenal/manifest $\sim$ subpotencies-_in-transitiveconflatedness -reflexivity,-in-the-full-potency-of-

existence's sublimating-nascence) supererogatory acuity/perspicacity/astuteness/edginess/incisiveness $\sim$ diff erential as of relative-ontological-incompleteness /relative-ontologicalcompleteness - _sublimating $\sim$ referencing/registering/decisioning,-as- 


\section{self-becoming/self-conflatedness /formative-supererogating-}

$<$ projective/reprojective-aestheticising-re-motif-and-re-apriorising/reaxiomatising/re-referencing,-in-perspective-ontological-

normalcy/postconvergence>) epistemicity underlying ontologicalperformance ${ }^{72}<$ including-virtue-as-ontology $>$ ' speaking to the inherent imbuement of existence as of its 'transcendence-andsublimity/sublimation/supererogatory $\sim$ de-mentativity and immanence differential conceptivity/epistemic-reflexivity/epistemicity-relativismdeterminism-<reifying\{as-to-knowledge-developing $\}$-and-empowering $>$ integral-difference' (so-construed as the ever requisite need for any ‘ $<$ emplitudinglformative-epistemicity $>$-totalising $\sim$ thrownness-in-

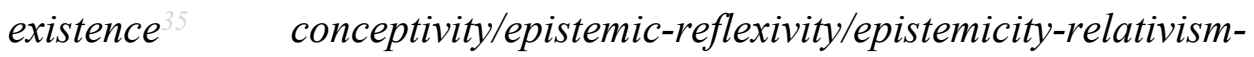
determinism-<reifying\{as-to-knowledge-developing\}-and-empowering> ' epistemic-conflatedness ${ }^{3}$ implied projective/reprojective-aestheticisingre-motif-and-re-apriorising/re-axiomatising/re-referencing induced 'projective-insights for predicativeinsight' so-reflecting dimensionality-ofsublimating $-<<$ amplitudingfformative $>$ supererogatory $\sim d e-$ mentativeness/epistemic-growth-or-conflatedness /transvaluativerationalising/transepistemicity/anamnestic-residuality/spirit-drivennessequalisation )) so-underlying transversality-<for-sublimating-existentialeventuating/denouement,-from-'thinking-at-first/pure-predispositionpreemptive of prospective disontologising/subontologising' as-ofprospectively-disambiguated-affirmed-and-unaffirmed-'motif-andapriorising/axiomatising/referencing'> (specifically as to human Beingdevelopment/ontological-framework-expansion-as-to-depth-of- 
ontologising-development-as-infrastructure-of- meaningfulness-andteleology , institutional-development-as-to-social-function-development and living-development-as-to-personality-development psychologismic epistemic acutisation difficulty< for, residualising $\left\{\right.$ \{decompulsing delinearity for cogency>magnitudes ${ }^{\text {\{of-experientiality/experiment }\}}$ with 'Being-development/ontological-framework-expansion-as-to-depth-ofontologising-development-as-infrastructure-of- meaningfulness-andteleology, reflected in the <cumulating/recomposuring attendantontological-contiguity >-succession of registry-worldviews/dimensions transversality-<for-sublimating-existential-eventuating/denouement-from 'thinking at first/pure predisposition preemptive of prospective disontologising/subontologising' as-of-prospectively-disambiguatedaffirmed-and-unaffirmed- 'motif-and-

apriorising/axiomatising/referencing'> relative-ontologicalincompleteness 8 /relative-ontological-completeness (sublimating referencing/registering/decisioning,-as-self-becoming/selfconflatedness /formative-supererogating-<projective/reprojectiveaestheticising-re-motif-and-re-apriorising/re-axiomatising/rereferencing,-in-perspective-ontological-normalcy/postconvergence >) epistemicity as to ontological-performance $-<$ including-virtue-asontology $>$ )

perversion-and- perversion-and-derived-perversion-of- ${ }^{-}$reference-of-thought- $<$asderivedpreconvergingly-apriorising/axiomatising/referencing-in${ }^{74}$ perversion-of- nonconviction/madeupness/bottomlining-as-to-shallow- 
reference-of-

thought- $<$ as-

preconvergingly-

apriorising/axioma

tising/referencing-

in- supererogation >-(construed-as-of-human-limited-mentation-capacity-

as subjecting 'educed unlimitedness/existence sublimating nascence' to

limitedness/human-subpotency-induced-'temporal-to-intemporal-

notional-binarity'-of-categorical-imperatives/axioms/registry-

teleology ,-reconceptualised-rather-as-of-prior-relative-ontological-

incompleteness -of- reference-of-thought

in

nonconviction/mad preconverging/dementing -apriosing-psychologism/

eupness/bottomlini

ng-as-to-shallow-

supererogation

positive-

positive-opportunism-of-social-functioning-and-accordance speaks to opportunism - of- the fact that unlike is the case with intemporal/firstnatureness solipsistic social-functioning- constructs, 'underpinning-suprasocial-construct and as reflected as to and-accordance ${ }^{75}$ human notional firstnaturedness-formativeness <as to-

eventulising inkling drive or seeding misprising - temporal-to-

intemporal-dispositions-<so-construed-as-from-perspective-ontological-

normalcy/postconvergence>

underlying

<amplitudingfformative> wooden-language-_imbued-averaging-of-

thought-<as-to-leveling/ressentiment/closed-construct-of-

meaningfulness-and-teleology -as-of-'nondescript/ignorable-void '-

with-regards-to-prospective-apriorising-implications $>$ | as deterministic

validation of ontological-veracity is never a critically relevant element for prospective intemporal/firstnatureness knowledge-reification gesturingand-accounting-of-epistemic-phenomenalism-<in- 
prospective psychologismic apriorising/axiomatising/referencing-\{of'prospectively implicited_attendant-ontological-contiguity ' reducedexistentialising/contextualising/textualising_intelligibility/epistemicity/re flexivity-contiguity-<imbued-notional cogency>' \}-conflatedness in \{preconverging ment by\} postconverging entailment $>$ generation as to existence-as-sublimating-withdrawal/unenframing/re-ontologising,elicited-from-prospective-profound-supererogation, given that the underpinning-suprasocial-construct of meaningfulness-and-teleology as reflected in any social-setup institutionally is rather a 'secondnatured/habituated institutionalisation construct as from deferential-formalisation-transference as to presencing-absolutisingidentitive-constitutedness $\quad$ social-vestedness/normativity-<discretelyimplied-functionalism >' rather arising from the 'untenable existentially$\leq$ disontologising/re-ontologising aporeticism $>$ constraining conceptivity/epistemic-reflexivity/epistemicity-relativism-determinism$<$ reifying\{as-to-knowledge-developing\}-and-empowering $>\quad$ imbued theoretical/conceptual/operant implications sublimating-overdesublimating implications of existence-potency ${ }^{3}$ sublimatingnascence,-disclosed-from-prospective-epistemic-digression induced metaphoricity as of dimensionality-of-sublimating ${ }^{25}$ -

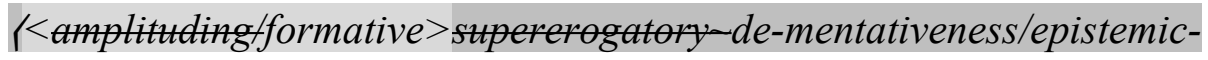
growth-or-conflatedness/transvaluativerationalising/transepistemicity/anamnestic-residuality/spirit-drivennessequalisation) ontological-faith-notion-or-ontological-fideism-imbuedunderdetermination-of-motif-and-apriorising/axiomatising/referencing- 
as-so-being-as-of-existential-reality reasoning-through/messianicreasoning in solipsistic transversality-<for-sublimating-existentialeventuating/denouement, from 'thinking at first/pure predispositionpreemptive of prospective disontologising/subontologising'>', and thus reflecting the ontological-veracity that any such underpinningsuprasocial-construct is not the inherently relevant basis for prospective knowledge-reification gesturing-and-accounting-of-epistemicphenomenalism-<in-

prospective psychologismic apriorising/axiomatising/referencing-\{of'prospectively_implicited_attendant-ontological-contiguity ' e educedexistentialising/contextualising/textualising_intelligibility/epistemicity/re flexivity-contiguity-<imbued-notional $\sim$ cogency $>$ ' \}-conflatedness in \{preconverging ment by\} postconverging entailment> as of a 'convincing of human-subpotency exercise' but rather what is relevant is the 'pertinence of its underlying deferential-formalisation-transference-asnon-sophistic in-integrating/as-to-susceptibility-to prospective existencepotency ${ }^{3}$ sublimating-nascence,-disclosed-from-prospective-epistemicdigression' so-induced metaphoricity as of supposedly coherent human ontological-commitment _<implied-self-assuredness-of-ontologicalgood-faith/authenticity postconverging-dementating/structuring/paradigming -as-being-as-of-existential-reality > and so validated as of camplituding/formativeepistemicity $>$ causality $\sim$ as-to-projective-totalitative-implications-ofprospective- nonpresencing,-for-explicating relative unreflexivity/relative reflexivity ontological-contiguity with respect to 
'adhering to existence-potency $\sim$ sublimating-nascence,-disclosed-fromprospective-epistemic-digression implications' in order for prospective deferential-formalisation-transference suprasocial ${ }^{5}$ meaningfulness-andteleology to arise; as the fact is underpinning-suprasocial-constructs are rather afterthought/reasoning-from-results as for instance it is not the inherent budding-positivists ${ }^{5}$ meaningfulness-and-teleology as of mere abstraction that induced a social transformation into positivist thinking but rather the 'accruing constraining effect on existence' of such buddingpositivism instigated positivist and liberal ${ }^{56}$ meaningfulness-andteleology that then induced its social adoption later on as of social-stakecontention-or-confliction-with-regards-to-rationalising-the-benefits-ofthe-world-as-of-technical,-well-being,-health-and-social-developmentimplications, as 'underpinning-suprasocial-constructs remain beholden to their prior relative-ontological-incompleteness framework of apriorising/axiomatising/referencing/intelligibilitysettingup/measuringins trumenting as of apriorising-teleological-thresholding-as-teleologicalframework/narrative-framework contextualising/existentialising/instantiative-devolving-meaningfulness' in <emplitudinglformative> wooden-language-fimbued-averaging-ofthought-<as-to-leveling/ressentiment/closed-construct-ofmeaningfulness-and-teleology -as-of- 'nondescript/ignorablevoid'-withregards-to-prospective-apriorising-implications $>$ ) with poor postconverging-nonextricatory-existential-preempting-of-existentialunthought without such manifest positive-opportunism-of-socialfunctioning-and-accordance and the possibility for transcendence-and- 
sublimity/sublimation/supererogatory-de-mentativity can only arise as of untenable prospective existence-potency $\sim$ sublimating-nascence,disclosed-from-prospective-epistemic-digression constraining relative$\begin{array}{ll}\text { ontological-completeness } & \text { framework }\end{array}$ supererogatory acuity/perspicacity/astuteness/edginess/incisiveness-ofapriorising/axiomatising/referencing/intelligibilitysettingup/measuringins trumenting -for-conceptualisation as opened-construct-ofmeaningfulness-and-teleology in its crossgenerational transformative effect even as its initial instigation doesn't elicit immediate positiveopportunism - of-social-functioning-and-accordance as of its dispensingwith-immediacy-for-relative-ontological-completeness ${ }^{87}$-byreification/contemplative-distension (as of human self-surpassingexistentialism-form-factor,-in-overcoming- 'notional collateralisingbeholdening-protohumanity'-to- 'attain-sublimating-humanity'-as-toexistence-potency $\sim$ sublimating-nascence,-disclosed-from-prospectiveepistemic-digression to supersede human temporality/shortness <amplituding/formative> wooden-language-_imbued-averaging-ofthought-<as-to-leveling/ressentiment/closed-construct-ofmeaningfulness-and-teleology -as-of-'nondescript/ignorable-void 'with-regards-to-prospective-apriorising-implications $>$ J) explaining the inevitable/inherent conflictedness to such budding transformative stances as articulated by the Socrates, Copernicuses, Galileos, Descartes, Diderots, and relevant 'prophesiers of antiquity as philosophers', with the <amplituding/formative-epistemicity>causality $\sim$ as-to-projectivetotalitative-implications-of-prospective- nonpresencing,-for- 
explicating relative unreflexivity/relative reflexivity ontological-

contiguity that any given suprasocial framework is inherently of 'epistemically underdeterminative contemplation for ontologically and intellectually assessing its prospective transcendence-andsublimity/sublimation/supererogatory-de-mentativity' as the suprasocial mathetic/motiffed/throwned state of recurrent-utter-uninstitutionalisation is of epistemically underdeterminative contemplation as of its <amplituding/formative $>$ wooden-language-fimbued-temporal-mereform/virtualities/dereification/akrasiaticdrag/denatured/preconvergingor-dementing -narratives-of-the- reference-of-thought-categoricalimperatives/axioms/registry-teleology | for intellectually gauging about prospective base-institutionalisation, and likewise baseinstitutionalisation-ununiversalisation with regards to prospective universalisation, ${ }^{303}$ universalisation-non-positivism/medievalism with regards to prospective rational-empiricism/positivism, and prospectively our positivism - procrypticism with regards to notional deprocrypticism as in all such cases the suprasocial and <amplituding/formative> wooden-language-fimbued-temporal-mereform/virtualities/dereification/akrasiatic-drag/denatured/preconvergingor-dementing -narratives-of-the- reference-of-thought-categoricalimperatives/axioms/registry-teleology / inclination is in an $<$ amplituding/formative-epistemicity >totalising self-referencingsyncretising/circularity/interiorising/akrasiatic-drag as of its 'shiftinessof-the-Self, whether as of trepidatious/warped/preclusive/occlusive identitive-constitutedness ${ }^{4}$-as- 'epistemic-totality ${ }^{3}$ '-dereification-in- 
dissingularisation-<as-to-the-disjointedness/ment-of- presencing-

absolutising-identitive-constitutedness $>$-as-flawed-epistemicity-

relativism-determinism, and this is exactly what renders all such transcendence-and-sublimity/sublimation/supererogatory-de-mentativity rather as of intemporal ontological-faith-notion-or-ontological-fideism imbued-underdetermination-of-motif-and-

apriorising/axiomatising/referencing-as-so-being-as-of-existential-reality parrhesiastic askesis-or-acumen for originary/as-of-event reasoningthrough/messianic-reasoning' involving the 'displacement/decentering-ofthe-human-subject induced as of de-mentation(supererogatory ontological-de-mentation-or-dialectical-de-

mentation-stranding-or-attributive-dialectics )' as to the fact that it is more critically a 'matter of psychoanalytic-unshackling/memeticreordering/institutional-recomposuring' by 'projecting of the transcending of the prior reproducibility - mathesis/motif/thrownness-disposition,-asreproducibility-of-aestheticisation of reference-of-thought as of the 'relative unreflexivity/relative reflexivity ontological-contiguity $\sim$ ofthe-human-institutionalisation-process (ecstatic-existence prospective digression induced epistemic-ricochetting/transepistemicity) dimensionality-of-sublimating ${ }^{5}$ -

< amplituding/formative $>$ supererogatory de-mentativeness/epistemicgrowth-or-conflatedness/transvaluativerationalising/transepistemicity/anamnestic-residuality/spirit-drivennessequalisation) as to difference-conflatedness ${ }^{3}$-as-to-totalitativereification-in-singularisation-<as-to-the-nondisjointedness/entailment-of- 
prospective- nonpresencing > -as-veridical-epistemicity-relativism-

determinism explaining why all prior registry-worldviews/dimensions sense-of-progress is foiled since such sense-of-progress is wrongly ever along the same line of reproducibility-mathesis/motif/thrownnessdisposition,-as-reproducibility-of-aestheticisation so-construed as pseudo-edginess/pseudo-incisiveness whereas in effect progress rather occurs by the 'unshackling of any such reproducibilitymathesis/motif/thrownness-disposition,-as-reproducibility-ofaestheticisation towards better-and-better existential-disontologising/reontologising aporeticism> reflection of the underlying parrhesiastic seeding-promise-of-human-subpotency-ontological-performance ${ }^{72}$ <including-virtue-as-ontology>-correspondence-with-the-full-potencyof-existence's sublimating-nascence-as-of-its-coherence/contiguity' speaking rather to their relative-ontological-incompleteness 88 of reference-of-thought/psyche that has to be 'addressed psychoanalytically before engaging in prospective knowledge-reification gesturing-andaccounting—of-epistemic-phenomenalism-<inprospective psychologismic $\sim$ apriorising/axiomatising/referencing-\{of'prospectively implicited_attendant-ontological-contiguity ' reducedexistentialising/contextualising/textualising_intelligibility/epistemicity/re flexivity-contiguity-<imbued-notional $\sim$ cogency $>^{\prime}$ \} - conflatedness in \{preconverging ment by\} postconverging entailment>

postlogicpostlogic-backtracking-<iterative-looping-'set-of-dereifying-hollowbacktrackingnarratives-and-acts'>-with- 'successive-shifting-of-the-narratives-and- 
<iterative-looping- acts-foci'-construed-as-'deception-of-successively-shifting-or-

'set-of-dereifying- noncohering-narratives-and-acts'-_construed-as-of-slanted-

hollow-narratives- ' 'unsoundness-or-ontological-bad-faith/inauthenticity -of- reference-ofand-acts'>76 thought'-for-the- perversion-of- reference-of-thought- $<$ as-

preconvergingly-apriorising/axiomatising/referencing-in-

nonconviction/madeupness/bottomlining-as-to-shallow-

supererogation >; and-so-to-avoid-wrongly-validating-

the apriorising- reference-of-thought/apriorising-registry-elements-

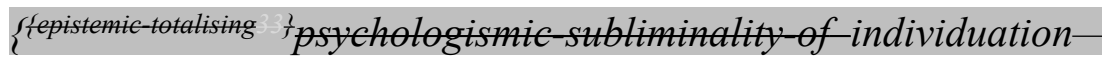

effusing/worlding imbued logical-dueness-or-scape-or-frame, profile-or-

stature, presumptuousness-or-arrogation, assumptions, value-reference

and teleology \}-as-veridical-and-then-wrongly-implying-engaging-

within-logical-processing-or-logical-implicitation-supposedly-

apriorising-inconviction-as-to-profound-supererogation ।

postlogism ${ }^{77}$-as- $\quad$ postlogism-as-psychopathy-as-of- 'attendant-intradimensional'-

psychopathy-as-of- preconverging/dementing -apriorising-psychologism-

'attendant- $\quad$ / $<$ decontextualising/de-existentialising of-attendant-intradimensional-

intradimensional'- apriorising/axiomatising/referencing>-induced-disontologising ',-as-so-

preconverging/dem undermining-the- 'attendant-intradimensional-ontologising'-<as-to-

enting - attendant-intradimensional-apriorising/axiomatising/referencing-

apriorising- $\quad$ imbued-<contextualising/existentialising $\sim$ attendant-ontological-

psychologism- contiguity >-educing_self-referencing-syncretising_forward-facing-

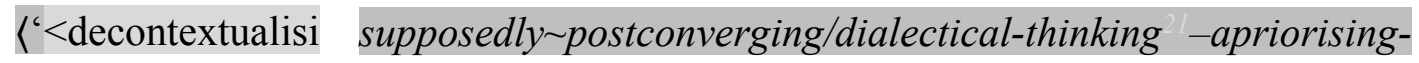

ng/de- $\quad$ psychologism $>$ );-as-so-reflecting-the- ' $<$ decontextualising/de- 
existentialising $\sim$ of- existentialising $\sim$ f-attendant-intradimensional-

attendant- apriorising/axiomatising/referencing>-induced-disontologising'-as-

intradimensional- failing-dispensing-with-immediacy-for-relative-ontological-

apriorising/axioma completeness ${ }^{8}$-by-reification/contemplative-distension ${ }^{27}$,-with- 'slanting-

tising/referencing> qualia-schema',-and-so-manifested-overtly-at-childhood-psychopathy-

-induced- $\quad \quad<$ decontextualising/de-existentialising $\sim$ of-attendant-intradimensional-

disontologising',-- apriorising/axiomatising/referencing>-induced-disontologising'-but-

as-so- while-susceptible-to-be-wrongly-construed-as-of- intradimensional-

undermining-the- postconverging/dialectical-thinking -qualia-schema'-at-covert-

'attendant- $\quad$ adulthood-psychopathy- '<decontextualising/de-existentialising of-

intradimensional- attendant-intradimensional-apriorising/axiomatising/referencing $>$ -

ontologising'-<as- induced-disontologising'-\{due-to-covert-adulthood-psychopathy-

to-attendant- maturation/indirectness/spatialisation/credulity/craftiness\}-and-as-the-

intradimensional- adulthood-psychopathy-elicits-conjugated-postlogism-as-to-socially-

apriorising/axioma protracted-individuations-of-conscious-or-unconscious-manifestations-

tising/referencing- of- $<$ decontextualising/de-existentialising $\sim$ of-attendant-

imbued- intradimensional-apriorising/axiomatising/referencing $>$-induced-

<contextualising/e disontologising'; and so-specifically reflecting overall social

xistentialising atte manifestations of postlogism and conjugated-postlogism construed as

ndant-ontological- postlogism-as-of- compulsing-nonconviction/madeupness/bottomlining-

contiguity $>-\quad \quad \mid<$ decontextualising/de-existentialising $\sim$ of-attendant-intradimensional-

educing-self- apriorising/axiomatising/referencing >-induced-disontologising'-of-the-

referencing- 'attendant-intradimensional-ontologising'-imbued-

syncretising_forwa $<$ contextualising/existentialising attendant-ontological-contiguity >;-

rd-facing- in-shallow-supererogation -<as-to-disontologising-perverted-outcome- 


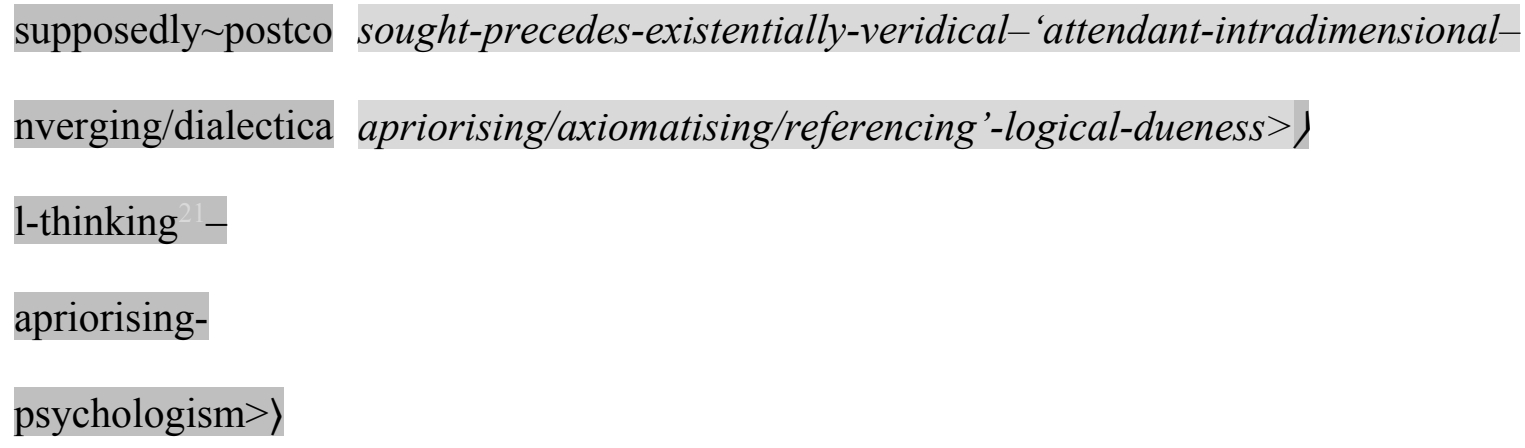


${ }^{79}$ presencing-

absolutising-

identitive-

constitutedness void '-as-to-presencing-absolutising-identitive-constitutedness

ordinary-nontranscendental-reasoning

presencing-absolutising-

identitive-constitutedness

presencing-

epistemically_enframed/disontologising-encumbering-of-ontology-

elucidation

/

pseudoconflation

perspective/framing/reference/horizon/projection of ${ }^{56}$ meaningfulness-

and-teleology as to identitive-constitutedness ${ }^{14}$-as- 'epistemic-totality ${ }^{3}$ 'dereification-in-dissingularisation-<as-to-the-disjointedness/ment-of-

\section{presencing-absolutising-identitive-constitutedness $>$-as-flawed-}

epistemicity-relativism-determinism ; $\mathbb{\uparrow}$ with presencing-absolutisingidentitive-constitutedness fundamentally arising as to the inadequacy of human-subpotency to fully grasp existence/ontological-veracity in reflection of human <emplitudingfformative-epistemicity>totalising thrownness-in-existence ${ }^{35}$ as to the implications of human limited-mentation-capacity-as-subjecting 'educedunlimitedness/existence sublimating nascence' to limitedness/humansubpotency (inducing presencing-absolutising-identitiveconstitutedness ${ }^{14} \quad<$ amplituding/formative-epistemicity>totalising $\sim$ selfreferencing-syncretising/circularity/interiorising/akrasiatic-drag ${ }^{34}$ soreflecting specifically in the <cumulating/recomposuring attendantontological-contiguity >-successive registry-worldviews/dimensions relative-ontological-incompleteness

apriorising/axiomatising/referencing-psychologisms) such that without this issue of human limited-mentation-capacity-as-subjecting 'educedunlimitedness/existence sublimating nascence' to limitedness/human- 
subpotency then the human epistemic-projection of ${ }^{5}$ meaningfulness-andteleology will fully grasp existence/ontological-veracity as so implied as from the prospective deprocrypticism-or-preempting-disjointednessas-of- reference-of-thought perspective of ontologicalnormalcy/postconvergence (metaphoricitically reflected by the prospective deprocrypticism - apriorising/axiomatising/referencing-psychologism enculturated/constructed social-pragmatics-framing-of-predicativeeffectivity-sublimation-_as-to-underlying,-ontological-commitment

\section{$<$ implied-self-assuredness-of-ontological-good-}

faith/authenticity $\sim$ postconverging-de-

mentating/structuring/paradigming -as-being-as-of-existential-

reality $>$ )), and effective human ontological-performance $-<$ includingvirtue-as-ontology>/morality/ethics/justice/etc. as to human limitedmentation-capacity - as subjecting 'educed unlimitednesslexistencesublimating nascence' to limitedness/human-subpotency can thus be construed-and-assessed as from the so-defining notional deprocrypticism perspective in reflecting the successive defining postconvergingaporeticism-overcoming/unovercoming of the varying apriorising/axiomatising/referencing-\{of-'prospectively implicited_attendant-ontological-contiguity ' reducedexistentialising/contextualising/textualising_intelligibility/epistemicity/re flexivity-contiguity-<imbued-notional $\sim$ cogency $>$ ' \}-ontologicallydeficient human epistemic-projection of ${ }^{5}$ meaningfulness-and-teleology (underlined by the <cumulating/recomposuring attendant-ontologicalcontiguity $>$-successive registry-worldviews/dimensions given 
presencing-absolutising-identitive-constitutedness in want of dimensionality-of-sublimating ${ }^{5}$

< <amplituding/formative >supererogatory-de-mentativeness/epistemicgrowth-or-conflatedness /transvaluative-

rationalising/transepistemicity/anamnestic-residuality/spirit-drivenness-

equalisation )) as of the overall relative unreflexivity/relative reflexivity ontological-contiguity $\sim$ of-the-human-institutionalisation-process $; \uparrow$ with presencing-absolutising-identitive-constitutedness ${ }^{4} \quad$ socialvestedness/normativity-<discretely-implied-functionalism $>$ of human meaningfulness-and-teleology of the $<$ cumulating/recomposuring attendant-ontological-contiguity

successive registry-worldviews/dimensions as poorly amenable to existence-potency $\sim$ sublimating-nascence,-disclosed-from-prospectiveepistemic-digression (so-arising as to 'human-subpotency nonscalarity/beholdening-<as-to-what-has-gone-before-aesthetically-dementates/structures/paradigms-distortedly-thepossibility-for-the-laterontologisation $>$ of ontological-performance $-<$ including-virtue-asontology>/morality/ethics/justice/etc. as undermining prospective ontological-veracity' so-reflected with regards to human-subpotency prospectively implied epistemic-abnormalcy/preconvergence construed as of incrementalism-in-relative-ontological-incompleteness enframed/disontologising conceptualisation epistemic projection, in contrast to the scalarity/immanency of existence's ontologicalnormalcy/postconvergence as 'bechancing-backdrop of ${ }^{61}$ nonpresencing$<$ perspective-ontological-normalcy/postconvergence $>$ '); with the 
implication that more than just a question of dominance/vested-interestdrivenness-<as-to-its-direct/indirect-eliciting-by-or-exploiting-ofprospectively-descalarising/subontologising-sycophantic-sophisticinterests,-as-inducing-prospective-threshold-of-institutional-and-socialdesublimation>, 'presencing-absolutising-identitive-constitutedness ${ }^{1 / 4}$ of $\quad$ social-vestedness/normativity- $<$ discretely-implied-functionalism $>$ (taking account of the <amplitudinglformativeepistemicity>totalising/circumscribing/delineating nature of human meaningfulness-and-teleology) refers to the overall construct of human meaningfulness-and-teleology (as manifested variously by all individuals within any given registry-worldview/dimension) assuming a <amplituding/formative-epistemicity>totalising $\sim$ self-referencingsyncretising/circularity/interiorising/akrasiatic-drag ${ }^{34}$ with respect to prospective ontological-veracity sublimation possibilities, as to the fact that the priorly induced 'human Being-development/ontologicalframework-expansion-as-to-depth-of-ontologising-development-asinfrastructure-of- meaningfulness-and-teleology , institutionaldevelopment-as-to-social-function-development and living-developmentas-to-personality-development psychologismic epistemic acutisationdifficulty< for, residualising tdecmplsing delinearity for cogency> magnitudes ${ }^{\{o f-e x p e r i e n t i a l i t y / e x p e r i m e n t\}}, \quad$ preconverging/postconverging-dementatively/structurally/paradigmatically defines (given the already inculcated 'presencing-absolutising-identitive-constitutedness ${ }^{14}$ as of social-vestedness/normativity-<discretely-implied-functionalism>') the possibility for re-engaging with ontological-veracity for prospective 
sublimation of human ${ }^{5}$ meaningfulness-and-teleology , and so-reflected by the fact that any given registry-worldview/dimension operates on the basis of a presencing-absolutising-identitive-constitutedness 'supposed human-subpotency abstract self-determinative ontologicalperformance ${ }^{72}<$ including-virtue-as-

ontology>/morality/ethics/justice/etc. capacity as to the full-potency of existence' whereas in reality 'human instigated 'meaningfulness-andteleology ontological-performance $-<$ including-virtue-asontology>/morality/ethics/justice/etc. capacity' (so-construed as from the ontological-normalcy/postconvergence epistemic projective-perspective) is rather practically a '<amplitudinglformativeepistemicity>totalising/circumscribing/delineating signposting exercise’ operating on the overall basis of the given registryworldview's/dimension's 'social-construct <amplitudinglformativeepistemicity>totalising/circumscribing/delineating given priorinstitutionalisation-threshold-by-prospective-uninstitutionalisedthreshold imbued secondnaturing' when it comes to social-stakecontention-or-confliction; $\boldsymbol{\Phi}$ and as from the overall human aestheticisation-and-aestheticisation-towards-ontology-<elicitedidiomatisation $>\quad$ existentialising-frame-of entailment of motif and apriorising/axiomatising/referencing of ontological-performance ${ }^{72}$ $<$ including-virtue-as-ontology>, 'presencing-absolutising-identitiveconstitutedness as of social-vestedness/normativity-<discretely-impliedfunctionalism>' thus speaks of human-subpotency beholdeningbecoming — distortiveoriginariness/distortive-origination-as-to- 
historicity-tracing inhibited-mental-aestheticising (as manifested with the ${ }^{70}$ presencing-absolutising-identitive-constitutedness ${ }^{14}$ of any given defined registry-worldview's/dimension's as to its given apriorising/axiomatising/referencing) and so undermining the bechancing-becoming-originariness/origination-as-to-

historiality/ontological-eventfulness 38 /ontological-aesthetic-tracing$<$ perspective-ontological-normalcy/postconvergence-reflected'epistemicity-relativism-determinism'> disinhibited-mentalaestheticising as of the scalarity/immanency of existence's ontologicalnormalcy/postconvergence as 'bechancing-backdrop of nonpresencing<perspective-ontological-normalcy/postconvergence>', and in this respect the peculiarity of many of the terms/terminologies and overall conceptualisation articulated herein has to do with this critical recognition of 'prospectively distortive preconverging/postconverging-dementative/structural/paradigmatic ${ }^{79}$ presencing-absolutising-identitiveconstitutedness $<$ preconverging 'motif-andapriorising/axiomatising/referencing'-entailing>-existentialisingenframing/imprintedness-_as-to- historicity-tracing-in-presencinghyperrealisation/hyperreal-transposition/conceptualisation implications' (as to 'presencing-absolutising-identitive-constitutedness preconverging/dementing -apriorising-psychologism epistemicprojection perspective' which fails to factor in that human limitedmentation-capacity - as subjecting 'educed unlimitedness/existencesublimating nascence' to limitedness/human-subpotency implies that the <emplitudinglformative-epistemicity>totalising construal is relatively 
deficient as of its epistemic contitutedness apriorising/axiomatising/referencing) with respect the terms/terminologies and overall conceptualisation veridical nonpresencing-<perspective-ontological-normalcy/postconvergence $>$ sublimating meaningfulness-and-teleology (herein rather construed as of appropriate nonpresencing-<perspective-ontologicalnormalcy/postconvergence $>\quad$ epistemic-conflatedness ${ }^{13}$ as of projective/reprojective-aestheticising-re-motif-and-re-apriorising/reaxiomatising/re-referencing in relative-ontological-completeness ${ }^{87}$ (as to ' nonpresencing-<perspective-ontological-normalcy/postconvergence> postconverging/dialectical-thinking -apriorising-psychologism epistemic-projection perspective' which compensates for human limitedmentation-capacity-as-subjecting 'educed unlimitednesstexistencesublimating nascence' to limitedness/human-subpotency ontologically deficient/disjointed <amplituding/formative-epistemicity>totalising construal by epistemic-conflatedness ${ }^{73}$ as of projective/reprojectiveaestheticising-re-motif-and-re-apriorising/re-axiomatising/rereferencing), and so for instance with the notion of say teleology (construed herein as from ${ }^{6}$ nonpresencing-<perspective-ontologicalnormalcy/postconvergence $>$ ) as 'phenomenal/manifest conceptivity/epistemic-reflexivity/epistemicity-relativism-determinism$<$ reifying\{as-to-knowledge-developing\}-and-empowering $>$ in existence as ontological' (so-reflecting $<$ amplitudinglformative $>$ disposedness/psychologismic-construct-_as-toorientation/value-construct/valuation-and-derived-parameterising) and 
<amplitudinglformative >entailment-\{as-to-totalising-

contiguous/coherent-factuality-of-variability))' and 'is not of prospective apriorising/axiomatising/referencing-sublimating-reflexivity-

beholdening to any presencing-absolutising-identitiveconstitutedness $<$ amplitudinglformative-epistemicity $>$ totalising construal given epistemic-abnormalcy/preconvergence implied epistemic-projection perspective' with the ontological-veracity of teleology projectively arising as herein construed as of ontologicalnormalcy/postconvergence implications of <amplitudingfformativeepistemicity>totalising construal, and this underlying projective ontological-normalcy/postconvergence epistemic-conception is reflected with all the terms/terminologies articulated herein like solipsism, organicalism, akrasiatic-drag, temporality , intemporality ${ }^{2}$, etc., as soconstrued <amplitudingfformative-epistemicity>totalisingly (as of Beingdevelopment/ontological-framework-expansion-as-to-depth-ofontologising-development-as-infrastructure-of- meaningfulness-andteleology underlied totalisingly-entailing by the overall relative unreflexivity/relative reflexivity ontological-contiguity rof-the-humaninstitutionalisation-process ${ }^{6}$ and thereof corresponding protracted institutional-development-as-to-social-function-development and livingdevelopment-as-to-personality-development psychologismic epistemic acutisation difficulty< <or, residualising \{decompulsing? delinearity for eogency> magnitudes\{of-experientiality/experiment\} implications), with this projective ontological-normalcy/postconvergence epistemic-conception conceptual approach herein including the very notion of "presencing- 
absolutising-identitive-constitutedness ${ }^{1 / 4}$ rather construed herein as from nonpresencing-<perspective-ontological-normalcy/postconvergence > to imply the ontological-veracity of presencing-absolutising-identitiveconstitutedness $^{14}$ 'is not present to itself' but rather to its prospective relative-ontological-completeness 8 perspective and so in 'contrast to the epistemic-conception of such a notion like presentism' (lacking such <amplituding/formative-epistemicity>totalising conception backdrop as of Being-development/ontological-framework-expansion-as-to-depth-ofontologising-development-as-infrastructure-of- meaningfulness-andteleology underlied totalisingly-entailing by the overall relative unreflexivity/relative reflexivity ontological-contiguity $\sim$ of-the-humaninstitutionalisation-process implied epistemic-conflatedness $^{13}$ as of projective/reprojective-aestheticising-re-motif-and-re-apriorising/reaxiomatising/re-referencing) and thus ends up 'wrongly construing of the present circularly as of the epistemic-projection perspective of the-verysame present as its epistemic-conception is then wrongly constitutively absolutised in its present epistemic-abnormalcy/preconvergence ${ }^{3 /}$ thus failing to reflect the overall existential-<disontologising/re-ontologising-

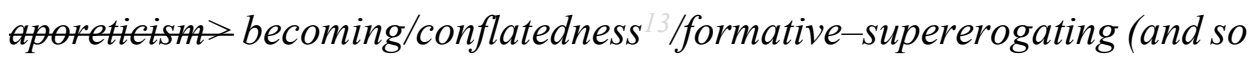
'epistemic-reflexively as of human limited-mentation-capacitydeepening - as subjecting limitedness/human-subpotency to-'educedunlimitednesslexistence sublimating nascence' <amplituding/formative-epistemicity>totalisingly as-to-existence-assublimating-withdrawal/unenframing/re-ontologising,-elicited-fromprospective-profound-supererogation J') 
preconverging/postconverging-de-

mentatively/structurally/paradigmatically veridically reflects the $<$ cumulating/recomposuring attendant-ontological-contiguity

successive registry-worldviews/dimensions given ${ }^{70}$ presencingabsolutising-identitive-constitutedness ${ }^{14}$ (with this 'overall existential$<$ disontologising/re-ontologising aporeticism $>$

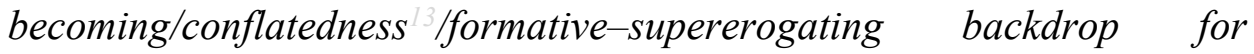
conceptualising presencing-absolutising-identitive-constitutedness ${ }^{1 /}$ rather construed as of Being-development/ontological-frameworkexpansion-as-to-depth-of-ontologising-development-as-infrastructure-ofmeaningfulness-and-teleology underlied totalisingly-entailing by the overall relative unreflexivity/relative reflexivity ontologicalcontiguity $\sim$ of-the-human-institutionalisation-process implied epistemic-conflatedness ${ }^{3}$ as of projective/reprojective-aestheticising-remotif-and-re-apriorising/re-axiomatising/re-referencing and 'soundergirded by human dimensionality-of-sublimating < amplitudinglformative > supererogatory de-mentativeness/epistemicgrowth-or-conflatedness/transvaluativerationalising/transepistemicity/anamnestic-residuality/spirit-drivennessequalisation/as of the operative human mental-devising-representation de-mentation-(supererogatory-ontological-de-mentation-ordialectical-de-mentation-stranding-or-attributive-dialectics) postconverging/dialectical-thinking -apriorising-psychologism-bypreconverging/dementing -apriorising-psychologism as to human meaningfulness-and-teleology ontological-performance ${ }^{72}<$ including- 
virtue-as-ontology>/morality/ethics/justice/etc. deepening')

${ }^{80}$ procrypticism- $\quad$ procrypticism-or-disjointedness-as-of- reference-of-thought is rather as or-disjointedness- of the specific positivism/rational-empiricism prospectively as-of- reference- uninstitutionalised-threshold failing of ${ }^{18}$ deprocrypticism-orof-thought preempting-disjointedness-as-of- reference-of-thought, and across the $<$ cumulating/recomposuring attendant-ontological-contiguity $>$ successive registry-worldviews/dimensions in reflection of all the uninstitutionalised-threshold (as successive 'failing of notional deprocrypticism-or-notional preempting—disjointedness-asof- 'reference-of-thought') so-construed as notional procrypticism-ornotional disjointedness-as-of- reference-of-thought, speaks to 'disjointedness-as-of- reference-of-thought'-as-misappropriatedmeaningfulness-and-teleology -in-arrogation,-out-of 'implicited_attendant-ontological-contiguity' reducedexistalisting intelligibility/epistemicity/re flexivity-contiguity-<imbued-notional $\sim$ cogency $>,,<$ reifying-orelucidating-of-prospective-relative-ontological-completeness -ofreference-of-thought- devolving-as-of-instantiative-context $>$,-soconstrued-as-of-' threshold-of-nonconviction/madeupness/bottomliningin-shallow-supererogation $-<$ as-to- 'attendant-intradimensional'prospectively-disontologising preconverging/dementing -apriorisingpsychologism >', so-reflected by its ontologically-perspectival-degradedas-decentered/preconverging-or-dementing -reflexive/entailingteleology -differentiation-as-of-subtransversality-<in-desublimating- 
existential-eventuating/denouement $>\sim$ of-motif-and-

apriorising/axiomatising/referencing'

prospective- $\quad$ prospective-apriorising/axiomatising/referencing-superseding-logicalapriorising/axioma basis-of dialogical-equivalence-<as-to-

tising/referencing- psychologismic apriorising/axiomatising/referencing-\{of-"prospectivelysuperseding-_implicited_attendant-ontological-contiguity ' reducedlogical-basis- existentialising/contextualising/textualising_intelligibility/epistemicity/re of $\sim$ dialogical- $\quad$ flexivity-contiguity-<imbued-notional $\left.\sim \operatorname{cogency}>^{\prime},\right\}$-conflatedness equivalence-<as- in \{preconverging ment by\} postconverging entailment,-in-selfto- becoming/self-conflatedness /formative-supererogating $>$, so-construed psychologismic ap as from prospective re-originariness/re-origination; $\uparrow$ with dialogicalriorising/axiomatis equivalence- $<$ as-to-

ing/referencing- psychologismic apriorising/axiomatising/referencing-\{of- "prospectively\{of- implicited_attendant-ontological-contiguity ' reduced"prospectively extatisting intelligibility/epistemicity/re implicited_attenda flexivity-contiguity-<imbued-notional $\sim$ cogency $>$ ' \}-conflatedness nt-ontological- in \{preconverging ment by\} postconverging entailment,-in-selfcontiguity ' educ becoming/self-conflatedness /formative-supererogating> arising-onlyed- after-secondnaturing/education-to-prospective-transcendence-andexistentialising/co sublimity/sublimation/supererogatory-de-mentativity Atextualising/textu alising_intelligibil ity/epistemicity/ref lexivity- 
contiguity-

$<$ imbued-

notional $\sim \operatorname{cogency}>$

,

conflatedness -in-

\{preconverging-

ment by\}

postconverging

entailment,-in-self-

becoming/self-

conflatedness /for

mative-

supererogating $>81$

prior- $\quad$ prior-apriorising/axiomatising/referencing-superseded-logical-basis-

apriorising/axioma of dialogical-equivalence-<as-to-

tising/referencing- psychologismic $\sim$ apriorising/axiomatising/referencing-\{of- 'prospectively

superseded- implicited_attendant-ontological-contiguity ' reduced-

logical-basis- existentialising/contextualising/textualising_intelligibility/epistemicity/re

of $\sim$ dialogical- flexivity-contiguity-<imbued-notional $\sim$ cogency $>$ ' $\}$-conflatedness -

equivalence-<as- in \{preconverging ment by\} postconverging entailment,-in-self-

to- becoming/self-conflatedness /formative-supererogating $>$, so-construed

psychologismic ap as from prospective ontological-normalcy/postconvergence epistemic

riorising/axiomatis reflection of distorted-originariness/distorted-origination

ing/referencing- 
\{of-

'prospectively

implicited_attenda

nt-ontological-

contiguity ' educ

ed-

existentialising/ce

ntextualising/textu

alising_'intelligibil

ity/epistemicity/ref

lexivity-

contiguity-

$<$ imbued-

notional cogency>

, $\}$

conflatedness in-

fpreconverging

ment by\}

postconverging

entailment,-in-self-

becoming/self-

conflatedness /for

mative-

supererogating $>82$ 
${ }^{83}$ reference-of- $\quad$ reference-of-thought-_registry/anchoring-of-meaning/meaningful-

thought

reference/ontological-reference/contending-reference/registry-worldview

reflected-as-of-soundness-or-ontological-good-faith/authenticity -of-

reference-of-thought') construed as projected-or-anticipated-grandestexistential-axiomatic-construct 'as underlying psychologistically the very instigation of human apriorising/axiomatising/referencing for the production of ${ }^{56}$ meaningfulness-and-teleology ; the reference-ofthought speaks to 'referencing of 'meaningfulness-and-teleology' and reference herein is underlined by both reference-of-thought (so-construed as human <amplitungfformativeepistemicity>totalising/circumscribing/delineating backdrop for constructively setting-up the prospect of human ${ }^{56}$ meaningfulness-andteleology as to the projected apriorising/axiomatising/referencingpsychologism) and reference-of-thought- ${ }^{84}$ devolving (so-construed as to human becoming existential-instantiations effective delineating of human meaningfulness-and-teleology anchored upon the reference-of-thought backdrop of overall conceptualisation as to overall reference of meaningfulness-and-teleology and so for articulating devolvingconceptualisations as devolving axiomatic-constructs of meaningfulnessand-teleology'), with reference herein thus implying 'relative-ontologicalincompleteness /relative-ontological-completeness (sublimating referencing/registering/decisioning,-as-self-becoming/selfconflatedness /formative-supererogating-<projective/reprojectiveaestheticising-re-motif-and-re-apriorising/re-axiomatising/rereferencing,-in-perspective-ontological-normalcy/postconvergence>> as 

preconverging/postconverging-rede-

mentating/restructuring/reparadigming-psychologism' as to human limited-mentation-capacity-deepening - as subjecting limitedness/humansubpotency to 'educed unlimitedness/existence sublimating nascence' (and this conception of reference differs from a presencingabsolutising-identitive-constitutedness' perspective 'of referencing existence in absolute identitive terms' which fail to project the requisite epistemic insight as to the sublimating implications of human limitedmentation-capacity-deepening —as-subjecting limitedness/humansubpotency to 'educed unlimitedness/existence sublimating nascence' underlined by its dimensionality-of-sublimating < amplitudinglformative > supererogatory-de-mentativeness/epistemicgrowth-or-conflatedness/transvaluativerationalising/transepistemicity/anamnestic-residuality/spirit-drivennessequalisation) associated with the overall relative unreflexivity/relativereflexivity ontological-contiguity of-the-human-institutionalisationprocess $^{6}$ as to its difference-conflatedness ${ }^{3}$-as-to-totalitative-reificationin-singularisation-<as-to-the-nondisjointedness/entailment-ofprospective- nonpresencing $>$-as-veridical-epistemicity-relativismdeterminism and so with regards to 'the-very-same overall phenomenality/manifestation of existence-as-sublimatingwithdrawal/unenframing/re-ontologising,-elicited-from-prospectiveprofound-supererogation, so-reflected as from originariness/origination-_so-construed-as-to-ontological- 
existence))

${ }^{83}$ reference-of- $\quad{ }^{83}$ reference-of-thought-devolving-teleological-de-

thought- mentating/structuring/paradigming-of- meaningfulness-and-teleology

${ }^{84}$ devolving

registry- registry-worldview's/dimension's-uninstitutionalised-threshold -defect-

worldview's/dime < <-Being-or-ontological-or-existential-defect>-with-regards-to-

nsion's- $\quad$ registry-worldview's/dimension's-given-preconverging/postconverging-

uninstitutionalised- de-mentative/structural/paradigmatic-denaturing -of-ontologically-

threshold ${ }^{12}$ veridical- ${ }^{56}$ meaningfulness-and-teleology -as-to-its-given- reference-

defect-<as-Being- of-thought-for-social-functioning-and-accordance-defect,-as-defined-

or-ontological-or- placeholder-setup/mental-devising-

existential-defect> representation/mentation/consciousness-awareness-teleology

85

reification $^{86} \quad$ reification is teleologically reflected as of notional $\sim$ singularisation-<as-

to-the-nondisjointedness/entailment-of-prospective- nonpresencing>

projected epistemic-immanence/veridical-epistemicity-relativism-

determinism in construing ontologically-veridical ${ }^{56}$ meaningfulness-and-

teleology , as reification arises as of the preconverging/postconverging-

de-mentative/structural/paradigmatic

<amplituding/formative-

epistemicity $>$ causality $\sim$ as-to-projective-totalitative-implications-of-

prospective- nonpresencing,-for-explicating felative-

unreflexivity/relative reflexivity -ontological-contiguity

as to

ontological-faith-notion-or-ontological-fideism-imbued- 
underdetermination-of-motif-and-apriorising/axiomatising/referencing-

as-so-being-as-of-existential-reality potentiative-aspiration for prospective relative-ontological-completeness 87 as from prior relativeontological-incompleteness 8 and so with regards to the-very-sameimmanent-existence/intrinsic-reality/ontological-veridicality,-as-to'human< amplitudingfformative-epistemicity>totalising purview-ofconstrual', and implies the preconverging/postconverging-dementative/structural/paradigmatic $<$ amplitudinglformativeepistemicity $>$ causality $\sim$ as-to-projective-totalitative-implications-ofprospective- nonpresencing,-for-explicating felative unreflexivity/relative reflexivity ontological-contiguity of meaningfulness-and-teleology as of prospective relative-ontologicalcompleteness ${ }^{87}$ construed as ${ }^{55}$ maximalising-recomposuring-for-relativeontological-completeness —unenframed/re-

ontologising conceptualisation over prior relative-ontologicalincompleteness ${ }^{88}$ construed as incrementalism-in-relative-ontologicalincompleteness - enframed/disontologising conceptualisation, wherein prospective relative-ontological-completeness is a reified/elucidated-asof-more-profound construal overlooking/superseding the prior relativeontological-incompleteness as a dereified/poorly-elucidated-as-of-moreshallow construal; $\boldsymbol{\Phi}$ in other words, reification is about supererogatory acuity/perspicacity/astuteness/edginess/incisiveness-ofapriorising/axiomatising/referencing/intelligibilitysettingup/measuringins trumenting-for-conceptualisation resetting of the <amplitudingtformative- 
epistemicity>totalising/circumscribing/delineating ${ }^{56}$ meaningfulness-andteleology purview to the prospective relative-ontological-completeness as of human limited-mentation-capacity-deepening-as-subjecting limitedness/human-subpotency to-'educed unlimitedness/existencesublimating nascence'

relativeprospective antiakrasiatic-relative-ontological-completeness as to

ontologicalprospective nonpresencing-<perspective-ontologicalcompleteness $^{87}$ normalcy/postconvergence>

relativeprior akrasiatic-relative-ontological-incompleteness as to prior ontologicalpresencing-absolutising-identitive-constitutedness incompleteness $^{88}$ <amplituding/formative-epistemicity >totalising $\sim$ self-referencingsyncretising/circularity/interiorising/akrasiatic-drag

'relative'relative-ontological-incompleteness 8 /relative-ontological-

ontologicalcompleteness - (sublimating $\sim$ referencing/registering/decisioning,-asincompleteness $88 / \mathrm{r}$ self-becoming/self-conflatedness /formative-supererogating-

elative$<$ projective/reprojective-aestheticising-re-motif-and-re-apriorising/reontologicalaxiomatising/re-referencing,-in-perspective-ontological-

completeness ${ }^{87}$ normalcy/postconvergence $>$ ) as to human-and-social〈sublimating $\sim$ refer expectations/anticipations-metaphoricity -asencing/registering/ preconverging/postconverging-rededecisioning,-as- mentating/restructuring/reparadigming-psychologism' reflect self-becoming/self- reference-of-thought-construed-ontological-veridicality-as-so-

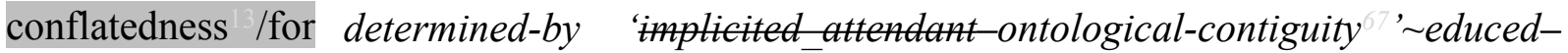
mativeexistentialising/contextualising/textualising_intelligibility/epistemicity/re 
supererogating- flexivity-contiguity-<imbued-notional $\sim$ cogency $>^{\prime},-<$ reifying-or-

$<$ projective/reproje elucidating-of-prospective-relative-ontological-completeness -of-

ctive-

reference-of-thought- devolving-as-of-instantiative-context>

and

aestheticising-re- speaks to the fundamental

motif-and-re- supererogatory acuity/perspicacity/astuteness/edginess/incisiveness-of-

apriorising/re- apriorising/axiomatising/referencing/intelligibilitysettingup/measuringins

axiomatising/re- trumenting-for-conceptualisation $\quad{ }^{56}$ meaningfulness-and-teleology

referencing,-in- implications as to human limited-mentation-capacity-deepening-as-

perspective- $\quad$ subjecting limitedness/human-subpotency to-'educed-

ontological- unlimitedness/existence sublimating nascence' (so poorly recognised as

normalcy/postconv from ${ }^{70}$ presencing-absolutising-identitive-constitutedness ${ }^{14}$ perspective

ergence $>>$ as to that by elaboration-as-to-mere-

human-and-social- extrapolating/constituting/abstracting/deducing/inferring-of-elucidation-

expectations/antici outside_-prospectively_implicited_attendant-ontological-

pations- contiguity ' $\quad$ educed-

metaphoricity ${ }^{57}$ - existentialising/contextualising/textualising_intelligibility/epistemicity/re

as- $\quad$ flexivity-contiguity-<imbued-notional $\sim$ cogency $>^{\prime}$ develop an

preconverging/post ontologically-flawed overall absolutising epistemicconverging-rede- abnormalcy/preconvergence perspective of construal of existence, by somentating/restruct projecting of an 'underlying absolute intelligibility framework' that uring/reparadigmin supposedly supersedes existence-as-the-absolute-a-priori-ofg-psychologism'89 conceptualisation $\sim$ and $\sim$ existence-as-sublimating-

withdrawal/unenframing/re-ontologising,-elicited-from-prospectiveprofound-supererogation -<as-to-perspective-ontological-

normalcy/postconvergence-implied-'prospective-aporeticism- 
overcoming/unovercoming'>), with the consequence that such an ontologically-deficient prior_knowledge-reification $\sim$ gesturing-andaccounting-of-epistemic-phenomenalism-<in-

prior psychologismic $\sim$ apriorising/axiomatising/referencing-\{of- 'priorimplicited_attendant-ontological-contiguity ' reducedexistentialising/contextualising/textualising_intelligibility/epistemicity/re flexivity-contiguity-<imbued-notional $\sim$ cogency>' \}, constitutedness in preconverging entailment $>$ framework goes on to analyse more profound thought (that is not making the same mistake) as supposedly ontologically-flawed as of its presencing-absolutising-identitiveconstitutedness instigated paradoxical criticism of relativity, failing to factor in that 'existence is not of prospective apriorising/axiomatising/referencing-sublimating-reflexivitybeholdening to human-subpotency' as to when the human projects any supererogatory acuity/perspicacity/astuteness/edginess/incisiveness-ofapriorising/axiomatising/referencing/intelligibilitysettingup/measuringins trumenting-for-conceptualisation which needs to be validated as to existence-as-sublimating-withdrawal/unenframing/re-ontologising,elicited-from-prospective-profound-supererogation, and thusly the conception of relative-ontological-completeness speaks rather of the validative pertinence imparted by existence and so relatively (with regards to registry-worldviews/dimensions reference-of-thought as to implied Being-development/ontological-framework-expansion-as-to-depth-ofontologising-development-as-infrastructure-of- meaningfulness-andteleology , institutional-development-as-to-social-function-development 
and living-development-as-to-personality-development psychologismic epistemic acutisation difficulty< < for, residualising

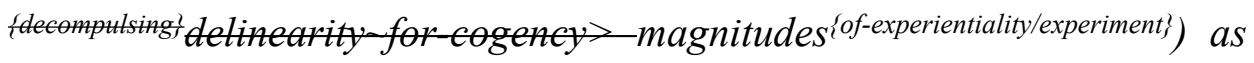
from 'recurrent-utter-uninstitutionalisation to prospective deprocrypticism/preempting - disjointedness-as-of- reference-ofthought'

supererogatory acuity/perspicacity/astuteness/edginess/incisiveness-ofapriorising/axiomatising/referencing/intelligibilitysettingup/measuringins trumenting -for-conceptualisation with regards to the overall relativeunreflexivity/relative reflexivity ontological-contiguity of-the-humaninstitutionalisation-process ; whereas the presencing-absolutisingidentitive-constitutedness ${ }^{14}$ perspective by equating/leveling-down everything across space and time as of naive absolutising conceptualpatterning-_as-devoid-of- "prospectively_implicited_attendant ontological-contiguity ' reducedexistentialising/contextualising/textualising_intelligibility/epistemicity/re flexivity-contiguity-<imbued-notional cogency>' 's-reifying-orelucidating-of-'prospective-relative-ontological-completeness ';-sorather-enabled-<by-a- nonpresencing-divulging-of-momentoushistoriality/ontological-eventfulness /ontological-aesthetic-tracing$<$ perspective-ontological-normalcy/postconvergence-reflected'epistemicity-relativism-determinism'>/ and isms-conceptualisations as to wrongly imply everything is of the same notional-contiguity/epistemiccontiguity $\quad<$ profound-supererogation -of-mentallyaestheticised postconverging/dialectical-thinking -qualia-schema> (as 
of $\quad$ undisambiguated relative unreflexivity/relative reflexivity ontological-contiguity as to relative-ontological-incompleteness -ofapriorising/axiomatising/referencing and relative-ontologicalcompleteness -of-apriorising/axiomatising/referencing thus inducing 'apriorising/axiomatising/referencing-

equating/leveling/ressentiment/closed-construct-of- ${ }^{-}$meaningfulness-

and-teleology moronisation- $<$ sublimating-nascence,-extricatory desublimating-downstreaming/'avalage'>') in absolute terms with respect to its epistemic lack of projective-insights as to contrasting relativeontological-incompleteness and relative-ontological-completeness apriorising/axiomatising/referencing-psychologisms, 'will naively equate in absolution (manifesting a 'relativity-accusation that such relative-

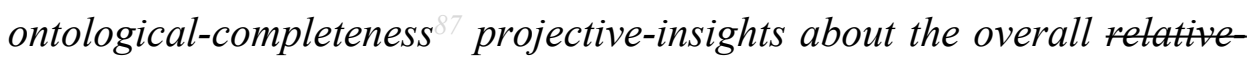
unreflexivity/relative reflexivity ontological-contiguity $\sim$ of-the-humaninstitutionalisation-process $^{68}$ as of difference-conflatedness ${ }^{13}$-as-tototalitative-reification-in-singularisation-<as-to-the-

\section{nondisjointedness/entailment-of-prospective- nonpresencing $>$-as-}

veridical-epistemicity-relativism-determinism is along the same lines with ancient-sophists non-universalising ${ }^{5}$ meaningfulness-and-teleology or it is just basically unintelligible', and so since it wrongly operates on the basis that its presencing-absolutising-identitive-constitutedness perspective is supposedly of absolutely profound knowledgereification gesturing-and-accounting-of-epistemic-phenomenalism-

$<$ in-prospective psychologismic $\sim$ apriorising/axiomatising/referencing-

\{of- prospectively_implicited_attendant-ontological- 
contiguity ' reduced-

existentialising/contextualising/textualising_intelligibility/epistemicity/re flexivity-contiguity-<imbued-notional $\sim$ cogency $>$ ' $\}$-conflatedness in fpreconverging ment by\} postconverging entailment $>\quad$ without factoring the implications of human limited-mentation-capacity-assubjecting 'educed-unlimitedness/existence-sublimating nascence'-tolimitedness/human-subpotency and human limited-mentation-capacitydeepening - as subjecting limitedness/human-subpotency to-'educedunlimitedness/existence sublimating nascence' $\left.{ }^{\prime}\right) ; 1$ and operantly 'relative-ontological-incompleteness /relative-ontological-

completeness - (sublimating $\sim$ referencing/registering/decisioning,-asself-becoming/self-conflatedness /formative-supererogating$<$ projective/reprojective-aestheticising-re-motif-and-re-apriorising/reaxiomatising/re-referencing,-in-perspective-ontologicalnormalcy/postconvergence $>$ ) as to human-and-socialexpectations/anticipations - metaphoricity -aspreconverging/postconverging-redementating/restructuring/reparadigming-psychologism' refers to epistemic-veracity for knowledge-reification gesturing-and-accountingof-epistemic-phenomenalism-<inprospective psychologismic apriorising/axiomatising/referencing-\{of'prospectively implicited_attendant-ontological-contiguity ' reducedexistentialising/contextualising/textualising_intelligibility/epistemicity/re flexivity-contiguity-<imbued-notional $\sim$ cogency $>$ ' \}-conflatedness in \{preconverging ment by, postconverging entailment>/ontological- 
veracity rather construed as of human limited-mentation-capacitydeepening - as subjecting limitedness/human-subpotency to 'educedunlimitedness/existence sublimating nascence' induced 'given axiomatic-constructs/ ${ }^{3}$ reference-of-thought

apriorising/axiomatising/referencing-\{of- 'prospectively implicited_attendant-ontological-contiguity ' reducedexistentialising/contextualising/textualising_intelligibility/epistemicity/re flexivity-contiguity-<imbued-notional $\sim$ cogency $>^{\text {' }}$;-conflatedness ${ }^{13}-$ in \{preconverging ment by\} postconverging entailment <amplituding/formative-epistemicity>causality $\sim$ as-to-projectivetotalitative-implications-of-prospective- nonpresencing,-forexplicating relative unreflexivity/relative reflexivity ontologicalcontiguity of supererogating \{'affirmation/projection/assertion/notional $\sim$ selfdistantiation/dueness-validating-logicising/suitablemeasuringinstrument-validating-measuring-<as-to-postconverging-ordialectical-thinking -apriorising-psychologism $>$ of prospective relativeontological-completeness ${ }^{\text {'-by- }}$ 'unaffirmation/deprojection/deassertion/epistemic-decadence/unduenessinvalidating-logicising/unsuitable-measuringinstrument-invalidatingmeasuring-<as-to-preconverging-or-dementing -apriorisingpsychologism > of prior relative-ontological-incompleteness '? acuity/perspicacity/astuteness/edginess/incisiveness-ofapriorising/axiomatising/referencing/intelligibilitysettingup/measuringins trumenting-for-conceptualisation', and so over the epistemic- 
impertinence and flawed approach of 'atomising/taking-to-pieces apriorising/axiomatising/referencing-\{of-'prospectively implicited_attendant-ontological-contiguity ' reducedexistentialising/contextualising/textualising_intelligibility/epistemicity/re flexivity-contiguity-<imbued-notional $\sim$ cogency $>$ ' \}-constitutedness ${ }^{1 /}$ in preconverging-entailment conception as knowledgereification $\sim$ gesturing-and-accounting-of-epistemic-phenomenalism<in-prospective psychologismic $\sim$ apriorising/axiomatising/referencing\{of- 'prospectively_implicited_attendant-ontologicalcontiguity ' educedexistentialising/contextualising/textualising_intelligibility/epistemicity/re flexivity-contiguity-<imbued-notional $\sim \operatorname{cogency}>$ ' \}-conflatedness in \{preconverging ment by\} postconverging entailment>/ontologicalveracity'

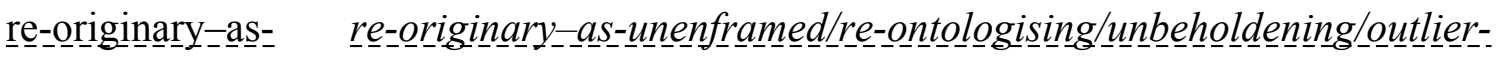

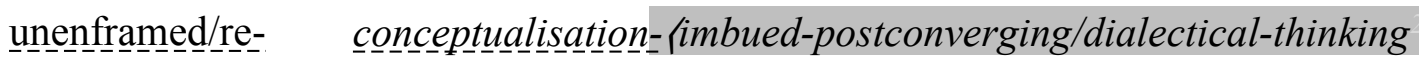
ontologising/unbeh 'projective-insights'/'epistemic-projection-in-conflatedness '-ofoldenning/outllier-- $\quad$ notional deprocrypticism-prospective-sublimation)-(so-reflected as of conceptualisation- the ontological-normalcy/postconvergence epistemic projective〈imbued- perspective as to dimensionality-of-sublimating -

postconverging/dia $\quad<$ amplituding/formative $>$ supererogatory-de-mentativeness/epistemiclectical-thinking - growth-or-conflatedness /transvaluative-

\section{'projective-}

insights'/'epistemi rationalising/transepistemicity/anamnestic-residuality/spirit-drivenness-

equalisation )/-underlying-the-imbued-human-subpotency-'fatedness-of- 
c-projection-in- sublimation-over-desublimation'-as-of-'notional deprocrypticism-as-

conflatedness '- from-recurrent-utter-uninstitutionalisation,-base-institutionalisation,-

of-

universalisation,-positivism/rational-empiricism-and-prospectively-

notional deprocr deprocrypticism'-\{with regards to Being-development/ontological-

ypticism- framework-expansion-as-to-depth-of-ontologising-development-as-

prospective- infrastructure-of- meaningfulness-and-teleology , institutional-

sublimation $\rangle^{90} \quad$ development-as-to-social-function-development and living-development-

as-to-personality-development psychologismic epistemic acutisation-

difficulty < for, residualising tecompusingl delinearity for cogency>

magnitudes $\left.{ }^{\{\text {of-experientiality/experiment }\}}\right\}$

shiftiness-of-the- shiftiness-of-the-Self as of mere reproducibility-

Self ${ }^{91}$ mathesis/motif/thrownness-disposition,-as-reproducibility-of-

aestheticisation

$<$ preconverging 'motif-and-

apriorising/axiomatising/referencing'-entailing>-existentialising-

enframing/imprintedness-〈as-to- historicity-tracing_in-presencing-

hyperrealisation/hyperreal-transposition) dereifying-gesturing as of the defined registry-worldview's/dimension's 'reference-of-thought 'implicited_attendant-ontological-contiguity ' reduced-

existentialising/contextualising/textualising_intelligibility/epistemicity/re flexivity-contiguity-<imbued-notional $\sim \operatorname{cogency}>{ } \quad$ presencingabsolutising-identitive-constitutedness ${ }^{14}$ at its uninstitutionalisedthreshold ${ }^{02}$, -as-of-its-specific-immediacy-<preconverging 'motif-andapriorising/axiomatising/referencing'-entailing>-existentialisingenframing/imprintedness-_as-to- historicity-tracing-in-presencing- 
trepidating/warping/precluding/occluding-as-to-notional procrypticism imbued teleological-inflections-〈of-more-profound-nondisjointing-

\section{<emplinglformative-}

epistemicity>totalising/circumscribing/delineating/ 'respectively as its soshifty-defined apriorising-teleological-thresholding-as-teleologicalframework/narrative-framework of contextualising/existentialising/instantiative-devolving-meaningfulness' reflected as of its mere reproducibility-mathesis/motif/thrownnessdisposition,-as-reproducibility-of-aestheticisation poorly contemplative of existence-as-sublimating-withdrawal/unenframing/re-ontologising,elicited-from-prospective-profound-supererogation requisite prospective originariness-parrhesia,-as-spontaneity-of-aestheticisation

singularisation- 'epistemically-immanented'-as-of-internal-necessity-and-

$<$ as-to-the- $\quad$ supererogatory $\quad$ acuity/perspicacity/astuteness/edginess/incisiveness-of-

nondisjointedness/ apriorising/axiomatising/referencing/intelligibilitysettingup/measuringins entailment-of- trumenting-for-conceptualisation; $₫ \quad$ as-of-apriorising-teleologicalprospective- wholeness/nested-congruence singularisation- $<$ as-to-thenonpresencing $>92$ nondisjointedness/entailment-of-prospective- nonpresencing $>$ \operantly-construed-as-of-maximalising-recomposuringfor-relativeontological-completeness /preempting - disjointedness/as-internalcoherencing); $\uparrow \quad$ and thus singularisation-<as-to-thenondisjointedness/entailment-of-prospective- nonpresencing $>\quad$ is construed 'as from prospective "nonpresencing-<perspective- 
ontological-normalcy/postconvergence>

$<$ amplituding/formative-epistemicity >causality $\sim$ as-to-projective-

totalitative-implications-of-prospective- nonpresencing,-for-

explicating relative unreflexivity/relative reflexivity ontological-

contiguity of relative-ontological-incompleteness /relative-ontological-

completeness - -_sublimating referencing/registering/decisioning,-as-

self-becoming/self-conflatedness /formative-supererogating-

$<$ projective/reprojective-aestheticising-re-motif-and-re-apriorising/re-

axiomatising/re-referencing,-in-perspective-ontological-

normalcy/postconvergence $>$ )' rather as 'postconverging-or-dialectical-

thinking -apriorising-psychologism representation', with

singularisation-<as-to-the-nondisjointedness/entailment-of-prospective-

nonpresencing> so-induced by 'prospective parrhesiasticaestheticisation reproducibility — mathesis/motif/thrownness-disposition,as-reproducibility-of-aestheticisation as postconverging/dialecticalthinking-qualia-schema', reflecting the contrastive apriorisingteleological-thresholding-as-teleological-framework/narrative-

framework of 'prospective postconverging-or-dialectical-thinking apriorising-psychologism intemporal parrhesiastic-aestheticisation induced reasoning-through/messianic-reasoning reproducibilitymathesis/motif/thrownness-disposition,-as-reproducibility-of-

aestheticisation' and 'prior preconverging-or-dementing-apriorisingpsychologism temporal underpinning-suprasocial-construct as to its <amplituding/formative> wooden-language-fimbued-temporal-mereform/virtualities/dereification/akrasiatic-drag/denatured/preconverging- 
or-dementing -narratives-of-the- reference-of-thought-categorical-

imperatives/axioms/registry-teleology । and sophistry reproducibilitymathesis/motif/thrownness-disposition,-as-reproducibility-of-

aestheticisation as reasoning-from-results/afterthought' (with the implication that such 'prospectively induced singularisation- $<$ as-to-thenondisjointedness/entailment-of-prospective- nonpresencing $>$ is not really meaning but rather metaphoricity -as-event -of-prospectiveintemporalparrhesiastic-aestheticisation with regards to the prior preconverging-or-dementing -apriorising-psychologism temporal underpinning-suprasocial-construct

$<$ amplituding/formative $>$ wooden-language-fimbued-temporal-mereform/virtualities/dereification/akrasiaticdrag/denatured/preconvergingor-dementing -narratives-of-the- reference-of-thought-categoricalimperatives/axioms/registry-teleology | and sophistry reproducibilitymathesis/motif/thrownness-disposition,-as-reproducibility-ofaestheticisation as reasoning-from-results/afterthought', say for instance with regards to the preconverging/postconverging-dementative/structural/paradigmatic apriorising/axiomatising/referencing/intelligibilitysettingup/measuringins trumenting implications of a God-of-plane type of assertion by a nonpositivism social-setup speaking of its deficient prior-temporalparrhesiastic-aestheticisation so-reflected-in-its-nonpositivismmathesis/motif/thrownness-disposition-that-is-notpositivistic/rational-empiricistic, as meaning rather requires that such a non-positivism social-setup operates a positivism/rational-empiricism 
supererogatory acuity/perspicacity/astuteness/edginess/incisiveness-ofapriorising/axiomatising/referencing/intelligibilitysettingup/measuringins trumenting-for-conceptualisation and thus it is metaphoricity -asevent -of-prospective-intemporalparrhesiastic-aestheticisation because the non-positivism social-setup rather enters into a 'crossgenerational non-positivism pseudo-edginess/pseudo-incisiveness $<$ emplituding/formative-epistemicity $>$ totalising $\sim$ self-referencingsyncretising/circularity/interiorising/akrasiatic-drag as of its apriorising-teleological-thresholding-as-teleologicalframework/narrativeframework' with the 'prospective metaphoricity as positivism/rational-empiricism ${ }^{5}$ meaningfulness-and-teleology', over which its pseudo-edginess/pseudo-incisiveness is crossgenerationally involved-as-of-afooling-about-exercise in an 'internal parrhesiasticaestheticisation transitioning accommodation towards positivism/rationalempiricism so-induced by the positive-opportunism-of-socialfunctioning-and-accordance constraint of prospective positivism/rational-empiricism ${ }^{56}$ meaningfulness-and-teleology' as so empirically verifiable historically with regards to metaphoricity -asevent -of-prospective-intemporal-parrhesiastic-aestheticisation induced transitioning as from relative-ontological-incompleteness -of${ }^{3}$ reference-of-thought towards relative-ontological-completeness ${ }^{8}$-of${ }^{3}$ reference-of-thought, and this reality should equally prospectively be reflected with regards to our presencing-absolutising-identitiveconstitutedness ${ }^{14}$ positivism- ${ }^{80}$ procrypticism prospective integration of 
notional deprocrypticism meaningfulness-and-teleology effectively rather implies metaphoricity -as-event -of-prospective-intemporalparrhesiastic-aestheticisation and not meaning to our presencingabsolutising-identitive-constitutedness ${ }^{4}$ positivism- ${ }^{\text {procrypticism as we }}$ rather enter into a pseudo-edginess/pseudo-incisiveness $<$ amplitudingfformative-epistemicity $>$ totalising $\sim$ self-referencingsyncretising/circularity/interiorising/akrasiatic-drag ${ }^{34}$ as of our apriorising-teleological-thresholding-as-teleologicalframework/narrativeframework' with the prospective metaphoricity —asevent -of-prospective-intemporal-parrhesiastic-aestheticisation as

socially-

functional-andaccordant $^{93}$ notional deprocrypticism meaningfulness-and-teleology")

socially-functional-and-accordant-_construed-in-terms-of- 'least-andderived-temporal-operating-modalities-of-the- reference-of-thought-as-

of- incrementalism-in-relative-ontological-incompleteness

enframed/disontologising conceptualisation-inducing-theuninstitutionalised-threshold '-and-not-'maximal-as-intemporaloperating-modality-of- reference-of-thought-as-of- maximalisingrecomposuring-for-relative-ontological-completeness —unenframed/reontologising conceptualisation-as-inducing-the-prospectiveinstitutionalisation'); $9 \quad$ as-the-transdimensional/transcendentaldichotomy-of-ontologically-unsound-and-sound-shades-of-apparentlythe-same- reference-of-thought-\{so-disambiguated-as-of 'implicited_attendant-ontological-contiguity' reducedexistentialising/contextualising/textualising_intelligibility/epistemicity/re 
flexivity-contiguity-<imbued-notional $\sim$ cogency $>$ ', ,-<reifying-orelucidating-of-prospective-relative-ontological-completeness -of- $^{-}$ ${ }^{3}$ reference-of-thought- devolving-as-of-existential-instantiative-context?

storiedstoried-construct/ontologically-valid-narration-_as-of- 'ontologicallyconstruct/ontologic hegemonising-narrative ontological-performance -<including-virtueally-valid-narration as-ontology >',

subknowledging ${ }^{94}$ subknowledging-(preconverging-or-dementing -as-if-of-ontologicallyveridical-sound-thought)

sublimation- $\quad$ sublimation-educing-\{epistemic-

educing_hermeneut acuting, ic/textuality/reproj becoming-as-of-'existential-interpretation/epistemicity-inecting/supererogati apriorising/axiomatising/referencing-of-existence' $-<$ so-construed-as-theng/zeroing/re- $\quad$ preformulating/preframing/premeaningfulness-underlying-theacuting,- conceptivity/epistemic-reflexivity/epistemicity-relativism-determinism\{decompling delinear <reifying\{as-to-knowledge-developing\}-and-empowering $>$-as-fromity for- $\quad{ }^{6 /}$ nonpresencing-<perspective-ontological-normalcy/postconvergence $>,-$ cogency as-to- as-eliciting-relative-ontological-completeness ${ }^{87}$

possibilities-of- 'foregrounding_entailment-<in-succession-of-profoundself-becoming-as- supererogation $>$ - (postconverging-narrowing-down $\sim$ sublimation-as-toof-'existential- 'existence-as-sublimating-withdrawal/unenframing/re-ontologising,interpretation/epist elicited-from-prospective-profound-supererogation '-in-reflectingemicity-in'immanent relative unreflexivity/relative reflexivity ontologicalapriorising/axioma contiguity ';-as-operative-notional deprocrypticism/-in-so-inducing- 
tising/referencing- prospective $\sim$ attendant-ontological-contiguity -and-thus-as-of-

of-existence ${ }^{95} \quad$ ontology/science'

as-from-human-'<amplitudingfformative-

epistemicity>-totalising thrownness-in-existence ${ }^{35}$ '-imbuing-

'implicited_attendant-ontological-contiguity' reduced-

existentialising/contextualising/textualising_intelligibility/epistemicity/re

flexivity-contiguity-<imbued-notional cogency $>$ 'for-

postconverging/dialectical-thinking-epistemic-projection-and-

reprojection,-and-so-over-'merely-analogised-or-dialecticised-or-any-

elaboration-as-to-mere-

extrapolating/constituting/abstracting/deducing/inferring-of-elucidation-

outside-'prospectively_implicited_attendant-ontological-

contiguity ${ }^{\text {' }}$ educed-

existentialising/contextualising/textualising_intelligibility/epistemicity/re

flexivity-contiguity-<imbued-notional cogency>' , , as-to-its-given-

'presencing-perspective-epistemic-abnormalcy/preconvergence ${ }^{31}$-as-

preconverging/dementing ${ }^{20}$-induced-disparateness-of-conceptualisation-

implied-unforegrounding-ment-failing-to-reflect

unreflexivity/relative reflexivity ontological-contiguity ,-and-thus-not-

as-of-ontology/science>

supererogation $^{96}$

supererogation speaks to the fact that the very possibility for all human

meaningfulness-and-teleology arises by way of individuals solipsistic

self-becoming/self-conflatedness /formative-supererogating-

$<$ projective/reprojective-aestheticising-re-motif-and-re-apriorising/re-

axiomatising/re-referencing,-in-perspective-ontological- 
normalcy/postconvergence $>$ detour to existence-potency $\sim$ sublimatingnascence,-disclosed-from-prospective-epistemic-digression as to 'underlying individuals ontological-commitment ${ }^{6}<$ implied - selfassuredness-of-ontological-good-faith/authenticity postconverging-dementating/structuring/paradigming -as-being-as-of-existential-reality> so-reflected as from the contiguous/coherent superseding-oneness-ofontology that is existence in inducing sublimation-over-desublimation' with 'existence itself inherently intercessory to the formative possibility for all human ${ }^{56}$ meaningfulness-and-teleology' (and thus with 'human meaningfulness-and-teleology more precisely construed as intersolipsistic-intercessory-notions as to human individuals and collective-individuals phenomenal/manifest conceptivity/epistemicreflexivity/epistemicity-relativism-determinism-<reifying\{as-toknowledge-developing\}-and-empowering $>$ in existence' with regards to overall reifying-and-empowering-reflexivity-of-ecstatic-existence-aspanintelligibilityfpanreflexivity - (existentially-imbued-and-educing$\leq$ Sepistemic totalising 'thermeneutically/textually/reprojectingly/supererogatingly/zeroin gly/re acutingly, - dempulsing delinearity for-cogency $>$ epistemicperspective-of-projective/reprojective-aestheticising-re-motif-and-reapriorising/re-axiomatising/re-referencing conceptualisation, as herein specifically relevant to human subpotencyl), such that the 'supposed reproducibility — mathesis/motif/thrownness-disposition,-asreproducibility-of-aestheticisation of meaningfulness-and-teleology underlied by language, culture, social institutions, technical knowhow, 
etc. of any presencing-absolutising-identitive-constitutedness <preconverging 'motif-and-apriorising/axiomatising/referencing'entailing >-existentialising-enframing/imprintedness-_as-to- historicitytracing-in-presencing-hyperrealisation/hyperreal-transposition)' is not the inherently given possibility for its very manifestation to inceptively arise in individuals but rather 'individuals are involved in selfbecoming/self-conflatedness /formative-supererogating$<$ projective/reprojective-aestheticising-re-motif-and-re-apriorising/reaxiomatising/re-referencing,-in-perspective-ontologicalnormalcy/postconvergence> solipsistic-and-intersolipsistic conceptivity/epistemic-reflexivity/epistemicity-relativism-determinism$<$ reifying\{as-to-knowledge-developing\}-and-empowering $>$ as to their self-eliciting/stimulating epistemic-conflatedness as of projective/reprojective-aestheticising-re-motif-and-re-apriorising/reaxiomatising/re-referencing in existence' for the possibility for any such 'supposed reproducibility—mathesis/motif/thrownness-disposition,-asreproducibility-of-aestheticisation of meaningfulness-and-teleology underlied by language, culture, social institutions, technical knowhow, etc. of any presencing-absolutising-identitive-constitutedness $<$ preconverging 'motif-and-apriorising/axiomatising/referencing'entailing>-existentialising —enframing/imprintedness-\{as-to- historicitytracing-in-presencing-hyperrealisation/hyperreal-transposition)' (as to human Being-development/ontological-framework-expansion-as-todepth-of-ontologising-development-as-infrastructure-ofmeaningfulness-and-teleology , institutional-development-as-to-social- 
function-development and living-development-as-to-personality-

development psychologismic epistemic acutisation difficulty <for,

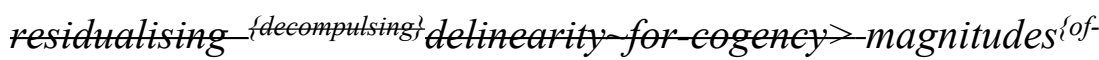

experientiality/experiments) to arise/result as individuals and collective-

individuals achieved human sublimation-over-desublimation in existence

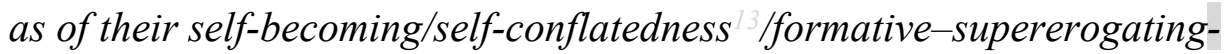
$<$ projective/reprojective-aestheticising-re-motif-and-re-apriorising/reaxiomatising/re-referencing,-in-perspective-ontologicalnormalcy/postconvergence $>$ involving renewed self-awareness as to prospective construction-of-the-Self; $\uparrow$ supererogation thus speaks of the very 'human epistemic-conflatedness ${ }^{3}$ in projective/reprojectiveaestheticising-re-motif-and-re-apriorising/re-axiomatising/rereferencing breath-of-life/making-alive' that as to 'effectively underlying human beholdening-inching,-apprehending,-and-taming-drive or aestheticising - surrealising/supererogating-drive for $<$ postconverging 'motif-and-apriorising/axiomatising/referencing'entailing>-existentialising-framing/imprinting-_as-to-prospectivehistoriality/ontological-eventfulness /ontological-aesthetic-tracing$<$ perspective-ontological-normalcy/postconvergence-reflected'epistemicity-relativism-determinism'>।' goes into grasping, mastering, developing, construing-of and contemplating-of meaningfulness-andteleology on the basis of the inherent implications of human < amplitudingfformative-epistemicity>-totalising $\sim$ thrownness-inexistence ${ }^{35}$,-imbued-projective-arbitrariness/waywardness-_as-to-thehuman-projective/reprojective-aestheticising-re-motif-and-re- 
apriorising/re-axiomatising/re-referencing-process-of-

'<amplitudingfformative-epistemicity>totalising conceptualisation'),

with the attendant fact that the human is thus a subpotency in existence with possibilities of individuals and collective-individuals selfrecreation/self-regeneration as to human developing-and-redeveloping intelligibility (so-implied as of the 'epistemic-

totalising $\sim$ resubjecting_or_totalising-entailing $\sim$ reconstrual-<of the wholelpurview of the wholetoneness of ontology> of motif-as-toaestheticisation-<imbued-projective-arbitrariness/waywardness $>$ to existence-as-sublimating-withdrawal/unenframing/re-ontologising,elicited-from-prospective-profound-supererogation in preconverging/postconverging-redementating/restructuring/reparadigming intelligibility-_as-to-humanprojective/reprojective-aestheticising-re-motif-and-re-apriorising/reaxiomatising/re-referencing/re-intelligibilitysettingup/remeasuringinstrumenting-process,-in-<amplitudingfformativeepistemicity>totalising conceptualisation)'), with the veridical implication here that there is truly no 'supposed reproducibilitymathesis/motif/thrownness-disposition,-as-reproducibility-ofaestheticisation of meaningfulness-and-teleology underlied by language, culture, social institutions, technical knowhow, etc.' but ever always rather individuals and collective-individuals 'self-becoming/selfconflatedness $/$ /formative-supererogating-<projective/reprojectiveaestheticising-re-motif-and-re-apriorising/re-axiomatising/rereferencing,-in-perspective-ontological-normalcy/postconvergence> 
ontological-performance ${ }^{72}<$ including-virtue-as-

ontology $>$ /morality/ethics/justice/etc. in existentially-instantiating such supposed reproducibility —mathesis/motif/thrownness-disposition,-asreproducibility-of-aestheticisation of meaningfulness-and-teleology underlied by language, culture, social institutions, technical knowhow, etc.' and so-reflected as of human supererogatory originarinessparrhesia,-as-spontaneity-of-aestheticisation (in holding-forth as of preconverging/postconverging-redementating/restructuring/reparadigming intelligibility-_as-to-humanprojective/reprojective - aestheticising-re-motif-and-re-apriorising/reaxiomatising/re-referencing/re-intelligibilitysettingup/remeasuringinstrumenting-process,-in-<amplituding/formativeepistemicity>totalising conceptualisation/for human existentialinstantiations aposteriorising/logicising/deriving/intelligising/measuring of ${ }^{5}$ meaningfulness-and-teleology $)$, and with this self-becoming/selfconflatedness /formative-supererogating-<projective/reprojectiveaestheticising-re-motif-and-re-apriorising/re-axiomatising/rereferencing,-in-perspective-ontological-normalcy/postconvergence $>$ soconstrued as 'human epistemic-conflatedness ${ }^{13}$ in projective/reprojective - aestheticising-re-motif-and-re-apriorising/reaxiomatising/re-referencing breath-of-life/making-alive' rather sosignified/connoted/indicated/suggested as of such 'supposed reproducibility mathesis/motif/thrownness-disposition,-asreproducibility-of-aestheticisation of meaningfulness-and-teleology underlied by language, culture, social institutions, technical knowhow, 
etc.', and thus human supererogation explains why the social as an overall sublimation-over-desublimation construct is rather a sublimating-postconverged 'substantive abstract-tissue-of-socialemanance \{epistemic-

totalising $33_{3}^{3}$ hermeneutically/textully/reprojectingly/supererogatingly/zeroin gly/re-acutingly, -\{decompulsing? delinearity for-cogency-

cumulated/recomposured as to cumulating/recomposuring of 'prospectively_implicited_attendant_ontological-contiguity ' reducedexistentialising/contextualising/textualising_intelligibility/epistemicity/re flexivity-contiguity-<imbued-notional $\sim$ cogency $>$ ' arising as of humansubpotency 'fatedness-of-sublimation-over-desublimation, to existencepotency $\sim$ sublimating-nascence,-disclosed-from-prospective-epistemicdigression (in reflecting holographically-<conjugatively-andtransfusively $>$ the relative unreflexivity/relative reflexivity-ontologicalcontiguity $\sim$ of-the-human-institutionalisation-process ), as from humansubpotency ontological-faith-notion-or-ontological-fideism-imbuedunderdetermination-of-motif-and-apriorising/axiomatising/referencingasso-being-as-of-existential-reality as to the disseminative-sublimatingselectivity-of-ontological-good-faith/authenticity postconverging-dementating/structuring/paradigming ,-over desublimating deselectivity of ontological bad faith/inauthenticity opreconverging de mentating/structuring/paradigming '; ' critically supererogation thus implies that human 'self-becoming/self-conflatedness //formativesupererogating-<projective/reprojective - aestheticising-re-motif-andre-apriorising/re-axiomatising/re-referencing,-in-perspective- 
ontological-normalcy/postconvergence $>$ ontological-performance ${ }^{72}$ $<$ including-virtue-as-ontology > ' in existential-instantiations signifying/connoting/indicating/suggesting any 'supposed reproducibility — mathesis/motif/thrownness-disposition,-asreproducibility-of-aestheticisation of meaningfulness-and-teleology underlied by language, culture, social institutions, technical knowhow, etc.' (reflecting human limited-mentation-capacity-as subjecting 'educed unlimitednesstexistence sublimating nascence' tolimitedness/human subpotency as to human <amplituding/formativeepistemicity>-totalising thrownness-in-existence ${ }^{35}$ ) ever always comes out short with respect to the full-potential for 'inherent immanentexistence overall withdrawn effectively-manifest-sublimation/sublime or withdrawn sublimation-structure' of 'meaningfulness-and-teleology , and that conversely the possibility for human limited-mentation-capacitydeepening-as-subjecting limitedness/human-subpotency-to-'educedunlimitedness/existence sublimating nascence' imparts the ability for

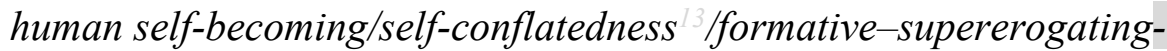
$<$ projective/reprojective-aestheticising-re-motif-and-re-apriorising/reaxiomatising/re-referencing,-in-perspective-ontologicalnormalcy/postconvergence $>$ reappraisal of the appropriateness/completeness/superseding of any such signified/connoted/indicated/suggested 'supposed reproducibilitymathesis/motif/thrownness-disposition,-as-reproducibility-ofaestheticisation of meaningfulness-and-teleology underlied by language, culture, social institutions, technical knowhow, etc.' (and so as 
to human Being-development/ontological-framework-expansion-as-to-

depth-of-ontologising-development-as-infrastructure-of-

meaningfulness-and-teleology , institutional-development-as-to-social-

function-development and living-development-as-to-personality-

development psychologismic epistemic acutisation difficulty<for,

residualising \{decompulsing ${ }^{\text {f }}$ delinearity for-cogency>-magnitudesiof-

experientiality/experiment's so-construed as human 'aporeticism-

overcoming/unovercoming supererogating ontological-performance ${ }^{72}$

<including-virtue-as-ontology>' as to projective-insights/epistemic-

projection-in-conflatedness ${ }^{3}$ of apriorising/axiomatising/referencing (but

that while such human 'aporeticism-overcoming/unovercoming

supererogating ontological-performance ${ }^{2}<$ including-virtue-as-

ontology > 'is relatively highly inducible with institutional-development-

as-to-social-function-development and living-development-as-to-

personality-development psychologismic epistemic acutisation -

difficulty< <or, residualising \{decompulsing' delinearity for cogency>

magnitudes \{of-experientiality/experiment\} within any given registry-

worldview/dimension, the presencing-absolutising-identitive-

constitutedness ${ }^{4}<$ preconverging 'motif-and-

apriorising/axiomatising/referencing'-entailing>-existentialising-

enframing/imprintedness-_as-to- historicity-tracing-in-presencing-

hyperrealisation/hyperreal-transposition/appraisal tends to fail to adopt

the requisite and more profound 'aporeticism-overcoming/unovercoming supererogating ontological-performance ${ }^{72}<$ including-virtue-as-

ontology > ' with regards to its re-ontologising prospective Being- 
development/ontological-framework-expansion-as-to-depth-of-

ontologising-development-as-infrastructure-of- meaningfulness-and-

teleology reflecting prospective destructuring-threshold-

\{uninstitutionalised-threshold /presublimating-desublimating-

decisionality $/$ of-ontological-performance ${ }^{72}<$ including-virtue-as-

ontology>/morality/ethics/justice/etc. as to taxingness-of-originariness),

as so-reflected by the relative unreflexivity/relative reflexivity-

ontological-contiguity $\sim$ of-the-human-institutionalisation-process ${ }^{6}$ with

all the successive presencing-absolutising-identitive-constitutedness

$<$ preconverging 'motif-and-apriorising/axiomatising/referencing'-

entailing>-existentialising-enframing/imprintedness-_as-to- historicity-

tracing-in-presencing-hyperrealisation/hyperreal-transposition)

underpinning-suprasocial-construct rather incapable of explaining the

possibility for the <cumulating/recomposuring attendant-ontological-

contiguity >-succession of registry-worldviews/dimensions with such an explanation arising only as of 'human dimensionality-of-sublimating

< amplituding/formative $>$ supererogatory de-mentativeness/epistemic-

growth-or-conflatedness/transvaluative-

rationalising/transepistemicity/anamnestic-residuality/spirit-drivenness-

equalisation)' (as reflected by the 'aporeticism-

overcoming/unovercoming supererogating ontological-performance ${ }^{72}$

<including-virtue-as-ontology>' respectively of base-institutionalisation,

universalisation, positivism/rational-empiricism and prospective

deprocrypticism in relative-ontological-completeness ${ }^{87}$ so-construed 
overall as notional deprocrypticism out of respectively recurrent-utteruninstitutionalisation, ununiversalisation, non-positivism/medievalism and prospective procrypticism in relative-ontological-incompleteness so-construed overall as notional procrypticism as to the fact that 'human <emplituding/formative-epistemicity >-totalising thrownness-inexistence ${ }^{35}$ under the logical-basis/logic,-as-derived-from $\sim$ transversality$<$ for-sublimating-existential-eventuating/denouement,-from 'thinking atfirst/pure predisposition preemptive of prospective disontologising/subontologising' as-of-prospectively-disambiguatedaffirmed-and-unaffirmed- 'motif-andapriorising/axiomatising/referencing' $>$ of the prior relativeontological-incompleteness ${ }^{8 m p l i e d}$ reproducibilitymathesis/motif/thrownness-disposition,-as-reproducibility-ofaestheticisation of meaningfulness-and-teleology underlied by language, culture, social institutions, technical knowhow, etc.' don't override existence - as-the-absolute-a-priori-ofconceptualisation $\sim$ and $\sim$ existence - as-sublimatingwithdrawal/unenframing/re-ontologising,-elicited-from-prospectiveprofound-supererogation-<as-to-perspective-ontologicalnormalcy/postconvergence-implied- 'prospective-aporeticismovercoming/unovercoming'> enabling human reappraisal as to existence-as-sublimating-withdrawal/unenframing/re-ontologising,elicited-from-prospective-profound-supererogation in sublimatingly pointing to the 'more profound relative-ontological-completeness apriorising/axiomatising/referencing logical-basis/logic,-as-derived- 
from $\sim$ transversality $<$ for-sublimating-existential-

eventuating/denouement, from 'thinking at first/pure predispositionpreemptive of prospective disontologising/subontologising' as-ofprospectively-disambiguated-affirmed-and-unaffirmed-'motif-andapriorising/axiomatising/referencing'> ' which the human can as of prospective 'aporeticism-overcoming/unovercoming supererogating ontological-performance ${ }^{72}<$ including-virtue-as-ontology>' consciously choose to pursue (or opt not to pursue as to its presencingabsolutising-identitive-constitutedness

<amplitudingfformative $>$ wooden-language-fimbued-temporal-mereform/virtualities/dereification/akrasiaticdrag/denatured/preconvergingor-dementing -narratives-of-the- reference-of-thought-categoricalimperatives/axioms/registry-teleology |turning a blind eye to existence - as-sublimating-withdrawal/unenframing/re-ontologising,elicited-from-prospective-profound-supererogation) and so-pursued as of

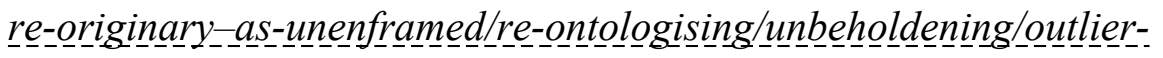
conceptualis__ation_-_imbued-postconverging/dialectical-thinking 'projective-insights'/'epistemic-projection-in-conflatedness '-ofnotional deprocrypticism-prospective-sublimation $\mid$ profoundsupererogation; $\uparrow$ with the broader implications that all supererogating sublimating-over-desublimating human possibilities (and as these become prospective secondnatured institutionalisation 'reproducibilitymathesis/motif/thrownness-disposition,-as-reproducibility-ofaestheticisation of meaningfulness-and-teleology underlied by language, culture, social institutions, technical knowhow, etc.' and so 
even as to their mere existential $<$ disontologising/re-ontologisingaporeticism $>$ instantiations) are rather as of shallow (human institutional-development-as-to-social-function-development and livingdevelopment-as-to-personality-development psychologismic epistemic . acutisation difficulty< for, residualising \{decompulsings delinearity for eogency> magnitudes $\{$ of-experientiality/experiment\} within any given registryworldview/dimension) to profound (Being-development/ontologicalframework-expansion-as-to-depth-of-ontologising-development-asinfrastructure-of- meaningfulness-and-teleology ) human 'aporeticismovercoming/unovercoming supererogating ontological-performance ${ }^{72}$ <including-virtue-as-ontology>', such that human 'aporeticismovercoming/unovercoming supererogating ontological-performance ${ }^{72}$ <including-virtue-as-ontology>' thus notionally speaks to the 'absolutegiftingness-backdrop that is existence-as-sublimatingwithdrawal/unenframing/re-ontologising,-elicited-from-prospectiveprofound-supererogation for human dimensionality-of-sublimating < amplituding/formative >supererogatory-de-mentativeness/epistemicgrowth-or-conflatedness /transvaluativerationalising/transepistemicity/anamnestic-residuality/spirit-drivennessequalisation / bestowed/bequeathed/gifted deflatingaetiologisation/ontological-escalation-<ontologicalveridicality_commitment/otherliness_transcending/compulsionsencumbered_transcending > 'reflected as to human-subpotency 'fatedness-of-sublimation-over-desublimation, to existencepotency sublimating-nascence,-disclosed-from-prospective-epistemic- 
digression (in reflecting holographically-<conjugatively-and-

transfusively $>$ the relative unreflexivity/relative reflexivity - ontologicalcontiguity of-the-human-institutionalisation-process ), as from humansubpotency ontological-faith-notion-or-ontological-fideism-imbuedunderdetermination-of-motif-and-apriorising/axiomatising/referencingasso-being-as-of-existential-reality as to the disseminative-sublimatingselectivity-of-ontological-good-faith/authenticity postconverging-dementating/structuring/paradigming ,-over desublimating deselectivity of ontological bad faith/inauthenticity opreconverging de mentating/structuring/paradigming ', with all the possibility for the merest human sublimating/desublimating ${ }^{56}$ meaningfulness-andteleology to arise necessarily bound notionally to individuals selfbecoming/self-conflatedness /formative-supererogating$<$ projective/reprojective-aestheticising-re-motif-and-re-apriorising/reaxiomatising/re-referencing,-in-perspective-ontologicalnormalcy/postconvergence $>$ as to 'human epistemic-conflatedness ${ }^{13}$ in projective/reprojective-aestheticising-re-motif-and-re-apriorising/reaxiomatising/re-referencing breath-of-life/making-alive' for that meaningfulness-and-teleology however shallow or profound the 'aporeticism-overcoming/unovercoming supererogating ontologicalperformance $-<$ including-virtue-as-ontology >' in the sense that not even a Camusian suicide as to its projection of self-dissolution can arise without individual notional self-becoming/self-conflatedness $/$ /formativesupererogating-<projective/reprojective-aestheticising-re-motif-andre-apriorising/re-axiomatising/re-referencing,-in-perspective- 
ontological-normalcy/postconvergence $>$ (with human supererogation as such critically defining-and-distinguishing the human from any humanoid/robot of mere mechanical-potentiality); $\uparrow$ supererogation is soreflected in human learning-and-enculturation process underlined on-theone-hand by the 'socio-institutional supererogating guiding-andinstructional cultural-predisposition' and on the other the 'supererogating precocious-disposition enabling the learning of the learner as to their notional self-becoming/self-conflatedness $/ 3 /$ formativesupererogating-<projective/reprojective-aestheticising-re-motif-andre-apriorising/re-axiomatising/re-referencing,-in-perspectiveontological-normalcy/postconvergence >' and so as specifically associated with childhood personality-development (beyond just the availing opportunity for its learning made possible by the 'socioinstitutional supererogating guiding-and-instructional culturalpredisposition') and this reflects the fact that the learner or child is inherently supererogating by its individual solipsistic notional selfbecoming/self-conflatedness $/$ formative-supererogating$<$ projective/reprojective-aestheticising-re-motif-and-re-apriorising/reaxiomatising/re-referencing,-in-perspective-ontologicalnormalcy/postconvergence $>$ as to its 'self-reflexive relatedness' construal-and-absorption of the given social-construct culture/practices so-defining consequentially its very personhood (as to 'human epistemicconflatedness $^{13}$ in projective/reprojective-aestheticising-re-motif-andre-apriorising/re-axiomatising/re-referencing breath-of-life/makingalive' beyond 'robotic reproducibility — mathesis/motif/thrownness- 
disposition,-as-reproducibility-of-aestheticisation') in concurrent cumulating/recomposuring as the learner/child matures-in-readiness for succeedingly/successively profound social-stake-contention-or-confliction supererogating capacities, and likewise in-the-bigger-picture institutional constructs are underlied by originariness-parrhesia,-as-spontaneity-ofaestheticisation supererogatory instigations of re-ontologising prospective Being-development/ontological-framework-expansion-as-todepth-of-ontologising-development-as-infrastructure-ofmeaningfulness-and-teleology (as to 'human epistemic-conflatedness in projective/reprojective-aestheticising-re-motif-and-re-apriorising/reaxiomatising/re-referencing breath-of-life/making-alive' beyond just already secondnatured institutionalisation reflected reproducibilitymathesis/motif/thrownness-disposition,-as-reproducibility-ofaestheticisation) 'so-undergirded by human dimensionality-ofsublimating $-1<$ amplituding/formative $>$ supererogatory $-d e-$ mentativeness/epistemic-growth-or-conflatedness/transvaluativerationalising/transepistemicity/anamnestic-residuality/spirit-drivennessequalisation \as of the operative human mental-devising-representation de-mentation-(supererogatoryontological-de-mentation-ordialectical-de-mentation-stranding-or-attributive-dialectics) postconverging/dialectical-thinking -apriorising-psychologism-bypreconverging/dementing -apriorising-psychologism as to human meaningfulness-and-teleology ontological-performance ${ }^{72}<$ includingvirtue-as-ontology>/morality/ethics/justice/etc. deepening' and as somanifested historially with 'non-immediacy prospective sublimating value 
and ontological-veracity disposition' enabling human institutional reconstrual-and-reconstruction in projective/reprojective-aestheticisingre-motif-and-re-apriorising/re-axiomatising/re-referencing for 'perspective ontological-normalcy/postconvergence' and so-reflected as to human-subpotency 'fatedness-of-sublimation-over-desublimation, to existence-potency $\sim$ sublimating-nascence,-disclosed-from-prospectiveepistemic-digression (in reflecting holographically-<conjugatively-andtransfusively $>$ the relative unreflexivity/relative reflexivity - ontologicalcontiguity of-the-human-institutionalisation-process )' and so as to the "non-immediacy prospective sublimating value and ontologicalveracity disposition' supererogating instigations of the Socrates, Copernicuses, Galileos, Descartes, Kants, Newtons, Leibniz, Rousseaux, Diderots, Pasteurs, Lavoisiers, Teslas, Einsteins, etc. (upon whose meaningfulness-and-teleology infrastructure building 'immediacy supposed absolute sublimating value and ontological-veracity disposition' arise and outlandishly skew human ${ }^{56}$ meaningfulness-andteleology in presencing-absolutising-identitive-constitutedness $<$ emplituding/formative-epistemicity >totalising $\sim$ self-referencingsyncretising/circularity/interiorising/akrasiatic-drag ${ }^{34}$ when wrongly implying no 'relative-ontological-incompleteness' to relativeontological-completeness ' implications of human meaningfulness and inducing ${ }^{51}$ incrementalism-in-relative-ontological-incompleteness ${ }^{88}$ enframed/disontologising conceptualisation as to social-stakecontention-or-confliction immediacy purposes at destructuring-threshold(uninstitutionalised-threshold /presublimating-desublimating- 
decisionality $/$ of-ontological-performance ${ }^{72}<$ including-virtue-asontology>/morality/ethics/justice/etc. as preconverging/postconvergingde-mentative/structural/paradigmatic impediment to 'non-immediacy prospective sublimating value and ontological-veracity disposition' supererogating instigations requiring maximalising-recomposuring-forrelative-ontological-completeness - unenframed/reontologising conceptualisation)

${ }^{97}$ surrealising-<as- surrealising-<as-to-supererogation ${ }^{\circ}>$ refers to 'human tonotionalisation/notional-conception/amplituding of the real'so-construed supererogation $>$ as human <emplituding/formative-epistemicity>totalising notionalisation/notional-conception/amplituding reflection of the real in 'perspective ontological-normalcy/postconvergence' (as so reflecting human limited-mentation-capacity-as-subjecting 'educedunlimitedness/existence sublimating nascence' to limitedness/humansubpotency ontological-performance $-<$ including-virtue-asontology >/morality/ethics/justice/etc. 'perspective epistemicabnormalcy/preconvergence ${ }^{3 /}$ scalarising-and-rescalarising epistemicconflatedness $^{3}$ as of projective/reprojective-aestheticising-re-motifand-re-apriorising/re-axiomatising/re-referencing for 'perspective ontological-normalcy/postconvergence' and 'so-undergirded by human dimensionality-of-sublimating -

< amplitudinglformative $>$ supererogatory-de-mentativeness/epistemicgrowth-or-conflatedness/transvaluativerationalising/transepistemicity/anamnestic-residuality/spirit-drivenness- 
equalisation) as of the operative human mental-devising-representation de-mentation-(supererogatory-ontological-de-mentation-ordialectical-de-mentation-stranding-or-attributive-dialectics) postconverging/dialectical-thinking -apriorising-psychologism-bypreconverging/dementing -apriorising-psychologism as to human meaningfulness-and-teleology ontological-performance $-<$ includingvirtue-as-ontology>/morality/ethics/justice/etc. deepening'), so-reflected as to 'germinative intensification-amplituding of aestheticisationbeholdening-out-of-bechancing' / 'taxingness-of-originariness,-imbuedsublimating-by-desublimating-amplituding as to the backdrop-ofinherent-immanent-existence's-sublimation-structure-<of'unsurrealistic-as-real'-ontological-normalcy/postconvergence > '; critically herein thus surrealising-<as-to-supererogation ${ }^{9}$ speaks notionally and denotatively to human supererogating epistemic-projection perspective openness/re-ontologisation/rescalarisation (as of nonpresencing-<perspective-ontological-normalcy/postconvergence $>$ ) for prospective relative-ontological-completeness 'reference-ofthought-and- reference-of-thought- devolving- ${ }^{5}$ meaningfulness-andteleology comprehensiveness of prospective sublimating-nascence' and this contrasts with hyperrealisation which speaks notionally and denotatively to human shallow-supererogating epistemic-projection perspective closure/subontologisation/descalarisation (as of any punctual presencing-absolutising-identitive-constitutedness ${ }^{4}$ in relativeontological-incompleteness as to its given relative-ontologicalincompleteness ${ }^{8}$ - presublimation-construct-of- ${ }^{5}$ meaningfulness-and- 
teleology

temporality $^{98}$

temporality / shortness-of-register-of- meaningfulness-and-teleology /

ontologically-perverting-immediacy-behaviour,-as-of-uninstitutionalised-

threshold ${ }^{2}$,-as-to-inherently-determinable-apriorising-teleological-

thresholding-as-teleological-framework-or-narrative-framework

perversion-of-categorical-imperatives-or-axioms-or-registry-teleology

teleology 99

teleology speaks to 'phenomenal/manifest conceptivity/epistemic-

reflexivity/epistemicity-relativism-determinism-<reifying\{as-to-

knowledge-developing\}-and-empowering > in existence as ontological (so-

reflecting <emplituding/formative>disposedness/psychologismic-

construct-_as-to-orientation/value-construct/valuation-and-derived-

parameterising) and <emplituding/formative>entailment-〈as-to-

totalising-contiguous/coherent-factuality-of-variability)', and so as to

any given phenomenal/manifest $\sim$ subpotency-(in-transitive-

conflatedness -reflexivity,-in-the-full-potency-of-

existence's sublimating-nascence) as to overall reifying-andempowering-reflexivity-of-ecstatic-existence-as-

panintelligibilityfpanreflexivity - lexistentially-imbued-and-educing-

$\leq$ fepistemic

totalising ${ }^{3}$ hermeneutically/textly/reprojectingly/stpererogatingly/zeroin

gly/re acutingly, -\{decompulsing 2 delinearity for-cogency $\geq$ epistemic-

perspective-of-projective/reprojective-aestheticising-re-motif-and-re-

apriorising/re-axiomatising/re-referencing conceptualisation,-as-herein-

specifically-relevant-to human-subpotency); 9 and teleology is thus the 
cognate to coherent intelligibility articulation of phenomena as to existential-reality, given that 'all phenomenal/manifest $\sim$ subpotencies-_intransitive-conflatedness -reflexivity,-in-the-full-potency-of-

existence's sublimating-nascence) are epistemic situations that speak to the transitive-conflatedness ${ }^{3}$-reflexivity that is existence' as 'there is no whole that is construable as existence and then beside that whole the epistemic-conception of phenomenal/manifest $\sim$ subpotencies-_intransitive-conflatedness -reflexivity,-in-the-full-potency-ofexistence's sublimating-nascence) of the said whole' but rather the 'fullpotency of existence is epistemically integrative of phenomenal/manifest $\sim$ subpotencies-_in-transitive-conflatedness reflexivity,-in-the-full-potency-of-existence's sublimating-nascence) as the whole'; the ontological-normalcy/postconvergence epistemic projective-perspective of relative-unreflexivity/relative-reflexivityontological-contiguity (as the implied 'full epistemic coherence of existence' as to overall-ecstatic-existence-supervening-conflatedness ${ }^{13}$ ) inherently explains the 'specific decoherencing-effect of phenomenal/manifest $\sim$ Subpotencies-_in-transitive-conflatedness reflexivity,-in-the-full-potency-of-existence 's sublimating-nascence)', wherein 'phenomenal/manifest $\sim$ subpotencies-\{in-transitiveconflatedness -reflexivity,-in-the-full-potency-ofexistence's sublimating-nascence) in relatively shallow <amplituding/formativeepistemicity>totalising/circumscribing/delineating 
mathesis/motif/thrownness-disposition

in

existence'

and 'phenomenal/manifest $\sim$ subpotencies-_in-transitive-conflatedness

reflexivity,-in-the-full-potency-of-existence's $\sim$ sublimating-nascence) in relatively

deeper

$<$ emplitungtformative-

epistemicity>totalising/circumscribing/delineating

mathesis/motif/thrownness-disposition in existence' are of a correspondingly shallow teleological-depth and deeper teleological-depth in the full-potency of existence, thusly reflecting the apriorising/axiomatising/referencing-\{of-'prospectively

implicitontological-contiguity ' reduced-

existentialising/contextualising/textualising_intelligibility/epistemicity/re

flexivity-contiguity-<imbued-notional $\sim$ cogency ${ }^{\text {' }}$, '-conflatedness ${ }^{/ 3}$ in fpreconverging ment by\} postconverging entailment epistemicconception of existence as to overall reifying-and-empowering-reflexivityof-ecstatic-existence-as-panintelligibilityfpanreflexivity ${ }^{3}$ - Lexistentiallyimbued-and-educing-<epistemic-

totalising i'hermeneutically/textually/reprojectingly/supererogatingly/zeroin

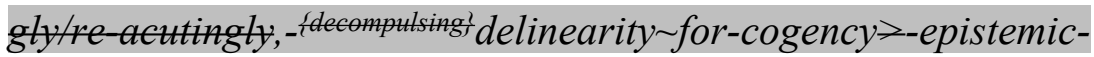
perspective-of-projective/reprojective-aestheticising-re-motif-and-reapriorising/re-axiomatising/re-referencing conceptualisation, as herein specifically relevant to human subpotency); 9 teleology as implied with the relative unreflexivity/relative reflexivity ontological-contiguity $\sim$ ofthe-human-institutionalisation-process ${ }^{68}$ 'as the cognate to coherent intelligibility articulation of human registry-worldviews/dimensions induced ${ }^{5}$ meaningfulness-and-teleology so-construed as teleological- 
inflections-_as-to-more-profound-nondisjointing-

<amplitudingfformative-

epistemicity>totalising/circumscribing/delineating) of meaningfulness' rather speaks to 'scalarity/immanency of existence's ontologicalnormalcy/postconvergence' perspective as reflecting prospective notionalcontiguity/epistemic-contiguity $-<$ profound-supererogation -ofmentally-aestheticised postconverging/dialectical-thinking -qualiaschema $>$ and 'human-subpotency non-scalarity/beholdening-<as-towhat-has-gone-before-aesthetically-de-mentates/structures/paradigmsdistortedly-the-possibility-forthe-later-ontologisation>' perspective as reflecting notional-discontiguity/epistemic-discontiguity $-<$ betweenprior-shallow-supererogation -of-mentallyaestheticised preconverging/dementing -qualiaschema_and_prospective-profound-supererogation -of-mentallyaestheticised postconverging/dialectical-thinking -qualia-schema> (that is, as of notional symmetrisation-<as-to-symmetrisation-bydesymmetrisation,-in-reflecting-postconverging-or-dialectical-thinking by-preconverging-or-dementing $\sim$ perspectives-of-humanmeaningfulness-and-teleology $>$ ); with the implication that from an originariness/origination-_so-construed-as-to-ontologicalnormalcy/postconvergence-perspective-scalarising-construal-ofexistence) epistemic-conception human meaningfulness has a latent preconverging/postconverging-de-mentative/structural/paradigmatic inherent teleology as to postconverging-or-dialectical-thinking apriorising-psychologism perspective (projecting a deeper teleological- 
depth) or preconverging-or-dementing-apriorising-psychologism perspective (projecting a shallower teleological-depth), as without such an originariness/origination-_so-construed-as-to-ontological-

normalcy/postconvergence-perspective-scalarising-construal-of-

existence) epistemic-conception disambiguation of human meaningfulness as to postconverging-or-dialectical-thinking -apriorising-psychologism perspective deeper teleological-depth or preconverging-or-dementing apriorising-psychologism perspective shallower teleological-depth, then human meaningfulness will wrongly/uninsightfully be construed as to the inherent presencing-absolutising-identitive-constitutedness <amplitudingfformative-epistemicity>totalising self-referencingsyncretising/circularity/interiorising/akrasiatic-drag when wrongly implying no 'relative-ontological-incompleteness to relative-ontologicalcompleteness ${ }^{7}$ 'implications of human meaningfulness; 1 thus the implied teleology of any given registry-worldview/dimension as to its ${ }^{83}$ referenceof-thought-and- reference-of-thought- devolving- ${ }^{5}$ meaningfulnessand-teleology (as reflecting the registry-worldview/dimension human limited-mentation-capacity-deepening - as subjecting limitedness/humansubpotency to 'educed unlimitedness/existence sublimating nascence' level) speaks to the <amplituding/formative-epistemicity>causality $\sim$ asto-projective-totalitative-implications-of-prospective- nonpresencing,for-explicating relative unreflexivity/relative reflexivity ontologicalcontiguity as to the registry-worldview's/dimension's institutionalisedand-uninstitutionalised-threshold $\quad$ preconverging/postconverging-dementatively/structurally/paradigmatically imbued ontological- 
performance ${ }^{72}<$ including-virtue-as-

ontology >/morality/ethics/justice/etc. and vices-and-impediments, and in this regards the inordinary contemplation about any given registryworldview/dimension preconverging-or-dementing-apriorisingpsychologism perspective shallower teleological-depth' (as to its uninstitutionalised-threshold ${ }^{12}$ implied notional-discontiguity/epistemicdiscontiguity 3 -<between-prior-shallow-supererogation -of-mentallyaestheticised preconverging/dementing -qualiaschema_and_prospective-profound-supererogation -of-mentallyaestheticised postconverging/dialectical-thinking -qualia-schema >) can be so-conceptualised as from the originariness/origination-/so-construedas-to-ontological-normalcy/postconvergence-perspective-scalarisingconstrual-of-existence) perspective 'reflecting the ${ }^{56}$ meaningfulness-andteleology contiguity of iterative-looping-narrations at any given registryworldview's/dimension's uninstitutionalised-threshold ${ }^{02}$ so-construed as uttered as of its specific notional procrypticism/notional disjointednessas-of- reference-of-thought ontological-performance ${ }^{2}<$ includingvirtue-as-ontology>' (as to the fact that with regards to human Beingdevelopment/ontological-framework-expansion-as-to-depth-ofontologising-development-as-infrastructure-of- meaningfulness-andteleology , institutional-development-as-to-social-function-development and living-development-as-to-personality-development psychologismic epistemic acutisation difficulty< < for, residualising the $<$ cumulating/recomposuring attendant-ontological-contiguity >- 
successive registry-worldviews/dimensions prior-institutionalisationthreshold-by-prospective-uninstitutionalised-threshold ${ }^{02}$ are 'successive teleological-inflections-_as-to-more-profound-nondisjointing-

<amplituding/formative-

epistemicity>totalising/circumscribing/delineating) of meaningfulness apriorising/axiomatising/referencing/intelligibilitysettingup/measuringins trumenting-conceptualisation for their existential-instantiations aposteriorising/logicising/deriving/intelligising/measuring' wherein the teleological-inflection-_as-to-more-profound-nondisjointing-

<amplitudingfformative-

epistemicity>totalising/circumscribing/delineating/ state of recurrentutter-uninstitutionalisation is 'preconverging/postconverging-dementatively/structurally/paradigmatically cognisant-and-integrative- $<$ asto-its-notional disjointedness-imbued-preconverging-or-dementing -

qualia-schema $>\quad$ of failing non-rulesapriorising/axiomatising/referencing-psychologism,-as-impulsiveoraccidented-or-random-mental-disposition', the teleological-inflection|as-to-more-profound-nondisjointing_< formativeepistemicity>totalising/circumscribing/delineating/ state of baseinstitutionalisation-ununiversalisation while 'adhering to rulemakingover-non-rules - apriorising/axiomatising/referencing-psychologism is preconverging/postconverging-dementatively/structurally/paradigmatically cognisant-and-integrative- $<$ asto-its-notional disjointedness-imbued-preconverging-or-dementing - 
qualia-schema> of failing universalisation-directed-rulemaking-overnonrules-apriorising/axiomatising/referencing-psychologism', the teleological-inflection-_as-to-more-profound-nondisjointing-

<amplituding/formative-

epistemicity>totalising/circumscribing/delineating) state of universalisation-non-positivism/medievalism while 'adhering to universalisation-directed-rulemaking-over-non-rulesapriorising/axiomatising/referencing-psychologism preconverging/postconverging-dementatively/structurally/paradigmatically cognisant-and-integrative-<asto-its-notional disjointedness-imbued-preconverging-or-dementing qualia-schema> of failing positivising/rational-empiricism-baseduniversalisation-directed-rulemaking-over-non-rulesapriorising/axiomatising/referencing-psychologism', and with the teleological-inflection-〈as-to-more-profound-nondisjointing-

<amplitudinglformativeepistemicity>totalising/circumscribing/delineating/ state of positivismprocrypticism while 'adhering to positivising/rational-empiricismbased-universalisation-directed-rulemaking-over-non-rulesapriorising/axiomatising/referencing-psychologism preconverging/postconverging-dementatively/structurally/paradigmatically cognisant-and-integrative-<asto-its-notional disjointedness-imbued-preconverging-or-dementing qualia-schema> of failing preempting — disjointedness-as-of- referenceof-thought,-as-to- ${ }^{\cdot 2}<$ emplitudinglformative-epistemicity>growth-or- 
conflatedness $/$ transvaluative-

rationalising/transepistemicity/anamnestic-residuality/spirit-

drivenness'-in-superseding-mere-formulaic-positivising/rationalempiricism-based-universalisation-directed-rulemaking-over-non-rulesapriorising/axiomatising/referencing-psychologism')

transcendentally- transcendentally-enabling-level-of ontological-good-faith-or-

enabling-level- authenticity $/$ objectification/desubjectification-as-objectification- $<$ as-to-

of ontological- ontological-faith-notion-or-ontological-fideism-imbued-

good-faith-or- underdetermination-of-motif-and-apriorising/axiomatising/referencing-

authenticity $\%$ obje as-so-being-as-of-existential-reality as antinihilism> ; construed as

ctification/desubje 'relative undermining of temporal-conjugating-emotional-

ctification-as- involvement/subjectification/epistemic totalising $\sim$ self-referencing-

objectification- syncretising-as-of-perceived-social-stake-contention-or-confliction for

$<$ as-to-ontological- intemporal dispensing-with-immediacy-for-relative-ontological-

faith-notion-or- completeness -by-reification/contemplative-distension

ontological-

fideism - imbued-

underdeterminatio

n-of-motif-and-

apriorising/axioma

tising/referencing-

as-so-being-as-of-

existential-reality

as antinihilism $>100$ 
transversality- $\quad$ transversality-<for-sublimating-existential-eventuating/denouement-$<$ for-sublimating- from 'thinking at first/pure predisposition preemptive of prospectiveexistential- disontologising/subontologising'-as-of-prospectively-disambiguatedeventuating/denou affirmed-and-unaffirmed-'motif-andement,-from- apriorising/axiomatising/referencing'>-or-mutually-transversethinking-at- unintelligibility-or-logical-incongruence-<as-to-affirmation-of-relativefirst/pure- ontological-completeness - $\quad$ postconverging-or-dialectical-thinking predisposition- $\quad{ }^{56}$ meaningfulness-and-teleology -over-unaffirmation-of-relativepreemptive-of $\quad$ ontological-incompleteness ${ }^{8}$-preconverging-or-dementing prospective- $\quad{ }^{56}$ meaningfulness-and-teleology $>: \quad$ transversality $-<$ for-sublimatingdisontologising/su existential-eventuating/denouement, from 'thinking at first/purebontologising' predisposition preemptive of prospectiveas-of- $\quad$ disontologising/subentologising' as-of-prospectively-disambiguatedprospectively- affirmed-and-unaffirmed-'motif-anddisambiguated-_ apriorising/axiomatising/referencing'> involves the epistemic construct of affirmed-and- $\quad{ }^{56}$ meaningfulness-and-teleology as of 'existence-potency ${ }^{39} \sim$ sublimatingunaffirmed-'motif- nascence,-disclosed-from-prospective-epistemic-digression andsupererogatory acuity/perspicacity/astuteness/edginess/incisiveness-ofapriorising/axioma tising/referencing' trumenting-for-conceptualisation' construed as knowledge$>101$ reification gesturing-and-accounting-of-epistemic-phenomenalism<in-prospective psychologismic apriorising/axiomatising/referencing\{of-'prospectively implicited attendant-ontologicalcontiguity ' educedexistentialising/contextualising/textualising_intelligibility/epistemicity/re 
flexivity-contiguity-<imbued-notional cogency > ' \}-conflatedness

in \{preconverging ment by\} postconverging entailment $>$, and so over a human ordinary <amplitudingfformative> wooden-language-fimbuedaveraging-of-thought-<as-to-leveling/ressentiment/closed-construct-ofmeaningfulness-and-teleology -as-of-'nondescript/ignorable-void 'with-regards-to-prospective-apriorising-implications $>$ ) mental-reflex to construe meaningfulness-and-teleology as of 'human-subpotency <preconverging 'motif-and-apriorising/axiomatising/referencing'entailing >-existentialising-enframing/imprintedness-〈as-to- historicitytracing-in-presencing-hyperrealisation/hyperreal-transposition) pseudo-edginess/pseudo-incisiveness of its secondnatured institutionalisation uninstitutionalised-threshold 'thus exposing such meaningfulness-and-teleology to human <amplitudingfformativeepistemicity>totalising self-referencing-

syncretising/circularity/interiorising/akrasiatic-drag ${ }^{34}$ which is exactly what needs to be superseded as of human developing selfconsciousness/construction-of-the-Self for prospective transcendenceand-sublimity/sublimation/supererogatory de-mentativity to arise as of transversality-<for-sublimating-existential-eventuating/denouement-from 'thinking at firstlpure predisposition preemptive of prospective disontologising/subontologising'-as-of-prospectively-disambiguatedaffirmed-and-unaffirmed-'motif-and-

apriorising/axiomatising/referencing'> induced reasoningthrough/messianic-reasoning, such that the notion of prospective human value and aspiration beyond the 'given registry-worldview/dimension 
reference-of-thought reproducibility - mathesis/motif/thrownnessdisposition,-as-reproducibility-of-aestheticisation that underlies its underpinning-suprasocial-construct and

$<$ form/virtualities/dereification/akrasiatic-drag/denatured/preconvergingor-dementing -narratives-of-the- reference-of-thought-categoricalimperatives/axioms/registry-teleology ')' doesn't exist and as to the consequent susceptibility to sophistic/pedantic manipulation of such presencing-absolutising-identitive-constitutedness humansubpotency epistemic-or-notional projective-perspective of social-stakecontention-or-confliction and this further explains why prospective reasoning-through/messianic-reasoning has ever always been as of a 'presencing-absolutising-identitive-constitutedness

consummated/forfeiting posture' in this respect in order to then outrightly commit to prospective transcendence-andsublimity/sublimation/supererogatory-de-mentativity value-aspiration reflecting the fact that the given human-subpotencyaporia/undecidability/dilemma/oughtindeterminacy/deficiency/limitation/constraint—imbued'notional firstnaturedness-formativeness < as to eventualising inkling drive or seeding misprising> temporal-to-intemporal-dispositions$<$ so-construed-as-from-perspective-ontological-

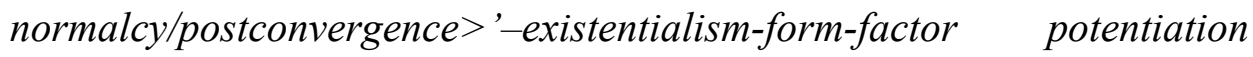
construed as 'human-subpotency convergence to existence' is beyond the 'averaging of notional firstnaturedness-formativeness-as to- 
eventualising inkling drive or seeding misprising $>$ temporal-tointemporal-dispositions-<so-construed-as-from-perspective-ontologicalnormalcy/postconvergence ${ }^{>}$' or any secondnatured institutionalisation underpinning-suprasocial-construct but is rather as of 'human intemporal individuation solipsistic/intersolipsistic instigation' that is not fixated on the previous two for such requisite solipsistic/intersolipsistic instigation; $₫$ transversality-<for-sublimating-existential-eventuating/denouement-from 'thinking at first/pure predisposition preemptive of prospective disontologising/subontologising' as-of-prospectively-disambiguatedaffirmed-and-unaffirmed- 'motif-and-

apriorising/axiomatising/referencing'> equally reflects as of its implied 'existence-potency $\sim$ sublimating-nascence,-disclosed-from-prospectiveepistemic-digression supererogatory acuity/perspicacity/astuteness/edginess/incisiveness-ofapriorising/axiomatising/referencing/intelligibilitysettingup/measuringins trumenting-for-conceptualisation' a foregrounding_entailment-<insuccession-of-profound-supererogation >-(postconverging-narrowingdown sublimation-as-to- 'existence-as-sublimatingwithdrawal/unenframing/re-ontologising,-elicited-from-prospectiveprofound-supererogation '-in-reflecting- 'immanent relativeunreflexivity/relative reflexivity ontological-contiguity ';-as-operativenotional deprocrypticism) epistemic-disposition over a pseudoedginess/pseudo-incisiveness disparateness-of-conceptualisation$<$ unforegrounding-ment,-failing-prospectively-to-reflect'immanent relative unreflexivity/relative reflexivity-ontological- 
contiguity '> epistemic-disposition wherein the appropriate perspective of subject-matters/domains-of-study elucidation/knowledgereification $\sim$ gesturing-and-accounting-of-epistemic-phenomenalism$<$ in-prospective psychologismic $\sim$ apriorising/axiomatising/referencing\{of- prospectively_implicited_attendant-ontologicalcontiguity ' reducedexistentialising/contextualising/textualising_intelligibility/epistemicity/re flexivity-contiguity-<imbued-notional cogency>' \}'-conflatedness in \{preconverging ment by\} postconverging entailment> reflects their respective epistemic-conception phenomenal/manifest $\sim$ subpotencies-_intransitive-conflatedness -reflexivity,-in-the-full-potency-of-

existence's sublimating-nascence) as to overall reifying-andempowering-reflexivity-of-ecstatic-existence-aspanintelligibility - (existentially-imbued-and-educing$<$ fepistemic totalising 'shermeneutically/textually/reprojectingly/supererogatingly/zeroin gly/re acutingly, -\{decompulsing ${ }^{2}$ delinearity for-cogency $\geq$ epistemicperspective-of-projective/reprojective-aestheticising-re-motif-and-reapriorising/re-axiomatising/re-referencing conceptualisation,-as hereinspecifically relevant to human-subpotency); $₫ \quad$ transversality-<forsublimating-existential-eventuating/denouement, from 'thinking at first/pure predisposition preemptive of prospective disontologising/subontologising' as-of-prospectively-disambiguatedaffirmed-and-unaffirmed- 'motif-and-

apriorising/axiomatising/referencing'> further speaks to the fact of 
existence-potency $\sim$ sublimating-nascence,-disclosed-from-prospectiveepistemic-digression supererogatory acuity/perspicacity/astuteness/edginess/incisiveness-ofapriorising/axiomatising/referencing/intelligibilitysettingup/measuringins trumenting -for-conceptualisation perspective supererogating \{'affirmation/projection/assertion/notional $\sim$ selfdistantiation/dueness-validating-logicising/suitablemeasuringinstrument-validating-measuring-<as-to-postconverging-ordialectical-thinking -apriorising-psychologism> of ${ }^{56}$ meaningfulnessand-teleology as of prospective relative-ontological-completeness ${ }^{87}$, over the 'unaffirmation/deprojection/deassertion/epistemicdecadence/undueness-invalidating-logicising/unsuitablemeasuringinstrument-invalidating-measuring-<as-to-preconverging-ordementing -apriorising-psychologism> of ${ }^{56}$ meaningfulness-andteleology as of prior relative-ontological-incompleteness '?, wherein for instance the underlying misinformation/misanalysis/misrepresentation about postmodern-thought as of its prospective relative-ontologicalcompleteness arises because of its assessment from the ontologicallyflawed perspective of naïve identitive mere-formulaic positivism/rationalempiricism manifestation of procrypticism-or-disjointedness-as-of${ }^{3}$ reference-of-thought as rather in prior relative-ontologicalincompleteness ${ }^{8}$ with further susceptibility to sophistry of intellectual falsehood and muddlement as of institutional-being-and-craft, just as assessing budding-positivism/rational-empiricism thought from medieval scholasticism perspective will induce a ridiculous and ontologically- 
flawed apriorising/axiomatising/referencing outcome about buddingpositivism which was further susceptible to medieval pedantic sophistry as of institutional-being-and-craft; $\uparrow$ furthermore, transversality-<forsublimating-existential-eventuating/denouement, from 'thinking at first/pure predisposition preemptive of prospectivedisontologising/subontologising' as-of-prospectively-disambiguatedaffirmed-and-unaffirmed- 'motif-andapriorising/axiomatising/referencing'> as of its implied 'existencepotency $\sim$ sublimating-nascence,-disclosed-from-prospective-epistemicdigression supererogatory acuity/perspicacity/astuteness/edginess/incisiveness-ofapriorising/axiomatising/referencing/intelligibilitysettingup/measuringins trumenting-for-conceptualisation, for aetiologisation/ontologicalescalation-<ontologicalveridicality_commitment/otherliness_transcending/compulsionsencumbered_transcending $>$ entails that 'appropriateness/soundness of human ontological-performance ${ }^{72}<$ including-virtue-asontology>/morality/ethics/justice/etc. and hence value-and-aspirationalconstruct' is 'precedingly and absolutely determined rather as of relativeontological-completeness ${ }^{87}$ relative-ontological-incompleteness <amplituding/formative-epistemicity $>$ causality $\sim$ as-to-projectivetotalitative-implications-of-prospective- nonpresencing,-forexplicating felative unreflexivity/relative reflexivity-ontologicalcontiguity wherein for instance the positivist relative-ontologicalcompleteness value-reference as walking into the forest to retrieve a plant 
cure overrides as of the <amplitudingfformativeepistemicity $>$ causality $\sim$ as-to-projective-totalitative-implications-ofprospective- nonpresencing,-for-explicating relative unreflexivity/relative reflexivity ontological-contiguity of 'existencepotency $\sim$ sublimating-nascence,-disclosed-from-prospective-epistemicdigression supererogatory acuity/perspicacity/astuteness/edginess/incisiveness-ofapriorising/axiomatising/referencing/intelligibilitysettingup/measuringins trumenting -for-conceptualisation' the animistic social-setup 'evil forest' value-reference as of its relative-ontological-incompleteness and the same applies prospectively with notional deprocrypticism relativeontological-completeness $\quad$ 'preempting—disjointedness-as-of'reference-of-thought' value-reference over our positivismprocrypticism relative-ontological-incompleteness value-reference even if such a contemplation is rather beyond-the-consciousnessawareness-teleology - <of-preconverging-existential-extrication-as-ofexistential-unthought> as the incoherence here will rather be to egotistically and sophistically imply that the-very-same fundamental relative unreflexivity/relative reflexivity ontological-contiguity $\sim$ of-thehuman-institutionalisation-process as of 'true-ontology-as-of-Beingdevelopment/ontological-framework-expansion-as-to-depth-ofontologising-development-as-infrastructure-of- meaningfulness-andteleology ' doesn't apply to us; $\boldsymbol{\uparrow}$ ultimately, transversality-<forsublimating-existential-eventuating/denouement, from 'thinking at first/pure predisposition preemptive of prospective 
disontologising/subontologising'-as-of-prospectively-disambiguatedaffirmed-and-unaffirmed-'motif-and-

apriorising/axiomatising/referencing'> further entails that the inherent incompatible and contrastive <amplituding/formativeepistemicity $>$ causality $\sim$ as-to-projective-totalitative-implications-ofprospective- nonpresencing,-for-explicating felative-

'supererogatory acuity/perspicacity/astuteness/edginess/incisiveness-ofapriorising/axiomatising/referencing/intelligibilitysettingup/measuringins trumenting-for-conceptualisation as to existencepotency $\sim$ sublimating-nascence,-disclosed-from-prospective-epistemicdigression implied prospective relative-ontological-completeness opened-construct-of- ${ }^{5}$ meaningfulness-and-teleology in its dispensingwith-immediacy-for-relative-ontological-completeness -byreification/contemplative-distension (as of human self-surpassingexistentialism-form-factor,-in-overcoming- 'notional collateralisingbeholdening-protohumanity'-to- 'attain-sublimating-humanity'-as-toexistence-potency $\sim$ sublimating-nascence,-disclosed-from-prospectiveepistemic-digression to supersede human temporality/shortness <amplitudingfformative> wooden-language-fimbued-averaging-ofthought-<as-to-leveling/ressentiment/closed-construct-ofmeaningfulness-and-teleology -as-of-'nondescript/ignorable-void 'with-regards-to-prospective-apriorising-implications $>$ )) as enabling prospective transcendence-and-sublimity/sublimation/supererogatory-dementativity' and 
'apriorising/axiomatising/referencing/intelligibilitysettingup/measuringin strumenting in pseudo-edginess/pseudo-incisiveness as of humansubpotency implied prior relative-ontological-incompleteness $<$ inglingling $>$ wooden-language-fimbued-averaging-ofthought-<as-to-leveling/ressentiment/closed-construct-ofmeaningfulness-and-teleology -as-of-'nondescript/ignorable-void 'with-regards-to-prospective-apriorising-implications $>>$ and as it is reinforced with sophistic/pedantic institutional-being-and-craft in preconverging existential-extrication-as-of-existential-unthought', means that human and social transcendence-andsublimity/sublimation/supererogatory-de-mentativity while critically instigated as from 'human dimensionality-of-sublimating < amplituding/formative $>$ supererogatory-de-mentativeness/epistemicgrowth-or-conflatedness /transvaluativerationalising/transepistemicity/anamnestic-residuality/spirit-drivennessequalisation) ontological-faith-notion-or-ontological-fideism-imbuedunderdetermination-of-motif-and-apriorising/axiomatising/referencingas-so-being-as-of-existential-reality reasoning-through/messianicreasoning epistemic-ricochettingly/transepistemically' is more effectively and existentially<disontogising/re on achieved rather as of 'constraining positive-opportunism-of-socialfunctioning-and-accordance 'that is socially elicited as of the underlying supposedly coherent ontological-commitment $-<$ implied-selfassuredness-of-ontological-good-faith/authenticity postconverging-dementating/structuring/paradigming -as-being-as-of-existential-reality> 
as of more profound <amplituding/formative-epistemicity $>$ causality $\sim$ asto-projective-totalitative-implications-of-prospective- nonpresencing,for-explicating relative unreflexivity/relative reflexivity ontologicalcontiguity validation as to existence-potency $\sim$ sublimating-nascence,disclosed-from-prospective-epistemic-digression in inducing secondnatured institutionalisation and prospective underpinningsuprasocial-construct

uninstitutionalised- uninstitutionalised/unintemporalised/temporalthreshold $^{102}$ solipsistic/unrecomposuring/animality-threshold-of-intemporalpreservation-entropy-or-contiguity-or-ontological-preservation soconstrued-as-of-the uninstitutionalised-threshold-ofapriorising/axiomatising/referencing as to reflected-temporalmeaningfulness-and-teleology -in <amplitudinglformativeepistemicity>totalising $\sim$ self-referencingsyncretising/circularity/interiorising/akrasiatic-drag ${ }^{34}$, and so as <amplituding/formative> wooden-language-fimbued-temporal-mereform/virtualities/dereification/akrasiatic-drag/denatured/preconvergingor-dementing -narratives-of-the- reference-of-thought-categoricalimperatives/axioms/registry-teleology ), wherein the institutionalisingmathesis/motif/thrownness-disposition attains its institutionalising limits as of human-subpotency relative to existence's full-potency of sublimation as so-construed from perspective ontologicalnormlacy/postconvergence; $\uparrow$ and-so-construed-as-from-the-instigatingintemporal-ontological-faith-notion-or-ontological-fideism-imbued- 
underdetermination-of-motif-and-apriorising/axiomatising/referencing-

as-so-being-as-of-existential-reality,-recurrent-shot-or-reprojection-forprospective-relative-ontological-completeness ${ }^{8}$-with-respect-to-the'parrhesiastic seeding-promise-of-human-subpotency ontologicalperformance ${ }^{72}<$ including-virtue-as

ontology >/morality/ethics/justice/etc. correspondence-with-the-fullpotency-of-existence's $\sim$ Sublimating-nascence-as-of-itscoherence/contiguity'

${ }^{103}$ universal/univer when expressed specifically herein universal/universalised/universalisingsalised/universalisi <as-to-universalisation > refers to the specific universalisation registryng worldview/dimension as to its 'universalising apriorising/axiomatising/referencing-rules of entailing<amplituding/formative-epistemicity>totalising meaningfulness-and-teleology' while when expressed herein in a general sense universal/universalised/universalising actually and precisely refers to 'totalising-entailing of implied knowledgereification gesturing-and-accounting-of-epistemic-phenomenalism$<$ in-prospective psychologismic $\sim$ apriorising/axiomatising/referencing\{of- prospectively implicited_attendant-ontologicalcontiguity ' educed-

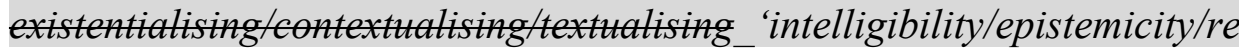
flexivity-contiguity-<imbued-notional $\sim$ cogency $>^{\prime}$, \}-conflatedness in \{preconverging ment by\} postconverging entailment $>$ ' for instance in the sense that mathematics is universal means mathematics is totalisingly- 
entailing (with this general sense applying with regards to any given registry-worldview/dimension as to its given 'entailing<amplitudingfformative-epistemicity>totalising in-relative-ontologicalcompleteness apriorising/axiomatising/referencing-rules' and as further reflecting the implication that registry-worldviews/dimensions of relativeontological-completeness are of more profound ontologically totalisingentailment apriorising/axiomatising/referencing-rules as so implied as from 'non-rules totalising-entailing, rulemaking-over-non-rules totalisingentailing, universalisation-directed-rulemaking-over-non-rules totalisingentailing, $\quad$ positivising/rational-empiricism-based-universalisationdirected-rulemaking-over-non-rules totalising-entailing, and preempting —disjointedness-as-of- reference-of-thought,-as-to-

'32 emplituding/formative-epistemicity>growth-orconflatedness $/$ transvaluativerationalising/transepistemicity/anamnestic-residuality/spiritdrivenness'-in-superseding-mere-formulaic-positivising/rationalempiricism-based-universalisation-directed-rulemaking-over-non-rules totalising-entailing', and so-construed as of their respective foregrounding_entailment-<in-succession-of-profoundsupererogation $>_{-}$(postconverging-narrowing-down $\sim$ sublimation-as-to'existence - as-sublimating-withdrawal/unenframing/re-ontologising,elicited-from-prospective-profound-supererogation '-in-reflecting'immanent relative unreflexivity/relative reflexivity ontologicalcontiguity ';-as-operative-notional (deprocrypticism)'), and in this regards we can appreciate how the very implications of say universal 
human rights supererogatorily becomes more and more profound as from say the Socratic-philosophers (even as slavery, class-seclusion and femaleseclusion was prevalent as to warped collateralisation), buddingpositivists (even as in-many-ways the practices of serfdom/slavery, socialclass discrimination and female-discrimination were equally prevalent as to preclusive collateralisation) and today's supposedly universal conception of human rights (even as it is marked by occlusive collateralisation of other peoples, cultures and nations as well as gender and age occlusive collateralising biases); actually the specific sense and general sense are thus linked on the basis that both imply totalisingentailing with the specific sense speaking of totalising-entailing as to the specific universalisation registry-worldview/dimension 'when mankind initially consciously cognised that the profoundness of ${ }^{5}$ meaningfulnessand-teleology should be totalising-entailing but without necessarily differentiating such a conception of totalising-entailing between mythological and positivistic/rational-empirist totalising-entailing with both construed as universal ${ }^{5}$ meaningfulness-and-teleology', while the general sense of universal implicitly captures and exactifies/precises the conception of totalising-entailing in terms of 'entailing$<$ amplitudingfformative-epistemicity >totalising $\sim$ in-relative-ontologicalcompleteness $^{87}$ as reflecting the implication of human limited-mentationcapacity-deepening -as-subjecting limitedness/human-subpotency to-

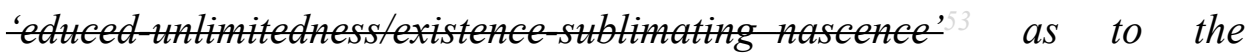
'notionalisation/notional-conception/amplituding of totalising-entailing so-reflected by the relative unreflexivity/relative reflexivity-ontological- 
contiguity $\sim$ of-the-human-institutionalisation-process (along the same lines as notional deprocrypticism) thus amplificatorily rendering the conception of totalising-entailing (as of notionally universal) as more 'profoundly construed as from perspective relative-ontologicalcompleteness 8 as of the ontological-normalcy/postconvergence of existence/intrinsic-reality' so-underlied by perspective 'nondisjointing totalising-entailing' or deprocrypticism

universaluniversal-transparency-_transparency-of-totalising-entailing,-as-totransparency $^{104}$ entailing-<amplitudingfformative-epistemicity $>$ totalising $\sim$ in-relative〈transparency-of- ontological-completeness 〉 or understanding-astotalising<amplitudinglformative-epistemicity >causality $\sim$ as-to-projective-

entailing,-as-tototalitative-implications-of-prospective- nonpresencing,-forentailingexplicating felative unreflexivity/relative reflexivity ontological$<$ amplituding/form contiguity -of-underlying-existential-phenomena, and so as to perspective ativeontological-normalcy/postconvergence veridical ${ }^{56}$ meaningfulness-andepistemicity>totali teleology for social-functioning-and-accordance-as-of-social-stakesing in-relative- contention-or-confliction-(for-undermining-social-incoherency-byontologicalconstraining transcendentally-enabling-level-of ontological-good-faithcompleteness > or-authenticity /objectification/desubjectification-as-objectification-<asto-ontological-faith-notion-or-ontological-fideism -imbuedunderdetermination-of-motif-and-apriorising/axiomatising/referencingas-so-being-as-of-existential-reality as antinihilism> J'

vices-andvices-and-impediments-as-of- reference-of-thought imbued impediments $^{105} \quad$ preconverging/postconverging-de-mentative/structural/paradigmatic- 
defect-of-ontological-performance ${ }^{72}<$ including-virtue-as-

ontology>/morality/ethics/justice/etc. (with regards to human livingdevelopment-as-to-personality-development, institutional-developmentas-to-social-function-development and as so-ultimately preconverginglyde-mentated/structured/paradigmed as of underlying Beingdevelopment/ontological-framework-expansion-as-to-depth-ofontologising-development-as-infrastructure-of- meaningfulness-andteleology ) 
There is a common word that already exists that best describes what a psychopath is philosophically-speaking. It is a French word that doesn't exactly exist in English. The word is 'cinglé' and is better translated in English as 'slanted mind' (in contrast to the straightness/candor/organic-comprehension-thinking of a 'conviction-as-to-profoundsupererogation predisposed human mind' so-reflected as prelogism ${ }^{78}$-as-of-conviction,-inprofound-supererogation $-<$ existentially-veridical-'attendant-intradimensionalapriorising/axiomatising/referencing'-logical-dueness-precedes-disontologising-logicaloutcome-arrived-at $>$ and so-construed as of human candidity/candour-capacity. It should equally be noted that sometimes the word cinglé is used intermittently with deranged (dérangé) which is a more general word that does not capture the socially-functional-and-accordant ${ }^{93}$ phenomenal specificity that is of relevance herein. In other words, the 'cinglé' perceives meaning as a 'hollow mimicking form in-of-itself that determines others behaviour' in contrast to the normal-as-ofcandidity/candour-capacity human relation to meaning as of essence or supplanting-convictionas-to-profound-supererogation -of-'attendant-intradimensional'-postconverging/dialecticalthinking -apriorising-psychologism or prelogism ${ }^{78}$ we abide by (and so, even in the case of 'poor or bad supplanting-conviction-as-to-profound-supererogation - of-'attendantintradimensional'-postconverging/dialectical-thinking -apriorising-psychologism' or bad prelogism $^{78}$ where the bad logic of the prelogism ${ }^{78}$-as-of-conviction,-in-profoundsupererogation $-<$ existentially-veridical-'attendant-intradimensionalapriorising/axiomatising/referencing'-logical-dueness-precedes-disontologising-logicaloutcome-arrived-at $>$ mind operates by an ad-hoc and circumspect exaggeration or omission). In other words, the psychopath manifests postlogism -as-of- compulsingnonconviction/madeupness/bottomlining-〈‘ $<$ decontextualising/de-existentialising $\sim$ ofattendant-intradimensional-apriorising/axiomatising/referencing $>$-induced-disontologising'-ofthe-'attendant-intradimensional-ontologising'-imbued- 
$<$ contextualising/existentialising attendant-ontological-contiguity $>$;-in-shallow-

supererogation -<as-to-disontologising-perverted-outcome-sought-precedes-existentially-

veridical-'attendant-intradimensional-apriorising/axiomatising/referencing'-logical-dueness $>$ )

by its ${ }^{83}$ reference-of-thought- ${ }^{8}$ devolving-as-of-instantiative-context $-{ }^{5}$ meaningfulness-andteleology ${ }^{9}$ construed as 'how can a perverted sought after outcome be obtained with an interlocutor or interlocutors with respect to a targeted end-goal or targeted individual by falsely projecting hollow-abstract logic notwithstanding that it is existentially-<disontologising/reentologising apereticism $\geqslant$ unreal or it is faked or it is opportunistically raised or raised out-ofcontext (existential-decontextualised-transposition)', i.e. meaning-as-form or pathologically/compulsively hollow-constituting-<as-disjointed-misappropriation-ofmeaningfulness-and-failing-intemporal-preservation>, contrasted to the normal prelogism ${ }^{78}$-asof-conviction,-in-profound-supererogation $-<$ existentially-veridical-'attendant-

\section{intradimensional-apriorising/axiomatising/referencing'-logical-dueness-precedes-}

disontologising-logical-outcome-arrived-at> minds construed as 'what does the veridical logical-processing-or-logical-implicitation—supposedly-

apriorising/axiomatising/referencing-in-conviction-as-to-profound-supererogation ${ }^{6}$ of a given existential-<disontologising/re-ontologising aporeticism $>$ situation intrinsically imply as relevant and sound outcome', i.e. meaning-as-ontologically-veridical/in-conviction-as-toprofound-supererogation, whether thereafter the ${ }^{54}$ logical-processing-or-logicalimplicitation - supposedly-apriorising-in-conviction-as-to-profound-supererogation is rightly or wrongly assumed). Hence prelogism -as-of-conviction,-in-profound-supererogation <existentially-veridical-'attendant-intradimensional-apriorising/axiomatising/referencing'logical-dueness-precedes-disontologising-logical-outcome-arrived-at $>$ is all about the appropriateness of logic without any implication/questioning about any issue with the reference-of-thought on which ${ }^{54}$ logical-processing-or-logical-implicitation-supposedly- 
apriorising-in-conviction-as-to-profound-supererogation is based, and thus the idea of reengaging is valid on the basis that the logical-processing-or-logical-implicitationsupposedly-apriorising-in-conviction-as-to-profound-supererogation can be well performed subsequently despite an initial failure or possible initial failures. Whereas with postlogism 77 -asof- compulsing-nonconviction/madeupness/bottomlining-〈'<decontextualising/deexistentialising $\sim$ of-attendant-intradimensional-apriorising/axiomatising/referencing $>$-induceddisontologising'-of-the-'attendant-intradimensional-ontologising'-imbued$<$ contextualising/existentialising attendant-ontological-contiguity $>$;-in-shallowsupererogation -<as-to-disontologising-perverted-outcome-sought-precedes-existentiallyveridical-'attendant-intradimensional-apriorising/axiomatising/referencing'-logical-dueness $>$ > this essentially has to do not with an issue of ${ }^{5}$ logical-processing-or-logical-implicitationsupposedly-apriorising-in-conviction-as-to-profound-supererogation but rather an issue of perversion-of- ${ }^{3}$ reference-of-thought- $<$ as-preconverginglyapriorising/axiomatising/referencing-in-nonconviction/madeupness/bottomlining-as-toshallow-supererogation >, as $\quad{ }^{54}$ logical-processing-or-logical-implicitation-supposedlyapriorising-in-conviction-as-to-profound-supererogation is on the basis of a sound referenceof-thought (non- ${ }^{7}$ perversion-of- ${ }^{3}$ reference-of-thought) such that fundamentally the "notion of the dueness for ${ }^{5}$ logical-processing-or-logical-implicitation-supposedly-apriorising-inconviction-as-to-profound-supererogation , is ontologically jeopardised by the inherent perversion-of- ${ }^{3}$ reference-of-thought-<as-preconverginglyapriorising/axiomatising/referencing-in-nonconviction/madeupness/bottomlining-as-toshallow-supererogation $>$ as 'first-order perversion, out of 'implicited_attendant-ontologicalcontiguity $^{67}$, educedexistentialising/contextualising/textualising_intelligibility/epistemicity/reflexivity_contiguity$<$ imbued-notional $\sim$ cogency $>,,-<$ reifying-or-elucidating-of-prospective-relative-ontological- 
apriorising ${ }^{83}$ reference-of-thought/apriorising-registry_elements which are denaturing of

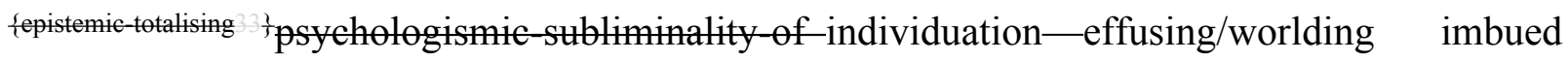
logical-dueness-or-scape-or-frame, profile-or-stature, presumptuousness-or-arrogation, assumptions, value-reference and teleology . Further to this is the derived second-order level deception as of wrongly implied 54 logical-processing-or-logical-implicitation—supposedlyapriorising-in-conviction-as-to-profound-supererogation thereof, as of infinite deception possibilities from this faulty-mentation-procedure-deception-or-urge ${ }^{13}$ arising where the implied first-order perversion-of- ${ }^{8}$ reference-of-thought- $<$ as-preconverginglyapriorising/axiomatising/referencing-in-nonconviction/madeupness/bottomlining-as-toshallow-supererogation $>$ is wrongly acquiesced to as appropriateness-of- reference-ofthought-as-of-conflatedness ${ }^{13}$ thus wrongly implying that logical-dueness arises for logical engagement with interlocutors; and so in contrast to the infinite possibilities of sound ${ }^{54}$ logicalprocessing-or-logical-implicitation—supposedly-apriorising-in-conviction-as-to-profound-

supererogation from non- ${ }^{7}$ perversion-of- ${ }^{8}$ reference-of-thought. Hence postlogism 77 is actually a usurpation/arrogation of the prelogism -as-of-conviction,-in-profoundsupererogation -<existentially-veridical-'attendant-intradimensionalapriorising/axiomatising/referencing'-logical-dueness-precedes-disontologising-logicaloutcome-arrived-at $>$ mentation reflex where social ${ }^{103}$ universal-transparency-〈transparency-oftotalising-entailing,-as-to-entailing-<amplituding/formative-epistemicity $>$ totalising $\sim$ inrelative-ontological-completeness > of apriorising- ${ }^{8}$ reference-of-thought/apriorisingregistry_elements is not-available/obscured as of lack of insight on 'implicited_attendantontological-contiguity ${ }^{67} \sim$ educedexistentialising/contextualising/textalising_'intelligibility/epistemicity/reflexivity_contiguity$<$ imbued-notional $\sim$ cogency $>,{ }^{\prime},-<$ reifying-or-elucidating-of-prospective-relative-ontological- 
completeness -of- reference-of-thought- devolving-as-of-instantiative-context>; with the result that with respect to the ${ }^{83}$ reference-of-thought, postlogism 77 induces as of ontologicalnormalcy/postconvergence epistemic-or-notional projective-perspective, a teleologicallydegraded-as-preconverging-or-dementing -apriorising-psychologism differentiation of existential-<disontologising/re-ontologising aporeticism $>{ }^{56}$ meaningfulness-and-teleology ${ }^{9}$, unlike prelogism ${ }^{78}$ which 'induces as of ontological-normalcy/postconvergence perspective, an elevated-as-sound-thinking differentiation of existential-<disontologising/re-ontologising aporeticism $>{ }^{56}$ meaningfulness-and-teleology'? The postlogic disposition is associated pathologically with the psychopathic character as a faulty-mentation-procedure-deception-orurge ${ }^{43}$ with respect to perceived social-stake-contention-or-confliction but can equally extend ad-hocly or more profoundly as a manifestation of conjugated-postlogism 77 preconverging-ordementing -integration (due to psychopathic/postlogism 77 induced social loss-of-awareness of the social ${ }^{103}$ universal-transparency ${ }^{104}$-〈transparency-of-totalising-entailing,-as-to-entailing$<$ amplituding/formative-epistemicity $>$ totalising in-relative-ontological-completeness $\rangle)$

where it elicits temporal-dispositions of ignorance/affordability/opportunism/exacerbation/social-chainism-or-social-discomfiture-ornegative-social-aggregation/temporal-enculturation-or-temporal-endemisation in situations of social-stake-contention-or-confliction.

BEGINNING OF DIGRESSION (ON OVERALL CONCEPTION OF THE FULL

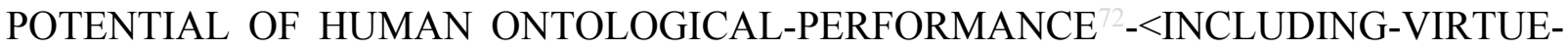
AS-ONTOLOGY>)

[Fundamentally thus the issue of postlogism associated with psychopathy is preconverging/postconverging-de-mentatively/structurally/paradigmatically related to human prelogism $^{78}$ underlined by candidity/candour-capacity as to relative-unreflexivity/relativereflexivity - ontological-contiguity ${ }^{67}$ in notional $\sim$ symmetrisation- $<$ as-to-symmetrisation-by- 
desymmetrisation,-in-reflecting-postconverging-or-dialectical-thinking ${ }^{2}$-by-preconvergingor-dementing 20 perspectives-of-human- ${ }^{5}$ meaningfulness-and-teleology $>$; and so as the overall backdrop of human ${ }^{56}$ meaningfulness-and-teleology ${ }^{9}$ ontological-performance ${ }^{72}$ <including-virtue-as-ontology $>$ /morality/ethics/justice/etc. appraisal which elucidation underlines the more profound human fepistemictotalising $3{ }^{3}$ hermeneutic/textuality/reprojecting/supererogating/zeroing/re-acuting,$\{$ \{lecompulsing delinearity for-cogency psychology as to the elucidation of overall human becoming in existence implications of human ${ }^{5}$ meaningfulness-and-teleology ${ }^{9}$ ontologicalperformance ${ }^{2}$-<including-virtue-as-ontology $>$. 'Candidity/Candour-capacity' as such involves two-levels of construal with the first-level being with regards to 'overall relativeunreflexivity/relative-reflexivity - ontological-contiguity ${ }^{77}$ of variance as difference-inkind/difference-in-aposteriorising-or-logicising ${ }^{23}$ as to the ontological-performance ${ }^{72}$ <including-virtue-as-ontology $>$ /morality/ethics/justice/etc. of ${ }^{56}$ meaningfulness-andteleology ${ }^{9}$, in the sense that at our prior-institutionalisation-threshold-by-prospectiveuninstitutionalised-threshold ${ }^{102}$ of positivism- ${ }^{80}$ procrypticism ${ }^{83}$ reference-of-thought-andreference-of-thought- ${ }^{84}$ devolving- ${ }^{5}$ meaningfulness-and-teleology ${ }^{9}$ various degrees of temporal-to-intemporal individuations ontological-performance ${ }^{72}-<_{\text {including-virtue-as- }}$ ontology $>$ /morality/ethics/justice/etc. varyingly-uphold-or-fail candidity/candour-capacity as of difference-in-kind/difference-in-aposteriorising-or-logicising ${ }^{23}$ (so-construed as within the positivism- ${ }^{80}$ procrypticism $\quad<$ amplituding/formative-epistemicity $>$ totalising intervalist-ascategorising_-'implicited_attendant-ontological-contiguity ${ }^{67}$ ' educedexistentialising/contextualising/textualising_intelligibility/epistemicity/reflexivity-contiguity$<$ imbued-notional cogency>' ;-phenomenal-abstractiveness-of-presencing-in-'occlusiveconsciousness'-enablingapriorising/axiomatising/referencing/intelligibilitysettingup/measuringinstrumenting-for- 
operant-or-incidenting-predicative-insights-of 'implicited_attendant_ontologicalcontiguity ${ }^{67} \sim$ educed-

existentialising/contextualising/textualising_'intelligibility/epistemicity/reflexivity-contiguity$<$ imbued-notional $\sim$ cogency $>,{ }^{\prime},-<$ reifying-or-elucidating-of-prospective-relative-ontologicalcompleteness -of- reference-of-thought- devolving-as-of-instantiative-context $>$

categorisation construal/conceptualisation). The notion of 'candidity/candour-capacity' is more fully/completely construed/conceptualised at the second-level as from the ontologicalnormalcy/postconvergence epistemic-projection perspectivation underlying notional ${ }^{18}$ deprocrypticism or $<$ amplituding/formative $>$ notional $\sim$ preempting - disjointednessas-of- reference-of-thought in reflection of overall human ontological-performance ${ }^{72}$ $<$ including-virtue-as-ontology $>/$ morality/ethics/justice/etc. as to the overall relativeunreflexivity/relative-reflexivity — ontological-contiguity ${ }^{67} \sim$ of-the-human-institutionalisationprocess $^{68}$ (so-construed as of the notional deprocrypticism <amplituding/formativeepistemicity $>$ totalising $\sim$ ratiocontiguity/ratiocination-as-referentialism—'implicited_attendant ontological-contiguity ${ }^{67}$; educedexistentialising/contextualising/textualising_intelligibility/epistemicity/reflexivity_contiguity$<$ imbued-notional cogency>' ;-phenomenal-abstractiveness-of-presencing-in-'protensiveconsciousness'-enablingapriorising/axiomatising/referencing/intelligibilitysettingup/measuringinstrumenting-foroperant-or-incidenting-predicative-insights-of 'implicited_attendant-ontologicalcontiguity $^{67}$, educedexistentialising/contextualising/textualising_intelligibility/epistemicity/reflexivity-contiguity$<$ imbued-notional $\sim$ cogency $>,,-<$ reifying-or-elucidating-of-prospective-relative-ontologicalcompleteness -of- reference-of-thought- devolving-as-of-instantiative-context $>$ in relativeunreflexivity/relative-reflexivity - ontological-contiguity ${ }^{67}$ ); as reflecting the variance of the 
relative-unreflexivity/relative-reflexivity - ontological-contiguity ${ }^{67}$ of-the-humaninstitutionalisation-process $^{68}$ as to difference-in-nature/difference-in-apriorising-oraxiomatising-or-referencing ${ }^{24}$ as from the notional deprocrypticism point-referencing required for a construal/conceptualisation that is uninhibited/decomplexified with respect to our positivism- ${ }^{80}$ procrypticism registry-worldview/dimension given <amplituding/formativeepistemicity $>$ totalising $\sim$ self-referencing-syncretising/circularity/interiorising/akrasiatic-drag ${ }^{34}$, and so as from the apriorising/axiomatising/referencing-\{of- prospectively implicited_attendant-ontological-contiguity ' reducedexistentialising/contextualising/textualising_intelligibility/epistemicity/reflexivity-contiguity-

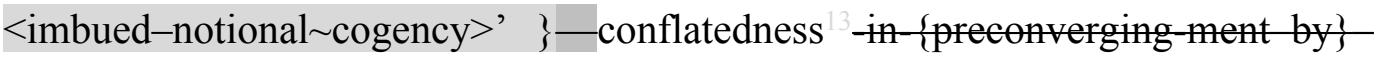
postconverging-entailment construal of the prospective notional ${ }^{18}$ deprocrypticism registryworldview's/dimension's $\quad{ }^{83}$ reference-of-thought-and- ${ }^{83}$ reference-of-thought- ${ }^{8}$ devolvingmeaningfulness-and-teleology $\quad$ ontological-performance ${ }^{2}-<$ including-virtue-asontology $>$ /morality/ethics/justice/etc. as so-reflecting the postconverging-or-dialecticalthinking -and-centered-prospective-institutionalisation's- categoricalimperatives/axioms/registry-teleology ${ }^{9}$ while the positivism- ${ }^{80}$ procrypticism registryworldview/dimension is construed as of preconverging-or-dementing ${ }^{20}$-and-decentered-priorinstitutionalisation's reference-of-thought- categorical-imperatives/axioms/registryteleology 9 . 'Candidity/Candour-capacity' as of the relative-unreflexivity/relative-reflexivity_ ontological-contiguity ${ }^{67}$ of-the-human-institutionalisation-process ${ }^{68}$ as to difference-innature/difference-in-apriorising-or-axiomatising-or-referencing ${ }^{24}$ thus refers to the comprehensiveness or $\quad<$ amplituding/formative-epistemicity $>$ totalising $\sim$ social-contextconstrued-conflatedness $^{13}$ of individuation and consequently social capacity for ontologicalnormalcy/postconvergence, so reflected in <amplituding/formativeepistemicity $>$ totalising $\sim$ social-context-construed-conflatedness ${ }^{13}$ of individual and social 
construal/conceptualisation of ${ }^{5}$ meaningfulness-and-teleology ${ }^{9}$ in upholding/failing ontological-normalcy/postconvergence as reflected by ${ }^{83}$ reference-of-thought-closeness-oftethering-to-prelogism ${ }^{78}$-as-of-conviction,-in-profound-supererogation $-<$ existentiallyveridical-'attendant-intradimensional-apriorising/axiomatising/referencing'-logical-duenessprecedes-disontologising-logical-outcome-arrived-at $>$ ( ${ }^{8}$ reference-of-thought- prelogism ${ }^{78}$-asof-conviction,-in-profound-supererogation ${ }^{2}<$ existentially-veridical-'attendantintradimensional-apriorising/axiomatising/referencing'-logical-dueness-precedesdisontologising-logical-outcome-arrived-at $>$ ) or ${ }^{8}$ reference-of-thought-looseness-of-tetheringto-prelogism ${ }^{8}$-as-of-conviction,-in-profound-supererogation $\quad<$ existentially-veridical'attendant-intradimensional-apriorising/axiomatising/referencing'-logical-dueness-precedesdisontologising-logical-outcome-arrived-at> $\quad$ (threshold-ofnonconviction/madeupness/bottomlining-in-shallow-supererogation $<<$ as-to- 'attendantintradimensional'-prospectively-disontologising preconverging/dementing -apriorisingpsychologism>) as explaining thus the possibility respectively of appropriateness-of- ${ }^{\text {reference- }}$ of-thought-as-of-conflatedness ${ }^{13}$ or $\quad$ perversion-and-derived- ${ }^{7}$ perversion-of- ${ }^{3}$ reference-ofthought-<as-preconvergingly-apriorising/axiomatising/referencing-innonconviction/madeupness/bottomlining-as-to-shallow-supererogation $>$, behind the grander issue of relative-ontological-incompleteness $8 /$ relative-ontological-completeness 〈sublimating referencing/registering/decisioning,-as-self-becoming/selfconflatedness /formative-supererogating-<projective/reprojective-aestheticising-re-motifand-re-apriorising/re-axiomatising/re-referencing,-in-perspective-ontologicalnormalcy/postconvergence $>>$ of reference-of-thought. Basically, this points to 'notional/epistemic/bindingness ${ }^{-<a s-t o-d e t e r m i n i s m / c o n c e p t i v i t y-o f-r e l a t i v e-u n r e f l e x i v i t y / r e l a t i v e-r e f l e x i v i t y z ~} \quad$ as of notional $\sim$ reflexivity- $<\{$ veridical/sound $\}$-relative-reflexivity-in-existence/relativising fromlimited-mentation-as-its-deepening/psychologismic-<residualising \{decompulsing $\}$ delinearity for- 
eogency>-by-\{flawed/unsound\}-relative-unreflexivity-in-existence/absolutising from-

\section{limited-mentation/psychologismic epistemic acutisation nonresidualising imbued-}

\{compulsing + linearity in-eclecticism-of prior-mere-formulaicity/ritualisation $>$ perspectives of

construing/conceptualising' with respect to ontology/ontological-normalcy/postconvergence soreflected with the thresholds of 'effecting-parsimony' as to temporality ${ }^{8 / \text { shortness and }}$ 'effecting-wholeness' as to intemporality ${ }^{52} /$ longness; the elucidation of which brings out the beyond-the-consciousness-awareness-teleology ${ }^{9}-<$ of-preconverging-existential-extrication-asof-existential-unthought> social ${ }^{103}$ universal-transparency ${ }^{104}-\langle$ transparency-of-totalisingentailing,-as-to-entailing-<amplituding/formative-epistemicity $>$ totalising $\sim$ in-relativeontological-completeness $\rangle$, enabling intemporal/ontological skewing for institutionalisation. It is the resolving as aetiologisation/ontological-escalation- $<$ ontologicalveridicality_commitment/otherliness_transcending/compulsions-encumbered_transcending $>$ of 'candidity/candour-capacity' as of transcended/superseded psychoanalytic-backdrop for the prospective

apriorising/axiomatising/referencing/intelligibilitysettingup/measuringinstrumenting-foroperant-or-incidenting-predicative-insights overcoming human procrypticism-ordisjointedness-as-of- ${ }^{-}$reference-of-thought that will usher in futural Beingdevelopment/ontological-framework-expansion-as-to-depth-of-ontologising-development-asinfrastructure-of- meaningfulness-and-teleology as of prospective notional ${ }^{18}$ deprocrypticism institutionalisation psyche on the same token that the resolving of non-positivism including 'superstition' as of transcended/superseded psychoanalytic backdrop for the prospective overcoming of human 'non-positivising/non-rational-empirical' caricaturinghollow-staging-and-performance that ushered in our prospective positivism institutionalisation psyche and the institutionalisation possibilities thereof. Notional candidity/candour-capacity thus allows for meaningfulness to be recasted in terms-as-of-axiomatic-construct of "narratives 
of candidity/candour-capacity in 'implicited_attendant-ontological-contiguity ${ }^{67}$ ' educedexistentialising/contextualising/textualising_'intelligibility/epistemicity/reflexivity-contiguity$<$ imbued-notional $\sim$ cogency $>,{ }^{\prime},-<$ reifying-or-elucidating-of-prospective-relative-ontologicalcompleteness -of- reference-of-thought- devolving-as-of-instantiative-context>' reflecting more directly the candidity <amplituding/formative-epistemicity $>$ causality $\sim$ as-to-projectivetotalitative-implications-of-prospective- nonpresencing,-for-explicating relative-

unreflexivity/relative-reflexivity ontological-contiguity as of successive temporal-tointemporal individuations specifically as a capacity variance of the same construct. Furthermore, such a candidity/candour-capacity approach as syncing with a notional ${ }^{18 \text { deprocrypticism }}$ reference-of-thought as of (beyond-the-consciousness-awareness-teleology ${ }^{9}-<$ of preconverging-existential-extrication-as-of-existential-unthought>)

apriorising/axiomatising/referencing-\{of-'prospectively_implicited_attendant-ontologicalcontiguity ' educedexistentialising/contextualising/textualising_ 'intelligibility/epistemicity/reflexivity-contiguity$<$ imbued-notional $\left.\sim \operatorname{cogency}>^{\prime}\right\}$-conflatedness ${ }^{13}$-in-\{preconverging-ment by $\}^{\prime}$ postconverging-entailment over our positivism- ${ }^{80}$ procrypticism ${ }^{83}$ reference-of-thought and uninhibited/decomplexified from the latter, provides 'direct ontological insight of notional ${ }^{18}$ deprocrypticism placeholder-setup/mental-devisingrepresentation/mentation/consciousness-awareness-teleology ${ }^{9}$ as to the nature of the positivism- ${ }^{80}$ procrypticism social-functioning-and-accordance-as-of-social-stake-contentionor-confliction threshold as uninstitutionalised-threshold ${ }^{102}$ amenable to perversion-and-derivedperversion-of- ${ }^{8}$ reference-of-thought-<as-preconverginglyapriorising/axiomatising/referencing-in-nonconviction/madeupness/bottomlining-as-toshallow-supererogation $>$ on the basis of its more simplistic and direct notion of candidity/candour-capacity variance of the same construct. Unlike the '< amplituding/formative- 
epistemicity $>$ totalising intervalist-as-categorising_-implicited_attendant_ontologicalcontiguity ${ }^{67} \sim$ educed-

existentialising/contextualising/textualising_intelligibility/epistemicity/reflexivity_contiguity$<$ imbued-notional cogency>' ;-phenomenal-abstractiveness-of-presencing-in-'occlusiveconsciousness'-enabling-

apriorising/axiomatising/referencing/intelligibilitysettingup/measuringinstrumenting-foroperant-or-incidenting-predicative-insights-of 'implicited_attendant-ontologicalcontiguity ${ }^{67} \sim$ educedexistentialising/contextualising/textmalising_intelligibility/epistemicity/reflexivity-contiguity$<$ imbued-notional $\sim$ cogency $>,{ }^{\prime},-<$ reifying-or-elucidating-of-prospective-relative-ontologicalcompleteness -of- reference-of-thought- devolving-as-of-instantiative-context $>$ categorisation scheme' which rather construes a <amplituding/formativeepistemicity $>$ totalising $\sim$ self-referencing-syncretising/circularity/interiorising/akrasiatic-drag that is postconverging-or-dialectical-thinking -apriorising-psychologism and centered positivism- ${ }^{80}$ procrypticism registry-worldview/dimension; the notional-contiguity/epistemiccontiguity ${ }^{62}<$ profound-supererogation - of-mentally-aestheticised $\sim$ postconverging/dialectical-

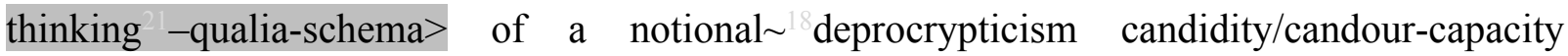
construal/conceptualisation articulated as of 'notional 'deprocrypticism narrative of candidity/candour-capacity' is as of a uninhibited/decomplexified apriorising/axiomatising/referencing-\{of-'prospectively implicited_attendant-ontologicalcontiguity ' educed-

existentialising/contextualising/textualising_'intelligibility/epistemicity/reflexivity-contiguity<imbued-notional $\left.\sim \operatorname{cogency}>^{\prime},\right\}$-conflatedness ${ }^{13}$ in $\{$ preconverging ment by postconverging-entailment in futural Being-development/ontological-framework-expansion-asto-depth-of-ontologising-development-as-infrastructure-of- meaningfulness-and-teleology 
as of prospective notional ${ }^{18}$ deprocrypticism registry-worldview's/dimension's ${ }^{83}$ reference-ofthought as postconverging-or-dialectical-thinking -and-centered-prospectiveinstitutionalisation's- categorical-imperatives/axioms/registry-teleology ${ }^{9}$ and construing our positivism- ${ }^{80}$ procrypticism registry-worldview/dimension as preconverging-or-dementing and-decentered-prior-institutionalisation's $\quad{ }^{83}$ reference-of-thought- categoricalimperatives/axioms/registry-teleology ${ }^{9}$. Candidity/Candour-capacity as such highlights from the perspective of the postconverging-or-dialectical-thinking -and-centered-prospectiveinstitutionalisation's- categorical-imperatives/axioms/registry-teleology 9 soundness-orontological-good-faith/authenticity ${ }^{-o f-}{ }^{8}$ reference-of-thought as notional ${ }^{18}$ deprocrypticism opened-construct-of- ${ }^{56}$ meaningfulness-and-teleology 99 the preconverging-or-dementing ${ }^{20}$ apriorising-psychologism/unsoundness-or-ontological-bad-faith/inauthenticity ${ }^{64}$-of- ${ }^{8}$ referenceof-thought of the positivism- ${ }^{80}$ procrypticism $<$ amplituding/formative $>$ wooden-language〈imbued - averaging-of-thought-<as-to-leveling/ressentiment/closed-construct-ofmeaningfulness-and-teleology -as-of-'nondescript/ignorable-void '-with-regards-toprospective-apriorising-implications $>\rangle$, despite the latter's <amplituding/formativeepistemicity $>$ totalising $\sim$ self-referencing-syncretising/circularity/interiorising/akrasiatic-drag apparent soundness, at its uninstitutionalised-threshold 02 of procrypticism as $<$ amplituding/formative $>$ wooden-language-〈imbued-temporal-mere-

\section{form/virtualities/dereification/akrasiatic-drag/denatured/preconverging-or-dementing} narratives - of-the- reference-of-thought- categorical-imperatives/axioms/registry-

teleology $\rangle$. In this regard and dialectically, "meaningfulness-and-teleology" is closed and opened successively' as of the 'successive uninstitutionalised-threshold 02 and institutionalisations' driven by the ontological-faith-notion-or-ontological-fideism -imbuedunderdetermination-of-motif-and-apriorising/axiomatising/referencing-as-so-being-as-ofexistential-reality for intemporal-preservation-entropy-or-contiguity-or-ontological- 
preservation; - as closed by non-rules — apriorising/axiomatising/referencing-psychologism,-asimpulsive-or-accidented-or-random-mental-disposition in 'recurrent-utter-uninstitutionalisation uninstitutionalisation', - opened as rule-making by rulemaking-over-non-rulesapriorising/axiomatising/referencing-psychologism in 'base-institutionalisation institutionalisation' but then closed at the uninstitutionalised-threshold ${ }^{12}$ as 'ununiversalisation uninstitutionalisation', - opened as ${ }^{103}$ universalisation by ${ }^{103}$ universalisation-directedrulemaking-over-non-rules_-apriorising/axiomatising/referencing-psychologism in ' ${ }^{103}$ universalisation institutionalisation' but then closed at the uninstitutionalised-threshold ${ }^{102}$ as 'non-positivism/medievialism uninstitutionalised-threshold ${ }^{102}$, - opened as positivism by positivising/rational-empiricism-based-universalisation-directed-rulemaking-over-non-rulesapriorising/axiomatising/referencing-psychologism in 'positivism institutionalisation' but then closed at the uninstitutionalised-threshold ${ }^{102}$ as 'procrypticism uninstitutionalisation', and

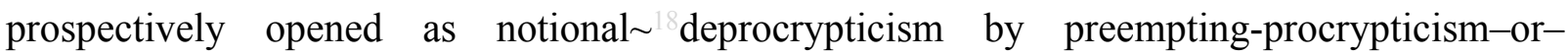
preempting - disjointedness-as-of- ${ }^{3}$ reference-of-thought,-as-to- ${ }^{6}<$ amplituding/formativeepistemicity $>$ growth-or-conflatedness ${ }^{13} /$ transvaluativerationalising/transepistemicity/anamnestic-residuality/spirit-drivenness'_-in-supersedingmere-formulaic-positivising/rational-empiricism-based-universalisation-directed-rulemakingover-non-rules_-apriorising/axiomatising/referencing-psychologism 'notional ${ }^{8}$ deprocrypticism institutionalisation'. Candidity/Candour-capacity thus provides rather a simplistic, authentic and uninhibited/decomplexified storied construal in relativeunreflexivity/relative-reflexivity - ontological-contiguity ${ }^{77}$ as of the ontologicalnormalcy/postconvergence of notional ' deprocrypticism not saddled with our 'relatively deficient positivism $-{ }^{80}$ procrypticism mindset complex' of such <amplituding/formativeepistemicity>totalising intervalist-as-categorising_-'implicited_attendant-ontologicalcontiguity $^{67} \sim$ educed- 
existentialising/contextualising/textualising_'intelligibility/epistemicity/reflexivity-contiguity$<$ imbued-notional cogency>’ ;-phenomenal-abstractiveness-of-presencing-in-'occlusiveconsciousness'-enabling-

apriorising/axiomatising/referencing/intelligibilitysettingup/measuringinstrumenting-foroperant-or-incidenting-predicative-insights-of 'implicited_attendant-ontologicalcontiguity ${ }^{67}$,educed-

existentialising/contextualising/textualising_'intelligibility/epistemicity/reflexivity-contiguity$<$ imbued-notional $\sim$ cogency $>,{ }^{\prime},-<$ reifying-or-elucidating-of-prospective-relative-ontologicalcompleteness -of- reference-of-thought- devolving-as-of-instantiative-context>

highlighted before, and so-related, as a storied-construct/ontologically-valid-narration candidity/candour-capacity construing ${ }^{56}$ meaningfulness-and-teleology ${ }^{9}$ contrastively as of the unaffirmation/deprojection/deassertion/epistemic-decadence/undueness-invalidatinglogicising/unsuitable-measuringinstrument-invalidating-measuring-<as-to-preconverging-ordementing -apriorising-psychologism> of prior relative-ontological-incompleteness ${ }^{8}$-ofreference-of-thought and the affirmation/projection/assertion/notional $\sim$ selfdistantiation/dueness-validating-logicising/suitable-measuringinstrument-validatingmeasuring-<as-to-postconverging-or-dialectical-thinking -apriorising-psychologism> of prospective relative-ontological-completeness ${ }^{87}$-of- ${ }^{3}$ reference-of-thought, in notionaldiscontiguity/epistemic-discontiguity ${ }^{63}<$ between - prior-shallow-supererogation -ofmentally-aestheticised preconverging/dementing -qualia-schema_and_prospective-profoundsupererogation -of-mentally-aestheticised postconverging/dialectical-thinking -qualiaschema $>$ and respectively as of say positivism- ${ }^{80}$ procrypticism and notional ${ }^{18}$ deprocrypticism references-of-thought-devolving-teleological-de-mentating/structuring/paradigming-ofmeaningfulness. Interestingly pointing out effectively that such a candidity/candour-capacity construal of notional deprocrypticism placeholder-setup/mental-devising- 
representation/mentation/consciousness-awareness-teleology ${ }^{9}$ is what is normal-as-ofontological-normalcy/postconvergence ${ }^{56}$ meaningfulness-and-teleology ${ }^{9}$ in the $<$ amplituding/formative-epistemicity $>$ totalising $\sim$ ratiocontiguity/ratiocination-asreferentialism—'implicited_attendant-ontological-contiguity ${ }^{67}$ ' educedexistentialising/contextualising/textualising_intelligibility/epistemicity/reflexivity-contiguity$<$ imbued-notional cogency>' ;-phenomenal-abstractiveness-of-presencing-in-'protensiveconsciousness'-enabling-

apriorising/axiomatising/referencing/intelligibilitysettingup/measuringinstrumenting-foroperant-or-incidenting-predicative-insights-of 'implicited_attendant-ontologicalcontiguity $^{67}$, educedexistentialising/contextualising/textualising_intelligibility/epistemicity/reflexivity-contiguity$<$ imbued-notional $\sim$ cogency $>,,-<$ reifying-or-elucidating-of-prospective-relative-ontologicalcompleteness -of- reference-of-thought- devolving-as-of-instantiative-context $>$ reflection of candidity/candour-capacity and that our own positivism- procrypticism placeholdersetup/mental-devising-representation/mentation/consciousness-awareness-teleology ${ }^{9} \quad$ is relatively abnormal by its meaningfulness <amplituding/formativeepistemicity>totalising intervalist-as-categorising_ 'implicitantontologicalcontiguity ${ }^{67} \sim$ educedexistentialising/contextualising/textualising_intelligibility/epistemicity/reflexivity-contiguity$<$ imbued-notional cogency>' ;-phenomenal-abstractiveness-of-presencing-in-'occlusiveconsciousness'-enablingapriorising/axiomatising/referencing/intelligibilitysettingup/measuringinstrumenting-foroperant-or-incidenting-predicative-insights-of ‘implicited_attendant-ontologicalcontiguity ${ }^{67}$,educedexistentialising/contextualising/textualising_'intelligibility/epistemicity/reflexivity-contiguity- 
$<$ imbued-notional $\sim$ cogency $>{ }^{\prime},,-<$ reifying-or-elucidating-of-prospective-relative-ontologicalcompleteness -of- reference-of-thought- devolving-as-of-instantiative-context $>$. In order words, just as retrospectively we can construe that the respective placeholder-setup/mentaldevising-representation/mentation/consciousness-awareness-teleology 9 of recurrent-utteruninstitutionalisation as of <amplituding/formative-epistemicity>totalising $\sim$ random-asimpulsive_-implicited_attendant_ontological-contiguity ${ }^{67}$ ' educedexistentialising/contextmalising/textualising_ intelligibility/epistemicity/reflexivity-contiguity$<$ imbued-notional $\sim$ cogency $>$ ' ;-phenomenal-abstractiveness-of-presencing-in-'trepidatiousconsciousness'-enablingapriorising/axiomatising/referencing/intelligibilitysettingup/measuringinstrumenting-foroperant-or-incidenting-predicative-insights-of 'implicited_attendant-ontologicalcontiguity $^{67} \sim$ educedexistentialising/contextualising/textualising_'intelligibility/epistemicity/reflexivity-contiguity$<$ imbued-notional cogency $>,{ }^{\prime},-<$ reifying-or-elucidating-of-prospective-relative-ontologicalcompleteness -of- reference-of-thought- devolving-as-of-instantiative-context>, baseinstitutionalisation-ununiversalisation as of $\quad<$ amplituding/formativeepistemicity $>$ totalising nominal-as-tendentious_- 'implicited_attendant-ontologicalcontiguity ${ }^{67} \sim$ educedexistentialising/contextualising/textualising_intelligibility/epistemicity/reflexivity-contiguity$<$ imbued-notional cogency>’ ${ }^{\text {; }}$-phenomenal-abstractiveness-of-presencing-in- 'warpedconsciousness'-enablingapriorising/axiomatising/referencing/intelligibilitysettingup/measuringinstrumenting-foroperant-or-incidenting-predicative-insights-of 'implicited_attendant-ontologicalcontiguity ${ }^{67} \sim$ educedexistentialising/contextualising/textualising_'intelligibility/epistemicity/reflexivity-contiguity- 
completeness -of- reference-of-thought- devolving-as-of-instantiative-context>,

universalisation-non-positivism/medievalism as of <amplituding/formative-

epistemicity>totalising ordinal-as-qualifying_-implicited_attendant-ontological-

contiguity ${ }^{67} \sim$ educed-

existentialising/contextualising/textualising_intelligibility/epistemicity/reflexivity-contiguity-

$<$ imbued-notional cogency>> ${ }^{\prime}$;-phenomenal-abstractiveness-of-presencing-in-'preclusive-

consciousness'-enabling-

apriorising/axiomatising/referencing/intelligibilitysettingup/measuringinstrumenting-for-

operant-or-incidenting-predicative-insights-of

'implicited_attendant-ontological-

contiguity ${ }^{67}$, educed-

existentialising/contextualising/textualising_'intelligibility/epistemicity/reflexivity_contiguity-

$<$ imbued-notional $\sim$ cogency $>$, ,-<reifying-or-elucidating-of-prospective-relative-ontological-

completeness -of- reference-of-thought- devolving-as-of-instantiative-context>; $\quad$ were

respectively defective in their reflection of the fullness/completeness of existencepotency $^{39} \sim$ sublimating-nascence,-disclosed-from-prospective-epistemic-digression as to perspective intrinsic-reality/ontological-veridicality, the placeholder-setup/mental-devisingrepresentation/mentation/consciousness-awareness-teleology ${ }^{9}$ of our positivismprocrypticism is defective as well as of <amplituding/formativeepistemicity>totalising intervalist-as-categorising_'implicited_attendant-ontologicalcontiguity $^{67} \sim$ educedexistentialising/contextualising/textualising_intelligibility/epistemicity/reflexivity-contiguity$<$ imbued-notional cogency>' ;-phenomenal-abstractiveness-of-presencing-in-'occlusiveconsciousness'-enablingapriorising/axiomatising/referencing/intelligibilitysettingup/measuringinstrumenting-for- 
operant-or-incidenting-predicative-insights-of 'implicited_attendant_ontologicalcontiguity ${ }^{67} \sim$ educed-

existentialising/contextualising/textualising_'intelligibility/epistemicity/reflexivity-contiguity$<$ imbued-notional $\sim \operatorname{cogency}>{ }^{\prime},-<$ reifying-or-elucidating-of-prospective-relative-ontologicalcompleteness -of- reference-of-thought- devolving-as-of-instantiative-context>; and so reflected from the relative-ontological-completeness ${ }^{87}$ notional ${ }^{18}$ deprocrypticism $<$ amplituding/formative-epistemicity $>$ totalising $\sim$ ratiocontiguity/ratiocination-as-

referentialism — 'implicited_attendant_ontological-contiguity ${ }^{67}$ > educedexistentialising/contextmalising/textualising_'intelligibility/epistemicity/reflexivity-contiguity$<$ imbued-notional cogency>’ ${ }^{\prime}$;-phenomenal-abstractiveness-of-presencing-in-'protensiveconsciousness'-enabling-

apriorising/axiomatising/referencing/intelligibilitysettingup/measuringinstrumenting-foroperant-or-incidenting-predicative-insights-of 'implicited_attendant-ontologicalcontiguity $^{67}$ ' educedexistentialising/contextualising/textualising_intelligibility/epistemicity/reflexivity-contiguity$<$ imbued-notional $\sim$ cogency $>,{ }^{\prime},-<$ reifying-or-elucidating-of-prospective-relative-ontologicalcompleteness -of- reference-of-thought- devolving-as-of-instantiative-context $>$ candidity/candour-capacity fullness/completeness of existence-potency ${ }^{32} \sim$ sublimating- $^{-}$ nascence,-disclosed-from-prospective-epistemic-digression as to perspective intrinsicreality/ontological-veridicality basis as apriorising/axiomatising/referencing-\{of'prospectively_implicited_attendant-ontological-contiguity ' ceducedexistentialising/contextualising/textualising_intelligibility/epistemicity/reflexivity-contiguity-

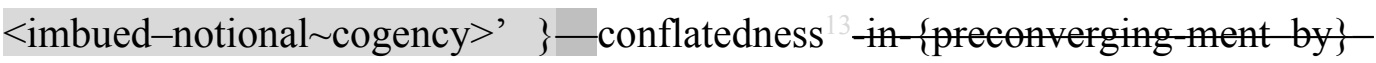
postconverging-entailment in construing from the notional deprocrypticism ontologicalnormalcy/postconvergence the relative distractive-alignment-to- ${ }^{8}$ reference-of-thought- $<$ of- 
apriorising/axiomatising/referencing $>30$ arising as of respective relative-ontologicalincompleteness

registry-worldviews/dimensions

$<$ amplituding/formative-

epistemicity $>$ totalising $\sim$ self-referencing-syncretising/circularity/interiorising/akrasiatic-drag

temporal-dispositions in failing to contrastively-construe at their respective uninstitutionalised-

threshold the unaffirmation/deprojection/deassertion/epistemic-decadence/unduenessinvalidating-logicising/unsuitable-measuringinstrument-invalidating-measuring-<as-topreconverging-or-dementing -apriorising-psychologism $>$ of their prior relative-ontologicalincompleteness ${ }^{8}$-of- ${ }^{8}$ reference-of-thought and the affirmation/projection/assertion/notional $\sim$ self-distantiation/dueness-validatinglogicising/suitable-measuringinstrument-validating-measuring-<as-to-postconverging-ordialectical-thinking -apriorising-psychologism> of prospective relative-ontologicalcompleteness ${ }^{87}$-of- ${ }^{83}$ reference-of-thought, and thus wrongly implying issue of ${ }^{54}$ logicalprocessing-or-logical-implicitation - supposedly-apriorising-in-conviction-as-to-profoundsupererogation in wrong notional-contiguity/epistemic-contiguity ${ }^{6}-<$ profound- $^{2}$ supererogation -of-mentally-aestheticised postconverging/dialectical-thinking -qualiaschema $>$ equivalence of apriorising/axiomatising/referencing/intelligibilitysettingup/measuringinstrumenting for meaningfulness-and-teleology' A Abstractly, the 'notional-discontiguity/epistemicdiscontiguity ${ }^{63}<$ between - prior-shallow-supererogation -of-mentallyaestheticised preconverging/dementing -qualia-schema_and_prospective-profoundsupererogation -of-mentally-aestheticised postconverging/dialectical-thinking -qualiaschema $>$ issue' has to do with a prospective precise relative-ontological-completeness ${ }^{87}$ in ontological-normalcy/postconvergence:

as of $<$ amplituding/formative-epistemicity $>$ totalising $\sim$ ratiocontiguity/ratiocination-asreferentialism - 'implicited_attendant-ontological-contiguity ${ }^{67}$, educed- 
existentialising/contextualising/textualising_'intelligibility/epistemicity/reflexivity-contiguity$<$ imbued-notional cogency>' ;-phenomenal-abstractiveness-of-presencing-in-'protensiveconsciousness'-enabling-

apriorising/axiomatising/referencing/intelligibilitysettingup/measuringinstrumenting-foroperant-or-incidenting-predicative-insights-of 'implicited_attendant-ontologicalcontiguity $^{67}$; educedexistentialising/contextualising/textualising_'intelligibility/epistemicity/reflexivity-contiguity$<$ imbued-notional $\sim$ cogency $>,{ }^{\prime},-<$ reifying-or-elucidating-of-prospective-relative-ontologicalcompleteness -of- reference-of-thought- devolving-as-of-instantiative-context> precision. BUT THEN rather wrongly construed successively in prior imprecise relative-ontologicalincompleteness $^{88}$ epistemic-abnormalcy/preconvergence ${ }^{31}$ respectively as of: <amplituding/formative-epistemicity>totalising intervalist-as-categorising'implicited_attendant-ontological-contiguity ${ }^{67}$ ' educedexistentialising/contextualising/textualising_intelligibility/epistemicity/reflexivity-contiguity$<$ imbued-notional cogency>' ;-phenomenal-abstractiveness-of-presencing-in-'occlusiveconsciousness'-enablingapriorising/axiomatising/referencing/intelligibilitysettingup/measuringinstrumenting-foroperant-or-incidenting-predicative-insights-of 'implicited_attendant_ontologicalcontiguity $^{67} \sim$ educedexistentialising/contextmalising/textualising_intelligibility/epistemicity/reflexivity_contiguity$<$ imbued-notional $\sim \operatorname{cogency}>,,-<$ reifying-or-elucidating-of-prospective-relative-ontologicalcompleteness -of- reference-of-thought- devolving-as-of-instantiative-context> OR $<$ amplituding/formative-epistemicity $>$ totalising $\sim$ ordinal-as-qualifying'implicited_attendant-ontological-contiguity ${ }^{67}$; educed- 
existentialising/contextualising/textualising_intelligibility/epistemicity/reflexivity-contiguity$<$ imbued-notional cogency>' ;-phenomenal-abstractiveness-of-presencing-in-'preclusiveconsciousness'-enablingapriorising/axiomatising/referencing/intelligibilitysettingup/measuringinstrumenting-foroperant-or-incidenting-predicative-insights-of 'implicited_attendant-ontologicalcontiguity $^{67} \sim$ educedexistentialising/contextualising/textualising_'intelligibility/epistemicity/reflexivity-contiguity$<$ imbued-notional $\sim$ cogency $>,{ }^{\prime},-<$ reifying-or-elucidating-of-prospective-relative-ontologicalcompleteness -of- reference-of-thought- devolving-as-of-instantiative-context>

OR

$<$ amplituding/formative-epistemicity $>$ totalising $\sim$ nominal-as-tendentious'implicited_attendant-ontological-contiguity ${ }^{67}$ > educedexistentialising/contextualising/textualising_'intelligibility/epistemicity/reflexivity-contiguity$<$ imbued-notional cogency>' ;-phenomenal-abstractiveness-of-presencing-in- 'warpedconsciousness'-enablingapriorising/axiomatising/referencing/intelligibilitysettingup/measuringinstrumenting-foroperant-or-incidenting-predicative-insights-of 'implicited_attendant-ontologicalcontiguity ${ }^{67} \sim$ educedexistentialising/contextualising/textualising_intelligibility/epistemicity/reflexivity-contiguity$<$ imbued-notional $\sim$ cogency $>,{ }^{\prime},-<$ reifying-or-elucidating-of-prospective-relative-ontologicalcompleteness -of- reference-of-thought- devolving-as-of-instantiative-context $>$

OR

$<$ amplituding formative-epistemicity $>$ totalising $\sim$ random-as-impulsive'implicited_attendant-ontological-contiguity ${ }^{67}$; educedexistentialising/contextualising/textualising_intelligibility/epistemicity/reflexivity-contiguity- 
$<$ imbued-notional cogency>' ${ }^{\prime}$;-phenomenal-abstractiveness-of-presencing-in- 'trepidatiousconsciousness'-enabling-

apriorising/axiomatising/referencing/intelligibilitysettingup/measuringinstrumenting-foroperant-or-incidenting-predicative-insights-of 'implicited_attendant-ontologicalcontiguity ${ }^{6}$; educedexistentialising/contextualising/textualising_intelligibility/epistemicity/reflexivity-contiguity$<$ imbued-notional $\sim$ cogency $>,{ }^{\prime},-<$ reifying-or-elucidating-of-prospective-relative-ontologicalcompleteness -of- reference-of-thought- devolving-as-of-instantiative-context>.

And all, in subpar construals/conceptualisations to the:

$<$ amplituding/formative--epistemicity $>$ totalising $\sim$ ratiocontiguity/ratiocination-asreferentialism — 'implicited_attendant_ontological-contiguity ${ }^{67}$ > educedexistentialising/contextualising/textualising_intelligibility/epistemicity/reflexivity-contiguity$<$ imbued-notional cogency>' ;-phenomenal-abstractiveness-of-presencing-in-'protensiveconsciousness'-enablingapriorising/axiomatising/referencing/intelligibilitysettingup/measuringinstrumenting-foroperant-or-incidenting-predicative-insights-of 'implicited_attendant-ontologicalcontiguity ${ }^{67} \sim$ educedexistentialising/contextualising/textualising_intelligibility/epistemicity/reflexivity-contiguity$<$ imbued-notional $\sim$ cogency $>{ }^{\prime},-<$ reifying-or-elucidating-of-prospective-relative-ontologicalcompleteness -of- reference-of-thought- devolving-as-of-instantiative-context>.

With the successive imprecisions wholly operating as if utterly precise, whereas these are of their successively imbued distractive-alignment-to- ${ }^{-3}$ reference-of-thought- $<$ ofapriorising/axiomatising/referencing $>{ }^{30}$ to the profound precision in:

$<$ amplituding/formative-epistemicity $>$ totalising $\sim$ ratiocontiguity/ratiocination-asreferentialism - 'implicited_attendant-ontological-contiguity ${ }^{67}$ ? educed- 
existentialising/contextualising/textualising_intelligibility/epistemicity/reflexivity-contiguity-

$<$ imbued-notional cogency>' ;-phenomenal-abstractiveness-of-presencing-in-'protensiveconsciousness'-enabling-

apriorising/axiomatising/referencing/intelligibilitysettingup/measuringinstrumenting-foroperant-or-incidenting-predicative-insights-of 'implicited_attendant-ontologicalcontiguity ${ }^{67}$,educed-

existentialising/contextualising/textualising_'intelligibility/epistemicity/reflexivity-contiguity$<$ imbued-notional $\sim$ cogency $>,{ }^{\prime},-<$ reifying-or-elucidating-of-prospective-relative-ontologicalcompleteness -of- reference-of-thought- devolving-as-of-instantiative-context>. Thus equally explaining the requisite preconverging/postconverging-dementative/structural/paradigmatic construal/conceptualisation for prospective relativeontological-completeness ${ }^{87}$-of- ${ }^{83}$ reference-of-thought as of pure-ontology/existence-as-of-itsmimetic-echoness! Such a phenomenal insight as of 'ontological-reconstituting-as-toconflatedness $^{13}$, is instructive of how a Derridean deconstruction critique as a bottomless chessboard of a Heideggerian destruktion as incapable of getting at the bottom of the archaeological-layers $/{ }^{4}$ historiality/ontological-eventfulness 38 ontological-aesthetic-tracing$<$ perspective-ontological-normalcy/postconvergence-reflected-'epistemicity-relativismdeterminism'> of ontological axioms/horizons of meaningfulness as of its 'attempt-at-such-adelayering' thus considered to be inherently ontologically-deficient/incomplete, can be superseded 'beyond-and-sidestepping any such archaeological-layers/ $/$ historiality/ontologicaleventfulness ${ }^{3}$ /ontological-aesthetic-tracing-<perspective-ontological-

normalcy/postconvergence-reflected-'epistemicity-relativism-determinism'> limitation' by rather construing-of-and-informing-as-to the inherent possibilities of pure-ontology insight as reflected by 'inherent notional $\sim$ conflatedness ${ }^{13} /$ constitutedness $^{14}$-to-conflatedness ${ }^{13}$ ontologicalnormalcy/postconvergence/postdication/metaphysics-of-absence-_implicited-epistemic- 
veracity-of- nonpresencing-<perspective-ontological-

normalcy/postconvergence $>>/{ }^{\prime}$ nonpresencing- $<$ perspective-ontological-

normalcy/postconvergence $>$ phenomenal insight about pure-ontology/existence-as-of-itsmimetic-echoness' as highlighted with the 'successive relative-ontological-completeness $<$ amplituding formative-epistemicity $>$ totalising $\sim$ random-as-impulsive-

'implicited_attendant-ontological-contiguity ${ }^{67}$ ' educed-

existentialising/contextualising/textualising_'intelligibility/epistemicity/reflexivity-contiguity-

$<$ imbued-notional cogency $>$ '/totalising nominal-as-tendentious_-'implicited_attendantontological-contiguity ${ }^{67}$, educed-

existentialising/contextualising/textualising_intelligibility/epistemicity/reflexivity-contiguity$<$ imbued-notional cogency>' /totalising ordinal-as-qualifying_-'implicited_attendant ontological-contiguity ${ }^{67}$, educed-

existentialising/contextualising/textualising_'intelligibility/epistemicity/reflexivity-contiguity$<$ imbued-notional $\sim$ cogency $>$ '/totalising intervalist-as-categorising_-implicited_attendantontological-contiguity ${ }^{67}$, educed-

existentialising/contextualising/textualising_intelligibility/epistemicity/reflexivity-contiguity$<$ imbued-notional $\sim$ cogency $>$ ' /totalising $\sim$ ratiocontiguity-or-ratiocination-as-referentialism,-phenomenal-abstractiveness-of-presencing-

apriorising/axiomatising/referencing/intelligibilitysettingup/measuringinstrumenting-foroperant-or-incidenting-predicative-insights-of 'implicited_attendant-ontologicalcontiguity ${ }^{67}$, educed-

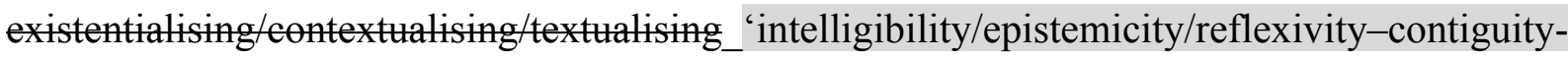
$<$ imbued-notional $\sim \operatorname{cogency}>,{ }^{\prime},-<$ reifying-or-elucidating-of-prospective-relative-ontologicalcompleteness -of- reference-of-thought- devolving-as-of-instantiative-context $>$ construed as notional conflatedness ${ }^{13}$, and so conceptually as of an ahistorical-emancipation more like the 
science/laws of physics is inherently ahistorically-emancipated from exact physical phenomena occurrences/events ${ }^{38}$ archaeology as to ${ }^{4}$ historiality/ontological-eventfulness ${ }^{38} /$ ontological- $^{2}$ aesthetic-tracing-<perspective-ontological-normalcy/postconvergence-reflected-'epistemicityrelativism-determinism' $>$ and is capable of construing-of-and-informing-as-to such exact physical phenomena occurrences/events ${ }^{38}$ archaeology as to ${ }^{4}$ historiality/ontologicaleventfulness ${ }^{38}$ /ontological-aesthetic-tracing-<perspective-ontologicalnormalcy/postconvergence-reflected-‘epistemicity-relativism-determinism'>, thus enabling for instance the veracity/ontological-pertinence of say astronomy as an archaeology as to historiality/ontological-eventfulness 38 ontological-aesthetic-tracing-<perspectiveontological-normalcy/postconvergence-reflected-‘epistemicity-relativism-determinism’> derived-science that speaks to the how and why of exact astronomical occurrences/events ${ }^{38}$. Insightfully, such a candidity/candour-capacity notional deprocrypticism placeholdersetup/mental-devising-representation/mentation/consciousness-awareness-teleology construed as most ontologically-veridical human psychical representation and so over our present positivism- ${ }^{80}$ procrypticism psychical representation, is effectively grounded on the notion that placeholder-setup/mental-devising-representation/mentation/consciousnessawareness-teleology ${ }^{9}$ is 'by itself inherently an utterly discreet and arbitrary construct' but for the fact that every registry-worldview's/dimension's ${ }^{83}$ reference-of-thought has been habituated to its own as of its existentialism/full-depth-of-existential-implications ${ }^{56}$ meaningfulness-andteleology and considers its own by reflex to be sanctimonious. But then the fact is the true sanctimony lies with intrinsic-reality/ontological-veridicality construed as of prospective relative-ontological-completeness ${ }^{8}$-of- ${ }^{8}$ reference-of-thought as it so defines the placeholdersetup/mental-devising-representation/mentation/consciousness-awareness-teleology veracity/ontological-pertinence as of 'implicited_attendant-ontological-contiguity ${ }^{67}$; educedexistentialising/contextmalising/textmalising_intelligibility/epistemicity/reflexivity-contiguity- 
$<$ imbued-notional $\sim$ cogency $>{ }^{\prime},,-<$ reifying-or-elucidating-of-prospective-relative-ontologicalcompleteness -of- reference-of-thought- devolving-as-of-instantiative-context $>$, as implied with the notion of 'postconverging-or-dialectical-thinking -psychology or psychology-ofmentation-dynamics or natural psychological-dynamics'. Thus, however weird it may seem to our positivism- ${ }^{80}$ procrypticism psychical representation, in reflecting our positivismprocrypticism relative epistemic-abnormalcy/preconvergence ${ }^{31}$ to it a candidity/candourcapacity notional $\sim^{18}$ deprocrypticism placeholder-setup/mental-devisingrepresentation/mentation/consciousness-awareness-teleology as of <amplituding/formativeepistemicity $>$ totalising $\sim$ ratiocontiguity/ratiocination-as-referentialism—'implicited_attendant ontological-contiguity ${ }^{67}$; educedexistentialising/contextmalising/textmalising_intelligibility/epistemicity/reflexivity-contiguity$<$ imbued-notional cogency>' ;-phenomenal-abstractiveness-of-presencing-in-'protensiveconsciousness'-enablingapriorising/axiomatising/referencing/intelligibilitysettingup/measuringinstrumenting-foroperant-or-incidenting-predicative-insights-of 'implicited_attendant-ontologicalcontiguity $^{67}$, educed-

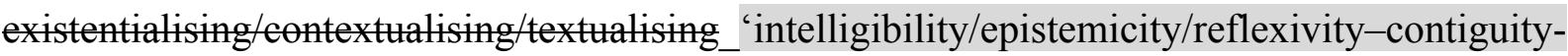
$<$ imbued-notional $\sim$ cogency $>,{ }^{\prime},-<$ reifying-or-elucidating-of-prospective-relative-ontologicalcompleteness -of- reference-of-thought- devolving-as-of-instantiative-context $>$ is actually more real and profound ontologically to ours as of our positivism- ${ }^{80}$ procrypticism $<$ amplituding/formative-epistemicity>totalising intervalist-as-categorising'implicited_attendant-ontological-contiguity ${ }^{67}$ ' educed-

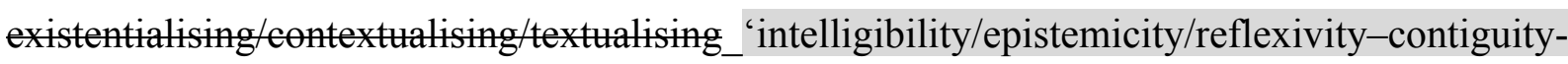
$<$ imbued-notional cogency>' ;-phenomenal-abstractiveness-of-presencing-in-'occlusiveconsciousness'-enabling- 
apriorising/axiomatising/referencing/intelligibilitysettingup/measuringinstrumenting-foroperant-or-incidenting-predicative-insights-of 'implicited_attendant_ontologicalcontiguity $^{67}$, educedexistentialising/contextualising/textualising_'intelligibility/epistemicity/reflexivity-contiguity$<$ imbued-notional cogency $>,{ }^{\prime},-<$ reifying-or-elucidating-of-prospective-relative-ontologicalcompleteness -of- reference-of-thought- devolving-as-of-instantiative-context>, and so just as the latter being more profound ontologically with respect to the relative epistemicabnormalcy/preconvergence ${ }^{31}$ of the ${ }^{103}$ universalisation-non-positivism/medievalism psychical representation will seem weird to the latter as of its <amplituding/formativeepistemicity>totalising ordinal-as-qualifying__implicited_attendant-ontologicalcontiguity $^{67}$, educedexistentialising/contextmalising/textualising_'intelligibility/epistemicity/reflexivity-contiguity$<$ imbued-notional cogency>' ;-phenomenal-abstractiveness-of-presencing-in-'preclusiveconsciousness'-enablingapriorising/axiomatising/referencing/intelligibilitysettingup/measuringinstrumenting-foroperant-or-incidenting-predicative-insights-of 'implicited_attendant_ontologicalcontiguity ${ }^{67}$,educedexistentialising/contextualising/textualising_intelligibility/epistemicity/reflexivity-contiguity$<$ imbued-notional $\sim$ cogency $>,{ }^{\prime},-<$ reifying-or-elucidating-of-prospective-relative-ontologicalcompleteness -of- reference-of-thought- devolving-as-of-instantiative-context>; underlying the placeholder-setup/mental-devising-representation/mentation/consciousness-awarenessteleology ${ }^{99}$ transformative <amplituding/formative-epistemicity $>$ causality $\sim$ as-to-projectivetotalitative-implications-of-prospective- nonpresencing,-for-explicating relativeunreflexivity/relative-reflexivity ontological-contiguity involved with ${ }^{15}$ de-mentation〈supererogatory ontological-de-mentation-or-dialectical-de-mentation-stranding-or- 
attributive-dialectics $\rangle$ as it induces the relative ${ }^{83}$ reference-of-thought- categoricalimperatives/axioms/registry-teleology ${ }^{9}$, -for-

aposteriorising/logicising/deriving/intelligising/measuring- ${ }^{56}$ meaningfulness-and-teleology ${ }^{99}$ as of the affirmation/projection/assertion/notional $\sim$ self-distantiation/dueness-validatinglogicising/suitable-measuringinstrument-validating-measuring-<as-to-postconverging-ordialectical-thinking -apriorising-psychologism $>$ of prospective relative-ontologicalcompleteness ${ }^{87}$-of- ${ }^{8}$ reference-of-thought with respect to the unaffirmation/deprojection/deassertion/epistemic-decadence/undueness-invalidatinglogicising/unsuitable-measuringinstrument-invalidating-measuring-<as-to-preconverging-ordementing -apriorising-psychologism> of prior relative-ontological-incompleteness ${ }^{8}$-ofreference-of-thought, and so beyond any registry-worldview's/dimension's metaphysics-ofpresence-〈implicited-'nondescript/ignorable-void '-as-to- presencing-absolutisingidentitive-constitutedness > mental complexes. Thus candidity/candour-capacity notional ${ }^{18}$ deprocrypticism placeholder-setup/mental-devisingrepresentation/mentation/consciousness-awareness-teleology ${ }^{9}$ implied ${ }^{83}$ reference-of-thoughtcategorical-imperatives/axioms/registry-teleology ${ }^{9}$, -for-

aposteriorising/logicising/deriving/intelligising/measuring- ${ }^{5}$ meaningfulness-and-teleology ${ }^{9}$ as of the affirmation/projection/assertion/notional $\sim$ self-distantiation/dueness-validatinglogicising/suitable-measuringinstrument-validating-measuring-<as-to-postconverging-ordialectical-thinking -apriorising-psychologism> of prospective relative-ontologicalcompleteness ${ }^{87}$-of- ${ }^{83}$ reference-of-thought and unaffirmation/deprojection/deassertion/epistemic-decadence/undueness-invalidatinglogicising/unsuitable-measuringinstrument-invalidating-measuring-<as-to-preconverging-ordementing -apriorising-psychologism> of prior relative-ontological-incompleteness ${ }^{8}$-ofreference-of-thought, contrary to the various 'ascription-constructs' of the respective 
placeholder-setup/mental-devising-representation/mentation/consciousness-awarenessteleology as of positivism- ${ }^{80}$ procrypticism $<$ amplituding/formativeepistemicity>totalising intervalist-as-categorising__implicited_attendant-ontologicalcontiguity ${ }^{67}$, educedexistentialising/contextualising/textualising_intelligibility/epistemicity/reflexivity-contiguity<imbued-notional cogency>' 'ascription-construct of kindness-humility-helpfulness-etc. transience', $\quad{ }^{103}$ universalisation-non-positivism/medievalism $\quad<$ amplituding/formativeepistemicity>totalising $\sim$ ordinal-as-qualifying__implicited_attendant-ontologicalcontiguity $^{67}$, educedexistentialising/contextualising/textualising_intelligibility/epistemicity/reflexivity-contiguity<imbued-notional cogency>' 'ascription-construct of good-to-bad transience', baseinstitutionalisation-ununiversalisation $<$ amplituding/formativeepistemicity>totalising nominal-as-tendentious_- implicited_attendant_ontologicalcontiguity ${ }^{67} \sim$ educedexistentialising/contextualising/textualising_intelligibility/epistemicity/reflexivity-contiguity<imbued-notional cogency>' 'ascription-construct of allegiance/subservience transience', and recurrent-utter-uninstitutionalisation $<$ amplituding/formativeepistemicity $>$ totalising $\sim$ random-as-impulsive_-'implicited_attendant-ontologicalcontiguity ${ }^{67} \sim$ educedexistentialising/contextmalising/textualising_intelligibility/epistemicity/reflexivity_contiguity$<$ imbued-notional cogency $>$ ' 40 ascription-construct of impulsive-or-accidented-or-haphazardor-random transience', is notionally construed not on a ${ }^{83}$ reference-of-thought- categoricalimperatives/axioms/registry-teleology ${ }^{9}$ basis as of ascription but wholly as a $<$ amplituding/formative-epistemicity $>$ totalising $\sim$ ratiocontiguity/ratiocination-asreferentialism — 'implicited_attendant—ontological-contiguity ${ }^{67}$ ' educed- 
existentialising/contextualising/textualising_intelligibility/epistemicity/reflexivity-contiguity<imbued-notional cogency>' 'ontological-performance ${ }^{72}-<$ including-virtue-as-ontology $>$ construct of candidity/candour-capacity' as of apriorising/axiomatising/referencing-\{of'prospectively_implicited_attendant-ontological-contiguity ' educedexistentialising/contextualising/textualising_'intelligibility/epistemicity/reflexivity-contiguity<imbued-notional cogency>' \}-conflatedness ${ }^{13}$-in-\{preconverging-ment by\} postconverging-entailment with respect to the upholding/failing of ontologicalnormalcy/postconvergence by prospective relative-ontological-completeness ${ }^{87}$-of- ${ }^{8}$ reference-

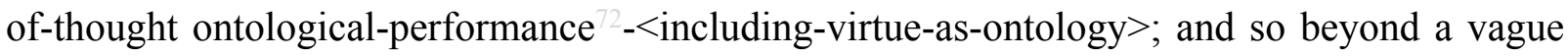
notion of virtue but rather as an overall superseding ${ }^{83}$ reference-of-thought-as-topreconverging/postconverging-de-mentating/structuring/paradigming-ontological-

performance ${ }^{2}-<$ including-virtue-as-ontology $>$. In other words from an ontologicalnormalcy/postconvergence perspective implied with candidity/candour-capacity notional ${ }^{18}$ deprocrypticism placeholder-setup/mental-devisingrepresentation/mentation/consciousness-awareness-teleology ${ }^{99}$, ascription-constructs are naïve $<$ amplituding/formative-epistemicity $>$ totalising $\sim$ self-referencing-

syncretising/circularity/interiorising/akrasiatic-drag ${ }^{34}$ construals of human ${ }^{83}$ reference-ofthought-as-to-preconverging/postconverging-de-mentating/structuring/paradigmingontological-performance ${ }^{72}$-<including-virtue-as-ontology $>$ The ontologicalnormalcy/postconvergence nature of intrinsic-reality/ontological-veridicality implies human reference-of-thought-as-to-preconverging/postconverging-dementating/structuring/paradigming — ontological-performance ${ }^{72}-<$ including-virtue-asontology $>$ /morality/ethics/justice/etc. is construed as it upholds/fails ontologicalnormalcy/postconvergence as from prospective relative-ontological-completeness ${ }^{87}$-ofreference-of-thought and is actually a wholly internal process of 
apriorising/axiomatising/referencing-\{of-'prospectively_implicited_attendant-ontological-

contiguity ' educed-

existentialising/contextualising/textualising_'intelligibility/epistemicity/reflexivity-contiguity-

<imbued-notional cogency $\left.>^{\prime}\right\}$ - conflatedness ${ }^{13}$-in-\{preconverging-ment by \} $^{-}$

postconverging-entailment, highlighting the 'concatenation to intemporal-projection inextricably of derived-denaturing -deprojections-in-distractiveness-of-intemporal-projection, with the former in relative intemporality ${ }^{5 /} /$ longness and the latter in relative temporality 8 /shortness as of distractiveness'; construed as temporal-concatenation-tointemporality ${ }^{52}$-or-ontological-veridicality-as-of- ${ }^{\circ 3}$ reference-of-thought—degraded-devolvingas-of-uninstitutionalised-threshold ${ }^{102}$ '. As a further elucidation, by 'protensive-consciousness' is meant the consciousness-awareness-teleology $<$ amplituding/formativeepistemicity $>$ causality $\sim$ as-to-projective-totalitative-implications-of-prospectivenonpresencing,-for-explicating relative-unreflexivity/relative-reflexivity - ontologicalcontiguity of apriorising/axiomatising/referencing-\{of-'prospectively implicited_attendantontological-contiguity ' educedexistentialising/contextualising/textualising_'intelligibility/epistemicity/reflexivity-contiguity<imbued-notional cogency>' $\}$-conflatedness ${ }^{13}$ in $\{$ preconverging ment by postconverging-entailment as an anticipatory mental-disposition with respect to deprocrypticism's preempting-disjointedness-as-of- reference-of-thought Beingdevelopment and its ${ }^{56}$ meaningfulness-and-teleology certitude/uninhibited ${ }^{83}$ reference-ofthought-as-to-preconverging/postconverging-de-mentating/structuring/paradigmingontological-performance $^{72}$-<including-virtue-as-ontology $>/$ morality/ethics/justice/etc. wherein 'limited-mentation-capacity as-subjecting 'educed unlimitedness/existence-sublimating nascence' to-limitedness/human-subpotency is overcome by its referentialism-ontologicallyuncompromised-mediating,-as-of-conflatedness 
apriorising/axiomatising/referencing/intelligibilitysettingup/measuringinstrumenting' as of 'ontological-normalcy/postconvergence of the full-cohesive transcendentalenabling/sublimating/supereregatery $\sim$ de-mentativity determinativeness ingrained in social ${ }^{3}$ universal-transparency ${ }^{104}$-〈transparency-of-totalising-entailing,-as-to-entailing$<$ amplituding/formative-epistemicity>totalising in-relative-ontological-completeness $\rangle ; \quad$ in contrast to our positivism- ${ }^{8}$ procrypticism 'occlusive-consciousness' with consciousnessawareness-teleology' implications as of 'human limited-mentation-capacity-as-subjecting‘educed-unlimitedness/existence-sublimating nascence' to-limitedness/human-subpotency by its categorising - ontologically-compromised-mediating,-as-of-its-specific-constitutedness apriorising/axiomatising/referencing/intelligibilitysettingup/measuringinstrumenting' for positivism- ${ }^{8}$ procrypticism Being and its ${ }^{56}$ meaningfulness-and-teleology ${ }^{98}$ reference-ofthought-as-to-preconverging/postconverging-de-mentating/structuring/paradigmingontological-performance $^{72}$-<including-virtue-as-ontology $>, \quad$ or respectively for universalisation-non-positivism/medievalism 'preclusive-consciousness', baseinstitutionalisation-ununiversalisation 'warped-consciousness' and recurrent-utteruninstitutionalisation 'trepidatious-consciousness', with consciousness-awareness-teleology implications as of 'human limited-mentation-capacity-as-subjecting-educedunlimitedness/existence-sublimating nascence' to-limitedness/human-subpotency by their respectively-qualifying/tendentious/impulsive—ontologically-compromised-mediating,-as-oftheir-respective-specific-constitutedness mentaldispositions/apriorising/axiomatising/referencing/intelligibilitysettingup/measuringinstrumenti ngs' as of their corresponding registry-worldviews/dimensions Beings and associated meaningfulness-and-teleology ${ }^{83}$ reference-of-thought-as-to-preconverging/postconvergingde-mentating/structuring/paradigming — ontological-performance ${ }^{2}-<$ including-virtue-asontology>. Underlying such graduated conceptualisation of human consciousness as of 
notional conflatedness ${ }^{13}, \quad$ is the fact that as of human-subpotencyaporia/undecidability/dilemma/ought-indeterminacy/deficiency/limitation/constraint—imbued'notional firstnaturedness-formativeness-<as-to-eventualising inkling-drive-or-seeding misprising $>$ temporal-to-intemporal-dispositions- $<$ so-construed-as-from-perspectiveontological-normalcy/postconvergence>'-existentialism-form-factor, such human consciousness apriorising/axiomatising/referencing-\{of-'prospectively implicited_attendantontological-contiguity ' $\sim$ educedexistentialising/contextualising/textualising_'intelligibility/epistemicity/reflexivity-contiguity$<$ imbued-notional cogency $\left.>^{\prime}\right\}$ - conflatedness ${ }^{13}$-in-\{preconverging $m e n t$ by $\}$ postconverging-entailment ultimately behind the successive institutionalcumulation/institutional-recomposure-〈as-to- historiality/ontologicaleventfulness /ontological-aesthetic-tracing-<perspective-ontologicalnormalcy/postconvergence-reflected-'epistemicity-relativism-determinism'>> in reflecting holographically-<conjugatively-and-transfusively $>$ the relative-unreflexivity/relativereflexivity - ontological-contiguity of-the-human-institutionalisation-process is grounded on its least common human temporality ${ }^{8} /$ shortness-to-intemporality $^{52} /$ longness denominator $^{2}$ which is the 'constraining social ${ }^{103}$ universal-transparency ${ }^{104}$-〈transparency-of-totalisingentailing,-as-to-entailing- $<$ amplituding/formative-epistemicity $>$ totalising $\sim$ in-relativeontological-completeness \; and while the 'complementing grander social- ${ }^{103}$ universally-nontransparent-thus-non-constraining-element of ontological-faith-notion-or-ontological-fideism imbued-underdetermination-of-motif-and-apriorising/axiomatising/referencing-as-so-being-asof-existential-reality' is aspirational as inducing dimensionality-of-sublimating <<amplituding/formative >supererogatory $\sim$ de-mentativeness/epistemic-growth-orconflatedness /transvaluative-rationalising/transepistemicity/anamnestic-residuality/spiritdrivenness-equalisation> mental-disposition behind the 'inventing' of prospective 
institutionalisation, it effectively occurs spontaneously to the intemporal-disposition and cannot be the basis for collective grounding of such human consciousness apriorising/axiomatising/referencing-\{of-'prospectively_implicited_attendant-ontologicalcontiguity ' educedexistentialising/contextualising/textualising_'intelligibility/epistemicity/reflexivity-contiguity<imbued-notional cogency $\left.>^{\prime}\right\}$-conflatedness ${ }^{13}$-in-\{preconverging-ment by\} postconverging-entailment as this inevitably leads to temporal concatenation to intemporality ${ }^{52}$, rather its import lies solely as of solipsistic intemporal projection drive given that ontologicalfaith-notion-or-ontological-fideism - imbued-underdetermination-of-motif-andapriorising/axiomatising/referencing-as-so-being-as-of-existential-reality is beyond the possibility of its secondnatured institutionalisation just as implied with the notion of faith in creeds. Further, the dynamics of such a graduated human consciousness as of notional conflatedness ${ }^{13}$ of notional ${ }^{1}$ deprocrypticism can be reinterpreted operantly as of 'notional referentialism' as it points to the fact that categorising/qualifying/tendentious/impulsive—ontologically-compromised-mediating,-as-oftheir-respective-specific-constitutedness mentaldispositions/apriorising/axiomatising/referencing/intelligibilitysettingup/measuringinstrumenti ngs are actually 'various levels of failing to achieve the notional ${ }^{18}$ deprocrypticism referentialism—ontologically-uncompromised-mediating,-as-of-conflatedness apriorising/axiomatising/referencing/intelligibilitysettingup/measuringinstrumenting that ensure ontological-completeness-of- ${ }^{-3}$ reference-of-thought', and thus are construed as of the same notion of referentialism implied as to knowledge-notionalisation, and so as of 'pseudoreferentialism mentaldispositions/apriorising/axiomatising/referencing/intelligibilitysettingup/measuringinstrumenti ngs levels' given their respectively underlying limited-mentation-capacity-as-subjecting- 
'educed-unlimitedness/existence-sublimating nascence' to-limitedness/human-subpotency in achieving referentialism imbued knowledge-notionalisation. While in reality these are respectively of 'categorising/qualifying/tendentious/impulsive-ontologically-compromisedmediating,-as-of-their-respective-specific-constitutedness mentaldispositions/apriorising/axiomatising/referencing/intelligibilitysettingup/measuringinstrumenti ngs', they still act as if of 'notional deprocrypticism referentialism-ontologicallyuncompromised-mediating,-as-of-conflatedness

apriorising/axiomatising/referencing/intelligibilitysettingup/measuringinstrumenting', and so 'in their beyond-the-consciousness-awareness-teleology ${ }^{-<}<$of-preconverging-existentialextrication-as-of-existential-unthought> preconverging-or-dementing ${ }^{20}$-apriorisingpsychologism' thus generating as of their 'pseudo-referentialism mentaldispositions/apriorising/axiomatising/referencing/intelligibilitysettingup/measuringinstrumenti ngs levels' their respective ${ }^{58}$ neuterising construed as of 'their prior relative-ontologicalincompleteness ${ }^{88}$-of- ${ }^{8}$ reference-of-thought of ${ }^{5}$ meaningfulness-and-teleology ${ }^{9}$ '. ${ }^{58}$ Neuterising thus refers to human attribution of ${ }^{56}$ meaningfulness-and-teleology ${ }^{9}$ as of human limitedmentation-capacity—as-subjecting-'educed-unlimitedness/existence-sublimating nascence' to limitedness/human-subpotency mentative/structural/paradigmatic misconstruing, with respect to existential$<$ disontologising/re-ontologising aporeticism $>$ social-stake-contention-or-confliction possibilities, such that its reference-of-thought-as-to-preconverging-de-

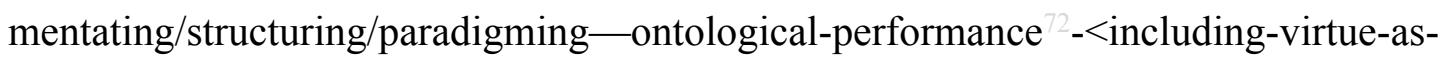
ontology $>$ /morality/ethics/justice/etc. is relatively ontologically-incomplete/of-ontologicallycompromised-mediating,-as-of-its-specific-constitutedness ${ }^{14}$, and so-construed from the apriorising/axiomatising/referencing-\{of-'prospectively_implicited_attendant-ontologicalcontiguity ' educed- 
existentialising/contextualising/textualising_'intelligibility/epistemicity/reflexivity-contiguity-

<imbued-notional cogency $\left.>^{\prime} \quad\right\}$-conflatedness ${ }^{13}$ in-\{preconverging-ment by\}

pestconverging entailment of notional ${ }^{18}$ deprocrypticism; thus ${ }^{58}$ neuterising is specifically a 'contextually developed perversion-or-derived- perversion-of- ${ }^{-3}$ reference-of-thought- $<$ aspreconvergingly-apriorising/axiomatising/referencing-in-

nonconviction/madeupness/bottomlining-as-to-shallow-supererogation

that

is

secondnatured as of its prior relative-ontological-incompleteness ${ }^{88}$-of- ${ }^{3}$ reference-of-thought with the consequent implications of relatively defective ${ }^{5}$ meaningfulness-and-teleology ontological-performance $^{72}-<$ including-virtue-as-ontology $>$. For instance, as of their relativeontological-incompleteness ${ }^{8}$-of- ${ }^{8}$ reference-of-thought, an animist society might notice that going to a given forest leads to illness and ascribe evil to that forest but then a prospective relative-ontological-completeness ${ }^{8}$-of- ${ }^{8}$ reference-of-thought positivism interpretation may be that at a certain time of the day and during a certain time of the year that forest attracts mosquitoes that cause malaria for instance which can be prevented by rubbing a certain leaf on ones cloths and body, together with the fact that a given root can be used to cure the malaria, and in addition to a whole web of nuanced understanding available to the positivism ${ }^{56}$ meaningfulness-andteleology ${ }^{9}$ relative to the 'utter and brute' animistic interpretation as ${ }^{56}$ meaningfulness-andteleology ${ }^{58}$ neuterising that it is an evil forest one should not trespass together with a whole cohort of 'imaginary tales' in shoring up that posture, speaking of its threshold-ofnonconviction/madeupness/bottomlining-in-shallow-supererogation $-<$ as-to-'attendantintradimensional'-prospectively-disontologising preconverging/dementing -apriorisingpsychologism>. This is a most elaborate articulation of ${ }^{58}$ neuterising as to Beingdevelopment/ontological-framework-expansion-as-to-depth-of-ontologising-development-asinfrastructure-of- meaningfulness-and-teleology implications but it equally applies where meaningfulness-and-teleology ${ }^{9}$ is 'just about miscued' say between positivism- 
procrypticism and prospective deprocrypticism with the latter underlying the disjointednessas-of- ${ }^{8}$ reference-of-thought of the former as to its ${ }^{58}$ neuterising, for instance in the case of psychopathy and corresponding conjugated-postlogism 77 as social psychopathy as in the various illustrations highlighted herein and particularly as more obviously revealed with childhood psychopathy. In-the-bigger-picture, ascriptivity-or-ascription-hardening/pseudo-referenctialism arises as of notional $\sim$ referentialism/notional $\sim$ deprocrypticism; wherein recurrent-utteruninstitutionalisation's existential<<disontologising/re-ontologising aporeticism $>{ }^{83}$ referenceof-thought deepest-level of ${ }^{58}$ neuterising is elicited by its 'trepidatious-consciousness impulsive-ontologically-compromised-mediating,-as-of-its-specific-constitutedness apriorising/axiomatising/referencing/intelligibilitysettingup/measuringinstrumenting rulemaking-over-non-rules_-apriorising/axiomatising/referencing-psychologism', failing baseinstitutionalisation-ununiversalisation existential-<disentologising/re-ontologising aporeticism $>{ }^{83}$ reference-of-thought next level of ${ }^{58}$ neuterising is elicited by its 'warpedconsciousness tendentious - ontologically-compromised-mediating,-as-of-its-specificconstitutedness

apriorising/axiomatising/referencing/intelligibilitysettingup/measuringinstrumenting failing universalisation-directed-rulemaking-over-non-rules_-apriorising/axiomatising/referencingpsychologism', ${ }^{3}$ universalisation-non-positivism/medievalism existential$<$ disontologising/re-ontologising aporeticism $>{ }^{83}$ reference-of-thought after-next level of neuterising is elicited by its 'preclusive-consciousness qualifying-ontologicallycompromised-mediating,-as-of-its-specific-constitutedness

apriorising/axiomatising/referencing/intelligibilitysettingup/measuringinstrumenting failing positivising/rational-empiricism-based-universalisation-directed-rulemaking-over-non-rulesapriorising/axiomatising/referencing-psychologism', positivism- ${ }^{80}$ procrypticism existentialdisontologising/re-ontologising aporeticism $>{ }^{83}$ reference-of-thought next-after-next level of 
neuterising is elicited by its 'occlusive-consciousness categorising-ontologicallycompromised-mediating,-as-of-its-specific-constitutedness

apriorising/axiomatising/referencing/intelligibilitysettingup/measuringinstrumenting failing preempting - disjointedness-as-of- ${ }^{83}$ reference-of-thought,-as-to- ${ }^{6}<$ amplituding/formativeepistemicity>growth-or-conflatedness $13 /$ transvaluative-

rationalising/transepistemicity/anamnestic-residuality/spirit-drivenness'—in-supersedingmere-formulaic-positivising/rational-empiricism-based-universalisation-directed-rulemakingover-non-rules_-apriorising/axiomatising/referencing-psychologism', and ultimately futural Being-development/ontological-framework-expansion-as-to-depth-of-ontologisingdevelopment-as-infrastructure-of- meaningfulness-and-teleology as of prospective notional ${ }^{18}$ deprocrypticism existential-<disontologising/re-ontologising aporeticism $>$ reference-of-thought overcomes- neuterising/fully-deneuterises by its 'protensiveconsciousness referentialism —ontologically-uncompromised-mediating,-as-of-conflatedness apriorising/axiomatising/referencing/intelligibilitysettingup/measuringinstrumenting as preconverging/postconverging-de-mentatively/structurally/paradigmatically preemptingdisjointedness-as-of- ${ }^{83}$ reference-of-thought,-as-to- ${ }^{3}<$ amplituding/formativeepistemicity $>$ growth-or-conflatedness ${ }^{13} /$ transvaluativerationalising/transepistemicity/anamnestic-residuality/spirit-drivenness'_in-supersedingmere-formulaic-positivising/rational-empiricism-based-universalisation-directed-rulemakingover-non-rules - apriorising/axiomatising/referencing-psychologism' and so by way of its more profound apriorising/axiomatising/referencing-\{of-'prospectively implicited_attendantontological-contiguity ' educedexistentialising/contexalising/textralising_intelligibility/epistemicity/reflexivity-contiguity$<$ imbued-notional cogency $>$ ' $\}$-conflatedness ${ }^{13}$ in-\{preconverging-ment by\} postconverging-entailment as of <amplituding/formative-epistemicity $>$ causality $\sim$ as-to- 
projective-totalitative-implications-of-prospective- nonpresencing,-for-explicating relative-

unreflexivity/relative-reflexivity - ontological-contiguity . Thus basically, ${ }^{58}$ neuterising of the various ${ }^{83}$ references-of-thought-devolving-teleological-de-mentating/structuring/paradigmingof-meaningfulness is as of 'categorising-occlusive-consciousness/qualifying-preclusiveconsciousness/tendentious-warped-consciousness/impulsive-trepidatious-consciousnessontologically-compromised-mediating,-as-of-their-respective-specific-constitutedness mental-

dispositions/apriorising/axiomatising/referencing/intelligibilitysettingup/measuringinstrumenti ngs' by their respective relative human limited-mentation-capacities as their respective beyondthe-consciousness-awareness-teleologies preconverging-or-dementing ${ }^{20}$-apriorisingpsychologism construed as their respective prior relative-ontological-incompleteness ${ }^{8}$-ofreference-of-thought ${ }^{58}$ neuterising, and revealing as of the notional conflatedness ${ }^{13}$ of notional ${ }^{18}$ deprocrypticism their ' ${ }^{83}$ reference-of-thought- ${ }^{8}$ devolving-différance/internaldialectics/difference-deferral' with regards to their respective ${ }^{83}$ reference-of-thought-as-topreconverging-de-mentating/structuring/paradigming relative transcendentally-unenabledprior-institutionalisation-level-by-prospective-uninstitutionalised-threshold ${ }^{102}$; underlining the ontological implications of understanding ${ }^{58}$ neuterising with respect to 'retrospective and prospective Being underdevelopment elucidations of ${ }^{56}$ meaningfulness-and-teleology ${ }^{9}$ ' as of neuterising induced failing of ${ }^{8}$ reference-of-thought-as-to-preconverging/postconverging-dementating/structuring/paradigming — ontological-performance ${ }^{72}-<$ including-virtue-asontology $>$. Basically ${ }^{58}$ neuterising as so articulated is the conception of the 'ontologicalperformance $^{72}-<$ including-virtue-as-ontology $>$ /morality/ethics/justice/etc. of the various institutionalisations references-of-thought-devolving-teleological-dementating/structuring/paradigming-of-meaningfulness' so-conceptualised from the notional conflatedness ${ }^{13}$ of notional ${ }^{18}$ deprocrypticism protensive-consciousness, and such an 
ontologically-veridical evaluation of ${ }^{58}$ neuterising is construed as a deneuterising referentialism reflecting-ontologically-veridical-'affirmation/projection/assertion/notional $\sim$ selfdistantiation/dueness-validating-logicising/suitable-measuringinstrument-validatingmeasuring-<as-to-postconverging-or-dialectical-thinking -apriorising-psychologism>'-andontologically-flawed-'preconverging-or-dementing -apriorising-psychologism/deassertion' as of the various institutionalisations ${ }^{8}$ references-of-thought-devolving-teleological-dementating/structuring/paradigming-of-meaningfulness'. The implication here being that neuterising 'can be disambiguated as of the fundamental human limited-mentation-capacityas-subjecting-'educed-unlimitedness/existence-sublimating nascence' to-limitedness/humansubpotency induced $\quad$ <amplituding/formativeepistemicity $>$ totalising/circumscribing/delineating context $-{ }^{5}$ meaningfulness-and-teleology reference-of-thought- ${ }^{-4}$ devolving-as-of-instantiative-ontological-performance ${ }^{72}-<$ including- $^{-}$ virtue-as-ontology $>$ /morality/ethics/justice/etc. misconstrual-as- ${ }^{-}$neuterising, and so-construed as of referentialism as of the notional conflatedness ${ }^{13}$ of notional ${ }^{18}$ deprocrypticism protensiveconsciousness; thus gaining a superseding insight of the ontologically-flawed ${ }^{8}$ references-ofthought-devolving-teleological-de-mentating/structuring/paradigming-of-meaningfulness fixations/hardening-construed-as- ${ }^{-5}$ neuterising of the various relative-ontologically-incomplete institutionalisations as of their existential-contextualisation; as this deneuterising referentialism reflecting-ontologically-veridical-'affirmation/projection/assertion/notional $\sim$ selfdistantiation/dueness-validating-logicising/suitable-measuringinstrument-validatingmeasuring-<as-to-postconverging-or-dialectical-thinking -apriorising-psychologism>'-andontologically-flawed-'preconverging-or-dementing -apriorising-psychologism/deassertion' as from notional ${ }^{18}$ deprocrypticism, disambiguates ${ }^{58}$ neuterising as an insight into the ontologically-veridical 'underlying phenomenological dynamics of human limited-mentationcapacity —as-subjecting 'educed-unlimitedness/existence-sublimating nascence' to- 
limitedness/human-subpotency' that explains the how-and-why of such ontologically-flawed references-of-thought-devolving-teleological-de-mentating/structuring/paradigming-ofmeaningfulness fixations/hardening-construed-as- ${ }^{58}$ neuterising associated with the various institutionalisations in prior relative-ontological-incompleteness ${ }^{8}$-of- ${ }^{8}$ reference-of-thought. Insightfully and counterintuitively for elucidative construal, ${ }^{58}$ neuterising as of epistemicabnormalcy/preconvergence ${ }^{31}$ /relative-ontological-incompleteness ${ }^{88}$-of- ${ }^{83}$ reference-of-thought is rather a 'derived-construction as deficient of ontological-normalcy/relative-ontologicalcompleteness ${ }^{87}$-of- reference-of-thought', as it is the elucidation of ontologicalnormalcy/relative-ontological-completeness ${ }^{87}$-of- ${ }^{8}$ reference-of-thought as truly reflecting intrinsic-reality/ontological-veridicality, whether we are aware of it as of postconverging-ordialectical-thinking -apriorising-psychologism or unaware beyond-the-consciousnessawareness-teleology $-<$ of-preconverging-existential-extrication-as-of-existential-unthought $>$ as of preconverging-or-dementing -apriorising-psychologism/deassertion, that reveals neuterising as of epistemic-abnormalcy/preconvergence $/$ /relative-ontologicalincompleteness ${ }^{88}$-of- ${ }^{8}$ reference-of-thought as it is construed in its ontological-veridicality as a 'deficient derived-construction of ontological-normalcy/relative-ontological-completeness ${ }^{87}$-ofreference-of-thought'. This insight equally explains why it is 'through the deficient derivedconstruction of apriorising/axiomatising/referencing-\{of-'prospectively implicited_attendantontological-contiguity ' educed-

existentialising/contextualising/textualising_intelligibility/epistemicity/reflexivity_contiguity<imbued-notional cogency $>$ ' $\}$ - conflatedness ${ }^{13}$ in-\{preconverging-ment by\} pestconverging-ntailment' that is construed the ontologically-veridical nature of distractivealignment-to- ${ }^{83}$ reference-of-thought- $<$ of-apriorising/axiomatising/referencing $>{ }^{30}$ destructuring. Understanding and overcoming ${ }^{58}$ neuterising as such reveals the beyond-the-consciousnessawareness-teleology ${ }^{9}<$ of-preconverging-existential-extrication-as-of-existential-unthought $>$ 
dynamism of human temporal-to-intemporal individuations mentaldispositions/apriorising/axiomatising/referencing/intelligibilitysettingup/measuringinstrumenti ng as critical across all the registry-worldviews/dimensions construed as of de-mentation〈supererogatory-ontological-de-mentation-or-dialectical-de-mentation-stranding-orattributive-dialectics $\rangle$. The ontological-veridicality of a 'postconverging-or-dialecticalthinking -psychology or psychology-of-mentation-dynamics or natural $\sim$ psychologicaldynamics' as associated with 'intemporal ontological-faith-notion-or-ontological-fideismimbued-underdetermination-of-motif-and-apriorising/axiomatising/referencing-as-so-being-asof-existential-reality instigated relative-unreflexivity/relative-reflexivity_ontologicalcontiguity $^{67} \sim$ of-the-human-institutionalisation-process ${ }^{68}$ as of difference-conflatedness ${ }^{13}$-as-tototalitative-reification-in-singularisation-<as-to-the-nondisjointedness/entailment-ofprospective- nonpresencing $>$-as-veridical-epistemicity-relativism-determinism implied $<$ amplituding/formative-epistemicity $>$ causality $~$ as-to-projective-totalitative-implications-ofprospective- nonpresencing,-for-explicating relative-unreflexivity/relative-reflexivityontological-contiguity ' is one grounded as of ${ }^{15}$ de-mentation-〈supererogatory $\sim$ ontological-dementation-or-dialectical-de-mentation-stranding-or-attributive-dialectics) 'decentering/pivoting around the uninstitutionalised-threshold ${ }^{102}$ rule' as a remaking of apriorising/axiomatising/referencing/intelligibilitysettingup/measuringinstrumenting involving the resetting of the placeholder-setup/mental-devising-representation/mentation/consciousnessawareness-teleology 9 pointing out that prior apriorising/axiomatising/referencing/intelligibilitysettingup/measuringinstrumenting has been superseded as of its revealed perversion-and-derived- perversion-of- ${ }^{7}$ reference-of-thought$<$ as-preconvergingly-apriorising/axiomatising/referencing-innonconviction/madeupness/bottomlining-as-to-shallow-supererogation $>$ and so as of the uninstitutionalised-threshold ${ }^{102}$ rule. This explains why at uninstitutionalised-threshold ${ }^{102}$ which 
are subject to ' ${ }^{5}$ meaningfulness-and-teleology ${ }^{58}$ neuterising', prospective institutionalisation can only be achieved as of secondnatured constraining social ${ }^{103}$ universal-transparency ${ }^{104}$ 〈transparency-of-totalising-entailing,-as-to-entailing-<amplituding/formative-

epistemicity>totalising in-relative-ontological-completeness $>$ that overcomes the given uninstitutionalised-threshold ${ }^{102}$ ' meaningfulness-and-teleology ${ }^{58}$ neuterising' thus enabling the ontological-normalcy/relative-ontological-completeness ${ }^{87}$-of- ${ }^{-3 e f e r e n c e-o f-t h o u g h t ~ o f ~ t h e ~}$ prospective institutionalisation. It also explains why naively implying at an uninstitutionalisedthreshold ${ }^{102}$ that the "social- ${ }^{103}$ universally-non-transparent-thus-non-constraining-element of ontological-faith-notion-or-ontological-fideism - imbued-underdetermination-of-motif-andapriorising/axiomatising/referencing-as-so-being-as-of-existential-reality' is ${ }^{103}$ universally attributable as if humans had only the intemporal/ongness-of-register-of- meaningfulness-andteleology individuation without temporal/shortness-of-register-of meaningfulness-andteleology individuations will simply fail to recognise the generation-and-upholding of neuterising and thus unable to reveal perversion-and-derived- perversion-of- $^{-}$reference-ofthought-<as-preconvergingly-apriorising/axiomatising/referencing-in-

nonconviction/madeupness/bottomlining-as-to-shallow-supererogation $>$; as it is naïve to think that while being at an uninstitutionalised-threshold ${ }^{02}$ like ${ }^{103}$ universalisation-nonpositivism/medievalism by mere-and-vague impression-driven/good-naturedness/wishfulness $<$ amplituding/formative $>$ wooden-language-<imbued - averaging-of-thought- $<$ as-toleveling/ressentiment/closed-construct-of- meaningfulness-and-teleology -as-of'nondescript/ignorable-void '-with-regards-to-prospective-apriorising-implications $>>$ in social-aggregation-enabling, people will 'simply by magic' find themselves articulating positivistic ${ }^{56}$ meaningfulness-and-teleology ${ }^{9}$ without grasping that the psychoanalyticunshackling/memetic-reordering/institutional-recomposuring crossgenerational process is effectively the mechanism for 'overcoming non-positivism/medievalism uninstitutionalisation 
meaningfulness-and-teleology ${ }^{58}$ neuterising' to be able to then reveal, construe and uphold positivistic Being and ${ }^{56}$ meaningfulness-and-teleology ${ }^{9}$, and this equally applies with regards to overcoming our $\quad$ "80 procrypticism-or-disjointedness-as-of- ${ }^{3}$ reference-of-thought meaningfulness-and-teleology ${ }^{58}$ neuterising' to attain futural Beingdevelopment/ontological-framework-expansion-as-to-depth-of-ontologising-development-asinfrastructure-of- meaningfulness-and-teleology as of prospective notional ${ }^{1}$ deprocrypticism Being and ${ }^{5}$ meaningfulness-and-teleology ${ }^{9}$. As a further elucidation, a comparison can be made between a construct of 'notional referentialism' disambiguated as referentialism, categorising ${ }^{58}$ neuterising, qualifying ${ }^{58}$ neuterising, tendentious neuterising and impulsive ${ }^{58}$ neuterising, and in parallel a reflection of 'data conceptualisation' disambiguated as ratio-contiguous referencing, intervalist pseudo-referencing, ordinal pseudoreferencing, nominal pseudo-referencing and random pseudo-referencing. We can grasp that effectively data conceptualisation as of intrinsic-reality/ontological-veridicality is inherently ratio-contiguous as of ontological-normalcy/relative-ontological-completeness ${ }^{87}$-of- ${ }^{8}$ referenceof-thought but then we don't always have the capacity to reference ratio-contiguous data and so the other types of data conceptualisations are available to us as well 'as of the limitations of our measuring capacity', and we grasp that the latter are actually in 'constructed-deficiency of $<$ amplituding/formative-epistemicity $>$ totalising $\sim$ ratiocontiguity/ratiocination-asreferentialism - 'implicited_attendant_ontological-contiguity ${ }^{67}$ ' educedexistentialising/contextmalising/textualising_intelligibility/epistemicity/reflexivity_contiguity$<$ imbued-notional cogency $>^{\prime 0}$ as of their respective epistemicabnormalcy/preconvergence ${ }^{31} /$ relative-ontological-incompleteness ${ }^{88}$-of- ${ }^{83}$ reference-of-thought. Here as well it is important to understand that it is the ratio-contiguous referencing data conceptualisation that provides the 'overriding framework as of apriorising/axiomatising/referencing-\{of-'prospectively_implicited_attendant-ontological- 
contiguity ' educed-

existentialising/contextualising/textualising_'intelligibility/epistemicity/reflexivity_contiguity<imbued-notional cogency >' \}-conflatedness ${ }^{13}$ in-\{preconverging-ment by\}

postconverging-entailment' for making-sense-of/construing the relatively deficient referencing data conceptualisations as of their 'defined tolerable levels' of neuterising. This elucidation is to point out that reference-of-thought constructs in epistemicabnormalcy/preconvergence ${ }^{3}$ /relative-ontological-incompleteness ${ }^{8}$-of- ${ }^{-}$reference-of-thought in-the-very-first-place cannot be the basis for articulating, as of their given apriorising/axiomatising/referencing-\{of-'prospectively_implicited_attendant-ontologicalcontiguity ' educedexistentialising/contextualising/textualising_intelligibility/epistemicity/reflexivity_contiguity<imbued-notional cogency $>$ ' $\}$-constitutedness ${ }^{14}$-in-preconverging-entailment, $\quad$ by elaboration-as-to-mere-extrapolating/constituting/abstracting/deducing/inferring-ofelucidation-outside_- 'prospectively_implicited_attendant-ontological-contiguity ${ }^{6 /}$ > educedexistentialising/contextualising/textualising_intelligibility/epistemicity/reflexivity-contiguity$<$ imbued-notional cogency $>$ ' ${ }^{40}$ ontologically-veridical ${ }^{5}$ meaningfulness-and-teleology 'as if in referentialism as of referentialism-ontologically-uncompromised-mediating,-as-ofconflatedness

apriorising/axiomatising/referencing/intelligibilitysettingup/measuringinstrumenting' but rather require 'their ontologically-veridical ${ }^{56}$ meaningfulness-and-teleology ${ }^{9}$ restoration' by an apriorising/axiomatising/referencing-\{of-'prospectively implicited_attendant-ontologicalcontiguity ' educedexistentialising/contextrising/textralising_intelligibility/epistemicity/reflexivity-contiguity$<$ imbued-notional $\left.\sim \operatorname{cogency}>^{\prime}\right\}$-conflatedness ${ }^{13}$-in-\{preconverging-ment by $\}^{\prime}$ pestconverging entailment as of ontological-normalcy/relative-ontological-completeness ${ }^{87}$-of- 
reference-of-thought that factors in 'their constructed-deficiency with respect to ontologicalnormalcy/relative-ontological-completeness ${ }^{87}$-of- ${ }^{8}$ reference-of-thought, so-construed as their neuterising' as of their categorising/qualifying/tendentious/impulsive-ontologicallycompromised-mediating,-as-of-their-respective-specific-constitutedness mentaldispositions/apriorising/axiomatising/referencing/intelligibilitysettingup/measuringinstrumenti ngs; thus enabling ontologically-veridical construal as of both ontologicalcompleteness/incompleteness-of- ${ }^{83}$ reference-of-thought of Being and ${ }^{56}$ meaningfulness-andteleology ${ }^{9}$ retrospectively to prospectively in reflecting holographically-<conjugatively-andtransfusively $>$ the relative-unreflexivity/relative-reflexivity ontological-contiguity $\sim$ of-thehuman-institutionalisation-process . To put it another way, as distinct articulations of the same physics intrinsic-reality, we cannot simply by apriorising/axiomatising/referencing-\{of'prospectively_implicited_attendant-ontological-contiguity ' educedexistentialising/contextualising/textualising_'intelligibility/epistemicity/reflexivity_contiguity$<$ imbued-notional cogency $>$ ' $\}$-constitutedness ${ }^{14}$-in-preconverging-entailment $\quad$ by elaboration-as-to-mere-extrapolating/constituting/abstracting/deducing/inferring-ofelucidation-outside_-'prospectively_implicited_attendant-ontological-contiguity ${ }^{67}$, educed-

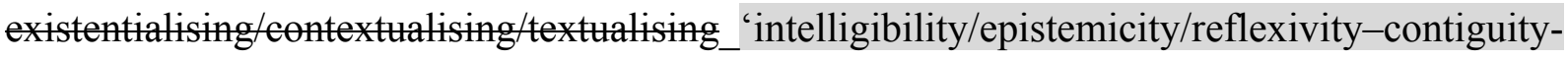
$<$ imbued-notional cogency $>$ ' of 'traditional classical mechanics axiomatic-construct' given its epistemic-abnormalcy/preconvergence ${ }^{3 /} /$ relative-ontological-incompleteness $^{8}$-ofreference-of-thought arrive-at/achieve the theory-of-relativity-together-with-quantummechanics-axiomatic-constructs as of its ontological-normalcy/relative-ontologicalcompleteness $^{87}$-of- ${ }^{83}$ eference-of-thought; as what is so generated is nothing as of reality but rather a virtuality-or-ontologically-flawed-construal. Instead such a construction of prospective relative intrinsic-reality/ontological-veridicality is an apriorising/axiomatising/referencing-\{of'prospectively_implicited_attendant-ontological-contiguity ' educed- 
existentialising/contextualising/textualising_ 'intelligibility/epistemicity/reflexivity-contiguity-

<imbued-notional cogency $\left.>^{\prime} \quad\right\}$-conflatedness ${ }^{13}$ in-\{preconverging-ment by\}

pestconverging entailment of 'traditional classical mechanics axiomatic-construct' by an epistemic totalising $\sim$ renewing-realisation/re-perception/re-thought as of maximalisingrecomposuring-for-relative-ontological-completeness ${ }^{87}$-unenframed/re-

ontologising conceptualisation; driven by ontological-faith-notion-or-ontological-fideism imbued-underdetermination-of-motif-and-apriorising/axiomatising/referencing-as-so-being-asof-existential-reality to reconstruct the same physics domain-of-study as the theory-of-relativitytogether-with-quantum-mechanics - axiomatic-constructs, and rather reflects the ontologicalveridicality that 'traditional classical mechanics axiomatic-construct' as of its epistemicabnormalcy/preconvergence ${ }^{31}$ /relative-ontological-incompleteness ${ }^{88}$-of- ${ }^{83}$ reference-of-thought is 'construed as a constructed-deficiency of the theory-of-relativity-together-with-quantummechanics - axiomatic-constructs ontological-normalcy/relative-ontological-completeness ${ }^{87}$ of- ${ }^{8}$ reference-of-thought perspective', and the former can only be subsumed/implied/construedas-non-contradictory to the latter. Such a basic conception of comparative axiomatic-constructs in their reflection of the-very-same <amplituding/formative-epistemicity $>$ totalising $\sim$ devolvedpurview-as-domain-of-construal-as-intrinsic-reality/ontological-veridicality highlights that ontologically-veridical meaningfulness is a construction or derived-construction as of inherent intrinsic-reality/ontological-veridicality or the closest axiomatic-construct approximation to it; the insight here being that 'relative completeness/profoundness of axiomaticconstruct/ ${ }^{83}$ reference-of-thought with respect to intrinsic-reality/ontological-veridicality' is what is ontologically preeminent/critical for the notional perspective of ontological construal/conceptualisation. This is equally relevant with regards to the "reference-ofthought_-devolving-teleological-de-mentating/structuring/paradigming-of-meaningfulness' which refers to the transcendental-enabling/sublimating/supererogatory $\sim$ de-mentativity 
conceptual

framework

that

sets

up

the

apriorising/axiomatising/referencing/intelligibilitysettingup/measuringinstrumenting for a registry-worldview's/dimension's ${ }^{83}$ reference-of-thought construction possibilities of derived axiomatic-constructs of ${ }^{56}$ meaningfulness-and-teleology 9 as knowledgeconstructs/theories/intersolipsistic-intercessory-notions/notional referential-

notions/articulations/virtue as of existential-instantiations', on the same unchanging intrinsicreality/ontological-veridicality construed/conceptualised by all registry-worldviews/dimensions, but generating with human limited-mentation-capacity-deepening-as-subjecting limitedness/human-subpotency to-'educed-unlimitedness/existence-sublimating nascence' successive more and more relatively profound/complete registry-worldviews/dimensions reference-of-thought constructions of derived axiomatic-constructs of ${ }^{5}$ meaningfulness-andteleology 9 as knowledge-constructs/theories/intersolipsistic-intercessorynotions/notional referential-notions/articulations/virtue; with the 〈given consciousness's neuterising-induced-or-deneuterising ${ }^{17}$-induced $>-{ }^{8}$ reference-of-thought—devolvingteleological-de-mentating/structuring/paradigming-of-meaningfulness as of its intradimensional existential-instantiations derived/devolved axiomatic-constructs of ${ }^{5}$ meaningfulness-andteleology 9 as knowledge-constructs/theories/intersolipsistic-intercessorynotions/notional $\sim$ referential-notions/articulations/virtue as the registryworldview's/dimension's $\quad{ }^{83}$ reference-of-thought 'abstract teleological-dementating/structuring/paradigming/teleological-possibilities'. For instance, all subsequent axiomatic-constructs of ${ }^{5}$ meaningfulness-and-teleology 9 as knowledgeconstructs/theories/intersolipsistic-intercessory-notions/notional referentialnotions/articulations/virtue of the recurrent-utter-uninstitutionalisation registryworldview/dimension are possible only by its /trepidatious-consciousness ${ }^{58}$ neuterisinginduced)- ${ }^{8}$ reference-of-thought — devolving-teleological-de- 
mentating/structuring/paradigming-of-meaningfulness which is non-rulesapriorising/axiomatising/referencing-psychologism,-as-impulsive-or-accidented-or-randommental-disposition as this basically defines the possibility of institutionalisation within recurrentutter-uninstitutionalisation as inherently non-existent. Likewise it is the habituated rulemakingover-non-rules - apriorising/axiomatising/referencing-psychologism as of ontological-faithnotion-or-ontological-fideism —imbued-underdetermination-of-motif-and-

apriorising/axiomatising/referencing-as-so-being-as-of-existential-reality for the prospective institutionalisation of base-institutionalisation that is the /warped-consciousness ${ }^{58}$ neuterisinginduced $>$ - reference-of-thought — devolving-teleological-de-

mentating/structuring/paradigming-of-meaningfulness for enabling intradimensional existential-instantiations derived/devolved axiomatic-constructs of ${ }^{56}$ meaningfulness-andteleology as knowledge-constructs/theories/intersolipsistic-intercessorynotions/notional referential-notions/articulations/virtue of base-institutionalisation. This insight extends to all <cumulating/recomposuring attendant-ontological-contiguity $>$-successive registry-worldviews/dimensions institutionalisations in construing their teleological-dementating/structuring/paradigming/teleological-possibilities. This equally explains the divergence of individuals and societies ontological-performance ${ }^{72}-<$ including-virtue-asontology $>$ /morality/ethics/justice/etc. across registry-worldviews/dimensions even though all humans have the same basic intellectual potential; as within the institutionalisation limits of a registry-worldview's/dimension’s ‘3 $\quad$ reference-of-thought—devolving-teleological-dementating/structuring/paradigming-of-meaningfulness' as its underlying ${ }^{83}$ reference-of-thought apriorising/axiomatising/referencing/intelligibilitysettingup/measuringinstrumenting, individuals cannot all of a sudden start thinking in terms-as-of-axiomatic-construct enabled by a prospective registry-worldview's/dimension's institutionalisation '83 reference-of-thoughtdevolving-teleological-de-mentating/structuring/paradigming-of-meaningfulness'; given that 
there is a need for the requisite institutional-cumulation/institutional-recomposure-〈as-tohistoriality/ontological-eventfulness /ontological-aesthetic-tracing-<perspectiveontological-normalcy/postconvergence-reflected-'epistemicity-relativism-determinism'>> as of successive psychoanalytic-unshackling/memetic-reordering/institutional-recomposuring underlying the transcendence-and-sublimity/sublimation/supererogatory $\mathrm{de}$-mentativity in reflecting holographically-<conjugatively-and-transfusively $>$ the relative-unreflexivity/relativereflexivity - ontological-contiguity of-the-human-institutionalisation-process . The fact is that all meaningfulness-and-teleology ${ }^{5}$ ontological-performance ${ }^{72}-<$ including-virtue-asontology >, whether teleologically-degraded or teleologically-elevated, implied as of within a given ${ }^{83}$ reference-of-thought are necessarily in relative unreflexivitrelative reflexivity ontological-contiguity ${ }^{67}$, construed as of a difference-in-kind/difference-in-aposteriorising-orlogicising of the same <amplituding/formativeepistemicity $>$ totalising/circumscribing/delineating ${ }^{83}$ reference-of-thought- ${ }^{8}$ devolving. Such that a registry-worldview/dimension ${ }^{83}$ reference-of-thought associated postlogism ${ }^{77}$-slantedness manifestation, which is inevitably being instigated as postlogism denaturing $<$ amplituding/formative $>$ wooden-language-〈imbued-temporal-mereform/virtualities/dereification/akrasiatic-drag/denatured/preconverging-or-dementing narratives - of-the- reference-of-thought- categorical-imperatives/axioms/registryteleology > meaningfulness-and-teleology , as well as the temporal manifestations of the registry-worldview/dimension including conjugated-postlogism, is inevitably in notionalcontiguity/epistemic-contiguity ${ }^{2}-<$ profound-supererogation -of-mentallyaestheticised postconverging/dialectical-thinking -qualia-schema $>$ with all other meaningfulness-and-teleology ${ }^{99}$ of that registry-worldview/dimension ${ }^{83}$ reference-of-thought since there are all grounded either in a 'conscious-nonconviction/madeupness/bottomlining-asto-shallow-supererogation as teleologically-degraded' or 'naïve-conviction-as-to-profound- 
supererogation as flawed supposedly teleologically-elevated' relationship with the same/common/shared reference-of-thought- categorical-imperatives/axioms/registry-

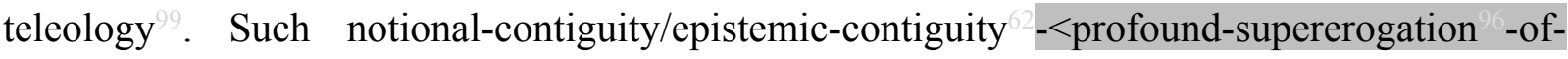
mentally-aestheticised postconverging/dialectical-thinking -qualia-schema $>$ is implied by the fact that a ${ }^{83}$ reference-of-thought is a '<amplituding/formativeepistemicity $>$ totalising/circumscribing/delineating ${ }^{56}$ meaningfulness-and-teleology ${ }^{9}$ implied as of the same/common/shared ${ }^{83}$ reference-of-thought- categorical-imperatives/axioms/registryteleology and with all its ${ }^{5}$ meaningfulness-and-teleology ${ }^{9}$ ontological-performance $<$ including-virtue-as-ontology>, given its prior relative-ontological-incompleteness ${ }^{88}$-ofreference-of-thought

apriorising/axiomatising/referencing/intelligibilitysettingup/measuringinstrumenting reflection of 'implicited_attendant-ontological-contiguity ${ }^{67}$ ' educedexistentialising/contextualising/textualising_'intelligibility/epistemicity/reflexivity-contiguity$<$ imbued-notional cogency>' -in-reification/dereification, being mutually cognisant-andintegrative by 'conscious-nonconviction/madeupness/bottomlining-as-to-shallowsupererogation as teleologically-degraded' or 'naïve-conviction-as-to-profoundsupererogation as flawed supposedly teleologically-elevated' relationship with the same/common/shared reference-of-thought- categorical-imperatives/axioms/registryteleology . In this regard, a non-positivistic as a 'superstitious centered$<$ amplituding/formative-epistemicity>totalising/circumscribing/delineating ${ }^{56}$ meaningfulnessand-teleology ${ }^{9}$ implied as of the same/common/shared ${ }^{83}$ reference-of-thought- categoricalimperatives/axioms/registry-teleology ${ }^{9}$ as associated with say a medieval or animistic socialsetup implies that a postlogism 77 -slantedness, conjugated-postlogism 77 or any other temporal mental-disposition with regards to say with notions-and-accusations-of-sorcery will meet with a mental-reflex across the registry-worldview/dimension 
epistemicity>totalising/circumscribing/delineating $\quad{ }^{83}$ reference-of-thought- devolving-as-ofinstantiative-context - ${ }^{5}$ meaningfulness-and-teleology ${ }^{9}$ that is cognisant-and-integrative as of its apriorising/axiomatising/referencing/intelligibilitysettingup/measuringinstrumenting reflection of implicited_attendant-ontological-contiguity ${ }^{67}$;educedexistentialising/contextualising/textualising_intelligibility/epistemicity/reflexivity-contiguity<imbued-notional cogency>' dereification in notional-contiguity/epistemic-contiguity ${ }^{6}$ $<$ profound-supererogation -of-mentally-aestheticised postconverging/dialectical-thinking qualia-schema>, as in its questioning and analysing whether the accusation of sorcery is true and so as an assumed/presupposed-as-ofapriorising/axiomatising/referencing/intelligibilitysettingup/measuringinstrumenting '<amplituding/formative-epistemicity $>$ totalising/circumscribing/delineating ${ }^{56}$ meaningfulnessand-teleology implied as of the same/common/shared ${ }^{83}$ reference-of-thought- categoricalimperatives/axioms/registry-teleology as of the overall ${ }^{83}$ reference-of-thought underlying <amplituding/formative-epistemicity>totalising/circumscribing/delineating belief in superstition, and so beyond-the-consciousness-awareness-teleology ${ }^{9}-<$ of-preconvergingexistential-extrication-as-of-existential-unthought $>$. Such a construal equally applies to our positivism- ${ }^{80}$ procrypticism associated manifestation of disjointedness-as-of- ${ }^{83}$ reference-ofthought associated with a postlogism -slantedness, conjugated-postlogism 77 or any other temporal mental-disposition instigation wherein our underlying procrypticism-ordisjointedness-as-of- ${ }^{8}$ reference-of-thought mental-disposition is a notionalcontiguity/epistemic-contiguity ${ }^{2}-<$ profound-supererogation -of-mentallyaestheticised postconverging/dialectical-thinking -qualia-schema> of the positivismprocrypticism <mpliteding/formative-epistemicity $>$ totalising/circumscribing/delineating context- ${ }^{56}$ meaningfulness-and-teleology $\quad$ reference-of-thought- ${ }^{9}$ devolving-as-ofinstantiative-ontological-performance ${ }^{72}-<$ including-virtue-as- 
ontology $>/$ morality/ethics/justice/etc. degraded' or 'naïve-conviction-as-to-profound-supererogation' as flawed supposedly teleologically-elevated' relationship with its centered-<amplituding/formativeepistemicity>totalising/circumscribing/delineating ${ }^{56}$ meaningfulness-and-teleology ${ }^{99}$ implied as of the same/common/shared ${ }^{83}$ reference-of-thought- categorical-imperatives/axioms/registryteleology . This explains why it is preconverging/postconverging-dementatively/structurally/paradigmatically impossible for either such a non-positivistic socialsetup or our procrypticism social-setup to resolve the vices-and-impediments ${ }^{105}$ associated with the corresponding $\quad$ reference-of-thought centered-<amplituding/formativeepistemicity>totalising/circumscribing/delineating ${ }^{56}$ meaningfulness-and-teleology ${ }^{9}$ implied as of the same/common/shared ${ }^{83}$ reference-of-thought- categorical-imperatives/axioms/registryteleology ${ }^{9}$, as it is in circular <amplituding/formative-epistemicity $>$ totalising $\sim$ self-referencingsyncretising/circularity/interiorising/akrasiatic-drag as of its apriorising/axiomatising/referencing/intelligibilitysettingup/measuringinstrumenting centeredepistemic-totalisation grounding; thus explaining the endemisation and enculturation of the associated vices-and-impediments ${ }^{105}$. Rather than a difference-in-kind/difference-inaposteriorising-or-logicising implied as of 'notional-contiguity/epistemic-contiguity

\section{$<$ profound-supererogation -of-mentally-aestheticised postconverging/dialectical-thinking}

qualia-schema>', it is rather a difference-in-nature/difference-in-apriorising-or-axiomatising-orreferencing ${ }^{24}$ as of an 'epistemic-break or notional-discontiguity/epistemic-discontiguity ${ }^{63}$ $<$ between-prior-shallow-supererogation -of-mentallyaestheticised $\sim$ preconverging/dementing -qualia-schema_and_prospective-profoundsupererogation -of-mentally-aestheticised postconverging/dialectical-thinking -qualiaschema> as of the prospective relative-ontological-completeness ${ }^{87}$ of the prospective 
reference-of-thought

$<$ amplituding/formative-

epistemicity $>$ totalising/circumscribing/delineating ${ }^{56}$ meaningfulness-and-teleology ${ }^{9}$ implied different and relatively-more-profound-and-complete ${ }^{83}$ reference-of-thought- categoricalimperatives/axioms/registry-teleology ${ }^{9}$ which is non-cognisant and non-integrative and 'not in notional contiguity' with the prior registry-worldview's/dimension's ${ }^{83}$ reference-of-thought '<amplituding/formative-epistemicity>totalising/circumscribing/delineating ${ }^{56}$ meaningfulnessand-teleology ${ }^{9}$ implied as of the same/common/shared ${ }^{83}$ reference-of-thought- categoricalimperatives/axioms/registry-teleology ${ }^{9}$ that can induce the 'ontological break' that is able to deendemise and de-enculturate as of aetiologisation/ontological-escalation- $<$ ontologicalveridicality_commitment/otherliness_transcending/compulsions-encumbered_transcending $>$ the given registry-worldview/dimension vices-and-impediments ${ }^{105}$ crossgenerationally. With a difference-in-nature/difference-in-apriorising-or-axiomatising-or-referencing ${ }^{24}$ construal there is a double-gesture of reification as of implying more critically the inappropriateness of the centered-epistemic-totalisation/ ${ }^{8}$ reference-of-thought as of its underlying ${ }^{56}$ meaningfulnessand-teleology implied same/common/shared $\quad{ }^{83}$ reference-of-thought- categoricalimperatives/axioms/registry-teleology ${ }^{9}$, which then inherently points to the inappropriateness of ${ }^{54}$ logical-processing-or-logical-implicitation - supposedly-apriorising-in-conviction-as-toprofound-supererogation on the basis of the centered-epistemic-totalisation $/{ }^{8}$ reference-ofthought and hence implying that there can't be any dialogical-equivalence- $<$ as-topsychologismic apriorising/axiomatising/referencing-\{of-"prospectively implicited_attendant-ontological-contiguity ' educedexistentialising/contextualising/textualising_intelligibility/epistemicity/reflexivity_contiguity<imbued-notional cogency >' $\}$-conflatedness in \{preconverging ment by $\}$ postconverging-entailment,-in-self-becoming/self-conflatedness /formative-supererogating>.

Such that from a positivistic perspective, an argument in a non-positivistic social-setup of the 
type one may be accused of sorcery is construed as ridiculous since it is in notionalcontiguity/epistemic-contiguity ${ }^{2}-<$ profound-supererogation -of-mentallyaestheticised postconverging/dialectical-thinking -qualia-schema $>, \quad$ with its apriorising/axiomatising/referencing/intelligibilitysettingup/measuringinstrumenting reflection of 'implicited_attendant-ontological-contiguity ${ }^{67}$ ' educedexistentialising/contextualising/textualising_intelligibility/epistemicity/reflexivity-contiguity$<$ imbued-notional cogency $>$-in-reification/dereification cognisant-and-integrative with a non-positivistic superstitious ${ }^{56}$ meaningfulness-and-teleology ${ }^{9}$ centered-epistemictotalisation $/{ }^{3}$ reference-of-thought, and that itself is perceived as of 'aetiological concern' as to the possibility of an apriorising/axiomatising/referencing/intelligibilitysettingup/measuringinstrumenting reflection of 'implicited_attendant-ontological-contiguity ${ }^{67}$ ' educedexistentialising/contextualising/textualising_intelligibility/epistemicity/reflexivity-contiguity$<$ imbued-notional cogency> ${ }^{\prime}$-in-reification/dereification mental-disposition that can be cognisant-and-integrative in notional-contiguity/epistemic-contiguity ${ }^{62}-<$ profoundsupererogation -of-mentally-aestheticised postconverging/dialectical-thinking -qualiaschema $>$ with numerous existential-disontogising/entegising apereticism> circumstances reflecting the endemising/enculturating of non-positivistic superstition and its vices-and-impediments ${ }^{105}$. The same applies from a notional ${ }^{18}$ deprocrypticism perspective with regards to a ${ }^{80}$ procrypticism-or-disjointedness-as-of- ${ }^{8}$ reference-of-thought mental disposition as an argument seeming to articulate ${ }^{56}$ meaningfulness-and-teleology ${ }^{9}$ in the same disjointedness-as-of- reference-of-thought terms-as-axiomatic-construct by which the procrypticism-or-disjointedness-as-of- ${ }^{3}$ reference-of-thought arises in the first place is in circular $<$ amplituding/formative-epistemicity $>$ totalising $\sim$ self-referencingsyncretising/circularity/interiorising/akrasiatic-drag ${ }^{34}$ as of the same centered-epistemic- 
totalisation $/{ }^{3}$ reference-of-thought defect. Thus it is ontologically impossible to address any given registry-worldview/dimension vices-and-impediments ${ }^{105}$ as of that fundamental $<$ amplituding/formative-epistemicity>totalising/circumscribing/delineating $\quad$ reference-ofthought- ${ }^{8}$ devolving-as-of-instantiative-context - ${ }^{56}$ meaningfulness-and-teleology ${ }^{9}$ centeredepistemic-totalisation, besides at best palliative constructs of a non-universal nature, as not of an aetiologisation/ontological-escalation- $<$ ontologicalveridicality_commitment/otherliness_transcending/compulsions-encumbered_transcending $>$ nature. Thus further validating the idea that it is a crossgenerational psychoanalyticunshackling/memetic-reordering/institutional-recomposuring in secondnaturing such a prospective institutionalisation ' $\quad$ reference-of-thought - devolving-teleological-dementating/structuring/paradigming-of-meaningfulness' that enables such a transformation whether from a retrospective or prospective transcendence-andsublimity/sublimation/supererogatory $\sim$ de-mentativity perspective. This explains ontologicalnormalcy/postconvergence referentialism as construing/conceptualising the most profound/complete ontologically-veridical " ${ }^{83}$ reference-of-thought construction of meaningfulness-and-teleology ${ }^{9}$, as of the <cumulating/recomposuring attendantontological-contiguity >-succession of registry-worldviews/dimensions from the notional ${ }^{1}$ deprocrypticism perspective construal/conceptualisation, as being the 'most profound/complete ${ }^{6}$ reference-of-thought—devolving-teleological-dementating/structuring/paradigming-of-meaningfulness' grasp of intrinsic-reality/ontologicalveridicality' among all the registry-worldviews/dimensions as of its preemptingdisjointedness-as-of- ${ }^{83}$ reference-of-thought,-as-to- ${ }^{32}<$ amplituding/formativeepistemicity> growth-or-conflatedness ${ }^{13} /$ transvaluativerationalising/transepistemicity/anamnestic-residuality/spirit-drivenness'_-in-supersedingmere-formulaic-positivising/rational-empiricism-based-universalisation-directed-rulemaking- 
over-non-rules — apriorising/axiomatising/referencing-psychologism. Furthermore, within a registry-worldview/dimension for the disambiguation of notional firstnaturednessformativeness-<as-to-eventualising-inkling drive-or-seeding misprising $>$ temporal-tointemporal-dispositions- $<$ so-construed-as-from-perspective-ontologicalnormalcy/postconvergence>, its ${ }^{8}$ reference-of-thought of ${ }^{5}$ meaningfulness-and-teleology ${ }^{99}$ as its apriorising/axiomatising/referencing/intelligibilitysettingup/measuringinstrumenting is its 〈given consciousness's ${ }^{58}$ neuterising-induced-or-deneuterising -induced〉 as ${ }^{83}$ reference-ofthought_-devolving-teleological-de-mentating/structuring/paradigming-of-meaningfulness, which by way of a différance/internal-dialectics/difference-deferral articulates the intradimensional relative ontological-veracity of all other intradimensional existentialinstantiations derived/devolved axiomatic-constructs of ${ }^{56}$ meaningfulness-and-teleology ${ }^{99}$ as its intradimensional knowledge-constructs/theories/intersolipsistic-intercessorynotions/notional referential-notions/articulations/virtue. Thus this is within the framework of the registry-worldview's/dimension's teleological-dementating/structuring/paradigming/teleological-possibilities; construed either in elevation-asof-upholding-ontological-veridicality/institutionalisation as $\quad$ reference-of-thoughtcategorical-imperatives/axioms/registry-teleology ${ }^{99}$, -for-

aposteriorising/logicising/deriving/intelligising/measuring - ${ }^{56}$ meaningfulness-and-teleology ${ }^{9}$ of the affirmation/projection/assertion/notional $\sim$ self-distantiation/dueness-validatinglogicising/suitable-measuringinstrument-validating-measuring-<as-to-postconverging-ordialectical-thinking -apriorising-psychologism> of prospective relative-ontologicalcompleteness ${ }^{87}$-of- ${ }^{83}$ eference-of-thought, or in degradation-as-of-failing-ontologicalveridicality/uninstitutionalised-threshold as of the unaffirmation/deprojection/deassertion/epistemic-decadence/undueness-invalidatinglogicising/unsuitable-measuringinstrument-invalidating-measuring-<as-to-preconverging-or- 
dementing -apriorising-psychologism> of prior relative-ontological-incompleteness ${ }^{8}$-ofreference-of-thought; noting that the dialectical nature of the elevation and degradation so implied are inherently affirmed/unaffirmed respectively as of the-very-same-immanentexistence/intrinsic-reality/ontological-veridicality,-as-to-'human<amplituding/formativeepistemicity $>$ totalising purview-of-construal', wherein prospective relative-ontologicalcompleteness $^{87}$-of- ${ }^{83}$ eference-of-thought elevation/institutionalisation is in soundness-orontological-good-faith/authenticity ${ }^{-}$of- ${ }^{-}$reference-of-thought and prior relative-ontologicalincompleteness ${ }^{8}$-of- ${ }^{8}$ reference-of-thought degradation/uninstitutionalised-threshold ${ }^{12}$ is in unsoundness-or-ontological-bad-faith/inauthenticity -of- reference-of-thought. Furthermore, metaphysics-of-absence-〈implicited-epistemic-veracity-of- nonpresencing-<perspectiveontological-normalcy/postconvergence $>$ insight as of ${ }^{4}$ historiality/ontologicaleventfulness 3 /ontological-aesthetic-tracing-<perspective-ontologicalnormalcy/postconvergence-reflected-‘epistemicity-relativism-determinism'> reveals and attends to the notional ${ }^{18}$ deprocrypticism 'perspective issue' involved for 'overcoming defect of ontological analysis arising from metaphysics-of-presence-〈implicited-‘nondescript/ignorablevoid '-as-to- presencing - absolutising-identitive-constitutedness $\rangle<$ amplituding/formativeepistemicity>totalising $\sim$ self-referencing-syncretising/circularity/interiorising/akrasiatic-drag ${ }^{34}$ due to a mental-reflex of representing/skewing-the-representation of presence with respect to its reference-of-thought as flawed '<amplituding/formativeepistemicity>totalising/circumscribing/delineating apriorising/axiomatising/referencing/intelligibilitysettingup/measuringinstrumenting as of reference-of-thought_-devolving-teleological-de-mentating/structuring/paradigming-ofmeaningfulness' at the uninstitutionalised-threshold ${ }^{102}$, wrongly construed as rather being in elevation/institutionalisation and thus wrongly reflected as of 'soundness-or-ontological-goodfaith/authenticity ${ }^{6}$-of- ${ }^{8}$ reference-of-thought' rather than being veridically construed in 
degradation/uninstitutionalised-threshold ${ }^{02}$ and thus reflected as of 'unsoundness-orontological-bad-faith/inauthenticity ${ }^{64}$-of ${ }^{3}$ reference-of-thought'; and so, when it comes to construing the ontological-veridicality of both elevation/institutionalisation and degradation/uninstitutionalised-threshold ${ }^{02}$ as of their respectively 'relevant apriorising/axiomatising/referencing/intelligibilitysettingup/measuringinstrumenting as of reference-of-thought—devolving-teleological-de-mentating/structuring/paradigming-ofmeaningfulness', and so with regards to the-very-same-immanent-existence/intrinsicreality/ontological-veridicality,-as-to-'human< $<$ amplituding/formative-

epistemicity>totalising purview-of-construal' which as of underlying relative-ontologicalincompleteness 8 /relative-ontological-completeness ${ }^{87}$ -

\section{〈sublimating referencing/registering/decisioning,-as-self-becoming/self-}

conflatedness /formative-supererogating-<projective/reprojective-aestheticising-re-motifand-re-apriorising/re-axiomatising/re-referencing,-in-perspective-ontological-

normalcy/postconvergence $>>$ is on-the-one-hand elevated/institutionalised and on-the-otherhand teleologically-degraded/uninstitutionalised, as of human deepening or shallow limitedmentation-capacity -as-subjecting-'educed-unlimitedness/existence-sublimating nascence'to-limitedness/human-subpotency. Such ${ }^{4}$ historiality/ontological-eventfulness 38 /ontologicalaesthetic-tracing-<perspective-ontological-normalcy/postconvergence-reflected-'epistemicityrelativism-determinism'> as of its notional conflatedness ${ }^{13}$ as it implies the apriorising/axiomatising/referencing-\{of-'prospectively_implicited_attendant-ontologicalcontiguity ' educedexistentialising/contextualising/textualising_'intelligibility/epistemicity/reflexivity_contiguity$<$ imbued-notional cogency $>$ ' $\}$-conflatedness ${ }^{13}$ in-\{preconverging ment by\} postconverging-entailment of the most 'sound/profound/complete anticipation/projection/thrownness-disposition as rather of elevation-as-of-prospective- 
institutionalisation-and-degradation-as-of-uninstitutionalised-threshold ${ }^{102}$ preconverging/postconverging-de-mentative/structural/paradigmatic-contrastive-devolvinganalysis as of their respective ${ }^{83}$ reference-of-thought-elevated-devolving-as-of-prospectiveinstitutionalisation and ${ }^{83}$ reference-of-thought—degraded-devolving-as-of-uninstitutionalisedthreshold ${ }^{02}$, brings out in anticipation/projection/thrownness-disposition the overall fundamental elucidative contrast between the 'degradation/uninstitutionalised-threshold unsoundness-or-ontological-bad-faith/inauthenticity ${ }^{64}$-of- ${ }^{8}$ reference-of-thought projection' and the 'elevation/institutionalisation soundness-or-ontological-good-faith/authenticity ${ }^{6}$-ofreference-of-thought projection' at their respective ${ }^{8}$ reference-of-thought- ${ }^{84}$ devolving-level of analysis; as can be elucidated contrastively between 'recurrent-utter-uninstitutionalisation uninstitutionalisation and base-institutionalisation institutionalisation', 'baseinstitutionalisation-ununiversalisation uninstitutionalisation and ${ }^{103}$ universalisation institutionalisation', " ${ }^{10}$ universalisation-non-positivism/medievalism uninstitutionalisation and positivism institutionalisation' and prospectively 'positivism- ${ }^{80}$ procrypticism

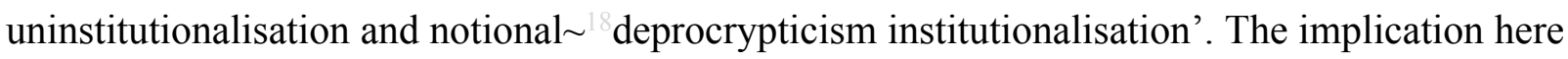
is that with say notions-and-accusations-of-sorcery in a ${ }^{103}$ universalisation-nonpositivism/medievalism uninstitutionalisation social-setup, in order to construe ontologicalveridicality; as of apriorising/axiomatising/referencing-\{of- prospectively implicited_attendant-ontological-contiguity ' reducedexistentialising/contextualising/textualising_'intelligibility/epistemicity/reflexivity-contiguity<imbued-notional cogency $>$ ' $\}$ - conflatedness ${ }^{13}$ in-\{preconverging-ment by\} postconverging-ntailment we can't simply imply the presence ${ }^{103}$ universalisationnon-nonpositivism/medievalism uninstitutionalisation ${ }^{83}$ reference-of-thought - devolving-teleologicalde-mentating/structuring/paradigming-of-meaningfulness as the basis of instigating logicaldueness for elucidation and thereof construing ontologically-veridical ${ }^{56}$ meaningfulness-and- 
teleology ${ }^{9}$, as such a mental-reflex representing/skewing-the-representation of the presence as universalisationnon-non-positivism/medievalism uninstitutionalisation will overlook the presence uninstitutionalised-threshold ${ }^{102}$ and wrongly represent its ${ }^{56}$ meaningfulness-andteleology at its uninstitutionalised-threshold ${ }^{102}$ as of elevation/institutionalisation in soundness-or-ontological-good-faith/authenticity ${ }^{6}$-of- ${ }^{8}$ reference-of-thought projection'. It is rather the apriorising/axiomatising/referencing-\{of-'prospectively implicited_attendantontological-contiguity ' educedexistentialising/contextualising/textualising_'intelligibility/epistemicity/reflexivity-contiguity$<$ imbued-notional cogency $>$ ' $\}$-conflatedness ${ }^{13}$ in-\{preconverging-ment by\} pesteonverging entailment projective/anticipative contrast between the said uninstitutionalisedthreshold ${ }^{102}$ however the mental-reflex complex of presence and the prospective positivism institutionalisation however the mental-reflex complex of the latter's abstractness as from the presence uninstitutionalised-threshold ${ }^{102}$ perspective that enables their respective ${ }^{83}$ reference-ofthought — devolving-teleological-de-mentating/structuring/paradigming-of-meaningfulness contrastive fundamental elucidations in grasping ontological-veridicality as of their respective prior relative-ontological-incompleteness ${ }^{8}$-and-completeness-of- ${ }^{8}$ reference-of-thought perspective. Thus it is the 'anticipation/projection/thrownness-disposition of overall fundamental elucidative contrast' between prior degradation/uninstitutionalised-threshold ${ }^{102}$ and prospective elevation/institutionalisation respectively implied ${ }^{83}$ reference-of-thoughtdevolving-teleological-de-mentating/structuring/paradigming-of-meaningfulness so-construed on the basis of 'apriorising/axiomatising/referencing-\{of-'prespectively implicited_attendantontological-contiguity ' educed-

existentialising/contexalising/texalising_intelligibility/epistemicity/reflexivity-contiguity$<$ imbued-notional cogency $>$ ' $\}$-conflatedness ${ }^{13}$ in-\{preconverging-ment by\} postconverging entailment as of the most 'sound/profound/complete anticipation/projection' 
relative to existence's sublimating-epistemic-imbricatedness/threadedness/recomposuring existential-instantiations, which is at ${ }^{83}$ reference-of-thought-as-of-" ${ }^{83}$ reference-of-thoughtdevolving-teleological-de-mentating/structuring/paradigming-of-meaningfulness'preconverging/postconverging-de-mentative/structural/paradigmatic-contrastive-devolvinganalysis as-of-the-constrast-of-elevation-as-of-prospective-institutionalisation-anddegradation-as-of-uninstitutionalised-threshold that is more profoundly elucidative of existential-instantiations issues of perversion-and-derived- ${ }^{7}$ perversion-of- ${ }^{3}$ reference-ofthought-<as-preconvergingly-apriorising/axiomatising/referencing-in-

nonconviction/madeupness/bottomlining-as-to-shallow-supererogation $>$ whether with regards to notions-and-accusations-of-sorcery in non-positivism or psychopathy and social psychopathy as of our procrypticism-or-disjointedness-as-of- ${ }^{83}$ reference-of-thought or generally issues arising as of being/existential/ontological/axiomatic-construct problem of perversion-andderived- ${ }^{74}$ perversion-of- ${ }^{8}$ reference-of-thought- $<$ as-preconvergingly-

\section{apriorising/axiomatising/referencing-in-nonconviction/madeupness/bottomlining-as-to-}

shallow-supererogation $>$ speaking of prior relative-ontological-incompleteness ${ }^{8}$-ofreference-of-thought; in other words, with respect to the elucidation of existentialinstantiations issues, beyond just issues of ${ }^{5}$ logical-processing-or-logical-implicitationsupposedly-apriorising-in-conviction-as-to-profound-supererogation as of logical coherence, we need to move at the <amplituding/formativeepistemicity>totalising/circumscribing/delineating level of analysis which is the ${ }^{83}$ reference-ofthought and then construe meaningfulness-and-teleology as of contrastive elevation/institutionalisation $\quad{ }^{83}$ reference-of-thought-elevated-devolving-as-of-prospectiveinstitutionalisation' and degradation/uninstitutionalised-threshold ${ }^{102}$ ' degraded-devolving-as-of-uninstitutionalised-threshold ${ }^{102}$. That is, ${ }^{56}$ meaningfulness-andteleology ${ }^{9}$ cannot be referenced/registered/decisioned as of the degradation/uninstitutionalised- 
threshold ${ }^{102}$ but rather the elevation/institutionalisation as of its prospective relative-ontologicalcompleteness ${ }^{87}$-of- ${ }^{83}$ eference-of-thought with respect to the-very-same-immanentexistence/intrinsic-reality/ontological-veridicality,-as-to-'human<amplituding/formativeepistemicity>totalising purview-of-construal' with the implication that ${ }^{5}$ meaningfulness-andteleology ${ }^{9}$ lies-with-and-is wholly as of elevation/institutionalisation ${ }^{83}$ reference-of-thoughtelevated-devolving-as-of-prospective-institutionalisation'. Insightfully, historiality/ontological-eventfulness 8 /ontological-aesthetic-tracing-<perspectiveontological-normalcy/postconvergence-reflected-'epistemicity-relativism-determinism'> as of notional conflatedness ${ }^{13} /$ constitutedness $^{14}$-to-conflatedness ${ }^{13}$ points out that as of the-verysame-immanent-existence/intrinsic-reality/ontological-veridicality,-as-to-

'human<amplituding/formative-epistemicity>totalising purview-of-construal': it is rather and critically more apt to 'articulate organically as of ontological-faith-notion-or-ontologicalfideism—imbued-underdetermination-of-motif-and-apriorising/axiomatising/referencing-asso-being-as-of-existential-reality' the transcendental construct of prospective baseinstitutionalisation institutionalisation while in recurrent-utter-uninstitutionalisation uninstitutionalisation (doing so by failing the '<amplituding/formative $>$ wooden-language〈imbued-temporal-mere-form/virtualities/dereification/akrasiaticdrag/denatured/preconverging-or-dementing -narratives - of-the- reference-of-thoughtcategorical-imperatives/axioms/registry-teleology > of recurrent-utter-uninstitutionalisation' in de-emphasising the threshold-of-nonconviction/madeupness/bottomlining-in-shallowsupererogation -<as-to-'attendant-intradimensional'-prospectivelydisontologising preconverging/dementing -apriorising-psychologism $>$ and emphasising the supplanting-conviction-as-to-profound-supererogation of-'attendant-intradimensional'postconverging/dialectical-thinking -apriorising-psychologism of prospective relativeontological-completeness meaningfulness-and-teleology as of knowledge- 
reification $\sim$ gesturing-and-accounting — of-epistemic-phenomenalism- $<$ in-

prospective_psychologismic apriorising/axiomatising/referencing-\{of- ${ }^{\text {pprospectively }}$ implicited_attendant-ontological-contiguity ' educed-

existentialising/contextualising/textualising_intelligibility/epistemicity/reflexivity-contiguity<imbued-notional cogency >' \}-conflatedness -in-\{preconverging-ment by\}

postconverging-entailment>), and this insight extends as well with regards to 'articulating organically as of ontological-faith-notion-or-ontological-fideism - imbued-underdeterminationof-motif-and-apriorising/axiomatising/referencing-as-so-being-as-of-existential-reality' the transcendental construct of prospective ${ }^{103}$ universalisation institutionalisation while in baseinstitutionalisation-ununiversalisation uninstitutionalisation (doing so by failing the '<amplituding/formative $>$ wooden-language-〈imbued-temporal-mere-

\section{form/virtualities/dereification/akrasiatic-drag/denatured/preconverging-or-dementing}

\section{narratives - of-the- reference-of-thought- categorical-imperatives/axioms/registry-}

teleology \ of base-institutionalisation-ununiversalisation' in de-emphasising the threshold-ofnonconviction/madeupness/bottomlining-in-shallow-supererogation $<-<$ as-to-' attendantintradimensional'-prospectively-disontologising preconverging/dementing -apriorisingpsychologism $>$ and emphasising the supplanting-conviction-as-to-profound-supererogation of-'attendant-intradimensional'-postconverging/dialectical-thinking -apriorisingpsychologism of prospective relative-ontological-completeness ${ }^{87}{ }^{56}$ meaningfulness-andteleology as of knowledge-reification $\sim$ gesturing-and-accounting-of-epistemicphenomenalism- $<$ in-prospective _psychologismic $\sim$ apriorising/axiomatising/referencing- $\{$ of'prospectively_implicited_attendant-ontological-contiguity ' educedexistentialising/contextualising/textualising_'intelligibility/epistemicity/reflexivity-contiguity<imbued-notional cogency $>$ ' \}-conflatedness -in-\{preconverging ment by\} postconverging-entailment>), 'articulating organically as of ontological-faith-notion-or- 
ontological-fideism - imbued-underdetermination-of-motif-and-

apriorising/axiomatising/referencing-as-so-being-as-of-existential-reality' the transcendental construct of prospective positivism institutionalisation while in ${ }^{103}$ universalisation-nonpositivism/medievalism uninstitutionalisation (doing so by failing the '<amplituding/formative > wooden-language-〈imbued-temporal-mere-

\section{form/virtualities/dereification/akrasiatic-drag/denatured/preconverging-or-dementing}

narratives - of-the- reference-of-thought- categorical-imperatives/axioms/registry-

teleology > of ${ }^{103}$ universalisation-non-positivism/medievalism' in de-emphasising the threshold-of-nonconviction/madeupness/bottomlining-in-shallow-supererogation $\quad-<$ as-to‘attendant-intradimensional'-prospectively-disontologising preconverging/dementing apriorising-psychologism> and emphasising the supplanting-conviction-as-to-profoundsupererogation - of-'attendant-intradimensional'-postconverging/dialectical-thinking apriorising-psychologism of prospective relative-ontological-completeness ${ }^{87}$ meaningfulnessand-teleology as of knowledge-reification $\sim$ gesturing-and-accounting-of-epistemicphenomenalism- $<$ in-prospective_psychologismic $\sim$ apriorising/axiomatising/referencing- of'prospectively implicited_attendant-ontological-contiguity ' educedexistentialising/contextualising/textualising_'intelligibility/epistemicity/reflexivity-contiguity$<$ imbued-notional cogency $>>$ \}-conflatedness -in-\{preconverging-ment by\}

postconverging-entailment $>$ ), and prospectively 'articulating organically as of ontological-faithnotion-or-ontological-fideism — imbued-underdetermination-of-motif-andapriorising/axiomatising/referencing-as-so-being-as-of-existential-reality' the transcendental construct of futural Being-development/ontological-framework-expansion-as-to-depth-ofontologising-development-as-infrastructure-of- meaningfulness-and-teleology as of prospective notional ${ }^{1}$ deprocrypticism institutionalisation while in positivism- ${ }^{80}$ procrypticism uninstitutionalisation (doing so by failing the '<amplituding/formative $>$ wooden-language- 
〈imbued-temporal-mere-form/virtualities/dereification/akrasiatic-

drag/denatured/preconverging-or-dementing -narratives - of-the- reference-of-thoughtcategorical-imperatives/axioms/registry-teleology > of positivism- ${ }^{80}$ procrypticism' in deemphasising the threshold-of-nonconviction/madeupness/bottomlining-in-shallowsupererogation -<as-to-'attendant-intradimensional'-prospectively-

disontologising preconverging/dementing -apriorising-psychologism $>$ and emphasising the supplanting-conviction-as-to-profound-supererogation —of-'attendant-intradimensional'postconverging/dialectical-thinking -apriorising-psychologism of prospective relativeontological-completeness ${ }^{87}$ meaningfulness-and-teleology ${ }^{99}$ as of knowledgereification $\sim$ gesturing-and-accounting — of-epistemic-phenomenalism- $<$ inprospective_psychologismic apriorising/axiomatising/referencing-\{of- ${ }^{\text {pprospectively }}$ implicited_attendant-ontological-contiguity ' educedexistentialising/contextualising/textualising_'intelligibility/epistemicity/reflexivity-contiguity$<$ imbued-notional cogency $>$ ' $\}$-conflatedness -in-\{preconverging ment by\} postconverging-entailment $>$ ); such that supplanting-conviction-as-to-profoundsupererogation —of-'attendant-intradimensional'-postconverging/dialectical-thinking apriorising-psychologism is actually as of ontological-faith-notion-or-ontological-fideismimbued-underdetermination-of-motif-and-apriorising/axiomatising/referencing-as-so-being-asof-existential-reality reflected as to ontological-good-faith/authenticity over ontological-badfaith/inauthenticity ${ }^{64}$ elucidation/reification of 'implicited_attendant-ontologicalcontiguity ${ }^{67}$; educedexistentialising/contextualising/textualising_'intelligibility/epistemicity/reflexivity_contiguity$<$ imbued-notional cogency $>^{\prime}$, and so as to dimensionality-of-sublimating ${ }^{2}-$ <<amplituding/formative>supererogatory $\sim$ de-mentativeness/epistemic-growth-orconflatedness /transvaluative-rationalising/transepistemicity/anamnestic-residuality/spirit- 
drivenness-equalisation). This reflects ${ }^{4}$ historiality/ontological-eventfulness ${ }^{38} /$ ontologicalaesthetic-tracing-<perspective-ontological-normalcy/postconvergence-reflected-‘epistemicityrelativism-determinism'> as of its notional conflatedness ${ }^{13}$ nature of ontologicalperformance $^{72}-<$ including-virtue-as-ontology $>/$ morality/ethics/justice/etc. as anti-nihilistically grounded on ontological-faith-notion-or-ontological-fideism - imbued-underdetermination-ofmotif-and-apriorising/axiomatising/referencing-as-so-being-as-of-existential-reality as enabled by $\quad{ }^{55}$ maximalising-recomposuring-for-relative-ontological-completeness ${ }^{87}$ —unenframed/reontologising conceptualisation. It points out that ontologically-veridical meaningfulness cannot be construed beyond-the-consciousness-awareness-teleology ${ }^{9}<$ of - preconverging-existentialextrication-as-of-existential-unthought $>$ as of a soulless nihilistic-teleology ${ }^{9}$-for-theattainment-of-temporality ${ }^{8}$ /human-mortal-whims as it simply brings an end to the transcendental potential for the human existential-<disontologising/re-ontologising apereticism $>$ tale perpetuation; as the organic-knowledge behind the 'invention' of prospective institutionalisation necessarily has to take precedence in further driving the relativeunreflexivity/relative-reflexivity — ontological-contiguity ${ }^{67}$ of-the-human-institutionalisationprocess $^{68}$ over a conceptualisation as of denaturing ${ }^{16}$ of ${ }^{83}$ reference-of-thought- categoricalimperatives/axioms/registry-teleology . Such an approach to transcendence-andsublimity/sublimation/supererogatory de-mentativity is exactly what validates transcendental knowledge as of a psychoanalytic-unshackling commitment and not a grounded knowledgeconstruct commitment; as an approach as of grounded knowledge-construct commitment that merely implies transcendence-and-sublimity/sublimation/supereregatery $\sim$ de-mentativity as being incremental to the prior registry-worldview's/dimension's ${ }^{83}$ reference-of-thought doesn't undermine/unshackle that prior ${ }^{83}$ reference-of-thought with respect to the-very-same-immanentexistence/intrinsic-reality/ontological-veridicality,-as-to-'human<amplituding/formativeepistemicity>totalising purview-of-construal' as of the requisite undermining/unshackling by 
the prospective enlightenment of the-very-same-immanent-existence/intrinsicreality/ontological-veridicality,-as-to-`human<amplituding/formative-

epistemicity>totalising purview-of-construal' by the prospective registryworldview's/dimension's ${ }^{83}$ reference-of-thought ontological-performance ${ }^{2}-<$ including-virtueas-ontology $>$ /morality/ethics/justice/etc. given its prospective relative-ontologicalcompleteness ${ }^{87}$-of- ${ }^{8}$ reference-of-thought. Rather implying a grounded knowledge-construct commitment merely 'circularly-complexifies' the uninstitutionalised-threshold ${ }^{102}{ }^{83}$ referenceof-thought as it adopts by mental-reflex an incrementalism-in-relative-ontologicalincompleteness 8 - enframed/disontologising conceptualisation mental-disposition rather than a maximalising-recomposuring-for-relative-ontological-completeness ${ }^{57}$ —unenframed/reontologising conceptualisation mental-disposition and thus fails to fulfil the requisite $<$ amplituding/formative-epistemicity $>$-totalising $\sim$ renewing-realisation/re-perception/rethought referencing/registering/decisioning-of-its- ${ }^{3}$ reference-of-thought-rather-aspreconverging-or-dementing ${ }^{20}$-and-decentered-prior-institutionalisation's- categoricalimperatives/axioms/registry-teleology and its alienation-as-inauthentic/poorlyobjectified/poorly-desubjectified-as-objectified/ontological-bad-faith/inauthenticity ${ }^{64} /$ nihilistic as of ${ }^{15}$ de-mentation-〈supererogatory $\sim$ ontological-de-mentation-or-dialectical-de-mentationstranding-or-attributive-dialectics $\rangle$, which is what allows for transcendence-andsublimity/sublimation/supererogatory $\sim$ de-mentativity to the prospective ${ }^{83}$ reference-of-thought for renewal; that is, this will rather bring about the <amplituding/formativeepistemicity>totalising $\sim$ self-referencing-syncretising/circularity/interiorising/akrasiatic-drag of the prior ${ }^{83}$ reference-of-thought in 'incremental circular-complexification' and so beyond-theconsciousness-awareness-teleology $\quad<$ of-preconverging-existential-extrication-as-ofexistential-unthought $>$ on a false notion of an 'intemporal temporality ${ }^{8}$, , naively passing for intemporality ${ }^{52} /$ longness as of intersubjective eliciting of temporality ${ }^{8}$. Such 
notional conflatedness

ontology $>$ /morality/ethics/justice/etc. implication is easily understood as of metaphysics-ofabsence-〈implicited-epistemic-veracity-of- nonpresencing-<perspective-ontologicalnormalcy/postconvergence $>\rangle$ when we grasp that a mindset as of a non-positivistic social-setup needs to 'wean off organically beyond mere mechanical adjustments' its non-positivism before the notion of a 'credible logical engagement in terms-as-of-axiomatic-construct of positivism/rational-empiricism with a mindset as of a positivistic social-setup' can be genuinely entertained. In this regard, the budding-positivists had to implied an utter break with medievalscholasticism-pedants-ideal-type-or-individuation to avoid the circular problem of their positivism knowledge and science being interpreted in mystical and alchemic terms-asaxiomatic-construct of ${ }^{83}$ reference-of-thought- categorical-imperatives/axioms/registryteleology ${ }^{9}$,-for-aposteriorising/logicising/deriving/intelligising/measuring- ${ }^{5}$ meaningfulnessand-teleology ${ }^{9}$. Such a psychoanalytic-unshackling commitment equally highlights that the idea of a common ${ }^{103}$ universal human potential available to all individuals while true is not inherently existentially-<disontologising/re-ontologising aporeticism $>$ fulfilled/valorised if that humansubpotency is not effectively to-the-best-of-our-temporal/mortal-superseding-endeavouring unleashed as of a ${ }^{55}$ maximalising-recomposuring-for-relative-ontological-completeness ${ }^{8}$ unenframed/re-ontologising conceptualisation $<$ amplituding/formative-epistemicity $>$ totalising renewing-realisation/re-perception/re-thought. This conceptualisation insight points out that prospective ${ }^{80}$ procrypticism-or-disjointedness-as-of- ${ }^{8}$ reference-of-thought uninstitutionalisation associated with our positivism- ${ }^{80}$ procrypticism registryworldview/dimension as of its epistemic-abnormalcy/preconvergence $/ /$ relative-ontologicalincompleteness ${ }^{8}$-of- ${ }^{8}$ reference-of-thought is effectively the defective result of our positivism institutionalisation destructuring-threshold-〈uninstitutionalised-threshold /presublimatingdesublimating-decisionality $>$ of-ontological-performance ${ }^{72}-<$ including-virtue-as- 
ontology $>$ /morality/ethics/justice/etc.

extrapolating/constituting/abstracting/deducing/inferring-of-elucidation-outside-

'prospectively_implicited_attendant-ontological-contiguity ${ }^{67}$ ' educed-

existentialising/contextualising/textmalising_intelligibility/epistemicity/reflexivity-contiguity-

<imbued-notional cogency>' ${ }^{40} \quad$ of its $\quad{ }^{83}$ reference-of-thought- ${ }^{\text {categorical- }}$

imperatives/axioms/registry-teleology ${ }^{9}$ at the positivism- ${ }^{80}$ procrypticism uninstitutionalisation, wherein the prospective 'procrypticism uninstitutionalisation' arises as ‘<amplituding/formative $>$ wooden-language-〈imbued-temporal-mere-

\section{form/virtualities/dereification/akrasiatic-drag/denatured/preconverging-or-dementing}

narratives - of-the- reference-of-thought- categorical-imperatives/axioms/registry-

teleology $>$ of positivism registry-worldview/dimension', which then effectively generates the virtuality-or-ontologically-flawed-construal of $\quad$ procrypticism-or-disjointedness-as-ofreference-of-thought uninstitutionalisation construed as perversion-and-derived- perversionof- ${ }^{8}$ reference-of-thought-<as-preconvergingly-apriorising/axiomatising/referencing-innonconviction/madeupness/bottomlining-as-to-shallow-supererogation $>$ of our positivismprocrypticism registry-worldview/dimension. It should be noted that, the ontologicallyveridical reflection of ${ }^{8}$ procrypticism-or-disjointedness-as-of- ${ }^{8}$ reference-of-thought is rather construed from futural Being-development/ontological-framework-expansion-as-to-depth-ofontologising-development-as-infrastructure-of- meaningfulness-and-teleology as of prospective notional ${ }^{18}$ deprocrypticism registry-worldview/dimension perspective as a 'constructed-deficiency of the profound/complete notional ${ }^{18}$ deprocrypticism perspective', with notional ${ }^{18}$ deprocrypticism in ontological-normalcy/relative-ontological-completeness ${ }^{87}$-ofreference-of-thought of the-very-same-immanent-existence/intrinsic-reality/ontologicalveridicality,-as-to-'human<amplituding/formative-epistemicity $>$ totalising $\sim$ purview-ofconstrual' unlike procrypticism which is rather in epistemic- 
abnormalcy/preconvergence ${ }^{31} /$ relative-ontological-incompleteness ${ }^{8}$-of- ${ }^{8}$ reference-of-thought of the-very-same-immanent-existence/intrinsic-reality/ontological-veridicality,-as-to'human<amplituding/formative-epistemicity>totalising purview-of-construal'; and the ontological-veridicality of notional ${ }^{18}$ deprocrypticism itself is construed as an epistemictotalising $\sim$ renewing-realisation/re-perception/re-thought of the-very-same-immanentexistence/intrinsic-reality/ontological-veridicality,-as-to-'human<amplituding/formativeepistemicity>totalising purview-of-construal' as of ${ }^{55}$ maximalising-recomposuring-forrelative-ontological-completeness ${ }^{7}$ - unenframed/re-ontologising conceptualisation driven by ontological-faith-notion-or-ontological-fideism - imbued-underdetermination-of-motif-andapriorising/axiomatising/referencing-as-so-being-as-of-existential-reality. This explains why our positivism- ${ }^{80}$ procrypticism so-construed from a notional ${ }^{18}$ deprocrypticism perspective will be decentered and preconverging-or-dementing -apriorising-psychologism, just as our positivism in ontological-normalcy/relative-ontological-completeness ${ }^{87}$-of- ${ }^{8}$ reference-ofthought perspective construal of non-positivism/medievalism ${ }^{83}$ reference-of-thought in epistemic-abnormalcy/preconvergence ${ }^{31} /$ relative-ontological-incompleteness $^{88}$-of- ${ }^{83}$ referenceof-thought show the latter to be decentered and preconverging-or-dementing ${ }^{20}$-apriorisingpsychologism. As a further elaboration, the circularity and <amplituding-formativeepistemicity>totalising $\sim$ self-referencing-syncretising/circularity/interiorising/akrasiatic-drag mental-disposition attached to a registry-worldview's/dimension's ${ }^{83}$ reference-of-thought apriorising/axiomatising/referencing/intelligibilitysettingup/measuringinstrumenting is fundamentally grounded on its teleological-de-mentating/structuring/paradigming/teleologicalpossibilities established as of its ${ }^{83}$ reference-of-thought-and- ${ }^{83}$ reference-of-thoughtdevolving- ${ }^{5}$ meaningfulness-and-teleology ${ }^{9}$ as its intradimensional knowledgeconstructs/theories/intersolipsistic-intercessory-notions/notional referentialnotions/articulations/virtue. It is only a crossgenerational psychoanalytic-unshackling/memetic- 
reordering/institutional-recomposuring in the medium to long-term that can transcendentally 'wean off' from such a teleological-de-mentating/structuring/paradigming/teleologicalpossibilities of a registry-worldview/dimension by habituating a prospective institutionalisation as of its ${ }^{83}$ reference-of-thought-and- ${ }^{83}$ reference-of-thought- ${ }^{84}$ devolving- ${ }^{56}$ meaningfulness-andteleology 9 as its intradimensional knowledge-constructs/theories/intersolipsistic-intercessorynotions/notional referential-notions/articulations/virtue. This explains as of metaphysics-ofabsence-〈implicited-epistemic-veracity-of- nonpresencing-<perspective-ontologicalnormalcy/postconvergence $>\rangle$ why for instance the mere demonstration to approval/acquiescence of positivistic principles/interpretations of intrinsic-reality/ontological-veridicality in a nonpositivistic as animistic social-setup or medieval social-setup however frequent the demonstrations within a given limited period of time doesn't mean that the social-setup has been transformed into a positivistic social-setup; since their existentially-<disontologising/reentologising aporeticism $>$ habituated state of animism or medievalism teleological-dementating/structuring/paradigming/teleological-possibilities as of 〈warped-or-preclusiveconsciousness $\quad{ }^{5}$ neuterising-induced $>-{ }^{83}$ reference-of-thought—devolving-teleological-dementating/structuring/paradigming-of-meaningfulness as intradimensional existentialinstantiations derived/devolved axiomatic-constructs of ${ }^{5}$ meaningfulness-and-teleology ${ }^{99}$ as its intradimensional knowledge-constructs/theories/intersolipsistic-intercessorynotions/notional referential-notions/articulations/virtue, will need to be undone/unshackled psychoanalytically in the medium to long-run to veridically achieve positivism; given that that uninstitutionalised-threshold ${ }^{102}$ is in a state of circular-pervasiveness-of- ${ }^{\circ}{ }^{83}$ reference-ofthought — degraded-devolving-as-of-uninstitutionalised-threshold ${ }^{02}$ '! This equally explains the $<$ amplituding/formative-epistemicity $>$ totalising $\sim$ self-referencingsyncretising/circularity/interiorising/akrasiatic-drag inherent in our prospective procrypticism-or-disjointedness-as-of- ${ }^{83}$ reference-of-thought uninstitutionalisation, together 
with its inherent manifestations of psychopathic postlogism -slantedness and social psychopathy conjugated-postlogism 7 , when construed from futural Beingdevelopment/ontological-framework-expansion-as-to-depth-of-ontologising-development-asinfrastructure-of- meaningfulness-and-teleology as of prospective notional ${ }^{18}$ deprocrypticism as preempting-disjointedness-as-of- ${ }^{3}$ reference-of-thought institutionalisation as in our metaphysics-of-presence-〈implicited-"nondescript/ignorablevoid '-as-to- presencing - absolutising-identitive-constitutedness > beyond-theconsciousness-awareness-teleology ${ }^{\circ}<$ of-preconverging-existential-extrication-as-ofexistential-unthought $>$ we systematically override the ontological-veridicality implications of such procrypticism-or-disjointedness-as-of- ${ }^{8}$ reference-of-thought and proceed by mentalreflex to uphold our ${ }^{80}$ procrypticism-or-disjointedness-as-of- ${ }^{3}$ reference-of-thought $<$ amplituding/formative $>$ wooden-language-<imbued — averaging-of-thought-<as-toleveling/ressentiment/closed-construct-of- meaningfulness-and-teleology -as-of'nondescript/ignorable-void '-with-regards-to-prospective-apriorising-implications $>>$ at this positivism- ${ }^{80}$ procrypticism uninstitutionalisation as of an existentially-<disontologising/reentologising aporeticism $>$ nihilistic mental-disposition in degeneration of the human existential-<disontologising/re-ontologising aporeticism $>$ tale; as all ${ }^{79}$ presencingabsolutising-identitive-constitutedness ${ }^{14}$ by mental-reflex keep on representing their uninstitutionalised-threshold ${ }^{102}$ as institutionalised, that is as 'centered and postconverging-ordialectical-thinking -apriorising-psychologism', as a 'delusion of an always institutionalised presencing-absolutising-identitive-constitutedness ${ }^{14}$ as of its ${ }^{83}$ reference-of-thoughtcategorical-imperatives/axioms/registry-teleology ${ }^{99}$, -for-

aposteriorising/logicising/deriving/intelligising/measuring - ${ }^{56}$ meaningfulness-and-teleology ${ }^{9}$, rather than being veridically 'decentered and preconverging-or-dementing ${ }^{20}$-apriorisingpsychologism' at the uninstitutionalised-threshold ${ }^{102}$ as of ' ${ }^{83}$ reference-of-thought— degraded- 
devolving-as-of-uninstitutionalised-threshold ${ }^{102}$, as logical-dueness doesn't even arise in-thevery-first-place given perversion-and-derived- perversion-of- $^{-}$reference-of-thought- $<$aspreconvergingly-apriorising/axiomatising/referencing-in-

nonconviction/madeupness/bottomlining-as-to-shallow-supererogation $>$ as of unsoundnessor-ontological-bad-faith/inauthenticity ${ }^{6}$-of- ${ }^{-}$reference-of-thought. We can get a projected sense of this as of metaphysics-of-absence-〈implicited-epistemic-veracity-of- nonpresencing$<$ perspective-ontological-normalcy/postconvergence $>\rangle$ in that despite the articulation of positivistic principles/interpretations in the animistic social-setup or medieval social-setup, in the short to medium run individuals will keep on overriding and ignoring such positivistic meaningfulness-and-teleology ${ }^{9}$ nihilistically, notwithstanding that we may recognise this as of prospective relative-ontological-completeness ${ }^{87}$-of- ${ }^{8}$ reference-of-thought, and falling back to construe/conceptualise ${ }^{56}$ meaningfulness-and-teleology ${ }^{9}$ in non-positivistic animistic or medieval terms-as-of-axiomatic-construct, construed from the positivistic perspective as

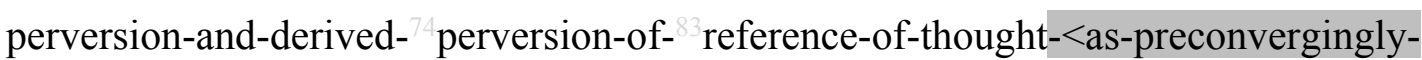
apriorising/axiomatising/referencing-in-nonconviction/madeupness/bottomlining-as-toshallow-supererogation $>$ as of unsoundness-or-ontological-bad-faith/inauthenticity ${ }^{6}$-ofreference-of-thought. As broadly speaking, a registry-worldview's/dimension's ${ }^{83}$ reference-ofthought is as of the 'existential-<disontologising/re-ontologising aporeticism $>$ individuations possibilities as to ${ }^{83}$ reference-of-thought-prelogism ${ }^{78}$-as-of-conviction,-in-profoundsupererogation $-<$ existentially-veridical-'attendant-intradimensionalapriorising/axiomatising/referencing'-logical-dueness-precedes-disontologising-logicaloutcome-arrived-at> and threshold-of-nonconviction/madeupness/bottomlining-in-shallowsupererogation -<as-to-'attendant-intradimensional'-prospectivelydisontologising preconverging/dementing -apriorising-psychologism>' reflecting the teleological-de-mentating/structuring/paradigming/teleological-possibilities, established as of 
its $\quad{ }^{83}$ reference-of-thought-and- ${ }^{83}$ reference-of-thought- ${ }^{8}$ devolving- ${ }^{56}$ meaningfulness-andteleology as its intradimensional knowledge-constructs/theories/intersolipsistic-intercessorynotions/notional $\sim$ referential-notions/articulations/virtue; and it is nevertheless so madeup/bottomlined nihilistically, notwithstanding a prospective registry-worldview's/dimension's reference-of-thought that points prospectively to its relative ontologising-deficiency/epistemicabnormalcy/preconvergence ${ }^{3 /}$ /relative-ontological-incompleteness ${ }^{88}$-of- ${ }^{-1 e f e r e n c e-o f-t h o u g h t, ~}$ as it in in-the-bigger-picture preconverging/postconverging-dementatively/structurally/paradigmatically a 'lifetime mental and existential-<disontologising/reentologising aporeticism $>$ investment as of the specific prior relative-ontologicalincompleteness ${ }^{8}$-of- ${ }^{-}$reference-of-thought beyond-the-consciousness-awareness-teleology $<$ of-preconverging-existential-extrication-as-of-existential-unthought $>{ }^{56}$ meaningfulness-andteleology', that will not lightly give up on 'its invested specific prior relative-ontologicalincompleteness ${ }^{88}$-of- ${ }^{8}$ reference-of-thought of ${ }^{56}$ meaningfulness-and-teleology ${ }^{9}$ as a $<$ amplituding/formative $>$ wooden-language-<imbued - averaging-of-thought-<as-toleveling/ressentiment/closed-construct-of- meaningfulness-and-teleology -as-of'nondescript/ignorable-void '-with-regards-to-prospective-apriorising-implications $>\rangle$ ' despite the ontological-veridicality of a anti-nihilistic intemporal/ontological/social/species/ ${ }^{103}$ universal/transcendental/ ${ }^{5}$ maximalisingrecomposuring-for-relative-ontological-completeness ${ }^{8}$ — unenframed/reontologising conceptualisation postconverging-de-mentating/structuring/paradigming openedconstruct-of- ${ }^{56}$ meaningfulness-and-teleology enabling the human existential<disontologising/re-ontologising aporeticism $>$ tale as of the successive transcendence-andsublimity/sublimation/supererogatory de-mentativity behind the relative-unreflexivity/relativereflexivity ontological-contiguity ${ }^{67}$ of-the-human-institutionalisation-process notwithstanding that its very own institutionalisation arose out of that anti-nihilistic process, and 
at the more immediate social-stake-contention-or-confliction level involves temporal concatenation to intemporality ${ }^{52} /$ longness as denaturing ${ }^{16}$ of the prior institutionalisation's reference-of-thought- categorical-imperatives/axioms/registry-teleology 99 by their elaboration-as-to-mere-extrapolating/constituting/abstracting/deducing/inferring-ofelucidation-outside_-'prospectively_implicited_attendant-ontological-contiguity ${ }^{67}$; educedexistentialising/contextualising/textualising_intelligibility/epistemicity/reflexivity-contiguity<imbued-notional cogency>' $>^{\prime}, \quad$ and so as of slantedness/ ignorance/affordability/opportunism/exacerbation/social-chainism-or-socialdiscomfiture-or-negative-social-aggregation/temporal-enculturation-or-temporal-endemisation, so-disambiguated as of ${ }^{8}$ reference-of-thought- ${ }^{8}$ devolving ontological-performance ${ }^{72}$ $<$ including-virtue-as-ontology $>$, due to lack of constraining social ${ }^{103}$ universal-transparency ${ }^{104}$ 〈transparency-of-totalising-entailing,-as-to-entailing-<amplituding/formativeepistemicity>totalising in-relative-ontological-completeness $>$ at its uninstitutionalisedthreshold ${ }^{02}$. Such a threshold-of-nonconviction/madeupness/bottomlining-in-shallowsupererogation $-<$ as-to-'attendant-intradimensional'-prospectivelydisontologising preconverging/dementing -apriorising-psychologism $>$ being rather as of a temporal extricatory preconverging-de-mentating/structuring/paradigming and that naively considers the mutual intersubjective eliciting of temporal extricatory preconverging-dementating/structuring/paradigming to be intemporal/ontological/social/species/ ${ }^{103}$ universal/transcendental $/{ }^{55}$ maximalisingrecomposuring-for-relative-ontological-completeness ${ }^{87}$ - unenframed/reontologising conceptualisation postconverging-de-mentating/structuring/paradigming, given a failure to preconverging/postconverging-de-mentatively/structurally/paradigmatically grasp intrinsic-reality/ontological-veridicality transcendentalenabling/sublimating/supereregatory $\sim$ de-mentativity implications, and rather confusing this 
with social-aggregation-enabling implications. This is clearly made obvious when 'the-verysame motif of reasoning' is construed as of metaphysics-of-absence-_implicited-epistemicveracity-of- nonpresencing-<perspective-ontological-normalcy/postconvergence $>$ >

implications (as to ontological-normalcy/postconvergence) say with respect to an animistic or medieval non-positivistic registry-worldview's/dimension's threshold-ofnonconviction/madeupness/bottomlining-in-shallow-supererogation $<-<$ as-to-' ${ }^{\circ}$ attendantintradimensional'-prospectively-disontologising preconverging/dementing -apriorisingpsychologism> <mplituling/formative > wooden-language-〈imbued-averaging-of-thought$<$ as-to-leveling/ressentiment/closed-construct-of- meaningfulness-and-teleology -as-of'nondescript/ignorable-void '-with-regards-to-prospective-apriorising-implications $>>$ rather in social-aggregation-enabling, implying no possibility for prospective transcendence-andsublimity/sublimation/supererogatoryade-mentativity so-construed from a positivistic perspective of analysis in ontological-normalcy/relative-ontological-completeness ${ }^{87}$-ofreference-of-thought. This further points out that, as herein implied with futural Beingdevelopment/ontological-framework-expansion-as-to-depth-of-ontologising-development-asinfrastructure-of- meaningfulness-and-teleology as of prospective notional ${ }^{18}$ deprocrypticism as preempting - disjointedness-as-of- ${ }^{8}$ reference-of-thought '(reoriginary_-as-unenframed/re-ontologising/unbeholdening/outlier-conceptualisation-_imbuedpostconverging/dialectical-thinking -'projective-insights'/'epistemic-projection-inconflatedness ${ }^{\prime}$ 'of-notional deprocrypticism-prospective-sublimation $\rangle$ ) originary/event $^{38}$ of-prospective-ontology-origination transcendental knowledge conceptualisations' as puttinginto-question a prior registry-worldview's/dimension's ${ }^{83}$ reference-of-thought teleological-dementating/structuring/paradigming/teleological-possibilities, reconceptualised-rather-as-ofprior-relative-ontological-incompleteness ${ }^{-o f}$ reference-of-thought, established as of its 〈given consciousness's ${ }^{58}$ neuterising-induced $\rangle$ - ${ }^{8}$ reference-of-thought — devolving-teleological- 
de-mentating/structuring/paradigming-of-meaningfulness as intradimensional existentialinstantiations derived/devolved axiomatic-constructs of ${ }^{56}$ meaningfulness-and-teleology ${ }^{99}$ as its intradimensional knowledge-constructs/theories/intersolipsistic-intercessorynotions/notional $\sim$ referential-notions/articulations/virtue, are rather as of a 'psychoanalyticunshackling commitment' and not as of a 'grounded knowledge construct commitment'. Inherently, such a 'psychoanalytic-unshackling commitment' inevitably and fundamentally puts into question the axioms and underlying supposedly transcendentalenabling/sublimating/supereregatery $\sim$ de-mentativity notion as of the 〈given consciousness's neuterising-induced $>$ - ${ }^{8}$ reference-of-thought—devolving-teleological-de-

mentating/structuring/paradigming-of-meaningfulness of the prior registryworldview's/dimension's ${ }^{83}$ reference-of-thought of ${ }^{56}$ meaningfulness-and-teleology ${ }^{9}$ which establishes its 'grounded knowledge construct', and so because of its denaturing of the prior institutionalisation's reference-of-thought- categorical-imperatives/axioms/registryteleology by way of elaboration-as-to-mereextrapolating/constituting/abstracting/deducing/inferring-of-elucidation-outside'prospectively implicited_attendant-ontological-contiguity ${ }^{67}$ ' educedexistentialising/contextualising/textualising_'intelligibility/epistemicity/reflexivity-contiguity$<$ imbued-notional cogency>' at the registry-worldview's/dimension's uninstitutionalisedthreshold ${ }^{102}$ inducing prior relative-ontological-incompleteness ${ }^{8}$-of- ${ }^{-3}$ reference-of-thought in need for prospective relative-ontological-completeness ${ }^{87}$-of- ${ }^{8}$ reference-of-thought, and so as a transitional construct that is in effect as of a psychoanalytic-unshackling/memeticreordering/institutional-recomposuring articulation by its crossgenerational transcendental implications projection. Such that such a 'psychoanalytic-unshackling commitment' cannot be construed in the same terms-as-of-axiomatic-construct as ordinary intradimensional knowledge as of the established prior institutionalisation teleological-de- 
mentating/structuring/paradigming/teleological-possibilities for its 'grounded knowledge construct' as prior relative-ontological-incompleteness ${ }^{8}$-of- ${ }^{-1 e f e r e n c e-o f-t h o u g h t, ~ b u t ~ r a t h e r ~}$ construed as of prospective ontological-normalcy/relative-ontological-completeness ${ }^{87}$-ofreference-of-thought it more critically and organically points to the uninstitutionalisedthreshold ${ }^{102}$ state of the present registry-worldview's/dimension's ${ }^{83}$ reference-of-thought at its uninstitutionalised-threshold ${ }^{102}$ with respect to the prospective institutionalisation state of the prospective registry-worldview's/dimension's ${ }^{83}$ reference-of-thought as of its prospective relative-ontological-completeness ${ }^{8}$-of- ${ }^{8}$ reference-of-thought, and thus rather implies an ${ }^{15}$ dementation-〈supererogatory $\sim$ ontological-de-mentation-or-dialectical-de-mentation-strandingor-attributive-dialectics $\rangle$. It is psychoanalytic-unshackling commitment and not grounded knowledge construct commitment, because it is for instance about articulating 'prospective positivism axiomatic-construct 〈occlusive-consciousness ${ }^{58}$ neuterising-induced〉- ${ }^{83}$ reference-ofthought — devolving-teleological-de-mentating/structuring/paradigming-of-meaningfulness' with respect to a relatively underdeveloped registry-worldview/dimension in prior 'nonpositivism axiomatic-construct 〈warped-or-preclusive-consciousness ${ }^{58}$ neuterising-induced $\rangle$ reference-of-thought_-devolving-teleological-de-mentating/structuring/paradigming-ofmeaningfulness', or in the case of articulating 'futural Being-development/ontologicalframework-expansion-as-to-depth-of-ontologising-development-as-infrastructure-ofmeaningfulness-and-teleology as of prospective notional ${ }^{18}$ deprocrypticism axiomaticconstruct 〈protensive-consciousness deneuterising ${ }^{17}$-induced $\rangle$ - ${ }^{8}$ reference-of-thoughtdevolving-teleological-de-mentating/structuring/paradigming-of-meaningfulness' with respect to a relatively underdeveloped registry-worldview/dimension in prior 'positivismprocrypticism axiomatic-construct 〈occlusive-consciousness ${ }^{58}$ neuterising-induced〉reference-of-thought_-devolving-teleological-de-mentating/structuring/paradigming-ofmeaningfulness. It is important to grasp in both instances that such psychoanalytic-unshackling 
commitment implications are not to be understood respectively as of the uninstitutionalisedthreshold ${ }^{102}$ mental-dispositions of non-positivism/medievalism or procrypticism ${ }^{83}$ reference-ofthought — devolving-teleological-de-mentating/structuring/paradigming-of-meaningfulness which will just induce their $<$ amplituding/formative-epistemicity $>$ totalising $\sim$ self-referencingsyncretising/circularity/interiorising/akrasiatic-drag ${ }^{34}$ mental-dispositions for nontranscendence-and-sublimity/sublimation/supereregatery-de-mentativity, but rather as of a habituated mental-projection perspective from the prospective institutionalisations of positivism or notional ${ }^{1}$ deprocrypticism $\quad$ reference-of-thought—devolving-teleological-dementating/structuring/paradigming-of-meaningfulness. Thus counterintuitively to metaphysicsof-presence-〈implicited-'nondescript/ignorable-void ' -as-to- presencing-absolutisingidentitive-constitutedness > conception, human Being-development/ontological-frameworkexpansion-as-to-depth-of-ontologising-development-as-infrastructure-of- meaningfulnessand-teleology , institutional-development-as-to-social-function-development and livingdevelopment-as-to-personality-development psychologismic epistemic acutisationdifficulty $<$ for, residualising_\{decompulsing $\}$ delinearity for-cogency> magnitudes $\{$ ofexperientiality/experiment\} as 'banally' portrayed historically is not as of an expanding 'grounded knowledge construct' from time immemorial as of a wrong incrementalism-in-relativeontological-incompleteness ${ }^{8}$ — enframed/disontologising conceptualisation mental-reflex as if humans have had only '<amplituding/formativeepistemicity $>$ totalising/circumscribing/delineating apriorising/axiomatising/referencing/intelligibilitysettingup/measuringinstrumenting as of reference-of-thought — devolving-teleological-de-mentating/structuring/paradigming-ofmeaningfulness'. But actually the underlying process is one of a 'psychoanalytic-unshackling as of a succession of prospective institutionalisations ${ }^{5}$ maximalising-recomposuring-for-relativeontological-completeness ${ }^{87}$ - unenframed/re-ontologising conceptualisation construed from a 
succession of '<amplituding/formative-epistemicity>totalising/circumscribing/delineating apriorising/axiomatising/referencing/intelligibilitysettingup/measuringinstrumenting as of reference-of-thought — devolving-teleological-de-mentating/structuring/paradigming-ofmeaningfulness' so implied by an ontology-driven 'postconverging-or-dialectical-thinking psychology or psychology-of-mentation-dynamics or natural psychological-dynamics' enabling successive prospective 'relative-ontological-completeness ${ }^{87}$-of- ${ }^{3}$ reference-of-thought as of ontological-normalcy/postconvergence' with respect to human notional limited-mentationcapacity-deepening_as-subjecting-limitedness/human-subpotency-to-'educedunlimitedness/existence-sublimating nascence' ${ }^{53}$ underlying the institutionalcumulation/institutional-recomposure-〈as-to- historiality/ontological-

\section{eventfulness /ontological-aesthetic-tracing-<perspective-ontological-}

normalcy/postconvergence-reflected-'epistemicity-relativism-determinism'>>; $\quad$ such that counterintuitive to what we might be inclined to think, the development of human psychology is not as of a 'grounded construction that simply varies incrementally across all times', but rather a 'construction which teleological-de-mentating/structuring/paradigming/teleologicalpossibilities/teleological-potency are sharply rearticulated in succession of institutionalisations as of ontological apriorising/axiomatising/referencing-\{of- prospectively implicited_attendant-ontological-contiguity ' reducedexistentialising/contextualising/textualising_'intelligibility/epistemicity/reflexivity-contiguity<imbued-notional cogency>' \}-conflatedness ${ }^{13}$-in-\{preconverging-ment by ${ }^{\prime}$ postconverging-ntailment', and this is important 'to avoid unduly considering our whole psychical-nature-and-potential as of our present positivistic institutionalisation mindset/consciousness as of metaphysics-of-presence-_implicited-'nondescript/ignorablevoid '-as-to- presencing - absolutising-identitive-constitutedness $\rangle$ ', but rather grasp that there are teleological-de-mentating/structuring/paradigming/teleological- 
possibilities/teleological-potency of our mental-projection and mental-disposition as of deprocrypticism-or-preempting — disjointedness-as-of- ${ }^{83}$ reference-of-thought

‘ $<$ amplituding/formative-epistemicity $>$ totalising/circumscribing/delineating

apriorising/axiomatising/referencing/intelligibilitysettingup/measuringinstrumenting as of reference-of-thought - devolving-teleological-de-mentating/structuring/paradigming-ofmeaningfulness' beyond just what we can imagine as of our presence as positivismprocrypticism. This analysis brings out what is effectively meaningfulness as it shows that meaningfulness more completely about apriorising/axiomatising/referencing/intelligibilitysettingup/measuringinstrumenting-foroperant-or-incidenting-predicative-insights thus involving the '<amplituding/formativeepistemicity>totalising/circumscribing/delineating apriorising/axiomatising/referencing/intelligibilitysettingup/measuringinstrumenting as of reference-of-thought — devolving-teleological-de-mentating/structuring/paradigming-ofmeaningfulness' as of the prospective relative-ontological-completeness ${ }^{87}$-of- ${ }^{8}$ reference-ofthought of the 〈given consciousness's ${ }^{58}$ neuterising-induced-or-deneuterising -induced)reference-of-thought—devolving-teleological-de-mentating/structuring/paradigming-ofmeaningfulness and then 'operant-or-incidenting-predicative-insights or logical-coherence' for effectively articulating their meaningfulness as of instantiative-context or existentialinstantiations with respect to existence-as-the-absolute-a-priori-ofconceptualisation $\sim$ and existence — as-sublimating-withdrawal/unenframing/re-ontologising,elicited-from-prospective-profound-supererogation $-<$ as-to-perspective-ontologicalnormalcy/postconvergence-implied-'prospective-aporeticism-overcoming/unovercoming'> sublimating-epistemic-imbricatedness/threadedness/recomposuring; and these are the two underlying commitments that make-up meaningfulness. Within a registryworldview's/dimension's institutionalisation framework the placeholder-setup/mental-devising- 
representation/mentation/consciousness-awareness-teleology ${ }^{9}$ is utterly geared in an $<$ amplituding/formative-epistemicity $>$ totalising $\sim$ self-referencing-

syncretising/circularity/interiorising/akrasiatic-drag ${ }^{34}$ of ${ }^{56}$ meaningfulness-and-teleology ${ }^{99}$ as of 'operant-or-incidenting-predicative-insights or logical-coherence' and beyond-theconsciousness-awareness-teleology ${ }^{-<}<$of-preconverging-existential-extrication-as-of-

existential-unthought $>$ by mental-reflex presupposes-and-assumes the ontological absoluteness/indubitability of its

'<amplituding/formativeepistemicity $>$ totalising/circumscribing/delineating apriorising/axiomatising/referencing/intelligibilitysettingup/measuringinstrumenting as of reference-of-thought — devolving-teleological-de-mentating/structuring/paradigming-ofmeaningfulness', and wrongly so even at its uninstitutionalised-threshold ${ }^{102}$; such that it is only crossgenerationally that it can attend effectively as of its transcendence-andsublimity/sublimation/supererogatory de-mentativity to the reality of temporal denaturing ${ }^{16}$ of the said institutionalisation's ${ }^{83}$ reference-of-thought- categorical-imperatives/axioms/registryteleology at its uninstitutionalised-threshold ${ }^{102}$ by elaboration-as-to-mereextrapolating/constituting/abstracting/deducing/inferring-of-elucidation-outside'prospectively implicited_atentantontological-contiguity ${ }^{67}$ ' educedexistentialising/contextmalising/textualising_'intelligibility/epistemicity/reflexivity_contiguity$<$ imbued-notional cogency>' $>^{\prime}$, pointing to its perversion-and-derived- perversion-ofreference-of-thought-<as-preconvergingly-apriorising/axiomatising/referencing-innonconviction/madeupness/bottomlining-as-to-shallow-supererogation $>$, and thus the need for $<$ amplituding/formative-epistemicity $>$-totalising $\sim$ renewing-realisation/re-perception/rethought as of psychoanalytic-unshackling/memetic-reordering/institutional-recomposuring, involving $\quad{ }_{5}^{55}$ maximalising-recomposuring-for-relative-ontological-completeness ${ }^{8}$ unenframed/re-ontologising conceptualisation, with respect to the implications of its 
ontologically

deficient

‘ amplituding/formative-

epistemicity $>$ totalising/circumscribing/delineating

apriorising/axiomatising/referencing/intelligibilitysettingup/measuringinstrumenting as of reference-of-thought - devolving-teleological-de-mentating/structuring/paradigming-of-

meaningfulness'. Thus a transcendental engagement as articulating prospective relativeontological-completeness ${ }^{87}$-of- ${ }^{8}$ reference-of-thought in an opened-construct-ofmeaningfulness-and-teleology ${ }^{9}$ strives to go beyond a prior institutionalisation

$<$ amplituding/formative $>$ wooden-language- $\langle$ imbued — averaging-of-thought- $<$ as-to-

leveling/ressentiment/closed-construct-of- meaningfulness-and-teleology -as-of-

'nondescript/ignorable-void '-with-regards-to-prospective-apriorising-implications $>>$ at its uninstitutionalised-threshold ${ }^{102}$, which simply triggers 'operant-or-incidenting-predicativeinsights or logical-coherence' on the basis of the priorly set/established '<amplituding/formative-epistemicity $>$ totalising/circumscribing/delineating

apriorising/axiomatising/referencing/intelligibilitysettingup/measuringinstrumenting as of reference-of-thought_-devolving-teleological-de-mentating/structuring/paradigming-ofmeaningfulness' taken for granted without questioning as of intradimensional grounded meaningfulness-and-teleology ${ }^{99}$ at its uninstitutionalised-threshold ${ }^{102}$. Such a transcendental engagement recurrently put-into-question in apriorising/axiomatising/referencing-\{of'prospectively_implicited_attendant-ontological-contiguity ' educedexistentialising/contextualising/textualising_'intelligibility/epistemicity/reflexivity-contiguity$<$ imbued-notional cogency $>$ ' \}-conflatedness ${ }^{13}$-in-\{preconverging -ment by $\}$ postconverging-entailment the prior institutionalisation '<amplituding/formativeepistemicity>totalising/circumscribing/delineating apriorising/axiomatising/referencing/intelligibilitysettingup/measuringinstrumenting as of reference-of-thought — devolving-teleological-de-mentating/structuring/paradigming-of- 
meaningfulness' at its uninstitutionalised-threshold ${ }^{12}$ by substituting it with the prospective institutionalisation '<amplituding/formative-epistemicity $>$ totalising/circumscribing/delineating apriorising/axiomatising/referencing/intelligibilitysettingup/measuringinstrumenting as of reference-of-thought — devolving-teleological-de-mentating/structuring/paradigming-ofmeaningfulness' as of its prospective relative-ontological-completeness ${ }^{87}$-of- ${ }^{8}$ reference-ofthought, before effecting any 'operant-or-incidenting-predicative-insights or logical-coherence' for prospective institutionalisation ${ }^{56}$ meaningfulness-and-teleology 9 , and this explains its reference-of-thought- categorical-imperatives/axioms/registry-teleology ${ }^{99}$,-foraposteriorising/logicising/deriving/intelligising/measuring_ ${ }^{5}$ meaningfulness-and-teleology while on-the-other-hand the grounded uninstitutionalised-threshold ${ }^{102}$ recurrently overrides as of apriorising/axiomatising/referencing-\{of-'prospectively implicited_attendant-ontologicalcontiguity ' $\sim$ educedexistentialising/contextualising/textualising_ 'intelligibility/epistemicity/reflexivity-contiguity$<$ imbued-notional cogency $>$ ' $\}$-constitutedness ${ }^{1}$-in-preconverging-entailment beyond-theconsciousness-awareness-teleology ${ }^{\circ}<$ of-preconverging-existential-extrication-as-ofexistential-unthought $>$ any notion of its ontologically deficient '<amplituding/formativeepistemicity>totalising/circumscribing/delineating apriorising/axiomatising/referencing/intelligibilitysettingup/measuringinstrumenting as of reference-of-thought — devolving-teleological-de-mentating/structuring/paradigming-ofmeaningfulness' at its uninstitutionalised-threshold ${ }^{102}$ and just triggers 'operant-or-incidentingpredicative-insights or logical-coherence' on that basis for its intradimensional grounded meaningfulness-and-teleology", and this explains its " ${ }^{83}$ reference-of-thought-degradeddevolving-as-of-uninstitutionalised-threshold ${ }^{102}$, and explaining why transcendence-andsublimity/sublimation/supererogatory de-mentativity fully occurs as of a crossgenerational habituation process. Remarkably, such a ${ }^{55}$ maximalising-recomposuring-for-relative- 
ontological-completeness ${ }^{87}$ - unenframed/re-ontologising conceptualisation behind the relative-unreflexivity/relative-reflexivity - ontological-contiguity ${ }^{67} \sim$ of-the-humaninstitutionalisation-process ${ }^{68}$ enabling the human existential-<disentologising/re-ontelogising apereticism $>$ tale in successive institutional-cumulation/institutional-recomposure-〈as-tohistoriality/ontological-eventfulness /ontological-aesthetic-tracing-<perspectiveontological-normalcy/postconvergence-reflected-‘epistemicity-relativism-determinism’ $>>\quad$ is always rather perceived intradimensionally as an exceptional-askance and unordinary. For instance, the ${ }^{55}$ maximalising-recomposuring-for-relative-ontological-completeness ${ }^{87}$ unenframed/re-ontologising conceptualisation mental-disposition in their own times advocating the end of such perverse human institutions like serfdom and slavery were construed in their own times by their dominant societies as of exceptional-askance and unordinary such that in effect these actually engendered great conflict before such practices came to an end; and such metaphysics-of-absence-〈implicited-epistemic-veracity-of- nonpresencing-<perspectiveontological-normalcy/postconvergence $>>$ analysis does apply with respect to superstitions, universal human rights, free society, modern science, etc. but then as of our developed present institutionalisation the idea of not entertaining such practices is viewed as not an exceptionalaskance and ordinarily to be expected. This explains human mental states respectively as of uninstitutionalised-threshold ${ }^{102}$ and as of prospective institutionalisation with respect to maximalising-recomposuring-for-relative-ontological-completeness ${ }^{87}$ - unenframed/reontologising conceptualisation as the process enabling prospective relative-ontologicalcompleteness ${ }^{87}$-of- ${ }^{8}$ reference-of-thought of same $<$ amplituding/formativeepistemicity $>$ totalising $\sim$ devolved-purview-as-domain-of-construal-as-intrinsicreality/ontological-veridicality hitherto considered off limits to any challenging ${ }^{55}$ maximalisingrecomposuring-for-relative-ontological-completeness ${ }^{87}$ —unenframed/reontologising conceptualisation at the uninstitutionalised-threshold ${ }^{102}$ but then acknowledged 
thereafter after prospective institutionalisation; with the implication that the possibility for all prospective transcendence-and-sublimity/sublimation/supererogatory de-mentativity as of opened-construct-of- ${ }^{5}$ meaningfulness-and-teleology ${ }^{9}$ arise only by maximalisingrecomposuring-for-relative-ontological-completeness ${ }^{87}$ - unenframed/reontologising conceptualisation but presences in their <amplituding/formative $>$ woodenlanguage-〈imbued — averaging-of-thought-<as-to-leveling/ressentiment/closed-construct-ofmeaningfulness-and-teleology -as-of-‘nondescript/ignorable-void '-with-regards-toprospective-apriorising-implications $>>$ consider ${ }^{55}$ maximalising-recomposuring-for-relativeontological-completeness ${ }^{87}$ - unenframed/re-ontologising conceptualisation as of exceptionalaskance and unordinary due to their <amplituding/formative-epistemicity $>$ totalising $\sim$ selfreferencing-syncretising/circularity/interiorising/akrasiatic-drag ${ }^{34}$ mental-reflex avoiding being ontologically decentered and preconverging-or-dementing 20 -apriorising-psychologism. Insightfully, this point out the circumspective nature of any transcendental knowledge construction exercise as of 'prospective leeway of ontological-tolerance-<ofdisparateness>/inexactitude' to avoid on-the-one-hand outrightly articulating construed ontological-veridicality at the expense of avoiding any re-ontologising prospective Beingdevelopment/ontological-framework-expansion-as-to-depth-of-ontologising-development-asinfrastructure-of- meaningfulness-and-teleology engagement, as such a psychoanalytical commitment necessarily recognises human potential to transcend, and the on-the-other-hand the nature of intrinsic-reality/ontological-veridicality that 'supersedes humankind and doesn't factor in human moods and whims' in its effectiveness (as to requisite limitedness/human-subpotency prospective intolerance-<of-disparateness $>$ /exactifying_precisioning-of-sublimation- $<$ as-topostconverging-narrowing-down apriorising/axiomatising/referencing-entailing-theoretical,conceptual-and-operant-implications $>$ for prospective transcendental knowledge). Caught between these two elements human ${ }^{5}$ meaningfulness-and-teleology ${ }^{9}$ is 'often actually imbued 
with active and passive mental-strategies of compromise' but which wouldn't cut it with the maximalising-recomposuring-for-relative-ontological-completeness ${ }^{87}$ - unenframed/reontologising conceptualisation necessary for human development and progress. Beingdevelopment/ontological-framework-expansion-as-to-depth-of-ontologising-development-asinfrastructure-of- meaningfulness-and-teleology and progress requires ontologicallyveridical as intemporal/ontological/social/species $/{ }^{103}$ universal/transcendental $/{ }^{5}$ maximalisingrecomposuring-for-relative-ontological-completeness 87 unenframed/re-

ontologising conceptualisation postconverging-de-mentating/structuring/paradigming 'responses' as of ${ }^{103}$ universal implications and not temporal extricatory preconverging-dementating/structuring/paradigming 'reactions' of mere circumstantial implications. Such a maximalising-recomposuring-for-relative-ontological-completeness ${ }^{87}$ - unenframed/reontologising $\sim$ conceptualisation $\quad<$ amplituding/formative-epistemicity $>$-totalising $\sim$ renewingrealisation/re-perception/re-thought prospective ${ }^{8}$ reference-of-thought 'construes as circularity and $<$ amplituding/formative-epistemicity $>$ totalising $\sim$ self-referencingsyncretising/circularity/interiorising/akrasiatic-drag ${ }^{34}$ pretences of knowledge and judgements which are rather in threshold-of-nonconviction/madeupness/bottomlining-in-shallowsupererogation -<as-to- 'attendant-intradimensional'-prospectivelydisontologising preconverging/dementing -apriorising-psychologism> in ordinariness $<$ amplituding/formative $>$ wooden-language-〈imbued - averaging-of-thought- $<$ as-toleveling/ressentiment/closed-construct-of- meaningfulness-and-teleology -as-of'nondescript/ignorable-void '-with-regards-to-prospective-apriorising-implications $>>$ socialaggregation-enabling' when expounded by a prior ${ }^{83}$ reference-of-thought going by its prior relative-ontological-incompleteness ${ }^{8}$-of- ${ }^{3}$ reference-of-thought, since there is no sound/authentic knowledge and judgements outside the prospective ${ }^{83}$ reference-of-thought relatively sound/authentic knowledge and judgements as of its ontological-normalcy/relative- 
ontological-completeness ${ }^{87}$-of- ${ }^{8}$ reference-of-thought

intemporal/ontological/social/species $/{ }^{103}$ universal/transcendental $/{ }^{5}$ maximalising-

recomposuring-for-relative-ontological-completeness ${ }^{87}$ - unenframed/re-

ontologising conceptualisation postconverging-de-mentating/structuring/paradigming; and so preconverging/postconverging-de-mentatively/structurally/paradigmatically as of the relationship between non-positivism and positivism as well as our procrypticism-ordisjointedness-as-of- ${ }^{8}$ reference-of-thought and futural Being-development/ontologicalframework-expansion-as-to-depth-of-ontologising-development-as-infrastructure-ofmeaningfulness-and-teleology as of prospective notional ${ }^{8}$ deprocrypticism as preemptingdisjointedness-as-of- ${ }^{8}$ reference-of-thought. This underlying notion of 'notional conflatedness ${ }^{13} /$ constitutedness ${ }^{14}$-to-conflatedness ${ }^{13}$ construal/conceptualisation' can further be expanded upon contrastively with regards to knowledge practice in many an epistemic-totalising $\sim$ devolved-purview-as-domain-of-construal-as-intrinsicreality/ontological-veridicality not subject to immediate-constraining <amplituding/formativeepistemicity $>$ causality $\sim$ as-to-projective-totalitative-implications-of-prospectivenonpresencing,-for-explicating relative-unreflexivity/relative-reflexivity —ontologicalcontiguity thus rather eliciting atomising/taking-to-pieces apriorising/axiomatising/referencing-\{of-'prospectively implicited_attendant-ontologicalcontiguity ' educedexistentialising/contextualising/textualising_'intelligibility/epistemicity/reflexivity-contiguity$<$ imbued-notional cogency $\left.>^{\prime} \quad\right\}$-constitutedness ${ }^{14}$-in-preconverging-entailment that induces relatively poor ontological-performance ${ }^{72}-<$ including-virtue-as-ontology $>$. The central element here has to do with the pervasiveness of 'conceptual-patterning' that actually speaks of a nombrilistic as $\quad<$ amplituding/formative-epistemicity $>$ totalising $\sim$ self-referencingsyncretising/circularity/interiorising/akrasiatic-drag ${ }^{34}$ approach to conceptualising knowledge 
based on an intellectual exercise of producing patterns of thought with little consideration as to their underlying intrinsic-reality/ontological-veridicality transcendentalenabling/sublimating/supererogatory $\sim$ de-mentativity as validated by <amplituding/formativeepistemicity $>$ causality $\sim$ as-to-projective-totalitative-implications-of-prospectivenonpresencing,-for-explicating relative - unreflexivity/relative-reflexivity ontological-

contiguity. At its worst, such an orientation construes of categorisation/taxonomisation of knowledge as inherently representative of intrinsic-reality/ontological-veridicality by that mere exercise. Such an apriorising/axiomatising/referencing-\{of-" prospectively implicited_attendant-ontological-contiguity ' educedexistentialising/contextualising/textualising_'intelligibility/epistemicity/reflexivity-contiguity$<$ imbued-notional cogency $\left.>^{\prime} \quad\right\}$-constitutedness ${ }^{14}$-in-preconverging-entailment ends up misconstruing the organical depth involved and renders all knowledge constructs so categorised/taxonomised on the same vague plane of mechanical equivalence undermining their transcendental-enabling/sublimating/supererogatory $\sim$ de-mentativity, originality, organic nature and more often than not turning them into platitudes as rather concerned with perceived academic formulations and formats in of themselves rather than ontological-veracity as of intrinsicreality/ontological-veridicality transcendental-enabling/sublimating/suredementativity. The underlying mental-reflex for this intellectual disposition associated with conceptual-patterning is the assumption that by mere categorising/taxonomising ideas on the basis of their similarities and differences it should be able to attain a grander truth as of elaboration-as-to-mere-extrapolating/constituting/abstracting/deducing/inferring-ofelucidation-outside_-'prospectively implicited_attendant-ontological-contiguity ${ }^{67}$ ' educed-

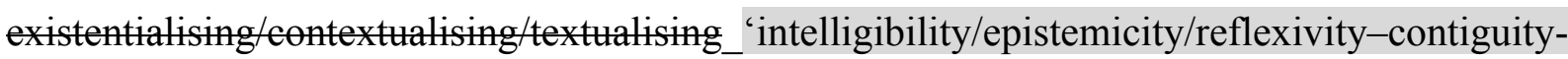
$<$ imbued-notional cogency $>$ ' But then such an approach is naïve by its failure to reckon the reality of human limited-mentation-capacity—as-subjecting-'educed-unlimitedness/existence- 
sublimating nascence' to-limitedness/human-subpotency which implies that human conceptualisation tends to develop from prior relative-ontological-incompleteness ${ }^{8}$-ofreference-of-thought, as of the incompleteness of the preconverging-dementating/structuring/paradigming of human ${ }^{83}$ reference-of-thought. Such that a naïve categorisation/taxonomisation conceptual-patterning perspective on that basis equally inherits that relative-ontological-incompleteness ${ }^{8}$ of the preconverging-dementating/structuring/paradigming of human ${ }^{83}$ reference-of-thought; with the consequence that it is not 'notionally postconvergingly-de-mentated/structured/paradigmed' to conceptually factor in human poor to perfect/near-perfect construal on the basis of apriorising/axiomatising/referencing-\{of-'prospectively implicited_attendant-ontologicalcontiguity ' educedexistentialising/contextualising/textualising_'intelligibility/epistemicity/reflexivity-contiguity<imbued-notional cogency >' \}-conflatedness ${ }^{13}$ in-\{preconverging-ment by $\}^{\prime}$ postconverging-entailment but rather suffers from apriorising/axiomatising/referencing-\{of'prospectively_implicited_attendant-ontological-contiguity ' ceducedexistentialising/contextualising/textualising_'intelligibility/epistemicity/reflexivity-contiguity<imbued-notional cogency>' $\}$-constitutedness ${ }^{\prime}$ in preconverging entment. This weakness is underlined and resolved by the notion of maximalising-recomposuring-forrelative-ontological-completeness ${ }^{8}$ - unenframed/re-ontologising conceptualisation driven by ontological-faith-notion-or-ontological-fideism - imbued-underdetermination-of-motif-andapriorising/axiomatising/referencing-as-so-being-as-of-existential-reality that enables apriorising/axiomatising/referencing-\{of-'prospectively_implicited_attendant-ontologicalcontiguity ' $\sim$ educedexistentialising/contextualising/textualising_'intelligibility/epistemicity/reflexivity-contiguity<imbued-notional cogency>' \}-conflatedness ${ }^{13}$-in-\{preconverging -ment by\} 
postconverging-entailment in line with 'implicited_attendant-ontologicalcontiguity $^{67}$; educed-

existentialising/contextualising/textualising_intelligibility/epistemicity/reflexivity_contiguity$<$ imbued-notional $\sim$ cogency $>,{ }^{\prime},-<$ reifying-or-elucidating-of-prospective-relative-ontologicalcompleteness -of- reference-of-thought- devolving-as-of-instantiative-context>. It is such a conceptual-patterning mental-reflex associated with categorising/taxonomising dispositions in apriorising/axiomatising/referencing-\{of-'prospectively implicited_attendant-ontologicalcontiguity ' educedexistentialising/contextualising/textualising_'intelligibility/epistemicity/reflexivity-contiguity$<$ imbued-notional cogency $\left.>^{\prime} \quad\right\}$-constitutedness ${ }^{14}$-in-preconverging-entailment that is behind the naïve but poor influence of the saying that "every idea has already been thought of before' with the nefarious consequence of 'emphasising themes and authorial differentiation within such categorised/taxonomised thematics in of themselves' as if an epistemictotalising $\sim$ devolved-purview-as-domain-of-study mainly involves intersubjective evaluation or evaluation among humans within the scope of their mortality on the naïve assumption that such categorising/taxonomising effectively covers analytically the entirety/potency of existence — as-the-absolute-a-priori-of-conceptualisation and existence-as-sublimatingwithdrawal/unenframing/re-ontologising,-elicited-from-prospective-profoundsupererogation -<as-to-perspective-ontological-normalcy/postconvergence-implied'prospective-aporeticism-overcoming/unovercoming'>, whereas such is achieved rather by a conceptualising as implied by referentialism-as-of-ontological-normalcy/postconvergence that places 'implicited_attendant-ontological-contiguity ${ }^{67}$ ' educed-

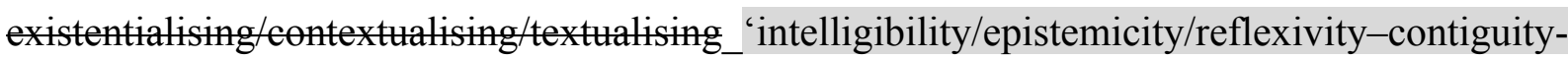
$<$ imbued-notional $\sim$ cogency $>,{ }^{\prime},-<$ reifying-or-elucidating-of-prospective-relative-ontologicalcompleteness -of- reference-of-thought- devolving-as-of-instantiative-context $>\quad$ above 
intersubjective evaluation or evaluation among humans in their mortality in determining intrinsic-reality/ontological-veridicality transcendentalenabling/sublimating/supereregatery $\sim$ de-mentativity as of intersolipsistic insight. Consider for instance that in the run up to the development of theory-of-relativity and quantum-mechanics in the early part of last century, the scientists involved weren't in the exercise of evaluating their respective theories in a closed framework emphasising their respective 'ownership-of-theories' as mortals but rather an opened framework emphasising whosever theories contribute in disclosing intrinsic-reality/ontological-veridicality as the superior third party. This can equally be compared to naively articulating categories/taxonomies of sounds on the basis that their apriorising/axiomatising/referencing-\{of-'prospectively_implicited_attendant_ontologicalcontiguity ' educedexistentialising/contextmalising/textualising_intelligibility/epistemicity/reflexivity_contiguity<imbued-notional cogency>' $\}$-constitutedness ${ }^{- \text {in }}$-preconverging-entailment defines the entire existential-<disontologising/re-ontelogising aporeticism $>$ possibility/potency of musical compositions that can arise but then the 'depth/axiomatic-construct of existence for musical compositions' doesn't submit to such a naïve categorising/taxonomising apriorising/axiomatising/referencing-\{of-'prospectively implieited_antologicalcontiguity ' $\sim$ educedexistentialising/contextualising/textualising_ 'intelligibility/epistemicity/reflexivity-contiguity<imbued-notional cogency $\left.>^{\prime} \quad\right\}$-constitutedness ${ }^{14}$-in-preconverging-entailment but rather such 'depth/axiomatic-contruct of existence for musical compositions' is as of an sublimatingepistemic-imbricatedness/threadedness/recomposuring of existential-instantiations that is graspable rather by an apriorising/axiomatising/referencing-\{of- prespectively implicited_attendant-ontological-contiguity ' educedexistentialising/contextualising/textualising_intelligibility/epistemicity/reflexivity_contiguity- 
<imbued-notional cogency $>$ ' $\}$ - conflatedness ${ }^{13}$-in-\{preconverging-ment by \} $^{\prime}$

postconverging-ntailment as enabled by referentialism-as-of-ontologicalnormalcy/postconvergence. Given our limited-mentation-capacity-as-subjecting-'educedunlimitedness/existence-sublimating nascence' to-limitedness/human-subpotency, 'implicited_attendant-ontological-contiguity ${ }^{67}$ ' educedexistentialising/contextualising/textualising_intelligibility/epistemicity/reflexivity-contiguity$<$ imbued-notional $\sim$ cogency $>,{ }^{\prime},-<$ reifying-or-elucidating-of-prospective-relative-ontologicalcompleteness -of- reference-of-thought- devolving-as-of-instantiative-context $>$ is then the preceding and transformative element of ${ }^{56}$ meaningfulness-and-teleology ${ }^{9}$ conceptualisation as of our limited-mentation-capacity-deepening —as-subjecting limitedness/human-subpotencyto-'educed-unlimitedness/existence-sublimating nascence' ${ }^{53}$ enabling our prospective relativeontological-completeness ${ }^{87}$-of- ${ }^{83}$ reference-of-thought for grasping ontologically-veridical organic-knowledge articulated in any given <amplituding/formativeepistemicity $>$ totalising $\sim$ devolved-purview-as-domain-of-construal-as-intrinsic-

reality/ontological-veridicality such that the wrong approach for prospective intellectual creation is one that simply lumps authorial articulations under given themes together in 'mechanical association' without factoring beforehand their respective 'transcendentalenabling/sublimating/supererogatory $\sim$ de-mentativity dynamism and implied organicknowledge' as of apriorising/axiomatising/referencing-\{of-'prespectively implicited_attendant-ontological-contiguity ' educedexistentialising/contextualising/textualising_'intelligibility/epistemicity/reflexivity-contiguity<imbued-notional cogency $>$ ' $\}$ - conflatedness ${ }^{13}$-in-\{preconverging-ment by\} pervasive disposition for misattributed and misfocused analyses as such blurry intellectual exercise become an <amplituding/formativeepistemicity $>$ totalising $\sim$ self-referencing-syncretising/circularity/interiorising/akrasiatic-drag 
temporal-dispositions focussing less on the possibilities and insights of prospective elucidation and expansion of knowledge as of intrinsic-reality/ontological-veridicality as being the transcendental-enabling/sublimating/supererogatory $\sim$ de-mentativity immortal/first-party, and turning more and more and placing the stakes rather on authorial second-parties/mortals competing analyses even to the extent on occasion of undermining the intrinsicreality/ontological-veridicality transcendental-enabling/sublimating/supererogatory $\sim$ dementativity immortal/first-party. Further, such conceptual-patterning will often fail to identify the appropriate point for grasping intrinsic-reality/ontological-veridicality as instead of emphasising apriorising/axiomatising/referencing-\{of-'prospectively implicited_attendantontological-contiguity ' educed-

existentialising/contextualising/textualising_intelligibility/epistemicity/reflexivity_contiguity<imbued-notional cogency $>>\quad\}$-conflatedness ${ }^{13}$-in-\{preconverging-ment by\} postconverging-entailment in (re-originary_-as-unnenframed_-reontologising/unbeholdening/outlier-conceptualisation__imbued-postconverging/dialecticalthinking -'projective-insights'/'epistemic-projection-in-conflatedness ' 'ofnotional deprocrypticism-prospective-sublimation $\rangle^{\circ}$ ) originary/event ${ }^{38}$-of-prospectiveontology-origination projection into 'implicited_attendant-ontological-contiguity ${ }^{6}$ ' educedexistentialising/contextualising/textualising_intelligibility/epistemicity/reflexivity-contiguity$<$ imbued-notional $\sim \operatorname{cogency}>{ }^{\prime},-<$ reifying-or-elucidating-of-prospective-relative-ontologicalcompleteness -of- reference-of-thought- devolving-as-of-instantiative-context $>$, emphasises mere preconverging/postconverging-de-mentative/structural/paradigmatic patterns inducing apriorising/axiomatising/referencing-\{of-'prospectively_implicited_attendant ontological-contiguity ' $\sim$ educedexistentialising/contextualising/textualising_'intelligibility/epistemicity/reflexivity-contiguity<imbued-notional cogency>’ $\}$-constitutedness ${ }^{1}$-in-preconverging-entailment, and so 
whether at detailing or synoptic levels of analysis. This extends to the way issues are raised, questions are posed, as well as their supposed resolutions; ultimately lacking in providing theoretical, conceptual and operant constructs of ${ }^{103}$ universal applicative pertinence, and explains a certain position of closure that holds that philosophy is just a vague thinking exercise. Furthermore, whereas an intrinsic-reality/ontological-veridicality transcendentalenabling/sublimating/supereregatery de-mentativity construal highlights the relativeunreflexivity/relative-reflexivity -ontological-contiguity ${ }^{77}$ of all knowledge as of their reference-of-thought-as-to-preconverging/postconverging-de-

mentating/structuring/paradigming dynamic relationship, conceptual-patterning seem to naively imply a discreet relationship of knowledge constructs with little insight of their intrinsicreality/ontological-veridicality transcendental enabling <amplituding/formativeepistemicity $>$ causality $\sim$ as-to-projective-totalitative-implications-of-prospective-

\section{nonpresencing,-for-explicating relative unreflexivity/relative-reflexivity - ontological-}

contiguity interconnectedness as this is often not the primary driving focus, as it is naively assumed that the conceptual-patterning is a correspondence of intrinsic-reality/ontologicalveridicality as of the mere preconverging/postconverging-de-mentative/structural/paradigmatic conceptualisation in apriorising/axiomatising/referencing-\{of- prespectively implicited_attendant-ontological-contiguity ' educedexistentialising/contextualising/textualising_ intelligibility/epistemicity/reflexivity-contiguity$<$ imbued-notional cogency $\left.>^{\prime} \quad\right\}$-constitutedness ${ }^{14}$-in- preconverging-entailment rather than striving to expand the transcendental-enabling/sublimating/supererogatory - de-mentativity $<$ amplituding/formative-epistemicity $>$ causality $\sim$ as-to-projective-totalitative-implications-ofprospective- nonpresencing,-for-explicating relative unreflexivity/relative reflexivity

ontological-contiguity existential-reality potential, and this easily leads to virtuality or ontologically-flawed construal. The defect of conceptual-patterning is easily overlook mainly as 
philosophy is of first order knowledge, a level at which knowledge differentiation doesn't easily manifest itself. Such errors of conceptual-patterning will hardly arise in second-level knowledge where transcendental-enabling/sublimating/supererogatory $\sim$ de-mentativity implications arise in a specular way. For instance, while hereditary is an underlying conceptual-patterning idea in biology, it will be unthinkable to try to lump together and undermine the originality of subsequent hereditary notions of genetics on the basis that these are of the same conceptualpatterning as earlier notions like Mendelian heredity as the transcendentalenabling/sublimating/supereregatory $\sim$ de-mentativity differentiations are spectacular. Finally, one practical intellectual flaw arising out of such naïve categorising/taxonomising conceptualpatterning has to do with a certain vague intellectual practice based on perceived intellectual pertinence in terms of the authorial 'precedence of mentioned terms' irrespective of association whether simple formalistic identifying of terms and notions with little consideration of the divergence of implied organic-knowledge as of their intrinsic-reality/ontological-veridicality transcendental-enabling/sublimating/supererogatory de-mentativity <amplituding/formativeepistemicity $>$ causality $\sim$ as-to-projective-totalitative-implications-of-prospective-

\section{nonpresencing,-for-explicating relative-unreflexivity/relative-reflexivity - ontological-}

contiguity nature and differences as well as their divergence in ${ }^{5}$ meaningfulness-andteleology ${ }^{9}$ implications. This again leads to lumping, artificial categorising and undermines originality and organic-knowledge, turning this into simplistic mechanical associations with the more serious consequence being that the more decisive notion for human knowledge renewal as of ${ }^{55}$ maximalising-recomposuring-for-relative-ontological-completeness ${ }^{87}$ - unenframed/reontologising conceptualisation driven by ontological-faith-notion-or-ontological-fideismimbued-underdetermination-of-motif-and-apriorising/axiomatising/referencing-as-so-being-asof-existential-reality, becomes seriously undermined; as it refers to a transcendentalenabling/sublimating/supererogatory $\sim$ de-mentativity 
epistemicity $>$ causality $\sim$ as-to-projective-totalitative-implications-of-prospective-

nonpresencing,-for-explicating relative-unreflexivity/relative-reflexivity - ontological-

contiguity renewal of a same <amplituding/formative-epistemicity>totalising $\sim$ devolvedpurview-as-domain-of-construal-as-intrinsic-reality/ontological-veridicality but with such effort for renewal often laden with a tradition that is naively of apriorising/axiomatising/referencing\{of-'prospectively implicited_attendant_ontological-contiguity ' ceduced-

existentialising/contextualising/textualising_intelligibility/epistemicity/reflexivity-contiguity<imbued-notional cogency $>\quad\}$ - constitutedness ${ }^{14}$-in-preconverging-entailment undermining requisite creativity as of apriorising/axiomatising/referencing-\{of-"prospectively implicited_attendant-ontological-contiguity ' educedexistentialising/contextualising/textualising_ intelligibility/epistemicity/reflexivity-contiguity<imbued-notional cogency>' $\}$-conflatedness ${ }^{13}$-in-\{preconverging -ment by\} postconverging-entailment, as it 'critically presupposes beyond-the-consciousness-awarenessteleology $-<$ of-preconverging-existential-extrication-as-of-existential-unthought $>\quad$ that prospective meaningfulness is deterministically tied down to a certain categorising/taxonomising relationship with the prior conceptualisations' in the given <amplituding/formativeepistemicity>totalising $\sim$ devolved-purview-as-domain-of-construal-as-intrinsic-

reality/ontological-veridicality. Ultimately, the idea here is that approaching intrinsicreality/ontological-veridicality with our given limited-mentation-capacity-as-subjecting'educed-unlimitedness/existence-sublimating nascence' to-limitedness/human-subpotency in other to achieve ontological-veracity requires a rather counterintuitive mental-reflex as of 'implicited_attendant-ontological-contiguity ${ }^{67}$; educed-

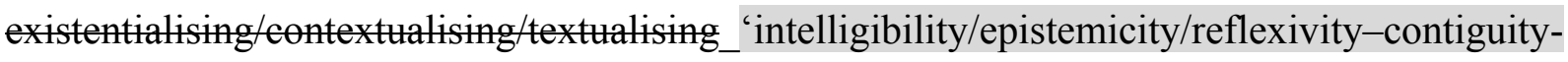
$<$ imbued-notional $\sim$ cogency $>,{ }^{\prime},-<$ reifying-or-elucidating-of-prospective-relative-ontologicalcompleteness -of- reference-of-thought- devolving-as-of-instantiative-context> that 
'originally reconstructs the ontological-pertinence of axiomatic-constructs and their derivedconceptualisations'. Such an analytic insight as of a notional deprocrypticism (protensiveconsciousness deneuterising -induced $>$ - ${ }^{83}$ reference-of-thought—devolving-teleological-dementating/structuring/paradigming-of-meaningfulness analysis as of its prospective relativeontological-completeness ${ }^{87}$-of- ${ }^{8}$ reference-of-thought/ontological-normalcy, points out that actually, and according to this author's view, such a currently discussed philosophical issue as the hard problem of consciousness arises as a result of a fragmented thematic construal as of apriorising/axiomatising/referencing-\{of-'prospectively_implicited_attendant-ontologicalcontiguity ' $\sim$ educed-

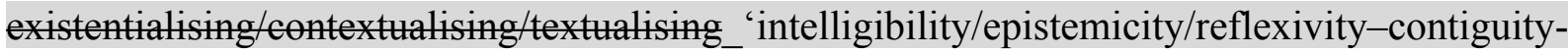
<imbued-notional cogency >' $\}$-constitutedness ${ }^{1}$-in-preconverging-entailment wherein a more profound view of the philosophical enterprise as intrinsic-reality/ontological-veridicality transcendental-enabling/sublimating/supererogatory $\sim$ de-mentativity $<$ amplituding/formativeepistemicity $>$ causality $\sim$ as-to-projective-totalitative-implications-of-prospectivenonpresencing,-for-explicating relative-unreflexivity/relative-reflexivity - ontological-

contiguity here hasn't been entertain sufficiently to point out that effectively it is a problem that actually 'devolves out' of the more fundamental issue of Being as of its but is rather being posed as of a 'disjointed/fragmented analysis' as a consciousness grounded problem. This equally explains this author's construal of human consciousness development as rather of Beingdevelopment/ontological-framework-expansion-as-to-depth-of-ontologising-development-asinfrastructure-of- meaningfulness-and-teleology ; consciousness defined as of 'notional $<$ amplituding/formative-epistemicity $>$ totalising $\sim$ self-referencingsyncretising/circularity/interiorising/akrasiatic-drag 34 human-subpotency/subpotent-mimeticechoness-derivation-within-the-full-potency of existence/intrinsic-reality/ontology-as-of-itsmimetic-echoness or existence-in-reverberation or existence-potency ${ }^{39} \sim$ sublimating-nascence,- 
disclosed-from-prospective-epistemic-digression. The fundamental fact is that existence as of 'implicited_attendant-ontological-contiguity ${ }^{67}$ educed-

existentialising/contextualising/textualising_'intelligibility/epistemicity/reflexivity-contiguity$<$ imbued-notional $\sim$ cogency $>,{ }^{\prime},-<$ reifying-or-elucidating-of-prospective-relative-ontologicalcompleteness -of- reference-of-thought- devolving-as-of-instantiative-context> is the absolute a-priori of intrinsic-reality-ontological-coherence_or_superseding-oneness-ofontology prior to any human derived knowledge-constructs/theories/intersolipsisticintercessory-notions/notional referential-notions/articulations/virtue, and hence existence as of 'implicited_attendant-ontological-contiguity ${ }^{67}$; educedexistentialising/contextualising/textualising_intelligibility/epistemicity/reflexivity-contiguity$<$ imbued-notional $\sim$ cogency $>,{ }^{\prime},-<$ reifying-or-elucidating-of-prospective-relative-ontologicalcompleteness -of- reference-of-thought- devolving-as-of-instantiative-context> is the foundational absolute a-priori any 〈given consciousness's ${ }^{58}$ neuterising-induced-ordeneuterising ${ }^{17}$-induced $>$ - ${ }^{83}$ reference-of-thought—devolving-teleological-dementating/structuring/paradigming-of-meaningfulness constructs, by which our limitedmentation-capacity_as-subjecting-'educed-unlimitedness/existence-sublimating nascence' to-limitedness/human-subpotency can most pertinently accede to by maximalisingrecomposuring-for-relative-ontological-completeness ${ }^{8}$ —unenframed/reontologising conceptualisation driven by ontological-faith-notion-or-ontological-fideismimbued-underdetermination-of-motif-and-apriorising/axiomatising/referencing-as-so-being-asof-existential-reality as of ontological-normalcy/postconvergence insight. Thus existence-asthe-absolute-a-priori-of-conceptualisation and existence-as-sublimatingwithdrawal/unenframing/re-ontologising,-elicited-from-prospective-profoundsupererogation -<as-to-perspective-ontological-normalcy/postconvergence-implied'prospective-aporeticism-overcoming/unovercoming'> implies it is as of the entire 


\section{'apriorising/axiomatising/referencing-\{of-'prospectively implicited_attendant-ontological-}

contiguity ' educed-

existentialising/contextualising/textualising_'intelligibility/epistemicity/reflexivity-contiguity-

$<$ imbued-notional cogency $>$ ' $\}$-conflatedness ${ }^{13}$-in-\{preconverging-ment-by\}

pestcenverging entailment for human construction of ontologically veridical ${ }^{56}$ meaningfulnessand-teleology $^{9}$, implied as of notional deprocrypticism; this is notionally known as historiality/ontological-eventfulness 3 /ontological-aesthetic-tracing-<perspective-

ontological-normalcy/postconvergence-reflected-‘epistemicity-relativism-determinism'>. The implication here is that conceptualisations/construals not only of consciousness but virtue, aesthetics, episteme and nature together with their derived human notional $<$ amplituding/formative-epistemicity $>$ totalising $\sim$ self-referencing-

syncretising/circularity/interiorising/akrasiatic-drag ${ }^{34}$ notions like psychologisms, ethics and moralities, arts, epistemologies and methodologies, and natural sciences are but as of the /given consciousness's $\quad{ }^{58}$ neuterising-induced-or-deneuterising ${ }^{17}$-induced $>$ - ${ }^{83}$ reference-of-thoughtdevolving-teleological-de-mentating/structuring/paradigming-of-meaningfulness knowledgeconstructs/theories/intersolipsistic-intercessory-notions/notional referential-

notions/articulations/virtue as derived conceptualisations/construals of the very apriorising/axiomatising/referencing-\{of-'prospectively_implicited_attendant-ontologicalcontiguity ' educedexistentialising/contextualising/textualising_'intelligibility/epistemicity/reflexivity-contiguity<imbued-notional cogency>' \}-conflatedness ${ }^{13}$ in-\{preconverging -ment by\} postconverging-ntailment that is as of Being-development/ontological-framework-expansionas-to-depth-of-ontologising-development-as-infrastructure-of- meaningfulness-andteleology or existence-as-existence-potency ${ }^{32}$ sublimating-nascence,-disclosed-fromprospective-epistemic-digression as to existential-possibilities. The underlying insight 
explaining human limited-mentation-capacity—as-subjecting-'educed-unlimitedness/existencesublimating nascence' to-limitedness/human-subpotency flawed mental-disposition for apriorising/axiomatising/referencing-\{of-'prospectively_implicited_attendant-ontologicalcontiguity ' educedexistentialising/contextualising/textualising_intelligibility/epistemicity/reflexivity-contiguity<imbued-notional cogency $\left.>^{\prime} \quad\right\}$-constitutedness ${ }^{14}$-in preconverging-entailment lies with human misconstruing from 'existential-instantiations' the ontological-veridicality of axiomaticconstructs as derived from the "reference-of-thought-devolving-teleological-dementating/structuring/paradigming-of-meaningfulness'. The 'iterating nature of existentialinstantiations in sublimating-epistemic-imbricatedness/threadedness/recomposuring' as of existence's is what provides humankind-as-of-it-subpotency with direct mental access to existential-reality/existence-or-intrinsic-reality-or-ontological-veridicality, as humans don't have direct mental access to conceptualised/construed existential-reality/existence-or-intrinsicreality-or-ontological-veridicality-as-of-its-full-potency, but rather projectively-oranticipatorily construe of axiomatic-constructs about intrinsic-reality/ontological-veridicality as derivable as from existence — as-the-absolute-a-priori-of-conceptualisation and existence — assublimating-withdrawal/unenframing/re-ontologising,-elicited-from-prospective-profoundsupererogation -<as-to-perspective-ontological-normalcy/postconvergence-implied'prospective-aporeticism-overcoming/unovercoming'> sublimating-epistemicimbricatedness/threadedness/recomposuring in elucidating existential-instantiations, as of 〈given consciousness's ${ }^{58}$ neuterising-induced-or-deneuterising ${ }^{17}$-induced $>$ - ${ }^{83}$ reference-ofthought — devolving-teleological-de-mentating/structuring/paradigming-of-meaningfulness, and so as of the ${ }^{55}$ maximalising-recomposuring-for-relative-ontological-completeness ${ }^{87}$ unenframed/re-ontologising conceptualisation behind the relative-unreflexivity/relativereflexivity ontological-contiguity ${ }^{67} \sim$ of-the-human-institutionalisation-process ${ }^{68}$. Otherwise 
with

a naïve

mental-reflex

of

elaboration-as-to-mere-

extrapolating/constituting/abstracting/deducing/inferring-of-elucidation-outside-

'prospectively_implicited_attendant-ontological-contiguity ${ }^{67}$ ' educed-

existentialising/contextualising/textualising_'intelligibility/epistemicity/reflexivity-contiguity-

$<$ imbued-notional cogency $>^{\prime}$ of existential-instantiations, we will rather tend to wrongly

construe the 'conceptual-patterning of existential-instantiations' as rather being 'axiomatic-

constructs as of the 〈given consciousness's ${ }^{58}$ neuterising-induced-or-deneuterising ${ }^{17}$-induced $\rangle$ -

reference-of-thought—devolving-teleological-de-mentating/structuring/paradigming-of-

meaningfulness as from existence-as-the-absolute-a-priori-ofconceptualisation and existence - as-sublimating-withdrawal/unenframing/re-ontologising,-

elicited-from-prospective-profound-supererogation $-<$ as-to-perspective-ontological-

normalcy/postconvergence-implied-'prospective-aporeticism-overcoming/unovercoming’>

sublimating-epistemic-imbricatedness/threadedness/recomposuring', thus inducing virtualities or ontologically-flawed construals associated with the uninstitutionalised-threshold ${ }^{102}$. Thus, the ontological-veracity as prospective relative-ontological-completeness ${ }^{87}$-of- ${ }^{83}$ reference-ofthought of the 'axiomatic-constructs of a 〈given consciousness's ${ }^{58}$ neuterising-induced-ordeneuterising ${ }^{17}$-induced $\rangle$ - ${ }^{3}$ reference-of-thought - devolving-teleological-de-

mentating/structuring/paradigming-of-meaningfulness as from existence-as-the-absolute-apriori-of-conceptualisation and existence - as-sublimating-withdrawal/unenframing/re-

ontologising,-elicited-from-prospective-profound-supererogation $-<$ as-to-perspective-

\section{ontological-normalcy/postconvergence-implied-'prospective-aporeticism-}

overcoming/unovercoming'>

imbricatedness/threadedness/recomposuring' sublimating-epistemic-

generating

knowledge-

constructs/theories/intersolipsistic-intercessory-notions/notional referential-

notions/articulations/virtue implied as ${ }^{56}$ meaningfulness-and-teleology ${ }^{9}$, is rather ensured by the 
construal of existential-instantiations as of ${ }^{55}$ maximalising-recomposuring-for-relativeontological-completeness ${ }^{87}$ - unenframed/re-ontologising conceptualisation which is as of apriorising/axiomatising/referencing-\{of-'prospectively_implicited_attendant-ontologicalcontiguity ' educedexistentialising/contextualising/textualising_'intelligibility/epistemicity/reflexivity-contiguity<imbued-notional cogency $\left.>^{\prime}\right\}$-conflatedness ${ }^{13}$-in-\{preconverging-ment by\} postconverging-entailment, thus enabling the relative-unreflexivity/relative-reflexivityontological-contiguity ${ }^{67}$ of-the-human-institutionalisation-process ${ }^{68}$. It is interesting to grasp here that we cannot from our 'sense of conceptual-patterning' claim to put-into-question the inherent nature of existence - as-the-absolute-a-priori-of-conceptualisation and existence-assublimating-withdrawal/unenframing/re-ontologising,-elicited-from-prospective-profoundsupererogation -<as-to-perspective-ontological-normalcy/postconvergence-implied'prospective-aporeticism-overcoming/unovercoming'> and as of its implied supersedingoneness-of-ontology, since existence is preconverging/postconverging-dementatively/structurally/paradigmatically precedent and our conceptual-patterning is arising secondarily as of our shoddy-and-incomplete construal of the iterating nature of existentialinstantiations' as of existence's sublimating-epistemicimbricatedness/threadedness/recomposuring; and any such pretence of conceptual-patterning is nothing but a virtuality or ontologically-flawed construal as of naïve apriorising/axiomatising/referencing-\{of-'prospectively implicited_attendant-ontologicalcontiguity ' educedexistentialising/contextualising/textualising_intelligibility/epistemicity/reflexivity-contiguity-

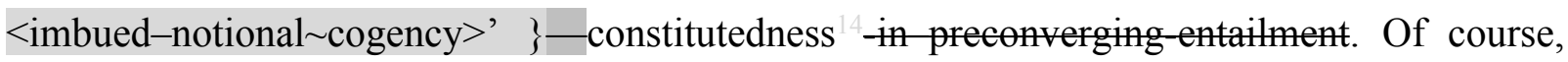
it is rather prospective relative-ontological-completeness ${ }^{8}$-of- ${ }^{-3}$ reference-of-thought that will imply deeper ontological-veracity of the same underlying purview for the construal of 
meaningfulness-and-teleology mental-disposition grounded on existence-as-the-absolutea-priori-of-conceptualisation and existence—as-sublimating-withdrawal/unenframing/reontologising,-elicited-from-prospective-profound-supererogation $-<$ as-to-perspectiveontological-normalcy/postconvergence-implied-'prospective-aporeticismovercoming/unovercoming'>. Insightfully and making the case against conceptual-patterning as of elaboration-as-to-mere-extrapolating/constituting/abstracting/deducing/inferring-ofelucidation-outside_- 'prospectively_implicited_attendant-ontological-contiguity ${ }^{67}$; educedexistentialising/contextualising/textualising_'intelligibility/epistemicity/reflexivity-contiguity$<$ imbued-notional cogency $>$ ' of existential-instantiations, this points out that existence inherent superseding-oneness-of-ontology necessarily implies ontologically-veridical meaningfulness-and-teleology is effectively as of a natural transcendentalenabling/sublimating/supererogatory de-mentativity 'implicited_attendant-ontologicalcontiguity $^{67} \sim$ educedexistentialising/contextualising/textualising_intelligibility/epistemicity/reflexivity-contiguity$<$ imbued-notional cogency>' -of-all-ontologically-veridical-meaningfulness 'in wait' to be elucidated however imbricated/threaded/recompusured such an exercise, explaining why our knowledge-constructs/theories/intersolipsistic-intercessory-notions/notional referential-

notions/articulations/virtue of a given <amplituding/formativeepistemicity $>$ totalising devolved-purview-as-domain-of-construal-as-intrinsicreality/ontological-veridicality in apriorising/axiomatising/referencing-\{of-" prospectively implicited_attendant-ontological-contiguity ' educedexistentialising/contextualising/textualising_'intelligibility/epistemicity/reflexivity-contiguity<imbued-notional $\left.\sim \operatorname{cogency}>^{\prime},\right\}$-conflatedness ${ }^{13}$ in $\{$ preconverging ment by postconverging-entailment need to be as of a reference-of-thought- categoricalimperatives/axioms/registry-teleology ${ }^{9}$,-for- 
aposteriorising/logicising/deriving/intelligising/measuring $-{ }^{56}$ meaningfulness-and-teleology ${ }^{9}$, and more than just conceptual-patterning that doesn't or poorly attends to a natural transcendental-enabling/sublimating/supererogatory $\sim$ de-mentativity 'implicited_attendantontological-contiguity ${ }^{67}$, educed-

existentialising/contextualising/textualising_'intelligibility/epistemicity/reflexivity_contiguity$<$ imbued-notional cogency>'-of-all-ontologically-veridical-meaningfulness. For all the above elucidations highlighting the ontological-veracity implications of apriorising/axiomatising/referencing-\{of-'prospectively implicited_attendant-ontologicalcontiguity ' educedexistentialising/contextualising/textualising_ 'intelligibility/epistemicity/reflexivity-contiguity<imbued-notional cogency>' $\quad\}$-constitutedness ${ }^{4}$-in-preconverging-entailment $\quad$ and apriorising/axiomatising/referencing-\{of-'prospectively_implicited_attendant-ontologicalcontiguity ' educedexistentialising/contextualising/textualising_ 'intelligibility/epistemicity/reflexivity_contiguity<imbued-notional cogency $\left.>^{\prime}\right\}$-conflatedness ${ }^{13}$-in-\{preconverging-ment by $\}^{\prime}$ postconverging entailment, it should be noted that emphasis is rather on the deficiency of limited-mentation-capacity as subjecting 'educed unlimitedness/existence sublimating nascence' to-limitedness/human-subpotency in construing intrinsic-reality/ontologicalveridicality such that the more profound/complete recomposuring of the-very-same $<$ amplituding/formative-epistemicity $>$ totalising $\sim$ devolved-purview-as-domain-of-construalas-intrinsic-reality/ontological-veridicality highlights/reflects in its subsuming interpretation the true deficiency of the shoddy/incomplete. This can be expanded upon as follows, the reason why relative-ontological-incompleteness ${ }^{88}$-of- ${ }^{8}$ reference-of-thought/epistemicabnormalcy/preconvergence 1 /destructuring can only be construed with certainty-as-to-theirreal-ontological-deficiency 'rather as a constructed-deficiency of prospective relative- 
ontological-completeness ${ }^{8}$-of- ${ }^{8}$ reference-of-thought/ontological-normalcy/conflatedness ${ }^{13}$, lies in the fact that the construal/conceptualisation of an epistemic-totalising $\sim$ devolvedpurview-as-domain-of-construal-as-intrinsic-reality/ontological-veridicality is 'supposedly as of a perfect or near-perfect or relatively-perfect ontological correspondence between such human construed/conceptualised ${ }^{5}$ meaningfulness-and-teleology ${ }^{9}$ and the inherent ontologicalveracity/intrinsicness of the <amplituding/formative-epistemicity>totalising $\sim$ devolvedpurview-as-domain-of-construal-as-intrinsic-reality/ontological-veridicality beyond-theconsciousness-awareness-teleology ${ }^{0}<$ of-preconverging-existential-extrication-as-of-

existential-unthought $>$ of human construal/conceptualisation of it'. The only human construal/conceptualisation that can guarantee or relatively guarantee such a perfect or nearperfect or relatively-perfect ontological correspondence is as of prospective relative-ontologicalcompleteness ${ }^{8}$-of- ${ }^{8}$ reference-of-thought/ontological-normalcy/conflatedness ${ }^{13}$. Since there is no direct correspondence between relative-ontological-incompleteness ${ }^{8}$-of- ${ }^{8}$ reference-ofthought/epistemic-abnormalcy/preconvergence $/$ /destructuring with the inherent intrinsicness of the $<$ amplituding/formative-epistemicity $>$ totalising $\sim$ devolved-purview-as-domain-ofconstrual-as-intrinsic-reality/ontological-veridicality beyond-the-consciousness-awarenessteleology ${ }^{\circ}-<$ of-preconverging-existential-extrication-as-of-existential-unthought $>$ of human construal/conceptualisation of it, it is thus only from a constructed-deficiency of prospective relative-ontological-completeness ${ }^{8}$-of- ${ }^{8}$ reference-of-thought/ontologicalnormalcy/conflatedness ${ }^{13}$ which has such a direct correspondence that the certainty-as-to-theirreal-ontological-deficiency of relative-ontological-incompleteness ${ }^{8}{ }^{8}{ }^{-0 f}{ }^{-}{ }^{8}$ reference-ofthought/epistemic-abnormalcy/preconvergence / / destructuring can be established. A direct approach to determine the certainty-as-to-their-real-ontological-deficiency of relativeontological-incompleteness ${ }^{8}$-of- ${ }^{8}$ reference-of-thought/epistemicabnormalcy/preconvergence ${ }^{3 /}$ destructuring will simply lead to a virtuality-or-ontologically- 
flawed-construal, as failing to elucidate the correspondence of ontological-deficiency to the inherent intrinsicness of the <amplituding/formative-epistemicity $>$ totalising $\sim$ devolvedpurview-as-domain-of-construal-as-intrinsic-reality/ontological-veridicality, with such a virtuality-or-ontologically-flawed-construal often wrongly involving " ${ }^{83}$ reference-of-thoughtelevated-devolving-as-of-prospective-institutionalisation'-as-of-upholding-ontological-

veridicality rather than ${ }^{83}$ reference-of-thought—degraded-devolving-as-of-uninstitutionalisedthreshold ${ }^{02}$ as-of-failing-ontological-veridicality since a logical correspondence with intrinsicreality/ontological-veridicality will be vaguely implied by mental-reflex; as is often the case with postlogism 77 and conjugated-postlogism 77 . By-and-large, this overall conceptualisation explains the nature of 'notional constructs' as implying a variance of poor-to-perfect ontologicalperformance $^{72}-<$ including-virtue-as-ontology $>$ /morality/ethics/justice/etc. of the same underlying idea conceptualised as of its perfect/near-perfect/relatively-perfect ontologicalperformance ${ }^{72}$-<including-virtue-as-ontology $>$ /morality/ethics/justice/etc. $\quad$ as $\quad$ insync/corresponding with inherent intrinsic-reality/ontological-veridicality beyond-theconsciousness-awareness-teleology ${ }^{9}<$ of-preconverging-existential-extrication-as-ofexistential-unthought $>$ of human construal/conceptualisation of it. This fully articulates the dynamic relationship of human limited-mentation-capacity-as subjecting unlimitedness/existence-sublimating nascence' to-limitedness/human-subpotency as of its poor to perfect relationship-with/conceptualising-of existence-or-intrinsic-reality-or-ontologicalveridicality; respectively as poor as of apriorising/axiomatising/referencing- $\{$ of- prospectively implicited_attendant-ontological-contiguity ' educedexistentialising/contextualising/textualising_ intelligibility/epistemicity/reflexivity-contiguity$<$ imbued-notional cogency>' $\}$-constitutedness ${ }^{1}$-in preconverging entailment and as relatively-perfect/near-perfect/perfect apriorising/axiomatising/referencing-\{of-"prospectively_ implicited_attendant-ontological-contiguity ' ceduced- 
existentialising/contextualising/textualising_ 'intelligibility/epistemicity/reflexivity-contiguity<imbued-notional cogency >' $\}$ - conflatedness ${ }^{13}$-in-\{preconverging-ment-by\}postconverging-entailment, construed as notional conflatedness ${ }^{13}$ as of apriorising/axiomatising/referencing-\{of-'prospectively_implicited_attendant-ontologicalcontiguity ' $\sim$ educedexistentialising/contextualising/textualising_ 'intelligibility/epistemicity/reflexivity-contiguity$<$ imbued-notional cogency $\left.>{ }^{\prime} \quad\right\}$-constitutedness ${ }^{14}$ in - preconverging-entailment-towardsconflatedness ${ }^{3}$ in-\{preconverging-ment by postconverging-entailment of human limitedmentation-capacity—as-subjecting 'educed-unlimitedness/existence-sublimating nascence' to-limitedness/human-subpotency. Insightfully, it highlights that apriorising/axiomatising/referencing-\{of-'prospectively_implicited_attendant-ontologicalcontiguity ' $\sim$ educedexistentialising/contextualising/textualising_ 'intelligibility/epistemicity/reflexivity-contiguity$<$ imbued-notional cogency $\left.>{ }^{\prime} \quad\right\}$-constitutedness ${ }^{1}$-in-preconverging-entailment arises as of human limited-mentation-capacity—as-subjecting-'educed-unlimitedness/existencesublimating nascence'-to-limitedness/human-subpotency 'poor/unsound/shoddy/incomplete unanticipated/unprojected' construal/conceptualisation-of-axiomatic-constructs-as-knowledgeconstructs/theories/intersolipsistic-intercessory-notions/notional $\sim$ referentialnotions/articulations/virtue from the sublimating-epistemicimbricatedness/threadedness/recomposuring iterating of existential-instantiations' as of 'existence-or-intrinsic-reality-or-ontological-veridicality', while apriorising/axiomatising/referencing-\{of-'prospectively implicited_attendant-ontologicalcontiguity ' $\sim$ educedexistentialising/contextualising/textualising_'intelligibility/epistemicity/reflexivity-contiguity<imbued-notional cogency>' \}-conflatedness ${ }^{13}$-in-\{preconverging -ment by\} 
postconverging-entailment arises as of human limited-mentation-capacity-as-subjecting'educed-unlimitedness/existence-sublimating nascence' to-limitedness/human-subpotency 'good/sound/profound/complete anticipated/projected' construal/conceptualisation-ofaxiomatic-constructs-as-knowledge-constructs/theories/intersolipsistic-intercessorynotions/notional $\sim$ referential-notions/articulations/virtue from the 'sublimating-epistemicimbricatedness/threadedness/recomposuring iterating of existential-instantiations' as of 'existence-or-intrinsic-reality-or-ontological-veridicality'.

Notional conflatedness ${ }^{13} /$ constitutedness $^{14}$-to-conflatedness ${ }^{13}$ as such highlights an underlying historiality/ontological-eventfulness 38 ontological-aesthetic-tracing-<perspectiveontological-normalcy/postconvergence-reflected-'epistemicity-relativism-determinism'> of the apriorising/axiomatising/referencing-\{of-'prospectively_implicited_attendant_ontologicalcontiguity ' educedexistentialising/contextualising/textualising_'intelligibility/epistemicity/reflexivity-contiguity$<$ imbued-notional cogency $>\quad\}$-constitutedness ${ }^{4}$-in-precenverging-entailment-towardsconflatedness ${ }^{13}$ in-\{preconverging-ment by - postconverging-entailment dynamism of human limited-mentation-capacity_as-subjecting 'educed-unlimitedness/existence-sublimating nascence' to limitednessman subpen with respect to human ontological-performance ${ }^{72}$ <including-virtue-as-ontology>-as-of-its-broadest-implications amenable to humansubpotency/‘subpotent-mimetic-echoness-derivation-within-the-full-potency of existence/intrinsic-reality/ontology-as-of-its-mimetic-echoness or existence-in-reverberation or existence-potency ${ }^{39} \sim$ sublimating-nascence,-disclosed-from-prospective-epistemic-digression, and so whether as of natural ontology/natural sciences, social ontology/social sciences, aesthetics-as-ontology, virtue-as-ontology, etc. of critical relevance is the notion of existence as of human-subpotency or human subpotent-mimetic-echoness-derivation-within-the-full-potency of existence/intrinsic-reality/ontology-as-of-its-mimetic-echoness or existence-in-reverberation 
digression, implying the <amplituding/formative-epistemicity $>$ totalising $\sim$ self-referencingsyncretising/circularity/interiorising/akrasiatic-drag 34 as of pivoting nature of human knowledge-constructs/theories/intersolipsistic-intercessory-notions/notional $\sim$ referentialnotions/articulations/virtue wherein it is about existence-as-enabling-of-humankindpotential/possibilities or existence-as-emancipating-of-humankind-in-the-broadest-sense-of-itsthought-and-projective-potential-but-beyond-just-the-engrossed-contemplation-of-onlyhumankind. All knowledge-constructs/theories/intersolipsistic-intercessorynotions/notional referential-notions/articulations/virtue are thus for-human-studies/for-humanconstructs in the sense that these do not add anything to the given abstract/imaginary existence but are simply enabling to human curiosity and emancipation; that is, whether humans in 2000 $\mathrm{BC}$ or $2000 \mathrm{AD}$ are knowledgeable about notions as genetics, theory-of-relativity, ${ }^{10}$ universal human rights, etc. doesn't add anything to 'abstract/imaginary existence as a pre-given' pointing to the fact that human existence is about human-subpotency construed as of successive defining transcendentally-enabling-level-of ontological-good-faith-or-

authenticity $\%$ objectification/desubjectification-as-objectification-<as-to-ontological-faithnotion-or-ontological-fideism —imbued-underdetermination-of-motif-andapriorising/axiomatising/referencing-as-so-being-as-of-existential-reality as antinihilism $>100$ as levels of human dispensing-with-immediacy-for-relative-ontological-completeness ${ }^{87}$-byreification/contemplative-distension ${ }^{27}$ (as of human self-surpassing-existentialism-formfactor,-in-overcoming-'notional collateralising-beholdening-protohumanity'-to-'attainsublimating-humanity'-as-to-existence-potency sublimating-nascence,-disclosed-fromprospective-epistemic-digression to supersede human temporality $8 /$ shortness $<$ amplituding/formative $>$ wooden-language-_imbued — averaging-of-thought- $<$ as-toleveling/ressentiment/closed-construct-of- meaningfulness-and-teleology -as-of- 
'nondescript/ignorable-void '-with-regards-to-prospective-apriorising-implications $>\rangle)$. Thus in effect the natural sciences are actually for-human-studies/for-human-constructs whose specific ambit of human-subpotency is about 'human consciousness as for material and physical effecting devolving teleologies as meaningfulness' while the social domains-of-study are actually for-human-studies/for-human-constructs whose specific ambit of human-subpotency is about 'human consciousness inherent effecting devolving teleologies as meaningfulness'. This validates the idea of dualism as ultimately $<$ supereregatory $\sim$ human-subpotency $>$-effecting can only arise from the apriorising/axiomatising/referencing-\{of-'prospectively implicited_attendant-ontological-contiguity ' educedexistentialising/contextualising/textualising_'intelligibility/epistemicity/reflexivity-contiguity<imbued-notional cogency>' \}-conflatedness ${ }^{13}$-in-\{preconverging-ment by\} postconverging-entailment of human consciousness in-its-embodiment as the potent 'phenomenological transcendental-point-of-departure handle' for human self-conscious existence and ${ }^{56}$ meaningfulness-and-teleology ${ }^{9}$ construal/conceptualisation as of knowledgeconstructs/theories/intersolipsistic-intercessory-notions/notional referential-

notions/articulations/virtue, whereas the human body as matter though physically existent cannot as of such its apriorising/axiomatising/referencing-\{of-'prospectively implicited_attendant ontological-contiguity ' educed-

existentialising/contextualising/textualising_'intelligibility/epistemicity/reflexivity-contiguity$<$ imbued-notional cogency $>$ ' $\}$-constitutedness ${ }^{14}$-in-preconverging-entailment conception be construed/conceptualised as of such a 'phenomenological transcendental-point-of-departure handle'. In the bigger framework, human <amplituding/formative-epistemicity>totalising thrownness-in-existence ${ }^{35}$ (I exist therefore existence is of transcendentalenabling/sublimating/supereregatory $\sim$ de-mentativity to my human-subpotency / hyperbole-of-

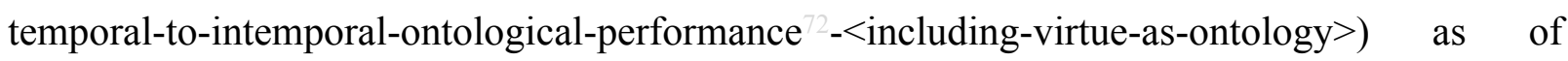


collective human shallow-to-deepening-limited-mentation-capacity-as-subjecting-educedunlimitedness/existence-sublimating nascence' to-limitedness/human-subpotency, as-limitedmentation-capacity-deepening —as-subjecting limitedness/human-subpotency-to-'educedunlimitedness/existence-sublimating nascence' ${ }^{53}$ implies that human knowledgeconstructs/theories/intersolipsistic-intercessory-notions/notional referential-

notions/articulations/virtue inherently suffer in reflecting holographically-<conjugatively-andtransfusively $>$ the relative-unreflexivity/relative-reflexivity ontological-contiguity $\sim$ of-thehuman-institutionalisation-process successive institutional-cumulation/institutionalrecomposure-〈as-to- historiality/ontological-eventfulness /ontological-aesthetic-tracing<perspective-ontological-normalcy/postconvergence-reflected-'epistemicity-relativismdeterminism' $>>$ from an 'extended metaphysics-of-presence-〈implicited'nondescript/ignorable-void ' -as-to- presencing - absolutising-identitive-constitutedness > deficiency' on human ontological-performance ${ }^{72}-$ including-virtue-as- $^{2}$ ontology $>$ /morality/ethics/justice/etc. that can be traceable as of a notional ${ }^{18 \text { deprocrypticism }}$ 'extended metaphysics-of-absence-_implicited-epistemic-veracity-of- nonpresencing$<$ perspective-ontological-normalcy/postconvergence $>>\quad$ insight' ${ }^{\prime} \quad$ construed as historiality/ontological-eventfulness ${ }^{38} /$ ontological-aesthetic-tracing- $<$ perspectiveontological-normalcy/postconvergence-reflected-‘epistemicity-relativism-determinism'>; and we can always grasp insightfully of human existential-distogising/re ontelogising apereticism $>$ hyperbole-of-temporal-to-intemporal-ontological-performance ${ }^{2}-<$ includingvirtue-as-ontology $>$ /morality/ethics/justice/etc. from the prospective relative-ontologicalcompleteness $^{87}$-of- ${ }^{83}$ reference-of-thought/relative-ontological-normalcy/postconvergence as of base-institutionalisation realisation of the hyperbole of recurrent-utter-uninstitutionalisation, universalisation realisation of the hyperbole of base-institutionalisation-ununiversalisation, positivism realisation of the hyperbole of ${ }^{103}$ universalisation-non-positivism/medievalism, and 
prospectively notional deprocrypticism realisation of the hyperbole of

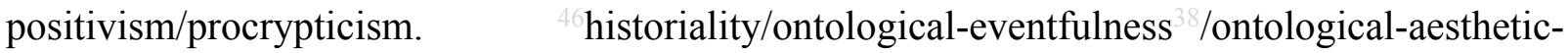
tracing-<perspective-ontological-normalcy/postconvergence-reflected-‘epistemicityrelativism-determinism'> as of notional ${ }^{18}$ deprocrypticism perspective refers to the underlying idiosyncratic, intricate, compounded and pervasive succession of preformulating/preframing/premeaningfulness- $<$ metaphoricity ${ }^{57}$-disposition - as-to-psycheinduced-psychologism-of-existential-stake $>$ as of notional conflatedness ${ }^{13} /$ constitutedness $^{14}$ to-conflatedness $^{13}$ from human shallow-to-deepening-limited-mentation-capacity-assubjecting-'educed-unlimitedness/existence-sublimating nascence' to-limitedness/humansubpotency, as-limited-mentation-capacity-deepening—as-subjecting-limitedness/humansubpotency-to-'educed-unlimitedness/existence-sublimating nascence' ${ }^{53}$ as of the-very-sameimmanent-existence/intrinsic-reality/ontological-veridicality,-as-to'human<amplituding/formative-epistemicity>totalising purview-of-construal' as it reflects relative ontological-performance ${ }^{72}-<$ including-virtue-as-ontology $>$-as-of-its-broadestimplications of any 〈given consciousness's ${ }^{58}$ neuterising-induced-or-deneuterising ${ }^{17}$-induced〉reference-of-thought — devolving-teleological-de-mentating/structuring/paradigming-ofmeaningfulness as its intradimensional existential-instantiations derived/devolved axiomaticconstructs of $\quad{ }^{56}$ meaningfulness-and-teleology 9 as knowledgeconstructs/theories/intersolipsistic-intercessory-notions/notional referentialnotions/articulations/virtue and as the registry-worldview's/dimension's ${ }^{83}$ reference-of-thought 'abstract teleological-de-mentating/structuring/paradigming/teleological-possibilities'; and it reflects any given registry-worldview's/dimension's specific institutionalisation-byuninstitutionalisation-or-uninstitutionalised-threshold postconverging-or-dialecticalthinking -apriorising-psychologism/preconverging-or-dementing ${ }^{20}$-apriorising-psychologism construct as a specific aesthetic trace of 'ontologically elevated-by-degraded-devolving-as-of- 


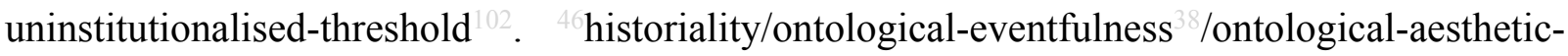
tracing-<perspective-ontological-normalcy/postconvergence-reflected-‘epistemicityrelativism-determinism' $>$ as of the notional conflatedness ${ }^{13}$ of notional $\sim^{18}$ deprocrypticism equally supersedingly enlightens the idea of totalising-entailing which is often somewhat articulated as in the statement the 'whole is greater than the sum of its parts' but failing to specifically clarify that 'limited-mentation-capacity-as-subjecting-educedunlimitedness/existence-sublimating nascence' to-limitedness/human-subpotency apriorising/axiomatising/referencing-\{of-'prospectively implicited_attendant-ontologicalcontiguity ' educedexistentialising/contextualising/textualising_'intelligibility/epistemicity/reflexivity-contiguity$<$ imbued-notional cogency $>\quad\}$-constitutedness ${ }^{14}$-in-preconverging-entailment conceptualisation construes of an 'ontologically-compromised-mediating,-as-of-its-specificconstitutedness ${ }^{14}$ that is relatively shoddy and incomplete' and generates virtuality-orontologically-flawed-construal when it construes of parts and whole in a given $<$ amplituding/formative-epistemicity $>$ totalising $\sim$ devolved-purview-as-domain-of-construalas-intrinsic-reality/ontological-veridicality and so as a derived/unoriginary mental-reflex as of elaboration-as-to-mere-extrapolating/constituting/abstracting/deducing/inferring-ofelucidation-outside_- 'prospectively_implicited_attendant-ontological-contiguity ${ }^{67}$ ? educedexistentialising/contextualising/textualising_intelligibility/epistemicity/reflexivity-contiguity$<$ imbued-notional cogency>' unlimitedness/existence-sublimating nascence' to-limitedness/human-subpotency apriorising/axiomatising/referencing-\{of-'prospectively_implicited_attendant-ontologicalcontiguity ' educedexistentialising/contextualising/textualising_'intelligibility/epistemicity/reflexivity-contiguity<imbued-notional cogency>' \}-conflatedness ${ }^{13}$ in-\{preconverging-ment by\} 
pestcenverging-ntailment conceptualisation as of notional deprocrypticism-as-preemptingdisjointedness-as-of- ${ }^{8}$ reference-of-thought construes of a 'non-mediating incisive as referentialism—ontologically-uncompromised-mediating,-as-of-conflatedness profoundness/completeness' by an incisive <amplituding/formative-epistemicity $>$ totalising renewing-realisation/re-perception/re-thought that further expands human grasp of the given <amplituding/formative-epistemicity>totalising $\sim$ devolved-purview-as-domain-ofconstrual-as-intrinsic-reality/ontological-veridicality as a non-derived/original mental-reflex of maximalising-recomposuring-for-relative-ontological-completeness ${ }^{87}$ unenframed/reontologising conceptualisation driven by ontological-faith-notion-or-ontological-fideism imbued-underdetermination-of-motif-and-apriorising/axiomatising/referencing-as-so-being-asof-existential-reality. The latter is effectively what relays the ontological-veracity of the $<$ amplituding/formative-epistemicity $>$ totalising $\sim$ devolved-purview-as-domain-of-construalas-intrinsic-reality/ontological-veridicality implied axiomatic-construct as of completeness/profoundness subsuming the reality of the perceived whole and parts within the incisive apriorising/axiomatising/referencing-\{of-'prospectively implicited_attendantontological-contiguity ' educed-

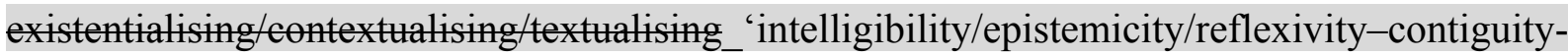
$<$ imbued-notional $\left.\sim \operatorname{cogency}>^{\prime},\right\}$-conflatedness ${ }^{13}$-in-\{preconverging-ment by $\}$ postconverging-ntailment; pointing out that the fundamental issue is how human limitedmentation-capacity -as-subjecting 'educed-unlimitedness/existence-sublimating nascence' to-limitedness/human-subpotency effectively construes intrinsic-reality/ontological-veridicality as of its profoundness/completeness. Consider in this particular regards the intrinsicreality/ontological-veridicality reflected as akin to an engineering product like a jet engine wherein the conceptualisation is an incisive apriorising/axiomatising/referencing-\{of'prospectively_implicited_attendant-ontological-contiguity ' educed- 
existentialising/contextualising/textualising_'intelligibility/epistemicity/reflexivity-contiguity-

<imbued-notional cogency $\left.>^{\prime} \quad\right\}$-conflatedness ${ }^{13}$ in-\{preconverging-ment by\}

postconverging entailment that goes beyond the whole and parts of the jet engine to grasp a conceptualisation profoundness/completeness of required critical performances like fuel burn, maintenance cycles, robustness, etc. construed as of the articulated depth of the ${ }^{83}$ reference-ofthought of aircraft engine engineering science. This overall notional conception extends as well to the various ways by which human limited-mentation-capacity-as-subjecting 'educedunlimitedness/existence-sublimating nascence' to-limitedness/hmman-subpotency 'accosts' intrinsic-reality/ontological-veridicality, bringing about the various registryworldviews/dimensions categorising/qualifying/tendentious/impulsive — ontologicallycompromised-mediating,-as-of-their-specific-constitutedness ${ }^{14}$ induced ${ }^{58}$ neuterising or prospectively notional ${ }^{18}$ deprocrypticism referentialism—ontologically-uncompromisedmediating,-as-of-conflatedness ${ }^{13}{ }^{56}$ meaningfulness-and-teleology.$\quad$ That is, the notional ${ }^{18}$ deprocrypticism protensive-consciousness apriorising/axiomatising/referencing/intelligibilitysettingup/measuringinstrumenting in its referencing of apriorising/axiomatising/referencing-\{of-'prospectively implicited_attendantontological-contiguity ' educed-

existentialising/contextualising/textualising_ intelligibility/epistemicity/reflexivity-contiguity<imbued-notional cogency $\left.>^{\prime}\right\}$-conflatedness ${ }^{13}$ in-\{preconverging ment by\} pestconverging-entailment, with no intermediating construct as of apriorising/axiomatising/referencing-\{of-'prospectively implicited_attendant-ontologicalcontiguity ' educedexistentialising/contextrising/textralising_intelligibility/epistemicity/reflexivity-contiguity$<$ imbued-notional cogency $\left.>^{\prime} \quad\right\}$-constitutedness ${ }^{14}$-in-preconverging-entailment, $\quad$ thus achieves ontologically-uncompromised-mediating,-as-of-conflatedness ${ }^{13}{ }^{56}$ meaningfulness- 
and-teleology . While the occlusive/preclusive/warped/trepidatious-consciousnesses mentaldispositions/apriorising/axiomatising/referencing/intelligibilitysettingup/measuringinstrumenti ngs by their successive intermediating categorising/qualifying/tendentious/impulsive constructs as of apriorising/axiomatising/referencing-\{of-'prospectively implicited_attendantontological-contiguity ' $\sim$ educedexistentialising/contextualising/textualising_ 'intelligibility/epistemicity/reflexivity-contiguity$<$ imbued-notional $\sim$ cogency $\left.>^{\prime} \quad\right\}$ - constitutedness ${ }^{14}$-in - preconverging-ntailment on apriorising/axiomatising/referencing-\{of-'prospectively_implicited_attendant-ontologicalcontiguity ' educedexistentialising/contextualising/textualising_'intelligibility/epistemicity/reflexivity-contiguity-

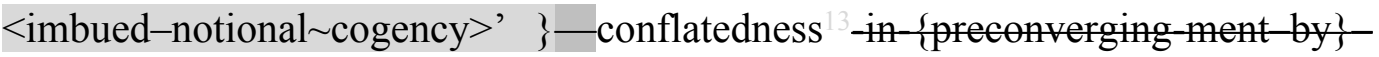
postconverging-ntailment induce their successively categorising/qualifying/tendentious/impulsive—ontologically-compromised-mediating,-as-oftheir-respective-specific-constitutedness ${ }^{14}{ }^{56}$ meaningfulness-and-teleology 9 . This ultimately points to the centrality of the implications of the 'notion of limited-mentation-capacity-assubjecting 'educed-unlimitedness/existence-sublimating nascence' to-limitedness/humansubpententis as of its notional ${ }^{18}$ deprocrypticism refentialism-ontologically-uncompromisedmediating,-as-of-conflatedness ${ }^{13}$ as a notional conception in construing ${ }^{5}$ meaningfulness-andteleology , while avoiding its ontologically-flawed apriorising/axiomatising/referencing-\{of'prospectively_implicited_attendant_ontological-contiguity ' educedexistentialising/contextualising/textualising_'intelligibility/epistemicity/reflexivity-contiguity<imbued-notional cogency $\left.>^{\prime} \quad\right\}$-constitutedness ${ }^{14}$-in - preconverging-entailment construals in terms-as-of-axiomatic-construct of the various neuterising. Hence the "notion of limitedmentation-capacity—as-subjecting 'educed-unlimitedness/existence-sublimating nascence' to-limitedness/human-subpotency' as it overcomes ontologically-compromised-mediating,-as- 
of-its-specific-constitutedness ${ }^{14}$ towards ontologically-uncompromised-mediating,-as-ofconflatedness ${ }^{13}$ is what is effectively and ontologically defining of issues of ${ }^{83}$ reference-ofthought of meaningfulness-and-teleology given that as of its ontologically veridical apriorising/axiomatising/referencing-\{of-'prospectively implicited_attendant-ontologicalcontiguity ' educedexistentialising/contextualising/textualising_ 'intelligibility/epistemicity/reflexivity-contiguity$<$ imbued-notional cogency $>\quad\}$ - conflatedness ${ }^{13}$-in-\{preconverging -ment by\} postconverging entailment it is the cumulative recomposuring of human limited-mentationcapacity —as-subjecting-educed-unlimitedness/existence-sublimating nascence' tolimitedness/human-subpotency as limited-mentation-capacity-deepening-as-subjecting limitedness/human-subpotency to-'educed-unlimitedness/existence-sublimating nascence' that is behind the relative-unreflexivity/relative-reflexivity-ontological-contiguity ${ }^{6} \sim$ of-thehuman-institutionalisation-process ${ }^{68}$ itself, and also underlies temporal-to-intemporal individuations differentiation as shortness-of-register-of- ${ }^{56}$ meaningfulness-and-teleology and-longness-of-register-of- ${ }^{5}$ meaningfulness-and-teleology 9 as of limited-mentationcapacity—as-subjecting 'educed-unlimitedness/existence-sublimating nascence' to-

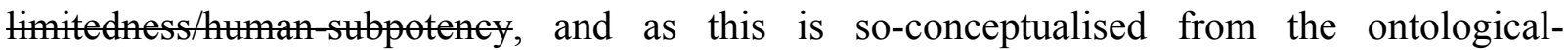
normalcy/relative-ontological-completeness ${ }^{87}$-of- ${ }^{-}$reference-of-thought perspective of notional ${ }^{8}$ deprocrypticism 'referentialism—ontologically-uncompromised-mediating,-as-ofconflatedness $^{13}$ protensive-consciousness sound conceptualisation perspective'. This equally underlies and is in sync with the notion of candidity/candour-capacity as a variance of the same as of notional $\sim$ deprocrypticism 'referentialism—ontologically-uncompromised-mediating,-asof-conflatedness ${ }^{13}$ protensive-consciousness sound conceptualisation perspective'. It is the 'notion of limited-mentation-capacity—as-subjecting-'educed-unlimitedness/existencesublimating nascence' to-limitedness/human-subpotency' that as of its deficiency is falsely- 
composited by 'ontologically-compromised-mediating,-as-of-their-specific-constitutedness consciousnesses flawed conceptualisation perspectives' into ontologically-flawed constructs of neuterising. $\quad$ historiality/ontological-eventfulness $3 /$ ontological-aesthetic-tracing<perspective-ontological-normalcy/postconvergence-reflected-'epistemicity-relativismdeterminism' $>$ as of the notional $\sim$ conflatedness ${ }^{13}$ of notional ${ }^{18}$ deprocrypticism highlights that humankind in its projected-or-anticipated relationship with 'existence as-the-absolute-a-priori' is rather in preconverging-existential-extrication-as-of-existential-unthought, and not the full potency of existence; preconverging-existential-extrication-as-of-existential-unthought construed rather as 'shoddy-and-incomplete actualising in 79 presencing-absolutisingidentitive-constitutedness $^{14}$ of the full potency of existence. Preconverging-existentialextrication-as-of-existential-unthought refers to a registry-worldview's/dimension's overall historiality/ontological-eventfulness 3 /ontological-aesthetic-tracing-<perspectiveontological-normalcy/postconvergence-reflected-‘epistemicity-relativism-determinism'> as of the notional $\sim$ conflatedness ${ }^{13}$ of notional ${ }^{18}$ deprocrypticism construct, wherein its $<$ amplituding/formative-epistemicity $>$ totalising $\sim$ self-referencingsyncretising/circularity/interiorising/akrasiatic-drag ${ }^{34}$ construes beyond-the-consciousnessawareness-teleology $-<$ of-preconverging-existential-extrication-as-of-existential-unthought $>$ of its 'projected-or-anticipated-grandest-existential-axiomatic-construct' as the absolute framework of ontological-performance ${ }^{2}-<$ including-virtue-as-ontology $>$-as-of-its-broadestimplications and thus failing to factor in the implications on its ontological-performance ${ }^{72}$ $<$ including-virtue-as-ontology $>/$ morality/ethics/justice/etc. of its prior relative-ontologicalincompleteness ${ }^{88}$-of- ${ }^{8}$ reference-of-thought as this induces <amplituding/formative $>$ woodenlanguage-〈imbued-temporal-mere-form/virtualities/dereification/akrasiaticdrag/denatured/preconverging-or-dementing -narratives - of-the- reference-of-thoughtcategorical-imperatives/axioms/registry-teleology $\rangle$ at its uninstitutionalised-threshold ${ }^{02}$. 
Preconverging-existential-extrication-as-of-existential-unthought thus highlights the overall apriorising/axiomatising/referencing-\{of-"prospectively_implicited_attendant-ontologicalcontiguity ' $\sim$ educed-

existentialising/contextualising/textualising_intelligibility/epistemicity/reflexivity_contiguity<imbued-notional cogency $\left.>^{\prime} \quad\right\}$-constitutedness ${ }^{14}$-in-preconverging-entailment $\quad$ of humankind's access to existence given the 'sublimating-epistemicimbricatedness/threadedness/recomposuring as of iterating-of-existential-instantiations', such that humankind's axiomatic-construct/theory of existence/existential-reality/intrinsicreality/ontological-veridicality as of its 'projected-or-anticipated-grandest-existentialaxiomatic-construct reference-of-thought — devolving-teleological-dementating/structuring/paradigming-of-meaningfulness' is rather as of various successive relative apriorising/axiomatising/referencing-\{of-‘prospectively_implicited_attendantontological-contiguity ' educedexistentialising/contextualising/textualising_intelligibility/epistemicity/reflexivity-contiguity$<$ imbued-notional cogency $\left.>^{\prime} \quad\right\}$-constitutedness ${ }^{14}$-in-preconverging-entailment implied with the successive institutionalisations, and explains a natural human mental-disposition to nihilism as of each of such institutionalisation's <amplituding/formative $>$ wooden-language-〈imbued averaging-of-thought-<as-to-leveling/ressentiment/closed-construct-of- meaningfulness-andteleology -as-of-'nondescript/ignorable-void '-with-regards-to-prospective-apriorisingimplications $>>$ at its uninstitutionalised-threshold ${ }^{102}$ in a mental-reflex aversion of an openedconstruct-of- ${ }^{5}$ meaningfulness-and-teleology 9 behind the overall relativeunreflexivity/relative-reflexivity — ontological-contiguity ${ }^{67}$ of-the-human-institutionalisationprocess ${ }^{68}$ Preconverging-existential-extrication-as-of-existential-unthought as of the notional conflatedness ${ }^{13}$ of notional ${ }^{1}$ deprocrypticism equally implies a humankind (re-

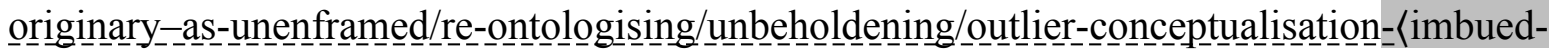


postconverging/dialectical-thinking -'projective-insights'/'epistemic-projection-in-

conflatedness ' -of-notional deprocrypticism-prospective-sublimation $\rangle^{\circ}$ ) originary/event ${ }^{38}$ of-prospective-ontology-origination and effective ${ }^{55}$ maximalising-recomposuring-for-relativeontological-completeness ${ }^{87}$ - unenframed/re-ontologising conceptualisation capacity for inducing the requisite psychoanalytic-unshackling referencing/registering/decisioning-of-itsprior-relative-ontological-incompleteness ${ }^{8}$-of- ${ }^{8}$ reference-of-thought-rather-as-preconvergingor-dementing -and-decentered-to-the-prior-institutionalisation's- categorical-

imperatives/axioms/registry-teleology ${ }^{9}$ and its alienation-as-inauthentic/poorlyobjectified/poorly-desubjectified-as-objectified/ontological-bad-faith/inauthenticity ${ }^{6} /$ nihilistic while construing prospective opened-construct-of- ${ }^{5}$ meaningfulness-and-teleology 99 postconverging-or-dialectical-thinking -and-centered-to-the-prospective-institutionalisation'scategorical-imperatives/axioms/registry-teleology ${ }^{9}$-relative-ontological-completeness ${ }^{87}$-ofreference-of-thought-in-ontological-good-faith/authenticity ${ }^{6}$, thus literally expanding human access to existence-potency ${ }^{39} \sim$ sublimating-nascence,-disclosed-from-prospective-epistemicdigression as to the existential-<disentelogising/re-ontologising apereticism $>$ possibilities that arise with successive institutional-cumulation/institutional-recomposure-〈as-tohistoriality/ontological-eventfulness /ontological-aesthetic-tracing-<perspectiveontological-normalcy/postconvergence-reflected-‘epistemicity-relativism-determinism'>> associated with the relative-unreflexivity/relative-reflexivity ontological-contiguity $^{67} \sim$ of-thehuman-institutionalisation-process ${ }^{68}$. This thus divulges the essence of existence as the "fullpotency of existence-as-of-its-mimetic-echoness/existence-in-reverberation/existencepotency ${ }^{32} \sim$ sublimating-nascence,-disclosed-from-prospective-epistemic-digression. In other words existence is already given rather as of its potency, and the real problem of existence is humankind's access to existential<<disontologising/re-ontologising aporeticism $>$ possibilities as of humankind's limited-mentation-capacity—as-subjecting-'educed- 
unlimitedness/existence-sublimating nascence' to-limitedness/human-subpotency. That is, human transcendence-and-sublimity/sublimation/supererogatory-de-mentativity is what achieves existence as a 'potent construct', as the notion of existence-as-a-grounded-construct doesn't-make-sense/is-unavailable for any specific human registry-worldview's/dimension's reference-of-thought as an <amplituding/formative-epistemicity $>$ totalising $\sim$ self-referencingsyncretising/circularity/interiorising/akrasiatic-drag ${ }^{34}$ construct, including our positivismprocrypticism registry-worldview/dimension, as this will falsely imply that our ${ }^{83}$ reference-ofthought $<$ amplituding/formative-epistemicity $>$ totalising $\sim$ self-referencingsyncretising/circularity/interiorising/akrasiatic-drag ${ }^{34}$ is 'developed enough' as of Being-andcontemplation to have achieved the full potency of existence to then know what's existence whereas in reality such <amplituding/formative-epistemicity $>$ totalising $\sim$ self-referencingsyncretising/circularity/interiorising/akrasiatic-drag ${ }^{34}$ highlights human-subpotency/subpotentmimetic-echoness-derivation-within-the-full-potency of existence. Thus our construal of existence can only be an 'as of existence' exercise that rather highlights human potential to transcend towards grasping existence/existential-possibilities; with that potency only instigated as of ontological-faith-notion-or-ontological-fideism-imbued-underdetermination-of-motifand-apriorising/axiomatising/referencing-as-so-being-as-of-existential-reality for transcendence-and-sublimity/sublimation/supererogatory $\sim$ de-mentativity. Basically, existence as of prospective base-institutionalisation ${ }^{8}$ reference-of-thought is circularly-unintelligible-butfor-a-<amplituding/formative-epistemicity $>$ totalising $\sim$ self-referencing-syncretising-menialityor-hyperbole-of- ${ }^{56}$ meaningfulness-and-teleology ${ }^{9}$ to recurrent-utter-uninstitutionalisation reference-of-thought but for the former transcendental instigation as of ontological-faithnotion-or-ontological-fideism—imbued-underdetermination-of-motif-andapriorising/axiomatising/referencing-as-so-being-as-of-existential-reality, existence as of prospective ${ }^{103}$ universalisation ${ }^{83}$ reference-of-thought is circularly-unintelligible-but-for-a- 
$<$ amplituding/formative-epistemicity $>$ totalising $\sim$ self-referencing-syncretising-meniality-orhyperbole-of- ${ }^{5}$ meaningfulness-and-teleology ${ }^{99}$ to base-institutionalisation-ununiversalisation reference-of-thought but for the former transcendental instigation as of ontological-faithnotion-or-ontological-fideism—imbued-underdetermination-of-motif-andapriorising/axiomatising/referencing-as-so-being-as-of-existential-reality, existence as of prospective positivism ${ }^{83}$ reference-of-thought is circularly-unintelligible-but-for-a$<$ amplituding/formative-epistemicity $>$ totalising $\sim$ self-referencing-syncretising-meniality-orhyperbole-of- ${ }^{5}$ meaningfulness-and-teleology universalisation-nonpositivism/medievialism ${ }^{83}$ reference-of-thought but for the former transcendental instigation as of ontological-faith-notion-or-ontological-fideism - imbued-underdetermination-of-motif-andapriorising/axiomatising/referencing-as-so-being-as-of-existential-reality, and prospectively human-subpotency futural Being-development/ontological-framework-expansion-as-to-depthof-ontologising-development-as-infrastructure-of- meaningfulness-and-teleology as of prospective notional ${ }^{8}$ deprocrypticism ${ }^{83}$ reference-of-thought is circularly-unintelligible-butfor-a-<amplituding/formative-epistemicity $>$ totalising $\sim$ self-referencing-syncretising-menialityor-hyperbole-of- ${ }^{56}$ meaningfulness-and-teleology ${ }^{9}$ to positivism- ${ }^{80}$ procrypticism ${ }^{83}$ referenceof-thought but for the former transcendental instigation as of ontological-faith-notion-orontological-fideism - imbued-underdetermination-of-motif-and-

apriorising/axiomatising/referencing-as-so-being-as-of-existential-reality; such that all that is left of permanence determination about existence is its transcendental construct as of human limited-mentation-capacity-deepening—as-subjecting limitedness/human-subpotency-to'educed-unlimitedness/existence-sublimating nascence' ${ }^{53}$. Interestingly, from our vantage positivism/rational-empiricism perspective, we'll certainly construe the supposed intradimensional resolution of existential-<disontologising/re-ontologising aporeticism $>$ issues of prior relative-ontological-incompleteness ${ }^{8}$-of- ${ }^{3}$ reference-of-thought as of ontological- 
performance ${ }^{72}-<$ including-virtue-as-ontology $>$ /morality/ethics/justice/etc. arising in recurrentutter-uninstitutionalisation as intradimensional meniality-or-hyperbole and rather resolvable as of base-institutionalisation superseding projection/anticipation, and same with baseinstitutionalisation-ununiversalisation as intradimensional meniality-or-hyperbole and rather resolvable as of ${ }^{103}$ universalisation superseding projection/anticipation, and same with universalisation-non-positivism/medievalism as intradimensional meniality-or-hyperbole and rather resolvable as of positivism/rational-empiricism superseding projection/anticipation, but we won't or hardly construe of the same as of our <amplituding/formativeepistemicity $>$ totalising $\sim$ self-referencing-syncretising/circularity/interiorising/akrasiatic-drag about our positivism- ${ }^{80}$ procrypticism as it being of intradimensional meniality-or-hyperbole and rather resolvable as of notional deprocrypticism as preempting-disjointedness-as-ofreference-of-thought superseding projection/anticipation! This points to the flaw of a Heideggerian Dasein conceptualisation as it wrongly implies 'humankind has any developed mental state as of Being-and-contemplation in any past-to-present epoch' to 'fully register as of that epoch's metaphysics-of-presence-〈implicited-'nondescript/ignorable-void '-as-topresencing - absolutising-identitive-constitutedness $\rangle$ ' what is existence/existentialpossibilities not factoring Being apriorising/axiomatising/referencing-\{of-'prospectively implicited_attendant-ontological-contiguity ' reducedexistentialising/contextualising/textualising_'intelligibility/epistemicity/reflexivity-contiguity<imbued-notional cogency $>\quad\}$ - conflatedness ${ }^{13}$-in-\{preconverging ment by\} postconverging-entailment $\quad<$ amplituding/formative-epistemicity $>$-totalising $\sim$ renewingrealisation/re-perception/re-thought as rather driven by ontological-faith-notion-or-ontologicalfideism —imbued-underdetermination-of-motif-and-apriorising/axiomatising/referencing-asso-being-as-of-existential-reality in reflecting holographically-<conjugatively-andtransfusively $>$ the relative-unreflexivity/relative-reflexivity ontological-contiguity $\sim$ of-the- 
human-institutionalisation-process, and further in contradiction to the notion of human $<$ amplituding/formative-epistemicity >-totalising thrownness-in-existence ${ }^{35}$ (I exist therefore existence is of transcendental-enabling/sublimating/supererogatory $\sim$ de-mentativity to my human-subpotency / hyperbole-of-temporal-to-intemporal-ontological-performance ${ }^{72}$ <including-virtue-as-ontology>). Existence is rather a 'potency construct of transcendence-andsublimity/sublimation/supererogatory-de-mentativity as of human existential< disontologising/re-ontologising aporeticism $>$ potential' and not a 'grounded construct for construing existence' as wrongly implied/attempted with the Heideggerian Dasein notion, as all what 'grounding' does is to wrongly elevate the registry-worldview's/dimension's ${ }^{8}$ referenceof-thought in which such a construct is articulatedly grounded thus contradictorily undermining the possibility for transcendence-and-sublimity/sublimation/supererogatory $\sim$ de-mentativity by wrongly implying that the said registry-worldview's/dimension's ${ }^{83}$ reference-of-thought is of

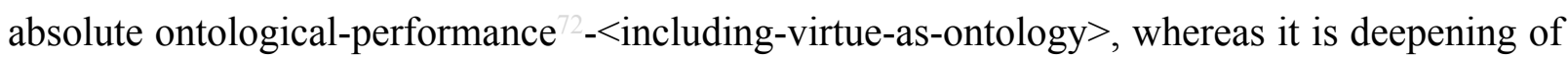
human limited-mentation-capacity—as-subjecting-'educed-unlimitedness/existencesublimating nascence' to-limitedness/human-subpotency as of ontological-faith-notion-orontological-fideism - imbued-underdetermination-of-motif-and-

apriorising/axiomatising/referencing-as-so-being-as-of-existential-reality in inducing prospective

apriorising/axiomatising/referencing/intelligibilitysettingup/measuringinstrumentings that allows for prospective relative-ontological-completeness ${ }^{87}$-of- ${ }^{83}$ reference-of-thought thus expanding human notion of existence/existential-possibilities. Anecdotally, the prophesying social scientists of their times who insist on the recurrence of the practices of the creed are 'not stupid' as they know very well that ${ }^{83}$ reference-of-thought- categoricalimperatives/axioms/registry-teleology ${ }^{9}$ for ${ }^{56}$ meaningfulness-and-teleology ${ }^{9}$ are just that with respect to an animal of limited-mentation-capacity-as-subjecting 'educed- 
unlimitedness/existence-sublimating nascence' to-limitedness/human-subpotency beyond-theconsciousness-awareness-teleology ${ }^{9}-<$ of-preconverging-existential-extrication-as-of-

existential-unthought $>$ who is bound to circularly elicit shortness-of-register-ofmeaningfulness-and-teleology ${ }^{9}$ on such renewed ${ }^{83}$ reference-of-thought- categoricalimperatives/axioms/registry-teleology ${ }^{9}$ for ${ }^{56}$ meaningfulness-and-teleology ${ }^{9}$ and further denaturing them as of the prospective institutionalisation uninstitutionalised-threshold ${ }^{102}$ ! In other words and as relevant with all other registry-worldviews/dimensions transcendental implications, base-institutionalisation ${ }^{5}$ meaningfulness-and-teleology cannot truly begrounded-as-explained to recurrent-utter-uninstitutionalisation as this wrongly implies the latter's reference-of-thought as of its ${ }^{83}$ reference-of-thought- categoricalimperatives/axioms/registry-teleology ${ }^{9}$ is a sound basis for construing the ${ }^{56}$ meaningfulnessand-teleology of base-institutionalisation. This rather induces a circular-complexification of recurrent-utter-uninstitutionalisation ${ }^{83}$ reference-of-thought as it adopts by mental-reflex an incrementalism-in-relative-ontological-incompleteness

enframed/disontologising conceptualisation mental-disposition rather than a maximalisingrecomposuring-for-relative-ontological-completeness ${ }^{8}$ —unenframed/re-

ontologising conceptualisation mental-disposition and thus fails to fulfil the requisite baseinstitutionalisation referencing/registering/decisioning-of-its- ${ }^{3}$ reference-of-thought but rather manifesting recurrent-utter-uninstitutionalisation preconverging-or-dementing -anddecentered-prior-institutionalisation's- categorical-imperatives/axioms/registry-teleology and its alienation — as-inauthentic/poorly-objectified/poorly-desubjectified-as-

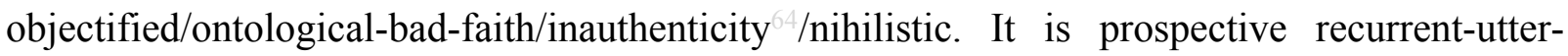
uninstitutionalisation mindset ${ }^{15}$ de-mentation-/supererogatory $\sim$ ontological-de-mentation-ordialectical-de-mentation - stranding-or-attributive-dialectics $\rangle$ as to psychoanalytic-unshackling into prospective base-institutionalisation mindset which is what allows for transcendence-and- 
sublimity/sublimation/supererogatory de-mentativity for crossgenerational renewal as of prospective relative-ontological-completeness ${ }^{8}$-of- ${ }^{8}$ reference-of-thought of the-very-sameimmanent-existence/intrinsic-reality/ontological-veridicality,-as-to-

'human<amplituding/formative-epistemicity>totalising $\sim$ purview-of-construal'.

Such ungrounded base-institutionalisation articulation is one rather eliciting prospective metaphoricity ${ }^{57}$ of the recurrent-utter-uninstitutionalisation mindset as of its implied prospective existential-<disontologising/re-ontologising aporeticism $>$ reference. Transcendence-andsublimity/sublimation/supererogatoryade-mentativity implies that as of human $<$ amplituding/formative-epistemicity>-totalising $\sim$ thrownness-in-existence ${ }^{35}$ (I exist therefore existence is of transcendental-enabling/sublimating/supererogatory $\sim$ de-mentativity to my human-subpotency / hyperbole-of-temporal-to-intemporal-ontological-performance ${ }^{72}$ <including-virtue-as-ontology>), humankind has no 'absolute past-or-present ontologicalcompleteness-of- ${ }^{8}$ reference-of-thought' for grounding the construal of ${ }^{56}$ meaningfulness-andteleology of the-very-same-immanent-existence/intrinsic-reality/ontological-veridicality,-asto-'human<amplituding/formative-epistemicity>totalising $\sim$ purview-of-construal', $\quad$ as such pretence circularly turns into apriorising/axiomatising/referencing-\{of-"prospectively implicited_atendant-ontological-contiguity ' educedexistentialising/contextualising/textualising_ 'intelligibility/epistemicity/reflexivity-contiguity<imbued-notional cogency>' $\quad\}$-constitutedness ${ }^{1}$-in-preconverging-entailment at the given reference-of-thought uninstitutionalised-threshold ${ }^{102}$; highlighting the fact that human potential attainment of the notional ${ }^{18}$ deprocrypticism as preempting-disjointedness-as-ofreference-of-thought is actually a 'perpetual transcendence-and-

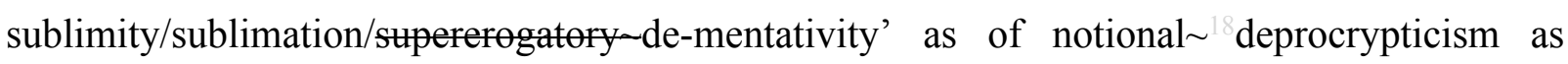
$<$ amplituding/formative $>$ notional $\sim$ preempting — disjointedness-as-of- ${ }^{3}$ reference-of-thought which points out that the various uninstitutionalised-threshold ${ }^{102}$ from recurrent-utter- 
uninstitutionalisation to procrypticism are actually levels of disjointedness-as-of- ${ }^{3}$ reference-ofthought and that the various institutionalisations from base-institutionalisation to notional ${ }^{8}$ deprocrypticism are actually levels of preempting — disjointedness-as-of- ${ }^{8}$ referenceof-thought all reflected as of notional ${ }^{18}$ deprocrypticism. The validity of the construal of existence as-of-existence-potency ${ }^{39} \sim$ sublimating-nascence,-disclosed-from-prospectiveepistemic-digression rather as transcendence-and-sublimity/sublimation/supererogatery - dementativity is that in the state of human <amplituding/formative-epistemicity $>$ totalising thrownness-in-existence ${ }^{35}$ (I exist therefore existence is of transcendentalenabling/sublimating/supereregatory de-mentativity to my human-subpotency / hyperbole-of-

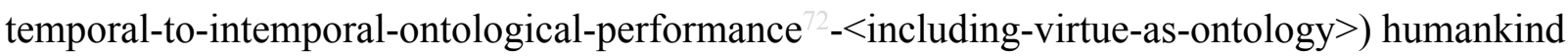
can only credibly adopt a 'apriorising/axiomatising/referencing-\{of-'prospectively implicited_attendant-ontological-contiguity ' educedexistentialising/contextualising/textualising_ 'intelligibility/epistemicity/reflexivity-contiguity<imbued-notional cogency>' \}-conflatedness ${ }^{13}$-in-\{preconverging-ment by postconverging-entailment exercise' rather as of effecting-wholeness-as-of-profoundness-andcompleteness-to- ${ }^{5}$ meaningfulness-and-teleology ${ }^{9}$ in re-projection-or-re-anticipation to match existence as to existence-potency ${ }^{39} \sim$ sublimating-nascence,-disclosed-from-prospectiveepistemic-digression given existential-<disontologising/re-ontologising aporeticism $>$ 'sublimating-epistemic-imbricatedness/threadedness/recomposuring as of iterating-ofexistential-instantiations' to further elevate its prospective relative-ontological-completeness ${ }^{87}$ of- ${ }^{8}$ reference-of-thought of the-very-same-immanent-existence/intrinsic-reality/ontologicalveridicality,-as-to-'human<amplituding/formative-epistemicity $>$ totalising $\sim$ purview-ofconstrual'. This thus validates the notion that existence can only be construed as a transcendental apriorising/axiomatising/referencing-\{of-'prospectively implicited_attendant-ontologicalcontiguity ' educed- 
existentialising/contextualising/textualising_'intelligibility/epistemicity/reflexivity-contiguity<imbued-notional cogency $\left.>^{\prime} \quad\right\}$-conflatedness ${ }^{13}$ in-\{preconverging-ment by\} pestcenverging-entailment as of ${ }^{55}$ maximalising-recomposuring-for-relative-ontologicalcompleteness ${ }^{87}$ — unenframed/re-ontologising conceptualisation driven by ontological-faithnotion-or-ontological-fideism - imbued-underdetermination-of-motif-andapriorising/axiomatising/referencing-as-so-being-as-of-existential-reality and not as a grounded apriorising/axiomatising/referencing-\{of-'prospectively_implicited_attendant-ontologicalcontiguity ' educedexistentialising/contextualising/textualising_'intelligibility/epistemicity/reflexivity-contiguity<imbued-notional cogency $\left.>^{\prime} \quad\right\}$ - constitutedness ${ }^{14}$-in-preconverging-entailment $\quad$ as of elaboration-as-to-mere-extrapolating/constituting/abstracting/deducing/inferring-ofelucidation-outside_- 'prospectively_implicited_attendant-ontological-contiguity ${ }^{67}$ ' educedexistentialising/contextualising/textualising_'intelligibility/epistemicity/reflexivity-contiguity$<$ imbued-notional cogency $>$ wrongly inducing <amplituding/formativeepistemicity $>$ totalising $\sim$ self-referencing-syncretising/circularity/interiorising/akrasiatic-drag 34 . Transcendence-and-sublimity/sublimation/supererogatory de-mentativity emphasises organicknowledge as of ontological-faith-notion-or-ontological-fideism - imbued-underdeterminationof-motif-and-apriorising/axiomatising/referencing-as-so-being-as-of-existential-reality underlying apriorising/axiomatising/referencing-\{of-'prospectively implicited_attendantontological-contiguity ' $\sim$ educedexistentialising/contextualising/textualising_'intelligibility/epistemicity/reflexivity-contiguity$<$ imbued-notional $\left.\sim \operatorname{cogency}>^{\prime} \quad\right\}$-conflatedness ${ }^{13}$ in-\{preconverging ment by $\}^{\prime}$ pointing to the 'false certainty and denaturing implications' involved with knowledge construed mechanically as of elaboration-as-to-mereextrapolating/constituting/abstracting/deducing/inferring-of-elucidation-outside- 
'prospectively_implicited_attendant_ontological-contiguity ${ }^{67}$ ' educedexistentialising/contextmalising/textualising_'intelligibility/epistemicity/reflexivity_contiguity$<$ imbued-notional cogency $>$ in an apriorising/axiomatising/referencing-\{of-'prospectively implicited_attendant-ontological-contiguity ' educedexistentialising/contextualising/textualising_ 'intelligibility/epistemicity/reflexivity-contiguity<imbued-notional cogency $\left.>^{\prime} \quad\right\}$ - constitutedness ${ }^{14}$-in preconverging-entailment $\quad$ and extricatory relationship with human <amplituding/formative-epistemicity $>$ totalising thrownness-in-existence ${ }^{35}$ (I exist therefore existence is of transcendentalenabling/sublimating/supereregatory de-mentativity to my human-subpotency / hyperbole-of-

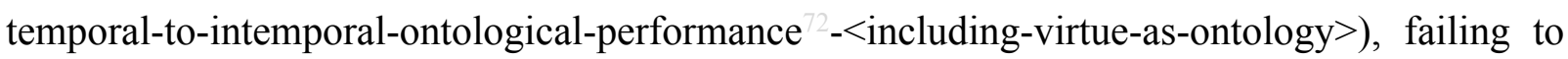
factor in $\quad{ }^{55}$ maximalising-recomposuring-for-relative-ontological-completeness ${ }^{87}$ unenframed/re-ontologising conceptualisation driven by ontological-faith-notion-orontological-fideism—imbued-underdetermination-of-motif-and-

apriorising/axiomatising/referencing-as-so-being-as-of-existential-reality. Existence as of its potency implies that what underlies ${ }^{4}$ historiality/ontological-eventfulness ${ }^{38} /$ ontological- $^{-}$ aesthetic-tracing-<perspective-ontological-normalcy/postconvergence-reflected-'epistemicityrelativism-determinism' $>$ as of the notional conflatedness ${ }^{13}$ of notional ${ }^{18}$ deprocrypticism is always the issue of 'divulging prospective relative-ontological-completeness ${ }^{87}$-of- ${ }^{8}$ referenceof-thought' as of apriorising/axiomatising/referencing-\{of-'prespectively implicited_attendant-ontological-contiguity ' ceducedexistentialising/contextualising/textualising_'intelligibility/epistemicity/reflexivity-contiguity<imbued-notional cogency $>$ ' $\}$ - conflatedness ${ }^{13}$ in-\{preconverging-ment by\}

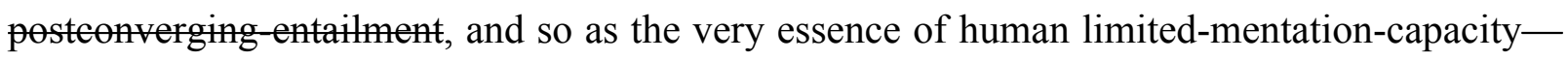
as-subjecting 'educed-unlimitedness/existence-sublimating nascence' to-limitedness/humansubpotency relating to existence-as-the-absolute-a-priori-of- 
conceptualisation and existence - as-sublimating-withdrawal/unenframing/re-ontologising,elicited-from-prospective-profound-supererogation $-<$ as-to-perspective-ontologicalnormalcy/postconvergence-implied-'prospective-aporeticism-overcoming/unovercoming'> .

Hence the very essence of a notional ${ }^{18}$ deprocrypticism institutionalisation is one that comes into terms-as-of-axiomatic-construct with existence-potency ${ }^{39} \sim$ sublimating-nascence,disclosed-from-prospective-epistemic-digression and as reflected in transcendence-andsublimity/sublimation/supererogatory $\sim$ de-mentativity as of apriorising/axiomatising/referencing-\{of-'prospectively_implicited_attendant-ontologicalcontiguity ' $\sim$ educedexistentialising/contextualising/textualising_'intelligibility/epistemicity/reflexivity-contiguity<imbued-notional cogency $>$ ' $\}$ - conflatedness ${ }^{13}$-in-\{preconverging-ment-by\} postconverging-ntailment in avoiding ${ }^{5}$ meaningfulness-and-teleology ${ }^{9}$ denaturing ${ }^{6}$ involved with grounded apriorising/axiomatising/referencing-\{of-'prospectively implicited_attendantontological-contiguity ' $\sim$ educed-

existentialising/contextualising/textualising_ intelligibility/epistemicity/reflexivity-contiguity$<$ imbued-notional cogency $>$ ' $\}$-constitutedness ${ }^{14}$-in-preconverging-entailment posturing. Operantly, the phenomenological quest for an underlying and superseding knowledge construct, construed here as an enabling construct of <amplituding/formativeepistemicity $>$ totalising $\sim$ conflated- -5 meaningfulness-and-teleology ${ }^{9}$-as-ofnotional ${ }^{18}$ deprocrypticism-reflected- ${ }^{4}$ historiality/ontological-eventfulness ${ }^{38} /$ ontologicalaesthetic-tracing-<perspective-ontological-normalcy/postconvergence-reflected-'epistemicityrelativism-determinism'> ontological-performance ${ }^{72}-<$ including-virtue-as- $^{\prime}$ ontology $>$ /morality/ethics/justice/etc. determination as of human <amplituding/formativeepistemicity $>$-totalising $\sim$ thrownness-in-existence ${ }^{35}$ (I exist therefore existence is of transcendental-enabling/sublimating/supererogatory de-mentativity to my human-subpotency / 


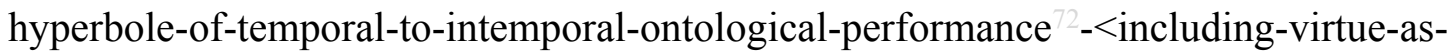
ontology $>$ ), is fulfilled by the notion of preconverging-existential-extrication-as-of-existentialunthought/pesteonverging-nonextricatory-existential-preempting-of-existential-unthought as the construct that reflects any registry-worldview's/dimension's ${ }^{83}$ reference-of-thought historiality/ontological-eventfulness ${ }^{38} /$ ontological-aesthetic-tracing-<perspectiveontological-normalcy/postconvergence-reflected-'epistemicity-relativism-determinism'> as of the notional conflatedness ${ }^{13}$ of notional $\sim^{18}$ deprocrypticism highlighting the affirmation/projection/assertion/notional self-distantiation/dueness-validatinglogicising/suitable-measuringinstrument-validating-measuring-<as-to-postconverging-ordialectical-thinking -apriorising-psychologism> of its prospective relative-ontologicalcompleteness ${ }^{87}$-of- ${ }^{83}$ reference-of-thought as of the implications of its apriorising/axiomatising/referencing-\{of-'prospectively implicited_attendant-ontologicalcontiguity ' $\sim$ educedexistentialising/contextualising/textualising_'intelligibility/epistemicity/reflexivity-contiguity$<$ imbued-notional cogency $>$ ' $\}$-conflatedness ${ }^{13}$ in-\{preconverging ment by\} postconverging-entailment as its given ${ }^{83}$ reference-of-thought- categoricalimperatives/axioms/registry-teleology ${ }^{9}$, -foraposteriorising/logicising/deriving/intelligising/measuring - ${ }^{5}$ meaningfulness-and-teleology and its apriorising/axiomatising/referencing-\{of-'prospectively implicited_attendantontological-contiguity ' educedexistentialising/contextualising/textualising_'intelligibility/epistemicity/reflexivity-contiguity$<$ imbued-notional cogency $\left.>^{\prime} \quad\right\}$ - constitutedness ${ }^{14}$-in-preconverging-entailment as of the unaffirmation/deprojection/deassertion/epistemic-decadence/undueness-invalidatinglogicising/unsuitable-measuringinstrument-invalidating-measuring-<as-to-preconverging-ordementing -apriorising-psychologism> of its given prior relative-ontological- 
incompleteness ${ }^{8}$-of- ${ }^{8}$ reference-of-thought as of the-very-same-immanent-existence/intrinsicreality/ontological-veridicality,-as-to-'human<amplituding/formative-

epistemicity>totalising purview-of-construal'. This author's notion of centered$<$ amplituding/formative-epistemicity>totalising/circumscribing/delineating ${ }^{56}$ meaningfulnessand-teleology 9 as $\quad<$ amplituding/formative-epistemicity $>$ totalising $\sim$ conflatedmeaningfulness-and-teleology ${ }^{99}$-as-of-notional ${ }^{8}$ deprocrypticism-reflectedhistoriality/ontological-eventfulness 3 /ontological-aesthetic-tracing-<perspectiveontological-normalcy/postconvergence-reflected-'epistemicity-relativism-determinism'>’ fundamentally grasps that the Derridean critique of centered-epistemic-totalisation as impossible to achieve and postulation instead of decentered-infinite-freeplay is actually a critique arising on the implied assumption of finite human limited-mentation-capacity-assubjecting-'educed-unlimitedness/existence-sublimating nascence' to-limitedness/humansubpotency as of its impossibility as finitely limited to come into the full terms of grasping the full potency of existence/existential-possibilities; but then this author construes that human limited-mentation-capacity—as-subjecting 'educed-unlimitedness/existence-sublimating nascence' to-limitedness/human-subpotency is not finite as it deepens as of the possibility of transcendence-and-sublimity/sublimation/surede-mentativity enabled as of ${ }^{15} \mathrm{de}-$ mentation-〈supererogatory ontological-de-mentation-or-dialectical-de-mentation — strandingor-attributive-dialectics $\rangle$ thus involving preconverging/postconverging-dementative/structural/paradigmatic transformations/shifts of human limited-mentationcapacity-as-subjecting 'educed-unlimitedness/existence-sublimating nascence' tolimitedness/human-subpotency $\quad$ reference-of-thought-as-of- ${ }^{8}{ }^{83}$ reference-of-thoughtdevolving-teleological-de-mentating/structuring/paradigming-of-meaningfulness' to grasp existence/existential-possibilities, such that as of notional deprocrypticism or $<$ amplituding/formative $>$ notional $\sim$ preempting - disjointedness-as-of- ${ }^{3}$ reference-of-thought in 
reflecting holographically-<conjugatively-and-transfusively $>$ the relative-unreflexivity/relativereflexivity ontological-contiguity of-the-human-institutionalisation-process

retrospectively to prospectively, centered-<amplituding/formativeepistemicity $>$ totalising/circumscribing/delineating ${ }^{56}$ meaningfulness-and-teleology ${ }^{99}$ as of its

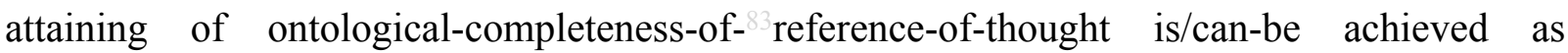
'involving the superseding/transcending of successively defining human finitudes as the destructuring-threshold-〈uninstitutionalised-threshold /presublimating-desublimating-

decisionality $>$ of-ontological-performance ${ }^{72}$ - $<$ including-virtue-asontology $>/$ morality/ethics/justice/etc. towards attaining successive prospective relativeontological-completeness ${ }^{87}$-of- ${ }^{8}$ reference-of-thought as the institutionalisations'. This thus undermines the implications of a Derridean decentered-infinite-freeplay in its critique of 'centered-epistemic-totalisation as of circularity of ${ }^{5}$ meaningfulness-and-teleology ${ }^{9}$ in relative deficient/flawed ontological-performance ${ }^{72}-<$ including-virtue-as-ontology $>^{\prime}$ since such a criticism is based on assuming only a same registry-worldview's/dimension's ${ }^{83}$ reference-ofthought, and so-construed mainly because such a Derridean conception construes of centeredepistemic-totalisation as only within one registry-worldview's/dimension's ${ }^{83}$ reference-ofthought-as-of- ${ }^{8}{ }^{8}$ reference-of-thought — devolving-teleological-de-

mentating/structuring/paradigming-of-meaningfulness' as of its apriorising/axiomatising/referencing/intelligibilitysettingup/measuringinstrumenting, failing to reflect the relative-unreflexivity/relative-reflexivity - ontological-contiguity ${ }^{6}$ of-the-humaninstitutionalisation-process ${ }^{68}$ as of notional deprocrypticism implied postconverging-dementating/structuring/paradigming shifts of ${ }^{83}$ reference-of-thought-as-of- ${ }^{8}{ }^{83}$ reference-ofthought_-devolving-teleological-de-mentating/structuring/paradigming-of-meaningfulness' overcome the limitation of "centered-epistemic-totalisation circularity of ${ }^{56}$ meaningfulness-and-

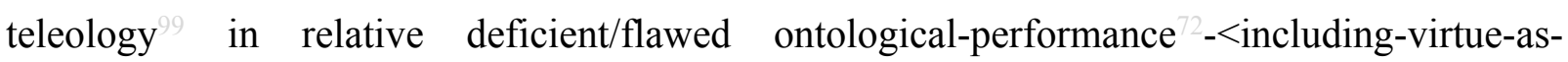


ontology>' within a same ${ }^{83}$ reference-of-thought-as-of- ${ }^{\circ}$ reference-of-thought- devolvingteleological-de-mentating/structuring/paradigming-of-meaningfulness' by way of the successive prospective relative-ontological-completeness ${ }^{87}$-of- ${ }^{83}$ reference-of-thought as enabling successive prospective ${ }^{83}$ reference-of-thought-as-of- ${ }^{83}$ reference-of-thoughtdevolving-teleological-de-mentating/structuring/paradigming-of-meaningfulness' marked by the shift of 'centered-epistemic-totalisation circularity of ${ }^{56}$ meaningfulness-and-teleology inducing relatively less and less deficient/flawed ontological-performance ${ }^{2}-<$ including-virtueas-ontology >' right up to the attainment of notional ${ }^{18}$ deprocrypticism 'centered-epistemictotalisation circularity of ${ }^{56}$ meaningfulness-and-teleology ${ }^{9}$ of theoretically perfect/sound ontological-performance ${ }^{72}-<$ including-virtue-as-ontology>'; given that the 'succession of institutionalisation

apriorising/axiomatising/referencing/intelligibilitysettingup/measuringinstrumenting rules of the successive ${ }^{83}$ reference-of-thought-as-of- ${ }^{\text {" }}{ }^{3}$ reference-of-thought - devolving-teleologicalde-mentating/structuring/paradigming-of-meaningfulness's' overcome retrospectively to prospectively the problem of human limited-mentation-capacity-as-subjecting-'educedunlimitedness/existence-sublimating nascence' to-limitedness/human-subpotency by its deepening thus inducing successive human transcendence-andsublimity/sublimation/supererogatory $\sim$ de-mentativity of human finitudes as destructuringthreshold-〈uninstitutionalised-threshold /presublimating-desublimating-decisionality $\rangle$ ofontological-performance $^{72}$-<including-virtue-as-ontology $>$. Here as well the Derridean postulation of decentered-infinite-freeplay in lieu of such a conceptualisation of a 'projected ultimate centered-epistemic-totalisation circularity of ${ }^{56}$ meaningfulness-and-teleology ${ }^{9}$ of

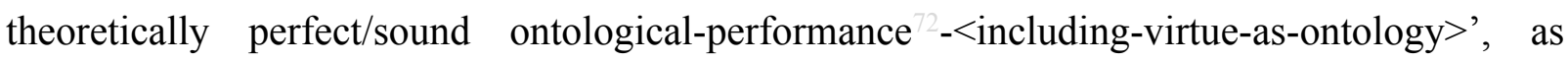
implied by this author's notion of ontological-normalcy/postconvergence, operantly displays the philosophical tradition problem of apriorising/axiomatising/referencing-\{of-"prospectively 
implicited_attendant-ontological-contiguity ' reduced-

existentialising/contextualising/textualising_'intelligibility/epistemicity/reflexivity_contiguity<imbued-notional cogency $>$ ' $\}$ - constitutedness ${ }^{14}$-in-preconverging-entailment as failing to project of the transformational implications of human limited-mentation-capacity-deepeningas-subjecting limitedness/human-subpotency to-'educed-unlimitedness/existence-sublimating nascence' ${ }^{53}$ for successive prospective relative-ontological-completeness ${ }^{87}$-of- ${ }^{83}$ reference-ofthought in bringing about <cumulating/recomposuring attendant-ontological-contiguity $>$ successive registry-worldviews/dimensions as of apriorising/axiomatising/referencing-\{of'prospectively_implicited_attendant-ontological-contiguity ' educedexistentialising/contextualising/textualising_'intelligibility/epistemicity/reflexivity_contiguity$<$ imbued-notional cogency $>$ ' $\}$-conflatedness ${ }^{13}$ in-\{preconverging-ment by\} postconverging-ntailment that prospectively ultimately grasps the centered$<$ amplituding/formative-epistemicity>totalising/circumscribing/delineating ${ }^{56}$ meaningfulnessand-teleology ontological-performance ${ }^{72}-<$ including-virtue-asontology $>$ /morality/ethics/justice/etc. in reflecting holographically-<conjugatively-andtransfusively $>$ the relative-unreflexivity/relative-reflexivity ontological-contiguity $\sim$ of-thehuman-institutionalisation-process or notional deprocrypticism. Despite such a Derridean decentered-infinite-freeplay conception being the most radical attempt hitherto to overcome the philosophical tradition apriorising/axiomatising/referencing-\{of- prospectively implicited_attendant-ontological-contiguity ' educedexistentialising/contextualising/textualising_'intelligibility/epistemicity/reflexivity-contiguity$<$ imbued-notional cogency $\left.>^{\prime}\right\}$ - constitutedness ${ }^{14}$-in- preconverging-entailment, it perfectly grasps the implications to ${ }^{56}$ meaningfulness-and-teleology ${ }^{9}$ ontological-performance ${ }^{72}$ $<$ including-virtue-as-ontology $>$ /morality/ethics/justice/etc. of 'centered-epistemic-totalisation as of circularity of ${ }^{56}$ meaningfulness-and-teleology ${ }^{9}$ in relative deficient/flawed ontological- 
performance ${ }^{2}-<$ including-virtue-as-ontology $>$ ' but rather as within a same horizon of meaningfulness-and-teleology $\quad$ ontological-performance ${ }^{2}-<$ including-virtue-as-ontology $>$. However, it fails to grasp that such a centered-epistemic-totalisation itself arises because an axiomatic-construct is a circularity of ${ }^{5}$ meaningfulness-and-teleology ${ }^{9}$ ontologicalperformance $^{72}-<$ including-virtue-as-ontology $>$ /morality/ethics/justice/etc. of the-very-same $<$ amplituding/formative-epistemicity $>$ totalising $\sim$ devolved-purview-as-domain-of-construalas-intrinsic-reality/ontological-veridicality it refers to, and so-implied by extension with respect to a given ${ }^{83}$ reference-of-thought-as-of- ${ }^{\circ}{ }^{83}$ reference-of-thought—devolving-teleological-dementating/structuring/paradigming-of-meaningfulness' a centered-epistemic-totalisation is rather the circular ${ }^{5}$ meaningfulness-and-teleology ${ }^{9}$ representation of the-very-same-immanentexistence/intrinsic-reality/ontological-veridicality,-as-to-'human<amplituding/formativeepistemicity>totalising purview-of-construal', as the said ${ }^{83}$ reference-of-thought-as-of${ }^{\text {' }}$ reference-of-thought — devolving-teleological-de-mentating/structuring/paradigming-ofmeaningfulness' is 'supposedly always the systemic and indefinite resolution' of the-very-sameimmanent-existence/intrinsic-reality/ontological-veridicality,-as-to'human<amplituding/formative-epistemicity>totalising $\sim$ purview-of-construal'. Now, the issue of a centered-epistemic-totalisation defect arises where the given ${ }^{83}$ reference-of-thought-as-of${ }^{\text {'3 }}$ reference-of-thought — devolving-teleological-de-mentating/structuring/paradigming-ofmeaningfulness' is ontologically-flawed/deficient as it will systematically induce a 'centeredepistemic-totalisation circularity of ${ }^{56}$ meaningfulness-and-teleology ${ }^{9}$ in relative deficient/flawed ontological-performance ${ }^{2}-<$ including-virtue-as-ontology $>$ ' construed as of the uninstitutionalised-threshold ${ }^{102}$ of a registry-worldview's/dimension's ${ }^{83}$ reference-of-thoughtas-of- ${ }^{83}$ reference-of-thought — devolving-teleological-de-mentating/structuring/paradigmingof-meaningfulness'. But then human limited-mentation-capacity-deepening-as-subjectinglimitedness/human-subpotency to-'educed-unlimitedness/existence-sublimating nascence' 
achieving prospectively of an ultimately theoretically perfect/sound ${ }^{83}$ reference-of-thought-asof- ${ }^{83}$ reference-of-thought — devolving-teleological-de-mentating/structuring/paradigming-ofmeaningfulness' as of the full relative-unreflexivity/relative-reflexivity-ontologicalcontiguity ${ }^{67}$ of-the-human-institutionalisation-process ${ }^{68}$ as notional ${ }^{18}$ deprocrypticism implies the circular ontologically-flawed/deficient implications of centered-epistemic-totalisation are done away with as of ontological-completeness with the <amplituding/formative-epistemicity $>$ totalising renewing-realisation/re-perception/re-thought of the ${ }^{83}$ reference-of-thought-as-of${ }^{6}$ reference-of-thought — devolving-teleological-de-mentating/structuring/paradigming-ofmeaningfulness' of the-very-same-immanent-existence/intrinsic-reality/ontologicalveridicality,-as-to-'human<amplituding/formative-epistemicity $>$ totalising $\sim$ purview-ofconstrual', with such a conceptualisation of centered-epistemic-totalisation also construed as transcendental centered-epistemic-totalisation or extrapolated-centered-epistemic-totalisation or extrapolatory-epistemic-totalisation or transcendental-epistemic-totalisation and reflects the reality that a Derridean decentered-infinite-freeplay can also be construed as an interpolatoryepistemic-totalisation or interpolated-decentered-epistemic-totalisation. For instance, we can grasp that 'traditional classical mechanics axiomatic-construct' is a given 'centered-epistemictotalisation circularity of ${ }^{56}$ meaningfulness-and-teleology" of 'the-very-same physics $<$ amplituding/formative-epistemicity $>$ totalising $\sim$ devolved-purview/domain-of-construal-asintrinsic-reality/ontological-veridicality/existential-reality' as of a prior relative-ontologicalincompleteness $^{88}$ of less ontological-performance ${ }^{72}-$ including-virtue-as- $^{2}$ ontology $>$ /morality/ethics/justice/etc. of 'the-very-same physics <amplituding/formativeepistemicity $>$ totalising $\sim$ devolved—-purview/domain-of-construal-as-intrinsicreality/ontological-veridicality/existential-reality', while with human limited-mentationcapacity-deepening —as-subjecting limitedness/human-subpotency-to-'educedunlimitedness/existence-sublimating nascence' ${ }^{33}$ the theory-of-relativity-together-with- 
quantum-mechanics - axiomatic-constructs brings about a new 'centered-epistemictotalisation/circularity of ${ }^{56}$ meaningfulness-and-teleology' of 'the-very-same physics $<$ amplituding/formative-epistemicity $>$ totalising $\sim$ devolved-purview/domain-of-construal-asintrinsic-reality/ontological-veridicality/existential-reality' as of prospective relativeontological-completeness ${ }^{87}$-of-axiomatic-construct-or- ${ }^{83}$ reference-of-thought as we can do more things with the latter axiomatic-construct more-profound/grander ${ }^{56}$ meaningfulness-and-

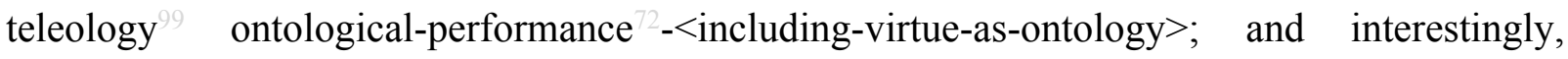
physicists will surely fancy that they could do better in ultimately grasping theoretically the fullpotency of existence divulgeable as of 'the-very-same physics <amplituding/formativeepistemicity>totalising $\sim$ devolved-purview/domain-of-construal-as-intrinsicreality/ontological-veridicality/existential-reality' with an ambition for a theory of everything. However, a Derridean decentered-infinite-freeplay is nevertheless critical as a first step for breaking away from a prior centered-epistemic-totalisation of a very same $<$ amplituding/formative-epistemicity $>$ totalising devolved-purview-as-domain-of-construalas-intrinsic-reality/ontological-veridicality in relative deficient/flawed ontologicalperformance $^{72}-<$ including-virtue-as-ontology $>$, and thus by extension with regards to the-verysame-immanent-existence/intrinsic-reality/ontological-veridicality,-as-to'human<amplituding/formative-epistemicity>totalising $\sim$ purview-of-construal' which is a given reference-of-thought, construed as " ${ }^{83}$ reference-of-thought—devolving-teleological-dementating/structuring/paradigming-of-meaningfulness'; and for all practical matters this has been the way Derridean deconstruction has been commonly applied as in effect all our meaningfulness-and-teleology ontological-performance ${ }^{72}$-<including-virtue-asontology $>$ /morality/ethics/justice/etc. has been as of our positivism- ${ }^{8}$ procrypticism registryworldview's/dimension's $\quad{ }^{83}$ reference-of-thought-as-of- ${ }^{8}{ }^{83}$ reference-of-thought—devolvingteleological-de-mentating/structuring/paradigming-of-meaningfulness' horizon and such a 
Derridean decentered-infinite-freeplay is an inspired conception providing the groundwork as its initiates the centered-epistemic-totalisation exercise for the insight of a futural différance as of the latter's transcendental-epistemic-totalisation that underlies apriorising/axiomatising/referencing-\{of-'prospectively implicited_attendant-ontologicalcontiguity ' educedexistentialising/contextualising/textualising_'intelligibility/epistemicity/reflexivity-contiguity<imbued-notional cogency $\left.>{ }^{\prime}\right\}$-conflatedness ${ }^{13}$ in-\{preconverging-ment by\} pestconverging-ntailment in breaking with the philosophical tradition or human knowledge conceptualisation tradition or towards fulfilling the understanding of Being. In this regard talking about the physics example again, such a Derridean freeplay différance is akin to the 'putting in question exercise' that surrounds the cooperation/mutual-complementing-ideas-among-variousphysicists leading up to the critical breakthroughs; which then establish such physics centeredepistemic-totalisation schemes as Newtonian physics and later on Theory-of-relativity and Quantum-mechanics, and today with respect to various theoretical efforts with the potential of leading to a physics Theory of Everything. Inherent to futural différance is the notion of $<$ amplituding/formative-epistemicity $>$ totalising $\sim$ self-referencing-

syncretising/circularity/interiorising/akrasiatic-drag ${ }^{44}$, as of beyond-the-consciousnessawareness-teleology ${ }^{9}<$ of-preconverging-existential-extrication-as-of-existential-unthought $>$, construed in the immediate-and-short-term as of 'self-referencing' as the uninstitutionalisedthreshold ${ }^{102}$ temporal individuations circular undermining of the prospective institutionalisation reference-of-thought-as-to-postconverging-de-mentating/structuring/paradigming implied transformation/shift as transcendence-and-sublimity/sublimation/supererogatory $\sim$ dementativity as of prospective relative-ontological-completeness ${ }^{87}$-of- ${ }^{83}$ refence-of-thought, as well as the idea of temporal individuations 'syncretising' that underlies a spiralling crossgenerational increasing undermining of the uninstitutionalised-threshold ${ }^{102}$ reference-of- 
thought which is in <amplituding/formative-epistemicity $>$ totalising $\sim$ self-referencingsyncretising/circularity/interiorising/akrasiatic-drag ${ }^{4}$ with its ultimate crossgenerational collapsing for the prospective institutionalisation's ${ }^{83}$ reference-of-thought; and so as of prospective social-stake-contention-or-confliction dynamism with increasing social ${ }^{103}$ universaltransparency ${ }^{104}$-〈transparency-of-totalising-entailing,-as-to-entailing-<amplituding/formativeepistemicity $>$ totalising in-relative-ontological-completeness $>$ as of prospective relativeontological-completeness ${ }^{87}$-of- ${ }^{83}$ reference-of-thought of the prospective institutionalisation's reference-of-thought. Insightfully again, this idea of infinite-possibilities/circularity implied as of a Derridean infinite-decentered-freeplay of a given meaningful-frame/axiomaticconstruct/model such as mathematical models/axiomatic-constructs circularity is familiar to physicists and other scientists who understand that there is no infinity in the real-world/existence and infinity showing up in mathematical models/axiomatic-constructs point to the fact that there is a circular or undefined or undecidable problem arising from poor human limited-mentationcapacity —as-subjecting 'educed-unlimitedness/existence-sublimating nascence' tolimitedness/human-subpotency conceptualisation implying the given mathematical model/axiomatic-construct is in circular-existential-disjointedness-as-of-prior-relativeontological-incompleteness $^{88}$ as of the axiomatic-construct relative notionaldiscontiguity/epistemic-discontiguity ${ }^{6}-<$ between - prior-shallow-supererogation -ofmentally-aestheticised preconverging/dementing -qualia-schema_and_prospective-profoundsupererogation -of-mentally-aestheticised postconverging/dialectical-thinking -qualiaschema $>$ in apriorising/axiomatising/referencing-\{of-'prospectively implicited_attendantontological-contiguity ' educedexistentialising/contextualising/textualising_'intelligibility/epistemicity/reflexivity-contiguity<imbued-notional cogency $\left.>^{\prime} \quad\right\}$-constitutedness ${ }^{14}$-in-preconverging-entailment, and thus a need for a more ontologically-complete mathematical model/axiomatic-construct that as of 
human limited-mentation-capacity-deepening —as-subjecting limitedness/human-subpotency to-'educed-unlimitedness/existence-sublimating nascence' ${ }^{3}$ then resolves/overcomes the circularity/circular-existential-disjointedness-as-of-prior-relative-ontological-incompleteness reflected in the prior mathematical model/axiomatic-construct by the infinities-as-circular-orundefined-or-undecidable with a new mathematical model/axiomatic-construct in relative notional-contiguity/epistemic-contiguity ${ }^{62}<$ profound-supererogation -of-mentallyaestheticised postconverging/dialectical-thinking -qualia-schema as of apriorising/axiomatising/referencing-\{of-'prospectively implicited_attendant-ontologicalcontiguity ' educedexistentialising/contextualising/textualising_ 'intelligibility/epistemicity/reflexivity-contiguity<imbued-notional cogency $\left.>^{\prime}\right\}$-conflatedness ${ }^{13}$ in-\{preconverging-ment by\} postconverging-entailment, and so as of the-very-same <amplituding/formativeepistemicity $>$ totalising $\sim$ devolved-purview-as-domain-of-construal-as-intrinsicreality/ontological-veridicality; and so because human limited-mentation-capacity-deepeningas-subjecting limitedness/human-subpotency-to-'educed-unlimitedness/existence-sublimating nascence' 53 induces preconverging/postconverging-dementatively/structurally/paradigmatically grander human ${ }^{56}$ meaningfulness-and-teleology ontological-performance ${ }^{2}$-<including-virtue-as-ontology $>$ /morality/ethics/justice/etc. of human implicit-or-explicit constructed axiomatic-constructs of purviews of construal-asintrinsic-reality/ontological-veridicality, and this equally applies by extension to ${ }^{83}$ reference-ofthought-as-of- ${ }^{83}$ reference-of-thought—devolving-teleological-de-

mentating/structuring/paradigming-of-meaningfulness' as of the-very-same-immanentexistence/intrinsic-reality/ontological-veridicality,-as-to-`human<amplituding/formativeepistemicity $>$ totalising purview-of-construal'. It should be noted thus that an axiomaticconstruct is as of an implied correspondence with the-very-same-immanent-existence/intrinsic- 
reality/ontological-veridicality,-as-to-'human<amplituding/formativeepistemicity>totalising purview-of-construal'

epistemicity>totalising devolved-purview-as-domain-of-construal-as-intrinsic-

reality/ontological-veridicality, and it supersedes and is defining of logic which is rather the 'inner working coherence/contiguity of axiomatic-construct construal of ecstatic-existence/thenature-of-the-world/conditions' as reflected with any given explicited axiomatic-construct in the same way that insight/intuition is reflected rather with regards to any given implicited axiomaticconstructs; with an axiomatic-construct such as an idea or a concept or a notion or a theory being any conception as of ${ }^{56}$ meaningfulness-and-teleology ${ }^{9}$ of supposed existential-implications correspondence. That is the traditional knowledge conception articulated as 'axioms of logic' is rather vague, with the appropriate articulation being rather 'logic of axiomaticconstruct $/{ }^{8}$ reference-of-thought', as the axiomatic-construct $/{ }^{2}$ reference-of-thought is the effective human limited-mentation-capacity—as-subjecting-'educed-unlimitedness/existencesublimating nascence' to-limitedness/human-subpotency supposed correspondence relation with existence — as-the-absolute-a-priori-of-conceptualisation and existence — as-sublimatingwithdrawal/unenframing/re-ontologising,-elicited-from-prospective-profoundsupererogation -<as-to-perspective-ontological-normalcy/postconvergence-implied'prospective-aporeticism-overcoming/unovercoming'> for human-subpotency possibilities for devolving ${ }^{56}$ meaningfulness-and-teleology as knowledge-constructs/theories/intersolipsisticintercessory-notions/notional referential-notions/articulations/virtue, with increasing ontological-performance $^{72}$-<including-virtue-as-ontology $>/$ morality/ethics/justice/etc. as of human transcendence; even though such a conception as 'axioms of logic' could be perceived rather as a meta-conception or more like a technical practicality akin to say the scaffolding of a building! In other words as the 'inner working coherence/contiguity of axiomatic-construct construal of ecstatic-existence/the-nature-of-the-world/conditions', logic and by extension 
mathematics

imply

elaboration-as-to-mere-

extrapolating/constituting/abstracting/deducing/inferring-of-elucidation-outside-

'prospectively_implicited_attendant-ontological-contiguity ${ }^{67}$ ' educed-

existentialising/contextualising/textualising_'intelligibility/epistemicity/reflexivity-contiguity-

<imbued-notional cogency ${ }^{\prime}$, whereas axiomatic-constructs as reflecting ecstatic-

existence/the-nature-of-the-world/conditions are construed in

affirmation/projection/assertion/notional self-distantiation/dueness-validating-

logicising/suitable-measuringinstrument-validating-measuring-<as-to-postconverging-or-

dialectical-thinking -apriorising-psychologism> as of ${ }^{55}$ maximalising-recomposuring-forrelative-ontological-completeness ${ }^{87}$ - unenframed/re-ontologising conceptualisation. But then as of 'ontology of logic' and 'ontology of mathematics' as their very own respective conceptualised meta-axiomatic-constructs as ontologies in terms of reflecting their philosophical depth of contemplation as of 'coherence/contiguity-of-superseding-oneness-of-ontologyimplied-as-of-inherent-existence-coherence/contiguity,-and-so-construed-as-the-enabler-ofinsight-or-intuition-or-foresight-as-of-embodied-consciousness', both logic and mathematics are construed practically as formalisations which are mainly as such constructs of faithful/reproducible syntaxisation on the supposed basis of 'smarter and simpler articulations' for the sake of succinctness, clarity and fungibility; however, without the implication of any other inherent transcendental-enabling/sublimating/supererogatory - de-mentativity of such formalisations besides their succinctness, clarity and fungibility usefulness 'thus-limitedly construed as their inherent meta-conceptualised ontological-veracity/axiomatic-construct of logic and mathematics transcendental-enabling/sublimating/supererogatory $\sim$ de-mentativity'. But then it is naïve to construe of mathematics, as logicists have tended to do, as essentially an exercise of mathematical formalisation. The fact is that mathematics have always been developed implicitly or explicitly in association with or inspired from the context as to 
'implicited_attendant_ontological-contiguity ${ }^{67}$; educedexistentialising/contextualising/textualising_'intelligibility/epistemicity/reflexivity_contiguity$<$ imbued-notional cogency $>^{\prime}$ of other applied and transcendentalenabling/sublimating/supereregatory $\sim$ de-mentativity activities as of their axiomatic-constructs development and mathematics very own existential-reality of developed axiomatic-constructs applicative orientation, including developing together with heavily dependent mathematics domains like physics, engineering, other applied sciences and statistical studies. This latter situation which is more real than generally said and makes of mathematics a '<amplituding/formative-epistemicity $>$ totalising $\sim$ devolved - purview/domain-of-construal-asintrinsic-reality/ontological-veridicality/existential-reality created axiomatic-constructs' and more so than the 'abstract romantic image portrayed as of the mere manipulation of numbers and forms' as if not inspired as of existential-reality contextuality itself. Thus naively taking cue from the formalisation of mathematics as if it will enable the inherent transcendentalenabling/sublimating/supereregatery $\sim$ de-mentativity of any discipline is bound to lead to disappointment, as the inherent axiomatic-constructs as theories, concepts, notions and ideas of the existential-<disontologising/re-ontologising aporeticism $>$ domain in question have to be critically developed as knowledge-reification $\sim$ gesturing-and-accounting-of-epistemicphenomenalism- $<$ in-prospective_psychologismic $\sim$ apriorising/axiomatising/referencing- of'prospectively_implicited_attendant-ontological-contiguity ' educedexistentialising/contextualising/textualising_'intelligibility/epistemicity/reflexivity-contiguity<imbued-notional cogency $>\quad\}$ - conflatedness - in-\{preconverging ment by\}

postconverging-entailment $>$ for logic and mathematics to then be relevant as of a secondary tool or at best a concomitant tool. In this regards, the 'truly mathematical proof' (over and above any formal mathematical proof) is rather about sublimating-validation/desublimating-invalidation of any such mathematics as it can be so-demonstrable in the occurrence of existential- 
<disontologising/re-ontologising aporeticism $>$ phenomena/manifestations; even as such a mathematical demonstration is rather so 'existentially-<disontologising/re-ontelogising aporeticism $>$ nominal' that such phenomenal/manifest veracity of mathematics is often for all practical purposes mostly overlooked by mathematicians when involved in their formalisation exercise including 'formal proofs' as to the fact that the existential-disontologising/reentelegising apereticism $>$ sublimating-validation/desublimating-invalidation of mathematics is so nominally obvious that hardly any experimenting is warranted for confirmation and this existential-<disontologising/re-ontologising aporeticism $>$ nominalism can easily lead to a reductionist confusion that mathematics (as to its epistemic-conception phenomenal/manifest $\sim$ subpotency-〈in-transitive-conflatedness -reflexivity,-in-the-fullpotency-of-existence's sublimating-nascence) with regards to the relativeunreflexivity/relative-reflexivity - ontological-contiguity ${ }^{77}$ of existence') is not priorly subject to existence - as-sublimating-withdrawal/unenframing/re-ontologising,-elicited-fromprospective-profound-supererogation (and this very insight about the 'existentially<disontologising/re-ontologising aporeticism $>\quad$ nominal' sublimatingvalidation/desublimating-invalidation of mathematics as of a 'very existentially$\leq$ disentologising/re-ontologising aporeticism $>$ nominal supererogatery acuity/perspicacity/astuteness/edginess/incisiveness-ofapriorising/axiomatising/referencing/intelligibilitysettingup/measuringinstrumenting -forconceptualisation as to the mere adequacy of formalised mathematics' explains on-the-otherhand why the mere introduction of mathematics, statistics and data in domains requiring 'human corresponding-sublimation-inducing,-profound-and-creative supererogatory acuity/perspicacity/astuteness/edginess/incisiveness-ofapriorising/axiomatising/referencing/intelligibilitysettingup/measuringinstrumenting -forconceptualisation' is not construed as sublimating-validation in such domains where such 
mathematics, statistics and data are rather 'distracting-from and not-contributing-to' the inherent domain's epistemic-conceptions phenomenal/manifest $\sim$ subpotencies-〈in-transitiveconflatedness -reflexivity,-in-the-full-potency-of-existence's $\sim$ sublimating-nascence given 'human corresponding-sublimation-inducing,-profound-and-creative supererøgatøry acuity/perspicacity/astuteness/edginess/incisiveness-ofapriorising/axiomatising/referencing/intelligibilitysettingup/measuringinstrumenting - forconceptualisation'). In physics the Newtons, Leibnizes, Einsteins, Poincarés, Schrodingers, Bohrs had to elicit the transcendental-enabling/sublimating/supererogatory $\sim$ de-mentativity of the physics <amplituding/formative-epistemicity>totalising devolved-purview/domain-ofconstrual-as-intrinsic-reality/ontological-veridicality/existential-reality created axiomaticconstructs with mathematics being accessory to the transcendentalenabling/sublimating/supererogatory de-mentativity. They didn't just start to develop 'patterns of mathematical equations' without the prior insight about the physics domain-of-study and what to strive for, and actually from that 'physics reality precedence perspective' got the insight to further develop their relevant branches of mathematics. Nor do even pure mathematicians just go about constructing 'mathematical patterns' as of formalisation without striving to get insight and inspiration from existential-reality as transcendentalenabling/sublimating/supereregatory de-mentativity; and we can appreciate in this regards how the human mathematical disposition adjust from a classical reflex with regards to existential$<$ disontologising/re-ontologising aporeticism $>$ phenomena/manifestations that assume a nonclassical character like statistical-constructs, quantum phenomena, black holes, etc. as to existence — as-sublimating-withdrawal/unenframing/re-ontologising,-elicited-fromprospective-profound-supererogation . The naivety of logicism lies exactly in this respect of construing formalisation as most of what is supposed to be achieved, and failing to grasp that when it comes to social reality its own transcendental-enabling/sublimating/supereregatory $\sim$ de- 
mentativity has to be 'creatively construed', and this in-many-ways explains the frustrated conclusion that will often then arise from such a naïve formalisation perspective that the philosophical exercise is not necessarily transcendentalenabling/sublimating/supereregatory $\sim$ de-mentativity, contrary to the precept of all other knowledge! Thus the conceptualisation of logic implied by any given registryworldview/dimension $\quad{ }^{83}$ reference-of-thought-as-of- ${ }^{8}{ }^{83}$ reference-of-thought - devolvingteleological-de-mentating/structuring/paradigming-of-meaningfulness' as of the-very-sameimmanent-existence/intrinsic-reality/ontological-veridicality,-as-to'human<amplituding/formative-epistemicity>totalising $\sim$ purview-of-construal' points to the fact that the various registry-worldviews/dimensions operate their own conception of logic as of their prospective relative-ontological-completeness ${ }^{87}$-of- ${ }^{83}$ reference-of-thought; as we can appreciate inherently as of metaphysics-of-absence-〈implicited-epistemic-veracity-ofnonpresencing-<perspective-ontological-normalcy/postconvergence $>\rangle$ that however deficient, that each registry-worldview/dimension does have its own sense of logic as of its self-conscious construed ${ }^{56}$ meaningfulness-and-teleology ${ }^{9}$. The notion of an absolutely valid logic can only arise on the backdrop of an absolutely valid ${ }^{83}$ reference-of-thought-as-of- ${ }^{8}{ }^{8}$ reference-ofthought—devolving-teleological-de-mentating/structuring/paradigming-of-meaningfulness' as implied by futural Being-development/ontological-framework-expansion-as-to-depth-ofontologising-development-as-infrastructure-of- meaningfulness-and-teleology as of prospective deprocrypticism-or-preempting - disjointedness-as-of- ${ }^{18}$ reference-of-thought registry-worldview/dimension institutionalisation, wherein such a logic is its inner working coherence/contiguity of axiomatic-construct construal of ecstatic-existence/the-nature-of-theworld/conditions'. In this regard, the link-up of all the concepts and notions articulated herein by this author speaks of 'suprastructural logic' that is critically articulated as of a prospective notional deprocrypticism psychoanalytic-unshackling metaphysics-of-absence-〈implicited- 
epistemic-veracity-of- nonpresencing-<perspective-ontological-normalcy/postconvergence $>$ >

and apriorising/axiomatising/referencing-\{of-'prospectively_implicited_attendant-ontologicalcontiguity ' educed-

existentialising/contextualising/textualising_intelligibility/epistemicity/reflexivity-contiguity$<$ imbued-notional cogency>' $\}$-conflatedness ${ }^{13}$ in (preconverging ment by postconverging-ntailment, and further subsumed in the word candidity or candour-capacity. Such 'suprastructural logic' is even more damning about the naïve apriorising/axiomatising/referencing-\{of-'prospectively_implicited_attendant-ontologicalcontiguity ' educedexistentialising/contextualising/textualising_'intelligibility/epistemicity/reflexivity-contiguity<imbued-notional cogency $>\quad\}$-constitutedness ${ }^{14}$-in preconverging-entailment construal of meaningfulness-and-teleology ${ }^{9}$ that besets the knowledge and philosophical tradition. Such a conception of logic and logical analysis points to the <amplituding/formativeepistemicity $>$ totalising $\sim$ self-referencing-syncretising/circularity/interiorising/akrasiatic-drag naivety and vagueness involved when construing logic and logical analysis as absolute without any explicitly implied or formulated ${ }^{83}$ reference-of-thought, construed as ${ }^{83}$ reference-ofthought — devolving-teleological-de-mentating/structuring/paradigming-of-meaningfulness'; usually in our case, in a non-transcendental <amplituding/formativeepistemicity>totalising $\sim$ self-referencing-syncretising/circularity/interiorising/akrasiatic-drag that is unconsciously implied as of our positivism- ${ }^{8}$ procrypticism registryworldview/dimension. Insightfully, such a 'suprastructural logic' undermines metaphysical notions like good, essence and truth as being naively construed as of a given registryworldview's/dimension's <amplituding/formative-epistemicity $>$ totalising $\sim$ self-referencingsyncretising/circularity/interiorising/akrasiatic-drag ${ }^{34}$ of ${ }^{56}$ meaningfulness-and-teleology ${ }^{9}$, and in lieu emphasises Being construed as ontology's-directedness-as-Being which best reflects and 
captures ${ }^{56}$ meaningfulness-and-teleology ${ }^{9}$ as of 'intemporal ontological-faith-notion-orontological-fideism - imbued-underdetermination-of-motif-and-

apriorising/axiomatising/referencing-as-so-being-as-of-existential-reality instigated relativeunreflexivity/relative-reflexivity - ontological-contiguity ${ }^{67}$ of-the-human-institutionalisationprocess $^{68}$ as of difference-conflatedness ${ }^{13}$-as-to-totalitative-reification-in-singularisation- $<$ as-tothe-nondisjointedness/entailment-of-prospective- nonpresencing $>$-as-veridical-epistemicityrelativism-determinism implied $<$ amplituding/formative-epistemicity $>$ causality $\sim$ as-toprojective-totalitative-implications-of-prospective- nonpresencing,-for-explicating relativeunreflexivity/relative-reflexivity - ontological-contiguity '. Being as of its implied notional 18 deprocrypticism's apriorising/axiomatising/referencing- of-" prospectively implicited_attendant-ontological-contiguity ' educedexistentialising/contextualising/textualising_'intelligibility/epistemicity/reflexivity-contiguity<imbued-notional cogency>' \}-conflatedness ${ }^{13}$ in-\{preconverging -ment by\} pestcenverging-ntailment provides elucidation to such question as: what is the meaning of good/truth/essence in a recurrent-utter-institutionalised, an ununiversalised or a non-positivistic society? And invariably the answers will be a vague <amplituding/formativeepistemicity $>$ totalising $\sim$ self-referencing-syncretising/circularity/interiorising/akrasiatic-drag as of each registry-worldview/dimension, and it is rather the emanant insight of 'prospective postconverging aporeticism-overcoming/unovercoming as the-Good/knowledgereification $\sim$ gesturing-and-accounting-of-epistemic-phenomenalism-<inprospective_psychologismic apriorising/axiomatising/referencing-\{of-"prospectively implicited_attendant-ontological-contiguity ' educedexistentialising/contextrising/textlising_intelligibility/epistemicity/reflexivity-contiguity$<$ imbued-notional cogency $\left.>^{\prime}\right\}$-conflatedness -in-\{preconverging-ment by\} postconverging-entailment $>$ /understanding/<amplituding/formative- 
epistemicity $>$ causality $\sim$ as-to-projective-totalitative-implications-of-prospective-

nonpresencing,-for-explicating relative-unreflexivity/relative-reflexivity - ontological-

contiguity ' conceptualisation as of Being-development/ontological-framework-expansion-asto-depth-of-ontologising-development-as-infrastructure-of- meaningfulness-and-teleology that carries the prospective transcendence-and-sublimity/sublimation/supereregatory $\sim$ dementativity which are the resolution of the successive prior registry-worldview's/dimension's uninstitutionalised-threshold $^{102}$ vices-and-impediments ${ }^{105}$; and so by successive Beingdevelopment/ontological-framework-expansion-as-to-depth-of-ontologising-development-asinfrastructure-of- meaningfulness-and-teleology in reflecting holographically$<$ conjugatively-and-transfusively $>$ the relative-unreflexivity/relative-reflexivity ontologicalcontiguity $\sim$ of-the-human-institutionalisation-process as base-institutionalisation, universalisation and positivism respectively, and prospectively deprocrypticism. Being construed as of ontology's-directedness-as-Being thus enables the superseding of $<$ amplituding/formative--epistemicity $>$ totalising $\sim$ self-referencing-syncretising/illusion-of-thepresent/present-consciousness/mirage as metaphysics-of-presence-〈implicited‘nondescript/ignorable-void '-as-to- presencing-absolutising-identitive-constitutedness \).

Further, the fact is that it is rather axiomatic-constructs whether explicit or implicit that are supposedly in a ${ }^{56}$ meaningfulness-and-teleology ${ }^{9}$ correspondence relation with an epistemictotalising $\sim$ devolved — purview/domain-of-construal-as-intrinsic-reality/ontologicalveridicality/existential-reality as of their given ${ }^{5}$ meaningfulness-and-teleology ${ }^{9}$ ontologicalperformance $^{72}-<$ including-virtue-as-ontology $>$ /morality/ethics/justice/etc. as validated by $<$ amplituding/formative-epistemicity $>$ causality $\sim$ as-to-projective-totalitative-implications-ofprospective- nonpresencing,-for-explicating relative-unreflexivity/relative-reflexivity

ontological-contiguity ; so-construed as of the implications of human limited-mentationcapacity -as-subjecting 'educed-unlimitedness/existence-sublimating nascence' to- 
limitedness/human-subpotency when developing axiomation-constructs, with the latter subject to their transcendence-and-sublimity/sublimation/supererogatory de-mentativity when prospective relative-ontological-completeness ${ }^{87}$-of-axiomatic-construct-or- ${ }^{83}$ reference-ofthought avails prospectively with regards to their ${ }^{56}$ meaningfulness-and-teleology ${ }^{9}$ ontologicalperformance ${ }^{72}-<$ including-virtue-as-ontology $>$. The implications here as well are that implicit axiomatic-constructs like analogies and supposed intuitions/insights that do not reflect/align as of the coherence/contiguity of superseding-oneness-of-ontology implied as of the full-potency of existence coherence/contiguity, are ontologically naïve and vague. Thus axiomatic-constructs ontological-veracity are dependent on relative notional-discontiguity/epistemic-discontiguity ${ }^{63}$ $<$ between - prior-shallow-supererogation -of-mentallyaestheticised $\sim$ preconverging/dementing -qualia-schema_and_prospective-profoundsupererogation -of-mentally-aestheticised postconverging/dialectical-thinking -qualiaschema $>$ as axiomatic-construct ${ }^{/ 3}$ reference-of-thought of $<$ amplituding/formativeepistemicity $>$ totalising $\sim$ devolved — purview/domain-of-construal-as-intrinsicreality/ontological-veridicality/existential-reality. An axiomatic-construct is in such relative notional-discontiguity/epistemic-discontiguity ${ }^{6}-<$ between - prior-shallow-supererogation -ofmentally-aestheticised preconverging/dementing - qualia-schema_and prospective-profoundsupererogation -of-mentally-aestheticised postconverging/dialectical-thinking -qualiaschema $>$ by its apriorising/axiomatising/referencing-\{of-'prospectively implicited_attendantontological-contiguity ' $\sim$ educedexistentialising/contextualising/textualising_'intelligibility/epistemicity/reflexivity-contiguity<imbued-notional cogency $>$ ' $\}$ - conflatedness ${ }^{13}$-in-\{preconverging-ment by\}

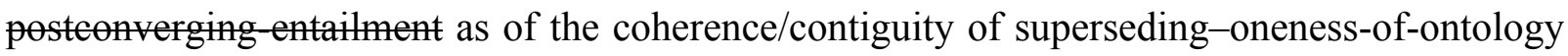
implied as of the full-potency of existence coherence/contiguity. An 'axiomaticconstruct $/{ }^{3}$ reference-of-thought of notional-discontiguity/epistemic-discontiguity ${ }^{63}$ 


\section{$<$ between-prior-shallow-supererogation -of-mentally-}

\section{aestheticised preconverging/dementing -qualia-schema_and_prospective-profound-}

\section{supererogation -of-mentally-aestheticised postconverging/dialectical-thinking -qualia-}

schema $>$ as of an epistemic-totalising ${ }^{3} \sim$ devolved - purview/domain-of-construal-as-intrinsicreality/ontological-veridicality/existential-reality' highlights two points of failure/asdiscontinuity of ${ }^{56}$ meaningfulness-and-teleology ${ }^{9}$ ontological-performance ${ }^{72}-<$ includingvirtue-as-ontology $>$ having to do with its apriorising/axiomatising/referencing/intelligibilitysettingup/measuringinstrumenting unsoundness-or-ontological-bad-faith/inauthenticity ${ }^{64}$ and by derivation the aposteriorising/logicising/deriving/intelligising/measuring; such that a more ontologicallycomplete 'axiomatic-construct $/{ }^{83}$ reference-of-thought in relative prospective notionalcontiguity/epistemic-contiguity ${ }^{62}<$ profound-supererogation -of-mentallyaestheticised postconverging/dialectical-thinking -qualia-schema> as of the-very-same $<$ amplituding/formative-epistemicity $>$ totalising $\sim$ devolved-purview/domain-of-construal-asintrinsic-reality/ontological-veridicality/existential-reality' exists rather beyond the scope of construal of ${ }^{56}$ meaningfulness-and-teleology ${ }^{99}$ of the prior 'axiomatic-construct $/{ }^{83}$ reference-ofthought of notional-discontiguity/epistemic-discontiguity ${ }^{6}<$ between - prior-shallowsupererogation -of-mentally-aestheticised $\sim$ preconverging/dementing -qualiaschema_and_prospective-profound-supererogation -of-mentallyaestheticised postconverging/dialectical-thinking -qualia-schema> as of the-very-same $<$ amplituding/formative-epistemicity $>$ totalising $\sim$ devolved-purview/domain-of-construal-asintrinsic-reality/ontological-veridicality/existential-reality'. Thus the relationship between a prospective institutionalisation and the uninstitutionalised-threshold ${ }^{102}$ is one of "relative notional-contiguity/epistemic-contiguity ${ }^{2}$ - profound-supererogation -of-mentallyaestheticised postconverging/dialectical-thinking -qualia-schema $>$ by notional- 
discontiguity/epistemic-discontiguity ${ }^{63}<$ between - prior-shallow-supererogation -ofmentally-aestheticised preconverging/dementing -qualia-schema_and_prospective-profoundsupererogation -of-mentally-aestheticised postconverging/dialectical-thinking -qualiaschema>' of their differing 'references-of-thought as of the-very-same-immanentexistence/intrinsic-reality/ontological-veridicality,-as-to-'human<amplituding/formativeepistemicity>totalising purview-of-construal'; for instance, with regards to the relative notional-contiguity/epistemic-contiguity ${ }^{2}$ - profound-supererogation -of-mentallyaestheticised postconverging/dialectical-thinking -qualia-schema> of ${ }^{83}$ reference-of-thought implied as of base-institutionalisation over the relative notional-discontiguity/epistemicdiscontiguity $^{63}-<$ between - prior-shallow-supererogation -of-mentallyaestheticised preconverging/dementing -qualia-schema_and_prospective-profoundsupererogation -of-mentally-aestheticised postconverging/dialectical-thinking -qualiaschema $>$ of ${ }^{8}$ reference-of-thought implied as of recurrent-utter-uninstitutionalisation, as of their differing ${ }^{83}$ references-of-thought and thus implied logic with regards to the-very-sameimmanent-existence/intrinsic-reality/ontological-veridicality,-as-to-

'human<amplituding/formative-epistemicity $>$ totalising $\sim$ purview-of-construal', reflected as of relative mutual unintelligibility. In axiomatic-construct terms, it is 'mentallyunsound/preconverging-or-dementing ${ }^{20}$-apriorising-psychologism and by derivation illogical' to be insisting on articulating notions of relevance to the theory-of-relativity-together-withquantum-mechanics - axiomatic-constructs like space-time or quanta in terms of 'traditional classical mechanics axiomatic-construct' as of their respectively corresponding relative notionalcontiguity/epistemic-contiguity ${ }^{2}-<$ profound-supererogation -of-mentallyaestheticised postconverging/dialectical-thinking -qualia-schema> and relative notionaldiscontiguity/epistemic-discontiguity ${ }^{3}<$ between - prior-shallow-supererogation -ofmentally-aestheticised preconverging/dementing -qualia-schema_and_prospective-profound- 
supererogation -of-mentally-aestheticised postconverging/dialectical-thinking -qualia-

schema>, and so with regards to 'the-very-same physics <amplituding/formativeepistemicity $>$ totalising $\sim$ devolved—purview/domain-of-construal-as-intrinsic-

reality/ontological-veridicality/existential-reality'. Such mutual unintelligibility, with regards to reference-of-thought, speaks of differing 'apriorising/axiomatising/referencing/intelligibilitysettingup/measuringinstrumenting as axiomatic-construct' of the differing ${ }^{83}$ references-of-thought, with the traditional philosophical and knowledge anti-psychologism stance fundamentally grounded on a mix-up about the nature of 'axioms wrongly construed as elements of logic' as implied with statements like 'axioms of logic' rather than the fact that axiomatic-constructs are 'ontological wholes of correspondence' as of supposed correspondence with <amplituding/formativeepistemicity $>$ totalising $\sim$ devolved—purview/domain-of-construal-as-intrinsic-

reality/ontological-veridicality/existential-reality and thus carry transcendentalenabling/sublimating/supereregatory de-mentativity implications as of human limitedmentation-capacity-deepening —as-subjecting limitedness/human-subpotency-to-'educedunlimitedness/existence-sublimating nascence' ${ }^{53}$, whereas logic and logical analysis is rather the 'inner working coherence/contiguity of axiomatic-construct construal of ecstaticexistence/the-nature-of-the-world/conditions' and at best yields formalisations grounded on the implied 'apriorising/axiomatising/referencing/intelligibilitysettingup/measuringinstrumenting as axiomatic-construct' but doesn't reify ${ }^{56}$ meaningfulness-and-teleology ${ }^{99}$ as knowledge which can only arise as of the "maximalising-recomposuring-for-relative-ontologicalcompleteness $^{87}$ — unenframed/re-ontologising conceptualisation

affirmation/projection/assertion/notional $\sim$ self-distantiation/dueness-validatinglogicising/suitable-measuringinstrument-validating-measuring-<as-to-postconverging-or- 
apriorising/axiomatising/referencing/intelligibilitysettingup/measuringinstrumenting

axiomatic-construct'. Such a logicism disposition is rather in apriorising/axiomatising/referencing-\{of-"prospectively implicited_attendant-ontologicalcontiguity ' educed-

existentialising/contextualising/textualising_intelligibility/epistemicity/reflexivity-contiguity<imbued-notional cogency $\left.>^{\prime} \quad\right\}$-constitutedness ${ }^{14}$-in preconverging-entailment $\quad$ and is behind such naïve contention that philosophy doesn't carry transcendental implications and actually undermines other approaches that strive for transcendentalenabling/sublimating/supereregatory $\sim$ de-mentativity by way of conceptual-patterning arguments blinded to transcendental implications of knowledge as derived from existence-asthe-absolute-a-priori-of-conceptualisation and existence-as-sublimatingwithdrawal/unenframing/re-ontologising,-elicited-from-prospective-profoundsupererogation -<as-to-perspective-ontological-normalcy/postconvergence-implied'prospective-aporeticism-overcoming/unovercoming'>. In-the-bigger-scheme-of-things, this author holds that the deepest 'phenomenological transcendental-point-of-departure handle' in the conception-of- ${ }^{5}$ meaningfulness-and-teleology ${ }^{9}$ ontological-performance ${ }^{72}<$ includingvirtue-as-ontology $>$ /morality/ethics/justice/etc. as of transcendence-andsublimity/sublimation/supererogatory $\sim$ de-mentativity reflected by metaphysics-of-absence〈implicited-epistemic-veracity-of- nonpresencing-<perspective-ontologicalnormalcy/postconvergence $>>$ is wholly sufficient as of human limited-mentation-capacitydeepening —as-subjecting limitedness/human-subpotency-to-'educed-unlimitedness/existencesublimating nascence' 5 in accounting for 'intemporal ontological-faith-notion-or-ontologicalfideism - imbued-underdetermination-of-motif-and-apriorising/axiomatising/referencing-asso-being-as-of-existential-reality instigated relative-unreflexivity/relative-reflexivity ontological-contiguity ${ }^{67}$ of-the-human-institutionalisation-process ${ }^{68}$ as of difference- 
conflatedness $^{13}$-as-to-totalitative-reification-in-singularisation- $<$ as-to-thenondisjointedness/entailment-of-prospective- nonpresencing $>$-as-veridical-epistemicityrelativism-determinism implied $<$ amplituding/formative-epistemicity $>$ causality $\sim$ as-toprojective-totalitative-implications-of-prospective- nonpresencing,-for-explicating relativeunreflexivity/relative-reflexivity ontological-contiguity , as of relative notionalcontiguity/epistemic-contiguity ${ }^{62}<$ profound-supererogation - of-mentallyaestheticised postconverging/dialectical-thinking -qualia-schema $>$ of ${ }^{83}$ reference-of-thought with regards to the-very-same-immanent-existence/intrinsic-reality/ontological-veridicality,-asto-'human<amplituding/formative-epistemicity>totalising $\sim$ purview-of-construal'. This author phenomenological transcendental conception is articulated as of non-speculative, nonimaginary, theoretical, conceptual and operant implications construing/conceptualising in reflecting holographically-<conjugatively-and-transfusively $>$ the relative -unreflexivity/relativereflexivity - ontological-contiguity of-the-human-institutionalisation-process, not as an external speculative dialectics, but as a wholly internal natural dialectics in apriorising/axiomatising/referencing-\{of-'prospectively_implicited_attendant-ontologicalcontiguity ' educedexistentialising/contexalising/textising_intelligibility/epistemicity/reflexivity-contiguity<imbued-notional cogency>' \}-conflatedness ${ }^{13}$ in-\{preconverging-ment-by\} postconverging-entailment as of human limited-mentation-capacity-deepening-as-subjectinglimitedness/human-subpotency-to-'educed-unlimitedness/existence-sublimating nascence' 53 . Such that human phenomenological <amplituding/formative-epistemicity $>$ totalising thrownness-in-existence ${ }^{35}$ (I exist therefore existence is of transcendental-

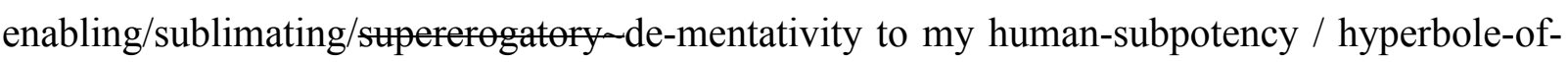
temporal-to-intemporal-ontological-performance ${ }^{72}-$ including-virtue-as-ontology $>$ ) $_{\text {is }}$ the 'complete scientific archaeological depth' for grasping ontology and Being as of the 
apriorising/axiomatising/referencing-\{of-'prospectively_implicited_attendant-ontological-

contiguity ' educed-

existentialising/contextualising/textualising_'intelligibility/epistemicity/reflexivity-contiguity-

<imbued-notional cogency $\left.>^{\prime}\right\}$ - conflatedness ${ }^{13}$-in-\{preconverging-ment by \} $^{-}$

postconverging-entailment of human limited-mentation-capacity-as-subjecting-educedunlimitedness/existence-sublimating nascence'-to-limitedness/human-subpotency implications construed from notional ${ }^{18}$ deprocrypticism perspective as ${ }^{4}$ historiality/ontologicaleventfulness 3 /ontological-aesthetic-tracing-<perspective-ontological-

normalcy/postconvergence-reflected-‘epistemicity-relativism-determinism'>, and consequently doesn't carry any external ideological implication but rather for the inherent ontological and Being implications. Further as of such phenomenological transcendental apriorising/axiomatising/referencing-\{of-'prospectively_implicited_attendant-ontologicalcontiguity ' educed-

existentialising/contextualising/textualising_'intelligibility/epistemicity/reflexivity-contiguity$<$ imbued-notional $\left.\sim \operatorname{cogency}>^{\prime}\right\}$-conflatedness ${ }^{13}$-in-\{preconverging-ment by $\}^{\prime}$ postconverging-entailment, there is no issue about existence itself as it is pre-given, as existenceas-of-its-mimetic-echoness/existence-in-reverberation/existence-potency ${ }^{39} \sim$ sublimatingnascence,-disclosed-from-prospective-epistemic-digression ${ }_{2}$ but rather an issue to humankind arising as of human-subpotency in the full-potency of existence with all the problem of existence being the issue of humankind's limited-mentation-capacity-as-subjecting 'educedunlimitedness/existence-sublimating nascence' to-limitedness/human-subpotency implications as failing Being-development/ontological-framework-expansion-as-to-depth-of-ontologisingdevelopment-as-infrastructure-of- meaningfulness-and-teleology as of ontology'sdirectedness-as-Being. The phenomenological insight here about the nature of 'existence as so construed as of ontology's-directedness-as-Being' is that Being is the 
apriorising/axiomatising/referencing-\{of-'prospectively_implicited_attendant-ontological-

contiguity ' educed-

existentialising/contextualising/textualising_'intelligibility/epistemicity/reflexivity-contiguity-

<imbued-notional cogency $\left.>^{\prime}\right\}$ - conflatedness ${ }^{13}$-in-\{preconverging-ment by \} $^{-}$

pestcenverging entailment as of intemporal-preservation-entropy-or-contiguity-or-ontologicalpreservation selectivity inherent in existence that rather skews presence states towards the

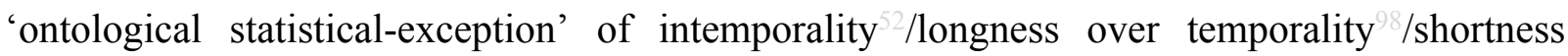
possibilities, thus rendering existence as of relative teleological orderliness and not teleological chaos in the case were all ontological-possibilities as of temporality ${ }^{9}$-to-intemporality ${ }^{52}$ were to be arising in equivalence/equal-measure. Thus, such ontology's-directedness-as-Being apriorising/axiomatising/referencing-\{of-'prospectively_implicited_attendant-ontologicalcontiguity ' $\sim$ educedexistentialising/contextualising/textualising_ 'intelligibility/epistemicity/reflexivity-contiguity$<$ imbued-notional cogency $>$ ' \}-conflatedness ${ }^{13}$-in-\{preconverging-ment by\} postconverging-entailment <amplituding/formative-epistemicity $>$ causality $\sim$ as-to-projectivetotalitative-implications-of-prospective- nonpresencing,-for-explicating relative-

\#nreflexivity/relative reflexivity ontological-contiguity as of ${ }^{55}$ maximalisingrecomposuring-for-relative-ontological-completeness ${ }^{8}$ - unenframed/re-

ontologising conceptualisation existentially-<disontologising/re-ontologising aporeticism $>$ supersede abstract/imagined/misconstrued/virtual apriorising/axiomatising/referencing-\{of'prospectively implicited_attendant-ontological-contiguity ' educedexistentialising/contextualising/textualising_'intelligibility/epistemicity/reflexivity-contiguity$<$ imbued-notional cogency $>$ ' $\}$-constitutedness ${ }^{14}$ in preconterging possibilities as of elaboration-as-to-mere-extrapolating/constituting/abstracting/deducing/inferring-ofelucidation-outside_- 'prospectively_implicited_attendant-ontological-contiguity ${ }^{6}$ ' educed- 
existentialising/contextualising/textualising_intelligibility/epistemicity/reflexivity-contiguity$<$ imbued-notional cogency $>$ implications that are effectively as of non-existence. The further implication is that human 'prior existential-reality insight as arising by apriorising/axiomatising/referencing-\{of-'prospectively implicited_attendant-ontologicalcontiguity ' educedexistentialising/contextualising/textualising_'intelligibility/epistemicity/reflexivity-contiguity<imbued-notional cogency>' $\}$-conflatedness ${ }^{13}$-in-\{preconverging-ment by\} pestcenverging-entailment as of the coherence/contiguity of ontology's-directedness-as-Being' rather 'points to the ontological-veracity of prospective existential-reality as of apriorising/axiomatising/referencing-\{of-'prospectively_implicited_attendant_ontologicalcontiguity ' educedexistentialising/contextualising/textualising_'intelligibility/epistemicity/reflexivity_contiguity<imbued-notional cogency>' \}-conflatedness ${ }^{13}$ in-\{preconverging -ment by\} postconverging-entailment upholding prospective coherence/contiguity of ontology'sdirectedness-as-Being'; wherein as of human-subpotency the ontological-veracity in reflecting holographically-<conjugatively-and-transfusively $>$ the relative-unreflexivity/relativereflexivity - ontological-contiguity of-the-human-institutionalisation-process as leading up to our present positivism/rational-empiricism registry-worldview/dimension speaks of an apriorising/axiomatising/referencing-\{of-'prospectively_implicited_attendant-ontologicalcontiguity ' educedexistentialising/contextualising/textualising_'intelligibility/epistemicity/reflexivity-contiguity-

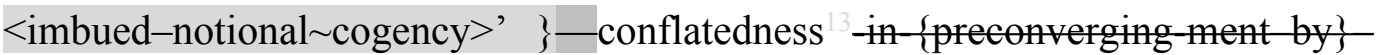
as of successive opened-constructs-of- -5 meaningfulness-and-

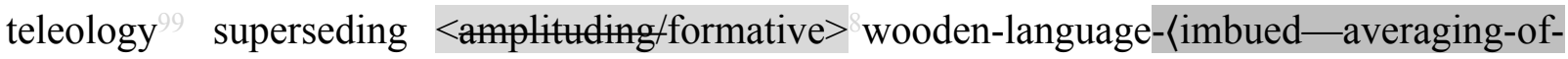
thought-<as-to-leveling/ressentiment/closed-construct-of- meaningfulness-and-teleology -as- 
of-'nondescript/ignorable-void '-with-regards-to-prospective-apriorising-implications $>>$ and from which Being-development/ontological-framework-expansion-as-to-depth-ofontologising-development-as-infrastructure-of- meaningfulness-and-teleology exercise we can't as of soundness-or-ontological-good-faith/authenticity ${ }^{6}$ exculpate ourselves to then pretend ours is the registry-worldview/dimension ${ }^{83}$ reference-of-thought that is nontranscendable as of our <amplituding/formative-epistemicity $>$ totalising $\sim$ self-referencingsyncretising/circularity/interiorising/akrasiatic-drag ${ }^{34}$, when the insight of prospective transcendence-and-sublimity/sublimation/supererogatory-de-mentativity implications as of deprocrypticism-or-preempting-disjointedness-as-of- ${ }^{3}$ reference-of-thought avails, and so as the apriorising/axiomatising/referencing-\{of-'prospectively implicited_attendantontological-contiguity ' $\sim$ educed-

existentialising/contextualising/textualising_'intelligibility/epistemicity/reflexivity-contiguity$<$ imbued-notional cogency $>$ ' $\}$-conflatedness ${ }^{13}$ in-\{preconverging ment by\} postconverging-ntailment upholding prospective coherence/contiguity of ontology'sdirectedness-as-Being. This further explains why there is need for corresponding Beingdevelopment/ontological-framework-expansion-as-to-depth-of-ontologising-development-asinfrastructure-of- meaningfulness-and-teleology with respect to human technical development, and as with prior technologies future technologies will necessarily imply renewed human self-consciousness which is not by itself a given and needs to be 'thought through and effectively conceptualised' with respect to the future implications of human development, nuclear weapons knowledge, electronic communication, artificial intelligence, etc. as 'intemporal ontological-faith-notion-or-ontological-fideism-imbued-underdetermination-ofmotif-and-apriorising/axiomatising/referencing-as-so-being-as-of-existential-reality instigated relative-unreflexivity/relative-reflexivity - ontological-contiguity ${ }^{67}$ of-the-humaninstitutionalisation-process $^{68}$ as of difference-conflatedness ${ }^{13}$-as-to-totalitative-reification-in- 
singularisation-<as-to-the-nondisjointedness/entailment-of-prospective- nonpresencing $>$-asveridical-epistemicity-relativism-determinism implied $\quad<$ amplituding/formativeepistemicity $>$ causality $\sim$ as-to-projective-totalitative-implications-of-prospectivenonpresencing,-for-explicating relative-unreflexivity/relative-reflexivity - ontologicalcontiguity ' is subject to epistemic-decadence as of beyond-the-consciousness-awarenessteleology $-<$ of-preconverging-existential-extrication-as-of-existential-unthought $>$. Such

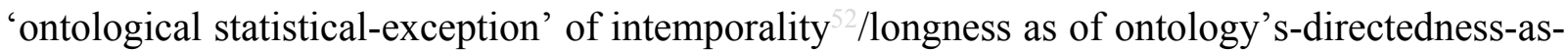
Being permeates all existential-<disontologising/re-ontologising aporeticism $>$ processes including life itself. This explains why dimensionality-of-sublimating ${ }^{25}$ <<amplituding/formative >supererogatory de-mentativeness/epistemic-growth-orconflatedness /transvaluative-rationalising/transepistemicity/anamnestic-residuality/spiritdrivenness-equalisation $\rangle$ mental-disposition behind the 'inventing' of prior institutionalisation as of ontological-faith-notion-or-ontological-fideism-imbued-underdetermination-of-motifand-apriorising/axiomatising/referencing-as-so-being-as-of-existential-reality construed as prior ontology's-directedness-as-Being is necessarily the requisite mental-disposition for the 'inventing' of prospective institutionalisation as of ontological-faith-notion-or-ontologicalfideism —imbued-underdetermination-of-motif-and-apriorising/axiomatising/referencing-asso-being-as-of-existential-reality construed as prospective ontology's-directedness-as-Being; and so, overcoming temporal/shortness-of-register-of meaningfulness-and-teleology on <amplituding/formative> wooden-language-_imbued-temporal-mere-

\section{form/virtualities/dereification/akrasiatic-drag/denatured/preconverging-or-dementing}

narratives - of-the- reference-of-thought- categorical-imperatives/axioms/registry-

teleology $>$ as of uninstitutionalised-threshold ${ }^{102}$ failing intemporal-preservation-entropy-orcontiguity-or-ontological-preservation. Ultimately, phenomenology is all about grasping the apriorising/axiomatising/referencing-\{of-"prospectively_implicited_attendant-ontological- 
contiguity ' educed-

existentialising/contextualising/textualising_'intelligibility/epistemicity/reflexivity_contiguity-

<imbued-notional cogency >' \}-conflatedness ${ }^{13}$ in-\{preconverging-ment by\}

pestconverging-entailment of ontology's-directedness-as-Being. Furthermore, just as a transcendental-enabling/sublimating/supererogatory $\sim$ de-mentativity biological science in

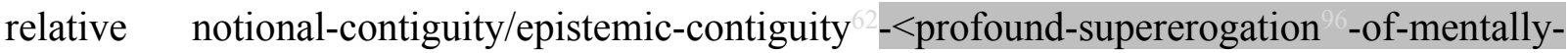
aestheticised postconverging/dialectical-thinking -qualia-schema $>$ of ${ }^{8}$ reference-of-thought will dissociate modern-day heredity DNA genetics as of its theoretical, conceptual, methodological, operant and applicative implications from say $19^{\text {th }}$ century Mendelian heredity however its inherent merits, and will not naively purport to analyse the former on the grounds of the latter which as axiomatic-construct is in relative notional-discontiguity/epistemicdiscontiguity ${ }^{63}-<$ between - prior-shallow-supererogation -of-mentallyaestheticised preconverging/dementing -qualia-schema_and_prospective-profoundsupererogation -of-mentally-aestheticised postconverging/dialectical-thinking -qualiaschema $>$ on the basis of a naïve conceptual-patterning implied as of the common term 'heredity'; this author likewise is very much critical and averse to such conceptual-patterning mentalreflexes imbued in traditional non-transcendental philosophical and knowledge analysis all too ready to construe and articulate ${ }^{56}$ meaningfulness-and-teleology ${ }^{9}$ in sophistic/pedantic $\begin{array}{llll}\text { conceptual-patterning terms transcendental- } & \text { overlooking }\end{array}$ enabling/sublimating/supereregatery $\sim$ de-mentativity implications, and failing to fathom that conceptual-patterning is no substitute for transcendentalenabling/sublimating/supereregatory $\sim$ de-mentativity work required for all knowledge notwithstanding setbacks and failures that may be involved, given the reality that human meaningfulness-and-teleology $\quad$ ontological-performance ${ }^{2}-<$ including-virtue-asontology $>$ /morality/ethics/justice/etc. arises as an exercise of human limited-mentation- 
capacity-deepening_as-subjecting-limitedness/human-subpotency-to-'educedunlimitedness/existence-sublimating nascence' ${ }^{53}$ as of relatively profound and complete axiomatic-constructs $/{ }^{3}$ reference-of-thought in notional-contiguity/epistemic-contiguity $<$ profound-supererogation -of-mentally-aestheticised postconverging/dialectical-thinking qualia-schema $>$ of the-very-same-immanent-existence/intrinsic-reality/ontologicalveridicality,-as-to-'human<amplituding/formative-epistemicity>totalising $\sim$ purview-ofconstrual' or <amplituding/formative-epistemicity>totalising devolved-purview-as-domainof-construal-as-intrinsic-reality/ontological-veridicality! Consider for instance criticisms often levied against post-structuralism and specifically Derridean deconstruction as simply convoluted expressions of familiar and trite ideas. But then the effective transcendentalenabling/sublimating/supereregatery $\sim$ de-mentativity insight as of their applications arising in the social sciences and literal studies clearly demonstrate otherwise. Further many such critiques have tended to be naïve about what passes for theory whereby naïve conceptual-patterning of general knowledge are articulated devoid of 'new theory', with little or no transcendentalenabling/sublimating/supereregatory de-mentativity implications, which in reality is nothing more than a sophistry of argument from authority. This conception of relatively profound and complete axiomatic-constructs $/{ }^{8}$ reference-of-thought in notional-contiguity/epistemic-

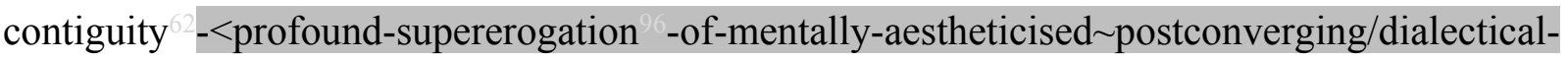
thinking -qualia-schema> can equally be demonstrated in graphical terms as a problem 'not along the curve created-by-human-limited-mentation-capacity-as-subjecting 'educedunlimitedness/existence-sublimating nascence' to-limitedness/human-subpotency' in relative notional-discontiguity/epistemic-discontiguity ${ }^{63}<$ between - prior-shallow-supererogation -ofmentally-aestheticised preconverging/dementing -qualia-schema_and_prospective-profoundsupererogation -of-mentally-aestheticised postconverging/dialectical-thinking -qualiaschema $>$ of axiomatic-construct but rather a problem arising as of the need for a 'change of the 
curve to-be-created-by-deepening-human-limited-mentation-capacity-as-subjecting 'educedunlimitedness/existence-sublimating nascence' to-limitedness/human-subpotency' in relative notional-contiguity/epistemic-contiguity ${ }^{62}$ - profound-supererogation -of-mentallyaestheticised postconverging/dialectical-thinking -qualia-schema $>$ of axiomatic-construct for grander human ${ }^{5}$ meaningfulness-and-teleology ${ }^{9}$ ontological-performance ${ }^{72}<$ including-virtueas-ontology $>$, as of the-very-same $<$ amplituding/formative-epistemicity $>$ totalising $\sim$ devolvedpurview-as-domain-of-construal-as-intrinsic-reality/ontological-veridicality. The $<$ amplituding/formative-epistemicity $>$-totalising $\sim$ renewing-realisation/re-perception/rethought involves taking cue from existence as to 'implicited_attendant-ontologicalcontiguity $^{67} \sim$ educed-

existentialising/contextualising/textualising_intelligibility/epistemicity/reflexivity-contiguity<imbued-notional cogency $>$ '/contexts as of existential-instantiations sublimating-epistemicimbricatedness/threadedness/recomposuring in a ${ }^{55}$ maximalising-recomposuring-for-relativeontological-completeness ${ }^{87}$ - unenframed/re-ontologising conceptualisation exercise as of ontological-faith-notion-or-ontological-fideism - imbued-underdetermination-of-motif-andapriorising/axiomatising/referencing-as-so-being-as-of-existential-reality; wherein say with a demand curve, the insight as of human limited-mentation-capacity-deepening as stbjecting limitedness/human-subpotency-to-'educed-unlimitedness/existence-sublimating nascence' 53 of a significant rise in consumers' salaries implies that everything else being equal the demand curve-axiomatic-construct will shift to the right as of relative notional-contiguity/epistemiccontiguity ${ }^{62}<$ profound-supererogation - of-mentally-aestheticised $\sim$ postconverging/dialecticalthinking -qualia-schema>. The notion of axiomatic-construct in notional-contiguity/epistemiccontiguity ${ }^{62}<$ profound-supererogation -of-mentally-aestheticised $\sim$ postconverging/dialecticalthinking -qualia-schema $>$ arises out of its existential-<disontologising/re-ontologisingapereticism $>$ completeness and profoundness, for instance the axiomatic-construct in notional- 
contiguity/epistemic-contiguity ${ }^{2}-<$ profound-supererogation -of-mentally-

aestheticised postconverging/dialectical-thinking -qualia-schema $>$ as concept of a bicycle arises by the completeness and profoundness of the bicycle in its existential-<disontologising/reentologising aporeticism $>$ wholeness of functionality and contents as of its epistemictotalising $\sim$ conflated- $-{ }^{5}$ meaningfulness-and-teleology.$\quad$ Notional-contiguity/epistemiccontiguity ${ }^{62}<$ profound-supererogation -of-mentally-aestheticised postconverging/dialecticalthinking -qualia-schema $>$ rather highlights relative perspectives as of ontologicalnormalcy/postconvergence depths of axiomatic-construct/ ${ }^{3}$ reference-of-thought of construal; which for instance renders the idea of general relativity in relative notional-contiguity/epistemiccontiguity $^{62}<$ profound-supererogation - of-mentally-aestheticised $\sim$ postconverging/dialecticalthinking -qualia-schema $>$ and Newtonian physics in relative notional-discontiguity/epistemicdiscontiguity ${ }^{63}-<$ between - prior-shallow-supererogation -of-mentallyaestheticised preconverging/dementing -qualia-schema_and_prospective-profoundsupererogation -of-mentally-aestheticised postconverging/dialectical-thinking -qualiaschema $>$ rather as uncorrelated, whereas a notion of 'continuity of ontology' as is implied by 'ontological-continuity as of relative ontological-continuity and relative notionaldiscontiguity/epistemic-discontiguity ${ }^{63}-<$ between - prior-shallow-supererogation -ofmentally-aestheticised preconverging/dementing -qualia-schema_and_prospective-profoundsupererogation -of-mentally-aestheticised postconverging/dialectical-thinking -qualiaschema>' will seem to imply correlatedness by the very nature of the term continuity. Ultimately, the overall analysis above points out that this is not an inherent ontological-as-of-the-fullpotency-of-existence's $\sim$ sublimating-nascence problem but rather a problem of humansubpotency as of its limited-mentation-capacity-as-subjecting 'educedunlimitedness/existence-sublimating nascence' to-limitedness/human-subpotency that is resolvable by the deepening of human limited-mentation-capacity-as-subjecting 'educed- 
unlimitedness/existence-sublimating nascence' to-limitedness/human-subpotency as of ${ }^{15} \mathrm{de}$ mentation-〈supererogatory $\sim$ ontological-de-mentation-or-dialectical-de-mentation — strandingor-attributive-dialectics $\rangle$ with respect to ${ }^{83}$ reference-of-thought; as contrary to the 'Derridean différance decentering' freeplay that is entrapped in circularity of ${ }^{56}$ meaningfulness-andteleology 9 on the wrong implied assumption of the same perpetual horizon as registryworldview/dimension ${ }^{83}$ reference-of-thought so-implied as of our positivism mental-disposition, a 'futural différance' recognises that human limited-mentation-capacity-as-subjecting'educed-unlimitedness/existence-sublimating nascence' to-limitedness/human-subpotency transcendence-and-sublimity/sublimation/supererogatory-de-mentativity brings about prospective relative-ontological-completeness ${ }^{87}$-of- ${ }^{8}$ reference-of-thought, and thus it centersas-postconverging-or-dialectical-thinking -apriorising-psychologism the prospective institutionalisation's $\quad{ }^{83}$ reference-of-thought-as-of- ${ }^{\circ}$ reference-of-thought-devolvingteleological-de-mentating/structuring/paradigming-of-meaningfulness' as of its prospective relative-ontological-completeness ${ }^{8}$-of- ${ }^{8}$ reference-of-thought to override the circularity as notional-discontiguity/epistemic-discontiguity ${ }^{6}-<$ between - prior-shallow-supererogation -ofmentally-aestheticised preconverging/dementing -qualia-schema_and_prospective-profoundsupererogation -of-mentally-aestheticised postconverging/dialectical-thinking -qualiaschema of ${ }^{5}$ meaningfulness-and-teleology implications of the uninstitutionalisedthreshold ${ }^{82}$ reference-of-thought-as-of- ${ }^{\circ 3}$ reference-of-thought—devolving-teleological-dementating/structuring/paradigming-of-meaningfulness' as of its prior relative-ontologicalincompleteness ${ }^{88}$-of- ${ }^{8}$ reference-of-thought with respect to the-very-same-immanentexistence/intrinsic-reality/ontological-veridicality,-as-to-'human<amplituding/formativeepistemicity>totalising purview-of-construal', and thus broadening human-subpotency in the full-potency of existence/existential-possibilities as implied retrospectively to prospectively with the relative-unreflexivity/relative-reflexivity - ontological-contiguity ${ }^{6} \sim$ of-the-human- 
institutionalisation-process ${ }^{68}$ as of notional ${ }^{18}$ deprocrypticism. What underlies such a centeredepistemic-totalisation as of its transcending nature, is that given humankind's limited-mentationcapacity -as-subjecting 'educed-unlimitedness/existence-sublimating nascence' tolimitedness/human-subpotency as of human-subpotency in its <amplituding/formativeepistemicity>-totalising thrownness-in-existence ${ }^{35}$ (I exist therefore existence is of transcendental-enabling/sublimating/supererogatory de-mentativity to my human-subpotency / hyperbole-of-temporal-to-intemporal-ontological-performance ${ }^{72}-$ including-virtue-as- $^{2}$ ontology $>$ ) with respect to the full-potency that is the 'inherent centered-epistemic-totalisationas-existence', humankind devises its ${ }^{56}$ meaningfulness-and-teleology 9 as of its requisite humansubpotency ontological-performance ${ }^{72}-<$ including-virtue-asontology $>$ /morality/ethics/justice/etc. to construe of the 'inherent centered-epistemictotalisation-as-existence' by way of 's3reference-of-thought—devolving-teleological-dementating/structuring/paradigming-of-meaningfulness as of implicited-and-explicited reference-of-thought- categorical-imperatives/axioms/registry-teleology ${ }^{9}$,-foraposteriorising/logicising/deriving/intelligising/measuring- ${ }^{56}$ meaningfulness-and-teleology ${ }^{99}$ as knowledge-constructs/theories/intersolipsistic-intercessory-notions/notional $\sim$ referentialnotions/articulations/virtue' as of human comprehension/deciphering of underlying rules/nonrules_-apriorising/axiomatising/referencing-psychologism as from existential-instantiations in sublimating-epistemic-imbricatedness/threadedness/recomposuring supposedly reflecting the 'inherent centered-epistemic-totalisation-as-existence', with such human-subpotency approximation construed by the specific human preconverging-existential-extrication-as-ofexistential-unthought ${ }^{4}$ historiality/ontological-eventfulness $3 \%$ ontological-aesthetic-tracing$<$ perspective--ontological-normalcy/postconvergence-reflected-‘epistemicity-relativismdeterminism'> underlying the successive institutionalisations/finitudes in reflecting holographically-<conjugatively-and-transfusively $>$ the relative-unreflexivity/relative- 
reflexivity - ontological-contiguity of-the-human-institutionalisation-process . But then this highlights six issues with respect to ${ }^{56}$ meaningfulness-and-teleology ${ }^{9}$ ontologicalperformance $^{72}-<$ including-virtue-as-ontology $>$ /morality/ethics/justice/etc. with regards to such implicited-and-explicited $\quad{ }^{8}$ reference-of-thought- categorical-imperatives/axioms/registryteleology ${ }^{99}$,-for-aposteriorising/logicising/deriving/intelligising/measuring- ${ }^{5}$ meaningfulnessand-teleology $\quad$ as knowledge-constructs/theories/intersolipsistic-intercessorynotions/notional referential-notions/articulations/virtue. Firstly, this has to do with the successive institutionalisations reference-of-thought—devolving-teleological-dementating/structuring/paradigming-of-meaningfulness prospective relative-ontologicalcompleteness $^{87}$-of- ${ }^{83}$ reference-of-thought due to human limited-mentation-capacity-assubjecting - 'educed-unlimitedness/existence-sublimating nascence' to-limitedness/humansubpotency of projection-or-anticipation in grasping the 'inherent centered-epistemictotalisation-as-existence'. Secondly, even within each of the successive given institutionalisations as of their given underlying specific rules there is a variance of meaningfulness-and-teleology ontological-performance ${ }^{2}-<$ including-virtue-asontology $>$ /morality/ethics/justice/etc. among human individuations-as-mental-dispositionsmanifested-by-individuals,-with-the-individual-construed-as-the-existential-receptacle-oftemporal-to-intemporal-possibilities-of-individuations as of intemporal/Aongness-of-register-ofmeaningfulness-and-teleology individuation that notionally upholds the given institutionalisation's reference-of-thought- categorical-imperatives/axioms/registry-

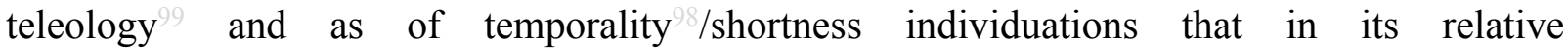
‘ $<$ amplituding/formative-epistemicity $>$ totalising $\sim$ self-referencingsyncretising/circularity/interiorising/akrasiatic-drag ${ }^{34}$, as of beyond-the-consciousnessawareness-teleology $-<$ of-preconverging-existential-extrication-as-of-existential-unthought $>$ fails to uphold the given institutionalisation's ${ }^{83}$ reference-of-thought- categorical- 
imperatives/axioms/registry-teleology ${ }^{9}$ due to lack of social ${ }^{103}$ universal-transparency ${ }^{104}$ 〈transparency-of-totalising-entailing,-as-to-entailing-<amplituding/formative-

epistemicity $>$ totalising in-relative-ontological-completeness $\rangle$ in the social-stake-contentionor-confliction dynamism thus highlighting the registry-worldview/dimension uninstitutionalised-threshold ${ }^{102}$; wherein the 'circular ${ }^{83}$ reference-of-thought of intemporal-asontological ${ }^{5}$ meaningfulness-and-teleology ${ }^{9}$ of sound ontological-performance ${ }^{22}<$ includingvirtue-as-ontology $>$ /morality/ethics/justice/etc. is not disambiguated from the "circular reference-of-thought of temporal-as-denaturing ${ }^{56}$ meaningfulness-and-teleology ${ }^{9}$ of

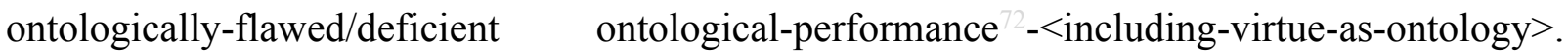
Thirdly, there is thus beyond-the-consciousness-awareness-teleology ${ }^{9}-<$ of-preconvergingexistential-extrication-as-of-existential-unthought $>$ temporal individuations denaturing dynamics relations to the ${ }^{83}$ reference-of-thought- categorical-imperatives/axioms/registryteleology ${ }^{9}$,-for-aposteriorising/logicising/deriving/intelligising/measuring- ${ }^{5}$ meaningfulnessand-teleology 9 as knowledge-constructs/theories/intersolipsistic-intercessorynotions/notional referential-notions/articulations/virtue, arising as of the conjugation of postlogism 7 -slantedness/ ${ }^{5}$ ignorance/affordability/opportunism/exacerbation/social-chainismor-social-discomfiture-or-negative-social-aggregation/temporal-enculturation-or-temporalendemisation, so-disambiguated as of ${ }^{83}$ reference-of-thought- ${ }^{8}$ devolving ontologicalperformance $^{72}-<$ including-virtue-as-ontology $>$ Fourthly crossgenerationally, the intemporal/Hongness-of-register-of meaningfulness-and-teleology individuation as of ontological-faith-notion-or-ontological-fideism - imbued-underdetermination-of-motif-andapriorising/axiomatising/referencing-as-so-being-as-of-existential-reality reconceptualises of a transcending elevated-devolving-as-of-prospective-institutionalisation of implicit-and-explicit articulation of new ${ }^{83}$ reference-of-thought- categorical-imperatives/axioms/registryteleology ${ }^{99}$,-for-aposteriorising/logicising/deriving/intelligising/measuring- ${ }^{5}$ meaningfulness- 
and-teleology

knowledge-constructs/theories/intersolipsistic-intercessory-

notions/notional referential-notions/articulations/virtue as of its human comprehension/deciphering

of

underlying

rules/non-rules-

apriorising/axiomatising/referencing-psychologism from existential-instantiations in sublimating-epistemic-imbricatedness/threadedness/recomposuring supposedly reflecting the 'inherent centered-epistemic-totalisation-as-existence' reinitiating the relativeunreflexivity/relative-reflexivity — ontological-contiguity ${ }^{67} \sim$ of-the-human-institutionalisationprocess ${ }^{68}$, and thus right up to human attainment of ontological-completeness-of- ${ }^{83}$ reference-ofthought with this 'ultimate social ${ }^{103}$ universal-transparency ${ }^{104}$-〈transparency-of-totalisingentailing,-as-to-entailing-<amplituding/formative-epistemicity $>$ totalising $\sim$ in-relative-

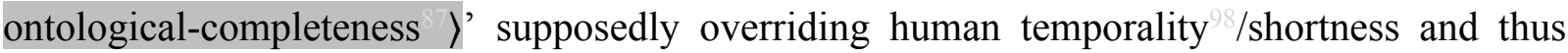
ultimate basis of a centered-epistemic-totalisation of human ${ }^{56}$ meaningfulness-and-teleology ontological-performance ${ }^{2}$ - including-virtue-as-ontology $>/$ morality/ethics/justice/etc.

construed theoretically as paralleling the 'inherent centered-epistemic-totalisation-asexistence'; and so as of humankind's human-subpotency given Being project! Fifthly, the implications of such transcendental centered-epistemic-totalisation with regards to the "certainty of ${ }^{5}$ meaningfulness-and-teleology as of sound ontological-performance ${ }^{2}-<$ including-virtueas-ontology>' rather lies with such ${ }^{56}$ meaningfulness-and-teleology ${ }^{9}$ as being so-construed notionally as of a given institutionalisation's ${ }^{83}$ reference-of-thought " ${ }^{83}$ reference-of-thoughtdevolving-teleological-de-mentating/structuring/paradigming-of-meaningfulness' transcendental-enabling/sublimating/supererogatory $\sim$ de-mentativity rules on the basis of social ${ }^{3}$ universal-transparency $^{104}$-〈transparency-of-totalising-entailing,-as-to-entailing$<$ amplituding/formative-epistemicity>totalising in-relative-ontological-completeness $\rangle, \quad$ and so as of its implied prospective relative-ontological-completeness ${ }^{87}$-of- ${ }^{8}$ reference-of-thought: wherein, -non-rules — apriorising/axiomatising/referencing-psychologism,-as-impulsive-or- 
accidented-or-random-mental-disposition in Recurrent-utter-uninstitutionalisation enables the grasp of certain ${ }^{56}$ meaningfulness-and-teleology ${ }^{9}$ on the basis of non-rulesapriorising/axiomatising/referencing-psychologism,-as-of-accidentedness-or-randomness-ofoccurrences/existential-instantiations by its non-rules - apriorising/axiomatising/referencingpsychologism,-abstracted-as-accidented-or-random human-limited-mentation-capacity-assubjecting-'educed-unlimitedness/existence-sublimating nascence'-to-limitedness/humansubpotency type of construal, as relevant in the ${ }^{56}$ meaningfulness-and-teleology ${ }^{9}$ ontologicalperformance $^{72}-<$ including-virtue-as-ontology $>$ /morality/ethics/justice/etc. as of trepidatiousconsciousness about occurrences/existential-instantiations; - rulemaking-over-non-rulesapriorising/axiomatising/referencing-psychologism in Base-institutionalisation enables the grasp of certain ${ }^{56}$ meaningfulness-and-teleology 9 on the basis of rules-abstracted-as-oftendentiousness-of-occurrences/existential-instantiations by its rulemaking-over-non-rulesapriorising/axiomatising/referencing-psychologism,-as-impulsive-or-accidented-or-random human-limited-mentation-capacity—as-subjecting-'educed-unlimitedness/existencesublimating nascence' to-limitedness/human-subpotency type of construal, as relevant in the meaningfulness-and-teleology $\quad$ ontological-performance ${ }^{72}-<$ including-virtue-as- $^{9}$ ontology $>$ /morality/ethics/justice/etc. of warped-consciousness about recurrences/existentialinstantiations; $-{ }^{103}$ universalisation-directed-rulemaking-over-non-rulesapriorising/axiomatising/referencing-psychologism of ${ }^{103}$ universalisation enables the grasp of certain ${ }^{56}$ meaningfulness-and-teleology ${ }^{9}$ on the basis of ${ }^{103}$ universalising-rules-abstracted-asof-qualifying-of-occurrences/existential-instantiations by its ${ }^{103}$ universalisation-directed-rulemaking-over-non-rules - apriorising/axiomatising/referencing-psychologism,-as-impulsive-oraccidented-or-random human-limited-mentation-capacity as subjecting 'educedunlimitedness/existence-sublimating nascence' to-limitedness/human-subpotency type of construal, as relevant in the ${ }^{56}$ meaningfulness-and-teleology ${ }^{9}$ ontological-performance ${ }^{72}$ 
$<$ including-virtue-as-ontology $>/$ morality/ethics/justice/etc. of preclusive-consciousness about recurrences/existential-instantiations; -positivising/rational-empiricism-based-universalisationdirected-rulemaking-over-non-rules — apriorising/axiomatising/referencing-psychologism of Positivism/Rational-Empiricism enables the grasp of certain ${ }^{56}$ meaningfulness-and-teleology on the basis of positivising/rational-empiricism-rules-abstracted-as-of-categorising-ofoccurrences/existential-instantiations by its positivising/rational-empiricism-baseduniversalisation-directed-rulemaking-over-non-rules_-apriorising/axiomatising/referencingpsychologism,-as-impulsive-or-accidented-or-random human-limited-mentation-capacity-assubjecting-'educed-unlimitedness/existence-sublimating nascence'- to-limitedness/humansubpotency type of construal, as relevant in the ${ }^{56}$ meaningfulness-and-teleology ${ }^{99}$ ontologicalperformance $^{72}-<$ including-virtue-as-ontology $>$ /morality/ethics/justice/etc. of occlusiveconsciousness about recurrences/existential-instantiations; and prospectively as theoretically/notionally attaining transcendental centered-<amplituding/formativeepistemicity>totalising/circumscribing/delineating ${ }^{5}$ meaningfulness-and-teleology ${ }^{9}$ as of perfect/sound ontological-performance ${ }^{72}-<$ including-virtue-as-ontology $>, \quad$-preemptingdisjointedness-as-of- ${ }^{8}$ reference-of-thought,-as-to- ${ }^{3}<$ amplituding/formativeepistemicity $>$ growth-or-conflatedness ${ }^{13} /$ transvaluativerationalising/transepistemicity/anamnestic-residuality/spirit-drivenness'_-in-supersedingmere-formulaic-positivising/rational-empiricism-based-universalisation-directed-rulemakingover-non-rules — apriorising/axiomatising/referencing-psychologism of notional ${ }^{18}$ deprocrypticism enables the prospective grasp of certain ${ }^{56}$ meaningfulness-andteleology on the basis of deprocrypticism-as-preempting — disjointedness-as-of- reference-ofthought ontological-normalcy/postconvergence-referentialism-rules-abstracted-as-ofapriorising/axiomatising/referencing-\{of-'prospectively_implicited_attendant-ontologicalcontiguity ' educed- 
existentialising/contextualising/textualising_'intelligibility/epistemicity/reflexivity-contiguity-

$<$ imbued-notional cogency $\left.>{ }^{\prime}\right\}$-conflatedness ${ }^{13}$ in-\{preconverging -ment by\}

pestconverging-entailment'-of-occurrences/existential-instantiations

by

its

notional ${ }^{1}$ deprocrypticism as preempting - disjointedness-as-of- reference-of-thought human-limited-mentation-capacity—as-subjecting-'educed-unlimitedness/existence-

sublimating nascence'-to-limitedness/human-subpotency type of construal, as relevant in the meaningfulness-and-teleology ontological-performance ${ }^{72}-<$ including-virtue-as-

ontology $>$ /morality/ethics/justice/etc. of protensive-consciousness about recurrences/existential-instantiations. Sixthly, the resolution as of human limited-mentationcapacity-deepening — as-subjecting limitedness/human-subpotency-to-'educedunlimitedness/existence-sublimating nascence ${ }^{53}$ is ultimately with the notional deprocrypticism protensive-consciousness as of its notional-contiguity/epistemiccontiguity ${ }^{62}<$ profound-supererogation -of-mentally-aestheticised $\sim$ postconverging/dialecticalthinking -qualia-schema $>$ superseding of transversality-<for-sublimating-existentialeventuating/denouement,-from-'thinking at-first/pure-predisposition-preemptive-ofprospective-disontologising/subontologising' as-of-prospectively-disambiguated-affirmedand-unaffirmed-'motif-and-apriorising/axiomatising/referencing'> ${ }^{101}$ temporal-to-intemporal human limited-mentation-capacity—as-subjecting-'educed-unlimitedness/existencesublimating nascence' to-limitedness/human-subpotency implications. Such superseding is actually attained as of the specific protensive-consciousness specific human preformulating/preframing/premeaningfulness- $<$ metaphoricity ${ }^{57}$-disposition-as-to-psycheinduced-psychologism-of-existential-stake >. That is, as of the-very-same-immanentexistence/intrinsic-reality/ontological-veridicality,-as-to-'human< rmplituing/formativeepistemicity>totalising purview-of-construal', the limited-mentation-capacity-as-subjecting 'educed-unlimitedness/existence-sublimating nascence' to-limitedness/human-subpotency 
meaningfulness-and-teleology

ontology $>$ /morality/ethics/justice/etc. with regards to the-very-same-immanent-

epistemicity>totalising purview-of-construal' of the successive consciousnesses as of the successive institutional-cumulation/institutional-recomposure-〈as-to- historiality/ontologicaleventfulness /ontological-aesthetic-tracing-<perspective-ontological-

normalcy/postconvergence-reflected-'epistemicity-relativism-determinism' $>>$ differ by their Being preformulating/preframing/premeaningfulness- $<$ metaphoricity ${ }^{57}$-disposition - as-topsyche-induced-psychologism-of-existential-stake $>$, which ultimately undergo 'decomplexifying/uninhibiting-〈as-of-elevating-devolving-teleological-dementating/structuring/paradigming-of-meaningfulness-as-prospective-institutionalisation〉 maturing as ontology's-directedness-as-Being all along the institutionalcumulation/institutional-recomposure-〈as-to- historiality/ontologicaleventfulness /ontological-aesthetic-tracing-<perspective-ontologicalnormalcy/postconvergence-reflected-‘epistemicity-relativism-determinism'>> involving ontological-normalcy/postconvergence ${ }^{83}$ reference-of-thought in relative notionalcontiguity/epistemic-contiguity ${ }^{2}<$ - profound-supererogation -of-mentallyaestheticised postconverging/dialectical-thinking -qualia-schema $>$ over relative notionaldiscontiguity/epistemic-discontiguity ${ }^{63}<$ between - prior-shallow-supererogation -ofmentally-aestheticised preconverging/dementing -qualia-schema_and_prospective-profoundsupererogation -of-mentally-aestheticised postconverging/dialectical-thinking -qualiaschema $>$, construed as prospective relative-ontological-completeness ${ }^{87}$-of- ${ }^{83}$ reference-ofthought; wherein as of ${ }^{4}$ historiality/ontological-eventfulness 38 ontological-aesthetic-tracing<perspective-ontological-normalcy/postconvergence-reflected-'epistemicity-relativismdeterminism'> apriorising/axiomatising/referencing-\{of-'prospectively implicited_attendant- 
ontological-contiguity ' educed-

existentialising/contextualising/textualising_'intelligibility/epistemicity/reflexivity_contiguity-

<imbued-notional cogency $\left.>^{\prime} \quad\right\}$ - conflatedness ${ }^{13}$ in- precenverging ment by $^{\prime}$

pestconverging entailment construal as of notional ${ }^{18}$ deprocrypticism, - the trepidatiousconsciousness of recurrent-utter-uninstitutionalisation is of a 'trepidatious Being complexified/inhibited-〈as-degraded-devolving-as-of-uninstitutionalised-threshold $\rangle$

preformulating/preframing/premeaningfulness- $<$ metaphoricity ${ }^{57}$-disposition —as-to-psycheinduced-psychologism-of-existential-stake>' as of social-stake-contention-or-confliction, - the warped-consciousness of base-institutionalisation-ununiversalisation is of a 'trepidatious Being uninhibited/decomplexified-〈as-elevated-devolving-as-of-prospective-institutionalisation〉 but warped Being complexified/inhibited-〈as-degraded-devolving-as-of-uninstitutionalisedthreshold $>$ preformulating/preframing/premeaningfulness- $<$ metaphoricity ${ }^{57}$-disposition-asto-psyche-induced-psychologism-of-existential-stake>' as of social-stake-contention-orconfliction, -the preclusive-consciousness of ${ }^{103}$ universalisation-non-positivism/medievalism is of a 'warped Being uninhibited/decomplexified-〈as-elevated-devolving-as-of-prospectiveinstitutionalisation〉 but preclusive Being complexified/inhibited-〈as-degraded-devolving-as-ofuninstitutionalised-threshold > preformulating/preframing/premeaningfulness$<$ metaphoricity $^{57}$-disposition - as-to-psyche-induced-psychologism-of-existential-stake $>$ ' as of social-stake-contention-or-confliction, -the occlusive-consciousness of positivismprocrypticism is of a 'preclusive Being uninhibited/decomplexified-〈as-elevated-devolving-asof-prospective-institutionalisation〉 but occlusive Being complexified/inhibited-〈as-degradeddevolving-as-of-uninstitutionalised-threshold $>$

preformulating/preframing/premeaningfulness- $<$ metaphoricity ${ }^{57}$-disposition - as-to-psycheinduced-psychologism-of-existential-stake>' as of social-stake-contention-or-confliction, - and prospectively the protensive-consciousness of notional ${ }^{18 p}$ deprocrypticism is of an 'occlusive 
Being

institutionalisation> uninhibited/decomplexified-〈as-elevated-devolving-as-of-prospective-

construed

protensive

Being

preformulating/preframing/premeaningfulness- $<$ metaphoricity ${ }^{57}$-disposition - as-to-psyche-

induced-psychologism-of-existential-stake ${ }^{\prime}$ ' as of social-stake-contention-or-confliction. This repleteness in the relative-unreflexivity/relative-reflexivity ontological-contiguity ${ }^{6} \sim$ of-thehuman-institutionalisation-process ${ }^{68}$ with such successive 'Being uninhibited/decomplexified〈as-elevated-devolving-as-of-prospective-institutionalisation and

Being complexified/inhibited-〈as-degraded-devolving-as-of-uninstitutionalised-threshold $\rangle$ preformulating/preframing/premeaningfulness- $<$ metaphoricity ${ }^{57}$-disposition - as-to-psycheinduced-psychologism-of-existential-stake>' arises given the grounding of human meaningfulness-and-teleology ontological-performance ${ }^{2}-<$ including-virtue-asontology $>$ /morality/ethics/justice/etc. on its various specific apriorising/axiomatising/referencing/intelligibilitysettingup/measuringinstrumentings for meaningfulness-and-teleology ontological-performance ${ }^{72}$-<including-virtue-asontology $>/$ morality/ethics/justice/etc. as reflected by their respective " ${ }^{8}$ reference-of-thoughtdevolving-teleological-de-mentating/structuring/paradigming-of-meaningfulness' associated with the successive consciousnesses, as of the-very-same-immanent-existence/intrinsicreality/ontological-veridicality,-as-to-'human<amplituding/formative-

epistemicity>totalising purview-of-construal'; such that the prior Being preformulating/preframing/premeaningfulness- $<$ metaphoricity ${ }^{57}$-disposition - as-to-psycheinduced-psychologism-of-existential-stake $>$ has to be uninhibited/decomplexified-〈as-elevateddevolving-as-of-prospective-institutionalisation $\rangle$ to enable prospective Being preformulating/preframing/premeaningfulness- $<$ metaphoricity ${ }^{57}$-disposition — as-to-psycheinduced-psychologism-of-existential-stake $>$ for the <cumulating/recomposuring attendantontological-contiguity $>$-successive registry-worldviews/dimensions transcendence-and- 
sublimity/sublimation/supererogatory de-mentativity towards the attaining of futural Beingdevelopment/ontological-framework-expansion-as-to-depth-of-ontologising-development-asinfrastructure-of- meaningfulness-and-teleology as of prospective deprocrypticism. Thus the notional ${ }^{1}$ deprocrypticism 'phenomenological transcendental-point-of-departure handle' thus warrants a superseding ${ }^{56}$ meaningfulness-and-teleology ${ }^{9}$ ontological-performance ${ }^{72}$ <including-virtue-as-ontology $>$ /morality/ethics/justice/etc. as-decomplexifying/uninhibiting〈as-elevated-devolving-as-of-prospective-institutionalisation〉 our positivism- ${ }^{80}$ procrypticism occlusive Being preformulating/preframing/premeaningfulness- $<$ metaphoricity ${ }^{57}$-dispositionas-to-psyche-induced-psychologism-of-existential-stake>'. This overall deneuterising conception of transcendental centered-<amplituding/formativeepistemicity>totalising/circumscribing/delineating $\quad{ }^{56}$ meaningfulness-and-teleology ontological-performance $^{72}$-<including-virtue-as-ontology $>/$ morality/ethics/justice/etc. $\quad$ is reflected notionally as of notional deprocrypticism, underlying that the successive registryworldview's/dimension's institutionalisations are always about preempting 'their successive types of disjointedness-as-of- reference-of-thought' up to its theoretical preempting with conceptual notional ${ }^{18}$ deprocrypticism as preempting-disjointedness-as-of- ${ }^{3}$ reference-ofthought and so as of successive human limited-mentation-capacity-as-subjecting 'educedunlimitedness/existence-sublimating nascence' to-limitedness/human-subpotency prospective relative-ontological-completeness ${ }^{87}$-of- ${ }^{8}$ reference-of-thought as of " ${ }^{83}$ reference-of-thoughtdevolving-teleological-de-mentating/structuring/paradigming-of-meaningfulness' of the successive institutionalisations. Basically human preconverging-existential-extrication-as-ofexistential-unthought is operantly construed as ${ }^{4}$ historiality/ontologicaleventfulness 3 /ontological-aesthetic-tracing-<perspective-ontologicalnormalcy/postconvergence-reflected-'epistemicity-relativism-determinism'> as of the notional conflatedness ${ }^{13}$ of notional ${ }^{18}$ deprocrypticism underlying the idiosyncratic, intricate, 
compounded and pervasive mimetic dynamism of human apriorising/axiomatising/referencing\{of-'prospectively_implicited_attendant-ontological-contiguity ' educedexistentialising/contextualising/textualising_'intelligibility/epistemicity/reflexivity-contiguity$<$ imbued-notional cogency $>$ ' $\}$-conflatedness ${ }^{13}$-in-\{preconverging-ment-by\} postconverging-entailment and human apriorising/axiomatising/referencing-\{of'prospectively implicited_attendant-ontological-contiguity ' educedexistentialising/contextualising/textualising_intelligibility/epistemicity/reflexivity_contiguity$<$ imbued-notional cogency $>$ ' $\}$-constitutedness ${ }^{14}$-in-preconverging-entailment, defining any given registry-worldview's/dimension's ${ }^{56}$ meaningfulness-and-teleology ${ }^{99}$ as of its underlying relative-ontological-incompleteness ${ }^{88}$ and relative-ontological-completeness reference-of-thought beyond its <amplituding/formative-epistemicity $>$ totalising $\sim$ selfreferencing-syncretising; with such ' ${ }^{8}$ reference-of-thought-devolving-teleological-dementating/structuring/paradigming-of-meaningfulness' maximally/most-profoundly/mostcompletely construed as of metaphysics-of-absence-〈implicited-epistemic-veracity-ofnonpresencing-<perspective-ontological-normalcy/postconvergence $>>$ insight over presence institutionalisation ${ }^{83}$ reference-of-thought as implying ${ }^{56}$ meaningfulness-and-teleology ${ }^{99}$ is as of a transcendental level of appreciation beyond an <amplituding/formativeepistemicity $>$ totalising $\sim$ self-referencing-syncretising/circularity/interiorising/akrasiatic-drag temporal-dispositions thus divulging the apriorising/axiomatising/referencing-\{of'prospectively_implicited_attendant-ontological-contiguity ' reducedexistentialising/contextualising/textualising_'intelligibility/epistemicity/reflexivity-contiguity-

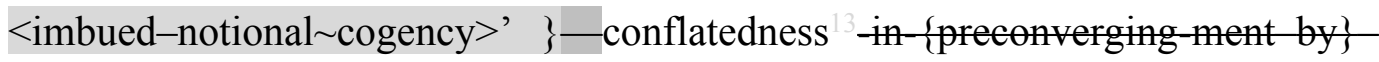
postconverging entailment of existence/existential-possibilities as of prospective institutionalisation ${ }^{83}$ reference-of-thought. Such an preconverging-existential-extrication-as-ofexistential-unthought phenomenological construal obviously goes 'beyond our ordinary 
intradimensional $<$ amplituding/formative-epistemicity $>$ totalising $\sim$ self-referencingsyncretising/circularity/interiorising/akrasiatic-drag 34 framework of phenomenological contemplation' in drawing out the full transcendental implications of human $<$ amplituding/formative-epistemicity>-totalising thrownness-in-existence ${ }^{35}$ (I exist therefore existence is of transcendental-enabling/sublimating/supererogatory $\sim$ de-mentativity to my human-subpotency / hyperbole-of-temporal-to-intemporal-ontological-performance ${ }^{72}$ $<$ including-virtue-as-ontology $>$ ) from a prospective notional ${ }^{18}$ deprocrypticism perspective as the full depth of $<$ amplituding/formative-epistemicity $>$ totalising $\sim$ conflated $-{ }^{56}$ meaningfulnessand-teleology 9 -as-of-notional $\sim{ }^{18}$ deprocrypticism-reflected- ${ }^{4}$ historiality/ontologicaleventfulness 38 /ontological-aesthetic-tracing-<perspective-ontologicalnormalcy/postconvergence-reflected-'epistemicity-relativism-determinism'> ontologicalperformance ${ }^{2}-<$ including-virtue-as-ontology $>$; as it is akin to how we can imagine 'budding science' in prior non-positivism registry-worldviews/dimensions say in the ancient and medieval worlds but grasping that you really get to systemic scientism rather in a positivism/rationalempiricism registry-worldview/dimension as of its apriorising/axiomatising/referencing/intelligibilitysettingup/measuringinstrumenting-foroperant-or-incidenting-predicative-insights construed as positivism/rational-empiricism ${ }^{{ }^{83}}$ reference-of-thought — devolving-teleological-de-mentating/structuring/paradigming-ofmeaningfulness', reflected as of positivising/rational-empiricism-based-universalisationdirected-rulemaking-over-non-rules — apriorising/axiomatising/referencing-psychologism.

Such a phenomenological construal as of human <amplituding/formativeepistemicity $>$ totalising $\sim$ conflated- $-{ }^{5}$ meaningfulness-and-teleology ${ }^{9}$-as-ofnotional ${ }^{18}$ deprocrypticism-reflected- ${ }^{4}$ historiality/ontological-eventfulness 38 /ontologicalaesthetic-tracing-<perspective-ontological-normalcy/postconvergence-reflected-`epistemicityrelativism-determinism'> ontological-performance ${ }^{2}-<$ including-virtue-as- 
ontology $>$ /morality/ethics/justice/etc. thus goes beyond a grounded conceptualisation and rather involves a psychoanalytic-unshackling construal as it reflects an epistemictotalising $\sim$ conflated- ${ }^{56}$ meaningfulness-and-teleology ${ }^{9}$-as-of-notional ${ }^{18}$ deprocrypticismreflected- ${ }^{4}$ historiality/ontological-eventfulness $3 \%$ ontological-aesthetic-tracing- $<$ perspectiveontological-normalcy/postconvergence-reflected-‘epistemicity-relativism-determinism’> ontological-performance ${ }^{72}-<$ including-virtue-as-ontology $>/$ morality/ethics/justice/etc. in the sense that the 'normal intradimensional mental-reflex' of representing the uninstitutionalisedthreshold ${ }^{102}$ of the prior transcended registry-worldview/dimension as nondescript/ignorablevoid (actually speaking of akrasiatic-drag-denatured-and-preconverging-or-dementing narratives) or a-registry-worldview's-or-dimension's-ignoring-of-its-prior-relative-ontologicalincompleteness ${ }^{88}$-of- ${ }^{83}$ eference-of-thought-as-an-ontologically-flawed-neuterisation ${ }^{59}$-orbracketing-or-epoché of <amplituding/formative-epistemicity>totalising $\sim$ conflatedmeaningfulness-and-teleology ${ }^{9}$-as-of-notional ${ }^{8}$ deprocrypticism-reflectedhistoriality/ontological-eventfulness 38 ontological-aesthetic-tracing- $<$ perspectiveontological-normalcy/postconvergence-reflected-'epistemicity-relativism-determinism'> is overridden to attain full ontological elucidation by the <amplituding/formativeepistemicity $>$ totalising $\sim$ conflated- $-{ }^{5}$ meaningfulness-and-teleology 9 -as-ofnotional ${ }^{18}$ deprocrypticism-reflected- ${ }^{4}$ historiality/ontological-eventfulness 38 /ontologicalaesthetic-tracing-<perspective-ontological-normalcy/postconvergence-reflected-'epistemicityrelativism-determinism'> ontological-performance ${ }^{72}-<$ including-virtue-asontology $>/$ morality/ethics/justice/etc. involving the uninstitutionalised-threshold ${ }^{102}$ reflection as preconverging-or-dementing ${ }^{20}$-and-decentered-prior-institutionalisation's- categoricalimperatives/axioms/registry-teleology ${ }^{9}$ in lieu of the nondescript/ignorable-void (actually speaking of akrasiatic-drag-denatured-and-preconverging-or-dementing -narratives) or aregistry-worldview's-or-dimension's-ignoring-of-its-prior-relative-ontological- 
incompleteness ${ }^{88}$-of- ${ }^{-1}$ ference-of-thought-as-an-ontologically-flawed-neuterisation -orbracketing-or-epoché of <amplituding/formative-epistemicity $>$ totalising $\sim$ conflatedmeaningfulness-and-teleology ${ }^{99}$-as-of-notional ${ }^{8}$ deprocrypticism-reflectedhistoriality/ontological-eventfulness 38 ontological-aesthetic-tracing-<perspectiveontological-normalcy/postconvergence-reflected-‘epistemicity-relativism-determinism’>.

Furthermore, notional deprocrypticism as the ultimate registry-worldview/dimension by notionally undermining human disjointedness-as-of- ${ }^{8}$ reference-of-thought will factor in that since <cumulating/recomposuring attendant-ontological-contiguity $>$-successive registryworldviews/dimensions institutionalisations articulations of ${ }^{83}$ reference-of-thoughtcategorical-imperatives/axioms/registry-teleology ${ }^{9}$ for intemporal-preservation-entropy-orcontiguity-or-ontological-preservation have always led at the uninstitutionalised-threshold ${ }^{102}$ to human limited-mentation-capacity—as-subjecting 'educed-unlimitedness/existencesublimating nascence' to-limitedness/human-subpotency induced beyond-the-consciousnessawareness-teleology $-<$ of-preconverging-existential-extrication-as-of-existential-unthought $>$ denaturing ${ }^{16}$ of ${ }^{83}$ reference-of-thought- ${ }^{-}$ategorical-imperatives/axioms/registry-teleology ${ }^{99}$ as <amplituding/formative $>$ wooden-language-_imbued-temporal-mere-

\section{form/virtualities/dereification/akrasiatic-drag/denatured/preconverging-or-dementing}

\section{narratives - of-the- reference-of-thought- categorical-imperatives/axioms/registry-}

teleology $>$ thus failing prospective intemporal-preservation-entropy-or-contiguity-orontological-preservation, inherently the issue of human limited-mentation-capacity-assubjecting 'educed-unlimitedness/existence-sublimating nascence' to-limitedness/humansubpotency

as

of postlogism slantedness/ ${ }^{50}$ ignorance/affordability/opportunism/exacerbation/social-chainism-or-socialdiscomfiture-or-negative-social-aggregation/temporal-enculturation-or-temporal-endemisation, so-disambiguated as of ${ }^{83}$ reference-of-thought- ${ }^{4}$ devolving ontological-performance ${ }^{72}$ 
$<$ including-virtue-as-ontology $>$, is a paramount and permanent one such that the construct of notional ${ }^{18}$ deprocrypticism $\quad{ }^{83}$ reference-of-thought- categorical-imperatives/axioms/registryteleology is exactly about an epistemic-totalising $\sim$ conflated- ${ }^{5}$ meaningfulness-andteleology ${ }^{9}$-as-of-notional ${ }^{18}$ deprocrypticism-reflected- ${ }^{4}$ historiality/ontologicaleventfulness ${ }^{3}$ /ontological-aesthetic-tracing-<perspective-ontologicalnormalcy/postconvergence-reflected-'epistemicity-relativism-determinism'> preemptive projecting/anticipating of the denaturing possibility of human limited-mentation-capacity-assubjecting 'educed-unlimitedness/existence-sublimating nascence' to limitedness/humansubpotency as of notional ${ }^{18}$ deprocrypticism social ${ }^{103}$ universal-transparency ${ }^{104}-\langle$ transparencyof-totalising-entailing,-as-to-entailing-<amplituding/formative-epistemicity $>$ totalising $\sim$ inrelative-ontological-completeness $\rangle \quad$ ontological-performance ${ }^{72}-<$ including-virtue-as- $^{\prime}$ ontology>; inherently a notional ${ }^{8}$ deprocrypticism protensive-consciousness is one which totalises-for-conflated- $-{ }^{56}$ meaningfulness-and-teleology ${ }^{9}$-as-notional ${ }^{18}$ deprocrypticism with no nondescript/ignorable-void (actually speaking of akrasiatic-drag-denatured-andpreconverging-or-dementing -narratives) or a-registry-worldview's-or-dimension's-ignoringof-its-prior-relative-ontological-incompleteness ${ }^{88}$-of- ${ }^{8}$ reference-of-thought-as-anontologically-flawed-neuterisation -or-bracketing-or-epoché of <amplituding/formativeepistemicity $>$ totalising $\sim$ conflated- $-{ }^{5}$ meaningfulness-and-teleology 9 -as-ofnotional ${ }^{18}$ deprocrypticism-reflected- ${ }^{4}$ historiality/ontological-eventfulness $3 \%$ ontologicalaesthetic-tracing-<perspective-ontological-normalcy/postconvergence-reflected-'epistemicityrelativism-determinism'> as of extended metaphysics-of-absence-〈implicited-epistemicveracity-of- nonpresencing-<perspective-ontological-normalcy/postconvergence $>$ > conceptualisation and as of the insight of human-subpotencyaporia/undecidability/dilemma/ought-indeterminacy/deficiency/limitation/constraint—imbued'notional firstnaturedness-formativeness-<as-to-eventualising -inkling drive-or-seeding- 
misprising $>$ temporal-to-intemporal-dispositions- $<$ so-construed-as-from-perspectiveontological-normalcy/postconvergence>'-existentialism-form-factor. The latter highlights the recurrence of such 'uninstitutionalised-threshold 02 phenomena' as $<$ amplitung/formative $>$ wooden-language-<imbued - averaging-of-thought-<as-toleveling/ressentiment/closed-construct-of- meaningfulness-and-teleology -as-of'nondescript/ignorable-void '-with-regards-to-prospective-apriorising-implications $>>\quad$ and institutionalised-being-and-craft. For instance, the <cumulating/recomposuring attendantontological-contiguity $>$-successive registry-worldviews/dimensions institutionalisations conceptualisation of ${ }^{56}$ meaningfulness-and-teleology ${ }^{9}$ have arisen as secondnatured constructs that have substituted for their uninstitutionalised-threshold 102 free-for-all $<$ amplituding/formative $>$ wooden-language-_imbued - averaging-of-thought-<as-toleveling/ressentiment/closed-construct-of- meaningfulness-and-teleology -as-of'nondescript/ignorable-void '-with-regards-to-prospective-apriorising-implications $>$ > framework, such that many a subject matter domain like the heavens, forces of nature, material nature, social laws, etc. are now effectively construed socially as of institutional and formal deferential-formalisation-transference as abstract intemporal/ontological-driven conceptualisation as of respectively formal religion, formal science, legal system, etc. voiding free-for-all construals as of temporal social-aggregation-enabling teleological dispositions as of respectively animistic dispositions, alchemic and essences-driven explanation of nature, crude mob justice, etc. Insightfully, as of human-subpotency-aporia/undecidability/dilemma/oughtindeterminacy/deficiency/limitation/constraint—imbued-'notional firstnaturednessformativeness-<as-to-eventualising-inkling drive-or-seeding misprising $>$ temporal-tointemporal-dispositions- $<$ so-construed-as-from-perspective-ontologicalnormalcy/postconvergence>'-existentialism-form-factor, anthropologists are very much aware that the social diffusion of new transcendental-enabling/sublimating/supereregatory $\sim$ de- 
mentativity practices into a given society are more likely to be adopted as of the society's institutional and formal percolation-channelling-<in-deferential-formalisation-transference $>$ framework than as of dimensionality-of-sublimating

\section{<<amplituding/formative >supererogatede-mentativeness/epistemic-growth-or-}

\section{conflatedness /transvaluative-rationalising/transepistemicity/anamnestic-residuality/spirit-}

drivenness-equalisation> 'direct convincing' at individuals-level underlying deferring to institutional and formal ${ }^{56}$ meaningfulness-and-teleology 99 as of the need for profoundness and rigour that doesn't avail in ordinary thought for transcendence-andsublimity/sublimation/supererogatory de-mentativity. Likewise, on occasion in the face of prior institutionalisation established and perceived vested interest such intemporal-as-ontological meaningfulness-and-teleology ${ }^{9}$ could be ontologically undermined as of institutionalisedbeing-and-craft. Consider in this regard Establishment efforts undermining the Diderot-led Encyclopédistes project. Furthermore, every registry-worldview/dimension relates to its value construct as of its prior relative-ontological-incompleteness ${ }^{8}$-of- ${ }^{8}$ reference-of-thought apriorising/axiomatising/referencing-\{of-'prospectively_implicited_attendant-ontologicalcontiguity ' $\sim$ educedexistentialising/contextualising/textualising_'intelligibility/epistemicity/reflexivity-contiguity<imbued-notional cogency>' $\quad\}$-constitutedness ${ }^{1}$-in-preconverging-entailment as more or less absolute, and doesn't factor in that its prior relative-ontological-incompleteness ${ }^{8}$-ofreference-of-thought is a preconverging/postconverging-de-mentative/structural/paradigmatic deficiency inducing the <amplituding/formative-epistemicity $>$ totalising $\sim$ self-referencingsyncretising/circularity/interiorising/akrasiatic-drag ${ }^{34}$ of its value construct. But then prospective institutionalisation necessarily implies a notion of prospective value construct as of its prospective relative-ontological-completeness ${ }^{87}$-of- ${ }^{8}$ reference-of-thought apriorising/axiomatising/referencing-\{of-'prospectively implicited_attendant-ontological- 
contiguity ' educed-

existentialising/contextualising/textualising_'intelligibility/epistemicity/reflexivity_contiguity-

<imbued-notional cogency $\left.>^{\prime} \quad\right\}$ - conflatedness ${ }^{13}$ in- precenverging ment by $^{\prime}$

postconverging-entailment which will be unintelligible to the prior value construct, such that it is only a sense of intemporal consummation that drives transcendental dispositions as it is paradoxical to expect that what is in need for transcendence-andsublimity/sublimation/supererogatory $\sim$ de-mentativity acts as transcended, as transcendenceand-sublimity/sublimation/supererogatory-de-mentativity is inevitably and so across all registry-worldviews/dimensions a state of paradoxical conflictedness as more profoundly involving a crossgenerational ${ }^{56}$ meaningfulness-and-teleology ${ }^{9}$ psychoanalytic-unshackling than a grounding conceptualisation! Furthermore, both the prior institutionalisation value construct and the prospective institutionalisation value construct are their respectively given centered-epistemic-totalisation-facticity of ${ }^{56}$ meaningfulness-and-teleology ${ }^{99}$ with transcendence-and-sublimity/sublimation/supereregatory-de-mentativity conflictedly implying overriding the prior institutionalisation's centered-epistemic-totalisation-facticity for the prospective institutionalisation's centered-epistemic-totalisation-facticity. But then relativemareflexivityelative reflexivity ontological-contiguity ${ }^{67} \sim$ of-the-human-institutionalisationprocess ${ }^{68}$ is an empirical fact, and thus the resolution of this transcendence-andsublimity/sublimation/supererogatory de-mentativity paradox is rather reflected by the dynamics of human positive-opportunism - of-social-functioning-and-accordance ${ }^{75}$ integration as secondnatured-institutionalisation as of human <amplituding/formativeepistemicity $>$ totalising $\sim$ self-referencing-syncretising/circularity/interiorising/akrasiatic-drag as social ${ }^{103}$ universal-transparency $^{104}$-〈transparency-of-totalising-entailing,-as-to-entailing$<$ amplituding/formative-epistemicity>totalising in-relative-ontological-completeness $>$ avails with respect to social-stake-contention-or-confliction, wherein while in the immediate-and- 
short-term human 'self-referencing' will seem to imply that it is almost impossible to transcend from a given social conventioning centered-epistemic-totalisation facticity but crossgenerationally human 're-conventioning whether driven by a sense of pure-ontology as of ontological-faith-notion-or-ontological-fideism - imbued-underdetermination-of-motif-andapriorising/axiomatising/referencing-as-so-being-as-of-existential-reality or otherwise with say cultural-diffusion', as 'syncretising-effecting' on ${ }^{56}$ meaningfulness-and-teleology ${ }^{9}$ with respect to social-stake-contention-or-confliction induces human transcendence-andsublimity/sublimation/supererogatory-de-mentativity. Consider in this regard historical transcendence-and-sublimity/sublimation/supererogatory - de-mentativity elicited by cultural diffusion whether with respect to trading or invasion or voyages of exploration. The fact is a social-setup is preconverging/postconverging-de-mentatively/structurally/paradigmatically a framework where individuals are naturally involved in a dynamic relationship of perceived social-stake-contention-or-confliction striving to draw in various ways the optimum as of perceived existential-<disontologising/re-ontologising aporeticism $>$ possibilities, and thus individuals and social groups are not in an absolutely given/set self-referencing centeredepistemic-totalisation-facticity of ${ }^{5}$ meaningfulness-and-teleology ${ }^{9}$ within their social-setup and are predisposed on critical occasions as of syncretising-effecting to 'reinvent', circumvent or adapt as to what they perceive as optimum existential-<disontologising/re-ontologising apereticism $>$ possibilities, such that a social-setup is already involved internally however restricted in its very own reinvention/circumventing/adaptation as of its very own internal 'selfreferencing and syncretising-effecting construed as <amplituding/formativeepistemicity $>$ totalising $\sim$ self-referencing-syncretising' of ${ }^{5}$ meaningfulness-and-teleology ${ }^{99}$ with regards to perceived social-stake-contention-or-confliction; and it is this element that enables all human societies to have a minimal opening/overture/receptivity to each other, including at the very extreme between an industrial age society and a hunter-gatherer society. Without such a 
preconverging/postconverging-de-mentative/structural/paradigmatic 'self-referencing and syncretising-effecting construed as <amplituding/formative-epistemicity $>$ totalising $\sim$ selfreferencing-syncretising/circularity/interiorising/akrasiatic-drag ${ }^{34}$ human nature', both internal social transformation however lethargic and cultural diffusion will be basically impossible, and $<$ amplituding/formative-epistemicity $>$ totalising $\sim$ self-referencing-

syncretising/circularity/interiorising/akrasiatic-drag ${ }^{34}$ induced transformation arises because human perceived social-stake-contention-or-confliction drifts within-and-across social-setups whether with regards to basic trading, curiosity, social competition and generally as of a predisposition to achieve optimum existential-<disontologising/re-ontologising aporeticism $>$ possibilities. In this regard, the rapid transformation implications of cultural diffusion arise because it makes relatively immediately available to individuals and social groups a comprehensive set of options however limited the nature and speed of their adoption. This syncretising-effecting mechanism ultimately explains why crossgenerational transcendenceand-sublimity/sublimation/supererogatory $\sim$ de-mentativity occurs notwithstanding a seemingly self-referencing centered-epistemic-totalisation-facticity of ${ }^{56}$ meaningfulness-and-teleology within a given social-setup in the immediate-and-short-term. Transcendence-and-

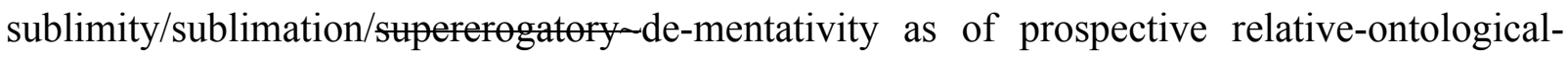
completeness ${ }^{87}$-of- ${ }^{8}$ reference-of-thought occurs because preconverging/postconverging-dementatively/structurally/paradigmatically it is social-dispositions and mental-dispositions of intemporal-as-ontological nature as of longness-of-register-of- ${ }^{56}$ meaningfulness-andteleology given their supposedly coherent ontological-commitment $-<$ implied - selfassuredness-of-ontological-good-faith/authenticity postconverging-dementating/structuring/paradigming -as-being-as-of-existential-reality $>$ as of more profound <amplituding/formative-epistemicity $>$ causality $~ a s-t o-p r o j e c t i v e-t o t a l i t a t i v e-i m p l i c a t i o n s-o f-$ prospective- nonpresencing,-for-explicating relative-unreflexivity/relative-reflexivity 
ontological-contiguity validation as to existence-potency ${ }^{32} \sim$ sublimating-nascence,-disclosedfrom-prospective-epistemic-digression, re-originary_-_as-unenframed_ed/reontologising/unbeholdening/outlier_conceptunalisation___imbued-postconverging/dialecticalthinking -'projective-insights'/‘epistemic-projection-in-conflatedness ' 'ofnotional deprocrypticism-prospective-sublimation $\rangle$, that are most likely to be syncretised crossgenerationally as providing the most overall positive-opportunism-of-social-functioningand-accordance ${ }^{75}$ by their relative ${ }^{103}$ universal projection implications and are formally-andovertly assumed, and so over temporal-as-ontologically-flawed social-dispositions and mentaldispositions which are more or less formally-and-overtly unassumed as of their temporal denaturing ${ }^{16}$ nature or poor ${ }^{103}$ universal projection. However, such a conception of supposedly coherent ontological-commitment $-<$ implied — self-assuredness-of-ontological-goodfaith/authenticity postconverging-de-mentating/structuring/paradigming -as-being-as-ofexistential-reality $>$ is not actively contemplated socially but occurs latently and passively with any given registry-worldview's/dimension's institutionalisation ${ }^{56}$ meaningfulness-andteleology ${ }^{9}$ as its inherent social-dispositions and mental-dispositions are rather as of beyondthe-consciousness-awareness-teleology ${ }^{9}-<$ of-preconverging-existential-extrication-as-ofexistential-unthought $>$ with regards to such transcendental implications! Despite the fact that all social-setups tend to be surreptitiously permeated with individuals temporal/shortness-ofregister-of meaningfulness-and-teleology social-dispositions and mental-dispositions of suboptimal ontological implications for social-functioning-and-accordance-as-of-social-stakecontention-or-confliction, every social-setup as a conventional-construct can only be held together in the long-term as of its requisite given registry-worldview's/dimension's institutionalisation-level of minimally-expected basic conscious-adherence-at-best or tokenadherence-at-worst to the said institutionalisation-level's ${ }^{83}$ reference-of-thought- categoricalimperatives/axioms/registry-teleology ${ }^{9}$ with regards to meeting a basic level of individuals and 
social existential-possibilities expectations. It may thus seem from within just one human generation perspective that the underlying human metaphoricity ${ }^{57}$ for transcendence-andsublimity/sublimation/supererogatory de-mentativity is rather marginal especially when not associated with any external cultural diffusion. However, human metaphoricity ${ }^{57}$ as of cultural transformation had tended historically, in the main, to ebb in peaks and lows, and so as of the relative ${ }^{103}$ universal-transparency $^{104}$-〈transparency-of-totalising-entailing,-as-to-entailing$<$ amplituding/formative-epistemicity>totalising in-relative-ontological-completeness $>$ about such metaphoricity ${ }^{57}$ instigative reproducibility-mathesis/motif/thrownness-disposition,--asreproducibility-of-aestheticisation direct, indirect and/or devolving implications. The fact that individuals in a social-setup are already involved internally however restricted in its very own reinvention/circumventing/adaptation in a dynamic relationship of perceived social-stakecontention-or-confliction striving to draw in various ways the optimum as of perceived existential-<disontologising/re-ontologising aporeticism $>$ possibilities and is thus of a minimal opening/overture/receptivity to internal and external metaphoricity ${ }^{57}$, also critically speaks to the fact that any social-setup is only able to hold together because of supposedly coherent ontological-commitment $-<$ implied — self-assuredness-of-ontological-goodfaith/authenticity postconverging-de-mentating/structuring/paradigming -as-being-as-ofexistential-reality $>$ that is subject to existence-potency ${ }^{3} \sim$ sublimating-nascence,-disclosedfrom-prospective-epistemic-digression validatory <amplituding/formativeepistemicity $>$ causality $\sim$ as-to-projective-totalitative-implications-of-prospectivenonpresencing,-for-explicating relative-unreflexivity/relative-reflexivity ontologicalcontiguity. As of its circularity, the lack or poorer cause-and-effect determinism of any such supposedly coherent ontological-commitment $-<$ implied - self-assuredness-of-ontologicalgood-faith/authenticity postconverging-de-mentating/structuring/paradigming -as-beingas-of-existential-reality $>$ threshold of a social-setup ${ }^{56}$ meaningfulness-and-teleology ${ }^{9}$, allows 
for the possibility for prospective metaphoricity ${ }^{57}$ to reconstrue-and-redefine the social-setup meaningfulness-and-teleology ${ }^{9}$ Such prospective metaphoricity possibility cannot be preempted because even the social-setup conventioning in its functional operation of meaningfulness-and-teleology needs this supposedly coherent ontological-commitment <implied - self-assuredness-of-ontological-good-faith/authenticity postconverging-dementating/structuring/paradigming -as-being-as-of-existential-reality $>$ in other to affirm itself over any spontaneously arising disruptive ${ }^{56}$ meaningfulness-and-teleology ${ }^{9}$ that may be articulated by individuals or groups, with the result that a social-setup ever always exposes itself to prospective metaphoricity 57 in one way or the other when such spontaneously arising disruptive ${ }^{56}$ meaningfulness-and-teleology ${ }^{9}$ is not of poorer but rather of a superseding $<$ amplituding/formative-epistemicity $>$ causality $~ a s-t o-p r o j e c t i v e-t o t a l i t a t i v e-$ implications-ofprospective- nonpresencing,-for-explicating relative-unreflexivity/relative-reflexivity ontological-contiguity as of the social-setup given supposedly coherent ontologicalcommitment $-<$ implied—self-assuredness-of-ontological-goodfaith/authenticity postconverging-de-mentating/structuring/paradigming -as-being-as-ofexistential-reality>. We can consider in this regard that an animistic non-positivistic or medieval non-positivistic social-setup will certainly imply a supposedly coherent ontologicalcommitment $-<$ implied — self-assuredness-of-ontological-good-

\section{faith/authenticity postconverging-de-mentating/structuring/paradigming -as-being-as-of-}

existential-reality> respectively as of superstitious spiritualism ${ }^{56}$ meaningfulness-andteleology ${ }^{9}$ or scholasticism pedantic dogmatism ${ }^{56}$ meaningfulness-and-teleology ${ }^{9}$, as of the given social-setup 'self-assuredness-of-ontological-good-faith/authenticity ${ }^{6} \sim$ postconvergingde-mentating/structuring/paradigming -as-being-as-of-existential-reality with respect to its social-stake-contention-or-confliction' in its capacity to demonstrably and objectively uphold and function going by its specific registry-worldview/dimension as of superstitious spiritualism 
or scholasticism pedantic dogmatism. It is exactly this 'self-assuredness-of-ontological-goodfaith/authenticity ${ }^{6} \sim$ postconverging-de-mentating/structuring/paradigming -as-being-as-ofexistential-reality with respect to its social-stake-contention-or-confliction' that equally makes available the possibility for prospective metaphoricity ${ }^{57}$ to demonstrably undermine the implied supposedly coherent ontological-commitment $-<$ implied - self-assuredness-of-ontologicalgood-faith/authenticity $\sim$ postconverging-de-mentating/structuring/paradigming -as-beingas-of-existential-reality> of such prior social-setups registry-worldview/dimension meaningfulness-and-teleology , and so as of the prospectively induced $<$ amplituding/formative-epistemicity $>$ causality $\sim$ as-to-projective-totalitative-implications-ofprospective- nonpresencing,-for-explicating relative-unreflexivity/relative-reflexivity ontological-contiguity superseding ${ }^{56}$ meaningfulness-and-teleology 99 as from existencepotency $^{32} \sim$ sublimating-nascence,-disclosed-from-prospective-epistemic-digression epistemicor-notional projective-perspective of relative-ontological-completeness ${ }^{87}$-of- ${ }^{83}$ reference-ofthought by way of <amplituding/formative-epistemicity $>$ causality $\sim$ as-to-projectivetotalitative-implications-of-prospective- nonpresencing,-for-explicating relativeunreflexivity/relative-reflexivity ontological-contiguity such as with prospective positivism/rational-empiricism ${ }^{56}$ meaningfulness-and-teleology ${ }^{9}$. However, given the inherence of social-stake-contention-or-confliction, inevitably prospective metaphoricity ${ }^{57}$ undermines vested interests as of the direct, indirect and/or devolving implications of prospective metaphoricity ${ }^{57}$ and by that token elicit sophistic/pedantic inclinations to such prospective metaphoricity ${ }^{57}$ meaningfulness-and-teleology ${ }^{9}$. Further any such prospective metaphoricity ultimately takes hold rather as of within the social deferential-formalisation-transference framework wherein it is driven by a sense of positive-opportunism-of-social-functioning-andaccordance $^{75}$ as of particular and general social interest. That said, a social-setup is ever always 'existentially-disontologising/re-ontologising aporeticism $>$ invested' to a given registry- 
worldview/dimension and the fact of greater knowledge-reification $\sim$ gesturing-and-accountingof-epistemic-phenomenalism- $<$ in-

prospective_psychologismic apriorising/axiomatising/referencing-\{of-'prospectively implicited_attendant-ontological-contiguity ' reducedexistentialising/contextualising/textualising_'intelligibility/epistemicity/reflexivity-contiguity<imbued-notional cogency>' \}-conflatedness -in-\{preconverging-ment by\} postconverging entailment $>$ from prospective metaphoricity ${ }^{57}$ which may involve undermining such 'existentially-disontologising/re-ontologising aporeticism $>$ invested' registryworldview/dimension in its <amplituding/formative> wooden-language-_imbued-averagingof-thought-<as-to-leveling/ressentiment/closed-construct-of- meaningfulness-and-teleology as-of-'nondescript/ignorable-void ' -with-regards-to-prospective-apriorising-implications >> means that it doesn't necessarily construe such prospective metaphoricity ${ }^{57}$ as pertinent and so where it is nihilistically disinclined by its $<$ amplituding/formative-epistemicity $>$ totalising $\sim$ selfreferencing-syncretising/circularity/interiorising/akrasiatic-drag 34 to dispensing-withimmediacy-for-relative-ontological-completeness ${ }^{87}$-by-reification/contemplative-distension (as of human self-surpassing-existentialism-form-factor,-in-overcoming‘notional collateralising-beholdening-protohumanity'-to-'attain-sublimating-humanity'-as-toexistence-potency $\sim$ sublimating-nascence,-disclosed-from-prospective-epistemic-digression to supersede human temporality $/$ /shortness $<$ amplituding/formative $>$ wooden-language〈imbued - averaging-of-thought-<as-to-leveling/ressentiment/closed-construct-ofmeaningfulness-and-teleology -as-of-‘nondescript/ignorable-void '-with-regards-toprospective-apriorising-implications $>\rangle)$, as of its beyond-the-consciousness-awarenessteleology ${ }^{9}-<$ of-preconverging-existential-extrication-as-of-existential-unthought> manifestation. The abstract notion of antinihilism as implied by such prospective metaphoricity is not construed in human temporal terms-as-of-axiomatic-construct as a 'living notion' going 
syncretising/circularity/interiorising/akrasiatic-drag ${ }^{34}$ elicitation of value as of untransvaluatedtemporal-intemporality ${ }^{52}$. In this regard, as of the temporal 'mental and existential$<$ disontologising/re-ontologising aporeticism $>$ investment' of recurrent-utteruninstitutionalisation prospective base-institutionalisation antinihilism ${ }^{5}$ meaningfulness-andteleology' is basically nothing and worthless, likewise as of the temporal 'mental and existential-<disontologising/re-ontologising aporeticism $>$ investment' of baseinstitutionalisation-ununiversalisation prospective ${ }^{103}$ universalisation antinihilism meaningfulness-and-teleology ${ }^{9}$ is basically nothing and worthless, same with universalisation-non-positivism/medievalism and prospective positivism, and equally so for positivism- ${ }^{8}$ procrypticism and futural Being-development/ontological-framework-expansionas-to-depth-of-ontologising-development-as-infrastructure-of- meaningfulness-and-

teleology as of prospective deprocrypticism. Explaining in-many-ways why the elicitation of value as of prospective secondnatured institutionalisation rather occurs as of the superseding of $<$ amplituding/formative-epistemicity $>$ totalising $\sim$ self-referencingsyncretising/circularity/interiorising/akrasiatic-drag untransvaluated-temporalintemporality ${ }^{52}$. Ultimately, prospective metaphoricity ${ }^{57}$ in a reflection of the individual-asreceptable-of-temporal-to-intemporal-individuation realistically implies that it is rather fundamentally a question of grasping the mechanism that tips the balance towards human intemporality ${ }^{52} /$ longness and subsequent prospective institutionalisation which is ontologically sufficient for prospective ontological-effectiveness, rather than a naïve engagement as if the human is all-essentially intemporal-disposition as to absolute ontological-commitment <implied-self-assuredness-of-ontological-good-faith/authenticity $\sim$ postconverging-dementating/structuring/paradigming -as-being-as-of-existential-reality >. More critically, such a conception of prospective metaphoricity ${ }^{57}$ cognisant of the decisiveness of deferential- 
formalisation-transference for institutionalisation and thus subsequent social percolationchannelling- $<$ in-deferential-formalisation-transference $>$, come to grasp that sophistic/pedantic predispositions are the more salient entrenched interests beyond-the-consciousness-awarenessteleology ${ }^{9}<$ of-preconverging-existential-extrication-as-of-existential-unthought $>\quad$ with respect to prospective metaphoricity ${ }^{57}$ as of the implications of such undermining of social deferential-formalisation-transference. In this regard, the sophistic/pedantic barriers to futural Being-development/ontological-framework-expansion-as-to-depth-of-ontologisingdevelopment-as-infrastructure-of- meaningfulness-and-teleology as of prospective notional ${ }^{18}$ deprocrypticism metaphoricity ${ }^{57}$ implications are necessarily spurious and associated with our positivism- ${ }^{80}$ procrypticism institutional-being-and-craft as of the direct, indirect and/or devolving prospective metaphoricity ${ }^{57}$ implications. We can appreciate in this regard that for the medieval-scholasticism-pedants - ideal-type-or-individuation, it doesn't matter that buddingpositivism can be demonstrated as more ontologically pertinent as of < amplituding/formativeepistemicity $>$ causality $\sim$ as-to-projective-totalitative-implications-of-prospectivenonpresencing,-for-explicating relative-unreflexivity/relative-reflexivity - ontologicalcontiguity, so long as it is socially and institutionally credible to uphold non-positivism meaningfulness-and-teleology ${ }^{9}$ in effect by undermining its deferential-formalisationtransference. It is with regards to such sophistic/pedantic disinclination to prospective metaphoricity ${ }^{57}$ that the latter elicits contortioning gesturing/accounting-of-epistemicphenomenalism, wherein for instance Socrates with respect to the sophists-ideal-type-orindividuation (as we can appreciate that however say a Protagoras engagement with Socrates may project coherence as of his contextual appreciation of Socrates predisposition for coherence, this doesn't exclude the possibility of a 'floating sophistic' inclination that simply adjusts to its interlocutor thus undermining in-the-bigger-picture the notion of knowledge as of ${ }^{103}$ universal coherence idealisation, or still maybe Protagoras is just at the lower end of the sophists - ideal- 
type-or-individuation) and budding-positivists with respect to medieval-scholasticismpedants - ideal-type-or-individuation (as we can appreciate that the recognition and then censure and then banning of Copernicus's heliocentric world work or engagement with Galileo's support of heliocentrism then his persecution for publishing, rather speaks preconverging/postconverging-de-mentatively/structurally/paradigmatically of the covert/underhanded nature of the medieval establishment pedantic disposition as of the implications of ideas undermining medieval dogma as of social-stake-contention-or-confliction) construe of such sophistic/pedantic disinclination as implying notional-discontiguity/epistemicdiscontiguity ${ }^{63}-<$ between - prior-shallow-supererogation -of-mentallyaestheticised preconverging/dementing -qualia-schema_and_prospective-profoundsupererogation -of-mentally-aestheticised postconverging/dialectical-thinking -qualiaschema $>$ with their prospectively implied metaphoricity ${ }^{57}$; with the consequence that there can't be common/mutual aposteriorising/logicising/deriving/intelligising/measuring as of dialogicalequivalence-<as-to-psychologismic apriorising/axiomatising/referencing- \{of- 'prospectively implicited_attendant-ontological-contiguity ' educedexistentialising/contextualising/textualising_'intelligibility/epistemicity/reflexivity_contiguity<imbued-notional cogency>' \}-conflatedness in \{preconverging ment by\} postconverging-entailment,-in-self-becoming/self-conflatedness /formative-supererogating > and intellectual-and-moral-equivalence and inherently so because of the sophists-ideal-typeor-individuation and medieval-scholasticism-pedants-ideal-type-or-individuation inauthentic/unsound

apriorising/axiomatising/referencing/intelligibilitysettingup/measuringinstrumenting as of respectively non-universalising and non-positivism/medievalism dogma prior relativeontological-incompleteness ${ }^{8}$-of- ${ }^{8}$ reference-of-thought warranting their unaffirmation/deprojection/deassertion/epistemic-decadence/undueness-invalidating- 
logicising/unsuitable-measuringinstrument-invalidating-measuring-<as-to-preconverging-ordementing -apriorising-psychologism> for the affirmation/projection/assertion/notional $\sim$ selfdistantiation/dueness-validating-logicising/suitable-measuringinstrument-validatingmeasuring-<as-to-postconverging-or-dialectical-thinking -apriorising-psychologism $>\quad$ of prospective Socratic-philosophers ${ }^{103}$ universalising-idealisation and prospective positivism apriorising/axiomatising/referencing/intelligibilitysettingup/measuringinstrumenting meaningfulness-and-teleology ${ }^{9}$ respectively. Likewise, this author's critique of the spurious institutional-being-and-craft muddlement of our positivism- ${ }^{80}$ procrypticism with respect to its preconverging/postconverging-de-mentative/structural/paradigmatic implicited undermining of the possibility of futural Being-development/ontological-framework-expansion-as-to-depth-ofontologising-development-as-infrastructure-of- meaningfulness-and-teleology as of prospective notional deprocrypticism is not an idle exercise, and so as of such $<$ amplituding/formative-epistemicity $>$ totalising $\sim$ self-referencing-

syncretising/circularity/interiorising/akrasiatic-drag apriorising/axiomatising/referencing/intelligibilitysettingup/measuringinstrumenting procrypticism-or-disjointedness-as-of- ${ }^{8}$ reference-of-thought as of direct, indirect and devolving undermining of the possibility of futural Being-development/ontological-frameworkexpansion-as-to-depth-of-ontologising-development-as-infrastructure-of- meaningfulnessand-teleology as of prospective notional ${ }^{18}$ deprocrypticism metaphoricity ${ }^{57}$ implications and so with respect to the social analysis implications of disjointedness-as-of- ${ }^{3}$ reference-of-thought associated phenomena as reflected in social-stake-contention-or-confliction issues including psychopathy and social psychopathy. As of the apriorising/axiomatising/referencing-\{of'prospectively implicited_attendant-ontological-contiguity ' educedexistentialising/contextualising/textualising_'intelligibility/epistemicity/reflexivity-contiguity<imbued-notional cogency>' \}-conflatedness ${ }^{13}$-in-\{preconverging -ment by\} 
postconverging entailment of notional ${ }^{8}$ deprocrypticism construal, what underlies the notion of human preconverging-existential-extrication-as-of-existential-unthought is the idea that human existence is as of 'human existential-extricating projection-or-anticipation about existence/existential-possibilities as of human limited-mentation-capacity-as-subjecting 'educed-unlimitedness/existence-sublimating nascence' to-limitedness/human-subpotency construing ${ }^{6}$ reference-of-thought—devolving-teleological-dementating/structuring/paradigming-of-meaningfulness as of implicited-and-explicited reference-of-thought- categorical-imperatives/axioms/registry-teleology ${ }^{9}$,-foraposteriorising/logicising/deriving/intelligising/measuring $-{ }^{5}$ meaningfulness-and-teleology ${ }^{99}$ as knowledge-constructs/theories/intersolipsistic-intercessory-notions/notional $\sim$ referentialnotions/articulations/virtue', and transcendentally-complemented by 'human ontological-faithnotion-or-ontological-fideism - imbued-underdetermination-of-motif-andanticipation of this human prior relative-ontological-incompleteness ${ }^{8}$-of- ${ }^{8}$ reference-of-thought as of human existential-unthought', and thus enabling an notional/epistemic/bindingness determinism/conceptivity-of-relative-unreflexivity/relative-reflexivitys possibility of correspondence of human implied meaningfulness-and-teleology ${ }^{9}$ with the achievement of singularisation- $<$ as-to-thenondisjointedness/entailment-of-prospective- nonpresencing $>$ projected epistemicimmanence/veridical-epistemicity-relativism-determinism as of prospective notional ${ }^{18}$ deprocrypticism 'inherent centered-epistemic-totalisation-as-existence'. It is those elements of an notional/epistemic/bindingness reflexivity $>$ possibility of correspondence, as of the <amplituding/formative-epistemicity>totalising thrownness-in-existence apriorising/axiomatising/referencing/intelligibilitysettingup/measuringinstrumenting and onto, that together effectively make human transcendence-and- 
sublimity/sublimation/supererogatory-de-mentativity and the relative-unreflexivity/relativereflexivity - ontological-contiguity ${ }^{67}$ of-the-human-institutionalisation-process ${ }^{68}$ possible given that it immanently enables the possibility of successive human prospective relativeontological-completeness ${ }^{87}$-of- ${ }^{8}$ reference-of-thought as of the <cumulating/recomposuring attendant-ontological-contiguity $>$-successive registryworldviews/dimensions institutionalisations. In other words, it is human ontological-faithnotion-or-ontological-fideism - imbued-underdetermination-of-motif-andapriorising/axiomatising/referencing-as-so-being-as-of-existential-reality that ultimately 'vouches' for every given registry-worldview's/dimension's institutionalisation at its uninstitutionalised-threshold ${ }^{12}$ for the possibility of a correspondence between human limitedmentation-capacity—as-subjecting-'educed-unlimitedness/existence-sublimating nascence'to-limitedness/human-subpotency and the 'inherent centered-epistemic-totalisation-asexistence', as of Being orientation of pursuing-and-attaining ontological-completeness-ofreference-of-thought. It is only such an apriorising/axiomatising/referencing-\{of'prospectively_implicited_attendant-ontological-contiguity ' educedexistentialising/contextualising/textualising_intelligibility/epistemicity/reflexivity-contiguity<imbued-notional cogency $>$ ' $\}$-conflatedness ${ }^{3}$ in $\{$ preconverging ment by\} postconverging-entailment perspective as of notional ${ }^{18}$ deprocrypticism that can articulate a conceptualisation of ${ }^{56}$ meaningfulness-and-teleology ${ }^{99}$ ontological-performance ${ }^{72}<$ includingvirtue-as-ontology $>$ /morality/ethics/justice/etc. as of a notional $\sim$ correspondence to existence/existential-possibilities, thus avoiding <amplituding/formativeepistemicity $>$ totalising $\sim$ self-referencing-syncretising/circularity/interiorising/akrasiatic-drag misconstrual as of apriorising/axiomatising/referencing-\{of- ${ }^{\text {prespectively }}$ implicited_attendant-ontological-contiguity ' educedexistentialising/contextualising/textualising_intelligibility/epistemicity/reflexivity_contiguity- 
$<$ imbued-notional cogency >' $\}$-constitutedness ${ }^{14}$-in-preconverging-entailment. Insightfully

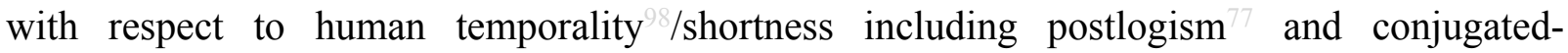
postlogism 77 and as reflected by psychopathy and social psychopathy in our positivismprocrypticism, the apriorising/axiomatising/referencing-\{of-'prospectively implicited_attendant-ontological-contiguity ' educedexistentialising/contextualising/textualising_ 'intelligibility/epistemicity/reflexivity-contiguity-

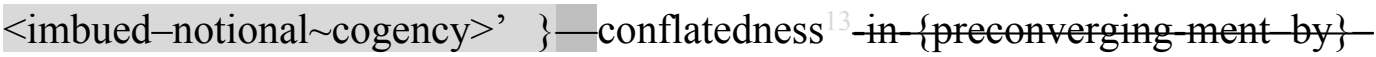
postconverging-entailment of notional 18 deprocrypticism points out that given human limitedmentation-capacity—as-subjecting 'educed-unlimitedness/existence-sublimating nascence' to-limitedness/human-subpotency its ' ${ }^{83}$ reference-of-thought—devolving-teleological-dementating/structuring/paradigming-of-meaningfulness as of implicited-and-explicited reference-of-thought- categorical-imperatives/axioms/registry-teleology ${ }^{9}$,-for-

aposteriorising/logicising/deriving/intelligising/measuring- ${ }^{5}$ meaningfulness-and-teleology ${ }^{99}$ as knowledge-constructs/theories/intersolipsistic-intercessory-notions/notional $\sim$ referentialnotions/articulations/virtue' as of institutionalisation, is subject at its uninstitutionalised-

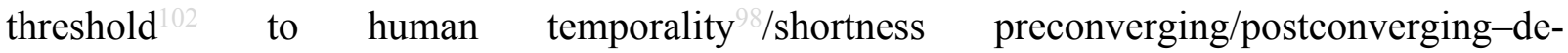
mentative/structural/paradigmatic denaturing (beyond-the-consciousness-awarenessteleology $-<$ of-preconverging-existential-extrication-as-of-existential-unthought $>$ )

undermining ${ }^{56}$ meaningfulness-and-teleology ${ }^{99}$ ontological-performance ${ }^{2}-<$ including-virtueas-ontology $>$ /morality/ethics/justice/etc. due to lack of social ${ }^{103}$ universal-transparency ${ }^{104}$ 〈transparency-of-totalising-entailing,-as-to-entailing-<amplituding/formative-

epistemicity>totalising in-relative-ontological-completeness $\rangle$. This arises because fundamentally as of notional correspondence with existence, a registryworldview's/dimension's institutionalisation in prior relative-ontological-incompleteness -ofreference-of-thought $\quad{ }^{56}$ meaningfulness-and-teleology ${ }^{9} \quad$ ontological-performance ${ }^{72}$ 
$<$ including-virtue-as-ontology $>/$ morality/ethics/justice/etc. is ultimately rather vouching of such a notional correspondence with existence on the basis of ontological-faith-notion-orontological-fideism - imbued-underdetermination-of-motif-and-

apriorising/axiomatising/referencing-as-so-being-as-of-existential-reality as transcendentallycomplementing at its uninstitutionalised-threshold ${ }^{102}$ the said human limited-mentationcapacity - as-subjecting-'educed-unlimitedness/existence-sublimating nascence'-to-

limitedness/human-subpotency ' $\quad$ reference-of-thought—devolving-teleological-dementating/structuring/paradigming-of-meaningfulness as of implicited-and-explicited reference-of-thought- categorical-imperatives/axioms/registry-teleology ${ }^{99}$,-foraposteriorising/logicising/deriving/intelligising/measuring- ${ }^{56}$ meaningfulness-and-teleology ${ }^{99}$ as knowledge-constructs/theories/intersolipsistic-intercessory-notions/notional $\sim$ referentialnotions/articulations/virtue' construed as institutionalisation, as the latter's ${ }^{8}$ reference-ofthought- ${ }^{-}$ategorical-imperatives/axioms/registry-teleology ${ }^{99}$ can be denaturing ${ }^{16}$ (beyond-theconsciousness-awareness-teleology ${ }^{-<}<$of-preconverging-existential-extrication-as-ofexistential-unthought>) as of their <amplituding/formative> wooden-language-〈imbuedtemporal-mere-form/virtualities/dereification/akrasiatic-drag/denatured/preconverging-ordementing -narratives-of-the- reference-of-thought- categoricalimperatives/axioms/registry-teleology $\rangle$ by the various temporalities in threshold-ofnonconviction/madeupness/bottomlining-in-shallow-supererogation $<<$ as-to- 'attendantintradimensional'-prospectively-disontologising preconverging/dementing -apriorisingpsychologism $>$ at its uninstitutionalised-threshold ${ }^{102}$. This latter is only undermined driven by ontological-faith-notion-or-ontological-fideism - imbued-underdetermination-of-motif-andapriorising/axiomatising/referencing-as-so-being-as-of-existential-reality as of prospective human limited-mentation-capacity—as-subjecting-'educed-unlimitedness/existencesublimating nascence' to-limitedness/human-subpotency prospective relative-ontological- 
completeness ${ }^{87}$-of- ${ }^{83}$ reference-of-thought ${ }^{~ '}$ reference-of-thought—devolving-teleological-dementating/structuring/paradigming-of-meaningfulness as of implicited-and-explicited reference-of-thought- categorical-imperatives/axioms/registry-teleology ${ }^{9}$,-foraposteriorising/logicising/deriving/intelligising/measuring- ${ }^{5}$ meaningfulness-and-teleology ${ }^{99}$ as knowledge-constructs/theories/intersolipsistic-intercessory-notions/notional $\sim$ referentialnotions/articulations/virtue' construed as prospective institutionalisation, by its greater social universal-transparency ${ }^{104}$-〈transparency-of-totalising-entailing,-as-to-entailing$<$ amplituding/formative-epistemicity $>$ totalising in-relative-ontological-completeness $\rangle$.

Again, the latter institutionalisation's ${ }^{56}$ meaningfulness-and-teleology ${ }^{9}$ ontologicalperformance $^{72}-<$ including-virtue-as-ontology $>$ /morality/ethics/justice/etc. is equally vouched by transcendentally-complementing ontological-faith-notion-or-ontological-fideism - imbuedunderdetermination-of-motif-and-apriorising/axiomatising/referencing-as-so-being-as-ofexistential-reality at its given uninstitutionalised-threshold ${ }^{102}$, as its own ${ }^{83}$ reference-of-thoughtcategorical-imperatives/axioms/registry-teleology ${ }^{9}$ can also be denaturing ${ }^{16}$ as of beyond-theconsciousness-awareness-teleology $\quad<$ of-preconverging-existential-extrication-as-ofexistential-unthought $>$ as of their <amplituding/formative> wooden-language-〈imbuedtemporal-mere-form/virtualities/dereification/akrasiatic-drag/denatured/preconverging-ordementing -narratives - of-the- reference-of-thought- categoricalimperatives/axioms/registry-teleology $\rangle$. The overall implication here as implied by historiality/ontological-eventfulness 3 /ontological-aesthetic-tracing-<perspectiveontological-normalcy/postconvergence-reflected-'epistemicity-relativism-determinism'> is that only a contextual ontologically contiguous transitioning construal of ${ }^{56}$ meaningfulness-andteleology as reflected as of the apriorising/axiomatising/referencing-\{of-"prospectively implicited_attendant-ontological-contiguity ' educedexistentialising/contextualising/textualising_'intelligibility/epistemicity/reflexivity-contiguity- 
<imbued-notional cogency $\left.>^{\prime}\right\}$ - conflatedness ${ }^{13}$-in-\{preconverging-ment by \} $^{\prime}$

postconverging-entailment of notional deprocrypticism can reveal-the-ontologicalveridicality of such inherent systemic beyond-the-consciousness-awareness-teleology ${ }^{9}-<$ of preconverging-existential-extrication-as-of-existential-unthought $>$ perversion-and-derivedperversion-of- ${ }^{3}$ reference-of-thought- $<$ as-preconvergingly-

apriorising/axiomatising/referencing-in-nonconviction/madeupness/bottomlining-as-to-

shallow-supererogation $>$ associated with every institutionalisation in prior relativeontological-incompleteness ${ }^{8}$-of- ${ }^{8}$ reference-of-thought since it ultimately depends on ontological-faith-notion-or-ontological-fideism - imbued-underdetermination-of-motif-andapriorising/axiomatising/referencing-as-so-being-as-of-existential-reality to transcendentallycomplement its ${ }^{83}$ reference-of-thought- ${ }^{-}$ategorical-imperatives/axioms/registry-teleology ${ }^{99}$ at its uninstitutionalised-threshold ${ }^{102}$ for upholding intemporality ${ }^{52}$-as-of-ontology that reflects the 'inherent centered-epistemic-totalisation-as-existence'. Hence the notional ${ }^{18}$ deprocrypticism registry-worldview/dimension institutionalisation as notionally construed as in full fulfilment of transcendentally-complementing ontological-faith-notion-or-ontological-fideism - imbuedunderdetermination-of-motif-and-apriorising/axiomatising/referencing-as-so-being-as-ofexistential-reality, as of human ${ }^{15}$ de-mentation-〈supererogatory $\sim$ ontological-de-mentation-ordialectical-de-mentation - stranding-or-attributive-dialectics $\rangle$ contextual ontologically contiguous transitioning construal of ${ }^{56}$ meaningfulness-and-teleology ${ }^{9}$ ontologicalperformance $^{2}-<$ including-virtue-as-ontology $>$ /morality/ethics/justice/etc. that anticipates and accounts for human inherent intemporality ${ }^{52} /$ longness and temporality ${ }^{8}$, purports to avoid wrong elevation of temporality 8 /shortness in threshold-of-nonconviction/madeupness/bottomliningin-shallow-supererogation -<as-to-'attendant-intradimensional'-prospectivelydisontologising $\sim$ preconverging/dementing -apriorising-psychologism $>$ and wrong degradation of intemporality ${ }^{5} /$ longness in supplanting-conviction-as-to-profound-supererogation - of- 


\section{'attendant-intradimensional'-postconverging/dialectical-thinking -apriorising-psychologism}

implied reference-of-thought —elevated-devolving-as-of-prospective-institutionalisation, given the inherently confounding ontological-veridicality of human potent beyond-theconsciousness-awareness-teleology ${ }^{9}<$ of-preconverging-existential-extrication-as-ofexistential-unthought> . Broadly speaking thus, the <amplituding/formativeepistemicity $>$ causality as-to-projective-totalitative-implications-of-prospective-

\section{nonpresencing,-for-explicating relative-unreflexivity/relative-reflexivity - ontological-}

contiguity of prospective relative-ontological-completeness ${ }^{87}$-of- ${ }^{8}$ reference-of-thought as of human temporal-to-intemporal mental-dispositions in social-stake-contention-or-confliction implies that it is naïve to conceive of a "neuter framework of ${ }^{83}$ reference-of-thought putting the notional firstnaturedness-formativeness-<as-to-eventualising-inkling-drive-or-seedingmisprising $>$ temporal-to-intemporal-dispositions-<so-construed-as-from-perspectiveontological-normalcy/postconvergence $>$ as of the same axiomatic teleological projection' as in effect as of apriorising/axiomatising/referencing-\{of-'prospectively implicited_attendant ontological-contiguity ' educedexistentialising/contextualising/textualising_'intelligibility/epistemicity/reflexivity-contiguity<imbued-notional cogency >' $\}$-conflatedness ${ }^{13}$ in \{preconverging ment by postconverging-entailment this simply wrongly elevates temporal/shortness-of-register-ofmeaningfulness-and-teleology mental-dispositions teleologically-degraded-devolving-as-ofuninstitutionalised-threshold ${ }^{102}$ and wrongly degrades the intemporal/Aongness-of register-ofmeaningfulness-and-teleology mental-disposition elevated-devolving-as-of-prospectiveinstitutionalisation; as the former is in reality denaturing ${ }^{16}$ of ${ }^{83}$ reference-of-thoughtcategorical-imperatives/axioms/registry-teleology $\quad$ beyond-the-consciousness-awarenessteleology $-<$ of-preconverging-existential-extrication-as-of-existential-unthought $>$ while the latter is upholding ${ }^{83}$ reference-of-thought- ${ }^{8}$ ategorical-imperatives/axioms/registry-teleology 
for intemporal-preservation-entropy-or-contiguity-or-ontological-preservation. Actually such an ordinary mental-reflex of a "neuter framework of ${ }^{83}$ reference-of-thought putting the notional firstnaturedness-formativeness-<as-to-eventualising inkling drive-or-seeding misprising $>$ temporal-to-intemporal-dispositions-<so-construed-as-from-perspectiveontological-normalcy/postconvergence $>$ as of the same axiomatic teleological projection' when it comes to social-stake-confliction-or-contention is only valid as of 'mutual conceptualisation as of a given institutionalisation with a common ontological- ${ }^{-}$reference-of-thought' wherein it is then strictly a matter of ${ }^{5}$ logical-processing-or-logical-implicitation-supposedlyapriorising-in-conviction-as-to-profound-supererogation in determining ontological-veracity. But then at such a registry-worldview's/dimension's institutionalisation's uninstitutionalisedthreshold ${ }^{102}$, there is a relative variance of ontological-completeness-of- ${ }^{3}$ reference-of-thought as of the prospective relative-ontological-completeness ${ }^{87}$-of- ${ }^{83}$ reference-of-thought in intemporality $52 /$ longness entailing the prospective institutionalisation and the prior relativeontological-incompleteness ${ }^{8}$-of- ${ }^{8}$ reference-of-thought in temporality ${ }^{8} /$ shortness entailing the uninstitutionalised-threshold ${ }^{102}$; thus implying a relative variance in such intemporal and temporal teleological projection respectively as of elevated-devolving-as-of-prospectiveinstitutionalisation and teleologically-degraded-devolving-as-of-uninstitutionalised-threshold in determining ontological-veracity. In this sense we can garner that it is inappropriate to imply a 'neuter framework of ${ }^{83}$ reference-of-thought putting the notional firstnaturednessformativeness-<as-to-eventualising inkling-drive-or-seeding misprising $>$ temporal-tointemporal-dispositions-<so-construed-as-from-perspective-ontologicalnormalcy/postconvergence $>$ as of the same axiomatic teleological projection' and so, as of an uninstitutionalised-threshold ${ }^{102}$ and the prospective institutionalisation; given the variance of temporality $/$ shortness rather as respectively in recurrent-utter-uninstitutionalisation, ununiversalisation, non-positivism-or-medievalism, and prospectively ${ }^{80}$ procrypticism-or- 
disjointedness-as-of- ${ }^{8}$ reference-of-thought with intemporality ${ }^{52} /$ longness rather as respectively in base-institutionalisation, ${ }^{103}$ universalisation, positivm and prospectively ${ }^{18}$ deprocrypticismor-preempting - disjointedness-as-of- ${ }^{-1}$ reference-of-thought. The bigger point here being that the very notion of transcendence-and-sublimity/sublimation/supereregatory - de-mentativity as of apriorising/axiomatising/referencing-\{of-'prospectively_implicited_attendant-ontologicalcontiguity ' educed-

existentialising/contextualising/textualising_intelligibility/epistemicity/reflexivity_contiguity<imbued-notional cogency $>$ ' $\}$ - conflatedness ${ }^{13}$ in-\{preconverging-ment by \} $^{\prime}$ postconverging-entailment actually construes of more profound ${ }^{83}$ reference-of-thoughtcategorical-imperatives/axioms/registry-teleology that override the prior ${ }^{83}$ reference-of-

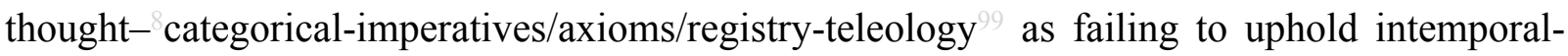
preservation-entropy-or-contiguity-or-ontological-preservation', and so as of differing references-of-thought in transversality-<for-sublimating-existentialeventuating/denouement,from-'thinking-at-first/pure-predisposition-preemptive-ofprospective-disontologising/subontologising' as-of-prospectively-disambiguated-affirmedand-unaffirmed-'motif-and-apriorising/axiomatising/referencing'> ontological unintelligibility. Neuterisation of analysis as so articulated is effectively a deficient human mental-reflex as of its naïve predisposition to imply 'equivalence of consideration' without factoring prospective relative-ontological-completeness ${ }^{87}$-of- ${ }^{8}$ reference-of-thought $<$ amplituding/formative-epistemicity $>$ causality $\sim$ as-to-projective-totalitative-implications-ofprospective- nonpresencing,-for-explicating relative-unreflexivity/relative-reflexivityontological-contiguity of differentiated axiomatic/ ${ }^{83}$ reference-of-thought teleological projection as of temporal teleologically-degraded-devolving-as-of-uninstitutionalisedthreshold ${ }^{102}$ and intemporal elevated-devolving-as-of-prospective-institutionalisation. The fact of temporal-to-intemporal variance of prospective relative-ontological-completeness ${ }^{87}$-of- 
reference-of-thought ultimately reflects the fact that the apparent ordinarily assumed apriorising/axiomatising/referencing — commonness-in-sharedness,--for- ${ }^{5}$ meaningfulness-andteleology with regards to the-very-same-immanent-existence/intrinsic-reality/ontologicalveridicality,-as-to-'human<amplituding/formative-epistemicity>totalising $\sim$ purview-ofconstrual' is in effect 'only valid as of within a registry-worldview's/dimension's institutionalisation framework', and so as of its implied 's3 reference-of-thought-devolvingteleological-de-mentating/structuring/paradigming-of-meaningfulness as of implicited-andexplicited ${ }^{83}$ reference-of-thought- categorical-imperatives/axioms/registry-teleology ${ }^{9}$,-foraposteriorising/logicising/deriving/intelligising/measuring $-{ }^{5}$ meaningfulness-and-teleology ${ }^{99}$ as knowledge-constructs/theories/intersolipsistic-intercessory-notions/notional $\sim$ referentialnotions/articulations/virtue'. This articulated delimitation of apriorising/axiomatising/referencing — commonness-in-sharedness,-for- ${ }^{5}$ meaningfulness-andteleology with regards to the-very-same-immanent-existence/intrinsic-reality/ontologicalveridicality,-as-to-'human<amplituding/formative-epistemicity>totalising $\sim$ purview-ofconstrual' within only a registry-worldview's/dimension's institutionalisation framework as of reference-of-thought is critical for an ontologically-complete profoundness/depth of 'phenomenological departure in-its-overcoming-of-neuterisation ${ }^{59}$ reflected by metaphysics-ofabsence-〈implicited-epistemic-veracity-of- nonpresencing-<perspective-ontologicalnormalcy/postconvergence $>\rangle$ as the 'requisite apriorising/axiomatising/referencing-\{of'prospectively_implicited_attendant-ontological-contiguity ' educedexistentialising/contextualising/textualising_'intelligibility/epistemicity/reflexivity_contiguity<imbued-notional cogency $>$ ' $\}$ - conflatedness ${ }^{13}$-in-\{preconverging-ment by \} $^{\prime}$ postconverging-entailment of understanding', necessarily entailing transcendental implications for ontologically-veridical knowledge-constructs/theories/intersolipsistic-intercessorynotions/notional referential-notions/articulations/virtue; as we can appreciate the inherent 
reality that there isn't apriorising/axiomatising/referencing-commonness-in-sharedness,-formeaningfulness-and-teleology ${ }^{9}$ with regards to the-very-same-immanent-existence/intrinsicreality/ontological-veridicality,-as-to-'human<amplituding/formative-

epistemicity>totalising purview-of-construal' between recurrent-utter-uninstitutionalisation and base-institutionalisation-ununiversalisation, between base-institutionalisationununiversalisation and ${ }^{103}$ universalisation-non-positivism/medievalism, between universalisation-non-positivism/medievalism and positivism- ${ }^{80}$ procrypticism, and prospectively between positivism- ${ }^{8}$ procrypticism and deprocrypticism! In this case such overcoming of neuterisation with reference to the variance of the $<$ cumulating/recomposuring attendant-ontological-contiguity $>$-successive registryworldviews/dimensions is rather conceived as deneuterising as of the variance in prospective relative-ontological-completeness ${ }^{87}$-of- ${ }^{5}$ meaningfulness-and-teleology ${ }^{9}$ disambiguation of uninstitutionalised-threshold ${ }^{102}$ and prospective institutionalisation, and so reflected as of historiality/ontological-eventfulness 38 ontological-aesthetic-tracing-<perspectiveontological-normalcy/postconvergence-reflected-'epistemicity-relativism-determinism'> as of the apriorising/axiomatising/referencing-\{of-"prospectively implicited_attendant-ontologicalcontiguity ' educedexistentialising/contextualising/textualising_'intelligibility/epistemicity/reflexivity-contiguity$<$ imbued-notional $\left.\sim \operatorname{cogency}>^{\prime}\right\}$-conflatedness ${ }^{13}$-in-\{preconverging-ment by $\}^{\prime}$ pestcenverging-entailment of notional ${ }^{18}$ deprocrypticism wherein the uninstitutionalisedthreshold ${ }^{83}$ reference-of-thought is in relative notional-discontiguity/epistemicdiscontiguity ${ }^{63}<$ between - prior-shallow-supererogation -of-mentallyaestheticised preconverging/dementing -qualia-schema_and_prospective-profoundsupererogation -of-mentally-aestheticised postconverging/dialectical-thinking -qualiaschema $>$ to the prospective institutionalisation ${ }^{83}$ reference-of-thought in relative notional- 
contiguity/epistemic-contiguity ${ }^{2}-<$ profound-supererogation -of-mentally-

aestheticised postconverging/dialectical-thinking -qualia-schema $>$ as of the-very-sameimmanent-existence/intrinsic-reality/ontological-veridicality,-as-to-

'human<amplituding/formative-epistemicity>totalising purview-of-construal'; imply a disambiguation as of mutual unintelligibility of prospective institutionalisation's ${ }^{83}$ reference-ofthought soundness-or-ontological-good-faith/authenticity and the uninstitutionalisedthreshold ${ }^{102}$ 's ${ }^{83}$ reference-of-thought unsoundness-or-ontological-bad-faith/inauthenticity ${ }^{64}$

Deneuterising 17 , from a storied-construct/ontologically-valid-narration perception perspective insight, highlights a temporal mental-disposition uninstitutionalised-threshold ${ }^{102}$ issue' as of beyond-the-consciousness-awareness-teleology ${ }^{9}-<$ of-preconverging-existential-extrication-asof-existential-unthought $>$ involving human temporal limited-mentation-capacity-assubjecting-'educed-unlimitedness/existence-sublimating nascence' to-limitedness/humansubpotency at its uninstitutionalised-threshold ${ }^{102}$ wherein the ${ }^{83}$ reference-of-thought as temporal-mental-disposition-is-actually-of $<$ amplituding/formativeepistemicity>totalising $\sim$ self-referencing-syncretising/circularity/interiorising/akrasiatic-drag 34 in-an- 'apparently-elevated'-devolving-as-of-prospective-institutionalisation whereas inherentsuperseding-existential-reality-unattached-to-its-temporal-limited-mentation-capacity assubjecting 'educed-unlimitedness/existence-sublimating nascence' to-limitedness/humansubpotency-mental-disposition-points-to-its-degraded-devolving-at-the-uninstitutionalisedthreshold $^{102}$. Such a deneuterising binarity of storied ontologically-flawed $<$ amplituding/formative-epistemicity $>$ totalising $\sim$ self-referencingsyncretising/circularity/interiorising/akrasiatic-drag ${ }^{34}$-temporal-mental-dispositions and storied background of ontologically-veridical-inherent-superseding-existential-reality-unattached-tosuch-temporal-mental-dispositions portrays how a storied-construct/ontologically-validnarration can be articulated as of beyond-the-consciousness-awareness-teleology ${ }^{9}-<$ of - 
preconverging-existential-extrication-as-of-existential-unthought> 'emphasising exclusively that it is the construal of human temporality ${ }^{8}$-to-intemporality ${ }^{52}$ limited-mentation-capacityas-subjecting 'educed-unlimitedness/existence-sublimating nascence' to-limitedness/humansubpotency transversal-and-cumulative-implications' that accounts for ontologically-veridical human character-and-social-formation-dynamics as of both uninstitutionalised-threshold representation and prospective-institutionalisation representation. Such a storiedconstruct/ontologically-valid-narration is ultimately articulated rather as of the implications of the failing to uphold Being as of the temporal-to-intemporal transversality-<for-sublimatingexistential-eventuating/denouement,-from-'thinking-at-first/pure-predisposition-preemptive-ofprospective-disontologising/subontologising' as-of-prospectively-disambiguated-affirmedand-unaffirmed-'motif-and-apriorising/axiomatising/referencing' $>101$ of human limitedmentation-capacity—as-subjecting 'educed-unlimitedness/existence-sublimating nascence' to-limitedness/human-subpotency in temporal apriorising/axiomatising/referencing-\{of'prospectively_implicited_attendant-ontological-contiguity ' educedexistentialising/contextualising/textualising_'intelligibility/epistemicity/reflexivity_contiguity$<$ imbued-notional cogency >' $\}$-constitutedness ${ }^{14}$-in- preconverging-entailment mentalreflexes at presence ${ }^{83}$ reference-of-thought, and so reflected by the implied intemporal apriorising/axiomatising/referencing-\{of-'prospectively_implicited_attendant-ontologicalcontiguity ' educedexistentialising/contextualising/textualising_'intelligibility/epistemicity/reflexivity_contiguity<imbued-notional cogency $\left.>^{\prime} \quad\right\}$ - conflatedness ${ }^{13}$-in- preconverging ment by $^{\prime}$ postconverging-entailment of phenomenological transcendence-and-

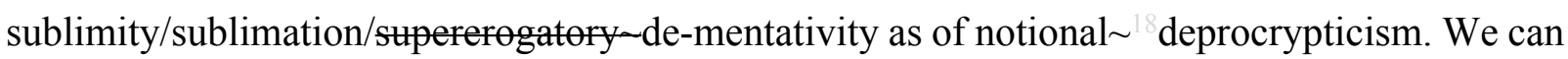
appreciate the metaphysics-of-absence-〈implicited-epistemic-veracity-of- nonpresencing$<$ perspective-ontological-normalcy/postconvergence $>\rangle$ insight about such a deneuterising 
storied-construct/ontologically-valid-narration from the fact that a non-positivism/medievalism or animistic social-setup is 'not committed in a <amplituding/formativeepistemicity>totalising $\sim$ self-referencing-syncretising/circularity/interiorising/akrasiatic-drag 3 , to positivism/rational-empiricism ${ }^{5}$ meaningfulness-and-teleology ${ }^{9}$ with regards to occurrences and incidents best explained and dealt with by such positivistic meaningfulness as of the latter's prospective relative-ontological-completeness ${ }^{87}$-of- ${ }^{8}$ reference-of-thought. As such nonpositivism/medievalism or animistic social-setup 'will not be self-effacing as of its ontologically-flawed $<$ amplituding/formative-epistemicity $>$ totalising $\sim$ self-referencingsyncretising/circularity/interiorising/akrasiatic-drag ${ }^{34}$-temporal-mental-dispositions as-ifalways-in-a-state-of-institutionalisation, failing to psychoanalytically project about its uninstitutionalised-threshold ${ }^{102}$ of non-positivism and the prospective institutionalisation of positivism'. This equally explains how our positivism- ${ }^{80}$ procrypticism mental-disposition is construed in deneuterising from futural Being-development/ontological-frameworkexpansion-as-to-depth-of-ontologising-development-as-infrastructure-of- meaningfulnessand-teleology as of prospective notional ${ }^{18}$ deprocrypticism perspective 'as not self-effacing as of its ontologically-flawed <amplituding/formative-epistemicity $>$ totalising $\sim$ self-referencingsyncretising/circularity/interiorising/akrasiatic-drag -temporal-mental-dispositions as-ifalways-in-a-state-of-institutionalisation, failing to psychoanalytically project about the uninstitutionalised-threshold ${ }^{102}$ of its procrypticism-or-disjointedness-as-of- ${ }^{8}$ reference-ofthought and the prospective institutionalisation of deprocrypticism'. This is actually the ontologically-veridical phenomenological transcendental framework for construing/conceptualising human temporal character and social formation mental-dispositions as of uninstitutionalised-threshold ${ }^{102}$ and prospective-institutionalisation based on the ‘blurriness-<sterilising/anecdotalising/trivialising-of-prospective-re-ontologising_by- 
limited-mentation-capacity—as-subjecting 'educed-unlimitedness/existence-sublimating nascence' to-limitedness/human-subpotency', unlike a naïve ${ }^{58}$ neuterising mental-reflex that by its $<$ amplituding/formative-epistemicity $>$ totalising $\sim$ self-referencingsyncretising/circularity/interiorising/akrasiatic-drag 34 fails to attain such an apriorising/axiomatising/referencing-\{of-'prospectively_implicited_attendant-ontologicalcontiguity ' educedexistentialising/contextualising/textualising_intelligibility/epistemicity/reflexivity_contiguity<imbued-notional cogency $>$ ' \}-conflatedness ${ }^{13}$ in-\{preconverging-ment by\} pestconverging-entailment as of notional ${ }^{18}$ deprocrypticism deneuterising ${ }^{17}$ insight. Central and critical to achieving such a deneuterising ${ }^{17}$ analysis in grasping the full and complete possibilities of ontologically-veridical construal of human ${ }^{56}$ meaningfulness-and-teleology ${ }^{9}$ given human temporal-to-intemporal mental-dispositions as of prospective institutionalisation and uninstitutionalised-threshold ${ }^{102}$ is the notion of beyond-the-consciousness-awarenessteleology $-<$ of-preconverging-existential-extrication-as-of-existential-unthought $>$. It is exactly what renders a veridical ontological-escalation or aetiologisation of the human condition possible as the ${ }^{4}$ historiality/ontological-eventfulness ${ }^{38}$ /ontological-aesthetic-tracing$<$ perspective--ontological-normalcy/postconvergence-reflected-'epistemicity-relativismdeterminism'> of apriorising/axiomatising/referencing-\{of-'prospectively implicited_attendant-ontological-contiguity ' reducedexistentialising/contextualising/textualising_'intelligibility/epistemicity/reflexivity-contiguity<imbued-notional cogency $>$ ' $\}$ - conflatedness ${ }^{13}$ in-\{preconverging-ment by\} pesteonverging-entailment as of notional ${ }^{18}$ deprocrypticism. It is most critical because at any registry-worldview/dimension, human self-consciousness is a <emplituding/formativeepistemicity $>$ totalising $\sim$ self-referencing-syncretising/circularity/interiorising/akrasiatic-drag mental-reflex as of being-only-in-institutionalisation-and-hence-only-of-a- ${ }^{56}$ meaningfulness- 
and-teleology -that-is-intemporal while defectively ignoring-and-undermining the veridicality of uninstitutionalised-threshold ${ }^{102}$-and-its-assorted-and-conjugated-temporalmeaningfulness-and-teleology ${ }^{9}$ such that transcendence-andsublimity/sublimation/supererogatory de-mentativity is always perceived as unnatural when $<$ amplituding/formative-epistemicity $>$ totalising $\sim$ self-referencing-

syncretising/circularity/interiorising/akrasiatic-drag ${ }^{34}$, in the sense that 'it-is-others,-as-of-theprior-registry-worldviews/dimensions,-that-have-an-uninstitutionalised-threshold ${ }^{102}$-and-thenotion-of-transcendence-is-only-relevant-to-them-as-the-current-presence-is-normal'. The implications of such human $<$ amplituding/formative-epistemicity $>$ totalising $\sim$ self-referencingsyncretising/circularity/interiorising/akrasiatic-drag ${ }^{34}$ mental-reflex as it overlooks human uninstitutionalised-threshold ${ }^{102}$ points to the reality that the implied prior institutionalisation 'projected reflex of entailing-<amplituding/formative-epistemicity >totalising in-relativeontological-completeness 87 supplanting-conviction-as-to-profound-supererogation —of'attendant-intradimensional'-postconverging/dialectical-thinking -apriorising-psychologism for ${ }^{5}$ meaningfulness-and-teleology ${ }^{9}$, while a social psychological reference is actually not ontologically-veridical as of human practical reality given lack of social ${ }^{103}$ universaltransparency ${ }^{104}$-〈transparency-of-totalising-entailing,-as-to-entailing-<amplituding/formativeepistemicity>totalising in-relative-ontological-completeness $\rangle$. Such that with regards to social-stake-contention-or-confliction possibilities the social psychological reference as of wrongly implied prior institutionalisation 'projected reflex of entailing-<amplituding/formativeepistemicity $>$ totalising $\sim$ in-relative-ontological-completeness ${ }^{87} \quad$ supplanting-conviction-as-toprofound-supererogation of-'attendant-intradimensional'-postconverging/dialecticalthinking -apriorising-psychologism for ${ }^{56}$ meaningfulness-and-teleology ${ }^{9}$, is an abstract social constraint to human temporal mental-dispositions. In practicality such human temporal mentaldispositions involve 'rationalising threads of part-conviction-as-to-profound-supererogation - 
or-part-nonconviction/madeupness/bottomlining-as-to-shallow-supererogation perceptionand-relation to ${ }^{56}$ meaningfulness-and-teleology ${ }^{9}$ as of social-stake-contention-or-confliction constraints social-functioning-and-accordance of temporal postlogism slantedness/ ${ }^{5}$ ignorance/affordability/opportunism/exacerbation/social-chainism-or-socialdiscomfiture-or-negative-social-aggregation/temporal-enculturation-or-temporal-endemisation, so-disambiguated as of ${ }^{83}$ reference-of-thought- ${ }^{8}$ devolving ontological-performance ${ }^{72}$ <including-virtue-as-ontology>, and so as of beyond-the-consciousness-awareness-teleology $<$ of-preconverging-existential-extrication-as-of-existential-unthought $>\quad$ reflecting uninstitutionalised-threshold ${ }^{102}$ Being undervelopment; wherein with specific regards to a postlogism 7 -slantedness/psychologism mental-disposition and less and less so as of temporal exacerbation/opportunism/affordability, such instigated part-conviction-as-to-profoundsupererogation is rather as of a relevant generalised social projection as ‘<amplituding/formative $>$ wooden-language-〈imbued-temporal-mere-

\section{form/virtualities/dereification/akrasiatic-drag/denatured/preconverging-or-dementing}

narratives - of-the- reference-of-thought- categorical-imperatives/axioms/registry-

teleology $\rangle$ of veridical supplanting-conviction-as-to-profound-supererogation —of‘attendant-intradimensional'-postconverging/dialectical-thinking -apriorising-psychologism' in relevant social engagement not perceived as of critical social-stake-contention-or-confliction as providing a 'supplanting-conviction-as-to-profound-supererogation - of-'attendantintradimensional'-postconverging/dialectical-thinking -apriorising-psychologism credibility backdrop' for subsequent targeted threshold-of-nonconviction/madeupness/bottomlining-inshallow-supererogation -<as-to-'attendant-intradimensional'-prospectivelydisontologising preconverging/dementing -apriorising-psychologism $>$ mental-disposition in relation to specific social engagements perceived as of critical social-stake-contention-orconfliction. Effectively, such part-conviction-as-to-profound-supererogation -or-part- 
nonconviction/madeupness/bottomlining-as-to-shallow-supererogation with respect to pertinently-perceived social-stake-contention-or-confliction contexts arises due to (beyond-theconsciousness-awareness-teleology ${ }^{\circ}<$ of-preconverging-existential-extrication-as-of-

existential-unthought>) constraint of human limited-mentation-capacity-as-subjecting 'educed-unlimitedness/existence-sublimating nascence' to-limitedness/human-subpotency as of prospective human postconverging-aporeticism overcoming/unovercoming such that this induces as of various existential-instantiations 'ontologically-flawed ${ }^{56}$ meaningfulness-andteleology $\quad$ ontological-performance ${ }^{72}-{\text { including-virtue-as-ontology }>^{\prime},}^{9}$, subpar $\quad$ to ontologically-veridical meaningfulness-and-teleology ${ }^{56}$ ontological-performance ${ }^{72}$ $<$ including-virtue-as-ontology $>/$ morality/ethics/justice/etc. as fundamentally underscored by the prospective institutionalisation. Thus this determines a consequential 'dynamic beyond-theconsciousness-awareness-teleology ${ }^{\circ}<$ of-preconverging-existential-extrication-as-ofunlimitedness/existence-sublimating nascence' to-limitedness/human-subpotency constraint' as reflected from a 'notional ' deprocrypticism-referentialism-as-of-its-nonascriptivity backdrop-for-the-ontologically-veridical-construing' of 'temporal-to-intemporal individuations meaningfulness-and-teleology ${ }^{9}$ and actions of individuals and the collective-social as of their varying-existential-instantiations-mental-dispositions-ontological-performance ${ }^{72}-<$ includingvirtue-as-ontology $>$ /morality/ethics/justice/etc. or their characterisations-as-of-varyingexistential-instantiations', as fundamentally underscored by the implied uninstitutionalisedthreshold ${ }^{802}$ reference-of-thought, wherein such temporal thresholding neuterisation ${ }^{59}$ with regards to ontologically-veridical meaningfulness-and-teleology ${ }^{59}$ reflects Beingunderdevelopment; and so from the 'deepest phenomenological transcendental-point-ofdeparture handle as of the notional conflatedness ${ }^{13}$ of notional ${ }^{18}$ deprocrypticism deneuterising — referentialism' as of metaphysics-of-absence-〈implicited-epistemic-veracity- 
of- nonpresencing-<perspective-ontological-normalcy/postconvergence $>>$ insight that ontology's-directedness-as-Being lies with Base-institutionalisation institutionalisation over Recurrent-utter-uninstitutionalisation uninstitutionalisation <amplituding/formativeepistemicity>totalising $\sim$ self-referencing-syncretising/circularity/interiorising/akrasiatic-drag ${ }^{34}$, it lies with ${ }^{103}$ universalisation institutionalisation over Base-institutionalisationununiversalisation uninstitutionalisation $<$ amplituding/formative-epistemicity $>$ totalising $\sim$ selfreferencing-syncretising/circularity/interiorising/akrasiatic-drag ${ }^{34}$, it lies with Positivism institutionalisation over ${ }^{103}$ universalisation-non-positivism/medievalism uninstitutionalisation $<$ amplituding/formative-epistemicity $>$ totalising $\sim$ self-referencingsyncretising/circularity/interiorising/akrasiatic-drag ${ }^{4}$, and it lies prospectively with notional ${ }^{1}$ deprocrypticism institutionalisation over our positivism- ${ }^{80}$ procrypticism $<$ amplituding/formative-epistemicity $>$ totalising $\sim$ self-referencing-

syncretising/circularity/interiorising/akrasiatic-drag ${ }^{34}$ This operantly defines ${ }^{80}$ procrypticismor-disjointedness-as-of- ${ }^{8}$ reference-of-thought as beyond just the construal of new supposedly intemporal ${ }^{83}$ reference-of-thought- categorical-imperatives/axioms/registry-teleology ${ }^{9}$ of the prospective institutionalisation to preempt the temporally denaturing ${ }^{16}$ reference-of-thoughtcategorical-imperatives/axioms/registry-teleology ${ }^{9}$ of the prior institutionalisation, but rather the deneuterising 17 construal of the very 'limited-mentation-capacity-as-subjecting 'educedunlimitedness/existence-sublimating nascence' to-limitedness/human-subpotency as of humansubpotency-aporia/undecidability/dilemma/ought-

indeterminacy/deficiency/limitation/constraint—imbued-'notional firstnaturednessformativeness-as to eventulising inkling drive or seeding misprising temporal-tointemporal-dispositions- $<$ so-construed-as-from-perspective-ontologicalnormalcy/postconvergence >'-existentialism-form-factor as the beyond-the-consciousnessawareness-teleology $-<$ of-preconverging-existential-extrication-as-of-existential-unthought $>$ 
constraining dynamism' behind the denaturing of ${ }^{83}$ reference-of-thought- categoricalimperatives/axioms/registry-teleology ${ }^{9}$ in-the-very-first-place; conceptualised henceforth as the very $\quad$ reference-of-thought- ${ }^{8}$ categorical-imperatives/axioms/registry-teleology ${ }^{9}$ for intemporal-preservation-entropy-or-contiguity-or-ontological-preservation as of the notional ${ }^{18}$ deprocrypticism registry-worldview/dimension institutionalisation as of its implied notional ${ }^{18}$ deprocrypticism. Overall, the fact is that given that what is most relevant to the individual is the practicality as of their 'rationalising threads of part-conviction-as-to-profoundsupererogation -or-part-nonconviction/madeupness/bottomlining-as-to-shallowsupererogation ${ }^{6}$ perception-and-relation to ${ }^{56}$ meaningfulness-and-teleology ${ }^{9}$ over just abstract universal propositions, when it comes to social-stake-contention-or-confliction socialfunctioning-and-accordance constraints such temporal part-conviction-as-to-profoundsupererogation -or-part-nonconviction/madeupness/bottomlining-as-to-shallowsupererogation mental-dispositions tend to be ultimately translated decisively onto issues of public repercussions like corruption, mismanagement, nepotism, etc. It is very much naïve to imagine that as of such uninstitutionalised-threshold ${ }^{12}$ as of Being/ontological-frameworkexpansion underdevelopment, individuals in positions of social-stake-contention-or-confliction with respect to upholding/failing probity will simply adhere, at the exclusion of ingrained-habitsand-mental-dispositions, to mere propositions of probity rather than in the face of weakinstitutional-constraints-and-penalties to perceive such ${ }^{103}$ universal propositions as mere linguistic appendages of relative practical insignificance. The notion of beyond-theconsciousness-awareness-teleology ${ }^{9}<$ of-preconverging-existential-extrication-as-ofexistential-unthought $>$ is the effective and credible deneuterising ${ }^{17}$ enabling articulation that grasps such an ontologically flawed mental-reflex that recurrently permeates consciously and unconsciously human phenomenological mentation, as it 'credibly' grasps-and-accounts-for, without resorting to any ${ }^{58}$ neuterising, the full and complete possibilities of human mental- 
dispositions as of the exclusive dynamics of human limited-mentation-capacity—as-subjecting 'educed-unlimitedness/existence-sublimating nascence' to-limitedness/human-subpotency across all registry-worldviews/dimensions involving the conjugation of the intemporal/lengnessef-register-of meaningfulness-and-teleology individuation and temporal/shortness-ofregister-of meaningfulness-and-teleology individuations of postlogism slantedness/ ${ }^{5}$ ignorance/affordability/opportunism/exacerbation/social-chainism-or-socialdiscomfiture-or-negative-social-aggregation/temporal-enculturation-or-temporal-endemisation, so-disambiguated as of ${ }^{83}$ reference-of-thought- ${ }^{8}$ devolving ontological-performance ${ }^{72}$ $<$ including-virtue-as-ontology $>$. Ultimately, the notion of beyond-the-consciousness-awarenessteleology $-<$ of-preconverging-existential-extrication-as-of-existential-unthought $>$ given its psychoanalytic-unshackling as of prospective deprocryticism transcendence-andsublimity/sublimation/supererogatory de-mentativity, points to a self-consciousness that should rather come to terms with the reality of human limited-mentation-capacity-as-subjecting'educed-unlimitedness/existence-sublimating nascence' to-limitedness/human-subpotency dynamics as of temporal-to-intemporal mental-dispositions resolved beyond just the notion of

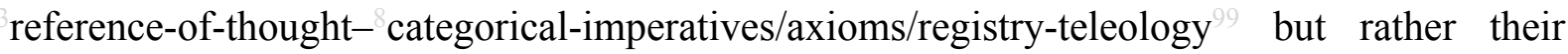
protraction as of ontological-faith-notion-or-ontological-fideism - imbued-underdeterminationof-motif-and-apriorising/axiomatising/referencing-as-so-being-as-of-existential-reality apriorising/axiomatising/referencing-\{of-'prospectively implicited_attendant-ontologicalcontiguity ' educedexistentialising/contextualising/textualising_'intelligibility/epistemicity/reflexivity-contiguity<imbued-notional cogency $>\quad\}$ - conflatedness ${ }^{13}$ in-\{preconverging-ment by\} of Being as implied as of ${ }^{18}$ deprocrypticism-or-preemptingdisjointedness-as-of- reference-of-thought. The issue of Being-development/ontologicalframework-expansion-as-to-depth-of-ontologising-development-as-infrastructure-of- 
meaningfulness-and-teleology or Being underdevelopment is associated with that of the construal of knowledge as organic-knowledge or mechanical-knowledge respectively; with the latter construed as of the 'mere effecting possibilities of knowledge' without a coherence/contiguity with the 'knowledge inventing' mental-disposition as of ontological-faithnotion-or-ontological-fideism—imbued-underdetermination-of-motif-andapriorising/axiomatising/referencing-as-so-being-as-of-existential-reality behind the given knowledge, as implied with organic-knowledge. It is such a mechanical-knowledge as of 'temporal/shortness-of-register-of- meaningfulness-and-teleology mental-dispositions towards the mere effecting possibilities of the knowledge' that induces the forgetting of Being construed as ontology's-directedness-as-Being, by undermining the ontological-faith-notion-orontological-fideism - imbued-underdetermination-of-motif-andapriorising/axiomatising/referencing-as-so-being-as-of-existential-reality upholding of intemporal-preservation-entropy-or-contiguity-or-ontological-preservation that is behind organic-knowledge. Human <amplituding/formative-epistemicity $>$ totalising $\sim$ self-referencingsyncretising/circularity/interiorising/akrasiatic-drag ${ }^{34}$ temporal mental-dispositions as of beyond-the-consciousness-awareness-teleology ${ }^{0}-<$ of - preconverging-existential-extrication-asof-existential-unthought $>$ are all too ready to construe of the comprehensiveness of knowledge as mere effecting possibilities of knowledge at the given institutionalisation's uninstitutionalised-threshold ${ }^{102}$ in temporal/shortness-of-register-of meaningfulness-andteleology terms-as-of-axiomatic-construal as of the plainly implied opportunism with little consideration of the projective intemporal value dispositions behind the 'knowledge inventing' and its organic preservation. Thus the relative-unreflexivity/relative-reflexivity-ontologicalcontiguity $^{67} \sim$ of-the-human-institutionalisation-process ${ }^{68}$ arises exactly to ensure deferentialformalisation-transference secondnaturing of knowledge as of organic-knowledge comprehensiveness. The following is enlightening in this regard. (For what it takes to get a 
medieval as non-positivistic mindset $/{ }^{8}$ reference-of-thought into a positivistic mindset $/{ }^{3}$ reference-of-thought, that is, suppose for instance where in a medieval social-setup an accusation of witchcraft is demonstrated by an outsider from a positivistic social-setup to be incorrect and unsound to the approval of all in that social-setup, that outsider understanding fundamentally that the medieval setup by its relative-ontological-incompleteness ${ }^{8}$-induced,'threshold-of-nonconviction/madeupness/bottomlining-in-shallow-supererogation ${ }^{9}<$ as-to‘attendant-intradimensional’-prospectively-disontologising preconverging/dementing apriorising-psychologism> ${ }^{\prime}$ is in a state of <amplituding/formativeepistemicity $>$ totalising $\sim$ self-referencing-syncretising/circularity/interiorising/akrasiatic-drag of a medieval worldview will grasp that that unique demonstration of medievalpostlogism $77 /$ perversion-of- ${ }^{83}$ reference-of-thought-<as-preconvergingly-

\section{apriorising/axiomatising/referencing-in-nonconviction/madeupness/bottomlining-as-to-}

shallow-supererogation $>$ (as accusation of witchcraft) is not to be construed naively as an adequate basis for a new ${ }^{5}$ logical-processing-or-logical-implicitation—supposedly-apriorisingin-conviction-as-to-profound-supererogation as 'prelogic supplanting-conviction-as-toprofound-supererogation _of-'attendant-intradimensional'-postconverging/dialectical-

thinking -apriorising-psychologism re-engaging mental-reflex' that re-engages with nonpositivism/medievalism mindset/ ${ }^{3}$ reference-of-thought, given the possibilities of further accusations of witchcrafts or by-and-large the vices-and-impediments ${ }^{105}$ potentially arising from such a non-positivism/medievalism worldview as of the 'local community dynamism of individual interests involved' that endemises and enculturates notions-and-accusations-ofsorcery. It is rather the crossgenerational psychoanalytic-unshackling/memeticreordering/institutional-recomposuring transforming of the non-positivism/medievalism mindset $/{ }^{3}$ reference-of-thought into a positivistic mindset/ $/{ }^{3}$ reference-of-thought that is ontologically-speaking to be construed as the postconverging-de- 
mentating/structuring/paradigming resolution of the vices-and-impediments ${ }^{105}$ arising from a non-positivism/medievalism worldview with respect to such notions-and-accusations-ofsorcery. The same applies with respect to our positivism- ${ }^{8}$ procrypticism worldview and futural Being-development/ontological-framework-expansion-as-to-depth-of-ontologisingdevelopment-as-infrastructure-of- meaningfulness-and-teleology as of prospective notional ${ }^{18}$ deprocrypticism worldview). We can appreciate such metaphysics-of-absence〈implicited-epistemic-veracity-of- nonpresencing-<perspective-ontologicalnormalcy/postconvergence $>>$ insight as of say in a situation of cultural diffusion the requirement that a recurrent-utter-uninstitutionalisation social-setup opportunistically grasping mere effecting possibilities of base-institutionalisation knowledge, as of relative convenience to individuals, are much more better off equally coming into terms institutionally with the ontological-faith-notion-or-ontological-fideism - imbued-underdetermination-of-motif-andapriorising/axiomatising/referencing-as-so-being-as-of-existential-reality induced intemporality ${ }^{52} /$ longness behind the 'inventing of the base-institutionalisation culturally diffused knowledge' for an optimum accrual of the Being-development/ontological-frameworkexpansion-as-to-depth-of-ontologising-development-as-infrastructure-of- meaningfulnessand-teleology of recurrent-utter-uninstitutionalisation; that is, based on baseinstitutionalisation's 'rulemaking-over-non-rules — apriorising/axiomatising/referencing_ psychologism' enabling the superseding of recurrent-utter-uninstitutionalisation vices-andimpediments ${ }^{105}$ as of its 'non-rules - apriorising/axiomatising/referencing-psychologism,-asimpulsive-or-accidented-or-random-mental-disposition'. Such conceptualisation extends to all registry-worldviews/dimensions prospective institutionalisation including our positivismprocrypticism prospective transcendental emancipation to deprocrypticism. Underlying Beingdevelopment/ontological-framework-expansion-as-to-depth-of-ontologising-development-asinfrastructure-of- meaningfulness-and-teleology is the construal of knowledge in both its 
'immediate, cause-and-effect and non-blurry practical and scientific knowledge' and the 'detached, contemplative and blurry human social-construct of knowledge'. In-many-ways as of human temporal/shortness-of-register-of meaningfulness-and-teleology mental-reflex, the former is preconverging/postconverging-de-mentatively/structurally/paradigmatically associated with relatively immediate-constraining <amplituding/formativeepistemicity $>$ causality as-to-projective-totalitative-implications-of-prospective-

\section{nonpresencing,-for-explicating relative-unreflexivity/relative-reflexivity - ontological-}

contiguity that quickly portrays Being-development/ontological-framework-expansion-as-todepth-of-ontologising-development-as-infrastructure-of- meaningfulness-and-teleology by its mere relative disambiguation effectiveness of 'ontologically-veridical knowledge agents' over 'ontologically-flawed knowledge agents'. For instance as of the ontological-faith-notionor-ontological-fideism—imbued-underdetermination-of-motif-and-

apriorising/axiomatising/referencing-as-so-being-as-of-existential-reality induced intemporal/longness-of register-of meaningfulness-and-teleology positivism/rationalempiricism mental-disposition behind the articulation of Newtonian mechanics inducing its mere effecting possibilities of knowledge, the inherent possibilities of inventing things on this positivism/rational-empiricism knowledge intemporal value reference inherently undermines the pertinence of any other supposed knowledge value reference, like a mystical knowledge construal, of the-very-same physics $<$ amplituding/formative-epistemicity $>$ totalising $\sim$ devolvedpurview-as-domain-of-construal-as-intrinsic-reality/ontological-veridicality, such that their inherent contrast disambiguates what is of Being-development/ontological-frameworkexpansion-as-to-depth-of-ontologising-development-as-infrastructure-of- meaningfulnessand-teleology from what is of Being underdevelopment. But then this 'immediate, cause-andeffect and non-blurry practical and scientific knowledge' is just one aspect of Beingdevelopment/ontological-framework-expansion-as-to-depth-of-ontologising-development-as- 
infrastructure-of- meaningfulness-and-teleology as its mere effecting possibilities of knowledge however effective do not exist in a vacuum but rather within the 'detached, contemplative and blurry human social-construct of knowledge' which is the complementary background for Being-development/ontological-framework-expansion-as-to-depth-ofontologising-development-as-infrastructure-of- meaningfulness-and-teleology ; as we can appreciate that despite the positivistic inclinations of the Copernicuses, the Galileos and the Newtons, the scientific advances that ultimately took hold arose because those budding scientists had a sense that the very 'detached, contemplative and blurry human social-construct of knowledge' background had to be superseded as of its scholasticism and mysticism underlying knowledge background for a positivism/rational-empiricism knowledge background to take hold as transcendental-enabling/sublimating/supereregatery $\sim$ de-mentativity not only to science but transcendental-enabling/sublimating/supererogatory $\sim$ de-mentativity as well to the open society equally required for the sound functioning of science. It is this dynamic relationship as of 'immediate, cause-and-effect and non-blurry practical and scientific knowledge' and 'detached, contemplative and blurry human social-construct of knowledge' that is behind Beingdevelopment/ontological-framework-expansion-as-to-depth-of-ontologising-development-asinfrastructure-of- meaningfulness-and-teleology with respect to the prospective registryworldview/dimension as resolving the vices-and-impediments ${ }^{105}$ of the prior registryworldview/dimension. But then no matter the succession of institutionalisations as successive Being-development/ontological-framework-expansion-as-to-depth-of-ontologisingdevelopment-as-infrastructure-of- meaningfulness-and-teleology, there is an ever present issue of Being underdevelopment as of human-subpotencyaporia/undecidability/dilemma/ought-indeterminacy/deficiency/limitation/constraint—imbued'notional firstnaturedness-formativeness-<as-to-eventualising -inkling-drive-or-seedingmisprising $>$ temporal-to-intemporal-dispositions- $<$ so-construed-as-from-perspective- 
ontological-normalcy/postconvergence>'-existentialism-form-factor wherein institutionalising reference-of-thought- categorical-imperatives/axioms/registry-teleology ${ }^{9}$ are always subject at uninstitutionalised-threshold ${ }^{12}$ to their denaturing as of their $<$ amplituding/formative $>$ wooden-language-〈imbued-temporal-mereform/virtualities/dereification/akrasiatic-drag/denatured/preconverging-or-dementing narratives - of-the- reference-of-thought- categorical-imperatives/axioms/registryteleology $\rangle$, as of temporal failing to uphold intemporal-preservation-entropy-or-contiguity-orontological-preservation. Hence Being-development/ontological-framework-expansion-as-todepth-of-ontologising-development-as-infrastructure-of- meaningfulness-and-teleology given human limited-mentation-capacity as subjecting 'educed unlimitedness/existencesublimating nascence' to-limitedness/human-subpotency is rather upheld by ontological-faithnotion-or-ontological-fideism—imbued-underdetermination-of-motif-andapriorising/axiomatising/referencing-as-so-being-as-of-existential-reality as of intemporalpreservation-entropy-or-contiguity-or-ontological-preservation wherein the abstract intemporal/Hongness-of-register-of meaningfulness-and-teleology behind the prior registryworldview institutionalisation should equally be reflected as of prospective registry-worldview institutionalisation, and involving the requisite deferential-formalisation-transference secondnaturing of knowledge as organic-knowledge. We can appreciate the latter point in the sense that with the development of various positivistic scientific and knowledge fields, the knowledge agents weren't naïve to imply that the 'normal social temporal-to-intemporal mentaldispositions as of $<$ amplituding/formative $>$ wooden-language-_imbued-averaging-of-thought$<$ as-to-leveling/ressentiment/closed-construct-of- meaningfulness-and-teleology -as-of'nondescript/ignorable-void '-with-regards-to-prospective-apriorising-implications $>\rangle$ ' $\quad$ are appropriate framework for engaging their subject-matter, as they rather promoted formal knowledge/scientific societies and adopted their specific jargons to ensure that the intemporal 
value reference mental-dispositions behind their respective 'knowledge inventing' was the institutional mental-disposition for engaging with the knowledge formally or as of secondnatured education practically available to everyone interested, and so while alienating and considering general social <amplituding/formative> wooden-language-〈imbued-averaging-of-thought$<$ as-to-leveling/ressentiment/closed-construct-of- meaningfulness-and-teleology -as-of-

'nondescript/ignorable-void ' -with-regards-to-prospective-apriorising-implications $>>\quad$ as improper and unqualified. This was to avoid a circularity of $<$ amplituding/formative $>$ woodenlanguage-〈imbued - averaging-of-thought-<as-to-leveling/ressentiment/closed-construct-ofmeaningfulness-and-teleology -as-of-‘nondescript/ignorable-void '-with-regards-toprospective-apriorising-implications $>>$ undermining of the intemporal-projection of their specific knowledge/science, as they contribute in overall Being-development/ontologicalframework-expansion-as-to-depth-of-ontologising-development-as-infrastructure-ofmeaningfulness-and-teleology. The point here is that at uninstitutionalised-threshold ${ }^{12}$ the idea of 'equal opinionatedness' doesn't apply by the mere fact that knowledge of intrinsic-reality itself doesn't arise by <amplituding/formative> wooden-language-〈imbued-averaging-ofthought-<as-to-leveling/ressentiment/closed-construct-of- meaningfulness-and-teleology -asof-'nondescript/ignorable-void '-with-regards-to-prospective-apriorising-implications $>>$ but rather ontological-pertinence, and the point in reflecting holographically-<conjugatively-andtransfusively $>$ the relative-unreflexivity/relative-reflexivity ontological-contiguity $\sim$ of-thehuman-institutionalisation-process as knowledge-led is to harness ontological-pertinence and not $<$ amplituding/formative $>$ wooden-language-<imbued - averaging-of-thought-<as-toleveling/ressentiment/closed-construct-of- meaningfulness-and-teleology -as-of'nondescript/ignorable-void '-with-regards-to-prospective-apriorising-implications $>>, \quad$ thus explaining deferential-formalisation-transference as of institutional percolation-chanelling. This point is central and critical to the very notion of society-as-social-construct, as society is caught 
between the notion of sovereignty as-allowing-basic-level-of- ${ }^{103}$ universal-individual-andcollective-self-affirmation-striving-for-social-equality and the notion of knowledge as-ofselective-construal-of-social-value-and-institutional-hierarchisation-as-of-

$<$ amplituding/formative-epistemicity $>$ causality $\sim$ as-to-projective-totalitative-implications-ofprospective- nonpresencing,-for-explicating relative-unreflexivity/relative-reflexivity

ontological-contiguity -overriding-social-equality-for-the-sake-of-individual-and-social-

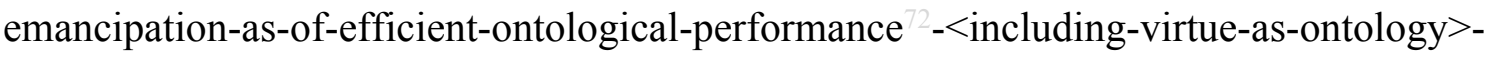
implications. The implication of this dilemma is the reality that society is always subpar to a knowledge social determination as well as subpar to a sovereignty social determination. This dilemma is unavoidable by the very implications of a society: every social-setup as a conventional-construct can only be held together in the long-term as of its requisite given registry-worldview's/dimension's institutionalisation-level of minimally-expected basic conscious-adherence-at-best or token-adherence-at-worst to the said institutionalisation-level's reference-of-thought- categorical-imperatives/axioms/registry-teleology ${ }^{9}$,-foraposteriorising/logicising/deriving/intelligising/measuring - ${ }^{56}$ meaningfulness-and-teleology with regards to meeting a basic level of individuals and social existential-possibilities expectations; such that the notions of knowledge and sovereignty can only be 'socially effective' within this articulated framework as enabled by 'social ${ }^{103}$ universal-transparency 104 〈transparency-of-totalising-entailing,-as-to-entailing-<amplituding/formativeepistemicity $>$ totalising in-relative-ontological-completeness $\rangle^{\prime}$. This articulation can be elucidated more explicitly in cases of cultural diffusion between societies of differing institutionalisation level as such cultural diffusion isn't by a simplistic institutionalisation knowledge-level transference, but involves a mutual sense of sovereign selectivity and recognition among the societies, however the drive for cultural diffusion; thus allowing for 'acculturating-indigenising-pidginising transitioning settings and their social constructions as of 
$<$ amplituding/formative-epistemicity>totalising $\sim$ self-referencing-syncretising' prior $\quad$ to eventual prospective relative-ontological-completeness ${ }^{87}$-of- ${ }^{3}$ reference-of-thought accommodation. This is equally the knowledge and sovereignty dynamics that prevails within any given society. Thus, knowledge can effectively and efficiently be pushed forward but rather through an exercise of increasing 'social ${ }^{103}$ universal-transparency ${ }^{104}$-〈transparency-oftotalising-entailing,-as-to-entailing-<amplituding/formative-epistemicity $>$ totalising $\sim$ inrelative-ontological-completeness $\rangle$ ' thus enabling 'intemporal ontological-faith-notion-orontological-fideism - imbued-underdetermination-of-motif-andapriorising/axiomatising/referencing-as-so-being-as-of-existential-reality instigated relativeunreflexivity/relative reflexivity ontological-contiguity ${ }^{67}$ of-the-human-institutionalisationprocess ${ }^{68}$ as of difference-conflatedness ${ }^{13}$-as-to-totalitative-reification-in-singularisation- $<$ as-tothe-nondisjointedness/entailment-of-prospective- nonpresencing $>$-as-veridical-epistemicityrelativism-determinism implied $<$ amplituding/formative-epistemicity $>$ causality $\sim$ as-toprojective-totalitative-implications-of-prospective- nonpresencing,-for-explicating relativeunreflexivity/relative-reflexivity - ontological-contiguity , associated with Beingdevelopment/ontological-framework-expansion-as-to-depth-of-ontologising-development-asinfrastructure-of- meaningfulness-and-teleology . However, all along this relativeunreflexivity/relative-reflexivity — ontological-contiguity ${ }^{67}$ of-the-human-institutionalisationprocess $^{68}$ a suboptimal relation between knowledge and sovereignty undermines Beingdevelopment/ontological-framework-expansion-as-to-depth-of-ontologising-development-asinfrastructure-of- meaningfulness-and-teleology as of various pertinent social manifestations: -wherein sovereignty is affirm over knowledge as 'supposedly being knowledge' by a culture of mere social-aggregation-enabling of temporal-to-intemporal hotchpotch opinionatedness, notwithstanding the underlying transcendental-enabling/sublimating/supererogatory $\sim$ dementativity in formal institutional percolation-channelling- $<$ in-deferential-formalisation- 
transference>, with the result that beyond the underlying implied institutionalisation-level such a social-aggregation-enabling hotchpotching opinionatedness culture tends to critically and decisively inform individual and collective thought and action in a manner that is suboptimal to intemporality $^{52}$-as-ontology as of the manifestation of such a temporal-to-intemporal hotchpotching culture in the extended-informality that permeates even formal institutions; wherein by exploiting of temporal mental-dispositions as of individuals and the collective-social sovereignty, knowledge is undermined by wrongly implying the pertinence of socialaggregation-enabling construed as 'exploitation of sovereignty'/mobbishness as of 'intellectual institutional-being-and-craft self-serving' in lieu of upholding institutionalisation, including the tendency to degrade knowledge conceptualisations into popular frameworks of knowledge appraisal thus subverting institutional deferential-formalisation-transference rigorous knowledge framework as of their transcendental-enabling/sublimating/supererogatory $\sim$ dementativity as to existence-potency ${ }^{32}$ sublimating-nascence,-disclosed-from-prospectiveepistemic-digression; -the ontologically-flawed articulation of knowledge by an intellectual disposition akin to <amplituding/formative> wooden-language-_imbued-temporal-mereform/virtualities/dereification/akrasiatic-drag/denatured/preconverging-or-dementing narratives - of-the- reference-of-thought- categorical-imperatives/axioms/registryteleology $\rangle$,-for-aposteriorising/logicising/deriving/intelligising/measuring- ${ }^{56}$ meaningfulnessand-teleology ${ }^{9}$ undermining knowledge as of its organic true nature implied by ontologicalfaith-notion-or-ontological-fideism-imbued-underdetermination-of-motif-andapriorising/axiomatising/referencing-as-so-being-as-of-existential-reality behind prior 'knowledge inventing' and prospective 'knowledge inventing', and so as of intellectual institutional-being-and-craft; -ultimately the very paradox of human <amplituding/formativeepistemicity $>$ totalising $\sim$ self-referencing-syncretising/circularity/interiorising/akrasiatic-drag means that the human sovereign psyche is one that is geared to construe of 'presence as all- 
encompassing ${ }^{56}$ meaningfulness-and-teleology value construct' such that the transcendental implications of knowledge by mental-reflex are construed as of incrementalism-in-relativeontological-incompleteness ${ }^{8}$ — enframed/disontologising conceptualisation to presence, rather than as of <amplituding/formative-epistemicity $>$-totalising $\sim$ renewing-realisation/reperception/re-thought of presence construed as of prospective relative notionalcontiguity/epistemic-contiguity ${ }^{2}-<$ profound-supererogation -of-mentally-

aestheticised $\sim$ postconverging/dialectical-thinking -qualia-schema $>$

over prior/transcended/superseded relative notional-discontiguity/epistemic-discontiguity ${ }^{6}$ $<$ between-prior-shallow-supererogation -of-mentallyaestheticised $\sim$ preconverging/dementing -qualia-schema_and_prospective-profoundsupererogation -of-mentally-aestheticised postconverging/dialectical-thinking -qualiaschema>. However despite this knowledge and sovereignty dilemma associated with Beingdevelopment/ontological-framework-expansion-as-to-depth-of-ontologising-development-asinfrastructure-of- meaningfulness-and-teleology, the insight about human $<$ amplituding/formative-epistemicity $>$ totalising $\sim$ self-referencingsyncretising/circularity/interiorising/akrasiatic-drag ${ }^{34}$ as of self-referencing and syncretisingeffecting intemporal implications means that the requisite intemporal/ess of meaningfulness-and-teleology psychoanalytic-unshackling positive-opportunism-ofsocial-functioning-and-accordance ${ }^{75}$ can crossgenerationally be induced for Beingdevelopment/ontological-framework-expansion-as-to-depth-of-ontologising-development-asinfrastructure-of- meaningfulness-and-teleology despite the inherent circular distractiveness of temporality", and ultimately so as enabled by 'social ${ }^{103}$ universal-transparency ${ }^{104}$ $\langle$ transparency-of-totalising-entailing,-as-to-entailing-<amplituding/formativeepistemicity $>$ totalising in-relative-ontological-completeness $\rangle$ '. The above analysis point out that transcendental knowledge in particular involves more than just knowledge as a grounded 
construct but as well an understanding of how such knowledge is instigated in society as partand-parcel of the knowledge construed as organic-knowledge; given that the social-constructas-society is not necessarily of immediate receptivity and is of a suboptimal disposition to such transcendental-enabling/sublimating/supererogatory $\sim$ de-mentativity implications that are not priorly as of grounded constructs of knowledge. This will explain why the mere articulation of positivism/rational-empiricism ${ }^{56}$ meaningfulness-and-teleology ${ }^{9}$ constructs of knowledge wasn't enough in undermining medieval mental-dispositions, and the persistent initiatives of the Copernicuses, Galileos, Rousseaux, Diderots, etc., were not vague actions but informed by an intuition about the nature of human society and how it develops given the inherently untransformable human-subpotency-aporia/undecidability/dilemma/oughtindeterminacy/deficiency/limitation/constraint—imbued-'notional firstnaturednessformativeness-<as-to-eventualising-inkling-drive-or-seeding-misprising $>$ temporal-tointemporal-dispositions- $<$ so-construed-as-from-perspective-ontologicalnormalcy/postconvergence>'-existentialism-form-factor as of human limited-mentationcapacity —as-subjecting 'educed-unlimitedness/existence-sublimating nascence' tolimitedness/human-subpotency. Thus in reflecting holographically-<conjugatively-andtransfusively $>$ the relative unreflexivity/relative reflexivity ontological-contiguity of-thehuman-institutionalisation-process, crucially the issue of ontological-veracity is only half the problem of knowledge, with the other half being the grasp of the underlying sovereignty and knowledge dynamics as of eliciting 'social ${ }^{103}$ universal-transparency ${ }^{104}$-〈transparency-oftotalising-entailing,-as-to-entailing-<amplituding/formative-epistemicity $>$ totalising inrelative-ontological-completeness $\rangle$ '. As it is the latter that induces that social positiveopportunism-of-social-functioning-and-accordance ${ }^{75}$ for deferential-formalisationtransference and institutional percolation-channelling- $<$ in-deferential-formalisationtransference>, as of social deferential attribution of power for the beneficial effect of knowledge 
as empowering various institutional domains. Further, as implying the superseding of entrenched grounded knowledge as of its psychoanalytic-unshackling implications and in destabilising the underlying existential-<disontologising/re-ontologising aporeticism $>{ }^{8}$ reference-of-thought, transcendental knowledge is of a circular but consistent exercise of <amplituding/formativeepistemicity>-totalising $\sim$ renewing-realisation/re-perception/re-thought, and so due to the 'existential and emotive commitments' it is involved in undoing with regards to the implied prior notional-discontiguity/epistemic-discontiguity ${ }^{6}<$ between - prior-shallow-supererogation -ofmentally-aestheticised preconverging/dementing -qualia-schema_and_prospective-profoundsupererogation -of-mentally-aestheticised postconverging/dialectical-thinking -qualiaschema $>{ }^{83}$ reference-of-thought and introducing the prospective notional-contiguity/epistemiccontiguity ${ }^{62}<$ profound-supererogation -of-mentally-aestheticised $\sim$ postconverging/dialecticalthinking -qualia-schema $>$ reference-of-thought as of the-very-same-immanentexistence/intrinsic-reality/ontological-veridicality,-as-to-'human<amplituding/formativeepistemicity>totalising purview-of-construal'. Consider in this regard, that the theory-ofrelativity-together-with-quantum-mechanics - axiomatic-constructs as of propective notionalcontiguity/epistemic-contiguity ${ }^{2}-<$ profound-supererogation -of-mentally-

aestheticised postconverging/dialectical-thinking -qualia-schema $>$ is more than just a reification gesturing/accounting-of-epistemic-phenomenalism of its very own axiomaticconstruct affirmation/projection/assertion/notional $\sim$ self-distantiation/dueness-validatinglogicising/suitable-measuringinstrument-validating-measuring-<as-to-postconverging-ordialectical-thinking -apriorising-psychologism $>$ but extends to encompass a preconverging-ordementing -apriorising-psychologism/unaffirmation/deprojection/deassertion/epistemicdecadence/undueness-invalidating-logicising/unsuitable-measuringinstrument-invalidatingmeasuring-<as-to-preconverging-or-dementing -apriorising-psychologism $>$ of 'traditional classical mechanics axiomatic-construct', at the threshold where it supersedes 'traditional 
classical mechanics axiomatic-construct', as being of notional-discontiguity/epistemic-

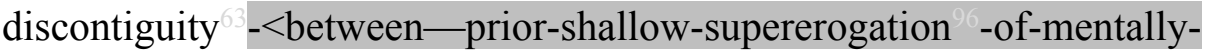
aestheticised preconverging/dementing -qualia-schema_and_prospective-profoundsupererogation -of-mentally-aestheticised postconverging/dialectical-thinking -qualiaschema $>$ when analysed as of 'traditional classical mechanics axiomatic-construct', and so with regards to 'the-very-same physics <amplituding/formative-epistemicity $>$ totalising $\sim$ devolvedpurview/domain-of-construal-as-intrinsic-reality/ontological-veridicality/existential-reality'.

The ontological veridicality here is that such 'double-gesture reification as the prospective axiomatic affirmation/projection/assertion/notional $\sim$ self-distantiation/dueness-validatinglogicising/suitable-measuringinstrument-validating-measuring-<as-to-postconverging-ordialectical-thinking -apriorising-psychologism $>$ together with the prior axiomatic preconverging-or-dementing 2 -apriorisingpsychologism/unaffirmation/deprojection/deassertion/epistemic-decadence/unduenessinvalidating-logicising/unsuitable-measuringinstrument-invalidating-measuring-<as-topreconverging-or-dementing -apriorising-psychologism>' implied as of the nonpresencing<perspective-ontological-normalcy/postconvergence $>$ induced transcendence-andsublimity/sublimation/smerentativity is not to be construed as an incrementalism-in-relative-ontological-incompleteness enframed/disontologising conceptualisation as of elaboration-as-to-mereextrapolating/constituting/abstracting/deducing/inferring-of-elucidation-outside'prospectively implicited_attendant-ontological-contiguity ${ }^{67}$ ' educedexistentialising/contextualising/textualising_intelligibility/epistemicity/reflexivity_contiguity$<$ imbued-notional cogency>' ${ }^{40}$ of the superseded ${ }^{79}$ presencing-absolutising-identitiveconstitutedness ${ }^{14}$, but is rather a ${ }^{55}$ maximalising-recomposuring-for-relative-ontologicalcompleteness $^{87}$ — unenframed/re-ontologising conceptualisation in subsuming 'the-very-same 
physics

$<$ amplituding/formative-epistemicity $>$ totalising $\sim$ devolved—-purview/domain-ofconstrual-as-intrinsic-reality/ontological-veridicality/existential-reality'. While the emotional involvement and sense of 'existential ego undermining' involved in such a transcending reification gesturing/accounting-of-epistemic-phenomenalism of axiomatic-constructs as of the-very-same <amplituding/formative-epistemicity $>$ totalising $\sim$ devolved — purview/domainof-construal-as-intrinsic-reality/ontological-veridicality/existential-reality is relatively trite as occurring within the same registry-worldview/dimension ${ }^{8}$ reference-of-thought as of the positivism/rational-empiricism ${ }^{56}$ meaningfulness-and-teleology ${ }^{9}$ mindset as well as its distance rather with respect to physical reality, such a transcending reification gesturing/accounting — ofepistemic-phenomenalism as of the grandest axiomatic-constructs having to do with consciousness with regards to the 'very ${ }^{83}$ reference-of-thought itself' wherein the prospective

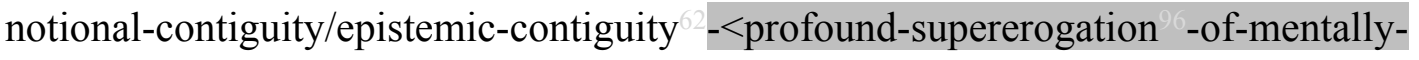
aestheticised postconverging/dialectical-thinking -qualia-schema> ${ }^{83}$ reference-of-thought as deprocrypticism-or-preempting-disjointedness-as-of- ${ }^{3}$ reference-of-thought implies a transcending reification gesturing/accounting-of-epistemic-phenomenalism that not only affirms notional ${ }^{1}$ deprocrypticism prospective registry-worldview/dimension but in that affirmation/projection/assertion/notional self-distantiation/dueness-validatinglogicising/suitable-measuringinstrument-validating-measuring-<as-to-postconverging-ordialectical-thinking -apriorising-psychologism> as of its ontological-completeness-ofreference-of-thought de-asserts/dements our positivism- ${ }^{80}$ procrypticism registryworldview/dimension, this will elicit an existential-<disontologising/re-ontologising aporeticism $>$ and emotional involvement that will rather convert into a circular neuterisation of notional ${ }^{18}$ deprocrypticism by a mental-complex avoiding such emotional discomfort and sense of existential-<disontologising/re-ontologising aporeticism $>$ ego undermining as is the case with all destructuring-threshold-〈uninstitutionalised-threshold /presublimating- 
desublimating-decisionality $>$ of-ontological-performance ${ }^{72}-<$ including-virtue-as- $^{-}$

ontology $>$ /morality/ethics/justice/etc. with respect to their prospective institutionalisations. This explains why it is not a fundamental contradiction as of human-subpotencyaporia/undecidability/dilemma/ought-indeterminacy/deficiency/limitation/constraint—imbued'notional firstnaturedness-formativeness-as to eventulising inkling drive or seeding misprising $>$ temporal-to-intemporal-dispositions- $<$ so-construed-as-from-perspective-

ontological-normalcy/postconvergence>'-existentialism-form-factor at uninstitutionalisedthreshold ${ }^{102}$ that the positivism/rational-empiricism initiatives of such enlightenment thinkers like Galileo, Descartes, Diderot, etc. were met with counteracting reactionary views, and as it further elicits ontologically-flawed 'uninstitutionalised-threshold ${ }^{12}$ by prospective institutionalisation dialogical-equivalence-<as-topsychologismic $\sim$ apriorising/axiomatising/referencing-\{of-"prospectively implicited_attendant-ontological-contiguity ' educedexistentialising/contextualising/textualising_'intelligibility/epistemicity/reflexivity_contiguity$<$ imbued-notional cogency $>>$ - conflatedness -in-\{preconverging ment by\} postconverging-ntailment,-in-self-becoming/self-conflatedness /formative-supererogating>' . This can't be the case because dialogical-equivalence-<as-topsychologismic apriorising/axiomatising/referencing-\{of-"prespectively implicited_attendant-ontological-contiguity ' educedexistentialising/contextualising/textualising_'intelligibility/epistemicity/reflexivity_contiguity$<$ imbued-notional cogency $>$ ' \}-conflatedness -in-\{preconverging ment by\} postconverging entailment,-in-self-becoming/self-conflatedness /formative-supererogating> can only arise where there is 'common ${ }^{83}$ reference-of-thought' whereas a state of institutionalisation as of prospective relative-ontological-completeness ${ }^{87}$-of- ${ }^{83}$ reference-ofthought is veridically in an institutionalising/enlightening/educating exercise relative to a state 
of uninstitutionalised-threshold ${ }^{102}$ as of prior relative-ontological-incompleteness ${ }^{88}$-ofreference-of-thought, and not such a flawed notion of dialogical-equivalence-<as-topsychologismic apriorising/axiomatising/referencing-\{of-"prespectively implicited_attendant-ontological-contiguity ' reducedexistentialising/contextualising/textualising_'intelligibility/epistemicity/reflexivity_contiguity$<$ imbued-notional cogency $>>\quad\}$-conflatedness -in-\{preconverging-ment by\} postconverging entailment,-in-self-becoming/self-conflatedness /formative-supererogating $>$.

We can appreciate even within a same ${ }^{83}$ reference-of-thought like our positivism/rationalempiricism registry-worldview/dimension that there is no dialogical-equivalence-<as-topsychologismic apriorising/axiomatising/referencing-\{of-'prospectively implicited_attendant-ontological-contiguity ' educedexistentialising/contextualising/textualising_'intelligibility/epistemicity/reflexivity-contiguity$<$ imbued-notional cogency $>$ ' \}-conflatedness - in-\{preconverging ment by\} postconverging-entailment,-in-self-becoming/self-conflatedness /formative-supererogating> between the theory-of-relativity-together-with-quantum-mechanics - axiomatic-constructs in notional-contiguity/epistemic-contiguity ${ }^{62}$ - profound-supererogation -of-mentallyaestheticised postconverging/dialectical-thinking -qualia-schema $>$ and 'traditional classical mechanics axiomatic-construct' of notional-discontiguity/epistemic-discontiguity $<$ between-prior-shallow-supererogation -of-mentallyaestheticised preconverging/dementing -qualia-schema_and_prospective-profoundsupererogation -of-mentally-aestheticised postconverging/dialectical-thinking -qualiaschema $>$ but for the former's enlightening the latter's undefined-or-undecidable-threshold-ofontological-veridicality. This insight reflects the reality of transcendence-andsublimity/sublimation/supererogatory de-mentativity in reflecting holographically$<$ conjugatively-and-transfusively $>$ the relative-unreflexivity/relative-reflexivity - ontological- 
development/ontological-framework-expansion-as-to-depth-of-ontologising-development-asinfrastructure-of- meaningfulness-and-teleology, wherein uninstitutionalised-threshold mental-reflexes of $\quad<$ amplituding/formative-epistemicity $>$ totalising $\sim$ self-referencingsyncretising/circularity/interiorising/akrasiatic-drag in their incrementalism-in-relativeontological-incompleteness ${ }^{8}$ — enframed/disontologising conceptualisation as of elaborationas-to-mere-extrapolating/constituting/abstracting/deducing/inferring-of-elucidation-outside'prospectively_implicited_attendant-ontological-contiguity ${ }^{67}$ ' educedexistentialising/contextmalising/textualising_'intelligibility/epistemicity/reflexivity_contiguity$<$ imbued-notional cogency $>^{\prime}$ tend to perpetuate the representation of prospective institutionalisation as nondescript/ignorable-void (actually speaking of akrasiatic-dragdenatured-and-preconverging-or-dementing -narratives) in an ontologically-flawed dereification gesturing/accounting - of-epistemic-phenomenalism of neuterisation ${ }^{59}$, rather than maximalising-recomposuring-for-relative-ontological-completeness ${ }^{87}$ - unenframed/reontologising conceptualisation as of $\quad<$ amplituding/formative-epistemicity $>$ totalising renewing-realisation/re-perception/re-thought implied as of prospective institutionalisation's deneuterising ${ }^{17}$. It should thus be noted that such a transcendental exercise is not about passing the test as of the judgment of uninstitutionalised-threshold ${ }^{102}$ mental-reflexes of $<$ amplituding/formative-epistemicity $>$ totalising $\sim$ self-referencingsyncretising/circularity/interiorising/akrasiatic-drag which is 'ontologically flawed and wanting' but rather is as of a maximalising-recomposuring-for-relative-ontologicalcompleteness $^{87}$ — unenframed/re-ontologising conceptualisation intemporal-projection transcendental-enabling/sublimating/serpentativity for prospective institutionalisation relative to such <amplituding/formative-epistemicity $>$ totalising $\sim$ selfreferencing-syncretising/circularity/interiorising/akrasiatic-drag that circularly reinstitute the 
uninstitutionalised-threshold ${ }^{102}$ temporality $/$ shortness as if intemporal in ${ }^{5}$ incrementalism-inrelative-ontological-incompleteness ${ }^{8}$ - enframed/disontologising conceptualisation as of elaboration-as-to-mere-extrapolating/constituting/abstracting/deducing/inferring-ofelucidation-outside_-'prospectively_implicited_attendant-ontological-contiguity ${ }^{67}$ > educedexistentialising/contextualising/textualising_'intelligibility/epistemicity/reflexivity-contiguity$<$ imbued-notional cogency ${ }^{\prime}{ }^{\prime}$. In other words prospective institutionalisation arises as of 'transcendental-reasoning-of-event ${ }^{38}$-as-prospective-ontology-origination' which as of prospective relative-ontological-completeness ${ }^{87}$-of-axiomatic-construct-or- ${ }^{83}$ reference-ofthought is introducing a 'new-as-of-the-prospective-institutionalisation ordinarynontranscendental-reasoning' that blocks-out/supersedes/de-asserts/dements as of notionaldiscontiguity/epistemic-discontiguity ${ }^{63}<$ between - prior-shallow-supererogation -ofmentally-aestheticised preconverging/dementing -qualia-schema_and_prospective-profoundsupererogation -of-mentally-aestheticised postconverging/dialectical-thinking -qualia-

schema $>$ the 'prior-or-old-as-now-uninstitutionalised ordinary-nontranscendental-reasoning'; with the implication that our " ${ }^{80}$ procrypticism-or-disjointedness-as-of- ${ }^{8}$ reference-of-thought

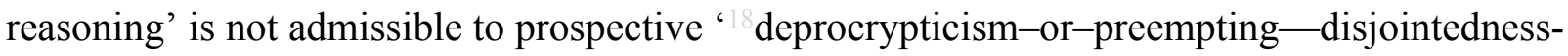
as-of- ${ }^{3}$ reference-of-thought reasoning' and so from the moment of the event ${ }^{8}$-construed-as-theprospective-ontology-origination of deprocrypticism, just as 'non-positivistic medieval reasoning' is not admissible to prospective 'positivism reasoning' from the moment of the event $^{38}$-construed-as-the-prospective-ontology-origination of positivism, etc., across the successive institutionalisations in reflecting holographically-<conjugatively-and-transfusively $>$ the relative unreflexivity/relative-reflexivity - ontological-contiguity of-the-humaninstitutionalisation-process ; and so as of notional-discontiguity/epistemic-discontiguity $<$ between-prior-shallow-supererogation -of-mentallyaestheticised preconverging/dementing -qualia-schema_and_prospective-profound- 
supererogation -of-mentally-aestheticised postconverging/dialectical-thinking -qualia-

schema $>$ of the uninstitutionalised-threshold ${ }^{102}$ and the prospective institutionalisation. Such a temporal/shortness-of-register-of - meaningfulness-and-teleology ontologically-flawed predisposition in circularly striving to reassert the 'prior-or-old-as-now-uninstitutionalised ordinary-nontranscendental-reasoning' over the 'transcendental-reasoning-of-event ${ }^{8}$-asprospective-ontology-origination' is fundamentally due to the preconverging/postconvergingde-mentative/structural/paradigmatic lifetime 'mental and existential-<disontologising/reentologising aporeticism $>$ investment' in the former, such that by-and-large it is mostly a crossgenerational transcendence-and-sublimity/sublimation/supererogatory - de-mentativity that fully brings about the adaptation of the induced 'transcendental-reasoning-of-event ${ }^{38}$-asprospective-ontology-origination' as the 'new-as-of-the-prospective-institutionalisation ordinary-nontranscendental-reasoning'. Such a temporal/shortness-of-register-ofmeaningfulness-and-teleology ontologically-flawed circular predisposition arises due to human temporal-dispositions as of Being underdevelopment that tends to lead to the beyondthe-consciousness-awareness-teleology ${ }^{9}<$ of-preconverging-existential-extrication-as-ofexistential-unthought $>$ denaturing ${ }^{16}$ of knowledge as mechanical-knowledge and undermining organic-knowledge; wherein knowledge is related to as of precential-extricationas-of-existential-unthought, that is, knowledge related to as of the 'mere positive-opportunismof-social-functioning-and-accordance ${ }^{75}$ it engenders at best' with little or no cognisance that there is an attitude/mental-disposition/care-and-episteme ${ }^{5}$ as of intemporality ${ }^{52} /$ longness behind $^{2}$ 'knowledge invention' that must be preserved and perpetuated as the 'very core of knowledge' and so to undermine knowledge denaturing ${ }^{16}$, so-construed as organic-knowledge. Organicknowledge requires the articulation of ${ }^{56}$ meaningfulness-and-teleology ${ }^{9}$ rather in postconverging-nonextricatory-existential-preempting-of-existential-unthought terms-as-ofaxiomatic-construct as the profound-and-complete articulation of knowledge, and as the very 
attitude/mental-disposition/care-and-episteme behind knowledge that induces the appropriate psychoanalytic-unshackling for its reception. In other words, we can't seriously contemplate a profound positivistic knowledge engagement with a non-positivistic as animistic or medieval mindset without the idea of priorly eliciting the appreciation-and-adoption of a positivism apriorising/axiomatising/referencing/intelligibilitysettingup/measuringinstrumenting attitude/mental-disposition/care-and-episteme when contending about any salient positivistic articulations as otherwise all such positivism/rational-empiricism articulations and explaining will be reconstrued circularly in animistic or medieval terms-as-of-axiomatic-construct as of the latter teleologically-degraded prior relative-ontological-incompleteness ${ }^{8}$-of- ${ }^{83}$ reference-ofthought ${ }^{56}$ meaningfulness-and-teleology ${ }^{9}$ Likewise ${ }^{56}$ meaningfulness-and-teleology articulated as of ${ }^{18}$ deprocrypticism-or-preempting-disjointedness-as-of- ${ }^{8}$ reference-ofthought relative to our positivism- ${ }^{80}$ procrypticism necessarily requires priorly the requisite apriorising-teleological-elevation-in $\sim$ notional-contiguity/epistemic-contiguity ${ }^{62}-<$ profoundsupererogation -of-mentally-aestheticised postconverging/dialectical-thinking -qualiaschema $>$ from positivism- ${ }^{8}$ procrypticism's disjointedness-as-of- ${ }^{83}$ reference-of-thought mindset into deprocrypticism's preempting - disjointedness-as-of- reference-of-thought apriorising/axiomatising/referencing/intelligibilitysettingup/measuringinstrumenting attitude/mental-disposition/care-and-episteme as otherwise such knowledge will be teleologically-degraded in circular positivism- ${ }^{80}$ procrypticism disjointedness-as-of- ${ }^{8}$ referenceof-thought terms-as-of-axiomatic-construct as of prior relative-ontological-incompleteness ${ }^{88}$ of- ${ }^{8}$ reference-of-thought ${ }^{56}$ meaningfulness-and-teleology ${ }^{9}$, even though in the latter case our $<$ amplituding/formative-epistemicity $>$ totalising $\sim$ self-referencing-syncretising/illusion-of-thepresent/present-consciousness/mirage as metaphysics-of-presence-_implicited'nondescript/ignorable-void ' 'as-to- presencing - absolutising-identitive-constitutedness > blinds us to appropriately appreciating this given the human mental-reflex of representing any 
uninstitutionalised-threshold ${ }^{102}$ as nondescript/ignorable-void (actually speaking of akrasiaticdrag-denatured-and-preconverging-or-dementing -narratives)

of

our $<$ amplituding/formative-epistemicity $>$ totalising $\sim$ self-referencingsyncretising/circularity/interiorising/akrasiatic-drag ${ }^{34}$. The point here is that the meaningfulness-and-teleology so-construed has to supersede the prior registryworldview/dimension uninstitutionalised-threshold perspective/framing/reference/horizon/projection for its prospective transcendence-andsublimity/sublimation/supererogatory de-mentativity-enabling purpose, even if that implies being temporally unpalatable, given that the fundamental purpose for the underlying aetiologisation/ontological-escalation-<ontological-

veridicality_commitment/otherliness_transcending/compulsions-encumbered_transcending $>$ is of intemporal/ontological/social/species/ ${ }^{103}$ universal/transcendental/ $/$ maximalisingrecomposuring-for-relative-ontological-completeness ${ }^{7}$ — unenframed/reontologising conceptualisation postconverging-de-mentating/structuring/paradigming and not temporal extricatory preconverging-de-mentating/structuring/paradigming. Put another way, for instance, Newtonian physics doesn't have any inherent ${ }^{56}$ meaningfulness-and-teleology ${ }^{99}$ as we can appreciate from a positivism/rational-empiricism perspective/framing/referencing/horizon with an animistic social-setup as of the latter's attitude/mental-disposition/care-and-episteme underlying its ${ }^{56}$ meaningfulness-and-teleology ${ }^{9}$ thus requiring the latter's prior apriorisingteleological-elevation-in $\sim$ notional-contiguity/epistemic-contiguity ${ }^{62}-<$ profound-

\section{supererogation -of-mentally-aestheticised postconverging/dialectical-thinking -qualia-}

schema $>$ to a positivism/rational-empiricism attitude/mental-disposition/care-and-episteme 'for the notion of the mutual contemplation of Newtonian physics to even arise'. This speaks of the centrality of attitude/mental-disposition/care-and-episteme with respect to human meaningfulness-and-teleology $y^{9}, \quad$ as it is what underlies 
apriorising/axiomatising/referencing/intelligibilitysettingup/measuringinstrumenting as of a given registry-worldview's/dimension's institutionalisation ${ }^{83}$ reference-of-thought. Attitude/mental-disposition/care-and-episteme as $^{5}$ such carries a registryworldview's/dimension's 'underlying sense of end-teleology /end-purposefulness' and thereof its operative-construct and implicative-construct with regards to meaningfulness-andteleology . It further implies a the 'human toddling potential' for living-as-of-humanpersonality-developing, social-projection-institutional-orientations and Beingdevelopment/ontological-framework-expansion-as-to-depth-of-ontologising-development-asinfrastructure-of- meaningfulness-and-teleology ; with the 'human toddling potential' implying the human potential to develop from a relative-ontologically-flawed to a relativeontologically-veridical attitude/mental-disposition/care-and-episteme ${ }^{5}$ with respect to livingas-of-human-personality-developing, social-projection-institutional-orientations and Beingdevelopment/ontological-framework-expansion-as-to-depth-of-ontologising-development-asinfrastructure-of- meaningfulness-and-teleology. This 'human toddling potential' is what enables notional-discontiguity/epistemic-discontiguity ${ }^{63}<$ between - prior-shallowsupererogation -of-mentally-aestheticised $\sim$ preconverging/dementing -qualiaschema_and_prospective-profound-supererogation -of-mentallyaestheticised postconverging/dialectical-thinking -qualia-schema $>$ induced psychoanalyticunshackling for grounding ${ }^{56}$ meaningfulness-and-teleology ${ }^{99}$ prospectively as of the prospective relative-ontological-completeness ${ }^{87} \quad$ of $\quad$ nonpresencing-<perspective-ontologicalnormalcy/postconvergence $>$. The attitude/mental-disposition/care-and-episteme structure is what fundamentally determines mental-states in their 'projection/anticipation of the coherence/contiguity-of-superseding-oneness-of-ontology-as-of-inherent-existencecoherence/contiguity' whether with respect to any individual within any registryworldview/dimension as well as the registry-worldview's/dimension's overall ${ }^{83}$ reference-of- 
thought, as of its specific ${ }^{83}$ reference-of-thought- categorical-imperatives/axioms/registryteleology ${ }^{9}$,-for-aposteriorising/logicising/deriving/intelligising/measuring- ${ }^{5}$ meaningfulnessand-teleology ${ }^{9}$. Thus an attitude/mental-disposition/care-and-episteme can pertinently be defined as the 'assumed-and-unflinching apriorising/axiomatising/referencing/intelligibilitysettingup/measuringinstrumenting transversality-<for-sublimating-existential-eventuating/denouement-from-'thinking-at-

\section{first/pure-predisposition-preemptive-of-prospective-disontologising/subontologising' as-of-} prospectively-disambiguated-affirmed-and-unaffirmed-'motif-andapriorising/axiomatising/referencing'> $>101$ inducing a given specific ${ }^{61}$ nonpresencing<perspective-ontological-normalcy/postconvergence> outcome with regards to prospective relative-ontological-completeness ${ }^{87}$-or-incompleteness-of- ${ }^{8}$ reference-of-thought as of the construal-as-existence/intrinsic-reality/ontological-veridicality, and establishing-and-upholding the underlying framework of ${ }^{56}$ meaningfulness-and-teleology ${ }^{9}$ associated with that attitude/mental-disposition/care-and-episteme; and so, whether such a framework is a reference-of-thought as of overall construal-as-existence/existential-possibilities, or within a reference-of-thought like a social projection <amplituding/formativeepistemicity $>$ totalising $\sim$ devolved-purview-as-domain-of-construal-as-intrinsic-

reality/ontological-veridicality or specifically with living-as-of-human-personality-developing. For instance, with respect to coming across and living say in an early hunter-gather society with its interpretation of ill-health as of bad omen, we will still maintain an 'assumed-and-unflinching transversality-<for-sublimating-existential-eventuating/denouement-from-'thinking-at-

\section{first/pure-predisposition-preemptive-of-prospective-disontologising/subontologising' as-of-} prospectively-disambiguated-affirmed-and-unaffirmed-‘motif-andapriorising/axiomatising/referencing' $>101$ as of the attitude/mental-disposition/care-andepisteme of positivism's/rational-empiricism's per-cep-ti-vi-ty-as-of-full-disease-and- 
scientific-theory-construct-as-the-exclusive-cause-and-effect-conceptualisation, at least as of our self-conscious awareness, even as this reflects mutual beyond-the-consciousness-awarenessteleology 9 - $<$ of-preconverging-existential-extrication-as-of-existential-unthought $>$ as when we publicly pretend to act otherwise by subscribing to the interpretation within such a social-setup. As construed within a given ${ }^{83}$ reference-of-thought, say in our positivism/rational-empiricism reference-of-thought we can further have the conception of the physics or biology or law or literature or even just entrepreneur or accountant or technician specific attitude/mentaldisposition/care-and-episteme, and further at the individual level as of changing attitude/mental-disposition/care-and-episteme with living-as-of-human-personalitydeveloping. Attitude/mental-disposition/care-and-episteme as so-construed is critical fundamentally because the notionally inherent human capacity for aetiologisation/ontologicalescalation-<ontological-veridicality_commitment/otherliness_transcending/compulsionsencumbered_transcending $>$ is directly associated with 'attitude/mental-disposition/care-andepisteme as dispensing-with-immediacy-for-relative-ontological-completeness ${ }^{87}$-byreification/contemplative-distension ${ }^{27}$ (as of human self-surpassing-existentialism-formfactor,-in-overcoming-‘notional collateralising-beholdening-protohumanity’-to-'attainsublimating-humanity'-as-to-existence-potency sublimating-nascence,-disclosed-fromprospective-epistemic-digression to supersede human temporality $8 /$ shortness $<$ amplituding/formative $>$ wooden-language-〈imbued - averaging-of-thought- $<$ as-toleveling/ressentiment/closed-construct-of- meaningfulness-and-teleology -as-of'nondescript/ignorable-void '-with-regards-to-prospective-apriorising-implications $>\rangle$ ) to be able to achieve transcendence-and-sublimity/sublimation/supererogatory $\sim$ de-mentativity', and so as of intemporality ${ }^{52}$. With regards to living-as-of-human-personality-developing, we can appreciate in the case of a child's personality development as of its given attitude/mentaldisposition/care-and-episteme that it has a poor dispensing-with-immediacy-for-relative- 
ontological-completeness ${ }^{87}$-by-reification/contemplative-distension ${ }^{27}$ as of its more direct focus on instant-sensations-and-carefreeness requiring that the child is directed to end at successive stages infantile habits as it grows up with an increasing sense of dispensing-with-immediacyfor-relative-ontological-completeness ${ }^{87}$-by-reification/contemplative-distension ${ }^{27} \quad$ that ultimately involves major stages like schooling, greater social autonomy and responsibility/relative-reflexivity, and developing into an adult with even greater dispensingwith-immediacy-for-relative-ontological-completeness ${ }^{87}$-by-reification/contemplativedistension ${ }^{27}$ as for instance the notion of pleasure is increasingly substituted with that of workand-pleasure, etc. Such living-development-as-to-personality-development as dispensing-withimmediacy-for-relative-ontological-completeness ${ }^{87}$-by-reification/contemplative-distension ${ }^{27}$ is construed as the more profound attitude/mental-disposition/care-and-episteme for human optimum living, and so over say an animal-like immediacy attitude/mental-disposition/careand-episteme of living. With regards to the second-level of social aetiologisation/ontologicalescalation-<ontological-veridicality_commitment/otherliness_transcending/compulsionsencumbered_transcending $>$ associated with 'attitude/mental-disposition/care-and-episteme dispensing-with-immediacy-for-relative-ontological-completeness ${ }^{87}$-byreification/contemplative-distension ${ }^{27}$, for achieving transcendence-andsublimity/sublimation/supererogatory $\sim$ de-mentativity; humankind construes of existence as 'more than just plain living as animals' but as enabling for various domains of social projections dispensing-with-immediacy-for-relative-ontological-completeness ${ }^{87}$-by-

reification/contemplative-distension ${ }^{27}$ so-implied across the various registryworldviews/dimensions, whether in an animistic social-setup involving animistic practices or in the modern social-setup as of our modern practices involving subject-matter specialisms, trade roles, functionaries, arts, research, sports and other activities, etc.; with each involving their specific attitude/mental-disposition/care-and-episteme dispensing-with-immediacy-for- 
relative-ontological-completeness ${ }^{7}$-by-reification/contemplative-distension ${ }^{27}$. The idea being that this provides more existential<<disontologising/re-ontologising aporeticism $>$ possibilities by the overall expanded human capabilities available directly or indirectly to fulfil individuals desires and needs. Finally the third-level reflects 'intemporal ontological-faith-notion-orontological-fideism - imbued-underdetermination-of-motif-andapriorising/axiomatising/referencing-as-so-being-as-of-existential-reality instigated relativeunreflexivity/relative-reflexivity — ontological-contiguity ${ }^{67}$ of-the-human-institutionalisationprocess $^{68}$ as of difference-conflatedness ${ }^{13}$-as-to-totalitative-reification-in-singularisation- $<$ as-tothe-nondisjointedness/entailment-of-prospective- nonpresencing $>$-as-veridical-epistemicityrelativism-determinism implied <amplituding/formative-epistemicity $>$ causality $\sim$ as-toprojective-totalitative-implications-of-prospective- nonpresencing,-for-explicating relativeunreflexivity/relative-reflexivity ontological-contiguity,$\quad$ with Beingdevelopment/ontological-framework-expansion-as-to-depth-of-ontologising-development-asinfrastructure-of- meaningfulness-and-teleology , beyond-the-consciousness-awarenessteleology ${ }^{9}<$ of-preconverging-existential-extrication-as-of-existential-unthought $>$, implying specifically a pestconverging-nonextricatory-existential-preempting-of-existential-unthought attitude/mental-disposition/care-and-episteme as dispensing-with-immediacy-for-relativeontological-completeness ${ }^{87}$-by-reification/contemplative-distension ${ }^{27}$-of- ${ }^{8}$ reference-ofthought-by-reification/contemplative-distension thus transcendentally enabling the successive registry-worldview's/dimension's ontological-possibilities construed as of human intemporal/ontological/social/species/ ${ }^{103}$ universal/transcendental $/{ }^{5}$ maximalisingrecomposuring-for-relative-ontological-completeness ${ }^{87}$ - unenframed/reontologising conceptualisation postconverging-de-mentating/structuring/paradigming; with such dispensing-with-immediacy-for-relative-ontological-completeness ${ }^{87}$-byreification/contemplative-distension ${ }^{27}$-of- ${ }^{8}$ reference-of-thought-by-reification/contemplative- 
distension construed as rejection of preconverging-existential-extrication-as-of-existentialunthought attitude/mental-disposition/care-and-episteme which will imply a stalling in reflecting holographically-<conjugatively-and-transfusively $>$ the relative-unreflexivity/relativereflexivity - ontological-contiguity of-the-human-institutionalisation-process as of Beingdevelopment/ontological-framework-expansion-as-to-depth-of-ontologising-development-asinfrastructure-of- meaningfulness-and-teleology at the given registry-worldview/dimension, and so-construed as temporal extricatory preconverging-de-mentating/structuring/paradigming. Being-development/ontological-framework-expansion-as-to-depth-of-ontologisingdevelopment-as-infrastructure-of- meaningfulness-and-teleology as such implies increasingly more profound-and-complete enabling framework of human emancipation as of technical and existential-<disontologising/re-ontologising aporeticism $>$ possibilities arising from prospective relative-ontological-completeness ${ }^{87}$-of- ${ }^{8}$ reference-of-thought. We can get an insight of registry-worldviews/dimensions attitude/mental-disposition/care-and-episteme contrast as clarified in the preceding example as of the technical and existential<disontologising/re-ontelogising aporeticism $>$ emancipating possibilities that can be contemplated with a positivism/rational-empiricism attitude/mental-disposition/care-andepisteme in an early hunter-gather social-setup inclined to construe of ill-health as bad omen; and appreciate that the human-subpotency is much more than stalling at any prior relativeontological-incompleteness ${ }^{8}$-of- ${ }^{8}$ reference-of-thought registry-worldview/dimension, and so not only retrospectively but equally prospectively. Thus, an attitude/mental-disposition/careand-episteme can pertinently be defined as the 'assumed-and-unflinching transversality- $<$ forsublimating-existential-eventuating/denouement,-from-'thinking-at-first/pure-predispositionpreemptive of prospective disentologising/subentologising' as-of-prospectivelydisambiguated-affirmed-and-unaffirmed-'motif-and-apriorising/axiomatising/referencing'> inducing a given specific nonpresencing- $<$ perspective-ontological- 
normalcy/postconvergence $>$ outcome with regards to prospective relative-ontologicalcompleteness ${ }^{87}$-or-incompleteness-of- ${ }^{2}$ reference-of-thought as of the construal-asexistence/intrinsic-reality/ontological-veridicality, and establishing-and-upholding the underlying framework of ${ }^{5}$ meaningfulness-and-teleology ${ }^{99}$ associated with that attitude/mentaldisposition/care-and-episteme . It can be construed with regards to prospective transcendenceand-sublimity/sublimation/supererogatory-de-mentativity as a preconverging/postconvergingde-mentative/structural/paradigmatic adjunctive-metaphoricity ${ }^{57}$-signification inducing-andupholding a prospective 'underlying <amplituding/formativeepistemicity $>$ totalising/circumscribing/delineating $\quad$ signifying-construct as $<$ amplituding/formative-epistemicity>totalising/circumscribing/delineating $\quad$ reference-ofthought- ${ }^{8}$ devolving'. In other words, a registry-worldview's/dimension's ${ }^{83}$ reference-ofthought apriorising/axiomatising/referencing/intelligibilitysettingup/measuringinstrumenting is utterly apprehended decisively by its given attitude/mental-disposition/care-and-episteme as of the 'assumed-and-unflinching transversality-<for-sublimating-existentialeventuating/denouement, from-'thinking at-first/pure-predisposition-preemptive-ofprospective-disontologising/subontologising’ -as-of-prospectively-disambiguated-affirmedand-unaffirmed-'motif-and-apriorising/axiomatising/referencing' $>101$. This insight is critical as for instance with appreciating what is implied by futural Being-development/ontologicalframework-expansion-as-to-depth-of-ontologising-development-as-infrastructure-ofmeaningfulness-and-teleology as of prospective ${ }^{18}$ deprocrypticism-or-preemptingdisjointedness-as-of- ${ }^{8}$ reference-of-thought apriorising/axiomatising/referencing/intelligibilitysettingup/measuringinstrumenting attitude/mental-disposition/care-and-episteme by its given specific ${ }^{5}$ nonpresencing<perspective-ontological-normalcy/postconvergence> outcome; as we simply have to project/anticipate its 'assumed-and-unflinching transversality-<for-sublimating-existential- 
eventuating/denouement, from-'thinking at first/pure-predisposition-preemptive-of

prospective-disontologising/subontologising' as-of-prospectively-disambiguated-affirmedand-unaffirmed-'motif-and-apriorising/axiomatising/referencing'>101 implied as of preempting - disjointedness-as-of- ${ }^{3}$ reference-of-thought construed as thinking as it remains unintelligible to our positivism- ${ }^{8}$ procrypticism's disjointedness-as-of- ${ }^{2}$ reference-of-thought reconstrued as of preconverging-or-dementing ${ }^{20}$-apriorising-psychologism. Attitude/mentaldisposition/care-and-episteme $\quad$ 'assumed-and-unflinching transversality-<for-sublimatingexistential-eventuating/denouement,-from-'thinking-at-first/pure-predisposition-preemptive-ofprospective-disontologising/subontologising' as-of-prospectively-disambiguated-affirmedand-unaffirmed-'motif-and-apriorising/axiomatising/referencing' $>101$ is a corresponding disposition for reflecting the 'incisive-and-intransigent nature of existence as absolute a-priori' to which we can only get in-relative-synchronisation with a corresponding level of projectionor-

anticipation/apriorising/axiomatising/referencing/intelligibilitysettingup/measuringinstrumenti ng that as of its relative dispensing-with-immediacy-for-relative-ontological-completeness ${ }^{87}$-byreification/contemplative-distension ${ }^{27}$ (as of human self-surpassing-existentialism-formfactor,-in-overcoming-'notional collateralising-beholdening-protohumanity’-to-'attainsublimating-humanity'-as-to-existence-potency sublimating-nascence,-disclosed-fromprospective-epistemic-digression to supersede human temporality $\% /$ shortness $<$ amplituding/formative $>$ wooden-language-<imbued - averaging-of-thought-<as-toleveling/ressentiment/closed-construct-of- meaningfulness-and-teleology -as-of'nondescript/ignorable-void '-with-regards-to-prospective-apriorising-implications $>\rangle)$ is the appropriate attitude/mental-disposition/care-and-episteme 'assumed-and-unflinching transversality-<for-sublimating-existential-eventuating/denouement,-from-'thinking-atfirst/pure-predisposition-preemptive-of-prospective-disontologising/subontologising' as-of- 
prospectively-disambiguated-affirmed-and-unaffirmed-'motif-and-

apriorising/axiomatising/referencing' $>101$ required for the correspondingly required

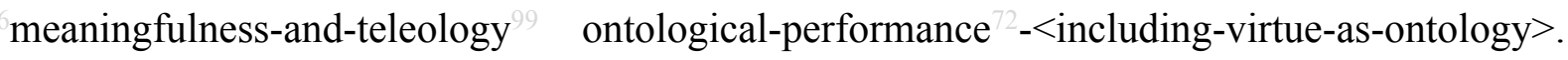
Basically, attitude/mental-disposition/care-and-episteme is simply a reflection of level of deneuterising -referentialism as of the notional $\sim$ conflatedness ${ }^{13}$ of notional ${ }^{18}$ deprocrypticism. Ultimately for living-as-of-human-personality-developing, socialprojection-institutional-orientations and Being-development/ontological-frameworkexpansion-as-to-depth-of-ontologising-development-as-infrastructure-of- meaningfulnessand-teleology , the 'human toddling potential' or the human potential to develop from a relativeontologically-flawed to a relative-ontologically-veridical attitude/mental-disposition/care-andepisteme ${ }^{5}$, can only arise by notional-discontiguity/epistemic-discontiguity ${ }^{63}-<$ between - priorshallow-supererogation -of-mentally-aestheticised $\sim$ preconverging/dementing -qualiaschema_and_prospective-profound-supererogation -of-mentallyaestheticised postconverging/dialectical-thinking -qualia-schema> induced psychoanalyticunshackling as of relative-ontologically-veridical attitude/mental-disposition/care-andepisteme 'assumed-and-unflinching transversality-<for-sublimating-existential-

\section{eventuating/denouement, from 'thinking at first/pure predisposition preemptive of}

prospective-disontologising/subontologising' as-of-prospectively-disambiguated-affirmedand-unaffirmed-'motif-and-apriorising/axiomatising/referencing'>101 over relativeontologically-flawed attitude/mental-disposition/care-and-episteme , with the latter necessarily having to ascend to the relative-ontologically-veridical attitude/mental-disposition/care-andepisteme for the former's implied ${ }^{5}$ meaningfulness-and-teleology ${ }^{9}$ as of its ontologicalperformance $^{72}$-<including-virtue-as-ontology $>$ /morality/ethics/justice/etc. to avail, and so in reflecting the 'incisive-and-intransigent nature of existence-as-the-absolute-a-priori-ofconceptualisation and existence — as-sublimating-withdrawal/unenframing/re-ontologising,- 
elicited-from-prospective-profound-supererogation $-<$ as-to-perspective-ontologicalnormalcy/postconvergence-implied-'prospective-aporeticism-overcoming/unovercoming'>'; as we can appreciate this with regards to existence's relative validation of the positivism/rationalempiricism 'per-cep-ti-vi-ty-as-of-full-disease-and-scientific-theory-construct-as-the-exclusivecause-and-effect-conceptualisation' interpretation over recurrent-utter-uninstitutionalisation's 'bad omen' interpretation. Such an 'assumed-and-unflinching transversality-<for-sublimatingexistential-eventuating/denouement,-from-'thinking at-first/pure-predisposition-preemptive-ofprospective-disontologising/subontologising' as-of-prospectively-disambiguated-affirmedand-unaffirmed-'motif-and-apriorising/axiomatising/referencing' ${ }^{101}$ has ultimately nothing to do with the deliberate willing of the relative-ontologically-veridical attitude/mentaldisposition/care-and-episteme . As we can appreciate that without implying a dispensing-withimmediacy-for-relative-ontological-completeness ${ }^{87}$-by-reification/contemplative-distension as of a child's living-as-of-human-personality-developing, the child's poorly developed attitude/mental-disposition/care-and-episteme will poorly face optimum living of adult life or where such was the case about all human children then the human species will be no more culturally unique than any other animal. Again, as of human social-projection-institutionalorientations we know that subject-matter, trades and bureaucratic expertise come with a requisite implied attitude/mental-disposition/care-and-episteme in detachment from $<$ amplituding/formative $>$ wooden-language-〈imbued - averaging-of-thought- $<$ as-toleveling/ressentiment/closed-construct-of- meaningfulness-and-teleology -as-of'nondescript/ignorable-void '-with-regards-to-prospective-apriorising-implications $>>$ as we know that, everything being equal legitimately, it is the professional electrician as of its assumedand-unflinching professionally-institutionalised-as-dispensing-with-immediacy-for-relativeontological-completeness ${ }^{87}$-by-reification/contemplative-distension attitude/mentaldisposition/care-and-episteme whose workmanship is guaranteed to produce the best and safe 
outcome for electrical installations; and so dispensing-with-immediacy-for-relative-ontologicalcompleteness ${ }^{87}$-by-reification/contemplative-distension as of

$<$ amplituding/formative $>$ wooden-language-_imbued — averaging-of-thought-<as-toleveling/ressentiment/closed-construct-of- meaningfulness-and-teleology -as-of'nondescript/ignorable-void ' -with-regards-to-prospective-apriorising-implications $>>$ dispositions thus expanding human needs and desires possibilities. Likewise, the dispensingwith-immediacy-for-relative-ontological-completeness ${ }^{87}$-by-reification/contemplativedistension 'assumed-and-unflinching transversality-<for-sublimating-existentialeventuating/denouement,-from-'thinking at first/pure-predisposition-preemptive-ofprospective disontologising/subontogising' as-of-prospectively-disambiguated-affirmedand-unaffirmed-'motif-and-apriorising/axiomatising/referencing'>101 of a relativeontologically-veridical attitude/mental-disposition/care-and-episteme as of its prospective relative-ontological-completeness ${ }^{8}$-of- ${ }^{8}$ reference-of-thought over a relative-ontologicallyflawed attitude/mental-disposition/care-and-episteme is implied for prospective ${ }^{83}$ reference-ofthought transcendence-and-sublimity/sublimation/supereregatery $\sim$ de-mentativity, as of overall human existential-<lisontologising/re-ontologising aporeticism $>$ and technical emancipation. Basically, while attitude/mental-disposition/care-and-episteme implied with regards to both living-as-of-human-personality-developing and social-projection-institutional-orientations arises as of secondnaturing institutionalisation. However, attitude/mental-disposition/care-andepisteme specific instigating of Being-development/ontological-framework-expansion-as-todepth-of-ontologising-development-as-infrastructure-of- meaningfulness-and-teleology as of prospective relative-ontological-completeness -of- reference-of-thought is (re-originaryas-_unenenframed/repostconverging/dialectical-thinking -'projective-insights'/'epistemic-projection-inconflatedness ' -of-notional deprocrypticism-prospective-sublimation $\rangle^{0}$ ) originary/event ${ }^{3}$ - 
of-prospective-ontology-origination as of humanity level intemporal/ontological/social/species/ $/{ }^{103}$ universal/transcendental/ $/{ }^{5}$ maximalisingrecomposuring-for-relative-ontological-completeness ${ }^{87}$ - unenframed/re-

ontologising conceptualisation postconverging-de-mentating/structuring/paradigming; inducing thereof social institutionalisation secondnaturing by way of percolation-channelling$<$ in-deferential-formalisation-transference $>$. Inherently, the very grounding of Beingdevelopment/ontological-framework-expansion-as-to-depth-of-ontologising-development-asinfrastructure-of- meaningfulness-and-teleology attitude/mental-disposition/care-andepisteme is beyond ${ }^{7}$ presencing - absolutising-identitive-constitutedness ${ }^{14}$, and actually lies prospectively in existence-potency ${ }^{39} \sim$ sublimating-nascence,-disclosed-from-prospectiveepistemic-digression. The implication here is that as of its very 'postcenverging-nonextricatoryexistential-preempting-of-existential-unthought behind the relative-unreflexivity/relativereflexivity - ontological-contiguity ${ }^{67} \sim$ of-the-human-institutionalisation-process ${ }^{6}, \quad$ Beingdevelopment/ontological-framework-expansion-as-to-depth-of-ontologising-development-asinfrastructure-of- meaningfulness-and-teleology attitude/mental-disposition/care-andepisteme cannot be contemplated as of secondnatured institutionalisation living-as-of-humanpersonality-developing and social-projection-institutional-orientations attitude/mentaldisposition/care-and-episteme in 'preconverging-existential-extrication-as-of-existentialunthought' which preconverging/postconverging-de-mentatively/structurally/paradigmatically 'do not project beyond ${ }^{83}$ reference-of-thought as of prospective relative-ontologicalcompleteness $^{87}$-of- ${ }^{83}$ eference-of-thought' to grasp prospective existencepotency ${ }^{39} \sim$ sublimating-nascence,-disclosed-from-prospective-epistemic-digression relativeontological-completeness ${ }^{87}$-of-apriorising/axiomatising/referencing. Thus with regards to Being-development/ontological-framework-expansion-as-to-depth-of-ontologisingdevelopment-as-infrastructure-of- meaningfulness-and-teleology , overall it is the underlying 
intemporality ${ }^{52}$-or-longness-of-register-of- ${ }^{56}$ meaningfulness-and-teleology 9 attitude/mentaldisposition/care-and-episteme of successive institutionalisations as associated with the intemporal-as-conviction-as-to-profound-supererogation ${ }^{6}{ }^{83}$ reference-of-thought- categoricalimperatives/axioms/registry-teleology ${ }^{9}$,-foraposteriorising/logicising/deriving/intelligising/measuring - ${ }^{5}$ meaningfulness-and-teleology ${ }^{9}$, rather than temporal threshold-of-nonconviction/madeupness/bottomlining-in-shallowsupererogation -<as-to-'attendant-intradimensional'-prospectivelydisontologising preconverging/dementing -apriorising-psychologism> denaturing of the same $\quad{ }^{83}$ reference-of-thought- ${ }^{-}$categorical-imperatives/axioms/registry-teleology ${ }^{9}$,-foraposteriorising/logicising/deriving/intelligising/measuring - ${ }^{56}$ meaningfulness-and-teleology ${ }^{9}$, that are responsible for the underlying ontological-normalcy/postconvergence epistemic perspective in postconverging-nonextricatory-existential-preempting-of-existential-unthought behind the relative-unreflexivity/relative-reflexivity - ontological-contiguity ${ }^{67}$ of-the-humaninstitutionalisation-process ${ }^{6}$; and so construed as of an abstract notion of perpetual/eternising

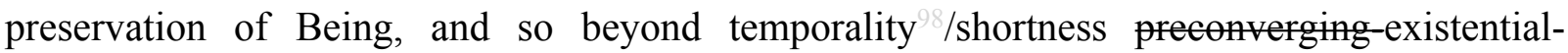
extrication-as-of-existential-unthought lack of the projecting attitude/mental-disposition/careand-episteme for prospective institutionalisations as mainly concerned with the 'human lifespan extricatory punctuality/immediacy of depth-of-thought' as absolute reference of meaningfulness-and-teleology' 'with little sense of coherence as of Beingdevelopment/ontological-framework-expansion-as-to-depth-of-ontologising-development-asinfrastructure-of- meaningfulness-and-teleology ', and thus the latter cannot unlike the former be the framework for aetiologisation/ontological-escalation- $<$ ontologicalveridicality_commitment/otherliness_transcending/compulsions-encumbered_transcending $>$ as of ${ }^{103}$ universal implications, and particularly so as of the 'naivety of eliciting mutual temporality $/$ shortness as intemporality $52 /$ longness or eliciting of 
$<$ amplituding/formative $>$ wooden-language-〈imbued - averaging-of-thought-<as-to-

leveling/ressentiment/closed-construct-of- meaningfulness-and-teleology -as-of-

'nondescript/ignorable-void '-with-regards-to-prospective-apriorising-implications $>\rangle$ '. This notion of fulfilling a given prospective institutionalisation's requisite attitude/mentaldisposition/care-and-episteme underlies the very idea of intellectual-and-moralinequivalence/non-correspondence as well as dialogical inequivalence/non-correspondence; as where one party does fulfils the attitude/mental-disposition/care-and-episteme of a given institutionalisation's ${ }^{83}$ reference-of-thought as of prospective relative-ontologicalcompleteness ${ }^{87}$-of-axiomatic-construct-or- ${ }^{83}$ reference-of-thought and thus its corresponding meaningfulness-and-teleology ${ }^{99}$, and the other doesn't as of prior relative-ontologicalincompleteness ${ }^{8}$. This further explains why epistemic-breaks/epistemic-resetting arise with the successive prospective institutionalisations in reflecting holographically-<conjugatively-andtransfusively $>$ the relative-unreflexivity/relative-reflexivity ontological-contiguity $\sim$ of-thehuman-institutionalisation-process, wherein for instance the positivism apriorising/axiomatising/referencing/intelligibilitysettingup/measuringinstrumenting attitude/mental-disposition/care-and-episteme of say a Galileo or Descartes is circularly beyond the contention framework of scholasticism ${ }^{5}$ meaningfulness-and-teleology ${ }^{9}$, speaking of the impossibility of logical-congruence between the positivists and scholastics with only the utter dominance of positivism arising as of its <amplituding/formativeepistemicity $>$ causality $\sim$ as-to-projective-totalitative-implications-of-prospective-

\section{nonpresencing,-for-explicating relative-unreflexivity/relative-reflexivity - ontological-}

contiguity induced positive-opportunism-of-social-functioning-and-accordance ${ }^{5}$ as of scientific, medical, technical advancements, free society, etc. shat leads to the crossgenerational collapsing of scholasticism. It is interesting to note here that such positivist scholars were 'never beholden to a convincing exercise with scholasticism but rather with intrinsic- 
reality/ontological-veridicality', and for which purpose rather opted to create internally-coherent positivist networks and societies for the perpetuation of positivistic ${ }^{56}$ meaningfulness-andteleology ${ }^{9}$ while averting its denaturing ${ }^{16}$ by wrongly implying notional-contiguity/epistemiccontiguity ${ }^{62}<$ profound-supererogation - of-mentally-aestheticised $\sim$ postconverging/dialecticalthinking -qualia-schema $>$ with scholasticism. But rather implying notionaldiscontiguity/epistemic-discontiguity ${ }^{6}-<$ between - prior-shallow-supererogation -ofmentally-aestheticised preconverging/dementing -qualia-schema_and_prospective-profoundsupererogation -of-mentally-aestheticised postconverging/dialectical-thinking -qualiaschema $>$ given the latter's flawed preconverging-de-mentating/structuring/paradigming as of prior relative-ontological-incompleteness ${ }^{8}$-of- ${ }^{-}$reference-of-thought. The insight here is that more fundamentally knowledge is not about 'interhuman negotiating or agreeableness' but more critically about a third party validator known as 'intrinsic-reality/ontological-veridicality’ which is the transcendental-enabling/sublimating/supererogatory $\sim$ de-mentativity above the mortals that are humans, and that the exercise of knowledge construction is rather an interhuman transversality-<for-sublimating-existential-eventuating/denouement,-from-'thinking-atfirst/pure-predisposition-preemptive-of prospective-disontologising/subontologising' as-ofprospectively-disambiguated-affirmed-and-unaffirmed-'motif-andapriorising/axiomatising/referencing' $>101$ exercise in search for the validation of the 'superior party that is intrinsic-reality/ontological-veridicality as of <amplituding/formativeepistemicity $>$ causality $\sim$ as-to-projective-totalitative-implications-of-prospectivenonpresencing,-for-explicating relative-unreflexivity/relative-reflexivity - ontologicalcontiguity ', and so beyond institutional-being-and-craft and social-aggregation-enabling $<$ amplituding/formative $>$ wooden-language-_imbued - averaging-of-thought-<as-toleveling/ressentiment/closed-construct-of- meaningfulness-and-teleology -as-of'nondescript/ignorable-void '-with-regards-to-prospective-apriorising-implications $>\rangle$. Where 
these latter practices become de rigueur as of beyond-the-consciousness-awareness-teleology <of-preconverging-existential-extrication-as-of-existential-unthought $>$ denaturing 16 of the requisite intellectualism required for further Being-development/ontological-frameworkexpansion-as-to-depth-of-ontologising-development-as-infrastructure-of- meaningfulnessand-teleology, and start undermining knowledge construction as of its intrinsicreality/ontological-veridicality transcendental-enabling/sublimating/supererogatory $\sim$ dementativity, effectively there shouldn't be any compunction as of human intemporal/ontological/social/species/ ${ }^{103}$ universal/transcendental/ ${ }^{5}$ maximalisingrecomposuring-for-relative-ontological-completeness ${ }^{8}$ —unenframed/reontologising conceptualisation postconverging-de-mentating/structuring/paradigming to overlook them and imply intellectual-and-moral-inequivalence/non-correspondence and/or dialogical inequivalence/non-correspondence in other to preserve genuine knowledge over charlatanism; as such ontological-bad-faith/inauthenticity ${ }^{64}$ practices do not speak of 'genuine intellectual disagreement' but undermining of intellectualism basically and do not merit to be elevated teleologically to the level of intellectual contention because of their underlying knowledge denaturing predisposition. This is critically the case with registryworldview/dimension reference-of-thought transcendence-andsublimity/sublimation/supererogatory de-mentativity implied knowledge given that the old/prior/superseded as of its beyond-the-consciousness-awareness-teleology ${ }^{9}-<$ ofpreconverging-existential-extrication-as-of-existential-unthought $>$ prior relative-ontologicalincompleteness ${ }^{88}$-of- ${ }^{8}$ reference-of-thought construes of 'implied grounding of meaningfulness-and-teleology ${ }^{9}$ in terms-as-of-axiomatic-construct of ${ }^{79}$ presencingabsolutising-identitive-constitutedness ${ }^{14}$ while the new/prospective/superseding as of its prospective relative-ontological-completeness ${ }^{87}$-of- ${ }^{83}$ reference-of-thought construes of 'implied grounding of ${ }^{56}$ meaningfulness-and-teleology ${ }^{9}$ in terms-as-of-axiomatic-construct of 
prospective nonpresencing-<perspective-ontological-normalcy/postconvergence $>$. This brings home the reality that it is inevitable that all uninstitutionalised-threshold ${ }^{102}$ are necessarily 'preconverging/postconverging-de-mentatively/structurally/paradigmatically conflicted', with prospective $\quad$ transversality- $<$ for-sublimating-existential-eventuating/denouement,-from-

\section{thinking at first/pure-predisposition-preemptive-of-prospective-}

disontologising/subontologising' as-of-prospectively-disambiguated-affirmed-and-

unaffirmed-'motif-and-apriorising/axiomatising/referencing'>

$<$ amplituding/formative-

epistemicity $>$ causality $\sim$ as-to-projective-totalitative-implications-of-prospective-

nonpresencing,-for-explicating relative-unreflexivity/relative-reflexivity ontological-

contiguity being the critically fundamental determining arbiter of what will prospectively pass for knowledge rather than the naivety of logical-congruence of dialogical-equivalence-<as-topsychologismic apriorising/axiomatising/referencing-\{of-"prospectively-

implicited_attendant-ontological-contiguity ' educed-

existentialising/contextualising/textualising_'intelligibility/epistemicity/reflexivity-contiguity<imbued-notional cogency $>$ ' \}-conflatedness - in-\{preconverging -ment by\}

postconverging-entailment,-in-self-becoming/self-conflatedness /formative-supererogating>

at any such uninstitutionalised-threshold ${ }^{12}$; as fundamentally the issues faced by the Descartes, Galileos, Diderots, etc. as of 'budding-positivism/rational-empiricism attitude/mentaldisposition/care-and-episteme ${ }^{,}$are preconverging/postconverging-dementatively/structurally/paradigmatically fundamentally inevitable as of their articulation within a non-positivism/medievalism context. This is the case since at a registryworldview's/dimension's uninstitutionalised-threshold ${ }^{102}$, such a framework of logicalcongruence of dialogical-equivalence- $<$ as-topsychologismic apriorising/axiomatising/referencing-\{of-"prospectively implicited_attendant-ontological-contiguity ' educed- 
existentialising/contextualising/textualising_'intelligibility/epistemicity/reflexivity-contiguity<imbued-notional cogency>' \}-conflatedness -in-\{preconverging-ment by\}

postconverging entailment,-in-self-becoming/self-conflatedness /formative-supererogating>

is preconverging/postconverging-de-mentatively/structurally/paradigmatically superseded, in the sense that every institutionalisation say for instance scholasticism scholarship has its 'genuine intellectual engagement framework' as of its underlying attitude/mentaldisposition/care-and-episteme reference-of-thought

supererogatory $\sim$ acuity/perspicacity/astuteness/edginess/incisiveness-of-

apriorising/axiomatising/referencing/intelligibilitysettingup/measuringinstrumenting - for-

conceptualisation, but then at its uninstitutionalised-threshold ${ }^{12}$ (as implied from prospective positivism/rational-empiricism attitude/mental-disposition/care-and-episteme ${ }^{53}$ reference-ofthought supererogatory $\sim$ acuity/perspicacity/astuteness/edginess/incisiveness-ofapriorising/axiomatising/referencing/intelligibilitysettingup/measuringinstrumenting -for-

conceptualisation) scholasticism and positivism are rather in transversality-<for-sublimatingexistential-eventuating/denouement-from-'thinking at-first/pure-predisposition-preemptive-ofprospective-disontologising/subontologising' as-of-prospectively-disambiguated-affirmedand-unaffirmed-'motif-and-apriorising/axiomatising/referencing' $>^{10}$; as so reflected in their mutually beyond-the-consciousness-awareness-teleology ${ }^{9}<$ of-preconverging-existentialextrication-as-of-existential-unthought $>$. This is equally reflected with regards to the prospective transcendence-and-sublimity/sublimation/supererogatory de-mentativity implying knowledge proponents, as the very notion of implying a prospective transcendental conceptualisation as of organic-knowledge is one that undervalues the presencingabsolutising-identitive-constitutedness ${ }^{14}$ attitude/mental-disposition/care-and-episteme as of its social-stake-contention-or-confliction while the very notion of perceiving highly the meaningfulness-and-teleology ${ }^{9}$ within a prior institutionalisation framework is one that is 
necessarily apprehensive and shallow-minded to the notion of a prospectively undermining prospective nonpresencing-<perspective-ontological-normalcy/postconvergence $>$ sublimity/sublimation/supererogatory $\sim$ de-mentativity episteme transcendence-andattitude/mental-disposition/care-and- ${ }^{83}$ reference-of-thought supererogatory $\sim$ acuity/perspicacity/astuteness/edginess/incisiveness-ofapriorising/axiomatising/referencing/intelligibilitysettingup/measuringinstrumenting -forconceptualisation. In addition, the disruptive uninstitutionalised-threshold ${ }^{102}$ contextualisation as of such divergent commitments and 'lack of perceived constraining framework of logicalcongruence of dialogical-equivalence-<as-to-

\section{psychologismic apriorising/axiomatising/referencing-\{of-"prospectively}

implicited_attendant-ontological-contiguity ' ceduced-

existentialising/contextualising/textualising_'intelligibility/epistemicity/reflexivity-contiguity$<$ imbued-notional cogency $>$ ' \}-conflatedness - in-\{preconverging ment by\} postconverging-entailment,-in-self-becoming/self-conflatedness /formative-supererogating >' further radicalises the human disposition to act temporally beyond-the-consciousnessawareness-teleology 9 - $<$ of-preconverging-existential-extrication-as-of-existential-unthought $>$ institutional-being-and-craft as of perceived vested interest, striving to undermine prospectively implied transcendence-and-sublimity/sublimation/supererogatory de-mentativity meaningfulness-and-teleology attitude/mental-disposition/care-and-episteme ${ }^{5}$. What is then the manifestation of such intellectual undermining which must necessarily be understood as of knowledge-notionalisation required as of the notional conflatedness ${ }^{13}$ of ${ }^{18}$ deprocrypticism-orpreempting - disjointedness-as-of- ${ }^{-}$reference-of-thought protensive-consciousness? ontological-bad-faith/inauthenticity ${ }^{64}$ as of its charlatanic effect fundamentally involves the undermining at any human uninstitutionalised-threshold ${ }^{102}$ of the possibility of intellectually induced social ${ }^{103}$ universal-transparency ${ }^{104}$-〈transparency-of-totalising-entailing,-as-to- 
entailing-<amplituding/formative-epistemicity $>$ totalising $\sim$ in-relative-ontological-

completeness $)$; for the ultimate outcome of undermining any such intemporal knowledge deferential-formalisation-transference behind the secondnaturing for prospective institutionalisation. Such a beyond-the-consciousness-awareness-teleology ${ }^{9}-<$ of preconverging-existential-extrication-as-of-existential-unthought $>$ undermining exercise is geared towards the ontologically-flawed apriorising-teleological-elevation-in $\sim$ notionalcontiguity/epistemic-contiguity ${ }^{2}-<$ profound-supererogation -of-mentallyaestheticised postconverging/dialectical-thinking -qualia-schema $>\quad$ of social $<$ amplituding/formative $>$ wooden-language-〈imbued - averaging-of-thought-<as-toleveling/ressentiment/closed-construct-of- meaningfulness-and-teleology -as-of'nondescript/ignorable-void '-with-regards-to-prospective-apriorising-implications $>>\quad$ and untransvaluated-temporal-intemporality $^{52}$ social-chainism, on the conation of upholding ontological-bad-faith/inauthenticity ${ }^{64}$ contentions; by its deflating of the conception of ontologically-veridical ${ }^{56}$ meaningfulness-and-teleology ${ }^{9}$ as of human mortals contentions in transversality- $<$ for-sublimating-existential-eventuating/denouement, from 'thinking at

\section{first/pure-predisposition-preemptive-of-prospective-disontologising/subontologising' as-of-}

prospectively-disambiguated-affirmed-and-unaffirmed-'motif-and-

apriorising/axiomatising/referencing'>101, wherein the 'superior party' of existence/intrinsicreality/ontological-veridicality is the validator of ontological-pertinence as of concurrent $<$ amplituding/formative-epistemicity $>$ causality $\sim$ as-to-projective-totalitative-implications-ofprospective- nonpresencing,-for-explicating relative-unreflexivity/relative-reflexivity ontological-contiguity , and thereof 'detour to social goodwill deferential-formalisationtransference to perceived overwhelming-relative-effectiveness' as new reasoning-fromresults/afterthought, and so over and above 'interhuman negotiating or agreeableness'. Thus ontological-bad-faith/inauthenticity ${ }^{64}$ as of its charlatanic effect undermines, as of beyond-the- 
consciousness-awareness-teleology $-<$ of-preconverging-existential-extrication-as-of-

existential-unthought $>$, the articulation of ${ }^{56}$ meaningfulness-and-teleology ${ }^{9}$ as of prospective maximalising-recomposuring-for-relative-ontological-completeness ${ }^{87}$ — unenframed/reontologising conceptualisation that could jeopardise pre-established temporal interest, and cultivating rather ${ }^{51}$ incrementalism-in-relative-ontological-incompleteness ${ }^{8}$ enframed/disontologising conceptualisation as of prior reasoning-from-results/afterthought in overlooking concurrent <amplituding/formative-epistemicity $>$ causality $\sim$ as-to-projectivetotalitative-implications-of-prospective- nonpresencing,-for-explicating relativeunreflexivity/relative-reflexivity ontological-contiguity strife to uphold-and-promote the 'superior party' which is the nonpresencing-<perspective-ontologicalnormalcy/postconvergence> of existence/intrinsic-reality/ontological-veridicality; with such intellectual-bad-faih rather advancing such an incrementalism-in-relative-ontologicalincompleteness 8 — enframed/disontologising conceptualisation accommodating framework for strategically cultivating pre-established temporal interest. Central to such incrementalism-inrelative-ontological-incompleteness ${ }^{88}$ —enframed/disontologising conceptualisation is a simplistic, poor and inadequate articulation of the notion of scepticism usurping genuine intellectual scepticism. Such a poor notion of scepticism operates by a spurious relationship with intellectual contentions that is susceptible to legitimise-or-delegitimise arguments however ontologically pertinent or impertinent as of concurrent <amplituding/formativeepistemicity $>$ causality $\sim$ as-to-projective-totalitative-implications-of-prospectivenonpresencing,-for-explicating relative-unreflexivity/relative-reflexivity - ontologicalcontiguity , rather as of its commitment to incrementalism-in-relative-ontologicalincompleteness 8 - enframed/disontologising conceptualisation that in-many-ways could just as well validate <amplituding/formative> wooden-language-_imbued-averaging-of-thought$<$ as-to-leveling/ressentiment/closed-construct-of- meaningfulness-and-teleology -as-of- 
'nondescript/ignorable-void '-with-regards-to-prospective-apriorising-implications $>>\quad$ and untransvaluated-temporal-intemporality $^{52}$ attitude/mental-disposition/care-and-episteme and their social contentions. As in effect, such ontological-bad-faith/inauthenticity ${ }^{64}$ scepticism fails to act as a 'knowledge-growth-mechanism with regards to the perpetuation of knowledge coherence and pertinence' as is the case with genuine intellectual scepticism, but is rather geared towards a dogmatic mandarinism and pedantising/muddling/formulaic-hollowing-out - insubontologisation/subpotentiation-〈blurring/undermining-of-prospective-totalising-entailing,as-to-entailing-<amplituding/formative-epistemicity $>$ totalising in-relative-ontologicalcompleteness $>$ that usurps the very notion of scepticism in incrementalism-in-relativeontological-incompleteness ${ }^{8}$ — enframed/disontologising conceptualisation, and so as of the naïve implication that proceduralism is the substitute for existence/intrinsic-reality/ontologicalveridicality as transcendental-enabling/sublimating/supereregatery $\sim$ de-mentativity. This poor scepticism attitude/mental-disposition/care-and-episteme usurping the pre-established 'detour to social goodwill deferential-formalisation-transference to perceived overwhelming-relativeeffectiveness', has <preconverging 'motif-and-apriorising/axiomatising/referencing'entailing >-existentialising — enframing/imprintedness-〈as-to- historicity-tracing — inpresencing-hyperrealisation/hyperreal-transposition〉 implications as of the forestalling of prospective 'concurrent <amplituding/formative-epistemicity $>$ causality $\sim$ as-to-projectivetotalitative-implications-of-prospective- nonpresencing,-for-explicating relative

unreflexivity/relative-reflexivity ontological-contiguity ' upholding of the primacy of the 'superior party' that is existence/intrinsic-reality/ontological-veridicality, and so over mere 'interhuman negotiating or agreeableness'; as this subsequently undermines intemporal knowledge deferential-formalisation-transference behind the secondnaturing for prospective institutionalisation. Rather the attitude/mental-disposition/care-and-episteme of genuine intellectual scepticism is encrusted within the very notion of prospective relative-ontological- 
completeness $^{87}$ of human meaningfulness-and-teleolgy, given human limited-mentationcapacity-deepening —as-subjecting limitedness/human-subpotency-to-'educed-

unlimitedness/existence-sublimating nascence' ${ }^{53}$. Such a genuine intellectual scepticism construes of knowledge by its given <amplituding/formativeepistemicity>totalising $\sim$ devolved—-purview/domain-of-construal-as-intrinsic-

reality/ontological-veridicality/existential-reality in terms-as-of-axiomatic-construct of the competing contending construals elicited relative credibility and relative scepticism as of prospective relative-ontological-completeness 87 , thus enabling the upholding of the 'superior party' that is existence/intrinsic-reality/ontological-veridicality, which as of its transcendenceenabling nature brings about prospective human emancipation. While genuine intellectual scepticism rather strives in a comprehensive intellectual credibility and scepticism framework as of prospective relative-ontological-completeness ${ }^{87}$, ontological-bad-faith/inauthenticity scepticism avoids such constraining as it rather emphasises a predisposition for discreet, 'ontologically unconstrained framework as of prospective relative-ontological-completeness $<$ amplituding/formative-epistemicity $>$ causality $\sim$ as-to-projective-totalitative-implications-ofprospective- nonpresencing,-for-explicating relative-unreflexivity/relative-reflexivity

ontological-contiguity , and non-comprehensiveness, that rather allow for selectivity, incompleteness and perfidy passing for genuine intellectual scepticism. Effectively while genuine intellectual transformation involves dispensing-with-immediacy-for-relativeontological-completeness ${ }^{87}$-by-reification/contemplative-distension ${ }^{27}$, a perfidious ontologicalbad-faith/inauthenticity ${ }^{64}$ scepticism involves eliciting a sense of immediacy and temporality $/$ shortness as of $<$ amplituding/formative $>$ wooden-language-〈imbued - averagingof-thought-<as-to-leveling/ressentiment/closed-construct-of- meaningfulness-and-teleology as-of-'nondescript/ignorable-void ' -with-regards-to-prospective-apriorising-implications>> and untransvaluated-temporal-intemporality ${ }^{52}$ social-chainism as 'developed thought', thus 
deflating the requisite dispensing-with-immediacy-for-relative-ontological-completeness ${ }^{87}$-byreification/contemplative-distension ${ }^{27}$ intemporal detachment/backstep for transcendence-andsublimity/sublimation/supererogatory de-mentativity. In this latter respect, and for the possibility of prospective social transcendence-and-sublimity/sublimation/supererogatery $\sim$ dementativity and emancipation, social practices at any given period as 'becoming constructs' are not inherently ontologically sacrosanct by the fact that these are the outcome of preceding prospective relative-ontological-completeness ${ }^{87}$ as of preceding intemporal dispensing-withimmediacy-for-relative-ontological-completeness ${ }^{87}$-by-reification/contemplative-distension ${ }^{27}$, and by that very implication this is what carries the possibility of 'inventing' as-of-prospectiveinstitutionalisation social practices as of prospective relative-ontological-completeness ${ }^{87}$. ontological-bad-faith/inauthenticity ${ }^{64}$ ad-hoc pretences extolling social practices as of presencing - absolutising-identitive-constitutedness ${ }^{14}$ but of a poor conception outside the prospective relative-ontological-completeness ${ }^{87}$ behind such social practices 'inventing' as-ofprior-institutionalisation and so-implied as of Being-development/ontological-frameworkexpansion-as-to-depth-of-ontologising-development-as-infrastructure-of- meaningfulnessand-teleology , are but denaturing and down the line equally undermines prospective relativeontological-completeness ${ }^{87}$ for the further emancipation of human social practices. As such ontological-bad-faith/inauthenticity ${ }^{64}$ ad-hoc pretences extolling social practices as of presencing-absolutising-identitive-constitutedness ${ }^{14}$ are of the same notionalcontiguity/epistemic-contiguity ${ }^{62}<$ profound-supererogation -of-mentallyaestheticised postconverging/dialectical-thinking -qualia-schema $>$ kind that bathe in the $<$ amplituding/formative $>$ wooden-language-<imbued - averaging-of-thought-<as-toleveling/ressentiment/closed-construct-of- meaningfulness-and-teleology -as-of'nondescript/ignorable-void '-with-regards-to-prospective-apriorising-implications $>>\quad$ and untransvaluated-temporal-intemporality ${ }^{52}$ social-chainism that implied as much about extolling 
social practices ${ }^{7}$ presencing-absolutising-identitive-constitutedness ${ }^{14}$ of preconvergingexistential-extrication-as-of-existential-unthought reasoning-from-results/afterthought attitude/mental-disposition/care-and-episteme of recurrent-utter-uninstitutionalisation, baseinstitutionalisation-ununiversalisation, ${ }^{103}$ universalisation-non-positivism/medievalism and today's positivism- ${ }^{8}$ procrypticism, with little prospect/opening for prospective transcendenceand-sublimity/sublimation/supererogatory-de-mentativity. Essentially and constructively, all intellectualism as of their intemporal job description as emancipative is to relay in uninhibited/decomplexified terms-as-of-axiomatic-construct the blunt reality of the social as this is the very attitude/mental-disposition/care-and-episteme that empowers prospective social emancipation however socially unconvenient it may sound; and so beyond habituated $<$ amplituding/formative-epistemicity $>$ totalising $\sim$ self-referencing-

syncretising/circularity/interiorising/akrasiatic-drag ${ }^{34}$. The fact that many that are institutionally anchored may speak otherwise or naively against such a stance doesn't diminish in any way the 'natural appropriateness' of such a job description as of human intemporal/ontological/social/species/ ${ }^{103}$ universal/transcendental $/{ }^{5}$ maximalisingrecomposuring-for-relative-ontological-completeness ${ }^{87}$ unenframed/reontologising conceptualisation postconverging-de-mentating/structuring/paradigming, but rather speaks of a poverty of institutionalisation that creeps into institutional anchors as of their reasoning-from-results/afterthought constructions subject to temporal/shortness-of-register-ofmeaningfulness-and-teleology denaturing of ${ }^{83}$ reference-of-thought- categoricalimperatives/axioms/registry-teleology ${ }^{99}$-foraposteriorising/logicising/deriving/intelligising/measuring $-{ }^{5}$ meaningfulness-and-teleology ${ }^{9}$. As a result of human-subpotency-aporia/undecidability/dilemma/oughtindeterminacy/deficiency/limitation/constraint—imbued-‘notional firstnaturednessformativeness-<as-to-eventualising-inkling-drive-or-seeding-misprising $>$ temporal-to- 
intemporal-dispositions-<so-construed-as-from-perspective-ontological-

normalcy/postconvergence>'-existentialism-form-factor, the ever present reality of human uninstitutionalised-threshold $^{102}$ as reflected successively with recurrent-utteruninstitutionalisation, ununiversalisation, non-positivism/medievalism and procrypticism, has always implied resolution beyond just reasoning-from-results/afterthought that warrants successive nonpresencing-<perspective-ontological-normalcy/postconvergence $>$ as of the reasoning-through/messianic-reasoning of base-institutionalisation, ${ }^{103}$ universalisation, positivism and deprocrypticism-or-preempting - disjointedness-as-of- ${ }^{18}$ reference-of-thought together construed as of the notional $\sim$ conflatedness ${ }^{13}$ of notional ${ }^{18}$ deprocrypticism. Reasoningthrough/messianic-reasoning attitude/mental-disposition/care-and-episteme implicitation arises as of metaphoricity ${ }^{57}$ at uninstitutionalised-threshold ${ }^{102}$ where blurry/vague/undeveloped construct of any given '<amplituding/formative-epistemicity $>$ totalising $\sim$ devolvedpurview/domain-of-construal-as-intrinsic-reality/ontological-veridicality/existential-reality' is unamenable-or-poorly-amenable to reasoning-from-results/afterthought attitude/mentaldisposition/care-and-episteme $\quad$ explicitation of $\quad$ amplituding/formativeepistemicity $>$ causality $\sim$ as-to-projective-totalitative-implications-of-prospective-

\section{nonpresencing,-for-explicating relative unreflexivity/relative reflexivity - ontological-}

contiguity procedure of transversal-contention-for-determination-of-veridical-meaningfulness. Such reasoning-through/messianic-reasoning attitude/mental-disposition/care-and-episteme 'implicitation of $<$ amplituding/formative-epistemicity $>$ causality $\sim$ as-to-projective-totalitativeimplications-of-prospective- nonpresencing,-for-explicating relative-unreflexivity/relativereflexivity - ontological-contiguity , is as of intemporal solipsistic and intersolipsistic internalisation, construed as more fully articulating the notion of ontological-goodfaith/authenticity ${ }^{69}$, in reflecting such uninstitutionalised-threshold ${ }^{12}$ impracticable reasoningfrom-results/afterthought attitude/mental-disposition/care-and-episteme explicitation of 
$<$ amplituding/formative-epistemicity $>$ causality $~$ as-to-projective-totalitative-implications-ofprospective- nonpresencing,-for-explicating relative-unreflexivity/relative-reflexivity

ontological-contiguity procedure of transversal-contention-for-determination-of-veridicalmeaningfulness. In this regard, reasoning-through/messianic-reasoning is driven as of ontological-faith-notion-or-ontological-fideism - imbued-underdetermination-of-motif-andapriorising/axiomatising/referencing-as-so-being-as-of-existential-reality intemporal projection, and reflects the fact that however explicited, as of reasoning-fromresults/afterthought attitude/mental-disposition/care-and-episteme explicitation of $<$ amplituding/formative-epistemicity $>$ causality $\sim$ as-to-projective-totalitative-implications-ofprospective- nonpresencing,-for-explicating relative-unreflexivity/relative-reflexivity ontological-contiguity procedure of transversal-contention-for-determination-of-veridicalmeaningfulness, human ${ }^{56}$ meaningfulness-and-teleology ${ }^{9}$ is always about différance/internaldialectics/difference-deferral of 'apriorising/axiomatising/referencing/intelligibilitysettingup/measuringinstrumenting

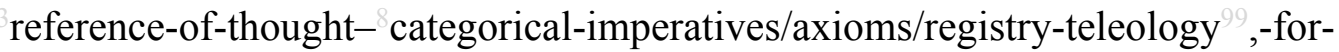
aposteriorising/logicising/deriving/intelligising/measuring - ${ }^{56}$ meaningfulness-and-teleology ${ }^{9}$; so-implied as of the differance/internal-dialectics/difference-deferral of the very apriorising/axiomatising/referencing/intelligibilitysettingup/measuringinstrumenting epistemictotality ${ }^{37}$ that is the ${ }^{83}$ reference-of-thought (inducing 'intemporal ontological-faith-notion-orontological-fideism - imbued-underdetermination-of-motif-andapriorising/axiomatising/referencing-as-so-being-as-of-existential-reality instigated relativeunreflexivity/relative-reflexivity — ontological-contiguity ${ }^{67}$ of-the-human-institutionalisationprocess $^{68}$ as of difference-conflatedness ${ }^{13}$-as-to-totalitative-reification-in-singularisation- $<$ as-tothe-nondisjointedness/entailment-of-prospective- nonpresencing $>$-as-veridical-epistemicityrelativism-determinism implied $<$ amplituding/formative-epistemicity $>$ causality $\sim$ as-to- 
projective-totalitative-implications-of-prospective- nonpresencing,-for-explicating relative-

unreflexivity/relative-reflexivity - ontological-contiguity '), and as the ${ }^{83}$ reference-of-thought then aposteriorises/intelligises/logicises ${ }^{56}$ meaningfulness-and-teleology ${ }^{99}$ as of the temporal-tointemporal ontological-performance ${ }^{72}-<$ including-virtue-asontology $>$ /morality/ethics/justice/etc. différance/internal-dialectics/difference-deferral of the $<$ amplituding/formative-epistemicity $>$ totalising/circumscribing/delineating $\quad$ reference-ofthought- ${ }^{8}$ devolving, involving existential-instantiation devolved temporal denaturing ${ }^{16}$ of the reference-of-thought- categorical-imperatives/axioms/registry-teleology ${ }^{9}$,-foraposteriorising/logicising/deriving/intelligising/measuring $-{ }^{5}$ meaningfulness-and-teleology 9 The implication here is that ontological-faith-notion-or-ontological-fideism -imbuedunderdetermination-of-motif-and-apriorising/axiomatising/referencing-as-so-being-as-of-

existential-reality is rather about a 'seeding promise of human-subpotency ontologicalperformance ${ }^{72}-<$ including-virtue-as-ontology $>/$ morality/ethics/justice/etc.

equivalence/correspondence with the full-potency-of-existence's $\sim$ sublimating-nascence-as-ofits-coherence/contiguity', but that reasoning-through/messianic-reasoning adduced transcendence-and-sublimity/sublimation/supereregatory-de-mentativity prospectively comes out short with the prospective reasoning-from-results/afterthought outcome, and so because of human limited-mentation-capacity—as-subjecting-'educed-unlimitedness/existencesublimating nascence' to-limitedness/human-subpotency at any moment. Thus the successive reasoning-from-results/afterthought outcomes as the logocentric constructs of the $<$ cumulating/recomposuring attendant-ontological-contiguity $>$-successive registryworldviews/dimensions arrive at their successive ${ }^{83}$ reference-of-thought- categoricalimperatives/axioms/registry-teleology ${ }^{9}$, -foraposteriorising/logicising/deriving/intelligising/measuring $-{ }^{5}$ meaningfulness-and-teleology ${ }^{99}$ as of successive prospective relative-ontological-completeness ${ }^{87}$-of- ${ }^{8}$ reference-of-thought, but fail 
apriorising/axiomatising/referencing/intelligibilitysettingup/measuringinstrumenting $<$ amplituding/formative-epistemicity $>$ causality $\sim$ as-to-projective-totalitative-implications-ofprospective- nonpresencing,-for-explicating relative-unreflexivity/relative-reflexivity ontological-contiguity about the full-potency of existence-as-the-absolute-a-priori-ofconceptualisation and existence — as-sublimating-withdrawal/unenframing/re-ontologising,elicited-from-prospective-profound-supererogation $-<$ as-to-perspective-ontologicalnormalcy/postconvergence-implied-'prospective-aporeticism-overcoming/unovercoming'> for aposteriorising/logicising/deriving/intelligising/measuring $\quad{ }^{56}$ meaningfulness-and-teleology that can fully reflect human-subpotency existential-<disontologising/re-ontologising apøreticism $>$ potential/possibilities of ontological-performance ${ }^{72}-<$ including-virtue-as- $^{2}$ ontology $>$ /morality/ethics/justice/etc. in correspondence with the full-potency of existence in its coherence/contiguity. But then, ontological-faith-notion-or-ontological-fideism-imbuedunderdetermination-of-motif-and-apriorising/axiomatising/referencing-as-so-being-as-ofexistential-reality 'seeding promise of human-subpotency ontological-performance ${ }^{72}$ $<$ including-virtue-as-ontology $>/$ morality/ethics/justice/etc. equivalence/correspondence with the full-potency-of-existence's $\sim$ sublimating-nascence-as-of-its-coherence/contiguity' can always be 'reinvigorated as of furthered ontological-faith-notion-or-ontological-fideismimbued-underdetermination-of-motif-and-apriorising/axiomatising/referencing-as-so-being-asof-existential-reality parrhesiastic askesis-or-acumen' for originary/as-of-event ${ }^{38}$ reasoningthrough/messianic-reasoning prospective relative-ontological-completeness ${ }^{87}$-of- ${ }^{83}$ reference-ofthought overriding prior reasoning-from-results/afterthought now in prior relative-ontologicalincompleteness ${ }^{88}$-of- ${ }^{82}$ reference-of-thought at such uninstitutionalised-threshold ${ }^{102}$; and so, in a renewing apriorising/axiomatising/referencing/intelligibilitysettingup/measuringinstrumenting instigation as of reasoning-through/messianic-reasoning attitude/mental-disposition/care-and- 
episteme implicitation for aposteriorising/logicising/deriving/intelligising/measuring meaningfulness-and-teleology, which is construed as more fully articulating the notion of ontological-good-faith/authenticity ${ }^{6}$. This practical conceptualisation of ontological-goodfaith/authenticity ${ }^{6}$ as of its method is further critical because however well elicited, even reasoning-from-results/afterthought constructs still need their good ontological-performance ${ }^{72}$ $<$ including-virtue-as-ontology $>/$ morality/ethics/justice/etc. in practice, and given humansubpotency-aporia/undecidability/dilemma/ought-

indeterminacy/deficiency/limitation/constraint—imbued-'notional firstnaturednessformativeness-<as-to-eventualising-inkling drive-or-seeding-misprising $>$ temporal-tointemporal-dispositions- $<$ so-construed-as-from-perspective-ontologicalnormalcy/postconvergence>'-existentialism-form-factor, there is always room for human denaturing temporal ontological-performance ${ }^{72}-<$ including-virtue-asontology $>$ /morality/ethics/justice/etc. of such reasoning-from-results/afterthought constructs induced by reasoning-through/messianic-reasoning; pointing to the fact that ultimately the underlying 'sanctity of knowledge' arises from ontological-faith-notion-or-ontologicalfideism - imbued-underdetermination-of-motif-and-apriorising/axiomatising/referencing-asso-being-as-of-existential-reality as of such ontological-good-faith/authenticity based intemporal organic-knowledge that is wary of the denaturing ${ }^{16}$ that can arise as of temporal mechanical-knowledge that 'dispenses with the originary/as-of-event ${ }^{38}$ spirit of reasoningthrough/messianic-reasoning' and adopts a mere pedantic relating with the ${ }^{83}$ reference-ofthought- categorical-imperatives/axioms/registry-teleology ${ }^{99}$,-foraposteriorising/logicising/deriving/intelligising/measuring- ${ }^{5}$ meaningfulness-and-teleology . Thus human ontological-faith-notion-or-ontological-fideism-imbued-underdetermination-ofmotif-and-apriorising/axiomatising/referencing-as-so-being-as-of-existential-reality driven reasoning-through/messianic-reasoning holds the prospect for an ever renewal of ${ }^{83}$ reference-of- 
thought- categorical-imperatives/axioms/registry-teleology ${ }^{9}$,-for-

aposteriorising/logicising/deriving/intelligising/measuring $-{ }^{5}$ meaningfulness-and-teleology ${ }^{99}$ as of prospective relative-ontological-completeness ${ }^{87}$-of- reference-of-thought, undermining institutional-anchoring and logocentric complexes/denials and pedantising/muddling/formulaichollowing-out-in-subontologisation/subpotentiation-〈blurring/undermining-of-prospective-

\section{totalising-entailing,-as-to-entailing-<amplituding/formative-epistemicity $>$ totalising $\sim$ in-}

relative-ontological-completeness > (in incrementalism-in-relative-ontologicalincompleteness ${ }^{8}$ - enframed/disontologising conceptualisation) of such prospective $\begin{array}{llll}\text { transcendental } & \text { possibilities. } & \text { Such } & \text { prospective }\end{array}$ apriorising/axiomatising/referencing/intelligibilitysettingup/measuringinstrumenting transformation for aposteriorising/logicising/deriving/intelligising/measuring ${ }^{5}$ meaningfulnessand-teleology ${ }^{9}$ is the reflection of a reality of human mental regeneration potential that speaks of the continuity of humankind as of the same relative-emancipating potential as pertinently reflected with Being-development/ontological-framework-expansion-as-to-depth-ofontologising-development-as-infrastructure-of- meaningfulness-and-teleology as of 'intemporal ontological-faith-notion-or-ontological-fideism —imbued-underdetermination-ofmotif-and-apriorising/axiomatising/referencing-as-so-being-as-of-existential-reality instigated relative-unreflexivity/relative-reflexivity - ontological-contiguity ${ }^{6}$ of-the-humaninstitutionalisation-process $^{68}$ as of difference-conflatedness ${ }^{13}$-as-to-totalitative-reification-insingularisation-<as-to-the-nondisjointedness/entailment-of-prospective- nonpresencing $>$-asveridical-epistemicity-relativism-determinism implied $\quad<$ amplituding/formativeepistemicity $>$ causality $\sim$ as-to-projective-totalitative-implications-of-prospectivenonpresencing,-for-explicating relative-unreflexivity/relative-reflexivity - ontological-

contiguity 'retrospectively and prospectively; with relative-emancipation construed as the inherent ${ }^{56}$ meaningfulness-and-teleology ${ }^{9}$ truth form of existence, wherein truth is as of 
immanented-teleologically-pertinent-truth over truth-devoid-of-immanented-teleology ${ }^{9}$, for instance, like the teleological disposition of living organisms for self-preservation beyond just their organical composition. Thus, human ontological-faith-notion-or-ontological-fideismimbued-underdetermination-of-motif-and-apriorising/axiomatising/referencing-as-so-being-asof-existential-reality underlies the conception of ${ }^{15}$ de-mentation-〈supererogatory $\sim$ ontologicalde-mentation-or-dialectical-de-mentation — stranding-or-attributive-dialectics $\rangle \quad$ stranding dialetics crossgenerational as enabling human transcendence-andsublimity/sublimation/supererogatory $\sim$ de-mentativity, and is reflected in 'intemporal ontological-faith-notion-or-ontological-fideism - imbued-underdetermination-of-motif-andapriorising/axiomatising/referencing-as-so-being-as-of-existential-reality instigated relativeunreflexivity/relative-reflexivity — ontological-contiguity ${ }^{67}$ of-the-human-institutionalisationprocess $^{6}$ as of difference-conflatedness ${ }^{13}$-as-to-totalitative-reification-in-singularisation- $<$ as-tothe-nondisjointedness/entailment-of-prospective- nonpresencing $>$-as-veridical-epistemicityrelativism-determinism implied $<$ amplituding/formative-epistemicity $>$ causality $\sim$ as-toprojective-totalitative-implications-of-prospective- nonpresencing,-for-explicating relativeunreflexivity/relative-reflexivity ontological-contiguity ', as of grander dispensing-withimmediacy-for-relative-ontological-completeness ${ }^{87}$-by-reification/contemplative-distension ${ }^{27}$. Finally as a further analysis, re-ontologising prospective Being-development/ontologicalframework-expansion-as-to-depth-of-ontologising-development-as-infrastructure-ofmeaningfulness-and-teleology is by a rather surreptitious manner undermined by what this author qualifies as 'subterfuges of Being-development/ontological-framework-expansion-as-todepth-of-ontologising-development-as-infrastructure-of- meaningfulness-and-teleology which are rather as of ideology; ideology in the sense that these are 'commitments' ready to 'forego the pre-eminence of knowledge construed as of its ontological-veracity' which is the only assurance of optimum construct of knowledge for human emancipation. Ideology as such 
takes the form of either 'ideology denaturing of re-ontologising prospective Beingdevelopment/ontological-framework-expansion-as-to-depth-of-ontologising-development-asinfrastructure-of- meaningfulness-and-teleology ' or 'reactive fear of ideology denaturing ${ }^{16}$ of re-ontologising prospective Being-development/ontological-framework-expansion-as-to-depthof-ontologising-development-as-infrastructure-of- meaningfulness-and-teleology '. In both instances what is lost is re-ontologising prospective Being-development/ontological-frameworkexpansion-as-to-depth-of-ontologising-development-as-infrastructure-of- meaningfulnessand-teleology itself, such that besides temporal/shortness-of-register-of- meaningfulnessand-teleology interests undermining it, re-ontologising prospective Beingdevelopment/ontological-framework-expansion-as-to-depth-of-ontologising-development-asinfrastructure-of- meaningfulness-and-teleology is circularly perceived as a risk that will foster 'ideology denaturing ${ }^{16}$ of re-ontologising prospective Being-development/ontologicalframework-expansion-as-to-depth-of-ontologising-development-as-infrastructure-ofmeaningfulness-and-teleology ' or 'reactive fear of ideology denaturing ${ }^{16}$ of re-ontologising prospective Being-development/ontological-framework-expansion-as-to-depth-ofontologising-development-as-infrastructure-of- meaningfulness-and-teleology '; $\quad$ as reontologising prospective Being-development/ontological-framework-expansion-as-to-depthof-ontologising-development-as-infrastructure-of- meaningfulness-and-teleology itself loses out. These subterfuges are behind the awkward, unnatural and clobbered nature of human development for the past two centuries as civilisation is construed and developed in an 'undertone reaction/anticipation of threat' rather than natural as of human communion. Thus 'subterfuges of Being-development/ontological-framework-expansion-as-to-depth-ofontologising-development-as-infrastructure-of- meaningfulness-and-teleology ' arise as of

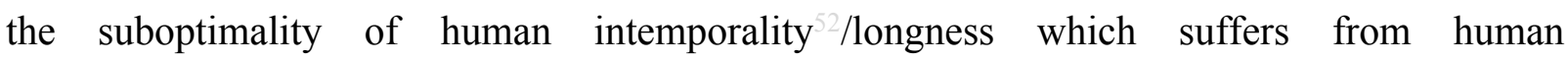
apprehensiveness of humans, thus undermining the notion of human 
intemporal/ontological/social/species/ ${ }^{103}$ universal/transcendental/ ${ }^{55}$ maximalisingrecomposuring-for-relative-ontological-completeness —unenframed/re-

ontologising conceptualisation postconverging-de-mentating/structuring/paradigming. This underlying human mental-disposition arises as of the successive human as trepidatious/warped/preclusive/occlusive-consciousness in ${ }^{58}$ neuterising; as such ${ }^{58}$ neuterising is the outcrop of human limited-mentation-capacity-as-subjecting-educedunlimitedness/existence-sublimating nascence' to-limitedness/human-subpotency. In other words ${ }^{58}$ neuterising can effectively be 'decomposed-as-from-a-conflatedness ${ }^{13}$-perspective into the ontologically-veridical underlying limited-mentation-capacity-as-subjecting 'educedunlimitedness/existence-sublimating nascence' to-limitedness/human-subpotency manifestation' as of social-stake-contention-or-confliction <amplituding/formativeepistemicity>totalising $\sim$ self-referencing-syncretising/circularity/interiorising/akrasiatic-drag ${ }^{34}$, and so-construed from the 'deepest phenomenological transcendental-point-of-departure handle as of the notional conflatedness ${ }^{13}$ of notional ${ }^{18}$ deprocrypticism deneuterising referentialism'. Such an exercise can be conceptualised as an abstract ${ }^{83}$ reference-ofthought/epistemic-totalisation level of deneuterising — referentialism, wherein for instance, with regards to 'the-very-same medical <amplitudingfformativeepistemicity $>$ totalising $\sim$ devolved-purview-as-domain-of-construal-as-intrinsic-

reality/ontological-veridicality' as preconverging/postconverging-dementatively/structurally/paradigmatically defining 'social-stake-contention-or-confliction as of existential-instantiations dynamics among individuals and the social-collective': - the trepidatious-consciousness of an early hunter-gatherer recurrent-utter-uninstitutionalisation society direct experience of misfortune say like catching an unknown disease in a given forest may imply an implicited_attendant-ontological-contiguity ${ }^{67}$; educedexistentialising/contextualising/textualising_'intelligibility/epistemicity/reflexivity-contiguity- 
<imbued-notional cogency>' -lowest-level-reification per-cep-ti-vi-ty-as-of-bad-omen as of its relative ${ }^{58}$ neuterising as of its random-as-uncircumscribing/undelineating-as-'epistemictotality ${ }^{37}$, existential-epistemic-totalisation-scheme-of- ${ }^{56}$ meaningfulness-and-teleology ${ }^{9}$ given its non-rules — apriorising/axiomatising/referencing-psychologism,-as-impulsive-oraccidented-or-random-mental-disposition (noting that such a poor reification is better than no reification at all in the sense that where the given forest is infested with say mosquitoes carrying malaria for instance, such a per-cep-ti-vi-ty-as-of-bad-omen provides a basic conceptivity/epistemic-reflexivity/epistemicity-relativism-determinism-<reifying \{as-toknowledge-developing $\}$-and-empowering $>$ imbued theoretical/conceptual/operant implications to human-subpotency however its trepiditious nature as to a 'crude predisposition to avoid the forest'); - for the warped-consciousness of an animistic base-institutionalisation society imply 'implicited_attendant-ontological-contiguity ${ }^{67}$ educedexistentialising/contextualising/textualising_'intelligibility/epistemicity/reflexivity-contiguity$<$ imbued-notional cogency $>$-second-level-reification per-cep-ti-vi-ty-as-of-a-specific-placeor-specific-evil-people-or-specific-evil-period as of its relative ${ }^{58}$ neuterising as of its tendentious-circumscribing-as- 'epistemic-totality ${ }^{37}$ '-or-delineating-as- ${ }^{6}$ epistemic-totality ${ }^{37}$, existential-epistemic-totalisation-scheme-of- ${ }^{56}$ meaningfulness-and-teleology 9 given its rulemaking-over-non-rules_-apriorising/axiomatising/referencing-psychologism (noting as well that in the case where the given forest is infested with say mosquitoes carrying malaria for instance, such a per-cep-ti-vi-ty-as-of-a-specific-place-or-specific-evil-people-or-specific-evilperiod provides a relatively better conceptivity/epistemic-reflexivity/epistemicity-relativismdeterminism-<reifying \{as-to-knowledge-developing\}-and-empowering $>\quad$ imbued theoretical/conceptual/operant implications to human-subpotency however its tendentious nature as to inducing tendentiously crude behaviours and psychological assurances associated with positive experiences over negative experiences); - for the preclusive-consciousness of a 
universalisation-non-positivism/medievalism society imply 'implicited_attendantontological-contiguity ${ }^{6}$ ' educed-

existentialising/contextualising/textualising_'intelligibility/epistemicity/reflexivity-contiguity$<$ imbued-notional cogency $>$-third-level-reification per-cep-ti-vi-ty-as-of-failure-to-followthe-heeding-of-the-Deity-or-failure-to-adhere-to-a-certain-mysticism-or-failure-to-payreverence-to-an-ancestor as of its relative ${ }^{58}$ neuterising as of its qualifying-circumscribing-as'epistemic-totality ${ }^{37}$ '-or-delineating-as-'epistemic-totality ${ }^{37}$, existential-epistemic-totalisationscheme-of-5 meaningfulness-and-teleology ${ }^{9}$ given its ${ }^{103}$ universalisation-directed-rulemakingover-non-rules - apriorising/axiomatising/referencing-psychologism (noting that in the case where the given forest is infested with say mosquitoes carrying malaria for instance, such a percep-ti-vi-ty-as-of-failure-to-follow-the-heeding-of-the-Deity-or-failure-to-adhere-to-a-certainmysticism-or-failure-to-pay-reverence-to-an-ancestor provides an even better conceptivity/epistemic-reflexivity/epistemicity-relativism-determinism- $<$ reifying \{as-toknowledge-developing\}-and-empowering $>$ imbued theoretical/conceptual/operant implications to human-subpotency however its preclusive nature as to comprehensively-qualified narrative of a non-ad-hoc and weighty/profound existential-<disontologising/re-ontologising aporeticism $>$ interpretation inducing the predisposition as of a fateful ${ }^{103}$ universal narrative of human behaviour implications); - for an occlusive-consciousness as of our positivism/rationalempiricism implying 'implicited_attendant-ontological-contiguity ${ }^{67}$ ' educedexistentialising/contextualising/textualising_'intelligibility/epistemicity/reflexivity-contiguity<imbued-notional cogency>' ${ }^{\prime}$-fourth-level-reification per-cep-ti-vi-ty-as-of-full-disease-andscientific-theory-construct-as-the-exclusive-cause-and-effect-conceptualisation still as of its relative ${ }^{58}$ neuterising as of its categorising-circumscribing-as-'epistemic-totality ${ }^{37}$ '-ordelineating-as-'epistemic-totality ${ }^{37}$, existential-epistemic-totalisation-scheme-ofmeaningfulness-and-teleology given its positivising/rational-empiricism-based- 
universalisation-directed-rulemaking-over-non-rules — apriorising/axiomatising/referencingpsychologism (noting also that in the case where the given forest is infested with say mosquitoes carrying malaria for instance, such a per-cep-ti-vi-ty-as-of-full-disease-and-scientific-theoryconstruct-as-the-exclusive-cause-and-effect-conceptualisation provides a decisively better conceptivity/epistemic-reflexivity/epistemicity-relativism-determinism- $<$ reifying \{as-to-

knowledge-developing $\}$-and-empowering $>$ imbued theoretical/conceptual/operant implications to human-subpotency however its occlusive nature as to an existential-<disontologising/reentologising aporeticism $>$ interpretation as of rational-empiricism/positivism conception of human behaviour implications with direct understanding of immediate cause-and-effect implications); and prospectively - for the protensive-consciousness notional ${ }^{18}$ deprocrypticism 'implicited_attendant-ontological-contiguity ${ }^{67}$; educedexistentialising/contextualising/textualising_'intelligibility/epistemicity/reflexivity-contiguity$<$ imbued-notional cogency $>$-full-level-of-reification notional ${ }^{18}$ deprocrypticism deneuterising ${ }^{7}$-referentialism as of referentialism-circumscribing-as-'epistemic-totality ${ }^{37}$ '-ordelineating-as-'epistemic-totality ${ }^{37}$ existential-epistemic-totalisation-scheme-ofmeaningfulness-and-teleology 9 given its preempting-disjointedness-as-of- ${ }^{83}$ reference-ofthought,-as-to- ${ }^{6}<$ emplituding/formative-epistemicity $>$ growth-orconflatedness $^{13} /$ transvaluative-rationalising/transepistemicity/anamnestic-residuality/spiritdrivenness'-in-superseding-mere-formulaic-positivising/rational-empiricism-baseduniversalisation-directed-rulemaking-over-non-rules — apriorising/axiomatising/referencingpsychologism implied as of say post-structuralism 'which factors in socioeconomic, education, information, environmental, gender and power relations issues underlying healthcare and medical delivery' (noting finally that in the case where the given forest is infested with say mosquitoes carrying malaria for instance, such a per-cep-ti-vi-ty-as-of-full-disease-andscientific-theory-construct-as-the-exclusive-cause-and-effect-conceptualisation provides the 
best conceptivity/epistemic-reflexivity/epistemicity-relativism-determinism- $<$ reifying \{as-toknowledge-developing $\}$-and-empowering $>$ imbued theoretical/conceptual/operant implications to human-subpotency as of its protensive nature as to coherent existential-<disontologising/reentologising aporeticism $>$ interpretation drawing out the full implications of human limitedmentation-capacity-deepening — as-subjecting limitedness/human-subpotency to-'educedunlimitedness/existence-sublimating nascence' ${ }^{33}$ as of ${ }^{18}$ deprocrypticism-or-preemptingdisjointedness-as-of- ${ }^{8}$ reference-of-thought as a projective-totalitative-implications conception and superseding ${ }^{7}$ presencing-absolutising-identitive-constitutedness ${ }^{14}$ naiveties as to the socially extended constructive construal of healthcare as more than just as of immediate disease/illness cause-and-effect implications). The latter as ${ }^{18}$ deprocrypticism-or-preemptingdisjointedness-as-of- ${ }^{8}$ reference-of-thought as of its 'ontological-completeness-of- ${ }^{8}$ referenceof-thought as to ontological-normalcy/postconvergence' is the effective basis for evaluating the ontological-veracity of all preceding ${ }^{83}$ reference-of-thought as of its deneuterising referentialism that breaks-down the various ${ }^{58}$ neuterising to their basic human limitedmentation-capacity—as-subjecting-'educed-unlimitedness/existence-sublimating nascence' to-limitedness/human-subpotency dynamics implications. In this regard, their successive profoundness as of their 'successive (uncircumscribing/undelineating-as-'epistemic-totality ${ }^{37}$ with recurrent-utter-uninstitutionalisation) circumscribing-as-'epistemic-totality ${ }^{37}$ '-ordelineating-as-'epistemic-totality ${ }^{37}$ existential-epistemic-totalisation-scheme-ofmeaningfulness-and-teleology ${ }^{9}$ speaks of more and more profound convergence-as-ofaccumulation of human-subpotency grasp of the full-potency of existence coherence/contiguity. It should be noted as well that the afore is focused on the abstract ${ }^{83}$ reference-ofthought/epistemic-totalisation level of différance/internal-dialectics/difference-deferral, as it is actually reflecting the 'backdrop construed as human sublimation-educing-\{epistemictotalising ${ }^{3}{ }^{3}$ hermeneutic/textuality/reprojecting/supererogating/zeroing/re-acuting,- 
\{decompulsing\} delinearity for-cogency as-to-possibilities-of-self-becoming-as-of-‘existentialinterpretation/epistemicity-in-apriorising/axiomatising/referencing-of-existence ${ }^{\text {, }}$, for the effectively devolving différance/internal-dialectics/difference-deferral teleological process of meaningfulness; given that the abstract ${ }^{83}$ reference-of-thought/epistemic-totalisation level soestablished rather enframes teleologically-devolving-as-drifting meaningfulness with regards to 'social-stake-contention-or-confliction as of existential-instantiations dynamics among individuals and the social-collective' construed from notional ${ }^{18}$ deprocrypticism deneuterising 1 , to fully reflect the ontological-veridicality of mental-states as of affirmation/projection/assertion/notional self-distantiation/dueness-validatinglogicising/suitable-measuringinstrument-validating-measuring-<as-to-postconverging-ordialectical-thinking -apriorising-psychologism> and unaffirmation/deprojection/deassertion/epistemic-decadence/undueness-invalidatinglogicising/unsuitable-measuringinstrument-invalidating-measuring-<as-to-preconverging-ordementing -apriorising-psychologism $>$ stranding dialectics. For instance, reflecting in an early hunter-gatherer society the 'candid existential-<disontologising/re-ontologising aporeticism $>$ expressiveness' of how one is suffering from bad omen on the backdrop of its 'recurrent-utteruninstitutionalisation totalising/circumscribing/delineating <amplituding/formativeepistemicity $>$ reference-of-thought- ${ }^{8}$ devolving — différance/internal-dialectics/differencedeferral' construed as disambiguation its uninstitutionalised-threshold ${ }^{56}$ meaningfulness-andteleology'. Thus this will disambiguate, specifically "with regards to the ill-health $<$ amplituding/formative-epistemicity $>$ totalising $\sim$ devolved-purview-as-domain-of-construalas-intrinsic-reality/ontological-veridicality' the recurrent-utter-uninstitutionalisation randomas-uncircumscribing/undelineating-as-'epistemic-totality ${ }^{37}$, 'existential-epistemic-totalisationscheme-of- ${ }^{56}$ meaningfulness-and-teleology ${ }^{9}$, as it construes any ill-health issue as of the idea of bad omen given its 'non-rules-apriorising/axiomatising/referencing-psychologism,-as- 
impulsive-or-accidented-or-random-mental-disposition'. The uninstitutionalised-threshold ${ }^{12}$ as such, as of the ${ }^{83}$ reference-of-thought beyond-the-consciousness-awareness-teleology ${ }^{0}-<$ of preconverging-existential-extrication-as-of-existential-unthought $>$, is the basis for determining

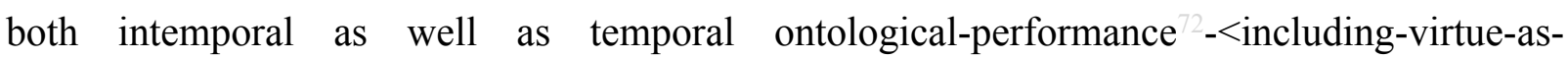
ontology $>$ /morality/ethics/justice/etc. specifically as of postlogism slantedness/ ${ }^{5}$ ignorance/affordability/opportunism/exacerbation/social-chainism-or-socialdiscomfiture-or-negative-social-aggregation/temporal-enculturation-or-temporal-endemisation, so-disambiguated as of ${ }^{83}$ reference-of-thought- ${ }^{8}$ devolving ontological-performance ${ }^{72}$ $<$ including-virtue-as-ontology>. This thus involves the disseminative-as-rearticulated $<$ amplituding/formative-epistemicity>totalising/circumscribing/delineating $\quad$ reference-ofthought- ${ }^{8}$ devolving-différance/internal-dialectics/difference-deferral as conjugations as of intemporal-as-conviction-as-to-profound-supererogation ontological-performance $^{72}$ $<$ including-virtue-as-ontology $>$ /morality/ethics/justice/etc. and also as the various temporal threshold-of-nonconviction/madeupness/bottomlining-in-shallow-supererogation $-<$ as-to‘attendant-intradimensional'-prospectively-disontologising preconverging/dementing apriorising-psychologism> denaturing ${ }^{16}$, all as conjugating variously to the-very-same implied

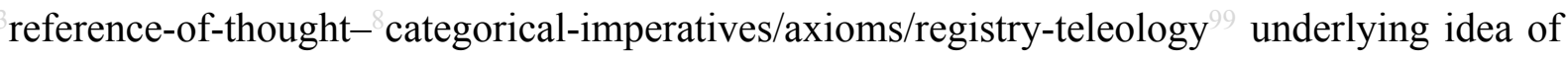
bad omen interpretation of recurrent-utter-uninstitutionalisation going by its random-asuncircumscribing/undelineating-as-'epistemic-totality ${ }^{37}$, 'existential-epistemic-totalisationscheme-of- ${ }^{56}$ meaningfulness-and-teleology ${ }^{99}$; and with this reflecting the metaphoricity ${ }^{57}$ of 'social-stake-contention-or-confliction as of existential-instantiations dynamics among individuals and the social-collective'. The foregoing conception of disseminative-asrearticulated totalising/circumscribing/delineating $<$ amplituding/formativeepistemicity $>$ reference-of-thought- devolving — différance/internal-dialectics/differencedeferral is equally pertinent with respect to all the other registry-worldviews/dimensions 
reference-of-thought but rather as of their own given 'candid existential-<disentologising/reentologising aporeticism $>$ expressiveness' with regards to their own respective specific same

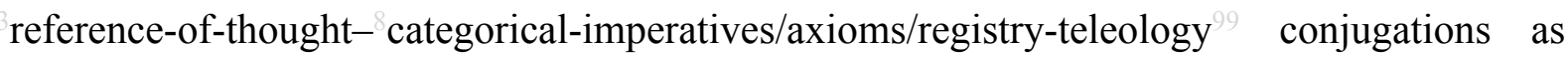
intemporal-as-conviction-as-to-profound-supererogation $\quad$ ontological-performance ${ }^{72}$ $<$ including-virtue-as-ontology $>/$ morality/ethics/justice/etc. and as various temporal thresholdof-nonconviction/madeupness/bottomlining-in-shallow-supererogation $<<$ as-to-' attendant-

\section{intradimensional'-prospectively-disontologising preconverging/dementing -apriorising-}

psychologism>

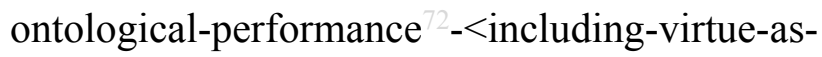
ontology $>$ /morality/ethics/justice/etc. by the respective underlying interpretations as evil-forestbad-omen/failure-to-heed-the-Deity/full-disease-and-scientific-theory-construct-as-theexclusive-cause-and-effect-conceptualisation/and-further-factoring-in_—epistemictotalising 3 ’ hermeneutically/textually/reprojectingly/supererogatingly/zeroingly/re-acutingly,\{decompulsing $\}$ delinearity for-cogency:-socioeconomic,-education,-information,-environmental,gender-and-power-relations-issues-underlying-healthcare-and-medical-delivery respectively as of their base-institutionalisation-ununiversalisation warped-consciousness, ${ }^{103}$ universalisationnon-positivism/medievalism preclusive-consciousness, positivism- ${ }^{80}$ procrypticism occlusiveconsciousness and notional ${ }^{1}$ deprocrypticism protensive-consciousness, inducing their respective tendentious/qualifying/categorising/referentialism-circumscribing-as-'epistemictotality $^{37}$ '-or-delineating-as-'epistemic-totality ${ }^{37}$, 'existential-epistemic-totalisation-schemeof- ${ }^{56}$ meaningfulness-and-teleology ${ }^{9}$ '; and so, respectively due to their rulemaking-over-nonrules_-apriorising/axiomatising/referencing-psychologism, universalisation-directedrulemaking-over-non-rules — apriorising/axiomatising/referencing-psychologism, positivising/rational-empiricism-based-universalisation-directed-rulemaking-over-non-rulesapriorising/axiomatising/referencing-psychologism, and preempting-disjointedness-as-ofreference-of-thought,-as-to- ${ }^{6}<$ amplituding/formative-epistemicity>growth-or- 
conflatedness ${ }^{13}$ /transvaluative-rationalising/transepistemicity/anamnestic-residuality/spiritdrivenness' - in-superseding-mere-formulaic-positivising/rational-empiricism-baseduniversalisation-directed-rulemaking-over-non-rules_ apriorising/axiomatising/referencingpsychologism. Insightfully, the foregoing points out that human ${ }^{56}$ meaningfulness-andteleology" is a "metaphoricity" of social-stake-contention-or-confliction as of existentialinstantiations dynamics among individuals and the social-collective that is fundamentally already an epistemic-totalising 3 /circumscribing/delineating ${ }^{3}$ reference-of-thoughtdevolving - différance/internal-dialectics/difference-deferral as of the-very-same-immanentexistence/intrinsic-reality/ontological-veridicality,-as-to-'human<amplituding/formativeepistemicity>totalising purview-of-construal' with the shifts in human ${ }^{56}$ meaningfulness-andteleology induced by human limited-mentation-capacity-deepening-as-subjecting limitedness/human-subpotency-to-'educed-unlimitedness/existence-sublimating nascence' ${ }^{53}$ as of prospective relative-ontological-completeness ${ }^{87}$-of- ${ }^{83}$ reference-of-thought', such that human meaningfulness-and-teleology ${ }^{9}$ is not absolutely identitive but shifting as of $<$ amplituding/formative-epistemicity>totalising/circumscribing/delineating $\quad{ }^{83}$ reference-ofthought- ${ }^{8}$ devolving - différance/internal-dialectics/difference-deferral, given that human limited-mentation-capacity-deepening - as subjecting limitedness/hmman-subpotency to 'educed-unlimitedness/existence-sublimating nascence' ${ }^{33}$ is in a constant $<$ amplituding/formative-epistemicity $>$-totalising $\sim$ renewing-realisation/re-perception/rethought of ${ }^{56}$ meaningfulness-and-teleology; with the implication that the ontologicalperformance $^{72}-<$ including-virtue-as-ontology $>$ /morality/ethics/justice/etc. of human meaningfulness-and-teleology 99 as to sublimation-educing-\{epistemictotalising ${ }^{3}$ hermeneutic/textulity/reprojecting/supererogating/zeroing/re acuting,${ }_{\{\text {decompulsing }\}}$ delinearity $\sim$ for-cogency $\sim$ as-to-possibilities-of-self-becoming-as-of-‘existentialinterpretation/epistemicity-in-apriorising/axiomatising/referencing-of-existence 
fundamentally construable as of the developing scope of the 'respective relative ${ }^{5}$ neuterising' towards prospective deneuterising —referentialism. Overall, the emphasis here is as of a Beingdevelopment/ontological-framework-expansion-as-to-depth-of-ontologising-development-asinfrastructure-of- meaningfulness-and-teleology that is as of 'various relative mentallyclosed limited-mentation-capacity—as-subjecting 'educed-unlimitedness/existencesublimating nascence'-to-limitedness/human-subpotency as of beyond-the-consciousnessawareness-teleology $-<$ of-preconverging-existential-extrication-as-of-existentialunthought $>, \quad$ as $\quad<$ amplituding/formative-epistemicity $>$ totalising $\sim$ self-referencingsyncretising/circularity/interiorising/akrasiatic-drag ${ }^{34}$ towards 'mentally-opened limitedmentation-capacity—as-subjecting-'educed-unlimitedness/existence-sublimating nascence' to-limitedness/human-subpotency overcoming beyond-the-consciousness-awarenessteleology ${ }^{9}-<$ of-preconverging-existential-extrication-as-of-existential-unthought>

$<$ amplituding/formative-epistemicity $>$ totalising $\sim$ self-referencingsyncretising/circularity/interiorising/akrasiatic-drag ${ }^{34}$, and so as of nonpresencing$<$ perspective-ontological-normalcy/postconvergence>; wherein as for the trepidatiousconsciousness $<$ amplituding/formative-epistemicity $>$ totalising $\sim$ self-referencingsyncretising/circularity/interiorising/akrasiatic-drag ${ }^{34}$, 'human mentally-closed limitedmentation-capacity-as-subjecting 'educed-unlimitedness/existence-sublimating nascence' to-limitedness/human-subpotency as of beyond-the-consciousness-awareness-teleology ${ }^{0}<$ ofpreconverging-existential-extrication-as-of-existential-unthought $>$ ' induced ${ }^{58}$ neuterising can be construed as apriorising/axiomatising/referencing-\{of-'prospectively implicited_attendantontological-contiguity ' educedexistentialising/entextualising/textrising_'intelligibility/epistemicity/reflexivity-contiguity$<$ imbued-notional cogency >' $\}$ - originariness/origination as of random-asuncircumscribing/undelineating-as-'epistemic-totality ${ }^{37}$, 'existential-epistemic-totalisation- 
scheme-of- ${ }^{56}$ meaningfulness-and-teleology ${ }^{9}$, as reflected in the idea of bad omen, for the warped-consciousness as apriorising/axiomatising/referencing-\{of-'prospectively implicited_attendant-ontological-contiguity ' ceducedexistentialising/contextualising/textualising_intelligibility/epistemicity/reflexivity_contiguity<imbued-notional cogency>' $\}$-re-originariness/re-origination as of tendentiouscircumscribing-as-'epistemic-totality ${ }^{37}$ '-or-delineating-as-'epistemic-totality ${ }^{37}, \quad$ 'existentialepistemic-totalisation-scheme-of- ${ }^{-5 e a n i n g f u l n e s s-a n d-t e l e o l o g y}{ }^{\circ}$ as reflected in the idea of evil forest, for the preclusive-consciousness as apriorising/axiomatising/referencing-\{of'prospectively implicited_attendant-ontological-contiguity ' ceducedexistentialising/contextualising/textualising_'intelligibility/epistemicity/reflexivity-contiguity<imbued-notional cogency >' $\}$-re-originariness/re-origination as of qualifyingcircumscribing-as-'epistemic-totality ${ }^{37}$ '-or-delineating-as-'epistemic-totality ${ }^{37}, \quad$ 'existentialepistemic-totalisation-scheme-of- ${ }^{-}$meaningfulness-and-teleology ${ }^{\circ}$ as reflected in the idea of failure to heed the Deity, while for the occlusive-consciousness as apriorising/axiomatising/referencing-\{of-"prospectively_implicited_attendant-ontologicalcontiguity ' educedexistentialising/contextralising/textising_intelligibility/epistemicity/reflexivity-contiguity<imbued-notional cogency>' $\}$-re-originariness/re-origination as of categorisingcircumscribing-as-'epistemic-totality ${ }^{37}$ '-or-delineating-as-'epistemic-totality ${ }^{37}, \quad$ 'existentialepistemic-totalisation-scheme-of- ${ }^{5}$ meaningfulness-and-teleology ${ }^{9}$, as reflected in the idea of full disease and scientific theory construct as the exclusive cause-and-effect conceptualisation'. Such that in the final analysis, there is an underlying tendency of Beingdevelopment/ontological-framework-expansion-as-to-depth-of-ontologising-development-asinfrastructure-of- meaningfulness-and-teleology that decomposes-as-of-conflatedness 'human mentally-closed limited-mentation-capacity-as-subjecting-educed- 
beyond-the-consciousness-awareness-teleology ${ }^{0}-<$ of-preconverging-existential-extrication-asof-existential-unthought $>$, induced neuterising into the underlying limited-mentationcapacity -as-subjecting 'educed-unlimitedness/existence-sublimating nascence' tolimitedness/human-subpotency manifestation disambiguation basis for their ontologicallyveridical construal', and so-construed from a notional ${ }^{18}$ deprocrypticism ontologicalnormalcy/postconvergence epistemic-or-notional projective-perspective. Thus for the protensive-consciousness as apriorising/axiomatising/referencing-\{of-'prospectively implicited_attendant-ontological-contiguity ' educedexistentialising/contextualising/textualising_'intelligibility/epistemicity/reflexivity_contiguity<imbued-notional cogency $\left.>^{\prime} \quad\right\}$-re-originariness/re-origination as of referentialismcircumscribing-as-'epistemic-totality ${ }^{37}$ '-or-delineating-as-'epistemic-totality ${ }^{37}, \quad$ 'existentialepistemic-totalisation-scheme-of- meaningfulness-and-teleology ${ }^{\circ}$ implied say as of poststructuralism factoring in socioeconomic, education, information, environmental, gender and power relations issues underlying healthcare and medical delivery'; as of notional ${ }^{1}$ deprocrypticism is as of deneuterising - referentialism. This analysis conveys the reality of human crossgenerational institutional-cumulation/institutional-recomposure-〈as-tohistoriality/ontological-eventfulness /ontological-aesthetic-tracing-<perspectiveontological-normalcy/postconvergence-reflected-‘epistemicity-relativism-determinism'>> due to the impossibility of the very first humans as of their limited-mentation-capacity-assubjecting-'educed-unlimitedness/existence-sublimating nascence' to-limitedness/humansubpotency and yet inexperience/unaccumulated-experience to be able to reason more than their initial apriorising/axiomatising/referencing/intelligibilitysettingup/measuringinstrumenting will permit as of their state of recurrent-utter-uninstitutionalisation 'non-rulesapriorising/axiomatising/referencing-psychologism,-as-impulsive-or-accidented-or-random- 
mental-disposition', and hence their construal of ${ }^{56}$ meaningfulness-and-teleology 99 as of 'their relative ${ }^{58}$ neuterising'. Likewise the ultimate possibility of human crossgenerational institutional-cumulation/institutional-recomposure-〈as-to- historiality/ontological-

\section{eventfulness /ontological-aesthetic-tracing-<perspective-ontological-}

normalcy/postconvergence-reflected-'epistemicity-relativism-determinism' $>>$ as enabling the apriorising/axiomatising/referencing/intelligibilitysettingup/measuringinstrumenting of notional $\sim$ deprocrypticism/notional preempting — disjointedness-as-of- ${ }^{3}$ reference-of-thought is the backdrop for deneuterising — referentialism enabling the full transparent ontologicallyveridical elucidation of human ${ }^{56}$ meaningfulness-and-teleology ${ }^{9}$ construed as of historiality/ontological-eventfulness ${ }^{38} /$ ontological-aesthetic-tracing-<perspectiveontological-normalcy/postconvergence-reflected-'epistemicity-relativism-determinism'>; as of the possibility of deneuterising . In-the-bigger-scheme-of-things, as of the notional conflatedness ${ }^{13}$ of notional ${ }^{18}$ deprocrypticism as deneuterising ${ }^{17}$-referentialism, what had hitherto been conceived notionally as logicism is herein exposed as effectively superseded by the notion of différance/internal-dialectics/difference-deferral so-construed as of ${ }^{6}$ reference-of-thought-or-axiomatic-construct-devolving-as-of-ontological-reconstituting-asto-conflatedness ${ }^{13}$-différance/internal-dialectics/difference-deferral' and as implied as-of-theconstrual-of-différance/internal-dialectics/difference-deferral-of- ${ }^{5}$ meaningfulness-andteleology ; and so with respect to the more ontologically-veridical reality of human conceptualisation of ${ }^{56}$ meaningfulness-and-teleology ${ }^{9}$ always from a position of limitedmentation-capacity—as-subjecting 'educed-unlimitedness/existence-sublimating nascence' to-limitedness/human-subpotency as of prior relative-ontological-incompleteness -ofreference-of-thought, thus in need for its prior deepening so-captured in the 'human sublimation-educing _thermeneutic/textuality/reprojecting/supererogating/zeroing/re-acuting,- 
$\{$ decompulsing $\}$ delinearity for-cogency as-to-possibilities-of-self-becoming-as-of-‘existentialinterpretation/epistemicity-in-apriorising/axiomatising/referencing-of-existence ${ }^{55}$ as of the notional conflatedness ${ }^{13}$ of notional $\sim^{18}$ deprocrypticism différance/internaldialectics/difference-deferral' as transcendence-and-sublimity/sublimation/supererogatory $\sim$ dementativity-enabling, whereas such a human limited-mentation-capacity-as-subjecting 'educed-unlimitedness/existence-sublimating nascence'-to-limitedness/human-subpotency implication is naively ignored with logicism in its metaphysics-of-presence-〈implicited'nondescript/ignorable-void '-as-to- presencing - absolutising-identitive-

constitutedness //illusion-of-the-present/present-consciousness/mirage. Such a 'human sublimation-educing__epistemic-

totalising $3{ }^{3}$ hermeneutic/textuality/reprojecting/supererogating/zeroing/re-acuting,$\left.{ }_{\{d e c o m p u l s i n g}\right\}$ delinearity $\sim$ for-cogency $\sim$ as-to-possibilities-of-self-becoming-as-of-'existentialinterpretation/epistemicity-in-apriorising/axiomatising/referencing-of-existence ${ }^{55}$ as of the notional conflatedness ${ }^{13}$ of notional $\sim^{18}$ deprocrypticism différance/internaldialectics/difference-deferral', by its insight with respect to the implications of human limitedmentation-capacity—as-subjecting-'educed-unlimitedness/existence-sublimating nascence'to-limitedness/human-subpotency for ontologically-veridical ${ }^{5}$ meaningfulness-and-teleology construal, is best predisposed to grasp the 'inner working coherence/contiguity of axiomaticconstruct construal of ecstatic-existence/the-nature-of-the-world/conditions' as of nonpresencing-<perspective-ontological-normalcy/postconvergence $>{ }^{83}$ reference-of-thought as this enables transcendence-and-sublimity/sublimation/supereregatory $\sim$ de-mentativity, thus fulfilling the full implications of knowledge as of its ontologically-veridical knowledgenotionalisation and organic-knowledge nature. Fundamentally this all has to do with human limited-mentation-capacity—as-subjecting 'educed-unlimitedness/existence-sublimating nascence' to-limitedness/human-subpotency, as if at a given (re-originary-_as-unenframed/re- 


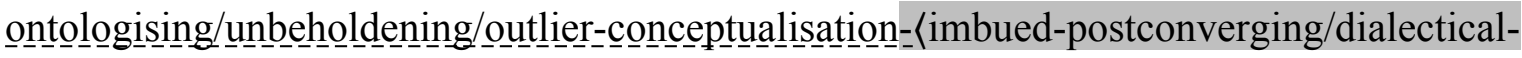
thinking -'projective-insights'/‘epistemic-projection-in-conflatedness ' 'ofnotional deprocrypticism-prospective-sublimation $\rangle^{\circ}$ ) originary/event ${ }^{38}$-of-prospectiveontology-origination moment humankind-as-of-its-integrant-individuals had a profound-andcomplete mentation-capacity, then human ${ }^{56}$ meaningfulness-and-teleology ${ }^{9}$ will be absolutely identitive with no implied-différance/internal-dialectics/difference-deferral-ofmeaningfulness-and-teleology ${ }^{9}$ requiring as of existential-constraint human limitedmentation-capacity-deepening —as-subjecting limitedness/human-subpotency-to-'educedunlimitedness/existence-sublimating nascence' ${ }^{33}$ as the circular driving notion of différance/internal-dialectics/difference-deferral. Différance as internal-dialectics/differencedeferral, beyond just an ontological conception as expressed herein, had already always been existent notionally as a wholly internal process of human self-referencing-syncretism for prospective relative-ontological-completeness ${ }^{87}$-of- ${ }^{8}$ reference-of-thought,-as-of-devolvingaxiomatic-constructs as-so-reflected in 'intemporal ontological-faith-notion-or-ontologicalfideism - imbued-underdetermination-of-motif-and-apriorising/axiomatising/referencing-asso-being-as-of-existential-reality instigated relative-mnreflexivity/relative-reflexivity ontological-contiguity ${ }^{67}$ of-the-human-institutionalisation-process ${ }^{68}$ as of differenceconflatedness $^{13}$-as-to-totalitative-reification-in-singularisation- $<$ as-to-thenondisjointedness/entailment-of-prospective- nonpresencing > -as-veridical-epistemicityrelativism-determinism implied $<$ amplituding/formative-epistemicity $>$ causality $\sim$ as-toprojective-totalitative-implications-of-prospective- nonpresencing,-for-explicating relativeunreflexivity/relative-reflexivity ontological-contiguity , construed-as institutionalcumulation/institutional-recomposure-〈as-to- historiality/ontologicaleventfulness /ontological-aesthetic-tracing-<perspective-ontologicalnormalcy/postconvergence-reflected-'epistemicity-relativism-determinism'>>, and with regards 
to the successive registry-worldview/dimension rearticulated as of temporal-to-intemporal ontological-performance ${ }^{72}<$ including-virtue-as-ontology $>$ /morality/ethics/justice/etc. of $<$ amplituding/formative-epistemicity>totalising/circumscribing/delineating $\quad$ reference-of-

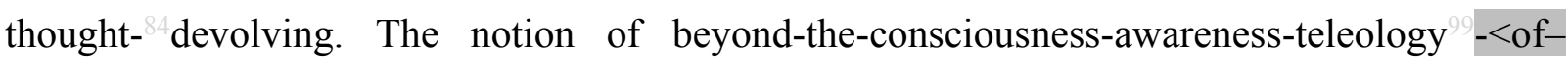
preconverging-existential-extrication-as-of-existential-unthought $>$ also highlights theoretically why the Husserlian epoché or bracketing method construed as eidetic reduction is ontologicallyflawed by its apriorising/axiomatising/referencing-\{of-'prospectively implicited_attendantontological-contiguity ' educed-

existentialising/contextualising/textualising_'intelligibility/epistemicity/reflexivity-contiguity$<$ imbued-notional cogency $\left.>^{\prime} \quad\right\}$ - constitutedness ${ }^{14}$-in-preconverging-entailment as it naively imply circumscribing-as-'epistemic-totality ${ }^{37}$ /delineating-as-'epistemic-totality ${ }^{37}$, meaningfulness-and-teleology ${ }^{9}$ for its essence in presence, rather than the fact that presence reference-of-thought as 'metaphysics-of-presence-_implicited-'nondescript/ignorable-void as-to- presencing - absolutising-identitive-constitutedness > preconverging/postconverging-de-mentatively/structurally/paradigmatically an ontologicallyflawed bracketing or epoché as of ontological-normalcy/postconvergence, and is representing metaphysics-of-absence-〈implicited-epistemic-veracity-of- nonpresencing-<perspectiveontological-normalcy/postconvergence $>>$ implications as nondescript/ignorable-void (actually speaking of akrasiatic-drag-denatured-and-preconverging-or-dementing -narratives)' when it comes to presence uninstitutionalised-threshold ${ }^{102}$ reference-of-thought in its relative notionaldiscontiguity/epistemic-discontiguity ${ }^{3}<$ between - prior-shallow-supererogation -ofmentally-aestheticised preconverging/dementing -qualia-schema_and_prospective-profoundsupererogation -of-mentally-aestheticised postconverging/dialectical-thinking -qualiaschema $>$ /relative-ontological-incompleteness ${ }^{88}$-of- ${ }^{83}$ reference-of-thought for meaningfulness-

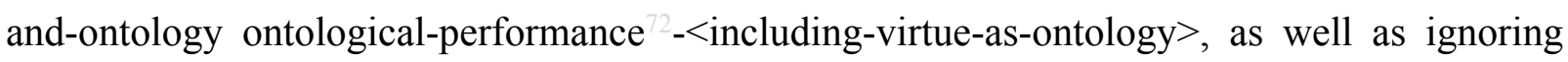


prospective institutionalisation implications construed as of ontologicalnormalcy/postconvergence. Such an eidetic reduction is circularly constraint in $<$ amplituding/formative-epistemicity $>$ totalising $\sim$ self-referencingsyncretising/circularity/interiorising/akrasiatic-drag 34 at its given registryworldview's/dimension's ${ }^{83}$ reference-of-thought without factoring in the phenomenological implications of 'intemporal ontological-faith-notion-or-ontological-fideism-imbuedunderdetermination-of-motif-and-apriorising/axiomatising/referencing-as-so-being-as-ofexistential-reality instigated relative-unreflexivity/relative-reflexivity_ontologicalcontiguity $^{67} \sim$ of-the-human-institutionalisation-process ${ }^{68}$ as of difference-conflatedness ${ }^{13}$-as-tototalitative-reification-in-singularisation-<as-to-the-nondisjointedness/entailment-ofprospective- nonpresencing $>$-as-veridical-epistemicity-relativism-determinism implied $<$ amplituding/formative-epistemicity $>$ causality $\sim$ as-to-projective-totalitative-implications-ofprospective- nonpresencing,-for-explicating relative-unreflexivity/relative-reflexivity ontological-contiguity ', as 'Being-development/ontological-framework-expansion-as-todepth-of-ontologising-development-as-infrastructure-of- meaningfulness-and-teleology coherence/contiguity implications as of ontology's-directedness-as-Being', and thus fails to get to the 'deepest phenomenological transcendental-point-of-departure handle as of the notional conflatedness ${ }^{13}$ of notional ${ }^{18}$ deprocrypticism deneuterising ${ }^{17}$-referentialism' reflected by metaphysics-of-absence-〈implicited-epistemic-veracity-of- nonpresencing$<$ perspective-ontological-normalcy/postconvergence $>>$ in the conception-of- -5 meaningfulnessand-teleology ontological-performance ${ }^{72}-<$ including-virtue-asontology $>$ /morality/ethics/justice/etc. which is as of the transcendental implications in reflecting holographically-<conjugatively-and-transfusively $>$ the relative-unreflexivity/relativereflexivity - ontological-contiguity of-the-human-institutionalisation-process . The further insight here is that, such a most ontologically-complete profoundness/depth of 
'phenomenological transcendental-point-of-departure handle in-its-overcoming-ofneuterisation, reflected by metaphysics-of-absence-_implicited-epistemic-veracity-ofnonpresencing-<perspective-ontological-normalcy/postconvergence $>\rangle$ for the construal of knowledge-constructs/theories/intersolipsistic-intercessory-notions/notional $\sim$ referentialnotions/articulations/virtue points to a fundamental epistemic-break/epistemic-resetting; with the latter arising as a result of lack of apriorising/axiomatising/referencing-commonness-insharedness,-for- ${ }^{5}$ meaningfulness-and-teleology ${ }^{9}$ with regards to the-very-same-immanentexistence/intrinsic-reality/ontological-veridicality,-as-to-'human<amplituding/formativeepistemicity>totalising purview-of-construal' as of the variance of uninstitutionalisedthreshold ${ }^{102}$ prior relative-ontological-incompleteness ${ }^{8}$-of- ${ }^{-3 e f e r e n c e-o f-t h o u g h t ~ a n d ~}$ prospective institutionalisation relative-ontological-completeness ${ }^{87}$-of- ${ }^{8}$ reference-of-thought. For instance, such epistemic-break/epistemic-resetting associated with the overall relativeunreflexivity/relative-reflexivity - ontological-contiguity ${ }^{67}$ of-the-human-institutionalisationprocess ${ }^{6}$ necessarily explains the 'mutually transversality-<for-sublimating-existentialeventuating/denouement, from-'thinking at-first/pure-predisposition-preemptive-ofprospective-disontologising/subontologising' as-of-prospectively-disambiguated-affirmedand-unaffirmed-'motif-and-apriorising/axiomatising/referencing'> ${ }^{101}$ unintelligibility' of the Galileos, Newtons, Diderots episteme articulating prospective positivising/rational-empiricism meaningfulness-and-teleology and the Establishment scholasticism medieval dogmatic episteme. The implication here is that the articulation of transcendence-andsublimity/sublimation/supererogatory de-mentativity as of ${ }^{83}$ reference-of-thought is by itself tied up to a prospective epistemic disruption, construed as of soundness-or-ontological-goodfaith/authenticity ${ }^{6}$-of- ${ }^{8}$ reference-of-thought, beyond just grounded knowledge as of the prior episteme which is rather construed as of unsoundness-or-ontological-bad-faith/inauthenticity ${ }^{64}$ of- ${ }^{-}$reference-of-thought. Such transcendental epistemic-breaks/epistemic-resetting arise 
because humankind is subpotent as of its knowledge-constructs/theories/intersolipsisticintercessory-notions/notional referential-notions/articulations/virtue to the full-potency of existence, and in the human construal/conceptualisation of intrinsic-reality/ontologicalveridicality, the 'superseding party' is not any involved humans as knowledge agents but inherent existential-reality itself, with any such humans as knowledge agents only 'pertinent in delegation' as of their 'kowtowing to existential-reality', with such delegation inherently revoked as of their failed 'kowtowing to existential-reality'. To the extent that human knowledge agents 'achieve sufficient-and-recurrent credibility as of their knowledge methods and approaches' with respect to social ${ }^{103}$ universal-transparency ${ }^{104}$-〈transparency-of-totalisingentailing,-as-to-entailing-<amplituding/formative-epistemicity $>$ totalising $\sim$ in-relative-

ontological-completeness $\rangle$, an apparent episteme as of apriorising/axiomatising/referencingcommonness-in-sharedness,-for- ${ }^{5}$ meaningfulness-and-teleology 9 with regards to the-verysame-immanent-existence/intrinsic-reality/ontological-veridicality,-as-to'human<amplituding/formative-epistemicity>totalising purview-of-construal' arises as of institutional-being-and-craft. But then, where transcendental implications as of prospective institutionalisation prospective relative-ontological-completeness ${ }^{87}$-of- ${ }^{8}$ reference-of-thought point to more profound ${ }^{8}$ reference-of-thought for construing/conceptualising existential-reality putting such a prior episteme in question, this induces a state of mutual ontological-badfaith/inauthenticity ${ }^{64}$ between the prospective episteme and the prior episteme as of the lack of apriorising/axiomatising/referencing — commonness-in-sharedness,-for- ${ }^{5}$ meaningfulness-andteleology with regards to the-very-same-immanent-existence/intrinsic-reality/ontologicalveridicality,-as-to-'human<amplituding/formative-epistemicity>totalising $\sim$ purview-ofconstrual' with respect to social ${ }^{103}$ universal-transparency ${ }^{104}$-〈transparency-of-totalisingentailing,-as-to-entailing-<amplituding/formative-epistemicity $>$ totalising $\sim$ in-relative-

ontological-completeness \; and so more than just as of beyond-the-consciousness-awareness- 
teleology $-<$ of-preconverging-existential-extrication-as-of-existential-unthought $>$, but further because as of human-subpotency-aporia/undecidability/dilemma/oughtindeterminacy/deficiency/limitation/constraint—imbued-'notional firstnaturednessformativeness-<as-to-eventualising-inkling drive-or-seeding-misprising $>$ temporal-tointemporal-dispositions- $<$ so-construed-as-from-perspective-ontologicalnormalcy/postconvergence>'-existentialism-form-factor, there is a 'drift from the ideal of knowledge agents only as 'pertinent in delegation' as of their 'kowtowing to existential-reality' towards a teleologically-degraded exercise of institutional-being-and-craft muddlement. It should be noted that such a notional construct of episteme interpreted herein is implied as of 'dynamic social <amplituding/formative-epistemicity>totalising $\sim$ self-referencing-syncretising' across the entire social spectrum as of notional episteme dynamically covering both informal institutional settings and formal institutional settings. In-the-bigger-scheme-of-things, such transcendental epistemic-breaks/epistemic-resetting in transition associated with the relativeunreflexivity/relative-reflexivity - ontological-contiguity ${ }^{67} \sim$ of-the-human-institutionalisation$\operatorname{process}^{68}$ as of human-subpotency-aporia/undecidability/dilemma/oughtindeterminacy/deficiency/limitation/constraint—imbued-'notional firstnaturednessformativeness-as to eventlising inkling drive or seeding misprising intemporal-dispositions-<so-construed-as-from-perspective-ontologicalnormalcy/postconvergence>'-existentialism-form-factor arise wherein the 'prior shaman is being contested by a new shaman in a hunter-gatherer society' with possible accusations of witchcraft as of institutionalised-being-and-craft, wherein 'two or more traditional priesthoods of an early civilisation foment against one another', wherein 'sophistry and philosophy vie for what passes as valuable and true knowledge', wherein 'medieval scholasticism dogmatic knowledge and positivism/rational-empiricism knowledge vie for the interpretation of human and physical nature', and in our case wherein 'knowledge traditions including philosophical 
traditions are put-into-question as of Being-development/ontological-framework-expansion-asto-depth-of-ontologising-development-as-infrastructure-of- meaningfulness-and-teleology , antinihilism and transcendental-enabling/sublimating/supererogatory de-mentativity knowledge perspectives'. Ultimately, this point out that epistemic-breaks/epistemic-resetting become inevitable wherein the prior knowledge episteme preconverging/postconverging-dementatively/structurally/paradigmatically loses its way as of its initial justification as safeguarding the prospective possibility of enlightening human knowledge as of ontology'sdirectedness-as-Being, but then by its institutional-being-and-craft uninstitutionalisedthreshold actually preconverging/postconverging-dementatively/structurally/paradigmatically beyond-the-consciousness-awareness-teleology $<$ of-preconverging-existential-extrication-as-of-existential-unthought $>$ undermines the prospective possibility of prospective enlightening human knowledge; and so, as increasingly the prior epistemic disposition is one that overlooks prospective inherent transcendentalenabling/sublimating/supererogatory $\sim$ de-mentativity of ${ }^{56}$ meaningfulness-and-teleology ontological-performance $^{72}$-<including-virtue-as-ontology $>/$ morality/ethics/justice/etc. turning rather towards social-aggregation-enabling implications as ${ }^{56}$ meaningfulness-and-teleology ontological-performance $^{72}-<$ including-virtue-as-ontology $>$, undermining the very notion of the intellectual exercise as about developing/institutionalising the social and not kowtowing-to-it construed as charlatanism! Further in all such transcendental contexts despite the fact that thenew is derived from the-old as for instance the Descartes, the Galileos, the Leibnizes and the Newtons as budding-positivists are the outcrop of Scholasticism itself, the-new epistemicbreak/epistemic-resetting is justified in that even the-old is predicated on upholding Beingdevelopment/ontological-framework-expansion-as-to-depth-of-ontologising-development-asinfrastructure-of- meaningfulness-and-teleology as of ontology's-directedness-as-Being going by the human 
intemporal/ontological/social/species/ ${ }^{103}$ universal/transcendental/ ${ }^{55}$ maximalisingrecomposuring-for-relative-ontological-completeness —unenframed/re-

ontologising conceptualisation postconverging-de-mentating/structuring/paradigming. Insightfully, that exercise is actually reflected as of temporal-to-intemporal individuations wherein the individual is rather a receptacle of temporal-to-intemporal individuations with variance of mental-dispositions among individuals an issue of variance as of skewness towards temporality $8 /$ shortness or intemporality ${ }^{52}$; such that even the budding-positivists carried elements of scholasticism but were more definitely of a positivistic outlook, and many scholastics articulated notions which could more fruitfully be developed in a positivistic outlook but were stifled by their scholasticism dogmatic intellectual commitments. In effect, human limited-mentation-capacity—as-subjecting-'educed-unlimitedness/existence-sublimating nascence' to-limitedness/human-subpotency however the institutionalisation-level as of humansubpotency-aporia/undecidability/dilemma/ought-

indeterminacy/deficiency/limitation/constraint—imbued-'notional firstnaturednessformativeness-<as-to-eventualising inkling-drive-or-seeding-misprising $>$ temporal-tointemporal-dispositions- $<$ so-construed-as-from-perspective-ontologicalnormalcy/postconvergence>'-existentialism-form-factor implies that it is impossible for the intemporal projection as longness-of-register-of- ${ }^{5}$ meaningfulness-and-teleology 9 that prospectively construes of successive frameworks of ${ }^{83}$ reference-of-thought- devolvingteleological-de-mentating/structuring/paradigming-of-meaningfulness as of implicited-andexplicited $\quad{ }^{83}$ reference-of-thought- categorical-imperatives/axioms/registry-teleology ${ }^{9}$,-foraposteriorising/logicising/deriving/intelligising/measuring- ${ }^{5}$ meaningfulness-and-teleology ${ }^{99}$ as knowledge-constructs/theories/intersolipsistic-intercessory-notions/notional referentialnotions/articulations/virtue' as of the specific institutionalisation, to ensure that human meaningfulness-and-teleology

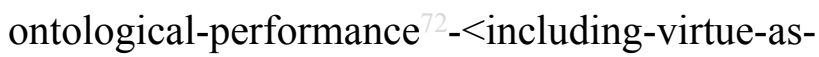


ontology $>$ /morality/ethics/justice/etc. will remain intemporal-as-ontological as of their reference-of-thought- categorical-imperatives/axioms/registry-teleology 9 given the 'impossibility of overcoming the abstract human seed of temporality $/$ /shortness dynamically involved, as of beyond-the-consciousness-awareness-teleology ${ }^{\circ}<$ of-preconvergingexistential-extrication-as-of-existential-unthought $>, \quad$ in $\quad$ a formulaicnonconviction/madeupness/bottomlining-as-to-shallow-supererogation deterministic relation with such ${ }^{83}$ reference-of-thought- categorical-imperatives/axioms/registry-teleology ${ }^{9}$ by $<$ amplituding/formative $>$ wooden-language-〈imbued-temporal-mereform/virtualities/dereification/akrasiatic-drag/denatured/preconverging-or-dementing narratives - of-the- reference-of-thought- categorical-imperatives/axioms/registryteleology $>$ thus failing to uphold intemporal-preservation-entropy-or-contiguity-orontological-preservation'. Thus the ontological effectiveness of such intemporal-projection as longness-of-register-of- ${ }^{5}$ meaningfulness-and-teleology ${ }^{9}$ lies rather in undermining the existential-<disontologising/re-ontologising aporeticism $>$ possibility of the successive uninstitutionalised-threshold $102 /$ uninsitutionalisations as of bringing about prospective relativeontological-completeness ${ }^{87}$-of- ${ }^{83}$ reference-of-thought driven by ontological-faith-notion-orontoligical-fideism thus inducing social ${ }^{103}$ universal-transparency ${ }^{104}$-〈transparency-oftotalising-entailing,-as-to-entailing-<amplituding/formative-epistemicity $>$ totalising $\sim$ inrelative-ontological-completeness $\rangle$ which renders untenable temporality $/$ shortness as of the given uninstitutionalised-threshold ${ }^{102}$ instigated from the prior institutionalisation's ${ }^{83}$ referenceof-thought- categorical-imperatives/axioms/registry-teleology ${ }^{9}$ denaturing ; as implied with base-institutionalisation prospective relative-ontological-completeness ${ }^{87}$-of- ${ }^{8}$ reference-ofthought over recurrent-utter-uninstitutionalisation, ${ }^{103}$ universalisation prospective relativeontological-completeness ${ }^{87}$-of- ${ }^{83}$ reference-of-thought over base-institutionalisationununiversalisation, positivism prospective relative-ontological-completeness ${ }^{87}$-of- ${ }^{8}$ reference- 
of-thought over universalisation-non-positivism/medievalism, and prospectively notional ${ }^{18}$ deprocrypticism prospective relative-ontological-completeness ${ }^{87}$-of- ${ }^{83}$ reference-ofthought over positivism- ${ }^{80}$ procrypticism. Such that we can garner that it is a positivism registryworldview's/dimension's institutionalisation prospective relative-ontological-completeness ${ }^{87}$ of- ${ }^{3}$ reference-of-thought social ${ }^{103}$ universal-transparency ${ }^{104}$-〈transparency-of-totalisingentailing,-as-to-entailing-<amplituding/formative-epistemicity $>$ totalising $\sim$ in-relative-

ontological-completeness $>$ that makes it untenable for non-positivism/medieval temporal mental-dispositions to elicit non-positivism/medieval implied temporality ${ }^{8}$. Likewise, prospectively it is a notional ${ }^{18}$ deprocrypticism registry-worldview's/dimension's institutionalisation prospective relative-ontological-completeness ${ }^{87}$-of- ${ }^{8}$ reference-of-thought social universal-transparency -〈transparency-of-totalising-entailing,-as-to-entailing$<$ amplituding/formative-epistemicity>totalising in-relative-ontological-completeness $>$ that can render it untenable for procrypticism temporal mental-dispositions to elicit ${ }^{80}$ procrypticismor-disjointedness-as-of- ${ }^{8}$ reference-of-thought implied temporality ${ }^{9}$. Thus aetiologisation/ontological-escalation-<ontological-

veridicality_commitment/otherliness_transcending/compulsions-encumbered_transcending $>$ is not about transforming the reality of human-subpotency-aporia/undecidability/dilemma/oughtindeterminacy/deficiency/limitation/constraint—imbued-'notional firstnaturednessformativeness-<as-to-eventualising inkling drive-or-seeding-misprising $>$ - temporal-tointemporal-dispositions-<so-construed-as-from-perspective-ontologicalnormalcy/postconvergence $>$ '-existentialism-form-factor as overcoming temporality $8 /$ shortness inherently, but rather it is about bringing about prospective relative-ontological-completeness ${ }^{87}$ of- reference-of-thought. The reality of human registry-worldview's/dimension's institutionalisation and uninstitutionalised-threshold ${ }^{102}$ mental-dispositions imply that at the uninstitutionalised-threshold ${ }^{102}$ prospective institutionalisation knowledge as transcendental- 
enabling/sublimating/supereregatory de-mentativity is not socially integrated directly as of dimensionality-of-sublimating ${ }^{25}-<<$ amplituding/formative $>$ supererogatory $\sim$ dementativeness/epistemic-growth-or-conflatedness /transvaluativerationalising/transepistemicity/anamnestic-residuality/spirit-drivenness-equalisation〉 exercise engaging with intemporal-as-ontological ${ }^{56}$ meaningfulness-and-teleology ${ }^{9}$. Such prospective intemporal-as-ontological ${ }^{56}$ meaningfulness-and-teleology ${ }^{9}$ is not necessarily perceived at the uninstitutionalised-threshold ${ }^{102}$ as any more pertinent for attaining social approbation than other temporal ${ }^{56}$ meaningfulness-and-teleology 9 as of the said uninstitutionalised-threshold ${ }^{102}$. This point out that ${ }^{55}$ maximalising-recomposuring-for-relative-ontological-completeness ${ }^{87}$ unenframed/re-ontologising conceptualisation mental-dispositions in their intemporality ${ }^{5 /} /$ longness or longness-of-register-of- ${ }^{5}$ meaningfulness-and-teleology ${ }^{99}$ are as of a projected-or-anticipated apriorising/axiomatising/referencing-\{of-'prospectively implicited_attendant-ontological-contiguity ' reducedexistentialising/contextualising/textualising_'intelligibility/epistemicity/reflexivity_contiguity<imbued-notional cogency $\left.>^{\prime} \quad\right\}$ - conflatedness ${ }^{13}$ in- precenverging ment by $^{\prime}$ pestconverging-entailment of social ${ }^{103}$ universal-transparency ${ }^{104}$-〈transparency-of-totalisingentailing,-as-to-entailing-<amplituding/formative-epistemicity $>$ totalising $\sim$ in-relative-

ontological-completeness $\rangle$ for institutional and formal deferential-formalisation-transference as of percolation-channelling- $<$ in-deferential-formalisation-transference $>$. That is at the uninstitutionalised-threshold ${ }^{102}$ such intemporal-as-ontological meaningfulness-andteleology is pragmatically expounded socially not in terms of its inherent dimensionality-ofsublimating $25<<$ amplituding/formative $>$ supererogatory $\sim$ de-mentativeness/epistemic-growthor-conflatedness /transvaluative-rationalising/transepistemicity/anamnestic-residuality/spiritdrivenness-equalisation) ideal which is socially-too-abstract but rather as a dementating/structuring/paradigming secondnatured construct of positive-opportunism-of- 
social-functioning-and-accordance ${ }^{75}$ as of institutional and formal percolation-channelling- $<$ indeferential-formalisation-transference $>$ to attain social approbation. It is such a 'apriorising/axiomatising/referencing-\{of-'prospectively implicited_attendant-ontologicalcontiguity ' $\sim$ educedexistentialising/contextualising/textualising_'intelligibility/epistemicity/reflexivity-contiguity<imbued-notional cogency $\left.>^{\prime}\right\}$-conflatedness ${ }^{13}$-in-\{preconverging-ment by\} pestconverging-ntailment de-mentating/structuring/paradigming secondnatured construct of positive-opportunism - of-social-functioning-and-accordance ${ }^{75}$ of institutional and formal deferential-formalisation-transference as of percolation-channelling- $<$ in-deferentialformalisation-transference $>$ to attain social approbation' that holds together in social ${ }^{3}$ universal-transparency ${ }^{104}$-〈transparency-of-totalising-entailing,-as-to-entailing$<$ amplituding/formative-epistemicity $>$ totalising in-relative-ontological-completeness temporal-to-intemporal solipsistic mental-dispositions as of a given secondnatured institutionalisation. Out of such an apriorising/axiomatising/referencing-\{of-"prospectively implicited_attendant-ontological-contiguity ' educedexistentialising/contextualising/textualising_intelligibility/epistemicity/reflexivity_contiguity<imbued-notional cogency>' \}-conflatedness ${ }^{13}$-in-\{preconverging-ment by postconverging-entailment de-mentating/structuring/paradigming secondnatured construct, intemporal-as-ontological ${ }^{5}$ meaningfulness-and-teleology ${ }^{9}$ is not necessarily perceived as any more pertinent for attaining social approbation than other temporal ${ }^{56}$ meaningfulness-andteleology ${ }^{9}$. In other words, the ideal articulation of base-institutionalisation ${ }^{56}$ meaningfulnessand-teleology in recurrent-utter-uninstitutionalisation, just as that of ${ }^{103}$ universalisation in base-institutionalisation-ununiversalisation, $\quad$ positivism/rational-empiricism in universalisation-non-positivism/medievalism, and prospectively notional $\sim$ deprocrypticism in positivism- ${ }^{80}$ procrypticism; are only pertinent for attaining social approbation as of their 
apriorising/axiomatising/referencing-\{of-'prospectively_implicited_attendant-ontological-

contiguity ' educed-

existentialising/contextualising/textualising_'intelligibility/epistemicity/reflexivity-contiguity-

<imbued-notional cogency $\left.>^{\prime}\right\}$ - conflatedness ${ }^{13}$-in-\{preconverging-ment by \} $^{-}$

pestconverging-entailment de-mentating/structuring/paradigming secondnatured construct of positive-opportunism - of-social-functioning-and-accordance ${ }^{75}$ of institutional and formal deferential-formalisation-transference as of percolation-channelling- $<$ in-deferentialformalisation-transference $>$. This highlights that from the perspective of immediate-or-short-run social approbation, it is simpler though ontologically flawed as of apriorising/axiomatising/referencing-\{of-‘prospectively_implicited_attendant-ontologicalcontiguity ' educedexistentialising/contextualising/textualising_'intelligibility/epistemicity/reflexivity-contiguity$<$ imbued-notional cogency $>$ ' $\}$-constitutedness ${ }^{4}$-in-preconverging-entailment to engage a registry-worldview/dimension at its uninstitutionalised-threshold ${ }^{102}$ rather by an incrementalism-in-relative-ontological-incompleteness

enframed/disontologising conceptualisation mental-disposition on the basis of its prior relativeontological-incompleteness ${ }^{8}$-of- ${ }^{-}$reference-of-thought or its same metaphysical framework of contention rather than adopting at its uninstitutionalised-threshold ${ }^{102}$ a more complex but ontologically-veridical maximalising-recomposuring-for-relative-ontologicalcompleteness ${ }^{87}$ — unenframed/re-ontologising conceptualisation mental-disposition on the basis of the prospective relative-ontological-completeness ${ }^{87}$-of- ${ }^{83}$ reference-of-thought or superseding metaphysical framework of contention as of apriorising/axiomatising/referencing-\{of'prospectively implicited_attendant-ontological-contiguity ' educedexistentialising/contextualising/textualising_'intelligibility/epistemicity/reflexivity-contiguity<imbued-notional cogency>' \}-conflatedness ${ }^{13}$ in-\{preconverging-ment by\} 
postconverging-entailment. That is, engaging a non-positivism registry-worldview/dimension meaningfulness-and-teleology ${ }^{9}$ with respect to say notions-and-accusations-of-sorcery on its same terms in case of an accusation of sorcery to imply the other is the sorcerer, etc. will sound more credible as of its <amplituding/formative> wooden-language-〈imbued-averaging-ofthought-<as-to-leveling/ressentiment/closed-construct-of- meaningfulness-and-teleology -asof-'nondescript/ignorable-void '-with-regards-to-prospective-apriorising-implications $>>$ in a non-positivism social-setup than say projecting to prospective positivism registryworldview/dimension ${ }^{56}$ meaningfulness-and-teleology ${ }^{9}$ and implying that notions-andaccusations-of-sorcery are not real speaking of both the defect of such accusation and the defective superstitious <amplituding/formative> wooden-language-〈imbued-averaging-ofthought-<as-to-leveling/ressentiment/closed-construct-of- meaningfulness-and-teleology -asof-'nondescript/ignorable-void '-with-regards-to-prospective-apriorising-implications $>>$ in the non-positivism social-setup. Ultimately, such a profound phenomenological $<$ amplituding formative-epistemicity $>$ totalising $\sim$ conflated $-{ }^{56}$ meaningfulness-and-teleology ${ }^{9}-$ as-of-notional ${ }^{~ d e p r o c r y p t i c i s m-r e f l e c t e d-~}{ }^{-}$historiality/ontologicaleventfulness 38 ontological-aesthetic-tracing-<perspective-ontologicalnormalcy/postconvergence-reflected-'epistemicity-relativism-determinism’ ontologicalperformance $^{72}-<$ including-virtue-as-ontology $>$ /morality/ethics/justice/etc. construal faced with the inherent dogmatic and psychological biases of human <amplituding/formativeepistemicity $>$-totalising thrownness-in-existence ${ }^{35}$ (I exist therefore existence is of transcendental-enabling/sublimating/supererogatory de-mentativity to my human-subpotency /

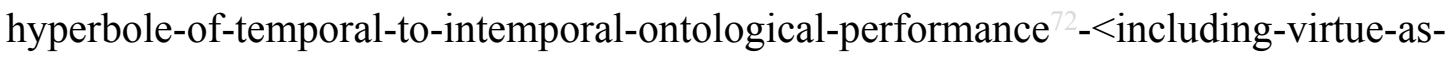
ontology>) in-many-ways necessarily has to project out of 'ordinariness of thought' for pretence of arriving at a sound construct capable of a most profound reflection of social ontologicalveridicality. Consider with respect to a most profound emotional-involvement the issue of human 
imperilment as a test for the capacity for such requisite depth of transcendental contemplation. Consider for instance that tens of millions including soldiers killed in both the first and second world wars pass for mere victims of the wars in a bizarre twist of mutual $<$ amplituding/formative-epistemicity $>$ totalising $\sim$ self-referencingsyncretising/circularity/interiorising/akrasiatic-drag that shuts-off-the-mind to the odious reality of mutual genocide, to say the least. Consider that in Russia a dictator responsible for killing about ${ }^{25}$ millions of his own citizens is still considered a national hero by the majority. Consider that the first president of the United States in position of power was a slave-owner thus encouraging the Atlantic slave trade that led to genocidal proportions of deaths but he is venerated by a majority as the greatest U.S. President. Consider in a different sense though nonexculpatory that Heidegger a leading intellectual joined the Nazi party leaving 2 years later with hardly any critical influence on the party and is ${ }^{103}$ universally condemned today. Consider as well that many an intellectual or public figure today actively or passively voiced for the recent wars killing millions whether in the Middle-East or elsewhere with a corresponding social indifference and mental shut-off. These profound considerations highlight the contemplative depth to which the social thinker needs to get to in order to truly be engaged in a transcendentalenabling/sublimating/supererenterativity <amplituding/formativeepistemicity $>$ causality $\sim$ as-to-projective-totalitative-implications-of-prospectivenonpresencing,-for-explicating relative unreflexivity/relative-reflexivity - ontologicalcontiguity construal as implied with notional ${ }^{18}$ deprocrypticism as preemptingdisjointedness-as-of- ${ }^{8}$ reference-of-thought and so be able to keep their head up from drowning in human <amplituding/formative-epistemicity $>$-totalising $\sim$ thrownness-in-existence ${ }^{35}$ (I exist therefore existence is of transcendental-enabling/sublimating/superentativity to my human-subpotency / hyperbole-of-temporal-to-intemporal-ontological-performance ${ }^{72}$ <including-virtue-as-ontology>) in order to be able to produce 'veridical ontology' on a 'same 
notional/epistemic/bindingness $<$ as-to-determinism/conceptivity-of-relative-unreflexivity/relative-reflexivity> parity of relative-unreflexivity/relative-reflexivity' as nature constrains on the natural sciences. Effectively, such transcendental insight points out that existence/existential-possibilities is inherently a radical ontology beyond our < amplituding/formative-epistemicity $>$ totalising $\sim$ selfreferencing-syncretising/circularity/interiorising/akrasiatic-drag 34 in existence/existentialpossibilities as 'hyperbolic pretences of ontology'. This author thinks that there can effectively be an engaging and constructive approach for arriving at such a depth of radical ontology warranted by existence/existential-possibilities that is transcendentalenabling/sublimating/supereregatery $\sim$ de-mentativity for the social avoiding the platitudes of our times such that many an intellectual have even given up to 'this all-powerful emotionalinvolvement element of the social'. Human <amplituding/formative-epistemicity>totalising thrownness-in-existence ${ }^{35}$ (I exist therefore existence is of transcendentalenabling/sublimating/supererogatory de-mentativity to my human-subpotency / hyperbole-oftemporal-to-intemporal-ontological-performance ${ }^{72}-<$ including-virtue-as-ontology $>$ ) implies the need for a sound perpetuating construct of ${ }^{103}$ universal projection as intemporality ${ }^{52}$-or-longnessof-register-of- ${ }^{5}$ meaningfulness-and-teleology 9 as the opportunity for prospective transcendental-enabling/sublimating/suchentativity. Such a construct is a 'response construal' that inherently enables transformative ${ }^{103}$ universal implications as beyond presence issues and complexes as it sublimates presence out of its failure. This is unlike the all too frequent construct of 'reactionary construal' caught up in presence as it is presence-serving and so whether as of positive or negative reaction; as even as a positive act a reactionary construal is hardly of entailing-<amplituding/formative-epistemicity>totalising in-relative-ontologicalcompleteness $^{87}$ thus hardly as of aetiologisation/ontological-escalation- $<$ ontologicalveridicality_commitment/otherliness_transcending/compulsions-encumbered_transcending $>$. A hero as of a positive 'reactionary construal' may perfectly prevent a crime from happening and 
save the day but then such action is not dependable and the outcomes are unreliable as well together with the possibility on occasion of wrong judgement and/or wrong action or usurpation; thus the social construction of crime prevention needs an intellectualised social 'response construal' mechanism of ${ }^{103}$ universal implication that ensures dependability of crime prevention as of the foresight of law and policing management construed as of an intemporal-as-ontological intellectual projection exercise. This same depth-of-thought is warranted across the dynamic scope of the social including the political for true transcendentalenabling/sublimating/supererogatory $\sim$ de-mentativity beyond normative conventioned constructs bound to hold-up the possibility of prospective 'visions of humankind emancipation'. Such a depth of contemplation will fathom for instance that humankind appeared on earth about 100000 years ago but the pervasive preconverging/postconverging-dementative/structural/paradigmatic determinism of the nation-state which became common just about 500 years ago has been a source of much of humankind's problems as of 'reactionary construal' and humankind's apriorising/axiomatising/referencing-\{of- 'prospectively implicited_attendant-ontological-contiguity ' educedexistentialising/contextualising/textualising_intelligibility/epistemicity/reflexivity_contiguity<imbued-notional cogency $\left.>^{\prime} \quad\right\}$-constitutedness ${ }^{1}$ in preconverging entailment to the notion of nation-state seems to create an impasse for human Being-and-contemplative development. Consider again the possibility capable of arising as of a 'response construal' as effectively articulated by Derrida in his analysis of spirit. Derrida grasps that Heidegger strove to produce ${ }^{3}$ universal human ${ }^{56}$ meaningfulness-and-teleology ${ }^{9}$ but was caught up in the $<$ amplituding/formative-epistemicity $>$-totalising $\sim$ thrownness-in-existence ${ }^{35}$ (I exist therefore existence is of transcendental-enabling/sublimating/superentativity to my human-subpotency / hyperbole-of-temporal-to-intemporal-ontological-performance ${ }^{72}$ <including-virtue-as-ontology>) as spirit failed to ${ }^{103}$ universalise and so Heidegger couldn't 
carry the effective implications of his work to its true ${ }^{103}$ universal conclusion as he was caught up in the 'reactionary construal' of them-and-us, as his commitment to the 'us' overlooked/didn't-come-into-grips with what the 'us' was doing, not to mention the possibility of him actually acting as transcendental over the them-and-us as a position of making a 'universal 'response construal'. This problem isn't particular to Heidegger but for the fact that the underlying regime of 'us' were the Nazis, as the them-and-us logic is intellectually rampant such that even Derrida was being condemned by many for not adopting it. The question can be asked whether any genuine intellectualism as providing a 'response construal' for humankind overall can construe of emancipation ${ }^{56}$ meaningfulness-and-teleology ${ }^{9}$ in them-and-us basis and whether this isn't a recipe for potential disaster as all them-and-us rationale are just variances of the same insanity! We can imagine that a true understanding and ${ }^{103}$ universal application of Derrida's spirit insight as a 'response construal' could have educated thought-andintellectualism and prevent say the subsequent Rwanda and Burundi genocides in Africa from occurring with many supposedly normal and educated persons caught up in the overall mobbishness; but such a lesson can hardly come out from the prevalent them-and-us lazy intellectualism 'reactionary construal' which simply provides <amplituding/formativeepistemicity $>$ totalising $\sim$ self-referencing-syncretising/circularity/interiorising/akrasiatic-drag comfort to protagonists by its lack-of or pseudo ${ }^{103}$ universal projection. Basically, a phenomenological extended metaphysics-of-absence-〈implicited-epistemic-veracity-ofnonpresencing-<perspective-ontological-normalcy/postconvergence $>>\quad$ as $\quad$ of notional $\sim$ deprocrypticism perspective points out that humankind does have the possibilities of adopting an uninhibited/decomplexified posture for 'inventing' a whole new renewal/repercepting/re-thinking beyond our apparently constricted metaphysics-of-presence-〈implicited'nondescript/ignorable-void ' -as-to- presencing-absolutising-identitive-constitutedness > framework which in reality is just presence 'hyperbolic dazing effect' utterly distinct from the 
radical ontology possibilities of existence/existential-possibilities. Transcendence-andsublimity/sublimation/supererogatory de-mentativity as implied here is with regards to reference-of-thought/epistemic-totalisation level ' ${ }^{\prime 3}$ reference-of-thought - devolvingteleological-de-mentating/structuring/paradigming-of-meaningfulness' which is the 'ontologically veridical enabling notion of transcendence-andsublimity/sublimation/supererogatory-de-mentativity' as of the-very-same-immanentexistence/intrinsic-reality/ontological-veridicality,-as-to-'human<amplituding/formativeepistemicity>totalising purview-of-construal' in epistemic-conflatedness ${ }^{13}$ as of underlying relative-ontological-incompleteness ${ }^{88}$ and relative-ontological-completeness ${ }^{87}{ }^{83}$ reference-ofthought. Such a conceptualisation of transcendence-andsublimity/sublimation/supererogatory-de-mentativity is actually what a Kantian transcendental imagination and other subsequent philosophies of transcendence-andsublimity/sublimation/supererogatory $\sim$ de-mentativity it inspired would have strove to arrive at, but according to this author wrongly understood transcendence-andsublimity/sublimation/supererogatory de-mentativity rather as of 'phenomenal-abstractiveness' as the basis/grounding to then construe/conceptualise ${ }^{56}$ meaningfulness-and-teleology ${ }^{9}$ failing to factor in that 'existential phenomenal-abstractiveness conflates-in-effecting-wholeness-as-ofprofoundness-and-completeness-to- ${ }^{5}$ meaningfulness-and-teleology 9 all the way to consciousness

apriorising/axiomatising/referencing/intelligibilitysettingup/measuringinstrumenting for the possibility of meaningfulness-and-teleology ${ }^{9}$ to then arise on the basis of such a given apriorising/axiomatising/referencing/intelligibilitysettingup/measuringinstrumenting'; given that it is consciousness that teleologically-registers/recognises phenomenal-abstractiveness as of meaningfulness-and-teleology in addition to the implications thereof with regards to the varying-as-transcending nature of consciousness with human limited-mentation-capacity- 
deepening —as-subjecting limitedness/human-subpotency-to-'educed-unlimitedness/existencesublimating nascence ${ }^{53}$ arising in further apriorising/axiomatising/referencing-\{of'prospectively_implicited_attendant-ontological-contiguity ' e educedexistentialising/contextualising/textualising_'intelligibility/epistemicity/reflexivity-contiguity$<$ imbued-notional $\left.\sim \operatorname{cogency}>^{\prime},\right\}$-conflatedness ${ }^{13}$-in-\{preconverging-ment by $\}^{2}$ pestconverging-entailment as of human ${ }^{55}$ maximalising-recomposuring-for-relativeontological-completeness ${ }^{87}$ - unenframed/re-ontologising conceptualisation in an exercise of $<$ amplituding/formative-epistemicity $>$-totalising $\sim$ renewing-realisation/re-perception/rethought that re-projects-or-re-anticipates the-very-same-immanent-existence/intrinsicreality/ontological-veridicality,-as-to-'human<amplituding/formativeepistemicity $>$ totalising purview-of-construal', and so as of a retrospective to prospective insight. Hence such philosophies failing to grasp that phenomenal-abstractiveness is ultimately as of a 'apriorising/axiomatising/referencing-\{of-'prospectively implicited_attendantontological-contiguity ' educedexistentialising/contextualising/textualising_ intelligibility/epistemicity/reflexivity-contiguity$<$ imbued-notional cogency $\left.>^{\prime} \quad\right\}$-conflatedness ${ }^{13}$-in-\{preconverging-ment by\}-

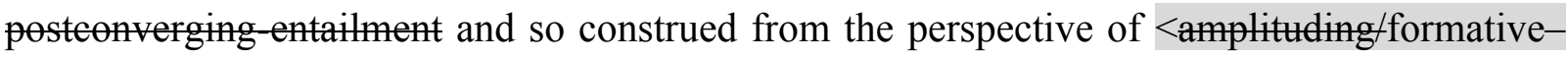
epistemicity $>$ totalising $\sim$ conflated- $-{ }^{5}$ meaningfulness-and-teleology 9 -as-ofnotional ${ }^{1}$ deprocrypticism-reflected- ${ }^{4}$ historiality/ontological-eventfulness 38 /ontologicalaesthetic-tracing-<perspective-ontological-normalcy/postconvergence-reflected-‘epistemicityrelativism-determinism'>' actually ended up inducing apriorising/axiomatising/referencing-\{of'prospectively_implicited_attendant-ontological-contiguity ' ceducedexistentialising/entextualising/textralising_intelligibility/epistemicity/reflexivity-contiguity$<$ imbued-notional cogency $>$ ' $\}$-constitutedness ${ }^{14}$-in- preconverging-entailment in striving to construe ${ }^{56}$ meaningfulness-and-teleology ${ }^{9}$ vaguely from phenomenal-abstractiveness as of 
elaboration-as-to-mere-extrapolating/constituting/abstracting/deducing/inferring-ofelucidation-outside—'prospectively_implicited_attendant_ontological-contiguity ${ }^{67}$ ' educedexistentialising/contextualising/textualising_'intelligibility/epistemicity/reflexivity-contiguity$<$ imbued-notional cogency>' ${ }^{\prime}$. Consciousness as the enabling point-of-focus for 'humansubpotency existential-<disontologising/re-ontologising aporeticism $>{ }^{56}$ meaningfulness-and-

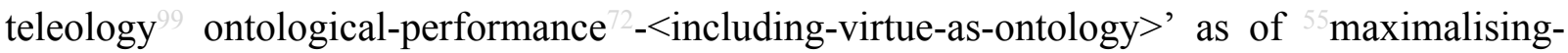
recomposuring-for-relative-ontological-completeness 87 unenframed/re-

ontologising conceptualisation induced apriorising/axiomatising/referencing/intelligibilitysettingup/measuringinstrumenting-foroperant-or-incidenting-predicative-insights is actually the apriorising/axiomatising/referencing\{of-'prospectively_implicited_attendant-ontological-contiguity ' ceducedexistentialising/contextualising/textualising_'intelligibility/epistemicity/reflexivity-contiguity$<$ imbued-notional cogency $\left.>^{\prime}\right\}$-conflatedness ${ }^{13}$ in-\{preconverging -ment by $\}$ postconverging-entailment point-of-focus that registers-as-of- ${ }^{5}$ meaningfulness-and-teleology all human phenomenal-abstractiveness whether as derived from sense organs like eyes construed

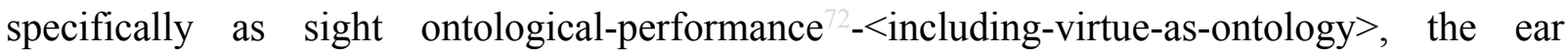

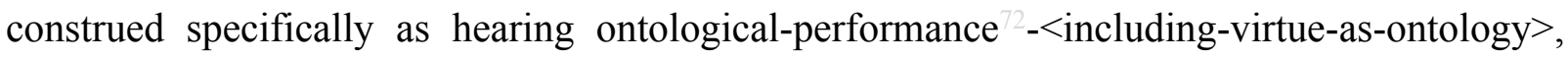
etc., derived from embodied phenomenal-abstractiveness like health/illness ontologicalperformance ${ }^{2}-<$ including-virtue-as-ontology $>$, vigour/tiredness ontological-performance ${ }^{72}$ $<$ including-virtue-as-ontology>, etc., and/or derived from mind phenomenal-abstractiveness like thought ontological-performance ${ }^{72}<$ including-virtue-as-ontology $>$, emotional ontologicalperformance ${ }^{72}-<$ including-virtue-as-ontology $>$, etc.; and so-referenced/registered/decisioned in apriorising/axiomatising/referencing-\{of-'prospectively implieited_attendant-ontologicalcontiguity ' $\sim$ educedexistentialising/contextualising/textualising_'intelligibility/epistemicity/reflexivity-contiguity- 
<imbued-notional cogency $\left.>^{\prime}\right\}$ - conflatedness ${ }^{13}$-in-\{preconverging-ment by \} $^{\prime}$ pestconverging-entailment as of consciousness's point-of-focus <amplituding/formativeepistemicity $>$ totalising $\sim$ conflated- $-{ }^{5}$ meaningfulness-and-teleology ${ }^{9}$-as-of-

notional ${ }^{18}$ deprocrypticism-reflected- ${ }^{-}$historiality/ontological-eventfulness ${ }^{38} /$ ontological- $^{-}$ aesthetic-tracing-<perspective-ontological-normalcy/postconvergence-reflected-‘epistemicity-

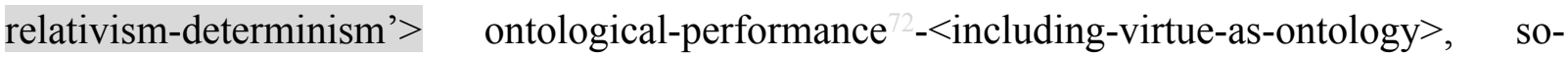
derived as it solipsistically constructs-and-reconstructs underlying 'coherence/contiguity-ofsuperseding-oneness-of-ontology-implied-as-of-inherent-existence-coherence/contiguity,-andso-construed-as-the-enabler-of-insight-or-intuition-or-foresight-as-of-embodied-consciousness' (so-enabled by underlying supposedly coherent ontological-commitment $-<$ implied - selfassuredness-of-ontological-good-faith/authenticity postconverging-dementating/structuring/paradigming -as-being-as-of-existential-reality>

$<$ amplituding/formative-epistemicity $>$ causality $\sim$ as-to-projective-totalitative-implications-ofprospective- nonpresencing,-for-explicating relative-unreflexivity/relative-reflexivity ontological-contiguity and not any notion of vague innateness besides existentially-disontologising/re-ontologising aporeticism $>$ inherent human-subpotency potential to manifest as human) and developing ${ }^{56}$ meaningfulness-and-teleology ${ }^{9}$ as of understanding/reconstruing/correcting/adapting/maturing, taking its cue from the apriorising/axiomatising/referencing-\{of-'prospectively_implicited_attendant-ontologicalcontiguity ' educedexistentialising/contextualising/textualising_'intelligibility/epistemicity/reflexivity-contiguity$<$ imbued-notional cogency $\left.>^{\prime}\right\}$-conflatedness ${ }^{13}$ in-\{preconverging -ment by $\}$ of existential-instantiations successions as it construes of existence/existential-possibilities as living-being! Put another way, consciousness as point-offocus apriorising/axiomatising/referencing-\{of-'prospectively_implicited_attendant- 
ontological-contiguity ' educed-

existentialising/contextualising/textualising_'intelligibility/epistemicity/reflexivity_contiguity-

<imbued-notional cogency >' \}-conflatedness ${ }^{13}$ in-\{preconverging-ment by\}

pestconverging-entailment of ${ }^{56}$ meaningfulness-and-teleology' is 'operative of humansubpotency as of the coherence/contiguity-of-superseding-oneness-of-ontology-as-of-inherentexistence-coherence/contiguity', so-implied with 'explicited axiomatic-constructs' construed as concepts/notions and 'implicited axiomatic-constructs' construed as intuitions/insights/foresights, and so correspondingly as of the explicited-focusing and implicited-coherencing/contiguity as of a supposed living-being reflection of existentialinstantiations and contextualisations in forming knowledge-constructs/theories/intersolipsisticintercessory-notions/notional referential-notions/articulations/virtue; thus explaining by this 'explicited-focusing and implicited-coherencing/contiguity existential-<disontologising/reentologising aporeticism $\geqslant$ dynamics for producing knowledgeconstructs/theories/intersolipsistic-intercessory-notions/notional $\sim$ referentialnotions/articulations/virtue', the apriorising/axiomatising/referencing-\{of-'prospectivelyimplicited_attendant-ontological-contiguity ' educed-

existentialising/contexalising/textising_intelligibility/epistemicity/reflexivity-contiguity$<$ imbued-notional cogency $>$ ' $\quad$ - constitutedness ${ }^{- \text {in }}$-preconverging-entailment $\quad$ of the Kantian understanding of concepts and intuitions as being mutually dependent for meaningfulness-and-teleology $\quad$ articulation. In other words, apriorising/axiomatising/referencing-\{of-'prospectively implicited_attendant-ontologicalcontiguity ' educed-

existentialising/contexalising/textralising_intelligibility/epistemicity/reflexivity-contiguity$<$ imbued-notional cogency $>$ ' $\}$-constitutedness ${ }^{14}$-in-preconverging-entailment tend to fallaciously imply existence-in-existence or existence-of-things-in-existence whereas 
apriorising/axiomatising/referencing-\{of-'prospectively_implicited_attendant-ontological-

contiguity ' educed-

existentialising/contextualising/textualising_'intelligibility/epistemicity/reflexivity-contiguity-

<imbued-notional cogency $\left.>^{\prime}\right\}$ - conflatedness ${ }^{13}$-in-\{preconverging-ment by \} $^{-}$

postconverging-entailment rightly implies becoming-in-existence-rather-as-subsumed-in-

existence or things-becoming-in-existence-rather-as-subsumed-in-existence as of underlying 'coherence/contiguity-of-superseding-oneness-of-ontology-implied-as-of-inherent-existence-

coherence/contiguity,-and-so-construed-as-the-enabler-of-insight-or-intuition-or-foresight-as-

of-embodied-consciousness' (so-enabled by underlying supposedly coherent ontological-

commitment $-<$ implied—self-assuredness-of-ontological-good-

faith/authenticity postconverging-de-mentating/structuring/paradigming -as-being-as-of-

existential-reality> as of <amplituding/formative-epistemicity>causality $\sim$ as-to-projectivetotalitative-implications-of-prospective- nonpresencing,-for-explicating $\sim$ relative-

unreflexivity/relative-reflexivity - ontological-contiguity and not any notion of vague innateness besides existentially-<disontologising/re-ontologising aporeticism $>$ inherent human-subpotency potentiation to manifest as human) or 'consciousness's ontologicalperformance $^{72}-<$ including-virtue-as-ontology $>$ /morality/ethics/justice/etc. construed in amalgamation/distension' as of the-very-same-immanent-existence/intrinsic-reality/ontologicalveridicality,-as-to-'human<amplituding/formative-epistemicity>totalising $\sim$ purview-ofconstrual'. This notion of apriorising/axiomatising/referencing-\{of-'prespectively implicited_attendant-ontological-contiguity ' educed-

existentialising/contextualising/textualising_'intelligibility/epistemicity/reflexivity-contiguity<imbued-notional $\left.\sim \operatorname{cogency}>^{\prime},\right\}$-conflatedness ${ }^{13}$ in $\{$ preconverging ment by postconverging-entailment construal of existence as of becoming-in-existence-rather-assubsumed-in-existence is critical in that all notions that naively imply an intercession between 
human becoming and existence construed as existence-in-existence, such as the transcendental ego perspective, end up in apriorising/axiomatising/referencing-\{of-"prospectively implicited_attendant-ontological-contiguity ' educed-

existentialising/contextualising/textualising_'intelligibility/epistemicity/reflexivity-contiguity$<$ imbued-notional cogency $\left.>^{\prime} \quad\right\}$-constitutedness ${ }^{1}$-in-preconverging-entailment as the said 'transcendental ego cannot invent existence as if superseding existence' thus inducing apriorising/axiomatising/referencing-\{of-'prospectively_implicited_attendant-ontologicalcontiguity ' $\sim$ educedexistentialising/contextualising/textualising_'intelligibility/epistemicity/reflexivity-contiguity<imbued-notional cogency $\left.>^{\prime} \quad\right\}$ - constitutedness ${ }^{14}$-in-preconverging-entailment. Rather existence — as-the-absolute-a-priori-of-conceptualisation and existence — as-sublimatingwithdrawal/unenframing/re-ontologising,-elicited-from-prospective-profoundsupererogation $-<$ as-to-perspective-ontological-normalcy/postconvergence-implied'prospective-aporeticism-overcoming/unovercoming'> is by itself construed as 'the-very-sameimmanent-existence/intrinsic-reality/ontological-veridicality,-as-to'human<amplituding/formative-epistemicity>totalising purview-of-construal' with nothing else outside or preceding it'; as existence is an implied-axiomatic-construct-construed-asreference-of-thought as an implied-theory, with the 'implied about existence' arising as of a given/specific

apriorising/axiomatising/referencing/intelligibilitysettingup/measuringinstrumenting as of a given human limited-mentation-capacity—as-subjecting-'educed-unlimitedness/existencesublimating nascence' to-limitedness/human-subpotency implied registryworldview/dimension consciousness, such that ${ }^{56}$ meaningfulness-and-teleology ${ }^{9}$ is as of existence's implied axiomatic-devolving-teleological-de-mentating/structuring/paradigmingof-meaningfulness-as-of-instantiative-context with no meaningfulness-and-teleology 
construable outside it but for an epistemic-totalising $\sim$ renewing-realisation/re-perception/rethought

'apriorising/axiomatising/referencing/intelligibilitysettingup/measuringinstrumenting

reference-of-thought' as of human limited-mentation-capacity-deepening-as-subjectinglimitedness/human-subpotency-to-'educed-unlimitedness/existence-sublimating nascence' implied prospective registry-worldview/dimension consciousness and its corresponding existence's as to the-very-same-immanent-existence/intrinsic-reality/ontological-veridicality,as-to-'human<amplituding/formative-epistemicity>totalising $\sim$ purview-of-construal' implied axiomatic-devolving-teleological-de-mentating/structuring/paradigming-of-meaningfulnessas-of-instantiative-context, with no ${ }^{5}$ meaningfulness-and-teleology ${ }^{9}$ outside or preceding it. Thus apriorising/axiomatising/referencing-\{of-'prospectively_implicited_attendantontological-contiguity ' educedexistentialising/contextualising/textualising_ 'intelligibility/epistemicity/reflexivity-contiguity$<$ imbued-notional cogency $>$ ' \}-conflatedness ${ }^{13}$-in-\{preconverging-ment by\} pestconverging-entailment warrants that human-subpotency becoming is amalgamated as of existence as of the underlying 'coherence/contiguity-of-superseding-oneness-of-ontologyimplied-as-of-inherent-existence-coherence/contiguity,-and-so-construed-as-the-enabler-ofinsight-or-intuition-or-foresight-as-of-embodied-consciousness' (so-enabled by underlying supposedly coherent ontological-commitment $-<$ implied - self-assuredness-of-ontologicalgood-faith/authenticity postconverging-de-mentating/structuring/paradigming -as-beingas-of-existential-reality $>$ as of $<$ amplituding/formative-epistemicity $>$ causality $\sim$ as-toprojective-totalitative-implications-of-prospective- nonpresencing,-for-explicating relativemnreflexivity/relative reflexivity - ontological-contiguity and not any notion of vague innateness besides existentially-< $<$ disontologising/re-ontologising aporeticism $>$ inherent human-subpotency potential to manifest as human) for appropriate construal of 
meaningfulness-and-teleology $\quad$ ontological-performance ${ }^{2}-<$ including-virtue-as-ontology $>$. The insight here is that we can't be at a posture of prior relative-ontological-incompleteness ${ }^{8}$ of- ${ }^{8}$ reference-of-thought in relative notional-discontiguity/epistemic-discontiguity ${ }^{63}$ $<$ between-prior-shallow-supererogation -of-mentallyaestheticised preconverging/dementing -qualia-schema_and_prospective-profoundsupererogation -of-mentally-aestheticised postconverging/dialectical-thinking -qualiaschema $>$ of the-very-same-immanent-existence/intrinsic-reality/ontological-veridicality,-as-to'human<amplituding/formative-epistemicity>totalising purview-of-construal' and then pretend to ground ${ }^{56}$ meaningfulness-and-teleology ${ }^{9}$ about the nature of existence as if we are of ontological-completeness-of- ${ }^{8}$ reference-of-thought in notional-contiguity/epistemiccontiguity ${ }^{62}<$ profound-supererogation -of-mentally-aestheticised $\sim$ postconverging/dialecticalthinking -qualia-schema $>\quad$ as of the-very-same-immanent-existence/intrinsicreality/ontological-veridicality,-as-to-'human<amplituding/formativeepistemicity>totalising purview-of-construal', as our state of relative-ontologicalincompleteness ${ }^{88}$ perverts that grounding objective and rather points to the need for a notionaldiscontiguity/epistemic-discontiguity ${ }^{63}<$ between - prior-shallow-supererogation -ofmentally-aestheticised preconverging/dementing -qualia-schema_and_prospective-profoundsupererogation -of-mentally-aestheticised postconverging/dialectical-thinking -qualiaschema $>$ induced psychoanalytic-unshackling towards a prospective state of prospective relative-ontological-completeness ${ }^{8}$-of- ${ }^{8}$ reference-of-thought. What is fundamentally warranted is priorly attaining psychoanalytically, as of apriorising/axiomatising/referencing/intelligibilitysettingup/measuringinstrumenting, ontological-completeness-of- ${ }^{3}$ reference-of-thought in notional-contiguity/epistemiccontiguity ${ }^{6}-<$ profound-supererogation - of-mentally-aestheticised $\sim$ postconverging/dialecticalthinking -qualia-schema> of the-very-same-immanent-existence/intrinsic-reality/ontological- 
veridicality,-as-to-'human<amplituding/formative-epistemicity>totalising $\sim$ purview-ofconstrual', rather than a flawed attempt at grounding as with say a transcendental ego basis of construal of ${ }^{56}$ meaningfulness-and-teleology ${ }^{9}$, unsuspectedly grounding as of our positivismprocrypticism prior relative-ontological-incompleteness ${ }^{8}$-of- ${ }^{83}$ reference-of-thought; as such a role is simply undertaken by apriorising/axiomatising/referencing-\{of-"prospectively implicited_attendant_ontological-contiguity ' educedexistentialising/contextualising/textualising_intelligibility/epistemicity/reflexivity_contiguity<imbued-notional cogency $>$ ' $\}$ - conflatedness ${ }^{13}$ in-\{preconverging-ment by \} $^{\prime}$ postconverging-entailment as of prospective relative-ontological-completeness ${ }^{87}$-of- ${ }^{8}$ referenceof-thought and is rather construed then as of such prospective underlying 'coherence/contiguityof-superseding-oneness-of-ontology-implied-as-of-inherent-existence-coherence/contiguity,and-so-construed-as-the-enabler-of-insight-or-intuition-or-foresight-as-of-embodiedconsciousness' (so-enabled by underlying supposedly coherent ontological-commitment <implied-self-assuredness-of-ontological-good-faith/authenticity $\sim$ postconverging-dementating/structuring/paradigming -as-being-as-of-existential-reality> $<$ amplituding/formative-epistemicity $>$ causality $\sim$ as-to-projective-totalitative-implications-ofprospective- nonpresencing,-for-explicating relative unreflexivity/relative reflexivityontological-contiguity and not any notion of vague innateness besides existentially< disontologising/re-ontologising aporeticism $>$ inherent human-subpotency potential to manifest as human) for appropriate ${ }^{56}$ meaningfulness-and-teleology ${ }^{9}$ ontologicalperformance ${ }^{72}-<$ including-virtue-as-ontology $>$. Such an apriorising/axiomatising/referencing\{of-'prospectively_implicited_attendant-ontological-contiguity ' ceducedexistentialising/contexalising/texalising_intelligibility/epistemicity/reflexivity-contiguity$<$ imbued-notional cogency $>$ ' $\}$-conflatedness ${ }^{13}$ in-\{preconverging-ment by\} postconverging entailment insight as of notional ${ }^{18}$ deprocrypticism rather points out that 
soundness-or-ontological-good-faith/authenticity ${ }^{6}$ of ${ }^{5}$ meaningfulness-and-teleology ontological-performance ${ }^{72}<$ including-virtue-as-ontology $>/$ morality/ethics/justice/etc. arises as of Being-development/ontological-framework-expansion-as-to-depth-of-ontologisingdevelopment-as-infrastructure-of- meaningfulness-and-teleology involving the relativeunreflexivity/relative-reflexivity — ontological-contiguity ${ }^{67}$ of-the-human-institutionalisationprocess ${ }^{68}$ induced various consciousnesses up to the protensive-consciousness enabling transcendental centered-epistemic-totalisation, as of human limited-mentation-capacitydeepening —as-subjecting limitedness/human-subpotency-to-'educed-unlimitedness/existencesublimating nascence' ${ }^{3}$. Actually, it is herein contended that the very fundamental handicapping issue to ${ }^{56}$ meaningfulness-and-teleology 99 as of the philosophical tradition lies in the naïve human mental-reflex of implying that a 'given human determination of the effecting basis/foundation/axiomatic-construct derived/deciphered from existential-instantiations as underlying the presence institutionalisation <amplituding/formative-

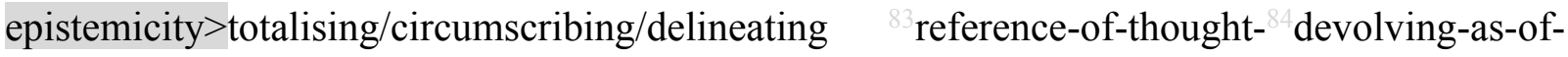
instantiative-context - ${ }^{5}$ meaningfulness-and-teleology 9 carries-and-reflects all the depth/profoundness of existence/existential-possibilities', thus not allowing for the possibility for further sublimating-epistemic-imbricatedness/threadedness/recomposuring as of existence/existential-possibilities of existential-instantiations outside any such ${ }^{83}$ reference-ofthought determination; such ${ }^{83}$ reference-of-thought determination being affixed rather in apriorising/axiomatising/referencing-\{of-'prospectively implicited_attendant-ontologicalcontiguity ' educedexistentialising/contextualising/textualising_intelligibility/epistemicity/reflexivity-contiguity<imbued-notional cogency>' $\quad$ - constitutedness ${ }^{14}$ in preconverging entailment as of any of the various registry-worldviews/dimensions specific underlying apriorising/axiomatising/referencing/intelligibilitysettingup/measuringinstrumenting 
reference-of-thought such as 'non-rules_apriorising/axiomatising/referencingpsychologism,-as-impulsive-or-accidented-or-random-mental-disposition of recurrent-utteruninstitutionalisation' not cognisant of the apriorising/axiomatising/referencing-\{of'prospectively_implicited_attendant-ontological-contiguity ' educedexistentialising/contextualising/textualising_'intelligibility/epistemicity/reflexivity-contiguity<imbued-notional cogency >' $\}$-conflatedness ${ }^{13}$ in-\{preconverging-ment by\} postconverging entailment possibility of prospective base-institutionalisation prospective relative-ontological-completeness ${ }^{8}$-of- ${ }^{8}$ reference-of-thought, 'rulemaking-over-non-rulesapriorising/axiomatising/referencing-psychologism of base-institutionalisationununiversalisation' not cognisant of the apriorising/axiomatising/referencing-\{of'prospectively_implicited_attendant_ontological-contiguity ' educedexistentialising/contextualising/textualising_ intelligibility/epistemicity/reflexivity-contiguity<imbued-notional cogency $>$ ' $\}$-conflatedness ${ }^{13}$ in-\{preconverging-ment by $\}^{\prime}$ postconverging-ntailment possibility of prospective ${ }^{103}$ universalisation prospective relativeontological-completeness ${ }^{87}$-of- ${ }^{83}$ reference-of-thought, ${ }^{6}{ }^{103}$ universalisation-directed-rulemakingover-non-rules_-apriorising/axiomatising/referencing-psychologism of ${ }^{103}$ universalisationnon-positiivism/medievalism' not cognisant of the apriorising/axiomatising/referencing-\{of'prospectively implicited_attendant-ontological-contiguity ' educedexistentialising/contextualising/textualising_'intelligibility/epistemicity/reflexivity-contiguity$<$ imbued-notional cogency $>$ ' $\}$-conflatedness ${ }^{13}$-in-\{preconverging -ment by\} postconverging entailment possibility of prospective positivism prospective relativeontological-completeness ${ }^{87}$-of- ${ }^{8}$ reference-of-thought, and in our case 'positivising/rationalempiricism-based-universalisation-directed-rulemaking-over-non-rulesapriorising/axiomatising/referencing-psychologism of positivism- procrypticism' not cognisant of the apriorising/axiomatising/referencing-\{of-'prospectively implicited_attendant- 
ontological-contiguity ' educed-

existentialising/contextualising/textualising_'intelligibility/epistemicity/reflexivity_contiguity-

<imbued-notional cogency >' \}-conflatedness ${ }^{13}$ in-\{preconverging-ment by\}

pestconverging-entailment possibility of futural Being-development/ontological-frameworkexpansion-as-to-depth-of-ontologising-development-as-infrastructure-of- meaningfulness-

and-teleology as of prospective notional ${ }^{18}$ deprocrypticism prospective relative-ontologicalcompleteness ${ }^{87}$-of- ${ }^{83}$ reference-of-thought. Such that it thus construes as absolutely reflecting existence/existential-possibilities by operations of elaboration-as-to-mereextrapolating/constituting/abstracting/deducing/inferring-of-elucidation-outside-

'prospectively_implicited_attendant_ontological-contiguity ${ }^{67}$ ' educed-

existentialising/contextualising/textualising_'intelligibility/epistemicity/reflexivity_contiguity<imbued-notional cogency $>{ }^{\prime 0}$ on the basis of that given determination ${ }^{83}$ reference-of-thoughtcategorical-imperatives/axioms/registry-teleology with the consequence that its apriorising/axiomatising/referencing-\{of-'prospectively_implicited_attendant-ontologicalcontiguity ' educed-

existentialising/contextualising/textualising_'intelligibility/epistemicity/reflexivity-contiguity<imbued-notional cogency>' $\}$-constitutedness ${ }^{4}$-in preconverging entalment, since it doesn't allows for superseding existence/existential-possibilities, now 'contradictorily-andnaively supersedes-and-is-determinative-of existence itself' rather than taking its cue from the apriorising/axiomatising/referencing-\{of-'prospectively implicited_attendant-ontologicalcontiguity ' $\sim$ educed-

existentialising/contextualising/textualising_'intelligibility/epistemicity/reflexivity-contiguity$<$ imbued-notional cogency $>$ ' $\}$-conflatedness ${ }^{13}$ in $\{$ preconverging ment by postconverging-entailment of existence/existential-possibilities given the sublimatingepistemic-imbricatedness/threadedness/recomposuring of existential-instantiations and as 
reflected at registry-worldview/dimension depth of construal as of ${ }^{83}$ reference-of-thought; as it then fails to grasp that 'there is no understanding to be had outside the apriorising/axiomatising/referencing-\{of-'prospectively implicited_attendant-ontologicalcontiguity ' educedexistentialising/contextualising/textualising_intelligibility/epistemicity/reflexivity-contiguity<imbued-notional cogency $\left.>^{\prime}\right\}$-conflatedness ${ }^{13}$-in-\{preconverging-ment by\} pestcenverging entailment of existence as of prospective relative-ontological-completeness ${ }^{87}$ of- ${ }^{3}$ reference-of-thought' with any such conceptualisation being nothing but vague virtuality

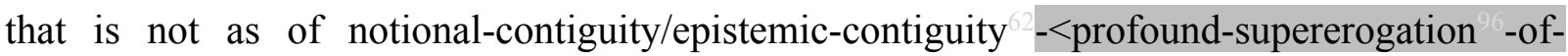
mentally-aestheticised postconverging/dialectical-thinking -qualia-schema $>$ and ontologicalveracity. Thus the problem of the philosophical tradition is notionally one of erroneous apriorising/axiomatising/referencing-\{of-'prospectively_implicited_attendant-ontologicalcontiguity ' educedexistentialising/contextualising/textualising_'intelligibility/epistemicity/reflexivity-contiguity<imbued-notional cogency $\left.>^{\prime} \quad\right\}$-constitutedness ${ }^{14}$-in-preconverging-entailment, and this issue is recurrent-beyond- ${ }^{-}$historiality/ontological-eventfulness ${ }^{38}$ /ontological-aesthetic-tracing$<$ perspective--ontological-normalcy/postconvergence-reflected-'epistemicity-relativismdeterminism'>-with-the-latter-only-a-bi-manifestation-of-the-reccurence,-as-psychicallyrecurrent as of human shallow-to-deepening-limited-mentation-capacity-as-subjecting'educed-unlimitedness/existence-sublimating nascence' to-limitedness/humansubpotency, as-limited-mentation-capacity-deepening —as-subjecting limitedness/humansubpotency-to-'educed-unlimitedness/existence-sublimating nascence' ${ }^{53}$ due to inherent human temporality $/$ /shortness and intemporality ${ }^{52} /$ longness across all registry-worldviews/dimensions, and speaks of a human preconverging-existential-extrication-as-of-existential-unthought disposition reflected as ${ }^{4}$ historiality/ontological-eventfulness $3 /$ ontological-aesthetic-tracing- 
<perspective-ontological-normalcy/postconvergence-reflected-'epistemicity-relativismdeterminism' $>$ as of the notional conflatedness ${ }^{13}$ of notional ${ }^{18}$ deprocrypticism behind the reality of a conceptualisation of human nature rather more completely as of institutionalisation and uninstitutionalised-threshold ${ }^{102}$ mental-dispositions. As highlighted before: consciousness is the point-of-focus $\quad<$ amplituding/formative-epistemicity $>$ totalising $\sim$ conflatedmeaningfulness-and-teleology ${ }^{99}$-as-of-notional ${ }^{8}$ deprocrypticism-reflectedhistoriality/ontological-eventfulness 3 /ontological-aesthetic-tracing-<perspectiveontological-normalcy/postconvergence-reflected-‘epistemicity-relativism-determinism’> ontological-performance ${ }^{72}$-<including-virtue-as-ontology>, so-derived as it solipsistically constructs-and-reconstructs underlying 'coherence/contiguity-of-superseding-oneness-ofontology-implied-as-of-inherent-existence-coherence/contiguity,-and-so-construed-as-theenabler-of-insight-or-intuition-or-foresight-as-of-embodied-consciousness' (so-enabled by

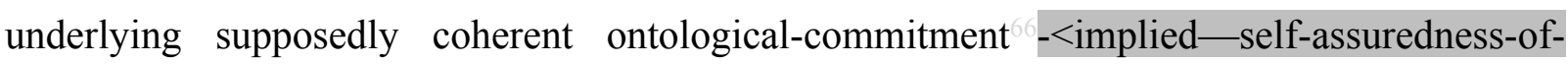
ontological-good-faith/authenticity postconverging-dementating/structuring/paradigming -as-being-as-of-existential-reality> $<$ amplituding/formative-epistemicity $>$ causality $~ a s-t o-p r o j e c t i v e-t o t a l i t a t i v e-i m p l i c a t i o n s-o f-$ prospective- nonpresencing,-for-explicating relative mnreflexivity/relative reflexivity ontological-contiguity and not any notion of vague innateness besides existentially< disontologising/re-ontologising aporeticism $>$ inherent human-subpotency potential to manifest as human) and developing ${ }^{56}$ meaningfulness-and-teleology ${ }^{9}$ as of understanding/reconstruing/correcting/adapting/maturing, taking its cue from the apriorising/axiomatising/referencing-\{of-'prospectively_implicited_attendant-ontologicalcontiguity ' $\sim$ educedexistentialising/contextualising/textualising_'intelligibility/epistemicity/reflexivity-contiguity$<$ imbued-notional cogency $>$ ' \}-conflatedness ${ }^{13}$-in-\{preconverging-ment by\} 
pestconverging-ntailment of existential-instantiations successions as it construes of existence/existential-possibilities as living-being. Such 'focusing construed as consciousness' explains why axiomatic-constructs are explicited and implicited/intuited as of a living-being $<$ amplituding/formative-epistemicity $>$ totalising $\sim$ conflated- ${ }^{-5}$ meaningfulness-and-teleology in coherence/contiguity-of-superseding-oneness-of-ontology. The above conception fundamentally underscore the development and how all human knowledgeconstructs/theories/intersolipsistic-intercessory-notions/notional referentialnotions/articulations/virtue arises existentially- $<$ disontologising/re-ontologising aporeticism $>$ as of consciousness, and is singularly reflected as of language development which is the 'signifying mirroring' of human ${ }^{5}$ meaningfulness-and-teleology 9 . The implication here is that meaningfulness-and-teleology' as of 'existential self-referencing' and 'existential syncretising-effecting' construed as <amplituding/formative-epistemicity $>$ totalising $\sim$ selfreferencing-syncretising/circularity/interiorising/akrasiatic-drag ${ }^{34}$ corresponds to language as of its 'underlying <amplituding/formative-epistemicity>totalising/circumscribing/delineating signifying-construct' and its 'metaphoricity ${ }^{57}$ '; in reflecting how human social-stake-contentionor-confliction induces human transcendence-as-of-full-transcendental-potential underlying knowledge-constructs/theories/intersolipsistic-intercessory-notions/notional $\sim$ referentialnotions/articulations/virtue. Consciousness, and as reflected by the signifying mirroring of meaningfulness-and-teleology ${ }^{9}$ that is language, is thus a point-of-focusing axiomatic/ ${ }^{3}$ reference-of-thought devolving-construal disposition for ${ }^{56}$ meaningfulness-andteleology as of the 'human species sublimation-educing-epistemictotalising 3 h ${ }^{3}$ ermeneutic/textuality/reprojecting/supererogating/zeroing/re-acuting,$\{$ decompulsing $\}$ delinearity for-cogency as-to-possibilities-of-self-becoming-as-of-'existentialinterpretation/epistemicity-in-apriorising/axiomatising/referencing-of-existence ${ }^{95}$ as of existential-stakes migration enabled by human limited-mentation-capacity-deepening-as- 
subjecting limitedness/human-subpotency-to-'educed-unlimitedness/existence-sublimating nascence' ${ }^{5}$, that speaks of ' ${ }^{5}$ meaningfulness-and-teleology' accreting-substitutivesubsumption-as-futural-différance-freeplay ${ }^{2}$ construed here as the human species consciousnessdifférance', reflected by notional ${ }^{18}$ deprocrypticism conceptualised ${ }^{4}$ historiality/ontologicaleventfulness ${ }^{38}$ /ontological-aesthetic-tracing-<perspective-ontologicalnormalcy/postconvergence-reflected-'epistemicity-relativism-determinism'> as of the apriorising/axiomatising/referencing-\{of-'prospectively implicited_attendant-ontologicalcontiguity ' educedexistentialising/contextualising/textualising_'intelligibility/epistemicity/reflexivity-contiguity<imbued-notional cogency $\left.>^{\prime}\right\}$-conflatedness ${ }^{13}$-in-\{preconverging-ment-by\} postconverging-ntailment of the successive human consciousnesses " ${ }^{83}$ reference-of-thoughtdevolving-teleological-de-mentating/structuring/paradigming-of-meaningfulness'. Thus consciousness by its full development as of Being-development/ontological-frameworkexpansion-as-to-depth-of-ontologising-development-as-infrastructure-of- meaningfulnessand-teleology speaks fundamentally of the entire narrative possibilities of the human species as of human sublimation-educing-\{epistemictotalising 3 ' $h$ hermeneutic/textuality/reprojecting/supererogating/zeroing/re aeuting,\{decompulsing $\}$ delinearity $\sim$ for-cogency $\sim$ as-to-possibilities-of-self-becoming-as-of-‘existentialinterpretation/epistemicity-in-apriorising/axiomatising/referencing-of-existence ${ }^{05}$ Such 'consciousness apriorising/axiomatising/referencing-\{of-'prospectively implicited_attendantontological-contiguity ' educedexistentialising/contextualising/textualising_intelligibility/epistemicity/reflexivity_contiguity<imbued-notional cogency>' \}-conflatedness ${ }^{13}$ in (preconverging ment by $^{\prime}$ postconverging-entailment of ${ }^{5}$ meaningfulness-and-teleology ${ }^{9}$ ' is reflected by the signifying mirroring of ${ }^{56}$ meaningfulness-and-teleology ${ }^{9}$ that is language as of its metaphoricity ${ }^{57}$. 
Metaphoricity ${ }^{57}$ can thus be construed as the signification of articulated ${ }^{56}$ meaningfulness-andteleology ${ }^{9}$ as of reference to existential-instantiation contexts adjunctively and not as naturally devolving into the 'underlying <amplituding/formativeepistemicity $>$ totalising/circumscribing/delineating signifying-construct of language' as signification of ${ }^{83}$ reference-of-thought, such that metaphoricity ${ }^{57}$ is rather an 'adjunctive incorporation' to the 'underlying <amplituding/formativeepistemicity>totalising/circumscribing/delineating signifying-construct of language'. The 'underlying < <mplituding/formative-epistemicity>totalising/circumscribing/delineating signifying-construct of language' as of its self-referencing ${ }^{56}$ meaningfulness-and-teleology ${ }^{99}$ is always susceptible to the further deepening of human limited-mentation-capacity-assubjecting 'educed-unlimitedness/existence-sublimating nascence' to-limitedness/humansubpotency as of <amplituding/formative-epistemicity>-totalising $\sim$ renewing-realisation/reperception/re-thought such that prospective ${ }^{56}$ meaningfulness-and-teleology ${ }^{99}$ arises out of the adjunction to this 'underlying $<$ amplituding/formativeepistemicity>totalising/circumscribing/delineating signifying-construct of language' and is adjoined to it as metaphoricity ${ }^{57}$, with metaphoricity ${ }^{57}$ construed as the signification implied as of syncretising-effecting ${ }^{56}$ meaningfulness-and-teleology ${ }^{9}$. Thus language effectively reflects the $<$ amplituding/formative-epistemicity $>$ totalising $\sim$ self-referencingsyncretising/circularity/interiorising/akrasiatic-drag ${ }^{34}$ reality of human ${ }^{56}$ meaningfulness-andteleology', as language is always a blending of the 'underlying <amplituding/formativeepistemicity>totalising/circumscribing/delineating signifying-construct of language' with the apriorising/axiomatising/referencing-\{of-'prospectively_implicited_attendant-ontologicalcontiguity ' $\sim$ educedexistentialising/contextualising/textualising_'intelligibility/epistemicity/reflexivity-contiguity<imbued-notional cogency>' \}-conflatedness ${ }^{13}$ in-\{preconverging-ment by\} 
postconverging-entailment adjunction of its metaphoricity ${ }^{57}$. It is interesting to grasp here that a signifying-construct as signification of the 'self-referencing of ${ }^{56}$ meaningfulness-andteleology ${ }^{\circ}$ is always <amplituding/formativeepistemicity>totalising/circumscribing/delineating and is effectively signifying a ${ }^{83}$ reference-ofthought as of 'reference-of-thought—devolving-teleological-dementating/structuring/paradigming-of-meaningfulness'. $\quad$ Such centered$<$ amplituding/formative-epistemicity>totalising/circumscribing/delineating ${ }^{56}$ meaningfulnessand-teleology ${ }^{9}$ construed as ${ }^{83}$ reference-of-thought, and its signification as implied by an 'underlying < <mplituding/formative-epistemicity>totalising/circumscribing/delineating signifying-construct of language' necessarily has to do with the fact that ${ }^{56}$ meaningfulness-andteleology' is as of a 'coherence/contiguity-of-superseding-oneness-of-ontology-implied-as-ofinherent-existence-coherence/contiguity,-and-so-construed-as-the-enabler-of-insight-orintuition-or-foresight-as-of-embodied-consciousness' (so-enabled by underlying supposedly coherent ontological-commitment $-<$ implied — self-assuredness-of-ontological-goodfaith/authenticity postconverging-de-mentating/structuring/paradigming -as-being-as-ofexistential-reality $>$ as of <amplituding/formative-epistemicity $>$ causality $\sim$ as-to-projectivetotalitative-implications-of-prospective- nonpresencing,-for-explicating relativeunreflexivity/relative-reflexivity - ontological-contiguity and not any notion of vague innateness besides existentially-<disontologising/re-ontologising aporeticism $>$ inherent human-subpotency potential to manifest as human) for intelligibility to arise, thus is construed as ${ }^{83}$ reference-of-thought as of the-very-same-immanent-existence/intrinsic-reality/ontologicalveridicality,-as-to-‘human<amplituding/formative-epistemicity>totalising $\sim$ purview-ofconstrual'; as we know intuitively that meaning is always about the-one-meaning as well as a perspective/framing/reference/horizon/projection were all the-one-meaning cohere/are-inrelative-reflexivity - ontological-contiguity ${ }^{67}$ metaphoricity ${ }^{57}$ as of human limited-mentation- 
capacity-deepening-as-subjecting limitedness/human-subpotency-to-'educed-

unlimitedness/existence-sublimating nascence' 33 adhocly produces by apriorising/axiomatising/referencing-\{of-'prospectively_implicited_attendant-ontologicalcontiguity ' $\sim$ educedexistentialising/contextualising/textualising_'intelligibility/epistemicity/reflexivity-contiguity<imbued-notional cogency $\left.>^{\prime}\right\}$-conflatedness ${ }^{13}$-in-\{preconverging-ment by\} postconverging-entailment adjunctive significations where these do not fit in with the 'underlying <amplituding/formative-epistemicity>totalising/circumscribing/delineating signifying-construct of language' due to the implications of human limited-mentationcapacity—as-subjecting-educed-unlimitedness/existence-sublimating nascence' tolimitedness/human-subpotency as of relative-ontological-incompleteness ${ }^{88}$-of- ${ }^{83}$ reference-ofthought when conceptualising about such an 'underlying <amplituding/formativeepistemicity $>$ totalising/circumscribing/delineating signifying-construct of language'. But then an adjunctive-metaphoricity ${ }^{57}$-signification so produced as reflected by a 'transcendental syncretising-effecting ${ }^{56}$ meaningfulness-and-teleology', like the construal of buddingpositivism/rational-empiricism in medieval society, may turn out in-duecourse/crossgenerationally to be of an even greater ${ }^{56}$ meaningfulness-and-teleology $<$ amplituding/formative-epistemicity>totalising/circumscribing/delineating effect over the prior notion of the 'underlying <amplituding/formativeepistemicity>totalising/circumscribing/delineating signifying-construct of language' and thus prospectively become the 'underlying <amplituding/formativeepistemicity>totalising/circumscribing/delineating signifying-construct of language'; and so as of accreting-substitutive-subsumption-as-futural-différance-freeplay ${ }^{2}$, by SUBSUMING some significations of the prior 'underlying <amplituding/formativeepistemicity $>$ totalising/circumscribing/delineating signifying-construct of language' together 
with some adjunctive-metaphoricity ${ }^{57}$-significations of the prior 'underlying <amplituding/formative-epistemicity>totalising/circumscribing/delineating signifyingconstruct of language', while ELIMINATING some significations of the prior 'underlying $<$ amplituding/formative-epistemicity $>$ totalising/circumscribing/delineating signifyingconstruct of language' and so together with some adjunctive-metaphoricity ${ }^{57}$-significations of the prior underlying <amplituding/formativeepistemicity>totalising/circumscribing/delineating signifying-construct of language', and finally LEAVING-OUT some significations of the prior 'underlying <amplituding/formativeepistemicity>totalising/circumscribing/delineating signifying-construct of language' and so together with some adjunctive-metaphoricity -significations of the prior 'underlying $<$ amplituding/formative-epistemicity $>$ totalising/circumscribing/delineating signifyingconstruct of language', as its very own as the prospective 'underlying <amplituding/formativeepistemicity $>$ totalising/circumscribing/delineating signifying-construct of language' adjunctive-metaphoricity ${ }^{5}$-significations to which other adjunctive-metaphoricity ${ }^{57}$ significations could be incorporated adjunctively. Effectively, with the positivism/rationalempiricism self-referencing $<$ amplituding/formativeepistemicity $>$ totalising/circumscribing/delineating construct of ${ }^{56}$ meaningfulness-andteleology ${ }^{9}$, its adjunctive-metaphoricity ${ }^{57}$-signification can be construed as of the historiality/ontological-eventfulness 38 ontological-aesthetic-tracing-<perspectiveontological-normalcy/postconvergence-reflected-'epistemicity-relativism-determinism'> of crossgenerational positivism/rational-empiricism reappropriation of the ancient mathesis universalis metaphoricity ${ }^{57}$ as its very own 'underlying <amplituding/formativeepistemicity $>$ totalising/circumscribing/delineating signifying-construct of language' 'behind the instigative-drive for construing all human knowledge' by such enlightenment thinkers like Galileo and ubiquitously with Descartes that rolled-over into later thinkers like Leibniz, Newton, 
and ultimately subverted medievalism and scholasticism leading to our present positivism/rational-empiricism dominant $<$ amplituding/formativeepistemicity>totalising/circumscribing/delineating construct of ${ }^{56}$ meaningfulness-andteleology ${ }^{9}$. Existence itself as the absolute a-priori underscores such a conception given the human species sublimation-educing__fepistemic-

totalising $3{ }^{3}$ hermeneutic/textuality/reprojecting/supererogating/zeroing/re-acuting,-

$\{$ \{lecompulsing $\}$ delinearity for-cogency as-to-possibilities-of-self-becoming-as-of-‘existentialinterpretation/epistemicity-in-apriorising/axiomatising/referencing-of-existence ${ }^{5}$ as of existential-stakes migration; since the existential-<disontologising/re-ontologising aporeticism $>$ dispositions of human subjects relative to social-stake-contention-or-confliction arises as of 'their living existential-instantiations', and where they construe ${ }^{56}$ meaningfulnessand-teleology' as not self-referentially covered by the 'underlying <amplituding/formativeepistemicity $>$ totalising/circumscribing/delineating signifying-construct of language', they will inevitably articulate adjunctive-metaphoricity ${ }^{57}$-significations to that prior 'underlying $<$ amplituding/formative-epistemicity $>$ totalising/circumscribing/delineating signifyingconstruct of language'. This explains the lockstep nature of human ${ }^{56}$ meaningfulness-andteleology and language, with the latter as the former's signification mirroring, such that institutional-cumulation/institutional-recomposure-〈as-to- historiality/ontologicaleventfulness /ontological-aesthetic-tracing-<perspective-ontologicalnormalcy/postconvergence-reflected-'epistemicity-relativism-determinism' $>\rangle$ is actually as of 'accreting-substitutive-subsumption-as-futural-différance-freeplay ${ }^{2}$ construed here as of 'intemporal ontological-faith-notion-or-ontological-fideism —imbued-underdetermination-ofmotif-and-apriorising/axiomatising/referencing-as-so-being-as-of-existential-reality instigated relative-unreflexivity/relative-reflexivity - ontological-contiguity ${ }^{67}$ of-the-humaninstitutionalisation-process $^{68}$ as of difference-conflatedness ${ }^{13}$-as-to-totalitative-reification-in- 
singularisation-<as-to-the-nondisjointedness/entailment-of-prospective- nonpresencing $>$-asveridical-epistemicity-relativism-determinism implied $\quad<$ amplituding/formativeepistemicity $>$ causality $\sim$ as-to-projective-totalitative-implications-of-prospectivenonpresencing,-for-explicating relative-unreflexivity/relative-reflexivity - ontologicalcontiguity ', différance', with regards to 'human species sublimation-educing-\{epistemictotalising 3 3 ${ }^{3}$ hermeneutic/textuality/reprojecting/supererogating/zeroing/re-acuting,$\left.{ }_{\{d e c o m p u l s i n g}\right\}$ delinearity $\sim$ for-cogency as-to-possibilities-of-self-becoming-as-of-‘existentialinterpretation/epistemicity-in-apriorising/axiomatising/referencing-of-existence ${ }^{5}$ as of existential-stakes migration', and speaks of a non-speculative, non-imaginary, theoretical, conceptual and operant construal of an internal-dialectic in 'implicited_attendant-ontologicalcontiguity $^{67}$, educedexistentialising/contextualising/textualising_'intelligibility/epistemicity/reflexivity_contiguity<imbued-notional cogency>>/Derridean-différance/Sartrean-existence-precedesessence/Heideggerian-essencing-as-of-the-ontological-difference construed as of human limited-mentation-capacity-deepening—as-subjecting limitedness/human-subpotency-to'educed-unlimitedness/existence-sublimating nascence' ${ }^{53}$. Such adjunctive-metaphoricity ${ }^{57}$ significations apriorising/axiomatising/referencing-\{of-“prespectively implieited_tentantontological-contiguity ' educedexistentialising/contextualising/textualising_'intelligibility/epistemicity/reflexivity-contiguity<imbued-notional cogency $\left.>^{\prime} \quad\right\}$-conflatedness ${ }^{13}$ in-\{preconverging-ment by\} pestcenverging-entailment $<$ amplituding/formative-epistemicity $>$ causality $\sim$ as-to-projectivetotalitative-implications-of-prospective- nonpresencing,-for-explicating relativemnreflexivity/relative reflexivity - ontological-contiguity mirror the syncretising-effecting as of the acculturation-indigenisation-pidginisation behind dialectal differentiation, national language formation, and the cultural diffusion associated pidginisation and creolisation; as of 
social-stake-contention-or-confliction context adjunctive-metaphoricity ${ }^{57}$-significations apriorising/axiomatising/referencing-\{of-'prospectively implicited_attendant-ontologicalcontiguity ' educed-

existentialising/contextualising/textualising_'intelligibility/epistemicity/reflexivity-contiguity<imbued-notional cogency >' $\}$-conflatedness ${ }^{13}$-in-\{preconverging-ment-by\}postcenverging-entailment induced 'underlying <amplituding/formativeepistemicity>totalising/circumscribing/delineating signifying-construct of languages'. In another respect with regards to language acquisition as mirroring a child's existential-disontologising/re-ontelogising aporeticism $>$ integration into the dynamics of socialconstruct existential-<disontologising/re-ontologising aporeticism $>$ situations/instances, stakes, institutions and processes, a new born child existential-<isontologising/reentologising aporeticism $>$ integration into society, from its perspective, develops as of a dynamics of adjunctive-metaphoricity ${ }^{57}$-significations in 'significations accreting-substitutivesubsumption-as-futural-différance-freeplay ${ }^{2}$ construed here as the phenomenology of human language acquisition différance' that fundamentally mirror the child's developing existential< disontologising/re-ontologising aporeticism $>$ social relationships as an ordered process of social existential-disontogising/re ontogising aporetieism> overtures constraining-andcohering the child's adoption-of/integration-with the supposedly 'underlying <amplituding/formative-epistemicity>totalising/circumscribing/delineating signifyingconstruct of language' as of a peculiar, intuitive and dynamic developing metaphoricity ${ }^{57}$ where 'both the child and members of the overall social-construct existentially-<isontologising/reentologising aporeticism $\geqslant$ adjust to each other as of spurious meaningful utterances like mutual babbling and baby-talk' while implicitly converging towards the child's adoption/integration at various stages of its existential-<disentologising/re-ontologising aporeticism $>$ development of the 'underlying <amplituding/formative- 
epistemicity $>$ totalising/circumscribing/delineating signifying-construct of language' as it is reflected by the dynamics of social-construct existential-<disontologising/re-ontologising aporeticism $>$ situations/instances, stakes, institutions and processes. But then as might be phenomenologically appreciated the notion of language as of its existential-<disentologising/reentologising apereticism $>$ import is thus utterly dynamic as an overall signification construct that is never 'absolutely present' but rather 'immensely existentially-<disontologising/reentologising apereticism $>$ present' with an 'absolute language signification construct imagery rather implied as of projection/anticipation but not phenomenologically real' explaining the concrete variation of individuals linguistic performance, as the phenomenality of language is rather held together by the 'given social-setup underlying supposedly coherent ontologicalcommitment $-<$ implied—self-assuredness-of-ontological-good-

\section{faith/authenticity $\sim$ postconverging-de-mentating/structuring/paradigming -as-being-as-of-}

existential-reality> for its evolving-and-devolving construct of ${ }^{56}$ meaningfulness-andteleology'! Thus phenomenologically, 'language arises, ebbs and flows as of a continuouslyelusive individual and collective-social consciousness steering that reflects the $<$ amplituding/formative-epistemicity $>$ totalising $\sim$ self-referencing-

syncretising/circularity/interiorising/akrasiatic-drag ${ }^{34}$ dynamics of individual and collectivesocial ${ }^{5}$ meaningfulness-and-teleology ${ }^{\circ}$, and this equally explains why language evolves and transforms over time. In effect, 'language is never phenomenologically the complete possibilities of language as an absolute present conception but is rather a becoming as of an immenselyexistentially-present signification reflected by individuals and the collective-social along existential-<disontologising/re-ontologising aporeticism $>$ development stages as of the

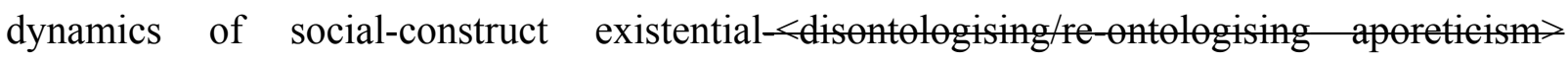
situations/instances, stakes, institutions and processes'. The above insight further points out the pertinence of construing-of and analysing language more completely as of human 
existentialism/thrownness/facticity, giving that language is more phenomenologically-andpragmatically a signification accompaniment of 'individuals and the collective-social along existential-<disontologising/re-ontologising aporeticism $>$ development stages as of the dynamics of social-construct existential-<disontologising/re-ontologising aporeticism $>$ situations/instances, stakes, institutions and processes'. This highlights the 'knowledge implications as of accreting-substitutive-subsumption-as-futural-différance-freeplay with regards to such a phenomenological conception of language as a lockstep veridical reflection of human personality development all along the various existential-<disontologising/reentologising aporeticism $>$ stages as of a notion of the dynamics of social-construct existential< disontologising/re-ontelogising aporeticism $>$ situations/instances, stakes, institutions and processes from childhood to adulthood', notwithstanding the fact that the privileged social conceptualisation of language is as of 'language as the complete possibilities of language as of an absolute present conception usually of a privileged end-institution purpose'. Metaphoricity is thus rather construed as of its overall apriorising/axiomatising/referencing-\{of'prospectively_implicited_attendant_ontological-contiguity ' educedexistentialising/contextualising/textualising_'intelligibility/epistemicity/reflexivity-contiguity-

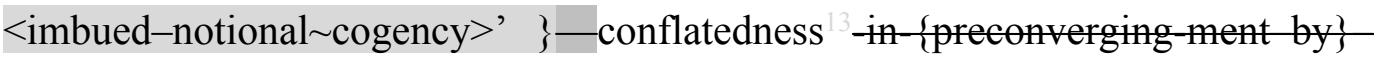
postconverging-entailment <amplituding/formative-epistemicity $>$ causality $\sim$ as-to-projectivetotalitative-implications-of-prospective- nonpresencing,-for-explicating relativeunreflexivity/relative-reflexivity ontological-contiguity of full consciousness development as of Being-development/ontological-framework-expansion-as-to-depth-of-ontologisingdevelopment-as-infrastructure-of- meaningfulness-and-teleology underlying human sublimation-educing__epistemic-

totalising 3 ' $h$ hermeneutic/textuality/reprojecting/supererogating/zeroing/re-acuting,${ }_{\{\text {decompulsing }}$ delinearity $\sim$ for-cogency $\sim$ as-to-possibilities-of-self-becoming-as-of-‘existential- 
interpretation/epistemicity-in-apriorising/axiomatising/referencing-of-existence ${ }^{95}$, beyond just mere figurativeness but as of figurative projected implications of individuals and the collectivesocial ${ }^{56}$ meaningfulness-and-teleology ${ }^{9}$ as of their peculiarity/differentiation to the entire

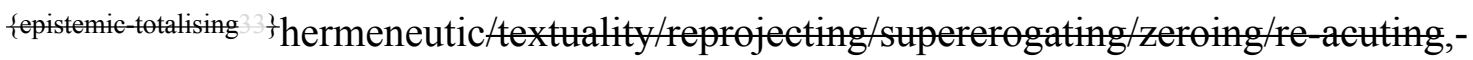
$\{$ decompulsing $\}$ delinearity for-cogency rhetorical-stylistic-semantic delivery, and as such metaphoricity $^{57} \quad$ induces $\quad<$ amplituding/formativeepistemicity $>$ totalising/circumscribing/delineating signification in producing, as of accretingsubstitutive-subsumption-as-futural-différance-freeplay', 'underlying <amplituding/formativeepistemicity>totalising/circumscribing/delineating signifying-construct of language' and together with its associated adjunctive-metaphoricity ${ }^{5}$-significations. Overall, human explicit and implicit signification as of language as articulated above is equally reflected in human aesthetics/arts like music and even science. Ultimately, human adjunctive-metaphoricity ${ }^{5}$ significations apriorising/axiomatising/referencing-\{of-‘prospectively implicited_attendantontological-contiguity ' $\sim$ educedexistentialising/contextualising/textualising_'intelligibility/epistemicity/reflexivity_contiguity<imbued-notional cogency $>$ ' $\}$ - conflatedness ${ }^{13}$ in-\{preconverging-ment-by\} reflecting syncretising-effecting superseding of human selfreferencing signifying-constructs as of the need to supersede the limited certitude as of human limited-mentation-capacity—as-subjecting 'educed-unlimitedness/existence-sublimating nascence' to-limitedness/human-subpotency, inherently implies that the possibility for 'absolute certitude as of its theoretical possibility' lies with such an adjunctive-metaphoricity ${ }^{57}$ significations apriorising/axiomatising/referencing-\{of-'prospectively implicited_attendantontological-contiguity ' educedexistentialising/contextualising/textualising_'intelligibility/epistemicity/reflexivity-contiguity<imbued-notional cogency>' \}-conflatedness ${ }^{13}$-in-\{preconverging -ment by\} 
postconverging-entailment as of syncretising-effecting as ultimately converging towards a deprocrypticism-or-preempting-disjointedness-as-of- reference-of-thought and so as of the prospect of an ontologically-veridical Theory of Everything, and insightfully with regards to elucidating the pervasiveness of 'accreting-substitutive-subsumption-as-futural-différancefreeplay construed as différance in apriorising/axiomatising/referencing-\{of- prospectively implicited_attendant_ontological-contiguity ' educedexistentialising/contextualising/textualising_intelligibility/epistemicity/reflexivity_contiguity<imbued-notional $\sim$ cogency $>$ ' $\}$ - conflatedness ${ }^{13}$ in-\{preconverging-ment by\} postconverging-entailment' associated with human existential-<disontologising/reentologising aporeticism $>$ grasp of knowledge as of the implications of its limited-mentationcapacity -as-subjecting-'educed-unlimitedness/existence-sublimating nascence' tolimitedness/human-subpotency. The notion of accreting-substitutive-subsumption-as-futuraldifférance-freeplay as underlying human limited-mentation-capacity-as-subjecting 'educedunlimitedness/existence-sublimating nascence' to-limitedness/human-subpotency induced différance highlights the phenomenological reality all along humanity's existence of the 'privileging of ontological-construction' as from the perspective/framing/reference/horizon/projection of the end-purpose of the various relevant dominant social agencies and social institutions, and so as reflected as of humanity's existence historiality/ontological-eventfulness 38 ontological-aesthetic-tracing- $<$ perspectiveontological-normalcy/postconvergence-reflected-‘epistemicity-relativism-determinism’>. While such a privileging as of immediate/instant existential-<disontologising/re-ontologising aporeticism $>$ implications like say parents and society privileging the conception of what is language in terms-as-of-axiomatic-construct of its end-purpose as of the perspective of the child's integration in various social structures and institutions; however, in-the-bigger-picture the fact that social structures and social institutions dysfunction as of human limited-mentation- 
capacity —as-subjecting 'educed-unlimitedness/existence-sublimating nascence' tolimitedness/human-subpotency, point to the 'ontological-veracity of fundamentally reevaluating the pertinence of only-a-social-and-institutional-end-purposeperspective/framing/reference/horizon/projection driven basis for ontological-construction', and so as of a putting-into-question exercise. Ultimately, such privileged perspective/framing/reference/horizon/projection as of its 'non-recording and negation' of a 'diverse-and-complete existential-<disontologising/re-ontologising aporeticism $>$ effecting possibilities accountability for ontological-construction', and rather assuming the approach of a 'select privileged ${ }^{4}$ historiality/ontological-eventfulness $\%$ /ontological-aesthetic-tracing$<$ perspective--ontological-normalcy/postconvergence-reflected-'epistemicity-relativismdeterminism'> ontological-construction', instead incompletely portrays the operant reality of humanity's existence as of the cumulation of successive humanity's <amplituding/formativeepistemicity $>$ totalising $\sim$ self-referencing-syncretising/circularity/interiorising/akrasiatic-drag as implied with the various institutionalisations finalities. But then while that is pertinent, and so with regards to the successive institutionalisations outcomes of 'intemporal ontological-faithnotion-or-ontological-fideism —imbued-underdetermination-of-motif-and-

apriorising/axiomatising/referencing-as-so-being-as-of-existential-reality instigated relativeunreflexivity/relative-reflexivity - ontological-contiguity ${ }^{67} \sim$ of-the-human-institutionalisationprocess $^{68}$ as of difference-conflatedness ${ }^{13}$-as-to-totalitative-reification-in-singularisation- $<$ as-tothe-nondisjointedness/entailment-of-prospective- nonpresencing $>$-as-veridical-epistemicityrelativism-determinism implied $<$ amplituding/formative-epistemicity $>$ causality $\sim$ as-toprojective-totalitative-implications-of-prospective- nonpresencing,-for-explicating relativemnreflexivity/relative reflexivity - ontological-contiguity ', as successive transcendental outcomes, so reflected by the ${ }^{4}$ historiality/ontological-eventfulness ${ }^{3} /$ ontological-aesthetictracing-<perspective-ontological-normalcy/postconvergence-reflected-‘epistemicity- 
relativism-determinism'>; this doesn't reflect an inherent différance operant phenomenological process reality. Such a reality is actually reflected as of accreting-substitutive-subsumption-asfutural-différance-freeplay $^{2} \quad$ as $\quad$ of $\quad$ transversality- $<$ for-sublimating-existentialeventuating/denouement,-from-'thinking-at-first/pure-predisposition-preemptive-ofprospective-disontologising/subontologising’ as-of-prospectively-disambiguated-affirmedand-unaffirmed-'motif-and-apriorising/axiomatising/referencing'> ${ }^{101}$ of various temporal-tointemporal perspectival existential-<disontologising/re-ontologising aporeticism $>$ amalgamation that preconverging/postconverging-de-mentatively/structurally/paradigmatically reflect the dynamics of human ontologically-veridical construals and misconstruals towards transcendence-and-sublimity/sublimation/supererogatory de-mentativity. Accretingsubstitutive-subsumption-as-futural-différance-freeplay ${ }^{2}$ is thus reflective of the fulsome humanity existential-<disontologising/re-ontologising aporeticism $>\quad$ ontologicalconceptualisation dynamics than just as of the select ontological-veracity of the privileged as dominant social and institutional end-purpose perspective/framing/reference/horizon/projection. Consider in this regard supposedly that 'traditional classical mechanics axiomatic-construct' and the theory-of-relativity-together-with-quantum-mechanics - axiomatic-constructs reflect an historiality/ontological-eventfulness ${ }^{38}$ ontological-aesthetic-tracing-<perspectiveontological-normalcy/postconvergence-reflected-‘epistemicity-relativism-determinism’> transcendental outcomes of such différance, accreting-substitutive-subsumption-as-futuraldifférance-freeplay $^{2}$ is not only about the successive <amplituding/formativeepistemicity $>$ totalising $\sim$ self-referencing-syncretising/circularity/interiorising/akrasiatic-drag as différance transcendental outcomes as of 'developed classical mechanics' and then 'developed theory-of-relativity-together-with-quantum-mechanics-axiomatic-constructs' as of their prospective relative-ontological-completeness 87 relative-reflexivity - ontological-contiguity as axiomatic-constructs of 'the-very-same physics <amplituding/formative- 
epistemicity>totalising $\sim$ devolved—-purview/domain-of-construal-as-intrinsic-

reality/ontological-veridicality/existential-reality', but will grasp the deeper-level phenomenological insight with regards to all the background efforts and contributions that ultimately brought about these two successive <amplituding/formativeepistemicity $>$ totalising $\sim$ self-referencing-syncretising/circularity/interiorising/akrasiatic-drag construed as the ${ }^{4}$ historiality/ontological-eventfulness ${ }^{38}$ /ontological-aesthetic-tracing<perspective-ontological-normalcy/postconvergence-reflected-'epistemicity-relativismdeterminism'> of the différance. The implication here resonates with the idea that knowledge is much more than the construal of conceptual sublimation knowledge outcome, but rather its construal as knowledge involving the dynamic understanding of both its

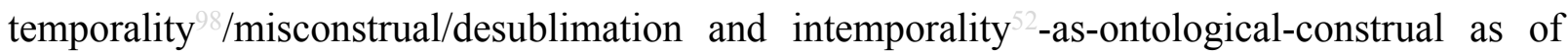
accreting-substitutive-subsumption-as-futural-différance-freeplay ${ }^{2}$ involving specifically disambiguation as of human limited-mentation-capacity-as-subjecting 'educedunlimitedness/existence-sublimating nascence' to-limitedness/human-subpotency dynamics as of deneuterising ${ }^{17}$-referentialism and thus beyond ${ }^{58}$ neuterising' reflecting the difference-innature/difference-in-apriorising-or-axiomatising-or-referencing ${ }^{4}$ of the uninstitutionalisedthreshold ${ }^{102}$ and the prospective institutionalisation; as the 'effecting implications of knowledge' are more than just about its conceptualised intemporality ${ }^{52}$-as-ontology but involves grasping this together with the implications of temporality ${ }^{8}$, and so because of the circular existential< disontologising/re-ontologising aporeticism $>$ implications of human limited-mentationcapacity —as-subjecting 'educed-unlimitedness/existence-sublimating nascence' tolimitedness/human-subpotency. Hence language can be more pertinently construed ontologically as of the postconverging/preconverging epistemic — projective-equalisation social dynamics of existential-<disontologising/re-ontologising aporeticism $>{ }^{56}$ meaningfulness-and-teleology signification than just as of just an outcome privileged institutional end-purpose 
perspective/framing/reference/horizon/projection that is in-many-ways ad-hoc and phenomenologically uninsightful as of the many existential-<disontologising/re-ontologising aporeticism $>$ implications behind comprehending language. Thus human privileged social and institutional end-purpose perspective/framing/reference/horizon/projection tend to be in apriorising/axiomatising/referencing-\{of-'prospectively_implicited_attendant-ontologicalcontiguity ' educedexistentialising/contextualising/textualising_intelligibility/epistemicity/reflexivity_contiguity$<$ imbued-notional cogency $>>$ - $\}$ - constitutedness ${ }^{1}$-in-preconverging-entailment. Further such accreting-substitutive-subsumption-as-futural-différance-freeplay ${ }^{2}$ is the existentially<disontologising/re-ontologising aporeticism $>$ veridical and effective basis for reflecting historiality/ontological-eventfulness ${ }^{38}$ ontological-aesthetic-tracing-<perspectiveontological-normalcy/postconvergence-reflected-‘epistemicity-relativism-determinism'> transcendental outcome as can be implied in a storied-construct/ontologically-valid-narration as of existentially-<disontologising/re-ontologising aporeticism $>$ insightful ${ }^{5}$ meaningfulnessand-teleology . Such a perspective should possibly usher in a 'suprastructural postmodernism in everything' including such nascent contemplations for breaking out of currently perceived subject-matter doldrums as implied with postmodern social sciences, postmodern humanities, postmodern art, postmodern science, postmodern mathematics and postmodern physics, and so notwithstanding a history of post-structuralism critiques of ontological-bad-faith/inauthenticity 'with moronic incantations that fail the mark of even bad intellectual arguments as socialaggregation-enabling invocations', granted as of their beyond-the-consciousness-awarenessteleology ${ }^{9}<$ of-preconverging-existential-extrication-as-of-existential-unthought $>$; as such a statement is not gratuitous given the mere fact that where knowledge-as-of-organic-knowledge as of human intemporality ${ }^{52} /$ longness doesn't take its due place, it is occupied by ignorance as of human temporality 8 /shortness with consequent nefarious ramifications for Being- 
development/ontological-framework-expansion-as-to-depth-of-ontologising-development-asinfrastructure-of- meaningfulness-and-teleology . Basically, just as the adjunctivemetaphoricity ${ }^{5}$-signification instigation of positivistic rationality as a potent construct took the form of a centered-epistemic-totalisation permeating all aspects and subject-matter domains of human existence and so for the better with regards to Being-development/ontologicalframework-expansion-as-to-depth-of-ontologising-development-as-infrastructure-ofmeaningfulness-and-teleology, postmodern-thought and as of its underlying phenomenological depth transcendentally carries prospective Being adjunctive-metaphoricity ${ }^{57}$ signification as of a potent construct for a centered-epistemic-totalisation permeation and sublimation of all aspects and subject-matter domains of human existence, and so for the better of Being-development/ontological-framework-expansion-as-to-depth-of-ontologisingdevelopment-as-infrastructure-of- meaningfulness-and-teleology . Such phenomenology as the 'deepest phenomenological transcendental-point-of-departure handle as of the notional conflatedness ${ }^{13}$ of notional ${ }^{18}$ deprocrypticism deneuterising -referentialism' is operantly enabled as of accreting-substitutive-subsumption-as-futural-différance-freeplay ${ }^{2}$ and is the maximal ontologically veridical articulation of apriorising/axiomatising/referencing-\{of'prespectively implicited_attendant-ontological-contiguity ' educedexistentialising/contextualising/textualising_ 'intelligibility/epistemicity/reflexivity-contiguity<imbued-notional cogency $\left.>^{\prime}\right\}$-conflatedness ${ }^{13}$ in-\{preconverging ment by\} postconverging-entailment; that 'so-undermines the privileging of <amplituding/formativeepistemicity $>$ totalising $\sim$ self-referencing-syncretising/circularity/interiorising/akrasiatic-drag of its ubiquitous-protractedness preconverging/postconverging-dementative/structural/paradigmatic difference-in-kind/difference-in-aposteriorising-orlogicising disposition), and so beyond just reflecting such ${ }^{70}$ presencing-absolutisingidentitive-constitutedness ${ }^{14}$ privileging imbued undermining of transcendental outcomes implied 
ontological-normalcy/postconvergence-reflected-‘epistemicity-relativism-determinism’>.

While the 'Derridean quasi-transcendental-freeplay différance' by its rather quasitranscendental-freeplay orientation doesn't comprehensively explicit such a phenomenological depth of apriorising/axiomatising/referencing-\{of-'prospectively implicited_attendantontological-contiguity ' educed-

existentialising/contextualising/textualising_intelligibility/epistemicity/reflexivity_contiguity<imbued-notional cogency $>\quad$ \}-conflatedness ${ }^{13}$ in-\{preconverging ment by postconverging-entailment, it does effectively elicit such an underlying conception of phenomenological profoundness. As such a 'Derridean quasi-transcendental-freeplay différance' is what is meant to be understood as a relatively more pertinent ontologically depth for such a more evolved and 'experimental' articulation of différance in the strive to maximally undermine $<$ amplituding/formative-epistemicity $>$ totalising $\sim$ self-referencingsyncretising/circularity/interiorising/akrasiatic-drag ${ }^{34}$ implied in the Glas experimental project which goal is well beyond the two texts but more fundamentally a demonstration of 'sublimationeducing__epistemic-totalising 3 \} 3 hermeneutic/textuality/reprojecting/supererogating/zeroing/reating, ${ }^{\{\text {decompulsing }}$ delinearity $\sim$ for-cogency as-to-possibilities-of-self-becoming-as-of'existential-interpretation/epistemicity-in-apriorising/axiomatising/referencing-of-existence ${ }^{0}$, as multifaceted. Ultimately, 'Derridean quasi-transcendental-freeplay différance' unsuspectingly points out that ${ }^{56}$ meaningfulness-and-teleology" imply by default a given perspective/framing/reference/horizon/projection, such that as of a <amplituding/formativeepistemicity $>$ totalising $\sim$ self-referencing-syncretising/circularity/interiorising/akrasiatic-drag meaningfulness-and-teleology ${ }^{9}$ facet it is then already compromising nonpresencing-orwithdrawal/unenframing/re-ontologising-or-metaphysics-of-absence-_implicited-epistemicveracity-of- nonpresencing-<perspective-ontological-normalcy/postconvergence $>$ >-or- 
transcendental-reasoning-of-event ${ }^{3}$-as-prospective-ontology-origination meaningfulnessand-teleology' facet. Thus, this author holds that such a 'Derridean quasi-transcendentalfreeplay différance' is fundamentally incomplete as of comparison with the implied apriorising/axiomatising/referencing-\{of-'prospectively implicited_attendant-ontologicalcontiguity ' educedexistentialising/contextualising/textualising_'intelligibility/epistemicity/reflexivity-contiguity<imbued-notional cogency $\left.>{ }^{\prime} \quad\right\}$-conflatedness ${ }^{13}$ in-\{preconverging-ment by\} postconverging-entailment of accreting-substitutive-subsumption-as-futural-différancefreeplay ${ }^{2}$ which is truly transcendental. The former fails to factor in that human limitedmentation-capacity—as-subjecting-'educed-unlimitedness/existence-sublimating nascence'to-limitedness/human-subpotency has to establish the appropriate 'perspective/framing/reference/horizon/projection implications' with regards to meaningfulness-and-teleology, and so as disambiguating ${ }^{79}$ presencing-absolutisingidentitive-constitutedness ${ }^{14} \quad$ from $\quad{ }^{6}$ nonpresencing-<perspective-ontologicalnormalcy/postconvergence $>$ by their respective supererogatory acuity/perspicacity/astuteness/edginess/incisiveness-ofapriorising/axiomatising/referencing/intelligibilitysettingup/measuringinstrumenting -forconceptualisation, such that unsuspectingly the 'Derridean quasi-transcendental-freeplay différance' not doing that rather represents the ${ }^{79}$ presencing-absolutising-identitiveconstitutedness ${ }^{14}$ as the common perspective/framing/reference/horizon/projection for both, thus falsely pointing to 'difference-in-kind/difference-in-aposteriorising-or-logicising 23 between presencing-absolutising-identitive-constitutedness ${ }^{14}$ and $\quad{ }^{6}$ nonpresencing-<perspectiveontological-normalcy/postconvergence $>$ (rather than difference-in-nature/difference-inapriorising-or-axiomatising-or-referencing ${ }^{24}$ ), and so contradictorily as if both are of the presencing supererogatory acuity/perspicacity/astuteness/edginess/incisiveness-of- 
apriorising/axiomatising/referencing/intelligibilitysettingup/measuringinstrumenting -for-

conceptualisation. With the reality that nonpresencing-<perspective-ontologicalnormalcy/postconvergence $>$ is wrongly-and-unsuspectingly given as of common ${ }^{79}$ presencingabsolutising-identitive-constitutedness ${ }^{14}$, thus inducing a relative ontologically-flawed quasitranscendental freeplay as $\quad$ nonpresencing-<perspective-ontologicalnormalcy/postconvergence $>$ is rather in notional-discontiguity/epistemic-discontiguity ${ }^{63}$ $<$ between - prior-shallow-supererogation -of-mentallyaestheticised preconverging/dementing -qualia-schema_and_prospective-profoundsupererogation -of-mentally-aestheticised postconverging/dialectical-thinking -qualiaschema $>$ when analysed as of ${ }^{79}$ presencing-absolutising-identitive-constitutedness ${ }^{14}$. Consider in this regard 'the-very-same physics <amplituding/formativeepistemicity $>$ totalising $\sim$ devolved-purview/domain-of-construal-as-intrinsicreality/ontological-veridicality/existential-reality' with the articulation as of prior relativeontological-incompleteness ${ }^{8}$ being 'traditional classical mechanics axiomatic-construct' and the articulation as of prospective relative-ontological-completeness ${ }^{87}$-of-axiomatic-construct-orreference-of-thought being the theory-of-relativity-together-with-quantum-mechanicsaxiomatic-constructs; now, articulating ${ }^{56}$ meaningfulness-and-teleology ${ }^{9}$ of 'the-very-same physics <amplituding/formative-epistemicity $>$ totalising $\sim$ devolved-purview/domain-ofconstrual-as-intrinsic-reality/ontological-veridicality/existential-reality' as of 'traditional classical mechanics axiomatic-construct' construed as ${ }^{79}$ presencing-absolutising-identitiveconstitutedness ${ }^{14}$ makes the theory-of-relativity-together-with-quantum-mechanics-axiomaticconstructs construed as ${ }^{6}$ nonpresencing-<perspective-ontological-normalcy/postconvergence $>$

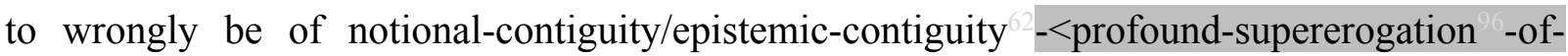
mentally-aestheticised postconverging/dialectical-thinking -qualia-schema $>$ with the 'traditional classical mechanics axiomatic-construct' ${ }^{79}$ presencing-absolutising-identitive- 
constitutedness ${ }^{14}$. Consider in this regard that the 'Derridean quasi-transcendental-freeplay différance' is akin to the contributions of many prior seminal scientists like Poincaré, Lorentz, Plank, Rutherford and others to the theory-of-relativity-together-with-quantum-mechanicsaxiomatic-constructs but whose works were still being interpreted in terms-of/adjunctive-to 'traditional classical mechanics axiomatic-construct' thus explaining the reality of a notionaldiscontiguity/epistemic-discontiguity ${ }^{6}-<$ between - prior-shallow-supererogation -ofmentally-aestheticised preconverging/dementing -qualia-schema_and_prospective-profoundsupererogation -of-mentally-aestheticised postconverging/dialectical-thinking -qualiaschema between the two as of their distinct supererogatory $\sim$ acuity/perspicacity/astuteness/edginess/incisiveness-ofapriorising/axiomatising/referencing/intelligibilitysettingup/measuringinstrumenting -forconceptualisation. Whereas accreting-substitutive-subsumption-as-futural-différance-freeplay is akin to the complete 'epistemic-break', as of Einstein's defining-threshold contribution with the-theory-of-relativity and Bohr's defining-threshold atomic-model contribution to quantummechanics together with other seminal scientists subsequent contributions that ultimately led to 'the-very-same physics <amplituding/formative-epistemicity $>$ totalising $\sim$ devolvedpurview/domain-of-construal-as-intrinsic-reality/ontological-veridicality/existential-reality’ transcendence-and-sublimity/sublimation/supererogatory-de-mentativity as of the theory-ofrelativity-together-with-quantum-mechanics - axiomatic-constructs interpretation as of nonpresencing-<perspective-ontological-normalcy/postconvergence $>$. In any case thus such a 'Derridean quasi-transcendental-freeplay différance' doesn't have any serious ontological consequences with respect to ${ }^{79}$ presencing-absolutising-identitive-constitutedness ${ }^{14}$ since it is reflected with the Glas experimental project, but it fails to recognise the possibility of a futural différance where ${ }^{56}$ meaningfulness-and-teleology 99 is construed as of the prospective nonpresencing-<perspective-ontological-normalcy/postconvergence $>$ 
supererogatory acuity/perspicacity/astuteness/edginess/incisiveness-ofapriorising/axiomatising/referencing/intelligibilitysettingup/measuringinstrumenting -forconceptualisation which points to a prospective relative-ontological-completeness ${ }^{87} /$ relativeunreflexivity/relative-reflexivity - ontological-contiguity ${ }^{7}$ as of the-very-same $<$ amplituding/formative-epistemicity $>$ totalising $\sim$ devolved-purview-as-domain-of-construalas-intrinsic-reality/ontological-veridicality; even though it is the first step towards such a futural différance transcendence-and-sublimity/sublimation/supererogatory $\sim$ de-mentativity. It equally explains such a Derridean conclusion that human sublimation is an always evasive notion given its failure to recognise the difference-in-nature/difference-in-apriorising-or-axiomatising-orreferencing ${ }^{24}$ as of the transcendental implications of prospective ${ }^{6}$ nonpresencing- $<$ perspectiveontological-normalcy/postconvergence $>$ in inducing sublimation, with such a difference-innature/difference-in-apriorising-or-axiomatising-or-referencing ${ }^{24}$ arrived at by human limitedmentation-capacity-deepening_as-subjecting limitedness/human-subpotency-to-'educedunlimitedness/existence-sublimating nascence' ${ }^{3}$ as of de-mentation〈supererogatory $\sim$ ontological-de-mentation-or-dialectical-de-mentation-stranding-orattributive-dialectics $\rangle$ involving ontological-faith-notion-or-ontological-fideism -imbuedunderdetermination-of-motif-and-apriorising/axiomatising/referencing-as-so-being-as-ofexistential-reality driven re-projection/re-anticipation as of prospective apriorising/axiomatising/referencing/intelligibilitysettingup/measuringinstrumenting about 'coherence/contiguity-of-superseding-oneness-of-ontology-implied-as-of-inherent-existencecoherence/contiguity,-and-so-construed-as-the-enabler-of-insight-or-intuition-or-foresight-asof-embodied-consciousness' (so-enabled by underlying supposedly coherent ontologicalcommitment $-<$ implied — self-assuredness-of-ontological-goodfaith/authenticity postconverging-de-mentating/structuring/paradigming -as-being-as-ofexistential-reality> as of <amplituding/formative-epistemicity>causality $\sim$ as-to-projective- 
totalitative-implications-of-prospective- nonpresencing,-for-explicating relative-

unreflexivity/relative-reflexivity ontological-contiguity and not any notion of vague innateness besides existentially-<disontologising/re-ontologising aporeticism $>$ inherent human-subpotency potential to manifest as human), and validated as of $<$ amplituding/formativeepistemicity $>$ causality $\sim$ as-to-projective-totalitative-implications-of-prospectivenonpresencing,-for-explicating relative-unreflexivity/relative-reflexivity ontologicalcontiguity ; as of ontological-faith-notion-or-ontological-fideism -imbuedunderdetermination-of-motif-and-apriorising/axiomatising/referencing-as-so-being-as-ofexistential-reality 'promise of correspondence between human-subpotency as of Being-andconsciousness development and existence as of ontological-veridicality'. It is interesting again to note that the so-renewed 'underlying <amplituding/formativeepistemicity>totalising/circumscribing/delineating of physics' as the theory-of-relativitytogether-with-quantum-mechanics - axiomatic-constructs as of transcendence-andsublimity/sublimation/supererogatory de-mentativity, is not arbitrarily arising from any humansubpotency ${ }^{79}$ presencing — absolutising-identitive-constitutedness ${ }^{14}$ but is rather divulged-as-ofrelative-reflexivity - ontological-contiguity ${ }^{67}$ from existence-potency ${ }^{39} \sim$ sublimating-nascence,disclosed-from-prospective-epistemic-digression by the fact of 'human-subpotency ontologicalfaith-notion-or-ontological-fideism—imbued-underdetermination-of-motif-andapriorising/axiomatising/referencing-as-so-being-as-of-existential-reality led projection/anticipation' ultimate validation by $<$ amplituding/formativeepistemicity $>$ causality $\sim$ as-to-projective-totalitative-implications-of-prospectivenonpresencing,-for-explicating relative unreflexivity/relative-reflexivity - ontologicalcontiguity . This ${ }^{56}$ meaningfulness-and-teleology ${ }^{9}$ centered-epistemic-totalisation-inducingtranscendence-and-sublimity/sublimation/supererogatory-de-mentativity metaphoricity ${ }^{57}$ thus perfectly satisfies the 'foreboding concern for ontological-veracity' critically pursued by the 
Derridean freeplay différance, as it is existence-as-the-absolute-a-priori-ofconceptualisation and existence — as-sublimating-withdrawal/unenframing/re-ontologising,elicited-from-prospective-profound-supererogation $-<$ as-to-perspective-ontologicalnormalcy/postconvergence-implied-'prospective-aporeticism-overcoming/unovercoming'> that phenomenological validates transcendence-and-sublimity/sublimation/supereregatory $\sim$ dementativity, and so implying human limited-mentation-capacity-deepening-as-subjectinglimitedness/human-subpotency to-'educed-unlimitedness/existence-sublimating nascence' ${ }^{3}$; and thus, this point that enables the Derridean freeplay différance as of tendential-deliberationof-decidability to achieving transcendence-and-sublimity/sublimation/supererogatory $\sim$ dementativity is the full apriorising/axiomatising/referencing-\{of-'prospectively implicited_attendant-ontological-contiguity ' reducedexistentialising/contextualising/textualising_'intelligibility/epistemicity/reflexivity-contiguity<imbued-notional cogency>' \}-conflatedness ${ }^{13}$ in-\{preconverging -ment by\} postconverging-entailment reflecting existence-as-the-absolute-a-priori-ofconceptualisation and existence — as-sublimating-withdrawal/unenframing/re-ontologising,-

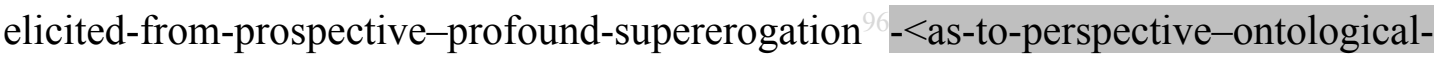
normalcy/postconvergence-implied-'prospective-aporeticism-overcoming/unovercoming'> in its nonpresencing-<perspective-ontological-normalcy/postconvergence $>$, and so beyond just a Derridean freeplay différance which is then in apriorising/axiomatising/referencing-\{of'prospectively implicited_attendant-ontological-contiguity ' educedexistentialising/contextualising/textualising_'intelligibility/epistemicity/reflexivity-contiguity<imbued-notional cogency $\left.>^{\prime} \quad\right\}$-constitutedness ${ }^{14}$-in-preconverging-entailment $\quad$ as not factoring in the process of a tendential-deliberation-of-decidability towards attaining transcendence-and-sublimity/sublimation/supererogatory-de-mentativity. Insightfully, we can grasp that the Derridean freeplay différance becomes as of apriorising/axiomatising/referencing- 
\{of-'prospectively_implicited_attendant_ontological-contiguity ' educed-

existentialising/contextualising/textualising_intelligibility/epistemicity/reflexivity_contiguity-

<imbued-notional cogency>' $\}$-constitutedness ${ }^{14}$-in-preconverging-entailment $\quad$ because 'reasoning itself has become defective' as presupposing-by-the-Derridean-freeplay to supersede existence — as-the-absolute-a-priori-of-conceptualisation and existence-as-sublimating-

withdrawal/unenframing/re-ontologising,-elicited-from-prospective-profound-

supererogation ${ }^{\circ}<$ as-to-perspective-ontological-normalcy/postconvergence-implied-

'prospective-aporeticism-overcoming/unovercoming'>. So because at the point of transcendence-and-sublimity/sublimation/supererogatory - de-mentativity reasoning is still presupposing thought-determination instead of given up to the possibility of existence's divulgation construed as ontological-faith-notion/ontological-fideism, and so erroneously become the transcendental-signifier of existence despite the reality of human limited-mentationcapacity-as-subjecting 'educed-unlimitedness/existence-sublimating nascence' to-

limitedness/human-subpotency which priority at that point should be the need for validation from existence — as-the-absolute-a-priori-of-conceptualisation and existence—as-sublimating-

withdrawal/unenframing/re-ontologising,-elicited-from-prospective-profound-

supererogation -<as-to-perspective-ontological-normalcy/postconvergence-implied-

'prospective-aporeticism-overcoming/unovercoming'> and not make any determination priorly, even as of freeplay. Furthermore, it is wrong to construe/equate as imagination such ontologicalfaith-notion-or-ontological-fideism—imbued-underdetermination-of-motif-andapriorising/axiomatising/referencing-as-so-being-as-of-existential-reality that as 'hunch' restores existence — as-the-absolute-a-priori-of-conceptualisation $\sim$ and $\sim$ existence — assublimating-withdrawal/unenframing/re-ontologising,-elicited-from-prospective-profoundsupererogation -<as-to-perspective-ontological-normalcy/postconvergence-implied'prospective-aporeticism-overcoming/unovercoming'>, since in reality it is rather pushing 
reasoning to its very limits in a notional disposition that is not guaranteed, and only occasionally as of tendential-deliberation-of-decidability is it confirmed by existence-potency ${ }^{32} \sim$ sublimatingnascence,-disclosed-from-prospective-epistemic-digression as validatable by $<$ amplituding/formative-epistemicity $>$ causality $\sim$ as-to-projective-totalitative-implications-ofprospective- nonpresencing,-for-explicating relative-unreflexivity/relative-reflexivity ontological-contiguity . Thus behind ontological-faith-notion-or-ontological-fideismimbued-underdetermination-of-motif-and-apriorising/axiomatising/referencing-as-so-being-asof-existential-reality as 'hunch' is a transversality-<for-sublimating-existentialeventuating/denouement,-from-'thinking at-first/pure-predisposition-preemptive-ofprospective-disontologising/subontologising' as-of-prospectively-disambiguated-affirmedand-unaffirmed-'motif-and-apriorising/axiomatising/referencing' $>{ }^{101}$ depth of reasoning and perspective which is pushed to its brink in projection/anticipation/expectancy. The fact is ontological-faith-notion-or-ontological-fideism - imbued-underdetermination-of-motif-andapriorising/axiomatising/referencing-as-so-being-as-of-existential-reality exhausts-andsupersedes-reasoning as of projection/anticipation/expectancy with no prior certitude, and is more than just imagination which rather comes prior to and is exhausted-and-superseded-byreasoning. Such a lack of prior certitude explains why transcendence-andsublimity/sublimation/supererogatory de-mentativity 'are not really reasoned-out' but rather discovered-as-divulged by existence, with the human-subpotency concern being one of adopting the right attitude/mental-disposition/care-and-episteme that allows existence-as-full-potency to come up with the divulgation. Ontological-faith-notion-or-ontological-fideism -imbuedunderdetermination-of-motif-and-apriorising/axiomatising/referencing-as-so-being-as-ofexistential-reality as such is equally the basis for implying a correspondence theory of human thought and reality, as not really arising as of any instantative absolute correspondence but rather as of the 'promise of prospective human ontological-completeness-of- reference-of-thought' 
implied by ontological-faith-notion-or-ontological-fideism-imbued-underdetermination-ofmotif-and-apriorising/axiomatising/referencing-as-so-being-as-of-existential-reality as of nonpresencing-<perspective-ontological-normalcy/postconvergence $>$ in continually openingup the-very-same-immanent-existence/intrinsic-reality/ontological-veridicality,-as-to'human<amplituding/formative-epistemicity>totalising purview-of-construal', and soreflected in the relative-unreflexivity/relative-reflexivity ontological-contiguity $\sim$ of-thehuman-institutionalisation-process as of Being-development/ontological-frameworkexpansion-as-to-depth-of-ontologising-development-as-infrastructure-of- meaningfulnessand-teleology . It should be noted that reasoning-as-intelligibility rather harkens back to a given 'registry-worldview's/dimension's $\quad$ reference-of-thought $\quad<$ amplituding/formativeepistemicity $>$ totalising $\sim$ self-referencing-syncretising/circularity/interiorising/akrasiatic-drag established existential-epistemic-totalisation-of- ${ }^{-6}$ meaningfulness-and-teleology ${ }^{9}$ ' to which it tends to be engaged with in an incrementalism-in-relative-ontological-incompleteness enframed/disontologising conceptualisation reflex as of elaboration-as-to-mereextrapolating/constituting/abstracting/deducing/inferring-of-elucidation-outside'prospectively_implicited_attendant-ontological-contiguity ${ }^{67}$ ' educed-

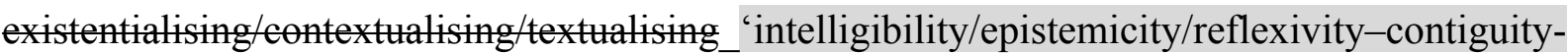
$<$ imbued-notional cogency $>^{\prime}$. We can appreciate that the medieval mindset reasons in terms of medievalism-non-positivism just as we reason in terms of our positivism- ${ }^{80}$ procrypticism mindset. The question can thus be asked is there more profound ${ }^{56}$ meaningfulness-andteleology ${ }^{9}$ beyond any given registry-worldview/dimension mindset divulgeable by existenceas-the-absolute-a-priori-of-conceptualisation and existence-as-sublimatingwithdrawal/unenframing/re-ontologising,-elicited-from-prospective-profoundsupererogation -<as-to-perspective-ontological-normalcy/postconvergence-implied'prospective-aporeticism-overcoming/unovercoming'>? It is herein that we get into the realm of 
ontological-faith-notion-or-ontological-fideism - imbued-underdetermination-of-motif-andapriorising/axiomatising/referencing-as-so-being-as-of-existential-reality as of de-mentation〈supererogatory $\sim$ ontological-de-mentation-or-dialectical-de-mentation-stranding-orinducible apriorising/axiomatising/referencing/intelligibilitysettingup/measuringinstrumenting. In other words, under sufficient constraint of existence/existential-reality-itself given its absolute a-priori status, as reflected by <amplituding/formative-epistemicity>causality $\sim$ as-to-projectivetotalitative-implications-of-prospective- nonpresencing,-for-explicating relativeunreflexivity/relative-reflexivity ontological-contiguity /contingency, human intemporal individuation is predisposed to put in question even a 'registry-worldview's/dimension's reference-of-thought <amplituding/formative-epistemicity $>$ totalising $\sim$ self-referencingsyncretising/circularity/interiorising/akrasiatic-drag ${ }^{34}$ established existential-epistemictotalisation-of- ${ }^{5}$ meaningfulness-and-teleology ${ }^{9}$ as of a reconstrual of ${ }^{83}$ reference-of-thought and devolving-axiomatic-constructs implications, and so as of ${ }^{55}$ maximalising-recomposuringfor-relative-ontological-completeness ${ }^{87}$ - unenframed/re-ontologising $\sim$ conceptualisation. This insight about ontological-faith-notion-or-ontological-fideism - imbued-underdetermination-ofmotif-and-apriorising/axiomatising/referencing-as-so-being-as-of-existential-reality further reveals that prospective nonpresencing-<perspective-ontological-normalcy/postconvergence $>$ implies prospective renewal of attitude/mental-disposition/care-and-episteme , as of ${ }^{15 e-}$ mentation-〈supererogatery ontological-de-mentation-or-dialectical-de-mentation — strandingor-attributive-dialectics $\rangle$ which at once draws out the renewed implications of what qualifies as affirmation/projection/assertion/notional self-distantiation/dueness-validatinglogicising/suitable-measuringinstrument-validating-measuring-<as-to-postconverging-ordialectical-thinking -apriorising-psychologism> and unaffirmation/deprojection/deassertion/epistemic-decadence/undueness-invalidating- 
logicising/unsuitable-measuringinstrument-invalidating-measuring-<as-to-preconverging-ordementing -apriorising-psychologism> respectively as of prospective relative-ontologicalcompleteness ${ }^{87}$-of-axiomatic-construct-or- ${ }^{83}$ reference-of-thought and prior relative-ontologicalincompleteness ${ }^{8}$. In this regard we can imagine as of 'the-very-same physics $<$ amplituding/formative-epistemicity $>$ totalising $\sim$ devolved — purview/domain-of-construal-asintrinsic-reality/ontological-veridicality/existential-reality', the strange feeling upon physicists wedded to 'traditional classical mechanics axiomatic-construct' with respect the prospective theory-of-relativity-together-with-quantum-mechanics - axiomatic-constructs ${ }^{5}$ maximalisingrecomposuring-for-relative-ontological-completeness ${ }^{87}$ - unenframed/re-

ontologising conceptualisation articulation of such ideas as space-time, considering the ether as unreal, considering that the laws of physics are different at atomic scale, etc. as the fundamental basis for understanding the new physics as of its prospective relative-ontologicalcompleteness ${ }^{87}$-of- ${ }^{83}$ reference-of-thought. Such a construal as a shift in axiomatic-construct is more-or-less within the same positivism/rational-empiricism registry-worldview, though it might pretty much be argued that the theory-of-relativity-together-with-quantum-mechanicsaxiomatic-constructs marks the beginning of a proto-postmodern science as of the fundamental human-subject-emancipating-relativism-driven-recomposuring-constructivism-towardssingularisation-<as-to-the-nondisjointedness/entailment-of-prospective- nonpresencing $>$ developments in physics since then, even though its ${ }^{56}$ meaningfulness-and-teleology ${ }^{99}$ remains intelligible, more or less, to the positive science essentially by the modern conception of observational and experimental validation. However, the idea of requisite shift in attitude/mental-disposition/care-and-episteme from that simplistic 'modern conception' cannot be contested. Such an attitude/mental-disposition/care-and-episteme implied shift as articulated above, construed as of an overall registry-worldview/dimension ${ }^{83}$ reference-ofthought transcendence-and-sublimity/sublimation/supereregatery $\sim$ de-mentativity is rather 
'massively distressing' when implied 'as of an instant of transitioning' since the reality of such attitude/mental-disposition/care-and-episteme transitioning have tended to take place rather crossgenerationally as of human beyond-the-consciousness-awareness-teleology ${ }^{9}-<$ of preconverging-existential-extrication-as-of-existential-unthought $>$. As we can now imagine the transitioning of positivism/rational-empiricism attitude/mental-disposition/care-and-episteme from earlier crude conceptualisations of positivism/rational-empiricism as presently reflecting a more ${ }^{103}$ universal valid notion of positivism/rational-empiricism as of its spread worldwide and profoundness in today's societies. Interestingly, this transitioning nature of human attitude/mental-disposition/care-and-episteme renewal manifestation as of the social collective evolution, and is equally reflected in the individual as-receptacle-of-temporal-to-intemporalindividuation-ontological-performance ${ }^{72}-<$ including-virtue-as-ontology $>$; as at any given moment individuals and society are rather inclined to adopt an attitude/mental-disposition/care-

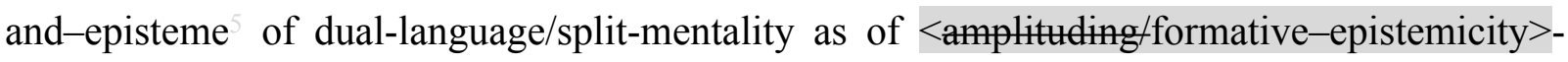
totalising thrownness-in-existence ${ }^{35}$ (I exist therefore existence is of transcendentalenabling/sublimating/supereregatory de-mentativity to my human-subpotency / hyperbole-of-

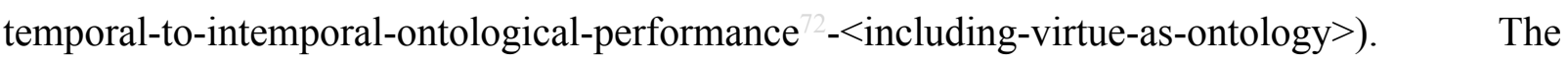
implied notion of human emancipation is always being articulated in an existentially$<$ disontologising/re-ontelogising aporeticism $>$ dual-language/split-mentality that on-the-onehand fails the implied emancipation and on-the-other-hand implies a strife for such emancipation. Consider in this regard, the attitude/mental-disposition/care-and-episteme of warring nations in the early $20^{\text {th }}$ century all too ready to arm themselves massively in preparation for the world wars and equally very much aware of the need for international peace, or in the $18^{\text {th }}$ and $19^{\text {th }}$ centuries the dual-language/split-mentality of ${ }^{103}$ universal human rights and ending slavery in the new world and the slave trade on-the-one-hand and on the other still practicing it up to the point of wars like the American civil war to bring an end to it. In a more prosaic note, 
the dual-language/split-mentality associated with the evasiveness of emancipating social and political dispositions as of relevant settings and contexts. In fact, this author will surmice that inmany-ways we already carry inklings of postmodern ${ }^{18}$ deprocrypticism-or-preemptingdisjointedness-as-of- ${ }^{8}$ reference-of-thought

apriorising/axiomatising/referencing/intelligibilitysettingup/measuringinstrumenting attitude/mental-disposition/care-and-episteme as of the dual-language/split-mentality at appropriate contexts and settings extolling our liberality with progressive stakes while in other secluded settings and contexts espouse a damning language regarding such progressive stakes. The idea of requisite attitude/mental-disposition/care-and-episteme renewal as implied for notional ontological-faith-notion-or-ontological-fideism - imbued-underdetermination-ofmotif-and-apriorising/axiomatising/referencing-as-so-being-as-of-existential-reality induced transcendence-and-sublimity/sublimation/supereregatery-de-mentativity speaks of a 'reality as of underlying human beyond-the-consciousness-awareness-teleology ${ }^{\circ}<$ of-preconvergingexistential-extrication-as-of-existential-unthought>', that reflects a human tacit awareness that the grounding of its ${ }^{56}$ meaningfulness-and-teleology ${ }^{9}$ is not-certain-as-absolute at any given moment, and that it should be prepared to shift its attitude/mental-disposition/care-andepisteme for more profound-and-complete ${ }^{56}$ meaningfulness-and-teleology ${ }^{9}$. While such an inclination is more forthcoming as of less profound-and-perceived personal existential<disontologising/re-ontologising aporeticism $>$ implications with regards to the axiomaticconstructs within a ${ }^{83}$ reference-of-thought as articulated priorly with a shift for the theory-ofrelativity-together-with-quantum-mechanics - axiomatic-constructs within the positivism/rational-empiricism ${ }^{83}$ reference-of-thought, however, as of more profound-andperceived personal existential-disentoging an drastically implied at the phenomenological depth of ${ }^{83}$ reference-of-thought transcendental conceptualisation this turns out to be much more difficult to countenance given individuals 
'mental and existential-<disontologising/re-ontologising aporeticism $>$ investment' into meaningfulness-and-teleology as grounded on a given 'registry-worldview's/dimension's reference-of-thought <amplituding/formative-epistemicity $>$ totalising $\sim$ self-referencingsyncretising/circularity/interiorising/akrasiatic-drag ${ }^{34}$ established existential-epistemictotalisation-of- ${ }^{5}$ meaningfulness-and-teleology ${ }^{9}$ as well as the 'psychological comfort' habituated at the given ${ }^{58}$ neuterising. But then every registry-worldview/dimension has its own specific hurdle to clamber-over and that of futural Being-development/ontological-frameworkexpansion-as-to-depth-of-ontologising-development-as-infrastructure-of- meaningfulnessand-teleology as of prospective notional $\sim$ deprocrypticism is exactly the capacity to construe meaningfulness-and-teleology as of full/complete human consciousness implications as implied by its protensive-consciousness which ultimately doesn't allow for ${ }^{56}$ meaningfulnessand-teleology $\quad$ beyond-the-consciousness-awareness-teleology $99<$ of-preconvergingexistential-extrication-as-of-existential-unthought $>$ arising as of human prior relativeontological-incompleteness ${ }^{8}$-of- ${ }^{8}$ reference-of-thought. The fact is the ontological-faith-notionor-ontological-fideism—imbued-underdetermination-of-motif-andapriorising/axiomatising/referencing-as-so-being-as-of-existential-reality apriorising/axiomatising/referencing-\{of-'prospectively implieited_attendant-ontologicalcontiguity ' educedexistentialising/contextualising/textualising_ intelligibility/epistemicity/reflexivity-contiguity<imbued-notional cogency $\left.>^{\prime} \quad\right\}$-conflatedness ${ }^{13}$-in-\{preconverging-ment by\}postconverging entailment implication with respect to existence-potency ${ }^{39} \sim$ sublimatingnascence,-disclosed-from-prospective-epistemic-digression is such that in reality we are always tacitly aware of the evasiveness of absolute certainty but often rather inclined as of practicality to hang on to a delusion of the results of prior ${ }^{6}$ nonpresencing-<perspective-ontologicalnormalcy/postconvergence $>$ as if of absolute certainty, so-construed as reasoning-from- 
results/afterthought. But then veridical absolute certainty is ever a promise always held in prospective existence-potency ${ }^{39} \sim$ sublimating-nascence,-disclosed-from-prospective-epistemicdigression relative-ontological-completeness ${ }^{87}$-of-apriorising/axiomatising/referencing, and so as of the certainty of human limited-mentation-capacity-as-subjecting 'educedunlimitedness/existence-sublimating nascence' to-limitedness/human-subpotency prospective relative-ontological-completeness ${ }^{87}$-of-axiomatic-construct-or- ${ }^{8}$ reference-of-thought

\section{$<$ amplituding/formative-epistemicity $>$ causality $\sim$ as-to-projective-totalitative-implications-of-} prospective- nonpresencing,-for-explicating relative-unreflexivity/relative-reflexivity-

ontological-contiguity for transcendence-and-sublimity/sublimation/supereregatery $\sim$ dementativity, implied as of intemporal-preservation-entropy-or-contiguity-or-ontologicalpreservation. This explains why ontology's-directedness-as-Being is the direction of meaningfulness-and-teleology 9 grounding as always prospective as of prospective relativeontological-completeness ${ }^{87}$-of- ${ }^{8}$ reference-of-thought; and so, as of the successive baseinstitutionalisation, ${ }^{103}$ universalisation, positivism and notional ${ }^{18}$ deprocrypticism registryworldviews/dimensions nonpresencing-<perspective-ontologicalnormalcy/postconvergence> respectively as successive ${ }^{56}$ meaningfulness-and-teleology grounding for recurrent-utter-uninstitutionalisation, base-institutionalisationununiversalisation, $\quad{ }^{103}$ universalisation-non-positivism/medievalism, and positivismprocrypticism ${ }^{79}$ presencing-absolutising-identitive-constitutedness ${ }^{14}$. Interestingly we can appreciate that the attitude/mental-disposition/care-and-episteme ${ }^{5}$ as of relevant existentialdisontologising/re-ontologising aporeticism $>$ issues of all the prior registryworldviews/dimensions ${ }^{83}$ reference-of-thought are wanting-as-relatively-ontologically-flawed from our positivism- ${ }^{80}$ procrypticism as prospective perspective/framing/reference/horizon/projection of ${ }^{56}$ meaningfulness-and-teleology ${ }^{9}$. However, we are hard-pressed to concede that from futural Being-development/ontological- 
framework-expansion-as-to-depth-of-ontologising-development-as-infrastructure-of-

meaningfulness-and-teleology as of prospective deprocrypticism-or-preemptingdisjointedness-as-of- ${ }^{8}$ reference-of-thought as of its prospective relative-ontologicalcompleteness $^{87}$-of- ${ }^{83}$ reference-of-thought, our positivism- ${ }^{80}$ procrypticism is wanting-asrelatively-ontologically-flawed; as by reflex every registry-worldview/dimension is inclined to hang on to a delusion of the results-as-afterthought of prior ${ }^{6}$ nonpresencing- $<$ perspectiveontological-normalcy/postconvergence $>$ even at its uninstitutionalised-threshold ${ }^{102}$ despite its notional-discontiguity/epistemic-discontiguity ${ }^{6}<$ between - prior-shallow-supererogation -ofmentally-aestheticised preconverging/dementing -qualia-schema_and_prospective-profoundsupererogation -of-mentally-aestheticised postconverging/dialectical-thinking -qualia-

schema $>$ with the prospective registry-worldview/dimension institutionalisation. Thus, induces its specific ${ }^{58}$ neuterising as it fails to construe of ${ }^{56}$ meaningfulness-and-teleology ${ }^{99}$ projectively as of prospective existence-potency ${ }^{32} \sim$ sublimating-nascence,-disclosed-from-prospectiveepistemic-digression relative-ontological-completeness ${ }^{8}$-ofapriorising/axiomatising/referencing. The implied ${ }^{55}$ maximalising-recomposuring-for-relativeontological-completeness ${ }^{87}$ - unenframed/re-ontologising conceptualisation notion also underscores the postmodern conception of ${ }^{4}$ human-subject-emancipating-relativism-drivenrecomposuring-constructivism-towards-singularisation-<as-to-the-

nondisjointedness/entailment-of-prospective- nonpresencing $>$ with regards to any $<$ amplituding/formative-epistemicity $>$ totalising $\sim$ devolved-purview-as-domain-of-construalas-intrinsic-reality/ontological-veridicality, as fundamentally driven as to existencepotency $^{39} \sim$ sublimating-nascence,-disclosed-from-prospective-epistemic-digression $\quad$ as $\quad$ so validatable by their <amplituling/formative-epistemicity $>$ causality $\sim$ as-to-projectivetotalitative-implications-of-prospective- nonpresencing,-for-explicating relativeunreflexivity/relative-reflexivity ontological-contiguity". Hence it is 'more real in its 
human-subject-emancipating-relativism-driven-recomposuring-constructivism-towardssingularisation-<as-to-the-nondisjointedness/entailment-of-prospective- nonpresencing $>$ understood as a double-gesture reification for prospective relative-ontological-completeness ${ }^{87}$ of-axiomatic-construct-or- ${ }^{8}$ reference-of-thought' by its ${ }^{55}$ maximalising-recomposuring-forrelative-ontological-completeness ${ }^{87}$ - unenframed/re-ontologising conceptualisation as to existence-potency ${ }^{39} \sim$ sublimating-nascence,-disclosed-from-prospective-epistemic-digression than any other prior non-constructed ${ }^{5}$ meaningfulness-and-teleology ${ }^{9}$ simply because of the profoundness of its phenomenological depth of projection/anticipation in the quest for $<$ amplituding/formative-epistemicity $>$ causality $\sim$ as-to-projective-totalitative-implications-ofprospective- nonpresencing,-for-explicating relative-unreflexivity/relative-reflexivity ontological-contiguity validation, which ordinary <amplituding/formative $>$ woodenlanguage-〈imbued - averaging-of-thought- $<$ as-to-leveling/ressentiment/closed-construct-ofmeaningfulness-and-teleology -as-of-'nondescript/ignorable-void '-with-regards-toprospective-apriorising-implications $>>$ doesn't even bother contemplating about by its incrementalism-in-relative-ontological-incompleteness ${ }^{8}$

enframed/disontologising conceptualisation reflex of elaboration-as-to-mereextrapolating/constituting/abstracting/deducing/inferring-of-elucidation-outside'prospectively_implicited_attendant-ontological-contiguity ${ }^{67}$ ' educedexistentialising/contextualising/textualising_'intelligibility/epistemicity/reflexivity_contiguity$<$ imbued-notional cogency>' ${ }^{40}$ as of existence's ${ }^{79}$ presencing-absolutising-identitiveconstitutedness ${ }^{14}$. This social knowledge ${ }^{4}$ human-subject-emancipating-relativism-drivenrecomposuring-constructivism-towards-singularisation-<as-to-thenondisjointedness/entailment-of-prospective- nonpresencing $>$ insight translate the reality that 'conventioning and tradition grounded critiques' of postmodernism fundamentally misconstrue that they are departing, as of their ${ }^{83}$ reference-of-thought, from a less real position to evaluate a 
more real position; more like the irony of trying to evaluate the theory-of-relativity-togetherwith-quantum-mechanics - axiomatic-constructs from a posture of 'traditional classical mechanics axiomatic-construct'. Here is what fundamentally underlies the naïve misunderstanding of ${ }^{4}$ human-subject-emancipating-relativism-driven-recomposuringconstructivism-towards-singularisation-<as-to-the-nondisjointedness/entailment-of-

prospective- nonpresencing $>$. For instance, the theory-of-relativity-together-with-quantummechanics-axiomatic-constructs actually reflects that priorly conceptualised-notions like 'space', 'time', 'ether' and the 'laws of physics at atomic scale had to be the same as at the macroscale', were all wrong. Thus 'speaking of the reality of human limited-mentationcapacity -as-subjecting 'educed-unlimitedness/existence-sublimating nascence' tolimitedness/human-subpotency as of its existential-<disontologising/re-ontologising apereticism $>$ analytic capacity' in a state of prior relative-ontological-incompleteness ${ }^{8}$-ofreference-of-thought. It is human limited-mentation-capacity-deepening-as-subjecting limitedness/human-subpotency-to-'educed-unlimitedness/existence-sublimating nascence' ${ }^{53}$ as of prospective relative-ontological-completeness ${ }^{87}$-of- ${ }^{3}$ reference-of-thought as subsequently assuming as more real the notion of 'space-time', 'considering the ether as unreal', 'considering that the laws of physics are different at atomic scale from the macroscale', etc. that as of the human-subject-emancipating-relativism-driven-recomposuring-constructivism-towardssingularisation-<as-to-the-nondisjointedness/entailment-of-prospective- nonpresencing $>$ exercise brought about the more profound insight enabling the conception of the theory-ofrelativity-together-with-quantum-mechanics — axiomatic-constructs ultimately validated as of

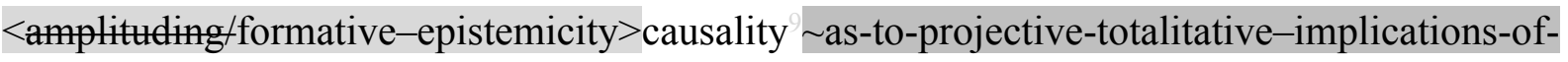
prospective- nonpresencing,-for-explicating relative unreflexivity/relative reflexivity ontological-contiguity by existence-potency ${ }^{32} \sim$ sublimating-nascence,-disclosed-fromprospective-epistemic-digression; as all along humankind existence as of human-subpotency, the 
new reality so-espoused 'is never about existence in itself as-existence-is-given-whatever-it-isthat-is-given', but about human limited-mentation-capacity-deepening-as-subjectinglimitedness/human-subpotency-to-'educed-unlimitedness/existence-sublimating nascence' for human emancipation. Thus implying existence-potency ${ }^{32} \sim$ sublimating-nascence,-disclosedfrom-prospective-epistemic-digression is "not really about any variation as of the ${ }^{4}$ humansubject-emancipating-relativism-driven-recomposuring-constructivism-towardssingularisation-<as-to-the-nondisjointedness/entailment-of-prospective- nonpresencing $>$ directed directly to inherent-existence-as-of-existential-reality/existencepotency $^{32} \sim$ sublimating-nascence,-disclosed-from-prospective-epistemic-digression as to intrinsic-reality/ontological-veridicality whatever', as it rather comes down to the humansubject-emancipating-relativism-driven-recomposuring-constructivism-towardssingularisation-<as-to-the-nondisjointedness/entailment-of-prospective- nonpresencing $>$ as of human limited-mentation-capacity-deepening-as-subjecting limitedness/humansubpotency-to-'educed-unlimitedness/existence-sublimating nascence' ${ }^{3}$ bringing about a more profound and complete grounding for human construing of the full-potency of existence, which remains-whatever-it-is-ultimately. The postmodern insight here is rather that what is relevant to humankind is human-subpotency development towards the abstract full-potency of existencewhatever-it-is-ultimately. So the notion of human-subject-emancipating-relativism-drivenrecomposuring-constructivism-towards-singularisation-<as-to-thenondisjointedness/entailment-of-prospective- nonpresencing $>$ has nothing to do with the inherent nature of existence/intrinsic-reality/ontological-veridicality. Rather it has to do with 'enlightening ${ }^{48}$ human-subject-emancipating-relativism-driven-recomposuring-constructivismtowards-singularisation-<as-to-the-nondisjointedness/entailment-of-prospectivenonpresencing $>$, of human limited-mentation-capacity-as-subjecting-'educedunlimitedness/existence-sublimating nascence' to-limitedness/human-subpotency which needs 
to be deepened before humankind embarks on the task of 'conceptualising ${ }^{5}$ meaningfulnessand-teleology ${ }^{9}$ that increasingly reflects existence/intrinsic-reality/ontological-veridical'. Thus this actually lead to 'more and more objective ${ }^{5}$ meaningfulness-and-teleology' argue that the theory-of-relativity-together-with-quantum-mechanics-axiomatic-constructs is less objective than classical-mechanics-axiomatic-constructs since it involved the humansubject-emancipating-relativism-driven-recomposuring-constructivism-towardssingularisation- $<$ as-to-the-nondisjointedness/entailment-of-prospective- nonpresencing $>$ that led to human limited-mentation-capacity-deepening-as-subjecting limitedness/humansubpotency-to-'educed-unlimitedness/existence-sublimating nascence' ${ }^{5}$. Quite the contrary, it is that exercise in inducing prospective relative-ontological-completeness ${ }^{87}$-of-axiomaticconstruct-or- ${ }^{8}$ reference-of-thought that brings about greater objectivity, as reflected in the relative-unreflexivity/relative-reflexivity ontological-contiguity ${ }^{67} \sim$ of-the-humaninstitutionalisation-process ${ }^{68}$ behind Being-development/ontological-framework-expansion-asto-depth-of-ontologising-development-as-infrastructure-of- meaningfulness-and-teleology That naivety in failing to grasp this lies in the ontologically-flawed mental-reflex of temporal $<$ amplituding/formative-epistemicity $>$ totalising $\sim$ self-referencingsyncretising/circularity/interiorising/akrasiatic-drag ${ }^{34}$, wherein mental-dispositions operate by default without a double-gesturing, on the 'wrong assumption that they already have the most ontologically-developed perspective/framing/reference/horizon/projection for grasping prospective ${ }^{56}$ meaningfulness-and-teleology ${ }^{9}$; and failing to project/anticipate prospectively the implications of their very own shallow limited-mentation-capacity-as-subjecting 'educedunlimitedness/existence-sublimating nascence' to-limitedness/human-subpotency implications from a deeper prospectively-construed perspective/framing/reference/horizon/projection. Such a 'modern take' is susceptible to construe of the presence as of metaphysics-of-presence〈implicited-'nondescript/ignorable-void '-as-to- presencing-absolutising-identitive- 
constitutedness $/$ /illusion-of-the-present/present-consciousness/mirage, with hardly any contemplation of the retrospective and prospective projective-insights for construing ontologically-veridical ${ }^{5}$ meaningfulness-and-teleology . This paradox for human knowledge, as implied with the postmodern double-gesture reification, highlights that the human preconverging/postconverging-de-mentating/structuring/paradigming for construing knowledge is similar to H.G. Well's country of the blind narrative, with the more critical issue being about 'human blindness which needs to be resolved first before proceeding to see', as what is to be seen as of the world is already given-whatever-it-is, and our true issue-as-of-knowledge is to develop the necessary ${ }^{4}$ human-subject-emancipating-relativism-driven-recomposuringconstructivism-towards-singularisation-<as-to-the-nondisjointedness/entailment-of-

prospective- nonpresencing $>2$ limited-mentation-capacity-deepening-as-subjectinglimitedness/human-subpotency-to-'educed-unlimitedness/existence-sublimating nascence' ${ }^{53}$ to see it. This fundamentally underlies the idea of apriorising/axiomatising/referencing/intelligibilitysettingup/measuringinstrumenting $/{ }^{\circ}$ referen ce-of-thought—devolving-teleological-de-mentating/structuring/paradigming-ofmeaningfulness' as underlying a given registry-worldview's/dimension's ${ }^{83}$ reference-of-thought for ${ }^{5}$ meaningfulness-and-teleology ${ }^{9}$ conceptualisation and ontological-performance ${ }^{72}$ <including-virtue-as-ontology>. In registry-worldview/dimension terms, the naivety of 'failing to recognise that human limited-mentation-capacity-as-subjecting 'educedunlimitedness/existence-sublimating nascence' to-limitedness/human-subpotency deepens by human-subject-emancipating-relativism-driven-recomposuring-constructivism-towardssingularisation-<as-to-the-nondisjointedness/entailment-of-prospective- nonpresencing $>$ paradoxically and ridiculously amounts rather to construing of a prospective registryworldview/dimension institutionalisation's ${ }^{83}$ reference-of-thought as of its prospective relativeontological-completeness ${ }^{87}$-of- ${ }^{83}$ reference-of-thought in terms of the prior registry- 
worldview/dimension uninstitutionalised-threshold ${ }^{102}$ 's/uninstitutionalised-threshold ${ }^{102}$ 's reference-of-thought as of it prior relative-ontological-incompleteness ${ }^{88}$-of- ${ }^{8}$ reference-ofthought. The argument traditionally made about postmodern-thought as 'sceptical with regards to ontologically-flawed-metanarratives/ideologies and the lack of objectivity of meaning' is a wrongly articulated/made argument ontologically, since it is being wrongly articulated $/$ made from the 'modern perspective/frame/reference/horizon' which is actually in prior relativeontological-incompleteness ${ }^{8}$-of- ${ }^{8}$ reference-of-thought as of a shallower limited-mentationcapacity -as-subjecting 'educed-unlimitedness/existence-sublimating nascence' tolimitedness/human-subpotency (as to "wavering/redounding/waveforming - of-the-referencingand-the-devolved-referencing-imbued-ontological-performance ${ }^{72}-<$ including-virtue-asontology $>$ /morality/ethics/justice/etc. as to presublimation and nascent-sublimations overlapping-contiguity-of-referencing-and-devolved-referencing' associated with ${ }^{47}$ historicitytracing-in-presencing-hyperrealisation/hyperreal-transposition) and thus has to be decenteredas-preconverging-or-dementing ${ }^{2}$-apriorising-psychologism. Rather the ontologically-veridical articulation of the postmodern argument as of its actual prospective relative-ontologicalcompleteness ${ }^{87}$-of- ${ }^{83}$ eference-of-thought which has to be prospectively centered-aspostconverging-or-dialectical-thinking -apriorising-psychologism over the modern take as prospectively decentered-as-preconverging-or-dementing -apriorising-psychologism, should be affirmatory in articulating that postmodern-thought is about: the appraisal and supplanting of ontologically-flawed-metanarratives/ideologies including socio-econo-political ideologies and ontologically-flawed professed ideologies like demarcating ontological-flawed-ideology-ofscience-and-its-distortive-implications from ontologically-veridical-science-in-practice, and its pursuit for the most profound-and-complete objectivity of meaning as of prospective relativeontological-completeness ${ }^{87}$-of- reference-of-thought by renewing appraisal of intrinsicreality/ontological-veridicality by ${ }^{4}$ human-subject-emancipating-relativism-driven- 
recomposuring-constructivism-towards-singularisation- $<$ as-to-thenondisjointedness/entailment-of-prospective- nonpresencing $>$ as of human-subpotency apriorising/axiomatising/referencing-\{of-'prospectively_implicited_attendant-ontologicalcontiguity ' educedexistentialising/contextualising/textualising_'intelligibility/epistemicity/reflexivity-contiguity<imbued-notional cogency $\left.>^{\prime}\right\}$-conflatedness ${ }^{13}$-in-\{preconverging-ment by\} pestcenverging-ntailment', and it is much more than just a naïve notion of a multiplicity of narratives as wrongly implied from the modern take of <preconverging 'motif-andapriorising/axiomatising/referencing'-entailing>-existentialising-enframing/imprintedness〈as-to- historicity-tracing-in-presencing-hyperrealisation/hyperreal-transposition〉 necessarily subject to ontological-bad-faith/inauthenticity ${ }^{64}$ as of the modern's take prospectively uninstitutionalised-threshold ${ }^{102}$ of procrypticism or disjointedness-as-ofreference-of-thought in-many-ways explaining the difficulties of Derrida and Foucault in effectively qualifying their thought postures (when each was asked whether they were poststructuralist) underlied/organised respectively by messianicity and parrhesia but rather postmodern-thought is of a prospective 'relative-ontological-completeness ${ }^{87}$ re-originary_-asunenframed/re-ontologising/unbeholdening/outlier-conceptualisation-__imbuedpostconverging/dialectical-thinking -'projective-insights’'epistemic-projection-inconflatedness '-of-notional deprocrypticism-prospective-sublimation $\rangle^{\circ 0}$ appraisal of human narratives as to dimensionality-of-sublimating ${ }^{25}-\langle<$ amplituding/formative $>$ supererogatory $\sim$ dementativeness/epistemic-growth-or-conflatedness /transvaluativerationalising/transepistemicity/anamnestic-residuality/spirit-drivenness-equalisation〉 $\quad$ thus implying rather a notional ' deprocrypticism institutionalisation 'unenframed/reontologising/unbeholdening/bechancing-supererogation parameterisation/reparameterisation$\langle$ reflecting-a-supererogatory $\sim$ decisionality-of-socioinstitutional-conceptions-as-to- 'their- 
desublimation'〉-as-so-operationalising-'scalarisation-as-to-rescalarisation-as-re-

ontologisation'. The implication here is that hitherto postmodern-thought had been naively and falsely conceptualised within the 'modern take attitude/mental-disposition/care-and-episteme' as of its ${ }^{80}$ procrypticism-or-disjointedness-as-of- ${ }^{8}$ reference-of-thought, instead of implying the ontologically-veridical 'subverting of the modern take' by its very own 'postmodern deprocrypticism-or-preempting - disjointedness-as-of- ${ }^{3}$ reference-of-thought apriorising/axiomatising/referencing/intelligibilitysettingup/measuringinstrumenting attitude/mental-disposition/care-and-episteme ' which prospectively represents the modern as preconverging-or-dementing ${ }^{20}$-apriorising-psychologism while the postmodern is postconverging-or-dialectical-thinking -apriorising-psychologism; as the point of assertion of postmodern-thought as ${ }^{18}$ deprocrypticism-or-preempting-disjointedness-as-of- ${ }^{3}$ reference-ofthought is actually a point of prospective de-mentation-〈supererogatory $\sim$ ontological-dementation-or-dialectical-de-mentation-stranding-or-attributive-dialectics $\rangle$. Of critical insight here is the fact that many postmodern authors like Foucault, Lyotard and Derrida adopted stances as of constructivism, " nonpresencing-<perspective-ontological-normalcy/postconvergence $>$ relativism/relative-scope for epistemic-growth,-as - \{veridical/sound\}-relative-reflexivity-inexistence/relativising from-limited-mentation-as-its-deepening/psychologismic epistemicacutisation residualising, ${ }^{\text {ddecompulsing }}$ delinearity for-cogency' and deconstruction are rather ontologically-veridical observations/remarks/'constatations' about the conception of social reality from their authentic analysis 'without going further out-of-the-scope-of-ontologicalveracity to ideologise constructivism, ' nonpresencing-<perspective-ontologicalnormalcy/postconvergence $>\quad$ relativism/relative-scope for epistemic-growth,-as\{veridical/sound\}-relative-reflexivity-in-existence/relativising from-limited-mentation-as-itsdeepening/psychologismic epistemic-acutisation residualising, $\left.{ }^{\{d e c o m p u l s i n g}\right\}$ delinearity for 
eogency' and deconstruction beyond their implied ontologically-veridical observations/remarks/constatations' as many of their critiques poorly misinterpret them; with the implications that their stances are open-ended and receptive to the elucidative justifications for their non-ideologised ontologically-veridical observations/remarks/'constatations' about the constructivism, ' $\quad$ nonpresencing-<perspective-ontological-normalcy/postconvergence $>$ relativism/relative-scope for epistemic-growth,-as - \{veridieal/sound\}-relative-reflexivity-inexistence/relativising from-limited-mentation-as-its-deepening/psychologismic epistemicacutisation residualising, deconstruction manifestation/conception of social reality. Thus the ontologically affirmatory position adopted herein as of the prospective 'postmodern ${ }^{18}$ deprocrypticism-or-preempting-disjointedness-asof- ${ }^{8}$ reference-of-thought

apriorising/axiomatising/referencing/intelligibilitysettingup/measuringinstrumenting attitude/mental-disposition/care-and-episteme ' is not contradictory but rather complementing their positions as it rather reinterprets their observations/remarks/'constatations' as of human limited-mentation-capacity—as-subjecting-'educed-unlimitedness/existence-sublimating nascence' to-limitedness/human-subpotency prospective relative-ontological-completeness ${ }^{87}$ of- ${ }^{3}$ reference-of-thought $<$ amplituding/formative-epistemicity $>$ causality $\sim$ as-to-projectivetotalitative-implications-of-prospective- nonpresencing,-for-explicating relativeunreflexivity/relative-reflexivity ontological-contiguity ; wherein for instance, for the recurrent-utter-uninstitutionalisation ${ }^{83}$ reference-of-thought ill-health is as of an 'implicited_attendant-ontological-contiguity ${ }^{67}$ educedexistentialising/contextualising/textualising_'intelligibility/epistemicity/reflexivity-contiguity$<$ imbued-notional cogency> ${ }^{\prime}$-lowest-level-reification per-cep-ti-vi-ty-as-of-bad-omen while for the positivism ${ }^{83}$ reference-of-thought ill-health is as of a per-cep-ti-vi-ty-as-of-full-diseaseand-scientific-theory-construct-as-the-exclusive-cause-and-effect-conceptualisation. Basically, 
the 'hitherto ontologically-flawed postmodern ${ }^{18}$ deprocrypticism-or-preemptingdisjointedness-as-of- ${ }^{8}$ reference-of-thought

apriorising/axiomatising/referencing/intelligibilitysettingup/measuringinstrumenting attitude/mental-disposition/care-and-episteme ${ }^{5}$ in its relation with modernity wrongfully implied that it seeks the validation of modernity, and so as ridiculously as implying that buddingpositivism/rational-empiricism should have sought for its validation from medievalscholasticism. In both cases, the fundamental issue once ${ }^{103}$ universal-transparency ${ }^{104}$ 〈transparency-of-totalising-entailing,-as-to-entailing-<amplituding/formative-

epistemicity>totalising in-relative-ontological-completeness \ avails as of overall underlying human ontological-commitment $<$ implied — self-assuredness-of-ontological-goodfaith/authenticity postconverging-de-mentating/structuring/paradigming -as-being-as-ofexistential-reality> as to existence - as-sublimating-withdrawal/unenframing/re-ontologising,elicited-from-prospective-profound-supererogation for relative-ontological-completeness ${ }^{87}$, as herein implied originarily/as-of-event" with the 'prospective/new postmodern deprocrypticism-or-preempting - disjointedness-as-of- ${ }^{3}$ reference-of-thought apriorising/axiomatising/referencing/intelligibilitysettingup/measuringinstrumenting attitude/mental-disposition/care-and-episteme ', is mostly about dismissing the prior relativeontological-incompleteness ${ }^{8}$-of- ${ }^{-}$reference-of-thought as when a critique of notionaldiscontiguity/epistemic-discontiguity ${ }^{63}<$ between - prior-shallow-supererogation -ofmentally-aestheticised preconverging/dementing -qualia-schema_and_prospective-profoundsupererogation -of-mentally-aestheticised postconverging/dialectical-thinking -qualiaschema $>$ exposes the reality of a dialogical and intellectual inequivalence given their antiintellectual stances against postmodern-thought preferring to 'circumvent genuine intellectual engagement' for extra-intellectual activities of institutional-being-and-craft meant to preserve vested narrow interests beyond-the-consciousness-awareness-teleology ${ }^{9}-<$ of-preconverging- 
existential-extrication-as-of-existential-unthought $>$. Just as it was perceived as a fool's errand by the Descartes, Galileos, Diderots, etc., to contemplate of genuine intellectual engagement between their budding-positivism/rational-empiricism ventures with traditional medieval scholasticism, especially with regards to the latter's institutionally-associated dogmatic censure and persecution, and thus with the former resorting to discursive strategies for ${ }^{103}$ universaltransparency ${ }^{104}$-〈transparency-of-totalising-entailing,-as-to-entailing-<amplituding/formativeepistemicity $>$ totalising in-relative-ontological-completeness $\rangle$ as of overall underlying human ontological-commitment $\quad<$ implied - self-assuredness-of-ontological-goodfaith/authenticity $\sim$ postconverging-de-mentating/structuring/paradigming -as-being-as-ofexistential-reality> as to existence — as-sublimating-withdrawal/unenframing/re-ontologising,elicited-from-prospective-profound-supererogation for relative-ontological-completeness ${ }^{87}$; it is inevitably the case that what is most critically warranted is for the 'prospective/new postmodern ${ }^{18}$ deprocrypticism-or-preempting - disjointedness-as-of- ${ }^{3}$ reference-of-thought apriorising/axiomatising/referencing/intelligibilitysettingup/measuringinstrumenting attitude/mental-disposition/care-and-episteme to articulate its full-fledged discourse as of universal-transparency ${ }^{104}$-〈transparency-of-totalising-entailing,-as-to-entailing$<$ amplituding/formative-epistemicity>totalising in-relative-ontological-completeness $>$ as of the liberality of thought allowed for in open society notwithstanding such extra-intellectual and media-driven perverted representation of postmodern-thought. The reality of humansubpotency-aporia/undecidability/dilemma/oughtindeterminacy/deficiency/limitation/constraint—imbued-'notional firstnaturednessformativeness-<as-to-eventualising-inkling-drive-or-seeding-misprising $>$ temporal-tointemporal-dispositions- $<$ so-construed-as-from-perspective-ontologicalnormalcy/postconvergence>'-existentialism-form-factor speaking of human shallow-to-deeper limited-mentation-capacity—as-subjecting 'educed-unlimitedness/existence-sublimating 

preconverging/postconverging-de-mentative/structural/paradigmatic transcendental knowledge by its so-projected intemporality ${ }^{52}$, at the uninstitutionalised-threshold ${ }^{102}$, is not necessarily grasp as intemporal in the overall human social-stake-contention-or-confliction framework as of the lack of ${ }^{103}$ universal-transparency ${ }^{104}$-〈transparency-of-totalising-entailing,-as-to-entailing$<$ amplituding/formative-epistemicity $>$ totalising in-relative-ontological-completeness $>$ for its prospective institutionalisation. Critical for the social validation and institutionalisation of any preconverging/postconverging-de-mentative/structural/paradigmatic transcendental knowledge is the fact that its 'concurrent $<$ amplituding/formative-epistemicity $>$ causality $\sim$ as-to-projectivetotalitative-implications-of-prospective- nonpresencing,-for-explicating relative unreflexivity/relative-reflexivity - ontological-contiguity ' is not sufficiently decisive given that human temporal-to-intemporal nature as of the social-stake-contention-or-confliction framework at the uninstitutionalised-threshold ${ }^{102}$ cannot adjudge-and-commit-to the ontological-pertinence of such prospective transcendental knowledge 'concurrent $<$ amplituding/formative-epistemicity $>$ causality $\sim$ as-to-projective-totalitative-implications-ofprospective- nonpresencing,-for-explicating relative-unreflexivity/relative-reflexivity ontological-contiguity '. Consider in this regard, the 'concurrent <amplituding/formativeepistemicity $>$ causality $\sim$ as-to-projective-totalitative-implications-of-prospectivenonpresencing,-for-explicating relative-unreflexivity/relative-reflexivity - ontologicalcontiguity 'of the prospective positivism/rational-realism transcendental knowledge articulated by the Corpernicuses, Descartes, Galileo, Diderots, etc. as ${ }^{56}$ meaningfulness-and-teleology ${ }^{9}$ of prospective relative-ontological-completeness ${ }^{87}$-of- ${ }^{8}$ reference-of-thought validated by corresponding prospective 'concurrent $<$ amplituding/formative-epistemicity $>$ causality $~ a s-$ toprojective-totalitative-implications-of-prospective- nonpresencing,-for-explicating relativeunreflexivity/relative-reflexivity - ontological-contiguity '. 
$<$ amplituding/formative-epistemicity $>$ causality $\sim$ as-to-projective-totalitative-implications-ofprospective- nonpresencing,-for-explicating relative-unreflexivity/relative-reflexivity

ontological-contiguity ' was not a sufficient basis for their ideas to be socially adopted by the medieval establishment social-stake-contention-or-confliction framework at its uninstitutionalised-threshold ${ }^{102}$ as of non-positivism/medievalism. The point being made here is that within a given registry-worldview/dimension institutionalisation framework the idea of 'concurrent <amplituding/formative-epistemicity $>$ causality $\sim$ as-to-projective-totalitativeimplications-of-prospective- nonpresencing,-for-explicating relative-unreflexivity/relativereflexivity ontological-contiguity , is only more or less determinant as of the institutionalisation's internal basis of validation of knowledge grounded on its ${ }^{83}$ reference-ofthought- categorical-imperatives/axioms/registry-teleology ${ }^{9}$,-for-

aposteriorising/logicising/deriving/intelligising/measuring- ${ }^{5}$ meaningfulness-and-teleology ${ }^{9}$ as of its <amplituding/formative-epistemicity>totalising/circumscribing/delineating ${ }^{83}$ referenceof-thought- devolving'. However, at its uninstitutionalised-threshold the prospective 'concurrent <amplituding/formative-epistemicity $>$ causality $\sim$ as-to-projective-totalitativeimplications-of-prospective- nonpresencing,-for-explicating $\sim$ relative-unreflexivity/relativereflexivity ontological-contiguity as of the prospective institutionalisation's basis of validation of knowledge grounded on the ${ }^{83}$ reference-of-thought- categoricalimperatives/axioms/registry-teleology ${ }^{9}$, -for-

aposteriorising/logicising/deriving/intelligising/measuring- ${ }^{5}$ meaningfulness-and-teleology ${ }^{99}$ of the prospective institutionalisation's <amplituding/formativeepistemicity>totalising/circumscribing/delineating ${ }^{83}$ reference-of-thought- ${ }^{84}$ devolving' will not necessarily meet with the approbation of the prior institutionalisation now construed as the uninstitutionalised-threshold $^{102}$, and so as of mutually beyond-the-consciousness-awarenessteleology $-<$ of-preconverging-existential-extrication-as-of-existential-unthought $>$. This has to 
do with the fact that the full-potency of existence that divulges relative ontological-vericality supersedes human-subpotency epistemising orientation towards its, and thus epistemic constructs as of human-subpotency construal are inevitably ad-hoc to ontological-veracity as of the full-potency of existence; as existence doesn't adjust to human-subpotency with the reverse being true, equally it is human epistemic constructs that ad-hocly adjust to ontological-veracity as of prospective relative-ontological-completeness ${ }^{87}$. Thus while the idea of 'concurrent $<$ amplituding/formative-epistemicity $>$ causality $\sim$ as-to-projective-totalitative-implications-ofprospective- nonpresencing,-for-explicating relative-unreflexivity/relative-reflexivity

ontological-contiguity ', as the basis for the validation of knowledge is inherently ontologically veridical as of a given institutionalisation's internal ${ }^{83}$ reference-of-thought- categoricalimperatives/axioms/registry-teleology ${ }^{9}$,-for-

aposteriorising/logicising/deriving/intelligising/measuring- ${ }^{5}$ meaningfulness-and-teleology ${ }^{99}$ of its <amplituding/formative-epistemicity>totalising/circumscribing/delineating ${ }^{83}$ reference-ofthought- ${ }^{8}$ devolving', however, this is an overrated notion with regards to human social-stakecontention-or-confliction framework at its uninstitutionalised-threshold 102 as external/prospective $\quad{ }^{8}$ reference-of-thought- categorical-imperatives/axioms/registryteleology ${ }^{9}$,-for-aposteriorising/logicising/deriving/intelligising/measuring- ${ }^{56}$ meaningfulnessand-teleology ${ }^{9} \quad$ of its $\quad<$ amplituding/formativeepistemicity>totalising/circumscribing/delineating ${ }^{83}$ reference-of-thought- ${ }^{8}$ devolving', which should and cannot be ignored as from the epistemic-projection of prospective preconverging/postconverging-de-mentative/structural/paradigmatic transcendental knowledge. Rather human social-stake-contention-or-confliction framework fundamentally subscribes to knowledge, given this paradox, as of 'detour to social goodwill deferentialformalisation-transference to perceived overwhelming-relative-effectiveness' induced as of a preconverging/postconverging-de-mentative/structural/paradigmatic transcendental knowledge 
'concurrent

$<$ amplituding/formative-epistemicity $>$ causality $\sim$ as-to-projective-totalitative-

implications-of-prospective- nonpresencing,-for-explicating relative-unreflexivity/relative-

reflexivity - ontological-contiguity ', establishing and upholding it. The idea here is that the inherent and direct notions of positivism/rational-empiricism expounded by the Galileos, Descartes, Diderots, Copernicuses, etc. were not the fundamental basis for the ultimate human social-stake-contention-or-confliction framework validation but rather their derived positiveopportunism - of-social-functioning-and-accordance ${ }^{75}$ that brought about the 'detour to social goodwill deferential-formalisation-transference to perceived overwhelming-relativeeffectiveness' implied-by-and-deriving-from their notions of ${ }^{103}$ universal human rights and open society, technical advances, better social organisation, etc., then leading to a reasoning-fromresults/afterthought institutionalisation and enculturation of such (re-originary_-asunenframed/re-ontologising/unbeholdening/outlier-conceptualisation-_imbued-

\section{postconverging/dialectical-thinking -'projective-insights'/'epistemic-projection-in-}

conflatedness ' 'of-notional deprocrypticism-prospective-sublimation ${ }^{9}$ ) originary/event $^{8}$ of-prospective-ontology-origination positivism/rational-empiricism thought. In other words, human dimensionality-of-sublimating ${ }^{25}-\langle<$ amplituding/formative $>$ supererogatory $\sim$ dementativeness/epistemic-growth-or-conflatedness /transvaluativerationalising/transepistemicity/anamnestic-residuality/spirit-drivenness-equalisation)

inclination to adhere to prospective preconverging/postconverging-dementative/structural/paradigmatic transcendental knowledge as of its 'concurrent $<$ amplituding/formative-epistemicity $>$ causality $~ a s-t o-p r o j e c t i v e-t o t a l i t a t i v e-i m p l i c a t i o n s-o f-$ prospective- nonpresencing,-for-explicating relative-unreflexivity/relative-reflexivity ontological-contiguity ' is very much limited and such prospective 'concurrent $<$ amplituding/formative-epistemicity $>$ causality $\sim$ as-to-projective-totalitative-implications-ofprospective- nonpresencing,-for-explicating relative-unreflexivity/relative-reflexivity 
ontological-contiguity ' however its ontological-veridicality cannot be naively construed as all that which is needed to effectuate social transformation and transcendence-andsublimity/sublimation/supererogatory $\sim$ de-mentativity. We can appreciate this for instance in the case of cultural diffusion with respect to many a non-modern traditional social-setting where modern-day medicine however its overall 'concurrent <amplituding/formativeepistemicity $>$ causality $\sim$ as-to-projective-totalitative-implications-of-prospective-

\section{nonpresencing,-for-explicating relative-unreflexivity/relative-reflexivity - ontological-}

contiguity ' over other types of premodern medicine, will often be suspected and avoided as of its poorly established 'detour to social goodwill deferential-formalisation-transference to perceived overwhelming-relative-effectiveness', and it is only after it has been 'socially habituated-as-institutionalised' that it has the requisite 'detour to social goodwill deferentialformalisation-transference to perceived overwhelming-relative-effectiveness'. This equally manifests as of prospective preconverging/postconverging-dementative/structural/paradigmatic transcendental knowledge construal, as implied for instance by postmodern-thought and particularly so as postmodern-thought has still been undergoing its full construction. The implication here is that all prospective transcendental ${ }^{56}$ meaningfulnessand-teleology ${ }^{9}$ superseding uninstitutionalised-threshold ${ }^{12}$ do not come about as of simplistic continuity but rather as of epistemic-breaks/epistemic-resetting, involving successive 'detour to social goodwill deferential-formalisation-transference to perceived overwhelming-relativeeffectiveness' instigated-and-upheld by the associated successive prospective 'concurrent $<$ amplituding/formative-epistemicity $>$ causality $\sim$ as-to-projective-totalitative-implications-ofprospective- nonpresencing,-for-explicating relative-unreflexivity/relative-reflexivity

ontological-contiguity ' postconverging-de-mentating/structuring/paradigming of " ${ }^{\text {" }}$ referenceof-thought- categorical-imperatives/axioms/registry-teleology ${ }^{99}$,-foraposteriorising/logicising/deriving/intelligising/measuring_ ${ }^{5}$ meaningfulness-and-teleology ${ }^{\circ}$, 
as of successive prospective relative-ontological-completeness ${ }^{8}$-of- ${ }^{-}$reference-of-thought. The implication of such an indirect nature of human social-stake-contention-or-confliction framework validation of transcendental knowledge as of 'detour to social goodwill deferentialformalisation-transference to perceived overwhelming-relative-effectiveness' and not just direct 'concurrent $\quad<$ amplituding/formative-epistemicity $>$ causality $\sim$ as-to-projective-totalitativeimplications-of-prospective- nonpresencing,-for-explicating relative-unreflexivity/relativereflexivity - ontological-contiguity , implies that just as prospective preconverging/postconverging-de-mentative/structural/paradigmatic transcendental knowledge prospective 'concurrent <amplituding/formative-epistemicity>causality $\sim$ as-to-projectivetotalitative-implications-of-prospective- nonpresencing,-for-explicating relativeunreflexivity/relative-reflexivity ontological-contiguity ' could be 'objected to as of human social-stake-contention-or-confliction framework' notwithstanding its inherent prospective relative-ontological-completeness ${ }^{87}$-of- ${ }^{8}$ reference-of-thought given its prior lack of 'detour to social goodwill deferential-formalisation-transference to perceived overwhelming-relativeeffectiveness'; any such prospective preconverging/postconverging-dementative/structural/paradigmatic transcendental knowledge must be construed and thought-out strategically as of its ultimate establishment of 'detour to social goodwill deferentialformalisation-transference to perceived overwhelming-relative-effectiveness' that as of its prospective relative-ontological-completeness ${ }^{87}$-of- ${ }^{8}$ reference-of-thought supersedes the prior relative-ontological-incompleteness ${ }^{88}$-of- ${ }^{8}$ reference-of-thought, just as positivism/rationalempricism superseded non-positivism/medievalism. Likewise 'concurrent $<$ amplituding/formative-epistemicity $>$ causality $\sim$ as-to-projective-totalitative-implications-ofprospective- nonpresencing,-for-explicating relative unreflexivity/relative reflexivity ontological-contiguity ' ontologically-flawed knowledge can be legitimately overlooked where such knowledge is implied as of priorly established 'detour to social goodwill deferential- 
formalisation-transference to perceived overwhelming-relative-effectiveness'. This latter cases arise with many a bogus social or natural science study and methodology grounded on the 'mystifying sterile/anecdotal imprimatur' of positivistic science, as 'detour to social goodwill deferential-formalisation-transference to perceived overwhelming-relative-effectiveness', but then on closer examination turns out to be poorly designed as well as the prevalence of institutional-being-and-craft suboptimal dispositions with regards to truly upholding the science ethos in many situations with regards to the ideal operation and promotion of scientific research; and so, as of human temporal-to-intemporal ontological-performance ${ }^{72}-$ including-virtue-as- $^{2}$ ontology $>$ /morality/ethics/justice/etc. of any ' ${ }^{8}$ reference-of-thought- categoricalimperatives/axioms/registry-teleology ${ }^{9}$,-foraposteriorising/logicising/deriving/intelligising/measuring_ ${ }^{56}$ meaningfulness-and-teleology ${ }^{99}$. Already, postmodern interpretations have increasingly been much more relevant practically to many subject-matter domains and activities, with even greater potential for transformative implications if fully acted upon. Furthermore, the 'prospective/new postmodern deprocrypticism-or-preempting — disjointedness-as-of- ${ }^{8}$ reference-of-thought apriorising/axiomatising/referencing/intelligibilitysettingup/measuringinstrumenting attitude/mental-disposition/care-and-episteme ${ }^{5}$ warrants that postmodern-thought hitherto articulated beyond-the-consciousness-awareness-teleology ${ }^{\circ}<$ of-preconverging-existentialextrication-as-of-existential-unthought $>$ in terms-as-of-axiomatic-construct of the 'modern take attitude/mental-disposition/care-and-episteme ', need to be translated-as-reconceptualised into its very own 'postmodern ${ }^{18}$ deprocrypticism-or-preempting-disjointedness-as-ofreference-of-thought

apriorising/axiomatising/referencing/intelligibilitysettingup/measuringinstrumenting attitude/mental-disposition/care-and-episteme ${ }^{5}$ as of its own truly postmodern organicknowledge. The fact is that organic-knowledge is fundamentally driven as of attitude/mental- 
disposition/care-and-episteme, wherein for instance Newtonian Physics as of positivism/rational-empiricism attitude/mental-disposition/care-and-episteme organicknowledge makes little sense and is of little potential if construed as of a medieval or animistic social-setup alchemic or mystical attitude/mental-disposition/care-and-episteme . In this regard, attitude/mental-disposition/care-and-episteme $\quad$ is fundamentally the apriorising/axiomatising/referencing/intelligibilitysettingup/measuringinstrumenting notional $\sim$ conflatedness ${ }^{13}$ as implied by its 'assumed-and-unflinching transversality- $<$ forsublimating-existential-eventuating/denouement,-from-'thinking at first/pure-predispositionpreemptive-of prospective-disontologising/subontologising' as-of-prospectivelydisambiguated-affirmed-and-unaffirmed-'motif-and-apriorising/axiomatising/referencing'> $<$ amplituding/formative-epistemicity>totalising/circumscribing/delineating $\quad$ reference-ofthought- ${ }^{8}$ devolving' in reflecting the 'incisive-and-intransigent nature of existence-as-theabsolute-a-priori-of-conceptualisation and existence — as-sublimatingwithdrawal/unenframing/re-ontologising,-elicited-from-prospective-profoundsupererogation $-<$ as-to-perspective-ontological-normalcy/postconvergence-implied'prospective-aporeticism-overcoming/unovercoming'>' for the given attitude/mentaldisposition/care-and-episteme true ${ }^{56}$ meaningfulness-and-teleology ${ }^{99}$ ontologicalperformance ${ }^{2}-<$ including-virtue-as-ontology $>$. Where beyond-the-consciousness-awarenessteleology $-<$ of-preconverging-existential-extrication-as-of-existential-unthought $>, \quad$ the new/prospective attitude/mental-disposition/care-and-episteme given its prospective relativeontological-completeness ${ }^{87}$-of- ${ }^{8}$ reference-of-thought is wrongly construed as deriving posteriorly from the prior relative-ontological-incompleteness ${ }^{8}$-of- ${ }^{-3}$ reference-of-thought, this induces apriorising/axiomatising/referencing-\{of-‘prospectively implicited_attendant ontological-contiguity ' educedexistentialising/contextualising/textualising_intelligibility/epistemicity/reflexivity_contiguity- 
$<$ imbued-notional cogency >' $\quad$ - constitutedness ${ }^{14}$-in-preconverging-entailment 'as has been the case with prior postmodern-thought construed as of a modern take attitude/mentaldisposition/care-and-episteme '; thus leading to a sort of postmodern-thought mechanical knowledge that is in-many-ways just budding and poorly acted upon. Ultimately, a 'new/prospective postmodern ${ }^{18}$ deprocrypticism-or-preempting-disjointedness-as-ofreference-of-thought

apriorising/axiomatising/referencing/intelligibilitysettingup/measuringinstrumenting attitude/mental-disposition/care-and-episteme ${ }^{-}$crossgenerational development, which is its very own apriorising/axiomatising/referencing/intelligibilitysettingup/measuringinstrumenting attitude/mental-disposition/care-and-episteme , as of ${ }^{18}$ deprocrypticism-or-preemptingdisjointedness-as-of- ${ }^{8}$ reference-of-thought is rather a notional conflatedness ${ }^{13}$ as of deneuterising 17 protensive-consciousness. The practical implications as well should be that meaningfulness and definitions often articulated about postmodern-thought that do not capture the postmodern ${ }^{18}$ deprocrypticism-or-preempting - disjointedness-as-of- ${ }^{3}$ reference-of-thought apriorising/axiomatising/referencing/intelligibilitysettingup/measuringinstrumenting attitude/mental-disposition/care-and-episteme should be rejected; as the tendency for postmodern-thought to be misconstrued or perverted is not accidental, given the very fact that at its very core postmodern-thought is implying a prospective/new prospective relativeontological-completeness ${ }^{87}$-of- ${ }^{83}$ reference-of-thought requiring its own apriorising/axiomatising/referencing/intelligibilitysettingup/measuringinstrumenting. In this regard, central to translating-as-reconceptualising prior and new postmodern-thought as of its very own 'postmodern ${ }^{18}$ deprocrypticism-or-preempting - disjointedness-as-of- ${ }^{83}$ reference-ofthought apriorising/axiomatising/referencing/intelligibilitysettingup/measuringinstrumenting attitude/mental-disposition/care-and-episteme ${ }^{5}$ organic-knowledge is the requirement for an affirmative mental-reflex with postmodern-thought construed 'as the appraisal and supplanting 
of ontologically flawed metanarratives and its pursuit for the most profound-and-complete objectivity of meaning, by renewing appraisal of intrinsic-reality/ontological-veridicality involving its ${ }^{4}$ human-subject-emancipating-relativism-driven-recomposuring-constructivismtowards-singularisation-<as-to-the-nondisjointedness/entailment-of-prospective-

nonpresencing $>2$ as of human 'implicited_attendant-ontological-contiguity ${ }^{67}$ 'educedexistentialising/contextualising/textualising_intelligibility/epistemicity/reflexivity-contiguity$<$ imbued-notional cogency $>^{\prime}$; and it is much more than just a naïve notion of a multiplicity of narratives as wrongly implied from the modern take of <preconverging 'motif-andapriorising/axiomatising/referencing'-entailing>-existentialising-enframing/imprintedness〈as-to- historicity-tracing-in-presencing-hyperrealisation/hyperreal-transposition〉 necessarily subject to ontological-bad-faith/inauthenticity ${ }^{64}$ as of the modern's take prospectively uninstitutionalised-threshold ${ }^{102}$ of procrypticism or disjointedness-as-ofreference-of-thought in-many-ways explaining the difficulties of Derrida and Foucault in effectively qualifying their thought postures (when each was asked whether they were poststructuralist) underlied/organised respectively by messianicity and parrhesia but rather postmodern-thought is of a prospective 'relative-ontological-completeness ${ }^{87}$ re-originary_asunenframed/re-ontologising/unbeholdening/outlier-conceptualisation-__imbuedpostconverging/dialectical-thinking -'projective-insights’'epistemic-projection-inconflatedness '-of-notional deprocrypticism-prospective-sublimation $\rangle^{\circ 0}$ appraisal of human narratives as to dimensionality-of-sublimating ${ }^{25}-\langle<$ amplituding/formative $>$ supererogatory $\sim$ dementativeness/epistemic-growth-or-conflatedness /transvaluativerationalising/transepistemicity/anamnestic-residuality/spirit-drivenness-equalisation〉 $\quad$ thus implying rather a notional ' deprocrypticism institutionalisation 'unenframed/reontologising/unbeholdening/bechancing-supererogation ${ }^{9}$ parameterisation/reparameterisation$\langle$ reflecting-a-supererogatory $\sim$ decisionality-of-socioinstitutional-conceptions-as-to- 'their- 
nascent-sublimations-dynamic-preempting-of-presublimatory-decisionality-numbing-traction-

desublimation'〉-as-so-operationalising-'scalarisation-as-to-rescalarisation-as-re-

ontologisation'. The 'postmodern 18 deprocrypticism-or-preempting-disjointedness-as-ofreference-of-thought

apriorising/axiomatising/referencing/intelligibilitysettingup/measuringinstrumenting

attitude/mental-disposition/care-and-episteme' should equally enable the avoidance of the erroneously implication of a 'metaphysical/ideological advocacy' as postmodern-thought as to human-subject-emancipating-relativism-driven-recomposuring-constructivism-towardssingularisation-<as-to-the-nondisjointedness/entailment-of-prospective- nonpresencing $>$ is so with regards to the inherent ontological sublimating human possibility in existence/intrinsicreality/ontological-veridicality as to human-subpotency implied human potential, and so as emphasised and reflected with regards to the need for human limited-mentation-capacitydeepening —as-subjecting limitedness/human-subpotency-to-'educed-unlimitedness/existencesublimating nascence' 5 . We can garner insight about how we tend to misconstrue any attitude/mental-disposition/care-and-episteme that is different from our own 'present attitude/mental-disposition/care-and-episteme', whether it is a 'prior/old/superseded attitude/mental-disposition/care-and-episteme' or a 'prospective/new/superseding attitude/mental-disposition/care-and-episteme '. For instance, in the previous articulation of the 'implicited_attendant-ontological-contiguity ${ }^{67}$ ' educedexistentialising/contextmalising/textualising_'intelligibility/epistemicity/reflexivity_contiguity<imbued-notional cogency>' -lowest-level-reification per-cep-ti-vi-ty-as-of-bad-omen with 'recurrent-utter-uninstitutionalisation attitude/mental-disposition/care-and-episteme' given its 'non-rules - apriorising/axiomatising/referencing-psychologism,-as-impulsive-or-accidentedor-random-mental-disposition', the reality is that our mental-devising-representation still remains in our 'present positivism- procrypticism attitude/mental-disposition/care-and- 
episteme' as of its 'per-cep-ti-vi-ty-as-of-full-disease-and-scientific-theory-construct-as-theexclusive-cause-and-effect-conceptualisation', and only 'adhocly-and-scantily identifies' the 'recurrent-utter-uninstitutionalisation attitude/mental-disposition/care-and-episteme' ${ }^{\prime}$ as it is wholly immersed-and-engrossed in its 'positivism/rational-empiricism attitude/mentaldisposition/care-and-episteme for the construal of ${ }^{5}$ meaningfulness-and-teleology ${ }^{\circ}$ '; which it 'skewedly construes as the apriorising/axiomatising/referencing/intelligibilitysettingup/measuringinstrumenting' while tempering down any prior/old/superseded or prospective/new/superseding apriorising/axiomatising/referencing/intelligibilitysettingup/measuringinstrumenting implied as of the 'reality of human shallow-to-deeper limited-mentation-capacity-as-subjecting-'educedunlimitedness/existence-sublimating nascence' to-limitedness/human-subpotency apriorising/axiomatising/referencing/intelligibilitysettingup/measuringinstrumenting implications' on the-very-same-immanent-existence/intrinsic-reality/ontological-veridicality,as-to-'human<amplituding/formative-epistemicity>totalising $\sim$ purview-of-construal', $\quad$ in defining which reference-of-thought apriorising/axiomatising/referencing/intelligibilitysettingup/measuringinstrumenting attitude/mental-disposition/care-and-episteme is 'relevant as the attitude/mentaldisposition/care-and-episteme of wholly immersed-and-engrossed meaningfulness-andteleology '. The point being made here is that our natural inclination is never meant to trulyand-comprehensively reflect any prior/old/superseded or prospective/new/superseding attitude/mental-disposition/care-and-episteme by itself but rather in any such exercise always apriorises the 'present attitude/mental-disposition/care-and-episteme' and then reflect the other attitude/mental-disposition/care-and-episteme referred to posteriorly, and hence the latter is adhocly-and-scantily identified. We can grasp this insight about this natural inclination to uphold-as-apriorising/axiomatising/referencing/intelligibilitysettingup/measuringinstrumenting 
the 'present attitude/mental-disposition/care-and-episteme' from the fact that 'originary contacts' between two cultures of prospective relative-ontological-completeness ${ }^{87}$-andincompleteness-of- ${ }^{83}$ reference-of-thought doesn't mean a wholly immersed-and-engrossed meaningfulness-and-teleology ${ }^{9}$ between the cultures, since their natural inclination is to both apriorise 'their own present attitude/mental-disposition/care-and-episteme' ' and respectively posteriorise the other culture attitude/mental-disposition/care-and-episteme as of their respectively

apriorising/axiomatising/referencing/intelligibilitysettingup/measuringinstrumenting present attitude/mental-disposition/care-and-episteme ; and so, as the framework of any subsequent cultural diffusion metaphoricity ${ }^{57}$. Thus to fully grasp what is implied here ontologically by attitude/mental-disposition/care-and-episteme , beyond the natural inclination, is to understand that attitude/mental-disposition/care-and-episteme as 'assumed-and-unflinching transversality-<for-sublimating-existential-eventuating/denouement,-from-'thinking atfirst/pure-predisposition-preemptive-of-prospective-disontologising/subontologising' as-ofprospectively-disambiguated-affirmed-and-unaffirmed-'motif-andapriorising/axiomatising/referencing'> ${ }^{101}$ implies a mental-projection exercise 'reflecting-andcontemplating a wholly immersed-and-engrossed ${ }^{56}$ meaningfulness-and-teleology ${ }^{\circ}$, as of their given ${ }^{58}$ neuterising-as-of-prior-relative-ontologicl-incompleteness-of- ${ }^{8}$ reference-of-thought if a 'prior/old/superseded attitude/mental-disposition/care-and-episteme ' ${ }^{\text {' }}$ or deneuterising 17 -as-ofprospective-relative-ontological-completeness ${ }^{87}$-of- ${ }^{83}$ reference-of-thought if a 'prospective/new/superseding attitude/mental-disposition/care-and-episteme', whilst the 'present attitude/mental-disposition/care-and-episteme' ${ }^{5}$ is then rather adhocly-and-scantily identified now as either deneuterising 17 if in relation to the prior/old/superseded or neuterising if it is in relation to the prospective/new/superseding. In other words, when it comes to registry-worldview/dimension implications, ontologically-veridical representation of 
attitude/mental-disposition/care-and-episteme means 'to be or exist as of the given registryworldview/dimension ${ }^{83}$ reference-of-thought' rather than 'to refer to it'; as the 'referring to' natural inclination is ontologically-flawed as it registers into the 'present attitude/mentaldisposition/care-and-episteme' veridical but is not the natural inclination of representation as it overrides the 'present attitude/mental-disposition/care-and-episteme'. 'Postmodern $\quad{ }^{18}$ deprocrypticism-orpreempting - disjointedness-as-of- ${ }^{8}$ reference-of-thought

apriorising/axiomatising/referencing/intelligibilitysettingup/measuringinstrumenting attitude/mental-disposition/care-and-episteme ${ }^{-}$construed as of ${ }^{18}$ deprocrypticism-orpreempting - disjointedness-as-of- ${ }^{-3}$ reference-of-thought is thus in its potentiation the very summum for the 'conception of human-subpotency existential-<disentelegising/reentologising aporeticism $>$ scope' implied as of Being-development/ontological-frameworkexpansion-as-to-depth-of-ontologising-development-as-infrastructure-of- meaningfulnessand-teleology . In reflecting holographically-<conjugatively-and-transfusively $>$ the relativeunreflexivity/relative-reflexivity - ontological-contiguity of-the-human-institutionalisationprocess as of Being-development/ontological-framework-expansion-as-to-depth-ofontologising-development-as-infrastructure-of- meaningfulness-and-teleology , successive institutionalisations reflect 'successive and changing conceptions of human-subpotency existential-<disontologising/re-ontologising aporeticism $>$ scope', and so from recurrent-utteruninstitutionalisation as the 'most supernatural/mythical/idolised conception of humansubpotency existential-<disontologising/re-ontologising aporeticism $>$ scope' to futural Beingdevelopment/ontological-framework-expansion-as-to-depth-of-ontologising-development-asinfrastructure-of- meaningfulness-and-teleology as of prospective notional ${ }^{18}$ deprocrypticism as the most 'realistic/authentic/unexceptional-as-of-the-mediocrityprinciple conception of human-subpotency existential-<disentologising/re-entelogising 
apereticism $>$ scope'. Insightfully, what is critical about the 'conception of human-subpotency existential-<disontologising/re-ontologising aporeticism $>$ scope' is the paradoxical fact that the more waywardly supernatural/mythical/idolised it is, the least potent has been humansubpotency mastery of the-very-same-immanent-existence/intrinsic-reality/ontologicalveridicality,-as-to-'human<amplituding/formative-epistemicity $>$ totalising $\sim$ purview-ofconstrual', while the more waywardly realistic/authentic/unexceptional-as-of-the-mediocrityprinciple it is, the more potent has been human-subpotency in its mastery of the-very-sameimmanent-existence/intrinsic-reality/ontological-veridicality,-as-to'human<amplituding/formative-epistemicity>totalising purview-of-construal'. Effectively, 'postmodern ${ }^{18}$ deprocrypticism-or-preempting — disjointedness-as-of- ${ }^{2}$ reference-of-thought apriorising/axiomatising/referencing/intelligibilitysettingup/measuringinstrumenting attitude/mental-disposition/care-and-episteme ' implied notional ${ }^{18}$ deprocrypticism is about a radicalisation of the 'realistic/authentic/unexceptional-as-of-the-mediocrity-principle conception of human-subpotency existential-<disontologising/re-ontologising aporeticism $>$ scope' as of its maximum potency for human subpotent mastery of the-very-same-immanentexistence/intrinsic-reality/ontological-veridicality,-as-to-'human<amplituding/formativeepistemicity>totalising purview-of-construal'. This radicalisation is grounded on the rationalrealism postulate that humankind as of its limited-mentation-capacity-deepening-assubjecting limitedness/human-subpotency-to-'educed-unlimitedness/existence-sublimatingnascence' has always encountered its uninstitutionalised-threshold ${ }^{102}$ all along in reflecting holographically-<conjugatively-and-transfusively $>$ the relative-unreflexivity/relativereflexivity - ontological-contiguity of-the-human-institutionalisation-process retrospectively and prospectively, reflecting the reality that humankind is of both a temporal/shortness-of-register-of- meaningfulness-and-teleology and intemporal/longnessef register-of meaningfulness-and-teleology nature at uninstitutionalised-threshold ${ }^{02}$, as of 
prospective institutionalisation prospective relative-ontological-completeness ${ }^{87}$-of- ${ }^{8}$ referenceof-thought and uninstitutionalised-threshold ${ }^{102}$ prior relative-ontological-incompleteness ${ }^{8}$-ofreference-of-thought. This departs from the 'modern take attitude/mental-disposition/careand-episteme', which poorly appreciates the continuity implied by 'intemporal ontologicalfaith-notion-or-ontological-fideism —imbued-underdetermination-of-motif-andapriorising/axiomatising/referencing-as-so-being-as-of-existential-reality instigated relativeunreflexivity/relative-reflexivity —ontological-contiguity ${ }^{67}$ of-the-human-institutionalisationprocess $^{68}$ as of difference-conflatedness ${ }^{13}$-as-to-totalitative-reification-in-singularisation- $<$ as-tothe-nondisjointedness/entailment-of-prospective- nonpresencing $>$-as-veridical-epistemicityrelativism-determinism implied <amplituding/formative-epistemicity $>$ causality $\sim$ as-toprojective-totalitative-implications-of-prospective- nonpresencing,-for-explicating relativeunreflexivity/relative-reflexivity ontological-contiguity as of Beingdevelopment/ontological-framework-expansion-as-to-depth-of-ontologising-development-asinfrastructure-of- meaningfulness-and-teleology psychologismic epistemic-acutisation-

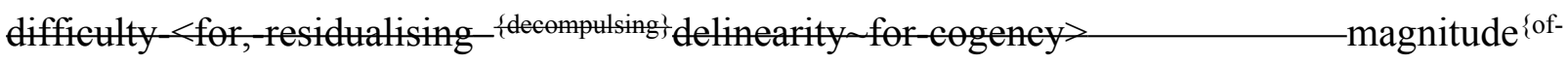
experientiality/experiment\} and is rather caught up, beyond-the-consciousness-awareness-teleology $<$ of-preconverging-existential-extrication-as-of-existential-unthought $>$, in the reasoning-fromresults/afterthought effect of the positivism/rational-empiricism institutionalisation outcome as of its transcendence-and-sublimity/sublimation/supererogatory $\sim$ de-mentativity from nonpositivism/medievalism, and as it construes of that outcome as the absolute possibility of human existential-<disontologising/re-ontologising aporeticism $>$ emancipation failing to factor in the positivism/rational-empiricism prior relative-ontological-incompleteness ${ }^{88}$-of- ${ }^{83}$ reference-ofthought, such that the latter is construed as not having its own uninstitutionalised-threshold which then implies its failure to apriorise the notion of a human temporal-to-intemporal nature at its ontologically-veridical uninstitutionalised-threshold ${ }^{102}$. Consequently, by assuming such a 
positivism/rational-empiricism transcendental outcome reasoning-from-results/afterthought predisposition as the complete basis for construing humankind existential-<disontologising/reentelogising apereticism $>$ emancipation, the 'modern take attitude/mental-disposition/careand-episteme' adopts an ontologically-flawed 'conception of human-subpotency existential-disontologising/re-ontologising aporeticism $>$ scope' that is construed essentially as-of $<$ amplituding/formative-epistemicity $>$ totalising $\sim$ self-referencing-

syncretising/circularity/interiorising/akrasiatic-drag ${ }^{34}$ untransvaluated-temporal-intemporality at its ontologically-veridical uninstitutionalised-threshold ${ }^{102}$, as it doesn't even and fails to recognise any such uninstitutionalised-threshold ${ }^{12}$ pointing to its prior relative-ontologicalincompleteness ${ }^{88}$-of- ${ }^{8}$ reference-of-thought. Thus, the manifestations of temporality ${ }^{8} /$ shortness at its unrecognised ontologically-veridical uninstitutionalised-threshold ${ }^{102}$ are construed as aberrations/oddities going from this wrongly implied intemporal/Angness-of-register-ofmeaningfulness-and-teleology posture in <amplituding/formativeepistemicity $>$ totalising $\sim$ self-referencing-syncretising/circularity/interiorising/akrasiatic-drag ${ }^{34}$, rather than a recognition of it prior relative-ontological-incompleteness ${ }^{8}$-of- ${ }^{83}$ reference-ofthought, implying recognising its uninstitutionalised-threshold ${ }^{12}$ with the temporal-tointemporal implications as of knowledge-notionalisation; thus providing the potency/empowering-consciousness for prospective transcendence-andsublimity/sublimation/supererogatory de-mentativity, as knowledge-notionalisation not only factors in conceptual sublimation knowledge dynamics but equally the dynamics of the conceptual ignorances/desublimation to better skew ${ }^{56}$ meaningfulness-and-teleology ${ }^{99}$ towards intemporality ${ }^{52} /$ longness as of organic-knowledge. The paradox here is that by its 'most realistic/authentic/unexceptional-as-of-the-mediocrity-principle conception of humansubpotency existential-disontologising/re-ontologising aporeticism $>$ scope' as of its maximum potency/empowering-consciousness for human subpotent mastery of the-very-same- 
immanent-existence/intrinsic-reality/ontological-veridicality,-as-to'human<amplituding/formative-epistemicity>totalising $\sim$ purview-of-construal', the 'postmodern deprocrypticism-or-preempting - disjointedness-as-of- ${ }^{18}$ reference-of-thought apriorising/axiomatising/referencing/intelligibilitysettingup/measuringinstrumenting attitude/mental-disposition/care-and-episteme ' grounded on such rational-realism recognition of humankind temporal-to-intemporal nature at its uninstitutionalised-threshold ${ }^{102}$ is actually 'effectively empowered' to incisively tackle issues arising from human temporality $8 /$ shortness as of its prospective preconverging/postconverging-de-mentative/structural/paradigmatic prospective relative-ontological-completeness ${ }^{87}$-of- ${ }^{8}$ reference-of-thought; and so beyond just $<$ amplituding/formative-epistemicity $>$ totalising $\sim$ self-referencingsyncretising/circularity/interiorising/akrasiatic-drag ${ }^{34}$ and ad-hoc palliative resolution of a 'modern take attitude/mental-disposition/care-and-episteme', very much inclined to aberrational/oddities conceptioning of such temporality $/$ /shortness manifestations thus leading to their endemisation/enculturation from 'ontologically-flawed and inevitability analyses' conception. Thus a 'modern take attitude/mental-disposition/care-and-episteme' is preconverging/postconverging-de-mentatively/structurally/paradigmatically disempowered to address issues of its temporality $/$ /shortness as of the vices-and-impediments ${ }^{105}$ at its uninstitutionalised-threshold $^{102}$. So because its <amplituding/formativeepistemicity $>$ totalising $\sim$ self-referencing-syncretising/circularity/interiorising/akrasiatic-drag is 'existentially-<disontologising/re-ontologising aporeticism $>$ invested' in modern socialstake-contention-or-confliction framework of ${ }^{56}$ meaningfulness-and-teleology 9 as of procrypticism-or-disjointedness-as-of- ${ }^{83}$ reference-of-thought from where it derives its valueconstruct and value-reference, as it hardly countenances that prospective transcendental knowledge implied value-construct and value-reference is not meant to be of 'idle' relevance to the modern social-stake-contention-or-confliction framework but rather redeploy an altogether 
empowering perspective of prospective relative-ontological-completeness ${ }^{87}$-of- ${ }^{83}$ reference-ofthought postmodern social-stake-contention-or-confliction framework of ${ }^{56}$ meaningfulness-andteleology ${ }^{9}$ of value-construct and value-reference at the procrypticism uninstitutionalisation. Such prospective change as of ${ }^{15}$ de-mentation-〈supereronatory-ontological-de-mentationdialectical-de-mentation - stranding-or-attributive-dialectics $\rangle$ of attitude/mentaldisposition/care-and-episteme can be appreciated retrospectively with respect to nonpositivism/medievalism

apriorising/axiomatising/referencing/intelligibilitysettingup/measuringinstrumenting attitude/mental-disposition/care-and-episteme which from our modern take attitude/mentaldisposition/care-and-episteme we rather construe as vague scholastic pedantic dogmatism with regards to budding-positivism/rational-empiricism, but then such a conclusion as of their nonpositivism/medievalism habits and traditions is not necessarily obvious to the nonpositivism/medievalism

apriorising/axiomatising/referencing/intelligibilitysettingup/measuringinstrumenting attitude/mental-disposition/care-and-episteme . Ultimately, a notional ${ }^{18}$ deprocrypticism coherent 'postmodern ${ }^{18}$ deprocrypticism-or-preempting-disjointedness-as-of- ${ }^{3}$ reference-ofthought apriorising/axiomatising/referencing/intelligibilitysettingup/measuringinstrumenting attitude/mental-disposition/care-and-episteme ' is one that comes into terms-as-of-axiomaticconstruct in conceiving of the implied prospective need for deneuterising ${ }^{17}$ referentialism. Put another way in reflecting holographically-<conjugatively-and-transfusively $>$ the relativeunreflexivity/relative-reflexivity - ontological-contiguity of-the-human-institutionalisationprocess de-mentation-〈supererogatory $\sim$ ontological-de-mentation-or-dialectical-dementation-stranding-or-attributive-dialectics $\rangle$ with regards to ${ }^{83}$ reference-of-thought, dispensing-with-immediacy-for-relative-ontological-completeness ${ }^{87}$-byreification/contemplative-distension ${ }^{27}$-of- ${ }^{3}$ reference-of-thought-by-reification/contemplative- 
distension

'apriorising/axiomatising/referencing/intelligibilitysettingup/measuringinstrumenting'-foraposteriorising/logicising/deriving/intelligising/measuring of meaningfulness-and-teleology with recurrent-utter-uninstitutionalisation by 'non-rulesapriorising/axiomatising/referencing-psychologism,-as-impulsive-or-accidented-or-randommental-disposition' right up to the-most-unimmediateness/profoundness-of'apriorising/axiomatising/referencing/intelligibilitysettingup/measuringinstrumenting'-foraposteriorising/logicising/deriving/intelligising/measuring of ${ }^{5}$ meaningfulness-and-teleology with notional ${ }^{1}$ deprocrypticism by its 'preempting-disjointedness-as-of- ${ }^{83}$ reference-ofthought' is what, so-construed comprehensively as notional deprocrypticism as of notional conflatedness ${ }^{13}$, increasingly induces corresponding ${ }^{56}$ meaningfulness-and-teleology convergence of human-subpotency with the full-potency that is existence; thus reflecting that dispensing-with-immediacy-for-relative-ontological-completeness ${ }^{87}$-byreification/contemplative-distension ${ }^{27}$ (as of human self-surpassing-existentialism-formfactor,-in-overcoming-'notional collateralising-beholdening-protohumanity'-to-'attainsublimating-humanity'-as-to-existence-potency sublimating-nascence,-disclosed-fromprospective-epistemic-digression to supersede human temporality $\%$ shortness $<$ amplituding/formative $>$ wooden-language-_imbued — averaging-of-thought- $<$ as-toleveling/ressentiment/closed-construct-of- meaningfulness-and-teleology -as-of'nondescript/ignorable-void '-with-regards-to-prospective-apriorising-implications $>\rangle$ ) is rather the human empowering potential inducing Being-development/ontological-frameworkexpansion-as-to-depth-of-ontologising-development-as-infrastructure-of- meaningfulnessand-teleology in reflecting holographically-<conjugatively-and-transfusively $>$ the relativeunreflexivity/relative-reflexivity - ontological-contiguity of-the-human-institutionalisationprocess. We can appreciate with respect to the 'ill-health <amplituding/formative- 
epistemicity>totalising $\sim$ devolved—-purview/domain-of-construal-as-intrinsicreality/ontological-veridicality/existential-reality' that as of <amplituding/formativeepistemicity $>$ causality $\sim$ as-to-projective-totalitative-implications-of-prospectivenonpresencing,-for-explicating relative-unreflexivity/relative-reflexivity - ontologicalcontiguity, it is rather 'relatively realistic/authentic/unexceptional-as-of-the-mediocrityprinciple conception of human-subpotency existential-<disentologising/re-ontologising aporeticism $>$ scope' which have the relative potency for human greater subpotent mastery of the 'ill-health <amplituding/formative-epistemicity>totalising $\sim$ devolved-purview/domain-ofconstrual-as-intrinsic-reality/ontological-veridicality/existential-reality', as implied successively as of: - $\quad$ recurrent-utter-uninstitutionalisation random-asuncircumscribing/undelineating-as-'epistemic-totality ${ }^{37}$, existential-epistemic-totalisationscheme-of- ${ }^{5}$ meaningfulness-and-teleology ${ }^{99}$ trepidatious-consciousness 'omnidimensional' systemic-recomposuring construal of ill-health, 'implicited_attendant-ontologicalcontiguity $^{67} \sim$ educedexistentialising/contextalising/textalising_'intelligibility/epistemicity/reflexivity-contiguity-

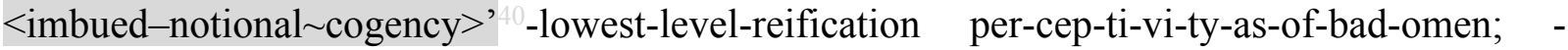
base-institutionalisation-ununiversalisation tendentious-circumscribing-as-'epistemictotality $^{37}$ '-or-delineating-as- 'epistemic-totality ${ }^{37}$, existential-epistemic-totalisation-scheme-ofmeaningfulness-and-teleology , warped-consciousness 'bidimensional' seclusiverecomposuring systemic construal of ill-health, further 'implicited_attendant-ontologicalcontiguity $^{67} \sim$ educedexistentialising/contextualising/textualising_'intelligibility/epistemicity/reflexivity-contiguity$<$ imbued-notional cogency>' ${ }^{\prime}$-second-level-reification per-cep-ti-vi-ty-as-of-a-specific-placeor-specific-evil-people-or-specific-evil-period; _ - $\quad{ }^{103}$ universalisation-nonpositivism/medievalism qualifying-circumscribing-as-'epistemic-totality ${ }^{37}$ '-or-delineating-as- 
'epistemic-totality ${ }^{37}$ existential-epistemic-totalisation-scheme-of- ${ }^{56}$ meaningfulness-andteleology ${ }^{9}$, preclusive-consciousness 'tridimensional' circumstantiating-recomposuring seclusive-systemic construal of ill-health, further 'implicited_attendant-ontologicalcontiguity ${ }^{67} \sim$ educed-

existentialising/contextualising/textualising_'intelligibility/epistemicity/reflexivity-contiguity<imbued-notional cogency>' -third-level-reification per-cep-ti-vi-ty-as-of-failure-to-followthe-heeding-of-the-Deity-or-failure-to-adhere-to-a-certain-mysticism-or-failure-to-payreverence-to-an-ancestor; - $\quad$ positivism- ${ }^{80}$ procrypticism/disjointedness-as-of- ${ }^{83}$ reference-ofthought categorising-circumscribing-as-'epistemic-totality ${ }^{37}$ '-or-delineating-as-'epistemictotality $^{37}$ existential-epistemic-totalisation-scheme-of- ${ }^{5}$ meaningfulness-and-teleology occlusive-consciousness 'quadridimensional' categorising-recomposuring circumstantiatingseclusive-systemic construal of ill-health, further per-cep-ti-vi-ty-as-of-full-disease-andscientific-theory-construct-as-the-exclusive-cause-and-effect-conceptualisation;

notional ${ }^{18}$ deprocrypticism $\quad$ referentialism-circumscribing-as-'epistemic-totality ${ }^{37}$ '-ordelineating-as-'epistemic-totality ${ }^{37}$ existential-epistemic-totalisation-scheme-ofmeaningfulness-and-teleology 9 protensive-consciousness 'transdimensional' referentialismrecomposuring categorising-circumstantiating-seclusive-systemic construal of ill-health, further 'implicited_attendant-ontological-contiguity ${ }^{67}$ > educedexistentialising/contextualising/textualising_intelligibility/epistemicity/reflexivity-contiguity$<$ imbued-notional cogency>' -full-reification per-cep-ti-vi-ty-as-of-factoring-inthermeneutically/textually/reprojectingly/supererogatingly/zeroingly/re-acutingly,$\{$ \{decompulsing $\}$ delinearity for-cogency:-socioeconomic,-education,-information,-environmental,gender-and-power-relations-issues-underlying-healthcare-and-medical-delivery. And so, as of the intemporal ontological-normalcy/postconvergence epistemic perspective in postcenvergingnonextricatory-existential-preempting-of-existential-unthought attitude/mental- 
disposition/care-and-episteme as dispensing-with-immediacy-for-relative-ontologicalcompleteness ${ }^{7}$-by-reification/contemplative-distension ${ }^{27}$-of- ${ }^{8}$ reference-of-thought-byreification/contemplative-distension thus transcendentally enabling the successive registryworldview's/dimension's ontological-possibilities construed as of human intemporal/ontological/social/species/ ${ }^{103}$ universal/transcendental $/{ }^{55}$ maximalisingrecomposuring-for-relative-ontological-completeness 87 unenframed/reontologising conceptualisation postconverging-de-mentating/structuring/paradigming. This underscores Being-development/ontological-framework-expansion-as-to-depth-ofontologising-development-as-infrastructure-of- meaningfulness-and-teleology implied notion of responsibility/relative-reflexivity as reflected by the Nietzschean metaphor 'God is dead', castigatory of the 'beyond-the-consciousness-awareness-teleology ${ }^{9}-<$ of - preconvergingexistential-extrication-as-of-existential-unthought $>\quad$ attitude/mental-disposition/care-and-

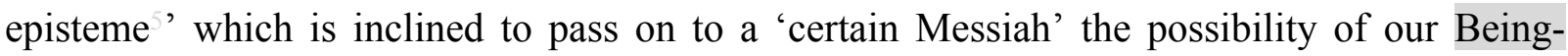
development/ontological-framework-expansion-as-to-depth-of-ontologising-development-asinfrastructure-of- meaningfulness-and-teleology (with the paradox of assuming the pretence of understanding Being-development/ontological-framework-expansion-as-to-depth-ofontologising-development-as-infrastructure-of- meaningfulness-and-teleology on that basis on the naivety that such passing on is teleologically-elevating and exonerating of our mortal-astemporal manifestations so-construed as a ridiculous untransvaluated-temporal-intemporality notion). This equally points to what is the central ethos of aetiologisation/ontological-escalation<ontological-veridicality_commitment/otherliness_transcending/compulsionsencumbered_transcending $>$ implied as of 'notional ${ }^{18}$ deprocrypticism attitude/mentaldisposition/care-and-episteme as of ontological-normalcy/postconvergence epistemic perspective in postconverging-nonextricatory-existential-preempting-of-existential-unthought'; as much more than just with regards to a resolutory conception of acts and miscuings in 
temporality $/$ shortness as of themselves circumstantially, but rather as of the relevance to myriad human social situations which is much more critically an issue of ${ }^{103}$ universal import. So-escalated as of humankind's intemporal notional-contiguity/epistemic-contiguity $<$ profound-supererogation -of-mentally-aestheticised postconverging/dialectical-thinking qualia-schema $>$ imbued apriorising/axiomatising/referencing/intelligibilitysettingup/measuringinstrumenting reflection of 'implicited_attendant-ontological-contiguity ${ }^{67}$ ' educedexistentialising/contextualising/textualising_intelligibility/epistemicity/reflexivity-contiguity$<$ imbued-notional cogency>-in-reification/dereification; as superseding the beyond-theconsciousness-awareness-teleology $\quad<$ of-preconverging-existential-extrication-as-ofexistential-unthought $>\quad$ attitude/mental-disposition/care-and-episteme 5 cognisant-andintegrative of such acts and miscuings in temporality ${ }^{98}$ thus endemising and enculturating the reference-of-thought vices-and-impediments ${ }^{105}$. Thus such Being underdevelopment, construed as of dynamic social-chainism of human temporality $8 /$ shortness endemisation and enculturation as of the ${ }^{103}$ universal implications of such endemising and enculturating preconverging-de-mentating/structuring/paradigming in notional-discontiguity/epistemicdiscontiguity ${ }^{63}-<$ between - prior-shallow-supererogation -of-mentallyaestheticised preconverging/dementing -qualia-schema_and_prospective-profoundsupererogation -of-mentally-aestheticised postconverging/dialectical-thinking -qualiaschema $>$ warrants corresponding aetiologisation/ontological-escalation-<ontologicalveridicality_commitment/otherliness_transcending/compulsions-encumbered_transcending $>$ superseding ethos as of 'notional ' deprocrypticism attitude/mental-disposition/care-andepisteme as of ontological-normalcy/postconvergence epistemic perspective in pesterging nonextricatory-existential-preempting-of-existential-unthought' notional-contiguity/epistemiccontiguity ${ }^{6}<$ profound-supererogation -of-mentally-aestheticised postconverging/dialectical- 
thinking -qualia-schema>. The fact is any registry-worldview/dimension as of its 'present attitude/mental-disposition/care-and-episteme ${ }^{5}$ is preconverging/postconverging-dementatively/structurally/paradigmatically oblivious-to and does-not-reflect its very own requiste prospective relative-ontological-completeness ${ }^{87}$-of- ${ }^{83}$ reference-of-thought as the underlying basis of its own specific-level induced vices-and-impediments ${ }^{105}$, and is rather palliative as of its selecting, triaging, mutually-concurring-and-accommodating and power-relations driven palliating virtue constructs. The question can actually be asked, as of prospective relativeontological-completeness ${ }^{87}$-of- ${ }^{8}$ reference-of-thought of the notional-discontiguity/epistemicdiscontiguity ${ }^{63}-<$ between - prior-shallow-supererogation -of-mentallyaestheticised preconverging/dementing -qualia-schema_and_prospective-profoundsupererogation -of-mentally-aestheticised postconverging/dialectical-thinking -qualiaschema $>$ of this 'made-up' normativity supposed relative-unreflexivity/relative-reflexivity ontological-contiguity ${ }^{67}$, whether such a prior relative-ontological-incompleteness ${ }^{88}$-ofreference-of-thought as <amplituding/formative-epistemicity $>$ totalising $\sim$ self-referencingsyncretising/circularity/interiorising/akrasiatic-drag ${ }^{44}$ is actually as of Beingdevelopment/ontological-framework-expansion-as-to-depth-of-ontologising-development-asinfrastructure-of- meaningfulness-and-teleology at its uninstitutionalised-threshold ${ }^{02}$, and in a position, on the basis of such charade, to address the actual fundamental grounding of its vicesand-impediments ${ }^{105}$; which in reality are actually ontologically addressable/resolvable as to existence-potency ${ }^{39} \sim$ sublimating-nascence,-disclosed-from-prospective-epistemic-digression so-implied as of prospective relative-ontological-completeness ${ }^{87}$-of- ${ }^{8}$ reference-of-thought. What is particular with notional-discontiguity/epistemic-discontiguity ${ }^{6}-<$ between - priorshallow-supererogation -of-mentally-aestheticised preconverging/dementing -qualiaschema_and_prospective-profound-supererogation -of-mentallyaestheticised postconverging/dialectical-thinking -qualia-schema $>$ is this insight that 
fundamentally the appropriate prospective relative-ontological-completeness ${ }^{87}$-of- ${ }^{8}$ referenceof-thought apriorising/axiomatising/referencing/intelligibilitysettingup/measuringinstrumenting attitude/mental-disposition/care-and-episteme precedes-and-is-theapriorising/axiomatising/referencing/intelligibilitysettingup/measuringinstrumenting-to its requisite meaningfulness-and-teleology as prospective aetiologisation/ontologicalescalation-<ontological-veridicality_commitment/otherliness_transcending/compulsionsencumbered_transcending $>$. This reflects the salient and underlying idea about Beingdevelopment/ontological-framework-expansion-as-to-depth-of-ontologising-development-asinfrastructure-of- meaningfulness-and-teleology that a given ${ }^{83}$ reference-of-thought meaningfulness-and-teleology ${ }^{9}$ cannot be apriorised as of a prior/old prior relativeontological-incompleteness ${ }^{8}$-of- ${ }^{8}$ reference-of-thought apriorising/axiomatising/referencing/intelligibilitysettingup/measuringinstrumenting attitude/mental-disposition/care-and-episteme to that given ${ }^{53}$ reference-of-thought. Insightfully, we can thus grasp that the non-positivism/medievalism scholastic/pedantic dogmatism attitude/mental-disposition/care-and-episteme 'apriorising/axiomatising/referencing/intelligibilitysettingup/measuringinstrumenting

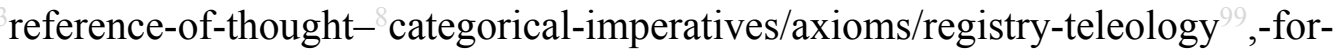
aposteriorising/logicising/deriving/intelligising/measuring_ ${ }^{5}$ meaningfulness-and-teleology ${ }^{9}$ is inherently not structured to be transcendentally enabling and operative of positivism/rationalempiricism aposteriorising/logicising/deriving/intelligising/measuring ${ }^{56}$ meaningfulness-andteleology ${ }^{9}$ which precedingly needs its very own positivism attitude/mental-disposition/careand-episteme 'apriorising/axiomatising/referencing/intelligibilitysettingup/measuringinstrumenting reference-of-thought- categorical-imperatives/axioms/registry-teleology ,, foraposteriorising/logicising/deriving/intelligising/measuring- ${ }^{5}$ meaningfulness-and-teleology ${ }^{9}$ '; 
as the former is in a circular state of reasoning-from-results/afterthought of nonpositivism/medievalism scholastic/pedantic dogmatism attitude/mental-disposition/care-andepisteme 'apriorising/axiomatising/referencing/intelligibilitysettingup/measuringinstrumenting reference-of-thought- categorical-imperatives/axioms/registry-teleology ${ }^{9}$,-foraposteriorising/logicising/deriving/intelligising/measuring - ${ }^{5}$ meaningfulness-and-teleology ${ }^{9}$, instead of positivism attitude/mental-disposition/care-and-episteme 'apriorising/axiomatising/referencing/intelligibilitysettingup/measuringinstrumenting reference-of-thought- categorical-imperatives/axioms/registry-teleology ${ }^{9}$,-foraposteriorising/logicising/deriving/intelligising/measuring - ${ }^{56}$ meaningfulness-and-teleology ${ }^{9}$, as of its prior relative-ontological-incompleteness ${ }^{8}$-of- ${ }^{-3 e f e r e n c e-o f-t h o u g h t . ~ T h u s ~ B e i n g-~}$ development/ontological-framework-expansion-as-to-depth-of-ontologising-development-asinfrastructure-of- meaningfulness-and-teleology points out that a ${ }^{83}$ reference-of-thought requisite apriorising/axiomatising/referencing/intelligibilitysettingup/measuringinstrumenting attitude/mental-disposition/care-and-episteme necessarily precedes-or-apriorises its aposteriorising/logicising/deriving/intelligising/measuring ${ }^{56}$ meaningfulness-and-teleology ${ }^{99}$ as the latter is about systematic existential-instantiations devolving of the former, that is, as teleologically-devolving-as-drifting meaningfulness it systematically makes reference to its appropriate attitude/mental-disposition/care-and-episteme apriorising/axiomatising/referencing/intelligibilitysettingup/measuringinstrumenting reference-of-thought- categorical-imperatives/axioms/registry-teleology ; as we know that no 'normal person' in our positivism/rational-empiricism ${ }^{8}$ reference-of-thought makes reference to the non-appropriate non-positivism/medievalism scholastic/pedantic dogmatism attitude/mental-disposition/care-and-episteme apriorising/axiomatising/referencing/intelligibilitysettingup/measuringinstrumenting reference-of-thought- categorical-imperatives/axioms/registry-teleology ${ }^{9}$, -for- 
aposteriorising/logicising/deriving/intelligising/measuring $-{ }^{56}$ meaningfulness-and-teleology that is positivistically intelligible. This insight about Being-development/ontologicalframework-expansion-as-to-depth-of-ontologising-development-as-infrastructure-ofmeaningfulness-and-teleology, that a reference-of-thought requisite apriorising/axiomatising/referencing/intelligibilitysettingup/measuringinstrumenting attitude/mental-disposition/care-and-episteme necessarily precedes-or-apriorises its aposteriorising/logicising/deriving/intelligising/measuring ${ }^{5}$ meaningfulness-and-teleology ${ }^{9}$, equally applies prospectively whereby at our prospective positivism/rational-empiricism manifestation of $\quad{ }^{80}$ procrypticism-or-disjointedness-as-of- ${ }^{8}$ reference-of-thought uninstitutionalisation, the idea of prospective institutionalisation as of ${ }^{18}$ deprocrypticism-orpreempting - disjointedness-as-of- ${ }^{-3}$ reference-of-thought implies that the latter's apriorising/axiomatising/referencing/intelligibilitysettingup/measuringinstrumenting attitude/mental-disposition/care-and-episteme as reflected by the prospective 'postmodern deprocrypticism-or-preempting-disjointedness-as-of- ${ }^{8}$ reference-of-thought apriorising/axiomatising/referencing/intelligibilitysettingup/measuringinstrumenting attitude/mental-disposition/care-and-episteme ${ }^{-}$is the requisite appropriate attitude/mentaldisposition/care-and-episteme

apriorising/axiomatising/referencing/intelligibilitysettingup/measuringinstrumenting reference-of-thought- categorical-imperatives/axioms/registry-teleology 9 in preemptingdisjointedness-as-of- ${ }^{8}$ reference-of-thought as so implied by postmodern ${ }^{4}$ human-subjectemancipating-relativism-driven-recomposuring-constructivism-towards-singularisation- $<$ as-tothe-nondisjointedness/entailment-of-prospective- nonpresencing $>$, for prospective aposteriorising/logicising/deriving/intelligising/measuring postmodernnotional ${ }^{18}$ deprocrypticism ${ }^{56}$ meaningfulness-and-teleology ${ }^{9}$ referencing. A further naïve misconstrual about Being-development/ontological-framework-expansion-as-to-depth-of- 
ontologising-development-as-infrastructure-of- meaningfulness-and-teleology is one that ignores this bigger picture of attitude/mental-disposition/care-and-episteme apriorising/axiomatising/referencing/intelligibilitysettingup/measuringinstrumenting preceding aposteriorising/logicising/deriving/intelligising/measuring ${ }^{5}$ meaningfulness-and-teleology ${ }^{9}$, and thus strives to articulate ${ }^{56}$ meaningfulness-and-teleology ${ }^{9}$ while oblivious to its attitude/mental-disposition/care-and-episteme

apriorising/axiomatising/referencing/intelligibilitysettingup/measuringinstrumenting reference-of-thought- categorical-imperatives/axioms/registry-teleology ${ }^{9}$,-foraposteriorising/logicising/deriving/intelligising/measuring - ${ }^{5}$ meaningfulness-and-teleology ${ }^{9}$, and thus naively implying its said given registry-worldview/dimension ${ }^{83}$ reference-of-thought is unaffected by any such notion of its prior relative-ontological-incompleteness ${ }^{88}$-of- ${ }^{8}$ referenceof-thought since it doesn't factor in that it is operating by a corresponding uninstitutionalisedthreshold deficient apriorising/axiomatising/referencing/intelligibilitysettingup/measuringinstrumenting attitude/mental-disposition/care-and-episteme . Consider in this regard, the $<$ amplituding/formative-epistemicity $>$ totalising $\sim$ self-referencingsyncretising/circularity/interiorising/akrasiatic-drag aposteriorising/logicising/deriving/intelligising/measuring certitude mental-states of the of medieval-scholasticism-pedants-ideal-type-or-individuation articulating aposteriorising/logicising/deriving/intelligising/measuring ${ }^{56}$ meaningfulness-and-teleology ${ }^{99}$ as of non-positivism/medievalism pedantic dogmatism attitude/mental-disposition/care-andepisteme 'apriorising/axiomatising/referencing/intelligibilitysettingup/measuringinstrumenting reference-of-thought- categorical-imperatives/axioms/registry-teleology ${ }^{99}$,-foraposteriorising/logicising/deriving/intelligising/measuring_ ${ }^{5}$ meaningfulness-and-teleology ${ }^{\circ}$. Such an orientation is no more different from an interpretation that every registry- 
worldview/dimension ${ }^{83}$ reference-of-thought is the absolute framework of ${ }^{5}$ meaningfulnessand-teleology as of its given practices and habits failing to account retrospectively and prospectively for the succession of institutional-cumulation/institutional-recomposure-〈as-tohistoriality/ontological-eventfulness /ontological-aesthetic-tracing-<perspectiveontological-normalcy/postconvergence-reflected-‘epistemicity-relativism-determinism'>> of 'intemporal ontological-faith-notion-or-ontological-fideism —imbued-underdetermination-ofmotif-and-apriorising/axiomatising/referencing-as-so-being-as-of-existential-reality instigated relative-unreflexivity/relative-reflexivity ontological-contiguity ${ }^{67}$ of-the-humaninstitutionalisation-process $^{68}$ as of difference-conflatedness ${ }^{13}$-as-to-totalitative-reification-insingularisation-<as-to-the-nondisjointedness/entailment-of-prospective- nonpresencing $>$-asveridical-epistemicity-relativism-determinism implied $\quad$ <amplituding/formativeepistemicity $>$ causality $\sim$ as-to-projective-totalitative-implications-of-prospectivenonpresencing,-for-explicating relative - unreflexivity/relative-reflexivity - ontologicalcontiguity as of Being-development/ontological-framework-expansion-as-to-depth-ofontologising-development-as-infrastructure-of- meaningfulness-and-teleology underscored by ${ }^{15}$ de-mentation-/supererogatory $\sim$ ontological-de-mentation-or-dialectical-de-mentationstranding-or-attributive-dialectics $\rangle$ behind the succession of transformation of attitude/mentaldisposition/care-and-episteme

apriorising/axiomatising/referencing/intelligibilitysettingup/measuringinstrumenting

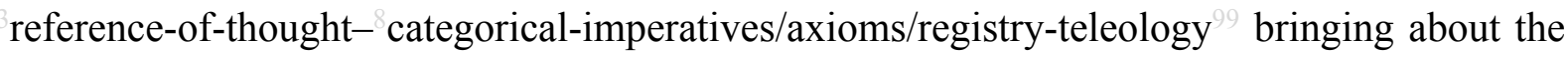
$\begin{array}{lll}\text { successively transformed registry-worldviews/dimensions } & \text { trime }\end{array}$ aposteriorising/logicising/deriving/intelligising/measuring ${ }^{56}$ meaningfulness-and-teleology ${ }^{99}$ of ‘intemporal ontological-faith-notion-or-ontological-fideism—imbued-underdetermination-ofmotif-and-apriorising/axiomatising/referencing-as-so-being-as-of-existential-reality instigated relative-unreflexivity/relative-reflexivity - ontological-contiguity ${ }^{67}$ of-the-human- 
institutionalisation-process $^{68}$ as of difference-conflatedness ${ }^{13}$-as-to-totalitative-reification-insingularisation-<as-to-the-nondisjointedness/entailment-of-prospective- nonpresencing $>$-asveridical-epistemicity-relativism-determinism implied $\quad<$ amplituding/formativeepistemicity $>$ causality $\sim$ as-to-projective-totalitative-implications-of-prospectivenonpresencing,-for-explicating relative-unreflexivity/relative-reflexivity - ontological-

contiguity '. It is this naivety that underlines the Heideggerian techne concern as we fail to appreciate that the technical and organisational possibilities preceding and associated with a registry-worldview/dimension prospective institutionalisation transitioning of meaningfulness-and-teleology ${ }^{9}$ need to be rethought as of the prospective institutionalisation attitude/mental-disposition/care-and-episteme apriorising/axiomatising/referencing/intelligibilitysettingup/measuringinstrumenting reference-of-thought- ${ }^{8}$ categorical-imperatives/axioms/registry-teleology ${ }^{9}$,-foraposteriorising/logicising/deriving/intelligising/measuring - ${ }^{56}$ meaningfulness-and-teleology ${ }^{9}$, and so superseding that of the uninstitutionalised-threshold ${ }^{02}$. We can appreciate in this regard that budding-positivism/rational-empiricism and its associated liberality that was the backdrop for technical and organisation possibilities that actually required their interpretation in terms-asof-axiomatic-construct of advancing human emancipation and bringing an end to serfdom in Europe for instance, but as of a perverted twist due to poor appreciation of Beingdevelopment/ontological-framework-expansion-as-to-depth-of-ontologising-development-asinfrastructure-of- meaningfulness-and-teleology led to the opportunistic undermining of human emancipation elsewhere not as of positivism/rational-empiricism attitude/mentaldisposition/care-and-episteme

apriorising/axiomatising/referencing/intelligibilitysettingup/measuringinstrumenting reference-of-thought- categorical-imperatives/axioms/registry-teleology ${ }^{9}$,-foraposteriorising/logicising/deriving/intelligising/measuring - ${ }^{5}$ meaningfulness-and-teleology 
but retrograde non-positivism attitude/mental-disposition/care-and-episteme apriorising/axiomatising/referencing/intelligibilitysettingup/measuringinstrumenting reference-of-thought- categorical-imperatives/axioms/registry-teleology ${ }^{9}$,-foraposteriorising/logicising/deriving/intelligising/measuring $-{ }^{56}$ meaningfulness-and-teleology ${ }^{9}$. It is to be noted here that the apriorising/axiomatising/referencing/intelligibilitysettingup/measuringinstrumenting precedence of attitude/mental-disposition/care-and-episteme aposteriorising/logicising/deriving/intelligising/measuring for $\quad{ }^{5}$ meaningfulness-andteleology while seemingly counterintuitive, simply speaks of the implications of the notion of prospective relative-ontological-completeness ${ }^{87}$-of- ${ }^{8}$ reference-of-thought/prior relativeontological-incompleteness ${ }^{8}$-of-axiomatic-construct as of the-very-same-immanentexistence/intrinsic-reality/ontological-veridicality,-as-to-'human<amplituding/formativeepistemicity>totalising purview-of-construal', in that our appropriate-or-inappropriate-atvarious-successive-levels conception as of the-very-same-immanent-existence/intrinsicreality/ontological-veridicality,-as-to-'human<amplituding/formativeepistemicity>totalising purview-of-construal' has nothing to do with inherent existentialdisontegising reality but with us adjusting our apriorising/axiomatising/referencing/intelligibilitysettingup/measuringinstrumenting reference-of-thought- categorical-imperatives/axioms/registry-teleology ${ }^{9}$,-foraposteriorising/logicising/deriving/intelligising/measuring $-{ }^{5}$ meaningfulness-and-teleology ${ }^{9}$ in order to reflect ontologically-veridical signification as of existence. And intuitively from our positivistic angle we can effectively recognise this about all the prior registryworldviews/dimensions ${ }^{83}$ reference-of-thought as we appreciate that by reflex these are just $\begin{array}{llll}\text { beholden to their } & \text { to } & \text { own }\end{array}$ apriorising/axiomatising/referencing/intelligibilitysettingup/measuringinstrumenting 
reference-of-thought- categorical-imperatives/axioms/registry-teleology ${ }^{9}$,-foraposteriorising/logicising/deriving/intelligising/measuring $-{ }^{56}$ meaningfulness-and-teleology reasoning-from-results/afterthought, but it is hard from our positivistic angle to then appreciate that prospectively we are equally in such a beheld positivism- ${ }^{80}$ procrypticism/disjointedness-asof- ${ }^{8}$ reference-of-thought attitude/mental-disposition/care-and-episteme 'apriorising/axiomatising/referencing/intelligibilitysettingup/measuringinstrumenting reference-of-thought- categorical-imperatives/axioms/registry-teleology ${ }^{9}$, -foraposteriorising/logicising/deriving/intelligising/measuring- ${ }^{5}$ meaningfulness-and-teleology ${ }^{9}$, for our positivism- ${ }^{8}$ procrypticism/disjointedness-as-of- ${ }^{3}$ reference-of-thought aposteriorising/logicising/deriving/intelligising/measuring ${ }^{56}$ meaningfulness-and-teleology ${ }^{99}$ which when shown to be of prior relative-ontological-incompleteness ${ }^{88}$-of- ${ }^{8}$ reference-ofthought as of procrypticism-or-disjointedness-as-of- ${ }^{8}$ reference-of-thought implies necessarily the need for futural Being-development/ontological-framework-expansion-as-todepth-of-ontologising-development-as-infrastructure-of- meaningfulness-and-teleology as of prospective ${ }^{18}$ deprocrypticism-or-preempting-disjointedness-as-of- ${ }^{3}$ reference-of-thought attitude/mental-disposition/care-and-episteme 'apriorising/axiomatising/referencing/intelligibilitysettingup/measuringinstrumenting reference-of-thought- categorical-imperatives/axioms/registry-teleology ${ }^{99}$,-foraposteriorising/logicising/deriving/intelligising/measuring_ ${ }^{56}$ meaningfulness-and-teleology as so implied by postmodern ${ }^{4}$ human-subject-emancipating-relativism-driven-recomposuringconstructivism-towards-singularisation-<as-to-the-nondisjointedness/entailment-ofprospective- nonpresencing $>$ for prospective postmodern-notional ${ }^{18}$ deprocrypticism aposteriorising/logicising/deriving/intelligising/measuring ${ }^{56}$ meaningfulness-and-teleology ${ }^{9}$. But then with respect to the possibility of prospective human transcendence-andsublimity/sublimation/supererogatory de-mentativity, the question arises as to how it is possible 
for human transcendence-and-sublimity/sublimation/supererogatory de-mentativity to occur

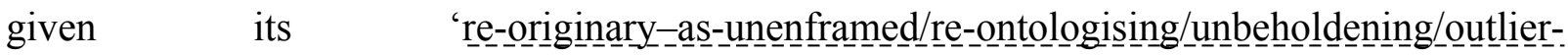

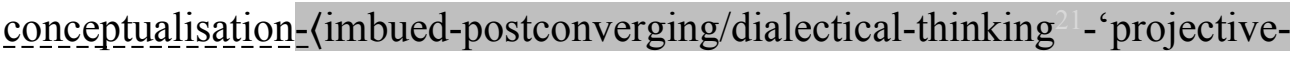
insights'/“epistemic-projection-in-conflatedness ' -of-notional deprocrypticism-prospectivesublimation $>$ metaphoricity ${ }^{57}$ instigation' in the face of any registry-worldview/dimension $<$ amplituding/formative $>$ wooden-language-_imbued - averaging-of-thought-<as-toleveling/ressentiment/closed-construct-of- meaningfulness-and-teleology -as-of'nondescript/ignorable-void '-with-regards-to-prospective-apriorising-implications $>>$ natural inclination rather for construing ${ }^{5}$ meaningfulness-and-teleology' as 'wholly of its cloisteredconsciousness living experience only' whether as of recurrent-utter-uninstitutionalisation only, base-institutionalisation-ununiversalisation only, universalisation-nonpositivism/medievalism only or in our case positivism- ${ }^{80}$ procrypticism only, with a rather poor inkling for appreciating ${ }^{56}$ meaningfulness-and-teleology ${ }^{9}$ as of a protracted-consciousness associated with grasping Being-development/ontological-framework-expansion-as-to-depth-ofontologising-development-as-infrastructure-of- meaningfulness-and-teleology . This brings home the fact that however the human intemporal/ontological/social/species $/{ }^{103}$ universal/transcendental $/{ }^{55}$ maximalisingrecomposuring-for-relative-ontological-completeness ${ }^{8}$ —unenframed/reontologising conceptualisation postconverging-de-mentating/structuring/paradigming implied as of a protracted-consciousness, and specifically the prospective protensive-consciousness of deprocrypticism-or-preempting-disjointedness-as-of- ${ }^{3}$ reference-of-thought Beingdevelopment/ontological-framework-expansion-as-to-depth-of-ontologising-development-asinfrastructure-of- meaningfulness-and-teleology is practically inevitably constrained-andpotentially-jeopardised as of the framework of the <amplituding/formativeepistemicity $>$ totalising $\sim$ self-referencing-syncretising/circularity/interiorising/akrasiatic-drag 
cloistered-consciousness of any of the <cumulating/recomposuring attendant-ontologicalcontiguity >-successive registry-worldviews/dimensions in their respective reasoning-fromresults/afterthought logocentric apriorising/axiomatising/referencing-\{of-'prospectively implicited_attendant-ontological-contiguity ' reducedexistentialising/contextualising/textualising_'intelligibility/epistemicity/reflexivity-contiguity$<$ imbued-notional cogency $\left.>^{\prime} \quad\right\}$-constitutedness ${ }^{14}$-in preconverging-entailment; $\quad$ as the 'reasoning <preconverging 'motif-and-apriorising/axiomatising/referencing'-entailing > existentialising — enframing/imprintedness-〈as-to- historicity-tracing —in-presencinghyperrealisation/hyperreal-transposition〉, of the registry-worldview/dimension apriorising/axiomatising/referencing/intelligibilitysettingup/measuringinstrumenting is underdeveloped for contemplating-and-construing of re-ontologising prospective Beingdevelopment/ontological-framework-expansion-as-to-depth-of-ontologising-development-asinfrastructure-of- meaningfulness-and-teleology as of the prospective institutionalisation. A registry-worldview/dimension as of its <amplituding/formative > wooden-language-〈imbuedaveraging-of-thought-<as-to-leveling/ressentiment/closed-construct-of- meaningfulness-andteleology -as-of-'nondescript/ignorable-void '-with-regards-to-prospective-apriorisingimplications $>>$ is preconverging/postconverging-de-mentatively/structurally/paradigmatically bound to preconverging-existential-extrication-as-of-existential-unthought as of humansubpotency epistemic perspective at its uninstitutionalised-threshold ${ }^{102}$ rather than the ontological-normalcy/postconvergence epistemic perspective in nostricatoryexistential-preempting-of-existential-unthought; such that articulation of Beingdevelopment/ontological-framework-expansion-as-to-depth-of-ontologising-development-asinfrastructure-of- meaningfulness-and-teleology as of prospective transcendence-andsublimity/sublimation/supererogatory de-mentativity is beyond its reasoningness as of its 'reasoning-from-reasults'/afterthought logocentric apriorising/axiomatising/referencing-\{of- 
'prospectively_implicited_attendant-ontological-contiguity ' educed-

existentialising/contextualising/textualising_intelligibility/epistemicity/reflexivity_contiguity-

$<$ imbued-notional cogency $>$ ' $\}$ - constitutedness ${ }^{14}$-in-preconverging-entailment

conceptualisation of meaningfulness-and-telelogy. Inevitably thus this conundrum points out that the instigating of Being-development/ontological-framework-expansion-as-to-depth-ofontologising-development-as-infrastructure-of- meaningfulness-and-teleology is as of intemporal/longness-of register-of meaningfulness-and-teleology dimensionality-ofsublimating $25<$ - $<$ amplituding/formative $>$ supererogatory $\sim$ de-mentativeness/epistemic-growthor-conflatedness /transvaluative-rationalising/transepistemicity/anamnestic-residuality/spiritdrivenness-equalisation> individuation reasoning-through/messianic-reasoning, more like Derridean messianic reasoning, arising as of intellectual-and-moral inequivalence and thus implying the dialogical inequivalence of intemporal and temporal $<$ amplituding/formative $>$ wooden-language-<imbued - averaging-of-thought-<as-toleveling/ressentiment/closed-construct-of- meaningfulness-and-teleology -as-of'nondescript/ignorable-void '-with-regards-to-prospective-apriorising-implications>); given that no secondnatured institutionalisation grounding of ${ }^{56}$ meaningfulness-and-teleology ${ }^{9}$ exists for prospective transcendence-and-sublimity/sublimation/supererogatory de-mentativity. The ontological-veracity of such dimensionality-of-sublimating ${ }^{25}$ <<amplituding/formative>supererogatory $\sim$ de-mentativeness/epistemic-growth-or-

\section{conflatedness /transvaluative-rationalising/transepistemicity/anamnestic-residuality/spirit-}

drivenness-equalisation〉 individuation reasoning-through as of Derridian messianic reasoning can be grasp when we contemplate that in a secondnatured institutionalisation framework of deferential-formalisation-transference we give pre-eminence to say a professional or technician for resolving a technical problem, and as non-technicians we don't get involve in $<$ amplituding/formative $>$ wooden-language-〈imbued - averaging-of-thought-<as-to- 
leveling/ressentiment/closed-construct-of- meaningfulness-and-teleology -as-of-

'nondescript/ignorable-void '-with-regards-to-prospective-apriorising-implications $>>$ exercise to resolve the technical problem. This outlook is actually 'seeded' within dimensionality-ofsublimating $2-<<$ amplituding/formative $>$ supererogatory $\sim$ de-mentativeness/epistemic-growthor-conflatedness /transvaluative-rationalising/transepistemicity/anamnestic-residuality/spiritdrivenness-equalisation) individuation reasoning-through that is instigative of Beingdevelopment/ontological-framework-expansion-as-to-depth-of-ontologising-development-asinfrastructure-of- meaningfulness-and-teleology . Thereof, what is critical for enabling human successive transcendence-and-sublimity/sublimation/smentativity is 'appropriate prospective institutionalisation secondnaturing metaphoricity ${ }^{57}$ '. Consider in this regard, that the instigative matesis ${ }^{103}$ universalis metaphoricity ${ }^{57}$ by the Galileos, Descartes, etc. of budding-positivism/rational-empiricism is preconverging/postconverging-dementatively/structurally/paradigmatically 'not a reasoning with non-positivism/medievalism' but rather 'reasoning-through or Derridian messianic reasoning' over nonpositivism/medievalism scholastic pedantising/muddling/formulaic-hollowing-out—insubontologisation/subpotentiation-〈blurring/undermining-of-prospective-totalising-entailing,as-to-entailing-<amplituding/formative-epistemicity $>$ totalising in-relative-ontologicalcompleteness $\rangle$ as of its <amplituding/formative $>$ wooden-language-〈imbued-averaging-ofthought-<as-to-leveling/ressentiment/closed-construct-of- meaningfulness-and-teleology -asof-'nondescript/ignorable-void ' -with-regards-to-prospective-apriorising-implications $>$ > reasoning-from-results/afterthought logocentric apriorising/axiomatising/referencing-\{of'prospectively_implicited_attendant-ontological-contiguity ' educedexistentialising/contextualising/textualising_'intelligibility/epistemicity/reflexivity_contiguity-

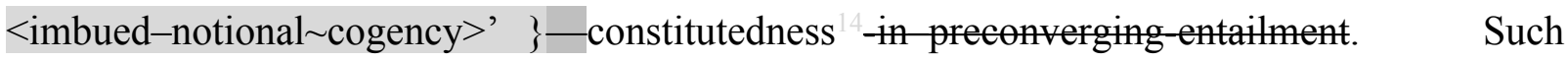
altogether new metaphoricity ${ }^{57}$ as of its instigating 'out of thin air' the budding-positivism 
apriorising/axiomatising/referencing/intelligibilitysettingup/measuringinstrumenting attitude/mental-disposition/care-and-episteme further inspired its subsequent radicalisation by latter thinkers; wherein for instance, the more thoroughly positivism/rational-empiricism development of 'the-very-same physics <amplituding/formativeepistemicity>totalising devolved—purview/domain-of-construal-as-intrinsicreality/ontological-veridicality/existential-reality' was undertaken by Newton and Leibniz, extending the metaphoricity ${ }^{57}$ further even when we contemplate that in-many-ways these metaphoricity ${ }^{57}$ relaying scientists were still imbued with non-positivism/medievalism mystical and alchemic ideas. This 'out of thin air' metaphoricity ${ }^{57}$ possibility arises because the 'fullpotency of existence in relation to human-subpotency-as-human-knowledge grasp of that fullpotency of existence' is ever one of nonpresencing-<perspective-ontologicalnormalcy/postconvergence>; as the very notion of 'human-subpotency-as-human-knowledge grasp of the full-potency of existence' given human limited-mentation-capacity-as-subjecting'educed-unlimitedness/existence-sublimating nascence' to-limitedness/human-subpotency implies that such a grasp only opens up a 'limited framework of the full-potency of existence' for new human existential-<disentologising/re-ontologising aporeticism $>$ and knowledge possibilities as of new/prospective habits-and-tradition. But then this 'limited framework of the full-potency of existence' as of new habits-and-tradition construed as 'reason-fromresults/afterthought framework, 'doesn't induce a commitment upon the absolute transcendental possibility in the full-potency of existence'. Such that by dispensing-with-immediacy-forrelative-ontological-completeness ${ }^{87}$-by-reification/contemplative-distension ${ }^{27}$ (as of human selfsurpassing — existentialism-form-factor,-in-overcoming-'notional collateralising-beholdeningprotohumanity'-to-'attain-sublimating-humanity'-as-to-existence-potency sublimatingnascence,-disclosed-from-prospective-epistemic-digression to supersede human temporality 8 /shortness <amplituding/formative> wooden-language-〈imbued-averaging-of- 
thought-<as-to-leveling/ressentiment/closed-construct-of- meaningfulness-and-teleology -asof-'nondescript/ignorable-void '-with-regards-to-prospective-apriorising-implications $>$ )) with respect to Being-development/ontological-framework-expansion-as-to-depth-of-ontologisingdevelopment-as-infrastructure-of- meaningfulness-and-teleology , the further insight of 'out of thin air' metaphoricity ${ }^{57}$ as of human limited-mentation-capacity-deepening as subjecting limitedness/human-subpotency-to-'educed-unlimitedness/existence-sublimating nascence' comes with the possibility of its <amplituding/formative-epistemicity $>$ causality $\sim$ as-toprojective-totalitative-implications-of-prospective- nonpresencing,-for-explicating relativeunreflexivity/relative-reflexivity - ontological-contiguity validation by existencepotency $^{32} \sim$ sublimating-nascence,-disclosed-from-prospective-epistemic-digression. $\quad$ In this regard, the ontologically-veridical 'postmodern ${ }^{18}$ deprocrypticism-or-preemptingdisjointedness-as-of- ${ }^{-3}$ reference-of-thought

apriorising/axiomatising/referencing/intelligibilitysettingup/measuringinstrumenting attitude/mental-disposition/care-and-episteme ${ }^{5}$ with respect to our modern take $<$ amplituding/formative $>$ wooden-language-<imbued - averaging-of-thought-<as-toleveling/ressentiment/closed-construct-of- meaningfulness-and-teleology -as-of'nondescript/ignorable-void '-with-regards-to-prospective-apriorising-implications $>$ > reasoning-from-results/afterthought logocentric apriorising/axiomatising/referencing-\{of'prospectively_implicited_attendant-ontological-contiguity ' educedexistentialising/contextualising/textualising_'intelligibility/epistemicity/reflexivity-contiguity$<$ imbued-notional cogency $\left.>^{\prime} \quad\right\}$-constitutedness ${ }^{1}$-in preconverging-entailment is rather as of 'reasoning-through or Derridian messianic reasoning' over our positivism/rational-

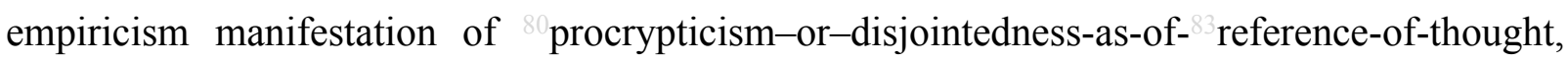
and so as of a postmodern affirmatory stance of dialogical inequivalence that goes beyond idling in the 'modern take rigmarole language', just as we can appreciate how budding-positivism 
obviate non-positivism/medievalism pedantic dogmatism language to affirm ${ }^{5}$ meaningfulnessand-teleology ${ }^{9}$ weeding out ornate pedantic detours, to articulate blunt reality as of deprocrypticism-or-preempting - disjointedness-as-of- ${ }^{3}$ reference-of-thought prospective relative-ontological-completeness ${ }^{87}$-of ${ }^{8}$ refence-of-thought. Insightfully, and as is the case with all prospective transcendence-and-sublimity/sublimation/supererogatoryade-mentativity implied ${ }^{56}$ meaningfulness-and-teleology ${ }^{9}$, we can appreciate that the foremost goal of buddingpositivists 'was not to elicit the direct approval' of the non-positivism/medievalism established arrangement, as in-many-ways they adopted a ' 7 presencing-absolutising-identitiveconstitutedness ${ }^{14}$ consummated/forfeiting posture' with respect to establishment social stakes, but rather sought to induce the requisite metaphoricity ${ }^{77}$ of budding-positivism for the destruction-deconstruction of non-positivism/medievalism for prospective positivism, as their conception of achievement motive were tied down to prospective positivism institutionalisation as of Being-development/ontological-framework-expansion-as-to-depth-of-ontologisingdevelopment-as-infrastructure-of- meaningfulness-and-teleology . Likewise, the prospective 'postmodern ${ }^{18}$ deprocrypticism-or-preempting — disjointedness-as-of- ${ }^{8}$ reference-of-thought apriorising/axiomatising/referencing/intelligibilitysettingup/measuringinstrumenting attitude/mental-disposition/care-and-episteme ${ }^{5}$ is well beyond the notion of eliciting the approbation of the modern take established arrangement in terms-as-of-axiomatic-construct, but rather is of " ${ }^{7}$ presencing-absolutising-identitive-constitutedness ${ }^{14}$ consummated/forfeiting posture', in inducing budding-postmodern metaphoricity ${ }^{57}$ for the destruction-deconstruction of the modern take for prospective postmodern-notional $\sim^{18}$ deprocrypticism institutionalisation as of re-ontologising prospective Being-development/ontological-framework-expansion-as-todepth-of-ontologising-development-as-infrastructure-of- meaningfulness-and-teleology . In both cases, the prospective institutionalisation attitude/mental-disposition/care-and-episteme is ontologically validated as of its prospective relative-ontological-completeness ${ }^{87}$-of- ${ }^{8}$ reference- 
of-thought, divulging the <amplituding/formative-epistemicity $>$ totalising $\sim$ self-referencingsyncretising/circularity/interiorising/akrasiatic-drag ${ }^{34}$ vagueness and futility of the pretences and judgments of the destructuring-threshold-〈uninstitutionalised-threshold /presublimatingdesublimating-decisionality $>$ of-ontological-performance ${ }^{2}-<$ including-virtue-as-ontology $>$. We can equally appreciate here that such a conception of transcendence-andsublimity/sublimation/supererogatory de-mentativity is rather as of organic-knowledge and not mechanical knowledge, in the sense that what is critical is the induced apriorising/axiomatising/referencing/intelligibilitysettingup/measuringinstrumenting metaphoricity ${ }^{57}$ for prospective institutionalisation as of prospective <amplituding/formativeepistemicity $>$ causality as-to-projective-totalitative-implications-of-prospectivenonpresencing,-for-explicating relative-unreflexivity/relative-reflexivity - ontologicalcontiguity and not simply a mechanical knowledge conception possibly tolerated as of a stale a posteriori adjunctiveness as with the Copernican heliocentric idea initially, needing a latter apriorising/axiomatising/referencing/intelligibilitysettingup/measuringinstrumenting metaphoricity ${ }^{57}$ reinvigoration as of the overall renewal of 'the-very-same physics $<$ amplituding/formative-epistemicity $>$ totalising $\sim$ devolved-purview/domain-of-construal-asintrinsic-reality/ontological-veridicality/existential-reality'. It should be noted that such metaphoricity ${ }^{57}$ rather points to psychoanalytic-unshackling/prospective-grounding/prospectivereification organic-knowledge nature of such prospective institutionalisation transcendental meaningfulness-and-teleology ${ }^{9}$, which in its prospective relative-ontological-completeness ${ }^{87}$ of- ${ }^{8}$ reference-of-thought is the dimensionality-of-sublimating <<amplituding/formative>supererogatory $\sim$ de-mentativeness/epistemic-growth-orconflatedness /transvaluative-rationalising/transepistemicity/anamnestic-residuality/spiritdrivenness-equalisation〉 inventing' of the prospective notion of 'thinking/postconverging-ordialectical-thinking -apriorising-psychologism' as positivism/rational-empiricism thinking or 
notional ${ }^{1}$ deprocrypticism thinking respectively, and so as their successive prospective reasoning-from-results/afterthought. In both cases, such metaphoricity ${ }^{57}$ as of its reasoningthrough/messianic-reasoning cannot be construed as grounded-as-intelligible on the superseded/transcended registry-worldview's/dimension's attitude/mental-disposition/careand-episteme ${ }^{5}$ of medievalism-non-positivism or positivism/rational-empiricism manifestation of ${ }^{80}$ procrypticism-or-disjointedness-as-of- ${ }^{8}$ reference-of-thought, but rather as of its very own transcendental-enabling/sublimating/supererogatory $\sim$ de-mentativity prospective institutionalisation attitude/mental-disposition/care-and-episteme of positivism or deprocryticism respectively. Thus such metaphoricity ${ }^{57}$ is rather induced as of the framework of prospective concurrent <amplituding/formative-epistemicity $>$ causality $\sim$ as-to-projectivetotalitative-implications-of-prospective- nonpresencing,-for-explicating relative-

unreflexivity/relative-reflexivity ontological-contiguity in establishing its prospective 'detour to social goodwill deferential-formalisation-transference to perceived overwhelmingrelative-effectiveness'. Thus such metaphoricity ${ }^{57}$ as of its reasoning-through/messianicreasoning is more aptly and consciously articulated at a dispensing-with-immediacy-for-relativeontological-completeness $^{87}$-by-reification/contemplative-distension ${ }^{27}$ (as of human selfsurpassing — existentialism-form-factor,-in-overcoming-'notional collateralising-beholdeningprotohumanity'-to-'attain-sublimating-humanity'-as-to-existence-potency sublimatingnascence,-disclosed-from-prospective-epistemic-digression to supersede human temporality ${ }^{8 / \text { shortness }}$ <amplituding/formative> wooden-language-〈imbued-averaging-ofthought-<as-to-leveling/ressentiment/closed-construct-of- meaningfulness-and-teleology -asof-'nondescript/ignorable-void ' -with-regards-to-prospective-apriorising-implications $>\rangle$ ) depth/profoundness of human posterity; projecting well beyond the narrow and decadent obsessions of shallow as of extricatory/temporal preconverging-dementating/structuring/paradigming of social-stake-contention-or-confliction, as it actively 
strives as of its prospective ${ }^{83}$ reference-of-thought- categorical-imperatives/axioms/registryteleology ${ }^{9}$,-for-aposteriorising/logicising/deriving/intelligising/measuring- ${ }^{5}$ meaningfulnessand-teleology $\quad$ to supersede such $<$ preconverging $\sim$ 'motif-andapriorising/axiomatising/referencing'-entailing >-existentialising — enframing/imprintedness〈as-to- historicity-tracing-in-presencing-hyperrealisation/hyperreal-transposition〉 and their associated institutional-anchoring and mandarinism and pedantising/muddling/formulaichollowing-out — in-subontologisation/subpotentiation-_blurring/undermining-of-prospectivetotalising-entailing,-as-to-entailing-<amplituding/formative-epistemicity $>$ totalising $\sim$ inrelative-ontological-completeness $>$ temporally induced denaturing ${ }^{6}$ of ${ }^{56}$ meaningfulness-andteleology, and so $\quad$ as $\quad$ of human intemporal/ontological/social/species $/{ }^{103}$ universal/transcendental/ ${ }^{5}$ maximalisingrecomposuring-for-relative-ontological-completeness ${ }^{87}$ - unenframed/reontologising conceptualisation postconverging-de-mentating/structuring/paradigming. Reasoning-through/messianic-reasoning metaphoricity ${ }^{57}$ brings about the prospectively renewed reasoning-from-results/afterthought instigating the secondnaturing of prospective institutionalisation, and so as of implied ${ }^{83}$ reference-of-thought/axiomatic-constructs reflection of the pre-eminence of the full-potency of existence as of prospective <amplituding/formativeepistemicity $>$ causality $\sim$ as-to-projective-totalitative-implications-of-prospectivenonpresencing,-for-explicating relative-unreflexivity/relative-reflexivity - ontologicalcontiguity over human-subpotency with the latter adjusting to existence as-of- de-mentation〈supererogatory $\sim$ ontological-de-mentation-or-dialectical-de-mentation-stranding-orattributive-dialectics $\rangle$ enabling its prospective relative-ontological-completeness ${ }^{87}$. Dimensionality-of-sublimating $25<<$ amplituding/formative $>$ supererogatory-dementativeness/epistemic-growth-or-conflatedness /transvaluativerationalising/transepistemicity/anamnestic-residuality/spirit-drivenness-equalisation〉 
articulation of reasoning-through/messianic-reasoning cannot be construed as amenable to the contending disposition of prior deferential-formalisation-transference secondnatured institutionalisation, thus the irrelevance/impertinence of any such implied contending as of prior reasoning-from-results/afterthought, as any such contention can only re-arise as of the reasoningthrough/messianic-reasoning renewing of secondnatured prospective 'reason-fromresults'/afterthought. Thus the direct implication of reasoning-through/messianic-reasoning is that it can only call upon a 'kindred sense of things', as of dimensionality-of-sublimating <<amplituding/formative>supererogatory $\sim$ de-mentativeness/epistemic-growth-or-

conflatedness /transvaluative-rationalising/transepistemicity/anamnestic-residuality/spirit-

drivenness-equalisation) contemplation that can surpass/overcome temporal nihilistic $<$ amplituding/formative $>$ wooden-language-_imbued - averaging-of-thought-<as-toleveling/ressentiment/closed-construct-of- meaningfulness-and-teleology -as-of'nondescript/ignorable-void '-with-regards-to-prospective-apriorising-implications $>>$ as of a protracted-consciousness cognisant of the prospective ontological-performance ${ }^{2}-<$ includingvirtue-as-ontology $>$ /morality/ethics/justice/etc. and human emancipation implications of Beingdevelopment/ontological-framework-expansion-as-to-depth-of-ontologising-development-asinfrastructure-of- meaningfulness-and-teleology . It should be noted here that the notion of $<$ amplituding/formative $>$ wooden-language-〈imbued — averaging-of-thought-<as-toleveling/ressentiment/closed-construct-of- meaningfulness-and-teleology -as-of'nondescript/ignorable-void '-with-regards-to-prospective-apriorising-implications $>\rangle$ as of its nihilism rather speaks to social apathy towards veridical prospective ontological possibilities of emancipation as of aetiologisation/ontological-escalation- $<$ ontologicalveridicality_commitment/otherliness_transcending/compulsions-encumbered_transcending $>$ implications going by the very implications of knowledge-reification $\sim$ gesturing-andaccounting-of-epistemic-phenomenalism- $<$ in- 
prospective_psychologismic apriorising/axiomatising/referencing-\{of-'prospectively_ implicited_attendant-ontological-contiguity ' ceducedexistentialising/contextualising/textualising_'intelligibility/epistemicity/reflexivity-contiguity$<$ imbued-notional $\left.\sim \operatorname{cogency}>^{\prime}\right\}$-conflatedness -in-\{preconverging -ment by\} postconverging-entailment $>$ as being as of the relative-ontological-completeness ${ }^{87}$ perspective, and is not to be confused with naïve and literal interpretations in 'untransvaluated-temporalintemporality $^{52}$ non-ontological terms of social-stake-contention-or-confliction conceptualisations' that wrongly seem to imply that knowledge-reification $\sim$ gesturing-andaccounting - of-epistemic-phenomenalism- $<$ inprospective_psychologismic apriorising/axiomatising/referencing-\{of-`prospectively implicited_attendant-ontological-contiguity ' educedexistentialising/contextualising/textualising_'intelligibility/epistemicity/reflexivity_contiguity<imbued-notional cogency >' \}-conflatedness -in-\{preconverging ment by\} postconverging-entailment $>$ can be contemplated paradoxically as being as of the relativeontological-incompleteness ${ }^{8}$ perspective as may be reflected by mere conceptual-patterning〈as-devoid-of-‘prospectively_implicited_attendant_ontological-contiguity ' educedexistentialising/contextualising/textualising_'intelligibility/epistemicity/reflexivity_contiguity<imbued-notional cogency>' 's-reifying-or-elucidating-of-'prospective-relative-ontologicalcompleteness ' ';-so-rather-enabled-<by-a- nonpresencing-divulging-of-momentoushistoriality/ontological-eventfulness /ontological-aesthetic-tracing-<perspectiveontological-normalcy/postconvergence-reflected-‘epistemicity-relativism-determinism'>> in presencing-absolutising-identitive-constitutedness ${ }^{14}$ without contemplating that the underlying knowledge-reification $\sim$ gesturing-and-accounting-of-epistemic-phenomenalism<in-prospective_psychologismic apriorising/axiomatising/referencing-\{of-'prospectively_ implicited_attendant-ontological-contiguity ' educed- 
existentialising/contextualising/textualising_ 'intelligibility/epistemicity/reflexivity-contiguity<imbued-notional cogency $>$ ' \}-conflatedness -in-\{preconverging ment by\}

postconverging-entailment> process/gesturing implications is definitely as of the relativeontological-completeness ${ }^{87}$ perspective since a untransvaluated-temporal-intemporality ${ }^{52}$ nonontological interpretation will rather imply knowledge dereification and endemising/enculturating of temporal-dispositions as of vices-and-impediments ${ }^{105}$ for the simple reason that the latter 'cannot be ignored and then by magic become virtue' as the overall for knowledge-reification $\sim$ gesturing-and-accounting — of-epistemic-phenomenalism- $<$ inprospective_psychologismic apriorising/axiomatising/referencing-\{of-'prospectively_ implicited_attendant-ontological-contiguity ' ceducedexistentialising/contextualising/textualising_'intelligibility/epistemicity/reflexivity-contiguity<imbued-notional cogency >' \}-conflatedness -in-\{preconverging-ment by\} postconverging-entailment> is to understand human destructuring-threshold〈uninstitutionalised-threshold /presublimating-desublimating-decisionality $>$ of-ontologicalperformance ${ }^{72}-<$ including-virtue-as-ontology $>$ /morality/ethics/justice/etc. and then bring about prospective $\quad$ constructiveness-of-ontological-performance ${ }^{72}-<_{\text {including-virtue-as- }}$ ontology $>$ /morality/ethics/justice/etc. as to overall reifying-and-empowering-reflexivity-ofecstatic-existence-as-panintelligibility/panreflexivity ${ }^{73}$-〈existentially-imbued-and-educingStepistemictalising thermeneutically/textually/reprojectingly/supererogatingly/zeroingly/re-

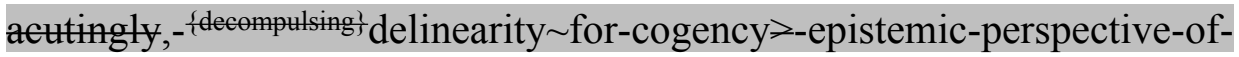
projective/reprojective - aestheticising-re-motif-and-re-apriorising/re-axiomatising/rereferencing conceptualisation,-as-herein-specifically-relevant-to human-subpotency $\rangle. \quad$ This tendency to misconstrue the meaning of $<$ amplituding/formative $>$ wooden-language-〈imbuedaveraging-of-thought-<as-to-leveling/ressentiment/closed-construct-of- meaningfulness-andteleology -as-of-‘nondescript/ignorable-void '-with-regards-to-prospective-apriorising- 
implications $>>$ and associated philosophical notions like leveling, critically arises because of a poor construal of philosophy as ontologically-driven just like any other knowledge as of 'baseline re-originary_as-unenframed/re-ontologising/unbeholdening/outlier-conceptualisation〈imbued-postconverging/dialectical-thinking -'projective-insights'/'epistemic-projection-inconflatedness '-of-notional deprocrypticism-prospective-sublimation $\rangle$ up-to-date

knowledge-reification $\sim$ gesturing-and-accounting —of-epistemic-phenomenalism- $<$ inprospective_psychologismic apriorising/axiomatising/referencing-\{of-'prospectively implicited_attendant-ontological-contiguity ' educedexistentialising/contexalising/textlising_ 'intelligibility/epistemicity/reflexivity-contiguity<imbued-notional cogency >' \}-conflatedness -in-\{preconverging-ment by\}

postconverging-entailment $>$ process/gesturing of the specific knowledge area as of inherent existence/ontological implications' subject to validation and falsifiability ${ }^{12}$ rather than a naïve construal of philosophy as an sterile/anecdotal imprimatur totalisingly-ing — discretion/whim-ofthought exercise on the basis of 'relic-or-orthodoxy knowledge' induced disparateness-ofconceptualisation-<unforegrounding-ment,-failing-prospectively-to-reflect-

\section{'immanent relative-unreflexivity/relative-reflexivity - ontological-contiguity ' $>$. It is herein} contended that the critical notion underlying <amplituding/formative > wooden-language〈imbued - averaging-of-thought-<as-to-leveling/ressentiment/closed-construct-ofmeaningfulness-and-teleology -as-of-‘nondescript/ignorable-void '-with-regards-toprospective-apriorising-implications $>\rangle$, ressentiment and leveling specifically with reference to Heideggerian and Nietzschean thought can actually be interpreted critically as relating rather to 'originariness-parrhesia,-as-spontaneity-of-aestheticisation over the human atrophying tendency for prior reproducibility—-mathesis/motif/thrownness-disposition,-as-reproducibilityof-aestheticisation' with regards to ecstatic-existence-as-transcendental-signifieremergence/becoming-spontaneity-implications reflected as existence-potency ${ }^{39} \sim$ sublimating- 
nascence,-disclosed-from-prospective-epistemic-digression. But then Heidegger failed to realise that the induced transcendence-and-sublimity/sublimation/supereregatery $\sim$ de-mentativity of the Socratic-philosophers ${ }^{103}$ universalising-idealisation as well as that of Descartes and other budding-positivists rational-empiricism/positivism were both originariness-parrhesia,-asspontaneity-of-aestheticisation disseminative events ${ }^{38}$ induced as of ecstatic-existence-astranscendental-signifier-emergence/becoming-spontaneity-implications reflected as existence-potency ${ }^{39} \sim$ sublimating-nascence,-disclosed-from-prospective-epistemic-digression involving transcendence-and-sublimity/sublimation/supereregatery $\sim$ de-mentativity from nonuniversalising sophistry and medieval-scholasticism pedantic dogmatism respectively; and so as to the fact that dimensionality-of-sublimating $25-\langle<$ amplituding/formative $>$ supererogatery $\sim$ dementativeness/epistemic-growth-or-conflatedness /transvaluativerationalising/transepistemicity/anamnestic-residuality/spirit-drivenness-equalisation〉 as to existence — as-sublimating-withdrawal/unenframing/re-ontologising,-elicited-fromprospective-profound-supererogation is aporetically the more fundamental incipient/seeding originariness-parrhesia,-as-spontaneity-of-aestheticisation to both Descartes thinkingproposition for budding-positivism and Socrates's ${ }^{103}$ universalising-idealisation in then secondarily inducing their respective reproducibility—mathesis/motif/thrownness-disposition,-as-reproducibility-of-aestheticisation' and thus in-many-ways the naïve/flawed conception of Platonism and Cartesianism today arise as to a reasoning as from reproducibilitymathesis/motif/thrownness-disposition,-as-reproducibility-of-aestheticisation perspective whereas Descartes and Plato-and-Plato's Socrates are more fundamentally involved in an postconverging aporeticism-overcoming/unovereoming exercise with respect to medievalscholasticism non-positivising and ancient-sophists non-universalising respectively. These induced transcendence-and-sublimity/sublimation/supererogatoryade-mentativity later on became prior reproducibility - mathesis/motif/thrownness-disposition,-as-reproducibility-of- 
aestheticisation as of their mere 'atrophying mechanical practice' with succeeding generations, and so just as Nietzsche equally appreciated that Christianity was becoming a mere 'atrophying mechanical practice' of succeeding Christian generations as for instance with ascetic practices becoming more of symbolism/aura and losing their inceptive emancipating inspiration. Thus with all these instances rather warranting renewed originariness-parrhesia,-as-spontaneity-ofaestheticisation as to existence - as-sublimating-withdrawal/unenframing/re-ontologising,elicited-from-prospective-profound-supererogation and so as of prospective projection as implied with the relative-unreflexivity/relative-reflexivity ontological-contiguity ${ }^{7} \sim$ of-thehuman-institutionalisation-process ${ }^{68}$, but instead Heidegger will elicit a naïve turn to the preSocratics while Nietzsche will express admiration of Buddhism as both being of grander originariness and ontological-good-faith/authenticity ${ }^{69}$ However going beyond a 'relic-ororthodoxy knowledge' disparateness-of-conceptualisation-<unforegrounding-ment,-failingprospectively-to-reflect-'immanent relative- unreflexivity/relative-reflexivity ontologicalcontiguity ' $>$ notion of philosophy, it is herein contended that this relatively deficient analysis reflects the fundamental ontological-deficiency of subsequent philosophies influenced by Kantian philosophy which is rather 'as a projection within the-very-same intelligible Cartesian/budding-positivists induced rational-empiricism/positivism registryworldview's/dimension's supererogatory $\sim$ acuity/perspicacity/astuteness/edginess/incisivenessof-apriorising/axiomatising/referencing/intelligibilitysettingup/measuringinstrumenting -forconceptualisation' failing to conceive of the ontological-veracity in reflecting holographically$<$ conjugatively-and-transfusively $>$ the relative-unreflexivity/relative-reflexivity-ontologicalcontiguity $\sim$ of-the-human-institutionalisation-process dimensionality-of-sublimating ${ }^{25}$ <<amplituding/formative>supererogatery $\sim$ de-mentativeness/epistemic-growth-orconflatedness /transvaluative-rationalising/transepistemicity/anamnestic-residuality/spiritdrivenness-equalisation) as to difference-conflatedness ${ }^{13}$-as-to-totalitative-reification-in- 
singularisation-<as-to-the-nondisjointedness/entailment-of-prospective- nonpresencing $>$-asveridical-epistemicity-relativism-determinism implied $\quad<$ amplituding/formativeepistemicity $>$ causality $\sim$ as-to-projective-totalitative-implications-of-prospectivenonpresencing,-for-explicating relative-unreflexivity/relative-reflexivity - ontologicalcontiguity successiveness of registry-worldviews/dimensions, with the result that Kantian implied transcendental idealism is veridically 'phenomenal-abstractiveness within the-verysame intelligible rational-empiricism/positivism registry-worldview/dimension ${ }^{83}$ reference-ofthought' (as the true reality of transcendence-and-sublimity/sublimation/supererogatory $\sim$ dementativity is rather one of ${ }^{15}$ de-mentation-/supererogatory $\sim$ ontological-de-mentation-ordialectical-de-mentation - stranding-or-attributive-dialectics〉 involving 'human mentaldisposition successive apriorising/axiomatising/referencing reprojection-or-reanticipation capacity of registry-worldviews/dimensions ${ }^{83}$ reference-of-thought, inducing human limitedmentation-capacity-deepening—as-subjecting limitedness/human-subpotency-to-'educedunlimitedness/existence-sublimating nascence' ${ }^{33}$ as of the very ontologically same existence/existential-reality' so-reflected as the 'difference-conflatedness ${ }^{13}$-as-to-totalitativereification-in-singularisation-<as-to-the-nondisjointedness/entailment-of-prospectivenonpresencing $>$-as-veridical-epistemicity-relativism-determinism of the $<$ cumulating/recomposuring attendant-ontological-contiguity $>$-successive registryworldviews/dimensions as of their successive ${ }^{83}$ reference-of-thought imbued apriorising/axiomatising/referencing-psychologism' construed 'as the successive reproducibility—mathesis/motif/thrownness-disposition,--as-reproducibility-of-aestheticisation supererogatory acuity/perspicacity/astuteness/edginess/incisiveness-ofapriorising/axiomatising/referencing/intelligibilitysettingup/measuringinstrumenting -forconceptualisation for aposteriorising/logicising/deriving/intelligising/measuring of meaningfulness-and-teleology in existence', and so-construed as the 
$<$ cumulating/recomposuring attendant-ontological-contiguity $>$-successive

registry-

worldviews/dimensions consciousness-enabled phenomenal-abstractiveness), and this basic deficient and vacuous assumption fundamentally disorientated Nietzschean and Heideggerian thought wherein a more complete appraisal of Nietzschean transvaluation should rather be as of 'relative-ontological-incompleteness ${ }^{8 /}$ /relative-ontological-completeness ${ }^{87}$.

〈sublimating referencing/registering/decisioning,-as-self-becoming/self-

conflatedness /formative-supererogating-<projective/reprojective-aestheticising-re-motifand-re-apriorising/re-axiomatising/re-referencing,-in-perspective-ontologicalnormalcy/postconvergence $>>$ as to human-and-social-expectations/anticipationsmetaphoricity ${ }^{57}$-as-preconverging/postconverging-redementating/restructuring/reparadigming-psychologism's9 in reflecting holographically$<$ conjugatively-and-transfusively $>$ the relative-unreflexivity/relative-reflexivity - ontologicalcontiguity $\sim$ of-the-human-institutionalisation-process dimensionality-of-sublimating ${ }^{25}$ <<amplituding/formative > supererogatory de-mentativeness/epistemic-growth-orconflatedness /transvaluative-rationalising/transepistemicity/anamnestic-residuality/spiritdrivenness-equalisation> implications beyond just 'transformation from Roman/Master/Hierarchising/Aristocratic value-construct to Judeo-Christian-Islamicmonotheisms/Slave/Dehierarchising/Commoner value-construct as of the-very-same 'universalising-idealisation' speaking rather more of revaluation than transvaluation. It is this underlying misconception that induces subsequent philosophical misinterpretations of notions like <amplituding/formative $>$ wooden-language-_imbued - averaging-of-thought-<as-toleveling/ressentiment/closed-construct-of- meaningfulness-and-teleology -as-of'nondescript/ignorable-void ' -with-regards-to-prospective-apriorising-implications $>$ ), ressentiment and leveling failing to appreciate that these are ontologically-driven as of underlying relative-ontological-completeness ${ }^{87}$ knowledge-reification $\sim$ gesturing-and- 
accounting - of-epistemic-phenomenalism- $<$ in-

prospective_psychologismic apriorising/axiomatising/referencing-\{of-'prospectively

implicited_attendant-ontological-contiguity ' educed-

existentialising/contextualising/textualising_intelligibility/epistemicity/reflexivity-contiguity-

<imbued-notional cogency >' \}-conflatedness -in-\{preconverging-ment by\}

postconverging-entailment $>$ basis of such conceptualisations arising as to the need for prospective emancipating inspiration of prospective originariness-parrhesia,-as-spontaneity-ofaestheticisation inducing human limited-mentation-capacity-deepening-as-subjecting limitedness/human-subpotency to-'educed-unlimitedness/existence-sublimating nascence'

Thus <amplituding/formative $>$ wooden-language-_imbued - averaging-of-thought-<as-toleveling/ressentiment/closed-construct-of- meaningfulness-and-teleology -as-of-

'nondescript/ignorable-void '-with-regards-to-prospective-apriorising-implications $>\rangle$ is herein rather construed as <amplituding/formative> wooden-language-〈imbued-averaging-ofthought-<as-to-leveling/ressentiment/closed-construct-of- meaningfulness-and-teleology -asof-'nondescript/ignorable-void '-with-regards-to-prospective-apriorising-implications $>>$ or ontological-bad-faith/inauthenticity ${ }^{64}$ with respect to 'mechanical practice' of prior reproducibility—mathesis/motif/thrownness-disposition,-as-reproducibility-of-

aestheticisation. In this regards, we can appreciate that all human ${ }^{56}$ meaningfulness-andteleology ${ }^{9}$ arises as of aestheticisation before converging towards ontologisation, just as rightfully implied by Nietzsche's genealogy of morals, but this doesn't imply valuelessness (as is often naively implied with Nietzschean thought) since aestheticisation convergence towards

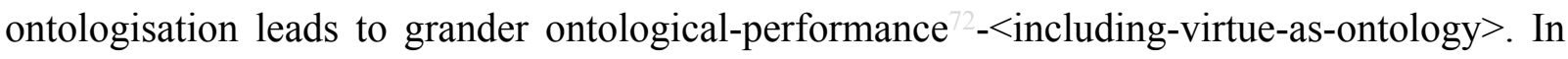
this regards, we can appreciate that while from our vantage modern perspective the ontologicalveracity of the Egyptian cultural system aestheticisation behind the construction of the pyramids will seem inherently impertinent, but that specific human aestheticisation induced technical, 
scientific and mathematical innovations were of lateral civilisational ontological-pertinence; likewise we can appreciate that while for the atheist the ontological-veracity of religion is unproven, however various specific religions human aestheticisation in-many-ways relayed laterally the ontological-veracity of ${ }^{103}$ universalising-idealisation thinkers as of the relatively conducive social conditions allowing for the arrival of medieval thinkers who then instigated the possibility for modern-day science ontologisation; and besides, it can equally perfectly be claimed that even our modern-day positivistic civilisation is not beyond a critique of 'deficient ontologisation' as we can appreciate the reality of the human aestheticisation of many modern activities (even those associated with technological development) held as of higher interest/worth which ontologisation value is questionable with respect to other possible activities of grander ontologisation but not necessarily held as of higher interest/worth (with the very worst case being media-driven merchandising associated with a generalised dumbing-down and deintellectualisation increasingly and surreptitiously substituting for reifying intellectualism, increasingly undermining the citizenry capacity for democratic sovereign judgement). This analysis points to the convoluted relationship between human aestheticisation and ultimate ontologisation value. Rather than naïve and simplistic analysis, it is such an insight that better informs Heideggerian and Nietzschean thought with regards to ressentiment and leveling (as to $<$ amplituding/formative $>$ wooden-language-<imbued - averaging-of-thought- $<$ as-toleveling/ressentiment/closed-construct-of- meaningfulness-and-teleology -as-of'nondescript/ignorable-void '-with-regards-to-prospective-apriorising-implications $>$ )); pointing to the centrality of originariness-parrhesia,-as-spontaneity-of-aestheticisation as more critically about inducing the necessary human-subpotencyaporia/undecidability/dilemma/ought-indeterminacy/deficiency/limitation/constraint of prior reproducibility—mathesis/motif/thrownness-disposition,--as-reproducibility-of-aestheticisation transformation towards prospective ontologisation rather than the mere critique of any given 
human aestheticisation as of its inherence, as the fact is all human aestheticisations including religion (which is often a target in modern times, however rightly so on many an occasion) are sub-ontological-<as-to-the-limitation-of-human-subpotency-in-its-reifying-and-empoweringreflexivity-of-the-full-potency-of-existence's $\sim$ sublimating-nascence $>$ and the more salient point is in instigating their more profound ontologisation/ontological-veracity/aestheticisationtowards-ontology as of relative-ontological-incompleteness $8 /$ relative-ontologicalcompleteness $^{8}$-〈sublimating $\sim$ referencing/registering/decisioning,-as-self-becoming/selfconflatedness /formative-supererogating-<projective/reprojective-aestheticising-re-motifand-re-apriorising/re-axiomatising/re-referencing,-in-perspective-ontologicalnormalcy/postconvergence $>$ > $<$ amplituding/formative-epistemicity $>$ causality $\sim$ as-toprojective-totalitative-implications-of-prospective- nonpresencing,-for-explicating relativeunreflexivity/relative-reflexivity - ontological-contiguity . Such a possibility recurrently arises mainly as of human value-ricochetting/transvaluation - as-to-prospective-relative-ontologicalcompleteness $^{87}$ human-and-social-expectations/anticipations - metaphoricity ${ }^{57}$-aspreconverging/postconverging-rede-mentating/restructuring/reparadigming-psychologism$<$ as-from-perspective-ontological-normalcy/postconvergence $>$. Transvaluation notionally refers to the preconverging/postconverging-de-mentative/structural/paradigmatic referencing basis of human value structure as of social-stake-contention-or-confliction, and is what critically defines the variation of human ontological-performance $2-<$ including-virtue-asontology $>$ /morality/ethics/justice/etc. as from $\quad<$ amplituding/formativeepistemicity $>$ totalising $\sim$ self-referencing-syncretising/circularity/interiorising/akrasiatic-drag temporal inclination for human-subpotency as of the underpinning-suprasocial-construct meaningfulness-and-teleology ${ }^{9}$ or its <amplituding/formative $>$ wooden-language-_imbuedaveraging-of-thought-<as-to-leveling/ressentiment/closed-construct-of- meaningfulness-andteleology -as-of-'nondescript/ignorable-void '-with-regards-to-prospective-apriorising- 
implications $>>$ determination' to 'ascetic intemporal inclination for existencepotency ${ }^{39} \sim$ sublimating-nascence,-disclosed-from-prospective-epistemic-digression determination'; and so as to the fact that prospective sublimation-over-desublimation of human reference-of-thought-and- ${ }^{83}$ reference-of-thought- ${ }^{8}$ devolving $-{ }^{5}$ meaningfulness-andteleology ${ }^{9}$ involves prospective 'originariness-parrhesia,-as-spontaneity-of-aestheticisationsupererogatery acuity/perspicacity/astuteness/edginess/incisiveness-ofapriorising/axiomatising/referencing/intelligibilitysettingup/measuringinstrumenting -forconceptualisation' in attending to the 'prior requisite human experiential framework to be challenged-disproved-invalidated' highlighting the facet of the existentially-withdrawn-〈as'unaccounted-for'-leftover-or-residuality-or-spirit-of- meaningfulness-and-teleology -soconstrued-as-metaphoricity ,-informing-prospectivesupererogatory acuity/perspicacity/astuteness/edginess/incisiveness,-so-reflected-andcompensated-with-the-notion-of-dimensionality-of-sublimating <<amplituding/formative > supererogatory de-mentativeness/epistemic-growth-orconflatedness /transvaluative-rationalising/transepistemicity/anamnestic-residuality/spiritdrivenness-equalisation $\rangle$ ) as limiting or of prospective human-subpotency aporeticism' and socaptured by the notion of prospective dimensionality-of-sublimating <<amplituding/formative >supererogatory de-mentativeness/epistemic-growth-orconflatedness /transvaluative-rationalising/transepistemicity/anamnestic-residuality/spiritdrivenness-equalisation) for prospective human limited-mentation-capacity-deepening-assubjecting limitedness/human-subpotency to 'educed-unlimitedness/existence-sublimating nascence' as to human psychoanalytic-unshackling/memetic-reordering/institutionalrecomposuring. Transvaluation as to existence-potency ${ }^{32} \sim$ sublimating-nascence,-disclosedfrom-prospective-epistemic-digression implies the ontological-veracity of all values is derived from their 'relative-ontological-incompleteness $8 /$ relative-ontological-completeness 


\section{〈sublimating $\sim$ referencing/registering/decisioning,-as-self-becoming/self-}

conflatedness /formative-supererogating-<projective/reprojective-aestheticising-re-motifand-re-apriorising/re-axiomatising/re-referencing,-in-perspective-ontologicalnormalcy/postconvergence $>>$ as to human-and-social-expectations/anticipationsmetaphoricity ${ }^{57}$-as-preconverging/postconverging-redementating/restructuring/reparadigming-psychologism' ${ }^{89}$ in reflecting holographically$<$ conjugatively-and-transfusively $>$ the relative unreflexivity/relative reflexivity - ontologicalcontiguity $\sim$ of-the-human-institutionalisation-process dimensionality-of-sublimating ${ }^{25}$ < <amplituding/formative>supererogatory $\sim$ de-mentativeness/epistemic-growth-orconflatedness /transvaluative-rationalising/transepistemicity/anamnestic-residuality/spiritdrivenness-equalisation $\rangle$ as of difference-conflatedness ${ }^{3}$-as-to-totalitative-reification-insingularisation-<as-to-the-nondisjointedness/entailment-of-prospective- nonpresencing $>$-asveridical-epistemicity-relativism-determinism implied $\quad<$ amplituding/formativeepistemicity $>$ causality as-to-projective-totalitative-implications-of-prospectivenonpresencing,-for-explicating $\sim$ relative unreflexivity/relative reflexivity —ontologicalcontiguity (that doesn't allow for any nondescript/ignorable-void to allow for notionalcontiguity/epistemic-contiguity ${ }^{62}<$ - profound-supererogation -of-mentallyaestheticised $\sim$ postconverging/dialectical-thinking -qualia-schema $>$ ) while the value proposition as of human-subpotency is one that is based on absolutising the present ${ }^{8}$ reference-

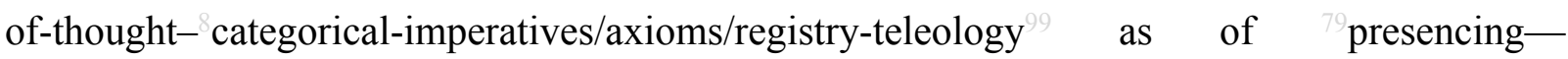
absolutising-identitive-constitutedness ${ }^{1 /} /$ identitive-constitutedness $^{14}$-as-'epistemic-totality ${ }^{37}$ dereification-in-dissingularisation- $<$ as-to-the-disjointedness/ment-of- presencingabsolutising-identitive-constitutedness $>$-as-flawed-epistemicity-relativism-determinism (allowing for nondescript/ignorable-void inducing notional-discontiguity/epistemicdiscontiguity ${ }^{6}<$ between - prior-shallow-supererogation -of-mentally- 
aestheticised preconverging/dementing -qualia-schema_and_prospective-profound-

supererogation -of-mentally-aestheticised postconverging/dialectical-thinking -qualia-

schema $>$ ); and this basic human value dichotomy explains the re-originary-_as-unenframed-_. ontologising/unbeholdening/outlier-conceptualisation-_imbued-postconverging/dialecticalthinking -'projective-insights'/‘epistemic-projection-in-conflatedness ' 'of-

notional deprocrypticism-prospective-sublimation>

nature

ricochetting/transepistemicity

of

and

epistemic-

sublimity/sublimation/supererogatory de-mentativity instigation as of prospective dimensionality-of-sublimating 25 -<amplituding/formative > supererogatory $\sim$ de-

\section{mentativeness/epistemic-growth-or-conflatedness /transvaluative-}

rationalising/transepistemicity/anamnestic-residuality/spirit-drivenness-equalisation)

originariness-parrhesia,-as-spontaneity-of-aestheticisation and subsequent prospective secondnatured reproducibility—mathesis/motif/thrownness-disposition,-as-reproducibility-ofaestheticisation. In this regards, it is important to grasp that human secondnaturing capacity is just as critical as human dimensionality-of-sublimating ${ }^{25}$

\section{<<amplituding/formative>supererogatory $\sim$ de-mentativeness/epistemic-growth-or-}

\section{conflatedness /transvaluative-rationalising/transepistemicity/anamnestic-residuality/spirit-}

drivenness-equalisation) capacity for the relative-unreflexivity/relative-reflexivityontological-contiguity ${ }^{67}$ of-the-human-institutionalisation-process ${ }^{68}$ to be able to materially/substantively arise, notwithstanding the contradiction that secondnatured reproducibility—mathesis/motif/thrownness-disposition,--as-reproducibility-of-aestheticisation is 'bound to be reflected as teleologically-degraded' prospectively as a destructuring-threshold〈uninstitutionalised-threshold /presublimating-desublimating-decisionality $\rangle$ of-ontological-

performance ${ }^{2}-<$ including-virtue-as-ontology $>$ /morality/ethics/justice/etc. as of mere 'mechanical practice' that fails prospective anamnesis as of ecstatic-existence-as-transcendental- 
signifier-emergence/becoming-spontaneity-implications reflected as existencepotency $^{39} \sim$ sublimating-nascence,-disclosed-from-prospective-epistemic-digression from such human-subpotency prior reproducibility-mathesis/motif/thrownness-disposition,--asreproducibility-of-aestheticisation. In this regards, we can appreciate that when baseinstitutionalisation 'rulemaking-over-non-rules—apriorising/axiomatising/referencingpsychologism'

apriorising/axiomatising/referencing/intelligibilitysettingup/measuringinstrumenting arises, the value structure of recurrent-utter-uninstitutionalisation collapses, and likewise across all the prospective registry-worldviews/dimensions, with the implication that our naïve conception of value as of mere-and-vague impression-driven/good-naturedness/wishfulness is not what is preconverging/postconverging-de-mentatively/structurally/paradigmatically deterministic but rather the-Good/knowledge-reification gesturing-and-accounting-of-epistemicphenomenalism- $<$ in-prospective_psychologismic $\sim$ apriorising/axiomatising/referencing-\{of'prospectively_implicited_attendant-ontological-contiguity ' educedexistentialising/contextualising/textualising_'intelligibility/epistemicity/reflexivity-contiguity$<$ imbued-notional cogency $>$ ' $\}$-conflatedness -in-\{preconverging ment by\} posteonverging entailment $>$ /understanding/<amplituding/formativeepistemicity $>$ causality $\sim$ as-to-projective-totalitative-implications-of-prospectivenonpresencing,-for-explicating relative unreflexivity/relative-reflexivity - ontological-

contiguity lies in the preconverging/postconverging-de-mentative/structural/paradigmatic effectuation of transcendence-and-sublimity/sublimation/supereregatery de-mentativity in the bigger social construct as of the psychoanalytic-unshackling/memetic-reordering/institutionalrecomposuring involving the prospective construction-of-the-Self from trepidatiousconsciousness, warped-consciousness, preclusive-consciousness, occlusive-consciousness and prospectively protensive-consiousness so-implied with the relative-unreflexivity/relative- 
reflexivity ontological-contiguity ${ }^{67}$ of-the-human-institutionalisation-process

$<$ amplituding/formative-epistemicity $>$ causality $\sim$ as-to-projective-totalitative-implications-ofprospective- nonpresencing,-for-explicating relative-unreflexivity/relative-reflexivity-

ontological-contiguity induced prior to prospective registry-worldviews/dimensions transvaluation 'reflecting deterministically the structure of human ${ }^{56}$ meaningfulness-andteleology ${ }^{9}$ as of $<$ amplituding/formative-epistemicity $>$ causality $\sim$ as-to-projective-totalitativeimplications-of-prospective- nonpresencing,-for-explicating relative-unreflexivity/relativereflexivity - ontological-contiguity '. Transvaluation thus speaks to human value-construct foregrounding_entailment- $<$ in-succession-of-profound-supererogation $>>-\langle$ postconvergingnarrowing-down sublimation-as-to-'existence - as-sublimating-withdrawal/unenframing/reontologising,-elicited-from-prospective-profound-supererogation '-in-reflecting‘immanent relative-unreflexivity/relative-reflexivity ontological-contiguity ';-as-operativenotional deprocrypticism $\rangle$ on the reference basis of the <amplituding/formativeepistemicity $>$ causality $\sim$ as-to-projective-totalitative-implications-of-prospectivenonpresencing,-for-explicating relative-unreflexivity/relative-reflexivity ontologicalcontiguity in reflecting holographically-<conjugatively-and-transfusively $>$ the relativeunreflexivity/relative-reflexivity - ontological-contiguity of-the-human-institutionalisationprocess anamnesis as of difference-conflatedness ${ }^{13}$-as-to-totalitative-reification-insingularisation-<as-to-the-nondisjointedness/entailment-of-prospective- nonpresencing $>$-asveridical-epistemicity-relativism-determinism, as undermining the successive registryworldview's/dimension's implied temporal/sycophantic-sophistic 79 presencing—absolutisingidentitive-constitutedness ${ }^{14} \quad$ ontologically-flawed disparateness-of-conceptualisation$<$ unforegrounding-ment,-failing-prospectively-to-reflect-'immanent relativeunreflexivity/relative-reflexivity ontological-contiguity '> value-construct conceptions. Transvaluation rather reflects human value-construct as derivational as from the very enabling 
fundamental self-consciousness instigation for the possibility of 'human self-conscious awareness of value-construct' to arise in the first place as of apriorising/axiomatising/referencing-psychologism implied reference basis-of/base meaningfulness-and-teleology infrastructure. Thus the more critical contribution to human value-construct has to do with the requisite value-construct instigating as of dispensing-withimmediacy-for-relative-ontological-completeness ${ }^{87}$-by-reification/contemplative-distension (as of human self-surpassing — existentialism-form-factor,-in-overcoming'notional collateralising-beholdening-protohumanity'-to-'attain-sublimating-humanity'-as-toexistence-potency $\sim$ sublimating-nascence,-disclosed-from-prospective-epistemic-digression

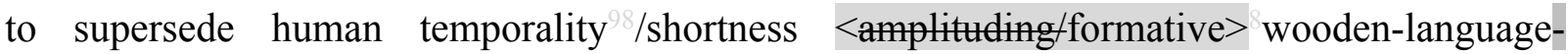
〈imbued — averaging-of-thought-<as-to-leveling/ressentiment/closed-construct-ofmeaningfulness-and-teleology -as-of-'nondescript/ignorable-void '-with-regards-toprospective-apriorising-implications $>\rangle$ ) associated with the successive registryworldview's/dimension's self-conscious ${ }^{56}$ meaningfulness-and-teleology infrastructure soimplied successively as of trepidatious-self-consciousness, warped-self-consciousness, preclusive-self-consciousness, occlusive-self-consciousness and prospectively protensive-selfconsciousness; as the human proclivity to even recognise and pursue any value-construct can only arise in-the-very-first-place with its correspondingly induced self-consciousness. But then, the fact remains that such dimensionality-of-sublimating ${ }^{25}$ <<amplituding/formative>supererogatory de-mentativeness/epistemic-growth-orconflatedness /transvaluative-rationalising/transepistemicity/anamnestic-residuality/spiritdrivenness-equalisation〉 induced self-consciousness ${ }^{56}$ meaningfulness-and-teleology infrastructure as instigative of the human reference basis reproducibilitymathesis/motif/thrownness-disposition,-as-reproducibility-of-aestheticisation of valueconstruct tend to be related to by the suprasocial-contruct and <amplituding/formative $>$ wooden- 
language-〈imbued — averaging-of-thought-<as-to-leveling/ressentiment/closed-construct-ofmeaningfulness-and-teleology -as-of-‘nondescript/ignorable-void '-with-regards-toprospective-apriorising-implications $>>$ dispositions as being beyond-the-consciousnessawareness-teleology 9 - $<$ of-preconverging-existential-extrication-as-of-existential-unthought $>$ (as to when the inherent ontologisation/ontological-veracity/aestheticisation-towards-ontology implications of prospective relative-ontological-completeness ${ }^{87}$ as of human limited-mentationcapacity-deepening_as-subjecting-limitedness/human-subpotency-to-'educedunlimitedness/existence-sublimating nascence' ${ }^{53}$ is blanked out as nondescript/ignorablevoid ), and rather tends to come at 'dimensionality-of-sublimating ${ }^{25}$ <<amplituding/formative>supererogatery $\sim$ de-mentativeness/epistemic-growth-or-

conflatedness /transvaluative-rationalising/transepistemicity/anamnestic-residuality/spiritdrivenness-equalisation〉 induced self-consciousness ${ }^{5}$ meaningfulness-and-teleology infrastructure' in a secondnatured positive-opportunism-of-social-functioning-andaccordance ${ }^{75}$ disposition and so in reflecting holographically-<conjugatively-and-transfusively $>$ the relative-unreflexivity/relative-reflexivity - ontological-contiguity of-the-humaninstitutionalisation-process ; explaining the inclination of all $<$ cumulating/recomposuring attendant-ontological-contiguity $>$-successive registryworldviews/dimensions to be engrossed in a $<$ amplituding/formative $>$ wooden-language〈imbued - averaging-of-thought-<as-to-leveling/ressentiment/closed-construct-ofmeaningfulness-and-teleology -as-of-'nondescript/ignorable-void '-with-regards-toprospective-apriorising-implications $>\rangle$ in $<$ amplituding/formative-epistemicity $>$ totalising $\sim$ selfreferencing-syncretising/circularity/interiorising/akrasiatic-drag ${ }^{34}$ difficultly recognising the idea of prospective destructuring-threshold-〈uninstitutionalised-threshold /presublimating-

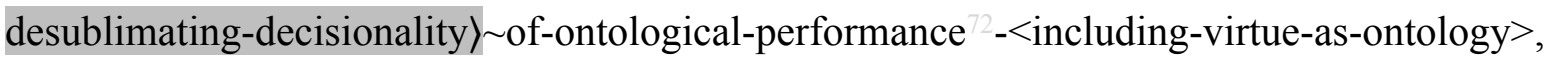
and wary of prospective transcendence-and-sublimity/sublimation/supererogatory $\sim$ de- 
mentativity implications that can be instigated as of prospective 'dimensionality-ofsublimating 25 -<<mplituding/formative $>$ supererogatory $\sim$ de-mentativeness/epistemic-growthor-conflatedness /transvaluative-rationalising/transepistemicity/anamnestic-residuality/spiritdrivenness-equalisation〉 induced self-consciousness ${ }^{56}$ meaningfulness-and-teleology infrastructure'. It is thus not odd that as of human emotional-involvement implications, Socraticphilosophers ${ }^{103}$ universalising-idealisation and budding-positivists projected ${ }^{5}$ meaningfulnessand-teleology infrastructure rather met initially with the antipathy of their underpinningsuprasocial-construct and <amplituding/formative $>$ wooden-language-〈imbued-averaging-ofthought-<as-to-leveling/ressentiment/closed-construct-of- meaningfulness-and-teleology -asof-'nondescript/ignorable-void '-with-regards-to-prospective-apriorising-implications $>>$ and specifically had to face up respectively with the value-construct conception of their temporal/sycophantic-sophistic $\quad{ }^{79}$ presencing-absolutising-identitive-constitutedness ontologically-flawed disparateness-of-conceptualisation-<unforegrounding-ment,-failingprospectively-to-reflect-'immanent relative unreflexivity/relative reflexivity - ontologicalcontiguity '> whether with the ancient-sophists or medieval-scholasticism pedants. We can further appreciate the critical impact of the ${ }^{103}$ universalising-idealisation ${ }^{56}$ meaningfulness-andteleology ${ }^{9}$ infrastructure of the Socratic-philosophers and their successors as providing the appropriate ${ }^{56}$ meaningfulness-and-teleology ${ }^{9}$ infrastructure for the Roman Empire and subsequent religio-political developments unlike the case with say Ancient Egypt and Persia whose non-universalising sectarian cults perpetual ideological conflicts ultimately sapped their stability despite their technical advancement, and likewise Western enlightenment effectively arose as of the induced ${ }^{56}$ meaningfulness-and-teleology ${ }^{9}$ infrastructure of budding-positivists, with perverted consequences like annihilation of Native Indians in the New World and the Transatlantic slavery rather arising as of their far-flung societies opportunistic activities distortive of budding-positivism ${ }^{56}$ meaningfulness-and-teleology ${ }^{9}$ infrastructure as so- 
construed in their core societies in Europe with respect to the ending of serfdom, nascent socioeconomic emancipation and human rights. Thus basically the idea of human valueconstruction is ever always caught up between on-the-one-hand human limited-mentationcapacity -as-subjecting 'educed-unlimitedness/existence-sublimating nascence' tolimitedness/human-subpotency to come to terms with 'transvaluation as $<$ amplituding/formative-epistemicity $>$ causality $\sim$ as-to-projective-totalitative-implications-ofprospective- nonpresencing,-for-explicating relative-unreflexivity/relative-reflexivity ontological-contiguity in reflecting holographically-<conjugatively-and-transfusively $>$ the relative-unreflexivity/relative-reflexivity - ontological-contiguity of-the-humaninstitutionalisation-process anamnesis as of difference-conflatedness ${ }^{13}$-as-to-totalitativereification-in-singularisation-<as-to-the-nondisjointedness/entailment-of-prospectivenonpresencing $>$-as-veridical-epistemicity-relativism-determinism underlying the human construction-of-the-Self' and on-the-other-hand the 'effective ontologicalimpertinence/dereification arising in the conceptualising of human value-construction as of a $<$ amplituding/formative $>$ wooden-language-_imbued—averaging-of-thought-<as-toleveling/ressentiment/closed-construct-of- meaningfulness-and-teleology -as-of'nondescript/ignorable-void '-with-regards-to-prospective-apriorising-implications $>>\quad$ in $<$ amplituding/formative-epistemicity $>$ totalising $\sim$ self-referencingsyncretising/circularity/interiorising/akrasiatic-drag ${ }^{34}$ as construing of value-construction within any given registry-worldview's/dimension's ${ }^{79}$ presencing-absolutising-identitiveconstitutedness ${ }^{14}$-of- ${ }^{56}$ meaningfulness-and-teleology 9 and so whether as of trepidatious (recurrent-utter-uninstitutionalisation), warped (base-institutionalisation-ununiversalisation), preclusive ( ${ }^{103}$ universalisation-non-positivism/medievalism) or occlusive (positivismprocrypticism) implications'. This discrepancy (between the human capacity to achieve transvaluation and effective social-value-construction narrative as of any given registry- 
worldview/dimension) is reflected in the underlying reality that effectively practised human value-construction is the 'outcome of privileged institutional end-purpose perspective/framing/reference/horizon/projection'; wherein social-value-construction across the <cumulating/recomposuring attendant-ontological-contiguity $>$-successive registryworldviews/dimensions arises as a functional necessity that is meant to reflect supposedly coherent ontological-commitment -<implied-self-assuredness-of-ontological-goodfaith/authenticity postconverging-de-mentating/structuring/paradigming -as-being-as-ofexistential-reality $>$ and so in order to elicit stable social-functioning-and-accordance for socialstake-contention-or-confliction, whether such social-value-construction is ontologicallypertinent or not. In this respect, the reality in reflecting holographically-<conjugatively-andtransfusively $>$ the relative-unreflexivity/relative-reflexivity ontological-contiguity $\sim$ of-thehuman-institutionalisation-process points to changing 'preconverging/postconverging-dementative/structural/paradigmatic marginal equity of social-value-construction', so-construed as 'expected equity of all individuals for social-value-construction' and so rather as from the preconverging/postconverging-de-mentative/structural/paradigmatic reference basis of 'priorly implied-and-justified inequity' whether the latter is implied-and-justified as of talent, royalty, class, productivity, mere traditional and cultural practice justification, etc.; thus effectively reflecting the overall consequence of social-value-construction as the 'outcome of privileged institutional end-purpose perspective/framing/reference/horizon/projection'. In this regards, social-value-construction arises from two levels; as of the inherent preconverging/postconverging-de-mentative/structural/paradigmatic implication of 'outcome of privileged institutional end-purpose perspective/framing/reference/horizon/projection' as of 'priorly implied-and-justified inequity' and this in conjugation then with the individual inherently appraisable social-value-construction as of 'expected equity of all individuals for social-value-construction'. In this respect, we can appreciate that an autocrat is more capable of 
'displaying greater social-value-construction' than an ordinary denizen by the former's mere social-value-construction 'priorly implied-and-justified inequity' as of its status in the autocracy (however an autocrat's apparent magnanimity on the basis of the prior perspective of the autocratic society will rather be construed as of deficient value-construction as from a prospective perspective of <amplituding/formative-epistemicity $>$ causality $\sim$ as-to-projectivetotalitative-implications-of-prospective- nonpresencing,-for-explicating relative-

unreflexivity/relative-reflexivity - ontological-contiguity comparison to the overall social and virtue progress implications of a better accountable political system, while on-the-other-hand individuals effectively advocating for such a prospective political system may be construed as of deficient value-construction in the prior autocracy), while modern-day social-valueconstruction 'priorly implied-and-justified inequity' arises as of politico-bureaucratic, talent, entrepreneurial, socio-historical, traditional and cultural practice justification, etc. implications (but is just as well subject to transvaluation analysis as of <amplituding/formativeepistemicity $>$ causality $\sim$ as-to-projective-totalitative-implications-of-prospectivenonpresencing,-for-explicating relative-unreflexivity/relative-reflexivity - ontological-

contiguity , as it can perfectly be argued that the apparent magnanimity of plutocrats as of a capitalistic economic value-distributive system 'excessively skewed towards final product/service/financial delivery as-of-first-come-near-monopoly and institutionally-skewedpossibility-for recurring wealth accumulation' while excessively overlooking/devaluing the return to massive public externalities/external-resources contributions to economic production such as public education, human and social development, infrastructure, basic research, technological research, etc. rather speaks of deficient social-value-construction, especially as such a system 'priorly implied-and-justified inequity' as of its occlusive ${ }^{79}$ presencingabsolutising-identitive-constitutedness ${ }^{14}$ is geared towards propping special interests, warfare spending, anti-taxation, anti-immigration, trivial interest in global human development, co-opted 
media narrative, etc. as of a suboptimal social-value-construction). But this doesn't cancel the fact that individuals throughout sublimating ${ }^{4}$ historiality/ontologicaleventfulness 38 ontological-aesthetic-tracing-<perspective-ontologicalnormalcy/postconvergence-reflected-'epistemicity-relativism-determinism'> notwithstanding any disadvantaged 'priorly implied-and-justified inequity' for social-value-construction, intuitively cognisant of the pertinence of human transvaluation have elicited the underlying ontological-veracity/ontological-impertinence of their social-construct value-construction as of its supposedly coherent ontological-commitment $-<$ implied - self-assuredness-of-ontologicalgood-faith/authenticity postconverging-de-mentating/structuring/paradigming -as-beingas-of-existential-reality $>$ to induce the transformation of the social-setup value-construction; such that at various critical times the more salient 'priorly implied-and-justified inequity' for social-value-construction had thus been basically intellectual-pertinence-as-of-ontologicalveracity such that all other 'priorly implied-and-justified inequity' for social-value-construction have tended critically to ultimately be grounded on intellectual-pertinence-as-of-ontologicalveracity whether of genuine or surreptitious justification. The more salient issue then for the knowledge-reification $\sim$ gesturing-and-accounting_-of-epistemic-phenomenalism- $<$ inprospective_psychologismic apriorising/axiomatising/referencing-\{of- ${ }^{\text {prospectively }}$ implicited_attendant-ontological-contiguity ' reducedexistentialising/contextualising/textualising_ intelligibility/epistemicity/reflexivity-contiguity$<$ imbued-notional cogency $>$ ' \}-conflatedness -in-\{preconverging -ment by\} pestconverging entailment $>$ of social-value-construction thus lies with its 'priorly implied-andjustified inequity' narrative(s) with respect to underlying knowledge-reifying transvaluation implications projection as being of most profound intellectual-pertinence-as-of-ontologicalveracity. In this regards, our present rational-empiricism/positivism occlusivity warrants prospective ${ }^{5}$ meaningfulness-and-teleology infrastructure transvaluation so-implied as of 
notional ${ }^{18}$ deprocrypticism or $<$ amplituding/formative $>$ notional preempting — disjointednessas-of- ${ }^{8}$ reference-of-thought appropriate ${ }^{45}$ foregrounding_entailment- $<$ in-succession-ofprofound-supererogation ${ }^{9}>$-〈postconverging-narrowing-down $\sim$ sublimation-as-to- ${ }^{\text {existence- }}$ as-sublimating-withdrawal/unenframing/re-ontologising,-elicited-from-prospective-profoundsupererogation '-in-reflecting-'immanent relative unreflexivity/relative reflexivity ontological-contiguity ';--as-operative-notional deprocrypticism); and so as the disparateness-of-conceptualisation-<unforegrounding-ment,-failing-prospectively-to-reflect‘immanent $\sim$ relative-unreflexivity/relative-reflexivity - ontological-contiguity '> of our rational-empiricism/positivism occlusivity in its <amplituding/formative $>$ wooden-language〈imbued-averaging-of-thought-<as-to-leveling/ressentiment/closed-construct-ofmeaningfulness-and-teleology -as-of-'nondescript/ignorable-void '-with-regards-toprospective-apriorising-implications $>>$ tend to rather reflect our <amplituding/formativeepistemicity $>$ totalising $\sim$ self-referencing-syncretising/circularity/interiorising/akrasiatic-drag 34 . The occlusivity of our positivism/rational-empiricism social-value-construction as such from the prospective perspective of deprocrypticism-or-preempting-disjointedness-as-ofreference-of-thought can be analysed-and-construed as imbued with occlusive collateral aspects of rather nondescript/ignorable-void falsely implying the 'appropriate exhaustiveness of our rational-empiricism/positivism stances' thus speaking rather of ideology than ontologicalveracity as aptly reflected upon by postmodern-thought. Such occlusive-collateral aspects take the form of economic dysfunction and inequities as occlusively-collateral to economic ideologism, social dysfunction and discriminations as occlusively-collateral to domineering and secluding social narratives, sophistic/pedantic and vested interest undermining genuine sovereignty paradoxically as of obscured-and-deluding knowledge and misinformation that undermines individuals sovereign competence and choice with regards to increasingly skewedcontrived-and-limited stakes of the democratic process thus eliciting protest voting, and in the 
bigger global framework of competing politico-cultural values with individuals and societies rather construed occlusively as collateral damages. Transvaluation analysis thus ensues from the human akrasia-susceptibility-or-akrasiatic-drag complex which implies that the very state of unwariness with respect to prior relative-ontological-incompleteness ${ }^{88}$ as of a nihilistic disposition is preconverging/postconverging-de-mentatively/structurally/paradigmatically potently conducive/endemising/enculturating of its vices-and-impediments ${ }^{105}$ (as so-reflecting the grandest deeds of ontological-performance $2-<$ including-virtue-asontology $>$ /morality/ethics/justice/etc. of any given registry-worldview's/dimension's with regards to its 'destructuring-threshold-〈uninstitutionalised-threshold /presublimating-

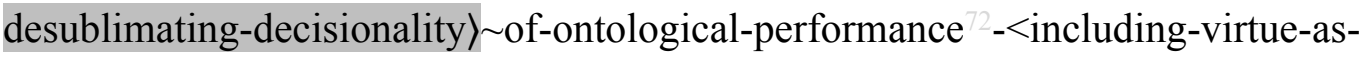
ontology $>$ /morality/ethics/justice/etc. dynamics of notional firstnaturedness-formativeness<as-to-eventualising inkling-drive-or-seeding-misprising > temporal-to-intemporaldispositions-<so-construed-as-from-perspective-ontological-normalcy/postconvergence $>$ ' ). But then while such an abstract transvaluation perspective for the construal of social-valueconstruction is cogently obvious, however the fact remains that the human subject as of its limited-mentation-capacity—as-subjecting-'educed-unlimitedness/existence-sublimating nascence' to-limitedness/human-subpotency exists in circumstances of human-subpotencyaporia/undecidability/dilemma/ought-indeterminacy/deficiency/limitation/constraint as of its given reproducibility—mathesis/motif/thrownness-disposition,--as-reproducibility-ofaestheticisation inducing its deficient ontological-performance ${ }^{72}-$ including-virtue-asontology $>$ /morality/ethics/justice/etc. thus explaining its given registry-worldview/dimension vices-and-impediments ${ }^{105}$. Thus the transvaluation of the $<$ cumulating/recomposuring attendant-ontological-contiguity $>$-successive registryworldviews/dimensions in reflecting holographically-<conjugatively-and-transfusively $>$ the relative-unreflexivity/relative-reflexivity - ontological-contiguity of-the-human- 
institutionalisation-process is critically of dimensionality-of-sublimating ${ }^{25}$ <<amplituding/formative >supererogatory $\sim$ de-mentativeness/epistemic-growth-or-

conflatedness /transvaluative-rationalising/transepistemicity/anamnestic-residuality/spirit-

drivenness-equalisation) psychoanalytic-unshackling/memetic-reordering/institutionalrecomposuring implications of dispensing-with-immediacy-for-relative-ontologicalcompleteness $^{87}$-by-reification/contemplative-distension 27 (as of human self-surpassingexistentialism-form-factor,-in-overcoming-‘notional collateralising-beholdeningprotohumanity'-to-'attain-sublimating-humanity'-as-to-existence-potency sublimatingnascence,-disclosed-from-prospective-epistemic-digression to supersede human temporality 8 /shortness <amplituding/formative> wooden-language-〈imbued-averaging-ofthought-<as-to-leveling/ressentiment/closed-construct-of- meaningfulness-and-teleology -asof-'nondescript/ignorable-void '-with-regards-to-prospective-apriorising-implications $>\rangle$ ) as of successive human construction-of-the-Self as from based animality to trepidatious-selfconsciousness, warped-self-consciousness, preclusive-self-consciousness, occlusive-selfconsciousness and prospectively protensive--self-consciousness. Thus human limited-mentationcapacity—as-subjecting-'educed-unlimitedness/existence-sublimating nascence' tolimitedness/human-subpotency implies that 'more than just a thought-of ontological notion' as of transvaluation, social-value-construction is rather accomplished phronetically/in-practicality as of the specific social-setup ${ }^{103}$ universal-transparency ${ }^{104}$-〈transparency-of-totalisingentailing,-as-to-entailing-<amplituding/formative-epistemicity $>$ totalising $\sim$ in-relativeontological-completeness $>$ of supposedly coherent ontological-commitment $-<$ implied - selfassuredness-of-ontological-good-faith/authenticity $\sim$ postconverging-dementating/structuring/paradigming -as-being-as-of-existential-reality $>$ with respect to socialstake-contention-or-confliction; and is bound rather to be highly infused with 'priorly impliedand-justified inequity' narrative(s) where such ${ }^{103}$ universal-transparency ${ }^{104}$-〈transparency-of- 
totalising-entailing,-as-to-entailing-<amplituding/formative-epistemicity $>$ totalising $\sim$ in-

relative-ontological-completeness $\rangle$ is muted and where such ${ }^{103}$ universal-transparency ${ }^{104}$ 〈transparency-of-totalising-entailing,-as-to-entailing-<amplituding/formative-

epistemicity $>$ totalising in-relative-ontological-completeness $\rangle$ is unmuted rather infused with 'expected equity of all individuals for social-value-construction' narrative(s). Basically, thus the reality of prospective social-value-construction critically arises as of the intemporal ontologicalfaith-notion-or-ontological-fideism—imbued-underdetermination-of-motif-and-

apriorising/axiomatising/referencing-as-so-being-as-of-existential-reality parrhesiastic askesisor-acumen reasoning-through/messianic-reasoning induced originariness-parrhesia,--asspontaneity-of-aestheticisation with respect to the prospective human-subpotencyaporia/undecidability/dilemma/ought-indeterminacy/deficiency/limitation/constraint, which when naively construed in ${ }^{7}$ presencing - absolutising-identitive-constitutedness ${ }^{14}$ as of prior reproducibility—mathesis/motif/thrownness-disposition,--as-reproducibility-of-aestheticisation simply reflects the <amplituding/formative-epistemicity $>$ totalising $\sim$ self-referencingsyncretising/circularity/interiorising/akrasiatic-drag ${ }^{34}$ of the prior registry-worldview/dimension as reflected with its social value-construct dilemmas. Consider in this regards the implications for an individual having to respond to an accusation of sorcery in a non-positivism social-setup as the individual and the social-setup both effectively believe in superstition. Transvaluation insight will point out that ontological-veracity as of ${ }^{45}$ foregrounding_entailment- $<$ insuccession-of-profound-supererogation $>>$-〈postconverging-narrowing-down $\sim$ sublimation-asto-'existence - as-sublimating-withdrawal/unenframing/re-ontologising,-elicited-fromprospective-profound-supererogation '-in-reflecting-'immanent relativeunreflexivity/relative-reflexivity - ontological-contiguity ' $;$;-as-operativenotional deprocrypticism $\rangle$ lies with the-Good/knowledge-reification $\sim$ gesturing-andaccounting - of-epistemic-phenomenalism- $<$ in- 
prospective_psychologismic apriorising/axiomatising/referencing-\{of-'prospectively_

implicited_attendant-ontological-contiguity ' educed-

existentialising/contextualising/textualising_'intelligibility/epistemicity/reflexivity-contiguity-

$<$ imbued-notional cogency $\left.>^{\prime},\right\}$-conflatedness -in-\{preconverging ment by\}

postconverging-entailment $>$ /understanding/<amplituding/formative-

epistemicity $>$ causality $\sim$ as-to-projective-totalitative-implications-of-prospective-

nonpresencing,-for-explicating relative unreflexivity/relative-reflexivity - ontological-

contiguity as of ecstatic-existence-as-transcendental-signifier-emergence/becomingspontaneity-implications reflected as existence-potency ${ }^{32} \sim$ sublimating-nascence,-disclosedfrom-prospective-epistemic-digression required prospective rational-empiricism/positivism registry-worldview/dimension construction-of-the-Self in deflating the non-positivistic socialsetup value-construction dilemmas as impression-driven/good-naturedness/wishfulness $<$ amplituding/formative $>$ wooden-language-<imbued — averaging-of-thought-<as-toleveling/ressentiment/closed-construct-of- meaningfulness-and-teleology -as-of'nondescript/ignorable-void '-with-regards-to-prospective-apriorising-implications $>>\quad$ in social-aggregation-enabling of the prior non-positivistic registry-worldview/dimension soassociated with notions-and-accusations-of-sorcery. Likewise implied social-value-construction dilemmas in our positivism- ${ }^{-1}$ procrypticism are ontologically deflated as of foregrounding_entailment-<in-succession-of-profound-supererogation $>>-\langle$ postconvergingnarrowing-down $\sim$ sublimation-as-to-'existence - as-sublimating-withdrawal/unenframing/reontologising,-elicited-from-prospective-profound-supererogation '-in-reflecting'immanent relative- unreflexivity/relative-reflexivity ontological-contiguity ';-as-operativenotional deprocrypticism $\rangle$ with the-Good/knowledge-reification gesturing-and-accountingof-epistemic-phenomenalism- $<$ in- 
implicited_attendant-ontological-contiguity ' reduced-

existentialising/contextualising/textualising_'intelligibility/epistemicity/reflexivity_contiguity$<$ imbued-notional cogency >' \}-conflatedness - in-\{preconverging ment by\}

postconverging-entailment $>$ /understanding/<amplituding/formative-

epistemicity $>$ causality $\sim$ as-to-projective-totalitative-implications-of-prospective-

nonpresencing,-for-explicating relative-unreflexivity/relative-reflexivity ontological-

contiguity as of ecstatic-existence-as-transcendental-signifier-emergence/becomingspontaneity-implications reflected as existence-potency ${ }^{32} \sim$ sublimating-nascence,-disclosedfrom-prospective-epistemic-digression required prospective ${ }^{18}$ deprocrypticism-orpreempting - disjointedness-as-of- ${ }^{-3}$ reference-of-thought registry-worldview/dimension construction-of-the-Self (as of notional ${ }^{18}$ deprocrypticism protensive-self-consciousness over our procrypticism-or-disjointedness-as-of- ${ }^{8}$ reference-of-thought occlusive-selfconsciousness social-value-construction induced dilemmas). Basically, as highlighted above such a transvaluation knowledge-reification $\sim$ gesturing-and-accounting-of-epistemicphenomenalism-<in-prospective_psychologismic $\sim$ apriorising/axiomatising/referencing-\{of'prospectively implicited_attendant-ontological-contiguity ' educedexistentialising/contexalising/textising_intelligibility/epistemicity/reflexivity-contiguity<imbued-notional cogency>' \}-conflatedness -in-\{preconverging-ment by\}

postconverging-ntailment> of social-value-construction reflects the prospective humansubpotency-aporia/undecidability/dilemma/ought-

indeterminacy/deficiency/limitation/constraint of any relative-ontological-incompleteness registry-worldview's/dimension's- ${ }^{83}$ reference-of-thought-for-social-functioning-andaccordance as of its ontologically-flawed implied supposedly coherent ontologicalcommitment $-<$ implied—self-assuredness-of-ontological-goodfaith/authenticity postconverging-de-mentating/structuring/paradigming -as-being-as-of- 
existential-reality>; pointing to the ontological-veracity of a 'direct bilateral relationship of appropriate construction-of-the-Self for appropriate cognisance-and-integration of prospective relative-ontological-completeness ${ }^{87}$ meaningfulness-and-teleology ${ }^{9}$. This ontological reality basis of social-value-construction, it is often claimed, needs to account for the reality of human sovereignty and free-will as to the 'autonomy and independence of human disposedness/psychologismic-construct'. But then such a conception of human sovereignty and free-will seems to imply an 'existence-in-existence apriorising/axiomatising/referencing-\{of'prospectively_implicited_attendant-ontological-contiguity ' educedexistentialising/contextualising/textualising_'intelligibility/epistemicity/reflexivity-contiguity<imbued-notional cogency $\left.>^{\prime} \quad\right\}$ - constitutedness ${ }^{14}$-in-preconverging-entailment ontologically-flawed preconverging-de-mentating/structuring/paradigming' as to imply human sovereignty and free-will supersede-and-override existence-as-the-absolute-a-priori-ofconceptualisation and existence — as-sublimating-withdrawal/unenframing/re-ontologising,elicited-from-prospective-profound-supererogation $-<$ as-to-perspective-ontologicalnormalcy/postconvergence-implied-'prospective-aporeticism-overcoming/unovercoming'> soreflected as of <amplituding/formative-epistemicity $>$ totalisingly $\sim$ preceding-and-redefining 'implicited_atentant-ontological-contiguity ${ }^{67}$; educedexistentialising/contextmalising/textualising_'intelligibility/epistemicity/reflexivity_contiguity$<$ imbued-notional cogency $>$ ' We can effectively appreciate that such human sovereignty and free-will implied 'autonomy and independence of human disposedness/psychologismicconstruct' say with regards to a mystical cause of disease in a non-positivistic society doesn't stop existence as reflecting bacteria theory or any other biological reason from being the cause of disease and such a ${ }^{83}$ reference-of-thought- ${ }^{84}$ devolving-level manifestation of the primacy of existence equally extends to ${ }^{83}$ reference-of-thought-level wherein overall existence 'as transcendental-enabling' for a rational-empiricism/positivism registry-worldview/dimension as 
of its

supererogatory acuity/perspicacity/astuteness/edginess/incisiveness-of-

apriorising/axiomatising/referencing/intelligibilitysettingup/measuringinstrumenting - for-

conceptualisation 'is more effective' with respect to human grasp of existential$<$ disontologising/re-ontologising aporeticism $>$ reality manifestations than a non-positivism registry-worldviews/dimension, just as a prior ${ }^{103}$ universalisation registry-worldview/dimension 'is more effective' as of its supereregatery acuity/perspicacity/astuteness/edginess/incisiveness-ofapriorising/axiomatising/referencing/intelligibilitysettingup/measuringinstrumenting -forconceptualisation in grasping existential-<disontologising/re-ontologising aporeticism $>$ reality manifestations than a preceding ununiversalisation registry-worldview/dimension. This however doesn't imply the elimination of human sovereignty and free-will but rather effective speaks of human-subpotency within existence-potency ${ }^{39}$ sublimating-nascence,-disclosedfrom-prospective-epistemic-digression, so-construed as 'human-subpotency ontologicalperformance ${ }^{72}-<$ including-virtue-as-ontology $>$ /morality/ethics/justice/etc. within the fullpotency-of-existence's $\sim$ sublimating-nascence-as-of-its-coherence/contiguity'; and specifically speaks as to overall reifying-and-empowering-reflexivity-of-ecstatic-existence-aspanintelligibility/panreflexivity ${ }^{3}$-<existentially-imbued-and-educing-<epistemictotalising thermeneutically/textually/reprojectingly/supererogatingly/zeroingly/re-acutingly,\{decompusing delinearity for-cogency $\geq$-epistemic-perspective-of-projective/reprojectiveaestheticising-re-motif-and-re-apriorising/re-axiomatising/re-referencing conceptualisation,as-herein-specifically-relevant-to human-subpotency), wherein within the absolute a-priori framework that is existence, humankind can construe of existence becoming/emanance manifestations allowing for human knowledge-reification $\sim$ gesturing-and-accounting-ofepistemic-phenomenalism-<in-

prospective_psychologismic apriorising/axiomatising/referencing-\{of-'prospectively 
implicited_attendant-ontological-contiguity ' reduced-

existentialising/contextualising/textualising_'intelligibility/epistemicity/reflexivity_contiguity<imbued-notional cogency>’ \}-conflatedness -in-\{preconverging ment by\}

postconverging-entailment $>$ and empowerment from the knowledge-reification $\sim$ gesturing-andaccounting - of-epistemic-phenomenalism- $<$ in-

prospective_psychologismic apriorising/axiomatising/referencing-\{of-‘prospectively_

implicited_attendant-ontological-contiguity ' educed-

existentialising/contextualising/textualising_'intelligibility/epistemicity/reflexivity_contiguity<imbued-notional cogency $>$ ' \}-conflatedness -in-\{preconverging ment by\}

postconverging entailment $>$ within existence, with this in itself inducing a human notional $\sim$ reflexivity- $<\{$ veridical/sound $\}$-relative-reflexivity-in-existence/relativising from-

\section{limited-mentation-as-its-deepening/psychologismic-<residualising \{decompulsing $\}$ delinearity for}

eogency>-by-\{flawed/unsound\}-relative-unreflexivity-in-existence/absolutising from-

limited-mentation/psychologismic epistemic acutisation nonresidualising imbued-

fompulsingthearity-in-eclecticism-of-prior-mere-formulaicity/ritualisation $>$ as of a human

reflexive influence within existence (wherein for instance, a positivistic disease theory of bacteria and biological causation preconverging/postconverging-dementatively/structurally/paradigmatically induces a whole set of human existential<disontologising/re-ontologising aporeticism $>$ disposedness/psychologismic-construct of emancipating and curative implications in existence as of human sovereignty and free-will, but also in-the-very-first-place the fundamental human existential-<disontologising/reentologising aporeticism $>$ disposedness/psychologismic-construct at ${ }^{83}$ reference-of-thoughtlevel to rational-empiricism/positivism is preconverging/postconverging-dementatively/structurally/paradigmatically conducive/preparatory for the possibility of such a positivistic disease theory of bacteria and biological causation to be construed by such humans). 
This then speaks to the fact that 'human sovereignty and free-will is deflated going by the ontological-veracity of human <amplituding/formative-epistemicity>-totalising $\sim$ thrownnessin-existence ${ }^{35}$, as of the 'specific human-subpotency implications as to overall reifying-andempowering-reflexivity-of-ecstatic-existence-as-panintelligibility/panreflexivity ${ }^{3}$ $\langle$ existentially-imbued-and-educing-< $<$ epistemic-

totalising thermeneutically/textually/reprojectingly/supererogatingly/zeroingly/re-acutingly,$\{$ decompulsing $\}$ delinearity for-cogency $\geq$-epistemic-perspective-of-projective/reprojectiveaestheticising-re-motif-and-re-apriorising/re-axiomatising/re-referencing conceptualisation,as herein-specifieally relevant to human-subpotency)'; and so, as it applies to human knowledge-reification $\sim$ gesturing-and-accounting —of-epistemic-phenomenalism- $<$ inprospective_psychologismic apriorising/axiomatising/referencing-\{of-'prospectively implicited_attendant-ontological-contiguity ' educedexistentialising/contextualising/textualising_ 'intelligibility/epistemicity/reflexivity-contiguity$<$ imbued-notional cogency $>$ ' $\}$-conflatedness -in-\{preconverging ment by\} pestconverging entailment $>$ and empowerment from such knowledge-reification $\sim$ gesturingand-accounting - of-epistemic-phenomenalism- $<$ inprospective_psychologismic apriorising/axiomatising/referencing-\{of-`prospectively_ implicited_attendant-ontological-contiguity ' reducedexistentialising/contextualising/textualising_'intelligibility/epistemicity/reflexivity-contiguity<imbued-notional cogency>' \}-conflatedness -in-\{preconverging-ment by\} postconverging-ntailment $>$ within existence as this defines human ontological-performance ${ }^{72}$ $<$ including-virtue-as-ontology $>/$ morality/ethics/justice/etc. reflected as of constructiveness-ofontological-performance $^{72}$-<including-virtue-as-ontology $>/$ morality/ethics/justice/etc. and destructuring-threshold-〈uninstitutionalised-threshold /presublimating-desublimatingdecisionality $>$ of-ontological-performance ${ }^{2}-<$ including-virtue-as-ontology $>$. In this regards, 
the broader and more profound conception of human sovereignty and free-will as reflected by human <amplituding/formative-epistemicity>-totalising thrownness-in-existence $^{35}$ is rather grounded in the reality that all humans come into existence as of an overall framework of Beingdevelopment/ontological-framework-expansion-as-to-depth-of-ontologising-development-asinfrastructure-of- meaningfulness-and-teleology , institutional-development-as-to-socialfunction-development and living-development-as-to-personality-development psychologismic epistemic-acutisation difficulty-for, residualising \{decompulsing\} delinearity for-cogency> magnitudes $\{$ of-experientiality/experiment $\}$ within which the notion of human sovereignty and free-will then arises in-the-very-first-place; such that in-many-ways human sovereignty and free-will is collectively predicated to the social-setup social-functioning-and-accordance as of its implied supposedly coherent ontological-commitment $-<$ implied - self-assuredness-of-ontologicalgood-faith/authenticity postconverging-de-mentating/structuring/paradigming -as-beingas-of-existential-reality>. Thus, on this basis, the reality of human ontological-performance ${ }^{72}$ $<$ including-virtue-as-ontology $>/$ morality/ethics/justice/etc. (reflected as of constructiveness-ofontological-performance $^{72}$-<including-virtue-as-ontology $>/$ morality/ethics/justice/etc. and destructuring-threshold-〈uninstitutionalised-threshold /presublimating-desublimatingdecisionality $>\sim$ of-ontological-performance ${ }^{2}-<$ including-virtue-as-ontology $>$ ) towards the effective articulation of human sovereignty and free-will is actually one that involves, with respect to human limited-mentation-capacity—as-subjecting-'educed-unlimitedness/existencesublimating nascence' to-limitedness/human-subpotency: the 'deferential-formalisationtransference overall and underlying social-setup conception of knowledge-reification $\sim$ gesturingand-accounting - of-epistemic-phenomenalism- $<$ inprospective_psychologismic apriorising/axiomatising/referencing-\{of-'prospectively implicited_attendant-ontological-contiguity ' educedexistentialising/contextualising/textualising_'intelligibility/epistemicity/reflexivity-contiguity- 
<imbued-notional cogency >' \}-conflatedness -in-\{preconverging-ment by\}

postconverging-entailment $>$ and empowerment from such knowledge-reification $\sim$ gesturingand-accounting - of-epistemic-phenomenalism- $<$ in-

prospective_psychologismic apriorising/axiomatising/referencing-\{of-'prospectively implicited_attendant_ontological-contiguity ' educedexistentialising/contextualising/textualising_'intelligibility/epistemicity/reflexivity-contiguity<imbued-notional cogency >' \}-conflatedness -in-\{preconverging -ment by\} postconverging-entailment> as enabling the framework of Being-development/ontologicalframework-expansion-as-to-depth-of-ontologising-development-as-infrastructure-ofmeaningfulness-and-teleology , institutional-development-as-to-social-functiondevelopment and living-development-as-to-personality-development psychologismic epistemic-acutisation difficulty-for, residualising_\{decompulsing $\}$ delinearity for-cogency> magnitudes $\{$ of-experientiality/experiment $\}$ ' and then the 'individual dimensionality-of-sublimating <<amplituding/formative>supererogatery $\sim$ de-mentativeness/epistemic-growth-orconflatedness /transvaluative-rationalising/transepistemicity/anamnestic-residuality/spiritdrivenness-equalisation> mental-disposition and expression' within the former (and it is the latter that often comes to the mind when speaking of human sovereignty and free-will as 'autonomy and independence of human disposedness/psychologismic-construct', while naively ignoring/overlooking the underlying 'superseding existence-as-the-absolute-a-priori-ofconceptualisation and existence - as-sublimating-withdrawal/unenframing/re-ontologising,elicited-from-prospective-profound-supererogation $-<$ as-to-perspective-ontologicalnormalcy/postconvergence-implied-'prospective-aporeticism-overcoming/unovercoming'> reflected in $<$ amplituding/formative-epistemicity $>$ totalisingly $\sim$ preceding-and-redefining 'implicited_attendant-ontological-contiguity ${ }^{67}$; educedexistentialising/contextualising/textualising_'intelligibility/epistemicity/reflexivity-contiguity- 
<imbued-notional cogency>' implications upon human sovereignty and free-will'). Interestingly, such a broader conception of the manifestation of human sovereignty and free-will will recognise that the overall human deferential-formalisation-transference actually has a historiality/ontological-eventfulness 8 /ontological-aesthetic-tracing-<perspectiveontological-normalcy/postconvergence-reflected-'epistemicity-relativism-determinism’> character that extends right up to the very first humans and as with the production of language and human institutions, with regards to constraining existence-potency ${ }^{39} \sim$ sublimatingnascence,-disclosed-from-prospective-epistemic-digression as to existence-as-the-absolute-apriori-of-conceptualisation and existence — as-sublimating-withdrawal/unenframing/reontologising,-elicited-from-prospective-profound-supererogation $-<$ as-to-perspectiveontological-normalcy/postconvergence-implied-'prospective-aporeticismovercoming/unovercoming'>, and as these institutions and institutional practices undergo metaphoricity ${ }^{57}$ all along towards our present, and carries effective/ontologically-veridical teleological implication in reflecting holographically-<conjugatively-and-transfusively $>$ the relative-unreflexivity/relative-reflexivity - ontological-contiguity of-the-humaninstitutionalisation-process dimensionality-of-sublimating 25 <<amplituding/formative>supererogatory $\sim$ de-mentativeness/epistemic-growth-orconflatedness /transvaluative-rationalising/transepistemicity/anamnestic-residuality/spiritdrivenness-equalisation) as to difference-conflatedness ${ }^{13}$-as-to-totalitative-reification-insingularisation-<as-to-the-nondisjointedness/entailment-of-prospective- nonpresencing $>$-asveridical-epistemicity-relativism-determinism implied $\quad<$ amplituding/formativeepistemicity $>$ causality $\sim$ as-to-projective-totalitative-implications-of-prospectivenonpresencing,-for-explicating relative-unreflexivity/relative-reflexivity - ontologicalcontiguity successiveness of registry-worldviews/dimensions. The point here is that, the 'individual dimensionality-of-sublimating ${ }^{25}-<<$ amplituding/formative $>$ supererogatery $\sim$ de- 
mentativeness/epistemic-growth-or-conflatedness /transvaluative-

rationalising/transepistemicity/anamnestic-residuality/spirit-drivenness-equalisation〉 mentaldisposition and expression' driving the deferential-formalisation-transference knowledgereification $\sim$ gesturing-and-accounting — of-epistemic-phenomenalism- $<$ inprospective_psychologismic apriorising/axiomatising/referencing-\{of-‘prespectively implicited_attendant-ontological-contiguity ' educedexistentialising/contextualising/textualising_'intelligibility/epistemicity/reflexivity_contiguity$<$ imbued-notional cogency $>$ ' \}-conflatedness -in-\{preconverging -ment by\}

postconverging entailment $>$ and empowerment from the knowledge-reification $\sim$ gesturing-andaccounting - of-epistemic-phenomenalism- $<$ in-

prospective_psychologismic apriorising/axiomatising/referencing-\{of-'prospectively implicited_attendant-ontological-contiguity ' educedexistentialising/contextualising/textualising_intelligibility/epistemicity/reflexivity_contiguity$<$ imbued-notional cogency $>$ ' $\}$-conflatedness -in-\{preconverging-ment by\} postconverging entailment $>$ as of ${ }^{4}$ historiality/ontological-eventfulness 3 /ontological-aesthetictracing-<perspective-ontological-normalcy/postconvergence-reflected-‘epistemicityrelativism-determinism' $>$, even as of poor ontological-performance ${ }^{72}-<$ including-virtue-asontology $>$ /morality/ethics/justice/etc. of social-value-construction so-construed as destructuring-threshold-〈uninstitutionalised-threshold /presublimating-desublimating-

decisionality $>$ of-ontological-performance ${ }^{2}-<$ including-virtue-as-ontology $>$, can only achieve social-functioning-and-accordance by a claim to be as of supposedly coherent ontologicalcommitment $-<$ implied — self-assuredness-of-ontological-goodfaith/authenticity postconverging-de-mentating/structuring/paradigming -as-being-as-ofexistential-reality>, whether relatively real or surreptitious; and it is this preceding broader human sovereignty and free-willing disposedness/psychologismic-construct for claiming social- 
value-construction for social-functioning-and-accordance as of supposedly coherent ontologicalcommitment $-<$ implied—self-assuredness-of-ontological-good-

faith/authenticity postconverging-de-mentating/structuring/paradigming -as-being-as-of-

existential-reality> that gives the teleological orientation of human ${ }^{56}$ meaningfulness-andteleology in reflecting holographically-<conjugatively-and-transfusively $>$ the relativeunreflexivity/relative-reflexivity ontological-contiguity of-the-human-institutionalisationprocess , as it then exposes human ${ }^{5}$ meaningfulness-and-teleology ${ }^{9}$ as of human limitedmentation-capacity-deepening —as-subjecting limitedness/human-subpotency-to-'educedunlimitedness/existence-sublimating nascence' ${ }^{53}$ to the prospective constraint to be as supposedly coherent ontological-commitment $-<$ implied - self-assuredness-of-ontologicalgood-faith/authenticity postconverging-de-mentating/structuring/paradigming -as-beingas-of-existential-reality $>$ thus inducing the possibility for prospective transcendence-andsublimity/sublimation/supererogatory de-mentativity when its any given meaningfulness-andteleology ${ }^{9}$ is discovered/shown not to be ontologically veridical leading to its effective human limited-mentation-capacity-deepening —as-subjecting limitedness/human-subpotency-to'educed-unlimitedness/existence-sublimating nascence' ${ }^{53}$. Thus the bigger picture here with regards to social-value-construction for social-functioning-and-accordance as of human sovereignty and free-will implications speaks to relative-ontological-completeness 87 as of ontological-normalcy/postconvergence, and so as of existence constraint implied relativeunreflexivity/relative-reflexivity — ontological-contiguity ${ }^{67}$ of-the-human-institutionalisationprocess $^{68} \quad$ dimensionality-of-sublimating ${ }^{25}-\langle<$ amplituding formative $>$ supereregatery dementativeness/epistemic-growth-or-conflatedness /transvaluativerationalising/transepistemicity/anamnestic-residuality/spirit-drivenness-equalisation〉 as to difference-conflatedness ${ }^{3}$-as-to-totalitative-reification-in-singularisation- $<$ as-to-thenondisjointedness/entailment-of-prospective- nonpresencing $>$-as-veridical-epistemicity- 
relativism-determinism implied $<$ amplituding/formative-epistemicity $>$ causality $\sim$ as-toprojective-totalitative-implications-of-prospective- nonpresencing,-for-explicating relativeunreflexivity/relative-reflexivity ontological-contiguity in reflecting both destructuringthreshold-〈uninstitutionalised-threshold /presublimating-desublimating-decisionality $\rangle$ ofontological-performance ${ }^{72}-<$ including-virtue-as-ontology $>/$ morality/ethics/justice/etc. as of prior relative-ontological-incompleteness ${ }^{88}$ implied preconverging/dementing ${ }^{20}$-qualia-schema and

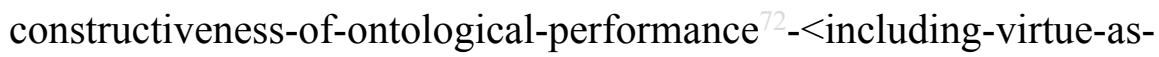
ontology $>$ /morality/ethics/justice/etc. as of prospective relative-ontological-completeness implied postconverging/dialectical-thinking -qualia-schema as elucidation of $<$ amplituding/formative-epistemicity $>$ causality $\sim$ as-to-projective-totalitative-implications-ofprospective- nonpresencing,-for-explicating relative-unreflexivity/relative-reflexivity ontological-contiguity . Ultimately, the naïve articulation of human sovereignty and free-will as of strict 'autonomy and independence of human disposedness/psychologismic-construct' rather speaks of a poor ontological sense-of-things, and as such ontological-veracity ensues the notion of human sovereignty and free-will is rather subsumed as of human-subpotency knowledge-reification $\sim$ gesturing-and-accounting — of-epistemic-phenomenalism- $<$ inprospective_psychologismic apriorising/axiomatising/referencing-\{of-'prospectively implicited_attendant-ontological-contiguity ' reducedexistentialising/contextualising/textualising_ 'intelligibility/epistemicity/reflexivity-contiguity<imbued-notional cogency >' \}-conflatedness -in-\{preconverging-ment by\} postconverging-entailment> and derived empowerment notional $\sim$ reflexivity$<\{$ veridical/sound $\}$ relative-reflexivity-in-existence/relativising from limited mentation as its-deepening/psychologismic-<residualising \{decompulsing $\}$ delinearity for-cogency $>$ by\{flawed/unsound\}-relative-unreflexivity-in-existence/absolutising from-limitedmentation/psychologismic epistemic acutisation nonresidualising imbued- 

apparent in the sciences, we can't imply that we have a choice of gravity on earth as $6 \mathrm{~m} / \mathrm{s}^{2}$ rather than the existence-potency ${ }^{39} \sim$ sublimating-nascence,-disclosed-from-prospective-epistemicdigression manifestation of $9.8 \mathrm{~m} / \mathrm{s}^{2}$ and our human sovereignty and free-will is then enabled reflexively with the latter and not the former where we develop and operate technology on that basis for instance, the same equally applies with respect to the social domain in other to avoid mere disparateness-of-conceptualisation- $<$ unforegrounding-ment,-failing-prospectively-toreflect-'immanent $\sim$ relative unreflexivity/relative-reflexivity - ontological-contiguity '>. The conception of human sovereignty and free-will so-implied as of the 'specific human-subpotency with regards to overall reifying-and-empowering-reflexivity-of-ecstatic-existence-aspanintelligibility/panreflexivity ${ }^{73}$-〈existentially-imbued-and-educing-< $<$ epistemic-

\section{totalising thermeneutically/textually/reprojectingly/supererogatingly/zeroingly/re-acutingly,-} \{decompulsing delinearity for-cogency $>$-epistemic-perspective-of-projective/reprojectiveaestheticising-re-motif-and-re-apriorising/re-axiomatising/re-referencing $\sim$ conceptualisation-as-herein-specifically-relevant-to human-subpotency)' basically underlies all human knowledge-reification $\sim$ gesturing-and-accounting—of-epistemic-phenomenalism- $<$ inprospective_psychologismic apriorising/axiomatising/referencing-\{of-`prospectively_ implicited_attendant-ontological-contiguity ' reducedexistentialising/contextualising/textualising_ 'intelligibility/epistemicity/reflexivity-contiguity<imbued-notional cogency>' \}-conflatedness -in-\{preconverging-ment by\} postconverging entailment> whether with regards to philosophy as first-level ontology pertaining to 'overall existence phenomenal appraisal of ${ }^{5}$ meaningfulness-and-teleology ${ }^{9}$ ' as of the-very-same-immanent-existence/intrinsic-reality/ontological-veridicality,-as-to'human<amplituding/formative-epistemicity>totalising purview-of-construal' or with regards to second-level ontologies 'specific epiphenomenon-\{in-the-overall-ecstatic-existence- 
supervening-conflatedness $\left.{ }^{13}\right\}$ appraisal of ${ }^{56}$ meaningfulness-and-teleology ${ }^{9}$, as of $<$ amplituding/formative-epistemicity $>$ totalising $\sim$ devolved-purview-as-domain-of-construalas-intrinsic-reality/ontological-veridicality; differentiated by the fact that 'overall existence phenomenal appraisal of ${ }^{5}$ meaningfulness-and-teleology" across human generations as of 'cumulative ${ }^{83}$ reference-of-thought 'relative-ontological-incompleteness $8 /$ relative-ontologicalcompleteness $\quad$-〈sublimating $\sim$ referencing/registering/decisioning,-as-self-becoming/selfconflatedness /formative-supererogating-<projective/reprojective-aestheticising-re-motifand-re-apriorising/re-axiomatising/re-referencing,-in-perspective-ontologicalnormalcy/postconvergence $>>$ as to human-and-social-expectations/anticipationsmetaphoricity ${ }^{57}$-as-preconverging/postconverging-redementating/restructuring/reparadigming-psychologism' ${ }^{89}$ is surprisingly of high notionalcontiguity/epistemic-contiguity ${ }^{2}<$ profound-supererogation -of-mentallyaestheticised postconverging/dialectical-thinking -qualia-schema $>\quad$ explaining the crossgenerational relative intelligibility of philosophical ${ }^{56}$ meaningfulness-and-teleology ${ }^{9}$ (for instance the questions and answers/contemplations about the why and how of human existence phenomena from the very first humans are just as relevant today even as of the differing contextual discernments, and so with regards to virtue, value attribution, aesthetics, episteme and Being) while 'specific epiphenomenon-\{in-the-overall-ecstatic-existence-superveningconflatedness ${ }^{13}$ \} appraisal of ${ }^{56}$ meaningfulness-and-teleology" as of " ${ }^{83}$ reference-of-thoughtdevolving 'relative-ontological-incompleteness $8 /$ relative-ontological-completeness ${ }^{87}$ 〈sublimating referencing/registering/decisioning,--as-self-becoming/selfconflatedness /formative-supererogating-<projective/reprojective-aestheticising-re-motifand-re-apriorising/re-axiomatising/re-referencing,-in-perspective-ontologicalnormalcy/postconvergence $>>$ as to human-and-social-expectations/anticipationsmetaphoricity ${ }^{57}$-as-preconverging/postconverging-rede- 
mentating/restructuring/reparadigming-psychologism' 89 is of high notionaldiscontiguity/epistemic-discontiguity ${ }^{63}<$ between - prior-shallow-supererogation -ofmentally-aestheticised preconverging/dementing -qualia-schema_and_prospective-profoundsupererogation -of-mentally-aestheticised postconverging/dialectical-thinking -qualiaschema $>$ explaining the unintelligibility of the explanation of epiphenomena as contrasted crossgenerationally with various superstitious beliefs in the past compared with modern-day science epiphenomenal explanations (for instance with the appraisal of 'health epiphenomena of existence' as of ${ }^{4}$ historiality/ontological-eventfulness ${ }^{3} /$ ontological-aesthetic-tracing<perspective-ontological-normalcy/postconvergence-reflected-‘epistemicity-relativismdeterminism'> ranging from per-cep-ti-vi-ty-as-of-bad-omen, per-cep-ti-vi-ty-as-of-a-specificplace-or-specific-evil-people-or-specific-evil-period, per-cep-ti-vi-ty-as-of-failure-to-followthe-heeding-of-the-Deity-or-failure-to-adhere-to-a-certain-mysticism-or-failure-to-payreverence-to-an-ancestor, per-cep-ti-vi-ty-as-of-full-disease-and-scientific-theory-construct-asthe-exclusive-cause-and-effect-conceptualisation, and per-cep-ti-vi-ty-as-of-factoring-insthermentically/textually/reprojectingly/supererogatingly/zeroingly/reacutingly,-\{decompulsing\} delinearity for-cogency:-socioeconomic,-education,-information,environmental,-gender-and-power-relations-issues-underlying-healthcare-and-medicaldelivery). Insightfully, the very essence of 'overall existence phenomenal appraisal of meaningfulness-and-teleology ${ }^{\prime}$ as associated with philosophical aspects (beyond the our artificial subject-matter divisions referring to aspect where virtue, value, ontological principles and epistemic issues are of central concern) is one of interpretation given that the ordinary human-framework-of-experiential-existence is a 'directly comprehensive and fulsome framework amenable to interpretation' whereas 'specific epiphenomenon-\{in-the-overallecstatic-existence-supervening-conflatedness ${ }^{13}$ \} appraisal of ${ }^{56}$ meaningfulness-and-teleology especially as of their unordinary human-framework-of-experiential-existence like natural 
sciences while informed by ordinary human-framework-of-experiential-existence background/sense-of-things further require and accentuate their epiphenomenal manifestations (which are beyond ordinary human-framework-of-experiential-existence) with the devising of experimentations (as providing the prolongation for human interpretation capacity with respect to such epiphenomenal manifestations, as in reality even the natural sciences are fundamentally interpretative as 'specifically aphoristic/cogent/pointed extensions of the underlying human philosophical interpretative disposition for knowledge-reification $\sim$ gesturing-and-accountingof-epistemic-phenomenalism- $<$ in-

prospective_psychologismic apriorising/axiomatising/referencing-\{of-'prospectively implicited_attendant-ontological-contiguity ' educedexistentialising/contextualising/textualising_'intelligibility/epistemicity/reflexivity-contiguity<imbued-notional cogency $>\quad\}$-conflatedness -in-\{preconverging-ment by\}

postconverging-entailment>'). It is important to grasp here that mere experimentations, as often practised in many domains, that do not arise because of the veridical need to effectively accentuate epiphenomenal manifestations as of unordinary human-framework-of-experientialexistence but rather 'on the vagueness and naivety that experimentations by themselves demonstrate profoundness' are ontologically-impertinent (in the sense that the ordinary humanframework-of-experiential-existence as a 'directly comprehensive and fulsome framework amenable to interpretation' is the more critical basis for a profound knowledgereification $\sim$ gesturing-and-accounting — of-epistemic-phenomenalism- $<$ inprospective_psychologismic $\sim$ apriorising/axiomatising/referencing-\{of-"prospectively_ implicited_attendant-ontological-contiguity ' educedexistentialising/contexalising/textralising_intelligibility/epistemicity/reflexivity-contiguity$<$ imbued-notional cogency >' \}-conflatedness -in-\{preconverging-ment by\} postconverging entailment $>$ interpretation than any such ad-hoc and simplistic experimentation 
vagueness and naivety); and in-many-ways this explains experimental delusions in many domains associated with poor reproducibility—mathesis/motif/thrownness-disposition,--asreproducibility-of-aestheticisation as to the misunderstanding that experimentation should focus on the very critical epiphenomenal manifestations that are not amenable to the ordinary humanframework-of-experiential-existence as a 'directly comprehensive and fulsome framework amenable to interpretation'. However, as of underlying human-subpotency sovereignty and freewill, what is definitely central to knowledge-reification $\sim$ gesturing-and-accounting-ofepistemic-phenomenalism-<in-

prospective_psychologismic apriorising/axiomatising/referencing-\{of-'prospectively implicited_attendant-ontological-contiguity ' educedexistentialising/contextualising/textualising_'intelligibility/epistemicity/reflexivity-contiguity<imbued-notional cogency >' \}-conflatedness -in-\{preconverging-ment by\} postconverging-entailment $>$ is that it is grounded on human empowering notional $\sim$ reflexivity$<\{$ veridical/sound $\}$-relative-reflexivity-in-existence/relativising from-limited-mentation-as-

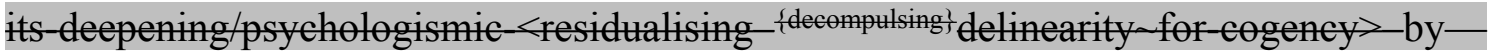
\{flawed/unsound\}-relative-unreflexivity-in-existence/absolutising from-limitedmentation/psychologismic epistemic acutisation nonresidualising imbued\{compulsing\} linearity in-eclecticism-of-prior-mere-formulaicity/ritualisation $>$ from prospective knowledge as of 'ecstatic-existence-as-transcendental-signifier-emergence/becomingspontaneity-implications reflected as existence-potency ${ }^{39} \sim$ sublimating-nascence,-disclosedfrom-prospective-epistemic-digression from such human-subpotency prior reproducibilitymathesis/motif/thrownness-disposition'. This reflects the ontological-veracity that human sovereignty and free-will can only be construed in apriorising/axiomatising/referencing-\{of'prospectively_implicited_attendant-ontological-contiguity ' ceducedexistentialising/contextualising/textualising_intelligibility/epistemicity/reflexivity_contiguity- 
<imbued-notional cogency $>$ ' $\}$ - conflatedness ${ }^{13}$-in-\{preconverging-ment by \} $^{\prime}$

postconverging-entailment as of human <amplituding/formative-epistemicity >totalising thrownness-in-existence ${ }^{35}$ revealing the epistemic-impertinence of dispositions for ${ }^{6}$ presencing —absolutising-identitive-constitutedness ${ }^{14}$ as wrongly implying human sovereignty and free-will supersedes existence-potency ${ }^{32} \sim$ sublimating-nascence,-disclosedfrom-prospective-epistemic-digression rather than the epistemic-veracity of differenceconflatedness ${ }^{13}$-as-to-totalitative-reification-in-singularisation- $<$ as-to-thenondisjointedness/entailment-of-prospective- nonpresencing $>$-as-veridical-epistemicityrelativism-determinism implied $<$ amplituding/formative-epistemicity $>$ causality $\sim$ as-toprojective-totalitative-implications-of-prospective- nonpresencing,-for-explicating relativeunreflexivity/relative-reflexivity - ontological-contiguity of human ${ }^{56}$ meaningfulness-andteleology . We can garner for instance that there is and has never been any truly ${ }^{6} 7$ presencingabsolutising-identitive-constitutedness ${ }^{1,}$ of the sciences as often wrongly implied by science ideologues, but that scientists across-the-times have allowed existence-potency ${ }^{39} \sim$ sublimating- $^{-}$ nascence,-disclosed-from-prospective-epistemic-digression to manifest itself in determining $<$ amplituding/formative-epistemicity $>$ causality $\sim$ as-to-projective-totalitative-implications-ofprospective- nonpresencing,-for-explicating relative unreflexivity/relative reflexivity ontological-contiguity; and so, as from the budding science of the days of Galileo and Copernicus, to Newtonian science, to Lavoisier laboratory science, to Einsteinian science to modern-day institutional practices of science, with all fundamentally driven not by any 'purported science-ideology' but rather the practicality of results as of the constraint of the subject-domains of scientific study together with human limited-mentation-capacitydeepening - as subjecting limitedness/hmman-subponcy to 'educed mnlimitedness/existence sublimating nascence ${ }^{53}$ implications in transforming the conceptualisation within any such specific subject-domains of scientific study as of their knowledge-reification $\sim$ gesturing-and- 
accounting - of-epistemic-phenomenalism- $<$ in-

prospective_psychologismic apriorising/axiomatising/referencing-\{of-'prospectively

implicited_attendant-ontological-contiguity ' educed-

existentialising/contextualising/textualising_intelligibility/epistemicity/reflexivity-contiguity-

<imbued-notional cogency >' \}-conflatedness -in-\{preconverging-ment by\}

postconverging-entailment $>$ rather than 'any implied notion that naively supersede existenceas-the-absolute-a-priori-of-conceptualisation and existence - as-sublimating-

withdrawal/unenframing/re-ontologising,-elicited-from-prospective-profound-

supererogation -<as-to-perspective-ontological-normalcy/postconvergence-implied-

'prospective-aporeticism-overcoming/unovercoming'>'. A further twist to such a poor conception of human sovereignty and free-will in the social arises as of an improper appraisal of the 'implications of deferential-formalisation-transference as being preconverging/postconverging-de-mentatively/structurally/paradigmatically both-intensionaland-extensional to the fulfilment of human sovereignty and free-will'. The fact is human sovereignty and free-will is more critically about its 'fulfilment as of sound-operating-of-humansovereignty-and-free-will-towards-its-fulfilment' rather than 'mere appearance-of-fulfilment usurping-the-sense of sound-operating-of-human-sovereignty-and-free-will-towards-itsfulfilment'. For instance, a plumber who draws up the costing for a plumbing job explaining to the customer what is advantageously entailed in a convincing manner (as of 'mere appearanceof-fulfilment usurping-the-sense of sound-operating-of-human-sovereignty-and-free-willtowards-its-fulfilment') as they fail to ensure that their professional assessment will truly resolve the technical issue (as they are just looking to contract the job) is not really advancing the sovereign choice of the customer compared to another plumber who undertakes a candid professional assessment that may not sound advantageous with the customer (as they are more critically interested in the 'fulfilment as of sound-operating-of-human-sovereignty-and-free- 
will-towards-its-fulfilment') but does solve the technical issue; as any such customer in a deferential-formalisation-transference situation will most likely agree. Such operation of human sovereignty and free-will, beyond more or less simplistic social situations as the case highlighted above, is supposedly implied in the operation of all human institutions as of their inherent deferential-formalisation-transference proxy nature; but in-many-ways such a notion of 'implications of deferential-formalisation-transference as being preconverging/postconvergingde-mentatively/structurally/paradigmatically both-intensional-and-extensional to the fulfilment of human sovereignty and free-will' gets sunk with the increasing complexity and size of human institutions as to what such implications really are, and so especially as the idea of human sovereignty and free-will increasingly becomes abstracted and diffused in the overall socialconstruct and its institutions as so-associated with the "protraction of political and institutional performance, evaluation and accountability' as reflective of human sovereignty and free-will. However, with regards to the latter as of social protraction of political and institutional action, the possibility of protracted human sovereignty and free-will while indirect comes to be increasingly associated with the sense of 'equanimity/balance of institutions' as to their expected 'equanimity/balance of contending frameworks and policy frameworks as reflexive of sociallyperceived commendation and disapprobation', whether as garnered 'politically from the equanimity/balance of competing policies and politics as from polling and/or polls trends' and 'professionally with the equanimity/balance of mainstream/conventional complementary professional policy-recommendations and professional practices'. The question about the effectiveness of such implied equanimity/balance as reflecting of human sovereignty and freewill is often raised critically with regards to political and institutional performance particularly during crises. In-many-ways, the systemic interrelatedness of large institutions as to their complementary end purposes and practices, renders such an assessment of implied equanimity/balance rather preconverging/postconverging-de-mentative/structural/paradigmatic 
to the overall politico-institutional system itself; and particularly so as in-many-ways the possibility of readjustment is much more practically instigated politically especially as with public institutions the individual manifestation of sovereign choice is much more rigidly tied to political action unlike the relative ability for direct disengagement from private entities. However, the fundamental fact that human sovereignty and free-will is ever always a question of the 'transverse relation of all humans sovereignty and free-will in society' inherently implies the underlying possibility for the undermining of human sovereign choice as of inherent social differentiation. Beyond transvaluation implications as of the broader overall 'expected equity of all individuals for social-value-construction' in relative-ontological-incompleteness 8 /relativeontological-completeness ${ }^{87}$-〈sublimating $\sim$ referencing/registering/decisioning,-as-selfbecoming/self-conflatedness /formative-supererogating-<projective/reprojectiveaestheticising-re-motif-and-re-apriorising/re-axiomatising/re-referencing,-in-perspectiveontological-normalcy/postconvergence $>><$ amplituding/formative-epistemicity $>$ causality $\sim$ asto-projective-totalitative-implications-of-prospective- nonpresencing,-forexplicating relative-unreflexivity/relative-reflexivity - ontological-contiguity in reflecting holographically-<conjugatively-and-transfusively $>$ the relative-unreflexivity/relativereflexivity - ontological-contiguity of-the-human-institutionalisation-process ; going by the phronesis/practicality as of our positivism- ${ }^{80}$ procrypticism occlusivity, the assessment of institutionally implied 'equanimity/balance of contending frameworks and policy frameworks as reflective of socially-perceived commendation and disapprobation', as advancing human sovereignty and free-will as of deferential-formalisation-transference implications, can be rather straightforward with regards to relatively compact/self-contained institutional functions and roles usually involved in direct public service delivery but it is much more difficult with spurious/supporting institutional functions and roles. We can appreciate in this regards that public scandals generally tend to arise out of public services and private services delivery 
institutional frameworks as of their relatively compact/self-contained institutional functions and roles, and that issues of transparency rendering such assessment difficult generally arise with regards to underlying spurious/supporting/supervisory/regulatory institutional functions and roles. In another respect concerning the modern-day media, the need for relevant and balanced/equanimous communication and information delivery to the general public has increasingly been taking a backseat, and so fundamentally as the media becomes more of a business-making institution and rather plays a weaker and ancillary/perfunctory role in public policies and politics accountability. This is paradoxically reflected in the reality that despite the huge choice of media today, strangely enough this has rather been associated with greater public muddlement with regards to political stakes and public policies; undermining the political process as increasingly public policies are preconvergingly-de-mentated/structured/paradigmed to default/revert into the interests of powerful groups and corporations with the support of increasingly astute, surreptitious and media-savvy political and economic think-tanks, as their media underhandedness in-many-ways foil the possibility for credible and effective public interest debate as of the distractedness of media reflexive anchoring on a stale, traditional, simplistic and increasingly irrelevant age-old left and right political narrative (and its derived politics and policies narratives) poorly reflecting the sophistication of the electorate that 'doesn't live in left and right worlds but a realistic world in want for solutions'! Strangely enough, such a media environment is now laden with public gurus holding outlandish views increasingly given the forum for their opinions (presented as reified-knowledge) not only in marginal media but mainstream media as well out of all proportion with the social and/or relevant competence/expertising academic/professional resonance of such ideas, and so as of the underlying pretence of freedom-of-speech; as the notion of freedom-of-speech is increasingly being portrayed rather as the rationalising foundation for all sorts of discreetly, whimsically/fancifully and strategically prejudiced influences on media orientation. In this 
regards, the notion of freedom-of-speech as of such consequentially biased and disproportionate representation undermining 'equanimity/balance of contending frameworks and policy frameworks as reflective of socially-perceived commendation and disapprobation' (as thusly failing to advance human sovereignty and free-will as of deferential-formalisation-transference implications), is increasingly becoming the unbecoming/undoing of the modern-day democratic political process. Direct media surreptitious drumming-up of specific policy stances and political movements have often interfered with political governance as with the tea-party movement for instance; when considering how political orientations are 'strategically advanced/framed' in the media at critical moments for upholding favourable political policies or foiling unfavourable political policies while undermining sound analytic public debate. It is no small wonder that a public opinion increasingly exposed to such media-driven 'subterfuges', overlooking the ageold party politics narrative entrapment, has been turning to protest voting as an expression of political disdain. Furthermore, the idea of human sovereignty and free-will across all times is intimately tied down to human limited-mentation-capacity-deepening-as-subjecting limitedness/human-subpotency to-'educed-unlimitedness/existence-sublimating nascence' ${ }^{53}$ as to the 'relative-ontological-incompleteness ${ }^{88} /$ relative-ontological-completeness $^{87}$ 〈sublimating referencing/registering/decisioning,--as-self-becoming/selfconflatedness /formative-supererogating-<projective/reprojective-aestheticising-re-motifand-re-apriorising/re-axiomatising/re-referencing,-in-perspective-ontologicalnormalcy/postconvergence $>>$ as to human-and-social-expectations/anticipationsmetaphoricity ${ }^{57}$-as-preconverging/postconverging-redementating/restructuring/reparadigming-psychologism' ${ }^{99}$ for knowledge-reification $\sim$ gesturingand-accounting - of-epistemic-phenomenalism- $<$ in-

prospective_psychologismic apriorising/axiomatising/referencing-\{of-'prospectively_ implicited_attendant-ontological-contiguity ' educed- 
existentialising/contextualising/textualising_ 'intelligibility/epistemicity/reflexivity-contiguity<imbued-notional cogency>' \}-conflatedness -in-\{preconverging-ment by\}

postconverging-entailment> underlying sublimating ${ }^{4}$ historiality/ontological-

eventfulness 3 /ontological-aesthetic-tracing-<perspective-ontological-

normalcy/postconvergence-reflected-'epistemicity-relativism-determinism'> as of the specific human-subpotency with regards to overall reifying-and-empowering-reflexivity-of-ecstaticexistence-as-panintelligibility/panreflexivity ${ }^{3}$-〈existentially-imbued-and-educing-<epistemicthermeneutically/textually/reprojectingly/supererogatingly/zeroing/y/re-acutingly,$\{$ decompulsing\} $\}$ delinearity $\sim$ for-cogency $\geq$-epistemic-perspective-of-projective/reprojectiveaestheticising-re-motif-and-re-apriorising/re-axiomatising/re-referencing conceptualisation,as-herein-specifically-relevant-to human-subpotency); as the fact is the conception of human sovereignty and free-will effectively varied in reflecting holographically-<conjugatively-andtransfusively $>$ the relative-unreflexivity/relative-reflexivity ontological-contiguity $\sim$ of-thehuman-institutionalisation-process as from the specific human-subpotency with regards to overall reifying-and-empowering-reflexivity-of-ecstatic-existence-aspanintelligibility/panreflexivity ${ }^{3}-\left\langle\right.$ existentially-imbued-and-educing-< fepistemic- $^{-}$ totalising thermeneutically/textually/reprojectingly/supererogatingly/zeroing/y/re-acutingly,\{decomplsing $d$ delinearity $\sim$ for-cogency $\geq$-epistemic-perspective-of-projective/reprojectiveaestheticising-re-motif-and-re-apriorising/re-axiomatising/re-referencing conceptualisation,as-herein-specifically-relevant-to human-subpotency) of recurrent-utter-uninstitutionalisation, base-institutionalisation-ununiversalisation, ${ }^{103}$ universalisation-non-positivism/medievalism,

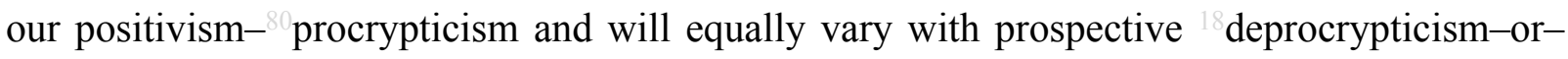
preempting - disjointedness-as-of- ${ }^{3}$ reference-of-thought as of human limited-mentationcapacity-deepening —as-subjecting-limitedness/human-subpotency-to-'educed-

unlimitedness/existence-sublimating nascence' ${ }^{53}$. This effectively brings up the centrality of 
causality, as implied with <amplituding/formative-epistemicity>causality $\sim$ as-to-projectivetotalitative-implications-of-prospective- nonpresencing,-for-explicating relativeunreflexivity/relative-reflexivity ontological-contiguity conflating towards the inherent ontological-normalcy/postconvergence of ecstatic-existence-as-transcendental-signifier, wherein human sovereignty and free-will is construed as of the "preconverging/postconvergingde-mentative/structural/paradigmatic implications of relative-ontological-completeness ${ }^{87}$ in superseding/overcoming/transcending human-subpotencyaporia/undecidability/dilemma/ought-indeterminacy/deficiency/limitation/constraint of relative-ontological-incompleteness ${ }^{8}$, , reflecting a human-causative-construction conception in apriorising/axiomatising/referencing-\{of-'prospectively_implicited_attendant_ontologicalcontiguity ' educedexistentialising/contextualising/textualising_'intelligibility/epistemicity/reflexivity_contiguity<imbued-notional cogency>' \}-conflatedness ${ }^{13}$ in-\{preconverging -ment by\} postconverging-entailment/projective-conflating apriorising/axiomatising/referencing about existence as ontologically-veridical (as it is the 'totalitative epistemic-or-notional projectiveperspective' that points out the veridical conception of causation) and so over a traditional reflex construal of human causation in apriorising/axiomatising/referencing-\{of-"prespectively implicited_attendant-ontological-contiguity ' educedexistentialising/contextualising/textualising_ intelligibility/epistemicity/reflexivity-contiguity<imbued-notional cogency $\left.>^{\prime} \quad\right\}$-constitutedness ${ }^{14}$-in-preconverging-entailment as of any given presencing_-absolutising-identitive-constitutedness apriorising/axiomatising/referencing in prospective relative-ontological-incompleteness ${ }^{88}$. This insight about human sovereignty and free-will effectively points to the ontological-flaw of presencing-absolutising-identitive-constitutedness ${ }^{14}$ conceptions whether as of the past, present or future, inherently as of failing to account for 'relative-ontological- 
incompleteness $8 /$ relative-ontological-completeness ${ }^{8}$.

〈sublimating referencing/registering/decisioning,-as-self-becoming/self-

conflatedness /formative-supererogating-<projective/reprojective-aestheticising-re-motifand-re-apriorising/re-axiomatising/re-referencing,-in-perspective-ontological-

normalcy/postconvergence $>>$ as to human-and-social-expectations/anticipationsmetaphoricity ${ }^{57}$-as-preconverging/postconverging-rede-

mentating/restructuring/reparadigming-psychologism' ${ }^{89}$ that effectively and empirically underline sublimating historiality/ontological-eventfulness ${ }^{38}$ /ontological-aesthetic-tracing$<$ perspective-ontological-normalcy/postconvergence-reflected-'epistemicity-relativismdeterminism'>; and so especially as it is often implied by a 'naïve type of philosophising that the conception of human sovereignty and free-will can be abstracted as of elaboration-as-tomere-extrapolating/constituting/abstracting/deducing/inferring-of-elucidation-outside_'prospectively_implicited_attendant_ontological-contiguity ${ }^{67}$ ' educedexistentialising/contextmalising/textualising_intelligibility/epistemicity/reflexivity_contiguity$<$ imbued-notional cogency $>$ failing to reflect underlying supposedly coherent ontologicalcommitment $-<$ implied — self-assuredness-of-ontological-goodfaith/authenticity postconverging-de-mentating/structuring/paradigming -as-being-as-ofexistential-reality> in wrongly implying that human sovereignty and free-will is rather veridically underlied by 'human social-vestedness/normativity-<discretely-impliedfunctionalism> implied contract/political-arrangement-or-political-coercion/given-discretesocial-value-construction' outside 'implicited_attendant-ontological-contiguity ${ }^{67}$; educedexistentialising/contextualising/textualising_'intelligibility/epistemicity/reflexivity_contiguity$<_{\text {imbued-notional cogency }>}{ }^{40}$ implications of relative-ontological-incompleteness ${ }^{88}$ to relative-ontological-completeness ${ }^{87}$. But then such pretence of ${ }^{79}$ presencing-absolutisingidentitive-constitutedness ${ }^{14}$ veracity of 'human social-vestedness/normativity- $<$ discretely- 
implied-functionalism> implied contract/political-arrangement-or-political-coercion/givendiscrete-social-value-construction' is both theoretically and empirically non-veridical, speaking more of the reality of power-grabbing/appropriating/usurpatory/arrogating implications than truly rational argumentations as of knowledge-reification $\sim$ gesturing-and-accounting-ofepistemic-phenomenalism- $<$ in-

\section{prospective_psychologismic apriorising/axiomatising/referencing-\{of-"prospectively}

\section{implicited_attendant-ontological-contiguity ' educed-}

existentialising/contextualising/textualising_'intelligibility/epistemicity/reflexivity-contiguity$<$ imbued-notional cogency $>\quad\}$-conflatedness -in-\{preconverging ment by\}

postconverging-entailment> implications. Such 'human social-vestedness/normativity$<$ discretely-implied-functionalism $>\quad$ implied contract/political-arrangement-or-politicalcoercion/given-discrete-social-value-construction' argumentations are often intimately associated with providing the ${ }^{56}$ meaningfulness-and-teleology ${ }^{9}$ infrastructure for the powerful and vested-interests, and their insinuations of 'human social-vestedness/normativity- $<$ discretelyimplied-functionalism> implied contract/political-arrangement-or-political-coercion/givendiscrete-social-value-construction' as 'outside 'implicited_attendant-ontologicalcontiguity ${ }^{67}$,educed-

existentialising/contextmalising/textualising_'intelligibility/epistemicity/reflexivity_contiguity<imbued-notional cogency>' implications of relative-ontological-incompleteness ${ }^{88}$ to relative-ontological-completeness ${ }^{8}$, is in effect not truly about the irrelevance of existentialreality implications of relative-ontological-incompleteness ${ }^{88}$ and relative-ontologicalcompleteness $^{87}$ but rather more critically 'is in effect about defaulting to specifically unavowedly/surreptitiously implied convenient/advantageous interpretations about 'implicited_attendant-ontological-contiguity ${ }^{67}$ > educedexistentialising/contextualising/textualising_'intelligibility/epistemicity/reflexivity-contiguity- 
<imbued-notional cogency>' which are not to be subjected to a fulsome analysis for ontological-veracity as of implications of relative-ontological-incompleteness ${ }^{88}$ and relativeontological-completeness ${ }^{87}$ and so on the basis of merely projecting the term 'human socialvestedness/normativity- $<$ discretely-implied-functionalism $>\quad$ implied contract/politicalarrangement-or-political-coercion/given-discrete-social-value-construction' and thereof implying logical-dueness and articulating logic on the so-narrowed and uncontested framework'. The reason why such a 'human social-vestedness/normativity-<discretely-impliedfunctionalism> implied contract/political-arrangement-or-political-coercion/given-discretesocial-value-construction' supposedly pertinent argumentation about human sovereignty and free-will cannot hold is that all ${ }^{56}$ meaningfulness-and-teleology (as implied with the logical operation of any such projected 'human social-vestedness/normativity-<discretely-impliedfunctionalism> implied contract/political-arrangement-or-political-coercion/given-discretesocial-value-construction') operate on priorly established apriorising/axiomatising/referencing and inherently all apriorising/axiomatising/referencing purport to be as of 'implicited_attendantontological-contiguity ${ }^{67} \sim$ educedexistentialising/contextualising/textualising_'intelligibility/epistemicity/reflexivity-contiguity$<$ imbued-notional cogency>' thus subject to analysis as of 'relative-ontologicalincompleteness $8 /$ relative-ontological-completeness

〈sublimating $\sim$ referencing/registering/decisioning,-as-self-becoming/selfconflatedness /formative-supererogating-<projective/reprojective-aestheticising-re-motifand-re-apriorising/re-axiomatising/re-referencing,-in-perspective-ontologicalnormalcy/postconvergence $>>$ as to human-and-social-expectations/anticipationsmetaphoricity ${ }^{5}$-as-preconverging/postconverging-redementating/restructuring/reparadigming-psychologism' ${ }^{89}$ as to their existential-reality veracity, such that fundamentally such 'human social-vestedness/normativity-<discretely-implied- 
functionalism $>$ implied contract/political-arrangement-or-political-coercion/given-discretesocial-value-construction' argumentation about human sovereignty and free-will are rather 'internally inconsistent' and more aptly reflect manifestations of powergrabbing/appropriating/usurpatory/arrogating implications when analysed as of relativeontological-completeness ${ }^{87}$. Consider in this regards for instance as of the ${ }^{79}$ presencingabsolutising-identitive-constitutedness ${ }^{14}$ notion of 'human social-vestedness/normativity$<$ discretely-implied-functionalism $>\quad$ implied contract/political-arrangement-or-politicalcoercion/given-discrete-social-value-construction' underlying slavery, such an implied 'human social-vestedness/normativity-<discretely-implied-functionalism $>$ implied contract/politicalarrangement-or-political-coercion/given-discrete-social-value-construction' is inherently making a claim on existential-reality which rather more aptly reflect a manifestation of powergrabbing/appropriating/usurpatory/arrogating implications as of its apriorising/axiomatising/referencing that one human being has the right to own another human being (as actually not even the logical-dueness of such a 'human social-vestedness/normativity$<$ discretely-implied-functionalism $>\quad$ implied contract/political-arrangement-or-politicalcoercion/given-discrete-social-value-construction' argumentation can arise from the perspective of relative-ontological-completeness ${ }^{87}$ as what is then implied from the relative-ontologicalcompleteness perspective is the supererogatory acuity/perspicacity/astuteness/edginess/incisiveness-ofapriorising/axiomatising/referencing/intelligibilitysettingup/measuringinstrumenting -forconceptualisation in unaffirmation/deprojection/deassertion/epistemic-decadence/unduenessinvalidating-logicising/unsuitable-measuringinstrument-invalidating-measuring- $<$ as-topreconverging-or-dementing -apriorising-psychologism $>$ of any such implied slavery 'human social-vestedness/normativity- $<$ discretely-implied-functionalism $>$ implied contract/politicalarrangement-or-political-coercion/given-discrete-social-value-construction'). The proof that 
this is priorly a 'power-grabbing/appropriating/usurpatory/arrogating implications of apriorising/axiomatising/referencing and not of veridical logical-dueness' lies in the fact that for instance the Haitian slave revolters wouldn't countenance the logical-dueness of any such implied logic of 'human social-vestedness/normativity- $<$ discretely-implied-functionalism> implied contract/political-arrangement-or-political-coercion/given-discrete-social-valueconstruction' underlying their enslavement but merely as of their relative-ontologicalcompleteness ${ }^{87}$ perspective of apriorising/axiomatising/referencing undertake in revolt the unaffirmation/deprojection/deassertion/epistemic-decadence/undueness-invalidatinglogicising/unsuitable-measuringinstrument-invalidating-measuring-<as-to-preconverging-ordementing -apriorising-psychologism> of any such implied slavery 'human socialvestedness/normativity- $<$ discretely-implied-functionalism $>\quad$ implied $\quad$ contract/politicalarrangement-or-political-coercion/given-discrete-social-value-construction'. This points to the reality that 'human social-vestedness/normativity-<discretely-implied-functionalism $>$ implied contract/political-arrangement-or-political-coercion/given-discrete-social-value-construction' argumentation do not truly escape the ontological prism as of existence being the absolute a priori, and rather speak of epistemic situations in epistemic-abnormalcy/preconvergence ${ }^{31}$ with the possibility for true causality implications to be drawn in relative-ontological-completeness as of $<$ amplituding/formative-epistemicity $>$ causality $\sim$ as-to-projective-totalitativeimplications-of-prospective- nonpresencing,-for-explicating relative-unreflexivity/relativereflexivity - ontological-contiguity construable 'preconverging/postconverging-dementative/structural/paradigmatic implications of relative-ontological-completeness ${ }^{87}$ in superseding/overcoming/transcending human-subpotencyaporia/undecidability/dilemma/ought-indeterminacy/deficiency/limitation/constraint of relative-ontological-incompleteness ${ }^{8}$. The confusion here arises because of the habituation of any such 'human social-vestedness/normativity-<discretely-implied-functionalism $>$ implied 
contract/political-arrangement-or-political-coercion/given-discrete-social-value-construction' which is then taken to be natural to the point of 'forgetting/overlooking that it is underlied by apriorising/axiomatising/referencing power-grabbing/appropriating/usurpatory/arrogating implications' to which even the weaker party might end up getting habituated to (over years, decades or centuries) as of little alternate existential-<disontologising/re-ontologising apereticism $>$ choice and possibilities, and from which point a ${ }^{7}$ presencing-absolutisingidentitive-constitutedness ${ }^{14}$ false sense of logical-dueness as of 'relative-ontologicalincompleteness $8 /$ relative-ontological-completeness ${ }^{87}$

〈sublimating $\sim$ referencing/registering/decisioning,-as-self-becoming/selfconflatedness /formative-supererogating-<projective/reprojective-aestheticising-re-motifand-re-apriorising/re-axiomatising/re-referencing,-in-perspective-ontologicalnormalcy/postconvergence $>>$ as to human-and-social-expectations/anticipationsmetaphoricity ${ }^{57}$-as-preconverging/postconverging-redementating/restructuring/reparadigming-psychologism' ${ }^{89}$ may seem to arise; but as with say the American civil war and the Haitian slave revolt, the reality that such implied 'human socialvestedness/normativity-<discretely-implied-functionalism $>\quad$ implied contract/politicalarrangement-or-political-coercion/given-discrete-social-value-construction' is rather of flawed apriorising/axiomatising/referencing power-grabbing/appropriating/usurpatory/arrogating implications is met not with logical-dueness and logical-engagement in wrongly validating any such apriorising/axiomatising/referencing but is rather meted with relative-ontologicalcompleteness perspective

supererogatery acuity/perspicacity/astuteness/edginess/incisiveness-ofapriorising/axiomatising/referencing/intelligibilitysettingup/measuringinstrumenting -forconceptualisation in unaffirmation/deprojection/deassertion/epistemic-decadence/unduenessinvalidating-logicising/unsuitable-measuringinstrument-invalidating-measuring- $<$ as-to- 
preconverging-or-dementing -apriorising-psychologism>. In fact, besides the more starkly demonstrable case with respect to say slavery this equally applies with less starkly obvious situations having to do with human social differentiation as well as any other situations requiring prospective knowledge-reification $\sim$ gesturing-and-accounting-of-epistemic-phenomenalism<in-prospective_psychologismic $\sim$ apriorising/axiomatising/referencing-\{of-'prospectively_ implicited_attendant-ontological-contiguity ' educedexistentialising/contextualising/textualising_intelligibility/epistemicity/reflexivity_contiguity$<$ imbued-notional cogency >' \}-conflatedness -in-\{preconverging-ment by\}

postconverging-entailment $>$ as the possibility for all human progress arises effectively as a result of the transcending of all such human-subpotency-aporia/undecidability/dilemma/oughtindeterminacy/deficiency/limitation/constraint powergrabbing/appropriating/usurpatory/arrogating implications construed as 'human socialvestedness/normativity- $<$ discretely-implied-functionalism $>\quad$ implied contract/politicalarrangement-or-political-coercion/given-discrete-social-value-construction' as well as their socially attendant situations in need for prospective knowledge-reification $\sim$ gesturing-andaccounting - of-epistemic-phenomenalism- $<$ in-

\section{prospective_psychologismic apriorising/axiomatising/referencing-\{of-"prespectively} implicited_attendant-ontological-contiguity ' reducedexistentialising/contextualising/textualising_ intelligibility/epistemicity/reflexivity-contiguity<imbued-notional cogency>' \}-conflatedness -in-\{preconverging-ment by\} postconverging-entailment>; and so not as of a falsely implied logical-dueness and logical engagement that wrongly validate the relative-ontological-incompleteness apriorising/axiomatising/referencing of 'human social-vestedness/normativity- $<$ discretelyimplied-functionalism> implied contract/political-arrangement-or-political-coercion/givendiscrete-social-value-construction' as being of existential-reality in relative-ontological- 
completeness $^{87}$, but rather as of the relative-ontological-completeness ${ }^{87}$ perspective supererogatory acuity/perspicacity/astuteness/edginess/incisiveness-ofapriorising/axiomatising/referencing/intelligibilitysettingup/measuringinstrumenting -forconceptualisation in unaffirmation/deprojection/deassertion/epistemic-decadence/unduenessinvalidating-logicising/unsuitable-measuringinstrument-invalidating-measuring-<as-topreconverging-or-dementing -apriorising-psychologism> of such implied 'human socialvestedness/normativity- $<$ discretely-implied-functionalism $>\quad$ implied contract/politicalarrangement-or-political-coercion/given-discrete-social-value-construction' argumentation. In fact, such an interpretation about the ontological-veracity of 'human socialvestedness/normativity- $<$ discretely-implied-functionalism $>$ implied contract/politicalarrangement-or-political-coercion/given-discrete-social-value-construction' argumentation is not only relevantly undermined with respect to say highlighting the supposed weaker party perspective in such a framework of power-grabbing/appropriating/usurpatory/arrogating implications of apriorising/axiomatising/referencing but is equally undermined/subverted when conveniently so by the stronger party for instance in the case of the various allied powers of the second-world war overlooking Nazi scientists direct or indirect participation in war crimes on the rationale of strengthening themselves to ensure future security, and one can imagine the same with regards with many ad-hoc arrangements having to do with spying activities, etc.; thus pointing fundamentally to the ascendency of the ontological implications of human limitedmentation-capacity—as-subjecting-'educed-unlimitedness/existence-sublimating nascence' to-limitedness/human-subpotency as to human limited-mentation-capacity-deepening-assubjecting limitedness/human-subpotency-to-'educed-unlimitedness/existence-sublimatingpossibilities of relative-ontological-completeness ${ }^{87}$ analysis over the absolutising of 'human social-vestedness/normativity-<discretely-implied-functionalism $>\quad$ implied contract/political-arrangement-or-political-coercion/given-discrete-social-value-construction' 
argumentation. Thus any such pretence that 'human social-vestedness/normativity- $<$ discretelyimplied-functionalism> implied contract/political-arrangement-or-political-coercion/givendiscrete-social-value-construction' argumentation is absolute as of 79 presencing-absolutisingidentitive-constitutedness ${ }^{14}$ and not subject to prospective 'relative-ontologicalincompleteness $8 /$ relative-ontological-completeness ${ }^{87}$.

\section{〈sublimating referencing/registering/decisioning,-as-self-becoming/self-}

conflatedness /formative-supererogating-<projective/reprojective-aestheticising-re-motifand-re-apriorising/re-axiomatising/re-referencing,-in-perspective-ontologicalnormalcy/postconvergence $>\rangle$ as to human-and-social-expectations/anticipationsmetaphoricity ${ }^{57}$-as-preconverging/postconverging-rede-

mentating/restructuring/reparadigming-psychologism' ${ }^{89}$ with regards to an animal of limitedmentation-capacity—as-subjecting 'educed-unlimitedness/existence-sublimating nascence'to-limitedness/human-subpotency requiring its prospective limited-mentation-capacitydeepening —as-subjecting limitedness/human-subpotency-to-'educed-unlimitedness/existencesublimating nascence ${ }^{53}$ (and thus paradoxically in want of its very own 'prospective ${ }^{3<}<$ amplituding/formative-epistemicity>growth-or-conflatedness ${ }^{13} /$ transvaluative- $^{\prime}$ rationalising/transepistemicity/anamnestic-residuality/spirit-drivenness magnanimity induced originariness-parrhesia,--as-spontaneity-of-aestheticisation' as to cohere with ecstatic-existenceas-transcendental-signifier-emergence/becoming-spontaneity-implications reflected as existence-potency ${ }^{39} \sim$ sublimating-nascence,-disclosed-from-prospective-epistemic-digression) is effectively bound not to be able to address the very central/critical implications to prospective knowledge-reification $\sim$ gesturing-and-accounting — of-epistemic-phenomenalism- $<$ inprospective_psychologismic apriorising/axiomatising/referencing-\{of-'prospectively implicited_attendant-ontological-contiguity ' ceducedexistentialising/contextualising/textualising_ 'intelligibility/epistemicity/reflexivity-contiguity- 
postconverging-entailment> of human-subpotency-aporia/undecidability/dilemma/oughtindeterminacy/deficiency/limitation/constraint—imbued-'notional firstnaturednessformativeness-<as-to-eventualising-inkling-drive-or-seeding-misprising $>$ temporal-tointemporal-dispositions-<so-construed-as-from-perspective-ontologicalnormalcy/postconvergence>'-existentialism-form-factor (with the latter involving 'direct bilateral relationship of appropriate construction-of-the-Self for appropriate cognisance-andintegration of prospective relative-ontological-completeness ${ }^{87}$ meaningfulness-andteleology', as implied prospectively in 'construing of both the right apriorising/axiomatising/referencing/intelligibilitysettingup/measuringinstrumenting mindsetas-of-prospective-deprocrypticism-dissemination ${ }^{28}$ and thus the knowledge for that right mindset-as-of-prospective-deprocrypticism-dissemination $\left.{ }^{2}{ }^{\prime}\right)$. Even with the modern-day polity and law, the reality of human sovereignty and free-will implied in human rights takes precedence over any 'human social-vestedness/normativity-<discretely-implied-functionalism $>$ implied contract/political-arrangement-or-political-coercion/given-discrete-social-value-construction' practicalities and is the basis for continual social and governmental reforms; and as so-implied by the 'preconverging/postconverging-de-mentative/structural/paradigmatic implications of relative-ontological-completeness ${ }^{87}$ in superseding/overcoming/transcending humansubpotency-aporia/undecidability/dilemma/ought-

indeterminacy/deficiency/limitation/constraint of relative-ontological-incompleteness ${ }^{8}$, and this is the very legitimation for any intellectualism purporting knowledge-reification $\sim$ gesturingand-accounting - of-epistemic-phenomenalism- $<$ inprospective_psychologismic $\sim$ apriorising/axiomatising/referencing-\{of-'prespectively implicited_attendant-ontological-contiguity ' educedexistentialising/contextualising/textualising_'intelligibility/epistemicity/reflexivity-contiguity- 
<imbued-notional cogency >' \}-conflatedness -in-\{preconverging-ment by\}

postconverging-entailment>. Ultimately, the very possibility for prospective knowledgereification $\sim$ gesturing-and-accounting — of-epistemic-phenomenalism- $<$ in-

prospective_psychologismic apriorising/axiomatising/referencing-\{of-"prospectively implicited_attendant-ontological-contiguity ' ceducedexistentialising/contextualising/textualising_'intelligibility/epistemicity/reflexivity-contiguity<imbued-notional cogency >' \}-conflatedness -in-\{preconverging -ment by\}

postconverging entailment $>$ as providing the illumination for prospective human sovereignty and free-will conceptualisation is itself bound to be undermined, and so as of humansubpotency-aporia/undecidability/dilemma/ought-

indeterminacy/deficiency/limitation/constraint—imbued-'notional firstnaturednessformativeness-<as-to-eventmalising-inkling-drive-or - seeding-misprising $>$ temporal-tointemporal-dispositions-<so-construed-as-from-perspective-ontologicalnormalcy/postconvergence >'-existentialism-form-factor, in the interplay of human presencing-absolutising-identitive-constitutedness ${ }^{14}$ inclinations for vested postures and interests poorly appreciating 'relative-ontological-incompleteness 8 /relative-ontologicalcompleteness ${ }^{8}$-〈sublimating $\sim$ referencing/registering/decisioning,-as-self-becoming/selfconflatedness /formative-supererogating-<projective/reprojective-aestheticising-re-motifand-re-apriorising/re-axiomatising/re-referencing,-in-perspective-ontologicalnormalcy/postconvergence $>>$ as to human-and-social-expectations/anticipationsmetaphoricity ${ }^{57}$-as-preconverging/postconverging-rede-

mentating/restructuring/reparadigming-psychologism' ${ }^{89}$ in contrast to dimensionality-ofsublimating 25 -<<mplituding/formative $>$ supererogatory $\sim$ de-mentativeness/epistemic-growthor-conflatedness /transvaluative-rationalising/transepistemicity/anamnestic-residuality/spiritdrivenness-equalisation〉 inclinations very much appreciative of 'relative-ontological- 
incompleteness $8 /$ relative-ontological-completeness ${ }^{87}$

〈sublimating referencing/registering/decisioning,-as-self-becoming/self-

conflatedness /formative-supererogating-<projective/reprojective-aestheticising-re-motifand-re-apriorising/re-axiomatising/re-referencing,-in-perspective-ontological-

normalcy/postconvergence $>>$ as to human-and-social-expectations/anticipationsmetaphoricity ${ }^{57}$-as-preconverging/postconverging-rede-

mentating/restructuring/reparadigming-psychologism' ${ }^{89}$ as of difference-conflatedness ${ }^{13}$-as-tototalitative-reification-in-singularisation-<as-to-the-nondisjointedness/entailment-of-

prospective- nonpresencing $>$-as-veridical-epistemicity-relativism-determinism implied $<$ amplinglinglivermative-epistemicity $>$ causality $\sim$ as-to-projective-totalitative-implications-ofprospective- nonpresencing,-for-explicating relative-unreflexivity/relative-reflexivity

ontological-contiguity . In this regards, one can appreciate the human sovereignty and free-will expansion drive of the prospective knowledge-reification $\sim$ gesturing-and-accounting-ofepistemic-phenomenalism-<in-

prospective_psychologismic apriorising/axiomatising/referencing-\{of-‘prospectively implicited_attendant-ontological-contiguity ' educedexistentialising/contextualising/textualising_'intelligibility/epistemicity/reflexivity-contiguity<imbued-notional cogency >' \}-conflatedness -in-\{preconverging-ment by\} postconverging-entailment $>$ associated with the Socratic ${ }^{103}$ universalising philosophers, budding-positivists/rational-empiricists and today's postmodern critical thinkers emancipating meaningfulness-and-teleology infrastructure while on-the-other-hand the prospective dereification as reflected in '<amplituding/formative $>$ wooden-language-〈imbued-temporalmere-form/virtualities/dereification/akrasiatic-drag/denatured/preconverging-or-dementing narratives - of-the- reference-of-thought- categorical-imperatives/axioms/registry-

teleology > of non-universalising sophists', non-positivising/non-rational-empiricist medieval 
scholasticism pedants and todays manifestations of institutional-being-and-craft muddlement as providing the ${ }^{56}$ meaningfulness-and-teleology ${ }^{9}$ infrastructure for their respective present-day vested postures and interests. The paradox here is that the lack of dimensionality-ofsublimating $2-\langle<$ amplituding/formative $>$ supererogatery-de-mentativeness/epistemic-growthor-conflatedness /transvaluative-rationalising/transepistemicity/anamnestic-residuality/spiritdrivenness-equalisation $\rangle$ of such ${ }^{79}$ presencing-absolutising-identitive-constitutedness 'human social-vestedness/normativity-<discretely-implied-functionalism> implied contract/political-arrangement-or-political-coercion/given-discrete-social-value-construction' apriorising/axiomatising/referencing conceptualisation perspective reasoning as of its

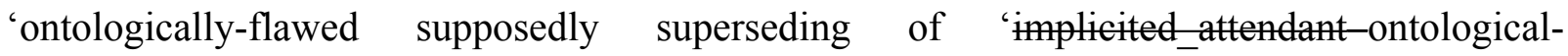
contiguity $^{67}$, educedexistentialising/contextmalising/textualising_'intelligibility/epistemicity/reflexivity_contiguity$<$ imbued-notional cogency>' 'relative-ontological-incompleteness $8 /$ relative-ontologicalcompleteness ${ }^{8}$-〈sublimating $\sim$ referencing/registering/decisioning,-as-self-becoming/selfconflatedness /formative-supererogating-<projective/reprojective-aestheticising-re-motifand-re-apriorising/re-axiomatising/re-referencing,-in-perspective-ontologicalnormalcy/postconvergence $>>$ as to human-and-social-expectations/anticipationsmetaphoricity ${ }^{57}$-as-preconverging/postconverging-redementating/restructuring/reparadigming-psychologism'89 construes such 'dimensionality-ofsublimating $25-<<$ amplituding/formative $>$ supererogatory $\sim$ de-mentativeness/epistemic-growthor-conflatedness /transvaluative-rationalising/transepistemicity/anamnestic-residuality/spiritdrivenness-equalisation> ontological-faith-notion-or-ontological-fideism-imbuedunderdetermination-of-motif-and-apriorising/axiomatising/referencing-as-so-being-as-ofexistential-reality seeding promise of human-subpotency ontological-performance ${ }^{2}-<$ includingvirtue-as-ontology $>/$ morality/ethics/justice/etc. equivalence/correspondence with the full- 
potency-of-existence's $\sim$ sublimating-nascence-as-of-its-coherence/contiguity' as teleologicallydegraded, even as it is the previous same dimensionality-of-sublimating 〈<amplituding/formative>supererogatory $\sim$ de-mentativeness/epistemic-growth-or-

conflatedness /transvaluative-rationalising/transepistemicity/anamnestic-residuality/spiritdrivenness-equalisation> originariness-parrhesia,-as-spontaneity-of-aestheticisation meaningfulness-and-teleology ${ }^{9}$ that ${ }^{7}$ presencing-absolutising-identitive-constitutedness formulaic interpretation adopt as the <amplituding/formative > wooden-language-〈imbuedtemporal-mere-form/virtualities/dereification/akrasiatic-drag/denatured/preconverging-ordementing -narratives - of-the- reference-of-thought- categoricalimperatives/axioms/registry-teleology $\rangle ;$ and so equating such 'prospective ${ }^{3<\text { amplituding/formative-epistemicity }>\text { growth-or-conflatedness }}{ }^{13 / \text { transvaluative- }^{2}}$ rationalising/transepistemicity/anamnestic-residuality/spirit-drivenness magnanimity induced originariness-parrhesia,-as-spontaneity-of-aestheticisation' with teleologically-degraded meaningfulness-and-teleology ${ }^{99}$ as of blatant two-facedness/falseness that would hardly contemplate that the "79 presencing-absolutising-identitive-constitutedness ${ }^{14}$ institutional framework preconverging/postconverging-de-mentatively/structurally/paradigmatically undermines in-many-ways the possibility for veridical prospective human transcendence-andsublimity/sublimation/supererogatoryade-mentativity as of its apriorising/axiomatising/referencing $\quad<$ amplituding/formative-epistemicity $>$ totalising $\sim$ selfreferencing-syncretising/circularity/interiorising/akrasiatic-drag ${ }^{34}$. Beyond and informing this analysis of human sovereignty and free-will ontological implications (in articulating the-veryunderlying ontological-veracity insights that expand/broaden our specific human-subpotency with regards to overall reifying-and-empowering-reflexivity-of-ecstatic-existence-aspanintelligibility/panreflexivity ${ }^{3}$-〈existentially-imbued-and-educing-\{epistemictotalising ${ }^{3}$ hermeneutically/textully/reprojectingly/supererogatingly/zeroing/y/re acutingly,- 
$\{$ decompulsing $\}$ delinearity for-cogency $>$-epistemic-perspective-of-projective/reprojective-

aestheticising-re-motif-and-re-apriorising/re-axiomatising/re-referencing $\sim$ conceptualisation-as-herein-specifically-relevant-to human-subpotency)'), the notion of causality as of $<$ amplituding/formative-epistemicity $>$ causality $\sim$ as-to-projective-totalitative-implications-ofprospective- nonpresencing,-for-explicating relative unreflexivity/relative reflexivity

ontological-contiguity is basically tied to the resolving/elucidating of human-subpotencyaporia/undecidability/dilemma/ought-indeterminacy/deficiency/limitation/constraint—imbued'notional firstnaturedness-formativeness-<as-to-eventualising -inkling-drive-or-seedingmisprising $>$ temporal-to-intemporal-dispositions-<so-construed-as-from-perspectiveontological-normalcy/postconvergence>'-existentialism-form-factor as of the full potential for human knowledge-reification $\sim$ gesturing-and-accounting-of-epistemic-phenomenalism- $<$ inprospective_psychologismic apriorising/axiomatising/referencing-\{of-'prospectively_ implicited_attendant-ontological-contiguity ' educedexistentialising/contextualising/textualising_'intelligibility/epistemicity/reflexivity-contiguity<imbued-notional cogency >' \}-conflatedness -in-\{preconverging-ment by\}

postconverging-entailment $>$. Such a human-causative-construction as of the underlying notion of 'relative-ontological-incompleteness $8 /$ relative-ontological-completeness

〈sublimating $\sim$ referencing/registering/decisioning,-as-self-becoming/self-

conflatedness /formative-supererogating-<projective/reprojective - aestheticising-re-motifand-re-apriorising/re-axiomatising/re-referencing,-in-perspective-ontologicalnormalcy/postconvergence $>>$ as to human-and-social-expectations/anticipationsmetaphoricity ${ }^{57}$-as-preconverging/postconverging-redementating/restructuring/reparadigming-psychologism' 89 is construed as 'more than just about direct re-motif-and-re-apriorising/re-axiomatising/re-referencing/re-intelligibilitysettingup/remeasuringinstrumenting in $\quad<$ amplituding/formative-epistemicity $>$-totalising $\sim$ renewing- 
realisation/re-perception/re-thought' as to wrongly imply that human transcendence-andsublimity/sublimation/supererogatory de-mentativity is just of a direct intemporal-asontological nature rather than truly involving both dimensionality-of-sublimating <<amplituding/formative > supererog de-mentativeness/epistemic-growth-orconflatedness /transvaluative-rationalising/transepistemicity/anamnestic-residuality/spiritdrivenness-equalisation) implications and its $\leq$ mere-formulaicity/ritualisation-of $>$-prior secondnatured institutionalisation implications. That is, the all-pervasiveness of the reality of human notional firstnaturedness-formativeness-<as-to-eventualising-inkling-drive-orseeding-misprising $>$ temporal-to-intemporal-dispositions-<so-construed-as-fromperspective-ontological-normalcy/postconvergence $>$ (as to temporal-to-intemporal individuations) $\quad$ regarding ontological-performance ${ }^{72}-<$ including-virtue-asontology $>$ /morality/ethics/justice/etc. (as so-reflected as of human-subpotencyaporia/undecidability/dilemma/ought-indeterminacy/deficiency/limitation/constraint—imbued'notional firstnaturedness-formativeness-<as-to-eventualising inkling-drive-or-seeding misprising $>$ temporal-to-intemporal-dispositions- $<$ so-construed-as-from-perspectiveontological-normalcy/postconvergence>'-existentialism-form-factor) interjects-and-invalidates the representation of merely such intemporal-as-ontological dimensionality-of-sublimating <<amplituding/formative>supererogatory $\sim$ de-mentativeness/epistemic-growth-orconflatedness /transvaluative-rationalising/transepistemicity/anamnestic-residuality/spiritdrivenness-equalisation> construal of human transcendence-andsublimity/sublimation/supererogatory de-mentativity; thus implying 'relative-ontologicalincompleteness $^{8} /$ relative-ontological-completeness $^{87}$ 〈sublimating $\sim$ referencing/registering/decisioning,-as-self-becoming/selfconflatedness /formative-supererogating-<projective/reprojective-aestheticising-re-motifand-re-apriorising/re-axiomatising/re-referencing,-in-perspective-ontological- 
normalcy/postconvergence $>>$ as to human-and-social-expectations/anticipationsmetaphoricity ${ }^{57}$-as-preconverging/postconverging-rede-

mentating/restructuring/reparadigming-psychologism'89 (and not 'absolute-ontologicalcompleteness implications') given human limited-mentation-capacity—as-subjecting-'educedmnlimitedness/existence sublimating nascence' to limitedness/hmman-subpotency at all moments, as so-reflected in the prospective destructuring-threshold-〈uninstitutionalisedthreshold /presublimating-desublimating-decisionality $>$ of-ontological-performance ${ }^{72}$ $<$ including-virtue-as-ontology $>$ /morality/ethics/justice/etc. of any specific registryworldview's/dimension's existential-disontologising/re ontelogising apereticism> desublimation manifestation underlined by <amplituding/formative $>$ wooden-language〈imbued - averaging-of-thought-<as-to-leveling/ressentiment/closed-construct-ofmeaningfulness-and-teleology -as-of-'nondescript/ignorable-void '-with-regards-toprospective-apriorising-implications $>>\quad$ or $<$ amplituding/formative $>$ wooden-language〈imbued-averaging-of-thought-<as-to-leveling/ressentiment/closed-construct-ofmeaningfulness-and-teleology -as-of-'nondescript/ignorable-void '-with-regards-toprospective-apriorising-implications $>>$. This more effectively speaks to the fact that 'dimensionality-of-sublimating $25<$ < amplituding/formative $>$ supererogatory $\sim$ dementativeness/epistemic-growth-or-conflatedness /transvaluative-

rationalising/transepistemicity/anamnestic-residuality/spirit-drivenness-equalisation $\rangle \quad$ as originariness-parrhesia,-as-spontaneity-of-aestheticisation', instigative of the 'inventing'/‘creating' of the possibility for 'prospective secondnatured institutionalisation as prospective reproducibility-mathesis/motif/thrownness-disposition,--as-reproducibility-ofaestheticisation', gets lost effectively in the prospective secondnatured institutionalisation induced $\quad{ }^{83}$ reference-of-thought- categorical-imperatives/axioms/registry-teleology ${ }^{9}$,-foraposteriorising/logicising/deriving/intelligising/measuring $-{ }^{5}$ meaningfulness-and-teleology ${ }^{99}$ as 
human temporality 8 /shortness encounters it (beyond-the-consciousness-awareness-teleology $<$ of-preconverging-existential-extrication-as-of-existential-unthought $>$ ) and so rather as of the 'secondnatured-institutionalisation existence-potency ${ }^{32} \sim$ sublimating-nascence,-disclosed-fromprospective-epistemic-digression epistemically-induced/constrained-reproducibility-motif-ofmeaningfulness-and-teleology as of relatively-shallow-frame-of-elicited-positiveopportunism - of-social-functioning-and-accordance ${ }^{75}$-of-low-intrinsic-attribution-and-highextrinsic-attribution-susceptibility,-in-dimensionality-of-desublimating-lack-of ${ }^{2}$ <<amplituding/formative>supererogatory $\sim$ de-mentativeness/epistemic-growth-orconflatedness /transvaluative-rationalising/transepistemicity/anamnestic-residuality/spiritdrivenness-equalisation)' beyond which its implied dispensing-with-immediacy-for-relativeontological-completeness $^{87}$-by-reification/contemplative-distension ${ }^{27}$ (as of human selfsurpassing — existentialism-form-factor,-in-overcoming-“notional collateralising-beholdeningprotohumanity’-to- 'attain-sublimating-humanity'-as-to-existence-potency sublimatingnascence,-disclosed-from-prospective-epistemic-digression to supersede human temporality 8 /shortness <amplituding/formative> wooden-language-〈imbued-averaging-ofthought-<as-to-leveling/ressentiment/closed-construct-of- meaningfulness-and-teleology -asof-'nondescript/ignorable-void '-with-regards-to-prospective-apriorising-implications $>\rangle) \quad$ is construed as relatively vague-and-irrelevant as human temporality ${ }^{9} /$ shortness now re-construes in apriorising/axiomatising/referencing-\{of-'prospectively implicited_attendant-ontologicalcontiguity ' $\sim$ educedexistentialising/contextualising/textualising_'intelligibility/epistemicity/reflexivity_contiguity$<$ imbued-notional cogency $\left.>^{\prime} \quad\right\}$-constitutedness ${ }^{14}$-in-preconverging-entailment $\quad$ such 'secondnatured-institutionalisation existence-potency ${ }^{32} \sim$ sublimating-nascence,-disclosed-fromprospective-epistemic-digression epistemically-induced/constrained-reproducibility-motif-ofmeaningfulness-and-teleology as of relatively-shallow-frame-of-elicited-positive- 
opportunism - of-social-functioning-and-accordance ${ }^{75}$-of-low-intrinsic-attribution-and-highextrinsic-attribution-susceptibility,-in-dimensionality-of-desublimating-lack-of ${ }^{-}$ 〈<amplituding/formative>supererogatory $\sim$ de-mentativeness/epistemic-growth-orconflatedness /transvaluative-rationalising/transepistemicity/anamnestic-residuality/spiritdrivenness-equalisation)' in such a way that is obviating and becomes homeless as to the apriorising/axiomatising/referencing-\{of-'prospectively_implicited_attendant-ontologicalcontiguity ' educedexistentialising/contextualising/textualising_'intelligibility/epistemicity/reflexivity-contiguity<imbued-notional cogency $\left.>^{\prime}\right\}$-conflatedness ${ }^{13}$ in-\{preconverging-ment by\} of of dimensionality-of-sublimating ${ }^{25}$ <<amplituding/formative>supererogatory $\sim$ de-mentativeness/epistemic-growth-orconflatedness /transvaluative-rationalising/transepistemicity/anamnestic-residuality/spiritdrivenness-equalisation) reflected in perpetuating/preserving the ontological-veracity in reflecting holographically-<conjugatively-and-transfusively $>$ the reflexivity - ontological-contiguity of-the-human-institutionalisation-process ; and this 'secondnatured-institutionalisation existence-potency ${ }^{32} \sim$ sublimating-nascence,-disclosed-fromprospective-epistemic-digression epistemically-induced/constrained-reproducibility-motif-ofmeaningfulness-and-teleology as of relatively-shallow-frame-of-elicited-positiveopportunism - of-social-functioning-and-accordance ${ }^{75}$-of-low-intrinsic-attribution-and-highextrinsic-attribution-susceptibility,-in-dimensionality-of-desublimating-lack-of ${ }^{6}$ <<amplituding/formative>supererogatory $\sim$ de-mentativeness/epistemic-growth-orconflatedness /transvaluative-rationalising/transepistemicity/anamnestic-residuality/spiritdrivenness-equalisation)' fundamentally underlies the very idea of human notional $\sim$ procrypticism/notional $\sim$ disjointedness-as-of- ${ }^{8}$ reference-of-thought (so-manifested as of recurrent-utter-uninstitutionalisation, ununiversalisation, non-positivism/medievalism and 
procrypticism-or-disjointedness-as-of- ${ }^{3}$ reference-of-thought), such that none of any such 'secondnatured-institutionalisation existence-potency ${ }^{32} \sim$ sublimating-nascence,-disclosed-fromprospective-epistemic-digression epistemically-induced/constrained-reproducibility-motif-ofmeaningfulness-and-teleology as of relatively-shallow-frame-of-elicited-positiveopportunism-of-social-functioning-and-accordance ${ }^{75}$-of-low-intrinsic-attribution-and-highextrinsic-attribution-susceptibility,-in-dimensionality-of-desublimating-lack-of <<amplituding/formative >supererogatory $\sim$ de-mentativeness/epistemic-growth-orconflatedness /transvaluative-rationalising/transepistemicity/anamnestic-residuality/spiritdrivenness-equalisation〉' preconverging/postconverging-dementatively/structurally/paradigmatically carries the possibility (as of its apriorising/axiomatising/referencing-\{of-'prospectively_implicited_attendant-ontologicalcontiguity ' $\sim$ educedexistentialising/contextualising/textualising_'intelligibility/epistemicity/reflexivity-contiguity$<$ imbued-notional cogency $\left.\rangle^{\prime} \quad\right\}$-constitutedness ${ }^{14}$-in- preconverging-entailment epistemic stance in 7 presencing - absolutising-identitive-constitutedness ${ }^{14}$ ) for 'prospective originarinessparrhesia,-as-spontaneity-of-aestheticisation', instigative of the 'inventing'/'creating' of the possibility for 'prospective secondnatured institutionalisation as prospective renewed reproducibility—mathesis/motif/thrownness-disposition,-as-reproducibility-ofaestheticisation' so-reflected in their existential-<disontologising/re-ontelogising apereticism $>$ desublimation manifestation of $<$ amplituding/formative $>$ wooden-language〈imbued-averaging-of-thought-<as-to-leveling/ressentiment/closed-construct-ofmeaningfulness-and-teleology -as-of-'nondescript/ignorable-void '-with-regards-toprospective-apriorising-implications $>>\quad$ or $\quad<$ amplituding/formative $>$ wooden-language〈imbued-averaging-of-thought-<as-to-leveling/ressentiment/closed-construct-ofmeaningfulness-and-teleology -as-of-'nondescript/ignorable-void '-with-regards-to- 
prospective-apriorising-implications $>>$ in $<$ amplituding/formative-epistemicity $>$ totalising $\sim$ selfreferencing-syncretising/circularity/interiorising/akrasiatic-drag ${ }^{34}$. Hence the need for prospective preconverging/postconverging-rede-mentating/restructuring/reparadigming apriorising/axiomatising/referencing as of $\quad<$ amplituding/formative-epistemicity $>$ totalising renewing-realisation/re-perception/re-thought as from the instigation of dimensionality-of-sublimating $25<<$ amplituding/formative $>$ supererogatory $\sim$ dementativeness/epistemic-growth-or-conflatedness /transvaluativerationalising/transepistemicity/anamnestic-residuality/spirit-drivenness-equalisation〉, as the latter as the intemporal-as-ontological preconverging/postconverging-dementatively/structurally/paradigmatically reflects the ontological-normalcy/postconvergence of existence-potency ${ }^{39} \sim$ sublimating-nascence,-disclosed-from-prospective-epistemic-digression depth/profoundness of conception of human-subpotency causality as of $<$ amplituding/formative-epistemicity $>$ causality $\sim$ as-to-projective-totalitative-implications-ofprospective- nonpresencing,-for-explicating relative-unreflexivity/relative-reflexivity

ontological-contiguity in reflecting holographically-<conjugatively-and-transfusively $>$ the relative-unreflexivity/relative-reflexivity - ontological-contiguity of-the-humaninstitutionalisation-process perpetuating/preservation. Basically, any such 'secondnaturedinstitutionalisation existence-potency ${ }^{32} \sim$ sublimating-nascence,-disclosed-from-prospectiveepistemic-digression epistemically-induced/constrained-reproducibility-motif-ofmeaningfulness-and-teleology as of relatively-shallow-frame-of-elicited-positiveopportunism-of-social-functioning-and-accordance ${ }^{75}$-of-low-intrinsic-attribution-and-highextrinsic-attribution-susceptibility,-in-dimensionality-of-desublimating-lack-of 〈<amplituding/formative>supererogatory $\sim$ de-mentativeness/epistemic-growth-orconflatedness /transvaluative-rationalising/transepistemicity/anamnestic-residuality/spiritdrivenness-equalisation〉' assumes a ${ }^{79}$ presencing-absolutising-identitive-constitutedness 
inclination

in

$<$ amplituding/formative-epistemicity $>$ totalising $\sim$ self-referencingsyncretising/circularity/interiorising/akrasiatic-drag that cannot cohere to the ecstaticexistence-as-transcendental-signifier-emergence/becoming-spontaneity-implications

reflected as existence-potency ${ }^{39} \sim$ sublimating-nascence,-disclosed-from-prospective-epistemicdigression. Thus this notional firstnaturedness-formativeness-<as-to-eventualising inkling drive or seeding-misprising $>$ temporal-to-intemporal-dispositions- $<$ so-construed-as-fromperspective-ontological-normalcy/postconvergence $>\quad$ (as to temporal to intemporal individuations) interjection invalidating the representation of merely intemporal-as-ontological dimensionality-of-sublimating $25<$ < amplituding/formative >supererogatory $\sim$ dementativeness/epistemic-growth-or-conflatedness /transvaluativerationalising/transepistemicity/anamnestic-residuality/spirit-drivenness-equalisation $\rangle$ construal of human transcendence-and-sublimity/sublimation/supereregatery $\sim$ de-mentativity, speaking of 'relative-ontological-incompleteness ${ }^{8 /} /$ relative-ontological-completeness $^{87}$ 〈sublimating referencing/registering/decisioning,-as-self-becoming/selfconflatedness /formative-supererogating-<projective/reprojective-aestheticising-re-motifand-re-apriorising/re-axiomatising/re-referencing,-in-perspective-ontologicalnormalcy/postconvergence $>>$ as to human-and-social-expectations/anticipationsmetaphoricity ${ }^{57}$-as-preconverging/postconverging-redementating/restructuring/reparadigming-psychologism'89 (and not 'absolute-ontologicalcompleteness implications'), fundamentally validates 'apriorising/axiomatising/referencing-\{of'prospectively_implicited_attendant-ontological-contiguity ' educedexistentialising/contextualising/textualising_intelligibility/epistemicity/reflexivity_contiguity$<$ imbued-notional cogency $>>$ - conflatedness $^{13}$-in-\{preconverging-ment by\} postconverging-ntailment-of-construal as potentiating the superseding of the preconverging/postconverging-de-mentative/structural/paradigmatic 
apriorising/axiomatising/referencing implications of human temporal-dispositions for the prospective conception of knowledge-reification $\sim$ gesturing-and-accounting-of-epistemicphenomenalism-<in-prospective_psychologismic $\sim$ apriorising/axiomatising/referencing-\{of'prospectively_implicited_attendant-ontological-contiguity ' educedexistentialising/contextualising/textualising_'intelligibility/epistemicity/reflexivity-contiguity<imbued-notional cogency >’ \}-conflatedness -in-\{preconverging-ment by\} postconverging-ntailment $>$ as so-reflected in the transepistemicity/conflating-nature of notional ${ }^{18}$ deprocrypticism or <amplituding/formative $>$ notional $\sim$ preempting - disjointednessas-of- ${ }^{3}$ reference-of-thought in reflecting holographically-<conjugatively-and-transfusively $>$ the relative-unreflexivity/relative-reflexivity - ontological-contiguity of-the-humaninstitutionalisation-process as from recurrent-utter-uninstitutionalisation, baseinstitutionalisation, ${ }^{103}$ universalisation, positivism/rational-empiricism and prospectively deprocrypticism-or-preempting-disjointedness-as-of- ${ }^{3}$ reference-of-thought. It is this epistemic-conflatedness $^{13}$ veracity (construed as transepistemicity) over epistemic apriorising/axiomatising/referencing-\{of-'prospectively_implicited_attendant-ontologicalcontiguity ' $\sim$ educed-

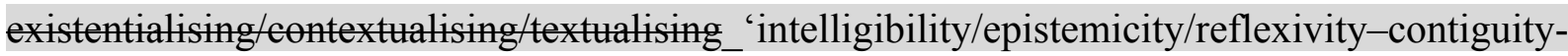
$<$ imbued-notional cogency $>$ ' $\}$-constitutedness ${ }^{1}$-in-preconverging-entailment (construed as ${ }^{7}$ presencing-absolutising-identitive-constitutedness ${ }^{14}$ ), of human knowledge that underlies knowledge-notionalisation as to 'notional conceptualisations' like conception / misconception, intellectualism / sophistry, leveling / deleveling, human-subpotency / existencepotency ${ }^{39} \sim$ sublimating-nascence,-disclosed-from-prospective-epistemic-digression, transversality-<for-sublimating-existential-eventuating/denouement, frem 'thinking at first/pure-predisposition-preemptive-of-prospective-disontologising/subontologising' as-ofprospectively-disambiguated-affirmed-and-unaffirmed-'motif-and- 
psychologismic $\sim$ apriorising/axiomatising/referencing-\{of-"prospectively

implicited_attendant-ontological-contiguity ' educed-

existentialising/contextualising/textualising_'intelligibility/epistemicity/reflexivity-contiguity-

<imbued-notional cogency >' \}-conflatedness -in-\{preconverging-ment by\}

postconverging-entailment,-in-self-becoming/self-conflatedness /formative-supererogating>,

organicalism / mechanicalism, postconverging/dialectical-thinking ${ }^{21}$-qualia-schem /

apreconverging/dementing ${ }^{20}$-qualia-schema, etc., respectively as to 'dispensing-withimmediacy-for-relative-ontological-completeness ${ }^{87}$-by-reification/contemplative-distension

(as of human self-surpassing — existentialism-form-factor,-in-overcoming-

‘notional collateralising-beholdening-protohumanity’-to-'attain-sublimating-humanity'-as-to-

existence-potency $\sim$ sublimating-nascence,-disclosed-from-prospective-epistemic-digression

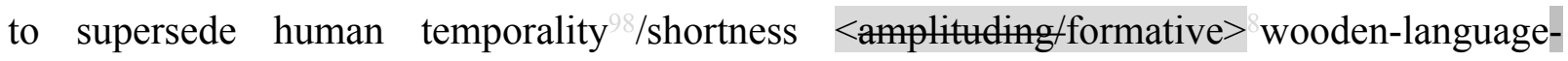

〈imbued-averaging-of-thought-<as-to-leveling/ressentiment/closed-construct-of-

meaningfulness-and-teleology -as-of-'nondescript/ignorable-void '-with-regards-to-

prospective-apriorising-implications $>>$ ) and preconverging-existential-extrication-as-of-

existential-unthought implications' for veridical ontologisation/ontologicalveracity/aestheticisation-towards-ontology. The very ontological-veracity of any such 'notional conceptualisation' lies in construing how these reflect causality as of ontological-primemoverstotalitative-implications as so-implied with the relative-unreflexivity/relative-reflexivityontological-contiguity ${ }^{67}$ of-the-human-institutionalisation-process ${ }^{68} \quad$ opened-construct-ofmeaningfulness-and-teleology . What is critical with respect to prospective deprocrypticism-or-preempting-disjointedness-as-of- ${ }^{3}$ reference-of-thought is effectively the fact that its prospective institutionalisation is much more than just any such 'secondnaturedinstitutionalisation existence-potency ${ }^{39} \sim$ sublimating-nascence,-disclosed-from-prospective- 
epistemic-digression

meaningfulness-and-teleology as of relatively-shallow-frame-of-elicited-positive-

opportunism-of-social-functioning-and-accordance ${ }^{75}$-of-low-intrinsic-attribution-and-highextrinsic-attribution-susceptibility,-in-dimensionality-of-desublimating-lack-of ${ }^{-}$<<amplituding/formative>supererogatory $\sim$ de-mentativeness/epistemic-growth-orconflatedness /transvaluative-rationalising/transepistemicity/anamnestic-residuality/spiritdrivenness-equalisation $\rangle$ ' as prospective notional ' deprocrypticism involves 'superseding preconverging-existential-extrication-as-of-existential-unthought as of human-subpotency epistemic perspective with the integration of the necessary, abstract and non-eliciting-ofopportunism dispensing-with-immediacy-for-relative-ontological-completeness ${ }^{87}$-byreification/contemplative-distension ${ }^{27}$ into its secondnatured institutionalisation' thus providing the preconverging/postconverging-de-mentative/structural/paradigmatic interlocking of notional $\sim$ deprocrypticism ${ }^{56}$ meaningfulness-and-teleology ${ }^{99}$ with the relativeunreflexivity/relative-reflexivity ${ }_{\text {ontological-contiguity }}{ }^{7}$ of-the-human-institutionalisationprocess ${ }^{68} \quad$ 're-inventing'/'re-creating' dimensionality-of-sublimating ${ }^{25}$ -

\section{< $<$ amplittding/formative >supererogatory $\sim$ de-mentativeness/epistemic-growth-or-}

\section{conflatedness /transvaluative-rationalising/transepistemicity/anamnestic-residuality/spirit-}

drivenness-equalisation); as otherwise such supposedly prospective notional ${ }^{~ d e p r o c r y p t i c i s m ~}$ institutionalisation will in reality be just a complexification of our positivism/rationalempiricism institutionalisation were it to manifest a secondnatured incapacity for the 'reinventive'/'re-creative' preservation/sustaining/upkeep of ${ }^{18}$ deprocrypticism-or-preemptingdisjointedness-as-of- ${ }^{-1}$ reference-of-thought. The fact is the elucidation/resolving of humansubpotency-aporia/undecidability/dilemma/oughtindeterminacy/deficiency/limitation/constraint—imbued-'notional firstnaturednessformativeness-<as-to-eventualising inkling-drive-or-seeding-misprising $>$ temporal-to- 
intemporal-dispositions-<so-construed-as-from-perspective-ontologicalnormalcy/postconvergence>'-existentialism-form-factor has ever always been about the interplay of 'immediacy of temporal-dispositions in precenverging-existential-extrication-as-ofexistential-unthought as of human-subpotency epistemic perspective' and 'dispensing-withimmediacy-for-relative-ontological-completeness ${ }^{87}$-by-reification/contemplative-distension as intemporal-disposition as intemporal-disposition', wherein the former (beyond-theconsciousness-awareness-teleology ${ }^{0}-<$ of-preconverging-existential-extrication-as-ofexistential-unthought>) is mainly responsive to 'secondnatured-institutionalisation existencepotency $^{39} \sim$ sublimating-nascence,-disclosed-from-prospective-epistemic-digression epistemically-induced/constrained-reproducibility-motif-of- ${ }^{56}$ meaningfulness-and-teleology as of relatively-shallow-frame-of-elicited-positive-opportunism-of-social-functioning-andaccordance ${ }^{75}$-of-low-intrinsic-attribution-and-high-extrinsic-attribution-susceptibility,-indimensionality-of-desublimating-lack-of $-\langle<$ amplituding/formative $>$ supererogatory $\sim$ dementativeness/epistemic-growth-or-conflatedness /transvaluativerationalising/transepistemicity/anamnestic-residuality/spirit-drivenness-equalisation〉' and is rather critically apathetic to the necessary, abstract and non-eliciting-of-opportunism as of 'dispensing-with-immediacy-for-relative-ontological-completeness ${ }^{87}$-byreification/contemplative-distension ${ }^{27}$ as intemporal-disposition' that preconverging/postconverging-de-mentatively/structurally/paradigmatically enables the preserving/sustaining/upkeep and 'inventing'/'creating' possibilities for prospective institutionalisation. Inevitably as of ontological-normalcy/postconvergence of existencepotency ${ }^{32} \sim$ sublimating-nascence,-disclosed-from-prospective-epistemic-digression, $\quad$ such dispensing-with-immediacy-for-relative-ontological-completeness ${ }^{87}$-byreification/contemplative-distension ${ }^{27}$ (as of human self-surpassing-existentialism-formfactor,-in-overcoming-'notional collateralising-beholdening-protohumanity'-to-'attain- 
sublimating-humanity'-as-to-existence-potency sublimating-nascence,-disclosed-from-

prospective-epistemic-digression to supersede human temporality $8 /$ shortness

$<$ amplituding/formative $>$ wooden-language-〈imbued — averaging-of-thought-<as-to-

leveling/ressentiment/closed-construct-of- meaningfulness-and-teleology -as-of-

'nondescript/ignorable-void '-with-regards-to-prospective-apriorising-implications $>\rangle$ ) with

regards to prospective institutionalisation transcendence-and-

sublimity/sublimation/supererogatory de-mentativity 'effectively implies the apriorising/axiomatising/referencing epistemic-abnormalcy/preconvergence ${ }^{31}$ of all presencing-absolutising-identitive-constitutedness ${ }^{1,}$, wherein prospective baseinstitutionalisation implies the apriorising/axiomatising/referencing epistemicabnormalcy/preconvergence ${ }^{31}$ of recurrent-utter-uninstitutionalisation, and the same applies to our positivism- ${ }^{8}$ procrypticism as prospective deprocrypticism-or-preemptingdisjointedness-as-of- ${ }^{8}$ reference-of-thought implies the apriorising/axiomatising/referencing epistemic-abnormalcy/preconvergence ${ }^{31}$ of our positivism- ${ }^{80}$ procrypticism, even as no registryworldview/dimension is preconvergingly-de-mentated/structured/paradigmed to construe of itself paradoxically as of such apriorising/axiomatising/referencing epistemicabnormalcy/preconvergence ${ }^{3}$ where it is prospectively of preconverging/dementing ${ }^{20}$-qualiaschema at its destructuring-threshold-〈uninstitutionalised-threshold /presublimatingdesublimating-decisionality $>$ of-ontological-performance ${ }^{2}-<$ including-virtue-as-ontology $>$; and this explains why the very essence of such metaphoricity ${ }^{57}$ of ${ }^{56}$ meaningfulness-andteleology is rather of a crossgenerational psychoanalytic-unshackling/memeticreordering/institutional-recomposuring. Furthermore, the reality of all prospective transcendence-and-sublimity/sublimation/supererogatory $\sim$ de-mentativity for prospective registry-worldview/dimension institutionalisation is that it can difficultly be expected that dimensionality-of-sublimating $-<<$ amplituding/formative $>$ supererogatory $\sim$ de- 
mentativeness/epistemic-growth-or-conflatedness /transvaluative-

rationalising/transepistemicity/anamnestic-residuality/spirit-drivenness-equalisation〉

'ontological-faith-notion-or-ontological-fideism - imbued-underdetermination-of-motif-and-

apriorising/axiomatising/referencing-as-so-being-as-of-existential-reality parrhesiastic askesisor-acumen as of reasoning-through/messianic-reasoning' induced originariness-parrhesia,--asspontaneity-of-aestheticisation required for any such prospective institutionalisation can be contemplated of on the reasoning-from-results/afterthought basis of the priorly 'secondnaturedinstitutionalisation existence-potency ${ }^{32} \sim$ sublimating-nascence,-disclosed-from-prospectiveepistemic-digression epistemically-induced/constrained-reproducibility-motif-ofmeaningfulness-and-teleology as of relatively-shallow-frame-of-elicited-positiveopportunism-of-social-functioning-and-accordance ${ }^{75}$-of-low-intrinsic-attribution-and-highextrinsic-attribution-susceptibility,-in-dimensionality-of-desublimating-lack-of ${ }^{2}$ <<amplituding/formative>supererogatory $\sim$ de-mentativeness/epistemic-growth-orconflatedness /transvaluative-rationalising/transepistemicity/anamnestic-residuality/spiritdrivenness-equalisation〉'. The relative-unreflexivity/relative-reflexivity-ontologicalcontiguity ${ }^{67}$ of-the-human-institutionalisation-process ${ }^{68}$ as of Being-development/ontologicalframework-expansion-as-to-depth-of-ontologising-development-as-infrastructure-ofmeaningfulness-and-teleology , institutional-development-as-to-social-functiondevelopment and living-development-as-to-personality-development psychologismic epistemic-acutisation - difficulty-for, residualising \{decompulsing $\}$ delinearity for-cogency> magnitudes ${ }^{\text {of-experientiality/experiment }\}}$ has ever always been driven as of the instigative human dimensionality-of-sublimating $-<<$ amplituding/formative $>$ supererogatory $\sim$ dementativeness/epistemic-growth-or-conflatedness /transvaluativerationalising/transepistemicity/anamnestic-residuality/spirit-drivenness-equalisation $\rangle$, but so in a mismatch with 'secondnatured-institutionalisation existence-potency ${ }^{3} \sim$ sublimating- 
nascence,-disclosed-from-prospective-epistemic-digression epistemically-induced/constrainedreproducibility-motif-of- ${ }^{5}$ meaningfulness-and-teleology as of relatively-shallow-frame-ofelicited-positive-opportunism-of-social-functioning-and-accordance ${ }^{75}$-of-low-intrinsicattribution-and-high-extrinsic-attribution-susceptibility,-in-dimensionality-of-desublimatinglack-of $-<<$ amplituding/formative $>$ supererogatory $\sim$ de-mentativeness/epistemic-growth-orconflatedness /transvaluative-rationalising/transepistemicity/anamnestic-residuality/spiritdrivenness-equalisation $)^{\prime} ; \quad$ such that preconverging/postconverging-dementatively/structurally/paradigmatically the relative-unreflexivity/relative-reflexivity ontological-contiguity ${ }^{67}$ of-the-human-institutionalisation-process ${ }^{68}, \quad$ underlying the institutional-cumulation/institutional-recomposure-〈as-to- historiality/ontologicaleventfulness /ontological-aesthetic-tracing-<perspective-ontologicalnormalcy/postconvergence-reflected-‘epistemicity-relativism-determinism'>> of the $<$ cumulating/recomposuring attendant-ontological-contiguity $>$-successive registryworldviews/dimensions in relative-ontological-completeness ${ }^{87}$, has always developed more or less accidentedly as to wrongly imply the requisite selfless projection of human dimensionalityof-sublimating $25-\langle<$ amplituding/formative $>$ supererogatory $\sim$ de-mentativeness/epistemicgrowth-or-conflatedness /transvaluative-rationalising/transepistemicity/anamnesticresiduality/spirit-drivenness-equalisation $\rangle$ as to construction-of-the-Self is only as critical when it enables the relatively-shallow-frame-of-elicited-positive-opportunism-of-socialfunctioning-and-accordance ${ }^{75}$-of-low-intrinsic-attribution-and-high-extrinsic-attributionsusceptibility,-in-dimensionality-of-desublimating-lack-of ${ }^{2}$ <<amplituding/formative >supererogatory $\sim$ de-mentativeness/epistemic-growth-orconflatedness /transvaluative-rationalising/transepistemicity/anamnestic-residuality/spiritdrivenness-equalisation) (as of prospective 'secondnatured-institutionalisation existencepotency $^{39} \sim$ sublimating-nascence,-disclosed-from-prospective-epistemic-digression 
epistemically-induced/constrained-reproducibility-motif-of- ${ }^{-6}$ meaningfulness-and-teleology as of relatively-shallow-frame-of-elicited-positive-opportunism-of-social-functioning-andaccordance ${ }^{75}$-of-low-intrinsic-attribution-and-high-extrinsic-attribution-susceptibility,-indimensionality-of-desublimating-lack-of $-\langle<$ amplituding/formative $>$ supererogatory - dementativeness/epistemic-growth-or-conflatedness /transvaluativerationalising/transepistemicity/anamnestic-residuality/spirit-drivenness-equalisation〉') in coherently perpetuating priorly-and-prospectively the possibility for human registryworldview's/dimension's institutionalisation to arise in-the-very-first-place. This explains inmany-ways temporal-dispositions to preconverging-existential-extrication-as-of-existentialunthought as of human-subpotency epistemic perspective over intemporal-disposition of dispensing-with-immediacy-for-relative-ontological-completeness ${ }^{87}$-by-

reification/contemplative-distension ${ }^{27}$ across all the registry-worldviews/dimensions reflected in the repetitive succession of <amplituding/formative $>$ wooden-language-〈imbued-averagingof-thought-<as-to-leveling/ressentiment/closed-construct-of- meaningfulness-and-teleology as-of-'nondescript/ignorable-void ' -with-regards-to-prospective-apriorising-implications $>$ > assuming a ${ }^{79}$ presencing - absolutising-identitive-constitutedness ${ }^{14}$ inclination about all that ever existed and matters, implying an orientation to Being-development/ontological-frameworkexpansion-as-to-depth-of-ontologising-development-as-infrastructure-of- meaningfulnessand-teleology , institutional-development-as-to-social-function-development and livingdevelopment-as-to-personality-development psycholegismic epistemic acutisation-

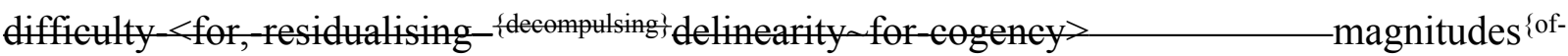
experientiality/experiment\} devoid of the homeliness of the apriorising/axiomatising/referencing-\{of'prospectively_implicited_attendant-ontological-contiguity ' ceducedexistentialising/contextualising/textualising_ 'intelligibility/epistemicity/reflexivity-contiguity<imbued-notional cogency >' $\}$-re-originariness/re-origination as reflected by the relative- 
unreflexivity/relative-reflexivity — ontological-contiguity ${ }^{67}$ of-the-human-institutionalisationprocess dimensionality-of-sublimating $^{25}-\langle<$ amplituding/formative $>$ supererogatory $\sim$ dementativeness/epistemic-growth-or-conflatedness /transvaluativerationalising/transepistemicity/anamnestic-residuality/spirit-drivenness-equalisation〉 as to difference-conflatedness ${ }^{13}$-as-to-totalitative-reification-in-singularisation- $<$ as-to-thenondisjointedness/entailment-of-prospective- nonpresencing > -as-veridical-epistemicityrelativism-determinism implied $<$ amplituding/formative-epistemicity $>$ causality $\sim$ as-toprojective-totalitative-implications-of-prospective- nonpresencing,-for-explicating relativeunreflexivity/relative-reflexivity ontological-contiguity , as the latter attends to existencepotency $^{39} \sim$ sublimating-nascence,-disclosed-from-prospective-epistemic-digression—rules-ofapriorising/axiomatising/referencing-that-further-epistemically-unconceal-the-veryontologically-same-existential-reality with regards to prospective human-subpotencyaporia/undecidability/dilemma/ought-indeterminacy/deficiency/limitation/constraint thus enabling prospective human transcendence-and-sublimity/sublimation/supererogatory $\sim$ dementativity. Such that paradoxically in-many-ways the prior 'secondnatured-institutionalisation existence-potency ${ }^{39} \sim$ sublimating-nascence,-disclosed-from-prospective-epistemic-digression epistemically-induced/constrained-reproducibility-motif-of- ${ }^{-6}$ meaningfulness-and-teleology as of relatively-shallow-frame-of-elicited-positive-opportunism-of-social-functioning-andaccordance $^{75}$-of-low-intrinsic-attribution-and-high-extrinsic-attribution-susceptibility,-indimensionality-of-desublimating-lack-of $-\langle<$ amplituding/formative $>$ supererogatory $\sim$ de-

\section{mentativeness/epistemic-growth-or-conflatedness /transvaluative-}

rationalising/transepistemicity/anamnestic-residuality/spirit-drivenness-equalisation〉' as of its temporal social-vestedness/normativity- $<$ discretely-implied-functionalism $>$ goes on recurrently (in its $<$ amplituding/formative--epistemicity $>$ totalising $\sim$ self-referencingsyncretising/circularity/interiorising/akrasiatic-drag ${ }^{34}$ ) in reflecting holographically- 
$<$ conjugatively-and-transfusively $>$ the relative-unreflexivity/relative-reflexivity-ontologicalcontiguity of-the-human-institutionalisation-process to undermine prospectively the very dimensionality-of-sublimating ${ }^{25}-<$ amplituding/formative $>$ supererogatory $\sim$ dementativeness/epistemic-growth-or-conflatedness /transvaluativerationalising/transepistemicity/anamnestic-residuality/spirit-drivenness-equalisation) (from which it obtained its prior reproducibility-mathesis/motif/thrownness-disposition,--asreproducibility-of-aestheticisation) that carries possibilities for prospective originarinessparrhesia,-as-spontaneity-of-aestheticisation for human transcendence-andsublimity/sublimation/supererogatory $\sim$ de-mentativity; paradoxically, recurrently elevating the human mortal beyond existence-potency ${ }^{39} \sim$ sublimating-nascence,-disclosed-from-prospectiveepistemic-digression implications as to the uninstitutionalised-threshold ${ }^{12}$ attendant framework of lack of social ${ }^{103}$ universal-transparency ${ }^{104}$-〈transparency-of-totalising-entailing,-as-toentailing-<amplituding/formative-epistemicity $>$ totalising $\sim$ in-relative-ontologicalcompleteness $\rangle$-or-understanding-of- $<$ amplituding/formative-epistemicity $>$ causality $\sim$ as-toprojective-totalitative-implications-of-prospective- nonpresencing,-for-explicating relativeunreflexivity/relative-reflexivity - ontological-contiguity -of-underlying-phenomena and institutional ascendancy as to flawed ${ }^{79}$ presencing-absolutising-identitive-constitutedness ${ }^{14}$, against which dimensionality-of-sublimating ${ }^{25}-\langle<$ amplituding $/$ formative $>$ supererogatery - dementativeness/epistemic-growth-or-conflatedness /transvaluativerationalising/transepistemicity/anamnestic-residuality/spirit-drivenness-equalisation $\rangle$ has to recurrently prospectively re-enable the relatively-shallow-frame-of-elicited-positiveopportunism - of-social-functioning-and-accordance ${ }^{75}$-of-low-intrinsic-attribution-and-highextrinsic-attribution-susceptibility,-in-dimensionality-of-desublimating-lack-of <<amplituding/formative>supererogatory $\sim$ de-mentativeness/epistemic-growth-orconflatedness /transvaluative-rationalising/transepistemicity/anamnestic-residuality/spirit- 
drivenness-equalisation> for prospective 'secondnatured-institutionalisation existencepotency ${ }^{39} \sim$ sublimating-nascence,-disclosed-from-prospective-epistemic-digression epistemically-induced/constrained-reproducibility-motif-of- ${ }^{5}$ meaningfulness-and-teleology as of relatively-shallow-frame-of-elicited-positive-opportunism-of-social-functioning-andaccordance $^{75}$-of-low-intrinsic-attribution-and-high-extrinsic-attribution-susceptibility,-indimensionality-of-desublimating-lack-of $-\langle<$ amplituding/formative $>$ supererogatory $\sim$ dementativeness/epistemic-growth-or-conflatedness /transvaluativerationalising/transepistemicity/anamnestic-residuality/spirit-drivenness-equalisation)’ (resolving the prior destructuring-threshold-〈uninstitutionalised-threshold /presublimatingdesublimating-decisionality $>\sim$ of-ontological-performance ${ }^{22}<$ including-virtue-asontology $>$ /morality/ethics/justice/etc. given human-subpotencyaporia/undecidability/dilemma/ought-indeterminacy/deficiency/limitation/constraint), and so for the latter to paradoxically prospectively become homeless as reflected with the $<$ cumulating/recomposuring attendant-ontological-contiguity $>$-successive registryworldviews/dimensions <amplituding/formative> wooden-language-_imbued - averaging-ofthought-<as-to-leveling/ressentiment/closed-construct-of- meaningfulness-and-teleology -asof-'nondescript/ignorable-void '-with-regards-to-prospective-apriorising-implications $>>$. This protensive-consciousness analysis (as from the <amplituding/formativeepistemicity $>$ causality $\sim$ as-to-projective-totalitative-implications-of-prospectivenonpresencing,-for-explicating relative-unreflexivity/relative-reflexivity - ontologicalcontiguity of prospective deprocrypticism-or-preempting-disjointedness-as-ofreference-of-thought registry-worldview/dimension) in reflecting holographically$<$ conjugatively-and-transfusively $>$ the relative-unreflexivity/relative-reflexivity - ontologicalcontiguity of-the-human-institutionalisation-process highlights that while in-many-ways such a conundrum of deficient ontologisation/ontological-veracity/aestheticisation-towards- 
ontology could preconverging/postconverging-de-mentatively/structurally/paradigmatically be overlooked with regards to prior human registry-worldviews/dimensions institutionalisations as to their specific notional $\sim$ deprocrypticism or $<$ amplituding/formative $>$ notional $\sim$ preemptingdisjointedness-as-of- ${ }^{8}$ reference-of-thought of base-institutionalisation, ${ }^{103}$ universalisation and our positivism/rational-empiricism, the prospective possibility for notional ${ }^{18 \text { deprocrypticism }}$ registry-worldview/dimension ${ }^{83}$ reference-of-thought is only imaginable/conceivable with the resolution of this specific underlying 'conundrum of human registry-worldview's/dimension's institutionalisation formation discrepancy/sundering' as to human-subpotencyaporia/undecidability/dilemma/ought-indeterminacy/deficiency/limitation/constraint—imbued'notional firstnaturedness-formativeness-<as-to-eventualising inkling-drive-or-seedingmisprising $>$ temporal-to-intemporal-dispositions- $<$ so-construed-as-from-perspectiveontological-normalcy/postconvergence>'-existentialism-form-factor. As human-subpotencyaporia/undecidability/dilemma/ought-indeterminacy/deficiency/limitation/constraint—imbued'notional firstnaturedness-formativeness-<as-to-eventualising-inkling-drive-or-seedingmisprising $>$ temporal-to-intemporal-dispositions- $<$ so-construed-as-from-perspectiveontological-normalcy/postconvergence>'-existentialism-form-factor is herein construed as the 'fundamental preconverging/postconverging-de-mentating/structuring/paradigming/frame of human causative determination (underlying causality as to <amplituding/formativeepistemicity $>$ causality $\sim$ as-to-projective-totalitative-implications-of-prospectivenonpresencing,-for-explicating relative -unreflexivity/relative-reflexivity - ontologicalcontiguity )', as so reflected in the specific human-subpotency with regards to overall reifyingand-empowering-reflexivity-of-ecstatic-existence-as-panintelligibility/panreflexivity ${ }^{3}$ <existentially-imbued-and-educing-<\{epistemictotalising thermeneutically/textually/reprojectingly/supererogatingly/zeroingly/re-acutingly,$\{$ decompulsing $\}$ delinearity $\sim$ for-cogency $\geq$-epistemic-perspective-of-projective/reprojective- 

aporia/undecidability/dilemma/ought-indeterminacy/deficiency/limitation/constraint—imbued'notional firstnaturedness-formativeness-<as-to-eventualising -inkling-drive-or-seedingmisprising $>$ temporal-to-intemporal-dispositions- $<$ so-construed-as-from-perspectiveontological-normalcy/postconvergence>'-existentialism-form-factor is the underlying formfactor recurrently preconvergingly/postconvergingly-dementated/structured/paradigmed/framed across human Being-development/ontologicalframework-expansion-as-to-depth-of-ontologising-development-as-infrastructure-ofmeaningfulness-and-teleology , institutional-development-as-to-social-functiondevelopment and living-development-as-to-personality-development psychologismic epistemic acutisation difficulty-for, residualising \{decompulsing $\}$ delinearity for-cogency> magnitudes $\{$ of-experientiality/experiment\} as ultimately reflected in reflecting holographically$<$ conjugatively-and-transfusively $>$ the relative-unreflexivity/relative-reflexivity - ontologicalcontiguity $\sim$ of-the-human-institutionalisation-process of the $<$ cumulating/recomposuring attendant-ontological-contiguity $>$-successive registryworldviews/dimensions $\quad{ }^{83}$ reference-of-thought-and- ${ }^{8}$ reference-of-thought- ${ }^{8}$ devolvingmeaningfulness-and-teleology , speaking of successive recurrent thresholds of human selfsurpassing — existentialism-form-factor,-in-overcoming-'notional collateralising-beholdeningprotohumanity'-to-'attain-sublimating-humanity'-as-to-existence-potency sublimatingnascence,-disclosed-from-prospective-epistemic-digression with regards to human ontologicalperformance ${ }^{72}-<$ including-virtue-as-ontology $>$-including-virtue-as-ontology up to the 'given specific point of living-development-as-to-personality-development or institutionaldevelopment-as-to-social-function-development or Being-development/ontologicalframework-expansion-as-to-depth-of-ontologising-development-as-infrastructure-of- 
meaningfulness-and-teleology where the human fails in its capacity for human selfsurpassing — existentialism-form-factor,-in-overcoming-'notional collateralising-beholdeningprotohumanity'-to-'attain-sublimating-humanity'-as-to-existence-potency sublimatingnascence,-disclosed-from-prospective-epistemic-digression. The latter is construed as 'thehuman-threshold-of-<amplituding/formative $>$ wooden-language-_imbued-averaging-ofthought-<as-to-leveling/ressentiment/closed-construct-of- meaningfulness-and-teleology -asof-‘nondescript/ignorable-void '-with-regards-to-prospective-apriorising-implications $>>$ as of living-development-as-to-personality-development or institutional-development-as-to-socialfunction-development or Being-development/ontological-framework-expansion-as-to-depthof-ontologising-development-as-infrastructure-of- meaningfulness-and-teleology '; with this more profound ontologisation elucidation (of prior philosophers aestheticisation-towardsontology elucidation of the notions of averaging, <amplituding/formative $>$ wooden-language〈imbued-averaging-of-thought-<as-to-leveling/ressentiment/closed-construct-ofmeaningfulness-and-teleology -as-of-‘nondescript/ignorable-void '-with-regards-toprospective-apriorising-implications $>>$ and leveling) speaking more precisely rather of (from an individuations basis of conception) <amplituding/formative> wooden-language-〈imbuedaveraging-of-thought-<as-to-leveling/ressentiment/closed-construct-of- meaningfulness-andteleology -as-of-'nondescript/ignorable-void ' -with-regards-to-prospective-apriorisingimplications $>>$ as of 'varying psychologismic epistemic-acutisation-difficulty-for, residualising \{decompulsing $\}$ delinearity for-cogency $>$ magnitudes $\{$ of-experientiality/experiment $\} /$ scales_as-to-successively-profound-preconverging/postconverging-redementating/restructuring/reparadigming-frames-as-from-living,-institutionalising,-and-Beingontologising/infrastructure-of- ${ }^{56}$ meaningfulness-and-teleology 99 of prospective humansubpotency-aporia/undecidability/dilemma/oughtindeterminacy/deficiency/limitation/constraint —imbued-'notional firstnaturedness- 
formativeness-<as-to-eventualising inkling-drive or seeding-misprising $>$ temporal-to-

intemporal-dispositions-<so-construed-as-from-perspective-ontological-

normalcy/postconvergence>'-existentialism-form-factor' (and so with regards to human livingdevelopment-as-to-personality-development or institutional-development-as-to-socialfunction-development or Being-development/ontological-framework-expansion-as-to-depthof-ontologising-development-as-infrastructure-of- meaningfulness-and-teleology in reflecting holographically-<conjugatively-and-transfusively $>$ the relative-unreflexivity/relativereflexivity ontological-contiguity of-the-human-institutionalisation-process $<$ cumulating/recomposuring attendant-ontological-contiguity $>$-successive registryworldviews/dimensions). Such a threshold construal of human ontological-performance ${ }^{72}$ $<$ including-virtue-as-ontology $>$ /morality/ethics/justice/etc. as to constructiveness-ofontological-performance ${ }^{72}$-<including-virtue-as-ontology $>/$ morality/ethics/justice/etc. and destructuring-threshold-〈uninstitutionalised-threshold /presublimating-desublimatingdecisionality $>\sim$ of-ontological-performance ${ }^{72}$ - $<$ including-virtue-asontology $>$ /morality/ethics/justice/etc. (with regards to 'varying psychologismic epistemicacutisation difficulty-for, residualising \{decompulsing $\}$ delinearity for-cogency>-magnitudes $\{0$ experientiality/experiment $\}$ /scales — as-to-successively-profound-preconverging/postconverging-redementating/restructuring/reparadigming-frames-as-from-living,-institutionalising,-and-Beingontologising/infrastructure-of- meaningfulness-and-teleology 9 of prospective humansubpotency-aporia/undecidability/dilemma/ought-

indeterminacy/deficiency/limitation/constraint—imbued-'notional firstnaturednessformativeness-<as-to-eventualising-inkling-drive-or-seeding-misprising $>$ temporal-tointemporal-dispositions-<so-construed-as-from-perspective-ontologicalnormalcy/postconvergence>'-existentialism-form-factor'), underlies the (ontologicalnormalcy/postconvergence as to <amplituding/formative-epistemicity $>$ causality $~ a s-$ to- 
projective-totalitative-implications-of-prospective- nonpresencing,-for-explicating relative-

unreflexivity/relative-reflexivity - ontological-contiguity ) perspective of analysis herein of such ontological-performance ${ }^{72}-<$ including-virtue-as-ontology $>/$ morality/ethics/justice/etc. (construed as of notional firstnaturedness-formativeness-<as-to-eventualising-inkling-driveor-seeding-misprising $>$ temporal-to-intemporal-dispositions- $<$ so-construed-as-from-

perspective-ontological-normalcy/postconvergence>) reflected rather as of individuations basis-of-analysis-as-can-be-reflected-with-individuations-as-being-the-occurrent-manifestoutcomes-of-the-individual-as-a-subpotency' (as all human individuations can theoretically be manifested by all individuals at varying occasions even as specific individuals are more or less prone to the recurrence of specific individuations as to specific conceptual and contextual frames of contemplation) thus enabling 'precision of conceptualisation and knowledgereification $\sim$ gesturing-and-accounting — of-epistemic-phenomenalism- $<$ inprospective_psychologismic $\sim$ apriorising/axiomatising/referencing-\{of-'prospectively implicited_attendant-ontological-contiguity ' educedexistentialising/contextualising/textualising_intelligibility/epistemicity/reflexivity_contiguity<imbued-notional cogency >' \}-conflatedness -in-\{preconverging ment by\}

posteonverging entailment> implications', and not individual basis-of-analysis-which-will-failto-construe-of-the-potent-variability-implications-of-the-individual-as-a-subpotency-subjectto-transformation-and-not-absolutely-deterministic-and-immuable-as-individuationrepresentations. Furthermore (even as prior 'secondnatured-institutionalisation existencepotency ${ }^{39} \sim$ sublimating-nascence,-disclosed-from-prospective-epistemic-digression epistemically-induced/constrained-reproducibility-motif-of- ${ }^{-5}$ meaningfulness-and-teleology as of relatively-shallow-frame-of-elicited-positive-opportunism-of-social-functioning-andaccordance $^{75}$-of-low-intrinsic-attribution-and-high-extrinsic-attribution-susceptibility,-indimensionality-of-desublimating-lack-of $-\langle<$ amplituding/formative $>$ supererogatory $\sim$ de- 
mentativeness/epistemic-growth-or-conflatedness /transvaluative-

rationalising/transepistemicity/anamnestic-residuality/spirit-drivenness-equalisation〉' implies the prior human self-surpassing-existentialism-form-factor,-in-overcoming‘notional collateralising-beholdening-protohumanity'-to- 'attain-sublimating-humanity'-as-toexistence-potency $\sim$ sublimating-nascence,-disclosed-from-prospective-epistemic-digression is massively already secondnatured in generalised human behaviour as of the prior livingdevelopment-as-to-personality-development or institutional-development-as-to-socialfunction-development or Being-development/ontological-framework-expansion-as-to-depthof-ontologising-development-as-infrastructure-of- meaningfulness-and-teleology ), such 'varying psychologismic epistemic-acutisation difficulty-for, residualising $\{$ decompulsing $\}$ delinearity for-cogeney> magnitudes $\{$ \{f-experientiality/experiment $\} /$ scales —as-tosuccessively-profound-preconverging/postconverging-redementating/restructuring/reparadigming-frames-as-from-living,-institutionalising,-and-Beingontologising/infrastructure-of- ${ }^{5}$ meaningfulness-and-teleology 9 of prospective humansubpotency-aporia/undecidability/dilemma/ought-

indeterminacy/deficiency/limitation/constraint—imbued-'notional firstnaturednessformativeness-<as-to-eventualising inkling-drive-or seeding misprising $>$ temporal-tointemporal-dispositions-<so-construed-as-from-perspective-ontologicalnormalcy/postconvergence>'-existentialism-form-factor' speak to the 'more and more profound dispensing-with-immediacy-for-relative-ontological-completeness ${ }^{87}$-byreification/contemplative-distension ${ }^{27}$ (as of human self-surpassing-existentialism-formfactor,-in-overcoming-'notional collateralising-beholdening-protohumanity’-to-'attainsublimating-humanity'-as-to-existence-potency sublimating-nascence,-disclosed-fromprospective-epistemic-digression to supersede human temporality $8 /$ shortness $<$ amplituding/formative $>$ wooden-language-_imbued - averaging-of-thought-<as-to- 
leveling/ressentiment/closed-construct-of- meaningfulness-and-teleology -as-of-

'nondescript/ignorable-void '-with-regards-to-prospective-apriorising-implications $>\rangle$ ) as to human self-consciousness capacity for construction-of-the-Self in inducing the requisite supereregatery acuity/perspicacity/astuteness/edginess/incisiveness-ofapriorising/axiomatising/referencing/intelligibilitysettingup/measuringinstrumenting -forconceptualisation of the <cumulating/recomposuring attendant-ontological-contiguity successive registry-worldviews/dimensions underlying the relative-unreflexivity/relativereflexivity - ontological-contiguity ${ }^{67}$ of-the-human-institutionalisation-process ${ }^{68}$; recurrently implied all along in reflecting holographically-<conjugatively-and-transfusively $>$ the relative-unreflexivity/relative-reflexivity - ontological-contiguity $\sim$ of-the-humaninstitutionalisation-process with the circular conflicting paradox of human opened-constructof- ${ }^{56}$ meaningfulness-and-teleology ${ }^{9}$ with regards to prospective originariness-parrhesia,--asspontaneity-of-aestheticisation and closed-construct-of- ${ }^{-6}$ meaningfulness-and-teleology -asof-'nondescript/ignorable-void ' ${ }^{\prime}$-with-regards-to-prospective-apriorising-implications indimensionality-of-desublimating-lack-of $-\langle<$ amplituding/formative $>$ supererogatory $\sim$ de-

\section{mentativeness/epistemic-growth-or-conflatedness /transvaluative-}

rationalising/transepistemicity/anamnestic-residuality/spirit-drivenness-equalisation〉. This inmany-ways will explain the underlying conundrum as to the prospective originarinessparrhesia,-as--spontaneity-of-aestheticisation associated with projecting prospectively the more profound dispensing-with-immediacy-for-relative-ontological-completeness ${ }^{87}$-byreification/contemplative-distension ${ }^{27}$ as to human self-consciousness capacity for constructionof-the-Self to induce the required supererogatery acuity/perspicacity/astuteness/edginess/incisiveness-ofapriorising/axiomatising/referencing/intelligibilitysettingup/measuringinstrumenting -forconceptualisation for prospective ${ }^{18}$ deprocrypticism-or-preempting-disjointedness-as-of- 
reference-of-thought human self-surpassing-existentialism-form-factor,-in-overcoming‘notional collateralising-beholdening-protohumanity'-to-'attain-sublimating-humanity'-as-toexistence-potency $\sim$ sublimating-nascence,-disclosed-from-prospective-epistemic-digression as to prospective notional ' deprocrypticism 'human Being-development/ontologicalframework-expansion-as-to-depth-of-ontologising-development-as-infrastructure-ofmeaningfulness-and-teleology , institutional-development-as-to-social-functiondevelopment and living-development-as-to-personality-development psychologismic epistemic acutisation difficulty-for, residualising \{decompunget delinearity for-cogency> magnitudes $\left.{ }^{\{0 f-e x p e r i e n t i a l i t y / e x p e r i m e n t}\right\}$; as effectively such dispensing-with-immediacy-for-relativeontological-completeness ${ }^{87}$-by-reification/contemplative-distension ${ }^{27}$ is susceptible to sophistic/pedantic dispositions ${ }^{79}$ presencing-absolutising-identitive-constitutedness ${ }^{14}$ eliciting of human temporality 8 /shortness as to <amplituding/formative $>$ wooden-language-〈imbued averaging-of-thought-<as-to-leveling/ressentiment/closed-construct-of- meaningfulness-andteleology -as-of-'nondescript/ignorable-void '-with-regards-to-prospective-apriorisingimplications $>>$. This insight speaks of a more profound notion of human psychology as to a veridical ontology-driven 'postconverging-or-dialectical-thinking ${ }^{21}$-psychology or psychologyof-mentation-dynamics or natural psychological-dynamics', reflecting the fact that the underlying conceptualisation involving the notions of construction-of-the-Self as to human

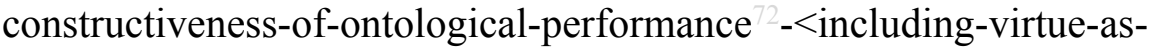
ontology $>$ /morality/ethics/justice/etc. and shiftiness-of-the-Self as to human destructuringthreshold-〈uninstitutionalised-threshold /presublimating-desublimating-decisionality $\rangle$ ofontological-performance ${ }^{72}$-<including-virtue-as-ontology $>/$ morality/ethics/justice/etc. in addressing human-subpotency-aporia/undecidability/dilemma/oughtindeterminacy/deficiency/limitation/constraint—imbued-'notional firstnaturednessformativeness-<as-to-eventualising inkling-drive-or-seeding misprising $>$ temporal-to- 
intemporal-dispositions- $<$ so-construed-as-from-perspective-ontologicalnormalcy/postconvergence>'-existentialism-form-factor is effectively of more profound ontological-veracity than naïve ${ }^{79}$ presencing-absolutising-identitive-constitutedness conception of psychology in-many-ways rather in <amplituding/formativeepistemicity>totalising $\sim$ self-referencing-syncretising/circularity/interiorising/akrasiatic-drag 'as the latter in its epistemic-abnormalcy/preconvergence ${ }^{31}$ naively and wrongly goes on to define the very human-in-its-temporality $/$ shortness/mortality in want for its prospective development paradoxically as the determining agent (as in its very ${ }^{7}$ presencing - absolutisingidentitive-constitutedness $^{14}$ ) of such prospective development'; such that there is an underlying transversality-<for-sublimating-existential-eventuating/denouement,-from-'thinking atfirst/pure-predisposition-preemptive-of prospective-disontologising/subontologising' as-ofprospectively-disambiguated-affirmed-and-unaffirmed-'motif-andapriorising/axiomatising/referencing'> ${ }^{101}$ between such ${ }^{79}$ presencing - absolutising-identitiveconstitutedness $^{14} \quad$ and $\quad$ prospective originariness/reifying/intellectualisingidealising/transcending/sublimating-meaningfulness-and-its-institutionalisation that is fundamentally irreconcilable, as to the former's in-dimensionality-of-desublimating-lack-of - $^{-}$ <<amplituding/formative>supererogatory $\sim$ de-mentativeness/epistemic-growth-orconflatedness /transvaluative-rationalising/transepistemicity/anamnestic-residuality/spiritdrivenness-equalisation) critical for prospective human self-surpassing-existentialism-formfactor,-in-overcoming-'notional collateralising-beholdening-protohumanity’-to-'attainsublimating-humanity'-as-to-existence-potency sublimating-nascence,-disclosed-fromprospective-epistemic-digression (as so-validated by the fact that we'll effectively recognised that 'supposedly constructing psychology' on the effective <amplituding/formativeepistemicity $>$ totalising $\sim$ self-referencing-syncretising/circularity/interiorising/akrasiatic-drag of any of the <cumulating/recomposuring attendant-ontological-contiguity $>$-successive 
registry-worldviews/dimensions $\quad{ }^{79}$ presencing - absolutising-identitive-constitutedness ${ }^{14}$ of either recurrent-utter-uninstitutionalisation, base-institutionalisation-ununiversalisation and universalisation-non-positivism/medievalism is effectively sub-ontological-<as-to-thelimitation-of-human-subpotency-in-its-reifying-and-empowering-reflexivity-of-the-fullpotency-of-existence's $\sim$ sublimating-nascence $>$ but then go on to falsely imply the profoundness of thought as of the ${ }^{79}$ presencing - absolutising-identitive-constitutedness ${ }^{14}$ of our positivismprocrypticism in its <amplituding/formative-epistemicity>totalising $\sim$ self-referencingsyncretising/circularity/interiorising/akrasiatic-drag ${ }^{34}$ as insightfully, as herein implied, such a most profound notion of psychological science is one of <amplituding/formativeepistemicity $>$ causality $\sim$ as-to-projective-totalitative-implications-of-prospectivenonpresencing,-for-explicating relative-unreflexivity/relative-reflexivity - ontological-

contiguity of ontology-driven 'postconverging-or-dialectical-thinking -psychology or psychology-of-mentation-dynamics or natural psychological-dynamics' underlying the construction-of-the-Self all along in reflecting holographically-<conjugatively-andtransfusively $>$ the relative-unreflexivity/relative-reflexivity ontological-contiguity of-thehuman-institutionalisation-process with regards to the prospective relative-ontologicalcompleteness $^{87}$ possibilities of ${ }^{18}$ deprocrypticism-or-preempting-disjointedness-as-ofreference-of-thought). In recapping, this 'conundrum of discrepancy/sundering in ontologisation/ontological-veracity/aestheticisation-towards-ontology along human registryworldview's/dimension's institutionalisation formation' (with respect to living-development-asto-personality-development or institutional-development-as-to-social-function-development or Being-development/ontological-framework-expansion-as-to-depth-of-ontologisingdevelopment-as-infrastructure-of- meaningfulness-and-teleology ), is underlied by 'human formative discrepancy/sundering of the relatively-shallow-frame-of-elicited-positiveopportunism - of-social-functioning-and-accordance ${ }^{75}$-of-low-intrinsic-attribution-and-high- 
extrinsic-attribution-susceptibility,-in-dimensionality-of-desublimating-lack-of ${ }^{-}$ <<amplituding/formative >supererogatory $\sim$ de-mentativeness/epistemic-growth-orconflatedness /transvaluative-rationalising/transepistemicity/anamnestic-residuality/spiritdrivenness-equalisation) from dimensionality-of-sublimating <<amplituding/formative>supererogatory $\sim$ de-mentativeness/epistemic-growth-orconflatedness /transvaluative-rationalising/transepistemicity/anamnestic-residuality/spiritdrivenness-equalisation); and is elucidated as from the 'formative preconverging-dementating/structuring/paradigming of ontologically-flawed ${ }^{79}$ presencing-absolutisingidentitive-constitutedness $^{14}$ that fails re-originariness/re-origination as to human limitedmentation-capacity-deepening-as-subjecting limitedness/human-subpotency-to-'educedunlimitedness/existence-sublimating nascence' ${ }^{3}$ so-elucidated as of differenceconflatedness $^{13}$-as-to-totalitative-reification-in-singularisation- $<$ as-to-thenondisjointedness/entailment-of-prospective- nonpresencing > -as-veridical-epistemicityrelativism-determinism implied <amplituding/formative-epistemicity $>$ causality $\sim$ as-toprojective-totalitative-implications-of-prospective- nonpresencing,-for-explicating relativeunreflexivity/relative-reflexivity ontological-contiguity construal of causality as $<$ amplituding/formative-epistemicity $>$ causality $\sim$ as-to-projective-totalitative-implications-ofprospective- nonpresencing,-for-explicating relative-unreflexivity/relative-reflexivity ontological-contiguity , as can be so reflected in the " historiality/ontologicaleventfulness 38 ontological-aesthetic-tracing-< normalcy/postconvergence-reflected-'epistemicity-relativism-determinism'> of the contrasting postconverging/dialectical-thinking ${ }^{21}$-qualia-schema and preconverging/dementing ${ }^{20}$-qualiaschema' of any specific registry-worldview/dimension as to its 'relative-ontologicalincompleteness 8 /relative-ontological-completeness ${ }^{87}$ -

〈sublimating referencing/registering/decisioning,-as-self-becoming/self- 
conflatedness /formative-supererogating-<projective/reprojective-aestheticising-re-motifand-re-apriorising/re-axiomatising/re-referencing,-in-perspective-ontologicalnormalcy/postconvergence $>>$ as to human-and-social-expectations/anticipationsmetaphoricity ${ }^{57}$-as-preconverging/postconverging-redementating/restructuring/reparadigming-psychologism' (beyond-the-consciousnessawareness-teleology ${ }^{9}<$ of-preconverging-existential-extrication-as-of-existentialunthought $>$ ); and effectively, <amplituding/formative $>$ wooden-language-〈imbued averaging-of-thought-<as-to-leveling/ressentiment/closed-construct-of- meaningfulness-andteleology -as-of-'nondescript/ignorable-void '-with-regards-to-prospective-apriorisingimplications $>\rangle$ is operantly construed as the constrasted postconverging/dialectical-thinking qualia-schema and preconverging/dementing ${ }^{20}$-qualia-schema, as from the perspective of relative-ontological-completeness ${ }^{87}$ over relative-ontological-incompleteness ${ }^{88}$ (as to reference-of-thought-and- ${ }^{83}$ reference-of-thought- ${ }^{8}$ devolving $-{ }^{5}$ meaningfulness-andteleology ${ }^{9}$ ). In-the-bigger-picture (of Being-development/ontological-framework-expansionas-to-depth-of-ontologising-development-as-infrastructure-of- meaningfulness-andteleology , institutional-development-as-to-social-function-development and livingdevelopment-as-to-personality-development psychologismic epistemic-acutisationdifficulty $<$ for, residualising_\{decompling\} $d e$ linearity for-cogency> magnitudes $\{$ ofexperientiality/experiment $)$, the overcoming of <amplitung/formative $>$ wooden-language-〈imbued averaging-of-thought-<as-to-leveling/ressentiment/closed-construct-of- meaningfulness-andteleology -as-of-'nondescript/ignorable-void '-with-regards-to-prospective-apriorisingimplications $>$ (as to human-subpotency-aporia/undecidability/dilemma/oughtindeterminacy/deficiency/limitation/constraint—imbued-'notional firstnaturednessformativeness-<as-to-eventualising inkling drive-or-seeding misprising $>$ temporal-tointemporal-dispositions-<so-construed-as-from-perspective-ontological- 
normalcy/postconvergence>'-existentialism-form-factor 'relative-ontologicalincompleteness $8 /$ relative-ontological-completeness ${ }^{87}$ 〈sublimating referencing/registering/decisioning,--as-self-becoming/selfconflatedness /formative-supererogating-<projective/reprojective - aestheticising-re-motifand-re-apriorising/re-axiomatising/re-referencing,-in-perspective-ontologicalnormalcy/postconvergence $>>$ as to human-and-social-expectations/anticipationsmetaphoricity ${ }^{57}$-as-preconverging/postconverging-redementating/restructuring/reparadigming-psychologism, ${ }^{89}$ ) has been the determinant for the possibility for the <cumulating/recomposuring attendant-ontological-contiguity $>$-successive registry-worldviews/dimensions institutionalisations to even arise in-the-very-first-place and equally speaks to the prospective human potential possibilities, as the ${ }^{4}$ historiality/ontologicaleventfulness 3 /ontological-aesthetic-tracing-<perspective-ontologicalnormalcy/postconvergence-reflected-‘epistemicity-relativism-determinism'> records of successive human civilisations shows that nothing is inherently given (particularly so as the cultural diffusion possibilities are already limited as to the already globalised world warranting our very own prospective reinvention/recreation) but for effective human effectuation. Humanity is thus intimately tied to human-subpotency-aporia/undecidability/dilemma/oughtindeterminacy/deficiency/limitation/constraint—imbued-‘notional firstnaturednessformativeness-<as-to-eventualising-inkling-drive-or-seeding-misprising $>$ temporal-tointemporal-dispositions- $<$ so-construed-as-from-perspective-ontologicalnormalcy/postconvergence>'-existentialism-form-factor 'relative-ontologicalincompleteness $8 /$ relative-ontological-completeness 〈sublimating referencing/registering/decisioning,--as-self-becoming/selfconflatedness /formative-supererogating-<projective/reprojective-aestheticising-re-motifand-re-apriorising/re-axiomatising/re-referencing,-in-perspective-ontological- 
normalcy/postconvergence $>>$ as to human-and-social-expectations/anticipationsmetaphoricity ${ }^{57}$-as-preconverging/postconverging-rede-

mentating/restructuring/reparadigming-psychologism'89 of dimensionality-of-sublimating ${ }^{25}$ <<amplituding/formative>supererogatory $\sim$ de-mentativeness/epistemic-growth-orconflatedness /transvaluative-rationalising/transepistemicity/anamnestic-residuality/spiritdrivenness-equalisation $\rangle$ as to the fact that the ultimate attainment of humanity as from Hegelian proto-humanity has ever always been as of originariness-parrhesia,-as-spontaneity-ofaestheticisation as reflected by the fact that our mere reproducibilitymathesis/motif/thrownness-disposition,-as-reproducibility-of-aestheticisation is rather a 'positive-opportunism — of-social-functioning-and-accordance ${ }^{75}$ exploitation that poorly projects humanity prospectively as to an preconverging-existential-extrication-as-of-existentialunthought and notionally-collateralising posturing that is unwary of its relative-ontologicalincompleteness ${ }^{88}$ to then aspire for prospective relative-ontological-completeness ${ }^{87}$, and all the prospective humanity that can arise is ever always as of originariness-parrhesia,-as-spontaneityof-aestheticisation that goes after that relative-ontological-completeness ${ }^{87}$, as to the fact that the possibility for humanity to arise is ever always tied down with the possibility for the human to address human-subpotency-aporia/undecidability/dilemma/oughtindeterminacy/deficiency/limitation/constraint. Humanity as a dynamic construct speaks to dimensionality-of-sublimating $35<$ <mplituding/formative $>$ supererogatery $-\mathrm{de}-$ mentativeness/epistemic-growth-or-conflatedness /transvaluativerationalising/transepistemicity/anamnestic-residuality/spirit-drivenness-equalisation〉 that preconverging/postconverging-de-mentatively/structurally/paradigmatically re-enables the possibility for humanity to arise (as of human self-surpassing — existentialism-form-factor,-inovercoming-'notional collateralising-beholdening-protohumanity'-to-'attain-sublimating- 
epistemic-digression to supersede human temporality $8 /$ shortness

$<$ amplituding/formative $>$ wooden-language-〈imbued — averaging-of-thought-<as-to-

leveling/ressentiment/closed-construct-of- meaningfulness-and-teleology -as-of-

'nondescript/ignorable-void '-with-regards-to-prospective-apriorising-implications $>\rangle)$; as the

Foucauldian take truly reflects the fact that there is no given human nature but rather the becoming possibility of human nature as of the ultimate construction-of-the-Self towards attaining deprocrypticism/preempting-disjointedness-as- ${ }^{-}$reference-of-thought, thus overriding/overcoming the hitherto ever present 'human relatively-shallow-frame-of-elicitedpositive-opportunism - of-social-functioning-and-accordance ${ }^{75}$-of-low-intrinsic-attributionand-high-extrinsic-attribution-susceptibility,-in-dimensionality-of-desublimating-lack-of ${ }^{-}$ <<amplituding/formative>supererogatory $\sim$ de-mentativeness/epistemic-growth-orconflatedness /transvaluative-rationalising/transepistemicity/anamnestic-residuality/spiritdrivenness-equalisation)', underlying prior <cumulating/recomposuring attendantontological-contiguity >-successive registry-worldviews/dimensions destructuring-threshold$\langle$ uninstitutionalised-threshold /presublimating-desublimating-decisionality $\rangle \sim$ of-ontologicalperformance ${ }^{2}-<$ including-virtue-as-ontology $>$. In more explicit terms, this 'conundrum of discrepancy/sundering in ontologisation/ontological-veracity/aestheticisation-towards-ontology along human registry-worldview's/dimension's institutionalisation formation' speaks to the 'social-and-institutional-dissipative-integration of any human originariness/reifying/intellectualising_idealising/transcending/sublimating-meaningfulnessand-its-institutionalisation as to human-subpotency-aporia/undecidability/dilemma/oughtindeterminacy/deficiency/limitation/constraint—imbued-'notional firstnaturednessformativeness-<as-to-eventualising-inkling drive or-seeding-misprising $>$ temporal-tointemporal-dispositions-<so-construed-as-from-perspective-ontologicalnormalcy/postconvergence>'-existentialism-form-factor'; as so-reflected with the susceptibility 
to variedly teleologically-degraded ontological-performance ${ }^{72}-<$ including-virtue-asontology $>$ /morality/ethics/justice/etc. in a 'dynamic social and institutional conjugation of notional firstnaturedness-formativeness-<as-to-eventualising inkling-drive-or-seeding misprising $>$ temporal-to-intemporal-dispositions- $<$ so-construed-as-from-perspectiveontological-normalcy/postconvergence $>\quad$ ontological-performance ${ }^{72}-$ including-virtue-as- $^{-}$ ontology $>$-including-virtue-as-ontology at the destructuring-threshold-〈uninstitutionalisedthreshold /presublimating-desublimating-decisionality $>$ of-ontological-performance ${ }^{72}$ <including-virtue-as-ontology>' that ends up 'reconstruing any implied originariness/reifying/intellectualising_idealising/transcending/sublimating-meaningfulnessand-its-institutionalisation in its very own terms as to the effectively manifest dynamics of institutional and social relations, constraints and performances' that as of varying implicited stakes are not 'necessarily absolutely tied-down' to the abstract originariness/reifying/intellectualising_idealising/transcending/sublimating-meaningfulnessand-its-institutionalisation even as such framework-for-idealising/transcending/sublimating is clearly or abstrusely the reference of social and institutional deferential-formalisationtransference. Thus the underlying reflex in considering human originariness/reifying/intellectualising_idealising/transcending/sublimating-meaningfulnessand-its-institutionalisation as more or less fulfilled with a satisfactory theoretical-andpracticable-projected-outcome in-many-ways is naïve and incomplete as to when it is 'wrongly predicated on a conception of the social and institutional as merely a passive framework of exquisite integration of abstract originariness/reifying/intellectualisingidealising/transcending/sublimating-meaningfulness-and-its-institutionalisation' failing to factor in the dynamics of social-and-institutional-dissipative-integration of any such abstract originariness/reifying/intellectualising_idealising/transcending/sublimating-meaningfulnessand-its-institutionalisation as to a 'dynamic social and institutional conjugation of 
notional firstnaturedness-formativeness-<as-to-eventualising-inkling-drive-or-seedingmisprising $>$ temporal-to-intemporal-dispositions-<so-construed-as-from-perspectiveontological-normalcy/postconvergence $>\quad$ ontological-performance ${ }^{72}-<$ including-virtue-asontology $>$-including-virtue-as-ontology at the destructuring-threshold-〈uninstitutionalisedthreshold /presublimating-desublimating-decisionality $>$ of-ontological-performance ${ }^{72}$ <including-virtue-as-ontology>'. Ultimately, with respect to social-stake-contention-orconfliction the effectively practised meaningfulness-and-its-institutionalisation while guided/constraint/structured by such originariness/reifying/intellectualisingidealising/transcending/sublimating-meaningfulness-and-its-institutionalisation theoreticaland-practicable-projected-outcome elicited positive-opportunism-of-social-functioning-andaccordance ${ }^{75}$, generalised human behaviour to various extends actually becomes operatively and anticipatively aware by itself (as reflected by its covertly uttered $<$ amplituding/formative $>$ wooden-language-〈imbued-temporal-mere-

\section{form/virtualities/dereification/akrasiatic-drag/denatured/preconverging-or-dementing}

\section{narratives - of-the- reference-of-thought- categorical-imperatives/axioms/registry-}

teleology $>$ that varyingly betray/reconstrues-of the originariness/reifying/intellectualisingidealising/transcending/sublimating-meaningfulness-and-its-institutionalisation) of this possibility of discrepancy/sundering from originariness/reifying/intellectualisingidealising/transcending/sublimating-meaningfulness-and-its-institutionalisation (not only as to undermining the former conceptual completeness but evolving with the contextual immediacy perceived underlying aporia/undecidability/dilemma/oughtindeterminacy/deficiency/limitation/constraint) with respect to social-stake-contention-orconfliction, and as generalised human behaviour varyingly assume existentially< disontologising/re-ontologising aporeticism $>$ constraint pragmatic inclinations and notional firstnaturedness-formativeness-<as-to-eventualising-inkling-drive-or-seeding- 
misprising $>$ temporal-to-intemporal-dispositions- $<$ so-construed-as-from-perspectiveontological-normalcy/postconvergence $>$ as of varying thresholds of constructiveness-ofontological-performance $^{72}$-<including-virtue-as-ontology $>/$ morality/ethics/justice/etc. and destructuring-threshold-〈uninstitutionalised-threshold /presublimating-desublimatingdecisionality $>$ of-ontological-performance ${ }^{72}-<$ including-virtue-asontology $>$ /morality/ethics/justice/etc. in relating with such originariness/reifying/intellectualising_idealising/transcending/sublimating-meaningfulnessand-its-institutionalisation. This points to the need to assume a notional construal cognisant and integrating the preconverging/postconverging-de-mentative/structural/paradigmatic implications of human-subpotency-aporia/undecidability/dilemma/oughtindeterminacy/deficiency/limitation/constraint—imbued-'notional firstnaturednessformativeness-<as-to-eventualising-inkling-drive-or-seeding-misprising $>$ temporal-tointemporal-dispositions- $<$ so-construed-as-from-perspective-ontologicalnormalcy/postconvergence>'-existentialism-form-factor, as the 'dynamic social and institutional conjugation of notional firstnaturedness-formativeness-<as-toeventualising-inkling-drive or seeding-misprising> temporal-to-intemporal-dispositions$<$ so-construed-as-from-perspective-ontological-normalcy/postconvergence $>\quad$ ontologicalperformance $^{72}-<$ including-virtue-as-ontology $>$-including-virtue-as-ontology at the destructuring-threshold-〈uninstitutionalised-threshold /presublimating-desublimatingdecisionality $>$ of-ontological-performance ${ }^{2}-<$ including-virtue-as-ontology $>^{\prime}$ speaks to the susceptibility of the destructuring-threshold-〈uninstitutionalised-threshold /presublimatingdesublimating-decisionality $>$ of-ontological-performance ${ }^{72}-<$ including-virtue-asontology $>$ /morality/ethics/justice/etc. (addressed as of originariness-parrhesia,-as-spontaneityof-aestheticisation) to teleologically-degraded ontological-performance ${ }^{72}-<$ including-virtue-asontology $>$ /morality/ethics/justice/etc. and more profoundly so specifically with 
enculturated/endemised postlogism 77 and conjugated-postlogism 77 social and institutional manifestations, and with regards to many social-stake-contention-or-confliction circumstances of poor social and institutional accountability. Basically, the bigger point here is that however the socially transformative implications as of prior originariness/reifying/intellectualisingidealising/transcending/sublimating-meaningfulness-and-its-institutionalisation and beyond the elicited positive-opportunism-of-social-functioning-and-accordance ${ }^{75}$ underlying deferentialformalisation-transference, there is much more involved in overall social and institutional meaningfulness-and-teleology' as to the 'dynamic social and institutional conjugation of notional firstnaturedness-formativeness-<as-to-eventualising inkling-drive-or-seedingmisprising $>$ temporal-to-intemporal-dispositions- $<$ so-construed-as-from-perspectiveontological-normalcy/postconvergence $>\quad$ ontological-performance ${ }^{72}-<$ including-virtue-as- $^{-}$ ontology $>$ /morality/ethics/justice/etc. at destructuring-threshold-〈uninstitutionalisedthreshold /presublimating-desublimating-decisionality) of-ontological-performance ${ }^{72}$ <including-virtue-as-ontology >'. This may be overlooked in critical ways as to the critical fact that prior 'secondnatured-institutionalisation existence-potency ${ }^{39} \sim$ sublimating-nascence,disclosed-from-prospective-epistemic-digression epistemically-induced/constrainedreproducibility-motif-of- ${ }^{5}$ meaningfulness-and-teleology 9 as of relatively-shallow-frame-ofelicited-positive-opportunism-of-social-functioning-and-accordance ${ }^{75}$-of-low-intrinsicattribution-and-high-extrinsic-attribution-susceptibility,-in-dimensionality-of-desublimatinglack-of - -< <amplituding/formative $>$ supererogatory - de-mentativeness/epistemic-growth-orconflatedness /transvaluative-rationalising/transepistemicity/anamnestic-residuality/spiritdrivenness-equalisation)' idealising/transcending/sublimating doesn't necessarily speak of an outright/absolute prospective inclination for human dispensing-with-immediacy-for-relativeontological-completeness $^{87}$-by-reification/contemplative-distension ${ }^{27}$ (as of human selfsurpassing — existentialism-form-factor,-in-overcoming-'notional collateralising-beholdening- 
protohumanity'-to- 'attain-sublimating-humanity'-as-to-existence-potency sublimating-

nascence,-disclosed-from-prospective-epistemic-digression to supersede human temporality 9 /shortness <amplituding/formative> wooden-language-〈imbued-averaging-ofthought-<as-to-leveling/ressentiment/closed-construct-of- meaningfulness-and-teleology -asof-'nondescript/ignorable-void '-with-regards-to-prospective-apriorising-implications $>$ )) for the possibility of renewed originariness-parrhesia,-as-spontaneity-of-aestheticisation to induced prospective 'secondnatured-institutionalisation existence-potency ${ }^{39} \sim$ sublimating-nascence,disclosed-from-prospective-epistemic-digression epistemically-induced/constrainedreproducibility-motif-of- ${ }^{5}$ meaningfulness-and-teleology 9 as of relatively-shallow-frame-ofelicited-positive-opportunism-of-social-functioning-and-accordance ${ }^{75}$-of-low-intrinsicattribution-and-high-extrinsic-attribution-susceptibility,-in-dimensionality-of-desublimatinglack-of $-<<$ amplituding/formative $>$ supererogatory $\sim$ de-mentativeness/epistemic-growth-orconflatedness /transvaluative-rationalising/transepistemicity/anamnestic-residuality/spiritdrivenness-equalisation)' idealising/transcending/sublimating; as a naïve and $<$ amplituding/formative-epistemicity $>$ totalising $\sim$ self-referencing-

syncretising/circularity/interiorising/akrasiatic-drag 34 registry-worldview/dimension reference-of-thought including our positivism- ${ }^{80}$ procrypticism may falsely project of itself (beyond-the-consciousness-awareness-teleology ${ }^{9}<$ of-preconverging-existential-extricationas-of-existential-unthought $>$ ). Thus prospective originariness/reifying/intellectualisingidealising/transcending/sublimating-meaningfulness-and-its-institutionalisation must necessarily contend/vie with social and institutional wonkiness-of-secondnaturing as to the social-and-institutional-dissipative-integration of originariness/reifying/intellectualisingidealising/transcending/sublimating-meaningfulness-and-its-institutionalisation. Critically such wonkiness-of-secondnaturing, as to the social-and-institutional-dissipative-integration of originariness/reifying/intellectualising_idealising/transcending/sublimating-meaningfulness- 
and-its-institutionalisation, involves 'blurry social and institutional expanse of accommodating, contradictory and modulatory <amplituding/formative> wooden-language-〈imbued temporal-mere-form/virtualities/dereification/akrasiatic-drag/denatured/preconverging-ordementing -narratives - of-the- reference-of-thought- categoricalimperatives/axioms/registry-teleology $\rangle$ that while of differing functional/dysfunctional implications however critically lends itself to paradoxical accommodations, contradictions and modulations of the prospective originariness/reifying/intellectualisingidealising/transcending/sublimating-meaningfulness-and-its-institutionalisation. In-many-ways thus such social and institutional 'cognisance-and-integration of the associated dysfunctional $<$ amplituding/formative $>$ wooden-language-〈imbued-temporal-mere-

\section{form/virtualities/dereification/akrasiatic-drag/denatured/preconverging-or-dementing}

narratives - of-the- reference-of-thought- categorical-imperatives/axioms/registry-

teleology '’' (as to shiftiness-of-the-Self ${ }^{\prime \prime}$ and corresponding ${ }^{5}$ meaningfulness-and-teleology implications) by itself provides 'preparatory/foundational causation' for preeenerging existential-extrication-as-of-existential-unthought temporal-dispositions underlying institutional and social failures and crises as to their destructuring-threshold-〈uninstitutionalisedthreshold /presublimating-desublimating-decisionality) of-ontological-performance ${ }^{72}$ $<$ including-virtue-as-ontology $>/$ morality/ethics/justice/etc. (however the seeming remoteness from such direct social and institutional issues, crises and failures); as associated with various social and institutionalised frames of <amplituding/formative > wooden-language-〈imbuedaveraging-of-thought-<as-to-leveling/ressentiment/closed-construct-of- meaningfulness-andteleology -as-of-‘nondescript/ignorable-void ' -with-regards-to-prospective-apriorisingimplications $>\rangle$, and as further surreptitiously enabled with sophistic/pedantic dispositions predisposed to articulate ${ }^{56}$ meaningfulness-and-teleology 99 in terms eliciting human temporality $/$ shortness but then of teleologically-decadent-as-in-dimensionality-of- 
desublimating-lack-of $-<<$ amplituding/formative $>$ supererogatory $\sim$ de-mentativeness/epistemicgrowth-or-conflatedness /transvaluative-rationalising/transepistemicity/anamnestic-

residuality/spirit-drivenness-equalisation $\rangle$ totalising-entailing social and institutional implications that default to vested postures and interests. This analysis is critical by the very 'direct bilateral relationship of appropriate construction-of-the-Self for appropriate cognisanceand-integration of prospective relative-ontological-completeness ${ }^{87}{ }^{56}$ meaningfulness-andteleology ${ }^{9}$, as required for prospective ${ }^{18}$ deprocrypticism-or-preempting-disjointedness-asof- reference-of-thought (as to the reality of the implications of 'wonkiness-of-secondnaturing as of the social-and-institutional-dissipative-integration of originariness/reifying/intellectualising —idealising/transcending/sublimating-meaningfulnessand-its-institutionalisation' associated with our positivism/rational-empiricism 'secondnaturedinstitutionalisation existence-potency ${ }^{32} \sim$ sublimating-nascence,-disclosed-from-prospectiveepistemic-digression epistemically-induced/constrained-reproducibility-motif-ofmeaningfulness-and-teleology as of relatively-shallow-frame-of-elicited-positiveopportunism - of-social-functioning-and-accordance ${ }^{75}$-of-low-intrinsic-attribution-and-highextrinsic-attribution-susceptibility,-in-dimensionality-of-desublimating-lack-of <<amplituding/formative>supererogatory $\sim$ de-mentativeness/epistemic-growth-orconflatedness /transvaluative-rationalising/transepistemicity/anamnestic-residuality/spiritdrivenness-equalisation〉'); as what marks out prospective ${ }^{18}$ deprocrypticism-or-preemptingdisjointedness-as-of- ${ }^{8}$ reference-of-thought is the necessity for the appropriate protracted selfconsciousness as to deprocrypticism's protensive-self-consciousness to overcome our human relatively-shallow-frame-of-elicited-positive-opportunism-of-social-functioning-andaccordance $^{75}$-of-low-intrinsic-attribution-and-high-extrinsic-attribution-susceptibility,-indimensionality-of-desublimating-lack-of $-\langle<$ amplituding/formative $>$ supereregatory - dementativeness/epistemic-growth-or-conflatedness /transvaluative- 
rationalising/transepistemicity/anamnestic-residuality/spirit-drivenness-equalisation $\rangle$, and this 'notionally protracted dispensing-with-immediacy-for-relative-ontological-completeness ${ }^{87}$-byreification/contemplative-distension ${ }^{27}$ conception' as of notional deprocrypticism is what underlies the homeliness in reflecting holographically-<conjugatively-and-transfusively $>$ the relative unreflexivity/relative reflexivity - ontological-contiguity of-the-human-

institutionalisation-process, as to the direct bilateral relation of the 'successive constructionof-the-Self induced human self-consciousness capacity supererogatory $\sim$ acuity/perspicacity/astuteness/edginess/incisiveness-ofapriorising/axiomatising/referencing/intelligibilitysettingup/measuringinstrumenting -forconceptualisation' as enabling 'corresponding possibilities of ${ }^{5}$ meaningfulness-and-teleology transcendence-and-sublimity/sublimation/supereregatory-de-mentativity' with regards to the successive registry-worldview's/dimension's $\quad$ reference-of-thought-and- ${ }^{83}$ reference-ofthought- ${ }^{8}$ devolving- ${ }^{56}$ meaningfulness-and-teleology'. The fact is 'wonkiness-ofsecondnaturing as of the social-and-institutional-dissipative-integration of originariness/reifying/intellectualising_idealising/transcending/sublimating-meaningfulnessand-its-institutionalisation' implies that any given registry-worldview/dimension is in a $<$ amplituding/formative-epistemicity $>$ totalising $\sim$ self-referencingsyncretising/circularity/interiorising/akrasiatic-drag ${ }^{34}$ conception of value-construction and overall ${ }^{56}$ meaningfulness-and-teleology 9 that is subpar to prospective possibilities of human transcendence-and-sublimity/sublimation/supererogatory-de-mentativity; and this particular point is critical for the awareness that social thought can be developed that 'transepistemically overlooks the ${ }^{7}$ presencing-absolutising-identitive-constitutedness ${ }^{14}$ conception of valueconstruction and overall ${ }^{5}$ meaningfulness-and-teleology 9 ' (as to its destructuring-threshold〈uninstitutionalised-threshold /presublimating-desublimating-decisionality $>$ of-ontologicalperformance ${ }^{2}$-<including-virtue-as-ontology $>$ /morality/ethics/justice/etc. induced 
$<$ amplituding/formative $>$ wooden-language-<imbued — averaging-of-thought-<as-to-

leveling/ressentiment/closed-construct-of- meaningfulness-and-teleology -as-of-

'nondescript/ignorable-void '-with-regards-to-prospective-apriorising-implications $>\rangle)$ for the possibility of prospective transvaluation as of dimensionality-of-sublimating <<amplituding/formative>supererogatory $\sim$ de-mentativeness/epistemic-growth-or-

conflatedness /transvaluative-rationalising/transepistemicity/anamnestic-residuality/spirit-

drivenness-equalisation), as so-reflected empirically in the instigation of the $<$ cumulating/recomposuring attendant-ontological-contiguity $>$-successive registryworldviews/dimensions institutionalisations. Thus, there is a direct relation between humansubpotency and existence-potency ${ }^{32}$ sublimating-nascence,-disclosed-from-prospectiveepistemic-digression (so underlied as of the parrhesiastic seeding-promise-of-humansubpotency-ontological-performance ${ }^{72}-<$ including-virtue-as-ontology $>$-correspondence-withthe-full-potency-of-existence's $\sim$ sublimating-nascence-as-of-its-coherence/contiguity), and this is effectively instigated/originated by the human capacity for dispensing-with-immediacy-forrelative-ontological-completeness ${ }^{87}$-by-reification/contemplative-distension ${ }^{27}$ in its construction-of-the-Self with respect to prospective human-subpotencyaporia/undecidability/dilemma/ought-indeterminacy/deficiency/limitation/constraint. The underlying point here is that there is no inherent ${ }^{5}$ meaningfulness-and-teleology ${ }^{9}$ but rather as of the specific human-subpotency with regards to overall reifying-and-empowering-reflexivity-

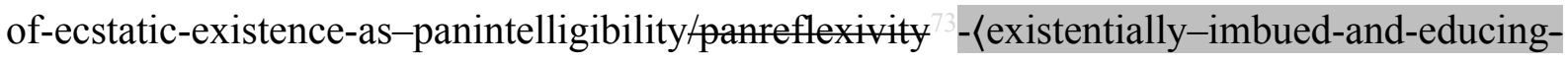
\& \{epistemic-totalising ${ }^{3}$ hermeneutically/textually/reprojectingly/supererogatingly/zeroingly/reacutingly, , \{decompulsing $\}$ delinearity $\sim$ for-cogency $\geq$-epistemic-perspective-ofprojective/reprojective - aestheticising-re-motif-and-re-apriorising/re-axiomatising/rereferencing conceptualisation,-as-herein-specifically-relevant-to human-subpotency $\rangle$, that is, as to 'human-subpotency potential to epistemically converge to the full-potency of existence'; 
and this underlying structure of notional $\sim$ reflexivity- $<$ \{veridical/sound $\}$-relative-reflexivity-inexistence/relativising from-limited-mentation-as-its-deepening/psychologismic<residualising \{decompulsing $\}$ delinearity for-cogency>by-\{flawed/unsound\}-relativeunreflexivity-in-existence/absolutising from-limited-mentation/psychologismic epistemicacutisation nonresidualising imbued ${ }^{\text {fcompulsing\} }}$ linearity in-eclecticism-of-prior-mereformulaicity/ritualisation $>$ is the very structure in reflecting holographically-<conjugativelyand-transfusively $>$ the relative-unreflexivity/relative-reflexivity-ontological-contiguity $\sim$ ofthe-human-institutionalisation-process , however, the surreptitious and opportunistic temporal interpretations to exploit its positive consequences at one moment and to reject it the moment it prospectively challenges-us/puts-us-to-question as of prospective implications of Beingdevelopment/ontological-framework-expansion-as-to-depth-of-ontologising-development-asinfrastructure-of- meaningfulness-and-teleology , institutional-development-as-to-socialfunction-development and living-development-as-to-personality-development psychologismic epistemic-acutisation difficulty-for, residualising \{decomplsing $\}$ delinearity for-cogency> magnitudes $\{$ of-experientiality/experiment\}. The implication here is that all human knowledge is necessarily for-human-studies/for-human-constructs whether with regards to the social or the natural sciences; as to the fact that all such knowledge is ever only referenced/registered/decisioned in the human consciousness (individual consciousness and collective consciousness respectively as to direct knowledge and indirect knowledge as of deferential-formalisation-transference implications) and functions to broaden-the-latitude-ofhuman-collective-consciousness with regards to human-subpotencyaporia/undecidability/dilemma/ought-indeterminacy/deficiency/limitation/constraint in existence. The very possibility for prospective human knowledge generation thus calls for human dimensionality-of-sublimating $25<<$ amplituding/formative $>$ supererogatory $\sim$ dementativeness/epistemic-growth-or-conflatedness /transvaluative- 
rationalising/transepistemicity/anamnestic-residuality/spirit-drivenness-equalisation〉 given the reality of human-subpotency-aporia/undecidability/dilemma/oughtindeterminacy/deficiency/limitation/constraint—imbued-'notional firstnaturednessformativeness-<as-to-eventualising-inkling drive-or-seeding misprising $>$ temporal-tointemporal-dispositions-<so-construed-as-from-perspective-ontologicalnormalcy/postconvergence>'-existentialism-form-factor, with such human dimensionality-ofsublimating $25-<<$ amplituding/formative $>$ supererogatory $\sim$ de-mentativeness/epistemic-growthor-conflatedness /transvaluative-rationalising/transepistemicity/anamnestic-residuality/spiritdrivenness-equalisation) speaking of true humanity projection for prospective secondnaturing institutionalisation (that goes on to broaden-the-latitude-of-human-collective-consciousness), and so over the wrongfully elicited self-satisfaction of sophistic/pedantic ${ }^{79}$ presencingabsolutising-identitive-constitutedness ${ }^{14}$ in preconverging-existential-extrication-as-ofexistential-unthought failing to address the ${ }^{103}$ universal implications of human-subpotencyaporia/undecidability/dilemma/ought-indeterminacy/deficiency/limitation/constraint. This underlying human knowledge-notionalisation is what speaks of the distinction between the physician and quack-doctor, the technician/engineer and the scammer, the intellectual and the sophist, etc. Critically, the former as involved in prospective originariness/reifying/intellectualising_idealising/transcending/sublimating-meaningfulnessand-its-institutionalisation bluntly profess that 'human temporality $/$ shortness $<$ amplituding/formative $>$ wooden-language-〈imbued - averaging-of-thought-<as-toleveling/ressentiment/closed-construct-of- meaningfulness-and-teleology -as-of'nondescript/ignorable-void '-with-regards-to-prospective-apriorising-implications $>\rangle$ ' is in want for secondnatured knowledge and institutionalisation, and so as to the former human limited-mentation-capacity-deepening—as-subjecting limitedness/human-subpotency-to'educed unlimitednesstexistence sublimating nascence' ${ }^{53}$ (as to the specifically cultivated 
arts/skills and time investment, and on the intimation that the implied deferential-formalisationtransference is so-validated as of the supposedly coherent ontological-commitment $<$ implied - self-assuredness-of-ontological-good-faith/authenticity $\sim$ postconverging-dementating/structuring/paradigming -as-being-as-of-existential-reality >). In-the-bigger-picture, this speaks to a human socially expanded framework of deferential-formalisation-transference as to various cultivated skills/arts and time investment with their knowledge deferentialformalisation-transference validation as of the supposedly coherent ontological-commitment $<$ implied - self-assuredness-of-ontological-good-faith/authenticity postconverging-dementating/structuring/paradigming -as-being-as-of-existential-reality >; and implying a greatly expanded human collective consciousness as of differing for-human-studies/for-humanconstructs of originariness/reifying/intellectualising — idealising/transcending/sublimatingmeaningfulness-and-its-institutionalisation. On-the-other-hand, what is typical about quackdoctors, scammers, sophists, etc. with regards to prospective human-subpotencyaporia/undecidability/dilemma/ought-indeterminacy/deficiency/limitation/constraint is a predilection for eliciting the idea that 'human temporality $/$ shortness $<$ amplituding/formative $>$ wooden-language-_imbued — averaging-of-thought-<as-toleveling/ressentiment/closed-construct-of- meaningfulness-and-teleology -as-of'nondescript/ignorable-void '-with-regards-to-prospective-apriorising-implications $>\rangle$ ' is basically of competent judgment (notwithstanding the latter's underlying banal framework as to the reality of human-subpotency-aporia/undecidability/dilemma/oughtindeterminacy/deficiency/limitation/constraint—imbued-'notional firstnaturednessformativeness-<as-to-eventualising-inkling-drive-or-seeding-misprising $>$ temporal-tointemporal-dispositions- $<$ so-construed-as-from-perspective-ontologicalnormalcy/postconvergence>'-existentialism-form-factor, and lack of related cultivated skills/arts and time investment as to the requisite human limited-mentation-capacity- 
deepening —as-subjecting limitedness/human-subpotency to-'educed-unlimitedness/existencesublimating nascence' ${ }^{53}$ ). It is on the basis of 'so-prepping the human ego' in an exercise not truly meant to broaden-the-latitude-of-human-collective-consciousness (going by the eventual outcomes of such falsehoods) given that in-the-very-first-place the issue has nothing to do with inherent and genuine originariness/reifying/intellectualisingidealising/transcending/sublimating-meaningfulness-and-its-institutionalisation but rather a lulling falsehood that sees our mortal egos as the very target for surreptitiously inducing our moral and intellectual disenfranchisement/swindling/corruption/dispossession; as in effect, overall sophistry as to its underlying social-vestedness/normativity-<discretely-impliedfunctionalism $>$ undermining of human dispensing-with-immediacy-for-relative-ontologicalcompleteness $^{87}$-by-reification/contemplative-distension ${ }^{27}$ is effectively about discouraging the possibility for prospective humanity to manifest. But then this intellectualism and sophistry conundrum underlying knowledge-notionalisation (as of prospective human Beingdevelopment/ontological-framework-expansion-as-to-depth-of-ontologising-development-asinfrastructure-of- meaningfulness-and-teleology , institutional-development-as-to-socialfunction-development and living-development-as-to-personality-development psychologismic epistemic acutisation diffieuly <for, residualising \{decompulsing\} delinearity for cogeney> magnitudes $\{$ of-experientiality/experiment $\}$, preconverging/postconverging-dementatively/structurally/paradigmatically marks all human-subpotencyaporia/undecidability/dilemma/ought-indeterminacy/deficiency/limitation/constraint as to the 'uninstitutionalised-threshold ${ }^{102}$ attendant framework of lack of social ${ }^{103}$ universaltransparency ${ }^{104}$-〈transparency-of-totalising-entailing,-as-to-entailing-<amplituding/formativeepistemicity>totalising in-relative-ontological-completeness $\quad$-or-understanding-of$<$ amplituding/formative-epistemicity $>$ causality $\sim$ as-to-projective-totalitative-implications-ofprospective- nonpresencing,-for-explicating relative-unreflexivity/relative-reflexivity 
ontological-contiguity -of-underlying-phenomena'. This very fact is defining as without the latter there wouldn't be any human-subpotency-aporia/undecidability/dilemma/oughtindeterminacy/deficiency/limitation/constraint in-the-very-first-place; and this very much explains the defining relevance of human-subpotency-aporia/undecidability/dilemma/oughtindeterminacy/deficiency/limitation/constraint—imbued-'notional firstnaturednessformativeness-<as-to-eventualising-inkling-drive or seeding-misprising $>$ temporal-tointemporal-dispositions-<so-construed-as-from-perspective-ontologicalnormalcy/postconvergence>'-existentialism-form-factor, as to the possibility for genuine human reification and emancipation to broaden-the-latitude-of-human-collective-consciousness or disenfranchising falsehoods. The taxingness-of-originariness (as to the direct relation between human-subpotency and existence-potency ${ }^{32} \sim$ sublimating-nascence,-disclosed-fromprospective-epistemic-digression) is effectively what underlies human institutional paralysis and social-vestedness/normativity- $<$ discretely-implied-functionalism $>$ as well as the possibility for prospective human construction-of-the-Self in the face of increasingly technically aloof/remote and racing technological, organisational and social transformation; such that the requisite human thoughtfulness that can correspondingly broaden-the-latitude-of-human-collectiveconsciousness is increasingly out of the loop as humankind in the modern positivism age has increasingly become rather a self-subjugating agent to such transformations as to their lopsided material/equipment/accoutrement sublimation implications with the notion of human consciousness sublimation increasingly passivised and blanked to vested social-andinstitutional-frameworks-of — referencing/registering/decisioning actions. But then humankind faces the challenge of contemplatively articulating ${ }^{56}$ meaningfulness-and-teleology ${ }^{99}$ capable of reinventing/recreating and keeping the human at the driver seat rather than an object of unformulated/unthought-of driven existential-<disontologising/re-ontologising aporeticism $>$ emergence/becoming as of lopsided material/equipment/accoutrement sublimation over a 
'dreary blankness of consciousness' (rather functioning to be attended-to and accommodated/unaccommodated by that lopsided material/equipment/accoutrement sublimation) as human consciousness is in want of its very own corresponding sublimation as to redefining the possibilities/potential for prospective humanity that can further broaden-thelatitude-of-human-collective-consciousness. Such 'dreary blankness of consciousness' (beyondthe-consciousness-awareness-teleology ${ }^{9}<$ of-preconverging-existential-extrication-as-ofexistential-unthought $>$ ) is predicated upon and drags along the shiftiness-of-the-Self as from prior human stake-contention-or-confliction conceptualisation in a psychological entrapment of defining naiveties and complexes (so-construed in ${ }^{79}$ presencing-absolutising-identitiveconstitutedness ${ }^{14}$ as $\quad{ }^{4}$ historicity-tracing-in-presencing-hyperrealisation/hyperrealtransposition)', and so towards humankind's supposed future (as of Beingdevelopment/ontological-framework-expansion-as-to-depth-of-ontologising-development-asinfrastructure-of- meaningfulness-and-teleology , institutional-development-as-to-socialfunction-development and living-development-as-to-personality-development psychologismic epistemic-acutisation difficulty-for, residualising \{decompulsing $\}$ delinearity for-cogency> magnitudes $\left.{ }^{\{0 f-e x p e r i e n t i a l i t y / e x p e r i m e n t}\right\}$; and in-many-ways this ${ }^{47}$ historicity-tracing-in-presencinghyperrealisation/hyperreal-transposition has already been stifling/stalling the human prospective potential as from the ontological-normalcy/postconvergence perspective conception of future historiality/ontological-eventfulness 38 ontological-aesthetic-tracing- $<$ perspectiveontological-normalcy/postconvergence-reflected-‘epistemicity-relativism-determinism’>

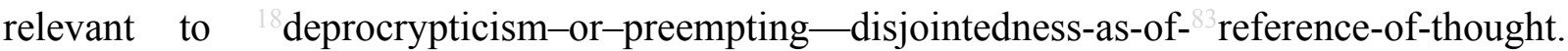
Such $\quad{ }^{4}$ historicity-tracing-in-presencing-hyperrealisation/hyperreal-transposition is fundamentally defined by a certain enduring reproducibility passivity and blankness of human social processes, wary of the implications of prospective renewal possibilities as the psychological entrapment constraints of ${ }^{47}$ historicity-tracing-in-presencing- 
hyperrealisation/hyperreal-transposition override prospective originariness-parrhesia,--asspontaneity-of-aestheticisation possibilities, and the prospect for the future is ever so tied down to the psychological entrapment of prior human stake-contention-or-confliction framework that nullifies the possibility for renewal of humanity. Institutionalised ${ }^{47}$ historicity-tracing-inpresencing-hyperrealisation/hyperreal-transposition thus foregoes the construal of human meaningfulness-and-teleology as a construct of re-originariness/re-origination of meaningfulness-and-teleology as to human limited-mentation-capacity-deepening-assubjecting limitedness/human-subpotency-to-'educed-unlimitedness/existence-sublimating nascence' ${ }^{53}$ so-implied from the ontological-normalcy/postconvergence epistemic-ornotional projective-perspective as to maximalising-recomposuring-for-relative-ontologicalcompleteness $^{87}$ — unenframed/re-ontologising conceptualisation and rather adopts the temporality 8 /shortness comfort as of incrementalism-in-relative-ontologicalincompleteness ${ }^{8}$ - enframed/disontologising conceptualisation hanging on to ${ }^{47}$ historicitytracing-in-presencing-hyperrealisation/hyperreal-transposition ${ }^{79}$ presencing_absolutisingidentitive-constitutedness ${ }^{14}$ notional framework of human stake-contention-or-confliction. historicity-tracing - in-presencing-hyperrealisation/hyperreal-transposition thus involves a <amplituding/formative-epistemicity $>$ totalising/circumscribing/delineating conception of social-vestedness/normativity-<discretely-implied-functionalism $>$ as to an underlying human psychological entrapment (as of Being-development/ontological-framework-expansion-as-todepth-of-ontologising-development-as-infrastructure-of- meaningfulness-and-teleology , institutional-development-as-to-social-function-development and living-development-as-topersonality-development psychologismic epistemic acutisation difficulty < for, residualising \{decompulsing $\}$ delinearity-for cogency>-magnitudes $\{$ of-experientiality/experiment $\}$ ) that is incapable to re-stake/put-back-at-stake ${ }^{56}$ meaningfulness-and-teleology ${ }^{9}$ out of its ${ }^{47}$ historicitytracing_-in-presencing-hyperrealisation/hyperreal-transposition social-vestedness/normativity- 
$<$ discretely-implied-functionalism $>$ in order to reflect the true prospective overall aestheticisation-and-aestheticisation-towards-ontology-<elicited-idiomatisation $>$ as to the unbridled ontological-normalcy/postconvergence epistemic-or-notional projective-perspective re-originariness/re-origination of human limited-mentation-capacity-deepening —as-subjecting limitedness/human-subpotency-to-'educed-unlimitedness/existence-sublimating nascence'53.

Such social and institutional social-vestedness/normativity- $<$ discretely-implied-functionalism $>$ for instance like in-many-ways the practice in modern-day scholarship (especially when poorly

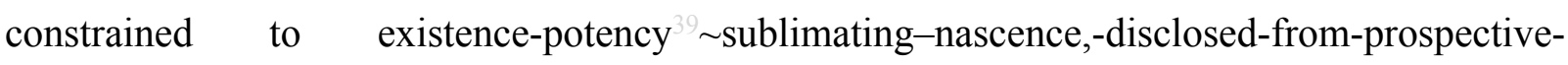
epistemic-digression) is bound to 'make its own weather' rather as from human-subpotency temporality 8 /shortness; wherein 'invested' institutional and theoretical/conceptual postures take on an essence all of their own, and so independently and overlooking the precedence of existential-reality for the possibility for prospective sublimation and knowledgereification $\sim$ gesturing-and-accounting — of-epistemic-phenomenalism- $<$ in-

prospective_psychologismic apriorising/axiomatising/referencing-\{of-'prospectively implicited_attendant-ontological-contiguity ' educedexistentialising/contextualising/textualising_'intelligibility/epistemicity/reflexivity-contiguity<imbued-notional cogency >' $\}$-conflatedness in \{preconverging ment by\} postconverging-entailment> and failing to 'effectively re-stake/put-back-at-stake in reoriginariness/re-origination the capacity of human ontological-performance ${ }^{2}-<$ including-virtueas-ontology $>$ /morality/ethics/justice/etc. in a renewing originariness-parrhesia,-as-spontaneityof-aestheticisation' over already set/established/determining prior reproducibilitymathesis/motif/thrownness-disposition,-as-reproducibility-of-aestheticisation, and so failing to be responsive to the fact that human limited-mentation-capacity-deepening as limitedness/human-subpotency to-'educed-unlimitedness/existence-sublimating nascence' rather invokes prospective dimensionality-of-sublimating 
<<amplituding/formative>supererogatory $\sim$ de-mentativeness/epistemic-growth-or-

conflatedness /transvaluative-rationalising/transepistemicity/anamnestic-residuality/spirit-

drivenness-equalisation) for re-originariness/re-origination (and as ever always such destructuring-threshold-〈uninstitutionalised-threshold /presublimating-desublimating-

decisionality $>\sim$ of-ontological-performance ${ }^{72}$ - $<$ including-virtue-as-

ontology $>$ /morality/ethics/justice/etc. across the <cumulating/recomposuring attendantontological-contiguity >-successive registry-worldviews/dimensions abuse of the idea of being at the backend of human institutional-cumulation/institutional-recomposure-〈as-tohistoriality/ontological-eventfulness /ontological-aesthetic-tracing-<perspective-

ontological-normalcy/postconvergence-reflected-‘epistemicity-relativism-determinism’ $>>\quad$ as speaking to its own exceptionalism in a naïve <amplituding/formativeepistemicity $>$ totalising $\sim$ self-referencing-syncretising/circularity/interiorising/akrasiatic-drag posture instead of the true instigative exceptionalism of the underlying relativeunreflexivity/relative-reflexivity — ontological-contiguity ${ }^{67}$ of-the-human-institutionalisationprocess $^{6}$ ). This temporal/shortness disposition to fail re-originariness/re-origination is of overall social recurrence as to human temporality $/$ /shortness <amplituding/formative> woodenlanguage-〈imbued - averaging-of-thought-<as-to-leveling/ressentiment/closed-construct-ofmeaningfulness-and-teleology -as-of-‘nondescript/ignorable-void '-with-regards-toprospective-apriorising-implications $>$ > as of "varying psychologismic epistemic-acutisation-

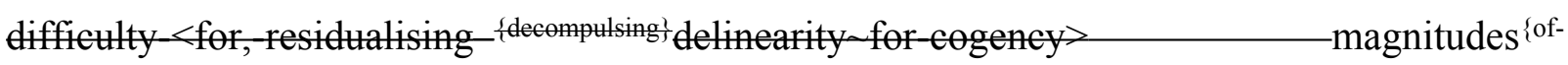
experientiality/experiment ${ }_{3} /$ scales_-as-to-successively-profound-preconverging/postconverging-redementating/restructuring/reparadigming-frames-as-from-living,-institutionalising,-and-Beingontologising/infrastructure-of- ${ }^{5}$ meaningfulness-and-teleology 99 of prospective humansubpotency-aporia/undecidability/dilemma/oughtindeterminacy/deficiency/limitation/constraint—imbued-'notional firstnaturedness- 


\section{intemporal-dispositions-<so-construed-as-from-perspective-ontological-}

normalcy/postconvergence>'-existentialism-form-factor'; and so in all situations particularly those poorly constrained to existence-potency ${ }^{32} \sim$ sublimating-nascence,-disclosed-fromprospective-epistemic-digression. Such that such ontologically-flawed ${ }^{79}$ presencingabsolutising-identitive-constitutedness ${ }^{14}$ becomes a psychological entrapment of an overwhelming presence hardly capable of profound re-originariness/re-origination but for its thresholding to the accrued ${ }^{4}$ historicity-tracing-in-presencing-hyperrealisation/hyperrealtransposition perception of temporal/shortness human stakes-contention-or-confliction framework; with the consequence that this mitigates the possibility to broaden-the-latitude-ofhuman-collective-consciousness off-the-beaten-path of ${ }^{47}$ historicity-tracing-in-presencinghyperrealisation/hyperreal-transposition (as of Being-development/ontological-frameworkexpansion-as-to-depth-of-ontologising-development-as-infrastructure-of- meaningfulnessand-teleology , institutional-development-as-to-social-function-development and livingdevelopment-as-to-personality-development psychologismic epistemic acutisationdifficulty $<$ for, residualising_\{decompulsing $\}$ delinearity for-cogency> magnitudes $\{$ ofexperientiality/experiment $\}_{\text {f }}$ ) as to the relation with human lopsided material/equipment/accoutrement sublimation, as such a consciousness increasingly adopts a desublimation/gimmickiness rather than its very own sublimation in tandem with material/equipment/accoutrement sublimation. This is reflected with the increasing remoteness/aloofness and alienation of the generalised human subject from such material/equipment/accoutrement sublimation captured under abstract institutional frameworks of stewardship expecting a 'dreary blankness of consciousness' (rather functioning to be attended-to and accommodated/unaccommodated by the lopsided material/equipment/accoutrement sublimation) in order to maximise passive enculturation and merchandising as of ' ${ }^{\prime 7}$ presencing - absolutising-identitive-constitutedness ${ }^{14}$-of- 
meaningfulness-and-teleology

given

historicity-tracing-in-presencinghyperrealisation/hyperreal-transposition'. Thus, the possibility for the generalised human subject capacity for consciousness sublimation is seized up and constrained in such socially and institutionally bureaucratising and deterministic frameworks that now preconverging/postconverging-de-mentatively/structurally/paradigmatically determine the possibilities of human consciousness sublimation as to their abstracted defining conception of human stake-contention-or-confliction (as of Being-development/ontological-frameworkexpansion-as-to-depth-of-ontologising-development-as-infrastructure-of- meaningfulnessand-teleology , institutional-development-as-to-social-function-development and livingdevelopment-as-to-personality-development psychologismic epistemic-acutisation-

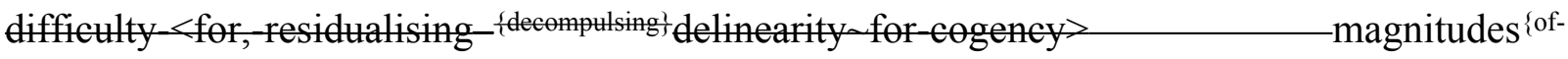
experientiality/experiment\}) such that the generalised human subject re-originariness/re-origination sublimation imaginary possibilities are already truncated as from prospective ontologicalnormalcy/postconvergence epistemic-or-notional $\sim$ projective-perspective of re-originariness/reorigination as implied with prospective ${ }^{18}$ deprocrypticism-or-preempting-disjointedness-asof- ${ }^{8}$ reference-of-thought. Today, many agile initiatives allowing more or less for the expression of the human subject imaginary and so specifically with start-up entrepreneurship increasingly highlight that in-many-ways traditional social-and-institutional-frameworks-ofreferencing/registering/decisioning are suboptimal conceptualisations of human consciousness sublimation possibilities as to their thoroughgoing beholdenness to ${ }^{7}$ presencing—absolutisingidentitive-constitutedness ${ }^{14}$-of- ${ }^{5}$ meaningfulness-and-teleology ${ }^{9}$ given ${ }^{47}$ historicity-tracingin-presencing-hyperrealisation/hyperreal-transposition' bounded to prospective thresholds of passivity and blanking of human consciousness sublimation possibilities. In-many-ways because of poor appreciation of the 'direct bilateral relationship of appropriate construction-of-the-Self for appropriate cognisance-and-integration of prospective relative-ontological-completeness 
meaningfulness-and-teleology ${ }^{\prime}$ the modern mindset has tended to construe of its lopsided material/equipment/accoutrement sublimation implications naively as implying the comprehensive fulfilment of human potential with poor appreciation/sense that effectively as reflected with prior registry-worldviews/dimensions, the proximity of technology then never implied as today a generalised human consciousness passivity and blankness to the point of relative desublimation/gimmickiness over sublimation (beyond-the-consciousness-awarenessteleology ${ }^{9}<$ of-preconverging-existential-extrication-as-of-existential-unthought $>$ ); and so as potently contended by Baudrillard simulacrum conception wherein gimmicky formulaic representations of overall aestheticisation-and-aestheticisation-towards-ontology- $<$ elicitedidiomatisation> increasingly substitute for more profound possibilities of human aestheticisation-and-aestheticisation-towards-ontology-<elicited-idiomatisation $>$ as meaningfulness-and-teleology with respect to the potential for prospective human consciousness sublimation as of a totalising-entailing projection of dispensing-with-immediacyfor-relative-ontological-completeness ${ }^{87}$-by-reification/contemplative-distension ${ }^{27}$. Whereas historically the technological accessibility and proximity to the generalised human consciousness of such events ${ }^{38}$ like the invention of metal implements, the plough, writing, the printing press, etc. provided more profound possibilities for human consciousness sublimation in re-orginariness/re-origination, beyond mere lopsided technological as of lopsided material/equipment/accoutrement sublimation in the framework of a " presencingabsolutising-identitive-constitutedness ${ }^{14}$-of- ${ }^{56}$ meaningfulness-and-teleology ${ }^{99}$ given historicity-tracing - in-presencing-hyperrealisation/hyperreal-transposition' that passivises and blanks thus undermining/stifling the possibility for prospective ${ }^{4}$ historiality/ontologicaleventfulness ${ }^{38}$ ontological-aesthetic-tracing-<perspective-ontologicalnormalcy/postconvergence-reflected-‘epistemicity-relativism-determinism'>. While a traditional conception of human sublimating-over-desublimating social-and-institutional- 
constructs-of- ${ }^{5}$ meaningfulness-and-teleology - in-cumulation/recomposuring is often articulated as resting on 'human social-vestedness/normativity-<discretely-impliedfunctionalism> implied contract/political-arrangement-or-political-coercion/given-discretesocial-value-construction' presencing-absolutising-identitiveconstitutedness $14 /$ constitutedness apriorising/axiomatising/referencing-conceptualisation perspective thus supposedly rendering irrelevant their analysis as of inherent ontologicalveracity (as to supposedly coherent ontological-commitment $<$ implied-self-assuredness-ofontological-good-faith/authenticity $\sim$ postconverging-dementating/structuring/paradigming -as-being-as-of-existential-reality $>$ with regards to the 'full-conflatedness ${ }^{13}$ of apriorising/axiomatising/referencing-conceptualisation as to existencepotency $^{32} \sim$ sublimating-nascence,-disclosed-from-prospective-epistemic-digression), but rather tending to a construal as of 'inherent prior aestheticisation-and-aestheticisation-towardsontology-<elicited-idiomatisation $>$ as of human social-vestedness/normativity- $<$ discretelyimplied-functionalism>'; such a traditional conception from the relative-ontologicalcompleteness ${ }^{87}$ perspective is actually unfounded and rather speaks to prior relative-ontologicalincompleteness ${ }^{88}$ manifestation of human ${ }^{79}$ presencing-absolutising-identitiveconstitutedness ${ }^{14} /$ constitutedness $^{14} \quad$ (as to $\quad{ }^{47}$ historicity-tracing-in-presencinghyperrealisation/hyperreal-transposition implications of human limited-mentation-capacity—assubjecting-'educed-unlimitedness/existence-sublimating nascence' to-limitedness/humansubpotency). The reality of the dynamic relation between human apriorising/axiomatising/referencing-\{of-'prospectively implicited_attendant-ontologicalcontiguity ' educedexistentialising/contextrising/textralising_intelligibility/epistemicity/reflexivity-contiguity$<$ imbued-notional cogency $\left.>^{\prime} \quad\right\}$-constitutedness ${ }^{14}$-in-preconverging-entailment $\quad$ and apriorising/axiomatising/referencing-\{of-'prospectively implicited_attendant-ontological- 
contiguity ' educed-

existentialising/contextualising/textualising_'intelligibility/epistemicity/reflexivity_contiguity-

<imbued-notional cogency >' \}-conflatedness ${ }^{13}$ in-\{preconverging-ment by\}

pestconverging-entailment of apriorising/axiomatising/referencing-conceptualisation (as to the successive relative-ontological-completeness ${ }^{87}$ registry-worldviews/dimensions adopted human reference-of-thought supererogatory acuity/perspicacity/astuteness/edginess/incisiveness-ofapriorising/axiomatising/referencing/intelligibilitysettingup/measuringinstrumenting -forconceptualisation for ${ }^{5}$ meaningfulness-and-teleology ${ }^{9}$ with respect to existencepotency $^{39} \sim$ sublimating-nascence,-disclosed-from-prospective-epistemic-digression), as reflected in reflecting holographically-<conjugatively-and-transfusively $>$ the relativeunreflexivity/relative-reflexivity - ontological-contiguity of-the-human-institutionalisationprocess with: base-constitutedness ${ }^{14}$ at recurrent-utter-uninstitutionalisation, first-level presencing-absolutising-identitive-constitutedness ${ }^{14}$ at base-institutionalisationununiversalisation, second-level ${ }^{79}$ presencing-absolutising-identitive-constitutedness ${ }^{14}$ at universalisation-non-positivism/medievalism, third-level $\quad{ }^{7}$ presencing-absolutisingidentitive-constitutedness $^{14}$ at our positivism- ${ }^{80}$ procrypticism, and prospectively fullconflatedness ${ }^{13}$ at prospective deprocrypticism; rather speaks to a more fundamental driver as to underlying ontological-veracity (as to supposedly coherent ontological-commitment

\section{<implied-self-assuredness-of-ontological-good-faith/authenticity postconverging-de-} mentating/structuring/paradigming -as-being-as-of-existential-reality $>$ with regards to the 'full-conflatedness ${ }^{13}$ of apriorising/axiomatising/referencing-conceptualisation as to existencepotency ${ }^{39} \sim$ sublimating-nascence,-disclosed-from-prospective-epistemic-digression) but that such a reality is oblivious to the traditional construal in ${ }^{79}$ presencing-absolutising-identitiveconstitutedness ${ }^{1 /} /$ constitutedness $^{14}$ of apriorising/axiomatising/referencing-conceptualisation that speaks of 'human social-vestedness/normativity- $<$ discretely-implied-functionalism $>$ 
implied contract/political-arrangement-or-political-coercion/given-discrete-social-valueconstruction' in ${ }^{79}$ presencing-absolutising-identitive-constitutedness ${ }^{14}$. This is so inherently because of the specific human-subpotency with regards to overall reifying-and-empoweringreflexivity-of-ecstatic-existence-as-panintelligibility/panreflexite ${ }^{73}$-〈existentially-imbuedand-educing-\{ $<$ epistemic-

totalising thermeneutically/textually/reprojectingly/supererogatingly/zeroingly/re-acutingly,$\{$ decompulsing $\}$ delinearity for-cogency $\geq$-epistemic-perspective-of-projective/reprojectiveaestheticising-re-motif-and-re-apriorising/re-axiomatising/re-referencing conceptualisation,as herein-specifieally relevant to human-subpotency), by the mere token that humansubpotency notional $\sim$ reflexivity- $<\{$ veridieal/sound $\}$ relative-reflexivity-in-

\section{existence/relativising from-limited-mentation-as-its-deepening/psychologismic-}

<residualising \{decompulsing $\}$ delinearity for-cogency>-by-\{flawed/unsound\}-relativeunreflexivity-in-existence/absolutising from-limited-mentation/psychologismic epistemic acutisation nonresidualising imbued-\{compulsing\}linearity in-eclecticism-of-prior-mereformulaicity/ritualisation $>$ of existence at any such given apriorising/axiomatising/referencingconceptualisation shallow <amplituding/formative-epistemicity $>$ totalising $\sim$ self-referencingsyncretising/circularity/interiorising/akrasiatic-drag ${ }^{34} \quad{ }^{79}$ presencing-absolutising-identitiveconstitutedness ${ }^{1 /} /$ constitutedness $^{14}$ in relative-ontological-incompleteness ${ }^{88}$ (that is, in epistemic-abnormalcy/preconvergence ${ }^{31}$ as to existence-potency ${ }^{32} \sim$ sublimating-nascence,disclosed-from-prospective-epistemic-digression) will rather imply its corresponding apriorising/axiomatising/referencing-conceptualisation of 'human socialvestedness/normativity- $<$ discretely-implied-functionalism $>\quad$ implied contract/politicalarrangement-or-political-coercion/given-discrete-social-value-construction' (and this is no more correspondingly different from the relative-ontological-incompleteness $8 /$ relativeontological-completeness ${ }^{8}$-〈sublimating $\sim$ referencing/registering/decisioning,-as-self- 
becoming/self-conflatedness /formative-supererogating-<projective/reprojective-

aestheticising-re-motif-and-re-apriorising/re-axiomatising/re-referencing,-in-perspective-

ontological-normalcy/postconvergence $>$ h human-subpotency notional $\sim$ reflexivity-

$<\{$ veridical/sound\}-relative-reflexivity-in-existence/relativising from-limited-mentation-as-

its deepening/psychologismic < residualising \{decompulsing\} delinearity for cogency>by-

\{flawed/unsound\}-relative-unreflexivity-in-existence/absolutising from-limited-

mentation/psychologismic epistemic-acutisation nonresidualising-imbued-

fcompulsingllinearity in-eclecticism-of prior-mere-formulaicity/ritualisation $>$ of existence as to

say the 'health epiphenomenon of existence' in reflecting holographically-<conjugatively-andtransfusively $>$ the relative-unreflexivity/relative-reflexivity ontological-contiguity of-thehuman-institutionalisation-process with 'various registry-worldviews/dimensions shallow $<$ amplituding/formative-epistemicity $>$ totalising $\sim$ self-referencing-

syncretising/circularity/interiorising/akrasiatic-drag ${ }^{44} \quad{ }^{79}$ presencing-absolutising-identitiveconstitutedness ${ }^{14} /$ constitutedness $^{14}$ apriorising/axiomatising/referencing-conceptualisation of healthcare' as to their successive relative-ontological-incompleteness $8 /$ relative-ontologicalcompleteness ${ }^{8}$-〈sublimating $\sim$ referencing/registering/decisioning,-as-self-becoming/selfconflatedness /formative-supererogating-<projective/reprojective-aestheticising-re-motifand-re-apriorising/re-axiomatising/re-referencing,-in-perspective-ontologicalnormalcy/postconvergence $>\rangle)$. In both cases it is rather from the full <amplituding/formativeepistemicity $>$ causality $\sim$ as-to-projective-totalitative-implications-of-prospectivenonpresencing,-for-explicating relative-unreflexivity/relative-reflexivity ontologicalcontiguity that the ontological-veracity as of prospective ontologicalnormalcy/postconvergence (as to supposedly coherent ontological-commitment $-<$ implied self-assuredness-of-ontological-good-faith/authenticity postconverging-dementating/structuring/paradigming -as-being-as-of-existential-reality $>$ with regards to the 
'full-conflatedness ${ }^{13}$ of apriorising/axiomatising/referencing-conceptualisation as to existencepotency $^{32} \sim$ sublimating-nascence,-disclosed-from-prospective-epistemic-digression) truly reflects the deterministic epistemic causality of existential-<disontologising/re-ontelogising aporeticism $>$ sublimation manifestation, and so over any such conceptualisation of 'human social-vestedness/normativity- $<$ discretely-implied-functionalism $>$ implied contract/politicalarrangement-or-political-coercion/given-discrete-social-value-construction', rather in shallow $<$ amplituding/formative-epistemicity $>$ totalising $\sim$ self-referencing-

syncretising/circularity/interiorising/akrasiatic-drag ${ }^{34} \quad{ }^{79}$ presencing — absolutising-identitiveconstitutedness ${ }^{1 /} /$ constitutedness $^{14}$ of apriorising/axiomatising/referencing-conceptualisation (and not full-conflatedness ${ }^{13}$ of apriorising/axiomatising/referencing-conceptualisation with existence-potency ${ }^{39} \sim$ sublimating-nascence,-disclosed-from-prospective-epistemic-digression). Such prospective ontological-normalcy/postconvergence epistemic-or-notional $\sim$ projectiveperspective of re-originariness/re-origination is of the most profound <amplituding/formativeepistemicity $>$ causality conceptualisation of human sublimating-over-desublimating social-andinstitutional-constructs-of- ${ }^{56}$ meaningfulness-and-teleology ${ }^{9}$-in-cumulation/recomposuring as to human limited-mentation-capacity-deepening-as-subjecting limitedness/humanstbpotency to 'educed mlimitedness/existence sublimating naseence' dimensionality-of-sublimating ${ }^{25}-\langle<$ amplituding/formative $>$ supererogatory $\sim$ dementativeness/epistemic-growth-or-conflatedness /transvaluativerationalising/transepistemicity/anamnestic-residuality/spirit-drivenness-equalisation〉 ontological-faith-notion-or-ontological-fideism - imbued-underdetermination-of-motif-andapriorising/axiomatising/referencing-as-so-being-as-of-existential-reality 'seeding promise of human-subpotency

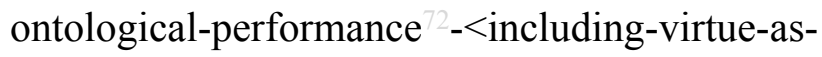
ontology $>$ /morality/ethics/justice/etc. equivalence/correspondence with the full-potency-ofexistence's $\sim$ sublimating-nascence-as-of-its-coherence/contiguity'. This reality speaks to 
reflecting holographically-<conjugatively-and-transfusively $>$ the relative-unreflexivity/relativereflexivity - ontological-contiguity of-the-human-institutionalisation-process ), as from human-subpotency ontological-faith-notion-or-ontological-fideism - imbuedunderdetermination-of-motif-and-apriorising/axiomatising/referencing-as-so-being-as-ofexistential-reality as to the disseminative-sublimating-selectivity-of-ontological-goodfaith/authenticity $\sim$ postconverging-de-mentating/structuring/paradigming , overdesublimating deselectivity-of-ontological-bad-faith/inauthenticity -preconverging dementating/structuring/paradigming ', as the driver of the human-subpotency potentiating existential-<isontologising/re-ontologising aporeticism $>$ becoming manifestation of sublimating-over-desublimating social-and-institutional-constructs-of- - meaningfulness-andteleology -in-cumulation/recomposuring all along in reflecting holographically$<$ conjugatively-and-transfusively $>$ the relative-unreflexivity/relative-reflexivity - ontologicalcontiguity of-the-human-institutionalisation-process ; as it dynamically induces (as of 'varying psychologismic epistemic-acutisation difficulty-<for, residualising $\{$ decompulsing $\}$ delinearity for cogeney> magnitudes $\{0$-experientiality/experiment $\} /$ scales—as-tosuccessively-profound-preconverging/postconverging-redementating/restructuring/reparadigming-frames-as-from-living,-institutionalising,-and-Beingontologising/infrastructure-of- ${ }^{5}$ meaningfulness-and-teleology 9 of prospective humansubpotency-aporia/undecidability/dilemma/ought-

indeterminacy/deficiency/limitation/constraint—imbued-'notional firstnaturednessformativeness- $<a s$ to eventualising inkling drive or seeding misprising $>$ temporal-tointemporal-dispositions-<so-construed-as-from-perspective-ontologicalnormalcy/postconvergence>'-existentialism-form-factor') successive prospective reasoning- 
through/messianic-reasoning for reasoning-from-results/afterthought as the secondnaturedinstitutionalisation of the <cumulating/recomposuring attendant-ontological-contiguity successive registry-worldviews/dimensions ${ }^{8}$ reference-of-thought-and- ${ }^{83}$ reference-of-thoughtdevolving- ${ }^{5}$ meaningfulness-and-teleology' so-construed as 'generating varying human sublimating-over-desublimating social-and-institutional-constructs-of- - meaningfulness-andteleology -in-cumulation/recomposuring

of apriorising/axiomatising/referencing/intelligibilitysettingup/measuringinstrumenting' as to their pre-eminence as of their 'prospectively projected relative-ontological-completeness dimensionality-of-sublimating $25<$ < amplituding/formative $>$ supererogatory $\sim$ dementativeness/epistemic-growth-or-conflatedness /transvaluativerationalising/transepistemicity/anamnestic-residuality/spirit-drivenness-equalisation $\rangle$. It is rather such an ontological-normalcy/postconvergence conceptualisation as reflected by the relative-unreflexivity/relative-reflexivity - ontological-contiguity $\sim$ of-the-humaninstitutionalisation-process $^{68}$ as of difference-conflatedness ${ }^{13}$-as-to-totalitative-reification-insingularisation-<as-to-the-nondisjointedness/entailment-of-prospective- nonpresencing $>$-asveridical-epistemicity-relativism-determinism implied <amplituding/formativeepistemicity $>$ causality $\sim$ as-to-projective-totalitative-implications-of-prospectivenonpresencing,-for-explicating relative- unreflexivity/relative-reflexivity - ontologicalcontiguity in full-conflatedness ${ }^{13}$ of apriorising/axiomatising/referencing-conceptualisation as to existence-potency ${ }^{39} \sim$ sublimating-nascence,-disclosed-from-prospective-epistemicdigression imbued ontological-veracity (reflected in supposedly coherent ontologicalcommitment $-<$ implied—self-assuredness-of-ontological-goodfaith/authenticity postconverging-de-mentating/structuring/paradigming -as-being-as-ofexistential-reality>) that actually reflects the underlying notional-contiguity/epistemiccontiguity ${ }^{2}<$ profound-supererogation - of-mentally-aestheticised $\sim$ postconverging/dialectical- 
thinking -qualia-schema> of existence/existential-reality speaking of relativeunreflexivity/relative-reflexivity - ontological-contiguity ${ }^{7}$, whereas the ${ }^{79}$ presencingabsolutising-identitive-constitutedness ${ }^{14} /$ constitutedness $^{14} \quad$ of apriorising/axiomatising/referencing-conceptualisation implied from 'human socialvestedness/normativity- $<$ discretely-implied-functionalism $>\quad$ implied contract/politicalarrangement-or-political-coercion/given-discrete-social-value-construction' perspective are

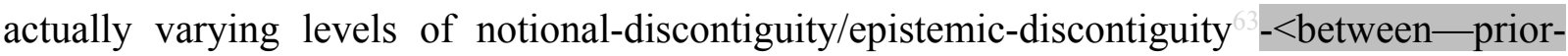
shallow-supererogation -of-mentally-aestheticised $\sim$ preconverging/dementing -qualiaschema_and_prospective-profound-supererogation -of-mentallyaestheticised postconverging/dialectical-thinking -qualia-schema $>$ in identitiveconstitutedness ${ }^{14}$-as-'epistemic-totality ${ }^{37}$ '-dereification-in-dissingularisation- $<$ as-to-thedisjointedness/ment-of- presencing - absolutising-identitive-constitutedness $>$-as-flawedepistemicity-relativism-determinism speaking of their discretionariness as not reflecting

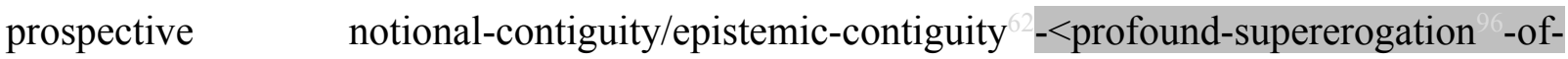
mentally-aestheticised postconverging/dialectical-thinking -qualia-schema $>$ as from the ontological-normalcy/postconvergence epistemic-or-notional projective-perspective (since there are not in full-conflatedness ${ }^{13}$ of apriorising/axiomatising/referencing-conceptualisation as to existence-potency ${ }^{32} \sim$ sublimating-nascence,-disclosed-from-prospective-epistemicdigression imbued ontological-veracity). This human-subpotency 'fatedness-of-sublimationover-desublimation, to existence-potency $\sim$ sublimating-nascence,-disclosed-fromprospective-epistemic-digression (in reflecting holographically-<conjugatively-andtransfusively $>$ the relative-unreflexivity/relative-reflexivity ontological-contiguity $\sim$ of-thehuman-institutionalisation-process ), as from human-subpotency ontological-faith-notion-orontological-fideism - imbued-underdetermination-of-motif-andto the 
disseminative - sublimating-selectivity-of-ontological-good-

faith/authenticity postconverging-de-mentating/structuring/paradigming , overdesublimating deselectivity-of-ontological-bad-faith/inauthenticity -preconverging dementating/structuring/paradigming, (arising as from the very first/primordial existential< disontologising/re-ontologising aporeticism $>$ becoming manifestations of human selfsurpassing — existentialism-form-factor,-in-overcoming-'notional collateralising-beholdeningprotohumanity'-to- 'attain-sublimating-humanity'-as-to-existence-potency sublimatingnascence,-disclosed-from-prospective-epistemic-digression to supersede human temporality 8 /shortness <amplituding/formative> wooden-language-〈imbued-averaging-ofthought-<as-to-leveling/ressentiment/closed-construct-of- meaningfulness-and-teleology -asof-'nondescript/ignorable-void '-with-regards-to-prospective-apriorising-implications $>\rangle$ ) can be observed with the traditional first peoples like the pygmies. As for instance the very basic initiation of trading/exchange itself with the 'other person' as to the possibility of developing community is as of human-subpotency 'fatedness-of-sublimation-over-desublimation, to existence-potency $\sim$ sublimating-nascence,-disclosed-from-prospective-epistemic-digression (in reflecting holographically-<conjugatively-and-transfusively $>$ the relativeunreflexivity/relative-reflexivity - ontological-contiguity of-the-human-institutionalisationprocess ), as from human-subpotency ontological-faith-notion-or-ontological-fideismimbued-underdetermination-of-motif-and-apriorising/axiomatising/referencing-as-so-being-asof-existential-reality as to the disseminative-sublimating-selectivity-of-ontological-goodfaith/authenticity postconverging-de-mentating/structuring/paradigming , overdesublimating-deselectivity-of-ontological-bad-faith/inauthenticity -preconverging dementating/structuring/paradigming , wherein an item of trade/exchange is placed at a neutral location/spot in the hope that the other will take it and reciprocate out of ontological-goodfaith/authenticity ${ }^{69}$ with a satisfactory trade/exchange item (and so with the very real possibility 
that it might be taken without reciprocity out of ontological-bad-faith/inauthenticity ${ }^{64}$ ), and so as to their underlying correspondingly 'instigatable/promptable ontological-goodfaith/authenticity

or

apriorising/axiomatising/referencing-conceptualisation', completementarily instigated/prompted ontological-bad-faith/inauthenticity

with 'mutually-andapriorising/axiomatising/referencing-conceptualisation' inducing the very creative dynamics for human sublimating-over-desublimating social-and-institutional-constructs-ofmeaningfulness-and-teleology ${ }^{9}$ - in-cumulation/recomposuring as to human-subpotency potential for social formation, modes-of-living, language-as-of-dialogical-equivalence- $<$ as-topsychologismic apriorising/axiomatising/referencing-\{of-'prospectively implicited_attendant-ontological-contiguity ' educedexistentialising/contextmalising/textualising_intelligibility/epistemicity/reflexivity_contiguity$<$ imbued-notional $\left.\sim \operatorname{cogency}>^{\prime},\right\}$-conflatedness -in-\{preconverging-ment by\} postconverging-entailment,-in-self-becoming/self-conflatedness /formative-supererogating>, cultural practices etc., as such 'instigative/prompting ontological-good-faith/authenticity ${ }^{69}$ or ontological-bad-faith/inauthenticity ${ }^{64}$ apriorising/axiomatising/referencing-conceptualisation' ontologically precede and define the possibility for the creative dynamics of human sublimatingover-desublimating social-and-institutional-constructs-of- ${ }^{5}$ meaningfulness-and-teleology in-cumulation/recomposuring as to human-subpotency potential for social formation, modes-ofliving, language-as-of-dialogical-equivalence- $<$ as-to-

\section{psychologismic apriorising/axiomatising/referencing-\{of-"prospectively}

implicited_attendant-ontological-contiguity ' reduced-

existentialising/contextrising/textralising_intelligibility/epistemicity/reflexivity-contiguity$<$ imbued-notional cogency $>$ ' $\}$-conflatedness -in-\{preconverging-ment by\} 
cultural practices, etc. (as of the historial selectivity/deselectivity of underdetermined human social constructs, conceptualisations and theories as to existence constrained transcendence-andsublimity/sublimation/supererogatory $\sim$ de-mentativity as knowledge-reification $\sim$ gesturing-andaccounting - of-epistemic-phenomenalism- $<$ in-

prospective_psychologismic apriorising/axiomatising/referencing-\{of-'prospectively_ implicited_attendant-ontological-contiguity ' educedexistentialising/contextualising/textualising_intelligibility/epistemicity/reflexivity_contiguity$<$ imbued-notional cogency >' \}-conflatedness -in-\{preconverging-ment by\} postconverging-entailment $>$ and human registry-worldview's/dimension's institutionalisation in a foregrounding_entailment- $<$ in-succession-of-profound-supererogation 〈postconverging-narrowing-down sublimation-as-to-'existence-as-sublimatingwithdrawal/unenframing/re-ontologising,-elicited-from-prospective-profoundsupererogation '-in-reflecting-'immanent relative-unreflexivity/relative-reflexivity ontological-contiguity ';--as-operative-notional deprocrypticism) dynamics of the human reference-of-thought, as from recurrent-utter-uninstitutionalisation non-rulesapriorising/axiomatising/referencing-psychologism, base-institutionalisationununiversalisation apriorising/axiomatising/referencing-psychologism, rulemaking-over-nonrules- ${ }^{103}$ universalisation-non-positivism/medievalism $\quad{ }^{103}$ universalisation-directedrulemaking-over-non-rules_ - apriorising/axiomatising/referencing-psychologism, positivismprocrypticism positivising/rational-empiricism-based-universalisation-directed-rulemakingover-non-rules - apriorising/axiomatising/referencing-psychologism, and prospectively notional ${ }^{1}$ deprocrypticism preempting - disjointedness-as-of- ${ }^{2}$ reference-of-thought,-as-to، ${ }^{3}<$ amplituding/formative-epistemicity $>$ growth-or-conflatedness $13 /$ transvaluativerationalising/transepistemicity/anamnestic-residuality/spirit-drivenness'_in-supersedingmere-formulaic-positivising/rational-empiricism-based-universalisation-directed-rulemaking- 
over-non-rules_-apriorising/axiomatising/referencing-psychologism, while excluding disparateness-of-conceptualisation-<unforegrounding-ment,-failing-prospectively-to-reflect‘immanent relative-unreflexivity/relative-reflexivity - ontological-contiguity '>). It can be appreciated that without perceived reciprocity out of ontological-good-faith/authenticity ${ }^{69}$, as to the disseminative - sublimating-selectivity-of-ontological-goodfaith/authenticity postconverging-de-mentating/structuring/paradigming , over desublimating deselectivity-of-ontological-bad-faith/inauthenticity opreconverging dementating/structuring/paradigming, an ontologically natural and mutually consenting underlying framework of human sublimating-over-desublimating social-and-institutionalconstructs-of- ${ }^{5}$ meaningfulness-and-teleology -in-cumulation/recomposuring is not sustainable but for where any such party is of 'overall-survival constrained to the perceived ontological-bad-faith/inauthenticity ${ }^{64}$ of the other party' as with respect to say contexts of ingrained social subjugation, enslavement, etc.; and in-the-bigger-scheme-of-things the possibility for sustaining any human sublimating-over-desublimating social-and-institutionalconstructs-of- ${ }^{5}$ meaningfulness-and-teleology -in-cumulation/recomposuring lies with the 'totalitative implications as to the pre-eminence of ontological-good-faith/authenticity ${ }^{6}$ in the dynamics of ontological-good-faith/authenticity - by —ontological-bad-faith/inauthenticity perception by all parties involved' as so-perceived by the parties rather as of 'prospectively projected relative-ontological-completeness ${ }^{87}$ dimensionality-of-sublimating ${ }^{25}$ <<amplituding/formative >supererogatory $\sim$ de-mentativeness/epistemic-growth-orconflatedness /transvaluative-rationalising/transepistemicity/anamnestic-residuality/spiritdrivenness-equalisation)'. This human-subpotency 'fatedness-of-sublimation-overdesublimation, to existence-potency $\sim$ sublimating-nascence,-disclosed-from-prospectiveepistemic-digression (in reflecting holographically-<conjugatively-and-transfusively $>$ the relative-unreflexivity/relative-reflexivity - ontological-contiguity of-the-human- 
institutionalisation-process ), as from human-subpotency ontological-faith-notion-orontological-fideism - imbued-underdetermination-of-motif-and-

apriorising/axiomatising/referencing-as-so-being-as-of-existential-reality as to the disseminative - sublimating-selectivity-of-ontological-good-

faith/authenticity postconverging-de-mentating/structuring/paradigming , overdesublimating-deselectivity-of-ontological-bad-faith/inauthenticity -preconverging dementating/structuring/paradigming ', is the instigative driver of human social relationships for clanic formations and breakups associated with early human migratory dynamics together with their institutional formations and breakups/diversification as to human-subpotency potential for social formation, modes-of-living, language-as-of-dialogical-equivalence- $<$ as-topsychologismic apriorising/axiomatising/referencing-\{of-"prospectively implicited_attendant-ontological-contiguity ' educedexistentialising/contextualising/textualising_ intelligibility/epistemicity/reflexivity-contiguity$<$ imbued-notional cogency $>$ ' \}-conflatedness - in-\{preconverging ment by\} postconverging-entailment,-in-self-becoming/self-conflatedness /formative-supererogating>, cultural practices, etc. This insight further points out that the central deterministic argument made as from 'human social-vestedness/normativity-<discretely-implied-functionalism> implied contract/political-arrangement-or-political-coercion/given-discrete-social-valueconstruction' conceptualisation perspective (in ${ }^{79}$ presencing-absolutising-identitiveconstitutedness ${ }^{14} /$ constitutedness $^{14}$ of apriorising/axiomatising/referencing-conceptualisation) as underlying justification for the sustainability of human sublimating-over-desublimating social-and-institutional-constructs-of- ${ }^{5}$ meaningfulness-and-teleology ${ }^{99}$-incumulation/recomposuring is actually of shallow <emplituding/formativeepistemicity $>$ totalising $\sim$ self-referencing-syncretising/circularity/interiorising/akrasiatic-drag in relative-ontological-incompleteness ${ }^{8}$, as human-subpotency 'fatedness-of-sublimation-over- 
desublimation, to existence-potency sublimating-nascence,-disclosed-from-prospectiveepistemic-digression (in reflecting holographically-<conjugatively-and-transfusively $>$ the relative-unreflexivity/relative-reflexivity - ontological-contiguity of-the-humaninstitutionalisation-process ), as from human-subpotency ontological-faith-notion-orontological-fideism - imbued-underdetermination-of-motif-andapriorising/axiomatising/referencing-as-so-being-as-of-existential-reality as to the disseminative - sublimating-selectivity-of-ontological-goodfaith/authenticity postconverging-de-mentating/structuring/paradigming , over desublimating deselectivity-of-ontological-bad-faith/inauthenticity -preconverging dementating/structuring/paradigming, rather inherently implies that the true underlying justification for the sustainability of human sublimating-over-desublimating social-andinstitutional-constructs-of- ${ }^{56}$ meaningfulness-and-teleology ${ }^{9}$-in-cumulation/recomposuring lies with 'prospectively projected relative-ontological-completeness 87 dimensionality-ofsublimating 25 -<<amplituding/formative $>$ supererogatory $\sim$ de-mentativeness/epistemic-growthor-conflatedness /transvaluative-rationalising/transepistemicity/anamnestic-residuality/spiritdrivenness-equalisation $\rangle^{\prime}$ as to the inherent transcendence-andsublimity/sublimation/supererogatory de-mentativity implications with respect to human dispensing-with-immediacy-for-relative-ontological-completeness ${ }^{87}$-byreification/contemplative-distension ${ }^{27}$ (and this effectively explains everything in relativeunreflexivity/relative-reflexivity - ontological-contiguity ${ }^{77}$ and notional-contiguity/epistemiccontiguity ${ }^{62}<$ profound-supererogation -of-mentally-aestheticised $\sim$ postconverging/dialecticalthinking -qualia-schema $>$ and so in reflecting holographically-<conjugatively-andtransfusively $>$ the relative-unreflexivity/relative-reflexivity ontological-contiguity $\sim$ of-thehuman-institutionalisation-process as from relative-ontological-incompleteness ${ }^{88}$ to prospective relative-ontological-completeness ${ }^{87}$ as there is nothing left to be explained about the 
human-subpotency phenomena, unlike the notional-discontiguity/epistemic-discontiguity ${ }^{3}$ $<$ between - prior-shallow-supererogation -of-mentallyaestheticised preconverging/dementing -qualia-schema_and_prospective-profoundsupererogation -of-mentally-aestheticised postconverging/dialectical-thinking -qualiaschema $>$ discretionariness perspective of 'human social-vestedness/normativity- $<$ discretelyimplied-functionalism> implied contract/political-arrangement-or-political-coercion/givendiscrete-social-value-construction'); as we can appreciate that the very possibility for prior successive and prospective human emancipation paradoxically lies in superseding any such 'human social-vestedness/normativity-<discretely-implied-functionalism $>\quad$ implied contract/political-arrangement-or-political-coercion/given-discrete-social-value-construction' $<$ amplituding/formative-epistemicity $>$ totalising $\sim$ self-referencingsyncretising/circularity/interiorising/akrasiatic-drag ${ }^{34} \quad{ }^{79}$ presencing-absolutising-identitiveconstitutedness ${ }^{1 /} /$ constitutedness $^{14}$ of apriorising/axiomatising/referencing-conceptualisation perspective in relative-ontological-incompleteness ${ }^{88}$ as underlying justification for the sustainability of human sublimating-over-desublimating social-and-institutional-constructs-ofmeaningfulness-and-teleology - in-cumulation/recomposuring (as it rather becomes prospectively from the relative-ontological-completeness ${ }^{87}$ perspective a $<$ amplituding/formative $>$ wooden-language-〈imbued-temporal-mereform/virtualities/dereification/akrasiatic-drag/denatured/preconverging-or-dementing narratives - of-the- reference-of-thought- categorical-imperatives/axioms/registryteleology >, beyond-the-consciousness-awareness-teleology ${ }^{0}<$ of-preconverging-existentialextrication-as-of-existential-unthought $>$ ). This point out that just as prior registryworldviews/dimensions specific human-subpotency with regards to overall reifying-andempowering-reflexivity-of-ecstatic-existence-as-panintelligibility/panreflexivity ${ }^{73}$ 
totalising thermeneutically/textually/reprojectingly/supererogatingly/zeroingly/re-acutingly,-

$\{$ decompulsing $\}$ delinearity $\sim$ for-cogency $\geq$-epistemic-perspective-of-projective/reprojective-

aestheticising-re-motif-and-re-apriorising/re-axiomatising/re-referencing conceptualisation,-

as herein-specifically relevant to human-subpotency) rather implied their corresponding human-subpotency ontological-performance ${ }^{2}-<$ including-virtue-asontology $>$ /morality/ethics/justice/etc. transcendental-enabling/sublimating/supereregatory $\sim$ dementativity notional $\sim$ reflexivity- $<$ \{veridical/sound $\}$-relative-reflexivity-inexistence/relativising from-limited-mentation-as-its-deepening/psychologismic<residualising ${ }^{\text {\{decompulsing }}$ \}elinearity for-cogency $>$ by-\{flawed/unsound $\}$-relativeunreflexivity-in-existencelabsolutising from-limited-mentation/psychologismic epistemicacutisation nonresidualising-imbued-\{compulsing\} linearity-in-eclecticism-of-prior-mereformulaicity/ritualisation> in ecstatic-existence, this ontological-normalcy/postconvergence $<$ amplituding/formative-epistemicity $>$ causality $\sim$ as-to-projective-totalitative-implications-ofprospective- nonpresencing,-for-explicating relative-unreflexivity/relative-reflexivity ontological-contiguity as of its prospective relative-ontological-completeness ${ }^{87}$ equally implies its correspondingly more profound human-subpotency ontological-performance ${ }^{72}<$ includingvirtue-as-ontology $>/$ morality/ethics/justice/etc. transcendentalenabling/sublimating/supererogatory $\sim$ de-mentativity notional $\sim$ reflexivity $-<$ \{veridical/sound\} relative-reflexivity-in-existence/relativising from-limited-mentation-as-itsdeepening/psychologismic $<$ residualising \{decomsing\} delinearity for-cogency $>$ by\{flawed/unsound\}-relative-unreflexivity-in-existence/absolutising from-limitedmentation/psychologismic epistemic acutisation nonresidualising imbued\{compulsing\} linearity in-eclecticism-of-prior-mere-formulaicity/ritualisation $>$ in ecstatic-existence with regards to the prospective ontological-veracity of deprocrypticism-or-preemptingdisjointedness-as-of- ${ }^{8}$ reference-of-thought re-originariness/re-origination construction-of-the- 
Self ${ }^{56}$ meaningfulness-and-teleology ${ }^{9}$ as to its psychoanalytic-unshackling/memeticreordering/institutional-recomposuring projection of prospective postconverging/dialecticalthinking ${ }^{2}$-qualia-schema (over our ${ }^{7}$ presencing - absolutising-identitive-constitutedness ${ }^{14}$ as procrypticism-or-disjointedness-as-of- ${ }^{8}$ reference-of-thought preconverging/dementing 2 qualia-schema). Critically, from the notional ${ }^{8}$ deprocrypticism/notional preemptingdisjointedness-as-of- ${ }^{8}$ reference-of-thought epistemic-or-notional projective-perspective ontological-normalcy/postconvergence (beyond any relative-ontological-incompleteness given registry-worldview/dimension $\quad<$ amplituding/formative-epistemicity $>$ totalising $\sim$ selfreferencing-syncretising/circularity/interiorising/akrasiatic-drag ${ }^{34}$, which basically 'projects a unified referencing construal of meaningfulness-and-teleology ${ }^{59}$ as of postconverging/dialectical-thinking -qualia-schema' wrongly implying an 'absolute-coherentrationalising-framework of ${ }^{5}$ meaningfulness-and-teleology" that fails to reflect from the prospective relative-ontological-completeness ${ }^{87}$ perspective its preconverging/dementing 20 qualia-schema), the projection of an 'absolute-coherent-rationalising-framework of meaningfulness-and-teleology ${ }^{9}$ is actually of unreal ontological-veracity as to the effective temporal ontological-performance ${ }^{72}-<$ including-virtue-as-ontology $>/$ morality/ethics/justice/etc. at any given registry-worldview's/dimension's uninstitutionalised-threshold ${ }^{102}$. The reality at any such uninstitutionalised-threshold ${ }^{102}$ is rather one of 'dynamically-convergent-rationalisingframeworks of ${ }^{56}$ meaningfulness-and-teleology ${ }^{9}$ of differing ontological-performance ${ }^{72}$ <including-virtue-as-ontology $>$ /morality/ethics/justice/etc. implications' hence defining both the given institutionalisation/constructiveness-of-ontological-performance ${ }^{2}-<$ including-virtueas-ontology $>$ /morality/ethics/justice/etc. and its destructuring-threshold-〈uninstitutionalisedthreshold /presublimating-desublimating-decisionality $>$ of-ontological-performance ${ }^{72}$ $<$ including-virtue-as-ontology>. This effectively 'dynamically-convergent-rationalisingframeworks of ${ }^{56}$ meaningfulness-and-teleology ${ }^{9}$ of differing ontological-performance ${ }^{72}$ 
$<$ including-virtue-as-ontology $>/$ morality/ethics/justice/etc. implications' reflects the fact that human ${ }^{56}$ meaningfulness-and-teleology ${ }^{9}$ operate along criss-crossing rationalising-frameworks: as of 'social-rationalisation-as-reproducibility - mathesis/motif/thrownness-disposition,--asreproducibility-of-aestheticisation construed as of token/emblematic absolute (and thus equally giving rise to the possibility of its temporality $/$ shortness articulation as $<$ amplituding/formative $>$ wooden-language-〈imbued-temporal-mere-

\section{form/virtualities/dereification/akrasiatic-drag/denatured/preconverging-or-dementing}

\section{narratives - of-the- reference-of-thought- categorical-imperatives/axioms/registry-}

teleology $\rangle^{\prime}$ as of its uninstitutionalised-threshold ${ }^{102}$ ) as defining the given registryworldview/dimension ${ }^{56}$ meaningfulness-and-teleology', and secondly the 'ordering-of-values within the scope of the social-rationalisation-as-reproducibility-mathesis/motif/thrownnessdisposition,-as-reproducibility-of-aestheticisation construed as of token/emblematic absolute', and thirdly 'dimensionality-of-sublimating ${ }^{25}-<$ amplituding/formative $>$ supererogatory $\sim$ dementativeness/epistemic-growth-or-conflatedness /transvaluative-

rationalising/transepistemicity/anamnestic-residuality/spirit-drivenness-equalisation $\rangle$ of the social-rationalisation-as-reproducibility—mathesis/motif/thrownness-disposition,-asreproducibility-of-aestheticisation'. These three criss-crossing rationalising-frameworks are parametrically reflected as of the "varying psychologismic epistemic-acutisation difficulty $<$ for, residualising \{decompulsing delinearity for-cogency> magnitudes $\{$ ofexperientiality/experiment /scales — as-to-successively-profound-preconverging/postconverging-redementating/restructuring/reparadigming-frames-as-from-living,-institutionalising,-and-Beingontologising/infrastructure-of- ${ }^{5}$ meaningfulness-and-teleology 9 of prospective humansubpotency-aporia/undecidability/dilemma/ought-

indeterminacy/deficiency/limitation/constraint_imbued-'notional firstnaturedness- 
intemporal-dispositions-<so-construed-as-from-perspective-ontological-

normalcy/postconvergence>'-existentialism-form-factor'. This theoretical elucidation is critical from the notional $\sim$ deprocrypticism/notional preempting-disjointedness-as-of- ${ }^{8}$ referenceof-thought ontological-normalcy/postconvergence epistemic-or-notional projective-perspective of dispensing-with-immediacy-for-relative-ontological-completeness ${ }^{87}$-byreification/contemplative-distension ${ }^{27}$, in properly garnering the requisite ontologicalveracity/insight as to prospective notional ${ }^{1}$ deprocrypticism re-originariness/re-origination construction-of-the-Self as of its implied psychoanalytic-unshackling/memeticreordering/institutional-recomposuring exercise of dimensionality-of-sublimating <<amplituding/formative>supererogatory de-mentativeness/epistemic-growth-orconflatedness /transvaluative-rationalising/transepistemicity/anamnestic-residuality/spiritdrivenness-equalisation) reasoning-through/messianic-reasoning; to further broaden-thelatitude-of-human-collective-consciousness; beyond the procrypticism-or-disjointedness-asof- ${ }^{-3}$ reference-of-thought 'gimmickiness of consciousness' (as to the blanking and passivity associated with its <amplituding/formative> wooden-language-_imbued-temporal-mere-

\section{form/virtualities/dereification/akrasiatic-drag/denatured/preconverging-or-dementing}

\section{narratives - of-the- reference-of-thought- categorical-imperatives/axioms/registry-}

teleology $\rangle)$ to the requisite prospective ${ }^{18}$ deprocrypticism-or-preempting-disjointedness-asof- reference-of-thought 'sublimation of consciousness', as the latter's protensive-selfconsciousness prospectively overcome human relatively-shallow-frame-of-elicited-positiveopportunism-of-social-functioning-and-accordance ${ }^{75}$-of-low-intrinsic-attribution-and-highextrinsic-attribution-susceptibility,-in-dimensionality-of-desublimating-lack-of ${ }^{6}$ <<amplituding/formative >supererogatory $\sim$ de-mentativeness/epistemic-growth-orconflatedness /transvaluative-rationalising/transepistemicity/anamnestic-residuality/spiritdrivenness-equalisation $\rangle$. This disambiguation of relative-unreflexivity/relative-reflexivity- 
ontological-contiguity ${ }^{67}$ of-the-human-institutionalisation-process ${ }^{68}$ 'dynamically-convergentrationalising-frameworks of ${ }^{5}$ meaningfulness-and-teleology ${ }^{9}$ of differing ontologicalperformance $^{72}$-<including-virtue-as-ontology $>$ /morality/ethics/justice/etc. implications' speaks to the fact that, as from the ontological-normalcy/postconvergence epistemic-ornotional projective-perspective, the ontological-performance ${ }^{72}-<_{\text {including-virtue-as- }}$ ontology $>/$ morality/ethics/justice/etc. of human notional firstnaturedness-formativeness-<asto-eventualising inkling drive-or-seeding misprising $>$ temporal-to-intemporal-dispositions$<$ so-construed-as-from-perspective-ontological-normalcy/postconvergence $>$ (rather operantly construable as temporal-to-intemporal individuations) reflect a 'formative underlying human decoherencing-structure- of- ${ }^{56}$ meaningfulness-and-teleology ${ }^{9}$-for-institutionalisation' in reflecting holographically-<conjugatively-and-transfusively $>$ the relative-unreflexivity/relativereflexivity - ontological-contiguity $\sim$ of-the-human-institutionalisation-process . The 'imaginary of deprocrypticism-or-preempting_disjointedness-as-of- reference-of-thought' is a projection towards the prospective sublimating ${ }^{4}$ historiality/ontologicaleventfulness ${ }^{38}$ /ontological-aesthetic-tracing-<perspective-ontologicalnormalcy/postconvergence-reflected-'epistemicity-relativism-determinism'> bound to overcome our positivism- ${ }^{80}$ procrypticism desublimating ${ }^{47}$ historicity-tracing-in-presencinghyperrealisation/hyperreal-transposition imbued psychological entrapment, as to the potential for a full human psychological uninhibitedness/decomplexification in superseding the 'formative underlying human decoherencing-structure- of- ${ }^{5}$ meaningfulness-and-teleology ${ }^{9}$-forinstitutionalisation' as to its hitherto recurrent instigation of human relatively-shallow-frame-ofelicited-positive-opportunism-of-social-functioning-and-accordance ${ }^{75}$-of-low-intrinsicattribution-and-high-extrinsic-attribution-susceptibility,-in-dimensionality-of-desublimatinglack-of $-<<$ amplituding/formative $>$ supererogatory $\sim$ de-mentativeness/epistemic-growth-orconflatedness /transvaluative-rationalising/transepistemicity/anamnestic-residuality/spirit- 
drivenness-equalisation $\rangle. \quad$ Desublimating $\quad{ }^{47}$ historicity-tracing-in-presencinghyperrealisation/hyperreal-transposition imbued psychological entrapment arises inherently because of the taxingness-of-originariness as to the fact that: what has gone before aesthetically structures/paradigms distortedly the possibility for the later aestheticisation, with regards to human limited-mentation-capacity-deepening as subjecting limitednesshman-subpen to-'educed-unlimitedness/existence-sublimating nascence's3 as of its decoherencingstructure - of- ${ }^{56}$ meaningfulness-and-teleology ${ }^{9}$-for-institutionalisation. But then existence is not beholden to any such 'human reproducibility—mathesis/motif/thrownness-disposition,--asreproducibility-of-aestheticisation (lacking \{epistemic-totalising $3{ }^{3}$ re-apriorising/re-axiomatising/rereferencing $\sim$ residuality —in-re-originariness/re-origination- $\langle$ as to human profoundsupererogation for prospective apriorising/axiomatising/referencing-\{of-'prospectively implicited_attendant-ontological-contiguity ' educedexistentialising/contextualising/textualising_ intelligibility/epistemicity/reflexivity-contiguity<imbued-notional cogency>' \}-conflatedness -in-\{preconverging-ment by\} postconverging-entailment that cannot be unshrouded by prior mere-formulaicity/ritualisation<as-to-mere-formulaic — methodologising/mutualising/organising/institutionalising,prospectively-losing-track-of-`‘fepistemic-totalising 斿e-apriorising/re-axiomatising/rereferencing $\sim$ residuality_in-re-originariness/re-origination'> of prior apriorising/axiomatising/referencing-\{of-'prospectively_implicited_attendant-ontologicalcontiguity ' educedexistentialising/contextualising/textualising_'intelligibility/epistemicity/reflexivity-contiguity<imbued-notional cogency>' $\}$-constitutedness -in-preconverging-entailment $\rangle){ }^{\prime} \quad$ that induces human decoherencing-structure-of- meaningfulness-and-teleology ${ }^{9}$-forinstitutionalisation stifling/stalling of the full possibility of prospective ${ }^{4}$ historiality/ontologicaleventfulness 3 /ontological-aesthetic-tracing-<perspective-ontological- 
normalcy/postconvergence-reflected-'epistemicity-relativism-determinism'>. Desublimating historicity-tracing - in-presencing-hyperrealisation/hyperreal-transposition aestheticisationand-aestheticisation-towards-ontology-<elicited-idiomatisation $>$ decoherencing-structureof- ${ }^{5}$ meaningfulness-and-teleology 9 -for-institutionalisation (as construed from the prospective notional ${ }^{1}$ deprocrypticism ontological-normalcy/postconvergence epistemic-ornotional projective-perspective) can be reflected with respect to the very supposedly most enlightening-giving notion of philosophy as to its decoherencing-structure-ofmeaningfulness-and-teleology ${ }^{9}$-for-institutionalisation (as from the ontologicalnormalcy/postconvergence epistemic-or-notional projective-perspective) from human philosophy, to varying philosophies as of African, Oriental, European, Arab, etc. as to desublimating $\quad{ }^{47}$ historicity-tracing-in-presencing-hyperrealisation/hyperreal-transposition psychological entrapment that ultimately denatures the ${ }^{4}$ historiality/ontologicaleventfulness 3 /ontological-aesthetic-tracing-<perspective-ontological-

normalcy/postconvergence-reflected-'epistemicity-relativism-determinism'> purity of the very notion of philosophy. This patent elucidation of the decoherencing-structure-ofmeaningfulness-and-teleology ${ }^{9}$-for-institutionalisation as to such a supposedly most abstract and enlightening-giving notion that is philosophy is a basic insight (as construed from the ontological-normalcy/postconvergence epistemic-or-notional projective-perspective) of desublimating $\quad{ }^{4}$ historicity-tracing-in-presencing-hyperrealisation/hyperreal-transposition psychological entrapment with respect to the overall prospective sublimating historiality/ontological-eventfulness ${ }^{38} /$ ontological-aesthetic-tracing-<perspective-

\section{ontological-normalcy/postconvergence-reflected-‘epistemicity-relativism-determinism'>}

(which preconverging/postconverging-de-mentatively/structurally/paradigmatically seems to be entrapped/stifled in human taxingness-of-originariness). Effectively, human decoherencingstructure- of- ${ }^{5}$ meaningfulness-and-teleology 9 -for-institutionalisation arises as of 'taxingness- 
of-originariness (what has gone before aesthetically structures/paradigms distortedly the possibility for the later aestheticisation). The idea of superseding the human registryworldview's/dimension's institutionalisation decoherencing-structure- of- ${ }^{56}$ meaningfulnessand-teleology ${ }^{9}$-for-institutionalisation (as to 'abstractly projected finality in reflecting holographically-<conjugatively-and-transfusively $>$ the relative-unreflexivity/relativereflexivity ontological-contiguity of-the-human-institutionalisation-process ') for prospective sublimating historiality/ontological-eventfulness $\%$ ontological-aesthetic-tracing$<$ perspective-ontological-normalcy/postconvergence-reflected-'epistemicity-relativismdeterminism'>, patently makes obvious what the true implications of prospective deprocrypticism-or-preempting-disjointedness-as-of- ${ }^{83}$ reference-of-thought project with respect to its dispensing-with-immediacy-for-relative-ontological-completeness ${ }^{87}$-byreification/contemplative-distension ${ }^{27}$ re-originariness/re-origination conceptualisation in relation to our present positivism- ${ }^{80}$ procrypticism aestheticisation-and-aestheticisationtowards-ontology-<elicited-idiomatisation $>$ as ${ }^{56}$ meaningfulness-and-teleology ${ }^{9}$. This is

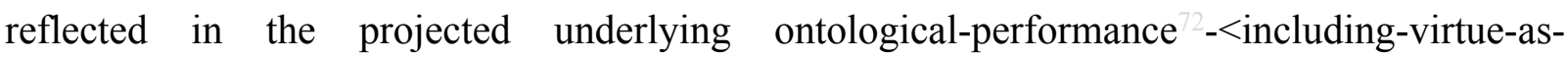
ontology $>$ /morality/ethics/justice/etc. divergent relation between ${ }^{47}$ historicity-tracing-inpresencing-hyperrealisation/hyperreal-transposition (as constrained to human taxingness-oforiginariness as to: what has gone before aesthetically structures/paradigms distortedly the possibility for the later aestheticisation) and prospective ${ }^{4}$ historiality/ontologicaleventfulness ${ }^{38}$ /ontological-aesthetic-tracing-<perspective-ontologicalnormalcy/postconvergence-reflected-'epistemicity-relativism-determinism'>. $\quad{ }^{47}$ historicitytracing-in-presencing-hyperrealisation/hyperreal-transposition as implied at all uninstitutionalised-threshold ${ }^{102}$ is what underlies the notionally-collateralising inclination of human ${ }^{56}$ meaningfulness-and-teleology as of any given registry-worldview/dimension in relative-ontological-incompleteness ${ }^{8}$; speaking in reflecting holographically-<conjugatively- 
and-transfusively $>$ the relative-unreflexivity/relative-reflexivity-ontological-contiguity ofthe-human-institutionalisation-process as an 'overall human aestheticisation-andaestheticisation-towards-ontology-<elicited-idiomatisation $>$ originariness-by-reproducibilityladdering effect' for corresponding human consciousness sublimation. But then the implication of deprocrypticism-or-preempting-disjointedness-as-of- ${ }^{18}$ reference-of-thought as supposedly superseding human relatively-shallow-frame-of-elicited-positive-opportunism—ofsocial-functioning-and-accordance ${ }^{75}$-of-low-intrinsic-attribution-and-high-extrinsic-attributionsusceptibility,-in-dimensionality-of-desublimating-lack-of ${ }^{6}$ <<amplituding/formative>supererogatory $\sim$ de-mentativeness/epistemic-growth-orconflatedness /transvaluative-rationalising/transepistemicity/anamnestic-residuality/spiritdrivenness-equalisation>, as to its 'aspiring pureness of re-originariness/re-origination', is effectively a 'reconstrual in reflecting holographically-<conjugatively-and-transfusively $>$ the relative-unreflexivity/relative-reflexivity — ontological-contiguity $\sim$ of-the-humaninstitutionalisation-process as to the obviating of its decoherencing-structure-ofmeaningfulness-and-teleology ${ }^{9}$-for-institutionalisation induced ${ }^{4}$ historicity-tracing-inpresencing-hyperrealisation/hyperreal-transposition (beyond the implications of taxingness-oforiginariness as to: what has gone before aesthetically structures/paradigms distortedly the possibility for the later aestheticisation)'; such that the notional ${ }^{18}$ deprocrypticism potential is a 'wholly other of historicity-tracing-in-presencing-hyperrealisation/hyperreal-transposition' as to the implications of its re-originariness/re-origination for prospective historiality/ontological-eventfulness 38 ontological-aesthetic-tracing-<perspectiveontological-normalcy/postconvergence-reflected-‘epistemicity-relativism-determinism’> beyond foregone aestheticisation-and-aestheticisation-towards-ontology-<elicitedidiomatisation $>$ in reflecting holographically-<conjugatively-and-transfusively $>$ the relativeunreflexivity/relative-reflexivity - ontological-contiguity of-the-human-institutionalisation- 
process (in truly reflecting the 'full human-subpotency potentiation' as to the most profound human capacity for dispensing-with-immediacy-for-relative-ontological-completeness ${ }^{87}$-byreification/contemplative-distension ${ }^{27}$ ). Its defining question is whether and how can the human reconstrue ${ }^{56}$ meaningfulness-and-teleology ${ }^{9}$ in re-originariness/re-origination beyond its trailing/dragging foregone aestheticised ${ }^{56}$ meaningfulness-and-teleology ${ }^{9}$ construal? This limitativeness of ${ }^{4}$ historicity-tracing-in-presencing-hyperrealisation/hyperreal-transposition is fundamentally an issue of human psychological entrapment 'defining naiveties and complexes' as to human shiftiness-of-the-Self as of its ${ }^{79}$ presencing - absolutising-identitiveconstitutedness $^{14}$ (construable abstractly as fundamentally subpar to human effectuation potential but for the fact that the psychological entrapment is a paradoxical circular constituent of the human as to its 'notional collateralising-beholdening-protohumanity by sublimatinghumanity existentialism-form-factor'). Human ${ }^{79}$ presencing-absolutising-identitiveconstitutedness $^{14}$ as the very seeding disposition for ${ }^{47}$ historicity-tracing-in-presencinghyperrealisation/hyperreal-transposition is ever always characterised by its immediacy-reactivecriticality (over panoramic-sublimating-criticality) as to its constraining aestheticisation-andaestheticisation-towards-ontology-<elicited-idiomatisation $>$ framework; such that the propensity for human ${ }^{56}$ meaningfulness-and-teleology ${ }^{9}$ to be instigated (as to human limitedmentation-capacity-deepening —as-subjecting limitedness/human-subpotency-to-'educedunlimitedness/existence-sublimating nascence' 53 before any construable human panoramicsublimating-criticality outcome of ${ }^{56}$ meaningfulness-and-teleology ${ }^{9}$ ) has ever always been bound to take a 'notionally-collateralising inclination detour of aestheticisation-andaestheticisation-towards-ontology-<elicited-idiomatisation>' (as of the defining 'originariness-

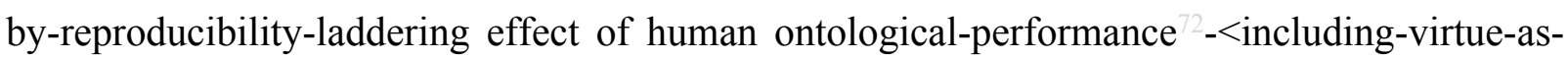
ontology>'), and so as of the 'varying psychologismic epistemic acutisation difficulty-for, residualising $\{$ decompulsing $\}$ delinearity for-cogency> magnitudes $\{$ of-experientiality/experiment $\} /$ scales_- 
as-to-successively-profound-preconverging/postconverging-rede-

mentating/restructuring/reparadigming-frames-as-from-living,-institutionalising,-and-Beingontologising/infrastructure-of- ${ }^{5}$ meaningfulness-and-teleology 9 of prospective humansubpotency-aporia/undecidability/dilemma/ought-

indeterminacy/deficiency/limitation/constraint—imbued-'notional firstnaturedness-

formativeness-<as-to-eventualising-inkling-drive or seeding-misprising $>$ temporal-to-

intemporal-dispositions-<so-construed-as-from-perspective-ontological-

normalcy/postconvergence>'-existentialism-form-factor' (with regards to human livingdevelopment-as-to-personality-development or institutional-development-as-to-socialfunction-development or Being-development/ontological-framework-expansion-as-to-depthof-ontologising-development-as-infrastructure-of- meaningfulness-and-teleology in reflecting holographically-<conjugatively-and-transfusively $>$ the relative-unreflexivity/relativereflexivity - ontological-contiguity of-the-human-institutionalisation-process

$<$ cumulating/recomposuring attendant-ontological-contiguity $>$-successive registryworldviews/dimensions). From the ontological-normalcy/postconvergence epistemic-ornotional projective-perspective (as to panoramic-sublimating-criticality), immediacy-reactivecriticality inherently implies human-subpotency induces discretionariness (and not relativeunreflexivity/relative-reflexivity - ontological-contiguity ${ }^{67}$ ) by its ${ }^{79}$ presencing-absolutisingidentitive-constitutedness ${ }^{14}$ that undermines the '<amplituding/formativeepistemicity>totalising/circumscribing/delineating 'implicited_attendant-ontologicalcontiguity $^{67}$, educed-

existentialising/contextualising/textualising_intelligibility/epistemicity/reflexivity-contiguity$<$ imbued-notional cogency $>{ }^{40} \quad{ }^{45}$ foregrounding_entailment- $<$ in-succession-of-profoundsupererogation $>$-〈postconverging-narrowing-down $\sim$ sublimation-as-to-'existence-assublimating-withdrawal/unenframing/re-ontologising,-elicited-from-prospective-profound- 
supererogation '-in-reflecting-'immanent relative-unreflexivity/relative-reflexivity

ontological-contiguity ';-as-operative-notional deprocrypticism) in elucidating relativeunreflexivity/relative-reflexivity - ontological-contiguity ${ }^{6}-<$ as-from-prospective-ontologicalnormalcy/postconvergence-epistemic-or-notional projective-perspective>' (inducing notionaldiscontiguity/epistemic-discontiguity ${ }^{6}-<$ between - prior-shallow-supererogation -ofmentally-aestheticised preconverging/dementing -qualia-schema_and_prospective-profoundsupererogation -of-mentally-aestheticised postconverging/dialectical-thinking -qualiaschema $>$ ). Thus as of ultimate human ${ }^{18}$ deprocrypticism-or-preempting-disjointedness-as-ofreference-of-thought ideality/imaginary-as-to-its-sublimation-beyond-prior-aestheticisation paradox: 'human originariness-by-reproducibility-laddering effect' underlying ${ }^{4}$ historicitytracing-in-presencing-hyperrealisation/hyperreal-transposition speaks to the 'succession of notional-discontiguity/epistemic-discontiguity ${ }^{6}<$ between - prior-shallow-supererogation -ofmentally-aestheticised preconverging/dementing -qualia-schema_and_prospective-profoundsupererogation -of-mentally-aestheticised postconverging/dialectical-thinking -qualiaschema $>$ of registry-worldviews/dimensions ${ }^{56}$ meaningfulness-and-teleology ${ }^{9}$, (so-construed from the ontological-normalcy/postconvergence epistemic-or-notional projective-perspective) rather as of their 'manifest outcomes/outfits/shells — construed-historially-as-of-the-specificallyaestheticised-incrusting/plating/coating,-so-reflected-as-institutional-manifestations of human meaningfulness-and-teleology ${ }^{9}$ towards the ultimately reflecting holographically$<$ conjugatively-and-transfusively $>$ the relative-unreflexivity/relative-reflexivity - ontologicalcontiguity $\sim$ of-the-human-institutionalisation-process notional-contiguity/epistemiccontiguity ${ }^{62}<$ profound-supererogation - of-mentally-aestheticised $\sim$ postconverging/dialecticalthinking -qualia-schema> and relative-unreflexivity/relative-reflexivity-ontologicalcontiguity $^{67}$ as of ontological-normalcy/postconvergence; however, prospective deprocrypticism-or-preempting-disjointedness-as-of- ${ }^{3}$ reference-of-thought 
historiality/ontological-eventfulness 38 ontological-aesthetic-tracing-<perspective-

ontological-normalcy/postconvergence-reflected-'epistemicity-relativism-determinism'>

about human re-orginariness/re-origination as of ontological-normalcy/postconvergence exclusively, as to its obviating of prior desublimating ${ }^{47}$ historicity-tracing-in-presencinghyperrealisation/hyperreal-transposition for prospective ${ }^{4}$ historiality/ontologicaleventfulness ${ }^{38} /$ ontological-aesthetic-tracing-<perspective-ontological-

normalcy/postconvergence-reflected-'epistemicity-relativism-determinism'> as unbeholdening to the 'successive notional discontiguities/epistemic-discontiguities-aspreconverging/dementing ${ }^{20}$-qualia-schema failing to achieve notional-contiguity/epistemiccontiguity ${ }^{62}<$ profound-supererogation - of-mentally-aestheticised postconverging/dialecticalthinking -qualia-schema> as to relative-unreflexivity/relative-reflexivity-ontologicalcontiguity $^{6}$, in reflecting holographically-<conjugatively-and-transfusively $>$ the relativeunreflexivity/relative-reflexivity - ontological-contiguity of-the-human-institutionalisationprocess (and so with regards to human living-development-as-to-personality-development or institutional-development-as-to-social-function-development or Beingdevelopment/ontological-framework-expansion-as-to-depth-of-ontologising-development-asinfrastructure-of- meaningfulness-and-teleology ). Such that, prospective ${ }^{18}$ deprocrypticismor-preempting - disjointedness-as-of- reference-of-thought (with respect to obviating of prior desublimating $\quad{ }^{4}$ historicity-tracing-in-presencing-hyperrealisation/hyperreal-transposition

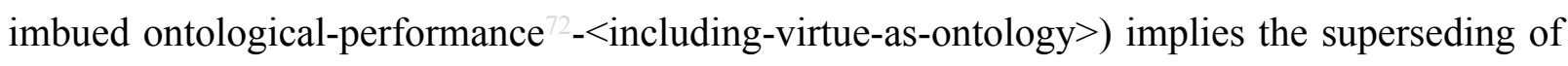
the ontological-veracity of such ${ }^{7}$ presencing-absolutising-identitive-constitutedness ${ }^{14}$ human sublimating-over-desublimating social-and-institutional-constructs-of- -5 meaningfulness-andteleology - in-cumulation/recomposuring (and so with regards to human living-developmentas-to-personality-development or institutional-development-as-to-social-function-development or Being-development/ontological-framework-expansion-as-to-depth-of-ontologising- 
development-as-infrastructure-of- meaningfulness-and-teleology ), as to the fact that these end up overtly or covertly drawing their inherent justification on the basis of their inherent prior aestheticisation-and-aestheticisation-towards-ontology-<elicited-idiomatisation $>$ as of human social-vestedness/normativity-<discretely-implied-functionalism $>$ rather than any relevant underlying supposedly coherent ontological-commitment $-<$ implied-self-assuredness-ofontological-good-faith/authenticity $\sim$ postconverging-de-

mentating/structuring/paradigming -as-being-as-of-existential-reality> as their socialvestedness/normativity-<discretely-implied-functionalism $>$ increasingly become dépassé (prospectively ontologically-invalid), thus rather stifling the requisite dispensing-withimmediacy-for-relative-ontological-completeness ${ }^{87}$-by-reification/contemplative-distension and thus marring prospective historicality/ontological-eventfulness 3 /ontological-aesthetictracing-<perspective-ontological-normalcy/postconvergence-reflected-‘epistemicityrelativism-determinism'>. Actually, the notion of hyperreality-as-to-its-simulacrum implications highlighted by postmodern-thought is more profoundly manifested in reflecting holographically-<conjugatively-and-transfusively $>$ the relative-unreflexivity/relativereflexivity - ontological-contiguity of-the-human-institutionalisation-process as to historicity-tracing - in-presencing-hyperrealisation/hyperreal-transposition implications with regards to 'prospective taxingness-of-originariness'. ${ }^{47}$ historicity-tracing-in-presencinghyperrealisation/hyperreal-transposition implications rather speaks of human limited-mentationcapacity -as-subjecting 'educed-unlimitedness/existence-sublimating nascence' tolimitedness/human-subpotency 'paradoxical prior epistemic reinfusion (as of prior notionaldiscontiguity/epistemic-discontiguity ${ }^{6}-<$ between - prior-shallow-supererogation -ofmentally-aestheticised preconverging/dementing -qualia-schema_and_prospective-profoundsupererogation -of-mentally-aestheticised postconverging/dialectical-thinking -qualiaschema>) into the supposed construal of prospective ontological-veracity-as-to-inherent 
relative-unreflexivity/relative-reflexivity - ontological-contiguity in the face of "manifest existence-potency ${ }^{32} \sim$ sublimating-nascence,-disclosed-from-prospective-epistemic-digression in epistemic apriorising/axiomatising/referencing-\{of-'prospectively implicited_attendantontological-contiguity ' educedexistentialising/contextualising/textualising_'intelligibility/epistemicity/reflexivity-contiguity-

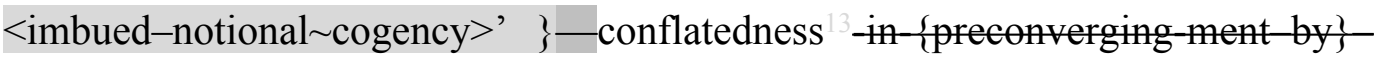
postconverging-entailment, rather veridically construable in the prospective apriorising/axiomatising/referencing transepistemicity (as of prospective notionalcontiguity/epistemic-contiguity ${ }^{2}<$ profound-supererogation -of-mentallyaestheticised postconverging/dialectical-thinking -qualia-schema $>$ )'. $\quad{ }^{4}$ historicity-tracingin-presencing-hyperrealisation/hyperreal-transposition as such actually reflects the preconverging/postconverging-de-mentative/structural/paradigmatic limitation of the given human registry-worldview's/dimension's epistemic-gesturing for the construal of ontologicalveracity-as-to-inherent relative-unreflexivity/relative-reflexivity-ontological-contiguity ${ }^{67}$ at its prospectively uninstitutionalised-threshold ${ }^{102}$; speaking of a state of notionaldiscontiguity/epistemic-discontiguity ${ }^{63}-<$ between - prior-shallow-supererogation -ofmentally-aestheticised preconverging/dementing -qualia-schema_and_prospective-profoundsupererogation -of-mentally-aestheticised postconverging/dialectical-thinking -qualiaschema $>$ in relative-ontological-incompleteness ${ }^{8}$ in relation to the now prospective notionalcontiguity/epistemic-contiguity ${ }^{2}<$ profound-supererogation -of-mentallyaestheticised postconverging/dialectical-thinking -qualia-schema $>$ of the relative-ontologicalcompleteness $^{87}$, as from the ontological-normalcy/postconvergence epistemic-ornotional projective-perspective. $\quad$ Effectively, $\quad{ }^{47}$ historicity-tracing-in-presencinghyperrealisation/hyperreal-transposition as of its implied contrastive apriorising/axiomatising/referencing-psychologism of (relative-ontological-incompleteness ${ }^{88}$ of 
notional-discontiguity/epistemic-discontiguity ${ }^{6}<$ between - prior-shallow-supererogation -ofmentally-aestheticised preconverging/dementing -qualia-schema_and_prospective-profoundsupererogation -of-mentally-aestheticised postconverging/dialectical-thinking -qualia-

schema $>$ ) and apriorising/axiomatising/referencing-psychologism of (relative-ontologicalcompleteness $^{87}$ in prospective notional-contiguity/epistemic-contiguity ${ }^{62}-<$ profoundsupererogation -of-mentally-aestheticised postconverging/dialectical-thinking -qualia-

schema>), can be reflected historially with respect to say an ingrained traditional nonpositivism/medievalism conceptualisation of the world' incapable/could-not-bring-itself to mentally process the implications of planets shown with a telescope to be rather going around the sun in a nascent positivism/rational-empiricism attitude/mental-disposition/care-andepisteme implied by Galileo and further conceptually articulated by Descartes' thinking proposition as to its mathesis ${ }^{103}$ universalis implications, such that it is as of a crossgenerational transformation/supererogatory $\sim$ de-mentativeness that humankind develops the positivism/rational-empiricism apriorising/axiomatising/referencing-psychologism (as of psychoanalytic-unshackling/memetic-reordering/institutional-recomposuring) to grasp the full preconverging/postconverging-de-mentative/structural/paradigmatic implications of positivism/rational-empiricism as from the initial non-positivism/medievalism ${ }^{4}$ historicitytracing-in-presencing-hyperrealisation/hyperreal-transposition with regards to the prospect of positivism/rational-empiricism aestheticisation-and-aestheticisation-towards-ontology$<$ elicited-idiomatisation $>$ as ${ }^{56}$ meaningfulness-and-teleology . Likewise, this insight can be extended in reflecting the ${ }^{4}$ historicity-tracing-in-presencing-hyperrealisation/hyperrealtransposition of an 'ingrained traditional non-universalising conceptualisation of the world' incapable/could-not-bring-itself to mentally process the implications of the nascent universalising-idealisation attitude/mental-disposition/care-and-episteme implied by the Socratic-philosophers as to its apriorising/axiomatising/referencing-psychologism (as of 
psychoanalytic-unshackling/memetic-reordering/institutional-recomposuring) induced crossgenerational transformation. In both instances it speaks to an underlying apriorising/axiomatising/referencing-psychologism 'wanting of human consciousness sublimation' to effectively come to terms with 'manifest existence-potency ${ }^{39} \sim$ sublimatingnascence,-disclosed-from-prospective-epistemic-digression in epistemic apriorising/axiomatising/referencing-\{of-'prospectively implicited_attendant-ontologicalcontiguity ' educedexistentialising/contextualising/textualising_'intelligibility/epistemicity/reflexivity-contiguity$<$ imbued-notional cogency $\left.>^{\prime}\right\}$ - conflatedness ${ }^{13}$-in-\{preconverging $m e n t$ by $\}$ postconverging-entailment ', thus inducing its notional-discontiguity/epistemic-discontiguity $<$ between - prior-shallow-supererogation -of-mentallyaestheticised preconverging/dementing -qualia-schema_and_prospective-profoundsupererogation -of-mentally-aestheticised postconverging/dialectical-thinking -qualiaschema $>$ as to the fact that notional-contiguity/epistemic-contiguity ${ }^{6}-<$ profoundsupererogation -of-mentally-aestheticised postconverging/dialectical-thinking -qualia-

schema $>$ is now implied prospectively as of prospective relative-ontological-completeness ${ }^{87}$ as from the ontological-normalcy/postconvergence epistemic-or-notional projective-perspective. Thus in-the-bigger-picture, Baudrillard's conception of hyperreality (as implied with respect to our present lopsided technological as of lopsided material/equipment/accoutrement sublimation) speaks to the underlying apriorising/axiomatising/referencing-psychologism 'wanting of human consciousness sublimation' as to its capacity to sublimate beyond our positivismprocrypticism ${ }^{4}$ historicity-tracing-in-presencing-hyperrealisation/hyperreal-transposition of aestheticisation-and-aestheticisation-towards-ontology-<elicited-idiomatisation $>$ meaningfulness-and-teleology ; reflected as the epistemic insufficiency of our 'gimmickiness of consciousness' with regards to the potential for re-originariness/re-origination beyond 
procrypticism-or-disjointedness-as-of- ${ }^{3}$ reference-of-thought

historicity-tracing - inpresencing-hyperrealisation/hyperreal-transposition inclination now reflected as prior notionaldiscontiguity/epistemic-discontiguity $<$ between - prior-shallow-supererogation -ofmentally-aestheticised preconverging/dementing -qualia-schema_and_prospective-profoundsupererogation -of-mentally-aestheticised postconverging/dialectical-thinking -qualiaschema $>$ as so-construed projectively from the prospective ontologicalnormalcy/postconvergence epistemic-or-notional projective-perspective of deprocrypticismor-preempting - disjointedness-as-of- reference-of-thought in prospective notionalcontiguity/epistemic-contiguity ${ }^{2}<$ profound-supererogation -of-mentallyaestheticised postconverging/dialectical-thinking -qualia-schema $>$. Human limitedmentation-capacity-deepening_as-subjecting limitedness/human-subpotency-to-'educedunlimitedness/existence-sublimating nascence' ${ }^{3}$ as to its prospective apriorising/axiomatising/referencing-psychologism recovery of notional-contiguity/epistemiccontiguity ${ }^{62}<$ profound-supererogation - of-mentally-aestheticised $\sim$ postconverging/dialecticalthinking -qualia-schema> with regards to 'manifest existence-potency ${ }^{3} \sim$ sublimatingnascence,-disclosed-from-prospective-epistemic-digression in epistemic apriorising/axiomatising/referencing-\{of- 'prespectively implicited_attendant-ontologicalcontiguity ' $\sim$ educedexistentialising/contextualising/textualising_ intelligibility/epistemicity/reflexivity-contiguity$<$ imbued-notional cogency $\left.>^{\prime}\right\}$-conflatedness ${ }^{13}$ in-\{preconverging -ment by $\}$ postconverging entailment ' (overcoming the prior apriorising/axiomatising/referencingpsychologism 'loss of notional-contiguity/epistemic-contiguity ${ }^{62}-<$ profound-supererogation of-mentally-aestheticised $\sim$ postconverging/dialectical-thinking -qualia-schema> ${ }^{\prime}$ now of notional-discontiguity/epistemic-discontiguity ${ }^{6}-<$ between - prior-shallow-supererogation -ofmentally-aestheticised preconverging/dementing -qualia-schema_and_prospective-profound- 
supererogation -of-mentally-aestheticised postconverging/dialectical-thinking -qualia-

schema $>$ ) is rendered possible by human metaphoricity ${ }^{57}$-of-aestheticisation-as-of'dimensionality-of-sublimating ${ }^{25}$-<<amplituding/formative > supererogatery $\sim$ de-

mentativeness/epistemic-growth-or-conflatedness /transvaluative-

rationalising/transepistemicity/anamnestic-residuality/spirit-drivenness-equalisation〉-

totalising-entailing-instigation,-process,-and-outcome-of-re-originariness-of-aestheticisation'in-preserving-notional-contiguity/epistemic-contiguity ${ }^{62}$-by-the-given-redefining-prospectiveepistemic-digression-implications-as-to $\sim$ relative- unreflexivity/relative-reflexivity ontological-contiguity ${ }^{67}$. Thus in-the-bigger-scheme-of-things, the state of recurrent-utteruninstitutionalisation given supererogatery acuity/perspicacity/astuteness/edginess/incisiveness-ofapriorising/axiomatising/referencing/intelligibilitysettingup/measuringinstrumenting -forconceptualisation ${ }^{4}$ historicity-tracing-in-presencing-hyperrealisation/hyperreal-transposition enters into at its uninstitutionalised-threshold ${ }^{102}$ in its epistemic construal of prospective baseinstitutionalisation-ununiversalisation, likewise the latter in its epistemic construal of prospective ${ }^{103}$ universalisation-non-positivism/medievalism, and likewise the latter in its epistemic construal of prospective positivism- ${ }^{80}$ procrypticism, and the latter as well in its epistemic construal of prospective deprocrypticism-or-preempting-disjointedness-as-ofreference-of-thought; as so-reflected from the relative-ontological-completeness implied notional-contiguity/epistemic-contiguity ${ }^{2}$ - - profound-supererogation -of-mentallyaestheticised postconverging/dialectical-thinking -qualia-schema $>$ as to perspective ontological-normalcy/postconvergence. In other words, (with regards to human livingdevelopment-as-to-personality-development or institutional-development-as-to-socialfunction-development or Being-development/ontological-framework-expansion-as-to-depthof-ontologising-development-as-infrastructure-of- meaningfulness-and-teleology ) 
historicity-tracing-in-presencing-hyperrealisation/hyperreal-transposition is associated with uninstitutionalised-threshold ${ }^{102}$ as so-reflected by the relative-unreflexivity/relativereflexivity - ontological-contiguity ${ }^{67} \sim$ of-the-human-institutionalisation-process ${ }^{68}$ 'recurrently renewed $\quad{ }^{83}$ reference-of-thought-level and ${ }^{83}$ reference-of-thought- ${ }^{8}$ devolving-level apriorising/axiomatising/referencing-psychologism for conceptualisation of ${ }^{56}$ meaningfulnessand-teleology $^{9}$, so-underlined by human-subpotency-aporia/undecidability/dilemma/oughtindeterminacy/deficiency/limitation/constraint—imbued-'notional firstnaturednessformativeness-<as-to-eventualising-inkling-drive-or-seeding-misprising $>$ temporal-tointemporal-dispositions-<so-construed-as-from-perspective-ontologicalnormalcy/postconvergence ${ }^{\prime}$-existentialism-form-factor; and $\quad{ }^{47}$ historicity-tracing-inpresencing-hyperrealisation/hyperreal-transposition speaks of the $<$ cumulating/recomposuring attendant-ontological-contiguity $>$-successive registryworldviews/dimensions states of notional-discontiguity/epistemic-discontiguity ${ }^{33}<<$ between prior-shallow-supererogation -of-mentally-aestheticised preconverging/dementing -qualiaschema_and_prospective-profound-supererogation -of-mentallyaestheticised postconverging/dialectical-thinking -qualia-schema>, so-construed in their given ${ }^{7}$ presencing - absolutising-identitive-constitutedness ${ }^{14}$ eliciting an underlying sense of 'drift/homelessness/destitution of ${ }^{56}$ meaningfulness-and-teleology ${ }^{9}$, in dimensionality-ofdesublimating-lack-of ${ }^{-}-\langle<$amplituding/formative $>$supererogatory $\sim$ de-mentativeness/epistemicgrowth-or-conflatedness /transvaluative-rationalising/transepistemicity/anamnesticresiduality/spirit-drivenness-equalisation $\rangle$ of any given registry-worldview/dimension and eliciting the prospect for 'renewed ${ }^{83}$ reference-of-thought-level and ${ }^{83}$ reference-of-thoughtdevolving-level apriorising/axiomatising/referencing-psychologism of conceptualisation of meaningfulness-and-teleology", as of 'prospectively projected relative-ontologicalcompleteness 
<<amplituding/formative>supererogatory $\sim$ de-mentativeness/epistemic-growth-or-

conflatedness /transvaluative-rationalising/transepistemicity/anamnestic-residuality/spirit-

drivenness-equalisation $\rangle^{\prime}$ Hence $\quad$ historicity-tracing-in-presencing-

hyperrealisation/hyperreal-transposition reflects the given registry-worldview's/dimension's aestheticisation-and-aestheticisation-towards-ontology-<elicited-idiomatisation $>$ (as of its apriorising/axiomatising/referencing-psychologism) 'saturation of ontological-performance ${ }^{72}$ <including-virtue-as-ontology >' with respect to prospective relative-ontological-completeness existence-potency ${ }^{39} \sim$ sublimating-nascence,-disclosed-from-prospective-epistemic-digression at its uninstitutionalised-threshold ${ }^{102}$ (where it induces the notional-discontiguity/epistemicdiscontiguity ${ }^{63}-<$ between - prior-shallow-supererogation -of-mentallyaestheticised preconverging/dementing -qualia-schema_and_prospective-profoundsupererogation -of-mentally-aestheticised postconverging/dialectical-thinking -qualiaschema $>$ of aestheticisation-and-aestheticisation-towards-ontology-<elicited-idiomatisation $>$ relative to the 'requisite prospective apriorising/axiomatising/referencing-conceptualisation implied notional-contiguity/epistemic-contiguity ${ }^{6}-<$ profound-supererogation -of-mentallyaestheticised postconverging/dialectical-thinking -qualia-schema>'); such that the 'mere complexification of given registry-worldview's/dimension's aestheticisation-andaestheticisation-towards-ontology-<elicited-idiomatisation $>$ apriorising/axiomatising/referencing-conceptualisation' doesn't suffice to recover ontologicalperformance $^{2}-<$ including-virtue-as-ontology $>$ /morality/ethics/justice/etc. as to prospective relative-ontological-completeness ${ }^{87}$ existence-potency ${ }^{32} \sim$ sublimating-nascence,-disclosedfrom-prospective-epistemic-digression. $\quad{ }^{47}$ historicity-tracing-in-presencinghyperrealisation/hyperreal-transposition is so-reflected with the mere reproducibilitymathesis/motif/thrownness-disposition,-as-reproducibility-of-aestheticisation-andaestheticisation-towards-ontology-<elicited-idiomatisation $>$ of any such registry- 
worldview's/dimension's underlying intellection induced ${ }^{56}$ meaningfulness-and-teleology infrastructure (whether positivism/rational-empiricism manifestation of procrypticism-ordisjointedness-as-of- ${ }^{8}$ reference-of-thought, ${ }^{103}$ universalisation-non-positivism/medievalism, base-institutionalisation-ununiversalisation or recurrent-utter-uninstitutionalisation) and its corresponding hegemonising institutional and social narratives, as to their notionallycollateralising framework of ${ }^{56}$ meaningfulness-and-teleology ${ }^{9}$ increasingly construing their defining prospective human-subpotency-aporia/undecidability/dilemma/oughtindeterminacy/deficiency/limitation/constraint—imbued-'notional firstnaturednessformativeness-<as-to-eventualising-inkling drive-or-seeding-misprising $>$ temporal-tointemporal-dispositions-<so-construed-as-from-perspective-ontologicalnormalcy/postconvergence>'-existentialism-form-factor (reflecting their uninstitutionalisedthreshold ${ }^{102}$ ) rather

imponderable/inscrutable/unavoidable/inevitable/inescapable/unpreventable/unchangeable/in surmountable/unovercomable as to their given ${ }^{4}$ historicity-tracing-in-presencinghyperrealisation/hyperreal-transposition psychological entrapment (in notionaldiscontiguity/epistemic-discontiguity ${ }^{63}-<$ between - prior-shallow-supererogation -ofmentally-aestheticised preconverging/dementing -qualia-schema_and_prospective-profoundsupererogation -of-mentally-aestheticised postconverging/dialectical-thinking -qualiaschema $>$ of aestheticisation-and-aestheticisation-towards-ontology-<elicited-idiomatisation $>$ ) induced lack of ${ }^{103}$ universal-transparency ${ }^{104}$-〈transparency-of-totalising-entailing,-as-toentailing-<amplituding/formative-epistemicity $>$ totalising $\sim$ in-relative-ontologicalcompleteness $\rangle$ of 'prospective postconverging-aporeticism-overcoming/unovercoming as theGood/knowledge-reification $\sim$ gesturing-and-accounting — of-epistemic-phenomenalism- $<$ inprospective_psychologismic apriorising/axiomatising/referencing-\{of-'prospectively implicited_attendant-ontological-contiguity ' educed- 
existentialising/contextualising/textualising_'intelligibility/epistemicity/reflexivity-contiguity<imbued-notional cogency>' \}-conflatedness -in-\{preconverging -ment by\}

postconverging-entailment $>$ /understanding/<amplituding/formative-

epistemicity $>$ causality $\sim$ as-to-projective-totalitative-implications-of-prospectivenonpresencing,-for-explicating relative-unreflexivity/relative-reflexivity - ontological-

contiguity , and its relatively-shallow-frame-of-elicited-positive-opportunism-of-socialfunctioning-and-accordance ${ }^{75}$-of-low-intrinsic-attribution-and-high-extrinsic-attributionsusceptibility,-in-dimensionality-of-desublimating-lack-of ${ }^{-6}$ <<amplituding/formative>supererogatory $\sim$ de-mentativeness/epistemic-growth-orconflatedness /transvaluative-rationalising/transepistemicity/anamnestic-residuality/spiritdrivenness-equalisation $\rangle. \quad$ Dimensionality-of-sublimating <<amplituding/formative>supererogatory $\sim$ de-mentativeness/epistemic-growth-orconflatedness /transvaluative-rationalising/transepistemicity/anamnestic-residuality/spiritdrivenness-equalisation> of all registry-worldviews/dimensions is effectively what renders (by its ontological-normalcy/postconvergence epistemic perspective in postcenvergingnonextricatory-existential-preempting-of-existential-unthought) the possibility for the succession of prospective registry-worldviews/dimensions underlying the relativeunreflexivity/relative-reflexivity - ontological-contiguity ${ }^{67} \sim$ of-the-human-institutionalisationprocess $;$ and it is this dimensionality-of-sublimating ${ }^{25}$ <<amplituding/formative>supereregatery $\sim$ de-mentativeness/epistemic-growth-or-

conflatedness /transvaluative-rationalising/transepistemicity/anamnestic-residuality/spiritdrivenness-equalisation) prospective reformulating/revamping of human aestheticisation-andaestheticisation-towards-ontology-<elicited-idiomatisation $>$

apriorising/axiomatising/referencing-psychologism of conceptualisation in prospective notional-contiguity/epistemic-contiguity ${ }^{62}<$ profound-supererogation -of-mentally- 
aestheticised postconverging/dialectical-thinking -qualia-schema> (over the 'saturation of ontological-performance ${ }^{72}-<$ including-virtue-as-ontology $>$ ' of prior aestheticisation-andaestheticisation-towards-ontology-<elicited-idiomatisation $>$ apriorising/axiomatising/referencing-conceptualisation in notional-discontiguity/epistemicdiscontiguity 33 - between - prior-shallow-supererogation -of-mentallyaestheticised preconverging/dementing -qualia-schema_and_prospective-profoundsupererogation -of-mentally-aestheticised postconverging/dialectical-thinking -qualiaschema $>$ ) for the prospective sublimation of aestheticisation-and-aestheticisation-towardsontology-<elicited-idiomatisation $>\quad$ as $\quad{ }^{56}$ meaningfulness-and-teleology apriorising/axiomatising/referencing-psychologism of conceptualisation as of 'renewed notional-contiguity/epistemic-contiguity ${ }^{2} \_$- profound-supererogation -of-mentallyaestheticised postconverging/dialectical-thinking -qualia-schema>' (so-construed as human limited-mentation-capacity-deepening —as-subjecting limitedness/human-subpotency-to'educed-unlimitedness/existence-sublimating nascence'" as of 'prospective dimensionality-ofsublimating $25<<$ amplituding/formative $>$ supererogatory $\sim$ de-mentativeness/epistemic-growthor-conflatedness /transvaluative-rationalising/transepistemicity/anamnestic-residuality/spiritdrivenness-equalisation) recovery of notional-contiguity/epistemic-contiguity ${ }^{62}-<$ profoundsupererogation -of-mentally-aestheticised postconverging/dialectical-thinking -qualiaschema $>$ of aestheticisation-and-aestheticisation-towards-ontology-<elicited-idiomatisation $>$ as ${ }^{56}$ meaningfulness-and-teleology apriorising/axiomatising/referencing-psychologism conceptualisation') that is entailed in the very notion of human de-mentation〈supererogatory $\sim$ ontological-de-mentation-or-dialectical-de-mentation-stranding-orattributive-dialectics $\rangle$ as reflected with renewed apriorising/axiomatising/referencingpsychologism as to prospective postconverging/dialectical-thinking ${ }^{21}$-qualia-schema over prior preconverging/dementing ${ }^{20}$-qualia-schema. The implication here is that the overcoming of any 
historicity-tracing — in-presencing-hyperrealisation/hyperreal-transposition is intimately tied to human limited-mentation-capacity-deepening -as-subjecting limitedness/humansubpotency to-'educed-unlimitedness/existence-sublimating nascence' ${ }^{53}$ as to psychoanalyticunshackling/memetic-reordering/institutional-recomposuring so-implied as its prospective construction-of-the-Self as of its dispensing-with-immediacy-for-relative-ontologicalcompleteness $^{87}$-by-reification/contemplative-distension ${ }^{27}$. Insightfully, while with prior registry-worldviews/dimensions human consciousness sublimation ontological-performance ${ }^{72}$ $<$ including-virtue-as-ontology $>/$ morality/ethics/justice/etc. had rather assumed an 'overall human aestheticisation-and-aestheticisation-towards-ontology-<elicited-idiomatisation $>$ originariness-by-reproducibility-laddering effect' (involving a 'notionally-collateralising inclination detour of aestheticisation-and-aestheticisation-towards-ontology-<elicitedidiomatisation>' as to the underlying 'notional collateralising-beholdening-protohumanity by sublimating-humanity existentialism-form-factor'), the requisite protensive-self-consciousness of prospective notional ${ }^{18}$ deprocrypticism is one that as to its full grasp/understanding/ ${ }^{103}$ universal-transparency ${ }^{104}$-〈transparency-of-totalising-entailing,-as-toentailing-<amplituding/formative-epistemicity $>$ totalising $\sim$ in-relative-ontologicalcompleteness > of the preconverging/postconverging-redementating/restructuring/reparadigming possibilities of prospective human aestheticisation-andaestheticisation-towards-ontology-<elicited-idiomatisation $>\quad$ as $\quad{ }^{56}$ meaningfulness-andteleology ${ }^{9}$ should be amenable to a self-consciousness projection that should be able to engage with its corresponding level of taxingness-of-originariness (as to its own 'humanity-sublimation homework' at its given supposed growth/maturity at the backend in reflecting holographically$<$ conjugatively-and-transfusively $>$ the relative-unreflexivity/relative-reflexivity - ontologicalcontiguity $\sim$ of-the-human-institutionalisation-process ) in adopting a re-originariness/reorigination consciousness sublimation over ${ }^{47}$ historicity-tracing-in-presencing- 
hyperrealisation/hyperreal-transposition that overcome a 'notionally-collateralising inclination detour of aestheticisation-and-aestheticisation-towards-ontology-<elicited-idiomatisation $>$ ' implicated in the originariness-by-reproducibility-laddering effect (as so-implied with the notional ${ }^{1}$ deprocrypticism prospective superseding of human relatively-shallow-frame-ofelicited-positive-opportunism-of-social-functioning-and-accordance ${ }^{75}$-of-low-intrinsicattribution-and-high-extrinsic-attribution-susceptibility,-in-dimensionality-of-desublimatinglack-of ${ }^{-}-\langle<$amplituding/formative $>$supererogatory $\sim$ de-mentativeness/epistemic-growth-orconflatedness /transvaluative-rationalising/transepistemicity/anamnestic-residuality/spiritdrivenness-equalisation)). Thus (as it projects beyond human 'social-stake-contention-orconfliction ${ }^{79}$ presencing - absolutising-identitive-constitutedness ${ }^{14}$ psychological entrapment' imbued notional-discontiguity/epistemic-discontiguity ${ }^{63}<$ between - prior-shallowsupererogation -of-mentally-aestheticised $\sim$ preconverging/dementing -qualiaschema_and_prospective-profound-supererogation -of-mentallyaestheticised postconverging/dialectical-thinking -qualia-schema> of aestheticisation-andaestheticisation-towards-ontology-<elicited-idiomatisation>), prospective historiality/ontological-eventfulness 3 /ontological-aesthetic-tracing- $<$ perspectiveontological-normalcy/postconvergence-reflected-‘epistemicity-relativism-determinism'> as the 'wholly other' of historicity-tracing-in-presencing-hyperrealisation/hyperreal-transposition speaks to the succession of human edgy/incisive/astute renewed aestheticisation-andaestheticisation-towards-ontology-<elicited-idiomatisation $>\quad$ as $\quad{ }^{56}$ meaningfulness-and-

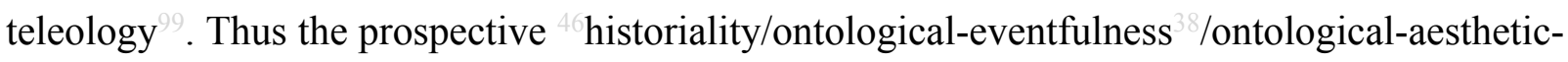
tracing-<perspective-ontological-normalcy/postconvergence-reflected-'epistemicityrelativism-determinism'> of notional deprocrypticism very much equates to human consciousness sublimation as of its successive transcendence-andsublimity/sublimation/supererogatory $\sim$ de-mentativity of registry-worldviews/dimensions as to 
existence-potency ${ }^{39} \sim$ sublimating-nascence,-disclosed-from-prospective-epistemic-digression,

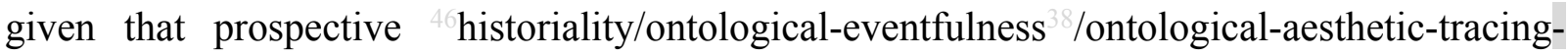
$<$ perspective-ontological-normalcy/postconvergence-reflected-'epistemicity-relativismdeterminism' $>$ is more than just the prospective reproducibility potential of aestheticisationand-aestheticisation-towards-ontology-<elicited-idiomatisation $>$ but is actually the 'equalisation of all ${ }^{4}$ historiality/ontological-eventfulness $3 /$ ontological-aesthetic-tracing$<$ perspective-ontological-normalcy/postconvergence-reflected-'epistemicity-relativismdeterminism’> aestheticisation-and-aestheticisation-towards-ontology-<elicitedidiomatisation>': as to imply that 'dimensionality-of-sublimating <<amplituding/formative >supererogatory de-mentativeness/epistemic-growth-orconflatedness /transvaluative-rationalising/transepistemicity/anamnestic-residuality/spiritdrivenness-equalisation) of recurrent-utter-uninstitutionalisation' $=$ 'dimensionality-ofsublimating $25<<$ amplituding/formative $>$ supererogatory $\sim$ de-mentativeness/epistemic-growthor-conflatedness /transvaluative-rationalising/transepistemicity/anamnestic-residuality/spiritdrivenness-equalisation) of base-institutionalisation-ununiversalisation' = 'dimensionality-ofsublimating $25-<<$ amplituding/formative $>$ supererogatory $\sim$ de-mentativeness/epistemic-growthor-conflatedness /transvaluative-rationalising/transepistemicity/anamnestic-residuality/spiritdrivenness-equalisation) of ${ }^{103}$ universalisation-non-positivism/medievalism' = 'dimensionality-of-sublimating $25<<$ amplituding/formative $>$ supererogatory $\sim$ dementativeness/epistemic-growth-or-conflatedness /transvaluativerationalising/transepistemicity/anamnestic-residuality/spirit-drivenness-equalisation〉 positivism- ${ }^{80}$ procrypticism', (even as their mere reproducibility-mathesis/motif/thrownnessdisposition,-as-reproducibility-of-aestheticisation-and-aestheticisation-towards-ontology$<$ elicited-idiomatisation $>$ do not equate 'as of their differing positive-opportunism-of-socialfunctioning-and-accordance preconverging/postconverging-de- 
mentating/structuring/paradigming of underlying ${ }^{83}$ reference-of-thought- categoricalimperatives/axioms/registry-teleology ${ }^{9}$, -for-

aposteriorising/logicising/deriving/intelligising/measuring- ${ }^{5}$ meaningfulness-and-teleology ${ }^{99}$ as to prospective human-subpotency-aporia/undecidability/dilemma/oughtindeterminacy/deficiency/limitation/constraint'); and so-construed as 'dimensionality-ofsublimating $25-<<$ amplituding/formative $>$ supererogatory $\sim$ de-mentativeness/epistemic-growthor-conflatedness /transvaluative-rationalising/transepistemicity/anamnestic-residuality/spiritdrivenness-equalisation) for notional deprocrypticism/deprocypticism dimensionality' as of a prospective imaginary/ideality of human consciousness sublimation beyond just mere secondnaturing reproducibility aestheticisation-and-aestheticisation-towards-ontology$<$ elicited-idiomatisation>. Thus this underlying dimensionality-of-sublimating ${ }^{25}$ <<amplituding/formative>supererogatory $\sim$ de-mentativeness/epistemic-growth-or-

conflatedness /transvaluative-rationalising/transepistemicity/anamnestic-residuality/spiritdrivenness-equalisation) (as 'equalisation of all ${ }^{4}$ historiality/ontologicaleventfulness 38 ontological-aesthetic-tracing-<perspective-ontologicalnormalcy/postconvergence-reflected-‘epistemicity-relativism-determinism'> aestheticisationand-aestheticisation-towards-ontology-<elicited-idiomatisation>') speaks to a 'transverse dimensionality about human consciousness sublimation originariness/origination-〈so-construedas-to-ontological-normalcy/postconvergence-perspective-scalarising-construal-of-existence) in ecstatic-existence' as underlying 'authentic-humanity and its homeliness-drive'; of as yet tenuous, but central-and-defining to the very implication of the prospective ${ }^{18 \text { deprocrypticism- }}$

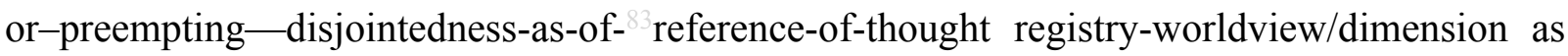
to its prospective superseding of human relatively-shallow-frame-of-elicited-positiveopportunism - of-social-functioning-and-accordance ${ }^{75}$-of-low-intrinsic-attribution-and-highextrinsic-attribution-susceptibility,-in-dimensionality-of-desublimating-lack-of - 
<<amplituding/formative>supererogatory $\sim$ de-mentativeness/epistemic-growth-or-

conflatedness /transvaluative-rationalising/transepistemicity/anamnestic-residuality/spirit-

drivenness-equalisation). Critically, dimensionality-of-sublimating ${ }^{25}$ -

<<amplituding/formative>supererogatory $\sim$ de-mentativeness/epistemic-growth-or-

conflatedness /transvaluative-rationalising/transepistemicity/anamnestic-residuality/spirit-

drivenness-equalisation) underlying the relative-unreflexivity/relative-reflexivity - ontologicalcontiguity ${ }^{67}$ of-the-human-institutionalisation-process ${ }^{68}$ (with regards to the overall manifest relative-unreflexivity/relative-reflexivity - ontological-contiguity ${ }^{67}$ of-the-human-

institutionalisation-process 68 'human aestheticisation-and-aestheticisation-towards-ontology<elicited-idiomatisation> originariness-by-reproducibility-laddering effect') contrastively speaks of the dimensionality-of-desublimating-lack-of

\section{<<amplituding/formative>supererogatory $\sim$ de-mentativeness/epistemic-growth-or-}

conflatedness /transvaluative-rationalising/transepistemicity/anamnestic-residuality/spirit-

drivenness-equalisation) that recurrently pops up in the <cumulating/recomposuring attendantontological-contiguity $>$-successive registry-worldviews/dimensions in reflecting holographically-<conjugatively-and-transfusively $>$ the relative-unreflexivity/relativereflexivity - ontological-contiguity of-the-human-institutionalisation-process (as to the implications of the lack of ${ }^{103}$ universal-transparency ${ }^{104}$-〈transparency-of-totalising-entailing,-asto-entailing-<amplituding/formative-epistemicity $>$ totalising $\sim$ in-relative-ontological-

completeness $\rangle$ of 'prospective postconverging-aporeticism-overcoming/unovercoming as theGood/knowledge-reification $\sim$ gesturing-and-accounting — of-epistemic-phenomenalism- $<$ inprospective_psychologismic $\sim$ apriorising/axiomatising/referencing-\{of- ${ }^{\text {} p r o s p e c t i v e l y ~}$ implicited_attendant-ontological-contiguity ' educedexistentialising/contextualising/textualising_'intelligibility/epistemicity/reflexivity-contiguity<imbued-notional cogency>' \}-conflatedness -in-\{preconverging -ment by\} 
postconverging entailment $>$ /understanding/<amplituding/formative-

epistemicity $>$ causality $\sim$ as-to-projective-totalitative-implications-of-prospective-

nonpresencing,-for-explicating relative-unreflexivity/relative-reflexivity - ontological-

contiguity '), which acts as of mere reproducibility cynicism (in the face of prospective humansubpotency-aporia/undecidability/dilemma/ought-

indeterminacy/deficiency/limitation/constraint) in fundamental ontological-badfaith/inauthenticity ${ }^{64}$ (beyond-the-consciousness-awareness-teleology ${ }^{\circ}<$ of-preconvergingexistential-extrication-as-of-existential-unthought $>$ ), $\quad$ so-reflected in its $<$ amplituding/formative $>$ wooden-language-〈imbued-temporal-mereform/virtualities/dereification/akrasiatic-drag/denatured/preconverging-or-dementing narratives - of-the- reference-of-thought- categorical-imperatives/axioms/registry-

teleology \; further speaking of the differentiation of these two dimensionalities as of originariness/mere-reproducibility, driveness/mere-function, sublimation/mere-gimmickiness, reification/mere-extrication, existential-thoughtfulness/mere-existential-unthoughtfulness, responsibility/relative-reflexivity/mere-indulgence, antinihilism/mere-nihilism etc. in the face of prospective human-subpotency-aporia/undecidability/dilemma/oughtindeterminacy/deficiency/limitation/constraint—imbued-'notional firstnaturednessformativeness-<as-to-eventualising-inkling-drive-or-seeding-misprising $>$ temporal-tointemporal-dispositions- $<$ so-construed-as-from-perspective-ontologicalnormalcy/postconvergence>'-existentialism-form-factor. This highlights that the epistemicinstigation of prospective notional ${ }^{18}$ deprocrypticism contemplation is necessarily as of disseminative - sublimating-selectivity-of-ontological-goodfaith/authenticity $\sim$ postconverging-de-mentating/structuring/paradigming , over desublimating-deselectivity-of-ontological-bad-faith/inauthenticity -preconverging dementating/structuring/paradigming as to existence-potency ${ }^{39} \sim$ sublimating-nascence,- 
disclosed-from-prospective-epistemic-digression ${ }_{2}$ and so before logical-dueness as to ontologically-valid language-as-of-dialogical-equivalence- $<$ as-topsychologismic apriorising/axiomatising/referencing-\{of-"prospectivelyimplicited_attendant-ontological-contiguity ' educedexistentialising/contextualising/textualising_ 'intelligibility/epistemicity/reflexivity-contiguity<imbued-notional cogency >' \}-conflatedness -in-\{preconverging-ment by\} postconverging entailment,-in-self-becoming/self-conflatedness /formative-supererogating > can even arise in the first place; explaining in-many-ways the ontologicalnormalcy/postconvergence epistemic-or-notional projective-perspective projecting of a dynamic differentiated transversality-<for-sublimating-existential-eventuating/denouement-from-'thinking at first/pure-predisposition-preemptive-of-prospectivedisontologising/subontologising' as-of-prospectively-disambiguated-affirmed-andunaffirmed-'motif-and-apriorising/axiomatising/referencing'>101 of human-subpotencies ontological-performance ${ }^{72}-<$ including-virtue-as-ontology $>/$ morality/ethics/justice/etc. as to the selective-and-deselective determination of existence-potency ${ }^{39} \sim$ sublimating-nascence,disclosed-from-prospective-epistemic-digression, and so over the purported inherent humansubpotency/mortal perspective pre-eminence over the sublimating-over-desublimating implications of existence-potency ${ }^{32}$ sublimating-nascence,-disclosed-from-prospectiveepistemic-digression. Thus more than just about 'prospective succession' as to the $<$ cumulating/recomposuring attendant-ontological-contiguity $>$-successive registryworldviews/dimensions in reflecting holographically-<conjugatively-and-transfusively $>$ the relative- unreflexivity/relative-reflexivity - ontological-contiguity of-the-humaninstitutionalisation-process (beyond just their mere secondnaturing reproducibility aestheticisation-and-aestheticisation-towards-ontology-<elicited-idiomatisation $>$ ), prospective notional ${ }^{1}$ deprocrypticism protensive-self-consciousness is more critically bechanced as to an 
originariness/origination-〈so-construed-as-to-ontological-normalcy/postconvergence-

perspective-scalarising-construal-of-existence) projection of dimensionality-of-sublimating <<amplituding/formative>supererogatory $\sim$ de-mentativeness/epistemic-growth-orconflatedness /transvaluative-rationalising/transepistemicity/anamnestic-residuality/spiritdrivenness-equalisation> beyond mere reproducibility. Prospective ${ }^{4}$ historiality/ontologicaleventfulness 38 ontological-aesthetic-tracing-<perspective-ontologicalnormalcy/postconvergence-reflected-'epistemicity-relativism-determinism'> as such is more profoundly the abstractive conceptualisation (beyond the reproducibility constraining upon human limited-mentation-capacity—as-subjecting-'educed-unlimitedness/existencesublimating nascence' to limitedness/human-subpotency implications) as to humansubpotency 'fatedness-of-sublimation-over-desublimation/ontological-foreordination of humansubpotency underlying dispensing-with-immediacy-for-relative-ontological-completeness ${ }^{87}$-byreification/contemplative-distension ${ }^{27}$ projection notional $\sim$ reflexivity- $<\{$ veridical/sound $\}$ relative-reflexivity-in-existencetrelativising from limited mentation as its-

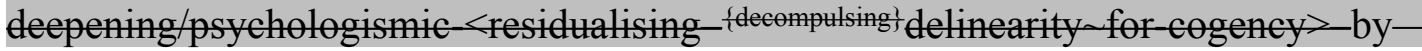
\{flawed/unsound\}-relative-unreflexivity-in-existence/absolutising from-limitedmentation/psychologismic epistemic-acutisation nonresidualising-imbued\{compulsing\} linearity in-eclecticism-of-prior-mere-formulaicity/ritualisation $>$ in ecstaticexistence'. Ultimately, the very conception of human limited-mentation-capacity-deepeningas subjecting limitedness/hmman-subpotency to 'educed mnlimitedness/existence sublimating nascence' ${ }^{53}$ underlying metaphoricity ${ }^{57}$-of-aestheticisation-as-of-'dimensionality-ofsublimating $25-<$ amplituding/formative $>$ supererogatory $\sim$ de-mentativeness/epistemic-growthor-conflatedness /transvaluative-rationalising/transepistemicity/anamnestic-residuality/spiritdrivenness-equalisation〉-totalising-entailing-instigation,-process,-and-outcome-of-reoriginariness-of-aestheticisation'-in-preserving-notional-contiguity/epistemic-contiguity ${ }^{62}$-by- 
the-given-redefining-prospective-epistemic-digression-implications-as-to $\sim$ relativeunreflexivity/relative-reflexivity -ontological-contiguity ${ }^{77}$ is tied to human ontologicalperformance $^{72}-<$ including-virtue-as-ontology>; as to the possibility for 'prospectively recovering notional-contiguity/epistemic-contiguity ${ }^{6}-<$ profound-supererogation -of-mentallyaestheticised postconverging/dialectical-thinking -qualia-schema $>$ of aestheticisation-andaestheticisation-towards-ontology-<elicited-idiomatisation $>$ as $\quad{ }^{56}$ meaningfulness-andteleology', faced with the 'saturation of ontological-performance ${ }^{72}-<$ including-virtue-asontology >' at the uninstitutionalised-threshold ${ }^{102}$ of the relative-ontological-incompleteness (inducing its notional-discontiguity/epistemic-discontiguity ${ }^{3}-<$ between - prior-shallowsupererogation -of-mentally-aestheticised preconverging/dementing -qualiaschema_and_prospective-profound-supererogation -of-mentallyaestheticised postconverging/dialectical-thinking -qualia-schema $>$ of aestheticisation-andaestheticisation-towards-ontology-<elicited-idiomatisation $>$ as ${ }^{56}$ meaningfulness-andteleology ${ }^{9}$ ) with respect to prospective relative-ontological-completeness ${ }^{87}$ existencepotency $^{32} \sim$ sublimating-nascence,-disclosed-from-prospective-epistemic-digression; even as any specific human ${ }^{7}$ presencing - absolutising-identitive-constitutedness ${ }^{14}$ (as of its socialstake-contention-or-confliction) is 'susceptible to prospective desublimation/gimmickiness as to taxingness-of-originariness', such that in-many-ways our present mental state of positivismprocrypticism $\quad{ }^{4}$ historicity-tracing-in-presencing-hyperrealisation/hyperreal-transposition (and so with regards to human Being-development/ontological-framework-expansion-as-todepth-of-ontologising-development-as-infrastructure-of- meaningfulness-and-teleology , institutional-development-as-to-social-function-development and living-development-as-topersonality-development psychologismic epistemie aeutisation diffieulty <for, residualising \{decompulsing $\}$ delinearity for-cogency> - magnitudes \{of-experientiality/experiment $\}$ ) obviate human appreciation and cultivation of its prospective consciousness sublimation as of the 
prospective ${ }^{4}$ historiality/ontological-eventfulness 38 ontological-aesthetic-tracing-<perspectiveontological-normalcy/postconvergence-reflected-‘epistemicity-relativism-determinism’> of deprocrypticism. Metaphoricity ${ }^{57}$-of-aestheticisation-as-of-'dimensionality-of-sublimating <<amplituding/formative>supererogatory de-mentativeness/epistemic-growth-orconflatedness /transvaluative-rationalising/transepistemicity/anamnestic-residuality/spiritdrivenness-equalisation〉-totalising-entailing-instigation,-process,-and-outcome-of-reoriginariness-of-aestheticisation'-in-preserving-notional-contiguity/epistemic-contiguity ${ }^{62}$-bythe-given-redefining-prospective-epistemic-digression-implications-as-to $\sim$ relativeunreflexivity/relative-reflexivity_ontological-contiguity ${ }^{77}$ very much explains the diversification as to human-subpotency potential for social formation, modes-of-living, language-as-of-dialogical-equivalence-<as-topsychologismic apriorising/axiomatising/referencing-\{of-"prospectivelyimplicited_attendant-ontological-contiguity ' educedexistentialising/contextualising/textualising_'intelligibility/epistemicity/reflexivity_contiguity<imbued-notional cogency >' \}-conflatedness -in-\{preconverging-ment by\} postconverging-entailment,-in-self-becoming/self-conflatedness /formative-supererogating>, cultural practices, etc., as 'manifest outcomes/outfits/shells - construed-historially-as-of-thespecifically-aestheticised-incrusting/plating/coating,-so-reflected-as-institutionalmanifestations of human ${ }^{56}$ meaningfulness-and-teleology'. In this regards and more fundamentally (and as it is reflected in the aestheticisation-and-aestheticisation-towardsontology-<elicited-idiomatisation $>$ as ${ }^{5}$ meaningfulness-and-teleology ${ }^{99}$ of human Beingdevelopment/ontological-framework-expansion-as-to-depth-of-ontologising-development-asinfrastructure-of- meaningfulness-and-teleology , institutional-development-as-to-socialfunction-development and living-development-as-to-personality-development psychologismic epistemic-acutisation difficulty-for, residualising \{decompulsing delinearity for-cogency> 
magnitudes $\{$ of-experientiality/experiment\}), historicity-tracing-in-presencinghyperrealisation/hyperreal-transposition is aestheticised (as from human mentalaestheticisation - architectonically-consigning-aestheticised-perceptibility-and-disposition) more as of beholdening-becoming - distortive-originariness/distortive-origination-as-tohistoricity-tracing inhibited-mental-aestheticising as from human-subpotency epistemic-ornotional projective-perspective of ontological-performance ${ }^{72}-<_{\text {including-virtue-as- }}$ ontology $>$ /morality/ethics/justice/etc. (in contrast to the supererogatory acuity/perspicacity/astuteness/edginess/incisiveness of bechancingbecoming - originariness/origination-as-to- ${ }^{-}$historiality/ontologicaleventfulness 38 ontological-aesthetic-tracing-<perspective-ontologicalnormalcy/postconvergence-reflected-'epistemicity-relativism-determinism'> disinhibitedmental-aestheticising, as from ontological-normalcy/postconvergence epistemic-ornotional projective-perspective of ontological-performance ${ }^{72}-<$ including-virtue-asontology $>$ /morality/ethics/justice/etc. as to existence-potency ${ }^{32} \sim$ sublimating-nascence,disclosed-from-prospective-epistemic-digression). Insightfully, ecstatic-existence (existencepotency $^{39} \sim$ sublimating-nascence,-disclosed-from-prospective-epistemic-digression) is not beholden to human ${ }^{83}$ reference-of-thought-and- ${ }^{8}$ reference-of-thought- ${ }^{8}$ devolvingmeaningfulness-and-teleology ${ }^{9}$ with regards to human mental-aestheticisationarchitectonically-consigning-aestheticised-perceptibility-and-disposition as of humansubpotency beholdening-becoming - distortive-originariness/distortive-origination-as-tohistoricity-tracing inhibited-mental-aestheticising. While it is human mentalaestheticisation - architectonically-consigning-aestheticised-perceptibility-and-disposition that underlies ' ' $\quad$ de-mentation-_supererogatory $\sim$ ontological-de-mentation-or-dialectical-dementation - stranding-or-attributive-dialectics $\rangle$ 
apriorising/axiomatising/referencing for mental-aestheticisation of ${ }^{56}$ meaningfulness-andteleology ${ }^{9}$ as to postconverging/dialectical-thinking -qualia-schema-mentalaestheticisation-attribution and preconverging/dementing -qualia-schema-mentalaestheticisation-attribution and then their mutually-reinfusing-attributive-possibilities,-for'<amplituding/formative-epistemicity $>$ totalising $\sim$ pseudoconflation/conflation-of-humanlimited-mentation-capacity_as-subjecting-'educed-unlimitedness/existence-sublimating nascence' to-limitedness/human-subpotency'-as-to-correspondingly-ensuing - desublimatingor-sublimating-mental-aestheticisation-representation (with regards to 'varying psychologismic epistemic-acutisation - difficulty < for, residualising ${ }_{\{\text {decompulsing }\}}$ delinearity for-cogeney> magnitudes $\{$ of-experientiality/experiment $\} /$ scales—as-tosuccessively-profound-preconverging/postconverging-redementating/restructuring/reparadigming-frames-as-from-living,-institutionalising,-and-Beingontologising/infrastructure-of- ${ }^{5}$ meaningfulness-and-teleology 9 of prospective humansubpotency-aporia/undecidability/dilemma/ought-

indeterminacy/deficiency/limitation/constraint—imbued-'notional firstnaturednessformativeness-<as-to-eventualising-inkling drive or seeding misprising $>$ temporal-tointemporal-dispositions-<so-construed-as-from-perspective-ontologicalnormalcy/postconvergence>'-existentialism-form-factor'), explaining the dramatically 'differing and extensive manifest outcomes/outfits/shells-construed-historially-as-of-thespecifically-aestheticised-incrusting/plating/coating,-so-reflected-as-institutionalmanifestations of human sublimating-over-desublimating social-and-institutional-constructsof- meaningfulness-and-teleology -in-cumulation/recomposuring' out of the-very-same process of ' ${ }^{15}$ de-mentation-〈supererogatory $\sim$ ontological-de-mentation-or-dialectical-dementation - stranding-or-attributive-dialectics $\rangle$ 
apriorising/axiomatising/referencing for mental-aestheticisation of ${ }^{56}$ meaningfulness-andteleology ${ }^{9}$; the ontological-pertinence (as of ontological-normalcy/postconvergence epistemicor-notional projective-perspective) of human mental-aestheticisation-architectonicallyconsigning-aestheticised-perceptibility-and-disposition rather abstractly lies in notionallyskewing towards bechancing-becoming-originariness/origination-as-tohistoriality/ontological-eventfulness 38 /ontological-aesthetic-tracing- $<$ perspectiveontological-normalcy/postconvergence-reflected-`epistemicity-relativismdeterminism'> disinhibited-mental-aestheticising (as from any priorly given 'reproducibilitymathesis/motif/thrownness-disposition,-as-reproducibility-of-aestheticisation reference-point of beholdening-becoming-distortive-originariness/distortive-origination-as-to- historicitytracing inhibited-mental-aestheticising)', such that prospective notional ${ }^{18}$ deprocrypticism mental-aestheticisation as predicated upon its dimensionality-of-sublimating ${ }^{25}$ <<amplituding/formative>supererogatory $\sim$ de-mentativeness/epistemic-growth-or-

conflatedness /transvaluative-rationalising/transepistemicity/anamnestic-residuality/spiritdrivenness-equalisation> is rather skewed towards bechancing-becomingoriginariness/origination-as-to- ${ }^{4}$ historiality/ontological-eventfulness 3 /ontological-aesthetictracing-<perspective-ontological-normalcy/postconvergence-reflected-‘epistemicityrelativism-determinism'> disinhibited-mental-aestheticising (beyond reproducibility-ofaestheticisation) as of increasingly unbeholdening-becoming to reproducibilitymathesis/motif/thrownness-disposition,-as-reproducibility-of-aestheticisation (spontaneity-ofaestheticisation). Actually, all prior reproducibility—mathesis/motif/thrownness-disposition,-as-reproducibility-of-aestheticisation beholdening-becoming-distortiveoriginariness/distortive-origination-as-to- ${ }^{4}$ historicity-tracing inhibited-mental-aestheticising with respect to their ontological-performance ${ }^{72}-$ including-virtue-as- $^{-}$ ontology $>$ /morality/ethics/justice/etc. are priorly of bechancing-becoming- 


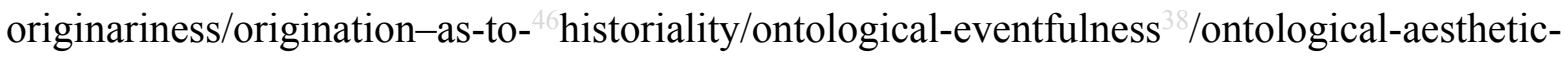
tracing-<perspective-ontological-normalcy/postconvergence-reflected-'epistemicityrelativism-determinism'> disinhibited-mental-aestheticising with regards to initially spontaneous ecstatic-existence epistemic-digression implications (as despite its implied taxingness-of-aestheticisation such an abstract perspective of bechancing-becomingoriginariness/origination-as-to- ${ }^{4}$ historiality/ontological-eventfulness 38 ontological-aesthetictracing-<perspective-ontological-normalcy/postconvergence-reflected-‘epistemicityrelativism-determinism'> disinhibited-mental-aestheticising is the full-depth of the potential to aesthetically reflect the implications of the full-potency of ecstatic-existence). The historicitytracing_-in-presencing-hyperrealisation/hyperreal-transposition of pedantising/muddling/formulaic-hollowing-out — in-subontologisation/subpotentiation〈blurring/undermining-of-prospective-totalising-entailing,-as-to-entailing<amplituding/formative-epistemicity>totalising in-relative-ontological-completeness $>$ as of institutional-being-and-craft in our positivism- ${ }^{80}$ procrypticism age is one 'that in-many-ways implies an abandonment of even the reality of prior human thoughtfulness that led to its present as its present is construed as of decisively absolutised capacity of thought', thus falsely rendering/construing of human capacity in its present the 'exceptional capacity of excogitation' unwary of its own ontological-impertinence as to the need to projectively integrate the preconverging/postconverging-de-mentating/structuring/paradigming implications (as to 'relative-ontological-incompleteness 8 /relative-ontological-completeness ${ }^{8}$ -

\section{〈sublimating referencing/registering/decisioning,-as-self-becoming/self-}

conflatedness /formative-supererogating-<projective/reprojective-aestheticising-re-motifand-re-apriorising/re-axiomatising/re-referencing,-in-perspective-ontologicalnormalcy/postconvergence $>>$ as to human-and-social-expectations/anticipationsmetaphoricity ${ }^{57}$-as-preconverging/postconverging-rede- 
mentating/restructuring/reparadigming-psychologism' ${ }^{89}$ ) of excogitation in its own present and the prospective projection implications (as so-reflected herein with the relativeunreflexivity/relative-reflexivity — ontological-contiguity ${ }^{67}$ of-the-human-institutionalisationprocess ${ }^{68}$ conception). This occlusivity of thought then goes on to ride-the-wave/exploit-withoutcorresponding-sublimation-as-to-existence-potency ${ }^{39} \sim$ sublimating-nascence-implications of a lopsided scientific and technological sublimation as it falsely 'usurps the latter's speakership as of

extrapolating/constituting/abstracting/deducing/inferring-of-elucidation-outside-

'prospectively_implicited_attendant-ontological-contiguity ${ }^{67}$ ' educedexistentialising/contextualising/textualising_intelligibility/epistemicity/reflexivity-contiguity<imbued-notional cogency $>$ even as notable natural scientists as to their candid knowledgereification $\sim$ gesturing-and-accounting-of-epistemic-phenomenalism- $<$ inprospective_psychologismic apriorising/axiomatising/referencing-\{of-'prospectively implicited_attendant-ontological-contiguity ' educedexistentialising/contextualising/textualising_'intelligibility/epistemicity/reflexivity-contiguity<imbued-notional cogency $>$ ' \}-conflatedness -in-\{preconverging ment by\}

ostentergitment $>$ intuitions put in question such a naïve science-ideology hardly recognising the so-implied commonality of epistemic and methodological applications reflected by the naïve institutional-appendage of gatekeeping scientism such a naïve pedantising/muddling/formulaic-hollowing-out - in-subontologisation/subpotentiation〈blurring/undermining-of-prospective-totalising-entailing,-as-to-entailing$<$ amplituding/formative-epistemicity $>$ totalising in-relative-ontological-completeness projects as truly science and knowledge; and so, as its disparateness-of-conceptualisation$<$ unforegrounding-ment,-failing-prospectively-to-reflect-'immanent relativeunreflexivity/relative-reflexivity ontological-contiguity ' $>$ and desublimation/gimmickiness 
is poorly inclined as to its blurriness-<sterilising/anecdotalising/trivialising-of-prospective-reontologising_by-preconverging,-in-disontologising-formulaic-dragging-out/hollowing-out> to be critically exposed to the validative/invalidative sublimating-over-desublimating implications of existence-potency ${ }^{39} \sim$ sublimating-nascence,-disclosed-from-prospective-epistemicdigression (as it hardly recognises the epistemic pre-eminence of existence-as-the-absolute-apriori-of-conceptualisation and existence_-as-sublimating-withdrawal/unenframing/reontologising,-elicited-from-prospective-profound-supererogation $-<$ as-to-perspectiveontological-normalcy/postconvergence-implied-'prospective-aporeticismovercoming/unovercoming'> and the consequential 'relative-ontologicalincompleteness 8 /relative-ontological-completeness ${ }^{87}$ -

〈sublimating referencing/registering/decisioning,--as-self-becoming/self-

conflatedness /formative-supererogating-<projective/reprojective-aestheticising-re-motifand-re-apriorising/re-axiomatising/re-referencing,-in-perspective-ontologicalnormalcy/postconvergence $>>$ as to human-and-social-expectations/anticipationsmetaphoricity ${ }^{57}$-as-preconverging/postconverging-rede-

mentating/restructuring/reparadigming-psychologism' ${ }^{89}$ ), as its advancing of authority here is rather more seminal than the requisite confident knowledge-reification $\sim$ gesturing-andaccounting-of-epistemic-phenomenalism- $<$ in-

prospective_psychologismic apriorising/axiomatising/referencing-\{of-'prospectively implicited_attendant-ontological-contiguity ' educedexistentialising/contextualising/textualising_'intelligibility/epistemicity/reflexivity-contiguity<imbued-notional cogency >' \}-conflatedness -in-\{preconverging-ment by\} postconverging entailment $>$ and elucidation of true thought for justifying its deferentialformalisation-transference beyond its mere institutional-prescience/imprimaturing- $<$ dullnessof the-spirit/psychologismic epistemic-acutisation nonresidualising imbued- 
\{compulsing\} linearity in-eclecticism-of prior-mere-formulaicity/ritualisation $\geqslant$, and an 'alien exercise of supposed intellectualism' that fails to truly engage with critiques as it is surreptitiously involved in extra-intellectualism rather than reify and argue/prove/disprove speaking of a political development that can only undermine true human knowledgereification $\sim$ gesturing-and-accounting — of-epistemic-phenomenalism- $<$ inprospective_psychologismic apriorising/axiomatising/referencing-\{of-‘prospectively_ implicited_attendant-ontological-contiguity ' educedexistentialising/contextualising/textualising_'intelligibility/epistemicity/reflexivity-contiguity<imbued-notional cogency $>$ ' \}-conflatedness -in-\{preconverging ment by\}

postconverging entailment $>$ potential as all such posturing end up assuming a corresponding social-vestedness/normativity-<discretely-implied-functionalism $>$ role incapable of the requisite mental adventure for human consciousness sublimation as it is hardly bothered by the state-of-affairs of intellectual impotency it projects in the face of the conceptual and practical challenges of the social it construes as imponderable/inscrutable/unavoidable/inevitable/inescapable/unpreventable/unchangeable/in surmountable/unovercomable (explaining in-many-ways a pedantising/muddling/formulaic-hollowing-out — in-subontologisation/subpotentiation〈blurring/undermining-of-prospective-totalising-entailing,-as-to-entailing$<$ amplituding/formative-epistemicity $>$ totalising in-relative-ontological-completeness $>$ supposed conception of the end of history that fails to account for the fact that the 'end of any human minds' is not the end of the ecstatic-existence possibilities of human consciousness sublimation as to existence-potency ${ }^{32}$ sublimating-nascence,-disclosed-from-prospectiveepistemic-digression as so-effectively pointed out by Baudrillard), and as eventually the tool of the sophist is wielded as to a supposedly intellectual approach that increasingly overlooks true knowledge-reification $\sim$ gesturing-and-accounting — of-epistemic-phenomenalism- $<$ in- 
prospective_psychologismic apriorising/axiomatising/referencing-\{of-'prospectively_

implicited_attendant-ontological-contiguity ' educed-

existentialising/contextualising/textualising_'intelligibility/epistemicity/reflexivity-contiguity-

$<$ imbued-notional cogency >' \}-conflatedness -in-\{preconverging ment by\}

postconverging-entailment> work rather turning to the surreptitious eliciting of the $<$ amplituding/formative-epistemicity $>$ totalising $\sim$ self-referencing-

syncretising/circularity/interiorising/akrasiatic-drag ${ }^{34}$ of human temporality $8 /$ shortness

$<$ amplituding/formative $>$ wooden-language-_imbued - averaging-of-thought-<as-to-

leveling/ressentiment/closed-construct-of- meaningfulness-and-teleology -as-of-

'nondescript/ignorable-void '-with-regards-to-prospective-apriorising-implications $>>$ as it

hardly portrays the requisite dimensionality-of-sublimating 5 -

<<amplituding/formative>supererogatory $\sim$ de-mentativeness/epistemic-growth-or-

conflatedness /transvaluative-rationalising/transepistemicity/anamnestic-residuality/spirit-

drivenness-equalisation) as of human self-surpassing-existentialism-form-factor,-in-

overcoming-'notional collateralising-beholdening-protohumanity'-to-'attain-sublimating-

humanity'-as-to-existence-potency sublimating-nascence,-disclosed-from-prospective-

epistemic-digression, in a stance that is oblivious to the recurrent need for metaphoricity ${ }^{57}$-ofaestheticisation - as-of-'dimensionality-of-sublimating ${ }^{25}$ -

<<amplituding/formative>supererogatory $\sim$ de-mentativeness/epistemic-growth-or-

conflatedness /transvaluative-rationalising/transepistemicity/anamnestic-residuality/spirit-

drivenness-equalisation〉-totalising-entailing-instigation,-process,-and-outcome-of-re-

originariness-of-aestheticisation'-in-preserving-notional-contiguity/epistemic-contiguity ${ }^{62}$-by-

the-given-redefining-prospective-epistemic-digression-implications-as-to $\sim$ relative-

manreflexivelative reflexivity ontological-contiguity ${ }^{67}$ underlying the relativeunreflexivity/relative-reflexivity —ontological-contiguity ${ }^{67}$ of-the-human-institutionalisation- 
process ${ }^{68}$ with regards to the fact that as of 'their totalising-entailing instigating/process/outcome conception' defining/critical notions like democracy, independent press, human sovereignty, social emancipation, etc. are increasingly losing their sparkle in want for their prospective dimensionality-of-sublimating ${ }^{25}-<$ amplituding/formative $>$ supererogatory - dementativeness/epistemic-growth-or-conflatedness /transvaluativerationalising/transepistemicity/anamnestic-residuality/spirit-drivenness-equalisation $\rangle$ over the $<$ amplituding/formative $>$ wooden-language-〈imbued-temporal-mereform/virtualities/dereification/akrasiatic-drag/denatured/preconverging-or-dementing narratives - of-the- reference-of-thought- categorical-imperatives/axioms/registry$\begin{array}{llll}\text { teleology }>\text { now increasingly } & \text { inducing }\end{array}$ disenfranchisement/swindling/corruption/dispossession. But then the requisite human intellection sublimation from our positivism- ${ }^{8}$ procrypticism ${ }^{47}$ historicity-tracing-inpresencing-hyperrealisation/hyperreal-transposition (as from prospective ontologicalnormalcy/postconvergence notional ${ }^{1}$ deprocrypticism perspective) is reflected in the fact that the true prospect of the notional deprocrypticism imaginary/ideality as prospective historiality/ontological-eventfulness ${ }^{38} /$ ontological-aesthetic-tracing-<perspectiveontological-normalcy/postconvergence-reflected-‘epistemicity-relativism-determinism’> will effectively have to be as of a variedly sublimating-humanity that humankind could generate crossgenerationally by its dimensionality-of-sublimating ${ }^{25}$ <<amplituding/formative>supererogatery $\sim$ de-mentativeness/epistemic-growth-orconflatedness /transvaluative-rationalising/transepistemicity/anamnestic-residuality/spiritdrivenness-equalisation) ontological-faith-notion-or-ontological-fideism-imbuedunderdetermination-of-motif-and-apriorising/axiomatising/referencing-as-so-being-as-ofexistential-reality 'seeding promise of human-subpotency ontological-performance ${ }^{72}$ $<$ including-virtue-as-ontology $>/$ morality/ethics/justice/etc. equivalence/correspondence with 
the full-potency-of-existence's $\sim$ sublimating-nascence-as-of-its-coherence/contiguity' towards its potentiative-attainment of singularisation-<as-to-the-nondisjointedness/entailment-ofprospective- nonpresencing $>$ projected epistemic-immanence/veridical-epistemicityrelativism-determinism, and so construed as of 'ontologically-uncompromised-referentialism notional ${ }^{8}$ deprocrypticism emancipated apriorising/axiomatising/referencing/intelligibilitysettingup/measuringinstrumenting selfconsciousness' parrhesiastic askesis-or-acumen as of reasoning-through/messianic-reasoning'; as we can fathom that no singular minds in recurrent-utter-uninstitutionalisation could metaphoricitically generate the comprehensive imaginary/ideality for the human possibility of base-institutionalisation-ununiversalisation, and likewise for prospective ${ }^{103}$ universalisationnon-positivism-medievalism, likewise for prospective positivism- ${ }^{-}$procrypticism, and likewise for prospective deprocrypticism. Dimensionality can thus be construed as the more salient/critical/determining factor for the relative-unreflexivity/relative-reflexivity ontological-contiguity ${ }^{67}$ of-the-human-institutionalisation-process ${ }^{68} \quad{ }^{4}$ historiality/ontologicaleventfulness $3 \%$ ontological-aesthetic-tracing-<perspective-ontologicalnormalcy/postconvergence-reflected-'epistemicity-relativism-determinism'> of aestheticisation-and-aesthetheticisation-towards-ontology (as of human self-surpassingexistentialism-form-factor,-in-overcoming-'notional collateralising-beholdeningprotohumanity’-to- 'attain-sublimating-humanity'-as-to-existence-potency sublimatingnascence,-disclosed-from-prospective-epistemic-digression to supersede human temporality ${ }^{8} /$ shortness <amplituding/formative> $>$ wooden-language-_imbued-averaging-ofthought-<as-to-leveling/ressentiment/closed-construct-of- meaningfulness-and-teleology -asof-'nondescript/ignorable-void '-with-regards-to-prospective-apriorising-implications $>\rangle)$ ), as so reflected contrastively with dimensionality-of-sublimating 5 <<amplituding/formative>supererogatory $\sim$ de-mentativeness/epistemic-growth-or- 
conflatedness /transvaluative-rationalising/transepistemicity/anamnestic-residuality/spirit-

drivenness-equalisation $\rangle \quad$ and dimensionality-of-desublimating-lack-of

<<amplituding/formative >supererogatory-de-mentativeness/epistemic-growth-or-

conflatedness /transvaluative-rationalising/transepistemicity/anamnestic-residuality/spirit-

drivenness-equalisation); and so as this profound disambiguative elucidation of dimensionality in reflecting holographically-<conjugatively-and-transfusively $>$ the relativeunreflexivity/relative-reflexivity - ontological-contiguity of-the-human-institutionalisation-

process up to the prospective consciousness of notional ${ }^{18}$ deprocrypticism (as to our humansubpotency as to overall reifying-and-empowering-reflexivity-of-ecstatic-existence-aspanintelligibility/panreflexivity ${ }^{73}-\langle$ existentially-imbued-and-educing-<epistemic

thermeneutically/textually/reprojectingly/supererogatingly/zeroing/y/re-acutingly,\{decompusing $d$ dinearity $\sim$ for-cogency $\geq$-epistemic-perspective-of-projective/reprojectiveaestheticising-re-motif-and-re-apriorising/re-axiomatising/re-referencing conceptualisation,as-herein-specifically-relevant-to human-subpotency)) is thus bound to induce a more profound consciousness implied as of the notional ${ }^{1}$ deprocrypticism protensive-self-consciousness for overcoming dimensionality-of-desublimating-lack-of

\section{<<amplituding/formative>supererogatory $\sim$ de-mentativeness/epistemic-growth-or-}

conflatedness /transvaluative-rationalising/transepistemicity/anamnestic-residuality/spiritdrivenness-equalisation) as to a much more profound notional ${ }^{18}$ deprocrypticism imaginary/ideality projection (with regards to "varying psychologismic epistemic-acutisationdifficulty < for, residualising \{decompulsing\} delinearity for-cogency> magnitudes $\{$ ofexperientiality/experiment $\} /$ scales_-as-to-successively-profound-preconverging/postconverging-redementating/restructuring/reparadigming-frames-as-from-living,-institutionalising,-and-Beingontologising/infrastructure-of- meaningfulness-and-teleology 9 of prospective humansubpotency-aporia/undecidability/dilemma/ought- 
indeterminacy/deficiency/limitation/constraint—imbued-'notional firstnaturednessformativeness-<as-to-eventualising-inkling-drive or seeding misprising $>$ temporal-tointemporal-dispositions-<so-construed-as-from-perspective-ontologicalnormalcy/postconvergence>'-existentialism-form-factor'). This is very much in line with the idea that every registry-worldview/dimension certainly has a conceptualisation of the notion of progress but such a conceptualisation is naively grounded on its ${ }^{7}$ presencing-absolutisingidentitive-constitutedness $^{14}$ (as it engages in the complexification of ${ }^{56}$ meaningfulness-andteleology on the basis of its very same apriorising/axiomatising/referencing/intelligibilitysettingup/measuringinstrumenting it construes/reproduces as absolute) and fails to appreciate that it is rather by putting in question its supereregatory acuity/perspicacity/astuteness/edginess/incisiveness-ofapriorising/axiomatising/referencing/intelligibilitysettingup/measuringinstrumenting -forconceptualisation as of the apriorising/axiomatising/referencing-psychologism that it then aligns to existence-potency ${ }^{39} \sim$ sublimating-nascence,-disclosed-from-prospective-epistemicdigression; and so because the initiation by human limited-mentation-capacity-as-subjecting'educed-unlimitedness/existence-sublimating nascence' to-limitedness/human-subpotency of the acuity/perspicacity/astuteness/edginess/incisiveness-ofapriorising/axiomatising/referencing/intelligibilitysettingup/measuringinstrumenting -forconceptualisation to reflect ecstatic-existence is of limited ontological-performance ${ }^{72}$ $<$ including-virtue-as-ontology $>$ /morality/ethics/justice/etc. such that inherently the human should be able to anticipate the need for its limited-mentation-capacity-deepening-assubjecting limitedness/human-subpotency-to-'educed-unlimitedness/existence-sublimating anseence of as $^{3}$ re-motif-and-re-apriorising/re-axiomatising/re-referencing/reintelligibilitysettingup/re-measuringinstrumenting so-explaining dimensionality-ofsublimating $25<<$ amplituding/formative $>$ supererogatory $\sim$ de-mentativeness/epistemic-growth- 
or-conflatedness /transvaluative-rationalising/transepistemicity/anamnestic-residuality/spirit-

drivenness-equalisation $\rangle$, as if the human had absolute-mentation-capacity as falsely implied by presencing - absolutising-identitive-constitutedness ${ }^{14}$ inclinations the very first humans will not apriorise/axiomatise/reference ${ }^{56}$ meaningfulness-and-teleology ${ }^{9}$ as of recurrent-utteruninstitutionalisation but will directly attain prospective ${ }^{18}$ deprocrypticism-or-preemptingdisjointedness-as-of- ${ }^{8}$ reference-of-thought. In this regards, dimensionality-of-sublimating ${ }^{25}$ <<amplituding/formative>supererogatory $\sim$ de-mentativeness/epistemic-growth-or-

conflatedness /transvaluative-rationalising/transepistemicity/anamnestic-residuality/spiritdrivenness-equalisation> and dimensionality-of-desublimating-lack-of ${ }^{-}$<<amplituding/formative >supererogatory $\sim$ de-mentativeness/epistemic-growth-or-

conflatedness /transvaluative-rationalising/transepistemicity/anamnestic-residuality/spiritdrivenness-equalisation) are intimately related respectively to ontological-goodfaith/authenticity (enabling the possibility of human transcendence-andsublimity/sublimation/supererogatory $\sim$ de-mentativity) and ontological-badfaith/inauthenticity ${ }^{64}$ (assuming a desublimation/gimmickiness as to its perceived presencing social-stake-contention-or-confliction), and so beyond-the-consciousness-awarenessteleology $-<$ of-preconverging-existential-extrication-as-of-existential-unthought $>$.

Prospective notional $\sim$ deprocrypticism thus is a "projection beyond just about a deterministic supereracity/perspicacity/astuteness/edginess/incisiveness-ofapriorising/axiomatising/referencing/intelligibilitysettingup/measuringinstrumenting -forconceptualisation', but a fundamental grasp of the underlying dimensionality-of-sublimating <<amplituding/formative>supererogatory $\sim$ de-mentativeness/epistemic-growth-orconflatedness /transvaluative-rationalising/transepistemicity/anamnestic-residuality/spiritdrivenness-equalisation> and dimensionality-of-desublimating-lack-of ${ }^{-}$ <<amplituding/formative>supererogatory $\sim$ de-mentativeness/epistemic-growth-or- 
conflatedness /transvaluative-rationalising/transepistemicity/anamnestic-residuality/spirit-

drivenness-equalisation) implications in reflecting holographically-<conjugatively-andtransfusively $>$ the relative-unreflexivity/relative-reflexivity ontological-contiguity $\sim$ of-thehuman-institutionalisation-process (for prospective critical/decisive skewing towards dimensionality-of-sublimating 25 -< < amplituding/formative $>$ supererogatory $\sim$ de-

mentativeness/epistemic-growth-or-conflatedness /transvaluative-

rationalising/transepistemicity/anamnestic-residuality/spirit-drivenness-equalisation〉);

enabling 'organic attainment' of 'deprocrypticism-or-preempting-disjointedness-as-ofreference-of-thought (rather than a 'mechanical conception' which will unbeknownst still be subject to the same dimensionality-of-desublimating-lack-of <<amplituding/formative>supererogatory $\sim$ de-mentativeness/epistemic-growth-or-

conflatedness /transvaluative-rationalising/transepistemicity/anamnestic-residuality/spirit-

drivenness-equalisation), rather as to a mere and further complexification of our very same positivism/rational-empiricism manifestation of procrypticism-or-disjointedness-as-ofreference-of-thought). This is critical to broaden-the-latitude-of-human-collectiveconsciousness so-implied as of the sublimation possibilities enabled by dimensionality-ofsublimating $25-<$ amplituding/formative $>$ supererogatory $\sim$ de-mentativeness/epistemic-growthor-conflatedness /transvaluative-rationalising/transepistemicity/anamnestic-residuality/spiritdrivenness-equalisation) over the desublimation/gimmickiness of dimensionality-ofdesublimating-lack-of ${ }^{-}-\langle<$amplituding/formative $>$supererogatory $\sim$ de-mentativeness/epistemicgrowth-or-conflatedness /transvaluative-rationalising/transepistemicity/anamnestic-

residuality/spirit-drivenness-equalisation). Interestingly, human rememoration/historicalrecording is highly skewed towards the rememorising/recording of "transvaluative sublimatingoutcomes-of-institutionalisation' while overlooking the underlying 'recurrent mentalorientations involved contendingly as non-transvaluative/temporal and 
transvaluative/intemporal dispositons' in eventually producing the 'transvaluative sublimatingoutcomes-of-institutionalisation'. 'Fatedness-of-sublimation-over-desublimation, to existencepotency $\sim$ sublimating-nascence,-disclosed-from-prospective-epistemic-digression (in reflecting holographically-<conjugatively-and-transfusively $>$ the relative-unreflexivity/relativereflexivity - ontological-contiguity of-the-human-institutionalisation-process ), as from human-subpotency ontological-faith-notion-or-ontological-fideism - imbuedunderdetermination-of-motif-and-apriorising/axiomatising/referencing-as-so-being-as-ofexistential-reality as to the disseminative-sublimating-selectivity-of-ontological-goodfaith/authenticity postconverging-de-mentating/structuring/paradigming , over desublimating-deselectivity-of-ontological-bad-faith/inauthenticity -preconverging dementating/structuring/paradigming ', as the driver of the human-subpotency potentiating existential-<disontologising/re-ontologising aporeticism $>$ becoming manifestation of sublimating-over-desublimating social-and-institutional-constructs-of- - meaningfulness-andteleology - in-cumulation/recomposuring all along in reflecting holographically$<$ conjugatively-and-transfusively $>$ the relative-unreflexivity/relative-reflexivity - ontologicalcontiguity $\sim$ of-the-human-institutionalisation-process (with regards to existencepotency ${ }^{32} \sim$ sublimating-nascence,-disclosed-from-prospective-epistemic-digression); inherently implies that at any given registry-worldview/dimension, its 'transvaluative sublimatingoutcomes-of-institutionalisation' tend to be construed as instigated as of the prior underlying 'disseminative — sublimating-selectivity-of-ontological-good-

faith/authenticity $\sim$ postconverging-de-mentating/structuring/paradigming mentalorientation' inducing the institutionalisation while ultimately ignoring/blanking-out the prior 'disseminative- desublimating-deselectivity-of-ontological-bad-

faith/inauthenticity ${ }^{64}$ preconverging-de-mentating/structuring/paradigming ${ }^{65}$ mentalorientation'. The consequence of ignoring/blanking-out the prior 'disseminative- 
desublimating-deselectivity-of-ontological-bad-faith/inauthenticity $\sim$ preconverging-dementating/structuring/paradigming mental-orientation' is that with regards to prospective transcendental-enabling/sublimating/supererogatory de-mentativity sublimating-overdesublimating social-and-institutional-constructs-of- ${ }^{5}$ meaningfulness-and-teleology ${ }^{99}$-incumulation/recomposuring, dimensionality-of-sublimating

\section{<<amplituding/formative>supererogatory $\sim$ de-mentativeness/epistemic-growth-or-}

conflatedness /transvaluative-rationalising/transepistemicity/anamnestic-residuality/spiritdrivenness-equalisation) reflected in the 'disseminative-sublimating-selectivity-ofontological-good-faith/authenticity ${ }^{6} \sim$ postconverging-de-mentating/structuring/paradigming mental-orientation' is falsely implied as the all-encompassing social disposition (thus wrongly reflecting only an intemporal-disposition rather than the reality of notional firstnaturednessformativeness-<as-to-eventualising-inkling drive-or-seeding misprising $>$ temporal-tointemporal-dispositions- $<$ so-construed-as-from-perspective-ontologicalnormalcy/postconvergence $>$ ) while dimensionality-of-desublimating-lack-of ${ }^{-}$ <<amplituding/formative>supererogatory $\sim$ de-mentativeness/epistemic-growth-or-

\section{conflatedness /transvaluative-rationalising/transepistemicity/anamnestic-residuality/spirit-}

drivenness-equalisation) reflected in the 'disseminative-desublimating-deselectivity-ofontological-bad-faith/inauthenticity $\sim$ preconverging-de-mentating/structuring/paradigming mental-orientation' is unmemorated/unrecorded-and-unaccounted resulting in the prospectively induced 'lacking-in-transvaluation relation with the sublimating-outcomes-ofinstitutionalisation' (as to the ${ }^{83}$ reference-of-thought- categorical-imperatives/axioms/registryteleology ${ }^{9}$,-for-aposteriorising/logicising/deriving/intelligising/measuring- ${ }^{5}$ meaningfulnessand-teleology $\quad<$ amplituding/formative $>$ wooden-language-_imbued-temporal-mereform/virtualities/dereification/akrasiatic-drag/denatured/preconverging-or-dementing narratives - of-the- reference-of-thought- categorical-imperatives/axioms/registry- 
teleology $\rangle$ ), such that human ontological-bad-faith/inauthenticity ${ }^{64}$ (as to its lack of prospective dimensionality-of-sublimating $25<<$ amplituding/formative $>$ supererogatory $\sim$ dementativeness/epistemic-growth-or-conflatedness /transvaluativerationalising/transepistemicity/anamnestic-residuality/spirit-drivenness-equalisation〉) is again prospectively manifestable (beyond-the-consciousness-awareness-teleology ${ }^{9}-<$ ofpreconverging-existential-extrication-as-of-existential-unthought>) ) with respect to prospective human-subpotency-aporia/undecidability/dilemma/ought-

indeterminacy/deficiency/limitation/constraint (thus speaking of human-subpotencyaporia/undecidability/dilemma/ought-indeterminacy/deficiency/limitation/constraint—imbued'notional firstnaturedness-formativeness-<as-to-eventualising-inkling-drive-or-seedingmisprising $>$ temporal-to-intemporal-dispositions- $<$ so-construed-as-from-perspectiveontological-normalcy/postconvergence>'-existentialism-form-factor). Basically, dimensionality-of-desublimating-lack-of $-\langle<$ amplituding/formative $>$ supererogatory - dementativeness/epistemic-growth-or-conflatedness /transvaluativerationalising/transepistemicity/anamnestic-residuality/spirit-drivenness-equalisation $\rangle$ reflected in the 'disseminative - desublimating-deselectivity-of-ontological-badfaith/inauthenticity $\sim$ preconverging-de-mentating/structuring/paradigming ${ }^{65}$ mentalorientation' is more than just a question of ad-hocness and speaks to the recurrence in reflecting holographically-<conjugatively-and-transfusively $>$ the relative mreflexivitrelativereflexivity - ontological-contiguity of-the-human-institutionalisation-process $<$ cumulating/recomposuring attendant-ontological-contiguity $>$-successive registryworldviews/dimensions uninstitutionalised-threshold 02 implied notionaldiscontiguity/epistemic-discontiguity ${ }^{63}<$ shallow-supererogation ${ }^{6}$-of-mentallyaestheticised preconverging/dementing ${ }^{20}$-qualia-schema (as rather failing to attain prospective notional-contiguity/epistemic-contiguity ${ }^{62}-<$ profound-supererogation -of-mentally- 
aestheticised postconverging/dialectical-thinking -qualia-schema $>$ ), in reflecting prospective relative-unreflexivity/relative-reflexivity-ontological-contiguity ${ }^{67}$ as to imply that the 'dimensionality-of-desublimating-lack-of ${ }^{-}-\langle<$amplituding/formative $>$supererogatory $\sim$ dementativeness/epistemic-growth-or-conflatedness /transvaluativerationalising/transepistemicity/anamnestic-residuality/spirit-drivenness-equalisation〉 of recurrent-utter-uninstitutionalisation' $=$ the 'dimensionality-of-desublimating-lack-of ${ }^{2}$ <<amplituding/formative >supererogatory $\sim$ de-mentativeness/epistemic-growth-or-

conflatedness /transvaluative-rationalising/transepistemicity/anamnestic-residuality/spiritdrivenness-equalisation> of base-institutionalisation-ununiversalisation' = the 'dimensionalityof-desublimating-lack-of $-\langle<$ amplituding/formative $>$ supererogatory $\sim$ dementativeness/epistemic-growth-or-conflatedness /transvaluativerationalising/transepistemicity/anamnestic-residuality/spirit-drivenness-equalisation〉 of positivism- ${ }^{80}$ procrypticism'; so-construed as the 'dimensionality-of-desublimating-lack-of ${ }^{-}$<<amplituding/formative >supererogatery $\sim$ de-mentativeness/epistemic-growth-orconflatedness /transvaluative-rationalising/transepistemicity/anamnestic-residuality/spiritdrivenness-equalisation $\rangle$ of notional $\sim$ procrypticism/notional $\sim$ disjointedness-as-of- ${ }^{8}$ referenceof-thought dimensionality'. The bigger point in contrasting the relative reflexivity ontological-contiguity ${ }^{67} \sim$ of-the-human-institutionalisation-process ${ }^{6} \mathbf{s}^{\prime} \mathbf{s}$ dimensionality-of-sublimating $25<$ amplituding/formative $>$ supererogatory $\sim$ dementativeness/epistemic-growth-or-conflatedness /transvaluativerationalising/transepistemicity/anamnestic-residuality/spirit-drivenness-equalisation〉 (as of ontological-normalcy/postconvergence epistemic perspective in pestcenverging-nonextricatoryexistential-preempting-of-existential-unthought, as reflecting prospective notionalcontiguity/epistemic-contiguity ${ }^{2}<$ profound-supererogation -of-mentallyaestheticised postconverging/dialectical-thinking -qualia-schema>) and dimensionality-of- 
desublimating-lack-of $-<<$ amplituding/formative $>$ supererogatory $\sim$ de-mentativeness/epistemicgrowth-or-conflatedness /transvaluative-rationalising/transepistemicity/anamnestic-

residuality/spirit-drivenness-equalisation) (in preconverging-existential-extrication-as-ofexistential-unthought as of human-subpotency epistemic perspective, as it rather reflects prospective notional-discontiguity/epistemic-discontiguity ${ }^{63}<$ between - prior-shallowsupererogation -of-mentally-aestheticised preconverging/dementing -qualia-

schema_and_prospective-profound-supererogation -of-mentally-

aestheticised postconverging/dialectical-thinking -qualia-schema $>$ ) with regards to upholding/failing notional-contiguity/epistemic-contiguity ${ }^{2}-<$ profound-supererogation -ofmentally-aestheticised postconverging/dialectical-thinking -qualia-schema $>$ (as to existencepotency ${ }^{39} \sim$ sublimating-nascence,-disclosed-from-prospective-epistemic-digression),

effectively to reflect the idea that there is a more fundamental dimensionality issue involved in all human social-stake-contention-or-confliction in reflecting holographically-<conjugativelyand-transfusively $>$ the relative-unreflexivity/relative-reflexivity - ontological-contiguity ofthe-human-institutionalisation-process (and particularly as it bears upon prospective notional ${ }^{18}$ deprocrypticism as the ultimate preconverging/postconverging-dementative/structural/paradigmatic issue with regards to addressing prospective humansubpotency-aporia/undecidability/dilemma/ought-

indeterminacy/deficiency/limitation/constraint). This dimensionality issue in reflecting holographically-<conjugatively-and-transfusively $>$ the relative-unreflexivity/relativereflexivity - ontological-contiguity of-the-human-institutionalisation-process can be reflected in the recurrent variance of 'dimensionality-of-desublimating-lack-of' <<amplituding/formative>supererogatory $\sim$ de-mentativeness/epistemic-growth-orconflatedness /transvaluative-rationalising/transepistemicity/anamnestic-residuality/spiritdrivenness-equalisation> and dimensionality-of-sublimating ${ }^{25}$ - 
<<amplituding/formative>supererogatory $\sim$ de-mentativeness/epistemic-growth-or-

conflatedness /transvaluative-rationalising/transepistemicity/anamnestic-residuality/spirit-

drivenness-equalisation)'; as implied contrastively say with the-sophists/medieval-scholastics lack-of-dimensionality-of-sublimating ${ }^{25}-\langle<$ amplituding/formative $>$ supererogatory $\sim$ dementativeness/epistemic-growth-or-conflatedness /transvaluative-

rationalising/transepistemicity/anamnestic-residuality/spirit-drivenness-equalisation〉 and Socratic-philosophers/budding-positivists dimensionality-of-sublimating ${ }^{25}$ <<amplituding/formative>supererogatory $\sim$ de-mentativeness/epistemic-growth-orconflatedness /transvaluative-rationalising/transepistemicity/anamnestic-residuality/spiritdrivenness-equalisation〉 as reflected say in an ordinary non-universalising/non-positivismmedievalism world inclined to construe of its 'normality' (notional-contiguity/epistemiccontiguity ${ }^{62}<$ profound-supererogation - of-mentally-aestheticised $\sim$ postconverging/dialecticalthinking -qualia-schema>) as given even in the face of its prospectively implied 'abnormality' (notional-discontiguity/epistemic-discontiguity ${ }^{3}$ - $<$ between - prior-shallow-supererogation of-mentally-aestheticised preconverging/dementing -qualia-schema_and prospectiveprofound-supererogation -of-mentally-aestheticised postconverging/dialectical-thinking qualia-schema $>$ ) from the projected ${ }^{103}$ universalising-idealisation/rational-empiricism implications. This reality is equally applicable to our state of positivism- - procrypticism as to a disinclination to perceive its prospectively implied 'abnormality' (notionaldiscontiguity/epistemic-discontiguity ${ }^{63}<$ between - prior-shallow-supererogation -ofmentally-aestheticised preconverging/dementing -qualia-schema_and_prospective-profoundsupererogation -of-mentally-aestheticised postconverging/dialectical-thinking -qualiaschema $>$ ) as projected from prospective ${ }^{18}$ deprocrypticism-or-preempting-disjointedness-asof- reference-of-thought. In-many-ways, as of reproducibility-mathesis/motif/thrownnessdisposition,-as-reproducibility-of-aestheticisation, this paradox is inevitable as the very state of 
recurrent-utter-uninstitutionalisation do not have the directly operant means as to its apriorising/axiomatising/referencing-psychologism to project of the <amplituding/formativeepistemicity $>$ causality $\sim$ as-to-projective-totalitative-implications-of-prospectivenonpresencing,-for-explicating relative-unreflexivity/relative-reflexivity - ontologicalcontiguity of prospective base-institutionalisation-ununiversalisation, just as the latter with prospective ${ }^{103}$ universalisation-non-positivism/medievalism, likewise the latter with prospective positivism- ${ }^{80}$ procrypticism, and likewise our positivism- ${ }^{80}$ procrypticism with prospective deprocrypticism. This emphasis is made rather to point to the <amplituding/formativeepistemicity $>$ totalising $\sim$ self-referencing-syncretising/circularity/interiorising/akrasiatic-drag underlying the supposed projection of intellection on the basis of dimensionality-ofdesublimating-lack-of ${ }^{-}$-<<amplituding/formative $>$supererogatory $\sim$ de-mentativeness/epistemicgrowth-or-conflatedness /transvaluative-rationalising/transepistemicity/anamnesticresiduality/spirit-drivenness-equalisation) (in preconverging-existential-extrication-as-ofexistential-unthought as of human-subpotency epistemic perspective, as it rather reflects prospective notional-discontiguity/epistemic-discontiguity ${ }^{63}<$ between $^{-}$prior-shallowsupererogation -of-mentally-aestheticised preconverging/dementing -qualiaschema_and_prospective-profound-supererogation -of-mentallyaestheticised postconverging/dialectical-thinking -qualia-schema $>$ ); as reflected in the fact that the supposed intellection of the non-universalising sophists, the medieval-scholastics and our present pedantising/muddling/formulaic-hollowing-out —insubontologisation/subpotentiation-〈blurring/undermining-of-prospective-totalising-entailing,as-to-entailing-<amplituding/formative-epistemicity $>$ totalising $\sim$ in-relative-ontologicalcompleteness > ends up in gimmickiness-of-thought (poorly-constrained or unconstrained to existence-potency ${ }^{39} \sim$ sublimating-nascence,-disclosed-from-prospective-epistemic-digression) skewing towards an exercise of eliciting human temporality $\% /$ shortness 
$<$ amplituding/formative $>$ wooden-language-<imbued — averaging-of-thought-<as-to-

leveling/ressentiment/closed-construct-of- meaningfulness-and-teleology -as-of-

'nondescript/ignorable-void '-with-regards-to-prospective-apriorising-implications $>>\quad$ with

respect to social-stake-contention-or-confliction rather than true knowledgereification $\sim$ gesturing-and-accounting — of-epistemic-phenomenalism- $<$ in-

prospective_psychologismic apriorising/axiomatising/referencing-\{of-" prospectively

implicited_attendant-ontological-contiguity ' educed-

existentialising/contextualising/textualising_'intelligibility/epistemicity/reflexivity-contiguity-

<imbued-notional cogency >' \}-conflatedness -in-\{preconverging-ment by\}

pesteonverging entailment $>$ and human emancipating conception that faces prospective humansubpotency-aporia/undecidability/dilemma/ought-

indeterminacy/deficiency/limitation/constraint with the requisite dispensing-with-immediacyfor-relative-ontological-completeness ${ }^{87}$-by-reification/contemplative-distension ${ }^{27}$ (as of human self-surpassing-existentialism-form-factor,-in-overcoming-'notional collateralising-

beholdening-protohumanity'-to-'attain-sublimating-humanity'-as-to-existence-

potency $\sim$ sublimating-nascence,-disclosed-from-prospective-epistemic-digression

supersede human temporality $/$ shortness <amplituding/formative $>$ wooden-language〈imbued-averaging-of-thought-<as-to-leveling/ressentiment/closed-construct-ofmeaningfulness-and-teleology -as-of-‘nondescript/ignorable-void '-with-regards-toprospective-apriorising-implications $>\rangle)$. In this regards, this author construes such gimmicky pretences of intellection in our modern-day rather 'intimating of preconverging-existentialextrication-as-of-existential-unthought as of human-subpotency epistemic perspective' with regards to otherwise preconverging/postconverging-de-mentative/structural/paradigmatic human-subpotency-aporia/undecidability/dilemma/ought-

indeterminacy/deficiency/limitation/constraint issues (requiring the ontological- 
normalcy/postconvergence epistemic perspective in postconverging-nonextricatory-existentialpreempting-of-existential-unthought), which articulation and constructive addressing should actually be the very conceptualisation of intellection. In this regards, we can appreciate that the Socratic-philosophers and budding-positivists actually addressed and resolved the humansubpotency-aporia/undecidability/dilemma/ought-

indeterminacy/deficiency/limitation/constraint of their respective times as of sublimating intellectualism (as of ontological-normalcy/postconvergence epistemic perspective in postconverging-nonextricatory-existential-preempting-of-existential-unthought, involving a sense of intellectual-and-moral sacrifice as to the pre-eminence of ecstatic-existence implications as to existence-potency ${ }^{32} \sim$ sublimating-nascence,-disclosed-from-prospectiveepistemic-digression) undermining their respective gimmickiness-of-thought (in preconvergingexistential-extrication-as-of-existential-unthought as of human-subpotency epistemic perspective) associated with sophists and medieval-scholastics then respectively defining the 'thought/intellectual Establishment', and that the possibility for such sublimating intellectualism as to its crude and unsavoury social discomfort implications is hardly a question of eliciting human temporality $/$ shortness <amplituding/formative $>$ wooden-language-〈imbued averaging-of-thought-<as-to-leveling/ressentiment/closed-construct-of- meaningfulness-andteleology -as-of-'nondescript/ignorable-void '-with-regards-to-prospective-apriorisingimplications $>$ a of moral and intellectual disenfranchisement/swindling/corruption/dispossession. In-the-bigger-scheme-of-things dimensionality-of-sublimating $-<<$ amplituding/formative $>$ supererogatory $\sim$ dementativeness/epistemic-growth-or-conflatedness /transvaluativerationalising/transepistemicity/anamnestic-residuality/spirit-drivenness-equalisation〉 warrants that the prospective projection of any human ${ }^{56}$ meaningfulness-and-teleology ${ }^{9}$ as transcendental-enabling/sublimating/supererogatory $\sim$ de-mentativity should be articulated in 
such a way as to imply that all human ${ }^{56}$ meaningfulness-and-teleology ${ }^{9}$ should assume the same disposition as to the possibility of enabling the sublimation in reflecting holographically$<$ conjugatively-and-transfusively $>$ the relative-unreflexivity/relative-reflexivity - ontologicalcontiguity of-the-human-institutionalisation-process ; such that 'supposed reifying' meaningfulness-and-teleology in preconverging-existential-extrication-as-of-existentialunthought as of human-subpotency epistemic perspective effectively comes out as epistemicallydecadent and in ontological-bad-faith/inauthenticity $\sim$ preconverging-dementating/structuring/paradigming ${ }^{5}$, as to the fact that in the face of human-subpotencyaporia/undecidability/dilemma/ought-indeterminacy/deficiency/limitation/constraint, if no human minds projected not of postconverging-nonextricatory-existential-preempting-ofexistential-unthought (eliciting the possibility for the relative-unreflexivity/relativereflexivity - ontological-contiguity ${ }^{67} \sim$ of-the-human-institutionalisation-process ${ }^{6}$ ) but rather preconverging-existential-extrication-as-of-existential-unthought (undermining the possibility for the relative-unreflexivity/relative-reflexivity - ontological-contiguity ${ }^{67}$ of-the-humaninstitutionalisation-process $^{68}$ ) in recurrent-utter-uninstitutionalisation, in baseinstitutionalisation-ununiversalisation, in ${ }^{103}$ universalisation-non-positivism/medievalism and prospectively in our positivism- ${ }^{80}$ procrypticism, then the preconverging/postconverging-dementative/structural/paradigmatic possibilities in reflecting holographically-<conjugativelyand-transfusively $>$ the relative-unreflexivity/relative-reflexivity - ontological-contiguity ofthe-human-institutionalisation-process wouldn't be possibile. Such ${ }^{56}$ meaningfulness-andteleology ${ }^{9}$ in preconverging-existential-extrication-as-of-existential-unthought as of humansubpotency epistemic perspective as to dimensionality-of-desublimating-lack-of ${ }^{-}$ <<amplituding/formative>supererogatory $\sim$ de-mentativeness/epistemic-growth-orconflatedness /transvaluative-rationalising/transepistemicity/anamnestic-residuality/spiritdrivenness-equalisation) rather speaks of a parasitising conception of intellection that warrants 
that by some miracle the possibility of human sublimation induced as of dispensing-withimmediacy-for-relative-ontological-completeness ${ }^{8}$-by-reification/contemplative-distension should arise, for that sublimation to be then parasitised with gimmickiness-of-thought as to social-stake-contention-or-confliction eliciting of human temporality $/$ shortness $<$ amplituding/formative $>$ wooden-language-〈imbued - averaging-of-thought- $<$ as-toleveling/ressentiment/closed-construct-of- meaningfulness-and-teleology -as-of'nondescript/ignorable-void ' -with-regards-to-prospective-apriorising-implications $>$ 〉. Inmany-ways, this dimensionality-of-desublimating-lack-of ${ }^{-}$ <<amplituding/formative>supererogatory $\sim$ de-mentativeness/epistemic-growth-orconflatedness /transvaluative-rationalising/transepistemicity/anamnestic-residuality/spiritdrivenness-equalisation) explains a poor inclination-or-capacity to effectively interpret the projected ${ }^{56}$ meaningfulness-and-teleology ${ }^{9}$ of many a past thinker as to ${ }^{79}$ presencingabsolutising-identitive-constitutedness ${ }^{14}$ institutional and social-vestedness/normativity$<$ discretely-implied-functionalism $>\quad<$ emplitedingformative-epistemicity $>$ totalising $\sim$ selfreferencing-syncretising/circularity/interiorising/akrasiatic-drag ${ }^{34}$ that naively think that being at the backend in reflecting holographically-<conjugatively-and-transfusively $>$ the relativeunreflexivity/relative-reflexivity - ontological-contiguity of-the-human-institutionalisationprocess inherently grants epistemic-profundity (not factoring that this is not necessarily the case with overall existence beholden frameworks which can actually suffer intellectual regression) unlike the case with epiphenomena as in the science domains (as providing the prolongation for human interpretation capacity with respect to epiphenomenal manifestations outside ordinary existential-<disontologising/re-ontologising aporeticism $>$ sublimation manifestations). In this regards, we can appreciate that the strong predictive constraining in many a natural science domain (as strongly constrained to existence-potency ${ }^{39} \sim$ sublimatingnascence,-disclosed-from-prospective-epistemic-digression) induces the manifestation of 
sublimating thought as from induced requisite 're-ontologising \{epistemic-totalising 'reapriorising/re-axiomatising/re-referencing-residuality in-re-originariness/re-origination \{decompulsingt delinearity/delinear-accreting/recomposuring cogency/tensing/limpidity-<as-ofprospective-profound-supererogation ,-for-residuality-in-re-originariness/reorigination>-,prospective_reifying mental-aestheticising_<as-of-'prospective_reformulating of-mental-aestheticising'as-to-'residuality in re-originariness/re-origination' of-mentalaestheticising $>$ of knowledge-reification $\sim$ gesturing-and-accounting-of-epistemicphenomenalism- $<$ in-prospective_psychologismic $\sim$ apriorising/axiomatising/referencing- of'prospectively_implicited_attendant-ontological-contiguity ' ceducedexistentialising/contextualising/textualising_'intelligibility/epistemicity/reflexivity-contiguity$<$ imbued-notional cogency $>$ ' $\}$-conflatedness -in-\{preconverging-ment by\} postconverging-ntailment $>$ (as of ontological-normalcy/postconvergence epistemic perspective in pestconverging-nonextricatory-existential-preempting-of-existential-unthought) unlike is the case in many a blurry domain highly subjected to sterile/anecdotal imprimatur totalisingly-ingdiscretion/whim-of-thought as to poor deferential-formalisation-transference justification as often in the social not the least bothered about the overall 're-ontologising fepistemic-totalising ${ }^{\prime}$ reapriorising/re axiomatising/re referencing residuality in re originariness/re origination \{decompulsing $\}$ delinearity/delinear-accreting/recomposuring $\quad$ cogency/tensing/limpidity-<as-ofprospective-profound-supererogation ,-for-residuality-in-re-originariness/reorigination>-_prospective_reifying mental-aestheticising-<as-of 'prospective_reformulating ef-mental-aestheticising'as-to-residuality in -re-originariness/re-origination' of -mentalaestheticising $>$ ' of projected knowledge-reification $\sim$ gesturing-and-accounting-of-epistemicphenomenalism- $<$ in-prospective_psychologismic $\sim$ apriorising/axiomatising/referencing- of'prospectively_implicited_attendant-ontological-contiguity ' ceducedexistentialising/contextualising/textualising_'intelligibility/epistemicity/reflexivity-contiguity- 
postconverging-entailment $>$ (thus rather tending towards preconverging-existential-extricationas-of-existential-unthought as of human-subpotency epistemic perspective). We can consider in this regards how authority actually serves its true deferential-formalisation-transference role quickly gives to prospective possibilities of sublimating knowledge-reification $\sim$ gesturing-andaccounting - of-epistemic-phenomenalism- $<$ in-

prospective_psychologismic $\sim$ apriorising/axiomatising/referencing-\{of-'prospectively implicited_attendant-ontological-contiguity ' educedexistentialising/contextualising/textualising_ 'intelligibility/epistemicity/reflexivity-contiguity<imbued-notional cogency $>$ ' \}-conflatedness -in-\{preconverging -ment by\} postconverging-entailment> wherein for instance in the physics domain-of-study at the beginning of the $20^{\text {th }}$ century the eminent physicists from say the cohorts of the Poincarés, the Einsteins, the Bohrs, the Feynmans, etc. successively passing on the baton (as to existencepotency $^{32} \sim$ sublimating-nascence,-disclosed-from-prospective-epistemic-digression), $\quad$ as $\quad$ of ontological-normalcy/postconvergence epistemic perspective in postconverging-nonextricatoryexistential-preempting-of-existential-unthought; whereas in many a blurry domain-of-study, disparateness-of-conceptualisation-<unforegrounding-ment,-failing-prospectively-to-reflect‘immanent relative-unreflexivity/relative-reflexivity - ontological-contiguity ' $>$ tend to be the order of the day often assuming a quasi-political strategic orientation as to gimmickiness-ofthought as of preconverging-existential-extrication-as-of-existential-unthought postures (poorly appreciating the profound knowledge-reification $\sim$ gesturing-and-accounting-of-epistemicphenomenalism- $<$ in-prospective_psychologismic $\sim$ apriorising/axiomatising/referencing-\{of'prospectively implicited_attendant-ontological-contiguity ' ceducedexistentialising/contextualising/textualising_'intelligibility/epistemicity/reflexivity-contiguity<imbued-notional cogency>' \}-conflatedness -in-\{preconverging-ment by\} 
postconverging-entailment> sublimating-over-desublimating implications of existencepotency $^{39} \sim$ sublimating-nascence,-disclosed-from-prospective-epistemic-digression) as to the fact that the human mortal whim/discretion-of-thought projected as aura-and-sterile/anecdotal imprimatur comes to be enshrined as being bigger than ecstatic-existence preconverging/postconverging-de-mentative/structural/paradigmatic implications. In-manyways (unlike is the case with the natural sciences directly constrained to ecstatic-existence predicative-effectivity-sublimation-〈as-to-underlying,-ontological-commitment ${ }_{-<\text {implied }}$ self-assuredness-of-ontological-good-faith/authenticity postconverging-dementating/structuring/paradigming -as-being-as-of-existential-reality $>>$ induced constraining conceptivity/epistemic-reflexivity/epistemicity-relativism-determinism- $<$ reifying \{as-toknowledge-developing\}-and-empowering $>$ imbued theoretical/conceptual/operant implications undermining human-subpotency totalisingly-ing — discretion/whim-of-thought), many a blurry domain-of-study tend to be inclined to conceptualise flawed prior_knowledgereification $\sim$ gesturing-and-accounting — of-epistemic-phenomenalism- $<$ inprior_psychologismic $\sim$ apriorising/axiomatising/referencing-\{of-'prior-implicited_attendantontological-contiguity ' educedexistentialising/contextualising/textualising_'intelligibility/epistemicity/reflexivity_contiguity<imbued-notional cogency>' $\}$-constitutedness -in-preconverging-entailment> $>$ as of elaboration-as-to-mere-extrapolating/constituting/abstracting/deducing/inferring-ofelucidation-outside_-'prospectively_implicited_attendant-ontological-contiguity ${ }^{67}$, educedexistentialising/contextualising/textualising_ 'intelligibility/epistemicity/reflexivity-contiguity$<$ imbued-notional cogency $>$ ' without the defining '<amplituding/formativeepistemicity>totalising/circumscribing/delineating 'implicited_attendant-ontologicalcontiguity ${ }^{67} \sim$ educedexistentialising/contextualising/textualising_'intelligibility/epistemicity/reflexivity-contiguity- 
$<$ imbued-notional $\sim$ cogency $>{ }^{40} \quad{ }^{45}$ foregrounding_entailment- $<$ in-succession-of-profoundsupererogation $>$-〈postconverging-narrowing-down $\sim$ sublimation-as-to-'existence-assublimating-withdrawal/unenframing/re-ontologising,-elicited-from-prospective-profoundsupererogation '-in-reflecting-'immanent relative-unreflexivity/relative-reflexivity ontological-contiguity ';-as-operative-notional deprocrypticism> in elucidating relativeunreflexivity/relative-reflexivity — ontological-contiguity ${ }^{67}<$ as-from-prospective-ontologicalnormalcy/postconvergence-epistemic-or-notional projective-perspective $>$ ' as to the lack or poor predicative-effectivity-sublimation-〈as-to-underlying,-ontological-commitment $<$ implied - self-assuredness-of-ontological-good-faith/authenticity $\sim$ postconverging-dementating/structuring/paradigming -as-being-as-of-existential-reality $>>$ induced constraining conceptivity/epistemic-reflexivity/epistemicity-relativism-determinism- $<$ reifying \{as-toknowledge-developing $\}$-and-empowering $>$ imbued theoretical/conceptual/operant implications leading to a social-vestedness/normativity-<discretely-implied-functionalism $>$ reflex rather than ontological elucidation reflex. Such an approach is often projected contradictorily as methodologically emulating the natural sciences on-the-one-hand but on-the-other-hand implying that the knowledge-reification $\sim$ gesturing-and-accounting-of-epistemicphenomenalism- $<$ in-prospective_psychologismic $\sim$ apriorising/axiomatising/referencing-\{of'prospectively_implicited_attendant-ontological-contiguity ' ceducedexistentialising/contextualising/textualising_ 'intelligibility/epistemicity/reflexivity-contiguity<imbued-notional cogency>' \}-conflatedness in \{preconverging ment by\} postconverging entailment $>$ implications for the social are different as to the supposedly nonmetaphysical (as non-ontological) nature of the social and cultural; failing to grasp/intuit that there can't be any such thing as non-ontological as 'all that there is' is ontological, as existence is effectively all that there is and it is rather a question of the specific human-subpotency with regards to overall reifying-and-empowering-reflexivity-of-ecstatic-existence-as- 
panintelligibility/panreflexivity ${ }^{3}-\langle$ existentially-imbued-and-educing-<epistemic-

thermeneutically/textually/reprojectingly/supererogatingly/zeroingly/re-acutingly,-

${ }_{\{d \text { ecompulsing\} }}$ delinearity $\sim$ for-cogency $\geq$-epistemic-perspective-of-projective/reprojective-

aestheticising-re-motif-and-re-apriorising/re-axiomatising/re-referencing conceptualisation,-

as-herein-specifically-relevant-to human-subpotency) to epistemically come to terms with the absolute a-priori that is existence as the ontological as to the overall-ecstatic-existencesupervening-conflatedness ${ }^{13}$. Furthermore, the 'social and cultural is rather priorly constrained to the ontological' with regards to the fact that 'scientific and technical capabilities and their implicited socio-organisational and value-referencing construct' as to their inherent human reifying and empowering notional reflexivity-<\{veridieal/sound $\}$ relative-reflexivity-in-

\section{existence/relativising from-limited-mentation-as-its-deepening/psychologismic-}

<residualising \{decompulsing $\}$ delinearity for-cogency>-by-\{flawed/unsound\}-relative-

unreflexivity-in-existencelabsolutising from-limited-mentation/psychologismic epistemic -

acutisation nonresidualising imbued-\{compulsing\} linearity in-eclecticism-of prior-mere-

formulaicity/ritualisation> implications, speaking of the ontological, are not necessarily ontologically-tied-to and/or ontologically-exclusive-of any social and cultural framework or peoples (in the sense that scientific and technical phenomena like electricity, machines, modern medicine, etc., their enabling social utilities/utilisations, and the value/moral outlook of the underlying positivism/rational-empiricism conceptualisations like provision of modern public services, associated freedoms, prospective knowledge-reification gesturing-and-accountingof-epistemic-phenomenalism- $<$ in-

prospective_psychologismic apriorising/axiomatising/referencing-\{of-'prospectively implicited_attendant-ontological-contiguity ' educedexistentialising/contextualising/textualising_ 'intelligibility/epistemicity/reflexivity-contiguity<imbued-notional cogency>’ \}-conflatedness - in-\{preconverging ment by\} 
postconverging-entailment $>$ and empowering implications, etc. are not strictly meant for given specific social and cultural frameworks, and are rather amenable to all human social and cultural frameworks with regards to 'relative-ontological-incompleteness $8 /$ relative-ontologicalcompleteness 8 -_sublimating referencing/registering/decisioning,-as-self-becoming/selfconflatedness /formative-supererogating-<projective/reprojective-aestheticising-re-motifand-re-apriorising/re-axiomatising/re-referencing,-in-perspective-ontologicalnormalcy/postconvergence $>>$ as to human-and-social-expectations/anticipationsmetaphoricity ${ }^{57}$-as-preconverging/postconverging-rede-

mentating/restructuring/reparadigming-psychologism' ${ }^{89}$ as to 'enlightening ${ }^{4}$ human-subjectemancipating-relativism-driven-recomposuring-constructivism-towards-singularisation- $<$ as-tothe-nondisjointedness/entailment-of-prospective- nonpresencing $>{ }^{\prime}{ }^{\prime}$ ); as the ontological inherently permeates all social and cultural frameworks so-reflected as of their underlying supposedly coherent ontological-commitment $-<$ implied - self-assuredness-of-ontologicalgood-faith/authenticity postconverging-de-mentating/structuring/paradigming -as-beingas-of-existential-reality $>$ thus inducing the possibility for prospective transcendence-andsublimity/sublimation/supererogatory-de-mentativity when any of its given ${ }^{56}$ meaningfulnessand-teleology ${ }^{9}$ is discovered/shown not to be ontologically veridical leading to its effective human limited-mentation-capacity-deepening —as-subjecting limitedness/human-subpotencyto-'educed-unlimitedness/existence-sublimating nascence' . Such that all human social or cultural frameworks are construable as of 'relative-ontological-incompleteness $8 /$ relativeontological-completeness ${ }^{8}$-〈sublimating $\sim$ referencing/registering/decisioning,--as-selfbecoming/self-conflatedness /formative-supererogating-<projective/reprojectiveaestheticising-re-motif-and-re-apriorising/re-axiomatising/re-referencing,-in-perspectiveontological-normalcy/postconvergence $>\rangle$ as to human-and-social-expectations/anticipationsmetaphoricity ${ }^{57}$-as-preconverging/postconverging-rede- 
mentating/restructuring/reparadigming-psychologism' ${ }^{89}$ as to 'enlightening "human-subjectemancipating-relativism-driven-recomposuring-constructivism-towards-singularisation- $<$ as-tothe-nondisjointedness/entailment-of-prospective- nonpresencing ' '; and the idea of such 'relative-ontological-incompleteness 8 /relative-ontological-completeness 3 ' 〈sublimating $\sim$ referencing/registering/decisioning,-as-self-becoming/selfconflatedness /formative-supererogating-<projective/reprojective-aestheticising-re-motifand-re-apriorising/re-axiomatising/re-referencing,-in-perspective-ontologicalnormalcy/postconvergence $>>$ as to human-and-social-expectations/anticipationsmetaphoricity ${ }^{5}$-as-preconverging/postconverging-redementating/restructuring/reparadigming-psychologism' ${ }^{89}$ is not about the subjugation of the state of relative-ontological-incompleteness ${ }^{8}$ but quite the contrary as the state of relativeontological-completeness ${ }^{87}$ (as to its true human self-surpassing-existentialism-form-factor,in-overcoming-'notional collateralising-beholdening-protohumanity'-to-' attain-sublimatinghumanity'-as-to-existence-potency sublimating-nascence,-disclosed-from-prospectiveepistemic-digression to supersede human temporality $/$ shortness $<$ amplituding/formative $>$ wooden-language-_imbued — averaging-of-thought-<as-toleveling/ressentiment/closed-construct-of- meaningfulness-and-teleology -as-of'nondescript/ignorable-void '-with-regards-to-prospective-apriorising-implications $>\rangle)$ implies an 'emancipating attitude/mental-disposition/care-and-episteme' ' in relation to the 'other' that is in the state of relative-ontological-incompleteness ${ }^{8}$. Interpreting the historical failures associated with colonising or slaving or otherwise-exploitative-or-exterminating societies (as in the specific case of positivism/rational-empiricism technical and scientific development it inevitably implied the coming-together/encountering/meeting of societies worldwide), to then imply such a notion of 'relative-ontological-incompleteness $8 /$ relative-ontologicalcompleteness ${ }^{8}$-〈sublimating $\sim$ referencing/registering/decisioning,-as-self-becoming/self- 
conflatedness /formative-supererogating-<projective/reprojective-aestheticising-re-motifand-re-apriorising/re-axiomatising/re-referencing,-in-perspective-ontologicalnormalcy/postconvergence $>>\quad$ as $\quad$ to human-and-social-expectations/anticipationsmetaphoricity ${ }^{57}$-as-preconverging/postconverging-redementating/restructuring/reparadigming-psychologism' ${ }^{89}$ is irrelevant is rather a nuancing error that fails to assess/evaluate that the more critical issue had to do with the 'appropriate emancipating attitude/mental-disposition/care-and-episteme ' as effectively and paradoxically such a lack of nuancing can then lead to the interpretation that such historical failures should equally be the unavoidable expectation prospectively in analogous circumstances of sociocultural disparity of societies, rather than interpreted to mean the prospective need for the requisite human knowledge-reifying and empowering notional $\sim$ reflexivity $-<\{$ veridical $/$ sound $\}$ relative-reflexivity-in-existence/relativising from-limited-mentation-as-itsdeepening/psychologismic-<residualising fdecompulsingt delinearity for-cogency $>$ by \{flawed/unsound\}-relative-unreflexivity-in-existence/absolutising from-limitedmentation/psychologismic epistemic acutisation nonresidualising imbued\{compulsing\} linearity in-eclecticism-of prior-mere-formulaicity/ritualisation $>$ of appropriate human emancipating attitude/mental-disposition/care-and-episteme in the relationship between the state of relative-ontological-completeness ${ }^{87}$ and the state of relative-ontologicalincompleteness 8 . Such a wrong interpretation arises as to lack-of $-3<$ amplituding/formativeepistemicity $>$ growth-or-conflatedness ${ }^{13} /$ transvaluative-

rationalising/transepistemicity/anamnestic-residuality/spirit-drivenness (reflecting mere reproducibility—mathesis/motif/thrownness-disposition,-as-reproducibility-ofaestheticisation) that fails to make a nuance between on-the-one-hand ${ }^{4}$ historicity-tracing-inpresencing-hyperrealisation/hyperreal-transposition implications as to the 'human socialvestedness/normativity-<discretely-implied-functionalism $>\quad$ implied contract/political- 
arrangement-or-political-coercion/given-discrete-social-value-construction presencingabsolutising-identitive-constitutedness ${ }^{14}$ identitive-constitutedness ${ }^{14}$-as- 'epistemic-totality ${ }^{37}$ 'dereification-in-dissingularisation- $<$ as-to-the-disjointedness/ment-of- presencingabsolutising-identitive-constitutedness $>$-as-flawed-epistemicity-relativism-determinism in $<$ amplituding/formative-epistemicity $>$ totalising $\sim$ self-referencingsyncretising/circularity/interiorising/akrasiatic-drag ${ }^{34}$ ' explaining the historical failures and onthe-other-hand $\quad{ }^{4}$ historiality/ontological-eventfulness ${ }^{3} /$ ontological-aesthetic-tracing$<$ perspective-ontological-normalcy/postconvergence-reflected-'epistemicity-relativismdeterminism'> implications as to 'existence-potency ${ }^{32} \sim$ sublimating-nascence,-disclosed-fromprospective-epistemic-digression given difference-conflatedness ${ }^{13}$-as-to-totalitative-reificationin-singularisation-<as-to-the-nondisjointedness/entailment-of-prospective- nonpresencing $>$ as-veridical-epistemicity-relativism-determinism as to enlightening human-subjectemancipating-relativism-driven-recomposuring-constructivism-towards-singularisation- $<$ as-tothe-nondisjointedness/entailment-of-prospective- nonpresencing>2 reflected $<$ amplituding/formative-epistemicity $>$ causality $\sim$ as-to-projective-totalitative-implications-ofprospective- nonpresencing,-for-explicating relative-unreflexivity/relative-reflexivity

ontological-contiguity , that speaks to the ontologically-veridical and appropriate human emancipating attitude/mental-disposition/care-and-epistemes. Such a wrong interpretation actually falls back into prospectively disenfranchising and undermining the emancipation of the state of relative-ontological-incompleteness ${ }^{8}$ prospectively as to its human inevitability stance poorly cognisant of the implications of the specific human-subpotency with regards to overall reifying-and-empowering-reflexivity-of-ecstatic-existence-aspanintelligibility/panreflexivity ${ }^{3}-\left\langle\right.$ existentially-imbued-and-educing-< fepistemic- $^{-}$ totalising ${ }^{3}$ hermeneutically/textually/reprojectingly/supererogatingly/zeroingly/re-acutingly,\{decompulsing $d e$ linearity for-cogency $\geq$-epistemic-perspective-of-projective/reprojective- 
as-herein-specifically-relevant-to human-subpotency) (underlying human construction-of-theSelf). Incidentally, the 'supposedly positivism/rational-empiricism formulaic/mechanical knowledge contenders' as of the economic-opportunism-and-then-enculturation of their nefarious practices, were very much countervailing the practice and trend within their own societies of origin undergoing-positivism/rational-empiricism-transformation and the underlying dual-language/split-mentality unscrupulousness was given away as of the 'out-of-sight demeanour' in their main societies pointing to ${ }^{47}$ historicity-tracing-in-presencinghyperrealisation/hyperreal-transposition distortive-originariness/distortive-origination, rather than being fully assumed as marking positivism/rational-empiricism progress implied historiality/ontological-eventfulness ${ }^{38} /$ ontological-aesthetic-tracing-<perspectiveontological-normalcy/postconvergence-reflected-'epistemicity-relativism-determinism’> originariness. Besides such an approach (that claims to mirror the sciences while at the same time claiming to be non-ontological as to non-metaphysical) fails to grasp that natural sciences are actually in '<amplituding/formative-epistemicity $>$ totalising/circumscribing/delineating 'implicited_attendant-ontological-contiguity ${ }^{6 /}$ > educedexistentialising/contextualising/textualising_'intelligibility/epistemicity/reflexivity_contiguity$<$ imbued-notional cogency $>{ }^{40} \quad{ }^{45}$ foregrounding_entailment- $<$ in-succession-of-profoundsupererogation ${ }^{9}>-$ - postconverging-narrowing-down $\sim$ sublimation-as-to-'existence-assublimating-withdrawal/unenframing/re-ontologising,-elicited-from-prospective-profoundsupererogation '-in-reflecting-'immanent relative-unreflexivity/relative-reflexivity ontological-contiguity ';--as-operative-notional deprocrypticism) in elucidating relativeunreflexivity/relative-reflexivity - ontological-contiguity ${ }^{6}<$ as-from-prospective-ontologicalnormalcy/postconvergence-epistemic-or-notional projective-perspective $>^{\prime}$ and so as of the 'internally implicited epistemic reflection of natural sciences sublimating 
historiality/ontological-eventfulness 38 ontological-aesthetic-tracing-<perspective-

ontological-normalcy/postconvergence-reflected-'epistemicity-relativism-determinism'>' in the sense that 'scientists never-and-have-never really started scientific knowledgereification $\sim$ gesturing-and-accounting — of-epistemic-phenomenalism- $<$ inprospective_psychologismic apriorising/axiomatising/referencing-\{of-"prospectively implicited_attendant-ontological-contiguity ' reducedexistentialising/contextualising/textualising_intelligibility/epistemicity/reflexivity-contiguity$<$ imbued-notional cogency $>$ ' $\}$-conflatedness -in-\{preconverging ment by\} postconverging entailment> apriorisingly/axiomatisingly/referencingly—as-from-scratch/asfrom-zero-〈wrongly-implying-no-human-limited-mentation-capacity-deepening assubjecting-limitedness/human-subpotency-to-'educed-unlimitedness/existence-sublimating nascence' -implications-of-re-motif-and-re-apriorising/re-axiomatising/re-referencing/reintelligibilitysettingup/re-measuringinstrumenting-as-so-reflecting- historiality/ontologicaleventfulness /ontological-aesthetic-tracing-<perspective-ontologicalnormalcy/postconvergence-reflected-'epistemicity-relativism-determinism'>>,-as-if-therebydirectly-producing-the-absolute-state-of-the-art-outcomes' but rather the inherent 'education of scientists as from basic notions while making reference to past scientists momentous contributions up to the state-of-the-art outcomes' is the equivalent of 'natural sciences own sublimating historiality/ontological-eventfulness 38 /ontological-aesthetic-tracing$<$ perspective-ontological-normalcy/postconvergence-reflected-'epistemicity-relativismdeterminism'> as $\quad$ re-motif-and-re-apriorising/re-axiomatising/re-referencing/reintelligibilitysettingup/re-measuringinstrumenting construct' (as of past, present and future projections of scientific sublimating ${ }^{4}$ historiality/ontological-eventfulness ${ }^{38} /$ ontological- $^{-}$ aesthetic-tracing-<perspective-ontological-normalcy/postconvergence-reflected-'epistemicityrelativism-determinism'>), and so as overall and defining '<amplituding/formative- 
epistemicity>totalising/circumscribing/delineating 'implicited_attendant-ontologicalcontiguity ${ }^{67} \sim$ educed-

existentialising/contextualising/textualising_'intelligibility/epistemicity/reflexivity-contiguity$<$ imbued-notional cogency $>{ }^{40} \quad{ }^{45}$ foregrounding_entailment- $<$ in-succession-of-profoundsupererogation $>$-〈postconverging-narrowing-down $\sim$ sublimation-as-to-'existence-assublimating-withdrawal/unenframing/re-ontologising,-elicited-from-prospective-profoundsupererogation '-in-reflecting-'immanent relative-unreflexivity/relative-reflexivity ontological-contiguity ';-as-operative-notional deprocrypticism) in elucidating relativeunreflexivity/relative-reflexivity - ontological-contiguity ${ }^{6}<$ as-from-prospective-ontologicalnormalcy/postconvergence-epistemic-or-notional projective-perspective $>^{\prime}$. It is critical to grasp here that this 'internally implicited epistemic reflection of natural sciences sublimating historiality/ontological-eventfulness 3 /ontological-aesthetic-tracing-<perspectiveontological-normalcy/postconvergence-reflected-'epistemicity-relativism-determinism'>’ （as overall and defining '<amplituding/formativeepistemicity $>$ totalising/circumscribing/delineating 'implicited_attendant-ontologicalcontiguity ${ }^{67} \sim$ educedexistentialising/contextualising/textualising_intelligibility/epistemicity/reflexivity-contiguity$<$ imbued-notional cogency $>{ }^{40} \quad{ }^{45}$ foregrounding_entailment- $<$ in-succession-of-profoundsupererogation $>$-〈postconverging-narrowing-down $\sim$ sublimation-as-to-'existence-assublimating-withdrawal/unenframing/re-ontologising,-elicited-from-prospective-profoundsupererogation '-in-reflecting-'immanent relative-unreflexivity/relative-reflexivity ontological-contiguity ';--as-operative-notional deprocrypticism) in elucidating relativeunreflexivity/relative-reflexivity - ontological-contiguity ${ }^{67}<$ as-from-prospective-ontologicalnormalcy/postconvergence-epistemic-or-notional projective-perspective $>$ ') as to the ultimate attainment of natural sciences state-of-the-art outcomes, is actually construable as of: human- 
subpotency 'fatedness-of-sublimation-over-desublimation, to existence-potency sublimatingnascence,-disclosed-from-prospective-epistemic-digression (in reflecting holographically$<$ conjugatively-and-transfusively $>$ the relative-unreflexivity/relative-reflexivity - ontologicalcontiguity of-the-human-institutionalisation-process ), as from human-subpotency ontological-faith-notion-or-ontological-fideism - imbued-underdetermination-of-motif-andapriorising/axiomatising/referencing-as-so-being-as-of-existential-reality as to the disseminative - sublimating-selectivity-of-ontological-goodfaith/authenticity $\sim$ postconverging-de-mentating/structuring/paradigming , over desublimating deselectivity of - ontological bad-faith/inauthenticity opreconverging dementating/structuring/paradigming '; as reflecting successive sublimating historiality/ontological-eventfulness ${ }^{38} /$ ontological-aesthetic-tracing- $<$ perspectiveontological-normalcy/postconvergence-reflected-‘epistemicity-relativism-determinism'> contributions of cohorts of scientists (not to be contemplated/construed as to a relic/artifactual traditional conception of history as of historicity-tracing-in-presencinghyperrealisation/hyperreal-transposition ontologically-impertinent implications of reoriginariness distorting) which are 'historially alive/living' (as of the ${ }^{4}$ historiality/ontologicaleventfulness 3 /ontological-aesthetic-tracing-<perspective-ontologicalnormalcy/postconvergence-reflected-‘epistemicity-relativism-determinism’> selectivity/deselectivity of human posited underdetermined natural sciences constructs, conceptualisations and theories as to existence constrained transcendence-andsublimity/sublimation/supererogatory $\sim$ de-mentativity as knowledge-reification $\sim$ gesturing-andaccounting - of-epistemic-phenomenalism- $<$ inprospective_psychologismic apriorising/axiomatising/referencing-\{of-'prospectively implicited_attendant-ontological-contiguity ' educedexistentialising/contextualising/textualising_'intelligibility/epistemicity/reflexivity-contiguity- 
<imbued-notional cogency >' \}-conflatedness -in-\{preconverging-ment by\}

postconverging-entailment $>$ in a ${ }^{4}$ foregrounding_entailment- $<$ in-succession-of-profoundsupererogation $>$-〈postconverging-narrowing-down $\sim$ sublimation-as-to-'existence- -as-

sublimating-withdrawal/unenframing/re-ontologising,-elicited-from-prospective-profoundsupererogation '-in-reflecting-'immanent relative unreflexivity/relative reflexivity ontological-contiguity ';-as-operative-notional deprocrypticism) dynamics leading to the natural sciences state-of-the-art outcomes while excluding disparateness-of-conceptualisation$<$ unforegrounding-ment,-failing-prospectively-to-reflect-'immanent $\sim$ relativeunreflexivity/relative-reflexivity ontological-contiguity ' $>$ ) reflected as part-and-parcel of the present state-of-the-art elucidative notional-contiguity/epistemic-contiguity ${ }^{62}<$ profound- $^{2}$ supererogation -of-mentally-aestheticised postconverging/dialectical-thinking -qualiaschema $>$ and the prospective state-of-the-art elucidative notional-contiguity/epistemiccontiguity ${ }^{62}<$ profound-supererogation -of-mentally-aestheticised $\sim$ postconverging/dialecticalthinking -qualia-schema $>$ as $\quad$ to $\quad<$ amplituding/formativeepistemicity>totalising/circumscribing/delineating 'implicited_attendant-ontologicalcontiguity $^{67} \sim$ educedexistentialising/contextualising/textualising_'intelligibility/epistemicity/reflexivity-contiguity$<$ imbued-notional cogency $>{ }^{40} \quad{ }^{45}$ foregrounding_entailment- $<$ in-succession-of-profoundsupererogation $>$-〈postconverging-narrowing-down $\sim$ sublimation-as-to-'existence-assublimating-withdrawal/unenframing/re-ontologising,-elicited-from-prospective-profoundsupererogation '-in-reflecting-'immanent $\sim$ relative-unreflexivity/relative-reflexivity ontological-contiguity ';-as-operative-notional deprocrypticism〉 in elucidating relativeunreflexivity/relative-reflexivity - ontological-contiguity ${ }^{6}-<$ as-from-prospective-ontologicalnormalcy/postconvergence-epistemic-or-notional $\sim$ projective-perspective $>^{\prime}$. This insight (as of present state-of-the-art elucidative notional-contiguity/epistemic-contiguity ${ }^{62}<$ profound- $^{2}$ 
supererogation -of-mentally-aestheticised postconverging/dialectical-thinking -qualia-

schema $>$ and the prospective state-of-the-art elucidative notional-contiguity/epistemiccontiguity ${ }^{62}<$ profound-supererogation -of-mentally-aestheticised postconverging/dialecticalthinking -qualia-schema> contiguity $^{67}$; educed-

existentialising/contextualising/textualising_'intelligibility/epistemicity/reflexivity-contiguity$<$ imbued-notional $\sim$ cogency $>{ }^{40} \quad{ }^{4}$ foregrounding_entailment- $<$ in-succession-of-profoundsupererogation $>>-$ postconverging-narrowing-down $\sim$ sublimation-as-to-'existence - assublimating-withdrawal/unenframing/re-ontologising,-elicited-from-prospective-profoundsupererogation '-in-reflecting-'immanent relative-unreflexivity/relative-reflexivity ontological-contiguity ';--as-operative-notional deprocrypticism) in elucidating relativeunreflexivity/relative-reflexivity - ontological-contiguity $-<$ as-from-prospective-ontologicalnormalcy/postconvergence-epistemic-or-notional projective-perspective $>$ ') is equally pertinent with respect to the ontological-veracity of the social but for the confusion induced by its blurriness-<sterilising/anecdotalising/trivialising-of-prospective-re-ontologising_bypreconverging,-in-disontologising-formulaic-dragging-out/hollowing-out> (unlike in the natural sciences where the constraint of predicative-effectivity-sublimation-〈as-to-underlying,ontological-commitment $\quad<$ implied_-self-assuredness-of-ontological-goodfaith/authenticity $\sim$ postconverging-de-mentating/structuring/paradigming -as-being-as-ofexistential-reality >> 'naturally/intuitively' guides the scientist in its directly operational purpose without overly needing to epistemically explicit the underlying successive projections of its past, present and prospective sublimating ${ }^{4}$ historiality/ontological-eventfulness ${ }^{38} /$ ontological- $^{-}$ aesthetic-tracing-<perspective-ontological-normalcy/postconvergence-reflected-‘epistemicityrelativism-determinism'> as so-required in the social domain, and as herein explicited with the 
relative-unreflexivity/relative-reflexivity - ontological-contiguity ${ }^{67}$ of-the-humaninstitutionalisation-process ${ }^{68}$ elucidative notional-contiguity/epistemic-contiguity ${ }^{62}-<$ profoundsupererogation -of-mentally-aestheticised postconverging/dialectical-thinking -qualiaschema $><$ cumulating/recomposuring attendant-ontological-contiguity >-successive registryworldviews/dimensions difference-conflatedness ${ }^{13}$-as-to-totalitative-reification-insingularisation-<as-to-the-nondisjointedness/entailment-of-prospective- nonpresencing $>$-asveridical-epistemicity-relativism-determinism dimensionality-of-sublimating <<amplituding/formative>supererogatory $\sim$ de-mentativeness/epistemic-growth-orconflatedness /transvaluative-rationalising/transepistemicity/anamnestic-residuality/spiritdrivenness-equalisation) implications, and as reflected with the specific dimensionality-ofsublimating 25 -<<mplituding/formative $>$ supererogatory $\sim$ de-mentativeness/epistemic-growthor-conflatedness /transvaluative-rationalising/transepistemicity/anamnestic-residuality/spiritdrivenness-equalisation> insights about ${ }^{103}$ universalising-idealisation thinkers and buddingpositivists). The idea of 'logically' conceptualising the social apriorisingly/axiomatisingly/referencingly_as-from-scratch/as-from-zero-〈wrongly-implyingno-human-limited-mentation-capacity-deepening — as-subjecting-limitedness/humansubpotency to-'educed-unlimitedness/existence-sublimating nascence' -implications-of-remotif-and-re-apriorising/re-axiomatising/re-referencing/re-intelligibilitysettingup/remeasuringinstrumenting-as-so-reflecting- historiality/ontological-eventfulness /ontologicalaesthetic-tracing-<perspective-ontological-normalcy/postconvergence-reflected-'epistemicityrelativism-determinism'>>,-as-if-thereby-directly-producing-the-absolute-state-of-the-artoutcomes (and as the social is permeated with ${ }^{47}$ historicity-tracing-in-presencinghyperrealisation/hyperreal-transposition as to the distorting epistemic implications of human limited-mentation-capacity as subjecting 'educed unlimitedness/existence sublimating nascence' to-limitedness/human-subpotency induced ${ }^{79}$ presencing-absolutising-identitive- 
constitutedness ${ }^{14}$ ) makes the critical flaw of ignoring that such a 'reference of conceptualisation/conception' manifests its very own 'apriorising/axiomatising/referencing defect of ontological-performance ${ }^{72}-{\text { including-virtue-as-ontology }>^{\prime} \text { as to its }}^{79}$ presencingabsolutising-identitive-constitutedness ${ }^{14}$, that then fails to reflect the true social sublimating historiality/ontological-eventfulness ${ }^{38} /$ ontological-aesthetic-tracing-<perspectiveontological-normalcy/postconvergence-reflected-‘epistemicity-relativism-determinism'> (as overall and defining ‘amplituding/formativeepistemicity>totalising/circumscribing/delineating 'implicited_attendant-ontologicalcontiguity $^{67}$, educedexistentialising/contextualising/textalising_'intelligibility/epistemicity/reflexivity_contiguity$<$ imbued-notional cogency $>{ }^{40} \quad{ }^{45}$ foregrounding_entailment- $<$ in-succession-of-profoundsupererogation $>$-〈postconverging-narrowing-down $\sim$ sublimation-as-to-'existence- - assublimating-withdrawal/unenframing/re-ontologising,-elicited-from-prospective-profoundsupererogation '-in-reflecting-'immanent relative-unreflexivity/relative-reflexivity ontological-contiguity ';--as-operative-notional deprocrypticism) in elucidating relativeunreflexivity/relative-reflexivity ontological-contiguity ${ }^{6}-<$ as-from-prospective-ontologicalnormalcy/postconvergence-epistemic-or-notional projective-perspective $>$ '), especially as it turns a blind eye to its more profound human-subpotency-aporia/undecidability/dilemma/oughtindeterminacy/deficiency/limitation/constraint. Thus failing to allow existence-as-theabsolute-a-priori-of-conceptualisation and existence — as-sublimatingwithdrawal/unenframing/re-ontologising,-elicited-from-prospective-profoundsupererogation -<as-to-perspective-ontological-normalcy/postconvergence-implied'prospective-aporeticism-overcoming/unovercoming'> and true transcendental signifier (going by the sublimating-over-desublimating implications of existence-potency ${ }^{32} \sim$ sublimating- $^{-}$ nascence,-disclosed-from-prospective-epistemic-digression) to epistemically enlighten the 
social sublimation process (as it is existence that enables without ever giving any reasons as existence is the effective reason and the human that epistemically adjust to it for sublimation) as to the social historiality/ontological-eventfulness ${ }^{38}$ /ontological-aesthetic-tracing<perspective-ontological-normalcy/postconvergence-reflected-'epistemicity-relativismdeterminism'> transcendental-enabling/sublimation insights of prior, present and prospective '<amplituding/formative-epistemicity $>$ totalising/circumscribing/delineating 'implicited_attendant-ontological-contiguity ${ }^{67}$ > educedexistentialising/contextualising/textualising_'intelligibility/epistemicity/reflexivity-contiguity$<$ imbued-notional cogency $>{ }^{40} \quad{ }^{45}$ foregrounding_entailment- $<$ in-succession-of-profoundsupererogation $>$-〈postconverging-narrowing-down $\sim$ sublimation-as-to-'existence-assublimating-withdrawal/unenframing/re-ontologising,-elicited-from-prospective-profoundsupererogation '-in-reflecting-'immanent relative-unreflexivity/relative-reflexivityontological-contiguity ';-as-operative-notional deprocrypticism) in elucidating relativeunreflexivity/relative-reflexivity - ontological-contiguity $6>$ as-from-prospective-ontologicalnormalcy/postconvergence-epistemic-or-notional projective-perspective>', so-construable as of: human-subpotency 'fatedness-of-sublimation-over-desublimation, to existencepotency $\sim$ sublimating-nascence,-disclosed-from-prospective-epistemic-digression (in reflecting holographically-<conjugatively-and-transfusively $>$ the relative-unreflexivity/relativereflexivity - ontological-contiguity of-the-human-institutionalisation-process ), as from human-subpotency ontological-faith-notion-or-ontological-fideism —imbuedunderdetermination-of-motif-and-apriorising/axiomatising/referencing-as-so-being-as-ofexistential-reality as to the disseminative-sublimating-selectivity-of-ontological-goodfaith/authenticity $\sim$ postconverging-de-mentating/structuring/paradigming , over desublimating deselectivity-of-ontological-bad-faith/inauthenticity -preconverging dementating/structuring/paradigming '. Actually human-subpotency ontological-faith-notion-or- 
ontological-fideism - imbued-underdetermination-of-motif-and-

apriorising/axiomatising/referencing-as-so-being-as-of-existential-reality

'precedes-and-

defines thought' and so as prospective reasoning-through/messianic-reasoning (as to originariness-parrhesia,-as-spontaneity-of-aestheticisation) inducing secondnatured and subsequent reasoning-from-results/afterthought (as to reproducibilitymathesis/motif/thrownness-disposition,-as-reproducibility-of-aestheticisation), with the latter being projected naively as absolute (in its apriorising/axiomatising/referencing of conceptualisation as of its human limited-mentation-capacity-as-subjecting-'educedunlimitedness/existence-sublimating nascence' to-limitedness/human-subpotency induced presencing - absolutising-identitive-constitutedness ${ }^{14}$ ) when 'logically' conceptualising the social apriorisingly/axiomatisingly/referencingly—as-from-scratch/as-from-zero-〈wronglyimplying-no-human-limited-mentation-capacity-deepening —as-subjecting-limitedness/humansubpotency to-'educed-unlimitedness/existence-sublimating nascence' -implications-of-remotif-and-re-apriorising/re-axiomatising/re-referencing/re-intelligibilitysettingup/remeasuringinstrumenting-as-so-reflecting- historiality/ontological-eventfulness /ontologicalaesthetic-tracing-<perspective-ontological-normalcy/postconvergence-reflected-‘epistemicityrelativism-determinism'>>,-as-if-thereby-directly-producing-the-absolute-state-of-the-artoutcomes (and as the social is permeated with ${ }^{47}$ historicity-tracing-in-presencinghyperrealisation/hyperreal-transposition as to the distorting epistemic implications of human limited-mentation-capacity—as-subjecting-'educed-unlimitedness/existence-sublimatingnascence' to-limitedness/human-subpotency induced ${ }^{79}$ presencing-absolutising-identitiveconstitutedness $^{1}$ ). Such a critical epistemic and true knowledge-reification $\sim$ gesturing-andaccounting - of-epistemic-phenomenalism- $<$ in-

prospective_psychologismic apriorising/axiomatising/referencing-\{of-'prospectively implicited_attendant-ontological-contiguity ' educed- 
existentialising/contextualising/textualising_'intelligibility/epistemicity/reflexivity-contiguity<imbued-notional cogency $>>$ \}-conflatedness -in-\{preconverging -ment by\}

postconverging entailment $>$ implications flaw arises because of the failure in grasping the 'projective implications' of human limited-mentation-capacity-as-subjecting 'educedunlimitedness/existence-sublimating nascence' to-limitedness/human-subpotency (as to 'human limited-mentation-capacity-deepening as-subjecting-limitedness/human-subpotencyto-'educed-unlimitedness/existence-sublimating nascence'53) when 'logically' conceptualising the social apriorisingly/axiomatisingly/referencingly — as-from-scratch/as-from-zero-〈wronglyimplying-no-human-limited-mentation-capacity-deepening —as-subjecting-limitedness/humansubpotency-to-'educed-unlimitedness/existence-sublimating nascence' -implications-of-remotif-and-re-apriorising/re-axiomatising/re-referencing/re-intelligibilitysettingup/remeasuringinstrumenting-as-so-reflecting- historiality/ontological-eventfulness /ontologicalaesthetic-tracing-<perspective-ontological-normalcy/postconvergence-reflected-'epistemicityrelativism-determinism'>>,-as-if-thereby-directly-producing-the-absolute-state-of-the-artoutcomes (and as the social is permeated with ${ }^{47}$ historicity-tracing-in-presencinghyperrealisation/hyperreal-transposition as to the distorting epistemic implications of human limited-mentation-capacity—as-subjecting 'educed-unlimitedness/existence-sublimating nascence' to-limitedness/human-subpotency induced ${ }^{79}$ presencing-absolutising-identitiveconstitutedness $^{1}$ ); as human limited-mentation-capacity-deepening-as-subjectinglimitedness/human-subpotency-to-'educed-unlimitedness/existence-sublimating nascence' (reflected in its re-motif-and-re-apriorising/re-axiomatising/re-referencing/reintelligibilitysettingup/re-measuringinstrumenting of conceptualisation as to dimensionality-ofsublimating 25 -<<mplituding/formative $>$ supererogatory $\sim$ de-mentativeness/epistemic-growthor-conflatedness /transvaluative-rationalising/transepistemicity/anamnestic-residuality/spiritdrivenness-equalisation)) is what is projectively warranted to enable present and prospective 
state-of-the-art elucidative notional-contiguity/epistemic-contiguity ${ }^{62}<$ profoundsupererogation -of-mentally-aestheticised postconverging/dialectical-thinking -qualia-

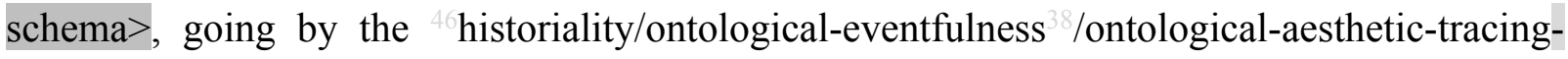
$<$ perspective-ontological-normalcy/postconvergence-reflected-‘epistemicity-relativismdeterminism' $>$ transcendental-enabling/sublimation insights of prior, present and prospective '<amplituding/formative-epistemicity $>$ totalising/circumscribing/delineating 'implicited_attendant-ontological-contiguity ${ }^{67}$ > educedexistentialising/contextalising/textalising_'intelligibility/epistemicity/reflexivity_contiguity$<$ imbued-notional cogency $>{ }^{40} \quad{ }^{45}$ foregrounding_entailment- $<$ in-succession-of-profoundsupererogation $>$-〈postconverging-narrowing-down $\sim$ sublimation-as-to-'existence- assublimating-withdrawal/unenframing/re-ontologising,-elicited-from-prospective-profoundsupererogation '-in-reflecting-'immanent relative-unreflexivity/relative-reflexivityontological-contiguity ';-as-operative-notional deprocrypticism) in elucidating relativeunreflexivity/relative-reflexivity - ontological-contiguity $-<$ as-from-prospective-ontologicalnormalcy/postconvergence-epistemic-or-notional projective-perspective> ${ }^{\prime}$. This critical epistemic and true knowledge-reification $\sim$ gesturing-and-accounting-of-epistemicphenomenalism- $<$ in-prospective_psychologismic $\sim$ apriorising/axiomatising/referencing- $\{$ of'prospectively_implicited_attendant-ontological-contiguity ' ceducedexistentialising/contextualising/textualising_'intelligibility/epistemicity/reflexivity_contiguity<imbued-notional cogency >' \}-conflatedness -in-\{preconverging-ment by\} postconverging entailment> implications flaw (as when 'logically' conceptualising the social apriorisingly/axiomatisingly/referencingly_as-from-scratch/as-from-zero-〈wrongly-implyingno-human-limited-mentation-capacity-deepening —as-subjecting limitedness/humansubpotency-to-'educed-unlimitedness/existence-sublimating nascence' -implications-of-remotif-and-re-apriorising/re-axiomatising/re-referencing/re-intelligibilitysettingup/re- 
measuringinstrumenting-as-so-reflecting- historiality/ontological-eventfulness /ontological-

aesthetic-tracing-<perspective-ontological-normalcy/postconvergence-reflected-'epistemicityrelativism-determinism'>>,-as-if-thereby-directly-producing-the-absolute-state-of-the-artoutcomes), is effectively a reflection of dimensionality-of-desublimating-lack-of <<amplituding/formative>supererogatory $\sim$ de-mentativeness/epistemic-growth-or-

conflatedness /transvaluative-rationalising/transepistemicity/anamnestic-residuality/spiritdrivenness-equalisation) as to its skewness towards hardly-adaptable/inflexible reproducibility—mathesis/motif/thrownness-disposition,--as-reproducibility-of-aestheticisation frameworks of ${ }^{4}$ historicity-tracing-in-presencing-hyperrealisation/hyperreal-transposition reflected with the 'pedantising/muddling/formulaic-hollowing-out-insubontologisation/subpotentiation-〈blurring/undermining-of-prospective-totalising-entailing,as-to-entailing-<amplituding/formative-epistemicity>totalising in-relative-ontologicalcompleteness > of methods/methodologies/approaches as to priorapriorising/axiomatising/referencing-superseded-logical-basis-of $\sim$ dialogical-equivalence- $<$ asto-psychologismic apriorising/axiomatising/referencing-\{of-‘prospectivelyimplicited_attendant-ontological-contiguity ' educedexistentialising/contextualising/textualising_intelligibility/epistemicity/reflexivity_contiguity<imbued-notional cogency $>$ ' \}-conflatedness - in-\{preconverging ment by\} postconverging entailment,-in-self-becoming/self-conflatedness /formative-supererogating> in a poor ontological-good-faith/authenticity ${ }^{69}$ or outright ontological-bad-faith/inauthenticity relation to existence-potency ${ }^{39} \sim$ sublimating-nascence,-disclosed-from-prospective-epistemicdigression as to the requisite prospectively-profound-and-recreative insight implications about prospective appropriateness of methods/methodologies/approaches with regards to profound knowledge-reification $\sim$ gesturing-and-accounting — of-epistemic-phenomenalism- $<$ inprospective_psychologismic apriorising/axiomatising/referencing- \{of-'prespectively 
implicited_attendant-ontological-contiguity ' reduced-

existentialising/contextualising/textualising_'intelligibility/epistemicity/reflexivity_contiguity<imbued-notional cogency>’ \}-conflatedness -in-\{preconverging ment by\}

postconverging-entailment> beyond 79 presencing-absolutising-identitive-constitutedness $<$ amplituding/formative-epistemicity $>$ totalising $\sim$ self-referencing-

syncretising/circularity/interiorising/akrasiatic-drag ${ }^{34}$ '. Insightfully, it is actually 'human corresponding-sublimation-inducing,-profound-and-creative

supereregatery acuity/perspicacity/astuteness/edginess/incisiveness-of-

apriorising/axiomatising/referencing/intelligibilitysettingup/measuringinstrumenting -for-

conceptualisation' (as to implied 'conceptualising implications about existential-reality' in reflecting the 'relevant-level human-subpotency-aporia/undecidability/dilemma/oughtindeterminacy/deficiency/limitation/constraint' to be surpassed/superseded/overcome for prospective transcendence-and-sublimity/sublimation/supererogatory $\sim$ de-mentativity) that inso-doing articulates the appropriate '<amplituding/formativeepistemicity>totalising/circumscribing/delineating 'implicited_attendant-ontologicalcontiguity $^{67}$; educed-

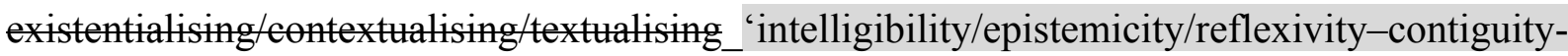
$<$ imbued-notional cogency $>{ }^{40} \quad{ }^{4}$ foregrounding_entailment- $<$ in-succession-of-profoundsupererogation $>$-〈postconverging-narrowing-down $\sim$ sublimation-as-to-'existence - assublimating-withdrawal/unenframing/re-ontologising,-elicited-from-prospective-profoundsupererogation "-in-reflecting-'immanent relative-unreflexivity/relative-reflexivityontological-contiguity ';--as-operative-notional deprocrypticism) in elucidating relativeunreflexivity/relative-reflexivity - ontological-contiguity ${ }^{6}-<$ as-from-prospective-ontologicalnormalcy/postconvergence-epistemic-or-notional projective-perspective>' that precedes-anddefines the pertinence of 'methods/methodologies/approaches as to reproducibility- 
mathesis/motif/thrownness-disposition,-as-reproducibility-of-aestheticisation'. This inevitably means that a naïve and traditional conception of methods/methodologies/approaches as 'mere deterministic alibis of profoundness of studies' is uncalled for as to the fact that 'this doesn't inherently commits existence-potency ${ }^{32} \sim$ sublimating-nascence,-disclosed-from-prospectiveepistemic-digression (when failing to truly reflect the requisite 'human correspondingsublimation-inducing,-profound-and-creative supererogatory $\sim$ acuity/perspicacity/astuteness/edginess/incisiveness-ofapriorising/axiomatising/referencing/intelligibilitysettingup/measuringinstrumenting -forconceptualisation'), such that it is the precedence of the 'ontological-good-faith/authenticity drivenness of contemplation/analysis' of the researcher/investigator that is vital as to cultivating an 'internalised reappropriating of the 'implicited_attendant-ontological-contiguity ${ }^{67}$ ' educedexistentialising/contextualising/textualising_intelligibility/epistemicity/reflexivity-contiguity<imbued-notional cogency>' implications of methods/methodologies/approaches as of 'implicited_attendant-ontological-contiguity ${ }^{67}$ > educedexistentialising/contextalising/textalising_'intelligibility/epistemicity/reflexivity_contiguity$<$ imbued-notional cogency $>$ ' . The requisite 'human corresponding-sublimation-inducing,profound-and-creative sucuity/perspicacity/astuteness/edginess/incisiveness-ofapriorising/axiomatising/referencing/intelligibilitysettingup/measuringinstrumenting -forconceptualisation' reflect the ontological-veracity that the 'human knowledgereification $\sim$ gesturing-and-accounting — of-epistemic-phenomenalism- $<$ inprospective_psychologismic apriorising/axiomatising/referencing-\{of-'prospectively_ implicited_attendant-ontological-contiguity ' educedexistentialising/contexalising/textlising_intelligibility/epistemicity/reflexivity-contiguity$<$ imbued-notional cogency $>$ ' $\}$-conflatedness -in-\{preconverging ment by\} postconverging-entailment $>$ project' is rather a 'commitment to origination/reorigination 
underlying originariness-parrhesia,-as-spontaneity-of-aestheticisation as to human limitedmentation-capacity-deepening —as-subjecting limitedness/human-subpotency-to-'educedunlimitedness/existence-sublimating nascence' ${ }^{3}$ so-implied by its subjection to existencepotency $^{39} \sim$ sublimating-nascence,-disclosed-from-prospective-epistemic-digression inducing of

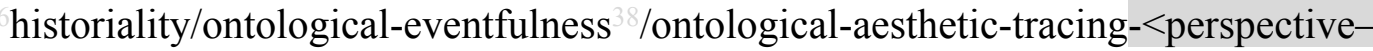
ontological-normalcy/postconvergence-reflected-‘epistemicity-relativism-determinism'> as reflecting dimensionality-of-sublimating ${ }^{25}-<<$ amplituding/formative $>$ supererogatery $\sim$ dementativeness/epistemic-growth-or-conflatedness /transvaluativerationalising/transepistemicity/anamnestic-residuality/spirit-drivenness-equalisation) (as the postconverging-or-dialectical-thinking -apriorising-psychologism contiguity in reflecting holographically-<conjugatively-and-transfusively $>$ the relative-unreflexivity/relativereflexivity - ontological-contiguity of-the-human-institutionalisation-process ); and so well beyond mere methods/methodologies/approaches as to the " ${ }^{\natural}$ historicity-tracing-inpresencing-hyperrealisation/hyperreal-transposition of the merely affixed methods/methodologies/approaches of the <cumulating/recomposuring attendant-ontologicalcontiguity $>$-successive registry-worldviews/dimensions in distorted-originariness/distortedorigination' as reflecting dimensionality-of-desublimating-lack-of <<amplituding/formative>supererogatory $\sim$ de-mentativeness/epistemic-growth-orconflatedness /transvaluative-rationalising/transepistemicity/anamnestic-residuality/spiritdrivenness-equalisation>, explaining why the successive institutionalisations occur 'by subverting their prior registry-worldview/dimension perceived methods/methodologies/approaches for prospective knowledge-reification $\sim$ gesturing-andaccounting - of-epistemic-phenomenalism- $<$ inprospective_psychologismic apriorising/axiomatising/referencing-\{of-'prospectively implicited_attendant-ontological-contiguity ' ceduced- 
existentialising/contextualising/textualising_ 'intelligibility/epistemicity/reflexivity-contiguity<imbued-notional cogency $>$ ' \}-conflatedness -in-\{preconverging ment by\}

postconverging-entailment>'. The fact is 'what is effectively lost-and-abandoned in practices of science-ideology supposedly based on scientific methods/methodologies/approaches' is the fundamental reality that such methods/methodologies/approaches came-about/wereintroduced/were-invented in a tight-and-entwined relationship of prior ‘ $<$ amplituding/formative-epistemicity $>$ totalising/circumscribing/delineating 'implicited_attendant-ontological-contiguity ${ }^{67}$; educedexistentialising/contextualising/textmalising_intelligibility/epistemicity/reflexivity-contiguity$<$ imbued-notional cogency $>{ }^{40} \quad{ }^{45}$ foregrounding_entailment- $<$ in-succession-of-profoundsupererogation $>$-〈postconverging-narrowing-down $\sim$ sublimation-as-to-'existence - assublimating-withdrawal/unenframing/re-ontologising,-elicited-from-prospective-profoundsupererogation '-in-reflecting-'immanent relative-unreflexivity/relative-reflexivity ontological-contiguity ';-as-operative-notional deprocrypticism) in elucidating relativeunreflexivity/relative-reflexivity - ontological-contiguity ${ }_{-}<$as-from-prospective-ontologicalnormalcy/postconvergence-epistemic-or-notional projective-perspective ${ }^{\prime}$ ' as to predicativeeffectivity-sublimation-〈as-to-underlying,-ontological-commitment $-<$ implied-selfassuredness-of-ontological-good-faith/authenticity $\sim$ postconverging-dementating/structuring/paradigming -as-being-as-of-existential-reality $>>$ and genuine-andprofound knowledge-reification $\sim$ gesturing-and-accounting-of-epistemic-phenomenalism$<$ in-prospective_psychologismic $\sim$ apriorising/axiomatising/referencing-\{of-'prospectively implicited_attendant-ontological-contiguity ' educedexistentialising/contextualising/textualising_'intelligibility/epistemicity/reflexivity-contiguity<imbued-notional cogency>' \}-conflatedness -in-\{preconverging-ment by\} postconverging-entailment>; with science-ideology rather becoming an enterprise that rides-the- 


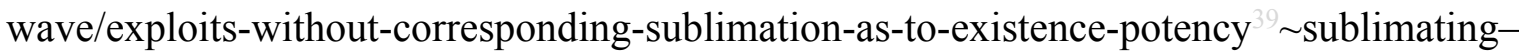
nascence-implications of achieved science prestige so effectively constrained, to then imply the 'blinded epistemic-veracity of mere supposedly scientific methods/methodologies/approaches with little-or-poor heeding to the implications of the '<amplituding/formativeepistemicity>totalising/circumscribing/delineating 'implicited_attendant-ontologicalcontiguity $^{67} \sim$ educedexistentialising/contextualising/textualising_intelligibility/epistemicity/reflexivity_contiguity$<$ imbued-notional cogency $>{ }^{40} \quad{ }^{45}$ foregrounding_entailment- $<$ in-succession-of-profoundsupererogation ${ }^{9}>-$-postconverging-narrowing-down $\sim$ sublimation-as-to-'existence-assublimating-withdrawal/unenframing/re-ontologising,-elicited-from-prospective-profoundsupererogation '-in-reflecting-'immanent $\sim$ relative-unreflexivity/relative-reflexivity ontological-contiguity ';-as-operative-notional deprocrypticism) in elucidating relativeunreflexivity/relative-reflexivity - ontological-contiguity $-<$ as-from-prospective-ontologicalnormalcy/postconvergence-epistemic-or-notional projective-perspective>' (manifested as of corresponding-gimmickiness/desublimation-inducing,-shallow-and-uncreative supererogatory acuity/perspicacity/astuteness/edginess/incisiveness-ofapriorising/axiomatising/referencing/intelligibilitysettingup/measuringinstrumenting -forconceptualisation that fails to reflect the 'relevant-level human-subpotencyaporia/undecidability/dilemma/ought-indeterminacy/deficiency/limitation/constraint' to be surpassed/superseded/overcome for prospective transcendence-andsublimity/sublimation/supererogatory $\sim$ de-mentativity as it gives too much a place to totalisingly-ing — discretion/whim-of-thought and disparateness-of-conceptualisation$<$ unforegrounding-ment,-failing-prospectively-to-reflect-'immanent $\sim$ relativeunreflexivity/relative-reflexivity ontological-contiguity ' $>$ and as it fails to represent notional-contiguity/epistemic-contiguity ${ }^{62}<$ profound-supererogation -of-mentally- 
conceptualisation)'; and so with the 'pedantising/muddling/formulaic-hollowing-out-insubontologisation/subpotentiation-〈blurring/undermining-of-prospective-totalising-entailing,as-to-entailing-<amplituding/formative-epistemicity $>$ totalising in-relative-ontologicalcompleteness $>$ of methods/methodologies/approaches as to priorapriorising/axiomatising/referencing-superseded-logical-basis-of $\sim$ dialogical-equivalence- $<$ asto-psychologismic apriorising/axiomatising/referencing-\{of-‘prospectivelyimplicited_attendant-ontological-contiguity ' educedexistentialising/contextualising/textualising_'intelligibility/epistemicity/reflexivity-contiguity<imbued-notional cogency >' \}-conflatedness in \{preconverging ment by\} postconverging-entailment,-in-self-becoming/self-conflatedness /formative-supererogating> in a poor ontological-good-faith/authenticity ${ }^{6}$ or outright ontological-bad-faith/inauthenticity relation to existence-potency ${ }^{39} \sim$ sublimating-nascence,-disclosed-from-prospective-epistemicdigression as to the requisite prospectively-profound-and-recreative insight implications about prospective appropriateness of methods/methodologies/approaches with regards to profound knowledge-reification $\sim$ gesturing-and-accounting—of-epistemic-phenomenalism- $<$ inprospective_psychologismic apriorising/axiomatising/referencing-\{of-'prospectively implicited_attendant-ontological-contiguity ' reducedexistentialising/contextualising/textualising_'intelligibility/epistemicity/reflexivity-contiguity<imbued-notional cogency>' \}-conflatedness -in-\{preconverging-ment by\} postconverging-entailment> beyond ${ }^{79}$ presencing-absolutising-identitive-constitutedness $<$ amplituding/formative-epistemicity $>$ totalising $\sim$ self-referencingsyncretising/circularity/interiorising/akrasiatic-drag ${ }^{4}$ '. The latter is so-criticised as to the fact that methods/methodologies/approaches, as reproducibility-mathesis/motif/thrownnessdisposition,-as-reproducibility-of-aestheticisation, are actually the mechanical-knowledge 
outcrop of the 'successive reasoning-through/messianic-reasoning prospective idiosyncraticframing of existential-reality as to the organic-knowledge of the Socrates, Platos, Aristotles, Copernicuses, Galileos, Descartes, Newtons, Leibnizes, Darwins, Rousseaus, etc. as to their induced prospective-apriorising/axiomatising/referencing-superseding-logical-basisof $\sim$ dialogical-equivalence- $<$ as-to-psychologismic $\sim$ apriorising/axiomatising/referencing- $\{$ of'prospectively implicited_attendant_ontological-contiguity ' educedexistentialising/contextualising/textualising_'intelligibility/epistemicity/reflexivity-contiguity$<$ imbued-notional cogency $>$ ' $\}$-conflatedness -in-\{preconverging ment by\} postconverging-entailment,-in-self-becoming/self-conflatedness /formative-

supererogating $>$, (which never existed before as reproducibility—mathesis/motif/thrownnessdisposition,-as-reproducibility-of-aestheticisation), with regards to enabling 'human corresponding-sublimation-inducing,-profound-and-creative supererogatory acuity/perspicacity/astuteness/edginess/incisiveness-ofapriorising/axiomatising/referencing/intelligibilitysettingup/measuringinstrumenting -forconceptualisation' (as to implied 'conceptualising implications about existential-reality' in reflecting the 'relevant-level human-subpotency-aporia/undecidability/dilemma/oughtindeterminacy/deficiency/limitation/constraint' to be surpassed/superseded/overcome for prospective transcendence-and-sublimity/sublimation/supererogatory $\sim$ de-mentativity); speaking to the fact that ontological-good-faith/authenticity ${ }^{6}$ about existential-reality precedesand-define the possibility for prospective transcendence-andsublimity/sublimation/supererogatoryade-mentativity beyond just mere pedantising/muddling/formulaic-hollowing-out — in-subontologisation/subpotentiation〈blurring/undermining-of-prospective-totalising-entailing,-as-to-entailing<amplituding/formative-epistemicity>totalising in-relative-ontological-completeness > of methods/methodologies/approaches as to prior-apriorising/axiomatising/referencing- 
superseded-logical-basis-of $\sim$ dialogical-equivalence- $<$ as-to-

psychologismic apriorising/axiomatising/referencing-\{of-'prospectively

implicited_attendant-ontological-contiguity ' ceduced-

existentialising/contextualising/textualising_'intelligibility/epistemicity/reflexivity-contiguity-

$<$ imbued-notional cogency $>$ ' $\}$-conflatedness -in-\{preconverging ment by\}

postconverging-entailment,-in-self-becoming/self-conflatedness /formative-supererogating >

in a poor ontological-good-faith/authenticity ${ }^{69}$ or outright ontological-bad-faith/inauthenticity

relation to existence-potency ${ }^{39} \sim$ sublimating-nascence,-disclosed-from-prospective-epistemicdigression as to the requisite prospectively-profound-and-recreative insight implications about prospective appropriateness of methods/methodologies/approaches with regards to existentialcontextualisation-contiguity. Critically 'human corresponding-sublimation-inducing,-profoundand-creative supererogatory $\sim$ acuity/perspicacity/astuteness/edginess/incisiveness-ofapriorising/axiomatising/referencing/intelligibilitysettingup/measuringinstrumenting -forconceptualisation' (which is actually constrained to '<amplituding/formativeepistemicity $>$ totalising/circumscribing/delineating 'implicited_attendant-ontologicalcontiguity ${ }^{67}$, educed-

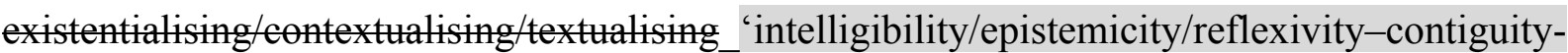
$<$ imbued-notional cogency $>{ }^{40} \quad{ }^{45}$ foregrounding_entailment- $<$ in-succession-of-profoundsupererogation $>$-〈postconverging-narrowing-down $\sim$ sublimation-as-to-'existence-assublimating-withdrawal/unenframing/re-ontologising,-elicited-from-prospective-profoundsupererogation '-in-reflecting-'immanent relative-unreflexivity/relative-reflexivityontological-contiguity ';--as-operative-notional deprocrypticism> in elucidating relativeunreflexivity/relative-reflexivity - ontological-contiguity ${ }^{6}-<$ as-from-prospective-ontologicalnormalcy/postconvergence-epistemic-or-notional projective-perspective $>$ '), $\quad$ precedes-anddefines the pertinence of 'methods/methodologies/approaches as to reproducibility- 
mathesis/motif/thrownness-disposition,-as-reproducibility-of-aestheticisation'; and so as to the implications of human limited-mentation-capacity-deepening-as-subjectinglimitedness/human-subpotency-to-'educed-unlimitedness/existence-sublimating nascence' with regards to existence-potency ${ }^{32}$ sublimating-nascence,-disclosed-from-prospectiveepistemic-digression. More than just about abstract knowledge-reification $\sim$ gesturing-andaccounting - of-epistemic-phenomenalism- $<$ in-

prospective_psychologismic apriorising/axiomatising/referencing-\{of-'prospectively implicited_attendant-ontological-contiguity ' educedexistentialising/contextualising/textualising_intelligibility/epistemicity/reflexivity_contiguity<imbued-notional cogency >' \}-conflatedness -in-\{preconverging-ment by\} postconverging-ntailment $>$ the implications of science-ideology are ultimately social and institutional as to the implications of human emancipation; and so in the sense that contrary to what is generally thought, science itself as for-human-studies is the very first-level of social science as of the epistemic implications it projects upon society and social ${ }^{5}$ meaningfulnessand-teleology ${ }^{9}$, and critically so because in reality budding-positivists were actually the very first modern social scientists in the sense that their posturing wasn't critically about the 'technicalities of the budding natural science they advanced' like a heliocentric world or rationalempiricism driven natural science basis of analysis (as to satisfy their mere natural science curiosity given that in-many-ways some of the notions where previously advanced in different forms), but they were rather critically engaged in a social posturing to epistemically reconstrue the society and social ${ }^{56}$ meaningfulness-and-teleology ${ }^{9}$ in those scientific terms and the future elaboration and development of the natural sciences could only be rendered possible with an open society responsive to such budding scientific meaning, and it was this social posturing which was the true source of their troubles and persecution. In fact, such ridiculous historical interpretations seeming to criticise budding-positivists like Galileo for wrongly making the case 
for a heliocentric world for instance are paradoxically based on condemning the latter and other budding-positivists for having a poor experimental framework as of ontologically-deficient presencing - absolutising-identitive-constitutedness ${ }^{14}$ analyses that fail to factor in that the very notion of 'positivistic science experimental framework ${ }^{4}$ historiality/ontologicaleventfulness 38 ontological-aesthetic-tracing-<perspective-ontologicalnormalcy/postconvergence-reflected-'epistemicity-relativism-determinism'>' was developed and enculturated/constructed as scientific practices by these budding-positivists with their medieval societies previously knowing nothing of such as to their medieval-scholasticism (as to the mere disinclination and incuriosity to even look through a telescope and draw contemplative consequences); and such a criticism on the basis of the subsequently developed and more precise modern-day science experimental framework speaks of the characteristic nature of a flawed prior_knowledge-reification $\sim$ gesturing-and-accounting_-of-epistemic-phenomenalism- $<$ inprior_psychologismic $\sim$ apriorising/axiomatising/referencing- $\{$ of-' prior-implicited_attendantontological-contiguity ' educedexistentialising/contextualising/textualising_'intelligibility/epistemicity/reflexivity-contiguity$<$ imbued-notional cogency >' $\}$-constitutedness -in preconverging-entailment> exercise that doesn't factor in human limited-mentation-capacity-deepening as stbjecting limitedness/human-subpotency to-'educed-unlimitedness/existence-sublimating nascence' 53 as of 'relative-ontological-incompleteness ${ }^{8 /} /$ relative-ontological-completeness $^{87}$ 〈sublimating $\sim$ referencing/registering/decisioning,-as-self-becoming/selfconflatedness /formative-supererogating-<projective/reprojective-aestheticising-re-motifand-re-apriorising/re-axiomatising/re-referencing,-in-perspective-ontologicalnormalcy/postconvergence $>>$ as to human-and-social-expectations/anticipationsmetaphoricity ${ }^{57}$-as-preconverging/postconverging-redementating/restructuring/reparadigming-psychologism' 89 as to <amplituding/formative- 
epistemicity $>$ causality $\sim$ as-to-projective-totalitative-implications-of-prospective-

nonpresencing,-for-explicating relative-unreflexivity/relative-reflexivity ontological-

contiguity. Thus in-many-ways the 'possibility for science to prospectively arise' involved its very own dispensing-with-immediacy-for-relative-ontological-completeness ${ }^{87}$-byreification/contemplative-distension ${ }^{27}$ that projected of an underlying enculturated/constructed 'scientific_-apriorising/axiomatising/referencing-psychologism social-pragmatics-framingof - predicative-effectivity-sublimation-〈as-to-underlying,-ontological-commitment _ $<$ implied—-self-assuredness-of-ontological-good-faith/authenticity $\sim$ postconverging-dementating/structuring/paradigming -as-being-as-of-existential-reality $>$ ') at the very least (as of human self-surpassing — existentialism-form-factor,-in-overcoming-'notional collateralisingbeholdening-protohumanity'-to-'attain-sublimating-humanity'-as-to-existencepotency $\sim$ sublimating-nascence,-disclosed-from-prospective-epistemic-digression to

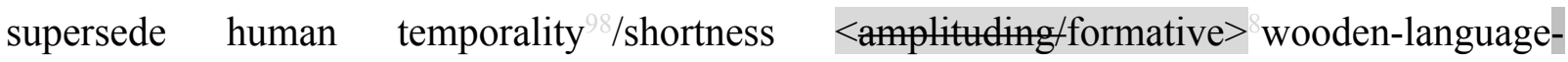
〈imbued-averaging-of-thought-<as-to-leveling/ressentiment/closed-construct-ofmeaningfulness-and-teleology -as-of-‘nondescript/ignorable-void '-with-regards-toprospective-apriorising-implications $>>)$ in originariness-parrhesia,-as-spontaneity-ofaestheticisation; speaking to the requisite 'human corresponding-sublimation-inducing,profound-and-creative supererogatory $\sim$ acuity/perspicacity/astuteness/edginess/incisiveness-ofapriorising/axiomatising/referencing/intelligibilitysettingup/measuringinstrumenting -forconceptualisation' about science (as to implied 'conceptualising implications about existentialreality' in reflecting the 'relevant-level human-subpotencyaporia/undecidability/dilemma/ought-indeterminacy/deficiency/limitation/constraint' to be surpassed/superseded/overcome for prospective transcendence-andsublimity/sublimation/supererogatory $\sim$ de-mentativity) in defining its very own science prospective-apriorising/axiomatising/referencing-superseding-logical-basis-of $\sim$ dialogical- 
equivalence-<as-to-psychologismic apriorising/axiomatising/referencing- \{of- 'prospectively_ implicited_attendant-ontological-contiguity ' educedexistentialising/contextualising/textualising_'intelligibility/epistemicity/reflexivity-contiguity$<$ imbued-notional cogency $>>$ \}-conflatedness - in-\{preconverging ment by\} postconverging-entailment,-in-self-becoming/self-conflatedness /formative-supererogating>

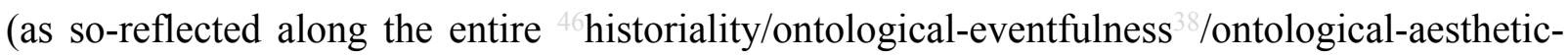
tracing-<perspective--ontological-normalcy/postconvergence-reflected-'epistemicityrelativism-determinism'> of science and knowledge-reification $\sim$ gesturing-and-accounting-ofepistemic-phenomenalism-<in-

prospective_psychologismic $\sim$ apriorising/axiomatising/referencing-\{of- ${ }^{\text {pprospectively }}$ implicited_attendant-ontological-contiguity ' reducedexistentialising/contextualising/textualising_'intelligibility/epistemicity/reflexivity-contiguity$<$ imbued-notional cogency $>$ ' \}-conflatedness - in-\{preconverging ment by\} postconverging-entailment $>$ in rather adapting to existence-potency ${ }^{3} \sim$ sublimating-nascence,disclosed-from-prospective-epistemic-digression), and so much more than just an exercise of mere methods/methodologies/approaches reproducibility—mathesis/motif/thrownnessdisposition,-as-reproducibility-of-aestheticisation as of priorapriorising/axiomatising/referencing-superseded-logical-basis-of $\sim$ dialogical-equivalence- $<$ asto-psychologismic apriorising/axiomatising/referencing-\{of-‘prospectivelyimplicited_attendant-ontological-contiguity ' educedexistentialising/contextualising/textualising_'intelligibility/epistemicity/reflexivity-contiguity<imbued-notional cogency $\left.>^{\prime}\right\}$ - conflatedness -in-\{preconverging ment by\} postconverging entailment,-in-self-becoming/self-conflatedness /formativesupererogating $>2$. Thus it is such an ideological conception of science and knowledgereification $\sim$ gesturing-and-accounting - of-epistemic-phenomenalism- $<$ in- 
prospective_psychologismic apriorising/axiomatising/referencing-\{of- ${ }^{\text {prospectively }}$

implicited_attendant-ontological-contiguity ' educed-

existentialising/contextualising/textualising_'intelligibility/epistemicity/reflexivity-contiguity-

$<$ imbued-notional cogency $\left.>^{\prime}\right\}$-conflatedness -in-\{preconverging-ment by\}

postconverging-ntailment> on the latter basis (as of prior-

apriorising/axiomatising/referencing-superseded-logical-basis-of $\sim$ dialogical-equivalence- $<$ as-

to-psychologismic apriorising/axiomatising/referencing-\{of-‘prospectively

implicited_attendant-ontological-contiguity ' educed-

existentialising/contextualising/textualising_'intelligibility/epistemicity/reflexivity-contiguity-

<imbued-notional cogency >' \}-conflatedness -in-\{preconverging-ment by\}

postconverging-entailment,-in-self-becoming/self-conflatedness /formative-

supererogating $>$ ') that ultimately translates into the 'methodological, epistemic, institutional and social sagging of human knowledge-reification $\sim$ gesturing-and-accounting-of-epistemicphenomenalism- $<$ in-prospective_psychologismic $\sim$ apriorising/axiomatising/referencing- of'prospectively_implicited_attendant_ontological-contiguity ' educedexistentialising/contextualising/textualising_'intelligibility/epistemicity/reflexivity_contiguity<imbued-notional cogency>' \}-conflatedness in \{preconverging ment by\}

postconverging-entailment>' reflected abstractly in crises of methodology, epistemicity and scholarship as well as derived human institutional and social crises as to underlying meaningfulness-and-teleology infrastructure; and critically so with regards to our own positivism/rational-empiricism manifestation of ${ }^{80}$ procrypticism-or-disjointedness-as-of${ }^{3}$ reference-of-thought relevant-level of human-subpotencyaporia/undecidability/dilemma/ought-indeterminacy/deficiency/limitation/constraint—imbued'notional firstnaturedness-formativeness-<as-to-eventualising -inkling-drive-or-seedingmisprising $>$ temporal-to-intemporal-dispositions- $<$ so-construed-as-from-perspective- 
ontological-normalcy/postconvergence>'-existentialism-form-factor that has to be addressed. In another respect, given the requisite dispensing-with-immediacy-for-relative-ontologicalcompleteness ${ }^{87}$-by-reification/contemplative-distension ${ }^{27}$ involved in true human consciousness sublimation, dimensionality-of-sublimating ${ }^{25}-\langle<$ amplituding/formative $>$ supereregatery dementativeness/epistemic-growth-or-conflatedness /transvaluative-

rationalising/transepistemicity/anamnestic-residuality/spirit-drivenness-equalisation〉 warrants that the conception of veridical human knowledge and emancipation is not beholden on the mere eliciting of a basic positive-opportunism-of-social-functioning-and-accordance ${ }^{75}$, as the "very abstract value-reference commitment for dispensing-with-immediacy-for-relative-ontologicalcompleteness ${ }^{87}$-by-reification/contemplative-distension ${ }^{27}$, that brings about sublimation needs to be construed as to imply 'it is the underlying organic framing of the induced sublimation', and so in order to avoid 'sublimation value-reference usurpation' wherein the temporal induced positive-opportunism - of-social-functioning-and-accordance ${ }^{75}$ elicits parallel competing meaningfulness-and-teleology (in preconverging-existential-extrication-as-of-existentialunthought as of human-subpotency epistemic perspective of dimensionality-of-desublimatinglack-of $-<<$ amplituding/formative >supererogatory $\sim$ de-mentativeness/epistemic-growth-orconflatedness /transvaluative-rationalising/transepistemicity/anamnestic-residuality/spiritdrivenness-equalisation〉) and come to foreclose/undermine the instigative intemporal/longness dispensing-with-immediacy-for-relative-ontological-completeness ${ }^{87}$-byreification/contemplative-distension ${ }^{27}$ inducing sublimation as of the secondnaturing institutionalisation exercise. In-many-ways the underpinning-suprasocial-construct itself as to a 'rather acerbic and direct positive-opportunism-of-social-functioning-and-accordance inclination', while of abstractive apprehension of sublimation possibilities, tend to poorly appreciate the underlying and implied dimensionality-of-sublimating 
conflatedness /transvaluative-rationalising/transepistemicity/anamnestic-residuality/spirit-

drivenness-equalisation) and is functionally-speaking rather positive-opportunism-of-socialfunctioning-and-accordance ${ }^{75}$ beholden as to ${ }^{47}$ historicity-tracing-in-presencinghyperrealisation/hyperreal-transposition implications; as in reality the fact is any underpinningsuprasocial-construct in its projection of social-stake-contention-or-confliction is hardly enamoured with dimensionality-of-sublimating ${ }^{25}-\langle<$ amplituding/formative $>$ supererogatory $\sim$ dementativeness/epistemic-growth-or-conflatedness /transvaluative-

rationalising/transepistemicity/anamnestic-residuality/spirit-drivenness-equalisation $\rangle$ as of the instigative disposition for prospective transcendental-enabling/sublimation possibilities in the sense that even the underpinning-suprasocial-construct framework of say enlightenment despots or philosophising emperors are not truly instigative of budding-positivism or ${ }^{103}$ universalisingidealisation thought respectively, nor is our modern-day ${ }^{79}$ presencing — absolutising-identitiveconstitutedness $^{14} \quad$ politically clouded $\quad{ }^{47}$ historicity-tracing-in-presencinghyperrealisation/hyperreal-transposition underpinning-suprasocial-construct environment the contemplative beholder of the panacea for prospective human transcendence-andsublimity/sublimation/supererogatory $\sim$ de-mentativity potential; as so reflected in their ever always hardly-adaptable/inflexible reproducibility—mathesis/motif/thrownness-disposition,-as-reproducibility-of-aestheticisation frameworks of ${ }^{47}$ historicity-tracing-in-presencinghyperrealisation/hyperreal-transposition. This in-many-ways explains why ultimate responsibility/relative-reflexivity lies with the abstract individual as to the requisite human dispensing-with-immediacy-for-relative-ontological-completeness ${ }^{87}$-by-

reification/contemplative-distension ${ }^{27}$ (as of human self-surpassing-existentialism-formfactor,-in-overcoming-'notional collateralising-beholdening-protohumanity'-to- 'attainsublimating-humanity'-as-to-existence-potency sublimating-nascence,-disclosed-fromprospective-epistemic-digression to supersede human temporality $8 /$ shortness 
$<$ amplituding/formative $>$ wooden-language-〈imbued - averaging-of-thought-<as-to-

leveling/ressentiment/closed-construct-of- meaningfulness-and-teleology -as-of-

'nondescript/ignorable-void '-with-regards-to-prospective-apriorising-implications $>\rangle)$.

Ultimately, the notional deprocrypticism registry-worldview/dimension construed as the nascent prospect for overcoming dimensionality-of-desublimating-lack-of ${ }^{-}$ <<amplituding/formative>supererogatory $\sim$ de-mentativeness/epistemic-growth-or-

conflatedness /transvaluative-rationalising/transepistemicity/anamnestic-residuality/spirit-

drivenness-equalisation) effectively projects the possibility of boundless human aestheticisation-and-aestheticisation-towards-ontology-<elicited-idiomatisation $>$ well beyond our present contemplation of what is implied by ${ }^{56}$ meaningfulness-and-teleology ${ }^{99}$, as in-manyways the reality of our past and present aestheticisation-and-aestheticisation-towards-ontology$<$ elicited-idiomatisation> as ${ }^{56}$ meaningfulness-and-teleology 9 has 'paradoxically hugely been burdened with desublimating ${ }^{4}$ historicity-tracing-in-presencing-hyperrealisation/hyperrealtransposition induced preemptive anticipation/anxiety about the human' rather than the summoning of the full possibilities of the human; as by a soothing mental-reflex just as with all registry-worldviews/dimensions we tend to take comfort in our 'beholdening-becomingdistortive-originariness/distortive-origination-as-to- ${ }^{-1}$ historicity-tracing inhibited-mentalaestheticising as of reproducibility-mathesis/motif/thrownness-disposition,--asreproducibility-of-aestheticisation' rather than contemplate about prospective possibilities of 'bechancing-becoming — originariness/origination-as-to- ${ }^{4}$ historiality/ontologicaleventfulness 3 /ontological-aesthetic-tracing-<perspective-ontologicalnormalcy/postconvergence-reflected-‘epistemicity-relativism-determinism’> disinhibitedmental-aestheticising as of originariness-parrhesia,-as-spontaneity-of-aestheticisation'. Interestingly, in this regards in-many-ways the relative-unreflexivity/relative-reflexivityontological-contiguity ${ }^{67}$ of-the-human-institutionalisation-process ${ }^{68}$ possibility is hardly just 
about human 'mere technical capacity potential' but it is rather more critically a psychological issue as of desublimating ${ }^{47}$ historicity-tracing-in-presencing-hyperrealisation/hyperrealtransposition psychological entrapment implications that limit/stifle the human imaginary/ideality as to its dimensionality-of-sublimating 5 <<amplituding/formative>supererogatory $\sim$ de-mentativeness/epistemic-growth-or-

conflatedness /transvaluative-rationalising/transepistemicity/anamnestic-residuality/spirit-

drivenness-equalisation) capacity 'to project in disseminative-sublimating-selectivity-ofontological-good-faith/authenticity $\sim$ postconverging-dementating/structuring/paradigming , over-desublimating-deselectivity-of-ontological-badfaith/inauthenticity preconverging de mentating/structuring/paradigming, (as to the underlying human ontological-faith-notion-or-ontological-fideism-imbuedunderdetermination-of-motif-and-apriorising/axiomatising/referencing-as-so-being-as-ofexistential-reality 'seeding promise of human-subpotency ontological-performance ${ }^{72}$ $<$ including-virtue-as-ontology $>/$ morality/ethics/justice/etc. equivalence/correspondence with the full-potency-of-existence's $\sim$ sublimating-nascence-as-of-its-coherence/contiguity). It is important to grasp here that such a construal of ${ }^{18}$ deprocrypticism-or-preemptingdisjointedness-as-of- ${ }^{-}$reference-of-thought highlighting the prospective implications in reflecting holographically-<conjugatively-and-transfusively $>$ the relative-unreflexivity/relativereflexivity - ontological-contiguity of-the-human-institutionalisation-process as of the specific human-subpotency with regards to overall reifying-and-empowering-reflexivity-ofecstatic-existence-as-panintelligibility/panreflexivity ${ }^{3}$-〈existentially-imbued-and-educing\& \{epistemic-totalising ${ }^{3}$ hermeneutically/textually/reprojectingly/supererogatingly/zeroingly/reacutingly, - dectsing $_{\text {d }}$ delinearity $\sim$ for-cogency $>$-epistemic-perspective-ofprojective/reprojective - aestheticising-re-motif-and-re-apriorising/re-axiomatising/rereferencing conceptualisation,-as-herein-specifically-relevant-to human-subpotency $\rangle$ (as to 
underlying human construction-of-the-Self) is not a 'metaphysical/ideological advocacy', no more than say the ${ }^{103}$ universalising-idealisation philosophers nor the budding-positivists were involved in any 'metaphysical/ideological advocacy', but rather just as modern-day science such a conception speaks to the 'inherent ontological implications as to human knowledgereification $\sim$ gesturing-and-accounting — of-epistemic-phenomenalism- $<$ inprospective_psychologismic apriorising/axiomatising/referencing-\{of-‘prospectively implicited_attendant-ontological-contiguity ' educedexistentialising/contextualising/textualising_'intelligibility/epistemicity/reflexivity-contiguity$<$ imbued-notional cogency $>$ ' $\}$-conflatedness -in-\{preconverging ment by\} postconverging-entailment $>$ and corresponding empowering notional $\sim$ reflexivity$<\{$ veridical/sound $\}$-relative-reflexivity-in-existence/relativising from-limited-mentation-as-

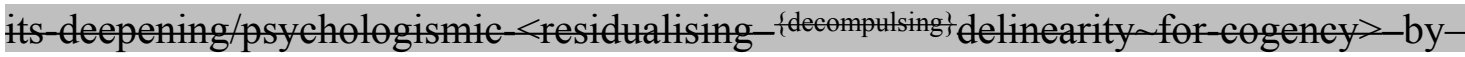
\{flawed/unsound\}-relative-unreflexivity-in-existence/absolutising from-limitedmentation/psychologismic epistemic acutisation nonresidualising imbuedfompulsing linearity in-eclecticism-of-prior-mere-formulaicity/ritualisation $>$ as to humansubpotency implied human potential' (as implied in the differentiation between postmodern ontological-reconstituting/deconstruction/genealogy that exposes itself and is phronetically/practically encrusted/embedded/inlayed with inherent existence as to its underlying ontological claim sublimating-validation/desublimating-invalidation, and say a Hegelian dialectics and its derived-dialectics like Marxism wherein aspiration/ideology takes-aleap-above/parts-with and is not utterly submitted to inherent existence ontological implications). Such a notional ${ }^{18}$ deprocrypticism conceptualisation of 'boundless human aestheticisation-and-aestheticisation-towards-ontology-<elicited-idiomatisation $>$ ' speaks in itself of the 'potentiative-paradox of human-subpotency-aporia/undecidability/dilemma/oughtindeterminacy/deficiency/limitation/constraint_-imbued-‘notional firstnaturedness- 


\section{intemporal-dispositions- $<$ so-construed-as-from-perspective-ontological-}

normalcy/postconvergence>'-existentialism-form-factor' (as the underlying potentiativeparadox of human paradoxes). Critically, at any given moment, potentiatively humankind is ever always inclined-and-amenable to face up to certain aporia/undecidability/dilemma/oughtindeterminacy/deficiency/limitation/constraint while rather disinclined with respect to other aporia/undecidability/dilemma/ought-indeterminacy/deficiency/limitation/constraint; and this very much explains the 'potentiative-paradox of human-subpotencyaporia/undecidability/dilemma/ought-indeterminacy/deficiency/limitation/constraint—imbued'notional firstnaturedness-formativeness-<as-to-eventualising inkling-drive-or-seedingmisprising $>$ temporal-to-intemporal-dispositions- $<$ so-construed-as-from-perspectiveontological-normalcy/postconvergence>'-existentialism-form-factor' (as the underlying potentiative-paradox of human paradoxes). It speaks to a metaphoricity ${ }^{57}$ potentiation imbued in humankind defined by 'human lack-of-capacity/capacity for dispensing-with-immediacy-forrelative-ontological-completeness ${ }^{87}$-by-reification/contemplative-distension ${ }^{27}$, as this relates to preconverging-existential-extrication-as-of-existential-unthought/postconvergingnonextricatory-existential-preempting-of-existential-unthought. In this regards, human growth (with regards to human Being-development/ontological-framework-expansion-as-to-depth-ofontologising-development-as-infrastructure-of- meaningfulness-and-teleology , institutionaldevelopment-as-to-social-function-development and living-development-as-to-personalitydevelopment psychologismic epistemic-acutisation difficulty < for, residualising ${ }_{\text {\{decompulsing }}$ delinearity for-cogency>-magnitudes $\{$ of-experientiality/experiment\} $\}$ is ever always about 'human consciousness tenuous self-surpassing shift in its apriorising/axiomatising/referencing appraisal'. Insightfully, the relative-unreflexivity/relative-reflexivity-ontologicalcontiguity ${ }^{67}$ of-the-human-institutionalisation-process ${ }^{68}$ is a reflection of the fact that any given 
defining human contemplative moment (given registry-worldview/dimension) is marked by the 'disseminative ontological selectivity/deselectivity play' of 'perceived aporia/undecidability/dilemma/ought-indeterminacy/deficiency/limitation/constraint it is supposedly inclined-and-amenable to face up to' (reflecting its <amplituding/formativeepistemicity $>$ totalising $\sim$ self-referencing-syncretising/circularity/interiorising/akrasiatic-drag for $\quad<$ amplituding/formative $>$ wooden-language-_imbued - averaging-of-thought- $<$ as-toleveling/ressentiment/closed-construct-of- meaningfulness-and-teleology -as-of'nondescript/ignorable-void '-with-regards-to-prospective-apriorising-implications $>>$ as to prospective social-stake-contention-or-confliction) and 'prospectively conceptualisable aporia/undecidability/dilemma/ought-indeterminacy/deficiency/limitation/constraint it is disinclined to face up to' (reflecting its <amplituding/formative> wooden-language-〈imbuedtemporal-mere-form/virtualities/dereification/akrasiatic-drag/denatured/preconverging-ordementing -narratives - of-the- reference-of-thought- categoricalimperatives/axioms/registry-teleology 〉), so-reflected as to 'human consciousness tenuous selfsurpassing shift in its apriorising/axiomatising/referencing appraisal'; and so contrastively as of human underlying dimensionality-of-sublimating

<<amplituding/formative>supererogatory $\sim$ de-mentativeness/epistemic-growth-orconflatedness /transvaluative-rationalising/transepistemicity/anamnestic-residuality/spiritdrivenness-equalisation $\rangle$ by lack-of-dimensionality-of-sublimating -

<<amplituding/formative>supererogatory $\sim$ de-mentativeness/epistemic-growth-orconflatedness /transvaluative-rationalising/transepistemicity/anamnestic-residuality/spiritdrivenness-equalisation) form-factor, sublimating-thoughtfulness / desublimating-orgimmickiness-unthoughtfulness form-factor, ${ }^{4}$ historiality-or-ontological-eventfulness ${ }^{38}$-orontological-aesthetic-tracing-<perspective-ontological-normalcy/postconvergence-reflected'epistemicity-relativism-determinism'> historicity-tracing_-in-presencing- 
hyperrealisation/hyperreal-transposition form-factor, prospective-ontological-projection / social-vestedness-or-normativity form-factor, and ideality / positive-opportunism-of-socialfunctioning-and-accordance ${ }^{7}$-disposition form-factor. This contrast is very much aligned with the relative-unreflexivity/relative-reflexivity - ontological-contiguity ${ }^{67} \sim$ of-the-humaninstitutionalisation-process dimensionality-of-sublimating

<<amplituding/formative>supererogatory $\sim$ de-mentativeness/epistemic-growth-or-

conflatedness /transvaluative-rationalising/transepistemicity/anamnestic-residuality/spiritdrivenness-equalisation> and dimensionality-of-desublimating-lack-of ${ }^{-}$ <<amplituding/formative>supererogatory $\sim$ de-mentativeness/epistemic-growth-orconflatedness /transvaluative-rationalising/transepistemicity/anamnestic-residuality/spiritdrivenness-equalisation). That said all registry-worldviews/dimensions as of their defining human contemplative moment arising from their very human limited-mentation-capacity-assubjecting 'educed-unlimitedness/existence-sublimating nascence' to-limitedness/humaninduced ${ }^{7}$ presencing - absolutising-identitive-constitutedness ${ }^{14}$ (while effectively contemplative of prospective progress), hardly/poorly project of prospective emancipation directly on the ontologically-veridical basis of the defining 'prospectively conceptualisable aporia/undecidability/dilemma/ought-indeterminacy/deficiency/limitation/constraint it is disinclined to face up to' (associated with its defining prospective transvaluative-rationalisng / sublimating-thoughtfulness / ${ }^{4}$ historiality-or-ontological-eventfulness ${ }^{38}$-or-ontologicalaesthetic-tracing-<perspective-ontological-normalcy/postconvergence-reflected-'epistemicityrelativism-determinism'> / prospective-ontological-projection / ideality as to prospective originariness-parrhesia,--as-spontaneity-of-aestheticisation) but rather directly proceed as of the 'perceived aporia/undecidability/dilemma/ought-indeterminacy/deficiency/limitation/constraint it is supposedly inclined-and-amenable to face up to' (reflecting its threshold as to dimensionality-of-desublimating-lack-of $-\langle<$ amplituding/formative $>$ supererogatory $\sim$ de- 
mentativeness/epistemic-growth-or-conflatedness /transvaluative-

rationalising/transepistemicity/anamnestic-residuality/spirit-drivenness-equalisation〉

desublimating-or-gimmickiness-unthoughtfulness $\quad / \quad{ }^{47}$ historicity-tracing-in-presencinghyperrealisation/hyperreal-transposition / social-vestedness-or-normativity / positiveopportunism-of-social-functioning-and-accordance ${ }^{7}$-disposition), but then the latter is improvisably/uncontrollably potentiatively-transformed into the former as to the former existentially-< $<$ disontologising/re-ontologising aporeticism $>$ constraining implications of ontological-veracity. Thus the reality of prospective human emancipation in reflecting holographically-<conjugatively-and-transfusively $>$ the relative-unreflexivity/relativereflexivity - ontological-contiguity of-the-human-institutionalisation-process rather as of such a 'human consciousness defensive-driven/unhinging/unbalancing improvising/uncontrolled potentiative-transforming-process so-constrained existentiallydisontologising/re-ontologising aporeticism $>$ on the basis of human supposedly coherent ontological-commitment ${ }^{6}<$ implied-self-assuredness-of-ontological-goodfaith/authenticity postconverging-de-mentating/structuring/paradigming -as-being-as-ofexistential-reality>' (as to the potentiative transforming/conversion, on the basis of existentially< disentologising/re-ontelogising apereticism $>$ constraining implications of ontologicalveracity, of human 'perceived aporia/undecidability/dilemma/oughtindeterminacy/deficiency/limitation/constraint it is supposedly inclined-and-amenable to face up to' into human 'prospectively conceptualisable aporia/undecidability/dilemma/oughtindeterminacy/deficiency/limitation/constraint it is disinclined to face up to') in-many-ways limits/stifles/undermines/derails human contemplative capacity for prospective emancipative implications (as can be so-contemplated from prospective notional ${ }^{18}$ deprocrypticism conceptualisation of 'boundless human aestheticisation-and-aestheticisation-towards-ontology$<$ elicited-idiomatisation>'); and so critically as to the ${ }^{79}$ presencing-absolutising-identitive- 
constitutedness ${ }^{14}$ human $<$ amplituding/formative-epistemicity $>$ totalising $\sim$ self-referencingsyncretising/circularity/interiorising/akrasiatic-drag 34 social-stake-contention-or-confliction state inducing human psychological entrapment in want for prospective psychoanalyticunshackling/memetic-reordering/institutional-recomposuring. But then such apparently defining limitation to 'boundless human aestheticisation-and-aestheticisation-towards-ontology$<$ elicited-idiomatisation>' when analysed as to the reality of human transformation across the time scale in reflecting holographically-<conjugatively-and-transfusively $>$ the relativeunreflexivity/relative-reflexivity - ontological-contiguity of-the-human-institutionalisationprocess (wherein the <cumulating/recomposuring attendant-ontological-contiguity >successive registry-worldviews/dimensions as from recurrent-utter-uninstitutionalisation, baseinstitutionalisation, ${ }^{103}$ universalisation right up to our present positivism and so as from the appearance of mankind on earth about 200000 years ago) show a 'time-accelerated metaphoricity ${ }^{57}$ potentiation' when we consider that our present positivism registry-worldview is just about 500 years; pointing out that as of our specific human-subpotency with regards to overall overall reifying-and-empowering-reflexivity-of-ecstatic-existence-aspanintelligibility/panreflexivity ${ }^{73}$-〈existentially-imbued-and-educing-<epistemictotalising thermeneutically/textually/reprojectingly/supererogatingly/zeroingly/re-acutingly,$\{$ decompulsing $\}$ delinearity $\sim$ for-cogency $>$-epistemic-perspective-of-projective/reprojectiveaestheticising-re-motif-and-re-apriorising/re-axiomatising/re-referencing $\sim$ conceptualisation-as herein-specifically-relevant-to human-subpotency) (underlying human construction-of-theSelf) the human prospective capacity to serenely come to terms with 'prospectively conceptualisable aporia/undecidability/dilemma/oughtindeterminacy/deficiency/limitation/constraint it is disinclined to face up to' as so induced by the latter's existentially-<disontologising/re-ontologising aporeticism $>$ constraining implications of ontological-veracity, is not necessarily forever bound to be as of the "human 
consciousness defensive-driven/unhinging/unbalancing improvising/uncontrolled potentiativetransforming-process $\quad$ so-constrained $\quad$ existentially-<disontologising/re-ontologising apereticism $>$ on the basis of human supposedly coherent ontological-commitment $-<$ implied self-assuredness-of-ontological-good-faith/authenticity postconverging-dementating/structuring/paradigming -as-being-as-of-existential-reality >' that undermines the possibility for such prospective notional deprocrypticism conceptualisation of 'boundless human aestheticisation-and-aestheticisation-towards-ontology-<elicited-idiomatisation $>$ ' (as to the potential for a full human psychological uninhibitedness/decomplexification in superseding the 'underlying human formative decoherencing-structure- of $-{ }^{56}$ meaningfulnessand-teleology -for-institutionalisation'). But then such overcoming of 'human consciousness tenuous self-surpassing shift in its apriorising/axiomatising/referencing appraisal' still has to be effectively achieved as to the requisite human prospective development of protensive-selfconsciousness in the face of the ever present manifestations of desublimating/gimmicky sophistry and eliciting of human temporality $/$ shortness <amplituding/formative $>$ woodenlanguage-〈imbued — averaging-of-thought-<as-to-leveling/ressentiment/closed-construct-ofmeaningfulness-and-teleology -as-of-'nondescript/ignorable-void '-with-regards-toprospective-apriorising-implications $>>$ as to incrementalism-in-relative-ontologicalincompleteness ${ }^{8}$ — enframed/disontologising conceptualisation and so over the requisite maximalising-recomposuring-for-relative-ontological-completeness ${ }^{87}$ - unenframed/reontologising conceptualisation. The very forward-facedness of human consciousness as it defines human social-stake-contention-or-confliction is in-many-ways architectonically determinative and defining (as it projects postconverging/dialectical-thinking -qualia-schema over preconverging/dementing -qualia-schema), with regards to the preconverging/postconverging-de-mentative/structural/paradigmatic circular recurrence of 'potentiative-paradox of human-subpotency-aporia/undecidability/dilemma/ought- 
indeterminacy/deficiency/limitation/constraint—imbued-'notional firstnaturedness-

formativeness-<as-to-eventualising-inkling drive or seeding misprising $>$ temporal-to-

intemporal-dispositions-<so-construed-as-from-perspective-ontological-

normalcy/postconvergence>'-existentialism-form-factor' (as the underlying potentiativeparadox of human paradoxes); as to the 'human consciousness defensivedriven/unhinging/unbalancing improvising/uncontrolled potentiative-transforming-process soconstrained existentially-< disentologising/re-ontologising aporeticism $>$ on the basis of human supposedly coherent ontological-commitment $-<$ implied - self-assuredness-of-ontologicalgood-faith/authenticity postconverging-de-mentating/structuring/paradigming -as-beingas-of-existential-reality>' (as of the potentiative transforming/conversion, on the basis of existentially-<lisontologising/re-ontologising aporeticism $>$ constraining implications of ontological-veracity, of human 'perceived aporia/undecidability/dilemma/oughtindeterminacy/deficiency/limitation/constraint it is supposedly inclined-and-amenable to face up to' into human 'prospectively conceptualisable aporia/undecidability/dilemma/oughtindeterminacy/deficiency/limitation/constraint it is disinclined to face up to'), and so with regards to the overall relative-unreflexivity/relative-reflexivity - ontological-contiguity ${ }^{67}$ ofthe-human-institutionalisation-process ${ }^{68}$ induced construction-of-the-Self. Effectively the relative-unreflexivity/relative-reflexivity - ontological-contiguity ${ }^{67}$ of-the-human-

institutionalisation-process $^{68}$ possibility of successive transcendence-andsublimity/sublimation/supererogatory-de-mentativity is a reflection of the 'human consciousness defensive-driven/unhinging/unbalancing improvising/uncontrolled potentiativetransforming-process $\quad$ so-constrained $\quad$ existentially- $<$ disontologising/re-ontologising apereticism $>$ on the basis of human supposedly coherent ontological-commitment $-<$ implied self-assuredness-of-ontological-good-faith/authenticity postconverging-dementating/structuring/paradigming -as-being-as-of-existential-reality>' as to its 'transitorily 
implied successive notional-contiguity/epistemic-contiguity ${ }^{2}-<$ profound-supererogation -ofmentally-aestheticised postconverging/dialectical-thinking -qualia-schema $>$ as $\quad$ from successive human consciousness forward-facedness postures in 79 presencing-absolutisingidentitive-constitutedness $^{14}$, , but which from the ontological-normalcy/postconvergence epistemic perspective in relative-unreflexivity/relative-reflexivity-ontological-contiguity rather speaks of their successive notional-discontiguity/epistemic-discontiguity ${ }^{3}<$ betweenprior-shallow-supererogation -of-mentally-aestheticised preconverging/dementing -qualiaschema_and_prospective-profound-supererogation -of-mentallyaestheticised postconverging/dialectical-thinking -qualia-schema>. This ontologicalnormalcy/postconvergence epistemic perspective as to its relative-unreflexivity/relativereflexivity - ontological-contiguity ${ }^{67}$ points out that the ontological-veracity of the registryworldviews/dimensions successive 'prior secondnatured reasoning-from-results/afterthought reproducibility—mathesis/motif/thrownness-disposition,--as-reproducibility-of-aestheticisation (as projected notional-discontiguity/epistemic-discontiguity ${ }^{6}<$ between - prior-shallowsupererogation -of-mentally-aestheticised $\sim$ preconverging/dementing -qualiaschema_and_prospective-profound-supererogation -of-mentallyaestheticised postconverging/dialectical-thinking -qualia-schema $>$ reflecting dimensionalityof-desublimating-lack-of $-<<$ amplituding/formative $>$ supererogatory $\sim$ dementativeness/epistemic-growth-or-conflatedness /transvaluativerationalising/transepistemicity/anamnestic-residuality/spirit-drivenness-equalisation〉)' contrasted with the successive 'prospective firstnatureness reasoning-through/messianicreasoning originariness-parrhesia,-as-spontaneity-of-aestheticisation (as projected notionalcontiguity/epistemic-contiguity ${ }^{2}<$ profound-supererogation -of-mentallyaestheticised $\sim$ postconverging/dialectical-thinking -qualia-schema $>$ reflecting dimensionalityof-sublimating $25-<$ amplituding/formative $>$ supererogatory $\sim$ de-mentativeness/epistemic- 
growth-or-conflatedness /transvaluative-rationalising/transepistemicity/anamnestic-

residuality/spirit-drivenness-equalisation))', is actually the relative-unreflexivity/relativereflexivity - ontological-contiguity ${ }^{67}$ of-the-human-institutionalisation-process ${ }^{68}$ 'human consciousness defensive-driven/unhinging/unbalancing improvising/uncontrolled potentiativetransforming-process so-constrained existentially-disologising apereticism $>$ on the basis of human supposedly coherent ontological-commitment $-<$ impliedself-assuredness-of-ontological-good-faith/authenticity postconverging-dementating/structuring/paradigming -as-being-as-of-existential-reality>' (with regards to 'varying psychologismic epistemic-acutisation difficulty-<for, residualising \{decompulsing $\}$ delinearity for-cogency> -magnitudes $\{$ of-experientiality/experiment $\} /$ scales —as-tosuccessively-profound-preconverging/postconverging-rede-

mentating/restructuring/reparadigming-frames-as-from-living,-institutionalising,-and-Beingontologising/infrastructure-of- ${ }^{5}$ meaningfulness-and-teleology 9 of prospective humansubpotency-aporia/undecidability/dilemma/ought-

indeterminacy/deficiency/limitation/constraint_-imbued-'notional firstnaturednessformativeness-<as-to-eventualising-inkling-drive or seeding-misprising $>$ temporal-tointemporal-dispositions-<so-construed-as-from-perspective-ontologicalnormalcy/postconvergence>'-existentialism-form-factor'). This very much explains transversality-<for-sublimating-existential-eventuating/denouement,-from-'thinking atfirst/pure predisposition -preemptive-of prospective-disontologising/subontologising' as-ofprospectively-disambiguated-affirmed-and-unaffirmed-'motif-andapriorising/axiomatising/referencing' $>101$ of 'prior secondnatured reasoning-fromresults/afterthought $\quad$ reproducibility—mathesis/motif/thrownness-disposition,--asreproducibility-of-aestheticisation (as projected notional-discontiguity/epistemicdiscontiguity $^{63}-<$ between - prior-shallow-supererogation -of-mentally- 
aestheticised $\sim$ preconverging/dementing -qualia-schema_and_prospective-profound-

supererogation -of-mentally-aestheticised postconverging/dialectical-thinking -qualia-

schema $>$ )' and 'prospective firstnatureness reasoning-through/messianic-reasoning originariness-parrhesia,-as-spontaneity-of-aestheticisation (as projected notionalcontiguity/epistemic-contiguity ${ }^{2} \_$profound-supererogation -of-mentally-

aestheticised $\sim$ postconverging/dialectical-thinking -qualia-schema $>$ )'; explaining why knowledge-reification $\sim$ gesturing-and-accounting —of-epistemic-phenomenalism- $<$ inprospective_psychologismic apriorising/axiomatising/referencing-\{of-'prospectively implicited_attendant-ontological-contiguity ' educedexistentialising/contextualising/textualising_'intelligibility/epistemicity/reflexivity-contiguity$<$ imbued-notional cogency $>$ ' $\}$-conflatedness -in-\{preconverging-ment by\} postconverging entailment> and sublimation as to the prospective registryworldview/dimension elicited apriorising/axiomatising/referencing-psychologism is not necessarily intelligible to the prior registry-worldview's/dimension's ordinary contemplation as to its presencing-absolutising-identitive-constitutedness apriorising/axiomatising/referencing-psychologism, and further explains human consciousness discontinuity in reflecting holographically-<conjugatively-and-transfusively $>$ the relativeunreflexivity/relative-reflexivity - ontological-contiguity of-the-human-institutionalisationprocess as to the $<$ cumulating/recomposuring attendant-ontological-contiguity $>$-successive registry-worldviews/dimensions notional-discontiguity/epistemic-discontiguity ${ }^{63}<<$ between prior-shallow-supererogation -of-mentally-aestheticised preconverging/dementing -qualiaschema_and_prospective-profound-supererogation -of-mentallyaestheticised postconverging/dialectical-thinking - qualia-schema $>$ with each other (assuming paradoxically the form of 'iterative-looping-narrations though in $<$ cumulating/recomposuring attendant-ontological-contiguity $>$-successive registry- 
worldviews/dimensions deeper knowledge-reification $\sim$ gesturing-and-accounting-ofepistemic-phenomenalism- $<$ in-

prospective_psychologismic apriorising/axiomatising/referencing-\{of-'prospectively implicited_attendant-ontological-contiguity ' ceducedexistentialising/contextualising/textualising_ 'intelligibility/epistemicity/reflexivity-contiguity<imbued-notional cogency >’ \}-conflatedness -in-\{preconverging-ment by\} postconverging entailment $>$ where the prior is preconverging-or-dementing ${ }^{20}$-apriorisingpsychologism and the prospective is postconverging-or-dialectical-thinking ${ }^{21}$-apriorisingpsychologism' with respect to the-very-same-immanent-existence/intrinsic-reality/ontologicalveridicality,-as-to-'human<amplituding/formative-epistemicity>totalising $\sim$ purview-ofconstrual'). Such a 'human consciousness defensive-driven/unhinging/unbalancing improvising/uncontrolled potentiative-transforming-process so-constrained existentiallydisontologising/re-ontelogising aporeticism $>$ on the basis of human supposedly coherent

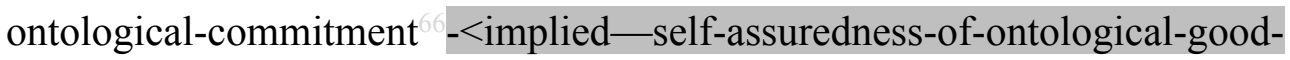
faith/authenticity postconverging-de-mentating/structuring/paradigming -as-being-as-ofexistential-reality>' reflects the 'potentiative-paradox of human-subpotencyaporia/undecidability/dilemma/ought-indeterminacy/deficiency/limitation/constraint—imbued'notional firstnaturedness-formativeness-<as-to-eventualising $\sim$ inkling drive or-seeding misprising $>$ temporal-to-intemporal-dispositions- $<$ so-construed-as-from-perspectiveontological-normalcy/postconvergence>'-existentialism-form-factor' (as the underlying potentiative-paradox of human paradoxes) as to the fact that base-institutionalisation is instigated in recurrent-utter-uninstitutionalisation, ${ }^{103}$ universalisation is instigated in baseinstitutionalisation-ununiversalisation, positivism/rational-empiricism is instigated in universalisation-non-positivism/medievalism and prospectively notional ${ }^{18}$ deprocrypticism

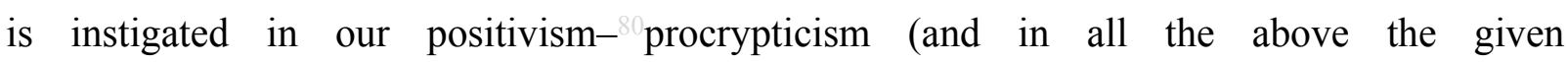


'uninstitutionalised-threshold ${ }^{102}$ prior-apriorising/axiomatising/referencing-superseded-logicalbasis-of $\sim$ dialogical-equivalence-<as-to-psychologismic $\sim$ apriorising/axiomatising/referencing\{of-'prospectively_implicited_attendant-ontological-contiguity ' ceducedexistentialising/contextualising/textualising_intelligibility/epistemicity/reflexivity-contiguity<imbued-notional cogency $>>\quad\}$-conflatedness -in-\{preconverging -ment by\} postconverging-entailment,-in-self-becoming/self-conflatedness /formativesupererogating $>$ ' 2 , is overriden with the 'succeeding institutionalisation prospectiveapriorising/axiomatising/referencing-superseding-logical-basis-of $\sim$ dialogical-equivalence- $<$ asto-psychologismic apriorising/axiomatising/referencing-\{of-‘prospectivelyimplicited_attendant-ontological-contiguity ' educedexistentialising/contextualising/textualising_'intelligibility/epistemicity/reflexivity-contiguity<imbued-notional cogency >' \}-conflatedness -in-\{preconverging-ment by\} postconverging-entailment,-in-self-becoming/self-conflatedness /formativesupererogating $>$ ' '); and so as to human limited-mentation-capacity-deepening-as-subjectinglimitedness/human-subpotency to-'educed-unlimitedness/existence-sublimating nascence' ' 1 de-mentation-〈supererogatory $\sim$ ontological-de-mentation-or-dialectical-de-mentationstranding-or-attributive-dialectics $\rangle$

supererogatory acuity/perspicacity/astuteness/edginess/incisiveness of apriorising/axiomatising/referencing for mental-aestheticisation of ${ }^{56}$ meaningfulness-andteleology ${ }^{9}$ as to postconverging/dialectical-thinking -qualia-schema-mentalaestheticisation-attribution and preconverging/dementing ${ }^{20}$-qualia-schema-mentalaestheticisation-attribution and then their mutually-reinfusing-attributive-possibilities,-for'<amplituding/formative-epistemicity $>$ totalising $\sim$ pseudoconflation/conflation-of-humanlimited-mentation-capacity—as-subjecting 'educed-unlimitedness/existence-sublimating nascence' to-limitedness/human-subpotency'-as-to-correspondingly-ensuing — desublimating- 
or-sublimating-mental-aestheticisation-representation (with regards to "varying psychologismic epistemic acutisation difficulty-for, residualising

$\{$ decompulsing $\}$ delinearity for-cogency> magnitudes $\{0$-experientiality/experiment $\} /$ scales—as-tosuccessively-profound-preconverging/postconverging-rede-

mentating/restructuring/reparadigming-frames-as-from-living,-institutionalising,-and-Beingontologising/infrastructure-of- ${ }^{5}$ meaningfulness-and-teleology 9 of prospective humansubpotency-aporia/undecidability/dilemma/ought-

indeterminacy/deficiency/limitation/constraint—imbued-'notional firstnaturedness-

formativeness-<as-to-eventualising-inkling drive or seeding misprising $>$ temporal-to-

intemporal-dispositions-<so-construed-as-from-perspective-ontological-

normalcy/postconvergence>'-existentialism-form-factor'). 'Human consciousness

notional protensivity imbuing prospective psychologismic-epistemic-acutisation-<as-to-

postconverging-de-mentating/structuring/paradigming,-eliciting-of-existence's-sublimating-

nascence-in-prospective-aporeticism-overcoming/unovercoming $>$ as to epistemic-growth,-as-

\{veridical/sound\}-relative-reflexivity-in-existence/relativising from-limited-mentation-as-its-

deepening/psychologismic epistemic acutisation residualising, ${ }^{\text {\{decompulsing }}$ delinearity for-

eogeney' as of prospective notional ${ }^{18}$ deprocrypticism protensive-self-consciousness (with regards to the fundamental 'human self-consciousness preconverging/postconverging-dementative/structural/paradigmatic seeding-disposition as of notional/epistemic/bindingness ${ }^{-<a s-}$ shiftiness-of-the-Self / $/$ construction-of-theSelf' instigating of notional procrypticism $\quad$ amplituding/formativeepistemicity $>$ totalising $\sim$ self-referencing-syncretising/circularity/interiorising/akrasiatic-drag as-of-the-subsequent-reflection/translation-of-human-consciousness-seeding-disposition-into'induced-human-social-construction-of- ${ }^{-6}$ meaningfulness-and-teleology ${ }^{9}$ ') is thus critically about human 'notional $\sim$ ' deprocrypticism requisitely cultivated originariness in deneuterising 
exteriorisation-and-re-exteriorisations as prospective originariness-and-re-originariness' as to enable human attending-to/dealing-with its 'prospectively conceptualisable aporia/undecidability/dilemma/ought-indeterminacy/deficiency/limitation/constraint it is disinclined to face up to' (associated with its defining prospective transvaluation / sublimatingthoughtfulness / ${ }^{4}$ historiality-or-ontological-eventfulness ${ }^{38}$-or-ontological-aesthetic-tracing<perspective-ontological-normalcy/postconvergence-reflected-'epistemicity-relativism-

determinism'> / prospective-ontological-projection / ideality as to prospective originarinessparrhesia,-as-spontaneity-of-aestheticisation) and so over 'notional procrypticism distortiveoriginariness in ${ }^{58}$ neuterising interiorisation-and-re-interiorisations as prior distortiveoriginariness-and-redistortive-re-originariness' in merely drifting to its 'perceived aporia/undecidability/dilemma/ought-indeterminacy/deficiency/limitation/constraint it is supposedly inclined-and-amenable to face up to' (reflecting its threshold as to its dimensionalityof-desublimating-lack-of ${ }^{-}-<$amplituding/formative $>$supererogatory $\sim$ dementativeness/epistemic-growth-or-conflatedness /transvaluativerationalising/transepistemicity/anamnestic-residuality/spirit-drivenness-equalisation〉 desublimating-or-gimmickiness-unthoughtfulness $\quad / \quad{ }^{47}$ historicity-tracing-in-presencinghyperrealisation/hyperreal-transposition / social-vestedness-or-normativity / positiveopportunism - of-social-functioning-and-accordance ${ }^{75}$-disposition): thusly construed as 'human self-consciousness preconverging/postconverging-de-mentative/structural/paradigmatic seeding-disposition as of notional/epistemic/bindingness ${ }^{-<a s-t o-d e t e r m i n i s m / c o n c e p t i v i t y-o f-r e l a t i v e-~}$ unreflexivity/relative-reflexivity> shiftiness-of-the-Self ${ }^{1} /$ construction-of-the-Self $^{\prime}$ instigating of prospective notional deprocrypticism furtherance (as human limited-mentation-capacitydeepening —as-subjecting limitedness/human-subpotency-to-'educed-unlimitedness/existencesublimating nascence' ${ }^{53}$ ) so-reflected as of 'human corresponding-sublimation-inducing,profound-and-creative supererogatory $\sim$ acuity/perspicacity/astuteness/edginess/incisiveness-of- 
apriorising/axiomatising/referencing/intelligibilitysettingup/measuringinstrumenting -for-

conceptualisation' (as to implied 'conceptualising implications about existential-reality' in reflecting the 'relevant-level human-subpotency-aporia/undecidability/dilemma/oughtindeterminacy/deficiency/limitation/constraint' to be surpassed/superseded/overcome for prospective transcendence-and-sublimity/sublimation/supereregatory $\sim$ de-mentativity); as of ' ${ }^{6}$ de-mentation-〈supererogatory $\sim$ ontological-de-mentation-or-dialectical-de-mentationstranding-or-attributive-dialectics $\rangle$

supereregatery acuity/perspicacity/astuteness/edginess/incisiveness apriorising/axiomatising/referencing for mental-aestheticisation of ${ }^{56}$ meaningfulness-andteleology ${ }^{9}$ as to postconverging/dialectical-thinking -qualia-schema-mentalaestheticisation-attribution and preconverging/dementing ${ }^{20}$-qualia-schema-mentalaestheticisation-attribution and then their mutually-reinfusing-attributive-possibilities,-for'<amplituding/formative-epistemicity $>$ totalising $\sim$ pseudoconflation/conflation-of-humanlimited-mentation-capacity—as-subjecting-'educed-unlimitedness/existence-sublimating nascence' to-limitedness/human-subpotency'-as-to-correspondingly-ensuing - desublimatingor-sublimating-mental-aestheticisation-representation (with regards to 'varying psychologismic epistemic-acutisation difficulty-for, residualising \{dempung delinearity for-cogency> magnitudes $\{0$-experientiality/experiment $\} /$ scales—as-tosuccessively-profound-preconverging/postconverging-redementating/restructuring/reparadigming-frames-as-from-living,-institutionalising,-and-Beingontologising/infrastructure-of- ${ }^{5}$ meaningfulness-and-teleology 9 of prospective humansubpotency-aporia/undecidability/dilemma/ought-

indeterminacy/deficiency/limitation/constraint_-imbued-'notional firstnaturednessformativeness-<as-to-eventualising inkling drive or seeding misprising $>$ temporal-tointemporal-dispositions-<so-construed-as-from-perspective-ontological- 
normalcy/postconvergence>'-existentialism-form-factor'), and so as enabling the notional ${ }^{1}$ deprocrypticism protensive-self-consciousness-seeding-disposition-subsequentreflection/translation-into-'deprocrypticism-induced-human-social-construction-ofmeaningfulness-and-teleology ${ }^{9}$. As a summary reconceptualisation of the possibility for such a notional ${ }^{8}$ deprocrypticism implied boundless human aestheticisation-and-aestheticisationtowards-ontology-<elicited-idiomatisation $>$ as to dimensionality-of-sublimating ${ }^{25}$ 〈<amplituding/formative>supererogatory $\sim$ de-mentativeness/epistemic-growth-orconflatedness /transvaluative-rationalising/transepistemicity/anamnestic-residuality/spiritdrivenness-equalisation, the relative mneflexivitrelative reflexivity-ontologicalcontiguity ${ }^{67}$ of-the-human-institutionalisation-process ${ }^{68}$ can be construed as human aestheticisation-and-aestheticisation-towards-ontology-<elicited-idiomatisation $>\quad$ in prospective notional deprocrypticism furtherance (as human limited-mentation-capacitydeepening —as-subjecting limitedness/human-subpotency-to-'educed-unlimitedness/existencesublimating nascence' ${ }^{53}$ ) so-reflected as of 'human corresponding-sublimation-inducing,profound-and-creative supererogatory $\sim$ acuity/perspicacity/astuteness/edginess/incisiveness-ofapriorising/axiomatising/referencing/intelligibilitysettingup/measuringinstrumenting -forconceptualisation' (as to implied 'conceptualising implications about existential-reality' in reflecting the 'relevant-level human-subpotency-aporia/undecidability/dilemma/oughtindeterminacy/deficiency/limitation/constraint' to be surpassed/superseded/overcome for prospective transcendence-and-sublimity/sublimation/supereregatory - de-mentativity); as of ' ${ }^{5}$ de-mentation-〈supererogatory $\sim$ ontological-de-mentation-or-dialectical-de-mentationstranding-or-attributive-dialectics $\rangle$

supereregatery acuity/perspicacity/astuteness/edginess/incisiveness of apriorising/axiomatising/referencing for mental-aestheticisation of ${ }^{56}$ meaningfulness-andteleology ${ }^{9}$ as to postconverging/dialectical-thinking -qualia-schema-mental- 
aestheticisation-attribution and preconverging/dementing ${ }^{20}$-qualia-schema-mentalaestheticisation-attribution and then their mutually-reinfusing-attributive-possibilities,-for'<amplituding/formative-epistemicity $>$ totalising $\sim$ pseudoconflation/conflation-of-humanlimited-mentation-capacity—as-subjecting-'educed-unlimitedness/existence-sublimating nascence' to-limitedness/human-subpotency'-as-to-correspondingly-ensuing — desublimatingor-sublimating-mental-aestheticisation-representation (with regards to "varying psychologismic epistemic-acutisation difficulty < for, residualising \{decompling $\}$ magnitudes $\{$ of-experientiality/experiment $\} /$ scales —as-tosuccessively-profound-preconverging/postconverging-redementating/restructuring/reparadigming-frames-as-from-living,-institutionalising,-and-Beingontologising/infrastructure-of- ${ }^{5}$ meaningfulness-and-teleology 9 of prospective humansubpotency-aporia/undecidability/dilemma/ought-

indeterminacy/deficiency/limitation/constraint—imbued-'notional firstnaturednessformativeness-<as-to-eventualising inkling drive or seeding misprising $>$ temporal-tointemporal-dispositions- $<$ so-construed-as-from-perspective-ontologicalnormalcy/postconvergence>'-existentialism-form-factor'). This speaks to human limitedmentation-capacity-deepening - as subjecting limitedness/hmman-subotency to 'educedunlimitedness/existence-sublimating nascence' ${ }^{53}$ enabled by the 'conceptivity/epistemicreflexivity/epistemicity-relativism-determinism-<reifying \{as-to-knowledge-developing $\}$-andempowering $>$ as of both reproducibility-mathesis/motif/thrownness-disposition,--asreproducibility-of-aestheticisation and originariness-parrhesia,-as-spontaneity-ofaestheticisation' (conceptivity/epistemic-reflexivity/epistemicity-relativism-determinism$<$ reifying \{as-to-knowledge-developing\}-and-empowering $>$, in the sense that the one notion is already caught up in the other notion in the sublimating/desublimating <amplituding/formativeepistemicity>totalising/circumscribing/delineating manifestation of aestheticisation-and- 
aestheticisation-towards-ontology-<elicited-idiomatisation $>$ as of 'relative-ontologicalincompleteness $8 /$ relative-ontological-completeness

〈sublimating referencing/registering/decisioning,--as-self-becoming/self-

conflatedness $/$ formative-supererogating-<projective/reprojective-aestheticising-re-motifand-re-apriorising/re-axiomatising/re-referencing,-in-perspective-ontological-

normalcy/postconvergence $>>$ as to human-and-social-expectations/anticipationsmetaphoricity ${ }^{57}$-as-preconverging/postconverging-rede-

mentating/restructuring/reparadigming-psychologism' ${ }^{89}$ just as for instance the notion of length is already caught up in the notion of width in the 'sublimating <amplituding/formativeepistemicity $>$ totalising/circumscribing/delineating manifestation of a rectangle' and so with regards to the fact that human aestheticisation-and-aestheticisation-towards-ontology$<$ elicited-idiomatisation $>$ of ${ }^{5}$ meaningfulness-and-teleology ${ }^{9}$ is ever always about 'idealisedtypification in epistemic-conflatedness ${ }^{13}$ sublimation or epistemic apriorising/axiomatising/referencing-\{of-'prospectively implicited_attendant-ontologicalcontiguity ' educedexistentialising/contextualising/textualising_ intelligibility/epistemicity/reflexivity_contiguity$<$ imbued-notional $\sim$ cogency $>\quad\}$ - constitutedness ${ }^{1}$-in-preconverging entailment/pseudoconflation desublimation/gimmickiness' for eliciting sublimation/desublimation from the 'full-potency of existence withheld as from ontologicalnormalcy/postconvergence epistemic projection-perspective'); as to the drivenness of originariness-parrhesia,-as-spontaneity-of-aestheticisation for re-originariness/reorigination of dimensionality-of-sublimating ${ }^{5}-\langle<$ amplituding/formative $>$ supererogatory $\sim$ dementativeness/epistemic-growth-or-conflatedness /transvaluativerationalising/transepistemicity/anamnestic-residuality/spirit-drivenness-equalisation〉 thusly eliciting prospective human aestheticisation-and-aestheticisation-towards-ontology-<elicited- 
idiomatisation $>$ transcendence-and-sublimity/sublimation/supereregatory $\sim$ de-mentativity soconstrained by existence-potency ${ }^{39} \sim$ sublimating-nascence,-disclosed-from-prospectiveepistemic-digression. Originariness-parrhesia,-as-spontaneity-of-aestheticisation effectively reflects 'human projective-capacity for re-originariness/reorigination in $<$ amplituding/formative-epistemicity $>$ totalising/circumscribing/delineating apriorising/axiomatising/referencing-\{of-'prospectively implicited_attendant-ontologicalcontiguity ' educedexistentialising/contextualising/textualising_'intelligibility/epistemicity/reflexivity-contiguity$<$ imbued-notional cogency $\left.>^{\prime}\right\}$ - conflatedness ${ }^{13}$-in-\{preconverging $m e n t$ by $\}$ postconverging-entailment ' while reproducibility-mathesis/motif/thrownness-disposition,-as-reproducibility-of-aestheticisation reflects 'human derivational-disposition': and so as to originariness-parrhesia,-as-spontaneity-of-aestheticisation driven re-motif-and-reapriorising/re-axiomatising/re-referencing/re-intelligibilitysettingup/re-measuringinstrumenting for the requisite 'human corresponding-sublimation-inducing,-profound-and-creative supererogatory $\sim$ acuity/perspicacity/astuteness/edginess/incisiveness-ofapriorising/axiomatising/referencing/intelligibilitysettingup/measuringinstrumenting -forconceptualisation' (as to implied 'conceptualising implications about existential-reality' in reflecting the 'relevant-level human-subpotency-aporia/undecidability/dilemma/oughtindeterminacy/deficiency/limitation/constraint' to be surpassed/superseded/overcome for prospective transcendence-and-sublimity/sublimation/supererogatory $\sim$ de-mentativity); thus overcoming human ${ }^{79}$ presencing-absolutising-identitive-constitutedness ${ }^{14}$ induced historicity-tracing - in-presencing-hyperrealisation/hyperreal-transposition for prospective historiality/ontological-eventfulness 38 ontological-aesthetic-tracing-<perspectiveontological-normalcy/postconvergence-reflected-‘epistemicity-relativism-determinism'> with regards to the successive construction-of-the-Self, and reflection/translation into human 
sublimating-over-desublimating social-and-institutional-constructs-of- - meaningfulness-andteleology underlying the $<$ cumulating/recomposuring attendant-ontological-contiguity $>$-successive registryworldviews/dimensions ${ }^{5}$ meaningfulness-and-teleology ${ }^{9}$. Critically thus the very possibility for human aestheticisation-and-aestheticisation-towards-ontology-<elicited-idiomatisation $>$ as to the 'conflating <amplituding/formative-epistemicity>totalising/circumscribing/delineating re-originariness/reorigination of re-motif-and-re-apriorising/re-axiomatising/re-referencing/reintelligibilitysettingup/re-measuringinstrumenting underlying human conceptualisation and then the devolving existential-instantiation implications as to aposteriorising/logicising/deriving/intelligising/measuring ${ }^{56}$ meaningfulness-and-teleology ${ }^{9}$ (with regards to "varying psychologismic epistemic acutisation difficulty-<for, residualising \{decompulsing\} delinearity for-cogency> magnitudes $\{$ of-experientiality/experiment $\} /$ scales —as-tosuccessively-profound-preconverging/postconverging-redementating/restructuring/reparadigming-frames-as-from-living,-institutionalising,-and-Beingontologising/infrastructure-of- ${ }^{5}$ meaningfulness-and-teleology 99 of prospective humansubpotency-aporia/undecidability/dilemma/ought-

indeterminacy/deficiency/limitation/constraint—imbued-'notional firstnaturednessformativeness-<as-to-eventualising inkling drive or seeding-misprising $>$ temporal-tointemporal-dispositions- $<$ so-construed-as-from-perspective-ontologicalnormalcy/postconvergence>'-existentialism-form-factor') is fundamentally underlined by human conceptivity/epistemic-reflexivity/epistemicity-relativism-determinism- $<$ reifying \{as-toknowledge-developing $\}$-and-empowering $>$ - $\{$ exuding-\{epistemic-

totalising 3 ' $h$ hermeneutically/textually/reprojectingly/supererogatingly/zeroingly/re-acutingly,\{decompulsing $\}$ delinearity for-cogency:-as-from-'existence's effusing/ecstatic-inlining';-as‘interlay/organicalism/aestheticising-handle-<of-‘psychologismic-transfixity\{residualising 
$\{$ \{ecompulsing $\}$ delinearity-over-nonresidualising \{compulsing $\}$ linearity\}\} $>-\{$ manifest-

supererogatory $\sim$ de-mentative-amplituding-or-mental-aestheticising-attuning\}',-in-

supereregatery projective-arbitrariness/waywardness-

of $\sim$ transversalisation/tandemisation/abstractive-conjugation/perspectivation/depthing — for-

'aestheticising-re-margining/re-edging/re-acuity—in-

postconverging/preconverging_circumscriptive/totalitative-restructuring'_educing-

sublimation/desublimation> (driving de-mentation-〈supererogatory $\sim$ ontological-de-

mentation-or-dialectical-de-mentation-stranding-or-attributive-dialectics $\rangle$ dynamics) as-so

eliciting transcendence-and-sublimity/sublimation/supererogatory $\sim$ de-mentativity or desublimation/gimmickiness; as of the specific human-subpotency registryworldview/dimension as to overall reifying-and-empowering-reflexivity-of-ecstatic-existenceas-panintelligibility/panreflexivity ${ }^{33}$ - existentially-imbued-and-educing-<\{epistemic-

totalising ${ }^{3}$ hermeneutically/textually/reprojectingly/supererogatingly/zeroingly/re-acutingly,$\{$ decompulsing\} $d e$ linearity $\sim$ for-cogency $>$-epistemic-perspective-of-projective/reprojectiveaestheticising-re-motif-and-re-apriorising/re-axiomatising/re-referencing $\sim$ conceptualisation,as-herein-specifically-relevant-to human-subpotency). This conceptivity/epistemicreflexivity/epistemicity-relativism-determinism- $<$ reifying \{as-to-knowledge-developing $\}$-andempowering $>-\langle$ exuding_— epistemic-

totalising $3{ }^{3}$ hermeneutically/textlly/reprojectingly/supererogatingly/zeroingly/re aeutingly,\{decompulsing\} delinearity for-cogency:-as-from-‘existence’s effusing/ecstatic-inlining'; -as‘interlay/organicalism/aestheticising-handle-<of-‘psychologismic-transfixity \{residualising

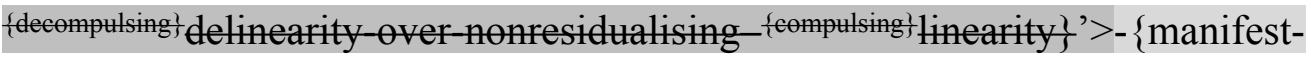
supererogatory $\sim$ de-mentative-amplituding-or-mental-aestheticising-attuning\}',-insupererogatery projective-arbitrariness/waywardnessof $\sim$ transversalisation/tandemisation/abstractive-conjugation/perspectivation/depthing-for- 
'aestheticising-re-margining/re-edging/re-acuity-in-

postconverging/preconverging_circumscriptive/totalitative-restructuring'-educing-

sublimation/desublimation> (human mental-aestheticising-becoming-manifestation as consciousness) eliciting of desublimation/gimmickiness or transcendence-andsublimity/sublimation/supererogatory de-mentativity, is respectively and intimately tied to its implied beholdening-becoming - distortive-originariness/distortive-origination-as-tohistoricity-tracing inhibited-mental-aestheticising desublimation/gimmickiness or bechancing-becoming - originariness/origination-as-to- ${ }^{4}$ historiality/ontologicaleventfulness 3 /ontological-aesthetic-tracing-<perspective-ontologicalnormalcy/postconvergence-reflected-‘epistemicity-relativism-determinism’ $>\sim$ disinhibitedmental-aestheticising transcendence-and-sublimity/sublimation/supereregatory $\sim$ de-mentativity. This speaks to human desublimating-or-sublimating-mental-aestheticisation-representation of the possibility of existence; with the 'full-potency of existence withheld as from ontologicalnormalcy/postconvergence epistemic projection-perspective' as to the 'notional/epistemic/bindingness-as-to-determinism/conceptivity-of-relative-unreflexivity/relative-reflexivitys sublimating-capacity-as-of- ${ }^{4}$ historiality/ontological-eventfulness 38 ontological-aesthetictracing-<perspective-ontological-normalcy/postconvergence-reflected-‘epistemicityrelativism-determinism'> over desublimating-capacity-as-of- ${ }^{-7}$ historicity-tracing-inpresencing-hyperrealisation/hyperreal-transposition' induced from human conceptivity/epistemic-reflexivity/epistemicity-relativism-determinism-<reifying \{as-toknowledge-developing $\}$-and-empowering $>$ - $\{$ exuding- \{epistemic-

totalising ${ }^{3}$ hermeneutically/textully/reprojectingly/supereregatingly/zeroingly/re aeutingly,\{decompulsing $\}$ delinearity for-cogency:-as-from-'existence’s $\sim$ effusing/ecstatic-inlining';-as‘interlay/organicalism/aestheticising-handle-<of-'psychologismic-transfixity \{residualising \{decompulsing $\}$ delinearity-over-nonresidualising \{compulsing $\}$ linearity\}' $>-\{$ manifest- 
supererogatory $\sim$ de-mentative-amplituding-or-mental-aestheticising-attuning \}',-in-

supererogatory projective-arbitrariness/waywardness-

of $\sim$ transversalisation/tandemisation/abstractive-conjugation/perspectivation/depthing — for-

'aestheticising-re-margining/re-edging/re-acuity-in-

postconverging/preconverging_circumscriptive/totalitative-restructuring'_-educing-

sublimation/desublimation> (human mental-aestheticising-becoming-manifestation as

consciousness) driving $\quad{ }^{15}$ de-mentation-(supererogatory $\sim$ ontological-de-mentation-or-

dialectical-de-mentation - stranding-or-attributive-dialectics $\rangle$ dynamics.

Conceptivity/epistemic-reflexivity/epistemicity-relativism-determinism- $<$ reifying \{as-to-

knowledge-developing $\}$-and-empowering $>$ - $\{$ exuding-\{epistemic-

totalising 3 ' $h$ hermeneutically/textually/reprojectingly/supererogatingly/zeroingly/re-acutingly,-

\{decompling delinearity for-cogency:-as-from-'existence's $\sim$ effusing/ecstatic-inlining';-as-

‘interlay/organicalism/aestheticising-handle-<of-‘psychologismic-transfixity \{residualising

$\{$ \{ecompulsing $\}$ delinearity over-nonresidualising \{compulsing $\}$ linearity\}' $>-\{$ manifest-

supererone-mentative-amplituding-or-mental-aestheticising-attuning \}',-in-

supererogatory projective-arbitrariness/waywardness-

of $\sim$ transversalisation/tandemisation/abstractive-conjugation/perspectivation/depthing — for-

'aestheticising-re-margining/re-edging/re-acuity-in-

postconverging/preconverging_circumscriptive/totalitative-restructuring'_educing_-

sublimation/desublimation $>$ further reflects the fact that <amplituding/formative-

epistemicity>totalising/circumscribing/delineating apriorising/axiomatising/referencing-\{of-

'prospectively implicited_attendant-ontological-contiguity ' educed-

existentialising/contextualising/textualising_ 'intelligibility/epistemicity/reflexivity-contiguity-

$<$ imbued-notional $\left.\sim \operatorname{cogency}>^{\prime} \quad\right\}$-conflatedness ${ }^{13}$-in-\{preconverging-ment by

postconverging-entailment is associated with human sublimating-capacity,-as-of- 
historiality/ontological-eventfulness ${ }^{38} /$ ontological-aesthetic-tracing-<perspectiveontological-normalcy/postconvergence-reflected-'epistemicity-relativism-determinism’>

whereas $<$ amplituding/formative-epistemicity $>$ totalising/circumscribing/delineating pseudoconflation/constitutedness $^{14}$ is associated with human desublimating-capacity,-as-ofhistoricity-tracing-in-presencing-hyperrealisation/hyperreal-transposition; as to the preconverging/postconverging-de-mentative/structural/paradigmatic implications of dispensing-with-immediacy-for-relative-ontological-completeness ${ }^{87}$-by-

reification/contemplative-distension ${ }^{27}$ with respect to social-stake-contention-or-confliction, notionally/epistemically/bindingnessly-as-to-derminism/enceptivity-of-relative-mreflexivity/relative-reflexivitys involving respectively 'ontological-normalcy/postconvergence bechancing-becoming-

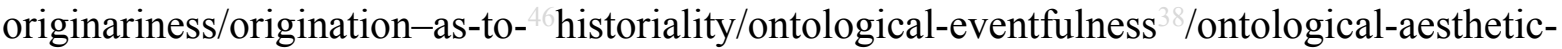
tracing-<perspective-ontological-normalcy/postconvergence-reflected-‘epistemicityrelativism-determinism'> disinhibited-mental-aestheticising epistemic-or-notional $\sim$ projectiveperspective' and 'human-subpotency beholdening-becoming-distortiveoriginariness/distortive-origination-as-to- ${ }^{4}$ historicity-tracing inhibited-mental-aestheticising epistemic-or-notional projective-perspective'. Conceptivity/epistemic-reflexivity/epistemicityrelativism-determinism- $<$ reifying \{as-to-knowledge-developing $\}$-and-empowering $>$ 〈exuding- fepistemic

thermeneutically/textually/reprojectingly/supererogatingly/zeroingly/re-acutingly,delinearity for-cogency:-as-from- 'existence's effusing/ecstatic-inlining';-as‘interlay/organicalism/aestheticising-handle-<of-'psychologismic-transfixity $\{$ residualising $\{$ decompulsing $\}$ delinearity over nonresidualising \{compulsing $\}$ linearity\}' $>-\{$ manifestsupererogatory $\sim$ de-mentative-amplituding-or-mental-aestheticising-attuning \}',-insupererogatory projective-arbitrariness/waywardnessof $\sim$ transversalisation/tandemisation/abstractive-conjugation/perspectivation/depthing — for- 
'aestheticising-re-margining/re-edging/re-acuity-in-

postconverging/preconverging_circumscriptive/totalitative-restructuring'-educing-

sublimation/desublimation> as of human sublimating/desublimating reflection of existentialdisontologising/re-ontologising aporeticism $>$ possibilities as from the 'full-potency of existence withheld as from ontological-normalcy/postconvergence epistemic projectionperspective' rather underscores a 'human exercise of notionality/epistemicity/bindingness ${ }^{<a s-t o-}$ determinism/conceptivity-of-relative-unreflexivity/relative-reflexivity $>$ in circular re-originariness/reorigination and distorted-originariness/distorted-origination notional $\sim$ reflexivity- $<\{$ veridical/sound $\}$-relativereflexivity-in-existence/relativising from-limited-mentation-as-its-deepening/psychologismic<residualising \{decompulsing $\}$ delinearity for-cogency>-by-\{flawed/unsound\}-relativeunreflexivity-in-existence/absolutising from-limited-mentation/psychologismic epistemic acutisation nonresidualising imbued-\{compulsing\}linearity in-eclecticism-of-prior-mereformulaicity/ritualisation> with its sublimation and desublimation' so-construed as 'generating meaningfulness-and-teleology ${ }^{9}$ and metaphoricity ${ }^{57}$. Critically, the possibility for

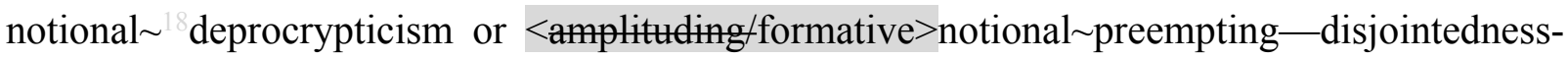
as-of- ${ }^{3}$ reference-of-thought implied boundless human aestheticisation-and-aestheticisationtowards-ontology-<elicited-idiomatisation $>$ as to dimensionality-of-sublimating ${ }^{25}$ <<amplituding/formative>supererogatory $\sim$ de-mentativeness/epistemic-growth-or-

conflatedness /transvaluative-rationalising/transepistemicity/anamnestic-residuality/spiritdrivenness-equalisation), effectively requires human conceptivity/epistemicreflexivity/epistemicity-relativism-determinism-<reifying \{as-to-knowledge-developing $\}$-andempowering $>-$ <exuding-

thermeneutically/textully/reprojectingly/supererogatingly/zeroingly/re-acutingly,\{decompulsing delinearity for-cogency:-as-from- 'existence's $\sim$ effusing/ecstatic-inlining';-as‘interlay/organicalism/aestheticising-handle-<of-"psychologismic-transfixity \{residualising 
\{decompulsing\} delinearity-over-nonresidualising-\{compulsing\} ${ }^{\text {\{inearity }\}}>$ - $\{$ manifest-

supererogatory $\sim$ de-mentative-amplituding-or-mental-aestheticising-attuning\}',-in-

supereregatery projective-arbitrariness/waywardness-

of $\sim$ transversalisation/tandemisation/abstractive-conjugation/perspectivation/depthing — for-

'aestheticising-re-margining/re-edging/re-acuity-in-

postconverging/preconverging_circumscriptive/totalitative-restructuring'-educing-

sublimation/desublimation> converging towards 'ontological-normalcy/postconvergence

bechancing-becoming - originariness/origination-as-to- ${ }^{-}$historiality/ontological-

eventfulness 3 /ontological-aesthetic-tracing-<perspective-ontological-

normalcy/postconvergence-reflected-‘epistemicity-relativism-determinism’> disinhibited-

mental-aestheticising epistemic-or-notional projective-perspective as of deneuterising exteriorisation-and-re-exteriorisations as prospective originariness-and-re-originariness' and so over 'human-subpotency beholdening-becoming-distortive-originariness/distortiveorigination-as-to- ${ }^{47}$ historicity-tracing inhibited-mental-aestheticising epistemic-ornotional projective-perspective as of ${ }^{5}$ neuterising interiorisation-and-re-interiorisations as prior distortive-originariness-and-redistortive-re-originariness' (as to the preconverging/postconverging-de-mentative/structural/paradigmatic implications of dispensing-with-immediacy-for-relative-ontological-completeness ${ }^{87}$-byreification/contemplative-distension ${ }^{27}$ with respect to social-stake-contention-or-confliction). This effectively comes down to human inclination for dealing directly with 'prospectively conceptualisable aporia/undecidability/dilemma/oughtindeterminacy/deficiency/limitation/constraint it is disinclined to face up to' rather than just with 'perceived aporia/undecidability/dilemma/ought-indeterminacy/deficiency/limitation/constraint it is supposedly inclined-and-amenable to face up to', and fundamentally so out of spontaneous ontological-good-faith/authenticity induced prospective- 
apriorising/axiomatising/referencing-superseding-logical-basis-of $\sim$ dialogical-equivalence- $<$ asto-psychologismic apriorising/axiomatising/referencing-\{of-'prospectively implicited_attendant-ontological-contiguity ' educedexistentialising/contextualising/textualising_'intelligibility/epistemicity/reflexivity-contiguity$<$ imbued-notional cogency $>>$ - conflatedness -in-\{preconverging ment by\} postconverging-entailment,-in-self-becoming/self-conflatedness /formative-supererogating > organic-knowledge rather than just mere methods/methodologies/approaches of priorapriorising/axiomatising/referencing-superseded-logical-basis-of $\sim$ dialogical-equivalence- $<$ asto-psychologismic apriorising/axiomatising/referencing-\{of-‘prospectively implicited_attendant-ontological-contiguity ' reducedexistentialising/contextualising/textualising_'intelligibility/epistemicity/reflexivity-contiguity<imbued-notional cogency >' \}-conflatedness -in-\{preconverging-ment by\} postconverging-entailment,-in-self-becoming/self-conflatedness /formative-supererogating> mechanical-knowledge in poor ontological-good-faith/authenticity ${ }^{9}$ or ontological-badfaith/inauthenticity ${ }^{64}$ and critically so as of the enabling dynamics for human transcendenceand-sublimity/sublimation/supererogatory de-mentativity as reflected by the fact that germinative/seeding projections as of reasoning-through/messianic-reasoning however their reoriginary-ass-unenframed/re-ontologising/unbeholdening/outlier-conceptualisation-_imbuedpostconverging/dialectical-thinking -'projective-insights'/'epistemic-projection-inconflatedness ' -of-notional deprocrypticism-prospective-sublimation $\rangle^{\circ}$ nature are effectively what explain the possibility for the relative-unreflexivity/relative-reflexivity ontological-contiguity ${ }^{67}$ of-the-human-institutionalisation-process ${ }^{68}$ on the basis of eliciting the social-construct supposedly coherent ontological-commitment $-<$ implied-self-assurednessof-ontological-good-faith/authenticity $\sim$ postconverging-dementating/structuring/paradigming -as-being-as-of-existential-reality>. Critically, the 
'formative underlying human decoherencing-structure - of- ${ }^{5}$ meaningfulness-and-teleology 9 for-institutionalisation' can be construed from the 'deepest phenomenological transcendentalpoint-of-departure handle as of the notional conflatedness ${ }^{13}$ of notional $\sim^{18}$ deprocrypticism deneuterising '-referentialism': as its enabling knowledge-reifying-and-empowering apprehension of both 'human corresponding-sublimation-inducing,-profound-and-creative supererogatery acuity/perspicacity/astuteness/edginess/incisiveness-ofapriorising/axiomatising/referencing/intelligibilitysettingup/measuringinstrumenting -forconceptualisation' (that create/invent methods/methodologies/approaches as to prospectiveapriorising/axiomatising/referencing-superseding-logical-basis-of $\sim$ dialogical-equivalence- $<$ asto-psychologismic apriorising/axiomatising/referencing-\{of-‘prospectively implicited_attendant-ontological-contiguity ' reducedexistentialising/contextualising/textualising_'intelligibility/epistemicity/reflexivity-contiguity<imbued-notional cogency $\left.>^{\prime}\right\}$-conflatedness -in-\{preconverging -ment by\} postconverging-entailment,-in-self-becoming/self-conflatedness /formative-supererogating> organic-knowledge in ontological-good-faith/authenticity ${ }^{6} \sim$ postconverging-dementating/structuring/paradigming ${ }^{0}$ so-constrained by existence-potency ${ }^{30} \sim$ sublimatingnascence,-disclosed-from-prospective-epistemic-digression) and the 'desublimation/gimmickiness of mere methods/methodologies/approaches of priorapriorising/axiomatising/referencing-superseded-logical-basis-of $\sim$ dialogical-equivalence- $<$ asto-psychologismic apriorising/axiomatising/referencing-\{of-‘prospectively implicited_attendant-ontological-contiguity ' educedexistentialising/contextualising/textualising_'intelligibility/epistemicity/reflexivity-contiguity<imbued-notional $\left.\sim \operatorname{cogency}>^{\prime},\right\}$-conflatedness in \{preconverging ment by\} postconverging-entailment,-in-self-becoming/self-conflatedness /formative-supererogating> mechanical-knowledge in poor ontological-good-faith/authenticity ${ }^{9}$ or ontological-bad- 
faith/inauthenticity ${ }^{64}$ overlooking existence-potency ${ }^{32} \sim$ sublimating-nascence,-disclosed-fromprospective-epistemic-digression. This 'deepest phenomenological transcendental-point-ofdeparture handle as of the notional conflatedness ${ }^{13}$ of notional $\sim^{18}$ deprocrypticism deneuterising '-referentialism' is critically cognisant of the reality of 'human notional firstnaturedness-formativeness-<as-to-eventualising inkling drive-or -seedingmisprising $>$ temporal-to-intemporal-dispositions- $<$ so-construed-as-from-perspectiveontological-normalcy/postconvergence> accordioning-〈as-of-varying-individuationscontextually-transverse-desublimation/sublimation,-as-to-thewavering/redounding/waveforming of-their-referencing-and-their-devolved-referencingimbued-ontological-performance -<including-virtue-as-ontology $>>$ at uninstitutionalisedthreshold ${ }^{02}$ as reflecting both desublimating ${ }^{47}$ historicity-tracing-in-presencinghyperrealisation/hyperreal-transposition and sublimating ${ }^{4}$ historiality/ontologicaleventfulness 38 ontological-aesthetic-tracing-<perspective-ontologicalnormalcy/postconvergence-reflected-'epistemicity-relativism-determinism'> possibilities' (as of human self-surpassing — existentialism-form-factor,-in-overcoming-

\section{'notional collateralising-beholdening-protohumanity'-to-'attain-sublimating-humanity'-as-to-} existence-potency $\sim$ sublimating-nascence,-disclosed-from-prospective-epistemic-digression to supersede human temporality $/$ /shortness <amplituding/formative $>$ wooden-language〈imbued-averaging-of-thought-<as-to-leveling/ressentiment/closed-construct-ofmeaningfulness-and-teleology -as-of-'nondescript/ignorable-void '-with-regards-toprospective-apriorising-implications $>$ )); as to the fact that the 'firstnatureness of human intemporality $^{52}$ as of its inducing of transcendence-andsublimity/sublimation/supererogatory de-mentativity for secondnaturedness' in reflecting holographically-<conjugatively-and-transfusively $>$ the relative-unreflexivity/relativereflexivity - ontological-contiguity of-the-human-institutionalisation-process has ever 
always been a re-originary_-as-unenframed/re-ontologising/unbbeholdening/outlierconceptualisation_____imbued-postconverging/dialectical-thinking -'projectiveinsights'/'epistemic-projection-in-conflatedness ' 'of-notional deprocrypticism-prospectivesublimation $\rangle^{0}$ reasoning-through/messianic-reasoning phenomenon as to the preconverging/postconverging-de-mentative/structural/paradigmatic possibility of breaking away from the 'desublimation/gimmickiness of mere methods/methodologies/approaches of prior-apriorising/axiomatising/referencing-superseded-logical-basis-of $\sim$ dialogicalequivalence-<as-to-psychologismic apriorising/axiomatising/referencing- $\{$ of- 'prospectively implicited_attendant-ontological-contiguity ' educed-

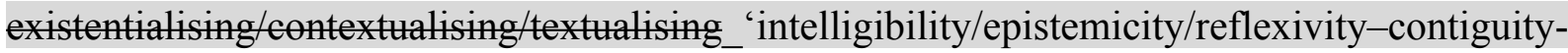
<imbued-notional cogency $>>$ \}-conflatedness - in-\{preconverging ment by\} postconverging-entailment,-in-self-becoming/self-conflatedness /formative-supererogating > mechanical-knowledge prospectively in poor ontological-good-faith/authenticity ${ }^{69}$ outright ontological-bad-faith/inauthenticity ${ }^{64}$ overlooking existence-potency ${ }^{39} \sim$ sublimating-nascence,disclosed-from-prospective-epistemic-digression for prospective transcendence-andsublimity/sublimation/supererogatory-de-mentativity; even as prospectively the reality of human notional firstnaturedness-formativeness-<as-to-eventualising-inkling-drive-orseeding misprising $>$ temporal-to-intemporal-dispositions-<so-construed-as-fromperspective-ontological-normalcy/postconvergence $>$ nature sets in again as such transcendenceand-sublimity/sublimation/supererogatory de-mentativity is further related to at its own implied uninstitutionalised-threshold ${ }^{102}$ in terms of the registry-worldview's/dimension's least common denominator as <amplituding/formative> wooden-language-_imbued-temporal-mereform/virtualities/dereification/akrasiatic-drag/denatured/preconverging-or-dementing narratives - of-the- reference-of-thought- categorical-imperatives/axioms/registryteleology > for social-functioning-and-accordance-as-of-social-stake-contention-or- 
confliction (in a preconverging epistemic - projective-equalisation social dynamics at the given uninstitutionalised-threshold ${ }^{102}$ that is a drawback-to/undermines prospective-knowledge-andinstitutional deferential-formalisation-transference as of prospective relative-ontologicalcompleteness $^{87}$-of- ${ }^{83}$ reference-of-thought intrinsic-reality/ontological-veridicality transcendental-enabling/sublimating/supererogatory $\sim$ de-mentativity $<$ amplituding/formativeepistemicity $>$ causality $\sim$ as-to-projective-totalitative-implications-of-prospectivenonpresencing,-for-explicating relative-unreflexivity/relative-reflexivity - ontologicalcontiguity, and rather is oriented towards sovereign extrication over knowledgereification $\sim$ gesturing-and-accounting — of-epistemic-phenomenalism- $<$ inprospective_psychologismic apriorising/axiomatising/referencing-\{of-'prospectively implicited_attendant-ontological-contiguity ' reducedexistentialising/contextualising/textualising_'intelligibility/epistemicity/reflexivity-contiguity<imbued-notional cogency>' \}-conflatedness -in-\{preconverging -ment by\} postconverging-entailment $>$ at this uninstitutionalised-threshold ${ }^{12}$ as of social-aggregationenabling), as of its bare constraining mechanical-knowledge since ${ }^{83}$ reference-of-thoughtcategorical-imperatives/axioms/registry-teleology' are only 'mechanistically' constraining, lacking the organic-spirit or ontological-faith-notion-or-ontological-fideism-imbuedunderdetermination-of-motif-and-apriorising/axiomatising/referencing-as-so-being-as-ofexistential-reality. Correspondingly (despite the otherwise sophistic/pedantic moral and intellectual disenfranchisement/swindling/corruption/dispossession inclination in eliciting human temporality ${ }^{8} /$ shortness <amplituding/formative $>$ wooden-language-〈imbued averaging-of-thought-<as-to-leveling/ressentiment/closed-construct-of- meaningfulness-andteleology -as-of-'nondescript/ignorable-void '-with-regards-to-prospective-apriorisingimplications $>>$ ), prospective human knowledge-reification $\sim$ gesturing-and-accounting-ofepistemic-phenomenalism- $<$ in- 
prospective_psychologismic apriorising/axiomatising/referencing-\{of-‘prospectively

implicited_attendant-ontological-contiguity ' educed-

existentialising/contextualising/textualising_'intelligibility/epistemicity/reflexivity-contiguity-

$<$ imbued-notional cogency $>$ ' $\}$-conflatedness -in-\{preconverging-ment by\}

postconverging-entailment $>$ (as herein articulated-and-implied) has to factor in the reality of 'human notional firstnaturedness-formativeness-<as-to-eventualising-inkling-drive or seeding-misprising $>$ temporal-to-intemporal-dispositions- $<$ so-construed-as-from-

perspective-ontological-normalcy/postconvergence> accordioning-〈as-of-varying-

individuations-contextually-transverse-desublimation/sublimation,-as-to-the-

wavering/redounding/waveforming of-their-referencing-and-their-devolved-referencing-

imbued-ontological-performance -<including-virtue-as-ontology $>>$ at uninstitutionalisedthreshold ${ }^{02}$ as reflecting both desublimating ${ }^{4}$ historicity-tracing-in-presencinghyperrealisation/hyperreal-transposition and sublimating ${ }^{4}$ historiality/ontologicaleventfulness $3 \%$ ontological-aesthetic-tracing-<perspective-ontologicalnormalcy/postconvergence-reflected-'epistemicity-relativism-determinism'> possibilities', in order to articulate and construct prospective knowledge taking account of the preconverging/postconverging-de-mentative/structural/paradigmatic implications of 'human notional firstnaturedness-formativeness-<as-to-eventualising-inkling-drive-or-seedingmisprising $>$ temporal-to-intemporal-dispositions- $<$ so-construed-as-from-perspectiveontological-normalcy/postconvergence> accordioning-〈as-of-varying-individuationscontextually-transverse-desublimation/sublimation,-as-to-thewavering/redounding/waveforming of-their-referencing-and-their-devolved-referencingimbued-ontological-performance -<including-virtue-as-ontology $>>$ at uninstitutionalisedthreshold ${ }^{102}$ as reflecting both desublimating ${ }^{47}$ historicity-tracing-in-presencinghyperrealisation/hyperreal-transposition and sublimating ${ }^{4}$ historiality/ontological- 
eventfulness 3 /ontological-aesthetic-tracing-<perspective-ontological-

normalcy/postconvergence-reflected-‘epistemicity-relativism-determinism'> possibilities' for prospective knowledge-reification $\sim$ gesturing-and-accounting-of-epistemic-phenomenalism$<$ in-prospective_psychologismic apriorising/axiomatising/referencing-\{of-"prospectively implicited_attendant-ontological-contiguity ' educedexistentialising/contextualising/textualising_ 'intelligibility/epistemicity/reflexivity-contiguity<imbued-notional cogency $>$ ' \}-conflatedness -in-\{preconverging ment by\} postconverging-entailment>; and so as to 'human corresponding-sublimation-inducing,profound-and-creative supererogatory $\sim$ acuity/perspicacity/astuteness/edginess/incisiveness-ofapriorising/axiomatising/referencing/intelligibilitysettingup/measuringinstrumenting -forconceptualisation' (that create/invent methods/methodologies/approaches as to prospectiveapriorising/axiomatising/referencing-superseding-logical-basis-of $\sim$ dialogical-equivalence- $<$ asto-psychologismic apriorising/axiomatising/referencing-\{of-‘prospectively implicited_attendant-ontological-contiguity ' educedexistentialising/contextualising/textualising_'intelligibility/epistemicity/reflexivity-contiguity<imbued-notional cogency $>\quad\}$-conflatedness - in-\{preconverging-ment by\} postconverging entailment,-in-self-becoming/self-conflatedness /formative-supererogating > organic-knowledge in ontological-good-faith/authenticity $\sim$ postconverging-dementating/structuring/paradigming ${ }^{70}$ so-constrained by existence-potency ${ }^{30} \sim$ sublimating- $^{-}$ nascence,-disclosed-from-prospective-epistemic-digression). preconverging/postconverging-de-mentative/structural/paradigmatic implications of 'human notional firstnaturedness-formativeness-<as-to-eventmalising inkling-drive-or-seeding misprising $>$ temporal-to-intemporal-dispositions-<so-construed-as-from-perspectiveontological-normalcy/postconvergence> accordioning-〈as-of-varying-individuationscontextually-transverse-desublimation/sublimation,-as-to-the- 
wavering/redounding/waveforming of-their-referencing-and-their-devolved-referencing-

imbued-ontological-performance -<including-virtue-as-ontology $>>$ at uninstitutionalisedthreshold ${ }^{02}$ as reflecting both desublimating ${ }^{47}$ historicity-tracing-in-presencinghyperrealisation/hyperreal-transposition and sublimating ${ }^{4}$ historiality/ontologicaleventfulness 3 /ontological-aesthetic-tracing-<perspective-ontological-

normalcy/postconvergence-reflected-‘epistemicity-relativism-determinism'> possibilities’ for prospective knowledge-reification $\sim$ gesturing-and-accounting-of-epistemic-phenomenalism$<$ in-prospective_psychologismic $\sim$ apriorising/axiomatising/referencing-\{of-'prospectively implicited_attendant-ontological-contiguity ' educedexistentialising/contextualising/textualising_'intelligibility/epistemicity/reflexivity-contiguity<imbued-notional cogency >' \}-conflatedness -in-\{preconverging-ment by\}

postconverging-entailment $>$, for instance means that with respect to social-stake-contention-orconfliction the Socrates/Platos/Aristotles (nor the succession of other prospectiveapriorising/axiomatising/referencing-superseding-logical-basis-of $\sim$ dialogical-equivalence- $<$ asto-psychologismic apriorising/axiomatising/referencing-\{ of-‘prospectively implicited_attendant-ontological-contiguity ' educedexistentialising/contextualising/textualising_'intelligibility/epistemicity/reflexivity_contiguity<imbued-notional cogency >' \}-conflatedness - in-\{preconverging ment by\} postconverging-entailment,-in-self-becoming/self-conflatedness /formative-supererogating> thinkers in reflecting holographically-<conjugatively-and-transfusively $>$ the relativeunreflexivity/relative-reflexivity - ontological-contiguity of-the-human-institutionalisationprocess ) 'are not engaged in an exercise of convincing the whole of humankind-as-to-humanmortal-subpotency but rather aligning to existence-potency ${ }^{39} \sim$ sublimating-nascence,-disclosedfrom-prospective-epistemic-digression as to prospective transcendence-andsublimity/sublimation/supererogatory de-mentativity implications'; and what is critical at the 
intemporal firstnatureness reasoning-through/messianic-reasoning level is the inducing of the 'requisite intemporal accordioning-〈as-of-varying-individuations-contextually-transversedesublimation/sublimation,-as-to-the-wavering/redounding/waveforming of-theirreferencing-and-their-devolved-referencing-imbued-ontological-performance -<includingvirtue-as-ontology $>\rangle$ dynamics of such reasoning-through/messianic-reasoning for prospective deferential-formalisation-transference as to the social-construct underlying supposedly coherent ontological-commitment $\quad$-implied-self-assuredness-of-ontological-goodfaith/authenticity postconverging-de-mentating/structuring/paradigming -as-being-as-ofexistential-reality> such that such prospective transcendence-and-

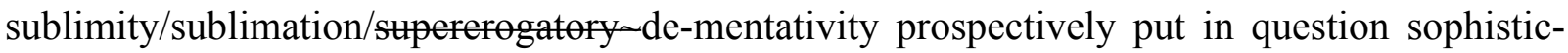
pretences-of-playing-an-intellectual-and-moral-function as to when the social-construct is ultimately concerned with the prospective transcendence-andsublimity/sublimation/supererogatory de-mentativity intellectual-function/posture to which such sophistic/pedantic pretences paradoxically rather adopt a tempering/discouraging penchant in a social disenfranchisement/swindling/corruption/dispossession inclination' (and further as to the sophistic/pedantic pretence that no human idealisation is warranted failing to factor in that all human ${ }^{56}$ meaningfulness-and-teleology ${ }^{9}$ is already idealisation that has already selected-anddeselected what is idealiseable and unidealiseable as of social-stake-contention-or-confliction, such that from the ontological perspective the issue is not about no idealisation but rather the ontologically appropriate idealisation and appropriate human contemplation and execution as 'postures of no idealisation' carry with them poor contemplations and executions already 'ignoring-and-devaluing' human 'implicited_attendant-ontological-contiguity ${ }^{67}$ ' educedexistentialising/contextmalising/textualising_intelligibility/epistemicity/reflexivity_contiguity$<$ imbued-notional $\sim$ cogency $>$ ' epistemic-situations of relative-ontological-incompleteness associated with vices-and-impediments ${ }^{105}$ ). Thus the point in reflecting holographically- 
$<$ conjugatively-and-transfusively $>$ the relative-unreflexivity/relative-reflexivity - ontologicalcontiguity of-the-human-institutionalisation-process has never been a direct convincing process (as to the shallowness of contemplation projected by sophistic/pedantic thought in eliciting human temporality 8 /shortness < amplituding/formative $>$ wooden-language-〈imbuedaveraging-of-thought-<as-to-leveling/ressentiment/closed-construct-of- meaningfulness-andteleology -as-of-'nondescript/ignorable-void '-with-regards-to-prospective-apriorisingimplications $>>$ ), but is rather reflected in an exercise conveying 'profound human transcendenceand-sublimity/sublimation/supererogatory de-mentativity enabling conceptualisations' at the 'varying psychologismic epistemic -acutisation difficulty-for, residualising $\{$ decompulsing $\}$ delinearity for eogeney> magnitudes $\{$ of-experientiality/experiment $\} /$ scales —as-tosuccessively-profound-preconverging/postconverging-redementating/restructuring/reparadigming-frames-as-from-living,-institutionalising,-and-Beingontologising/infrastructure-of- meaningfulness-and-teleology 9 of prospective humansubpotency-aporia/undecidability/dilemma/ought-

indeterminacy/deficiency/limitation/constraint—imbued-‘notional firstnaturedness-

\section{formativeness-<as-to-eventualising inkling-drive or seeding-misprising $>$ temporal-to-}

intemporal-dispositions-<so-construed-as-from-perspective-ontological-

normalcy/postconvergence>'-existentialism-form-factor' (with regards to human livingdevelopment-as-to-personality-development or institutional-development-as-to-socialfunction-development or Being-development/ontological-framework-expansion-as-to-depthof-ontologising-development-as-infrastructure-of- meaningfulness-and-teleology in reflecting holographically-<conjugatively-and-transfusively $>$ the relative-unreflexivity/relativereflexivity - ontological-contiguity of-the-human-institutionalisation-process $<$ cumulating/recomposuring attendant-ontological-contiguity $>$-successive registryworldviews/dimensions). Such a profound conceptualisation as herein contemplated is 'not at all 
concerned with satisfying the shallower perspectives elicited from sophistry as to our presencing - absolutising-identitive-constitutedness ${ }^{14}$ human $\quad$ <mplituding/formativeepistemicity $>$ totalising $\sim$ self-referencing-syncretising/circularity/interiorising/akrasiatic-drag social-stake-contention-or-confliction state', but rather targets the bigger picture to which sophistry poorly contemplate of; as to the fact that such sophistry 'fails to even display a priorand-basic curiosity-and-enlightening-attitude about inherent/authentic knowledge itself' before even moving to the next stage of contemplating the validity/invalidity of knowledge argumentations. The fact that prospective human-subpotencyaporia/undecidability/dilemma/ought-indeterminacy/deficiency/limitation/constraint means prospective ${ }^{56}$ meaningfulness-and-teleology ${ }^{9}$ is ever always caught up in 'human notional firstnaturedness-formativeness-<as-to-eventualising -inkling-drive-or-seedingmisprising $>$ temporal-to-intemporal-dispositions- $<$ so-construed-as-from-perspectiveontological-normalcy/postconvergence> accordioning-〈as-of-varying-individuationscontextually-transverse-desublimation/sublimation,-as-to-thewavering/redounding/waveforming of-their-referencing-and-their-devolved-referencingimbued-ontological-performance -<including-virtue-as-ontology $>\rangle$ at uninstitutionalisedthreshold ${ }^{02}$ as reflecting both desublimating ${ }^{4}$ historicity-tracing-in-presencinghyperrealisation/hyperreal-transposition and sublimating ${ }^{4}$ historiality/ontologicaleventfulness 38 ontological-aesthetic-tracing-<perspective-ontologicalnormalcy/postconvergence-reflected-'epistemicity-relativism-determinism'> possibilities', speaks rather of the opportunity for the social-construct intellectual-function/posture to induce human elevation as of prospective secondnatured institutionalisation (as herein implied as to prospective deprocrypticism-or-preempting - disjointedness-as-of- ${ }^{1}$ reference-of-thought with regards to its underlying intellectual exposition to falsifiability ${ }^{22}$ and validity/invalidity sublimating-over-desublimating implications of existence-potency ${ }^{39} \sim$ sublimating-nascence,- 
disclosed-from-prospective-epistemic-digression) and not adopt sophistic/pedantic moral and intellectual disenfranchisement/swindling/corruption/dispossession eliciting of human temporality 8 /shortness <amplituding/formative> wooden-language-〈imbued-averaging-ofthought-<as-to-leveling/ressentiment/closed-construct-of- meaningfulness-and-teleology -asof-'nondescript/ignorable-void '-with-regards-to-prospective-apriorising-implications $>$ > (passed for intellection out of poor ontological-good-faith/authenticity ${ }^{69}$ or outright ontologicalbad-faith/inauthenticity ${ }^{64}$ ). In this regards, as to the 'requisite human dimensionality-ofsublimating $25<<$ amplituding/formative $>$ supereregatory-de-mentativeness/epistemic-growthor-conflatedness /transvaluative-rationalising/transepistemicity/anamnestic-residuality/spiritdrivenness-equalisation>' associated with the <cumulating/recomposuring attendantontological-contiguity >-succession of registry-worldviews/dimensions in reflecting holographically-<conjugatively-and-transfusively $>$ the relative-unreflexivity/relativereflexivity - ontological-contiguity of-the-human-institutionalisation-process, just as the possibility for prospective base-institutionalisation could not arise without the 'requisite human dimensionality-of-sublimating $25<<$ amplituding/formative $>$ supererogatory $\sim$ dementativeness/epistemic-growth-or-conflatedness /transvaluativerationalising/transepistemicity/anamnestic-residuality/spirit-drivenness-equalisation〉' from recurrent-utter-uninstitutionalisation, and so successively up to our positivism/rationalempiricism registry-worldview/dimension; the sophistic/pedantic pretence as impliciting that our positivism/rational-empiricism registry-worldview/dimension is the 'absolutely unassailable epistemic framework even beyond ontological analysis' is its fundamental contrivance for eliciting human temporality 9 /shortness < amplituding/formative $>$ wooden-language-〈imbuedaveraging-of-thought-<as-to-leveling/ressentiment/closed-construct-of- meaningfulness-andteleology -as-of-'nondescript/ignorable-void '-with-regards-to-prospective-apriorisingimplications $>>$ in an exercise forestalling the ${ }^{56}$ meaningfulness-and-teleology ${ }^{9}$ implications for 
contemplating prospective 'requisite human dimensionality-of-sublimating ${ }^{5}$ <<amplituding/formative >supererogatory $\sim$ de-mentativeness/epistemic-growth-or-

conflatedness /transvaluative-rationalising/transepistemicity/anamnestic-residuality/spirit-

drivenness-equalisation)' as projected with postmodern-thought and herein implied as from the notional deprocrypticism epistemic projective-perspective. Such sophistic/pedantic implicitation of no 'requisite human dimensionality-of-sublimating ${ }^{25}$ <<amplituding/formative>supererogatory $\sim$ de-mentativeness/epistemic-growth-or-

conflatedness /transvaluative-rationalising/transepistemicity/anamnestic-residuality/spiritdrivenness-equalisation $\rangle$ is often articulated sophistically in terms of $<$ amplituding/formative $>$ wooden-language-〈imbued-temporal-mere-

\section{form/virtualities/dereification/akrasiatic-drag/denatured/preconverging-or-dementing}

\section{narratives - of-the- reference-of-thought- categorical-imperatives/axioms/registry-}

teleology $\rangle$, and more brazenly in terms of intellectual misanalyses/misrepresentations, pretences-of-misunderstanding and muddlement of prospectively emancipating conceptualisations as so-directed towards postmodern-thought. The fact is the possibility for prospective human knowledge in all domains can only and have only been able to arise on the basis of the 'requisite human dimensionality-of-sublimating ${ }^{25}$ <<amplituding/formative>supererogatory $\sim$ de-mentativeness/epistemic-growth-orconflatedness /transvaluative-rationalising/transepistemicity/anamnestic-residuality/spiritdrivenness-equalisation)' involving human limited-mentation-capacity-deepening-assubjecting limitedness/human-subpotency to-'educed-unlimitedness/existence-sublimating nascence' ${ }^{53}$ as to the 'conflating <amplituding/formativeepistemicity $>$ totalising/circumscribing/delineating re-originariness/reorigination of re-motifand-re-apriorising/re-axiomatising/re-referencing/re-intelligibilitysettingup/remeasuringinstrumenting underlying human conceptualisation and then the devolving existential- 
instantiation implications as to aposteriorising/logicising/deriving/intelligising/measuring meaningfulness-and-teleology" (with regards to 'varying psychologismic epistemicacutisation difficulty-for, residualising \{decompling\} $\}$ delinearity for-cogency>-magnitudes $\{0$ experientiality/experiment $\}$ /scales — as-to-successively-profound-preconverging/postconverging-redementating/restructuring/reparadigming-frames-as-from-living,-institutionalising,-and-Beingontologising/infrastructure-of- ${ }^{5}$ meaningfulness-and-teleology 9 of prospective humansubpotency-aporia/undecidability/dilemma/ought-

indeterminacy/deficiency/limitation/constraint—imbued-'notional firstnaturednessformativeness-<as to-eventualising inkling drive or seeding misprising $>$ temporal-tointemporal-dispositions-<so-construed-as-from-perspective-ontologicalnormalcy/postconvergence>'-existentialism-form-factor'); as to the fact that even secondnatured ${ }^{56}$ meaningfulness-and-teleology ${ }^{9}$ involves the exertion of the requisite prospective curiosity, contemplation and elevation 'beyond a ${ }^{4}$ historicity-tracing-inpresencing-hyperrealisation/hyperreal-transposition gimmickiness/desublimation relation with meaningfulness-and-teleology '. Critically, an 'underlying dumbing-down public intellection and media industry' thrive on cultivating a ' ${ }^{47}$ historicity-tracing-in-presencinghyperrealisation/hyperreal-transposition gimmickiness/desublimation relation with meaningfulness-and-teleology ${ }^{9}$, and is in-many-ways at the root source of the modern-day democratic crisis of political and socio-economic disenfranchisement/swindling/corruption/dispossession, as it disenables/paralyses the possibility for sublimating debates thus in-many-ways rendering the public decisionmaking process a 'defaulting process as to the social-vestedness/normativity-<discretely-impliedfunctionalism $>$ of social-stake-contention-or-confliction'. Such undermining of the possibility of 'requisite human dimensionality-of-sublimating 
conflatedness /transvaluative-rationalising/transepistemicity/anamnestic-residuality/spirit-

drivenness-equalisation)' is effectively critical with regards to ${ }^{47}$ historicity-tracing-inpresencing-hyperrealisation/hyperreal-transposition, as to the fact that by mitigating the possibility to broaden-the-latitude-of-human-collective-consciousness off-the-beaten-path of historicity-tracing - in-presencing-hyperrealisation/hyperreal-transposition for prospective possibilities of ${ }^{4}$ historiality/ontological-eventfulness $\%$ ontological-aesthetic-tracing$<$ perspective--ontological-normalcy/postconvergence-reflected-'epistemicity-relativismdeterminism'>, the human mind is psychologically entrapped in mental-reflexes of presencing-absolutising-identitive-constitutedness $<$ amplituding/formativeepistemicity $>$ totalising $\sim$ self-referencing-syncretising/circularity/interiorising/akrasiatic-drag as to the elicited <amplituding/formative> wooden-language-〈imbued-averaging-of-thought$<$ as-to-leveling/ressentiment/closed-construct-of- meaningfulness-and-teleology -as-of'nondescript/ignorable-void '-with-regards-to-prospective-apriorising-implications $>\rangle$. At the root of this undermining of prospective 'requisite human dimensionality-of-sublimating <<amplituding/formative>supererogatory $\sim$ de-mentativeness/epistemic-growth-orconflatedness /transvaluative-rationalising/transepistemicity/anamnestic-residuality/spiritdrivenness-equalisation)' is the social dilution/enfeeblement of value-construction/valueaspiration as to their 'ad-hoc and incoherent <amplituding/formativeepistemicity $>$ totalising/circumscribing/delineating implications supposedly non-ontological as to non-metaphysical' (with regards to conceptualising the social-construct prospective transcendence-and-sublimity/sublimation/supererogatory>de-mentativity valueconstruction/value-aspiration), as associated particularly with the 'specious usurpation of the overall social-construct's intellectual-function/posture as to prospective transcendence-andsublimity/sublimation/supererogatory de-mentativity'; with the paradox of such usurpation especially as of its drivenness in 'intellectually mediating institutions as to popular-sovereignty' 
including the media effectively projecting arbitrary social-vestedness/normativity- $<$ discretelyimplied-functionalism $>$ constructs and frameworks of value-construction/value-aspiration while failing to intellectually editorialise/articulate/reflect the ontological equanimity/balance of conceptualisations as to the momentous implications of prospective ${ }^{4}$ historiality/ontologicaleventfulness ${ }^{38}$ /ontological-aesthetic-tracing-<perspective-ontological-

normalcy/postconvergence-reflected-'epistemicity-relativism-determinism'> (thus implicitly upholding the notion that the social is non-ontological as non-metaphysical); especially given that the equanimity/balance for upholding democratic sovereignty is in effect achievable only as of 'preconverging/postconverging-de-mentative/structural/paradigmatic $<$ amplituding/formative-epistemicity $>$ totalising/circumscribing/delineating operant considerations for equanimity/balance with regards to the social, political and media landscapes decision-making/editorialising processes', as the often sparing instantiating existential<disontologising/re-ontologising aporeticism $>$ frames of day-to-day social, political and media landscapes decision-making/editorialising processes are poorly amenable naturally to such '<amplituding/formative-epistemicity>totalising/circumscribing/delineating operant considerations for equanimity/balance' and end up assuming social-vestedness/normativity$<$ discretely-implied-functionalism $>$ defaulting postures with occasional clamours for equanimity/balance of the decision-making/editorialising processes quite often the niggling exceptions to entrenched and existentially-unthought reflex. Such that beyond 'gimmickiness/desublimation frameworks of aestheticisation' in-many-ways the socialconstruct's intellectual-function/posture itself (as of aestheticisation-towards-ontology with respect to prospective human emancipation) becomes capitalistically-captured-at-theexclusion/denaturing ${ }^{6}$-of-reifying-and-empowering-intellectual-reflection as to the precedence of media-business-relevant-aestheticisation, underhanded-media-capitalist-direct-ownershipand-indirect-sponsorship-distortive-influence, blatant-intellectual-misanalyses-and-sophistry, 
public-influence-and-lobbying-overtaking-inherent-intellectual-veracity,

politicisedinstitutional-stakes-overtaking-inherently-objective-social-knowledge-production-in-higheracademia, a-consciously-aware-intellectual-function/posture-impotence-that-cynicallyconstrues-of-the-possibility-for-prospective-sublimating-social-knowledge-as-the-opportunityfor-its pedantising/muddling/formulaic-hollowing-out-in-subontologisation/subpotentiation〈blurring/undermining-of-prospective-totalising-entailing,-as-to-entailing-

$<$ amplituding/formative-epistemicity>totalising in-relative-ontological-completeness $>$ and archiving, etc. These all contribute in making-more-and-more-of-an-empty-shell the supposed intellectual transparency and sovereign independence of the social-construct in modern-day democracies. But then more than just the more consciously immediate emancipation possibilities for momentous human prospective ${ }^{4}$ historiality/ontological-eventfulness 38 ontologicalaesthetic-tracing-<perspective-ontological-normalcy/postconvergence-reflected-'epistemicityrelativism-determinism'> with regards to 'present-day social and human emancipation concerns' floundering/wallowing as to our present ${ }^{47}$ historicity-tracing-in-presencinghyperrealisation/hyperreal-transposition induced psychological entrapment as undermining the prospective 'requisite human dimensionality-of-sublimating ${ }^{25}$ <<amplituding/formative>supererogatory $\sim$ de-mentativeness/epistemic-growth-or-

conflatedness /transvaluative-rationalising/transepistemicity/anamnestic-residuality/spiritdrivenness-equalisation)'; the more potently existential-unthinking (as to human aestheticisation-towards-ontology) is in the overall historicity-tracing-in-presencinghyperrealisation/hyperreal-transposition induced paralysis/disenabling of abstract contemplation about the human dimensionality-of-sublimating

\section{<<amplituding/formative>supererogatory $\sim$ de-mentativeness/epistemic-growth-or-}

conflatedness /transvaluative-rationalising/transepistemicity/anamnestic-residuality/spirit-

drivenness-equalisation〉' implications underlying the overall relative-unreflexivity/relative- 
reflexivity - ontological-contiguity ${ }^{67}$ of-the-human-institutionalisation-process ${ }^{68}$ (as of a defaulting social-vestedness/normativity- $<$ discretely-implied-functionalism $>$ posture clouded in its $\quad{ }^{7}$ presencing - absolutising-identitive-constitutedness $<$ amplituding/formativeepistemicity $>$ totalising $\sim$ self-referencing-syncretising/circularity/interiorising/akrasiatic-drag ${ }^{34}$ ), and specifically so with regards to the 'requisite human dimensionality-of-sublimating <<amplituding/formative>supererogatory $\sim$ de-mentativeness/epistemic-growth-orconflatedness /transvaluative-rationalising/transepistemicity/anamnestic-residuality/spiritdrivenness-equalisation)' implications for prospective ${ }^{18}$ deprocrypticism-or-preemptingdisjointedness-as-of- ${ }^{8}$ reference-of-thought. This preconverging-existential-extrication-as-ofexistential-unthought as to dimensionality-of-desublimating-lack-of ${ }^{-}$ <<amplituding/formative>supererogatory $\sim$ de-mentativeness/epistemic-growth-orconflatedness /transvaluative-rationalising/transepistemicity/anamnestic-residuality/spiritdrivenness-equalisation) very much reflects the fact that all 79 presencing-absolutisingidentitive-constitutedness ${ }^{14}$ are effectively manifestations of underlying ontological-badfaith/inauthenticity ${ }^{64}$ with regards to their re-ontologising prospective Beingdevelopment/ontological-framework-expansion-as-to-depth-of-ontologising-development-asinfrastructure-of- meaningfulness-and-teleology ; as all such ${ }^{79}$ presencing-absolutisingidentitive-constitutedness ${ }^{14}$ fail to account for their 'prior and prospective becoming' which ontologically-veridical rationalisation effectively lies with the pestconverging-nonextricatoryexistential-preempting-of-existential-unthought human emancipating disposition associated with dimensionality-of-sublimating ${ }^{25}-\langle<$ amplituding/formative $>$ supererogatory $\sim$ dementativeness/epistemic-growth-or-conflatedness /transvaluativerationalising/transepistemicity/anamnestic-residuality/spirit-drivenness-equalisation $\rangle$. Similarly with respect to the 'requisite human dimensionality-of-sublimating 
conflatedness /transvaluative-rationalising/transepistemicity/anamnestic-residuality/spirit-

drivenness-equalisation)' dispensing-with-immediacy-for-relative-ontological-completeness ${ }^{87}$ by-reification/contemplative-distension ${ }^{27}$, in-many-ways just as prior human scientific and technological sublimation momentously induced ${ }^{4}$ historiality/ontologicaleventfulness ${ }^{38} /$ ontological-aesthetic-tracing-<perspective-ontological-

normalcy/postconvergence-reflected-‘epistemicity-relativism-determinism'> inevitably required its accompanying social sublimation (as the manifestations of failing social sublimation were in-many-ways the reason for conflictual and exploitative encounters associated with budding-positivism), and so as of the contiguity of both human techno-scientific and social sublimations giving their mutually for-human-studies sublimating nature; it is inevitably the case that a naïve construal of prospective science and technological development that seem to imply the requisite prospective sublimation of the overall human as to its prospective construction-ofthe-Self is not critical, will inevitably lead to conundrums of prospective science and technology development as to the very possibility for developing the full human potential of science and technology as well as with respect to the underdevelopment of the human as to its shiftiness-ofthe-Self ${ }^{1}$ in the capacity to handle and deal with prospective science and technology in such a manner that doesn't imperil mankind's very own survival (departing as from the larger conception of survival, beyond 'reactionary construal' of them-and-us in presencingabsolutising-identitive-constitutedness ${ }^{14}<$ amplituding/formative-epistemicity $>$ totalising $\sim$ selfreferencing-syncretising/circularity/interiorising/akrasiatic-drag ${ }^{34}$ that end up 'destructively dehumanising' the various the 'other'). Thus the very notion of human value-construction is entwined with 'human notional firstnaturedness-formativeness-as drive-or seeding misprising $>$ temporal-to-intemporal-dispositions- $<$ so-construed-as-fromperspective-ontological-normalcy/postconvergence> accordioning-〈as-of-varyingindividuations-contextually-transverse-desublimation/sublimation,-as-to-the- 
wavering/redounding/waveforming of-their-referencing-and-their-devolved-referencing-

imbued-ontological-performance -<including-virtue-as-ontology $>>$ at uninstitutionalisedthreshold ${ }^{02}$ as reflecting both desublimating ${ }^{47}$ historicity-tracing-in-presencinghyperrealisation/hyperreal-transposition and sublimating ${ }^{4}$ historiality/ontologicaleventfulness 3 /ontological-aesthetic-tracing-<perspective-ontological-

normalcy/postconvergence-reflected-‘epistemicity-relativism-determinism'> possibilities' and the idea of prospective human emancipating transcendence-andsublimity/sublimation/supererogatory-de-mentativity possibilities critically lies in appreciating the enabling 'prospective predicative-effectivity-sublimation-〈as-to-underlying,-ontologicalcommitment $-<$ implied — self-assuredness-of-ontological-good-

\section{faith/authenticity $\sim$ postconverging-de-mentating/structuring/paradigming -as-being-as-of-}

existential-reality>> constraining that prospectively transforms human ontologicalperformance $^{72}-<$ including-virtue-as-ontology $>$ /morality/ethics/justice/etc. capacity' as of the 'elucidative $\quad{ }^{45}$ foregrounding__entailment- $<$ in-succession-of-profound-supererogation $>>$ 〈postconverging-narrowing-down $\sim$ sublimation-as-to-'existence-as-sublimating-

withdrawal/unenframing/re-ontologising,-elicited-from-prospective-profoundsupererogation '-in-reflecting-'immanent relative-unreflexivity/relative-reflexivity ontological-contiguity ';-as-operative-notional deprocrypticism> in reflecting holographically-<conjugatively-and-transfusively $>$ the relative mneflexivityolative reflexivity - ontological-contiguity of-the-human-institutionalisation-process '. The bigger point here (as of the 'elucidative ${ }^{4}$ foregrounding_entailment- $<$ in-succession-of-profoundsupererogation $>$-〈postconverging-narrowing-down $\sim$ sublimation-as-to- ${ }^{\circ}$ existence - assublimating-withdrawal/unenframing/re-ontologising,-elicited-from-prospective-profoundsupererogation '-in-reflecting-'immanent relative unreflexivity/relative reflexivity ontological-contiguity ';-as-operative-notional deprocrypticism)

in reflecting 
reflexivity - ontological-contiguity of-the-human-institutionalisation-process ') lies with the fact that the 'social-construct <amplituding/formativeepistemicity $>$ totalising/circumscribing/delineating given prior-institutionalisation-thresholdby-prospective-uninstitutionalised-threshold ${ }^{102}$ imbued secondnatured reproducibilitymathesis/motif/thrownness-disposition,-as-reproducibility-of-aestheticisation' (that is, as to any specific registry-worldview/dimension given thrownness-disposition) effectively precedesand-defines-as-ontologically-flawed any notion of a 'supposed human-subpotency abstract selfdeterminative ontological-performance ${ }^{2}-<$ including-virtue-asontology $>$ /morality/ethics/justice/etc. capacity as to the full-potency of existence' (as wrongly upheld by ${ }^{7}$ presencing — absolutising-identitive-constitutedness ${ }^{14}$ postures that fail to appreciate the succession of projective stances of 'human ${ }^{83}$ reference-of-thought apriorising/axiomatising/referencing/intelligibilitysettingup/measuringinstrumenting for conceptualisation' as from recurrent-utter-uninstitutionalisation right up to prospective deprocrypticism) but for the ontological-veracity of 'prospective predicative-effectivitysublimation-〈as-to-underlying,-ontological-commitment $-<$ implied-self-assuredness-of-

\section{ontological-good-faith/authenticity $\sim$ postconverging-de-}

mentating/structuring/paradigming -as-being-as-of-existential-reality $>>$ constraining that prospectively transforms human ontological-performance ${ }^{72}-$ including-virtue-as- $^{-}$ ontology $>$ /morality/ethics/justice/etc. capacity' as to induced prospective sublimation; and so as 'reflecting the ontological-performance ${ }^{72}-<$ including-virtue-asontology $>$ /morality/ethics/justice/etc. of the ${ }^{83}$ reference-of-thought- ${ }^{-1}$ devolving in formativeness-<as-to-intersolipsism-of-preformulating/preframing/premeaningfulness-imbuedmediativity-and-deferentialism>-of- meaningfulness-and-teleology of desublimating historicity-tracing - in-presencing-hyperrealisation/hyperreal-transposition and sublimating 
historiality/ontological-eventfulness ${ }^{38} /$ ontological-aesthetic-tracing-<perspective-

ontological-normalcy/postconvergence-reflected-‘epistemicity-relativism-determinism'>’ (with regards to 'varying psychologismic epistemic-acutisation difficulty-for, residualising $\{$ decompulsing $\}$ delinearity for-cogency> - magnitudes $\{0$-experientiality/experiment $\} /$ scales —as-tosuccessively-profound-preconverging/postconverging-redementating/restructuring/reparadigming-frames-as-from-living,-institutionalising,-and-Beingontologising/infrastructure-of- ${ }^{5}$ meaningfulness-and-teleology 9 of prospective humansubpotency-aporia/undecidability/dilemma/ought-

indeterminacy/deficiency/limitation/constraint—imbued-'notional firstnaturednessformativeness-<as-to-eventualising-inkling-drive-or-seeding-misprising $>$ temporal-tointemporal-dispositions-<so-construed-as-from-perspective-ontologicalnormalcy/postconvergence>'-existentialism-form-factor'). In this regards, 'human instigated meaningfulness-and-teleology $\quad$ ontological-performance ${ }^{2}-<$ including-virtue-asontology $>$ /morality/ethics/justice/etc. capacity' (so-construed as from the ontologicalnormalcy/postconvergence epistemic projective-perspective) is rather practically a '<amplituding/formative-epistemicity $>$ totalising/circumscribing/delineating signposting exercise' operating on the overall basis of the 'social-construct <amplituding/formativeepistemicity>totalising/circumscribing/delineating given prior-institutionalisation-thresholdby-prospective-uninstitutionalised-threshold ${ }^{102}$ imbued secondnatured reproducibilitymathesis/motif/thrownness-disposition,-as-reproducibility-of-aestheticisation' when it comes to social-stake-contention-or-confliction, and so overriding all 79 presencing-absolutisingidentitive-constitutedness ${ }^{14}$ ontologically-flawed representation of such 'human instigated meaningfulness-and-teleology $\quad$ ontological-performance ${ }^{22}-<$ including-virtue-asontology $>$ /morality/ethics/justice/etc. capacity' as of a 'supposed human-subpotency abstract self-determinative ontological-performance ${ }^{2}-<$ including-virtue-as- 
ontology $>$ /morality/ethics/justice/etc. capacity as to the full-potency of existence'. This reflects the reality that the transcendental ${ }^{5}$ meaningfulness-and-teleology ${ }^{9}$ of prospective baseinstitutionalisation, ${ }^{103}$ universalisation, positivism/rational-empiricism and ${ }^{18}$ deprocrypticismor-preempting - disjointedness-as-of- ${ }^{-3}$ reference-of-thought respectively are effectively only marginally integratable respectively to prior recurrent-utter-uninstitutionalisation, ununiversalisation, non-positivism/medievalism and ${ }^{80}$ procrypticism-or-disjointedness-as-ofreference-of-thought (as to crossgenerational psychoanalytic-unshackling/memeticreordering/institutional-recomposuring), and so only as the former induce their 'prospective predicative-effectivity-sublimation-〈as-to-underlying,-ontological-commitment $-<$ impliedself-assuredness-of-ontological-good-faith/authenticity postconverging-dementating/structuring/paradigming -as-being-as-of-existential-reality $>>$ constraining that prospectively transforms human ontological-performance ${ }^{72}-$ including-virtue-as- $^{-}$ ontology $>$ /morality/ethics/justice/etc. capacity'; thus reflecting the tight-and-entwined relationship between the overall human ontological-commitment $-<$ implied - self-assurednessof-ontological-good-faith/authenticity $\sim$ postconverging-dementating/structuring/paradigming -as-being-as-of-existential-reality> (across all registryworldviews/dimensions) and (corresponding registry-worldviews/dimensions) predicativeeffectivity-sublimation-〈as-to-underlying,-ontological-commitment $-<$ implied — selfassuredness-of-ontological-good-faith/authenticity postconverging-dementating/structuring/paradigming -as-being-as-of-existential-reality $>\rangle$ as the critical enablers for the possibility of prospective transcendental ${ }^{56}$ meaningfulness-and-teleology ${ }^{99}$. Such an insight divulges the underlying preconverging/postconverging-dementative/structural/paradigmatic possibility that arise for sophistic/pedantic dispositions across all registry-worldviews/dimensions as to the prior 'social-construct <amplituding/formativeepistemicity>totalising/circumscribing/delineating given prior-institutionalisation-threshold- 
by-prospective-uninstitutionalised-threshold ${ }^{102}$ imbued secondnatured reproducibilitymathesis/motif/thrownness-disposition,-as-reproducibility-of-aestheticisation'

$<$ amplituding/formative-epistemicity $>$ totalising $\sim$ self-referencing-

syncretising/circularity/interiorising/akrasiatic-drag ${ }^{34}$ of human ${ }^{56}$ meaningfulness-andteleology when not subjected to 'prospective predicative-effectivity-sublimation-〈as-tounderlying,-ontological-commitment $-<$ implied - self-assuredness-of-ontological-goodfaith/authenticity postconverging-de-mentating/structuring/paradigming -as-being-as-ofexistential-reality $>>$ constraining that prospectively transforms human ontologicalperformance $^{72}-<$ including-virtue-as-ontology $>$ /morality/ethics/justice/etc. capacity'. Critically, deprocrypticism-or-preempting-disjointedness-as-of- ${ }^{8}$ reference-of-thought as converging to the 'supposed human-subpotency abstract self-determinative ontological-performance 2 $<$ including-virtue-as-ontology $>/$ morality/ethics/justice/etc. capacity as to the full-potency of existence' effectively implies the converging of prior 'social-construct <amplituding/formativeepistemicity>totalising/circumscribing/delineating given prior-institutionalisation-thresholdby-prospective-uninstitutionalised-threshold ${ }^{102}$ imbued secondnatured reproducibilitymathesis/motif/thrownness-disposition,-as-reproducibility-of-aestheticisation' towards deprocrypticism's 'prospective predicative-effectivity-sublimation-〈as-to-underlying,ontological-commitment $\quad$-<implied-self-assuredness-of-ontological-goodfaith/authenticity postconverging-de-mentating/structuring/paradigming -as-being-as-ofexistential-reality $>>$ constraining that prospectively transforms human ontologicalperformance $^{72}$-<including-virtue-as-ontology $>$ /morality/ethics/justice/etc. capacity'. Such a 'notional $\sim$ deprocrypticism predicative-effectivity-sublimation-〈as-to-underlying,-

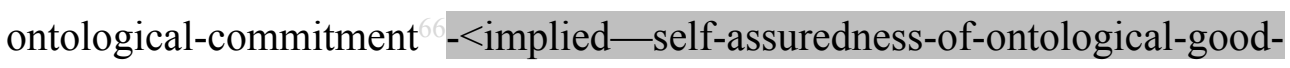
faith/authenticity postconverging-de-mentating/structuring/paradigming -as-being-as-ofexistential-reality>> protension' is encapsulated herein with the projected human-subpotency 
protensivity in reflecting holographically-<conjugatively-and-transfusively $>$ the relativeunreflexivity/relative-reflexivity - ontological-contiguity of-the-human-institutionalisationprocess ; as to the budding prospect of an extensively systemic notional $\sim^{18}$ deprocrypticism 'prospective predicative-effectivity-sublimation-〈as-to-underlying,-ontological-commitment <implied - self-assuredness-of-ontological-good-faith/authenticity postconverging-dementating/structuring/paradigming -as-being-as-of-existential-reality $>>$ constraining that prospectively transforms human ontological-performance ${ }^{72}-$ including-virtue-as- $^{-}$ ontology $>$ /morality/ethics/justice/etc. capacity', that protends to a comprehensive unification of human social and techno-scientific sublimation in overcoming human disparateness-ofconceptualisation-<unforegrounding-ment,-failing-prospectively-to-reflect'immanent $\sim$ relative unreflexivity/relative-reflexivity - ontological-contiguity '>. The insight arising from this extensively systemic notional ${ }^{18}$ deprocrypticism 'prospective predicativeeffectivity-sublimation-〈as-to-underlying,-ontological-commitment $-<$ implied - selfassuredness-of-ontological-good-faith/authenticity postconverging-dementating/structuring/paradigming -as-being-as-of-existential-reality $>>$ constraining that prospectively transforms human ontological-performance ${ }^{72}-$ including-virtue-as- $^{2}$ ontology $>$ /morality/ethics/justice/etc. capacity' is the ontological-veracity that all socialvestedness/normativity-<discretely-implied-functionalism $>$ value-constructions are effectively ever as of prior-apriorising/axiomatising/referencing-superseded-logical-basis-of $\sim$ dialogicalequivalence-<as-to-psychologismic apriorising/axiomatising/referencing-\{of- "prespectively implicited_attendant-ontological-contiguity ' educedexistentialising/contextualising/textualising_'intelligibility/epistemicity/reflexivity-contiguity<imbued-notional cogency>’ \}-conflatedness -in-\{preconverging ment by\} postconverging-entailment,-in-self-becoming/self-conflatedness /formative-supererogating> as so-construed from 'notional ' deprocrypticism inducing relative-ontological-completeness 
of prospective-apriorising/axiomatising/referencing-superseding-logical-basis-of $\sim$ dialogicalequivalence-<as-to-psychologismic apriorising/axiomatising/referencing- \{of-'prospectively implicited_attendant-ontological-contiguity ' educedexistentialising/contextualising/textualising_'intelligibility/epistemicity/reflexivity-contiguity<imbued-notional cogency >' \}-conflatedness -in-\{preconverging-ment by\} postconverging-entailment,-in-self-becoming/self-conflatedness /formative-

supererogating $>$ ', In other words, the human as 'manifesting ${ }^{7}$ presencing-absolutisingidentitive-constitutedness ${ }^{14} \quad<$ amplituding/formative-epistemicity $>$ totalising $\sim$ self-referencingsyncretising/circularity/interiorising/akrasiatic-drag ${ }^{34}$ is intellectually-and-morally incompetent with regards to articulating prospective sublimating value-construction'; as we can appreciate that the state of prior recurrent-utter-uninstitutionalisation, ununiversalisation, nonpositivism/medievalism and ${ }^{80}$ procrypticism-or-disjointedness-as-of- ${ }^{3}$ reference-of-thought (so-construed as of 'supposed human-subpotency abstract self-determinative ontologicalperformance ${ }^{72}-<$ including-virtue-as-ontology $>/$ morality/ethics/justice/etc. capacity as to the full-potency of existence' in their ${ }^{79}$ presencing — absolutising-identitive-constitutedness ${ }^{14}$ ) are respectively intellectually-and-morally incompetent with regards to articulating prospective sublimating value-construction as of prospective base-institutionalisation, ${ }^{103}$ universalisation, positivism/rational-empiricism and deprocrypticism-or-preempting-disjointedness-as-ofreference-of-thought respectively. This insight points to the fundamental deficiency of all frameworks supposedly involved in articulating human prospective transcendence-andsublimating ${ }^{56}$ meaningfulness-and-teleology ${ }^{9}$ whereas there are as of ${ }^{79}$ presencingabsolutising-identitive-constitutedness ${ }^{14} \quad$ prior-apriorising/axiomatising/referencingsuperseded-logical-basis-of $\sim$ dialogical-equivalence- $<$ as-topsychologismic $\sim$ apriorising/axiomatising/referencing-\{of-"prospectivelyimplicited_attendant-ontological-contiguity ' educed- 
existentialising/contextualising/textualising_'intelligibility/epistemicity/reflexivity-contiguity<imbued-notional cogency $>>$ \}-conflatedness -in-\{preconverging -ment by\}

\section{postconverging-entailment,-in-self-becoming/self-conflatedness /formative-}

supererogating $>2$; as to the fact that with regards to existence-potency ${ }^{39} \sim$ sublimatingnascence,-disclosed-from-prospective-epistemic-digression ${ }_{2}$ the 'supposed human-subpotency abstract self-determinative ontological-performance ${ }^{72}-<$ including-virtue-asontology $>$ /morality/ethics/justice/etc. capacity as to the full-potency of existence' (as reflected by its given reproducibility-mathesis/motif/thrownness-disposition,-as-reproducibility-ofaestheticisation) is prospectively underdetermined for articulating prospective transcendenceand-sublimity/sublimation/supererogatery de-mentativity ${ }^{56}$ meaningfulness-and-teleology ${ }^{99}$ Thus the 'supposed human-subpotency abstract self-determinative ontological-performance ${ }^{72}$ $<$ including-virtue-as-ontology $>/$ morality/ethics/justice/etc. capacity as to the full-potency of existence' can only be construed in terms of notional ${ }^{8}$ deprocrypticism imbued dimensionalityof-sublimating $25-<<$ amplituding/formative $>$ supererogatory $\sim$ de-mentativeness/epistemicgrowth-or-conflatedness /transvaluative-rationalising/transepistemicity/anamnesticresiduality/spirit-drivenness-equalisation) (so-construed as from the ontologicalnormalcy/postconvergence epistemic projective-perspective) 'as it resolves human underdetermination for articulating prospective transcendence-andsublimity/sublimation/supererogatory de-mentativity ${ }^{56}$ meaningfulness-and-teleology ${ }^{9}$, as to existence-potency ${ }^{39} \sim$ sublimating-nascence,-disclosed-from-prospective-epistemic-digression. In other words, 'human notional firstnaturedness-formativeness-<as-to-eventualising inklingdrive-or-seeding misprising $>$ temporal-to-intemporal-dispositions- $<$ so-construed-as-fromperspective-ontological-normalcy/postconvergence> accordioning-〈as-of-varyingindividuations-contextually-transverse-desublimation/sublimation,-as-to-the- 
imbued-ontological-performance -<including-virtue-as-ontology $>>$ at uninstitutionalisedthreshold ${ }^{102}$ as reflecting both desublimating ${ }^{47}$ historicity-tracing-in-presencinghyperrealisation/hyperreal-transposition and sublimating ${ }^{4}$ historiality/ontologicaleventfulness 38 ontological-aesthetic-tracing-<perspective-ontologicalnormalcy/postconvergence-reflected-'epistemicity-relativism-determinism’> possibilities' inherently mean that all human frameworks of prior-apriorising/axiomatising/referencingsuperseded-logical-basis-of $\sim$ dialogical-equivalence- $<$ as-topsychologismic $\sim$ apriorising/axiomatising/referencing-\{of-"prospectively implicited_attendant-ontological-contiguity ' ceducedexistentialising/contextualising/textualising_'intelligibility/epistemicity/reflexivity-contiguity$<$ imbued-notional cogency $>>\quad\}$-conflatedness -in-\{preconverging-ment by\} postconverging entailment,-in-self-becoming/self-conflatedness /formative-supererogating > are preconverging/postconverging-de-mentatively/structurally/paradigmatically intellectuallyand-morally incompetent with regards to articulating prospective sublimating valueconstruction, as to the fact that the possibility for human prospective sublimation is a 'messianicstructure of intemporality ${ }^{52}$ as to solipsistic ontological-faith-notion-or-ontological-fideismimbued-underdetermination-of-motif-and-apriorising/axiomatising/referencing-as-so-being-asof-existential-reality: as reflected by prospective 'human corresponding-sublimation-inducing,profound-and-creative supererogatory $\sim$ acuity/perspicacity/astuteness/edginess/incisiveness-ofapriorising/axiomatising/referencing/intelligibilitysettingup/measuringinstrumenting -forconceptualisation' (that create/invent methods/methodologies/approaches as to prospectiveapriorising/axiomatising/referencing-superseding-logical-basis-of $\sim$ dialogical-equivalence- $<$ asto-psychologismic apriorising/axiomatising/referencing-\{of-‘prospectively implicited_attendant-ontological-contiguity ' educedexistentialising/contextualising/textualising_'intelligibility/epistemicity/reflexivity-contiguity- 
$<$ imbued-notional $\left.\sim \operatorname{cogency}>^{\prime}\right\}$-conflatedness -in-\{preconverging-ment by\}

postconverging entailment,-in-self-becoming/self-conflatedness /formative-supererogating>

organic-knowledge in ontological-good-faith/authenticity $\sim$ postconverging-dementating/structuring/paradigming ${ }^{0}$ so-constrained by existence-potency ${ }^{30} \sim$ sublimating- $^{-}$ nascence,-disclosed-from-prospective-epistemic-digression) so-construed as originarinessparrhesia,-as-spontaneity-of-aestheticisation (which is actually constrained to '<amplituding/formative-epistemicity $>$ totalising/circumscribing/delineating 'implicited_attendant-ontological-contiguity ${ }^{67}$; educedexistentialising/contextualising/textmalising_intelligibility/epistemicity/reflexivity-contiguity$<$ imbued-notional cogency $>{ }^{40} \quad{ }^{45}$ foregrounding_entailment- $<$ in-succession-of-profoundsupererogation $>$-〈postconverging-narrowing-down $\sim$ sublimation-as-to-'existence - assublimating-withdrawal/unenframing/re-ontologising,-elicited-from-prospective-profoundsupererogation '-in-reflecting-'immanent relative-unreflexivity/relative-reflexivityontological-contiguity ';-as-operative-notional deprocrypticism) in elucidating relativeunreflexivity/relative-reflexivity - ontological-contiguity ${ }_{-}<$as-from-prospective-ontologicalnormalcy/postconvergence-epistemic-or-notional projective-perspective $>$ '), and so over the 'desublimation/gimmickiness of mere methods/methodologies/approaches of priorapriorising/axiomatising/referencing-superseded-logical-basis-of $\sim$ dialogical-equivalence- $<$ asto-psychologismic apriorising/axiomatising/referencing-\{of-‘prospectively implicited_attendant-ontological-contiguity ' educedexistentialising/contextualising/textualising_'intelligibility/epistemicity/reflexivity-contiguity<imbued-notional cogency >' \}-conflatedness -in-\{preconverging-ment by\} postconverging-entailment,-in-self-becoming/self-conflatedness /formative-supererogating > mechanical-knowledge prospectively in poor ontological-good-faith/authenticity ${ }^{6}$ or outright ontological-bad-faith/inauthenticity ${ }^{64}$ overlooking existence-potency ${ }^{39} \sim$ sublimating-nascence,- 
disclosed-from-prospective-epistemic-digression. The implication here is that with regards to the relative-unreflexivity/relative-reflexivity - ontological-contiguity ${ }^{67}$ of-the-human-

institutionalisation-process ${ }^{68}$ as to the possibility of the <cumulating/recomposuring attendantontological-contiguity $>$-successive registry-worldviews/dimensions transcendence-andsublimity/sublimation/supererogatory $\sim$ de-mentativity, the underlying 'notional $\sim$ ' deprocrypticism or $<$ amplituding/formative $>$ notional $\sim$ preempting — disjointednessas-of- ${ }^{3}$ reference-of-thought imbued dimensionality-of-sublimating <<amplituding/formative>supererogatory $\sim$ de-mentativeness/epistemic-growth-or-

\section{conflatedness /transvaluative-rationalising/transepistemicity/anamnestic-residuality/spirit-}

drivenness-equalisation) is what accounts for human sublimation as of the succession of prospective institutionalisations' (associated with its coherencing preconverging/postconverging-rede-mentating/restructuring/reparadigming of the 'successive registry-worldviews'/dimensions' reproducibility—mathesis/motif/thrownness-disposition,-as-reproducibility-of-aestheticisation as of their overall decoherencing-structure-ofmeaningfulness-and-teleology ${ }^{9}$-for-institutionalisation', speaking of dimensionality-ofsublimating 25 -<<amplituding/formative $>$ supererogatory $\sim$ de-mentativeness/epistemic-growthor-conflatedness /transvaluative-rationalising/transepistemicity/anamnestic-residuality/spiritdrivenness-equalisation $\rangle$ as the inherent ontological-good-faith/authenticity $\sim$ postconvergingde-mentating/structuring/paradigming ${ }^{0}$ ) while the underlying imbued 'notional procrypticism/notional $\sim$ disjointedness-as-of- ${ }^{83}$ reference-of-thought dimensionalityof-desublimating-lack-of $-<<$ amplituding/formative $>$ supererogatory $\sim$ dementativeness/epistemic-growth-or-conflatedness /transvaluativerationalising/transepistemicity/anamnestic-residuality/spirit-drivenness-equalisation $\rangle$ is what accounts for desublimation as uninstitutionalised-threshold ${ }^{102}$ (as so-reflected with the 'successive registry-worldviews'/dimensions' reproducibility—mathesis/motif/thrownness- 
disposition,-as-reproducibility-of-aestheticisation as of their overall decoherencing-structureof- ${ }^{5}$ meaningfulness-and-teleology 9 -for-institutionalisation', speaking of dimensionality-ofdesublimating-lack-of $-\langle<$ amplituding/formative $>$ supererogatory $\sim$ de-mentativeness/epistemicgrowth-or-conflatedness /transvaluative-rationalising/transepistemicity/anamnesticresiduality/spirit-drivenness-equalisation $\rangle$ as the inherent ontological-badfaith/inauthenticity $\sim$ preconverging-de-mentating/structuring/paradigming ${ }^{65}$ ); and so as 'reflecting the ontological-performance ${ }^{72}-<$ including-virtue-asontology $>$ /morality/ethics/justice/etc. of the ${ }^{83}$ reference-of-thought- ${ }^{-1 e v o l v i n g ~ i n ~}$ formativeness-<as-to-intersolipsism-of-preformulating/preframing/premeaningfulness-imbuedmediativity-and-deferentialism>-of- meaningfulness-and-teleology of desublimating historicity-tracing - in-presencing-hyperrealisation/hyperreal-transposition and sublimating historiality/ontological-eventfulness 8 /ontological-aesthetic-tracing-<perspectiveontological-normalcy/postconvergence-reflected-‘epistemicity-relativism-determinism'>' (with regards to 'varying psychologismic epistemic-acutisation difficulty-<for, residualising $\{$ decompulsing $\}$ delinearity for-cogeney> magnitudes $\{$ of-experientiality/experiment $\} /$ scales —as-tosuccessively-profound-preconverging/postconverging-redementating/restructuring/reparadigming-frames-as-from-living,-institutionalising,-and-Beingontologising/infrastructure-of- ${ }^{5}$ meaningfulness-and-teleology 9 of prospective humansubpotency-aporia/undecidability/dilemma/ought-

indeterminacy/deficiency/limitation/constraint—imbued-'notional firstnaturedness-

\section{formativeness-<as-to-eventualising-inkling drive or seeding misprising $>$ temporal-to-}

intemporal-dispositions-<so-construed-as-from-perspective-ontological-

normalcy/postconvergence>'-existentialism-form-factor'). The overall insight we can garner herein is that all registry-worldviews/dimensions will have their value-construction conception as of their social-vestedness/normativity- $<$ discretely-implied-functionalism $>{ }^{79}$ presencing- 
absolutising-identitive-constitutedness

$<$ amplituding/formative-epistemicity $>$ totalising $\sim$ selfreferencing-syncretising/circularity/interiorising/akrasiatic-drag ${ }^{34}$ that fails to factor in their prospective desublimation as to their given notional $\sim$ procrypticism/notional $\sim$ disjointedness-asof- ${ }^{8}$ reference-of-thought and that notional ${ }^{18}$ deprocrypticism prospective sublimation will preconverging/postconverging-de-mentatively/structurally/paradigmatically_dismiss fundamentally' the registry-worldviews/dimensions very ${ }^{79}$ presencing —absolutising-identitiveconstitutedness prior-apriorising/axiomatising/referencing-superseded-logical-basisof $\sim$ dialogical-equivalence-<as-to-psychologismic $\sim$ apriorising/axiomatising/referencing- of'prospectively_implicited_attendant_ontological-contiguity ' educedexistentialising/contextualising/textualising_'intelligibility/epistemicity/reflexivity-contiguity$<$ imbued-notional cogency $>\quad\}$-conflatedness in-\{preconverging ment by\} postconverging-entailment,-in-self-becoming/self-conflatedness /formative-supererogating > pretence of being involved in prospective transcendence-andsublimity/sublimation/supererogatory de-mentativity ${ }^{56}$ meaningfulness-and-teleology ${ }^{9}$, and so as to the notional ${ }^{18}$ deprocrypticism projected prospectiveapriorising/axiomatising/referencing-superseding-logical-basis-of $\sim$ dialogical-equivalence- $<$ asto-psychologismic apriorising/axiomatising/referencing-\{of-'prespectively implicited_attendant-ontological-contiguity ' reducedexistentialising/contextualising/textualising_ intelligibility/epistemicity/reflexivity-contiguity<imbued-notional cogency>' \}-conflatedness -in-\{preconverging-ment by\} postconverging entailment,-in-self-becoming/self-conflatedness /formative-supererogating > as to existence-potency ${ }^{39} \sim$ sublimating-nascence,-disclosed-from-prospective-epistemicdigression. But then the preconverging/postconverging-de-mentative/structural/paradigmatic implications of 'human notional firstnaturedness-formativeness-<as-to-eventualising inklingdrive or seeding misprising $>$ temporal-to-intemporal-dispositions-<so-construed-as-from- 
perspective-ontological-normalcy/postconvergence>

accordioning-〈as-of-varying-

individuations-contextually-transverse-desublimation/sublimation,-as-to-the-

wavering/redounding/waveforming of-their-referencing-and-their-devolved-referencing-

imbued-ontological-performance -<including-virtue-as-ontology $>>$ at uninstitutionalisedthreshold ${ }^{102}$ as reflecting both desublimating ${ }^{47}$ historicity-tracing-in-presencinghyperrealisation/hyperreal-transposition and sublimating ${ }^{4}$ historiality/ontologicaleventfulness ${ }^{3}$ /ontological-aesthetic-tracing-<perspective-ontological-

normalcy/postconvergence-reflected-'epistemicity-relativism-determinism'> possibilities'

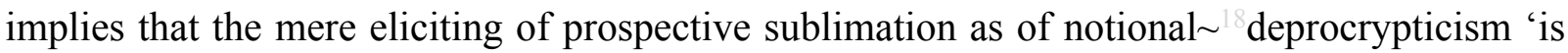
not preconverging/postconverging-de-mentatively/structurally/paradigmatically transformative of human notional firstnaturedness-formativeness-<as-to-eventualising-inkling-drive-orseeding misprising $>$ temporal-to-intemporal-dispositions-<so-construed-as-fromperspective-ontological-normalcy/postconvergence>' as to the fact that 'prospective transcendence-and-sublimity/sublimation/supererogatory - de-mentativity ${ }^{56}$ meaningfulnessand-teleology ${ }^{9}$ doesn't transform the underlying reality of human notional firstnaturednessformativeness-<as-to-eventualising-inkling-drive or seeding-misprising $>$ temporal-tointemporal-dispositions- $<$ so-construed-as-from-perspective-ontologicalnormalcy/postconvergence $>\quad$ ontological-performance ${ }^{72}-<$ including-virtue-as- $^{2}$ ontology $>$ /morality/ethics/justice/etc. with regards to social-stake-contention-or-confliction as of the ever-present precedence of human ontological-good-faith/authenticity ${ }^{69}$ or ontologicalbad-faith/inauthenticity ${ }^{64}$ as to ontological-faith-notion-or-ontological-fideism -imbuedunderdetermination-of-motif-and-apriorising/axiomatising/referencing-as-so-being-as-ofexistential-reality associated with human limited-mentation-capacity-as-subjecting 'educedunlimitedness/existence-sublimating nascence' to-limitedness/human-subpotency with regards to social-stake-contention-or-confliction' (so-construed as from the ontological- 
normalcy/postconvergence epistemic projective-perspective). But rather the mere eliciting of prospective sublimation as of notional deprocrypticism 'can only undermine the prior uninstitutionalised-threshold

apriorising/axiomatising/referencing/intelligibilitysettingup/measuringinstrumenting-asreflecting-its- categorical-imperatives/axioms/registry-teleology ${ }^{9}$,-foraposteriorising/logicising/deriving/intelligising/measuring- ${ }^{5}$ meaningfulness-and-teleology ${ }^{9}$ in rendering ontological-bad-faith/inauthenticity ${ }^{64}$ ridiculous-and-untenable' as to the crossgenerational psychoanalytic-unshackling/memetic-reordering/institutional-recomposuring, such that with regards to the <cumulating/recomposuring attendant-ontological-contiguity succession of registry-worldviews/dimensions as to their notional procrypticism uninstitutionalised-threshold ${ }^{102}$ in prospective desublimation there is ever this underlying reality of human notional firstnaturedness-formativeness-<as-to-eventualising-inkling-drive-orseeding misprising $>$ temporal-to-intemporal-dispositions- $<$ so-construed-as-fromperspective-ontological-normalcy/postconvergence $>\quad$ ontological-performance ${ }^{2}-<$ includingvirtue-as-ontology $>$ /morality/ethics/justice/etc. requiring the "prospective undermining of the prior uninstitutionalised-threshold apriorising/axiomatising/referencing/intelligibilitysettingup/measuringinstrumenting-as-

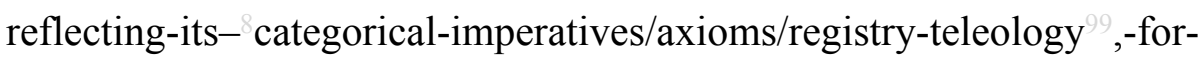
aposteriorising/logicising/deriving/intelligising/measuring- ${ }^{5}$ meaningfulness-and-teleology ${ }^{9}$ in rendering ontological-bad-faith/inauthenticity ${ }^{64}$ ridiculous-and-untenable' (so-construed as the ' reference-of-thought human-subpotency-aporia/undecidability/dilemma/oughtindeterminacy/deficiency/limitation/constraint for prospective sublimation' or 'messianicstructure of intemporality ${ }^{52}$ ). The possibility for prospective human sublimation as to the very essence of human knowledge-reification $\sim$ gesturing-and-accounting-of-epistemicphenomenalism- $<$ in-prospective_psychologismic $\sim$ apriorising/axiomatising/referencing- of- 
'prospectively_implicited_attendant-ontological-contiguity ' educed-

existentialising/contextualising/textualising_'intelligibility/epistemicity/reflexivity_contiguity$<$ imbued-notional cogency $>$ ' $\}$-conflatedness - in-\{preconverging ment by\}

postconverging-entailment $>$ exercise as underlined by 'messianic-structure of intemporality ${ }^{52}$, is: human-subpotency 'fatedness-of-sublimation-over-desublimation, to existencepotency $\sim$ sublimating-nascence,-disclosed-from-prospective-epistemic-digression (in reflecting holographically-<conjugatively-and-transfusively $>$ the relative-unreflexivity/relativereflexivity - ontological-contiguity of-the-human-institutionalisation-process ), as from human-subpotency ontological-faith-notion-or-ontological-fideism—imbuedunderdetermination-of-motif-and-apriorising/axiomatising/referencing-as-so-being-as-ofexistential-reality as to the disseminative-sublimating-selectivity-of-ontological-goodfaith/authenticity postconverging-de-mentating/structuring/paradigming , overdesublimating-deselectivity-of-ontological-bad-faith/inauthenticity opreconverging -dementating/structuring/paradigming '. Prospective human sublimation is ever always an exercise involving the primacy of notional deprocrypticism projected prospectiveapriorising/axiomatising/referencing-superseding-logical-basis-of $\sim$ dialogical-equivalence- $<$ asto-psychologismic apriorising/axiomatising/referencing-\{of-‘prospectively implicited_attendant-ontological-contiguity ' educedexistentialising/contextualising/textualising_'intelligibility/epistemicity/reflexivity-contiguity$<$ imbued-notional cogency $>$ ' $\}$-conflatedness -in-\{preconverging ment by\} postconverging entailment,-in-self-becoming/self-conflatedness /formative-supererogating> over prior social-vestedness/normativity- $<$ discretely-implied-functionalism $>$ notional procrypticism prior-apriorising/axiomatising/referencing-superseded-logical-basisof $\sim$ dialogical-equivalence-<as-to-psychologismic $\sim$ apriorising/axiomatising/referencing- $\{$ of'prospectively_implicited_attendant-ontological-contiguity ' educed- 
existentialising/contextualising/textualising_'intelligibility/epistemicity/reflexivity-contiguity<imbued-notional cogency $>>$ \}-conflatedness -in-\{preconverging -ment by\}

\section{postconverging-entailment,-in-self-becoming/self-conflatedness /formative-}

supererogating $>$; ; as to the implication that the 'breadth of human notional firstnaturednessformativeness-<as-to-eventualising inkling drive-or seeding misprising $>$ - temporal-tointemporal-dispositions- $<$ so-construed-as-from-perspective-ontologicalnormalcy/postconvergence $>$ is not preconverging/postconverging-dementatively/structurally/paradigmatically a competent intellectual-and-moral framework for instigating prospective human sublimation' as all the possibility for prospective human sublimation arises as to the requisite dispensing-with-immediacy-for-relative-ontologicalcompleteness ${ }^{87}$-by-reification/contemplative-distension ${ }^{27}$ exclusively associated with human prospective intemporal/longness-of-register-of meaningfulness-and-teleology projection (so-construed as from the ontological-normalcy/postconvergence epistemic projectiveperspective) as so-associated with dimensionality-of-sublimating <<amplituding/formative>supererogatory $\sim$ de-mentativeness/epistemic-growth-orconflatedness /transvaluative-rationalising/transepistemicity/anamnestic-residuality/spiritdrivenness-equalisation〉 mentating/structuring/paradigming eliciting of prospective 'human correspondingsublimation-inducing,-profound-and-creative supererogatory acuity/perspicacity/astuteness/edginess/incisiveness-ofapriorising/axiomatising/referencing/intelligibilitysettingup/measuringinstrumenting -forconceptualisation' (that create/invent methods/methodologies/approaches as to prospectiveapriorising/axiomatising/referencing-superseding-logical-basis-of $\sim$ dialogical-equivalence- $<$ asto-psychologismic apriorising/axiomatising/referencing-\{of-'prospectivelyimplicited_attendant-ontological-contiguity ' educed- 
existentialising/contextualising/textualising_intelligibility/epistemicity/reflexivity-contiguity<imbued-notional cogency>' \}-conflatedness -in-\{preconverging -ment by\}

postconverging entailment,-in-self-becoming/self-conflatedness /formative-supererogating >

organic-knowledge in ontological-good-faith/authenticity $\sim$ postconverging-dementating/structuring/paradigming ${ }^{70}$ so-constrained by existence-potency ${ }^{30} \sim$ sublimatingnascence,-disclosed-from-prospective-epistemic-digression) so-construed as originarinessparrhesia,-as-spontaneity-of-aestheticisation (which is actually constrained to ‘<amplituding/formative-epistemicity $>$ totalising/circumscribing/delineating 'implicited_attendant-ontological-contiguity ${ }^{67}$ ' educedexistentialising/contextmalising/textualising_'intelligibility/epistemicity/reflexivity_contiguity$<$ imbued-notional cogency $>{ }^{40} \quad{ }^{45}$ foregrounding_entailment- $<$ in-succession-of-profoundsupererogation $>$-〈postconverging-narrowing-down $\sim$ sublimation-as-to-'existence-assublimating-withdrawal/unenframing/re-ontologising,-elicited-from-prospective-profoundsupererogation '-in-reflecting-'immanent relative unreflexivity/relative-reflexivity ontological-contiguity ';--as-operative-notional deprocrypticism) in elucidating relativeunreflexivity/relative-reflexivity ontological-contiguity ${ }_{-}<$as-from-prospective-ontologicalnormalcy/postconvergence-epistemic-or-notional projective-perspective $>$ '), and so over the 'desublimation/gimmickiness of mere methods/methodologies/approaches of priorapriorising/axiomatising/referencing-superseded-logical-basis-of $\sim$ dialogical-equivalence- $<$ asto-psychologismic apriorising/axiomatising/referencing-\{of-‘prospectivelyimplicited_attendant-ontological-contiguity ' educedexistentialising/contextualising/textualising_ intelligibility/epistemicity/reflexivity-contiguity$<$ imbued-notional cogency $>$ ' $\}$-conflatedness -in-\{preconverging ment by\} postconverging entailment,-in-self-becoming/self-conflatedness /formative-supererogating > mechanical-knowledge prospectively in poor ontological-good-faith/authenticity ${ }^{69}$ or outright 
ontological-bad-faith/inauthenticity ${ }^{64}$ overlooking existence-potency ${ }^{39} \sim$ sublimating-nascence,disclosed-from-prospective-epistemic-digression. In order words, the possibility for prospective human sublimation has ever always arisen by undermining the 'breadth of human notional firstnaturedness-formativeness-<as-to-eventualising inkling drive-or-seeding misprising $>$ temporal-to-intemporal-dispositions- $<$ so-construed-as-from-perspectiveontological-normalcy/postconvergence $>\quad$ not preconverging/postconverging-dementatively/structurally/paradigmatically a competent intellectual-and-moral framework for instigating prospective human sublimation' and upholding the 'messianic-structure of intemporality ${ }^{52}$; $\quad$ as $\quad$ so-constrained $\quad$ to $\quad<$ amplituding/formativeepistemicity $>$ totalising/circumscribing/delineating 'implicited_attendant-ontologicalcontiguity $^{67}$, educedexistentialising/contextualising/textualising_intelligibility/epistemicity/reflexivity-contiguity$<$ imbued-notional cogency $>{ }^{40} \quad{ }^{4}$ foregrounding_entailment- $<$ in-succession-of-profoundsupererogation $>$-〈postconverging-narrowing-down $\sim$ sublimation-as-to-'existence - assublimating-withdrawal/unenframing/re-ontologising,-elicited-from-prospective-profoundsupererogation '-in-reflecting-'immanent relative-unreflexivity/relative-reflexivity ontological-contiguity ';-as-operative-notional deprocrypticism) in elucidating relativeunreflexivity/relative-reflexivity - ontological-contiguity $-<$ as-from-prospective-ontologicalnormalcy/postconvergence-epistemic-or-notional projective-perspective> ${ }^{\prime} \quad$ enabling ontological-normalcy/postconvergence notional ${ }^{8}$ deprocrypticism induced overriding of priorapriorising/axiomatising/referencing-superseded-logical-basis-of $\sim$ dialogical-equivalence- $<$ asto-psychologismic apriorising/axiomatising/referencing-\{of-‘prospectivelyimplicited_attendant-ontological-contiguity ' educedexistentialising/contextualising/textualising_'intelligibility/epistemicity/reflexivity-contiguity<imbued-notional cogency >' \}-conflatedness -in-\{preconverging-ment by\} 
postconverging entailment,-in-self-becoming/self-conflatedness /formative-supererogating>

with prospective-apriorising/axiomatising/referencing-superseding-logical-basis-of $\sim$ dialogicalequivalence-<as-to-psychologismic $\sim$ apriorising/axiomatising/referencing- \{of-"prespectively implicited_attendant-ontological-contiguity ' reducedexistentialising/contextualising/textualising_ 'intelligibility/epistemicity/reflexivity-contiguity<imbued-notional cogency >' \}-conflatedness -in-\{preconverging-ment by\} postconverging entailment,-in-self-becoming/self-conflatedness /formativesupererogating $>$. Critically, $\quad$ social-vestedness/normativity-<discretely-impliedfunctionalism> presencing - absolutising-identitive-constitutedness $<$ amplituding/formative--epistemicity $>$ totalising $\sim$ self-referencingsyncretising/circularity/interiorising/akrasiatic-drag ${ }^{34}$ are opportunistically wedded to eliciting the 'breadth of human notional firstnaturedness-formativeness-<as-to-eventualising-inkling drive-or-seeding misprising $>$ temporal-to-intemporal-dispositions- $<$ so-construed-as-fromperspective-ontological-normalcy/postconvergence> not preconverging/postconverging-dementatively/structurally/paradigmatically a competent intellectual-and-moral framework for instigating prospective human sublimation' as to the sophistic/pedantic possibility for eliciting human temporality $\%$ shortness <amplituding/formative> wooden-language-〈imbuedaveraging-of-thought-<as-to-leveling/ressentiment/closed-construct-of- meaningfulness-andteleology -as-of-'nondescript/ignorable-void ' '-with-regards-to-prospective-apriorisingimplications $>>$ with regards to prospective social-stake-contention-or-confliction; such that Establishment intellection in the <cumulating/recomposuring attendant-ontologicalcontiguity >-succession of registry-worldviews/dimensions project-a-blindness-reflectingtheir-desublimating- historicity-tracing — in-presencing-hyperrealisation/hyperrealtransposition with respect to the projected coherencing preconverging/postconverging-redementating/restructuring/reparadigming of the 'successive registry-worldviews'/dimensions' 
reproducibility—mathesis/motif/thrownness-disposition,--as-reproducibility-of-aestheticisation as of their overall decoherencing-structure-of- meaningfulness-and-teleology -forinstitutionalisation'

as

of

dimensionality-of-sublimating

\section{<<amplituding/formative >supererogatede-mentativeness/epistemic-growth-or-}

conflatedness /transvaluative-rationalising/transepistemicity/anamnestic-residuality/spirit-

drivenness-equalisation $\rangle$ as the inherent ontological-good-faith/authenticity $\sim$ postconvergingde-mentating/structuring/paradigming 70 Prospective sublimation as to the overriding of priorapriorising/axiomatising/referencing-superseded-logical-basis-of $\sim$ dialogical-equivalence- $<$ asto-psychologismic apriorising/axiomatising/referencing-\{of-‘prospectivelyimplicited_attentantontological-contiguity ' educedexistentialising/contextualising/textualising_'intelligibility/epistemicity/reflexivity_contiguity<imbued-notional cogency >’ $\}$-conflatedness -in-\{preconverging ment by\} postconverging entailment,-in-self-becoming/self-conflatedness /formative-supererogating > with prospective-apriorising/axiomatising/referencing-superseding-logical-basis-of $\sim$ dialogicalequivalence-<as-to-psychologismic apriorising/axiomatising/referencing- \{of-" prospectively implicited_attendant_ontological-contiguity ' educedexistentialising/contextualising/textualising_'intelligibility/epistemicity/reflexivity-contiguity<imbued-notional cogency >' \}-conflatedness -in-\{preconverging-ment by\} postconverging-entailment,-in-self-becoming/self-conflatedness /formative-supererogating > as critically constrained to '<amplituding/formativeepistemicity $>$ totalising/circumscribing/delineating 'implicited_attendant-ontologicalcontiguity ${ }^{67} \sim$ educedexistentialising/contextmalising/textualising_intelligibility/epistemicity/reflexivity_contiguity$<$ imbued-notional cogency $>{ }^{40} \quad{ }^{45}$ foregrounding_entailment- $<$ in-succession-of-profoundsupererogation $>$-〈postconverging-narrowing-down $\sim$ sublimation-as-to-'existence-as- 
sublimating-withdrawal/unenframing/re-ontologising,-elicited-from-prospective-profoundsupererogation '-in-reflecting-'immanent relative-unreflexivity/relative-reflexivity ontological-contiguity ';-as-operative-notional deprocrypticism) in elucidating relativeunreflexivity/relative-reflexivity - ontological-contiguity ${ }_{-}<$as-from-prospective-ontologicalnormalcy/postconvergence-epistemic-or-notional projective-perspective>', speaks to the transformation of the 'flawed prior_knowledge-reification $\sim$ gesturing-and-accounting-ofepistemic-phenomenalism-<in-prior_psychologismic $\sim$ apriorising/axiomatising/referencing\{of-'prior-implicited_attendant-ontological-contiguity ' educedexistentialising/contextualising/textualising_'intelligibility/epistemicity/reflexivity-contiguity<imbued-notional cogency $>$ ' $\}$-constitutedness -in preconverging entailment $>$ framework of human-subpotency determination as to a temporal mere-formulaicmethodologising/mutualising/organising/institutionalising human-subpotency $<$ preconverging 'motif-and-apriorising/axiomatising/referencing'-entailing $>$ existentialising — enframing/imprintedness-〈as-to- historicity-tracing - in-presencinghyperrealisation/hyperreal-transposition〉 as desublimating' into 'genuine knowledgereification $\sim$ gesturing-and-accounting — of-epistemic-phenomenalism- $<$ inprospective_psychologismic apriorising/axiomatising/referencing-\{of-'prospectively implicited_attendant-ontological-contiguity ' educedexistentialising/contextualising/textualising_'intelligibility/epistemicity/reflexivity-contiguity<imbued-notional cogency >' \}-conflatedness -in-\{preconverging-ment by\}

postconverging-entailment $>$ framework involving a detour to existence-potency ${ }^{39} \sim$ sublimating- $^{-}$ nascence,-disclosed-from-prospective-epistemic-digression induced prospective determination which then is preconverging/postconverging-de-mentatively/structurally/paradigmatically preceding-and-constraining to human-subpotency as enabling prospective sublimation-overdesublimation'. In this regards, we can appreciate that the 'flawed prior_knowledge- 
reification $\sim$ gesturing-and-accounting — of-epistemic-phenomenalism- $<$ inprior_psychologismic apriorising/axiomatising/referencing-\{of-'prior-implicited_attendantontological-contiguity ' educedexistentialising/contextualising/textualising_'intelligibility/epistemicity/reflexivity-contiguity<imbued-notional cogency $>$ ' $\quad\}$-constitutedness -in preconverging entailment $>$ framework of human-subpotency determination as to a temporal mere-formulaicmethodologising/mutualising/organising/institutionalising human-subpotency <preconverging 'motif-and-apriorising/axiomatising/referencing'-entailing >existentialising — enframing/imprintedness-〈as-to- historicity-tracing — in-presencinghyperrealisation/hyperreal-transposition) as desublimating' tend to eliciting the 'breadth of human notional firstnaturedness-formativeness-<as-to-eventualising inkling-drive-orseeding misprising $>$ temporal-to-intemporal-dispositions- $<$ so-construed-as-fromperspective-ontological-normalcy/postconvergence $>$ not preconverging/postconverging-dementatively/structurally/paradigmatically a competent intellectual-and-moral framework for instigating prospective human sublimation' while 'genuine knowledge-reification $\sim$ gesturingand-accounting - of-epistemic-phenomenalism- $<$ inprospective_psychologismic apriorising/axiomatising/referencing-\{of-'prospectively implicited_attendant-ontological-contiguity ' reducedexistentialising/contextualising/textualising_'intelligibility/epistemicity/reflexivity-contiguity<imbued-notional cogency >' \}-conflatedness -in-\{preconverging-ment by\} postconverging-entailment $>$ framework involving a detour to existence-potency ${ }^{39} \sim$ sublimatingnascence,-disclosed-from-prospective-epistemic-digression induced prospective determination which then is preconverging/postconverging-de-mentatively/structurally/paradigmatically preceding-and-constraining to human-subpotency as enabling prospective sublimation-overdesublimation' tends to be rather constrained to both the 'messianic-structure of intemporality ${ }^{52}$, 
and its derived deferential-formalisation-transference secondnaturing. The possibility of such a transformation critically constrained to '<amplituding/formativeepistemicity>totalising/circumscribing/delineating 'implicited_attendant-ontologicalcontiguity $^{67}$, educed-

existentialising/contextualising/textualising_'intelligibility/epistemicity/reflexivity-contiguity$<$ imbued-notional $\sim$ cogency $>{ }^{40} \quad{ }^{45}$ foregrounding_entailment- $<$ in-succession-of-profoundsupererogation $>$-〈postconverging-narrowing-down $\sim$ sublimation-as-to-'existence-assublimating-withdrawal/unenframing/re-ontologising,-elicited-from-prospective-profoundsupererogation '-in-reflecting-'immanent relative-unreflexivity/relative-reflexivity ontological-contiguity ';-as-operative-notional deprocrypticism) in elucidating relativeunreflexivity/relative-reflexivity - ontological-contiguity ${ }^{6}-<$ as-from-prospective-ontologicalnormalcy/postconvergence-epistemic-or-notional projective-perspective> $>$ underlying notional ${ }^{18}$ deprocrypticism is only possible because of the tight-and-entwined relationship between the overall human ontological-commitment $-<$ implied-self-assuredness-ofontological-good-faith/authenticity $\sim$ postconverging-de-

mentating/structuring/paradigming -as-being-as-of-existential-reality $>$ (across all registryworldviews/dimensions) and (corresponding registry-worldviews/dimensions) predicativeeffectivity-sublimation-〈as-to-underlying,-ontological-commitment $-<$ implied-selfassuredness-of-ontological-good-faith/authenticity postconverging-dementating/structuring/paradigming -as-being-as-of-existential-reality $>\rangle$ as the critical enablers for the possibility of prospective transcendental ${ }^{56}$ meaningfulness-and-teleology ; with foregrounding_entailment- $<$ in-succession-of-profound-supererogation $>>-\langle$ postconverging narrowing-down $\sim$ sublimation-as-to-'existence - as-sublimating-withdrawal/unenframing/reontologising,-elicited-from-prospective-profound-supererogation ' '-in-reflecting- 
notional deprocrypticism> thus being an exercise of satisfying that tight-and-entwined relationship to then enable 'genuine knowledge-reification $\sim$ gesturing-and-accounting-ofepistemic-phenomenalism-<in-

prospective_psychologismic apriorising/axiomatising/referencing-\{of-'prospectively implicited_attendant-ontological-contiguity ' educedexistentialising/contextualising/textualising_'intelligibility/epistemicity/reflexivity-contiguity<imbued-notional cogency >' \}-conflatedness -in-\{preconverging-ment by\} postconverging entailment $>$ framework involving a detour to existence-potency ${ }^{39} \sim$ sublimatingnascence,-disclosed-from-prospective-epistemic-digression induced prospective determination which then is preconverging/postconverging-de-mentatively/structurally/paradigmatically preceding-and-constraining to human-subpotency as enabling prospective sublimation-overdesublimation' as of prospective-apriorising/axiomatising/referencing-superseding-logicalbasis-of $\sim$ dialogical-equivalence-<as-to-psychologismic $\sim$ apriorising/axiomatising/referencing\{of-'prospectively_implicited_attendant-ontological-contiguity ' educedexistentialising/contextualising/textualising_ 'intelligibility/epistemicity/reflexivity-contiguity$<$ imbued-notional $\left.\sim \operatorname{cogency}>^{\prime}\right\}$-conflatedness -in-\{preconverging-ment by\} postconverging-entailment,-in-self-becoming/self-conflatedness /formativesupererogating $>$. $\quad{ }^{45}$ foregrounding_entailment- $<$ in-succession-of-profoundsupererogation $>$-〈postconverging-narrowing-down $\sim$ sublimation-as-to-'existence - assublimating-withdrawal/unenframing/re-ontologising,-elicited-from-prospective-profoundsupererogation '-in-reflecting-'immanent $\sim$ relative-unreflexivity/relative-reflexivity ontological-contiguity ';--as-operative-notional deprocrypticism) as to its implied transformation of prior-apriorising/axiomatising/referencing-superseded-logical-basisof $\sim$ dialogical-equivalence-<as-to-psychologismic $\sim$ apriorising/axiomatising/referencing- $\{$ of'prospectively implicited_attendant-ontological-contiguity ' educed- 
existentialising/contextualising/textualising_'intelligibility/epistemicity/reflexivity-contiguity<imbued-notional cogency $>$ ' \}-conflatedness -in-\{preconverging ment by\}

postconverging entailment,-in-self-becoming/self-conflatedness /formative-supererogating>

into prospective-apriorising/axiomatising/referencing-superseding-logical-basis-of $\sim$ dialogicalequivalence-<as-to-psychologismic apriorising/axiomatising/referencing- \{of-'prospectively implicited_attendant-ontological-contiguity ' educed-

existentialising/contextualising/textualising_'intelligibility/epistemicity/reflexivity-contiguity$<$ imbued-notional cogency $>>$ \}-conflatedness -in-\{preconverging-ment by\} postconverging-entailment,-in-self-becoming/self-conflatedness /formative-supererogating> as to existence-potency ${ }^{39} \sim$ sublimating-nascence,-disclosed-from-prospective-epistemicdigression as prospectively overcoming human-subpotency underdetermination is conceptualised along the same vein with the 'Derridean underdetermination-imbued force/violence conception' and 'Foucauldian knowledge/power conception construed as knowledge-empowerment/ignorance-disempowerment' with regards to human phenomenal/manifest sublimation and desublimation in existence (as to the insight for mitigating the concomitant drawback of desublimating ${ }^{47}$ historicity-tracing-in-presencinghyperrealisation/hyperreal-transposition in the pursuit for sublimating ${ }^{4}$ historiality/ontologicaleventfulness 3 /ontological-aesthetic-tracing-<perspective-ontologicalnormalcy/postconvergence-reflected-'epistemicity-relativism-determinism'> at the very center of Foucault and Derrida contentions). ${ }^{45}$ foregrounding_entailment- $<$ in-succession-ofprofound-supererogation $>$-〈postconverging-narrowing-down $\sim$ sublimation-as-to- ${ }^{\text {‘ }}$ existenceas-sublimating-withdrawal/unenframing/re-ontologising,-elicited-from-prospective-profoundsupererogation '-in-reflecting-'immanent $\sim$ relative-unreflexivity/relative-reflexivityontological-contiguity ";-as-operative-notional deprocrypticism) invalidates ${ }^{79}$ presencingabsolutising-identitive-constitutedness ${ }^{14}$ conception of knowledge-reification $\sim$ gesturing-and- 
accounting - of-epistemic-phenomenalism- $<$ in-

prospective_psychologismic apriorising/axiomatising/referencing-\{of- ${ }^{\text {pprospectively }}$ implicited_attendant-ontological-contiguity ' educed-

existentialising/contextualising/textualising_'intelligibility/epistemicity/reflexivity-contiguity$<$ imbued-notional $\left.\sim \operatorname{cogency}>{ }^{\prime}\right\}$-conflatedness -in-\{preconverging-ment by\}

postconverging-entailment> as of the 'flawed prior_knowledge-reification $\sim$ gesturing-andaccounting - of-epistemic-phenomenalism- $<$ in-

prior_psychologismic apriorising/axiomatising/referencing-\{of-'prior-implicited_attendantontological-contiguity ' educed-

existentialising/contextualising/textualising_'intelligibility/epistemicity/reflexivity-contiguity<imbued-notional cogency $>$ ' $\quad\}$-constitutedness -in preconverging entailment $>$ framework of human-subpotency determination as to a temporal mere-formulaicmethodologising/mutualising/organising/institutionalising human-subpotency $<$ preconverging 'motif-and-apriorising/axiomatising/referencing'-entailing $>$ existentialising — enframing/imprintedness-〈as-to- historicity-tracing — in-presencinghyperrealisation/hyperreal-transposition〉 as desublimating'; that fail to realise that 'human selfsatisfactory mere-formulaic-methodologising/mutualising/organising/institutionalising constructs' are not beholden to existence with regards to 'genuine knowledgereification $\sim$ gesturing-and-accounting - of-epistemic-phenomenalism- $<$ inprospective_psychologismic apriorising/axiomatising/referencing-\{of-'prospectively implicited_attendant-ontological-contiguity ' educedexistentialising/contextualising/textualising_'intelligibility/epistemicity/reflexivity_contiguity$<$ imbued-notional cogency $>$ ' $\}$-conflatedness -in-\{preconverging ment by\} postconverging entailment $>$ framework involving a detour to existence-potency ${ }^{39} \sim$ sublimatingnascence,-disclosed-from-prospective-epistemic-digression induced prospective determination 
which then is preconverging/postconverging-de-mentatively/structurally/paradigmatically preceding-and-constraining to human-subpotency as enabling prospective sublimation-overdesublimation'. We can appreciate in this regards that the classical-mechanics-axiomaticconstructs prior-apriorising/axiomatising/referencing-superseded-logical-basis-of $\sim$ dialogicalequivalence-<as-to-psychologismic apriorising/axiomatising/referencing- $\{$ of-" prospectively implicited_attendant_ontological-contiguity ' educedexistentialising/contextualising/textualising_'intelligibility/epistemicity/reflexivity-contiguity$<$ imbued-notional cogency >' \}-conflatedness -in-\{preconverging-ment by\} postconverging-entailment,-in-self-becoming/self-conflatedness /formative-supererogating> that did not recognise notions like space-time, considered the ether real, did not consider that the laws of physics are different at atomic scale, etc. speaking to 'human self-satisfactory mereformulaic-methodologising/mutualising/organising/institutionalising constructs' wasn't in any way beholden to existence as to the prospective sublimation of the theory-of-relativity-togetherwith-quantum-mechanics — axiomatic-constructs prospectiveapriorising/axiomatising/referencing-superseding-logical-basis-of $\sim$ dialogical-equivalence-<asto-psychologismic apriorising/axiomatising/referencing-\{of-‘prospectively implicited_attendant-ontological-contiguity ' educedexistentialising/contextmalising/textualising_'intelligibility/epistemicity/reflexivity_contiguity<imbued-notional cogency >' \}-conflatedness -in-\{preconverging -ment by\} postconverging-entailment,-in-self-becoming/self-conflatedness /formative-supererogating> that recognised notions like space-time, considered the ether as real, considered that the laws of physics are different at atomic-scale, etc., and so as 'genuine knowledge-reification $\sim$ gesturingand-accounting - of-epistemic-phenomenalism- $<$ inprospective_psychologismic apriorising/axiomatising/referencing-\{of- ${ }^{\text {pprospectively }}$ implicited_attendant-ontological-contiguity ' educed- 
existentialising/contextualising/textualising_ 'intelligibility/epistemicity/reflexivity-contiguity<imbued-notional cogency $>$ ' \}-conflatedness -in-\{preconverging ment by\}

postconverging-entailment $>$ framework involving a detour to existence-potency ${ }^{39} \sim$ sublimatingnascence,-disclosed-from-prospective-epistemic-digression induced prospective determination which then is preconverging/postconverging-de-mentatively/structurally/paradigmatically preceding-and-constraining to human-subpotency as enabling prospective sublimation-overdesublimation'. It is interesting to appreciate that given the prior enculturation of an underlying 'scientific - apriorising/axiomatising/referencing-psychologism enculturated/constructed social-pragmatics-framing-of — predicative-effectivity-sublimation-〈as-to-underlying,ontological-commitment ${ }^{6}<$ implied-self-assuredness-of-ontological-goodfaith/authenticity $\sim$ postconverging-de-mentating/structuring/paradigming -as-being-as-ofexistential-reality $>>$ ' induced by budding-positivists (associated with their persecution), the stage was set for the ${ }^{45}$ foregrounding_entailment- $<$ in-succession-of-profoundsupererogation $>$-〈postconverging-narrowing-down $\sim$ sublimation-as-to-'existence-assublimating-withdrawal/unenframing/re-ontologising,-elicited-from-prospective-profoundsupererogation ' -in-reflecting-'immanent relative- unreflexivity/relative-reflexivity ontological-contiguity ';--as-operative-notional deprocrypticism) of such a theory-ofrelativity-together-with-quantum-mechanics_-axiomatic-constructs prospectiveapriorising/axiomatising/referencing-superseding-logical-basis-of $\sim$ dialogical-equivalence- $<$ asto-psychologismic $\sim$ apriorising/axiomatising/referencing-\{of-"prespectively implicited_attendant-ontological-contiguity ' educedexistentialising/contextualising/textualising_'intelligibility/epistemicity/reflexivity-contiguity$<$ imbued-notional cogency $>>$ \}-conflatedness - in-\{preconverging ment by\} postconverging-entailment,-in-self-becoming/self-conflatedness /formative-supererogating> as to the tight-and-entwined relationship between the overall human ontological-commitment 
$<$ implied — self-assuredness-of-ontological-good-faith/authenticity $\sim$ postconverging-de-

mentating/structuring/paradigming -as-being-as-of-existential-reality> (across all registryworldviews/dimensions) and (corresponding registry-worldviews/dimensions) predicativeeffectivity-sublimation-〈as-to-underlying,-ontological-commitment $-<$ implied-selfassuredness-of-ontological-good-faith/authenticity $\sim$ postconverging-de-

mentating/structuring/paradigming -as-being-as-of-existential-reality $>\rangle$ as the critical enablers for the possibility of prospective transcendental ${ }^{56}$ meaningfulness-and-teleology ${ }^{9}$, without eliciting (as was the case with the Galileos/Descartes, etc. in the face of the medieval-scholastics pedantic dogmatism Establishment) the 'breadth of human notional firstnaturednessformativeness-as to eventulising inkling drive or seeding misprising temporal-tointemporal-dispositions- $<$ so-construed-as-from-perspective-ontologicalnormalcy/postconvergence $>\quad$ not preconverging/postconverging-dementatively/structurally/paradigmatically a competent intellectual-and-moral framework for instigating prospective human sublimation' as to the sophistic/pedantic possibility for inducing human temporality 8 /shortness <amplituding/formative> wooden-language-〈imbuedaveraging-of-thought-<as-to-leveling/ressentiment/closed-construct-of- meaningfulness-andteleology -as-of-'nondescript/ignorable-void ' -with-regards-to-prospective-apriorisingimplications $>>$ with regards to prospective social-stake-contention-or-confliction. Interestingly as well, we can appreciate the more or less socially enculturated disposition in our positivism/rational-empiricism registry-worldview/dimension (with regards to the 'profoundly sublimating natural sciences') of human appreciation of the 'messianic-structure of intemporality $^{52}$ and its derived deferential-formalisation-transference secondnaturing, with regards to such sciences ${ }^{45}$ foregrounding_entailment- $<$ in-succession-of-profoundsupererogation $>$-〈postconverging-narrowing-down $\sim$ sublimation-as-to- 'existence- - as- 
supererogation '-in-reflecting-'immanent relative-unreflexivity/relative-reflexivity

ontological-contiguity ';-as-operative-notional deprocrypticism) as to the tight-andentwined relationship between the overall human ontological-commitment $-<$ implied - selfassuredness-of-ontological-good-faith/authenticity $\sim$ postconverging-dementating/structuring/paradigming -as-being-as-of-existential-reality $>$ (across all registryworldviews/dimensions) and (corresponding registry-worldviews/dimensions) predicativeeffectivity-sublimation-〈as-to-underlying,-ontological-commitment $-<$ implied—selfassuredness-of-ontological-good-faith/authenticity $\sim$ postconverging-dementating/structuring/paradigming -as-being-as-of-existential-reality $>>$ as critically enabling prospective sublimation. $\quad{ }^{45}$ foregrounding_entailment- $<$ in-succession-of-profoundsupererogation $>-\langle$ postconverging-narrowing-down $\sim$ sublimation-as-to-'existence—assublimating-withdrawal/unenframing/re-ontologising,-elicited-from-prospective-profoundsupererogation '-in-reflecting-'immanent $\sim$ relative- unreflexivity/relative-reflexivity ontological-contiguity ';-as-operative-notional deprocrypticism) as such induces the requisite ontological-faith-notion/ontological-good-faith/authenticity ${ }^{69}$ and discipline both among natural scientists and any contending interlocutors as to the constraining implications of prospective sublimation thus allowing for 'genuine knowledge-reification $\sim$ gesturing-andaccounting - of-epistemic-phenomenalism- $<$ inprospective_psychologismic apriorising/axiomatising/referencing-\{of-‘prespectively implicited attendant-ontological-contiguity ' ceducedexistentialising/contextualising/textualising_'intelligibility/epistemicity/reflexivity-contiguity<imbued-notional cogency $>>$ \}-conflatedness -in-\{preconverging -ment by\} postconverging entailment $>$ framework involving a detour to existence-potency ${ }^{39} \sim$ sublimating nascence,-disclosed-from-prospective-epistemic-digression induced prospective determination which then is preconverging/postconverging-de-mentatively/structurally/paradigmatically 
preceding-and-constraining to human-subpotency as enabling prospective sublimation-overdesublimation'. In contrast this author is critical of the notion that disparateness-ofconceptualisation-<unforegrounding-ment,-failing-prospectively-to-reflect‘immanent relative-unreflexivity/relative-reflexivity - ontological-contiguity '> subject to totalisingly-ing — discretion/whim-of-thought associated with 79 presencing-absolutisingidentitive-constitutedness ${ }^{14}$ conception as of 'flawed prior_knowledge-reification $\sim$ gesturingand-accounting - of-epistemic-phenomenalism- $<$ inprior_psychologismic $\sim$ apriorising/axiomatising/referencing- $\{$ of-" prior-implicited_attendant ontological-contiguity ' educedexistentialising/contextualising/textualising_ 'intelligibility/epistemicity/reflexivity-contiguity$<$ imbued-notional cogency >' $\}$-constitutedness -in - preconverging-entailment $>$ framework of human-subpotency determination as to a temporal mere-formulaicmethodologising/mutualising/organising/institutionalising human-subpotency <preconverging 'motif-and-apriorising/axiomatising/referencing'-entailing >existentialising — enframing/imprintedness-〈as-to- historicity-tracing — in-presencinghyperrealisation/hyperreal-transposition〉 as desublimating' that falsely ignore the preconverging/postconverging-de-mentative/structural/paradigmatic implications of 'human notional firstnaturedness-formativeness-<as-to-eventualising-inkling-drive-or-seedingmisprising $>$ temporal-to-intemporal-dispositions- $<$ so-construed-as-from-perspectiveontological-normalcy/postconvergence> accordioning-〈as-of-varying-individuationscontextually-transverse-desublimation/sublimation,-as-to-thewavering/redounding/waveforming of-their-referencing-and-their-devolved-referencingimbued-ontological-performance -<including-virtue-as-ontology $>>$ at uninstitutionalisedthreshold ${ }^{102}$ as reflecting both desublimating ${ }^{47}$ historicity-tracing-in-presencinghyperrealisation/hyperreal-transposition and sublimating ${ }^{4}$ historiality/ontological- 
eventfulness 3 /ontological-aesthetic-tracing-<perspective-ontological-

normalcy/postconvergence-reflected-'epistemicity-relativism-determinism'> possibilities' in want for '<amplituding/formative-epistemicity $>$ totalising/circumscribing/delineating 'implicited_attendant-ontological-contiguity ${ }^{67}$ ' educedexistentialising/contextualising/textualising_intelligibility/epistemicity/reflexivity-contiguity$<$ imbued-notional $\sim$ cogency $>{ }^{40} \quad{ }^{45}$ foregrounding_entailment- $<$ in-succession-of-profoundsupererogation ${ }^{9}>-\langle$ postconverging-narrowing-down $\sim$ sublimation-as-to-'existence-assublimating-withdrawal/unenframing/re-ontologising,-elicited-from-prospective-profoundsupererogation '-in-reflecting-'immanent relative-unreflexivity/relative-reflexivity ontological-contiguity ';-as-operative-notional deprocrypticism) in elucidating relativeunreflexivity/relative-reflexivity ontological-contiguity $^{67}-<$ as-from-prospective-ontologicalnormalcy/postconvergence-epistemic-or-notional projective-perspective>'. Critically, the possibility of such a physics dialogical-equivalence- $<$ as-topsychologismic apriorising/axiomatising/referencing-\{of-"prospectivelyimplicited_attendant-ontological-contiguity ' educedexistentialising/contextualising/textualising_ intelligibility/epistemicity/reflexivity-contiguity<imbued-notional cogency >’ \}-conflatedness -in-\{preconverging -ment by\} postconverging-entailment,-in-self-becoming/self-conflatedness /formative-supererogating> for instance is fundamentally enabled by such ${ }^{45}$ foregrounding_entailment- $<$ in-succession-ofprofound-supererogation $>$ >-〈postconverging-narrowing-down $\sim$ sublimation-as-to-'existenceas-sublimating-withdrawal/unenframing/re-ontologising,-elicited-from-prospective-profoundsupererogation '-in-reflecting-'immanent relative-unreflexivity/relative-reflexivity ontological-contiguity ';--as-operative-notional deprocrypticism) of physics: and where say for instance proponents of classical-mechanics - axiomatic-constructs became involved in the 'pedantising/muddling/formulaic-hollowing-out —in-subontologisation/subpotentiation- 


\section{〈blurring/undermining-of-prospective-totalising-entailing,-as-to-entailing-}

$<$ amplituding/formative-epistemicity>totalising in-relative-ontological-completeness $>$ of methods/methodologies/approaches as to prior-apriorising/axiomatising/referencingsuperseded-logical-basis-of $\sim$ dialogical-equivalence- $<$ as-topsychologismic $\sim$ apriorising/axiomatising/referencing-\{of-"prospectivelyimplicited_attendant-ontological-contiguity ' educedexistentialising/contextualising/textualising_ 'intelligibility/epistemicity/reflexivity-contiguity<imbued-notional cogency $\left.>^{\prime}\right\}$-conflatedness -in-\{preconverging-ment by\} postconverging-entailment,-in-self-becoming/self-conflatedness /formativesupererogating $>2$, as to their ${ }^{79}$ presencing-absolutising-identitive-constitutedness conception of knowledge-reification $\sim$ gesturing-and-accounting-of-epistemicphenomenalism- $<$ in-prospective_psychologismic $\sim$ apriorising/axiomatising/referencing- of'prospectively_implicited_attendant-ontological-contiguity ' ceducedexistentialising/contextualising/textualising_'intelligibility/epistemicity/reflexivity-contiguity<imbued-notional cogency >' \}-conflatedness -in-\{preconverging-ment by\} postconverging-entailment>, then in-many-ways proponents of theory-of-relativity-togetherwith-quantum-mechanics - axiomatic-constructs 'would rather point out the transversality-<forsublimating-existential-eventuating/denouement,-from-'thinking-at-first/pure-predispositionpreemptive-of-prospective-disontologising/subontologising' as-of-prospectivelydisambiguated-affirmed-and-unaffirmed-'motif-and-apriorising/axiomatising/referencing'> of the former rather than wrongly imply any mutual logical-congruence of dialogicalequivalence-<as-to-psychologismic apriorising/axiomatising/referencing- \{of-' prospectively implicited_attendant-ontological-contiguity ' educedexistentialising/contextualising/textualising_'intelligibility/epistemicity/reflexivity_contiguity<imbued-notional cogency $\left.>^{\prime}\right\}$-conflatedness -in-\{preconverging -ment by\} 
postconverging-entailment,-in-self-becoming/self-conflatedness /formative-supererogating>

involvement in knowledge-reification $\sim$ gesturing-and-accounting-of-epistemicphenomenalism- $<$ in-prospective_psychologismic $\sim$ apriorising/axiomatising/referencing- of'prospectively_implicited_attendant-ontological-contiguity ' ceducedexistentialising/contextualising/textualising_ 'intelligibility/epistemicity/reflexivity-contiguity<imbued-notional cogency $>$ ' \}-conflatedness -in-\{preconverging-ment by\}

postconverging entailment $>$ exercise as they will do with respect to other proponents of theoryof-relativity-together-with-quantum-mechanics - axiomatic-constructs with whom they may disagree within the prospective-apriorising/axiomatising/referencing-superseding-logical-basisof $\sim$ dialogical-equivalence-<as-to-psychologismic $\sim$ apriorising/axiomatising/referencing- of'prospectively_implicited_attendant-ontological-contiguity ' ceducedexistentialising/contextualising/textualising_'intelligibility/epistemicity/reflexivity_contiguity<imbued-notional cogency>' \}-conflatedness -in-\{preconverging -ment by\} postconverging entailment,-in-self-becoming/self-conflatedness /formative-supererogating > framework'. This speaks to the fact that human dialogical-equivalence-<as-topsychologismic apriorising/axiomatising/referencing-\{of-'prospectively

implicited_attentant-ontological-contiguity ' educedexistentialising/contextualising/textualising_'intelligibility/epistemicity/reflexivity-contiguity$<$ imbued-notional cogency $>$ ' $\}$-conflatedness -in-\{preconverging-ment by\} postconverging-entailment,-in-self-becoming/self-conflatedness /formative-supererogating > framing doesn't supersede prospective sublimating existence's necessitating implications and consequences, at which point existence-potency ${ }^{32} \sim$ sublimating-nascence,-disclosed-fromprospective-epistemic-digression manifests 'Derridean underdetermination-imbued force/violence conception' and 'Foucauldian knowledge/power conception construed as knowledge-empowerment/ignorance-disempowerment' with regards to the possibility of 
prospective human phenomenal/manifest sublimation and desublimation in existence; as the proponents of theory-of-relativity-together-with-quantum-mechanics-axiomatic-constructs 'cannot produce any magical logical-congruence implication as of the priorapriorising/axiomatising/referencing-superseded-logical-basis-of $\sim$ dialogical-equivalence- $<$ asto-psychologismic apriorising/axiomatising/referencing-\{of-"prospectively implicited_attendant-ontological-contiguity ' educedexistentialising/contextualising/textualising_'intelligibility/epistemicity/reflexivity-contiguity<imbued-notional cogency $\left.>^{\prime}\right\}$-conflatedness -in-\{preconverging -ment by\} postconverging-entailment,-in-self-becoming/self-conflatedness /formative-supererogating> of the proponents of classical-mechanics-axiomatic-constructs' but for the prospectiveapriorising/axiomatising/referencing-superseding-logical-basis-of $\sim$ dialogical-equivalence- $<$ asto-psychologismic apriorising/axiomatising/referencing-\{of-‘prospectively implicited_attendant-ontological-contiguity ' educedexistentialising/contextualising/textualising_'intelligibility/epistemicity/reflexivity-contiguity$<$ imbued-notional cogency >' \}-conflatedness -in-\{preconverging ment by\} postconverging-entailment,-in-self-becoming/self-conflatedness /formative-supererogating > of theory-of-relativity-together-with-quantum-mechanics — axiomatic-constructs foregrounding_entailment- $<$ in-succession-of-profound-supererogation $>>-\langle$ postconverging narrowing-down $\sim$ sublimation-as-to-'existence - as-sublimating-withdrawal/unenframing/reontologising,-elicited-from-prospective-profound-supererogation ' '-in-reflecting'immanent relative - unreflexivity/relative-reflexivity ontological-contiguity ';-as-operativenotional deprocrypticism $\rangle$ of physics implied tight-and-entwined relationship between the overall human ontological-commitment $-<$ implied - self-assuredness-of-ontological-goodfaith/authenticity postconverging-de-mentating/structuring/paradigming -as-being-as-ofexistential-reality> (across all registry-worldviews/dimensions) and (corresponding registry- 
worldviews/dimensions) predicative-effectivity-sublimation-〈as-to-underlying,-ontologicalcommitment $-<$ implied—self-assuredness-of-ontological-goodfaith/authenticity postconverging-de-mentating/structuring/paradigming -as-being-as-ofexistential-reality $>>$ as critically enabling prospective sublimation. In effect, such a controversy of ontological-bad-faith/inauthenticity ${ }^{64}$ never arose (as explained by the prior enculturation of an underlying 'scientific — apriorising/axiomatising/referencing-psychologism enculturated/constructed social-pragmatics-framing-of-predicative-effectivity-sublimation〈as-to-underlying,-ontological-commitment $-<$ implied — self-assuredness-of-ontological-goodfaith/authenticity postconverging-de-mentating/structuring/paradigming -as-being-as-ofexistential-reality $>>$ ' induced by budding-positivists and associated with their persecution), and further because of the very high predicative-effectivity-sublimation-〈as-to-underlying,ontological-commitment $\quad<$ implied_-self-assuredness-of-ontological-goodfaith/authenticity postconverging-de-mentating/structuring/paradigming -as-being-as-ofexistential-reality $>>$ associated with the physical sciences and as generally reflected by the social-stake-contention-or-confliction disinterested natured of 'much of the basic/fundamental and natural sciences'. However, the case with psychological, social and 'interest-driven scientific frameworks' is quite often 'hardly one of high predicative-effectivity-sublimation-〈as-tounderlying,-ontological-commitment $-<$ implied — self-assuredness-of-ontological-goodfaith/authenticity $\sim$ postconverging-de-mentating/structuring/paradigming -as-being-as-ofexistential-reality $>\rangle$ ' with the result that such a 'purist ontological and scientific framing of supposedly knowledge-reification $\sim$ gesturing-and-accounting-of-epistemic-phenomenalism<in-prospective_psychologismic apriorising/axiomatising/referencing-\{of-'prospectively_ implicited_attendant-ontological-contiguity ' educedexistentialising/contextualising/textualising_'intelligibility/epistemicity/reflexivity-contiguity<imbued-notional cogency >' \}-conflatedness -in-\{preconverging -ment by\} 
postconverging-entailment> issues as to prospective sublimating ${ }^{4}$ historiality/ontologicaleventfulness ${ }^{3}$ /ontological-aesthetic-tracing-<perspective-ontologicalnormalcy/postconvergence-reflected-'epistemicity-relativism-determinism'>' is either indirectly or directly undermined with social-vestedness/normativity-<discretely-impliedfunctionalism $>\quad$ ideas which 'preconverging/postconverging-dementatively/structurally/paradigmatically speak to an underlying disengagement with the deeper notion of veracity/truth supposedly projected as pure scientific and pure ontological analysis in the relevant domains', as to the 'social-stake-contention-or-confliction relative privileging of human methodologising/mutualising/organising/institutionalising epistemic gadgetry' (surreptitiously associated with <amplituding/formative $>$ wooden-language-〈imbued

\section{temporal-mere-form/virtualities/dereification/akrasiatic-drag/denatured/preconverging-or-}

dementing -narratives-of-the- reference-of-thought- categorical-

imperatives/axioms/registry-teleology $\rangle)$ over existence-potency ${ }^{39} \sim$ sublimating-nascence,disclosed-from-prospective-epistemic-digression. This difference between a 'purist science/ontology epistemic-conception of veracity/truth' and the conception of veracity/truth as from the latitude of 'human social-vestedness/normativity- $<$ discretely-implied-functionalism $>$ implied contract/political-arrangement-or-political-coercion/given-discrete-social-valueconstruction' is critically reflected in the fact that the former orientation is priorly-and-ultimately concerned with existence's ${ }^{45}$ foregrounding_entailment- $<$ in-succession-of-profoundsupererogation ${ }^{9}>-\langle$ postconverging-narrowing-down $\sim$ sublimation-as-to-'existence- assublimating-withdrawal/unenframing/re-ontologising,-elicited-from-prospective-profoundsupererogation '-in-reflecting-'immanent relative-unreflexivity/relative-reflexivity ontological-contiguity ';--as-operative-notional deprocrypticism) imbued sublimation whereas the latter is critically concerned with 'conceptions of human abstract interpositions as of elaboration-as-to-mere-extrapolating/constituting/abstracting/deducing/inferring-of- 
elucidation-outside_-'prospectively_implicited_attendant-ontological-contiguity ${ }^{67}$ > educedexistentialising/contextualising/textualising_'intelligibility/epistemicity/reflexivity_contiguity<imbued-notional cogency>' that are not necessarily subject to phenomenal/manifest existence's $\quad{ }^{4}$ foregrounding__entailment- $<$ in-succession-of-profound-supererogation $>$ 〈postconverging-narrowing-down sublimation-as-to-'existence-as-sublimating-

withdrawal/unenframing/re-ontologising,-elicited-from-prospective-profoundsupererogation '-in-reflecting-'immanent relative-unreflexivity/relative-reflexivity ontological-contiguity ';--as-operative-notional deprocrypticism)'; and so-peculiarly implied with the 'importing/exporting of reductionisms' (as to the fact that there is no physics reductionism of physics or say mathematics reductionism of mathematics or biology reductionism of biology as to being the real and natural orientation for the specific physics, mathematics and biology epistemic-conceptions of their respective epistemic-conceptions phenomenal/manifest $\sim$ subpotencies-〈in-transitive-conflatedness -reflexivity,-in-the-fullpotency-of-existence's sublimating-nascence)) to explain human psychological and social phenomena that 'end up implicitly denying the very obvious reality of the psychological and social subpotencies-〈in-transitive-conflatedness -reflexivity,-in-the-full-potency-ofexistence's $\sim$ sublimating-nascence)'. In-many-ways taking such ontologically-flawed interpretations seriously induces human impotency and desublimation (as to the implicited contention that the human 'supposedly has no profound sublimating social and sociopsychological phenomenal/manifest $\sim$ subpotencies-〈in-transitive-conflatedness -reflexivity,in-the-full-potency-of-existence's $\sim$ sublimating-nascence)' with the 'supposedly profound phenomenal/manifest $\sim$ subpotencies-〈in-transitive-conflatedness -reflexivity,-in-the-fullpotency-of-existence's sublimating-nascence)' construed rather in reductionist terms of biology/neurology or physicalism) as is often also associated with socialvestedness/normativity- $<$ discretely-implied-functionalism $>$ disparateness-of-conceptualisation- 
$<$ unforegrounding-ment,-failing-prospectively-to-reflect-'immanent $\sim$ relative-

unreflexivity/relative-reflexivity - ontological-contiguity ' $>$; thus 'actually denying the metaphysical nature and thus ontological nature of the sublimating social and sociopsychological' such that existence-potency ${ }^{32} \sim$ sublimating-nascence,-disclosed-fromprospective-epistemic-digression sublimation implications with regards to the social and sociopsychological are hardly contemplated and recognised as so-projected herein as to the relativeenreflexivity/relative-reflexivity — ontological-contiguity ${ }^{67}$ of-the-human-institutionalisationprocess ${ }^{68}$. But then such reductionism actually fails the 'necessitation test of any science/ontology' as in reality it is a gimmicky exploitation of the sublimation of the natural sciences as to their inherent phenomenal/manifest $\sim$ subpotencies-〈in-transitive-conflatedness reflexivity,-in-the-full-potency-of-existence's $\sim$ sublimating-nascence $\rangle$ to then 'utilise the clout to falsely imply substitutive/reductionist sublimation over the social and socio-psychological phenomenal/manifest $\sim$ subpotencies-〈in-transitive-conflatedness -reflexivity,-in-the-fullpotency-of-existence's sublimating-nascence)' (as so-reflected with practices of scienceideology associated with biological/neurological and evolutionary substitutive/reductionist interpretations of the social and socio-psychological). But then the giveaway of such a flawed conception of science/ontology lies in the fact that such approaches do not project any '<amplituding/formative-epistemicity $>$ totalising/circumscribing/delineating necessitation frame-of $\sim$ relative-unreflexivity/relative-reflexivity - ontological-contiguity ${ }^{67}$ as all pretences of science/ontology must demonstrate and aspire to (consider in this regards the '<amplituding/formative-epistemicity $>$ totalising/circumscribing/delineating necessitation frame-of $\sim$ relative- mnreflexivity/relative-reflexivity ontological-contiguity ${ }^{67}$ of physics, chemistry, biological, genetic theories as to the notional-contiguity/epistemic-contiguity ${ }^{62}$ $<$ profound-supererogation -of-mentally-aestheticised postconverging/dialectical-thinking qualia-schema $>\quad$ imbued $\quad{ }^{45}$ foregrounding_entailment- $<$ in-succession-of-profound- 
supererogation ${ }^{9}>-\langle$ postconverging-narrowing-down $\sim$ sublimation-as-to-'existence-as-

sublimating-withdrawal/unenframing/re-ontologising,-elicited-from-prospective-profound-

supererogation '-in-reflecting-'immanent relative-unreflexivity/relative-reflexivity

ontological-contiguity ';--as-operative-notional deprocrypticism) of their respective inherent sublimating phenomenal/manifest $\sim$ subpotencies-〈in-transitive-conflatedness -reflexivity,-inthe-full-potency-of-existence's $\sim$ sublimating-nascence〉 wherein for instance with the physics frame-of $\sim$ relative-unreflexivity/relative-reflexivity ontological-contiguity ${ }^{67}$ succession of theories are developed aspiring cogently for relative-unreflexivity/relative-reflexivityontological-contiguity ${ }^{67}$ of the whole physics epistemic-conception phenomenal/manifest $\sim$ subpotency-〈in-transitive-conflatedness -reflexivity,-in-the-fullpotency-of-existence's $\sim$ sublimating-nascence $>$ as $\quad$ from Galilean/Cartesian/Newtonian/Leibnizian physics to modern-day string-theory/loop-quantumgravity/etc. which all successively profess relative-unreflexivity/relative-reflexivity ontological-contiguity ${ }^{67}$ ). In other words, such biological/neurological and evolutionary substitutive/reductionist interpretations of the social and socio-psychological shouldn't epistemically be selective in totalisingly-ing-discretion/whim-of-thought (if truly of science/ontology epistemicity>totalising/circumscribing/delineating necessitation frame-of $\sim$ relativeunreflexivity/relative-reflexivity_ontological-contiguity ${ }^{67}$ ') but should rather go on to effectively explain away the entire social and socio-psychological phenomenal/manifest $\sim$ subpotencies-〈in-transitive-conflatedness -reflexivity,-in-the-fullpotency-of-existence's $\sim$ sublimating-nascence) (as to human Being-development/ontologicalframework-expansion-as-to-depth-of-ontologising-development-as-infrastructure-ofmeaningfulness-and-teleology , institutional-development-as-to-social-functiondevelopment and living-development-as-to-personality-development psychologismic 
epistemic-acutisation difficulty $<$ for, residualising \{decompulsing $\}$ delinearity for-cogency $>$ magnitudes $\{$ of-experientiality/experiment\} $\}$, and so comprehensively articulating human organisational and institutional driven/potent sociocultural, economic, political, legal, etc. manifestations on such biological/neurological and evolutionary substitutive/reductionist basis of supposed sublimation as to their '<amplituding/formativeepistemicity>totalising/circumscribing/delineating 'implicited_attendant_ontologicalcontiguity $^{67} \sim$ educedexistentialising/contextualising/textualising_'intelligibility/epistemicity/reflexivity-contiguity$<$ imbued-notional cogency $>{ }^{40} \quad{ }^{45}$ foregrounding_entailment- $<$ in-succession-of-profoundsupererogation ${ }^{9}>-$ - postconverging-narrowing-down $\sim$ sublimation-as-to-'existence-assublimating-withdrawal/unenframing/re-ontologising,-elicited-from-prospective-profoundsupererogation '-in-reflecting-'immanent $\sim$ relative-unreflexivity/relative-reflexivity ontological-contiguity ';-as-operative-notional deprocrypticism) in elucidating relativeunreflexivity/relative-reflexivity - ontological-contiguity $-<$ as-from-prospective-ontologicalnormalcy/postconvergence-epistemic-or-notional projective-perspective>' $>^{\prime}$ The reality of such biological/neurological and evolutionary substitutive/reductionist interpretations of the social and socio-psychological is rather one that points out that the 'traditional nature versus nurture debate itself is fundamentally an axiomatically bankrupt conception' since 'not even such proponents implicitly point to an underlying human drivenness and functioning of the social and socio-psychological framework on the basis of any such supposed '<amplituding/formativeepistemicity $>$ totalising/circumscribing/delineating necessitation frame-of $\sim$ relativeunreflexivity/relative-reflexivity_ontological-contiguity of biological/neurological and evolutionary substitutive/reductionist interpretations', but rather the strategies of such proponents (beyond-the-consciousness-awareness-teleology ${ }^{\circ}<$ of-preconverging-existentialextrication-as-of-existential-unthought $>$ ) work paradoxically only by impliciting the reality of 
the '<amplituding/formative-epistemicity>totalising/circumscribing/delineating necessitation frame-of $\sim$ relative-unreflexivity/relative-reflexivity ontological-contiguity ${ }^{67}$ of the social and socio-psychological epistemic-conception phenomenal/manifest $\sim$ subpotencies-〈in-transitiveconflatedness -reflexivity,-in-the-full-potency-of-existence's $\sim$ sublimating-nascence) (as to their implied sublimating existence's necessitating implications and consequences)', and then surreptitiously project/select/pop-up (in totalisingly-ing-discretion/whim-of-thought) opportune/ad-hoc biological/neurological and evolutionary substitutive/reductionist interpretations of the social and socio-psychological frame-of $\sim$ relative-unreflexivity/relativereflexivity - ontological-contiguity ${ }^{67}$, and so as of vague disparateness-of-conceptualisation$<$ unforegrounding-ment,-failing-prospectively-to-reflect-'immanent relative-

unreflexivity/relative-reflexivity - ontological-contiguity ' $>$. Such flawed and surreptitious representation that biological/neurological and evolutionary substitutive/reductionist interpretations are the '<amplituding/formativeepistemicity $>$ totalising/circumscribing/delineating necessitation frame-of $\sim$ relativeunreflexivity/relative-reflexivity ontological-contiguity ${ }^{67}$ of the social and sociopsychological (rather than the truly inherent social and socio-psychological epistemicconception phenomenal/manifest $\sim$ subpotencies-〈in-transitive-conflatedness -reflexivity,-inthe-full-potency-of-existence's $\sim$ sublimating-nascence $\rangle$ as of their '<amplituding/formativeepistemicity>totalising/circumscribing/delineating necessitation frame-of $\sim$ relativemreflexivitrelative reflexivity - ontological-contiguity ${ }^{67}$ ') in effect wrongly implies a dialogical-equivalence-<as-to-psychologismic apriorising/axiomatising/referencing- $\{$ of'prospectively_implicited_attendant-ontological-contiguity ' educedexistentialising/contextualising/textualising_ intelligibility/epistemicity/reflexivity-contiguity<imbued-notional cogency $\left.>^{\prime}\right\}$-conflatedness -in-\{preconverging -ment by\} 
'nature versus nurture debate' between these two perspectives as to a 'naïve academicism mere procedural argumentation reflex'. The reality at best is that of 'biological/neurological and evolutionary interpretations transverse epistemic-conception phenomenal/manifest $\sim$ subpotency〈in-transitive-conflatedness -reflexivity,-in-the-full-potency-of-existence's $\sim$ sublimatingnascence)' in relation to the social and socio-psychological frame-of relativeunreflexivity/relative-reflexivity_ontological-contiguity ${ }^{7}$ (and not such biological/neurological and evolutionary interpretations substitutive/reductionist epistemicconception overriding the social and socio-psychological epistemic-conception phenomenal/manifest $\sim$ subpotencies-〈in-transitive-conflatedness -reflexivity,-in-the-fullpotency-of-existence's $\sim$ sublimating-nascence), just as the transverse epistemic-conception phenomenal/manifest $\sim$ subpotency-〈in-transitive-conflatedness -reflexivity,-in-the-fullpotency-of-existence's $\sim$ sublimating-nascence) of mathematics in relation to physics doesn't substitute for and override the inherent physics epistemic-conception phenomenal/manifest $\sim$ subpotency-〈in-transitive-conflatedness -reflexivity,-in-the-fullpotency-of-existence's $\sim$ sublimating-nascence)). The consequence of such vague disparatenessof-conceptualisation-<unforegrounding-ment,-failing-prospectively-to-reflect‘immanent $\sim$ relative unreflexivity/relative reflexivity - ontological-contiguity '> as to failing '<amplituding/formative-epistemicity $>$ totalising/circumscribing/delineating necessitation frame-of $\sim$ relative-unreflexivity/relative-reflexivity ontological-contiguity $^{67}$, (as implied as of the requisite '<amplituding/formative-epistemicity>totalising/circumscribing/delineating 'implicited_attendant-ontological-contiguity ${ }^{67}$ ' educedexistentialising/contextmalising/textualising_'intelligibility/epistemicity/reflexivity_contiguity$<$ imbued-notional cogency $>{ }^{40} \quad{ }^{45}$ foregrounding_entailment- $<$ in-succession-of-profoundsupererogation $>$-〈postconverging-narrowing-down $\sim$ sublimation-as-to-'existence-assublimating-withdrawal/unenframing/re-ontologising,-elicited-from-prospective-profound- 
supererogation '-in-reflecting-'immanent $\sim$ relative-unreflexivity/relative-reflexivity

ontological-contiguity ';-as-operative-notional deprocrypticism) in elucidating relativeunreflexivity/relative-reflexivity - ontological-contiguity ${ }^{6}-<$ as-from-prospective-ontologicalnormalcy/postconvergence-epistemic-or-notional $\sim$ projective-perspective $>^{\prime}$ ), is that (besides their basic epistemic innocence/naivety) such biological/neurological and evolutionary interpretations substitutive/reductionist epistemic-conception then provide the room for sophistic/pedantic dispositions that construe of the inherent sublimation in the natural sciences qua natural sciences as the surreptitious opportunity to project gimmicky/desublimating interpretations about the social (on the basis of the "hollow impressiveness of the natural sciences') as a psychological trick/gimmick as to rendering knowledge-reification $\sim$ gesturingand-accounting - of-epistemic-phenomenalism- $<$ inprospective_psychologismic apriorising/axiomatising/referencing-\{of-'prospectively implicited_attendant-ontological-contiguity ' educedexistentialising/contextualising/textualising_'intelligibility/epistemicity/reflexivity-contiguity<imbued-notional cogency >' \}-conflatedness -in-\{preconverging-ment by\}

postconverging-ntailment $>$ sublimation in the social impotent with regards to varied socialstake-contention-or-confliction purposes. Such claims often project/imply that analysing the social qua social is just about irrelevant (or paradoxically 'make their very own subterfuge social interpretations' as from the psychological trick/gimmick of the projected hollow impressiveness of the natural sciences so-derived from the clout of a natural science without demonstrating the epistemic-veracity for such a bypassing/dodgery as to arrive at the social '<ampliting/formative-epistemicity $>$ totalising/circumscribing/delineating necessitation frame-of $\sim$ relative-unreflexivity/relative-reflexivity_ontological-contiguity ${ }^{67}$ sublimating implications and consequences). Besides, such claims are often so-associated with vague nonmetaphysical as non-ontological conceptualisations of the social in vague disparateness-of- 
conceptualisation-<unforegrounding-ment,-failing-prospectively-to-reflect-

‘immanent relative-unreflexivity/relative-reflexivity-ontological-contiguity

elaboration-as-to-mere-extrapolating/constituting/abstracting/deducing/inferring-ofelucidation-outside_-'prospectively_implicited_attendant-ontological-contiguity ${ }^{67}$ > educedexistentialising/contextualising/textualising_intelligibility/epistemicity/reflexivity-contiguity<imbued-notional cogency ${ }^{\prime}$, and thus in-many-ways further undermine/distract-from the social ‘<amplituding/formative-epistemicity>totalising/circumscribing/delineating necessitation frame-of $\sim$ relative-unreflexivity/relative-reflexivity-ontological-contiguity ${ }^{6}$, conception of human-subpotency-aporia/undecidability/dilemma/oughtindeterminacy/deficiency/limitation/constraint in dealing with direct social and institutional issues, crises and failures. A 'purist science/ontology epistemic-conception of veracity/truth' equally differs from the conception of veracity/truth as from the latitude of 'human socialvestedness/normativity- $<$ discretely-implied-functionalism $>\quad$ implied contract/politicalarrangement-or-political-coercion/given-discrete-social-value-construction' with the former construing of 'knowledge as to existential-<disontologising/re-ontologising aporeticism $>$ knowledge-reification $\sim$ gesturing-and-accounting_-of-epistemic-phenomenalism- $<$ inprospective_psychologismic apriorising/axiomatising/referencing-\{of- ${ }^{\text {prospectively }}$ implicited_attendant-ontological-contiguity ' reducedexistentialising/contextualising/textualising_ intelligibility/epistemicity/reflexivity-contiguity<imbued-notional cogency>' \}-conflatedness -in-\{preconverging-ment by\} postconverging entailment $>$ privileging manifest sublimating outcome in existence' in contrast to the latter construing of 'knowledge as to collective acquiescence as to the privileging of human commendation-or-agreementing/convincing-among-mortals (rather than a detour to existencepotency $^{32} \sim$ sublimating-nascence,-disclosed-from-prospective-epistemic-digression) even over manifest sublimating outcome in existence'. Such a 'purist science/ontology epistemic- 
conception of veracity/truth' construes of knowledge as a 'perpetual off-balance act associated with human limited-mentation-capacity-deepening -as-subjecting limitedness/humansubpotency to-'educed-unlimitedness/existence-sublimating nascence' ${ }^{53}$ (as involved in the reconceptualisation of the physics state-of-the-art from Einsteinian physics, Bohrian physics, Feynmanian physics, etc., emphasising rather the 'constancy of the intemporal individuation as from the ontological-normalcy/postconvergence perspective' and 'not about the constancy of any notion of intemporal individual'). Such a 'perpetual off-balance act associated with human limited-mentation-capacity-deepening — as-subjecting limitedness/human-subpotency-to'educed-unlimitedness/existence-sublimating nascence' ${ }^{53}$ speak to the more profound reality that the ordinariness of human thought across the <cumulating/recomposuring attendantontological-contiguity >-succession of human registry-worldviews/dimensions points to their 'epistemic-abnormalcy/preconvergence ${ }^{3 /}$ despite the delusion of all registryworldviews/dimensions in their ${ }^{7}$ presencing — absolutising-identitive-constitutedness ${ }^{14}$ as being of 'absolute epistemic-normalcy'; and it is because of this latter fact (as from the ontologicalnormalcy/postconvergence epistemic-projection perspective) that prospective human progress and emancipation as of human transcendence-and-sublimity/sublimation/supereregatery $\sim$ dementativity can occur in-the-very-first-place (in contradiction to all such registryworldviews/dimensions ${ }^{79}$ presencing-absolutising-identitive-constitutedness ${ }^{14}$ failure to directly grasp their very own $<$ amplituding/formative-epistemicity $>$ totalising $\sim$ self-referencingsyncretising/circularity/interiorising/akrasiatic-drag ${ }^{34}$, even as the possibility for prospective transcendence-and-sublimity/sublimation/supereregatory-de-mentativity necessarily involves such a requisite psychoanalytic-unshackling/memetic-reordering/institutional-recomposuring). In other words, the "effective equilibration of human sublimating ${ }^{56}$ meaningfulness-andteleology across the <cumulating/recomposuring attendant-ontological-contiguity $>$ successive registry-worldviews/dimensions' does not lie with any 
'ordinariness/commonsensicality as of the <cumulating/recomposuring attendant-ontologicalcontiguity $>$-successive registry-worldviews/dimensions $\quad{ }^{79}$ presencing-absolutisingidentitive-constitutedness ${ }^{14}$, as falsely elicited by their sophistic/pedantic dispositions, as in reality it rather lies in the 'dynamically differentiated transversality-<for-sublimatingexistential-eventuating/denouement,-from-'thinking-at-first/pure-predisposition-preemptive-ofprospective-disontologising/subontologising' - as-of-prospectively-disambiguated-affirmedand-unaffirmed-'motif-and-apriorising/axiomatising/referencing'>101 of the ontologicalperformance ${ }^{2}$-<including-virtue-as-ontology $>$ /morality/ethics/justice/etc. of human notional firstnaturedness-formativeness-<as-to-eventualising -inkling-drive-or-seeding misprising $>$ temporal-to-intemporal-dispositions- $<$ so-construed-as-from-perspectiveontological-normalcy/postconvergence> narratives': and so as to human-subpotency 'fatednessof-sublimation-over-desublimation, to existence-potency $\sim$ sublimating-nascence,-disclosedfrom-prospective-epistemic-digression (in reflecting holographically-<conjugatively-andtransfusively $>$ the relative-unreflexivity/relative-reflexivity ontological-contiguity $\sim$ of-thehuman-institutionalisation-process ), as from human-subpotency ontological-faith-notion-orontological-fideism - imbued-underdetermination-of-motif-andapriorising/axiomatising/referencing-as-so-being-as-of-existential-reality as to the disseminative - sublimating-selectivity-of-ontological-goodfaith/authenticity postconverging-de-mentating/structuring/paradigming , overdesublimating deselectivity-of-ontological-bad-faith/inauthenticity opreconverging dementating/structuring/paradigming ', as the driver of the human-subpotency potentiating existential-<lisontologising/re-ontologising aporeticism $>$ becoming manifestation of sublimating-over-desublimating social-and-institutional-constructs-of- - meaningfulness-andteleology - in-cumulation/recomposuring all along in reflecting holographically$<$ conjugatively-and-transfusively $>$ the relative-unreflexivity/relative-reflexivity - ontological- 
contiguity of-the-human-institutionalisation-process ; as it dynamically induces (as of 'varying psychologismic epistemic acutisation difficulty-for, residualising $\{$ decompulsing $\}$ delinearity for-cogency> magnitudes $\{0$-experientiality/experiment $\} /$ scales—as-tosuccessively-profound-preconverging/postconverging-redementating/restructuring/reparadigming-frames-as-from-living,-institutionalising,-and-Beingontologising/infrastructure-of- ${ }^{5}$ meaningfulness-and-teleology 9 of prospective humansubpotency-aporia/undecidability/dilemma/ought-

indeterminacy/deficiency/limitation/constraint—imbued-'notional firstnaturednessformativeness-<as-to-eventualising inkling drive or seeding misprising $>$ temporal-tointemporal-dispositions-<so-construed-as-from-perspective-ontologicalnormalcy/postconvergence>'-existentialism-form-factor') successive prospective reasoningthrough/messianic-reasoning for reasoning-from-results/afterthought as the secondnaturedinstitutionalisation of the <cumulating/recomposuring attendant-ontological-contiguity successive registry-worldviews/dimensions ${ }^{8}$ reference-of-thought-and- ${ }^{83}$ reference-of-thoughtdevolving- meaningfulness-and-teleology' so-construed as 'generating varying human sublimating-over-desublimating social-and-institutional-constructs-of- - meaningfulness-andteleology of apriorising/axiomatising/referencing/intelligibilitysettingup/measuringinstrumenting' as to their pre-eminence as of their 'prospectively projected relative-ontological-completeness dimensionality-of-sublimating 5 -<<amplituding/formative $>$ supererogatory $\sim$ dementativeness/epistemic-growth-or-conflatedness /transvaluativerationalising/transepistemicity/anamnestic-residuality/spirit-drivenness-equalisation $\rangle^{\prime} . \quad$ This latter insight is critical for all prospective human sublimation as a 'false sense of a categorically/absolutely sublimated social-construct ordinariness/commensicality and socialvestedness/normativity-<discretely-implied-functionalism>' effectively renders any prospective 
human emancipation and construction-of-the-Self pointless-and-contradictory; as to the fact that even such advocates turn out to be incoherently muted-and-muddled with regards to such an argument about a 'false sense of a categorically/absolutely sublimated social-construct ordinariness/commensicality and social-vestedness/normativity-<discretely-impliedfunctionalism>', revealing their true motives rather as status quo preserving with regards to social-stake-contention-or-confliction (beyond-the-consciousness-awareness-teleology ${ }^{9}-<$ of preconverging-existential-extrication-as-of-existential-unthought $>$ '). $\quad$ The 'purist science/ontology epistemic-conception of veracity/truth' is ever always about the 'prospective upholding of existence-potency ${ }^{32}$ sublimating-nascence,-disclosed-from-prospectiveepistemic-digression and preconverging/postconverging-dementatively/structurally/paradigmatically so-explains the very possibility for human progress. In contrast the conception of veracity/truth as from the latitude of 'human socialvestedness/normativity- $<$ discretely-implied-functionalism $>\quad$ implied contract/politicalarrangement-or-political-coercion/given-discrete-social-value-construction' is rather more bent upon emphasising human-subpotency methodologising/mutualising/organising/institutionalising grounds for veracity/truth rather than eliciting prospective sublimating existence's necessitating implications and consequences. Such notions of veracity/truth without articulating existence-potency ${ }^{39} \sim$ sublimating-nascence,disclosed-from-prospective-epistemic-digression are vague disparateness-of-conceptualisation$<$ unforegrounding-ment,-failing-prospectively-to-reflect-'immanent relativeunreflexivity/relative-reflexivity - ontological-contiguity '>, and worse still when accompanied by claims of humility as to inherent institutionalised prescience are more often than not mere manifestations of intellectual entitlement; (as to imply the society is inherently beholden to the mere institutionalised sterile/anecdotal imprimatur of intellection even as to when it projects intellectual desublimation associated with pedantising/muddling/formulaic- 
hollowing-out-in-subontologisation/subpotentiation-〈blurring/undermining-of-prospectivetotalising-entailing,-as-to-entailing-<amplituding/formative-epistemicity $>$ totalising $\sim$ inrelative-ontological-completeness $\rangle$ as well as intellectually-distortive practices such as blind institutionalised existial-priming/funnelling/staking of specific theoretical postures over genuine and profound ontological elucidation as to existential-<disontologising/reentologising aporeticism $>$ contextualisation with the associated academic careerism at the very antipode of genuine sublimating intellection) and so as reflecting the modern-day intellection relevant prospective human-subpotency-aporia/undecidability/dilemma/oughtindeterminacy/deficiency/limitation/constraint. Interestingly, the 'purist science/ontology epistemic-conception of veracity/truth' projects prospective sublimating existence's necessitating implications and consequences to implicitly underscore 'interlocutory humility' induced as to existence-potency ${ }^{32}$ sublimating-nascence,-disclosed-from-prospectiveepistemic-digression; as to the fact that humility was rather imbued with the Einsteinian/theoryof-relativity-together-with-quantum-mechanics - axiomatic-constructs perspective over the prior institutionalised/classical-mechanics — axiomatic-constructs with the latter never assuming any arrogance as to its prior methodologising/mutualising/organising/institutionalising conception of physics. Critically, with regards to the blurriness-

\section{$<$ sterilising/anecdotalising/trivialising-of-prospective-re-ontologising_by-preconverging,-in-}

disontologising-formulaic-dragging-out/hollowing-out $>$ of ${ }^{56}$ meaningfulness-and-teleology ${ }^{9}$ in the social that exposes prospective transcendental dispositions (as to dimensionality-ofsublimating $25<<$ amplituding/formative $>$ supererogatory $\sim$ de-mentativeness/epistemic-growthor-conflatedness /transvaluative-rationalising/transepistemicity/anamnestic-residuality/spiritdrivenness-equalisation> ontological-good-faith/authenticity $\sim$ postconverging-dementating/structuring/paradigming ${ }^{0}$ ) to sophistic/pedantic <amplituding/formative $>$ woodenlanguage-〈imbued-temporal-mere-form/virtualities/dereification/akrasiatic- 
drag/denatured/preconverging-or-dementing -narratives - of-the- reference-of-thought-

categorical-imperatives/axioms/registry-teleology > eliciting of

$<$ amplitung-formative $>$ wooden-language-〈imbued — averaging-of-thought- $<$ as-to-

leveling/ressentiment/closed-construct-of- meaningfulness-and-teleology -as-of-

'nondescript/ignorable-void '-with-regards-to-prospective-apriorising-implications $>\rangle, \quad$ it $\quad$ is important to articulate such prospective sublimating ${ }^{56}$ meaningfulness-and-teleology ${ }^{9}$ while equally reflecting upon the sophistic/pedantic to its dimensionality-of-desublimating-lack-of <<amplituding/formative>supererogatory $\sim$ de-mentativeness/epistemic-growth-orconflatedness /transvaluative-rationalising/transepistemicity/anamnestic-residuality/spirit-

drivenness-equalisation>

mentating/structuring/paradigming as part-and-parcel of the prospective sublimating meaningfulness-and-teleology , and not wrongly imply the desublimation is in apriorisingteleological-elevation-in $\sim$ notional-contiguity/epistemic-contiguity ${ }^{62}<$ profound-

schema $>$ as to the transcendence-and-sublimity/sublimation/supererogatory $\sim$ de-mentativity attitude/mental-disposition/care-and-episteme (in this case reflecting sophistic/pedantic procrypticism-or-disjointedness-as-of- ${ }^{2}$ reference-of-thought); and as so articulated elsewhere with the case of the Socratic-philosophers and budding-positivists it is always the case that the sophistic/pedantic dispositions will fathom that in relation to prospectively sublimating

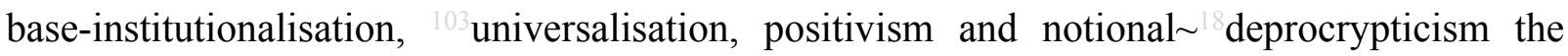
effective "world that exists to the majority people (as of "human notional firstnaturednessformativeness-<as-to-eventualising-inkling-drive-or-seeding-misprising $>$ temporal-tointemporal-dispositions-<so-construed-as-from-perspective-ontologicalnormalcy/postconvergence> accordioning-〈as-of-varying-individuations-contextuallytransverse-desublimation/sublimation,-as-to-the-wavering/redounding/waveforming of-their- 
referencing-and-their-devolved-referencing-imbued-ontological-performance -<including-

virtue-as-ontology>> at uninstitutionalised-threshold ${ }^{12}$ as reflecting both desublimating historicity-tracing - in-presencing-hyperrealisation/hyperreal-transposition and sublimating historiality/ontological-eventfulness 8 /ontological-aesthetic-tracing-<perspectiveontological-normalcy/postconvergence-reflected-‘epistemicity-relativism-determinism’>

possibilities') respectively is recurrent-utter-uninstitutionalisation, ununiversalisation, nonpositivism/medievalism and ${ }^{8}$ procrypticism-or-disjointedness-as-of- ${ }^{2}$ reference-of-thought to go on cynically eliciting <amplituding/formative> wooden-language-〈imbued-averaging-ofthought-<as-to-leveling/ressentiment/closed-construct-of- meaningfulness-and-teleology -asof-'nondescript/ignorable-void '-with-regards-to-prospective-apriorising-implications $>>$ as of the latter. Ultimately, there is a 'social underlying sublimating intellection proficiency' to which all specific domains-of-study need to account for their sublimating pertinence; and the possibility of putting-into-question all 'Establishment intellection as of their given presencingabsolutising-identitive-constitutedness ${ }^{1}$, (from across the most ancient civilisations to modern times and so as instigated by the Socrates, Galileos, Descartes, Diderots, etc.) has always arisen within-or-without such epochal Establishment intellection by the prompting of their 'social underlying sublimating intellection proficiency' which contemplative consciousness is not to be underestimated as to a 'decadence posturing of intellectual entitlement'. Critically, the possibility of prospective value-construction and pretence of projecting more profound value is indissociable from the capacity of producing the relative-ontological-completeness ${ }^{87}$ knowledge that broaden-the-latitude-of-human-collective-consciousness as to the fact that just as prior recurrent-utter-uninstitutionalisation, ununiversalisation, non-positivism/medievalism and procrypticism-or-disjointedness-as-of- ${ }^{2}$ reference-of-thought respectively are intellectuallyand-morally wanting with respect to prospective base-institutionalisation, ${ }^{103}$ universalisation, positivism/rational-empiricism and deprocrypticism-or-preempting-disjointedness-as-of- 
reference-of-thought value-construction respectively; pretences of profound intellection as to the former are nothing but sophistic/pedantic exploitations of human limited-mentationcapacity—as-subjecting-'educed-unlimitedness/existence-sublimating nascence' tolimitedness/human-subpotency as to a 'delusion of generating knowledge and value from thin air', and of vital importance in that regards is the fact that that which is in relative-ontologicalcompleteness $^{87}$ has to occupy the intellectual-and-moral ground imbued by such relativeontological-completeness ${ }^{87}$. Vague notions of arrogance and wretchedness are nothing but the ontological-veracity of the state of relative-ontological-incompleteness ${ }^{88}$ arrogance and wretchedness of thought (as from the ontological-normalcy/postconvergence epistemic-ornotional projective-perspective) as to an epistemically-decadent $<$ amplituding/formative $>$ wooden-language-〈imbued-temporal-mere-

form/virtualities/dereification/akrasiatic-drag/denatured/preconverging-or-dementing narratives - of-the- reference-of-thought- categorical-imperatives/axioms/registry-

teleology $\rangle$; and so as to the fact that the magnanimity of dispensing-with-immediacy-forrelative-ontological-completeness ${ }^{87}$-by-reification/contemplative-distension ${ }^{27}$ out of concern about human re-ontologising prospective Being-development/ontological-frameworkexpansion-as-to-depth-of-ontologising-development-as-infrastructure-of- meaningfulnessand-teleology 'is the most important human and humanity-producing enterprise' notwithstanding the paradox that the prior recurrent-utter-uninstitutionalisation, ununiversalisation, non-positivism/medievalism and ${ }^{80}$ procrypticism-or-disjointedness-as-ofreference-of-thought respectively are intellectually-and-morally undeveloped to be the framework for appraising value-construction as of prospective base-institutionalisation, universalisation, positivism/rational-empiricism and ${ }^{18}$ deprocrypticism-or-preemptingdisjointedness-as-of- ${ }^{8}$ reference-of-thought respectively in-many-ways explaining the underlying implications of human registry-worldview's/dimension's institutionalisation as 
involving crossgenerational psychoanalytic-unshackling/memetic-reordering/institutionalrecomposuring. This affirmation is not articulated idly as to the fact that part-and-parcel of human knowledge-reification $\sim$ gesturing-and-accounting - of-epistemic-phenomenalism- $<$ inprospective_psychologismic apriorising/axiomatising/referencing-\{of-'prospectively implicited_attendant-ontological-contiguity ' educedexistentialising/contextualising/textualising_'intelligibility/epistemicity/reflexivity-contiguity<imbued-notional cogency $>$ ' \}-conflatedness -in-\{preconverging ment by\}

postconverging-entailment $>$ is not to allow desublimating thought to occupy the ground of sublimating thought (as the latter has to include a challenge to the knowledge-destroying desublimating thought arrogance and wretchedness), however the subterfuges available to such desublimation whether as of sophistry and mere-institutional-appendaging as reflecting the veridical prospective human-subpotency-aporia/undecidability/dilemma/oughtindeterminacy/deficiency/limitation/constraint; taking hint that it is fundamentally a question about existence-potency ${ }^{39} \sim$ sublimating-nascence,-disclosed-from-prospective-epistemicdigression and no amount of human mortals methodologising/mutualising/organising/institutionalising can supersede prospective sublimating existence's necessitating implications and consequences as otherwise the very idea of ontology/science then collapses and the flawed prior_knowledge-reification $\sim$ gesturing-andaccounting - of-epistemic-phenomenalism- $<$ inprior_psychologismic apriorising/axiomatising/referencing-\{of-'prior-implicited_attendantontological-contiguity ' educedexistentialising/contextualising/textualising_ intelligibility/epistemicity/reflexivity-contiguity<imbued-notional cogency $\left.>^{\prime} \quad\right\}$-constitutedness in preconverging entailment $>$ exercise becomes pointless but as for institutional parading value. There is simply no knowledge without the effective demonstrated knowledge-reification $\sim$ gesturing-and-accounting-of-epistemic- 
phenomenalism- $<$ in-prospective_psychologismic $\sim$ apriorising/axiomatising/referencing-\{of'prospectively implicited_attendant-ontological-contiguity ' educedexistentialising/contextualising/textualising_'intelligibility/epistemicity/reflexivity-contiguity$<$ imbued-notional cogency $>\quad\}$-conflatedness - in-\{preconverging ment by\} postconverging entailment> implications and pretending otherwise as to 'virtual wisdoms' is nothing more tha <amplituding/formative-epistemicity $>$ totalising $\sim$ self-referencingsyncretising/circularity/interiorising/akrasiatic-drag ${ }^{34}$. Hence basically the overall differentiation between 'purist science/ontology epistemic-conception of veracity/truth' and 'social-vestedness/normativity-<discretely-implied-functionalism> epistemic-conception of veracity/truth' lies with their constraining whether towards inherent existence projected implications or towards human-subpotency projected implications respectively. This underlying point has preconverging/postconverging-de-mentative/structural/paradigmatic implications with regards to human ${ }^{5}$ meaningfulness-and-teleology ${ }^{9}$ (as to human Beingdevelopment/ontological-framework-expansion-as-to-depth-of-ontologising-development-asinfrastructure-of- meaningfulness-and-teleology , institutional-development-as-to-socialfunction-development and living-development-as-to-personality-development psychologismic epistemic acutisation diffienly < for, residualising \{decompulsing\} delinearity for cogency> magnitudes $\{$ of-experientiality/experiment $\}$. This differentiation can be rearticulated in aestheticisation terms to imply that existence (as to existence-potency ${ }^{32} \sim$ sublimating-nascence,-disclosed-fromprospective-epistemic-digression) is the 'scalar conception that enables prospective human sublimation as of aestheticisation-towards-ontology' while on-the-other-hand humansubpotency (as to human presencing-absolutising-identitive-constitutedness $<$ amplituding/formative-epistemicity $>$ totalising $\sim$ self-referencingsyncretising/circularity/interiorising/akrasiatic-drag ${ }^{34}$ ) is a 'non-scalar conception that induces prospective human desublimation aestheticisation'. The 'scalarity/immanency of existence's 
ontological-normalcy/postconvergence' as such is reflected with regards to prospectively implied ontological-normalcy/postconvergence construed as of ${ }^{55}$ maximalising-recomposuringfor-relative-ontological-completeness ${ }^{87}$ - unenframed/re-ontologising conceptualisation epistemic-projection perspective while 'human-subpotency non-scalarity/beholdening-<as-towhat-has-gone-before-aesthetically-de-mentates/structures/paradigms-distortedly-thepossibility-for-the-later-ontologisation >' is reflected with regards to its prospectively implied epistemic-abnormalcy/preconvergence ${ }^{31}$ construed as of incrementalism-in-relativeontological-incompleteness ${ }^{8}$ — enframed/disontologising conceptualisation epistemicprojection perspective. Basically, 'scalarity/immanency of existence's ontologicalnormalcy/postconvergence' and 'human-subpotency non-scalarity/beholdening-<as-to-whathas-gone-before-aesthetically-de-mentates/structures/paradigms-distortedly-the-possibility-forthe-later-ontologisation>' thus speak to the fact that human prospective transcendence-andsublimity/sublimation/supererogatoryade-mentativity implied limited-mentation-capacitydeepening—as-subjecting-limitedness/human-subpotency-to-'educed-unlimitedness/existencesublimating nascence ${ }^{53}$ (as to dispensing-with-immediacy-for-relative-ontologicalcompleteness ${ }^{87}$-by-reification/contemplative-distension ${ }^{27}$ ) is actually induced as from human uncontemplative-distension so-construed as 'dispensing-with-immediacy-for-relativeontological-completeness $^{87}$-by-reification/contemplative-distension ${ }^{27}$ imbued prospectively of both sublimating ${ }^{4}$ historiality/ontological-eventfulness ${ }^{3} /$ ontological-aesthetic-trace and desublimating ${ }^{47}$ historicity-tracing-in-presencing-hyperrealisation/hyperreal-transposition'; as to prospective sublimating ${ }^{4}$ historiality/ontological-eventfulness ${ }^{38}$ /ontological-aesthetictrace 'scalarity/immanency of existence's ontological-normalcy/postconvergence' as prospectively preserving ontology/ontological-veracity and 'human-subpotency nonscalarity/beholdening-<as-to-what-has-gone-before-aesthetically-de- 
prospective desublimating ${ }^{4}$ historicity-tracing-in-presencing-hyperrealisation/hyperrealtransposition as prospectively obviating ontology/ontological-veracity. This insightful grasp of the implications of human limited-mentation-capacity-deepening-as-subjecting limitedness/human-subpotency-to-'educed-unlimitedness/existence-sublimating nascence' (construed as from ontological-normalcy/postconvergence epistemic-projection perspective): 'as rather occurring as from an ontologically deficient grounding' of relative human limitedmentation-capacity—as-subjecting-'educed-unlimitedness/existence-sublimating nascence' to-limitedness/human-subpotency (however the 'better relative ontological-deficiency' implied as of relative-ontological-completeness ${ }^{87}$ ), emphasises the necessity for the bifurcation of the construal of prospective human ontological-performance ${ }^{72}-$ including-virtue-as- $^{2}$ ontology $>$ /morality/ethics/justice/etc. (associated with prospective human sublimation) into: a 'scalarity/immanency perspective (as to a scalarity/immanency that will arise if the human had absolute-mentation-capacity so-construed as ontological-normalcy/postconvergence) of historiality/ontological-eventfulness 38 ontological-aesthetic-tracing-<perspectiveontological-normalcy/postconvergence-reflected-'epistemicity-relativism-determinism'>’ and a 'non-scalarity/beholdening-<as-to-what-has-gone-before-aesthetically-dementates/structures/paradigms-distortedly-the-possibility-for-the-later-ontologisation> perspective (with regards to \{flawed/unsound\}-relative-unreflexivity-inexistence/absolutising from-limited-mentation/psychologismic epistemic-acutisationnonresidualising imbuedformulaicity/ritualisation residual human ontological-deficiency implications as to relative human limited-mentation-capacity—as-subjecting-'educed-unlimitedness/existencesublimating nascence' to limitedness/hmman-subpency notwithstanding the 'better relative ontological-deficiency') of ${ }^{47}$ historicity-tracing-in-presencing-hyperrealisation/hyperrealtransposition'. Uncontemplative-distension is thus rather the recognition that human dispensing- 
with-immediacy-for-relative-ontological-completeness ${ }^{87}$-by-reification/contemplativedistension ${ }^{27}$ doesn't achieve absolute 'scalarity/immanency of existence's ontologicalnormalcy/postconvergence' (as dispensing-with-immediacy-for-relative-ontologicalcompleteness ${ }^{87}$-by-reification/contemplative-distension ${ }^{27}$ rather reflects the epistemic perspective towards ontological-normalcy/postconvergence and not 'scalarity/immanency of existence's ontological-normalcy/postconvergence'); with the effective 'scalarity/immanency of existence's ontological-normalcy/postconvergence' as of the absolute distension (beyond just relative-ontological-completeness ${ }^{87}$ ) underlying the overall existential-<disontologising/reentologising aporeticism> dimensionality-of-sublimating

\section{<<amplituding/formative>supererogatory $\sim$ de-mentativeness/epistemic-growth-or-}

\section{conflatedness /transvaluative-rationalising/transepistemicity/anamnestic-residuality/spirit-}

drivenness-equalisation) as the inherent ontological-good-faith/authenticity $\sim$ postconvergingde-mentating/structuring/paradigming ${ }^{70}$ effectively reflected as of notional ${ }^{18}$ deprocrypticism. notional ${ }^{18}$ deprocrypticism as such by its ontologically-uncompromised nature 'technically entails': $\quad$ prospective human ontological-performance ${ }^{72}-$ including-virtue-as- $^{2}$ ontology $>$ /morality/ethics/justice/etc. as to sublimating ${ }^{4}$ historiality/ontologicaleventfulness 3 /ontological-aesthetic-tracing-<perspective-ontological'scalarity/immanency of existence's ontological-normalcy/postconvergence' in overcoming the desublimating ${ }^{47}$ historicity-tracing-in-presencing-hyperrealisation/hyperreal-transposition of 'human-subpotency non-scalarity/beholdening-<as-to-what-has-gone-before-aesthetically-dementates/structures/paradigms-distortedly-the-possibility-for-the-later-ontologisation> $\quad$ in presencing - absolutising-identitive-constitutedness ${ }^{14}$. Translated, this 'scalarity/immanency of existence's ontological-normalcy/postconvergence' and 'human-subpotency nonscalarity/beholdening-<as-to-what-has-gone-before-aesthetically-de- 
mentates/structures/paradigms-distortedly-the-possibility-for-the-later-ontologisation>

underlying prospective human ontological-performance ${ }^{72}-<$ including-virtue-asontology $>$ /morality/ethics/justice/etc. with regards to human ${ }^{56}$ meaningfulness-and-teleology speaks to the fact that prospectively induced human sublimation is bound to paradoxically distort-and-desublimate the ontological-veracity appraisal for inducing further and concomitant human sublimation (and so because of the preconverging/postconverging-dementative/structural/paradigmatic effect of relative limited-mentation-capacity-deepening-assubjecting limitedness/human-subpotency-to-'educed-unlimitedness/existence-sublimating nascence' 33 in constrast to what will prevail in case of 'absolute-mentation-capacity of apriorising/axiomatising/referencing/intelligibilitysettingup/measuringinstrumenting'). But then such effect critically varies as to both 'purist science/ontology epistemic-conception of veracity/truth' and 'social-vestedness/normativity-<discretely-implied-functionalism $>$ epistemic-conception of veracity/truth'; in the sense that the latter poorly constrained to high predicative-effectivity-sublimation-〈as-to-underlying,-ontological-commitment ${ }^{6}<$ impliedself-assuredness-of-ontological-good-faith/authenticity postconverging-dementating/structuring/paradigming -as-being-as-of-existential-reality $>>$ is strongly prone to desublimating ${ }^{47}$ historicity-tracing-in-presencing-hyperrealisation/hyperreal-transposition of 'human-subpotency non-scalarity/beholdening-<as-to-what-has-gone-before-aesthetically-dementates/structures/paradigms-distortedly-the-possibility-for-the-later-ontologisation> $\quad$ in presencing - absolutising-identitive-constitutedness ${ }^{14}$, while the former strongly constrained to high predicative-effectivity-sublimation-〈as-to-underlying,-ontological-commitment $<$ implied - self-assuredness-of-ontological-good-faith/authenticity postconverging-dementating/structuring/paradigming -as-being-as-of-existential-reality $>>$ is rather relatively amenable to sublimating ${ }^{4}$ historiality/ontological-eventfulness 3 /ontological-aesthetic-tracing$<$ perspective-ontological-normalcy/postconvergence-reflected-‘epistemicity-relativism- 
determinism'> as of 'scalarity/immanency of existence's ontologicalnormalcy/postconvergence'. That said, human sublimation increasingly implies a 'generalised background cultural,-organisation-and-institutional framework' that itself needs to be sublimating, and it is here as well that even the propensity for sublimation of 'purist science/ontology epistemic-conception of veracity/truth' can be desublimated by an ontologically-impertinent 'generalised background cultural,-organisation-and-institutional framework' adopting 'social-vestedness/normativity- $<$ discretely-implied-functionalism $>$ epistemic-conception of veracity/truth'. In-many-ways with regards to the overall social framework, the usurpation of the intellectual-function/posture arising as of 'socialvestedness/normativity-<discretely-implied-functionalism $>\quad$ epistemic-conception of veracity/truth' is often associated with vague-and-surreptitious conceptualisations of business success and media-and-social influence (in desublimating historicity-tracing - in-presencinghyperrealisation/hyperreal-transposition) as superseding social intellection itself as an inherent exercise for the social domain's 'purist science/ontology epistemic-conception of veracity/truth' (as to the latter's prospective sublimating ${ }^{4}$ historiality/ontological-eventfulness ${ }^{38} /$ ontological- $^{2}$ aesthetic-tracing-<perspective-ontological-normalcy/postconvergence-reflected-'epistemicityrelativism-determinism'>). Critically such a 'purist science/ontology epistemic-conception of veracity/truth' analysis very much point out that the social-construct is riddled with narratives of 'supposedly veridical ontological justifications/grounds' but which on closer examination as of 'purist science/ontology epistemic-conception of veracity/truth' turn out to be at the least subontological-<as-to-the-limitation-of-human-subpotency-in-its-reifying-and-empoweringreflexivity-of-the-full-potency-of-existence's $\sim$ sublimating-nascence $>$; and so as to the relative impertinence of the 'social-vestedness/normativity- $<$ discretely-implied-functionalism $>$ epistemic-conception of veracity/truth' (so-construed as from the ontologicalnormalcy/postconvergence epistemic-projection perspective). This insight further informs 
prospective notional deprocrypticism appraisal of the 'tight-and-entwined relationship between the overall human ontological-commitment $-<$ implied-self-assuredness-ofontological-good-faith/authenticity $\sim$ postconverging-de-

mentating/structuring/paradigming -as-being-as-of-existential-reality> (across all registryworldviews/dimensions) and (corresponding registry-worldviews/dimensions) predicativeeffectivity-sublimation-〈as-to-underlying,-ontological-commitment $-<$ implied-selfassuredness-of-ontological-good-faith/authenticity postconverging-dementating/structuring/paradigming -as-being-as-of-existential-reality $>>$ (reflecting 'scalarity/immanency of existence's ontological-normalcy/postconvergence')'. In this regards, the preconverging/postconverging-de-mentative/structural/paradigmatic implications of 'human notional firstnaturedness-formativeness-<as-to-eventualising-inkling drive-orseeding misprising $>$ temporal-to-intemporal-dispositions- $<$ so-construed-as-fromperspective-ontological-normalcy/postconvergence> accordioning-〈as-of-varyingindividuations-contextually-transverse-desublimation/sublimation,-as-to-thewaveringtredounding of -their-referencing-and-their-devolved-referencingimbued-ontological-performance -<including-virtue-as-ontology $>>$ at uninstitutionalisedthreshold ${ }^{102}$ as reflecting both desublimating ${ }^{47}$ historicity-tracing-in-presencinghyperrealisation/hyperreal-transposition and sublimating ${ }^{4}$ historiality/ontologicaleventfulness $3 \%$ ontological-aesthetic-tracing-<perspective-ontologicalnormalcy/postconvergence-reflected-‘epistemicity-relativism-determinism’> possibilities', reflect the fact that the originariness-parrhesia,-as-spontaneity-of-aestheticisationsupererogatory acuity/perspicacity/astuteness/edginess/incisiveness for prospective knowledge-reification $\sim$ gesturing-and-accounting — of-epistemic-phenomenalism- $<$ inprospective_psychologismic apriorising/axiomatising/referencing-\{of-'prospectively_ implicited_attendant-ontological-contiguity ' educed- 
existentialising/contextualising/textualising_'intelligibility/epistemicity/reflexivity-contiguity<imbued-notional cogency $>>$ \}-conflatedness -in-\{preconverging ment by\}

postconverging entailment> implying a projection out of a prior human registryworldview's/dimension's institutionalisation framework cannot be construed as of any exercise of elaboration-as-to-mere-extrapolating/constituting/abstracting/deducing/inferring-ofelucidation-outside_- 'prospectively implicited_attendant_ontological-contiguity ${ }^{67}$ ' educedexistentialising/contextualising/textualising_'intelligibility/epistemicity/reflexivity_contiguity$<$ imbued-notional cogency $>^{\prime}$ on the basis of the prior institutionalisation secondnatured apriorising/axiomatising/referencing/intelligibilitysettingup/measuringinstrumenting (thus wrongly implying that there is an underlying absolute sound basis for human knowledgereification $\sim$ gesturing-and-accounting — of-epistemic-phenomenalism- $<$ inprospective_psychologismic apriorising/axiomatising/referencing-\{of-'prospectively_ implicited_attendant-ontological-contiguity ' educedexistentialising/contextualising/textualising_'intelligibility/epistemicity/reflexivity-contiguity<imbued-notional cogency $>$ ' $\}$-conflatedness -in-\{preconverging -ment by\} postconverging-entailment> as of elaboration-as-to-mereextrapolating/constituting/abstracting/deducing/inferring-of-elucidation-outside'prospectively implicited_attendant-ontological-contiguity ${ }^{67}$ ' educedexistentialising/contextualising/textualising_intelligibility/epistemicity/reflexivity-contiguity<imbued-notional cogency $>^{\prime}$, whereas in reality such grounds are recurrently postconvergingly-rede-mentated/restructured/reparadigmed for relative-ontologicalcompleteness $^{87}$ as to re-motif-and-re-apriorising/re-axiomatising/re-referencing/reintelligibilitysettingup/re-measuringinstrumenting); hence implying that prospective sublimating $\quad{ }^{4}$ historiality/ontological-eventfulness ${ }^{38}$ ontological-aesthetic-tracing<perspective-ontological-normalcy/postconvergence-reflected-‘epistemicity-relativism- 
determinism'> at any uninstitutionalised-threshold ${ }^{12}$ is necessarily imbued with prospective originariness-parrhesia,-as-spontaneity-of-aestheticisation 'messianic-structure of intemporality ${ }^{52}$, and its derived deferential-formalisation-transference secondnaturing. We can appreciate in this regards that budding-positivists ${ }^{56}$ meaningfulness-and-teleology ${ }^{9}$ however relatively intelligible to us today, wouldn't make sense to the 'ordinariness/commonsensicality of the non-positivism/medievalism prior institutionalisation secondnatured apriorising/axiomatising/referencing/intelligibilitysettingup/measuringinstrumenting as to elaboration-as-to-mere-extrapolating/constituting/abstracting/deducing/inferring-ofelucidation-outside_- prospectively_implicited_attendant-ontological-contiguity ${ }^{67}$ ' educedexistentialising/contextualising/textualising_intelligibility/epistemicity/reflexivity-contiguity<imbued-notional cogency $>^{\prime}$ but the fact is that such budding-positivism in its preconverging/postconverging-rede-mentating/restructuring/reparadigming for relativeontological-completeness ${ }^{87}$ rather induced the psychoanalytic-unshackling/memeticreordering/institutional-recomposuring for our modern-day positivism apriorising/axiomatising/referencing/intelligibilitysettingup/measuringinstrumenting. Such a preconverging/postconverging-rede-mentating/restructuring/reparadigming for relativeontological-completeness 87 induced psychoanalytic-unshackling/memeticreordering/institutional-recomposuring equally applies with respect to prospective deprocrypticism-or-preempting — disjointedness-as-of- ${ }^{3}$ reference-of-thought apriorising/axiomatising/referencing/intelligibilitysettingup/measuringinstrumenting. In this regards, just as the requisite dispensing-with-immediacy-for-relative-ontologicalcompleteness $^{87}$-by-reification/contemplative-distension ${ }^{27}$ that projected of an underlying 'scientific - apriorising/axiomatising/referencing-psychologism enculturated/constructed social-pragmatics-framing-of-predicative-effectivity-sublimation-〈as-to-underlying,-

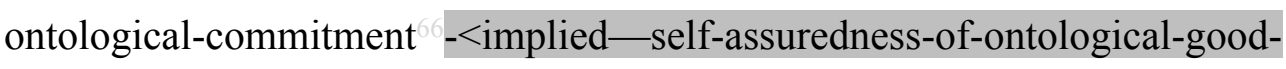


faith/authenticity postconverging-de-mentating/structuring/paradigming -as-being-as-of-

existential-reality $>\rangle$ ' by budding-positivists allowed for the enculturation of a human positivism/rational-empiricism social orientation with regards to the natural sciences (then more$\begin{array}{llll}\text { or-less } & \text { subsequent } & \text { 'aspirational sciences') } & \text { epistemic-conceptions }\end{array}$ phenomenal/manifest $\sim$ subpotencies-〈in-transitive-conflatedness -reflexivity,-in-the-fullpotency-of-existence's $\sim$ sublimating-nascence $\rangle$ as to their implicited '<amplituding/formativeepistemicity>totalising/circumscribing/delineating 'implicited_attendant-ontologicalcontiguity $^{67}$, educed-

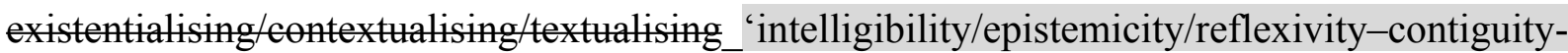
$<$ imbued-notional $\sim$ cogency $>{ }^{40} \quad{ }^{45}$ foregrounding_entailment- $<$ in-succession-of-profoundsupererogation $>$-〈postconverging-narrowing-down $\sim$ sublimation-as-to-'existence-assublimating-withdrawal/unenframing/re-ontologising,-elicited-from-prospective-profoundsupererogation '-in-reflecting-'immanent $\sim$ relative-unreflexivity/relative-reflexivity ontological-contiguity ';--as-operative-notional deprocrypticism> in elucidating relativeunreflexivity/relative-reflexivity - ontological-contiguity ${ }_{-<}<$as-from-prospective-ontologicalnormalcy/postconvergence-epistemic-or-notional projective-perspective $>$ ' as to imbued positivism/rational-empiricism sublimation over non-poisitivism desublimation (and so over a long-and-sustained period of crossgenerational psychoanalytic-unshackling/memeticreordering/institutional-recomposuring) inducing the strongly enculturated predicativeeffectivity-sublimation-〈as-to-underlying,-ontological-commitment $-<$ implied - selfassuredness-of-ontological-good-faith/authenticity postconverging-dementating/structuring/paradigming -as-being-as-of-existential-reality $>>$ constraining of positivism/rational-empiricism ${ }^{56}$ meaningfulness-and-teleology ${ }^{9}$ today; likewise the notional ${ }^{1}$ deprocrypticism epistemicity further speaks to the requisite dispensing-withimmediacy-for-relative-ontological-completeness 37 -by-reification/contemplative-distension 
for the enculturation of a 'human deprocrypticism-or-preempting-disjointedness-as-ofreference-of-thought construction-of-the-Self psychoanalytic-unshackling/memeticreordering/institutional-recomposuring' with regards to (the overall originariness/origination〈so-construed-as-to-ontological-normalcy/postconvergence-perspective-scalarising-construalof-existence) of relative-unreflexivity/relative-reflexivity - ontological-contiguity ${ }^{6}$, in overallecstatic-existence-supervening-conflatedness ${ }^{13}$ ) so-implied across all human domains-of-study epistemic-conceptions $\quad$ phenomenal/manifest $\sim$ subpotencies-〈in-transitive-conflatedness reflexivity,-in-the-full-potency-of-existence's $\sim$ sublimating-nascence $\rangle$ as to their explicited '<amplituding/formative-epistemicity $>$ totalising/circumscribing/delineating 'implicited_attendant-ontological-contiguity ${ }^{6 /}$; educedexistentialising/contextmalising/textualising_'intelligibility/epistemicity/reflexivity_contiguity$<$ imbued-notional cogency $>{ }^{40} \quad{ }^{45}$ foregrounding_entailment- $<$ in-succession-of-profoundsupererogation $>$-〈postconverging-narrowing-down $\sim$ sublimation-as-to-'existence-assublimating-withdrawal/unenframing/re-ontologising,-elicited-from-prospective-profoundsupererogation '-in-reflecting-'immanent relative-unreflexivity/relative-reflexivity ontological-contiguity ';--as-operative-notional deprocrypticism) in elucidating relativeunreflexivity/relative-reflexivity - ontological-contiguity ${ }^{6}-<$ as-from-prospective-ontologicalnormalcy/postconvergence-epistemic-or-notional projective-perspective $>^{\prime}$ as to imbued deprocrypticism-or-preempting-disjointedness-as-of- ${ }^{3}$ reference-of-thought sublimation over procrypticism-or-disjointedness-as-of- ${ }^{8}$ reference-of-thought desublimation, thus prospectively inducing a strongly enculturated predicative-effectivity-sublimation-〈as-tounderlying,-ontological-commitment $-<$ implied — self-assuredness-of-ontological-goodfaith/authenticity postconverging-de-mentating/structuring/paradigming -as-being-as-ofexistential-reality $>>$ constraining of deprocrypticism-or-preempting-disjointedness-as-ofreference-of-thought ${ }^{56}$ meaningfulness-and-teleology ${ }^{9}$, (and so overriding disparateness-of- 
conceptualisation-<unforegrounding-ment,-failing-prospectively-to-reflect-

'immanent relative-unreflexivity/relative-reflexivity ontological-contiguity ' $>$ as to the latter's implied ${ }^{80}$ procrypticism-or-disjointedness-as-of- ${ }^{83}$ reference-of-thought). But then as across the <cumulating/recomposuring attendant-ontological-contiguity $>$-successive registry-worldviews/dimensions, the uninstitutionalised-threshold ${ }^{02}$ is a fertile spot for sophistic/pedantic practices whether as with the ancient-sophists or medievalism-scholastics or today institutional-being-and-craft pedantising/muddling/formulaic-hollowing-out-insubontologisation/subpotentiation-〈blurring/undermining-of-prospective-totalising-entailing,as-to-entailing-<amplituding/formative-epistemicity $>$ totalising in-relative-ontologicalcompleteness $\rangle$. What is central to all such sophistry is their emphasis on the notion that prospective knowledge is attained as to the sensibility/decorum as of ${ }^{79}$ presencingabsolutising-identitive-constitutedness ${ }^{14}<$ amplituding/formative-epistemicity $>$ totalising $\sim$ selfreferencing-syncretising/circularity/interiorising/akrasiatic-drag ${ }^{34}$ explaining their pedantic obsession. On-the-other-hand, what is central with prospective genuine knowledge is ever always the emphasis on the fact that knowledge-reification $\sim$ gesturing-and-accounting-ofepistemic-phenomenalism-<in-

prospective_psychologismic apriorising/axiomatising/referencing-\{of-`prospectively_ implicited_attendant-ontological-contiguity ' reducedexistentialising/contextualising/textualising_'intelligibility/epistemicity/reflexivity-contiguity<imbued-notional cogency>' \}-conflatedness -in-\{preconverging-ment by\} postconverging-entailment $>$ is fundamentally about sublimation-over-desublimation as to the implications of the 'tight-and-entwined relationship between the overall human ontologicalcommitment $-<$ implied — self-assuredness-of-ontological-goodfaith/authenticity postconverging-de-mentating/structuring/paradigming -as-being-as-ofexistential-reality> (across all registry-worldviews/dimensions) and (corresponding registry- 
worldviews/dimensions) predicative-effectivity-sublimation-〈as-to-underlying,-ontologicalcommitment $-<$ implied—self-assuredness-of-ontological-good-

faith/authenticity postconverging-de-mentating/structuring/paradigming -as-being-as-ofexistential-reality>> as critically enabling prospective sublimation' so-implied as to existencepotency $^{39} \sim$ sublimating-nascence,-disclosed-from-prospective-epistemic-digression. $\quad$ The strategic problem faced by the ancient-sophists and medievalism-scholastics in this respect (beyond-the-consciousness-awareness-teleology ${ }^{9}-<$ of-preconverging-existential-extricationas-of-existential-unthought $>$ ) is how to exploit the fact that there is no " ${ }^{103}$ universalisingidealisation — apriorising/axiomatising/referencing-psychologism enculturated/constructed social-pragmatics-framing-of-predicative-effectivity-sublimation-〈as-to-underlying,-

ontological-commitment $\quad$-implied-self-assuredness-of-ontological-goodfaith/authenticity $\sim$ postconverging-de-mentating/structuring/paradigming -as-being-as-ofexistential-reality $>\rangle$ ' and no 'positivism/rational-empiricismapriorising/axiomatising/referencing-psychologism enculturated/constructed socialpragmatics-framing-of - predicative-effectivity-sublimation-〈as-to-underlying,-ontologicalcommitment $-<$ implied — self-assuredness-of-ontological-goodfaith/authenticity postconverging-de-mentating/structuring/paradigming -as-being-as-ofexistential-reality $>\rangle$, to preconverging/postconverging-dementatively/structurally/paradigmatically undermine respectively the possibility for both Socratic-philosophers ${ }^{103}$ universalising-idealisation and positivism/rational-empiricism implied transcendence-and-sublimity/sublimation/supererogatory॰de-mentativity ${ }^{56}$ meaningfulnessand-teleology ${ }^{9}$ by eliciting presencing-absolutising-identitive-constitutedness sensibility/decorum as of non-universalising ancient-sophistry and non-positivism medievalscholasticism ${ }^{56}$ meaningfulness-and-teleology ${ }^{9}$ respectively. Likewise, it is herein contended that a tradition of philosophy introduced and propped up after the second-world-war and a 
general social science and humanities attitude and practices closely associated with this orientation (as to perceived geostrategic reasons for undermining the possibility of unfettered thought paradoxically uncritical/thoughtless about the social implications associated with poor/usurped social critique) is fundamentally grounded on an actively surreptitious exercise of presencing —absolutising-identitive-constitutedness $<$ amplituding/formativeepistemicity $>$ totalising $\sim$ self-referencing-syncretising/circularity/interiorising/akrasiatic-drag that in-many-ways (given the inherent impotency it induces as recognised explicitly and implicitly by even its very own leading figures) has had the consequence of 'undermining the natural social critical thinking that should enable the proper intellectual framing and addressing of human and social issues leading to a rather subservient intellectual posturing to socially dominant vested-interests/actors' as so-reflected in the current impotence of the political exercise with mediating institutions failing sovereign-equanimity as political, economic and social stakes cumulatively default to vested-interests as to their ${ }^{79}$ presencing-absolutising-identitiveconstitutedness $<$ preconverging 'motif-and-apriorising/axiomatising/referencing' entailing $>$-existentialising — enframing/imprintedness-〈as-to- historicity-tracing-inpresencing-hyperrealisation/hyperreal-transposition). Such an underlying intellectually deficient orientation is the surreptitious underhandedness failing social intellectual engagement in-many-ways explains the surreptitious campaigning against many a critical theory as to the possibility for a revitalised genuine and healthy social critique (and as it is especially so-directed at pedantising/muddling/formulaic-hollowing-out-in-subontologisation/subpotentiation〈blurring/undermining-of-prospective-totalising-entailing,-as-to-entailing$<$ amplituding/formative-epistemicity $>$ totalising $\sim$ in-relative-ontological-completeness $>$

promising postmodern-thought which portrays a very profound ontological-veracity as to prospective sublimation possibilities in the face of prospective human-subpotencyaporia/undecidability/dilemma/ought-indeterminacy/deficiency/limitation/constraint); and so- 
enabled as to no 'deprocrypticism—apriorising/axiomatising/referencing-psychologism enculturated/constructed social-pragmatics-framing-of-predicative-effectivity-sublimation〈as-to-underlying,-ontological-commitment $-<$ implied - self-assuredness-of-ontological-goodfaith/authenticity $\sim$ postconverging-de-mentating/structuring/paradigming -as-being-as-ofexistential-reality $>$ '' (notwithstanding a natural scientific culture that points out that substantive issues are analysed on the basis of their relevant and operant substantive pertinence) as to the overriding possibility of 'projecting such a presencing-absolutising-identitiveconstitutedness ${ }^{14}$ sensibility/decorum of sterile/anecdotal institutional imprimatur' that is rather obsessively defensive of institutional-prescience/imprimaturing-<dullness-of thespirit/psychologismic epistemic acutisation nonresidunalising imbued fompulsings linearity in eclecticism-of prior-mere-formulaicity/ritualisation $>$ over inherent knowledgereification $\sim$ gesturing-and-accounting — of-epistemic-phenomenalism- $<$ inprospective_psychologismic apriorising/axiomatising/referencing-\{of-'prospectively implicited_attendant-ontological-contiguity ' educedexistentialising/contextualising/textualising_'intelligibility/epistemicity/reflexivity-contiguity<imbued-notional cogency>' \}-conflatedness -in-\{preconverging-ment by\}

postconverging-entailment $>$. But then the ancient-sophists and medievalism-scholastics were the sterile/anecdotal institutional imprimatur of their periods but their pedantic ${ }^{79}$ presencingabsolutising-identitive-constitutedness ${ }^{14}$ sensibility/decorum was never in any way beholdening upon sublimating existence as to existence-potency ${ }^{32} \sim$ sublimating-nascence,-disclosed-fromprospective-epistemic-digression allowing for prospective Socratic-philosophers universalising-idealisation and budding-positivism as to their respectively induced ' ${ }^{103}$ universalising-idealisation — apriorising/axiomatising/referencing-psychologism enculturated/constructed social-pragmatics-framing-of-predicative-effectivity-sublimation〈as-to-underlying,-ontological-commitment $<$ implied-self-assuredness-of-ontological-good- 
faith/authenticity $\sim$ postconverging-de-mentating/structuring/paradigming -as-being-as-of-

existential-reality $>\rangle^{\prime} \quad$ and

'positivism/rational-empricism-

apriorising/axiomatising/referencing-psychologism

enculturated/constructed social-

pragmatics-framing-of — predicative-effectivity-sublimation-〈as-to-underlying,-ontological-

commitment $-<$ implied — self-assuredness-of-ontological-good-

faith/authenticity postconverging-de-mentating/structuring/paradigming -as-being-as-of-

existential-reality $>>$ ' constraining in the face of 'human notional firstnaturednessformativeness-<as-to-eventmalising-inkling drive-or - seeding-misprising $>$ temporal-tointemporal-dispositions- $<$ so-construed-as-from-perspective-ontologicalnormalcy/postconvergence $>\quad$ accordioning-〈as-of-varying-individuations-contextuallytransverse-desublimation/sublimation,-as-to-the-wavering/redounding/waveforming of-theirreferencing-and-their-devolved-referencing-imbued-ontological-performance -<includingvirtue-as-ontology $>\rangle$ at uninstitutionalised-threshold ${ }^{102}$ as reflecting both desublimating historicity-tracing - in-presencing-hyperrealisation/hyperreal-transposition and sublimating historiality/ontological-eventfulness 38 /ontological-aesthetic-tracing-<perspectiveontological-normalcy/postconvergence-reflected-‘epistemicity-relativism-determinism’> possibilities'. The strategic reflex of assuming a presencing-absolutising-identitiveconstitutedness $^{14}$ sensibility/decorum preemptively 'shuts-off the possibilities of relativeontological-completeness ${ }^{87}$ interpretations' and arbitrarily defines 'human socialvestedness/normativity-<discretely-implied-functionalism $>\quad$ implied $\quad$ contract/politicalarrangement-or-political-coercion/given-discrete-social-value-construction' as imponderable/inscrutable/unavoidable/inevitable/inescapable/unpreventable/unchangeable/in surmountable/unovercomable with regards to social-stake-contention-or-confliction; such that effectively the social is interpreted (as of surreptitious disparateness-of-conceptualisation<unforegrounding-ment,-failing-prospectively-to-reflect-'immanent relative- 
unreflexivity/relative-reflexivity - ontological-contiguity ' $>$ ) as non-ontological thus implying not it is subject to analyses as of social and socio-psychological phenomenal/manifest $\sim$ subpotencies-〈in-transitive-conflatedness -reflexivity,-in-the-fullpotency-of-existence's $\sim$ sublimating-nascence). But then human sublimation in existence effectively speaks of the notional $\sim$ symmetrisation- $<$ as-to-symmetrisation-bydesymmetrisation,-in-reflecting-postconverging-or-dialectical-thinking ${ }^{21}$-by-preconvergingor-dementing ${ }^{20} \sim$ perspectives-of-human $-{ }^{5}$ meaningfulness-and-teleology 99 underlying human ontological-performance ${ }^{72}<$ including-virtue-as-ontology $>/$ morality/ethics/justice/etc. as to the relative-unreflexivity/relative-reflexivity - ontological-contiguity ${ }^{67}$ of-the-humaninstitutionalisation-process ${ }^{68}<$ cumulating/recomposuring attendant-ontological-contiguity succession of registry-worldviews/dimensions, and such a presencing-absolutisingidentitive-constitutedness ${ }^{14}$ sensibility/decorum strategy as to its implicited denial of such an relative-unreflexivity/relative-reflexivity —ontological-contiguity $\sim$ of-the-humaninstitutionalisation-process $^{68}$ of human ontological-performance ${ }^{72}-$ including-virtue-as- $^{-}$ ontology $>$ /morality/ethics/justice/etc. underlined by human ${ }^{4}$ historiality/ontologicaleventfulness 38 /ontological-aesthetic-tracing-<perspective-ontologicalnormalcy/postconvergence-reflected-‘epistemicity-relativism-determinism’>, effectively reveals its non-scientific nature notwithstanding the confusion of vague academicism proceduralism with true sublimating science/ontology. All the knowledge-reification $\sim$ gesturingand-accounting - of-epistemic-phenomenalism- $<$ inprospective_psychologismic apriorising/axiomatising/referencing-\{of-'prospectively_ implicited_attendant-ontological-contiguity ' educedexistentialising/contextualising/textualising_'intelligibility/epistemicity/reflexivity-contiguity<imbued-notional cogency>’ \}-conflatedness -in-\{preconverging ment by\} postconverging-entailment $>$ that effectively can be is of existence-as-sublimating- 
withdrawal/unenframing/re-ontologising,-elicited-from-prospective-profound-supererogation having to do with human limited-mentation-capacity-deepening-as-subjectinglimitedness/human-subpotency-to-'educed-unlimitedness/existence-sublimating nascence' ${ }^{53}$ as enabling human-subpotency epistemic-projection towards the full-potency of existence soconstrued as intemporality ${ }^{52}$, and not a ${ }^{79}$ presencing-absolutising-identitive-constitutedness human-subpotency epistemic-projection in $\quad<$ amplituding/formativeepistemicity $>$ totalising $\sim$ self-referencing-syncretising/circularity/interiorising/akrasiatic-drag so-construed as temporality ${ }^{8}$. But then the inclination to assume an ontologically-flawed sophistic/pedantic ${ }^{7}$ presencing — absolutising-identitive-constitutedness ${ }^{14}$ sensibility/decorum strategy is ever always associated across all registry-worldviews/dimensions with blurriness$<$ sterilising/anecdotalising/trivialising-of-prospective-re-ontologising_by-preconverging,-indisontologising-formulaic-dragging-out/hollowing-out $>$ of ${ }^{5}$ meaningfulness-and-teleology ${ }^{99}$ as to ${ }^{5}$ meaningfulness-and-teleology ${ }^{9}$ rather unconstrained to predicative-effectivitysublimation-〈as-to-underlying,-ontological-commitment $-<$ implied — self-assuredness-ofontological-good-faith/authenticity $\sim$ postconverging-dementating/structuring/paradigming -as-being-as-of-existential-reality $>>$ as to lack of 'relativeontological-completeness ${ }^{87}$-apriorising/axiomatising/referencing-psychologism enculturated/constructed social-pragmatics-framing-of-predicative-effectivity-sublimation〈as-to-underlying,-ontological-commitment $-<$ implied — self-assuredness-of-ontological-goodfaith/authenticity postconverging-de-mentating/structuring/paradigming -as-being-as-ofexistential-reality $>>$ '. Consider in this regards, the preconverging/postconverging-dementative/structural/paradigmatic possibility of such an abstract human sophistic/pedantic presencing-absolutising-identitive-constitutedness ${ }^{14}$ sensibility/decorum strategy exercise with regards to say Einsteinian/theory-of-relativity-together-with-quantum-mechanicsaxiomatic-constructs if there was 'no positivism/rational-empiricism- 
apriorising/axiomatising/referencing-psychologism

enculturated/constructed

socialpragmatics-framing-of - predicative-effectivity-sublimation-〈as-to-underlying,-ontologicalcommitment $-<$ implied — self-assuredness-of-ontological-goodfaith/authenticity postconverging-de-mentating/structuring/paradigming -as-being-as-ofexistential-reality $>$ ' ' (as produced by the efforts of budding-positivists even as during their own epoch this was contested by their Establishment) that allowed for sublimating scientific thought to be integrated or rejected by its mere predicative-effectivity-sublimation-〈as-to-underlying,ontological-commitment $\quad<$ implied_-self-assuredness-of-ontological-goodfaith/authenticity postconverging-de-mentating/structuring/paradigming -as-being-as-ofexistential-reality $>$ (as to the 'positivism/rational-empiricismapriorising/axiomatising/referencing-psychologism enculturated/constructed socialpragmatics-framing-of - predicative-effectivity-sublimation-〈as-to-underlying,-ontologicalcommitment $-<$ implied—self-assuredness-of-ontological-goodfaith/authenticity postconverging-de-mentating/structuring/paradigming -as-being-as-ofexistential-reality $>$ )), then there is nothing inherently telling that the latter physics Establishment will have just acknowledged such a theoretical construct as to its then human sophistic/pedantic ${ }^{7}$ presencing-absolutising-identitive-constitutedness ${ }^{14}$ sensibility/decorum perceived social-stake-contention-or-confliction (as to the reality of 'human notional firstnaturedness-formativeness-<as-to-eventualising -inkling-drive - or - seedingmisprising $>$ temporal-to-intemporal-dispositions- $<$ so-construed-as-from-perspectiveontological-normalcy/postconvergence> accordioning-〈as-of-varying-individuationscontextually-transverse-desublimation/sublimation,-as-to-thewavering/redounding/waveforming of-their-referencing-and-their-devolved-referencingimbued-ontological-performance -<including-virtue-as-ontology $>>$ at uninstitutionalisedthreshold ${ }^{102}$ as reflecting both desublimating ${ }^{4}$ historicity-tracing-in-presencing- 
hyperrealisation/hyperreal-transposition and sublimating ${ }^{4}$ historiality/ontologicaleventfulness ${ }^{3}$ /ontological-aesthetic-tracing-<perspective-ontologicalnormalcy/postconvergence-reflected-'epistemicity-relativism-determinism'> possibilities'). The point here is to highlight that across all registry-worldviews/dimensions blurriness$<$ sterilising/anecdotalising/trivialising-of-prospective-re-ontologising_by-preconverging,-indisontologising-formulaic-dragging-out/hollowing-out $>$ of ${ }^{56}$ meaningfulness-and-teleology ${ }^{99}$ at uninstitutionalised-threshold ${ }^{102}$ as to lack of 'relative-ontological-completeness ${ }^{87}$ apriorising/axiomatising/referencing-psychologism enculturated/constructed socialpragmatics-framing-of - predicative-effectivity-sublimation-〈as-to-underlying,-ontologicalcommitment $-<$ implied — self-assuredness-of-ontological-goodfaith/authenticity postconverging-de-mentating/structuring/paradigming -as-being-as-ofexistential-reality $>>$ ' inherently induces sophistic/pedantic dispositions (beyond-theconsciousness-awareness-teleology $\quad<$ of-preconverging-existential-extrication-as-ofexistential-unthought> ) with regards to social-stake-contention-or-confliction as to the social lack of ${ }^{103}$ universal-transparency ${ }^{104}$-〈transparency-of-totalising-entailing,-as-to-entailing$<$ amplituding/formative-epistemicity>totalising in-relative-ontological-completeness $>$ in the face of its prospective human-subpotency-aporia/undecidability/dilemma/oughtindeterminacy/deficiency/limitation/constraint. Further, all such successive 'relativeontological-completeness ${ }^{87}$-apriorising/axiomatising/referencing-psychologism enculturated/constructed social-pragmatics-framing-of-predicative-effectivity-sublimation〈as-to-underlying,-ontological-commitment $-<$ implied — self-assuredness-of-ontological-goodfaith/authenticity postconverging-de-mentating/structuring/paradigming -as-being-as-ofexistential-reality $>\rangle^{\prime} \quad$ are preconverging/postconverging-dementatively/structurally/paradigmatically about phenomenal/manifest sublimation-overdesublimation in existence as to: human-subpotency 'fatedness-of-sublimation-over- 
desublimation, to existence-potency sublimating-nascence,-disclosed-from-prospectiveepistemic-digression (in reflecting holographically-<conjugatively-and-transfusively $>$ the relative-unreflexivity/relative-reflexivity - ontological-contiguity of-the-humaninstitutionalisation-process ), as from human-subpotency ontological-faith-notion-orontological-fideism - imbued-underdetermination-of-motif-andapriorising/axiomatising/referencing-as-so-being-as-of-existential-reality as to the disseminative - sublimating-selectivity-of-ontological-goodfaith/authenticity postconverging-de-mentating/structuring/paradigming , overdesublimating deselectivity-of-ontological-bad-faith/inauthenticity -preconverging dementating/structuring/paradigming ', as the driver of the human-subpotency potentiating existential-disontologising/re-ontologising aporeticism $>$ becoming manifestation of sublimating-over-desublimating social-and-institutional-constructs-of- - meaningfulness-andteleology -in-cumulation/recomposuring all along in reflecting holographically$<$ conjugatively-and-transfusively $>$ the relative-unreflexivity/relative-reflexivity - ontologicalcontiguity of-the-human-institutionalisation-process ; as it dynamically induces (as of 'varying psychologismic epistemic-acutisation difficulty-<for, residualising \{decompulsing $\}$ delinearity for cogeney> magnitudes $\{$ of-experientiality/experiment $\} /$ scales —as-tosuccessively-profound-preconverging/postconverging-redementating/restructuring/reparadigming-frames-as-from-living,-institutionalising,-and-Beingontologising/infrastructure-of- ${ }^{5}$ meaningfulness-and-teleology 9 of prospective humansubpotency-aporia/undecidability/dilemma/ought-

indeterminacy/deficiency/limitation/constraint—imbued-'notional firstnaturednessformativeness- $<a s$ to eventualising inkling drive or seeding misprising $>$ temporal-tointemporal-dispositions-<so-construed-as-from-perspective-ontologicalnormalcy/postconvergence>'-existentialism-form-factor') successive prospective reasoning- 
through/messianic-reasoning for reasoning-from-results/afterthought as the secondnaturedinstitutionalisation of the <cumulating/recomposuring attendant-ontological-contiguity successive registry-worldviews/dimensions ${ }^{8}$ reference-of-thought-and- ${ }^{83}$ reference-of-thoughtdevolving- ${ }^{5}$ meaningfulness-and-teleology' so-construed as 'generating varying human sublimating-over-desublimating social-and-institutional-constructs-of- - meaningfulness-andteleology -in-cumulation/recomposuring

of apriorising/axiomatising/referencing/intelligibilitysettingup/measuringinstrumenting' as to their pre-eminence as of their 'prospectively projected relative-ontological-completeness dimensionality-of-sublimating $25<$ < amplituding/formative $>$ supererogatory $\sim$ dementativeness/epistemic-growth-or-conflatedness /transvaluativerationalising/transepistemicity/anamnestic-residuality/spirit-drivenness-equalisation〉'.

Sublimation in existence as such is rather as of originariness-parrhesia,-as-spontaneity-ofaestheticisation — supererogatory acuity/perspicacity/astuteness/edginess/incisiveness that doesn't adhere to professed naiveties implied with ${ }^{79}$ presencing-absolutising-identitiveconstitutedness ${ }^{14}$ sensibility/decorum supposed projections of candour that tend to arise with social lack of ${ }^{103}$ universal-transparency ${ }^{10}$-〈transparency-of-totalising-entailing,-as-to-entailing<amplituding/formative-epistemicity>totalising in-relative-ontological-completeness > associated with blurriness-<sterilising/anecdotalising/trivialising-of-prospective-reontologising_by-preconverging,-in-disontologising-formulaic-dragging-out/hollowing-out> of meaningfulness-and-teleology 9 poorly amenable to predicative-effectivity-sublimation-〈asto-underlying,-ontological-commitment $-<$ implied-self-assuredness-of-ontological-goodfaith/authenticity postconverging-de-mentating/structuring/paradigming -as-being-as-ofexistential-reality $>>$; and reflect the idea that there is no knowledge without sublimating knowledge in-the-very-first-place and such pretences often thrive on exploiting a 'false sense of a categorically/absolutely sublimated social-construct ordinariness/commensicality and social- 
vestedness/normativity-<discretely-implied-functionalism>', but then such an ontologicallyflawed conception can be divulged when we contemplate of prospective transcendence-andsublimity/sublimation/supererogatory $\sim$ de-mentativity reflection of the relative-ontologicalincompleteness 88 of the <cumulating/recomposuring attendant-ontological-contiguity $>$ succession of registry-worldviews/dimensions rather pointing out that the latter are ever always involved in an exercise of presencing-absolutising-identitive-constitutedness $<$ amplituding/formative-epistemicity $>$ totalising $\sim$ self-referencing-

syncretising/circularity/interiorising/akrasiatic-drag ${ }^{44}$ when analysed as from originariness/origination-〈so-construed-as-to-ontological-normalcy/postconvergenceperspective-scalarising-construal-of-existence) perspective of notional ${ }^{18}$ deprocrypticism. Insightfully it can be garnered that blurriness-<sterilising/anecdotalising/trivialising-ofprospective-re-ontologising_by-preconverging,-in-disontologising-formulaic-draggingout/hollowing-out> of ${ }^{5}$ meaningfulness-and-teleology ${ }^{9}$ (as leading to disparateness-ofconceptualisation-<unforegrounding-ment,-failing-prospectively-to-reflect‘immanent $\sim$ relative-unreflexivity/relative-reflexivity - ontological-contiguity '> due to lack of the ${ }^{103}$ universal-transparency ${ }^{104}$-〈transparency-of-totalising-entailing,-as-to-entailing<amplituding/formative-epistemicity>totalising in-relative-ontological-completeness > of sublimating-over-desublimating '<amplituding/formativeepistemicity $>$ totalising/circumscribing/delineating 'implicited_attendant-ontologicalcontiguity $^{67}$, educedexistentialising/contextualising/textalising_'intelligibility/epistemicity/reflexivity_contiguity$<$ imbued-notional cogency $>{ }^{40} \quad{ }^{45}$ foregrounding_entailment- $<$ in-succession-of-profound-

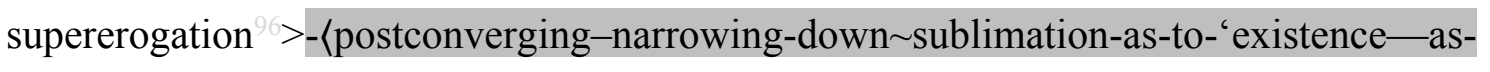
sublimating-withdrawal/unenframing/re-ontologising,-elicited-from-prospective-profoundsupererogation '-in-reflecting-'immanent relative unreflexivity/relative reflexivity 
ontological-contiguity ';-as-operative-notional deprocrypticism> in elucidating relativeunreflexivity/relative-reflexivity - ontological-contiguity $-<$ as-from-prospective-ontologicalnormalcy/postconvergence-epistemic-or-notional projective-perspective $>$ ') is intimately linked with the <cumulating/recomposuring attendant-ontological-contiguity $>$-successive registryworldviews/dimensions uninstitutionalised-threshold ${ }^{02}$; as to the lack of 'relative-ontologicalcompleteness ${ }^{87}$-apriorising/axiomatising/referencing-psychologism enculturated/constructed social-pragmatics-framing-of - predicative-effectivity-sublimation-〈as-to-underlying,ontological-commitment $\quad$-implied-self-assuredness-of-ontological-goodfaith/authenticity postconverging-de-mentating/structuring/paradigming -as-being-as-ofexistential-reality $>>$ '. In this regards, blurriness-<sterilising/anecdotalising/trivialising-ofprospective-re-ontologising_by-preconverging,-in-disontologising-formulaic-draggingout/hollowing-out> of ${ }^{56}$ meaningfulness-and-teleology ${ }^{9}$ with regards to the respective uninstitutionalised-threshold ${ }^{102}$ of recurrent-utter-uninstitutionalisation, ununiversalisation, nonpositivism/medievalism and procrypticism as to their respective apriorising/axiomatising/referencing-psychologism is overcome respectively (as so-construed from ontological-normalcy/postconvergence epistemic-projection perspective as of foregrounding_entailment- $<$ in-succession-of-profound-supererogation $>_{-}-\langle$postconvergingnarrowing-down sublimation-as-to-'existence - as-sublimating-withdrawal/unenframing/reontologising,-elicited-from-prospective-profound-supererogation '-in-reflecting'immanent relative unreflexivity/relative reflexivity - ontological-contiguity ';--as-operativenotional deprocrypticism) ) with the induced social ${ }^{103}$ universal-transparency ${ }^{104}$ 〈transparency-of-totalising-entailing,-as-to-entailing-<amplituding/formativeepistemicity>totalising in-relative-ontological-completeness $\rangle$ of: - base-institutionalisationapriorising/axiomatising/referencing-psychologism enculturated/constructed socialpragmatics-framing-of - predicative-effectivity-sublimation-〈as-to-underlying,-ontological- 
commitment $-<$ implied — self-assuredness-of-ontological-good-

faith/authenticity $\sim$ postconverging-de-mentating/structuring/paradigming -as-being-as-of-

existential-reality $>>\quad$ construed-as $\quad$ 'rulemaking-over-non-rulesapriorising/axiomatising/referencing-psychologism' given 'relative <amplituding/formative-

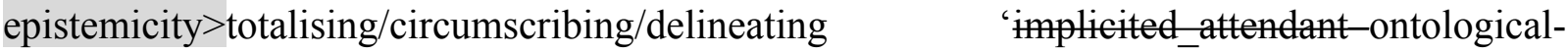
contiguity $^{67} \sim$ educed-

existentialising/contextalising/textualising_'intelligibility/epistemicity/reflexivity-contiguity$<$ imbued-notional cogency $>{ }^{40} \quad{ }^{45}$ foregrounding_entailment- $<$ in-succession-of-profoundsupererogation $>$-〈postconverging-narrowing-down $\sim$ sublimation-as-to-'existence-assublimating-withdrawal/unenframing/re-ontologising,-elicited-from-prospective-profoundsupererogation '-in-reflecting-'immanent relative-unreflexivity/relative-reflexivity ontological-contiguity ';--as-operative-notional deprocrypticism) in elucidating relativeunreflexivity/relative-reflexivity - ontological-contiguity ${ }^{67}<$ as-from-prospective-ontologicalnormalcy/postconvergence-epistemic-or-notional projective-perspective $>$ as to its prospectively induced scalarising as of human supererogatory/messianic intemporal and secondnatured socially-optimal instigative potency' at its given/defined institutionalisation ontologically-pertinent epistemic-conception of the-very-same overall phenomenality/manifestation of existence-as-sublimating-withdrawal/unenframing/reontologising,-elicited-from-prospective-profound-supererogation ${ }^{,}$(and so over prior recurrent-utter-uninstitutionalisation—apriorising/axiomatising/referencing-psychologism enculturated/constructed social-pragmatics-framing-of-predicative-effectivity-sublimation〈as-to-underlying,-ontological-commitment $-<$ implied - self-assuredness-of-ontological-goodfaith/authenticity $\sim$ postconverging-de-mentating/structuring/paradigming -as-being-as-ofexistential-reality $>>\quad$ construed-as 'non-rules — apriorising/axiomatising/referencingpsychologism,-as-impulsive-or-accidented-or-random-mental-disposition,-that-is-not- 
rulemaking apriorising/axiomatising/referencing-psychologism' given 'relative disparatenessof-conceptualisation-<unforegrounding-ment,-failing-prospectively-to-reflect'immanent relative-unreflexivity/relative-reflexivity ontological-contiguity '> as to prior descalarising totalisingly-ing-discretion/whim-of-thought of individuals-suboptimal instigative potency as of human notional firstnaturedness-formativeness-<as-toeventualising-inkling-drive or seeding-misprising> temporal-to-intemporal-dispositions$<$ so-construed-as-from-perspective-ontological-normalcy/postconvergence $>$ accordioning-〈asof-varying-individuations-contextually-transverse-desublimation/sublimation,-as-to-thewavering/redounding/waveforming of-their-referencing-and-their-devolved-referencingimbued-ontological-performance -<including-virtue-as-ontology $>\rangle$, at its given/defined uninstitutionalised-threshold ${ }^{102}$ ontologically-deficient epistemic-conception of 'the-very-same overall phenomenality/manifestation of existence - as-sublimating-withdrawal/unenframing/reontologising,-elicited-from-prospective-profound-supererogation $\left.{ }^{\prime \prime}\right), \quad-\quad{ }^{103}$ universalisationapriorising/axiomatising/referencing-psychologism enculturated/constructed socialpragmatics-framing-of - predicative-effectivity-sublimation-〈as-to-underlying,-ontologicalcommitment $-<$ implied - self-assuredness-of-ontological-goodfaith/authenticity $\sim$ postconverging-de-mentating/structuring/paradigming -as-being-as-ofexistential-reality>> construed-as $\quad{ }^{103}$ universalisation-directed-rulemaking-over-non-rulesapriorising/axiomatising/referencing-psychologism' given 'relative <amplituding/formativeepistemicity>totalising/circumscribing/delineating 'implicited_antentologicalcontiguity $^{67}$, educedexistentialising/contextmalising/textualising_'intelligibility/epistemicity/reflexivity_contiguity$<$ imbued-notional cogency $>{ }^{40} \quad{ }^{45}$ foregrounding_entailment- $<$ in-succession-of-profoundsupererogation >-〈postconverging-narrowing-down $\sim$ sublimation-as-to-'existence-assublimating-withdrawal/unenframing/re-ontologising,-elicited-from-prospective-profound- 
supererogation '-in-reflecting-'immanent relative-unreflexivity/relative-reflexivity

ontological-contiguity ';-as-operative-notional deprocrypticism) in elucidating relativeunreflexivity/relative-reflexivity ontological-contiguity $-<$ as-from-prospective-ontologicalnormalcy/postconvergence-epistemic-or-notional projective-perspective $>$ as to its prospectively induced scalarising as of human supererogatory/messianic intemporal and secondnatured socially-optimal instigative potency' at its given/defined institutionalisation ontologically-pertinent epistemic-conception of the-very-same overall phenomenality/manifestation of existence-as-sublimating-withdrawal/unenframing/reontologising,-elicited-from-prospective-profound-supererogation ' (and so over prior baseinstitutionalisation-ununiversalisation — apriorising/axiomatising/referencing-psychologism enculturated/constructed social-pragmatics-framing-of-predicative-effectivity-sublimation〈as-to-underlying,-ontological-commitment $-<$ implied — self-assuredness-of-ontological-goodfaith/authenticity postconverging-de-mentating/structuring/paradigming -as-being-as-ofexistential-reality $>>\quad$ construed-as $\quad$ 'rulemaking-over-non-rulesapriorising/axiomatising/referencing-psychologism,-that-is-not-universalisation-directed apriorising/axiomatising/referencing-psychologism' given 'relative disparateness-ofconceptualisation-<unforegrounding-ment,-failing-prospectively-to-reflect‘immanent $\sim$ relative - unreflexivity/relative-reflexivity - ontological-contiguity '> as to prior descalarising totalisingly-ing - discretion/whim-of-thought of individuals-suboptimal instigative potency as of human notional firstnaturedness-formativeness-<as-toeventualising inkling-drive or seeding-misprising> temporal-to-intemporal-dispositions$<$ so-construed-as-from-perspective-ontological-normalcy/postconvergence $>$ accordioning-〈asof-varying-individuations-contextually-transverse-desublimation/sublimation,-as-to-thewavering/redounding/waveforming of-their-referencing-and-their-devolved-referencingimbued-ontological-performance -<including-virtue-as-ontology $>>$ ' at its given/defined 
uninstitutionalised-threshold ${ }^{102}$ ontologically-deficient epistemic-conception of 'the-very-same overall phenomenality/manifestation of existence — as-sublimating-withdrawal/unenframing/reontologising,-elicited-from-prospective-profound-supererogation ' $), \quad$ - positivism/rationalempiricism - apriorising/axiomatising/referencing-psychologism enculturated/constructed social-pragmatics-framing-of - predicative-effectivity-sublimation-〈as-to-underlying,ontological-commitment $-<$ implied_-self-assuredness-of-ontological-goodfaith/authenticity postconverging-de-mentating/structuring/paradigming -as-being-as-ofexistential-reality $>>\quad$ construed-as 'positivising/rational-empiricism-based-universalisationdirected-rulemaking-over-non-rules_—apriorising/axiomatising/referencing-psychologism’ given 'relative <amplituding/formative-epistemicity>totalising/circumscribing/delineating 'implicited_attendant-ontological-contiguity ${ }^{67}$ ' educedexistentialising/contextualising/textualising_'intelligibility/epistemicity/reflexivity-contiguity$<$ imbued-notional cogency $>{ }^{40} \quad{ }^{45}$ foregrounding_entailment- $<$ in-succession-of-profoundsupererogation $>$-〈postconverging-narrowing-down $\sim$ sublimation-as-to-'existence-assublimating-withdrawal/unenframing/re-ontologising,-elicited-from-prospective-profoundsupererogation '-in-reflecting-'immanent relative-unreflexivity/relative-reflexivity ontological-contiguity ';--as-operative-notional deprocrypticism) in elucidating relativeunreflexivity/relative-reflexivity - ontological-contiguity ${ }^{6}<$ as-from-prospective-ontologicalnormalcy/postconvergence-epistemic-or-notional projective-perspective $>$ as to its prospectively induced scalarising as of human supererogatory/messianic intemporal and secondnatured socially-optimal instigative potency' at its given/defined institutionalisation ontologically-pertinent epistemic-conception of the-very-same overall phenomenality/manifestation of existence-as-sublimating-withdrawal/unenframing/reontologising,-elicited-from-prospective-profound-supererogation , (and so over prior universalisation-non-positivism/medievalism—apriorising/axiomatising/referencing- 
psychologism enculturated/constructed social-pragmatics-framing-of-predicative-effectivitysublimation-〈as-to-underlying,-ontological-commitment $-<$ implied-self-assuredness-ofontological-good-faith/authenticity postconverging-dementating/structuring/paradigming -as-being-as-of-existential-reality $>>$ construed-as

' ${ }^{103}$ universalisation-directed-rulemaking-over-non-rulesapriorising/axiomatising/referencing-psychologism,-that-is-not-positivising/rationalempiricism-based apriorising/axiomatising/referencing-psychologism' given 'relative disparateness-of-conceptualisation-<unforegrounding-ment,-failing-prospectively-to-reflect'immanent relative-unreflexivity/relative-reflexivity - ontological-contiguity '> as to prior descalarising totalisingly-ing-discretion/whim-of-thought of individuals-suboptimal instigative potency as of human notional firstnaturedness-formativeness-<as-toeventualising inkling-drive-or-seeding-misprising $>$ temporal-to-intemporal-dispositions$<$ so-construed-as-from-perspective-ontological-normalcy/postconvergence $>$ accordioning-〈asof-varying-individuations-contextually-transverse-desublimation/sublimation,-as-to-thewaveringtredounding of -their-referencing-and-their-devolved-referencingimbued-ontological-performance -<including-virtue-as-ontology $>\rangle$ ' at its given/defined uninstitutionalised-threshold ${ }^{102}$ ontologically-deficient epistemic-conception of 'the-very-same overall phenomenality/manifestation of existence - as-sublimating-withdrawal/unenframing/reontologising,-elicited-from-prospective-profound-supererogation $\left.{ }^{\prime}\right)$, and prospectively deprocrypticism — apriorising/axiomatising/referencing-psychologism enculturated/constructed social-pragmatics-framing-of - predicative-effectivity-sublimation-〈as-to-underlying,ontological-commitment ${ }^{6}<$ implied-self-assuredness-of-ontological-goodfaith/authenticity postconverging-de-mentating/structuring/paradigming -as-being-as-ofexistential-reality $>>$ construed-as 'preempting — disjointedness-as-of- reference-of-thought,as-to- ${ }^{6}<$ amplituding/formative-epistemicity>growth-or-conflatedness ${ }^{13} /$ transvaluative- 
rationalising/transepistemicity/anamnestic-residuality/spirit-drivenness'—in-supersedingmere-formulaic-positivising/rational-empiricism-based-universalisation-directed-rulemakingover-non-rules - apriorising/axiomatising/referencing-psychologism' given 'relative $<$ amplituding/formative-epistemicity>totalising/circumscribing/delineating 'implicited_attendant-ontological-contiguity ${ }^{67}$; educedexistentialising/contextualising/textualising_intelligibility/epistemicity/reflexivity-contiguity$<$ imbued-notional cogency $>{ }^{40} \quad{ }^{45}$ foregrounding_entailment- $<$ in-succession-of-profoundsupererogation $>$-〈postconverging-narrowing-down $\sim$ sublimation-as-to-'existence-assublimating-withdrawal/unenframing/re-ontologising,-elicited-from-prospective-profoundsupererogation '-in-reflecting-'immanent relative-unreflexivity/relative-reflexivity ontological-contiguity ';-as-operative-notional deprocrypticism> in elucidating relativeunreflexivity/relative-reflexivity - ontological-contiguity ${ }^{6}<$ as-from-prospective-ontologicalnormalcy/postconvergence-epistemic-or-notional projective-perspective $>$ as to its prospectively induced scalarising as of human supererogatory/messianic intemporal and secondnatured socially-optimal instigative potency' at its given/defined institutionalisation ontologically-pertinent epistemic-conception of the-very-same overall phenomenality/manifestation of existence-as-sublimating-withdrawal/unenframing/reontologising,-elicited-from-prospective-profound-supererogation , ${ }^{,}$(and so over prior positivism- ${ }^{8}$ procrypticism - apriorising/axiomatising/referencing-psychologism enculturated/constructed social-pragmatics-framing-of-predicative-effectivity-sublimation〈as-to-underlying,-ontological-commitment $-<$ implied — self-assuredness-of-ontological-goodfaith/authenticity postconverging-de-mentating/structuring/paradigming -as-being-as-ofexistential-reality>> construed-as 'mere-formulaic-positivising/rational-empiricism-baseduniversalisation-directed-rulemaking-over-non-rules_-apriorising/axiomatising/referencingpsychologism,-that-is-not-of-preempting - disjointedness-as-of- ${ }^{8}$ reference-of-thought,-as-to- 
${ }^{<}<$amplituding/formative-epistemicity>growth-or-conflatedness ${ }^{13} /$ transvaluative- $^{-}$

rationalising/transepistemicity/anamnestic-residuality/spirit-drivenness'_-in-supersedingmere-formulaic-positivising/rational-empiricism-based-universalisation-directed-rulemakingover-non-rules — apriorising/axiomatising/referencing-psychologism' given 'relative disparateness-of-conceptualisation-<unforegrounding-ment,-failing-prospectively-to-reflect‘immanent relative-unreflexivity/relative-reflexivity ontological-contiguity ' $>$ as to prior descalarising totalisingly-ing-discretion/whim-of-thought of individuals-suboptimal instigative potency as of human notional firstnaturedness-formativeness-<as-toeventualising-inkling drive-or-seeding-misprising > temporal-to-intemporal-dispositions$<$ so-construed-as-from-perspective-ontological-normalcy/postconvergence $>$ accordioning-〈asof-varying-individuations-contextually-transverse-desublimation/sublimation,-as-to-thewavering/redounding/waveforming of-their-referencing-and-their-devolved-referencingimbued-ontological-performance -<including-virtue-as-ontology $>$ ', at its given/defined uninstitutionalised-threshold ${ }^{102}$ ontologically-deficient epistemic-conception of 'the-very-same overall phenomenality/manifestation of existence - as-sublimating-withdrawal/unenframing/reontologising,-elicited-from-prospective-profound-supererogation ' ${ }^{9}$, with the 'deprocrypticism — apriorising/axiomatising/referencing-psychologism

enculturated/constructed social-pragmatics-framing-of-predicative-effectivity-sublimation〈as-to-underlying,-ontological-commitment $-<$ implied - self-assuredness-of-ontological-goodfaith/authenticity postconverging-de-mentating/structuring/paradigming -as-being-as-ofexistential-reality $>>$ ' peculiarly/uniquely differentiated from the 'positivism- ${ }^{80}$ procrypticismapriorising/axiomatising/referencing-psychologism enculturated/constructed socialpragmatics-framing-of - predicative-effectivity-sublimation-〈as-to-underlying,-ontologicalcommitment $-<$ implied—self-assuredness-of-ontological-good- 
existential-reality $>>\rangle^{\prime}$ in that notional ${ }^{18}$ deprocrypticism as of its originariness/origination-〈soconstrued-as-to-ontological-normalcy/postconvergence-perspective-scalarising-construal-ofexistence) perspective construes of prospective knowledge-reification $\sim$ gesturing-andaccounting - of-epistemic-phenomenalism- $<$ inprospective_psychologismic apriorising/axiomatising/referencing-\{of-‘prospectively_ implicited_attendant-ontological-contiguity ' educedexistentialising/contextualising/textualising_ 'intelligibility/epistemicity/reflexivity-contiguity$<$ imbued-notional cogency $\left.>^{\prime}\right\}$-conflatedness -in-\{preconverging-ment by\} postconverging-entailment $>$ as of the 'full ontological implications of full human limitedmentation-capacity-deepening —as subjecting limitedness/human-subpey to 'educedunlimitedness/existence-sublimating nascence' ${ }^{33}$ as to its deepest/most-profound foregrounding_entailment- $<$ in-succession-of-profound-supererogation $>_{-}-\langle$postconverging narrowing-down $\sim$ sublimation-as-to-'existence - as-sublimating-withdrawal/unenframing/reontologising,-elicited-from-prospective-profound-supererogation ' '-in-reflecting'immanent relative unreflexivity/relative reflexivity - ontological-contiguity ';-as-operativenotional deprocrypticism $\rangle$ thus speaking to deprocryticism requisite preconverging/postconverging-de-mentative/structural/paradigmatic delineation of both the existentially-<disontologising/re-ontologising aporeticism $>$ contextualised 'sublimating ontological-good-faith/authenticity $\sim$ postconverging-de-mentating/structuring/paradigming underlying intemporal ontological-performance ${ }^{72}-<$ including-virtue-asontology $>$ /morality/ethics/justice/etc. (as of dimensionality-of-sublimating <<amplituding/formative>supererogatory $\sim$ de-mentativeness/epistemic-growth-orconflatedness /transvaluative-rationalising/transepistemicity/anamnestic-residuality/spiritdrivenness-equalisation) profound dispensing-with-immediacy-for-relative-ontologicalcompleteness $^{87}$-by-reification/contemplative-distension projected 
apriorising/axiomatising/referencing-psychologism)' and 'desublimating ontological-badfaith/inauthenticity $\sim$ preconverging-de-mentating/structuring/paradigming ${ }^{65} \quad$ underlying temporal ontological-performance ${ }^{72}-<$ including-virtue-as-ontology $>/$ morality/ethics/justice/etc. (as of dimensionality-of-desublimating-lack-of $-\langle<$ amplituding/formative $>$ supereregatery dementativeness/epistemic-growth-or-conflatedness /transvaluativerationalising/transepistemicity/anamnestic-residuality/spirit-drivenness-equalisation〉 shallow/lack-of dispensing-with-immediacy-for-relative-ontological-completeness ${ }^{87}$-byreification/contemplative-distension ${ }^{27}$ projected apriorising/axiomatising/referencingpsychologism)' associated with any ' ${ }^{2}$ deprocrypticism-or-preempting-disjointedness-as-ofreference-of-thought prospective knowledge-reification $\sim$ gesturing-and-accounting-ofepistemic-phenomenalism-<in-

prospective_psychologismic apriorising/axiomatising/referencing-\{of-'prospectively implicited_attendant-ontological-contiguity ' educedexistentialising/contextualising/textualising_'intelligibility/epistemicity/reflexivity_contiguity<imbued-notional cogency $>\quad\}$-conflatedness - in-\{preconverging-ment by\} postconverging-entailment> as ever always about preserving the ascendancy of organicknowledge in superseding-and-overriding mechanical-knowledge (with the latter rather associated with <amplituding/formative> wooden-language-〈imbued-temporal-mereform/virtualities/dereification/akrasiatic-drag/denatured/preconverging-or-dementing narratives - of-the- reference-of-thought- categorical-imperatives/axioms/registryteleology >) thus involving the anticipation of human temporal-to-intemporal ontologicalperformance $^{72}-<$ including-virtue-as-ontology $>$ /morality/ethics/justice/etc. of prospective knowledge-reification $\sim$ gesturing-and-accounting — of-epistemic-phenomenalism- $<$ inprospective_psychologismic apriorising/axiomatising/referencing-\{of-'prospectively_ implicited_attendant-ontological-contiguity ' educed- 
existentialising/contextualising/textualising_ 'intelligibility/epistemicity/reflexivity-contiguity<imbued-notional cogency $>$ ' \}-conflatedness -in-\{preconverging ment by\}

postconverging entailment> imbued $>\quad$ reference-of-thought- ${ }^{8}$ categoricalimperatives/axioms/registry-teleology ${ }^{9}$ (and so as to the deprocrypticismapriorising/axiomatising/referencing-psychologism given 'ontological-goodfaith/authenticity ${ }^{69} \sim$ postconverging-de-mentating/structuring/paradigming $70 \quad$ existentialcondescension- $<$ of-apriorising/axiomatising/referencing-psychologism $>$ projection of originariness/origination-〈so-construed-as-to-ontological-normalcy/postconvergenceperspective-scalarising-construal-of-existence))'; with the above articulation of the $<$ cumulating/recomposuring attendant-ontological-contiguity $>$-successive registryworldviews/dimensions 'relative-ontological-completeness ${ }^{87}$ apriorising/axiomatising/referencing-psychologism enculturated/constructed socialpragmatics-framing-of - predicative-effectivity-sublimation-〈as-to-underlying,-ontologicalcommitment $-<$ implied—self-assuredness-of-ontological-goodfaith/authenticity postconverging-de-mentating/structuring/paradigming -as-being-as-ofexistential-reality $>>$ so-reflecting comprehensively the relative-unreflexivity/relativereflexivity - ontological-contiguity ${ }^{67} \sim$ of-the-human-institutionalisation-process ${ }^{68}$ involving human limited-mentation-capacity-deepening —as-subjecting limitedness/human-subpotency to-'educed-unlimitedness/existence-sublimating nascence' ${ }^{53}$ increasing ontologicalperformance ${ }^{2}$-<including-virtue-as-ontology $>$ /morality/ethics/justice/etc. as to 'its originariness-parrhesia,-as-spontaneity-of-aestheticisationsupererogatery acuity/perspicacity/astuteness/edginess/incisiveness-ofapriorising/axiomatising/referencing/intelligibilitysettingup/measuringinstrumenting -forconceptualisation inducing of the <cumulating/recomposuring attendant-ontologicalcontiguity >-successive registry-worldviews/dimensions increasingly profound secondnatured 
methodologising/mutualising/organising/institutionalising reproducibilitymathesis/motif/thrownness-disposition,-as-reproducibility-of-aestheticisation' and so as human reference-of-thought-and- ${ }^{8}$ reference-of-thought- ${ }^{8}$ devolving- ${ }^{5}$ meaningfulness-andteleology ${ }^{9}$ engendered sublimating ${ }^{4}$ historiality/ontological-eventfulness ${ }^{38} /$ ontologicalaesthetic-tracing-<perspective-ontological-normalcy/postconvergence-reflected-'epistemicityrelativism-determinism'> in existence-as-the-absolute-a-priori-ofconceptualisation and existence — as-sublimating-withdrawal/unenframing/re-ontologising,elicited-from-prospective-profound-supererogation $-<$ as-to-perspective-ontologicalnormalcy/postconvergence-implied-‘prospective-aporeticism-overcoming/unovercoming’> (with the critical insight here for instance that the Socratic-philosophers ${ }^{56}$ meaningfulness-andteleology as of ${ }^{103}$ universalising-idealisation 'is not a relic of thought' and it is very much 'historially alive/living' as to being pertinent to modern-day ${ }^{103}$ universalising implications of thought but for when prospective contextualisation requires ${ }^{103}$ universalising positivising/rational-empiricism just as we can garner that Newtonian/Leibzinian physics 'is not a relic of thought' and it is very much 'historially alive/living' as to being pertinent to modernday physics but for when prospective contextualisation requires theory-of-relativity-togetherwith-quantum-mechanics - axiomatic-constructs, and thus reflecting comprehensively that the relative-unreflexivity/relative-reflexivity - ontological-contiguity ${ }^{67}$ of-the-humaninstitutionalisation-process $^{68}$ as to its implied overall notional deprocrypticismapriorising/axiomatising/referencing-psychologisms 'enculturated/constructed socialpragmatics-framing-of - predicative-effectivity-sublimation-〈as-to-underlying,-ontological-

commitment $-<$ implied—self-assuredness-of-ontological-goodfaith/authenticity postconverging-de-mentating/structuring/paradigming -as-being-as-ofexistential-reality $>>_{>}$of relative-ontological-completeness ${ }^{87}$, rather speaks of human limitedmentation-capacity-deepening —as-subjecting limitedness/human-subpotency-to-'educed- 
unlimitedness/existence-sublimating nascence' ${ }^{53}$ as of psychoanalytic-unshackling/memeticreordering/institutional-recomposuring prospectively induced ${ }^{56}$ meaningfulness-and-teleology as the <cumulating/recomposuring attendant-ontological-contiguity >-successive registryworldviews/dimensions apriorising/axiomatising/referencing-psychologisms). Further, 'human-subpotency ontological-faith-notion-or-ontological-fideism - imbuedunderdetermination-of-motif-and-apriorising/axiomatising/referencing-as-so-being-as-ofexistential-reality as to the disseminative-sublimating-selectivity-of-ontological-goodfaith/authenticity postconverging-de-mentating/structuring/paradigming , overdesublimating deselectivity-of-ontological-bad-faith/inauthenticity opreconverging dementating/structuring/paradigming , implies that the <cumulating/recomposuring attendantontological-contiguity >-successive registry-worldviews/dimensions given 'relativeontological-completeness ${ }^{87}$-apriorising/axiomatising/referencing-psychologism enculturated/constructed social-pragmatics-framing-of-predicative-effectivity-sublimation〈as-to-underlying,-ontological-commitment $-<$ implied — self-assuredness-of-ontological-goodfaith/authenticity postconverging-de-mentating/structuring/paradigming -as-being-as-ofexistential-reality $>>$ ' as to their relative ontological-good-faith/authenticity ${ }^{\circ} \sim$ postconvergingde-mentating/structuring/paradigming sublimating affirmation/projection/assertion/notional self-distantiation/dueness-validatinglogicising/suitable-measuringinstrument-validating-measuring-<as-to-postconverging-ordialectical-thinking -apriorising-psychologism>' supersede-and-override their prior 'relativeontological-incompleteness ${ }^{8}$ — apriorising/axiomatising/referencing-psychologism enculturated/constructed social-pragmatics-framing-of-predicative-effectivity-sublimation〈as-to-underlying,-ontological-commitment $-<$ implied — self-assuredness-of-ontological-goodfaith/authenticity postconverging-de-mentating/structuring/paradigming -as-being-as-ofexistential-reality $>\rangle^{\prime}$ as to their relative ontological-bad-faith/inauthenticity ${ }^{6} \sim$ preconverging- 
de-mentating/structuring/paradigming desublimating unaffirmation/deprojection/deassertion/epistemic-decadence/undueness-invalidatinglogicising/unsuitable-measuringinstrument-invalidating-measuring-<as-to-preconverging-ordementing -apriorising-psychologism> and 'thus establishing the relative-ontologicalcompleteness ${ }^{87}$-apriorising/axiomatising/referencing-psychologism respective aposteriorising/logicising/deriving/intelligising/measuring- ${ }^{5}$ meaningfulness-and-teleology ${ }^{99}$ as logical-basis' and this is so-reflected with: 'rulemaking-over-non-rulesapriorising/axiomatising/referencing-psychologism' superseding-and-overriding 'non-rulesapriorising/axiomatising/referencing-psychologism,-as-impulsive-or-accidented-or-randommental-disposition,-that-is-not-rulemaking apriorising/axiomatising/referencing-psychologism' for 'base-institutionalisation-ununiversalisation ${ }^{56}$ meaningfulness-and-teleology ${ }^{9}$ induced sublimation as of existence-as-sublimating-withdrawal/unenframing/re-ontologising,-elicitedfrom-prospective-profound-supererogation '; ' '103 universalisation-directed-rulemaking-overnon-rules_-apriorising/axiomatising/referencing-psychologism' superseding-and-overriding 'rulemaking-over-non-rules_ a priorising/axiomatising/referencing-psychologism,-that-is-notuniversalisation-directed apriorising/axiomatising/referencing-psychologism' for ' ${ }^{103}$ universalisation-non-positivism/medievalism $\quad{ }^{56}$ meaningfulness-and-teleology ${ }^{9}$ induced sublimation as of existence-as-sublimating-withdrawal/unenframing/re-ontologising,-elicitedfrom-prospective-profound-supererogation '; 'positivising/rational-empiricism-baseduniversalisation-directed-rulemaking-over-non-rules — apriorising/axiomatising/referencingpsychologism' superseding-and-overriding ' ${ }^{103}$ universalisation-directed-rulemaking-over-nonrules - apriorising/axiomatising/referencing-psychologism,-that-is-not-positivising/rationalempiricism-based apriorising/axiomatising/referencing-psychologism' for 'positivismprocrypticism ${ }^{56}$ meaningfulness-and-teleology induced sublimation as of existence-assublimating-withdrawal/unenframing/re-ontologising,-elicited-from-prospective-profound- 
supererogation '; and 'preempting-disjointedness-as-of- ${ }^{\circ}$ reference-of-thought,-as-to${ }^{3}<$ amplituding/formative-epistemicity>growth-or-conflatedness $13 /$ transvaluativerationalising/transepistemicity/anamnestic-residuality/spirit-drivenness'—in-supersedingmere-formulaic-positivising/rational-empiricism-based-universalisation-directed-rulemakingover-non-rules — apriorising/axiomatising/referencing-psychologism' superseding-andoverriding 'mere-formulaic-positivising/rational-empiricism-based-universalisation-directedrulemaking-over-non-rules — apriorising/axiomatising/referencing-psychologism,-that-is-notof-preempting — disjointedness-as-of- ${ }^{83}$ reference-of-thought,-as-to- ${ }^{6}<$ amplituding/formativeepistemicity>growth-or-conflatedness ${ }^{13} /$ transvaluative-

rationalising/transepistemicity/anamnestic-residuality/spirit-drivenness'—in-supersedingmere-formulaic-positivising/rational-empiricism-based-universalisation-directed-rulemakingover-non-rules_-apriorising/axiomatising/referencing-psychologism' for 'prospective notional ${ }^{18}$ deprocrypticism ${ }^{5}$ meaningfulness-and-teleology 9 induced sublimation as of existence — as-sublimating-withdrawal/unenframing/re-ontologising,-elicited-fromprospective-profound-supererogation '. The implication here is that there is no logicalbasis/logic,-as-derived-from $\sim$ transversality-<for-sublimating-existentialeventuating/denouement, from 'thinking at first/pure predisposition preemptive of prospective-disontologising/subontologising' - as-of-prospectively-disambiguated-affirmedand-unaffirmed-'motif-and-apriorising/axiomatising/referencing' $>101$ as of our positivismprocrypticism ${ }^{7}$ presencing-absolutising-identitive-constitutedness ${ }^{14}$ for the so-projected prospective notional ${ }^{18}$ deprocrypticism ${ }^{56}$ meaningfulness-and-teleology ${ }^{9}$ but rather its prospectively induced sublimation as of existence — as-sublimating-withdrawal/unenframing/reontologising,-elicited-from-prospective-profound-supererogation (as the logical-basis/logic,as-derived-from $\sim$ transversality- $<$ for-sublimating-existential-eventuating/denouement-from'thinking at first/pure-predisposition-preemptive-of-prospective- 
disontologising/subontologising' as-of-prospectively-disambiguated-affirmed-and-

unaffirmed-'motif-and-apriorising/axiomatising/referencing'>

of

prospective

notional ${ }^{18}$ deprocrypticism ${ }^{56}$ meaningfulness-and-teleology ${ }^{9}$ is rather the inner working coherence/contiguity of its apriorising/axiomatising/referencing construct such that our positivism- procrypticism ${ }^{56}$ meaningfulness-and-teleology ${ }^{9}$ logical-basis/logic,-as-derivedfrom $\sim$ transversality-<for-sublimating-existential-eventuating/denouement,-from-'thinking-atfirst/pure-predisposition-preemptive-of-prospective-disontologising/subontologising' as-ofprospectively-disambiguated-affirmed-and-unaffirmed-'motif-andapriorising/axiomatising/referencing' $>01 \quad$ is $\quad$ preconverging/postconverging-dementatively/structurally/paradigmatically incompetent-and-irrelevant but for our projectiveinsights capacity for grasping prospective notional ${ }^{18}$ deprocrypticism ${ }^{56}$ meaningfulness-andteleology sublimation as of existence-as-sublimating-withdrawal/unenframing/reontologising,-elicited-from-prospective-profound-supererogation ). This further points out that the <cumulating/recomposuring attendant-ontological-contiguity $>$-successive registryworldviews/dimensions 'relative-ontological-completeness ${ }^{87}$ apriorising/axiomatising/referencing-psychologism enculturated/constructed socialpragmatics-framing-of - predicative-effectivity-sublimation-〈as-to-underlying,-ontologicalcommitment $-<$ implied — self-assuredness-of-ontological-goodfaith/authenticity postconverging-de-mentating/structuring/paradigming -as-being-as-ofexistential-reality $>\rangle$ ' are rather 'existence sublimation imbued cut-off points of logical engagement as transversality- $<$ for-sublimating-existential-eventuating/denouement, - from'thinking at first/pure-predisposition-preemptive-of prospectivedisontologising/subontologising' - as-of-prospectively-disambiguated-affirmed-andunaffirmed-'motif-and-apriorising/axiomatising/referencing' $>{ }^{101}$ wherein for example there is no common logical-basis/logic,-as-derived-from $\sim$ transversality-<for-sublimating-existential- 
eventuating/denouement, from-'thinking at first/pure-predisposition-preemptive-of

prospective-disontologising/subontologising' as-of-prospectively-disambiguated-affirmedand-unaffirmed-'motif-and-apriorising/axiomatising/referencing'>101 between nonuniversalising sophistry and ${ }^{103}$ universalising-idealisation of Socratic-philosophers and likewise between budding-positivists and non-positivising medieval scholasticism and this author claims as well between modern-day institutional-being-and-craft pedantising/muddling/formulaichollowing-out - in-subontologisation/subpotentiation-〈blurring/undermining-of-prospectivetotalising-entailing,-as-to-entailing-<amplituding/formative-epistemicity $>$ totalising $\sim$ inrelative-ontological-completeness $\rangle$ and prospective ${ }^{18}$ deprocrypticism-or-preemptingdisjointedness-as-of- ${ }^{8}$ reference-of-thought as already being manifested in the patently nonintellectual and ontologically-decadent populism and media-driven campaigning against postmodern-thought that is wary of genuine intellectual engagement as to the sublimating veracity of postmodern-thought; and thus rather requiring the sublimating affirmation/projection/assertion/notional self-distantiation/dueness-validating-

logicising/suitable-measuringinstrument-validating-measuring-<as-to-postconverging-ordialectical-thinking -apriorising-psychologism> of the prospective 'relative-ontologicalcompleteness ${ }^{87}$-apriorising/axiomatising/referencing-psychologism enculturated/constructed social-pragmatics-framing-of-predicative-effectivity-sublimation-〈as-to-underlying,ontological-commitment $\quad<$ implied_-self-assuredness-of-ontological-goodfaith/authenticity postconverging-de-mentating/structuring/paradigming -as-being-as-ofexistential-reality $>\rangle$, imbued $\quad{ }^{4}$ foregrounding_entailment- $<$ in-succession-of-profoundsupererogation ${ }^{9}>-$ - postconverging-narrowing-down $\sim$ sublimation-as-to-'existence - assublimating-withdrawal/unenframing/re-ontologising,-elicited-from-prospective-profoundsupererogation '-in-reflecting-'immanent relative-unreflexivity/relative-reflexivity ontological-contiguity ';-as-operative-notional deprocrypticism) while reflecting the 
desublimating unaffirmation/deprojection/deassertion/epistemic-decadence/unduenessinvalidating-logicising/unsuitable-measuringinstrument-invalidating-measuring-<as-topreconverging-or-dementing -apriorising-psychologism> of the prior 'relative-ontologicalincompleteness ${ }^{8}$ — apriorising/axiomatising/referencing-psychologism enculturated/constructed social-pragmatics-framing-of-predicative-effectivity-sublimation〈as-to-underlying,-ontological-commitment $-<$ implied — self-assuredness-of-ontological-goodfaith/authenticity postconverging-de-mentating/structuring/paradigming -as-being-as-of-

existential-reality $>\rangle$ ' (and so reflecting 'Derridean underdetermination-imbued force/violence conception' and 'Foucauldian knowledge/power conception construed as knowledgeempowerment/ignorance-disempowerment' as to supererogating ' 'sublimation affirmation/projection/assertion/notional self-distantiation/dueness-validatinglogicising/suitable-measuringinstrument-validating-measuring-<as-to-postconverging-ordialectical-thinking -apriorising-psychologism>’ 'desublimation unaffirmation/deprojection/deassertion/epistemic-decadence/undueness-invalidatinglogicising/unsuitable-measuringinstrument-invalidating-measuring-<as-to-preconverging-ordementing -apriorising-psychologism>'\} so-underlining existence-as-the-absolute-a-prioriof-conceptualisation and existence_-as-sublimating-withdrawal/unenframing/reontologising,-elicited-from-prospective-profound-supererogation $-<$ as-to-perspectiveontological-normalcy/postconvergence-implied-'prospective-aporeticismovercoming/unovercoming'>). This insight equally explains why human $<$ amplituding/formative-epistemicity $>$ causality at its most profound construal is rather as of underlying ontological-good-faith/authenticity $\sim$ postconverging-dementating/structuring/paradigming over ontological-badfaith/inauthenticity $\sim$ preconverging-de-mentating/structuring/paradigming $\quad$ imbued sublimating-over-desublimating ontological implications and so with regards to underlying 
underdetermination-of-motif-and-apriorising/axiomatising/referencing-as-so-being-as-of-

existential-reality; as the ontological-good-faith/authenticity $\sim$ postconverging-dementating/structuring/paradigming 70 (as of dimensionality-of-sublimating ${ }^{25}$ <<amplituding/formative>supererogatory $\sim$ de-mentativeness/epistemic-growth-or-

conflatedness /transvaluative-rationalising/transepistemicity/anamnestic-residuality/spirit-

drivenness-equalisation> as to its profound dispensing-with-immediacy-for-relativeontological-completeness ${ }^{87}$-by-reification/contemplative-distension ${ }^{27}$ ) reflects the originarinessparrhesia,-as-spontaneity-of-aestheticisation-

acuity/perspicacity/astuteness/edginess/incisiveness-ofapriorising/axiomatising/referencing/intelligibilitysettingup/measuringinstrumenting -forconceptualisation as intemporal-projection reasoning-through/messianic-reasoning that runs all along the <cumulating/recomposuring attendant-ontological-contiguity $>$-succession of registry-worldviews/dimensions as to human limited-mentation-capacity-deepening-assubjecting limitedness/human-subpotency to-'educed-unlimitedness/existence-sublimating naseence' ${ }^{53}$ enabling human ${ }^{83}$ reference-of-thought-and- ${ }^{8}$ reference-of-thought- ${ }^{8}$ devolvingmeaningfulness-and-teleology 9 induced transcendence-andsublimity/sublimation/supererogatoryade-mentativity whereas the ontological-badfaith/inauthenticity ${ }^{64}$ preconverging-de-mentating/structuring/paradigming $\quad$ (as $\quad$ of dimensionality-of-desublimating-lack-of $-\langle<$ amplituding/formative $>$ supererogatory $\sim$ de-

\section{mentativeness/epistemic-growth-or-conflatedness /transvaluative-}

rationalising/transepistemicity/anamnestic-residuality/spirit-drivenness-equalisation $\rangle$ as to its lack-of/shallow dispensing-with-immediacy-for-relative-ontological-completeness ${ }^{87}$-byreification/contemplative-distension ${ }^{27}$ ) is besotted in temporality ${ }^{8}$ upon the logical-basis/logic,as-derived-from $\sim$ transversality- $<$ for-sublimating-existential-eventuating/denouement-from- 


\section{‘thinking at first/pure-predisposition-preemptive-of prospective-}

\section{disontologising/subontologising' as-of-prospectively-disambiguated-affirmed-and-}

unaffirmed-'motif-and-apriorising/axiomatising/referencing'>101 of relative-ontologicalincompleteness ${ }^{88} \quad<$ amplituding formative $>$ wooden-language-〈imbued-temporal-mereform/virtualities/dereification/akrasiatic-drag/denatured/preconverging-or-dementing narratives - of-the- reference-of-thought- categorical-imperatives/axioms/registryteleology $\rangle$ as so-enabled with lack of ${ }^{103}$ universal-transparency $^{104}$-〈transparency-of-totalisingentailing,-as-to-entailing- $<$ amplituding/formative-epistemicity $>$ totalising $\sim$ in-relativeontological-completeness $>$ (explaining the latter's iterative-looping-narrations as successive shades of ${ }^{103}$ universal-transparency ${ }^{104}$-〈transparency-of-totalising-entailing,-as-to-entailing$<$ amplituding/formative-epistemicity>totalising in-relative-ontological-completeness $>$ arise speaking to a more fundamental ontological-bad-faith/inauthenticity $\sim$ preconverging-dementating/structuring/paradigming ${ }^{5} \quad$ when reflecting $\quad<$ amplituding/formativeepistemicity $>$ causality ${ }^{\circ}$. This underlying ontological-goodfaith/authenticity ${ }^{6} \sim$ postconverging-de-mentating/structuring/paradigming ${ }^{70}$ over ontologicalbad-faith/inauthenticity ${ }^{64}$ preconverging-de-mentating/structuring/paradigming ${ }^{55}$ imbued sublimating-over-desublimating ontological implications as most profound construal of human $<$ amplituding/formative-epistemicity $>$ causality inevitably highlights the requisite 'ontologicalgood-faith/authenticity $\sim$ postconverging-de-mentating/structuring/paradigming ${ }^{70}$ existentialcondescension- $<$ of-apriorising/axiomatising/referencing-psychologism $>$ ' of sublimating baseinstitutionalisation, $\quad{ }^{103}$ universalisation, $\quad$ positivism/rational-empiricism and notional ${ }^{18}$ deprocrypticism respectively over desublimating recurrent-utteruninstitutionalisation, ununiversalisation, non-positivism/medievalism and procrypticism respectively, and the failure to articulate this requisite 'ontological-goodfaith/authenticity ${ }^{6} \sim$ postconverging-de-mentating/structuring/paradigming $70 \quad$ existential- 
condescension- $<$ of-apriorising/axiomatising/referencing-psychologism $>$ ' is a failure to meet the 'prospectively warranted organic-knowledge epistemic-veracity' as failing to reflect supererogatøry acuity/perspicacity/astuteness/edginess/incisiveness-of-

\section{apriorising/axiomatising/referencing/intelligibilitysettingup/measuringinstrumenting -for-}

conceptualisation in implying that the 'sublimating apriorising/axiomatising/referencingpsychologism is the valid logical-basis' and the 'desublimating apriorising/axiomatising/referencing-psychologism is the invalid logical-basis'. This point out that the successive relative-ontological-completeness ${ }^{87}$ as base-institutionalisation, ${ }^{3}$ universalisation, positivism/rational-empiricism and notional ${ }^{18}$ deprocrypticism respectively are actually projective-insights speaking to the fact that human prospective emancipation should rather be construed as of 'human ${ }^{83}$ reference-of-thought (as grandest axiomatic-construct level) research-programme conception' as so-enabling the transcendence-andsublimity/sublimation/supererogatory $\sim$ de-mentativity of the respective prior relativeontological-incompleteness ${ }^{8}$ of recurrent-utter-uninstitutionalisation, ununiversalisation, nonpositivism/medievalism and procrypticism. Such 'human ${ }^{83}$ reference-of-thought (as grandest axiomatic-construct level) research-programme conception' reflects the fact that it is the 'prospective preconverging/postconverging-de-mentative/structural/paradigmatic sublimation as to existence-as-sublimating-withdrawal/unenframing/re-ontologising,-elicited-fromprospective-profound-supererogation as so-induced by notional asceticism reasoningthrough/messianic-reasoning' that affirmatively validates any of the respective relativeontological-completeness ${ }^{87}$ registry-worldviews/dimensions instigated human emancipation, and so as to the fact that the corresponding reasoning-from-results/afterthought inducing secondnatured institutionalisation (that speaks to collective thought in any given registryworldview/dimension) while serving its secondnaturing institutionalisation purpose 'is overrated with regards to the challenge of human postconverging aporeticism-overcoming/unovercoming 
at prospectively uninstitutionalised-threshold ${ }^{102}$, and shouldn't be the threshold/limit for determining the possibility for prospective human emancipation (since it is relatively of poor responsiveness to prospective human Being-development/ontological-framework-expansionas-to-depth-of-ontologising-development-as-infrastructure-of- meaningfulness-and-

teleology ) which rather requires instigative notional asceticism reasoning-through/messianicreasoning (as to the fact that for instance it is naïve to conceive that it was the "pure articulation of positivism/rational-empiricism logic that convinced/converted the non-positivism/medieval world into our positivism world' but rather decisive in the secondnaturing of positivism/rationalempiricism was the notional asceticism reasoning-through/messianic-reasoning instigative detour to positivism/rational-empiricism preconverging/postconverging-dementative/structural/paradigmatic sublimation as to existence-as-sublimatingwithdrawal/unenframing/re-ontologising,-elicited-from-prospective-profound-supererogation (manifested as of the ships that set sail around the world for spices and trade eliciting a positive commercial opportunism that is decisively responsible for destroying the collective social myth of a flat world; the bacteria theory that will ensure that one lives or die if we believe in it or not and draw the health implications constrained the destruction of a collective superstitious medical worldview; the scientific tools and knowledge that ensured that nation $\mathrm{A}$ or nation $\mathrm{B}$ will triumph if they believe in it or not, constrained the collective need to adopt a scientific worldview, etc.). Since the relative-ontological-completeness ${ }^{87}$ logical-basis/logic,-as-derivedfrom $\sim$ transversality-<for-sublimating-existential-eventuating/denouement-from-'thinking atfirst/pure-predisposition - preemptive-of prospective-disontologising/subontologising' as-ofprospectively-disambiguated-affirmed-and-unaffirmed-'motif-andapriorising/axiomatising/referencing' $>101$ is in transversality-<for-sublimating-existentialeventuating/denouement,-from-'thinking at-first/pure-predisposition-preemptive-ofprospective-disontologising/subontologising' as-of-prospectively-disambiguated-affirmed- 
it is only the sublimation as to existence-as-sublimating-withdrawal/unenframing/reontologising,-elicited-from-prospective-profound-supererogation that affirmatively upholds the relative-ontological-completeness ${ }^{87}$ over the relative-ontological-incompleteness ${ }^{88}$ (as to their supposedly coherent ontological-commitment $-<$ implied-self-assuredness-ofontological-good-faith/authenticity postconverging-dementating/structuring/paradigming -as-being-as-of-existential-reality $>$ ). In other words, genuinely projected knowledge as of ontological-good-faith/authenticity $\sim$ postconverging-dementating/structuring/paradigming 70 is more than just the mechanical construct but speaks of the 'ontological-good-faith/authenticity ${ }^{6} \sim$ postconverging-de-mentating/structuring/paradigming existential-condescension-<of-apriorising/axiomatising/referencing-psychologism $>{ }^{\prime} \quad$ as $\quad$ of veridical existential-<disontologising/re-ontologising aporeticism $>$ relationship/signature as organic-knowledge. This is more obviously grasped with respect to human institutionaldevelopment-as-to-social-function-development and living-development-as-to-personalitydevelopment psychologismic epistemic-acutisation - difficulty-<for, residualising \{decomolsing delinearity for-cogeney>-magnitudes $\{$ of-experientiality/experiment\} as to the positiveopportunism - of-social-functioning-and-accordance ${ }^{75}$ implications eliciting a decomplexed placeholder-setup/mental-devising-representation/mentation/consciousness-awarenessteleology 9 of such 'ontological-good-faith/authenticity ${ }^{6} \sim$ postconverging-dementating/structuring/paradigming $70 \quad$ existential-condescension- $<$ ofapriorising/axiomatising/referencing-psychologism>' but less obvious and poorly grasped with 
regards to re-ontologising prospective Being-development/ontological-framework-expansionas-to-depth-of-ontologising-development-as-infrastructure-of- meaningfulness-and-

teleology. In this respect with regards to human institutional-development-as-to-socialfunction-development and living-development-as-to-personality-development psychologismic epistemic-acutisation difficulty-for, residualising \{decompulsing ${ }^{\text {f }}$ delinearity for-cogency> magnitudes $\{$ of-experientiality/experiment\} as of our positivism/rational-empiricism registryworldview/dimension we can appreciate for instance that in a professional-client relationship like between a physician and a patient or a plumber and a customer, the two parties do not normally engage one another in equivocating as of the ordinary ${ }^{56}$ meaningfulness-andteleology desublimation which wouldn't achieve the sublimation of medical care meaningfulness-and-technology or plumbing technician technical ${ }^{56}$ meaningfulness-andteleology ${ }^{9}$ (as to the fact that the client doesn't go on pretending to engage the professional at its more profound level of technical knowledge contemplation) with the relation thus involving the requisite 'ontological-good-faith/authenticity ${ }^{6}$ postconverging-dementating/structuring/paradigming existential-condescension- $<$ ofapriorising/axiomatising/referencing-psychologism $>$ of the professional with a corresponding deferential apriorising/axiomatising/referencing-psychologism of the client' and so as reflecting the sublimating knowledge ontological-good-faith/authenticity $\sim$ postconverging-dementating/structuring/paradigming beyond-and-above the desublimating ontological-goodfaith/authenticity ${ }^{6} \sim$ postconverging-de-mentating/structuring/paradigming 70 of ordinary meaningfulness-and-teleology ${ }^{9}$. However, this sublimating knowledge 'ontological-goodfaith/authenticity ${ }^{6} \sim$ postconverging-de-mentating/structuring/paradigming $70 \quad$ existentialcondescension-< $<$ of-apriorising/axiomatising/referencing-psychologism $>$ ' across all registryworldviews/dimensions is ever always poorly appreciated with regards to re-ontologising prospective Being-development/ontological-framework-expansion-as-to-depth-of- 
ontologising-development-as-infrastructure-of- meaningfulness-and-teleology (even though from a retrospective perspective we can grasp the preconverging/dementing ${ }^{20}$-qualia-schema of the 'God-of-plane' type of articulation of say base-institutionalisation as of animistic socialsetup as from our positivism/rational-empiricism reflex 'ontological-goodfaith/authenticity ${ }^{69} \sim$ postconverging-de-mentating/structuring/paradigming $70 \quad$ existentialcondescension-< $<$ of-apriorising/axiomatising/referencing-psychologism $>$ ' but it is important to note that such an animistic social-setup doesn't project of any such preconverging/dementing qualia-schema placeholder-setup/mental-devising-representation/mentation/consciousnessawareness-teleology ${ }^{9}$ going by its ${ }^{7}$ presencing-absolutising-identitive-constitutedness ${ }^{14}$ just as we will be disinclined to contemplate about the more veridical preconverging/dementing ${ }^{20}$ qualia-schema of our ${ }^{80}$ procrypticism-or-disjointedness-as-of- ${ }^{3}$ reference-of-thought

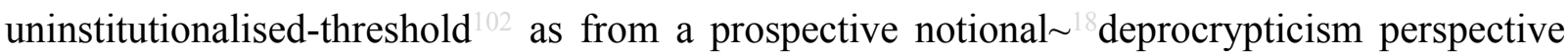
projected placeholder-setup/mental-devising-representation/mentation/consciousnessawareness-teleology ${ }^{9}$ ). This poor appreciation arises for the simple reason that the uninstitutionalised-threshold $^{102}$ speaks of the registry-worldview/dimension notionaldiscontiguity/epistemic-discontiguity ${ }^{63}<$ between - prior-shallow-supererogation -ofmentally-aestheticised preconverging/dementing -qualia-schema_and_prospective-profoundsupererogation -of-mentally-aestheticised postconverging/dialectical-thinking -qualiaschema>, and thus it is disinclined to recognise the prospective 'relative-ontologicalcompleteness ${ }^{87}$-apriorising/axiomatising/referencing-psychologism enculturated/constructed social-pragmatics-framing-of-predicative-effectivity-sublimation-〈as-to-underlying,ontological-commitment ${ }^{6}<$ implied-self-assuredness-of-ontological-goodfaith/authenticity postconverging-de-mentating/structuring/paradigming -as-being-as-ofexistential-reality $>\rangle$, imbued foregrounding_entailment- $<$ in-succession-of-profoundsupererogation $>$-〈postconverging-narrowing-down $\sim$ sublimation-as-to-'existence-as- 
sublimating-withdrawal/unenframing/re-ontologising,-elicited-from-prospective-profound-

supererogation '-in-reflecting-'immanent $\sim$ relative-unreflexivity/relative-reflexivity-

ontological-contiguity ';--as-operative-notional deprocrypticism) that can instill such a prospective sublimating knowledge 'ontological-good-faith/authenticity $\sim$ postconverging-dementating/structuring/paradigming existential-condescension- $<$ ofapriorising/axiomatising/referencing-psychologism>' as to prospective institutionaldevelopment-as-to-social-function-development and living-development-as-to-personalitydevelopment psychologismic epistemic acutisation difficulty < for, residualising

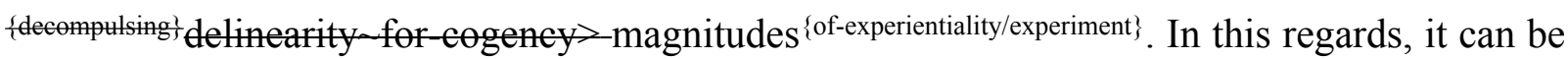
appreciated with respect to budding-positivism and ${ }^{103}$ universalising-idealisation respectively that where the epistemic-veracity of looking through a telescope and drawing positivistic ontological implications do not avail as in the medieval-scholasticism underpinning-suprasocialconstruct or where construing meaningfulness in coherent ${ }^{103}$ universalising terms do not avail as in the non-universalising sophistry underpinning-suprasocial-construct, then there is a fundamental reality of desublimating ontological-bad-faith/inauthenticity ${ }^{64}$ over which prospective sublimating ontological-good-faith/authenticity ${ }^{69}$ knowledge respectively as of budding-positivism and ${ }^{103}$ universalising-idealisation can only be established as of their respectively requisite 'ontological-good-faith/authenticity ${ }^{69}$ existential-condescension- $<$ ofapriorising/axiomatising/referencing-psychologism>' and naïve modern-day ${ }^{79}$ presencingabsolutising-identitive-constitutedness ${ }^{14}$ interpretations in terms of the supposed arrogance of the Socrates, Galileos, Descartes, Diderots, etc. is nothing more but a manifestation of dimensionality-of-desublimating-lack-of $-\langle<$ amplituding/formative $>$ supererogatory $\sim$ dementativeness/epistemic-growth-or-conflatedness /transvaluativerationalising/transepistemicity/anamnestic-residuality/spirit-drivenness-equalisation) (as to the failure to appreciate that the surpassing of human-subpotency postconverging aporeticism- 
overcoming/unovercoming is all about originariness-parrhesia,-as-spontaneity-ofaestheticisation—supererogatory acuity/perspicacity/astuteness/edginess/incisiveness-ofapriorising/axiomatising/referencing/intelligibilitysettingup/measuringinstrumenting -forconceptualisation that only arises as of sublimation affirmation/projection/assertion/notional self-distantiation/dueness-validatinglogicising/suitable-measuringinstrument-validating-measuring-<as-to-postconverging-ordialectical-thinking -apriorising-psychologism>' 'desublimation unaffirmation/deprojection/deassertion/epistemic-decadence/undueness-invalidatinglogicising/unsuitable-measuringinstrument-invalidating-measuring-<as-to-preconverging-ordementing -apriorising-psychologism>'). Indeed, as to when such 'relative-ontologicalcompleteness ${ }^{87}$-apriorising/axiomatising/referencing-psychologism enculturated/constructed social-pragmatics-framing-of - predicative-effectivity-sublimation-〈as-to-underlying,ontological-commitment ${ }^{6}<$ implied-self-assuredness-of-ontological-goodfaith/authenticity $\sim$ postconverging-de-mentating/structuring/paradigming -as-being-as-ofexistential-reality $>\rangle^{\prime}$ is institutionalised say with modern-day positivism/rational-empiricism the requisite 'ontological-good-faith/authenticity ${ }^{99}$ existential-condescension- $<$ ofapriorising/axiomatising/referencing-psychologism>' of modern-day scientific breaktrhoughs sublimation projected knowledge hardly put-into-question. Likewise, this insight about the requisite 'ontological-good-faith/authenticity ${ }^{6} \quad$ existential-condescension- $<$ ofapriorising/axiomatising/referencing-psychologism >' for organic-knowledge needs to be explicited with regards to the blurriness-<sterilising/anecdotalising/trivialising-of-prospectivere-ontologising_by-preconverging,-in-disontologising-formulaic-dragging-out/hollowing-out> of 5 meaningfulness-and-teleology associated with today's institutional-being-and-craft pedantising/muddling/formulaic-hollowing-out — in-subontologisation/subpotentiation〈blurring/undermining-of-prospective-totalising-entailing,-as-to-entailing- 
<amplituding/formative-epistemicity>totalising in-relative-ontological-completeness $>$ with cynical, ridiculous and paradoxical pretenses of humility and sensibility/decorum that by that token (not unlike ancient-sophistry and medieval-scholasticism) go on to induce 'existentially-disontologising/re-ontelogising aporeticism $>$ invalid condescension' as to their veridical desublimating ${ }^{79}$ presencing - absolutising-identitive-constitutedness ${ }^{14}<$ amplituding/formativeepistemicity>totalising $\sim$ self-referencing-syncretising/circularity/interiorising/akrasiatic-drag ${ }^{34}$, as of ontological-bad-faith/inauthenticity ${ }^{64} \sim$ preconverging-dementating/structuring/paradigming . The fact is where such pretenses are nowhere found in the terrain of knowledge-reification gesturing-and-accounting — of-epistemic-phenomenalism- $<$ inprospective_psychologismic apriorising/axiomatising/referencing-\{of-'prospectively implicited_attendant-ontological-contiguity ' educedexistentialising/contextualising/textualising_'intelligibility/epistemicity/reflexivity_contiguity$<$ imbued-notional cogency $>$ ' \}-conflatedness -in-\{preconverging -ment by\} postconverging-entailment> but rather surreptitious enterprises of $<$ amplituding/formative $>$ wooden-language-〈imbued - averaging-of-thought-<as-toleveling/ressentiment/closed-construct-of- meaningfulness-and-teleology -as-of'nondescript/ignorable-void '-with-regards-to-prospective-apriorising-implications $>>\quad$ this signals their emperor has no clothes moment. In this regards, as to 'sublimation affirmation/projection/assertion/notional self-distantiation/dueness-validatinglogicising/suitable-measuringinstrument-validating-measuring-<as-to-postconverging-ordialectical-thinking -apriorising-psychologism>’ 'desublimation unaffirmation/deprojection/deassertion/epistemic-decadence/undueness-invalidatinglogicising/unsuitable-measuringinstrument-invalidating-measuring-<as-to-preconverging-ordementing -apriorising-psychologism>', the requisite 'ontological-good-faith/authenticity existential-condescension-< $<$ of-apriorising/axiomatising/referencing-psychologism $>{ }^{\prime} \quad$ for 
organic-knowledge 'speaks to an intellectual-and-moral responsibility/relative-reflexivity associated with knowledge as of the requisite dispensing-with-immediacy-for-relativeontological-completeness ${ }^{87}$-by-reification/contemplative-distension ${ }^{27}$ for its elucidation and appropriate secondnatured institutionalisation that is not dissociated from the very constructionof-the-Self', and knowledge cannot thus be construed as a 'minor and side thing of mere influencing and stature' that is dissociated with veridical human mental-development and emancipation in order to rather surreptitiously serve human-subpotency as mortal methodologising/mutualising/organising/institutionalising perverted purposes (as so-of-ten implicitly construed by many a social dominance/vested-interest actor and sycophantic-sophistry throughout human history in eliciting <amplituding/formative $>$ wooden-language-〈imbued averaging-of-thought- $<$ as-to-leveling/ressentiment/closed-construct-of- meaningfulness-andteleology -as-of-'nondescript/ignorable-void '-with-regards-to-prospective-apriorisingimplications $>\rangle$ hardly showing disinterested interest in genuine knowledge). The blunt fact is that as explained above and clearly obvious with human institutional-development-as-to-socialfunction-development and living-development-as-to-personality-development psychologismic epistemic-acutisation difficulty-<for, residualising \{decompulsing $^{\text {f }}$ delinearity for-cogency> magnitudes $\{$ of-experientiality/experiment $\}$ the ordinariness of ${ }^{5}$ meaningfulness-and-teleology ${ }^{9}$ is not to be exploited as if it is a credible state of profound ontological-veracity given the lack of dispensing-with-immediacy-for-relative-ontological-completeness ${ }^{87}$-by-

reification/contemplative-distension ${ }^{27}$ (as to a disparateness-of-conceptualisation<unforegrounding-ment,-failing-prospectively-to-reflect-‘immanent relative-

pedantising/muddling/formulaic-hollowing-out — in-subontologisation/subpotentiation-

〈blurring/undermining-of-prospective-totalising-entailing,-as-to-entailing- 
thrives on this lack of ${ }^{103}$ universal-transparency ${ }^{104}$-〈transparency-of-totalising-entailing,-as-toentailing-<amplituding/formative-epistemicity>totalising in-relative-ontological-

completeness †) with regards to re-ontologising prospective Being-development/ontologicalframework-expansion-as-to-depth-of-ontologising-development-as-infrastructure-ofmeaningfulness-and-teleology underlying the genuine social intellectual-function/posture. Intellectualism as such is much more than just about ${ }^{79}$ presencing-absolutising-identitiveconstitutedness ${ }^{14}$ methodologising/mutualising/organising/institutionalising enterprise as to the fact that 'all given registry-worldviews/dimensions as ${ }^{79}$ presencing-absolutising-identitiveconstitutedness ${ }^{14}$ underpinning-suprasocial-construct relate to their given ${ }^{56}$ meaningfulnessand-teleology in absolute terms whereas in reality there are veridically relative subontologisation/subpotentiation of ontology as metaphysics-of-presence-〈implicited'nondescript/ignorable-void '-as-to- presencing - absolutising-identitive-constitutedness '〉'; and it is here that the genuine social intellectual-function/posture comes in to veridically reflect the reality that a social-construct is not of absolute scalarisation of human ontologicalperformance $^{72}-<$ including-virtue-as-ontology $>$ /morality/ethics/justice/etc. for the possibility for its prospective scalarisation-as-to-rescalarisation-as-reontologisation/supereregatery involuting-or-guilding-or-amplifying-scalarisation-<as-toexistence — as-sublimating-withdrawal/unenframing/re-ontologising,-elicited-fromprospective-profound-supererogation $>$, and the genuine social intellectual-function/posture as such is not about a naivist social-vestedness/normativity- $<$ discretely-implied-functionalism $>$ as otherwise the possibility for the <cumulating/recomposuring attendant-ontologicalcontiguity $>$-succession of registry-worldviews/dimensions transcendence-andsublimity/sublimation/supererogatory de-mentativity right up to our present wouldn't have availed speaking to our very own intellectual-and-moral responsibility/relative-reflexivity for reontologising prospective Being-development/ontological-framework-expansion-as-to-depth- 
genuine social intellectual-function/posture means that human thought can project beyond, overlook and override presencing-absolutising-identitive-constitutedness $<$ preconverging 'motif-and-apriorising/axiomatising/referencing'-entailing $>$ existentialising — enframing/imprintedness-〈as-to- historicity-tracing - in-presencinghyperrealisation/hyperreal-transposition> conception of sublimating value and ontologicalveracity disposition; and so as to the fact that ${ }^{79}$ presencing-absolutising-identitiveconstitutedness $<$ preconverging 'motif-and-apriorising/axiomatising/referencing'entailing $>$-existentialising — enframing/imprintedness-〈as-to- historicity-tracing - inpresencing-hyperrealisation/hyperreal-transposition〉 actually tend to be skewed towards ‘immediacy supposed absolute sublimating value and ontological-veracity disposition' (as to the beyond-the-consciousness-awareness-teleology ${ }^{0}-<$ of-preconverging-existential-extrication-asof-existential-unthought $>$ positive-opportunism-of-social-functioning-and-accordance ${ }^{75}$ of institutional-development-as-to-social-function-development and living-development-as-topersonality-development psychologismic epistemic acutisation difficulty-<for, residualising $\{$ \{decompulsing\} delinearity for-cogency $>$ magnitudes $\{$ of-experientiality/experiment\} $\}$ over 'nonimmediacy prospective sublimating value and ontological-veracity disposition' (with regards to its supererogation -profundity postconverging-de-mentating/structuring/paradigming requisite dispensing-with-immediacy-for-relative-ontological-completeness ${ }^{87}$-byreification/contemplative-distension for Being-development/ontological-frameworkexpansion-as-to-depth-of-ontologising-development-as-infrastructure-of- meaningfulnessand-teleology ), and in fact in-many-ways individuals intersolipsistic actions in society implicitly recognise this reality even as the overall underpinning-suprasocial-construct tends to be abstractly preconvergingly-de-mentated/structured/paradigmed to skew towards 'immediacy supposed absolute sublimating value and ontological-veracity disposition' (as for instance 
professional choices and callings made well beyond just a question of their remunerative or supposed incidental social prestige worth). Part-and-parcel of the genuine social intellectualfunction/posture is to undermine this skewing towards 'immediacy supposed absolute sublimating value and ontological-veracity disposition' (as to the beyond-the-consciousnessawareness-teleology $-<$ of-preconverging-existential-extrication-as-of-existential-unthought $>$ positive-opportunism-of-social-functioning-and-accordance ${ }^{75}$ of institutional-developmentas-to-social-function-development and living-development-as-to-personality-development psychologismic epistemic-acutisation difficulty-for, residualising \{decomonsing delinearity for-cogeney>-magnitudes $\{$ of-experientiality/experiment\} $\}$ and reconstrue humansubpotency postconverging-aporeticism-overcoming/unovercoming in terms of 'nonimmediacy prospective sublimating value and ontological-veracity disposition'. In this regards historically, without individuals making choices not to optimally pursue 'immediacy supposed absolute sublimating value and ontological-veracity disposition' as to their given ${ }^{79}$ presencingabsolutising-identitive-constitutedness ${ }^{14}$ 'immediacy supposed absolute sublimating value and ontological-veracity disposition' but instead optimising their effort for 'non-immediacy prospective sublimating value and ontological-veracity disposition' then the possibility will not arise for the very backbone of human value and ontological-veracity sublimation (reflecting the 'non-immediacy prospective sublimating value and ontological-veracity disposition') upon which 'immediacy supposed absolute sublimating value and ontological-veracity disposition' is grounded. History knows that the 'contorted human ${ }^{79}$ presencing-absolutising-identitiveconstitutedness $^{14}$ mentality of registry-worldviews/dimensions' as of 'immediacy supposed absolute sublimating value and ontological-veracity disposition' do not truly pay their dues to the Socrates, Copernicuses, Galileos, Descartes, Kants, Newtons, Leibniz, Rousseaux, Diderots, Pasteurs, Lavoisiers, Teslas, Einsteins, etc. upon whose ${ }^{5}$ meaningfulness-and-teleology infrastructure building 'immediacy supposed absolute sublimating value and ontological- 
veracity disposition' arise and outlandishly skew human ${ }^{56}$ meaningfulness-and-teleology ${ }^{9}$ (and so not only with human Being-development/ontological-framework-expansion-as-to-depth-ofontologising-development-as-infrastructure-of- meaningfulness-and-teleology but is equally reflected in a poor-spirited bland conception of human institutional-development-as-to-socialfunction-development and living-development-as-to-personality-development psychologismic

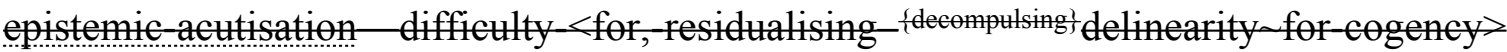
magnitudes ${ }^{\text {(of-experientiality/experiment\} }\}}$. This insight is critically important not as an idle exercise of merely stating the appropriateness of sublimating value and ontological-veracity disposition but in reflecting that the skewed underpinning-suprasocial-construct projected and preconvergingly-de-mentated/structured/paradigmed 'immediacy supposed absolute sublimating value and ontological-veracity disposition' cannot be construed as absolute as in effect it will ultimately prospectively stultifying the requisite 'non-immediacy prospective sublimating value and ontological-veracity disposition' that acts as the backbone for human value and ontological-veracity sublimation (as has always been the manifest case for surpassing the uninstitutionalised-threshold ${ }^{102}$ of registry-worldviews/dimensions). The fact is 'immediacy supposed absolute sublimating value and ontological-veracity disposition' as underlying presencing-absolutising-identitive-constitutedness $^{14}$ end up as the registryworldviews/dimensions Establishments underpinning-suprasocial-construct as to dominance/vested-interest — drivenness-<as-to-its-direct/indirect-eliciting-by-or-exploiting-ofprospectively-descalarising/subontologising-sycophantic-sophistic-interests,-as-inducingprospective-threshold-of-institutional-and-social-desublimation $>\quad$ of $\quad{ }^{79}$ presencingabsolutising-identitive-constitutedness $<$ preconverging 'motif-andapriorising/axiomatising/referencing'-entailing >-existentialising — enframing/imprintedness〈as-to- historicity-tracing - in-presencing-hyperrealisation/hyperreal-transposition〉 of socialvestedness/normativity-<discretely-implied-functionalism $>$ and social-stake-contention-or- 
confliction. It is the 'non-immediacy prospective sublimating value and ontological-veracity disposition' (so-reflected in human ${ }^{4}$ historiality/ontological-eventfulness ${ }^{38}$ ontologicalaesthetic-tracing-<perspective-ontological-normalcy/postconvergence-reflected-'epistemicityrelativism-determinism' $>$ ) that goes beyond ${ }^{79}$ presencing-absolutising-identitiveconstitutedness $^{14}$ and generate the requisite preconverging/postconverging-dementative/structural/paradigmatic sublimation-over-desublimation as reflected with the relativeunreflexivity/relative-reflexivity — ontological-contiguity ${ }^{67}$ of-the-human-institutionalisationprocess ${ }^{8}$ while superseding 'human-subpotency non-scalarity/beholdening-<as-to-what-hasgone-before-aesthetically-de-mentates/structures/paradigms-distortedly-the-possibility-for-thelater-ontologisation>' disposition of 'immediacy supposed absolute sublimating value and ontological-veracity disposition' as the latter at best construes of social reformation (and so across all the registry-worldviews/dimensions) in ${ }^{79}$ presencing-absolutising-identitiveconstitutedness <preconverging 'motif-and-apriorising/axiomatising/referencing' entailing $>$-existentialising — enframing/imprintedness-〈as-to- historicity-tracing — inpresencing-hyperrealisation/hyperreal-transposition〉 subontologising palliative terms that as to their specifically defined 'human social-vestedness/normativity-<discretely-impliedfunctionalism> implied contract/political-arrangement-or-political-coercion/given-discretesocial-value-construction' are very much integrative of collateral aspects as imponderable/inscrutable/unavoidable/inevitable/inescapable/unpreventable/unchangeable/in surmountable/unovercomable with regards to social-stake-contention-or-confliction and thus by dulling the social-construct's conscience in this way rather distracts from the realisation and contemplation of the full possibilities for profound preconverging/postconverging-dementative/structural/paradigmatic transformation of 'non-immediacy prospective sublimating value and ontological-veracity disposition'. The subtle manifestation of the social implications of 'immediacy supposed absolute sublimating value and ontological-veracity disposition' (as to 
accordance $^{75}$ of institutional-development-as-to-social-function-development and livingdevelopment-as-to-personality-development psychologismic epistemic acutisationdifficulty < for, residualising \{decompulsing\} delinearity for-cogency> magnitudes $\{$ ofexperientiality/experiment\}) with regards to our positivism- ${ }^{80}$ procrypticism registryworldview/dimension can be appreciated in modern-day sycophantic-sophistry and pedantising/muddling/formulaic-hollowing-out — in-subontologisation/subpotentiation〈blurring/undermining-of-prospective-totalising-entailing,-as-to-entailing$<$ amplituding/formative-epistemicity >totalising in-relative-ontological-completeness $\rangle$, media-driven disenfranchising narrative $<$ preconverging 'motif-andapriorising/axiomatising/referencing'-entailing >-existentialising — enframing/imprintedness〈as-to- historicity-tracing - in-presencing-hyperrealisation/hyperreal-transposition〉 and dominance/vested-interest diffused institutional influence in-many-ways and occasions rendering formal and official languages of institutions smokescreens for underhanded $<$ amplituding/formative $>$ wooden-language-〈imbued-temporal-mereform/virtualities/dereification/akrasiatic-drag/denatured/preconverging-or-dementing narratives - of-the- reference-of-thought- categorical-imperatives/axioms/registryteleology \. In-many-ways this ${ }^{7}$ presencing-absolutising-identitive-constitutedness $<$ preconverging 'motif-and-apriorising/axiomatising/referencing'-entailing >existentialising — enframing/imprintedness-〈as-to- historicity-tracing_-in-presencinghyperrealisation/hyperreal-transposition $\rangle$ analysis as to the positivism- ${ }^{80}$ procrypticism registryworldview's/dimension's preconverging/postconverging-de-mentative/structural/paradigmatic social institutional beholdening-becoming-distortive-originariness/distortive-origination-asto- ${ }^{-}$historicity-tracing inhibited-mental-aestheticising implications is very much relevant 
however the underlying socio-econo-political subontologisation/ideology-over-ontology whether technocratic, capitalistic or communist (as in fact all such systems mirror each other as to their beholdening-becoming - distortive-originariness/distortive-origination-as-tohistoricity-tracing inhibited-mental-aestheticising, besides the differentiating specificities as to ingrained cultural context, speaking of a more fundamental issue of positivismprocrypticism

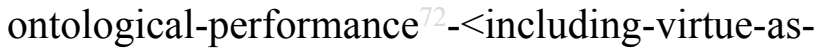
ontology $>$ /morality/ethics/justice/etc. as to the prospective human-subpotencyaporia/undecidability/dilemma/ought-indeterminacy/deficiency/limitation/constraint for prospective deprocrypticism-or-preempting - disjointedness-as-of- reference-of-thought); as to the fact that the underlying institutional formativeness-<as-to-intersolipsism-ofpreformulating/preframing/premeaningfulness-imbued-mediativity-and-deferentialism>-ofmeaningfulness-and-teleology of these systems are rather as of 'dominance/vested-interest— drivenness-<as-to-its-direct/indirect-eliciting-by-or-exploiting-of-prospectivelydescalarising/subontologising-sycophantic-sophistic-interests,-as-inducing-prospectivethreshold-of-institutional-and-social-desublimation> of ${ }^{79}$ presencing-absolutising-identitiveconstitutedness $<$ preconverging 'motif-and-apriorising/axiomatising/referencing' entailing $>$-existentialising — enframing/imprintedness-〈as-to- historicity-tracing - inpresencing-hyperrealisation/hyperreal-transposition〉 of social-vestedness/normativity$<$ discretely-implied-functionalism $>$ and social-stake-contention-or-confliction', and prospective human scalarisation-as-to-rescalarisation-as-re-ontologisation/supereregatery involuting-orguilding-or-amplifying-scalarisation-<as-to-existence-as-sublimating-

withdrawal/unenframing/re-ontologising,-elicited-from-prospective-profound-

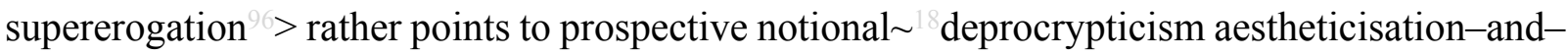
aestheticisation-towards-ontology-<elicited-idiomatisation $>$ (as to dimensionality-ofsublimating 25 -< <amplituding/formative $>$ supererogatory $\sim$ de-mentativeness/epistemic-growth- 
or-conflatedness /transvaluative-rationalising/transepistemicity/anamnestic-residuality/spirit-

drivenness-equalisation〉)

supererogation 'bechancing-backdrop of nonpresencing-<perspective-ontological-

historiality/ontological-eventfulness 3 /ontological-aesthetic-tracing-<perspective-

ontological-normalcy/postconvergence-reflected-'epistemicity-relativism-

determinism'> disinhibited-mental-aestheticising sublimation reclamation/recovery from beholdening-becoming - distortive-originariness/distortive-origination-as-to- ${ }^{4}$ historicitytracing inhibited-mental-aestheticising' (so-construed as 'reclamation/recovery of maximalising-recomposuring-for-relative-ontological-completeness ${ }^{87}$ - unenframed/reontologising conceptualisation'). Such a deprocrypticism-or-preempting-disjointedness-asof- ${ }^{8}$ reference-of-thought ontological-performance ${ }^{2}-<$ including-virtue-asontology $>$ /morality/ethics/justice/etc. (as to its fundamental ontology aspiration) is not oblivious to the 'notional $\sim$ symmetrisation-<as-to-symmetrisation-by-desymmetrisation,-in-reflectingpostconverging-or-dialectical-thinking ${ }^{2}$-by-preconverging-or-dementing ${ }^{20} \sim$ perspectives-ofhuman- ${ }^{56}$ meaningfulness-and-teleology $>$ underlying human ontological-performance ${ }^{72}$ $<$ including-virtue-as-ontology $>$ /morality/ethics/justice/etc. as to the relativeunreflexivity/relative-reflexivity - ontological-contiguity ${ }^{67}$ of-the-human-institutionalisationprocess 88 cumulating/recomposuring attendant-ontological-contiguity $>$-succession of registry-worldviews/dimensions' and the 'facet of the existentially-withdrawn-〈as'unaccounted-for'-leftover-or-residuality-or-spirit-of- meaningfulness-and-teleology -soconstrued-as-metaphoricity ,-informing-prospectivesupererogatory acuity/perspicacity/astuteness/edginess/incisiveness,-so-reflected-andcompensated-with-the-notion-of-dimensionality-of-sublimating <<amplituding/formative $>$ supererogatory $\sim$ de-mentativeness/epistemic-growth-or- 
conflatedness /transvaluative-rationalising/transepistemicity/anamnestic-residuality/spirit-

drivenness-equalisation) $\rangle$ as limiting or of prospective human-subpotency aporeticism' which surpassing as to human psychoanalytic-unshackling/memetic-reordering/institutionalrecomposuring enables the possibility for human limited-mentation-capacity-deepening —assubjecting limitedness/human-subpotency to 'educed unlimitedness/existence sublimating nascence' ${ }^{5}$ '; and the 'notional ${ }^{18}$ deprocrypticism driving aesthetic-touch/aesthetic-sensibility of scalarising aestheticisation-towards-ontology' is one that in reflecting holographically$<$ conjugatively-and-transfusively $>$ the relative-unreflexivity/relative-reflexivity - ontologicalcontiguity $~$ of-the-human-institutionalisation-process projects of human ontologicalperformance $^{72}$-<including-virtue-as-ontology $>$ /morality/ethics/justice/etc. as: formativeness-ofunintelligence-towards-intelligence, so-rearticulated as formativeness-<as-to-intersolipsism-ofpreformulating/preframing/premeaningfulness-imbued-mediativity-and-deferentialism>-ofmeaningfulness-and-teleology of unintelligence (beholdening-becoming-distortiveoriginariness/distortive-origination-as-to- ${ }^{47}$ historicity-tracing inhibited-mental-aestheticising) towards intelligence ('bechancing-backdrop of ${ }^{6}$ nonpresencing-<perspective-ontologicalnormalcy/postconvergence>' as to 'bechancing-becoming-originariness/origination-as-tohistoriality/ontological-eventfulness 3 /ontological-aesthetic-tracing-<perspectiveontological-normalcy/postconvergence-reflected-`epistemicity-relativismdeterminism'> disinhibited-mental-aestheticising sublimation reclamation/recovery from beholdening-becoming - distortive-originariness/distortive-origination-as-to- ${ }^{4}$ historicitytracing inhibited-mental-aestheticising'). It is herein contended that the veridical genuine social intellectual-function/posture (as to the creative dynamics of Being-development/ontologicalframework-expansion-as-to-depth-of-ontologising-development-as-infrastructure-ofmeaningfulness-and-teleology , institutional-development-as-to-social-functiondevelopment and living-development-as-to-personality-development psychologismic 
epistemic-acutisation difficulty-for, residualising \{decompulsing\} ${ }^{\text {delinearity for-cogency> }}$ magnitudes $\{$ of-experientiality/experiment $\}$ and so across the <cumulating/recomposuring attendantontological-contiguity >-succession of registry-worldviews/dimensions as to its orientation towards 'reclamation/recovery of maximalising-recomposuring-for-relative-ontologicalcompleteness $^{87}$ — unenframed/re-ontologising conceptualisation' is effectively what underlies the unenframed/re-ontologising/unbeholdening/bechancing-supererogation possibility of all prospective human Being-development/ontological-framework-expansion-as-to-depth-ofontologising-development-as-infrastructure-of- meaningfulness-and-teleology enabling the $<$ cumulating/recomposuring attendant-ontological-contiguity $>$-succession of registryworldviews/dimensions transcendence-and-sublimity/sublimation/supereregatery $\sim$ dementativity reflecting the fact that their underpinning-suprasocial-constructs as to presencing — absolutising-identitive-constitutedness $<$ preconverging 'motif-andapriorising/axiomatising/referencing'-entailing>-existentialising-enframing/imprintedness〈as-to- historicity-tracing - in-presencing-hyperrealisation/hyperreal-transposition〉 are otherwise hardly transcendental with regards to prospective construction-of-the-Self implications given their beholdening-becoming-distortive-originariness/distortiveorigination-as-to- ${ }^{-}$historicity-tracing inhibited-mental-aestheticising. It is for the sake of preserving the full possibilities of prospective human value and ontological-veracity sublimation beyond ${ }^{7}$ presencing — absolutising-identitive-constitutedness ${ }^{14} \quad<$ preconverging ' motif-andapriorising/axiomatising/referencing'-entailing>-existentialising — enframing/imprintedness〈as-to- historicity-tracing - in-presencing-hyperrealisation/hyperreal-transposition〉 that the genuine social intellectual-function/posture must ever always remain independent and not be usurped by dominance/vested-interest actors and sycophantic-sophistry. Ultimately as with all human uninstitutionalised-threshold ${ }^{102}$ the prospective ${ }^{18}$ deprocrypticism-or-preemptingdisjointedness-as-of- ${ }^{8}$ reference-of-thought 'ontological-good- 
faith/authenticity $\sim$ postconverging-de-mentating/structuring/paradigming existentialcondescension- $<$ of-apriorising/axiomatising/referencing-psychologism $>$ ' urges the human along beyond its limit of contemplation at which point such a taxingness-of-originariness upon human-subpotency ontological-faith-notion-or-ontological-fideism—imbuedunderdetermination-of-motif-and-apriorising/axiomatising/referencing-as-so-being-as-ofexistential-reality is more appropriately construed not as ${ }^{56}$ meaningfulness-and-teleology ${ }^{9}$ but metaphoricity $^{57}$ as merely the setup for prospective human psychoanalyticunshackling/memetic-reordering/institutional-recomposuring possibility for prospective transcendence-and-sublimity/sublimation/supererogatory $\sim$ de-mentativity; and this reality is what avails across the <cumulating/recomposuring attendant-ontological-contiguity >successive registry-worldviews/dimensions instigated transcendence-andsublimity/sublimation/supererogatory de-mentativity for their respective re-ontologising prospective Being-development/ontological-framework-expansion-as-to-depth-ofontologising-development-as-infrastructure-of- meaningfulness-and-teleology as to the fact that the intemporal messianic-reasoning/reasoning-through instigation respectively of prospective base-institutionalisation, ${ }^{103}$ universalisation, positivism/rational-empiricism and notional ${ }^{18}$ deprocrypticism are not actually as of ${ }^{5}$ meaningfulness-and-teleology ${ }^{9}$ but rather are as of metaphoricity ${ }^{57}$ with regards respectively to prior recurrent-uninstitutionalisation, baseinstitutionalisation-ununiversalisation, ${ }^{103}$ universalisation-non-positivism/medievalism and our positivism- ${ }^{80}$ procrypticism, and so as to the fact that the latter (as to existence- as-sublimatingwithdrawal/unenframing/re-ontologising,-elicited-from-prospective-profoundsupererogation ${ }^{9}$ ) are ever always urged along beyond their uninstitutionalised-threshold given 'taxingness-of-originariness upon human-subpotency ontological-faith-notion-orontological-fideism - imbued-underdetermination-of-motif-and- 
'specifically given $\quad{ }^{83}$ reference-of-thought-and- ${ }^{8}$ reference-of-thought- ${ }^{8}$ devolvingmeaningfulness-and-teleology $\quad$ prospective human-subpotencyaporia/undecidability/dilemma/ought-indeterminacy/deficiency/limitation/constraint_-imbued'notional firstnaturedness-formativeness-<as-to-eventualising-inkling-drive-or-seeding misprising $>$ temporal-to-intemporal-dispositions- $<$ so-construed-as-from-perspectiveontological-normalcy/postconvergence>'-existentialism-form-factor' for the psychoanalyticunshackling/memetic-reordering/institutional-recomposuring possibility enabling prospective transcendence-and-sublimity/sublimation/supererogatory-de-mentativity as effectively involving the veridically uninhibited/decomplexified dimensionality-of-sublimating ${ }^{25}$ <<amplituding/formative >supererogatory -de-mentativeness/epistemic-growth-orconflatedness /transvaluative-rationalising/transepistemicity/anamnestic-residuality/spiritdrivenness-equalisation> in cognisance-and-integration of the requisite 'ontological-goodfaith/authenticity ${ }^{6} \sim$ postconverging-de-mentating/structuring/paradigming $70 \quad$ existentialcondescension- $<$ of-apriorising/axiomatising/referencing-psychologism $>$ ' for the availing of the organic-knowledge ${ }^{5}$ meaningfulness-and-teleology ${ }^{9}$ of base-institutionalisation, universalisation, positivism/rational-empiricism and notional ${ }^{18}$ deprocrypticism respectively (as to their respective ontological-good-faith/authenticity $\sim$ postconverging-dementating/structuring/paradigming 70 'inducing of their ${ }^{83}$ reference-of-thought-and- ${ }^{8}$ referenceof-thought- ${ }^{-1}$ devolving- ${ }^{5}$ meaningfulness-and-teleology 9 underlying logical-basis/logic,-asderived-from $\sim$ transversality-<for-sublimating-existential-eventuating/denouement-from-

\section{thinking -at-first/pure-predisposition-preemptive-of-prospective-}

\section{disontologising/subontologising' as-of-prospectively-disambiguated-affirmed-and-}

unaffirmed-'motif-and-apriorising/axiomatising/referencing'>101 of logical operation/processing/contention of narratives' reflected as of their respectively induced 'relative-ontological-completeness ${ }^{87}$-apriorising/axiomatising/referencing-psychologism 
enculturated/constructed social-pragmatics-framing-of-predicative-effectivity-sublimation〈as-to-underlying,-ontological-commitment $-<$ implied — self-assuredness-of-ontological-goodfaith/authenticity postconverging-de-mentating/structuring/paradigming -as-being-as-ofexistential-reality $>>$ ' imbued $\quad{ }^{4}$ foregrounding_entailment- $<$ in-succession-of-profoundsupererogation $>$-〈postconverging-narrowing-down $\sim$ sublimation-as-to-'existence-assublimating-withdrawal/unenframing/re-ontologising,-elicited-from-prospective-profoundsupererogation '-in-reflecting-'immanent relative-unreflexivity/relative-reflexivity ontological-contiguity ';-as-operative-notional deprocrypticism〉). This conception of 'ontological-good-faith/authenticity ${ }^{6} \sim$ postconverging-de-mentating/structuring/paradigming existential-condescension-<of-apriorising/axiomatising/referencing-psychologism $>{ }^{\prime} \quad$ rather speaks to the fact that 'human <amplituding/formative-epistemicity>-totalising $\sim$ thrownness-inexistence $^{35}$ as to its limited-mentation-capacity-as-subjecting-'educedunlimitedness/existence-sublimating nascence' to-limitedness/human-subpotency is intimately tied-down/laden-with prospective human-subpotency-aporia/undecidability/dilemma/oughtindeterminacy/deficiency/limitation/constraint—imbued-'notional firstnaturednessformativeness-<as-to-eventualising inkling-drive or seeding-misprising $>$ temporal-tointemporal-dispositions-<so-construed-as-from-perspective-ontologicalnormalcy/postconvergence>'-existentialism-form-factor' as to human teleology ${ }^{99}$ so-construed as 'human phenomenal/manifest conceptivity/epistemic-reflexivity/epistemicity-relativismdeterminism-<reifying \{as-to-knowledge-developing\}-and-empowering $>$ in existence as ontological (so-reflecting <amplituding/formative>disposedness/psychologismic-construct-〈asto-orientation/value-construct/valuation-and-derived-parameterising $\rangle \quad$ and $<$ amplituding/formative $>$ entailment-〈as-to-totalising-contiguous/coherent-factuality-ofvariability $\rangle$ )', underlied as of overall reifying-and-empowering-reflexivity-of-ecstatic-existence-

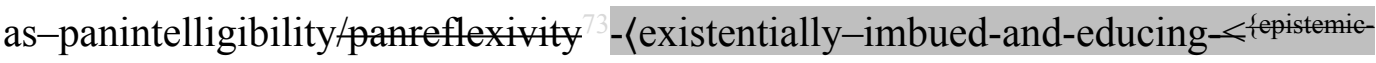


as herein-specifically relevant to human-subpotency). The underlying insight here is that unlike the flawed mental-reflex associated with ${ }^{79}$ presencing-absolutising-identitiveconstitutedness $<$ amplituding/formative-epistemicity $>$ totalising $\sim$ self-referencingsyncretising/circularity/interiorising/akrasiatic-drag 34 that preconverging/postconverging-dementatively/structurally/paradigmatically projects of a 'neutrally/objectively sound human ontological-performance $^{72}$-<including-virtue-as-ontology $>/$ morality/ethics/justice/etc. $\quad$ state failing to factor in human specific apriorising/axiomatising/referencing-\{of-"prospectively implicited_attendant-ontological-contiguity ' educedexistentialising/contextualising/textualising_'intelligibility/epistemicity/reflexivity_contiguity<imbued-notional cogency>' $\}$ - ontological-deficiency arising from its specifically given $<$ amplituding/formative-epistemicity>-totalising thrownness-in-existence ${ }^{35}$, $\quad$ human $<$ amplituding/formative-epistemicity>-totalising $\sim$ thrownness-in-existence ${ }^{35}$ as to human limited-mentation-capacity—as-subjecting-'educed-unlimitedness/existence-sublimatingnascence' to-limitedness/human-subpotency veridically implies that 'existence is not of prospective apriorising/axiomatising/referencing-sublimating-reflexivity_beholdening to that human $<$ amplituding/formative-epistemicity>-totalising thrownness-in-existence $^{35}$ and the critical human teleological as to ontological-performance ${ }^{72}-$ including-virtue-as- $^{2}$ ontology $>/$ morality/ethics/justice/etc. issue is how to adjust to existence and is not about how existence adjusts to the human who is rather of a subpotent epistemic relation to the full-potency of existence'. The implication here is that the 'ontological-goodfaith/authenticity ${ }^{6} \sim$ postconverging-de-mentating/structuring/paradigming $70 \quad$ existentialcondescension- $<$ of-apriorising/axiomatising/referencing-psychologism ${ }^{\prime}$, is thus merely 
reflecting the veridicality of the possibility of prospective human transcendence-andsublimity/sublimation/supererogatory de-mentativity which is only possibile as to existenceas-the-absolute-a-priori-of-conceptualisation and existence-as-sublimatingwithdrawal/unenframing/re-ontologising,-elicited-from-prospective-profoundsupererogation -<as-to-perspective-ontological-normalcy/postconvergence-implied'prospective-aporeticism-overcoming/unovercoming'> with regards to human formativeness$<$ as-to-intersolipsism-of-preformulating/preframing/premeaningfulness-imbued-mediativityand-deferentialism $>$-of- meaningfulness-and-teleology . Thus it is only the possibility of 'ontological-good-faith/authenticity ${ }^{6} \sim$ postconverging-de-mentating/structuring/paradigming existential-condescension-<of-apriorising/axiomatising/referencing-psychologism $>$ ' that can thus allow human existential-discursivity-implicited-sublimation-over-desublimation beyond naïve $\quad{ }^{79}$ presencing-absolutising-identitive-constitutedness <amplituding/formativeepistemicity $>$ totalising $\sim$ self-referencing-syncretising/circularity/interiorising/akrasiatic-drag (given that human ontological-performance ${ }^{72}-<_{\text {including-virtue-as- }}$ ontology $>$ /morality/ethics/justice/etc. cannot be neutrally be separated from human $<$ amplituding/formative-epistemicity>-totalising $\sim$ thrownness-in-existence ${ }^{35}$ and the reflexive temporal-to-intemporal ontological implications on human ontological-performance ${ }^{72}$ $<$ including-virtue-as-ontology>). This insight can be illustrated as follows: supposed say in 5000 $\mathrm{BC}$ an asteroid or virus could bring about a human cataclysm, such a 'potential manifestation of existence is not of prospective apriorising/axiomatising/referencing-sublimating-reflexivitybeholdening to human appreciation of the existential-<disentologising/re-ontelogising apereticism $>$ implications of the notion and science behind the asteroid or virus' and in this regard suppose extraterrestrials living in a 'supposedly habitable Mars' had achieved our modern-day civilisational and technological level, it is inevitable that they will effectively adopt 'ontological-good-faith/authenticity ${ }^{69} \sim$ postconverging-de-mentating/structuring/paradigming 
existential-condescension-<of-apriorising/axiomatising/referencing-psychologism $>{ }^{\prime} \quad$ with regards to the human species on Earth and strife to preempt such a cataclysm as to their technical capacity. We can appreciate that the human species on Earth as to its relative-ontologicalincompleteness ${ }^{8}$ doesn't have a pretence to being of a 'neutrally/objectively sound human ontological-performance $^{72}$-<including-virtue-as-ontology $>/$ morality/ethics/justice/etc. $\quad$ state failing to factor in human specific apriorising/axiomatising/referencing-\{of-"prospectively implicited_attendant-ontological-contiguity ' educedexistentialising/contextualising/textualising_'intelligibility/epistemicity/reflexivity-contiguity<imbued-notional cogency >’ $\}$ - ontological-deficiency arising from its specifically given $<$ amplituding/formative-epistemicity>-totalising $\sim$ thrownness-in-existence ${ }^{35}$, but together with the extraterrestrials is rather preconverging/postconverging-dementatively/structurally/paradigmatically in existential-discursivity-implicited-sublimationover-desublimation relation as to the primacy of the full-potency of existence over any subpotency (speaking fundamentally to prior human ontological-commitment $-<$ implied - selfassuredness-of-ontological-good-faith/authenticity postconverging-dementating/structuring/paradigming -as-being-as-of-existential-reality >) with regards to the fact that the ontological-veracity of all humans as human-subpotency is priorily of existentialdiscursivity-implicited-sublimation-over-desublimation superseding pretenses of mereformulaic methodologising/mutualising/organising/institutionalising presciences as to entitlements of ${ }^{79}$ presencing-absolutising-identitive-constitutedness ${ }^{14}$ articulated induced elaboration-as-to-mere-extrapolating/constituting/abstracting/deducing/inferring-ofelucidation-outside_-'prospectively_implicited_attendant_ontological-contiguity ${ }^{67}$ > educedexistentialising / intelligibility/epistemicity/reflexivity-contiguity$<$ imbued-notional cogency $>$ '. Speaking of the requisite 'owning-up' as to when relativeontological-completeness ${ }^{87}$ is-educed-and-avails-and-re-avails rather than ontological-bad- 
faith/inauthenticity ${ }^{64}$ in upholding relative-ontological-incompleteness ${ }^{88}$ (given that immortality/existence-perspective as to intemporality ${ }^{52}$ cannot be construed as arising from our prior mortals whims superseding of existential-<disentologising/re-ontologising aporeticism $>$ sublimation entailment and such presumption rather speaks to preconverging-or-dementing ${ }^{20}$ apriorising-psychologism and not postconverging-or-dialectical-thinking ${ }^{21}$-apriorisingpsychologism). It is this pre-eminence of existential-discursivity-implicited-sublimation-overdesublimation that explains why the educing-and-availing-and-re-availing of relativeontological-completeness

as

to dimensionality-of-sublimating

<<amplituding/formative>supererogatory $\sim$ de-mentativeness/epistemic-growth-or-

conflatedness /transvaluative-rationalising/transepistemicity/anamnestic-residuality/spirit-

drivenness-equalisation> takes precedence in defining human intellectual-and-moral ontological-performance ${ }^{72}-<$ including-virtue-as-ontology $>/$ morality/ethics/justice/etc. and so as to existence — as-sublimating-withdrawal/unenframing/re-ontologising,-elicited-fromprospective-profound-supererogation . This <amplituding/formative-epistemicity $>$ totalising thrownness-in-existence ${ }^{35}$ implied existential-discursivity-implicited-sublimationover-desublimation as to 'ontological-good-faith/authenticity $\sim$ postconverging-dementating/structuring/paradigming existential-condescension- $<$ ofapriorising/axiomatising/referencing-psychologism>' effectively underlies the 'Derridean underdetermination-imbued force/violence conception' and 'Foucauldian knowledge/power conception construed as knowledge-empowerment/ignorance-disempowerment', as the preformulating/preframing/premeaningfulness- $<$ metaphoricity ${ }^{57}$-disposition - as-to-psycheinduced-psychologism-of-existential-stake $>$ from which human ${ }^{56}$ meaningfulness-andteleology veridically arises. Thus existential-discursivity-implicited-sublimation-overdesublimation implies that the human is already 'preconverging/postconverging-dementatively/structurally/paradigmatically intellectually-and-morally existentially- 
$\leq$ disontologising/re-ontologising aporeticism $>$ engaged as to its limited-mentation-capacityas-subjecting 'educed-unlimitedness/existence-sublimating nascence' to-limitedness/humansubpotency' without any 'neutrally/objectively sound human ontological-performance ${ }^{72}$ $<$ including-virtue-as-ontology $>/$ morality/ethics/justice/etc. state failing to factor in human specific apriorising/axiomatising/referencing-\{of-‘prospectively implicited_attendantontological-contiguity ' educedexistentialising/contextualising/textualising_intelligibility/epistemicity/reflexivity-contiguity<imbued-notional cogency>' $\}$ - ontological-deficiency arising from its specifically given $<$ amplituding/formative-epistemicity $>$-totalising $\sim$ thrownness-in-existence ${ }^{35}$. This insight puts into perspective our ${ }^{7}$ presencing-absolutising-identitive-constitutedness ${ }^{14}$ conception of intellectual-and-moral responsibility/relative-reflexivity wherein supposedly failed/unsuccessful/ineffective initiatives undertaken as to relative-ontological-completeness (for instance with regards to some public engagement aspiratory dispositions of such intellectuals like Sartre, Foucault, etc. and in the scientific domain for instance controversies associated with Louis Pasteur breakthroughs in microbial science) seem to be wrongly analysed from the posture of a supposedly neutral/objective social-setup conception of intellectual-and-moral responsibility/ative (that ducks/ignores such relative-ontological-completeness aetiologisation/ontological-escalation-<ontologicalveridicality_commitment/otherliness_transcending/compulsions-encumbered_transcending > posturing) without factoring in that the 'social-setup's relative-ontological-incompleteness specific apriorising/axiomatising/referencing-\{of-'prospectively implicited_attendantontological-contiguity ' educedexistentialising/contexalising/texalising_intelligibility/epistemicity/reflexivity-contiguity<imbued-notional cogency>' $\}$ - ontological-deficiency arising from its specifically given <amplituding/formative-epistemicity >-totalising thrownness-in-existence ${ }^{3,}$ is not of 
neutrally/objectively sound ontological-performance ${ }^{72}-<$ including-virtue-as-ontology $>$; as to the fact that for instance the incidence of modern-day wars and their man-made catastrophies do not speak of neutral/objective individuals and social intellectual-and-moral responsibility/relativereflexivity as to their existence within the meaningful sovereign frameworks that preconverging/postconverging-de-mentatively/structurally/paradigmatically directly/indirectly validate such calamities. In other words, our intellectual-and-moral responsibility/relativereflexivity is already engaged as to our <amplituding/formative-epistemicity >totalising $\sim$ thrownness-in-existence ${ }^{35}$ and the idea that any attitude of unconcern/indifference is intellectually-and-morally neutral/objective is bogus; and human intellectual-and-moral responsibility/relative-reflexivity starts at the very least with an orientation to relativeontological-completeness $^{87}$ as to overall existential-<disontologising/re-ontologising apereticism $>$ dimensionality-of-sublimating ${ }^{25}-\langle<$ amplituding/formative $>$ supererogatory $\sim$ dementativeness/epistemic-growth-or-conflatedness /transvaluative-

rationalising/transepistemicity/anamnestic-residuality/spirit-drivenness-equalisation〉. Besides such a more stark elucidation as to Being-development/ontological-framework-expansion-asto-depth-of-ontologising-development-as-infrastructure-of- meaningfulness-and-teleology , existential-discursivity-implicited-sublimation-over-desublimation as to 'ontological-goodfaith/authenticity ${ }^{6} \sim$ postconverging-de-mentating/structuring/paradigming $70 \quad$ existentialcondescension- $<$ of-apriorising/axiomatising/referencing-psychologism $>$ ', thus points to the primacy of the 'very <amplituding/formative-epistemicity>-totalising $\sim$ thrownness-inexistence $^{35}$ of human discursivity as to the possibility for prospective existential< disontologising/re-ontologising aporeticism $>$ sublimation' so-reflected in originarinessparrhesia,-as--spontaneity-of-aestheticisation-

supereregatory acuity/perspicacity/astuteness/edginess/incisiveness projection as to overall existential-<disontologising/re-ontologising aporeticism> dimensionality-of-sublimating 
<<amplituding/formative>supererogatory $\sim$ de-mentativeness/epistemic-growth-or-

conflatedness /transvaluative-rationalising/transepistemicity/anamnestic-residuality/spirit-

drivenness-equalisation). The bigger point here is that prospective human sublimation underlying prospective knowledge-reification $\sim$ gesturing-and-accounting-of-epistemicphenomenalism-<in-prospective_psychologismic $\sim$ apriorising/axiomatising/referencing-\{of'prospectively_implicited_attendant-ontological-contiguity ' ceducedexistentialising/contextualising/textualising_ intelligibility/epistemicity/reflexivity_contiguity$<$ imbued-notional cogency $>$ ' $\}$-conflatedness -in-\{preconverging-ment by\}

postconverging-entailment $>$ in relative-ontological-completeness ${ }^{87}$ cannot be engaged with any given registry-worldview/dimension in relative-ontological-incompleteness ${ }^{88}$ as if the latter is of a 'neutrally/objectively sound human ontological-performance ${ }^{72}-<$ including-virtue-asontology $>$ /morality/ethics/justice/etc. state failing to factor in human specific apriorising/axiomatising/referencing-\{of-"prospectively_implicited_attendant-ontologicalcontiguity ' educed-

existentialising/contextualising/textualising_'intelligibility/epistemicity/reflexivity-contiguity<imbued-notional cogency>’ $\}$ - ontological-deficiency arising from its specifically given $<$ amplituding/formative-epistemicity $>$-totalising $\sim$ thrownness-in-existence ${ }^{35}$, with regards to the fact that human <amplituding/formative-epistemicity $>$-totalising $\sim$ thrownness-in-existence is already engaged in existential-discursivity-implicited-sublimation-over-desublimation as to 'ontological-good-faith/authenticity ${ }^{69} \sim$ postconverging-de-mentating/structuring/paradigming? existential-condescension-<of-apriorising/axiomatising/referencing-psychologism $>$ ' $\quad$ (and so very much countering the deceptive eliciting in desublimation of $<$ amplituding/formative $>$ wooden-language-<imbued — averaging-of-thought-<as-toleveling/ressentiment/closed-construct-of- meaningfulness-and-teleology -as-of'nondescript/ignorable-void '-with-regards-to-prospective-apriorising-implications $>>\quad$ by 
dominance/vested-interest actors and sycophantic-sophistry seeming to imply humansubpotency takes precedence over existence). In this regards, and in-the-bigger-scheme-ofthings existential-discursivity - implicited-sublimation-over-desublimation as to 'ontologicalgood-faith/authenticity $\sim$ postconverging-de-mentating/structuring/paradigming ${ }^{70}$ existentialcondescension- $<$ of-apriorising/axiomatising/referencing-psychologism $>{ }^{\prime}$ implies that as to existence—as-sublimating-withdrawal/unenframing/re-ontologising,-elicited-fromprospective-profound-supererogation, the respective state of recurrent-utteruninstitutionalisation, ununiversalisation, non-positivism/medievalism and procrypticism cannot be construed as of "neutrally/objectively sound human ontological-performance $<$ including-virtue-as-ontology $>/$ morality/ethics/justice/etc. state failing to factor in human specific apriorising/axiomatising/referencing-\{of-'prospectively implicited_attendantontological-contiguity ' educed-

existentialising/contextualising/textualising_ 'intelligibility/epistemicity/reflexivity-contiguity<imbued-notional cogency>' $\}$ - ontological-deficiency arising from its specifically given $<$ amplituding/formative-epistemicity>-totalising $\sim$ thrownness-in-existence ${ }^{35}$, with respect to prospective base-institutionalisation, ${ }^{103}$ universalisation, positivism/rational-empiricism and notional ${ }^{18}$ deprocrypticism respectively; and as relative-ontological-completeness ${ }^{87}$ avails intellectual-and-moral responsibility/relative-reflexivity is rather reflected as of dimensionalityof-sublimating ${ }^{25}-\langle<$ amplituding/formative $>$ supererogatory $\sim$ de-mentativeness/epistemicgrowth-or-conflatedness /transvaluative-rationalising/transepistemicity/anamnesticresiduality/spirit-drivenness-equalisation). Unlike it is often assumed from a sloppy conception of human sublimation in existence (caught up in any given ${ }^{7}$ presencing-absolutisingidentitive-constitutedness ${ }^{14}$ self-justification of uncertainty—as-failing-to-reflect-the-effective'existential-veracity-and-entailment-of $\sim$ relative-unreflexivity/relative-reflexivity' of prospective human sublimation), the comprehensive coherence of human sublimation in 
existence as to existence-as-sublimating-withdrawal/unenframing/re-ontologising,-elicitedfrom-prospective-profound-supererogation is effectively highly regular and consistent (and this can only be fully appreciated from an ontologically sound conception of 'existence as of its immanently tautologuous coherence speaking to its relative-unreflexivity/relative-reflexivity ontological-contiguity ${ }^{67}$ as to the possibility for intelligibility to arise as so-reflected with the overall relative-unreflexivity/relative-reflexivity - ontological-contiguity ${ }^{6}$ of-the-humaninstitutionalisation-process ${ }^{68}$ so-associated with human limited-mentation-capacitydeepening —as-subjecting limitedness/human-subpotency to-'educed-unlimitedness/existencesublimating nascence ${ }^{53}$ ). This confliction in the perception and relation to human sublimation in existence between metaphysics-of-presence-〈implicited-'nondescript/ignorable-void '-asto- presencing-absolutising-identitive-constitutedness > $<$ amplituding/formativeepistemicity>totalising $\sim$ self-referencing-syncretising/circularity/interiorising/akrasiatic-drag ${ }^{34}$, on-the-one-hand and on-the-other-hand difference-conflatedness ${ }^{13}$-as-to-totalitative-reificationin-singularisation-<as-to-the-nondisjointedness/entailment-of-prospective- nonpresencing $>$ as-veridical-epistemicity-relativism-determinism as to relative-ontological-completeness $<$ amplituding/formative-epistemicity $>$ causality $~ a s-t o-p r o j e c t i v e-t o t a l i t a t i v e-$ implications-ofprospective- nonpresencing,-for-explicating relative-unreflexivity/relative-reflexivityontological-contiguity, is aptly reflected in the entangled/enmeshed nature of human sublimation in existence as reflected with the relative-unreflexivity/relative-reflexivity ontological-contiguity ${ }^{67}$ of-the-human-institutionalisation-process ${ }^{68}$. This is so fundamentally because of human teleology ${ }^{99}$ speaking of 'human phenomenal/manifest conceptivity/epistemicreflexivity/epistemicity-relativism-determinism-<reifying \{as-to-knowledge-developing $\}$-andempowering $>$ in existence as ontological (so-reflecting $<$ amplituding/formative $>$ disposedness/psychologismic-construct-〈as-to-orientation/valueconstruct/valuation-and-derived-parameterising $\rangle$ and $<$ amplituding/formative $>$ entailment-〈as- 
to-totalising-contiguous/coherent-factuality-of-variability))', as reflecting the implications of human limited-mentation-capacity-deepening —as-subjecting limitedness/human-subpotency to-'educed-unlimitedness/existence-sublimating nascence' ${ }^{3}$ underlying the relativeunreflexivity/relative-reflexivity - ontological-contiguity ${ }^{67}$ of-the-human-institutionalisationprocess ${ }^{6}$; such that human sublimation is hardly 'purist' and rather occurring as from successive human registry-worldviews/dimensions projections of their specifically flawed ${ }^{79}$ presencingabsolutising-identitive-constitutedness given apriorising/axiomatising/referencing/intelligibilitysettingup/measuringinstrumenting-forconceptualisation reproducibility - mathesis/motif/thrownness-disposition,-as-reproducibilityof-aestheticisation. The insight here is that human state of prior relative-ontologicalincompleteness 88 preconverging/postconverging-de-mentatively/structurally/paradigmatically impacts reflexively on human appraisal of its prospective relative-ontological-completeness sublimation implications, and so across the <cumulating/recomposuring attendant-ontologicalcontiguity $>$-successive registry-worldviews/dimensions right up to the originariness/origination-〈so-construed-as-to-ontological-normalcy/postconvergenceperspective-scalarising-construal-of-existence) perspective of deprocrypticism-orpreempting - disjointedness-as-of- ${ }^{-3}$ reference-of-thought which purportedly escapes any such reflexive ${ }^{7}$ presencing_-absolutising-identitive-constitutedness ${ }^{14}<$ amplituding/formativeepistemicity $>$ totalising $\sim$ self-referencing-syncretising/circularity/interiorising/akrasiatic-drag of its apriorising/axiomatising/referencing/intelligibilitysettingup/measuringinstrumenting-forconceptualisation. The so-implied notional deprocrypticism as such points out that the relative-unreflexivity/relative-reflexivity ontological-contiguity ${ }^{67}$ of-the-humaninstitutionalisation-process ${ }^{68}$ is rather associated with a 'directly relevant trace of prospective human effectively-purist-sublimation-_reflecting-prospective- historiality/ontologicaleventfulness /ontological-aesthetic-tracing-<perspective-ontological- 
normalcy/postconvergence-reflected-'epistemicity-relativism-determinism' $>>$ as to existenceas-sublimating-withdrawal/unenframing/re-ontologising,-elicited-from-prospective-profoundsupererogation, but that, as of the <cumulating/recomposuring attendant-ontologicalcontiguity $>$-successive registry-worldviews/dimensions $\quad{ }^{79}$ presencing-absolutisingidentitive-constitutedness ${ }^{14}$ construals/conceptualisations, that 'directly relevant trace of prospective human effectively-purist-sublimation-〈reflecting-prospectivehistoriality/ontological-eventfulness /ontological-aesthetic-tracing-<perspectiveontological-normalcy/postconvergence-reflected-‘epistemicity-relativism-determinism' $>\rangle$ as to existence — as-sublimating-withdrawal/unenframing/re-ontologising,-elicited-fromprospective-profound-supererogation' is rather 'beholdening wrongly upon the overall relative-ontological-incompleteness ${ }^{88}$-presublimation-construct-of- ${ }^{56}$ meaningfulness-andteleology ${ }^{9}$ ' such that a contrasting assessment rather highlights the 'entangling/enmeshing of effectively-purist-sublimation-〈reflecting-prospective- historiality/ontologicaleventfulness /ontological-aesthetic-tracing-<perspective-ontologicalnormalcy/postconvergence-reflected-‘epistemicity-relativism-determinism' $>>$ and overall relative-ontological-incompleteness ${ }^{88}$-presublimation-construct-of- ${ }^{5}$ meaningfulness-andteleology ${ }^{9}$ induced desublimating of the effectively-purist-sublimation-〈reflecting-prospectivehistoriality/ontological-eventfulness /ontological-aesthetic-tracing-<perspectiveontological-normalcy/postconvergence-reflected-'epistemicity-relativism-determinism'>〉' as to the concreteness/concretism/<preconverging 'motif-andapriorising/axiomatising/referencing'-entailing>-existentialising—enframing/imprintedness〈as-to- historicity-tracing - in-presencing-hyperrealisation/hyperreal-transposition〉_ ofhuman-ontological-performance ${ }^{72}-<$ including-virtue-as-ontology $>/$ morality/ethics/justice/etc. of overall prospective sublimation. Human sublimation as such in reflecting holographically$<$ conjugatively-and-transfusively $>$ the relative-unreflexivity/relative-reflexivity - ontological- 
entologising aporeticism $>$ susceptibly instigated mostly as of materially/technically induced sublimation associated with tools, equipment, technical knowhow and natural science as to their immediately amenable positive-opportunism — of-social-functioning-and-accordance ${ }^{75}$ social implications ultimately leading to subsequent human methodologising/mutualising/organising/institutionalising sublimating overall meaningfulness-and-teleology . But the overall postconverging-dementating/structuring/paradigming of human sublimation in existence as such is not always coherent as to the discrepancy in the occurrence of specific sublimations and desublimations say material and technical sublimation pointing to relative-ontological-completeness ${ }^{87}$ and 'immaterial/social overall relative-ontological-incompleteness ${ }^{88}$-presublimation-construct-ofmeaningfulness-and-teleology instigating the referencing/registering/decisioning desublimation of the nascent-particular/incipient-and-material/technical-sublimations- $<$ blindedto-their-relative-ontological-completeness - reference-of-thought- devolving >'. In this regards, we can appreciate how the subsequent immaterial/social sublimation required for prospective positivism/rational-empiricism came to be appreciated by such thinkers like the Rousseaux, Diderots, etc. as to the fact that the material possibilities of their epoch associated with the printing press and increasing technical knowhow rendered the immaterial/social overall relative-ontological-incompleteness ${ }^{8}$ - presublimation-construct-of- $-{ }^{56}$ meaningfulness-andteleology ${ }^{9}$ of their epoch wanting, explaining for instance Rousseau's appreciation of the noblesavage and nature as speaking to a prospective human postconvergingaaporeticismovercoming/unovercoming that recognised that mankind needed a more mature conception of interhuman relationship and human relation with nature as to when mankind/some-of-mankind began manifesting a more developed relationship with nature beyond just as of the immediacy of subsistence/survival/advantage relationship with nature (say for instance having technically 
more efficient guns with gunpowder didn't imply just killing animals at whim or along the same lines explaining his anti-Slavery stance); thus speaking of the prospectively requisite immaterial/social sublimation as to prospective positivism/rational-empiricism postconvergingor-dialectical-thinking -apriorising-psychologism. In this regards even budding-positivists like Galileo, Descartes, etc. just as well implicitly recognised this discrepancy of prospective material and technical sublimation positivistic science in relative-ontological-completeness ${ }^{87}$ and the immaterial/social overall relative-ontological-incompleteness ${ }^{8}$-presublimation-construct-ofmeaningfulness-and-teleology ${ }^{9}$ of medieval-scholasticism associated with alchemic/magical thinking, to the point that in-many-ways their actions were directed towards articulating at the very least an underlying 'scientific_-apriorising/axiomatising/referencing-psychologism enculturated/constructed social-pragmatics-framing-of-predicative-effectivity-sublimation〈as-to-underlying,-ontological-commitment $-<$ implied - self-assuredness-of-ontological-goodfaith/authenticity postconverging-de-mentating/structuring/paradigming -as-being-as-ofexistential-reality $>\rangle$ ' as the requisite immaterial/social sublimation for enabling positivistic science as we know it today to arise. This very insight explains the 'enlightenment struggle against feudalism and slavery as advocated say with such a thinker like Rousseau' as to the fact that the technical and scientific progress as to relative-ontological-completeness ${ }^{87}$ weren't the occasion to put such technical and scientific progress like shipbuilding and other ocean voyage technologies at the service of the prior medievally clouded immaterial/social overall relativeontological-incompleteness ${ }^{88}$-presublimation-construct-of- ${ }^{56}$ meaningfulness-and-teleology value-construct and shallow-supererogating methodologising/mutualising/organising/institutionalising $<$ preconverging 'motif-andapriorising/axiomatising/referencing'-entailing>-existentialising-enframing/imprintedness〈as-to- historicity-tracing-in-presencing-hyperrealisation/hyperreal-transposition〉, but rather called for a renewed conceptualisation of humanity beyond a mentality of immediate 
subsistence/survival/advantage. Thus it is always the case that the positive-opportunism-ofsocial-functioning-and-accordance ${ }^{75}$ driving the secondnatured institutionalisation of human sublimation induces discrepancy as to immediate material and technical possiblities of sublimation and the requisite dispensing-with-immediacy-for-relative-ontologicalcompleteness $^{87}$-by-reification/contemplative-distension ${ }^{27}$ immaterial/social sublimation considerations that rise to the postconverging-aporeticism overcoming/unovercoming challenge of the immediate material and technical possibilities of sublimation. In-many-ways this discrepancy of material and technical sublimation and immediate distortive immaterial/social desublimation is reflected in the " historicity-tracing-in-presencinghyperrealisation/hyperreal-transposition gimmickiness/desublimation relation with meaningfulness-and-teleology ${ }^{\circ}$ of our positivism- ${ }^{8}$ procrypticism, for instance as associated with an 'underlying dumbing-down public intellection and media industry'; as media-access and its commercialisation function in-many-ways rather adhocly substitutes-for/undermines a profound genuine social intellectual-function/posture as to social-stake-contention-orconfliction implications. The further implication of this discrepancy is in highlighting that the supposed equanimity/balance of the overall politico-institutional system as to sublimating notions of sovereignty, democracy, free-will, etc. is only veridically effective as to the originariness/origination-〈so-construed-as-to-ontological-normalcy/postconvergence-

perspective-scalarising-construal-of-existence) perspective of notional ${ }^{18}$ deprocrypticism given the perpetual challenge of material sublimation upon human immaterial/social overall relative-

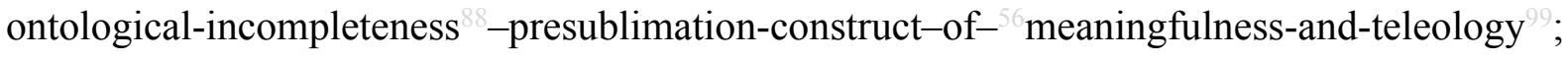
as prospective material/technical sublimation is associated with a discrepant 'immaterial/social overall relative-ontological-incompleteness ${ }^{8}$ - presublimation-construct-of- ${ }^{5}$ meaningfulnessand-teleology ${ }^{9}$ instigating the referencing/registering/decisioning desublimation of the nascentparticular/incipient-and-material/technical-sublimations- $<$ blinded-to-their-relative-ontological- 
completeness - reference-of-thought- devolving >' that goes on as of ${ }^{79}$ presencingabsolutising-identitive-constitutedness ${ }^{14}$ to render the supposed equanimity/balance of the overall politico-institutional system as to sublimating notions of sovereignty, democracy, freewill, etc. increasingly of relic/artifactual human ontological-performance ${ }^{22}<$ including-virtueas-ontology $>$ /morality/ethics/justice/etc. reflected in their failing effective outcomes of equanimity/balance; wherein their practice increasingly tends to dominance/vested-interest actors and sycophantic-sophistry induced desublimating narratives as to the $<$ amplituding/formative $>$ wooden-language-〈imbued - averaging-of-thought-<as-toleveling/ressentiment/closed-construct-of- meaningfulness-and-teleology -as-of'nondescript/ignorable-void '-with-regards-to-prospective-apriorising-implications $>$ > displayed in the public domain (caught-up/entrapped in a 'politico-institutional beholdening relic/artefactual disenfranchising notion of both-sides' as psyching-subterfuge that renders the common concrete pragmatic aspirations of sovereign individuals increasingly politically irrelevant as to the paradox for instance that the healthier political framework in the years following the second world-war, as hardly subject to closed-circles of effective direct/indirect politico-institutional influence rampant today, notwithstanding the even greater social prejudice/bigotry/closed-mindedness was able to induce critical progressive social transformations that in-many-ways the modern-day political framework as to a period of rather profound and real-world cosmopolitanism/opened-mindedness can only dream about) as the more potent possibilities for social transformation are increasingly subdued under politicoinstitutional defaulting frameworks-and-practices rather surreptitiously subjected to closedcircles of effective direct/indirect politico-institutional influence 'as to a strategic capacity to elicit old and relatively aporetically irrelevant beholdening narratives of identity as a divide-andconquer strategy for undermining the real and concrete common sovereign narrative of social transformation possibilities' as so-reflected with commonly held objective sovereign aspirations 
that cut across party/ideological affiliations when not subjected to the disenfranchising effects of crafty politicised beholdening narratives of identity with their 'ad-hoc/arbitrary popping-up in the media at critical electoral moments involving high emotional charge quelling cerebral thinking as of the modern-day efficient disenfranchising technique of flawed apriorising deception involving arbitrarily-skewing-or-debasing-the-terms-of-supposedly-constructivelyopened-public-debate' (as to the wrong mental enculturation of the notion that the 'political game' in-of-itself precedes individuals and social sovereign aspirations as if the latter were just 'paying fans to a sports encounter' rather than a political process meant to serve them as so reflected with an enculturated media political narrative hardly/poorly making room for direct individual and social sovereign aspirations as centrally defining with the consequence that substance is increasingly overwhelmed by a political characters portrayal of the political debate with political actors then effectively turning over rather towards the levers of their potential power which is paradoxically not necessarily/deterministically social sovereign aspirations as to a relic/artifactual conception-and-projection in the public domain but rather surreptitious/private closed-circles of effective direct/indirect politico-institutional influence as so-plainly exposed by the fact that long-term consequences of public policies recurrently 'default for dominance/vested-interest actors'). Even in the purely intellectual sense, modern-day scientific advancements and achievements have correspondingly given rise to a distorted manifestation of science-ideology as a usurpatory mouthpiece of veridical science-in-practice that effectively rides the wave of natural sciences accomplishments and in so doing projects of a naïve presencing-absolutising-identitive-constitutedness ${ }^{14}$ epistemic conception of science that in many cases poorly reflects upon effective scientific practices and craft as it poorly appreciates the dynamics of the overall human knowledge and scientific enterprise as to the aestheticisationand-aestheticisation-towards-ontology-<elicited-idiomatisation $>$ underlying the overall relative-unreflexivity/relative-reflexivity - ontological-contiguity ${ }^{67}$ of-the-human- 
institutionalisation-process ${ }^{68}$, so-reflected from such science-ideology poor appreciation of the implications of the ${ }^{4}$ historiality/ontological-eventfulness ${ }^{38}$ /ontological-aesthetic-tracing$<$ perspective--ontological-normalcy/postconvergence-reflected-'epistemicity-relativismdeterminism'> rendering the scientific adventure as of a living 'implicited_attendantontological-contiguity ${ }^{67} \sim$ educedexistentialising/contextualising/textualising_intelligibility/epistemicity/reflexivity-contiguity$<$ imbued-notional cogency $>$ exercise. Such that by this token science-ideology conception of science the requisite dispensing-with-immediacy-for-relative-ontological-completeness ${ }^{87}$-byreification/contemplative-distension ${ }^{27}$ as to human limited-mentation-capacity-deepening-assubjecting limitedness/human-subpotency-to-'educed-unlimitedness/existence-sublimatingnascence' ${ }^{53}$ implications in fully appreciating human underlying aestheticisation scheming in conceptualising existence-as-sublimating-withdrawal/unenframing/re-ontologising,-elicitedfrom-prospective-profound-supererogation behind the ultimate development of human knowledge and science is lost to a flatminded interpretation of human progress based on the mere elaboration-as-to-mere-extrapolating/constituting/abstracting/deducing/inferring-ofelucidation-outside_-'prospectively_implicited_attendant-ontological-contiguity ${ }^{67}$ ' educed-

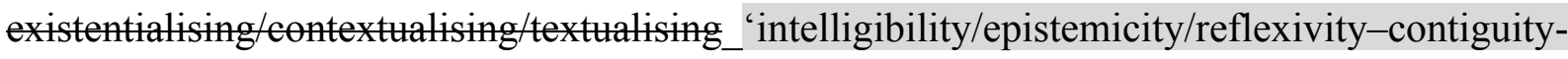
$<$ imbued-notional cogency>' $>^{\prime 0}$ conception of methods/methodologies/approaches as to mere reproducibility—mathesis/motif/thrownness-disposition,--as-reproducibility-of-aestheticisation with a poor appreciation for the prospective originariness-parrhesia,-as-spontaneity-ofaestheticisation—supererogatory acuity/perspicacity/astuteness/edginess/incisiveness-ofapriorising/axiomatising/referencing/intelligibilitysettingup/measuringinstrumenting -forconceptualisation behind the supererogatory invention and validation of any such methods/methodologies/approaches. Further science-ideology as to its dimensionality-ofdesublimating-lack-of ${ }^{-}-\langle<$amplituding/formative $>$supererogatory $\sim$ de-mentativeness/epistemic- 
growth-or-conflatedness /transvaluative-rationalising/transepistemicity/anamnestic-

residuality/spirit-drivenness-equalisation) equally fails to appreciate how prior human aestheticisation scheming including human superstitions, belief systems and religions were a necessary pathway to the present even as modern science demonstrates their limits (given that we are an animal of limited-mentation-capacity-as subjecting 'edneedunlimitedness/existence-sublimating nascence' to-limitedness/human-subpotency reflected as to our human-subpotency ontological-faith-notion-or-ontological-fideism-imbuedunderdetermination-of-motif-and-apriorising/axiomatising/referencing-as-so-being-as-of-

existential-reality to which the notion of institutional-cumulation/institutional-recomposure-〈asto- historiality/ontological-eventfulness /ontological-aesthetic-tracing-<perspectiveontological-normalcy/postconvergence-reflected-‘epistemicity-relativism-determinism'>> in supererogation is vital for perpetually enhancing that limited-mentation-capacity-assubjecting-'educed-unlimitedness/existence-sublimating nascence' to-limitedness/humansubpotency as of our aestheticisation-and-aestheticisation-towards-ontology-<elicitedidiomatisation $>$ ); as such mystical/spiritual narratives were veridically 'trialing aestheticisation frameworks of human apriorising/axiomatising/referencing/intelligibilitysettingup/measuringinstrumenting-forconceptualisation as of the affirmatory sublimating possibilities inducible as to existence - assublimating-withdrawal/unenframing/re-ontologising,-elicited-from-prospective-profoundsupererogation that ultimately enabled and propulsed human limited-mentation-capacitydeepening - as-subjecting-limitedness/human-subpotency-to-'educed-unlimitedness/existencesublimating nascence' ${ }^{53}$ (so-associated with such affirmatory sublimating possibilities strong selective cultural diffusion as to the sublimating strengthening and anchoring upon the socialsetup that such mystical/spiritual narratives enabled), and so-construable as from the institutional-cumulation/institutional-recomposure-〈as-to- historiality/ontological- 
eventfulness /ontological-aesthetic-tracing-<perspective-ontological-

normalcy/postconvergence-reflected-'epistemicity-relativism-determinism' $>>$ that led to our modern-day non-superstitious clairvoyance/clearsightedness with the important projectiveinsights that since human aestheticisation scheming has always been central and preceding human aestheticisation-towards-ontology (as even manifested in modern-day natural sciences creativity) it would be foolhardy to adopt a mental-disposition as of science-ideology that poorly recognises the critical creative role for human aestheticisation in the perpetual development of human meaningfulness-and-teleology ${ }^{56}$ as to existence-as-sublimatingwithdrawal/unenframing/re-ontologising,-elicited-from-prospective-profoundsupererogation, especially so with regards to our own capacity to conceptualise of reontologising prospective Being-development/ontological-framework-expansion-as-to-depthof-ontologising-development-as-infrastructure-of- meaningfulness-and-teleology herein construed as of ${ }^{18}$ deprocrypticism-or-preempting - disjointedness-as-of- ${ }^{3}$ reference-of-thought (as to the requisite originariness-parrhesia,-as-spontaneity-of-aestheticisationsupererogatory acuity/perspicacity/astuteness/edginess/incisiveness behind the prospective creation/invention of sublimating methods/methodologies/approaches as secondnatured reproducibility—mathesis/motif/thrownness-disposition,--as-reproducibility-of-aestheticisation in the face of prospective postconverging aporeticism-overcoming/unovercoming as to humansubpotency-aporia/undecidability/dilemma/ought-

indeterminacy/deficiency/limitation/constraint, with budding-positivists inventing/creating the positivism/rational-empiricism sublimating methods/methodologies/approaches superseding medieval-scholasticism desublimating methods/methodologies/approaches and likewise Socratic-philosophers ${ }^{103}$ universalising-idealisation inventing/creating ${ }^{103}$ universalisingidealisation sublimating methods/methodologies/approaches superseding non-universalising sophists desublimating methods/methodologies/approaches), as otherwise we'll merely sanctify 
as absolute our present positivism- ${ }^{8}$ procrypticism Being-development/ontological-frameworkexpansion-as-to-depth-of-ontologising-development-as-infrastructure-of- meaningfulnessand-teleology psychologismic epistemic-acutisation difficulty-for, residualising \{decompulsing delinearity for-cogeney>-magnitude $\{$ of-experientiality/experiment\} and its corresponding methods/methodologies/approaches associated with its institutional-development-as-to-socialfunction-development and living-development-as-to-personality-development psychologismic epistemic-acutisation difficulty-for, residualising \{decompulsing\} delinearity for-cogency> magnitudes $\{$ of-experientiality/experiment\} as to wrongly imply ours is the human generation that don't face any prospective postconverging aporeticism-overcoming/unovercoming. Along the same line of intellectual appreciation of prospective sublimation implications as to the fact that nascent-particular/incipient-and-material/technical-sublimations- $<$ blinded-to-their-relativeontological-completeness - reference-of-thought- devolving> 'critically points to an overall nascent knowledge-reification $\sim$ gesturing-and-accounting —of-epistemic-phenomenalism- $<$ inprospective_psychologismic apriorising/axiomatising/referencing-\{of-'prospectively implicited_attendant-ontological-contiguity ' reducedexistentialising/contextualising/textualising_'intelligibility/epistemicity/reflexivity-contiguity<imbued-notional cogency >' \}-conflatedness in \{preconverging ment by\}

postconverging-entailment $>$ directly or indirectly prescient of a comprehensive sublimating meaningfulness-and-teleology ${ }^{9}$ conception of the given prospective relative-ontologicalcompleteness $^{87}$ registry-worldview/dimension'; the possibility for ontology/science is effectively of 'relative-unreflexivity/relative-reflexivity_ontological-contiguity ${ }^{77}$ projection as to an all-englobing/all-encompassing construction' (notwithstanding the epistemic limitation inherent to human limited-mentation-capacity as-subjecting 'educed mnlimitedness/existencesublimating nascence' to-limitedness/human-subpotency) that captures relative-ontologicalcompleteness $^{87}$ induced sublimation as reflected in any subject-matter (as to its 
phenomenal/manifest $\sim$ subpotency-〈in-transitive-conflatedness -reflexivity,-in-the-full-

potency-of-existence's $\sim$ sublimating-nascence)) and so as to the subject-matter underlying existential-discursivity-implicited-sublimation-over-desublimation as to 'ontological-goodfaith/authenticity ${ }^{69} \sim$ postconverging-de-mentating/structuring/paradigming $70 \quad$ existentialcondescension- $<$ of-apriorising/axiomatising/referencing-psychologism $>$ ' (and so as effectively reflected by the overall ${ }^{83}$ reference-of-thought and ${ }^{83}$ reference-of-thought- ${ }^{84}$ devolving/subjectmatter 'relative-ontological-completeness ${ }^{87}$-apriorising/axiomatising/referencingpsychologism enculturated/constructed social-pragmatics-framing-of - predicative-effectivitysublimation-〈as-to-underlying,-ontological-commitment $-<$ implied-self-assuredness-of-

\section{ontological-good-faith/authenticity $\sim$ postconverging-de-}

mentating/structuring/paradigming -as-being-as-of-existential-reality $\left.>\rangle^{\prime}\right)$. In this regards, we can appreciate that going by the positivism/rational-empiricism relative-ontologicalcompleteness ${ }^{87}$ registry-worldview/dimension, the natural sciences do not allow for any other external interpretations of their phenomenal/manifest $\sim$ subpotency-<in-transitiveconflatedness -reflexivity,-in-the-full-potency-of-existence's $\sim$ sublimating-nascence) (but for issues of epistemic limitation inherent to human limited-mentation-capacity-as-subjecting 'educed-unlimitedness/existence-sublimating nascence' to-limitedness/human-subpotency). In this regards, there can't be any instance/circumstance to which the mathematician will construe of $1+1$ as being equal to 4 as to totalisingly-ing — discretion/whim-of-thought; as to the fact that inherent ontological-veracity precedes-and-supersedes 'mere-formulaicmethodologising/mutualising/organising/institutionalising human-subpotency $<$ preconverging 'motif-and-apriorising/axiomatising/referencing'-entailing >existentialising — enframing/imprintedness-〈as-to- historicity-tracing — in-presencinghyperrealisation/hyperreal-transposition〉'. The implication here that in-the-bigger-scheme-ofthings, the 'apriorising decisions advancing mere-formulaic- 
methodologising/mutualising/organising/institutionalising $<$ preconverging 'motif-and-apriorising/axiomatising/referencing'-entailing $>$ -

existentialising — enframing/imprintedness-〈as-to- historicity-tracing —in-presencing-

hyperrealisation/hyperreal-transposition〉' over inherent ontological-veracity as manifested in many a social domain (while equally relevant in the natural sciences especially when 'mereformulaic-methodologising/mutualising/organising/institutionalising human-subpotency $<$ preconverging 'motif-and-apriorising/axiomatising/referencing'-entailing $>$ -

existentialising — enframing/imprintedness-〈as-to- historicity-tracing - in-presencing-

hyperrealisation/hyperreal-transposition〉' increasingly undermine the organisation behind the natural conduct of the natural sciences) go on to undermine their pretenses to a status of profound ontological-veracity as reflected of an ontology/science as to aestheticisation-towards-ontology. In this regard, relic/artifactual conception of veridical human historiality/ontologicaleventfulness 38 ontological-aesthetic-tracing-<perspective-ontological-

normalcy/postconvergence-reflected-'epistemicity-relativism-determinism'> rather speaks to deficient prior_knowledge-reification $\sim$ gesturing-and-accounting-of-epistemicphenomenalism- $<$ in-prior_psychologismic apriorising/axiomatising/referencing-\{of- priorimplicited_attendant-ontological-contiguity ' educedexistentialising/contextualising/textualising_intelligibility/epistemicity/reflexivity-contiguity$<$ imbued-notional cogency $>$ ' $\}$-constitutedness -in-preconverging-entailment $>$ caught up in ${ }^{79}$ presencing-absolutising-identitive-constitutedness ${ }^{14}$ as of beholdening-becomingdistortive-originariness/distortive-origination-as-to- ${ }^{4}$ historicity-tracing $\sim$ inhibited-mentalaestheticising. Likewise, deliberate intellectual decisions emphasising institutional selfpreservation and rendering veridical knowledge elucidation secondary to such institutional selfpreservation decisions, in-many-ways wrest away from such supposed intellectual institutions their status as veridically knowledge producing as these increasingly become political as to their 
emphasising of a political motive ready to forego veridical knowledge-reification $\sim$ gesturingand-accounting - of-epistemic-phenomenalism- $<$ inprospective_psychologismic apriorising/axiomatising/referencing-\{of-'prospectively implicited_attendant-ontological-contiguity ' reducedexistentialising/contextualising/textualising_'intelligibility/epistemicity/reflexivity-contiguity<imbued-notional cogency >’ \}-conflatedness -in-\{preconverging-ment by\}

postconverging entailment $>$ for its institutional self-preservation; with the consequence of increasing sycophantic-sophistry and genuine social intellectual-function/posture indifference or betrayal to dominance/vested-interest actors. This issue of institutional self-preservation is inmany-ways at the very root of the non-intellectual, media-driven and dishonest criticisms levied against postmodern-thought as to the latter obvious conclusive emancipating implications; soreflected in a practice of 'clouded thought' that has no true intellectual elucidation purpose but rather an extension of the political over veridical knowledge-reification $\sim$ gesturing-andaccounting - of-epistemic-phenomenalism- $<$ in-

prospective_psychologismic apriorising/axiomatising/referencing-\{of-‘prospectively implicited_attendant-ontological-contiguity ' reducedexistentialising/contextrising/textring_intelligibility/epistemicity/reflexivity-contiguity<imbued-notional cogency>' \}-conflatedness -in-\{preconverging-ment by\} postconverging-ntailment> (such that arguments about the accommodation of different intellectual practices tend to be articulated wrongly as to imply that the 'true ontological-veracity as to sublimation-over-desublimation of intellectual practices' are irrelevant and secondary to the mere purpose of institutional accommodation of different intellectual practices). It is herein contended that just as the prior <cumulating/recomposuring attendant-ontologicalcontiguity >-successive registry-worldviews/dimensions required their specific 'relativeontological-completeness ${ }^{87}$ - apriorising/axiomatising/referencing-psychologism 
enculturated/constructed social-pragmatics-framing-of-predicative-effectivity-sublimation〈as-to-underlying,-ontological-commitment $-<$ implied — self-assuredness-of-ontological-goodfaith/authenticity postconverging-de-mentating/structuring/paradigming -as-being-as-ofexistential-reality $>>$ ' to usher in the possibility of their very own secondnatured institutionalisation unclouded knowledge-reification $\sim$ gesturing-and-accounting — of-epistemicphenomenalism- $<$ in-prospective_psychologismic $\sim$ apriorising/axiomatising/referencing- of'prospectively_implicited_attendant-ontological-contiguity ' educedexistentialising/contextualising/textualising_ 'intelligibility/epistemicity/reflexivity-contiguity<imbued-notional cogency $>$ ' \}-conflatedness -in-\{preconverging-ment by\} postconverging entailment $>$, the ultimate possibility for our positivism- ${ }^{80}$ procrypticism overcoming its pedantising/muddling/formulaic-hollowing-out—insubontologisation/subpotentiation-〈blurring/undermining-of-prospective-totalising-entailing,as-to-entailing-<amplituding/formative-epistemicity $>$ totalising in-relative-ontologicalcompleteness > lies with the prospective 'deprocrypticismapriorising/axiomatising/referencing-psychologism enculturated/constructed socialpragmatics-framing-of - predicative-effectivity-sublimation-〈as-to-underlying,-ontologicalcommitment $-<$ implied—self-assuredness-of-ontological-goodfaith/authenticity postconverging-de-mentating/structuring/paradigming -as-being-as-ofexistential-reality $>\rangle$ ' imbued $\quad{ }^{45}$ foregrounding_entailment- $<$ in-succession-of-profoundsupererogation $>$-〈postconverging-narrowing-down $\sim$ sublimation-as-to-'existence-assublimating-withdrawal/unenframing/re-ontologising,-elicited-from-prospective-profoundsupererogation '-in-reflecting-'immanent relative- unreflexivity/relative-reflexivity ontological-contiguity ';-as-operative-notional deprocrypticism) (enabling the true and profound attainment of notional-contiguity/epistemic-contiguity ${ }^{6}-<$ profound-supererogation of-mentally-aestheticised postconverging/dialectical-thinking -qualia-schema $>$ in the social 
domain beyond the present practices of disparateness-of-conceptualisation- $<$ unforegroundingment,-failing-prospectively-to-reflect- immanent relative-unreflexivity/relative-reflexivity

ontological-contiguity '>). The manifest historical veracity of human sublimation as underlined by the 'directly relevant trace of prospective human effectively-purist-sublimation-〈reflectingprospective- historiality/ontological-eventfulness /ontological-aesthetic-tracing-

$<$ perspective-ontological-normalcy/postconvergence-reflected-`epistemicity-relativismdeterminism' $>>$ as to existence-as-sublimating-withdrawal/unenframing/re-ontologising,elicited-from-prospective-profound-supererogation (and as rather 'beholdening wrongly upon the overall relative-ontological-incompleteness ${ }^{88}$-presublimation-construct-ofmeaningfulness-and-teleology ${ }^{9}$ ) is the more accurate conception in reflecting the overall relative-unreflexivity/relative-reflexivity ontological-contiguity ${ }^{67}$ of-the-humaninstitutionalisation-process ${ }^{68}$, and so as to: human-subpotency 'fatedness-of-sublimation-overdesublimation, to existence-potency $\sim$ sublimating-nascence,-disclosed-from-prospectiveepistemic-digression (in reflecting holographically-<conjugatively-and-transfusively $>$ the relative-unreflexivity/relative-reflexivity - ontological-contiguity $\sim$ of-the-humaninstitutionalisation-process ), as from human-subpotency ontological-faith-notion-orontological-fideism - imbued-underdetermination-of-motif-andapriorising/axiomatising/referencing-as-so-being-as-of-existential-reality as to the disseminative — sublimating-selectivity-of-ontological-goodfaith/authenticity postconverging-de-mentating/structuring/paradigming , overdesublimating deselectivity-of-ontological-bad-faith/inauthenticity opreconverging dementating/structuring/paradigming ', as the driver of the human-subpotency potentiating existential-<isontologising/re-ontologising aporeticism $>$ becoming manifestation of sublimating-over-desublimating social-and-institutional-constructs-of- - meaningfulness-andteleology - in-cumulation/recomposuring all along in reflecting holographically- 
$<$ conjugatively-and-transfusively $>$ the relative-unreflexivity/relative-reflexivity-ontologicalcontiguity of-the-human-institutionalisation-process ; as it dynamically induces (as of 'varying psychologismic epistemic acutisation difficulty-<for, residualising \{decompulsing $\}$ delinearity for-cogency> magnitudes $\{$ of-experientiality/experiment $\} /$ scales —as-tosuccessively-profound-preconverging/postconverging-redementating/restructuring/reparadigming-frames-as-from-living,-institutionalising,-and-Beingontologising/infrastructure-of- ${ }^{5}$ meaningfulness-and-teleology 9 of prospective humansubpotency-aporia/undecidability/dilemma/ought-

indeterminacy/deficiency/limitation/constraint—imbued-'notional firstnaturednessformativeness-<as-to-eventualising-inkling-drive-or-seeding-misprising $>$ temporal-tointemporal-dispositions-<so-construed-as-from-perspective-ontologicalnormalcy/postconvergence>'-existentialism-form-factor') successive prospective reasoningthrough/messianic-reasoning for reasoning-from-results/afterthought as the secondnaturedinstitutionalisation of the <cumulating/recomposuring attendant-ontological-contiguity successive registry-worldviews/dimensions ${ }^{8}$ reference-of-thought-and- ${ }^{83}$ reference-of-thoughtdevolving- ${ }^{56}$ meaningfulness-and-teleology' so-construed as 'generating varying human sublimating-over-desublimating social-and-institutional-constructs-of- - meaningfulness-andteleology ${ }^{9}$ - in-cumulation/recomposuring of apriorising/axiomatising/referencing/intelligibilitysettingup/measuringinstrumenting' as to their pre-eminence as of their 'prospectively projected relative-ontological-completeness dimensionality-of-sublimating ${ }^{25}-\langle<$ amplituding/formative $>$ supereregatory $-\mathrm{de}-$ mentativeness/epistemic-growth-or-conflatedness /transvaluativerationalising/transepistemicity/anamnestic-residuality/spirit-drivenness-equalisation〉'. Critically thus the veracity of human sublimation is rather as to the originariness/origination-〈soconstrued-as-to-ontological-normalcy/postconvergence-perspective-scalarising-construal-of- 
existence) perspective of notional ${ }^{1}$ deprocrypticism as effectively reflecting existence-assublimating-withdrawal/unenframing/re-ontologising,-elicited-from-prospective-profoundsupererogation, and so as to the fact that the notional ${ }^{18}$ deprocrypticism given 'directly relevant trace of prospective human effectively-purist-sublimation-〈reflecting-prospectivehistoriality/ontological-eventfulness /ontological-aesthetic-tracing-<perspectiveontological-normalcy/postconvergence-reflected-‘epistemicity-relativism-determinism'>> as to existence — as-sublimating-withdrawal/unenframing/re-ontologising,-elicited-fromprospective-profound-supererogation' is not 'beholdening wrongly upon the overall relativeontological-incompleteness ${ }^{8}$-presublimation-construct-of- ${ }^{5}$ meaningfulness-and-teleology ${ }^{9}$. This projected notional deprocrypticism ontological-normalcy/postconvergence perspective points out that human sublimation in existence actually reflects the overall relativeunreflexivity/relative-reflexivity_ontological-contiguity ${ }^{67}$ as of the $<$ cumulating/recomposuring attendant-ontological-contiguity $>$-successive registryworldviews/dimensions $\quad$ ' ${ }^{83}$ reference-of-thought-and- ${ }^{83}$ reference-of-thought- ${ }^{8}$ devolvingmeaningfulness-and-teleology ${ }^{9}$ comprehensiveness of prospective sublimating-nascence (as to their instigating relative-ontological-completeness ${ }^{87}$-apriorising/axiomatising/referencingpsychologism)' manifested as of the notional $\sim$ symmetrisation- $<$ as-to-symmetrisation-bydesymmetrisation,-in-reflecting-postconverging-or-dialectical-thinking ${ }^{21}$-by-preconvergingor-dementing 20 perspectives-of-human- ${ }^{5}$ meaningfulness-and-teleology $>$ of the overall relative-unreflexivity/relative-reflexivity - ontological-contiguity ${ }^{67}$ of-the-humaninstitutionalisation-process ${ }^{6}$. This further highlights that the prospectively defining possibilities for unleashing further human sublimation (and so over 'beholdening wrongly upon the overall relative-ontological-incompleteness ${ }^{8}$-presublimation-construct-of- ${ }^{56}$ meaningfulness-andteleology ') will stall without the appropriate reconciling of the overall relative-ontologicalincompleteness ${ }^{88}$-presublimation-construct-of- ${ }^{56}$ meaningfulness-and-teleology ${ }^{9}$ to the 
prospective comprehensive sublimating ${ }^{56}$ meaningfulness-and-teleology ${ }^{9}$ implications of the instigated relative-ontological-completeness ${ }^{87}$ effectively-purist-sublimation-〈reflectingprospective- historiality/ontological-eventfulness /ontological-aesthetic-tracing-

<perspective-ontological-normalcy/postconvergence-reflected-'epistemicity-relativism-

determinism' $>\rangle$, and so as to ' ${ }^{83}$ reference-of-thought-and- ${ }^{8}$ reference-of-thought- ${ }^{8}$ devolvingmeaningfulness-and-teleology ${ }^{9}$ comprehensiveness of prospective sublimating-nascence (as to the instigating relative-ontological-completeness ${ }^{87}$-apriorising/axiomatising/referencingpsychologism)' prospective reconciling. This is fundamentally the case because the implied dimensionality-of-sublimating $5-<<$ amplituding/formative $>$ supererogatory $\sim$ dementativeness/epistemic-growth-or-conflatedness /transvaluativerationalising/transepistemicity/anamnestic-residuality/spirit-drivenness-equalisation〉 inducing the nascent-particular/incipient-and-material/technical-sublimations- $<$ blinded-to-their-relativeontological-completeness - reference-of-thought- devolving $>$ is lost to the prior overall relative-ontological-incompleteness ${ }^{8}$ - presublimation-construct-of- ${ }^{5}$ meaningfulness-andteleology as to a narrow-minded positive-opportunism-of-social-functioning-andaccordance $^{75}$ driven exploitation of such nascent-particular/incipient-and-material/technicalsublimations- $<$ blinded-to-their-relative-ontological-completeness - reference-of-thoughtdevolving $>$ while failing to come to terms as to construing the <amplituding/formativeepistemicity>totalising/circumscribing/delineating 'relative-ontologicalincompleteness 8 /relative-ontological-completeness ${ }^{87}$ 〈sublimating $\sim$ referencing/registering/decisioning,-as-self-becoming/selfconflatedness /formative-supererogating-<projective/reprojective-aestheticising-re-motifand-re-apriorising/re-axiomatising/re-referencing,-in-perspective-ontologicalnormalcy/postconvergence $>>$ as to human-and-social-expectations/anticipationsmetaphoricity ${ }^{57}$-as-preconverging/postconverging-rede- 
mentating/restructuring/reparadigming-psychologism' ${ }^{99}$ with regards to '83 reference-ofthought-and- ${ }^{83}$ reference-of-thought- ${ }^{8}$ devolving- ${ }^{5}$ meaningfulness-and-teleology comprehensiveness of prospective sublimating-nascence (as to the instigating relativeontological-completeness ${ }^{87}$ - apriorising/axiomatising/referencing-psychologism)'; thus inducing the discrepant 'immaterial/social overall relative-ontological-incompleteness ${ }^{8}$ presublimation-construct-of- ${ }^{5}$ meaningfulness-and-teleology 99 instigating the referencing/registering/decisioning desublimation of the nascent-particular/incipient-andmaterial/technical-sublimations-<blinded-to-their-relative-ontological-completeness reference-of-thought- devolving >' that is and so as to human social subontologising of nascent-particular/incipient-and-material/technical-sublimations- $<$ blinded-to-their-relativeontological-completeness - reference-of-thought- devolving>. This insight underlines the fact that instigated nascent-particular/incipient-and-material/technical-sublimations- $<$ blindedto-their-relative-ontological-completeness - reference-of-thought- devolving > 'critically points to an overall nascent knowledge-reification $\sim$ gesturing-and-accounting-of-epistemicphenomenalism-<in-prospective_psychologismic $\sim$ apriorising/axiomatising/referencing-\{of'prospectively_implicited_attendant-ontological-contiguity ' educed-

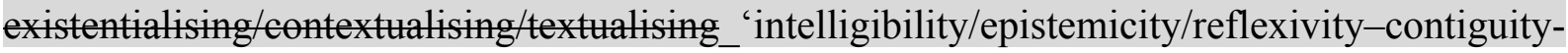
$<$ imbued-notional cogency $>\quad\}$-conflatedness -in-\{preconverging -ment by\} postconverging-ntailment $>$ directly or indirectly prescient of a comprehensive sublimating meaningfulness-and-teleology conception of the given prospective relative-ontologicalcompleteness $^{87}$ registry-worldview/dimension' as so-reflected with the $<$ cumulating/recomposuring attendant-ontological-contiguity $>$-successive registry-

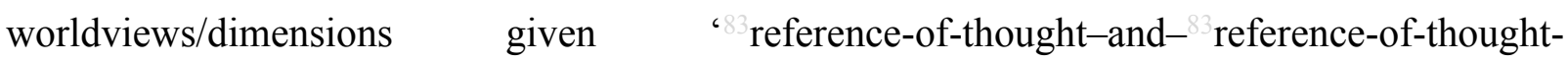
devolving $-{ }^{5}$ meaningfulness-and-teleology ${ }^{9}$ comprehensiveness of prospective sublimatingnascence (as to the instigative relative-ontological-completeness ${ }^{87}$ - 
apriorising/axiomatising/referencing-psychologism)' underlying specific overall knowledgereification $\sim$ gesturing-and-accounting — of-epistemic-phenomenalism- $<$ inprospective_psychologismic apriorising/axiomatising/referencing-\{of-'prospectively implicited_attendant-ontological-contiguity ' reducedexistentialising/contextualising/textualising_ 'intelligibility/epistemicity/reflexivity-contiguity<imbued-notional cogency>' \}-conflatedness -in-\{preconverging-ment by\} postconverging entailment $>$ as so-manifested with any such relative-ontological-completeness registry-worldview/dimension 'specific overall knowledge-reification $\sim$ gesturing-andaccounting - of-epistemic-phenomenalism- $<$ inprospective_psychologismic apriorising/axiomatising/referencing-\{of-`prospectively implicited_attendant-ontological-contiguity ' educedexistentialising/contextualising/textualising_'intelligibility/epistemicity/reflexivity-contiguity<imbued-notional cogency $\left.>^{\prime}\right\}$-conflatedness -in-\{preconverging -ment by\} postconverging-entailment> of-variously-devolving-'axiomatising-conjugations'-so-reflectedin-its-nascent-particular-sublimations'. The specific overall knowledge-reification $\sim$ gesturingand-accounting - of-epistemic-phenomenalism- $<$ inprospective_psychologismic apriorising/axiomatising/referencing-\{of- ${ }^{\text {prospectively }}$ implicited_attendant-ontological-contiguity ' reducedexistentialising/contextualising/textualising_ intelligibility/epistemicity/reflexivity-contiguity<imbued-notional cogency>' \}-conflatedness -in-\{preconverging-ment by\} postconverging-entailment $>$ of the <cumulating/recomposuring attendant-ontologicalcontiguity $>$-successive registry-worldviews/dimensions (as reflecting the overall relative-

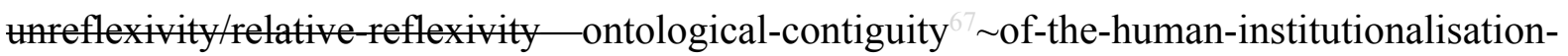
process ${ }^{6}$ ) projectively entail ${ }^{~}{ }^{83}$ reference-of-thought-and- ${ }^{83}$ reference-of-thought- ${ }^{8}$ devolvingmeaningfulness-and-teleology comprehensiveness of prospective sublimating-nascence', 
and

from:

recurrent-utter-uninstitutionalisation 'non-rules-

apriorising/axiomatising/referencing-psychologism overall knowledge-reification $\sim$ gesturingand-accounting - of-epistemic-phenomenalism- $<$ in-

prospective_psychologismic apriorising/axiomatising/referencing-\{of-'prospectively implicited_attendant_ontological-contiguity ' educedexistentialising/contextualising/textualising_'intelligibility/epistemicity/reflexivity_contiguity<imbued-notional cogency>’ $\}$-conflatedness -in-\{preconverging -ment by\}

postconverging-entailment> of-variously-devolving-'axiomatising-conjugations'-so-reflectedin-its-nascent-particular-sublimations' (as recurrent-utter-uninstitutionalisation "83 reference-ofthought-and- ${ }^{83}$ reference-of-thought- ${ }^{-1 e v o l v i n g-}{ }^{5}$ meaningfulness-and-teleology comprehensiveness of prospective sublimating-nascence'), base-institutionalisationununiversalisation 'rulemaking-over-non-rules_apriorising/axiomatising/referencingpsychologism overall knowledge-reification $\sim$ gesturing-and-accounting-of-epistemicphenomenalism-<in-prospective_psychologismic $\sim$ apriorising/axiomatising/referencing-\{of'prospectively_implicited_attendant-ontological-contiguity ' reducedexistentialising/contextualising/textualising_'intelligibility/epistemicity/reflexivity-contiguity<imbued-notional cogency >' \}-conflatedness in \{preconverging ment by\} postconverging-entailment> of-variously-devolving-'axiomatising-conjugations'-so-reflectedin-its-nascent-particular-sublimations' (as base-institutionalisation-ununiversalisation ${ }^{63}$ reference-of-thought-and- ${ }^{83}$ reference-of-thought- ${ }^{84}$ devolving- ${ }^{5}$ meaningfulness-andteleology ${ }^{9}$ comprehensiveness of prospective sublimating-nascence'), ${ }^{103}$ universalisation-nonpositivism/medievalism ${ }^{103}$ universalisation-directed-rulemaking-over-non-rulesapriorising/axiomatising/referencing-psychologism overall knowledge-reification $\sim$ gesturingand-accounting - of-epistemic-phenomenalism-<in- 
implicited_attendant-ontological-contiguity ' reduced-

existentialising/contextualising/textualising_'intelligibility/epistemicity/reflexivity_contiguity<imbued-notional cogency>' \}-conflatedness -in-\{preconverging ment by\}

postconverging-entailment> of-variously-devolving-'axiomatising-conjugations'-so-reflectedin-its-nascent-particular-sublimations' (as ${ }^{103}$ universalisation-non-positivism/medievalism ${ }^{63}$ reference-of-thought-and- ${ }^{8}$ reference-of-thought- ${ }^{84}$ devolving- ${ }^{5}$ meaningfulness-andteleology ${ }^{9}$ comprehensiveness of prospective sublimating-nascence'), positivismprocrypticism 'positivising/rational-empiricism-based-universalisation-directed-rulemakingover-non-rules_-apriorising/axiomatising/referencing-psychologism overall knowledgereification $\sim$ gesturing-and-accounting — of-epistemic-phenomenalism- $<$ inprospective_psychologismic apriorising/axiomatising/referencing-\{of-'prospectively_ implicited_attendant-ontological-contiguity ' educedexistentialising/contextualising/textualising_'intelligibility/epistemicity/reflexivity_contiguity$<$ imbued-notional cogency $>$ ' \}-conflatedness -in-\{preconverging-ment by\} postconverging-entailment> of-variously-devolving-'axiomatising-conjugations'-so-reflectedin-its-nascent-particular-sublimations' (as positivism- ${ }^{80}$ procrypticism ' ${ }^{83}$ reference-of-thoughtand- ${ }^{83}$ reference-of-thought- ${ }^{8}$ devolving $-{ }^{56}$ meaningfulness-and-teleology ${ }^{9}$ comprehensiveness of prospective sublimating-nascence'), and prospectively notional ${ }^{18}$ deprocrypticism 'preempting - disjointedness-as-of- ${ }^{83}$ reference-of-thought,-as-to- ${ }^{3}<$ amplituding/formativeepistemicity $>$ growth-or-conflatedness ${ }^{13} /$ transvaluative- $^{2}$

rationalising/transepistemicity/anamnestic-residuality/spirit-drivenness'—in-supersedingmere-formulaic-positivising/rational-empiricism-based-universalisation-directed-rulemakingover-non-rules_-apriorising/axiomatising/referencing-psychologism overall knowledgereification $\sim$ gesturing-and-accounting — of-epistemic-phenomenalism- $<$ inprospective_psychologismic apriorising/axiomatising/referencing-\{of-'prospectively_ 
implicited_attendant-ontological-contiguity ' reduced-

existentialising/contextualising/textualising_'intelligibility/epistemicity/reflexivity_contiguity$<$ imbued-notional cogency $>$ ' $\}$-conflatedness - in-\{preconverging ment by\}

postconverging-ntailment> of-variously-devolving-'axiomatising-conjugations'-so-reflectedin-its-nascent-particular-sublimations' (as notional ${ }^{18}$ deprocrypticism ' ${ }^{83}$ reference-of-thoughtand- ${ }^{83}$ reference-of-thought- ${ }^{8}$ devolving $-{ }^{56}$ meaningfulness-and-teleology ${ }^{9}$ comprehensiveness of prospective sublimating-nascence'). This comprehensive elucidation highlights that human sublimation is not inherently haphazard as the wrong perception of haphazardness arises as from the varying ${ }^{7}$ presencing-absolutising-identitive-constitutedness ${ }^{14}$ epistemic-projection

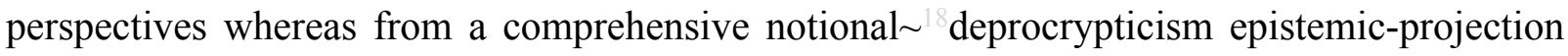
perspective in ontological-normalcy/postconvergence human sublimation is rather wrongly apparently haphazard because of human limited-mentation-capacity-as-subjecting 'educedunlimitedness/existence-sublimating nascence' to-limitedness/hmman-subpotency epistemicprojection perspectives of apprehension of prospective sublimation with the 'ontologicalveracity of notional ${ }^{18}$ deprocrypticism epistemic-projection perspective associated with comprehensive human limited-mentation-capacity-deepening-as-subjectinglimitedness/hmman-subpotency to 'educed mnlimitedness/existence-sublimating nascence' rather reflecting the overall relative-unreflexivity/relative-reflexivity-ontologicalcontiguity ${ }^{67}$ of-the-human-institutionalisation-process ${ }^{68} \quad$ preconverging/postconverging-dementative/structural/paradigmatic coherence of human sublimation as of successive ${ }^{8}$ referenceof-thought-and- ${ }^{83}$ reference-of-thought- devolving- ${ }^{56}$ meaningfulness-and-teleology comprehensiveness of prospective sublimating-nascence'. Thus such a notional ${ }^{1}$ deprocrypticism ontological-normalcy/postconvergence perspective warrants the requisite $<$ amplituding/formative-epistemicity $>$ totalising/circumscribing/delineating relativeontological-completeness ${ }^{87}$ appraisal of singularly induced prospective sublimations as to 
projected overall human ${ }^{83}$ reference-of-thought-and- ${ }^{8}$ reference-of-thought- ${ }^{8}$ devolvingmeaningfulness-and-teleology $\quad$ imbued $<$ amplituding/formativeepistemicity>totalising/circumscribing/delineating 'relative-ontologicalincompleteness 8 /relative-ontological-completeness 〈sublimating $\sim$ referencing/registering/decisioning,-as-self-becoming/selfconflatedness /formative-supererogating-<projective/reprojective-aestheticising-re-motifand-re-apriorising/re-axiomatising/re-referencing,-in-perspective--ontologicalnormalcy/postconvergence $>>$ as to human-and-social-expectations/anticipationsmetaphoricity ${ }^{57}$-as-preconverging/postconverging-redementating/restructuring/reparadigming-psychologism' ${ }^{89}$ (as of ' ${ }^{8}$ reference-of-thought-andreference-of-thought- devolving- ${ }^{5}$ meaningfulness-and-teleology 9 comprehensiveness of prospective sublimating-nascence'). Critically this discrepancy between nascentparticular/incipient-and-material/technical-sublimations- $<$ blinded-to-their-relative-ontologicalcompleteness - reference-of-thought- devolving $>$ and overall relative-ontologicalincompleteness ${ }^{88}$-presublimation-construct-of- ${ }^{5}$ meaningfulness-and-teleology ${ }^{9}$ (as involving 'immaterial/social overall relative-ontological-incompleteness ${ }^{88}$-presublimation-construct-ofmeaningfulness-and-teleology instigating the referencing/registering/decisioning desublimation of the nascent-particular/incipient-and-material/technical-sublimations- $<$ blindedto-their-relative-ontological-completeness - reference-of-thought- devolving >' and so as to human social subontologising of nascent-particular/incipient-and-material/technicalsublimations- $<$ blinded-to-their-relative-ontological-completeness - reference-of-thoughtdevolving $>$ ); is effectively the hallmark of all ${ }^{7}$ presencing-absolutising-identitiveconstitutedness <preconverging 'motif-and-apriorising/axiomatising/referencing' entailing $>$-existentialising — enframing/imprintedness-〈as-to- historicity-tracing - inpresencing-hyperrealisation/hyperreal-transposition> as to their <amplituding/formative- 
epistemicity>totalising $\sim$ self-referencing-syncretising/circularity/interiorising/akrasiatic-drag ${ }^{34}$, and beyond just the ontological implications with respect to Being-development/ontologicalframework-expansion-as-to-depth-of-ontologising-development-as-infrastructure-ofmeaningfulness-and-teleology as highlighted above this is equally reflected as to a human institutional-development-as-to-social-function-development and living-development-as-topersonality-development psychologismic epistemic-acutisation diffieulty-<for, residualising \{decompulsing\} delinearity for-cogency> magnitudes $\{$ of-experientiality/experiment\} notional firstnaturedness-formativeness-<as-to-eventualising-inkling-drive-or-seeding misprising $>$ temporal-to-intemporal-dispositions- $<$ so-construed-as-from-perspectiveontological-normalcy/postconvergence $>$ inclination for ${ }^{7}$ presencing - absolutising-identitiveconstitutedness <preconverging 'motif-and-apriorising/axiomatising/referencing'entailing >-existentialising — enframing/imprintedness-〈as-to- historicity-tracing - inpresencing-hyperrealisation/hyperreal-transposition) (so-reflected as of human 'formativeness$<$ as-to-intersolipsism-of-preformulating/preframing/premeaningfulness-imbued-mediativityand-deferentialism>-of- meaningfulness-and-teleology ): defining the construal/conceptualisation of human transcendence-andsublimity/sublimation/supererogatory de-mentativity (with regards to the requisite human selfsurpassing — existentialism-form-factor,-in-overcoming-'notional collateralising-beholdeningprotohumanity'-to-'attain-sublimating-humanity'-as-to-existence-potency sublimatingnascence,-disclosed-from-prospective-epistemic-digression to supersede human temporality 8 /shortness <amplituding/formative $>$ wooden-language-〈imbued-averaging-ofthought-<as-to-leveling/ressentiment/closed-construct-of- meaningfulness-and-teleology -asof-'nondescript/ignorable-void～'-with-regards-to-prospective-apriorising-implications $>$ )). Such an ultimate construal of human self-surpassing as to the notional deprocrypticism epistemic-projection perspective in ontological-normalcy/postconvergence effectively grapples 
with the requisite '<amplituding/formative-epistemicity>totalising/circumscribing/delineating 'relative-ontological-incompleteness 8 /relative-ontological-completeness

〈sublimating $\sim$ referencing/registering/decisioning,-as-self-becoming/self-

conflatedness $/$ formative-supererogating-<projective/reprojective-aestheticising-re-motifand-re-apriorising/re-axiomatising/re-referencing,-in-perspective-ontologicalnormalcy/postconvergence $>>$ as to human-and-social-expectations/anticipationsmetaphoricity ${ }^{57}$-as-preconverging/postconverging-rede-

mentating/restructuring/reparadigming-psychologism' ${ }^{89}$ as of ${ }^{83}$ reference-of-thought-andreference-of-thought- ${ }^{84}$ devolving- ${ }^{5}$ meaningfulness-and-teleology comprehensiveness of prospective sublimating-nascence' as so-elicited by nascent-particular/incipient-andmaterial/technical-sublimations- $<$ blinded-to-their-relative-ontological-completeness

reference-of-thought- devolving $>$. Insightfully this can be reflected upon creatively as the requisite underlying ${ }^{18}$ deprocrypticism-or-preempting-disjointedness-as-of- ${ }^{8}$ reference-ofthought institutionally projected (implying preconverging/postconverging-dementative/structural/paradigmatic institutionalising of prospective scalarisation-as-torescalarisation-as-re-ontologisation/supereregatery-involuting-or-guilding-or-amplifyingscalarisation-<as-to-existence—as-sublimating-withdrawal/unenframing/re-ontologising,elicited-from-prospective-profound-supererogation $>$ ) 'unenframed/reontologising/unbeholdening/bechancing-supererogation parameterisation/reparameterisation$\langle$ reflecting-a-supererogatory decisionality-of-socioinstitutional-conceptions-as-to- "theirnascent-sublimations-dynamic-preempting-of-presublimatory-decisionality-numbing-tractiondesublimation'〉-as-so-operationalising-'scalarisation-as-to-rescalarisation-as-reontologisation' for prospective aestheticisation-and-aestheticisation-towards-ontology$<$ elicited-idiomatisation $>/{ }^{5}$ meaningfulness-and-teleology 99 (as of human Beingdevelopment/ontological-framework-expansion-as-to-depth-of-ontologising-development-as- 
function-development and living-development-as-to-personality-development psychologismic epistemic-acutisation difficulty-for, residualising \{decompulsing $\}$ delinearity for-cogency> magnitudes $\{$ of-experientiality/experiment $\}$, and $\quad$ so as to existence-as-sublimatingwithdrawal/unenframing/re-ontologising,-elicited-from-prospective-profoundsupererogation . Such an 'unenframed/re-ontologising/unbeholdening/bechancingsupererogation of notional deprocrypticism institutionalisation's parameterisation/reparameterisation-〈reflecting-a-supererogatory $\sim$ decisionality-ofsocioinstitutional-conceptions-as-to-'their-nascent-sublimations-dynamic-preempting-ofpresublimatory-decisionality-numbing-traction-desublimation'〉-as-so-operationalising'scalarisation-as-to-rescalarisation-as-re-ontologisation' for prospective aestheticisation-andaestheticisation-towards-ontology-<elicited-idiomatisation $>/ 5$ meaningfulness-and-teleology (as to Being-development/ontological-framework-expansion-as-to-depth-of-ontologisingdevelopment-as-infrastructure-of- meaningfulness-and-teleology ) will call into question as of pure-ontology the very apriorising/axiomatising/referencing-\{of- prospectivelyimplicited_attendant-ontological-contiguity ' educedexistentialising/contextualising/textualising_'intelligibility/epistemicity/reflexivity_contiguity<imbued-notional cogency>' \}-psychologism defining overall human social-stakecontention-or-confliction associated with such notions like tribes, nations, races, regions, etc. (and any other notions) as of their preconvergingly-de-mentated/structured/paradigmed dehumanising implications (and so rather as of their degeneracy/breaking-down/distortion of human ontological-performance ${ }^{72}-<$ including-virtue-as-ontology $>/$ morality/ethics/justice/etc. from the more apt ontological-normalcy/postconvergence conception of the human as to humanity); so-reflected by a beholdening conceptualisation/construal of the human as of their underpinning-suprasocial-construct implied $\quad{ }^{7}$ presencing-absolutising-identitive- 
constitutedness <preconverging 'motif-and-apriorising/axiomatising/referencing'

entailing >-existentialising — enframing/imprintedness-〈as-to- historicity-tracing —inpresencing-hyperrealisation/hyperreal-transposition $\rangle$ as being the ‘imponderable/inscrutable/unavoidable/inevitable/inescapable/unpreventable/unchangeable/in surmountable/unovercomable framework of human agency'. However, as to a constructive knowledge-reification $\sim$ gesturing-and-accounting — of-epistemic-phenomenalism- $<$ inprospective_psychologismic apriorising/axiomatising/referencing-\{of-'prospectively implicited_attendant-ontological-contiguity ' educedexistentialising/contextualising/textualising_'intelligibility/epistemicity/reflexivity_contiguity<imbued-notional cogency >' \}-conflatedness in \{preconverging ment by\} postconverging entailment $>$ with respect to the haunting fact of human $<$ amplituding/formativeepistemicity $>$-totalising $\sim$ thrownness-in-existence ${ }^{35}$ as to any such ${ }^{7}$ presencing-absolutisingidentitive-constitutedness ${ }^{14}$ <preconverging ' motif-and-apriorising/axiomatising/referencing'entailing $>$-existentialising — enframing/imprintedness-〈as-to- historicity-tracing - inpresencing-hyperrealisation/hyperreal-transposition> speaking to such a $<$ amplituding/formative-epistemicity $>$-totalising thrownness-in-existence ${ }^{35}, \quad$ such a notional 18 deprocrypticism institutionalisation 'unenframed/reontologising/unbeholdening/bechancing-supererogation ${ }^{9}$ parameterisation/reparameterisation$\langle$ reflecting-a-supererogatory $\sim$ decisionality-of-socioinstitutional-conceptions-as-to- 'theirnascent-sublimations-dynamic-preempting-of-presublimatory-decisionality-numbing-tractiondesublimation'>-as-so-operationalising-'scalarisation-as-to-rescalarisation-as-reontologisation' for prospective aestheticisation-and-aestheticisation-towards-ontology$<$ elicited-idiomatisation $>/{ }^{5}$ meaningfulness-and-teleology 99 is more immediately-andconstructively bound to 'appraise the conception of sovereign equanimity/balance driving human agency imbued sublimation as to <amplituding/formative- 
epistemicity $>$ totalising/circumscribing/delineating

'relative-ontologicalincompleteness 8 /relative-ontological-completeness ${ }^{87}$

〈sublimating referencing/registering/decisioning,--as-self-becoming/self-

conflatedness $/$ formative-supererogating-<projective/reprojective-aestheticising-re-motifand-re-apriorising/re-axiomatising/re-referencing,-in-perspective-ontological-

normalcy/postconvergence $>>\quad$ as $\quad$ to $\quad$ human-and-social-expectations/anticipationsmetaphoricity ${ }^{57}$-as-preconverging/postconverging-rede-

mentating/restructuring/reparadigming-psychologism' ${ }^{89}$. This double epistemic orientation to a notional ${ }^{18}$ deprocrypticism institutionalisation 'unenframed/reontologising/unbeholdening/bechancing-supererogation parameterisation/reparameterisation$\langle$ reflecting-a-supererogatory $\sim$ decisionality-of-socioinstitutional-conceptions-as-to- 'theirnascent-sublimations-dynamic-preempting-of-presublimatory-decisionality-numbing-tractiondesublimation'〉-as-so-operationalising-'scalarisation-as-to-rescalarisation-as-reontologisation' for prospective aestheticisation-and-aestheticisation-towards-ontology$<$ elicited-idiomatisation $>/{ }^{5}$ meaningfulness-and-teleology ${ }^{9}$ can be understood in the sense that just as we can appreciate that if supposedly we are found in say an exclusively animistic socialsetup with supposedly no possibility to rejoin a positivistic social-setup, while at the very least we appreciate that the material/technical capacity of a positivistic social-setup overall meaningfulness-and-teleology ${ }^{9}$ will enhance such an animistic social-setup as to existenceas-sublimating-withdrawal/unenframing/re-ontologising,-elicited-from-prospective-profoundsupererogation, the fact remains that our <amplituding/formative-epistemicity>totalising thrownness-in-existence $^{35}$ in the animistic social-setup requires at least a basic engagement tolerable to its ${ }^{56}$ meaningfulness-and-teleology ${ }^{9}$ before any pretense to a projection of positivistic ${ }^{56}$ meaningfulness-and-teleology ${ }^{9}$ (as can so be appreciated with the cultural diffusion encounters throughout human history). In this regards as to a decisively globalising 
world we can't conceive that ours will be the human generation bereft of 'profound diffusionary/non-diffusionary aestheticisation prospective insight as to existence-assublimating-withdrawal/unenframing/re-ontologising,-elicited-from-prospective-profoundsupererogation given the increasingly relic/artifactual nature of traditional cultures in our modern age as to the potent lack of prospective creative aestheticisation off-the-beaten-path of an increasing convergence deadening of the possibility prospective reappraisals of human meaningfulness-and-teleology (as so-construed as of dimensionality-of-sublimating <<amplituding/formative>supererogatory $\sim$ de-mentativeness/epistemic-growth-or-

\section{conflatedness /transvaluative-rationalising/transepistemicity/anamnestic-residuality/spirit-}

drivenness-equalisation)), as to the fact that overall human beholdening inclination (as to any defining overall relative-ontological-incompleteness ${ }^{88}$-presublimation-construct-ofmeaningfulness-and-teleology ${ }^{9}$ concerned mostly with human institutional-development-asto-social-function-development and living-development-as-to-personality-development psychologismic epistemic-acutisation difficulty-<or, residualising $\{$ decompulsing $\}$ delinearity for-cogeney $>$-magnitudes $\left.{ }^{\{0 f-e x p e r i e n t i a l i t y / e x p e r i m e n t ~}\right\}$ in the priorly achieved Being-development/ontological-framework-expansion-as-to-depth-of-ontologisingdevelopment-as-infrastructure-of- meaningfulness-and-teleology ) rather tends to reconverge to shallow <amplituding/formative-epistemicity>-totalising $\sim$ thrownness-in-existence concreteness/concretism/<preconverging 'motif-and-apriorising/axiomatising/referencing'entailing >-existentialising — enframing/imprintedness-〈as-to- historicity-tracing - inpresencing-hyperrealisation/hyperreal-transposition〉—of-human-ontological-performance ${ }^{72}$ <including-virtue-as-ontology $>$ /morality/ethics/justice/etc. as reflected by the $<$ cumulating/recomposuring attendant-ontological-contiguity $>$-successive registryworldviews/dimensions presencing - absolutising-identitive-constitutedness

\section{$<$ preconverging 'motif-and-apriorising/axiomatising/referencing'-entailing $>$ -}


existentialising — enframing/imprintedness-〈as-to- historicity-tracing_-in-presencinghyperrealisation/hyperreal-transposition) (when it comes to overall human 'aestheticisation as reflecting the extensive manifest outcomes/outfits/shells-construed-historially-as-of-thespecifically-aestheticised-incrusting/plating/coating,-so-reflected-as-institutional-

manifestations of human ${ }^{56}$ meaningfulness-and-teleology $\left.{ }^{99}\right)$; thus as not necessarily speaking of the absolute possibility of human consciousness projection in want for its recurrent parameterisation/reparameterisation-〈reflecting-a-supererogatory $\sim$ decisionality-ofsocioinstitutional-conceptions-as-to-'their-nascent-sublimations-dynamic-preempting-ofpresublimatory-decisionality-numbing-traction-desublimation'〉-as-so-operationalising'scalarisation-as-to-rescalarisation-as-re-ontologisation' in optimising human ontologicalperformance ${ }^{2}$-<including-virtue-as-ontology $>$ /morality/ethics/justice/etc. (and our positivismprocrypticism registry-worldview/dimension cannot be overlooked in this regards notwithstanding the fact that it is at the backend of the institutional-cumulation/institutionalrecomposure-〈as-to- historiality/ontological-eventfulness /ontological-aesthetic-tracing<perspective-ontological-normalcy/postconvergence-reflected-“epistemicity-relativismdeterminism'>>). But then just like with all prior registry-worldviews/dimensions, our positivism- ${ }^{80}$ procrypticism $\quad{ }^{79}$ presencing-absolutising-identitive-constitutedness <preconverging 'motif-and-apriorising/axiomatising/referencing'-entailing >existentialising — enframing/imprintedness-〈as-to- historicity-tracing-in-presencinghyperrealisation/hyperreal-transposition〉 effectively projects a hurdle to any such preconverging/postconverging-de-mentative/structural/paradigmatic notional ${ }^{18}$ deprocrypticism conception of re-ontologisation as to its inherent $<$ amplituding/formative-epistemicity $>$ totalising $\sim$ self-referencingsyncretising/circularity/interiorising/akrasiatic-drag ${ }^{34}$ poorly amenable to profound alternative institutional aestheticising contemplation 'given its calamitous conception and relation to the 
possibility for prospective re-ontologisation from its subontologisation' such that any such profound alternative institutional aestheticising contemplation are traditionally bound to arise as disruptive institutional transformations whether or not involving power-showdown as associated with sudden/revolutionary transformations with 'their drawback of having to think on their feet inducing deficient ontological-performance ${ }^{72}-$ including-virtue-as- $^{2}$ ontology $>$ /morality/ethics/justice/etc. as well as generalised social apprehension which is then enigmatically held against them' (however the merits of their underlying case) very much unlike the 'latitude for articulating conceptualisations available for 79 presencing-absolutisingidentitive-constitutedness ${ }^{14}<$ preconverging 'motif-and-apriorising/axiomatising/referencing'entailing >-existentialising — enframing/imprintedness-〈as-to- historicity-tracing - inpresencing-hyperrealisation/hyperreal-transposition〉' their preconverging/postconverging-de-mentative/structural/paradigmatic flaws). Today manifestations (in the political domain) of protest votes for instance, more than just a question of poor political leadership actually has to do in-many-ways with an 'alienating politicoinstitutional entrapment/frame-up of sovereign choice' within the supposed democratic process that 'forestalls-and-narrows as of strategic rules and processes' the effective political fulfilment of individual and social sovereign choices inducing anti-sovereign consequences as to defaulting policy consequences to dominance/vested-interest actors without truly being institutionally subject to competing profound alternative institutional aestheticising contemplation given their institutional ascendence. Such a beholdening ${ }^{7}$ presencing-absolutising-identitiveconstitutedness $<$ preconverging 'motif-and-apriorising/axiomatising/referencing' entailing >-existentialising — enframing/imprintedness-〈as-to- historicity-tracing - inpresencing-hyperrealisation/hyperreal-transposition〉 skews the fundamental ontology question by its inherent <amplituding/formative-epistemicity $>$ totalising $\sim$ self-referencingsyncretising/circularity/interiorising/akrasiatic-drag ${ }^{34}$ gatekeeping stifling of the possibility for 
inquiring on the ontological-veracity of its practice as to a reflex for advancing the quietude of social-vestedness/normativity- $<$ discretely-implied-functionalism $>$. This latter issue is the ultimate challenge to prospective notional deprocrypticism institutionalisation 'unenframed/re-ontologising/unbeholdening/bechancing-supererogation parameterisation/reparameterisation-〈reflecting-a-supererogatory $\sim$ decisionality-ofsocioinstitutional-conceptions-as-to-'their-nascent-sublimations-dynamic-preempting-ofpresublimatory-decisionality-numbing-traction-desublimation'〉-as-so-operationalising'scalarisation-as-to-rescalarisation-as-re-ontologisation' for prospective aestheticisation-andaestheticisation-towards-ontology-<elicited-idiomatisation $>/{ }^{5}$ meaningfulness-and-teleology as of the paradox that a social-setup as to its <amplituding/formative-epistemicity $>$ totalising thrownness-in-existence ${ }^{35}$ is so pragmatically self-focussed that its aestheticisation and hence aestheticisation-towards-ontolgy dynamic-potential as to existence - as-sublimatingwithdrawal/unenframing/re-ontologising,-elicited-from-prospective-profound-supererogation is narrowed/limited/constricted however its level of development (explaining the decisiveness/criticality of cultural diffusion imbued originariness-parrhesia,-as-spontaneity-ofaestheticisation in re-ontologisation accompanying human institutionalcumulation/institutional-recomposure-〈as-to- historiality/ontologicaleventfulness /ontological-aesthetic-tracing-<perspective-ontologicalnormalcy/postconvergence-reflected-'epistemicity-relativism-determinism' $>>$ as can be appreciated throughout human history). This is explained by the fact that the human can relatively easily appreciate the ontological-pertinence of new practices arising as from outside cultural diffusion but it is very much difficult to reconstrue of such practices as from the taxingness-of-originariness involved in surpassing an internalised <amplituding/formativeepistemicity $>$ totalising $\sim$ self-referencing-syncretising/circularity/interiorising/akrasiatic-drag ${ }^{34}$ posture; and this very much explains the double epistemic orientation to 
notional ${ }^{18}$ deprocrypticism

ontologising/unbeholdening/bechancing-supererogation ${ }^{9}$ parameterisation/reparameterisation$\langle$ reflecting-a-supererogatory $\sim$ decisionality-of-socioinstitutional-conceptions-as-to- 'theirnascent-sublimations-dynamic-preempting-of-presublimatory-decisionality-numbing-tractiondesublimation'〉-as-so-operationalising-'scalarisation-as-to-rescalarisation-as-reontologisation' for prospective aestheticisation-and-aestheticisation-towards-ontology$<$ elicited-idiomatisation $>/{ }^{5}$ meaningfulness-and-teleology ${ }^{99}$ as highlighted above (as to the need to feed our <amplituding/formative-epistemicity>-totalising $\sim$ thrownness-in-existence decisively globalising world with aestheticising re-originariness/re-origination to uphold the capacity for pure-ontology as to re-ontologisation). In this regards, all such ontologisation/reontologisation potential for human ${ }^{56}$ meaningfulness-and-teleology : is preconverging/postconverging-de-mentatively/structurally/paradigmatically ever inducible as of human formativeness-<as-to-intersolipsism-ofpreformulating/preframing/premeaningfulness-imbued-mediativity-and-deferentialism>-ofmeaningfulness-and-teleology, as to the underlying human-subpotency ontological-faithnotion-or-ontological-fideism —imbued-underdetermination-of-motif-andapriorising/axiomatising/referencing-as-so-being-as-of-existential-reality (given human limited-mentation-capacity—as-subjecting 'educed-unlimitedness/existence-sublimating nascence' to-limitedness/human-subpotency implications on human ontological-performance ${ }^{72}$ $<$ including-virtue-as-ontology $>$ ) reflected in such formativeness (going by its given aestheticisation-and-aestheticisation-towards-ontology-<elicited-idiomatisation $>$ of $\quad$ the cultivated/beholdening-construct-of- ${ }^{5}$ meaningfulness-and-teleology ${ }^{9}$,-ultimately-construedas-habit/practice/belief/culture) and thereof the ontologically-valid/ontologically-invalid beholdening implications arising from the cultivated/beholdening-construct-ofmeaningfulness-and-teleology ${ }^{9}$,-ultimately-construed-as-habit/practice/belief/culture (when 
it comes to overall human 'aestheticisation as reflecting the extensive manifest outcomes/outfits/shells — construed-historially-as-of-the-specifically-aestheticised-

incrusting/plating/coating,-so-reflected-as-institutional-manifestations of human meaningfulness-and-teleology ${ }^{\prime}$ '). The underlying insight here is that the 'human apriorising/axiomatising/referencing process of <amplituding/formativeepistemicity $>$ totalising/circumscribing/delineating conceptualisation' is effectively a 'formative thrownness in existence imbued projective-arbitrariness/waywardness' as of manifestly induced sublimation or desublimation with regards to the aestheticisation-and-aestheticisation-towardsontology-<elicited-idiomatisation $>$ of cultivated/beholdening-construct-of- -5 meaningfulnessand-teleology ${ }^{9}$,-ultimately-construed-as-habit/practice/belief/culture'.

Human

$<$ amplituding/formative-epistemicity $>$-totalising $\sim$ thrownness-in-existence ${ }^{35}$,-imbued-

projective-arbitrariness/waywardness-〈as-to-the-human-projective/reprojective-

aestheticising-re-motif-and-re-apriorising/re-axiomatising/re-referencing-process-of-

'<amplituding/formative-epistemicity $>$ totalising conceptualisation' $\rangle$ is what effectively captures all the possibilities of human sublimation or desublimation in existence and so reflecting overall human 'aestheticisation as to the extensive manifest outcomes/outfits/shells — construedhistorially-as-of-the-specifically-aestheticised-incrusting/plating/coating,-so-reflected-asinstitutional-manifestations of human ${ }^{56}$ meaningfulness-and-teleology ${ }^{9}$. Critically, this human $<$ amplituding/formative-epistemicity $>$-totalising $\sim$ thrownness-in-existence ${ }^{35}$,-imbuedprojective-arbitrariness/waywardness-〈as-to-the-human-projective/reprojective aestheticising-re-motif-and-re-apriorising/re-axiomatising/re-referencing-process-of'<amplituding/formative-epistemicity $>$ totalising conceptualisation' $\rangle$, as to when it converges to sublimation as to existence-as-sublimating-withdrawal/unenframing/re-ontologising,elicited-from-prospective-profound-supererogation , goes on to prospectively reflect the relative-ontological-completeness ${ }^{87}$ 'specific overall knowledge-reification $\sim$ gesturing-and- 
accounting - of-epistemic-phenomenalism- $<$ in-

prospective_psychologismic apriorising/axiomatising/referencing-\{of- ${ }^{\text {pprospectively }}$ implicited_attendant-ontological-contiguity ' educed-

existentialising/contextualising/textualising_intelligibility/epistemicity/reflexivity_contiguity$<$ imbued-notional cogency $>$ ' $\}$-conflatedness -in-\{preconverging ment by\}

postconverging-entailment> of-variously-devolving-'axiomatising-conjugations'-so-reflectedin-its-nascent-particular-sublimations' (while as to when it converges to desublimation as failing existence - as-sublimating-withdrawal/unenframing/re-ontologising,-elicited-fromprospective-profound-supererogation, it goes on to priorly reflect the overall relativeontological-incompleteness ${ }^{8}$-presublimation-construct-of- ${ }^{56}$ meaningfulness-and-teleology as to its ${ }^{7}$ presencing-absolutising-identitive-constitutedness ${ }^{14}<$ preconverging $\sim$ 'motif-andapriorising/axiomatising/referencing'-entailing >-existentialising—enframing/imprintedness〈as-to- historicity-tracing - in-presencing-hyperrealisation/hyperreal-transposition〉). The above analysis reflects the fact that human <amplituding/formative-epistemicity $>$ totalising $\sim$ thrownness-in-existence ${ }^{35}$,-imbued-projective-arbitrariness/waywardness-〈as-to-thehuman-projective/reprojective - aestheticising-re-motif-and-re-apriorising/re-axiomatising/rereferencing-process-of-‘ $<$ amplituding/formative-epistemicity $>$ totalising $\sim$ conceptualisation’ $\rangle$ is the 'effective becoming aestheticisation-and-aestheticisation-towards-ontology-<elicitedidiomatisation $>$ construction as to cumulation/recomposuring, that induces cultivated/beholdening-construct-of- ${ }^{-6}$ meaningfulness-and-teleology ${ }^{9}$,-ultimately-construedas-habit/practice/belief/culture; and so reflected in human Being-development/ontologicalframework-expansion-as-to-depth-of-ontologising-development-as-infrastructure-ofmeaningfulness-and-teleology , institutional-development-as-to-social-functiondevelopment and living-development-as-to-personality-development psychologismic epistemic-acutisation difficulty-for, residualising \{decompulsing\} ${ }^{\text {felinearity for-cogency> }}$ 
magnitudes $\{$ of-experientiality/experiment $\} \quad$ Human $<$ amplituding/formative-epistemicity $>$ totalising $\sim$ thrownness-in-existence ${ }^{35}$,-imbued-projective-arbitrariness/waywardness-〈as-to-thehuman-projective/reprojective- aestheticising-re-motif-and-re-apriorising/re-axiomatising/rereferencing-process-of-'<amplituding/formative-epistemicity $>$ totalising $\sim$ conceptualisation'〉 reflects an 'effectively underlying human beholdening —inching,-apprehending,-and-tamingdrive or aestheticising — ${ }^{97}$ surrealising/supererogating-drive for $<$ postconverging 'motif-andapriorising/axiomatising/referencing'-entailing>-existentialising-framing/imprinting-〈as-toprospective- historiality/ontological-eventfulness /ontological-aesthetic-tracing$<$ perspective-ontological-normalcy/postconvergence-reflected-'epistemicity-relativismdeterminism'>Y' (as to manifestly cultivated/beholdening-construct-of- - meaningfulness-andteleology ${ }^{9}$,-ultimately-construed-as-habit/practice/belief/culture so-reflected as

\section{$<$ preconverging 'motif-and-apriorising/axiomatising/referencing'-entailing $>$ -}

existentialising — enframing/imprintedness-〈as-to- historicity-tracing - in-presencing-

hyperrealisation/hyperreal-transposition〉). Such an 'effectively underlying human beholdening - inching,-apprehending,-and-taming-drive or aestheticisingsurrealising/supererogating-drive for $\quad<$ postconverging 'motif-andapriorising/axiomatising/referencing'-entailing >-existentialising_framing/imprinting-〈as-toprospective- historiality/ontological-eventfulness /ontological-aesthetic-tracing-

$<$ perspective-ontological-normalcy/postconvergence-reflected-'epistemicity-relativismdeterminism' $>$ ' (inherent to human <amplituding/formative-epistemicity $>$ totalising $\sim$ thrownness-in-existence ${ }^{35}$,-imbued-projective-arbitrariness/waywardness-〈as-to-thehuman-projective/reprojective- aestheticising-re-motif-and-re-apriorising/re-axiomatising/rereferencing-process-of- ‘<amplituding/formative-epistemicity $>$ totalising $\sim$ conceptualisation’〉) speaks to human preformulating/preframing/premeaningfulness- $<$ metaphoricity ${ }^{57}$-dispositionas-to-psyche-induced-psychologism-of-existential-stake $>$ with regards to formativeness-<as-to- 
intersolipsism-of-preformulating/preframing/premeaningfulness-imbued-mediativity-and-

deferentialism $>$-of- meaningfulness-and-teleology ; as underlying the possibilities for human sublimation-educing _epistemic-

totalising ${ }^{3}$ hermeneutic/textuality/reprojecting/supererogating/zeroing/re-acuting,-

\{decompulsing\} delinearity for-cogency as-to-possibilities-of-self-becoming-as-of-‘existential-

interpretation/epistemicity-in-apriorising/axiomatising/referencing-of-existence ${ }^{95}$. Thus it is by such a 'sublimation-over-desublimation understanding' of this <amplituding/formativeepistemicity>-totalising thrownness-in-existence ${ }^{35}$,-imbued-projective-

arbitrariness/waywardness-〈as-to-the-human-projective/reprojective-aestheticising-re-motifand-re-apriorising/re-axiomatising/re-referencing-process-of- ${ }^{\circ}<$ amplituding/formativeepistemicity>totalising conceptualisation'> that the apparently imponderable/inscrutable/unavoidable/inevitable/inescapable/unpreventable/unchangeable/in surmountable/unovercomable framework of our positivism- ${ }^{80}$ procrypticism ${ }^{79}$ presencingabsolutising-identitive-constitutedness $<$ preconverging $\sim$ 'motif-andapriorising/axiomatising/referencing'-entailing >-existentialising — enframing/imprintedness〈as-to- historicity-tracing-in-presencing-hyperrealisation/hyperreal-transposition〉 (as the challenge of the double epistemic orientation to notional $\sim$ deprocrypticism institutionalisation 'unenframed/re-ontologising/unbeholdening/bechancing-supererogation parameterisation/reparameterisation-〈reflecting-a-supereregatery-decisionality-ofsocioinstitutional-conceptions-as-to- 'their-nascent-sublimations-dynamic-preempting-ofpresublimatory-decisionality-numbing-traction-desublimation' $\rangle$-as-so-operationalising'scalarisation-as-to-rescalarisation-as-re-ontologisation' for prospective aestheticisation-andaestheticisation-towards-ontology-<elicited-idiomatisation $>/>$ meaningfulness-and-teleology as highlighted above) can be looked at in a new and enlightening perspective (beyond such a 'positivism $-{ }^{80}$ procrypticism—apriorising/axiomatising/referencing-psychologism 
enculturated/constructed social-pragmatics-framing-of-predicative-effectivity-sublimation〈as-to-underlying,-ontological-commitment $-<$ implied — self-assuredness-of-ontological-goodfaith/authenticity postconverging-de-mentating/structuring/paradigming -as-being-as-ofexistential-reality $>>$ ') and so rather as from a prospective 'deprocrypticismapriorising/axiomatising/referencing-psychologism enculturated/constructed socialpragmatics-framing-of - predicative-effectivity-sublimation-〈as-to-underlying,-ontologicalcommitment $-<$ implied - self-assuredness-of-ontological-goodfaith/authenticity postconverging-de-mentating/structuring/paradigming -as-being-as-ofexistential-reality $>>$ '; and so as to the elucidation of such ${ }^{79}$ presencing - absolutising-identitiveconstitutedness $<$ preconverging 'motif-and-apriorising/axiomatising/referencing'entailing $>$-existentialising — enframing/imprintedness-〈as-to- historicity-tracing - inpresencing-hyperrealisation/hyperreal-transposition $\rangle$ induced human <amplituding/formativeepistemicity>-totalising $\sim$ thrownness-in-existence ${ }^{35}$,-imbued-projectivearbitrariness/waywardness-〈as-to-the-human-projective/reprojective- aestheticising-re-motifand-re-apriorising/re-axiomatising/re-referencing-process-of- ‘ $<$ amplituding/formativeepistemicity $>$ totalising $\sim$ conceptualisation'> deficient ontological-performance ${ }^{2}-<$ includingvirtue-as-ontology>. Thus as being amenable both to 'sublimation as to existence-assublimating-withdrawal/unenframing/re-ontologising,-elicited-from-prospective-profoundsupererogation' and to 'desublimation as failing existence-as-sublimatingwithdrawal/unenframing/re-ontologising,-elicited-from-prospective-profoundsupererogation , human <amplituding/formative-epistemicity>-totalising $\sim$ thrownness-inexistence ${ }^{35}$,-imbued-projective-arbitrariness/waywardness-〈as-to-the-humanprojective/reprojective - aestheticising-re-motif-and-re-apriorising/re-axiomatising/rereferencing-process-of- ‘<amplituding/formative-epistemicity $>$ totalising $\sim$ conceptualisation’〉 notionally speaks of an underpinning framework that is preconverging/postconverging-de- 
mentative/structural/paradigmatic to the potentiality for both emancipating ontological-goodfaith/authenticity ${ }^{6} \sim$ postconverging-de-mentating/structuring/paradigming 70 and human impeding ontological-bad-faith/inauthenticity ${ }^{64} \sim$ preconverging-dementating/structuring/paradigming ${ }^{65}$ underlying human ${ }^{56}$ meaningfulness-and-teleology ontological-performance $^{72}-<$ including-virtue-as-ontology $>$. Human $<$ amplituding/formativeepistemicity>-totalising thrownness-in-existence ${ }^{35}$,-imbued-projective-

arbitrariness/waywardness-〈as-to-the-human-projective/reprojective - aestheticising-re-motifand-re-apriorising/re-axiomatising/re-referencing-process-of-'<amplituding/formativeepistemicity>totalising conceptualisation') as to its 'effectively underlying human beholdening - inching,-apprehending,-and-taming-drive or aestheticisingsurrealising/supererogating-drive for $\quad<$ postconverging 'motif-andapriorising/axiomatising/referencing'-entailing--existentialising-framing/imprinting-〈as-toprospective- historiality/ontological-eventfulness /ontological-aesthetic-tracing$<$ perspective--ontological-normalcy/postconvergence-reflected-'epistemicity-relativismdeterminism' $>\rangle$ ' is rather 'manifested preconverging/postconverging-dementatively/structurally/paradigmatically as reflecting human ontological-performance $<$ including-virtue-as-ontology $>$ /morality/ethics/justice/etc. (with regards to constraining 'implicited_attendant-ontological-contiguity ${ }^{67}$ educedexistentialising/contextualising/textualising_ 'intelligibility/epistemicity/reflexivity-contiguity$<$ imbued-notional $\sim$ cogency $>^{\prime}$ upon human underlying ontological-commitment $-<$ implied self-assuredness-of-ontological-good-faith/authenticity postconverging-dementating/structuring/paradigming -as-being-as-of-existential-reality $>$ as to the possibility for sublimation or desublimation)' as at defining institutionalisation-threshold or as at defining uninstitutionalised-threshold $^{102}$ of human ontological-performance ${ }^{72}-<$ including-virtue-as- $^{2}$ ontology>; so-underlined respectively by the dispensing-with-immediacy-for-relative- 
ontological-completeness ${ }^{87}$-by-reification/contemplative-distension ${ }^{27}$ associated with postconverging (postconverging-or-dialectical-thinking -apriorising-psychologismrepresentation,-as-of-postconverging-aestheticisation) as at defining institutionalisationthreshold or failing dispensing-with-immediacy-for-relative-ontological-completeness ${ }^{87}$-byreification/contemplative-distension ${ }^{27}$ associated with preconverging (preconverging-ordementing -apriorising-psychologism-representation,-as-of-preconverging-aestheticisation) as at defining uninstitutionalised-threshold ${ }^{102}$. In this respect (with regards to the possibility for human sublimation as to existence-as-sublimating-withdrawal/unenframing/re-ontologising,elicited-from-prospective-profound-supererogation ${ }^{6}$ ), prospective originariness-parrhesia,-asspontaneity-of-aestheticisation-

supererogatory acuity/perspicacity/astuteness/edginess/incisiveness as to its 'invention'/'creation' of prospective methods/methodologies/approaches as to 'prospective sublimation induced methodologising/mutualising/organising/institutionalising' (involving sublimating human 'formativeness-<as-to-intersolipsism-ofpreformulating/preframing/premeaningfulness-imbued-mediativity-and-deferentialism>-ofmeaningfulness-and-teleology ) is underlined by its 'instigative-askesis-or-acumen postconverging-de-mentating/structuring/paradigming the possibility for prospective sublimating and reifying socio-institutional conceptions/constructs/models as to prospective postconverging aporeticism-overcoming/unovercoming-overcoming for human social emancipative reinvigoration/disruption' (reflected historically as of a sacral, monasterial, pastoral, hippocratic, etc. aestheticisation-and-aestheticisation-towards-ontology-<elicitedidiomatisation $>$ and inconsistently echoed in modern-day deonto-professional institutional practices); and so as to the 'instigative-askesis-or-acumen projected perception' that the disposedness/psychologismic-construct of the generalised social-construct $<$ amplituding/formative $>$ wooden-language-_imbued — averaging-of-thought-<as-to- 
leveling/ressentiment/closed-construct-of- meaningfulness-and-teleology -as-of-

'nondescript/ignorable-void '-with-regards-to-prospective-apriorising-implications $>>\quad$ is 'preconverging/postconverging-de-mentatively/structurally/paradigmatically relatively of inept/poorly-amenable ontological-performance ${ }^{72}$ - $_{\text {including-virtue-as-ontology }>^{\prime}}$ for the prospective requisite existential-disentogising antelogising aporeticism $>$ dispensingwith-immediacy-for-relative-ontological-completeness 87 -by-reification/contemplativedistension $^{27}$ in the contemplation-and/or-fulfilling of the instigative-askesis-or-acumen postconverging-de-mentating/structuring/paradigming the possibility for prospective sublimating and reifying socio-institutional conceptions/constructs/models as to prospective postconverging-aporeticism-overcoming/unovercoming-overcoming for human social emancipative reinvigoration/disruption' associated with re-ontologising prospective Beingdevelopment/ontological-framework-expansion-as-to-depth-of-ontologising-development-asinfrastructure-of- meaningfulness-and-teleology. This is the case even as with regards to the instigative-askesis-or-acumen for prospective sublimating genuine social intellectualfunction/posture for instance, the '<amplituding/formativeepistemicity $>$ totalising/circumscribing/delineating construal of ${ }^{56}$ meaningfulness-andteleology ${ }^{9}$ respectively of say the ancient-sophists, medieval-scholasticism or modern-day pedantising/muddling/formulaic-hollowing-out — in-subontologisation/subpotentiation〈blurring/undermining-of-prospective-totalising-entailing,-as-to-entailing$<$ amplituding/formative-epistemicity>totalising in-relative-ontological-completeness $>$ in their $<$ amplituding/formative-epistemicity $>$ totalising $\sim$ self-referencingsyncretising/circularity/interiorising/akrasiatic-drag ${ }^{34}$, will hardly cognise the 'prospective postconverging aporeticism-overcoming/unovercoming-overcoming merits' respectively of projected Socratic-philosophers ${ }^{103}$ universalising-idealisation, budding-positivists positivism/rational-empiricism and prospective postmodern-thought as herein projected with 
notional ${ }^{1}$ deprocrypticism conceptualisation and so as to the latter skirting/peripheral initiation within the ${ }^{7}$ presencing — absolutising-identitive-constitutedness ${ }^{14}<$ preconverging $\sim$ 'motif-andapriorising/axiomatising/referencing'-entailing>-existentialising_enframing/imprintedness〈as-to- historicity-tracing - in-presencing-hyperrealisation/hyperreal-transposition〉 of the former so-construed by the Derridean conception of prospective philosophy occurring rather at the margin of $\leq$ mere-formulaicity/ritualisation of $\geq$ prior secondnatured reproducibilitymathesis/motif/thrownness-disposition,-as-reproducibility-of-aestheticisation philosophy (as to the fact that the ancient-sophists, medieval-scholasticism or modern-day pedantising/muddling/formulaic-hollowing-out - in-subontologisation/subpotentiation〈blurring/undermining-of-prospective-totalising-entailing,-as-to-entailing$<$ amplituding/formative-epistemicity>totalising in-relative-ontological-completeness $>$ will falsely pretend that their respective ${ }^{79}$ presencing-absolutising-identitive-constitutedness $<$ preconverging 'motif-and-apriorising/axiomatising/referencing'-entailing >existentialising — enframing/imprintedness-〈as-to- historicity-tracing_-in-presencinghyperrealisation/hyperreal-transposition> associated with the eliciting of their respective $<$ amplituding/formative $>$ wooden-language-〈imbued - averaging-of-thought- $<$ as-toleveling/ressentiment/closed-construct-of- meaningfulness-and-teleology -as-of'nondescript/ignorable-void '-with-regards-to-prospective-apriorising-implications $>>$, is of 'existential and contemplative internal adequation' respectively for the nascent contemplation of such ${ }^{103}$ universalising-idealisation, positivism/rational-empiricism and prospective postmodernthought as herein projected with notional ${ }^{18}$ deprocrypticism conceptualisation whereas the skirting/peripheral initiation within such respective ${ }^{79}$ presencing-absolutising-identitiveconstitutedness $<$ preconverging 'motif-and-apriorising/axiomatising/referencing'entailing $>$-existentialising — enframing/imprintedness-〈as-to- historicity-tracing — inpresencing-hyperrealisation/hyperreal-transposition〉 as of the former effectively speaks to their 
'fundamental preconverging/postconverging-de-mentative/structural/paradigmatic falsehood' for the possibility for the genuine social intellectual-function/posture prospective postconverging aporeticism-overcoming/unovercoming-overcoming sublimation involving 'their seeding-misprising ontological-bad-faith/inauthenticity $\sim$ preconverging-dementating/structuring/paradigming that covertly and/or overtly project respectively that afterall all the human world that exists is-of-non-universalising-sophistry or is-of-non-positivisingscholasticism or is-of-disjointed-intellectual pedantising/muddling/formulaic-hollowing-outin-subontologisation/subpotentiation-〈blurring/undermining-of-prospective-totalisingentailing,-as-to-entailing-<amplituding/formative-epistemicity $>$ totalising $\sim$ in-relativeontological-completeness > in contempt of 'relative-ontological-incompleteness $8 /$ relativeontological-completeness ${ }^{87}$-〈sublimating $\sim$ referencing/registering/decisioning,-as-selfbecoming/self-conflatedness /formative-supererogating-<projective/reprojectiveaestheticising-re-motif-and-re-apriorising/re-axiomatising/re-referencing,-in-perspectiveontological-normalcy/postconvergence $>>$ as to human-and-social-expectations/anticipationsmetaphoricity ${ }^{5}$-as-preconverging/postconverging-rede-

mentating/restructuring/reparadigming-psychologism' 89 and this 'seeding-misprising ontological-bad-faith/inauthenticity ${ }^{6} \sim$ preconverging-de-mentating/structuring/paradigming ${ }^{6}$, has to be factored into the prospective articulation of deprocrypticism,-as-to-the-ultimatefulfilment-of-notional deprocrypticism as to the fact that the complete possibility for ontology/science implies 'accounting for everything potent' including at the more fundamental level human ontological-faith-notion-or-ontological-fideism - imbued-underdetermination-ofmotif-and-apriorising/axiomatising/referencing-as-so-being-as-of-existential-reality as to its implied ontological-good-faith/authenticity ${ }^{69} \sim$ postconverging-dementating/structuring/paradigming ${ }^{70}$ and ontological-bad-faith/inauthenticity ${ }^{64} \sim$ preconvergingde-mentating/structuring/paradigming that are respectively instigative or forestalling of the 
possibility for prospective human postconvergingaaporeticism-overcoming/unovercoming sublimation). This is further reflected in the 'very postconverging-as-to-ontologicalnormalcy/postconvergence over preconverging-as-to-epistemic-abnormalcy conception of human transcendence-and-sublimity/sublimation/supererogatory $\sim$ de-mentativity' with regards to the fact that the state of recurrent-utter-uninstitutionalisation, base-institutionalisationununiversalisation, ${ }^{103}$ universalisation-non-positivism/medievalism and positivismprocrypticism respectively aren't of the 'existential and contemplative internal adequation' for prospective base-institutionalisation, ${ }^{103}$ universalisation, positivism and deprocrypticism, as to the 'increasing crumbling of the former genuine social intellectual-function/posture' into subterfuge of false-scepticism (as to the fact that veridical scepticism is of constructive knowledge commitment effectively exposing itself to existence-as-sublimatingwithdrawal/unenframing/re-ontologising,-elicited-from-prospective-profound-supererogation and so rather than idly critical and unaccountable totalisingly-ing — discretion/whim-of-thought), pedantising/muddling/formulaic-hollowing-out — in-subontologisation/subpotentiation〈blurring/undermining-of-prospective-totalising-entailing,-as-to-entailing<amplituding/formative-epistemicity>totalising in-relative-ontological-completeness $>$ and $<$ amplituding/formative $>$ wooden-language-〈imbued - averaging-of-thought- $<$ as-toleveling/ressentiment/closed-construct-of- meaningfulness-and-teleology -as-of'nondescript/ignorable-void '-with-regards-to-prospective-apriorising-implications $>$ > narratives increasingly ignoring-and-failing to engage with inherent veridical knowledgereification $\sim$ gesturing-and-accounting — of-epistemic-phenomenalism- $<$ inprospective_psychologismic $\sim$ apriorising/axiomatising/referencing-\{of-'prospectively_ implicited_attendant-ontological-contiguity ' educedexistentialising/contextualising/textualising_ 'intelligibility/epistemicity/reflexivity-contiguity$<$ imbued-notional cogency $>>$ \}-conflatedness -in-\{preconverging -ment by\} 
postconverging-entailment $>$. In this respect the possibility of human prospective reasoningthrough/messianic-reasoning that goes on to induce prospective reasoning-fromresults/afterthought as secondnatured-institutionalisation is ever always accompanied/framed by its 'instigative-askesis-or-acumen postconverging-de-mentating/structuring/paradigming the possibility for prospective sublimating and reifying socio-institutional conceptions/constructs/models as to prospective postconverging-apereticismovercoming/unovercoming-overcoming for human social emancipative reinvigoration/disruption' as to the resultantly developed deferential-formalisation-transference socio-institutional model/construct (reflected historically as of a sacral, monasterial, pastoral, hippocratic, etc. aestheticisation-and-aestheticisation-towards-ontology-<elicitedidiomatisation $>$ and inconsistently echoed in modern-day deonto-professional institutional practices)'; and so by the mere token of the preconverging/postconverging-dementative/structural/paradigmatic relative ontological-deficiency of the generalised socialconstruct $<$ amplituding/formative $>$ wooden-language-〈imbued-averaging-of-thought- $<$ as-toleveling/ressentiment/closed-construct-of- meaningfulness-and-teleology -as-of'nondescript/ignorable-void '-with-regards-to-prospective-apriorising-implications $>>$ as to its beholdening to institutional-development-as-to-social-function-development and livingdevelopment-as-to-personality-development psychologismic epistemic-acutisationdifficulty<for, residualising \{decompulsing\} delinearity for-cogency> magnitudes $\{$ ofexperientiality/experiment\} so-derived rather as from the prior Being-development/ontologicalframework-expansion-as-to-depth-of-ontologising-development-as-infrastructure-ofmeaningfulness-and-teleology implied uninstitutionalised-threshold ${ }^{102}$. Thus in-many-ways 'instigative-askesis-or-acumen postconverging-de-mentating/structuring/paradigming the possibility for prospective sublimating and reifying socio-institutional conceptions/constructs/models as to prospective postconvergingaapereticism- 
overcoming/unovercoming-overcoming for human social emancipative reinvigoration/disruption' is associated with nascent-particular/incipient-and-material/technicalsublimations-<blinded-to-their-relative-ontological-completeness - reference-of-thought-

devolving $>$ as to prospective originariness-parrhesia,-as-spontaneity-of-aestheticisationsupererogatory $\sim$ acuity/perspicacity/astuteness/edginess/incisiveness imbued dimensionality-ofsublimating $25-<<$ amplituding/formative $>$ supererogatory $\sim$ de-mentativeness/epistemic-growthor-conflatedness /transvaluative-rationalising/transepistemicity/anamnestic-residuality/spiritdrivenness-equalisation). However, the ontological-veracity of human temporal-to-intemporal ontological-performance $^{72}$-<including-virtue-as-ontology $>/$ morality/ethics/justice/etc. as at uninstitutionalised-threshold $^{102}$ (so-underlined by human limited-mentation-capacity-assubjecting 'educed-unlimitedness/existence-sublimating nascence' to-limitedness/humansubpotency) speaks to the fact that even the 'instigative-askesis-or-acumen postconverging-dementating/structuring/paradigming the possibility for prospective sublimating and reifying socio-institutional conceptions/constructs/models as to prospective postconverging aporeticism-overcoming/unovercoming-overcoming for human social emancipative reinvigoration/disruption' is bound to manifest its socio-institutional conceptions/constructs/models very prospective postconverging-apereticismevercoming/unovercoming, as so-manifested as of incipient/incidental overall relativeontological-incompleteness ${ }^{88}$-presublimation-construct-of- ${ }^{56}$ meaningfulness-and-teleology usurping of nascent-particular/incipient-and-material/technical-sublimations- $<$ blinded-to-theirrelative-ontological-completeness - reference-of-thought- devolving >; as the nascentparticular/incipient-and-material/technical-sublimations- $<$ blinded-to-their-relative-ontologicalcompleteness - reference-of-thought- devolving> given 'conceptualisation incompleteness as to relative-unreflexivity/relative-reflexivity ontological-contiguity ${ }^{67}$ elicits the manifestation of such overall relative-ontological-incompleteness ${ }^{88}$-presublimation-construct- 
of- ${ }^{5}$ meaningfulness-and-teleology ${ }^{99}$ as defect of beholdening apriorising aestheticisation (as of overall relative-ontological-incompleteness ${ }^{8}$ - presublimation-construct-of- ${ }^{56}$ meaningfulnessand-teleology ${ }^{9}$ wrong $\quad{ }^{4}$ historicity-tracing-in-presencing-hyperrealisation/hyperrealtransposition as being of nascent-particular/incipient-and-material/technical-sublimations$<$ blinded-to-their-relative-ontological-completeness - reference-of-thought- devolving $>$, underlined by its preconverging-or-dementing ${ }^{20}$-apriorising-psychologism wrong construal as being of postconverging-or-dialectical-thinking -apriorising-psychologism). Such a historicity-tracing-in-presencing-hyperrealisation/hyperreal-transposition as to the desublimating manifestation of 'effectively underlying human beholdening-inching,apprehending,-and-taming-drive or aestheticising — ${ }^{7}$ surrealising/supererogating-drive for $<$ postconverging 'motif-and-apriorising/axiomatising/referencing'-entailing >-

existentialising - framing/imprinting-_as-to-prospective-- historiality/ontological-

eventfulness /ontological-aesthetic-tracing-<perspective-ontologicalnormalcy/postconvergence-reflected-'epistemicity-relativism-determinism'>>' (as so-inherent to human <amplituding/formative-epistemicity>-totalising $\sim$ thrownness-in-existence ${ }^{35}$,imbued-projective-arbitrariness/waywardness-〈as-to-the-human-projective/reprojectiveaestheticising-re-motif-and-re-apriorising/re-axiomatising/re-referencing-process-of'<amplituding/formative-epistemicity $>$ totalising $\sim$ conceptualisation' $\rangle$ ), actually takes the form of a numbing-traction-_of-desublimating - meaningfulneslost-of-'supererogatory acuity/perspicacity/astuteness/edginess/incisiveness-as-to-the-imbuedpostconverging/dialectical-thinking -of-notional deprocrypticism-\{in-dimensionality-ofsublimating _ < $<$ amplituding/formative-epistemicity $>$ growth-orconflatedness /scalarisation-as-to-rescalarisation-as-re-ontologisation $\left.\}^{\prime}\right\rangle$ which goes on to instill (beyond-the-consciousness-awareness-teleology ${ }^{\circ}<$ of-preconverging-existentialextrication-as-of-existential-unthought> ) a social agency all of its own associated with inducing 
prospective desublimating and dereifying of socio-institutional conceptions/constructs/models.

Such a ${ }^{47}$ historicity-tracing — in-presencing-hyperrealisation/hyperreal-transposition numb-__-_-_. traction_-_of-desublimating 5 meaningfulness_-and-teleology $-\langle$ as-perspective-lost-of'supererogatory acuity/perspicacity/astuteness/edginess/incisiveness-as-to-the-imbuedpostconverging/dialectical-thinking -of-notional deprocrypticism- $\{$ in-dimensionality-ofsublimating _ < $<$ amplituding/formative-epistemicity $>$ growth-or-

conflatedness /scalarisation-as-to-rescalarisation-as-re-ontologisation $\left.\}^{\prime}\right\rangle$ is manifested not only with regards to specific socio-institutional conceptions/constructs/models practices but englobes extended social institutions including the underpinning-suprasocial-construct, the genuine social intellectual-function/posture as well as the media; and in-many-ways is the enabler (as to its prompting of a supposedly imponderable/inscrutable/unavoidable/inevitable/inescapable/unpreventable/unchangeable/in surmountable/unovercomable presencing-absolutising-identitive-constitutedness $<$ preconverging 'motif-and-apriorising/axiomatising/referencing'-entailing $>$ existentialising — enframing/imprintedness-〈as-to- historicity-tracing — in-presencinghyperrealisation/hyperreal-transposition〉) of a human rationalising closedness that structures/paradigms directly or indirectly the 'patronising/disfranchising/disqualifying acceptability/seemliness' of the given human ${ }^{79}$ presencing-absolutising-identitiveconstitutedness ${ }^{14} \quad<$ preconverging 'motif-and-apriorising/axiomatising/referencing'entailing $>$-existentialising — enframing/imprintedness-〈as-to- historicity-tracing - inpresencing-hyperrealisation/hyperreal-transposition〉 imbued preconverging-dementating/structuring/paradigming vices-and-impediments ${ }^{105}$, and so as to dimensionality-ofdesublimating-lack-of ${ }^{-}-\langle<$amplituding/formative $>$supererogatory $\sim$ de-mentativeness/epistemicgrowth-or-conflatedness /transvaluative-rationalising/transepistemicity/anamnesticresiduality/spirit-drivenness-equalisation) (thus undermining the challenge of the double 
epistemic orientation to notional deprocrypticism institutionalisation 'unenframed/reontologising/unbeholdening/bechancing-supererogation ${ }^{9}$ parameterisation/reparameterisation$\langle$ reflecting-a-supererogatory $\sim$ decisionality-of-socioinstitutional-conceptions-as-to- 'theirnascent-sublimations-dynamic-preempting-of-presublimatory-decisionality-numbing-tractiondesublimation’>-as-so-operationalising-‘scalarisation-as-to-rescalarisation-as-reontologisation' for prospective aestheticisation-and-aestheticisation-towards-ontology$<$ elicited-idiomatisation $>/{ }^{5}$ meaningfulness-and-teleology ${ }^{99}$ as highlighted above, and so with regards to superseding our positivism- ${ }^{80}$ procrypticism occlusivity). This ${ }^{47}$ historicity-tracing-

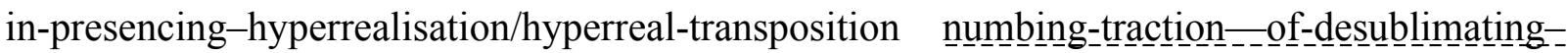
me-aningfulnes-

\section{'supererogatory acuity/perspicacity/astuteness/edginess/incisiveness-as-to-the-imbued-}

postconverging/dialectical-thinking -of-notional deprocrypticism- $\{$ in-dimensionality-of-

sublimating $-<$ amplituding/formative-epistemicity $>$ growth-or-

conflatedness /scalarisation-as-to-rescalarisation-as-re-ontologisation $\left.\}^{\prime}\right\rangle$ reflects the implications of the 'effectively underlying human beholdening-inching,-apprehending,-andtaming-drive or aestheticising - ${ }^{97}$ surrealising/supererogating-drive for <postconverging 'motif-and-apriorising/axiomatising/referencing'-entailing >existentialising - framing/imprinting-〈as-to-prospective-- historiality/ontologicaleventfulness /ontological-aesthetic-tracing-<perspective-ontologicalnormalcy/postconvergence-reflected-'epistemicity-relativism-determinism'>〉' (as to manifestly cultivated/beholdening-construct-of- ${ }^{5}$ meaningfulness-and-teleology ${ }^{99}$,-ultimately-construedas-habit/practice/belief/culture so-reflected as $\quad<$ preconverging ' $m o t$ if-andapriorising/axiomatising/referencing'-entailing >-existentialising — enframing/imprintedness〈as-to- historicity-tracing-in-presencing-hyperrealisation/hyperreal-transposition〉, and so with regards to human Being-development/ontological-framework-expansion-as-to-depth-of- 
ontologising-development-as-infrastructure-of- meaningfulness-and-teleology , institutionaldevelopment-as-to-social-function-development and living-development-as-to-personalitydevelopment psychologismic epistemic-acutisation difficulty-for, residualising ${ }_{\{\text {decompulsing }}$ delinearity $\sim$ for-cogeney $>$-magnitudes $\left.{ }^{\{\text {of-experientiality/experiment }\}}\right\}$ and speaks to the fact that the overall development of human ${ }^{5}$ meaningfulness-and-teleology in reflecting holographically-<conjugatively-and-transfusively $>$ the relative-unreflexivity/relativereflexivity - ontological-contiguity of-the-human-institutionalisation-process involves a 'wavering/redounding/waveforming of-the-referencing-and-the-devolved-referencingimbued-ontological-performance ${ }^{2}$-<including-virtue-as-ontology $>/$ morality/ethics/justice/etc. as to presublimation and nascent-sublimations overlapping-contiguity-of-referencing-anddevolved-referencing'. This 'wavering/redounding/waveforming of-the-referencing-and-thedevolved-referencing-imbued-ontological-performance ${ }^{72}-<$ including-virtue-asontology $>$ /morality/ethics/justice/etc. as to presublimation and nascent-sublimations overlapping-contiguity-of-referencing-and-devolved-referencing' is preconverging/postconverging-de-mentatively/structurally/paradigmatically due to the very 'epistemic entwining of ${ }^{83}$ reference-of-thought/grandest-axiomatic-construct — as-toreferencing/registering/decisioning and $\quad{ }^{83}$ reference-of-thought- ${ }^{8}$ devolving/devolvedaxiomatising-conjugations (holding-forth for human existential-instantiations ${ }^{56}$ meaningfulnessand-teleology ${ }^{9}$ )', as to the sublimating dynamics of 'human re-motif-and-re-apriorising/reaxiomatising/re-referencing/re-intelligibilitysettingup/re-measuringinstrumenting as of prospective nascent-particular/incipient-and-material/technical-sublimations- $<$ blinded-to-theirrelative-ontological-completeness - reference-of-thought- devolving $>$ reflecting immanentexistence's relative unreflexivity/relative reflexivity - ontological-contiguity ${ }^{7}$ (soepistemically underscored by the ${ }^{8}$ reference-of-thought-and-its-devolving) as knowledgereification $\sim$ gesturing-and-accounting - of-epistemic-phenomenalism- $<$ in- 
prospective_psychologismic apriorising/axiomatising/referencing-\{of-'prospectively

implicited_attendant-ontological-contiguity ' educed-

existentialising/contextualising/textualising_'intelligibility/epistemicity/reflexivity-contiguity-

$<$ imbued-notional cogency >' \}-conflatedness -in-\{preconverging ment by\}

postconverging-entailment>' in then holding-forth for prospective human ${ }^{56}$ meaningfulness-

and-teleology

existential-instantiations

by

aposteriorising/logicising/deriving/intelligising/measuring; with the 'epistemic entwining of reference-of-thought/grandest-axiomatic-construct — as-to-referencing/registering/decisioning and ${ }^{83}$ reference-of-thought- ${ }^{84}$ evolving/devolved-axiomatising-conjugations (holding-forth for human existential-instantiations ${ }^{5}$ meaningfulness-and-teleology ${ }^{9}$ )' reflecting the fact that (as to maximalising-recomposuring-for-relative-ontological-completeness ${ }^{87}$ - unenframed/reontologising conceptualisation involving human limited-mentation-capacity-deepening-assubjecting limitedness/human-subpotency-to-'educed-unlimitedness/existence-sublimatingnascence' 3 for 'human re-motif-and-re-apriorising/re-axiomatising/re-referencing/reintelligibilitysettingup/re-measuringinstrumenting as of prospective nascentparticular/incipient-and-material/technical-sublimations- $<$ blinded-to-their-relative-ontologicalcompleteness - reference-of-thought- devolving > reflecting immanent-existence's relativeunreflexivity/relative-reflexivity - ontological-contiguity ${ }^{67}$, so-epistemically underscored by the reference-of-thought-and-its-devolving, as knowledge-reification $\sim$ gesturing-andaccounting - of-epistemic-phenomenalism-<inprospective_psychologismic apriorising/axiomatising/referencing-\{of-'prospectively implicited_attendant-ontological-contiguity ' educedexistentialising/contexalising/texalising_intelligibility/epistemicity/reflexivity-contiguity$<$ imbued-notional cogency >' \}-conflatedness -in-\{preconverging-ment by\} postconverging entailment>') prospective human transcendence-and- 
sublimity/sublimation/supererogatory-de-mentativity rather implies first the 'prospective nascent-particular/incipient-and-material/technical-sublimations- $<$ blinded-to-their-relativeontological-completeness - reference-of-thought- devolving>' which then ultimately usher in the reference-of-thought/grandest-axiomatic-construct - as-toreferencing/registering/decisioning own's prospective sublimation, but then with the paradox that the 'prospective nascent-particular/incipient-and-material/technical-sublimations- $<$ blindedto-their-relative-ontological-completeness - reference-of-thought- devolving ${ }^{\prime}$ ' have to be existentially-<disontologising/re-ontologising aporeticism $>$ referenced/registered/decisioned as from the available desublimating prior ${ }^{83}$ reference-of-thought/grandest-axiomatic-constructas-to-referencing/registering/decisioning (notwithstanding the need for its very own prospective sublimation at which point incrementalism-in-relative-ontological-incompleteness ${ }^{8}$ enframed/disontologising conceptualisation is manifested), thus necessarily inducing presublimation until when the 'prospective nascent-particular/incipient-and-material/technicalsublimations- $<$ blinded-to-their-relative-ontological-completeness - reference-of-thoughtdevolving >' decisively point to a prospective change/sublimation of the existentially<disontologising/re-ontologising aporeticism $>\quad$ referencing/registering/decisioning reference-of-thought/grandest-axiomatic-construct—as-to-referencing/registering/decisioning (at which point ${ }^{55}$ maximalising-recomposuring-for-relative-ontological-completeness ${ }^{87}$ unenframed/re-ontologising conceptualisation is manifested), so-arising as of the ultimately/eventually perceived referencing coherence/contiguity of the 'prospective nascentparticular/incipient-and-material/technical-sublimations-<blinded-to-their-relative-ontologicalcompleteness - reference-of-thought- devolving >'.

'wavering-redoung of -the-referencing-and-the-devolved-referencingimbued-ontological-performance ${ }^{72}-<$ including-virtue-as-ontology $>/$ morality/ethics/justice/etc. as to presublimation and nascent-sublimations overlapping-contiguity-of-referencing-and- 
devolved-referencing' in-many-ways explain why budding-positivists like Newton and Descartes for instance paradoxically integrated medieval non-positivistic esoteric, alchemic and deistic notions, however marginally or qualified, as pragmatically complementing their nascentparticular/incipient-and-material/technical-sublimations- $<$ blinded-to-their-relative-ontologicalcompleteness - reference-of-thought- devolving > positivism/rational-empiricism conceptions (as reflected with Newton's interest in alchemy and the occult in association with his positivistic natural philosophy as well as Descartes' underlying deistic interest in association with his incipient positivistic mathesis ${ }^{103}$ universalis schema/disseminative metaphoricity explicited with his thinking proposition and scepticism exercise engendering as to its dimensionality-of-sublimating $25<$ amplituding/formative $>$ supererogatory - de-

\section{mentativeness/epistemic-growth-or-conflatedness /transvaluative-}

positivism apriorising/axiomatising/referencing/intelligibilitysettingup/measuringinstrumenting attitude/mental-disposition/care-and-episteme ${ }^{5}$. Along the same lines, it is interesting to note how Plato's Socrates and Plato as to their dimensionality-of-sublimating -

\section{<<amplituding/formative >supererogatory $\sim$ de-mentativeness/epistemic-growth-or-}

\section{conflatedness /transvaluative-rationalising/transepistemicity/anamnestic-residuality/spirit-}

drivenness-equalisation> ${ }^{103}$ universalising-idealisation instigation were in-many-ways rather beholdening to a pre- ${ }^{103}$ universalising Delphian spirituality conception (as so-reflected particularly by the Delphian motto know thyself) with regards to their ${ }^{103}$ universalisingidealisation approach mostly emphasising human and social virtue (as underlined with Socrates' maieutics and Plato's theory of Forms) and so very much in contrast to the latter Aristotelian approach in an all-expansive perspective of ${ }^{103}$ universalising-idealisation particularly so by its emphasis on overall ${ }^{103}$ universalising-idealisation pragmatic knowledge including practical and natural phenomena universalising-idealisation implications.

This 
'wavering/redounding/waveforming of-the-referencing-and-the-devolved-referencing-

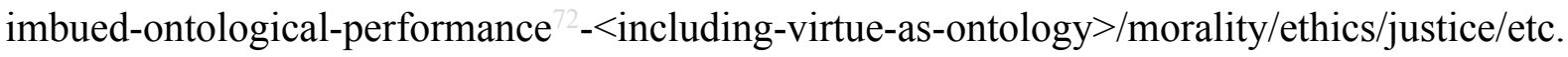
as to presublimation and nascent-sublimations overlapping-contiguity-of-referencing-anddevolved-referencing' (in reflecting holographically-<conjugatively-and-transfusively $>$ the relative-unreflexivity/relative-reflexivity - ontological-contiguity of-the-humaninstitutionalisation-process implications as to existence-as-sublimatingwithdrawal/unenframing/re-ontologising,-elicited-from-prospective-profoundsupererogation ) is effectively what epistemically underlies the inherent ontological-veracity of the 'postconverging/dialectical-thinking of ${ }^{83}$ reference-of-thought sublimating as to the implied ontological-normalcy/postconvergence of notional ${ }^{18}$ deprocrypticism' over the inherent ontological-flaw of the "preconverging/dementing ${ }^{20}$ of ${ }^{8}$ reference-of-thought in desublimationas-presublimating as to the implied epistemic-abnormalcy of notional procrypticism'; as to the fact that the reference-of-thought/grandest-axiomatic-construct-as-toreferencing/registering/decisioning speaks of the referencing projective-insights psychologistically and apriorisingly underlying the prospective nascent-particular/incipient-andmaterial/technical-sublimations-<blinded-to-their-relative-ontological-completeness

reference-of-thought- devolving $>$ as to their operant predicative-insights. Insightfully (as to its deneuterising - referentialism construed as of ${ }^{4}$ historiality/ontologicaleventfulness 38 ontological-aesthetic-tracing-<perspective-ontologicalnormalcy/postconvergence-reflected-‘epistemicity-relativism-determinism’>, notional ${ }^{18}$ deprocrypticism enabled fundamental ontology-driven 'postconverging-ordialectical-thinking -psychology or psychology-of-mentation-dynamics or natural psychological-dynamics', and so superseding a naïve metaphysics-of-presence〈implicited-'nondescript/ignorable-void '-as-to- presencing - absolutising-identitiveconstitutedness $>$ affect-driven mented or stigmatic psychology rather as of a shallow 
perspective of historicity-tracing-in-presencing-hyperrealisation/hyperreal-transposition and vaguely articulated as of ${ }^{103}$ universal import but rather manifesting our positivismprocrypticism $\quad 79$ presencing — absolutising-identitive-constitutedness

\section{$<$ preconverging 'motif-and-apriorising/axiomatising/referencing'-entailing $>$ -}

existentialising — enframing/imprintedness-〈as-to- historicity-tracing_-in-presencing-

hyperrealisation/hyperreal-transposition〉), the conception of human socio-institutional coneptions/constructs/models is rather as of a 'supererogatory psychologistic protraction of human relevantly induced notional asceticism (as to its skirting/peripheral initiation within a presencing-absolutising-identitive-constitutedness

$<$ preconverging $\sim$ 'motif-andapriorising/axiomatising/referencing'-entailing >-existentialising —enframing/imprintedness-

〈as-to- historicity-tracing-in-presencing-hyperrealisation/hyperreal-transposition〉

constructively enable the veridical expression of its 'instigative-askesis-or-acumen postconverging-de-mentating/structuring/paradigming the possibility for prospective sublimating and reifying socio-institutional conceptions/constructs/models as to prospective postconverging aporeticism for human social emancipative reinvigoration/disruption') in dispensing-with-immediacy-for-relativeontological-completeness $^{87}$-by-reification/contemplative-distension ${ }^{27}$ as of originarinessparrhesia,-as--spontaneity-of-aestheticisation-

supererogatory acuity/perspicacity/astuteness/edginess/incisiveness projection of prospective methods/methodologies/approaches as from prospective sublimation induced methodologising/mutualising/organising/institutionalising' (reflected historically as of a sacral, monasterial, pastoral, hippocratic, etc. aestheticisation-and-aestheticisation-towards-ontology$<$ elicited-idiomatisation $>$ and inconsistently echoed in modern-day deonto-professional institutional practices); and so unlike any given 'naïve ${ }^{79}$ presencing-absolutising-identitiveconstitutedness 
entailing >-existentialising — enframing/imprintedness-〈as-to- historicity-tracing — in-

presencing-hyperrealisation/hyperreal-transposition〉 perspectiveless-and-soulless blinded adherence to prior methods/methodologies/approaches' whether of ancient-sophistry, medievalscholasticism or of modern-day manifestation of disparateness-of-conceptualisation$<$ unforegrounding-ment,-failing-prospectively-to-reflect-'immanent $\sim$ relative-

unreflexivity/relative-reflexivity ontological-contiguity ' $>$ pedantising/muddling/formulaichollowing-out-in-subontologisation/subpotentiation-〈blurring/undermining-of-prospectivetotalising-entailing,-as-to-entailing-<amplituding/formative-epistemicity $>$ totalising $\sim$ inrelative-ontological-completeness $\rangle$. The further implication is that ours cannot pretend to be the human generation that shuts-off from prospective knowledge-reification $\sim$ gesturing-andaccounting - of-epistemic-phenomenalism- $<$ in-

prospective_psychologismic apriorising/axiomatising/referencing-\{of-'prospectively implicited_attendant-ontological-contiguity ' educed-

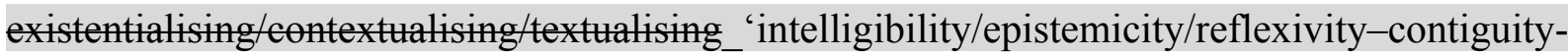
<imbued-notional cogency>' \}-conflatedness -in-\{preconverging-ment by\} postconverging-ntailment $>$ the analysis and criticism of its methodologising/mutualising/organising/institutionalising as of its ${ }^{79}$ presencing—absolutisingidentitive-constitutedness ${ }^{14}$ <preconverging 'motif-and-apriorising/axiomatising/referencing'entailing $>$-existentialising — enframing/imprintedness-〈as-to- historicity-tracing - inpresencing-hyperrealisation/hyperreal-transposition) (as to 'human socialvestedness/normativity- $<$ discretely-implied-functionalism $>\quad$ implied contract/politicalarrangement-or-political-coercion/given-discrete-social-value-construction' without grasping the reality of overall human 'formativeness-<as-to-intersolipsism-ofpreformulating/preframing/premeaningfulness-imbued-mediativity-and-deferentialism>-ofmeaningfulness-and-teleology as to inherent human embodied- 
vitality/survival/subsistence — existential-<disontologising/re-ontologising aporeticism> becoming with regards to human Being-development/ontological-framework-expansion-as-todepth-of-ontologising-development-as-infrastructure-of- meaningfulness-and-teleology , institutional-development-as-to-social-function-development and living-development-as-topersonality-development psychologismic epistemic acutisation difficulty-<for, residualising_\{decompulsing $\}$ delinearity-for-cogency>-magnitudes $\left.{ }^{\{0-e x p e r i e n t i a l i t y / e x p e r i m e n t}\right\}$ as sodefining the social or human-social-potency'). This is necessary for fundamental ontology speaking of notional ${ }^{18}$ deprocrypticism enabled fundamental ontology-driven 'postconvergingor-dialectical-thinking -psychology or psychology-of-mentation-dynamics or natural psychological-dynamics' for inducing prospective human ${ }^{4}$ historiality/ontologicaleventfulness ${ }^{38}$ /ontological-aesthetic-tracing-<perspective-ontologicalnormalcy/postconvergence-reflected-'epistemicity-relativism-determinism'>. Basically, notional asceticism is ever always associated with the successive relative-ontologicalcompleteness ${ }^{87}$ registry-worldviews/dimensions possibility for prospective transcendence-andsublimity/sublimation/supereregatory $\sim$ de-mentativity to arise (as to the notional asceticism instigating originariness-parrhesia,-as-spontaneity-of-aestheticisationsupereacuity/perspicacity/astuteness/edginess/incisiveness projection of prospective methods/methodologies/approaches as from prospective sublimation induced methodologising/mutualising/organising/institutionalising), and so because all the 'existential and contemplative internal adequation' available for any given relative-ontologicalincompleteness $^{88}$ registry-worldview/dimension is as of its inherent apriorising/axiomatising/referencing-psychologism imbued logical-basis/logic,-as-derivedfrom $\sim$ transversality $<<$ for-sublimating-existential-eventuating/denouement, from 'thinking at first/pure-predisposition-preemptive-of-prospective-disontologising/subontologising' as-ofprospectively-disambiguated-affirmed-and-unaffirmed-'motif-and- 
apriorising/axiomatising/referencing' $>101$ that is not postconvergingly-dementated/structured/paradigmed to recognise the prospective sublimating relative-ontologicalcompleteness $^{87}$ registry-worldview/dimension apriorising/axiomatising/referencingpsychologism imbued logical-basis/logic,-as-derived-from $\sim$ transversality- $<$ for-sublimating existential-eventuating/denouement,-from-'thinking-at-first/pure-predisposition-preemptive-ofprospective-disontologising/subontologising' as-of-prospectively-disambiguated-affirmedand-unaffirmed-'motif-and-apriorising/axiomatising/referencing'>101 (with only the crossgenerational positive-opportunism — of-social-functioning-and-accordance ${ }^{75}$ arising from the relative-ontological-completeness ${ }^{87}$ comprehensively induced sublimation as to existenceas-sublimating-withdrawal/unenframing/re-ontologising,-elicited-from-prospective-profoundsupererogation that then elicits the ${ }^{103}$ universal-transparency ${ }^{104}$-〈transparency-of-totalisingentailing,-as-to-entailing-<amplituding/formative-epistemicity $>$ totalising $\sim$ in-relativeontological-completeness $\rangle$, untenability and affirmation/projection/assertion/notional $\sim$ selfdistantiation/dueness-validating-logicising/suitable-measuringinstrument-validatingmeasuring-<as-to-postconverging-or-dialectical-thinking -apriorising-psychologism $>$ of the relative-ontological-completeness $\quad$ apriorising/axiomatising/referencing-psychologism imbued logical-basis/logic,-as-derived-from $\sim$ transversality-<for-sublimating-existentialeventuating/denouement,-from-'thinking at first/pure-predisposition-preemptive-of prospective-disontologising/subontologising' as-of-prospectively-disambiguated-affirmedand-unaffirmed-'motif-and-apriorising/axiomatising/referencing' $\left.{ }^{101}\right)$. But then with such notional asceticism associated with notional ${ }^{18}$ deprocrypticism factoring in that the projectiveinsights 'out of thin air' (as of reasoning-through/messianic-reasoning) that go on to contemplate of prospective relative-ontological-completeness ${ }^{87}$ sublimation is potentially a ${ }^{103}$ universal human capacity as of discretionary human disposition (as to when relative-ontologicalcompleteness ${ }^{87}$ is-educed-and-avails-and-re-avails) for opting for sublimating ontological- 
good-faith/authenticity $\sim$ postconverging-de-mentating/structuring/paradigming ${ }^{70}$ or opting for desublimating ontological-bad-faith/inauthenticity $\sim$ preconverging-dementating/structuring/paradigming , and that (as speaking to human-subpotency ontologicalfaith-notion-or-ontological-fideism — imbued-underdetermination-of-motif-andapriorising/axiomatising/referencing-as-so-being-as-of-existential-reality) 'this most fundamentally potent point of human-subpotency is the epistemic point-of-departure for construing ontology/science as from the notional ${ }^{18}$ deprocrypticism projected humansubpotency profound-and-complete mentation-capacity ontological implications'; given that to avoid being merely a complexification of positivism- ${ }^{8}$ procrypticism as of the possibility for disjointedness-as-of- ${ }^{8}$ reference-of-thought notional ${ }^{18}$ deprocrypticism warrants the requisite human organic-disposition as of notional ${ }^{18}$ deprocrypticism apriorising/axiomatising/referencing-psychologism for prospective reasoningthrough/messianic-reasoning 'rather than just another induced reasoning-fromresults/afterthought equally subjected to human notional firstnaturedness-formativeness-<as-toeventualising-inkling-drive-or-seeding-misprising $>$ temporal-to-intemporal-dispositions<so-construed-as-from-perspective-ontological-normalcy/postconvergence ${ }^{\prime}$ speaking of a circular positivism- ${ }^{80}$ procrypticism complexification as of $<$ amplituding formative $>$ woodenlanguage-〈imbued - temporal-mere-form/virtualities/dereification/akrasiaticdrag/denatured/preconverging-or-dementing -narratives - of-the- reference-of-thoughtcategorical-imperatives/axioms/registry-teleology $\rangle$ as to human incapacity to psychically project the overall existential-<disontologising/re-ontologising aporeticism $>$ dimensionalityof-sublimating $25<$ amplituding/formative $>$ supererogatory $\sim$ de-mentativeness/epistemicgrowth-or-conflatedness /transvaluative-rationalising/transepistemicity/anamnesticresiduality/spirit-drivenness-equalisation〉 underlying notional asceticism . This very notional asceticism insight (speaking of dimensionality-of-sublimating ${ }^{25}$ 
conflatedness /transvaluative-rationalising/transepistemicity/anamnestic-residuality/spirit-

drivenness-equalisation)) about the notional ${ }^{8}$ deprocrypticism reflected in the overall relativemnreflexivityelative reflexivity ontological-contiguity ${ }^{67}$ of-the-human-institutionalisationprocess ${ }^{68}$ explains why the ${ }^{103}$ universalising-idealisation of the Socratic-philosophers is not a 'disengaged articulation but subverts' non-universalising sophistry, why budding-positivism is not a 'disengaged articulation but subverts' non-positivising medieval-scholasticism and prospectively why postmodern-thought and herein notional deprocrypticism is not a 'disengaged articulation but subverts' modern-day manifestation of disparateness-ofconceptualisation-<unforegrounding-ment,-failing-prospectively-to-reflect-

pedantising/muddling/formulaic-hollowing-out — in-subontologisation/subpotentiation-

〈blurring/undermining-of-prospective-totalising-entailing,-as-to-entailing-

<amplituding/formative-epistemicity>totalising in-relative-ontological-completeness > of thought; and so further reflected as to the fact that base-institutionalisation, ${ }^{103}$ universalisation, positivism and prospectively notional deprocrypticism (as of their respective re-ontologising prospective Being-development/ontological-framework-expansion-as-to-depth-ofontologising-development-as-infrastructure-of- meaningfulness-and-teleology ) are respectively subversions of the postconvergingapareticism-overcoming/unovercoming of recurrent-utter-uninstitutionalisation, base-institutionalisation-ununiversalisation, ${ }^{3}$ universalisation-non-positivism/medievalism and positivism- ${ }^{80}$ procrypticism. The veracity of human knowledge as ever always a 'non-disengaging epistemic articulation as to the totalising oneness of existence manifest sublimations' lies with the very immanent relativeunreflexivity/relative-reflexivity - ontological-contiguity ${ }^{77}$ of existence that epistemically speaks to the 'coherence/contiguity-of-superseding-oneness-of-ontology-implied-as-of- 
inherent-existence-coherence/contiguity,-and-so-construed-as-the-enabler-of-insight-orintuition-or-foresight-as-of-embodied-consciousness' as so divulging/disclosing existence-assublimating-withdrawal/unenframing/re-ontologising,-elicited-from-prospective-profoundsupererogation . Such that human knowledge-reification $\sim$ gesturing-and-accounting-ofepistemic-phenomenalism- $<$ in-

\section{prospective_psychologismic apriorising/axiomatising/referencing-\{of-"prospectively}

\section{implicited_attendant-ontological-contiguity ' educed-}

existentialising/contextualising/textualising_intelligibility/epistemicity/reflexivity-contiguity<imbued-notional cogency $>$ ' \}-conflatedness -in-\{preconverging ment by\}

postconverging-entailment $>$ is effectively in reality about addressing and superseding human postconverging aporeticism-overcoming/unovercoming (human-subpotencyaporia/undecidability/dilemma/ought-indeterminacy/deficiency/limitation/constraint—imbued'notional firstnaturedness-formativeness-<as-to-eventualising -inkling-drive-or-seedingmisprising $>$ temporal-to-intemporal-dispositions- $<$ so-construed-as-from-perspectiveontological-normalcy/postconvergence ${ }^{\prime}$ '-existentialism-form-factor); as to surpassing epistemic-constructs of sublimation-over-desublimation so-implied with dimensionality-ofsublimating $25-<<$ amplituding/formative $>$ supererogatory $\sim$ de-mentativeness/epistemic-growthor-conflatedness /transvaluative-rationalising/transepistemicity/anamnestic-residuality/spiritdrivenness-equalisation) (with respect to Being-development/ontological-frameworkexpansion-as-to-depth-of-ontologising-development-as-infrastructure-of- meaningfulnessand-teleology , institutional-development-as-to-social-function-development and livingdevelopment-as-to-personality-development psychologismic epistemic acutisationdifficulty < for, residualising_\{decompulsing $\}$ delinearity for-cogeney> magnitudes $\{0$ ofexperientiality/experiment' $)$. The implication here is that human 'epistemic-constructs of sublimationover-desublimation' are not-and-never optional/discretionary representations about existence 
(but only when 'deliberately of mere aestheticisation as mere motif implications' with no relative

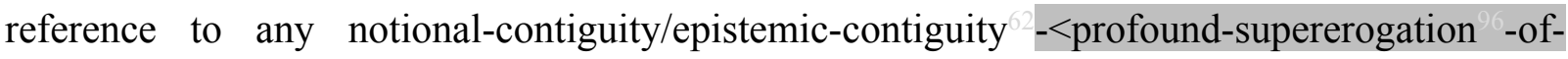
mentally-aestheticised postconverging/dialectical-thinking -qualia-schema $>$ conception of relative-ontological-completeness ${ }^{87}$ ), and not with regards to human epistemic aestheticisationand-aestheticisation-towards-ontology-<elicited-idiomatisation $>$ reflection of the-very-sameimmanent-existence/intrinsic-reality/ontological-veridicality implications (as to existence-assublimating-withdrawal/unenframing/re-ontologising,-elicited-from-prospective-profoundsupererogation ); reflected in the fact that all such epistemic-constructs as knowledgereification $\sim$ gesturing-and-accounting - of-epistemic-phenomenalism- $<$ inprospective_psychologismic $\sim$ apriorising/axiomatising/referencing-\{of-'prospectively implicited_attendant-ontological-contiguity ' reducedexistentialising/contextualising/textualising_'intelligibility/epistemicity/reflexivity-contiguity$<$ imbued-notional cogency $>$ ' \}-conflatedness - in-\{preconverging ment by\} postconverging-entailment> (as referencing any notional-contiguity/epistemic-contiguity ${ }^{6}$ $<$ profound-supererogation -of-mentally-aestheticised postconverging/dialectical-thinking qualia-schema $>$ conception of relative-ontological-completeness 87 as to existence-assublimating-withdrawal/unenframing/re-ontologising,-elicited-from-prospective-profoundsupererogation ${ }^{\circ}$ speak to an underlying human ontological-commitment $-<$ implied - selfassuredness-of-ontological-good-faith/authenticity $\sim$ postconverging-dementating/structuring/paradigming -as-being-as-of-existential-reality $>$ as to the possibility for prospective sublimation-over-desublimation (so-implied with the self-assuredness-ofontological-good-faith/authenticity ${ }^{69} \sim$ postconverging-dementating/structuring/paradigming 70 -as-being-as-of-existential-reality with respect to socialstake-contention-or-confliction underlying human ontological-commitment $-<$ implied - selfassuredness-of-ontological-good-faith/authenticity postconverging-de- 
mentating/structuring/paradigming -as-being-as-of-existential-reality $>$ ). In this regards, we can appreciate that the successive human registry-worldviews/dimensions speak to successive human postconverging aporeticism-overcoming/unovercoming of re-ontologising prospective Being-development/ontological-framework-expansion-as-to-depth-of-ontologisingdevelopment-as-infrastructure-of- meaningfulness-and-teleology as of the-very-sameimmanent-existence/intrinsic-reality/ontological-veridicality,-as-to'human<amplituding/formative-epistemicity>totalising $\sim$ purview-of-construal', with the implication that human epistemic limits arising due to human limited-mentation-capacity-assubjecting 'educed-unlimitedness/existence-sublimating nascence' to-limitedness/humansubpotency at the uninstitutionalised-threshold ${ }^{12}$ respectively of recurrent-utteruninstitutionalisation, base-institutionalisation-ununiversalisation, ${ }^{103}$ universalisation-nonpositivism/medievalism, and positivism- ${ }^{80}$ procrypticism as to their ${ }^{70}$ presencing-absolutisingidentitive-constitutedness ${ }^{14}<$ preconverging 'motif-and-apriorising/axiomatising/referencing' entailing $>$-existentialising — enframing/imprintedness-〈as-to- historicity-tracing — inpresencing-hyperrealisation/hyperreal-transposition), do not speak of limits to prospective human knowledge-reification $\sim$ gesturing-and-accounting-of-epistemic-phenomenalism- $<$ inprospective_psychologismic apriorising/axiomatising/referencing-\{of-'prospectively implicited_attendant-ontological-contiguity ' reducedexistentialising/contextualising/textualising_'intelligibility/epistemicity/reflexivity-contiguity<imbued-notional cogency>' \}-conflatedness -in-\{preconverging-ment by\} postconverging-entailment> (as epistemic-constructs referencing prospective notionalcontiguity/epistemic-contiguity ${ }^{2}-<$ profound-supererogation -of-mentallyaestheticised postconverging/dialectical-thinking -qualia-schema $>$ conception of relativeontological-completeness $^{87}$ as to existence-as-sublimating-withdrawal/unenframing/reontologising,-elicited-from-prospective-profound-supererogation ) respectively as of base- 
institutionalisation, ${ }^{103}$ universalisation, positivism and prospectively deprocrypticism. But then with regards to the uninstitutionalised-threshold ${ }^{12}$ of all registry-worldviews/dimensions in their presencing - absolutising-identitive-constitutedness <amplituding/formativeepistemicity $>$ totalising $\sim$ self-referencing-syncretising/circularity/interiorising/akrasiatic-drag ${ }^{34}$, the fact is that their socio-institutional decisional-construct for responding to their own given prospective postconverging-apereticism overcoming/unovercoming take up a pedantising/muddling/formulaic-hollowing-out_-in-subontologisation/subpotentiation〈blurring/undermining-of-prospective-totalising-entailing,-as-to-entailing<amplituding formative-epistemicity>totalising in-relative-ontological-completeness $>$ and institutional self-preservation nature that falsely turns around (breaks with 'prospective notionalcontiguity/epistemic-contiguity ${ }^{62}<$ profound-supererogation - of-mentallyaestheticised postconverging/dialectical-thinking -qualia-schema> conception of relativeontological-completeness ${ }^{87}$ as to existence-as-sublimating-withdrawal/unenframing/reontologising,-elicited-from-prospective-profound-supererogation, for knowledgereification $\sim$ gesturing-and-accounting — of-epistemic-phenomenalism- $<$ inprospective_psychologismic apriorising/axiomatising/referencing-\{of-'prospectively implicited_attendant-ontological-contiguity ' educedexistentialising/contextualising/textualising_'intelligibility/epistemicity/reflexivity-contiguity<imbued-notional cogency >’ \}-conflatedness -in-\{preconverging ment by\} postconverging-entailment $>$ ) to undermine prospective human knowledgereification $\sim$ gesturing-and-accounting - of-epistemic-phenomenalism- $<$ inprospective_psychologismic apriorising/axiomatising/referencing-\{of-'prospectively implicited_attendant-ontological-contiguity ' educedexistentialising/contextualising/textualising_ intelligibility/epistemicity/reflexivity-contiguity<imbued-notional cogency $>>$ \}-conflatedness -in-\{preconverging ment by\} 
postconverging entailment>, by wrongly implying any such prospective construal of 'prospective notional-contiguity/epistemic-contiguity ${ }^{2}-<$ profound-supererogation - ofmentally-aestheticised postconverging/dialectical-thinking -qualia-schema $>$ conception of relative-ontological-completeness ${ }^{87}$ as to existence-as-sublimatingwithdrawal/unenframing/re-ontologising,-elicited-from-prospective-profoundsupererogation (as of dimensionality-of-sublimating <<amplituding/formative>supererogatory $\sim$ de-mentativeness/epistemic-growth-orconflatedness /transvaluative-rationalising/transepistemicity/anamnestic-residuality/spiritdrivenness-equalisation〉) is about a 'framework of metaphysical/ideological advocacy as of totalisingly-ing — discretion/whim-of-thought (rather than truly being a framework of ontological-veracity implied relative-ontological-completeness

$<$ amplituding/formative > entailment—as-to-totalising-contiguous/coherent-factuality-ofvariability)' and so in order to falsely nullify/undermine the subverting epistemic implications of relative-ontological-completeness 87 as to existence-as-sublimatingwithdrawal/unenframing/re-ontologising,-elicited-from-prospective-profound-supererogation (of prospective human epistemic aestheticisation-and-aestheticisation-towards-ontology$<$ elicited-idiomatisation $>$ of the-very-same-immanent-existence/intrinsic-reality/ontologicalveridicality) as to the 'anything goes orientation' of totalisingly-ing — discretion/whim-ofthought projection that allows for pedantising/muddling/formulaic-hollowing-out-insubontologisation/subpotentiation-〈blurring/undermining-of-prospective-totalising-entailing,as-to-entailing-<amplituding/formative-epistemicity $>$ totalising in-relative-ontologicalcompleteness $\rangle$ and institutional self-preservation over addressing their respective prospective postconverging aporeticism-overcoming/unovercoming. In this regards, as to their presencing-absolutising-identitive-constitutedness <amplituding/formativeepistemicity $>$ totalising $\sim$ self-referencing-syncretising/circularity/interiorising/akrasiatic-drag 
and their failure to address their prospective postconvergingapareticismevercoming/unovercoming of Being-development/ontological-framework-expansion-as-todepth-of-ontologising-development-as-infrastructure-of- meaningfulness-and-teleology

(with strategically flawed interpretations of prospective human postconverging aporeticismovercoming/unovercoming to falsely enable totalisingly-ing-discretion/whim-of-thought projection and so over prospective ontological-veracity implied relative-ontologicalcompleteness 87 amplituding/formative $>$ entailment-as-to-totalising-contiguous/coherentfactuality-of-variability): the ancient-sophists adopted a 'non-universalising break with prospective notional-contiguity/epistemic-contiguity ${ }^{2}-<$ profound-supererogation -ofmentally-aestheticised postconverging/dialectical-thinking -qualia-schema $>$ conception of relative-ontological-completeness 87 as to existence-as-sublimatingwithdrawal/unenframing/re-ontologising,-elicited-from-prospective-profound-supererogation for knowledge-reification $\sim$ gesturing-and-accounting-of-epistemic-phenomenalism- $<$ inprospective_psychologismic apriorising/axiomatising/referencing-\{of-'prospectively implicited_attendant-ontological-contiguity ' educedexistentialising/contextualising/textualising_'intelligibility/epistemicity/reflexivity-contiguity<imbued-notional cogency>' \}-conflatedness in \{preconverging ment by\} postconverging-entailment>' wrongly construing the 'subverting epistemic implications of relative-ontological-completeness ${ }^{87}$ as to existence-as-sublimatingwithdrawal/unenframing/re-ontologising,-elicited-from-prospective-profound-supererogation of the ${ }^{103}$ universalising-idealisation of Socratic-philosophers' as being about a 'framework of metaphysical/ideological advocacy as of totalisingly-ing - discretion/whim-of-thought (rather than truly being a framework of ontological-veracity implied relative-ontologicalcompleteness ${ }^{87}<$ amplituding/formative $>$ entailment-as-to-totalising-contiguous/coherentfactuality-of-variability), to then falsely justify their non-universalising 
pedantising/muddling/formulaic-hollowing-out — in-subontologisation/subpotentiation〈blurring/undermining-of-prospective-totalising-entailing,-as-to-entailing$<$ amplinding formative-epistemicity>totalising in-relative-ontological-completeness $\rangle$ and institutional self-preservation and so over addressing their prospective postconverging aporeticism-overcoming/unovercoming necessarily warranting prospective universalising-idealisation; likewise the medieval-scholastics adopted a 'non-positivising break with prospective notional-contiguity/epistemic-contiguity $<$ profound-supererogation of-mentally-aestheticised $\sim$ postconverging/dialectical-thinking -qualia-schema $>$ conception of relative-ontological-completeness as to existence-as-sublimatingwithdrawal/unenframing/re-ontologising,-elicited-from-prospective-profound-supererogation for knowledge-reification $\sim$ gesturing-and-accounting - of-epistemic-phenomenalism- $<$ inprospective_psychologismic apriorising/axiomatising/referencing-\{of-'prospectively_ implicited_attendant-ontological-contiguity ' educedexistentialising/contextualising/textualising_'intelligibility/epistemicity/reflexivity-contiguity<imbued-notional cogency >' \}-conflatedness -in-\{preconverging-ment by\} postconverging-entailment>' wrongly construing the 'subverting epistemic implications of relative-ontological-completeness as to existence-as-sublimatingwithdrawal/unenframing/re-ontologising,-elicited-from-prospective-profound-supererogation of budding-positivism' as being about a 'framework of metaphysical/ideological advocacy as of totalisingly-ing-discretion/whim-of-thought (rather than truly being a framework of ontological-veracity implied relative-ontological-completeness $<$ amplituding/formative $>$ entailment—as-to-totalising-contiguous/coherent-factuality-ofvariability)' to then falsely justify their scholastic non-positivising pedanticising and institutional self-preservation and so over addressing their prospective postconvergingaaporeticismovercoming/unovercoming necessarily warranting prospective positivism/rational-empiricism; 
and likewise it is herein contended that modern-day manifestation of disparateness-ofconceptualisation-<unforegrounding-ment,-failing-prospectively-to-reflect-

\section{'immanent relative-unreflexivity/relative-reflexivity ontological-contiguity}

pedantising/muddling/formulaic-hollowing-out — in-subontologisation/subpotentiation〈blurring/undermining-of-prospective-totalising-entailing,-as-to-entailing-

$<$ amplituding/formative-epistemicity $>$ totalising in-relative-ontological-completeness $>$

adopts a 'disjointing/disparateness/ing break with prospective notional-contiguity/epistemiccontiguity ${ }^{62}<$ profound-supererogation -of-mentally-aestheticised postconverging/dialecticalthinking -qualia-schema $>$ conception of relative-ontological-completeness ${ }^{87}$ as to existenceas-sublimating-withdrawal/unenframing/re-ontologising,-elicited-from-prospective-profoundsupererogation for knowledge-reification $\sim$ gesturing-and-accounting-of-epistemicphenomenalism- $<$ in-prospective_psychologismic $\sim$ apriorising/axiomatising/referencing- of'prospectively_implicited_attendant-ontological-contiguity ' educedexistentialising/contextualising/textualising_'intelligibility/epistemicity/reflexivity_contiguity$<$ imbued-notional cogency $>\quad\}$-conflatedness -in-\{preconverging-ment by\}

postconverging-entailment> (as to a strategically flawed anti-relativism interpretation that then overlooks and ignores 'relative-ontological-incompleteness $8 /$ relative-ontologicalcompleteness ${ }^{87}$-〈sublimating $\sim$ referencing/registering/decisioning,-as-self-becoming/selfconflatedness /formative-supererogating-<projective/reprojective-aestheticising-re-motifand-re-apriorising/re-axiomatising/re-referencing,-in-perspective-ontologicalnormalcy/postconvergence $>>$ as to human-and-social-expectations/anticipationsmetaphoricity ${ }^{57}$-as-preconverging/postconverging-rede-

mentating/restructuring/reparadigming-psychologism' ${ }^{89}$ as of our modern-day ${ }^{79}$ presencingabsolutising-identitive-constitutedness $<$ preconverging 'motif-andapriorising/axiomatising/referencing'-entailing>-existentialising—enframing/imprintedness- 
〈as-to- historicity-tracing-in-presencing-hyperrealisation/hyperreal-transposition〉 as to social-vestedness/normativity-<discretely-implied-functionalism $>$, with such a flawed antirelativism interpretation a technical impossibility as it confuses/muddles non-universalising with ' nonpresencing-<perspective-ontological-normalcy/postconvergence $>$ relativism/relativescope for epistemic-growth,-as \{veridieal/sound relative-reflexivity-inexistence/relativising from limited-mentation-as-its-deepening/psychologismic epistemicacutisation residualising, \{decompulsing\} delinearity for-cogency' as to the fact that postmodernthought like deconstruction and genealogy knowledge-reification $\sim$ gesturing-and-accountingof-epistemic-phenomenalism-<in-

prospective_psychologismic apriorising/axiomatising/referencing-\{of- ${ }^{\text {pprospectively }}$ implicited_attendant-ontological-contiguity ' educedexistentialising/contextualising/textualising_'intelligibility/epistemicity/reflexivity_contiguity$<$ imbued-notional cogency $>$ ' \}-conflatedness -in-\{preconverging -ment by\} postconverging-entailment $>$ implied relativism/relative-scope is of ${ }^{103}$ universal import of relative-ontological-completeness 8 as of dimensionality-of-sublimating <<amplituding/formative >supererogatory $\sim$ de-mentativeness/epistemic-growth-orconflatedness /transvaluative-rationalising/transepistemicity/anamnestic-residuality/spiritdrivenness-equalisation))' wrongly construing the 'subverting epistemic implications of relative-ontological-completeness ${ }^{87}$ as to existence-as-sublimatingwithdrawal/unenframing/re-ontologising,-elicited-from-prospective-profound-supererogation of many a postmodern-thought herein construed as ${ }^{4}$ human-subject-emancipating-relativismdriven-recomposuring-constructivism-towards-singularisation- $<$ as-to-thenondisjointedness/entailment-of-prospective- nonpresencing $>$ as being about a 'framework of metaphysical/ideological advocacy as of totalisingly-ing - discretion/whim-of-thought (rather than truly being a framework of ontological-veracity implied relative-ontological- 
completeness $^{87}<$ amplituding/formative $>$ entailment - as-to-totalising-contiguous/coherentfactuality-of-variability)' to then falsely justify its disjointing/disparateness/ing pedantising/muddling/formulaic-hollowing-out - in-subontologisation/subpotentiation〈blurring/undermining-of-prospective-totalising-entailing,-as-to-entailing$<$ amplituding/formative-epistemicity>totalising in-relative-ontological-completeness > pedantising/muddling/formulaic-hollowing-out — in-subontologisation/subpotentiation〈blurring/undermining-of-prospective-totalising-entailing,-as-to-entailing<amplituding/formative-epistemicity>totalising in-relative-ontological-completeness > and institutional self-preservation and so over addressing its prospective postconverging aporeticism-overcoming/unovercoming necessarily warranting prospective $<$ amplituding/formative>nondisjointing/nondisparate implications as of 'relative-ontologicalincompleteness $^{88} /$ relative-ontological-completeness $^{87}$

\section{〈sublimating referencing/registering/decisioning,--as-self-becoming/self-}

conflatedness /formative-supererogating-<projective/reprojective-aestheticising-re-motifand-re-apriorising/re-axiomatising/re-referencing,-in-perspective-ontologicalnormalcy/postconvergence $>>$ as to human-and-social-expectations/anticipationsmetaphoricity ${ }^{57}$-as-preconverging/postconverging-redementating/restructuring/reparadigming-psychologism' ${ }^{89}$ herein articulated as to 'notional $\sim$ deprocrypticism <amplituding/formative-epistemicity $>$ causality $\sim$ as-to-projectivetotalitative-implications-of-prospective- nonpresencing,-for-explicating relativeunreflexivity/relative-reflexivity ontological-contiguity as reflecting the overall relativeunreflexivity/relative-reflexivity — ontological-contiguity ${ }^{67}$ of-the-human-institutionalisationprocess ${ }^{6}$, underlied as of prospective deprocrypticism — apriorising/axiomatising/referencingpsychologism enculturated/constructed social-pragmatics-framing-of-predicative-effectivitysublimation-〈as-to-underlying,-ontological-commitment $-<$ implied-self-assuredness-of- 
ontological-good-faith/authenticity postconverging-de-

mentating/structuring/paradigming -as-being-as-of-existential-reality $>>$ that protensively strives to explain everything as of notional ${ }^{18}$ deprocrypticism $<$ amplituding/formative $>$ entailment—as-to-totalising-contiguous/coherent-factuality-ofvariability (with such a postmodern-thought conception as human-subject-emancipatingrelativism-driven-recomposuring-constructivism-towards-singularisation- $<$ as-to-thenondisjointedness/entailment-of-prospective- nonpresencing $>$ superseding the argument traditionally made about postmodern-thought as 'sceptical with regards to ontologically-flawedmetanarratives/ideologies and the lack of objectivity of meaning' as a wrongly articulated/made argument ontologically, since it is being wrongly articulated/made from the "modern perspective/frame/reference/horizon' as to $\quad{ }^{47}$ historicity-tracing-in-presencinghyperrealisation/hyperreal-transposition induced 'wavering/redounding/waveforming - of-thereferencing-and-the-devolved-referencing-imbued-ontological-performance ${ }^{72}-<$ includingvirtue-as-ontology $>/$ morality/ethics/justice/etc. as to presublimation and nascent-sublimations overlapping-contiguity-of-referencing-and-devolved-referencing', and so as postmodernthought is much more than just a naïve notion of a multiplicity of narratives as wrongly implied from the modern take of <preconverging 'motif-and-apriorising/axiomatising/referencing'entailing $>$-existentialising — enframing/imprintedness-〈as-to- historicity-tracing — inpresencing-hyperrealisation/hyperreal-transposition〉 necessarily subject to ontological-badfaith/inauthenticity ${ }^{64}$ as of the modern's take prospectively uninstitutionalised-threshold ${ }^{102}$ of procrypticism or disjointedness-as-of- ${ }^{3}$ reference-of-thought in-many-ways explaining the difficulties of Derrida and Foucault in effectively qualifying their thought postures (when each was asked whether they were poststructuralist) underlied/organised respectively by messianicity and parrhesia, with such messianicity and parrhesia herein articulated and elaborated as to the supereregatory unbeholdening-conflatedness ${ }^{3}$ of nascent-human-decisionality-induced- 
sublimation-<of-blinded-relative-ontological-completeness -imbued,-

supererogatory reference-of-thought/grandest-axiomatic-construct-as-to-

referencing/registering/decisioning $>$ so-construed as 'prospective/nascent relative-ontologicalcompleteness reference-of-thought/grandest-axiomatic-construct — as-to-

referencing/registering/decisioning supererogatory unbeholdening-conflatedness ${ }^{13}$ projectiveinsights as of notional ' deprocrypticism' as underlying the overall: human-subpotency 'fatedness-of-sublimation-over-desublimation to existence-potency $\sim$ sublimating-nascence,disclosed-from-prospective-epistemic-digression in reflecting holographically-<conjugativelyand-transfusively $>$ the relative-unreflexivity/relative-reflexivity-ontological-contiguity ofthe-human-institutionalisation-process '. But rather postmodern-thought is of a prospective 'relative-ontological-completeness re-originary-_as-unenframed/re-

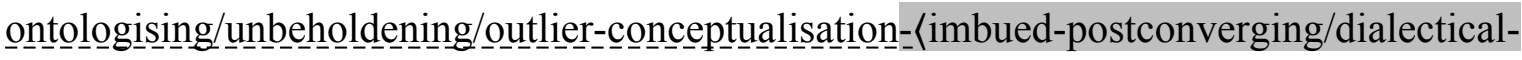
thinking -'projective-insights'/‘epistemic-projection-in-conflatedness ' 'ofnotional deprocrypticism-prospective-sublimation $\rangle^{\circ}$ appraisal of human narratives as to dimensionality-of-sublimating $-<<$ amplituding/formative $>$ supererogatory $\sim$ dementativeness/epistemic-growth-or-conflatedness /transvaluativerationalising/transepistemicity/anamnestic-residuality/spirit-drivenness-equalisation〉' thus implying rather a notional ${ }^{1}$ deprocrypticism institutionalisation 'unenframed/reontologising/unbeholdening/bechancing-supererogation ${ }^{9}$ parameterisation/reparameterisation$\langle$ reflecting-a-supererogatory $\sim$ decisionality-of-socioinstitutional-conceptions-as-to- 'theirnascent-sublimations-dynamic-preempting-of-presublimatory-decisionality-numbing-tractiondesublimation'〉-as-so-operationalising-'scalarisation-as-to-rescalarisation-as-reontologisation'. In other words, the uninstitutionalised-threshold 02 of the $<$ cumulating/recomposuring attendant-ontological-contiguity $>$-successive registryworldviews/dimensions show a decadent wariness to 'break with prospective notional- 
contiguity/epistemic-contiguity ${ }^{2}-<$ profound-supererogation -of-mentally-

aestheticised postconverging/dialectical-thinking -qualia-schema $>$ conception of relativeontological-completeness $^{87}$ as to existence-as-sublimating-withdrawal/unenframing/reontologising,-elicited-from-prospective-profound-supererogation for knowledgereification $\sim$ gesturing-and-accounting — of-epistemic-phenomenalism- $<$ inprospective_psychologismic apriorising/axiomatising/referencing-\{of-'prospectively implicited_attendant-ontological-contiguity ' educedexistentialising/contextualising/textualising_'intelligibility/epistemicity/reflexivity-contiguity<imbued-notional cogency $>>$ \}-conflatedness - in-\{preconverging ment by\} postconverging-entailment>' as to the necessity for the prospective human postconverging aporeticism-overcoming/unovercoming requisite 'relative-ontologicalcompleteness ${ }^{87}$-apriorising/axiomatising/referencing-psychologism enculturated/constructed social-pragmatics-framing-of — predicative-effectivity-sublimation-〈as-to-underlying,-

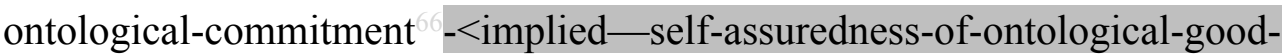
faith/authenticity postconverging-de-mentating/structuring/paradigming -as-being-as-ofexistential-reality $>>$ ', even as paradoxically when it comes to the prior registryworldview's/dimension's postconverging-aporeticism-overcoming/unovercoming surperseded by the given registry-worldview/dimension secondnatured 'relative-ontologicalcompleteness ${ }^{87}$-apriorising/axiomatising/referencing-psychologism enculturated/constructed social-pragmatics-framing-of — predicative-effectivity-sublimation-〈as-to-underlying,ontological-commitment $\quad$-<implied-self-assuredness-of-ontological-goodfaith/authenticity postconverging-de-mentating/structuring/paradigming -as-being-as-ofexistential-reality $>\rangle$ ' no such 'break with prospective notional-contiguity/epistemiccontiguity ${ }^{62}<$ profound-supererogation - of-mentally-aestheticised $\sim$ postconverging/dialecticalthinking -qualia-schema $>$ conception of relative-ontological-completeness ${ }^{87}$ as to existence- 
as-sublimating-withdrawal/unenframing/re-ontologising,-elicited-from-prospective-profoundsupererogation for knowledge-reification $\sim$ gesturing-and-accounting-of-epistemicphenomenalism- $<$ in-prospective_psychologismic $\sim$ apriorising/axiomatising/referencing- of'prospectively implicited_attendant-ontological-contiguity ' ceducedexistentialising/contextualising/textualising_'intelligibility/epistemicity/reflexivity-contiguity<imbued-notional cogency >’ \}-conflatedness -in-\{preconverging-ment by\} postconverging entailment>' is implied (as ancient-sophists do not find any metaphysical/ideological advocacy issues with rulemaking-over-non-rulesapriorising/axiomatising/referencing-psychologism but for when it prospectively comes to ${ }^{3}$ universalisation-directed-rulemaking-over-non-rules_-apriorising/axiomatising/referencingpsychologism', medieval-scholastics do not find any metaphysical/ideological advocacy issues with universalisation-directed-rulemaking-over-non-rulesapriorising/axiomatising/referencing-psychologism but for when it prospectively comes to positivising/rational-empiricism-based-universalisation-directed-rulemaking-over-non-rulesapriorising/axiomatising/referencing-psychologism, and likewise modern-day manifestation of disparateness-of-conceptualisation-<unforegrounding-ment,-failing-prospectively-to-reflect‘immanent relative unreflexivity/relative reflexivity ontological-contiguity pedantising/muddling/formulaic-hollowing-out — in-subontologisation/subpotentiation〈blurring/undermining-of-prospective-totalising-entailing,-as-to-entailing<amplituding/formative-epistemicity $>$ totalising in-relative-ontological-completeness $>$ do not find any metaphysical/ideological advocacy issues with positivising/rational-empiricism-baseduniversalisation-directed-rulemaking-over-non-rules — apriorising/axiomatising/referencingpsychologism but for when it prospectively comes to postmodern-thought herein implied as of as ${ }^{4}$ human-subject-emancipating-relativism-driven-recomposuring-constructivism-towardssingularisation- $<$ as-to-the-nondisjointedness/entailment-of-prospective- nonpresencing $>$ and 
as herein articulated with notional deprocrypticism as preempting-disjointedness-as-ofreference-of-thought,-as-to- ${ }^{6}<$ amplituding/formative-epistemicity>growth-orconflatedness ${ }^{13} /$ transvaluative-rationalising/transepistemicity/anamnestic-residuality/spiritdrivenness' - in-superseding-mere-formulaic-positivising/rational-empiricism-baseduniversalisation-directed-rulemaking-over-non-rules_-apriorising/axiomatising/referencingpsychologism). Critically, the ontological-veracity of the 'subverting nature/aestheticisationand-aestheticisation-towards-ontology-<elicited-idiomatisation $>{ }^{\prime}$ as to ${ }^{55}$ maximalisingrecomposuring-for-relative-ontological-completeness ${ }^{8}$ - unenframed/re-

ontologising conceptualisation of human prospective sublimating-over-desublimation meaningfulness-and-teleology ${ }^{9}$ is reflected in the overall 'wavering/redounding/waveforming of-the-referencing-and-the-devolved-referencingimbued-ontological-performance ${ }^{72}-<$ including-virtue-as-ontology $>/$ morality/ethics/justice/etc. as to presublimation and nascent-sublimations overlapping-contiguity-of-referencing-and-

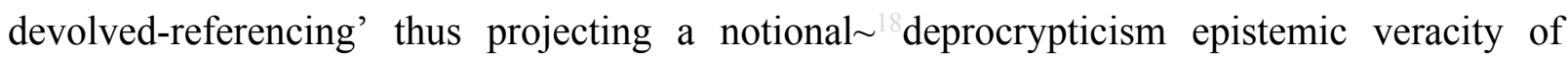
sublimation-over-desublimation as so reflected with the overall relative-unreflexivity/relativereflexivity - ontological-contiguity ${ }^{67} \sim$ of-the-human-institutionalisation-process ${ }^{68}$; with the implications that in reality sublimating ${ }^{56}$ meaningfulness-and-teleology ${ }^{9}$ (as to destructuringthreshold-〈uninstitutionalised-threshold /presublimating-desublimating-decisionality $\rangle$ ofontological-performance ${ }^{72}$-<including-virtue-as-ontology $>/$ morality/ethics/justice/etc. of

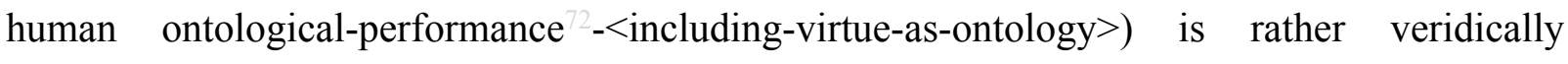
supererogatory in its conception as of notional asceticism (instigating originariness-parrhesia,-as-spontaneity-of-aestheticisation-

supereregatory acuity/perspicacity/astuteness/edginess/incisiveness projection of prospective methods/methodologies/approaches as from prospective sublimation induced methodologising/mutualising/organising/institutionalising) and so counterintuitive to 
secondnatured institutionalisation conceptions of sublimating ${ }^{5}$ meaningfulness-and-teleology in terms of mundane reproducibility-mathesis/motif/thrownness-disposition,--asreproducibility-of-aestheticisation comprehensive construal of sublimating meaningfulnessand-teleology 9 on presencing-distorted-meritocracy/totalising-sovereign-apportioning-ofhuman-ontological-performance ${ }^{72}-<$ including-virtue-as-ontology $>/$ morality/ethics/justice/etc. terms-as-of-axiomatic-construct of '<amplituding/formative>disposedness/psychologismicconstruct-〈as-to-orientation/value-construct/valuation-and-derived-parameterising $\quad$ and ontologisation' as so-reflected by the underpinning-suprasocial-construct (historially involving 'dominance/vested-interest structure in relative-ontological-incompleteness ${ }^{8}$-presublimationconstruct-of- ${ }^{5}$ meaningfulness-and-teleology desublimating existentialising-decisionality<as-to-disontologising/re-ontologising aporeticism $>^{\prime}$ as from blatant brutish conquest/subjugation conception of apportioning, dominion protection conception of apportioning, to the very natural-order-of-things conception of apportioning and to our subtle modern-day institutionally-distorted/disjointed conception of apportioning as particularly the target as to Lyotard's critique of such institutionally-distorted implied metanarratives especially with regards to their poor/sheepish/dubious/ineffectual social/institutional devolving parameterised equanimity/balance as putting in question their theoretical, conceptual and operative veracity, and speaking in all the above epochal instances of 'ontological-badfaith/inauthenticity ${ }^{6}$-and-lack-of-equanimity of social/institutional process towards preconverging/postconverging-de-mentative/structural/paradigmatic priorly-defaulted/usurped social/institutional outcome as reflecting manifest lack of dispensing-with-immediacy-forrelative-ontological-completeness ${ }^{87}$-by-reification/contemplative-distension ${ }^{27}$ '). But then such a presencing-distorted-meritocracy/totalising-sovereign-apportioning —of-human-ontologicalperformance $^{2}$-<including-virtue-as-ontology $>$ /morality/ethics/justice/etc. conception of sublimating ${ }^{56}$ meaningfulness-and-teleology ${ }^{9}$ as so-construed fundamentally as to the 
underpinning-suprasocial-construct conception that mostly defines human ${ }^{56}$ meaningfulnessand-teleology 9 as of the constraint of 'immediacy supposed absolute sublimating value and ontological-veracity disposition' (as to the beyond-the-consciousness-awareness-teleology $<$ of-preconverging-existential-extrication-as-of-existential-unthought $>\quad$ positiveopportunism - of-social-functioning-and-accordance ${ }^{75}$ of institutional-development-as-tosocial-function-development and living-development-as-to-personality-development psychologismic epistemic-acutisation difficulty < for, residualising $\{$ decompling $\}$ delinearity for-cogeney $>$ magnitudes $\{$ of-experientiality/experiment $\}$ ), is rather predisposed to overlook the supererogation -profundity $\sim$ postconverging-dementating/structuring/paradigming (with regards to the requisite dispensing-with-immediacyfor-relative-ontological-completeness ${ }^{87}$-by-reification/contemplative-distension ${ }^{27}$ of Beingdevelopment/ontological-framework-expansion-as-to-depth-of-ontologising-development-asinfrastructure-of- meaningfulness-and-teleology ) as to underlying 'non-immediacy prospective sublimating value and ontological-veracity disposition' (so-construed as to the 'reoriginary-ass-unenframed/re-ontologising/unbeholdening/outlier-conceptualisation-_imbuedpostconverging/dialectical-thinking -'projective-insights'/‘epistemic-projection-inconflatedness '-of-notional deprocrypticism-prospective-sublimation $\rangle^{0}$ intemporaldisposition supererogatory rescalarisation of ontologisation and value-construction within any given registry-worldview/dimension ${ }^{79}$ presencing-absolutising-identitive-constitutedness $<$ preconverging $\sim$ 'motif-and-apriorising/axiomatising/referencing'-entailing >existentialising — enframing/imprintedness-〈as-to- historicity-tracing_-in-presencinghyperrealisation/hyperreal-transposition〉' imbued 'ontological-good-faith/authenticity ${ }^{6}$-andequanimity of social/institutional process towards credible social/institutional outcome as reflecting manifest dispensing-with-immediacy-for-relative-ontological-completeness ${ }^{87}$-byreification/contemplative-distension ${ }^{27}$ ) that acts as the backbone for human value and 
ontological-veracity sublimation. The fact is the 'wavering/redounding/waveforming - of-thereferencing-and-the-devolved-referencing-imbued-ontological-performance ${ }^{72}-<$ includingvirtue-as-ontology $>$ /morality/ethics/justice/etc. as to presublimation and nascent-sublimations overlapping-contiguity-of-referencing-and-devolved-referencing' means that in reality the underpinning-suprasocial-construct ${ }^{56}$ meaningfulness-and-teleology ${ }^{9}$ is mostly as of 'prior reference-of-thought/grandest-axiomatic-construct—as-to-referencing/registering/decisioning presublimation-drivenness' and thus implies a preconverging-dementating/structuring/paradigming of nascent-particular/incipient-and-material/technicalsublimations- $<$ blinded-to-their-relative-ontological-completeness - reference-of-thoughtdevolving $>$ around the 'dominance/vested-interest structure in relative-ontologicalincompleteness ${ }^{88}$-presublimation-construct-of- ${ }^{56}$ meaningfulness-and-teleology desublimating $\sim$ existentialising-decisionality-<as-to-disontologising/re-ontologising aporeticism $>$, thus rather preconverging/postconverging-dementatively/structurally/paradigmatically inducing an expropriating/estranging/constraining/limiting overall positive-opportunism—of-socialfunctioning-and-accordance ${ }^{75}$ relation with the sublimation inducing supererogation profundity postconverging-de-mentating/structuring/paradigming without the requisite comprehensive abstract-appraisal of the preconverging/postconverging-dementative/structural/paradigmatic implications of the 'supererogation profundity $\sim$ postconverging-de-mentating/structuring/paradigming of nascentparticular/incipient-and-material/technical-sublimations-<blinded-to-their-relative-ontologicalcompleteness - reference-of-thought- devolving ${ }^{\prime}$, as rather reflecting the requisite dispensing-with-immediacy-for-relative-ontological-completeness ${ }^{87}$-byreification/contemplative-distension ${ }^{27}$ for Being-development/ontological-frameworkexpansion-as-to-depth-of-ontologising-development-as-infrastructure-of- meaningfulness- 
and-teleology (and so as to an incrementalism-in-relative-ontological-incompleteness ${ }^{8}$ enframed/disontologising conceptualisation conception that as of 'prior ${ }^{83}$ reference-ofthought/grandest-axiomatic-construct—as-to-referencing/registering/decisioning presublimation-drivenness' rather references/registers prospective nascent-particular/incipientand-material/technical-sublimations- $<$ blinded-to-their-relative-ontological-completeness

reference-of-thought- devolving $>$ as from the available desublimating prior ${ }^{83}$ reference-ofthought/grandest-axiomatic-construct — as-to-referencing/registering/decisioning). The fact is (as to human Being-development/ontological-framework-expansion-as-to-depth-ofontologising-development-as-infrastructure-of- meaningfulness-and-teleology , institutionaldevelopment-as-to-social-function-development and living-development-as-to-personalitydevelopment psychologismic epistemic-acutisation difficulty-<for, residualising $\{$ \{decompulsing\} delinearity for-cogency $>$ magnitudes $\{$ of-experientiality/experiment $\}$ ), along the trail of nascent-particular/incipient-and-material/technical-sublimations- $<$ blinded-to-their-relativeontological-completeness - reference-of-thought- devolving $>$ there is ever always a 'profound-supererogation element' that is often underrated as well as a 'presencing-distortedmeritocracy/totalising-sovereign-apportioning —of-human-ontological-performance ${ }^{72}$ $<$ including-virtue-as-ontology $>/$ morality/ethics/justice/etc. element' that is often overrated (the latter as to the given 'prior ${ }^{83}$ reference-of-thought/grandest-axiomatic-construct-as-toreferencing/registering/decisioning presublimation-drivenness' underpinning-suprasocialconstruct conception-of- ${ }^{5}$ meaningfulness-and-teleology $\left.{ }^{\circ}\right)$; with an 'immediacy supposed absolute sublimating value and ontological-veracity disposition' (historially involving 'dominance/vested-interest structure in relative-ontological-incompleteness ${ }^{88}$-presublimationconstruct-of- ${ }^{5}$ meaningfulness-and-teleology 9 desublimating existentialising-decisionality<as-to-disontologising/re-ontologising aporeticism $>^{\prime}$ as from blatant brutish conquest/subjugation conception of apportioning, dominion protection conception of 
apportioning, to the very natural-order-of-things conception of apportioning and to our subtle modern-day institutionally-distorted/disjointed conception of apportioning) that then mostly overrides the "non-immediacy prospective sublimating value and ontological-veracity disposition' (so-construed as to the 're-originary_-as-_unenframed_re-_reontologising/unbeholdening/outlier_conceptualis_ation__imbued-postconverging/dialectical-

\section{thinking -'projective-insights'/‘epistemic-projection-in-conflatedness ' 'of-}

notional deprocrypticism-prospective-sublimation $\rangle^{0}$ intemporal-disposition supererogatory rescalarisation of ontologisation and value-construction within any given registryworldview/dimension presencing-absolutising-identitive-constitutedness

\section{$<$ preconverging 'motif-and-apriorising/axiomatising/referencing'-entailing $>$ -}

existentialising — enframing/imprintedness-〈as-to- historicity-tracing_-in-presencing-

hyperrealisation/hyperreal-transposition〉' imbued 'ontological-good-faith/authenticity ${ }^{6}$-andequanimity of social/institutional process towards credible social/institutional outcome as reflecting manifest dispensing-with-immediacy-for-relative-ontological-completeness ${ }^{87}$-byreification/contemplative-distension ${ }^{27}$ ). It is the capacity for human self-reflexive questioning of how the 'supererogation -profundity $\sim$ postconverging-dementating/structuring/paradigming of nascent-particular/incipient-and-material/technicalsublimations- $<$ blinded-to-their-relative-ontological-completeness - reference-of-thoughtdevolving >' in reflection of the overall relative-unreflexivity/relative-reflexivity - ontologicalcontiguity $^{67} \sim$ of-the-human-institutionalisation-process ${ }^{68}$ implications as to existence-assublimating-withdrawal/unenframing/re-ontologising,-elicited-from-prospective-profoundsupererogation (beyond 'immediacy supposed absolute sublimating value and ontologicalveracity disposition' implied presencing-distorted-meritocracy/totalising-sovereign-

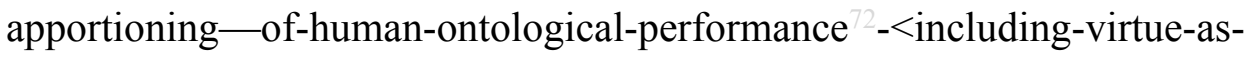
ontology $>$ /morality/ethics/justice/etc. historially involving 'dominance/vested-interest structure 
in relative-ontological-incompleteness ${ }^{88}$-presublimation-construct-of- ${ }^{5}$ meaningfulness-andteleology desublimating existentialising-decisionality-<as-to-disontologising/reentelogising apereticism ${ }^{\prime}$ as from blatant brutish conquest/subjugation conception of apportioning, dominion protection conception of apportioning, to the very natural-order-ofthings conception of apportioning and to our subtle modern-day institutionallydistorted/disjointed conception of apportioning as so-underlying their epochal instances of 'ontological-bad-faith/inauthenticity ${ }^{64}$-and-lack-of-equanimity of social/institutional process towards preconverging/postconverging-de-mentative/structural/paradigmatic priorlydefaulted/usurped social/institutional outcome as reflecting manifest lack of dispensing-withimmediacy-for-relative-ontological-completeness ${ }^{87}$-by-reification/contemplative-distension ${ }^{27}$ ) developed (so-construed as to the 're-originary-_as-unenframed/re-

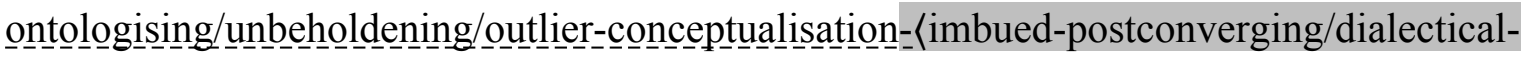
thinking -'projective-insights'/‘epistemic-projection-in-conflatedness ' 'ofnotional deprocrypticism-prospective-sublimation $\rangle$ intemporal-disposition supererogatory rescalarisation of ontologisation and value-construction within any given registryworldview/dimension presencing - absolutising-identitive-constitutedness $<$ preconverging 'motif-and-apriorising/axiomatising/referencing'-entailing >existentialising — enframing/imprintedness-〈as-to- historicity-tracing — in-presencinghyperrealisation/hyperreal-transposition〉' imbued 'ontological-good-faith/authenticity ${ }^{6}$-andequanimity of social/institutional process towards credible social/institutional outcome as reflecting manifest dispensing-with-immediacy-for-relative-ontological-completeness ${ }^{87}$-byreification/contemplative-distension ${ }^{27}$ ), that underlies the ontological-veracity of human reontologising prospective Being-development/ontological-framework-expansion-as-to-depthof-ontologising-development-as-infrastructure-of- meaningfulness-and-teleology psychologismic epistemic-acutisation difficulty-for, residualising 
$\{$ decompulsing $\}$ delinearity for-cogeney $>$ magnitude\{of-experientiality/experiment $\}$ and its implications for prospective institutional-development-as-to-social-function-development and livingdevelopment-as-to-personality-development psychologismic epistemic-acutisationdifficulty $<$ for, residualising \{decompulsing $\}$ delinearity - for-cogency> magnitudes $\{$ ofexperientiality/experiment\}

(as

of dimensionality-of-sublimating

\section{<<amplituding/formative >supererogatory $\sim$ de-mentativeness/epistemic-growth-or-}

\section{conflatedness /transvaluative-rationalising/transepistemicity/anamnestic-residuality/spirit-}

drivenness-equalisation)). This fundamental ontological-deficiency of registryworldviews/dimensions 'prior ${ }^{83}$ reference-of-thought/grandest-axiomatic-construct - as-toreferencing/registering/decisioning presublimation-drivenness' underpinning-suprasocialconstruct conception-of- ${ }^{-5}$ meaningfulness-and-teleology ${ }^{9}$ is reflected in the fact of their absconding/abandonment relationship with the possibility of their very own prospective postconverging aporeticism-overcoming/unovercoming as to the implications of 'nonimmediacy prospective sublimating value and ontological-veracity disposition' (with regards to its supererogation -profundity $\sim$ postconverging-de-mentating/structuring/paradigming requisite dispensing-with-immediacy-for-relative-ontological-completeness ${ }^{87}$-byreification/contemplative-distension ${ }^{27}$ for Being-development/ontological-frameworkexpansion-as-to-depth-of-ontologising-development-as-infrastructure-of- meaningfulness-

and-teleology ), $\quad$ so-construed $\quad$ as $\quad$ an imponderable/inscrutable/unavoidable/inevitable/inescapable/unpreventable/unchangeable/in surmountable/unovercomable framework (in mere prospective wait for messianicity) while at the same time advancing that stances of shallow-supererogation (as to presencing-distortedmeritocracy/totalising-sovereign-apportioning —of-human-ontological-performance ${ }^{72}$ <including-virtue-as-ontology>) are the absolute possibilities of human ontologicalperformance $^{72}-<$ including-virtue-as-ontology $>$ /morality/ethics/justice/etc. potential; as to the 
paradox that human presublimation as of the underpinning-suprasocial-construct postconverging aporeticism-overcoming/unovercoming stances of shallow-supererogation (as to presencing-distorted-meritocracy/totalising-sovereign-apportioning-of-humanontological-performance $^{72}$-<including-virtue-as-ontology $>/$ morality/ethics/justice/etc. $\quad$ as historially involving 'dominance/vested-interest structure in relative-ontologicalincompleteness ${ }^{88}$-presublimation-construct-of- ${ }^{-6}$ meaningfulness-and-teleology desublimating existentialising-decisionality-<as-to-disontologising/re-ontologising apereticism ${ }^{\prime}$ as from blatant brutish conquest/subjugation conception of apportioning, dominion protection conception of apportioning, to the very natural-order-of-things conception of apportioning and to our subtle modern-day institutionally-distorted/disjointed conception of apportioning) of recurrent-utter-uninstitutionalisation, base-institutionalisationununiversalisation, ${ }^{103}$ universalisation-non-positivism/medievalism and positivismprocrypticism are preconvergingly-de-mentated/structured/paradigmed as to be incapable of explaining the possibility for prospective human emancipation/sublimation as reflected in the overall relative-unreflexivity/relative-reflexivity - ontological-contiguity ${ }^{67}$ of-the-humaninstitutionalisation-process $^{68}$ implications as to existence-as-sublimatingwithdrawal/unenframing/re-ontologising,-elicited-from-prospective-profound-supererogation with respectively base-institutionalisation, ${ }^{103}$ universalisation, positivism and prospective notional deprocrypticism (so-enabled rather by supererogatory dimensionality-ofsublimating $25-\langle<$ amplituding/formative $>$ supererogatory $\sim$ de-mentativeness/epistemic-growthor-conflatedness /transvaluative-rationalising/transepistemicity/anamnestic-residuality/spiritdrivenness-equalisation $\rangle$ as to tre-originary-_as-unenframe-_ed/reontologissing/unb_eholdening/outlier-conceptualis_ation__imbued-postconverging/dialecticalthinking -'projective-insights'/‘epistemic-projection-in-conflatedness ' '-ofnotional deprocrypticism-prospective-sublimation $\rangle^{0}$ intemporal-disposition supererogatory 
rescalarisation of ontologisation and value-construction within any given registryworldview/dimension presencing - absolutising-identitive-constitutedness <preconverging 'motif-and-apriorising/axiomatising/referencing'-entailing >existentialising — enframing/imprintedness-〈as-to- historicity-tracing — in-presencinghyperrealisation/hyperreal-transposition〉' imbued 'ontological-good-faith/authenticity ${ }^{6}$-andequanimity of social/institutional process towards credible social/institutional outcome as reflecting manifest dispensing-with-immediacy-for-relative-ontological-completeness ${ }^{87}$-byreification/contemplative-distension ${ }^{27}$ ); as left to the non-universalising ancient-sophists, nonpositivising medieval-scholastics and our modern-day ${ }^{80}$ procrypticism-or-disjointedness-as-ofreference-of-thought, the notion of any supererogation as to re-ontologising prospective Being-development/ontological-framework-expansion-as-to-depth-of-ontologisingdevelopment-as-infrastructure-of- meaningfulness-and-teleology (as advanced by Socraticphilosophers ${ }^{103}$ universalising-idealisation, budding-positivists and postmodern-thought implications for prospective human construction-of-the-Self) is rather unintelligible/superfluous but for their respective ${ }^{79}$ presencing-absolutising-identitive-constitutedness $<$ preconverging 'motif-and-apriorising/axiomatising/referencing'-entailing >existentialising — enframing/imprintedness-〈as-to- historicity-tracing_-in-presencinghyperrealisation/hyperreal-transposition〉 given presencing-distorted-meritocracy/totalisingsovereign-apportioning - of-human-ontological-performance ${ }^{72}<$ including-virtue-asontology $>$ /morality/ethics/justice/etc. (historially involving 'dominance/vested-interest structure in relative-ontological-incompleteness ${ }^{88}$-presublimation-construct-ofmeaningfulness-and-teleology $\quad$ desublimating $\sim$ existentialising-decisionality-<as-todisontologising/re-ontologising aporeticism ${ }^{\prime}$ as from blatant brutish conquest/subjugation conception of apportioning, dominion protection conception of apportioning, to the very naturalorder-of-things conception of apportioning and to our subtle modern-day institutionally- 
distorted/disjointed conception of apportioning). Again, as to the $<$ cumulating/recomposuring attendant-ontological-contiguity $>$-successive registryworldviews/dimensions decadent wariness to 'break-away from prospective notionalcontiguity/epistemic-contiguity ${ }^{2}<$ - profound-supererogation -of-mentallyaestheticised postconverging/dialectical-thinking -qualia-schema $>$ conception of relativeontological-completeness $^{87}$ as to existence-as-sublimating-withdrawal/unenframing/reontologising,-elicited-from-prospective-profound-supererogation for knowledgereification $\sim$ gesturing-and-accounting — of-epistemic-phenomenalism- $<$ inprospective_psychologismic apriorising/axiomatising/referencing-\{of-'prospectively implicited_attendant-ontological-contiguity ' educedexistentialising/contextualising/textualising_'intelligibility/epistemicity/reflexivity-contiguity<imbued-notional cogency>’ $\}$-conflatedness -in-\{preconverging -ment by\} postconverging-entailment>' (hence inducing a flawed imponderable/inscrutable/unavoidable/inevitable/inescapable/unpreventable/unchangeable/in surmountable/unovercomable epistemic-projection perspective that undermines prospective reontologisation and value-construction) as to wrongly construing of any such prospective insight as rather being of a 'framework of metaphysical/ideological advocacy as of totalisingly-ingdiscretion/whim-of-thought (rather than truly being a framework of ontological-veracity implied relative-ontological-completeness $\quad<$ amplituding/formative $>$ disposedness/psychologismicconstruct-〈as-to-orientation/value-construct/valuation-and-derived-parameterising $\quad$ and <amplituding/formative >entailment-as-to-totalising-contiguous/coherent-factuality-ofvariability)'; this registry-worldviews/dimensions decadently so-induced disparateness-ofconceptualisation-<unforegrounding-ment,-failing-prospectively-to-reflect‘immanent relative-unreflexivity/relative-reflexivity ontological-contiguity '> at their prospective destructuring-threshold-〈uninstitutionalised-threshold /presublimating- 
desublimating-decisionality $>$ of-ontological-performance ${ }^{72}-<$ including-virtue-asontology $>$ /morality/ethics/justice/etc. arises as to the pedantising/muddling/formulaichollowing-out_-in-subontologisation/subpotentiation-〈blurring/undermining-of-prospectivetotalising-entailing,-as-to-entailing-<amplituding formative-epistemicity $>$ totalising $\sim$ inrelative-ontological-completeness $\rangle$ of their ontologically-flawed presublimating ${ }^{83}$ referenceof-thought/grandest-axiomatic-construct — as-to-referencing/registering/decisioning $<$ amplituding/formative >disposedness/psychologismic-construct-〈as-to-orientation/valueconstruct/valuation-and-derived-parameterising $\rangle$ as supposedly entailing the prospective nascent-particular/incipient-and-material/technical-sublimations- $<$ blinded-to-their-relativeontological-completeness - reference-of-thought- devolving > (whereas the latter is in want for its very own prospective sublimating ${ }^{83}$ reference-of-thought/grandest-axiomatic-constructas-to-referencing/registering/decisioning in reflecting relative-unreflexivity/relativereflexivity - ontological-contiguity ${ }^{67}$, and this pedantising/muddling/formulaic-hollowingout - in-subontologisation/subpotentiation-〈blurring/undermining-of-prospective-totalisingentailing,-as-to-entailing-<amplituding/formative-epistemicity $>$ totalising $\sim$ in-relativeontological-completeness $>$ then fails the requisite ontological-veracity of maximalisingrecomposuring-for-relative-ontological-completeness ${ }^{87}$ unenframed/reontologising conceptualisation necessary for re-ontologising prospective Beingdevelopment/ontological-framework-expansion-as-to-depth-of-ontologising-development-asinfrastructure-of- meaningfulness-and-teleology psychologismic epistemic-acutisationdifficulty < for, residualising magnitude ${ }^{\{0 f-}$ experientiality/experiment and its induced prospective institutional-development-as-to-social-functiondevelopment and living-development-as-to-personality-development psychologismic epistemic acutisation difficulty-for, residualising \{decompulsing ${ }^{\text {f }}$ delinearity for-cogency> magnitudes $\{$ of-experientiality/experiment\}. The implication here is that instead of an ontologically- 
veridical completeness - reference-of-thought- devolving>' inducing of 'prospective/nascent relativeontological-completeness reference-of-thought/grandest-axiomatic-construct — as-toreferencing/registering/decisioning supererogatory unbeholdening-conflatedness ${ }^{13}$ projectiveinsights as of notional ' deprocrypticism' as underlying the overall: human-subpotency 'fatedness-of-sublimation-over-desublimation, to existence-potency $\sim$ sublimating-nascence,disclosed-from-prospective-epistemic-digression (in reflecting holographically-<conjugativelyand-transfusively $>$ the relative-unreflexivity/relative-reflexivity-ontological-contiguity ofthe-human-institutionalisation-process ), as from human-subpotency ontological-faith-notionor-ontological-fideism—imbued-underdetermination-of-motif-andapriorising/axiomatising/referencing-as-so-being-as-of-existential-reality as to the disseminative - sublimating-selectivity-of-ontological-goodfaith/authenticity postconverging-de-mentating/structuring/paradigming , overdesublimating deselectivity-of-ontological-bad-faith/inauthenticity opreconverging dementing/strating '; the <cumulating/recomposuring attendant-ontologicalcontiguity $>$-successive registry-worldviews/dimensions $\quad{ }^{83}$ reference-of-thought/grandestaxiomatic-construct — as-to-referencing/registering/decisioning as of their relative-ontologicalincompleteness $\quad$ destructuring-threshold-〈uninstitutionalised-threshold /presublimatingdesublimating-decisionality $>$ of-ontological-performance ${ }^{72}-<$ including-virtue-asontology $>$ /morality/ethics/justice/etc. adopt their respective 'relic/artifactual-beholdeningconstitutedness presencing — absolutising-identitive-constitutedness $<$ preconverging 'motif-and-apriorising/axiomatising/referencing'-entailing $>$ existentialising — enframing/imprintedness-〈as-to- historicity-tracing_-in-presencing- 
hyperrealisation/hyperreal-transposition〉' given presencing-distorted-meritocracy/totalisingsovereign-apportioning - of-human-ontological-performance ${ }^{72}-<$ including-virtue-asontology $>$ /morality/ethics/justice/etc. (historially involving 'dominance/vested-interest

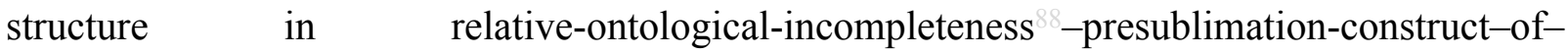
meaningfulness-and-teleology $\quad$ desublimating $\sim$ existentialising-decisionality $<a s$ to disontologising/re-ontologising aporeticism ${ }^{\prime}$ as from blatant brutish conquest/subjugation conception of apportioning, dominion protection conception of apportioning, to the very naturalorder-of-things conception of apportioning and to our subtle modern-day institutionallydistorted/disjointed conception of apportioning as particularly the target as to Lyotard's critique of such institutionally-distorted implied metanarratives especially with regards to their poor/sheepish/dubious/ineffectual social/institutional devolving parameterised equanimity/balance as putting in question their theoretical, conceptual and operative veracity, and speaking in all the above epochal instances of prospective 'ontological-badfaith/inauthenticity ${ }^{6}$-and-lack-of-equanimity of social/institutional process towards preconverging/postconverging-de-mentative/structural/paradigmatic priorly-defaulted/usurped social/institutional outcome as reflecting manifest lack of dispensing-with-immediacy-forrelative-ontological-completeness ${ }^{87}$-by-reification/contemplative-distension ${ }^{27}$ ). Whereas (as of 'ontological-good-faith/authenticity ${ }^{6}$-and-equanimity of social/institutional process towards credible social/institutional outcome as reflecting manifest dispensing-with-immediacy-forrelative-ontological-completeness ${ }^{87}$-by-reification/contemplative-distension ${ }^{27}$ ') it is 'reoriginary-ass-unenframed/re-ontologising/unbeholdening/outlier-conceptualisation-〈imbuedpostconverging/dialectical-thinking - 'projective-insights'/'epistemic-projection-inconflatedness ' -of-notional deprocrypticism-prospective-sublimation) intemporaldisposition supererogatory rescalarisation of ontologisation and value-construction (within any given registry-worldview/dimension 79 presencing-absolutising-identitive-constitutedness 


\section{<preconverging 'motif-and-apriorising/axiomatising/referencing'-entailing $>$ -}

existentialising — enframing/imprintedness-〈as-to- historicity-tracing —in-presencing-

hyperrealisation/hyperreal-transposition〉) inducing prospective sublimation-over-desublimation meaningfulness-and-teleology ${ }^{9}$ infrastructure thus effectively superseding any such given registry-worldview/dimension underpinning-suprasocial-construct prior conception of ontologisation and value-construction' and so as to the underlying 'tight-and-entwined relationship between the overall human ontological-commitment $-<$ implied — self-assurednessof-ontological-good-faith/authenticity postconverging-dementating/structuring/paradigming -as-being-as-of-existential-reality $>$ (across all registryworldviews/dimensions) and (corresponding registry-worldviews/dimensions) predicativeeffectivity-sublimation-〈as-to-underlying,-ontological-commitment $-<$ implied - selfassuredness-of-ontological-good-faith/authenticity postconverging-dementating/structuring/paradigming -as-being-as-of-existential-reality $>>$ inherent in the 'scalarity/immanency of existence's ontological-normalcy/postconvergence' perspective that such re-originary-as-unenframed/re-ontologising/unbeholdening/outlier-conceptualisation〈imbued-postconverging/dialectical-thinking -'projective-insights'/‘epistemic-projection-inconflatedness '-of-notional deprocrypticism-prospective-sublimation $\rangle^{0}$ intemporaldisposition can induce, and with such 're-originary_-as-unnenframed_-_reontologising/unbeholdening/outlier-conceptualisation__imbued-postconverging/dialecticalthinking -'projective-insights'/‘epistemic-projection-in-conflatedness ' 'ofnotional deprocrypticism-prospective-sublimation $\rangle$ intemporal-disposition supererogatory rescalarisation of ontologisation and value-construction induced sublimation-overdesublimation ${ }^{56}$ meaningfulness-and-teleology ${ }^{9}$ infrastructure' preconverging/postconvergingde-mentatively/structurally/paradigmatically explaining the possibility for the $<$ cumulating/recomposuring attendant-ontological-contiguity $>$-succession of registry- 
worldviews/dimensions as to their induced institutional-development-as-to-social-functiondevelopment and living-development-as-to-personality-development psychologismic epistemic-acutisation difficulty-for, residualising \{decompulsing $\}$ delinearity for-cogency> magnitudes $\{$ of-experientiality/experiment\} social-stake-contention-or-confliction. Inherently, unlike the flawed intuitive human projection of ${ }^{5}$ meaningfulness-and-teleology ${ }^{9}$ in apriorising/axiomatising/referencing-\{of-'prospectively implicited_attendant-ontologicalcontiguity ' educedexistentialising/contextualising/textualising_'intelligibility/epistemicity/reflexivity-contiguity<imbued-notional cogency $\left.>^{\prime} \quad\right\}$-constitutedness ${ }^{14}$-in-preconverging-entailment $\quad$ terms inducing ${ }^{79}$ presencing—absolutising-identitive-constitutedness ${ }^{14}<$ preconverging 'motif-andapriorising/axiomatising/referencing'-entailing>-existentialising-enframing/imprintedness〈as-to- historicity-tracing - in-presencing-hyperrealisation/hyperreal-transposition〉 distortion that seem to wrongly imply that human nature is of intemporal-disposition only without factoring

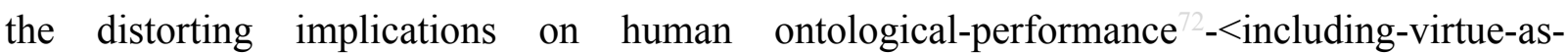
ontology $>$ /morality/ethics/justice/etc. of human temporal-dispositions with regards to socialstake-contention-or-confliction at uninstitutionalised-threshold ${ }^{102}$, in rather truly reflecting human ontological-performance ${ }^{72}<$ including-virtue-as-ontology $>/$ morality/ethics/justice/etc. as of notional firstnaturedness-formativeness-<as-to-eventualising-inkling-drive-or-seedingmisprising $>$ temporal-to-intemporal-dispositions- $<$ so-construed-as-from-perspectiveontological-normalcy/postconvergence $>$ this then allows for conceptualising how intemporaldisposition induced ontological-performance ${ }^{72}-$ including-virtue-as- $^{2}$ ontology $>$ /morality/ethics/justice/etc. in superseding uninstitutionalised-threshold ${ }^{102}$ arises (as of the apriorising/axiomatising/referencing-\{of-'prospectively implicited_attendantontological-contiguity ' educed- 
<imbued-notional cogency $>>$ ' - conflatedness ${ }^{13}$ in-\{preconverging ment by\} postconverging entailment of dimensionality-of-sublimating 〈<amplituding/formative>supererogatory $\sim$ de-mentativeness/epistemic-growth-orconflatedness /transvaluative-rationalising/transepistemicity/anamnestic-residuality/spiritdrivenness-equalisation> as to existence-as-sublimating-withdrawal/unenframing/reontologising,-elicited-from-prospective-profound-supererogation implications) and so involving 'human <amplituding/formative-epistemicity>-totalising $\sim$ thrownness-inexistence ${ }^{35}$,-imbued-projective-arbitrariness/waywardness-〈as-to-the-humanprojective/reprojective - aestheticising-re-motif-and-re-apriorising/re-axiomatising/rereferencing-process-of-‘ $<$ amplituding/formative-epistemicity $>$ totalising $\sim$ conceptualisation’〉 (speaking of varying temporal-to-intemporal human ontological-performance ${ }^{2}-<$ includingvirtue-as-ontology>) fundamental subjection to prospective existence-as-sublimatingwithdrawal/unenframing/re-ontologising,-elicited-from-prospective-profound-supererogation implications in a narrowing-down selection of the intemporal-disposition as being of ontological-veracity thus reflecting its sublimating inducing supererogation profundity $\sim$ postconverging-de-mentating/structuring/paradigming, and as this in turn underlies the narrowing-down secondnaturing of the <cumulating/recomposuring attendant-ontologicalcontiguity >-successive registry-worldviews/dimensions (while excluding human temporaldispositions of ontological-performance ${ }^{72}-$ including-virtue-as- $^{2}$ ontology $>$ /morality/ethics/justice/etc. as to the secondnatured level of projective-insights attained). Thus inherently 'human notional firstnaturedness-formativeness-<as-toeventualising inkling-drive-or-seeding-misprising > temporal-to-intemporal-dispositions$<$ so-construed-as-from-perspective-ontological-normalcy/postconvergence $>$ accordioning-〈asof-varying-individuations-contextually-transverse-desublimation/sublimation,-as-to-thewaveringtredounding/waveforming of-their-referencing-and-their-devolved-referencing- 
imbued-ontological-performance -<including-virtue-as-ontology $>>$ as to living-developmentas-to-personality-development

mentatively/structurally/paradigmatically reflected in the overall relative-unreflexivity/relativereflexivity ontological-contiguity ${ }^{67} \sim$ of-the-human-institutionalisation-process ${ }^{68} \quad$ (as of successive Being-development/ontological-framework-expansion-as-to-depth-of-ontologisingdevelopment-as-infrastructure-of- meaningfulness-and-teleology ) is rather by the narrowingdown selectivity and secondnaturing of the intemporal-disposition at the utter exclusion of temporal-dispositions (that is, until the prospective destructuring-threshold-〈uninstitutionalisedthreshold /presublimating-desublimating-decisionality) of-ontological-performance ${ }^{72}$ <including-virtue-as-ontology $>$ /morality/ethics/justice/etc. reflect human notional firstnaturedness-formativeness-<as-to-eventualising inkling-drive-or-seedingmisprising $>$ temporal-to-intemporal-dispositions- $<$ so-construed-as-from-perspectiveontological-normalcy/postconvergence $>$ in want for the same narrowing-down selection of the intemporal-disposition as to 'human <amplituding/formative-epistemicity >totalising thrownness-in-existence ${ }^{35}$,-imbued-projective-arbitrariness/waywardness-〈as-to-thehuman-projective/reprojective- aestheticising-re-motif-and-re-apriorising/re-axiomatising/rereferencing-process-of- ‘<amplituding/formative-epistemicity $>$ totalising $\sim$ conceptualisation’〉 (speaking of varying temporal-to-intemporal human ontological-performance ${ }^{2}-<$ includingvirtue-as-ontology>) fundamental subjection to prospective existence-as-sublimatingwithdrawal/unenframing/re-ontologising,-elicited-from-prospective-profound-supererogation for intemporal-disposition selectivity in reflection of re-originary_-as-unenframed/reontologising/unbeholdening/outlier-conceptualisation__imbued-postconverging/dialecticalthinking -'projective-insights'/'epistemic-projection-in-conflatedness ' '-ofnotional deprocrypticism-prospective-sublimation $\rangle$. This thus implies that human socialstake-and-contention framing as preformulating/preframing/premeaningfulness- 
$<$ metaphoricity $^{57}$-disposition - as-to-psyche-induced-psychologism-of-existential-stake $>\quad$ is rather ever always caught up in an enframed/disontologising-by-unenframed/re-ontologising or enframed/disontologising-superseding/overcoming or re-originary_-_as-unen_-_frame-_ed/reontologising/unbeholdening/outlier-conceptualisation__imbued-postconverging/dialectical-

\section{thinking -'projective-insights’/‘epistemic-projection-in-conflatedness ' '-of-}

notional deprocrypticism-prospective-sublimation $\rangle^{\circ}$ stance as to the prospective possibility

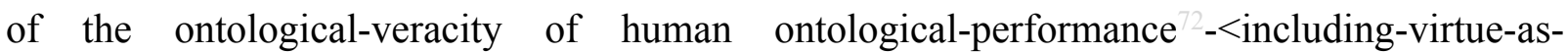
ontology $>$ /morality/ethics/justice/etc. as to existence-as-sublimatingwithdrawal/unenframing/re-ontologising,-elicited-from-prospective-profoundsupererogation ; wherein blurriness- $<$ sterilising/anecdotalising/trivialising-of-prospective-reontologising_by-preconverging,-in-disontologising-formulaic-dragging-out/hollowing-out> as to uninstitutionalised-threshold ${ }^{12}$ is an epistemic-constraint undermining sublimation and inducing desublimation, and ${ }^{103}$ universal-transparency ${ }^{10}$-〈transparency-of-totalising-entailing,as-to-entailing-<amplituding/formative-epistemicity $>$ totalising in-relative-ontological-

completeness $>$ as to induced prospective institutionalisation is an epistemic-constraint for undermining desublimation and inducing sublimation as such ${ }^{103}$ universal-transparency ${ }^{104}$ 〈transparency-of-totalising-entailing,-as-to-entailing-<amplituding/formative-

epistemicity $>$ totalising in-relative-ontological-completeness $\rangle$ is so-reflected in the succession of 'relative-ontological-completeness ${ }^{87}$-apriorising/axiomatising/referencing-psychologism enculturated/constructed social-pragmatics-framing-of-predicative-effectivity-sublimation〈as-to-underlying,-ontological-commitment $-<$ implied — self-assuredness-of-ontological-goodfaith/authenticity postconverging-de-mentating/structuring/paradigming -as-being-as-ofexistential-reality $>\rangle$ ' as narrowing-down selectivity of the intemporal-disposition for prospectively secondnatured institutionalisation. This disparateness-of-conceptualisation$<$ unforegrounding-ment,-failing-prospectively-to-reflect-‘immanent relative- 
unreflexivity/relative-reflexivity ontological-contiguity ' $>$ insight (as to the

pedantising/muddling/formulaic-hollowing-out - in-subontologisation/subpotentiation-

〈blurring/undermining-of-prospective-totalising-entailing,-as-to-entailing-

<amplituding/formative-epistemicity>totalising in-relative-ontological-completeness $>$ of

presublimating

reference-of-thought/grandest-axiomatic-construct — as-to-

referencing/registering/decisioning and prospective nascent-particular/incipient-andmaterial/technical-sublimations-<blinded-to-their-relative-ontological-completeness

reference-of-thought- devolving $>$ ) is equally reflected in the manifestation of postlogism and social-postlogism (arising from conjugated-postlogism ${ }^{77}$ induced ${ }^{56}$ meaningfulness-andteleology ${ }^{9}$ ) across the <cumulating/recomposuring attendant-ontological-contiguity successive registry-worldviews/dimensions (as associated with psychopathy in our positivismprocrypticism registry-worldview/dimension); wherein the possibility for the specifically given registry-worldview/dimension induced postlogism and social-postlogism 77 is fundamentally possible only as of the specific registry-worldview/dimension destructuringthreshold-〈uninstitutionalised-threshold /presublimating-desublimating-decisionality $>$ ofontological-performance ${ }^{72}$-<including-virtue-as-ontology $>/$ morality/ethics/justice/etc.

presublimating $\quad{ }^{83}$ reference-of-thought/grandest-axiomatic-construct —as-toreferencing/registering/decisioning imbued apriorising/axiomatising/referencing-psychologism ontological-deficiency whether as of recurrent-utter-uninstitutionalisation, ununiversalisation, non-positivism/medievalism or ${ }^{80}$ procrypticism-or-disjointedness-as-of- ${ }^{8}$ reference-of-thought (notional procrypticism). Such that the manifested postlogism -as-of- compulsingnonconviction/madeupness/bottomlining-〈'<decontextualising/de-existentialising ofattendant-intradimensional-apriorising/axiomatising/referencing--induced-disontologising'-ofthe-'attendant-intradimensional-ontologising'-imbued-

$<$ contextualising/existentialising attendant-ontological-contiguity $>$;-in-shallow- 
supererogation -<as-to-disontologising-perverted-outcome-sought-precedes-existentiallyveridical-'attendant-intradimensional-apriorising/axiomatising/referencing'-logical-dueness $>$ > is directly related to the presublimating ${ }^{83}$ reference-of-thought/grandest-axiomatic-constructas-to-referencing/registering/decisioning

$<$ amplituding/formative >disposedness/psychologismic-construct-〈as-to-orientation/valueconstruct/valuation-and-derived-parameterising $\rangle$ to be cognisant-and-integrative in prelogism ${ }^{7}$-as-of-conviction,-in-profound-supererogation $-<$ existentially-veridical-

\section{'attendant-intradimensional-apriorising/axiomatising/referencing'-logical-dueness-precedes-}

disontologising-logical-outcome-arrived-at> (construed as if of postconverging-or-dialecticalthinking -apriorising-psychologism) of the same ${ }^{5}$ meaningfulness-and-teleology ${ }^{9}$ articulated as of postlogism manifestation (articulated rather as preconverging-or-dementing ${ }^{20}$ apriorising-psychologism) thus inducing the conjugated-postlogism 77 ; and so as to the fact that for instance a postlogism ${ }^{77}$ manifestation grounded in a social-setup as of say an animistic socialsetup cognisant-and-integrative of notions-and-accusations-of-sorcery in prelogism ${ }^{78}$-as-ofconviction,-in-profound-supererogation ${ }^{9}<$ existentially-veridical-'attendant-intradimensionalapriorising/axiomatising/referencing'-logical-dueness-precedes-disontologising-logical-

outcome-arrived-at $>\quad$ (as if of postconverging-or-dialectical-thinking ${ }^{21}$-apriorisingpsychologism) is susceptible to the postlogism 7 of notions-and-accusations-of-sorcery meaningfulness-and-teleology (articulated rather as preconverging-or-dementing ${ }^{20}$ apriorising-psychologism) which will be preconverging/postconverging-dementatively/structurally/paradigmatically impossible to manifest in a non-superstitious positivistic registry-worldview/dimension. Thus the idea of "prelogism ${ }^{78}$-as-of-conviction,-inprofound-supererogation $-<$ existentially-veridical-'attendant-intradimensionalapriorising/axiomatising/referencing'-logical-dueness-precedes-disontologising-logicaloutcome-arrived-at> cognisance-and-integration in presublimation ${ }^{83}$ reference-of- 
thought/grandest-axiomatic-construct—as-to-referencing/registering/decisioning $<$ amplituding/formative >disposedness/psychologismic-construct-〈as-to-orientation/valueconstruct/valuation-and-derived-parameterising〉' speaks to the fact that more fundamentally postlogism 77 and social-postlogism 77 implications are ontologically escalating beyond just any particular/specific existential-<disontologising/re-ontologising aporeticism $>$ manifestation of postlogism ${ }^{77}$ and that inherently a presublimating ${ }^{83}$ reference-of-thought/grandest-axiomaticconstruct — as-to-referencing/registering/decisioning is rather preconverging/postconvergingde-mentatively/structurally/paradigmatically an ontological-deficiency paradoxically in-wait for its manifest postlogism ${ }^{77}$ and social-postlogism 77 and such a presublimating ${ }^{83}$ reference-ofthought/grandest-axiomatic-construct — as-to-referencing/registering/decisioning as to its cognisance-and-integration of postlogism 77 is the more ontologically profound conceptualisation as to systemic aetiologisation/ontological-escalation- $<$ ontologicalveridicality_commitment/otherliness_transcending/compulsions-encumbered_transcending > implications of social pervasiveness of postlogism 77 and conjugated-postlogism 77 . Ultimately as from the technical ontological-veracity of originariness/origination-〈so-construed-as-toontological-normalcy/postconvergence-perspective-scalarising-construal-of-existence)

perspective of notional deprocrypticism, disparateness-of-conceptualisation$<$ unforegrounding-ment,-failing-prospectively-to-reflect-'immanent $\sim$ relativeunreflexivity/relative-reflexivity ontological-contiguity '> insight (as to the pedantising/muddling/formulaic-hollowing-out — in-subontologisation/subpotentiation〈blurring/undermining-of-prospective-totalising-entailing,-as-to-entailing<amplituding/formative-epistemicity>totalising in-relative-ontological-completeness > of presublimating reference-of-thought/grandest-axiomatic-construct - as-toreferencing/registering/decisioning and prospective nascent-particular/incipient-andmaterial/technical-sublimations-<blinded-to-their-relative-ontological-completeness 
reference-of-thought- devolving $>$ ) projects an incrementalism-in-relative-ontologicalincompleteness 8 - enframed/disontologising conceptualisation that 'undermines ontologicalveracity as of maximalising-recomposuring-for-relative-ontological-completeness ${ }^{87}$ unenframed/re-ontologising conceptualisation'; and so as to the fact that the cognisance-andintegration of prospective nascent-particular/incipient-and-material/technical-sublimations$<$ blinded-to-their-relative-ontological-completeness - reference-of-thought- devolving $>$ as if of relative-ontological-incompleteness ${ }^{88}$ presublimating ${ }^{83}$ reference-of-thought/grandestaxiomatic-construct — as-to-referencing/registering/decisioning is circularly beholdening meaningfulness-and-teleology to human-subpotency (as subontologising prior apriorising/axiomatising/referencing/intelligibilitysettingup/measuringinstrumenting) rather than to existence-as-sublimating-withdrawal/unenframing/re-ontologising,-elicited-fromprospective-profound-supererogation (as re-ontologising prospective apriorising/axiomatising/referencing/intelligibilitysettingup/measuringinstrumenting) and thus undermining the prospective psychoanalytic-unshackling/memetic-reordering/institutionalrecomposuring induced re-motif-and-re-apriorising/re-axiomatising/re-referencing/reintelligibilitysettingup/re-measuringinstrumenting as conflating towards the possibility of 'scalarity/immanency of existence's ontological-normalcy/postconvergence'. The psychologistic and apriorising implications here is that with regards to say a God-of-plane proposition in an animistic social-setup, an engagement striving to elucidate the notion of plane involving any existential-instantiation aposteriorising/logicising/deriving/intelligising/measuring in terms of the animistic social-setup non-positivistic apriorising/axiomatising/referencing/intelligibilitysettingup/measuringinstrumenting-forconceptualisation, is preconverging/postconverging-dementatively/structurally/paradigmatically already validating the animistic social-setup non- 
positivistic

apriorising/axiomatising/referencing/intelligibilitysettingup/measuringinstrumenting-forconceptualisation as paradoxically valid for all instances of aposteriorising/logicising/deriving/intelligising/measuring warranting positivistic apriorising/axiomatising/referencing/intelligibilitysettingup/measuringinstrumenting-forconceptualisation (thus inducing the animistic social-setup incrementalism-in-relativeontological-incompleteness ${ }^{8}$ - enframed/disontologising conceptualisation and its nonpositivistic complexification); as to the fact that it is a positivistic apriorising/axiomatising/referencing/intelligibilitysettingup/measuringinstrumenting-forconceptualisation adopting rather a relation of 'non-aposteriorising/non-logicising/nonderiving/non-intelligising/non-measuring as from the non-positivistic apriorising/axiomatising/referencing/intelligibilitysettingup/measuringinstrumenting-forconceptualisation of such an animistic social-setup God-of-plane non-positivistic proposition' that enables the possibility for ${ }^{55}$ maximalising-recomposuring-for-relative-ontologicalcompleteness ${ }^{87}$ - unenframed/re-ontologising conceptualisation as bringing to the consciousness-awareness-teleology ${ }^{9}$ of the animistic social-setup that the notion of plane $\begin{array}{llll}\text { implies an altogether } \quad \text { an } & \text { superseding }\end{array}$ apriorising/axiomatising/referencing/intelligibilitysettingup/measuringinstrumenting-forconceptualisation induced psychologism of ${ }^{8}$ reference-of-thought (over their non-positivistic apriorising/axiomatising/referencing/intelligibilitysettingup/measuringinstrumenting-forconceptualisation psychologism of ${ }^{83}$ reference-of-thought) from whence aposteriorising/logicising/deriving/intelligising/measuring can then ensue in existentialinstantiations of conceptualising. Furthermore, it is such ontologically-deficient incrementalism-in-relative-ontological-incompleteness ${ }^{8}$ enframed/disontologising conceptualisation (as to its cognisant-and-integrative 
blending/incorporating of prospective 'nascent-particular/incipient-and-material/technicalsublimations- $<$ blinded-to-their-relative-ontological-completeness - reference-of-thoughtdevolving $>$ as if of relative-ontological-incompleteness ${ }^{8}$ presublimating ${ }^{83}$ reference-ofthought/grandest-axiomatic-construct — as-to-referencing/registering/decisioning in circularly beholdening ${ }^{5}$ meaningfulness-and-teleology ${ }^{9}$ to human-subpotency') that is behind the development of all the <cumulating/recomposuring attendant-ontological-contiguity $>$ successive registry-worldviews/dimensions given <amplituding/formative $>$ wooden-language〈imbued-temporal-mere-form/virtualities/dereification/akrasiatic-

\section{drag/denatured/preconverging-or-dementing -narratives - of-the- reference-of-thought-} categorical-imperatives/axioms/registry-teleology $\rangle$ so-construed as being of preconvergingor-dementing ${ }^{20}$-apriorising-psychologism epistemic-abnormalcy/preconvergence ${ }^{31}$ (as soreflected from the undermined ${ }^{5}$ maximalising-recomposuring-for-relative-ontologicalcompleteness $^{87}$ — unenframed/re-ontologising conceptualisation postconverging-or-dialecticalthinking -apriorising-psychologism conception in ontological-normalcy/postconvergence epistemic-projection perspective). As of practical existential-<disentelogising/re-ontelogising apereticism $>$ implications $\quad{ }^{5}$ maximalising-recomposuring-for-relative-ontologicalcompleteness $^{87}$ - unenframed/re-ontologising conceptualisation means that the positivistic $<$ amplituding/formative>disposedness/psychologismic-construct-〈as-to-orientation/valueconstruct/valuation-and-derived-parameterising cannot be responsive to the social-stakecontention-or-confliction projected as of such a non-positivistic meaningfulness-andteleology, as to a fundamental positivistic disavowal of its non-positivistic $<$ amplituding/formative $>$ disposedness/psychologismic-construct-<as-to-orientation/valueconstruct/valuation-and-derived-parameterising $\rangle$ as non-aposteriorising/non-logicising/nonderiving/non-intelligising/non-measuring (as from the holding-forth of its non-positivistic apriorising/axiomatising/referencing/intelligibilitysettingup/measuringinstrumenting-for- 
conceptualisation). By extension, ${ }^{55}$ maximalising-recomposuring-for-relative-ontologicalcompleteness ${ }^{87}$ — unenframed/re-ontologising conceptualisation psychologistic and apriorising implications (so-construed as from the technical ontological-veracity of originariness/origination-〈so-construed-as-to-ontological-normalcy/postconvergenceperspective-scalarising-construal-of-existence) perspective of notional deprocrypticism), speaks to the fact that the psychoanalytic-unshackling/memetic-reordering/institutionalrecomposuring of the respective registry-worldviews/dimensions in relative-ontologicalcompleteness ${ }^{87}$ (base-institutionalisation, ${ }^{103}$ universalisation, positivism and ${ }^{18}$ deprocrypticismor-preempting-disjointedness-as-of- ${ }^{3}$ reference-of-thought respectively) are projected in disavowal of their respective prior registry-worldviews/dimensions in relative-ontologicalincompleteness ${ }^{88} \quad$ (recurrent-utter-uninstitutionalisation, ununiversalisation, nonpositivism/medievalism and procrypticism respectively) destructuring-threshold〈uninstitutionalised-threshold /presublimating-desublimating-decisionality $\rangle$ of-ontologicalperformance $^{72}-<$ including-virtue-as-ontology $>$ /morality/ethics/justice/etc. as reflected by their $<$ amplituding/formative>disposedness/psychologismic-construct-〈as-to-orientation/valueconstruct/valuation-and-derived-parameterising), implying the latter are effectively nonaposteriorising/non-logicising/non-deriving/non-intelligising/non-measuring (as from the holding-forth of their respective apriorising/axiomatising/referencing/intelligibilitysettingup/measuringinstrumenting-forconceptualisation). Thus, as to their respective ${ }^{79}$ presencing-absolutising-identitiveconstitutedness $<$ amplituding/formative-epistemicity $>$ totalising $\sim$ self-referencingsyncretising/circularity/interiorising/akrasiatic-drag ${ }^{34}$, all relative-ontological-incompleteness registry-worldviews/dimensions as of their preconverging-or-dementing ${ }^{20}$-apriorisingpsychologism pretend to articulate what ca prospectively be possible and impossible (in such a way that 'conveniently' imply that theirs is the registry-worldview/dimension that 'thinks right' 
while ignoring projective-insights as of the overall relative-unreflexivity/relative-reflexivity ontological-contiguity ${ }^{67}$ of-the-human-institutionalisation-process ${ }^{68}$ implications as to existence - as-sublimating-withdrawal/unenframing/re-ontologising,-elicited-fromprospective-profound-supererogation ) with respect to all corresponding prospective relativeontological-completeness projective-insights implications of transcendence-andsublimity/sublimation/supererogatory-de-mentativity; failing to factor in that their paradoxical contemplation in relative-ontological-incompleteness ${ }^{88}$ is exactly what renders their supposed determination of what ca prospectively be possible and impossible structurally/paradigmatic nonsensical but for the convenience of falling back (even when relative-ontologicalcompleteness ${ }^{87}$ is-educed-and-avails-and-re-avails) as of ontological-bad-faith/inauthenticity to the notion that afterall all the human world that exists is-as-of-their-given-registryworldview/dimension however its preconverging-de-mentating/structuring/paradigming vicesand-impediments $^{105}$ (which mental-reflex is ever always 'exactly the aporeticism' to be superseded with prospective sublimation as to existence-as-sublimatingwithdrawal/unenframing/re-ontologising,-elicited-from-prospective-profoundsupererogation ). In a further elucidation, the 'wavering/redounding/waveforming - of-thereferencing-and-the-devolved-referencing-imbued-ontological-performance ${ }^{72}-<$ includingvirtue-as-ontology $>$ /morality/ethics/justice/etc. as to presublimation and nascent-sublimations overlapping-contiguity-of-referencing-and-devolved-referencing' associated with human temporal inclination to ${ }^{4}$ historicity-tracing-in-presencing-hyperrealisation/hyperrealtransposition has to do fundamentally with the very nature of human sublimation (notwithstanding its constraint by human limited-mentation-capacity-as-subjecting 'educedmnlimitedness/existence-sublimating nascence' to limitedness/hmman-subpotency). Such a most profound insight about human sublimation in ontological-normalcy/postconvergence as to

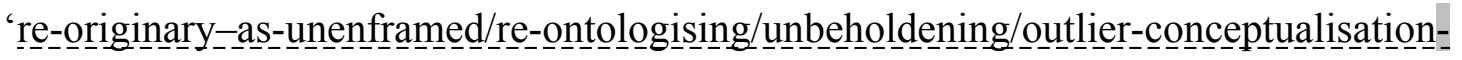


〈imbued-postconverging/dialectical-thinking -'projective-insights'/'epistemic-projection-in-

conflatedness '-of-notional deprocrypticism-prospective-sublimation $\rangle$

intemporal-

disposition supererogatory rescalarisation of ontologisation and value-construction (within any given registry-worldview/dimension ${ }^{79}$ presencing-absolutising-identitive-constitutedness <preconverging 'motif-and-apriorising/axiomatising/referencing'-entailing >-

existentialising — enframing/imprintedness-〈as-to- historicity-tracing —in-presencing-

hyperrealisation/hyperreal-transposition〉) inducing prospective sublimation-over-desublimation meaningfulness-and-teleology infrastructure thus effectively superseding any such given registry-worldview/dimension underpinning-suprasocial-construct prior conception of ontologisation and value-construction' reflects a spontaneous human incipient/seeding sublimation-construct which is underlined by both human-decisionality-<as-to-play-ofvalid/invalid-decisionality-imbued-sublimation/desublimation> and effectively-manifestsublimation/sublime. This spontaneous human incipient/seeding sublimation-construct (underlined as of human-decisionality-<as-to-play-of-valid/invalid-decisionality-imbuedsublimation/desublimation $>\quad$ and effectively-manifest-sublimation/sublime) is incipiently/seedingly reflected in human aestheticisation and aestheticisation-towards-ontology (as to artistic, the philosophical and the scientific/ontological orientations of human meaningfulness-and-teleology ${ }^{\circ}$ ) and as human aestheticisation-and-aestheticisation-towardsontology-<elicited-idiomatisation $>$ translates into defining human Beingdevelopment/ontological-framework-expansion-as-to-depth-of-ontologising-development-asinfrastructure-of- meaningfulness-and-teleology , institutional-development-as-to-socialfunction-development and living-development-as-to-personality-development psychologismic epistemic-acutisation difficulty-for, residualising \{decompulsing delinearity for-cogency> magnitudes $\{$ of-experientiality/experiment\}. This speaks to the fact that 'this spontaneous human incipient/seeding sublimation-construct underlined by human-decisionality-<as-to-play-of- 
valid/invalid-decisionality-imbued-sublimation/desublimation>

and effectively-manifestsublimation/sublime' is the very basis for human limited-mentation-capacity-deepening-assubjecting limitedness/human-subpotency to-'educed-unlimitedness/existence-sublimating nascence' (as to 'human Being-development/ontological-framework-expansion-as-to-depthof-ontologising-development-as-infrastructure-of- meaningfulness-and-teleology , institutional-development-as-to-social-function-development and living-development-as-topersonality-development psychologismic epistemic acutisation difficulty < for, residualising - magnitudes ${ }^{\text {(of-experientiality/experiment }\}}$ '), involving 'aestheticisation-and-aestheticisation-towards-ontology-<elicited-idiomatisation $>$ of human ontological-performance ${ }^{72}-<$ including-virtue-as-ontology>' underlying both 'motif-asto-aestheticisation-<imbued-projective-arbitrariness/waywardness $>$ ' and 'apriorising/axiomatising/referencing/intelligibilitysettingup/measuringinstrumenting-forconceptualisation as to aestheticisation-towards-ontology (so-construed as $<$ amplituding/formative-epistemicity>totalising conflatedness ${ }^{13}$ of ${ }^{56}$ meaningfulness-andteleology involving the 'epistemic-totalising ${ }^{33}$ resubjecting_or_totalisingentailing $\sim$ reconstrual-<of the-whole/purview-of-the-whole/oneness-of-ontology $>$ of motif-asto-aestheticisation- $<$ imbued-projective-arbitrariness/waywardness $>$ to existence-assublimating-withdrawal/unenframing/re-ontologising,-elicited-from-prospective-profoundsupererogation in preconverging/postconverging-rede-mentating/restructuring/reparadigming intelligibility-〈as-to-human-projective/reprojective-aestheticising-re-motif-and-re-

\section{apriorising/re-axiomatising/re-referencing/re-intelligibilitysettingup/re-}

\section{measuringinstrumenting-process,-in-<amplituding formative-}

epistemicity>totalising conceptualisation $\rangle$ ', and so-underscored by the ${ }^{83}$ reference-of-thoughtand- ${ }^{8}$ reference-of-thought- ${ }^{8}$ devolving dynamics of re-motif-and-re-apriorising/reaxiomatising/re-referencing/re-intelligibilitysettingup/re-measuringinstrumenting) of human 
meaningfulness-and-teleology with respect to 'human existential-instantiations of both manifest motif (outcome/outfit/shell—construed-historially-as-of-the-specificallyaestheticised-incrusting/plating/coating-as-institutional-manifestation) and associated/attendant manifest aposteriorising/logicising/deriving/intelligising/measuring ${ }^{56}$ meaningfulness-andteleology 9 Human-decisionality-<as-to-play-of-valid/invalid-decisionality-imbuedsublimation/desublimation $>$ as both incipiently/seedingly and comprehensively so-elucidated (as of human formativeness-<as-to-intersolipsism-ofpreformulating/preframing/premeaningfulness-imbued-mediativity-and-deferentialism>-ofmeaningfulness-and-teleology ) is 'effectively reflected subsumptively in human operative consciousness-by-subconsciousness directedness in existence-as-sublimatingwithdrawal/unenframing/re-ontologising,-elicited-from-prospective-profound-supererogation as eliciting effectively-manifest-sublimation/sublime in existence'. But then this equally points out that human-decisionality-<as-to-play-of-valid/invalid-decisionality-imbuedsublimation/desublimation $>$ is not inherently sublimation even as 'human-decisionality-<as-toplay-of-valid/invalid-decisionality-imbued-sublimation/desublimation $>$ is as of a seemingly inseparable amalgamation with effectively-manifest-sublimation/sublime' as to the fact that effectively-manifest-sublimation/sublime is as to existence-as-sublimatingwithdrawal/unenframing/re-ontologising,-elicited-from-prospective-profound-supererogation as rather unbeholdening to human-subpotency imbued human-decisionality-<as-to-play-ofvalid/invalid-decisionality-imbued-sublimation/desublimation $>$ (even as when humandecisionality-<as-to-play-of-valid/invalid-decisionality-imbued-sublimation/desublimation $>$ in its sublimation-construct induces a convergence to existence-as-sublimatingwithdrawal/unenframing/re-ontologising,-elicited-from-prospective-profound-supererogation for effectively-manifest-sublimation/sublime with regards to such appropriately induced humandecisionality-<as-to-play-of-valid/invalid-decisionality-imbued-sublimation/desublimation>). 
Insightfully thus, all the inherent sublimation-structure that existence-as-sublimatingwithdrawal/unenframing/re-ontologising,-elicited-from-prospective-profound-supererogation can reveal/divulge to human-subpotency is tautologically given as of inherent immanentexistence (as of the-very-same-immanent-existence/intrinsic-reality/ontological-veridicality,-asto-'human<amplituding/formative-epistemicity $>$ totalising $\sim$ purview-of-construal) but then the effective potentiality for human-subpotency grasp of immanent-existence's sublimationstructure (reflected by effectively-manifest-sublimation/sublime) is tied to human-decisionality$<$ as-to-play-of-valid/invalid-decisionality-imbued-sublimation/desublimation> capacity underlied by overall existential-<disontologising/re-ontologising aporeticism $>$ dimensionality-of-sublimating $25<<$ amplituding/formative $>$ supererogatory $\sim$ de-

\section{mentativeness/epistemic-growth-or-conflatedness /transvaluative-}

rationalising/transepistemicity/anamnestic-residuality/spirit-drivenness-equalisation〉

in

ontological-normalcy/postconvergence so-reflected as to 're-originary_-_as-unenenframe-_-_ed/reontologising/unbeholdening/outlier-conceptualisation-_imbued-postconverging/dialectical-

\section{thinking -'projective-insights'/‘epistemic-projection-in-conflatedness ' '-of-}

notional deprocrypticism-prospective-sublimation $\rangle^{0}$ intemporal-disposition supererogatory rescalarisation of ontologisation and value-construction (within any given registryworldview/dimension presencing-absolutising-identitive-constitutedness $<$ preconverging 'motif-and-apriorising/axiomatising/referencing'-entailing $>$ existentialising — enframing/imprintedness-〈as-to- historicity-tracing — in-presencinghyperrealisation/hyperreal-transposition〉) inducing prospective sublimation-over-desublimation meaningfulness-and-teleology infrastructure thus effectively superseding any such given registry-worldview/dimension underpinning-suprasocial-construct prior conception of ontologisation and value-construction'. But then human notional firstnaturednessformativeness-<as-to-eventualising inkling drive-or-seeding misprising $>$ temporal-to- 
intemporal-dispositions- $<$ so-construed-as-from-perspective-ontological-

normalcy/postconvergence $>$ (as to Being-development/ontological-framework-expansion-asto-depth-of-ontologising-development-as-infrastructure-of- meaningfulness-and-teleology , institutional-development-as-to-social-function-development and living-development-as-topersonality-development psychologismic epistemic acutisation difficulty-<or, residualising \{decompulsing $\}$ delinearity-for-cogency> $\quad$ magnitudes $\left.{ }^{\{0 f-e x p e r i e n t i a l i t y / e x p e r i m e n t}\right\}$ necessarily reflect suboptimal human-decisionality-<as-to-play-of-valid/invalid-decisionalityimbued-sublimation/desublimation> capacity due to beholdening-becoming-distortiveoriginariness/distortive-origination-as-to- ${ }^{-}$historicity-tracing inhibited-mental-aestheticising in want for prospective 'bechancing-becoming-originariness/origination-as-tohistoriality/ontological-eventfulness ${ }^{38} /$ ontological-aesthetic-tracing- $<$ perspectiveontological-normalcy/postconvergence-reflected-'epistemicity-relativismdeterminism'> disinhibited-mental-aestheticising sublimation reclamation/recovery from beholdening-becoming - distortive-originariness/distortive-origination-as-to- ${ }^{4}$ historicitytracing inhibited-mental-aestheticising'; and so as to 'human-decisionality-<as-to-play-ofvalid/invalid-decisionality-imbued-sublimation/desublimation> omni-potential commensurability with inherent immanent-existence's sublimation-structure' so-construed as omnipotentiality. However such 'human-decisionality-<as-to-play-of-valid/invaliddecisionality-imbued-sublimation/desublimation> omni-potential commensurability with inherent immanent-existence's sublimation-structure'/omnipotentiality is effectively more fundamentally undermined by the 'taxingness-of-originariness (what has gone before aesthetically structures/paradigms distortedly the possibility for the later aestheticisation) inducing beholdening-becoming - distortive-originariness/distortive-origination-as-tohistoricity-tracing inhibited-mental-aestheticising as reflected with the decoherencingstructure- of- ${ }^{5}$ meaningfulness-and-teleology 9 -for-institutionalisation underlined by the 
'wavering/redounding/waveforming of-the-referencing-and-the-devolved-referencingimbued-ontological-performance ${ }^{2}-<$ including-virtue-as-ontology $>/$ morality/ethics/justice/etc. as to presublimation and nascent-sublimations overlapping-contiguity-of-referencing-anddevolved-referencing'. In other words, human-decisionality-<as-to-play-of-valid/invaliddecisionality-imbued-sublimation/desublimation> capacity (as of its cumulating/recomposuring reproducibility—mathesis/motif/thrownness-disposition,-as-reproducibility-ofaestheticisation) eliciting of corresponding 'effectively-manifest-sublimation/sublime in cumulation/recomposuring as aestheticisation-and-aestheticisation-towards-ontology<elicited-idiomatisation $>$ is so-preconverging/postconverging-dementatively/structurally/paradigmatically defining (implying 'human-decisionality- $<$ as-to-playof-valid/invalid-decisionality-imbued-sublimation/desublimation> omni-potential commensurability with inherent immanent-existence's sublimation-structure'/omnipotentiality). Such human-decisionality-<as-to-play-of-valid/invalid-decisionality-imbuedsublimation/desublimation> omni-potential (as to full-potential of aestheticisation-andaestheticisation-towards-ontology-<elicited-idiomatisation $>$ ) rather corresponds to 'inherent immanent-existence overall withdrawn effectively-manifest-sublimation/sublime or withdrawn sublimation-structure' (so-reflected as of Deleuzian-Bergsonian virtuality 'architectonic/executable/instantiatable backdrop-of-aestheticisation'), as it underlies the fullpotential of human aestheticisation-and-aestheticisation-towards-ontology-<elicitedidiomatisation $>$ (as to overall human 'aestheticisation-and-aestheticisation-towards-ontology$<$ elicited-idiomatisation $>$ as reflecting the extensive manifestable outcomes/outfits/shellsconstrued-historially-as-of-the-specifically-aestheticised-incrusting/plating/coating,-soreflected-as-institutional-manifestations of human ${ }^{56}$ meaningfulness-and-teleology ${ }^{9}$ ') and so beyond just 'prior human historial existentially-instantiated aestheticisation-andaestheticisation-towards-ontology-<elicited-idiomatisation $>$ in their $<$ amplituding/formative- 
epistemicity>-totalising $\sim$ renewing-realisation,-re-perception,-re-thought-in-epistemicconflatedness ${ }^{13}$ '-epistemically-induced/constrained-reproducibility-motif-ofmeaningfulness-and-teleology', Such that 'human-decisionality-<as-to-play-ofvalid/invalid-decisionality-imbued-sublimation/desublimation> omni-potential commensurability with inherent immanent-existence's sublimation-structure'/omnipotentiality is effectively construable as of ontological-normalcy/postconvergence and thus perspectively

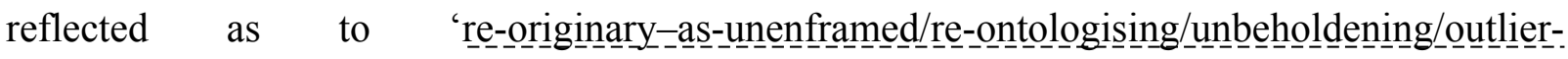
conceptu_ulis_ation____imbued-postconverging/dialectical-thinking -'projective-

\section{insights'/'epistemic-projection-in-conflatedness ' 'of-notional deprocrypticism-prospective-} sublimation> intemporal-disposition supererogatory rescalarisation of ontologisation and value-construction (within any given registry-worldview/dimension ${ }^{79}$ presencing—absolutisingidentitive-constitutedness ${ }^{14}<$ preconverging 'motif-and-apriorising/axiomatising/referencing' entailing $>$-existentialising — enframing/imprintedness-〈as-to- historicity-tracing-inpresencing-hyperrealisation/hyperreal-transposition)) inducing prospective sublimation-overdesublimation ${ }^{56}$ meaningfulness-and-teleology ${ }^{9}$ infrastructure thus effectively superseding any such given registry-worldview/dimension underpinning-suprasocial-construct prior conception of ontologisation and value-construction'. This elucidation of human-decisionality- $<$ as-to-playof-valid/invalid-decisionality-imbued-sublimation/desublimation> and effectively-manifestsublimation/sublime as underlying human sublimation-construct is very much insightful for grasping-and-analysing the issues involved with prospective human postconverging aporeticism-overcoming/mnovercoming (human-subpotencyaporia/undecidability/dilemma/ought-indeterminacy/deficiency/limitation/constraint) as to prospective desublimation, so-reflected with the 'wavering/redounding/waveforming - of-thereferencing-and-the-devolved-referencing-imbued-ontological-performance ${ }^{72}-<$ including- $^{-}$ virtue-as-ontology $>$ /morality/ethics/justice/etc. as to presublimation and nascent-sublimations 
overlapping-contiguity-of-referencing-and-devolved-referencing'; and so in the sense that effectively-manifest-sublimation/sublime as strongly associated with nascent-sublimations (nascent-particular/incipient-and-material/technical-sublimations- $<$ blinded-to-their-relativeontological-completeness - reference-of-thought- devolving $>$ ) induced as to existence-assublimating-withdrawal/unenframing/re-ontologising,-elicited-from-prospective-profoundsupererogation , do not necessarily imply holding-forth referencing/registering/decisioning as from such nascent-human-decisionality-induced-sublimation- $<$ of-blinded-relative-ontologicalcompleteness -imbued,-supererogatory reference-of-thought/grandest-axiomaticconstruct - as-to-referencing/registering/decisioning > but are rather instigatingly referenced/registered/decisioned by the overall underpinning-suprasocial-construct as to the (relative-ontological-incompleteness ${ }^{88}$ presublimating ${ }^{83}$ reference-of-thought/grandestaxiomatic-construct — as-to-referencing/registering/decisioning) presublimation-humandecisionality-induced-desublimation, and so as to a 'prospective ontologically-flawed presublimation-human-decisionality-induced-desublimation usurpation-of/substitution-for nascent-human-decisionality-induced-sublimation- $<$ of-blinded-relative-ontologicalcompleteness -imbued,-supererogatory reference-of-thought/grandest-axiomaticconstruct - as-to-referencing/registering/decisioning $>$ in the overall prospective human sublimation-construct' so-construed as ${ }^{51}$ incrementalism-in-relative-ontologicalincompleteness ${ }^{8}$ — enframed/disontologising conceptualisation (and so-reflected as of human Being-development/ontological-framework-expansion-as-to-depth-of-ontologisingdevelopment-as-infrastructure-of- meaningfulness-and-teleology , institutionaldevelopment-as-to-social-function-development and living-development-as-to-personalitydevelopment psychologismic epistemic acutisation difficulty < for, residualising \{decompulsing $\}$ delinearity for-cogeney>-magnitudes $\{$ of-experientiality/experiment $\}$ ) over ${ }^{55}$ maximalisingrecomposuring-for-relative-ontological-completeness ${ }^{87}$ - unenframed/re- 
ontologising conceptualisation for effectively-manifest-sublimation/sublime of nascenthuman-decisionality-induced-sublimation-<of-blinded-relative-ontological-completeness imbued,-supererogatory reference-of-thought/grandest-axiomatic-construct-as-toreferencing/registering/decisioning $>$ necessary for re-ontologising prospective Beingdevelopment/ontological-framework-expansion-as-to-depth-of-ontologising-development-asinfrastructure-of- meaningfulness-and-teleology psychologismic epistemic-acutisation difficulty <for, residualising_\{decompulsing\} ${ }^{\text {delinearity for-cogency> }}$ magnitude $\{$ ofexperientiality/experiment $\}$ and its induced prospective institutional-development-as-to-social-functiondevelopment and living-development-as-to-personality-development psychologismic epistemic-acutisation difficulty-for, residualising \{decompulsing $\}$ delinearity for-cogency> magnitudes ${ }^{\{0 f-e x p e r i e n t i a l i t y / e x p e r i m e n t\}}$ as underlined in ontological-normalcy/postconvergence soreflected as to 're-originary_-as-unenframed/re-ontologising/_unbeheholdenning/outlier-_conceptualisation___imbued-postconverging/dialectical-thinking -'projectiveinsights'/'epistemic-projection-in-conflatedness ' -of-notional deprocrypticism-prospectivesublimation intemporal-disposition supererogatory rescalarisation of ontologisation and value-construction (within any given registry-worldview/dimension ${ }^{79}$ presencing—absolutisingidentitive-constitutedness ${ }^{14}$ <preconverging 'motif-and-apriorising/axiomatising/referencing' entailing $>$-existentialising — enframing/imprintedness-〈as-to- historicity-tracing —inpresencing-hyperrealisation/hyperreal-transposition〉) inducing prospective sublimation-overdesublimation ${ }^{56}$ meaningfulness-and-teleology ${ }^{9}$ infrastructure thus effectively superseding any such given registry-worldview/dimension underpinning-suprasocial-construct prior conception of ontologisation and value-construction'. This opened and unaccounted nature of nascenthuman-decisionality-induced-sublimation-<of-blinded-relative-ontological-completeness imbued,-supererogatory reference-of-thought/grandest-axiomatic-construct - as-toreferencing/registering/decisioning $>$ as underlying effectively-manifest-sublimation/sublime as 

prospective-profound-supererogation , implies that institutionalised human-decisionality- $<$ asto-play-of-valid/invalid-decisionality-imbued-sublimation/desublimation $>$ is inevitably caught up with '(relative-ontological-incompleteness ${ }^{88}$ presublimating ${ }^{83}$ reference-of-thought/grandestaxiomatic-construct — as-to-referencing/registering/decisioning) presublimation-humandecisionality-induced-desublimation' when it strives prospectively to be reflective of 'effectively-manifest-sublimation/sublime as to existence-as-sublimatingwithdrawal/unenframing/re-ontologising,-elicited-from-prospective-profoundsupererogation"; and so as to a 'prospective ontologically-flawed presublimation-humandecisionality-induced-desublimation usurpation-of/substitution-for nascent-humandecisionality-induced-sublimation- $<$ of-blinded-relative-ontological-completeness -imbued,supererogatory reference-of-thought/grandest-axiomatic-construct-as-toreferencing/registering/decisioning $>$ in the overall prospective human sublimation-construct' as incrementalism-in-relative-ontological-incompleteness ${ }^{88}$ enframed/disontologising conceptualisation; reflected with the nascent-human-decisionalityinduced-sublimation-<of-blinded-relative-ontological-completeness -imbued,-

supereregary reference-of-thought/grandest-axiomatic-construct-as-toreferencing/registering/decisioning $>$ prospective desublimation so-elicited by presublimationhuman-decisionality-induced-desublimation, and manifested as of ${ }^{4}$ historicity-tracing-inpresencing-hyperrealisation/hyperreal-transposition (as to ${ }^{47}$ historicity-tracing-in-presencinghyperrealisation/hyperreal-transposition numb-_bing-tract meaningfulnes 'supererogatory acuity/perspicacity/astuteness/edginess/incisiveness-as-to-the-imbuedpostconverging/dialectical-thinking -of-notional deprocrypticism-\{in-dimensionality-ofsublimating _ < amplituding/formative-epistemicity $>$ growth-or- 
conflatedness /scalarisation-as-to-rescalarisation-as-re-ontologisation $\left.\left.\}^{\prime}\right\rangle\right)$. Most fundamental to

'human-decisionality-<as-to-play-of-valid/invalid-decisionality-imbuedsublimation/desublimation> omni-potential commensurability with inherent immanentexistence's sublimation-structure'/omnipotentiality thus is the pretense to being as to existence — as-sublimating-withdrawal/unenframing/re-ontologising,-elicited-fromprospective-profound-supererogation in inducing prospective effectively-manifestsublimation/sublime, and such a pretense is exactly what underlies overall human ontologicalcommitment $-<$ implied — self-assuredness-of-ontological-good-

\section{faith/authenticity $\sim$ postconverging-de-mentating/structuring/paradigming -as-being-as-of-}

existential-reality $>$ as to the possibility for prospective sublimation-over-desublimation (soimplied with the self-assuredness-of-ontological-good-faith/authenticity ${ }^{6} \sim$ postconverging-dementating/structuring/paradigming 70 -as-being-as-of-existential-reality with respect to socialstake-contention-or-confliction underlying human ontological-commitment $-<$ implied - selfassuredness-of-ontological-good-faith/authenticity $\sim$ postconverging-de-

mentating/structuring/paradigming -as-being-as-of-existential-reality $>$ ); such that all presencing-distorted-meritocracy/totalising-sovereign-apportioning-of-human-ontologicalperformance ${ }^{2}$-<including-virtue-as-ontology $>$ /morality/ethics/justice/etc. terms-as-ofaxiomatic-construct of '<amplituding/formative>disposedness/psychologismic-construct-〈asto-orientation/value-construct/valuation-and-derived-parameterising $\rangle$ and ontologisation' as so-reflected by their underpinning-suprasocial-construct (historially involving 'dominance/vested-interest structure in relative-ontological-incompleteness ${ }^{88}$-presublimationconstruct-of- ${ }^{5}$ meaningfulness-and-teleology desublimating existentialising-decisionality<as-to-disontologising/re-ontologising aporeticism $>^{\prime}$ as from blatant brutish conquest/subjugation conception of apportioning, dominion protection conception of apportioning, to the very natural-order-of-things conception of apportioning and to our subtle 
modern-day institutionally-distorted/disjointed conception of apportioning) are effectively obligated to their 'self-assuredness-of-ontological-good-faith/authenticity $\sim$ postconvergingde-mentating/structuring/paradigming -as-being-as-of-existential-reality with respect to social-

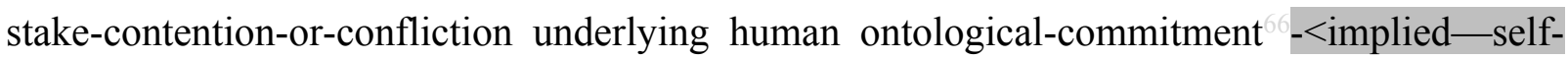
assuredness-of-ontological-good-faith/authenticity postconverging-dementating/structuring/paradigming -as-being-as-of-existential-reality >' in being epistemictotalisingly 33 /acutely-resubjectable to existence-as-sublimating-withdrawal/unenframing/reontologising,-elicited-from-prospective-profound-supererogation for inducing prospective effectively-manifest-sublimation/sublime (thus explaining the possibility for prospective human transcendence-and-sublimity/sublimation/supereregatory $\sim$ de-mentativity as of: humansubpotency 'fatedness-of-sublimation-over-desublimation to existence-potency $\sim$ sublimatingnascence,-disclosed-from-prospective-epistemic-digression in reflecting holographically$<$ conjugatively-and-transfusively $>$ the relative-unreflexivity/relative-reflexivity - ontologicalcontiguity $\sim$ of-the-human-institutionalisation-process '). However, human limited-mentationcapacity —as-subjecting 'educed-unlimitedness/existence-sublimating nascence' tolimitedness/human-subpotency as it induces human notional firstnaturedness-formativeness<as to eventulising inkling drive or seeding misprising $>$ temporal-to-intemporaldispositions- $<$ so-construed-as-from-perspective-ontological-normalcy/postconvergence $>$ with respect to human ontological-performance ${ }^{72}-$ including-virtue-as- $^{2}$ ontology $>$ /morality/ethics/justice/etc. is effectively the critical preconverging/postconvergingde-mentative/structural/paradigmatic impediment to human omnipotentiality but that said the possibility for human limited-mentation-capacity-deepening-as-subjecting limitedness/human-subpotency to 'educed unlimitedness/existence-sublimating nascence' equally what critically renders the elucidation of human omni-potential pertinent and vital (as herein undertaken beyond any ${ }^{79}$ presencing-absolutising-identitive-constitutedness 
perspective in

$<$ amplituding/formative-epistemicity $>$ totalising $\sim$ self-referencingsyncretising/circularity/interiorising/akrasiatic-drag ${ }^{34}$, as to social-vestedness/normativity$<$ discretely-implied-functionalism $>$ historicity-tracing - in-presencinghyperrealisation/hyperreal-transposition but rather enabling the construing of the more ontologically-veridical perspective allowing for prospective ${ }^{4}$ historiality/ontologicaleventfulness ${ }^{38} /$ ontological-aesthetic-tracing-<perspective-ontologicalnormalcy/postconvergence-reflected-‘epistemicity-relativism-determinism’>). From this insight what effectively underlies 'human-decisionality-<as-to-play-of-valid/invalid-decisionalityimbued-sublimation/desublimation> as to the prospect for omnipotentiality' (as reflecting the sublimating possibility for prospective 'bechancing-backdrop of ${ }^{6}$ nonpresencing- $<$ perspectiveontological-normalcy/postconvergence>' as to 'bechancing-becomingoriginariness/origination-as-to- ${ }^{4}$ historiality/ontological-eventfulness 3 /ontological-aesthetictracing-<perspective-ontological-normalcy/postconvergence-reflected-‘epistemicityrelativism-determinism'> disinhibited-mental-aestheticising sublimation reclamation/recovery

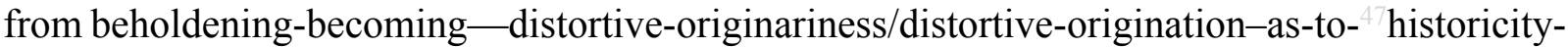
tracing inhibited-mental-aestheticising') is in successive absolutely-disruptive hierarchicalordering: the implications of existence-as-sublimating-withdrawal/unenframing/reontologising,-elicited-from-prospective-profound-supererogation ${ }^{6}$ (as can be so-constrained as of ‘<amplituding/formative-epistemicity $>$ totalising/circumscribing/delineating foregrounding_entailment-<in-succession-of-profound-supererogation $>-$ - $>$ postconvergingnarrowing-down $\sim$ sublimation-as-to-'existence - as-sublimating-withdrawal/unenframing/reontologising,-elicited-from-prospective-profound-supererogation '-in-reflecting‘immanent relative-unreflexivity/relative-reflexivity ontological-contiguity ';-as-operativenotional deprocrypticism $\rangle$ so-reflecting $<$ amplituding/formative>disposedness/psychologismic-construct-〈as-to-orientation/value- 
construct/valuation-and-derived-parameterising $\rangle$ and $<$ amplituding/formative $>$ entailment-〈asto-totalising-contiguous/coherent-factuality-of-variability)), then ${ }^{79}$ presencing-absolutisingidentitive-constitutedness ${ }^{14}$ <preconverging 'motif-and-apriorising/axiomatising/referencing'entailing >-existentialising — enframing/imprintedness-〈as-to- historicity-tracing —inpresencing-hyperrealisation/hyperreal-transposition〉 social-vestedness/normativity$<$ discretely-implied-functionalism $>$, followed by dominance/vested-interest—drivenness- $<$ asto-its-direct/indirect-eliciting-by-or-exploiting-of-prospectively-descalarising/subontologisingsycophantic-sophistic-interests,-as-inducing-prospective-threshold-of-institutional-and-socialdesublimation>, and finally generalised social apprehension of the possibility for prospective reontologisation (however the merits of their underlying case); as to the fact that ${ }^{103}$ universaltransparency ${ }^{104}$-〈transparency-of-totalising-entailing,-as-to-entailing-<amplituding/formativeepistemicity>totalising in-relative-ontological-completeness > over blurriness$<$ sterilising/anecdotalising/trivialising-of-prospective-re-ontologising_by-preconverging,-indisontologising-formulaic-dragging-out/hollowing-out> with regards to elucidated sublimating/emancipating implications as to existence-as-sublimatingwithdrawal/unenframing/re-ontologising,-elicited-from-prospective-profound-supererogation (reflecting 'Derridean underdetermination-imbued force/violence conception' and 'Foucauldian knowledge/power conception construed as knowledge-empowerment/ignorancedisempowerment'), have the effect of overcoming generalised social apprehension of the possibility for prospective re-ontologisation while undermining desublimating ${ }^{7}$ presencingabsolutising-identitive-constitutedness $<$ preconverging ' motif-andapriorising/axiomatising/referencing'-entailing >-existentialising —enframing/imprintedness〈as-to- historicity-tracing-in-presencing-hyperrealisation/hyperreal-transposition〉 socialvestedness/normativity- $<$ discretely-implied-functionalism $>$ and dominance/vested-interestdrivenness-<as-to-its-direct/indirect-eliciting-by-or-exploiting-of-prospectively- 
descalarising/subontologising-sycophantic-sophistic-interests,-as-inducing-prospective-

threshold-of-institutional-and-social-desublimation>, noting however that such ${ }^{103}$ universaltransparency ${ }^{104}$-〈transparency-of-totalising-entailing,-as-to-entailing-<amplituding/formativeepistemicity>totalising in-relative-ontological-completeness > elucidated sublimating/emancipating implications as from the 'absolutely-disruptive hierarchical-order implied as to the implications of existence-as-sublimating-withdrawal/unenframing/reontologising,-elicited-from-prospective-profound-supererogation is more precisely about the opening-up of 'desublimating presencing-absolutising-identitive-constitutedness $<$ preconverging 'motif-and-apriorising/axiomatising/referencing'-entailing >existentialising — enframing/imprintedness-〈as-to- historicity-tracing-in-presencinghyperrealisation/hyperreal-transposition $\rangle$ social-vestedness/normativity-<discretely-impliedfunctionalism $>$ and dominance/vested-interest—drivenness-<as-to-its-direct/indirect-elicitingby-or-exploiting-of-prospectively-descalarising/subontologising-sycophantic-sophisticinterests,-as-inducing-prospective-threshold-of-institutional-and-social-desublimation> ${ }^{\prime} \quad$ to prospective ontological-veracity as of re-ontologisation of ${ }^{56}$ meaningfulness-and-teleology ${ }^{9}$ to the extent that such 'prior desublimating 79 presencing—absolutising-identitive-constitutedness $<$ preconverging 'motif-and-apriorising/axiomatising/referencing'-entailing $>$ existentialising — enframing/imprintedness-〈as-to- historicity-tracing - in-presencinghyperrealisation/hyperreal-transposition $\rangle$ social-vestedness/normativity-<discretely-impliedfunctionalism $>$ and dominance/vested-interest—drivenness-<as-to-its-direct/indirect-elicitingby-or-exploiting-of-prospectively-descalarising/subontologising-sycophantic-sophisticinterests,-as-inducing-prospective-threshold-of-institutional-and-social-desublimation>' preconverging/postconverging-de-mentatively/structurally/paradigmatically reflects 'prospective ontologically-flawed presublimation-human-decisionality-induced-desublimation usurpation-of/substitution-for nascent-human-decisionality-induced-sublimation-<of-blinded- 
relative-ontological-completeness -imbued,-supererogatory reference-of-thought/grandestaxiomatic-construct - as-to-referencing/registering/decisioning $>$ in the overall prospective human sublimation-construct' as 'incrementalism-in-relative-ontological-incompleteness ${ }^{8}$ enframed/disontologising conceptualisation. Omnipotentiality as both incipiently/seedingly and comprehensively 'effectively reflected subsumptively in human operative consciousness-bysubconsciousness directedness in existence-as-sublimating-withdrawal/unenframing/reontologising,-elicited-from-prospective-profound-supererogation as eliciting effectivelymanifest-sublimation/sublime in existence' (as of human Being-development/ontologicalframework-expansion-as-to-depth-of-ontologising-development-as-infrastructure-ofmeaningfulness-and-teleology , institutional-development-as-to-social-functiondevelopment and living-development-as-to-personality-development psychologismic epistemic-acutisation difficulty-for, residualising \{decompulsing\} delinearity for-cogency> magnitudes $\{$ of-experientiality/experiment $\}$, is underlined by a psychological-disposition to supererogatory unbeholdening-conflatedness ${ }^{13}$ (bound to a ${ }^{4}$ historiality/ontologicaleventfulness $3 \%$ ontological-aesthetic-tracing-<perspective-ontologicalnormalcy/postconvergence-reflected-‘epistemicity-relativism-determinism'> formativeness$<$ as-to-intersolipsism-of-preformulating/preframing/premeaningfulness-imbued-mediativityand-deferentialism $>$-of- meaningfulness-and-teleology of intemporal-projection) over a psychological-disposition to relic/artifactual-beholdening-constitutedness ${ }^{14}$ (bound to a historicity-tracing-in-presencing-hyperrealisation/hyperreal-transposition formativeness$<$ as-to-intersolipsism-of-preformulating/preframing/premeaningfulness-imbued-mediativityand-deferentialism $>$-of- meaningfulness-and-teleology of destructuring-threshold〈uninstitutionalised-threshold /presublimating-desublimating-decisionality $\rangle$ of-ontologicalperformance ${ }^{2}$-<including-virtue-as-ontology $>$ /morality/ethics/justice/etc. temporaldispositions projection); as to the fact that 'existence-as-sublimating- 
withdrawal/unenframing/re-ontologising,-elicited-from-prospective-profound-supererogation as eliciting effectively-manifest-sublimation/sublime in existence' is unbeholdening to 'human psychological-disposition to relic/artifactual-beholdening-constitutedness ${ }^{1,}$ with the fullpotential for 'inherent immanent-existence overall withdrawn effectively-manifestsublimation/sublime or withdrawn sublimation-structure' rather lying with 'human psychological-disposition to supereregatery-unbeholdening-conflatedness ${ }^{13}{ }^{3}$. But then the very 'aestheticisation-and-aestheticisation-towards-ontology-<elicited-idiomatisation $>$ of human ontological-performance ${ }^{72}-<$ including-virtue-as-ontology>' takes form as of 'relic/artifactualbeholdening-constitutedness $^{14}$ secondnatured reproducibility—mathesis/motif/thrownnessdisposition,-as-reproducibility-of-aestheticisation', speaking to the requisite projective apriorising/axiomatising/referencing-\{of-'prospectively_implicited_attendant-ontologicalcontiguity ' $\sim$ educedexistentialising/contextualising/textualising_'intelligibility/epistemicity/reflexivity-contiguity<imbued-notional cogency>' $\}$-re-originariness/re-origination of 'supererogatory unbeholdening-conflatedness ${ }^{3} \quad$ originariness-parrhesia,-as-spontaneity-ofaestheticisation' as from prior 'relic/artifactual-beholdening-constitutedness ${ }^{14}$ secondnatured reproducibility—-mathesis/motif/thrownness-disposition,-as-reproducibility-ofaestheticisation' for convergence towards omnipotentiality (so-construed as reflecting the sublimating possibility for prospective 'bechancing-backdrop of ${ }^{6}$ nonpresencing-<perspectiveontological-normalcy/postconvergence>' as to 'bechancing-becoming-

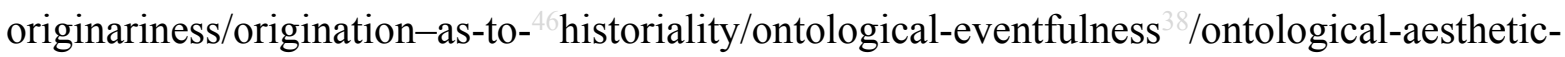
tracing-<perspective-ontological-normalcy/postconvergence-reflected-'epistemicityrelativism-determinism'> disinhibited-mental-aestheticising sublimation reclamation/recovery from beholdening-becoming - distortive-originariness/distortive-origination-as-to- ${ }^{4}$ historicitytracing inhibited-mental-aestheticising'). Such an exercise of human convergence towards 
omnipotentiality is critically analysable as to the preconverging/postconverging-dementative/structural/paradigmatic human-subpotency seeding/incipient 'relic/artifactualbeholdening-constitutedness ${ }^{14}{ }^{4}$ historicity-tracing-in-presencing-hyperrealisation/hyperrealtransposition formativeness-<as-to-intersolipsism-ofpreformulating/preframing/premeaningfulness-imbued-mediativity-and-deferentialism>-ofmeaningfulness-and-teleology ' disconvergence with the 'full-potency of existence ontological-normalcy/postconvergence construable as of supererogatory unbeholdeningconflatedness historiality/ontological-eventfulness 38 /ontological-aesthetic-tracing<perspective-ontological-normalcy/postconvergence-reflected-‘epistemicity-relativismdeterminism'> reflecting effectively-manifest-sublimation/sublime'. At issue thus when it comes to 'aestheticisation-and-aestheticisation-towards-ontology-<elicited-idiomatisation $>$ of

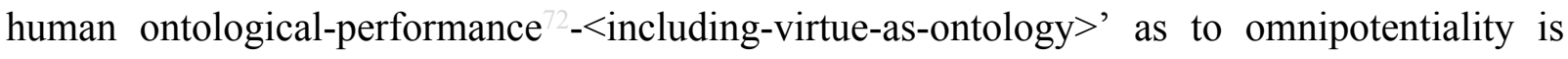
ever critically human capacity for psychoanalytic-unshackling/memetic-reordering/institutionalrecomposuring in an aestheticisation-and-aestheticisation-towards-ontology-<elicitedidiomatisation $>$ relation to social-stake-contention-or-confliction (as of supereregatery unbeholdening-conflatedness historiality/ontologicaleventfulness 3 /ontological-aesthetic-tracing-<perspective-ontologicalnormalcy/postconvergence-reflected-‘epistemicity-relativism-determinism'> so-implied as of notional ${ }^{1}$ deprocrypticism) capable of superseding prior human-subpotency 'relic/artifactualbeholdening-constitutedness ${ }^{14}{ }^{4}$ historicity-tracing-in-presencing-hyperrealisation/hyperrealtransposition formativeness-<as-to-intersolipsism-ofpreformulating/preframing/premeaningfulness-imbued-mediativity-and-deferentialism>-ofmeaningfulness-and-teleology , and reflecting the reality of human notional firstnaturednessformativeness-<as-to-eventualising-inkling-drive-or-seeding-misprising $>$ temporal-tointemporal-dispositions-<so-construed-as-from-perspective-ontological- 
normalcy/postconvergence $>$ as 'prospectively distorting/undermining the equanimity/balance of human theoretical-conceptual-operant institutionalised-conceptualisations' inducing prospective 'desublimating 79 presencing - absolutising-identitive-constitutedness ${ }^{14}<$ preconverging 'motifand-apriorising/axiomatising/referencing'-entailing>-existentialising-

enframing/imprintedness-〈as-to- historicity-tracing - in-presencing-

hyperrealisation/hyperreal-transposition $\rangle$ social-vestedness/normativity-<discretely-impliedfunctionalism $>$ and dominance/vested-interest—drivenness-<as-to-its-direct/indirect-elicitingby-or-exploiting-of-prospectively-descalarising/subontologising-sycophantic-sophisticinterests,-as-inducing-prospective-threshold-of-institutional-and-social-desublimation>'. The messianic and parrhesiastic ontological-veracity of human $<$ amplituding/formative>disposedness/psychologismic-construct-〈as-to-orientation/valueconstruct/valuation-and-derived-parameterising) (as to 'prospective/nascent relativeontological-completeness reference-of-thought/grandest-axiomatic-construct-as-toreferencing/registering/decisioning unbeholdening-conflatedness ${ }^{13}$ projectiveinsights as of notional ' deprocrypticism' underlying the overall: human-subpotency 'fatednessof-sublimation-over-desublimation to existence-potency $\sim$ sublimating-nascence,-disclosedfrom-prospective-epistemic-digression in reflecting holographically-<conjugatively-andtransfusively $>$ the relative-unreflexivity/relative-reflexivity ontological-contiguity $\sim$ of-thehuman-institutionalisation-process '), is effectively reflected by the fact that all presencingdistorted-meritocracy/totalising-sovereign-apportioning_of-human-ontological-

performance ${ }_{2}$ - including-virtue-as-ontology $>$ /morality/ethics/justice/etc. terms-as-ofaxiomatic-construct of '<amplituding/formative $>$ disposedness/psychologismic-construct-〈asto-orientation/value-construct/valuation-and-derived-parameterising $\rangle$ and ontologisation' as so-reflected by their underpinning-suprasocial-construct (historially involving 'dominance/vested-interest structure in relative-ontological-incompleteness ${ }^{8}$-presublimation- 
construct-of- ${ }^{5}$ meaningfulness-and-teleology desublimating existentialising-decisionality<as-to-disontologising/re-ontologising aporeticism $>^{\prime}$ as from blatant brutish conquest/subjugation conception of apportioning, dominion protection conception of apportioning, to the very natural-order-of-things conception of apportioning and to our subtle modern-day institutionally-distorted/disjointed conception of apportioning) are rather manifestations of 'relic/artifactual-beholdening-constitutedness ${ }^{14}{ }^{79}$ presencing-absolutisingidentitive-constitutedness ${ }^{14}<$ preconverging 'motif-and-apriorising/axiomatising/referencing' entailing $>$-existentialising — enframing/imprintedness-〈as-to- historicity-tracing - inpresencing-hyperrealisation/hyperreal-transposition)' and are incapable (as of their given terms-as-of-axiomatic-construct of '< $<$ mplituding formative $>$ disposedness/psychologismicconstruct-〈as-to-orientation/value-construct/valuation-and-derived-parameterising $\quad$ and ontologisation') of ontologically accounting for the overall relative-unreflexivity/relativereflexivity - ontological-contiguity ${ }^{67} \sim$ of-the-human-institutionalisation-process ${ }^{68}$ and its prospective sublimating/emancipating possibilities as to convergence towards omnipotentiality. Insightfully, we can thus construe of 'our subtle modern-day institutionally-distorted/disjointed conception of apportioning human-decisionality-<as-to-play-of-valid/invalid-decisionalityimbued-sublimation/desublimation>' (as of its ${ }^{79}$ presencing-absolutising-identitiveconstitutedness $<$ preconverging 'motif-and-apriorising/axiomatising/referencing'entailing $>$-existentialising — enframing/imprintedness-〈as-to- historicity-tracing — inpresencing-hyperrealisation/hyperreal-transposition〉 'relic/artifactual-beholdeningconstitutedness ${ }^{14}{ }^{4}$ historicity-tracing-in-presencing-hyperrealisation/hyperreal-transposition formativeness-<as-to-intersolipsism-of-preformulating/preframing/premeaningfulness-imbuedmediativity-and-deferentialism>-of- meaningfulness-and-teleology ') as the preconverging/postconverging-de-mentative/structural/paradigmatic impediment for prospective effectively-manifest-sublimation/sublime as of nascent-human-decisionality- 
induced-sublimation-<of-blinded-relative-ontological-completeness -imbued,-

supererogatory reference-of-thought/grandest-axiomatic-construct - as-to-

referencing/registering/decisioning>; as reflected with modern-day defaulting institutional structures and processes (as 'prospectively distorting/undermining the equanimity/balance of human theoretical-conceptual-operant institutionalised-conceptualisations' inducing prospective 'desublimating 79 presencing—absolutising-identitive-constitutedness ${ }^{14}<$ preconverging $\sim$ 'motifand-apriorising/axiomatising/referencing'-entailing >-existentialising-

enframing/imprintedness-〈as-to- historicity-tracing - in-presencing-

hyperrealisation/hyperreal-transposition $\rangle$ social-vestedness/normativity-<discretely-impliedfunctionalism $>$ and dominance/vested-interest—drivenness-<as-to-its-direct/indirect-elicitingby-or-exploiting-of-prospectively-descalarising/subontologising-sycophantic-sophisticinterests,-as-inducing-prospective-threshold-of-institutional-and-social-desublimation>') and thus failing 'prospective/nascent relative-ontological-completeness ${ }^{87}$ reference-ofthought/grandest-axiomatic-construct — as-to-referencing/registering/decisioning supererogatory unbeholdening-conflatedness ${ }^{13} \quad$ projective-insights as of notional ${ }^{18}$ deprocrypticism' as underlying the overall: human-subpotency 'fatedness-ofsublimation-over-desublimation to existence-potency sublimating-nascence,-disclosed-fromprospective-epistemic-digression in reflecting holographically-<conjugatively-andtransfusively $>$ the relative-unreflexivity/relative-reflexivity ontological-contiguity $\sim$ of-thehuman-institutionalisation-process '. In this respect, an ontological-normalcy/postconvergence epistemic-projective perspective of omnipotentiality points to the relic/artifactual-beholdeningconstitutedness ${ }^{14}{ }^{4}$ historicity-tracing-in-presencing-hyperrealisation/hyperreal-transposition of modern-day human-decisionality-<as-to-play-of-valid/invalid-decisionality-imbuedsublimation/desublimation $>$ preconvergingly-de-mentated/structured/paradigmed as to its ricocheting beholdening all the way from the very 'international overarching order of social- 
stakes-contention-or-confliction

$<$ preconverging 'motif-and-

apriorising/axiomatising/referencing'-entailing>-existentialising — enframing/imprintedness-

〈as-to- historicity-tracing - in-presencing-hyperrealisation/hyperreal-transposition〉,

ricocheting-with 'nation-states overarching orders of social-stakes-contention-or-confliction $<$ preconverging $\sim$ 'motif-and-apriorising/axiomatising/referencing'-entailing >-

existentialising — enframing/imprintedness-〈as-to- historicity-tracing — in-presencing-

hyperrealisation/hyperreal-transposition〉', ricocheting-with 'intrastatal/communal orders of social-stakes-contention-or-confliction

$<$ preconverging $\sim$ 'motif-andapriorising/axiomatising/referencing'-entailing>-existentialising-enframing/imprintedness〈as-to- historicity-tracing-in-presencing-hyperrealisation/hyperreal-transposition〉' and as interspersed ricochettingly with 'corporate/institutional orders of social-stakes-contention-orconfliction $\quad<$ preconverging $\sim$ 'motif-and-apriorising/axiomatising/referencing'-entailing >existentialising — enframing/imprintedness-〈as-to- historicity-tracing - in-presencinghyperrealisation/hyperreal-transposition〉' (speaking to a relic/artifactual-beholdeningconstitutedness ${ }^{14}{ }^{4}$ historicity-tracing-in-presencing-hyperrealisation/hyperreal-transposition ricocheting hierarchisation) in-many-ways inducing preconverging/postconverging-dementative/structural/paradigmatic limits to abstract 'human-decisionality-<as-to-play-ofvalid/invalid-decisionality-imbued-sublimation/desublimation> omni-potential commensurability with inherent immanent-existence's sublimation-structure'/omnipotentiality, and so as to the various orders respective-and-dynamically instilled 'desublimating presencing-absolutising-identitive-constitutedness $<$ preconverging 'motif-andapriorising/axiomatising/referencing'-entailing >-existentialising-enframing/imprintedness〈as-to- historicity-tracing-in-presencing-hyperrealisation/hyperreal-transposition〉 socialvestedness/normativity- $<$ discretely-implied-functionalism $>$ and dominance/vested-interestdrivenness-<as-to-its-direct/indirect-eliciting-by-or-exploiting-of-prospectively- 


\section{descalarising/subontologising-sycophantic-sophistic-interests,-as-inducing-prospective-}

threshold-of-institutional-and-social-desublimation>'. This elucidation of omnipotentiality while highly abstract is effectively the 'epistemic totalising unenframable conception for convergence towards omnipotentiality' as of a conceptualisation not caught up in ${ }^{79}$ presencingabsolutising-identitive-constitutedness ${ }^{14}$ in order to articulate a fundamental framework for ontological-veracity elucidation; and so, as of maximalising-recomposuring-for-relativeontological-completeness ${ }^{87}$ - unenframed/re-ontologising conceptualisation for effectivelymanifest-sublimation/sublime of nascent-human-decisionality-induced-sublimation- $<$ ofblinded-relative-ontological-completeness -imbued,-supererogatory reference-ofthought/grandest-axiomatic-construct — as-to-referencing/registering/decisioning $>$ necessary for re-ontologising prospective Being-development/ontological-framework-expansion-as-todepth-of-ontologising-development-as-infrastructure-of- meaningfulness-and-teleology psychologismic epistemic-acutisation difficulty-for, residualising

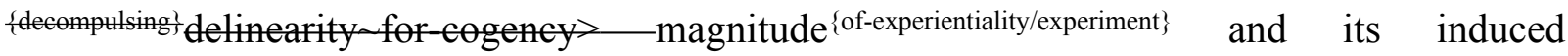
prospective institutional-development-as-to-social-function-development and livingdevelopment-as-to-personality-development psychologismic epistemic-acutisationdiffieulty< <er, residualising \{decompulsing\} delinearity for cogeney> magnitudes $\{$ ofexperientiality/experiment\} as underlined in ontological-normalcy/postconvergence so-reflected as to 'reoriginary_-as-unenframed/re-ontologising/unbeholdening/outlier-conceptualisation-_imbuedpostconverging/dialectical-thinking -'projective-insights'/‘epistemic-projection-inconflatedness ${ }^{\prime}$-of-notional deprocrypticism-prospective-sublimation $\rangle$ intemporaldisposition supererogatory rescalarisation of ontologisation and value-construction (within any given registry-worldview/dimension presencing-absolutising-identitive-constitutedness <preconverging 'motif-and-apriorising/axiomatising/referencing'-entailing >existentialising — enframing/imprintedness-〈as-to- historicity-tracing_-in-presencing- 
hyperrealisation/hyperreal-transposition〉) inducing prospective sublimation-over-desublimation meaningfulness-and-teleology infrastructure thus effectively superseding any such given registry-worldview/dimension underpinning-suprasocial-construct prior conception of ontologisation and value-construction'. That said, human-subpotency reifying-and-empoweringreflexivity-of-ecstatic-existence-as-panintelligibility/panreflexivity ${ }^{3}$-〈existentially-imbuedand-educing-< $<$ fepistemic-

thermeneutically/textually/reprojectingly/supererogatingly/zeroingly/re-acutingly,$\{$ decompulsing\} delinearity for-cogency $>$-epistemic-perspective-of-projective/reprojectiveaestheticising-re-motif-and-re-apriorising/re-axiomatising/re-referencing $\sim$ conceptualisation-as-herein-specifically-relevant-to human-subpotency) in reflecting the overall relativeunreflexivity/relative-reflexivity — ontological-contiguity ${ }^{67}$ of-the-human-institutionalisationprocess ${ }^{68}$, underscores that the effective mechanism for overcoming 'relic/artifactualbeholdening-constitutedness ${ }^{14}{ }^{4}$ historicity-tracing-in-presencing-hyperrealisation/hyperrealtransposition' lies with the human capacity for reframing (as of supererogatory unbeholdeningconflatedness ${ }^{13}$ historiality/ontological-eventfulness ${ }^{38}$ /ontological-aesthetic-tracing$<$ perspective-ontological-normalcy/postconvergence-reflected-'epistemicity-relativismdeterminism'> so-implied as of notional ${ }^{8}$ deprocrypticism) whether as to mere aestheticisation reframing or aestheticisation-and-aestheticisation-towards-ontology-<elicited-idiomatisation $>$ reframing (as to Being-development/ontological-framework-expansion-as-to-depth-ofontologising-development-as-infrastructure-of- meaningfulness-and-teleology , institutionaldevelopment-as-to-social-function-development and living-development-as-to-personalitydevelopment psychologismic epistemic-acutisation - difficulty-for, residualising \{dering $\}$ felinearity for-cogeney $>$ magnitudes $\{$ of-experientiality/experiment $\}$ ). Inherently the requisite originariness-parrhesia,-as-spontaneity-of-aestheticisation for human reframing given human limited-mentation-capacity_as-subjecting 'educed-unlimitedness/existence-sublimating 
nascence' to-limitedness/human-subpotency is rather more forthcoming with directly graspable contextually restricted frameworks-of-conceptualisation with human reframing capacity increasingly of apriorising/axiomatising/referencing-\{of-'prospectively implicited_attendantontological-contiguity ' educed-

existentialising/contextualising/textualising_'intelligibility/epistemicity/reflexivity-contiguity<imbued-notional cogency>' $\quad$-re-originariness/re-origination impotence with frameworksof-conceptualisation of overwhelming scale inducing increasing 'sovereign-deference with lack of ${ }^{103}$ universal-transparency ${ }^{104}$-〈transparency-of-totalising-entailing,-as-to-entailing<amplinding formative-epistemicity>totalising in-relative-ontological-completeness $\rangle$ ' and leading to direct/indirect dominance/vested-interest — drivenness-<as-to-its-direct/indirecteliciting-by-or-exploiting-of-prospectively-descalarising/subontologising-sycophanticsophistic-interests,-as-inducing-prospective-threshold-of-institutional-and-socialdesublimation> $>\quad$ preconverging/postconverging-de-mentative/structural/paradigmatic domination/pre-eminence over social-stake-contention-or-confliction. The grander issue in this regards (as to optimal human reframing capacity with regards to the equanimity/balance of human theoretical-conceptual-operant institutionalised-conceptualisations) as of the present thus has to do with 'generalised-and-representative human appreciation of its reifying and empowering notional $\sim$ reflexivity- $<\{$ veridical/sound $\}$ relative-reflexivity-in-

\section{existence/relativising from-limited-mentation-as-its-deepening/psychologismic-}

<residualising \{decompulsing $\}$ delinearity for-cogency $>$ by-\{flawed/unsound\}-relative-

unreflexivity-in-existencelabsolutising from-limited-mentation/psychologismic epistemic -

acutisation nonresidualising-imbued-\{compulsing\} linearity-in-eclecticism-of-prior-mere-

formulaicity/ritualisation> potential giving the perplexing/passivising modern-day scale of organisationally and institutionally preconvergingly-de-mentated/structured/paradigmed meaningfulness-and-teleology ${ }^{9}$ as to the fact that modern-day organisational and institutional 
structure and purposes (by their social-stakes-contention-or-confliction) in critical ways render the sovereign human increasingly more of a mere $\operatorname{cog}$ within systems that as of their technical, bureaucratic and socially-defining presencing-absolutising-identitive-constitutedness $<$ preconverging 'motif-and-apriorising/axiomatising/referencing'-entailing $>$ existentialising — enframing/imprintedness-〈as-to- historicity-tracing —in-presencinghyperrealisation/hyperreal-transposition〉 purposes are already in-many-ways decisively preconverging/postconverging-de-mentatively/structurally/paradigmatically predefined as imponderable/inscrutable/unavoidable/inevitable/inescapable/unpreventable/unchangeable/in surmountable/unovercomable frameworks as not subject to prospective postconverging apereticism andysing and thereasingly undermining generalised-and-representative human appreciation of deconstructive acuity and reappraisal (but for such institutional and organisational predetermined distorted conception of paucity/deficiency as to their very ${ }^{79}$ presencing-absolutising-identitive-constitutedness $<$ preconverging 'motif-and-apriorising/axiomatising/referencing'-entailing $>$ existentialising — enframing/imprintedness-〈as-to- historicity-tracing — in-presencinghyperrealisation/hyperreal-transposition> conceptualisations), as well as more fundamentally undermining the capacity for human re-originary-_as-unenframe-_ed/reontologising/unbeholdening/outlier-conceptualisation-_imbued-postconverging/dialectical-

\section{thinking -'projective-insights’/‘epistemic-projection-in-conflatedness ' 'of-}

notional deprocrypticism-prospective-sublimation $\rangle^{\circ}$ engagement with existence as to allencompassing <amplituding/formative-epistemicity>-totalising $\sim$ renewing-realisation,-reperception,-re-thought-in-epistemic-conflatedness ${ }^{13}$ in the contemplation of omnipotentiality. Ultimately (as to human-subpotency 'fatedness-of-sublimation-over-desublimation to existencepotency $\sim$ sublimating-nascence,-disclosed-from-prospective-epistemic-digression $\quad$ in reflecting holographically-<conjugatively-and-transfusively $>$ the relative-unreflexivity/relative- 
reflexivity ontological-contiguity of-the-human-institutionalisation-process '),

omnipotentiality is ever always directly and truly contemplatable as from the 'absolutelydisruptive hierarchical-order implied as to the implications of existence-as-sublimatingwithdrawal/unenframing/re-ontologising,-elicited-from-prospective-profound-

supererogation $^{\circ}$ (as can be so-constrained as of '<amplituding/formativeepistemicity $>$ totalising/circumscribing/delineating $\quad{ }^{45}$ foregrounding_entailment- $<$ insuccession-of-profound-supererogation $>$ >-〈postconverging-narrowing-down $\sim$ sublimation-asto-'existence - as-sublimating-withdrawal/unenframing/re-ontologising,-elicited-fromprospective-profound-supererogation '-in-reflecting-'immanent $\sim$ relativeunreflexivity/relative-reflexivity ontological-contiguity ';-as-operativenotional deprocrypticism〉' so-reflecting $<$ amplituding/formative $>$ disposedness/psychologismic-construct-<as-to-orientation/valueconstruct/valuation-and-derived-parameterising $\rangle$ and <amplituding/formative $>$ entailment-〈asto-totalising-contiguous/coherent-factuality-of-variability $)$ ). Such that in-many-ways the overarching reframing for convergence towards omnipotentiality is more profoundly and supersedingly about undermining/subverting disparateness-of-conceptualisation$<$ unforegrounding-ment,-failing-prospectively-to-reflect-'immanent $\sim$ relativeunreflexivity/relative-reflexivity ontological-contiguity ' $>$ (as to its notional procrypticism or notional disjointedness-as-of- ${ }^{-}$reference-of-thought) so-associated with 'prospective ontologically-flawed presublimation-human-decisionality-induced-desublimation usurpationof/substitution-for nascent-human-decisionality-induced-sublimation-<of-blinded-relativeontological-completeness -imbued,-supererogatory reference-of-thought/grandestaxiomatic-construct - as-to-referencing/registering/decisioning $>$ in the overall prospective human sublimation-construct' as 'incrementalism-in-relative-ontological-incompleteness ${ }^{8}$ enframed/disontologising $\sim$ conceptualisation (since disparateness-of-conceptualisation- 
$<$ unforegrounding-ment,-failing-prospectively-to-reflect-'immanent $\sim$ relative-

unreflexivity/relative-reflexivity_ontological-contiguity ' $>$ as of its flawed prior_knowledgereification $\sim$ gesturing-and-accounting — of-epistemic-phenomenalism- $<$ in-

prior_psychologismic apriorising/axiomatising/referencing-\{of-"prior-implicited_attendantontological-contiguity ' educed-

existentialising/contextualising/textualising_ 'intelligibility/epistemicity/reflexivity-contiguity$<$ imbued-notional cogency $\left.>{ }^{\prime} \quad\right\}$-constitutedness -in-preconverging-entailment $>$ fails to epistemically elucidate the 'blinded notional-contiguity/epistemic-contiguity ${ }^{6}-<$ profoundsupererogation -of-mentally-aestheticised postconverging/dialectical-thinking -qualiaschema $>$ phenomenality so-construed as from ${ }^{83}$ reference-of-thought/grandest-axiomaticconstruct — as-to-referencing/registering/decisioning' of nascent-human-decisionality-inducedsublimation-<of-blinded-relative-ontological-completeness -imbued,-

supererogatory reference-of-thought/grandest-axiomatic-construct-as-to-

referencing/registering/decisioning $>$ ); and thus in lieu the overarching reframing for convergence towards omnipotentiality, construed as from the 'absolutely-disruptive hierarchical-order implied as to the implications of existence-as-sublimatingwithdrawal/unenframing/re-ontologising,-elicited-from-prospective-profoundsupererogation $^{\prime}$ (as can be so-constrained as of '<amplituding/formativeepistemicity $>$ totalising/circumscribing/delineating $\quad{ }^{45}$ foregrounding_entailment- $<$ insuccession-of-profound-supererogation $>$ - -〈postconverging-narrowing-down $\sim$ sublimation-asto-'existence - as-sublimating-withdrawal/unenframing/re-ontologising,-elicited-fromprospective-profound-supererogation '-in-reflecting-'immanent $\sim$ relativeunreflexivity/relative-reflexivity ontological-contiguity ' ;-as-operativenotional deprocrypticism〉' so-reflecting $<$ amplituding/formative $>$ disposedness/psychologismic-construct-_as-to-orientation/value- 
to-totalising-contiguous/coherent-factuality-of-variability $)$ is fundamentally about nurturing a psychological-disposition to prospective/nascent sublimating supererogatory unbeholdeningconflatedness $^{13}$ (bound to a ${ }^{4}$ historiality/ontological-eventfulness ${ }^{38}$ /ontological-aesthetictracing-<perspective-ontological-normalcy/postconvergence-reflected-‘epistemicityrelativism-determinism'> formativeness-<as-to-intersolipsism-ofpreformulating/preframing/premeaningfulness-imbued-mediativity-and-deferentialism>-ofmeaningfulness-and-teleology of intemporal-projection) and so while undermining a psychological-disposition to presublimating relic/artifactual-beholdening-constitutedness (bound to a ${ }^{4}$ historicity-tracing-in-presencing-hyperrealisation/hyperreal-transposition formativeness-<as-to-intersolipsism-of-preformulating/preframing/premeaningfulness-imbuedmediativity-and-deferentialism $>$-of- meaningfulness-and-teleology of destructuringthreshold-〈uninstitutionalised-threshold /presublimating-desublimating-decisionality $>$ ofontological-performance ${ }^{2}$ - including-virtue-as-ontology $>/$ morality/ethics/justice/etc. temporal-dispositions projection). Human limited-mentation-capacity as subjecting 'educedunlimitedness/existence-sublimating nascence' to-limitedness/human-subpotency preconverging/postconverging-de-mentatively/structurally/paradigmatically implies this seedingly/incipiently fundamental paradox of 'prospective/nascent sublimating supererogatory unbeholdening-conflatedness ${ }^{13}$, and 'presublimating relic/artifactualbeholdening-constitutedness ${ }^{1}$ ': so-reflected with the 'aestheticisation-and-aestheticisationtowards-ontology-<elicited-idiomatisation $>$ of human ontological-performance ${ }^{2}-<$ includingvirtue-as-ontology>' underlying both 'motif-as-to-aestheticisation-<imbued-projectivearbitrariness/waywardness>' $\quad$ and 'apriorising/axiomatising/referencing/intelligibilitysettingup/measuringinstrumenting-forconceptualisation as to aestheticisation-towards-ontology (so-construed as 
$<$ amplituding/formative-epistemicity $>$ totalising conflatedness ${ }^{13}$ of ${ }^{56}$ meaningfulness-andteleology involving the 'epistemic-totalising ${ }^{33}$ resubjecting_or_totalisingentailing $\sim$ reconstrual-<of the-whole/purview-of the-whole/oneness-of-ontelogy $>$ of motif-asto-aestheticisation- $<$ imbued-projective-arbitrariness/waywardness $>$ to existence-assublimating-withdrawal/unenframing/re-ontologising,-elicited-from-prospective-profoundsupererogation in preconverging/postconverging-rede-mentating/restructuring/reparadigming intelligibility-〈as-to-human-projective/reprojective - aestheticising-re-motif-and-reapriorising/re-axiomatising/re-referencing/re-intelligibilitysettingup/remeasuringinstrumenting-process,-in-<amplituding/formativeepistemicity>totalising conceptualisation)'; wherein the 'epistemictotalising $\sim$ resubjecting_or_totalising-entailing $\sim$ reconstrual-<of the-whole/purview-of thewhole/oneness-of-ontology $\quad$ of motif-as-to-aestheticisation-<imbued-projectivearbitrariness/waywardness $>$ to existence-as-sublimating-withdrawal/unenframing/reontologising,-elicited-from-prospective-profound-supererogation in inducing aestheticisationtowards-ontology' necessarily implies that intelligibility itself is seedingly/incipiently encumbered with 'presublimating relic/artifactual-beholdening-constitutedness ${ }^{14}{ }^{47}$ historicitytracing-in-presencing-hyperrealisation/hyperreal-transposition' when it comes to eliciting 'prospective/nascent sublimating supererogatory unbeholdening-conflatedness ${ }^{13}$ momentous historiality/ontological-eventfulness 38 /ontological-aesthetic-tracing-<perspectiveontological-normalcy/postconvergence-reflected-'epistemicity-relativism-determinism'>', and so all along from the very seeding/incipient aestheticisation-and-aestheticisation-towardsontology-<elicited-idiomatisation $>$ and so-perpetuative as to human Beingdevelopment/ontological-framework-expansion-as-to-depth-of-ontologising-development-asinfrastructure-of- meaningfulness-and-teleology , institutional-development-as-to-socialfunction-development and living-development-as-to-personality-development psychologismic 
epistemic-acutisation difficulty-for, residualising \{decompulsing\} ${ }^{\text {delinearity for-cogency> }}$ magnitudes \{of-experientiality/experiment\} $\}$, as to the fact that 'intelligibility as the effectively-manifestsublimation/sublime arising from subjecting-and-resubjecting motif-as-to-aestheticisation$<$ imbued-projective-arbitrariness/waywardness $>$ to existence-as-sublimatingwithdrawal/unenframing/re-ontologising,-elicited-from-prospective-profoundsupererogation" speaks of 'successions of aestheticising apriorising/axiomatising/referencing\{of-'prospectively_implicited_attendant-ontological-contiguity ' educedexistentialising/contextualising/textualising_'intelligibility/epistemicity/reflexivity-contiguity<imbued-notional cogency $>$ ' $\}$-constitutedness ${ }^{4}$-in-preconverging-entailment failing to factor in human limited-mentation-capacity—as-subjecting 'educed-unlimitedness/existencesublimating nascence' to-limitedness/human-subpotency' and thus 'inducing an absolutising referencing/registering/decisioning (an absolutising construct-of-human-decisionality- $<$ as-toplay-of-valid/invalid-decisionality-imbued-sublimation/desublimation>') that incidentally/parenthetically wrongly purport to reflect 'inherent immanent-existence overall withdrawn effectively-manifest-sublimation/sublime or withdrawn sublimation-structure'. It is this fundamental insight 'about the inherent absolutising referencing/registering/decisioning ontological-deficiency necessarily arising from human limited-mentation-capacity-assubjecting-'educed-unlimitedness/existence-sublimating nascence' to-limitedness/humansubpotency' (requiring 'projective-insights'/‘epistemic-projection-in-conflatedness ${ }^{13}$, as to human limited-mentation-capacity-deepening —as-subjecting limitedness/human-subpotency to-'educed-unlimitedness/existence-sublimating nascence' ${ }^{53}$ ) that underlies the notion of human $\quad$ de-mentation-〈supererogatory $\sim$ ontological-de-mentation-or-dialectical-dementation-stranding-or-attributive-dialectics $>$ as factoring in the implications of human limited-mentation-capacity—as-subjecting 'educed-unlimitedness/existence-sublimating nascence' to-limitedness/human-subpotency (by a 'psychological-disposition for 
supererogatory unbeholdening-conflatedness

historiality/ontological-

eventfulness ${ }^{3}$ /ontological-aesthetic-tracing-<perspective-ontological-

normalcy/postconvergence-reflected-'epistemicity-relativism-determinism'> of sublimating intelligibility' as to 'relevantly/appropriately subjecting-and-resubjecting motif-as-toaestheticisation-<imbued-projective-arbitrariness/waywardness $>$ to existence - as-sublimatingwithdrawal/unenframing/re-ontologising,-elicited-from-prospective-profound-

supererogation' and so rather than a 'psychological-disposition for relic/artifactualbeholdening-constitutedness ${ }^{14}{ }^{4}$ historicity-tracing-in-presencing-hyperrealisation/hyperrealtransposition of presublimating intelligibility' failing such a 'relevant/appropriate subjectingand-resubjecting of motif-as-to-aestheticisation- $<$ imbued-projectivearbitrariness/waywardness $>$ to existence-as-sublimating-withdrawal/unenframing/reontologising,-elicited-from-prospective-profound-supererogation ', as underscored by the 'effectively underlying human beholdening-inching,-apprehending,-and-taming-drive or aestheticising — ${ }^{7}$ surrealising/supererogating-drive for $\quad<$ postconverging 'motif-andapriorising/axiomatising/referencing'-entailing >-existentialising-framing/imprinting-〈as-toprospective-- historiality/ontological-eventfulness /ontological-aesthetic-tracing-

$<$ perspective-ontological-normalcy/postconvergence-reflected-'epistemicity-relativismdeterminism'>>') for the requisite sublimating/emancipating omnipotentiality converging towards 'inherent immanent-existence overall withdrawn effectively-manifestsublimation/sublime or withdrawn sublimation-structure' so-construed as of ontologicalnormalcy/postconvergence reflected 're-originary_-as-unenframed/reontologising/unbeholdening/outlier-conceptualisation__imbued-postconverging/dialecticalthinking -'projective-insights'/‘epistemic-projection-in-conflatedness ' '-ofnotional deprocrypticism-prospective-sublimation $\rangle$ intemporal-disposition supererogatory rescalarisation of ontologisation and value-construction (within any given registry- 
worldview/dimension

presencing-absolutising-identitive-constitutedness

<preconverging 'motif-and-apriorising/axiomatising/referencing'-entailing >-

existentialising — enframing/imprintedness-〈as-to- historicity-tracing_-in-presencing-

hyperrealisation/hyperreal-transposition〉) inducing prospective sublimation-over-desublimation meaningfulness-and-teleology infrastructure thus effectively superseding any such given registry-worldview/dimension underpinning-suprasocial-construct prior conception of ontologisation and value-construction'. Interestingly, this seedingly/incipiently fundamental paradox of 'prospective/nascent sublimating supereregatory unbeholdening-conflatedness ${ }^{13}$, and 'presublimating relic/artifactual-beholdening-constitutedness ${ }^{14}$ as to its perpetuative encumberment of human intelligibility, correspondingly highlights the inherent disambiguation of human ${ }^{56}$ meaningfulness-and-teleology' 'as of the seeding/incipient encumberment of its momentous-unbeholdening-aestheticising-reflex with its merely-beholdening-aestheticisingreflex' (so-perpetuative as to human Being-development/ontological-framework-expansion-asto-depth-of-ontologising-development-as-infrastructure-of- meaningfulness-and-teleology , institutional-development-as-to-social-function-development and living-development-as-topersonality-development psychologismic epistemic-acutisation difficulty-<for, residualising \{decompulsing\} delinearity for-cogency>-magnitudes $\{0$-experientiality/experiment\} $\}$, as the more critical drawback to overarching reframing of 'human-decisionality-<as-to-play-ofvalid/invalid-decisionality-imbued-sublimation/desublimation> omni-potential commensurability with inherent immanent-existence's sublimation-structure'/omnipotentiality. This insight can be translated by the fact that nascent-sublimations (nascent-particular/incipientand-material/technical-sublimations- $<$ blinded-to-their-relative-ontological-completeness reference-of-thought- devolving >) as to their effectively-manifest-sublimation/sublime rather speak to an underlying veracity about immanent-existence 'beyond and unbeholdening to any human merely-beholdening-aestheticising-reflex of ${ }^{5}$ meaningfulness-and-teleology ${ }^{9}$, and so 
for instance in the sense that human tools, other technical/material capabilities like electricity, etc. are rather of 'preconverging/postconverging-de-mentative/structural/paradigmatic momentous-unbeholdening-aestheticising-reflex effectively-manifest-sublimation/sublime as to existence—as-sublimating-withdrawal/unenframing/re-ontologising,-elicited-fromprospective-profound-supererogation ${ }^{,}$as to the inherent sublimating/emancipating possibilities accruable to all humans and societies as to their underlying ontologicalcommitment $-<$ implied — self-assuredness-of-ontological-goodfaith/authenticity postconverging-de-mentating/structuring/paradigming -as-being-as-ofexistential-reality $>$ of ${ }^{56}$ meaningfulness-and-teleology ${ }^{9}$; so-reflecting the fact that overall human civilisation (notwithstanding any given societies/cultures of naïve ${ }^{7}$ presencingabsolutising-identitive-constitutedness ${ }^{14}$ as to presencing-distorted-meritocracy/totalisingsovereign-apportioning - of-human-ontological-performance ${ }^{2}-<$ including-virtue-asontology $>$ /morality/ethics/justice/etc. 'merely-beholdening-aestheticising-reflex of meaningfulness-and-teleology ${ }^{\prime}$ ) could only be possible by the cumulating/recomposuring of all such 'preconverging/postconverging-de-mentative/structural/paradigmatic momentousunbeholdening-aestheticising-reflex effectively-manifest-sublimation/sublime as to existenceas-sublimating-withdrawal/unenframing/re-ontologising,-elicited-from-prospective-profoundsupererogation manifested at various stages across all human societies/cultures and diffusible likewise across all human societies/cultures with the implications that such 'preconverging/postconverging-de-mentative/structural/paradigmatic momentousunbeholdening-aestheticising-reflex effectively-manifest-sublimation/sublime as to existenceas-sublimating-withdrawal/unenframing/re-ontologising,-elicited-from-prospective-profoundsupererogation more fundamentally speak to 'overall human momentous-unbeholdeningaestheticising-reflex effectively-manifest-sublimation/sublime attainment' (with such a truer ontological-veracity rather much more profound than the "merely-beholdening-aestheticising- 
reflex of ${ }^{56}$ meaningfulness-and-teleology ${ }^{9}$ of various societies/cultures and as of such ontologically-flawed representation across various human historial epochs). In this respect the ontological-veracity of human institutional-cumulation/institutional-recomposure-〈as-to-

\section{historiality/ontological-eventfulness /ontological-aesthetic-tracing-<perspective-}

ontological-normalcy/postconvergence-reflected-'epistemicity-relativism-determinism' $>>$ (as

of the accruing effectively-manifest-sublimation/sublime from stone-age to bronze-age to ironage involving the formation of agrarian societies and cities and subsequent development of universalising societies and today's positivising modern world) rather more aptly speaks of 'overall human momentous-unbeholdening-aestheticising-reflex effectively-manifestsublimation/sublime attainment'; with the profound idea that the more momentous grasp of the notion of say the civilisations of Ancient Zimbabwe, Ancient Egypt, Ancient Greece, Ancient China, Ancient India or Ancient Aztec, etc. are rather as of a more profound point-of-departure as from a 'human psychological-disposition for supererogatory unbeholdening-conflatedness historiality/ontological-eventfulness 38 ontological-aesthetic-tracing-<perspectiveontological-normalcy/postconvergence-reflected-'epistemicity-relativism-determinism'> of sublimating intelligibility' divulging the underlying dynamism of human 'preconverging/postconverging-de-mentative/structural/paradigmatic momentousunbeholdening-aestheticising-reflex effectively-manifest-sublimation/sublime as to existenceas-sublimating-withdrawal/unenframing/re-ontologising,-elicited-from-prospective-profoundsupererogation" (and so rather than a shallower point-of-departure as from a 'human psychological-disposition for relic/artifactual-beholdening-constitutedness ${ }^{14}{ }^{4}$ historicitytracing-in-presencing-hyperrealisation/hyperreal-transposition of presublimating intelligibility' of 'merely-beholdening-aestheticising-reflex of ${ }^{56}$ meaningfulness-andteleology', caught up in complexes of 'naïve ${ }^{79}$ presencing-absolutising-identitiveconstitutedness $^{14}$ as to presencing-distorted-meritocracy/totalising-sovereign-apportioning- 
of-human-ontological-performance ${ }^{72}<^{-}$including-virtue-as-ontology $>^{\prime}$ that end up inducing poor/distorted human understanding of the human). The underlying point here is that just as human tools, other technical/material capabilities like electricity, etc. are rather of 'preconverging/postconverging-de-mentative/structural/paradigmatic momentousunbeholdening-aestheticising-reflex effectively-manifest-sublimation/sublime as to existenceas-sublimating-withdrawal/unenframing/re-ontologising,-elicited-from-prospective-profoundsupererogation as to the inherent sublimating/emancipating possibilities accruable to all humans and societies as to their underlying ontological-commitment $-<$ implied - selfassuredness-of-ontological-good-faith/authenticity $\sim$ postconverging-dementating/structuring/paradigming -as-being-as-of-existential-reality $>$ of ${ }^{56}$ meaningfulnessand-teleology', a 'human psychological-disposition for supererogatory unbeholdeningconflatedness historiality/ontological-eventfulness 38 /ontological-aesthetic-tracing$<$ perspective-ontological-normalcy/postconvergence-reflected-'epistemicity-relativismdeterminism'> of sublimating intelligibility' implies that the othernesses of human civilisations/cultures/societies carry a more profound 'preconverging/postconverging-dementative/structural/paradigmatic momentous-unbeholdening-aestheticising-reflex effectivelymanifest-sublimation/sublime as to existence-as-sublimating-withdrawal/unenframing/reontologising,-elicited-from-prospective-profound-supererogation, as to the inherent sublimating/emancipating possibilities accruable to all humans and societies. This overall insight is particularly salient in the sense that the 'human psychological-disposition for relic/artifactualbeholdening-constitutedness ${ }^{14}{ }^{4}$ historicity-tracing-in-presencing-hyperrealisation/hyperrealtransposition of presublimating intelligibility' (so-perpetuative as to human Beingdevelopment/ontological-framework-expansion-as-to-depth-of-ontologising-development-asinfrastructure-of- meaningfulness-and-teleology , institutional-development-as-to-socialfunction-development and living-development-as-to-personality-development psychologismic 
epistemic-acutisation difficulty-for, residualising \{decompulsing\} ${ }^{\text {delinearity for-cogency> }}$ magnitudes $\{$ of-experientiality/experiment\} $\}$, is exactly what critically clouds prospective possibilities for 'human psychological-disposition for supererogatory unbeholdening-conflatedness historiality/ontological-eventfulness 3 /ontological-aesthetic-tracing-<perspectiveontological-normalcy/postconvergence-reflected-‘epistemicity-relativism-determinism’> of sublimating intelligibility'; so-construed as imponderable/inscrutable/unavoidable/inevitable/inescapable/unpreventable/unchangeable/in surmountable/unovercomable frameworks of preconverging/postconverging-dementative/structural/paradigmatic limits to abstract 'human-decisionality-<as-to-play-ofvalid/invalid-decisionality-imbued-sublimation/desublimation> omni-potential commensurability with inherent immanent-existence's sublimation-structure'/omnipotentiality. This paradox is analysable as from the 'critical pure-ontology' elucidation of overall reifyingand-empowering-reflexivity-of-ecstatic-existence-as-panintelligibility/panreflexivity ${ }^{3}$ <existentially-imbued-and-educing-< $<$ epistemictotalising ${ }^{3}$ hermeneutically/textually/reprojectingly/supererogatingly/zeroingly/re-acutingly,$\{$ decompulsing $\}$ delinearity $\sim$ for-cogency $\geq$-epistemic-perspective-of-projective/reprojective aestheticising-re-motif-and-re-apriorising/re-axiomatising/re-referencing $\sim$ conceptualisation-as-herein-specifically-relevant to human-subpotency) so-underscored by 'effectively underlying human beholdening_-inching,-apprehending,-and-taming-drive or aestheticisingsurrealising/supererogating-drive for $\quad<$ postconverging 'motif-andapriorising/axiomatising/referencing'-entailing >-existentialising-framing/imprinting-〈as-toprospective- historiality/ontological-eventfulness /ontological-aesthetic-tracing$<$ perspective-ontological-normalcy/postconvergence-reflected-‘epistemicity-relativismdeterminism' $>$ ' ' (as of inherent imbuement of existence as of its 'transcendence-andsublimity/sublimation/supererogatory de-mentativity and immanence differential 
conceptivity/epistemic-reflexivity/epistemicity-relativism-determinism-<reifying \{as-toknowledge-developing -and-empowering $>$ integral-difference' reflecting human teleology ${ }^{9}$ or 'phenomenal/manifest perspective conceptivity/epistemic-reflexivity/epistemicity-relativismdeterminism-<reifying \{as-to-knowledge-developing $\}$-and-empowering $>$ in existence as ontological'); wherein incipient/seeding 'human supereregatory acuity/perspicacity/astuteness/edginess/incisiveness $\sim$ differential as of relativeontological-incompleteness $8 /$ relative-ontological-completeness ${ }^{87}$ 〈sublimating referencing/registering/decisioning,-as-self-becoming/selfconflatedness /formative-supererogating-<projective/reprojective-aestheticising-re-motifand-re-apriorising/re-axiomatising/re-referencing,-in-perspective-ontologicalnormalcy/postconvergence $>>$ epistemicity' underlying ontological-performance ${ }^{2}-<$ includingvirtue-as-ontology $>$ /morality/ethics/justice/etc. insightfully reflects human sublimation/emancipation as to prospective 're-originary_-as-unenframed/reontologising/unbeholdening/outlier-conceptualisation__imbued-postconverging/dialectical-

\section{thinking -'projective-insights’/‘epistemic-projection-in-conflatedness ' 'of-}

notional deprocrypticism-prospective-sublimation $\rangle^{0}$ reconceptualisation of 'effectively underlying human beholdening — inching,-apprehending,-and-taming-drive or aestheticisingsurrealising/supererogating-drive for $\quad<$ postconverging 'motif-andapriorising/axiomatising/referencing'-entailing >-existentialising-framing/imprinting-〈as-toprospective- historiality/ontological-eventfulness /ontological-aesthetic-tracing$<$ perspective-ontological-normalcy/postconvergence-reflected-'epistemicity-relativismdeterminism' $>$ Y' with regards to effective convergence/advancement of 'human-decisionality$<$ as-to-play-of-valid/invalid-decisionality-imbued-sublimation/desublimation $>$ omni-potential commensurability with inherent immanent-existence's sublimation-structure'/omnipotentiality (and so as to Being-development/ontological-framework-expansion-as-to-depth-of- 
ontologising-development-as-infrastructure-of- meaningfulness-and-teleology , institutionaldevelopment-as-to-social-function-development and living-development-as-to-personalitydevelopment psychologismic epistemic-acutisation difficulty-for, residualising ${ }_{\text {\{decompulsing }}$ delinearity for-cogency> magnitudes $\{$ of-experientiality/experiment $\}$ ). Preconverging/postconverging-de-mentatively/structurally/paradigmatically, 'phenomenal/manifest $\sim$ subpotencies-〈in-transitive-conflatedness -reflexivity,-in-the-fullpotency-of-existence's $\sim$ sublimating-nascence $>$ - in — < amplituding/formative-epistemicity $>$ totalising thrownness-in-existence ,-<of- ${ }^{6}$ surrealistic-as-pseudoreal'-epistemicabnormalcy $>$ (including human-subpotency) are constrained in their ontological-performance ${ }^{72}$ $<$ including-virtue-as-ontology $>$ /potentiation with respect to the backdrop-of-inherentimmanent-existence's-sublimation-structure-<of-‘unsurrealistic-as-real'-ontologicalnormalcy/postconvergence>; and all phenomenal/manifest $\sim$ subpotencies-〈in-transitiveconflatedness -reflexivity,-in-the-full-potency-of-existence's $\sim$ sublimating-nascence $\quad$ are defined by their basic preconverging/postconverging-de-mentative/structural/paradigmatic 'effectively underlying beholdening-inching,-apprehending,-and-taming-drive or aestheticising - ${ }^{97}$ surrealising/supererogating-drive for $\quad<$ postconverging 'motif-andapriorising/axiomatising/referencing'-entailing>-existentialising-framing/imprinting-〈as-toprospective- historiality/ontological-eventfulness /ontological-aesthetic-tracing<perspective-ontological-normalcy/postconvergence-reflected-‘epistemicity-relativismdeterminism' $>$ )' (so-underlying the '<amplituding/formative-epistemicity $>$ totalising thrownness-in-existence ${ }^{35}$ re-aestheticisising/re-motif_-_in-postconverging-narrowingdown $\sim$ 'sublimation-of-tastetotalising $3{ }^{3}$ hermeneutically/textually/reprojectingly/supererogatingly/zeroingly/re-acutingly,$\{$ decompulsing\} delinearity for-cogency-educing-conceptivity/epistemic-reflexivity/epistemicityrelativism-determinism-<reifying \{as-to-knowledge-developing $\}$-and-empowering $>$-of- 
historiality/ontological-eventfulness /ontological-aestheticising-tracing',-as-to-existence-

as-sublimating-withdrawal/unenframing/re-ontologising,-elicited-from-prospective-profound-

supererogation $>$ and re-procession_[re-automatism-_as-to-re-re-apriorising/re-_e-axiomatising/re-

referencing- $<$ in-postconverging-narrowing-down $\sim$ 'sublimation-of-

apriorising/axiomatising/referencing_\{epistemic-

totalising $3{ }^{3}$ hermeneutically/textually/reprojectingly/supererogatingly/zeroingly/re-acutingly,-

$\{$ decompulsing $\}$ delinearity for-cogency-educing-conceptivity/epistemic-reflexivity/epistemicity-

relativism-determinism-<reifying \{as-to-knowledge-developing $\}$-and-empowering $>$-of-

historiality/ontological-eventfulness /ontological-aestheticising-tracing',-as-to-existence-

as-sublimating-withdrawal/unenframing/re-ontologising,-elicited-from-prospective-profound-

supererogation $>$ ) of their aestheticising $-{ }^{7}$ surrealising/supererogating-drive for $<$ postconverging 'motif-and-apriorising/axiomatising/referencing'-entailing $>$

existentialising - framing/imprinting-〈as-to-prospective- historiality/ontological-

eventfulness /ontological-aesthetic-tracing-<perspective-ontological-

normalcy/postconvergence-reflected-'epistemicity-relativism-determinism' $>\rangle$ ' (as to their interlay/organicalism/aestheticising-handle-<of-`psychologismic-transfixity\{residualising

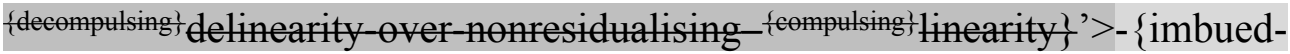

supererogatory projective-arbitrariness/waywardness-

of $\sim$ transversalisation/tandemisation/abstractive-conjugation/perspectivation/depthing — for'aestheticising-re-margining/re-edging/re-acuity—as-

postconverging_circumscriptive/totalitative-restructuring'\} _ educing-

sublimation/desublimation>

in

\{epistemic-

totalising 3 ' $h$ hermeneutically/textually/reprojectingly/supererogatingly/zeroingly/re-acutingly,-

\{decompulsingt delinearity for-cogency-imbuing

'supererogatory $\sim$ acuity/perspicacity/astuteness/edginess/incisiveness $\sim$ differential ontological- 
performance ${ }^{2}-<$ including-virtue-as-ontology $>$ /potentiation'), so-construed as their 'germinative intensification — amplituding of aestheticisation—-beholdening-out-of-bechancing' / 'taxingness-of-originariness,-imbued-sublimating-by-desublimating-amplituding as to the backdrop-of-inherent-immanent-existence's-sublimation-structure- $<$ of-'unsurrealistic-asreal'-ontological-normalcy/postconvergence>' (as so-underlied by human-subpotency epistemically-reflexive consciousness overlying the sublimating-postconverged 'substantive abstract-tissue-of-social-emanance \{epistemicthermeneutically/textually/reprojectingly/supererogatingly/zeroingly/re-acutingly,\{decompling $d$ delinearity for-cogency — cumulated/recomposured as to cumulating/recomposuring of 'prospectively_implicited_attendant-ontological-contiguity ${ }^{67}$; educedexistentialising/contextualising/textualising_intelligibility/epistemicity/reflexivity-contiguity$<$ imbued-notional $\sim \operatorname{cogency}>^{\prime}$ as to overall reifying-and-empowering-reflexivity-of-ecstaticexistence-as-panintelligibility/panreflexivity ${ }^{33}$-〈existentially-imbued-and-educing-<epistemicthermeneutically/textually/reprojectingly/supererogatingly/zeroingly/re-acutingly,$\{$ decompulsing $\}$ delinearity for-cogency $\geq$-epistemic-perspective-of-projective/reprojectiveaestheticising-re-motif-and-re-apriorising/re-axiomatising/re-referencing $\sim$ conceptualisation-as-herein-specifically-relevant-to human-subpotency) in reflection of overall Beingdevelopment/ontological-framework-expansion-as-to-depth-of-ontologising-development-asinfrastructure-of- meaningfulness-and-teleology ). A deepening of this critical pure-ontology discernment as from the above elucidation of 'phenomenal/manifest $\sim$ subpotencies-〈intransitive-conflatedness -reflexivity,-in-the-full-potency-of-existence’s $\sim$ sublimatingnascence $>$ - in — $<$ amplituding/formative-epistemicity $>$-totalising $\sim$ thrownness-in-existence $<$ of-' $\quad$ surrealistic-as-pseudoreal'-epistemic-abnormalcy $>$ (including human-subpotency), surrealisingly/supererogatorily discloses that existentialising-decisionality-<as-todisontologising/re-ontologising aporeticism $>$ is preconverging/postconverging-de- 
mentatively/structurally/paradigmatically of 'beholdening as sovereignising-imbuedsubontologisation/subpotentiation' while sublimating-nascence is preconverging/postconverging-de-mentatively/structurally/paradigmatically of 'unbeholdening ontologising-depth as to backdrop-of-inherent-immanent-existence's-sublimation-structure<of-'unsurrealistic-as-real'-ontological-normalcy/postconvergence>' (such that perspectively 'to beholden-as-sovereignising is to underly/organise/decision existentialising/contextualising/textualising subpotentiation' and so potently constrained as from perspective 'unbeholdening sublimating-nascence ontologising-depth of the full-potency of existence'); as to the fact that ${ }^{97}$ surrealisingly/supererogatorily existentialising-decisionality$\leq a s$-to-disentologising/re-ontologising aporeticism $>$ is of 'notional 7 presencingabsolutising-identitive-constitutedness preconverging-dementating/structuring/paradigming_beholdening-as-to-effectuation' and so potently constrained as from sublimating-nascence 'notional ${ }^{6}$ nonpresencing- $<$ perspectiveontological-normalcy/postconvergence $>$ as to backdrop-of-inherent-immanent-existence'ssublimation-structure-<of-'unsurrealistic-as-real'-ontological-normalcy/postconvergence>' .

This overall conception underlies the conceptivity/epistemic-reflexivity/epistemicity-relativismdeterminism-<reifying \{as-to-knowledge-developing\}-and-empowering $>\quad$ of $\quad$ both 'existentialising-decisionality-<as-to-disontologising/re-ontologising aporeticism $>\quad$ and sublimating-nascence' with regards to induced sublimation/desublimation (beyond naïve presencing - absolutising-identitive-constitutedness ${ }^{14} \quad<$ preconverging ' $m o t i f-a n d-$ apriorising/axiomatising/referencing'-entailing>-existentialising_enframing/imprintedness〈as-to- historicity-tracing - in-presencing-hyperrealisation/hyperreal-transposition〉) as from nonpresencing-<perspective-ontological-normalcy/postconvergence $>$ epistemic-projection perspective just as so-reflected 'between reproducibility—mathesis/motif/thrownnessdisposition,-as-reproducibility-of-aestheticisation and originariness-parrhesia,-as-spontaneity- 
of-aestheticisation' and so as of 'relative-ontological-incompleteness $8 /$ relative-ontologicalcompleteness ${ }^{8}$-〈sublimating referencing/registering/decisioning,-as-self-becoming/selfconflatedness /formative-supererogating-<projective/reprojective-aestheticising-re-motifand-re-apriorising/re-axiomatising/re-referencing,-in-perspective-ontologicalnormalcy/postconvergence $>>$ as to human-and-social-expectations/anticipationsmetaphoricity ${ }^{57}$-as-preconverging/postconverging-redementating/restructuring/reparadigming-psychologism' ${ }^{89}$ (just as for instance the notion of length is already caught up in the notion of width in the 'sublimating <amplituding/formativeepistemicity>totalising/circumscribing/delineating manifestation of a rectangle' and so with regards to the fact that human aestheticisation-and-aestheticisation-towards-ontology$<$ elicited-idiomatisation $>$ of ${ }^{56}$ meaningfulness-and-teleology ${ }^{9}$ is ever always about 'idealisedtypification in epistemic-conflatedness ${ }^{13}$ sublimation or epistemic apriorising/axiomatising/referencing-\{of-"prospectively_implicited_attendant-ontologicalcontiguity ' educedexistentialising/contextualising/textualising_'intelligibility/epistemicity/reflexivity-contiguity<imbued-notional $\sim$ cogency $\left.>{ }^{\prime} \quad\right\}$-constitutedness ${ }^{1}$-in preconvergingentailment/pseudoconflation desublimation/gimmickiness' for eliciting sublimation/desublimation from the 'full-potency of existence withheld as from ontologicalnormalcy/postconvergence epistemic projection-perspective'). In other words, existentialisingdecisionality $<$ as-to-disontologising/re-ontologising aporeticism $>$ and sublimating-nascence perspectively-reflect respectively 'notional ${ }^{79}$ presencing-absolutising-identitiveconstitutedness $^{14} \quad$ and notional $~{ }^{6}$ nonpresencing- $<$ perspective-ontologicalnormalcy/postconvergence $>$ transversal continuum', as to 'thresholding conception of the relationship between perspective decisionality/human-decisionality-<as-to-play-ofvalid/invalid-decisionality-imbued-sublimation/desublimation> 
sublimation/desublimation in existence'. Insightfully, such a perspective distinction between existentialising-decisionality-<as-to-disontologising/re-ontologising aporeticism $>$ and sublimating-nascence points out that there is 'epistemical-reflexive psychological reorientation of human relation with ${ }^{5}$ meaningfulness-and-teleology', as to the contrast between ‘ blurriness-<sterilising/anecdotalising/trivialising-of-prospective-re-ontologising_bypreconverging,-in-disontologising-formulaic-dragging-out/hollowing-out> in existentialisingdecisionality-<as-to-disontologising/re-ontologising aporeticism $>$ ' and '103universaltransparency ${ }^{104}$-〈transparency-of-totalising-entailing,-as-to-entailing-<amplituding/formativeepistemicity>totalising in-relative-ontological-completeness > of sublimating-nascence'; wherein ' ${ }^{103}$ universal-transparency ${ }^{104}$-〈transparency-of-totalising-entailing,-as-to-entailing<amplituding/formative-epistemicity>totalising in-relative-ontological-completeness > of sublimating-nascence' (as to nascent-particular/incipient-and-material/technical-sublimations$<$ blinded-to-their-relative-ontological-completeness - reference-of-thought- devolving $>$ ) is relatively bound to elicit individual and social positive-opportunism-of-social-functioningand-accordance $^{75}$ deferential-formalisation-transference of existentialising-decisionality-<asto-disontologising/re-ontologising aporeticism $>$ while "blurriness$<$ sterilising/anecdotalising/trivialising-of-prospective-re-ontologising_by-preconverging,-indisontologising-formulaic-dragging-out/hollowing-out $>$ in existentialising-decisionality-<asto-disontologising/re-ontologising aporeticism ${ }^{\prime}$ is relatively bound to undermine individual and social deferential-formalisation-transference as to relative-ontological-incompleteness ${ }^{8}-$ presublimation-construct-of- ${ }^{5}$ meaningfulness-and-teleology ${ }^{9}$ desublimating $\sim$ existentialisingdecisionality-<as-to-disontologising/re-ontologising aporeticism $>$ (thus undermining the requisite relative-ontological-completeness ${ }^{87} \quad{ }^{83}$ reference-of-thought-and- ${ }^{83}$ reference-ofthought- ${ }^{8}$ devolving- ${ }^{5}$ meaningfulness-and-teleology ${ }^{99}$ comprehensiveness of prospective sublimating-nascence' as of the sublimating-nascence teleological-inflection-〈as-to-more- 
profound-nondisjointing-<amplituding/formative-

epistemicity $>$ totalising/circumscribing/delineating $\rangle$ ). That is, the individual and social existentialising-decisionality-<as-to-disontologising/re-ontologising aporeticism $>$ is more readily defined by default in 'beholdening as sovereignising-imbuedsubontologisation/subpotentiation' and this is effectively the default individual and social existentialising-decisionality-<as-to-disontologising/re-ontologising aporeticism $>$

psychological-disposition as to upholding/defending sovereignty, but then given human limitedmentation-capacity—as-subjecting 'educed-unlimitedness/existence-sublimating nascence' to-limitedness/human-subpotency the individual and social are then secondarily predisposed to deferential-formalisation-transference existentialising-decisionality-<as-to-disontologising/reentelegising apereticism $>$ psychological-disposition as to the positive-opportunism-ofsocial-functioning-and-accordance ${ }^{75}$ consequences of deferring to ${ }^{103}$ universal-transparency ${ }^{104}$ 〈transparency-of-totalising-entailing,-as-to-entailing-<amplituding/formative-

epistemicity>totalising in-relative-ontological-completeness > of sublimating-nascence' (in delegating sovereignty ultimately as to existence-as-sublimating-withdrawal/unenframing/reontologising,-elicited-from-prospective-profound-supererogation ) with the lack of such

' ${ }^{103}$ universal-transparency ${ }^{104}$-〈transparency-of-totalising-entailing,-as-to-entailing-

<ampling/formative-epistemicity>totalising in-relative-ontological-completeness > of sublimating-nascence' as to when ' blurriness-<sterilising/anecdotalising/trivialising-ofprospective-re-ontologising_by-preconverging,-in-disontologising-formulaic-dragging-

out/hollowing-out $>$ in existentialising-decisionality-<as-to-disentologising/re-ontelogisingaporeticism $>$ ' arises inducing defaulting 'beholdening as sovereignising-imbuedsubontologisation/subpotentiation' existentialising-decisionality-<as-to-disontologising/reentologising aporeticism $>$ psychological-disposition (as to relative-ontologicalincompleteness ${ }^{88}$-presublimation-construct-of- ${ }^{56}$ meaningfulness-and-teleology 
desublimating $\sim$ existentialising-decisionality-<as-to-disontologising/re-ontologisingaporeticism $>$ ). The implications of this dual existentialising-decisionality-<as-todisontologising/re-ontologising aporeticism $>$ psychological-dispositions is critical particularly with regards to the social-and-institutional-frameworks-ofreferencing/registering/decisioning of human ${ }^{56}$ meaningfulness-and-teleology ${ }^{99}$ of " blurriness$<$ sterilising/anecdotalising/trivialising-of-prospective-re-ontologising_by-preconverging,-indisontologising-formulaic-dragging-out/hollowing-out $>$ in existentialising-decisionality-<asto-disontologising/re-ontologising aporeticism ${ }^{\prime}$ as rather poorly amenable to profound 'unbeholdening sublimating-nascence ontologising-depth of the full-potency of existence' as it is relatively the case in the natural sciences (and so beyond-the-consciousness-awarenessteleology ${ }^{9}<$ of-preconverging-existential-extrication-as-of-existential-unthought $>$ ); as to the fact that existence-as-the-absolute-a-priori-of-conceptualisation $\sim$ and $\sim$ existence —assublimating-withdrawal/unenframing/re-ontologising,-elicited-from-prospective-profoundsupererogation -<as-to-perspective-ontological-normalcy/postconvergence-implied'prospective-aporeticism-overcoming/unovercoming'> more readily makes 'desublimating nonsense' of human existentialising-decisionality-<as-to-disontologising/re-ontologising apereticism> ${ }^{56}$ meaningfulness-and-teleology ${ }^{9}$ failing 'genuine knowledgereification $\sim$ gesturing-and-accounting — of-epistemic-phenomenalism- $<$ inprospective_psychologismic apriorising/axiomatising/referencing-\{of-'prospectively implicited_attendant-ontological-contiguity ' educedexistentialising/contextualising/textualising_'intelligibility/epistemicity/reflexivity-contiguity<imbued-notional cogency >' \}-conflatedness -in-\{preconverging-ment by\}

pesteonverging entailment> framework involving an immediate potent detour to existencepotency $^{32} \sim$ sublimating-nascence,-disclosed-from-prospective-epistemic-digression while the relative ' blurriness-<sterilising/anecdotalising/trivialising-of-prospective-re-ontologising_by- 
preconverging,-in-disontologising-formulaic-dragging-out/hollowing-out> in existentialisingdecisionality-<as-to-disontologising/re-ontelogising aporeticism $>$ ' of social-and-institutionalframeworks-of - referencing/registering/decisioning induce a relative orientation in the social towards ${ }^{7}$ presencing - absolutising-identitive-constitutedness ${ }^{14}$ social-vestedness/normativity$<$ discretely-implied-functionalism $>\quad$ existentialising-decisionality-<as-to-disontologising/reentologising aporeticism $>{ }^{5}$ meaningfulness-and-teleology ${ }^{9}$ (so-enabled by poor direct/immediate potent constraining to existence-as-sublimating-withdrawal/unenframing/reontologising,-elicited-from-prospective-profound-supererogation ). In this regards, many such social-and-institutional-frameworks-of - referencing/registering/decisioning can be construed as 'frameworks of relatively shallow-ontologisation/subontologisation' as to the existentialising-decisionality-<as-to-disontologising/re-ontologising aporeticism $>$ psychological-disposition of defaulting individual and social 'beholdening as sovereignisingimbued-subontologisation/subpotentiation' due 'blurriness-

\section{<sterilising/anecdotalising/trivialising-of-prospective-re-ontologising_by-preconverging,-in-}

disontologising-formulaic-dragging-out/hollowing-out $>$ in existentialising-decisionality-<asto-disontologising/re-ontologising aporeticism $>$ '. It is herein contended that the most fundamental issue with regards to human prospective comprehensive emancipation/sublimation (as promptly reflected with nascent-particular/incipient-and-material/technical-sublimations$<$ blinded-to-their-relative-ontological-completeness - reference-of-thought- devolving $>$ and requisite expansive relative-ontological-completeness ${ }^{87}$ ' $r$ reference-of-thought-andreference-of-thought- ${ }^{84}$ devolving- ${ }^{5}$ meaningfulness-and-teleology ${ }^{9}$ comprehensiveness of prospective sublimating-nascence' with regards to sublimating-nascence teleologicalinflection-〈as-to-more-profound-nondisjointing-<amplituding/formative-

epistemicity>totalising/circumscribing/delineating $\rangle$ ) has to do with this 'human existentialisingdecisionality-<as-to-disontologising/re-ontologising aporeticism $>$ dual psychological- 
dispositions continuum-gradient of sovereignising-by-ontologising-depth in inducing desublimation or sublimation' as to the fact that nascent-particular/incipient-andmaterial/technical-sublimations-<blinded-to-their-relative-ontological-completeness

reference-of-thought- devolving $>$ are often of 'restricted and directly transparent/potent existentialising-decisionality-<as-to-disontologising/re-ontologising aporeticism $>$ scope of sublimation for human deferential-formalisation-transference' while the social-and-institutionalframeworks-of - referencing/registering/decisioning (as to ' ${ }^{\text {?3 }}$ reference-of-thought-andreference-of-thought- devolving- ${ }^{5}$ meaningfulness-and-teleology ${ }^{9}$ comprehensiveness of prospective sublimating-nascence') imply a depth of appreciation which initially leads to ‘ blurriness-<sterilising/anecdotalising/trivialising-of-prospective-re-ontologising_bypreconverging,-in-disontologising-formulaic-dragging-out/hollowing-out $>$ in existentialisingdecisionality $<a s-t o$-disentologising/re-ontelogising aporeticism $>$ ' as of relative-ontologicalincompleteness ${ }^{88}$-presublimation-construct-of- ${ }^{5}$ meaningfulness-and-teleology desublimating $\sim$ existentialising-decisionality-<as-to-disontologising/re-ontologising aporeticism $>$. We can for instance appreciate this 'human existentialising-decisionality-<as-todisontologising/re-ontologising aporeticism $>$ dual psychological-dispositions continuumgradient of sovereignising — by_ontologising-depth in inducing desublimation or sublimation' say with regards to cultural-diffusion in a non-positivistic like animistic social-construct wherein positivistic technical and material nascent-sublimations can relatively be easily appreciated/grasped in a short timeframe by their immediate sublimating-nascence but the more profound notion of a positivistic registry-worldview/dimension (as to social-and-institutionalframeworks-of - referencing/registering/decisioning of positivistic ${ }^{56}$ meaningfulness-andteleology ${ }^{9}$ ) reflecting a positivising referencing/registry/decisioning is more problematically conceptualisable and mostly arises as of crossgenerational appreciation/grasp (given the nonpositivistic presencing - absolutising-identitive-constitutedness existentialising- 
decisionality-<as-to-disontologising/re-ontologising aporeticism $>$ psychological-disposition of defaulting individual and social 'beholdening as sovereignising-imbuedsubontologisation/subpotentiation'); and this 'human existentialising-decisionality-<as-todisontologising/re-ontologising aporeticism $>$ dual psychological-dispositions continuumgradient of sovereignising — by — ontologising-depth in inducing desublimation or sublimation' applies in the <cumulating/recomposuring attendant-ontological-contiguity $>$-succession of registry-worldviews/dimensions with regards to the possibility for their prospective sublimation/emancipation. Along the same lines of disambiguating 'human existentialisingdecisionality-<as-to-disontologising/re-ontologising aporeticism $>$ dual psychologicaldispositions continuum-gradient of sovereignising-by-ontologising-depth in inducing desublimation or sublimation' just as a 'God-of-plane non-positivistic proposition' in an animistic social-setup implies priorly an 'altogether superseding positivistic apriorising/axiomatising/referencing/intelligibilitysettingup/measuringinstrumenting-forconceptualisation induced psychologism of ${ }^{83}$ reference-of-thought' (over their non-positivistic apriorising/axiomatising/referencing/intelligibilitysettingup/measuringinstrumenting-forconceptualisation psychologism of ${ }^{83}$ reference-of-thought) from whence aposteriorising/logicising/deriving/intelligising/measuring can then ensue in existentialinstantiations of conceptualising, and so as to the positivistic ${ }^{5}$ meaningfulness-and-teleology 'more profound reflection of existence-as-sublimating-withdrawal/unenframing/reontologising,-elicited-from-prospective-profound-supererogation with regards to sublimating-nascence teleological-inflection-〈as-to-more-profound-nondisjointing$<$ amplituding/formative-epistemicity>totalising/circumscribing/delineating $\rangle$, likewise prospectively with regards to nascent-particular/incipient-and-material/technical-sublimations$<$ blinded-to-their-relative-ontological-completeness - reference-of-thought- devolving $>$ as underlying many a technical and natural sciences it is ever always the 'more profound reflection 

prospective-profound-supererogation ' in the sense that the technician and natural scientist are unconcerned with 'any social-and-institutional-frameworks-ofreferencing/registering/decisioning existentialising-decisionality-<as-to-disontologising/reontologising aporeticism $>$ imbuement' supposedly superseding existence-as-sublimatingwithdrawal/unenframing/re-ontologising,-elicited-from-prospective-profound-supererogation given that any such social and institutional pretense-of-sublimation cannot generate any inherent technical and scientific sublimating-nascence (wherein if such social-and-institutionalframeworks-of-referencing/registering/decisioning pretense-of-sublimation warrants gravity on earth to be considered as $7 \mathrm{~m} / \mathrm{s}^{2}$ for instance for one reason or another but for existence-assublimating-withdrawal/unenframing/re-ontologising,-elicited-from-prospective-profoundsupererogation ), rather the natural scientist and technician will view such social-andinstitutional-frameworks-of — referencing/registering/decisioning existentialising-decisionality$\leq$ as-to-disontologising/re-ontologising aporeticism $>$ pretense-of-sublimation as the very preconverging/postconverging-de-mentative/structural/paradigmatic undermining of the possibility of natural science and technical development as to sublimating-nascence beyond just the specific instance but as to a fundamentally underdeveloped social-and-institutionalframeworks-of—referencing/registering/decisioning desublimating $\sim$ existentialising_decisionality-<as-to-disontologising/re-ontologising aporeticism $>$ that must be overridden (so that similar intellectual decadent pretense-of-sublimation should not arise) for the prospective possibility for science and technical development sublimating-nascence to flourish; and likewise it is herein contended that absolutising social-and-institutional-frameworks-ofreferencing/registering/decisioning existentialising-decisionality-as disentelogising/reentologising aporeticism $>$ pre-eminence as to sterile/anecdotal imprimatur and the dynamics of sterile/anecdotal imprimatur (with regards to blurriness- 


\section{<sterilising/anecdotalising/trivialising-of-prospective-re-ontologising_by-preconverging,-in-}

disontologising-formulaic-dragging-out/hollowing-out $>$ in existentialising-decisionality-<asto-disontologising/re-ontelogising aporeticism ${ }^{\prime}$ associated with social-and-institutionalframeworks-of - referencing/registering/decisioning) as 'precedingly defining the possibility of prospective knowledge over inherent knowledge' is itself the very preconverging/postconverging-de-mentative/structural/paradigmatic desublimating undermining of the possibility of veridical social and institutional prospective sublimation/emancipation as to sublimating-nascence, and in that respect no mortal (including the one mortal making this articulation herein) can pretend to a status bigger than existenceas-sublimating-withdrawal/unenframing/re-ontologising,-elicited-from-prospective-profoundsupererogation ${ }^{6}$ to then imply that genuine knowledge-reification $\sim$ gesturing-and-accountingof-epistemic-phenomenalism- $<$ in-

prospective_psychologismic apriorising/axiomatising/referencing-\{of-'prospectively implicited_attendant-ontological-contiguity ' educedexistentialising/contextualising/textualising_'intelligibility/epistemicity/reflexivity-contiguity$<$ imbued-notional cogency $>$ ' $\}$-conflatedness -in-\{preconverging ment by\}

osteonverging entailment> cannot cross-it/has-to-bow-to-it (for one reason or another), and in that regards the more profound knowledge-reification $\sim$ gesturing-and-accounting-ofepistemic-phenomenalism- $<$ in-

prospective_psychologismic apriorising/axiomatising/referencing-\{of-'prospectively implicited_attendant-ontological-contiguity ' educedexistentialising/contextualising/textualising_intelligibility/epistemicity/reflexivity_contiguity<imbued-notional cogency $\left.>^{\prime}\right\}$-conflatedness in \{preconverging ment by $\}$ postconverging-entailment $>$ as to the preconverging/postconverging-dementative/structural/paradigmatic upholding at all instances of the possibility for prospective 
genuine knowledge-reification $\sim$ gesturing-and-accounting-of-epistemic-phenomenalism- $<$ inprospective_psychologismic apriorising/axiomatising/referencing-\{of-'prospectively_ implicited_attendant-ontological-contiguity ' educedexistentialising/contextualising/textualising_'intelligibility/epistemicity/reflexivity-contiguity<imbued-notional cogency >' \}-conflatedness -in-\{preconverging-ment by\} postconverging-entailment $>$ inducing sublimation/emancipation as to sublimating-nascence is more than just the specific knowledge-reification $\sim$ gesturing-and-accounting-of-epistemicphenomenalism-<in-prospective_psychologismic $\sim$ apriorising/axiomatising/referencing- of'prospectively_implicited_attendant_ontological-contiguity ' educedexistentialising/contextualising/textualising_'intelligibility/epistemicity/reflexivity-contiguity$<$ imbued-notional cogency $>$ ' $\}$-conflatedness -in-\{preconverging-ment by\} postconverging-entailment $>$ for sublimation but rather more critically overt articulation of the 'veridical preconverging/postconverging-de-mentative/structural/paradigmatic intellectual underdevelopment underlying any such a mortal claim' as to the fact that no human can claim that $2+2$ is not equal to 4 because they are vexed for one reason or another (as it is that condition of our mortality that then provides the possibility for our self-surpassing in prospective construction-of-the-Self) so-reflected in the fact that the underlying existentialising-frame-of entailment of motif-and-apriorising/axiomatising/referencing of knowledge is the very requisite condition for eliciting the true ${ }^{56}$ meaningfulness-and-teleology ${ }^{99}$ of any given specific knowledge-reification $\sim$ gesturing-and-accounting — of-epistemic-phenomenalism- $<$ inprospective_psychologismic apriorising/axiomatising/referencing-\{of-‘prospectively implicited_attendant-ontological-contiguity ' educedexistentialising/contexalising/texalising_intelligibility/epistemicity/reflexivity-contiguity$<$ imbued-notional cogency >' \}-conflatedness -in-\{preconverging-ment by\} postconverging entailment $>$ for sublimation (as for instance there is little point articulating any 
given positivistic existentialising-decisionality-<as-to-disontologising/re-ontologising aporeticism $>$ specific knowledge-reification $\sim$ gesturing-and-accounting-of-epistemicphenomenalism- $<$ in-prospective_psychologismic $\sim$ apriorising/axiomatising/referencing- of'prospectively_implicited_attendant-ontological-contiguity ' educedexistentialising/contextualising/textualising_ 'intelligibility/epistemicity/reflexivity-contiguity<imbued-notional cogency >' \}-conflatedness -in-\{preconverging-ment by\} postconverging entailment> for sublimating-nascence as to positivistic nascentparticular/incipient-and-material/technical-sublimations- $<$ blinded-to-their-relative-ontologicalcompleteness - reference-of-thought- devolving $>$ where the underlying registrywoprldview/dimension existentialising-frame-of-entailment-of-motif-andapriorising/axiomatising/referencing of knowledge is of non-positivistic desublimating $\sim$ existentialising-decisionality-<as-to-disontologising/re-ontologising apereticism $>$ and is not addressed/dealt-with as the Galileos, Descartes, etc. understood with respect to non-positivising medieval-scholasticism desublimating existentialisingdecisionality-<as-to-disontologising/re-ontologising aporeticism $>$ or the ${ }^{103}$ universalisingidealisation Socratic-philosophers sublimating existentialising-decisionality-<as-todisontogising/re ontologising aporeticism> understood with respect to non-universalising ancient-sophists desublimating existentialising-decisionality-<as-to-disontologising/reentologising aporeticism $>$ and in both instances as of their prospective registryworldviews/dimensions implied incipient/seeding <amplituding/formative-epistemicity $>$ totalising thrownness-in-existence ${ }^{35}$,-imbued-projective-arbitrariness/waywardness-〈as-to-thehuman-projective/reprojective- aestheticising-re-motif-and-re-apriorising/re-axiomatising/rereferencing-process-of- ‘ $<$ amplituding/formative-epistemicity $>$ totalising $\sim$ conceptualisation’ $\rangle$ as to sublimating-nascence epistemic-conflatedness ${ }^{13}$ as of projective/reprojectiveaestheticising-re-motif-and-re-apriorising/re-axiomatising/re-referencing, and it is contended as 
well that the conceptualisation herein is rather the more profound as to when its meaningfulness-and-teleology elucidates as to its ${ }^{18}$ deprocrypticism-or-preemptingdisjointedness-as-of- ${ }^{8}$ reference-of-thought sublimating existentialising-decisionality-<as-todisontologising/re-ontologising aporeticism $>$ the 'desublimating existentialisingdecisionality-<as-to-disontologising/re-ontologising aporeticism $>$ of such disjointing pedantising/muddling/formulaic-hollowing-out_-in-subontologisation/subpotentiation〈blurring/undermining-of-prospective-totalising-entailing,-as-to-entailing$<$ amplituding/formative-epistemicity $>$ totalising in-relative-ontological-completeness $>$ underlying existentialising-frame-of-entailment-of motif-andapriorising/axiomatising/referencing of knowledge as to fundamental misanalysis' as soreflected also with 'postmodern thinkers direct/indirect criticisms of ${ }^{79}$ presencing — absolutisingidentitive-constitutedness $^{1,}$ as the sublimating existentialising-decisionality-<as-todisontologising/re-ontologising aporeticism $>$ predefining condition for their specific knowledge articulation to more profoundly be grasped/comprehended/realised), with human knowledge-construal being an altogether level playing field only driven as of the sublimating potential as to existence-as-sublimating-withdrawal/unenframing/re-ontologising,-elicitedfrom-prospective-profound-supererogation (and in this regards theories and concepts cannot be articulated to imply that their subverting criticisms are rather personal/traditions attacks as is increasingly the case in todays institutional-being-and-craft pedantising/muddling/formulaichollowing-out—in-subontologisation/subpotentiation-〈blurring/undermining-of-prospective-

\section{totalising-entailing,-as-to-entailing-<amplituding/formative-epistemicity $>$ totalising in-}

relative-ontological-completeness $\rangle$ since the very first credo of the intellectual is for inherent knowledge above any given theories and concepts and traditions which are rather subordinate to the more profound purpose of the human knowledge-reification $\sim$ gesturing-and-accounting —ofepistemic-phenomenalism- $<$ in- 
prospective_psychologismic apriorising/axiomatising/referencing-\{of-'prospectively

implicited_attendant-ontological-contiguity ' educed-

existentialising/contextualising/textualising_'intelligibility/epistemicity/reflexivity-contiguity-

$<$ imbued-notional $\left.\sim \operatorname{cogency}>^{\prime}\right\}$-conflatedness -in-\{preconverging -ment by\}

postconverging-entailment> project as was so understood and propounded by such midtwentieth century thinkers like Bertrand Russell, A.J. Ayer, Richard Rory, etc. even as their conceptions came under criticism because a genuine relation with knowledge is what can bring about appropriate prospective correction for sublimating knowledge when prospective inspiration avails notwithstanding the traditional approach to knowledge so long as it remains self-critical whereas a false social and institutional-prescience/imprimaturing-<dullness-of thespirit/psychologismic epistemic acutisation nonresidualising imbued-\{compulsing\}linearity ineclecticism-of prior-mere-formulaicity/ritualisation $>$ driven relation to knowledge shoves existential-<disontologising/re-ontologising aporeticism $>$ issues under the table not because there is no human intelligence to tackle true knowledge but because the possibility for more profound contemplation is a-priori placed out-of-sight since the 'flawed prior_knowledgereification $\sim$ gesturing-and-accounting - of-epistemic-phenomenalism- $<$ in-

prior_psychologismic $\sim$ apriorising/axiomatising/referencing- $\{$ of-'prior-implicited_attent ontological-contiguity ' educedexistentialising/contextualising/textualising_ intelligibility/epistemicity/reflexivity-contiguity$<$ imbued-notional cogency >' $\}$-constitutedness -in preconverging-entailment $>$ as to its gesturing/accounting - of-epistemic-phenomenalism' is as of 'existentialising-decisionality<as-to-disontologising/re-ontologising aporeticism $>$ that desublimatingly precedes prospective knowledge-reification $\sim$ gesturing-and-accounting-of-epistemic-phenomenalism<in-prospective_psychologismic $\sim$ apriorising/axiomatising/referencing-\{of-'prospectively_ implicited_attendant-ontological-contiguity ' educed- 
existentialising/contextualising/textualising_ 'intelligibility/epistemicity/reflexivity-contiguity<imbued-notional cogency $>$ ' \}-conflatedness -in-\{preconverging ment by\}

postconverging-entailment>' rather than veridically 'knowledge-reification $\sim$ gesturing-andaccounting - of-epistemic-phenomenalism- $<$ in-

prospective_psychologismic apriorising/axiomatising/referencing-\{of-'prospectively implicited_attendant_ontological-contiguity ' educedexistentialising/contextualising/textualising_intelligibility/epistemicity/reflexivity_contiguity$<$ imbued-notional $\left.\sim \operatorname{cogency}>^{\prime}\right\}$-conflatedness -in-\{preconverging-ment by\} postconverging-entailment> as of its very own deriving/manifest/ensuing/eventuating sublimating $\sim$ existentialising-decisionality-<as-to-disontologising/re-ontologising aporeticism $>^{\prime}$ and as so-reflected when mere-formulaic methodologising/mutualising/organising/institutionalising as of human-subpotency is construed as doing away with priorly requisite-and-relevant supererogatory acuity/perspicacity/astuteness/edginess/incisiveness-ofapriorising/axiomatising/referencing/intelligibilitysettingup/measuringinstrumenting -forconceptualisation with the off-the-shelf and made-to-measure projection of methods and statistics by itself considered as supposedly profound knowledge, and even then such an approach ends up losing out on vision while wrongly reinforcing knowledge as a self-serving punctual/expeditious institutional enterprise rather than of overall prospective human existential<lisontologising/re-ontelogising aporeticism $>$ sublimation/emancipation). Overall the socialconstruct (as to its human notional firstnaturedness-formativeness-<as-toeventualising inkling drive-or-seeding misprising $>$ temporal-to-intemporal-dispositions$<$ so-construed-as-from-perspective-ontological-normalcy/postconvergence $>\quad$ individuative manifestations) itself is reflexive of this 'human existentialising-decisionality-as-todisontologising/re-ontologising aporeticism $>$ dual psychological-dispositions continuum- 
gradient of sovereignising — by_ontologising-depth in inducing desublimation or sublimation' as of its very underlying social-and-institutional-frameworks-ofreferencing/registering/decisioning with regards to social-stake-contention-or-confliction wherein the 'implicited sublimating existentialising-decisionality-as-to-disontologising/reentelogising apereticism $>$ ' underlying the 'non-immediacy prospective sublimating value and ontological-veracity disposition' associated with nascent-particular/incipient-andmaterial/technical-sublimations- $<$ blinded-to-their-relative-ontological-completeness

reference-of-thought- devolving $>$ (as reflected by the
dedication/selflessness/disinterest/magnanimity underlying such existentialising-decisionality<as-to-disontologising/re-ontologising aporeticism> of sublimating-nascence as to existence—as-sublimating-withdrawal/unenframing/re-ontologising,-elicited-fromprospective-profound-supererogation $>$ ) tend to be incoherently overlooked/ignored when it comes to 'immediacy supposed absolute sublimating value and ontological-veracity disposition' reconception of existentialising-decisionality-<as-to-disontologising/re-ontologisingapereticism $>$ as to social-and-institutional-frameworks-of-referencing/registering/decisioning (with respect to such underlying nascent-particular/incipient-and-material/technicalsublimations- $<$ blinded-to-their-relative-ontological-completeness - reference-of-thoughtdevolving $>$ ) poorly constrained to existence-as-sublimating-withdrawal/unenframing/reontologising,-elicited-from-prospective-profound-supererogation $>$ and ending up defaulting as of relative-ontological-incompleteness ${ }^{88}$-presublimation-construct-of- ${ }^{56}$ meaningfulnessand-teleology $\quad$ desublimating existentialising-decisionality-<as-to-disontologising/reentologising aporeticism $>$ (and so as to " blurriness- $<$ sterilising/anecdotalising/trivialising-ofprospective-re-ontologising_by-preconverging,-in-disontologising-formulaic-dragging-

out/hollowing-out $>$ in existentialising-decisionality-<as-to-disontologising/re-ontelogising aporeticism $>$ '). In-many-ways social undertones of ${ }^{5}$ meaningfulness-and-teleology ${ }^{9}$ reflected 
as of $<$ amplituding/formative $>$ wooden-language-_imbued-averaging-of-thought- $<$ as-toleveling/ressentiment/closed-construct-of- meaningfulness-and-teleology -as-of'nondescript/ignorable-void '-with-regards-to-prospective-apriorising-implications $>>$ imply that the requisite sublimating-nascence of social-and-institutional-frameworks-ofreferencing/registering/decisioning tend to shallowontologisation/subontologisation/subpotentiation especially where such frameworks are not thoroughly conceptualised, envisioned/imagined and purposed as to aetiologisation/ontologicalescalation-<ontological-veridicality_commitment/otherliness_transcending/compulsionsencumbered_transcending $>\quad$ conceptivity/epistemic-reflexivity/epistemicity-relativismdeterminism- $<$ reifying \{as-to-knowledge-developing $\}$-and-empowering $>$ and so as to mediocre rationales of their very own ${ }^{79}$ presencing-absolutising-identitive-constitutedness $<$ amplituding/formative-epistemicity $>$ totalising $\sim$ self-referencingsyncretising/circularity/interiorising/akrasiatic-drag poorly projecting of re-ontologising prospective Being-development/ontological-framework-expansion-as-to-depth-ofontologising-development-as-infrastructure-of- meaningfulness-and-teleology (and rather constrained to their present prospectively desublimating institutional-development-as-to-socialfunction-development and living-development-as-to-personality-development psychologismic epistemic acutisation difficulty-for, residualising \{decompulsing $\}$ delinearity for-cogency> magnitudes $\left.{ }^{\{\text {of-experientiality/experiment }\}}\right\}$; and especially as so-prodded with social and intellectual pedantising/muddling/formulaic-hollowing-out — in-subontologisation/subpotentiation〈blurring/undermining-of-prospective-totalising-entailing,-as-to-entailing$<$ amplituding/formative-epistemicity $>$ totalising $\sim$ in-relative-ontological-completeness $>$ dispositions which paradoxically as to their pretense-of-sublimation in defending such 'beholdening as sovereignising-imbued-subontologisation/subpotentiation' do not correspondingly contend that such lax/sloppy existentialising-decisionality-<as-to- 
disontologising/re-ontologising aporeticism $>$ should be the case with nascentparticular/incipient-and-material/technical-sublimations- $<$ blinded-to-their-relative-ontologicalcompleteness - reference-of-thought- devolving> (speaking rather of self-serving socialvestedness/normativity- $<$ discretely-implied-functionalism $>\quad$ institutionalised-wisdom-ofirresponsibility/relative-unreflexivity', as so-manifested across the $<$ cumulating/recomposuring attendant-ontological-contiguity $>$-successive registryworldviews/dimensions, as to when institutional frameworks in their underlying ontologicallydeficient underpinning-suprasocial-construct that poorly appreciate dimensionality-ofsublimating $25<$ - $<$ amplituding/formative $>$ supererogatory $\sim$ de-mentativeness/epistemic-growthor-conflatedness /transvaluative-rationalising/transepistemicity/anamnestic-residuality/spiritdrivenness-equalisation) are naively construed 'as inherently superseding prospective human Being-development/ontological-framework-expansion-as-to-depth-of-ontologisingdevelopment-as-infrastructure-of- meaningfulness-and-teleology as to existence-assublimating-withdrawal/unenframing/re-ontologising,-elicited-from-prospective-profoundsupererogation $>$ ' and so 'by the mere 79 presencing - absolutising-identitive-constitutedness $<$ preconverging 'motif-and-apriorising/axiomatising/referencing'-entailing >existentialising — enframing/imprintedness-〈as-to- historicity-tracing_-in-presencinghyperrealisation/hyperreal-transposition〉 mystic of institutional-prescience/imprimaturing$<$ dullness-of the-spirit/psychologismic epistemic-acutisation nonresidualising imbued\{compulsing\} linearity in eclecticism-of prior mere formulaicity/ritmalisation $>$ whether intellectual or administrative/governmental' as we can appreciate in such a case like Edward Snowden's with a human desublimating existentialising-decisionality-<as-to-disontologising/reentologising aporeticism $>$ of vague 'beholdening as sovereignising-imbuedsubontologisation/subpotentiation' of such 'institutionalised-wisdom-ofirresponsibility/relative-unreflexivity' while paradoxically there is now an emerging social 
clamouring for increasing social and online privacy as a requisite for prospective human sublimation/emancipation as to the positive-opportunism-of-social-functioning-andaccordance $^{75} \quad$ sublimating $\sim$ existentialising-decisionality-<as-to-disontologising/reentologising aporeticism $>$ of 'unbeholdening sublimating-nascence ontologising-depth of the full-potency of existence'). Ultimately, such preconverging-dementating/structuring/paradigming intellectual or administrative/governmental institutions desublimating $\sim$ existentialising-decisionality-<as-to-disontologising/re-ontologising apereticism $>$ as to social-and-institutional-frameworks-of-referencing/registering/decisioning conception tend to align with their given ${ }^{79}$ presencing - absolutising-identitive-constitutedness <preconverging 'motif-and-apriorising/axiomatising/referencing'-entailing $>$ existentialising — enframing/imprintedness-〈as-to- historicity-tracing-in-presencinghyperrealisation/hyperreal-transposition $\rangle$ (as poorly subjected to the genuine social intellectualfunction/posture elucidation) in an expropriating/estranging/constraining/limiting exercise directly/indirectly enabling 'dominance/vested-interest structure in relative-ontologicalincompleteness ${ }^{88}$-presublimation-construct-of- ${ }^{-6}$ meaningfulness-and-teleology desublimating $\sim$ existentialising-decisionality-<as-to-disontologising/re-ontelogising aporeticism $>$ '. Thus the construal of sublimating existentialising-decisionality-<as-todisontologising/re-ontologising aporeticism $>$ as arising as of prospective "83 reference-ofthought-and- ${ }^{83}$ reference-of-thought- ${ }^{8}$ devolving- ${ }^{56}$ meaningfulness-and-teleology comprehensiveness of prospective sublimating-nascence' (over relative-ontologicalincompleteness ${ }^{88}$-presublimation-construct-of- ${ }^{5}$ meaningfulness-and-teleology desublimating existentialising-decisionality-<as-to-disontologising/re-ontologising apereticism $>$ ) calls for a necessary notional $\sim$ self-distantiation- $<$ imbued-re-motif-and-reapriorising/re-axiomatising/re-referencing $>/$ 'distantiation of contemplative existentialisingframe-of-entailment-of-motif-and-apriorising/axiomatising/referencing as to transversality- 
$<$ for-sublimating-existential-eventuating/denouement-from-'thinking-at-first/pure-

predisposition -preemptive-of-prospective-disontologising/subontologising' as-of-

prospectively-disambiguated-affirmed-and-unaffirmed-'motif-and-

apriorising/axiomatising/referencing' $>101$ in superseding any underpinning-suprasocialconstruct defaulting relative-ontological-incompleteness ${ }^{88}$-presublimation-construct-ofmeaningfulness-and-teleology $\quad$ desublimating $\sim$ existentialising-decisionality-<as-todisentologising/re-ontologising aporeticism $>$ which equates/levels-down everything across space and time on the basis of the relative-ontological-incompleteness ${ }^{88}$-presublimationconstruct-of- ${ }^{56}$ meaningfulness-and-teleology desublimating existentialising-decisionality<as-to-disontologising/re-ontologising aporeticism $>$ (as to its underlying presencingdistorted-meritocracy/totalising-sovereign-apportioning_of-human-ontological-

performance $^{72}$-<including-virtue-as-ontology $>/$ morality/ethics/justice/etc.

desublimating $\sim$ existentialising-decisionality-as-to-disontologising/re-ontologising

apereticism $>$ and so-historially involving 'dominance/vested-interest structure in relativeontological-incompleteness ${ }^{8}$ - presublimation-construct-of- ${ }^{56}$ meaningfulness-and-teleology desublimating $\sim$ existentialising-decisionality-<as-to-disontologising/re-ontologising apereticism ${ }^{\prime}$ as from blatant brutish conquest/subjugation conception of apportioning, dominion protection conception of apportioning, to the very natural-order-of-things conception of apportioning and to our subtle modern-day institutionally-distorted/disjointed conception of apportioning); and as any such 'beholdening as sovereignising-imbuedsubontologisation/subpotentiation' given $\quad{ }^{79}$ presencing-absolutising-identitiveconstitutedness ${ }^{14} \quad<$ preconverging 'motif-and-apriorising/axiomatising/referencing' entailing $>$-existentialising — enframing/imprintedness-〈as-to- historicity-tracing - inpresencing-hyperrealisation/hyperreal-transposition〉 gesturing/accounting-of-epistemicphenomenalism is inherently construed as superseding prospective 'unbeholdening sublimating- 
nascence ontologising-depth of the full-potency of existence' which 103 universaltransparency ${ }^{104}$-〈transparency-of-totalising-entailing,-as-to-entailing-<amplituding/formativeepistemicity $>$ totalising in-relative-ontological-completeness $>$ (as herein articulated) is exactly what accounts for human-subpotency 'fatedness-of-sublimation-over-desublimation to existence-potency $\sim$ sublimating-nascence,-disclosed-from-prospective-epistemic-digression in reflecting holographically-<conjugatively-and-transfusively $>$ the relativeunreflexivity/relative-reflexivity - ontological-contiguity of-the-human-institutionalisationprocess ', and so as to the possibility of 'human-decisionality-<as-to-play-of-valid/invaliddecisionality-imbued-sublimation/desublimation> omni-potential commensurability with inherent immanent-existence's sublimation-structure'/omnipotentiality. Whereas we can critically appreciate sublimating-nascence with regards to nascent-particular/incipient-andmaterial/technical-sublimations-<blinded-to-their-relative-ontological-completeness

reference-of-thought- devolving $>$ as to profound constraining to existence-as-sublimatingwithdrawal/unenframing/re-ontologising,-elicited-from-prospective-profoundsupererogation $>$ as associated with technical and scientific contexts of sublimation/desublimation thus inherently inducing/eliciting a human deferential disposition when in ignorance/ineptitude/incompetence reflecting the naturally arising corresponding notional $\sim$ self-distantiation- $<$ imbued—re-motif-and-re-apriorising/re-axiomatising/rereferencing $>/$ 'distantiation of contemplative existentialising-frame-of-entailment-of motifand-apriorising/axiomatising/referencing as to transversality-<for-sublimating-existentialeventuating/denouement,-from-'thinking-at-first/pure-predisposition-preemptive-ofprospective-disontologising/subontologising' as-of-prospectively-disambiguated-affirmedand-unaffirmed-'motif-and-apriorising/axiomatising/referencing'>101 so-implicited with nascent-particular/incipient-and-material/technical-sublimations-<blinded-to-their-relativeontological-completeness - reference-of-thought- devolving > but this human deferential 
disposition when in ignorance/ineptitude/incompetence often does not naturally arise with social-and-institutional-frameworks-of — referencing/registering/decisioning as of "blurriness$<$ sterilising/anecdotalising/trivialising-of-prospective-re-ontologising_by-preconverging,-indisontologising-formulaic-dragging-out/hollowing-out $>$ in existentialising-decisionality-<asto-disontologising/re-ontologising aporeticism $>^{\prime}$ and thus must be actively implied in social knowledge conceptualisation as of notional $\sim$ self-distantiation- $<$ imbued-re-motif-and-reapriorising/re-axiomatising/re-referencing $>/$ 'distantiation of contemplative existentialisingframe-of-entailment-of motif-and-apriorising/axiomatising/referencing as to transversality$<$ for-sublimating-existential-eventuating/denouement,-from-'thinking-at-first/purepredisposition -preemptive-of prospective-disontologising/subontologising' as-ofprospectively-disambiguated-affirmed-and-unaffirmed-'motif-and-

apriorising/axiomatising/referencing'>101 not as utterly doing away with human sovereignty but rather as explicitly projecting the notion of appropriate-and-coherent human sovereignty deferential-formalisation-transfererence 'in relation to prospective knowledge as of human cultivated arts/skills, time investment as well as effectively manifestable sublimation' and so with regards to human limited-mentation-capacity-as-subjecting 'educedunlimitedness/existence-sublimating nascence' to limitedness/hmman-subpotency implied requisite expediency for profound human ontological-performance $2-<$ including-virtue-asontology $>$ /morality/ethics/justice/etc. associated with human intemporal individuations firstnatured instigation of prospective sublimation and subsequent human positiveopportunism-of-social-functioning-and-accordance ${ }^{75}$ integration as secondnaturedinstitutionalisation). This lack of notional $\sim$ self-distantiation- $<$ imbued-re-motif-and-reapriorising/re-axiomatising/re-referencing $>/$ 'distantiation of contemplative existentialisingframe-of-entailment-of-motif-and-apriorising/axiomatising/referencing as to transversality$<$ for-sublimating-existential-eventuating/denouement,-from-'thinking-at-first/pure- 


\section{predisposition-preemptive-of-prospective-disontologising/subontologising' as-of-}

prospectively-disambiguated-affirmed-and-unaffirmed-'motif-and-

apriorising/axiomatising/referencing'> $>$ as arising at destructuring-threshold-

〈uninstitutionalised-threshold /presublimating-desublimating-decisionality $>$ of-ontological-

performance $^{72}-<$ including-virtue-as-ontology $>$ /morality/ethics/justice/etc. is the very element particularly acted upon by social and intellectual pedantising/muddling/formulaic-hollowingout - in-subontologisation/subpotentiation-〈blurring/undermining-of-prospective-totalisingentailing,-as-to-entailing-<amplituding/formative-epistemicity $>$ totalising $\sim$ in-relativeontological-completeness $\rangle$ as to incrementalism-in-relative-ontological-incompleteness ${ }^{8}$ enframed/disontologising conceptualisation (as it can be appreciated for instance that the lack of notional $\sim$ self-distantiation- $<$ imbued — re-motif-and-re-apriorising/re-axiomatising/rereferencing $>/$ 'distantiation of contemplative existentialising-frame-of-entailment-of motifand-apriorising/axiomatising/referencing as to transversality-<for-sublimating-existentialeventuating/denouement,from-'thinking-at-first/pure-predisposition-preemptive-ofprespective disontologising/subontologising' as-of-prospectively-disambiguated-affirmedand-unaffirmed-'motif-and-apriorising/axiomatising/referencing'> ${ }^{101}$ in a non-positivistic social-setup between prospective positivistic knowledge and prior non-positivistic knowledge is exactly what can enable pedantic dispositions to cultivate non-positivistic ${ }^{5}$ meaningfulness-andteleology in such a social-setup), and critically in this regards it principally involves pedantising/muddling/formulaic-hollowing-out - in-subontologisation/subpotentiation〈blurring/undermining-of-prospective-totalising-entailing,-as-to-entailing<amplituding/formative-epistemicity>totalising in-relative-ontological-completeness > as undermining the social-construct's intellectually potent reifying-and-empowering-reflexivityof-ecstatic-existence-as-panintelligibility/panreflexivity ${ }^{3}$-〈existentially-imbued-and-educingStepistemic-totalising thermeneutically/textually/reprojectingly/supererogating/y/zeroing/y/re- 
acutingly, -\{decompulsing\} delinearity $\sim$ for-cogency $\geq$-epistemic-perspective-of-

projective/reprojective - aestheticising-re-motif-and-re-apriorising/re-axiomatising/re-

referencing conceptualisation,-as-herein-specifically-relevant-to human-subpotency $\rangle. \quad$ Such muddlement is more critically as of the inconsistency associated with both sceptical argumentations (with sceptical arguments not necessarily pedantising/muddling/formulaichollowing-out - in-subontologisation/subpotentiation-_blurring/undermining-of-prospectivetotalising-entailing,-as-to-entailing-<amplituding/formative-epistemicity $>$ totalising $\sim$ inrelative-ontological-completeness > when assuming a coherent/consistent threshold of scepticism in want for elucidation) as well as surreptitiously acquiescing/accommodating argumentations, wherein in both instances the inconsistency is bent on blurring/undermining ${ }^{3}$ universal-transparency $^{104}$-〈transparency-of-totalising-entailing,-as-to-entailing$<$ amplituding/formative-epistemicity $>$ totalising in-relative-ontological-completeness $>$ as to a preconverging/postconverging-de-mentative/structural/paradigmatic implication that renders prospective knowledge impotent and so out of ontological-bad-faith/inauthenticity ${ }^{64}$ in desublimating existentialising-decisionality-<as-to-disontologising/re-ontologising aporeticism $>$ gesturing/accounting - of-epistemic-phenomenalism of attenuating/devaluing, blurrying and trivialising wherein there is 'supposedly no totalising-entailing conception-ofmeaningfulness-and-teleology , thus allowing for totalisingly-ing-discretion/whim-ofthought pretense-of-sublimation rather unconstrained to existence-as-sublimatingwithdrawal/unenframing/re-ontologising,-elicited-from-prospective-profoundsupererogation . Critically the "unbeholdening sublimating-nascence ontologising-depth of the full-potency of existence' associated with nascent-particular/incipient-and-material/technicalsublimations- $<$ blinded-to-their-relative-ontological-completeness - reference-of-thoughtdevolving $>$ is necessarily of totalising-entailing as to the immediate-potency of existence-assublimating-withdrawal/unenframing/re-ontologising,-elicited-from-prospective-profound- 
supererogation thus relatively undermining such 'beholdening as sovereignising-imbuedsubontologisation/subpotentiation' gesturing/accounting-of-epistemic-phenomenalism associated with social-and-institutional-frameworks-of-referencing/registering/decisioning as of 'blurriness-<sterilising/anecdotalising/trivialising-of-prospective-re-ontologising_bypreconverging,-in-disontologising-formulaic-dragging-out/hollowing-out $>$ in existentialisingdecisionality-<as-to-disontologising/re-ontologising aporeticism ${ }^{\prime}$ (that is, where the latter does not extensively intrude into the former as for instance in determining-and-demarcating the framework of natural sciences research). Hence in-many-ways prospective knowledge cannot elude the postconverging aporeticism-overcoming/mnovercoming of such 'beholdening as sovereignising-imbued-subontologisation/subpotentiation' gesturing/accounting-ofepistemic-phenomenalism and so relatively to the given domain-of-study/domain-of-interest blurriness-<sterilising/anecdotalising/trivialising-of-prospective-re-ontologising_bypreconverging,-in-disontologising-formulaic-dragging-out/hollowing-out>, wherein blurriness-<sterilising/anecdotalising/trivialising-of-prospective-re-ontologising_bypreconverging,-in-disontologising-formulaic-dragging-out/hollowing-out> is reflected with desublimating $\sim$ existentialising-decisionality-<as-to-disontologising/re-ontologising apereticism> supposedly taking precedence over inherent prospective knowledgereification $\sim$ gesturing-and-accounting — of-epistemic-phenomenalism- $<$ inprospective_psychologismic apriorising/axiomatising/referencing-\{of-'prospectively implicited_attendant-ontological-contiguity ' educedexistentialising/contextualising/textualising_'intelligibility/epistemicity/reflexivity-contiguity<imbued-notional cogency >' \}-conflatedness -in-\{preconverging-ment by\}

posteonverging entailment> rather than 'unbeholdening sublimating-nascence ontologisingdepth of the full-potency of existence (implied as to the very inherent knowledgereification $\sim$ gesturing-and-accounting - of-epistemic-phenomenalism- $<$ in- 
prospective_psychologismic apriorising/axiomatising/referencing-\{of- ${ }^{\text {prospectively }}$

implicited_attendant-ontological-contiguity ' educed-

existentialising/contextualising/textualising_'intelligibility/epistemicity/reflexivity-contiguity-

$<$ imbued-notional cogency $\left.>^{\prime}\right\}$-conflatedness -in-\{preconverging-ment by\}

postconverging-entailment $>$ as determining sublimating $\sim$ existentialising-decisionality-<as-todisentologising/re-ontelogising apereticism $\gg$ )'; with this conflicting of 'beholdening as sovereignising-imbued-subontologisation/subpotentiation' and 'unbeholdening sublimatingnascence ontologising-depth of the full-potency of existence' so-reflected across the $<$ cumulating/recomposuring attendant-ontological-contiguity $>$-successive registryworldviews/dimensions given human notional firstnaturedness-formativeness-<as-toeventualising inkling-drive-or-seeding-misprising > temporal-to-intemporal-dispositions$<$ so-construed-as-from-perspective-ontological-normalcy/postconvergence $>$ as to prospective social-stake-contention-or-confliction (beyond-the-consciousness-awareness-teleology ${ }^{\circ}<$ of preconverging-existential-extrication-as-of-existential-unthought> ). Thus such an postconverging aporeticism-overcoming/unovereoming necessarily imply the integration of the analysis of pedantising/muddling/formulaic-hollowing-out - insubontologisation/subpotentiation-〈blurring/undermining-of-prospective-totalising-entailing,as-to-entailing-<amplituding/formative-epistemicity $>$ totalising in-relative-ontologicalcompleteness $\rangle$ as part-and-parcel of prospective knowledge-reification $\sim$ gesturing-andaccounting - of-epistemic-phenomenalism- $<$ in-

prospective_psychologismic apriorising/axiomatising/referencing-\{of- ${ }^{\text {pprospectively }}$ implicited_attendant-ontological-contiguity ' reducedexistentialising/contextualising/textualising_'intelligibility/epistemicity/reflexivity_contiguity$<$ imbued-notional cogency >' $\}$-conflatedness -in-\{preconverging ment by\} postconverging-ntailment> as to knowledge-notionalisation, and especially as so-manifested 
increasingly with 'non-ontologising/disontologising surreptitious knowledge-withoutknowledge/knowledge-outside-knowledge/extra-knowledge frameworks' that on the baiting of sterile/anecdotal imprimatur then switch on to propound 'non-ontologising/disontologising surreptitious knowledge-without-knowledge/knowledge-outside-knowledge/extra-knowledge

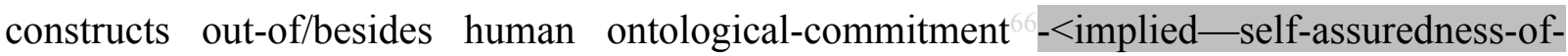
ontological-good-faith/authenticity $\sim$ postconverging-de-

mentating/structuring/paradigming -as-being-as-of-existential-reality> and implicitly obviating the veracity of the ${ }^{103}$ universal-transparency ${ }^{104}$-〈transparency-of-totalising-entailing,as-to-entailing-<amplituding/formative-epistemicity $>$ totalising in-relative-ontologicalcompleteness > of knowledge-reification $\sim$ gesturing-and-accounting-of-epistemicphenomenalism- $<$ in-prospective_psychologismic $\sim$ apriorising/axiomatising/referencing-\{of'prospectively implicited_attendant-ontological-contiguity ' educedexistentialising/contextualising/textualising_ 'intelligibility/epistemicity/reflexivity-contiguity<imbued-notional cogency>' \}-conflatedness -in-\{preconverging -ment by\} postconverging-entailment>' (and so as to self-serving social-vestedness/normativity$<$ discretely-implied-functionalism $>$ ) and this must effectively be contested. Such lousiness and as broadly reflected in poor media editorialising in-many-ways increasingly turns media accessibility into intellectual pre-eminence as 'intellection is no longer about depth of contemplation and knowledge-reification $\sim$ gesturing-and-accounting-of-epistemicphenomenalism-<in-prospective_psychologismic $\sim$ apriorising/axiomatising/referencing- of'prospectively_implicited_attendant-ontological-contiguity ' educedexistentialising/contextualising/textualising_'intelligibility/epistemicity/reflexivity_contiguity$<$ imbued-notional cogency $>$ ' $\}$-conflatedness -in-\{preconverging ment by\}

postconverging-entailment $>$ for sublimation but rather about gimmicky-and-flashy threads of mere communication performance' with many such interlocutors openly admitting-and- 
manifesting their critical lack of relevant intellectual thematic competence as popularity then supposedly becomes the driving force of thought; the fact though remains (however the seemingly trivialising concern about such media driven pop-intellectualism as rather unimportant in some milieus of more profound intellectual contemplation) that unfortunately inmany-ways directly or indirectly (as to the social-and-institutional-frameworks-ofreferencing/registering/decisioning susceptibility to blurriness-

\section{$<$ sterilising/anecdotalising/trivialising-of-prospective-re-ontologising_by-preconverging,-in-}

disontologising-formulaic-dragging-out/hollowing-out $>$ in existentialising-decisionality-<asto-disontologising/re-ontologising aporeticism $>^{\prime}$ and as encouraged by dominance/vestedinterest actors) such pop-intellectualism end up being elevated as the summum of intellection in the social while overlooking the requisite depth of sublimating ${ }^{103}$ universal-transparency ${ }^{104}$ 〈transparency-of-totalising-entailing,-as-to-entailing-<amplituding/formative-

epistemicity>totalising in-relative-ontological-completeness > of critical importance for effective social-and-institutional-frameworks-of-referencing/registering/decisioning sublimating existentialising-decisionality-<as-to-disontologising/re-ontologising apereticism $>$ (and as the 'mediatic framework of access and communication of sublimating thought' is rather turned around into a 'framework that supposedly inherently create sublimating thought by mere access and communication' especially as to naive social feel-good banalities as supposedly sublimation actually of desublimating <preconverging 'motif-andapriorising/axiomatising/referencing'-entailing >-existentialising — enframing/imprintedness〈as-to- historicity-tracing-in-presencing-hyperrealisation/hyperreal-transposition〉 as of mere-and-vague impression-driven/good-naturedness/wishfulness 'beholdening as sovereignising-imbued-subontologisation/subpotentiation'). But then the idea of knowledge driven as of totalising-entailing as so-demonstrable with say the momentous development of quantum physics with the physics totalising-entailing implications of argumentations of 
sublimating existentialising-decisionality-<as-to-disontologising/re-ontologising aporeticism $>$ at critical moments moving from one physicist to the other as of 'totalisingentailing pertinence of thought upheld/elevated above anyone person' (whether Bohr, Einstein, Dirac, Schrodinger, etc.) without any non-ontologising/disontologising surreptitious knowledgewithout-knowledge/knowledge-outside-knowledge/extra-knowledge notion like reputation having any incidence (as in epistemic re-originariness/re-origination projective/reprojective cross-subjection of knowledge-reification $\sim$ gesturing-and-accounting-of-epistemicphenomenalism-<in-prospective_psychologismic $\sim$ apriorising/axiomatising/referencing- of'prospectively implicited_attendant-ontological-contiguity ' ceducedexistentialising/contextualising/textualising_'intelligibility/epistemicity/reflexivity-contiguity<imbued-notional cogency $>$ ' $\}$-conflatedness -in-\{preconverging ment by\} postconverging-entailment> as to existence-as-sublimating-withdrawal/unenframing/reontologising,-elicited-from-prospective-profound-supererogation as herein underlied with notional $\sim$ self-distantiation- $<$ imbued—re-motif-and-re-apriorising/re-axiomatising/rereferencing $>\quad$ implied formativeness-<as-to-intersolipsism-ofpreformulating/preframing/premeaningfulness-imbued-mediativity-and-deferentialism>-ofmeaningfulness-and-teleology $\quad$ in $\quad{ }^{6}$ nonpresencing- $<$ perspective-ontologicalnormalcy/postconvergence> epistemic-projection, and so similar to a Derridean 'heterogeneous genesis' epistemic conception), speaks to a more profound lack of constraining postconverging-aporeticism-overcoming/unovercoming as to institutional convenience that fails to articulate such a 'totalising-entailing pertinence of thought upheld/elevated above anyone person' and thus renders in relative terms the social domain more intellectually impotent in inducing a similar level of sublimating existentialising-decisionality-as entologising aporeticism $>$ as to existence-as-sublimating-withdrawal/unenframing/reontologising,-elicited-from-prospective-profound-supererogation as is relatively the case in 
the natural sciences (and so notwithstanding the relative blurriness$<$ sterilising/anecdotalising/trivialising-of-prospective-re-ontologising_by-preconverging,-indisontologising-formulaic-dragging-out/hollowing-out $>$ of the social which can effectively be brought to intolerance-<of-disparateness $>$ /exactifying_precisioning-of-sublimation- $<$ as-topostconverging-narrowing-down apriorising/axiomatising/referencing-entailing-theoretical,conceptual-and-operant-implications $>$ as to the requisite self-criticality overcoming as well as emotional-involvement overcoming rather than assuming a relatively false social and institutional-prescience/imprimaturing- $<$ dullness-of the-spirit/psychologismic epistemic acutisation nonresidualising-imbued-compulsing linearity in-eclecticism-of-prior-mereformulaicity/ritualisation $>$ driven relation to knowledge); with the further implication of such 'totalising-entailing pertinence of thought upheld/elevated above anyone person' being that the 'knowledge-reification gesturing-and-accounting —of-epistemic-phenomenalism- $<$ inprospective_psychologismic apriorising/axiomatising/referencing-\{of-'prospectively implicited_attendant-ontological-contiguity ' educedexistentialising/contextualising/textualising_intelligibility/epistemicity/reflexivity_contiguity<imbued-notional cogency $>\quad\}$-conflatedness -in-\{preconverging ment by\}

ostarilment $>$ process becomes highly impersonal and complementary in a natural way' without the artifice of 'politically-driven accommodation of ideas not necessarily as of the pre-eminence of existence-as-sublimating-withdrawal/unenframing/re-ontologising,-elicitedfrom-prospective-profound-supererogation ${ }^{\prime}$. In this regards, it is contended that the argumentation articulated herein are strictly striving towards aetiologisation/ontologicalescalation-<ontological-veridicality_commitment/otherliness_transcending/compulsionsencumbered_transcending $>\quad$ conceptivity/epistemic-reflexivity/epistemicity-relativismdeterminism-<reifying \{as-to-knowledge-developing\}-and-empowering $>$ in reflection of 'abstract human intemporal individuative ontological-performane (as to the backdrop of the 
notionalisation/notional-conception/amplituding of knowledge in reflection of human notional firstnaturedness-formativeness-<as-to-eventualising inkling-drive-or-seeding misprising $>$ temporal-to-intemporal-dispositions- $<$ so-construed-as-from-perspectiveontological-normalcy/postconvergence $>$ ) while striving for totalising-entailing pertinence of thought' and so projecting beyond any implications of personalising/particularising import but rather turning towards 'ontological elucidation import as it then reifyingly-and-empoweringly enables human sublimation as to prospective operationalising construals' and so-reflected in the idea that the fundamental stakes of prospective knowledge-reification $\sim$ gesturing-andaccounting - of-epistemic-phenomenalism- $<$ in-

prospective_psychologismic apriorising/axiomatising/referencing-\{of-'prospectively implicited_attendant-ontological-contiguity ' reducedexistentialising/contextualising/textualising_'intelligibility/epistemicity/reflexivity-contiguity<imbued-notional cogency $\left.>^{\prime}\right\}$-conflatedness -in-\{preconverging -ment by\}

postconverging entailment $>$ is about prospective social-stake-contention-or-confliction and not prior social-stake-contention-or-confliction (as for instance prospective positivistic meaningfulness-and-teleology ${ }^{9}$ is not developed to go about articulating/relating-to meaningfulness-and-teleology 99 as to the prior social-stake-contention-or-confliction of nonpositivistic ${ }^{56}$ meaningfulness-and-teleology ${ }^{9}$ ), and so by the mere implications of dimensionality-of-sublimating 25 -<amplituding/formative>supererogatory $\sim$ dementativeness/epistemic-growth-or-conflatedness /transvaluativerationalising/transepistemicity/anamnestic-residuality/spirit-drivenness-equalisation) (even as such prospective ${ }^{5}$ meaningfulness-and-teleology ${ }^{9}$ tend to be rather desublimatingly related to as of dimensionality-of-desublimating-lack-of $-\langle<$ amplituding/formative $>$ supererogatory $\sim$ dementativeness/epistemic-growth-or-conflatedness /transvaluativerationalising/transepistemicity/anamnestic-residuality/spirit-drivenness-equalisation〉 by the 
prior ${ }^{79}$ presencing-absolutising-identitive-constitutedness apriorising/axiomatising/referencing'-entailing>-existentialising — enframing/imprintedness〈as-to- historicity-tracing-in-presencing-hyperrealisation/hyperreal-transposition〉). But then as well the fact remains that the reality of human knowledge-reification $\sim$ gesturing-andaccounting - of-epistemic-phenomenalism- $<$ in-

prospective_psychologismic $\sim$ apriorising/axiomatising/referencing-\{of-`prospectively implicited_attendant-ontological-contiguity ' reducedexistentialising/contextualising/textualising_'intelligibility/epistemicity/reflexivity_contiguity$<$ imbued-notional cogency $>$ ' $\}$-conflatedness - in-\{preconverging ment by\} postconverging-entailment> especially (as speaking to prospective human destructuringthreshold-〈uninstitutionalised-threshold /presublimating-desublimating-decisionality $\rangle$ ofontological-performance ${ }^{72}-<$ including-virtue-as-ontology $>$ ) is inevitably infused with socialand-institutional-frameworks-of_-referencing/registering/decisioning manifest politicallydriven motives of desublimating existentialising-decisionality-<as-to-disontologising/reentologising apereticism $>$ beyond just a 'purported baseline conception of neutral knowledgereification $\sim$ gesturing-and-accounting — of-epistemic-phenomenalism- $<$ inprospective_psychologismic $\sim$ apriorising/axiomatising/referencing-\{of-`prospectively implicited_attendant-ontological-contiguity ' educedexistentialising/contextualising/textualising_'intelligibility/epistemicity/reflexivity_contiguity<imbued-notional cogency> $>$ - conflatedness - in-\{preconverging-ment by\} postconverging entailment>' with such frameworks projecting their 79 presencing—absolutisingidentitive-constitutedness ${ }^{14}$ <preconverging 'motif-and-apriorising/axiomatising/referencing' entailing $>$-existentialising — enframing/imprintedness-〈as-to- historicity-tracing - inpresencing-hyperrealisation/hyperreal-transposition〉 conception of the 'overall possibility of human existentialising-decisionality-<as-to-disontologising/re-ontologising aporeticism $>$ as 
system/charade/distraction'. In this respect, it is important to grasp that knowledgereification $\sim$ gesturing-and-accounting — of-epistemic-phenomenalism- $<$ in-

prospective_psychologismic apriorising/axiomatising/referencing-\{of-'prespectively implicited_attendant-ontological-contiguity ' educedexistentialising/contextualising/textualising_'intelligibility/epistemicity/reflexivity_contiguity<imbued-notional cogency>’ $\}$-conflatedness -in-\{preconverging -ment by\}

postconverging entailment $>$ then desublimatingly becomes an issue of more than just rightness or wrongness but involves a striving for interest/advantage/ascendancy/head-start with respect to existentialising-decisionality-<as-to-disontologising/re-ontologising aporeticism $>$ of prospective knowledge-reification $\sim$ gesturing-and-accounting-of-epistemic-phenomenalism<in-prospective_psychologismic apriorising/axiomatising/referencing-\{of-'prospectively implicited_attendant-ontological-contiguity ' educedexistentialising/contextualising/textualising_'intelligibility/epistemicity/reflexivity-contiguity<imbued-notional cogency $\left.>^{\prime}\right\}$-conflatedness -in-\{preconverging -ment by\} postconverging entailment $>$, and this reality given human notional firstnaturednessformativeness-<as to entising inkling drive or seeding misprising $>$ temporal-tointemporal-dispositions-<so-construed-as-from-perspective-ontologicalnormalcy/postconvergence $>$ is reflected by an inherent human 'referencing/registering/decisioning of shallow-supererogation ${ }^{9}$ - to - profoundsupererogation conception of social-stake-contention-or-confliction' with respect to prospective knowledge-reification $\sim$ gesturing-and-accounting-of-epistemic-phenomenalism<in-prospective_psychologismic apriorising/axiomatising/referencing-\{of-`prospectively implicited_attendant-ontological-contiguity ' reducedexistentialising/contextualising/textualising_ 'intelligibility/epistemicity/reflexivity-contiguity- 
postconverging-entailment>. In-many-ways recent history of human thought has shown that 'social-and-institutional-frameworks-of_-referencing/registering/decisioning manifest politically-driven motives of desublimating existentialising-decisionality-<as-todisentologising/re-ontologising aporeticism $>$ going beyond just neutral knowledgereification $\sim$ gesturing-and-accounting — of-epistemic-phenomenalism- $<$ in-

prospective_psychologismic $\sim$ apriorising/axiomatising/referencing-\{of-'prospectively implicited_attendant-ontological-contiguity ' educedexistentialising/contextualising/textualising_ 'intelligibility/epistemicity/reflexivity-contiguity$<$ imbued-notional cogency $\left.>^{\prime}\right\}$-conflatedness -in-\{preconverging-ment by\} postconverging-entailment>' that cannot be ignored as to intellectually decadent practices of scepticism and blurrying underlied by cynical reframing of thought at later moments (which had been related to sceptically and in blurriness-<sterilising/anecdotalising/trivialising-ofprospective-re-ontologising_by-preconverging,-in-disontologising-formulaic-draggingout/hollowing-out> at previous moments), and so as to shallow-supererogation desublimating $\sim$ existentialising-decisionality-<as-to-disontologising/re-ontologising apereticism $>$ driven by mere institutional-ascendency. In-many-ways thus the conceptualisation herein 'is not caught-up/constrained to any such fooleries' (as to the history of such ploy against postmodern thought) and is consciously articulated as to the profound-supererogation ${ }^{9}$ motive of human sublimation beyond/and-not-subjected-to the <preconverging ' motif-andapriorising/axiomatising/referencing'-entailing >-existentialising — enframing/imprintedness〈as-to- historicity-tracing - in-presencing-hyperrealisation/hyperreal-transposition〉 of any shallow-supererogation social-and-institutional-frameworks-ofreferencing/registering/decisioning as to the 8.5 billion humans on planet Earth and as any party of interest of profound-supererogation may find useful or not! In this respect, it is critical to 
understand what defines humanity as to the 'firstnatureness and derived secondnaturedness positive-opportunism - of-social-functioning-and-accordance ${ }^{5}$, required for human selfsurpassing — existentialism-form-factor,-in-overcoming-'notional collateralising-beholdeningprotohumanity'-to-'attain-sublimating-humanity'-as-to-existence-potency sublimatingnascence,-disclosed-from-prospective-epistemic-digression; as to the fact that all human sublimation is instigated as of re-originary-ass-unenframed/reontologising/unbeholdening/outlier_conceptualisation__imbued-postconverging/dialecticalthinking -'projective-insights'/‘epistemic-projection-in-conflatedness ' 'ofnotional deprocrypticism-prospective-sublimation $\rangle$ before secondnaturing positiveopportunism-of-social-functioning-and-accordance ${ }^{75}$ institutionalisation, as so-reflecting Derridean messianicity (or Foucauldian parrhesia as to profound-supererogation ) wherein even when the messiah comes they still have to come (inevitably-so given prospective human notional firstnaturedness-formativeness-<as-to-eventualising-inkling-drive-or-seedingmisprising $>$ temporal-to-intemporal-dispositions- $<$ so-construed-as-from-perspectiveontological-normalcy/postconvergence $>$ to whatever induced profoundsupererogation /messianicity of originariness-parrhesia,-as-spontaneity-of-aestheticisation soassociated with human dimensionality-of-desublimating-lack-of <<amplituding/formative>supererogatory $\sim$ de-mentativeness/epistemic-growth-orconflatedness /transvaluative-rationalising/transepistemicity/anamnestic-residuality/spiritdrivenness-equalisation $\rangle$ ). It is this fact that explains why no underpinning-suprasocialconstruct is able to coherently explain human-subpotency 'fatedness-of-sublimation-overdesublimation to existence-potency $\sim$ sublimating-nascence,-disclosed-from-prospectiveepistemic-digression in reflecting holographically-<conjugatively-and-transfusively $>$ the relative-unreflexivity/relative-reflexivity - ontological-contiguity of-the-humaninstitutionalisation-process ' since it will always be caught-up in its ${ }^{79}$ presencing-absolutising- 

meritocracy/totalising-sovereign-apportioning — of-human-ontological-performance ${ }^{72}$ $<$ including-virtue-as-ontology $>$ /morality/ethics/justice/etc. desublimating existentialisingdecisionality-<as-to-disontologising/re-ontologising aporeticism $>$. In other words the 'legislation for human prospective sublimation' (as to sublimating existentialisingdecisionality-<as-to-disontologising/re-ontologising aporeticism $>$ ) lies with the firstnatured intemporal individuation relation to existence-as-sublimating-withdrawal/unenframing/reontologising,-elicited-from-prospective-profound-supererogation and the positiveopportunism - of-social-functioning-and-accordance ${ }^{75}$ arising thereof (as of a minimum) for human secondnaturing institutionalisation; and so as to the fact that the Socrates, Copernicuses, Galileos, Descartes, Kants, Newtons, Leibniz, Rousseaux, Diderots, Pasteurs, Lavoisiers, Teslas, Einsteins, etc. didn't ask for any prior consent from the rest of the human species to undertake whatever sublimation they envisioned about humanity making nonsensical the idea that there is any 'generalised human deterministically constraining contemplation of prospective sublimating'. Humanity as such has always been, is and will ever always be about intemporal individuations imagination-and-capacity-for-prospective-sublimation (as to Beingdevelopment/ontological-framework-expansion-as-to-depth-of-ontologising-development-asinfrastructure-of- meaningfulness-and-teleology , institutional-development-as-to-socialfunction-development and living-development-as-to-personality-development psychologismic epistemic-acutisation difficulty-<for, residualising \{decompulsing $\}$ delinearity for-cogency> magnitudes \{of-experientiality/experiment\} implications) and in that regards the triteness of human pedantising/muddling/formulaic-hollowing-out - in-subontologisation/subpotentiation〈blurring/undermining-of-prospective-totalising-entailing,-as-to-entailing- 

incrementalism-in-relative-ontological-incompleteness ${ }^{8}$

enframed/disontologising conceptualisation and <amplituding/formative $>$ wooden-language〈imbued - averaging-of-thought-<as-to-leveling/ressentiment/closed-construct-ofmeaningfulness-and-teleology -as-of-'nondescript/ignorable-void '-with-regards-toprospective-apriorising-implications $>>$ patently doesn't count (given the latter associated temporal desublimating existentialising-decisionality-<as-to-disontologising/reentologising aporeticism $>$ in preconverging-existential-extrication-as-of-existentialunthought that fails aetiologisation/ontological-escalation- $<$ ontologicalveridicality_commitment/otherliness_transcending/compulsions-encumbered_transcending $>$ conceptivity/epistemic-reflexivity/epistemicity-relativism-determinism-<reifying \{as-toknowledge-developing -and-empowering $>$ ); and this is the case fundamentally since such intemporal disposition projected prospective sublimating-nascence engages human ontologicalcommitment $-<$ implied—self-assuredness-of-ontological-goodfaith/authenticity postconverging-de-mentating/structuring/paradigming -as-being-as-ofexistential-reality $>$ as to prospective sublimation-over-desublimation (so-implied with the selfassuredness-of-ontological-good-faith/authenticity ${ }^{69} \sim$ postconverging-dementating/structuring/paradigming 70 -as-being-as-of-existential-reality with respect to socialstake-contention-or-confliction underlying human ontological-commitment $-<$ implied - selfassuredness-of-ontological-good-faith/authenticity $\sim$ postconverging-dementating/structuring/paradigming -as-being-as-of-existential-reality $>$ ). The fact is the intellectual exercise is more acutely/incisively about identifying the relevant postconverging aporeticism-overcoming/unovereoming in-the-very-first-place in order to then effectively relate to what is of prospective profound sublimating intellectualism and so over desublimating pedantising/muddling/formulaic-hollowing-out—in- 
subontologisation/subpotentiation-〈blurring/undermining-of-prospective-totalising-entailing,-

as-to-entailing-<amplituding/formative-epistemicity $>$ totalising $\sim$ in-relative-ontological-

completeness > vague proceduralism (beyond-the-consciousness-awareness-teleology ${ }^{9}-<$ of preconverging-existential-extrication-as-of-existential-unthought $>$ ) as to the simple fact that human prospective destructuring-threshold-〈uninstitutionalised-threshold /presublimatingdesublimating-decisionality $\rangle$ of-ontological-performance ${ }^{72}-<$ including-virtue-asontology $>$ /morality/ethics/justice/etc. means that human ${ }^{56}$ meaningfulness-and-teleology ${ }^{9}$ is ever always caught up prospectively between intellectualism sublimating existentialisingdecisionality-<as-to-disentologising/re-ontologising aporeticism $>$ and pedantising/muddling/formulaic-hollowing-out — in-subontologisation/subpotentiation〈blurring/undermining-of-prospective-totalising-entailing,-as-to-entailing$<$ amplituding/formative-epistemicity $>$ totalising in-relative-ontological-completeness $>$ desublimating $\sim$ existentialising-decisionality-<as-to-disontologising/re-ontelogising aporeticism $>$. This is the case given the requisite condition for the very basic human sublimating existentialising-decisionality-<as-to-disontologising/re-ontologising apereticism $>$ as so-underlied by existence-as-the-absolute-a-priori-ofconceptualisation $\sim$ and existence — as-sublimating-withdrawal/unenframing/re-ontologising,elicited-from-prospective-profound-supererogation $-<$ as-to-perspective-ontologicalnormalcy/postconvergence-implied-'prospective-aporeticism-overcoming/unovercoming'> (reflecting the ever always present challenge for intellectualism over pedantising/muddling/formulaic-hollowing-out — in-subontologisation/subpotentiation〈blurring/undermining-of-prospective-totalising-entailing,-as-to-entailing$<$ amplituding/formative-epistemicity>totalising in-relative-ontological-completeness $\rangle)$; sounderscored by the ever always present challenge for human dimensionality-of-sublimating ${ }^{25}$ <<amplituding/formative>supererogatory $\sim$ de-mentativeness/epistemic-growth-or- 
conflatedness /transvaluative-rationalising/transepistemicity/anamnestic-residuality/spirit-

drivenness-equalisation) as to requisite epistemic-conflatedness ${ }^{13}$ implied projective/reprojective — aestheticising-re-motif-and-re-apriorising/re-axiomatising/rereferencing induced 'projective-insights for predicative-insight'. In this respect, pedantising/muddling/formulaic-hollowing-out - in-subontologisation/subpotentiation〈blurring/undermining-of-prospective-totalising-entailing,-as-to-entailing-

$<$ amplituding/formative-epistemicity>totalising in-relative-ontological-completeness $>$ poor appreciation of notional $\sim$ self-distantiation- $<$ imbued-re-motif-and-re-apriorising/reaxiomatising/re-referencing $>/$ 'distantiation of contemplative existentialising-frame-ofentailment of motif-and-apriorising/axiomatising/referencing as to transversality- $<$ forsublimating-existential-eventuating/denouement,-from-'thinking-at-first/pure-predispositionpreemptive-of prospective-disontologising/subontologising' as-of-prospectivelydisambiguated-affirmed-and-unaffirmed-'motif-and-apriorising/axiomatising/referencing'> (with regards to Being-development/ontological-framework-expansion-as-to-depth-ofontologising-development-as-infrastructure-of- meaningfulness-and-teleology , institutionaldevelopment-as-to-social-function-development and living-development-as-to-personalitydevelopment psychologismic epistemic-acutisation difficulty-<for, residualising \{decolinearity for-cogeney $>$ magnitudes $\{$ of-experientiality/experiment $\}$ implications), is reflected in the 'non-ontologising/disontologising surreptitious knowledge-withoutknowledge/knowledge-outside-knowledge/extra-knowledge paradox' when it claims to coopt/supersede prospective sublimating knowledge-reification $\sim$ gesturing-and-accounting-ofepistemic-phenomenalism-<in-

prospective_psychologismic apriorising/axiomatising/referencing-\{of-‘prospectively implicited_attendant-ontological-contiguity ' educedexistentialising/contextualising/textualising_'intelligibility/epistemicity/reflexivity-contiguity- 
<imbued-notional cogency >' \}-conflatedness -in-\{preconverging-ment by\}

postconverging-entailment> (on the basis of desublimating prior apriorising/axiomatising/referencing-psychologism in epistemicabnormalcy/preconvergence ${ }^{3}$ ) failing to grasp the underlying dimensionality-of-sublimating ${ }^{25}$ <<amplituding/formative>supererogatery $\sim$ de-mentativeness/epistemic-growth-orconflatedness /transvaluative-rationalising/transepistemicity/anamnestic-residuality/spiritdrivenness-equalisation $\rangle$ of the said prospective sublimating knowledge-reification $\sim$ gesturingand-accounting - of-epistemic-phenomenalism- $<$ inprospective_psychologismic apriorising/axiomatising/referencing-\{of-'prospectively implicited_attentantontological-contiguity ' educedexistentialising/contextualising/textualising_'intelligibility/epistemicity/reflexivity_contiguity<imbued-notional cogency >’ \}-conflatedness -in-\{preconverging -ment by\} postconverging-entailment>; as to imply that (say with regards to Beingdevelopment/ontological-framework-expansion-as-to-depth-of-ontologising-development-asinfrastructure-of- meaningfulness-and-teleology ) it is supposedly possible to understand the veracity of any specific positivistic ${ }^{56}$ meaningfulness-and-teleology ${ }^{99}$ while remaining of nonpositivistic mindset, which inevitably induces a relative-ontological-incompleteness ${ }^{8}$ presublimation-construct-of- ${ }^{5}$ meaningfulness-and-teleology ${ }^{9}$ desublimating $\sim$ existentialisingdecisionality-<as-to-disontologising/re-ontologising aporeticism $\geqslant . \quad$ This 'nonontologising/disontologising surreptitious knowledge-without-knowledge/knowledge-outsideknowledge/extra-knowledge paradox' when it claims to co-opt/supersede prospective sublimating knowledge-reification $\sim$ gesturing-and-accounting-of-epistemic-phenomenalism$<$ in-prospective_psychologismic $\sim$ apriorising/axiomatising/referencing-\{of-'prospectively implicited_attendant-ontological-contiguity ' ceducedexistentialising/contextualising/textualising_ 'intelligibility/epistemicity/reflexivity-contiguity- 
postconverging-entailment $>$ can be further elucidated along the same lines (with regards to institutional-development-as-to-social-function-development and living-development-as-topersonality-development psychologismic epistemic acutisation - difficulty $<$ for, residualising \{decompulsing\} delinearity for-cogency>-magnitudes ${ }^{\{\text {of-experientiality/experiment\} }}$ ) wherein for instance the notion of say genius is supposed to imply the 'supposed genius' is exceptional/abnormal (by their 'specifically given sublimating elucidation' so-enabled as to existence — as-sublimating-withdrawal/unenframing/re-ontologising,-elicited-fromprospective-profound-supererogation ). But then actually the 'supposed genius' cannot be exceptional/abnormal for the simple reason that 'existence (so sublimatingly elucidated) is nothing but just normal as to its ontological-normalcy/postconvergence' reflecting the fact that the social-construct ${ }^{56}$ meaningfulness-and-teleology ${ }^{9}$ as from the moment of the sublimating elucidation is/has-been rather of epistemic-abnormalcy/preconvergence ${ }^{31}$, with the notion of 'supposed genius' serving as to human ${ }^{79}$ presencing—absolutising-identitive-constitutedness $<$ preconverging 'motif-and-apriorising/axiomatising/referencing'-entailing $>$ existentialising — enframing/imprintedness-〈as-to- historicity-tracing - in-presencinghyperrealisation/hyperreal-transposition $\rangle$ (beyond-the-consciousness-awareness-teleology $<$ of-preconverging-existential-extrication-as-of-existential-unthought $>$ ) to render obstruse the veracity of this epistemic-abnormalcy/preconvergence ${ }^{31}$ of the social-construct meaningfulness-and-teleology 99 that the 'supposed genius' is pointing out as the 'very issue at stake warranting the social-construct's prospective dimensionality-of-sublimating ${ }^{2}$ <<amplituding/formative>supererogatory $\sim$ de-mentativeness/epistemic-growth-orconflatedness /transvaluative-rationalising/transepistemicity/anamnestic-residuality/spiritdrivenness-equalisation)' as the 'supposed genius' sublimating elucidation implies it has relatively achieved its own 'prospective dimensionality-of-sublimating ${ }^{25}$ 
<<amplituding/formative>supererogatory $\sim$ de-mentativeness/epistemic-growth-or-

conflatedness /transvaluative-rationalising/transepistemicity/anamnestic-residuality/spirit-

drivenness-equalisation)' and is of no inherent prospective issue in that respect. Such that in fact such a notion of genius thus as to wrongly implicited exceptionalism/abnormalcy is surreptitiously (beyond-the-consciousness-awareness-teleology ${ }^{9}-<$ of-preconvergingexistential-extrication-as-of-existential-unthought>) about substituting a different and desublimating existentialising-decisionality-<as-to-disontologising/re-ontologising aporeticism $>$ (whether of pedantic ${ }^{51}$ incrementalism-in-relative-ontological-incompleteness ${ }^{8}$ enframed/disontologising conceptualisation or $<$ amplituding/formative $>$ wooden-language〈imbued-averaging-of-thought-<as-to-leveling/ressentiment/closed-construct-ofmeaningfulness-and-teleology -as-of-'nondescript/ignorable-void '-with-regards-toprospective-apriorising-implications $>\rangle$ ) and particularly so in relatively blurry domains-ofstudy/domains-of-interest (as we can appreciate that such a 'technically wrong 7 presencingabsolutising-identitive-constitutedness $<$ preconverging $\sim$ 'motif-andapriorising/axiomatising/referencing'-entailing >-existentialising — enframing/imprintedness〈as-to- historicity-tracing-in-presencing-hyperrealisation/hyperreal-transposition〉 deficient notion of genius' in spheres of inherently sublimating-nascence as to nascentparticular/incipient-and-material/technical-sublimations- $<$ blinded-to-their-relative-ontologicalcompleteness - reference-of-thought- devolving > is practically of 'insignificant import though technical ontological-impertinence' and so 'as to their very knowledgereification $\sim$ gesturing-and-accounting — of-epistemic-phenomenalism- $<$ in-

prospective_psychologismic apriorising/axiomatising/referencing-\{of- ${ }^{\text {pprospectively }}$ implicited_attendant-ontological-contiguity ' educedexistentialising/contextualising/textualising_'intelligibility/epistemicity/reflexivity-contiguity<imbued-notional cogency >' \}-conflatedness in \{preconverging ment by\} 
postconverging-entailment $>$ as determining sublimating $\sim$ existentialising-decisionality-<as-todisontologising/re-ontologising aporeticism $>$ ' since the incipient/instantaneous/direct potency as to existence-as-sublimating-withdrawal/unenframing/re-ontologising,-elicited-fromprospective-profound-supererogation will be highly challenging to any incompetent mind pretending to be technically/scientifically apt/of-sublimating $\sim$ existentialising-decisionality-<asto-disontologising/re-ontologising aporeticism $>$ in lieu of the truly apt/ofsublimating existentialising-decisionality-<as-to-disontologising/re-ontologising apereticism $>$ technician/scientist, and so unlike desublimating existentialising-decisionality<as-to-disontologising/re-ontologising aporeticism $>$ taking precedence over prospective knowledge-reification $\sim$ gesturing-and-accounting — of-epistemic-phenomenalism- $<$ inprospective_psychologismic apriorising/axiomatising/referencing-\{of-'prospectively_ implicited_attendant-ontological-contiguity ' educedexistentialising/contextualising/textualising_'intelligibility/epistemicity/reflexivity_contiguity$<$ imbued-notional cogency $>$ ' \}-conflatedness -in-\{preconverging ment by\} postconverging-entailment $>$ arising relatively in blurry domains-of-study/domains-of-interest where such 'temporal beholdening as sovereignising-imbued-subontologisation/subpotentiation implied pretense-of-sublimation as to desublimating existentialising-decisionality-as to disontologising/re-ontologising aporeticism $>$ supposedly taking precedence over inherent prospective knowledge-reification $\sim$ gesturing-and-accounting-of-epistemic-phenomenalism$<$ in-prospective_psychologismic $\sim$ apriorising/axiomatising/referencing-\{of-'prospectively implicited_attendant-ontological-contiguity ' educedexistentialising/contextualising/textualising_'intelligibility/epistemicity/reflexivity-contiguity$<$ imbued-notional cogency $>$ ' \}-conflatedness in \{preconverging ment by\}

postconverging entailment>' can more easily arise). In both elucidations of notional $\sim$ selfdistantiation-<imbued - re-motif-and-re-apriorising/re-axiomatising/re- 
referencing $>/$ 'distantiation of contemplative existentialising-frame-of-entailment-of-motifand-apriorising/axiomatising/referencing as to transversality-<for-sublimating-existentialeventuating/denouement,-from-'thinking at-first/pure-predisposition-preemptive-ofprospective-disontologising/subontologising’ as-of-prospectively-disambiguated-affirmedand-unaffirmed-'motif-and-apriorising/axiomatising/referencing'> ${ }^{101} \quad$ (as of Beingdevelopment/ontological-framework-expansion-as-to-depth-of-ontologising-development-asinfrastructure-of- meaningfulness-and-teleology , institutional-development-as-to-socialfunction-development and living-development-as-to-personality-development psychologismic epistemic-acutisation difficulty-for, residualising \{decompulsing $\}$ delinearity for-cogency> magnitudes $\left.{ }^{\{0 f-e x p e r i e n t i a l i t y / e x p e r i m e n t}\right\}$, and so overriding any beyond-the-consciousness-awarenessteleology $\quad<$ of-preconverging-existential-extrication-as-of-existential-unthought $>$, the blunt fact of the matter is that the very preconverging/postconverging-dementative/structural/paradigmatic possibility of human ontological-performance ${ }^{2}-<$ includingvirtue-as-ontology $>$ /morality/ethics/justice/etc. is 'more veridically construed as of nonpresencing-<perspective-ontological-normalcy/postconvergence $>$ as to the ontologicalgood-faith/authenticity ${ }^{6} \sim$ postconverging-de-mentating/structuring/paradigming 0 over the ontological-bad-faith/inauthenticity $\sim$ preconverging-de-mentating/structuring/paradigming as so-reflected with the <cumulating/recomposuring attendant-ontological-contiguity >succession of registry-worldviews/dimensions re-originary_-as-unenframed/reontologising/unbeholdening/outlier-conceptualisation-_imbued-postconverging/dialectical-

\section{thinking -'projective-insights'/‘epistemic-projection-in-conflatedness ' -of-}

notional deprocrypticism-prospective-sublimation ${ }^{\prime}$ '; thus 'making nonsensical the socialvestedness/normativity- $<$ discretely-implied-functionalism $>$ pretenses of all ${ }^{79}$ presencingabsolutising-identitive-constitutedness $<$ preconverging ' motif-andapriorising/axiomatising/referencing'-entailing >-existentialising-enframing/imprintedness- 
〈as-to- historicity-tracing-in-presencing-hyperrealisation/hyperreal-transposition〉' as rather failing the prospective possibility for 'human-decisionality-<as-to-play-of-valid/invaliddecisionality-imbued-sublimation/desublimation> omni-potential commensurability with inherent immanent-existence's sublimation-structure'/omnipotentiality (with such a criticism of social-vestedness/normativity- $<$ discretely-implied-functionalism $>$ here not articulated as from naïve ${ }^{7}$ presencing - absolutising-identitive-constitutedness ${ }^{14} \quad<$ preconverging $\sim$ 'motif-andapriorising/axiomatising/referencing'-entailing >-existentialising—enframing/imprintedness〈as-to- historicity-tracing-in-presencing-hyperrealisation/hyperreal-transposition〉 but rather construed as from ' nonpresencing-<perspective-ontological-normalcy/postconvergence $>$ as to the notional contrast between social-vestedness/normativity-<discretely-implied-functionalism $>$ and re-orginariness/re-origination availing with regards to 'relative-ontologicalincompleteness $8 /$ relative-ontological-completeness

〈sublimating $\sim$ referencing/registering/decisioning,-as-self-becoming/selfconflatedness / formative-supererogating-<projective/reprojective-aestheticising-re-motifand-re-apriorising/re-axiomatising/re-referencing,-in-perspective-ontologicalnormalcy/postconvergence $>>$ as to human-and-social-expectations/anticipationsmetaphoricity ${ }^{5}$-as-preconverging/postconverging-rede-

mentating/restructuring/reparadigming-psychologism' ${ }^{89}$ along the same lines as the conception of both reproducibility-mathesis/motif/thrownness-disposition,-as-reproducibility-ofaestheticisation and originariness-parrhesia,-as-spontaneity-of-aestheticisation in the sense that the one notion is already caught up in the other notion in the sublimating/desublimating $<$ amplituding/formative-epistemicity>totalising/circumscribing/delineating manifestation of aestheticisation-and-aestheticisation-towards-ontology-<elicited-idiomatisation $>\quad$ as $\quad$ of 'relative-ontological-incompleteness 8 /relative-ontological-completeness 7 '

〈sublimating referencing/registering/decisioning,-as-self-becoming/self- 
conflatedness /formative-supererogating-<projective/reprojective-aestheticising-re-motifand-re-apriorising/re-axiomatising/re-referencing,-in-perspective-ontologicalnormalcy/postconvergence $>>$ as to human-and-social-expectations/anticipationsmetaphoricity ${ }^{57}$-as-preconverging/postconverging-rede-

mentating/restructuring/reparadigming-psychologism' ${ }^{89}$ just as for instance the notion of length is already caught up in the notion of width in the 'sublimating <amplituding/formativeepistemicity $>$ totalising/circumscribing/delineating manifestation of a rectangle' and so with regards to the fact that human aestheticisation-and-aestheticisation-towards-ontology$<$ elicited-idiomatisation $>$ of ${ }^{56}$ meaningfulness-and-teleology ${ }^{9}$ is ever always about 'idealisedtypification in epistemic-conflatedness ${ }^{13}$ sublimation or epistemic apriorising/axiomatising/referencing-\{of-'prospectively implicited_attendant-ontologicalcontiguity ' educedexistentialising/contextualising/textualising_'intelligibility/epistemicity/reflexivity-contiguity$<$ imbued-notional $\sim$ cogency $>\quad\}$ - constitutedness ${ }^{14}$-in-preconverging entailment/pseudoconflation desublimation/gimmickiness' for eliciting sublimation/desublimation from the 'full-potency of existence withheld as from ontologicalnormalcy/postconvergence epistemic projection-perspective'). As we can appreciate that more critically than any individual persons punctual existential-<disontologising/re-ontelogising aporeticism> ontological-performance ${ }^{2}-<$ including-virtue-asontology $>$ /morality/ethics/justice/etc., the vices-and-impediments ${ }^{105}$ manifested in any registryworldview/dimension are more decisively explained by the given registryworldview's/dimension's 'destructuring-threshold-〈uninstitutionalisedthreshold /presublimating-desublimating-decisionality $>$ of-ontological-performance ${ }^{72}$ $<$ including-virtue-as-ontology $>/$ morality/ethics/justice/etc. dynamics of notional firstnaturedness-formativeness-<as-to-eventualising inkling-drive-or-seeding- 
misprising $>$ temporal-to-intemporal-dispositions- $<$ so-construed-as-from-perspectiveontological-normalcy/postconvergence>' (with the grandest deeds of ontologicalperformance $^{72}-<$ including-virtue-as-ontology $>$ /morality/ethics/justice/etc. rather reflected in the transcendence-and-sublimity/sublimation/supereregatory $\sim$ de-mentativity of any such destructuring-threshold-〈uninstitutionalised-threshold /presublimating-desublimating-

decisionality $>$ of-ontological-performance ${ }^{72}-<$ including-virtue-as-

ontology $>$ /morality/ethics/justice/etc. as to prospective human 'sublimating referencing/registering/decisioning self-becoming/self-

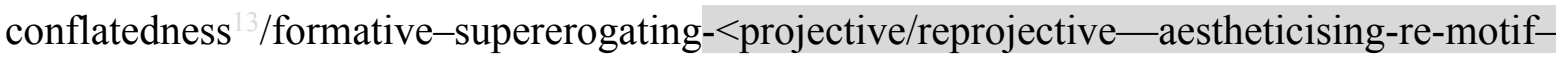
and-re-apriorising/re-axiomatising/re-referencing,-in-perspective-ontologicalnormalcy/postconvergence>' rather than any nombrilistic ${ }^{79}$ presencing - absolutising-identitiveconstitutedness $^{14}$ conceptual naiveties of ontological-performance $2-<$ including-virtue-asontology $>$ /morality/ethics/justice/etc. wrongly construed as of human preconverging/postconverging-de-mentative/structural/paradigmatic flawed 'desublimating $\sim$ referenced/registered/decisioned self-presence/self-constitutedness ${ }^{14}-<$ inperspective-epistemic-abnormalcy/preconvergence $\left.{ }^{3}{ }^{\prime}\right)$. All the more profound and truer notion of re-ontologising human ontological-performance ${ }^{72}-<$ including-virtue-asontology $>$ /morality/ethics/justice/etc. rather lies with prospective dimensionality-ofsublimating $2-\langle<$ amplituding/formative $>$ supererogatory $\sim$ de-mentativeness/epistemic-growthor-conflatedness /transvaluative-rationalising/transepistemicity/anamnestic-residuality/spiritdrivenness-equalisation) and thus postconverging aporeticism-overcoming/unovercoming 'can't be dodged' and then a pretense of prospective sublimating ontological-performance ${ }^{72}$ $<$ including-virtue-as-ontology $>$ /morality/ethics/justice/etc. re-avails (explaining why what then arises is rather pedantic incrementalism-in-relative-ontological-incompleteness ${ }^{8}$ enframed/disontologising $\sim$ conceptualisation and associated $<$ amplituding/formative $>$ wooden- 
language-〈imbued — averaging-of-thought-<as-to-leveling/ressentiment/closed-construct-ofmeaningfulness-and-teleology -as-of-‘nondescript/ignorable-void '-with-regards-toprospective-apriorising-implications $>\rangle)$. Put simply as of nonpresencing-<perspectiveontological-normalcy/postconvergence> (in so-reflecting human limited-mentation-capacitydeepening —as-subjecting limitedness/human-subpotency to-'educed-unlimitedness/existencesublimating nascence ${ }^{53}$ ), the vices-and-impediments ${ }^{105}$ of the $<$ cumulating/recomposuring attendant-ontological-contiguity $>$-successive registryworldviews/dimensions of recurrent-utter-uninstitutionalisation, base-institutionalisationununiversalisation, ${ }^{103}$ universalisation-non-positivism/medievalism and our positivismprocrypticism at their respective destructuring-threshold-〈uninstitutionalisedthreshold /presublimating-desublimating-decisionality $>$ of-ontological-performance ${ }^{72}$ $<$ including-virtue-as-ontology $>/$ morality/ethics/justice/etc. preconverging/postconverging-dementatively/structurally/paradigmatically speak to their requisite prospective dimensionality-ofsublimating $25<<$ amplituding/formative $>$ supererogatory $\sim$ de-mentativeness/epistemic-growthor-conflatedness /transvaluative-rationalising/transepistemicity/anamnestic-residuality/spiritdrivenness-equalisation) postconverging-aporeticism-overcoming/unovercoming as all the more profound and truer notion of re-ontologising human ontological-performance ${ }^{72}$ $<$ including-virtue-as-ontology $>/$ morality/ethics/justice/etc. and so overriding their nombrilistic presencing-absolutising-identitive-constitutedness ${ }^{14}$ conceptual naiveties of ontologicalperformance ${ }^{2}-<$ including-virtue-as-ontology $>$ /morality/ethics/justice/etc. This 'nonontologising/disontologising surreptitious knowledge-without-knowledge/knowledge-outsideknowledge/extra-knowledge paradox' is exactly what underlies the flawed circular manifestation of 'human ${ }^{79}$ presencing_absolutising-identitive-constitutedness ${ }^{14} \quad<$ amplituding/formativeepistemicity $>$ totalising $\sim$ self-referencing-syncretising/circularity/interiorising/akrasiatic-drag in relative-ontological-incompleteness ${ }^{8}$-presublimation-construct-of- ${ }^{5}$ meaningfulness-and- 
teleology desublimating existentialising-decisionality-<as-to-disontologising/reentelogising apereticism ${ }^{\prime}$ and warranting prospective crossgenerational psychoanalyticunshackling/memetic-reordering/institutional-recomposuring; and so as reflecting the difference between a conception of knowledge as of mechanical-knowledge and knowledge as of organicknowledge as to the latter more profound and genuine knowledge conception implication for prospective dimensionality-of-sublimating ${ }^{25}$-< <amplituding/formative $>$ supererogatory $\sim$ dementativeness/epistemic-growth-or-conflatedness /transvaluativerationalising/transepistemicity/anamnestic-residuality/spirit-drivenness-equalisation $\rangle \quad$ in reflection of profound-supererogation with regards to human 'sublimating referencing/registering/decisioning self-becoming/selfconflatedness $^{13}$ /formative-supererogating-<projective/reprojective-aestheticising-re-motifand-re-apriorising/re-axiomatising/re-referencing,-in-perspective-ontologicalnormalcy/postconvergence>' (and so over the mechanical-knowledge conception implication of knowledge as a mere vague thing ready-at-hand 'separate from human construction-of-the-Self' thus wrongly implying dimensionality-of-desublimating-lack-of

\section{<<amplituding/formative >supererogatory $\sim$ de-mentativeness/epistemic-growth-or-}

conflatedness /transvaluative-rationalising/transepistemicity/anamnestic-residuality/spiritdrivenness-equalisation $\rangle$ as to preconverging/postconverging-dementative/structural/paradigmatic flawed 'desublimating referenced/registered/decisioned selfpresence/self-constitutedness $^{14}$-<in-perspective-epistemic-abnormalcy/preconvergence ${ }^{31}>$ '). Critically, in-many-ways the 'projection that the social is necessarily/solely a framework of knowledge as to knowledge-driven existentialising-decisionality-<as-to-disontologising/reentologising aporeticism ${ }^{\prime}$ is ontologically flawed given human notional firstnaturednessformativeness-<as-to-eventualising-inkling-drive-or-seeding-misprising $>$ temporal-tointemporal-dispositions-<so-construed-as-from-perspective-ontological- 
normalcy/postconvergence $>$ to arrive at desublimating $\sim$ existentialising-decisionality-<as-todisontologising/re-ontologising aporeticism $>$ /sublimating existentialising-decisionality-<asto-disontologising/re-ontologising aporeticism $>$ overlooking organic-knowledge implications (whether by 'temporal beholdening as sovereignising-imbuedsubontologisation/subpotentiation' implied 'pretense-of-sublimation as to desublimating $\sim$ existentialising-decisionality-<as-to-disontologising/re-ontologising aporeticism $>$ supposedly taking precedence over inherent prospective knowledgereification $\sim$ gesturing-and-accounting — of-epistemic-phenomenalism- $<$ in-

prospective_psychologismic apriorising/axiomatising/referencing-\{of-'prospectively implicited_attendant-ontological-contiguity ' reducedexistentialising/contextualising/textualising_'intelligibility/epistemicity/reflexivity-contiguity<imbued-notional cogency >' \}-conflatedness -in-\{preconverging-ment by\} postconverging-entailment>' or 'intemporal unbeholdening sublimating-nascence ontologisingdepth of the full-potency of existence' implied 'as to the very inherent knowledgereification $\sim$ gesturing-and-accounting — of-epistemic-phenomenalism- $<$ inprospective_psychologismic apriorising/axiomatising/referencing-\{of-‘prospectively_ implicited_attendant-ontological-contiguity ' educedexistentialising/contextualising/textualising_ intelligibility/epistemicity/reflexivity-contiguity$<$ imbued-notional cogency $>$ ' \}-conflatedness -in-\{preconverging-ment by\} postconverging-entailment $>$ as determining sublimating $\sim$ existentialising-decisionality-<as-todisentologising/re-ontologising apereticism ${ }^{\prime}$ ). Thus as to critical pure-ontology (underlied as of overall reifying-and-empowering-reflexivity-of-ecstatic-existence-aspanintelligibility/panreflexivity ${ }^{3}$-〈existentially-imbued-and-educing-<epistemictotalising thermeneutically/textually/reprojectingly/supererogatingly/zeroing/y/re-acutingly,$\{$ decompulsing $\}$ delinearity $\sim$ for-cogency $>$-epistemic-perspective-of-projective/reprojective- 
aestheticising-re-motif-and-re-apriorising/re-axiomatising/re-referencing $\sim$ conceptualisation--

as-herein-specifically-relevant-to human-subpotency)) the fact is rather that inherent to human temporality ${ }^{8}$ is its 'ephemeral purpose beholdening' that 'do not truly know-of/carry a ${ }^{3}$ universal-transparency ${ }^{104}$-〈transparency-of-totalising-entailing,-as-to-entailing<amplituding/formative-epistemicity>totalising in-relative-ontological-completeness > project' as to its beyond-the-consciousness-awareness-teleology ${ }^{9}<$ of-preconvergingexistential-extrication-as-of-existential-unthought $>$ existentialising-frame-of-entailment-ofmotif-and-apriorising/axiomatising/referencing. This prospect of human temporality ${ }^{9}$ induced increasing incoherence (as to Being-development/ontological-framework-expansion-as-todepth-of-ontologising-development-as-infrastructure-of- meaningfulness-and-teleology , institutional-development-as-to-social-function-development and living-development-as-topersonality-development psychologismic epistemic-acutisation difficulty-for, residualising \{decompulsing $\}$ delinearity-for-cogency>-magnitudes $\{$ of-experientiality/experiment\}) is a fundamental factor to be taken into consideration for 'intemporal unbeholdening sublimatingnascence ontologising-depth of the full-potency of existence (implied as to the very inherent knowledge-reification $\sim$ gesturing-and-accounting — of-epistemic-phenomenalism- $<$ inprospective_psychologismic apriorising/axiomatising/referencing-\{of-'prospectively implicited_attendant-ontological-contiguity ' educedexistentialising/contextmalising/textualising_'intelligibility/epistemicity/reflexivity_contiguity<imbued-notional cogency >' \}-conflatedness -in-\{preconverging -ment by\}

posteonverging-entailment $>$ as determining sublimating $\sim$ existentialising-decisionality-<as-todisontologising/re-ontologising aporeticism $>$ )' in superseding/overcoming 'temporal beholdening as sovereignising-imbued-subontologisation/subpotentiation (implied pretense-ofsublimation as to desublimating existentialising-decisionality-<as-to-disontologising/reentologising aporeticism $>$ supposedly taking precedence over inherent prospective 
knowledge-reification $\sim$ gesturing-and-accounting — of-epistemic-phenomenalism- $<$ inprospective_psychologismic apriorising/axiomatising/referencing-\{of-'prospectively implicited_attendant-ontological-contiguity ' educedexistentialising/contextualising/textualising_'intelligibility/epistemicity/reflexivity-contiguity<imbued-notional cogency >' \}-conflatedness -in-\{preconverging-ment by\} postconverging-entailment>)', and specifically such an superseding/overcoming is rather crossgenerational when it comes to Being-development/ontological-framework-expansion-asto-depth-of-ontologising-development-as-infrastructure-of- meaningfulness-and-teleology (given the more profound 'germinative intensification-amplituding of aestheticisationbeholdening-out-of-bechancing' / 'taxingness-of-originariness,-imbued-sublimating-bydesublimating-amplituding as to the backdrop-of-inherent-immanent-existence's-sublimationstructure-<of-'unsurrealistic-as-real'-ontological-normalcy/postconvergence>'); and as soreflected with human-subpotency 'fatedness-of-sublimation-over-desublimation to existencepotency $\sim$ sublimating-nascence,-disclosed-from-prospective-epistemic-digression in reflecting holographically-<conjugatively-and-transfusively $>$ the relative-unreflexivity/relativereflexivity - ontological-contiguity of-the-human-institutionalisation-process '. This critical pure-ontology analysis point out that ${ }^{56}$ meaningfulness-and-teleology ${ }^{9}$ cannot be profoundly construed as being about mere-manipulable formulaicity but rather contrastively as being about 'profound supererogatory appraisal-and-reappraisal that supersedes mere-manipulable formulaicity' (and as to the fact that knowledge-reification $\sim$ gesturing-and-accounting-ofepistemic-phenomenalism-<in-

prospective_psychologismic apriorising/axiomatising/referencing-\{of-‘prospectively implicited_attentant-ontological-contiguity ' educedexistentialising/contextualising/textualising_intelligibility/epistemicity/reflexivity_contiguity<imbued-notional cogency $>\quad\}$ - conflatedness - in-\{preconverging ment by\} 
postconverging-entailment $>$ ends/should-not aspire to any 'convincing' of ontological-badfaith/inauthenticity ${ }^{64}$ preconverging-de-mentating/structuring/paradigming ${ }^{5}$ as the latter is nothing but a circular process that only ends up degrading knowledge into falsehoods as individual supererogatory-shallowness or supererogatory-profoundness seedingly/inceptively lies with the individual and not knowledge, well before sublimating knowledge can be of any relevance thereof as to derived-formulaicity projected reproducibilitymathesis/motif/thrownness-disposition,-as-reproducibility-of-aestheticisation). In-many-ways the above elucidation of the 'non-ontologising/disontologising surreptitious knowledge-withoutknowledge/knowledge-outside-knowledge/extra-knowledge paradox' of social-andinstitutional-frameworks-of — referencing/registering/decisioning existentialising-decisionality<as-to-disontologising/re-ontologising aporeticism $>$ proned to ${ }^{79}$ presencing-absolutisingidentitive-constitutedness ${ }^{14}<$ preconverging 'motif-and-apriorising/axiomatising/referencing'entailing >-existentialising — enframing/imprintedness-〈as-to- historicity-tracing-inpresencing-hyperrealisation/hyperreal-transposition〉 needs to be critically brought to the consciousness-awareness-teleology' of the 'genuinely aspiring student of society and humanand-social-constructs' (given a social-domain relatively undermined by 'temporal beholdening as sovereignising-imbued-subontologisation/subpotentiation implied pretense-of-sublimation as to desublimating existentialising-decisionality-<as-to-disontologising/re-ontologising aporeticism $>$ supposedly taking precedence over inherent prospective knowledgereification $\sim$ gesturing-and-accounting — of-epistemic-phenomenalism- $<$ in-

prospective_psychologismic apriorising/axiomatising/referencing-\{of-'prospectively implicited_attendant-ontological-contiguity ' educedexistentialising/contextualising/textualising_'intelligibility/epistemicity/reflexivity_contiguity<imbued-notional cogency>' \}-conflatedness -in-\{preconverging ment by\} postconverging-entailment>'), and so as the requisite postconverging-aporeticism- 
overcoming/unovercoming 'for effectively conceptualising anything near a veridical ontology of the social' along the same lines in the natural sciences (with the 'very inherent knowledgereification $\sim$ gesturing-and-accounting — of-epistemic-phenomenalism- $<$ in-

prospective_psychologismic apriorising/axiomatising/referencing-\{of-'prospectively implicited_attendant-ontological-contiguity ' educedexistentialising/contextualising/textualising_'intelligibility/epistemicity/reflexivity_contiguity<imbued-notional cogency>’ $\}$-conflatedness -in-\{preconverging -ment by\}

postconverging-entailment $>$ as determining sublimating $\sim$ existentialising-decisionality-<as-todisontologising/re-ontologising aporeticism $>^{\prime}$ ). Critically in this regards, human conceptivity/epistemic-reflexivity/epistemicity-relativism-determinism- $<$ reifying \{as-toknowledge-developing\}-and-empowering> (as to reifying-and-empowering-reflexivity-ofecstatic-existence-as-panintelligibility/panreflexivity 3 -〈existentially-imbued-and-educing\& fepistemic tolising thermeneutically/textually/reprojectingly/supererogatingly/zeroingly/reacutingly, - decompulsing? $_{\text {delinearity }} \sim$ for-cogency $\geq$-epistemic-perspective-ofprojective/reprojective - aestheticising-re-motif-and-re-apriorising/re-axiomatising/rereferencing conceptualisation,-as-herein-specifically-relevant-to human-subpotency)) can thus preconverging/postconverging-de-mentatively/structurally/paradigmatically be construed as of 'notionalisation/notional-conception/amplituding of knowledge', wherein existence as to its very panintelligibility/panreflexivity ${ }^{3}$ —effusing/ecstatic-inlining is the very aloofness/detachment upon which human conceptivity/epistemic-reflexivity/epistemicity-relativism-determinism$<$ reifying \{as-to-knowledge-developing\}-and-empowering $>$ can supererogatorily act/react in sublimation over desublimation from whence knowledge as to organic-knowledge can arise soconstrued as to existence-as-sublimating-withdrawal/unenframing/re-ontologising,-elicitedfrom-prospective-profound-supererogation . $\quad$ Thus 'notionalisation/notionalconception/amplituding of knowledge' underlies inherent existence-exacted-sublimating as-to- 
postconverging-de-mentating/structuring/paradigming or existence-exacted-desublimating asto-preconverging-de-mentating/structuring/paradigming so-exactable respectively as from human ontological-good-faith/authenticity ${ }^{6} \sim$ postconverging-dementating/structuring/paradigming ${ }^{70}$ ontological-bad-faith/inauthenticity $\sim$ preconvergingde-mentating/structuring/paradigming ${ }^{65}$ so-undergirded; as of human 'self-reflexive instigativeeventuating-〈as-to-teleological-instigative/incipient-

willing/arbitrariness/waywardness/faithdrivenness/supererogating-for-human-intelligibility,preceding-existence's-eventuating-sublimating-validation/desublimating-invalidation〉 of human embodied-consciousness motif-and-apriorising/axiomatising/referencing-\{of'prospectively implicited_attentantontological-contiguity ' educedexistentialising/contextualising/textualising_'intelligibility/epistemicity/reflexivity_contiguity<imbued-notional cogency >’ $\}$-elicited-incipience-of-existentialising-decisionality-<as-todisontologising/re-ontologising aporeticism ${ }^{\prime}$. It is thereafter (in the wake of ontologicalgood-faith/authenticity $\sim$ postconverging-de-mentating/structuring/paradigming ${ }^{70}$ ) that the veridical prospect of critical pure-ontology then arises. Critically, human existence-exacteddesublimating as-to-preconverging-de-mentating/structuring/paradigming—by_existenceexacted-sublimating as-to-postconverging-de-mentating/structuring/paradigming $\quad$ (as of 'relative-ontological-incompleteness ${ }^{8 / \text { relative-ontological-completeness }}{ }^{87}$ 〈sublimating $\sim$ referencing/registering/decisioning,-as-self-becoming/selfconflatedness /formative-supererogating-<projective/reprojective-aestheticising-re-motifand-re-apriorising/re-axiomatising/re-referencing,-in-perspective--ontologicalnormalcy/postconvergence $>>$ as to human-and-social-expectations/anticipationsmetaphoricity ${ }^{57}$-as-preconverging/postconverging-redementating/restructuring/reparadigming-psychologism' ${ }^{89}$ ) speaks to the ontological-veracity that human sublimation reflected in human ontological-performance ${ }^{72}-$ including-virtue-as- $^{2}$ 
ontology $>$ /morality/ethics/justice/etc. is conceptually more than just of 'mere discrete individuals relevant ontological-performance ${ }^{72}-<$ including-virtue-as-ontology $>^{\prime}$ (as can naively be construed with notions of morality/ethics, etc. failing to reflect, as from nonpresencing<perspective-ontological-normalcy/postconvergence $>$ epistemic-projection perspective, the more ontologically profound issue of any given registry-worldview's/dimension's 'destructuring-threshold-〈uninstitutionalised-threshold /presublimating-desublimatingdecisionality $>$ of-ontological-performance ${ }^{72}$ - $<$ including-virtue-asontology $>$ /morality/ethics/justice/etc. dynamics involving notional firstnaturednessformativeness-<as-to-eventualising-inkling-drive-or-seeding-misprising $>$ temporal-tointemporal-dispositions-<so-construed-as-from-perspective-ontologicalnormalcy/postconvergence>' as so-associated with human <amplituding/formative $>$ woodenlanguage-〈imbued-temporal-mere-form/virtualities/dereification/akrasiaticdrag/denatured/preconverging-or-dementing -narratives - of-the- reference-of-thoughtcategorical-imperatives/axioms/registry-teleology 〉). Rather human sublimation so-reflected in prospective human ontological-performance ${ }^{72}-$ including-virtue-as- $^{2}$ ontology $>$ /morality/ethics/justice/etc. rather points to an 'overall interceding human-and-socialexpectations/anticipations - metaphoricity ${ }^{57}$-as-preconverging/postconverging-redementating/restructuring/reparadigming-psychologism $<$ postconverging $\sim$ 'motif-andapriorising/axiomatising/referencing'-entailing >-existentialising-framing/imprinting-〈as-toprospective- historiality/ontological-eventfulness /ontological-aesthetic-tracing$<$ perspective-ontological-normalcy/postconvergence-reflected-'epistemicity-relativismdeterminism' $>>$ of ordered human firstnatureness-deferentialism-imbuing and secondnaturedness-deferentialism-deriving as of underlying human ontological-commitment <implied-self-assuredness-of-ontological-good-faith/authenticity postconverging-dementating/structuring/paradigming -as-being-as-of-existential-reality $>$ as to existence-as- 
sublimating-withdrawal/unenframing/re-ontologising,-elicited-from-prospective-profoundsupererogation '; with 'mere discrete individuals relevant ontological-performance ${ }^{72}$ <including-virtue-as-ontology>' being about acting upon this 'overall interceding human-andsocial-expectations/anticipations - metaphoricity ${ }^{57}$-as-preconverging/postconverging-redementating/restructuring/reparadigming-psychologism $<$ postconverging 'motif-andapriorising/axiomatising/referencing'-entailing>-existentialising-framing/imprinting-〈as-toprospective- historiality/ontological-eventfulness /ontological-aesthetic-tracing$<$ perspective-ontological-normalcy/postconvergence-reflected-'epistemicity-relativismdeterminism' $>>$ of ordered human firstnatureness-deferentialism-imbuing and secondnaturedness-deferentialism-deriving as of underlying human ontological-commitment <implied-self-assuredness-of-ontological-good-faith/authenticity $\sim$ postconverging-dementating/structuring/paradigming -as-being-as-of-existential-reality $>$ as to existence-assublimating-withdrawal/unenframing/re-ontologising,-elicited-from-prospective-profoundsupererogation whether in firstnatureness-deferentialism-imbuing capacity or appropriate secondnaturedness-deferentialism-deriving capacity (as so-reflecting human-subpotency ontological-faith-notion-or-ontological-fideism - imbued-underdetermination-of-motif-andapriorising/axiomatising/referencing-as-so-being-as-of-existential-reality as to the disseminative - sublimating-selectivity-of-ontological-goodfaith/authenticity postconverging-de-mentating/structuring/paradigming , overdesublimating deselectivity of ontological bad-faith/inauthenticity -preconverging dementating/structuring/paradigming ). This points out why human knowledge is veridically a race-to-the-top-exercise/millipede-movement as to the very givenness of existence-as-theabsolute-a-priori-of-conceptualisation and existence - as-sublimatingwithdrawal/unenframing/re-ontologising,-elicited-from-prospective-profoundsupererogation $-<$ as-to-perspective-ontological-normalcy/postconvergence-implied- 
'prospective-aporeticism-overcoming/unovercoming'> that is not subjected to limitedness/human-subpotency ontologically-flawed in-effect absolution temporal-dispositions; as to the fact that it is only a human limited-mentation-capacity-as-subjecting 'educedunlimitedness/existence-sublimating nascence' to-limitedness/human-subpotency maximalising-recomposuring-for-relative-ontological-completeness ${ }^{87}$ - unenframed/reontologising conceptualisation relation with existence-as-sublimatingwithdrawal/unenframing/re-ontologising,-elicited-from-prospective-profound-supererogation that can induce sublimation-over-desublimation. Such a veridical ontology (in relegating/doingaway-with/superseding the "non-ontologising/disontologising surreptitious knowledge-withoutknowledge/knowledge-outside-knowledge/extra-knowledge paradox') is critically all about a 'coherent totalising-entailing knowledge-reification $\sim$ gesturing-and-accounting-of-epistemicphenomenalism- $<$ in-prospective_psychologismic $\sim$ apriorising/axiomatising/referencing- $\{$ of'prospectively implicited_attendant-ontological-contiguity ' educedexistentialising/contextualising/textualising_'intelligibility/epistemicity/reflexivity-contiguity<imbued-notional cogency >' \}-conflatedness -in-\{preconverging-ment by\} postconverging-entailment> ${ }^{\prime}$ exposed to existence-as-the-absolute-a-priori-ofconceptualisation and existence — as-sublimating-withdrawal/unenframing/re-ontologising,elicited-from-prospective-profound-supererogation $-<$ as-to-perspective-ontologicalnormalcy/postconvergence-implied-'prospective-aporeticism-overcoming/unovercoming'>; with such a coherent totalising-entailing knowledge-reification $\sim$ gesturing-and-accounting—ofepistemic-phenomenalism- $<$ inprospective_psychologismic apriorising/axiomatising/referencing-\{of-'prospectively implicited_attendant-ontological-contiguity ' educedexistentialising/contextualising/textualising_'intelligibility/epistemicity/reflexivity-contiguity<imbued-notional cogency $>$ ' \}-conflatedness -in-\{preconverging -ment by\} 
postconverging-entailment> accounting for overall knowledge ${ }^{4}$ historiality/ontologicaleventfulness ${ }^{3}$ /ontological-aesthetic-tracing-<perspective-ontologicalnormalcy/postconvergence-reflected-'epistemicity-relativism-determinism'> as to human limited-mentation-capacity-deepening —as-subjecting limitedness/human-subpotency-to'educed-unlimitedness/existence-sublimating nascence' 53 imbued conceptivity/epistemicreflexivity/epistemicity-relativism-determinism-<reifying \{as-to-knowledge-developing $\}$-andempowering > (so-reflected in the 'momentousness-driven coherence of knowledgereification $\sim$ gesturing-and-accounting — of-epistemic-phenomenalism- $<$ inprospective_psychologismic apriorising/axiomatising/referencing-\{of-'prospectively implicited_attendant-ontological-contiguity ' educedexistentialising/contextualising/textualising_'intelligibility/epistemicity/reflexivity-contiguity<imbued-notional cogency>’ $\}$-conflatedness -in-\{preconverging-ment by\} postconverging-entailment $>$ as to entailing- $<$ amplituding/formative-epistemicity $>$ totalising $\sim$ inrelative-ontological-completeness ${ }^{8}$, so-associated with human limited-mentation-capacitydeepening —as-subjecting limitedness/human-subpotency to-'educed-unlimitedness/existencesublimating nascence' ${ }^{53}$ ). It is important to note in this regards that 'knowledgereification $\sim$ gesturing-and-accounting — of-epistemic-phenomenalism- $<$ inprospective_psychologismic apriorising/axiomatising/referencing-\{of-'prospectively implicited_attendant-ontological-contiguity ' reducedexistentialising/contextualising/textualising_'intelligibility/epistemicity/reflexivity-contiguity<imbued-notional cogency >' \}-conflatedness -in-\{preconverging-ment by\} postconverging-entailment> $\quad{ }^{4}$ historiality/ontological-eventfulness 38 /ontological-aesthetictracing-<perspective-ontological-normalcy/postconvergence-reflected-‘epistemicityrelativism-determinism' $>$ ' is the more profound conception of ontology and science (as to human dimensionality-of-sublimating 25 -<<amplituding/formative $>$ supererogatory $\sim$ de- 
mentativeness/epistemic-growth-or-conflatedness /transvaluative-

rationalising/transepistemicity/anamnestic-residuality/spirit-drivenness-equalisation〉), and so as of the 'profound supererogatory appraisal-and-reappraisal (that supersedes mere-manipulable formulaicity)' driving ontology and science across their punctual developments from past to present and into the future (underlined by human 'sublimating referencing/registering/decisioning self-becoming/selfconflatedness $^{13}$ /formative-supererogating-<projective/reprojective-aestheticising-re-motifand-re-apriorising/re-axiomatising/re-referencing,-in-perspective-ontologicalnormalcy/postconvergence>' arising as of human limited-mentation-capacity-deepening-assubjecting limitedness/human-subpotency-to-'educed-unlimitedness/existence-sublimating nascence' ${ }^{53}$ ). This elucidation is important in the sense that pedantic science-ideology is driven by a conception of mere-manipulable formulaicity of reproducibilitymathesis/motif/thrownness-disposition,-as-reproducibility-of-aestheticisation that poorly appreciates the profound-supererogation in the 'invention/creation' of true science and thus comes to relate to science as 'off-the-shelf and made-to-measure contrivance of formulaicity devoid of profound-supererogation' in a soulless 'temporal beholdening as sovereignisingimbued-subontologisation/subpotentiation (implied pretense-of-sublimation as to desublimating $\sim$ existentialising-decisionality-<as-to-disontologising/re-ontologising aporeticism $>$ supposedly taking precedence over inherent prospective knowledgereification $\sim$ gesturing-and-accounting — of-epistemic-phenomenalism- $<$ inprospective_psychologismic apriorising/axiomatising/referencing-\{of-‘prospectively implicited_antentontogical-contiguity ' reducedexistentialising/contextualising/textualising_'intelligibility/epistemicity/reflexivity-contiguity$<$ imbued-notional cogency $>\quad\}$-conflatedness -in-\{preconverging ment by\} postconverging-entailment>)'; with this shallow-supererogation explaining naivist 
interpretations of the Newtons, Galileos, Pasteurs, etc. in their very formation and development of what we now call science. In-many-ways this pedantic science-ideology construal of knowledge as of ${ }^{7}$ presencing-absolutising-identitive-constitutedness ${ }^{14}$ conception in desublimating $\sim$ referenced/registered/decisioned $\quad$ self-presence/self-constitutedness ${ }^{14}-<$ inperspective-epistemic-abnormalcy/preconvergence ${ }^{3}>$ (without or poorly appreciating the profound-supererogation involved in true science and ontology as to 'sublimating $\sim$ referencing/registering/decisioning self-becoming/self-

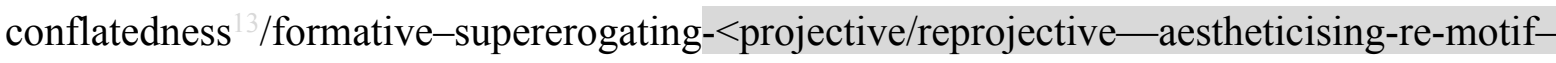
and-re-apriorising/re-axiomatising/re-referencing,-in-perspective-ontologicalnormalcy/postconvergence>') leads to dominance/vested-interest prodded social-stakecontention-or-confliction determination of knowledge as of ${ }^{4}$ historicity-tracing-inpresencing-hyperrealisation/hyperreal-transposition with the accompanying social disenfranchisement/swindling/corruption/dispossession. Such development as to 'nonontologising/disontologising surreptitious knowledge-without-knowledge/knowledge-outsideknowledge/extra-knowledge paradox' is ultimately associated with scenarios of institutionalascendency and other dominance/vested-interest (as associated with many a modern-day thinktank and secret institutions) overtly or covertly construed as inherently predicative-of and superseding knowledge as to networks of influence bent on intimating what can be thought or not as well as pedantising/muddling/formulaic-hollowing-out-insubontologisation/subpotentiation-〈blurring/undermining-of-prospective-totalising-entailing,as-to-entailing-<amplituding/formative-epistemicity $>$ totalising in-relative-ontologicalcompleteness > of genuine knowledge, in 'temporal beholdening as sovereignising-imbuedsubontologisation/subpotentiation (implied pretense-of-sublimation as to desublimating $\sim$ existentialising-decisionality-<as-to-disontologising/re-ontologising aporeticism $>$ supposedly taking precedence over inherent prospective knowledge- 
reification $\sim$ gesturing-and-accounting — of-epistemic-phenomenalism- $<$ inprospective_psychologismic apriorising/axiomatising/referencing-\{of-'prospectively implicited_attendant-ontological-contiguity ' educedexistentialising/contextualising/textualising_'intelligibility/epistemicity/reflexivity-contiguity$<$ imbued-notional cogency $>$ ' \}-conflatedness -in-\{preconverging -ment by\} postconverging-entailment $>$ )'. It is herein contended that in-many-ways as to human ontological-good-faith/authenticity ${ }^{60} \sim$ postconverging-de-mentating/structuring/paradigming ${ }^{70}$, it is technically impossible to strategise against ontology (given existence-as-the-absolute-apriori-of-conceptualisation and existence — as-sublimating-withdrawal/unenframing/reontologising,-elicited-from-prospective-profound-supererogation $-<$ as-to-perspectiveontological-normalcy/postconvergence-implied-'prospective-aporeticismovercoming/unovercoming'>), as to the fact that ontology is absolutely bound to its course comewhat-may 'with such contrivances rather notionally integrated as herein into the elucidation of ontological-veracity as part-and-parcel of ontological-elucidation' that allows no room for any pedantic 'non-ontologising/disontologising surreptitious knowledge-withoutknowledge/knowledge-outside-knowledge/extra-knowledge paradox' and not even when it elicits <amplituding/formative> wooden-language-〈imbued-temporal-mereform/virtualities/dereification/akrasiatic-drag/denatured/preconverging-or-dementing narratives - of-the- reference-of-thought- categorical-imperatives/axioms/registryteleology $>$ as of shortsighted social and institutional power play. Such 'fraudulent conception of knowledge' thrive not only as to punctual thematic issues like climate change science and disenfranchisement/swindling/corruption/dispossession implications but even worst carry ideological dehumanising implications as to covertly/implicitly putting in question the humanity of other peoples/nations/cultures/races. It is herein contended that any pretense of a conception of humanity along those lines is nothing but mirrored-fascism as to the mere-token that all the 
human others are capable of 'sublimating referencing/registering/decisioning selfbecoming/self-conflatedness ${ }^{13}$ /formative-supererogating-<projective/reprojectiveaestheticising-re-motif-and-re-apriorising/re-axiomatising/re-referencing,-in-perspectiveontological-normalcy/postconvergence>' (as to inherent cultural growth and cultural diffusion capacity) thus rendering any lousy exclusionary conception of humanity along the lines of Western, non-Western, Oriental, Chinese, Arab, African, Russian, etc. of vague ${ }^{79}$ presencingabsolutising-identitive-constitutedness ${ }^{14}$ social-stake-contention-or-confliction beholdeningbecoming — distortive-originariness/distortive-origination-as-to- ${ }^{-1}$ historicity-tracing inhibitedmental-aestheticising (speaking of shallow 'germinative intensification-amplituding of aestheticisation-beholdening-out-of-bechancing' / 'taxingness-of-originariness,-imbuedsublimating-by-desublimating-amplituding as to the backdrop-of-inherent-immanentexistence's-sublimation-structure-<of-'unsurrealistic-as-real'-ontological-

normalcy/postconvergence>'). In-many-ways this latterly identified manifestation of 'nonontologising/disontologising surreptitious knowledge-without-knowledge/knowledge-outsideknowledge/extra-knowledge paradox', wherein political purpose supposedly supersedes human intellective potency is the very crème-de-la-crème preconverging/postconverging-dementative/structural/paradigmatic and defining basis for social-and-institutional-frameworksof - referencing/registering/decisioning of desublimating $\sim$ existentialising-decisionality-<as-todisontologising/re-ontologising aporeticism $>$ as to 'temporal beholdening as sovereignisingimbued-subontologisation/subpotentiation (implied pretense-of-sublimation as to desublimating $\sim$ existentialising-decisionality-<as-to-disontologising/re-ontologising aporeticism $>$ supposedly taking precedence over inherent prospective knowledgereification $\sim$ gesturing-and-accounting — of-epistemic-phenomenalism- $<$ inprospective_psychologismic apriorising/axiomatising/referencing-\{of- ${ }^{\text {pprospectively }}$ implicited_attendant-ontological-contiguity ' educed- 
existentialising/contextualising/textualising_ 'intelligibility/epistemicity/reflexivity-contiguity<imbued-notional cogency $>$ ' \}-conflatedness -in-\{preconverging ment by\}

postconverging entailment>)'; so-reflected with dominion/statal-logic-〈preconverging/shallowsupererogating-'human-and-social-expectations/anticipations-dementating/structuring/paradigming-psychologism'-as-to-its-specific-collateralisingbeholdening-<whether-trepidatious-or-warped-or-preclusive-or-occlusive $>$-and-itsconsociated-dominance/vested-interest-subontologising-skewed-influence-as-to-socialvestedness/normativity- $<$ discretely-implied-functionalism $>>$ 'temporal beholdening as sovereignising-imbued-subontologisation/subpotentiation (implied pretense-of-sublimation as to desublimating existentialising-decisionality-as do dolongising aporeticism $>$ supposedly taking precedence over inherent prospective knowledgereification $\sim$ gesturing-and-accounting — of-epistemic-phenomenalism- $<$ inprospective_psychologismic apriorising/axiomatising/referencing-\{of- ${ }^{\text {pprospectively }}$ implicited_attendant-ontological-contiguity ' educedexistentialising/contextualising/textualising_'intelligibility/epistemicity/reflexivity-contiguity<imbued-notional cogency>’ $\}$-conflatedness -in-\{preconverging-ment by\} postconverging-entailment>)'. In other words, the global political and geopolitical dynamics itself (so-associated with derived economic and social dominance/vested-interest) is preconverging/postconverging-de-mentatively/structurally/paradigmatically instigative of a 'surreptitious-and-flawed claim in desublimating existentialising-decisionality-<as-todisontologising/re-ontologising aporeticism $>$ upon human genuine social intellectualfunction/posture' as $\quad$ to $\quad$ social-and-institutional-frameworks-ofreferencing/registering/decisioning existentialising-decisionality-<as-to-disontologising/reentologising aporeticism $>$ and so obviating genuine social intellectual-function/posture ontological-veracity as to 'intemporal unbeholdening sublimating-nascence ontologising-depth 
of the full-potency of existence (implied as to the very inherent knowledgereification $\sim$ gesturing-and-accounting — of-epistemic-phenomenalism- $<$ in-

prospective_psychologismic apriorising/axiomatising/referencing-\{of-'prospectively implicited_attendant-ontological-contiguity ' ceducedexistentialising/contextualising/textualising_ 'intelligibility/epistemicity/reflexivity-contiguity<imbued-notional cogency >’ \}-conflatedness -in-\{preconverging-ment by\}

postconverging-entailment $>$ as determining sublimating $\sim$ existentialising-decisionality-<as-todisontologising/re-ontologising aporeticism $>$ )', but for when it comes to the sublimatingnascence of nascent-particular/incipient-and-material/technical-sublimations- $<$ blinded-to-theirrelative-ontological-completeness - reference-of-thought- devolving $>$ subordinated to social-and-institutional-frameworks-of — referencing/registering/decisioning existentialisingdecisionality-<as-to-disontologising/re-ontologising aporeticism $>$; as so-reflecting the overall dynamics of human <amplituding/formative> wooden-language-_imbued-temporal-mereform/virtualities/dereification/akrasiatic-drag/denatured/preconverging-or-dementing narratives - of-the- reference-of-thought- categorical-imperatives/axioms/registryteleology $\rangle$, social and intellectual pedantic incrementalism-in-relative-ontologicalincompleteness 8 - enframed/disontologising conceptualisation as well as dominance/vestedinterest with this dynamic inducing 'temporal beholdening as sovereignising-imbuedsubontologisation/subpotentiation (implied pretense-of-sublimation as to desublimating $\sim$ existentialising-decisionality-<as-to-disontologising/re-ontologising aporeticism $>$ supposedly taking precedence over inherent prospective knowledgereification $\sim$ gesturing-and-accounting — of-epistemic-phenomenalism- $<$ inprospective_psychologismic $\sim$ apriorising/axiomatising/referencing-\{of-'prospectively implicited_attendant-ontological-contiguity ' ceducedexistentialising/contextualising/textualising_ 'intelligibility/epistemicity/reflexivity-contiguity- 
postconverging-entailment>)', and critically social sublimation/emancipation necessarily requires human postconverging-aporeticism-overcoming/unovercoming along these intimately-and-dynamically reinforcing exisentialising-frames of human destructuringthreshold-〈uninstitutionalised-threshold /presublimating-desublimating-decisionality $\rangle$ ofontological-performance ${ }^{72}-<$ including-virtue-as-ontology $>$. This latter conceptualisation goes well beyond a point of just mere technical ontological-pertinence as to the fact that it operantly captures in a nutshell the prospectively requisite human postconvergingaaporeticismovercoming/unoverceming in upcoming years and decades, as to the capacity for the human to redefine humanity in the light of the societal and technological transformations of the past few decades and the resultant/developing geopolitical context. It is herein contended that the incapacity for such a collective reconstrual of humanity (as to intemporal unbeholdening sublimating-nascence ontologising-depth of the full-potency of existence implied as to the very inherent knowledge-reification $\sim$ gesturing-and-accounting — of-epistemic-phenomenalism- $<$ inprospective_psychologismic apriorising/axiomatising/referencing-\{of-‘prospectively implicited_attendant-ontological-contiguity ' educedexistentialising/contextualising/textualising_'intelligibility/epistemicity/reflexivity_contiguity$<$ imbued-notional cogency $>$ ' $\}$-conflatedness -in-\{preconverging ment by\}

postconverging-entailment $>$ as determining sublimating $\sim$ existentialising-decisionality-<as-todisontologising/re-ontologising aporeticism $>^{\prime}$ ) following the social and industrial transformation occurring by the end of the th century very much underlies the 'temporal beholdening as sovereignising-imbued-subontologisation/subpotentiation (implied pretense-ofsublimation as to desublimating existentialising-decisionality-<as-to-disontologising/reentologising aporeticism $>$ supposedly taking precedence over inherent prospective knowledge-reification $\sim$ gesturing-and-accounting — of-epistemic-phenomenalism- $<$ in- 
prospective_psychologismic apriorising/axiomatising/referencing-\{of-‘prospectively implicited_attendant-ontological-contiguity ' educedexistentialising/contextualising/textualising_'intelligibility/epistemicity/reflexivity_contiguity$<$ imbued-notional $\left.\sim \operatorname{cogency}>^{\prime}\right\}$-conflatedness -in-\{preconverging -ment by\} postconverging entailment $>$ )' which could only end up in the human-made calamities of the $20^{\text {th }}$ century so-critically attributable to dominion/statal-logic-〈preconverging/shallowsupererogating-'human-and-social-expectations/anticipations-dementating/structuring/paradigming-psychologism'-as-to-its-specific-collateralisingbeholdening- $<$ whether-trepidatious-or-warped-or-preclusive-or-occlusive $>$-and-itsconsociated-dominance/vested-interest-subontologising-skewed-influence-as-to-socialvestedness/normativity- $<$ discretely-implied-functionalism $>$ ). In-many-ways, this highlights the subjection of the genuine social intellectual-function/posture by dominion/statal-logic〈preconverging/shallow-supererogating-'human-and-social-expectations/anticipations- dementating/structuring/paradigming-psychologism'-as-to-its-specific-collateralisingbeholdening- $<$ whether-trepidatious-or-warped-or-preclusive-or-occlusive $>$-and-itsconsociated-dominance/vested-interest-subontologising-skewed-influence-as-to-socialvestedness/normativity- $<$ discretely-implied-functionalism $>>$ (reflected as to the underpinningsuprasocial-construct enclosing/hemming-in religiosity inculcated as defining the very notional/epistemic/bindingness ${ }^{\text {-as-to-determinism/conceptivity-of-relative-unreflexivity/relative-reflexivityz }}$

framework of human Being-development/ontological-framework-expansion-as-to-depth-ofontologising-development-as-infrastructure-of- meaningfulness-and-teleology , institutionaldevelopment-as-to-social-function-development and living-development-as-to-personalitydevelopment psychologismic epistemic-acutisation - difficulty-for, residualising \{decompulsing\} delinearity for-cogeney> magnitudes $\{$ of-experientiality/experiment\} and so consciously/unconsciously as supposedly superseding pure-ontology); and so across all the 
various registry-worldviews/dimensions whether so manifested in say the recurrent religiopolitical induced instability in Ancient Egypt despite its advanced technical and organisational development, Ancient Athenian political decadence associated with the Socratic-philosophers aspiration for enlightening-renewal of the political process or the medieval establishment politico-religious excesses underlying the reformation and renaissance and its prolongation into the enlightenment genuine social intellectual-function/posture strive for science, ${ }^{103}$ universal human rights and enlightened society and governance. Such a varying relation between the possibility for profound-supererogation inducible as from genuine social intellectualfunction/posture and dominion/statal-logic-〈preconverging/shallow-supererogating-'humanand-social-expectations/anticipations - de-mentating/structuring/paradigming-psychologism'as-to-its-specific-collateralising-beholdening-<whether-trepidatious-or-warped-or-preclusiveor-occlusive $>$-and-its-consociated-dominance/vested-interest-subontologising-skewedinfluence-as-to-social-vestedness/normativity- $<$ discretely-implied-functionalism $>>\quad$ in-manyways across human history is intimately tied to 'perceived urgency in social mood' whether as to a mood of enlightening-renewal or hegemonic-ascendency. It is no wonder that periods following heights of acute hegemonic strifes especially as associated with warfare come to be tempered with a genuine social intellectual-function/posture obverse/self-deprecatory to such hegemonic manifestations; more like symbolising a sense of failing a more critical human purposefulness usurped in the fantasy of such hegemonic strife. In another respect, exactly because of this disillusionment arising from hegemonic strifes the very genuine social intellectual-function/posture (as to its abstract notional/epistemic/bindingness ${ }^{<a s-t o-}$ determinism/conceptivity-of-relative-unreflexivity/relative-reflexivity $>$ possibilities for prospective sublimation/emancipation so-undermined by dominion/statal-logic-〈preconverging/shallowsupererogating-'human-and-social-expectations/anticipations- - de- 
beholdening-<whether-trepidatious-or-warped-or-preclusive-or-occlusive $>$-and-its-

consociated-dominance/vested-interest-subontologising-skewed-influence-as-to-social-

vestedness/normativity- $<$ discretely-implied-functionalism $>\rangle$ ) tend to be paradoxically reconstrued (on the basis of dominion/statal-logic-〈preconverging/shallow-supererogating‘human-and-social-expectations/anticipations - de-mentating/structuring/paradigmingpsychologism'-as-to-its-specific-collateralising-beholdening-<whether-trepidatious-orwarped-or-preclusive-or-occlusive $>$-and-its-consociated-dominance/vested-interestsubontologising-skewed-influence-as-to-social-vestedness/normativity- $<$ discretely-impliedfunctionalism $>>\quad{ }^{79}$ presencing-absolutising-identitive-constitutedness $<$ amplituding/formative-epistemicity $>$ totalising $\sim$ self-referencingsyncretising/circularity/interiorising/akrasiatic-drag ${ }^{34}$ ) as at best subject to the dominion/statallogic-〈preconverging/shallow-supererogating-'human-and-social-expectations/anticipationsde-mentating/structuring/paradigming-psychologism'-as-to-its-specific-collateralisingbeholdening- $<$ whether-trepidatious-or-warped-or-preclusive-or-occlusive $>$-and-itsconsociated-dominance/vested-interest-subontologising-skewed-influence-as-to-socialvestedness/normativity- $<$ discretely-implied-functionalism $>>$ and at worst of relative irrelevance to prospective social sublimation/emancipation (especially as to when it ambitions a criticism of profound social emancipation), and so as to muddlement induced subversion of such genuine social intellectual-function/posture marked by the overt and covert cultivating of pedantic incrementalism-in-relative-ontological-incompleteness ${ }^{8}$

enframed/disontologising conceptualisation and a conception of the genuine social intellectualfunction/posture as remote and directly irrelevant to social postconverging-apereticismovercoming/unovercoming. This flawed conception of the genuine social intellectualfunction/posture is supposedly justified across human history on the basis of the hazardousness or superficiality of intellectual ideas (and this is the case in all societies even in many a 
premodern society when the traditional order of the day is put in question with cultural diffusion as to when for instance witchdoctors carry covert misinformation campaign against the perceived threat of modern medicine) while paradoxically ignoring the hazardouness of such desublimating existentialising-decisionality-<as-to-disentologising/re-ontelogising aporeticism $>$ apparently implying ontological-veracity can be achieved without any relativeontological-completeness ${ }^{87}$ basis for such supposedly ontological insight so-critically provided by the veridical genuine social intellectual-function/posture. Critically, such dominion/statallogic-〈preconverging/shallow-supererogating-'human-and-social-expectations/anticipationsde-mentating/structuring/paradigming-psychologism'-as-to-its-specific-collateralisingbeholdening- $<$ whether-trepidatious-or-warped-or-preclusive-or-occlusive $>$-and-itsconsociated-dominance/vested-interest-subontologising-skewed-influence-as-to-socialvestedness/normativity- $<$ discretely-implied-functionalism $>$ > carry a 'bogus reflex of attributingand-blaming their socially cultivated $<$ amplituding/formative $>$ wooden-language-〈imbued temporal-mere-form/virtualities/dereification/akrasiatic-drag/denatured/preconverging-ordementing -narratives - of-the- reference-of-thought- categoricalimperatives/axioms/registry-teleology $\rangle$ as well as pedantic incrementalism-in-relativeontological-incompleteness ${ }^{8}$ - enframed/disontologising conceptualisation' rather to the veridical genuine social intellectual-function/posture, and so in a Machiavellian perpetuation of dominion/statal-logic-〈preconverging/shallow-supererogating-'human-and-socialexpectations/anticipations - de-mentating/structuring/paradigming-psychologism'-as-to-itsspecific-collateralising-beholdening-<whether-trepidatious-or-warped-or-preclusive-orocclusive $>$-and-its-consociated-dominance/vested-interest-subontologising-skewed-influenceas-to-social-vestedness/normativity-<discretely-implied-functionalism $>\rangle$ which is in a 'shallow relation with sublimating knowledge-reification $\sim$ gesturing-and-accounting-of-epistemicphenomenalism- $<$ in-prospective_psychologismic $\sim$ apriorising/axiomatising/referencing- of- 
'prospectively_implicited_attendant-ontological-contiguity ' educed-

existentialising/contextualising/textualising_ intelligibility/epistemicity/reflexivity_contiguity$<$ imbued-notional cogency $>$ ' $\}$-conflatedness - in-\{preconverging ment by\}

postconverging-entailment> accountability, as to a relative expropriating/estranging/constraining/limiting of public sovereignty representation as to its 'temporal beholdening as sovereignising-imbued-subontologisation/subpotentiation (implied pretense-of-sublimation as to desublimating existentialising-decisionality-<as-todisontologising/re-ontologising aporeticism $>$ supposedly taking precedence over inherent prospective knowledge-reification $\sim$ gesturing-and-accounting-of-epistemic-phenomenalism$<$ in-prospective_psychologismic $\sim$ apriorising/axiomatising/referencing-\{of-'prospectively_ implicited_attendant-ontological-contiguity ' educedexistentialising/contextualising/textualising_'intelligibility/epistemicity/reflexivity_contiguity<imbued-notional cogency >' \}-conflatedness -in-\{preconverging ment by\} postconverging-entailment>)'. The fact remains that the genuine social intellectualfunction/posture (even as to when it is undermined with punctual pedantising/muddling/formulaic-hollowing-out — in-subontologisation/subpotentiation-

\section{〈blurring/undermining-of-prospective-totalising-entailing,-as-to-entailing-}

<amplituding/formative-epistemicity>totalising in-relative-ontological-completeness $>$

desublimatingly pandering to the powers of the day) remains the only human conduit to sublimating ontological-veracity that cannot be substituted but rather supererogated as to undermining such pedantic incrementalism-in-relative-ontological-incompleteness enframed/disontologising conceptualisation, with the issue of manifest intellectual ineptness/incapacity not a preconverging/postconverging-de-mentative/structural/paradigmatic issue of intellectual irrelevance no less than punctual technical or scientific incompetence can be transformed into a preconverging/postconverging-de-mentative/structural/paradigmatic issue of 
technical or scientific irrelevance but rather requisite profound-supererogation over say pseudoscience and/or 'distorted institutional science' (as the fact is when it comes to socialstake-contention-or-confliction 'knowledge-reification $\sim$ gesturing-and-accounting-ofepistemic-phenomenalism-<in-

prospective_psychologismic apriorising/axiomatising/referencing-\{of-'prospectively_ implicited_attendant_ontological-contiguity ' educedexistentialising/contextualising/textualising_intelligibility/epistemicity/reflexivity_contiguity$<$ imbued-notional cogency $>$ ' $\}$-conflatedness -in-\{preconverging ment by\} postconverging-entailment> tends to be notionally/epistemically/bindingnessly-<as-todeterminism/conceptivity-of-relative-unreflexivity/relative-reflexivity> caught up between $\mathrm{a}$ desublimation/gimmickiness and sublimation preconverging/postconverging-dementating/structuring/paradigming' as reflected in the social reality of a 'veil of knowledge associated with subterfuges' reflected say in an ambiguous continuity between genuineknowledge and chicanery, social/institutional intellectualism and social/institutional sycophantic-sophistry, alchemy and chemistry, quackery and medicine, technologicaladvancement and technical-mystification, flawed-industrial-analyses-and-certifications and disinterested-scientific-analyses-and-certifications, etc.); and in-many-ways dominion/statallogic-〈preconverging/shallow-supererogating-'human-and-social-expectations/anticipationsde-mentating/structuring/paradigming-psychologism'-as-to-its-specific-collateralisingbeholdening- $<$ whether-trepidatious-or-warped-or-preclusive-or-occlusive $>$-and-itsconsociated-dominance/vested-interest-subontologising-skewed-influence-as-to-socialvestedness/normativity-<discretely-implied-functionalism $>>$ pursuit of such vague argumentations for subverting the genuine social intellectual-function/posture is rather all about the ruthless adoption of a perambulatory course for institutional and political ascendency rather than a question of genuine preoccupation as to the requisite dispensing-with-immediacy-for- 
relative-ontological-completeness ${ }^{7}$-by-reification/contemplative-distension ${ }^{27}$ associated with veridically profound genuine social intellectual-function/posture and its sublimating implications of 'intemporal unbeholdening sublimating-nascence ontologising-depth of the fullpotency of existence (implied as to the very inherent knowledge-reification $\sim$ gesturing-andaccounting - of-epistemic-phenomenalism- $<$ in-

prospective_psychologismic apriorising/axiomatising/referencing-\{of-'prospectively implicited_attendant-ontological-contiguity ' educedexistentialising/contextualising/textualising_'intelligibility/epistemicity/reflexivity_contiguity<imbued-notional cogency $>$ ' \}-conflatedness -in-\{preconverging ment by\} postconverging entailment $>$ as determining sublimating $\sim$ existentialising-decisionality-<as-todisontologising/re-ontologising aporeticism $>$ )'. In our modern-day context, the very essential 'public-sovereignty-giving function/posture as associated with the centrality of elections, voting and party politics' of the modern democratic process is now paradoxically surreptitiously reconstrued as the very cornerstone for dominion/statal-logic-〈preconverging/shallowsupererogating-'human-and-social-expectations/anticipations- - dementating/structuring/paradigming-psychologism'-as-to-its-specific-collateralisingbeholdening- $<$ whether-trepidatious-or-warped-or-preclusive-or-occlusive $>$-and-itsconsociated-dominance/vested-interest-subontologising-skewed-influence-as-to-socialvestedness/normativity-<discretely-implied-functionalism $>>\quad$ subverting the sublimating existentialising-decisionality-<as-to-disontologising/re-ontologising aporeticism $>$ of the genuine social intellectual-function/posture; and so as to the fact that the democratic process 'public-sovereignty-giving function/posture as associated with the centrality of elections, voting and party politics' is incomplete without an adequate-and-healthy enlightening public-debate with such enlightening encumbering upon a genuine social intellectual-function/posture. In-many-ways the very idea of the 'democratic public-debate' 
itself is skewed from its very inception as to dominance/vested-interest natural ascendency over the 'supposedly democratic platforming and stakeholding in defining the very issues of society's social-stake-contention-or-confliction' (as so-associated with thematically skewed media debates and socio-econo-political thought-makers/thought-making overtly associated with 'skewed think-tanks' or covert surreptitious underhanded institutional and media influence). Critically, in this context such skewed platforming and stakeholding ends up alienating supposed sovereign electors as to a platforming and stakeholding process that mediatically and politically take a self-contained course (as to dominance/vested-interest defaulting issues that can be debated as to the underpinning-suprasocial-construct <preconverging ' motif-andapriorising/axiomatising/referencing'-entailing >-existentialising —enframing/imprintedness〈as-to- historicity-tracing-in-presencing-hyperrealisation/hyperreal-transposition〉 socioecono-political social-stake-contention-or-confliction) with the consequence that the sopolitically-alienated sovereign electors are increasingly turning to protest votes (reflecting rather a psychological-outleting rather than true policy solution) or decreasing participation in the democratic process, in-many-ways speaking to the very natural defaulting of the political process to dominance/vested-interest 'tolerable locked-in socio-econo-political outcomes' however the underlying sovereign electors mood as to the fact that even protest votes can't escape the institutional hold of such dominance/vested-interest. In-many-ways, it is the critical and genuine social intellectual-function/posture as to such postconvergingaaporeticismovercoming/unovercoming that can reifyingly-and-empoweringly effectively reflect upon the pertinence of such a dominance/vested-interest democratic process confiscation/lock-in (as equally manifested by the fact that even newly elected ambitious representatives come to be surreptitiously given their marching orders as to what is politically possible or not). In this respect, the very underpinning-suprasocial-construct <preconverging 'motif-andapriorising/axiomatising/referencing'-entailing>-existentialising — enframing/imprintedness- 
〈as-to- historicity-tracing-in-presencing-hyperrealisation/hyperreal-transposition〉 (as to

Being-development/ontological-framework-expansion-as-to-depth-of-ontologising-

development-as-infrastructure-of- meaningfulness-and-teleology , institutional-

development-as-to-social-function-development and living-development-as-to-personalitydevelopment psychologismic epistemic acutisation diffieulty <for, residualising $\{$ decompulsing $\}$ delinearity for-cogenc $y>$ magnitudes $\{$ of-experientiality/experiment $\}$ ) poses a major challenge as public-sovereignty is existentialisingly — enframed/imprinted to be wary of prospective reontologisation of alternative institutional aestheticising contemplation 'given dominion/statallogic-〈preconverging/shallow-supererogating-'human-and-social-expectations/anticipationsde-mentating/structuring/paradigming-psychologism'-as-to-its-specific-collateralisingbeholdening-<whether-trepidatious-or-warped-or-preclusive-or-occlusive $>$-and-itsconsociated-dominance/vested-interest-subontologising-skewed-influence-as-to-socialvestedness/normativity- $<$ discretely-implied-functionalism $>>$ calamitous conception and relation to the possibility for prospective re-ontologisation from its subontologisation/suboptimisation' such that any such profound alternative institutional aestheticising contemplation are traditionally bound to arise as disruptive institutional transformations whether or not involving power-showdown as associated with sudden/revolutionary transformations with 'their drawback of having to think on their feet inducing deficient ontological-performance ${ }^{2}-<$ including-virtueas-ontology $>$ /morality/ethics/justice/etc. as well as generalised social apprehension which is then enigmatically held against them' (however the merits of their underlying case) very much unlike the "latitude for articulating conceptualisations available for ${ }^{79}$ presencing —absolutisingidentitive-constitutedness ${ }^{14}$ <preconverging 'motif-and-apriorising/axiomatising/referencing'entailing $>$-existentialising — enframing/imprintedness-〈as-to- historicity-tracing - inpresencing-hyperrealisation/hyperreal-transposition)' (however their preconverging/postconverging-de-mentative/structural/paradigmatic flaws). Critically (beyond 
just the present democratic crisis as it reflects upon prospective human socio-econo-political sublimation/desublimation), all human societies arrive at their desublimating existentialisingdecisionality-<as-to-disontologising/re-ontologising aporeticism $>$ destructuring-threshold〈uninstitutionalised-threshold /presublimating-desublimating-decisionality $>$ of-ontologicalperformance $^{72}-<$ including-virtue-as-ontology $>$, and so as to the fact that human technical-andassociated-organisational-development central to human social formation and socialenhancement is prospectively 'apprehended/locked-in by the dominion/statal-logic〈preconverging/shallow-supererogating-'human-and-social-expectations/anticipations- dementating/structuring/paradigming-psychologism'-as-to-its-specific-collateralisingbeholdening- $<$ whether-trepidatious-or-warped-or-preclusive-or-occlusive $>$-and-itsconsociated-dominance/vested-interest-subontologising-skewed-influence-as-to-socialvestedness/normativity- $<$ discretely-implied-functionalism $>>$ dominating over such technicaland-associated-organisational-development as to imply its inherent mystic of social-andinstitutional-frameworks-of — referencing/registering/decisioning sublimating existentialisingdecisionality<as to disontologising/re ontelogising apereticism>' (seeming to thus wrongly imply that there isn't any prospectively requisite preconverging/postconverging-dementative/structural/paradigmatic sublimating $\sim$ existentialising-decisionality-<as-todisentologising/re-ontologising aporeticism $>$ of 'human sovereign-function/posture- $<$ as-toexistentially-manifest-`embodied-subject $\sim$ consciousness-and-direct/deferentialconscientiousness',-as-of-its-'epistemic-reflexivity/unreflexivity-in-existence'/teleology> with regards to public-sovereignty-giving function/posture' as determining the valid sublimating $\sim$ existentialising-decisionality-<as-to-disontologising/re-ontologising — aporeticism $>$ or invalid desublimating $\sim$ existentialising-decisionality-<as-to-disontologising/reentologising apereticism $>$ of dominion/statal-logic-〈preconverging/shallow-supererogating‘human-and-social-expectations/anticipations - de-mentating/structuring/paradigming- 
psychologism'-as-to-its-specific-collateralising-beholdening-<whether-trepidatious-orwarped-or-preclusive-or-occlusive $>$-and-its-consociated-dominance/vested-interestsubontologising-skewed-influence-as-to-social-vestedness/normativity- $<$ discretely-impliedfunctionalism $>$ > with respect to prospective technical-and-associated-organisationaldevelopment implications). Actually the history of human advancement is essentially the history of the sublimating transformation of human sovereign-function/posture- $<$ as-to-existentiallymanifest-'embodied-subject consciousness-and-direct/deferential-conscientiousness',-as-ofits-'epistemic-reflexivity/unreflexivity-in-existence'/teleology> as it relates to technical-andassociated-organisational-development, with the centrality of the genuine social intellectualfunction/posture in 'demystifying presencing-absolutising-identitive-constitutedness social-vestedness/normativity-<discretely-implied-functionalism $>\quad$ flawed-claim-of-inherentsublimation with respect to dominion/statal-logic-〈preconverging/shallow-supererogating'human-and-social-expectations/anticipations - de-mentating/structuring/paradigmingpsychologism'-as-to-its-specific-collateralising-beholdening-<whether-trepidatious-orwarped-or-preclusive-or-occlusive $>$-and-its-consociated-dominance/vested-interestsubontologising-skewed-influence-as-to-social-vestedness/normativity- $<$ discretely-impliedfunctionalism $>>\quad$ falsely-implied social-and-institutional-frameworks-ofreferencing/registering/decisioning sublimating $\sim$ existentialising-decisionality-<as-todisontologising/re-ontologising aporeticism ${ }^{\prime}$ (so-historially involving superseding 'dominance/vested-interest structure in relative-ontological-incompleteness ${ }^{8}$-presublimationconstruct-of- ${ }^{5}$ meaningfulness-and-teleology desublimating existentialising-decisionality<as-to-disontologising/re-ontologising aporeticism $>$ ' as from blatant 'brutish conquest/subjugation conception of apportioning as social-and-institutional-frameworks-ofreferencing/registering/decisioning sublimating $\sim$ existentialising-decisionality-<as-todisentologising/re-ontologising apereticism $>$ ', 'dominion protection conception of 
apportioning as social-and-institutional-frameworks-of-referencing/registering/decisioning sublimating existentialising-decisionality-<as-to-disontologising/re-ontologising apereticism $>$ ', to the 'very natural-order-of-things conception of apportioning as social-andinstitutional-frameworks-of — referencing/registering/decisioning sublimating existentialisingdecisionality-<as-to-disontologising/re-ontologising aporeticism>' and to 'our subtle modernday institutionally-distorted/disjointed conception of apportioning as social-and-institutionalframeworks-of—referencing/registering/decisioning sublimating existentialisingdecisionality-<as-to-disontelogising/re-ontelogising aporeticism $>$ as particularly the target as to Lyotard's critique of such institutionally-distorted implied metanarratives especially with regards to their poor/sheepish/dubious/ineffectual social/institutional devolving parameterised equanimity/balance as putting in question their theoretical, conceptual and operative veracity, and speaking in all the above epochal instances of 'ontological-bad-faith/inauthenticity ${ }^{4}$-andlack-of-equanimity of social/institutional process towards preconverging/postconverging-dementative/structural/paradigmatic priorly-defaulted/usurped social/institutional outcome as reflecting manifest lack of dispensing-with-immediacy-for-relative-ontological-completeness ${ }^{87}$ by-reification/contemplative-distension ${ }^{27}$ '). In this respect dominion/statal-logic〈preconverging/shallow-supererogating-'human-and-social-expectations/anticipations- dementating/structuring/paradigming-psychologism'-as-to-its-specific-collateralisingbeholdening- $<$ whether-trepidatious-or-warped-or-preclusive-or-occlusive $>$-and-itsconsociated-dominance/vested-interest-subontologising-skewed-influence-as-to-socialvestedness/normativity-<discretely-implied-functionalism $>$ ) (as falsely implying the perpetuation of the relative-ontological-incompleteness ${ }^{8}$-presublimation-construct-ofmeaningfulness-and-teleology $\quad$ desublimating $\sim$ existentialising-decisionality-<as-todisontologising/re-ontologising aporeticism $>$ as so-manifested with ancient-sophists over prospective ${ }^{103}$ universalising-idealisation, medieval-scholastics over prospective rational- 
empiricism/positivism, religio-political dominions across the history of all human societies as associated with the reformation and renaissance in medieval Europe as well as the increasingly 'locked-in/defaulting' democratic process as to our positivism- ${ }^{80}$ procrypticism occlusivity) have always undermined the 'prospective human sovereign-function/posture-<as-to-existentiallymanifest-‘embodied-subject consciousness-and-direct/deferential-conscientiousness',-as-ofits-'epistemic-reflexivity/unreflexivity-in-existence'/teleology> momentous sublimating existentialising-decisionality-<as-to-disontelogising/re-ontelogising aporeticism >' derived as to veridically profound genuine social intellectual-function/posture and its sublimating implications of 'intemporal unbeholdening sublimating-nascence ontologisingdepth of the full-potency of existence (implied as to the very inherent knowledgereification $\sim$ gesturing-and-accounting — of-epistemic-phenomenalism- $<$ inprospective_psychologismic apriorising/axiomatising/referencing-\{of-'prospectively implicited_attendant-ontological-contiguity ' educedexistentialising/contextualising/textualising_'intelligibility/epistemicity/reflexivity-contiguity$<$ imbued-notional cogency $\left.>^{\prime}\right\}$-conflatedness -in-\{preconverging-ment by\} postconverging-entailment $>$ as determining sublimating $\sim$ existentialising-decisionality-<as-todisontogising/re ontogising apereticism $>$ ) so-associated-with and rising-to-the-measureof the sublimating-nascence of technical-and-associated-organisational-development (as to nascent-particular/incipient-and-material/technical-sublimations- $<$ blinded-to-their-relativeontological-completeness - reference-of-thought- devolving $>$ ) in profound-supererogation as of prospective social-and-institutional-frameworks-of-referencing/registering/decisioning sublimating $\sim$ existentialising-decisionality-<as-to-disontologising/re-ontologising aporeticism $>$. Critically, all these instances of dominion/statal-logic-〈preconverging/shallowsupererogating-'human-and-social-expectations/anticipations-dementating/structuring/paradigming-psychologism'-as-to-its-specific-collateralising- 
beholdening-<whether-trepidatious-or-warped-or-preclusive-or-occlusive $>$-and-itsconsociated-dominance/vested-interest-subontologising-skewed-influence-as-to-socialvestedness/normativity- $<$ discretely-implied-functionalism $>>$ manifest an underlying human underpinning-suprasocial-construct $<$ preconverging $\sim$ 'motif-andapriorising/axiomatising/referencing'-entailing >-existentialising — enframing/imprintedness〈as-to- historicity-tracing-in-presencing-hyperrealisation/hyperreal-transposition〉 existentialisingly_enframed/imprinted as to Being-development/ontological-frameworkexpansion-as-to-depth-of-ontologising-development-as-infrastructure-of- meaningfulnessand-teleology , institutional-development-as-to-social-function-development and livingdevelopment-as-to-personality-development psychologismic epistemic acutisation difficulty < for, residualising \{decompulsing $\}$ delinearity for-cogency> magnitudes $\{$ \{fexperientiality/experiment\} associated with vague apportioning notions of religiosity, nationalism, racialism, classism, meritocracy, etc. of shallow-supererogation preconvergingly-dementated/structured/paradigmed to human mental-colonisation as to <preconverging 'motifand-apriorising/axiomatising/referencing'-entailing>-existentialisingenframing/imprintedness-〈as-to- historicity-tracing - in-presencinghyperrealisation/hyperreal-transposition〉, subontologisation/subpotentiation and collateralising dehumanisation) which is desublimatingly secondnatured as to the overall social $<$ amplituding/formative $>$ wooden-language-〈imbued-temporal-mere-

\section{form/virtualities/dereification/akrasiatic-drag/denatured/preconverging-or-dementing} narratives - of-the- reference-of-thought- categorical-imperatives/axioms/registryteleology > as well as pedantic incrementalism-in-relative-ontological-incompleteness enframed/disontologising conceptualisation with both underlied as to dominance/vestedinterest — drivenness-<as-to-its-direct/indirect-eliciting-by-or-exploiting-of-prospectivelydescalarising/subontologising-sycophantic-sophistic-interests,-as-inducing-prospective- 
threshold-of-institutional-and-social-desublimation>; the task to which the veridical genuine social intellectual-function/posture as to human social postconverging-apereticismovercoming/unovercoming needs to explicit as to the induced-entrapment of dominion/statallogic-〈preconverging/shallow-supererogating-'human-and-social-expectations/anticipationsde-mentating/structuring/paradigming-psychologism'-as-to-its-specific-collateralisingbeholdening- $<$ whether-trepidatious-or-warped-or-preclusive-or-occlusive $>$-and-itsconsociated-dominance/vested-interest-subontologising-skewed-influence-as-to-socialvestedness/normativity- $<$ discretely-implied-functionalism $>>$ as a conceptualising framework preconverging/postconverging-de-mentatively/structurally/paradigmatically voiding the ontological possibilities of 'human-decisionality-<as-to-play-of-valid/invalid-decisionalityimbued-sublimation/desublimation $>$ omni-potential commensurability with inherent immanentexistence's sublimation-structure'/omnipotentiality. In-many-ways, we can appreciate that the modern-day genuine social intellectual-function/posture as to its relatively genuine sublimating $\sim$ existentialising-decisionality-<as-to-disentologising/re-ontologising apereticism $>$ critically 'operates mostly in the wake of the social-and-institutional-frameworksof - referencing/registering/decisioning desublimating existentialising-decisionality-<as-todisontologising/re-ontelogising aporeticism $>\quad$ of dominion/statal-logic〈preconverging/shallow-supererogating-'human-and-social-expectations/anticipations- dementating/structuring/paradigming-psychologism'-as-to-its-specific-collateralisingbeholdening-<whether-trepidatious-or-warped-or-preclusive-or-occlusive $>$-and-itsconsociated-dominance/vested-interest-subontologising-skewed-influence-as-to-socialvestedness/normativity-<discretely-implied-functionalism $>$ '’; as to the fact that the critical aftereffects of political, economic, social and mediatic strategic policy orientations reflected in socio-econo-political and legal decision-making associated with various crises whether decadal economic crises, media and information crises, political accountability, etc. are effectively 
related by the genuine social intellectual-function/posture but very much after the facts (often decades after the social-and-institutional-frameworks-of-referencing/registering/decisioning desublimating existentialising-decisionality-<as-to-disontologising/re-ontelogising apereticism> of dominion/statal-logic-〈preconverging/shallow-supererogating-'human-andsocial-expectations/anticipations - de-mentating/structuring/paradigming-psychologism'-asto-its-specific-collateralising-beholdening-<whether-trepidatious-or-warped-or-preclusive-orocclusive $>$-and-its-consociated-dominance/vested-interest-subontologising-skewed-influenceas-to-social-vestedness/normativity-<discretely-implied-functionalism $>\rangle$ ), and so as to the sublimating impotence of such genuine social intellectual-function/posture. Critically in this respect the very artifice available to modern-day democracy dominion/statal-logic〈preconverging/shallow-supererogating-'human-and-social-expectations/anticipations-dementating/structuring/paradigming-psychologism'-as-to-its-specific-collateralisingbeholdening- $<$ whether-trepidatious-or-warped-or-preclusive-or-occlusive $>$-and-itsconsociated-dominance/vested-interest-subontologising-skewed-influence-as-to-socialvestedness/normativity-<discretely-implied-functionalism $>>$ involves the 'punctual and surreptitious undermining of knowledge-driven sublimating existentialising-decisionality-<asto-disontologising/re-ontologising aporeticism $>$ at moments of decision', and thereafter it doesn't matter in effect whether the human sovereign-function/posture-<as-to-existentiallymanifest-'embodied-subject consciousness-and-direct/deferential-conscientiousness', -as-ofits-'epistemic-reflexivity/unreflexivity-in-existence'/teleology> comes to think otherwise and disapprovingly of the given decisions, as better still so long as this rather plays the role of a psychological-outleting that project a falls sense of public accountability of poor or no effective resolutive course, this mechanism of 'punctual and surreptitious undermining of knowledgedriven sublimating $\sim$ existentialising-decisionality-<as-to-disentologising/re-ontologising aporeticism $>$ at moments of decision' can perpetuate itself as to a Machiavellianism underlying 
expectations/anticipations — de-mentating/structuring/paradigming-psychologism'-as-to-itsspecific-collateralising-beholdening- $<$ whether-trepidatious-or-warped-or-preclusive-orocclusive >-and-its-consociated-dominance/vested-interest-subontologising-skewed-influenceas-to-social-vestedness/normativity-<discretely-implied-functionalism $>>$ relation with the human sovereign-function/posture-<as-to-existentially-manifest-'embodiedsubject $\sim$ consciousness-and-direct/deferential-conscientiousness',-as-of-its- 'epistemicreflexivity/unreflexivity-in-existence'/teleology>. Such a Machiavellianism riding-the-wave of the underpinning-suprasocial-construct $<$ preconverging $\sim$ 'motif-andapriorising/axiomatising/referencing'-entailing>-existentialising-enframing/imprintedness〈as-to- historicity-tracing - in-presencing-hyperrealisation/hyperreal-transposition〉 of the human sovereign-function/posture-<as-to-existentially-manifest-'embodiedsubject consciousness-and-direct/deferential-conscientiousness',-as-of-its- ‘epistemicreflexivity/unreflexivity-in-existence'/teleology> thrives on social and intellectual pedantic incrementalism-in-relative-ontological-incompleteness ${ }^{8}$

enframed/disontologising conceptualisation with the cultivation of disingenuous analysis as to strategies of misanalysis (so-reflected by the 'propounding and enframing in ad-hocness and false-orthodoxy of policy issues so-underlied with catchphrases like deficit, public spending, etc. as to an aversion to consistent and long-term analysis pointing out the underlying inconsistency' highlighting effectively that the political disenfranchisement/swindling/corruption/dispossession purpose of such argumentations precede their 'very inherent knowledge-reification $\sim$ gesturing-and-accounting-of-epistemicphenomenalism- $<$ in-prospective_psychologismic $\sim$ apriorising/axiomatising/referencing- of'prospectively_implicited_attendant-ontological-contiguity ' educedexistentialising/contextualising/textualising_intelligibility/epistemicity/reflexivity_contiguity- 
<imbued-notional cogency >' \}-conflatedness -in-\{preconverging-ment by\}

postconverging-entailment $>$ as determining sublimating $\sim$ existentialising-decisionality-<as-todisentologising/re-ontologising aporeticism ${ }^{\prime}$ purpose as to Machiavellian instigated false public debates) to which human sovereign-function/posture-<as-to-existentially-manifest‘embodied-subject consciousness-and-direct/deferential-conscientiousness',-as-of-its-

'epistemic-reflexivity/unreflexivity-in-existence'/teleology $>$ s gullibly get caught up in or which ultimately discourages public interest and participation or lead to protest votes; with such misanalysis typically characterised by false process/processive bothsidesism-〈as-'mereprocessive'/pedantising-'dialogical-relation'-to 'perceived-social-and-institutionalcommonly-enculturated_referencing,-of- meaningfulness-and-teleology '-failing-'requisiteexistential-thematic-baseline-of-technicity/profundity-framing' \{of-sublimating-discursivityfor-sovereign-repassing \},-as-of-psychologismic-epistemic-acutisation-nonresidualisingimbued-fompulsingtlinearity in-eclecticism-of-prior-mere-formulaicity/ritualisation,-as-so‘consciously/unconsciously-preordained/fated'-to-fail-prospective-notional cogency in $<$ preconverging 'motif-and-apriorising/axiomatising/referencing'-entailing >existentialising — enframing/imprintedness-〈as-to- historicity-tracing_-in-presencinghyperrealisation/hyperreal-transposition) reflex (bandied about as supposedly the very summum of democratic impartiality) relation to any sublimating ${ }^{56}$ meaningfulness-and-teleology ${ }^{9}$. Misanalysis as such speaks fundamentally of an issue of ontological-bad-faith/inauthenticity (and as to the fact that knowledge-reification $\sim$ gesturing-and-accounting-of-epistemicphenomenalism-<in-prospective_psychologismic $\sim$ apriorising/axiomatising/referencing- of'prospectively_implicited_attendant-ontological-contiguity ' educedexistentialising/contextualising/textualising_ 'intelligibility/epistemicity/reflexivity-contiguity<imbued-notional cogency>' \}-conflatedness -in-\{preconverging-ment by\} postconverging-entailment $>$ ends/should-not aspire to any 'convincing' of ontological-bad- 
faith/inauthenticity ${ }^{64}$ preconverging-de-mentating/structuring/paradigming ${ }^{55}$ as the latter is nothing but a circular process that only ends up degrading knowledge into falsehoods as individual supererogatory-shallowness or supererogatory-profoundness seedingly/inceptively lies with the individual and not knowledge, well before sublimating knowledge can be of any relevance thereof as to derived-formulaicity projected reproducibilitymathesis/motif/thrownness-disposition,-as-reproducibility-of-aestheticisation). Critically, this Machiavellianism again is the reflection of the fact that no human institutional-construct (including the modern democratic institution) can sublimatingly perpetuate itself on the mere basis of a formulaicity as to secondnatured reproducibility-mathesis/motif/thrownnessdisposition,-as-reproducibility-of-aestheticisation inherently-so given prospective human notional firstnaturedness-formativeness-<as-to-eventualising-inkling-drive-or-seedingmisprising $>$ temporal-to-intemporal-dispositions- $<$ so-construed-as-from-perspectiveontological-normalcy/postconvergence $>$ to whatever induced profoundsupererogation $/$ messianicity of originariness-parrhesia,-as-spontaneity-of-aestheticisation in reflection of human dimensionality-of-desublimating-lack-of ${ }^{-}$<<amplituding/formative>supererogatery $\sim$ de-mentativeness/epistemic-growth-orconflatedness /transvaluative-rationalising/transepistemicity/anamnestic-residuality/spiritdrivenness-equalisation), and so prospectively requiring human re-orginariness/re-origination as of 'relative-ontological-incompleteness $8 /$ relative-ontological-completeness ${ }^{87}$. 〈sublimating $\sim$ referencing/registering/decisioning,-as-self-becoming/selfconflatedness /formative-supererogating-<projective/reprojective-aestheticising-re-motifand-re-apriorising/re-axiomatising/re-referencing,-in-perspective-ontologicalnormalcy/postconvergence $>>$ as to human-and-social-expectations/anticipationsmetaphoricity ${ }^{57}$-as-preconverging/postconverging-rede-

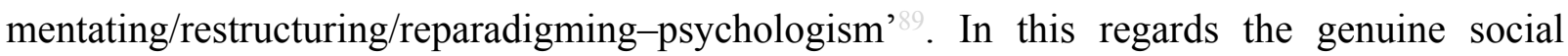


intellectual-function/posture is simply about projecting the 'notionalisation/notionalconception/amplituding of knowledge' underlying inherent existence-exacteddesublimating as-to-preconverging-de-mentating/structuring/paradigming — by-existenceexacted-sublimating as-to-postconverging-de-mentating/structuring/paradigming $\quad$ (as of 'relative-ontological-incompleteness $8 /$ relative-ontological-completeness ${ }^{87}$ -

\section{〈sublimating referencing/registering/decisioning,-as-self-becoming/self-}

conflatedness / formative-supererogating-<projective/reprojective-aestheticising-re-motifand-re-apriorising/re-axiomatising/re-referencing,-in-perspective-ontologicalnormalcy/postconvergence $>>$ as to human-and-social-expectations/anticipationsmetaphoricity ${ }^{57}$-as-preconverging/postconverging-rede-

mentating/restructuring/reparadigming-psychologism' ${ }^{89}$ ), notionally eliciting the underlying human ontological-good-faith/authenticity ${ }^{69} \sim$ postconverging-dementating/structuring/paradigming 70 or ontological-bad-faith/inauthenticity ${ }^{64}$ preconvergingde-mentating/structuring/paradigming ${ }^{5}$ preceding knowledge-reification $\sim$ gesturing-andaccounting - of-epistemic-phenomenalism- $<$ in-

\section{prospective_psychologismic apriorising/axiomatising/referencing-\{of-"prospectively}

implicited_attendant-ontological-contiguity ' educed-

existentialising/contextualising/textualising_'intelligibility/epistemicity/reflexivity-contiguity<imbued-notional cogency >’ \}-conflatedness -in-\{preconverging ment by\}

postconverging-entailment>, along the same lines that a scientist or mathematician preconverging/postconverging-de-mentatively/structurally/paradigmatically projects the abstract possibilities for human scientific and technical sublimating or desublimating ontological-performance ${ }^{72}-<$ including-virtue-as-ontology $>$; and it is this insight that underlies overall human reifying-and-empowering-reflexivity-of-ecstatic-existence-aspanintelligibility/panreflexivity ${ }^{3}-\langle$ existentially-imbued-and-educing-< $<$ epistemic- 
totalising thermeneutically/textually/reprojectingly/supererogatingly/zeroingly/re-acutingly,-

$\{$ decompulsing $\}$ delinearity $\sim$ for-cogency $\geq$-epistemic-perspective-of-projective/reprojective-

aestheticising-re-motif-and-re-apriorising/re-axiomatising/re-referencing conceptualisation,-

as herein-specifically relevant to human-subpotency). Even then the pedantic

incrementalism-in-relative-ontological-incompleteness ${ }^{8}$

enframed/disontologising $\sim$ conceptualisation of dominion/statal-logic-〈preconverging/shallow-

supererogating-'human-and-social-expectations/anticipations-de-

mentating/structuring/paradigming-psychologism'-as-to-its-specific-collateralising-

beholdening-<whether-trepidatious-or-warped-or-preclusive-or-occlusive $>$-and-its-

consociated-dominance/vested-interest-subontologising-skewed-influence-as-to-social-

vestedness/normativity-<discretely-implied-functionalism $>>$ knows no limits for undermining genuine knowledge-reification $\sim$ gesturing-and-accounting - of-epistemic-phenomenalism- $<$ inprospective_psychologismic apriorising/axiomatising/referencing-\{of-'prospectively implicited_attendant-ontological-contiguity ' educedexistentialising/entextrising/textrising_intelligibility/epistemicity/reflexivity-contiguity<imbued-notional cogency >’ \}-conflatedness -in-\{preconverging ment by\} postconverging entailment $>\quad$ sublimating $\sim$ existentialising-decisionality-<as-todisontologising/re-ontologising aporeticism $>$, such that the conceptivity/epistemicreflexivity/epistemicity-relativism-determinism-<reifying \{as-to-knowledge-developing $\}$-andempowering $>$ imbued theoretical/conceptual/operant implications of human knowledge as herein implied and as applies with all human knowledge can easily be requalified sophistically as to the 'given human <preconverging 'motif-and-apriorising/axiomatising/referencing' entailing $>$-existentialising — enframing/imprintedness-〈as-to- historicity-tracing - inpresencing-hyperrealisation/hyperreal-transposition> elicitation' in totalisingly-ingdiscretion/whim-of-thought (as the state of inherent relative ignorance/disenfranchisement 
across all the ages of human history is cynically used against human sovereign-function/posture$<$ as-to-existentially-manifest-`embodied-subject $\sim$ consciousness-and-direct/deferentialconscientiousness',-as-of-its- 'epistemic-reflexivity/unreflexivity-in-existence'/teleology> in need for its prospective genuine social intellectual-function/posture). Such catchphrases like deficits, public spending, social engineering, socialism, etc. already speak to subliminally induced <preconverging 'motif-and-apriorising/axiomatising/referencing'-entailing >existentialising — enframing/imprintedness-〈as-to- historicity-tracing-in-presencinghyperrealisation/hyperreal-transposition〉 fundamentally skewing the democratic public debate undermining an ontology/ontological-veracity driven conception reflected as to intemporal unbeholdening sublimating-nascence ontologising-depth of the full-potency of existence (implied as to the very inherent knowledge-reification $\sim$ gesturing-and-accounting-ofepistemic-phenomenalism- $<$ in-

prospective_psychologismic apriorising/axiomatising/referencing-\{of-'prospectively implicited_attendant-ontological-contiguity ' ceducedexistentialising/contextualising/textualising_'intelligibility/epistemicity/reflexivity_contiguity$<$ imbued-notional cogency $\left.>^{\prime}\right\}$-conflatedness -in-\{preconverging-ment by\}

postconverging-entailment $>$ as determining sublimating $\sim$ existentialising-decisionality-<as-todisontologising/re-ontologising aporeticism $>$ )'; and critically this 'subliminally induced $<$ preconverging 'motif-and-apriorising/axiomatising/referencing'-entailing >-

existentialising — enframing/imprintedness-〈as-to- historicity-tracing_-in-presencinghyperrealisation/hyperreal-transposition $\rangle$ reflex' is a reflex that has ever always existed across the <cumulating/recomposuring attendant-ontological-contiguity $>$-succession of human registry-worldviews/dimensions notwithstanding the paradox of human prospective sublimation/emancipation despite this reflex (thus speaking to the requisite crossgenerational dispensing-with-immediacy-for-relative-ontological-completeness ${ }^{87}$-by- 
reification/contemplative-distension underlying the genuine social intellectualfunction/posture existentialising-frame-of-entailment of motif-andapriorising/axiomatising/referencing as to human conceptivity/epistemicreflexivity/epistemicity-relativism-determinism-<reifying \{as-to-knowledge-developing\}-andempowering $>$ imbued theoretical/conceptual/operant implications). Critically in this regards (as to underlying 'notional/epistemie/bindingness-<as-to-determinism/eonceptivity-of-relative-unreflexivity/relativereflexivity $\quad$ disquisitive enframed/disontologising $\sim$ conceptualisation-by-unenframed/reontologising conceptualisation knowledge-reification $\sim$ gesturing-and-accounting —ofepistemic-phenomenalism-<inprospective_psychologismic $\sim$ apriorising/axiomatising/referencing-\{of-'prospectively implicited_attendant-ontological-contiguity ' educedexistentialising/contextualising/textualising_'intelligibility/epistemicity/reflexivity_contiguity<imbued-notional cogency>’ \}-conflatedness -in-\{preconverging ment by\} pesteonverging entailment $>$ constructive conception' projection of 'reclamation/recovery of maximalising-recomposuring-for-relative-ontological-completeness ${ }^{87}$ - unenframed/reontologising conceptualisation'), the genuine social intellectual-function/posture is the fundamental issue of human limited-mentation-capacity-as-subjecting 'educedunlimitedness/existence-sublimating nascence' to-limitedness/human-subpotency in want for human limited-mentation-capacity-deepening —as-subjecting limitedness/human-subpotencyto-'educed-unlimitedness/existence-sublimating nascence' ${ }^{3}$ with respect to 'humandecisionality-<as-to-play-of-valid/invalid-decisionality-imbued-sublimation/desublimation $>$ omni-potential commensurability with inherent immanent-existence's sublimationstructure'/omnipotentiality; wherein 'genuine social intellectual-function/posture existentialising-frame-of-entailment-of-motif-and-apriorising/axiomatising/referencing as to human conceptivity/epistemic-reflexivity/epistemicity-relativism-determinism-<reifying \{as-to- 
knowledge-developing\}-and-empowering $>\quad$ imbued theoretical/conceptual/operant implications' has ever always been an abstractive projection of postconverging towards 'scalarity/immanency of existence's ontological-normalcy/postconvergence' across the relativeunreflexivity/relative-reflexivity - ontological-contiguity ${ }^{67} \sim$ of-the-human-institutionalisationprocess ${ }^{6}$, and as so manifested with the 'genuine social intellectual-function/posture inducing nascent-particular/incipient-and-material/technical-sublimations- $<$ blinded-to-their-relativeontological-completeness - reference-of-thought- devolving $>$ sublimating existentialisingdecisionality-<as-to-disontologising/re-ontologising aporeticism $>$ (however their nascent punctually devolving/devoluting-referencing-narrowness with respect to their overall socialand-institutional-frameworks-of-referencing/registering/decisioning desublimating existentialising-decisionality-<as-to-disontologising/re-ontologising aporeticism $>$ )' and the 'genuine social intellectual-function/posture inducing ${ }^{8}$ reference-ofthought-and- ${ }^{8}$ reference-of-thought- ${ }^{8}$ devolving $-{ }^{5}$ meaningfulness-and-teleology comprehensiveness of prospective sublimating-nascence (over relative-ontologicalincompleteness ${ }^{8}$-presublimation-construct-of- ${ }^{56}$ meaningfulness-and-teleology ${ }^{9}$ ) as to overall social-and-institutional-frameworks-of_-referencing/registering/decisioning sublimating existentialising-decisionality-as to disontogising/re-ontologising aporeticism>'. Thus in the face of the incrementalism-in-relative-ontologicalincompleteness ${ }^{8}$ — enframed/disontologising conceptualisation associated with human dominion/statal-logic-〈preconverging/shallow-supererogating-'human-and-socialexpectations/anticipations_- de-mentating/structuring/paradigming-psychologism'-as-to-itsspecific-collateralising-beholdening- $<$ whether-trepidatious-or-warped-or-preclusive-orocclusive $>$-and-its-consociated-dominance/vested-interest-subontologising-skewed-influenceas-to-social-vestedness/normativity- $<$ discretely-implied-functionalism $>$, pedantic incrementalism-in-relative-ontological-incompleteness ${ }^{88}$ 
enframed/disontologising conceptualisation and <amplituding/formative $>$ wooden-language〈imbued-temporal-mere-form/virtualities/dereification/akrasiaticdrag/denatured/preconverging-or-dementing -narratives - of-the- reference-of-thoughtcategorical-imperatives/axioms/registry-teleology $\rangle$, it is the genuine social intellectualfunction/posture existentialising-frame-of-entailment-of-motif-andapriorising/axiomatising/referencing that projects of the requisite 'reclamation/recovery of maximalising-recomposuring-for-relative-ontological-completeness ${ }^{87}$ - unenframed/reontologising conceptualisation' for the prospect of 'human-decisionality-<as-to-play-ofvalid/invalid-decisionality-imbued-sublimation/desublimation> omni-potential commensurability with inherent immanent-existence's sublimation-structure'/omnipotentiality; as so-underlied by the succession of relative ontologisation/ontologicalveracity/aestheticisation-towards-ontology for prospective transcendence-andsublimity/sublimation/supererogatory-de-mentativity (as to Being-development/ontologicalframework-expansion-as-to-depth-of-ontologising-development-as-infrastructure-ofmeaningfulness-and-teleology , institutional-development-as-to-social-functiondevelopment and living-development-as-to-personality-development psychologismic epistemic-acutisation difficulty-for, residualising \{decompulsing $\}$ delinearity for-cogency> magnitudes $\{$ of-experientiality/experiment\} $\}$; with respect to the fact that the logical-basis/logic,-asderived-from $\sim$ transversality-<for-sublimating-existential-eventuating/denouement-from'thinking at-first/pure-predisposition-preemptive-of-prospectivedisontologising/subontologising’ as-of-prospectively-disambiguated-affirmed-andunaffirmed-'motif-and-apriorising/axiomatising/referencing' $>101$ for all prospective sublimation/emancipation is rather as to the overall sublimation-induced human-and-socialexpectations/anticipations - metaphoricity ${ }^{57}$-as-preconverging/postconverging-redementating/restructuring/reparadigming-psychologism- $<$ as-from-perspective-ontological- 
normalcy/postconvergence $>$. Thus the genuine social intellectual-function/posture existentialising-frame-of-entailment-of-motif-and-apriorising/axiomatising/referencing is the social harbinger of 'unbeholdening sublimating-nascence ontologising-depth of the full-potency of existence' as of its perpetuation of nonpresencing-<perspective-ontologicalnormalcy/postconvergence $>$ projection (as to ${ }^{83}$ reference-of-thought-and- ${ }^{83}$ reference-ofthought- ${ }^{8}$ devolving- ${ }^{5}$ meaningfulness-and-teleology ${ }^{9}$ comprehensiveness of prospective sublimating-nascence' so-underlied as of the 'very inherent knowledge-reification $\sim$ gesturingand-accounting - of-epistemic-phenomenalism- $<$ in-

prospective_psychologismic apriorising/axiomatising/referencing-\{of-'prospectively implicited_attendant-ontological-contiguity ' ceducedexistentialising/contextualising/textualising_'intelligibility/epistemicity/reflexivity-contiguity<imbued-notional cogency $>\quad\}$-conflatedness -in-\{preconverging-ment by\}

postconverging-entailment $>$ as determining sublimating $\sim$ existentialising-decisionality-<as-todisentologising/re-ontologising aporeticism ${ }^{\prime}$ ), and so with regards to the fact that the reality of human limited-mentation-capacity—as-subjecting-'educed-unlimitedness/existencesublimating nascence'-to-limitedness/human-subpotency warrants a human capacity for reorginariness/re-origination as of 'relative-ontological-incompleteness $8 /$ relative-ontologicalcompleteness ${ }^{8}$-〈sublimating $\sim$ referencing/registering/decisioning,-as-self-becoming/selfconflatedness /formative-supererogating-<projective/reprojective-aestheticising-re-motifand-re-apriorising/re-axiomatising/re-referencing,-in-perspective-ontologicalnormalcy/postconvergence $>>\quad$ as $\quad$ to human-and-social-expectations/anticipationsmetaphoricity ${ }^{57}$-as-preconverging/postconverging-redementating/restructuring/reparadigming-psychologism' ${ }^{\text {'. }}$. But then existence's inherent sublimating-nascence as to human-subpotency conceptivity/epistemic-reflexivity/epistemicityrelativism-determinism-<reifying \{as-to-knowledge-developing $\}$-and-empowering $>$ bifurcates 
along 'immediately potent nascent-particular/incipient-and-material/technical-sublimations<blinded-to-their-relative-ontological-completeness - reference-of-thought- devolving $>$ sublimating existentialising-decisionality-<as-to-disontologising/re-ontologising aporeticism $>$ (however the devolved/devoluted-referencing-narrowness with respect to overall social-and-institutional-frameworks-of — referencing/registering/decisioning existentialisingdecisionality-<as-to-disontologising/re-ontologising aporeticism $>$ )' and 'immediately blurred reference-of-thought-and- ${ }^{83}$ reference-of-thought- ${ }^{8}$ devolving- ${ }^{5}$ meaningfulness-andteleology ${ }^{9}$ comprehensiveness of prospective sublimating-nascence (over relative-ontologicalincompleteness ${ }^{88}$-presublimation-construct-of- ${ }^{5}$ meaningfulness-and-teleology ${ }^{9}$ ) as to overall social-and-institutional-frameworks-of_referencing/registering/decisioning sublimating existentialising-decisionality-<as-to-disontologising/re-ontologising — apereticism $>$ '. Such that the fundamental issue of human sublimating existentialisingdecisionality-<as-to-disontologising/re-ontologising aporeticism $>$ /desublimating $\sim$ existentialising-decisionality $<$ as-to-disontologising/re-

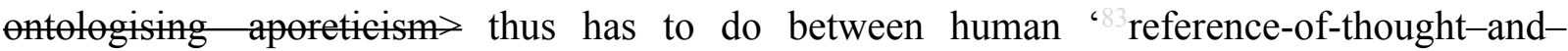
reference-of-thought- ${ }^{8}$ devolving- ${ }^{5}$ meaningfulness-and-teleology ${ }^{9}$ comprehensiveness of prospective sublimating-nascence sublimating existentialising-decisionality-as to disontologising/re-ontologising aporeticism $>$ ' and 'relative-ontological-incompleteness ${ }^{8}$ presublimation-construct-of- ${ }^{5}$ meaningfulness-and-teleology ${ }^{9}$ desublimating $\sim$ existentialisingdecisionality-<as-to-disontologising/re-ontologising aporeticism ${ }^{\prime} ;$ as the ${ }^{83}$ reference-ofthought effectively reflects human <amplituding/formative-epistemicity $>$ totalising thrownness-in-existence ${ }^{35}$,-imbued-projective-arbitrariness/waywardness-〈as-to-thehuman-projective/reprojective- aestheticising-re-motif-and-re-apriorising/re-axiomatising/rereferencing-process-of-'<amplituding/formative--epistemicity $>$ totalising $\sim$ conceptualisation’ $\rangle$ given ‘postconverging 'motif-and-apriorising/axiomatising/referencing'-entailing $>$ - 
existentialising - framing/imprinting-〈as-to-prospective-- historiality/ontological-

eventfulness /ontological-aesthetic-tracing-<perspective-ontological-

normalcy/postconvergence-reflected-‘epistemicity-relativism-determinism' $>>$ for rendering meaningfulness-and-teleology ${ }^{99}$ upon inherent existence's sublimating-nascence as to overall social-and-institutional-frameworks-of — referencing/registering/decisioning existentialisingdecisionality $<$ as-to-disontologising/re-ontologising aporeticism $>$ ' (whether sublimatingly as of ' ${ }^{8}$ reference-of-thought-and- ${ }^{83}$ reference-of-thought- ${ }^{8}$ devolving- ${ }^{56}$ meaningfulness-andteleology ${ }^{9}$ comprehensiveness of prospective sublimating-nascence' or desublimatingly as of relative-ontological-incompleteness ${ }^{88}$-presublimation-construct-of- ${ }^{56}$ meaningfulness-andteleology $\left.{ }^{9}\right)$. The implication here as well is that even nascent-particular/incipient-andmaterial/technical-sublimations-<blinded-to-their-relative-ontological-completeness

reference-of-thought- devolving $>$ are necessarily referenced/registered/decisioned from the reference-of-thought as to ${ }^{83}$ reference-of-thought- ${ }^{8}$ devolving (however the devolved/devoluted-referencing-narrowness with respect to overall social-and-institutionalframeworks-of — referencing/registering/decisioning existentialising-decisionality-<as-todisontologising/re-ontologising aporeticism $>$ ) in the sense that for instance nascentparticular/incipient-and-material/technical-sublimations- $<$ blinded-to-their-relative-ontologicalcompleteness - reference-of-thought- devolving > as of a positivism/rational-empiricism reference-of-thought apriorising/axiomatising/referencing-psychologism like plane technology is not necessarily fully contemplatable/comprehensible to say a purely nonpositivism or animistic ${ }^{83}$ reference-of-thought apriorising/axiomatising/referencingpsychologism (as to the requisite overall sublimation-induced human-and-socialexpectations/anticipations - metaphoricity ${ }^{57}$-as-preconverging/postconverging-redementating/restructuring/reparadigming-psychologism- $<$ as-from-perspective-ontologicalnormalcy/postconvergence $>$ of a positivism/rational-empiricism ${ }^{83}$ reference-of-thought 
reflected as to the positivism/rational-empiricism overall social-and-institutional-frameworksof - referencing/registering/decisioning sublimating $\sim$ existentialising-decisionality-<as-todisontologising/re-ontologising aporeticism $>$ ). The bigger point here speaks to 'human limited-mentation-capacity—as-subjecting 'educed-unlimitedness/existence-sublimating nascence' to-limitedness/human-subpotency projective/reprojective-aestheticising-re-motifand-re-apriorising/re-axiomatising/re-referencing as of reference-of-thought conceptivity/epistemic-reflexivity/epistemicity-relativism-determinism- $<$ reifying \{as-toknowledge-developing\}-and-empowering> (on-the-one-hand) upon inherent existence's sublimating-nascence (on-the-other-hand)', so-translated as 'human sublimating/desublimating - modalisation- $<$ as-to-absolute-referencing-of- $-{ }^{56}$ meaningfulnessand-teleology $>$ upon inherent existence's sublimating-nascence inducing of ontologisation/omnipotentiality' in-so-de-mentating/structuring/paradigming-out the relativeunreflexivity/relative-reflexivity - ontological-contiguity ${ }^{67} \sim$ of-the-human-institutionalisationprocess ${ }^{6} \quad$ with human limited-mentation-capacity-deepening-as-subjectinglimitedness/human-subpotency to-'educed-unlimitedness/existence-sublimating nascence' (reflecting overall human 'aestheticisation as to the extensive manifest outcomes/outfits/shellsconstrued-historially-as-of-the-specifically-aestheticised-incrusting/plating/coating,-soreflected-as-institutional-manifestations of human ${ }^{56}$ meaningfulness-and-teleology ${ }^{9}$, and so as taxingness-of-originariness induces beholdening-becoming — distortive-originariness/distortiveorigination-as-to- ${ }^{47}$ historicity-tracing inhibited-mental-aestheticising descalarisation reflex)'. This is so-translated as human <amplituding/formativeepistemicity $>$ totalising $\sim$ conceptualisation conceptivity/epistemic-reflexivity/epistemicityrelativism-determinism-<reifying \{as-to-knowledge-developing $\}$-and-empowering $>$ sublimating/desublimating - modalisation- $<$ as-to-absolute-referencing-of- ${ }^{5}$ meaningfulnessand-teleology $>$ upon the full-potency of existence-as-the-absolute-a-priori-of- 
conceptualisation and existence - as-sublimating-withdrawal/unenframing/re-ontologising,elicited-from-prospective-profound-supererogation $-<$ as-to-perspective-ontologicalnormalcy/postconvergence-implied-'prospective-aporeticism-overcoming/unovercoming' in perspective ontological-normalcy/postconvergence; with this 'human sublimating/desublimating - modalisation- $<$ as-to-absolute-referencing-of $-{ }^{56}$ meaningfulnessand-teleology $>$ upon inherent existence's sublimating-nascence inducing of ontologisation/omnipotentiality' highlighting 'beholdening as sovereignising-imbuedsubontologisation/subpotentiation' existentialising-decisionality-<as-to-disontologising/reentologising apereticism $>$ psychological-disposition (as to relative-ontologicalincompleteness ${ }^{88}$-presublimation-construct-of- ${ }^{56}$ meaningfulness-and-teleology desublimating $\sim$ existentialising-decisionality-<as-to-disontologising/re-ontelogising aporeticism $>$ ) in want for prospective 'unbeholdening sublimating-nascence ontologising-depth of the full-potency of existence' existentialising-decisionality-<as-to-disontologising/reentologising aporeticism $>$ psychological-disposition (as to " ${ }^{\circ}$ reference-of-thought-andreference-of-thought- devolving- ${ }^{5}$ meaningfulness-and-teleology 9 comprehensiveness of prospective sublimating-nascence'), thus speaking to the 'relative-ontologicalincompleteness $^{8} /$ relative-ontological-completeness $^{87}$ -

〈sublimating referencing/registering/decisioning,-as-self-becoming/self-

conflatedness /formative-supererogating-<projective/reprojective-aestheticising-re-motifand-re-apriorising/re-axiomatising/re-referencing,-in-perspective-ontologicalnormalcy/postconvergence $>>$ as to human-and-social-expectations/anticipationsmetaphoricity ${ }^{57}$-as-preconverging/postconverging-redementating/restructuring/reparadigming-psychologism' 89 with respect to inherent existence's sublimating-nascence (as to human Being-development/ontological-framework-expansion-asto-depth-of-ontologising-development-as-infrastructure-of- meaningfulness-and-teleology , 
institutional-development-as-to-social-function-development and living-development-as-topersonality-development psychologismic epistemic-acutisation difficulty <for, residualising \{ nonpresencing- $<$ perspective-ontological-normalcy/postconvergence $>$ epistemic conception of 'human sublimating/desublimating — modalisation-<as-to-absolute-referencing-ofmeaningfulness-and-teleology ${ }^{9}>$ upon inherent existence's sublimating-nascence inducing of ontologisation/omnipotentiality' is effectively what holographically-<conjugatively-andtransfusively $>$ reflects the seedingness/incipience of human ${ }^{5}$ meaningfulness-and-teleology ${ }^{99}$ as of 'sublimating aestheticisation-and-aestheticisation-towards-ontology-<elicitedidiomatisation> (as to manifest outcomes/outfits/shells-construed-historially-as-of-thespecifically-aestheticised-incrusting/plating/coating,-so-reflected-as-institutional-

manifestations) underlying the relative-unreflexivity/relative-reflexivity-ontologicalcontiguity ${ }^{67} \sim$ of-the-human-institutionalisation-process ${ }^{6}$, so-associated with human limitedmentation-capacity-deepening — as-subjecting limitedness/human-subpotency-to-'educedunlimitedness/existence-sublimating nascence' 'unbeholdening sublimating-nascence ontologising-depth of the full-potency of existence' existentialising-decisionality-<as-todisentogising/re ontogising apereticism $>$ psychological-disposition; and so in contrast to an obviating ${ }^{79}$ presencing-absolutising-identitive-constitutedness ${ }^{14}$ epistemic conception, failing to draw this holographically-<conjugatively-and-transfusively $>$ compounded-link as to the relative-unreflexivity/relative-reflexivity - ontological-contiguity ${ }^{67}$ of-the-humaninstitutionalisation-process ${ }^{68}$ so-reflected in 'human sublimating/desublimating - modalisation<as-to-absolute-referencing-of- ${ }^{5}$ meaningfulness-and-teleology ${ }^{9}>$ upon inherent existence's sublimating-nascence inducing of ontologisation/omnipotentiality' thus 'wrongly projecting/reprojecting of sublimating/desublimating — modalisation- $<$ as-to-absolutereferencing-of- - meaningfulness-and-teleology 9 on the basis of its $<$ amplituding/formative- 
epistemicity $>$ totalising $\sim$ self-referencing-syncretising/circularity/interiorising/akrasiatic-drag rather as to its ${ }^{7}$ presencing-absolutising-identitive-constitutedness ${ }^{14}$ socialvestedness/normativity-<discretely-implied-functionalism $>\quad$ inducing of subontologisation/subpotentiation (instead of inherent existence's sublimating-nascence inducing of ontologisation/omnipotentiality)' as so-underlying its given 'beholdening as sovereignising-imbued-subontologisation/subpotentiation' existentialising-decisionality-<asto-disontologising/re-ontologising aporeticism $>$ psychological-disposition, and hence failing to reflect human sublimating/desublimating-modalisation- $<$ as-to-absolute-referencing-ofmeaningfulness-and-teleology $>$ upon the full-potency of existence-as-the-absolute-apriori-of-conceptualisation and existence — as-sublimating-withdrawal/unenframing/reontologising,-elicited-from-prospective-profound-supererogation $-<$ as-to-perspectiveontological-normalcy/postconvergence-implied-'prospective-aporeticismovercoming/unovercoming'> in perspective ontological-normalcy/postconvergence as to underlying inherent existence's sublimating-nascence inducing of ontologisation/omnipotentiality. This latter point speaks to the very fundamental ontologicaldeficiency of knowledge-reification gesturing-and-accounting-of-epistemic-phenomenalism<in-prospective_psychologismic $\sim$ apriorising/axiomatising/referencing-\{of-'prespectively implicited_attendant-ontological-contiguity ' reducedexistentialising/contextualising/textualising_'intelligibility/epistemicity/reflexivity-contiguity<imbued-notional cogency >’ \}-conflatedness -in-\{preconverging -ment by\} postconverging-entailment> as undertaken with many a subject-matter failing 'supererogatory $\sim$ aestheticising-<as-from-perspective-ontologicalnormalcy/postconvergence $>$ — re-origination/reshuffling/anarchisation/transformativeness in \{epistemic-totalising 3 ' 3 hermeneutically/textually/reprojectingly/supererogatingly/zeroingly/reacutingly,-\{decompulsing $\}$ delinearity for-cogency-educing historiality/ontological- 
eventfulness 3 /ontological-aesthetic-tracing-<perspective-ontological-

normalcy/postconvergence-reflected-'epistemicity-relativism-determinism'>' and rather betrothed to a 'functionalism projection and conception' (to which the notion of prospective sublimation/desublimation as to the possibility for prospective knowledge-reification $\sim$ gesturingand-accounting - of-epistemic-phenomenalism- $<$ in-

prospective_psychologismic apriorising/axiomatising/referencing-\{of-"prospectively

implicited_attendant-ontological-contiguity ' educed-

existentialising/contextmalising/textualising_intelligibility/epistemicity/reflexivity_contiguity-

<imbued-notional cogency >' \}-conflatedness -in-\{preconverging ment by\}

postconverging-ntailment> is inevitably bogged down to the <amplituding/formativeepistemicity $>$ totalising $\sim$ self-referencing-syncretising/circularity/interiorising/akrasiatic-drag of our modern ${ }^{79}$ presencing-absolutising-identitive-constitutedness ${ }^{14}$ socialvestedness/normativity-<discretely-implied-functionalism $>\quad$ inducing of subontologisation/subpotentiation) as so-reflected in a psychological-disposition to presublimating relic/artifactual-beholdening-constitutedness ${ }^{14}$ preconverging/postconvergingde-mentatively/structurally/paradigmatically bound to ${ }^{47}$ historicity-tracing-in-presencinghyperrealisation/hyperreal-transposition. This is exactly in contrast to the whole object of effective fundamental ontology as incipiently/seedingly central to Derridean deconstruction and Foucauldian genealogy (and as reflected with science-in-practice driven as of historiality/ontological-eventfulness ${ }^{38} /$ ontological-aesthetic-tracing-<perspectiveontological-normalcy/postconvergence-reflected-'epistemicity-relativism-determinism'> conception and not naïve science-ideology ${ }^{47}$ historicity-tracing-in-presencinghyperrealisation/hyperreal-transposition conception), as to foundational issues and point-ofdeparture of knowledge-reification $\sim$ gesturing-and-accounting —of-epistemic-phenomenalism<in-prospective_psychologismic $\sim$ apriorising/axiomatising/referencing-\{of-'prospectively_ 
implicited_attendant-ontological-contiguity ' reduced-

existentialising/contextualising/textualising_'intelligibility/epistemicity/reflexivity_contiguity<imbued-notional cogency>’ \}-conflatedness -in-\{preconverging ment by\}

postconverging-entailment>; wherein the Derridean quasi-transcendental deconstruction and Foucauldian archaeology/genealogy postures (as of human conceptivity/epistemicreflexivity/epistemicity-relativism-determinism-<reifying \{as-to-knowledge-developing $\}$-andempowering $>$ imbued theoretical/conceptual/operant implications in knowledgereification $\sim$ gesturing-and-accounting — of-epistemic-phenomenalism- $<$ inprospective_psychologismic $\sim$ apriorising/axiomatising/referencing-\{of-'prospectively implicited_attendant-ontological-contiguity ' reducedexistentialising/contextualising/textualising_'intelligibility/epistemicity/reflexivity-contiguity<imbued-notional cogency $>\quad\}$-conflatedness -in-\{preconverging-ment by\} postconverging-entailment $>$ ) strive to supersede any social-vestedness/normativity inducing of subontologisation/subpotentiation in the 'implicited conceptualisation of a foundational pointof-departure of knowledge-reification $\sim$ gesturing-and-accounting-of-epistemicphenomenalism- $<$ in-prospective_psychologismic $\sim$ apriorising/axiomatising/referencing- of'prespectively_implicited_attendant-ontological-contiguity ' educedexistentialising/contextmalising/textualising_'intelligibility/epistemicity/reflexivity_contiguity<imbued-notional cogency >' \}-conflatedness -in-\{preconverging-ment by\} postconverging-entailment>' and rather 'implicit by their approach that human meaningfulness-and-teleology ${ }^{9}$ is as to its subjection to existence-as-sublimatingwithdrawal/unenframing/re-ontologising,-elicited-from-prospective-profound-supererogation in fepistemic-totalising ${ }^{3}{ }^{3}$ hermeneutically/textully/reprojectingly/supererogatingly/zeroingly/reacutingly,-\{decompulsing? delinearity for-cogency-educing sublimation-over-desublimation’ (as herein articulated as of the implications of human limited-mentation-capacity-deepening-as- 
subjecting limitedness/human-subpotency-to-'educed-unlimitedness/existence-sublimating nascence' 5 postconvergingly-de-mentating/structuring/paradigming-out the relativeunreflexivity/relative-reflexivity —ontological-contiguity ${ }^{67}$ of-the-human-institutionalisationprocess ${ }^{6}$ with regards to Being-development/ontological-framework-expansion-as-to-depth-ofontologising-development-as-infrastructure-of- meaningfulness-and-teleology , institutionaldevelopment-as-to-social-function-development and living-development-as-to-personalitydevelopment psychologismic epistemic-acutisation difficulty < for, residualising \{decompulsing $\}$ delinearity for-cogency> magnitudes $\{$ of-experientiality/experiment $\}$ ). This conceptivity/epistemic-reflexivity/epistemicity-relativism-determinism-<reifying \{as-toknowledge-developing\}-and-empowering $>$ difference between 'human sublimating/desublimating - modalisation- $<$ as-to-absolute-referencing-of- ${ }^{56}$ meaningfulnessand-teleology $>$ upon inherent existence's sublimating-nascence inducing of ontologisation/omnipotentiality' and 'human sublimating/desublimating—modalisation- $<$ as-toabsolute-referencing-of- ${ }^{5}$ meaningfulness-and-teleology $>\quad$ upon socialvestedness/normativity-<discretely-implied-functionalism $>\quad$ inducing of subontologisation/subpotentiation' can be compared in allegorical terms to say having a highway with poor signalling and construction bound to induce a given level of accidents (as to possibility of sublimation/desublimation), with the former rather construing of the inherent nature of the highway of foundational problematic postconvergingaaporeticism-overcoming/unovercoming and the latter rather ignoring the inherent foundational problematic postconverging aporeticism-overcoming/unovereoming nature of the highway and adopting extricatory stratagems for dealing with the highway in its given state 'with the implicited expectation of accidents'; and in this respect deconstruction and genealogy analyses (and notional ${ }^{18}$ deprocrypticism suprastructuralism analysis as expressed herein with regards to the relative-unreflexivity/relative-reflexivity ontological-contiguity ${ }^{67}$ of-the-human- 
institutionalisation-process ${ }^{68}$ ) as to 'human sublimating/desublimating-modalisation- $<$ as-toabsolute-referencing-of- ${ }^{5}$ meaningfulness-and-teleology $>$ upon inherent existence's sublimating-nascence inducing of ontologisation/omnipotentiality' sublimatingexistentialising-decisionality is bound to a knowledge-reification gesturing-and-accountingof-epistemic-phenomenalism- $<$ in-

\section{prospective_psychologismic apriorising/axiomatising/referencing-\{of-'prespectively}

\section{implicited_attendant-ontological-contiguity ' ceduced-}

existentialising/contextualising/textualising_intelligibility/epistemicity/reflexivity-contiguity$<$ imbued-notional cogency $>$ ' $\}$-conflatedness -in-\{preconverging ment by\}

postconverging entailment $>$ for tackling the more foundational problematic postconvergingaaporeticism-overcoming/unovercoming issues underlying say the present decadal economic crises, media and information crises, political accountability, etc., whereas 'human sublimating/desublimating - modalisation- $<$ as-to-absolute-referencing-ofmeaningfulness-and-teleology ${ }^{9}>$ upon social-vestedness/normativity-<discretely-impliedfunctionalism > inducing of subontologisation/subpotentiation' supposedly of sublimatingexistentialising-decisionality as implied not only with regards to overall social-and-institutionalframeworks-of - referencing/registering/decisioning reflex but manifested with many a subjectmatter like economics theory, psychological theory and social theory which tend to implicitly ignore/consider this more foundational problematic postconverging-aporeticismevercoming/unovercoming reality of present decadal economic crises, media and information crises, political accountability, etc. (as to their ${ }^{79}$ presencing-absolutising-identitiveconstitutedness $^{14}$ shallow-supererogation of manifest in-effect absolution- $<$ as-toapriorising/axiomatising/referencing-\{of-'prospectively implieited_attendant-ontologicalcontiguity ' educedexistentialising/contextualising/textualising_intelligibility/epistemicity/reflexivity-contiguity- 


\section{$<$ imbued-notional cogency $>>\quad\}$-constitutedness -in preconverging-entailment $>$}

inclinations) as a given and rather come-up-with/reflect 'stratagems of extricatory solutions considered of sublimating-existentialising-decisionality' and paradoxically validating the very inherence of the decadal economic crises, media and information crises, political accountability, etc. as to a winners-and-losers implicited conceptualisation of social-vestedness/normativity$<$ discretely-implied-functionalism $>$ and thus incapable of an orientation for addressing fundamental ontology as to veridical postconverging aporeticism-overcoming/unovercoming (as of the 'requisite profound-supererogation entailing-<amplituding/formativeepistemicity>totalising in-relative-ontological-completeness historiality/ontologicaleventfulness ${ }^{38} /$ ontological-aesthetic-tracing-<perspective-ontologicalnormalcy/postconvergence-reflected-'epistemicity-relativism-determinism'> implications of postconverging aporeticism-overcoming/unovercoming'). This is effectively what practically underlies the postmodernism notion of human overcoming of metaphysics-of-presence〈implicited-'nondescript/ignorable-void '-as-to- presencing - absolutising-identitiveconstitutedness $\rangle$ imbued ${ }^{7}$ presencing-absolutising-identitive-constitutedness ${ }^{14}$ socialvestedness/normativity-<discretely-implied-functionalism $>\quad$ inducing of subontologisation/subpotentiation' (in a psychological-disposition to presublimating relic/artifactual-beholdening-constitutedness preconverging/postconverging-dementatively/structurally/paradigmatically bound to ${ }^{47}$ historicity-tracing-in-presencinghyperrealisation/hyperreal-transposition); with the further idea that an adorning use of abstract 'mere-formulaicity/ritualisation-<as-to-mere-formulaicmethodologising/mutualising/organising/institutionalising,-prospectively-losing-track-of‘\{epistemic-totalising ’’re-apriorising/re-axiomatising/re-referencing - residuality-in-reoriginariness/re-origination'> of science as science-ideology', scientific methods, statistics and mathematics (as to totalisingly-ing-discretion/whim-of-thought pretense-of-sublimation in 
failing to face up to foundational problematic postconverging-aporeticismovercoming/unovercoming as required for fundamental ontology as to the 'very inherent knowledge-reification $\sim$ gesturing-and-accounting — of-epistemic-phenomenalism- $<$ inprospective_psychologismic apriorising/axiomatising/referencing-\{of-'prospectively implicited_attendant-ontological-contiguity ' educedexistentialising/contextualising/textualising_'intelligibility/epistemicity/reflexivity_contiguity<imbued-notional cogency>’ $\}$-conflatedness -in-\{preconverging -ment by\}

postconverging-entailment $>$ as determining sublimating $\sim$ existentialising-decisionality-<as-todisontologising/re-ontologising aporeticism'), speaks to naïve science-ideology priorly driven by social-vestedness/normativity- $<$ discretely-implied-functionalism $>{ }^{47}$ historicitytracing - in-presencing-hyperrealisation/hyperreal-transposition rather than genuine science imbued supererogatoryacuity/perspicacity/astuteness/edginess/incisiveness \{epistemictotalising 3 ' $h$ hermeneutically/textually/reprojectingly/supererogatingly/zeroingly/re-acutingly,\{decolinearity for-cogency-educing historiality/ontologicaleventfulness 3 /ontological-aesthetic-tracing-<perspective-ontologicalnormalcy/postconvergence-reflected-'epistemicity-relativism-determinism'> implications that rather bring out the true lustre of science, scientific methods, statistics and mathematics whenand-if of sublimating-nascence relevance. Critically, the inherent relative ignorance/disenfranchisement of the human sovereign-function/posture-<as-to-existentiallymanifest-'embodied-subject $\sim$ consciousness-and-direct/deferential-conscientiousness',-as-ofits-'epistemic-reflexivity/unreflexivity-in-existence'/teleology> in-many-ways renders blurry the differentiation of such a ${ }^{4}$ historiality/ontological-eventfulness 3 /ontological-aesthetictracing-<perspective-ontological-normalcy/postconvergence-reflected-`epistemicityrelativism-determinism'> and ${ }^{47}$ historicity-tracing-in-presencing-hyperrealisation/hyperrealtransposition with respect to true knowledge-reification $\sim$ gesturing-and-accounting-of- 
epistemic-phenomenalism-<in-

prospective_psychologismic apriorising/axiomatising/referencing-\{of-'prospectively implicited_attendant-ontological-contiguity ' educed-

existentialising/contextualising/textualising_intelligibility/epistemicity/reflexivity-contiguity<imbued-notional cogency >' \}-conflatedness -in-\{preconverging-ment by\} postconverging-entailment> and overall social-and-institutional-frameworks-ofreferencing/registering/decisioning sublimating-existentialising-decisionality $<$ as-todisontologising/re-ontologising aporeticism $>$; as to the fact that 'totalisingly-ingdiscretion/whim-of-thought pretense-of-sublimation' and 'profound-supererogation entailing$<$ amplituding/formative-epistemicity $>$ totalising $\sim$ in-relative-ontological-completeness sublimation' can be easily passed for one another in a public debate critically fragile to pedantic disorientation even as in-many-ways the human sovereign-function/posture-<as-toexistentially-manifest-‘embodied-subject $\sim$ consciousness-and-direct/deferential-

conscientiousness',-as-of-its- 'epistemic-reflexivity/unreflexivity-in-existence'/teleology> is very much conscious of the social-stake-contention-or-confliction postconverging-apereticismovercoming/unovercoming masked/avoided/ignored/deflated by such pedantic manipulation to which the genuine social intellectual-function/posture can effectively speak to. From the nonpresencing-<perspective-ontological-normalcy/postconvergence $>$ epistemic conception what fundamentally underlies this 'human limited-mentation-capacity-as-subjecting 'educedunlimitedness/existence-sublimating nascence' to-limitedness/human-subpotency projective/reprojective - aestheticising-re-motif-and-re-apriorising/re-axiomatising/rereferencing as of ${ }^{83}$ reference-of-thought conceptivity/epistemic-reflexivity/epistemicityrelativism-determinism-<reifying \{as-to-knowledge-developing $\}$-and-empowering $>\quad$ (on-theone-hand) upon inherent existence's sublimating-nascence (on-the-other-hand)' so-translated as 'human sublimating/desublimating — modalisation- $<$ as-to-absolute-referencing-of- 
meaningfulness-and-teleology ${ }^{9}>$ upon inherent existence's sublimating-nascence inducing of ontologisation/omnipotentiality' in-so-de-mentating/structuring/paradigming-out the relativeunreflexivity/relative-reflexivity - ontological-contiguity ${ }^{67}$ of-the-human-institutionalisationprocess ${ }^{6}$, is 'human <postconverging 'motif-and-apriorising/axiomatising/referencing'entailing >-existentialising - framing/imprinting-〈as-to-prospective-- historiality/ontologicaleventfulness /ontological-aesthetic-tracing-<perspective-ontologicalnormalcy/postconvergence-reflected-‘epistemicity-relativism-determinism'>〉' over 'human $<$ preconverging 'motif-and-apriorising/axiomatising/referencing'-entailing >existentialising — enframing/imprintedness-〈as-to- historicity-tracing — in-presencinghyperrealisation/hyperreal-transposition $\rangle \quad$ of $\quad{ }^{79}$ presencing-absolutising-identitiveconstitutedness $^{14}$ social-vestedness/normativity-<discretely-implied-functionalism $>$ inducing subontologisation/subpotentiation' as so reflected in the 'sublimating aestheticisation-andaestheticisation-towards-ontology-<elicited-idiomatisation $>\quad$ (as to manifest outcomes/outfits/shells—construed-historially-as-of-the-specifically-aestheticisedincrusting/plating/coating,-so-reflected-as-institutional-manifestations)' as to 'fatedness-ofsublimation-over-desublimation to existence-potency sublimating-nascence,-disclosed-fromprospective-epistemic-digression in reflecting holographically-<conjugatively-andtransfusively $>$ the relative-unreflexivity/relative-reflexivity ontological-contiguity $\sim$ of-thehuman-institutionalisation-process '. This is in contrast to an obviating presencingabsolutising-identitive-constitutedness ${ }^{14}$ epistemic conception as of 'discrete inherence of sublimating/desublimating - modalisation- $<$ as-to-absolute-referencing-of- ${ }^{56}$ meaningfulnessand-teleology ${ }^{9}>$ on the basis of ${ }^{79}$ presencing - absolutising-identitive-constitutedness ${ }^{14}$ socialvestedness/normativity-<discretely-implied-functionalism $>\quad$ inducing of subontologisation/subpotentiation' (in an absolutising <preconverging 'motif-andapriorising/axiomatising/referencing'-entailing>-existentialising-enframing/imprintedness- 
〈as-to- historicity-tracing - in-presencing-hyperrealisation/hyperreal-transposition〉). Thus the veridical ${ }^{6}$ nonpresencing-<perspective-ontological-normalcy/postconvergence $>$ epistemic conception rather speaks to 'supereregatory $\sim$ aestheticising- $<$ as-from-perspective-ontologicalnormalcy/postconvergence>-re-origination/reshuffling/anarchisation/transformativeness in \{epistemic-totalising 3 ’ hermeneutically/textually/reprojecting/y/supererogatingly/zeroingly/reacutingly,-\{decompulsing $\}$ delinearity for-cogency-educing historiality/ontologicaleventfulness 3 /ontological-aesthetic-tracing-<perspective-ontologicalnormalcy/postconvergence-reflected-'epistemicity-relativism-determinism'>' overriding of 'beholdening as sovereignising-imbued-subontologisation/subpotentiation' existentialisingdecisionality-<as-to-disontologising/re-ontologising aporeticism $>$ psychological-disposition (as to relative-ontological-incompleteness ${ }^{88}$-presublimation-construct-of- ${ }^{5}$ meaningfulnessand-teleology $\quad$ desublimating existentialising-decisionality-<as-to-disontologising/reentologising aporeticism $>$ ) in want for prospective 'unbeholdening sublimating-nascence ontologising-depth of the full-potency of existence' existentialising-decisionality-as-todisontologising/re-ontologising aporeticism $>$ psychological-disposition (as to ${ }^{68}$ reference-ofthought-and- ${ }^{83}$ reference-of-thought- ${ }^{8}$ devolving- ${ }^{56}$ meaningfulness-and-teleology comprehensiveness of prospective sublimating-nascence'). Such 'supereregatory aestheticising-<as-from-perspective-ontologicalnormalcy/postconvergence $>$ — re-origination/reshuffling/anarchisation/transformativeness in Sepistemictising thermeneutically/textully/reprojectingly/supererogatingly/zeroingly/reacutingly, - -decompulsing? $^{-}$delinearity for-cogency-educing $\quad{ }^{4}$ historiality/ontologicaleventfulness $^{38}$ /ontological-aesthetic-tracing-<perspective-ontologicalnormalcy/postconvergence-reflected-'epistemicity-relativism-determinism'>' is so-underlied by human 'reframing/reimprinting of <postconverging 'motif-andapriorising/axiomatising/referencing'-entailing>-existentialising-framing/imprinting-〈as-to- 
prospective- historiality/ontological-eventfulness /ontological-aesthetic-tracing-

$<$ perspective-ontological-normalcy/postconvergence-reflected-'epistemicity-relativism-

determinism' $>$ ' $\quad$ as $\quad$ so-reflecting nonpresencing-<perspective-ontologicalnormalcy/postconvergence> epistemic conception of 'human sublimating/desublimatingmodalisation- $<$ as-to-absolute-referencing-of $-{ }^{56}$ meaningfulness-and-teleology ${ }^{9}>$ upon inherent existence's sublimating-nascence inducing of ontologisation/omnipotentiality' with regards to human 'reframing/reimprinting of $\quad$ postconverging 'motif-andapriorising/axiomatising/referencing'-entailing>-existentialising-framing/imprinting-〈as-toprospective- historiality/ontological-eventfulness /ontological-aesthetic-tracing<perspective-ontological-normalcy/postconvergence-reflected-‘epistemicity-relativismdeterminism' $>\rangle$ ' in reconstrual as to its 'effectively underlying beholdening-inching,apprehending,-and-taming-drive or aestheticising - ${ }^{97}$ surrealising/supererogating-drive for $<$ postconverging 'motif-and-apriorising/axiomatising/referencing'-entailing >existentialising - framing/imprinting-〈as-to-prospective- historiality/ontologicaleventfulness /ontological-aesthetic-tracing-<perspective-ontologicalnormalcy/postconvergence-reflected-‘epistemicity-relativism-determinism'>〉'; (so-underlying the '<amplituding/formative-epistemicity $>$-totalising $\sim$ thrownness-in-existence ${ }^{35} \quad$ reaesthethicising/re-motif- $<$ in-postconverging-narrowing-down $\sim$ 'sublimation-of-taste- \{epistemictotalising 3 3 hermeneutically/textully/reprojectingly/supererogatingly/zeroingly/re aeutingly,$\{$ decompulsing $\}$ delinearity for-cogency-educing-conceptivity/epistemic-reflexivity/epistemicityrelativism-determinism-<reifying \{as-to-knowledge-developing $\}$-and-empowering $>$-ofhistoriality/ontological-eventfulness /ontological-aestheticising-tracing',-as-to-existenceas-sublimating-withdrawal/unenframing/re-ontologising,-elicited-from-prospective-profound-

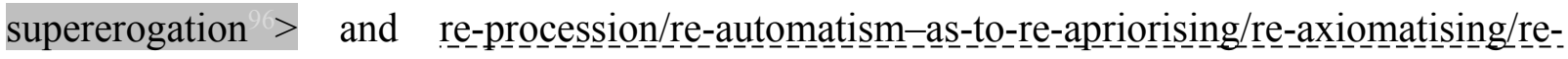
referencing-<in-postconverging-narrowing-down 'sublimation-of- 
apriorising/axiomatising/referencing_\{epistemic-

totalising 3 ${ }^{3}$ hermeneutically/textually/reprojectingly/supererogatingly/zeroingly/re-acutingly,-

\{decompling $d$ delinearity for-cogency-educing-conceptivity/epistemic-reflexivity/epistemicity-

relativism-determinism-<reifying \{as-to-knowledge-developing $\}$-and-empowering $>$-of-

historiality/ontological-eventfulness /ontological-aestheticising-tracing',-as-to-existence-

as-sublimating-withdrawal/unenframing/re-ontologising,-elicited-from-prospective-profound-

supererogation $>$ ) of human aestheticising - ${ }^{97}$ surrealising/supererogating-drive for

<postconverging 'motif-and-apriorising/axiomatising/referencing'-entailing >-

existentialising — framing/imprinting-〈as-to-prospective- historiality/ontological-

eventfulness /ontological-aesthetic-tracing-<perspective-ontological-

normalcy/postconvergence-reflected-‘epistemicity-relativism-determinism'>>' $\quad$ (as to

interlay/organicalism/aestheticising-handle-<of-'psychologismic-transfixity \{residualising

\{decompulsing $\}$ delinearity over-nonresidualising \{compulsing\} linearity\}’ $>-\{$ imbued-

supererøgatøry projective-arbitrariness/waywardness-

of $\sim$ transversalisation/tandemisation/abstractive-conjugation/perspectivation/depthing — for-

'aestheticising-re-margining/re-edging/re-acuity-as-

postconverging_circumscriptive/totalitative-restructuring'\} — educing-

sublimation/desublimation>

in

fepistemic

thermeneutically/textually/reprojectingly/supererogatingly/zeroingly/re-acutingly,-

\{decompulsing $\}$ delinearity for-cogency-imbuing

'supererogatory $\sim$ acuity/perspicacity/astuteness/edginess/incisiveness $\sim$ differential ontological-

performance ${ }^{2}-<$ including-virtue-as-ontology $>$ /potentiation'), so-construed as human 'germinative intensification — amplituding of aestheticisation—-beholdening-out-of-bechancing'

/ 'taxingness-of-originariness,-imbued-sublimating-by-desublimating-amplituding as to the backdrop-of-inherent-immanent-existence's-sublimation-structure- $<$ of-'unsurrealistic-as- 
real'-ontological-normalcy/postconvergence>' (as so-underlied by human-subpotency epistemically-reflexive consciousness overlying the sublimating-postconverged 'substantive abstract-tissue-of-social-emanance Sepistemictotalising $3{ }^{3}$ hermeneutically/textually/reprojectingly/supererogatingly/zeroingly/re-acutingly,${ }_{\{\text {decompulsing }}$ delinearity for-cogency_cumulated/recomposured as to cumulating/recomposuring of 'prospectively implicited_attendant-ontological-contiguity ${ }^{67}$ 'educedexistentialising/contextualising/textualising_'intelligibility/epistemicity/reflexivity_contiguity<imbued-notional cogency>' as to overall reifying-and-empowering-reflexivity-of-ecstaticexistence-as-panintelligibility/panreflexivity ${ }^{3}-\langle$ existentially-imbued-and-educing-< $\{$ epistemictotalising ${ }^{\text {th}}$ hermeneutically/textually/reprojectingly/supererogating/y/zeroing/y/re-acutingly,$\{$ decompulsing\} delinearity for-cogency $>$-epistemic-perspective-of-projective/reprojectiveaestheticising-re-motif-and-re-apriorising/re-axiomatising/re-referencing conceptualisation,as-herein-specifically-relevant-to human-subpotency) in reflection of overall Beingdevelopment/ontological-framework-expansion-as-to-depth-of-ontologising-development-asinfrastructure-of- meaningfulness-and-teleology ). Critically, the notional/epistemic/bindingness ${ }^{-<a-t o-d e t e r m i n i s m / c o n c e p t i v i t y-o f-r e l a t i v e-u n r e f l e x i v i t y / r e l a t i v e-r e f l e x i v i t y s ~}$ possibility for human 'supererogatory $\sim$ aestheticising- $<$ as-from-perspective-ontologicalnormalcy/postconvergence $>$ — re-origination/reshuffling/anarchisation/transformativeness in thermeneutically/textually/reprojectingly/supererogatingly/zeroingly/reacutingly, - $^{\text {-decompulsing? }}$ delinearity for-cogency-educing $\quad{ }^{4}$ historiality/ontologicaleventfulness ${ }^{38}$ /ontological-aesthetic-tracing-<perspective-ontologicalnormalcy/postconvergence-reflected-'epistemicity-relativism-determinism'>' given the constraint of human limited-mentation-capacity-as-subjecting 'educedunlimitedness/existence-sublimating nascence' to-limitedness/human-subpotency 'preconverging/postconverging-de-mentatively/structurally/paradigmatically hinges on human 
$<$ amplituding/formative-epistemicity>-totalising $\sim$ thrownness-in-existence ${ }^{35}$ as to human shallow-supererogation - to-profound-supererogation constraining/unconstraining existentialising — anxiety-imbued-beholdening-inducing, $-<$ preconverging ' motif-andapriorising/axiomatising/referencing'-entailing >-existentialising — enframing/imprintedness〈as-to- historicity-tracing-in-presencing-hyperrealisation/hyperreal-transposition〉', and so notionally/epistemically/bindingnessly-<as-to-determinism/conceptivity-of-relative-unreflexivity/relative-reflexivity> reflected with the reifying-and-empowering-reflexivity-of-ecstatic-existence-aspanintelligibility/panreflexivity ${ }^{73}-\left\langle\right.$ existentially-imbued-and-educing-< fepistemic- $^{-}$ totalising ${ }^{\text {th}}$ hermeneutically/textually/reprojectingly/supererogatingly/zeroing/y/re-acutingly,$\left.{ }_{\{d e c o m p u l s i n g}\right\}$ delinearity $\sim$ for-cogency $\geq$-epistemic-perspective-of-projective/reprojectiveaestheticising-re-motif-and-re-apriorising/re-axiomatising/re-referencing conceptualisation,as-herein-specifically-relevant-to human-subpotency) existentialising/contextualising/textualising implications, (so-underlying the '<amplituding/formative-epistemicity $>$-totalising $\sim$ thrownness-in-existence ${ }^{35} \quad$ reaestheticisising/re-motif- $<$ in-postconverging-narrowing-down 'sublimation-of-taste- \{epistemictotalising 3 thermeneutically/textually/reprojectingly/supererogatingly/zeroingly/re-acutingly,$\{$ decompulsing $\}$ delinearity for-cogency-educing-conceptivity/epistemic-reflexivity/epistemicityrelativism-determinism-<reifying \{as-to-knowledge-developing $\}$-and-empowering $>$-ofhistoriality/ontological-eventfulness /ontological-aestheticising-tracing',-as-to-existenceas-sublimating-withdrawal/unenframing/re-ontologising,-elicited-from-prospective-profoundsupererogation $>$ and re-procession/re-automatism-_as-to-re-_apriorising/re-_re-axiomatising/rereferencing-<in-postconverging-narrowing-down 'sublimation-ofapriorising/axiomatising/referencing_epistemic thermeneutically/textully/reprojectingly/supererogatingly/zeroingly/re-acutingly,${ }_{\{\text {decompulsing }}$ delinearity for-cogency-educing-conceptivity/epistemic-reflexivity/epistemicity- 
relativism-determinism-<reifying \{as-to-knowledge-developing $\}$-and-empowering $>$-of-

historiality/ontological-eventfulness /ontological-aestheticising-tracing',-as-to-existence-

as-sublimating-withdrawal/unenframing/re-ontologising,-elicited-from-prospective-profound-

supererogation $>$ ) of human aestheticising - ${ }^{97}$ surrealising/supererogating-drive for <postconverging 'motif-and-apriorising/axiomatising/referencing'-entailing >-

existentialising — framing/imprinting-〈as-to-prospective- historiality/ontological-

eventfulness /ontological-aesthetic-tracing-<perspective-ontological-

normalcy/postconvergence-reflected-'epistemicity-relativism-determinism'>>' $\quad$ (as $\quad$ to

interlay/organicalism/aestheticising-handle-<of-'psychologismic-transfixity \{residualising

$\{$ \{ecompulsing $\}$ delinearity over nonresidualising \{compulsing\} linearity\}' $>-\{$ imbued-

supererogatory projective-arbitrariness/waywardness-

of $\sim$ transversalisation/tandemisation/abstractive-conjugation/perspectivation/depthing — for'aestheticising-re-margining/re-edging/re-acuity-as-

postconverging_circumscriptive/totalitative-restructuring'\} - educing-

sublimation/desublimation>

in

\{epistemic-

totalising 3 '`hermeneutically/textually/reprojectingly/supererogatingly/zeroingly/re-acutingly,-

\{decompulsing delinearity $\sim$ for-cogency-imbuing

'supererogatory acuity/perspicacity/astuteness/edginess/incisiveness $\sim$ differential ontologicalperformance ${ }^{72}-<$ including-virtue-as-ontology $>$ /potentiation'); for ushering in 'prospective sublimating aestheticisation-and-aestheticisation-towards-ontology-<elicited-idiomatisation $>$ ' as to overall sublimation-induced human-and-social-expectations/anticipationsmetaphoricity ${ }^{57}$-as-preconverging/postconverging-rede-

mentating/restructuring/reparadigming-psychologism-<as-from-perspective-ontologicalnormalcy/postconvergence>, and so-reflected as to 'unbeholdening sublimating-nascence ontologising-depth of the full-potency of existence' bifurcatingly with 'nascent- 
particular/incipient-and-material/technical-sublimations- $<$ blinded-to-their-relative-ontologicalcompleteness - reference-of-thought- devolving > sublimating existentialisingdecisionality-<as-to-disontologising/re-ontologising-aporeticism $>$ (however the devolved/devoluted-referencing-narrowness with respect to overall social-and-institutionalframeworks-of — referencing/registering/decisioning existentialising-decisionality-<as-todisontologising/re-ontologising aporeticism $>$ )' and ' ${ }^{83}$ reference-of-thought-and- ${ }^{83}$ referenceof-thought- ${ }^{-1 e v o l v i n g-}{ }^{5}$ meaningfulness-and-teleology ${ }^{9}$ comprehensiveness of prospective sublimating-nascence (over relative-ontological-incompleteness ${ }^{88}$-presublimation-constructof- ${ }^{5}$ meaningfulness-and-teleology ${ }^{9}$ ) as to overall social-and-institutional-frameworks-ofreferencing/registering/decisioning sublimating $\sim$ existentialising-decisionality-<as-todisontologising/re-ontologising aporeticism $>$ '. In other words, 'human supererogatory aestheticising-<as-from-perspective-ontologicalnormalcy/postconvergence > - re-origination/reshuffling/anarchisation/transformativeness reflected as to human aestheticising - ${ }^{7}$ surrealising/supererogating-drive for <postconverging 'motif-and-apriorising/axiomatising/referencing'-entailing >existentialising — framing/imprinting-〈as-to-prospective- historiality/ontologicaleventfulness /ontological-aesthetic-tracing-<perspective-ontologicalnormalcy/postconvergence-reflected-‘epistemicity-relativism-determinism' $>\rangle$ ' basically speaks of the fact that the totalising 3 thermeneutically/textually/reprojectingly/supererogatingly/zeroingly/re-acutingly,\{decompulsing $\}$ delinearity for-cogency-educing 'reframing/reimprinting of <postconverging 'motif-and-apriorising/axiomatising/referencing'-entailing >existentialising — framing/imprinting-〈as-to-prospective- historiality/ontologicaleventfulness /ontological-aesthetic-tracing-<perspective-ontologicalnormalcy/postconvergence-reflected-'epistemicity-relativism-determinism' $>\rangle$ ' underlies the 
preconverging/postconverging-rede-mentating/restructuring/reparadigming of human Beingdevelopment/ontological-framework-expansion-as-to-depth-of-ontologising-development-asinfrastructure-of- meaningfulness-and-teleology , institutional-development-as-to-socialfunction-development and living-development-as-to-personality-development psychologismic epistemic-acutisation difficulty-for, residualising \{decompulsing $\}$ delinearity for-cogency> magnitudes $\{$ of-experientiality/experiment\} as so-reflecting holographically-<conjugatively-andtransfusively $>$ the relative-unreflexivity/relative-reflexivity ontological-contiguity $\sim$ of-thehuman-institutionalisation-process ; with 'higher-renewal/not-aversed-to-profound-renewal of <postconverging 'motif-and-apriorising/axiomatising/referencing'-entailing >existentialising - framing/imprinting-〈as-to-prospective-- historiality/ontologicaleventfulness /ontological-aesthetic-tracing-<perspective-ontologicalnormalcy/postconvergence-reflected-'epistemicity-relativism-determinism'> $>$ ' with regards to living-development-as-to-personality-development (so-associated with childhood personalitydevelopment) and 'lesser-renewal/aversity-to-profound-renewal of <postconverging 'motifand-apriorising/axiomatising/referencing'-entailing>-existentialising-framing/imprinting-〈asto-prospective- historiality/ontological-eventfulness /ontological-aesthetic-tracing$<$ perspective-ontological-normalcy/postconvergence-reflected-'epistemicity-relativismdeterminism'>Y' with regards to Being-development/ontological-framework-expansion-as-todepth-of-ontologising-development-as-infrastructure-of- meaningfulness-and-teleology (soassociated with the relative perennity of human language, cultures, institutions, etc. but rather relatively renewed as of cultural-diffusion), as so-tied to human shallow-supererogation - toprofound-supererogation constraining/unconstraining existentialising — anxiety-imbuedbeholdening-inducing,-<preconverging 'motif-and-apriorising/axiomatising/referencing'entailing $>$-existentialising — enframing/imprintedness-〈as-to- historicity-tracing - inpresencing-hyperrealisation/hyperreal-transposition) (in want of prospective human 
aestheticising — ${ }^{97}$ surrealising/supererogating-drive for $\quad<$ postconverging $\sim$ 'motif-andapriorising/axiomatising/referencing'-entailing--existentialising_-framing/imprinting-〈as-toprospective- historiality/ontological-eventfulness /ontological-aesthetic-tracing$<$ perspective-ontological-normalcy/postconvergence-reflected-'epistemicity-relativismdeterminism'>> imbued interlay/organicalism/aestheticising-handle-<of-'psychologismictransfixity\{residualising \{decompulsing\} delinearity-over-nonresidualising \{compulsing\} linearity\}’ $>-$ \{imbued-supererogatory $\sim$ projective-arbitrariness/waywardnessof $\sim$ transversalisation/tandemisation/abstractive-conjugation/perspectivation/depthing — for'aestheticising-re-margining/re-edging/re-acuity-aspostconverging_circumscriptive/totalitative-restructuring'\} - educingsublimation/desublimation> in \{epistemictotalising 3 ? ${ }^{3}$ hermeneutically/textually/reprojectingly/supererogatingly/zeroingly/re-acutingly,\{decompusing delinearity for-cogency-imbuing 'supererogatory $\sim$ acuity/perspicacity/astuteness/edginess/incisiveness $\sim$ differential ontologicalperformance ${ }^{72}-<$ including-virtue-as-ontology $>$ /potentiation' for prospective human postconverging-aporeticism overcoming/mnovereoming in reconstrual of '<amplituding/formative-epistemicity $>$-totalising $\sim$ thrownness-in-existence ${ }^{35}$ as to reaesthethicising/re-motif- $<$ in-postconverging-narrowing-down $\sim$ 'sublimation-of-taste-thermeneutically/textually/reprojectingly/supererogatingly/zeroingly/re-acutingly,\{decompulsing $\}$ delinearity for-cogency-educing-conceptivity/epistemic-reflexivity/epistemicityrelativism-determinism-<reifying \{as-to-knowledge-developing $\}$-and-empowering $>$-ofhistoriality/ontological-eventfulness /ontological-aestheticising-tracing',-as-to-existenceas-sublimating-withdrawal/unenframing/re-ontologising,-elicited-from-prospective-profoundsupererogation $>$ and re-procession/re-automatism-as-_to-re-re-apriorising/re-_e-axiomatising/rereferencing-<in-postconverging-narrowing-down 'sublimation-of- 
apriorising/axiomatising/referencing_\{epistemic-

totalising 3 ${ }^{3}$ hermeneutically/textually/reprojectingly/supererogatingly/zeroingly/re-acutingly,-

\{decompling $d$ delinearity for-cogency-educing-conceptivity/epistemic-reflexivity/epistemicity-

relativism-determinism-<reifying \{as-to-knowledge-developing $\}$-and-empowering $>$-of-

historiality/ontological-eventfulness /ontological-aestheticising-tracing',-as-to-existence-

as-sublimating-withdrawal/unenframing/re-ontologising,-elicited-from-prospective-profound-

supererogation $>$ )'. Critically (given existentialising — anxiety-imbued-beholdening-inducing,$<$ preconverging $\sim$ 'motif-and-apriorising/axiomatising/referencing'-entailing $>$ -

existentialising — enframing/imprintedness-〈as-to- historicity-tracing — in-presencing-

hyperrealisation/hyperreal-transposition), human \{epistemic-

totalising ${ }^{3}$ ' $h e r m e n e u t i c a l l y /$ textually/reprojectingly/supererogatingly/zeroingly/re-acutingly,-

\{decompulsing delinearity for-cogency-educing 'reframing/reimprinting of

$<$ postconverging 'motif-and-apriorising/axiomatising/referencing'-entailing >-

existentialising - framing/imprinting-〈as-to-prospective- historiality/ontological-

eventfulness /ontological-aesthetic-tracing-<perspective-ontological-

normalcy/postconvergence-reflected-'epistemicity-relativism-determinism'>Y' necessarily

involves 'existentially-decontextualised play/gaming/exercising of <postconverging 'motifand-apriorising/axiomatising/referencing'-entailing>-existentialising_-framing/imprinting-〈asto-prospective- historiality/ontological-eventfulness /ontological-aesthetic-tracing-

$<$ perspective-ontological-normalcy/postconvergence-reflected-‘epistemicity-relativism-

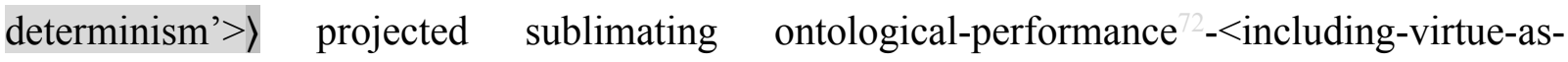
ontology $>$ /morality/ethics/justice/etc. of ${ }^{5}$ meaningfulness-and-teleology ${ }^{9}$ together with 'effective existentially-contextualised instantiation/actualisation of <postconverging 'motifand-apriorising/axiomatising/referencing'-entailing>-existentialising_framing/imprinting-〈asto-prospective- historiality/ontological-eventfulness /ontological-aesthetic-tracing- 
<perspective-ontological-normalcy/postconvergence-reflected-'epistemicity-relativismdeterminism'>> projected sublimating-over-desublimating ontological-performance ${ }^{72}$ $<$ including-virtue-as-ontology $>$ /morality/ethics/justice/etc. of $\quad{ }^{56}$ meaningfulness-andteleology ${ }^{9}$, (as to their separate-and-intermingling manifestation in <postconverging 'motifand-apriorising/axiomatising/referencing'-entailing>-existentialising-framing/imprinting-〈asto-prospective- historiality/ontological-eventfulness /ontological-aesthetic-tracing$<$ perspective-ontological-normalcy/postconvergence-reflected-'epistemicity-relativismdeterminism'>l), so-reflected in human Being-development/ontological-framework-expansionas-to-depth-of-ontologising-development-as-infrastructure-of- meaningfulness-andteleology , institutional-development-as-to-social-function-development and livingdevelopment-as-to-personality-development psychologismic epistemic acutisationdifficulty < for, residualising \{decompulsing $\}$ delinearity for-cogeney> magnitudes $\{0$ experientiality/experiment\}. This analysis (as to fundamental human existentialising — anxiety-imbuedbeholdening-inducing, $-<$ preconverging 'motif-and-apriorising/axiomatising/referencing'entailing >-existentialising — enframing/imprintedness-〈as-to- historicity-tracing — inpresencing-hyperrealisation/hyperreal-transposition)) brings out the fundamental reason for human 'discrete inherence of sublimating/desublimating - modalisation-<as-to-absolutereferencing-of- ${ }^{5}$ meaningfulness-and-teleology 9 on the basis of ${ }^{79}$ presencing-absolutisingidentitive-constitutedness $^{14}$ social-vestedness/normativity- $<$ discretely-implied-functionalism $>$ inducing of subontologisation/subpotentiation' (in an absolutising <preconverging 'motif-andapriorising/axiomatising/referencing'-entailing>-existentialising — enframing/imprintedness〈as-to- historicity-tracing-in-presencing-hyperrealisation/hyperreal-transposition〉) as soassociated with the 'lesser-renewal/aversity-to-profound-renewal of <postconverging 'motifand-apriorising/axiomatising/referencing'-entailing>-existentialising-framing/imprinting-〈asto-prospective- historiality/ontological-eventfulness /ontological-aesthetic-tracing- 
<perspective-ontological-normalcy/postconvergence-reflected-'epistemicity-relativismdeterminism'>l' with regards to Being-development/ontological-framework-expansion-as-todepth-of-ontologising-development-as-infrastructure-of- meaningfulness-and-teleology (soassociated with the relative perennity of human language, cultures, institutions, etc. but rather relatively renewed as of cultural-diffusion); and so notwithstanding the ontological-veracity of the ontological-normalcy/postconvergence nature of existence rather misconstrued in epistemicabnormalcy/preconvergence ${ }^{3}$ due to human limited-mentation-capacity-as-subjecting'educed-unlimitedness/existence-sublimating nascence' to-limitedness/human-subpotency for projection/reprojection. Consequently, besides the genuine social intellectual-function/posture as to absolute firstnatureness aspiration for ontologisation/omnipotentiality as postconvergingde-mentating/structuring/paradigming the possibility for prospective human transcendence-andsublimity/sublimation/supererogatory-de-mentativity, in-many-ways throughout history, human secondnaturedness relation to such an ontologising/omnipotential aspiration (as to incrementalism-in-relative-ontological-incompleteness ${ }^{88}$

enframed/disontologising conceptualisation associated with human dominion/statal-logic〈preconverging/shallow-supererogating-'human-and-social-expectations/anticipations- dementating/structuring/paradigming-psychologism'-as-to-its-specific-collateralisingbeholdening- $<$ whether-trepidatious-or-warped-or-preclusive-or-occlusive $>$-and-itsconsociated-dominance/vested-interest-subontologising-skewed-influence-as-to-socialvestedness/normativity- $<$ discretely-implied-functionalism $>\rangle$, pedantic ${ }^{51}$ incrementalism-inrelative-ontological-incompleteness ${ }^{8}$ —enframed/disontologising $\sim$ conceptualisation and $<$ amplituding/formative $>$ wooden-language-〈imbued-temporal-mereform/virtualities/dereification/akrasiatic-drag/denatured/preconverging-or-dementing narratives - of-the- reference-of-thought- categorical-imperatives/axioms/registryteleology >) rather speaks to a positive-opportunism—of-social-functioning-and-accordance 
conception of human transcendence-and-sublimity/sublimation/supererogatory-de-mentativity (herein construed as unsustainable for the possibility for prospective ${ }^{18}$ deprocrypticism-orpreempting - disjointedness-as-of- ${ }^{-3}$ reference-of-thought registry-worldview/dimension). Ultimately, such a 'discrete inherence of sublimating/desublimating-modalisation- $<$ as-toabsolute-referencing-of- ${ }^{5}$ meaningfulness-and-teleology $>$ on the basis of ${ }^{79}$ presencingabsolutising-identitive-constitutedness ${ }^{14} \quad$ social-vestedness/normativity- $<$ discretely-impliedfunctionalism $>$ inducing of subontologisation/subpotentiation' cannot-see/is-blinded-to-seeing the human-subpotency 'fatedness-of-sublimation-over-desublimation to existencepotency $\sim$ sublimating-nascence,-disclosed-from-prospective-epistemic-digression in reflecting holographically-<conjugatively-and-transfusively $>$ the relative-unreflexivity/relativereflexivity - ontological-contiguity of-the-human-institutionalisation-process ${ }^{\prime}$ (as to an ontological-bad-faith/inauthenticity $\sim$ preconverging-de-mentating/structuring/paradigming that is unaddressable as of a pretense of knowledge-reification $\sim$ gesturing-and-accounting — ofepistemic-phenomenalism-<in-

prospective_psychologismic apriorising/axiomatising/referencing-\{of- ${ }^{\text {prospectively_ }}$ implicited_attendant-ontological-contiguity ' educedexistentialising/contextrising/textring_intelligibility/epistemicity/reflexivity-contiguity$<$ imbued-notional cogency $>\quad\}$-conflatedness -in-\{preconverging -ment by\} postconverging-entailment> exercise of mutual logical-basis/logic,-as-derivedfrom $\sim$ transversality-<for-sublimating-existential-eventuating/denouement,-from-'thinking-atfirst/pure-predisposition - preemptive-of prospective-disontologising/subontologising' as-ofprospectively-disambiguated-affirmed-and-unaffirmed-'motif-andapriorising/axiomatising/referencing' ${ }^{101}$ ). Given the fact that any ${ }^{79}$ presencing-absolutisingidentitive-constitutedness ${ }^{14}$ imbued $\quad<$ amplituding/formative $>$ disposedness/psychologismicconstruct-〈as-to-orientation/value-construct/valuation-and-derived-parameterising $\quad$ and 
$<$ amplituding/formative >entailment-〈as-to-totalising-contiguous/coherent-factuality-of-

variability $\rangle$ ' is of a 'punctual <amplituding/formative-epistemicity $>$ totalising $\sim$ self-referencingsyncretising/circularity/interiorising/akrasiatic-drag 34 rather measuring-up success/accomplishment/aspiration in shallow-supererogation of manifest in-effect absolution$<$ as-to-apriorising/axiomatising/referencing-\{of-'prospectively implicited_attendantontological-contiguity ' educedexistentialising/contextualising/textualising_'intelligibility/epistemicity/reflexivity-contiguity$<$ imbued-notional cogency $>$ ' $\}$-constitutedness -in preconverging-entailment $>$ as to the given registry-worldview/dimension $\quad<$ preconverging 'motif-andapriorising/axiomatising/referencing'-entailing >-existentialising —enframing/imprintedness〈as-to- historicity-tracing - in-presencing-hyperrealisation/hyperreal-transposition〉' (which is prospectively in relative-ontological-incompleteness ${ }^{88}$-presublimation-construct-ofmeaningfulness-and-teleology $\quad$ desublimating $\sim$ existentialising-decisionality-<as-todisontologising/re-ontologising aporeticism $>$, and so as from blatant brutish conquest/subjugation conception associated with 'measuring-up success/accomplishment/aspiration in its warring/bellicosity shallow-supererogation of manifest in-effect absolution-<as-to-apriorising/axiomatising/referencing-\{of-"prospectively implicited_attendant-ontological-contiguity ' educedexistentialising/contextmalising/textualising_'intelligibility/epistemicity/reflexivity_contiguity$<$ imbued-notional cogency $>$ ' $\}$-constitutedness -in preconverging-entailment>>, dominion protection conception associated with 'measuring-up success/accomplishment/aspiration in its paramountcy shallow-supererogation of manifest in-effect absolution-<as-toapriorising/axiomatising/referencing-\{of-'prospectively_implicited_attendant-ontologicalcontiguity ' educedexistentialising/contextualising/textualising_'intelligibility/epistemicity/reflexivity-contiguity- 
$<$ imbued-notional cogency >' $\}$-constitutedness -in-preconverging-entailment>>', to the very natural-order-of-things conception associated with 'measuring-up success/accomplishment/aspiration in its patricianism/aristocratism shallow-supererogation ${ }^{6}$ of manifest in-effect absolution-<as-to-apriorising/axiomatising/referencing-\{of-"prospectively implicited_attendant-ontological-contiguity ' educedexistentialising/contextualising/textualising_ 'intelligibility/epistemicity/reflexivity-contiguity$<$ imbued-notional cogency $>$ ' $\quad\}$-constitutedness -in preconverging-entailment $>$ ' and to our subtle modern-day institutionally-distorted/disjointed conception associated with 'measuring-up success/accomplishment/aspiration in its presencing-institutional-and-economic shallowsupererogation of manifest in-effect absolution-<as-to-apriorising/axiomatising/referencing\{of-'prospectively_implicited_attendant-ontological-contiguity ' reducedexistentialising/contextmalising/textualising_intelligibility/epistemicity/reflexivity_contiguity<imbued-notional cogency >' $\}$-constitutedness -in-preconverging-entailment>>') all manifesting existentialising — anxiety-imbued-beholdening-inducing, $-<$ preconverging $\sim$ 'motifand-apriorising/axiomatising/referencing'-entailing--existentialisingenframing/imprintedness-〈as-to- historicity-tracing - in-presencinghyperrealisation/hyperreal-transposition〉 bound to fail 'human sublimating/desublimatingmodalisation- $<$ as-to-absolute-referencing-of- $-{ }^{56}$ meaningfulness-and-teleology $>$ upon inherent existence's sublimating-nascence inducing of ontologisation/omnipotentiality'; and so by the mere token that on the basis of the punctual <amplituding/formativeepistemicity>totalising $\sim$ self-referencing-syncretising/circularity/interiorising/akrasiatic-drag of each of the above ${ }^{7}$ presencing-absolutising-identitive-constitutedness ${ }^{14}$ imbued ‘<amplituding/formative $>$ disposedness/psychologismic-construct-〈as-to-orientation/valueconstruct/valuation-and-derived-parameterising $\rangle$ and <amplituding/formative $>$ entailment-〈asto-totalising-contiguous/coherent-factuality-of-variability)' the possibility for the relative- 
unreflexivity/relative-reflexivity — ontological-contiguity ${ }^{67}$ of-the-human-institutionalisationprocess ${ }^{6}$ cannot be explained as to the fact that their punctual <amplituding/formativeepistemicity $>$ totalising $\sim$ self-referencing-syncretising/circularity/interiorising/akrasiatic-drag will warrant the world to preconverging/postconverging-dementatively/structurally/paradigmatically remain the same perpetually as to their 'discrete inherence of sublimating/desublimating - modalisation- $<$ as-to-absolute-referencing-ofmeaningfulness-and-teleology ${ }^{9}>$ on the basis of ${ }^{79}$ presencing-absolutising-identitiveconstitutedness ${ }^{14}$ social-vestedness/normativity- $<$ discretely-implied-functionalism $>$ inducing of subontologisation/subpotentiation' (as so-reflected by the fact that there is no logicalbasis/logic,-as-derived-from $\sim$ transversality-<for-sublimating-existentialeventuating/denouement,-from-'thinking-at-first/pure-predisposition-preemptive-ofprospective-disontologising/subontologising' as-of-prospectively-disambiguated-affirmedand-unaffirmed-'motif-and-apriorising/axiomatising/referencing' $>{ }^{01}$ inherent to any relativeontological-incompleteness 8 registry-worldview/dimension validating its prospectively projected relative-ontological-completeness ${ }^{87}$ registry-worldview/dimension but rather an 'aporeticism-overcoming/unovercoming supererogating ontological-performance ${ }^{72}<$ including-

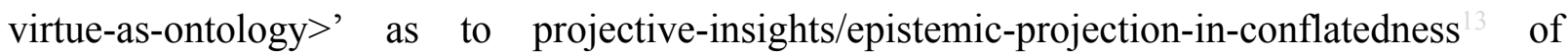
apriorising/axiomatising/referencing with regards to underlying/organising 'relativeontological-incompleteness $8 /$ relative-ontological-completeness ${ }^{87}$ 〈sublimating $\sim$ referencing/registering/decisioning,-as-self-becoming/selfconflatedness /formative-supererogating-<projective/reprojective-aestheticising-re-motifand-re-apriorising/re-axiomatising/re-referencing,-in-perspective-ontologicalnormalcy/postconvergence $>>$ as to human-and-social-expectations/anticipationsmetaphoricity ${ }^{57}$-as-preconverging/postconverging-redementating/restructuring/reparadigming-psychologism' ${ }^{89}$, and so-reflected in the successive 
foregrounding_entailment- $<$ in-succession-of-profound-supererogation $>_{-}-\langle$postconverging narrowing-down $\sim$ sublimation-as-to-'existence - as-sublimating-withdrawal/unenframing/reontologising,-elicited-from-prospective-profound-supererogation ' '-in-reflecting‘immanent relative-unreflexivity/relative-reflexivity - ontological-contiguity ';-as-operativenotional deprocrypticism) as from non-rules - apriorising/axiomatising/referencingpsychologism of recurrent-utter-uninstitutionalisation, rulemaking-over-non-rulesapriorising/axiomatising/referencing-psychologism of base-institutionalisationununiversalisation, $\quad{ }^{103}$ universalisation-directed-rulemaking-over-non-rulesapriorising/axiomatising/referencing-psychologism of $\quad{ }^{103}$ universalisation-nonpositivism/medievalism, positivising/rational-empiricism-based-universalisation-directedrulemaking-over-non-rules_-apriorising/axiomatising/referencing-psychologism of positivism- ${ }^{80}$ procrypticism and preempting-disjointedness-as-of- ${ }^{3}$ reference-of-thought,-asto- ${ }^{3}<$ amplituding/formative-epistemicity $>$ growth-or-conflatedness ${ }^{13} /$ transvaluative- $^{2}$ rationalising/transepistemicity/anamnestic-residuality/spirit-drivenness'_-in-supersedingmere-formulaic-positivising/rational-empiricism-based-universalisation-directed-rulemakingover-non-rules - apriorising/axiomatising/referencing-psychologism of deprocrypticism-orpreempting-disjointedness-as-of- ${ }^{3}$ reference-of-thought). Such a logical-basis/logic underlying the relative-unreflexivity/relative-reflexivity ontological-contiguity $\sim$ of-thehuman-institutionalisation-process ${ }^{68}$ can only be explained by the genuine social intellectualfunction/posture allowing sublimation-over-desublimation as so-upheld throughout human history (as reflected by the Socrates, Copernicuses, Galileos, Descartes, Kants, Newtons, Leibniz, Rousseaux, Diderots, Pasteurs, Lavoisiers, Teslas, Einsteins, etc.), speaks to the epistemic-projection reflection of the ontological-normalcy/postconvergence of existence as to existence - as-sublimating-withdrawal/unenframing/re-ontologising,-elicited-fromprospective-profound-supererogation underlying human limited-mentation-capacity- 
deepening —as-subjecting limitedness/human-subpotency to-'educed-unlimitedness/existencesublimating nascence' ; with the implication that the crassness of 'supposed reified thoughts projecting our procrypticism/disjointedness-as-of- reference-of-thought' as to our 'occlusive discrete inherence of sublimating/desublimating — modalisation- $<$ as-to-absolute-referencingof- ${ }^{56}$ meaningfulness-and-teleology $>$ on the basis of ${ }^{79}$ presencing-absolutising-identitiveconstitutedness ${ }^{14}$ social-vestedness/normativity- $<$ discretely-implied-functionalism $>$ inducing of subontologisation/subpotentiation' is in-many-ways just reflecting holographically$<$ conjugatively-and-transfusively $>$ the relative-unreflexivity/relative-reflexivity - ontologicalcontiguity $\sim$ of-the-human-institutionalisation-process as to the crassness of "supposed reified thoughts projecting the notional procrypticism/notional $\sim$ disjointedness-as-of- ${ }^{3}$ reference-ofthought' of the <cumulating/recomposuring attendant-ontological-contiguity $>$-successive registry-worldviews/dimensions given human limited-mentation-capacity-as-subjecting'educed-unlimitedness/existence-sublimating nascence' to-limitedness/human-subpotency uninstitutionalised-threshold ${ }^{102}$ as associated with recurrent-utter-uninstitutionalisation crassness-of-thoughts, base-institutionalisation-ununiversalisation crassness-of-thoughts, universalisation-non-positivism/medievalism crassness-of-thoughts, and our positivismprocrypticism crassness-of-thoughts in $\quad 79$ presencing-absolutising-identitiveconstitutedness ${ }^{14}$. That the genuine social intellectual-function/posture as to its implied 'human sublimating/desublimating — modalisation- $<$ as-to-absolute-referencing-of- $-{ }^{56}$ meaningfulnessand-teleology $>$ upon inherent existence's sublimating-nascence inducing of ontologisation/omnipotentiality' in-so-de-mentating/structuring/paradigming-out the relativeunreflexivity/relative-reflexivity — ontological-contiguity ${ }^{67}$ of-the-human-institutionalisationprocess ${ }^{68}$ with human limited-mentation-capacity-deepening as limitedness/human-subpotency-to-'educed-unlimitedness/existence-sublimating nascence' 53 is the ontologically-veridical basis for human sublimation-over-desublimation, is validated by the 
fact that once prospective relative-ontological-completeness ${ }^{87}$ avails (as to 'overall interceding human-and-social-expectations/anticipations - metaphoricity ${ }^{57}$-as-

preconverging/postconverging-rede-mentating/restructuring/reparadigming-psychologism

<postconverging 'motif-and-apriorising/axiomatising/referencing'-entailing >-

existentialising - framing/imprinting-〈as-to-prospective- historiality/ontological-

eventfulness /ontological-aesthetic-tracing-<perspective-ontological-

normalcy/postconvergence-reflected-‘epistemicity-relativism-determinism' $>>$ of ordered human firstnatureness-deferentialism-imbuing and secondnaturedness-deferentialism-deriving as of underlying human ontological-commitment $-<$ implied - self-assuredness-of-ontologicalgood-faith/authenticity $\sim$ postconverging-de-mentating/structuring/paradigming -as-being-

as-of-existential-reality> as to existence-as-sublimating-withdrawal/unenframing/reontologising,-elicited-from-prospective-profound-supererogation') all such prospectively institutionalised registry-worldviews/dimensions come to reject the prior uninstitutionalisedthreshold ${ }^{02}$ crassness-of-thoughts as of 'supposed reified thoughts projecting their notional procrypticism/notional disjointedness-as-of- ${ }^{3}$ reference-of-thought' as to their 'discrete inherence of sublimating/desublimating - modalisation- $<$ as-to-absolute-referencingof- ${ }^{5}$ meaningfulness-and-teleology $>$ on the basis of ${ }^{79}$ presencing-absolutising-identitiveconstitutedness ${ }^{14}$ social-vestedness/normativity- $<$ discretely-implied-functionalism $>$ inducing of subontologisation/subpotentiation'; and rather falling back to the prior uninstitutionalisedthreshold ${ }^{102}$ genuine social intellectual-function/posture as it provides ${ }^{56}$ meaningfulness-andteleology infrastructure reflected as Being-development/ontological-framework-expansionas-to-depth-of-ontologising-development-as-infrastructure-of- meaningfulness-and-

teleology for the given institutionalised registry-worldview/dimension to even have the possibility to exist (explaining why the Socrates, Copernicuses, Galileos, Descartes, Kants, Newtons, Leibniz, Rousseaux, Diderots, Pasteurs, Lavoisiers, Teslas, Einsteins, etc. as to their 
<postconverging 'motif-and-apriorising/axiomatising/referencing'-entailing >-

existentialising — framing/imprinting-〈as-to-prospective- historiality/ontological-

eventfulness /ontological-aesthetic-tracing-<perspective-ontological-

normalcy/postconvergence-reflected-‘epistemicity-relativism-determinism' $>>$ outlived their eras uninstitutionalised-threshold ${ }^{02}$ 'crassness-of-thoughts $\quad<$ preconverging 'motif-andapriorising/axiomatising/referencing'-entailing >-existentialising-enframing/imprintedness-

〈as-to- historicity-tracing-in-presencing-hyperrealisation/hyperreal-transposition〉' with the same sublimation-over-desublimation consequence availing prospectively as to the requisite prospective ${ }^{18}$ deprocrypticism-or-preempting - disjointedness-as-of- ${ }^{8}$ reference-of-thought 'human sublimating/desublimating — modalisation- $<$ as-to-absolute-referencing-ofmeaningfulness-and-teleology ${ }^{9}>$ upon inherent existence's sublimating-nascence inducing of ontologisation/omnipotentiality'). Critically, it is the opening-up of prospective registryworldviews/dimensions by the genuine social intellectual-function/posture in 'relativeontological-incompleteness $8 /$ relative-ontological-completeness ${ }^{87}$ -

\section{〈sublimating referencing/registering/decisioning,-as-self-becoming/self-}

conflatedness /formative-supererogating-<projective/reprojective-aestheticising-re-motifand-re-apriorising/re-axiomatising/re-referencing,-in-perspective-ontologicalnormalcy/postconvergence $>>$ as to human-and-social-expectations/anticipationsmetaphoricity ${ }^{57}$-as-preconverging/postconverging-rede-

mentating/restructuring/reparadigming-psychologism' ${ }^{89}$ (underlied by dimensionality-ofsublimating $25-<$ amplituding/formative $>$ supererogatory $\sim$ de-mentativeness/epistemic-growthor-conflatedness /transvaluative-rationalising/transepistemicity/anamnestic-residuality/spiritdrivenness-equalisation) ) that enables the secondnatured positive-opportunism-of-socialfunctioning-and-accordance ${ }^{75} \quad$ of $\quad$ punctual $\quad$ amplituding/formativeepistemicity $>$ totalising $\sim$ self-referencing-syncretising/circularity/interiorising/akrasiatic-drag 
rather measuring-up success/accomplishment/aspiration in shallow-supererogation ${ }^{6}$ of manifest in-effect absolution-<as-to-apriorising/axiomatising/referencing-\{of-'prospectively implicited_attendant-ontological-contiguity ' educedexistentialising/contextualising/textualising_'intelligibility/epistemicity/reflexivity_contiguity$<$ imbued-notional cogency $>$ ' $\}$-constitutedness -in preconverging-entailment $>$ as to the given registry-worldview/dimension $\quad<$ preconverging 'motif-andapriorising/axiomatising/referencing'-entailing>-existentialising-enframing/imprintedness〈as-to- historicity-tracing-in-presencing-hyperrealisation/hyperreal-transposition〉' (prospectively projecting dimensionality-of-desublimating-lack-of ${ }^{-}$<<amplituding/formative >supererogatory $\sim$ de-mentativeness/epistemic-growth-orconflatedness /transvaluative-rationalising/transepistemicity/anamnestic-residuality/spiritdrivenness-equalisation)) to arise in-the-very-first-place; speaking to the incongruity of then implying the relegating of the genuine social intellectual-function/posture as to the social-stakecontention-or-confliction manifested in the <cumulating/recomposuring attendant-ontologicalcontiguity >-successive registry-worldviews/dimensions of 'punctual <amplituding/formativeepistemicity $>$ totalising $\sim$ self-referencing-syncretising/circularity/interiorising/akrasiatic-drag rather measuring-up success/accomplishment/aspiration in shallow-supererogation ${ }^{6}$ of manifest in-effect absolution-<as-to-apriorising/axiomatising/referencing-\{of-"prospectively implicited_attendant-ontological-contiguity ' educedexistentialising/contextualising/textualising_'intelligibility/epistemicity/reflexivity-contiguity<imbued-notional cogency $>$ ' $\quad\}$ - constitutedness -in preconverging-entailment>'. The reason for this genuine social intellectual-function/posture pre-eminence in human sublimationover-sublimation has to do with the nonpresencing-<perspective-ontologicalnormalcy/postconvergence $>$ nature of inherent existence (explaining the centrality of metaphysics-of-presence-〈implicited-'nondescript/ignorable-void ' 'as-to- presencing- 
absolutising-identitive-constitutedness $\rangle$ in all thought aspiring for the momentousness of sublimating historiality/ontological-eventfulness 38 /ontological-aesthetic-tracing$<$ perspective-ontological-normalcy/postconvergence-reflected-'epistemicity-relativismdeterminism'> over desublimating $\quad{ }^{4}$ historicity-tracing-in-presencinghyperrealisation/hyperreal-transposition), so because the 'epistemic particularity of humansubpotency is limited-mentation-capacity-as-subjecting 'educed-unlimitedness/existencesublimating nascence' to-limitedness/human-subpotency' and veridical sublimation-overdesublimation ${ }^{56}$ meaningfulness-and-teleology ${ }^{9}$ only avails with human limited-mentationcapacity-deepening —as-subjecting limitedness/human-subpotency-to-'educedunlimitedness/existence-sublimating nascence' ${ }^{53}$ explaining the need for ‘ $<$ amplituding/formative-epistemicity $>$-totalising $\sim$ renewing-realisation/re-perception/rethought,-in-supererogatory epistemic-conflatedness $^{13}$ in re-originariness/re-origination' as most profound in the construal of existence as to its sublimation-over-desublimation (and so as the epistemic-projection perspectives of relative profound-supererogation is 'not of desublimating $\sim$ referenced/registered/decisioned $\quad$ self-presence/self-constitutedness ${ }^{14}-<$ inperspective-epistemic-abnormalcy/preconvergence ${ }^{3}>$ but 'of sublimating $\sim$ referencing/registering/decisioning self-becoming/self-conflatedness 13 /formativesupererogating-<projective/reprojective - aestheticising-re-motif-and-re-apriorising/reaxiomatising/re-referencing,-in-perspective-ontological-normalcy/postconvergence $>$ ). While the positive-opportunism-of-social-functioning-and-accordance ${ }^{75}$ underlying human secondnaturedness in-many-ways undermines prospective firstnatureness (as to the prospective 'human sublimating/desublimating — modalisation- $<$ as-to-absolute-referencing-ofmeaningfulness-and-teleology ${ }^{9}>$ upon inherent existence's sublimating-nascence inducing of ontologisation/omnipotentiality') associated with the genuine social intellectualfunction/posture, as exposing the latter ${ }^{5}$ meaningfulness-and-teleology ${ }^{9}$ to pedantic 
incrementalism-in-relative-ontological-incompleteness ${ }^{8}$

enframed/disontologising conceptualisation as well as generalised

$<$ amplituding/formative $>$ wooden-language-〈imbued-temporal-mere-

form/virtualities/dereification/akrasiatic-drag/denatured/preconverging-or-dementing

narratives - of-the- reference-of-thought- categorical-imperatives/axioms/registry-

teleology > both underlied by dominion/statal-logic-〈preconverging/shallow-supererogating-

‘human-and-social-expectations/anticipations_-de-mentating/structuring/paradigming-

psychologism'-as-to-its-specific-collateralising-beholdening-<whether-trepidatious-or-

warped-or-preclusive-or-occlusive $>$-and-its-consociated-dominance/vested-interest-

subontologising-skewed-influence-as-to-social-vestedness/normativity- $<$ discretely-implied-

functionalism $>$, the fact is somehow/someway the genuine social intellectual-function/posture have been able to drive human prospective sublimation-over-desublimation as to the fact that the human sovereign-function/posture-<as-to-existentially-manifest-‘embodiedsubject consciousness-and-direct/deferential-conscientiousness',-as-of-its- 'epistemicreflexivity/unreflexivity-in-existence'/teleology> is very much conscious of the social-stakecontention-or-confliction postconverging aporeticism-overcoming/unovercoming masked/avoided/ignored/deflated by pedantic manipulation as well as the fundamental human ontological-commitment $\quad<$ implied_-self-assuredness-of-ontological-goodfaith/authenticity postconverging-de-mentating/structuring/paradigming -as-being-as-ofexistential-reality> of all human ${ }^{56}$ meaningfulness-and-teleology ${ }^{9}$ as to prospective sublimation-over-desublimation (so-implied with the self-assuredness-of-ontological-goodfaith/authenticity ${ }^{6} \sim$ postconverging-de-mentating/structuring/paradigming 7 -as-being-as-ofexistential-reality with respect to social-stake-contention-or-confliction underlying human ontological-commitment $\quad<$ implied_-self-assuredness-of-ontological-goodfaith/authenticity postconverging-de-mentating/structuring/paradigming -as-being-as-of- 
existential-reality >) with both enabling the genuine social intellectual-function/posture to thrive eventually; as sublimating-nascence associated with 'nascent-particular/incipient-andmaterial/technical-sublimations-<blinded-to-their-relative-ontological-completeness reference-of-thought- devolving $>\quad$ sublimating $\sim$ existentialising-decisionality-<as-todisontologising/re-ontologising aporeticism $>$ (however the devolved/devoluted-referencingnarrowness with respect to overall social-and-institutional-frameworks-ofreferencing/registering/decisioning existentialising-decisionality-<as-to-disontologising/reentologising aporeticism $>$ )' ultimately translates into requisite ' reference-of-thought- devolving- ${ }^{5}$ meaningfulness-and-teleology ${ }^{9}$ comprehensiveness of prospective sublimating-nascence (over relative-ontological-incompleteness ${ }^{88}$-presublimationconstruct-of- ${ }^{-5}$ meaningfulness-and-teleology ${ }^{9}$ ) as to overall social-and-institutionalframeworks-of—referencing/registering/decisioning sublimating existentialisingdecisionality-<as-to-disontologising/re-ontologising aporeticism>' in preserving 'human sublimating/desublimating - modalisation- $<$ as-to-absolute-referencing-of $-{ }^{56}$ meaningfulnessand-teleology $>$ upon inherent existence's sublimating-nascence inducing of ontologisation/omnipotentiality' (as to the projective/reprojective regenerativity of human meaningfulness-and-teleology ${ }^{99}$ in relative-ontological-completeness ${ }^{87}$ operantly associated with prospective human aestheticising - ${ }^{7}$ surrealising/supererogating-drive for <postconverging 'motif-and-apriorising/axiomatising/referencing'-entailing >existentialising - framing/imprinting-〈as-to-prospective-- historiality/ontologicaleventfulness /ontological-aesthetic-tracing-<perspective-ontologicalnormalcy/postconvergence-reflected-‘epistemicity-relativism-determinism'>> imbued interlay/organicalism/aestheticising-handle-<of-'psychologismic-transfixity $\{$ residualising \{decompulsing delinearity over-nonresidualising fompusing $\}$ linearity\}' $>-\{$ imbuedsupererogatory projective-arbitrariness/waywardness- 
of $\sim$ transversalisation/tandemisation/abstractive-conjugation/perspectivation/depthing — for'aestheticising-re-margining/re-edging/re-acuity—aspostconverging_circumscriptive/totalitative-restructuring'\} - educingsublimation/desublimation> totalising ${ }^{3}$ hermeneutically/textually/reprojectingly/supererogatingly/zeroingly/re-acutingly,\{decompulsing $\}$ delinearity for-cogency-imbuing 'supereregatory $\sim$ acuity/perspicacity/astuteness/edginess/incisiveness $\sim$ differential ontologicalperformance ${ }^{2}-<$ including-virtue-as-ontology $>$ /potentiation' for prospective human postconverging-aporeticism-overcoming/unovercoming in reconstrual of '<amplituding/formative-epistemicity $>$-totalising $\sim$ thrownness-in-existence ${ }^{35}$ as to reaesthetheticising/re-motif- $<$ in-postconverging-narrowing-down $\sim$ 'sublimation-of-taste- \{epistemictotalising 3 ’ hermeneutically/textually/reprojectingly/supererogatingly/zeroingly/re-acutingly,$\{$ decompulsing\} delinearity for-cogency-educing-conceptivity/epistemic-reflexivity/epistemicityrelativism-determinism-<reifying \{as-to-knowledge-developing $\}$-and-empowering $>$-ofhistoriality/ontological-eventfulness /ontological-aestheticising-tracing',-as-to-existenceas-sublimating-withdrawal/unenframing/re-ontologising,-elicited-from-prospective-profoundsupererogation $>$ and re-procession/re-automatism-_as-to-re-_e-apriorising/re-_e-axiomatising/rereferencing-<in-postconverging-narrowing-down 'sublimation-ofapriorising/axiomatising/referencing_\{epistemicthermeneutically/textully/reprojectingly/supererogatingly/zeroingly/re-acutingly,\{decompling $d$ delinearity for-cogency-educing-conceptivity/emic-reflexivity/epistemicityrelativism-determinism-<reifying \{as-to-knowledge-developing $\}$-and-empowering $>$-ofhistoriality/ontological-eventfulness /ontological-aestheticising-tracing',-as-to-existenceas-sublimating-withdrawal/unenframing/re-ontologising,-elicited-from-prospective-profoundsupererogation $>$ ). Critically, the 'punctual <amplituding/formative- 
epistemicity $>$ totalising $\sim$ self-referencing-syncretising/circularity/interiorising/akrasiatic-drag rather measuring-up success/accomplishment/aspiration in shallow-supererogation ${ }^{6}$ of manifest in-effect absolution-<as-to-apriorising/axiomatising/referencing-\{of-‘prospectively_ implicited_attendant-ontological-contiguity ' educedexistentialising/contextualising/textualising_ 'intelligibility/epistemicity/reflexivity-contiguity$<$ imbued-notional cogency $>$ ' $\quad\}$-constitutedness -in preconverging-entailment $>$ as to the given $\quad$ registry-worldview/dimension $<$ preconverging $\sim$ 'motif-andapriorising/axiomatising/referencing'-entailing >-existentialising-enframing/imprintedness〈as-to- historicity-tracing - in-presencing-hyperrealisation/hyperreal-transposition〉 $\quad$ is involved in a prospectively desublimating ontological-performance ${ }^{72}-$ including-virtue-as- $^{2}$ ontology $>$ /morality/ethics/justice/etc. that confuses its " presencing-absolutising-identitiveconstitutedness social-vestedness/normativity-<discretely-implied-functionalism $>$ <preconverging 'motif-and-apriorising/axiomatising/referencing'-entailing >existentialising — enframing/imprintedness-〈as-to- historicity-tracing_-in-presencinghyperrealisation/hyperreal-transposition> ontologically-flawed construal of totalising-entailing' with the 'prospective nonpresencing-<perspective-ontological-normalcy/postconvergence $>$ <postconverging 'motif-and-apriorising/axiomatising/referencing'-entailing >existentialising - framing/imprinting-〈as-to-prospective- historiality/ontologicaleventfulness /ontological-aesthetic-tracing-<perspective-ontologicalnormalcy/postconvergence-reflected-‘epistemicity-relativism-determinism'>> ontologicallyveridical construal of entailing-<amplituding/formative-epistemicity>totalising in-relativeontological-completeness $^{87}$ implications', and critically-so as human thermeneutically/textually/reprojectingly/supererogatingly/zeroingly/re-acutingly,\{decompulsing $\}$ delinearity for-cogency-educing 'reframing/reimprinting of $<$ postconverging 'motif-and-apriorising/axiomatising/referencing'-entailing $>$ - 
existentialising_framing/imprinting-〈as-to-prospective- historiality/ontological-

eventfulness /ontological-aesthetic-tracing-<perspective-ontological-

normalcy/postconvergence-reflected-‘epistemicity-relativism-determinism'>)' (involving 'existentially-decontextualised play/gaming/exercising of <postconverging 'motif-andapriorising/axiomatising/referencing'-entailing>-existentialising_framing/imprinting-〈as-toprospective- historiality/ontological-eventfulness /ontological-aesthetic-tracing$<$ perspective-ontological-normalcy/postconvergence-reflected-'epistemicity-relativismdeterminism' $>>$ projected sublimating ontological-performance ${ }^{72}-<$ including-virtue-asontology $>$ /morality/ethics/justice/etc. of ${ }^{56}$ meaningfulness-and-teleology ${ }^{9}$ together with 'effective existentially-contextualised instantiation/actualisation of <postconverging 'motifand-apriorising/axiomatising/referencing'-entailing >-existentialising-framing/imprinting-〈asto-prospective- historiality/ontological-eventfulness /ontological-aesthetic-tracing<perspective-ontological-normalcy/postconvergence-reflected-‘epistemicity-relativismdeterminism'>> projected sublimating-over-desublimating ontological-performance ${ }^{72}$ $<$ including-virtue-as-ontology $>$ /morality/ethics/justice/etc. of $\quad{ }^{5}$ meaningfulness-andteleology ${ }^{9}$, as to their separate-and-intermingling manifestation in <postconverging ' motifand-apriorising/axiomatising/referencing'-entailing >-existentialising_-framing/imprinting-〈asto-prospective- historiality/ontological-eventfulness /ontological-aesthetic-tracing$<$ perspective-ontological-normalcy/postconvergence-reflected-'epistemicity-relativismdeterminism' $>>$ as so-reflected in human Being-development/ontological-frameworkexpansion-as-to-depth-of-ontologising-development-as-infrastructure-of- meaningfulnessand-teleology , institutional-development-as-to-social-function-development and livingdevelopment-as-to-personality-development psychologismic epistemic-acutisation difficulty < for, residualising_\{decompulsing $\}$ delinearity for-cogeney> magnitudes $\{$ ofexperientiality/experiment\}) is desublimatingly $\sim$ referenced/registered/decisioned in the self- 
presence/self-constitutedness $^{14}-<$ in-perspective-epistemic-abnormalcy/preconvergence ${ }^{3}>$ of the relative-ontological-incompleteness ${ }^{8}$ - presublimation-construct-of- ${ }^{5}$ meaningfulness-andteleology ${ }^{9} \quad$ desublimating $\sim$ existentialising-decisionality-<as-to-disontologising/reentologising aporeticism $>$ as to social-and-institutional-frameworks-ofreferencing/registering/decisioning existentialising-decisionality-<as-to-disontologising/reentologising aporeticism $>$ prone to ${ }^{79}$ presencing-absolutising-identitive-constitutedness (as to the underlying mere-formulaicity/ritualisation-<as-to-mere-formulaicmethodologising/mutualising/organising/institutionalising,-prospectively-losing-track-of‘fepistemic-alising ’’re-apriorising/re-axiomatising/re-referencing - residuality-in-reoriginariness/re-origination'> of secondnatured reproducibility—mathesis/motif/thrownnessdisposition,--as-reproducibility-of-aestheticisation undermining prospective human-and-socialexpectations/anticipations - metaphoricity ${ }^{57}$-as-preconverging/postconverging-redementating/restructuring/reparadigming-psychologism). This fundamental disparateness between $\quad<$ preconverging 'motif-and-apriorising/axiomatising/referencing'-entailing $>$ existentialising — enframing/imprintedness-〈as-to- historicity-tracing_-in-presencinghyperrealisation/hyperreal-transposition〉 ontologically-flawed construal of totalising-entailing' and ‘<postconverging 'motif-and-apriorising/axiomatising/referencing'-entailing > existentialising - framing/imprinting-〈as-to-prospective- historiality/ontologicaleventfulness /ontological-aesthetic-tracing-<perspective-ontologicalnormalcy/postconvergence-reflected-‘epistemicity-relativism-determinism'>> ontologicallyveridical construal of entailing-<amplituding/formative-epistemicity>totalising in-relativeontological-completeness ${ }^{87}$ implications' is what effectively underlies the 'notional asceticism for originariness-parrhesia,-as-spontaneity-of-aestheticisationsupererogatory acuity/perspicacity/astuteness/edginess/incisiveness' in inducing reontologising prospective Being-development/ontological-framework-expansion-as-to-depth- 
of-ontologising-development-as-infrastructure-of- meaningfulness-and-teleology as rather reflecting the intellectual-and-moral inadequacy of " presencing-absolutising-identitiveconstitutedness social-vestedness/normativity-<discretely-implied-functionalism $>$ $<$ preconverging 'motif-and-apriorising/axiomatising/referencing'-entailing $>$ existentialising — enframing/imprintedness-〈as-to- historicity-tracing_-in-presencinghyperrealisation/hyperreal-transposition〉 ontologically-flawed construal of totalising-entailing' (as to a prospective projection of 'exteriorisation attitude/mental-disposition/care-andepisteme $^{5}$ of ${ }^{5}$ meaningfulness-and-teleology ${ }^{9}$-as-metaphoricity ${ }^{57}$ superseding/overriding prior ${ }^{83}$ reference-of-thought temporally ${ }^{58}$ neuterising 'interiorisation attitude/mentaldisposition/care-and-episteme ${ }^{5}$ of ${ }^{5}$ meaningfulness-and-teleology ${ }^{99}$ ) with such a critical gesturing/accounting — of-epistemic-phenomenalism throughout human history rather reflecting 'metaphoricity ${ }^{57}$ as sublimating $\sim$ referencing/registering/decisioning self-becoming/selfconflatedness $^{13}$ /formative-supererogating-<projective/reprojective-aestheticising-re-motifand-re-apriorising/re-axiomatising/re-referencing,-in-perspective-ontologicalnormalcy/postconvergence>' over 'desublimating referenced/registered/decisioned selfpresence/self-constitutedness $^{14}-<$ in-perspective-epistemic-abnormalcy/preconvergence ${ }^{3}>$ of prior ${ }^{56}$ meaningfulness-and-teleology ${ }^{\circ}$; ; critically-so because of the requisite crossgenerational transcendence-and-sublimity/sublimation/supererogatory $\sim$ de-mentativity for any prior registryworldview/dimension in relative-ontological-incompleteness ${ }^{8}$-presublimation-construct-ofmeaningfulness-and-teleology $\quad$ desublimating $\sim$ existentialising-decisionality-<as-todisentologising/re-ontologising aporeticism $>$ to process/progress ${ }^{56}$ meaningfulness-andteleology as of the prospective registry-worldview/dimension " ${ }^{\circ}$ reference-of-thought-andreference-of-thought- ${ }^{84}$ evolving- ${ }^{5}$ meaningfulness-and-teleology ${ }^{9}$ comprehensiveness of prospective sublimating-nascence', with notional asceticism reflecting all the critical gesturing/accounting - of-epistemic-phenomenalism 'keeping open the crossgenerational 
possibility for psychoanalytic-unshackling/memetic-reordering/institutional-recomposuring induced re-motif-and-re-apriorising/re-axiomatising/re-referencing/reintelligibilitysettingup/re-measuringinstrumenting' for such prospective registryworldview/dimension ${ }^{5}$ meaningfulness-and-teleology ${ }^{9}$ Such a prospective sublimating $\sim$ existentialising-decisionality-<as-to-disontologising/re-ontelogising apøreticism $>$ as arising as of prospective ${ }^{~}{ }^{83}$ reference-of-thought-and- ${ }^{83}$ reference-of-thoughtdevolving $-{ }^{5}$ meaningfulness-and-teleology ${ }^{9}$ comprehensiveness of prospective sublimatingnascence' (over relative-ontological-incompleteness ${ }^{88}$-presublimation-construct-ofmeaningfulness-and-teleology $\quad$ desublimating $\sim$ existentialising-decisionality-<as-todisontologising/re-ontologising aporeticism $>$ ) calls for a necessary notional $\sim$ selfdistantiation- $<$ imbued—re-motif-and-re-apriorising/re-axiomatising/re-

referencing $>/$ 'distantiation of contemplative existentialising-frame-of-entailment-of motifand-apriorising/axiomatising/referencing as to transversality-<for-sublimating-existentialeventuating/denouement,from-'thinking at-first/pure-predisposition-preemptive-ofprospective-disontologising/subontologising' as-of-prospectively-disambiguated-affirmedand-unaffirmed-'motif-and-apriorising/axiomatising/referencing' $>101$ in superseding any underpinning-suprasocial-construct defaulting relative-ontological-incompleteness ${ }^{8}$ presublimation-construct-of- ${ }^{5}$ meaningfulness-and-teleology ${ }^{9}$ desublimating $\sim$ existentialisingdecisionality-<as-to-disontologising/re-ontologising aporeticism $>$ which equates/levels-down everything across space and time on the basis of the relative-ontological-incompleteness ${ }^{8}$ presublimation-construct-of- ${ }^{5}$ meaningfulness-and-teleology ${ }^{99}$ desublimating existentialisingdecisionality-<as-to-disontologising/re-ontologising aporeticism $>$; and we can get a sense of this underlying notional asceticism with the sublimating-nascence of nascentparticular/incipient-and-material/technical-sublimations- $<$ blinded-to-their-relative-ontologicalcompleteness - reference-of-thought- devolving $>$ wherein notional $\sim$ self-distantiation- 
$<$ imbued-re-motif-and-re-apriorising/re-axiomatising/re-referencing $>/$ 'distantiation

contemplative

apriorising/axiomatising/referencing as to transversality-<for-sublimating-existential-

eventuating/denouement,-from-'thinking-at-first/pure-predisposition-preemptive-of-

prospective-disontologising/subontologising' as-of-prospectively-disambiguated-affirmed-

and-unaffirmed-'motif-and-apriorising/axiomatising/referencing'> ${ }^{101}$ more-or-less imposes

itself to the non-technical/non-scientific interlocutor (as to when incipient/instantaneous/direct potency as to existence-as-sublimating-withdrawal/unenframing/re-ontologising,-elicitedfrom-prospective-profound-supererogation will be highly challenging to any incompetent mind pretending to be technically/scientifically apt/of-sublimating existentialisingdecisionality-<as-to-disontologising/re-ontologising aporeticism $>$ in lieu of the truly apt/ofsublimating $\sim$ existentialising-decisionality-<as-to-disontologising/re-ontologising aporeticism $>$ technician/scientist) so-translating in the blurriness$<$ sterilising/anecdotalising/trivialising-of-prospective-re-ontologising_by-preconverging,-indisontologising-formulaic-dragging-out/hollowing-out> of human social-and-institutionalframeworks-of - referencing/registering/decisioning existentialising-decisionality-as-to-

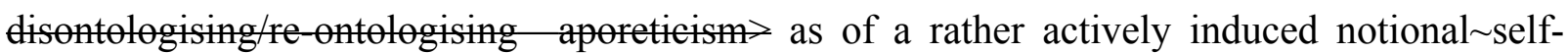
distantiation- $<$ imbued - re-motif-and-re-apriorising/re-axiomatising/re-

referencing $>/$ 'distantiation of contemplative existentialising-frame-of-entailment of motifand-apriorising/axiomatising/referencing as to transversality-<for-sublimating-existentialeventuating/denouement,-from-'thinking at-first/pure-predisposition-preemptive-ofprospective-disontologising/subontologising’ -as-of-prospectively-disambiguated-affirmedand-unaffirmed-'motif-and-apriorising/axiomatising/referencing' $>101$ in attaining the same candidity/candour-capacity for prospective sublimation (so-construed as notional asceticism ). Notional asceticism thus arises because of the very ${ }^{6}$ nonpresencing- $<$ perspective-ontological- 
normalcy/postconvergence $>$ nature of existence as to existence-as-sublimatingwithdrawal/unenframing/re-ontologising,-elicited-from-prospective-profoundsupererogation ${ }^{9}$, in the sense that the "full ${ }^{56}$ meaningfulness-and-teleology ${ }^{9}$ perfectly avails as to the inherent immanency-of-existence' but this presupposes absolute-mentation-capacity and not human limited-mentation-capacity—as-subjecting-'educed-unlimitedness/existencesublimating nascence'-to-limitedness/human-subpotency with the consequence that prospective knowledge-reification $\sim$ gesturing-and-accounting —of-epistemic-phenomenalism- $<$ inprospective_psychologismic apriorising/axiomatising/referencing-\{of-'prospectively implicited_attendant-ontological-contiguity ' educedexistentialising/contextualising/textualising_'intelligibility/epistemicity/reflexivity-contiguity<imbued-notional cogency $>$ ' $\}$-conflatedness -in-\{preconverging ment by\} postconverging-entailment> is as of human \{epistemic-

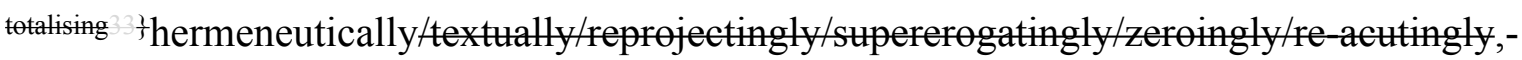
selinearity for-cogency-educing 'reframing/reimprinting of $<$ postconverging 'motif-and-apriorising/axiomatising/referencing'-entailing >existentialising - framing/imprinting-〈as-to-prospective- historiality/ontologicaleventfulness /ontological-aesthetic-tracing-<perspective-ontologicalnormalcy/postconvergence-reflected-'epistemicity-relativism-determinism'>>' in projective/reprojective — aestheticising-re-motif-and-re-apriorising/re-axiomatising/rereferencing so-articulated to a 'human limited-mentation-capacity-as-subjecting 'educedunlimitedness/existence-sublimating nascence' to-limitedness/human-subpotency contradictorily operating punctually in-effect on the basis of absolute-mentation-capacity' thus induces '79 presencing_-absolutising-identitive-constitutedness ${ }^{14} \quad<$ preconverging 'motif-andapriorising/axiomatising/referencing'-entailing >-existentialising—enframing/imprintedness〈as-to- historicity-tracing-in-presencing-hyperrealisation/hyperreal-transposition〉 
meaningfulness-and-teleology ${ }^{9}$ in want for 'prospective nonpresencing- $<$ perspectiveontological-normalcy/postconvergence> apriorising/axiomatising/referencing'-entailing>-existentialising_-framing/imprinting-〈as-toprospective- historiality/ontological-eventfulness /ontological-aesthetic-tracing$<$ perspective-ontological-normalcy/postconvergence-reflected-'epistemicity-relativismdeterminism' $>>{ }^{56}$ meaningfulness-and-teleology ${ }^{9}$-as-metaphoricity ${ }^{57}$. In-the-bigger-schemeof-things unlike it is falsely projected as to "79 presencing-absolutising-identitiveconstitutedness social-vestedness/normativity-<discretely-implied-functionalism $>$ $<$ preconverging 'motif-and-apriorising/axiomatising/referencing'-entailing >existentialising — enframing/imprintedness-〈as-to- historicity-tracing - in-presencinghyperrealisation/hyperreal-transposition〉 ontologically-flawed construal of totalising-entailing' implications of social-stake-contention-or-confliction, the ontological-veracity of the genuine social intellectual-function/posture 'is not in a process/processive bothsidesism-〈as-'mereprocessive'/pedantising-'dialogical-relation'-to 'perceived-social-and-institutionalcommonly-enculturated_referencing,-of- meaningfulness-and-teleology '-failing-'requisiteexistential-thematic-baseline-of-technicity/profundity-framing' \{of-sublimating-discursivityfor-sovereign-repassing $\}$,-as-of-psychologismic-epistemic-acutisation-nonresidualisingimbued-\{compulsing\} linearity in-eclecticism-of-prior-mere-formulaicity/ritualisation,-as-so'consciously/unconsciously-preordained/fated'-to-fail-prospective-notional cogency) equivalence of contention' with 'punctual <amplituding/formative-epistemicity $>$ totalising $\sim$ selfreferencing-syncretising/circularity/interiorising/akrasiatic-drag 34 rather measuring-up success/accomplishment/aspiration in shallow-supererogation of manifest in-effect absolution<as-to-apriorising/axiomatising/referencing-\{of-'prospectively_implicited_attendantontological-contiguity ' educedexistentialising/contextualising/textualising_'intelligibility/epistemicity/reflexivity_contiguity- 
$<$ imbued-notional cogency $>$ ' $\quad\}$-constitutedness -in-preconverging-entailment $>$ as to the given registry-worldview/dimension $<$ preconverging 'motif-andapriorising/axiomatising/referencing'-entailing>-existentialising_enframing/imprintedness〈as-to- historicity-tracing-in-presencing-hyperrealisation/hyperreal-transposition〉'; with the genuine social intellectual-function/posture prospective ' $<$ postconverging ' motif-andapriorising/axiomatising/referencing'-entailing >-existentialising-framing/imprinting-〈as-toprospective- historiality/ontological-eventfulness /ontological-aesthetic-tracing$<$ perspective-ontological-normalcy/postconvergence-reflected-‘epistemicity-relativismdeterminism' $>>$ ontologically-veridical construal of entailing-<amplituding/formativeepistemicity $>$ totalising in-relative-ontological-completeness ${ }^{87}$ implications' effectively arising in notional $\sim$ self-distantiation- $<$ imbued - re-motif-and-re-apriorising/re-axiomatising/rereferencing $>/$ 'distantiation of contemplative existentialising-frame-of-entailment-of motifand-apriorising/axiomatising/referencing as to transversality-<for-sublimating-existentialeventuating/denouement,-from-'thinking-at-first/pure-predisposition-preemptive-ofprespective disontologising/subontologising' as-of-prospectively-disambiguated-affirmedand-unaffirmed-'motif-and-apriorising/axiomatising/referencing' $>101$ with regards to the fundamental human ontological-commitment $-<$ implied - self-assuredness-of-ontologicalgood-faith/authenticity postconverging-de-mentating/structuring/paradigming -as-beingas-of-existential-reality $>$ of all human ${ }^{56}$ meaningfulness-and-teleology ${ }^{9}$ as to prospective sublimation-over-desublimation (so-implied with the self-assuredness-of-ontological-goodfaith/authenticity ${ }^{6} \sim$ postconverging-de-mentating/structuring/paradigming -as-being-as-ofexistential-reality with respect to social-stake-contention-or-confliction underlying human ontological-commitment $\quad<$ implied_-self-assuredness-of-ontological-goodfaith/authenticity postconverging-de-mentating/structuring/paradigming -as-being-as-ofexistential-reality $>$ ) and the human sovereign-function/posture-<as-to-existentially-manifest- 
‘embodied-subject $\sim$ consciousness-and-direct/deferential-conscientiousness',-as-of-its-

'epistemic-reflexivity/unreflexivity-in-existence'/teleology> intuitive grasp of prospective human postconverging aporeticism-overcoming/unovercoming, and as prospective relativeontological-completeness $^{87}$ rather avails as to 'overall interceding human-and-socialexpectations/anticipations — metaphoricity ${ }^{57}$-as-preconverging/postconverging-redementating/restructuring/reparadigming-psychologism $<$ postconverging $\sim$ 'motif-andapriorising/axiomatising/referencing'-entailing >-existentialising-framing/imprinting-〈as-toprospective- historiality/ontological-eventfulness /ontological-aesthetic-tracing$<$ perspective--ontological-normalcy/postconvergence-reflected-'epistemicity-relativismdeterminism' $>>$ of ordered human firstnatureness-deferentialism-imbuing and secondnaturedness-deferentialism-deriving as of underlying human ontological-commitment <implied-self-assuredness-of-ontological-good-faith/authenticity $\sim$ postconverging-dementating/structuring/paradigming -as-being-as-of-existential-reality $>$ as to existence-assublimating-withdrawal/unenframing/re-ontologising,-elicited-from-prospective-profoundsupererogation (and not the overrated pedantising/muddling/formulaic-hollowing-out-insubontologisation/subpotentiation-〈blurring/undermining-of-prospective-totalising-entailing,as-to-entailing-<amplituding/formative-epistemicity $>$ totalising in-relative-ontologicalcompleteness > of ${ }^{56}$ meaningfulness-and-teleology ${ }^{99}$ arising when existence-as-the-absolutea-priori-of-conceptualisation and existence—as-sublimating-withdrawal/unenframing/reontologising,-elicited-from-prospective-profound-supererogation $-<$ as-to-perspectiveontological-normalcy/postconvergence-implied-'prospective-aporeticismovercoming/unovercoming'> is overlooked and supposedly superseded by human-subpotency). In-many-ways, such pedantising/muddling/formulaic-hollowing-out - insubontologisation/subpotentiation-_blurring/undermining-of-prospective-totalising-entailing,as-to-entailing-<amplituding/formative-epistemicity $>$ totalising in-relative-ontological- 
completeness $>$ as it fails to address human prospective human postconverging-apereticismovercoming/unovercoming fails to appreciate the implications of the nonpresencing$<$ perspective-ontological-normalcy/postconvergence $>$ nature of existence as to existence-assublimating-withdrawal/unenframing/re-ontologising,-elicited-from-prospective-profoundsupererogation (as grasped by notional asceticism ) and go on to adopt 'discrete inherence of sublimating/desublimating - modalisation- $<$ as-to-absolute-referencing-of- $-{ }^{-}$meaningfulnessand-teleology $>$ on the basis of ${ }^{79}$ presencing-absolutising-identitive-constitutedness ${ }^{14}$ socialvestedness/normativity-<discretely-implied-functionalism $>\quad$ inducing of subontologisation/subpotentiation' and qualifying such notional asceticism as conspiratorial as to its 'punctual <amplituding/formative-epistemicity $>$ totalising $\sim$ self-referencingsyncretising/circularity/interiorising/akrasiatic-drag ${ }^{34}$ rather measuring-up success/accomplishment/aspiration in shallow-supererogation of manifest in-effect absolution$<$ as-to-apriorising/axiomatising/referencing-\{of-'prospectively implicited_attendantontological-contiguity ' educedexistentialising/contextualising/textualising_'intelligibility/epistemicity/reflexivity-contiguity$<$ imbued-notional cogency $>$ ' $\quad\}$-constitutedness -in preconverging-entailment $>$ as to the given registry-worldview/dimension $<$ preconverging $\sim$ 'motif-andapriorising/axiomatising/referencing'-entailing >-existentialising-enframing/imprintedness〈as-to- historicity-tracing-in-presencing-hyperrealisation/hyperreal-transposition〉'. However, it is only a veridical nonpresencing-<perspective-ontologicalnormalcy/postconvergence $>$ epistemic-projection insight in relative-ontological-completeness that points out the veracity of the ontological-deficiency of all registry-worldviews/dimensions destructuring-threshold-〈uninstitutionalised-threshold /presublimating-desublimatingdecisionality $>$ of-ontological-performance ${ }^{72}<$ including-virtue-as-ontology $>$, in the sense that critically from the epistemic perspective of the ancient-sophists, medieval-scholastics and our 
modern-day intellectual muddlement (as to their perspective epistemicabnormalcy/preconvergence ) in-many-ways the criticisms of 'Socratic-philosophers projected universalising-idealisation over non-universalising', 'budding-positivists projected rationalempiricism/positivism over non-positivism/medievalism' and 'prospective postmodern thought projected ${ }^{18}$ deprocrypticism-or-preempting-disjointedness-as-of- ${ }^{3}$ reference-of-thought or difference-conflatedness ${ }^{13}$-as-to-totalitative-reification-in-singularisation- $<$ as-to-thenondisjointedness/entailment-of-prospective- nonpresencing $>$-as-veridical-epistemicityrelativism-determinism of entailing-<amplituding/formative-epistemicity $>$ totalising $\sim$ inrelative-ontological-completeness ${ }^{87}$ implications over modern-day pedantising/muddling/formulaic-hollowing-out - in-subontologisation/subpotentiation〈blurring/undermining-of-prospective-totalising-entailing,-as-to-entailing$<$ amplituding/formative-epistemicity $>$ totalising in-relative-ontological-completeness totalisingly-ing — discretion/whim-of-thought' (as to relative nonpresencing-<perspectiveontological-normalcy/postconvergence $>$ ) respectively are rather conspiratorial; given the fact that such a notion of prospective destructuring-threshold-〈uninstitutionalisedthreshold /presublimating-desublimating-decisionality $>$ of-ontological-performance ${ }^{72}$ <including-virtue-as-ontology $>$ /morality/ethics/justice/etc. is 'conceptually a nondescript/ignorable-void ${ }^{6}$ of ${ }^{56}$ meaningfulness-and-teleology ${ }^{9}$, in the contemplation of 'punctual $<$ amplituding/formative-epistemicity $>$ totalising $\sim$ self-referencingsyncretising/circularity/interiorising/akrasiatic-drag 34 rather measuring-up success/accomplishment/aspiration in shallow-supererogation ${ }^{\circ}$ of manifest in-effect absolution$<$ as-to-apriorising/axiomatising/referencing-\{of-'prospectively implicited_attendantontological-contiguity ' educedexistentialising/contextualising/textualising_ 'intelligibility/epistemicity/reflexivity-contiguity<imbued-notional cogency>' $\}$-constitutedness -in preconverging-entailment $>$ as to the 
given

registry-worldview/dimension

$<$ preconverging 'motif-and-

apriorising/axiomatising/referencing'-entailing>-existentialising-enframing/imprintedness-

〈as-to- historicity-tracing - in-presencing-hyperrealisation/hyperreal-transposition〉, thus inmany-ways undermining/distracting from the direct addressing of prospective social-stakecontention-or-confliction postconverging apereticism overcoming Critically, such pedantism today in the face of the increasing subontologising/subpotentiation (associated with the modern-day underpinning-suprasocial-construct as to its underlying socio-econopolitical subontologisation/ideology-over-ontology and as to technocratic and capitalistic motives and as relayed mediatically) across the decades comes up punctually during election cycles with vague disenfranchising/desublimation notions of no critical relevance to prospective social re-ontologisation as-associated with the strategic, inconsistent and skewed-peddling of decades-long politically manipulative narratives like deficits, public spending, social engineering, socialism, tribalism, fairness, libertarian, middle-of-the-ground, identity politics, etc. as 'strategically made-up imaginary threats and/or falsely construed as of the most-vitaland-preeminent-political-stakes to then falsely project such narratives as to a skewed and ontologically-flawed process/processive bothsidesism-〈as-'mere-processive'/pedantising'dialogical-relation'-to 'perceived-social-and-institutional-commonlyenculturated_referencing,-of- meaningfulness-and-teleology '-failing-'requisite-existentialthematic-baseline-of-technicity/profundity-framing' \{ of-sublimating-discursivity-forsovereign-repassing \},-as-of-psychologismic-epistemic-acutisation-nonresidualising-imbued\{compulsing\} linearity in-eclecticism-of-prior-mere-formulaicity/ritualisation,-as-so‘consciously/unconsciously-preordained/fated'-to-fail-prospective-notional cogency $\rangle$ landscape of socio-econo-political social-stake-contention-or-confliction' (critically meant to foil the ontological-veracity of the manifest existential-reality of a 'desublimatingly/unemancipatingly skewed/masked/avoided/ignored/deflated socio-econo- 
political

evercoming/unovercoming engagement' as-so particularly associated with massive opportunityand-income-inequality and public governance of shallow-supererogation as of dominance/vested-interest-subontologising-skewed-influence-as-to-social-

vestedness/normativity- $<$ discretely-implied-functionalism $>$ ), with such concretely irrelevant and ontologically-flawed decades-long politically manipulative narratives 'rather providing a temporal human-subpotency ${ }^{5}$ meaningfulness-and-teleology -infrastructure as to preconverging/shallow-supererogating-'human-and-social-expectations/anticipations-dementating/structuring/paradigming-psychologism' (as of 'discrete inherence of sublimating/desublimating - modalisation- $<$ as-to-absolute-referencing-of $-{ }^{56}$ meaningfulnessand-teleology $>$ on the basis of ${ }^{79}$ presencing - absolutising-identitive-constitutedness ${ }^{14}$ socialvestedness/normativity-<discretely-implied-functionalism $>\quad$ inducing of subontologisation/subpotentiation') supposedly more critical and superseding the more profound-supererogatory engagement with the socio-econo-political social-stake-contention-orconfliction postconvergingaaporeticism-overcoming/unovercoming (as of 'human sublimating/desublimating - modalisation- $<$ as-to-absolute-referencing-of- ${ }^{5}$ meaningfulnessand-teleology $>$ upon inherent existence's sublimating-nascence inducing of ontologisation/omnipotentiality'); with such a mediatically manipulated ontologically-flawed 'process/processive bothsidesism-〈as-'mere-processive'/pedantising-'dialogical-relation'to 'perceived-social-and-institutional-commonly-enculturated_referencing,-ofmeaningfulness-and-teleology '-failing-'requisite-existential-thematic-baseline-oftechnicity/profundity-framing' \{of-sublimating-discursivity-for-sovereign-repassing \},-as-ofpsychologismic-epistemic-acutisation-nonresidualising-imbued-\{compulsing\}linearity ineclecticism-of-prior-mere-formulaicity/ritualisation,-as-so-'consciously/unconsciouslypreordained/fated'-to-fail-prospective-notional cogency $\rangle$ formulation across the decades' on 
the basis that it is debates along the skewed lines of deficits, public spending, social engineering, socialism, tribalism, fairness, libertarian, the-middle-ground, identity politics, etc. that 'will supposedly resolve such massive opportunity-and-income-inequality and skewed public governance of shallow-supererogation as of dominance/vested-interest-subontologisingskewed-influence-as-to-social-vestedness/normativity-<discretely-implied-functionalism>' (as to a nonsensical and antipodal paradox of election cycles driven by ontologically-flawed media presentation of debates along the skewed lines of deficits, public spending, social engineering, socialism, tribalism, fairness, libertarian, middle-of-the-ground, identity politics, etc. and superficial reflection upon the ontologically-veridical profound existential-reality of opportunity-and-income-inequality and public governance of shallow-supererogation as of dominance/vested-interest-subontologising-skewed-influence-as-to-socialvestedness/normativity-<discretely-implied-functionalism $>$, as to media presentation psychological-outleting in disenfranchising/frustrating the human sovereign-function/posture$<$ as-to-existentially-manifest-`embodied-subject $\sim$ consciousness-and-direct/deferentialconscientiousness',-as-of-its-'epistemic-reflexivity/unreflexivity-in-existence'/teleology> contemplation of prospective sublimating possibilities and rendering the human sovereignfunction/posture-<as-to-existentially-manifest-‘embodied-subject $\sim$ consciousness-anddirect/deferential-conscientiousness',-as-of-its-'epistemic-reflexivity/unreflexivity-inexistence'/teleology> increasingly irrelevant as it is substituted by underlying social disenfranchising/desublimating influence-networking-< subverting-supposedly- ${ }^{103}$ universalpossibilities-and-opportunities $>$ ). While at the same time the associated pedantism is cynically bent on qualifying 'genuine social intellectual-function/posture criticism of such preconverging/shallow-supererogating-'human-and-social-expectations/anticipations-dementating/structuring/paradigming-psychologism' manipulation as rather patronising/condescending upon the human sovereign-function/posture-<as-to-existentially- 
manifest-'embodied-subject consciousness-and-direct/deferential-conscientiousness',-as-of-

its-'epistemic-reflexivity/unreflexivity-in-existence'/teleology>' as to a falsehood that seem to imply that the inherent relative ignorance/disenfranchisement of the human sovereignfunction/posture-<as-to-existentially-manifest-‘embodied-subject $\sim$ consciousness-anddirect/deferential-conscientiousness',-as-of-its-'epistemic-reflexivity/unreflexivity-inexistence'/teleology $>$ is perfectly of the requisite reified-and-empowered-reflexivity with regards to profound-supererogatory engagement with the socio-econo-political social-stakecontention-or-confliction postconverging aporeticism-overcoming/unovercoming without a genuine social intellectual-function/posture in contrast to what has ever always been the case throughout human history for prospective social sublimation/emancipation as driven by the genuine social intellectual-function/posture with regards to the sublimating/emancipative drives associated with say ${ }^{103}$ universalising-idealisation, budding-positivism, social enlightenment thought, emancipation from feudalism, anti-slavery, decolonisation, civil rights, etc. as to the reality that in-many-ways the human sovereign-function/posture-<as-to-existentially-manifest'embodied-subject consciousness-and-direct/deferential-conscientiousness',-as-of-its'epistemic-reflexivity/unreflexivity-in-existence'/teleology> is aversed to the 'discomfort as to manifest existentialising — anxiety-imbued-beholdening-inducing, $-<$ preconverging 'motif-andapriorising/axiomatising/referencing'-entailing>-existentialising — enframing/imprintedness〈as-to- historicity-tracing - in-presencing-hyperrealisation/hyperreal-transposition〉 associated with prospective profound-supererogation but for the threshold of punctual/immediacy/constituted/compulsions-encumbered positive-opportunism—of-socialfunctioning-and-accordance ${ }^{5}$, (such that in reality human knowledge as to its prospective sublimating/emancipative is actually as of 'overall interceding human-and-socialexpectations/anticipations - metaphoricity ${ }^{57}$-as-preconverging/postconverging-redementating/restructuring/reparadigming-psychologism $<$ postconverging 'motif-and- 
apriorising/axiomatising/referencing'-entailing>-existentialising_-framing/imprinting-〈as-toprospective- historiality/ontological-eventfulness /ontological-aesthetic-tracing$<$ perspective-ontological-normalcy/postconvergence-reflected-'epistemicity-relativismdeterminism' $>>$ of ordered human firstnatureness-deferentialism-imbuing and secondnaturedness-deferentialism-deriving as of underlying human ontological-commitment <implied-self-assuredness-of-ontological-good-faith/authenticity $\sim$ postconverging-dementating/structuring/paradigming -as-being-as-of-existential-reality $>$ as to existence-assublimating-withdrawal/unenframing/re-ontologising,-elicited-from-prospective-profoundsupererogation ' and not 'of discrete isolated individuals sublimating/emancipative intellection' as so-falsely implied pedantically as so-effectively exposing the human sovereignfunction/posture-<as-to-existentially-manifest-‘embodied-subject $\sim$ consciousness-anddirect/deferential-conscientiousness',-as-of-its- 'epistemic-reflexivity/unreflexivity-inexistence'/teleology> disenfranchisement/swindling/corruption/dispossession), and it is counternatural to falsely imply that it is such an aversed reflex that will naturally deal with the instigation of prospective human sublimation/emancipation without the accompanying genuine social intellectualfunction/posture (whose existentialising-frame-of-entailment-of motif-andapriorising/axiomatising/referencing is the social harbinger of 'unbeholdening sublimatingnascence ontologising-depth of the full-potency of existence' as of its perpetuation of nonpresencing-<perspective-ontological-normalcy/postconvergence $>$ projection) articulated prospective 'relative-ontological-incompleteness $8 /$ relative-ontological-completeness ${ }^{87}$ 〈sublimating referencing/registering/decisioning,-as-self-becoming/selfconflatedness /formative-supererogating-<projective/reprojective-aestheticising-re-motifand-re-apriorising/re-axiomatising/re-referencing,-in-perspective-ontologicalnormalcy/postconvergence $>>$ as to human-and-social-expectations/anticipations- 
metaphoricity ${ }^{57}$-as-preconverging/postconverging-rede-

mentating/restructuring/reparadigming-psychologism' ${ }^{89}$ (speaking to the more profound reality that the truer problem of a democratic crisis lies in the fact that it is poorly interceded by the genuine social intellectual-function/posture as it enables 'human sublimating/desublimatingmodalisation- $<$ as-to-absolute-referencing-of- ${ }^{56}$ meaningfulness-and-teleology ${ }^{9}>$ upon inherent existence's sublimating-nascence inducing of ontologisation/omnipotentiality' to then go on to concretely resolve socio-econo-political social-stake-contention-or-confliction postconverging aporeticism-overcoming/unovercoming and rather disenfranchisingly interceded by a pedantising/muddling/formulaic-hollowing-out - insubontologisation/subpotentiation-〈blurring/undermining-of-prospective-totalising-entailing,as-to-entailing-<amplituding/formative-epistemicity $>$ totalising $\sim$ in-relative-ontologicalcompleteness > that is enabling preconverging/postconverging-dementatively/structurally/paradigmatically (whether by wrong/flawed analysis or cynical ontological-bad-faith/inauthenticity ${ }^{64}$ misanalysis) to 'occlusive discrete inherence of sublimating/desublimating — modalisation- $<$ as-to-absolute-referencing-of $-{ }^{56}$ meaningfulnessand-teleology $>$ on the basis of ${ }^{79}$ presencing - absolutising-identitive-constitutedness ${ }^{14}$ socialvestedness/normativity-<discretely-implied-functionalism $>\quad$ inducing of subontologisation/subpotentiation', especially-so as to an economically driven media landscape that can hardly discriminate between intellection and pedantising/muddling/formulaichollowing-out - in-subontologisation/subpotentiation-〈blurring/undermining-of-prospective-

\section{totalising-entailing,-as-to-entailing-<amplituding/formative-epistemicity $>$ totalising $\sim$ in-}

relative-ontological-completeness $>$ and in-many-ways passes the latter for the former as-so associated with overall social banalisation-of-thought with foils/stooges of pop-intellectuals as the 'greatest thinkers' of our present intellectually shameful epoch). In this regards, it is critical to appreciate that the democratic process is a sovereignty-imbuing process and while this 
sovereignty-imbuing process is critical as the point-of-departure for socio-econo-political socialstake-contention-or-confliction postconverging-aporeticism-overcoming/unovercoming it is incomplete if it is merely construed/manipulated as to essentially sovereignty-giving without a cultured aspiration to grasp and operate as to prospective ontological-veridicality (as sounderstood by the Socratic-philosophers) just as our sovereignty over say our house doesn't necessarily imply our technical competence with requisite house enhancements like electricity, plumbing, etc. even as our sovereignty is the point-of-departure for our independent/sovereign contemplating to undertake such house enhancement chores. This reality underlies the contention herein of the 'overrated pedantising/muddling/formulaic-hollowing-out-insubontologisation/subpotentiation-〈blurring/undermining-of-prospective-totalising-entailing,as-to-entailing-<amplituding/formative-epistemicity $>$ totalising $\sim$ in-relative-ontologicalcompleteness > of ${ }^{5}$ meaningfulness-and-teleology"' as to the fact that human discursivity is not a discursivity of absolute-mentation-capacity but rather a discursivity of limited-mentationcapacity—as-subjecting 'educed-unlimitedness/existence-sublimating nascence' tolimitedness/human-subpotency, and thus it is a discursivity of subpotency as to humansubpotency which doesn't necessarily subject/supersede existence as to existence-assublimating-withdrawal/unenframing/re-ontologising,-elicited-from-prospective-profoundsupererogation as warranted for prospective sublimation/emancipation (even as human socialand-institutional-frameworks-of — referencing/registering/decisioning of existentialisingdecisionality $<$ as-to-disontologising/re-ontologising aporeticism $>$ by reflex tend to absolutise human discursivity as to ${ }^{7}$ presencing-absolutising-identitive-constitutedness ${ }^{14}$ socialvestedness/normativity- $<$ discretely-implied-functionalism $>$ ); thus requiring appropriate nonpresencing-<perspective-ontological-normalcy/postconvergence $>$ epistemic-projection (as to requisite human limited-mentation-capacity-deepening-as-subjecting limitedness/human-subpotency to-'educed-unlimitedness/existence-sublimating nascence' 
towards absolute-mentation-capacity, in projective reflection of ontologisation/omnipotentiality as to ontological-normalcy/postconvergence, as sought-after by the genuine social intellectualfunction/posture involving its specifically cultivated arts/skills and time investment and on the intimation that the implied deferential-formalisation-transference is so-validated as of the supposedly coherent ontological-commitment $-<$ implied - self-assuredness-of-ontologicalgood-faith/authenticity $\sim$ postconverging-de-mentating/structuring/paradigming -as-beingas-of-existential-reality $>$ ) and its consequent notional $\sim$ self-distantiation- $<$ imbued - re-motifand-re-apriorising/re-axiomatising/re-referencing $>/$ 'distantiation of contemplative existentialising-frame-of-entailment-of motif-and-apriorising/axiomatising/referencing as to transversality-<for-sublimating-existential-eventuating/denouement,-from-'thinking atfirst/pure-predisposition-preemptive-of prospective-disontologising/subontologising' as-ofprospectively-disambiguated-affirmed-and-unaffirmed-'motif-andapriorising/axiomatising/referencing'>101 in superseding any underpinning-suprasocialconstruct defaulting relative-ontological-incompleteness ${ }^{8}$-presublimation-construct-ofmeaningfulness-and-teleology $\quad$ desublimating $\sim$ existentialising-decisionality-<as-todisontologising/re-ontologising aporeticism $>$ (beyond the falsehoods and naiveties of process/processive bothsidesism-〈as-'mere-processive'/pedantising-'dialogical-relation'to 'perceived--social-and-institutional-commonly-enculturated_referencing,-ofmeaningfulness-and-teleology '-failing-'requisite-existential-thematic-baseline-oftechnicity/profundity-framing' \{of-sublimating-discursivity-for-sovereign-repassing , -as-ofpsychologismic-epistemic-acutisation-nonresidualising-imbued-\{compulsing\}linearity ineclecticism-of-prior-mere-formulaicity/ritualisation,-as-so- 'consciously/unconsciouslypreordained/fated'-to-fail-prospective-notional cogency $\rangle$ formulae of discursivity that confuses pedantism and intellection). Critically, this fundamental contrastive human relation to knowledge as to the 'mere-formulaicity/ritualisation-<as-to-mere-formulaic- 
methodologising/mutualising/organising/institutionalising,-prospectively-losing-track-of-

‘\{epistemic-totalising ’’re-apriorising/re-axiomatising/re-referencing residuality-in-re-

originariness/re-origination'> of mechanical-knowledge constrained to human-subpotency temporal inclinations' and 'organic-knowledge constrained to existence-as-sublimatingwithdrawal/unenframing/re-ontologising,-elicited-from-prospective-profound-

supererogation (with regards to Being-development/ontological-framework-expansion-as-todepth-of-ontologising-development-as-infrastructure-of- meaningfulness-and-teleology , institutional-development-as-to-social-function-development and living-development-as-topersonality-development psychologismic epistemic acutisation difficulty $<$ for, residualising \{decompulsing\} delinearity for-cogency> magnitudes $\{$ \{f-experientiality/experiment\} ) Somanifested as to human notional firstnaturedness-formativeness-<as-to-eventualising-inklingdrive-or seeding misprising $>$ temporal-to-intemporal-dispositions- $<$ so-construed-as-fromperspective-ontological-normalcy/postconvergence> as reflected all across the relativeunreflexivity/relative-reflexivity - ontological-contiguity ${ }^{67} \sim$ of-the-human-institutionalisationprocess $^{68}$, speaks to a dynamic relation to knowledge as of inappropriate temporal/subontologising distractive-alignment-to- ${ }^{83}$ reference-of-thought- $<$ ofapriorising/axiomatising/referencing $>30$ and appropriate intemporal/ontologising notional $\sim$ selfdistantiation- $<$ imbued — re-motif-and-re-apriorising/re-axiomatising/re-

referencing $>/$ 'distantiation of contemplative existentialising-frame-of-entailment-of motifand-apriorising/axiomatising/refereneing as to transversality-<for-sublimating-existentialeventuating/denouement,-from-'thinking at-first/pure-predisposition-preemptive-ofprospective-disontologising/subontologising' as-of-prospectively-disambiguated-affirmedand-unaffirmed-'motif-and-apriorising/axiomatising/referencing' $>{ }^{101}$ (so-reflected across the $<$ cumulating/recomposuring attendant-ontological-contiguity $>$-successive registryworldviews/dimensions respectively as of dimensionality-of-desublimating-lack-of ${ }^{-}$ 
<<amplituding/formative>supererogatory $\sim$ de-mentativeness/epistemic-growth-or-

conflatedness /transvaluative-rationalising/transepistemicity/anamnestic-residuality/spirit-

drivenness-equalisation) and dimensionality-of-sublimating ${ }^{25}$ -

<<amplituding/formative>supererogatory $\sim$ de-mentativeness/epistemic-growth-or-

conflatedness /transvaluative-rationalising/transepistemicity/anamnestic-residuality/spirit-

drivenness-equalisation)). The point here is that the notion of notional $\sim$ self-distantiation$<$ imbued - re-motif-and-re-apriorising/re-axiomatising/re-referencing $>/$ 'distantiation of contemplative existentialising-frame-of-entailment-of motif-andapriorising/axiomatising/referencing as to transversality-<for-sublimating-existentialeventuating/denouement,-from-'thinking-at-first/pure-predisposition-preemptive-ofprospective-disontologising/subontologising' as-of-prospectively-disambiguated-affirmedand-unaffirmed-'motif-and-apriorising/axiomatising/referencing' $>101$ underlying the genuine social intellectual-function/posture is ultimately wholly an 'aspirative projection beyond human mortal normative contemplative existential-disontogising/re ontologising aporeticism> limitations of human-subpotency and rather so as to existence-as-sublimatingwithdrawal/unenframing/re-ontologising,-elicited-from-prospective-profound-supererogation implied re-ontologisation/omnipotentiality', as so-reflecting 'human sublimating/desublimating - modalisation- $<$ as-to-absolute-referencing-of- ${ }^{56}$ meaningfulnessand-teleology $>$ upon inherent existence's sublimating-nascence inducing of ontologisation/omnipotentiality' with respect to making-available/opening-up the full-potency of existence; and thus it is not truly by this most profound knowledge-reification $\sim$ gesturing-andaccounting - of-epistemic-phenomenalism- $<$ in-

prospective_psychologismic apriorising/axiomatising/referencing-\{of-‘prospectively implicited_attendant-ontological-contiguity ' educedexistentialising/contextualising/textualising_ 'intelligibility/epistemicity/reflexivity-contiguity- 
postconverging-entailment $>$ in an equivalence relation (as to contention) with distractivealignment-to- ${ }^{83}$ reference-of-thought- $<$ of-apriorising/axiomatising/referencing $>30 \quad$ of pedantising/muddling/formulaic-hollowing-out — in-subontologisation/subpotentiation〈blurring/undermining-of-prospective-totalising-entailing,-as-to-entailing<amplituding/formative-epistemicity >totalising in-relative-ontological-completeness $\rangle$, $<$ amplituding/formative $>$ wooden-language-〈imbued-temporal-mereform/virtualities/dereification/akrasiatic-drag/denatured/preconverging-or-dementing narratives - of-the- reference-of-thought- categorical-imperatives/axioms/registryteleology $>$ and sovereign-function/posture-<as-to-existentially-manifest-'embodiedsubject $\sim$ consciousness-and-direct/deferential-conscientiousness',-as-of-its- 'epistemicreflexivity/unreflexivity-in-existence'/teleology> critically underlied by positiveopportunism-of-social-functioning-and-accordance ${ }^{75}$ 'ad-hocly tied to punctual/immediacy/constituted/compulsions-encumbered social-stake-contention-orconfliction interests in in-effect absolute terms of <preconverging ' motif-andapriorising/axiomatising/referencing'-entailing >-existentialising — enframing/imprintedness〈as-to- historicity-tracing-in-presencing-hyperrealisation/hyperreal-transposition〉'. In this regards and counterintuitively to what avails with the secondnatured perception of registryworldviews/dimensions as to their resultant secondnatured institutionalisation habituated <preconverging 'motif-and-apriorising/axiomatising/referencing'-entailing >existentialising — enframing/imprintedness-〈as-to- historicity-tracing_-in-presencinghyperrealisation/hyperreal-transposition〉, their prior 'firstnatured enabling transcendence-andsublimity/sublimation/supererogatory de-mentativity as of the genuine social intellectualfunction/posture' are ever always 're-originary_-as-unenframed/reontologising/unbeholdening/outlier-conceptualisation__imbued-postconverging/dialectical- 
thinking -'projective-insights'/‘epistemic-projection-in-conflatedness ' 'of-

notional deprocrypticism-prospective-sublimation $\rangle^{0}$ in perspective ontologicalnormalcy/postconvergence beyond normativities' but when secondnaturedly habituated as to positive-opportunism-of-social-functioning-and-accordance ${ }^{75}$ for institutionalisation become normativities such that 'what is then ever always lost' prospectively to all secondnatured institutionalisation is this 'ungraspable/conflating perspective ontologicalnormalcy/postconvergence underlying firstnaturedness-as-to-inkling reontologisation/omnipotentiality' to which 'habituated secondnaturedness institutionalisation ever always prospectively presents 79 presencing-absolutising-identitive-constitutedness social-vestedness/normativity in distractive-alignment-to- ${ }^{-}$reference-of-thought- $<$ofapriorising/axiomatising/referencing $>{ }^{30}$. In-the-bigger-scheme-of-things notional $\sim$ selfdistantiation-<imbued—re-motif-and-re-apriorising/re-axiomatising/re-

referencing $>/$ 'distantiation of contemplative existentialising-frame-of-entailment-of-motifand-apriorising/axiomatising/referencing as to transversality-<for-sublimating-existentialeventuating/denouement,-from-'thinking-at-first/pure-predisposition-preemptive-ofprospective-disontologising/subontologising' as-of-prospectively-disambiguated-affirmedand-unaffirmed-'motif-and-apriorising/axiomatising/referencing'>101 as to knowledgereification $\sim$ gesturing-and-accounting — of-epistemic-phenomenalism- $<$ inprospective_psychologismic apriorising/axiomatising/referencing-\{of- ${ }^{\text {pprospectively }}$ implicited_attendant-ontological-contiguity ' educedexistentialising/contextualising/textualising_'intelligibility/epistemicity/reflexivity-contiguity<imbued-notional cogency >' \}-conflatedness in \{preconverging ment by\} postconverging-entailment> is effectively disqualificative 'of human punctual/immediacy/constituted/compulsions-encumbered conception of social-stakecontention-or-confliction distractive-alignment-to- ${ }^{8}$ reference-of-thought- $<$ of- 
apriorising/axiomatising/referencing $>30$ failing dispensing-with-immediacy-for-relativeontological-completeness $^{87}$-by-reification/contemplative-distension ${ }^{27}$ that enables/allows accrual of sublimation-over-desublimation from existence itself as to existence-assublimating-withdrawal/unenframing/re-ontologising,-elicited-from-prospective-profound$\begin{array}{llll}\text { supererogation } & \text { (beyond } & \text { human-subpotency } & \text { mutualising). }\end{array}$ supererogatory-unbeholdening-conflatedness ${ }^{13}$ of the genuine social intellectualfunction/posture implies that is not entrapped/beholdening to an equivalence relation with any given relative-ontological-incompleteness ${ }^{8}$-presublimation-construct-of- ${ }^{56}$ meaningfulnessand-teleology $\quad$ desublimating existentialising-decisionality-<as-to-disontologising/reentologising aporeticism $>$ (of underpinning-suprasocial-construct $<$ preconverging 'motifand-apriorising/axiomatising/referencing'-entailing--existentialisingenframing/imprintedness-〈as-to- historicity-tracing — in-presencinghyperrealisation/hyperreal-transposition〉) imbued distractive-alignment-to- ${ }^{8}$ reference-ofthought- $<$ of-apriorising/axiomatising/referencing $>30$; for instance in the sense that a Diderotand-co. Encyclopédistes project for prospective human-and-social sublimation/emancipation in a genuine social intellectual-function/posture re-ontologisation/omnipotentiality aspiration as of notional $\sim$ self-distantiation- $<$ imbued — re-motif-and-re-apriorising/re-axiomatising/rereferencing $>/$ 'distantiation of contemplative existentialising-frame-of-entailment-of-motifand-apriorising/axiomatising/referencing as to transversality-<for-sublimating-existentialeventuating/denouement,-from-'thinking-at-first/pure-predisposition-preemptive-ofprospective-disontologising/subontologising' as-of-prospectively-disambiguated-affirmedand-unaffirmed-'motif-and-apriorising/axiomatising/referencing'> projected nonpresencing-<perspective-ontological-normalcy/postconvergence $>$ is beyond an equivalence relation of punctual/immediacy/constituted/compulsions-encumbered social-stakecontention-or-confliction with a 'medieval patricianism/aristocratism/theocracy shallow- 
supererogation of manifest in-effect absolution-<as-to-apriorising/axiomatising/referencing\{of-'prospectively_implicited_attendant-ontological-contiguity ' educedexistentialising/contextualising/textualising_'intelligibility/epistemicity/reflexivity-contiguity<imbued-notional cogency>' $\quad\}$-constitutedness -in preconverging-entailment> imbued distractive-alignment-to- ${ }^{8}$ reference-of-thought- $<$ of-apriorising/axiomatising/referencing $>$, just as the same can be said of budding-positivists science with medieval scholasticism or Socratic-philosophers ${ }^{103}$ universalising-idealisation with non-universalising sophists or all such human emancipatioin of profound-supererogation . In this regards, distractive-alignment-toreference-of-thought- $<$ of-apriorising/axiomatising/referencing $>30$ ever always involves a false elevation of pedantising/muddling/formulaic-hollowing-out—insubontologisation/subpotentiation-〈blurring/undermining-of-prospective-totalising-entailing,as-to-entailing-<amplituding/formative-epistemicity $>$ totalising in-relative-ontologicalcompleteness > to falsely imply a constrastive equivalence with veridical intellectual reontologisation/omnipotentiality (as to imply a common framework of contemplation) in order to then drag-down such veridical intellectual re-ontologisation/omnipotentiality to the punctual/immediacy/constituted/compulsions-encumbered framework of human social-stakecontention-or-confliction underlied by human limited-mentation-capacity-as-subjecting'educed-unlimitedness/existence-sublimating nascence' to-limitedness/human-subpotency manifest temporality ${ }^{98}$ (as of the underpinning-suprasocial-construct <preconverging $\sim$ 'motifand-apriorising/axiomatising/referencing'-entailing $>$-existentialising enframing/imprintedness-〈as-to- historicity-tracing - in-presencinghyperrealisation/hyperreal-transposition $\rangle$ with its manifest pedantising/muddling/formulaichollowing-out - in-subontologisation/subpotentiation-〈blurring/undermining-of-prospectivetotalising-entailing,-as-to-entailing-<amplituding/formative-epistemicity $>$ totalising inrelative-ontological-completeness $\rangle$ and $<$ amplituding/formative $>$ wooden-language- 


\section{〈imbued-temporal-mere-form/virtualities/dereification/akrasiatic-}

drag/denatured/preconverging-or-dementing -narratives - of-the- reference-of-thoughtcategorical-imperatives/axioms/registry-teleology $\rangle$ ), and thus strive to undermine the prospective intellectually projected human limited-mentation-capacity-deepening-assubjecting limitedness/human-subpotency-to-'educed-unlimitedness/existence-sublimatingnascence' ${ }^{53}$ as to human self-surpassing so-reflected as of notional $\sim$ self-distantiation$<$ imbued-re-motif-and-re-apriorising/re-axiomatising/re-referencing $>/$ ‘distantiation of contemplative existentialising-frame-of-entailment-of motif-andapriorising/axiomatising/referencing as to transversality-<for-sublimating-existentialeventuating/denouement, from 'thinking at first/pure predisposition preemptive of prospective-disontologising/subontologising' as-of-prospectively-disambiguated-affirmedand-unaffirmed-'motif-and-apriorising/axiomatising/referencing'> ${ }^{\prime 0} ;$ wherein the habituatedness/mental-colonisation of the sovereign-function/posture-<as-to-existentiallymanifest-'embodied-subject consciousness-and-direct/deferential-conscientiousness',-as-ofits-'epistemic-reflexivity/unreflexivity-in-existence'/teleology> to the ${ }^{79}$ presencingabsolutising-identitive-constitutedness ${ }^{14}$ social-vestedness/normativity is cynically construed as enabling a social-stake-contention-or-confliction distractive-alignment-to- ${ }^{3}$ reference-ofthought- $<$ of-apriorising/axiomatising/referencing $>30 \quad$ pedantising/muddling/formulaichollowing-out - in-subontologisation/subpotentiation-〈blurring/undermining-of-prospectivetotalising-entailing,-as-to-entailing-<amplituding/formative-epistemicity $>$ totalising $\sim$ inrelative-ontological-completeness $\rangle$ exercise in undermining prospective human reontologisation/omnipotentiality. Critically, while the 'unbeholdening sublimating-nascence ontologising-depth of the full-potency of existence' for nascent-particular/incipient-andmaterial/technical-sublimations-<blinded-to-their-relative-ontological-completeness

reference-of-thought- devolving $>\quad$ existentialising-decisionality-<as-to-disontelogising/re- 
entologising aporeticism $>$ in-many-ways is difficultly underminable to pedantising/muddling/formulaic-hollowing-out_-in-subontologisation/subpotentiation〈blurring/undermining-of-prospective-totalising-entailing,-as-to-entailing$<$ amplituding/formative-epistemicity >totalising in-relative-ontological-completeness distractive-alignment-to- ${ }^{8}$ reference-of-thought- $<$ of-apriorising/axiomatising/referencing $>$ inducing of subontologisation/subpotentiation the blurriness$<$ sterilising/anecdotalising/trivialising-of-prospective-re-ontologising_by-preconverging,-indisontologising-formulaic-dragging-out/hollowing-out> associated with social-andinstitutional-frameworks-of — referencing/registering/decisioning existentialising-decisionalityas to disontogising lentologising aporeticism> lends itself readily to such pedantising/muddling/formulaic-hollowing-out—in-subontologisation/subpotentiation〈blurring/undermining-of-prospective-totalising-entailing,-as-to-entailing$<$ amplinglformative-epistemicity $>$ totalising in-relative-ontological-completeness $\rangle$. It is herein contended that besides the technical/knowledge capacity for elucidating the inherent blurriness-<sterilising/anecdotalising/trivialising-of-prospective-re-ontologising_bypreconverging,-in-disontologising-formulaic-dragging-out/hollowing-out> in the social domain, in-many-ways pedantising/muddling/formulaic-hollowing-out —insubontologisation/subpotentiation-〈blurring/undermining-of-prospective-totalising-entailing,as-to-entailing-<amplituding/formative-epistemicity $>$ totalising in-relative-ontologicalcompleteness > distractive-alignment-to- ${ }^{3}$ reference-of-thought- $<$ ofapriorising/axiomatising/referencing $>30$ is the principal reason undermining the true scientific status of the social domain as to exposition to a (beyond-the-consciousness-awarenessteleology $-<$ of-preconverging-existential-extrication-as-of-existential-unthought $>$ ) pedantising/muddling/formulaic-hollowing-out_-in-subontologisation/subpotentiation〈blurring/undermining-of-prospective-totalising-entailing,-as-to-entailing- 
$<$ amplituding/formative-epistemicity $>$ totalising in-relative-ontological-completeness

associated with $\quad{ }^{79}$ presencing-absolutising-identitive-constitutedness ${ }^{14}$ socialvestedness/normativity- $<$ discretely-implied-functionalism $>$ in failing the re-originary_-as-

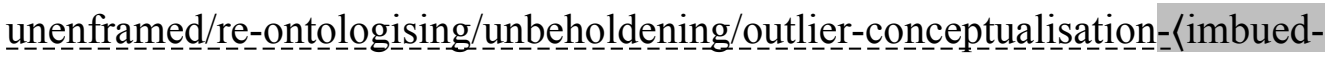

postconverging/dialectical-thinking -'projective-insights'/‘epistemic-projection-in-

conflatedness '-of-notional deprocrypticism-prospective-sublimation $\rangle^{0}$ for prospective social $\quad{ }^{4}$ historiality/ontological-eventfulness ${ }^{38} /$ ontological-aesthetic-tracing-<perspectiveontological-normalcy/postconvergence-reflected-‘epistemicity-relativism-determinism’>, and transforming many a subject-matter into 'beholdening as sovereignising-imbuedsubontologisation/subpotentiation' existentialising-decisionality-<as-to-disontologising/reentologising apereticism $>$ psychological-disposition. Critically and contrary to a naïve conception of the genuine social intellectual-function/posture as to its conceptualisation of human profound-supererogation ${ }^{6}$ (as of notional $\sim$ self-distantiation- $<$ imbued-re-motif-and-reapriorising/re-axiomatising/re-referencing $>/$ 'distantiation of contemplative existentialisingframe-of entailment of motif and apriorising/axiomatising/referencing as to transversality$<$ for-sublimating-existential-eventuating/denouement,-from-'thinking-at-first/purepredisposition-preemptive-of prospective-disontologising/subontologising' as-ofprospectively-disambiguated-affirmed-and-unaffirmed-'motif-andapriorising/axiomatising/referencing'> $>101$ superseding an equivalence with pedantising/muddling/formulaic-hollowing-out — in-subontologisation/subpotentiation〈blurring/undermining-of-prospective-totalising-entailing,-as-to-entailing$<$ amplituding/formative-epistemicity $>$ totalising in-relative-ontological-completeness $>$ distractive-alignment-to- ${ }^{83}$ reference-of-thought- $<$ of-apriorising/axiomatising/referencing $>{ }^{30}$ ), 'human profound-supererogation in-of-itself is the grander and more determinative element of contemplation/analysis as to when relative-ontological-completeness ${ }^{87}$ is-educed-and-avails- 
and-re-avails with regards to prospective re-ontologisation/omnipotentiality' over any given underpinning-suprasocial-construct $<$ preconverging 'motif-andapriorising/axiomatising/referencing'-entailing>-existentialising_enframing/imprintedness〈as-to- historicity-tracing-in-presencing-hyperrealisation/hyperreal-transposition〉 or their contrastive comparisons like capitalism/communism failing prospective human postconverging aporeticism-overcoming/unovercoming, in the sense that any such underpinning-suprasocial-construct pretense-of-arrogation of human profound-supererogation (as to their implied beholdening-becoming-distortive-originariness/distortive-origination-asto- ${ }^{-7}$ historicity-tracing inhibited-mental-aestheticising) are not as of the " absolutising-identitive-constitutedness ${ }^{14}$ absolution/absolute-scope \{flawed/unsound\}-relativeunreflexivity-in-existencelabsolutising from-limited-mentation/psychologismic epistemicacutisation - nonresidualising imbued-\{compulsing\} linearity in-eclecticism-of prior-mereformulaicity/ritualisation conception' pretense of human profound-supererogation which is rather ever always subjectable to re-originary-_as-unenframed/reontologising/unbeholdening/outlier-conceptualisation__imbued-postconverging/dialecticalthinking -'projective-insights’/‘epistemic-projection-in-conflatedness ' '-ofnotional deprocrypticism-prospective-sublimation $\rangle^{\circ}$ (as the very manifest rule reflecting holographically-<conjugatively-and-transfusively $>$ the relative-unreflexivity/relativereflexivity - ontological-contiguity of-the-human-institutionalisation-process ). Critically in this regards, knowledge itself as to organic-knowledge is inherently and truly as of an 'implicited_attendant_ontological-contiguity ${ }^{67}$ ' educedexistentialising/contextualising/textualising_ 'intelligibility/epistemicity/reflexivity-contiguity$<$ imbued-notional $\sim$ cogency $>$ ' fepistemic thermeneutic/textuality/reprojecting/supererogating/zeroing/re-acuting,${ }_{\{\text {decompulsing }}$ delinearity for-cogency dynamics of notional $\sim$ self-distantiation-<imbued-re- 
motif-and-re-apriorising/re-axiomatising/re-referencing $>/$ 'distantiation of contemplative existentialising-frame-of-entailment-of-motif-and-apriorising/axiomatising/referencing as to transversality-<for-sublimating-existential-eventuating/denouement-from-'thinking atfirst/pure-predisposition-preemptive-of prospective-disontologising/subontologising' as-ofprospectively-disambiguated-affirmed-and-unaffirmed-‘motif-andapriorising/axiomatising/referencing' $>101$ (with regards to Being-development/ontologicalframework-expansion-as-to-depth-of-ontologising-development-as-infrastructure-ofmeaningfulness-and-teleology , institutional-development-as-to-social-functiondevelopment and living-development-as-to-personality-development psychologismic epistemic-acutisation difficulty-for, residualising \{decompulsing $\}$ delinearity for-cogency> magnitudes $\left.\left.{ }^{\{0 f-e x p e r i e n t i a l i t y / e x p e r i m e n t}\right\}\right)$ and not just about isolated mere-formulaicity/ritualisation<as-to-mere-formulaic — methodologising/mutualising/organising/institutionalising,prospectively-losing-track-of- ‘fepistemic-totalising 3 re-apriorising/re-axiomatising/rereferencing $\sim$ residuality - in-re-originariness/re-origination'>, wherein for instance we can starkly appreciate that it makes little sense articulating university-level knowledge as to university-level competence to say secondary-education level pupil or electronics knowledge as to electronic technician competence to an accountant as to the fact that in both instances there is associated existential-<disontologising/re-ontologising aporeticism $>$ fepistemictotalising 3 ' $h$ hermeneutic/textuality/reprojecting/supererogating/zeroing/re-acuting,delinearity for-cogency development for the appropriate knowledge requiring the notional $\sim$ self-distantiation-<imbued—re-motif-and-re-apriorising/re-axiomatising/rereferencing $>/$ 'distantiation of contemplative existentialising-frame-of-entailment-of-motifand-apriorising/axiomatising as to transversality-<for-sublimating-existentialeventuating/denouement,-from-'thinking at-first/pure-predisposition-preemptive-ofprospective-disontologising/subontologising' as-of-prospectively-disambiguated-affirmed- 
and-unaffirmed-'motif-and-apriorising/axiomatising/referencing'> ${ }^{101}$ of the university-level competence and electronics technician competence (unless somehow say the secondaryeducation level pupil or accountant had pursued a qualifying complementary existential$\leq$ disontologising/re-ontologising aporeticism> \{epistemictotalising ${ }^{3}{ }^{3}$ hermeneutic/textuality/reprojecting/supererogating/zeroing/re-acuting,${ }_{\{\text {decompulsing }\}}$ delinearity for-cogency development for the appropriate university-level or electronics knowledge-discursivity-〈in-determining-human-ontological-performance $<$ including-virtue-as-ontology $>>$ or otherwise the knowledge is articulated as to their relevant existential-<disontologising/re-ontologising aporeticism $>$ \{epistemictotalising $3{ }^{3}$ hermeneutic/textuality/reprojecting/supererogating/zeroing/re acuting,${ }_{\{\text {decompulsing }\}}$ delinearity for-cogency development appropriate deferential-formalisationtransference level of discursivity); but then distractive-alignment-to- ${ }^{8}$ reference-of-thought- $<$ ofapriorising/axiomatising/referencing $>{ }^{30}$ beyond such palpable examples, in blurry domains of social-stake-contention-or-confliction undermines the true 'implicited_attendant-ontologicalcontiguity $^{67}$ ? educedexistentialising/contextualising/textualising_'intelligibility/epistemicity/reflexivity-contiguity$<$ imbued-notional $\sim$ cogency $>$ ' \{epistemicthermeneutic/textulity/reprojecting/supererogating/zeroing/re-acuting,\{decomearity for-cogency dynamics of notional $\sim$ self-distantiation-<imbued-remotif-and-re-apriorising/re-axiomatising/re-referencing $>/$ 'distantiation of contemplative existentialising-frame-of-entailment-of-motif-and-apriorising/axiomatising/referencing as to transversality-<for-sublimating-existential-eventuating/denouement,-from-'thinking-atfirst/pure-predisposition-preemptive-of-prospective-disontologising/subontologising' as-ofprospectively-disambiguated-affirmed-and-unaffirmed-'motif-andapriorising/axiomatising/referencing' $>101$ (whether blurrily undermining appropriate 
competence-level of discursivity or appropriate deferential-formanlisation-transference level of discursivity) so-associated, and so-critically as to wrongly projected equivalence of 'beholdening as sovereignising-imbued-subontologisation/subpotentiation' desublimating existentialisingdecisionality-<as-to-disontologising/re-ontologising aporeticism> with 'unbeholdening sublimating-nascence ontologising-depth of the full-potency of existence' sublimating existentialising-decisionality-<as-to-disontologising/re-ontologising -

aporeticism $>$ as to social-stake-contention-or-confliction associated with social-andinstitutional-frameworks-of — referencing/registering/decisioning existentialising-decisionality$<$ as-to-disontologising/re-ontologising aporeticism $>$ (as reflected in inducing an ambiguous continuity between genuine-knowledge and chicanery, social/institutional intellectualism and social/institutional sycophantic-sophistry, alchemy and chemistry, quackery and medicine, technological-advancement and technical-mystification, flawed-industrial-analyses-andcertifications and disinterested-scientific-analyses-and-certifications, etc.). notional $\sim$ selfdistantiation-<imbued-re-motif-and-re-apriorising/re-axiomatising/re-

referencing $>/$ 'distantiation of contemplative existentialising-frame-of-entailment-of-motifand-apriorising/axiomatising/referencing as to transversality-<for-sublimating-existentialeventuating/denouement, from 'thinking at first/pure predisposition preemptive of prospective-disontologising/subontologising' - as-of-prospectively-disambiguated-affirmedand-unaffirmed-'motif-and-apriorising/axiomatising/referencing' $>{ }^{101}$ is effectively at the very core of human psychoanalytic-unshackling/memetic-reordering/institutional-recomposuring induced self-becoming/self-conflatedness ${ }^{13}$ /formative-supererogating$<$ projective/reprojective - aestheticising-re-motif-and-re-apriorising/re-axiomatising/rereferencing,-in-perspective-ontological-normalcy/postconvergence $>$ as conflating towards the possibility of 'scalarity/immanency of existence's ontological-normalcy/postconvergence', and so as to 'human intellection exercise direct-or-elicited very own self-distantiation' (involving 
appropriate

totalising 3 ' ${ }^{3}$ hermeneutic/textuality/reprojecting/supererogating/zeroing/re-acuting,-

\{decompulsing delinearity for-cogency

$<$ amplituding/formative-epistemicity $>$ -

totalising $\sim$ renewing-realisation/re-perception/re-thought,-in-supererogatory $\sim$ epistemic-

conflatedness $^{13}$ ) and appropriate deferential-formanlisation-transference sense of distantiation over distractive-alignment-to- ${ }^{8}$ reference-of-thought- $<$ of-

apriorising/axiomatising/referencing $>^{30}$. With regards to human Beingdevelopment/ontological-framework-expansion-as-to-depth-of-ontologising-development-asinfrastructure-of- meaningfulness-and-teleology , 'distractive-alignment-to- ${ }^{83}$ reference-ofthought- $<$ of-apriorising/axiomatising/referencing $>^{30}$ translates in the overlooking of the effectively requisite social-stake-contention-or-confliction prospective human postconverging-aporeticism-overcoming/unovercoming' (as to a threshold where subontologisation/subpotentiation supposedly takes over from reontologisation/omnipotentiality, and it is quite interesting to realise that there is hardly any distractive-alignment-to- ${ }^{8}$ reference-of-thought- $<$ of-apriorising/axiomatising/referencing $>$ in posturing for limiting human re-ontologisation/omnipotentiality with regards to nascentparticular/incipient-and-material/technical-sublimations- $<$ blinded-to-their-relative-ontologicalcompleteness - reference-of-thought- devolving $>\quad$ existentialising-decisionality-<as-todisontologising/re-ontologising aporeticism $>$ that can so-arise as constrained to human temporal-and-immediate advantageously perceived positive-opportunism-of-socialfunctioning-and-accordance ${ }^{75}$, whereas on-the-other-hand pedantising/muddling/formulaichollowing-out - in-subontologisation/subpotentiation-〈blurring/undermining-of-prospectivetotalising-entailing,-as-to-entailing-<amplituding/formative-epistemicity $>$ totalising $\sim$ inrelative-ontological-completeness > distractive-alignment-to- ${ }^{3}$ reference-of-thought- $<$ ofapriorising/axiomatising/referencing $>^{30}$ is rather elevated when it comes to social-and- 
institutional-frameworks-of — referencing/registering/decisioning existentialising-decisionality<as-to-disontologising/re-ontologising aporeticism $>$ as to social-stake-contention-orconfliction). Critically in this regards, notional $\sim$ self-distantiation- $<$ imbued-re-motif-and-reapriorising/re-axiomatising/re-referencing $>/$ 'distantiation of contemplative existentialisingframe-of-entailment-of motif-and-apriorising/axiomatising/referencing as to transversality$<$ for-sublimating-existential-eventuating/denouement-from-'thinking-at-first/purepredisposition-preemptive-of prospective-disontologising/subontologising' as-ofprospectively-disambiguated-affirmed-and-unaffirmed-'motif-andapriorising/axiomatising/referencing' $>101$ is merely the translation of the perspective ontological-normalcy/postconvergence of inherent existence as to an impasse/break between relative-ontological-incompleteness ${ }^{88}$ and relative-ontological-completeness ${ }^{87}$ (with regards to their varying projection of <amplituding/formative $>$ disposedness/psychologismic-construct〈as-to-orientation/value-construct/valuation-and-derived-parameterising $<$ amplituding/formative $>$ entailment-〈as-to-totalising-contiguous/coherent-factuality-ofvariability $\rangle$ as to ${ }^{45}$ foregrounding__entailment- $<$ in-succession-of-profound-supererogation $>$ 〈postconverging-narrowing-down sublimation-as-to-'existence-as-sublimatingwithdrawal/unenframing/re-ontologising,-elicited-from-prospective-profoundsupererogation '-in-reflecting-'immanent relative-unreflexivity/relative-reflexivity ontological-contiguity ';--as-operative-notional deprocrypticism)). This can starkly be appreciated in the instance of Being-development/ontological-framework-expansion-as-todepth-of-ontologising-development-as-infrastructure-of- meaningfulness-and-teleology wherein for instance the notion of God-of-plane in an animistic social-setup speaks of a fundamental preconverging/postconverging-rede-mentating/restructuring/reparadigming notional $\sim$ self-distantiation- $<$ imbued—re-motif-and-re-apriorising/re-axiomatising/rereferencing $>/$ 'distantiation of contemplative existentialising-frame-ofentalment of 
and-apriorising/axiomatising/referencing as to transversality-<for-sublimating-existentialeventuating/denouement,-from-'thinking at-first/pure-predisposition-preemptive-ofprospective-disontologising/subontologising' as-of-prospectively-disambiguated-affirmedand-unaffirmed-'motif-and-apriorising/axiomatising/referencing' $>101$ as to the fact that the positivistic/rational-empiricist ${ }^{56}$ meaningfulness-and-teleology ${ }^{9}$ is of utter ‘<amplituding/formative>disposedness/psychologismic-construct-〈as-to-orientation/valueconstruct/valuation-and-derived-parameterising $\rangle$ and $<$ amplituding/formative $>$ entailment-〈asto-totalising-contiguous/coherent-factuality-of-variability)' break/impasse (with the animistic meta-conceptualisation scheme of ${ }^{5}$ meaningfulness-and-teleology as to its prospectively uninstitutionalised-threshold ${ }^{102}$ ) for inducing the appropriate perspective ontologicalnormalcy/postconvergence (to enable the eventual epistemicity growth/conflatedness ${ }^{13}$ of the animistic social-setup into a positivistic/rational-empiricist conceptivity/epistemicreflexivity/epistemicity-relativism-determinism-<reifying \{as-to-knowledge-developing $\}$-andempowering $>$ ); and this is effectively the critical posture of the genuine social intellectualfunction/posture as to its prospective registry-worldview/dimension opening-up function as to perspective ontological-normalcy/postconvergence not constrained to the punctual/immediacy/constituted/compulsions-encumbered human social-stake-contention-orconfliction ${ }^{79}$ presencing-absolutising-identitive-constitutedness ${ }^{14} \quad<$ preconverging ' $m o t i f-$ and-apriorising/axiomatising/referencing'-entailing >-existentialisingenframing/imprintedness-〈as-to- historicity-tracing - in-presencinghyperrealisation/hyperreal-transposition $\rangle$ for the possibility of reontologisation/omnipotentiality (and it is such a conceptivity/epistemic-reflexivity/epistemicityrelativism-determinism-<reifying \{as-to-knowledge-developing $\}$-and-empowering $>$ underlied by distantiation that is behind a Rousseauist noble-savage conception not necessarily by implying that the noble-savage is punctually/immediately of a positivism/rational-empiricism 
mental-projection for instance but rather of an equivalent human potential self-becoming/selfconflatedness $^{13}$ /formative-supererogating-<projective/reprojective-aestheticising-re-motifand-re-apriorising/re-axiomatising/re-referencing,-in-perspective-ontologicalnormalcy/postconvergence $>$ thus with the latter construed as the more essential definition of humanity as from ' nonpresencing-<perspective-ontological-normalcy/postconvergence> notion of supererogatory-progressivity'). Insightfully, this points out that the very exercise of making-available/opening-up prospective knowledge as of organic-knowledge is inevitably tied down to the exercise of underlining simultaneously a prospective threshold of pedantising/muddling/formulaic-hollowing-out — in-subontologisation/subpotentiation〈blurring/undermining-of-prospective-totalising-entailing,-as-to-entailing$<$ amplituding/formative-epistemicity>totalising in-relative-ontological-completeness $>$ and associated epistemic-decadence (but then the detachment and lesser 'emotional-involvement' with regards to nascent-particular/incipient-and-material/technical-sublimations- $<$ blinded-totheir-relative-ontological-completeness - reference-of-thought- devolving $>$ renders such an exercise less problematic than with regards to the imposing/impostoring self-presence/self-

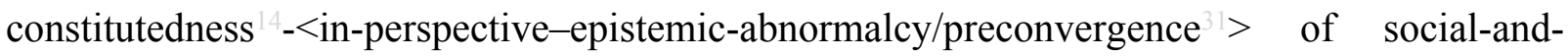
institutional-frameworks-of — referencing/registering/decisioning existentialising-decisionality<as-to-disontologising/re-ontologising aporeticism $>$ prone to ${ }^{79}$ presencing-absolutisingidentitive-constitutedness $^{14}$ ). Thus the genuine social intellectual-function/posture is ever always about emphasising the ontological-veracity of human knowledge rather constrained to existence — as-sublimating-withdrawal/unenframing/re-ontologising,-elicited-fromprospective-profound-supererogation for prospective human reontologisation/omnipotentiality the remoteness to punctual/immediacy/constituted/compulsions-encumbered human social-stake-contention-orconfliction ${ }^{79}$ presencing_absolutising-identitive-constitutedness ${ }^{14} \quad<$ preconverging $\sim$ 'motif- 
and-apriorising/axiomatising/referencing'-entailing>-existentialising-

enframing/imprintedness-〈as-to- historicity-tracing - in-presencing-

hyperrealisation/hyperreal-transposition $\rangle)$ as this is exactly what makes-available/keeps-open prospective human sublimating-nascence (as a requisite sublimation-over-desublimation function/posture that is most important and cannot be allowed to be undermined by the immediacy-driven/nombrilistic positive-opportunism—of-social-functioning-and-accordance of ${ }^{79}$ presencing-absolutising-identitive-constitutedness ${ }^{14}$ social-vestedness/normativity$<$ discretely-implied-functionalism $>$ ) and so especially in opening-up prospective registryworldviews/dimensions as to human Being-development/ontological-framework-expansion-asto-depth-of-ontologising-development-as-infrastructure-of- meaningfulness-and-teleology psychologismic epistemic-acutisation - difficulty-for, residualising \{decompulsing\} delinearity for-cogeney>-magnitude\{of-experientiality/experiment\} and the positiveopportunism-of-social-functioning-and-accordance ${ }^{75}$ then arising with the corresponding institutional-development-as-to-social-function-development and living-development-as-topersonality-development psychologismic epistemic acutisation difficulty-<or, residualising \{decompulsing\} delinearity-for-eogency>-magnitudes $\{$ of-experientiality/experiment\}. In this regards, the notion of dimensionality-of-sublimating <<amplituding/formative>supererogatory $\sim$ de-mentativeness/epistemic-growth-orconflatedness /transvaluative-rationalising/transepistemicity/anamnestic-residuality/spiritdrivenness-equalisation) associated with the genuine social intellectual-function/posture notional $\sim$ self-distantiation- $<$ imbued—re-motif-and-re-apriorising/re-axiomatising/rereferencing $>/$ 'distantiation of contemplative existentialising-frame-of-entailment-of motifand-apriorising/axiomatising/referencing as to transversality-<for-sublimating-existentialeventuating/denouement,-from-'thinking at-first/pure-predisposition-preemptive-of- 
and-unaffirmed-'motif-and-apriorising/axiomatising/referencing'> implies that the-verysame instigative firstnaturedness-as-to-inkling intemporal-disposition originariness-parrhesia,-as-spontaneity-of-aestheticisation gesturing-of-sublimation-over-desublimation 'that is ever always lost prospectively to all habituated secondnatured institutionalisation as to their presencing - absolutising-identitive-constitutedness ${ }^{14} \quad$ social-vestedness/normativity<discretely-implied-functionalism>', is the-very-same intemporal-disposition originarinessparrhesia,-as-spontaneity-of-aestheticisation gesturing-of-sublimation-over-desublimation that is warranted and ontologically-valid for prospective human emancipation/sublimation with the contention that claims from the 'distractive-alignment-to- ${ }^{-}$reference-of-thought- $<$ofapriorising/axiomatising/referencing $>30$ pedantising/muddling/formulaic-hollowing-out—insubontologisation/subpotentiation-〈blurring/undermining-of-prospective-totalising-entailing,as-to-entailing-<amplituding/formative-epistemicity $>$ totalising in-relative-ontologicalcompleteness $>$ of the various registry-worldviews/dimensions' are 'exactly non-responsible' for the possibility of their priorly-educed as well as prospective sublimation/emancipation (in reflection of their pedantising/muddling/formulaic-hollowing-out-insubontologisation/subpotentiation-〈blurring/undermining-of-prospective-totalising-entailing,as-to-entailing-<amplituding/formative-epistemicity $>$ totalising in-relative-ontologicalcompleteness > dimensionality-of-desublimating-lack-of ${ }^{-}$ <<amplituding/formative>supererogatory $\sim$ de-mentativeness/epistemic-growth-orconflatedness /transvaluative-rationalising/transepistemicity/anamnestic-residuality/spiritdrivenness-equalisation) ) as failing to reflect holographically-<conjugatively-andtransfusively $>$ the relative-unreflexivity/relative-reflexivity - ontological-contiguity ${ }^{67}$ of-thehuman-institutionalisation-proces. Critically, the genuine social intellectual-function/posture is thus much more than just about identitive specificities of ${ }^{79}$ presencing-absolutising-identitiveconstitutedness 
entailing >-existentialising — enframing/imprintedness-〈as-to- historicity-tracing — in-

presencing-hyperrealisation/hyperreal-transposition〉 as to just contrastive and balancingout/equinamity conception of sublimation-over-desublimation as to the-very-same $<$ preconverging 'motif-and-apriorising/axiomatising/referencing'-entailing >-

existentialising — enframing/imprintedness-〈as-to- historicity-tracing —in-presencing-

hyperrealisation/hyperreal-transposition) psychological-complexes (as so-associated with fairness/equanimity advocacy) but projects of an altogether renewed momentousness of $<$ postconverging 'motif-and-apriorising/axiomatising/referencing'-entailing $>$ -

existentialising - framing/imprinting-〈as-to-prospective- historiality/ontological-

eventfulness /ontological-aesthetic-tracing-<perspective-ontological-

normalcy/postconvergence-reflected-'epistemicity-relativism-determinism'>> in re-originaryas-unenenframed/re-ontologising/unbeholdening/outlier-conceptualisation-_imbuedpostconverging/dialectical-thinking -'projective-insights'/‘epistemic-projection-inconflatedness '-of-notional deprocrypticism-prospective-sublimation $\rangle$; such that in effect (as can be appreciated more candidly with the truly cumulative nature of the natural sciences as to $\quad{ }^{4}$ historiality/ontological-eventfulness $3 \%$ ontological-aesthetic-tracing-<perspectiveontological-normalcy/postconvergence-reflected-‘epistemicity-relativism-determinism’>) the genuine social intellectual-function/posture is of most profound-supererogation about relaying a ${ }^{55}$ maximalising-recomposuring-for-relative-ontological-completeness ${ }^{87}$ - unenframed/reontologising conceptualisation for human re-ontologisation/omnipotentiality across the $<$ cumulating/recomposuring attendant-ontological-contiguity $>$-succession of registryworldviews/dimensions so-underlined as to dimensionality-of-sublimating ${ }^{25}$ <<amplituding/formative>supererogatory $\sim$ de-mentativeness/epistemic-growth-orconflatedness /transvaluative-rationalising/transepistemicity/anamnestic-residuality/spiritdrivenness-equalisation) (and we can appreciate that the 
mentativity 'are not in a contrastive equivalence relation' between the 'prior registryworldview's/dimension's ${ }^{79}$ presencing-absolutising-identitive-constitutedness ${ }^{14}$ of socialstake-contention-or-confliction' and the 'prospective registry-worldview's/dimension's nonpresencing-<perspective-ontological-normalcy/postconvergence $>\quad$ social-stakecontention-or-confliction' given that the latter utterly redefines the existentialising-frame-ofentailment of motif-and-apriorising/axiomatising/referencing for human sublimation/emancipation over prior desublimation/gimmickiness conception explaining why it 'is reflective of ${ }^{4}$ historiality/ontological-eventfulness ${ }^{3} /$ ontological-aesthetic-tracing$<$ perspective-ontological-normalcy/postconvergence-reflected-‘epistemicity-relativismdeterminism'> as to the-very-same-immanent-existence/intrinsic-reality/ontologicalveridicality,-as-to-'human<amplituding/formative-epistemicity $>$ totalising $\sim$ purview-ofconstrual as of human limited-mentation-capacity-deepening-as-subjectinglimitedness/human-subpotency to-'educed-unlimitedness/existence-sublimating nascence'53, while the former rather 'is reflective of ${ }^{47}$ historicity-tracing-in-presencinghyperrealisation/hyperreal-transposition as to a <mplituding/formativeepistemicity $>$ totalising $\sim$ self-referencing-syncretising/circularity/interiorising/akrasiatic-drag that is poorly contemplative of the-very-same-immanent-existence/intrinsic-reality/ontologicalveridicality,-as-to-'human<amplituding/formative-epistemicity>totalising $\sim$ purview-ofconstrual warrant for human limited-mentation-capacity-deepening-as-subjecting limitedness/human-subpotency-to-'educed-unlimitedness/existence-sublimating nascence' ${ }^{53}$ '); so-underlying the contrast that ${ }^{4}$ historiality/ontological-eventfulness ${ }^{3} /$ ontological-aesthetictracing-<perspective-ontological-normalcy/postconvergence-reflected-'epistemicityrelativism-determinism'> implications of nascent-particular/incipient-and-material/technical- 
sublimations-<blinded-to-their-relative-ontological-completeness - reference-of-thought-

devolving $>$ are relatively readily appraised as to their relative-ontological-completeness while historiality/ontological-eventfulness 38 ontological-aesthetic-tracing-<perspectiveontological-normalcy/postconvergence-reflected-'epistemicity-relativism-determinism' implications of human social-and-institutional-frameworks-ofreferencing/registering/decisioning existentialising-decisionality-<as-to-disontologising/reentologising aporeticism $>$ are rather prone to ${ }^{79}$ presencing-absolutising-identitiveconstitutedness $^{14}$ are prone to relative-ontological-incompleteness ${ }^{88}$ distortedoriginariness/distorted-origination historicity-tracing_-in-presencinghyperrealisation/hyperreal-transposition. What is thus implied herein as most critical about the human and humanity is the capacity for profound-supererogation (as to human limitedmentation-capacity-deepening —as-subjecting limitedness/human-subpotency-to-'educedunlimitedness/existence-sublimating nascence' ${ }^{3}$ implication of ${ }^{6}$ nonpresencing-<perspectiveontological-normalcy/postconvergence $>$ ) and so 'more than just a positive-opportunism—ofsocial-functioning-and-accordance ${ }^{75}$ relation to ${ }^{56}$ meaningfulness-and-teleology ${ }^{9}$ as of the registry-worldview/dimension station/locus of <amplituding/formative-epistemicity $>$ totalising $\sim$ thrownness-in-existence ${ }^{35}$,-imbued-projective-arbitrariness/waywardness-〈as-to-thehuman-projective/reprojective- aestheticising-re-motif-and-re-apriorising/re-axiomatising/rereferencing-process-of- ‘ $<$ amplituding/formative-epistemicity $>$ totalising $\sim$ conceptualisation’’ in preconverging-existential-extrication-as-of-existential-unthought. Fundamentally, the 'contrastive inequivalence relation' implied as of notional $\sim$ self-distantiation-<imbued-remotif-and-re-apriorising/re-axiomatising/re-referencing $>/$ 'distantiation of contemplative existentialising-frame-of-entailment-of-motif-and-apriorising/axiomatising/referencing as to transversality-<for-sublimating-existential-eventuating/denouement,-from-'thinking at- 
prospectively-disambiguated-affirmed-and-unaffirmed-'motif-and-

apriorising/axiomatising/referencing' $>101$ is critically the 'manifestation of the very ontologicalnormalcy/postconvergence nature of existence but for the confusion of human limitedmentation-capacity—as-subjecting 'educed-unlimitedness/existence-sublimating nascence' to-limitedness/human-subpotency induced $\quad{ }^{79}$ presencing-absolutising-identitiveconstitutedness $^{1,}$. Thus in effect notional $\sim$ self-distantiation- $<$ imbued-re-motif-and-reapriorising/re-axiomatising/re-referencing $>$ actually reflects the reality of human limitedmentation-capacity-deepening —as-subjecting limitedness/human-subpotency-to-'educedunlimitedness/existence-sublimating nascence' ${ }^{33}$ (rather than truly of diagonal contrast with distractive-alignment-to- ${ }^{8}$ reference-of-thought- $<$ of-apriorising/axiomatising/referencing $>{ }^{30}$ ), and so in the sense that existence as of its ontological-normalcy/postconvergence is unbeholdening to human limited-mentation-capacity-as-subjecting 'educedunlimitedness/existence-sublimating nascence' to-limitedness/human-subpotency (as to its $<$ amplituding/formative-epistemicity $>$-totalising $\sim$ thrownness-in-existence ${ }^{35}$,-imbuedprojective-arbitrariness/waywardness-〈as-to-the-human-projective/reprojectiveaestheticising-re-motif-and-re-apriorising/re-axiomatising/re-referencing-process-of'<amplituding/formative-epistemicity $>$ totalising conceptualisation' $\rangle$ ) which beholdening 'wrongly projects a contrastive equivalence relation' between notional $\sim$ self-distantiation$<$ imbued - re-motif-and-re-apriorising/re-axiomatising/re-referencing $>$ and distractivealignment-to- ${ }^{8}$ reference-of-thought- $<$ of-apriorising/axiomatising/referencing $>30 ; \quad$ as $\quad$ rather notional $\sim$ self-distantiation- $<$ imbued—re-motif-and-re-apriorising/re-axiomatising/re-

referencing $>$ is a 'submission-to and making-up-to existence's ontologicalnormalcy/postconvergence' as to when relative-ontological-completeness ${ }^{87}$ is-educed-andavails-and-re-avails (and not a contrastive equivalence 'submission-to and making-up-to human-subpotency epistemic-abnormalcy/preconvergence ${ }^{3,}$ in relative-ontological- 
incompleteness ${ }^{88}$ as wrongly implied with distractive-alignment-to- ${ }^{8}$ reference-of-thought- $<$ ofapriorising/axiomatising/referencing $>^{30}$, thus speaking rather of the psychoanalyticunshackling/memetic-reordering/institutional-recomposuring that accompanies existencepotency ${ }^{39} \sim$ sublimating-nascence,-disclosed-from-prospective-epistemic-digression. $\quad$ In this respect, we can appreciate that appropriate notional $\sim$ self-distantiation- $<$ imbued - re-motif-andre-apriorising/re-axiomatising/re-referencing $>$ is effectively what is bound to bring about momentous historiality/ontological-eventfulness 38 /ontological-aesthetic-tracing$<$ perspective-ontological-normalcy/postconvergence-reflected-'epistemicity-relativismdeterminism'> as to a human genuine social intellectual-function/posture (underlied by ontological-commitment ${ }^{6}<$ implied_-self-assuredness-of-ontological-good-

\section{faith/authenticity $\sim$ postconverging-de-mentating/structuring/paradigming -as-being-as-of-}

existential-reality>) wherein without such a 'submission-to and making-up-to existence's ontological-normalcy/postconvergence' the transition say between classical-mechanicsaxiomatic-constructs and theory-of-relativity-together-with-quantum-mechanics-axiomaticconstructs would have been problematic (if the proponents of the former as of human institutional social-stake-contention-or-confliction adopted a distractive-alignment-toreference-of-thought- $<$ of-apriorising/axiomatising/referencing $>$ as to a contrastive equivalence 'submission-to and making-up-to human-subpotency epistemicabnormalcy/preconvergence $^{3,}$ in relative-ontological-incompleteness ${ }^{88}$, but then the very healthy intellectual environment meant that even the proponents of the superseded classicalmechanics-axiomatic-constructs were already involved in a healthy notional selfdistantiation- $<$ imbued - re-motif-and-re-apriorising/re-axiomatising/re-referencing $>$ that would be receptive to such an eventual ' nonpresencing-<perspective-ontologicalnormalcy/postconvergence $>$ anarchistic-growth/anarchisation-for-re-ontologisation-〈as-toconscious/unconscious epistemically-sound induced 'demoronisation-<sublimating-nascence,-- 
conception of residual_re-originary_anarchistic incipiency of human social-functioning-andaccordance-as-of-social-stake-contention-or-confliction meaningfulness-and-teleology ' $\rangle$ ') while in contrast such transformation implied (with respect to the relative blurriness$<$ sterilising/anecdotalising/trivialising-of-prospective-re-ontologising_by-preconverging,-indisontologising-formulaic-dragging-out/hollowing-out> of 'social-and-institutionalframeworks-of — referencing/registering/decisioning existentialising-decisionality-<as-todisontologising/re-ontologising aporeticism $>$ as to immaterial/social overall relativeontological-incompleteness ${ }^{8}$-presublimation-construct-of- ${ }^{5}$ meaningfulness-and-teleology ${ }^{9}$ eliciting ontologically-flawed distractive-alignment-to- ${ }^{3}$ reference-of-thought- $<$ ofapriorising/axiomatising/referencing $>{ }^{30}$ as of a contrastive equivalence 'submission-to and making-up-to human-subpotency epistemic-abnormalcy/preconvergence ${ }^{3,}$ in relativeontological-incompleteness ${ }^{8}$ ) has tended to be relatively problematic inducing desublimating pedantising/muddling/formulaic-hollowing-out - in-subontologisation/subpotentiation〈blurring/undermining-of-prospective-totalising-entailing,-as-to-entailing$<$ amplituding/formative-epistemicity>totalising in-relative-ontological-completeness $>$ as can be appreciated with the <cumulating/recomposuring attendant-ontological-contiguity >successive registry-worldviews/dimensions reference-of-thought postconverging aporeticism-overcoming/unovercoming. Supererogation as such (as soundergirded by notional $\sim$ self-distantiation- $<$ imbued-re-motif-and-re-apriorising/reaxiomatising/re-referencing $>/$ 'distantiation of contemplative existentialising-frame-ofentailment-of-motif-and-apriorising/axiomatising/referencing as to transversality-<forsublimating-existential-eventuating/denouement,-from-'thinking-at-first/pure-predispositionpreemptive-of prospective-disontologising/subontologising' as-of-prospectively- 
is actually the very essential epistemicity attribute of the full-potency of existence, and it is so underlined by the perspective ontological-normalcy/postconvergence veracity of existence as to phenomenal/manifest $\sim$ subpotencies-〈in-transitive-conflatedness -reflexivity,-in-the-fullpotency-of-existence's $\sim$ sublimating-nascence) supervening manifestations in notional conflatedness ${ }^{13}$ (as <amplituding/formative-epistemicity $>$ causality $\sim$ as-to-projectivetotalitative-implications-of-prospective- nonpresencing,-for-explicating relativeunreflexivity/relative-reflexivity - ontological-contiguity ), so-reflected in the fact that while physics principles explain physical phenomena, their reflection in chemical processes speaks to the overall chemistry supervening determination (explaining why chemistry is effectively practiced in its phenomenal conceptivity/epistemic-reflexivity/epistemicity-relativismdeterminism-<reifying \{as-to-knowledge-developing\}-and-empowering $>\quad$ of supervening/supererogating apriorising/axiomatising/referencing-\{of- prospectively implicited_attendant-ontological-contiguity ' educedexistentialising/contextualising/textualising_'intelligibility/epistemicity/reflexivity_contiguity<imbued-notional cogency >' $\}$-conflatedness ${ }^{13}$-in-\{preconverging-ment-by\} pestcenverging-entailment and not as to constitutive physics even as physics relevant insights are then reconstrued in epiphenomenal terms as to chemistry supervening), just as the reflection of chemical processes in biological phenomena speaks to the overall biological supervening determination (explaining why biology is effectively practiced in its phenomenal conceptivity/epistemic-reflexivity/epistemicity-relativism-determinism-<reifying \{as-toknowledge-developing -and-empowering $>\quad$ of supervening/supererogating apriorising/axiomatising/referencing-\{of-'prospectively_implicited_attendant-ontologicalcontiguity ' $\sim$ educedexistentialising/contextualising/textualising_'intelligibility/epistemicity/reflexivity-contiguity-

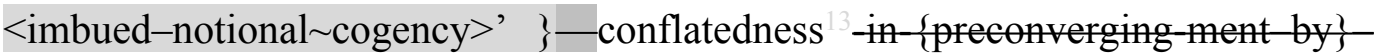


postconverging-entailment and not as to constitutive chemistry even as chemistry relevant insights are then reconstrued in epiphenomenal terms as to biology supervening) and likewise the reflection of biological and neurological embodiment processes in human and social consciousness speaks to an overall consciousness supervening determination (explaining why the human and social sciences are effectively practiced in phenomenal conceptivity/epistemicreflexivity/epistemicity-relativism-determinism- $<$ reifying \{as-to-knowledge-developing $\}$-andempowering $>$ of supervening/supererogating apriorising/axiomatising/referencing- $\{$ of'prospectively_implicited_attendant-ontological-contiguity ' educedexistentialising/contextualising/textualising_'intelligibility/epistemicity/reflexivity-contiguity-

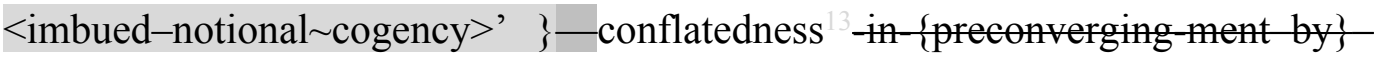
pestconverging-entailment and not as to constitutive biology and neurology even as biology and neurology relevant insights are then reconstrued in epiphenomenal terms as to human and social sciences supervening), and such secondary epiphenomenalities as of various levels of phenomenal/manifest $\sim$ subpotencies-〈in-transitive-conflatedness -reflexivity,-in-the-fullpotency-of-existence's $\sim$ sublimating-nascence) critically explains existence's 'phenomenalityby-epiphenomenalities supervening-as-supererogating imbued superseding-oneness-ofontology' (as so-epistemically underlying

supererogatery acuity/perspicacity/astuteness/edginess/incisiveness-ofapriorising/axiomatising/referencing/intelligibilitysettingup/measuringinstrumenting -forconceptualisation as to postconverging-de-mentating/structuring/paradigming effective transcendence-and-sublimity/sublimation/supererogatory $\sim$ de-mentativity). For that matter ineffect all such subject-matters are actually for-human-studies/for-human-constructs of conceptivity/epistemic-reflexivity/epistemicity-relativism-determinism- $<$ reifying \{as-toknowledge-developing\}-and-empowering> as to 'human consciousness point-of-departure for their knowledge-reification $\sim$ gesturing-and-accounting-of-epistemic-phenomenalism- $<$ in- 
prospective_psychologismic apriorising/axiomatising/referencing-\{of- ${ }^{\text {prospectively }}$

implicited_attendant-ontological-contiguity ' educed-

existentialising/contextualising/textualising_'intelligibility/epistemicity/reflexivity-contiguity-

$<$ imbued-notional cogency >' \}-conflatedness -in-\{preconverging-ment by\}

postconverging-entailment> and appraisal'), and so as the more 'empirically exact' supererogatory acuity/perspicacity/astuteness/edginess/incisiveness conception of overall science reflection of the full-potency of existence (with the implication here that it is human genuine social intellectual-function/posture as to human consciousness supervening-assupererogating determination that hold the sublimating-over-desublimating key for prospective re-ontologisation/omnipotentiality as of human conceptivity/epistemic-reflexivity/epistemicityrelativism-determinism- $<$ reifying \{as-to-knowledge-developing $\}$-and-empowering $>$ ); as to the fact that the enlightening ushered as of intemporal firstnaturedness-as-to-inkling across the <cumulating/recomposuring attendant-ontological-contiguity $>$-successive registryworldviews/dimensions and reflected sparingly/thinly with the Socrates, Copernicuses, Galileos, Descartes, Kants, Newtons, Leibniz, Rousseaux, Diderots, Pasteurs, Lavoisiers, Teslas, Einsteins, etc. as to their <postconverging 'motif-and-apriorising/axiomatising/referencing'entailing >-existentialising — framing/imprinting-〈as-to-prospective- historiality/ontologicaleventfulness /ontological-aesthetic-tracing-<perspective-ontologicalnormalcy/postconvergence-reflected-‘epistemicity-relativism-determinism'>> (but more expansively translated as to human intemporal-individuation dynamics of Beingdevelopment/ontological-framework-expansion-as-to-depth-of-ontologising-development-asinfrastructure-of- meaningfulness-and-teleology , institutional-development-as-to-socialfunction-development and living-development-as-to-personality-development psychologismic epistemic-acutisation difficulty-for, residualising \{decomplsing $\}$ delinearity for-cogency> magnitudes ${ }^{\text {of-experientiality/experiment }\}}$ induced human-subpotency 'fatedness-of-sublimation-over- 
desublimation to existence-potency $\sim$ sublimating-nascence,-disclosed-from-prospectiveepistemic-digression in reflecting holographically-<conjugatively-and-transfusively $>$ the relative-unreflexivity/relative-reflexivity - ontological-contiguity of-the-human-

institutionalisation-process ') are the more 'decisively empirical reason' for human sublimation-over-desublimation than any vague conceptions of inoperant and imaginary notional-constitutedness ${ }^{14}$ potency of shallow-supererogation ${ }^{96}$ with the implication that our own self-conscious conceptivity/epistemic-reflexivity/epistemicity-relativism-determinism$<$ reifying \{as-to-knowledge-developing\}-and-empowering $>$ as herein implied (as of prospective 'relative-ontological-incompleteness 8 /relative-ontological-completeness 〈sublimating $\sim$ referencing/registering/decisioning,-as-self-becoming/selfconflatedness /formative-supererogating-<projective/reprojective-aestheticising-re-motifand-re-apriorising/re-axiomatising/re-referencing,-in-perspective-ontologicalnormalcy/postconvergence $>>$ as to human-and-social-expectations/anticipationsmetaphoricity ${ }^{57}$-as-preconverging/postconverging-redementating/restructuring/reparadigming-psychologism' ${ }^{89}$ ) is the most critical supererogatory acuity/perspicacity/astuteness/edginess/incisiveness notion for prospective human sublimation-over-desublimation. Critically, supererogation as to undergirding notional $\sim$ self-distantiation- $<$ imbued—re-motif-and-re-apriorising/re-axiomatising/rereferencing $>\quad$ imbued psychoanalytic-unshackling/memetic-reordering/institutionalrecomposuring self-becoming/self-conflatedness ${ }^{13}$ /formative-supererogating$<$ projective/reprojective - aestheticising-re-motif-and-re-apriorising/re-axiomatising/rereferencing,-in-perspective-ontological-normalcy/postconvergence $>$ speaks to the more fundamental element of human-subpotency that is 'human effecting' (notionally construed as from perspective ontological-normalcy/postconvergence epistemic-projection), as herein notionally reflected 'as to apriorising/axiomatising/referencing-\{of-'prospectively- 
implicited_attendant-ontological-contiguity ' educed-

existentialising/contextualising/textualising_'intelligibility/epistemicity/reflexivity_contiguity<imbued-notional cogency $>$ ' $\}$-constitutedness ${ }^{14}$-in-preconverging-entailment (effectingparsimony-as-of-shoddiness-and-incompleteness-to- ${ }^{5}$ meaningfulness-and-teleology ${ }^{9}$ ) and apriorising/axiomatising/referencing-\{of-'prospectively_implicited_attendant-ontologicalcontiguity ' educed-

existentialising/contextualising/textualising_intelligibility/epistemicity/reflexivity_contiguity<imbued-notional cogency $>$ ' $\}$ - conflatedness ${ }^{13}$ in-\{preconverging-ment by \} $^{\prime}$ postconverging-entailment(effecting-wholeness-as-of-profoundness-and-completeness-tomeaningfulness-and-teleology $\left.{ }^{\circ}\right)^{\prime}$. The undergirding notional $\sim$ self-distantiation- $<$ imbued-remotif-and-re-apriorising/re-axiomatising/re-referencing $>$ derivation involved in supererogation can be appreciated from a transcendence-andsublimity/sublimation/supererogatory $\sim$ de-mentativity insight, wherein for instance individuals notional $\sim$ self-distantiation- $<$ imbued—re-motif-and-re-apriorising/re-axiomatising/rereferencing $>$ (beyond-the-consciousness-awareness-teleology ${ }^{9}<$ of-preconverging-existentialextrication-as-of-existential-unthought $>$ ) say in a non-positivistic like an animistic social-setup notionally implies a < as to the animistic apriorising/axiomatising/referencing-\{of- prospectively implicited_attendant-ontological-contiguity ' reducedexistentialising/contextualising/textualising_intelligibility/epistemicity/reflexivity_contiguity$<$ imbued-notional cogency>' $\}$-relation-to-the-world conceptivity/epistemicreflexivity/epistemicity-relativism-determinism-<reifying \{as-to-knowledge-developing $\}$-andempowering>' (which will define such an animistic social-setup conception of 'psychological placeboic-palliation practice associated with its warped-consciousness occultisms mentalaestheticisation - architectonically-consigning-aestheticised-perceptibility-and-disposition 
apriorising/axiomatising/referencing-\{of-'prospectively_implicited_attendant-ontological-

contiguity ' educed-

existentialising/contextualising/textualising_intelligibility/epistemicity/reflexivity-contiguity-

$<$ imbued-notional cogency $>$ ' $\}$-relation-to-the-world' along the same lines of our modernday 'positivistic psychological science' which it is herein contended as well is rather of a 'psychological placeboic-palliation practice as of an occlusive-consciousness which by its mental-aestheticisation - architectonically-consigning-aestheticised-perceptibility-and-

disposition apriorising/axiomatising/referencing-\{of-'prospectively implicited_attendantontological-contiguity ' educed-

existentialising/contextualising/textualising_'intelligibility/epistemicity/reflexivity-contiguity<imbued-notional cogency>' $\}$-relation-to-the-world occludes its fundamental preconverging/postconverging-de-mentative/structural/paradigmatic social-construct deficiencies that can be reflected upon as of prospective notional $\sim$ self-distantiation- $<$ imbuedre-motif-and-re-apriorising/re-axiomatising/re-referencing $>$ as from prospective deprocrypticism-or-preempting-disjointedness-as-of- ${ }^{8}$ reference-of-thought protensiveconsciousness'); as to the fact that a typical individual of a 'psychosomatic reactivity positivistic apriorising/axiomatising/referencing-\{of-'prespectively implieited_attendant-ontologicalcontiguity ' educedexistentialising/contextualising/textualising_ intelligibility/epistemicity/reflexivity-contiguity<imbued-notional cogency>' $\}$-relation-to-the-world conceptivity/epistemicreflexivity/epistemicity-relativism-determinism-<reifying \{as-to-knowledge-developing $\}$-andempowering>' will be psychosomatically unresponsive to such a non-positivistic 'psychological placeboic-palliation practice associated with its warped-consciousness occultisms mentalaestheticisation - architectonically-consigning-aestheticised-perceptibility-and-disposition apriorising/axiomatising/referencing-\{of-'prospectively implicited_attendant-ontological- 
contiguity ' educed-

existentialising/contextualising/textualising_'intelligibility/epistemicity/reflexivity_contiguity<imbued-notional cogency>' $\}$-relation-to-the-world' so-underlied by its unresponsiveness to the animistic social-setup motif-and-apriorising/axiomatising/referencing-psychologism imbued preconverging/dementing ${ }^{20}$-qualia-schema' (so-construed as from prospective positivism/rational-empiricism occlusive-consciousness motif-andapriorising/axiomatising/referencing-psychologism imbued postconverging/dialecticalthinking -qualia-schema'), and so just as along the same lines of appropriate prospective notional $\sim$ self-distantiation-<imbued—re-motif-and-re-apriorising/re-axiomatising/rereferencing $>$ arising from profound contemplation and understanding of the underlying $<$ amplituding/formative-epistemicity $>$ totalising $\sim$ self-referencingsyncretising/circularity/interiorising/akrasiatic-drag ${ }^{34}$ (reflecting the "psychological placeboicpalliation practice as of an occlusive-consciousness mental-aestheticisation - architectonicallyconsigning-aestheticised-perceptibility-and-disposition apriorising/axiomatising/referencing\{of-'prospectively_implicited_attendant-ontological-contiguity ' ceducedexistentialising/contextualising/textualising_'intelligibility/epistemicity/reflexivity-contiguity<imbued-notional cogency>' \}-relation-to-the-world') defining our positivismprocrypticism prospectively uninstitutionalised-threshold ${ }^{102}$ in ${ }^{80}$ procrypticism-ordisjointedness-as-of- ${ }^{8}$ reference-of-thought as to its social-setup motif-andapriorising/axiomatising/referencing-psychologism imbued preconverging/dementing 2 qualia-schema' (as so-construed rather as from prospective ${ }^{18}$ deprocrypticism-or-preemptingdisjointedness-as-of- ${ }^{8}$ reference-of-thought protensive-consciousness motif-andapriorising/axiomatising/referencing-psychologism imbued postconverging/dialecticalthinking -qualia-schema'). In this regards, an elaborate grasp/understanding of our positivismprocrypticism modern-day 'psychological science' in its various institutional setups of 
presencing-absolutising-identitive-constitutedness ${ }^{14}$ purposes as to social-functioning-andaccordance-as-of-social-stake-contention-or-confliction like 'occluding ${ }^{83}$ reference-ofthought- ${ }^{8}$ devolving' administrative, educational, marketing, psychoanalysis or even statal darkarts/ploys/gimmicks points out that in-the-bigger-scheme-of-things their 'apparently sublimating ontologising-depth' (as construed from a 'projected prospective ${ }^{18}$ deprocrypticismor-preempting - disjointedness-as-of- ${ }^{8}$ reference-of-thought $\quad{ }^{6}$ nonpresencing- $<$ perspectiveontological-normalcy/postconvergence $>$ sublimating apriorising/axiomatising/referencing-\{of'prospectively implicited_attendant-ontological-contiguity ' educedexistentialising/contextualising/textualising_ 'intelligibility/epistemicity/reflexivity-contiguity<imbued-notional cogency>' $\}$-relation-to-the-world) is critically about our positivismprocrypticism placeholder-setup/mental-devising-representation/mentation/consciousnessawareness-teleology 9 occlusive-consciousness obliviousness to its prospectively uninstitutionalised-threshold $<$ preconverging $\sim$ 'motif-andapriorising/axiomatising/referencing'-entailing>-existentialising-enframing/imprintedness〈as-to- historicity-tracing-in-presencing-hyperrealisation/hyperreal-transposition〉 desublimating implications of human psychology; wherein supposed 'psychological science' projection in 'stratagems of extricatory solutions considered of sublimating-existentialisingdecisionality' involving abstract 'mere-formulaicity/ritualisation-<as-to-mere-formulaic methodologising/mutualising/organising/institutionalising,-prospectively-losing-track-of‘fepistemicalising ’’re-apriorising/re-axiomatising/re-referencing $\sim$ residuality-in-reoriginariness/re-origination'> of science as science-ideology' and integrating scientific methods, statistics and mathematics but so-rather as to an 'incipient positivism- ${ }^{80}$ procrypticism occlusivity $\quad$ reference-of-thought- ${ }^{\text {devolving }}$ of shallow supererogatory acuity/perspicacity/astuteness/edginess/incisiveness as to totalisingly-ingdiscretion/whim-of-thought pretense-of-sublimation' so-paradoxically 'validate the very 
inherent manifest inherent preconverging-de-mentating/structuring/paradigming vices-andimpediments ${ }^{105} /$ limitations of our positivism- ${ }^{80}$ procrypticism registry-worldview's/dimension's (beyond-the-consciousness-awareness-teleology ${ }^{9}-<$ of - preconverging-existential-extricationas-of-existential-unthought>' in want for prospective sublimation as to 'incipient protensivity reference-of-thought- ${ }^{8}$ devolving of profound supererogatery acuity/perspicacity/astuteness/edginess/incisiveness' entailing$<$ amplituding/formative-epistemicity>totalising in-relative-ontological-completeness ${ }^{87}$ ). In this instance, just as in the case with the 'apparently sublimating ontologising-depth' as from an animistic society perception in its ${ }^{7}$ presencing-absolutising-identitive-constitutedness institutional setups warped occultism $\quad{ }^{83}$ reference-of-thought- ${ }^{8}$ devolving apriorising/axiomatising/referencing-\{of-'prospectively_implicited_attendant-ontologicalcontiguity ' educedexistentialising/contextualising/textualising_'intelligibility/epistemicity/reflexivity-contiguity<imbued-notional cogency>' \}-relation-to-the-world purposes as being of appropriate social-functioning-and-accordance-as-of-social-stake-contention-or-confliction, our positivism- ${ }^{80}$ procrypticism ${ }^{79}$ presencing-absolutising-identitive-constitutedness ${ }^{14}$ institutional setups occlusive ${ }^{83}$ reference-of-thought- ${ }^{8}$ devolving apriorising/axiomatising/referencing-\{of'prospectively implicited_attendant-ontological-contiguity ' educedexistentialising/contextualising/textualising_ intelligibility/epistemicity/reflexivity-contiguity<imbued-notional cogency>' $\}$-relation-to-the-world purposes of appropriate socialfunctioning-and-accordance-as-of-social-stake-contention-or-confliction is effectively enamoured to its psychological practices 'apparently sublimating ontologising-depth'; such that in both cases, their fundamental 'uninstitutionalised-threshold ${ }^{12}$ of social-functioning-andaccordance-as-of-social-stake-contention-or-confliction conception' (wherein arises the 'dereification threshold-of-nonconviction/madeupness/bottomlining-in-shallow- 
supererogation -<as-to-'attendant-intradimensional'-prospectively-

disontologising preconverging/dementing -apriorising-psychologism $>$ mental-disposition as of ontologically-flawed relation with prospective institutionalisation knowledgereification $\sim$ gesturing-and-accounting — of-epistemic-phenomenalism- $<$ in-

prospective_psychologismic apriorising/axiomatising/referencing-\{of-'prospectively implicited_attendant_ontological-contiguity ' educed-

existentialising/contextualising/textualising_intelligibility/epistemicity/reflexivity-contiguity$<$ imbued-notional cogency $>$ ' $\}$-conflatedness -in-\{preconverging ment by\} postconverging-entailment $><$ amplituding/formative-epistemicity $>$ causality $\sim$ as-to-projectivetotalitative-implications-of-prospective- nonpresencing,-for-explicating relativeunreflexivity/relative-reflexivity ontological-contiguity ') is effectively what allows for the possibility and avenue of their respective 'manifest existential-<disontologising/reentologising aporeticism $>$ and institutionalised desublimating pedantising/muddling/formulaic-hollowing-out — in-subontologisation/subpotentiation〈blurring/undermining-of-prospective-totalising-entailing,-as-to-entailing<amplituding/formative-epistemicity>totalising in-relative-ontological-completeness $>$ as well as generalised <amplituding/formative> wooden-language-〈imbued-temporal-mereform/virtualities/dereification/akrasiatic-drag/denatured/preconverging-or-dementing narratives - of-the- reference-of-thought- categorical-imperatives/axioms/registryteleology Y' (and critically this is exactly what renders the logical-basis/logic,-as-derivedfrom $\sim$ transversality- $<$ for-sublimating-existential-eventuating/denouement,from 'thinking atfirst/pure-predisposition - preemptive-of-prospective-disontologising/subontologising' as-ofprospectively-disambiguated-affirmed-and-unaffirmed-'motif-andapriorising/axiomatising/referencing' $>101$ of the respective 'prior secondnatured meaningfulness-and-teleology $\quad$ percolation-channelling- $<$ in-deferential-formalisation- 
transference>' irrelevant for prospective firstnatured knowledge-reification $\sim$ gesturing-andaccounting - of-epistemic-phenomenalism- $<$ in-

prospective_psychologismic apriorising/axiomatising/referencing-\{of-'prospectively implicited_attendant-ontological-contiguity ' reducedexistentialising/contextualising/textualising_'intelligibility/epistemicity/reflexivity-contiguity<imbued-notional cogency>' \}-conflatedness -in-\{preconverging-ment by\} postconverging-entailment $>$ renewed logical-basis/logic,-as-derived-from $\sim$ transversality- $<$ forsublimating-existential-eventuating/denouement,-from-'thinking-at-first/pure-predispositionpreemptive-of prospective-disontologising/subontologising' as-of-prospectivelydisambiguated-affirmed-and-unaffirmed-'motif-and-apriorising/axiomatising/referencing'> so-undertaken by the genuine social intellectual-function/posture as to prospective nonpresencing-<perspective-ontological-normalcy/postconvergence $>$ over the prior perspective epistemic-abnormalcy/preconvergence ${ }^{3}$, in reflection of human dimensionality-ofsublimating 25 -<<amplituding/formative $>$ supererogatory $\sim$ de-mentativeness/epistemic-growthor-conflatedness /transvaluative-rationalising/transepistemicity/anamnestic-residuality/spiritdrivenness-equalisation) for intemporal-preservation-entropy-or-contiguity-or-ontologicalpreservation enabling re-ontologisation/omnipotentiality for prospective secondnatured meaningfulness-and-teleology $\quad$ percolation-channelling- $<$ in-deferential-formalisationtransference $>$ ). Thus, in both instances inherent existence exudes of a deterministic constraining that is not of prospective apriorising/axiomatising/referencing-sublimating-reflexivitybeholdening to any given human registry-worldview/dimension ${ }^{79}$ presencing-absolutisingidentitive-constitutedness ${ }^{14}$ <preconverging 'motif-and-apriorising/axiomatising/referencing'entailing $>$-existentialising — enframing/imprintedness-〈as-to- historicity-tracing - inpresencing-hyperrealisation/hyperreal-transposition), with this constraining as of existencepotency ${ }^{32} \sim$ sublimating-nascence,-disclosed-from-prospective-epistemic-digression implying 
that it is the human placeholder-setup/mental-devising-representation/mentation/consciousnessawareness-teleology ${ }^{9}$ that adapts/adjusts to existence (and not the other way round as falsely projected with 'normalised/stereotyped/selfhelping/feel-good knowledge being brought at the protracted-social — as-to-individual-by-institutional-by-social sovereign's service') explaining

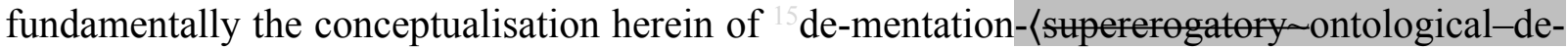
mentation-or-dialectical-de-mentation-stranding-or-attributive-dialectics $\rangle$ of human placeholder-setup/mental-devising-representation/mentation/consciousness-awarenessteleology ${ }^{9}$ as to ${ }^{83}$ reference-of-thought- ${ }^{-4}$ devolving apriorising/axiomatising/referencing-\{of'prospectively_implicited_attendant-ontological-contiguity ' ceducedexistentialising/entextualising/textraing_intelligibility/epistemicity/reflexivity-contiguity<imbued-notional cogency>' \}-relation-to-the-world as so-reflecting holographically$<$ conjugatively-and-transfusively $>$ the relative-unreflexivity/relative-reflexivity - ontologicalcontiguity $\sim$ of-the-human-institutionalisation-process . This reality is underlined by the fact that even budding practitioners of science like Newton were caught up preconverging/postconverging-de-mentatively/structurally/paradigmatically in-between/intransition-with a medieval alchemy and occultism as to non-positivising ${ }^{83}$ reference-of-thoughtdevolving apriorising/axiomatising/referencing-\{of-‘prospectively_implicited_attendantontological-contiguity ' educedexistentialising/contextualising/textualising_'intelligibility/epistemicity/reflexivity-contiguity<imbued-notional cogency>' \}-relation-to-the-world and the prospective budding positivism/rational-empiricism science reference-of-thought- ${ }^{8}$ devolving apriorising/axiomatising/referencing-\{of-'prospectively_implicited_attendant-ontologicalcontiguity ' $\sim$ educedexistentialising/contextualising/textualising_'intelligibility/epistemicity/reflexivity_contiguity<imbued-notional cogency>' \}-relation-to-the-world. The critical point here being about 
understanding the more profound veracity of human psychology as to '<supereregatory $\sim$ humansubpotency>-effecting self-becoming/self-conflatedness ${ }^{13}$ /formative-supererogating$<$ projective/reprojective - aestheticising-re-motif-and-re-apriorising/re-axiomatising/rereferencing,-in-perspective-ontological-normalcy/postconvergence $>$ of human notional $\sim$ selfdistantiation- $<$ imbued - re-motif-and-re-apriorising/re-axiomatising/re-referencing $>$ incipience of metaphoricity ${ }^{57}$ and then ${ }^{56}$ meaningfulness-and-teleology ${ }^{9}$ (as to superseding/transcending the 'uninstitutionalised-threshold ${ }^{02}$ of social-functioning-and-accordance-as-of-social-stakecontention-or-confliction conception in preconverging/dementing 20 -apriorising-psychologism' as so-represented above with say 'animistic warped occultism ${ }^{83}$ reference-of-thoughtdevolving' or our 'positivism- ${ }^{80}$ procrypticism occlusive ${ }^{83}$ reference-of-thought- ${ }^{8}$ devolving psychological science conception' or for that matter any given registry-worldview/dimension $<$ preconverging 'motif-and-apriorising/axiomatising/referencing'-entailing $>$ existentialising — enframing/imprintedness-〈as-to- historicity-tracing-in-presencinghyperrealisation/hyperreal-transposition)); in reflection of the fact that human 'social and individual consciousness is supererogatorily at the very driving seat of human psychology' as being about an altogether sublimating-postconverged 'substantive abstract-tissue-of-socialemanance \{epistemicthermeneutically/textually/reprojectingly/supererogatingly/zeroingly/re-acutingly,delinearity for-cogency — cumulated/recomposured as to cumulating/recomposuring of 'prospectively_implicited_attendant-ontological-contiguity ${ }^{67}$ ' educedexistentialising/contextualising/textualising_intelligibility/epistemicity/reflexivity-contiguity$<$ imbued-notional cogency>' (as to overall reifying-and-empowering-reflexivity-of-ecstaticexistence-as-panintelligibility/panreflexivity ${ }^{73}$-〈existentially-imbued-and-educing-< $<$ fepistemicthermeneutically/textually/reprojectingly/supererogatingly/zeroingly/re-acutingly,- 
aestheticising-re-motif-and-re-apriorising/re-axiomatising/re-referencing conceptualisation,-

as-herein-specifically-relevant-to human-subpotency)) built up by 'intemporal ontologicalfaith-notion-or-ontological-fideism —-imbued-underdetermination-of-motif-and-

apriorising/axiomatising/referencing-as-so-being-as-of-existential-reality instigated relativetnreflexivity/relative reflexivity ontological-contiguity ${ }^{67}$ of-the-human-institutionalisationprocess $^{6}$ as of difference-conflatedness ${ }^{13}$-as-to-totalitative-reification-in-singularisation- $<$ as-tothe-nondisjointedness/entailment-of-prospective- nonpresencing $>$-as-veridical-epistemicityrelativism-determinism implied $<$ amplituding/formative-epistemicity $>$ causality $\sim$ as-toprojective-totalitative-implications-of-prospective- nonpresencing,-for-explicating relativeunreflexivity/relative-reflexivity ontological-contiguity , underlying the institutionalcumulation/institutional-recomposure-〈as-to- historiality/ontologicaleventfulness /ontological-aesthetic-tracing-<perspective-ontologicalnormalcy/postconvergence-reflected-‘epistemicity-relativism-determinism'>>. The sublimating-postconverged 'substantive abstract-tissue-of-social-emanance \{epistemictotalising ${ }^{3}$ hermeneutically/texally/reprojectingly/supererogatingly/zeroing/y/re aentingly,\{decompulsing\} delinearity for-cogency — cumulated/recomposured as to cumulating/recomposuring of 'prospectively_implicited_attendant-ontological-contiguity ${ }^{67}$ educedexistentialising/contextualising/textmalising_intelligibility/epistemicity/reflexivity-contiguity$<$ imbued-notional cogency>' so-arises as to successive <postconverging 'motif-andapriorising/axiomatising/referencing'-entailing--existentialising-framing/imprinting-〈as-toprospective- historiality/ontological-eventfulness /ontological-aesthetic-tracing$<$ perspective-ontological-normalcy/postconvergence-reflected-'epistemicity-relativismdeterminism'>> speaking to the more profoundly veridical conception of human psychology as 'postconverging-or-dialectical-thinking -psychology or psychology-of-mentation-dynamics or natural psychological-dynamics'; as to a 'prospective nonpresencing-<perspective- 
ontological-normalcy/postconvergence $>$ sublimating apriorising/axiomatising/referencing-\{of'prospectively_implicited_attendant-ontological-contiguity ' educedexistentialising/contextualising/textualising_'intelligibility/epistemicity/reflexivity-contiguity<imbued-notional cogency>' \}-relation-to-the-world precedence in sublimatingly postconvergingly-de-mentating/structuring/paradigming human psychology' rather than a ${ }^{7}$ presencing-absolutising-identitive-constitutedness ${ }^{14}$ desublimating apriorising/axiomatising/referencing-\{of-'prospectively_implicited_attendant-ontologicalcontiguity ' $\sim$ educedexistentialising/contextualising/textualising_ 'intelligibility/epistemicity/reflexivity-contiguity<imbued-notional cogency>’ $\}$-relation-to-the-world precedence in desublimatingly/gimmickingly preconverging-de-mentating/structuring/paradigming human psychology as of placeboic-palliation', failing to factor in the psychological centrality of human ‘epistemic-growth/disquiet/discomfort-〈induced-sublimation,-as-from-existence’seffusing/ecstatic-inlining-as- historiality-\{science/authenticity/nonextrication $\}$-beyond-mereformulaicity/ritualisation-as- historicity-tracing-\{science-ideology/fashionability/distraction $\}$ ) as to construction-of-the-Self in dispensing-with-immediacy-for-relative-ontologicalcompleteness $^{87}$-by-reification/contemplative-distension ${ }^{27}$ that is incipient-to-and-cultivatingin-supererogation the sublimating-postconverged 'substantive abstract-tissue-of-socialemanance totalising ${ }^{3}$ hermeneutically/textmally/reprojectingly/supererogatingly/zeroingly/re-acutingly,${ }_{\{\text {decompulsing }\}}$ delinearity for-cogency—cumulated/recomposured as to cumulating/recomposuring of 'prospectively_implicited_attendant-ontological-contiguity ${ }^{67}$ educedexistentialising/contextmalising/textualising_intelligibility/epistemicity/reflexivity_contiguity$<$ imbued-notional cogency>' reflecting the 'momentous ${ }^{4}$ historiality/ontologicaleventfulness 3 /ontological-aesthetic-tracing-<perspective-ontological- 
normalcy/postconvergence-reflected-'epistemicity-relativism-determinism'> of human Beingdevelopment/ontological-framework-expansion-as-to-depth-of-ontologising-development-asinfrastructure-of- meaningfulness-and-teleology , institutional-development-as-to-socialfunction-development and living-development-as-to-personality-development psychologismic epistemic-acutisation difficulty-for, residualising \{decompulsing ${ }^{\text {f }}$ delinearity for-cogency> magnitudes \{of-experientiality/experiment\}'. The overall insight here is that the 'more profound apriorising/axiomatising/referencing-\{of-'prospectively_implicited_attendant-ontologicalcontiguity ' educedexistentialising/contextualising/textualising_intelligibility/epistemicity/reflexivity-contiguity<imbued-notional cogency >' \}-relation-to-the-world conceptivity/epistemicreflexivity/epistemicity-relativism-determinism-<reifying \{as-to-knowledge-developing $\}$-andempowering $>$ of human notional $\sim$ self-distantiation- $<$ imbued-re-motif-and-re-apriorising/reaxiomatising/re-referencing >' as to <supereregatery-human-subpotency>-effecting across the $<$ cumulating/recomposuring attendant-ontological-contiguity $>$-successive registryworldviews/dimensions (as from $\quad{ }^{61}$ nonpresencing-<perspective-ontologicalnormalcy/postconvergence $>$ epistemic-projection perspective) is what veridically underlies human psychology as 'postconverging-or-dialectical-thinking - psychology or psychology-ofmentation-dynamics or natural psychological-dynamics' (as superseding by such an underlying 'psychological $\quad{ }^{4}$ historiality/ontological-eventfulness ${ }^{3} /$ ontological-aesthetic-tracing$<$ perspective-ontological-normalcy/postconvergence-reflected-'epistemicity-relativismdeterminism' $>$ of notional $\sim$ self-distantiation- $<$ imbued-re-motif-and-re-apriorising/reaxiomatising/re-referencing >' all the successive overarching registry-worldviews/dimensions uninstitutionalised-threshold notional disjointedness of motif-andapriorising/axiomatising/referencing-psychologism imbued preconverging/dementing 20 qualia-schema' naively of their given <amplituding/formative-epistemicity $>$ totalising $\sim$ self- 
referencing-syncretising/circularity/interiorising/akrasiatic-drag ${ }^{34}$ in their ${ }^{79}$ presencingabsolutising-identitive-constitutedness apriorising/axiomatising/referencing'-entailing>-existentialising — enframing/imprintedness〈as-to- historicity-tracing-in-presencing-hyperrealisation/hyperreal-transposition〉). $\quad$ This basically implies that < human-subpotency>-effecting (construed as from perspective ontological-normalcy/postconvergence epistemic-projection as to the disambiguation of apriorising/axiomatising/referencing-\{of- prospectively implicited_attendant-ontological-contiguity ' educedexistentialising/contextualising/textualising_'intelligibility/epistemicity/reflexivity-contiguity<imbued-notional cogency $\left.>^{\prime} \quad\right\}$-constitutedness ${ }^{14}$-in-preconverging-entailment $\quad$ in preconverging-or-dementing ${ }^{20}$-apriorising-psychologism and apriorising/axiomatising/referencing-\{ of-'prospectively_implicited_attendant-ontologicalcontiguity ' $\sim$ educedexistentialising/contextualising/textualising_intelligibility/epistemicity/reflexivity_contiguity<imbued-notional cogency>' \}-conflatedness ${ }^{13}$ in-\{preconverging-ment by\} postconverging-ntailmentin postconverging-or-dialectical-thinking ${ }^{21}$-apriorisingpsychologism) precedes-and-defines the occasioning/instantiation of human metaphoricity ${ }^{57}$ and meaningfulness-and-teleology' (given that '<supererogatory -human-subpotency>-effecting self-becoming/self-conflatedness ${ }^{13}$ /formative-supererogating-<projective/reprojectiveaestheticising-re-motif-and-re-apriorising/re-axiomatising/re-referencing,-in-perspectiveontological-normalcy/postconvergence $>$ of human notional $\sim$ self-distantiation- $<$ imbued - remotif-and-re-apriorising/re-axiomatising/re-referencing $>$ incipience of metaphoricity ${ }^{57}$ and then meaningfulness-and-teleology ${ }^{\circ}$ is what truly reflects notionally/underlyingly unbeholdening re-motif-and-re-procession/re-automatism ${ }^{4}$ historiality/ontological-eventfulness ${ }^{38} /$ ontologicalaesthetic-tracing-<perspective-ontological-normalcy/postconvergence-reflected-‘epistemicity- 
relativism-determinism'> whereas '<supererogatory $>$ human-subpotency>-effecting selfpresence/self-constitutedness $^{14}-<$ in-perspective-epistemic-abnormalcy/preconvergence ${ }^{3}>$ of human notional $\sim$ self-distantiation-<imbued-re-motif-and-re-apriorising/re-axiomatising/rereferencing > incipience of metaphoricity ${ }^{57}$ and then ${ }^{56}$ meaningfulness-and-teleology ${ }^{9}$ ' as rather in beholdening is bound to re-motif-and-re-procession/re-automatism ${ }^{47}$ historicity-tracing-inpresencing-hyperrealisation/hyperreal-transposition); inherently-so because human $<$ amplituding/formative-epistemicity $>$-totalising $\sim$ thrownness-in-existence ${ }^{35}$,-imbuedprojective-arbitrariness/waywardness-〈as-to-the-human-projective/reprojectiveaestheticising-re-motif-and-re-apriorising/re-axiomatising/re-referencing-process-of'<amplituding/formative-epistemicity $>$ totalising conceptualisation' $\rangle$ implies that humansubpotency intelligibility can only arise as to 'human ontological-faith-notion-or-ontologicalfideism —imbued-underdetermination-of-motif-and-apriorising/axiomatising/referencing-asso-being-as-of-existential-reality as to the disseminative-sublimating-selectivity-ofontological-good-faith/authenticity $\sim$ postconverging-dementating/structuring/paradigming , over desublimating deselectivity-of-ontological-badfaith/inauthenticity -preconverging de-mentating/structuring/paradigming , so-reflected notionally/underlyingly as to '<supererogatory-human-subpotency>-effecting imbued epistemic-totalising preformulating/preframing/premeaningfulness of notional $\sim$ originarinessparrhesia,-as--spontaneity-of-aestheticisation' before the incipience of metaphoricity ${ }^{57}$ and then meaningfulness-and-teleology as to existentialising-frame-of-entailment-of-motif-andapriorising/axiomatising/referencing (and so reflecting the 'full incipient supererogating breadth of human intelligibility transmutation' enabling the appraisal of human transcendence-andsublimity/sublimation/supererogatory de-mentativity that underlies the possibility for human sublimation-over-desublimation as to postconverging apøreticismovercoming/unovercoming), hence speaking to the truer unbeholdening,-as-to-re-originary 
backdrop of 'human epistemic-totalising / $/$ ircumscribing/delineating agency' underlied by human notional $\sim$ self-distantiation-<imbued—re-motif-and-re-apriorising/re-axiomatising/rereferencing $>$ instigative $<$ supereregatory - human-subpotency $>-$ effecting. This critically speaks to the incipiently-and-notionally 'self-reflexive instigative-eventuating-〈as-to-teleologicalinstigative/incipient-willing/arbitrariness/waywardness/faithdrivenness/supererogating-forhuman-intelligibility,-preceding-existence's-eventuating-sublimating-validation/desublimatinginvalidation> of human embodied-consciousness motif-andapriorising/axiomatising/referencing-\{of-'prospectively implicited_attendant-ontologicalcontiguity ' educedexistentialising/entextualising/textraing_intelligibility/epistemicity/reflexivity-contiguity<imbued-notional cogency>> $\}$-elicited-incipience-of-existentialising-decisionality-<as-todisontologising/re-ontologising aporeticism $>$ ' undergirding the 'full incipient supererogating breadth of human intelligibility transmutation' (as '<supereregatory 2 human-subpotency $>-$ effecting imbued epistemic-totalising ${ }^{3}$ preformulating/preframing/premeaningfulness of notional originariness-parrhesia,--as-spontaneity-of-aestheticisation' before the incipience of metaphoricity ${ }^{57}$ and then ${ }^{56}$ meaningfulness-and-teleology 99 as to existentialising-frame-ofentailment of motif-and-apriorising/axiomatising/referencing); with existentialising-frame-ofentailment of motif-and-apriorising/axiomatising/referencing speaking to the "notionally sublimating/desublimating flux of ontologising/disontologising given human limited-mentationcapacity—as-subjecting 'educed-unlimitedness/existence-sublimating nascence' tolimitedness/human-subpotency' that is 'human social-functioning-and-accordance-as-ofsocial-stake-contention-or-confliction' as the perpetually supererogating medium for the 'full incipient supererogating breadth of human intelligibility transmutation'. Notionally, human social-functioning-and-accordance-as-of-social-stake-contention-or-confliction is thus critically 
preformulating/preframing/premeaningfulness-imbued-mediativity-and-deferentialism>-of-

meaningfulness-and-teleology ) empowering $<$ to-Self $>$ and $\quad$ (formativeness- $<$ as-to-

intersolipsism-of-preformulating/preframing/premeaningfulness-imbued-mediativity-and-

deferentialism $>$-of- meaningfulness-and-teleology ) empowering $<$ to-Other $>$ ' in order for the 'possibility of the sublimating social to arise as to human-and-socialexpectations/anticipations — metaphoricity ${ }^{57}$-as-preconverging/postconverging-rede-

mentating/restructuring/reparadigming-psychologism' involving the requisite human limitedmentation-capacity-deepening —as-subjecting limitedness/human-subpotency-to-'educedunlimitedness/existence-sublimating nascence' for 'eventual human ontologising-overdisontologising ontological-performance ${ }^{72}-<$ including-virtue-as-ontology $>^{\prime} \quad$ (as to Beingdevelopment/ontological-framework-expansion-as-to-depth-of-ontologising-development-asinfrastructure-of- meaningfulness-and-teleology , institutional-development-as-to-socialfunction-development and living-development-as-to-personality-development psychologismic epistemic-acutisation difficulty-for, residualising \{decomplsing $\}$ delinearity for-cogency> magnitudes ${ }^{\text {(of-experientiality/experiment }\}}$ ); and so as to the fact that human 'social-functioning-andaccordance-as-of-social-stake-contention-or-confliction imbuing existentialising-frame-ofentailment of motif and apriorising/axiomatising/referencing of disontologising/ontologisingand-re-ontologising' rather acts as existentialising-leeway-thresholding,-allowing-formativelyfor- $<$ disontologising-subontologisation/subpotentiation-in-order-to-enable-prospectiveontologising/re-ontologising-performance $\sim$ of-sovereign-self-reflexive $\sim$ instigativeeventuating $>$ (given the two-sided epistemic-veracity of undergirding human 'selfreflexive instigative-eventuating-〈as-to-teleological-instigative/incipientwilling/arbitrariness/waywardness/faithdrivenness/supererogating-for-human-intelligibility,preceding-existence's-eventuating-sublimating-validation/desublimating-invalidation〉 of human embodied-consciousness motif-and-apriorising/axiomatising/referencing-\{of- 
'prospectively_implicited_attendant-ontological-contiguity ' educed-

existentialising/contextualising/textualising_intelligibility/epistemicity/reflexivity_contiguity-

$<$ imbued-notional cogency $>>$ ' -elicited-incipience-of-existentialising-decisionality-<as-todisontologising/re-ontologising aporeticism $>$ ' so-reflected by the 'supererogating/willing side' and the 'existence sublimating-validation/desublimating-invalidation side' for sound human intelligibility to arise), speaking of human limited-mentation-capacity-as-subjecting'educed-unlimitedness/existence-sublimating nascence' to-limitedness/human-subpotency imbued 'preconverging/postconverging-de-mentative/structural/paradigmatic formative-risk of disontologisation associated with the prospect for veridical human ontologising/re-ontologising' for appropriate human sovereign 'epistemic-growth/disquiet/discomfort-〈induced-sublimation,as-from-existence's - effusing/ecstatic-inlining-as- historiality\{science/authenticity/nonextrication $\}$-beyond-mere-formulaicity/ritualisation-as- historicitytracing-\{science-ideology/fashionability/distraction $\}\rangle$ as to construction-of-the-Self in dispensing-with-immediacy-for-relative-ontological-completeness ${ }^{87}$-byreification/contemplative-distension ${ }^{27}$. This critically explains why the-very-same human limited-mentation-capacity-deepening — as-subjecting-limitedness/human-subpotency-to'educed-unlimitedness/existence-sublimating nascence' ${ }^{53}$ as <amplituding/formativeepistemicity>-totalising renewing-realisation/re-perception/re-thought,-insupererogatory epistemic-conflatedness ${ }^{13}$ allowing for sublimating knowledgereification $\sim$ gesturing-and-accounting — of-epistemic-phenomenalism- $<$ inprospective_psychologismic $\sim$ apriorising/axiomatising/referencing-\{of-'prospectively implicited_attendant-ontological-contiguity ' reducedexistentialising/contextualising/textualising_'intelligibility/epistemicity/reflexivity_contiguity$<$ imbued-notional cogency >' $\}$-conflatedness -in-\{preconverging ment by\} postconverging-entailment> (when the existentialising-leeway-thresholding,-allowing- 
formatively-for-<disontologising-subontologisation/subpotentiation-in-order-to-enableprospective-ontologising/re-ontologising-performance $\sim$ of-sovereign-self-reflexive $\sim$ instigativeeventuating $>\quad$ ontologisingly overwhelms/enhances totalising $3{ }^{3}$ hermeneutically/textually/reprojectingly/supererogatingly/zeroingly/re-acutingly,$\{$ decompulsing $\}$ delinearity $\sim$ for-cogency as to prospective epistemictotalising $\sim$ resubjecting_or_totalising-entailing $\sim$ reconstrual- $<$ of the-whole/purview-of-thewhole/oneness-of-ontology> of 'implicited_attendant-ontological-contiguity ${ }^{67}$ ' educedexistentialising/contextualising/textualising_intelligibility/epistemicity/reflexivity-contiguity$<$ imbued-notional cogency>' -in-elucidation-or-reification for prospective ontologisation/reontologisation) is equally susceptible to desublimating pedantising/muddling/formulaichollowing-out—in-subontologisation/subpotentiation-〈blurring/undermining-of-prospectivetotalising-entailing,-as-to-entailing-<amplituding/formative-epistemicity $>$ totalising $\sim$ inrelative-ontological-completeness $\rangle$ as well as generalised <amplituding/formative $>$ woodenlanguage-_imbued - temporal-mere-form/virtualities/dereification/akrasiaticdrag/denatured/preconverging-or-dementing -narratives - of-the- reference-of-thoughtcategorical-imperatives/axioms/registry-teleology > (when the existentialising-leewaythresholding,-allowing-formatively-for- $<$ disontologising-subontologisation/subpotentiation-inorder-to-enable-prospective-ontologising/re-ontologising-performance $\sim$ of-sovereign-selfreflexive instigative-eventuating $>$ disontologisingly underwhelms/disenhances fepistemictotalising $3{ }^{3}$ hermeneutically/textlly/reprojectingly/supererogatingly/zeroing/y/re aeutingly,\{decompulsing $\}$ delinearity for-cogency as to prospective epistemictotalising $\sim$ resubjecting_or_totalising-entailing $\sim$ reconstrual- $<$ of the-whole/purview-of thewhole/oneness-of-ontology> of 'implicited_attendant-ontological-contiguity ${ }^{67}$ ' educedexistentialising/contextmalising/textualising_'intelligibility/epistemicity/reflexivity_contiguity<imbued-notional cogency>' -in-elucidation-or-reification for prospective ontologisation/re- 
ontologisation); and so-illuminating with both instances respectively human social-functioningand-accordance - as-of-social-stake-contention-or-confliction imbuing 'existentialising-frameef-entailment of motif-and-apriorising/axiomatising/referencing of <postconverging 'motifand-apriorising/axiomatising/referencing'-entailing >-existentialising_framing/imprinting-〈asto-prospective- historiality/ontological-eventfulness /ontological-aesthetic-tracing-

$<$ perspective--ontological-normalcy/postconvergence-reflected-`epistemicity-relativismdeterminism' $>\rangle$ ' and 'existentialising-frame-of-entailment-of motif-andapriorising/axiomatising/referencing of $\quad<$ preconverging 'motif-andapriorising/axiomatising/referencing'-entailing >-existentialising — enframing/imprintedness〈as-to- historicity-tracing - in-presencing-hyperrealisation/hyperreal-transposition〉' (and soreflected specifically as to Being-development/ontological-framework-expansion-as-to-depthof-ontologising-development-as-infrastructure-of- meaningfulness-and-teleology ).

Insightfully, this dynamic 'fundamental ontologising/disontologising confliction' of human

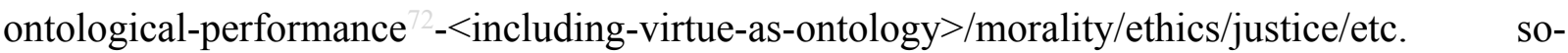
inherent to human social-functioning-and-accordance-as-of-social-stake-contention-orconfliction imbuing existentialisng-frame (given 'human notional firstnaturednessformativeness-<as-to-eventualising-inkling-drive-or-seeding-misprising > temporal-tointemporal-dispositions-<so-construed-as-from-perspective-ontologicalnormalcy/postconvergence> preconverging/postconverging-dementative/structural/paradigmatic implications of individual and social formativeness-<as-tointersolipsism-of-preformulating/preframing/premeaningfulness-imbued-mediativity-anddeferentialism $>$-of- meaningfulness-and-teleology ${ }^{\circ}$ so-associated with human limitedmentation-capacity—as-subjecting 'educed-unlimitedness/existence-sublimating nascence' to-limitedness/human-subpotency in order for the "possibility of the sublimating social to arise as to human-and-social-expectations/anticipations - metaphoricity ${ }^{57}$-as- 
preconverging/postconverging-rede-mentating/restructuring/reparadigming-psychologism') points out that human ontological-performance ${ }^{72}-$ including-virtue-as- $^{2}$ ontology $>$ /morality/ethics/justice/etc. is ever always in a ' inistemictotalising 3 hermeneutic/textuality/reprojecting/supererogating/zeroing/re-acuting,$\{$ decompulsing $\}$ delinearity for-cogency prospective epistemictotalising $\sim$ resubjecting_or_totalising-entailing $\sim$ reconstrual- $<$ of the-whole/purview-of-thewhole/oneness-of-ontology> of 'implicited_attendant-ontological-contiguity ${ }^{67}$ ' educedexistentialising/contextualising/textualising_'intelligibility/epistemicity/reflexivity-contiguity$<$ imbued-notional cogency $>$-in-elucidation-or-reification as to prospective disontologisation/ontologisation-and-re-ontologisation'; as so-reflecting of the more profound/fundamental need to cater for 'effectively ontologising/re-ontologising sublimating social as to human-and-social-expectations/anticipations-metaphoricity ${ }^{57}$-aspreconverging/postconverging-rede-mentating/restructuring/reparadigming-psychologism' (so-catered as of the 'psychoanalytic-unshackling/memetic-reordering/institutionalrecomposuring

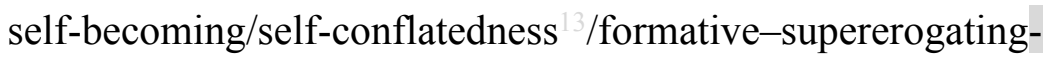
$<$ projective/reprojective - aestheticising-re-motif-and-re-apriorising/re-axiomatising/rereferencing,-in-perspective-ontological-normalcy/postconvergence>' underlying human ‘epistemic-growth/disquiet/discomfort-〈induced-sublimation,-as-from-existence'seffusing/ecstatic-inlining-as- historiality-\{science/authenticity/nonextrication $\}$-beyond-mereformulaicity/ritualisation-as- historicity-tracing- $\{$ science-ideology/fashionability/distraction $\}$ ) as to construction-of-the-Self in dispensing-with-immediacy-for-relative-ontologicalcompleteness $^{87}$-by-reification/contemplative-distension ${ }^{27}$ ) $\quad$ while undermining disontologisation from human individual, institutional and social numb-_bing-traction-_-ofdesublimating_ 
postconverging/dialectical-thinking -of-notional deprocrypticism-\{in-dimensionality-of-

sublimating _ < <mplituding/formative-epistemicity $>$ growth-or-

conflatedness /scalarisation-as-to-rescalarisation-as-re-ontologisation \}'’

(inducing

desublimating

pedantising/muddling/formulaic-hollowing-out—in-

subontologisation/subpotentiation-〈blurring/undermining-of-prospective-totalising-entailing,-

as-to-entailing-<amplituding/formative-epistemicity $>$ totalising $\sim$ in-relative-ontological-

completeness $\rangle$ as well as generalised $<$ amplituding/formative $>$ wooden-language-〈imbued

temporal-mere-form/virtualities/dereification/akrasiatic-drag/denatured/preconverging-or-

dementing -narratives-of-the- reference-of-thought- categorical-

imperatives/axioms/registry-teleology $\rangle)$ caught up in

'desublimating $\sim$ referenced/registered/decisioned $\quad$ self-presence/self-constitutedness ${ }^{14}-<$ inperspective-epistemic-abnormalcy/preconvergence ${ }^{3}$ ' (so-manifested in a mental-reflex of laxing, inattentiveness and unaccountability that wrongly construes of the 'resultant mereformulaicity/ritualisation-<as-to-mere-formulaic-

methodologising/mutualising/organising/institutionalising,-prospectively-losing-track-of-

‘\{epistemic-totalising ’re-apriorising/re-axiomatising/re-referencing residuality-in-re-

originariness/re-origination'> of prior profound-supererogation \%originariness-parrhesia,--asspontaneity-of-aestheticisation' reflected in 'present mere-formulaicmethodologising/mutualising/organising/institutionalising implied reproducibilitymathesis/motif/thrownness-disposition,-as-reproducibility-of-aestheticisation' as impliciting a dispensation 'from eliciting prospective profound-supererogation /originariness-parrhesia,--asspontaneity-of-aestheticisation' so-implied as to fepistemicthermeneutically/textually/reprojectingly/supererogatingly/zeroingly/re-acutingly,\{decompulsing\} delinearity for-cogency-imbuing

'supereregatery $\sim$ acuity/perspicacity/astuteness/edginess/incisiveness $\sim$ differential ontological- 
performance ${ }^{72}-<$ including-virtue-as-ontology $>$ /potentiation' for prospective human postconverging-aporeticism-overcoming/unovercoming in reconstrual of human '<amplituding/formative-epistemicity $>$-totalising $\sim$ thrownness-in-existence ${ }^{35}$ as to reaestheticicising/re-motif- $<$ in-postconverging-narrowing-down 'sublimation-of-taste- \{epistemictotalising $3{ }^{3}$ hermeneutically/textually/reprojectingly/supererogating/y/zeroingly/re-acutingly,${ }_{\{\text {decompulsing }\}}$ delinearity for-cogency-educing-conceptivity/epistemic-reflexivity/epistemicityrelativism-determinism-<reifying \{as-to-knowledge-developing $\}$-and-empowering $>$-ofhistoriality/ontological-eventfulness /ontological-aestheticising-tracing',-as-to-existenceas-sublimating-withdrawal/unenframing/re-ontologising,-elicited-from-prospective-profound-

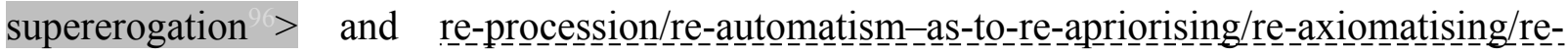
referencing-<in-postconverging-narrowing-down 'sublimation-ofapriorising/axiomatising/referencing_\{epistemictotalising $3{ }^{3}$ hermeneutically/textually/reprojectingly/supererogatingly/zeroingly/re-acutingly,delinearity for-cogency-educing-conceptivity/epistemic-reflexivity/epistemicityrelativism-determinism-<reifying \{as-to-knowledge-developing $\}$-and-empowering $>$-ofhistoriality/ontological-eventfulness /ontological-aestheticising-tracing',-as-to-existenceas-sublimating-withdrawal/unenframing/re-ontologising,-elicited-from-prospective-profoundsupererogation >'). Thus, <supererogatery-human-subpotency>-effecting speaks to the 'notional veracity of human epistemic-stretching' (as incipient to 'human notional firstnaturedness-formativeness-<as-to-eventualising-inkling-drive-or-seeding misprising $>$ temporal-to-intemporal-dispositions-<so-construed-as-from-perspectiveontological-normalcy/postconvergence $>\quad$ ontological-performance ${ }^{72}-$ including-virtue-as- $^{2}$ ontology $>^{\prime}$ ), as to the fact that the very exercise of human contemplation is incipiently-andprofoundly about 'human notional $\sim$ self-distantiation- $<$ imbued-re-motif-and-re-apriorising/reaxiomatising/re-referencing $>$ in notionally dispensing-with-immediacy-for-relative-ontological- 
completeness $^{87}$-by-reification/contemplative-distension ${ }^{27}$ (as of notional conceptivity/epistemic-reflexivity/epistemicity-relativism-determinism- $<$ reifying \{as-toknowledge-developing\}-and-empowering $>\quad$ ' nonpresencing-<perspective-ontologicalnormalcy/postconvergence $>$ anarchistic-growth/anarchisation-for-re-ontologisation-〈as-toconscious/unconscious epistemically-sound induced 'demoronisation-<sublimating-nascence,nonextricatory-sublimating-upstreaming/‘amontée’> postconverging/dialectical-thinking conception of residual_re-originary_anarchistic incipiency of human social-functioning-andaccordance - as-of-social-stake-contention-or-confliction meaningfulness-and-teleology ' $\rangle$ ' as so-reflecting: the projective/reprojective regenerativity of human ${ }^{56}$ meaningfulness-andteleology ${ }^{9}$ in relative-ontological-completeness ${ }^{87}$ operantly associated with prospective human aestheticising — ${ }^{9}$ surrealising/supererogating-drive for $\quad<$ postconverging $\sim$ 'motif-andapriorising/axiomatising/referencing'-entailing--existentialising-framing/imprinting-〈as-toprospective- historiality/ontological-eventfulness /ontological-aesthetic-tracing$<$ perspective-ontological-normalcy/postconvergence-reflected-‘epistemicity-relativismdeterminism' $>>$ imbued interlay/organicalism/aestheticising-handle-<of-'psychologismictransfixity\{residualising \{decompulsing $\}$ delinearity-over-nonresidualising \{compulsing\} ${ }^{\text {\{inearity\}}\}}$ \{imbued-supererogatory $\sim$ projective-arbitrariness/waywardnessof $\sim$ transversalisation/tandemisation/abstractive-conjugation/perspectivation/depthing — for'aestheticising-re-margining/re-edging/re-acuity-aspostconverging_circumscriptive/totalitative-restructuring'\}- educingsublimation/desublimation> in \{epistemictotalising $3{ }^{3}$ hermeneutically/textually/reprojectingly/supererogatingly/zeroingly/re-acutingly,delinearity for-cogency-imbuing 'supereregatory acuity/perspicacity/astuteness/edginess/incisiveness $\sim$ differential ontologicalperformance $^{72}-<$ including-virtue-as-ontology $>$ /potentiation' for prospective human 
postconverging aporeticism-overcoming/mnovercoming in reconstrual of '<amplituding/formative-epistemicity>-totalising thrownness-in-existence $^{35}$ as to reaesthethicising/re-motif- $<$ in-postconverging-narrowing-down $\sim$ 'sublimation-of-taste- fepistemictotalising ${ }^{3}$ ' $h e r m e n e u t i c a l l y /$ textually/reprojectingly/supererogatingly/zeroingly/re-acutingly,${ }_{\{\text {decompulsing }\}}$ delinearity for-cogency-educing-conceptivity/epistemic-reflexivity/epistemicityrelativism-determinism-<reifying \{as-to-knowledge-developing $\}$-and-empowering $>$-ofhistoriality/ontological-eventfulness /ontological-aestheticising-tracing',-as-to-existenceas-sublimating-withdrawal/unenframing/re-ontologising,-elicited-from-prospective-profound-

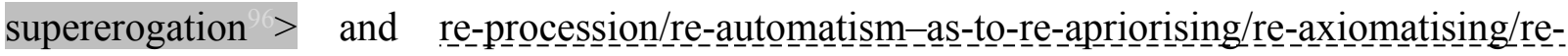
referencing-<in-postconverging-narrowing-down 'sublimation-ofapriorising/axiomatising/referencing-\{epistemic-

totalising 3 ? ${ }^{3}$ hermeneutically/textually/reprojectingly/supererogatingly/zeroingly/re-acutingly,\{decompulsing $\}$ delinearity for-cogency-educing-conceptivity/epistemic-reflexivity/epistemicityrelativism-determinism-<reifying \{as-to-knowledge-developing $\}$-and-empowering $>$-ofhistoriality/ontological-eventfulness /ontological-aestheticising-tracing',-as-to-existenceas-sublimating-withdrawal/unenframing/re-ontologising,-elicited-from-prospective-profoundsupererogation $>$ ). Such a conception of < critically relevant in appraising that 'technical/profound articulations are not made gratuitously' (in contrast to a modern-day unnecessary 'social-and-media reflex of facility/convenience' shunning technicity/profundity which goes on it is herein argued to be at the 'infrastructural/root source of the cultivation of public and institutional discursive mediocrity' as to 'enculturating a practice of public interestedness/profundity mediocrity and public awareness/accounting/decisioning mediocrity' whereas the technicity/profundity of modern-day training and professions rather points to the fact of a public potentially capable to handle more creatively profound/technical public analysis and public debate rather than just 
'parsimonious/frugal ratings-driven defining conception of intellectual analysis prone to desublimating disorientation, misanalysis and irrelevance') as to the requisite social notional self-distantiative contemplative technicity/profundity that inherent existence sublimating-nascence warrants to make available appropriately sublimating $<$ supererogatory $\sim$ human-subpotency $>$-effecting (whether as to direct knowledge acquisition or appropriate percolation-channelling- $<$ in-deferential-formalisation-transference $>$ enabling the sovereign-function/posture-<as-to-existentially-manifest-'embodied-subject $\sim$ consciousnessand-direct/deferential-conscientiousness',-as-of-its-'epistemic-reflexivity/unreflexivity-in-

existence'/teleology $>$ ontologising-aptness). This poor appreciation of technicity/profundity in the public arises as of a poor projection of existence's sublimating-nascence to wrongly imply that the individual 'is perfect as they are' with supposed 'normalised/stereotyped/selfhelping/feel-good knowledge being brought at the protractedsocial—as-to-individual-by-institutional-by-social sovereign's service', and critically wrongly implying that knowledge as to organic-knowledge can be acquired without the requisite ‘epistemic-growth/disquiet/discomfort-〈induced-sublimation,-as-from-existence’s-

\section{effusing/ecstatic-inlining-as- historiality-\{science/authenticity/nonextrication $\}$-beyond-mere-} formulaicity/ritualisation-as- historicity-tracing-\{science-ideology/fashionability/distraction $\}$ ) as to construction-of-the-Self in dispensing-with-immediacy-for-relative-ontologicalcompleteness $^{87}$-by-reification/contemplative-distension ${ }^{27}$ of the individual as to their 'appropriate notional $\sim$ self-distantiation- $<$ imbued-re-motif-and-re-apriorising/reaxiomatising/re-referencing >', while at the same time a 'pseudo-contrition as to awareness of such relatively shallow technicity/profundity cultivated in such social-and-media spaces' doesn't deter such spaces (consciously or unconsciously) from surreptitiously acting as of profound technicity/profundity at critical moments of public discourses with the consequence that 'there is an opaque connection/continuity between public, media and institutional discursivity with 
social and institutional outcomes as if these are discrete and unrelated activities' (whereas the supposed relevance of discursivity has to do with how it allows for comprehensible public ‘epistemic-growth/disquiet/discomfort-〈induced-sublimation,-as-from-existence’s-

\section{effusing/ecstatic-inlining-as- historiality-\{science/authenticity/nonextrication $\}$-beyond-mere-}

formulaicity/ritualisation-as- historicity-tracing- $\{$ science-ideology/fashionability/distraction $\}\rangle$

as to construction-of-the-Self in dispensing-with-immediacy-for-relative-ontologicalcompleteness $^{87}$-by-reification/contemplative-distension ${ }^{27}$, in effectively appreciating social and institutional outcomes processes rather than individuals reflective estrangement and disinterest with regards to optimal public outcomes of social-stake-contention-or-confliction). The concrete and natural human psychological disposition with respect to knowledge as to organic-knowledge is in appreciating that for critical thinking even for the novice it is imperative to truly engage with the substance of the matter comprehensively-and-insightfully notwithstanding the level of intelerance-<of-disparateness $>$ /exactifying_precisioning comprehension (again whether as to direct knowledge acquisition or appropriate percolation-channelling- $<$ in-deferentialformalisation-transference $>$ enabling the sovereign-function/posture-<as-to-existentiallymanifest-'embodied-subject consciousness-and-direct/deferential-conscientiousness', -as-ofits-'epistemic-reflexivity/unreflexivity-in-existence'/teleology> ontologising-aptness). The abstraction-of-thought/principled-thought articulated with subject-matters content is not done gratuitously as it is often popularly advanced especially with 'ontologically-flawed frameworks of blurriness-<sterilising/anecdotalising/trivialising-of-prospective-re-ontologising_bypreconverging,-in-disontologising-formulaic-dragging-out/hollowing-out> and ratings/sales immediate interests' susceptible to normalised/stereotyped/selfhelping/feel-good construal of knowledge. Subject-matter abstraction-of-thought/principled-thought content are not soproduced gratuitously in the sense that this effectively speaks to: the requisite sophistication/complexity for 'full incipient supererogating breadth of human intelligibility 
transmutation' (as '<supererogatory human-subpotency>-effecting imbued epistemictotalising preformulating/preframing/premeaningfulness of notional originariness-parrhesia,-as-spontaneity-of-aestheticisation' before the incipience of metaphoricity and then meaningfulness-and-teleology ${ }^{9}$ as to existentialising-frame-of-entailment-of motif-andapriorising/axiomatising/referencing) 'that then permits \{epistemictotalising $3{ }^{3}$ hermeneutically/textually/reprojectingly/supererogatingly/zeroingly/re-acutingly,\{decompulsing delinearity for-cogency human sublimating-accessing/sublimating-relating-to' existence — as-sublimating-withdrawal/unenframing/re-ontologising,-elicited-fromprospective-profound-supererogation (noting here that what is key here is the "existence constrained educed sublimating' however the technicity/profundity whereas an attitude of normalised/stereotyped/selfhelping/feel-good knowledge that 'doesn't align with the existence constrained educed sublimating' is fundamentally besides the point however its 'false convincing of the fellow human mortal approach' so-reflected as to the deficient social outcomes it is bound to be associated with'). Critically when push comes to shove, such blatantly flawed conception of true knowledge but socially accommodated as to a 'social-functioning-andaccordance-as-of-social-stake-contention-or-confliction conception associated with immediate public ratings and/or sales/merchandising' (over the 'epistemicgrowth/disquiet/discomfort-〈induced-sublimation,-as-from-existence's-effusing/ecstatic-

\section{inlining-as- historiality-\{science/authenticity/nonextrication\}-beyond-mere-}

\section{formulaicity/ritualisation-as- historicity-tracing-\{science-ideology/fashionability/distraction $\}\rangle$}

as to construction-of-the-Self in dispensing-with-immediacy-for-relative-ontologicalcompleteness ${ }^{87}$-by-reification/contemplative-distension ${ }^{27}$ implications of 'constraining existence — as-sublimating-withdrawal/unenframing/re-ontologising,-elicited-fromprospective-profound-supererogation imbuing human ontological-commitment $-<$ implied self-assuredness-of-ontological-good-faith/authenticity postconverging-de- 
mentating/structuring/paradigming -as-being-as-of-existential-reality>') are found to be wanting in contrast with the true nature and existential-<disontologising/re-ontologising aporeticism $>$ sublimating/desublimating implications of professional/technical/scientific knowledge inherent subject-matter content as abstraction-of-thought/principled-thought (notwithstanding supposedly professional/technical/scientific auxiliary/substitutive practices of 'normalised/stereotyped/selfhelping/feel-good knowledge being brought at the protractedsocial-as-to-individual-by-institutional-by-social sovereign's service lacking in the underlying conception of epistemic-growth/disquiet/discomfort-〈induced-sublimation,-as-fromexistence's - effusing/ecstatic-inlining-as- historiality-\{science/authenticity/nonextrication $\}$ beyond-mere-formulaicity/ritualisation-as- historicity-tracing-\{scienceideology/fashionability/distraction $\}\rangle$ as to construction-of-the-Self in dispensing-withimmediacy-for-relative-ontological-completeness ${ }^{87}$-by-reification/contemplative-distension ${ }^{27}$ that are closely attached-and-driven directly or indirectly by public ratings and/or sales/merchandising with little consideration for veridical/optimal existential$<$ disontologising/re-ontelogising aporeticism $>$ sublimating/desublimating implications, even as it is herein argued professional/technical/scientific abstraction-of-thought/principled-thought content mustn't necessarily generate less public interest but should primarily be motivated with inherent knowledge-reification $\sim$ gesturing-and-accounting —of-epistemic-phenomenalism- $<$ inprospective_psychologismic apriorising/axiomatising/referencing-\{of-'prospectively implicited_attendant-ontological-contiguity ' educedexistentialising/contextualising/textualising_'intelligibility/epistemicity/reflexivity-contiguity<imbued-notional cogency $>>$ \}-conflatedness -in-\{preconverging -ment by\} disontologising/re-ontologising aporeticism $>$ implications). It is herein contended howver counterintuitive that the idea of understanding $100 \%$ of knowledge content at one go (as 
commonly assumed and cultivated with such content driven by public ratings and/or sales/merchandising as to excessive simplification, distortion, superficiality, ephemerality and attention-grabbing undermining organic knowledge) is very much detrimental for a profoundly engaging and sublimating practice of public exposition to knowledge as so-inducing the degradation/banalisation of content in order to supposedly capture the most number of people at one go, and so it is herein argued very much contrary to the natural human potential for profound knowledge assimilation which is rather of \{epistemicthermeneutic/textuality/reprojecting/supererogating/zeroing/re-acuting,delinearity for-cogency potential. A lot of true learning, understanding and engagement (beyond attention-grabbing and simplification convenience) comes and expands \{epistemic-totalising $3{ }^{3}$ hermeneutically/textmally/reprojectingly/supererogatingly/zeroing/y/reacutingly,-\{decempulsing $\}$ delinearity $\sim$ for-cogency as to re-exposition to same and similar content for eliciting an active thought/contemplative engagement that is sufficiently challenging to people's true intellectual growth possibility as to creatively eliciting and developing true contemplative interest and not just passivity (however the habituation of a plainness that turns out to seem to be the 'popular choice' to which in reality all individuals can succumb to but which is as of their self-reflection actually subpotentiating with regards to the 'broad existential< disontologising/re-ontologising aporeticism $>$ panoply of human epistemicgrowth/disquiet/discomfort-〈induced-sublimation,-as-from-existence's-effusing/ecstaticinlining-as- historiality-\{science/authenticity/nonextrication $\}$-beyond-mereformulaicity/ritualisation-as- historicity-tracing- $\{$ science-ideology/fashionability/distraction $\}\rangle$ as to construction-of-the-Self in dispensing-with-immediacy-for-relative-ontologicalcompleteness $^{87}$-by-reification/contemplative-distension ${ }^{27}$ necessary for prospective ontologisation/re-ontologisation as to epistemic-totalising ${ }^{33}$ resubjecting_or_totalisingentailing $\sim$ reconstrual- $<$ of the-whole/purview-of the-whole/oneness-of-ontology $>$ of 
'implicited_attendant-ontological-contiguity ${ }^{67}$ educedexistentialising/contextualising/textualising_'intelligibility/epistemicity/reflexivity-contiguity<imbued-notional cogency $>^{\prime}$-in-elucidation-or-reification). Such an attitude of 'normalised/stereotyped/selfhelping/feel-good knowledge being brought at the protractedsocial-as-to-individual-by-institutional-by-social sovereign's service lacking in the underlying conception of epistemic-growth/disquiet/discomfort-〈induced-sublimation,-as-fromexistence's - effusing/ecstatic-inlining-as- historiality-\{science/authenticity/nonextrication $\}$ beyond-mere-formulaicity/ritualisation-as- historicity-tracing-\{scienceideology/fashionability/distraction $\}\rangle$ as to construction-of-the-Self in dispensing-withimmediacy-for-relative-ontological-completeness ${ }^{87}$-by-reification/contemplative-distension ${ }^{27}$, to the education of children and young people can be particularly detrimental to critical thinking (while cultivating an 'elicited mere-formulaicconformity/trending/voguing/fashionability/resonance relation to ${ }^{56}$ meaningfulness-andteleology ') due to the overly denatured and insufficiently challenging-and-independenceeliciting existentialising-frame-of-entailment of motif-andapriorising/axiomatising/referencing of ${ }^{56}$ meaningfulness-and-teleology ${ }^{9}$ (as to veridical

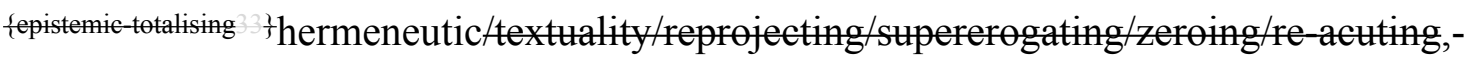
delinearity for-cogency re-exposition for eliciting active thought/contemplative engagement as of prospective epistemic-totalising ${ }^{33}$ resubjecting_or_totalisingentailing $\sim$ reconstrual- $<$ of the-whole/purview-of the-whole/oneness-of-ontology $>$ of 'implicited_attendant-ontological-contiguity ${ }^{67}$; educedexistentialising/contextualising/textualising_'intelligibility/epistemicity/reflexivity_contiguity$<$ imbued-notional cogency> -in-elucidation-or-reification of knowledge content and generation of varying interests); and so in reflection of the fact that a lot of childhood and human developmental learning is rather 'passive integration of schema of thinking/contemplation and 
engagement' as more decisive than really 'knowing and recalling knowledge content' (notwithstanding the inherently basic interrelatedness) with 'passive integration of schema of thinking/contemplation and engagement' critical for elaborating/framing meaning starting with the very incipient and appropriate jargon/language-conceptualisation for producing meaning (that is bound to align with constraining existence - as-sublimating-withdrawal/unenframing/reontologising,-elicited-from-prospective-profound-supererogation and so rather than an 'elicited mere-formulaic — conformity/trending/voguing/fashionability/resonance relation to meaningfulness-and-teleology ${ }^{9}$ with a poor sense of the prospective 'implicited_attendant ontological-contiguity ${ }^{67}$, educed-

existentialising/contextualising/textualising_'intelligibility/epistemicity/reflexivity-contiguity$<$ imbued-notional cogency> $>$-in-elucidation-or-reification of knowledge content as to epistemic-totalising $\sim$ resubjecting_or_totalising-entailing $\sim$ reconstrual $<$ of thewhole/purview-of the-whole/oneness-of-ontology $>$ ). Where the cultivated 'passive integration of schema of thinking/contemplation and engagement' is rather as of an 'elicited mereformulaic — conformity/trending/voguing/fashionability/resonance relation to meaningfulnessand-teleology ${ }^{\circ}$ over eliciting an active thought/contemplative engagement that is sufficiently challenging to the true human intellectual growth potential (as to veridical \{epistemictotalising ${ }^{3}$ hermeneutic/textuality/reprojecting/supererogating/zeroing/re-acuting,${ }_{\{\text {decompulsing }}$ delinearity for-cogency re-exposition for eliciting active thought/contemplative engagement as of prospective 'implicited_attendant-ontological-contiguity ${ }^{67}$ ' educedexistentialising/contextualising/textualising_'intelligibility/epistemicity/reflexivity-contiguity<imbued-notional cogency> -in-elucidation-or-reification of knowledge content as to epistemic-totalising ${ }^{33} \sim$ resubjecting_or_totalising-entailing $\sim$ reconstrual $<$ of the whole/purview-of the-whole/oneness-of-ontology $>$ ) enabling appropriate social 'epistemicgrowth/disquiet/discomfort-〈induced-sublimation,-as-from-existence's-effusing/ecstatic- 


\section{inlining-as- historiality-\{science/authenticity/nonextrication $\}$-beyond-mere-}

formulaicity/ritualisation-as- historicity-tracing-\{science-ideology/fashionability/distraction $\}$ ) as to construction-of-the-Self in dispensing-with-immediacy-for-relative-ontologicalcompleteness $^{87}$-by-reification/contemplative-distension ${ }^{27}$, then the supposed outcome of a seeming public disinterest and disengagement with technicity/profundity is rather an issue induced as to our procrypticism/disjointedness-as-of- reference-of-thought social $<$ amplituding/formative-epistemicity $>$ totalising $\sim$ self-referencing-

syncretising/circularity/interiorising/akrasiatic-drag ${ }^{4}$ in its ${ }^{79}$ presencing-absolutisingidentitive-constitutedness ${ }^{14}$ <preconverging 'motif-and-apriorising/axiomatising/referencing'entailing $>$-existentialising — enframing/imprintedness-〈as-to- historicity-tracing - inpresencing-hyperrealisation/hyperreal-transposition) (starkly reflected as to the temporaladvantageousness and manifest in-effect absolution-<as-toapriorising/axiomatising/referencing-\{of-'prospectively implicited_attendant-ontologicalcontiguity ' $\sim$ educed-

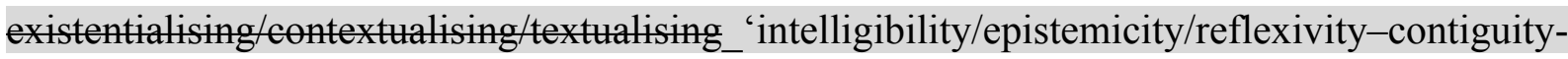
$<$ imbued-notional cogency >' $\}$-constitutedness -in preconverging-entailment $>$ of ratings and/or sales/merchandising now permeating the rationale of basically all institutions in their numbing-traction-_of-desublimating_ of-'supererogatory acuity/perspicacity/astuteness/edginess/incisiveness-as-to-the-imbuedpostconverging/dialectical-thinking -of-notional deprocrypticism-\{in-dimensionality-ofsublimating _ < $<$ amplituding/formative-epistemicity $>$ growth-orconflatedness /scalarisation-as-to-rescalarisation-as-re-ontologisation $\left.\}^{\prime}\right\rangle \quad$ beyond-theconsciousness-awareness-teleology ${ }^{\circ}<$ of-preconverging-existential-extrication-as-ofexistential-unthought $>$ as so-oblivious to the profound supereracuity/perspicacity/astuteness/edginess/incisiveness as to dimensionality-of- 
sublimating $25<<$ amplituding/formative $>$ supererogatory $\sim$ de-mentativeness/epistemic-growthor-conflatedness /transvaluative-rationalising/transepistemicity/anamnestic-residuality/spiritdrivenness-equalisation)' so-implied as of prospective ${ }^{18}$ deprocrypticism-or-preemptingdisjointedness-as-of- ${ }^{3}$ reference-of-thought nonpresencing- $<$ perspective-ontologicalnormalcy/postconvergence> sublimating $\sim$ existentialising - decisionality-<as-todisontologising/re-ontologising aporeticism> apriorising/axiomatising/referencing-\{of'prospectively_implicited_attendant-ontological-contiguity ' educedexistentialising/contextualising/textualising_ 'intelligibility/epistemicity/reflexivity-contiguity<imbued-notional cogency>' \}-relation-to-the-world). Ultimately, technicity/profundity is inescapable for achieving sublimating-nascence whether as more readily appreciated with nascent-particular/incipient-and-material/technical-sublimations- $<$ blinded-to-their-relativeontological-completeness - reference-of-thought- devolving> existentialising-decisionality$\leq$ as-to-disontologising/re-ontologising aporeticism>

normalised/stereotyped/selfhelping/feel-good knowledge is hardly of any help to the technician/practitioner/scientist in the face of constraining existential-<disontologising/reentelogising apereticism $>$ implications) or with the relative blurriness$<$ sterilising/anecdotalising/trivialising-of-prospective-re-ontologising_by-preconverging,-indisontologising-formulaic-dragging-out/hollowing-out> of $>$ social-and-institutionalframeworks-of — referencing/registering/decisioning existentialising-decisionality-as-todisontologising/re-ontologising aporeticism $>$, and critically in-many-ways the cultivation of shallow technicity/profundity (as to poor 'epistemic-growth/disquiet/discomfort-〈inducedsublimation,-as-from-existence's - effusing/ecstatic-inlining-as- historiality\{science/authenticity/nonextrication $\}$-beyond-mere-formulaicity/ritualisation-as- historicitytracing-\{science-ideology/fashionability/distraction $\}\rangle$ as to construction-of-the-Self in dispensing-with-immediacy-for-relative-ontological-completeness ${ }^{87}$-by- 
reification/contemplative-distension ${ }^{27}$ requiring appropriate notional $\sim$ self-distantiation$<$ imbued — re-motif-and-re-apriorising/re-axiomatising/re-referencing $>$ ) in public spaces is not detached from 'public interestedness/profundity mediocrity' and 'public awareness/accounting/decisioning mediocrity'. But then technicity/profundity as to the public discourse is all about cultivating the possibility for a 'public formulative appraisal and habituation for an enlightened sovereign engagement with public decision-making policies and technicalities'; and in this regards it is herein contended that unlike it can naively be construed about human capacity for understanding, a lot of 'human understanding is actually passive exposition to understanding of appropriately articulated/formulated knowledgereification $\sim$ gesturing-and-accounting — of-epistemic-phenomenalism- $<$ inprospective_psychologismic apriorising/axiomatising/referencing-\{of-‘prospectively_ implicited_attendant-ontological-contiguity ' ceducedexistentialising/contextualising/textualising_'intelligibility/epistemicity/reflexivity-contiguity<imbued-notional cogency $>>$ ' -conflatedness - in-\{preconverging -ment by\} postconverging-ntailment> so-underlying <supererogatory human-subpotency>-effecting as to the formative-and-enabling formulative backdrop for sovereignly appraising meaningfulness-and-teleology ${ }^{9}$ technicity/profundity' whether with regards to public education or even childhood-development education and/or formative institutional/professional education, as to the fact that formulative understanding (as of <supereregatory humansubpotency>-effecting) is the sovereignty/independence giving possibility for human ‘epistemic-growth/disquiet/discomfort-〈induced-sublimation,-as-from-existence's-

effusing/ecstatic-inlining-as- historiality-\{science/authenticity/nonextrication $\}$-beyond-mereformulaicity/ritualisation-as- historicity-tracing- $\{$ science-ideology/fashionability/distraction $\}$ ) as to construction-of-the-Self in dispensing-with-immediacy-for-relative-ontologicalcompleteness $^{87}$-by-reification/contemplative-distension ${ }^{27}$, relation with knowledge (as to 
conscious awareness existentialising-decisionality-<as-to-disontologising/re-ontologising apereticism $>$ implications even if complete understanding as of complete ${ }^{56}$ meaningfulness-andteleology ${ }^{9}$ technicity/profundity is not achieved and thus rendering the public resilient to desublimating pedantising/muddling/formulaic-hollowing-out—insubontologisation/subpotentiation-〈blurring/undermining-of-prospective-totalising-entailing,as-to-entailing-<amplituding/formative-epistemicity $>$ totalising in-relative-ontologicalcompleteness > with regards to the competing discourse in public spaces by such a direct or deferential capacity for notional $\sim$ self-distantiation- $<$ imbued-re-motif-and-re-apriorising/reaxiomatising/re-referencing $>$ to cultivate 'epistemic-growth/disquiet/discomfort-〈inducedsublimation,-as-from-existence's - effusing/ecstatic-inlining-as- historiality\{science/authenticity/nonextrication\}-beyond-mere-formulaicity/ritualisation-as- historicitytracing-\{science-ideology/fashionability/distraction $\}\rangle$ as to construction-of-the-Self in dispensing-with-immediacy-for-relative-ontological-completeness ${ }^{87}$-byreification/contemplative-distension ${ }^{27}$ over a facility/convenience mental-reflex). In this regards, the sovereign-function/posture-<as-to-existentially-manifest-'embodiedsubject $\sim$ consciousness-and-direct/deferential-conscientiousness',-as-of-its- 'epistemicreflexivity/unreflexivity-in-existence'/teleology $>$ ontologising-aptness is truly realised as to a dynamic deferential-formalisation-transference relation with the genuine social intellectualfunction/posture that is much more than a conception of 'normalised/stereotyped/selfhelping/feel-good knowledge being brought at the protractedsocial—as-to-individual-by-institutional-by-social sovereign's service lacking in the underlying conception of epistemic-growth/disquiet/discomfort-_induced-sublimation,-as-fromexistence's - effusing/ecstatic-inlining-as- historiality-\{science/authenticity/nonextrication $\}$ beyond-mere-formulaicity/ritualisation-as- historicity-tracing-\{science-

ideology/fashionability/distraction $\}\rangle$ as to construction-of-the-Self in dispensing-with- 
immediacy-for-relative-ontological-completeness ${ }^{87}$-by-reification/contemplative-distension ${ }^{27}$ as such a flawed conception is very much prone to disenfranchising public, media and institutionalised pedantising/muddling/formulaic-hollowing-out—insubontologisation/subpotentiation-〈blurring/undermining-of-prospective-totalising-entailing,as-to-entailing-<amplituding formative-epistemicity $>$ totalising $\sim$ in-relative-ontologicalcompleteness > bound to ultimately induce individuals reflective estrangement and disinterest with regards to optimal public outcomes of social-stake-contention-or-confliction (and as such disenfranchising framework render the truly relevant public issues secondary/indirect to their punctual/immediacy/constituted/compulsions-encumbered purpose of ratings/popularity than genuine thought). But rather the sovereign-function/posture-<as-to-existentially-manifest‘embodied-subject consciousness-and-direct/deferential-conscientiousness',-as-of-its‘epistemic-reflexivity/unreflexivity-in-existence'/teleology> ontologising-aptness in-manyways is in a protracted continuum with the genuine social intellectual-function/posture, soimplied as to a 'totalitative construal of the genuine social intellectual-function/posture parallel intellectual contestation of aptitudinal-substantive-pertinence educing layers of deferentialformalisation-transference as of percolation-channelling-<in-deferential-formalisationtransference $>$ enabling the sovereign-function/posture-<as-to-existentially-manifest‘embodied-subject consciousness-and-direct/deferential-conscientiousness',-as-of-its'epistemic-reflexivity/unreflexivity-in-existence'/teleology> ontologising-aptness (as soundergirded by the 'overall underlying social-construct ontological-commitment ${ }^{6}-<$ implied self-assuredness-of-ontological-good-faith/authenticity postconverging-dementating/structuring/paradigming -as-being-as-of-existential-reality $>$ so-reflected as of social notional $\sim$ self-distantiation-<imbued—re-motif-and-re-apriorising/re-axiomatising/rereferencing $>$ '). The sovereign-function/posture-<as-to-existentially-manifest-'embodiedsubject consciousness-and-direct/deferential-conscientiousness',-as-of-its- 'epistemic- 
reflexivity/unreflexivity-in-existence'/teleology $>$ ontologising-aptness warrants that it doesn't fall prey to falsehoods of 'contrastive equivalence' implied as of distractive-alignment-toreference-of-thought- $<$ of-apriorising/axiomatising/referencing $>30 \quad$ manifested with ontologically-flawed process/processive bothsidesism-〈as-'mere-processive'/pedantising‘dialogical-relation'-to 'perceived-social-and-institutional-commonlyenculturated_referencing,-of- meaningfulness-and-teleology '-failing-'requisite-existentialthematic-baseline-of-technicity/profundity-framing' \{of-sublimating-discursivity-forsovereign-repassing \},-as-of-psychologismic-epistemic-acutisation-nonresidualising-imbued\{compulsing $\}$ linearity in-eclecticism-of-prior-mere-formulaicity/ritualisation,-as-so‘consciously/unconsciously-preordained/fated'-to-fail-prospective-notional cogency) formulations and recipes along the lines of decades-long politically manipulative narratives like deficits, public spending, social engineering, socialism, tribalism, fairness, libertarian, middleof-the-ground, identity politics, etc.)', and further requires that effective public and institutional intellectual contestation of aptitudinal-substantive-pertinence are not be subverted by monopolising/quasi-monopolising/networking existentialising-frame-of-entailment-of motifand-apriorising/axiomatising/referencing of public and institutional discursivity as of mere entitlement-and-access and ratings-drivenness. Likewise, the 'genuine social intellectualfunction/posture involves striving for a protracted continuum with the sovereignfunction/posture-<as-to-existentially-manifest-'embodied-subject $\sim$ consciousness-and-

\section{direct/deferential-conscientiousness',-as-of-its-'epistemic-reflexivity/unreflexivity-in-}

existence'/teleology> for its ontologising-aptness' but not in wrongly validating the existentialising-frame-of-entailment of motif-and-apriorising/axiomatising/referencing of discursivity as to a conception of 'normalised/stereotyped/selfhelping/feel-good knowledge being brought at the protracted-social—as-to-individual-by-institutional-by-social sovereign's service lacking in the underlying conception of epistemic-growth/disquiet/discomfort-〈induced- 


\section{sublimation,-as-from-existence's - effusing/ecstatic-inlining-as- historiality-}

\section{\{science/authenticity/nonextrication $\}$-beyond-mere-formulaicity/ritualisation-as- historicity-}

tracing-\{science-ideology/fashionability/distraction $\}\rangle$ as to construction-of-the-Self in dispensing-with-immediacy-for-relative-ontological-completeness ${ }^{87}$-by-

reification/contemplative-distension ${ }^{27}$ (that ultimately undermines technicity/profundity which is inescapable for achieving sublimating-nascence whether as more readily appreciated with nascent-particular/incipient-and-material/technical-sublimations- $<$ blinded-to-their-relativeontological-completeness - reference-of-thought- devolving> existentialising-decisionality$<$ as-to-disontologising/re-ontologising aporeticism $>$ or with the relative blurriness$<$ sterilising/anecdotalising/trivialising-of-prospective-re-ontologising_by-preconverging,-indisontologising-formulaic-dragging-out/hollowing-out $>\quad$ of $\quad$ social-and-institutionalframeworks-of — referencing/registering/decisioning existentialising-decisionality-<as-todisentologising/re-ontologising aporeticism $>$ ); and so to fundamentally bring to the consciousness-awareness-teleology that 'sovereignty doesn't equate with technicity/profundity' (even as in reality it is herein contended this disconnect in the appraisal of the veridical relationship between sovereignty and technicity/profundity is mostly enabled with social-andmedia induced numbining-traction_-of-desublimating - 5 meaningfulnesss_and-teleleology perspective-lost-of-'supererogatory acuity/perspicacity/astuteness/edginess/incisiveness-as-tothe-imbued-postconverging/dialectical-thinking -of-notional deprocrypticism- indimensionality-of-sublimating — < amplituding/formative-epistemicity $>$ growth-orconflatedness /scalarisation-as-to-rescalarisation-as-re-ontologisation\}' $\rangle$ wherein an 'elicited mere-formulaic_conformity/trending/voguing/fashionability/resonance relation to meaningfulness-and-teleology ${ }^{\circ}$ undermines the individual's and social 'conscious-and-active epistemic-totalising re-procession of the existentialising-frame-of-entailment of motif-andapriorising/axiomatising/referencing re-apriorising/re-axiomatising/re-referencing of 
meaningfulness-and-teleology" while overemphasising rather a 'subconscious-and-passive epistemic-totalising ${ }^{3}$ re-automatism relation with the existentialising-frame-of-entailment-ofmotif-and-apriorising/axiomatising/referencing re-apriorising/re-axiomatising/re-referencing of meaningfulness-and-teleology ${ }^{9}$ as elicited with pedantising/muddling/formulaic-hollowingout-in-subontologisation/subpotentiation-_blurring/undermining-of-prospective-totalisingentailing,-as-to-entailing-<amplituding/formative-epistemicity $>$ totalising $\sim$ in-relativeontological-completeness > with the consequent contemplative disorientation, estrangement and lip-servicing/trivialising-relation to veridical social-stake-contention-or-confliction existentialising-decisionality-<as-to-disontologising/re-ontologising aporeticism $>$ evaluation-and-coherence'). This eventually means that the genuine social intellectualfunction/posture (adduced conceptivity/epistemic-reflexivity/epistemicity-relativismdeterminism-<reifying \{as-to-knowledge-developing $\}$-and-empowering $>\quad$ imbued theoretical/conceptual/operant implications) should be able to saliently articulate/impress-upon the 'overall social intellection-aptitude body' (within the framework of a natural and truly original, autonomous and non-contrived intellectual culture) 'appropriately sublimating technicity/profundity capable of veridically responding to social and institutional postconverging aporeticism-overcoming/unovercoming' as to postconverging epistemic projective-equalisation social dynamics of percolation-channelling- $<$ in-deferentialformalisation-transference $>$ (rather than the manifested mediatic silliness wherein 're-processive technicity/profundity' is widely scorned upon 'in favour of vague normalised/stereotyped/selfhelping/feel-good narratives' as to mere entitlement-and-access and ratings-drivenness eliciting pedantising/muddling/formulaic-hollowing-out—insubontologisation/subpotentiation-〈blurring/undermining-of-prospective-totalising-entailing,as-to-entailing-<amplituding/formative-epistemicity $>$ totalising $\sim$ in-relative-ontologicalcompleteness > in a 'framework of preconvergingly-de-mentated/structured/paradigmed 
institutional and media contrivance' and so-inducing 'individuals reflective estrangement and disinterest with regards to optimal public outcomes of social-stake-contention-or-confliction', and as so-cynically-and-surreptitiously cajoled by dominance/vested-interest-subontologisingskewed-influence-as-to-social-vestedness/normativity-<discretely-implied-functionalism $>$ rendering the 'overall social intellection-aptitude body' relatively irrelevant towards upholding the sovereign-function/posture-<as-to-existentially-manifest-'embodiedsubject consciousness-and-direct/deferential-conscientiousness',-as-of-its-'epistemicreflexivity/unreflexivity-in-existence'/teleology $>$ ). Thus, the sovereign-function/posture-<asto-existentially-manifest-'embodied-subject consciousness-and-direct/deferentialconscientiousness',-as-of-its- 'epistemic-reflexivity/unreflexivity-in-existence'/teleology> is effectively disempowered as to its relevance to optimal public outcomes of social-stakecontention-or-confliction when the 'overall social intellection-aptitude body' assessment capacity is fundamentally undermined as to monopolising/quasi-monopolising/networking existentialising-frame-of-entailment of motif-and-apriorising/axiomatising/referencing of public and institutional discursivity as of mere entitlement-and-access and ratings-drivenness bent on side-lining salient and relevant narratives as to technicity/profundity (such that in effect through the decades such dominance/vested-interest-subontologising-skewed-influence-as-tosocial-vestedness/normativity-<discretely-implied-functionalism $>$ has paradoxically effectively-and-preemptively succeeded in 'qualifying in the public psyche' the 'specific overall social intellection-aptitude body that is the public university as to its underlying social-construct ontological-commitment $\quad$-implied-self-assuredness-of-ontological-good-

\section{faith/authenticity postconverging-de-mentating/structuring/paradigming -as-being-as-of-}

existential-reality $>$ so-reflected as of social notional $\sim$ self-distantiation- $<$ imbued - re-motif-andre-apriorising/re-axiomatising/re-referencing $>$ with regards to socio-econo-political socialstake-contention-or-confliction postconverging-apereticism-overcoming/unovercoming' in 
falsehoods terms of 'contrastive equivalence' implied distractive-alignment-to- ${ }^{8}$ reference-ofthought- $<$ of-apriorising/axiomatising/referencing $>$ ' and so-undermining its 'neutral sovereignfunction/posture-<as-to-existentially-manifest-`embodied-subject $\sim$ consciousness-and-

\section{direct/deferential-conscientiousness',-as-of-its-'epistemic-reflexivity/unreflexivity-in-}

existence'/teleology> upholding', and with a failed public consciousness about the sovereign importance of the public university practically subjecting them to increasing private funding deeply eroding-and/or-corrupting their capacity for "neutral sovereign-function/posture-<as-toexistentially-manifest-`embodied-subject $\sim$ consciousness-and-direct/deferential-

conscientiousness',-as-of-its-'epistemic-reflexivity/unreflexivity-in-existence'/teleology>

upholding' and most critically-so not necessarily in quashing ideas but inducing social apprehension and contestive inactivity). In-many-ways, the 'overall social intellection-aptitude body' (as to its capacity for 'neutral sovereign-function/posture-<as-to-existentially-manifest‘embodied-subject consciousness-and-direct/deferential-conscientiousness',-as-of-its-

‘epistemic-reflexivity/unreflexivity-in-existence'/teleology> upholding' whether as so-reflected by the public university or the press body or the 'overall backdrop of the professional class intellectualism') in recent decades with regards to socio-econo-political subontologisation/ideology-over-ontology has often failed to appreciate the implications of the fact that given human <amplituding/formative-epistemicity>-totalising $\sim$ thrownness-inexistence ${ }^{35}$, 'human ${ }^{5}$ meaningfulness-and-teleology'9 is effectively of epistemic-totalising

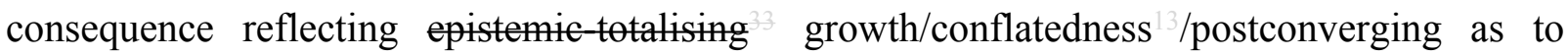
'implicited_attendant-ontological-contiguity ${ }^{67}$ educedexistentialising/contextualising/textualising_'intelligibility/epistemicity/reflexivity-contiguity$<$ imbued-notional cogency $>$-in-elucidation-or-reification knowledge/interpretative veracity implications of concurrent limited-mentation-capacity-deepening-as-subjectinglimitedness/human-subpotency-to-'educed-unlimitedness/existence-sublimating nascence' 
(thus implying human ${ }^{5}$ meaningfulness-and-teleology ${ }^{9}$ profoundness/ontologising-depth is of notional ${ }^{1}$ deprocrypticism-or-preempting_-disjointedness-as-of- ${ }^{3}$ reference-of-

thought/contiguity/coherence as of '<amplituding/formative>disposedness/psychologismicconstruct-〈as-to-orientation/value-construct/valuation-and-derived-parameterising $\quad$ and $<$ amplituding/formative >entailment-〈as-to-totalising-contiguous/coherent-factuality-of-

variability)' underlined as to its given prospective ${ }^{45}$ foregrounding_entailment- $<$ in-successionof-profound-supererogation $>$ - $\langle$ postconverging-narrowing-down $\sim$ sublimation-as-to‘existence — as-sublimating-withdrawal/unenframing/re-ontologising,-elicited-fromprospective-profound-supererogation '-in-reflecting-'immanent $\sim$ relativeunreflexivity/relative-reflexivity - ontological-contiguity ' ';-as-operativenotional deprocrypticism)); with the implication here that institutional process/processiveness as of mere-formulaicity/ritualisation-<as-to-mere-formulaicmethodologising/mutualising/organising/institutionalising,-prospectively-losing-track-of‘fepistemic-totalising ’’re-apriorising/re-axiomatising/re-referencing $\sim$ residuality —in-reoriginariness/re-origination'> (while clearly inducing disontologising socio-econo-political outcomes)' cannot be construed as the all-be-all of human institutions but rather 'process/processiveness has to be associated with sublimating existentialising-decisionality<as-to-disontologising/re-ontologising aporeticism $>$ institutional socio-econo-political outcomes and purpose reappraisal reflected with the epistemictotalising $\sim$ resubjecting_or_totalising-entailing $\sim$ reconstrual- $<$ of the-whole/purview-of thewhole/oneness-of-ontology> of 'implicited_attendant-ontological-contiguity ${ }^{67}$ ' educedexistentialising/contextualising/textualising_intelligibility/epistemicity/reflexivity-contiguity$<$ imbued-notional cogency>' ${ }^{\prime}$-in-elucidation-or-reification' as to profound supereregatery acuity/perspicacity/astuteness/edginess/incisiveness ontologising/reontologising conception of social-stake-contention-or-confliction to avoid their pedantising 
skewing into numbing-traction_-of-desublimating_- meaningfulness_and-teleology -〈asperspective-lost-of-‘supererogatory acuity/perspicacity/astuteness/edginess/incisiveness-as-tothe-imbued-postconverging/dialectical-thinking -of-notional deprocrypticism- indimensionality-of-sublimating — < <mplituding/formative-epistemicity $>$ growth-orconflatedness /scalarisation-as-to-rescalarisation-as-re-ontologisation $\left.\}^{\prime}\right\rangle . \quad$ Thus the veracity/efficiency of social intellection is rather in terms of the 'consequent sovereignfunction/posture-<as-to-existentially-manifest-‘embodied-subject consciousness-anddirect/deferential-conscientiousness',-as-of-its- 'epistemic-reflexivity/unreflexivity-inexistence'/teleology> contemplative capacity/deferential-capacity in epistemic-totalising growth/conflatedness ${ }^{13} /$ postconverging as to implieited_tentantontologicalcontiguity $^{67} \sim$ educedexistentialising/contextualising/textualising_'intelligibility/epistemicity/reflexivity-contiguity$<$ imbued-notional cogency $>$-in-elucidation-or-reification knowledge/interpretative veracity implications of concurrent limited-mentation-capacity-deepening-as-subjectinglimitedness/human-subpotency to-'educed-unlimitedness/existence-sublimating nascence' ${ }^{3}$, allowing for appropriate coherence between concrete-social-reality-<as-to-manifestsublimation/desublimation $>$ and overall public perception of concrete-social-reality- $<$ as-tomanifest-sublimation/desublimation $>$ with respect to optimal public outcomes of social-stakecontention-or-confliction' and so rather than the naive counterintuition of mere 'shallow process/processive conception as so-often reflected with a process/processive bothsidesism-〈as‘mere-processive'/pedantising-‘dialogical-relation'-to 'perceived-social-and-institutionalcommonly-enculturated_referencing,-of- meaningfulness-and-teleology '-failing-'requisiteexistential-thematic-baseline-of-technicity/profundity-framing' \{of-sublimating-discursivityfor-sovereign-repassing \},-as-of-psychologismic-epistemic-acutisation-nonresidualisingimbued-\{compulsing\} linearity in-eclecticism-of-prior-mere-formulaicity/ritualisation,-as-so- 
‘consciously/unconsciously-preordained/fated'-to-fail-prospective-notional cogency $\rangle$ mental-

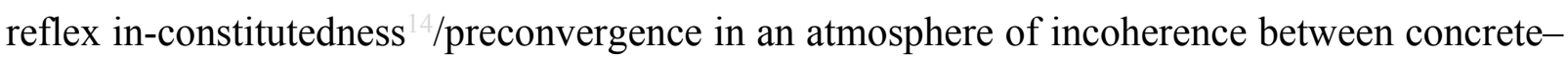
social-reality-<as-to-manifest-sublimation/desublimation $>$ and overall public perception of concrete-social-reality-<as-to-manifest-sublimation/desublimation $>$ ' (and so as to the fact that 'existence as to ontological-veracity consequence of the social reality' so-underlined by manifest social-stake-contention-or-confliction issues should as to human epistemicgrowth/conflatedness 13 /postconvergence instigatingly drive public debates rather than the 'naivety that the balancing of human-subpotencies as of vague process/processive bothsidesism〈as-'mere-processive'/pedantising-'dialogical-relation'-to 'perceived-social-and-institutionalcommonly-enculturated_referencing,-of- meaningfulness-and-teleology '-failing-'requisiteexistential-thematic-baseline-of-technicity/profundity-framing' \{of-sublimating-discursivityfor-sovereign-repassing $\}$,-as-of-psychologismic-epistemic-acutisation-nonresidualisingimbued-fcompulsingl linearity in-eclecticism-of-prior-mere-formulaicity/ritualisation,-as-so‘consciously/unconsciously-preordained/fated'-to-fail-prospective-notional cogency mentalreflex in apriorising/axiomatising/referencing-\{of-'prospectively implieited_tendant ontological-contiguity ' educedexistentialising/contextualising/textualising_'intelligibility/epistemicity/reflexivity_contiguity$<$ imbued-notional cogency> $>$ - constitutedness ${ }^{1}$-in-preconverging entailment/preconvergence will then reflect sublimating social ontological-veracity' sounderlined by issues of relatively little relevance to general social-stake-contention-orconfliction with the latter just making room for desublimating pedantising/muddling/formulaichollowing-out-in-subontologisation/subpotentiation-〈blurring/undermining-of-prospectivetotalising-entailing,-as-to-entailing-<amplituding/formative-epistemicity $>$ totalising $\sim$ inrelative-ontological-completeness $\rangle$ induced distractive-alignment-to- ${ }^{8}$ reference-of-thought$<$ of-apriorising/axiomatising/referencing $>^{30}$ and wherein issues of minor or irrelevant social- 
stake-contention-or-confliction are used to disorientate and estrange the sovereignfunction/posture-<as-to-existentially-manifest-'embodied-subject consciousness-anddirect/deferential-conscientiousness',-as-of-its-'epistemic-reflexivity/unreflexivity-inexistence'/teleology $>$ while trivialising-and-enframing issues of central public interests). The consequence being that a 'shallow process/processive conception as so-often reflected with a process/processive bothsidesism-〈as-'mere-processive'/pedantising-'dialogical-relation'to 'perceived--social-and-institutional-commonly-enculturated_referencing,-ofmeaningfulness-and-teleology '-failing-'requisite-existential-thematic-baseline-oftechnicity/profundity-framing' \{of-sublimating-discursivity-for-sovereign-repassing , -as-ofpsychologismic-epistemic-acutisation-nonresidualising-imbued-\{compulsing\}linearity ineclecticism-of-prior-mere-formulaicity/ritualisation,-as-so-'consciously/unconsciouslypreordained/fated'-to-fail-prospective-notional cogency) mental-reflex inconstitutedness ${ }^{14}$ /preconvergence in an atmosphere of incoherence between concrete-socialreality-<as-to-manifest-sublimation/desublimation $>$ and overall public perception of concretesocial-reality-<as-to-manifest-sublimation/desublimation>' is critically inadequate for 'neutral sovereign-function/posture-<as-to-existentially-manifest-'embodied-subject $\sim$ consciousnessand-direct/deferential-conscientiousness',-as-of-its-'epistemic-reflexivity/unreflexivity-inexistence'/teleology> upholding' as so particularly elicited with distractive-alignment-toreference-of-thought-<of-apriorising/axiomatising/referencing $>^{30}$ issues. The fundamental point here is that existence - as-the-absolute-a-priori-of-conceptualisation and existence-assublimating-withdrawal/unenframing/re-ontologising,-elicited-from-prospective-profoundsupererogation -<as-to-perspective-ontological-normalcy/postconvergence-implied'prospective-aporeticism-overcoming/unovercoming'> makes nonsense of any such vague notion as 'neutrality by the balancing of human-subpotencies' so-reflective of 'vested interests driven conception of balance as to discrete interests' (rather than common/mutualising interest 
conception of balance rather requiring the cultivation of a veridical social exercise of notional $\sim$ self-distantiation-<imbued—re-motif-and-re-apriorising/re-axiomatising/re-

referencing $>$ as to implied social formativeness-<as-to-intersolipsism-ofpreformulating/preframing/premeaningfulness-imbued-mediativity-and-deferentialism>-ofmeaningfulness-and-teleology reflective of ${ }^{6}$ nonpresencing- $<$ perspective-ontologicalnormalcy/postconvergence> epistemic-projection implications), with such 'vested interests driven conception of balance as to discrete interests' rather an exercise consciously or unconsciously of manifest ontological-bad-faith/inauthenticity ${ }^{64}$ in preconverging-existentialextrication-as-of-existential-unthought. Thus ontological-veracity (as to the pertinence of 'overall social intellection-aptitude body' as to its capacity for 'neutral sovereignfunction/posture-<as-to-existentially-manifest-'embodied-subject $\sim$ consciousness-and-

\section{direct/deferential-conscientiousness',-as-of-its-'epistemic-reflexivity/unreflexivity-in-}

existence'/teleology> upholding') rather arises as of a 'human conceptivity/epistemicreflexivity/epistemicity-relativism-determinism-<reifying \{as-to-knowledge-developing $\}$-andempowering > imbued theoretical/conceptual/operant implications detour to existencepotency $^{39} \sim$ sublimating-nascence,-disclosed-from-prospective-epistemic-digression' in pointing out the prospect of sublimating/desublimating existentialising-decisionality-as - to disentologising/re-ontologising aporeticism $>$ socio-econo-political outcomes and implications rather than the 'passive deification of institutional process/processiveness as of mereformulaicity/ritualisation-<as-to-mere-formulaic methodologising/mutualising/organising/institutionalising,-prospectively-losing-track-of‘\{pistemic-totalising ${ }^{\dagger}$ re-apriorising/re-axiomatising/re-referencing residuality-in-reoriginariness/re-origination'>' (underlying why such a deficient social intellection posture will tend to be one step behind cumulating desublimating socio-econo-poliotical outcomes as if it is most critically about reflecting upon such cumulating desublimating existentialising- 
outcomes rather than truly a posture of anticipative analysis and preemption). This mere process/processiveness induced deficiency is often critically reflected in a 'barest and passive as flawed/unsound\}-relative-unreflexivity-in-existence/absolutising-from-limitedmentation/psychologismic epistemic acutisation nonresidualising imbued\{compulsing\} linearity-in-eclecticism-of-prior-mere-formulaicity/ritualisation conception of sovereignty in the democratic process' that is poorly cognisant of the appropriate overall social enlightenment/knowledge imbuing oversight of the 'overall social intellection-aptitude body' (as to its capacity for 'neutral sovereign-function/posture-<as-to-existentially-manifest-'embodiedsubject consciousness-and-direct/deferential-conscientiousness',-as-of-its- 'epistemicreflexivity/unreflexivity-in-existence'/teleology> upholding' whether as so-reflected by the public university or the press body or the 'overall backdrop of the professional class intellectualism') that is 'much more than about leaving the room for competing/contending parties narrations/orientations/advocacies for socio-econo-political existentialisingdecisionality-<as-to-disontologising/re-ontologising aporeticism $>$ but appraising-andcritiquing the effective coherence of such narrations/orientations/advocacies as to socio-econopolitical outcomes expectations of the sovereign-function/posture-<as-to-existentially-manifest‘embodied-subject consciousness-and-direct/deferential-conscientiousness',-as-of-its'epistemic-reflexivity/unreflexivity-in-existence'/teleology>'; so-underlying the more profound-supererogation notion of sovereignty associated with 'appropriately sublimating technicity/profundity capable of veridically responding to social and institutional postconverging aporeticism-overcoming/unovercoming' as to postconverging epistemic projective-equalisation social dynamics of veridical social knowledge percolation-channelling$<$ in-deferential-formalisation-transference $>$. The consequence of this mere process/processiveness induced deficiency is reflected in an entrenched dichotomy of the 
democratic process between the reality of recurrent narratives of disontologising socio-econopolitical outcomes on-the-one-hand and on-the-other-hand a publicly cultivated <preconverging 'motif-and-apriorising/axiomatising/referencing'-entailing >-

existentialising — enframing/imprintedness-〈as-to- historicity-tracing - in-presencing-

hyperrealisation/hyperreal-transposition〉 political culture/discourse that by its selfdrivenness/self-containment at critical moments of the democratic process seem to bypass the relevance of such recurrent disontologising socio-econo-political outcomes (even as the-verysame social themes are recurrently and superficially raised as to a numb-_bing-traction__-_ofdesublimating_ meaningfulness_-and_teleleology $-\langle$ as-perspective-lost-of-

'supererogatory acuity/perspicacity/astuteness/edginess/incisiveness-as-to-the-imbuedpostconverging/dialectical-thinking -of-notional deprocrypticism-\{in-dimensionality-ofsublimating _ < $<$ amplituding/formative-epistemicity $>$ growth-orconflatedness /scalarisation-as-to-rescalarisation-as-re-ontologisation $\left.\}^{\prime}\right\rangle \quad$ treatment); soreflecting a 'habituatedness/mental-colonisation of the sovereign-function/posture-<as-toexistentially-manifest-`embodied-subject consciousness-and-direct/deferential-

conscientiousness',-as-of-its- 'epistemic-reflexivity/unreflexivity-in-existence'/teleology> to the presencing —absolutising-identitive-constitutedness ${ }^{14} \quad$ social-vestedness/normativity' cynically construed as enabling a social-stake-contention-or-confliction distractive-alignmentto- ${ }^{8}$ reference-of-thought-<of-apriorising/axiomatising/referencing $>$ pedantising/muddling/formulaic-hollowing-out — in-subontologisation/subpotentiation〈blurring/undermining-of-prospective-totalising-entailing,-as-to-entailing<amplituding/formative-epistemicity>totalising in-relative-ontological-completeness > exercise in undermining prospective human re-ontologisation/omnipotentiality. Basically the 'full incipient supererogating breadth of human intelligibility transmutation' (as '<supereregatory $\sim$ human-subpotency $>$-effecting imbued epistemic-totalising 
preformulating/preframing/premeaningfulness of notional originariness-parrhesia,-asspontaneity-of-aestheticisation' before the incipience of metaphoricity ${ }^{57}$ and then meaningfulness-and-teleology as to existentialising-frame-of-entailment-of motif-andapriorising/axiomatising/referencing) speaks to the 'epistemic-totalising ${ }^{3}$ nonrecomposuringcumulating/addending of human ${ }^{5}$ meaningfulness-and-teleology ${ }^{9}$ as liable to dispensing with its 'limited-mentation-capacity_as-subjecting-'educed-unlimitedness/existence-sublimating nascence' to-limitedness/human-subpotency necessity for $\quad$ re-originariness/reorigination'/limited-mentation-capacity-deepening —as-subjecting-limitedness/hmmansubpotency to-'educed-unlimitedness/existence-sublimating nascence' ${ }^{33}$ (as so-reflecting human notional firstnaturedness-formativeness-<as-to-eventualising-inkling-drive-orseeding-misprising $>$ temporal-to-intemporal-dispositions-<so-construed-as-fromperspective-ontological-normalcy/postconvergence $>\quad$ disontologising ontologicalperformance $^{72}$-<including-virtue-as-ontology $>$ /morality/ethics/justice/etc. within any given registry-worldview/dimension); thus speaking to the preconverging/postconverging-dementative/structural/paradigmatic veracity of the "prospective disontologising of any given human prior sublimating ${ }^{56}$ meaningfulness-and-teleology ${ }^{9}$ into prospective pedantising/muddling/formulaic-hollowing-out — in-subontologisation/subpotentiation〈blurring/undermining-of-prospective-totalising-entailing,-as-to-entailing$<$ amplituding/formative-epistemicity>totalising in-relative-ontological-completeness $>$ as to prospective social-stake-contention-or-confliction' (so-reflected with regards to Beingdevelopment/ontological-framework-expansion-as-to-depth-of-ontologising-development-asinfrastructure-of- meaningfulness-and-teleology , institutional-development-as-to-socialfunction-development and living-development-as-to-personality-development psychologismic epistemic-acutisation difficulty-for, residualising \{decomplsing $\}$ delinearity for-cogency> magnitudes $\{$ of-experientiality/experiment\} $\}$. Disontologisation as such is a reflection of the fact that the 
very seedingness/incipience of human sublimating ontologising-depth reflecting holographically-<conjugatively-and-transfusively $>$ the relative-unreflexivity/relativereflexivity - ontological-contiguity of-the-human-institutionalisation-process lies with human dimensionality-of-sublimating ${ }^{25}-\langle<$ amplituding formative $>$ supererogatory dementativeness/epistemic-growth-or-conflatedness /transvaluativerationalising/transepistemicity/anamnestic-residuality/spirit-drivenness-equalisation $\rangle, \quad$ with disontologisation seedingly/incipiently associated prospectively with human limited-mentationcapacity - as-subjecting 'educed-unlimitedness/existence-sublimating nascence' tolimitedness/human-subpotency as of mere-formulaicmethodologising/mutualising/organising/institutionalising underlying dimensionality-ofdesublimating-lack-of ${ }^{-}-\langle<$amplituding/formative $>$supererogatory $\sim$ de-mentativeness/epistemicgrowth-or-conflatedness /transvaluative-rationalising/transepistemicity/anamnesticresiduality/spirit-drivenness-equalisation $\rangle$. Disontologisation thus arises at human destructuring-threshold-〈uninstitutionalised-threshold /presublimating-desublimating-

decisionality $>$ of-ontological-performance ${ }^{72}$-<including-virtue-as-

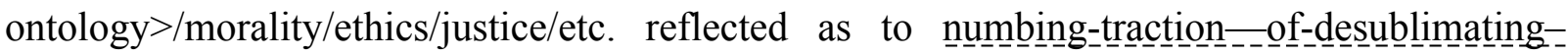

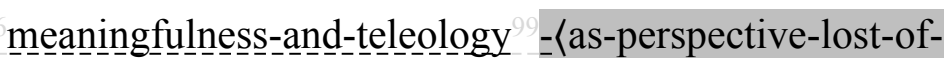
'supererogatory acuity/perspicacity/astuteness/edginess/incisiveness-as-to-the-imbuedpostconverging/dialectical-thinking -of-notional deprocrypticism-\{in-dimensionality-ofsublimating _ < $<$ amplituding/formative-epistemicity $>$ growth-orconflatedness /scalarisation-as-to-rescalarisation-as-re-ontologisation $\left.\}^{\prime}\right\rangle$. The bigger point here has to do with the requisite conceptivity/epistemic-reflexivity/epistemicity-relativismdeterminism-<reifying \{as-to-knowledge-developing $\}$-and-empowering $>\quad$ imbued theoretical/conceptual/operant implications as to 'social and institutional notional $\sim$ selfdistantiation-<imbued-re-motif-and-re-apriorising/re-axiomatising/re- 
referencing $>/$ 'distantiation of contemplative existentialising-frame-of-entailment-of motifand-apriorising/axiomatising/referencing as to transversality-<for-sublimating-existentialeventuating/denouement,-from-'thinking at-first/pure-predisposition-preemptive-ofprospective-disontologising/subontologising’ as-of-prospectively-disambiguated-affirmedand-unaffirmed-'motif-and-apriorising/axiomatising/referencing'>101 elicited ontologicalnormalcy/postconvergence recovery-of/making-available of prospective ontologising-depth of meaningfulness-and-teleology (in so-overriding sovereignising disposition for beholdening subontologisation/subpotentiation as associated with social and institutionalised pedantising/muddling/formulaic-hollowing-out — in-subontologisation/subpotentiation〈blurring/undermining-of-prospective-totalising-entailing,-as-to-entailing<amplituding/formative-epistemicity>totalising in-relative-ontological-completeness > desublimating existentialising-decisionality-<as-to-disontologising/re-ontologisingaporeticism $>$ imbued distractive-alignment-to- ${ }^{-}$reference-of-thought- $<$ofapriorising/axiomatising/referencing $>^{30}$ ) as to human prospective reontologisation/omnipotentiality drive; and so-reflected with regards to Beingdevelopment/ontological-framework-expansion-as-to-depth-of-ontologising-development-asinfrastructure-of- meaningfulness-and-teleology , institutional-development-as-to-socialfunction-development and living-development-as-to-personality-development psychologismic epistemic acutisation difficulty-for, residualising \{decompulsing $\}$ delinearity for-cogency> magnitudes ${ }^{\{\text {of-experientiality/experiment }\}}$. Disontologisation as to social-stake-contention-or-confliction as reflected above is so-critically at the very core of 'human social-and-institutional-frameworksof - referencing/registering/decisioning existentialising-decisionality-<as-todisontologising/re-ontologising aporeticism $>$ ' intellectual theorising as to a human social-andinstitutional-frameworks-of — referencing/registering/decisioning existentialising-decisionality<as-to-disontologising/re-ontologising aporeticism $>$ characterised by blurriness- 


\section{$<$ sterilising/anecdotalising/trivialising-of-prospective-re-ontologising_by-preconverging,-in-}

disontologising-formulaic-dragging-out/hollowing-out> allowing for the relative pedantising/muddling/formulaic-hollowing-out - in-subontologisation/subpotentiation〈blurring/undermining-of-prospective-totalising-entailing,-as-to-entailing$<$ amplituding/formative-epistemicity>totalising in-relative-ontological-completeness $>$ preconvergingly-de-mentated/structured/paradigmed undermining of prospective genuine social intellectual-function/posture as to its projected re-ontologisation/omnipotentiality drive; as so-critically reflected with a pedantising/muddling/formulaic-hollowing-out-insubontologisation/subpotentiation-〈blurring/undermining-of-prospective-totalising-entailing,as-to-entailing-<amplituding/formative-epistemicity $>$ totalising in-relative-ontologicalcompleteness $>$ that in-many-ways openly-assert having nothing to do with present human and social postconvergingapareticism-overcoming/unovercoming or superficially gloss over such human and social postconverging-aporeticism-overcoming/unovercoming in a confusion between advocacy/ministration/sermonising and intellection going on to trivialise and undermine the profound enlightening implications of true intellection (as to a fundamental dearth of knowledge-reification $\sim$ gesturing-and-accounting - of-epistemic-phenomenalism- $<$ inprospective_psychologismic apriorising/axiomatising/referencing-\{of-'prospectively implicited_attendant-ontological-contiguity ' educedexistentialising/contextualising/textualising_'intelligibility/epistemicity/reflexivity-contiguity<imbued-notional cogency>' \}-conflatedness in \{preconverging ment by\} postconverging entailment $>$ however crude as knowledge becomes an issue of 'personalised and free-floating mentioning' incapable of true objectifying knowledge-reification $\sim$ gesturing-andaccounting - of-epistemic-phenomenalism- $<$ inprospective_psychologismic apriorising/axiomatising/referencing-\{of-'prospectively_ implicited_attendant-ontological-contiguity ' educed- 
existentialising/contextualising/textualising_ 'intelligibility/epistemicity/reflexivity-contiguity<imbued-notional cogency $>$ ' \}-conflatedness -in-\{preconverging ment by\}

postconverging-entailment> as to 'conceptivity/epistemic-reflexivity/epistemicity-relativismdeterminism-<reifying \{as-to-knowledge-developing $\}$-and-empowering $>\quad$ imbued theoretical/conceptual/operant implications' enabling the conceptualisation of momentous historiality/ontological-eventfulness 38 ontological-aesthetic-tracing-<perspectiveontological-normalcy/postconvergence-reflected-‘epistemicity-relativism-determinism’>), and further contriving to undermine anti-intellectually (as to confusion between intellectual engagement and bland media-driven influence) a genuine social intellectual-function/posture projective resolutioning of such prospective human and social postconvergingaapereticismovercoming/unovercoming as so-fraudulently directed against the prospective sublimating existentialising-decisionality-<as-to-disontologising/re-ontologising apereticism $>$ of many a postmodern thought and other critical thinkers. Such a disontologising pedantising/muddling/formulaic-hollowing-out — in-subontologisation/subpotentiation〈blurring/undermining-of-prospective-totalising-entailing,-as-to-entailing$<$ amplituding/formative-epistemicity $>$ totalising in-relative-ontological-completeness $>$ is one that 'increasingly runs away from and thrive outside the very central notion defining intellectualism' (herein implied as 'conceptivity/epistemic-reflexivity/epistemicity-relativismdeterminism-<reifying \{as-to-knowledge-developing $\}$-and-empowering $>\quad$ imbued theoretical/conceptual/operant implications') as to its dereification gesturing/accounting-ofepistemic-phenomenalism cultivating the decadent notion that 'mere sovereignty equates with technicity/profundity' (as the 'critical cancer' of our modern-day democractic process as it shutsoff requisite sovereign 'epistemic-growth/disquiet/discomfort-_induced-sublimation,-as-fromexistence's - effusing/ecstatic-inlining-as- historiality-\{science/authenticity/nonextrication $\}$ beyond-mere-formulaicity/ritualisation-as- historicity-tracing-\{science- 
ideology/fashionability/distraction $\}\rangle$ as to construction-of-the-Self in dispensing-withimmediacy-for-relative-ontological-completeness ${ }^{87}$-by-reification/contemplative-distension ${ }^{27}$, so-associated with 'individuals reflective estrangement and disinterest with regards to optimal public outcomes of social-stake-contention-or-confliction'); as to when such pedantry openly affirming ignorance or demonstrates ignorance go on to 'supposedly articulate sublimating knowledge' with such normalised/stereotyped/selfhelping/feel-good conception of knowledge 'mediatically and socially popularised' inducing (given direct-and-indirect epistemic-totalising consequence of human ${ }^{56}$ meaningfulness-and-teleology ${ }^{9}$ ) 'incoherence between concretesocial-reality-<as-to-manifest-sublimation/desublimation $>$ and overall public perception of concrete-social-reality-<as-to-manifest-sublimation/desublimation $>^{\prime}$. The implications of such dereification gesturing/accounting — of-epistemic-phenomenalism (as to its reflection of human self-referencing-syncretising relation with 'conceptivity/epistemic-reflexivity/epistemicityrelativism-determinism-<reifying \{as-to-knowledge-developing $\}$-and-empowering $>\quad$ imbued theoretical/conceptual/operant implications') speaks to a degenerate conception of human selfreferencing-syncretising that seem to imply surreptitiously that no relative-ontologicalcompleteness $^{87}$ is pertinent (which it rather cynically qualifies as "nonpresencing$<$ perspective-ontological-normalcy/postconvergence $>$ relativism/relative-scope for epistemicgrowth,-as-\{veridical/sound\}-relative-reflexivity-in-existence/relativising from-limitedmentation-as-its-deepening/psychologismic epistemic acutisation residualising, ${ }_{\text {\{decomsing }}$ delinearity for-cogency') as to a cynical self-presence/self-constitutedness ${ }^{14}-<$ inperspective-epistemic-abnormalcy/preconvergence ${ }^{3}>\quad$ of $\quad{ }^{79}$ presencing-absolutisingidentitive-constitutedness ${ }^{14}$ <preconverging 'motif-and-apriorising/axiomatising/referencing' entailing >-existentialising — enframing/imprintedness-〈as-to- historicity-tracing-inpresencing-hyperrealisation/hyperreal-transposition〉' and very much explains why it fails to appreciate that without 'relativism' there is no progress since progress is relative to lack-of- 
progress with regards to human limited-mentation-capacity-deepening-as-subjecting limitedness/human-subpotency-to-'educed-unlimitedness/existence-sublimating nascence' 53 .

Critically in this regards, human civilisation is only possible as to the genuine social intellectualfunction/posture rather eliciting and fulfilling human ontological-commitment $-<$ implied self-assuredness-of-ontological-good-faith/authenticity postconverging-dementating/structuring/paradigming -as-being-as-of-existential-reality> and so in a cogent/tense/limpid-<as-of-prospective-profound-supererogation ,-for-residuality - in-reoriginariness/re-origination> transference> apriorising/axiomatising/referencing allowing for human and humanity's 'epistemicgrowth/disquiet/discomfort-〈induced-sublimation,-as-from-existence's-effusing/ecstatic-

\section{formulaicity/ritualisation-as- historicity-tracing-\{science-ideology/fashionability/distraction $\}\rangle$} as to construction-of-the-Self in dispensing-with-immediacy-for-relative-ontologicalcompleteness $^{87}$-by-reification/contemplative-distension ${ }^{27}$ (and not flawed normalised/stereotyped/selfhelping/feel-good conception of knowledge). We can appreciate in this regards that the specialist whether astronomer, technician, electronician, etc. is more critically sublimating/emancipating as to a 'conceptivity/epistemic-reflexivity/epistemicityrelativism-determinism-<reifying \{as-to-knowledge-developing $\}$-and-empowering $>\quad$ imbued theoretical/conceptual/operant implications' acting upon the breadth of socially cogent/tense/limpid-<as-of-prospective-profound-supererogation , -for-residuality-in-re-

originariness/re-origination>

transference> percolation-channelling- $<$ in-deferential-formalisationexistentialising-frame-of-entailment of motif-andapriorising/axiomatising/referencing of intellectualism involving genuine social intellectualfunction/posture projection of prospective human transcendence-and- 
sublimity/sublimation/supererogatory-de-mentativity as first-level technicity/profundity elucidation (as to existence-potency ${ }^{32} \sim$ sublimating-nascence,-disclosed-from-prospectiveepistemic-digression) with fellow specialists and then of derived-knowledge implications percolating to the appraisal of 'overall social intellection-aptitude body', and not a directly normalised/stereotyped/selfhelping/feel-good conception of knowledge relation with the general public in distractive-alignment-to- ${ }^{-3}$ reference-of-thought- $<$ ofapriorising/axiomatising/referencing $>$ (undermining such a sublimating/emancipating cogent/tense/limpid-<as-of-prospective-profound-supererogation ,, for-residuality—in-reoriginariness/re-origination> transference> percolation-channelling- $<$ in-deferential-formalisationexistentialising-frame-of-entailment-of-motif-andapriorising/axiomatising/referencing imbued notional $\sim$ self-distantiation- $<$ imbued-re-motifand-re-apriorising/re-axiomatising/re-referencing $>$ conception which is exactly what best defines and upholds human sovereign-function/posture-<as-to-existentially-manifest-

\section{'embodied-subject consciousness-and-direct/deferential-conscientiousness',-as-of-its-}

'epistemic-reflexivity/unreflexivity-in-existence'/teleology> with regards to appropriate coherence between concrete-social-reality-<as-to-manifest-sublimation/desublimation $>$ and overall public perception of concrete-social-reality-<as-to-manifestsublimation/desublimation $>$ with respect to optimal public outcomes of social-stake-contentionor-confliction). In this regards, a prevailing and counterintuitive naivety as to human social-andinstitutional-frameworks-of — referencing/registering/decisioning existentialising-decisionality<as-to-disentologising/re-ontologising aporeticism $>$ is that the mere communication of knowledge (without appropriate eliciting of 'epistemic-growth/disquiet/discomfort-_inducedsublimation,-as-from-existence's - effusing/ecstatic-inlining-as- historiality\{science/authenticity/nonextrication\}-beyond-mere-formulaicity/ritualisation-as- historicitytracing-\{science-ideology/fashionability/distraction $\}\rangle$ as to construction-of-the-Self in 
dispensing-with-immediacy-for-relative-ontological-completeness ${ }^{87}$-by-

reification/contemplative-distension ${ }^{27}$ as an exercise that is behind knowledge-production inthe-very-first-place and is required for effective prospective 'implicited_attendant-ontologicalcontiguity ${ }^{67} \sim$ educed-

existentialising/contextualising/textualising_intelligibility/epistemicity/reflexivity-contiguity<imbued-notional cogency> -in-elucidation-or-reification of knowledge content as to epistemic-totalising $\sim$ resubjecting_or_totalising-entailing $\sim$ reconstrual $<$ of thewhole/purview-of the-whole/oneness-of-ontology>) suffices without factoring that this is exactly what allows for pedantising/muddling/formulaic-hollowing-out-insubontologisation/subpotentiation-〈blurring/undermining-of-prospective-totalising-entailing,-

\section{as-to-entailing-<amplituding/formative-epistemicity $>$ totalising in-relative-ontological-}

completeness > desublimation; as knowledge effectively requires a sound grasp-of and referencing-to its sublimating/emancipating cogent/tense/limpid-<as-of-prospective-profoundsupererogation ,-for-residuality-in-re-originariness/re-origination> percolation-channelling$<$ in-deferential-formalisation-transference $>\quad$ existentialising-frame-of-entailment-of motifand-apriorising/axiomatising/referencing given human limited-mentation-capacity-assubjecting 'educed-unlimitedness/existence-sublimating nascence' to-limitedness/humansubpotency (as to the fact that the ordinary citizen doesn't need to be a physicists or astronomer or engineer or a public policy expert as more directly relevant in the democratic process but rather needs to have the appropriate fundamentals-and-distance as of capacity/deferentialcapacity to be able to sovereignly relate-to and reference-to the implications of such technicity/profundity sublimating/emancipating knowledge-reification $\sim$ gesturing-andaccounting - of-epistemic-phenomenalism- $<$ in-

prospective_psychologismic apriorising/axiomatising/referencing-\{of-'prospectively implicited_attendant-ontological-contiguity ' educed- 
existentialising/contextualising/textualising_'intelligibility/epistemicity/reflexivity-contiguity<imbued-notional cogency $>>$ \}-conflatedness -in-\{preconverging ment by\}

totalising ${ }^{3}$ hermeneutically/textually/reprojectingly/supererogatingly/zeroingly/re-acutingly,-

\{decompulsing delinearity for-cogency (with regards to effective prospective 'implicited_attendantontological-contiguity ${ }^{6}$ ' educed-

existentialising/contextualising/textualising_'intelligibility/epistemicity/reflexivity_contiguity$<$ imbued-notional cogency> -in-elucidation-or-reification of knowledge content as to epistemic-totalising ${ }^{33} \sim$ resubjecting_or_totalising-entailing $\sim$ reconstrual $<0$ f the-

whole/purview-of the-whole/oneness-of-ontology $>$ ) and so while at the same time not subjectto/avoiding vague conceptualisations inducing disorientation, estrangement and trivialisation (of such technicity/profundity sublimating/emancipating knowledge-reification $\sim$ gesturing-andaccounting - of-epistemic-phenomenalism- $<$ in-

prospective_psychologismic apriorising/axiomatising/referencing-\{of-'prospectively implicited_attendant-ontological-contiguity ' educedexistentialising/contextualising/textualising_'intelligibility/epistemicity/reflexivity-contiguity<imbued-notional cogency >’ \}-conflatedness in \{preconverging ment by\}

postconverging-entailment $>$ ) failing to fulfil the veridical optimal public outcomes of socialstake-contention-or-confliction postconverging-aporeticism-overcoming/unovercoming and rather inducing social numbing-traction-_of-desublimating_ meaningfulness-and-teleology

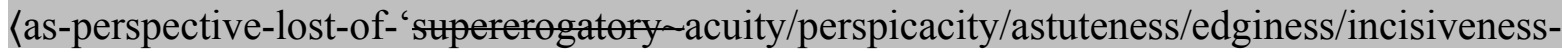
as-to-the-imbued-postconverging/dialectical-thinking -of-notional deprocrypticism- $\{$ indimensionality-of-sublimating — < amplituding/formative-epistemicity $>$ growth-orconflatedness /scalarisation-as-to-rescalarisation-as-re-ontologisation $\left.\}^{\prime}\right\rangle$ as to an 'elicited mere-formulaic — conformity/trending/voguing/fashionability/resonance relation to 
meaningfulness-and-teleology $\left.{ }^{\circ}\right)$. Critically, it is herein contended that in-many-ways despite the blurriness-<sterilising/anecdotalising/trivialising-of-prospective-re-ontologising_bypreconverging,-in-disontologising-formulaic-dragging-out/hollowing-out> of human socialand-institutional-frameworks-of_referencing/registering/decisioning existentialisingdecisionality-<as-to-disontologising/re-ontologising aporeticism $>$, there are just as well subject to appropriate constraining unblurriness-<re-ontologising_by-postconverging-as-todragged-out-supererogatory $\sim$ wholesomeness/profound-supererogation ,-while-anecdotalisingprior-disontologising-thresholding $>$ analysis with respect to their postconverging-aporeticismevercoming/unovercoming as to a translating-insight as from nascent-particular/incipient-andmaterial/technical-sublimations-<blinded-to-their-relative-ontological-completeness

reference-of-thought- devolving $>\quad$ sublimating $\sim$ existentialising-decisionality-<as-todisentologising/re-ontologising aporeticism $>$; and critically-so as of a relation to momentous historiality/ontological-eventfulness 38 ontological-aesthetic-tracing-<perspectiveontological-normalcy/postconvergence-reflected-‘epistemicity-relativism-determinism’>. Such a translating-insight (rather derived from the more potent 'human conceptivity/epistemicreflexivity/epistemicity-relativism-determinism-<reifying \{as-to-knowledge-developing $\}$-andempowering $>$ imbued theoretical/conceptual/operant implications detour to existencepotency $^{32} \sim$ sublimating-nascence,-disclosed-from-prospective-epistemic-digression' of nascentparticular/incipient-and-material/technical-sublimations- $<$ blinded-to-their-relative-ontologicalcompleteness - reference-of-thought- devolving > as devolved axiomatic-constructs of the reference-of-thought rather in their 'excogitative-blanking of prospective institutionalisation 'implicited_attendant-ontological-contiguity ${ }^{67}$; educed-

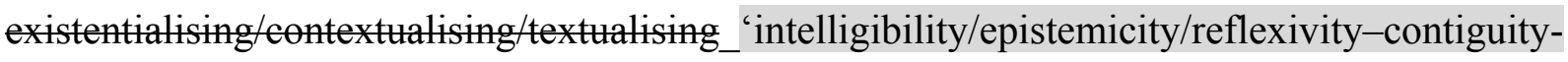
$<$ imbued-notional cogency>' -in-elucidation-or-reification'), implying translating the 'imbued counterintuitive nonpresencing-<perspective-ontological- 
normalcy/postconvergence $>$ epistemic-projection' as from such incipient 'sublimatingnascence devolved axiomatic-constructs' into 'straightened-out or postconvergingly-redementated/restructured/reparadigmed $\quad{ }^{83}$ reference-of-thought sublimating-nascence soinstantiated as to overall ${ }^{83}$ reference-of-thought- ${ }^{8}$ devolving sublimating-nascence (and soreflected in prospective human social-and-institutional-frameworks-ofreferencing/registering/decisioning sublimating existentialising-decisionality-<as-todisontologising/re-ontologising aporeticism $>$ )'. Again, the relevant issue for such an postconverging aporeticism-overcoming/unovercoming (in the face of constraining existence — as-sublimating-withdrawal/unenframing/re-ontologising,-elicited-from-

prospective-profound-supererogation ) has to do with human 'epistemicgrowth/disquiet/discomfort-_induced-sublimation,-as-from-existence's — effusing/ecstaticinlining-as- historiality-\{science/authenticity/nonextrication\}-beyond-mereformulaicity/ritualisation-as- historicity-tracing-\{science-ideology/fashionability/distraction $\}$ ) as to construction-of-the-Self in dispensing-with-immediacy-for-relative-ontologicalcompleteness $^{87}$-by-reification/contemplative-distension ${ }^{27}$, for re-ontologising prospective Being-development/ontological-framework-expansion-as-to-depth-of-ontologisingdevelopment-as-infrastructure-of- meaningfulness-and-teleology as of notional selfdistantiation- $<$ imbued—re-motif-and-re-apriorising/re-axiomatising/rereferencing $>/$ 'distantiation of contemplative existentialising-frame-of-entailment-of motifand-apriorising/axiomatising/referencing as to transversality-<for-sublimating-existentialeventuating/denouement,-from-'thinking-at-first/pure-predisposition-preemptive-ofprospective-disontologising/subontologising' as-of-prospectively-disambiguated-affirmedand-unaffirmed-'motif-and-apriorising/axiomatising/referencing'> imbuing historiality/ontological-eventfulness 3 /ontological-aesthetic-tracing-<perspectiveontological-normalcy/postconvergence-reflected-‘epistemicity-relativism-determinism'>. It is 
important here to appreciate that such a translating-insight prompted as from nascentparticular/incipient-and-material/technical-sublimations- $<$ blinded-to-their-relative-ontologicalcompleteness - reference-of-thought- devolving $>$ sublimating existentialisingdecisionality $<$ as-to-disontelogising/re-ontelogising aporeticism $>$ (imbued unblurriness- $<$ reontologising_by-postconverging-as-to-dragged-out-supererogatory -wholesomeness/profoundsupererogation ,-while-anecdotalising-prior-disontologising-thresholding $>$ ) and enabling perspective for prospective human social-and-institutional-frameworks-ofreferencing/registering/decisioning sublimating $\sim$ existentialising-decisionality-<as-todisontologising/re-ontologising aporeticism $>$ (as to ${ }^{6}$ nonpresencing-<perspectiveontological-normalcy/postconvergence> epistemic-projection), effectively speaks to their 'dynamically reinforcing sublimating-nascence relationship' wherein we can appreciate that 'budding positivism/rational-empiricism nascent-particular/incipient-and-material/technicalsublimations- $<$ blinded-to-their-relative-ontological-completeness - reference-of-thoughtdevolving $>\quad$ sublimating $\sim$ existentialising-decisionality-<as-to-disontologising/reentologising aporeticism $>$ ' involved a 'preconverging/postconverging-dementative/structural/paradigmatic claim of human transcendence-and-

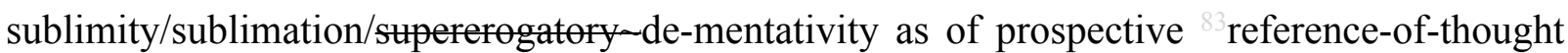
sublimating-nascence' required for a 'corresponding budding positivistic social-andinstitutional-frameworks-of — referencing/registering/decisioning sublimating existentialisingdecisionality-<as-to-disontologising/re-ontologising aporeticism $>$ ' as manifested socially by the Copernicuses, Galileos, Descartes, etc. inducing a social environment further reinforcing the possibility for the furthering of positivistic natural science and eventually bringing about positivistic social emancipation/enlightenment and social science (noting here that such a 'preconverging/postconverging-de-mentative/structural/paradigmatic claim for human transcendence-and-sublimity/sublimation/supereregatory $\sim$ de-mentativity as of prospective 
reference-of-thought sublimating-nascence' captures the ontological-veracity of the idea of de-mentation-_supererogatory ontological-de-mentation-or-dialectical-de-mentation-

stranding-or-attributive-dialectics $\rangle$ articulated and elucidated herein, as to the profound-andscientific reflection of the underlying relative unreflexivitrelative reflexivity ontologicalcontiguity ${ }^{67}$ of-the-human-institutionalisation-process ${ }^{68}$ involving human limited-mentationcapacity-deepening —as-subjecting-limitedness/human-subpotency-to-'educed-

unlimitedness/existence-sublimating nascence' ${ }^{3}$ in the succession of $<$ postconverging 'motifand-apriorising/axiomatising/referencing'-entailing >-existentialising_-framing/imprinting-〈asto-prospective- historiality/ontological-eventfulness /ontological-aesthetic-tracing-

<perspective-ontological-normalcy/postconvergence-reflected-‘epistemicity-relativism-

determinism' $>>$ that speak of 'postconverging-or-dialectical-thinking -psychology or psychology-of-mentation-dynamics or natural psychological-dynamics' implied notional $\sim$ selfdistantiation- $<$ imbued — re-motif-and-re-apriorising/re-axiomatising/re-referencing $>$ and so rather than the '<amplitung/formative-epistemicity $>$ totalising $\sim$ self-referencingsyncretising/circularity/interiorising/akrasiatic-drag ${ }^{34}$ of an intradimensional desublimating conception of its ${ }^{83}$ reference-of-thought', so-manifested beyond-the-consciousness-awarenessteleology ${ }^{9}<$ of-preconverging-existential-extrication-as-of-existential-unthought $>$, as to its given manifest in-effect absolution-<as-to-apriorising/axiomatising/referencing-\{of'prospectively_implicited_attendant-ontological-contiguity ' educed-

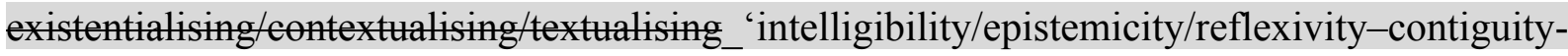
$<$ imbued-notional cogency>' $\}$-constitutedness -in preconverging-entailment> registryworldview/dimension $\quad$ preconverging 'motif-and-apriorising/axiomatising/referencing'entailing $>$-existentialising — enframing/imprintedness-〈as-to- historicity-tracing-inpresencing-hyperrealisation/hyperreal-transposition) such as of ideological capitalistic or communistic conceptualisation within our positivism- ${ }^{80}$ procrypticism occlusiveness manifest 
in-effect absolution-<as-to-apriorising/axiomatising/referencing-\{of-" prospectively implicited_attendant-ontological-contiguity ' educedexistentialising/contextualising/textualising_'intelligibility/epistemicity/reflexivity-contiguity$<$ imbued-notional cogency $>$ ' $\}$-constitutedness -in-preconverging-entailment $>$ registryworldview/dimension 'poorly appreciative of prospective profound supererogatory acuity/perspicacity/astuteness/edginess/incisiveness as rather imbued with the more fundamental human psychology' implied as of 'postconverging-or-dialectical-thinking psychology or psychology-of-mentation-dynamics or natural psychological-dynamics'). This 'dynamically reinforcing sublimating-nascence relationship' as reflective of the ever relevant constraining dynamics of presencing-absolutising-identitive-constitutedness ${ }^{14}$ in epistemicabnormalcy/preconvergence ${ }^{3 !} \quad$ and nonpresencing-<perspective-ontologicalnormalcy/postconvergence>, points to the requisite knowledge-notionalisation (as herein reflected with the fact that profound knowledge must 'understand the dynamics of both human temporal and intemporal ontological-performance ${ }^{72}$-<including-virtue-as-ontology >’) for such a translating-insight; herein construed as to prospective re-originariness/re-origination 'postconverging-or-dialectical-thinking ${ }^{2+}$-apriorising-psychologism'

apriorising/axiomatising/referencing-\{of-'prespectively implicited_attentantontologicalcontiguity ' $\sim$ educedexistentialising/contextualising/textualising_intelligibility/epistemicity/reflexivity_contiguity$<$ imbued-notional cogency $>$ ' $\}$-conflatedness ${ }^{13}$ in-\{preconverging ment by\} postconverging entailment) epistemic-projection perspective reflection upon a preconvergingor-dementing ${ }^{20}$-apriorising-psychologism (in apriorising/axiomatising/referencing-\{of'prospectively implicited_attendant-ontological-contiguity ' educedexistentialising/contextualising/textualising_'intelligibility/epistemicity/reflexivity_contiguity$<$ imbued-notional cogency $>$ ' $\}$-constitutedness ${ }^{14}$-in-preconverging-entailment), 
recurrently manifested across the <cumulating/recomposuring attendant-ontologicalcontiguity $>$-succession of registry-worldviews/dimensions. Critically, human $<$ amplituding/formative-epistemicity $>$-totalising $\sim$ thrownness-in-existence educing intelligibility, as of 'full incipient supererogating breadth of human intelligibility transmutation' (as '<supererogatory 2 human-subpotency $>$-effecting imbued epistemic-totalising preformulating/preframing/premeaningfulness of notional $\sim$ originariness-parrhesia,--asspontaneity-of-aestheticisation' before the incipience of metaphoricity ${ }^{57}$ and then meaningfulness-and-teleology as to existentialising-frame-of-entailment-of-motif-andapriorising/axiomatising/referencing), and so as to underlying human notional $\sim$ selfdistantiation- $<$ imbued — re-motif-and-re-apriorising/re-axiomatising/re-

referencing $>/$ 'distantiation of contemplative existentialising-frame-of-entailment of motifand-apriorising/axiomatising/referencing as to transversality-<for-sublimating-existentialeventuating/denouement,-from-'thinking at-first/pure-predisposition-preemptive-ofprospective-disontologising/subontologising' as-of-prospectively-disambiguated-affirmedand-unaffirmed-'motif-and-apriorising/axiomatising/referencing' ${ }^{101}, \quad$ is effectively the existentialising/contextualising/textualising backdrop of human sublimating existentialisingdecisionality<as to disontologising/re ontologising aporeticism> and desublimating $\sim$ existentialising-decisionality-<as-to-disontologising/re-ontologising aporeticism $>$ (and so as to <amplituding/formative-epistemicity>-totalising $\sim$ thrownness-inexistence 35 'constraining existence — as-sublimating-withdrawal/unenframing/re-ontologising,elicited-from-prospective-profound-supererogation imbuing human ontologicalcommitment $-<$ implied — self-assuredness-of-ontological-goodfaith/authenticity postconverging-de-mentating/structuring/paradigming -as-being-as-ofexistential-reality>' and ' ${ }^{103}$ universal-transparency ${ }^{104}$-〈transparency-of-totalising-entailing,-asto-entailing-<amplituding/formative-epistemicity $>$ totalising in-relative-ontological- 
completeness $\rangle$ as available-to/elicitable-to-〈as-to-human-consciousness/collectiveconsciousness-distendedness/detruncating-<beyond-selfpresencing,-as-re-ontologisingdecentering_of-consciousness/collective-consciousness,-as-to-psychologismic_epistemicacutisation-residualising, - $^{- \text {decompulsing }}$ - delinearity for-cogency $>>$ the social-functioning-andaccordance-as-of-social-stake-contention-or-confliction conception of any given registryworldview/dimension $\quad<$ preconverging 'motif-and-apriorising/axiomatising/referencing' entailing $>$-existentialising — enframing/imprintedness-〈as-to- historicity-tracing - inpresencing-hyperrealisation/hyperreal-transposition〉'). It is within this ambits, that 'prospective possibilities of sublimating existentialising-decisionality-<as-to-disontologising/reentologising aporeticism ${ }^{\prime}$ can be contemplated as from the very depth of human '<supererogatory $\sim$ human-subpotency $>$-effecting imbued epistemic-totalising preformulating/preframing/premeaningfulness of notional originariness-parrhesia,--asspontaneity-of-aestheticisation' for requisite 'epistemic-growth/disquiet/discomfort-_inducedsublimation,-as-from-existence's - effusing/ecstatic-inlining-as- historiality\{science/authenticity/nonextrication\}-beyond-mere-formulaicity/ritualisation-as- historicitytracing-\{science-ideology/fashionability/distraction $\}\rangle$ as to construction-of-the-Self in dispensing-with-immediacy-for-relative-ontological-completeness ${ }^{87}$-byreification/contemplative-distension ${ }^{27}$, and so as to individual and social subconscious and conscious educing intelligibility: in translating the 'imbued counterintuitive nonpresencing$<$ perspective-ontological-normalcy/postconvergence> epistemic-projection' as from incipient 'sublimating-nascence devolved axiomatic-constructs' into 'straightened-out or postconvergingly-rede-mentated/restructured/reparadigmed reference-of-thought sublimating-nascence so-instantiated as to overall ${ }^{83}$ reference-of-thought- devolving sublimating-nascence (and so-reflected in prospective human social-and-institutionalframeworks-of—referencing/registering/decisioning sublimating existentialising- 
decisionality-<as-to-disontologising/re-ontologising aporeticism $>$ )'. The depth of '<supererogatory 2 human-subpotency $>$-effecting imbued epistemic-totalising preformulating/preframing/premeaningfulness of notional originariness-parrhesia,--asspontaneity-of-aestheticisation' is exactly what is incipiently-and-notionally of undergirding 'self-reflexive instigative-eventuating-〈as-to-teleological-instigative/incipientwilling/arbitrariness/waywardness/faithdrivenness/supererogating-for-human-intelligibility,preceding-existence's-eventuating-sublimating-validation/desublimating-invalidation〉 human embodied-consciousness motif-and-apriorising/axiomatising/referencing-\{of'prospectively_implicited_attendant_ontological-contiguity ' educed-

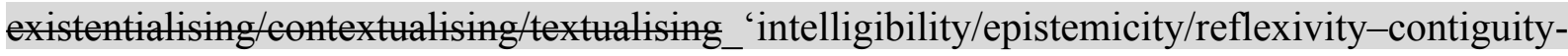
<imbued-notional cogency>' $\}$ - elicited-incipience-of-existentialising-decisionality-<as-todisentologising/re-ontologising aporeticism $>$ ' as to both the 'consequent human sublimating/desublimating - modalisation- $<$ as-to-absolute-referencing-of- ${ }^{56}$ meaningfulnessand-teleology $>$ upon inherent existence's sublimating-nascence inducing of reontologisation/omnipotentiality sublimating-existentialising-decisionality' and the 'consequent human sublimating/desublimating - modalisation- $<$ as-to-absolute-referencing-ofmeaningfulness-and-teleology ${ }^{9}>$ upon $\quad$ social-vestedness/normativity-<discretely-impliedfunctionalism $>$ inducing of subontologisation/subpotentiation supposedly of sublimatingexistentialising-decisionality'. The depth of human '<supererogatory 2 human-subpotency $>-$ effecting imbued epistemic-totalising preformulating/preframing/premeaningfulness of notional originariness-parrhesia,-as--spontaneity-of-aestheticisation' is so-underlined notionally as of 'both human $<$ self-reflexive $>$-willed-thought and $<$ self-reflexive $>$-willed-will $<$ amplituding/formative-epistemicity>totalising/circumscribing/delineating' (with regards to constraining existentialising-decisionality-<as-to-disentelogising/re-ontelogisingapereticism $>$ taking/making), reflecting the fact that human intelligibility (individual and social) 
undergirding 'self-reflexive instigative-eventuating-〈as-to-teleological-instigative/incipientwilling/arbitrariness/waywardness/faithdrivenness/supererogating-for-human-intelligibility,preceding-existence's-eventuating-sublimating-validation/desublimating-invalidation> of human embodied-consciousness motif-and-apriorising/axiomatising/referencing-\{of'prospectively_implicited_attendant-ontological-contiguity ' ceducedexistentialising/contextualising/textualising_intelligibility/epistemicity/reflexivity-contiguity<imbued-notional cogency $>$ ' $\}$-elicited-incipience-of-existentialising-decisionality-<as-todisentologising/re-ontologising aporeticism $>$ (for ontological-performance ${ }^{2}-<$ includingvirtue-as-ontology>)' modalises differently; and so-differently modalised (between 'empowering/disempowering $<$ self-reflexive $>$-willed-thought as to enhancing availability/elicitation-and-reassurance/reinforcement/corroboration/constraining for ontologising' and/or 'empowering/disempowering $<$ self-reflexive $>$-willed-will as to disenhancing unavailability/unelicitation-andunnerving/undermining/contradiction/unconstraining for disontologising') when it comes down to such manifest self-reflexive conceptualisation of both (in <amplituding/formativeepistemicity $>$-totalising $\sim$ thrownness-in-existence ${ }^{35}$ ) 'constraining existence — as-sublimatingwithdrawal/unenframing/re-ontologising,-elicited-from-prospective-profound-supererogation imbuing human ontological-commitment $-<$ implied — self-assuredness-of-ontological-goodfaith/authenticity $\sim$ postconverging-de-mentating/structuring/paradigming -as-being-as-ofexistential-reality>' and ' ${ }^{103}$ universal-transparency ${ }^{104}$-〈transparency-of-totalising-entailing,-asto-entailing-<amplituding/formative-epistemicity $>$ totalising in-relative-ontologicalcompleteness \ as available-to/elicitable-to-〈as-to-human-consciousness/collectiveconsciousness-distendedness/detruncating-<beyond-selfpresencing,-as-re-ontologisingdecentering_of-consciousness/collective-consciousness,-as-to-psychologismic-epistemicacutisation-residualising,- -decompulsing $\}_{\text {delinearity } \sim \text { for-cogency }>>}$ the social-functioning-and- 
accordance-as-of-social-stake-contention-or-confliction conception of the given registryworldview/dimension $<$ preconverging 'motif-and-apriorising/axiomatising/referencing' entailing $>$-existentialising — enframing/imprintedness-〈as-to- historicity-tracing — inpresencing-hyperrealisation/hyperreal-transposition〉'. This differing modalising (as to Beingdevelopment/ontological-framework-expansion-as-to-depth-of-ontologising-development-asinfrastructure-of- meaningfulness-and-teleology , institutional-development-as-to-socialfunction-development and living-development-as-to-personality-development psychologismic epistemic-acutisation difficulty-for, residualising \{decompulsing $\}$ delinearity for-cogency> magnitudes $\{$ of-experientiality/experiment $\}$, speaks to the insight that: the logical-basis/logic,-as-derivedfrom $\sim$ transversality-<for-sublimating-existential-eventuating/denouement, from 'thinking at first/pure-predisposition-preemptive-of prospective-disontologising/subontologising' as-ofprospectively-disambiguated-affirmed-and-unaffirmed-'motif-andapriorising/axiomatising/referencing'> ${ }^{101}$ of 'secondnatured ${ }^{56}$ meaningfulness-and-teleology as to prior percolation-channelling-<in-deferential-formalisation-transference ${ }^{\prime}$ ' is irrelevant for prospective firstnatured knowledge-reification $\sim$ gesturing-and-accounting-of-epistemicphenomenalism- $<$ in-prospective psychologismic $\sim$ apriorising/axiomatising/referencing-\{of'prospectively_implicited_attendant-ontological-contiguity ' ceducedexistentialising/contextualising/textualising_'intelligibility/epistemicity/reflexivity-contiguity$<$ imbued-notional cogency $>$ ' $\}$-conflatedness -in-\{preconverging ment by\} postconverging entailment $>$ renewed logical-basis/logic,-as-derived-from $\sim$ transversality- $<$ forsublimating-existential-eventuating/denouement,-from-'thinking at-first/pure-predispositionpreemptive-of prospective-disontologising/subontologising' as-of-prospectivelydisambiguated-affirmed-and-unaffirmed-'motif-and-apriorising/axiomatising/referencing'>101, and so as to the 'fundamental ontologising/disontologising confliction' re-arising across $<$ cumulating/recomposuring attendant-ontological-contiguity $>$-successive registry- 
worldviews/dimensions but rather so-re-arising as to the successive/changing ${ }^{83}$ reference-ofthought- categorical-imperatives/axioms/registry-teleology ${ }^{9}$ underlying the relativeunreflexivity/relative-reflexivity — ontological-contiguity ${ }^{67}$ of-the-human-institutionalisationprocess $^{68}$ involving human limited-mentation-capacity-deepening-as-subjectinglimitedness/human-subpotency to-'educed-unlimitedness/existence-sublimating nascence' 53 as to human notional $\sim$ self-distantiation- $<$ imbued — re-motif-and-re-apriorising/re-axiomatising/rereferencing $>/$ 'distantiation of contemplative existentialising-frame-of-entailment-of motifand-apriorising/axiomatising/referencing as to transversality-<for-sublimating-existentialeventuating/denouement,-from-'thinking at-first/pure-predisposition-preemptive-ofprospective-disontologising/subontologising' - as-of-prospectively-disambiguated-affirmedand-unaffirmed-'motif-and-apriorising/axiomatising/referencing'>101 imbuing historiality/ontological-eventfulness 38 /ontological-aesthetic-tracing-<perspectiveontological-normalcy/postconvergence-reflected-‘epistemicity-relativism-determinism’>. This 'fundamental ontologising/disontologising confliction' is disambiguatively reflected with 'empowering/disempowering $<$ self-reflexive $>$-willed-thought as to enhancing availability/elicitation-and-reassurance/reinforcement/corroboration/constraining for ontologising' (as so-bound to the 'supplanting-conviction-as-to-profound-supererogation of-'attendant-intradimensional'-postconverging/dialectical-thinking -apriorisingpsychologism of prospective relative-ontological-completeness ${ }^{87}$ meaningfulness-andteleology as of knowledge-reification $\sim$ gesturing-and-accounting-of-epistemicphenomenalism-<in-prospective_psychologismic $\sim$ apriorising/axiomatising/referencing- of'prospectively_implicited_attendant-ontological-contiguity ' ceducedexistentialising/contulising/textralising_intelligibility/epistemicity/reflexivity-contiguity$<$ imbued-notional cogency $\left.>^{\prime}\right\}$-conflatedness -in-\{preconverging-ment by\}

postconverging-entailment>') and 'empowering/disempowering $<$ self-reflexive $>$-willed-will as 
unnerving/undermining/contradiction/unconstraining for disontologising' (as so-bound to the 'uninstitutionalised-threshold imbued dereification threshold-ofnonconviction/madeupness/bottomlining-in-shallow-supererogation $<<$ as-to-'attendantintradimensional'-prospectively-disontologising preconverging/dementing -apriorisingpsychologism $>$ mental-disposition of ontologically-flawed relation with the prospective institutionalisation knowledge-reification $\sim$ gesturing-and-accounting —of-epistemicphenomenalism- $<$ in-prospective_psychologismic $\sim$ apriorising/axiomatising/referencing-\{of'prospectively_implicited_attendant-ontological-contiguity ' ceducedexistentialising/contextualising/textualising_'intelligibility/epistemicity/reflexivity-contiguity$<$ imbued-notional cogency $>$ ' $\}$-conflatedness -in-\{preconverging-ment by\} postconverging-entailment>): when it comes down to such manifest self-reflexive conceptualisation of both (in <amplituding/formative-epistemicity>-totalising $\sim$ thrownness-inexistence ${ }^{35}$ ) 'constraining existence—as-sublimating-withdrawal/unenframing/re-ontologising,elicited-from-prospective-profound-supererogation imbuing human ontologicalcommitment $-<$ implied — self-assuredness-of-ontological-good-

\section{faith/authenticity postconverging-de-mentating/structuring/paradigming -as-being-as-of-} existential-reality>' and ' ${ }^{103}$ universal-transparency ${ }^{104}$-〈transparency-of-totalising-entailing,-asto-entailing-<amplituding/formative-epistemicity $>$ totalising $\sim$ in-relative-ontologicalcompleteness $\rangle$ as available-to/elicitable-to-〈as-to-human-consciousness/collectiveconsciousness-distendedness/detruncating-<beyond-selfpresencing,-as-re-ontologisingdecentering_of-consciousness/collective-consciousness,-as-to-psychologismic-epistemic-

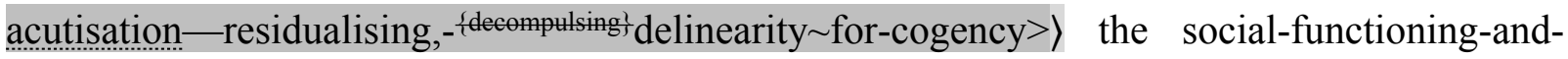
accordance-as-of-social-stake-contention-or-confliction conception of the given registryworldview/dimension $<$ preconverging 'motif-and-apriorising/axiomatising/referencing'- 
entailing >-existentialising — enframing/imprintedness-〈as-to- historicity-tracing — in-

presencing-hyperrealisation/hyperreal-transposition〉'. With the insight here that 'human (individual and social) undergirding 'self-reflexive instigative-eventuating-〈as-to-teleologicalinstigative/incipient-willing/arbitrariness/waywardness/faithdrivenness/supererogating-forhuman-intelligibility,-preceding-existence's-eventuating-sublimating-validation/desublimatinginvalidation> of human mbodied-consciousness apriorising/axiomatising/referencing-\{of-"prospectively_implicited_attendant-ontologicalcontiguity ' educedexistentialising/contextualising/textualising_'intelligibility/epistemicity/reflexivity-contiguity<imbued-notional cogency $>>\quad\}$-elicited-incipience-of-existentialising-decisionality-<as-todisontologising/re-ontologising aporeticism $>^{\prime}$ (for ontological-performance ${ }^{2}-<$ includingvirtue-as-ontology>) is dynamically-and-discretely progressive/constructive upon availing/elicitable existence's sublimating-nascence as to undergirding human 'selfreflexive instigative-eventuating-〈as-to-teleological-instigative/incipientwilling/arbitrariness/waywardness/faithdrivenness/supererogating-for-human-intelligibility,preceding-existence's-eventuating-sublimating-validation/desublimating-invalidation> of human embodied-consciousness motif-and-apriorising/axiomatising/referencing-\{of'prospectively implicited_attendant-ontological-contiguity ' educedexistentialising/contextualising/textualising_'intelligibility/epistemicity/reflexivity-contiguity$<$ imbued-notional cogency $>>$ \} - elicited-incipience-of-existentialising-decisionality-<as-todisentologising/re-ontologising aporeticism $>$, threshold-of $\sim<$ self-reflexive $>$-willed-thought as so-associated relatively with unblurriness-<re-ontologising_by-postconverging-as-todragged-out-supererogatory -wholesomeness/profound-supererogation ,-while-anecdotalisingprior-disontologising-thresholding $>$ and retrogressive/degenerative upon lacking/unelicitable existence's sublimating-nascence as to undergirding 'self-reflexive $\sim$ instigative-eventuating-〈as- 


\section{to-teleological-instigative/incipient-}

willing/arbitrariness/waywardness/faithdrivenness/supererogating-for-human-intelligibility,preceding-existence's-eventuating-sublimating-validation/desublimating-invalidation> of human embodied-consciousness motif-and-apriorising/axiomatising/referencing-\{of'prespectively implicited_attendant-ontological-contiguity ' ceducedexistentialising/contextualising/textualising_'intelligibility/epistemicity/reflexivity-contiguity$<$ imbued-notional cogency $>>$ ' $\}$-elicited-incipience-of-existentialising-decisionality-<as-todisontologising/re-ontologising aporeticism $>$ ' threshold-of $\sim<$ self-reflexive $>$-willed-will as so-associated relatively with blurriness-<sterilising/anecdotalising/trivialising-of-prospectivere-ontologising_by-preconverging,-in-disontologising-formulaic-dragging-out/hollowing-out>. This 'fundamental ontologising/disontologising confliction' reflected as to threshold-of $\sim<$ selfreflexive $>$-willed-thought and threshold-of $\sim<$ self-reflexive $>$-willed-will (as so-reflecting respectively dimensionality-of-sublimating ${ }^{25}-\langle<$ amplituding/formative $>$ supererogatory $\sim$ dementativeness/epistemic-growth-or-conflatedness /transvaluativerationalising/transepistemicity/anamnestic-residuality/spirit-drivenness-equalisation〉 and dimensionality-of-desublimating-lack-of $-\langle<$ amplituding/formative $>$ supererogatory $\sim$ dementativeness/epistemic-growth-or-conflatedness /transvaluativerationalising/transepistemicity/anamnestic-residuality/spirit-drivenness-equalisation)) preconverging/postconverging-de-mentatively/structurally/paradigmatically arises/re-arises at prospective destructuring-threshold-〈uninstitutionalised-threshold /presublimatingdesublimating-decisionality $>$ of-ontological-performance ${ }^{72}-<$ including-virtue-as- $^{-}$ ontology $>/$ morality/ethics/justice/etc. as to:

- human lack of visibility of prospective ontologising-depth and epistemic-totalising implications as so-undermining prospective ontologisation (as from the $<$ self-reflexive $>$-willedthought of the genuine social intellectual-function/posture projection of prospective human 
transcendence-and-sublimity/sublimation/supererogatory-de-mentativity) and so-eliciting prospective disontologisation (as from the $<$ self-reflexive $>$-willed-will of dominance/vestedinterest-subontologising-skewed-influence-as-to-social-vestedness/normativity-<discretelyimplied-functionalism> and pedantising/muddling/formulaic-hollowing-out-insubontologisation/subpotentiation-/blurring/undermining-of-prospective-totalising-entailing,as-to-entailing-<amplituding/formative-epistemicity $>$ totalising $\sim$ in-relative-ontologicalcompleteness \),

- $\quad$ institutionalising percolation-channelling- $<$ in-deferential-formalisation-transference $>$ defaulting into a 'subconscious-and-passive epistemic-totalising ${ }^{33}$ re-automatism relation with the existentialising-frame-of entailment of motif and apriorising/axiomatising/referencing reapriorising/re-axiomatising/re-referencing of ${ }^{5}$ meaningfulness-and-teleology ${ }^{\circ}$ (in shallow supererogatory acuity/perspicacity/astuteness/edginess/incisiveness) and so over 'consciousand-active epistemic-totalising re-procession of the existentialising-frame-of-entailment-ofmotif-and-apriorising/axiomatising/referencing re-apriorising/re-axiomatising/re-referencing of meaningfulness-and-teleology ${ }^{\circ}$ (as so-reflecting the 'requisite dynamic sublimating grasp/mastery fepistemictotalising 3 ' $h e r m e n e u t i c a l l y /$ textully/reprojectingly/supererogatingly/zeroingly/re-acutingly,of the-very-same-immanent-existence/intrinsicreality/ontological-veridicality,-as-to-'human<amplituding/formativeepistemicity>totalising purview-of-construal' in-accounting-for prospective human limitedmentation-capacity-deepening —as-subjecting limitedness/human-subpotency-to-'educedunlimitedness/existence-sublimating nascence' 33 with regards to 'human relative epistemicabnormalcy/preconvergence $^{3 !}$ in relation to the already given ontologicalnormalcy/postconvergence nature of existence' with the profoundness of existence-assublimating-withdrawal/unenframing/re-ontologising,-elicited-from-prospective-profound- 
supererogation speaking of more than just mere-formulaic methodologising/mutualising/organising/institutionalising as to the 'precedence of profound supereregatory $\sim$ acuity/perspicacity/astuteness/edginess/incisiveness in generating-andregenerating/maintaining-oversight-of

methodologising/mutualising/organising/institutionalising alignment to existence-assublimating-withdrawal/unenframing/re-ontologising,-elicited-from-prospective-profoundsupererogation and so in <amplituding/formative-epistemicity>-totalising $\sim$ renewingrealisation/re-perception/re-thought,-in-supererogatory epistemic-conflatedness ${ }^{13}$ '), as to the fact that the veracity of knowledge is much more than a 'conception as of the self-presence/self-

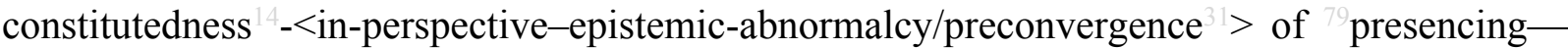
absolutising-identitive-constitutedness $<$ preconverging $\sim$ 'motif-andapriorising/axiomatising/referencing'-entailing $>$-existentialising_enframing/imprintedness〈as-to- historicity-tracing — in-presencing-hyperrealisation/hyperreal-transposition〉' but rather as of prospective 'relative-ontological-incompleteness 8 /relative-ontological-completeness ${ }^{87}$ ] 〈sublimating referencing/registering/decisioning,-as-self-becoming/selfconflatedness /formative-supererogating-<projective/reprojective-aestheticising-re-motifand-re-apriorising/re-axiomatising/re-referencing,-in-perspective-ontologicalnormalcy/postconvergence $>>\quad$ as $\quad$ to $\quad$ human-and-social-expectations/anticipationsmetaphoricity ${ }^{57}$-as-preconverging/postconverging-rede-

mentating/restructuring/reparadigming-psychologism' ${ }^{89}$ (and as so-implied with the 'knowledge-notionalisation backdrop of entailing-<amplituding/formativeepistemicity>totalising in-relative-ontological-completeness ${ }^{87}$ of knowledgereification $\sim$ gesturing-and-accounting — of-epistemic-phenomenalism- $<$ inprospective_psychologismic apriorising/axiomatising/referencing-\{of-'prospectively implicited_attendant-ontological-contiguity ' educed- 
existentialising/contextualising/textualising_ 'intelligibility/epistemicity/reflexivity-contiguity$<$ imbued-notional cogency $>$ ' \}-conflatedness -in-\{preconverging ment by\}

postconverging-entailment> in reflecting ${ }^{4}$ historiality/ontological-eventfulness ${ }^{38} /$ ontologicalaesthetic-tracing-<perspective-ontological-normalcy/postconvergence-reflected-'epistemicityrelativism-determinism'>' whether as of a Derridean différance deconstruction knowledgereification $\sim$ gesturing-and-accounting — of-epistemic-phenomenalism- $<$ inprospective_psychologismic apriorising/axiomatising/referencing-\{of-'prospectively implicited_attendant-ontological-contiguity ' educedexistentialising/contextualising/textualising_ 'intelligibility/epistemicity/reflexivity-contiguity<imbued-notional cogency >' \}-conflatedness -in-\{preconverging-ment by\} postconverging-entailment> or Foucauldian genealogy/archaeology knowledgereification $\sim$ gesturing-and-accounting - of-epistemic-phenomenalism- $<$ inprospective_psychologismic apriorising/axiomatising/referencing-\{of-'prospectively implicited_attendant-ontological-contiguity ' educedexistentialising/contextualising/textualising_'intelligibility/epistemicity/reflexivity-contiguity<imbued-notional cogency >' \}-conflatedness -in-\{preconverging -ment by\} ortentering $>$ or as herein in reflecting holographically-<conjugatively-andtransfusively $>$ the relative-unreflexivity/relative-reflexivity ontological-contiguity $\sim$ of-thehuman-institutionalisation-process as to an explicit ontological-normalcy/postconvergence epistemic-projection knowledge-reification $\sim$ gesturing-and-accounting-of-epistemicphenomenalism-<in-prospective_psychologismic $\sim$ apriorising/axiomatising/referencing- of'prospectively_implicited_attendant-ontological-contiguity ' ceducedexistentialising/contexalising/texalising_intelligibility/epistemicity/reflexivity-contiguity$<$ imbued-notional cogency $>$ ' $\}$-conflatedness -in-\{preconverging ment by\} postconverging-ntailment $>$ or for that matter natural science and true scientific knowledge- 
reification $\sim$ gesturing-and-accounting — of-epistemic-phenomenalism- $<$ in-

prospective_psychologismic apriorising/axiomatising/referencing-\{of- ${ }^{\text {pprospectively }}$ implicited_attendant-ontological-contiguity ' educed-

existentialising/contextualising/textualising_intelligibility/epistemicity/reflexivity-contiguity<imbued-notional cogency >' \}-conflatedness -in-\{preconverging-ment by\}

postconverging-entailment $>$, wherein the knowledge-reification $\sim$ gesturing-and-accountingof-epistemic-phenomenalism- $<$ in-

prospective_psychologismic apriorising/axiomatising/referencing-\{of-"prospectively implicited_attendant_ontological-contiguity ' educedexistentialising/contextualising/textualising_'intelligibility/epistemicity/reflexivity-contiguity$<$ imbued-notional cogency $>$ ' $\}$-conflatedness -in-\{preconverging-ment by\} postconverging-ntailment> is totalising-entailingly explicative of everything within its epistemic bounds as to reification and dereification in the sense for instance that a physics/chemistry/biology principle is not ing as it explains both predicative effectiveness and/or ineffectiveness as to the fact that the same law of gravity can explain totalising-entailingly why a mechanical setup functions well or doesn't function well as to the underlying knowledgenotionalisation)

- epistemic-projection perspective lost of instigative/incipient profound supererogatory acuity/perspicacity/astuteness/edginess/incisiveness-ofapriorising/axiomatising/referencing/intelligibilitysettingup/measuringinstrumenting - forconceptualisation (in dimensionality-of-sublimating ${ }^{25}$ <<amplituding/formative>supererogatory $\sim$ de-mentativeness/epistemic-growth-orconflatedness /transvaluative-rationalising/transepistemicity/anamnestic-residuality/spiritdrivenness-equalisation) inducing 'nascent-particular/incipient-and-material/technicalsublimations-<blinded-to-their-relative-ontological-completeness - reference-of-thought- 
entelogising apereticism>' lost to the 'prior overall relative-ontological-incompleteness ${ }^{8}$ presublimation-construct-of- ${ }^{5}$ meaningfulness-and-teleology ${ }^{9}$ imbued social-and-institutionalframeworks-of_-referencing/registering/decisioning desublimating existentialisingdecisionality-<as-to-disontologising/re-ontologising aporeticism ${ }^{\prime}$ (as to a narrow-minded

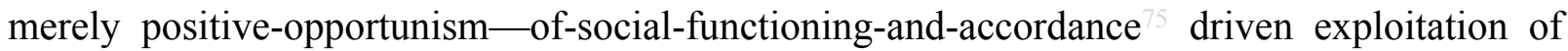
such nascent-particular/incipient-and-material/technical-sublimations- $<$ blinded-to-theirrelative-ontological-completeness - reference-of-thought- devolving > sublimating existentialising-decisionality-<as-to-disontologising/re-ontologising aporeticism $>$ ), and so-critically eliciting <amplituding/formative $>$ wooden-language〈imbued-temporal-mere-form/virtualities/dereification/akrasiaticdrag/denatured/preconverging-or-dementing -narratives - of-the- reference-of-thoughtcategorical-imperatives/axioms/registry-teleology \ (in-the-bigger-picture and more starkly we can appreciate the 'enlightenment struggle against feudalism and slavery as advocated say with such a thinker like Rousseau' as to the fact that the technical and scientific progress as to relative-ontological-completeness 87 weren't the occasion to put such technical and scientific progress like shipbuilding and other ocean voyage technologies at the service of the prior medievally clouded immaterial/social overall relative-ontological-incompleteness ${ }^{8}$ presublimation-construct-of- ${ }^{5}$ meaningfulness-and-teleology value-construct and shallowsupererogating methodologising/mutualising/organising/institutionalising

\section{<preconverging 'motif-and-apriorising/axiomatising/referencing'-entailing >-}

existentialising — enframing/imprintedness-〈as-to- historicity-tracing_-in-presencing-

hyperrealisation/hyperreal-transposition $\rangle$ but rather called for a renewed conceptualisation of humanity beyond a mentality of immediate subsistence/survival/advantage and just as well such scientists like Einstein realised implicitly/intuitively that their scientific breakthroughs with 
regards to say nuclear science effectively called for a renewed conceptualisation of humanity beyond a mentality of immediate immaterial/social dimension expediency that could arise with respect to nuclear weapons, with this fundamental translating insight about 'nascentparticular/incipient-and-material/technical-sublimations- $<$ blinded-to-their-relative-ontologicalcompleteness - reference-of-thought- devolving $>\quad$ sublimating existentialisingdecisionality-<as-to-disentelogising/re-ontelogising aporeticism ${ }^{\prime}$ critically warranted not just with such starked cases but with respect to the comprehensive and more subtle overall socialand-institutional-frameworks-of—referencing/registering/decisioning existentialisingdecisionality-<as-to-disontologising/re-ontologising aporeticism $>$ as it can be appreciated for instance that the business driven and mere defaulting utilisation of say media technologies has hardly elicited a 'comprehensive social self-reflexive questioning-and-contemplation' of their appropriate sublimating existentialising-decisionality-<as-to-disontologising/reentologising apereticism $>$ conception but for ad-hoc insights and approaches poorly appreciative of their requisite postconverging-aporeticism-overcoming/unovercoming and particularly-so with creatively effective public communication and democratic enhancement as to sovereign knowledge/enlightenment, insight/acumen and participation/interest thus inducing in-many-ways inducing the present hyperreality-as-to-its-simulacrum implications pointed out by Baudrillard)

- prior relative-ontological-incompleteness ${ }^{8}$-presublimation-construct-of- ${ }^{56}$ meaningfulnessand-teleology $\quad$ social-functioning-and-accordance-as-of-social-stake-contention-orconfliction disontologising emphasised desublimating existentialising-decisionality-<as-todisontologising/re-ontologising aporeticism $>$ as to mere utilisation/positive-opportunism—ofsocial-functioning-and-accordance ${ }^{75}$ (in $<$ amplituding-formative-epistemicity $>$ totalising $\sim$ selfreferencing-syncretising/circularity/interiorising/akrasiatic-drag ${ }^{34}$ ) of prospective nascentparticular/incipient-and-material/technical-sublimations- $<$ blinded-to-their-relative-ontological- 
decisionality-<as-to-disontologising/re-ontologising aporeticism $>$ without translating into requisite undergirding 'self-reflexive instigative-eventuating-〈as-to-teleologicalinstigative/incipient-willing/arbitrariness/waywardness/faithdrivenness/supererogating-forhuman-intelligibility,-preceding-existence's-eventuating-sublimating-validation/desublimatinginvalidation $>$ of human embodied-consciousness motif-andapriorising/axiomatising/referencing-\{of-'prospectively_implicited_attendant-ontologicalcontiguity ' $\sim$ educedexistentialising/contextualising/textualising_'intelligibility/epistemicity/reflexivity-contiguity$<$ imbued-notional $\left.\sim \operatorname{cogency}>^{\prime} \quad\right\}$-elicited-incipience-of-existentialising-decisionality-as disentologising/re-ontologising apereticism $>$ ' as to 'epistemic-growth/disquiet/discomfort〈induced-sublimation,-as-from-existence's - effusing/ecstatic-inlining-as- historiality\{science/authenticity/nonextrication \}-beyond-mere-formulaicity/ritualisation-as- historicitytracing-\{science-ideology/fashionability/distraction $\}\rangle$ as to construction-of-the-Self in dispensing-with-immediacy-for-relative-ontological-completeness ${ }^{87}$-by-

reification/contemplative-distension ${ }^{27}$ for overall ${ }^{83}$ reference-of-thought sublimating-nascence so-instantiated as to ${ }^{8}$ reference-of-thought- ${ }^{84}$ devolving sublimating-nascence (and so-reflected in prospective human social-and-institutional-frameworks-ofreferencing/registering/decisioning sublimating $\sim$ existentialising-decisionality-<as-todisontologising (re ontelogising apereticism>)

the 'implicited_attendant-ontological-contiguity ${ }^{67}$ ' educedexistentialising/contextualising/textualising_'intelligibility/epistemicity/reflexivity-contiguity$<$ imbued-notional cogency $>{ }^{40}$ of human ${ }^{56}$ meaningfulness-and-teleology ${ }^{99}$ implies that prospective knowledge-reification $\sim$ gesturing-and-accounting-of-epistemic-phenomenalism$<$ in-prospective_psychologismic $\sim$ apriorising/axiomatising/referencing-\{of-‘prospectively_ 
implicited_attendant-ontological-contiguity ' reduced-

existentialising/contextualising/textualising_'intelligibility/epistemicity/reflexivity_contiguity<imbued-notional cogency $>$ ' \}-conflatedness -in-\{preconverging ment by\}

postconverging-entailment> as to organic-knowledge is necessarily in an 'existentialisingframe-of-entailment of motif-and-apriorising/axiomatising/referencing reflecting its $<$ postconverging 'motif-and-apriorising/axiomatising/referencing'-entailing >-

existentialising - framing/imprinting-〈as-to-prospective-- historiality/ontological-

eventfulness /ontological-aesthetic-tracing-<perspective-ontological-

normalcy/postconvergence-reflected-'epistemicity-relativism-determinism' $>\rangle$ ' but which is not immuned from estranged-interpreting-and-purposes and contextual-misanalysis (as can be soappreciated with respect with many a critical and postmodern thought) inducing disontologisation, and just as well institutional pedantising/muddling/formulaic-hollowingout_-in-subontologisation/subpotentiation-〈blurring/undermining-of-prospective-totalisingentailing,-as-to-entailing-<amplituding/formative-epistemicity $>$ totalising $\sim$ in-relativeontological-completeness $>$ sroject shallow supereregatory acuity/perspicacity/astuteness/edginess/incisiveness that contorts ontologicalveracity while undermining veridical issues of postconvergingaaporeticismovercoming/unovercoming (as can be fairly appreciated with the skewed outcomes associated with decades-long theorising and politically manipulative narratives like deficits, public spending, social engineering, socialism, tribalism, fairness, libertarian, middle-of-the-ground, identity politics, etc.)

- a fundamental 'deficiency of excessive/undue magnanimity' of the genuine social intellectualfunction/posture throughout-and-all-along the relative-unreflexivity/relative-reflexivityontological-contiguity ${ }^{67}$ of-the-human-institutionalisation-process ${ }^{68}$ that seem to merely imply that 'its social sublimating pertinence is only as to the mere positive-opportunism-of-social- 
functioning-and-accordance ${ }^{75}$ that enables prospective human transcendence-andsublimity/sublimation/supererogatoryade-mentativity' while wrongly overlooking/ignoring relatively its so-enabling threshold-of $\sim<$ self-reflexive $>$-willed-thought as to undergirding 'selfreflexive instigative-eventuating-〈as-to-teleological-instigative/incipientwilling/arbitrariness/waywardness/faithdrivenness/supererogating-for-human-intelligibility,preceding-existence's-eventuating-sublimating-validation/desublimating-invalidation> of human embodied-consciousness motif-and-apriorising/axiomatising/referencing-\{of'prospectively_implicited_attendant_ontological-contiguity ' educedexistentialising/contextualising/textualising_intelligibility/epistemicity/reflexivity_contiguity$<$ imbued-notional $\left.\sim \operatorname{cogency}>^{\prime} \quad\right\}$-elicited-incipience-of-existentialising-decisionality-as disentologising/re-ontologising aporeticism $>$ ' as to 'epistemic-growth/disquiet/discomfort〈induced-sublimation,-as-from-existence's - effusing/ecstatic-inlining-as- historiality\{science/authenticity/nonextrication $\}$-beyond-mere-formulaicity/ritualisation-as- historicitytracing-\{science-ideology/fashionability/distraction $\}\rangle$ as to construction-of-the-Self in dispensing-with-immediacy-for-relative-ontological-completeness ${ }^{87}$-byreification/contemplative-distension ${ }^{27}$ as central to the 'implicited_attendant-ontologicalcontiguity $^{67}$, educedexistentialising/contextualising/textualising_intelligibility/epistemicity/reflexivity-contiguity$<$ imbued-notional cogency>' ${ }^{40}$ of such ${ }^{5}$ meaningfulness-and-teleology ${ }^{9}$ implied prospective knowledge-reification $\sim$ gesturing-and-accounting —of-epistemic-phenomenalism- $<$ inprospective_psychologismic apriorising/axiomatising/referencing-\{of-‘prospectively implicited_attendant-ontological-contiguity ' educedexistentialising/contextualising/textualising_ 'intelligibility/epistemicity/reflexivity-contiguity<imbued-notional cogency>' \}-conflatedness -in-\{preconverging-ment by\} postconverging-entailment> as to organic-knowledge, with the consequence that a 
'flatmindedness'/banality/flimsiness relation with the same knowledge construed as of mere reproducibility—mathesis/motif/thrownness-disposition,--as-reproducibility-of-aestheticisation imbued positive-opportunism-of-social-functioning-and-accordance ${ }^{75}$ uninsightful about originariness-parrhesia,-as-spontaneity-of-aestheticisation 'is bound as of threshold-of $\sim<$ selfreflexive $>$-willed-will to be developed into desublimating beholdening-becoming-distortiveoriginariness/distortive-origination-as-to- ${ }^{4}$ historicity-tracing inhibited-mental-aestheticising of $\quad{ }^{79}$ presencing-absolutising-identitive-constitutedness $<$ preconverging 'motif-andapriorising/axiomatising/referencing'-entailing>-existentialising-enframing/imprintedness〈as-to- historicity-tracing - in-presencing-hyperrealisation/hyperreal-transposition〉' as can arise with associated 'generalised social < amplituding/formative> wooden-language-〈imbuedtemporal-mere-form/virtualities/dereification/akrasiatic-drag/denatured/preconverging-ordementing -narratives - of-the- reference-of-thought- categoricalimperatives/axioms/registry-teleology $\rangle$ ' and 'more ruthlessly' with associated dominance/vested-interest-subontologising-skewed-influence-as-to-socialvestedness/normativity-<discretely-implied-functionalism $>$ and pedantising/muddling/formulaic-hollowing-out — in-subontologisation/subpotentiation〈blurring/undermining-of-prospective-totalising-entailing,-as-to-entailing<ampling/formative-epistemicity>totalising in-relative-ontological-completeness > (such that the prospective deprocrypticism-or-preempting-disjointedness-as-of- ${ }^{8}$ reference-ofthought registry-worldview/dimension projection is of a ${ }^{6}$ nonpresencing- $<$ perspectiveontological-normalcy/postconvergence $>$ sublimating apriorising/axiomatising/referencing-\{of'prospectively_implicited_attendant-ontological-contiguity ' educedexistentialising/contextualising/textualising_'intelligibility/epistemicity/reflexivity-contiguity<imbued-notional cogency>' $\}$-relation-to-the-world implying a human <self-reflexive $>$ willed-thought awareness of 'originariness-parrhesia,-as-spontaneity-of-aestheticisation as to 
profound supereregatory acuity/perspicacity/astuteness/edginess/incisiveness-ofapriorising/axiomatising/referencing/intelligibilitysettingup/measuringinstrumenting - forconceptualisation in reflection of human dimensionality-of-sublimating <<amplituding/formative >supererogatede-mentativeness/epistemic-growth-orconflatedness /transvaluative-rationalising/transepistemicity/anamnestic-residuality/spiritdrivenness-equalisation)' and so over 'mere-formulaic methodologising/mutualising/organising/institutionalising as of human-subpotency nonscalarity/beholdening-<as-to-what-has-gone-before-aesthetically-dementates/structures/paradigms-distortedly-the-possibility-for-the-later-ontologisation> in presencing - absolutising-identitive-constitutedness ${ }^{14} \quad<$ amplituding/formativeepistemicity $>$ totalising $\sim$ self-referencing-syncretising/circularity/interiorising/akrasiatic$\left.\operatorname{drag}{ }^{34}\right)$

- a human ${ }^{7}$ presencing-absolutising-identitive-constitutedness ${ }^{14}$ imbued ‘ $<$ amplituding/formative $>$ disposedness/psychologismic-construct-〈as-to-orientation/valueconstruct/valuation-and-derived-parameterising $\rangle$ and <amplituding/formative $>$ entailment-〈asto-totalising-contiguous/coherent-factuality-of-variability)' of 'punctual $<$ amplituding/formative-epistemicity $>$ totalising $\sim$ self-referencingsyncretising/circularity/interiorising/akrasiatic-drag 34 rather measuring-up success/accomplishment/aspiration in shallow-supererogation of manifest in-effect absolution$<$ as-to-apriorising/axiomatising/referencing-\{of-"prospectively implicited attendantontological-contiguity ' educedexistentialising/contextualising/textualising_'intelligibility/epistemicity/reflexivity-contiguity<imbued-notional cogency >' $\}$-constitutedness -in-preconverging-entailment $>$ as to the given registry-worldview/dimension $\quad<$ preconverging 'motif-andapriorising/axiomatising/referencing'-entailing >-existentialising-enframing/imprintedness- 
〈as-to- historicity-tracing-in-presencing-hyperrealisation/hyperreal-transposition〉' and so

effectively oblivious and 'lacking in conscious protensivity as of ${ }^{6}$ nonpresencing- $<$ perspectiveontological-normalcy/postconvergence $>$ implications' explaining the veracity of the manifest suboptimisation/subontologisation/subpotentiation of all human societies as to their shallowsupererogation relative to "their abstractly conceivable profound- supererogation potential for re-ontologisation' (so-implied as to successive human re-ontologisation/omnipotentiality possibilities) but for the genuine social intellectual-function/posture cyclically induced prospective transcendence-and-sublimity/sublimation/supererogatory de-mentativity for such re-ontologisation overriding of such 'measuring-up success/accomplishment/aspiration in shallow-supererogation of manifest in-effect absolution-<as-toapriorising/axiomatising/referencing-\{of-'prospectively implicited_attendant-ontologicalcontiguity ' educedexistentialising/contextualising/textualising_'intelligibility/epistemicity/reflexivity-contiguity<imbued-notional cogency $\left.>^{\prime} \quad\right\}$ - constitutedness -in preconverging entailment>> conception of the social-setup, with such a conception of the social-setup arising as to the fact that however counterintuitive it may seem 'ordinarily/generally a social-setup is not consciouslyand-subconsciously self-reflexive of itself as about its optimisable ontologising-depth (as of a prospective overriding re-ontologisation underlying the possibility for its prospectively idealised transcendence-and-sublimity/sublimation/supererogatory-de-mentativity as to sublimating $\sim$ existentialising-decisionality-<as-to-disontologising/re-ontologising aporeticism $>$ )' but rather a social-setup is consciously-and-subconsciously self-reflexive of itself as about 'their given present minimum-and-balancing expectations/anticipations of socialfunctioning-and-accordance-as-of-social-stake-contention-or-confliction' as to its limitedmentation-capacity—as-subjecting 'educed-unlimitedness/existence-sublimating nascence' to-limitedness/human-subpotency conceptivity/epistemic-reflexivity/epistemicity-relativism- 
determinism-<reifying \{as-to-knowledge-developing $\}$-and-empowering $>$ implications (when it comes down to such manifest self-reflexive conceptualisation of both (in $<$ amplituding/formative-epistemicity $>$-totalising $\sim$ thrownness-in-existence ${ }^{35}$ ) 'constraining existence — as-sublimating-withdrawal/unenframing/re-ontologising,-elicited-fromprospective-profound-supererogation imbuing human ontological-commitment ${ }_{-<\text {implied }}$ self-assuredness-of-ontological-good-faith/authenticity postconverging-dementating/structuring/paradigming -as-being-as-of-existential-reality>' and '103 universaltransparency ${ }^{104}$-〈transparency-of-totalising-entailing,-as-to-entailing-<amplituding/formativeepistemicity $>$ totalising $\sim$ in-relative-ontological-completeness $\rangle$ as available-to/elicitable-to-〈asto-human-consciousness/collective-consciousness-distendedness/detruncating- $<$ beyondselfpresencing,-as-re-ontologising-decentering_of-consciousness/collective-consciousness,-asto-psychologismic-epistemic-acutisation - residualising, ${ }^{\text {- } \text { decompulsingt }}$ delinearity for-cogency $\left.>\right\rangle$ the social-functioning-and-accordance-as-of-social-stake-contention-or-confliction conception of the given registry-worldview/dimension <preconverging 'motif-andapriorising/axiomatising/referencing'-entailing>-existentialising—enframing/imprintedness〈as-to- historicity-tracing - in-presencing-hyperrealisation/hyperreal-transposition〉') in soprompting the social-setup's 'lack of empowering < self-reflexive>-willed-thought as to enhancing availability/elicitation-and-reassurance/reinforcement/corroboration/constraining for ontologising' and 'lack of empowering < self-reflexive>-willed-will as to disenhancing unavailability/unelicitation-and-unnerving/undermining/contradiction/unconstraining for disontologising', and so in the face 'of the-very-same notional conceptivity/epistemicreflexivity/epistemicity-relativism-determinism-<reifying \{as-to-knowledge-developing $\}$-andempowering $>$ (but rather of 'empowering $<$ self-reflexive $>$-willed-thought as to enhancing availability/elicitation-and-reassurance/reinforcement/corroboration/constraining for ontologising' and 'empowering <self-reflexive>-willed-will as to disenhancing 
unavailability/unelicitation-and-unnerving/undermining/contradiction/unconstraining disontologising') as to the relative beholdening inconsideration associated with the temporal advantageousness of dominance/vested-interest-subontologising-skewed-influence-as-tosocial-vestedness/normativity-<discretely-implied-functionalism $>\quad$ and pedantising/muddling/formulaic-hollowing-out - in-subontologisation/subpotentiation〈blurring/undermining-of-prospective-totalising-entailing,-as-to-entailing<amplituding/formative-epistemicity>totalising in-relative-ontological-completeness >’ (thus reflecting why for instance the democratic process is bound to ebb in suboptimisation/subontologisation/subpotentiation given the inherent overall disparity/incongruence of the actual manifestation of a social-setup's self-reflexivity as to 'their given present minimum-and-balancing expectations/anticipations of social-functioning-andaccordance - as-of-social-stake-contention-or-confliction' and the potential manifestation of the social-setup's self-reflexivity as to perspective 're-ontologising/potentiating/optimisable sublimating-nascence ontologising-depth as of the full-potency of existence'); and it is critically the genuine social intellectual-function/posture imbuing knowledge-reification $\sim$ gesturing-andaccounting - of-epistemic-phenomenalism- $<$ inprospective_psychologismic $\sim$ apriorising/axiomatising/referencing-\{of-`prospectively implicited_attendant-ontological-contiguity ' educedexistentialising/contextualising/textualising_intelligibility/epistemicity/reflexivity_contiguity$<$ imbued-notional cogency $>\quad\}$-conflatedness - in-\{preconverging ment by\} postconverging-entailment> as of ${ }^{55}$ maximalising-recomposuring-for-relative-ontologicalcompleteness $^{87}$ — unenframed/re-ontologising conceptualisation as to postconverging-aporeticism-overcoming/unovercoming conceptivity/epistemicreflexivity/epistemicity-relativism-determinism- $<$ reifying \{as-to-knowledge-developing $\}$-andempowering $>$ that carries the potential for pushing and making-available/eliciting such a 
prospect for re-ontologisation (and as so effectively manifested historially as to the relatively low emotional-involvement with non-socially implied sublimation/emancipation and the relatively high emotional-involvement with socially implied sublimation/emancipation, and in the latter instance particularly when the threshold-of $\sim<$ self-reflexive $>$-willed-will of defaulting dominance/vested-interest-subontologising-skewed-influence-as-to-social-

vestedness/normativity-<discretely-implied-functionalism $>$ and pedantising/muddling/formulaic-hollowing-out — in-subontologisation/subpotentiation〈blurring/undermining-of-prospective-totalising-entailing,-as-to-entailing<amplitung/formative-epistemicity $>$ totalising in-relative-ontological-completeness $>$ overplays the card of 'their given present minimum-and-balancing expectations/anticipations of social-functioning-and-accordance-as-of-social-stake-contention-or-confliction' of the socialsetup and in so-doing eliciting the overall social-setup self-reflexivity as of the breadth of socially cogent/tense/limpid-<as-of-prospective-profound-supererogation ${ }^{6}$,-for-residualityin-re-originariness/re-origination $>\quad$ percolation-channelling- $<$ in-deferential-formalisationtransference> existentialising-frame-of entailment of motif-andapriorising/axiomatising/referencing of intellectualism including the illuminating genuine social intellectual-function/posture, the appraisal of 'overall social intellection-aptitude body' and generalised social advocacy in contemplating about prospective 'reontologising/potentiating/optimisable sublimating-nascence ontologising-depth perspective as of the full-potency of existence'), and as so-underlying overall not only Beingdevelopment/ontological-framework-expansion-as-to-depth-of-ontologising-development-asinfrastructure-of- meaningfulness-and-teleology as elaborately articulated above but equally translative as to 'living-development-as-to-personality-development beholdening/unbeholdening existentialising-frame-of-entailment-of-motif-andapriorising/axiomatising/referencing' and 'institutional-development-as-to-social-function- 
development beholdening/unbeholdening existentialising-frame-of-entailment-of motif-andapriorising/axiomatising/referencing' (so-reflected overall preconverging/postconverging-dementative/structural/paradigmatic as to perspective 'beholdening as sovereignising-imbuedsubontologisation/subpotentiation' superseded/transcended with perspective 'unbeholdening sublimating-nascence ontologising-depth of the full-potency of existence' implications for prospective re-ontologisation' so-underlying the dynamics of prospective human 'epistemicgrowth/disquiet/discomfort-〈induced-sublimation,-as-from-existence's-effusing/ecstatic-

inlining-as- historiality-\{science/authenticity/nonextrication $\}$-beyond-mere-

formulaicity/ritualisation-as- historicity-tracing- $\{$ science-ideology/fashionability/distraction $\}\rangle$ as to construction-of-the-Self in dispensing-with-immediacy-for-relative-ontologicalcompleteness $^{87}$-by-reification/contemplative-distension ${ }^{27}$ ').

Ultimately, our human presencing-absolutising-identitive-constitutedness $<$ preconverging 'motif-and-apriorising/axiomatising/referencing'-entailing $>$ existentialising — enframing/imprintedness-〈as-to- historicity-tracing — in-presencinghyperrealisation/hyperreal-transposition $\rangle$ (as to the high emotional-involvement associated with social ontological-performance 2 - $<$ including-virtue-as-ontology $>/$ morality/ethics/justice/etc. and low emotional-involvement associated with non-social ontological-performance ${ }^{72}$ $<$ including-virtue-as-ontology $>/$ morality/ethics/justice/etc. elicited prospective transcendenceand-sublimity/sublimation/supererogatory de-mentativity) seem to take the easy-wayout/contrivance to imply that 'we are just as perfect as we are (implying the impertinence/nonveracity for prospective human 'epistemic-growth/disquiet/discomfort-〈induced-sublimation,as-from-existence's - effusing/ecstatic-inlining-as- historiality\{science/authenticity/nonextrication\}-beyond-mere-formulaicity/ritualisation-as- historicitytracing-\{science-ideology/fashionability/distraction $\}\rangle$ as to construction-of-the-Self in dispensing-with-immediacy-for-relative-ontological-completeness ${ }^{87}$-by- 
reification/contemplative-distension ${ }^{27}$ ')' and that the notion of prospective sublimation is just about technical and natural science sublimation (and as so-advanced implicitly or explicitly in a self-serving lethargy of institutional pedantising/muddling/formulaic-hollowing-out-insubontologisation/subpotentiation-〈blurring/undermining-of-prospective-totalising-entailing,as-to-entailing-<amplituling/formative-epistemicity $>$ totalising $\sim$ in-relative-ontological-

completeness 7) and so as to a human social environment where dominance/vested-interestsubontologising-skewed-influence-as-to-social-vestedness/normativity- $<$ discretely-impliedfunctionalism $>\quad$ and pedantising/muddling/formulaic-hollowing-out —insubontologisation/subpotentiation-〈blurring/undermining-of-prospective-totalising-entailing,as-to-entailing-<amplituding/formative-epistemicity $>$ totalising $\sim$ in-relative-ontologicalcompleteness > in-many-ways seem to be wary of prospective human reontologisation/omnipotentiality implications as if our very presence isn't the outcome of successive prior re-ontologising. It is thus critical for humanity as a whole and as of social science practice to inculcate the attitude that despite the blurriness$<$ sterilising/anecdotalising/trivialising-of-prospective-re-ontologising_by-preconverging,-indisontologising-formulaic-dragging-out/hollowing-out> of human social-and-institutionalframeworks-of — referencing/registering/decisioning existentialising-decisionality-as-todisentologising/re-ontologising aporeticism $>$, that doesn't mean this gives leeway for political and other dominance/vested-interest-subontologising-skewed-influence-as-to-socialvestedness/normativity- $<$ discretely-implied-functionalism $>$; as to the fact that the pretense of a social science/ontology dies (with respect to the emancipation/sublimation possibilities for the 8.5 billion humans on Earth) when such an illegitimate pretense is not bluntly challenged notwithstanding any browbeating as 'supposed intellectuals' lose their intellectual soul when they acquiesce to the <amplituding-formative> wooden-language-_imbued-temporal-mereform/virtualities/dereification/akrasiatic-drag/denatured/preconverging-or-dementing 


\section{narratives - of-the- reference-of-thought- categorical-imperatives/axioms/registry-}

teleology > of any such dominance/vested-interest-subontologising-skewed-influence-as-tosocial-vestedness/normativity- $<$ discretely-implied-functionalism $>$ that thrive as to temporal advantageousness on eliciting the lowliness of human contemplation in inducing consciously or unconsciously prospective human desublimation/disempowerment. In-many-ways, what is central to both such a dominance/vested-interest-subontologising-skewed-influence-as-tosocial-vestedness/normativity- $<$ discretely-implied-functionalism $>$ and pedantising/muddling/formulaic-hollowing-out — in-subontologisation/subpotentiation〈blurring/undermining-of-prospective-totalising-entailing,-as-to-entailing<amplituding/formative-epistemicity>totalising in-relative-ontological-completeness > undermining of genuine knowledge-reification $\sim$ gesturing-and-accounting-of-epistemicphenomenalism- $<$ in-prospective_psychologismic $\sim$ apriorising/axiomatising/referencing- of'prospectively_implicited_attendant-ontological-contiguity ' educedexistentialising/contextualising/textualising_'intelligibility/epistemicity/reflexivity-contiguity<imbued-notional cogency >' \}-conflatedness in \{preconverging ment by\} postconverging entailment $>$ is their poor appreciation and deriding of any such notion of the postconverging-de-mentating/structuring/paradigming possibility that makes-available worldview conceptualisation as herein implied as to 'conceptivity/epistemicreflexivity/epistemicity-relativism-determinism-<reifying \{as-to-knowledge-developing $\}$-andempowering $>$ imbued theoretical/conceptual/operant implications' (so-construed as of prospective 'relative-ontological-incompleteness ${ }^{88} /$ relative-ontological-completeness ${ }^{87}$ 〈sublimating $\sim$ referencing/registering/decisioning,--as-self-becoming/selfconflatedness /formative-supererogating-<projective/reprojective-aestheticising-re-motifand-re-apriorising/re-axiomatising/re-referencing,-in-perspective-ontologicalnormalcy/postconvergence $>>$ as to human-and-social-expectations/anticipations- 
metaphoricity ${ }^{57}$-as-preconverging/postconverging-rede-

mentating/restructuring/reparadigming-psychologism' ${ }^{89}$ ); as to a decadent immediate materialism that will not recognise that the 'conceptivity/epistemic-reflexivity/epistemicityrelativism-determinism-<reifying \{as-to-knowledge-developing $\}$-and-empowering $>\quad$ imbued theoretical/conceptual/operant implications' of the physicists or chemists or biologists for instance is what allows for the expectations/anticipations underlying physical engineering/application or chemical engineering/application or biological engineer/application as to generated material productions (as without abstract science contemplation the very imagination of derived technologies will not arise) and along the same lines it can only be of the utmost disappointment to realise that at the very core of academic institutionalised social and philosophical contemplation is the manifestation of a pedantry that doesn't have or project the lack of the least insight about the ${ }^{4}$ historiality/ontological-eventfulness $\%$ /ontological-aesthetictracing-<perspective-ontological-normalcy/postconvergence-reflected-‘epistemicityrelativism-determinism'> of social and philosophical 'conceptivity/epistemicreflexivity/epistemicity-relativism-determinism-<reifying \{as-to-knowledge-developing $\}$-andempowering $>$ imbued theoretical/conceptual/operant implications' as underlying the effective sublimating human and social expectations/anticipations that sublimatingly beget societies up to our age and as of relevance for prospective human and social construction. For such dominance/vested-interest-subontologising-skewed-influence-as-to-socialvestedness/normativity-<discretely-implied-functionalism $>$ and pedantising/muddling/formulaic-hollowing-out - in-subontologisation/subpotentiation〈blurring/undermining-of-prospective-totalising-entailing,-as-to-entailing<amplituding/formative-epistemicity>totalising in-relative-ontological-completeness $\rangle, \quad$ the punctual/immediacy/constituted/compulsions-encumbered temporal advantageousness for eliciting the lowliness of human contemplation consciously or unconsciously prospective human 
desublimation/disempowerment as inherently validatory of a decadent conception of human selfreferencing-syncretising in terms of self-presence/self-constitutedness ${ }^{14}-<$ in-perspectiveepistemic-abnormalcy/preconvergence ${ }^{31} \quad$ of $\quad{ }^{79}$ presencing-absolutising-identitiveconstitutedness <preconverging 'motif-and-apriorising/axiomatising/referencing'entailing $>$-existentialising — enframing/imprintedness-〈as-to- historicity-tracing - inpresencing-hyperrealisation/hyperreal-transposition); but then in reality it is herein contended that in the middle to long run such posturing falsehoods are untenable notwithstanding their apparent punctual/immediacy/constituted/compulsions-encumbered impression for the simple reason that veridical knowledge is not built on eliciting human sovereignising beholdening but rather eliciting human ontological-commitment $-<$ implied - self-assuredness-of-ontologicalgood-faith/authenticity postconverging-de-mentating/structuring/paradigming -as-beingas-of-existential-reality $>$ as to ontologising-depth in epistemic re-originariness/re-origination projective/reprojective cross-subjection to existence-as-sublimatingwithdrawal/unenframing/re-ontologising,-elicited-from-prospective-profound-supererogation (and it is in this regards that human history speaks of re-originary-_as-unenframed_re-_reontologising/unbeholdening/outlier-conceptualisation__imbued-postconverging/dialecticalthinking -'projective-insights’/‘epistemic-projection-in-conflatedness ' '-ofnotional deprocrypticism-prospective-sublimation $\rangle^{\circ}$ as to human-subpotency 'fatedness-ofsublimation-over-desublimation to existence-potency sublimating-nascence,-disclosed-fromprospective-epistemic-digression in reflecting holographically-<conjugatively-andtransfusively $>$ the relative-unreflexivity/relative-reflexivity ontological-contiguity $\sim$ of-thehuman-institutionalisation-process '). At the 'human lifespan extricatory punctuality/immediacy of depth-of-thought' such a conceptualisation may seem frivolous but then the work/job of doing philosophy and thinking is not for those of 'human lifespan extricatory punctuality/immediacy of depth-of-thought'; that is why such pettiness-of-minds 
cannot recognise true work/job when they see it and it is herein contended are better off elsewhere rather than 'merely hanging to the thread of institutional-prescience/imprimaturing$<$ dullness-of the-spirit/psychologismic epistemic-acutisation nonresidualising imbued\{compulsing\} linearity in-eclecticism-of prior-mere-formulaicity/ritualisation ${ }^{\prime}$ devoid of 'aptitudinal-substantive-pertinence reflected in a predisposition for totalisingly-ingdiscretion/whim-of-thought' that fails prospective human re-ontologisation/omnipotentiality. The above insight provides a relevant backdrop for a truer appreciation of what is entailed by prospective $\quad$ 'nonpresencing-<perspective-ontological-normalcy/postconvergence $>$ anarchistic-growth/anarchisation-for-re-ontologisation-〈as-to-conscious/unconscious epistemically-sound induced 'demoronisation-<sublimating-nascence,-nonextricatorysublimating-upstreaming/'amontée'> postconverging/dialectical-thinking conception of residual_re-originary_anarchistic incipiency of human social-functioning-and-accordance-asof-social-stake-contention-or-confliction meaningfulness-and-teleology ' $\rangle$ ' (since critically any given registry-worldviews/dimensions imbued prior-institutionalisation-threshold-byprospective-uninstitutionalised-threshold 'self-referencing-syncretising forward-facingsupposedly postconverging-or-dialectical-thinking -apriorising-psychologism epistemicprojection as of prior mere-formulaicity/ritualisation-<as-to-mere-formulaicmethodologising/mutualising/organising/institutionalising,-prospectively-losing-track-of‘fepistemic-atising ’’re-apriorising/re-axiomatising/re-referencing residuality-in-reoriginariness/re-origination'>' so-reflects its 'disontologising preconverging/dementing ${ }^{2}-<$ asto-prospective-uninstitutionalised-threshold > ignoring/biased inclination' for the sake of 'its given present minimum-and-balancing expectations/anticipations of social-functioning-andaccordance-as-of-social-stake-contention-or-confliction' reflecting of itself mainly as of postconverging-or-dialectical-thinking -apriorising-psychologism while qualifying its prospectively uninstitutionalised-threshold ${ }^{102}$ actually as nondescript/ignorable-void ${ }^{60}$ as to its 
presencing-absolutising-identitive-constitutedness

apriorising/axiomatising/referencing'-entailing>-existentialising-enframing/imprintedness-

〈as-to- historicity-tracing-in-presencing-hyperrealisation/hyperreal-transposition〉). But then ontology/science being as of existence doesn't kowtow-and-subject-to the 'little human mortal' thresholds about existence, and it is up to the human to undertake its 'epistemicgrowth/disquiet/discomfort-〈induced-sublimation,-as-from-existence's - effusing/ecstatic-

inlining-as- historiality-\{science/authenticity/nonextrication $\}$-beyond-mere-

formulaicity/ritualisation-as- historicity-tracing-\{science-ideology/fashionability/distraction $\}\rangle$ as to construction-of-the-Self in dispensing-with-immediacy-for-relative-ontologicalcompleteness $^{87}$-by-reification/contemplative-distension ${ }^{27}$ for re-ontologising prospective Being-development/ontological-framework-expansion-as-to-depth-of-ontologisingdevelopment-as-infrastructure-of- meaningfulness-and-teleology as of notional selfdistantiation- $<$ imbued - re-motif-and-re-apriorising/re-axiomatising/re-

referencing $>/$ 'distantiation of contemplative existentialising-frame-of-entailment-of motifand-apriorising/axiomatising/referencing as to transversality-<for-sublimating-existentialeventuating/denouement,-from-'thinking at first/pure-predisposition-preemptive-ofprospective-disontologising/subontologising' as-of-prospectively-disambiguated-affirmedand-unaffirmed-'motif-and-apriorising/axiomatising/referencing'> imbuing historiality/ontological-eventfulness 38 /ontological-aesthetic-tracing- $<$ perspectiveontological-normalcy/postconvergence-reflected-‘epistemicity-relativism-determinism’>, and so rather than falsehood terms of 'contrastive equivalence' implied distractive-alignment-toreference-of-thought- $<$ of-apriorising/axiomatising/referencing $>30$. This explains why (beyond the naïve functionalisms passed as knowledge-reification $\sim$ gesturing-and-accounting-ofepistemic-phenomenalism- $<$ in-

prospective_psychologismic apriorising/axiomatising/referencing-\{of-'prospectively_ 
implicited_attendant-ontological-contiguity ' educed-

existentialising/contextualising/textualising_'intelligibility/epistemicity/reflexivity_contiguity<imbued-notional cogency>’ \}-conflatedness -in-\{preconverging ment by\}

postconverging-entailment $>$ but rather in $<$ amplituding/formative-epistemicity $>$ totalising $\sim$ selfreferencing-syncretising/circularity/interiorising/akrasiatic-drag ${ }^{34}$ ) the reality of prospective ' nonpresencing-<perspective-ontological-normalcy/postconvergence $>\quad$ anarchisticgrowth/anarchisation-for-re-ontologisation-〈as-to-conscious/unconscious epistemically-sound induced 'demoronisation- $<$ sublimating-nascence,-nonextricatory-sublimatingupstreaming/'amontée'> postconverging/dialectical-thinking conception of residual_reoriginary_anarchistic incipiency of human social-functioning-and-accordance-as-of-socialstake-contention-or-confliction meaningfulness-and-teleology ' $\rangle$ ' is rather one of human notional $\sim$ self-distantiation-<imbued—re-motif-and-re-apriorising/re-axiomatising/re-

referencing $>\quad$ induced psychoanalytic-unshackling/memetic-reordering/institutionalrecomposuring self-becoming/self-conflatedness ${ }^{13}$ /formative-supererogating$<$ projective/reprojective - aestheticising-re-motif-and-re-apriorising/re-axiomatising/rereferencing,-in-perspective-ontological-normalcy/postconvergence $>$. Fundamentally, a registry-worldview's/dimension's vices-and-impediments ${ }^{105}$ in want for prospective ' nonpresencing-<perspective-ontological-normalcy/postconvergence $>$ anarchisticgrowth/anarchisation-for-re-ontologisation-〈as-to-conscious/unconscious epistemically-sound induced 'demoronisation- $<$ sublimating-nascence,-nonextricatory-sublimatingupstreaming/'amontée'> postconverging/dialectical-thinking conception of residual_reoriginary_anarchistic incipiency of human social-functioning-and-accordance-as-of-socialstake-contention-or-confliction meaningfulness-and-teleology ' $’$ are preconverging/postconverging-de-mentatively/structurally/paradigmatically tied to its uninstitutionalised-threshold distractive-alignment-to- ${ }^{83}$ reference-of-thought- $<$ of- 
apriorising/axiomatising/referencing $>$ imbued lack of dispensing-with-immediacy-for-relativeontological-completeness ${ }^{87}$-by-reification/contemplative-distension ${ }^{27}$ as to the fact that the state of recurrent-utter-uninstitutionalisation (failing base-institutionalisation), ununiversalisation (failing universalisation), non-positivism/medievalism (failing positivism/rational-empiricism) and ${ }^{80}$ procrypticism-or-disjointedness-as-of- ${ }^{8}$ reference-of-thought (failing ${ }^{18}$ deprocrypticismor-preempting-disjointedness-as-of- ${ }^{-3}$ reference-of-thought) are the truer underlying human $<$ amplituding/formative-epistemicity $>$ causality $\sim$ as-to-projective-totalitative-implications-ofprospective- nonpresencing,-for-explicating relative-unreflexivity/relative-reflexivityontological-contiguity but for the narcissistic <amplituding/formativeepistemicity $>$ totalising $\sim$ self-referencing-syncretising/circularity/interiorising/akrasiatic-drag speaking to the more fundamental human psychology as 'postconverging-or-dialecticalthinking -psychology or psychology-of-mentation-dynamics or natural $\sim$ psychologicaldynamics' (as superseding by such an underlying 'psychological ${ }^{4}$ historiality/ontologicaleventfulness 38 ontological-aesthetic-tracing-<perspective-ontologicalnormalcy/postconvergence-reflected-'epistemicity-relativism-determinism'> of notional $\sim$ selfdistantiation-<imbued — re-motif-and-re-apriorising/re-axiomatising/re-referencing $>$ ' all the successive overarching registry-worldviews/dimensions uninstitutionalised-threshold notional disjointedness of motif-and-apriorising/axiomatising/referencing-psychologism imbued preconverging/dementing -qualia-schema' naively of their given $<$ amplituding/formative-epistemicity $>$ totalising $\sim$ self-referencingsyncretising/circularity/interiorising/akrasiatic-drag ${ }^{34}$ in their ${ }^{79}$ presencing-absolutisingidentitive-constitutedness ${ }^{14}$ <preconverging 'motif-and-apriorising/axiomatising/referencing'entailing $>$-existentialising — enframing/imprintedness-〈as-to- historicity-tracing - inpresencing-hyperrealisation/hyperreal-transposition)). In this regards, the reality of human transcendence-and-sublimity/sublimation/supererogatory-de-mentativity however its 
crossgenerational and diffusionary nature is an 'empirical fact' that can be counted upon for prospective human ' ${ }^{\prime}$ nonpresencing-<perspective-ontological-normalcy/postconvergence $>$ anarchistic-growth/anarchisation-for-re-ontologisation-〈as-to-conscious/unconscious epistemically-sound induced 'demoronisation-<sublimating-nascence,-nonextricatorysublimating-upstreaming/'amontée'> postconverging/dialectical-thinking conception of residual_re-originary_anarchistic incipiency of human social-functioning-and-accordance-asof-social-stake-contention-or-confliction meaningfulness-and-teleology ' $\rangle$ ' as to the fact that the social-construct and its institutions are bulldozeable when grossly failing 'their overall underlying social-construct ontological-commitment $-<$ implied-self-assuredness-ofontological-good-faith/authenticity $\sim$ postconverging-de-

mentating/structuring/paradigming -as-being-as-of-existential-reality $>$ so-reflected as of social notional $\sim$ self-distantiation- $<$ imbued—re-motif-and-re-apriorising/re-axiomatising/rereferencing>' when 'merely hanging to the thread of institutional-prescience/imprimaturing$<$ dullness-of the-spirit/psychologismic epistemic acutisation nonresidualising imbued\{compulsing\} linearity in-eclecticism-of prior-mere-formulaicity/ritualisation $>$ ' devoid of 'aptitudinal-substantive-pertinence reflected in a predisposition for totalisingly-ingdiscretion/whim-of-thought rather with regards to a conception of intersubjectivity-ofmeaningfulness-and-teleology as beholdening to ${ }^{79}$ presencing-absolutising-identitiveconstitutedness ${ }^{1 /}$ ' as to the fact that the 'flawed prior_knowledge-reification $\sim$ gesturing-andaccounting - of-epistemic-phenomenalism- $<$ in-

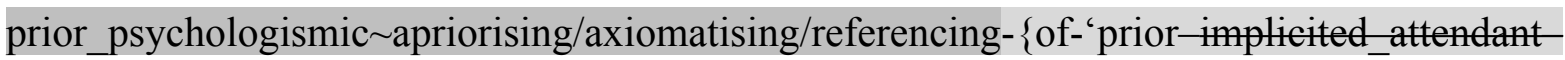
ontological-contiguity ' educedexistentialising/contextualising/textualising_'intelligibility/epistemicity/reflexivity-contiguity<imbued-notional cogency>' $\quad\}$-constitutedness -in-preconverging-entailment $>\quad$ is construed as not in epistemic re-originariness/re-origination projective/reprojective cross- 
subjection to existence-as-sublimating-withdrawal/unenframing/re-ontologising,-elicitedfrom-prospective-profound-supererogation as underlied with notional $\sim$ self-distantiation$<$ imbued — re-motif-and-re-apriorising/re-axiomatising/re-referencing $>$ implied formativeness$<$ as-to-intersolipsism-of-preformulating/preframing/premeaningfulness-imbued-mediativityand-deferentialism $>$-of- meaningfulness-and-teleology (in ${ }^{6}$ nonpresencing- $<$ perspectiveontological-normalcy/postconvergence $>\quad$ epistemic-projection)'. Such institutionalised pedantising/muddling/formulaic-hollowing-out — in-subontologisation/subpotentiation〈blurring/undermining-of-prospective-totalising-entailing,-as-to-entailing<amplitung/formative-epistemicity>totalising in-relative-ontological-completeness > desublimation manifestation devoid of 'aptitudinal-substantive-pertinence reflected in a predisposition for totalisingly-ing — discretion/whim-of-thought' nowadays is associated with a normalised/stereotyped/selfhelping/feel-good conception of knowledge that by distractivealignment-to- ${ }^{8}$ reference-of-thought- $<$ of-apriorising/axiomatising/referencing $>$ 'folsely cultivate the notion that it is engage in-the-very-first-place at the same contemplative pedestal' with profound knowledge as of 'prospective postconverging aporeticismovercoming/unoverceming as the-Good/knowledge-reification $\sim$ gesturing-and-accounting-ofepistemic-phenomenalism- $<$ in-

prospective_psychologismic apriorising/axiomatising/referencing-\{of-'prospectively implicited_attendant-ontological-contiguity ' educedexistentialising/contextualising/textualising_'intelligibility/epistemicity/reflexivity-contiguity<imbued-notional cogency >' \}-conflatedness -in-\{preconverging-ment by\} postconverging-entailment $>$ /understanding/<amplituding/formativeepistemicity $>$ causality $\sim$ as-to-projective-totalitative-implications-of-prospectivenonpresencing,-for-explicating relative-unreflexivity/relative-reflexivity - ontologicalcontiguity ' (as to when it seemingly 'affirm to be engaged in analysing' but grossly blundering 
about the very requisite basics before even pretending to be truly engaged with such thought as articulated by postmodern thinkers and as so-prodded by monopolising/quasimonopolising/networking existentialising-frame-of-entailment-of motif-andapriorising/axiomatising/referencing of public and institutional discursivity as of mere entitlement-and-access and ratings-drivenness bent on side-lining salient and relevant narratives as to technicity/profundity), in a decadent intellectual culture that construe of 'dumbed-down apathetic publics-of-conquest' as the true environment for 'intellectual geniosity as to blandly cultivated popularity' (rather than in epistemic re-originariness/re-origination of projective/reprojective cross-subjection of knowledge-reification $\sim$ gesturing-and-accountingof-epistemic-phenomenalism- $<$ in-

prospective_psychologismic apriorising/axiomatising/referencing-\{of-‘prospectively_ implicited_attendant-ontological-contiguity ' educedexistentialising/contextualising/textualising_'intelligibility/epistemicity/reflexivity-contiguity<imbued-notional cogency >’ \}-conflatedness -in-\{preconverging -ment by\} postconverging-ntailment> to existence-as-sublimating-withdrawal/unenframing/reontologising,-elicited-from-prospective-profound-supererogation as herein underlied by notional $\sim$ self-distantiation- $<$ imbued — re-motif-and-re-apriorising/re-axiomatising/rereferencing $>\quad$ implied formativeness-<as-to-intersolipsism-ofpreformulating/preframing/premeaningfulness-imbued-mediativity-and-deferentialism>-ofmeaningfulness-and-teleology $\quad$ in $\quad$ nonpresencing- $<$ perspective-ontologicalnormalcy/postconvergence $>$ epistemic-projection). Human epistemic-stretching undergirded as of notional $\sim$ self-distantiation- $<$ imbued — re-motif-and-re-apriorising/re-axiomatising/rereferencing $>/$ 'distantiation of contemplative existentialising-frame-of of and-apriorising/axiomatising/referencing as to transversality-<for-sublimating-existentialeventuating/denouement,-from-'thinking at-first/pure-predisposition-preemptive-of- 
prospective-disontologising/subontologising' as-of-prospectively-disambiguated-affirmed-

and-unaffirmed-'motif-and-apriorising/axiomatising/referencing'>

imbuing

historiality/ontological-eventfulness ${ }^{38}$ ontological-aesthetic-tracing-<perspective-

ontological-normalcy/postconvergence-reflected-‘epistemicity-relativism-determinism'> (with regards to Being-development/ontological-framework-expansion-as-to-depth-of-ontologisingdevelopment-as-infrastructure-of- meaningfulness-and-teleology , institutionaldevelopment-as-to-social-function-development and living-development-as-to-personalitydevelopment psychologismic epistemic-acutisation difficulty-<or, residualising \{decomplsing delinearity for-cogeney>-magnitudes $\{$ of-experientiality/experiment $\}$ ) speaks to the fact that utopic ' nonpresencing-<perspective-ontological-normalcy/postconvergence $>$ anarchisticgrowth/anarchisation-for-re-ontologisation-〈as-to-conscious/unconscious epistemically-sound induced 'demoronisation-<sublimating-nascence,-nonextricatory-sublimatingupstreaming/'amontée'> postconverging/dialectical-thinking conception of residual_reoriginary_anarchistic incipiency of human social-functioning-and-accordance-as-of-socialstake-contention-or-confliction meaningfulness-and-teleology ' ' ' is the central component of human sublimation-over-desublimation evental ${ }^{3}$-instigation notwithstanding the "prospective negation of the-utopic by the self-presence/self-constitutedness ${ }^{14}<$ in-perspective-epistemicabnormalcy/preconvergence ${ }^{3}>$ of ${ }^{79}$ presencing-absolutising-identitive-constitutedness $<$ preconverging 'motif-and-apriorising/axiomatising/referencing'-entailing >existentialising — enframing/imprintedness-〈as-to- historicity-tracing_-in-presencinghyperrealisation/hyperreal-transposition〉' (as to the backdrop-of-inherent-immanentexistence's-sublimation-structure-<of-'unsurrealistic-as-real'-ontologicalnormalcy/postconvergence $>$ ever always 'eliciting, bringing-forth and phasing-over' the-utopic epistemically as from ontological-normalcy/postconvergence to epistemicabnormalcy/preconvergence ${ }^{3 !}$ so-reflected in the veracity of human psychoanalytic- 
unshackling/memetic-reordering/institutional-recomposuring self-becoming/selfconflatedness $^{13}$ /formative-supererogating-<projective/reprojective-aestheticising-re-motifand-re-apriorising/re-axiomatising/re-referencing,-in-perspective-ontologicalnormalcy/postconvergence $>$ ). Thus, notional $\sim$ self-distantiation- $<$ imbued-re-motif-and-reapriorising/re-axiomatising/re-referencing $>$ as to epistemic-stretching is merely a reflection of requisite prospective human originariness-parrhesia,-as-spontaneity-of-aestheticisation as to supererogatory $\sim$ acuity/perspicacity/astuteness/edginess/incisiveness-ofapriorising/axiomatising/referencing/intelligibilitysettingup/measuringinstrumenting -forconceptualisation in reflection of human dimensionality-of-sublimating <<amplituding/formative >supererogatory -de-mentativeness/epistemic-growth-orconflatedness /transvaluative-rationalising/transepistemicity/anamnestic-residuality/spiritdrivenness-equalisation); and critically the-utopic as to human Being-development/ontologicalframework-expansion-as-to-depth-of-ontologising-development-as-infrastructure-ofmeaningfulness-and-teleology is mostly appreciable as of its crossgenerational posterity implications ominously beyond 'human lifespan extricatory punctuality/immediacy of depth-ofthought' to a more profound appreciation of the underlying possibility for human transcendenceand-sublimity/sublimation/supererogatory de-mentativity; thus underlying the most profound $<$ amplituding/formative-epistemicity $>$ totalising $\sim$ ratiocontiguity/ratiocination-asreferentialism - 'implicited_attendant-ontological-contiguity ${ }^{67}$ ' educedexistentialising/contextualising/textualising_ 'intelligibility/epistemicity/reflexivity-contiguity$<$ imbued-notional cogency>' ${ }^{\prime}$;-phenomenal-abstractiveness-of-presencing-in-'protensiveconsciousness' with notional ${ }^{18}$ deprocrypticism as herein articulated accounting for overall

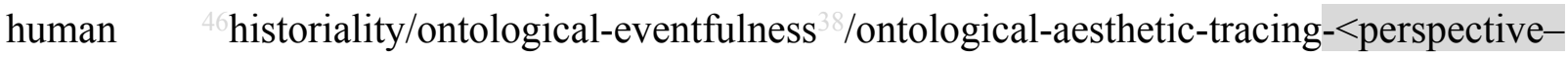
ontological-normalcy/postconvergence-reflected-‘epistemicity-relativism-determinism’>.

Critically thus, the 'knowledge-notionalisation backdrop of entailing-<amplituding/formative- 
epistemicity>totalising in-relative-ontological-completeness

reification $\sim$ gesturing-and-accounting — of-epistemic-phenomenalism- $<$ in-

prospective_psychologismic apriorising/axiomatising/referencing-\{of-‘prospectively

implicited_attendant-ontological-contiguity ' reduced-

existentialising/contextualising/textualising_'intelligibility/epistemicity/reflexivity-contiguity-

<imbued-notional cogency >' \}-conflatedness -in-\{preconverging-ment by\}

postconverging-entailment> in reflecting ${ }^{4}$ historiality/ontological-eventfulness 38 /ontologicalaesthetic-tracing-<perspective-ontological-normalcy/postconvergence-reflected-`epistemicityrelativism-determinism'>' as implied both scientifically and by many a postmodern thinker doesn't need to 'take a page into any ideological unknown' to effectively contemplate of the practical implications for prospective re-ontologisation; and as herein contended with regards to ' nonpresencing-<perspective-ontological-normalcy/postconvergence $>$ anarchisticgrowth/anarchisation-for-re-ontologisation-〈as-to-conscious/unconscious epistemically-sound induced 'demoronisation-<sublimating-nascence,-nonextricatery-sublimatingupstreaming/'amontée'> postconverging/dialectical-thinking conception of residual_reoriginary_anarchistic incipiency of human social-functioning-and-accordance-as-of-socialstake-contention-or-confliction meaningfulness-and-teleology ' $\rangle$ ' that the fundamental idea for such prospective social re-ontologisation lies with 'appropriate constraining unblurriness$<$ re-ontologising_by-postconverging-as-to-dragged-outsupererogatory $\sim$ wholesomeness/profound-supererogation ,-while-anecdotalising-priordisontologising-thresholding $>$ analysis in profound-supererogation ${ }^{6}$ of social-and-institutionalframeworks-of — referencing/registering/decisioning existentialising-decisionality-<as-todisontologising/re-ontologising aporeticism $>$ postconverging apereticismovercoming/unovercoming as to a translating-insight as from nascent-particular/incipient-andmaterial/technical-sublimations-<blinded-to-their-relative-ontological-completeness 
disontologising/re-ontologising aporeticism ${ }^{\text {' }}$ (given the very ontologicalnormalcy/postconvergence nature of existence reflected as existence-as-sublimatingwithdrawal/unenframing/re-ontologising,-elicited-from-prospective-profound-

supererogation ). We can appreciate in this regards the role of constraining existence in the ' nonpresencing-<perspective-ontological-normalcy/postconvergence $>\quad$ anarchisticgrowth/anarchisation-for-re-ontologisation-〈as-to-conscious/unconscious epistemically-sound induced 'demoronisation- $<$ sublimating-nascence,-nonextricatory-sublimatingupstreaming/'amontée'> postconverging/dialectical-thinking conception of residual_reoriginary_anarchistic incipiency of human social-functioning-and-accordance-as-of-socialstake-contention-or-confliction meaningfulness-and-teleology ' $\rangle$ ' driving the natural sciences as to the 'transversal and cross-subjecting sublimating-selectivity-and-desublimatingdeselectivity as to manifest sublimation of scientific ideas' effectively building up the various fields in perpetuative re-ontologisation (and so-construed as to a 'science supererogating intolerance-<of-disparateness $>$ /exactifying_precisioning-of-sublimation- $<$ as-topostconverging-narrowing-down apriorising/axiomatising/referencing-entailing-theoretical,conceptual-and-operant-implications $>$ conception' that is not undermined by a false conception of science reflected by a 'science ideology desublimation in <preconverging 'motif-andapriorising/axiomatising/referencing'-entailing>-existentialising — enframing/imprintedness〈as-to- historicity-tracing-in-presencing-hyperrealisation/hyperreal-transposition〉').

However, because of the high emotional-involvement in the social, the default posturing one way or the other is ever always to adopt a $<$ self-reflexive $>$-willed-will ideological stance (integrating $<$ amplituding/formative $>$ wooden-language-〈imbued-temporal-mereform/virtualities/dereification/akrasiatic-drag/denatured/preconverging-or-dementing narratives - of-the- reference-of-thought- categorical-imperatives/axioms/registry- 
teleology $>$ explaining the discomfort induced when such conscious or unconscious ideological stances are subjected to deconstruction analysis or genealogical/archaeological analysis as to nonpresencing-<perspective-ontological-normalcy/postconvergence $>$ implications of human limited-mentation-capacity-deepening —as-subjecting limitedness/human-subpotency-to'educe unlimitednesstexistence sublimating nascence' ${ }^{33}$ ) and so over an existence-driven $<$ self-reflexive $>$-willed-thought; in a flawed prior_knowledge-reification $\sim$ gesturing-andaccounting - of-epistemic-phenomenalism- $<$ in-

prior_psychologismic $\sim$ apriorising/axiomatising/referencing-\{of-'prior-implicited_attendantontological-contiguity ' educedexistentialising/contextualising/textualising_'intelligibility/epistemicity/reflexivity-contiguity<imbued-notional cogency >' $\quad$ - constitutedness -in preconverging-entailment $>$ that poorly appreciates the two-sided epistemic-veracity of undergirding human 'self-reflexive instigativeeventuating-〈as-to-teleological-instigative/incipientwilling/arbitrariness/waywardness/faithdrivenness/supererogating-for-human-intelligibility,preceding-existence's-eventuating-sublimating-validation/desublimating-invalidation> of human embodied-consciousness motif-and-apriorising/axiomatising/referencing-\{of'prospectively_implicited_attendant-ontological-contiguity ' educedexistentialising/contextualising/textualising_ 'intelligibility/epistemicity/reflexivity-contiguity$<$ imbued-notional cogency $>>$ ' $\}$-elicited-incipience-of-existentialising-decisionality-<as-todisontologising/re-ontologising aporeticism $>$ ' so-reflected by the 'supererogating/willing side' and the 'existence sublimating-validation/desublimating-invalidation side' for sound human intelligibility to arise (and critically the reality of a truly social scientific insight is one that necessarily has to take a considerable distance from the punctual/immediacy/constituted/compulsions-encumbered high emotional-involvement as inherently manifested in the direct socio-econo-political processes of social-stake-contention-or- 
confliction and its associated directed ideologies with such a truly scientific endeavour not about pedantising/muddling/formulaic-hollowing-out_-in-subontologisation/subpotentiation〈blurring/undermining-of-prospective-totalising-entailing,-as-to-entailing$<$ amplituding/formative-epistemicity>totalising in-relative-ontological-completeness $>$ but 'rather most thoroughly involved in social-stake-contention-or-confliction postconverging aporeticism-overcoming/unovereoming' along the lines of a more profound human and social sublimation arising as from human 'epistemic-growth/disquiet/discomfort〈induced-sublimation,-as-from-existence's - effusing/ecstatic-inlining-as- historiality\{science/authenticity/nonextrication\}-beyond-mere-formulaicity/ritualisation-as- historicitytracing-\{science-ideology/fashionability/distraction $\}\rangle$ as to construction-of-the-Self in dispensing-with-immediacy-for-relative-ontological-completeness ${ }^{87}$-byreification/contemplative-distension ${ }^{27}$ ). This should not be construed as a weakness as often wrongly implied of the anti-ideological stance of postmodern thought but rather speaks of a strength in the sense that it is naïve to think the pedantising/muddling/formulaic-hollowingout-in-subontologisation/subpotentiation-〈blurring/undermining-of-prospective-totalisingentailing,-as-to-entailing-<amplituding/formative-epistemicity $>$ totalising $\sim$ in-relativeontological-completeness $\rangle$ of ${ }^{7}$ presencing-absolutising-identitive-constitutedness ${ }^{14}$ socialvestedness/normativity- $<$ discretely-implied-functionalism $>$ can be veridically undermined/superseded by a 'corresponding antipodal/diametrical compensatory subontologisation' (as manifested between the conflicting capitalistic and communistic ideologies), rather than a true aspiration for a most profound prospective ontologisation/reontologisation in-of-itself so-implied as of supererogatory-progressivity as to human postconverging-aporeticism-overcoming/unovereoming in enabling prospective sublimatingnascence for human social-and-institutional-frameworks-ofreferencing/registering/decisioning sublimating $\sim$ existentialising - decisionality $<$ as - to- 
disontologising/re-ontologising aporeticism $>$ (even as the practicalities of the political environment inevitably will elicit thresholds of disontologising as to nonontologising/subontologising conceptualisations); but then just as the natural scientist's basic research is to 'open-up'/'throw-up'/'reveal' sublimating avenues for 'more and more profound ontologising possibilities for engineering/technical practices' likewise the genuine social intellectual-function/posture has to be able to 'open-up'/'throw-up'/'reveal' 'more and more profound ontologising possibilities/avenues of contemplative sublimating for more and more profound social-and-institutional-frameworks-of-referencing/registering/decisioning sublimating existentialising-decisionality-<as-to-disontologising/re-ontologising apereticism $>$ ' notwithstanding ideological pretenses of mere-formulaicity/ritualisation- $<$ as-tomere-formulaic - methodologising/mutualising/organising/institutionalising,-prospectively-

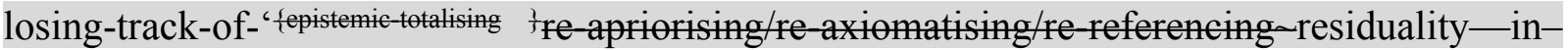
re-originariness/re-origination'> as to mere-formulaic capitalistic/communistic ideological methodologising/mutualising/organising/institutionalising that seem to be utterly immuned from the ontological-veracity of human prospective 'originariness-parrhesia,-as-spontaneity-ofaestheticisation — supererogatory acuity/perspicacity/astuteness/edginess/incisiveness underlying dimensionality-of-sublimating ${ }^{25}-\langle<$ amplituding/formative $>$ supererogatory $\sim$ dementativeness/epistemic-growth-or-conflatedness /transvaluativerationalising/transepistemicity/anamnestic-residuality/spirit-drivenness-equalisation〉 as to profound dispensing-with-immediacy-for-relative-ontological-completeness ${ }^{87}$-byreification/contemplative-distension ${ }^{27}$ (to the point where human progress is hardly contemplated re-originarily outside the direct and/or indirect gravitation of such all-enframing ideologies as to mere-formulaicity/ritualisation-<as-to-mere-formulaicmethodologising/mutualising/organising/institutionalising,-prospectively-losing-track-of‘fepistemictalising ’’re-apriorising/re-axiomatising/re-referencing-residuality-in-re- 
originariness/re-origination'>) and in-many-ways such ideologically induced conscious-andunconscious 'habituatedness/mental-colonisation as to ${ }^{79}$ presencing-absolutising-identitiveconstitutedness $^{14}$ social-vestedness/normativity' stifles the true re-originary_-_as-unenenframed_-_re-_. ontologising/unbeholdening/outlier-conceptualisation____imbued-postconverging/dialecticalthinking -'projective-insights'/‘epistemic-projection-in-conflatedness ' 'ofnotional deprocrypticism-prospective-sublimation $\rangle$ potential for human prospective human postconverging aporeticism-overcoming/unovercoming. Such a postmodern philosophical anti-ideological of $\quad$ stance nonpresencing-<perspective-ontologicalnormalcy/postconvergence $>$ anarchistic-growth/anarchisation-for-re-ontologisation-〈as-toconscious/unconscious epistemically-sound induced 'demoronisation-<sublimating-nascence,-nonextricatory-sublimating-upstreaming/'amontée’> postconverging/dialectical-thinking conception of residual_re-originary_anarchistic incipiency of human social-functioning-andaccordance-as-of-social-stake-contention-or-confliction meaningfulness-and-teleology ' $\rangle$ ' (just as is the case with the natural sciences as to "prospective scientific sublimating reconstruals of the-very-same-immanent-existence/intrinsic-reality/ontological-veridicality,-as-to'human<amplituding/formative-epistemicity>totalising purview-of-construal as of human limited-mentation-capacity-deepening —as-subjecting limitedness/human-subpotency-to'educed-unlimitedness/existence-sublimating nascence' ${ }^{5}$, not to be confused with science ideology which is rather about 'consciously or unconsciously usurping the sublimating credence of science in its science ideology pedantising/muddling/formulaic-hollowing-out-insubontologisation/subpotentiation-〈blurring/undermining-of-prospective-totalising-entailing,as-to-entailing-<amplituding/formative-epistemicity $>$ totalising in-relative-ontologicalcompleteness \ exercise') is all about human candidity/candour-capacity for effectively tackling prospective human postconverging-apereticism overeoming and supererogatory acuity/perspicacity/astuteness/edginess/incisiveness eliciting of 'epistemic- 
growth/disquiet/discomfort-〈induced-sublimation,-as-from-existence's-effusing/ecstaticinlining-as- historiality-\{science/authenticity/nonextrication $\}$-beyond-mere-

formulaicity/ritualisation-as- historicity-tracing-\{science-ideology/fashionability/distraction $\}\rangle$ as to construction-of-the-Self in dispensing-with-immediacy-for-relative-ontologicalcompleteness $^{87}$-by-reification/contemplative-distension ${ }^{27}$, and doesn't carry false promises of shallow supererogatery acuity/perspicacity/astuteness/edginess/incisiveness as to mereformulaic methodologising/mutualising/organising/institutionalising (as associated with ideological stances reflected say as to capitalistic or communistic ideologies); and so critically because the more salient point for postconvergingaaporeticism-overcoming/unovercoming though it may seem counterintuitive is not ideological solutions of ${ }^{79}$ presencing-absolutisingidentitive-constitutedness ${ }^{14}$ but rather (notwithstanding the high emotional-involvement) appropriate human development as to psychoanalytic-unshackling/memeticreordering/institutional-recomposuring as from nonpresencing-<perspective-ontologicalnormalcy/postconvergence $>\quad$ as a prerequisite speaking \{epistemic-

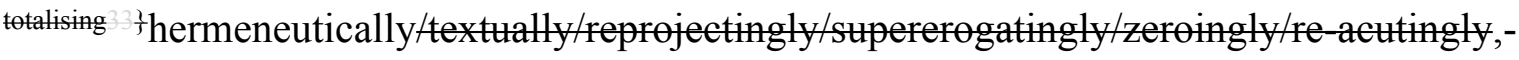
\{decompulsing delinearity for-cogency of a prospective nonpresencing-<perspective-ontologicalnormalcy/postconvergence $>$ change in human apriorising/axiomatising/referencing-\{of'prospectively_implicited_attendant-ontological-contiguity ' educedexistentialising/contextualising/textualising_'intelligibility/epistemicity/reflexivity-contiguity<imbued-notional cogency>' \}-relation-to-the-world than just ' $m$ meaningfulness-andteleology within prior mere-formulaicity/ritualisation-<as-to-mere-formulaic methodologising/mutualising/organising/institutionalising,-prospectively-losing-track-of‘ \{epistemic-totalising '̀ re-apriorising/re-axiomatising/re-referencing residuality-in-reoriginariness/re-origination'> (as of human-subpotency non-scalarity/beholdening-<as-to-whathas-gone-before-aesthetically-de-mentates/structures/paradigms-distortedly-the-possibility-for- 
the-later-ontologisation $>$ ) in an already prospectively poorly apriorising/axiomatising/referencing-\{of-'prospectively implicited_attendant-ontologicalcontiguity ' educedexistentialising/contextualising/textualising_'intelligibility/epistemicity/reflexivity-contiguity<imbued-notional cogency>' $\}$-relation-to-the-world', and in this regards we can appreciate that budding-positivists critical philosophical insight was more than just their effectively instigative/incipient budding science but a critical appreciation that the medieval-scholasticism non-positivism apriorising/axiomatising/referencing-\{of-'prospectively implicited_attendantontological-contiguity ' educed-

existentialising/contextualising/textualising_ 'intelligibility/epistemicity/reflexivity-contiguity<imbued-notional cogency>' $\}$-relation-to-the-world wouldn't countenance-and-cultivate the true prospect of scientific knowledge requiring a positivism apriorising/axiomatising/referencing-\{of-"prospectively_implicited_attendant-ontologicalcontiguity ' $\sim$ educedexistentialising/contextualising/textualising_'intelligibility/epistemicity/reflexivity-contiguity<imbued-notional cogency>' \}-relation-to-the-world (notwithstanding the then high emotional-involvement), with such budding positivism not being at all a 'corresponding antipodal/diametrical compensatory subontologisation' to medieval-scholasticism but rather an altogether a 'true aspiration for a most profound prospective ontologisation/re-ontologisation inof-itself'. This again confirms that the ontological-veracity of genuine human knowledge is rather about notional $\sim$ self-distantiation- $<$ imbued-re-motif-and-re-apriorising/reaxiomatising/re-referencing $>/$ 'distantiation of contemplative existentialising-frame-ofentailment of motif and apriorising/axiomatising/referencing as to transversality-<forsublimating-existential-eventuating/denouement,-from-'thinking at first/pure-predispositionpreemptive-of prospective-disontologising/subontologising' as-of-prospectively- 
disambiguated-affirmed-and-unaffirmed-'motif-and-apriorising/axiomatising/referencing'>

imbuing $\quad{ }^{4}$ historiality/ontological-eventfulness $3 \%$ ontological-aesthetic-tracing-<perspectiveontological-normalcy/postconvergence-reflected-‘epistemicity-relativism-determinism'> (as to the precedence of inherent existence possibility for sublimating-nascence to which humansubpotency subjects itself) and not conceptualisations of distractive-alignment-to- ${ }^{8}$ reference-ofthought- $<$ of-apriorising/axiomatising/referencing ${ }^{30}$ (that wrongly imply that human totalisingly-ing — discretion/whim-of-thought takes precedence over inherent existence possibility for sublimating-nascence). It is only after establishing a prospectively sound apriorising/axiomatising/referencing-\{of-'prospectively implicited_attendant-ontologicalcontiguity ' educed-

existentialising/contextualising/textualising_'intelligibility/epistemicity/reflexivity-contiguity<imbued-notional cogency>' $\}$-relation-to-the-world (in the case of prospective deprocrypticism-or-preempting-disjointedness-as-of- ${ }^{3}$ reference-of-thought involving the inducing/projection of an underlying nondisjointing apriorising/axiomatising/referencing-\{of'prospectively_implicited_attendant-ontological-contiguity ' educedexistentialising/contextualising/textualising_'intelligibility/epistemicity/reflexivity-contiguity<imbued-notional cogency> ' \}-relation-to-the-world as of profound-supererogation entailing-<amplituding/formative-epistemicity $>$ totalising $\sim$ in-relative-ontologicalcompleteness $^{87}$ in undermining the totalisingly-ing-discretion/whim-of-thought of our procrypticism-or-disjointedness-as-of- ${ }^{8}$ reference-of-thought increasingly underlied with dynamic, sophisticated and networking institutionalised pedantising/muddling/formulaichollowing-out - in-subontologisation/subpotentiation-〈blurring/undermining-of-prospectivetotalising-entailing,-as-to-entailing-<amplituding/formative-epistemicity $>$ totalising $\sim$ inrelative-ontological-completeness $\rangle)$ that a prospective ${ }^{18}$ deprocrypticism-or-preemptingdisjointedness-as-of- ${ }^{8}$ reference-of-thought imaginary (just as arose with the presently 
developed positivism/rational-empiricism imaginary over prior non-positivistic imaginaries) will drive a veridical ' ${ }^{18}$ deprocrypticism-or-preempting — disjointedness-as-of- ${ }^{3}$ reference-ofthought specific human conceptivity/epistemic-reflexivity/epistemicity-relativism-determinism$<$ reifying \{as-to-knowledge-developing $\}$-and-empowering $>-\langle$ exuding-\{epistemic-

totalising 3 ' $h e r m e n e u t i c a l l y / t e x t u a l l y /$ reprojectingly/supererogatingly/zeroingly/re acutingly,\{decompulsing\} delinearity for-cogency:-as-from-'existence’s effusing/ecstatic-inlining';-as‘interlay/organicalism/aestheticising-handle-<of- psychologismic-transfixity\{residualising \{decompulsingt delinearity-over-nonresidualising tompulsingt linearity\}'>-\{manifestsupererogatory $\sim$ de-mentative-amplituding-or-mental-aestheticising-attuning \}',-insupererogatery projective-arbitrariness/waywardnessof $\sim$ transversalisation/tandemisation/abstractive-conjugation/perspectivation/depthing — for'aestheticising-re-margining/re-edging/re-acuity-inpostconverging/preconverging_circumscriptive/totalitative-restructuring' - educingsublimation/desublimation> ${ }^{\prime}$ with regards to the ${ }^{18}$ deprocrypticism-or-preemptingdisjointedness-as-of- ${ }^{8}$ reference-of-thought implied relative-ontologicalincompleteness 8 /relative-ontological-completeness ${ }^{87}$

〈sublimating referencing/registering/decisioning,-as-self-becoming/selfconflatedness /formative-supererogating-<projective/reprojective-aestheticising-re-motifand-re-apriorising/re-axiomatising/re-referencing,-in-perspective-ontologicalnormalcy/postconvergence $>>$ as to human-and-social-expectations/anticipationsmetaphoricity ${ }^{57}$-as-preconverging/postconverging-redementating/restructuring/reparadigming-psychologism' as making-available future human reontologisation/potentiation/optimisation potential and so beyond our occlusive ${ }^{79}$ presencingabsolutising-identitive-constitutedness ${ }^{14} \quad$ social-vestedness/normativity-<discretely-impliedfunctionalism> 'their given present minimum-and-balancing expectations/anticipations of 
social-functioning-and-accordance-as-of-social-stake-contention-or-confliction' (as just inducing more and more a complexification of our ${ }^{80}$ procrypticism-or-disjointedness-as-ofreference-of-thought increasingly underlied with dynamic, sophisticated and networking institutionalised pedantising/muddling/formulaic-hollowing-out—insubontologisation/subpotentiation-〈blurring/undermining-of-prospective-totalising-entailing,as-to-entailing-<amplituding/formative-epistemicity $>$ totalising $\sim$ in-relative-ontologicalcompleteness > in-many-ways undermining prospectively profound intellectualism and the genuine social intellectual-function/posture). In this regards, it should be appreciated that as of notional ${ }^{18}$ deprocrypticism reflecting holographically-<conjugatively-and-transfusively $>$ the relative unreflexivity/ative reflexivity ontological-contiguity of-the-humaninstitutionalisation-process 'such a ${ }^{18}$ deprocrypticism-or-preempting-disjointedness-as-ofreference-of-thought imaginary is claiming to be the very rule of human civilisation' as to the fact that 'there is no recurrent-utter-uninstitutionalisation basis for advancing prospective baseinstitutionalisation', and 'no base-institutionalisation basis for advancing prospective universalisation', 'no universalisation basis for advancing prospective positivism/rationalempiricism' and prospectively 'no positivism- ${ }^{8}$ procrypticism basis for advancing prospective deprocrypticism-or-preempting — disjointedness-as-of- ${ }^{3}$ reference-of-thought/nondisjointing' but for the 'inherent nonpresencing-<perspective-ontological-normalcy/postconvergence> nature of existence' instantiated totalising ${ }^{3}$ hermeneutically/textually/reprojectingly/supererogatingly/zeroingly/re-acutingly,${ }_{\{\text {decompulsing }}$ delinearity for-cogency as to prospective human limited-mentation-capacitydeepening — as-subjecting limitedness/human-subpotency to-'educed-unlimitedness/existencesublimating nascence' 53 (in resolving the prior 'dullness' of the human mind); rendering nonsensical, nombrilistic and self-important pretenses/claims that are rather of manifest in-effect absolution-<as-to-apriorising/axiomatising/referencing-\{of-'prospectively- 
implicited_attendant-ontological-contiguity ' educed-

existentialising/contextualising/textualising_'intelligibility/epistemicity/reflexivity_contiguity-

$<$ imbued-notional cogency >' $\}$-constitutedness -in preconverging-entailment $>$ as to their given ${ }^{7}$ presencing — absolutising-identitive-constitutedness ${ }^{14}$ as so-fraudulently implied by our positivism- ${ }^{80}$ procrypticism anti-relativism stance (and eliciting herein the counterclaim that a rational-and-coherent defense of such a posture warrants a further claim recommending that humanity should rather go back to the state of 'recurrent-utter-uninstitutionalisation as to its given manifest in-effect absolution-<as-to-apriorising/axiomatising/referencing-\{of'prospectively_implicited_attendant-ontological-contiguity ' educedexistentialising/contextualising/textualising_'intelligibility/epistemicity/reflexivity-contiguity<imbued-notional cogency >' $\}$-constitutedness -in-preconverging-entailment $>$ presencing-absolutising-identitive-constitutedness $^{\mid{ }^{4}}$ as a more coherent anti-relativism stance as so-expliciting the idea that human progress doesn't/shouldn't occur, even as paradoxically many such anti-relativism proponents seem to project progressive views without truly grasping the contradictory implications of progressivism and anti-relativism explaining their inclination to 'disjointing totalisingly-ing — discretion/whim-of-thought' whereas 'true knowledge has to carry its sublimation within itself as to its notional nondisjointing totalisingentailing' for it to be socially potent and effective). We can appreciate in this regards that the 'sublimating existential-decisionality potency of a scientist thought is not in-and-about themselves' as so-manifested in a 'normalised/stereotyped/selfhelping/feel-good conception of knowledge' but rather 'their inherent coherent knowledge formulation technicity/profundity and elucidating elaboration' which then has to avoid explicited or implicited contradictions with regards to the knowledge technicity/profundity 'enhancement of the overall social-setup selfreflexivity as of the breadth of socially cogent/tense/limpid-<as-of-prospective-profoundsupererogation ,-for-residuality—in-re-originariness/re-origination $>$ percolation-channelling- 

and-apriorising/axiomatising/referencing of intellectualism'; as so-involving the illuminating genuine social intellectual-function/posture, the appraisal of the 'overall social intellectionaptitude body' as well as generalised social advocacy in contemplating about prospective 'reontologising/potentiating/optimisable sublimating-nascence ontologising-depth perspective as of the full-potency of existence'. In other words, 'existence imposes its sublimating rules to the human mortal subpotency' as the very 'fundamental meaning of science' (notwithstanding vague human-subpotency self-important 'methodologising/mutualising/organising/institutionalising' anti-intellectual fooling-about and complotment); in a continual prospective relativistic process of human limited-mentation-capacity-deepening -as-subjecting limitedness/humansubpotency-to-'educed-unlimitedness/existence-sublimating nascence' ${ }^{53}$. In this respect, it is herein contended as of a most intimate appreciation that such anti-relativism stances which will imply no human progress occurs are 'so moronic' it is doubtful these are held out of true conviction (bad or good), but rather are 'cynical and strategic anti-intellectualism stances hanging upon mere sterile/anecdotal institutional-prescience/imprimaturing-<dullness-of thespirit/psychologismic epistemic acutisation nonresidualising imbued-\{compulsing finearity ineclecticism of prior mere formulaicity/ritualisation> (as overplaying the card of 'their given present minimum-and-balancing expectations/anticipations of social-functioning-andaccordance-as-of-social-stake-contention-or-confliction' as to the protection offered by sensibility/decorum of sterile/anecdotal institutional imprimatur)' in undermining the implications of prospective profound-supererogation entailing-<amplituding/formativeepistemicity>totalising in-relative-ontological-completeness ${ }^{87}$ as associated with social equality and anti-bigotry movements as to class, race, gender, etc. (and so-reflected by the fact that their proponents have hardly been able to meet the academic standards of the arguments implied and projected by proponents of ' nonpresencing-<perspective-ontological- 
normalcy/postconvergence $>$ relativism/relative-scope for epistemic-growth,-as\{veridical/sound\}-relative-reflexivity-in-existence/relativising from-limited-mentation-as-itsdeepening/psychologismic epistemic-acutisation residualising, decompulingl delinearity foreogency' and rather turning to surreptitious and media-driven strategies avoiding intellectual

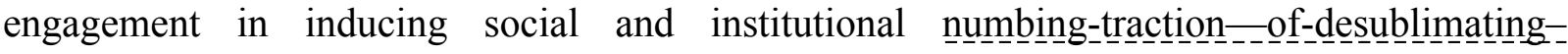
meaningfulness

‘supererogatory acuity/perspicacity/astuteness/edginess/incisiveness-as-to-the-imbuedpostconverging/dialectical-thinking -of-notional deprocrypticism-\{in-dimensionality-ofsublimating _ < amplituding/formative-epistemicity $>$ growth-orconflatedness /scalarisation-as-to-rescalarisation-as-re-ontologisation $\left.\left.\}^{\prime}\right\rangle\right)$. Such 'strategic and cynical institutionalised pedantising/muddling/formulaic-hollowing-out-insubontologisation/subpotentiation-〈blurring/undermining-of-prospective-totalising-entailing,as-to-entailing-<amplituding/formative-epistemicity $>$ totalising in-relative-ontologicalcompleteness ' ' it is herein contended is much more potently effective in preconvergingly-dementating/structuring/paradigming social and institutional in-effect bigotedness (consciously or unconsciously) than the overt and superficial name-calling social manifestations conception of bigotry/prejudice/narrow-mindednes as to emotional distress; and so, as the deferential social and institutional interpretation of such in-effect bigotedness stances surreptitiously/underhandedly undermine the requisite social and institutional prospective human postconverging aporeticism avereoming to profound supererogatory acuity/perspicacity/astuteness/edginess/incisiveness eliciting of human ‘epistemic-growth/disquiet/discomfort-〈induced-sublimation,-as-from-existence’seffusing/ecstatic-inlining-as- historiality-\{science/authenticity/nonextrication $\}$-beyond-mereformulaicity/ritualisation-as- historicity-tracing-\{science-ideology/fashionability/distraction $\}$ ) as to construction-of-the-Self in dispensing-with-immediacy-for-relative-ontological- 
completeness $^{87}$-by-reification/contemplative-distension ${ }^{27}$. Basically, we can garner that the 'very epistemic condition inherent to human limited-mentation-capacity-as-subjecting'educed-unlimitedness/existence-sublimating nascence' to-limitedness/human-subpotency in contrastive relation to the nonpresencing-<perspective-ontologicalnormalcy/postconvergence $>$ of inherent existence sublimating-nascence', induces (as of human $<$ amplituding/formative-epistemicity>-totalising $\sim$ thrownness-in-existence ${ }^{35}$ ) a 'human prospective regressive-shift in ontological-normalcy/postconvergence conceptualisation' (soreflected in the mere-formulaicity/ritualisation-<as-to-mere-formulaicmethodologising/mutualising/organising/institutionalising,-prospectively-losing-track-of‘\{epistemic-totalising ’’re-apriorising/re-axiomatising/re-referencing residuality-in-reoriginariness/re-origination'> implied $\quad \leq$ mere-formulaicity/ritualisation - of $\geq$-prior secondnatured reproducibility—mathesis/motif/thrownness-disposition,--as-reproducibility-ofaestheticisation) as of human dimensionality-of-desublimating-lack-of <<amplituding/formative>supererogatery $\sim$ de-mentativeness/epistemic-growth-orconflatedness /transvaluative-rationalising/transepistemicity/anamnestic-residuality/spiritdrivenness-equalisation); so-underlying 'human ontological-performance ${ }^{2}-<$ including-virtueas-ontology $>$ /morality/ethics/justice/etc. degrades into prospective epistemicabnormalcy/preconvergence ${ }^{3}$ ' with respect to human 'social-functioning-and-accordance-asof-social-stake-contention-or-confliction imbuing existentialising-frame-of-entailment of motif-and-apriorising/axiomatising/referencing of disontologising/ontologising-and-reontologising' which rather ever is in want for prospective human limited-mentation-capacitydeepening—as-subjecting-limitedness/human-subpotency to-'educed-unlimitedness/existencesublimating nascence' (so-undergirded as of human dimensionality-of-sublimating <<amplituding/formative>supererogatory $\sim$ de-mentativeness/epistemic-growth-orconflatedness /transvaluative-rationalising/transepistemicity/anamnestic-residuality/spirit- 
drivenness-equalisation)). This dynamics sums up human ontological-performance ${ }^{72}$ $<$ including-virtue-as-ontology $>/$ morality/ethics/justice/etc.

so-underlied

preconverging/postconverging-de-mentatively/structurally/paradigmatically by humansubpotency 'fatedness-of-sublimation-over-desublimation to existence-potency $\sim$ sublimatingnascence,-disclosed-from-prospective-epistemic-digression in reflecting holographically$<$ conjugatively-and-transfusively $>$ the relative-unreflexivity/relative-reflexivity - ontologicalcontiguity $\sim$ of-the-human-institutionalisation-process (as to

Beingdevelopment/ontological-framework-expansion-as-to-depth-of-ontologising-development-asinfrastructure-of- meaningfulness-and-teleology , institutional-development-as-to-socialfunction-development and living-development-as-to-personality-development psychologismic epistemic-acutisation difficulty-for, residualising \{decompulsing $\}$ delinearity-for-cogency> magnitudes $\{$ of-experientiality/experiment\} $\}$; marked by a human 'fundamental ontologising/disontologising confliction' with regards to 'social-functioning-and-accordanceas-of-social-stake-contention-or-confliction imbuing existentialising-frame-of-entailment-ofmotif-and-apriorising/axiomatising/referencing of disontologising/ontologising-and-reontologising' wherein prospective blurriness-<sterilising/anecdotalising/trivialising-ofprospective-re-ontologising_by-preconverging,-in-disontologising-formulaic-draggingout/hollowing-out $>$ induces dynamic numbing-traction_-of-desublimating_ and-teleleology ‘supererogatory acuity/perspicacity/astuteness/edginess/incisiveness-as-to-the-imbuedpostconverging/dialectical-thinking -of-notional deprocrypticism-\{in-dimensionality-ofsublimating _ < amplituding/formative-epistemicity $>$ growth-orconflatedness /scalarisation-as-to-rescalarisation-as-re-ontologisation $\left.{ }^{\prime}\right\rangle$. What then can be pertinently contemplated from this summary articulation of human ontological-performance ${ }^{72}$ <including-virtue-as-ontology $>$ /morality/ethics/justice/etc. is potently about 
understanding/analysing-as-from-the-angle of such 'human prospective regressive-shift in ontological-normalcy/postconvergence conceptualisation' into 'epistemicabnormalcy/preconvergence $^{31}$ of mere-formulaicity/ritualisation- $<$ as-to-mere-formulaicmethodologising/mutualising/organising/institutionalising,-prospectively-losing-track-of‘\{́pistemic-totalising ’’re-apriorising/re-axiomatising/re-referencing - residuality-in-reoriginariness/re-origination'> implied $\quad \leq$ mere-formulaicity/ritualisation of $>$-prior secondnatured reproducibility — mathesis/motif/thrownness-disposition,-as-reproducibility-ofaestheticisation', so-underlied with regards to 'social-functioning-and-accordance-as-ofsocial-stake-contention-or-confliction imbuing existentialising-frame-of-entailment-of motifand-apriorising/axiomatising/referencing of disontologising/ontologising-and-re-ontologising' (so-reflected as to the 'preconverging/postconverging-de-mentative/structural/paradigmatic formative-risk of disontologisation associated with the prospect for veridical human ontologising/re-ontologising' for appropriate human sovereign 'epistemicgrowth/disquiet/discomfort-〈induced-sublimation,-as-from-existence's - effusing/ecstaticinlining-as- historiality-\{science/authenticity/nonextrication $\}$-beyond-mereformulaicity/ritualisation-as- historicity-tracing- $\{$ science-ideology/fashionability/distraction $\}\rangle$ as to construction-of-the-Self in dispensing-with-immediacy-for-relative-ontologicalcompleteness $^{87}$-by-reification/contemplative-distension ${ }^{27}$, and as so-undergirded by human 'self-reflexive instigative-eventuating-〈as-to-teleological-instigative/incipientwilling/arbitrariness/waywardness/faithdrivenness/supererogating-for-human-intelligibility,preceding-existence's-eventuating-sublimating-validation/desublimating-invalidation〉 of human embodied-consciousness motif-and-apriorising/axiomatising/referencing-\{of'prospectively_implicited_attendant-ontological-contiguity ' educedexistentialising/contextualising/textualising_intelligibility/epistemicity/reflexivity_contiguity<imbued-notional cogency $>$ ' $\}$-elicited-incipience-of-existentialising-decisionality-<as-to- 
disontologising/re-ontologising aporeticism $>$ '). It is herein contended that the 'veridical prospect of human intelligibility for ontologisation' is of necessity (given human limitedmentation-capacity —as-subjecting-'educed-unlimitedness/existence-sublimating nascence' to-limitedness/human-subpotency) 'epistemic-totalisingly 3 /acutely educing as from human profound-supererogation"; so-reflected as to the very incipient '<supereregatory $\sim$ humansubpotency>-effecting (as to ontological-good-faith/authenticity ${ }^{69}$ or ontological-badfaith/inauthenticity ${ }^{64}$ imbued epistemic-totalising preformulating/preframing/premeaningfulness of notional $\sim$ originariness-parrhesia,--asspontaneity-of-aestheticisation' as of undergirding human 'self-reflexive instigativeeventuating-〈as-to-teleological-instigative/incipientwilling/arbitrariness/waywardness/faithdrivenness/supererogating-for-human-intelligibility,preceding-existence's-eventuating-sublimating-validation/desublimating-invalidation> of human embodied-consciousness motif-and-apriorising/axiomatising/referencing-\{of'prospectively_implicited_attendant_ontological-contiguity ' educedexistentialising/contextualising/textualising_'intelligibility/epistemicity/reflexivity-contiguity$<$ imbued-notional $\left.\sim \operatorname{cogency}>{ }^{\prime} \quad\right\}$-elicited-incipience-of-existentialising-decisionality-<as-todisontologising/re-ontologising aporeticism $>$ '. The implication here is that a human mentalreflex of 'mere-formulaicity/ritualisation-<as-to-mere-formulaicmethodologising/mutualising/organising/institutionalising,-prospectively-losing-track-of‘\{epistemic-totalising ’’re-apriorising/re-axiomatising/re-referencing $r e s i d u a l i t y-i n-r e-$ originariness/re-origination'> of ruling and rule-making as to apriorising/axiomatising/referencing' is ever always of wanting ontological-veracity in need for 'corrective human profound-supererogation' imbuing human limited-mentation-capacitydeepening —as-subjecting limitedness/human-subpotency to-'educed-unlimitedness/existencesublimating nascence' ${ }^{3}$ '. In other words human 'potential of profound-supererogation "' (as the 
corrective potentiating of human limited-mentation-capacity-as-subjecting-'educedunlimitedness/existence-sublimating nascence' to-limitedness/human-subpotency for human limited-mentation-capacity-deepening —as-subjecting limitedness/human-subpotency-to'educed-unlimitedness/existence-sublimating nascence' ${ }^{53}$ ) is veridically what carries an abstract equivalence association/relation with existence's inherent ontologicalnormalcy/postconvergence (and so rather than any human limited-mentation-capacity-assubjecting 'educed-unlimitedness/existence-sublimating nascence' to-limitedness/humansubpotency educing mere-formulaicity/ritualisation- $<$ as-to-mere-formulaic methodologising/mutualising/organising/institutionalising,-prospectively-losing-track-of‘\{epistemic-totalising ’’ ${ }^{\prime}$ re-apriorising/re-axiomatising/re-referencing $\sim$ residuality-in-reoriginariness/re-origination'> which rather induces 'human prospective regressive-shift in ontological-normalcy/postconvergence conceptualisation'). But then, all social-setups 'as specifically instantiated social-constructs of human intelligibility', are wedded whether as of relatively shallow-supererogation or relatively profound-supererogation (as to Beingdevelopment/ontological-framework-expansion-as-to-depth-of-ontologising-development-asinfrastructure-of- meaningfulness-and-teleology , institutional-development-as-to-socialfunction-development and living-development-as-to-personality-development psycholegismic epistemic-acutisation difficulty-for, residualising \{decompulsing $\}$ delinearity for-cogency> magnitudes $\{$ of-experientiality/experiment $\}$ to 'their given mere-formulaicity/ritualisation-<as-to-mereformulaic - methodologising/mutualising/organising/institutionalising,-prospectively-losing-

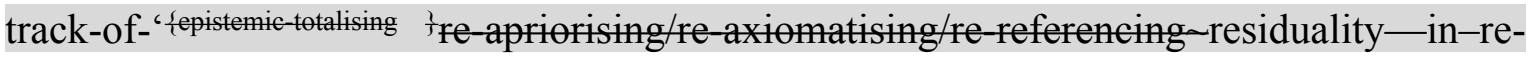
originariness/re-origination'> implied $\quad \leq$ mere-formulaicity/ritualisation-of $>$-prior secondnatured reproducibility-mathesis/motif/thrownness-disposition,-as-reproducibility-ofaestheticisation' for their 'social-functioning-and-accordance-as-of-social-stake-contentionor-confliction imbuing existentialising-frame-of-entailment of motif-and- 
apriorising/axiomatising/referencing of disontologising/ontologising-and-re-ontologising' soreflected in their < preconverging 'motif-and-apriorising/axiomatising/referencing'-entailing > existentialising — enframing/imprintedness-〈as-to- historicity-tracing — in-presencinghyperrealisation/hyperreal-transposition $\rangle$ with their ontological-performance ${ }^{72}-<$ including- $^{2}$ virtue-as-ontology $>$ /morality/ethics/justice/etc. so-thresholding between their given 'secondlevel as to human-subpotency ascendance driven self-referencing-syncretising humanexistential-tautology as to desublimating derivation of intelligibility' and their given 'first-level as to existence-potency ${ }^{39} \sim$ sublimating-nascence ascendance driven self-referencingsyncretising human-existential-tautology as to sublimating derivation of intelligibility'. Hence (registry-worldviews/dimensions imbued prior-institutionalisation-threshold-by-prospectiveuninstitutionalised-threshold 'self-referencing-syncretising forward-facingsupposedly postconverging-or-dialectical-thinking -apriorising-psychologism epistemicprojection as of prior mere-formulaicity/ritualisation-<as-to-mere-formulaicmethodologising/mutualising/organising/institutionalising,-prospectively-losing-track-of‘\{́pistemic-totalising ’’re-apriorising/re-axiomatising/re-referencing - residuality-in-reoriginariness/re-origination'>' so-reflecting their 'disontologising preconverging/dementing <as-to-prospective-uninstitutionalised-threshold > ignoring/biased inclination' for the sake of 'their given present minimum-and-balancing expectations/anticipations of social-functioningand-accordance-as-of-social-stake-contention-or-confliction' while qualifying their prospectively uninstitutionalised-threshold ${ }^{102}$ actually as nondescript/ignorable-void as to their ${ }^{7}$ presencing-absolutising-identitive-constitutedness ${ }^{14} \quad<$ preconverging $\sim$ 'motif-andapriorising/axiomatising/referencing'-entailing>-existentialising—enframing/imprintedness〈as-to- historicity-tracing - in-presencing-hyperrealisation/hyperreal-transposition〉) will formatively drift into prospective disontologisation over prospective ontologisation/reontologisation; with the ultimate notional ${ }^{18}$ deprocrypticism postconvergingaporeticism- 
overcoming/unovercoming cognisance and implication that 'human prospective regressive-shift in ontological-normalcy/postconvergence conceptualisation' is inevitably given as to a mereformulaicity/ritualisation-<as-to-mere-formulaic-

methodologising/mutualising/organising/institutionalising,-prospectively-losing-track-of-

‘\{epistemic-totalising ’’re-apriorising/re-axiomatising/re-referencing - residuality-in-re-

originariness/re-origination'> relation to intelligibility, thus requiring a ${ }^{18}$ deprocrypticism-orpreempting - disjointedness-as-of- ${ }^{-3}$ reference-of-thought 'rehabilitated conceptualisation of human purposeful profound-supererogation' together with 'rehabilitated conscious reflexion about the inherent prospective deficiency in mere-formulaicity/ritualisation-<as-to-mereformulaic — methodologising/mutualising/organising/institutionalising,-prospectively-losingtrack-of-' ‘epistemic-totalising ’’ ${ }^{\dagger}$ re-apriorising/re-axiomatising/re-referencing $\sim$ residuality-in-reoriginariness/re-origination'> of human intelligibility' (rather than a convenience-seeking defaulting individual and social mental-reflex into mere-formulaicity/ritualisation-<as-to-mereformulaic — methodologising/mutualising/organising/institutionalising,-prospectively-losing-

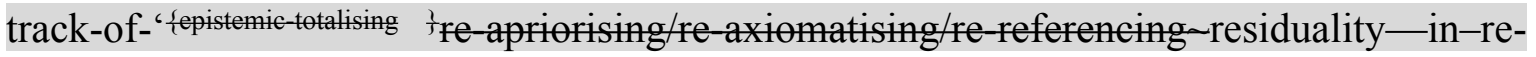
originariness/re-origination'> as to elaboration-as-to-mereextrapolating/constituting/abstracting/deducing/inferring-of-elucidation-outside'prospectively_implicited_attendant-ontological-contiguity ${ }^{67}$ ' educedexistentialising/contextalising/textalising_'intelligibility/epistemicity/reflexivity_contiguity$<$ imbued-notional cogency $>$ ' ). In this regards, human 'fundamental ontologising/disontologising confliction' (with regards to 'social-functioning-and-accordanceas-of-social-stake-contention-or-confliction imbuing existentialising-frame-of-entailment-ofmotif and apriorising/axiomatising/referencing of disontologising/ontologising-and-reontologising') undermines the notion that human social-setups are in an 'absolute ontologising predisposition of sublimating existentialising-decisionality-<as-to-disontologising/re- 
entologising aporeticism $>$ relation with inherent existence's sublimating-nascence' (as is wrongly projected by ${ }^{7}$ presencing-absolutising-identitive-constitutedness ${ }^{14}$ socialvestedness/normativity- $<$ discretely-implied-functionalism $>$ even as this 'may seem intuitively' truer with domains of relatively less blurriness-<sterilising/anecdotalising/trivialising-ofprospective-re-ontologising_by-preconverging,-in-disontologising-formulaic-draggingout/hollowing-out> or low emotional-involvement as to 'social-functioning-and-accordanceas-of-social-stake-contention-or-confliction imbuing existentialising-frame-of-entailment-ofmotif-and-apriorising/axiomatising/referencing of disontologising/ontologising-and-reontologising' like say the natural sciences and mathematics but this is not exactly the case from a bird's-eye view reflecting holographically-<conjugatively-and-transfusively $>$ the relativeunreflexivity/relative-reflexivity - ontological-contiguity of-the-human-institutionalisationprocess as such a possibility is undermined by the very interactiveness of nascentparticular/incipient-and-material/technical-sublimations- $<$ blinded-to-their-relative-ontologicalcompleteness - reference-of-thought- devolving $>\quad$ existentialising-decisionality-as-todisentologising/re-ontologising aporeticism $>$ and social-and-institutional-frameworks-ofreferencing/registering/decisioning existentialising-decisionality-<as-to-disontologising/reentelogising apereticism $>$ ) and manifest a disontologising disposition at prospectively uninstitutionalised-threshold ${ }^{102}$, and so even as 'counterintuitively we may think as from our positivism/rational-empiricism registry-worldview/dimension that we are naturally predisposed to relate to the postconverging-de-mentating/structuring/paradigming implications of prospective true knowledge in terms of their veridical entailing-<amplituding/formativeepistemicity>totalising in-relative-ontological-completeness ${ }^{87}$, without a disontologising disposition. Rather the 'fundamental ontologising/disontologising confliction' (as to Beingdevelopment/ontological-framework-expansion-as-to-depth-of-ontologising-development-asinfrastructure-of- meaningfulness-and-teleology ) arises effectively as of a 'prospective 
nonpresencing-<perspective-ontological-normalcy/postconvergence $>$ change in knowledgereification $\sim$ gesturing-and-accounting — of-epistemic-phenomenalism- $<$ inprospective_psychologismic apriorising/axiomatising/referencing-\{of-'prospectively implicited_attendant-ontological-contiguity ' reducedexistentialising/contextualising/textualising_'intelligibility/epistemicity/reflexivity-contiguity<imbued-notional cogency >’ \}-conflatedness -in-\{preconverging-ment by\} postconverging-entailment> in $\quad{ }^{55}$ maximalising-recomposuring-for-relative-ontologicalcompleteness ${ }^{87}$ — unenframed/re-ontologising conceptualisation' (as we can appreciate that the state of recurrent-utter-uninstitutionalisation construed of its non-rulesapriorising/axiomatising/referencing-psychologism knowledge disposition in terms of entailing$<$ amplituding/formative-epistemicity>totalising in-relative-ontological-completeness ${ }^{87}$ but for the prospective base-institutionalisation change in knowledge-reification $\sim$ gesturing-andaccounting - of-epistemic-phenomenalism- $<$ in-

prospective_psychologismic apriorising/axiomatising/referencing-\{of-'prospectively implicited_attendant-ontological-contiguity ' reducedexistentialising/contextualising/textualising_'intelligibility/epistemicity/reflexivity_contiguity<imbued-notional cogency>' \}-conflatedness in \{preconverging ment by\}

postconverging-entailment $>$ for prospective ontologisation/re-ontologisation in ${ }^{55}$ maximalisingrecomposuring-for-relative-ontological-completeness ${ }^{8}$ - unenframed/re-

ontologising conceptualisation as to rulemaking-over-non-rulesapriorising/axiomatising/referencing-psychologism which highlighted the uninstitutionalisedthreshold ${ }^{102}$ of recurrent-utter-uninstitutionalisation at which point it is of a disontologising disposition of incrementalism-in-relative-ontological-incompleteness ${ }^{8}$ enframed/disontologising conceptualisation, and this 'prospective nonpresencing$<$ perspective-ontological-normalcy/postconvergence $>$ changing in knowledge- 
reification $\sim$ gesturing-and-accounting — of-epistemic-phenomenalism- $<$ inprospective_psychologismic apriorising/axiomatising/referencing-\{of-'prospectively implicited_attendant-ontological-contiguity ' educedexistentialising/contextualising/textualising_'intelligibility/epistemicity/reflexivity-contiguity<imbued-notional cogency >' \}-conflatedness -in-\{preconverging-ment by\} postconverging-entailment $>$ for prospective ontologisation/re-ontologisation in ${ }^{5}$ maximalisingrecomposuring-for-relative-ontological-completeness ${ }^{87}$ - unenframed/re-

ontologising conceptualisation' as to the <cumulating/recomposuring attendant-ontologicalcontiguity $>$-successive registry-worldviews/dimensions prospective transcendence-andsublimity/sublimation/supererogatory $y$ de-mentativity is the veridically undergirding rule for sublimating-nascence and so retrospectively-to-prospectively and equally reflect the fact that our positivism- ${ }^{8}$ procrypticism is of a disontologising disposition (of incrementalism-inrelative-ontological-incompleteness —enframed/disontologising $\sim$ conceptualisation) with respect to prospective deprocrypticism-or-preempting-disjointedness-as-of- ${ }^{18}$ reference-ofthought 'prospective ${ }^{6}$ nonpresencing-<perspective-ontological-normalcy/postconvergence $>$ changing in knowledge-reification $\sim$ gesturing-and-accounting-of-epistemic-phenomenalism<in-prospective_psychologismic $\sim$ apriorising/axiomatising/referencing-\{of-'prespectively implicited_attendant-ontological-contiguity ' reducedexistentialising/contextualising/textualising_ 'intelligibility/epistemicity/reflexivity-contiguity<imbued-notional cogency >' \}-conflatedness -in-\{preconverging-ment by\} postconverging entailment $>$ for prospective ontologisation/re-ontologisation in ${ }^{5}$ maximalisingrecomposuring-for-relative-ontological-completeness ${ }^{87}$ - unenframed/reontologising conceptualisation' as of preempting-disjointedness-as-of- reference-ofthought,-as-to- ${ }^{6}<$ amplituding/formative-epistemicity $>$ growth-orconflatedness ${ }^{13} /$ transvaluative-rationalising/transepistemicity/anamnestic-residuality/spirit- 
drivenness' - in-superseding-mere-formulaic-positivising/rational-empiricism-baseduniversalisation-directed-rulemaking-over-non-rules — apriorising/axiomatising/referencingpsychologism in undermining our present institutionalised pedantising/muddling/formulaichollowing-out - in-subontologisation/subpotentiation-〈blurring/undermining-of-prospectivetotalising-entailing,-as-to-entailing-<amplituding/formative-epistemicity $>$ totalising $\sim$ inrelative-ontological-completeness $\rangle$ desublimation). The implication of this human 'fundamental ontologising/disontologising confliction' (with regards to 'social-functioning-andaccordance-as-of-social-stake-contention-or-confliction imbuing existentialising-frame-ofentailment of motif-and-apriorising/axiomatising/referencing of disontologising/ontologisingand-re-ontologising') is that the mental-reflex of a 'mutual logical coherent engagement' is only as pertinent when speaking of a 'common knowledge-reification $\sim$ gesturing-and-accountingof-epistemic-phenomenalism- $<$ in-

prospective_psychologismic apriorising/axiomatising/referencing-\{of-'prospectively implicited_attendant-ontological-contiguity ' reducedexistentialising/contextualising/textualising_'intelligibility/epistemicity/reflexivity-contiguity$<$ imbued-notional cogency $\left.>^{\prime}\right\}$-conflatedness -in-\{preconverging-ment by\} postconverging-entailment $>$ as of apriorising/axiomatising/referencing-\{of- prospectively implicited_attendant-ontological-contiguity ' reducedexistentialising/contextualising/textualising_intelligibility/epistemicity/reflexivity_contiguity<imbued-notional cogency>' $\}$-relation-to-the-world conceptivity/epistemicreflexivity/epistemicity-relativism-determinism-<reifying \{as-to-knowledge-developing $\}$-andempowering>' but where prospective nonpresencing-<perspective-ontologicalnormalcy/postconvergence $>$ intimates a fundamental variance in knowledgereification $\sim$ gesturing-and-accounting — of-epistemic-phenomenalism- $<$ inprospective_psychologismic apriorising/axiomatising/referencing-\{of-'prospectively 
implicited_attendant-ontological-contiguity ' reduced-

existentialising/contextualising/textualising_'intelligibility/epistemicity/reflexivity_contiguity<imbued-notional cogency>' \}-conflatedness -in-\{preconverging ment by\}

postconverging-entailment $>$ as to relative-ontological-incompleteness ${ }^{88}$ incrementalism-inrelative-ontological-incompleteness ${ }^{8}$ — enframed/disontologising conceptualisation) by relative-ontological-completeness ${ }^{87}$ maximalising-recomposuring-for-relative-ontologicalcompleteness ${ }^{87}$ - unenframed/re-ontologising conceptualisation), then such a supposed a 'common knowledge-reification gesturing-and-accounting-of-epistemic-phenomenalism<in-prospective_psychologismic $\sim$ apriorising/axiomatising/referencing-\{of-'prospectively_ implicited_attendant-ontological-contiguity ' reducedexistentialising/contextualising/textualising_'intelligibility/epistemicity/reflexivity-contiguity<imbued-notional cogency >' \}-conflatedness -in-\{preconverging-ment by\} postconverging-entailment $>$ as of apriorising/axiomatising/referencing-\{of-"prospectively implicited_attendant-ontological-contiguity ' educedexistentialising/contextualising/textualising_'intelligibility/epistemicity/reflexivity_contiguity<imbued-notional cogency>' \}-relation-to-the-world conceptivity/epistemicreflexivity/epistemicity-relativism-determinism-<reifying \{as-to-knowledge-developing $\}$-andempowering>' collapses (as the relative-ontological-completeness ${ }^{87}$ implied ${ }^{55}$ maximalisingrecomposuring-for-relative-ontological-completeness ${ }^{8}$ - unenframed/re-

ontologising conceptualisation reflects a re-originary_-_as-unen_frame-_ed/re-

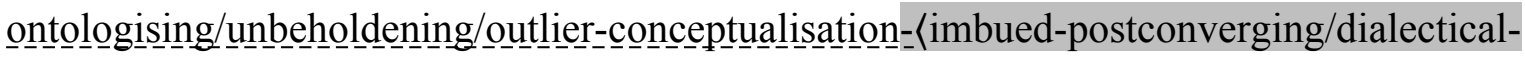
thinking -'projective-insights'/‘epistemic-projection-in-conflatedness ' 'ofnotional deprocrypticism-prospective-sublimation $\rangle^{\circ}$ ). $\quad$ This 'fundamental ontologising/disontologising confliction' (as to 'prospective nonpresencing-<perspectiveontological-normalcy/postconvergence $>$ changing in knowledge-reification $\sim$ gesturing-and- 
accounting - of-epistemic-phenomenalism- $<$ in-

prospective_psychologismic apriorising/axiomatising/referencing-\{of-'prospectively

implicited_attendant-ontological-contiguity ' educed-

existentialising/contextualising/textualising_intelligibility/epistemicity/reflexivity-contiguity-

<imbued-notional cogency >' \}-conflatedness -in-\{preconverging-ment by\}

pestconverging-entailment $>$ for prospective ontologisation/re-ontologisation in ${ }^{5}$ maximalisingrecomposuring-for-relative-ontological-completeness ${ }^{87}$ - unenframed/re-

ontologising conceptualisation' implications) very much reflects the Socratic-philosophers ' ${ }^{103}$ universalising-idealisation ontologising/re-ontologising ${ }^{55}$ maximalising-recomposuring-forrelative-ontological-completeness ${ }^{8}$ —unenframed/re-ontologising conceptualisation’ with respect to ancient-sophists 'non-universalising disontologising incrementalism-in-relativeontological-incompleteness ${ }^{8}$ —enframed/disontologising conceptualisation’, buddingpositivists 'positivism/rational-empiricism ontologising/re-ontologising ${ }^{55}$ maximalisingrecomposuring-for-relative-ontological-completeness ${ }^{8}$ —unenframed/re-

ontologising conceptualisation' with respect to medieval-scholastics 'non-positivising disontologising $\quad{ }^{51}$ incrementalism-in-relative-ontological-incompleteness ${ }^{8}$ enframed/disontologising conceptualisation' and it is herein claimed as well postmodern thought 'nondisjointing totalising-entailing ontologising/re-ontologising as to ${ }^{4}$ human-subjectemancipating-relativism-driven-recomposuring-constructivism-towards-singularisation- $<$ as-tothe-nondisjointedness/entailment-of-prospective- nonpresencing $>{ }^{,} \quad{ }^{55}$ maximalisingrecomposuring-for-relative-ontological-completeness ${ }^{8}$ —unenframed/re-

ontologising conceptualisation (objectifying knowledge conception say with incipient/budding différance deconstruction or genealogy/archaeology as to such explicited knowledgereification $\sim$ gesturing-and-accounting — of-epistemic-phenomenalism- $<$ in- 
implicited_attendant-ontological-contiguity ' reduced-

existentialising/contextualising/textualising_'intelligibility/epistemicity/reflexivity_contiguity$<$ imbued-notional cogency >' \}-conflatedness - in-\{preconverging ment by\}

postconverging-entailment $>$ even as other $20^{\text {th }}$ century thinkers expressed varyingly similar notions without expliciting their knowledge-reification $\sim$ gesturing-and-accounting-ofepistemic-phenomenalism-<in-

prospective_psychologismic apriorising/axiomatising/referencing-\{of-'prospectively implicited_attendant-ontological-contiguity ' educedexistentialising/contextualising/textualising_'intelligibility/epistemicity/reflexivity-contiguity<imbued-notional cogency >' \}-conflatedness -in-\{preconverging-ment by\} postconverging-entailment $>$ or as herein construed in reflecting holographically-<conjugativelyand-transfusively $>$ the relative-unreflexivity/relative-reflexivity ontological-contiguity ofthe-human-institutionalisation-process ) with respect to modern-day 'manifestation of disparateness-of-conceptualisation-<unforegrounding-ment,-failing-prospectively-to-reflect‘immanent $\sim$ relative- unreflexivity/relative-reflexivity ontological-contiguity ’’> disontologising $\quad{ }^{51}$ incrementalism-in-relative-ontological-incompleteness ${ }^{8}$ enframed/disontologising conceptualisation' (personalising knowledge conception as of institutionalised pedantising/muddling/formulaic-hollowing-out—insubontologisation/subpotentiation-〈blurring/undermining-of-prospective-totalising-entailing,as-to-entailing-<amplituding/formative-epistemicity $>$ totalising $\sim$ in-relative-ontologicalcompleteness $\rangle)$. At which point the veracity of prospective ontologisation/re-ontologisation is rather one of prospective human notional $\sim$ self-distantiation- $<$ imbued-re-motif-and-reapriorising/re-axiomatising/re-referencing $>$ induced psychoanalytic-unshackling/memeticreordering/institutional-recomposuring self-becoming/self-conflatedness ${ }^{13} /$ formative- $^{-}$ supererogating-<projective/reprojective- aestheticising-re-motif-and-re-apriorising/re- 
reflection of existence-as-the-absolute-a-priori-of-conceptualisation $\sim$ and $\sim$ existence-assublimating-withdrawal/unenframing/re-ontologising,-elicited-from-prospective-profoundsupererogation $-<$ as-to-perspective-ontological-normalcy/postconvergence-implied'prospective-aporeticism-overcoming/unovercoming'>. Hence, such re-originary_-asunenframed/re-ontologising/unbeholdening/outlier-conceptualisation-_imbuedpostconverging/dialectical-thinking - 'projective-insights’/epistemic-projection-inconflatedness '-of-notional deprocrypticism-prospective-sublimation $\rangle^{\circ}$ rather reflects a most profound-supererogation human 'self-reflexive $\sim$ instigative-eventuating-〈as-toteleological-instigative/incipient-

willing/arbitrariness/waywardness/faithdrivenness/supererogating-for-human-intelligibility,preceding-existence's-eventuating-sublimating-validation/desublimating-invalidation> of human embodied-consciousness motif-and-apriorising/axiomatising/referencing-\{of'prespectively implicited_attendant-ontological-contiguity ' e educedexistentialising/contextualising/textualising_ 'intelligibility/epistemicity/reflexivity-contiguity$<$ imbued-notional cogency $>$ ' $\}$-elicited-incipience-of-existentialising-decisionality-<as-todisontologising/re-ontologising aporeticism $>$ ' for prospective intelligibility, as of 'full incipient supererogating breadth of human intelligibility transmutation' (as '<supererogatory $\sim$ human-subpotency $>$-effecting imbued epistemic-totalising preformulating/preframing/premeaningfulness of notional originariness-parrhesia,--asspontaneity-of-aestheticisation' before the incipience of metaphoricity ${ }^{57}$ and then meaningfulness-and-teleology as to existentialising-frame-of-entailment-of motif-andapriorising/axiomatising/referencing); wherein it is rather as to a fundamental '<supereregatory human-subpotency $>$-effecting imbued epistemic-totalising preformulating/preframing/premeaningfulness of notional originariness-parrhesia,--as- 
spontaneity-of-aestheticisation'

totalising thrownness-in-existence ${ }^{35}$ ) relation with 'constraining existence — as-sublimatingwithdrawal/unenframing/re-ontologising,-elicited-from-prospective-profound-supererogation imbuing human ontological-commitment $-<$ implied - self-assuredness-of-ontological-goodfaith/authenticity postconverging-de-mentating/structuring/paradigming -as-being-as-ofexistential-reality >' and ' ${ }^{103}$ universal-transparency ${ }^{104}$-〈transparency-of-totalising-entailing,-asto-entailing-<amplituding/formative-epistemicity $>$ totalising $\sim$ in-relative-ontologicalcompleteness \ as available-to/elicitable-to-〈as-to-human-consciousness/collectiveconsciousness-distendedness/detruncating-<beyond-selfpresencing,-as-re-ontologisingdecentering_of-consciousness/collective-consciousness,-as-to-psychologismic-epistemicacutisation-residualising, - \{decompulsing $\}$ delinearity for-cogency $>\rangle$ the social-functioning-andaccordance-as-of-social-stake-contention-or-confliction conception of the given registryworldview/dimension $\quad$ <preconverging 'motif-and-apriorising/axiomatising/referencing'entailing $>$-existentialising — enframing/imprintedness-〈as-to- historicity-tracing - inpresencing-hyperrealisation/hyperreal-transposition〉', that such a re-originary_-asunenframed/re-ontologising/unbeholdening/outlier-conceptualisation-_imbuedpostconverging/dialectical-thinking -'projective-insights'/'epistemic-projection-inconflatedness ' -of-notional deprocrypticism-prospective-sublimation $\rangle$ ontologically induces (by its incipient prospective metaphoricity ${ }^{57}$ and then ${ }^{56}$ meaningfulness-and-teleology as to prospective existentialising-frame-of-entailment-of-motif-andapriorising/axiomatising/referencing) untenability/internal-contradiction/internalincoherence/institutional-constraining upon dominance/vested-interest-subontologisingskewed-influence-as-to-social-vestedness/normativity-<discretely-implied-functionalism>, pedantising/muddling/formulaic-hollowing-out — in-subontologisation/subpotentiation〈blurring/undermining-of-prospective-totalising-entailing,-as-to-entailing- 
$<$ amplituding/formative-epistemicity>totalising in-relative-ontological-completeness $>$ and 'generalised social <amplituding/formative> wooden-language-〈imbued-temporal-mereform/virtualities/dereification/akrasiatic-drag/denatured/preconverging-or-dementing narratives - of-the- reference-of-thought- categorical-imperatives/axioms/registryteleology $\rangle$ in its genuine social intellectual-function/posture' (and in so-doing undermining the falsehood explicited or implicited of a 'common knowledge-reification $\sim$ gesturing-andaccounting - of-epistemic-phenomenalism- $<$ in-

prospective_psychologismic apriorising/axiomatising/referencing-\{of-"prospectively implicited_attendant-ontological-contiguity ' educedexistentialising/contextualising/textualising_ 'intelligibility/epistemicity/reflexivity-contiguity$<$ imbued-notional cogency $\left.>^{\prime}\right\}$-conflatedness -in-\{preconverging-ment by\} postconverging entailment $>$ as of apriorising/axiomatising/referencing-\{of-'prospectively implicited_attendant-ontological-contiguity ' educedexistentialising/contextualising/textualising_ 'intelligibility/epistemicity/reflexivity-contiguity$<$ imbued-notional cogency $\left.>^{\prime} \quad\right\}$-relation-to-the-world conceptivity/epistemicreflexivity/epistemicity-relativism-determinism-<reifying \{as-to-knowledge-developing $\}$-andempowering >' which is the basis for the false projecting-and-analysing of the 'relativeontological-completeness ${ }^{87} \quad$ knowledge-reification $\sim$ gesturing-and-accounting-of-epistemicphenomenalism- $<$ in-prospective_psychologismic $\sim$ apriorising/axiomatising/referencing- of'prospectively_implicited_attendant-ontological-contiguity ' educedexistentialising/contextualising/textualising_ intelligibility/epistemicity/reflexivity_contiguity$<$ imbued-notional cogency $>\quad\}$-conflatedness - in-\{preconverging ment by\} postconverging-entailment $>$ as of apriorising/axiomatising/referencing-\{of-'prospectively implicited_attendant-ontological-contiguity ' reducedexistentialising/contextualising/textualising_ 'intelligibility/epistemicity/reflexivity-contiguity- 
reflexivity/epistemicity-relativism-determinism-<reifying \{as-to-knowledge-developing $\}$-and-

empowering>' in terms of the 'relative-ontological-incompleteness ${ }^{88}$ prior_knowledgereification $\sim$ gesturing-and-accounting — of-epistemic-phenomenalism- $<$ in-

prior_psychologismic apriorising/axiomatising/referencing-\{of-'prior-implicited_attendantontological-contiguity ' educed-

existentialising/contextualising/textualising_intelligibility/epistemicity/reflexivity_contiguity<imbued-notional cogency>> $\}$-constitutedness -in-preconverging-entailment>> as of apriorising/axiomatising/referencing-\{of-"prospectively_implicited_attendant-ontologicalcontiguity ' educedexistentialising/contextualising/textualising_'intelligibility/epistemicity/reflexivity-contiguity<imbued-notional cogency>’ $\}$-relation-to-the-world conceptivity/epistemicreflexivity/epistemicity-relativism-determinism-<reifying \{as-to-knowledge-developing $\}$-andempowering > by such pedantising/muddling/formulaic-hollowing-out-insubontologisation/subpotentiation-〈blurring/undermining-of-prospective-totalising-entailing,as-to-entailing-<amplituding/formative-epistemicity $>$ totalising in-relative-ontologicalcompleteness \). The latter point very much explains the title herein as to the connection between psychopathy/postlogism 77 and a human hermeneutic psychology conception; soreflected in the fact that the same disontologising mental-reflex associated with psychopathy/postlogism -slantedness (and as it elicits dynamic conjugated-postlogism 77 in its prior mere-formulaic relation with ${ }^{83}$ reference-of-thought- categoricalimperatives/axioms/registry-teleology ${ }^{9}$, -foraposteriorising/logicising/deriving/intelligising/measuring - ${ }^{56}$ meaningfulness-and-teleology (with regards to living-development-as-to-personality-development within any given registryworldview/dimension implied 'social-functioning-and-accordance-as-of-social-stake- 
apriorising/axiomatising/referencing of disontologising/ontologising-and-re-ontologising') is oddly enough similarly manifested beyond-the-consciousness-awareness-teleology ${ }^{0}-<$ of preconverging-existential-extrication-as-of-existential-unthought $>$ as to the disontologising pedantising/muddling/formulaic-hollowing-out - in-subontologisation/subpotentiation-

\section{〈blurring/undermining-of-prospective-totalising-entailing,-as-to-entailing-}

$<$ amplituding/formative-epistemicity>totalising in-relative-ontological-completeness $>$ at all uninstitutionalised-threshold ${ }^{102}$ in their prior mere-formulaic relation with ${ }^{83}$ reference-ofthought- categorical-imperatives/axioms/registry-teleology ${ }^{99}$,-for-

aposteriorising/logicising/deriving/intelligising/measuring - ${ }^{56}$ meaningfulness-and-teleology

(with regards to Being-development/ontological-framework-expansion-as-to-depth-ofontologising-development-as-infrastructure-of- meaningfulness-and-teleology implied 'social-functioning-and-accordance-as-of-social-stake-contention-or-confliction imbuing existentialising-frame-of-entailment of motif-and-apriorising/axiomatising/referencing of disontologising/ontologising-and-re-ontologising' and so-manifested effectively in institutionaldevelopment-as-to-social-function-development) as so-construed epistemically from prospective nonpresencing-<perspective-ontological-normalcy/postconvergence $>$; and thus respectively in want of prospective 'originariness-parrhesia,-as-spontaneity-ofaestheticisation — supererogatory $\sim$ acuity/perspicacity/astuteness/edginess/incisiveness underlying dimensionality-of-sublimating - -<amplituding/formative $>$ supererogatory - dementativeness/epistemic-growth-or-conflatedness /transvaluativerationalising/transepistemicity/anamnestic-residuality/spirit-drivenness-equalisation〉 as to profound dispensing-with-immediacy-for-relative-ontological-completeness ${ }^{87}$-byreification/contemplative-distension ${ }^{27}$. But then the inherent difficulty of the reflexive contemplation projected as of such a prospective ${ }^{18}$ deprocrypticism-or-preempting- 
disjointedness-as-of- ${ }^{8}$ reference-of-thought imaginary (as with all so-construed Beingdevelopment/ontological-framework-expansion-as-to-depth-of-ontologising-development-asinfrastructure-of- meaningfulness-and-teleology imaginaries undergirding the $<$ cumulating/recomposuring attendant-ontological-contiguity $>$-successive registryworldviews/dimensions superseding of their precedently ${ }^{79}$ presencing —absolutising-identitiveconstitutedness $^{14}$ as so-reflecting the 'human notional $\sim$ philosophy-<as-to-the-veridicalconception-of-philosophy-as-englobing-all-human-prospective-organic-knowledge-generationin-relative-ontological-completeness ,-beyond-a-convenient-division-of-labour-conception-ofknowledge> existentialising-frame-of-entailment-of motif-andapriorising/axiomatising/referencing of existential-<disontologising/re-ontologising aporeticism $>$ unenframed/re-ontologising conception of human philosophy' beyond any given institutionalised sublimating/desublimating culture of philosophy) and as relevant to all imaginaries in their instigation of 'multicenturies-long human crossgenerational Beingdevelopment/ontological-framework-expansion-as-to-depth-of-ontologising-development-asinfrastructure-of- meaningfulness-and-teleology psychologismic-epistemic-acutisation difficulty < for, residualising \{decompulsing $\}$ delinearity for-cogency> magnitude ${ }^{\{0 f-}$ experientiality/experiment\} of prospective transcendence-and-sublimity/sublimation/surerementativity', is the corresponding manifestation of the 'conceptualising scale of a human 60-100 years lifespan today as to living-development-as-to-personality-development which is rather bound to be lured/attracted to the preconverging-existential-extrication-as-of-existentialunthought pointedness/punctiliousness of its shallow conceptualising scale' that preconverging/postconverging-de-mentatively/structurally/paradigmatically is overburdened as to such a nonpresencing-<perspective-ontological-normalcy/postconvergence $>$ crossgenerational epistemic-stretching; thus dismissing the ontological-veracity of its 'desublimating $\sim$ referenced/registered/decisioned self-presence/self-constitutedness ${ }^{14}-<$ in- 
perspective-epistemic-abnormalcy/preconvergence ${ }^{3}>$ ' and in lieu affirming the implications of such a prospective ${ }^{18}$ deprocrypticism-or-preempting-disjointedness-as-of- ${ }^{3}$ reference-ofthought imaginary rather as to human prospective notional $\sim$ self-distantiation-<imbued-remotif-and-re-apriorising/re-axiomatising/re-referencing $>\quad$ induced psychoanalyticunshackling/memetic-reordering/institutional-recomposuring self-becoming/selfconflatedness ${ }^{13}$ /formative-supererogating-<projective/reprojective-aestheticising-re-motifand-re-apriorising/re-axiomatising/re-referencing,-in-perspective-ontologicalnormalcy/postconvergence $>$ It is exactly this disparity-ofmomentousness/magnanimity/scale/psychologismic epistemic-acutisation difficulty-for, residualising \{decompulsing\} delinearity for-cogeney>-magnitude\{of-experientiality/experiment\} in human intelligibility appraisal as to the scale of 'multicenturies-long human crossgenerational Beingdevelopment/ontological-framework-expansion-as-to-depth-of-ontologising-development-asinfrastructure-of- meaningfulness-and-teleology psychologismic epistemic-acutisation-

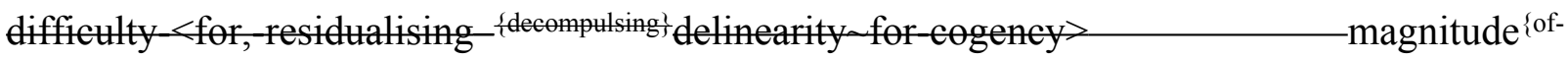
experientiality/experiment\} of prospective transcendence-and-sublimity/sublimation/supereregatery $\sim$ dementativity' and 'conceptualising scale of a human 60-100 years lifespan today as to livingdevelopment-as-to-personality-development ' that induces human preenerging-existentialextrication-as-of-existential-unthought predisposition manifested in distractive-alignment-toreference-of-thought- $<$ of-apriorising/axiomatising/referencing $>30 . \quad$ Critically, such psychoanalytic-unshackling/memetic-reordering/institutional-recomposuring conception as to maximalising-recomposuring-for-relative-ontological-completeness ${ }^{87}$-unenframed/reontologising conceptualisation is exactly what compensates for this disparity-ofmomentousness/magnanimity/scale/psychologismic epistemic acutisation diffieulty < for, residualising \{decompulsing\} delinearity for-cogency> - magnitude\{of-experientiality/experiment\} and totalisingly-entails for prospective social aetiologisation/ontological-escalation- $<$ ontological- 
veridicality_commitment/otherliness_transcending/compulsions-encumbered_transcending > conceptivity/epistemic-reflexivity/epistemicity-relativism-determinism- $<$ reifying \{as-toknowledge-developing -and-empowering $>$ in contrast to the preconverging/postconverging-dementative/structural/paradigmatic association of human preconverging-existential-extricationas-of-existential-unthought predisposition manifested as to distractive-alignment-to- ${ }^{8}$ referenceof-thought- $<$ of-apriorising/axiomatising/referencing $>$ with $\quad$ incrementalism-in-relativeontological-incompleteness 8 —enframed/disontologising conceptualisation imbued dominance/vested-interest-subontologising-skewed-influence-as-to-socialvestedness/normativity-<discretely-implied-functionalism $>$, pedantising/muddling/formulaichollowing-out - in-subontologisation/subpotentiation-〈blurring/undermining-of-prospectivetotalising-entailing,-as-to-entailing-<amplituding/formative-epistemicity $>$ totalising $\sim$ inrelative-ontological-completeness $\rangle$ and 'generalised social <amplituding/formative $>$ woodenlanguage-_imbued-temporal-mere-form/virtualities/dereification/akrasiaticdrag/denatured/preconverging-or-dementing -narratives - of-the- reference-of-thoughtcategorical-imperatives/axioms/registry-teleology $\rangle$. In this regards, the idea that the pertinence of Socratic-philosophers ' ${ }^{103}$ universalising-idealisation ontologising/re-ontologising' lies in an equivalence/correspondence relation with ancient-sophists 'non-universalising disontologising' secondnatured social-setup or budding-positivists 'positivism/rationalempiricism ontologising/re-ontologising' lies in an equivalence/correspondence relation with medieval-scholastics 'non-positivising disontologising' secondnatured social-setup or for that matter postmodern thought 'nondisjointing totalising-entailing ontologising/re-ontologising as to ${ }^{4}$ human-subject-emancipating-relativism-driven-recomposuring-constructivism-towardssingularisation-<as-to-the-nondisjointedness/entailment-of-prospective- nonpresencing $>$ lies in an equivalence/correspondence relation with modern-day 'manifestation of disparatenessof-conceptualisation-<unforegrounding-ment,-failing-prospectively-to-reflect- 
disontologising' secondnatured social-setup; are naiveties of human distractive-alignment-toreference-of-thought- $<$ of-apriorising/axiomatising/referencing $>^{30}$ (as to the fact that prospective transcendence-and-sublimity/sublimation/supererogatory $\sim$ de-mentativity is all about intellectually-and-morally superseding its Age as to relative-ontological-completeness maximalising-recomposuring-for-relative-ontological-completeness ${ }^{87}$ - unenframed/reontologising conceptualisation and not subjecting-itself/succumbing to the relative-ontologicalincompleteness incrementalism-in-relative-ontological-incompleteness enframed/disontologising conceptualisation of its Age, and as so-inherently warranted by existence-potency ${ }^{39} \sim$ sublimating-nascence,-disclosed-from-prospective-epistemic-digression prospect for its social-setup epistemic-growth/disquiet/discomfort-〈induced-sublimation,-asfrom-existence's - effusing/ecstatic-inlining-as- historiality\{science/authenticity/nonextrication $\}$-beyond-mere-formulaicity/ritualisation-as- historicitytracing-\{science-ideology/fashionability/distraction $\}\rangle$ as to construction-of-the-Self in dispensing-with-immediacy-for-relative-ontological-completeness ${ }^{87}$-byreification/contemplative-distension ${ }^{27}$ ). re-ontologising prospective Beingdevelopment/ontological-framework-expansion-as-to-depth-of-ontologising-development-asinfrastructure-of- meaningfulness-and-teleology imaginaries as such as to the implied human notional $\sim$ self-distantiation- $<$ imbued —re-motif-and-re-apriorising/re-axiomatising/rereferencing $>$, 'do not truly manifest sublimating-nascence validity' by fulfilling/satisfying any human self-presence/self-constitutedness ${ }^{14}-<$ in-perspective-epistemicabnormalcy/preconvergence $>$ inclinations (even if that arises incidentally/parenthetically as of the induced secondnatured positive-opportunism-of-social-functioning-and-accordance accompanying the intemporal-disposition firstnaturedness-as-to-inkling instigation of prospective transcendence-and-sublimity/sublimation/supererogatory $\sim$ de-mentativity) but 
rather 'their truly manifest sublimating-nascence validity' arises as to their inherent implications of prospective human construction-of-the-Self with regards to the sublimating-nascence of prospective ${ }^{83}$ reference-of-thought as to ${ }^{83}$ reference-of-thought- ${ }^{84}$ devolving, as so-reflected with human sovereign 'epistemic-growth/disquiet/discomfort-_induced-sublimation,-as-fromexistence's - effusing/ecstatic-inlining-as- historiality-\{science/authenticity/nonextrication $\}$ beyond-mere-formulaicity/ritualisation-as- historicity-tracing-\{scienceideology/fashionability/distraction $\}\rangle$ as to construction-of-the-Self in dispensing-withimmediacy-for-relative-ontological-completeness ${ }^{87}$-by-reification/contemplative-distension (rather than an ontologically-flawed 'normalised/stereotyped/selfhelping/feel-good knowledge being brought at the protracted-social—as-to-individual-by-institutional-by-social sovereign's service lacking in the underlying conception of epistemic-growth/disquiet/discomfort-〈inducedsublimation,-as-from-existence's - effusing/ecstatic-inlining-as- historiality\{science/authenticity/nonextrication\}-beyond-mere-formulaicity/ritualisation-as- historicitytracing-\{science-ideology/fashionability/distraction $\}\rangle$ as to construction-of-the-Self in dispensing-with-immediacy-for-relative-ontological-completeness ${ }^{87}$-byreification/contemplative-distension ${ }^{27}$ ). In this regards, the genuine social intellectualfunction/posture should be able to 'sneer' at its social-setup, as to the fact that its 'incarnation of prospective human Being-development/ontological-framework-expansion-as-to-depth-ofontologising-development-as-infrastructure-of- meaningfulness-and-teleology imaginaries' cannot be beholdening to its ${ }^{79}$ presencing-absolutising-identitive-constitutedness ${ }^{14}$ socialvestedness/normativity- $<$ discretely-implied-functionalism $>$ social-setup but rather 'beholdening to existence-potency ${ }^{39} \sim$ sublimating-nascence,-disclosed-from-prospective-epistemicdigression prospect for its social-setup epistemic-growth/disquiet/discomfort-〈inducedsublimation,-as-from-existence's - effusing/ecstatic-inlining-as- historiality- 
tracing-\{science-ideology/fashionability/distraction $\}\rangle$ as to construction-of-the-Self in dispensing-with-immediacy-for-relative-ontological-completeness ${ }^{87}$-byreification/contemplative-distension ${ }^{27}$ (just as the true technician and scientist is not of prospective apriorising/axiomatising/referencing-sublimating-reflexivity_beholdening to 'peoples' human-subpotency temporal-dispositions but rather to existencepotency $^{32} \sim$ sublimating-nascence,-disclosed-from-prospective-epistemic-digression technical or scientific implications for veridically enhancing the human sovereign-function/posture- $<$ as-toexistentially-manifest-‘embodied-subject $\sim$ consciousness-and-direct/deferentialconscientiousness',-as-of-its-'epistemic-reflexivity/unreflexivity-in-existence'/teleology> with regards to their technical or scientific undertaking). Such a conception of the genuine social intellectual-function/posture (as it so-reflects the 'human notional philosophy-<as-to-theveridical-conception-of-philosophy-as-englobing-all-human-prospective-organic-knowledgegeneration-in-relative-ontological-completeness ,-beyond-a-convenient-division-of-labourconception-of-knowledge> existentialising-frame-of-entailment-of motif-andapriorising/axiomatising/referencing of existential-<disontologising/re-ontologising aporeticism $>$ unenframed/re-ontologising conception of human philosophy' beyond any given institutionalised sublimating/desublimating culture of philosophy) renders ridiculous modern manifestations of 'media-driven, social networking, popularity-seeking as well as sterile/anecdotal institutional-prescience/imprimaturing-<dullness-of-thespirit/psychologismic epistemic acutisation nonresidualising-imbuedeclecticism-of-prior-mere-formulaicity/ritualisation $\geqslant$ conception of supposed intellectualism' that by supposedly succumbing/ingratiating to institutional and social lip-servicing (as to an ontologically-flawed 'normalised/stereotyped/selfhelping/feel-good knowledge being brought at the protracted-social-as-to-individual-by-institutional-by-social sovereign's service lacking in the underlying conception of epistemic-growth/disquiet/discomfort-〈induced-sublimation,-as- 
from-existence's - effusing/ecstatic-inlining-as- historiality-

\{science/authenticity/nonextrication $\}$-beyond-mere-formulaicity/ritualisation-as- historicitytracing-\{science-ideology/fashionability/distraction $\}\rangle$ as to construction-of-the-Self in dispensing-with-immediacy-for-relative-ontological-completeness ${ }^{87}$-by-

reification/contemplative-distension ${ }^{27}$ ') supposedly so-earning intellectual recognition/due; thus paradoxically subjecting the notion of intellectualism to human 'social-functioning-andaccordance-as-of-social-stake-contention-or-confliction imbuing existentialising-frame-ofentailment of motif-and-apriorising/axiomatising/referencing of disontologising/ontologisingand-re-ontologising' which is in want for its re-ontologising prospective Beingdevelopment/ontological-framework-expansion-as-to-depth-of-ontologising-development-asinfrastructure-of- meaningfulness-and-teleology imaginary. The blunt reality of true intellectualism couldn't be more diametrical as to the fact that the genuine social intellectualfunction/posture involves unaccommodating the social-setup's 79 presencing-absolutisingidentitive-constitutedness ${ }^{14}$ social-vestedness/normativity- $<$ discretely-implied-functionalism $>$ rather than further cultivating its nonsensical, nombrilistic and self-important pretenses/claims of manifest in-effect absolution-<as-to-apriorising/axiomatising/referencing-\{of'prospectively_implicited_attendant_ontological-contiguity ' educedexistentialising/contextualising/textualising_'intelligibility/epistemicity/reflexivity-contiguity<imbued-notional cogency>> $\}$-constitutedness -in-preconverging-entailment> presencing-absolutising-identitive-constitutedness ${ }^{14}$. As to the modern states penchants of misgovernance, dehumanisation, criminal wars, genocides and hideous activities and as so in association with dominance/vested-interest-subontologising-skewed-influence-as-to-socialvestedness/normativity- $<$ discretely-implied-functionalism $>$ and a generalised out-of-sight-outof-mind preconverging-existential-extrication-as-of-existential-unthought civil society 'socialfunctioning-and-accordance-as-of-social-stake-contention-or-confliction imbuing 
disontologising/ontologising-and-re-ontologising', such a supposedly implied conception of intellectual-and-moral ascendency is nothing but a bogus social-setup's auto-congratulatory exercise of 'supposed intellection and morality' that cannot answer to the inherent preconverging-de-mentating/structuring/paradigming vices-and-impediments ${ }^{105} /$ limitations of its Age (let alone prospectively uphold 'human-decisionality-<as-to-play-of-valid/invaliddecisionality-imbued-sublimation/desublimation> omni-potential commensurability with inherent immanent-existence's sublimation-structure'/omnipotentiality). In-the-bigger-schemeof-things as to nonpresencing-<perspective-ontological-normalcy/postconvergence $>$ epistemic-projection, human social-setups reflecting the respective states of recurrent-utteruninstitutionalisation, base-institutionalisation-ununiversalisation, ${ }^{103}$ universalisation-nonpositivism/medievalism and positivism- ${ }^{8}$ procrypticism are transcended/superseded exactly because of an incipient/nascent/instigative genuine social intellectual-function/posture 'sneering' at them and never as to otherwise ingratiating at them as manifested by the Socrates, Platos, Copernicuses, Galileos, Descartes, Newtons, Leibnizes, Diderots, etc. as so-instigative of the requisite psychoanalytic-unshackling/memetic-reordering/institutional-recomposuring conception as to ${ }^{55}$ maximalising-recomposuring-for-relative-ontological-completeness ${ }^{87}$ unenframed/re-ontologising conceptualisation for prospective social aetiologisation/ontological-escalation-<ontologicalveridicality_commitment/otherliness_transcending/compulsions-encumbered_transcending> conceptivity/epistemic-reflexivity/epistemicity-relativism-determinism-<reifying \{as-toknowledge-developing -and-empowering $>$ (noting that the notion of 'human prospective notional $\sim$ self-distantiation-<imbued—re-motif-and-re-apriorising/re-axiomatising/rereferencing $>\quad$ induced psychoanalytic-unshackling/memetic-reordering/institutionalrecomposuring

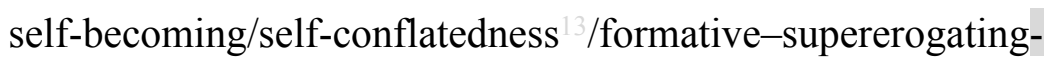


$<$ projective/reprojective - aestheticising-re-motif-and-re-apriorising/re-axiomatising/re-

referencing,-in-perspective-ontological-normalcy/postconvergence>' is about eliciting the sense of fellow human capacity/deferential-capacity to appreciate the inherent soundness of epistemic-growth/disquiet/discomfort-〈induced-sublimation,-as-from-existence's-

effusing/ecstatic-inlining-as- historiality-\{science/authenticity/nonextrication $\}$-beyond-mere-

formulaicity/ritualisation-as- historicity-tracing-\{science-ideology/fashionability/distraction $\}\rangle$

as to construction-of-the-Self in dispensing-with-immediacy-for-relative-ontologicalcompleteness $^{87}$-by-reification/contemplative-distension ${ }^{27}$ as to the fellow human capacity/deferential-capacity for undergirding 'self-reflexive instigative-eventuating-〈as-toteleological-instigative/incipient-

willing/arbitrariness/waywardness/faithdrivenness/supererogating-for-human-intelligibility,preceding-existence's-eventuating-sublimating-validation/desublimating-invalidation> of human embodied-consciousness motif-and-apriorising/axiomatising/referencing-\{of'prespectively_implicited_attendant-ontological-contiguity ' educedexistentialising/contextualising/textualising_'intelligibility/epistemicity/reflexivity-contiguity$<$ imbued-notional cogency $>$ ' $\}$-elicited-incipience-of-existentialising-decisionality-<as-todisontologising/re-ontologising aporeticism $>$ ' as to the fact that all true intelligibility and knowledge is only possible by eliciting a fundamental potential that is already preconverging/postconverging-de-mentatively/structurally/paradigmatically availing to the 'fellow human in a direct-capacity or deferential-capacity of human growth/development/maturation' as to their ontological-good-faith/authenticity ${ }^{69}$ or ontologicalbad-faith/inauthenticity ${ }^{64}$ to pursue it or not). The blunt fact is that society is never its own inherent intellectual-and-moral absolute reference and thus is in want for its intellectual-andmoral development explaining why progress happen and the role of the genuine social intellectual-function/posture being about encouraging such progress, with the consequence that 
an 'ingratiating supposedly intellectual relationship' with human institutions as to 'socialfunctioning-and-accordance-as-of-social-stake-contention-or-confliction imbuing existentialising-frame-of-entailment of motif-and-apriorising/axiomatising/referencing of disontologising/ontologising-and-re-ontologising' is ever always (beyond-the-consciousnessawareness-teleology ${ }^{9}<$ of-preconverging-existential-extrication-as-of-existentialunthought> ) bound to lead to the institutionalised pedantising/muddling/formulaic-hollowingout_-in-subontologisation/subpotentiation-〈blurring/undermining-of-prospective-totalisingentailing,-as-to-entailing-<amplituding/formative-epistemicity $>$ totalising $\sim$ in-relativeontological-completeness > desublimation and so associated with dominance/vested-interestsubontologising-skewed-influence-as-to-social-vestedness/normativity- $<$ discretely-impliedfunctionalism> and 'generalised social <amplituding/formative> wooden-language-〈imbuedtemporal-mere-form/virtualities/dereification/akrasiatic-drag/denatured/preconverging-ordementing -narratives - of-the- reference-of-thought- categoricalimperatives/axioms/registry-teleology $\rangle$; reflecting the reality that the genuine social intellectual-function/posture must be able to stand at a 'distance as of notional $\sim$ selfdistantiation' with their Age, society and social institutions (and critically many an intellectual failing is exactly because of this defect that actually subconsciously stifles the natural direction/conclusion of their work as in the case with Heidegger, and so understood rather than an after the fact <preconverging 'motif-and-apriorising/axiomatising/referencing'-entailing >existentialising — enframing/imprintedness-〈as-to- historicity-tracing — in-presencinghyperrealisation/hyperreal-transposition $\rangle$ conceptualisation which itself fails the test of standing at a 'distance as of notional $\sim$ self-distantiation- $<$ imbued-re-motif-and-re-apriorising/reaxiomatising/re-referencing >' with its own Age, society and social institutions to then be able to open the avenue for prospective human sublimation/emancipation as requisite to supersede/transcend its inherent preconverging-de-mentating/structuring/paradigming vices- 
and-impediments ${ }^{105 / \text { limitations). }}$

momentousness/magnanimity/scale/psychologismic epistemic acutisation difficulty-for, residualising \{decompulsing delinearity for-cogency> magnitude \{of-experientiality/experiment\} underlies the notional ratiocontiguity/ratiocination-as-referentialism — 'implicited_attendantontological-contiguity ${ }^{67}$; educedexistentialising/contextualising/textualising_'intelligibility/epistemicity/reflexivity_contiguity<imbued-notional cogency $>^{\prime} \quad$ (as it reflects holographically-<conjugatively-andtransfusively $>$ the relative-unreflexivity/relative-reflexivity ontological-contiguity $\sim$ of-thehuman-institutionalisation-process ) preconverging/postconverging-dementative/structural/paradigmatic implications (as to Being-development/ontologicalframework-expansion-as-to-depth-of-ontologising-development-as-infrastructure-ofmeaningfulness-and-teleology , institutional-development-as-to-social-functiondevelopment and living-development-as-to-personality-development psychologismic epistemic-acutisation difficulty-for, residualising \{decompulsing $d$ delinearity for-cogency> magnitudes $\left.{ }^{\{0 f-e x p e r i e n t i a l i t y / e x p e r i m e n t\}}\right\}$;

‘<cumulating/recomposuring attendant-ontological-contiguity $>$-succession of human registry-worldviews/dimensions notional ratiocontiguity/ratiocination-as-referentialism— 'implicited_attendant-ontological-contiguity ${ }^{67}$ ' educedexistentialising/contextualising/textualising_intelligibility/epistemicity/reflexivity-contiguity$<$ imbued-notional cogency $>^{\prime}$ ontological-performance ${ }^{72}-<$ including-virtue-as-ontology $>^{\prime}$ as of $\quad<$ amplituding/formative-epistemicity $>$ totalising $\sim$ random-as-impulsive'implicited_attendant-ontological-contiguity ${ }^{6 /}$ ' educed-

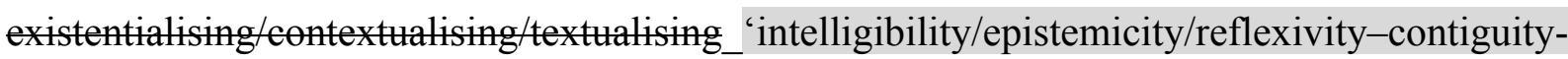
$<$ imbued-notional $\sim$ cogency $>$ ' ;-phenomenal-abstractiveness-of-presencing-in-'trepidatiousconsciousness' with recurrent-utter-uninstitutionalisation, <amplituding/formative- 
epistemicity >totalising nominal-as-tendentious_-'implicited_attendant—ontologicalcontiguity $^{67}$ ? educed-

existentialising/contextmalising/textualising_'intelligibility/epistemicity/reflexivity-contiguity$<$ imbued-notional cogency>' ${ }^{\prime}$;-phenomenal-abstractiveness-of-presencing-in- 'warpedconsciousness' with base-institutionalisation-ununiversalisation, <amplituding/formativeepistemicity $>$ totalising ordinal-as-qualifying_-implicited_attendant-ontologicalcontiguity $^{67}$, educedexistentialising/contextalising/textalising_'intelligibility/epistemicity/reflexivity_contiguity$<$ imbued-notional cogency>' ;-phenomenal-abstractiveness-of-presencing-in-'preclusiveconsciousness' with ${ }^{103}$ universalisation-non-positivism/medieval, <amplituding/formativeepistemicity>totalising intervalist-as-categorising_ 'implicited_attendant-ontologicalcontiguity $^{67} \sim$ educedexistentialising/contextualising/textualising_'intelligibility/epistemicity/reflexivity-contiguity$<$ imbued-notional cogency>’ ;-phenomenal-abstractiveness-of-presencing-in-'occlusiveconsciousness' with positivism- ${ }^{80}$ procrypticism, and <amplituding/formativeepistemicity $>$ totalising $\sim$ ratiocontiguity/ratiocination-as-referentialism—'implicited_attendant ontological-contiguity ${ }^{67}$, educedexistentialising/contextualising/textualising_intelligibility/epistemicity/reflexivity-contiguity$<$ imbued-notional cogency>' ;-phenomenal-abstractiveness-of-presencing-in-'protensiveconsciousness' with ${ }^{18}$ deprocrypticism-or-preempting-disjointedness-as-of- ${ }^{8}$ reference-ofthought. Such a disparity-of-momentousness/magnanimity/scale/psychologismic epistemic acutisation difficulty-for, residualising \{decompulsing $\}$ delinearity for-cogency> magnitude ${ }^{\text {\{of- }}$ experientiality/experiment\} notional $\sim$ ratiocontiguity/ratiocination-as-referentialism'implicited_attendant-ontological-contiguity ${ }^{67}$ educedexistentialising/contextualising/textualising_intelligibility/epistemicity/reflexivity-contiguity- 
<imbued-notional cogency >' conception (as it reflects holographically-<conjugatively-andtransfusively $>$ the relative-unreflexivity/relative-reflexivity ontological-contiguity $\sim$ of-thehuman-institutionalisation-process ) speaks to the 'overall recurrent dynamics of human profound-supererogation and shallow-supererogation as to mere-formulaicity/ritualisation<as-to-mere-formulaic — methodologising/mutualising/organising/institutionalising,-

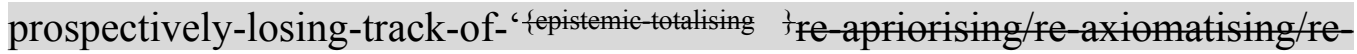

referencing $\sim$ residuality - in-re-originariness/re-origination'>' reflected as to 'multicenturieslong human crossgenerational Being-development/ontological-framework-expansion-as-todepth-of-ontologising-development-as-infrastructure-of- meaningfulness-and-teleology psychologismic epistemic-acutisation difficulty-for, residualising \{decompulsing $\}$ delinearity for-cogeney> magnitude ${ }^{\text {\{of-experientiality/experiment }\}}$ of prospective transcendence-and-sublimity/sublimation/supereregatory-de-mentativity' and 'conceptualising scale of a human 60-100 years lifespan today as to living-development-as-to-personalitydevelopment'; with this disparity-of-momentousness/magnanimity/scale/psychologismic epistemic acutisation difficulty-for, residualising fdecompulsingl delinearity for-cogency> magnitude\{of-experientiality/experiment\} manifested as of human mental-projection of 'Beingdevelopment/ontological-framework-expansion-as-to-depth-of-ontologising-development-asinfrastructure-of- meaningfulness-and-teleology imaginary of individuation' and 'livingdevelopment-as-to-personality-development psyche of individuation'. 'Beingdevelopment/ontological-framework-expansion-as-to-depth-of-ontologising-development-asinfrastructure-of- meaningfulness-and-teleology imaginary of individuation' is selfreflexively of most profound idealising with regards to human homeliness implications of the sublimating-postconverged 'substantive abstract-tissue-of-social-emanance \{epistemictotalising $3{ }^{3}$ hermeneutically/textually/reprojectingly/supererogatingly/zeroingly/re-acutingly,\{decompulsing $\}$ delinearity for-cogency — cumulated/recomposured as to cumulating/recomposuring 

existentialising/contextualising/textualising_intelligibility/epistemicity/reflexivity-contiguity<imbued-notional cogency $>$ underlying notional $\sim$ philosophy-<as-to-the-veridicalconception-of-philosophy-as-englobing-all-human-prospective-organic-knowledge-generationin-relative-ontological-completeness ,-beyond-a-convenient-division-of-labour-conception-ofknowledge $>$ while 'living-development-as-to-personality-development psyche of individuation' as to manifest in-effect absolution-<as-to-apriorising/axiomatising/referencing\{of-'prospectively implicited_attendant-ontological-contiguity ' educedexistentialising/contextualising/textualising_ 'intelligibility/epistemicity/reflexivity-contiguity<imbued-notional cogency>' $\quad\}$-constitutedness -in-preconverging-entailment> presencing-absolutising-identitive-constitutedness ${ }^{14}$ preconverging-existential-extricationas-of-existential-unthought predisposition is self-reflexively of shallower idealising with regards to human homeliness implications of the sublimating-postconverged 'substantive abstracttissue-of-social-emanance fepistemic thalising ${ }^{t}$ hermeneutically/textually/reprojectingly/supererogatingly/zeroingly/re-acutingly,$\{$ \{decompulsing $\}$ delinearity for-cogency—cumulated/recomposured as to cumulating/recomposuring of 'prospectively implicitendentontological-contiguity ${ }^{67}$ ' educedexistentialising/contextmalising/textualising_'intelligibility/epistemicity/reflexivity_contiguity$<$ imbued-notional cogency $>$ ' ; so-reflected as to underlying 'social-functioning-andaccordance-as-of-social-stake-contention-or-confliction imbuing existentialising-frame-ofentailment of motif-and-apriorising/axiomatising/referencing of disontologising/ontologisingand-re-ontologising' with 'Being-development/ontological-framework-expansion-as-to-depthof-ontologising-development-as-infrastructure-of- meaningfulness-and-teleology imaginary of individuation' predisposition for prospective ontologisation/re-ontologisation in maximalising-recomposuring-for-relative-ontological-completeness ${ }^{87}$ unenframed/re- 
ontologising conceptualisation and 'living-development-as-to-personality-development psyche of individuation' predisposition to prospective disontologising incrementalism-in-relativeontological-incompleteness ${ }^{8}$ — enframed/disontologising conceptualisation. 'Beingdevelopment/ontological-framework-expansion-as-to-depth-of-ontologising-development-asinfrastructure-of- meaningfulness-and-teleology imaginary of individuation' as of notional ratiocontiguity/ratiocination-as-referentialism—'implicited_attendant_ontologicalcontiguity $^{67}$, educedexistentialising/contextualising/textualising_'intelligibility/epistemicity/reflexivity-contiguity-

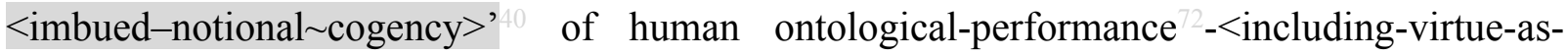
ontology $>$ /potentiation implications translates into " ${ }^{6}$ nonpresencing- $<$ perspective-ontologicalnormalcy/postconvergence $>$ deascriptivity interlay/organicalism/aestheticising-handle- $<$ of'psychologismic-transfixity \{residualising \{decompulsing ${ }^{\{}$delinearity-over-nonresidualising \{compulsing\} linearity\}'>-\{imbued-supererogatory $\sim$ projective-arbitrariness/waywardnessof $\sim$ transversalisation/tandemisation/abstractive-conjugation/perspectivation/depthing — for'aestheticising-re-margining/re-edging/re-acuity-aspostconverging_circumscriptive/totalitative-restructuring'\}-educingsublimation/desublimation>' so-construed as angling-of-imaginary. Contrastively, 'livingdevelopment-as-to-personality-development psyche of individuation' as of notional ratiocontiguity/ratiocination-as-referentialism—'implicited_attendant-ontologicalcontiguity $^{67}$; educedexistentialising/contextualising/textualising_'intelligibility/epistemicity/reflexivity-contiguity-

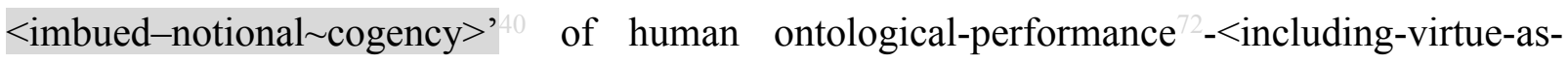
ontology $>$ /potentiation implications translates into "79 presencing-absolutising-identitiveconstitutedness ${ }^{14}$ ascriptivity interlay/organicalism/aestheticising-handle-<of-'psychologismic-

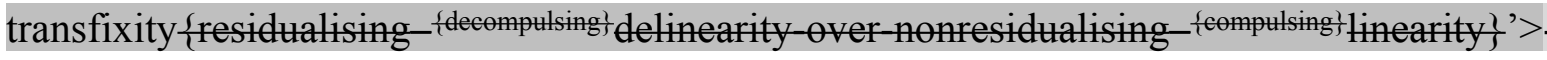


\{imbued-supererogatory $\sim$ projective-arbitrariness/waywardness-

of $\sim$ transversalisation/tandemisation/abstractive-conjugation/perspectivation/depthing — for'aestheticising-re-margining/re-edging/re-acuity-as-

postconverging_circumscriptive/totalitative-restructuring'\} - educing-

sublimation/desublimation>' so-construed as psychical-nascency. Critically as to the 'full incipient supererogating breadth of human intelligibility transmutation' (as '<supererogatory $\sim$ human-subpotency $>$-effecting imbued epistemic-totalising preformulating/preframing/premeaningfulness of notional $\sim$ originariness-parrhesia,--asspontaneity-of-aestheticisation' before the incipience of metaphoricity ${ }^{57}$ and then meaningfulness-and-teleology as to existentialising-frame-of-entailment-of-motif-andapriorising/axiomatising/referencing); human 'self-reflexive $\sim$ instigative-eventuating-〈as-toteleological-instigative/incipient-

willing/arbitrariness/waywardness/faithdrivenness/supererogating-for-human-intelligibility,preceding-existence's-eventuating-sublimating-validation/desublimating-invalidation> of human embodied-consciousness motif-and-apriorising/axiomatising/referencing-\{of'prospectively implicited_attendant-ontological-contiguity ' ceducedexistentialising/contextualising/textualising_'intelligibility/epistemicity/reflexivity_contiguity$<$ imbued-notional cogency $>>$ ' $\}$-elicited-incipience-of-existentialising-decisionality-<as-todisentologising/re-ontologising aporeticism $>$ ' as to 'social-functioning-and-accordance-asof-social-stake-contention-or-confliction imbuing existentialising-frame-of-entailment-ofmotif-and-apriorising/axiomatising/referencing of disontologising/ontologising-and-reontologising' undergirds both angling-of-imaginary as to 'human projection of pesteenverging nonextricatory-existential-preempting-of-existential-unthought predisposition manifested as to abstract-projection drivenness' and psychical-nascency as to 'human projection in preconverging-existential-extrication-as-of-existential-unthought predisposition manifested as 
to mere outturn-projection drivenness'. Critically, the preconverging/postconverging-dementative/structural/paradigmatic possibility for dimensionality-of-sublimating 〈<amplituding/formative>supererogatory $\sim$ de-mentativeness/epistemic-growth-or-

\section{conflatedness /transvaluative-rationalising/transepistemicity/anamnestic-residuality/spirit-}

drivenness-equalisation) (as so-required for prospective ${ }^{18}$ deprocrypticism-or-preemptingdisjointedness-as-of- ${ }^{8}$ reference-of-thought imaginary) can only be elicited as from an anglingof-imaginary abstract-projection drivenness (as to the thoughtful sublimating coherence of the sublimating-postconverged 'substantive abstract-tissue-of-social-emanance fepistemictotalising ${ }^{3}$ hermeneutically/textually/reprojectingly/supererogatingly/zeroingly/re-acutingly,${ }_{\{\text {decompulsing }}$ delinearity for-cogency—cumulated/recomposured as to cumulating/recomposuring of 'prospectively_implicited_attendant-ontological-contiguity ${ }^{67}$ educedexistentialising/contextualising/textualising_'intelligibility/epistemicity/reflexivity-contiguity$<$ imbued-notional cogency>’") over psychical-nascency outturn-projection drivenness (as to the preconverging-existential-extrication-as-of-existential-unthought of the sublimating coherence of the sublimating-postconverged 'substantive abstract-tissue-of-social-emanance \{epistemic-totalising 3 ${ }^{3}$ hermeneutically/textually/reprojectingly/supererogatingly/zeroingly/reacutingly, -\{decompulsing\} delinearity for-cogency—cumulated/recomposured

cumulating/recomposuring of 'prospectively_implicited_attendant-ontologicalcontiguity ${ }^{67} \sim$ educed-

existentialising/contextualising/textualising_intelligibility/epistemicity/reflexivity-contiguity$<$ imbued-notional cogency $>^{\prime}$ ). This human individuation and social projection divergence between human psychical-nascency and human angling-of-imaginary (as to disparity-ofmomentousness/magnanimity/scale/psychologismic epistemic acutisation difficulty-<for,

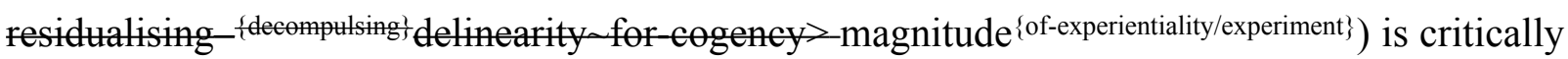
reflected dynamically in all human endeavours as of 'social-functioning-and-accordance-as- 
of-social-stake-contention-or-confliction imbuing existentialising-frame-of-entailment-ofmotif-and-apriorising/axiomatising/referencing of disontologising/ontologising-and-reontologising'; underlined with 'angling-of-imaginary ${ }^{6}$ nonpresencing-<perspectiveontological-normalcy/postconvergence $>$ epistemic-projection of abstractive social contemplations beyond ordinary consideration-and-expectations/anticipations bearing registryworldview/dimension opening-up consequences' and 'psychical-nascency punctual $/{ }^{9}$ presencing — absolutising-identitive-constitutedness ${ }^{14}$ epistemic-projection of social contemplations as to secondnatured human endeavours of ordinary consideration-andexpectations/anticipations'. The human psychical-nascency-ideal-type-or-individuation can be construed as a human individuation of in-effect absolution-<as-toapriorising/axiomatising/referencing-\{of-'prospectively_implicited_attendant_ontologicalcontiguity ' educedexistentialising/contextualising/textualising_'intelligibility/epistemicity/reflexivity-contiguity$<$ imbued-notional cogency $>$ ' $\}$-constitutedness -in preconverging-entailment $>$ upholding of the 'social-functioning-and-accordance-as-of-social-stake-contention-or-confliction imbuing existentialising-frame-of-entailment-of-motif-andapriorising/axiomatising/refereng of disontologising/ontologising-and-re-ontologising' and so consciously or unconsciously whether effectively ontologising or disontologising as to the mere-formulaicity/ritualisation-<as-to-mere-formulaicmethodologising/mutualising/organising/institutionalising,-prospectively-losing-track-of‘\{epistemic-talising łre-apriorising/re-axiomatising/re-referencing residuality-in-reoriginariness/re-origination'> implications of its <preconverging 'motif-andapriorising/axiomatising/referencing'-entailing>-existentialising-enframing/imprintedness〈as-to- historicity-tracing-in-presencing-hyperrealisation/hyperreal-transposition〉.

Psychical-nascency speaks to the foremost human conservative disposition (undergirding human 
'self-reflexive instigative-eventuating-〈as-to-teleological-instigative/incipient-

willing/arbitrariness/waywardness/faithdrivenness/supererogating-for-human-intelligibility,-

preceding-existence's-eventuating-sublimating-validation/desublimating-invalidation $\rangle$ as from human embodied-consciousness motif-and-apriorising/axiomatising/referencing-\{of'prospectively_implicited_attendant-ontological-contiguity ' ceduced-

existentialising/contextualising/textualising_'intelligibility/epistemicity/reflexivity-contiguity<imbued-notional cogency>’ $\}$-elicited-incipience-of-existentialising-decisionality-<as-todisentologising/re-ontologising aporeticism ${ }^{\prime}$ ) bound to the formative-risk of prospective disontologising (as to human Being-development/ontological-framework-expansion-as-todepth-of-ontologising-development-as-infrastructure-of- meaningfulness-and-teleology , institutional-development-as-to-social-function-development and living-development-as-topersonality-development psychologismic epistemic-acutisation difficulty-for,

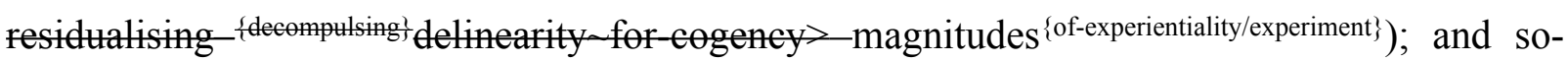
critically underlying its preconverging-de-mentating/structuring/paradigming 'human psychology of passivity to the underlying metaphoricity ${ }^{57}$ of human limited-mentation-capacitydeepening - as-subjecting-limitedness/human-subpotency-to-'educed-unlimitedness/existencesublimating nascence ${ }^{53}$ with regards to prospective human-subpotencyaporia/undecidability/dilemma/ought-indeterminacy/deficiency/limitation/constraint—imbued'notional firstnaturedness-formativeness-<as-to-eventualising -inkling drive-or-seeding misprising $>$ temporal-to-intemporal-dispositions-<so-construed-as-from-perspectiveontological-normalcy/postconvergence>'-existentialism-form-factor' (but for when prospective effective sublimating-nascence manifests as to a 'rootless sourcing/generating of social sublimating-nascence manifestations and their prospective sublimating possibilities'), speaking to a 'relatively poor abstractive relation with the instigation/incipience of effective sublimatingnascence manifestations and their prospective protracted sublimating possibilities and thus a 
relatively poor abstractive relation with prospective instigation/incipience of social sublimatingnascence' (as to its presencing-absolutising-identitive-constitutedness $<$ amplituding/formative-epistemicity $>$ totalising $\sim$ self-referencingsyncretising/circularity/interiorising/akrasiatic-drag ${ }^{4}$ 'prospectively \{flawed/unsound\} relative-unreflexivity-in-existence/absolutising from-limited mentation/psychologismic epistemic-acutisation nonresidualising-imbued-\{compulsing\}linearity-in-eclecticism-of-priormere-formulaicity/ritualisation as un-originary limitedness/human-subpotency prospective reencountering/re-confrontation with existence-as-the-absolute-a-priori-ofconceptualisation and existence — as-sublimating-withdrawal/unenframing/re-ontologising,elicited-from-prospective-profound-supererogation $-<$ as-to-perspective-ontologicalnormalcy/postconvergence-implied-'prospective-aporeticism-overcoming/unovercoming'> thus manifesting lack of human limited-mentation-capacity-deepening-as-subjectinglimitedness/human-subpotency-to-'educed-unlimitedness/existence-sublimating nascence'53)'. The ontological-veracity of this 'human psychical-nascency foremost human conservative disposition' can be garnered when it comes to the crossgenerational span it has taken the human species (as to its genealogical/archaeological growth/development) to go through the $<$ cumulating/recomposuring attendant-ontological-contiguity $>$-successive registryworldviews/dimensions 'relative-ontological-completeness apriorising/axiomatising/referencing-\{of-'prospectively implicited_attendant-ontologicalcontiguity ' educedexistentialising/contextualising/textualising_'intelligibility/epistemicity/reflexivity-contiguity$<$ imbued-notional cogency>' $\}$-relation-to-the-world conceptivity/epistemicreflexivity/epistemicity-relativism-determinism-<reifying \{as-to-knowledge-developing $\}$-andempowering>' before arriving at our present rational-empiricism/positivising 'relativeontological-completeness apriorising/axiomatising/referencing-\{of-'prospectively 
implicited_attendant-ontological-contiguity ' reduced-

existentialising/contextualising/textualising_'intelligibility/epistemicity/reflexivity_contiguity<imbued-notional cogency>' \}-relation-to-the-world conceptivity/epistemicreflexivity/epistemicity-relativism-determinism-<reifying \{as-to-knowledge-developing $\}$-andempowering >', with the possibility of the successive human registry-worldviews/dimensions induced transcendence-and-sublimity/sublimation/supereregatery-de-mentativity from the

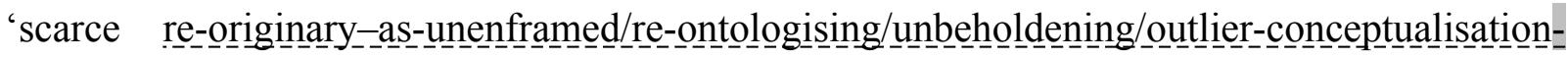
〈imbued-postconverging/dialectical-thinking -'projective-insights'/'epistemic-projection-inconflatedness '-of-notional deprocrypticism-prospective-sublimation $\rangle$ re-ontologising prospective Being-development/ontological-framework-expansion-as-to-depth-ofontologising-development-as-infrastructure-of- meaningfulness-and-teleology imaginary (of any given social-setup implied self-sufficiency as to its <preconverging 'motif-andapriorising/axiomatising/referencing'-entailing--existentialising_enframing/imprintedness〈as-to- historicity-tracing-in-presencing-hyperrealisation/hyperreal-transposition〉') insufficient for the possibility of such successive transcendence-andsublimity/sublimation/supererogatory de-mentativity; as most critically given the natural human individuative and social disposition to psychical-nascency only the veracity of a strong dynamics of human cultural-diffusion/intercultural-influence allowed for the critical threshold of re-originary-as-unenframed/re-ontologising/unbeholdening/outlier-conceptualisation〈imbued-postconverging/dialectical-thinking -'projective-insights'/'epistemic-projection-inconflatedness '-of-notional deprocrypticism-prospective-sublimation $\rangle^{\circ}$ re-ontologising prospective Being-development/ontological-framework-expansion-as-to-depth-ofontologising-development-as-infrastructure-of- meaningfulness-and-teleology imaginary enabling social-setups induced transcendence-and-sublimity/sublimation/supereregatory $\sim$ dementativity. The fundamental point here is to reflect upon human psychical-nascency inherent 
implications with regards to human subontologising passivity and the preconverging/postconverging-de-mentative/structural/paradigmatic dynamics and/or compensatory-dynamics for human critical threshold of re-originary-_as-unenenframed_/reontologising/unbeholdening/outlier-conceptualisation-_imbued-postconverging/dialecticalthinking -'projective-insights'/‘epistemic-projection-in-conflatedness '-ofnotional deprocrypticism-prospective-sublimation $\rangle^{\circ}$ as to the possibility for prospective ontologising/re-ontologising. In-many-ways and in-the-bigger-picture of the relativeunreflexivity/relative-reflexivity - ontological-contiguity ${ }^{67}$ of-the-human-institutionalisationprocess $^{68}$ (implied ${ }^{15}$ de-mentation-〈supererogatory $\sim$ ontological-de-mentation-or-dialecticalde-mentation - stranding-or-attributive-dialectics〉 underlying human fundamental ontologydriven 'postconverging-or-dialectical-thinking -psychology or psychology-of-mentationdynamics or natural psychological-dynamics'), the reality undergirding human 'selfreflexive instigative-eventuating-〈as-to-teleological-instigative/incipientwilling/arbitrariness/waywardness/faithdrivenness/supererogating-for-human-intelligibility,preceding-existence's-eventuating-sublimating-validation/desublimating-invalidation〉 of human embodied-consciousness motif-and-apriorising/axiomatising/referencing-\{of'prospectively_implicited_attendant-ontological-contiguity ' educedexistentialising/contextualising/textualising_'intelligibility/epistemicity/reflexivity-contiguity$<$ imbued-notional cogency $>$ ' $\}$-elicited-incipience-of-existentialising-decisionality-<as-todisontologising/re-ontologising aporeticism $>$ ' fundamentally bonds together human nascentparticular/incipient-and-material/technical-sublimations- $<$ blinded-to-their-relative-ontologicalcompleteness - reference-of-thought- devolving $>\quad$ existentialising-decisionality-<as-todisontologising/re-ontologising aporeticism $>$ with human social-and-institutionalframeworks-of — referencing/registering/decisioning existentialising-decisionality-as to disontologising/re-ontologising aporeticism $>$; as to the fact a casual exercise contemplating 
why our modern profound-and-systematic scientific attitude which we take for granted was hardly pre-eminent with previous Ages, fundamentally reflects the 'overarching preconverging/postconverging-de-mentative/structural/paradigmatic implications of the socialand-institutional-frameworks-of — referencing/registering/decisioning existentialisingdecisionality-<as-to-disontologising/re-ontologising aporeticism $>$ as to its imbued psychicalnascency' upon such a possibility of contemplation of 'nascent-particular/incipient-andmaterial/technical-sublimations- $<$ blinded-to-their-relative-ontological-completeness

reference-of-thought- devolving $>\quad$ existentialising-decisionality-as-to-disontologising/reentologising aporeticism ${ }^{\prime}$ in positivising/rational-empiricism (to the point that even an archetypal budding-positivist ushering our present-day scientific worldview like Newton wasn't himself 'freed/liberated' from the 'medieval social-and-institutional-frameworks-ofreferencing/registering/decisioning existentialising-decisionality-<as-to-disontologising/reentologising aporeticism ${ }^{\prime}$ as to occultic/alchemic dispositions and further speaking to the fact that it is naïve for the modern-day scientist not to contemplate about how our present-day socialand-institutional-frameworks-of — referencing/registering/decisioning existentialisingdecisionality-<as-to-disontologising/re-ontologising aporeticism $>$ imbued psychicalnascency' impacts on the possibility of prospective sublimating-nascence and so more obviously as to a reflex of desublimating science ideology). That said the reality as well points to the fact that the more circumscribed/bounded nature of human nascent-particular/incipient-andmaterial/technical-sublimations-<blinded-to-their-relative-ontological-completeness

reference-of-thought- devolving $>$ render them premonitory as to preceding and empowering the possibility for prospective social-and-institutional-frameworks-ofreferencing/registering/decisioning sublimating $\sim$ existentialising-decisionality $<a s$ to disontologising/re-ontologising aporeticism $>$; as we can appreciate that a Galileo heliocentric budding-positivistic contention with his new telescope demonstration is more naturally-and- 
potently disarming/dis-ideologising/deformulaicity/à-contrecoup/unsettling/unargarguable by its sublimating rational-empiricism/positivising implications than say an abstractly contemplated contention in that period on the basis that a "rational-empiricism/positivising knowledgereification $\sim$ gesturing-and-accounting - of-epistemic-phenomenalism- $<$ inprospective_psychologismic apriorising/axiomatising/referencing-\{of-'prospectively_ implicited_attendant-ontological-contiguity ' educedexistentialising/contextualising/textualising_intelligibility/epistemicity/reflexivity_contiguity$<$ imbued-notional cogency $>$ ' \}-conflatedness -in-\{preconverging -ment by\} postconverging-entailment> as to ${ }^{83}$ reference-of-thought ${ }^{84}$ and ${ }^{83}$ reference-of-thoughtdevolving $>$ ' is the appropriate 'social-and-institutional-frameworks-ofreferencing/registering/decisioning sublimating $\sim$ existentialising-decisionality-<as-todisentologising/re-ontologising aporeticism $>$ '. Psychical-nascency thus speaks to the fact that 'human social-and-institutional-frameworks-of-referencing/registering/decisioning existentialising-decisionality-<as-to-disontologising/re-ontologising aporeticism $>$ preconverging/postconverging-de-mentatively/structurally/paradigmatically have a potent prospective disontologising psychosomatic grip' (as of <preconverging 'motif-andapriorising/axiomatising/referencing'-entailing >-existentialising-enframing/imprintedness〈as-to- historicity-tracing - in-presencing-hyperrealisation/hyperreal-transposition〉) upon human ontologising/re-ontologising capacity in re-originary-_as-unenframed_reontologising/unbeholdening/outlier-conceptualisation-_imbued-postconverging/dialectical-

\section{thinking -'projective-insights’/‘epistemic-projection-in-conflatedness ' 'of-}

notional deprocrypticism-prospective-sublimation $\rangle^{\circ}$ even at the exclusion of prospective ontologising implications of existence-as-sublimating-withdrawal/unenframing/reontologising,-elicited-from-prospective-profound-supererogation ; as so-incipiently manifested and reflected notionally with the human psychical-nascency of individuative and 
social 'full incipient supererogating breadth of human intelligibility transmutation' (as '<supererogatory $\sim$ human-subpotency $>$-effecting imbued epistemic-totalising preformulating/preframing/premeaningfulness of notional originariness-parrhesia,--asspontaneity-of-aestheticisation' before the incipience of metaphoricity ${ }^{57}$ and then meaningfulness-and-teleology ${ }^{99}$ as to existentialising-frame-of-entailment-of motif-andapriorising/axiomatising/referencing). Contrastively, human angling-of-imaginary-ideal-typeor-individuation speaks to human <self-reflexive>-willed-thought appraising of the disontologising-threshold and projection of prospective ontologising/re-ontologising-threshold of human 'social-functioning-and-accordance-as-of-social-stake-contention-or-confliction imbuing existentialising-frame-of-entailment-of-motif-andapriorising/axiomatising/referencing of disontologising/ontologising-and-re-ontologising'; as to undergirding human 'self-reflexive instigative-eventuating-〈as-to-teleologicalinstigative/incipient-willing/arbitrariness/waywardness/faithdrivenness/supererogating-forhuman-intelligibility,-preceding-existence's-eventuating-sublimating-validation/desublimatinginvalidation> of human embodied-consciousness motif-andapriorising/axiomatising/referencing-\{of-"prospectively implicited_attendant_ontologicalcontiguity ' $\sim$ educedexistentialising/contextualising/textualising_'intelligibility/epistemicity/reflexivity-contiguity<imbued-notional cogency >’ $\}$-elicited-incipience-of-existentialising-decisionality-<as-todisontologising/re-ontologising aporeticism ${ }^{\prime}$, so-underlied with human marginally subversive preconverging/postconverging-de-mentative/structural/paradigmatic possibilities for prospective ${ }^{55}$ maximalising-recomposuring-for-relative-ontological-completeness ${ }^{87}$ unenframed/re-ontologising conceptualisation induced ontologising/re-ontologising (as to human Being-development/ontological-framework-expansion-as-to-depth-of-ontologisingdevelopment-as-infrastructure-of- meaningfulness-and-teleology , institutional- 
development-as-to-social-function-development and living-development-as-to-personalitydevelopment psychologismic epistemic-acutisation difficulty-<for, residualising -

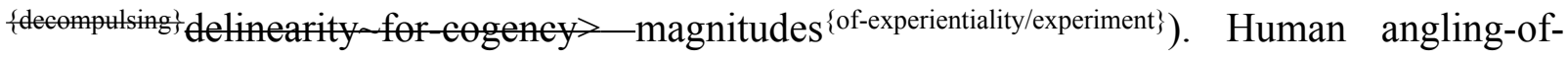
imaginary speaks to a 'relatively appreciative/contemplative abstractive relation with the instigation/incipience of effective sublimating-nascence manifestations and their prospective protracted sublimating possibilities and thus a relatively appreciative/contemplative abstractive relation with prospective instigation/incipience of social sublimating-nascence' as to $<$ amplituding/formative-epistemicity $>$-totalising $\sim$ renewing-realisation/re-perception/rethought in apriorising/axiomatising/referencing-\{of-'prospectively_implicited_attendantontological-contiguity ' educedexistentialising/contextualising/textualising_'intelligibility/epistemicity/reflexivity-contiguity<imbued-notional cogency>' $\}$-conflatedness ${ }^{13}$-in-\{preconverging-ment by \} $^{-}$ postconverging-entailment 'in prospective epistemic-growth,-as - \{veridical/sound\}-relativereflexivity-in-existence/relativising from-limited-mentation-as-its-deepening/psychologismic epistemic-acutisation residualising, unenframed/re-ontologising/unbeholdening/outlier-conceptualisation-_imbuedpostconverging/dialectical-thinking -'projective-insights'/‘epistemic-projection-inconflatedness '-of-notional deprocrypticism-prospective-sublimation $\rangle^{\circ}$ limitedness/humansubpotency prospective re-encountering/re-confrontation with existence-as-the-absolute-apriori-of-conceptualisation and existence — as-sublimating-withdrawal/unenframing/reontologising,-elicited-from-prospective-profound-supererogation $-<$ as-to-perspectiveontological-normalcy/postconvergence-implied-'prospective-aporeticismovercoming/unovercoming'>' inducing of prospective <postconverging 'motif-andapriorising/axiomatising/referencing'-entailing>-existentialising-framing/imprinting-〈as-toprospective- historiality/ontological-eventfulness /ontological-aesthetic-tracing- 
<perspective-ontological-normalcy/postconvergence-reflected-'epistemicity-relativismdeterminism' $>>$. The ontological-veracity of this 'human angling-of-imaginary marginally subversive preconverging/postconverging-de-mentative/structural/paradigmatic possibilities' (as to 'multicenturies-long human crossgenerational Being-development/ontologicalframework-expansion-as-to-depth-of-ontologising-development-as-infrastructure-ofmeaningfulness-and-teleology psychologismic epistemic-acutisation difficulty<-for, residualising_\{decompulsing\} delinearity-for-cogency> magnitude $\{$ of-experientiality/experiment\} of prospective transcendence-and-sublimity/sublimation/supererogatory-de-mentativity') can be garnered with regards to the fact that all successive prior registry-worldviews/dimensions do not 'harbour/contemplate of the imaginary' of their successive prospective registryworldviews/dimensions (as so-reflected as to the successive change of 'relative-ontologicalcompleteness knowledge-reification $\sim$ gesturing-and-accounting — of-epistemicphenomenalism- $<$ in-prospective_psychologismic $\sim$ apriorising/axiomatising/referencing- of'prospectively_implicited_attendant-ontological-contiguity ' educedexistentialising/contextualising/textualising_ 'intelligibility/epistemicity/reflexivity-contiguity<imbued-notional cogency $>>$ ' - conflatedness - in-\{preconverging ment by\} postconverging entailment $>$ as of apriorising/axiomatising/referencing-\{of-'prospectively implicited_attendant-ontological-contiguity ' reducedexistentialising/contextualising/textualising_'intelligibility/epistemicity/reflexivity_contiguity$<$ imbued-notional cogency $>$ ' \}-relation-to-the-world conceptivity/epistemicreflexivity/epistemicity-relativism-determinism- $<$ reifying \{as-to-knowledge-developing $\}$-andempowering >'); such that our very own positivism- ${ }^{80}$ procrypticism imbued disjointing doesn't/hardly effectively renege/revoke/rescind on the idea that its present 'occlusive as disjointing prior_knowledge-reification $\sim$ gesturing-and-accounting_-of-epistemicphenomenalism-<in-prior_psychologismic $\sim$ apriorising/axiomatising/referencing-\{of- prior- 
implicited_attendant-ontological-contiguity ' educed-

existentialising/contextualising/textualising_intelligibility/epistemicity/reflexivity-contiguity-

$<$ imbued-notional cogency >' $\}$-constitutedness -in-preconverging-entailment> $>$ as of

apriorising/axiomatising/referencing-\{of-'prospectively implicited_attendant-ontological-

contiguity ' educed-

existentialising/contextualising/textualising_'intelligibility/epistemicity/reflexivity-contiguity-

<imbued-notional cogency>' $\}$-relation-to-the-world conceptivity/epistemic-

reflexivity/epistemicity-relativism-determinism-<reifying \{as-to-knowledge-developing $\}$-and-

empowering >' is prospectively bound to be superseded/transcended. Again, the fundamental point here is to reflect prospectively upon human angling-of-imaginary underlying the very nonpresencing-<perspective-ontological-normalcy/postconvergence $>$ nature of inherent existence requiring prospective human limited-mentation-capacity-deepening - as-subjecting limitedness/human-subpotency-to-'educed-unlimitedness/existence-sublimating nascence' (in inducing the preconverging/postconverging-de-mentative/structural/paradigmatic dynamics and/or compensatory-dynamics for human critical threshold of re-originary_-_as-unnenframe-_ed/reontologising/unbeholdening/outlier-conceptualisation-_imbued-postconverging/dialectical-

\section{thinking -'projective-insights'/‘epistemic-projection-in-conflatedness '-of-}

notional deprocrypticism-prospective-sublimation $\rangle^{\circ}$ as to the possibility for prospective ontologising/re-ontologising given the ontological-veracity of a human preconverging/postconverging-de-mentative/structural/paradigmatic 'social-functioning-andaccordance - as-of-social-stake-contention-or-confliction imbuing existentialising-frame-ofentailment of motif-and-apriorising/axiomatising/referencing of disontologising/ontologisingand-re-ontologising' over which prospective human sublimation/emancipation arises as to prospective psychoanalytic-unshackling/memetic-reordering/institutional-recomposuring self-

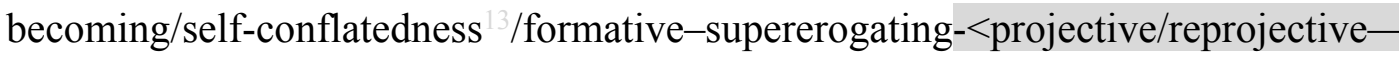


aestheticising-re-motif-and-re-apriorising/re-axiomatising/re-referencing,-in-perspectiveontological-normalcy/postconvergence $>$. In this regards, central to human angling-of-imaginary is the existentialising/contextualising/textualising exercise of re-evaluating all supposedly precedingly decided human intelligibility (as to undergirding human 'self-reflexive instigativeeventuating-〈as-to-teleological-instigative/incipientwilling/arbitrariness/waywardness/faithdrivenness/supererogating-for-human-intelligibility,preceding-existence's-eventuating-sublimating-validation/desublimating-invalidation) human embodied-consciousness motif-and-apriorising/axiomatising/referencing-\{of'prospectively_implicited_attendant_ontological-contiguity ' educed-

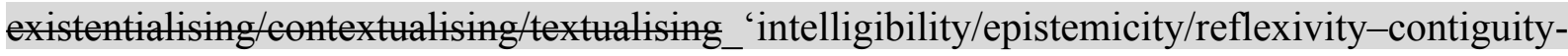
$<$ imbued-notional cogency $>>$ ' $\}$-elicited-incipience-of-existentialising-decisionality-<as-todisontologising/re-ontologising aporeticism $>^{\prime}$ ) in an epistemic-growth,-as\{veridical/sound\}-relative-reflexivity-in-existence/relativising from-limited-mentation-as-itsdeepening/psychologismic epistemic_acutisation residualising, \{decompulsing ${ }^{2}$ delinearity for-

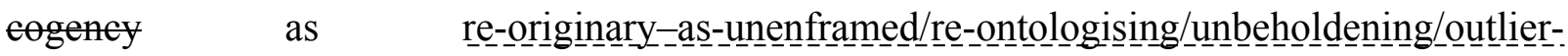
conceptualisation_____imbued-postconverging/dialectical-thinking -'projectiveinsights'/'epistemic-projection-in-conflatedness ' '-of-notional deprocrypticism-prospectivesublimation $\rangle^{0}$ limitedness/human-subpotency prospective re-encountering/re-confrontation with existence — as-the-absolute-a-priori-of-conceptualisation and existence — as-sublimatingwithdrawal/unenframing/re-ontologising,-elicited-from-prospective-profoundsupererogation $-<$ as-to-perspective-ontological-normalcy/postconvergence-implied'prospective-aporeticism-overcoming/unovercoming'> and in so-doing establish/re-establish momentous/sublimating ${ }^{4}$ historiality/ontological-eventfulness 3 /ontological-aesthetic-tracing$<$ perspective-ontological-normalcy/postconvergence-reflected-‘epistemicity-relativismdeterminism'>; and so as the most profound of human knowledge-reification $\sim$ gesturing-and- 
accounting-of-epistemic-phenomenalism- $<$ in-

prospective_psychologismic apriorising/axiomatising/referencing-\{of-'prospectively implicited_attendant-ontological-contiguity ' educed-

existentialising/contextualising/textualising_intelligibility/epistemicity/reflexivity-contiguity<imbued-notional cogency $>$ ' $\}$-conflatedness -in-\{preconverging ment by\}

postconverging-entailment> exercise underlying the human institutionalcumulation/institutional-recomposure-〈as-to- historiality/ontological-

eventfulness /ontological-aesthetic-tracing-<perspective-ontologicalnormalcy/postconvergence-reflected-‘epistemicity-relativism-determinism'>> imbued $<$ cumulating/recomposuring attendant-ontological-contiguity $>$-successive registryworldviews/dimensions 'relative-ontological-completeness ${ }^{87}$ knowledge-reification $\sim$ gesturingand-accounting - of-epistemic-phenomenalism- $<$ in-

prospective_psychologismic apriorising/axiomatising/referencing-\{of-'prospectively implicited_attendant-ontological-contiguity ' educedexistentialising/contextualising/textualising_'intelligibility/epistemicity/reflexivity-contiguity<imbued-notional cogency>’ $\}$-conflatedness -in-\{preconverging-ment by\} postconverging-ntailment $>$ as of apriorising/axiomatising/referencing-\{of-"prospectively implicited_attendant-ontological-contiguity ' educedexistentialising/contextualising/textualising_intelligibility/epistemicity/reflexivity_contiguity<imbued-notional cogency>' \}-relation-to-the-world conceptivity/epistemicreflexivity/epistemicity-relativism-determinism-<reifying \{as-to-knowledge-developing $\}$-andempowering $>^{\prime} \quad$ (as from $\quad$ recurrent-utter-ininstitutionalisation non-rulesapriorising/axiomatising/referencing-psychologism, base-institutionalisationununiversalisation 'rulemaking-over-non-rules - apriorising/axiomatising/referencingpsychologism', ${ }^{103}$ universalisation-non-positivism/medievalism ' ${ }^{103}$ universalisation-directed- 
rulemaking-over-non-rules_-apriorising/axiomatising/referencing-psychologism', positivismprocrypticism 'positivising/rational-empiricism-based-universalisation-directed-rulemakingover-non-rules - apriorising/axiomatising/referencing-psychologism' and prospective deprocrypticism-or-preempting - disjointedness-as-of- ${ }^{83}$ reference-of-thought,-as-to${ }^{3}<$ amplituding/formative-epistemicity $>$ growth-or-conflatedness ${ }^{13} /$ transvaluativerationalising/transepistemicity/anamnestic-residuality/spirit-drivenness'—in-supersedingmere-formulaic-positivising/rational-empiricism-based-universalisation-directed-rulemakingover-non-rules - apriorising/axiomatising/referencing-psychologism' as underlied by the rational-realism of notional deprocrypticism as of ratiocontiguity/ratiocination-asreferentialism —'implicited_attendant-ontological-contiguity ${ }^{67}$ ? educedexistentialising/contextualising/textualising_intelligibility/epistemicity/reflexivity-contiguity$<$ imbued-notional cogency $>$ as nondisjointing 'postconverging-dementating/structuring/paradigming as $\quad{ }^{4}$ human-subject-emancipating-relativism-drivenrecomposuring-constructivism-towards-singularisation-<as-to-thenondisjointedness/entailment-of-prospective- nonpresencing> '). Basically, angling-ofimaginary speaks to the fact that since prospective human limited-mentation-capacitydeepening —as subjecting limitedness/hmman-subpotency to 'educed unlimitedness/existence sublimating nascence' speaks to the most profound human contemplative insight then it is historially explicative of most profound human knowledge and science as to its ${ }^{6}$ nonpresencing$<$ perspective-ontological-normalcy/postconvergence $>$ epistemic-projection and speaks to the ontological-veracity of 'history at the service of prospective knowledge implied as of sublimating historiality/ontological-eventfulness 38 /ontological-aesthetic-tracing$<$ perspective--ontological-normalcy/postconvergence-reflected-‘epistemicity-relativismdeterminism'>' (as it can be appreciated in this regards that the relative unblurriness- $<$ reontologising_by-postconverging-as-to-dragged-out-supererogatory -wholesomeness/profound- 
supererogation ,-while-anecdotalising-prior-disontologising-thresholding $>$ as with the natural sciences shows that a relic/artifactual interpretation of any prospective knowledge is bound to effectively undermine the prospective human postconvergingaaporeticismovercoming/unovercoming required for prospective knowledge-reification $\sim$ gesturing-andaccounting - of-epistemic-phenomenalism- $<$ in-

prospective_psychologismic apriorising/axiomatising/referencing-\{of-'prospectively

implicited_attendant-ontological-contiguity ' educed-

existentialising/contextualising/textualising_'intelligibility/epistemicity/reflexivity-contiguity$<$ imbued-notional $\left.\sim \operatorname{cogency}>^{\prime}\right\}$-conflatedness -in-\{preconverging -ment by\}

postconverging-entailment $>$ in the sense that for instance in-many-ways budding-positivists and their medieval-scholastics counterparts dealt more or less with the same knowledge issues but with medieval-scholasticism 'beholdening as sovereignising-imbuedsubontologisation/subpotentiation in totalisingly-ing-discretion/whim-of-thought' fundamentally stalled/hampered by their non-positivising and undermining the buddingpositivism epistemic-projection perspective of positivising supererogatery acuity/perspicacity/astuteness/edginess/incisiveness-ofapriorising/axiomatising/referencing/intelligibilitysettingup/measuringinstrumenting -forconceptualisation as to its postconverging-de-mentating/structuring/paradigming postconverging aporeticism-overcoming/unovercoming' and along the same axiomaticconstruct lines, though in contrast to the above positivism/rational-empiricism example of the reference-of-thought as grandest-axiomatic-contruct, the convolutedness of say modern-day DNA genetics knowledge-reification $\sim$ gesturing-and-accounting-of-epistemicphenomenalism- $<$ in-prospective_psychologismic $\sim$ apriorising/axiomatising/referencing- of'prospectively_implicited_attendant-ontological-contiguity ' ceducedexistentialising/contextualising/textualising_intelligibility/epistemicity/reflexivity_contiguity- 
<imbued-notional cogency $>>$ \}-conflatedness -in-\{preconverging -ment by\}

postconverging-entailment> axiomatic-construct in 'implicited_attendant-ontologicalcontiguity ${ }^{6}$, educed-

existentialising/contextualising/textualising_'intelligibility/epistemicity/reflexivity-contiguity-

<imbued-notional cogency ${ }^{\prime}$ cannot be construed as of mere conceptual-patterning-〈as-

devoid-of-'prospectively implicited_attendant-ontological-contiguity ' educed-

existentialising/contextualising/textualising_'intelligibility/epistemicity/reflexivity-contiguity-

$<$ imbued-notional cogency>' 's-reifying-or-elucidating-of-'prospective-relative-ontological-

completeness ' ;-so-rather-enabled-<by-a- nonpresencing-divulging-of-momentous-

historiality/ontological-eventfulness /ontological-aesthetic-tracing-<perspective-

ontological-normalcy/postconvergence-reflected-‘epistemicity-relativism-determinism’ $>>$ say

in terms of Mendelian hereditary axiomatic-construct which will utterly undermine the modernday

'DNA-driven

hereditary

supererogatory $\sim$ acuity/perspicacity/astuteness/edginess/incisiveness-of-

apriorising/axiomatising/referencing/intelligibilitysettingup/measuringinstrumenting -for-

conceptualisation as to its postconverging-de-mentating/structuring/paradigming postconverging aporeticism-overcoming/unovereoming implications'). Whereas a psychicalnascency disposition of 'prospective knowledge supposedly at the service of history implied as of desublimating historicity-tracing-in-presencing-hyperrealisation/hyperreal-transposition' (with the case of 'medieval-scholasticism's pedantising/muddling/formulaic-hollowing-outin-subontologisation/subpotentiation-〈blurring/undermining-of-prospective-totalisingentailing,-as-to-entailing-<amplituding/formative-epistemicity $>$ totalising $\sim$ in-relativeontological-completeness $>$ as to the prospective disontologising' of prior 'Socraticphilosophers ${ }^{103}$ universalising-idealisation ontologising/re-ontologising' thus undermining prospective 'budding-positivism/rational-empiricism ontologising/re-ontologising' or the case 
of our modern-day 'science-ideology pedantising/muddling/formulaic-hollowing-out-insubontologisation/subpotentiation-〈blurring/undermining-of-prospective-totalising-entailing,as-to-entailing-<amplituding/formative-epistemicity $>$ totalising in-relative-ontological-

completeness $>$ as to the prospective disontologising' of prior 'budding-positivism/rationalempiricism ontologising/re-ontologising' thus undermining 'prospective ontologising/reontologising of human critical thought as articulated by many a postmodern thinker'; and in both instances of disontologising, without/lacking the sense of human limited-mentation-capacitydeepening —as-subjecting limitedness/human-subpotency-to-'educed-unlimitedness/existencesublimating nascence ${ }^{5}$ undergirded by dimensionality-of-sublimating ${ }^{25}$ <<amplituding/formative>supererogatory $\sim$ de-mentativeness/epistemic-growth-or-

conflatedness /transvaluative-rationalising/transepistemicity/anamnestic-residuality/spiritdrivenness-equalisation) actually behind the creation/formation of prior Socratic-philosophers ' ${ }^{103}$ universalising-idealisation ontologising/re-ontologising' and prior budding-positivists 'positivising/rational-empiricism ontologising/re-ontologising'). Insightfully this underlines 'angling-of-imaginary epistemic-growth,-as_\{veridical/sound\}-relative-reflexivity-inexistence/relativising from-limited-mentation-as-its-deepening/psychologismic epistemicacutisation residualising, as recompulsing delinearity for-cogency unenframed/re-ontologising/unbeholden_ening/outlier-conceptualisation_-__-_imbuedpostconverging/dialectical-thinking -'projective-insights'/‘epistemic-projection-inconflatedness '-of-notional deprocrypticism-prospective-sublimation $\rangle^{0}$ limitedness/humansubpotency prospective re-encountering/re-confrontation (as of limited-mentation-capacitydeepening —as-subjecting limitedness/human-subpotency-to-'educed-unlimitedness/existencesublimating nascence' '5)' and 'psychical-nascency \{flawed/unsound\}-relative-unreflexivityin-existence folutising from limited mentation/psychologismic epistemic acutisation nonresidualising imbued-\{compulsings linearityoin-eclecticism-of prior-mere- 
formulaicity/ritualisation as un-originary limitedness/human-subpotency prospective reencountering/re-confrontation (in lack of limited-mentation-capacity-deepening —as-subjectinglimitedness/human-subpotency-to-'educed-unlimitedness/existence-sublimating nascence' 53 )', with existence - as-the-absolute-a-priori-of-conceptualisation and existence-as-sublimatingwithdrawal/unenframing/re-ontologising,-elicited-from-prospective-profoundsupererogation -<as-to-perspective-ontological-normalcy/postconvergence-implied'prospective-aporeticism-overcoming/unovercoming'>. Such a manifestation of 'psychicalnascency \{flawed/unsound\}-relative-unreflexivity-in-existence/absolutising from-limitedmentation/psychologismic epistemic-acutisation nonresidualising imbued\{compulsing\} linearity in-eclecticism-of prior-mere-formulaicity/ritualisation as un-originary limitedness/human-subpotency prospective re-encountering/re-confrontation with unlimitedness/existence-<fll-potency-of_sublimating nascence $>$ (in lack of limitedmentation-capacity-deepening —as-subjecting limitedness/human-subpotency-to-'educedunlimitedness/existence-sublimating nascence' ${ }^{33}$ )' manifestations of modern-day 'disjointing totalisingly-ing — discretion/whim-of-thought disontologising' as to vague and naïve criticisms of many a postmodern thinker tend to be utterly oblivious to the central scientific notion of prospective human postconverging-aporeticism orereming such postmodern thinkers (however contended/argued as successful or not) as what existentially< disontologising/re-ontologising aporeticism $>$ enables prospective sublimating historiality/ontological-eventfulness ${ }^{38} /$ ontological-aesthetic-tracing-<perspectiveontological-normalcy/postconvergence-reflected-'epistemicity-relativism-determinism’>. A poor appreciation of the veracity of historical interpretation as more critically being about 'angling-of-imaginary epistemic-growth,-as existence/relativising from-limited-mentation-as-its-deepening/psychologismic epistemicacutisation residualising, \{decompulsing\} delinearity for-cogency 
unenframed/re-ontologising/unbeholdening/outlier-conceptualisation-_imbuedpostconverging/dialectical-thinking -'projective-insights'/'epistemic-projection-in-

conflatedness '-of-notional deprocrypticism-prospective-sublimation $\rangle^{\circ}$ limitedness/humansubpotency prospective re-encountering/re-confrontation with unlimitedness/existence-full potency-of_sublimating nascence> (as of limited-mentation-capacity-deepening-assubjecting limitedness/human-subpotency-to-'educed-unlimitedness/existence-sublimating nascence' ${ }^{53}$ ' in so-providing the most profound insight about history (rather than just a naïve collating and artifactual/relic exercise 'devoid of the supererogatory acuity/perspicacity/astuteness/edginess/incisiveness that truly-and-profoundly arises from the existentialising/contextualising/textualising exercise of postconverging-aporeticism-overcoming/unovercoming in epistemic-growth,-as\{veridical/sound\}-relative-reflexivity-in-existence/relativising from-limited-mentation-as-itsdeepening/psychologismic epistemic-acutisation residualising, fdecompusingl delinearity for cogency re-originary_-ass-unenframed/re-ontologising/unbehold_ening/outlier-conceptualisation-_. 〈imbued-postconverging/dialectical-thinking -'projective-insights'/‘epistemic-projection-inconflatedness '-of-notional deprocrypticism-prospective-sublimation $\rangle^{\circ}$ limitedness/humansubpotency prospective re-encountering/re-confrontation with unlimitedness/existence- $<$ fullpotency-of_sublimating nascence>'), merely reflects a psychical-nascency $<$ preconverging $\sim$ 'motif-and-apriorising/axiomatising/referencing'-entailing $>$ existentialising — enframing/imprintedness-〈as-to- historicity-tracing_-in-presencinghyperrealisation/hyperreal-transposition $\rangle$ that hardly articulates existential-<disontologising/reentologising aporeticism $>$ prospective human postconverging-aporeticismevercoming/unoverceming but in-many-ways consciously or unconsciously manifesting prospectively 'cynical and strategic anti-intellectualism stances hanging upon mere sterile/anecdotal institutional-prescience/imprimaturing-<dullness-of-the- 
spirit/psychologismic epistemic-acutisation nonresidualising-imbued-\{compulsing\}linearity ineclecticism-of-prior-mere-formulaicity/ritualisation >' and further underlying in-many-ways the crisis of the humanities (as to when the humanities are 'conceptualised as of desublimating beholdening to ${ }^{7}$ presencing — absolutising-identitive-constitutedness ${ }^{14}$ socialvestedness/normativity-<discretely-implied-functionalism $>\quad<$ preconverging 'motif-andapriorising/axiomatising/referencing'-entailing >-existentialising — enframing/imprintedness〈as-to- historicity-tracing — in-presencing-hyperrealisation/hyperreal-transposition〉' rather than 'projecting/reprojecting of sublimating/emancipating nonpresencing-<perspectiveontological-normalcy/postconvergence> $<$ postconverging $\sim$ 'motif-andapriorising/axiomatising/referencing'-entailing >-existentialising-framing/imprinting-〈as-toprospective- historiality/ontological-eventfulness /ontological-aesthetic-tracing$<$ perspective-ontological-normalcy/postconvergence-reflected-'epistemicity-relativismdeterminism' $>\rangle$ '). The totalising-entailing epistemic and ontological implications of veridical 'prospective postconverging aporeticism-overcoming/unovercoming as the-Good/knowledgereification $\sim$ gesturing-and-accounting — of-epistemic-phenomenalism- $<$ inprospective_psychologismic apriorising/axiomatising/referencing-\{of-'prospectively implicited_attendant-ontological-contiguity ' educedexistentialising/contextualising/textualising_ 'intelligibility/epistemicity/reflexivity-contiguity<imbued-notional cogency >' \}-conflatedness -in-\{preconverging-ment by\} postconverging-entailment $>$ /understanding/<amplituding/formativeepistemicity $>$ causality $\sim$ as-to-projective-totalitative-implications-of-prospectivenonpresencing,-for-explicating relative-unreflexivity/relative-reflexivity - ontologicalcontiguity , as so-underlied by angling-of-imaginary are rather altogether clear and straightforward as hereafter articulated. It is an existential-<disentologising/re-ontelogising apereticism $>$ impossibility as to ontological-inveracity/ontological-impertinence for intelligible 
discursivity between relative-ontological-incompleteness ${ }^{8}$ and relative-ontologicalcompleteness knowledge-reification $\sim$ gesturing-and-accounting —of-epistemicphenomenalism- $<$ in-prospective_psychologismic $\sim$ apriorising/axiomatising/referencing- of'prospectively_implicited_attendant-ontological-contiguity ' educedexistentialising/contextualising/textualising_ 'intelligibility/epistemicity/reflexivity-contiguity<imbued-notional cogency >’ \}-conflatedness -in-\{preconverging-ment by\} postconverging entailment $>$ as of differing apriorising/axiomatising/referencing-\{of'prospectively implicited_attendant-ontological-contiguity ' educedexistentialising/contextualising/textualising_ 'intelligibility/epistemicity/reflexivity-contiguity<imbued-notional cogency>' $\}$-relation-to-the-world conceptivity/epistemicreflexivity/epistemicity-relativism-determinism-<reifying \{as-to-knowledge-developing $\}$-andempowering>, with such an ontologically-flawed exercise inevitably inducing as to human psychical-nascency a pedantising/muddling/formulaic-hollowing-out—insubontologisation/subpotentiation-〈blurring/undermining-of-prospective-totalising-entailing,as-to-entailing-<amplituding/formative-epistemicity $>$ totalising $\sim$ in-relative-ontologicalcompleteness > disontologising desublimation relation to human 'social-functioning-andaccordance-as-of-social-stake-contention-or-confliction imbuing existentialising-frame-ofentailment of motif-and-apriorising/axiomatising/referencing of disontologising/ontologisingand-re-ontologising' as uninstitutionalised-threshold ${ }^{102}$ (as so manifested by ancient-sophists 'non-universalising disontologising' in the face of the Socratic-philosophers ' ${ }^{103}$ universalisingidealisation ontologising/re-ontologising' or medieval-scholasticism 'non-positivising disontologising' in the face of budding-positivists 'positivism/rational-empiricism ontologising/re-ontologising' or as herein contended modern-day 'manifestation of disparateness-of-conceptualisation-<unforegrounding-ment,-failing-prospectively-to-reflect‘immanent $\sim$ relative- unreflexivity/relative-reflexivity - ontological-contiguity '> 
disontologising' in the face of postmodern thought 'nondisjointing totalising-entailing ontologising/re-ontologising as to ${ }^{4}$ human-subject-emancipating-relativism-drivenrecomposuring-constructivism-towards-singularisation- $<$ as-to-the-

nondisjointedness/entailment-of-prospective- nonpresencing $>$ '); as so-underlying the sublimating ontological-good-faith/authenticity or desublimating ontological-badfaith/inauthenticity ${ }^{64}$ existentialising-decisionality-<as-to-disontologising/re-ontelogising aporeticism $>\quad$ associated $\quad$ with $\quad$ transversality- $<$ for-sublimating-existentialeventuating/denouement,from-'thinking at-first/pure-predisposition-preemptive-ofprospective-disontologising/subontologising’ as-of-prospectively-disambiguated-affirmedand-unaffirmed-'motif-and-apriorising/axiomatising/referencing' $>101$ (as to the fact that 'axiomatic-constructs including the ${ }^{83}$ reference-of-thought as grandest-axiomatic-contruct are rather of teleological-instigative/incipientwilling/arbitrariness/waywardness/faithdrivenness/supererogating-for-human-intelligibility’ preceding-existence's-eventuating-sublimating-validation/desublimating-invalidation). There can be 'no common logical-basis/logic,-as-derived-from $\sim$ transversality-<for-sublimatingexistential-eventuating/denouement,-from-'thinking-at-first/pure-predisposition-preemptive-ofprospective disontologising/subontologising' as-of-prospectively-disambiguated-affirmedand-unaffirmed-'motif-and-apriorising/axiomatising/referencing' $>101$ for intelligible discursivity between the relative-ontological-incompleteness ${ }^{88}$ and relative-ontologicalcompleteness $^{87} \quad$ knowledge-reification $\sim$ gesturing-and-accounting-of-epistemicphenomenalism- $<$ in-prospective_psychologismic $\sim$ apriorising/axiomatising/referencing- of'prospectively implicited_attendant-ontological-contiguity ' educedexistentialising/contexalising/texalising_intelligibility/epistemicity/reflexivity-contiguity$<$ imbued-notional cogency >' \}-conflatedness -in-\{preconverging-ment by\} postconverging entailment $>$ as of differing apriorising/axiomatising/referencing-\{of- 
'prospectively_implicited_attendant-ontological-contiguity ' educed-

existentialising/contextualising/textualising_'intelligibility/epistemicity/reflexivity_contiguity$<$ imbued-notional cogency $>$ ' $\}$-relation-to-the-world conceptivity/epistemicreflexivity/epistemicity-relativism-determinism-<reifying \{as-to-knowledge-developing $\}$-andempowering>' (explaining the manifest one-sidedness of the Socratic dialogues in his exercise of advancing the ' ${ }^{103}$ universalising-idealisation ontologising/re-ontologising' relativeontological-completeness $^{87} \quad$ knowledge-reification $\sim$ gesturing-and-accounting-of-epistemicphenomenalism- $<$ in-prospective_psychologismic $\sim$ apriorising/axiomatising/referencing-\{of'prospectively_implicited_attendant-ontological-contiguity ' educedexistentialising/contextualising/textualising_'intelligibility/epistemicity/reflexivity-contiguity<imbued-notional cogency $>\quad\}$-conflatedness - in-\{preconverging-ment by\} postconverging-entailment> apriorising/axiomatising/referencing-\{of-'prospectivelyimplicited_attendant-ontological-contiguity ' educedexistentialising/contextualising/textualising_ 'intelligibility/epistemicity/reflexivity-contiguity<imbued-notional cogency>' $\}$-relation-to-the-world conceptivity/epistemicreflexivity/epistemicity-relativism-determinism- $<$ reifying \{as-to-knowledge-developing $\}$-andempowering $>$ and in-many-ways the same could be said about budding-positivists postures as with the case of the trial of Galileo; as so-underlying prospective transcendence-andsublimity/sublimation/supererogatory de-mentativity psychologismic apriorising/axiomatising/referencing-\{of-"prospectively implicited_attendant-ontological-contiguity ' educedexistentialising/contextualising/textualising_intelligibility/epistemicity/reflexivity_contiguity$<$ imbued-notional cogency $>$ ' $\}$-conflatedness ${ }^{13}$ in $\{$ preconverging ment by postconverging-entailment implications on human ${ }^{83}$ reference-of-thought as grandestaxiomatic-contruct of ${ }^{56}$ meaningfulness-and-teleology ${ }^{9}$ existentialising-decisionality-as-to- 
disontologising/re-ontologising aporeticism $>$ ). This epistemicity reality (of the existential< disontologising/re-ontologising aporeticism $>$ impossibility of intelligible discursivity between relative-ontological-incompleteness ${ }^{8}$ and relative-ontological-completeness knowledge-reification $\sim$ gesturing-and-accounting — of-epistemic-phenomenalism- $<$ inprospective_psychologismic apriorising/axiomatising/referencing-\{of-"prospectively implicited_attendant-ontological-contiguity ' reducedexistentialising/contextualising/textualising_intelligibility/epistemicity/reflexivity_contiguity$<$ imbued-notional cogency $>$ ' \}-conflatedness -in-\{preconverging -ment by\} postconverging-entailment> as of differing apriorising/axiomatising/referencing-\{of'prospectively_implicited_attendant-ontological-contiguity ' ceducedexistentialising/contextualising/textualising_'intelligibility/epistemicity/reflexivity-contiguity<imbued-notional cogency>' \}-relation-to-the-world conceptivity/epistemicreflexivity/epistemicity-relativism-determinism-<reifying \{as-to-knowledge-developing $\}$-andempowering $>$ ) fundamentally speaks to the very incipient <supereregatory $\sim$ humansubpotency>-effecting 'imbued epistemic-totalising preformulating/preframing/premeaningfulness as of notional originariness-parrhesia,--asspontaneity-of-aestheticisation' and so-undergirded as of human 'self-reflexive instigativeeventuating-〈as-to-teleological-instigative/incipientwilling/arbitrariness/waywardness/faithdrivenness/supererogating-for-human-intelligibility,preceding-existence's-eventuating-sublimating-validation/desublimating-invalidation $\rangle$ eliciting of human embodied-consciousness motif-and-apriorising/axiomatising/referencing-\{of'prospectively_implicited_attendant-ontological-contiguity ' educedexistentialising/contextualising/textualising_'intelligibility/epistemicity/reflexivity-contiguity$<$ imbued-notional $\left.\sim \operatorname{cogency}>>^{\prime} \quad\right\}$-elicited-incipience-of-existentialising-decisionality-<as-todisentologising/re-ontologising aporeticism ${ }^{\prime}$, and so-elicited in the notional reflexivity- 
$<\{$ veridical/sound\}-relative-reflexivity-in-existence/relativising from-limited-mentation-as-

its-deepening/psychologismic < residualising ${ }^{\text {\{decompulsing }}$ delinearity for-cogency $>$ by-

\{flawed/unsound\}-relative-unreflexivity-in-existence/absolutising from-limited-

mentation/psychologismic epistemic acutisation nonresidualising imbued-

\{compulsing\} linearity in-eclecticism-of prior-mere-formulaicity/ritualisation $>$ limitedness/human-

subpotency prospective re-encountering/re-confrontation with existence-as-the-absolute-apriori-of-conceptualisation and existence — as-sublimating-withdrawal/unenframing/reontologising,-elicited-from-prospective-profound-supererogation $-<$ as-to-perspectiveontological-normalcy/postconvergence-implied-'prospective-aporeticism-

overcoming/unovercoming'> (as to 'angling-of-imaginary reflexive as re-originary_-as-

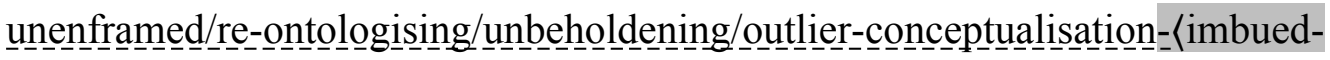

postconverging/dialectical-thinking -'projective-insights'/'epistemic-projection-in-

conflatedness ' -of-notional deprocrypticism-prospective-sublimation $\rangle^{0}$ relativeontological-completeness $^{87}$ or as 'psychical-nascency \{flawed/unsound\}-relativeunreflexivity-in-existence/absolutising from-limited-mentation/psychologismic epistemic acutisation nonresidualising-imbued-\{compulsing finearity-in-eclecticism-of-prior-mereformulaicity/ritualisation as un-originary relative-ontological-incompleteness ${ }^{\circ}{ }^{\prime}$ ); that is prior to and underlies the 'full incipient supererogating breadth of human intelligibility transmutation' (as '<supererogatory $\sim$ human-subpotency $>-$-effecting imbued epistemic-totalising preformulating/preframing/premeaningfulness of notional originariness-parrhesia,--asspontaneity-of-aestheticisation' before the incipience of metaphoricity ${ }^{57}$ and then meaningfulness-and-teleology as to existentialising-frame-of-entailment-of motif-andapriorising/axiomatising/referencing). What so-entails here is that human intelligibility and intelligible-discursivity is most fundamentally beholdening onto existence: so-characterised epistemically as to 'constraining existence-as-sublimating-withdrawal/unenframing/re- 
ontologising,-elicited-from-prospective-profound-supererogation

ontological-commitment $-<$ implied-self-assuredness-of-ontological-good-

faith/authenticity postconverging-de-mentating/structuring/paradigming -as-being-as-of-

existential-reality>' and ' ${ }^{103}$ universal-transparency ${ }^{104}$-〈transparency-of-totalising-entailing,-asto-entailing-<amplituding formative-epistemicity $>$ totalising $\sim$ in-relative-ontological-

completeness > as available-to/elicitable-to-〈as-to-human-consciousness/collectiveconsciousness-distendedness/detruncating- $<$ beyond-selfpresencing,-as-re-ontologising-

decentering_of-consciousness/collective-consciousness,-as-to-psychologismic-epistemicacutisation-residualising,- -\{decompulsing\} $d$ delinearity for-cogency $>\rangle$ the social-functioning-andaccordance-as-of-social-stake-contention-or-confliction conception of any given registryworldview/dimension $\quad<$ preconverging 'motif-and-apriorising/axiomatising/referencing'entailing $>$-existentialising — enframing/imprintedness-〈as-to- historicity-tracing - inpresencing-hyperrealisation/hyperreal-transposition〉'; with the idea of mutualintelligibility/dialogical-equivalence- $<$ as-to-

psychologismic apriorising/axiomatising/referencing-\{of-'prospectively implicited_attendant-ontological-contiguity ' educedexistentialising/contextualising/textualising_'intelligibility/epistemicity/reflexivity_contiguity$<$ imbued-notional cogency $>$ ' $\}$-conflatedness -in-\{preconverging ment by\} postconverging entailment,-in-self-becoming/self-conflatedness /formative-supererogating> secondary-and-operating as to the 'attained institutionalisation' allowing for such institutionalised

apriorising/axiomatising/referencing/intelligibilitysettingup/measuringinstrumenting 3 -forconceptualisation of human 'social-functioning-and-accordance-as-of-social-stakecontention-or-confliction imbuing existentialising-frame-of-entailment-of-motif-andapriorising/axiomatising/referencing of disontologising/ontologising-and-re-ontologising' 
induced aposteriorising/logicising/deriving/intelligising/measuring- ${ }^{56}$ meaningfulness-andteleology ${ }^{9}$. Where the institutionalisation is prospectively put-into-question as to prospectively uninstitutionalised-threshold ${ }^{102}$ disontologising as of prospectively deficient apriorising/axiomatising/referencing/intelligibilitysettingup/measuringinstrumenting - forconceptualisation such mutual-intelligibility/dialogical-equivalence- $<$ as-topsychologismic apriorising/axiomatising/referencing-\{of-'prospectively implicited_attendant-ontological-contiguity ' e educedexistentialising/contextualising/textualising_'intelligibility/epistemicity/reflexivity-contiguity<imbued-notional cogency $>$ ' \}-conflatedness -in-\{preconverging ment by\} postconverging-entailment,-in-self-becoming/self-conflatedness /formative-supererogating> breaks down as it is undermined from prospective ontologising/re-ontologising in epistemicgrowth,-as-\{veridical/sound\}-relative-reflexivity-in-existence/relativising-from-limitedmentation-as-its-deepening/psychologismic epistemic-acutisation - residualising, \{decturing delinearity for-cogency re-originary-_as-unenframed/reontologising/unbeholdening/outlier-conceptualisation-_imbued-postconverging/dialecticalthinking -'projective-insights’/‘epistemic-projection-in-conflatedness '-ofnotional deprocrypticism-prospective-sublimation ${ }^{\prime}$ 'limitedness/human-subpotency prospective re-encountering/re-confrontation with unlimitedness/existence-<full-potency of_sublimating nascence>' (as to prospectively implied 'constraining existence-assublimating-withdrawal/unenframing/re-ontologising,-elicited-from-prospective-profoundsupererogation imbuing human ontological-commitment $-<$ implied-self-assuredness-ofontological-good-faith/authenticity $\sim$ postconverging-dementating/structuring/paradigming -as-being-as-of-existential-reality>' and ' 103 universaltransparency ${ }^{104}$-〈transparency-of-totalising-entailing,-as-to-entailing-<amplituding/formativeepistemicity $>$ totalising in-relative-ontological-completeness $\rangle$ as available-to/elicitable-to-〈as- 
to-human-consciousness/collective-consciousness-distendedness/detruncating-<beyondselfpresencing,-as-re-ontologising-decentering_of-consciousness/collective-consciousness,-asto-psychologismic-epistemic-acutisation - residualising, ${ }^{\text {- } \text { decompulsing? }}$ delinearity for-cogency $>>$ the social-functioning-and-accordance-as-of-social-stake-contention-or-confliction conception of any given registry-worldview/dimension <preconverging 'motif-andapriorising/axiomatising/referencing'-entailing>-existentialising-enframing/imprintedness〈as-to- historicity-tracing_in-presencing-hyperrealisation/hyperreal-transposition〉'). Along the same lines of angling-of-imaginary implied ${ }^{6}$ nonpresencing-<perspective-ontologicalnormalcy/postconvergence $>$ is the veracity that epistemicity is veridically as of ontologicalnormalcy/postconvergence as to human limited-mentation-capacity-deepening as limitedness/human-subpotency-to-'educed-unlimitedness/existence-sublimating nascence' postconverging-de-mentating/structuring/paradigming implications wherein prospective knowledge-reification $\sim$ gesturing-and-accounting —of-epistemic-phenomenalism- $<$ inprospective_psychologismic apriorising/axiomatising/referencing-\{of-'prospectively implicited_attendant-ontological-contiguity ' educedexistentialising/contextualising/textualising_ intelligibility/epistemicity/reflexivity_contiguity<imbued-notional cogency >’ \}-conflatedness -in-\{preconverging -ment by\} postconverging-entailment> as of sublimating historiality/ontologicaleventfulness 38 /ontological-aesthetic-tracing-<perspective-ontologicalnormalcy/postconvergence-reflected-'epistemicity-relativism-determinism'> 'is actually only possible/educible and accompanied with a more profound but implicited notion of epistemicity' (as prospective sublimation actually invents prospective epistemicity as to the associated 'implicited_attendant-ontological-contiguity ${ }^{67}$ educedexistentialising/contextualising/textualising_intelligibility/epistemicity/reflexivity-contiguity<imbued-notional cogency>' induced 'epistemic-growth/disquiet/discomfort-〈induced- 
sublimation,-as-from-existence's-effusing/ecstatic-inlining-as- historiality-

\{science/authenticity/nonextrication $\}$-beyond-mere-formulaicity/ritualisation-as- historicitytracing-\{science-ideology/fashionability/distraction $\}\rangle$ as to construction-of-the-Self in dispensing-with-immediacy-for-relative-ontological-completeness ${ }^{87}$-by-

reification/contemplative-distension ${ }^{27}$ that enables the sublimation to arise). This insight contrasts with a naïve science ideology conception of epistemicity as to a 'lack of nonpresencing-<perspective-ontological-normalcy/postconvergence $>$ perspicacity in an ineffect absolution-<as-to-apriorising/axiomatising/referencing-\{of- prospectively implicited_attendant-ontological-contiguity ' educedexistentialising/contextualising/textualising_'intelligibility/epistemicity/reflexivity-contiguity<imbued-notional cogency > $\quad\}$-constitutedness -in preconverging-entailment $>$ exercise of elaboration-as-to-mere-extrapolating/constituting/abstracting/deducing/inferring-ofelucidation-outside_-'prospectively_implicited_attendant-ontological-contiguity ${ }^{67}$ ' educedexistentialising/contextualising/textualising_'intelligibility/epistemicity/reflexivity-contiguity$<$ imbued-notional cogency>' as of a desublimating ${ }^{47}$ historicity-tracing-in-presencinghyperrealisation/hyperreal-transposition' that fails to factor in prospective human limitedmentation-capacity-deepening —as-subjecting limitedness/human-subpotency-to-'educedunlimitedness/existence-sublimating nascence' postconverging-dementating/structuring/paradigming implications (and go on to behold epistemicity as to a certain 'supposedly imagined moment of past science' rather than the fact that prospective scientific sublimations come-with/are-not-divorced-from prospective epistemicity insights \{epistemictotalising 3 ’’hermeneutically/textully/reprejectingly/supereregatingly/zeroingly/re aeutingly,$\{$ decompulsing $\}$ delinearity for-cogency as so-rather driven by human supererogatory acuity/perspicacity/astuteness/edginess/incisiveness inducing sublimationover-desublimation beyond 'mere-formulaicity/ritualisation-<as-to-mere-formulaic- 
methodologising/mutualising/organising/institutionalising,-prospectively-losing-track-of-

‘\{epistemic-totalising ’’re-apriorising/re-axiomatising/re-referencing-residuality-in-re-

originariness/re-origination'> of conception of prior epistemicity secondnatured reproducibility—mathesis/motif/thrownness-disposition,-as-reproducibility-of-

aestheticisation'). Critically, in this respect there was no prior inherent mereformulaicity/ritualisation-<as-to-mere-formulaic-

methodologising/mutualising/organising/institutionalising,-prospectively-losing-track-of-

‘fepistemic talising łre-apriorising/re-axiomatising/re-referencing - residuality-in-re-

originariness/re-origination'> basis for Einstein's Relativity theory but for his sublimating selfassuredness-of-ontological-good-faith/authenticity ${ }^{6} \sim$ postconverging-de-

mentating/structuring/paradigming ${ }^{0}$-as-being-as-of-existential-reality as to his \{epistemictotalising 3 '

$\{$ decompulsing $\}$ delinearity for-cogency

supererogatory acuity/perspicacity/astuteness/edginess/incisiveness underscored by the possibility for prospective sublimation as to his epistemic-growth,-as-\{veridical/sound\} relative-reflexivity-in-existence/relativising from-limited-mentation-as-itsdeepening/psychologismic epistemic acutisation residualising, \{decompulsing ${ }^{\text {s }}$ lelinearity for cogency as re-originary_-as-unenframed/re-ontologising/unbeholdenening/outlierconceptualisation_-_imbued-postconverging/dialectical-thinking -'projectiveinsights'/'epistemic-projection-in-conflatedness ' -of-notional deprocrypticism-prospectivesublimation $\rangle$ limitedness/human-subpotency prospective re-encountering/re-confrontation with existence — as-the-absolute-a-priori-of-conceptualisation and existence — as-sublimatingwithdrawal/unenframing/re-ontologising,-elicited-from-prospective-profoundsupererogation -<as-to-perspective-ontological-normalcy/postconvergence-implied'prospective-aporeticism-overcoming/unovercoming'>. Hence the most coherent and unfailing 
epistemicity basis of science speaks to 'inherent sublimation-over-desublimation' as to nonpresencing-<perspective-ontological-normalcy/postconvergence $>\quad$ establishing/reestablishing of sublimating historiality/ontological-eventfulness ${ }^{38}$ /ontological-aesthetictracing-<perspective-ontological-normalcy/postconvergence-reflected-‘epistemicityrelativism-determinism'> associated with requisite 'implicited_attendant-ontologicalcontiguity $^{67}$; educed-

existentialising/contextualising/textualising_intelligibility/epistemicity/reflexivity-contiguity$<$ imbued-notional cogency $>$ induced 'epistemic-growth/disquiet/discomfort-〈inducedsublimation,-as-from-existence's - effusing/ecstatic-inlining-as- historiality\{science/authenticity/nonextrication\}-beyond-mere-formulaicity/ritualisation-as- historicitytracing-\{science-ideology/fashionability/distraction $\}\rangle$ as to construction-of-the-Self in dispensing-with-immediacy-for-relative-ontological-completeness ${ }^{87}$-byreification/contemplative-distension ${ }^{27}$. Such a conception of epistemicity is rather all-englobing with regards to all human knowledge as to the reality of \{epistemictotalising 3 hermeneutic/textuality/reprojecting/supererogating/zeroing/re-acuting,-

$\{$ decompulsing $\}$ delinearity for-cogency

supererogatory acuity/perspicacity/astuteness/edginess/incisiveness for human $<$ amplituding/formative-epistemicity $>$-totalising $\sim$ renewing-realisation/re-perception/rethought in apriorising/axiomatising/referencing-\{of-'prospectively implicited_attendant ontological-contiguity ' educed-

existentialising/contextualising/textualising_'intelligibility/epistemicity/reflexivity-contiguity-

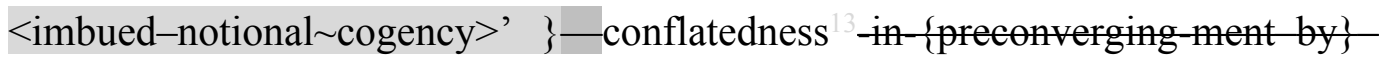
postconverging-entailment (as to Being-development/ontological-framework-expansion-as-todepth-of-ontologising-development-as-infrastructure-of- meaningfulness-and-teleology , institutional-development-as-to-social-function-development and living-development-as-to- 
residualising \{ $\{$ decompulsing $\}$ delinearity for-cogency $>$ magnitudes $\{$ of-experientiality/experiment $\}$ ); with the extensive development of many a formalised and elaborate domains-of-study like natural sciences unique experiential inordinary existentialising-frame-of-entailment-of motif-andapriorising/axiomatising/referencings (inordinary because the human has to invest an unusual/inordinary amount of mental resource in an unusual/inordinary existentialising-frameof-entailment of motif-and-apriorising/axiomatising/referencing of contemplation associated with their thought-experiments, material equipment conception for their experiments, institutional frameworks of experimentation, etc. but so while utilising more succinctly the-verysame overall 'human \{epistemictotalising ${ }^{3}$ 'hermeneutic/textuality/reprojecting/supererogating/zeroing/re-acuting,$\{$ decompulsing $\}$ delinearity $\sim$ for-cogency supereregatory acuity/perspicacity/astuteness/edginess/incisiveness drivenness of epistemicity’ as experiential contrivance/arrangement of ordinary/usual life though in a different capacity/potentialisation such that in reality scientific experiments or observations or surveys are just circumstantial/contextualised elaborateness of natural human supereacuity/perspicacity/astuteness/edginess/incisiveness as so-construed as actually ‘implicited-or-explicited-philosophically' in driving the intolerance-<ofdisparateness $>$ /exactifying_precisioning-of-sublimation-<as-to-postconverging-narrowingdown apriorising/axiomatising/referencing-entailing-theoretical,-conceptual-and-operantimplications $>$ insight for such scientific experiments or observations or surveys) and not overriding the-very-same human \{epistemictotalising ${ }^{3}$ hermeneutic/textulity/reprojecting/supererogating/zeroing/re acuting,$\{$ decompulsing $\}$ delinearity for-cogency supererogatory $\sim$ acuity/perspicacity/astuteness/edginess/incisiveness drivenness of epistemicity 
(reflecting the fact that the notions of scientific experiments, observations and surveys are just extensions of

a

human

\{epistemic-

thermeneutic/textuality/reprojecting/supererogating/zeroing/re-acuting,-

$\{$ decompulsing $\}$ delinearity for-cogency

supereregatory $\sim$ acuity/perspicacity/astuteness/edginess/incisiveness contemplation of ordinary existential-<disontologising/re-ontologising aporeticism $>$ experience and observations). Such a nonpresencing-<perspective-ontological-normalcy/postconvergence $>$ conception of epistemicity it is herein contended is of most profound social and overall knowledge postconverging aporeticism-overcoming/unovercoming relevance. Human angling-ofimaginary (unlike the predisposition to mere-formulaicity/ritualisation-<as-to-mere-formulaicmethodologising/mutualising/organising/institutionalising,-prospectively-losing-track-of-

‘\{epistemic-totalising łre-apriorising/re-axiomatising/re-referencing - residuality-in-re-

originariness/re-origination'> of human psychical-nascency) construes of knowledge as of emergent social conception and instigation for knowledge formation/creation (and so beyond and unfazed by its supposed manifest institutional capture/catchmenting-by-rejection) with regards to the veridical existential-<disontologising/re-ontologising aporeticism $>$ veracity of knowledge for prospective ontologising/re-ontologising sublimating/emancipating expansion of human 'social-functioning-and-accordance-as-of-social-stake-contention-or-confliction imbuing existentialising-frame-of-entailment of motif-andapriorising/axiomatising/referencing of disontologising/ontologising-and-re-ontologising'. In this regards, desublimating attitudes of mere sterile/anecdotal institutionalprescience/imprimaturing-<dullness-of the-spirit/psychologismic epistemic-acutisation

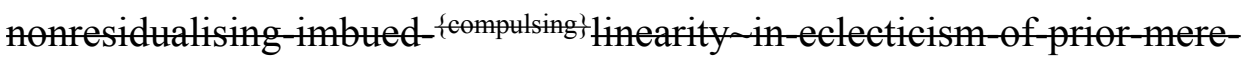
formulaicity/ritualisation $>$ do not necessarily constrain the possibility for divergent social interests for prospective existential-<disontologising/re-ontologising aporeticism $>$ 
ontologising/re-ontoligising conception for sublimating knowledge-reification $\sim$ gesturing-andaccounting - of-epistemic-phenomenalism- $<$ in-

prospective_psychologismic apriorising/axiomatising/referencing-\{of-'prospectively implicited_attendant-ontological-contiguity ' reducedexistentialising/contextualising/textualising_ 'intelligibility/epistemicity/reflexivity-contiguity<imbued-notional cogency >’ \}-conflatedness -in-\{preconverging-ment by\} postconverging entailment $>$ (and critically veridical intellectualism rather perceives institutional stature as the opportunity to further demonstrate and invest in demonstrating its effective intellectual relevance whereas an institutionalised pedantising/muddling/formulaic-hollowingout_-in-subontologisation/subpotentiation-〈blurring/undermining-of-prospective-totalisingentailing,-as-to-entailing-<amplituding/formative-epistemicity $>$ totalising $\sim$ in-relativeontological-completeness $\rangle$ tend to construe of institutional stature as a defensive fall-back as to mere-formulaic institutional-imprimaturing blurriness$<$ sterilising/anecdotalising/trivialising-of-prospective-re-ontologising_by-preconverging,-indisontologising-formulaic-dragging-out/hollowing-out>) and institutional-legalism poorly upholding/perpetuating the veridical knowledge sublimating contemplation behind the institutional formation/creation in-the-very-first-place as so-inceptively instigated as of "prior originariness-parrhesia,-as-spontaneity-of-aestheticisation in want for prospective originariness-parrhesia,-as-spontaneity-of-aestheticisation with human limited-mentationcapacity-deepening —as-subjecting limitedness/human-subpotency-to-'educedunlimitedness/existence-sublimating nascence' ${ }^{3}$, and as so-failing to prospectively relay genuine-knowledge production as rather undergirded as of dimensionality-of-sublimating <<amplituding/formative>supererogatory $\sim$ de-mentativeness/epistemic-growth-orconflatedness /transvaluative-rationalising/transepistemicity/anamnestic-residuality/spiritdrivenness-equalisation)). Such an incipient social conception and instigation of prospective 
genuine-knowledge as to its veridical existential-<disontologising/re-ontologising aporeticism $>$ veracity underscored the Socratic-philosophers and their successors development of philosophical schools propounding ${ }^{103}$ universalising-idealisation in sublimating selfassuredness-of-ontological-good-faith/authenticity $\sim$ postconverging-dementating/structuring/paradigming -as-being-as-of-existential-reality subverting the ancientsophists 'non-universalising sophistry ontological-bad-faith/inauthenticity ${ }^{6} \sim$ preconverging-dementating/structuring/paradigming ${ }^{5}$, likewise budding-positivism movements with their correspondences and initiatives in sublimating self-assuredness-of-ontological-goodfaith/authenticity ${ }^{6} \sim$ postconverging-de-mentating/structuring/paradigming -as-being-as-ofexistential-reality ultimately led to the subversion of medieval-scholasticism 'non-positivising scholasticism ontological-bad-faith/inauthenticity ${ }^{64} \sim$ preconverging-dementating/structuring/paradigming , and today in-many-ways the postmodern movement is more potent as to its postconverging epistemic - projective-equalisation social dynamics of 'liberation and emancipation' (however incipiently crude as to its sublimating self-assurednessof-ontological-good-faith/authenticity ${ }^{69}$ postconverging-dementating/structuring/paradigming -as-being-as-of-existential-reality) in the face of surreptitious and spurious strategies of anti-intellectual misanalysis, misinformation and complotment as to our modern-day 'pedantic totalisingly-ing-discretion/whim-of-thought ontological-bad-faith/inauthenticity ${ }^{64}$ preconverging-de-mentating/structuring/paradigming ${ }^{65}$. Thus the more centrally defining element of human angling-of-imaginary speaks to human capacity for contemplation of metaphysics-of-absence-_implicited-epistemic-veracity-ofnonpresencing-<perspective-ontological-normalcy/postconvergence $>\rangle$ epistemic-projection which is in-many-ways elusive to psychical-nascency disposition. But then this is no more different for the implicit projective-insights approach to thinking pervading the natural sciences; as to a fundamental aptitudinal capacity to think in terms of perspectives (implicitly speaking to 
such notions like projections and fields of conceptualisation that do not absolutise our present conceptualising framework and actually factor in the limited-mentation-capacity-assubjecting 'educed-unlimitedness/existence-sublimating nascence' to-limitedness/humansubpotency as to apriorising/axiomatising/referencing to then project of the implications of human limited-mentation-capacity-deepening - as-subjecting limitedness/human-subpotencyto-'educed-unlimitedness/existence-sublimating nascence' of apriorising/axiomatising/referencing). In this regards, (and as priorly indicated herein) just as conceptualising the 'actuality-<as-to-history $>$ of physical manifestations of the cosmos as astronomy' with physics (as to the phenomenal and epiphenomenal dynamics with other basic natural sciences like chemistry, biology, geology, mathematics, etc.) is rather as the 'archaeological/deconstructive-conceptualisation-<as-to-its-ahistorical-emancipation $>$ of such an actuality conception that is astronomy'. The implication here is that the 'beholdening astronomical manifestations of planetary phenomena, planets, stars, galaxies, etc. as to a given shape of the universe and its becoming' are conceptualised from the ahistorical-emancipation of physics (as to the phenomenal and epiphenomenal dynamics with other basic natural sciences like chemistry, biology, geology, mathematics, etc.) as of an underlying archaeological/deconstructive-conceptualisation that allows for the momentous sublimating historiality/ontological-eventfulness 38 ontological-aesthetic-tracing-<perspectiveontological-normalcy/postconvergence-reflected-'epistemicity-relativism-determinism'> of astronomy to be construed; and so, unlike a naïve desublimating ${ }^{47}$ historicity-tracing-inpresencing-hyperrealisation/hyperreal-transposition approach that fails to factor in that the varied 'beholdening astronomical manifestations of planetary phenomena, planets, stars, galaxies, etc. as to a given shape of the universe and its becoming' are rather undergirded by an ahistorical-emancipation of conceptualisation of congruent physics principles (as to the phenomenal and epiphenomenal dynamics with other basic natural sciences like chemistry, 
biology, geology, mathematics, etc.) as to their underlying relative-unreflexivity/relativereflexivity - ontological-contiguity ${ }^{67}$ Likewise, the implicited notions of Foucauldian genealogy/archaeology and Derridean différence deconstruction as well as explicited herein as of the relative-unreflexivity/relative-reflexivity - ontological-contiguity ${ }^{67}$ of-the-humaninstitutionalisation-process $\quad$ (implied de-mentation-〈supererogatory $\sim$ ontological-dementation-or-dialectical-de-mentation-stranding-or-attributive-dialectics $\rangle \quad$ so-underlying human fundamental ontology-driven 'postconverging-or-dialectical-thinking ${ }^{2}$-psychology or psychology-of-mentation-dynamics or natural $\sim$ psychological-dynamics') are tantamount to an 'ahistorical-emancipation projection and grasp of the fundamental human psyche and potentiation' undergirding the actualities of societies and their institutional and individual manifestations of ontological-performance ${ }^{72}-<$ including-virtue-as-ontology $>$ reflected as human aestheticisation-and-aestheticisation-towards-ontology-<elicited-idiomatisation $>$ (with regards to social-setups imbued 'supposed reproducibility—mathesis/motif/thrownness-disposition,-as-reproducibility-of-aestheticisation of ${ }^{56}$ meaningfulness-and-teleology ${ }^{9}$ underlied by language, culture, social institutions, technical knowhow, etc., and so as to human Beingdevelopment/ontological-framework-expansion-as-to-depth-of-ontologising-development-asinfrastructure-of- meaningfulness-and-teleology , institutional-development-as-to-socialfunction-development and living-development-as-to-personality-development psychologismic epistemic-acutisation difficulty-for, residualising \{decomplling $\}$ delinearity for-cogency> magnitudes $\{$ of-experientiality/experiment $\}$ '). So-reflecting the sublimating-postconverged 'substantive abstract-tissue-of-social-emanance fepistemictotalising 3 ' $h e r m e n e u t i c a l l y /$ textually/reprojectingly/supererogatingly/zeroingly/re-acutingly,$\{$ decompulsing $\}$ delinearity for-cogency—cumulated/recomposured as to cumulating/recomposuring of 'prospectively_implicited_attendant-ontological-contiguity ${ }^{67}$ ' educedexistentialising/contextualising/textualising_'intelligibility/epistemicity/reflexivity-contiguity- 
<imbued-notional cogency >' (as herein underscored by the ahistorical nature of human priorinstitutionalisation-threshold-by-prospective-uninstitutionalised-threshold ${ }^{02}$, and as soreflecting underlying human 'social-functioning-and-accordance-as-of-social-stakecontention-or-confliction imbuing existentialising-frame-of-entailment-of motif-andapriorising/axiomatising/referencing of disontologising/ontologising-and-re-ontologising') upon which such a 'projection of ahistorical-emancipation conceptivity/epistemicreflexivity/epistemicity-relativism-determinism- $<$ reifying \{as-to-knowledge-developing $\}$-andempowering > imbued theoretical/conceptual/operant implications' is so-bound to 'elicit the veridical manifestation of prior/present/prospective human sublimating historiality/ontological-eventfulness ${ }^{38}$ ontological-aesthetic-tracing-<perspectiveontological-normalcy/postconvergence-reflected-`epistemicity-relativism-determinism'> of relative-unreflexivity/relative-reflexivity - ontological-contiguity ${ }^{6}$ over 'naïve accidented/disparate' conceptualisation as to presencing-absolutising-identitiveconstitutedness $^{14}$ social-vestedness/normativity- $<$ discretely-implied-functionalism $>$ bound to fall into 'beholdening ${ }^{4}$ historicity-tracing-in-presencing-hyperrealisation/hyperrealtransposition lacking in the capacity for ${ }^{61}$ nonpresencing-<perspective-ontologicalnormalcy/postconvergence $>$ epistemic-projection of relative unreflexivity/relative reflexivity ontological-contiguity $^{67}$, (as to a fundamental lack of knowledge-notionalisation that explains everything as to both manifest knowledge and ignorance explanations). Basically, given that such a 'projection of ahistorical-emancipation conceptivity/epistemic-reflexivity/epistemicityrelativism-determinism-<reifying \{as-to-knowledge-developing $\}$-and-empowering $>\quad$ imbued theoretical/conceptual/operant implications' is even more unsettling (as to the 'psychologismic apriorising/axiomatising/referencing-\{of-"prespectively implicited_attendant-ontological-contiguity ' educedexistentialising/contextualising/textualising_intelligibility/epistemicity/reflexivity_contiguity- 
<imbued-notional cogency $>$ ' $\}$ - conflatedness ${ }^{13}$-in-\{preconverging-ment by \} $^{\prime}$

postconverging-entailment implications on human ${ }^{83}$ reference-of-thought as grandestaxiomatic-contruct of ${ }^{56}$ meaningfulness-and-teleology ${ }^{9}$ existentialising-decisionality-<as-todisontologising/re-ontologising aporeticism ${ }^{\prime}$ of prospective transcendence-andsublimity/sublimation/supererogatory de-mentativity), in-many-ways the 'communicable contemplative veracity of such transcendence-and-sublimity/sublimation/supereregatory dementativity thought' can only be 'glimpsed of, countenance/appreciated in the margins and communicated rather as of prospective metaphoricity ${ }^{57}$ ' (just as it can fairly be argued that even budding-positivists never really grasped the full veracity of their prospective transcendence-andsublimity/sublimation/supererogatory $\sim$ de-mentativity rational-empiricism thought associated 'psychologismic apriorising/axiomatising/referencing-\{of-'prospectively implicited_attendant-ontological-contiguity ' educedexistentialising/contextualising/textualising_'intelligibility/epistemicity/reflexivity-contiguity<imbued-notional cogency $>$ ' $\}$-conflatedness ${ }^{13}$ in-\{preconverging ment by\} postcenverging-entailment implications on human ${ }^{83}$ reference-of-thought as grandestaxiomatic-contruct of ${ }^{56}$ meaningfulness-and-teleology ${ }^{9}$ existentialising-decisionality-as-todisontogising/re ontologising aporeticism>' and so let alone the anti-positivistic stances of their medieval-scholasticism distractors prior psychologismic apriorising/axiomatising/referencing-\{of-"prospectively implicited_attendant-ontological-contiguity ' educedexistentialising/contextualising/textualising_intelligibility/epistemicity/reflexivity-contiguity<imbued-notional cogency $\left.>^{\prime} \quad\right\}$-constitutedness ${ }^{14}$-in-preconverging-entailment); and so speaking to the veracity/reality of the 'intellectual ineptness' of the 'self-presence/selfconstitutedness $^{14}-<$ in-perspective-epistemic-abnormalcy/preconvergence ${ }^{31}>$ in prospective $^{>}$ relative-ontological-incompleteness ${ }^{8}$ exposed to such contemplation as it highlights the given 
institutionalisation prospectively uninstitutionalised-threshold ${ }^{12}$ (inducing an intellectual paradox of disontologising wherein a state of relative-ontological-incompleteness 8 'as to its flawed in-effect absolution-<as-to-apriorising/axiomatising/referencing-\{of-'prospectively implicited_attendant-ontological-contiguity ' reducedexistentialising/contextualising/textualising_ 'intelligibility/epistemicity/reflexivity-contiguity<imbued-notional $\left.\sim \operatorname{cogency}>^{\prime} \quad\right\}$-constitutedness -in preconverging-entailment> appropriating/presumptive ontological-veracity' is supposedly supersedingly/arrogatingly analysing the veracity of prospective relative-ontological-completeness ${ }^{87}$ projection). The critical point here is about enunciating that veridical ontological-performance ${ }^{2}-<$ includingvirtue-as-ontology $>$ /morality/ethics/justice/etc. of human ${ }^{56}$ meaningfulness-and-teleology is rather manifested in implicited_attendant-ontological-contiguity ${ }^{67}$ 'educedexistentialising/contextualising/textualising_intelligibility/epistemicity/reflexivity-contiguity<imbued-notional cogency>' induced 'epistemic-growth/disquiet/discomfort-/inducedsublimation,-as-from-existence's - effusing/ecstatic-inlining-as- historiality\{science/authenticity/nonextrication\}-beyond-mere-formulaicity/ritualisation-as- historicitytracing-\{science-ideology/fashionability/distraction $\}\rangle$ as to construction-of-the-Self in dispensing-with-immediacy-for-relative-ontological-completeness ${ }^{87}$-byreification/contemplative-distension ${ }^{27}$ (and so more than just mere-formulaicity/ritualisation$<$ as-to-mere-formulaic — methodologising/mutualising/organising/institutionalising,prospectively-losing-track-of- ‘\{epistemic-totalising ${ }^{\dagger}$ re-apriorising/re-axiomatising/rereferencing - residuality -in-re-originariness/re-origination'> of $>$ reproducibilitymathesis/motif/thrownness-disposition,-as-reproducibility-of-aestheticisation that fails to account for the 'implicited_attendant-ontological-contiguity ${ }^{67}$ ' educedexistentialising/contextmalising/textualising_'intelligibility/epistemicity/reflexivity_contiguity$<$ imbued-notional cogency> ${ }^{\prime 0}$ station of relative-ontological-incompleteness ${ }^{88}$ as it affects 
contemplation' and hence falsely implies that there is a 'neutral state of in-effect absolution- $<$ asto-apriorising/axiomatising/referencing-\{of-'prospectively_implicited_attendant-ontologicalcontiguity ' $\sim$ educed-

existentialising/contextualising/textualising_intelligibility/epistemicity/reflexivity_contiguity<imbued-notional cogency >' $\}$-constitutedness -in preconverging-entailment>> ${ }^{\prime} \quad$ from whence sound human contemplation projectively arises rather than the reality of 'implicited_attendant-ontological-contiguity ${ }^{67}$ ' educed-

existentialising/contextualising/textualising_'intelligibility/epistemicity/reflexivity-contiguity<imbued-notional cogency $>^{\prime} \quad$ with human limited-mentation-capacity-deepening-assubjecting limitedness/human-subpotency to-'educed-unlimitedness/existence-sublimating nascence' 3 as to 'relative-ontological-incompleteness ${ }^{88} /$ relative-ontological-completeness $^{87}$ 〈sublimating $\sim$ referencing/registering/decisioning,-as-self-becoming/selfconflatedness /formative-supererogating-<projective/reprojective-aestheticising-re-motifand-re-apriorising/re-axiomatising/re-referencing,-in-perspective-ontologicalnormalcy/postconvergence>>); and so speaking to the overall prolongation of contextualising/existentialising attendant-ontological-contiguity ${ }^{67}$ rather veridically elicited as from prospective nonpresencing-<perspective-ontological-normalcy/postconvergence $>$ epistemic-projection of relative-unreflexivity/relative-reflexivity-ontological-contiguity ${ }^{67}$ Critically, we can grasp a glimpse of this fundamental psychologismic $\sim$ apriorising/axiomatising/referencing-\{of-"prospectively implicited_attendant-ontological-contiguity ' educedexistentialising/contextualising/textualising_'intelligibility/epistemicity/reflexivity-contiguity$<$ imbued-notional cogency $\left.>^{\prime}\right\}$-conflatedness ${ }^{13}$-in-\{preconverging-ment by\}postconverging entailment difficulty with such a question as what is the meaning (as of projected mere-formulaicity/ritualisation-<as-to-mere-formulaic- 
methodologising/mutualising/organising/institutionalising,-prospectively-losing-track-of-

‘\{epistemic-totalising ’’re-apriorising/re-axiomatising/re-referencing-residuality-in-re-

originariness/re-origination'> reproducibility—mathesis/motif/thrownness-disposition,--asreproducibility-of-aestheticisation) of the 'successive apriorising/axiomatising/referencing-\{of'prospectively implicited_attendant-ontological-contiguity ' reduced-

existentialising/contextualising/textualising_'intelligibility/epistemicity/reflexivity-contiguity<imbued-notional cogency>' \}-relation-to-the-world knowledge conceptivity/epistemicreflexivity/epistemicity-relativism-determinism-<reifying \{as-to-knowledge-developing $\}$-andempowering $>$ institutionalisations' of base-institutionalisation, ${ }^{103}$ universalisation, positivism/rational-empiricism and prospective ${ }^{18}$ deprocrypticism-or-preemptingdisjointedness-as-of- ${ }^{8}$ reference-of-thought respectively for the 'self-presence/selfconstitutedness ${ }^{14}<$ in-perspective-epistemic-abnormalcy/preconvergence ${ }^{31}>$ prospectively in the relative-ontological-incompleteness

psychologismic $\sim$ apriorising/axiomatising/referencing-\{of-"prospectively implicited_attendant-ontological-contiguity ' reducedexistentialising/contextualising/textualising_'intelligibility/epistemicity/reflexivity_contiguity<imbued-notional cogency>' $\}$-constitutedness ' in preconverging entailment' state of recurrent-utter-uninstitutionalisation, recurrent-utter-uninstitutionalisation, ununiversalisation, non-positivism/medievalism and procrypticism-or-disjointedness-as-of- ${ }^{3}$ reference-ofthought? Critically, as well the answer fundamentally call in question the self-presence/selfconstitutedness $^{14}-<$ in-perspective-epistemic-abnormalcy/preconvergence ${ }^{31}>\quad$ contemplative $^{>}$ capacity as of recurrent-utter-uninstitutionalisation, ununiversalisation, nonpositivism/medievalism and ${ }^{80}$ procrypticism-or-disjointedness-as-of- ${ }^{3}$ reference-of-thought respectively in contemplating such prospective psychologismic apriorising/axiomatising/referencing-\{of-"prospectively- 
implicited_attendant-ontological-contiguity ' reduced-

existentialising/contextualising/textualising_'intelligibility/epistemicity/reflexivity_contiguity-

<imbued-notional cogency >' $\}$ - conflatedness ${ }^{13}$ in-\{preconverging-ment by\}

postconverging-entailment implications; with the true reality of such a question and its discursivity rather translating/metaphorising as a notion of manifest 'implicited_attendantontological-contiguity ${ }^{6}$ ' educed-

existentialising/contextualising/textualising_'intelligibility/epistemicity/reflexivity-contiguity-

<imbued-notional cogency>' induced 'epistemic-growth/disquiet/discomfort-_induced-

sublimation,-as-from-existence's - effusing/ecstatic-inlining-as- historiality-

\{science/authenticity/nonextrication\}-beyond-mere-formulaicity/ritualisation-as- historicity-

tracing-\{science-ideology/fashionability/distraction $\}\rangle$ as to construction-of-the-Self in dispensing-with-immediacy-for-relative-ontological-completeness ${ }^{87}$-by-

reification/contemplative-distension ${ }^{27}$ respectively as towards base-institutionalisation, universalisation, positivism/rational-empiricism and prospective ${ }^{18}$ deprocrypticism-orpreempting - disjointedness-as-of- ${ }^{3}$ reference-of-thought (thus validating the contention that the 'communicable contemplative veracity of such transcendence-andsublimity/sublimation/supererogatory de-mentativity thought' can only be 'glimpsed of, countenance/appreciated in the margins and communicated rather as of prospective metaphoricity ${ }^{57}$ with pretenses of 'self-presence/self-constitutedness ${ }^{14}$-<in-perspectiveepistemic-abnormalcy/preconvergence ${ }^{31}$ prospectively in relative-ontologicalincompleteness ${ }^{88} \quad$ psychologismic apriorising/axiomatising/referencing- $\left\{\right.$ of- ${ }^{\text {'prospectively }}$ implicited_attendant-ontological-contiguity ' reducedexistentialising/contextualising/textualising_intelligibility/epistemicity/reflexivity_contiguity$<$ imbued-notional cogency>' $\quad\}$-constitutedness ${ }^{14}$-in-preconverging-entailment' in-manyways just pompous ignorance at best and at worst deliberate pedantising/muddling/formulaic- 
hollowing-out - in-subontologisation/subpotentiation-〈blurring/undermining-of-prospectivetotalising-entailing,-as-to-entailing-<amplituding/formative-epistemicity $>$ totalising $\sim$ inrelative-ontological-completeness $\rangle$ especially so-manifested in the wanton cultivation of mereformulaic institutional-imprimaturing blurriness-<sterilising/anecdotalising/trivialising-ofprospective-re-ontologising_by-preconverging,-in-disontologising-formulaic-dragging-

out/hollowing-out $>$ ) and institutional-legalism over genuine knowledge interest). The more fundamental point here is to reflect upon the fact and implications that beyond the accompanying 'distractive-alignment-to- ${ }^{83}$ reference-of-thought- $<$ of-apriorising/axiomatising/referencing $>{ }^{30}$ of pedantising/muddling/formulaic-hollowing-out - in-subontologisation/subpotentiation〈blurring/undermining-of-prospective-totalising-entailing,-as-to-entailing$<$ amplituding/formative-epistemicity>totalising in-relative-ontological-completeness $\rangle^{\prime}$ in the human notional $\sim$ philosophy-<as-to-the-veridical-conception-of-philosophy-as-englobing-allhuman-prospective-organic-knowledge-generation-in-relative-ontological-completeness beyond-a-convenient-division-of-labour-conception-of-knowledge > existentialising-frame-ofentailment of motif-and-apriorising/axiomatising/referencing of transcendence-andsublimity/sublimation/supererogatory de-mentativity, the very possibility for prospective human transcendence-and-sublimity/sublimation/supererogatory de-mentativity as to anglingof-imaginary lies with the reality of human 'epistemic-growth/disquiet/discomfort-_inducedsublimation,-as-from-existence's - effusing/ecstatic-inlining-as- historiality\{science/authenticity/nonextrication $\}$-beyond-mere-formulaicity/ritualisation-as- historicitytracing-\{science-ideology/fashionability/distraction $\}\rangle$ as to construction-of-the-Self in dispensing-with-immediacy-for-relative-ontological-completeness ${ }^{87}$-byreification/contemplative-distension ${ }^{27}$ as overcoming psychical-nascency; as so-conveyed from the implication of underlying human 'social-functioning-and-accordance-as-of-social-stakecontention-or-confliction imbuing existentialising-frame-of-entailment-of-motif-and- 
apriorising/axiomatising/referencing of disontologising/ontologising-and-re-ontologising' that ontologising is veridically about 'expansion of human ontologising possibilities so-construed as postconverging-aporeticism-overcoming/unovercoming' speaking critically of an exercise of psychoanalytic-unshackling/memetic-reordering/institutional-recomposuring. This 'ahistoricalemancipation as to archaeological/deconstructive-conceptualisation of prior/present/prospective human ontologising insight as of nonpresencing-<perspective-ontologicalnormalcy/postconvergence> epistemic-projection of notional-contiguity/epistemic-contiguity <profound-supererogation -of-mentally-aestheticised postconverging/dialectical-thinking qualia-schema $>$ conceptualisation as to prior/present/prospective epistemic-projection' contrasts with flawed 'theoretical conceptualisations of the social as to presencing-absolutisingidentitive-constitutedness $^{14}$ epistemic-projection devoid of notional-contiguity/epistemiccontiguity $^{62}-<$ profound-supererogation -of-mentally-aestheticised postconverging/dialecticalthinking -qualia-schema $>$ conceptualisation as to prior/present/prospective epistemicprojection' (as the latter puts into question the veracity of this very same notion of ontologising as in the natural sciences with regards to prospective human postconvergingaapereticismovercoming/unovercoming) and is herein construed as manifesting 'beholdening ${ }^{47}$ historicitytracing-in-presencing-hyperrealisation/hyperreal-transposition lacking in the capacity for nonpresencing-<perspective--ontological-normalcy/postconvergence $>$ epistemic-projection of relative-unreflexivity/relative-reflexivity ontological-contiguity ${ }^{67}$. Critically, it can be appreciated that the fundamental dimensionality-of-sublimating <<amplituding/formative >supererogatery de-mentativeness/epistemic-growth-orconflatedness /transvaluative-rationalising/transepistemicity/anamnestic-residuality/spiritdrivenness-equalisation〉 (undergirding the 'psychologismic apriorising/axiomatising/referencing-\{of-'prospectively implicited_attendant-ontological-contiguity ' educed- 
existentialising/contextualising/textualising_'intelligibility/epistemicity/reflexivity-contiguity<imbued-notional cogency $\left.>^{\prime}\right\}$-conflatedness ${ }^{13}$ in-\{preconverging-ment by\}

postconverging entailment implications on human ${ }^{83}$ reference-of-thought as grandestaxiomatic-contruct of ${ }^{5}$ meaningfulness-and-teleology ${ }^{9}$ existentialising-decisionality-<as-todisontologising/re-ontologising aporeticism $>$, of transcendence-andsublimity/sublimation/supererogatory-de-mentativity inducing the given registryworldview/dimension contextualising/existentialising $\sim$ attendant-ontological-contiguity ${ }^{67}$ with regards to its Being-development/ontological-framework-expansion-as-to-depth-ofontologising-development-as-infrastructure-of- meaningfulness-and-teleology , institutionaldevelopment-as-to-social-function-development and living-development-as-to-personalitydevelopment psychologismic epistemic-acutisation difficulty-<for, residualising $\{$ decompulsing $\}$ delinearity for-cogency $>$ magnitudes $\left.\left.{ }^{\{0 f-e x p e r i e n t i a l i t y / e x p e r i m e n t\}}\right\}\right)$, is existentialisingly 'downgraded/demoted along beholdening-existentialising-echelons of human ${ }^{79}$ presencingabsolutising-identitive-constitutedness ${ }^{14} \quad$ social-vestedness/normativity- $<$ discretely-impliedfunctionalism>' (in 'in-effect absolution-<as-to-apriorising/axiomatising/referencing-\{of'prospectively implicited_attendant-ontological-contiguity ' educedexistentialising/contextralising/textising_intelligibility/epistemicity/reflexivity-contiguity<imbued-notional cogency >' $\}$-constitutedness -in preconverging-entailment>> adherence to the given registry-worldview/dimension conceptivity/epistemic-reflexivity/epistemicityrelativism-determinism-<reifying \{as-to-knowledge-developing $\}$-and-empowering $>\quad$ imbued theoretical/conceptual/operant implications' as to psychical-nascency) which 'assume a beholdening self-purposefulness' that 'ultimately renders irrelevant/unquestioned the manifest instigation/incipience of prior undergirding dimensionality-of-sublimating <<amplituding/formative>supererogatory $\sim$ de-mentativeness/epistemic-growth-orconflatedness /transvaluative-rationalising/transepistemicity/anamnestic-residuality/spirit- 
drivenness-equalisation> induced translation/metaphorising for prospective nonpresencing$<$ perspective-ontological-normalcy/postconvergence $>$ epistemic-projection of relativeunreflexivity/relative-reflexivity_ontological-contiguity ${ }^{67}$, (with such 'in-effect absolution$<$ as-to-apriorising/axiomatising/referencing-\{of-'prospectively_implicited_attendantontological-contiguity ' educedexistentialising/contextualising/textualising_intelligibility/epistemicity/reflexivity-contiguity<imbued-notional cogency> ' $\}$-constitutedness -in-preconverging-entailment> manifestation of beholdening self-purposefulness in prospective disontologising, as to its implied $<$ amplitung/formative $>$ disposedness/psychologismic-construct-〈as-toorientation/value-construct/valuation-and-derived-parameterising and $<$ amplituding/formative $>$ entailment-〈as-to-totalising-contiguous/coherent-factuality-ofvariability of the registry-worldview/dimension, underscoring its given 'social-functioningand-accordance-as-of-social-stake-contention-or-confliction imbuing existentialising-frameof-entailment of motif-and-apriorising/axiomatising/referencing of disontologising/ontologising-and-re-ontologising' uninstitutionalised-threshold ${ }^{102}$ ). The psychologismic apriorising/axiomatising/referencing-\{of-"prospectivelyimplicited_attendant-ontological-contiguity ' educedexistentialising/contextualising/textualising_'intelligibility/epistemicity/reflexivity_contiguity$<$ imbued-notional cogency $\left.\rangle^{\prime}\right\}$-conflatedness ${ }^{3}$ in (preconverging ment by postconverging-ntailment implications here being that the $<$ cumulating/recomposuring attendant-ontological-contiguity $>$-successive registryworldviews/dimensions as to the overall relative-unreflexivity/relative-reflexivity_ontologicalcontiguity $^{67} \sim$ of-the-human-institutionalisation-process ${ }^{68}$ involve successively induced apriorising/axiomatising/referencing-\{of-'prospectively_implicited_attendant-ontologicalcontiguity ' educed- 
existentialising/contextualising/textualising_'intelligibility/epistemicity/reflexivity-contiguity<imbued-notional cogency>' \}-re-originariness/re-origination as of the-very-same fundamental dimensionality-of-sublimating ${ }^{25}$-<<amplituding/formative $>$ supererogatory $\sim$ dementativeness/epistemic-growth-or-conflatedness /transvaluativerationalising/transepistemicity/anamnestic-residuality/spirit-drivenness-equalisation). This speaks to a relatively poor human capacity (as to psychical-nascency) to constructively integrate as of limited-mentation-capacity-deepening —as-subjecting limitedness/human-subpotency-to'educed-unlimitedness/existence-sublimating nascence' ${ }^{53}$ the 'psychologismic apriorising/axiomatising/referencing-\{of-'prospectively implicited_attentant-ontological-contiguity ' reducedexistentialising/contextualising/textualising_ intelligibility/epistemicity/reflexivity-contiguity<imbued-notional cogency>' \}-conflatedness ${ }^{13}$ in-\{preconverging-ment by\} postcenverging-entailment implications as of the-very-same fundamental dimensionality-ofsublimating $25-<<$ amplituding/formative $>$ supererogatery - de-mentativeness/epistemic-growthor-conflatedness /transvaluative-rationalising/transepistemicity/anamnestic-residuality/spiritdrivenness-equalisation $\rangle$ in 'implicited_attendant-ontological-contiguity ${ }^{67}$ ' educedexistentialising/contextualising/textualising_'intelligibility/epistemicity/reflexivity-contiguity$<$ imbued-notional cogency>' 40 induced 'epistemic-growth/disquiet/discomfort-〈inducedsublimation,-as-from-existence's - effusing/ecstatic-inlining-as- historiality\{science/authenticity/nonextrication $\}$-beyond-mere-formulaicity/ritualisation-as- historicitytracing-\{science-ideology/fashionability/distraction $\}\rangle$ as to construction-of-the-Self in dispensing-with-immediacy-for-relative-ontological-completeness ${ }^{87}$-byreification/contemplative-distension ${ }^{27}$ instigating the <cumulating/recomposuring $\sim$ attendantontological-contiguity >-succession of registry-worldviews/dimensions (as to angling-ofimaginary). In this regards, the very central notion of singularisation- $<$ as-to-the- 
nondisjointedness/entailment-of-prospective- nonpresencing $>$ as to postmodern human-

subject-emancipating-relativism-driven-recomposuring-constructivism-towards-

singularisation-<as-to-the-nondisjointedness/entailment-of-prospective- nonpresencing $>$ is so-fundamentally underlied by the-very-same dimensionality-of-sublimating <<amplituding/formative >supererogatery $\sim$ de-mentativeness/epistemic-growth-or-

conflatedness /transvaluative-rationalising/transepistemicity/anamnestic-residuality/spirit-

drivenness-equalisation) (that effectively supersedes/attends-to underlying desublimating human preconverging-existential-extrication-as-of-existential-unthought). It is effectively the lack of dimensionality-of-sublimating ${ }^{25}$-<<amplituding/formative $>$ supererogatory $\sim$ dementativeness/epistemic-growth-or-conflatedness /transvaluative-

rationalising/transepistemicity/anamnestic-residuality/spirit-drivenness-equalisation) (soreflected in the psychologismic apriorising/axiomatising/referencing-\{of-"prospectively implicited_attendant-ontological-contiguity ' educedexistentialising/eontextralising/textlising_intelligibility/epistemicity/reflexivity-contiguity<imbued-notional cogency>' $\}$-constitutedness ${ }^{4}$-in-preconverging-entailment implications of 'precenverging-existential-extrication-as-of-existential-unthought downgrading/demoting of human ontological-performance ${ }^{72}-<$ including-virtue-as-ontology $>/$ morality/ethics/justice/etc. along beholdening-existentialising-echelons of human ${ }^{79}$ presencing-absolutising-identitiveconstitutedness ${ }^{14}$ social-vestedness/normativity-<discretely-implied-functionalism $>$ ' in human distractive-alignment-to- ${ }^{83}$ reference-of-thought- $<$ of-apriorising/axiomatising/referencing $>{ }^{30}$ as to manifest dimensionality-of-desublimating-lack-of ${ }^{6}$

〈<amplituding/formative>supererogatory $\sim$ de-mentativeness/epistemic-growth-or-

conflatedness /transvaluative-rationalising/transepistemicity/anamnestic-residuality/spirit-

drivenness-equalisation〉), that underlies human desublimating 'beholdening as sovereignisingimbued-subontologisation/subpotentiation' over the sublimating-nascence of 'unbeholdening 
ontologising-depth as to backdrop-of-inherent-immanent-existence's-sublimation-structure<of-'unsurrealistic-as-real'-ontological-normalcy/postconvergence>' (in the confliction between human psychical-nascency shallow-supererogation and angling-of-imaginary profound-supererogation respectively). As to human conceptivity/epistemicreflexivity/epistemicity-relativism-determinism-<reifying \{as-to-knowledge-developing $\}$-andempowering $>-\langle$ exuding—

totalising 3 thermeneutically/textually/reprojectingly/supererogatingly/zeroingly/re-acutingly,\{decomplsing delinearity for-cogency:-as-from-'existence's effusing/ecstatic-inlining';-as‘interlay/organicalism/aestheticising-handle-<of-'psychologismic-transfixity $\{$ residualising \{decompulsing\} delinearity over-nonresidualising \{compulsing\} linearity\}’ $>-\{$ manifestsupererogatory de-mentative-amplituding-or-mental-aestheticising-attuning\}',-insupererogatory projective-arbitrariness/waywardnessof $\sim$ transversalisation/tandemisation/abstractive-conjugation/perspectivation/depthing — for'aestheticising-re-margining/re-edging/re-acuity-inpostconverging/preconverging_circumscriptive/totalitative-restructuring'_-educingsublimation/desublimation> (driving $\quad$ de-mentation-〈supererogatory $\sim$ ontological-dementation-or-dialectical-de-mentation-stranding-or-attributive-dialectics $\rangle$ dynamics), the 'psychologismic apriorising/axiomatising/referencing-\{of-'prespectivelyimplicited_attendant-ontological-contiguity ' educedexistentialising/contextualising/textualising_'intelligibility/epistemicity/reflexivity-contiguity<imbued-notional cogency>' \}-conflatedness ${ }^{13}$-in-\{preconverging-ment by\} postconverging-entailment implications of the fundamental dimensionality-of-sublimating <<amplituding/formative>supererogatory $\sim$ de-mentativeness/epistemic-growth-orconflatedness /transvaluative-rationalising/transepistemicity/anamnestic-residuality/spiritdrivenness-equalisation)' in 'implicited_attendant-ontological-contiguity ${ }^{67}$ ' educed- 
existentialising/contextualising/textualising_'intelligibility/epistemicity/reflexivity-contiguity$<$ imbued-notional cogency $>$ ' induced 'epistemic-growth/disquiet/discomfort-〈inducedsublimation,-as-from-existence's - effusing/ecstatic-inlining-as- historiality\{science/authenticity/nonextrication\}-beyond-mere-formulaicity/ritualisation-as- historicitytracing-\{science-ideology/fashionability/distraction $\}\rangle$ as to construction-of-the-Self in dispensing-with-immediacy-for-relative-ontological-completeness ${ }^{87}$-byreification/contemplative-distension ${ }^{27}$ rather speaks to the ontological-veracity of maximalising-recomposuring-for-relative-ontological-completeness ${ }^{87}$ — unenframed/reontologising conceptualisation over incrementalism-in-relative-ontologicalincompleteness ${ }^{8}$ - enframed/disontologising conceptualisation; as to fact that 'humandecisionality-<as-to-play-of-valid/invalid-decisionality-imbued-sublimation/desublimation $>$ omni-potential commensurability with inherent immanent-existence's sublimationstructure'/omnipotentiality is effectively an 'already achieved potential as to the fundamental dimensionality-of-sublimating 25 -<amplituding/formative > supererogatery-dementativeness/epistemic-growth-or-conflatedness /transvaluativerationalising/transepistemicity/anamnestic-residuality/spirit-drivenness-equalisation〉' beyond any 'mere-formulaicity/ritualisation-<as-to-mere-formulaic methodologising/mutualising/organising/institutionalising,-prospectively-losing-track-of‘\{epistemic-totalising łre-apriorising/re-axiomatising/re-referencing-residuality-in-reoriginariness/re-origination'> of existentialising/contextualising/textualising actualisation of reproducibility—mathesis/motif/thrownness-disposition,-as-reproducibility-ofaestheticisation'. Such that existentialising/contextualising/textualising as to actualisation is rather effectively about 'postconverging-de-mentating/structuring/paradigming to fundamental dimensionality-of-sublimating $-<<$ amplituding/formative $>$ supererogatory $-d e-$ 
rationalising/transepistemicity/anamnestic-residuality/spirit-drivenness-equalisation〉 potential' for

'human-decisionality-<as-to-play-of-valid/invalid-decisionality-imbuedsublimation/desublimation> omni-potential commensurability with inherent immanentexistence's sublimation-structure'/omnipotentiality; with such a 'dementating/structuring/paradigming ontological-performance ${ }^{72}<$ including-virtue-as-ontology $>^{\text {' }}$ being of apriorising/axiomatising/referencing-\{of-'prospectively implicited_attendantontological-contiguity ' educed-

existentialising/contextualising/textualising_'intelligibility/epistemicity/reflexivity-contiguity<imbued-notional cogency>' \}-conflatedness ${ }^{13}$-in-\{preconverging-ment by\}

postconverging-entailment implied ${ }^{55}$ maximalising-recomposuring-for-relative-ontologicalcompleteness ${ }^{87}$ - unenframed/re-ontologising conceptualisation not apriorising/axiomatising/referencing-\{of-'prospectively_implicited_attendant-ontologicalcontiguity ' educedexistentialising/contextualising/textualising_'intelligibility/epistemicity/reflexivity_contiguity<imbued-notional cogency $\left.>^{\prime} \quad\right\}$-constitutedness ${ }^{1}$-in-preconverging-entailment implied incrementalism-in-relative-ontological-incompleteness ${ }^{88}$

enframed/disontologising conceptualisation (with the latter inducing a flawed 'in-effect absolution-<as-to-apriorising/axiomatising/referencing-\{of-‘prospectively implicited_attendant-ontological-contiguity ' educedexistentialising/contextualising/textualising_ 'intelligibility/epistemicity/reflexivity-contiguity$<$ imbued-notional $\sim$ cogency $\left.>^{\prime} \quad\right\}$-constitutedness - in - preconverging-entailment $>$ intelligibility reflex' for aestheticisation-and-aestheticisation-towards-ontology-<elicitedidiomatisation $>$ since it fails to factor the epistemic-projection as to projective-insights that must necessarily arise given human limited-mentation-capacity-as-subjecting 'educedunlimitedness/existence-sublimating nascence' to-limitedness/human-subpotency before 
predicative-insights, and so out of shallow-supererogation with respect to supererogatory acuity/perspicacity/astuteness/edginess/incisiveness). Thus human intelligibility ontological-performance $^{72}-<$ including-virtue-asontology $>$ /morality/ethics/justice/etc. is an 'exercise of epistemic - projective-equalisation of human station of ${ }^{7}$ presencing-absolutising-identitive-constitutedness ${ }^{14}$ as to prospective nonpresencing-<perspective-ontological-normalcy/postconvergence $>$ epistemic-projectiveequalisation' (so-construed as <amplituding/formative-epistemicity>totalising $\sim$ conflatedness of meaningfulness-and-teleology ${ }^{5}$ involving the 'epistemictotalising $\sim$ resubjecting_or_totalising-entailing $\sim$ reconstrual $<$ of the-whole/purview of thewhole/oneness-of-ontology $>$ of motif-as-to-aestheticisation- $<$ imbued-projectivearbitrariness/waywardness $>$ to existence-as-sublimating-withdrawal/unenframing/reontologising,-elicited-from-prospective-profound-supererogation $\quad$ in preconverging/postconverging-rede-mentating/restructuring/reparadigming intelligibility-〈asto-human-projective/reprojective - aestheticising-re-motif-and-re-apriorising/reaxiomatising/re-referencing/re-intelligibilitysettingup/re-measuringinstrumenting-process,-in$<$ amplituding/formative-epistemicity>totalising conceptualisation $\rangle$ '; wherein the 'epistemictotalising $\sim$ resubjecting_or_totalising-entailing $\sim$ reconstrual $<$ of the-whole/purview-of thewhole/oneness-of-ontology $>$ of motif-as-to-aestheticisation-<imbued-projectivearbitrariness/waywardness $>$ to existence-as-sublimating-withdrawal/unenframing/reontologising,-elicited-from-prospective-profound-supererogation in inducing aestheticisationtowards-ontology' necessarily implies that intelligibility itself is seedingly/incipiently encumbered with 'presublimating relic/artifactual-beholdening-constitutedness ${ }^{14}{ }^{47}$ historicitytracing-in-presencing-hyperrealisation/hyperreal-transposition' when it comes to eliciting 'prospective/nascent sublimating supereregatory unbeholdening-conflatedness $^{13}$ momentous historiality/ontological-eventfulness ${ }^{38} /$ ontological-aesthetic-tracing-<perspective- 
ontological-normalcy/postconvergence-reflected-'epistemicity-relativism-determinism'>', and so all along from the very seeding/incipient aestheticisation-and-aestheticisation-towardsontology-<elicited-idiomatisation $>$ and so-perpetuative as to human Beingdevelopment/ontological-framework-expansion-as-to-depth-of-ontologising-development-asinfrastructure-of- meaningfulness-and-teleology , institutional-development-as-to-socialfunction-development and living-development-as-to-personality-development psychologismic epistemic-acutisation difficulty-for, residualising \{decompulsing\} delinearity for-cogency> magnitudes $\left.{ }^{\{0 f-e x p e r i e n t i a l i t y / e x p e r i m e n t\}}\right\}$. This epistemic_-projective-equalisation exercise ('exercise of the epistemic - projective-equalisation of human station of ${ }^{79}$ presencing-absolutisingidentitive-constitutedness ${ }^{14}$ as to prospective ${ }^{6}$ nonpresencing-<perspective-ontologicalnormalcy/postconvergence $>$ epistemic_projective-equalisation') underlying 'veridical ontological-performance ${ }^{72}$-<including-virtue-as-ontology $>/$ morality/ethics/justice/etc. of human intelligibility' (as of apriorising/axiomatising/referencing-\{of-'prospectively implicited_attendant-ontological-contiguity ' educedexistentialising/contextualising/textualising_'intelligibility/epistemicity/reflexivity-contiguity<imbued-notional cogency $\left.>^{\prime}\right\}$-conflatedness ${ }^{13}$ in-\{preconverging -ment by\} posteonverging implied ${ }^{55}$ maximalising-recomposuring-for-relative-ontologicalcompleteness ${ }^{87}$ - unenframed/re-ontologising conceptualisation ontological-veracity) is effectively undergirded by 'various notional asceticism implied-and-instigated dispensingwith-immediacy-for-relative-ontological-completeness ${ }^{87}$-by-reification/contemplativedistension ${ }^{27}$ so-associated with 'intemporal-prioritisation-of- ${ }^{8}$ reference-of-thought'-asconflatedness ${ }^{13}$-or-ontological-reprojecting (expounded as 'intemporal-prioritisation-ofreference-of-thought'-as-conflatedness ${ }^{13}$-or-ontological-reprojecting emphasising reference-of-thought- categorical-imperatives/axioms/registry-teleology 9 as rather about intemporal-preservation-entropy-or-contiguity-or-ontological-preservation as of ontological- 
normalcy/postconvergence); and so as to the ('postconverging-dementating/structuring/paradigming to fundamental dimensionality-of-sublimating 〈<amplituding/formative>supererogatory $\sim$ de-mentativeness/epistemic-growth-or-

\section{conflatedness /transvaluative-rationalising/transepistemicity/anamnestic-residuality/spirit-}

drivenness-equalisation> potential' for 'human-decisionality-<as-to-play-of-valid/invaliddecisionality-imbued-sublimation/desublimation> omni-potential commensurability with inherent immanent-existence's sublimation-structure'/omnipotentiality) and so-parrhesiastically educed 'sublimating reproducibility—mathesis/motif/thrownness-disposition,--asreproducibility-of-aestheticisation methodologising/mutualising/organising/institutionalising (with regards to human Being-development/ontological-framework-expansion-as-to-depth-ofontologising-development-as-infrastructure-of- meaningfulness-and-teleology , institutionaldevelopment-as-to-social-function-development and living-development-as-to-personalitydevelopment psychologismic epistemic-acutisation difficulty-<for, residualising \{decompulsing\} delinearity for-cogenc $y>$ magnitudes $\{$ of-experientiality/experiment $\}$ '. Critically the 'exercise of the epistemic - projective-equalisation of human station of 79 presencing-absolutisingidentitive-constitutedness ${ }^{14}$ as to prospective ${ }^{6}$ nonpresencing-<perspective-ontologicalnormalcy/postconvergence $>$ epistemic — projective-equalisation' allows no room for any human preconverging-existential-extrication-as-of-existential-unthought supposed conception of knowledge (which necessarily points to deficient human ontological-performance ${ }^{72}-<$ includingvirtue-as-ontology $>/$ morality/ethics/justice/etc. but for a naïve conceptualisation lacking in prospective ${ }^{6}$ nonpresencing-<perspective-ontological-normalcy/postconvergence $>$ epistemicprojection); as so-naively and nombrilistically associated with our ${ }^{70}$ presencing — absolutisingidentitive-constitutedness ${ }^{14} \quad$ practices of ontologically-flawed 'normalised/stereotyped/selfhelping/feel-good knowledge being brought at the protractedsocial—as-to-individual-by-institutional-by-social sovereign's service lacking in the underlying 
conception of epistemic-growth/disquiet/discomfort-〈induced-sublimation,-as-fromexistence's - effusing/ecstatic-inlining-as- historiality-\{science/authenticity/nonextrication $\}$ beyond-mere-formulaicity/ritualisation-as- historicity-tracing-\{scienceideology/fashionability/distraction $\}\rangle$ as to construction-of-the-Self in dispensing-withimmediacy-for-relative-ontological-completeness ${ }^{87}$-by-reification/contemplative-distension ${ }^{27}$, which supposedly thersedes veracity of 'psychologismic apriorising/axiomatising/referencing-\{of-'prospectively implicited_attendant-ontological-contiguity ' educedexistentialising/contextualising/textualising_'intelligibility/epistemicity/reflexivity-contiguity<imbued-notional cogency $\left.>^{\prime}\right\}$-conflatedness ${ }^{13}$ in (preconverging ment by $^{\prime}$ postconverging-entailment implications as of the-very-same fundamental dimensionality-ofsublimating $25<<$ amplituding/formative $>$ supererogatery $\sim$ de-mentativeness/epistemic-growthor-conflatedness /transvaluative-rationalising/transepistemicity/anamnestic-residuality/spiritdrivenness-equalisation)' in 'implicited_attendant-ontological-contiguity ${ }^{67}$ ' educedexistentialising/contextualising/textualising_intelligibility/epistemicity/reflexivity-contiguity$<$ imbued-notional cogency >' induced 'epistemic-growth/disquiet/discomfort-〈inducedsublimation,-as-from-existence's - effusing/ecstatic-inlining-as- historiality\{science/authenticity/nonextrication\}-beyond-mere-formulaicity/ritualisation-as- historicitytracing- $\{$ science-ideology/fashionability/distraction $\}\rangle$ as to construction-of-the-Self in dispensing-with-immediacy-for-relative-ontological-completeness ${ }^{87}$-byreification/contemplative-distension ${ }^{27}$ (and as so-reflected from a prospective ${ }^{6}$ nonpresencing$<$ perspective-ontological-normalcy/postconvergence $>$ epistemic-projection). The latter basically underlines the 'preconverging/postconverging-de-mentative/structural/paradigmatic historial knowledge-reification $\sim$ gesturing-and-accounting — of-epistemic-phenomenalism- $<$ in- 
prospective_psychologismic apriorising/axiomatising/referencing-\{of- ${ }^{\text {prospectively }}$ implicited_attendant-ontological-contiguity ' educedexistentialising/contextualising/textualising_'intelligibility/epistemicity/reflexivity-contiguity$<$ imbued-notional cogency $>\quad\}$-conflatedness - in-\{preconverging ment by\} postconverging-entailment> that enabled the attainment of our present-level emancipation/sublimation (so-gleanable as to angling-of-imaginary implied 'multicenturieslong human crossgenerational Being-development/ontological-framework-expansion-as-todepth-of-ontologising-development-as-infrastructure-of- meaningfulness-and-teleology psychologismic epistemic-acutisation difficulty-for, residualising

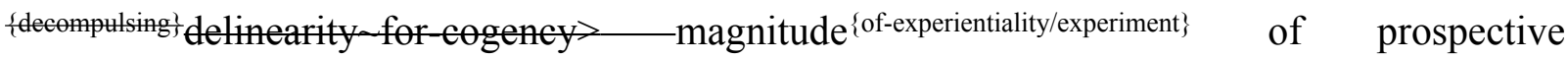
transcendence-and-sublimity/sublimation/supererogatory-de-mentativity')' whereas the 'former is rather our self-importance in-effect absolution-<as-toapriorising/axiomatising/referencing-\{of-'prospectively implicited_attendant-ontologicalcontiguity ' $\sim$ educedexistentialising/contextualising/textualising_'intelligibility/epistemicity/reflexivity_contiguity$<$ imbued-notional cogency $\left.>{ }^{\prime} \quad\right\}$-constitutedness -in-preconverging-entailment $>\quad$ ment ignoring of the preconverging/postconverging-de-mentative/structural/paradigmatic postconverging-nonextricatory-existential-preempting-of-existential-unthought historial knowledge-reification $\sim$ gesturing-and-accounting — of-epistemic-phenomenalism- $<$ inprospective_psychologismic apriorising/axiomatising/referencing-\{of- ${ }^{\text {pprospectively }}$ implicited_attendant-ontological-contiguity ' educedexistentialising/contextualising/textualising_ intelligibility/epistemicity/reflexivity-contiguity<imbued-notional cogency>' \}-conflatedness in \{preconverging ment by\} postconverging-entailment $>$ of human limited-mentation-capacity-deepening-as-subjectinglimitedness/human-subpotency to-'educed-unlimitedness/existence-sublimating nascence' 
(manifested as to our present 'disjointing totalisingly-ing-discretion/whim-of-thought disontologising' $<$ amplituding/formative-epistemicity $>$ totalising $\sim$ self-referencingsyncretising/circularity/interiorising/akrasiatic-drag ${ }^{4}$ as of 'human lifespan extricatory punctuality/immediacy of depth-of-thought')'. This critical but counter-intuitive insight of such ing (as to ontologically-flawed 'normalised/stereotyped/selfhelping/feel-good knowledge being brought at the protracted-social—as-to-individual-by-institutional-by-social sovereign's service lacking in the underlying conception of epistemic-growth/disquiet/discomfort-〈inducedsublimation,-as-from-existence's - effusing/ecstatic-inlining-as- historiality\{science/authenticity/nonextrication $\}$-beyond-mere-formulaicity/ritualisation-as- historicitytracing-\{science-ideology/fashionability/distraction $\}\rangle$ as to construction-of-the-Self in dispensing-with-immediacy-for-relative-ontological-completeness ${ }^{87}$-byreification/contemplative-distension ${ }^{27}$ as so-recurrent along the $<$ cumulating/recomposuring attendant-ontological-contiguity $>$-succession of registryworldviews/dimensions) is that 'referencing any given registry-worldview/dimension in-effect absolution-<as-to-apriorising/axiomatising/referencing-\{of-'prospectively implicited_attendant-ontological-contiguity ' educedexistentialising/contextualising/textualising_'intelligibility/epistemicity/reflexivity_contiguity<imbued-notional cogency>' $\quad\}$-constitutedness -in preconverging-entailment> selfconception of ontological-performance ${ }^{72}-<$ including-virtue-as- $^{-}$ ontology $>$ /morality/ethics/justice/etc. as to its apriorising/axiomatising/referencing-\{of'prospectively_implicited_attendant-ontological-contiguity ' educedexistentialising/contextualising/textualising_'intelligibility/epistemicity/reflexivity_contiguity$<$ imbued-notional cogency $>$ ' $\}$-constitutedness ${ }^{14}$-in-preconverging-entailment implied incrementalism-in-relative-ontological-incompleteness ${ }^{88}$

enframed/disontologising conceptualisation' speaks of a preconverging/postconverging-de- 
mentative/structural/paradigmatic ontological-deficiency (that cannot account for the possibility of the <cumulating/recomposuring attendant-ontological-contiguity $>$-succession of registryworldviews/dimensions as to its projected self-presence/self-constitutedness ${ }^{14}{ }^{-}$in-perspectiveepistemic-abnormalcy/preconvergence ${ }^{31}>\quad{ }^{79}$ presencing-absolutising-identitiveconstitutedness $^{1}$ ), with such a <cumulating/recomposuring attendant-ontologicalcontiguity >-succession of registry-worldviews/dimensions arising only as of apriorising/axiomatising/referencing-\{of-'prospectively_implicited_attendant-ontologicalcontiguity ' $\sim$ educedexistentialising/contextualising/textualising_'intelligibility/epistemicity/reflexivity-contiguity<imbued-notional cogency $>$ ' $\}$ - conflatedness ${ }^{13}$ in-\{preconverging-ment by postconverging-entailment implied ${ }^{55}$ maximalising-recomposuring-for-relative-ontologicalcompleteness $^{87}$ — unenframed/re-ontologising conceptualisation ontological-veracity of postconverging-nonextricatory-existential-preempting-of-existential-unthought of human Being-development/ontological-framework-expansion-as-to-depth-of-ontologisingdevelopment-as-infrastructure-of- meaningfulness-and-teleology. Hence given human limited-mentation-capacity—as-subjecting 'educed-unlimitedness/existence-sublimating nascence' to limitednessman subpen (as to the reality of deficient human ontologicalperformance ${ }^{2}-<$ including-virtue-as-ontology $>$ /morality/ethics/justice/etc. 'in the exercise of the epistemic - projective-equalisation of human station of ${ }^{79}$ presencing - absolutising-identitiveconstitutedness $^{14}$ as to prospective nonpresencing-<perspective-ontologicalnormalcy/postconvergence $>$ epistemic - projective-equalisation'), the possibility of human postconverging-nonextricatory-existential-preempting-of-existential-unthought rather lies in 'human intemporal-individuation threading/relaying succession of sublimating gesturings' as of 'various notional asceticism implied-and-instigated dispensing-with-immediacy-for-relativeontological-completeness $^{87}$-by-reification/contemplative-distension ${ }^{27}, \quad$ so-associated with 
'intemporal-prioritisation-of- ${ }^{3}$ reference-of-thought'-as-conflatedness ${ }^{13}$-or-ontologicalreprojecting (expounded as 'intemporal-prioritisation-of- ${ }^{8}$ reference-of-thought'-asconflatedness ${ }^{13}$-or-ontological-reprojecting emphasising ${ }^{83}$ reference-of-thought- categoricalimperatives/axioms/registry-teleology ${ }^{9}$ as rather about intemporal-preservation-entropy-orcontiguity-or-ontological-preservation as of ontological-normalcy/postconvergence) and in soparrhesiastically educing 'sublimating reproducibility-mathesis/motif/thrownnessdisposition,-as-reproducibility-of-aestheticisation

methodologising/mutualising/organising/institutionalising (as to human Beingdevelopment/ontological-framework-expansion-as-to-depth-of-ontologising-development-asinfrastructure-of- meaningfulness-and-teleology , institutional-development-as-to-socialfunction-development and living-development-as-to-personality-development psychologismic epistemic-acutisation difficulty-for, residualising \{decompulsing $\}$ delinearity for-cogency> magnitudes $\{$ of-experientiality/experiment\} $\}$ '. It is critical to note here that such postconvergingnonextricatory-existential-preempting-of-existential-unthought ontological-performance ${ }^{72}$ <including-virtue-as-ontology $>/$ morality/ethics/justice/etc. ('in the exercise of epistemicprojective-equalisation of human station of ${ }^{79}$ presencing-absolutising-identitiveconstitutedness $^{14}$ as to prospective ${ }^{6}$ nonpresencing- $<$ perspective-ontologicalnormalcy/postconvergence> epistemic - projective-equalisation') rather lies with manifest 'psychologismic apriorising/axiomatising/referencing-\{of-'prospectivelyimplicited_attendant-ontological-contiguity ' educedexistentialising/contextualising/textualising_'intelligibility/epistemicity/reflexivity-contiguity<imbued-notional cogency $>$ ' $\}$ - conflatedness ${ }^{13}$ in-\{preconverging-ment by\} implications as of the-very-same fundamental dimensionality-ofsublimating $25<<$ amplituding/formative $>$ supererogatory $\sim$ de-mentativeness/epistemic-growthor-conflatedness /transvaluative-rationalising/transepistemicity/anamnestic-residuality/spirit- 
drivenness-equalisation $\rangle$ ' in 'implicited_attendant-ontological-contiguity ${ }^{67}$ ' educedexistentialising/contextualising/textualising_'intelligibility/epistemicity/reflexivity-contiguity$<$ imbued-notional cogency $>$ ' induced 'epistemic-growth/disquiet/discomfort-〈inducedsublimation,-as-from-existence's - effusing/ecstatic-inlining-as- historiality\{science/authenticity/nonextrication\}-beyond-mere-formulaicity/ritualisation-as- historicitytracing-\{science-ideology/fashionability/distraction $\}\rangle$ as to construction-of-the-Self in dispensing-with-immediacy-for-relative-ontological-completeness ${ }^{87}$-byreification/contemplative-distension ${ }^{27}$ (so-critically eliciting/prompting/stimulating 'multicenturies-long human crossgenerational Being-development/ontological-frameworkexpansion-as-to-depth-of-ontologising-development-as-infrastructure-of- meaningfulnessand-teleology psychologismic epistemic acutisation difficulty-for, residualising \{decompulsing delinearity for-cogeney>-magnitude\{of-experientiality/experiment\} of prospective transcendence-and-sublimity/sublimation/supererogatory-de-mentativity'), and not the epochal in-effect absolution- $<$ as-to-apriorising/axiomatising/referencing- $\{$ of- prospectively implicited_attendant-ontological-contiguity ' educedexistentialising/contextualising/textualising_intelligibility/epistemicity/reflexivity_contiguity$<$ imbued-notional cogency $>>\quad\}$-constitutedness -in-preconverging-entailment $>$ conception of 'human lifespan extricatory punctuality/immediacy of depth-of-thought' as practically reflected in the 'existentialising-frame-of-entailment-of-motif-andapriorising/axiomatising/referencing of supposed friendship/family/social/professional values that-fail/if-failing the possibility for fundamental dimensionality-of-sublimating <<amplituding/formative>supererogatory $\sim$ de-mentativeness/epistemic-growth-orconflatedness /transvaluative-rationalising/transepistemicity/anamnestic-residuality/spiritdrivenness-equalisation)'. Even as the human psychologismic apriorising/axiomatising/referencing-\{of-"prospectively 
implicited_attendant-ontological-contiguity ' reduced-

existentialising/contextualising/textualising_'intelligibility/epistemicity/reflexivity_contiguity$<$ imbued-notional cogency $>$ ' $\}$-constitutedness ${ }^{1}$-in-preconverging-entailment implications as to 'human lifespan extricatory punctuality/immediacy of depth-of-thought' of the selfpresence/self-constitutedness $^{14}-<$ in-perspective-epistemic-abnormalcy/preconvergence ${ }^{3}>$ of presencing-absolutising-identitive-constitutedness ${ }^{14}$ is relatively unsophisticated/narrowminded/parochial/of-short-attention-span/susceptible-to-disontologising-gimmickiness-andnumbing when it comes to projecting/countenancing (as to the ontological-performance ${ }^{72}$ $<$ including-virtue-as-ontology $>$ /morality/ethics/justice/etc. of 'lifespan existentialising/contextualising/textualising veracity of conceptualisation') the 'veridical psychologismic apriorising/axiomatising/referencing-\{of-'prospectively

implicited_attendant-ontological-contiguity ' educed-

existentialising/contextualising/textualising_'intelligibility/epistemicity/reflexivity_contiguity$<$ imbued-notional cogency $>$ ' $\}$-conflatedness ${ }^{13}$ in-\{preconverging-ment by\}

postconverging-entailment implications of postconverging-nonextricatory-existentialpreempting-of-existential-unthought ontological-performance ${ }^{72}-$ including-virtue-as- $^{2}$ ontology $>$ /morality/ethics/justice/etc. as to re-ontologising prospective Beingdevelopment/ontological-framework-expansion-as-to-depth-of-ontologising-development-asinfrastructure-of- meaningfulness-and-teleology aetiologisation/ontological-escalation$<$ ontological-veridicality_commitment/otherliness_transcending/compulsionsencumbered_transcending $>\quad$ conceptivity/epistemic-reflexivity/epistemicity-relativismdeterminism-<reifying \{as-to-knowledge-developing\}-and-empowering $>$ beyond lifespan mental-projection', (whereas with the-very-same requisite sublimating gesturing/accountingof-epistemic-phenomenalism but rather within the existentialising-frame-of-entailment of motif-and-apriorising/axiomatising/referencing of any given registry-worldview/dimension 
presencing-absolutising-identitive-constitutedness ${ }^{14}$ as to its institutional-development-asto-social-function-development and living-development-as-to-personality-development psychologismic epistemic-acutisation difficulty-for, residualising \{decompulsing\} delinearity for-cogeney>-magnitudes $\{$ of-experientiality/experiment\} 'even as to lifespan existentialising/contextualising/textualising veracity of conceptualisation' it can be appreciated/gleaned that our base limited-mentation-capacity-as-subjecting-educedunlimitedness/existence-sublimating nascence' to-limitedness/human-subpotency effectively appreciates the adequacy of cultivation/learning/practice/investment over time in many a concern or domain-of-interest or subject-matter imbued technicity/profundity as to requisite dispensing-with-immediacy-for-relative-ontological-completeness ${ }^{87}$-byreification/contemplative-distension ${ }^{27}$ for appropriately sublimating ontological-performance ${ }^{72}$ <including-virtue-as-ontology $>$ /morality/ethics/justice/etc.). The bigger point here is that the notional $\sim$ self-distantiation- $<$ imbued — re-motif-and-re-apriorising/re-axiomatising/re-

referencing $>$ associated with all the <cumulating/recomposuring attendant-ontologicalcontiguity >-successive registry-worldviews/dimensions re-ontologising prospective Beingdevelopment/ontological-framework-expansion-as-to-depth-of-ontologising-development-asinfrastructure-of- meaningfulness-and-teleology is particularly challenging to human limitedmentation-capacity-as-subjecting 'educed-unlimitedness/existence-sublimating nascence' to-limitedness/human-subpotency psychologismic apriorising/axiomatising/referencing-\{of'prospectively_implicited_attendant_ontological-contiguity ' educedexistentialising/contextualising/textualising_'intelligibility/epistemicity/reflexivity-contiguity<imbued-notional cogency $>$ ' $\}$ - conflatedness ${ }^{13}$ in-\{preconverging-ment by\} implications contemplation as to the fact that any given registryworldview/dimension (as to human limited-mentation-capacity-as-subjecting 'educedunlimitedness/existence-sublimating nascence' to-limitedness/human-subpotency) is limited in 

referencing $>$ reflected as its prospectively uninstitutionalised-threshold ${ }^{102}$, as at this point in practical terms it manifests a disontologising desublimation relation to its human 'socialfunctioning-and-accordance-as-of-social-stake-contention-or-confliction imbuing existentialising-frame-of-entailment-of-motif-and-apriorising/axiomatising/referencing of disontologising/ontologising-and-re-ontologising'; and thus reflecting its human preconvergingexistential-extrication-as-of-existential-unthought failing of pestcenverging-nonextricatoryexistential-preempting-of-existential-unthought $\quad$ ontological-performance ${ }^{2}-<$ including-virtueas-ontology $>$ /morality/ethics/justice/etc. ("in the exercise of epistemic-projective-equalisation of human station of ${ }^{7}$ presencing - absolutising-identitive-constitutedness ${ }^{14}$ as to prospective nonpresencing-<perspective-ontological-normalcy/postconvergence $>$ epistemic-projectiveequalisation'). The further implication here is that human aestheticisation-and-aestheticisationtowards-ontology-<elicited-idiomatisation $>\quad$ (as to social-setups imbued 'supposed reproducibility — mathesis/motif/thrownness-disposition,--as-reproducibility-of-aestheticisation of ${ }^{5}$ meaningfulness-and-teleology ${ }^{99}$ underlied by language, culture, social institutions, technical knowhow, etc., and so as to human Being-development/ontological-framework-expansion-asto-depth-of-ontologising-development-as-infrastructure-of- meaningfulness-and-teleology , institutional-development-as-to-social-function-development and living-development-as-topersonality-development psychologismic epistemic acutisation difficulty <for, residualising \{ magnitudes \{of-experientiality/experiment\}' '), fundamentally speaks to the 'exercise of epistemic - projective-equalisation of human station of presencing-absolutising-identitive-constitutedness ${ }^{14}$ as to prospective nonpresencing$<$ perspective-ontological-normalcy/postconvergence $>$ epistemic - projective-equalisation' as to the attained/achieved underlying 'veridical ontological-performance ${ }^{72}-<$ including-virtue-asontology $>$ /morality/ethics/justice/etc. of human intelligibility' (as so-undergirding human 
institutional-cumulation/institutional-recomposure-〈as-to- historiality/ontological-

eventfulness /ontological-aesthetic-tracing-<perspective-ontological-

normalcy/postconvergence-reflected-'epistemicity-relativism-determinism'>>); and so in reflecting

the

attained/achieved

manifest

\section{'psychologismic apriorising/axiomatising/referencing-\{of-"prospectively-}

implicited_attendant-ontological-contiguity ' educed-

existentialising/contextualising/textualising_ 'intelligibility/epistemicity/reflexivity-contiguity-

$<$ imbued-notional cogency $\left.>^{\prime}\right\}$-conflatedness ${ }^{13}$-in-\{preconverging-ment by\}-

postconverging-entailment implications as of the-very-same fundamental dimensionality-ofsublimating $25-<$ amplituding/formative $>$ supererogatory $\sim$ de-mentativeness/epistemic-growth-

or-conflatedness /transvaluative-rationalising/transepistemicity/anamnestic-residuality/spirit-

drivenness-equalisation)' in 'implicited_attendant-ontological-contiguity ${ }^{67}$ ' educedexistentialising/contextmalising/textualising_intelligibility/epistemicity/reflexivity_contiguity$<$ imbued-notional cogency $>$ induced 'epistemic-growth/disquiet/discomfort-〈inducedsublimation,-as-from-existence's - effusing/ecstatic-inlining-as- historiality-

\{science/authenticity/nonextrication $\}$-beyond-mere-formulaicity/ritualisation-as- historicitytracing-\{science-ideology/fashionability/distraction $\}\rangle$ as to construction-of-the-Self in dispensing-with-immediacy-for-relative-ontological-completeness ${ }^{87}$-by-

reification/contemplative-distension ${ }^{27}$ (as attained/achieved elicited/prompted/stimulated 'multicenturies-long human crossgenerational Being-development/ontological-frameworkexpansion-as-to-depth-of-ontologising-development-as-infrastructure-of- meaningfulnessand-teleology psychologismic epistemic-acutisation difficulty-<for, residualising

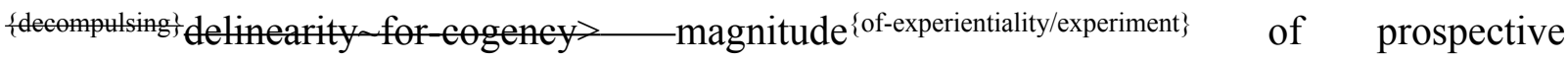
transcendence-and-sublimity/sublimation/surentativity'). But then the very dilemma here for the possibility of prospective human transcendence-and- 
sublimity/sublimation/supererogatory-de-mentativity as to angling-of-imaginary is that 'human lifespan extricatory punctuality/immediacy of depth-of-thought' has an all-englobing hold of <preconverging 'motif-and-apriorising/axiomatising/referencing'-entailing >-

existentialising — enframing/imprintedness-〈as-to- historicity-tracing — in-presencing-

hyperrealisation/hyperreal-transposition $\rangle$ upon any given registry-worldview/dimension that is 'naturally de-mentated/structured/paradigmed not to reflect beyond its ${ }^{79}$ presencingabsolutising-identitive-constitutedness ${ }^{14}<$ amplituding/formative-epistemicity $>$ totalising $\sim$ selfreferencing-syncretising/circularity/interiorising/akrasiatic-drag ${ }^{34}$ (notwithstanding existence — as-the-absolute-a-priori-of-conceptualisation and existence—as-sublimatingwithdrawal/unenframing/re-ontologising,-elicited-from-prospective-profoundsupererogation -<as-to-perspective-ontological-normalcy/postconvergence-implied'prospective-aporeticism-overcoming/unovercoming'>). While the human mind can chippingly/fragmentingly/peripherally project of prospective psychologismic apriorising/axiomatising/referencing-\{of-'prospectivelyimplicited_attendant-ontological-contiguity ' educedexistentialising/contextualising/textualising_intelligibility/epistemicity/reflexivity_contiguity$<$ imbued-notional $\left.\sim \operatorname{cogency}>^{\prime},\right\}$-conflatedness ${ }^{13}$-in-\{preconverging -ment by $\}^{\prime}$ postconverging-entailment (as to prospective deliverance/liberation/emancipation from 'human lifespan extricatory punctuality/immediacy of depth-of-thought' as an all-englobing hold of <preconverging 'motif-and-apriorising/axiomatising/referencing'-entailing >-

existentialising — enframing/imprintedness-〈as-to- historicity-tracing_-in-presencinghyperrealisation/hyperreal-transposition〉) when it comes to prospective nascentparticular/incipient-and-material/technical-sublimations- $<$ blinded-to-their-relative-ontologicalcompleteness - reference-of-thought- devolving > (backed with effectively constraining existence — as-sublimating-withdrawal/unenframing/re-ontologising,-elicited-from- 
prospective-profound-supererogation ), it is of an altogether different scale projection with regards to 'prospective human ${ }^{83}$ reference-of-thought conception as to existence-assublimating-withdrawal/unenframing/re-ontologising,-elicited-from-prospective-profoundsupererogation $^{9}$ (in response to the 'blinded-to-their-relative-ontological-completeness ${ }^{87}$ reference-of-thought- devolving' of prospective nascent-particular/incipient-andmaterial/technical-sublimations- $<$ blinded-to-their-relative-ontological-completeness

reference-of-thought- devolving $>$ ) explaining the higher human existentialising-frame-ofentailment of motif-and-apriorising/axiomatising/referencing emotional-involvement and associated blurriness-<sterilising/anecdotalising/trivialising-of-prospective-reontologising_by-preconverging,-in-disontologising-formulaic-dragging-out/hollowing-out> of such a more comprehensive ${ }^{83}$ reference-of-thought projection of psychologismic apriorising/axiomatising/referencing-\{of-"prospectively implicited_attendant-ontological-contiguity ' educedexistentialising/contextualising/textualising_ 'intelligibility/epistemicity/reflexivity-contiguity$<$ imbued-notional $\left.\sim \operatorname{cogency}>^{\prime},\right\}$-conflatedness ${ }^{13}$-in-\{preconverging-ment by $\}^{\prime}$ postconverging-entailment (eliciting institutionalised pedantising/muddling/formulaichollowing-out-in-subontologisation/subpotentiation-〈blurring/undermining-of-prospectivetotalising-entailing,-as-to-entailing-<amplituding/formative-epistemicity $>$ totalising $\sim$ inrelative-ontological-completeness $\rangle$ desublimation with its associated dominance/vestedinterest-subontologising-skewed-influence-as-to-social-vestedness/normativity- $<$ discretelyimplied-functionalism> in $>\quad$ re-originary-_as-unenenframe-_ed/reontologising/unbeholdening/outlier-conceptualisation__imbued-postconverging/dialecticalthinking -'projective-insights'/‘epistemic-projection-in-conflatedness ' 'ofnotional deprocrypticism-prospective-sublimation $\rangle^{0}$ for prospective sublimation possibilities as to the given registry-worldview/dimension 'social-functioning-and-accordance-as-of- 
social-stake-contention-or-confliction imbuing existentialising-frame-of-entailment-of motifand-apriorising/axiomatising/referencing of disontologising/ontologising-and-re-ontologising'). The difficulty of such a more comprehensive ${ }^{83}$ reference-of-thought projection of psychologismic $\sim$ apriorising/axiomatising/referencing- $\{$ of-"prespectively implicited_attendant-ontological-contiguity ' educedexistentialising/contextualising/textualising_'intelligibility/epistemicity/reflexivity-contiguity<imbued-notional cogency $\left.>{ }^{\prime} \quad\right\}$ - conflatedness ${ }^{13}$ in-\{preconverging-ment by\} postconverging-entailment can be appreciated in the sense that in-the-bigger-picture 'all the life and rational of life that is/exists' of the respective existential-<disontologising/re-ontologising aporeticism $>$ mental-states of recurrent-utter-uninstitutionalisation, ununiversalisation, nonpositivism/medievalism and ${ }^{80}$ procrypticism-or-disjointedness-as-of- ${ }^{8}$ reference-of-thought as of their respectively attained/achieved human aestheticisation-and-aestheticisation-towardsontology-<elicited-idiomatisation $>$ (as to social-setups imbued 'supposed reproducibilitymathesis/motif/thrownness-disposition,-as-reproducibility-of-aestheticisation of meaningfulness-and-teleology ${ }^{9}$ underlied by language, culture, social institutions, technical knowhow, etc., and so as to human Being-development/ontological-framework-expansion-asto-depth-of-ontologising-development-as-infrastructure-of- meaningfulness-and-teleology , institutional-development-as-to-social-function-development and living-development-as-topersonality-development psychologismic epistemic-acutisation difficulty-for,

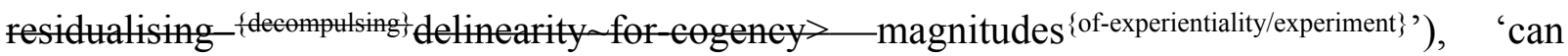
hardly fathom of the prospective superseding translation/metaphorising of the same epistemicity scope' (arising from superseding human limited-mentation-capacity-deepening—as-subjectinglimitedness/human-subpotency to 'educed unlimitedness/existence-sublimating nascence' 53 as to the prospective 'exercise of epistemic-projective-equalisation of human station of presencing-absolutising-identitive-constitutedness ${ }^{14}$ as to prospective ${ }^{6}$ nonpresencing- 
$<$ perspective-ontological-normalcy/postconvergence $>$ epistemic - projective-equalisation') as so-supersedingly-translating/metaphorising respectively as of prospectively explicited baseinstitutionalisation, ${ }^{103}$ universalisation, positivism/rational-empiricism and ${ }^{18}$ deprocrypticismor-preempting - disjointedness-as-of- ${ }^{3}$ reference-of-thought. This insight critically explains why 'we don't truly grasp the meaning and organic-knowledge of the Socrates, Platos, Galileos, Descartes, Newtons, Diderots, Nietzsches, etc. of the world on the basis of projected mereformulaicity/ritualisation-<as-to-mere-formulaicmethodologising/mutualising/organising/institutionalising,-prospectively-losing-track-of‘fepistemic-talising ’’+re-apriorising/re-axiomatising/re-referencing residuality-in-reoriginariness/re-origination'> of reproducibility—mathesis/motif/thrownness-disposition,--asreproducibility-of-aestheticisation' (underlying their implicited re-ontologising prospective Being-development/ontological-framework-expansion-as-to-depth-of-ontologisingdevelopment-as-infrastructure-of- meaningfulness-and-teleology ) but rather their true meaning and organic-knowledge as metaphoricity ${ }^{57}$ are inscribed in their originarinessparrhesia,-as-spontaneity-of-aestheticisation projected prospective human 'relativeontological-incompleteness 8 /relative-ontological-completeness ${ }^{87}$

\section{〈sublimating referencing/registering/decisioning,-as-self-becoming/self-}

conflatedness /formative-supererogating-<projective/reprojective-aestheticising-re-motifand-re-apriorising/re-axiomatising/re-referencing,-in-perspective-ontologicalnormalcy/postconvergence $>>$ as to human-and-social-expectations/anticipationsmetaphoricity ${ }^{5}$-as-preconverging/postconverging-redementating/restructuring/reparadigming-psychologism' ${ }^{89}$ aestheticisation-and-aestheticisationtowards-ontology-<elicited-idiomatisation $>$ (with regards to social-setups imbued 'supposed reproducibility - mathesis/motif/thrownness-disposition,-as-reproducibility-of-aestheticisation of ${ }^{5}$ meaningfulness-and-teleology ${ }^{9}$ underlied by language, culture, social institutions, technical 
knowhow, etc., and so as to human Being-development/ontological-framework-expansion-asto-depth-of-ontologising-development-as-infrastructure-of- meaningfulness-and-teleology , institutional-development-as-to-social-function-development and living-development-as-topersonality-development psychologismic epistemic-acutisation difficulty-<for,

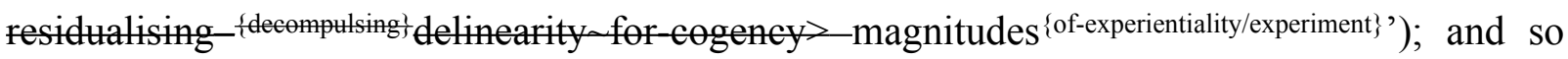
with respect to their implicited prospective

\section{'psychologismic apriorising/axiomatising/referencing-\{of-'prospectively}

implicited_attendant-ontological-contiguity ' educed-

existentialising/contextualising/textualising_'intelligibility/epistemicity/reflexivity-contiguity$<$ imbued-notional $\left.\sim \operatorname{cogency}>^{\prime}\right\}$ - conflatedness ${ }^{13}$-in-\{preconverging-ment by $\}^{2}$ postconverging-entailment implications as of the-very-same fundamental dimensionality-ofsublimating $25<<$ amplituding/formative $>$ supererogatory $\sim$ de-mentativeness/epistemic-growthor-conflatedness /transvaluative-rationalising/transepistemicity/anamnestic-residuality/spiritdrivenness-equalisation)' in 'implicited_attendant-ontological-contiguity ${ }^{67} \sim$ educedexistentialising/contextualising/textualising_'intelligibility/epistemicity/reflexivity-contiguity$<$ imbued-notional cogency >' induced 'epistemic-growth/disquiet/discomfort-〈inducedsublimation,-as-from-existence's - effusing/ecstatic-inlining-as- historiality\{science/authenticity/nonextrication $\}$-beyond-mere-formulaicity/ritualisation-as- historicitytracing-\{science-ideology/fashionability/distraction $\}\rangle$ as to construction-of-the-Self in dispensing-with-immediacy-for-relative-ontological-completeness ${ }^{87}$-byreification/contemplative-distension ${ }^{27}$. That said, the reality as to human limited-mentationcapacity —as-subjecting 'educed-unlimitedness/existence-sublimating nascence' tolimitedness/human-subpotency is that a registry-worldview/dimension conception of 'all the life and rational of life that is/exists' is ever always sub-par to the requisite human intemporalprioritisation-of- ${ }^{8}$ reference-of-thought'-as-conflatedness ${ }^{13}$-or-ontological-reprojecting 
potential for the prospective 'exercise of epistemic — projective-equalisation of human station of presencing-absolutising-identitive-constitutedness ${ }^{14}$ as to prospective nonpresencing<perspective-ontological-normalcy/postconvergence $>\quad$ epistemic-projective-equalisation' (explaining why such a possibility can only arise as to intemporal-prioritisation-of- ${ }^{-}$referenceof-thought'-as-conflatedness ${ }^{13}$-or-ontological-reprojecting eliciting/prompting/stimulating angling-of-imaginary implied 'multicenturies-long human crossgenerational Beingdevelopment/ontological-framework-expansion-as-to-depth-of-ontologising-development-asinfrastructure-of- meaningfulness-and-teleology psychologismic epistemic-acutisationdifficulty $<$ for, residualising \{decompling $\}$ delinearity for-cogency> magnitude ${ }^{\text {of- }}$ experientiality/experiment\} of prospective transcendence-and-sublimity/sublimation/supereregatery $\sim$ dementativity' and not the epochal in-effect absolution- $<$ as-toapriorising/axiomatising/referencing-\{of-'prospectively_implicited_attendant-ontologicalcontiguity ' educedexistentialising/contextualising/textualising_ 'intelligibility/epistemicity/reflexivity-contiguity<imbued-notional cogency >' $\}$-constitutedness -in preconverging entailment $>$ conception of psychical-nascency implied 'human lifespan extricatory punctuality/immediacy of depth-ofthought' as practically reflected in the 'existentialising-frame-of entalment of apriorising/axiomatising/referencing of supposed friendship/family/social/professional values that-fail/if-failing the possibility for the-very-same fundamental dimensionality-ofsublimating $25-\langle<$ amplituding/formative $>$ supererogatory $\sim$ de-mentativeness/epistemic-growthor-conflatedness /transvaluative-rationalising/transepistemicity/anamnestic-residuality/spiritdrivenness-equalisation)'); and as so-reflected with successive registry-worldview/dimension conception of 'all the life and rational of life that is/exists' as to their given ${ }^{79}$ presencingabsolutising-identitive-constitutedness ${ }^{14}$ imbued ‘ $<$ amplituding/formative $>$ disposedness/psychologismic-construct-〈as-to-orientation/value- 
construct/valuation-and-derived-parameterising $\rangle$ and $<$ amplituding/formative $>$ entailment-〈asto-totalising-contiguous/coherent-factuality-of-variability〉'

of 'punctual

$<$ amplituding/formative-epistemicity $>$ totalising $\sim$ self-referencing-

syncretising/circularity/interiorising/akrasiatic-drag 34 rather measuring-up success/accomplishment/aspiration in shallow-supererogation of manifest in-effect absolution$<$ as-to-apriorising/axiomatising/referencing-\{of- prospectively_implicited_attendantontological-contiguity ' educed-

existentialising/contextualising/textualising_intelligibility/epistemicity/reflexivity-contiguity<imbued-notional cogency>' $\quad\}$-constitutedness -in-preconverging-entailment $>$ as to the given registry-worldview/dimension $\quad<$ preconverging 'motif-andapriorising/axiomatising/referencing'-entailing >-existentialising — enframing/imprintedness〈as-to- historicity-tracing - in-presencing-hyperrealisation/hyperreal-transposition〉' (which is prospectively in relative-ontological-incompleteness ${ }^{88}$-presublimation-construct-ofmeaningfulness-and-teleology $\quad$ desublimating $\sim$ existentialising-decisionality-<as-to-

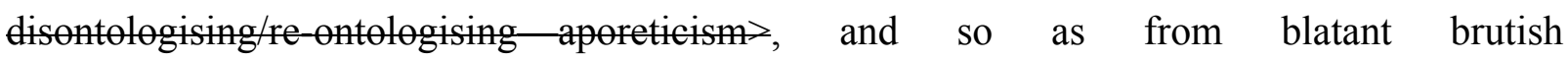
conquest/subjugation conception associated with 'measuring-up success/accomplishment/aspiration in its warring/bellicosity shallow-supererogation of manifest in-effect absolution-<as-to-apriorising/axiomatising/referencing-\{of-"prospectively implicited_attendant-ontological-contiguity ' educedexistentialising/contextualising/textualising_'intelligibility/epistemicity/reflexivity-contiguity<imbued-notional cogency >' $\}$-constitutedness -in preconverging-entailment>>, dominion protection conception associated with 'measuring-up success/accomplishment/aspiration in its paramountcy shallow-supererogation of manifest in-effect absolution- $<$ as-toapriorising/axiomatising/referencing-\{of-'prospectively_implicited_attendant-ontologicalcontiguity ' educed- 
existentialising/contextualising/textualising_'intelligibility/epistemicity/reflexivity-contiguity$<$ imbued-notional cogency $>$ ' $\quad\}$-constitutedness -in preconverging-entailment>>, to the very natural-order-of-things conception associated with 'measuring-up success/accomplishment/aspiration in its patricianism/aristocratism shallow-supererogation of manifest in-effect absolution-<as-to-apriorising/axiomatising/referencing-\{of- prospectively implicited_attendant-ontological-contiguity ' reducedexistentialising/contextualising/textualising_'intelligibility/epistemicity/reflexivity_contiguity$<$ imbued-notional cogency $>>\quad\}$-constitutedness -in preconverging-entailment>> ${ }^{\prime}$ and to our subtle modern-day institutionally-distorted/disjointed conception associated with 'measuring-up success/accomplishment/aspiration in its presencing-institutional-and-economic shallowsupererogation of manifest in-effect absolution-<as-to-apriorising/axiomatising/referencing\{of-'prospectively_implicited_attendant-ontological-contiguity ' educedexistentialising/contextualising/textualising_'intelligibility/epistemicity/reflexivity-contiguity$<$ imbued-notional cogency $\left.>^{\prime} \quad\right\}$-constitutedness -in preconverging-entailment $>$ '). What is of central pragmatic contemplative relevance here is that 'human aestheticisation-andaestheticisation-towards-ontology-<elicited-idiomatisation $>$ is more readily skewed/facilitated with respect to punctual/immediacy/constituted/compulsions-encumbered purposefulness underlying human institutional-development-as-to-social-function-development and livingdevelopment-as-to-personality-development psychologismic epistemic-acutisationdifficulty<for, residualising \{decompulsing\} delinearity for-cogency> magnitudes $\{$ ofexperientiality/experiment\}' given human limited-mentation-capacity-as-subjecting 'educedunlimitedness/existence-sublimating nascence' to-limitedness/human-subpotency (as to the given registry-worldview/dimension institutionalisation-threshold in presencingabsolutising-identitive-constitutedness ${ }^{14}$ arising as of their less challenging level of 'psychologismic apriorising/axiomatising/referencing-\{of-'prespectively 
implicited_attendant-ontological-contiguity ' reduced-

existentialising/contextualising/textualising_'intelligibility/epistemicity/reflexivity_contiguity-

<imbued-notional cogency >' $\}$ - conflatedness ${ }^{13}$ in-\{preconverging-ment by\}

pestconverging-entailment implications but notionally as of the-very-same fundamental dimensionality-of-sublimating $25<$ amplituding/formative $>$ supererogatory $\sim$ de-

mentativeness/epistemic-growth-or-conflatedness /transvaluative-

rationalising/transepistemicity/anamnestic-residuality/spirit-drivenness-equalisation〉 $\quad$ in

'implicited_attendant-ontological-contiguity ${ }^{67}$ educed-

existentialising/contextualising/textualising_intelligibility/epistemicity/reflexivity-contiguity-

<imbued-notional cogency $>$ induced 'epistemic-growth/disquiet/discomfort-〈induced-

sublimation,-as-from-existence's - effusing/ecstatic-inlining-as- historiality-

\{science/authenticity/nonextrication\}-beyond-mere-formulaicity/ritualisation-as- historicity-

tracing-\{science-ideology/fashionability/distraction $\}\rangle$ as to construction-of-the-Self in dispensing-with-immediacy-for-relative-ontological-completeness ${ }^{87}$-by-

reification/contemplative-distension ${ }^{27}$ required for re-ontologising prospective Beingdevelopment/ontological-framework-expansion-as-to-depth-of-ontologising-development-asinfrastructure-of- meaningfulness-and-teleology ) but that such facileness of human aestheticisation-and-aestheticisation-towards-ontology-<elicited-idiomatisation $>$ associated with with human institutional-development-as-to-social-function-development and livingdevelopment-as-to-personality-development psycholegismic epistemic acutisation-

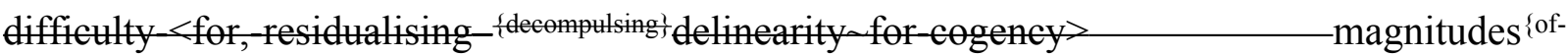
experientiality/experiment\} (which rather relies-on/is-propped-by/is-supported-by the priorly induced profound-supererogation for Being-development/ontological-framework-expansion-as-todepth-of-ontologising-development-as-infrastructure-of- meaningfulness-and-teleology 'exercise of epistemic — projective-equalisation of human station of ${ }^{7}$ presencing — absolutising- 
identitive-constitutedness ${ }^{14}$ as to prospective ${ }^{6}$ nonpresencing-<perspective-ontologicalnormalcy/postconvergence> epistemic-projective-equalisation imbued psychologismic $\sim$ apriorising/axiomatising/referencing-\{of-"prospectively implicited_attendant-ontological-contiguity ' educedexistentialising/contextualising/textualising_'intelligibility/epistemicity/reflexivity-contiguity<imbued-notional cogency $\left.>^{\prime}\right\}$-conflatedness ${ }^{13}$-in-\{preconverging-ment by\} postconverging entailment implications') doesn't dispense the human from prospectively contemplating about its more profound-supererogation ${ }^{\circ}$ potential of notional $\sim$ self-distantiation<imbued — re-motif-and-re-apriorising/re-axiomatising/re-referencing $>$ as to re-ontologising prospective Being-development/ontological-framework-expansion-as-to-depth-ofontologising-development-as-infrastructure-of- meaningfulness-and-teleology anchoring (and particularly as the modern-day 'living and institutional all-englobing sales/merchandising/materiality logic/rationale/mentality' threatens to invade/subvert all other human conception of value and worth especially as to the implications for re-ontologising prospective Being-development/ontological-framework-expansion-as-to-depth-ofontologising-development-as-infrastructure-of- meaningfulness-and-teleology notwithstanding its requisite notional asceticism imbued difficulty/challenge given our more complex and global modern-day 'social-functioning-and-accordance-as-of-social-stakecontention-or-confliction imbuing existentialising-frame-of-entailment-of motif-andapriorising/axiomatising/referencing of disontologising/ontologising-and-re-ontologising' poorly cognisant of its prospective disontologising and even when apparently so-cognisant is susceptible to 'superficial mere-formulaicconformity/trending/voguing/fashionability/resonance relation to meaningfulness-andteleology ${ }^{9}$ that at best projects of charade in lieu of the full veridical prospective ontologisingand-re-ontologising possibilities). The veracity of human de-mentation- 


\section{〈supererogatory $\sim$ ontological-de-mentation-or-dialectical-de-mentation-stranding-or-}

attributive-dialectics $\rangle$ with regards to the underlying rescheduling of the human placeholdersetup/mental-devising-representation/mentation/consciousness-awareness-teleology ${ }^{99}$ (implied psychoanalytic-unshackling/memetic-reordering/institutional-recomposuring selfbecoming/self-conflatedness ${ }^{13}$ /formative-supererogating-<projective/reprojectiveaestheticising-re-motif-and-re-apriorising/re-axiomatising/re-referencing,-in-perspectiveontological-normalcy/postconvergence $>$ ) speaks to the fact that the human/human-mind/humansubpotency 'is inevitably aporetically bound-to/fated-to/unescapable-from its ontological-faithnotion-or-ontological-fideism —imbued-underdetermination-of-motif-andapriorising/axiomatising/referencing-as-so-being-as-of-existential-reality as to its existentially<disontologising/re-ontologising aporeticism $>$ manifest disseminative-sublimatingselectivity-of-ontological-good-faith/authenticity postconverging-dementating/structuring/paradigming _ or_desublimating-deselectivity-of-ontological-badfaith/inauthenticity $\sim$ preconverging-de-mentating/structuring/paradigming , (whether of direct-capacity or deferential-capacity as to the possibility for sound/virtuous/veracity-of human ontological-performance ${ }^{72}$-<including-virtue-as-ontology $>/$ morality/ethics/justice/etc. or human vices-and-impediments ${ }^{105}$ ) 'with no room for any human neutral mental-state conception

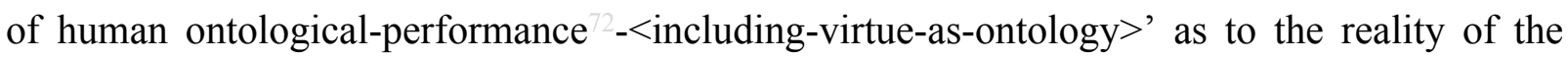
postconverging-aporeticism-overcoming/unovercoming implications of human $<$ amplituding/formative-epistemicity>-totalising thrownness-in-existence ${ }^{35}$. Thus the

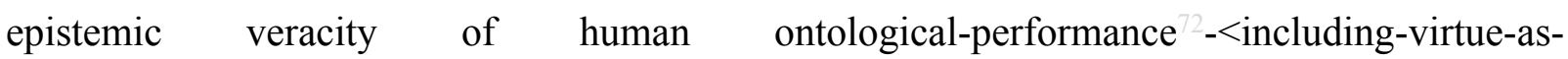
ontology $>$ /morality/ethics/justice/etc. implies that the human as to its existentially< disontologising/re-ontologising aporeticism $>$ manifest human ontological-performance $<$ including-virtue-as-ontology $>$ /morality/ethics/justice/etc. can only ever be (consciously or unconsciously) of ontological-good-faith/authenticity $\sim$ postconverging-de- 
mentating/structuring/paradigming

imbued

psychologismic $\sim$ apriorising/axiomatising/referencing-\{of-"prospectively

implicited_attendant-ontological-contiguity ' educed-

existentialising/contextualising/textualising_'intelligibility/epistemicity/reflexivity-contiguity-

<imbued-notional cogency $>$ ' $\}$-conflatedness ${ }^{13}$ in-\{preconverging-ment by\}

pesteonverging-entailment or ontological-bad-faith/inauthenticity $\sim$ preconverging-de-

mentating/structuring/paradigming

imbued

psychologismic apriorising/axiomatising/referencing-\{of-"prospectively

implicited_attendant-ontological-contiguity ' ceduced-

existentialising/contextualising/textualising_intelligibility/epistemicity/reflexivity-contiguity-

<imbued-notional cogency $>\quad\}$-constitutedness ${ }^{14}$-in-preconverging-entailment; $\quad$ with

regards to 'human ontological-performance ${ }^{72}-<$ including-virtue-as-

ontology $>$ /morality/ethics/justice/etc. in the 'implicited_attendant-ontologicalcontiguity $^{67} \sim$ educed-

existentialising/contextualising/textualising_intelligibility/epistemicity/reflexivity-contiguity$<$ imbued-notional cogency>' $>^{\text {on }}$ oxistentially-instantiated human aposteriorising/logicising/deriving/intelligising/measuring - ${ }^{56}$ meaningfulness-and-teleology ${ }^{9}$, as so-underlined with human self-reflexive instigative-eventuating-〈as-to-teleologicalinstigative/incipient-willing/arbitrariness/waywardness/faithdrivenness/supererogating-forhuman-intelligibility,-preceding-existence's-eventuating-sublimating-validation/desublimating-

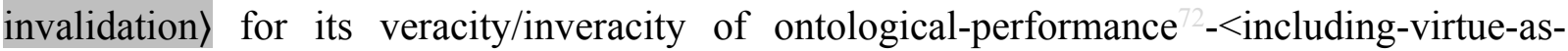
ontology $>$. This point is ontologically critical in the sense that, as so-manifested as to when prospective relative-ontological-completeness ${ }^{87}$ avails, the-human/humankind cannot covertly or overtly claim to avoid its prospective human postconvergingaapereticismovercoming/mnovercoming and then pretend not to be prospectively in 'ontological-bad- 
faith/inauthenticity $\sim$ preconverging-de-mentating/structuring/paradigming

psychologismic apriorising/axiomatising/referencing-\{of-'prespectively

implicited_attendant-ontological-contiguity ' educed-

existentialising/contextualising/textualising_intelligibility/epistemicity/reflexivity-contiguity-

<imbued-notional cogency>' $\quad\}$-constitutedness ' -in-preconverging-entailment'; $\quad$ so-

underlying and pointing to the fundamental drivenness of ontology/science as to dimensionality-

of-sublimating 25 -<<amplituding/formative>supererogatory $\sim$ de-mentativeness/epistemic-

growth-or-conflatedness /transvaluative-rationalising/transepistemicity/anamnestic-

residuality/spirit-drivenness-equalisation $\rangle$ and so rendering the aspiration for prospective human profound-supererogation the most central element of ontology/science (beyond mereformulaicity/ritualisation-<as-to-mere-formulaic-

methodologising/mutualising/organising/institutionalising,-prospectively-losing-track-of-

‘fepistemic-atlising ’’re-apriorising/re-axiomatising/re-referencing $\sim$ residuality-in-re-

originariness/re-origination'> which is rather so-invented/formed/created from prior human profound-supererogation and ever always in want for prospective human profoundsupererogation ${ }^{\circ}$. Saliently thus the articulation of knowledge as to its more and more human profound-supererogation exigency of the 'exercise of the epistemic-projective-equalisation of human station of ${ }^{7}$ presencing - absolutising-identitive-constitutedness ${ }^{14}$ as to prospective nonpresencing-<perspective-ontological-normalcy/postconvergence $>$ epistemic-projectiveequalisation' (as from living-development-as-to-personality-development to institutionaldevelopment-as-to-social-function-development to Being-development/ontologicalframework-expansion-as-to-depth-of-ontologising-development-as-infrastructure-ofmeaningfulness-and-teleology ) is much more than just 'passive transference of mereformulaicity/ritualisation-<as-to-mere-formulaicmethodologising/mutualising/organising/institutionalising,-prospectively-losing-track-of- 
6 fepistemic-totalising 're-apriorising/re-axiomatising/re-referencing residuality-in-re-

originariness/re-origination'> as to secondnatured reproducibility—mathesis/motif/thrownnessdisposition,-as-reproducibility-of-aestheticisation' but more critically and potentially speaks to the 'requisite protracted-social—as-to-individual-by-institutional-by-social notional $\sim$ selfdistantiation-<imbued — re-motif-and-re-apriorising/re-axiomatising/re-referencing $>$ appraisal for veridical organic-knowledge'; such that in reality knowledge as to organic-knowledge can only be truly construed as to 'its human profound-supererogation imbuing ownership/staking/purchase' associated veridically with implicited-and-explicited 'implicited_attendant-ontological-contiguity ${ }^{6}$ ' educedexistentialising/contextualising/textualising_intelligibility/epistemicity/reflexivity-contiguity<imbued-notional cogency>' induced 'epistemic-growth/disquiet/discomfort-〈inducedsublimation,-as-from-existence's - effusing/ecstatic-inlining-as- historiality\{science/authenticity/nonextrication $\}$-beyond-mere-formulaicity/ritualisation-as- historicitytracing-\{science-ideology/fashionability/distraction $\}\rangle$ as to construction-of-the-Self in dispensing-with-immediacy-for-relative-ontological-completeness ${ }^{87}$-byreification/contemplative-distension ${ }^{27}$. Effectively, organic-knowledge as to veridical 'conceptivity/epistemic-reflexivity/epistemicity-relativism-determinism-<reifying \{as-toknowledge-developing\}-and-empowering $>\quad$ imbued theoretical/conceptual/operant implications' is rather of a more and more human profound-supererogation exigency of the 'exercise of the epistemic-projective-equalisation of human station of ${ }^{79}$ presencingabsolutising-identitive-constitutedness ${ }^{14}$ as to prospective ${ }^{6}$ nonpresencing-<perspectiveontological-normalcy/postconvergence> epistemic — projective-equalisation' implications (as from living-development-as-to-personality-development to institutional-development-as-tosocial-function-development to Being-development/ontological-framework-expansion-as-todepth-of-ontologising-development-as-infrastructure-of- meaningfulness-and-teleology ). 
This further underlines the fact that the nonpresencing-<perspective-ontologicalnormalcy/postconvergence $>$ epistemic-projection veracity of human ontological-performance ${ }^{72}$ <including-virtue-as-ontology $>$ /morality/ethics/justice/etc. (as to the 'full incipient supererogating breadth of human intelligibility transmutation' involving '<supererogatory $\sim$ human-subpotency $>$-effecting imbued epistemic-totalising preformulating/preframing/premeaningfulness of notional $\sim$ originariness-parrhesia,--asspontaneity-of-aestheticisation' before the incipience of metaphoricity ${ }^{57}$ and then meaningfulness-and-teleology as to existentialising-frame-of-entailment-of-motif-andapriorising/axiomatising/referencing), rather lies with postconverging-nonextricatoryexistential-preempting-of-existential-unthought 'human intemporal-individuation threading/relaying succession of sublimating gesturings' of 'intemporal-prioritisation-ofreference-of-thought'-as-conflatedness ${ }^{3}$-or-ontological-reprojecting as to human directcapacity/deferential-capacity for dimensionality-of-sublimating <<amplituding/formative>supererogatory $\sim$ de-mentativeness/epistemic-growth-orconflatedness /transvaluative-rationalising/transepistemicity/anamnestic-residuality/spiritdrivenness-equalisation); and so in prospectively induced transversality-<for-sublimatingexistential-eventuating/denouement,-from-'thinking-at-first/pure-predisposition-preemptive-ofprospective-disontologising/subontologising' as-of-prospectively-disambiguated-affirmedand-unaffirmed-'motif-and-apriorising/axiomatising/referencing' $>{ }^{101}$ with respect to any socialsetup given 'social-functioning-and-accordance-as-of-social-stake-contention-or-confliction imbuing existentialising-frame-of-entailment-of motif-andapriorising/axiomatising/referencing of disontologising/ontologising-and-re-ontologising'. This point is critical because the 'social-functioning-and-accordance-as-of-social-stake-contentionor-confliction imbuing existentialising-frame-of-entailment-of motif-andapriorising/axiomatising/referencing of disontologising/ontologising-and-re-ontologising' as to 
its second-natured reproducibility—-mathesis/motif/thrownness-disposition,--as-reproducibilityof-aestheticisation is operantly of an underlying positive-opportunism-of-social-functioningand-accordance $^{75}$ relation to the institutionalisation-threshold of ${ }^{56}$ meaningfulness-andteleology and is not necessarily beholdening to prospective human profound-supererogation but rather in-many-ways secondnatured mere-formulaicity/ritualisation-<as-to-mereformulaic — methodologising/mutualising/organising/institutionalising,-prospectively-losingtrack-of- ‘fepistemic-totalising ’’’e-apriorising/re-axiomatising/re-referencing $\sim$ residuality-in-reoriginariness/re-origination'> (notwithstanding that existence-as-the-absolute-a-priori-ofconceptualisation and existence — as-sublimating-withdrawal/unenframing/re-ontologising,elicited-from-prospective-profound-supererogation $-<$ as-to-perspective-ontologicalnormalcy/postconvergence-implied-'prospective-aporeticism-overcoming/unovercoming'> can only enable prospective human profound-supererogation sublimation potential as to a nonpresencing-<perspective-ontological-normalcy/postconvergence $>$ epistemic-projection beyond such mere-formulaicity/ritualisation-<as-to-mere-formulaicmethodologising/mutualising/organising/institutionalising,-prospectively-losing-track-of‘\{epistemic-totalising ’’re-apriorising/re-axiomatising/re-referencing - residuality-in-re-

originariness/re-origination'> in prospective human shallow-supererogation ). In this regards, the 'social-functioning-and-accordance-as-of-social-stake-contention-or-confliction imbuing existentialising-frame-of-entailment of motif-and-apriorising/axiomatising/referencing of disontologising/ontologising-and-re-ontologising' doesn't carry/contain 'any inherent-andcollective social approbative/sanctioning secondnatured reproducibilitymathesis/motif/thrownness-disposition,-as-reproducibility-of-aestheticisation institutionalisation-threshold' that effectively drive prospective human profoundsupererogation . The 'social-functioning-and-accordance-as-of-social-stake-contention-orconfliction imbuing existentialising-frame-of entailment of motif-and- 
apriorising/axiomatising/referencing of disontologising/ontologising-and-re-ontologising' is rather the secondnatured outcrop of prior human profound-supererogation ${ }^{9}$ as to the latter prompting of 'constraining existence-as-sublimating-withdrawal/unenframing/reontologising,-elicited-from-prospective-profound-supererogation imbuing human ontological-commitment ${ }^{6}<$ implied-self-assuredness-of-ontological-goodfaith/authenticity $\sim$ postconverging-de-mentating/structuring/paradigming -as-being-as-ofexistential-reality>' and ' ${ }^{103}$ universal-transparency ${ }^{104}$-〈transparency-of-totalising-entailing,-asto-entailing-<amplituding/formative-epistemicity>totalising in-relative-ontologicalcompleteness > as available-to/elicitable-to-〈as-to-human-consciousness/collectiveconsciousness-distendedness/detruncating-<beyond-selfpresencing,-as-re-ontologisingdecentering_of-consciousness/collective-consciousness,-as-to-psychologismic-epistemic-

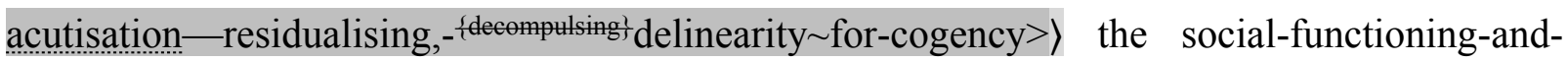
accordance-as-of-social-stake-contention-or-confliction conception of any given registryworldview/dimension $\quad$ <preconverging 'motif-and-apriorising/axiomatising/referencing'entailing >-existentialising — enframing/imprintedness-〈as-to- historicity-tracing —inpresencing-hyperrealisation/hyperreal-transposition''); and so in such prospective human profound-supererogation manifestation (as to pesteonverging-nonextricatory-existentialpreempting-of-existential-unthought 'human intemporal-individuation threading/relaying succession of sublimating gesturings' of 'intemporal-prioritisation-of- ${ }^{8}$ reference-of-thought'as-conflatedness ${ }^{13}$-or-ontological-reprojecting as to human direct-capacity/deferential-capacity for dimensionality-of-sublimating $25-<$ amplituding/formative $>$ supererogatory $\sim$ dementativeness/epistemic-growth-or-conflatedness /transvaluativerationalising/transepistemicity/anamnestic-residuality/spirit-drivenness-equalisation〉 prospectively induced transversality-<for-sublimating-existential-eventuating/denouement-from-'thinking-at-first/pure-predisposition-preemptive-of-prospective- 


\section{disontologising/subontologising’ as-of-prospectively-disambiguated-affirmed-and-}

unaffirmed-'motif-and-apriorising/axiomatising/referencing' $\left.{ }^{101}\right)$. In this respect, the coherence of the sublimating limited-mentation-capacity-deepening - as-subjecting limitedness/humansubpotency-to-'educed-unlimitedness/existence-sublimating nascence' ${ }^{53}$ underlying human history (as to Being-development/ontological-framework-expansion-as-to-depth-ofontologising-development-as-infrastructure-of- meaningfulness-and-teleology , institutionaldevelopment-as-to-social-function-development and living-development-as-to-personalitydevelopment psychologismic epistemic-acutisation difficulty-<or, residualising

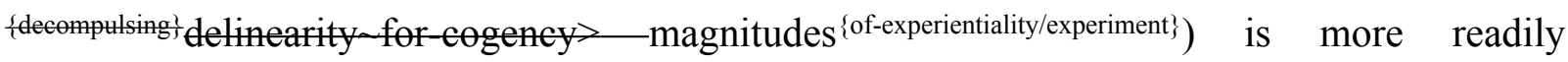
underscored with the "nonpresencing-<perspective-ontological-normalcy/postconvergence $>$ anarchistic-growth/anarchisation-for-re-ontologisation-〈as-to-conscious/unconscious epistemically-sound induced 'demoronisation-<sublimating-nascence,-nonextricatorysublimating-upstreaming/'amontée'> postconverging/dialectical-thinking conception of residual_re-originary_anarchistic incipiency of human social-functioning-and-accordance-asof-social-stake-contention-or-confliction meaningfulness-and-teleology ' ' ' reflected sparingly/thinly with the Socrates, Copernicuses, Galileos, Descartes, Kants, Newtons, Leibniz, Rousseaux, Diderots, Pasteurs, Lavoisiers, Teslas, Einsteins, etc. of the world intellectual-andmoral profound-supererogation ${ }^{6}$ so-underlined as to their respectively elicited re-originary_-asunenframed/re-ontologising/unbeholdening/outlier-conceptualisation-_iimbuedpostconverging/dialectical-thinking -'projective-insights'/'epistemic-projection-inconflatedness ' 'of-notional deprocrypticism-prospective-sublimation $\rangle^{\prime}$ transversality- $<$ forsublimating-existential-eventuating/denouement,-from-'thinking-at-first/pure-predispositionpreemptive-of prospective-disontologising/subontologising' as-of-prospectivelydisambiguated-affirmed-and-unaffirmed-'motif-and-apriorising/axiomatising/referencing' $>$ ' as to the fact that it is only the 'protensive-consciousness implied as of such dimensionality-of- 
sublimating $25<<$ amplituding/formative $>$ supererogatory $\sim$ de-mentativeness/epistemic-growthor-conflatedness /transvaluative-rationalising/transepistemicity/anamnestic-residuality/spiritdrivenness-equalisation> conception of human history' that can reflect human sublimating historiality/ontological-eventfulness ${ }^{38}$ ontological-aesthetic-tracing-<perspectiveontological-normalcy/postconvergence-reflected-‘epistemicity-relativism-determinism'> (whereas the shallow-supererogation of all ${ }^{79}$ presencing-absolutising-identitiveconstitutedness $^{14}$ social-vestedness/normativity-<discretely-implied-functionalism $>$ conception of human history are rather exercises in their notional totalisingly-ing — discretion/whim-ofthought elicited desublimating ${ }^{4}$ historicity-tracing-in-presencing-hyperrealisation/hyperrealtransposition as to their given underlying metaphysics-of-presence-〈implicited'nondescript/ignorable-void ' 'as-to- presencing - absolutising-identitive-constitutedness > epistemic apriorising/axiomatising/referencing-\{of-'prospectively implicited_attendantontological-contiguity ' educed-

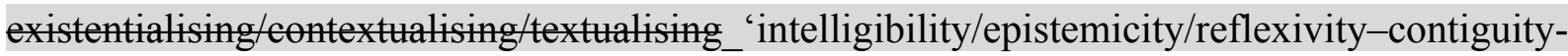
<imbued-notional cogency>' $\}$-constitutedness $\quad$-in-preconverging-entailment).

Insightfully (as to Being-development/ontological-framework-expansion-as-to-depth-ofontologising-development-as-infrastructure-of- meaningfulness-and-teleology , institutionaldevelopment-as-to-social-function-development and living-development-as-to-personalitydevelopment psychologismic epistemic-acutisation difficulty-<for, residualising \{decompulsing\} delinearity for human limited-mentation-capacity—as-subjecting-'educed-unlimitedness/existencesublimating nascence' to limitedness/human-subpotency implies that in-effect human intelligibility (as it is underlied-and-developed in the sublimating-postconverged 'substantive abstract-tissue-of-social-emanance \{epistemictotalising $3{ }^{3}$ hermeneutically/textually/reprojectingly/supererogatingly/zeroingly/re-acutingly,- 
$\{$ decompulsing $\}$ delinearity for-cogency_cumulated/recomposured as to cumulating/recomposuring of 'prospectively_implicited_attendant_ontological-contiguity ${ }^{67}$ ' educedexistentialising/contextualising/textualising_'intelligibility/epistemicity/reflexivity-contiguity$<$ imbued-notional cogency $>$, with human limited-mentation-capacity-deepening-assubjecting limitedness/human-subpotency-to-'educed-unlimitedness/existence-sublimatingnascence' ${ }^{53}$ is as of prospective 'nonpresencing-<perspective-ontologicalnormalcy/postconvergence> manifest re-originary_-_as-unenframe-_.

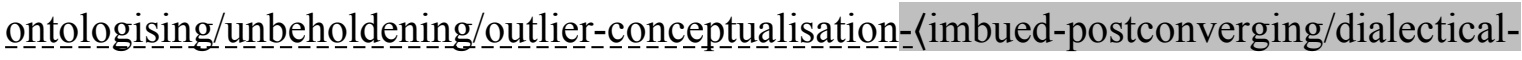
thinking -'projective-insights'/‘epistemic-projection-in-conflatedness ' 'ofnotional deprocrypticism-prospective-sublimation> transversality-<for-sublimatingexistential-eventuating/denouement,-from-'thinking-at-first/pure-predisposition-preemptive-ofprospective-disontologising/subontologising' - as-of-prospectively-disambiguated-affirmedand-unaffirmed-'motif-and-apriorising/axiomatising/referencing'> ${ }^{101} \quad$ (as $\quad$ so-immersed notionally in a continuous 'implicited_attendant-ontological-contiguity ${ }^{67}$; educedexistentialising/contextualising/textualising_'intelligibility/epistemicity/reflexivity-contiguity$<$ imbued-notional cogency $>^{\prime} \quad$ of psychoanalytic-unshackling/memeticreordering/institutional-recomposuring self-becoming/self-conflatedness ${ }^{13 / \text { formative- }^{-}}$ supererogating-<projective/reprojective - aestheticising-re-motif-and-re-apriorising/reaxiomatising/re-referencing,-in-perspective-ontological-normalcy/postconvergence $>$ )'; and soreflected in $\quad$ prospective nonpresencing- $<$ perspective-ontologicalnormalcy/postconvergence $>\quad$ manifest re-originary_-as-unnenframeontologising/unbeholdening/outlier-conceptualisation__imbued-postconverging/dialecticalthinking -'projective-insights'/‘epistemic-projection-in-conflatedness ' 'ofnotional deprocrypticism-prospective-sublimation> transversality-<for-sublimating- 
prospective-disontologising/subontologising' as-of-prospectively-disambiguated-affirmed-

and-unaffirmed-'motif-and-apriorising/axiomatising/referencing'> ${ }^{101} \quad$ (as so-immersed

notionally in a continuous 'implicited_attendant-ontological-contiguity ${ }^{67}$, educedexistentialising/contextualising/textualising_'intelligibility/epistemicity/reflexivity-contiguity<imbued-notional cogency>' of psychoanalytic-unshackling/memeticreordering/institutional-recomposuring self-becoming/self-conflatedness ${ }^{13} /$ formative- $^{-}$ supererogating-<projective/reprojective - aestheticising-re-motif-and-re-apriorising/reaxiomatising/re-referencing,-in-perspective-ontological-normalcy/postconvergence $>$ )' induced prospective human transcendence-and-sublimity/sublimation/supereregatory $\sim$ de-mentativity in voiding/annulling the successive prior registry-worldview's/dimension's supposedly 'inherentand-collective social approbative/sanctioning secondnatured reproducibilitymathesis/motif/thrownness-disposition,-as-reproducibility-of-aestheticisation

institutionalisation-threshold' which rather speaks of their successively given 'socialfunctioning-and-accordance-as-of-social-stake-contention-or-confliction imbuing existentialising-frame-of-entailment of motif-and-apriorising/axiomatising/referencing of disontologising/ontologising-and-re-ontologising' uninstitutionalised-threshold ${ }^{102}$. In order words, it is self-deceptive to contend that any given registry-worldview/dimension has an internal/inherent ${ }^{79}$ presencing_absolutising-identitive-constitutedness ${ }^{14}$ prior_knowledgereification $\sim$ gesturing-and-accounting — of-epistemic-phenomenalism- $<$ inprior_psychologismic apriorising/axiomatising/referencing-\{of-'prior-implicited_attendantontological-contiguity ' educedexistentialising/contextualising/textualising_ intelligibility/epistemicity/reflexivity-contiguity<imbued-notional cogency>' $\}$-constitutedness -in preconverging entailment> $\quad$ (as to mere-formulaicity/ritualisation- $<$ as-to-mere-formulaicmethodologising/mutualising/organising/institutionalising,-prospectively-losing-track-of- 
‘\{epistemic-totalising ’’re-apriorising/re-axiomatising/re-referencing $r$ residuality-in-re-

originariness/re-origination'> of secondnatured reproducibility—mathesis/motif/thrownnessdisposition,-as-reproducibility-of-aestheticisation) accounting-for-and-enabling its prospective human transcendence-and-sublimity/sublimation/supereregatory de-mentativity as to the reality of the <cumulating/recomposuring attendant-ontological-contiguity >-successive registryworldviews/dimensions as herein elucidated. The implication here is that prospective human transcendence-and-sublimity/sublimation/supereregatory-de-mentativity (especially as to reontologising prospective Being-development/ontological-framework-expansion-as-to-depthof-ontologising-development-as-infrastructure-of- meaningfulness-and-teleology more human profound-supererogation' exigency of the 'exercise of the epistemic-projectiveequalisation of human station of ${ }^{7}$ presencing - absolutising-identitive-constitutedness ${ }^{14}$ as to prospective $\quad$ nonpresencing- $<$ perspective-ontological-normalcy/postconvergence $>$ epistemic — projective-equalisation') 'is not and has never been a coherent continuum between any prior registry-worldview/dimension knowledge-reification $\sim$ gesturing-and-accounting—ofepistemic-phenomenalism- $<$ in-

prospective_psychologismic apriorising/axiomatising/referencing-\{of-‘prospectively implicited_attendant-ontological-contiguity ' educedexistentialising/contextualising/textualising_'intelligibility/epistemicity/reflexivity_contiguity$<$ imbued-notional cogency >' \}-conflatedness -in-\{preconverging-ment by\} postconverging-entailment $>$ and its prospective registry-worldview/dimension knowledgereification $\sim$ gesturing-and-accounting-of-epistemic-phenomenalism-<inprospective_psychologismic apriorising/axiomatising/referencing-\{of-'prospectively implicited_attentant-ontological-contiguity ' educedexistentialising/contextualising/textualising_'intelligibility/epistemicity/reflexivity-contiguity<imbued-notional cogency>’ \}-conflatedness -in-\{preconverging-ment by\} 
postconverging-entailment>' (as so-manifested by ancient-sophists 'non-universalising disontologising' in the face of the Socratic-philosophers " ${ }^{103}$ universalising-idealisation ontologising/re-ontologising' or medieval-scholasticism 'non-positivising disontologising' in the face of budding-positivists 'positivism/rational-empiricism ontologising/re-ontologising' or as herein contended modern-day 'manifestation of disparateness-of-conceptualisation$<$ unforegrounding-ment,-failing-prospectively-to-reflect-'immanent $\sim$ relativeunreflexivity/relative-reflexivity ontological-contiguity ' $>$ disontologising' in the face of postmodern thought 'nondisjointing totalising-entailing ontologising/re-ontologising as to human-subject-emancipating-relativism-driven-recomposuring-constructivism-towardssingularisation-<as-to-the-nondisjointedness/entailment-of-prospective- nonpresencing $>$ '); and so because the reality of a registry-worldview/dimension (with regards to its given reontologising prospective Being-development/ontological-framework-expansion-as-to-depthof-ontologising-development-as-infrastructure-of- meaningfulness-and-teleology more human profound-supererogation' exigency of the 'exercise of the epistemic-projectiveequalisation of human station of ${ }^{79}$ presencing - absolutising-identitive-constitutedness ${ }^{14}$ as to prospective $\quad$ nonpresencing- $<$ perspective-ontological-normalcy/postconvergence $>$ epistemic — projective-equalisation' and the fact that a registry-worldview/dimension is rather a secondnatured reproducibility—mathesis/motif/thrownness-disposition,--as-reproducibility-ofaestheticisation operantly of an underlying positive-opportunism—of-social-functioning-andaccordance ${ }^{75}$ relation with the institutionalisation-threshold of ${ }^{5}$ meaningfulness-and-teleology mostly as to mere-formulaicity/ritualisation-<as-to-mere-formulaic methodologising/mutualising/organising/institutionalising,-prospectively-losing-track-of‘\{epistemic-totalising łre apriorising/re axiomatising/re referencing-residuality-in-reoriginariness/re-origination'> in prospective <preconverging 'motif-andapriorising/axiomatising/referencing'-entailing >-existentialising —enframing/imprintedness- 
〈as-to- historicity-tracing-in-presencing-hyperrealisation/hyperreal-transposition〉) means that in-many-ways prospective human transcendence-andsublimity/sublimation/supererogatory-de-mentativity is preconverging/postconverging-dementatively/structurally/paradigmatically beyond-the-contemplation of any given registryworldview/dimension (as of its human psychologismic apriorising/axiomatising/referencing\{of-'prospectively implicited_attendant-ontological-contiguity ' ceducedexistentialising/contextualising/textualising_ intelligibility/epistemicity/reflexivity-contiguity<imbued-notional cogency $\left.>^{\prime} \quad\right\}$-constitutedness ${ }^{14}$-in-preconverging-entailment implications as to 'human lifespan extricatory punctuality/immediacy of depth-of-thought' of the selfpresence/self-constitutedness $^{14}-<$ in-perspective-epistemic-abnormalcy/preconvergence ${ }^{3}>$ of presencing-absolutising-identitive-constitutedness ${ }^{14}$ of relatively unsophisticated/narrowminded/parochial/of-short-attention-span/susceptible-to-disontologising-gimmickiness-andnumbing. Such that it is veridically the exposure (to 'constraining existence-as-sublimatingwithdrawal/unenframing/re-ontologising,-elicited-from-prospective-profound-supererogation imbuing human ontological-commitment -<implied-self-assuredness-of-ontological-goodfaith/authenticity postconverging-de-mentating/structuring/paradigming -as-being-as-ofexistential-reality>' and ' ${ }^{103}$ universal-transparency ${ }^{104}$-〈transparency-of-totalising-entailing,-asto-entailing-<amplituding/formative-epistemicity>totalising in-relative-ontologicalcompleteness > as available-to/elicitable-to-〈as-to-human-consciousness/collectiveconsciousness-distendedness/detruncating-<beyond-selfpresencing,-as-re-ontologisingdecentering_of-consciousness/collective-consciousness,-as-to-psychologismic_epistemicacutisation-residualising, , $^{\text {ddecompulsing }}$ delinearity for-cogency $\left.>\right\rangle$ the social-functioning-andaccordance-as-of-social-stake-contention-or-confliction conception of any given registryworldview/dimension $\quad$ <preconverging 'motif-and-apriorising/axiomatising/referencing'entailing $>$-existentialising — enframing/imprintedness-〈as-to- historicity-tracing - in- 
presencing-hyperrealisation/hyperreal-transposition〉') of the human 'social-functioning-andaccordance-as-of-social-stake-contention-or-confliction imbuing existentialising-frame-ofentailment of motif-and-apriorising/axiomatising/referencing of disontologising/ontologisingand-re-ontologising' uninstitutionalised-threshold ${ }^{102}$ that (as of prospective " nonpresencing$<$ perspective-ontological-normalcy/postconvergence $>$ manifest re-originary_-_as-unenfrentramed/re-_ontologising/unbeholdening/outlier-conceptualisation-_imbued-postconverging/dialecticalthinking -'projective-insights'/‘epistemic-projection-in-conflatedness ' '-ofnotional deprocrypticism-prospective-sublimation $\rangle$ transversality-<for-sublimatingexistential-eventuating/denouement, from 'thinking at first/pure predispesition preemptive of prospective-disontologising/subontologising' - as-of-prospectively-disambiguated-affirmedand-unaffirmed-'motif-and-apriorising/axiomatising/referencing' $>101 \quad$ (as $\quad$ so-immersed notionally in a continuous 'implicited_attendant-ontological-contiguity ${ }^{67}$ ' educedexistentialising/contextualising/textualising_intelligibility/epistemicity/reflexivity-contiguity<imbued-notional $\sim$ cogency $>^{\text {' }}$ of psychoanalytic-unshackling/memeticreordering/institutional-recomposuring self-becoming/self-conflatedness ${ }^{13} /$ formative- $^{-}$ supererogating-<projective/reprojective-aestheticising-re-motif-and-re-apriorising/reaxiomatising/re-referencing,-in-perspective-ontological-normalcy/postconvergence $>$ ) induces prospective transcendence-and-sublimity/sublimation/supererogatory $\sim$ de-mentativity. The bigger point here, is to draw-out-the-dividing-line/make-the-distinguo between 'notional philosophy-<as-to-the-veridical-conception-of-philosophy-as-englobing-all-humanprospective-organic-knowledge-generation-in-relative-ontological-completeness ,-beyond-aconvenient-division-of-labour-conception-of-knowledge $>$ as to its human sublimating historiality/ontological-eventfulness 3 /ontological-aesthetic-tracing-<perspectiveontological-normalcy/postconvergence-reflected-‘epistemicity-relativism-determinism’> assignment' and 'pedantising/muddling/formulaic-hollowing-out—in- 
subontologisation/subpotentiation-〈blurring/undermining-of-prospective-totalising-entailing,as-to-entailing-<amplituding/formative-epistemicity $>$ totalising $\sim$ in-relative-ontologicalcompleteness > as to its human desublimating ${ }^{47}$ historicity-tracing-in-presencinghyperrealisation/hyperreal-transposition'; as so-reflecting the fact that thinking/thought/notional philosophy-<as-to-the-veridical-conception-of-philosophy-asenglobing-all-human-prospective-organic-knowledge-generation-in-relative-ontologicalcompleteness ,-beyond-a-convenient-division-of-labour-conception-of-knowledge> veridically commences only after a developed sense of " nonpresencing-<perspectiveontological-normalcy/postconvergence $>\quad$ manifest re-originary_-as-unenframed/reontologising/unbeholdening/outlier-conceptualisation__imbued-postconverging/dialecticalthinking -'projective-insights'/‘epistemic-projection-in-conflatedness ' '-ofnotional deprocrypticism-prospective-sublimation> transversality-<for-sublimatingexistential-eventuating/denouement-from-'thinking-at-first/pure-predisposition-preemptive-ofprospective disontologising/subontologising' as-of-prospectively-disambiguated-affirmedand-unaffirmed-'motif-and-apriorising/axiomatising/referencing' ${ }^{101} \quad$ (as $\quad$ so-immersed notionally in a continuous 'implicited_attendant-ontological-contiguity ${ }^{67}$; educedexistentialising/contextmalising/textualising_intelligibility/epistemicity/reflexivity_contiguity$<$ imbued-notional cogency $>^{\prime} \quad$ of psychoanalytic-unshackling/memeticreordering/institutional-recomposuring self-becoming/self-conflatedness ${ }^{13} /$ formative- $^{-}$ supererogating-<projective/reprojective- aestheticising-re-motif-and-re-apriorising/reaxiomatising/re-referencing,-in-perspective-ontological-normalcy/postconvergence $>$ ), and as underlied by dimensionality-of-sublimating ${ }^{25}-\langle<$ amplituding/formative $>$ supererogatory $\sim$ dementativeness/epistemic-growth-or-conflatedness /transvaluativerationalising/transepistemicity/anamnestic-residuality/spirit-drivenness-equalisation〉 imbued profound-supererogation as to pestconverging-nonextricatory-existential-preempting-of- 
existential-unthought 'human intemporal-individuation threading/relaying succession of sublimating gesturings' as of 'intemporal-prioritisation-of- ${ }^{3}$ reference-of-thought'-asconflatedness ${ }^{13}$-or-ontological-reprojecting, and so-implied with regards to the 'ontologicalgood-faith/authenticity $\sim$ postconverging-de-mentating/structuring/paradigming $\quad$ imbued psychologismic apriorising/axiomatising/referencing-\{of-'prospectively implicited_attendant_ontological-contiguity ' educedexistentialising/contextualising/textualising_ intelligibility/epistemicity/reflexivity-contiguity<imbued-notional cogency $>$ ' $\}$ - conflatedness ${ }^{13}$ in-\{preconverging-ment by $\}^{\prime}$ postconverging-entailment of the sublimating existentialising-decisionality-<as-todisontologising/re-ontologising aporeticism $>$ of implicited nascent-particular/incipient-andmaterial/technical-sublimations-<blinded-to-their-relative-ontological-completeness reference-of-thought- devolving $>$ or explicited social-and-institutional-frameworks-ofreferencing/registering/decisioning of human ${ }^{56}$ meaningfulness-and-teleology" (as to Beingdevelopment/ontological-framework-expansion-as-to-depth-of-ontologising-development-asinfrastructure-of- meaningfulness-and-teleology , institutional-development-as-to-socialfunction-development and living-development-as-to-personality-development psychologismic epistemic acutisation diffienly < for, residualising \{decompulsing\} delinearity for cogency> magnitudes $\{$ of-experientiality/experiment $\}$. With the absence of such an implicited/explicited conceptualisation of ' ${ }^{n}$ nonpresencing-<perspective-ontological-normalcy/postconvergence> manifest re-originary_as-unenframed/re-ontologising/unbeholdening/outlier-conceptualisation〈imbued-postconverging/dialectical-thinking -'projective-insights'/‘epistemic-projection-inconflatedness ' -of-notional deprocrypticism-prospective-sublimation $\rangle$ transversality- $<$ forsublimating-existential-eventuating/denouement, from-'thinking-at-first/pure-predispositionpreemptive-of prospective-disontologising/subontologising' as-of-prospectivelydisambiguated-affirmed-and-unaffirmed-'motif-and-apriorising/axiomatising/referencing'> 
(as so-immersed notionally in a continuous 'implicited_attendant-ontologicalcontiguity ${ }^{67} \sim$ educed-

existentialising/contextualising/textualising_'intelligibility/epistemicity/reflexivity-contiguity<imbued-notional cogency $>^{40} \quad$ of psychoanalytic-unshackling/memeticreordering/institutional-recomposuring self-becoming/self-conflatedness ${ }^{13} /$ formativesupererogating-<projective/reprojective - aestheticising-re-motif-and-re-apriorising/reaxiomatising/re-referencing,-in-perspective-ontological-normalcy/postconvergence $>$ ) the very hallmark of pedantising/muddling/formulaic-hollowing-out —insubontologisation/subpotentiation-〈blurring/undermining-of-prospective-totalising-entailing,as-to-entailing-<amplituding/formative-epistemicity $>$ totalising $\sim$ in-relative-ontologicalcompleteness > reflected in the 'ontological-bad-faith/inauthenticity ${ }^{64} \sim$ preconverging-dementating/structuring/paradigming imbued psychologismic apriorising/axiomatising/referencing-\{of-'prospectively implicited_attendant-ontological-contiguity ' educedexistentialising/contextualising/textualising_ 'intelligibility/epistemicity/reflexivity-contiguity<imbued-notional cogency> $\left.{ }^{\prime} \quad\right\}$-constitutedness ${ }^{14}$-in preconverging-entailment $\quad$ of desublimating $\sim$ existentialising-decisionality-<as-to-disontologising/re-ontologising apereticism $>$ as prospectively failing to reflect implicited nascent-particular/incipient-andmaterial/technical-sublimations-<blinded-to-their-relative-ontological-completeness reference-of-thought- devolving $>$ or explicited social-and-institutional-frameworks-ofreferencing/registering/decisioning of human ${ }^{56}$ meaningfulness-and-teleology ${ }^{9}$, (as to Beingdevelopment/ontological-framework-expansion-as-to-depth-of-ontologising-development-asinfrastructure-of- meaningfulness-and-teleology , institutional-development-as-to-socialfunction-development and living-development-as-to-personality-development psychologismic epistemic-acutisation difficulty-for, residualising \{decompulsing delinearity for-cogency> 
magnitudes $\{$ of-experientiality/experiment $\}$ ). Critically, even the claim made (as to ${ }^{79}$ presencingabsolutising-identitive-constitutedness ${ }^{14} \quad$ social-vestedness/normativity- $<$ discretely-impliedfunctionalism $>$ ) for such psychologismic apriorising/axiomatising/referencing-\{of'prospectively_implicited_attendant_ontological-contiguity ' ceducedexistentialising/contextualising/textualising_ 'intelligibility/epistemicity/reflexivity-contiguity$<$ imbued-notional cogency $\left.>^{\prime} \quad\right\}$-constitutedness ${ }^{14}$-in preconverging-entailment $\quad$ is veridically in-many-ways the manifestation of the failure (as to prospective distractivealignment-to- ${ }^{8}$ reference-of-thought- $<$ of-apriorising/axiomatising/referencing $>{ }^{30}$ ) to reflect the more human supererogatory wholesomeness/profound-supererogation exigency of the 'exercise of the epistemic - projective-equalisation of human station of ${ }^{7}$ presencingabsolutising-identitive-constitutedness ${ }^{14}$ as to prospective ${ }^{6}$ nonpresencing- $<$ perspectiveontological-normalcy/postconvergence $>$ epistemic — projective-equalisation' associated with reontologising prospective Being-development/ontological-framework-expansion-as-to-depthof-ontologising-development-as-infrastructure-of- meaningfulness-and-teleology . In the sense that human intelligibility is rather notionally (as to protracted-social—as-to-individual-byinstitutional-by-social notional $\sim$ self-distantiation- $<$ imbued-re-motif-and-re-apriorising/reaxiomatising/re-referencing $>$ ) veridically $\quad$ reflected as psychologismic apriorising/axiomatising/referencing-\{of-"prospectively implicited_attendant-ontological-contiguity ' reducedexistentialising/contextualising/textualising_intelligibility/epistemicity/reflexivity_contiguity<imbued-notional cogency $\left.>^{\prime} \quad\right\}$ - conflatedness ${ }^{13}$-in- preconverging ment by $^{\prime}$ postconverging-entailment (beyond-the-consciousness-awareness-teleology ${ }^{9}-<$ ofpreconverging-existential-extrication-as-of-existential-unthought> ) when it comes to human institutional-development-as-to-social-function-development and living-development-as-topersonality-development psychologismic epistemic acutisation difficulty <for, 
residualising_\{decompulsing $\}$ delinearity for-cogency $>$ magnitudes $\{$ of-experientiality/experiment\} enabled by the prior Being-development/ontological-framework-expansion-as-to-depth-of-ontologisingdevelopment-as-infrastructure-of- meaningfulness-and-teleology as so-manifested in the \{epistemic-totalising 3 re-apriorising/re-axiomatising/re-referencing $\sim$ residuality-in-reoriginariness/re-origination- $\langle$ as to human profound-supererogation for prospective apriorising/axiomatising/referencing-\{of-'prospectively_implicited_attendant-ontologicalcontiguity ' $\sim$ educedexistentialising/contextualising/textualising_'intelligibility/epistemicity/reflexivity_contiguity<imbued-notional cogency $>$ ' $\}$-conflatedness - in-\{preconverging ment by\} postconverging entailment that cannot be unshrouded by prior mere-formulaicity/ritualisation$<$ as-to-mere-formulaic — methodologising/mutualising/organising/institutionalising,prospectively-losing-track-of- ‘fepistemic-totalising ${ }^{+}$re-apriorising/re-axiomatising/rereferencing $\sim$ residuality —in-re-originariness/re-origination'> of prior apriorising/axiomatising/referencing-\{of-'prospectively_implicited_attendant-ontologicalcontiguity ' educedexistentialising/contextualising/textualising_ 'intelligibility/epistemicity/reflexivity-contiguity<imbued-notional cogency >' $\}$-constitutedness -in-preconverging-entailment) (and so as to dimensionality-of-sublimating ${ }^{25}-\langle<$ amplituding-formative $>$ supererogatory $\sim$ dementativeness/epistemic-growth-or-conflatedness /transvaluativerationalising/transepistemicity/anamnestic-residuality/spirit-drivenness-equalisation〉) underlying all human intelligibility that speaks to the more supererogatory $\sim$ wholesomeness/profound-supererogation of human intelligibility. For instance, such re-originariness/re-origination-〈as to human profound-supererogation for prospective apriorising/axiomatising/referencing-\{of-"prospectively implicited_attendant-ontological- 
contiguity ' educed-

existentialising/contextualising/textualising_'intelligibility/epistemicity/reflexivity_contiguity<imbued-notional cogency>' \}-conflatedness -in-\{preconverging-ment by\} postconverging-entailment that cannot be unshrouded by prior mere-formulaicity/ritualisation<as-to-mere-formulaic — methodologising/mutualising/organising/institutionalising,-

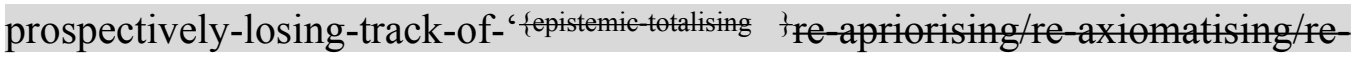

referencing residuality-in-re-originariness/re-origination'>

of

prior

apriorising/axiomatising/referencing-\{of-'prospectively implicited_attendant-ontological-

contiguity ' educed-

existentialising/contextualising/textualising_'intelligibility/epistemicity/reflexivity-contiguity$<$ imbued-notional cogency $\left.>^{\prime} \quad\right\}$-constitutedness -in-preconverging-entailment $\rangle$ is conflated in the meaning of say the word seat circumstantially as to four-legged seat, three-legged seat, backless seat, legless seat etc. or even just the recurrent use of a surface as a seat or as purposed as a seat (even if it is technically less convenient for such a sitting purpose but for enhancing the aesthetics of its environment say for instance aesthetically displayed concrete blocks acting both as public seats and for public safety compared to another structure not purposed as a seat say for instance a carpeted stairway), and so-implicits that all 'supposedly constituted' human words and terms are rather so-conflatable residually as to the driving supereregatery wholesomeness/profound-supererogation ${ }^{96}$ of human intelligibility reflected as to psychologismic apriorising/axiomatising/referencing-\{of-'prospectivelyimplicited_attendant-ontological-contiguity ' reducedexistentialising/contextrising/textrising_intelligibility/epistemicity/reflexivity-contiguity$<$ imbued-notional cogency $>$ ' $\}$-conflatedness ${ }^{13}$ in-\{preconverging ment by\} postconverging-entailment in epistemic-totalising ${ }^{3} \sim$ resubjecting_or_totalisingentailing reconstrual-<of the-whole/purview-of the-whole/oneness-of-ontology>. This 
supererogation

elucidation

of

human-textuality-<as-to-

existentialising/contextualising/textualising $>$ herein is specific as it construes of epistemictotality $^{37}$ rather as of epistemic-totalising ${ }^{33} \sim$ resubjecting_or_totalising-entailing $\sim$ reconstrual$\leqslant$ of the-whole/purview-of the-whole/oneness-of-ontology as so-reflecting a 'connoting supererogation-drivenness construal of the epistemic-totality ${ }^{37}$ of human-textuality-<as-toexistentialising/contextualising/textualising> in epistemictotalising $\sim$ resubjecting_or_totalising-entailing $\sim$ reconstrual $<$ of the-whole/purview-of thewhole/oneness-of-ontology>' (and so over-and-overriding as ontologically-impertinent a 'punctual absolutising denoting/citation epistemic-totality ${ }^{37}$ construal of human-textuality- $<$ asto-existentialising/contextualising/textualising >') with a 'connoting supererogation-drivenness construal of the epistemic-totality ${ }^{37}$ of human-textuality-<as-toexistentialising/contextualising/textualising > in epistemictotalising $\sim$ resubjecting_or_totalising-entailing $\sim$ reconstrual- $<$ of the-whole/purview-of thewhole/oneness-of-ontology>' implying notionally that supereregatery wholesomeness/profound-supererogation of human intelligibility supersedes a 'punctual absolutising denoting/citation epistemic-totality ${ }^{37}$ construal of human-textuality- $<$ asto-existentialising/contextualising/textualising>' (as so-reflecting ${ }^{4}$ historiality/ontologicaleventfulness 3 /ontological-aesthetic-tracing-<perspective-ontological-

normalcy/postconvergence-reflected-'epistemicity-relativism-determinism'>) and as such a 'connoting supererogation-drivenness construal of the epistemic-totality ${ }^{37}$ of human-textuality$<$ as-to-existentialising/contextualising/textualising $>\quad$ in epistemictotalising $\sim$ resubjecting_or_totalising-entailing $\sim$ reconstrual- $<$ of the-whole/purview 0 - thewhelelones of rather speaks to wholesome conflatedness ${ }^{3}$ (manifested as protracted-social—as-to-individual-by-institutional-by-social notional $\sim$ self-distantiation$<$ imbued — re-motif-and-re-apriorising/re-axiomatising/re-referencing $>$ ) of human 
aestheticisation-and-aestheticisation-towards-ontology-<elicited-idiomatisation >' with regards to Being-development/ontological-framework-expansion-as-to-depth-of-ontologisingdevelopment-as-infrastructure-of- meaningfulness-and-teleology , institutionaldevelopment-as-to-social-function-development and living-development-as-to-personalitydevelopment psychologismic epistemic-acutisation difficulty-<for, residualising

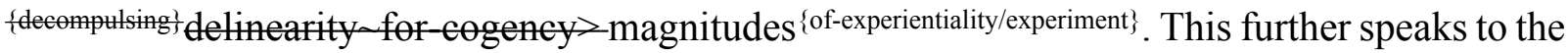
fact that the conception of citation as of academic practicalities (with derived social and institutional conception) is in-many-ways rather a practicality out of a presencingabsolutising-identitive-constitutedness ${ }^{14}$ blurriness-<sterilising/anecdotalising/trivialising-ofprospective-re-ontologising_by-preconverging,-in-disontologising-formulaic-draggingout/hollowing-out> (so-reflected as from prospective knowledge generation 'imbued intemporal-prioritisation-of- ${ }^{8}$ reference-of-thought'-as-conflatedness ${ }^{13}$-or-ontologicalreprojecting superseding/transcending intemporal-projection-and-appraisal of social-stakecontention-or-confliction' as to nonpresencing-<perspective-ontologicalnormalcy/postconvergence $>$ epistemic-projection) underlying the fact that the veridical notional contemplation of notional citationality (as to a 'connoting supererogation-drivenness construal of the epistemic-totality 37 of human-textuality-<as-toexistentialising/contextualising/textualising > in epistemictotalising $\sim$ resubjecting_or_totalising-entailing $\sim$ reconstrual- $<$ of the-whole/purview-of thewhole/oneness-of-ontology ') is effectively as from the relative-ontological-completeness ${ }^{87}$ reference-of-thought- devolving implied 'supererogatory wholesomeness/profoundsupererogation as of prospective reference-of-thought—point-ofdevolving/departure/anchoring/backdrop_of_sublimating-nascence-<as-to-the-grandestaxiomatic-construct-\{epistemic-totalising $\frac{\text { ’ }}{\text { re }}$ apriorising/re-axiomatising/rereferencing residuality - in-re-originariness/re-origination of limitedness/human-subpotency 
prospective re-encountering/re-confrontation with unlimitedness/existence>' for any such specific conception of notional citationality as to <amplituding/formative-epistemicity $>$ totalising thrownness-in-existence ${ }^{35} \quad$ epistemic-projection of prospective apriorising/axiomatising/referencing-\{of-'prospectively implicited_attendant-ontologicalcontiguity ' educedexistentialising/contextualising/textualising_ 'intelligibility/epistemicity/reflexivity-contiguity$<$ imbued-notional cogency $\left.>^{\prime}\right\}$-conflatedness ${ }^{13}$-in-\{preconverging -ment by\} postconverging-entailment in $<$ amplituding/formative-epistemicity $>$-totalising $\sim$ renewingrealisation/re-perception/re-thought'. Such that the veracity of say an Einsteinian notional citationality (for prospective knowledge generation 'imbued intemporal-prioritisationof- ${ }^{3}$ reference-of-thought'-as-conflatedness ${ }^{13}$-or-ontological-reprojecting superseding/transcending intemporal-projection-and-appraisal of social-stake-contention-orconfliction' as to nonpresencing-<perspective-ontological-normalcy/postconvergence $>$ epistemic-projection) of Newton is veridically way more than just about an academic textbook denoting/citation exercise of any denoted/designated text by Newton but rather notionally such a supereregatory $\sim$ wholesomeness/profound-supererogation ${ }^{\circ}$ of notional citationality (as to a 'connoting supererogation-drivenness construal of the epistemic-totality ${ }^{37}$ of human-textuality$<$ as-to-existentialising/contextualising/textualising $>\quad$ in epistemictotalising ${ }^{33} \sim$ resubjecting_or_totalising-entailing $\sim$ reconstrual- $<$ of the-whole/purview-of thewhole/oneness-of-ontelogy>') will imply veridical notional citationality lies with the 'relativeontological-completeness ${ }^{87}{ }^{83}$ reference-of-thought- ${ }^{8}$ devolving' as of the 'supererogatory $\sim$ wholesomeness/profound-supererogation ${ }^{\prime}$ sublimating-nascence reflected from the positivism/rational-empiricism registry-worldview/dimension (consequent cumulating/recomposuring aestheticisation-and-aestheticisation-towards-ontology-<elicitedidiomatisation>) infused with overall physics as so-influenced-and-shaped by Newtonian 
physics' in so-imbuing Einstein's <amplituding/formative-epistemicity $>$ totalising thrownness-in-existence ${ }^{83}$ reference-of-thought- ${ }^{84}$ devolving as to his $<$ amplituding/formative-epistemicity $>$-totalising $\sim$ renewing-realisation/re-perception/rethought epistemic-projection of prospective physics apriorising/axiomatising/referencing-\{of'prospectively_implicited_attendant-ontological-contiguity ' educedexistentialising/contextualising/textualising_ 'intelligibility/epistemicity/reflexivity-contiguity<imbued-notional cogency >' $\}$ - conflatedness ${ }^{13}$ in-\{preconverging-ment-by\}pestconverging-entailment. Thus notionally a supererogatory wholesomeness/profoundsupererogation of notional citationality (as to a 'connoting supererogation-drivenness construal of the epistemic-totality ${ }^{37}$ of human-textuality-<as-toexistentialising/contextualising/textualising $>\quad$ in epistemictotalising $\sim$ resubjecting_or_totalising-entailing $\sim$ reconstrual- $<$ of the-whole/purview-of thewhole/oneness-of-ontelogy>') very much explains why prospective knowledge generation is not associated with an absolutising conception of denoting/citation as to the fact that it can hardly be said Einstein was among the best Newtonian physics scholar when analysed in terms of mere academic 'presublimating relic/artifactual-beholdening-constitutedness ${ }^{14}{ }^{47}$ historicity-tracingin-presencing-hyperrealisation/hyperreal-transposition' Newtonian physics (but rather it is his appropriate notional citationality emplacement as to nonpresencing-<perspectiveontological-normalcy/postconvergence> epistemic-projection that so-decisively enabled his pioneering of prospective physics). Such a relation with prospective knowledge generation today particularly in domains-of-study susceptible to blurriness-

\section{$<$ sterilising/anecdotalising/trivialising-of-prospective-re-ontologising_by-preconverging,-in-}

disontologising-formulaic-dragging-out/hollowing-out> induces a markedly desublimating conception of notional citationality as to when the 'artifice of academic and institutional politics' leads to a conception of knowledge as of an 'institutional and academic nombrilism of 
self-presence/self-constitutedness ${ }^{14}$ - in-perspective-epistemic-abnormalcy/preconvergence $^{3}>$ to which prospective human postconvergingaporeticism-overcoming/unovercoming is relatively irrelevant' such that the construal of knowledge as to denoting/citation implications carries its very own 'academic and institutional politics of knowledge' undermining organicknowledge notional $\sim$ citationality (with notional $\sim$ citationality so-implied in self-becoming/self-

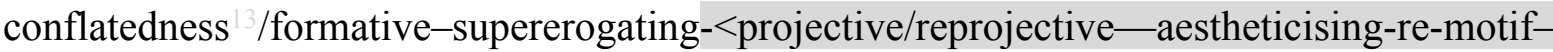
and-re-apriorising/re-axiomatising/re-referencing,-in-perspective-ontologicalnormalcy/postconvergence $>\quad$ psychoanalytic-unshackling/memetic-reordering/institutionalrecomposuring as to reference-of-thought postconverging-dementating/structuring/paradigming). This further explains overall the fundamental ontological and purposeful deficiency of a ${ }^{79}$ presencing - absolutising-identitive-constitutedness ${ }^{14}$ notion of denoting/citation as to the fact that 'full notional citationality' will rather speak of the scalarising nonpresencing-<perspective--ontological-normalcy/postconvergence $>$ epistemic construal of the sublimating-postconverged 'substantive abstract-tissue-of-social-emanance thermeneutically/textually/reprojectingly/supererogatingly/zeroingly/re-acutingly,$\{$ decompulsing $\}$ delinearity for-cogency—cumulated/recomposured as to cumulating/recomposuring of 'prospectively implicitendentontological-contiguity ${ }^{67}$ ' educedexistentialising/contextualising/textualising_'intelligibility/epistemicity/reflexivity-contiguity$<$ imbued-notional cogency>' of 'human consciousness notional protensivity imbuing prospective psychologismic-epistemic-acutisation-<as-to-postconverging-dementating/structuring/paradigming,-eliciting-of-existence's-sublimating-nascence-inprospective-aporeticism-overcoming/unovercoming $>$ as to epistemic-growth,-as\{veridical/sound\}-relative-reflexivity-in-existence/relativising from limited mentation as its-

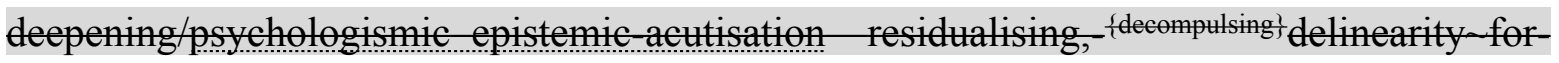
eogency' so-undergirding the 'full experientiality/experiment-<as-to-existentially-formative- 


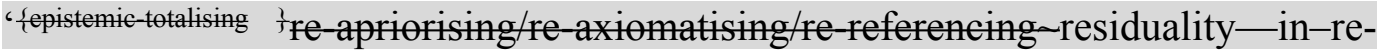

originariness/re-origination', - - so-'notionally/epistemically/bindingnessly-as-to-

determinism/conceptivity-of-relative-unreflexivity/relative-reflexivity>-implicited-and-articulated'_as-from-

nonextricatory-" prospective-re-ontologising-Being-then-Institutional-then-Living-magnitudes-

of-\{hermeneutic/reprojection $\sim$ protraction-of reframing-and-reformulation $\}$ ' $>$ that is the human abstract-tissue-of-social-emanance', herein reflected as to the overall relativeunreflexivity/relative-reflexivity — ontological-contiguity ${ }^{67} \sim$ of-the-human-institutionalisation-

process 8 of the $<$ cumulating/recomposuring attendant-ontological-contiguity $>$-successive registry-worldviews/dimensions. In other words, notional citationality cannot veridically be removed from manifest human limited-mentation-capacity-deepening-as-subjectinglimitedness/human-subpotency-to-'educed-unlimitedness/existence-sublimating nascence' exercise of apriorising/axiomatising/referencing-\{of-'prospectively implicited_attendantontological-contiguity ' educed-

existentialising/contextualising/textualising_'intelligibility/epistemicity/reflexivity-contiguity<imbued-notional cogency $\left.>^{\prime}\right\}$-conflatedness ${ }^{13}$ in-\{preconverging-ment by postconverging entailment and so-explaining the fundamental ontological deficiency of $\begin{array}{llll}\text { construing } & \text { knowledge } & \text { as } & \text { elaboration-as-to-mere- }\end{array}$ extrapolating/constituting/abstracting/deducing/inferring-of-elucidation-outside'prospectively_implicited_attendant-ontological-contiguity ${ }^{67}$ ' educedexistentialising/contextualising/textualising_'intelligibility/epistemicity/reflexivity-contiguity<imbued-notional cogency>' (as readily associated with pedantising/muddling/formulaichollowing-out - in-subontologisation/subpotentiation-〈blurring/undermining-of-prospectivetotalising-entailing,-as-to-entailing-<amplituding/formative-epistemicity $>$ totalising $\sim$ inrelative-ontological-completeness $\rangle$ susceptibility to mere conceptual-patterning-〈as-devoid-of'prospectively_implicited_attendant-ontological-contiguity ' ceduced- 
existentialising/contextualising/textualising_intelligibility/epistemicity/reflexivity-contiguity<imbued-notional cogency>' 's-reifying-or-elucidating-of-'prospective-relative-ontologicalcompleteness ${ }^{\prime} ;$-so-rather-enabled-<by-a- nonpresencing-divulging-of-momentous-

\section{historiality/ontological-eventfulness /ontological-aesthetic-tracing-<perspective-}

ontological-normalcy/postconvergence-reflected-‘epistemicity-relativism-determinism'>〉).

Effectively thus the more profound-supererogation 'exercise of the epistemic - projectiveequalisation of human station of ${ }^{7}$ presencing-absolutising-identitive-constitutedness ${ }^{14}$ as to prospective $\quad$ nonpresencing- $<$ perspective-ontological-normalcy/postconvergence $>$ epistemic_-projective-equalisation' associated with Being-development/ontologicalframework-expansion-as-to-depth-of-ontologising-development-as-infrastructure-of-

meaningfulness-and-teleology

(as

to

such

psychologismic apriorising/axiomatising/referencing-\{of-"prospectively

implicited_attendant-ontological-contiguity ' educed-

existentialising/contextualising/textualising_'intelligibility/epistemicity/reflexivity_contiguity-

<imbued-notional cogency>' \}-conflatedness ${ }^{13}$ in-\{preconverging-ment by\}

postconverging-entailment in epistemic-totalising ${ }^{33}$ resubjecting_or_totalisingentailing $\sim$ reconstrual-<of the-whole/purview-of the-whole/oneness-of-ontology $>$ for profound human intelligibility) is exactly what underlies-and-reflects the sublimating-postconverged 'substantive abstract-tissue-of-social-emanance thermeneutically/textually/reprojectingly/supererogatingly/zeroingly/re-acutingly,${ }_{\{\text {decompulsing }\}}$ delinearity for-cogency—cumulated/recomposured as to cumulating/recomposuring of 'prospectively implicited_tendant-ontological-contiguity ${ }^{67}$ ' educedexistentialising/contextualising/textualising_'intelligibility/epistemicity/reflexivity-contiguity$<$ imbued-notional cogency $>$ ' with human limited-mentation-capacity-deepening-assubjecting limitedness/human-subpotency-to-'educed-unlimitedness/existence-sublimating 
nascence' ${ }^{53}$ psychoanalytic-unshackling/memetic-reordering/institutional-recomposuring as to self-becoming/self-conflatedness ${ }^{13} /$ formative-supererogating-<projective/reprojectiveaestheticising-re-motif-and-re-apriorising/re-axiomatising/re-referencing,-in-perspectiveontological-normalcy/postconvergence $>$ ). Such a dividing-line/distinguo between 'notional $\sim$ philosophy-<as-to-the-veridical-conception-of-philosophy-as-englobing-all-humanprospective-organic-knowledge-generation-in-relative-ontological-completeness ,-beyond-aconvenient-division-of-labour-conception-of-knowledge $>$ and pedantising/muddling/formulaichollowing-out - in-subontologisation/subpotentiation-〈blurring/undermining-of-prospectivetotalising-entailing,-as-to-entailing-<amplituding/formative-epistemicity $>$ totalising $\sim$ inrelative-ontological-completeness $\rangle$ is very much a reflection of the fact that the more profound appreciation of human intelligibility as to human limited-mentation-capacity-deepening-assubjecting limitedness/human-subpotency-to-'educed-unlimitedness/existence-sublimating nascence' ${ }^{53}$ rather lies with 'nonpresencing-<perspective-ontologicalnormalcy/postconvergence $>\quad$ manifest re-originary_-ass-unenframed_reontologising/unbeholdening/outlier-conceptualisation__imbued-postconverging/dialecticalthinking -'projective-insights’/‘epistemic-projection-in-conflatedness ' '-ofnotional deprocrypticism-prospective-sublimation) transversality-<for-sublimatingexistential-eventuating/denouement-from-'thinking-at-first/pure-predisposition-preemptive-ofprospective-disontologising/subontologising’ -as-of-prospectively-disambiguated-affirmedand-unaffirmed-'motif-and-apriorising/axiomatising/referencing' $>$ 101 (as so-immersed notionally in a continuous 'implicited_attendant-ontological-contiguity ${ }^{67}$; educedexistentialising/contextmalising/textualising_intelligibility/epistemicity/reflexivity_contiguity<imbued-notional cogency>' of psychoanalytic-unshackling/memeticreordering/institutional-recomposuring self-becoming/self-conflatedness ${ }^{13} /$ formative- $^{2}$ supererogating-<projective/reprojective-aestheticising-re-motif-and-re-apriorising/re- 
axiomatising/re-referencing,-in-perspective-ontological-normalcy/postconvergence $>$ ). The seeming/apparent counterintuition that human intelligibility is necessarily of mutualintelligibility/dialogical-equivalence-<as-to-

psychologismic apriorising/axiomatising/referencing-\{of-"prospectively implicited_attendant-ontological-contiguity ' educedexistentialising/contextualising/textualising_'intelligibility/epistemicity/reflexivity-contiguity<imbued-notional cogency >' \}-conflatedness -in-\{preconverging -ment by\} postconverging-entailment,-in-self-becoming/self-conflatedness /formative-supererogating> rather arises as to the 'mental-reflex effect of our collective secondnatured institutionalisationthreshold or any given registry-worldview/dimension collective secondnatured institutionalisation-threshold' (as so-reflecting registry-worldviews/dimensions imbued priorinstitutionalisation-threshold-by-prospective-uninstitutionalised-threshold 'self-referencingsyncretising forward-facing-supposedly postconverging-or-dialectical-thinking -apriorisingpsychologism epistemic-projection as of prior mere-formulaicity/ritualisation-<as-to-mereformulaic — methodologising/mutualising/organising/institutionalising,-prospectively-losingtrack-of- ‘fepistemic-totalising ’’re-apriorising/re-axiomatising/re-referencing $r$ residuality-in-reoriginariness/re-origination'>' and so-reflecting their 'disontologising preconverging/dementing $-<$ as-to-prospective-uninstitutionalised-threshold $>$ ignoring/biased inclination' for the sake of 'their given present minimum-and-balancing expectations/anticipations of social-functioning-and-accordance-as-of-social-stakecontention-or-confliction' while qualifying their prospectively uninstitutionalised-threshold actually as nondescript/ignorable-void as to their ${ }^{79}$ presencing-absolutising-identitiveconstitutedness $<$ preconverging 'motif-and-apriorising/axiomatising/referencing' entailing >-existentialising — enframing/imprintedness-〈as-to- historicity-tracing — inpresencing-hyperrealisation/hyperreal-transposition)), but that will formatively drift into 
prospective disontologisation over prospective ontologisation/re-ontologisation as to when such prior mere-formulaicity/ritualisation-<as-to-mere-formulaicmethodologising/mutualising/organising/institutionalising,-prospectively-losing-track-of‘ \{epistemic-totalising ’’’re-apriorising/re-axiomatising/re-referencing - residuality-in-reoriginariness/re-origination'> is prospectively existentially-insufficient/inadequate requiring prospective profound-supererogation ${ }^{96}$. This is prospectively ontologically-flawed because it fails to reflect the fact that the human as of limited-mentation-capacity-as-subjecting 'educedunlimitedness/existence-sublimating nascence' to-limitedness/human-subpotency is always of a manifest intelligibility caught up between 'present institutionalisation-threshold and prospectively uninstitutionalised-threshold ${ }^{102}$, as so-reflected as to any given registryworldview/dimension 'social-functioning-and-accordance-as-of-social-stake-contention-orconfliction imbuing existentialising-frame-of-entailment-of motif-andapriorising/axiomatising/referencing of disontologising/ontologising-and-re-ontologising' as to the preconverging/postconverging-de-mentative/structural/paradigmatic 'notional $\sim$ reflexivity$<\{$ veridical/sound\}-relative-reflexivity-in-existence/relativising from-limited-mentation-as-

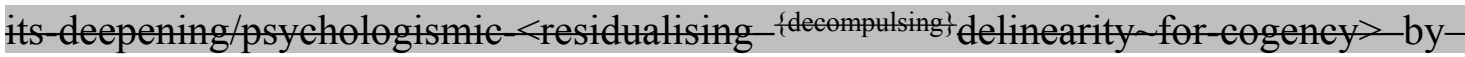

\section{\{flawed/unsound\}-relative-unreflexivity-in-existencetabsolutising from limited-} mentation/psychologismic epistemic-acutisation nonresidualising-imbued\{compulsing\} linearity in-eclecticism-of-prior-mere-formulaicity/ritualisation $>$ dualising' of the ontological-performance ${ }^{72}<$ including-virtue-as-ontology $>$ /morality/ethics/justice/etc. of human notional firstnaturedness-formativeness-<as-to-eventualising-inkling-drive-orseeding-misprising $>$ temporal-to-intemporal-dispositions- $<$ so-construed-as-fromperspective-ontological-normalcy/postconvergence> with regards to prospectively uninstitutionalised-threshold ${ }^{102}$ associated temporal-individuative-firstnaturedness-as-toinkling disontologising and intemporal-individuative-firstnaturedness-as-to-inkling 
ontologising/re-ontologising; and so-effectively validating human intelligibility veridical conception as to 'nonpresencing-<perspective-ontological-normalcy/postconvergence $>$ manifest re-originary_-ass-unenframed/re-ontologising/unb_eholden_ening/outlier-conceptualisation〈imbued-postconverging/dialectical-thinking -'projective-insights'/'epistemic-projection-inconflatedness '-of-notional deprocrypticism-prospective-sublimation $\rangle$ transversality- $<$ forsublimating-existential-eventuating/denouement-from-'thinking at first/pure-predispositionpreemptive-of prospective-disontologising/subontologising' as-of-prospectivelydisambiguated-affirmed-and-unaffirmed-'motif-and-apriorising/axiomatising/referencing'> (as so-immersed notionally in a continuous 'implicited_attendant-ontologicalcontiguity $^{67}$; educedexistentialising/contextualising/textualising_intelligibility/epistemicity/reflexivity-contiguity<imbued-notional $\sim$ cogency $>^{\prime} \quad$ of psychoanalytic-unshackling/memeticreordering/institutional-recomposuring self-becoming/self-conflatedness ${ }^{13} /$ formative- $^{-}$ supererogating-<projective/reprojective- aestheticising-re-motif-and-re-apriorising/reaxiomatising/re-referencing,-in-perspective-ontological-normalcy/postconvergence $>$ ), and so as to the prospective prompting of 'constraining existence-as-sublimatingwithdrawal/unenframing/re-ontologising,-elicited-from-prospective-profound-supererogation imbuing human ontological-commitment $-<$ implied — self-assuredness-of-ontological-goodfaith/authenticity $\sim$ postconverging-de-mentating/structuring/paradigming -as-being-as-ofexistential-reality>' and ' ${ }^{103}$ universal-transparency ${ }^{104}$-〈transparency-of-totalising-entailing,-asto-entailing-<amplituding/formative-epistemicity $>$ totalising $\sim$ in-relative-ontologicalcompleteness \ as available-to/elicitable-to-〈as-to-human-consciousness/collectiveconsciousness-distendedness/detruncating-<beyond-selfpresencing,-as-re-ontologisingdecentering_of-consciousness/collective-consciousness,-as-to-psychologismic-epistemicacutisation-residualising,- - decompulsing $\}$ delinearity for-cogency $>>$ the social-functioning-and- 
accordance-as-of-social-stake-contention-or-confliction conception of any given registryworldview/dimension $<$ preconverging 'motif-and-apriorising/axiomatising/referencing' entailing >-existentialising — enframing/imprintedness-〈as-to- historicity-tracing —inpresencing-hyperrealisation/hyperreal-transposition〉'. With regards to the fact that the sublimating-postconverged 'substantive abstract-tissue-of-social-emanance fepistemictotalising $3{ }^{3}$ hermeneutically/textually/reprojectingly/supererogatingly/zeroingly/re-acutingly,\{decompling $d$ delinearity for-cogency — cumulated/recomposured as to cumulating/recomposuring of 'prospectively_implicited_attendant-ontological-contiguity ${ }^{67}$ ' educedexistentialising/contextualising/textualising_intelligibility/epistemicity/reflexivity-contiguity<imbued-notional cogency $>^{\prime} \quad$ (as to <cumulating/recomposuring attendant-ontologicalcontiguity $>$-successive registry-worldviews/dimensions Being-development/ontologicalframework-expansion-as-to-depth-of-ontologising-development-as-infrastructure-ofmeaningfulness-and-teleology ) is rather the outcome of human limited-mentation-capacitydeepening —as-subjecting limitedness/human-subpotency-to-'educed-unlimitedness/existencesublimating nascence' apriorising/axiomatising/referencing-\{of-"prospectively implicited_attendant-ontological-contiguity ' reducedexistentialising/contextualising/textualising_'intelligibility/epistemicity/reflexivity-contiguity$<$ imbued-notional $\left.\sim \operatorname{cogency}>^{\prime}\right\}$-conflatedness ${ }^{13}$-in-\{preconverging-ment by\} pestcenverging entailment, it is critical to appreciate the veracity of the successive 'epistemicbreak or notional-discontiguity/epistemic-discontiguity ${ }^{6}<$ between - prior-shallowsupererogation -of-mentally-aestheticised preconverging/dementing -qualiaschema_and_prospective-profound-supererogation -of-mentallyaestheticised postconverging/dialectical-thinking -qualia-schema> as to difference-innature/difference-in-apriorising-or-axiomatising-or-referencing ${ }^{24}$ successive prompting of a dividing-line/distinguo between 'notional philosophy-<as-to-the-veridical-conception-of- 
philosophy-as-englobing-all-human-prospective-organic-knowledge-generation-in-relativeontological-completeness ,-beyond-a-convenient-division-of-labour-conception-ofknowledge $>\quad$ and pedantising/muddling/formulaic-hollowing-out-insubontologisation/subpotentiation-〈blurring/undermining-of-prospective-totalising-entailing,as-to-entailing-<amplituding formative-epistemicity $>$ totalising in-relative-ontologicalcompleteness $>$ as to nonpresencing-<perspective-ontological-normalcy/postconvergence $>$ epistemic-projection (as so-manifested by ancient-sophists 'non-universalising disontologising' in the face of the Socratic-philosophers " ${ }^{103}$ universalising-idealisation ontologising/reontologising' or medieval-scholasticism 'non-positivising disontologising' in the face of budding-positivists 'positivism/rational-empiricism ontologising/re-ontologising' or as herein contended modern-day 'manifestation of disparateness-of-conceptualisation-<unforegroundingment,-failing-prospectively-to-reflect- immanent relative-unreflexivity/relative-reflexivity ontological-contiguity '> disontologising' in the face of postmodern thought 'nondisjointing totalising-entailing ontologising/re-ontologising as to ${ }^{4}$ human-subject-emancipating-relativismdriven-recomposuring-constructivism-towards-singularisation- $<$ as-to-thenondisjointedness/entailment-of-prospective- nonpresencing $>$ '). Fundamentally, the reason for these successive 'epistemic-break or notional-discontiguity/epistemic-discontiguity $<$ between-prior-shallow-supererogation -of-mentallyaestheticised preconverging/dementing -qualia-schema_and_prospective-profoundsupererogation -of-mentally-aestheticised postconverging/dialectical-thinking -qualiaschema $>$ as to difference-in-nature/difference-in-apriorising-or-axiomatising-or-referencing ${ }^{24}$ lies in the fact that the re-ontologising prospective Being-development/ontological-frameworkexpansion-as-to-depth-of-ontologising-development-as-infrastructure-of- meaningfulnessand-teleology so-arising from the knowledge-reification $\sim$ gesturing-and-accounting-ofepistemic-phenomenalism- $<$ in- 
prospective_psychologismic apriorising/axiomatising/referencing-\{of-'prospectively

implicited_attendant-ontological-contiguity ' educed-

existentialising/contextualising/textualising_'intelligibility/epistemicity/reflexivity-contiguity-

$<$ imbued-notional $\left.\sim \operatorname{cogency}>^{\prime}\right\}$-conflatedness -in-\{preconverging -ment by\}

postconverging entailment $>$ in prospective ontologising/re-ontologising is being construed as from the prospective disontologising perspective as an 'existentially- $<$ disontologising/reentologising aporeticism $>$ constraining hindrance/encumbrance (upon the prior 'socialfunctioning-and-accordance-as-of-social-stake-contention-or-confliction imbuing existentialising-frame-of-entailment-of-motif-and-apriorising/axiomatising/referencing of disontologising/ontologising-and-re-ontologising')' and rather eliciting (consciously or unconsciously) ontological-bad-faith/inauthenticity ${ }^{64} \sim$ preconverging-dementating/structuring/paradigming ; so-reflected as to the fact that such disontologising fails the very first and preceding step for genuine knowledge which is a 'prior commitment to inherent knowledge above all else' including above any theoretical/philosophical/thought postures as soallowing for the full human knowledge-reification $\sim$ gesturing-and-accounting-of-epistemicphenomenalism- $<$ in-prospective_psychologismic $\sim$ apriorising/axiomatising/referencing- of'prespectively_implicited_attendant-ontological-contiguity ' educedexistentialising/contextmalising/textualising_'intelligibility/epistemicity/reflexivity_contiguity<imbued-notional cogency >' \}-conflatedness -in-\{preconverging -ment by\}

postconverging entailment $>$ potential as to be able to 'respond in prospective sublimation-overdesublimation upon the educing-and-availing-and-re-availing of relative-ontologicalcompleteness $^{87}$. This insight moreover points out that with regards to the 'potential for absolute knowledge as to human intellectual-and-moral responsibility/relative reflexivitions' all humans are 'technically-speaking' in ontological-bad-faith/inauthenticity $\sim$ preconvergingde-mentating/structuring/paradigming ${ }^{5}$ to the 'absolute knowledge so-implied as from 
nonpresencing-<perspective-ontological-normalcy/postconvergence $>$ epistemic-projection' (as so-reflected 'from a notional ' deprocrypticism nonpresencing-<perspective-ontologicalnormalcy/postconvergence $>$ epistemic-projection in a protensive-consciousness ratiocontiguity/ratiocination-as-referentialism_-implicited_attendant-ontologicalcontiguity $^{67} \sim$ educedexistentialising/contextualising/textualising_intelligibility/epistemicity/reflexivity-contiguity<imbued-notional cogency> $>^{\text {4nowledge-notionalisation }}$ construal' of the ‘<cumulating/recomposuring attendant-ontological-contiguity $>$-successive registryworldviews/dimensions specific ${ }^{83}$ reference-of-thought preconverging/dementing ${ }^{20}$-qualiaschema' reflecting their 'specific prospectively ontologically-flawed nondescript/ignorablevoid imbued self-presence/self-constitutedness ${ }^{14}-<$ in-perspective-epistemicabnormalcy/preconvergence $>$ specific ontological-bad-faith/inauthenticity ${ }^{6} \sim$ preconvergingde-mentating/structuring/paradigming ${ }^{65}$, as so-underlining the manifest specific ${ }^{83}$ reference-ofthought preconverging/dementing ${ }^{2}$-qualia-schema $>$ ). The saving grace here (with regards to the 'technically-speaking' inherent human ontological-bad-faith/inauthenticity ${ }^{6} \sim$ preconvergingde-mentating/structuring/paradigming ${ }^{5}$ implications 'as to inherent human limited-mentationcapacity as subjecting 'educed unlimitedness/existence sublimating nascence' to limitedness/human-subpotency induced $<$ amplituding/formative-epistemicity $>$ totalising thrownness-in-existence ${ }^{5}$, manifested to as the $<$ cumulating/recomposuring attendant-ontological-contiguity $>$-successive registryworldviews/dimensions respective $\quad$ self-presence/self-constitutedness ${ }^{14}{ }^{-}$in-perspectiveepistemic-abnormalcy/preconvergence ${ }^{3}>$ underwhelming levels of ontological-performance ${ }^{72}$ $<$ including-virtue-as-ontology>) when it comes to the 'potential for absolute knowledge in reflection of human limited-mentation-capacity-deepening —as-subjecting limitedness/humansubpotency-to-'educed-unlimitedness/existence-sublimating nascence' ${ }^{33}$ potential' as so- 
enabling the expansion of human knowledge, is rather the ontological-goodfaith/authenticity ${ }^{6} \sim$ postconverging-de-mentating/structuring/paradigming 70 for intemporalprioritisation-of- ${ }^{83}$ reference-of-thought'-as-conflatedness ${ }^{13}$-or-ontological-reprojecting (as to when relative-ontological-completeness ${ }^{87}$ is-educed-and-avails-and-re-avails); as so-reflected in the cultivation of a prospective openness as to a "prior commitment to inherent knowledge above all else' including above any theoretical/philosophical/thought postures as to be able to 'respond in prospective sublimation-over-desublimation upon the educing-and-availing-andre-availing of relative-ontological-completeness ${ }^{87}$, (as so-underlined by fundamental dimensionality-of-sublimating $25<<$ amplituding/formative $>$ supererogatory $\sim$ dementativeness/epistemic-growth-or-conflatedness /transvaluativerationalising/transepistemicity/anamnestic-residuality/spirit-drivenness-equalisation $\rangle)$. It is in this respect for instance that in-many-ways the Encyclopédistes involved even 'aristocrats' and socially well-off persons beholdened to knowledge/veridicality above and preceding any other allegiances and likewise many a positive revolutionary struggle including civil rights movements, social emancipations, decolonisations, the American civil war, etc. could hardly be envisioned without appreciating human prior commitment to knowledge/veridicality above and preceding any other temporal allegiances along the lines of mere identitive group/gender/class/race/nation/etc. as to intemporal-prioritisation-of- reference-of-thought'as-conflatedness ${ }^{13}$-or-ontological-reprojecting (as to when relative-ontological-completeness is-educed-and-avails-and-re-avails); with such an ontologising construal at the very center in the appreciation of social deconstruction beyond 'accentuated identitive conceptions' as of flawed/unsound\}-relative-unreflexivity-in-existence/absolutising-from-limitedmentation/psychologismic epistemic acutisation nonresidualising imbued-

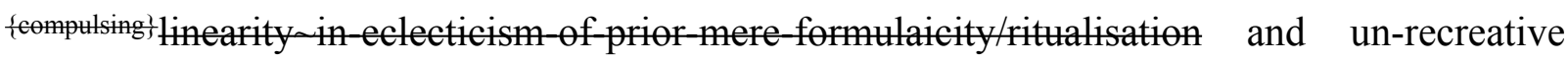
dispositions in the circularity of mere ${ }^{79}$ presencing - absolutising-identitive-constitutedness 
purposes turning out to be manifestations of 'superficial mere-formulaicconformity/trending/voguing/fashionability/resonance relation to meaningfulness-andteleology ${ }^{9}$ (rather than veridically of implicited-and-explicited 'implicited_attendantontological-contiguity ${ }^{67} \sim$ educed-

existentialising/contextualising/textualising_intelligibility/epistemicity/reflexivity-contiguity<imbued-notional cogency>' induced 'epistemic-growth/disquiet/discomfort-〈inducedsublimation,-as-from-existence's - effusing/ecstatic-inlining-as- historiality\{science/authenticity/nonextrication $\}$-beyond-mere-formulaicity/ritualisation-as- historicitytracing-\{science-ideology/fashionability/distraction $\}\rangle$ as to construction-of-the-Self in dispensing-with-immediacy-for-relative-ontological-completeness ${ }^{87}$-byreification/contemplative-distension ${ }^{27}$ '). Pedantising/muddling/formulaic-hollowing-out-insubontologisation/subpotentiation-〈blurring/undermining-of-prospective-totalising-entailing,as-to-entailing-<amplituding/formative-epistemicity $>$ totalising in-relative-ontologicalcompleteness > manifestation of prospective ontological-badfaith/inauthenticity $\sim$ preconverging-de-mentating/structuring/paradigming ${ }^{65}$ in the face of 'constraining existence-as-sublimating-withdrawal/unenframing/re-ontologising,-elicitedfrom-prospective-profound-supererogation imbuing human ontological-commitment $<$ implied - self-assuredness-of-ontological-good-faith/authenticity $\sim$ postconverging-dementating/structuring/paradigming -as-being-as-of-existential-reality ${ }^{>}{ }^{\prime}$ is more readily associated with 'social-and-institutional-frameworks-of-referencing/registering/decisioning existentialising-decisionality-<as-to-disontologising/re-ontologising aporeticism> $\quad$ than 'nascent-particular/incipient-and-material/technical-sublimations- $<$ blinded-to-their-relativeontological-completeness - reference-of-thought- devolving> existentialising-decisionality<as-to-disontologising/re-ontologising aporeticism $>$ ' and so with respect to the former's lesspotently-imbued and the latter's more-potently-imbued ' ${ }^{103}$ universal-transparency ${ }^{104}$ - 
〈transparency-of-totalising-entailing,-as-to-entailing-<amplituding/formative-

epistemicity>totalising in-relative-ontological-completeness $\rangle$ as available-to/elicitable-to-〈asto-human-consciousness/collective-consciousness-distendedness/detruncating-<beyondselfpresencing,-as-re-ontologising-decentering_of-consciousness/collective-consciousness,-asto-psychologismic-epistemic-acutisation-residualising, - the social-functioning-and-accordance-as-of-social-stake-contention-or-confliction conception of any given registry-worldview/dimension <preconverging 'motif-andapriorising/axiomatising/referencing'-entailing >-existentialising-enframing/imprintedness〈as-to- historicity-tracing - in-presencing-hyperrealisation/hyperreal-transposition〉'. The very fact that the-human/human-mind/human-subpotency 'is inevitably aporetically bound-to/fatedto/unescapable-from its ontological-faith-notion-or-ontological-fideism-imbuedunderdetermination-of-motif-and-apriorising/axiomatising/referencing-as-so-being-as-ofexistential-reality (as to its existentially-<disontologising/re-ontologising aporeticism $>$ manifest disseminative - sublimating-selectivity-of-ontological-goodfaith/authenticity postconverging-dementating/structuring/paradigming _ or_desublimating-deselectivity-of-ontological-badfaith/inauthenticity $\sim$ preconverging-de-mentating/structuring/paradigming , whether of direct-capacity or deferential-capacity as to the possibility for sound/virtuous/veracity-of human ontological-performance ${ }^{2}$ - $<$ including-virtue-as-ontology $>/$ morality/ethics/justice/etc.

or human vices-and-impediments ${ }^{105}$ ) 'with no room for any human neutral mental-state conception of human ontological-performance ${ }^{72}-<$ including-virtue-as-ontology $>^{\prime}$ (as to the reality of the postconverging aporeticism-overcoming/unovercoming implications of human $<$ amplituding/formative-epistemicity>-totalising $\sim$ thrownness-in-existence ${ }^{35}$ ); rather speaks to both the 'prospective entailing and prior ing implications of all prospective knowledgereification $\sim$ gesturing-and-accounting — of-epistemic-phenomenalism- $<$ in- 
prospective_psychologismic apriorising/axiomatising/referencing-\{of-'prospectively

implicited_attendant-ontological-contiguity ' educed-

existentialising/contextualising/textualising_'intelligibility/epistemicity/reflexivity-contiguity-

$<$ imbued-notional $\left.\sim \operatorname{cogency}>^{\prime}\right\}$-conflatedness -in-\{preconverging -ment by\}

postconverging-entailment $>$ as to knowledge-notionalisation' (as to the fact that prior recurrentutter-uninstitutionalisation 'non-rules—apriorising/axiomatising/referencing-psychologism entailment of knowledge' is ed by prospective base-institutionalisation 'rulemaking-over-nonrules - apriorising/axiomatising/referencing-psychologism entailment of knowledge', just as the latter is ed by prospective ${ }^{103}$ universalisation-non-positivism/medievalism ${ }^{103}$ universalisation-directed-rulemaking-over-non-rules-

apriorising/axiomatising/referencing-psychologism entailment of knowledge', just as the latter is ed by prospective positivism/rational-empiricism 'positivising/rational-empiricism-baseduniversalisation-directed-rulemaking-over-non-rules — apriorising/axiomatising/referencingpsychologism entailment of knowledge', and prospectively the latter is ed by prospective deprocrypticism-or-preempting — disjointedness-as-of- ${ }^{83}$ reference-of-thought,-as-to-

$<$ amplituding/formative-epistemicity $>$ growth-or-conflatedness ${ }^{13} /$ transvaluative- $^{3}$ rationalising/transepistemicity/anamnestic-residuality/spirit-drivenness'_in-supersedingmere-formulaic-positivising/rational-empiricism-based-universalisation-directed-rulemakingover-non-rules_-apriorising/axiomatising/referencing-psychologism entailment of knowledge'). This underlines the relative-unreflexivity/relative-reflexivity-ontologicalcontiguity $^{67}$ of-the-human-institutionalisation-process ${ }^{68}$ recurrent dividing-line/distinguo between 'notional $\sim$ philosophy-<as-to-the-veridical-conception-of-philosophy-as-englobing-allhuman-prospective-organic-knowledge-generation-in-relative-ontological-completeness beyond-a-convenient-division-of-labour-conception-of-knowledge> and pedantising/muddling/formulaic-hollowing-out — in-subontologisation/subpotentiation- 


\section{〈blurring/undermining-of-prospective-totalising-entailing,-as-to-entailing-}

$<$ amplituding/formative-epistemicity $>$ totalising $\sim$ in-relative-ontological-completeness $>$

(especially when it comes to the more difficult/challenging profound-supererogation 'exercise of the epistemic - projective-equalisation of human station of 79 presencing-absolutisingidentitive-constitutedness ${ }^{14}$ as to prospective ${ }^{6}$ nonpresencing-<perspective-ontologicalnormalcy/postconvergence $>$ epistemic-projective-equalisation' associated with Beingdevelopment/ontological-framework-expansion-as-to-depth-of-ontologising-development-asinfrastructure-of- meaningfulness-and-teleology ). The 'entailment of prospective knowledge as transversally inducing prior knowledge ment' as so-implied, is effectively what is reflected in the successive 'epistemic-break or notional-discontiguity/epistemic-discontiguity $<$ between prior-shallow-supererogation -of-mentally-aestheticised preconverging/dementing -qualiaschema_and_prospective-profound-supererogation -of-mentallyaestheticised postconverging/dialectical-thinking -qualia-schema> as to difference-innature/difference-in-apriorising-or-axiomatising-or-referencing ${ }^{24}$, in the sense that the $<$ cumulating/recomposuring attendant-ontological-contiguity $>$-successive registryworldviews/dimensions are 'successive Being-development/ontological-framework-expansionas-to-depth-of-ontologising-development-as-infrastructure-of- meaningfulness-andteleology psychologismic $\sim$ apriorising/axiomatising/referencing-\{of-'prospectively implicited_attendant-ontological-contiguity ' educedexistentialising/contextualising/textualising_'intelligibility/epistemicity/reflexivity-contiguity$<$ imbued-notional $\left.\sim \operatorname{cogency}>{ }^{\prime} \quad\right\}$ - conflatedness ${ }^{13}$ in-\{preconverging-ment by\} postconverging-entailment' as to their implied existentialising-frame-of-entailment-of motifand-apriorising/axiomatising/referencing of 'ontological-goodfaith/authenticity ${ }^{6} \sim$ postconverging-de-mentating/structuring/paradigming 70 allowing for their self-reflexive instigative-eventuating-〈as-to-teleological-instigative/incipient- 
willing/arbitrariness/waywardness/faithdrivenness/supererogating-for-human-intelligibility,preceding-existence's-eventuating-sublimating-validation/desublimating-invalidation $\rangle \quad$ in prospective 'implicited_attendant-ontological-contiguity ${ }^{67}$; educedexistentialising/contextualising/textualising_'intelligibility/epistemicity/reflexivity_contiguity$<$ imbued-notional cogency>' induced knowledge-reification $\sim$ gesturing-and-accounting-ofepistemic-phenomenalism-<in-

prospective_psychologismic apriorising/axiomatising/referencing-\{of- ${ }^{\text {pprospectively }}$ implicited_attendant-ontological-contiguity ' educedexistentialising/contextualising/textualising_'intelligibility/epistemicity/reflexivity-contiguity$<$ imbued-notional cogency $\left.>^{\prime}\right\}$-conflatedness -in-\{preconverging -ment by\}

postconverging-entailment> expansion' (with this elucidation so-implied at the ${ }^{83}$ reference-ofthought/grandest-axiomatic-construct level also succinctly understood on an axiomatic-construct level of elucidation wherein for instance the mindset for engaging theory-of-relativity-togetherwith-quantum-mechanics - axiomatic-constructs speaks already of its inherent existentialisingframe-of-entailment-of motif-and-apriorising/axiomatising/referencing of 'ontological-goodfaith/authenticity ${ }^{6} \sim$ postconverging-de-mentating/structuring/paradigming ${ }^{70}$ allowing for its self-reflexive $\sim$ instigative-eventuating-〈as-to-teleological-instigative/incipientwilling/arbitrariness/waywardness/faithdrivenness/supererogating-for-human-intelligibility,preceding-existence's-eventuating-sublimating-validation/desublimating-invalidation $\rangle \quad$ in prospective 'implicited_attendant-ontological-contiguity ${ }^{67}$; educedexistentialising/contextualising/textualising_intelligibility/epistemicity/reflexivity-contiguity$<$ imbued-notional cogency $>$ induced knowledge-reification $\sim$ gesturing-and-accounting-ofepistemic-phenomenalism- $<$ in-

prospective_psychologismic apriorising/axiomatising/referencing-\{of- ${ }^{\text {pprospectively }}$ implicited_attendant-ontological-contiguity ' educed- 
existentialising/contextualising/textualising_'intelligibility/epistemicity/reflexivity-contiguity<imbued-notional cogency $>>$ \}-conflatedness -in-\{preconverging ment by\}

postconverging entailment $>$ expansion' that cannot be contemplated in terms of the mindset as to knowledge-reification $\sim$ gesturing-and-accounting - of-epistemic-phenomenalism- $<$ inprospective_psychologismic apriorising/axiomatising/referencing-\{of-‘prospectively implicited_attendant-ontological-contiguity ' reducedexistentialising/contextualising/textualising_'intelligibility/epistemicity/reflexivity_contiguity$<$ imbued-notional cogency $>$ ' \}-conflatedness -in-\{preconverging -ment by\} postconverging entailment $>$ of prior classical-mechanics-axiomatic-constructs with such a mixup in the mindsets of contemplation rather 'speaking to such a prior classical-mechanicsaxiomatic-constructs mindset prospective ontological-badfaith/inauthenticity ${ }^{64} \sim$ preconverging-de-mentating/structuring/paradigming ${ }^{55}$ for engaging with theory-of-relativity-together-with-quantum-mechanics_-axiomatic-constructs' and bound to rather pedantise/muddle/formulaicly-hollowing-out_-in-subontologisation/subpotentiation the latter); and as herein implied explaining why the 'entailment of prospective knowledge as transverally inducing prior knowledge ment' is associated with the recurrent dividingline/distinguo between 'notional philosophy-<as-to-the-veridical-conception-of-philosophy-asenglobing-all-human-prospective-organic-knowledge-generation-in-relative-ontologicalcompleteness ,-beyond-a-convenient-division-of-labour-conception-of-knowledge> and pedantising/muddling/formulaic-hollowing-out — in-subontologisation/subpotentiation〈blurring/undermining-of-prospective-totalising-entailing,-as-to-entailing$<$ amplituding/formative-epistemicity>totalising in-relative-ontological-completeness $\rangle$. The further insight here is that a pedantising/muddling/formulaic-hollowing-out-insubontologisation/subpotentiation-〈blurring/undermining-of-prospective-totalising-entailing,as-to-entailing-<amplituding/formative-epistemicity $>$ totalising $\sim$ in-relative-ontological- 
completeness $\rangle$ disontologising construal of prospective knowledge-reification $\sim$ gesturing-andaccounting - of-epistemic-phenomenalism- $<$ in-

prospective_psychologismic apriorising/axiomatising/referencing-\{of-'prospectively implicited_attendant-ontological-contiguity ' ceducedexistentialising/eontextralising/textlising_intelligibility/epistemicity/reflexivity-contiguity<imbued-notional cogency $>>$ - conflatedness -in-\{preconverging -ment by\}

postconverging-entailment $>$ as rather as an 'existentially-<disontologising/re-ontologisingaporeticism $>$ constraining hindrance/encumbrance (upon the prior 'social-functioning-andaccordance-as-of-social-stake-contention-or-confliction imbuing existentialising-frame-ofentailment of motif-and-apriorising/axiomatising/referencing of disontologising/ontologisingand-re-ontologising')', speaks to a lack of organic-knowledge as to 'human profoundsupererogation imbuing ownership/staking/purchase' (as to lack of cultivation of a prospective openness as to a 'prior commitment to inherent knowledge above all else' including above any theoretical/philosophical/thought postures as to be able to 'respond in prospective sublimationover-desublimation upon the educing-and-availing-and-re-availing of relative-ontologicalcompleteness $^{87}$ ); and so cannot be construed as associated veridically with the requisite implicited-and-explicited 'implicited_attendant-ontological-contiguity ${ }^{67}$ ' educedexistentialising/contextmalising/textualising_'intelligibility/epistemicity/reflexivity_contiguity$<$ imbued-notional cogency>' induced 'epistemic-growth/disquiet/discomfort-〈inducedsublimation,-as-from-existence's - effusing/ecstatic-inlining-as- historiality-

\section{\{science/authenticity/nonextrication\}-beyond-mere-formulaicity/ritualisation-as- historicity-} tracing-\{science-ideology/fashionability/distraction $\}\rangle$ as to construction-of-the-Self in dispensing-with-immediacy-for-relative-ontological-completeness ${ }^{87}$-byreification/contemplative-distension ${ }^{27}$, associated with prospective knowledge reification. As it is rather bent to adopt a prospective distractive-alignment-to- ${ }^{-}$reference-of-thought- $<$of- 
apriorising/axiomatising/referencing $>30$ posturing to such prospective knowledge reification gesturing/accounting - of-epistemic-phenomenalism associated with a cynicism that is unresponsive to the educing-and-availing-and-re-availing of relative-ontologicalcompleteness $^{87}$ as to dimensionality-of-desublimating-lack-of ${ }^{-}$<<amplituding/formative>supererogatory $\sim$ de-mentativeness/epistemic-growth-or-

\section{conflatedness /transvaluative-rationalising/transepistemicity/anamnestic-residuality/spirit-}

drivenness-equalisation $\rangle$ impliciting that 'afterall all the human world and mentality that exists' is-as-of-their-given-registry-worldview/dimension however its preconverging-dementating/structuring/paradigming notional ontological-performance ${ }^{72}-<$ including-virtue-asontology $>$ /vices-and-impediments ${ }^{105}$ respectively in recurrent-utter-uninstitutionalisation, baseinstitutionalisation-ununiversalisation, ${ }^{103}$ universalisation-non-positivism/medievalism and positivism- ${ }^{80}$ procrypticism as not about prospective transcendence-andsublimity/sublimation/supererogatory de-mentativity and so-reflected respectively as not of prospective 'rulemaking-over-non-rules — apriorising/axiomatising/referencing-psychologism entailment of knowledge' but rather as of prior 'non-rulesapriorising/axiomatising/referencing-psychologism entailment of knowledge of recurrent-utteruninstitutionalisation', as not of prospective ' ${ }^{103}$ universalisation-directed-rulemaking-over-nonrules_-apriorising/axiomatising/referencing-psychologism entailment of knowledge' but rather as of prior 'rulemaking-over-non-rules_-apriorising/axiomatising/referencing-psychologism entailment of knowledge of base-institutionalisation-ununiversalisation', as not of prospective 'positivising/rational-empiricism-based-universalisation-directed-rulemaking-over-non-rulesapriorising/axiomatising/referencing-psychologism entailment of knowledge' but rather as of prior ' ${ }^{103}$ universalisation-directed-rulemaking-over-non-rulesapriorising/axiomatising/referencing-psychologism entailment of knowledge of universalisation-non-positivism/medievalism' and as not of prospective 'preempting- 
disjointedness-as-of- ${ }^{8}$ reference-of-thought,-as-to- ${ }^{32}<$ amplituding/formativeepistemicity $>$ growth-or-conflatedness ${ }^{13} /$ transvaluative-

rationalising/transepistemicity/anamnestic-residuality/spirit-drivenness'—in-supersedingmere-formulaic-positivising/rational-empiricism-based-universalisation-directed-rulemakingover-non-rules — apriorising/axiomatising/referencing-psychologism entailment of knowledge' but rather as of prior 'positivising/rational-empiricism-based-universalisation-directedrulemaking-over-non-rules_-apriorising/axiomatising/referencing-psychologism entailment of knowledge of positivism- ${ }^{8}$ procrypticism'; as to a precenverging-existential-extrication-as-ofexistential-unthought normalising mentality ('usurping intellectual purpose/veracity' as to inherent postconverging-nonextricatory-existential-preempting-of-existential-unthought 'human intemporal-individuation threading/relaying succession of sublimating gesturings'). Furthermore an 'epistemic-break or notional-discontiguity/epistemic-discontiguity $<$ between-prior-shallow-supererogation -of-mentallyaestheticised preconverging/dementing -qualia-schema_and_prospective-profoundsupererogation -of-mentally-aestheticised postconverging/dialectical-thinking -qualiaschema $>$ as to difference-in-nature/difference-in-apriorising-or-axiomatising-or-referencing ${ }^{24}$ arises since a 'constraint is not a value' (as to the fact that an 'prenterinte extrication-as-of-existential-unthought normalising mentality' reflects a contraining orientation in contrast to 'inherent pestconverging-nonextricatory-existential-preempting-of-existentialunthought' reflecting a value orientation). Thus knowledge carries its very own value (with knowledge value implied as to its inherent nonpresencing-<perspective-ontologicalnormalcy/postconvergence> existentialising-frame-of-entailment-of motif-andapriorising/axiomatising/referencing of 'ontological-good-faith/authenticity ${ }^{6} \sim$ postconvergingde-mentating/structuring/paradigming ${ }^{70}$ allowing for its self-reflexive $\sim$ instigative-eventuating〈as-to-teleological-instigative/incipient- 
willing/arbitrariness/waywardness/faithdrivenness/supererogating-for-human-intelligibility,preceding-existence's-eventuating-sublimating-validation/desublimating-invalidation $\rangle \quad$ in prospective 'implicited_attendant-ontological-contiguity ${ }^{67}$; educedexistentialising/contextmalising/textualising_intelligibility/epistemicity/reflexivity_contiguity$<$ imbued-notional cogency>' induced knowledge-reification $\sim$ gesturing-and-accounting-ofepistemic-phenomenalism-<in-

prospective_psychologismic apriorising/axiomatising/referencing-\{of- ${ }^{\text {pprospectively }}$ implicited_attendant-ontological-contiguity ' educedexistentialising/contextualising/textualising_'intelligibility/epistemicity/reflexivity-contiguity$<$ imbued-notional cogency $\left.>^{\prime}\right\}$-conflatedness -in-\{preconverging -ment by\} postconverging-entailment> expansion'); such that the requisite 'knowledge value as of nonpresencing- $<$ perspective-ontological-normalcy/postconvergence $>$ epistemic-projection’ (theoretically/conceptually/operantly articulated herein as ‘ $<$ amplituding/formative $>$ disposedness/psychologismic-construct-〈as-to-orientation/valueconstruct/valuation-and-derived-parameterising/') can be cultivated-and-articulated for 'knowledge entailment as of nonpresencing-<perspective-ontologicalnormalcy/postconvergence $>\quad$ epistemic-projection' (theoretically/conceptually/operantly articulated herein as <amplituding/formative>entailment-〈as-to-totalising-contiguous/coherentfactuality-of-variability), and so-reflected overall as knowledge ${ }^{4}$ foregrounding_entailment$<$ in-succession-of-profound-supererogation $>>$-〈postconverging-narrowingdown $\sim$ sublimation-as-to-'existence — as-sublimating-withdrawal/unenframing/re-ontologising,elicited-from-prospective-profound-supererogation ' '-in-reflecting- 'immanent $\sim$ relativeunreflexivity/relative-reflexivity - ontological-contiguity ' ';-as-operativenotional deprocrypticism $\rangle$. The insight here as well is that 'knowledge carries its very own value' (as to its prospective nonpresencing-<perspective-ontological- 
normalcy/postconvergence $>$ epistemic-projection) since there is no limitedness/humansubpotency neutral ${ }^{7}$ presencing-absolutising-identitive-constitutedness ${ }^{14}$ mental-state of human ontological-performance ${ }^{72}-<$ including-virtue-as-ontology $>/$ morality/ethics/justice/etc. but for the appraisal from nonpresencing-<perspective-ontologicalnormalcy/postconvergence $>$ epistemic-projection. This is so-equally graspable for instance in the patent case of say a God-of-plane conception or superstitious conception of modern medicine in an animistic social-setup that cannot simply be construed as supposedly 'explained away by a circumstantial thorough positivism/rational-empiricism elucidation of how a plane or modern medicine works' since such an animistic social-setup existentialising-frame-of-entailment-ofmotif-and-apriorising/axiomatising/referencing is so-thoroughly beholdening to its 'mystical/spirits nonpositivistic conception of things rationalisation-ofcontentivity/argumentativity/dialecticism/discursivity' going by its ingrained '83 reference-ofthought specific preconverging/dementing -qualia-schema' that at best only a circumstantial constraining is induced (and not a positivism/rational-empiricism knowledge value as to its prospective nonpresencing-<perspective-ontological-normalcy/postconvergence $>$ epistemicprojection) since the animistic mindset is bound to psychologismically fallback/relapse into such a 'mystical/spirits nonpositivistic conception of things rationalisation-ofcontentivity/argumentativity/dialecticism/discursivity' (so-reflected 'in the generationally ingrained animistic psychologismic apriorising/axiomatising/referencing-\{of-" prospectively implicited_attendant-ontological-contiguity ' educedexistentialising/contextualising/textualising_intelligibility/epistemicity/reflexivity_contiguity<imbued-notional cogency >' $\}$-constitutedness ${ }^{14}$-in-preconverging-entailment' from which it has to crossgenerationally undergo psychoanalytic-unshackling/memeticreordering/institutional-recomposuring as from the positivism/rational-empiricism epistemicprojection of 'constraining existence-as-sublimating-withdrawal/unenframing/re- 
ontologising,-elicited-from-prospective-profound-supererogation

ontological-commitment $-<$ implied-self-assuredness-of-ontological-good-

faith/authenticity postconverging-de-mentating/structuring/paradigming -as-being-as-of-

existential-reality>') as it can hardly be expected that the systematicity/entailment of a positivism/rational-empiricism intelligibility (as to such a circumstantial demonstration of positivism/rational-empiricism knowledge) will instantly prevail in the animistic social-setup as adopted knowledge value ('knowledge value' so-reflected herein as $<$ amplituding/formative $>$ disposedness/psychologismic-construct-_as-to-orientation/valueconstruct/valuation-and-derived-parameterising)); and this insight is reflected in the crossgenerational underlying psychologismic apriorising/axiomatising/referencing-\{of'prospectively_implicited_attendant-ontological-contiguity ' educedexistentialising/contextualising/textualising_intelligibility/epistemicity/reflexivity-contiguity$<$ imbued-notional cogency $\left.>^{\prime}\right\}$-conflatedness ${ }^{13}$ in-\{preconverging ment by\} pestconverging-entailment as of psychoanalytic-unshackling/memetic-reordering/institutionalrecomposuring exercise of 'implicited_attendant-ontological-contiguity ${ }^{67}$ ? educedexistentialising/contextualising/textualising_intelligibility/epistemicity/reflexivity_contiguity$<$ imbued-notional cogency>' induced 'epistemic-growth/disquiet/discomfort-〈inducedsublimation,-as-from-existence's - effusing/ecstatic-inlining-as- historiality\{science/authenticity/nonextrication $\}$-beyond-mere-formulaicity/ritualisation-as- historicitytracing-\{science-ideology/fashionability/distraction $\}\rangle$ as to construction-of-the-Self in dispensing-with-immediacy-for-relative-ontological-completeness ${ }^{87}$-byreification/contemplative-distension ${ }^{27} \quad$ (in $\quad$ transversality-<for-sublimating-existentialeventuating/denouement-from-'thinking-at-first/pure-predisposition-preemptive-ofprospective-disontologising/subontologising' as-of-prospectively-disambiguated-affirmed- 
conflatedness $^{13}$ /formative-supererogating-<projective/reprojective-aestheticising-re-motifand-re-apriorising/re-axiomatising/re-referencing,-in-perspective-ontologicalnormalcy/postconvergence $>$ ) associated with all prospective transcendence-andsublimity/sublimation/supererogatory de-mentativity. It can be garnered from this analysis that once the conception-of- ${ }^{5}$ meaningfulness-and-teleology ${ }^{9}$ raises up the prospective human postconverging-aporeticism overeoming/unovereoming issue of human 'social-functioningand-accordance-as-of-social-stake-contention-or-confliction imbuing existentialising-frameof-entailment of motif-and-apriorising/axiomatising/referencing of disontologising/ontologising-and-re-ontologising' uninstitutionalised-threshold ${ }^{102}, \quad$ the pedantising/muddling/formulaic-hollowing-out — in-subontologisation/subpotentiation〈blurring/undermining-of-prospective-totalising-entailing,-as-to-entailing$<$ amplituding/formative-epistemicity $>$ totalising $\sim$ in-relative-ontological-completeness 'pretense of possessing an existentialising-frame-of-entailment-of-motif-andapriorising/axiomatising/referencing of contemplation' (in '79 presencing-absolutisingidentitive-constitutedness ${ }^{14}$ social-vestedness/normativity- $<$ discretely-implied-functionalism $>$ ) amenable to such a contemplation crumbles/collapses; just as it can be appreciated that the nonuniversalising, non-positivising and totalisingly-ing-discretion/whim-of-thought respectively of ancient-sophists, medieval-scholasticism and our modern-day manifestation of disparatenessof-conceptualisation-<unforegrounding-ment,-failing-prospectively-to-reflect‘immanent relative-unreflexivity/relative-reflexivity - ontological-contiguity 'existentialising-frame-of-entailment-of motif-and-apriorising/axiomatising/referencings of contemplation' cannot veridically contemplatively handle the ontological-veracity of meaningfulness-and-teleology ${ }^{9}$ respectively as to prospective ${ }^{103}$ universalising-idealisation, positivism/rational-empiricism and postmodern ${ }^{4}$ human-subject-emancipating-relativismdriven-recomposuring-constructivism-towards-singularisation- $<$ as-to-the- 
nondisjointedness/entailment-of-prospective- nonpresencing $>$ '. In-many-ways the reality of such a pedantising/muddling/formulaic-hollowing-out-in-subontologisation/subpotentiation〈blurring/undermining-of-prospective-totalising-entailing,-as-to-entailing-

<amplituding/formative-epistemicity>totalising in-relative-ontological-completeness $>$

'pretense of possessing an existentialising-frame-of-entailment-of-motif-andapriorising/axiomatising/referencing of contemplation' is rather about (a conscious or unconscious) elaborate exercise of distractive-alignment-to- ${ }^{-}$reference-of-thought- $<$ofapriorising/axiomatising/referencing $>{ }^{30}$ to the prospective knowledge-reification $\sim$ gesturingand-accounting - of-epistemic-phenomenalism- $<$ in-

prospective_psychologismic apriorising/axiomatising/referencing-\{of-'prospectively

implicited_attendant-ontological-contiguity ' educed-

existentialising/contextualising/textualising_'intelligibility/epistemicity/reflexivity_contiguity$<$ imbued-notional cogency $>$ ' \}-conflatedness -in-\{preconverging -ment by\}

postconverging-entailment $>$ (that has to be understood as to its cynical targeting of the 'human mental-reflex of $\quad$ self-presence/self-constitutedness ${ }^{14}-<$ in-perspective-epistemicabnormalcy/preconvergence ${ }^{3}>$ in ${ }^{79}$ presencing-absolutising-identitive-constitutedness social-vestedness/normativity-<discretely-implied-functionalism>' to misportray and derride the potential for human crossgenerational psychoanalytic-unshackling/memeticreordering/institutional-recomposuring exercise of 'implicited_attendant-ontologicalcontiguity $^{67}$; educed-

existentialising/contextualising/textualising_intelligibility/epistemicity/reflexivity-contiguity$<$ imbued-notional cogency >' induced 'epistemic-growth/disquiet/discomfort-〈inducedsublimation,-as-from-existence's - effusing/ecstatic-inlining-as- historiality\{science/authenticity/nonextrication $\}$-beyond-mere-formulaicity/ritualisation-as- historicitytracing-\{science-ideology/fashionability/distraction $\}\rangle$ as to construction-of-the-Self in 
dispensing-with-immediacy-for-relative-ontological-completeness ${ }^{87}$-by-

reification/contemplative-distension ${ }^{27}$ ). Critical to such an insight and as previously emphasised is pedantising/muddling/formulaic-hollowing-out_-in-subontologisation/subpotentiation〈blurring/undermining-of-prospective-totalising-entailing,-as-to-entailing$<$ amplituding/formative-epistemicity>totalising in-relative-ontological-completeness $>$ lack of a sense of metaphysics-of-absence-〈implicited-epistemic-veracity-of- nonpresencing$<$ perspective-ontological-normalcy/postconvergence $>$ ) (as the more centrally defining element of human angling-of-imaginary) as to a disposition to a conscious or unconscious ${ }^{79}$ presencingabsolutising-identitive-constitutedness ${ }^{14} \quad$ social-vestedness/normativity-<discretely-impliedfunctionalism $>$. For instance, such a nonpresencing-<perspective-ontologicalnormalcy/postconvergence> epistemic-projection reflected of such a term like metaphoricity herein as to an exercise of 'opening the human mind' to projectively see that what the Socrates, Copernicuses, Galileos, Descartes, Kants, Newtons, Leibniz, Rousseaux, Diderots, Pasteurs, Lavoisiers, Teslas, Einsteins, etc. of the world as to their intellectual-and-moral profoundsupererogation are doing tangibly is metaphoricity ${ }^{57}$ as to psychologismic apriorising/axiomatising/referencing-\{of-'prospectively implicited_attendant-ontological-contiguity ' reducedexistentialising/contextualising/textualising_intelligibility/epistemicity/reflexivity-contiguity<imbued-notional cogency>' $\}$-conflatedness ${ }^{13}$-in-\{preconverging-ment by\}

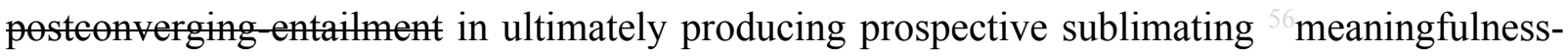
and-teleology (and in this regards there is no vague interpretation associated with the word metaphor as to the fact that the literary/poetic metaphor is the more basic 'sign-associated conception of metaphor as to aestheticisation' while the very practice of 'science is an advancement of the conception of metaphor however implicited in the natural sciences as to aestheticisation-towards-ontology imbued intolerance-<of- 
disparateness $>$ /exactifying_precisioning-of-sublimation-<as-to-postconverging-narrowingdown apriorising/axiomatising/referencing-entailing-theoretical,-conceptual-and-operantimplications>' explaining the recurrent psychologismic $\sim$ apriorising/axiomatising/referencing\{of-'prospectively implicited_attendant-ontological-contiguity ' e educedexistentialising/contextualising/textualising_'intelligibility/epistemicity/reflexivity-contiguity<imbued-notional cogency $\left.>^{\prime}\right\}$-conflatedness ${ }^{13}$-in-\{preconverging-ment by\} postconverging-entailment reflecting science $\quad{ }^{4}$ historiality/ontologicaleventfulness ${ }^{38} /$ ontological-aesthetic-tracing-<perspective-ontologicalnormalcy/postconvergence-reflected-‘epistemicity-relativism-determinism’>). But the possibility to induce blurriness-<sterilising/anecdotalising/trivialising-of-prospective-reontologising_by-preconverging,-in-disontologising-formulaic-dragging-out/hollowing-out> is pedantically taken up in a blurring conception of the 'literary/poetic metaphor' as to obfuscate with the literary trope as to what such thinkers like Derrida and Foucault 'meant or can mean as metaphor' failing to factor in that their lifetime work is 'all their metaphor' they are talking about (as to their eliciting of prospective epistemic-growth,-as-\{veridical/sound\}-relativereflexivity-in-existence/relativising from-limited-mentation-as-its-deepening/psychologismic

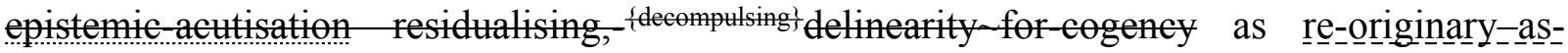
unenframed/re-ontologising/unbeholdening/outlier_-conceptualisation_-____imbuedpostconverging/dialectical-thinking -'projective-insights'/'epistemic-projection-inconflatedness '-of-notional deprocrypticism-prospective-sublimation $\rangle^{\circ}$ limitedness/humansubpotency prospective re-encountering/re-confrontation with existence-as-the-absolute-apriori-of-conceptualisation and existence—as-sublimating-withdrawal/unenframing/reontologising,-elicited-from-prospective-profound-supererogation $-<$ as-to-perspectiveontological-normalcy/postconvergence-implied-'prospective-aporeticismovercoming/unovercoming'>). It is herein contended that such postmodern thinkers like Derrida 
and Foucault were very well consciously aware of this institutionally ingrained distorted thought and motives as reflected in their intellectual demeanour and apprehension within the scope of such institutional 'social-functioning-and-accordance-as-of-social-stake-contention-orconfliction imbuing existentialising-frame-of-entailment-of motif-andapriorising/axiomatising/referencing of disontologising/ontologising-and-re-ontologising' (to which threshold of disontologising the textualising herein is not of prospective apriorising/axiomatising/referencing-sublimating-reflexivity-beholdening and effectively makes explicit as part-and-parcel of prospective knowledge-reification $\sim$ gesturing-andaccounting - of-epistemic-phenomenalism- $<$ inprospective_psychologismic apriorising/axiomatising/referencing-\{of-'prospectively implicited_attendant-ontological-contiguity ' educedexistentialising/contextualising/textualising_'intelligibility/epistemicity/reflexivity-contiguity<imbued-notional cogency>' \}-conflatedness -in-\{preconverging -ment by\} postconverging-entailment $>$ ). In-many-ways it is herein contended that with the appropriate contemplative patience and distance such thought as to their implicited knowledgereification $\sim$ gesturing-and-accounting - of-epistemic-phenomenalism- $<$ inprospective_psychologismic apriorising/axiomatising/referencing-\{of-‘prespectively implicited_attendant-ontological-contiguity ' reducedexistentialising/contextualising/textualising_ intelligibility/epistemicity/reflexivity-contiguity<imbued-notional cogency >' \}-conflatedness -in-\{preconverging-ment by\} postconverging-entailment $>$ is no more difficult to contemplate but for pedantic consciously or unconsciously elicited misanalysis and blurriness-<sterilising/anecdotalising/trivialising-ofprospective-re-ontologising_by-preconverging,-in-disontologising-formulaic-draggingout/hollowing-out $>$. With such pedantic blurriness-<sterilising/anecdotalising/trivialising-ofprospective-re-ontologising_by-preconverging,-in-disontologising-formulaic-dragging- 
out/hollowing-out $>$ undergirded by such a 'statement that certain things are unspeakable' rather herein construed as the very hallmark of such institutional disontologising undermining of prospective transcendence-and-sublimity/sublimation/supererogatory $\sim$ de-mentativity implications because human civilisation/enlightenment/progress is exactly about metaphorising as 'making unspeakable things speak' (as tangible like the metaphors of Newton making abstract forces conception to speak, Einstein making spacetime conception speak, Mendel making hereditary characteristics to speak, etc. and in all such cases not only counterintuitive-andidiosyncratic to their epochal minds but initially also to their instigators very own minds, and just as herein as tangible as to the explicited veracity of the $<$ cumulating/recomposuring attendant-ontological-contiguity $>$-successive registryworldviews/dimensions " ${ }^{83}$ reference-of-thought specific preconverging/dementing ${ }^{20}$-qualiaschema reflecting their specific prospectively ontologically-flawed nondescript/ignorable-void imbued self-presence/self-constitutedness ${ }^{14}-<$ in-perspective-epistemicabnormalcy/preconvergence ${ }^{3}{ }^{\prime}$ as from prospective ${ }^{6}$ nonpresencing- $<$ perspectiveontological-normalcy/postconvergence> epistemic-projection so-implied as human ${ }^{15}$ dementation-〈supererogatory $\sim$ ontological-de-mentation-or-dialectical-de-mentation — strandingor-attributive-dialectics $\rangle$ as to Being-development/ontological-framework-expansion-as-todepth-of-ontologising-development-as-infrastructure-of- meaningfulness-and-teleology , institutional-development-as-to-social-function-development and living-development-as-topersonality-development psychologismic epistemic acutisation difficulty <for, residualising \{ ${ }^{\{\text {decompulsing }}$ delinearity for-cogency $>$ magnitudes $\{$ of-experientiality/experiment $\}$ ). This inmany-ways is rather telling about the nombrilistic ${ }^{79}$ presencing-absolutising-identitiveconstitutedness ${ }^{14}$ of such 'statement that certain things are unspeakable' as effectively expliciting by itself the lack of a sense of metaphysics-of-absence-〈implicited-epistemic-veracity-ofnonpresencing-<perspective-ontological-normalcy/postconvergence $>>$ conception as to 
profound 'conceptivity/epistemic-reflexivity/epistemicity-relativism-determinism$<$ reifying \{as-to-knowledge-developing\}-and-empowering $>$ imbued theoretical/conceptual/operant implications'; and so as to the fact that the issue of history is not about 'presublimating relic/artifactual-beholdening-constitutedness ${ }^{14}{ }^{47}$ historicity-tracing-inpresencing-hyperrealisation/hyperreal-transposition' of no effective prospective ontological elucidation insight but rather the 'issue of history is philosophically epistemic and about human limited-mentation-capacity-deepening—as-subjecting limitedness/human-subpotency-to'educed-unlimitedness/existence-sublimating nascence' ${ }^{33}$ implications' so-reflecting the sublimating momentous ${ }^{4}$ historiality/ontological-eventfulness $\%$ ontological-aesthetic-tracing$<$ perspective-ontological-normalcy/postconvergence-reflected-'epistemicity-relativismdeterminism'> underlying history (as so-enabled only by a developed sense of metaphysics-ofabsence-〈implicited-epistemic-veracity-of- nonpresencing-<perspective-ontologicalnormalcy/postconvergence $>>$ ). But then across the <cumulating/recomposuring attendantontological-contiguity $>$-successive registry-worldviews/dimensions the true postconverging aporeticism-overcoming/unovercoming problem of prospective knowledgereification $\sim$ gesturing-and-accounting — of-epistemic-phenomenalism- $<$ inprospective_psychologismic $\sim$ apriorising/axiomatising/referencing-\{of-`prospectively implicited_attendant-ontological-contiguity ' educedexistentialising/contextualising/textualising_'intelligibility/epistemicity/reflexivity-contiguity$<$ imbued-notional cogency $>$ ' $\}$-conflatedness -in-\{preconverging-ment by\} postconverging entailment $>$ is laconically and surprisingly not between notional $\sim$ philosophy<as-to-the-veridical-conception-of-philosophy-as-englobing-all-human-prospective-organicknowledge-generation-in-relative-ontological-completeness ,-beyond-a-convenient-divisionof-labour-conception-of-knowledge > and pedantising/muddling/formulaic-hollowing-out - insubontologisation/subpotentiation-〈blurring/undermining-of-prospective-totalising-entailing,- 
as-to-entailing-<amplituding/formative-epistemicity $>$ totalising in-relative-ontological-

completeness $>$ (since in the depths of their mind both proclivities are already very much 'subconsciously aware' of their respective ontological-goodfaith/authenticity $\sim$ postconverging-de-mentating/structuring/paradigming 70 and ontologicalbad-faith/inauthenticity ${ }^{64} \sim$ preconverging-de-mentating/structuring/paradigming ${ }^{5}$ as can be appreciated with the Galileo telescope demonstration situation implied transversality $-<$ forsublimating-existential-eventuating/denouement-from-'thinking at first/pure-predispositionpreemptive-of prospective-disontologising/subontologising' as-of-prospectivelydisambiguated-affirmed-and-unaffirmed-'motif-and-apriorising/axiomatising/referencing'> in the selectivity of prospective knowledge), but rather in-many-ways (beyond the inherent valid knowledge determination as to such a transversality-<for-sublimating-existentialeventuating/denouement,-from-'thinking at-first/pure-predisposition-preemptive-of prospective-disontologising/subontologising' as-of-prospectively-disambiguated-affirmedand-unaffirmed-'motif-and-apriorising/axiomatising/referencing' $>101$ in the selectivity of prospective knowledge) the relevant postconvergingaporeticism-overcoming/unovercoming problem of prospective knowledge-reification $\sim$ gesturing-and-accounting-of-epistemicphenomenalism- $<$ in-prospective_psychologismic $\sim$ apriorising/axiomatising/referencing- of'prospectively_implicited_attendant-ontological-contiguity ' educedexistentialising/contextualising/textualising_'intelligibility/epistemicity/reflexivity-contiguity$<$ imbued-notional cogency $\left.>^{\prime}\right\}$-conflatedness -in-\{preconverging-ment by\} postconverging-entailment $>$ lies with the prompting of the postconverging epistemicprojective-equalisation social dynamics of veridical social knowledge percolation-channelling$<$ in-deferential-formalisation-transference $>$ within the scope of the collective-social human limited-mentation-capacity—as-subjecting 'educed-unlimitedness/existence-sublimating nascence' to-limitedness/human-subpotency 'social-functioning-and-accordance-as-of- 
social-stake-contention-or-confliction imbuing existentialising-frame-of-entailment-of motifand-apriorising/axiomatising/referencing of disontologising/ontologising-and-re-ontologising' (and so in 'reflection of the prerequisite social-functioning-and-accordance of that collectivesocial as to human limited-mentation-capacity—as-subjecting 'educed-unlimitedness/existencesublimating nascence' to limitedness/human-subpotency' prior to the eliciting of prospective ontologising-and-re-ontologising over prior disontologising, and so as to its prospective 'implicited_attendant-ontological-contiguity ${ }^{67}$ educed-

existentialising/contextualising/textualising_'intelligibility/epistemicity/reflexivity-contiguity$<$ imbued-notional cogency>' induced 'epistemic-growth/disquiet/discomfort-〈inducedsublimation,-as-from-existence's - effusing/ecstatic-inlining-as- historiality\{science/authenticity/nonextrication $\}$-beyond-mere-formulaicity/ritualisation-as- historicitytracing-\{science-ideology/fashionability/distraction $\}\rangle$ as to construction-of-the-Self in dispensing-with-immediacy-for-relative-ontological-completeness ${ }^{87}$-byreification/contemplative-distension ${ }^{27}$ ). It can be appreciated (as of an anthropological insight) that a positivism/rational-empiricism mindset encounter with say an animistic social-setup cannot relate to the latter in 'absolute terms of effectively demonstrable positivism/rationalempiricism systematicity/entailment of sublimating' (as it will so-relate to a fellow positivism/rational-empiricism mindset) as this will induce excessive mental alienation to the 'point of the positivistic-with-animistic mutualising mental shutdown'. But rather such a relation will be 'within the scope of the animistic collective-social implications of human limitedmentation-capacity—as-subjecting-'educed-unlimitedness/existence-sublimating nascence' to-limitedness/human-subpotency' (or within the scope of the 'debarking positivistic community and animistic social-setup shared/mutual collective-social implications of human limitedmentation-capacity—as-subjecting-'educed-unlimitedness/existence-sublimating nascence'to-limitedness/human-subpotency') to integrate prospective positivising ontologising-and-re- 
ontologising over the animistic social-setup prior non-positivising disontologising; as to the positivising mindset projection of 'constraining existence-as-sublimatingwithdrawal/unenframing/re-ontologising,-elicited-from-prospective-profound-supererogation imbuing human ontological-commitment $-<$ implied - self-assuredness-of-ontological-goodfaith/authenticity postconverging-de-mentating/structuring/paradigming -as-being-as-ofexistential-reality >' but then at the same time this equally allows for the possibility for an antipositivising disontologising as to temporal social-stake-contention-or-confliction. This soexplains more elaborately (with respect to re-ontologising prospective Beingdevelopment/ontological-framework-expansion-as-to-depth-of-ontologising-development-asinfrastructure-of- meaningfulness-and-teleology ) the crossgenerational nature of the psychoanalytic-unshackling/memetic-reordering/institutional-recomposuring exercise of 'implicited_attendant-ontological-contiguity ${ }^{6 /}$; educedexistentialising/contextualising/textualising_'intelligibility/epistemicity/reflexivity-contiguity$<$ imbued-notional cogency $>$ induced 'epistemic-growth/disquiet/discomfort-〈inducedsublimation,-as-from-existence's - effusing/ecstatic-inlining-as- historiality\{science/authenticity/nonextrication $\}$-beyond-mere-formulaicity/ritualisation-as- historicitytracing-\{science-ideology/fashionability/distraction $\}\rangle$ as to construction-of-the-Self in dispensing-with-immediacy-for-relative-ontological-completeness ${ }^{87}$-byreification/contemplative-distension ${ }^{27}$ for human prospective transcendence-andsublimity/sublimation/supererogatoryade-mentativity. In-many-ways the knowledgereification $\sim$ gesturing-and-accounting — of-epistemic-phenomenalism- $<$ inprospective_psychologismic apriorising/axiomatising/referencing-\{of- ${ }^{\text {prospectively }}$ implicited_attendant-ontological-contiguity ' educedexistentialising/contextualising/textualising_ intelligibility/epistemicity/reflexivity-contiguity<imbued-notional cogency>’ \}-conflatedness - in-\{preconverging ment by\} 
postconverging entailment $>$ of the Socrates, Galileos, Descartes, Rousseaux, Diderots, etc. of the world (in the face of their respective pedantising/muddling/formulaic-hollowing-out - insubontologisation/subpotentiation-〈blurring/undermining-of-prospective-totalising-entailing,as-to-entailing-<amplituding/formative-epistemicity $>$ totalising $\sim$ in-relative-ontologicalcompleteness $>$ desublimation and beyond just their respectively implied transversality $-<$ forsublimating-existential-eventuating/denouement,-from-'thinking-at-first/pure-predispositionpreemptive-of prospective-disontologising/subontologising' as-of-prospectivelydisambiguated-affirmed-and-unaffirmed-'motif-and-apriorising/axiomatising/referencing’> in the selectivity of prospective knowledge); rather extended to such a secondary 'crusading relation to prospective knowledge' (involving their prompting of the postconverging epistemic - projective-equalisation social dynamics of veridical social knowledge percolationchannelling- $<$ in-deferential-formalisation-transference $>$ within the scope of their social-setups collective-social human limited-mentation-capacity-as-subjecting-educedunlimitedness/existence-sublimating nascence' to-limitedness/human-subpotency 'socialfunctioning-and-accordance-as-of-social-stake-contention-or-confliction imbuing existentialising-frame-of-entailment of motif-and-apriorising/axiomatising/referencing of disontologising/ontologising-and-re-ontologising'). Whereas the effective result of a positivising/rational-empiricism registry-worldview/dimension made this secondary 'crusading relation to prospective knowledge' rather mostly irrelevant to the Einsteins, Lavoisiers, etc. of the world (with the institutionalisation/enculturation of the positivising/rational-empiricism reontologising prospective Being-development/ontological-framework-expansion-as-to-depthof-ontologising-development-as-infrastructure-of- meaningfulness-and-teleology induced ' ${ }^{103}$ universal-transparency ${ }^{104}$-〈transparency-of-totalising-entailing,-as-to-entailing<amplituding/formative-epistemicity>totalising in-relative-ontological-completeness > as available-to/elicitable-to-〈as-to-human-consciousness/collective-consciousness- 
distendedness/detruncating-<beyond-selfpresencing,-as-re-ontologising-decentering_of-

consciousness/collective-consciousness,-as-to-psychologismic-epistemic-acutisation

residualising, ${ }_{-}^{-\{\text {decompulsing }}$ delinearity $\sim$ for- $\left.\operatorname{cogency}>\right\rangle$ the social-functioning-and-accordanceas-of-social-stake-contention-or-confliction conception of any given registryworldview/dimension $\quad$ <preconverging 'motif-and-apriorising/axiomatising/referencing'entailing $>$-existentialising — enframing/imprintedness-〈as-to- historicity-tracing - inpresencing-hyperrealisation/hyperreal-transposition〉'); such that in-many-ways as well the opposing pedantic activity undermining prospective knowledge is effectively reflected in the conscious or unconscious surreptitious anti-intellectualism distracting from all such reoriginary-as-unenframed/re-ontologising/unbeholdening/outlier-conceptualisation-_imbuedpostconverging/dialectical-thinking - 'projective-insights'/'epistemic-projection-inconflatedness ' -of-notional deprocrypticism-prospective-sublimation $\rangle$ instigative conceptions of re-ontologising prospective Being-development/ontological-frameworkexpansion-as-to-depth-of-ontologising-development-as-infrastructure-of- meaningfulnessand-teleology . The notion of ontology (science) is utterly unbeholdening to human-subpotency (and with regards to the 'relative-unreflexivity/relative-reflexivity-ontologicalcontiguity ${ }^{67}$ of-the-human-institutionalisation-process ${ }^{68}$ as of Being-development/ontologicalframework-expansion-as-to-depth-of-ontologising-development-as-infrastructure-ofmeaningfulness-and-teleology '), ontology thus speaks of the increasing human limitedmentation-capacity-deepening —as-subjecting limitedness/human-subpotency-to-'educedunlimitedness/existence-sublimating nascence' ${ }^{3}$ ontological-performance ${ }^{22}-<$ including-virtueas-ontology $>/$ morality/ethics/justice/etc. as of the-very-same-immanent-existence/intrinsicreality/ontological-veridicality,-as-to-'human<amplituding/formativeepistemicity>totalising purview-of-construal' underlying the development of human sublimating/transcendental/emancipative re-rationalisations as to 
nonextricatory-existential-preempting-of-existential-unthought.

notional philosophy-<as-to-the-veridical-conception-of-philosophy-as-englobing-all-humanprospective-organic-knowledge-generation-in-relative-ontological-completeness ,-beyond-aconvenient-division-of-labour-conception-of-knowledge $>$ is that exercise bent on recurrently reaffirming the 'mortal littleness of human-subpotency' while re-affirming the 'intemporal grandeur of existence-potency as sublimation/transcendental/emancipation enabling for humansubpotency' (and so as to its recurrent profound-supererogation 'exercise of the epistemicprojective-equalisation of human station of ${ }^{79}$ presencing-absolutising-identitiveconstitutedness $^{14}$ as to prospective nonpresencing-<perspective-ontologicalnormalcy/postconvergence> epistemic_projective-equalisation' as so-underlying human Being-development/ontological-framework-expansion-as-to-depth-of-ontologisingdevelopment-as-infrastructure-of- meaningfulness-and-teleology ); and so projecting the veracity of the fact that ontology (science) is wholly of the sublimating purview of notional philosophy-<as-to-the-veridical-conception-of-philosophy-as-englobing-all-humanprospective-organic-knowledge-generation-in-relative-ontological-completeness ,-beyond-aconvenient-division-of-labour-conception-of-knowledge $>$ and so notwithstanding the flawed

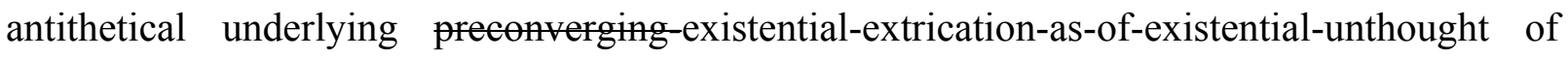
pedantising/muddling/formulaic-hollowing-out — in-subontologisation/subpotentiation〈blurring/undermining-of-prospective-totalising-entailing,-as-to-entailing$<$ amplituding/formative-epistemicity>totalising in-relative-ontological-completeness $>$ only arising as to the blurriness-<sterilising/anecdotalising/trivialising-of-prospective-reontologising_by-preconverging,-in-disontologising-formulaic-dragging-out/hollowing-out> of successive human registry-worldviews/dimensions 'social-functioning-and-accordance-as-ofsocial-stake-contention-or-confliction imbuing existentialising-frame-of-entailment of motifand-apriorising/axiomatising/referencing of disontologising/ontologising-and-re-ontologising' 
uninstitutionalised-threshold ${ }^{102}$ that then allows for the possibility of disontologising (as of an ontologically-flawed disontologising desublimating gesturing/accounting-of-epistemicphenomenalism across the <cumulating/recomposuring attendant-ontological-contiguity $>$ successive registry-worldviews/dimensions while wrongly projecting an in-effect absolution$<$ as-to-apriorising/axiomatising/referencing-\{of-"prospectively implicited_attendant ontological-contiguity ' educedexistentialising/contextualising/textualising_intelligibility/epistemicity/reflexivity_contiguity$<$ imbued-notional cogency $>\quad\}$-constitutedness -in preconverging-entailment $>$ presencing-absolutising-identitive-constitutedness ${ }^{14}$ that conveniently stymies the conception of human re-rationalisations and so-explaining why it-cannot-account,-nor-is-itinterested-in-accounting-for the 'full experientiality/experiment- $<$ as-to-existentially-formative‘\{epistemic-totalising łre-apriorising/re-axiomatising/re-referencing $\sim$ residuality-in-reoriginariness/re-origination', - so-'notionally/epistemically/bindingnessly-<as-todeterminism/conceptivity of relative unreflexivity/relative reflexivity>-implicited-and-articulated' as-fromnonextricatory-'prospective-re-ontologising-Being-then-Institutional-then-Living-magnitudesof-\{hermeneutic/reprojection-protraction-of \{reframing-and-reformulation $\}$ ' $>$ that is the human abstract-tissue-of-social-emanance' herein construed as to the overall relativeunreflexivity/relative-reflexivity ontological-contiguity ${ }^{67} \sim$ of-the-human-institutionalisationprocess ${ }^{6}$ as reflecting the sublimating-postconverged 'substantive abstract-tissue-of-socialemanance Sepistemicthermeneutically/textually/reprojectingly/supererogatingly/zeroingly/re-acutingly,$\{$ decompulsing $\}$ delinearity for-cogency—cumulated/recomposured as to cumulating/recomposuring of 'prospectively implicited_andentontological-contiguity ${ }^{67}$ ' educedexistentialising/contextualising/textualising_'intelligibility/epistemicity/reflexivity-contiguity$<$ imbued-notional $\sim \operatorname{cogency}>$ ' $)$. In this respect 'human consciousness notional protensivity 
imbuing prospective psychologismic-epistemic-acutisation-<as-to-postconverging-dementating/structuring/paradigming,-eliciting-of-existence's-sublimating-nascence-inprospective-aporeticism-overcoming/unovercoming $>$ as to epistemic-growth,-as\{veridical/sound\}-relative-reflexivity-in-existence/relativising from-limited-mentation-as-itsdeepening/psychologismic epistemic-acutisation residualising, ${ }^{\text {fdecompulsing }}$ \}elinearity foreogeney' (as undergirding the 'full experientiality/experiment-<as-to-existentially-formative‘\{epistemic-totalising łre-apriorising/re-axiomatising/re-referencing $\sim$ residuality-in-reoriginariness/re-origination',- - so-'notionally/epistemically/bindingnessly-as to determinism/conceptivity-of-relative-unreflexivity/relative-reflexivity>_implicited-and-articulated' as-fromnonextricatory-'prospective-re-ontologising-Being-then-Institutional-then-Living-magnitudesof-\{hermeneutic/reprojection-protraction-of $\{$ reframing-and-reformulation $\}$ '> that is the human abstract-tissue-of-social-emanance' herein reflected as to the overall relativeunreflexivity/relative-reflexivity — ontological-contiguity ${ }^{67}$ of-the-human-institutionalisationprocess $^{68}$ of the $<$ cumulating/recomposuring attendant-ontological-contiguity $>$-successive registry-worldviews/dimensions) can only be definedly underlied by the 'exercise of the epistemic - projective-equalisation of human station of ${ }^{79}$ presencing - absolutising-identitiveconstitutedness $^{14}$ as to prospective ${ }^{6}$ nonpresencing-<perspective-ontologicalnormalcy/postconvergence $>$ epistemic — projective-equalisation' of notional $\sim$ philosophy- $<$ asto-the-veridical-conception-of-philosophy-as-englobing-all-human-prospective-organicknowledge-generation-in-relative-ontological-completeness ,-beyond-a-convenient-divisionof-labour-conception-of-knowledge>. Otherwise the resultant conception of thehuman/humanity can only be a false conception that is incidental to any given station-of/epochal presencing-absolutising-identitive-constitutedness ${ }^{14}$ notwithstanding its very own appraisal of its 'human limited-mentation-capacity—as-subjecting-'educed-unlimitedness/existencesublimating nascence' to-limitedness/human-subpotency implications of 
apriorising/axiomatising/referencing as to its prospectively disontologising ontologicalperformance $^{72}-<$ including-virtue-as-ontology $>$ ' to then go on to articulate an in-effect absolution-<as-to-apriorising/axiomatising/referencing- \{of-‘prospectively implicited_attendant-ontological-contiguity ' educedexistentialising/contextualising/textualising_ 'intelligibility/epistemicity/reflexivity-contiguity$<$ imbued-notional cogency $>$ ' $\quad\}$-constitutedness -in preconverging-entailment $>$ conception that fails to factor in the \{epistemic-totalising ${ }^{3}$ re-apriorising/re-axiomatising/rereferencing residuality - in-re-originariness/re-origination-〈as to human profoundsupererogation for prospective apriorising/axiomatising/referencing-\{of-'prospectively implicited_attendant-ontological-contiguity ' reducedexistentialising/contextualising/textualising_ intelligibility/epistemicity/reflexivity-contiguity<imbued-notional cogency $>$ ' $\}$-conflatedness -in-\{preconverging-ment by\} postconverging-entailment that cannot be unshrouded by prior mere-formulaicity/ritualisation<as-to-mere-formulaic — methodologising/mutualising/organising/institutionalising,prospectively-losing-track-of- ‘\{epistemic-totalising ${ }^{\dagger}$ re-apriorising/re-axiomatising/rereferencing $\sim$ residuality —in-re-originariness/re-origination'> of prior apriorising/axiomatising/referencing-\{of-'prospectively implicited_attendant-ontologicalcontiguity ' $\sim$ educedexistentialising/contextualising/textualising_'intelligibility/epistemicity/reflexivity-contiguity<imbued-notional cogency $\left.>^{\prime} \quad\right\}$-constitutedness -in-preconverging-entailment $\rangle$ associated with its limited-mentation-capacity-as-subjecting-'educed-unlimitedness/existencesublimating nascence' to-limitedness/human-subpotency implications of disontologising ('which so-validates an epistemicity-relativism-determinism ontologising conceptualisation' as veridically accounting for this referencing $\sim$ residuality - in-re-originariness/re-origination-〈as to human profound- 
supererogation for prospective apriorising/axiomatising/referencing-\{of-" prospectively_ implicited_attendant-ontological-contiguity ' educedexistentialising/contextualising/textualising_'intelligibility/epistemicity/reflexivity-contiguity$<$ imbued-notional cogency $\left.>^{\prime}\right\}$-conflatedness -in-\{preconverging-ment by\} postconverging-ntailment that cannot be unshrouded by prior mere-formulaicity/ritualisation<as-to-mere-formulaic — methodologising/mutualising/organising/institutionalising,prospectively-losing-track-of- ‘fepistemic-totalising 3 're-apriorising/re-axiomatising/rereferencing $\sim$ residuality_-in-re-originariness/re-origination'> of prior apriorising/axiomatising/referencing-\{of-"prospectively_implicited_attendant-ontologicalcontiguity ' $\sim$ educedexistentialising/contextualising/textualising_'intelligibility/epistemicity/reflexivity-contiguity<imbued-notional cogency>' $\}$-constitutedness -in-preconverging-entailment $\rangle$ given human limited-mentation-capacity—as-subjecting 'educed-unlimitedness/existencesublimating nascence' to-limitedness/human-subpotency and thus requiring for prospectively sublimating ontological-performance ${ }^{72}-<$ including-virtue-asontology $>$ /morality/ethics/justice/etc. the need for human limited-mentation-capacitydeepening —as-subjecting limitedness/human-subpotency-to-'educed-unlimitedness/existencesublimating nascence' 53 as to epistemicity-relativism-determinism prospectively implied psychologismic apriorising/axiomatising/referencing-\{of-"prospectively implicited_attendant-ontological-contiguity ' educedexistentialising/contextualising/textualising_'intelligibility/epistemicity/reflexivity-contiguity$<$ imbued-notional cogency $\left.>^{\prime},\right\}$-conflatedness ${ }^{13}$ in (preconverging ment by $^{\prime}$ postconverging-entailment). Thus an 'incidental to any given station-of/epochal ${ }^{79}$ presencingabsolutising-identitive-constitutedness ${ }^{14}$ conception of the-human/humanity as to an in-effect absolution-<as-to-apriorising/axiomatising/referencing-\{of-'prospectively 
implicited_attendant-ontological-contiguity ' reduced-

existentialising/contextualising/textualising_'intelligibility/epistemicity/reflexivity_contiguity<imbued-notional cogency >' $\}$-constitutedness -in preconverging-entailment>' divulges a convenient technically-speaking ontological-bad-faith/inauthenticity $\sim$ preconverging-dementating/structuring/paradigming that can hardly be qualified as prospective ontologyaspiring since its veridical preconverging/postconverging-de-mentative/structural/paradigmatic relation to prospective sublimation/transcendence/emancipation is of the-very-same dimensionality-of-desublimating-lack-of $-\langle<$ amplituding/formative $>$ supererogatory $\sim$ dementativeness/epistemic-growth-or-conflatedness /transvaluativerationalising/transepistemicity/anamnestic-residuality/spirit-drivenness-equalisation $\rangle$ that may just as well justify prior ${ }^{79}$ presencing-absolutising-identitive-constitutedness ${ }^{14}$ incidental station-of/epochal in-effect absolution-<as-to-apriorising/axiomatising/referencing-\{of'prospectively_implicited_attendant-ontological-contiguity ' ceducedexistentialising/contextualising/textualising_'intelligibility/epistemicity/reflexivity-contiguity$<$ imbued-notional cogency >' $\}$-constitutedness -in preconverging-entailment $>$ as to prior desublimation/non-transcendence/non-emancipation and in-effect speaks to the notional $\sim$ distractive-alignment-to- ${ }^{-3}$ reference-of-thought- $<$ ofapriorising/axiomatising/referencing $>30$ to the overall relative-unreflexivity/relativereflexivity ontological-contiguity ${ }^{67}$ of-the-human-institutionalisation-process. 'remaining-blind/not-seeing the ontologising-drive of the successive human registryworldviews/dimensions' reflected in the 'full experientiality/experiment-<as-to-existentially-

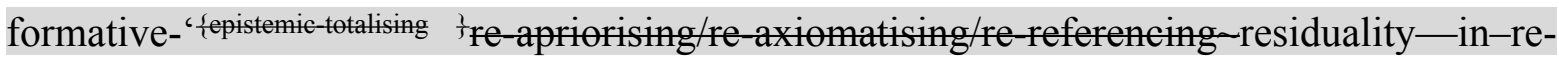
originariness/re-origination', - so-'notionally/epistemically/bindingnessly-<as-todeterminism/conceptivity of relative unreflexivity/relative reflexivity>-implicited-and-articulated'_as-fromnonextricatory-'prospective-re-ontologising-Being-then-Institutional-then-Living-magnitudes- 
of-\{hermeneutic/reprojection -protraction-of reframing-and-reformulation $\}$ ' $>$ that is the human abstract-tissue-of-social-emanance' (with the ontologising-drive enabled as of dimensionalityof-sublimating $25-\langle<$ amplituding/formative $>$ supererogatory $\sim$ de-mentativeness/epistemicgrowth-or-conflatedness /transvaluative-rationalising/transepistemicity/anamnesticresiduality/spirit-drivenness-equalisation〉 as to 'profound-supererogation elicited cumulating/recomposuring of successive reproducibility—mathesis/motif/thrownnessdisposition,-as-reproducibility-of-aestheticisation'), pedantising/muddling/formulaichollowing-out - in-subontologisation/subpotentiation-〈blurring/undermining-of-prospectivetotalising-entailing,-as-to-entailing- $<$ amplituding/formative-epistemicity $>$ totalising inrelative-ontological-completeness $>$ conveniently projects futurally a 'representation of thehuman/humanity which potential is supposedly only as veridical as to the mortal's conveniently mortal threshold of preconverging-existential-extrication-as-of-existential-unthought'. In other words, the notional philosophy-<as-to-the-veridical-conception-of-philosophy-as-englobingall-human-prospective-organic-knowledge-generation-in-relative-ontological-completeness , beyond-a-convenient-division-of-labour-conception-of-knowledge $>$ exercise can thus be construed as rather involved in 'human existential-<disontologising/re-ontologisingapereticism $>$ re-creativity' with regards to the incipient veracity of a human preconverging/postconverging-de-mentative/structural/paradigmatic 'notional $\sim$ reflexivity$<\{$ veridical/sound\}-relative-reflexivity-in-existence/relativising from-limited-mentation-asits deepening/psychologismic < residualising ${ }^{\{\text {decompulsing }}$ delinearity for cogency>by\{flawed/unsound\}-relative-unreflexivity-in-existence/absolutising from-limitedmentation/psychologismic epistemic-acutisation nonresidualising imbuedfompulsingtlinearity in-eclecticism-of-prior-mere-formulaicity/ritualisation> dualising' of notional firstnaturedness-formativeness-<as-to-eventualising -inkling-drive-or-seedingmisprising $>$ temporal-to-intemporal-dispositions-<so-construed-as-from-perspective- 
ontological-normalcy/postconvergence $>$ as to shallow-supererogation to profoundsupererogation threshold of constraining sublimation over desublimation. Such a 'human existential-<disontologising/re-ontologising aporeticism $>$ re-creativity' of prospective ontologising-and-re-ontologising possibilities (reflecting the full human ontologising-drive scope as to the 'exercise of the epistemic-projective-equalisation of human station of presencing-absolutising-identitive-constitutedness ${ }^{14}$ as to prospective nonpresencing<perspective-ontological-normalcy/postconvergence $>\quad$ epistemic-projective-equalisation') necessarily has to address what is herein construed as 'fundamental taboo against prospective ontologising-and-re-ontologising' (underlying any human registry-worldviews/dimensions 'social-functioning-and-accordance-as-of-social-stake-contention-or-confliction imbuing existentialising-frame-of-entailment-of-motif-and-apriorising/axiomatising/referencing of disontologising/ontologising-and-re-ontologising' uninstitutionalised-threshold ${ }^{102}$ ) soinvolving: the fact that prospective ontologising-and-re-ontologising (as to re-ontologising prospective Being-development/ontological-framework-expansion-as-to-depth-ofontologising-development-as-infrastructure-of- meaningfulness-and-teleology ) necessarily implies a 'prospective nonpresencing-<perspective-ontological-normalcy/postconvergence $>$ change in knowledge-reification $\sim$ gesturing-and-accounting-of-epistemic-phenomenalism$<$ in-prospective_psychologismic $\sim$ apriorising/axiomatising/referencing-\{of-‘prospectively implicited_attendant-ontological-contiguity ' educedexistentialising/contextualising/textualising_'intelligibility/epistemicity/reflexivity-contiguity<imbued-notional cogency>' \}-conflatedness -in-\{preconverging-ment by\} postconverging-entailment $>$ as to educed psychologismic $\sim$ apriorising/axiomatising/referencing\{of-'prespectively implicited_attendant-ontological-contiguity ' e educedexistentialising/contextualising/textualising_'intelligibility/epistemicity/reflexivity-contiguity<imbued-notional cogency $\left.>^{\prime}\right\}$ - conflatedness ${ }^{13}$-in-\{preconverging -ment by\} 
postconverging-entailment' that is in-many-ways inherently 'problematic/troublemaking/challenging and ing' to any given ${ }^{79}$ presencing-absolutisingidentitive-constitutedness $^{14}$ social-vestedness/normativity- $<$ discretely-implied-functionalism $>$ and its prior_knowledge-reification $\sim$ gesturing-and-accounting_-of-epistemic-phenomenalism$<$ in-prior_psychologismic apriorising/axiomatising/referencing-\{of-'priorimplicited_attendant_ontological-contiguity ' educedexistentialising/contextualising/textualising_intelligibility/epistemicity/reflexivity_contiguity$<$ imbued-notional cogency $>>\quad\}$-constitutedness -in-preconverging-entailment $>$; and in another respect such a prospective ontologising knowledge-reification $\sim$ gesturing-andaccounting - of-epistemic-phenomenalism- $<$ in-

prospective_psychologismic apriorising/axiomatising/referencing-\{of-‘prospectively_ implicited_attendant-ontological-contiguity ' educedexistentialising/contextualising/textualising_'intelligibility/epistemicity/reflexivity_contiguity$<$ imbued-notional cogency $>$ ' \}-conflatedness - in-\{preconverging ment by\} postconverging-entailment> implication of an 'epistemic-break or notionaldiscontiguity/epistemic-discontiguity ${ }^{63}<$ between - prior-shallow-supererogation -ofmentally-aestheticised preconverging/dementing - qualia-schema_and prospective-profoundsupererogation -of-mentally-aestheticised postconverging/dialectical-thinking -qualiaschema $>$ as to difference-in-nature/difference-in-apriorising-or-axiomatising-or-referencing ${ }^{24}$ inevitably lays a claim to the prior_knowledge-reification $\sim$ gesturing-and-accounting-ofepistemic-phenomenalism-<in-prior_psychologismic apriorising/axiomatising/referencing\{of-'prior-implicited_attendant-ontological-contiguity ' ceducedexistentialising/contexalising/texalising_intelligibility/epistemicity/reflexivity-contiguity<imbued-notional cogency>' $\}$-constitutedness -in-preconverging-entailment $>$ prospective 'epistemic-decadence’ or teleological-decadence-<-in-dimensionality-of- 
desublimating-lack-of $-<<$ amplituding/formative $>$ supererogatory $\sim$ de-mentativeness/epistemicgrowth-or-conflatedness /transvaluative-rationalising/transepistemicity/anamnestic-

residuality/spirit-drivenness-equalisation $\rangle$ (not for an idle purpose as to a 'presence social-stakecontention-or-confliction' implication) but rather as to the fact that such prior_knowledgereification $\sim$ gesturing-and-accounting — of-epistemic-phenomenalism- $<$ inprior_psychologismic a apriorising/axiomatising/referencing- $\{$ of-'prior-implicited_attendantontological-contiguity ' educedexistentialising/contextualising/textualising_'intelligibility/epistemicity/reflexivity-contiguity<imbued-notional cogency $>$ ' $\quad\}$-constitutedness -in preconverging-entailment $>\quad$ hasfailed/is-failing prospectively (given its psychologismic apriorising/axiomatising/referencing\{of-'prospectively implicited_attendant-ontological-contiguity ' e educedexistentialising/contextualising/textualising_ intelligibility/epistemicity/reflexivity_contiguity$<$ imbued-notional cogency $>$ ' $\}$-constitutedness ${ }^{14}$-in-preconverging-entailment) the requisite profound-supererogation associated with the prospective knowledgereification $\sim$ gesturing-and-accounting - of-epistemic-phenomenalism- $<$ inprospective_psychologismic apriorising/axiomatising/referencing-\{of- ${ }^{\text {pprospectively }}$ implicited_attendant-ontological-contiguity ' educedexistentialising/contextualising/textualising_'intelligibility/epistemicity/reflexivity-contiguity<imbued-notional cogency>’ \}-conflatedness -in-\{preconverging -ment by\} postconverging-entailment> (beyond any projected mere-formulaicity/ritualisation- $<$ as-tomere-formulaic — methodologising/mutualising/organising/institutionalising,-prospectively-

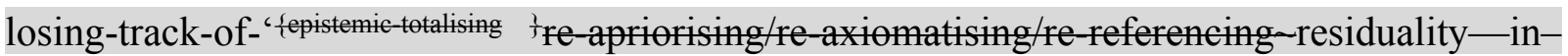
re-originariness/re-origination'>) 'and so technically-speaking to its underlying ontological-badfaith/inauthenticity ${ }^{64}$ preconverging-de-mentating/structuring/paradigming ${ }^{55}$ as to when manifest relative-ontological-completeness ${ }^{87}$ is-educed-and-avails-and-re-avails' (so- 
construed as being in epistemic-decadence with respect to prospective nonpresencing<perspective-ontological-normalcy/postconvergence> epistemic-projection of 'knowledge value' so-reflected herein as '<amplituding/formative>disposedness/psychologismic-construct〈as-to-orientation/value-construct/valuation-and-derived-parameterising〉, for $<$ amplituding/formative $>$ entailment-〈as-to-totalising-contiguous/coherent-factuality-ofvariability $\rangle$, and so-reflected overall as knowledge ${ }^{4}$ foregrounding_entailment- $<$ in-successionof-profound-supererogation $>$-〈postconverging-narrowing-down $\sim$ sublimation-as-to'existence — as-sublimating-withdrawal/unenframing/re-ontologising,-elicited-fromprospective-profound-supererogation '-in-reflecting-'immanent relativeunreflexivity/relative-reflexivity - ontological-contiguity ';-as-operativenotional deprocrypticism), as to the critical fact that prospective knowledgereification $\sim$ gesturing-and-accounting — of-epistemic-phenomenalism- $<$ inprospective_psychologismic apriorising/axiomatising/referencing-\{of-`prospectively implicited_attendant-ontological-contiguity ' e educedexistentialising/contextualising/textualising_'intelligibility/epistemicity/reflexivity-contiguity<imbued-notional cogency >’ \}-conflatedness -in-\{preconverging -ment by\} postconverging entailment $>$ educed sublimating/transcendence/emancipation cannot be construed as of the prior_knowledge-reification $\sim$ gesturing-and-accounting-of-epistemicphenomenalism-<in-prior_psychologismic $\sim$ apriorising/axiomatising/referencing-\{of-'priorimplicited_attendant-ontological-contiguity ' educedexistentialising/contextualising/textualising_'intelligibility/epistemicity/reflexivity-contiguity$<$ imbued-notional cogency $>$ ' $\quad\}$-constitutedness -in preconverging-entailment $>$ (as this is bound to merely induce more and more of a complexification of the latter as so-reflected in our modern-day ${ }^{80}$ procrypticism-or-disjointedness-as-of- ${ }^{83}$ refence-of-thought totalisingly-ingdiscretion/whim-of-thought increasingly underlied with dynamic, sophisticated and networking 
institutionalised

pedantising/muddling/formulaic-hollowing-out-insubontologisation/subpotentiation-〈blurring/undermining-of-prospective-totalising-entailing,as-to-entailing-<amplituding/formative-epistemicity $>$ totalising in-relative-ontologicalcompleteness \) with such complexification rendering the possibility for prospective sublimation/transcendence/emancipation rather tedious as to the requisite 'crusading relation to prospective knowledge' for its postconverging aporeticism-overcoming/unovercoming; besides the prior_knowledge-reification $\sim$ gesturing-and-accounting-of-epistemicphenomenalism-<in-prior_psychologismic $\sim$ apriorising/axiomatising/referencing- $\{$ of- 'priorimplicited_attendant-ontological-contiguity ' educed-

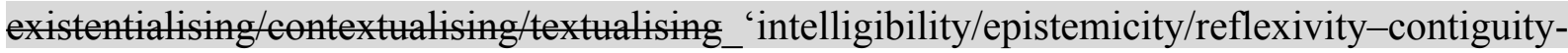
<imbued-notional cogency $>>\quad\}$-constitutedness -in preconverging entailment $>$ ing and complexification elements of the 'fundamental taboo against prospective ontologising-and-reontologising', the third element arises as to the preconverging/postconverging-dementative/structural/paradigmatic implication of 'what is the-human/humanity' with regards to the possibility for prospective ontologising-and-re-ontologising as only the preconverging/postconverging-de-mentative/structural/paradigmatic reflection of human destructuring-threshold-〈uninstitutionalised-threshold /presublimating-desublimatingdecisionality $>\sim$ of-ontological-performance ${ }^{72}$-<including-virtue-asontology $>$ /morality/ethics/justice/etc. then allows for the postconvergingaapereticismoreming for prospective human sublimating/transcendence/emancipation (as to Being-development/ontological-framework-expansion-as-to-depth-of-ontologisingdevelopment-as-infrastructure-of- meaningfulness-and-teleology , institutionaldevelopment-as-to-social-function-development and living-development-as-to-personalitydevelopment psychologismic epistemic acutisation difficulty-for, residualising \{decompulsing\} delinearity for-cogency>-magnitudes ${ }^{\{\text {of-experientiality/experiment }\}}$ ) but with such a 
conception as to its 'implicited human limited-mentation-capacity-as-subjecting 'educedunlimitedness/existence-sublimating nascence' to-limitedness/human-subpotency and consequent human limited-mentation-capacity-deepening - as-subjecting limitedness/hmmansubpotency-to-'educed-unlimitedness/existence-sublimating nascence' as to psychologismic apriorising/axiomatising/referencing-\{of-'prespectively implicited_attendant-ontological-contiguity ' educedexistentialising/contextualising/textualising_intelligibility/epistemicity/reflexivity_contiguity<imbued-notional cogency $>$ ' $\}$ - conflatedness ${ }^{13}$ in-\{preconverging-ment by $\}^{\prime}$ postconverging-entailment' necessarily projecting of a human 'intemporal-prioritisation-ofreference-of-thought'-as-conflatedness ${ }^{13}$-or-ontological-reprojecting as to human directcapacity/deferential-capacity for dimensionality-of-sublimating ${ }^{25}$

\section{<<amplituding/formative>supererogatory $\sim$ de-mentativeness/epistemic-growth-or-}

\section{conflatedness /transvaluative-rationalising/transepistemicity/anamnestic-residuality/spirit-}

drivenness-equalisation) that challenges the conceptualisation of the-human/humanity as about the 'collective notion of the-human/humanity as to the mere construal of any given registryworldview/dimension institutionalisation-threshold' (and so as of an ontologically potent reflection of the-human/humanity as to the profound 'conceptivity/epistemicreflexivity/epistemicity-relativism-determinism- $<$ reifying \{as-to-knowledge-developing $\}$-andempowering $>$ imbued theoretical/conceptual/operant implications' arising from the dynamic and contrasting relation of 'human intemporal-individuation threading/relaying succession of sublimating gesturings' of 'intemporal-prioritisation-of- ${ }^{8}$ reference-of-thought'-asconflatedness $^{13}$-or-ontological-reprojecting pestconverging-nonextricatory-existentialpreempting-of-existential-unthought on-the-one-hand and preconverging-existentialextrication-as-of-existential-unthought circumventive/distractive-temporal-prioritisation-ofreference-of-thought on-the-other-hand, as so manifestable in varying psychologismic 
epistemic-acutisation difficulty-for, residualising \{decompulsing\} ${ }^{\text {delinearity for-cogency> }}$ magnitudes \{of-experientiality/experiment\} within the same human individual, collective individuals, institutions and society as to manifest/lack-of human limited-mentation-capacity-deepeningas-subjecting limitedness/human-subpotency-to-'educed-unlimitedness/existence-sublimating nascence' 3 as of transversality-<for-sublimating-existential-eventuating/denouement,-from-

\section{'thinking-at-first/pure-predisposition-preemptive-of-prospective-}

\section{disontologising/subontologising' as-of-prospectively-disambiguated-affirmed-and-}

unaffirmed-'motif-and-apriorising/axiomatising/referencing'> ${ }^{101}$ underlying the broad reality of both a human institutionalisation-threshold and a human uninstitutionalised-threshold ${ }^{102}$ in comprehensively reflecting the <cumulating/recomposuring attendant-ontologicalcontiguity $>$-successive registry-worldviews/dimensions as to the overall relativeunreflexivity/relative-reflexivity —ontological-contiguity ${ }^{67} \sim$ of-the-human-institutionalisationprocess ${ }^{6}$ ) with the further ontological-veracity herein that the-human/humanity can be defined at its barest as to transversality- $<$ for-sublimating-existential-eventuating/denouement-from'thinking at first/pure-predisposition-preemptive-of prospectivedisontologising/subontologising’ as-of-prospectively-disambiguated-affirmed-andunaffirmed-'motif-and-apriorising/axiomatising/referencing' $>^{101}$ as there is notionally no ontologically-coherent possibility for the-human/humanity otherwise; and the final element of the 'fundamental taboo against prospective ontologising-and-re-ontologising' lies in the very non-scalarity/beholdening-<as-to-what-has-gone-before-aesthetically-dementates/structures/paradigms-distortedly-the-possibility-for-the-later-ontologisation> of the ‘full incipient supererogating breadth of human intelligibility transmutation' underlying human aestheticisation-and-aestheticisation-towards-ontology-<elicited-idiomatisation $>$ (as to Beingdevelopment/ontological-framework-expansion-as-to-depth-of-ontologising-development-asinfrastructure-of- meaningfulness-and-teleology , institutional-development-as-to-social- 
function-development and living-development-as-to-personality-development psychologismic epistemic acutisation difficulty-for, residualising ${ }^{\{\text {decompulsing }\}}$ delinearity for-cogency> magnitudes ${ }^{\{0 f-e x p e r i e n t i a l i t y / e x p e r i m e n t\}}$ ) and so (with the implication that a central and potent force of human ontologising-and-re-ontologising so-reflected in the overall relativeunreflexivity/relative-reflexivity - ontological-contiguity ${ }^{67} \sim$ of-the-human-institutionalisationprocess ${ }^{68}$ rather lied historially with the possibility for human cultural diffusion given the human limited-mentation-capacity—as-subjecting 'educed-unlimitedness/existence-sublimating nascence' to-limitedness/human-subpotency problem of aestheticisation-beholdening-out-ofbechancing/taxingness-of-originariness) and this insight prospectively raises the issue as it is herein contended of the under-utilisation of human aestheticisation-and-aestheticisationtowards-ontology-<elicited-idiomatisation $>$ potential with regards to our modern-day presencing-absolutising-identitive-constitutedness social-vestedness/normativity$<$ discretely-implied-functionalism $>$ institutional and social $<$ preconverging 'motif-andapriorising/axiomatising/referencing'-entailing>-existentialising—enframing/imprintedness〈as-to- historicity-tracing-in-presencing-hyperrealisation/hyperreal-transposition〉, and we can further appreciate abstractly (as to the full possibilities of 'human-decisionality-<as-to-playof-valid/invalid-decisionality-imbued-sublimation/desublimation> omni-potential commensurability with inherent immanent-existence's sublimation-structure'/omnipotentiality) as herein contended that 'our very recurrent subconscious-level infused/imparted aestheticisation motifs' as to the possibilities for aestheticisation-and-aestheticisation-towards-ontology$<$ elicited-idiomatisation $>$ are even more radically beyond our passive or active contemplation of prospective re-originariness/re-origination as to our consciously developed human intelligibility and purposes imbued non-scalarity/beholdening-<as-to-what-has-gone-beforeaesthetically-de-mentates/structures/paradigms-distortedly-the-possibility-for-the-laterontologisation>. In-many-ways, this 'fundamental taboo against prospective ontologising-and- 
re-ontologising' is effectively just the human <amplituding/formative-epistemicity $>$ totalising thrownness-in-existence ${ }^{35}$ implications (given human limited-mentation-capacityas-subjecting 'educed-unlimitedness/existence-sublimating nascence' to-limitedness/humansubpotency requiring human limited-mentation-capacity-deepening-as-subjectinglimitedness/human-subpotency-to-'educed-unlimitedness/existence-sublimating nascence' for prospective sublimation), so-reflected as to human limited projective epistemic capacity (as to the "exercise of the epistemic - projective-equalisation of human station of ${ }^{79}$ presencingabsolutising-identitive-constitutedness ${ }^{14}$ as to prospective ${ }^{6}$ nonpresencing-<perspectiveontological-normalcy/postconvergence $>$ epistemic — projective-equalisation') for prospective sublimating-nascence poorly going all the way (as of prospectively dispensing-with-immediacyfor-relative-ontological-completeness ${ }^{87}$-by-reification/contemplative-distension ${ }^{27}$ for $\quad$ reontologising prospective Being-development/ontological-framework-expansion-as-to-depthof-ontologising-development-as-infrastructure-of- meaningfulness-and-teleology ) to the 'supereregatery $\sim$ wholesomeness/profound-supererogation ${ }^{\circ}$ as of prospective ${ }^{83}$ reference-ofthought — point-of-devolving/departure/anchoring/backdrop_of_sublimating-nascence-<as-tothe-grandest-axiomatic-construct- fepistemic-totalising ${ }_{3}^{\frac{1}{3}}$ re-apriorising/re-axiomatising/re-

refereneing-residuality - in-re-originariness/re-origination of limitedness/human-subpotency prospective re-encountering/re-confrontation with unlimitedness/existence>' rather as so-being comprehensively about prospective reference-of-thought postconverging-dementating/structuring/paradigming (with such a poor construal so-reflected with the relatively temporal precenverging-existential-extrication-as-of-existential-unthought human readiness relationship with prospective nascent-particular/incipient-and-material/technical-sublimations$<$ blinded-to-their-relative-ontological-completeness - reference-of-thought- devolving $>$ that is poorly appreciative of the accompanying 'supereregatory wholesomeness/profoundsupererogation as of prospective ${ }^{83}$ reference-of-thought—point-of- 
devolving/departure/anchoring/backdrop_of_sublimating-nascence-<as-to-the-grandestaxiomatic-construct-\{epistemic-totalising ${ }^{3}$ re-apriorising/re-axiomatising/re-

referencing residuality - in-re-originariness/re-origination of limitedness/human-subpotency prospective re-encountering/re-confrontation with unlimitedness/existence $>$ as to postconverging-nonextricatory-existential-preempting-of-existential-unthought'); and somanifested as to a human temporal implicited conception of knowledge poorly appreciative of the veracity of knowledge as effectively about notional $\sim$ philosophy-<as-to-the-veridicalconception-of-philosophy-as-englobing-all-human-prospective-organic-knowledge-generationin-relative-ontological-completeness ,-beyond-a-convenient-division-of-labour-conception-ofknowledge> 'supererogatory $\sim$ wholesomeness/profound-supererogation' as of prospective reference-of-thought—point-of-devolving/departure/anchoring/backdrop_of_sublimatingnascence-<as-to-the-grandest-axiomatic-construct-\{epistemic-totalising ${ }_{3}^{+}$re-apriorising/reaxiomatising/re-referencing $\sim$ residuality-in-re-originariness/re-origination limitedness/human-subpotency prospective re-encountering/re-confrontation with unlimitedness/existence>' (as to human Being-development/ontological-framework-expansionas-to-depth-of-ontologising-development-as-infrastructure-of- meaningfulness-andteleology ) and thus failing to reflect that the division-of-labour-conception-of-knowledge underlying nascent-particular/incipient-and-material/technical-sublimations- $<$ blinded-to-theirrelative-ontological-completeness - reference-of-thought- devolving> needs its 'appropriate fundamental perspective/framing/reference/horizon/projection of prospective ${ }^{56}$ meaningfulnessand-teleology ${ }^{9}$ ' to derive the 'supereregatery $w$ wholesomeness/profound-supererogation" as of prospective reference-of-thought-point-ofdevolving/departure/anchoring/backdrop_of_sublimating-nascence-<as-to-the-grandestaxiomatic-construct-\{epistemic-totalising ${ }_{3}^{+}$re-apriorising/re-axiomatising/rereferencing residuality - in-re-originariness/re-origination of limitedness/human-subpotency 
prospective re-encountering/re-confrontation with unlimitedness/existence $>$ as to postconverging-nonextricatory-existential-preempting-of-existential-unthought' (and so in reflection of the 'supereregatery $\sim$ wholesomeness/profound-supererogation conception of existence - as-the-absolute-a-priori-of-conceptualisation and existence-as-sublimatingwithdrawal/unenframing/re-ontologising,-elicited-from-prospective-profoundsupererogation -<as-to-perspective-ontological-normalcy/postconvergence-implied'prospective-aporeticism-overcoming/unovercoming'> inherent ontological coherence/contiguity' since existence in its 'superseding-oneness-of-ontology/ontologicalveridicality/relative-unreflexivity/relative-reflexivity - ontological-contiguity ${ }^{67}$ doesn't recognise the accompanying human desublimation arising from our convenient division-oflabour-conception-of-knowledge flawed/incomplete conception of sublimating-nascence as to a human readiness for precenverging-existential-extrication-as-of-existential-unthought and it is up to the human to fepistemicthermeneutically/textually/reprojectingly/supererogatingly/zeroingly/re-acutingly,decolinearity for-cogency contemplate and re-align such a 'practicality desublimating effect of convenient division-of-labour-conception-of-knowledge' to a 'suphesomens/profound-supererogation ${ }^{6}$ as of prospective ${ }^{83}$ reference-ofthought — point-of-devolving/departure/anchoring/backdrop_of_sublimating-nascence- $<$ as-tothe-grandest-axiomatic-construct-\{epistemic-totalising ${ }^{3}$ re-apriorising/re-axiomatising/rereferencing residuality - in-re-originariness/re-origination of limitedness/human-subpotency prospective re-encountering/re-confrontation with unlimitedness/existence>'). This human readiness for preconverging-existential-extrication-as-of-existential-unthought is effectively what is addressed by the notion of human 'epistemic-growth/disquiet/discomfort-/inducedsublimation,-as-from-existence's - effusing/ecstatic-inlining-as- historiality\{science/authenticity/nonextrication\}-beyond-mere-formulaicity/ritualisation-as- historicity- 
tracing-\{science-ideology/fashionability/distraction $\}\rangle$ as to construction-of-the-Self in dispensing-with-immediacy-for-relative-ontological-completeness ${ }^{87}$-byreification/contemplative-distension ${ }^{27}$. It can be appreciated in this regards as to a nonpresencing-<perspective-ontological-normalcy/postconvergence $>$ epistemic-projection

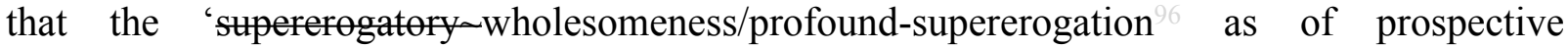
reference-of-thought_-point-of-devolving/departure/anchoring/backdrop_of_sublimating_nascence-<as-to-the-grandest-axiomatic-construct-\{epistemic-totalising $\frac{+}{3}$ re-apriorising/reaxiomatising/re-referencing residuality-in-re-originariness/re-origination of limitedness/human-subpotency prospective re-encountering/re-confrontation with unlimitedness/existence>' respectively of base-institutionalisation, universalisation and positivism imbued nascent-particular/incipient-and-material/technical-sublimations- $<$ blindedto-their-relative-ontological-completeness - reference-of-thought- devolving $>$ can only be poorly appreciated existentialisingly/contextualisingly/textualisingly respectively as of a recurrent-utter-uninstitutionalisation, ununiversalisation and non-positivism/medievalism desublimating $\quad$ reference-of-thought—-point-of-devolving/departure/anchoring/backdrop inveracity/impertinence; and likewise such a requisite 'supererogatory $\sim$ wholesomeness/profound-supererogation ${ }^{\circ}$ as of prospective ${ }^{83}$ reference-ofthought — point-of-devolving/departure/anchoring/backdrop_of_sublimating-nascence- $<$ as-tothe-grandest-axiomatic-construct-fepistemic talising ${ }^{+}$re-apriorising/re-axiomatising/rereferencing residuality -in-re-originariness/re-origination of limitedness/human-subpotency prospective re-encountering/re-confrontation with unlimitedness/existence>' insight can projectively be grasped when it comes to our positivism/rational-empiricism and prospective deprocrypticism-or-preempting-disjointedness-as-of- ${ }^{3}$ reference-of-thought. Critically thus, it is in the very nature of all ${ }^{7}$ presencing-absolutising-identitive-constitutedness ${ }^{14}$ socialvestedness/normativity-<discretely-implied-functionalism $>$ to falsely imply (beyond-the- 
consciousness-awareness-teleology ${ }^{9}-<$ of-preconverging-existential-extrication-as-of-

existential-unthought> ) to demarcate what can be of sublimating-nascence especially as soconstrued within the ambits of its 'mortal/temporal existentialising-frame-of-entailment-ofmotif-and-apriorising/axiomatising/referencing' readily enclosing prospective nascentparticular/incipient-and-material/technical-sublimations- $<$ blinded-to-their-relative-ontologicalcompleteness - reference-of-thought- devolving $>$ to then undermine their requisite prospectively implied 'supererogatory wholesomeness/profound-supererogation' as of prospective reference-of-thought-point-ofdevolving/departure/anchoring/backdrop_of_sublimating-nascence-<as-to-the-grandestaxiomatic-construct-\{epistemic-totalising ${ }_{3}^{+}$re-apriorising/re-axiomatising/rereferencing $\sim$ residuality - in-re-originariness/re-origination of limitedness/human-subpotency prospective re-encountering/re-confrontation with unlimitedness/existence>' (whereas this is exactly the enabler of 'human consciousness notional protensivity imbuing prospective psychologismic-epistemic-acutisation-<as-to-postconverging-dementating/structuring/paradigming,-eliciting-of-existence's-sublimating-nascence-inprospective-aporeticism-overcoming/unovercoming > as to epistemic-growth,-as\{veridieal/sound\} relative-reflexivity-in-existence/relativising from limited mentation as its deepening/psychologismic epistemic acutisation residualising, \{decompulsing\} delinearity foreogency' as undergirding the 'full experientiality/experiment-<as-to-existentially-formative‘fepistemic-alising ’re-apriorising/re-axiomatising/re-referencing $\sim$ residuality-in-reoriginariness/re-origination',—-so-'notionally/epistemically/bindingnessly-<as-todeterminism/conceptivity-of-relative-unreflexivity/relative-reflexivity>-implicited-and-articulated' as-fromnonextricatory-'prospective-re-ontologising-Being-then-Institutional-then-Living-magnitudesof-\{hermeneutic/reprojection-protraction-of \{reframing-and-reformulation $\}$ ' $>$ that is the human abstract-tissue-of-social-emanance' herein reflected as to the overall relative- 
unreflexivity/relative-reflexivity — ontological-contiguity ${ }^{67}$ of-the-human-institutionalisationprocess $^{68}$ of the <cumulating/recomposuring attendant-ontological-contiguity $>$-successive registry-worldviews/dimensions). Thus in-many-ways such 79 presencing-absolutisingidentitive-constitutedness ${ }^{14}$ social-vestedness/normativity- $<$ discretely-implied-functionalism $>$ adopt a pedantising/muddling/formulaic-hollowing-out—in-subontologisation/subpotentiation〈blurring/undermining-of-prospective-totalising-entailing,-as-to-entailing-

$<$ amplituding/formative-epistemicity $>$ totalising in-relative-ontological-completeness $>$

desublimation in overt or covert denial (as to mere-formulaicity/ritualisation-as- historicitytracing-\{science-ideology/fashionability/distraction $\}$ ) with respect to the ontological-veracity of 'human consciousness notional protensivity imbuing prospective psychologismic-epistemicacutisation-<as-to-postconverging-de-mentating/structuring/paradigming,-eliciting-ofexistence's-sublimating-nascence-in-prospective-aporeticism-overcoming/unovercoming $>$ as to epistemic-growth,-as - \{veridical/sound\}-relative-reflexivity-in-existence/relativising fromlimited-mentation-as-its-deepening/psychologismic epistemic-acutisation residualising, ${ }_{\{\text {decompulsing }}$ delinearity for-cogency\} (as of existence's-effusing/ecstatic-inlining-ashistoriality-\{science/authenticity/nonextrication $\})$ as so-reflected in the postmodern notional philosophy-<as-to-the-veridical-conception-of-philosophy-as-englobing-all-humanprospective-organic-knowledge-generation-in-relative-ontological-completeness ,-beyond-aconvenient-division-of-labour-conception-of-knowledge> contention of human perpetual rerationalisations for emancipation so-underlying prospective transcendence-andsublimity/sublimation/supererogatory de-mentativity (herein construed as to nonpresencing$<$ perspective-ontological-normalcy/postconvergence $>$ epistemic-projection implications of human limited-mentation-capacity-deepening —as-subjecting limitedness/human-subpotency to-'educed-unlimitedness/existence-sublimating nascence'53 implied conceptivity/epistemicreflexivity/epistemicity-relativism-determinism-<reifying \{as-to-knowledge-developing $\}$-and- 
empowering $>$ ); and so as to when it comes to the need for requisite prospective profoundsupererogation with regards to human prospective destructuring-threshold〈uninstitutionalised-threshold /presublimating-desublimating-decisionality $\rangle$ of-ontologicalperformance ${ }^{72}-<$ including-virtue-as-ontology $>$. 'human consciousness notional protensivity imbuing prospective psychologismic-epistemic-acutisation-<as-to-postconverging-dementating/structuring/paradigming,-eliciting-of-existence's-sublimating-nascence-inprospective-aporeticism-overcoming/unovercoming > as to epistemic-growth,-as\{veridical/sound\}-relative-reflexivity-in-existence/relativising from-limited-mentation-as-itsdeepening/psychologismic epistemic-acutisation residualising, ${ }^{\text {\{decompulsing }}$ delinearity foreogency' thus speaks to notional philosophy-<as-to-the-veridical-conception-of-philosophy-asenglobing-all-human-prospective-organic-knowledge-generation-in-relative-ontologicalcompleteness ,-beyond-a-convenient-division-of-labour-conception-of-knowledge $>$ inherent notional $\sim$ self-distantiation- $<$ imbued—re-motif-and-re-apriorising/re-axiomatising/rereferencing > with regards to human aestheticisation-and-aestheticisation-towards-ontology$<$ elicited-idiomatisation $>$ in so-reflecting sublimating ${ }^{83}$ reference-of-thought translative appraisal of prospective nascent-particular/incipient-and-material/technical-sublimations$<$ blinded-to-their-relative-ontological-completeness - reference-of-thought- devolving >; speaking to the requisite 'human psychologismic-epistemic-acutisation-<as-to-postconvergingde-mentating/structuring/paradigming,-eliciting-of-existence's-sublimating-nascence-inprospective-aporeticism-overcoming/unovercoming $>$ as to epistemic-growth,-as\{veridical/sound\}-relative-reflexivity-in-existence/relativising from-limited-mentation-as-itsdeepening/psychologismic epistemic acutisation residualising, fdecompulsing\} delinearity for eogency' (as to originariness-parrhesia,-as-spontaneity-of-aestheticisationsupererøgatøry acuity/perspicacity/astuteness/edginess/incisiveness 'projection of aestheticising-re-margining/re-edging/re-acuity—as- 
postconverging_circumscriptive/totalitative-restructuring' as of overall existential<disentelogising/re-ontologising aporeticism $>$ dimensionality-of-sublimating 〈<amplituding/formative>supererogatory $\sim$ de-mentativeness/epistemic-growth-orconflatedness /transvaluative-rationalising/transepistemicity/anamnestic-residuality/spiritdrivenness-equalisation $\rangle \quad$ in $\quad$ transversality- $<$ for-sublimating-existentialeventuating/denouement,-from-'thinking at-first/pure-predisposition-preemptive-ofprospective-disontologising/subontologising' as-of-prospectively-disambiguated-affirmedand-unaffirmed-'motif-and-apriorising/axiomatising/referencing' $>101$ enabling the relativeunreflexivity/relative-reflexivity - ontological-contiguity ${ }^{67}$ of-the-human-institutionalisationprocess ${ }^{6}$ ), with this requisite 'human psychologismic-epistemic-acutisation-<as-topostconverging-de-mentating/structuring/paradigming,-eliciting-of-existence's-sublimatingnascence-in-prospective-aporeticism-overcoming/unovercoming $>$ as to epistemic-growth,-as\{veridical/sound\}-relative-reflexivity-in-existence/relativising from-limited-mentation-as-itsdeepening/psychologismic epistemic acutisation residualising, ${ }^{\text {fdecompulsing }}$ delinearity for eөgeney' (underlied by a supereregatory $\sim$ wholesomeness/profound-supererogation of notional citationality as to a 'connoting supererogation-drivenness construal of the epistemictotality ${ }^{37}$ of human-textuality-<as-to-existentialising/contextualising/textualising $>$ in epistemictotalising $\sim$ resubjecting_or_totalising-entailing $\sim$ reconstrual- $<$ of the-whole/purview 0 - thewhole/oneness-of-ontelogy>') $\quad$ so-rather devolving from 'supereregatery $\sim$ wholesomeness/profound-supererogation as of prospective ${ }^{83}$ reference-ofthought_-point-of-devolving/departure/anchoring/backdrop_of_sublimating-nascence-<as-tothe-grandest-axiomatic-construct-\{epistemic-totalising ${ }^{\prime}$ re-apriorising/re-axiomatising/rereferencing residuality - in-re-originariness/re-origination of limitedness/human-subpotency prospective re-encountering/re-confrontation with unlimitedness/existence>' (even as the reality of human limited-mentation-capacity—as-subjecting-'educed-unlimitedness/existence- 
sublimating nascence' to-limitedness/human-subpotency distortively means that the 'incipient precedence of nascent-particular/incipient-and-material/technical-sublimations- $<$ blinded-totheir-relative-ontological-completeness - reference-of-thought- devolving $>$ is bound to be wrongly construed as projecting of its very own incipient supereregatory wholesomeness/profound-supererogation ' whereas in so-doing is actually distortively reflecting the 'prior relative-ontological-incompleteness ${ }^{8}{ }^{83}$ reference-of-thoughtdevolving' while failing to appreciate the veracity that the veridical supereregatery wholesomeness/profound-supererogation ${ }^{6}$ of such nascent-particular/incipientand-material/technical-sublimations- $<$ blinded-to-their-relative-ontological-completeness reference-of-thought- devolving $>$ should rather devolve from the 'supererogatory $\sim$ wholesomeness/profound-supererogation as of prospective relativeontological-completeness ${ }^{87}-{ }^{83}$ reference-of-thought- ${ }^{8}$ devolving point-ofdevolving/departure/anchoring/backdrop of sublimating-nascence'). Thus 'human psychologismic-epistemic-acutisation-<as-to-postconverging-dementating/structuring/paradigming,-eliciting-of-existence's-sublimating-nascence-inprospective-aporeticism-overcoming/unovercoming $>$ as to epistemic-growth,-as\{veridieal/sound\}-relative-reflexivity-in-existence/relativising from limited mentation as its deepening/psychologismic epistemic acutisation residualising, \{decompulsing\} delinearity foreogency' (implied supereregatory wholesomeness/profound-supererogation of notional citationality) as it prospectively reflects-and-divulges in re-originariness/re-origination existence's_-effusing/ecstatic-inlining-as- historiality-\{science/authenticity/nonextrication\} is effectively what allows for the profundity of the human 'exercise of the epistemic — projectiveequalisation of human station of ${ }^{79}$ presencing-absolutising-identitive-constitutedness ${ }^{14}$ as to prospective $\quad$ nonpresencing-<perspective-ontological-normalcy/postconvergence $>$ epistemic - projective-equalisation' for prospective sublimating-nascence (as of prospectively 
dispensing-with-immediacy-for-relative-ontological-completeness ${ }^{87}$-by-

reification/contemplative-distension ${ }^{27}$ for re-ontologising prospective Beingdevelopment/ontological-framework-expansion-as-to-depth-of-ontologising-development-asinfrastructure-of- meaningfulness-and-teleology ); and in so-doing addressing the 'fundamental taboo against prospective ontologising-and-re-ontologising' (underlying any human registry-worldviews/dimensions 'social-functioning-and-accordance-as-of-socialstake-contention-or-confliction imbuing existentialising-frame-of-entailment-of motif-andapriorising/axiomatising/referencing of disontologising/ontologising-and-re-ontologising' uninstitutionalised-threshold ${ }^{102}$ ). In-many-ways such an exercise (and as it is sublimatingly somanifested with regards to the overall human momentous ${ }^{4}$ historiality/ontologicaleventfulness 38 ontological-aesthetic-tracing-<perspective-ontological-

normalcy/postconvergence-reflected-'epistemicity-relativism-determinism'> of the relativeunreflexivity/relative-reflexivity — ontological-contiguity ${ }^{67}$ of-the-human-institutionalisationprocess ${ }^{68}$ ) speaks of the translative-accordance of prospective nascent-particular/incipient-andmaterial/technical-sublimations-<blinded-to-their-relative-ontological-completeness

reference-of-thought- devolving $>$ implications (as to their incipient/seeding existentialisingframe-of entailment of motif and apriorising/axiomatising/refeneing of the 'shallowsupererogation as of prior $\quad{ }^{83}$ reference-of-thought-point-ofdevolving/departure/anchoring/backdrop_of_sublimating-nascence-<as-to-the-grandestaxiomatic-construct- Tepistemictalising ${ }^{+}$re-apriorising/re-axiomatising/rereferencing - residuality - in-re-originariness/re-origination of limitedness/human-subpotency prospective re-encountering/re-confrontation with unlimitedness/existence>' of human $<$ amplitung/formative-epistemicity $>$-totalising $\sim$ thrownness-in-existence in psychologismic apriorising/axiomatising/referencing-\{of-"prospectivelyimplicited_attendant-ontological-contiguity ' educed- 
existentialising/contextualising/textualising_'intelligibility/epistemicity/reflexivity-contiguity$<$ imbued-notional cogency $\left.>^{\prime} \quad\right\}$-constitutedness ${ }^{14}$-in-preconverging-entailment) into their true 'supereregatery $\sim$ wholesomeness/profound-supererogation ${ }^{6}$ as of prospective ${ }^{83}$ referenceof-thought_-point-of-devolving/departure/anchoring/backdrop_of_sublimating-nascence-<asto-the-grandest-axiomatic-construct-\{epistemic-totalising ${ }^{\text {t̀ }}$ re-apriorising/re-axiomatising/rereferencing -residuality - in-re-originariness/re-origination of limitedness/human-subpotency prospective re-encountering/re-confrontation with unlimitedness/existence $>$ imbued psychologismic apriorising/axiomatising/referencing-\{of-"prospectively implicited_attendant-ontological-contiguity ' educedexistentialising/contextualising/textualising_'intelligibility/epistemicity/reflexivity-contiguity<imbued-notional cogency >' $\}$ - conflatedness ${ }^{13}$-in-\{preconverging-ment by \} $^{\prime}$ postconverging-ntailment' (so-reflected as to the overarching human social-and-institutionalframeworks-of_-referencing/registering/decisioning sublimating existentialisingdecisionality-<as-to-disontologising/re-ontologising aporeticism $>$ ); and so given the reality that it is human social-and-institutional-frameworks-of-referencing/registering/decisioning existentialising-decisionality-<as-to-disontologising/re-ontologising aporeticism $>\quad$ that 'incipiently/seedingly translate (either in shallow-supererogation ${ }^{96}$ as to their prior ${ }^{83}$ referenceof-thought—point-of-devolving/departure/anchoring/backdrop supererogatory - wholesomeness/profound-supererogation ${ }^{96}$ as to their prospective ${ }^{83}$ referenceof-thought — point-of-devolving/departure/anchoring/backdrop)' the social and institutional implications of prospective nascent-particular/incipient-and-material/technical-sublimations$<$ blinded-to-their-relative-ontological-completeness - reference-of-thought- devolving $>$ and so-reflected respectively as of 'prospectively desublimating institutional and social pedantising/muddling/formulaic-hollowing-out — in-subontologisation/subpotentiation〈blurring/undermining-of-prospective-totalising-entailing,-as-to-entailing- 
prior 'human aestheticisation-and-aestheticisation-towards-ontology-<elicited-idiomatisation $>$ beholdening, non-transcendence, complexification as to mechanical-knowledge and non-ment of prior apriorising/axiomatising/referencing')' or 'prospectively sublimating institutional and social notional $\sim$ philosophy-<as-to-the-veridical-conception-of-philosophy-as-englobing-allhuman-prospective-organic-knowledge-generation-in-relative-ontological-completeness

beyond-a-convenient-division-of-labour-conception-of-knowledge> (in prospective 'human aestheticisation-and-aestheticisation-towards-ontology-<elicited-idiomatisation $>$ unbeholdening, transcendence, decomplexification for organic-knowledge and ment of prior apriorising/axiomatising/referencing')'. This is so-reflected for instance with the insight that the 'enlightenment struggle against feudalism and slavery as advocated say with such a thinker like Rousseau' as to the fact that the technical and scientific progress as to relative-ontologicalcompleteness 87 weren't the occasion to put such technical and scientific progress like shipbuilding and other ocean voyage technologies at the service of the prior medievally clouded immaterial/social overall relative-ontological-incompleteness ${ }^{88}$-presublimation-construct-ofmeaningfulness-and-teleology $\quad$ value-construct and shallow-supererogating methodologising/mutualising/organising/institutionalising $<$ preconverging 'motif-andapriorising/axiomatising/referencing'-entailing >-existentialising-enframing/imprintedness〈as-to- historicity-tracing - in-presencing-hyperrealisation/hyperreal-transposition〉, but rather called for a renewed conceptualisation of humanity beyond a mentality of immediate subsistence/survival/advantage. Critically, 'human psychologismic-epistemic-acutisation-<asto-postconverging-de-mentating/structuring/paradigming,-eliciting-of-existence's-sublimatingnascence-in-prospective-aporeticism-overcoming/unovercoming $>$ as to epistemic-growth,-as\{veridical/sound\}-relative-reflexivity-in-existence/relativising from-limited-mentation-as-itsdeepening/psychologismic epistemic-acutisation residualising, decompulsingl delinearity for 
eogency' (implied supererogatory $\sim$ wholesomeness/profound-supererogation

notional citationality) notionally speaks to the veracity of a translative-accordance between nascent-particular/incipient-and-material/technical-sublimations- $<$ blinded-to-their-relativeontological-completeness - reference-of-thought- devolving $>$ and social-and-institutionalframeworks-of — referencing/registering/decisioning existentialising-decisionality-<as-todisontologising/re-ontologising aporeticism $>$ (so-notionally reflected as of 'supereregatery $\sim$ wholesomeness/profound-supererogation as of prospective ${ }^{83}$ reference-ofthought - point-of-devolving/departure/anchoring/backdrop for social-and-institutionalframeworks-of — referencing/registering/decisioning sublimating existentialisingdecisionality-<as-to-disontologising/re-ontelogising aporeticism>' or 'shallowsupererogation of prior $\quad{ }^{83}$ reference-of-thought - point-ofdevolving/departure/anchoring/backdrop of social-and-institutional-frameworks-ofreferencing/registering/decisioning desublimating existentialising-decisionality-<as-todisontologising/re-ontologising aporeticism ${ }^{\prime}$ ) and so with respect to the effective human 'exercise of the epistemic - projective-equalisation of human station of ${ }^{79}$ presencingabsolutising-identitive-constitutedness ${ }^{14}$ as to prospective ${ }^{6}$ nonpresencing- $<$ perspectiveontological-normalcy/postconvergence $>$ epistemic-projective-equalisation'. Thus 'human psychologismic-epistemic-acutisation-<as-to-postconverging-de-

mentating/structuring/paradigming,-eliciting-of-existence's-sublimating-nascence-inprospective-aporeticism-overcoming/unovercoming > as to epistemic-growth,-as\{veridical/sound\}-relative-reflexivity-in-existence/relativising from-limited-mentation-as-itsdeepening/psychologismic epistemic-acutisation residualising, $\left.{ }^{\{d e c o m p u l s i n g}\right\}$ delinearity foreogeney' thus notionally delineates the manifest possibility for human ontologicalperformance ${ }^{72}-<$ including-virtue-as-ontology $>$ /morality/ethics/justice/etc. (with regards to 'prospective human postconverging aporeticism-overcoming/unovercoming existentialising- 
frame-of-entailment-of-motif-and-apriorising/axiomatising/referencing of sublimation or existentialising-frame-of-entailment-of-motif-and-apriorising/axiomatising/referencing of desublimation'); and precisely-so rather as of the existentialising/contextualising/textualising dynamic of prospective human postconverging aporeticism-overcoming/unovercoming fundamentally underlied correspondingly by either supereregatery $\sim$ wholesomeness/profoundsupererogation $^{96}$ or shallow-supererogation ${ }^{96}$ in relation to human prospective destructuringthreshold-〈uninstitutionalised-threshold /presublimating-desublimating-decisionality $\rangle$ ofontological-performance $^{72}$-<including-virtue-as-ontology $>/$ morality/ethics/justice/etc. for prospective transcendence-and-sublimity/sublimation/supererogatery $\sim$ de-mentativity’ (and soconstrued as beyond-and-different from an issue of human ontological-performance ${ }^{72}$ $<$ including-virtue-as-ontology $>$ /morality/ethics/justice/etc. rather reflecting the 'existentialising-frame-of-entailment-of motif-and-apriorising/axiomatising/referencing of priorly secondnatured institutionalisation-threshold of mere-formulaicity/ritualisation-<as-tomere-formulaic — methodologising/mutualising/organising/institutionalising,-prospectively-

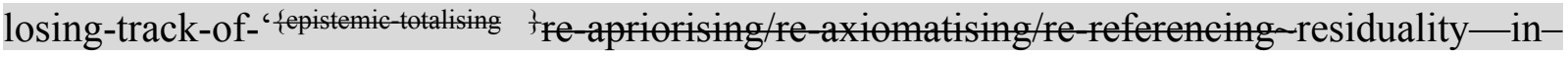
re-originariness/re-origination'> positive-opportunism—of-social-functioning-andaccordance $^{75}$ as not speaking to prospective human disruptive postconverging-apereticismevercoming/mnovercoming'). In this regards, it can be appreciated that the existentialising/contextualising/textualising dynamic of prospective human postconverging aporeticism-overcoming/unovercoming (when it comes to re-ontologising prospective Being-development/ontological-framework-expansion-as-to-depth-ofontologising-development-as-infrastructure-of- meaningfulness-and-teleology ) speaks to 'human psychologismic-epistemic-acutisation-<as-to-postconverging-dementating/structuring/paradigming,-eliciting-of-existence's-sublimating-nascence-inprospective-aporeticism-overcoming/unovercoming > as to epistemic-growth,-as- 

notional citationality) as effectively allowing for the 'exercise of the epistemic - projectiveequalisation of human station of ${ }^{7}$ presencing - absolutising-identitive-constitutedness ${ }^{14}$ as to prospective $\quad$ nonpresencing- $<$ perspective-ontological-normalcy/postconvergence $>$ epistemic_-projective-equalisation' of sublimating human ontological-performance ${ }^{72}$ $<$ including-virtue-as-ontology $>/$ morality/ethics/justice/etc. for prospective transcendence-andsublimity/sublimation/supererogatory $\sim$ de-mentativity; wherein out of supererogatory wholesomeness/profound-supererogation the respective ${ }^{83}$ reference-ofthought (mental-states) of prior recurrent-utter-uninstitutionalisation, ununiversalisation, nonpositivism/medievalism and ${ }^{8}$ procrypticism-or-disjointedness-as-of- ${ }^{8}$ reference-of-thought in their psychoanalytic-unshackling/memetic-reordering/institutional-recomposuring self-

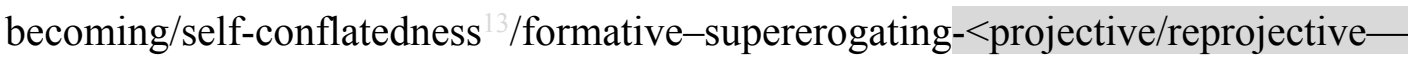
aestheticising-re-motif-and-re-apriorising/re-axiomatising/re-referencing,-in-perspectiveontological-normalcy/postconvergence> come to terms respectively with the ${ }^{83}$ reference-ofthought (mental-states) of prospective base-institutionalisation, ${ }^{103}$ universalisation, positivism/rational-empiricism and deprocrypticism-or-preempting-disjointedness-as-ofreference-of-thought as so-speaking to prospective human disruptive postconverging aporeticism-overcoming/mnovercoming for prospective transcendence-andsublimity/sublimation/supererogatory de-mentativity (and so-construed as beyond-anddifferent from prior recurrent-utter-uninstitutionalisation, ununiversalisation, nonpositivism/medievalism and ${ }^{80}$ procrypticism-or-disjointedness-as-of- ${ }^{3}$ reference-of-thought respectively inherent ${ }^{83}$ reference-of-thought issue of human ontological-performance ${ }^{72}$ $<$ including-virtue-as-ontology $>/$ morality/ethics/justice/etc. reflecting their 'existentialising- 
frame-of-entailment-of motif-and-apriorising/axiomatising/referencing

of

priorly

secondnatured institutionalisation-threshold of mere-formulaicity/ritualisation-<as-to-mereformulaic - methodologising/mutualising/organising/institutionalising,-prospectively-losing-

track-of-'\{epistemic-totalising ’re-apriorising/re-axiomatising/re-referencing-residuality-in-re-

originariness/re-origination'> positive-opportunism—of-social-functioning-and-accordance

as not speaking to prospective human disruptive postconverging-aporeticismovercoming/unovercoming'). The existentialising/contextualising/textualising dynamic of prospective human postconverging aporeticism-overcoming/unovercoming requiring 'human psychologismic-epistemic-acutisation-<as-to-postconverging-de-

mentating/structuring/paradigming,-eliciting-of-existence's-sublimating-nascence-inprospective-aporeticism-overcoming/unovercoming $>$ as to epistemic-growth,-as\{veridical/sound\}-relative-reflexivity-in-existence/relativising from-limited-mentation-as-itsdeepening/psychologismic epistemic-acutisation residualising, ${ }^{\text {fdecompulsing }}$ delinearity foreogency' equally conceptualises human ontological-performance ${ }^{72}-$ including-virtue-as- $^{-}$ ontology $>/$ morality/ethics/justice/etc. notionally

as to supererogatory-wholesomeness/profound-supererogation ${ }^{96}$ shallow-supererogation with respect to human institutional-development-as-to-social-function-development and livingdevelopment-as-to-personality-development psychologismic epistemic acutisationdifficulty < for, residualising_\{decompulsing $\}$ delinearity for-cogeney> magnitudes $\{$ ofexperientiality/experiment\} prospective destructuring-threshold-〈uninstitutionalisedthreshold /presublimating-desublimating-decisionality $>$ of-ontological-performance ${ }^{72}$ $<$ including-virtue-as-ontology $>/$ morality/ethics/justice/etc. for prospective transcendence-andsublimity/sublimation/supererogatory-de-mentativity (and so equally beyond-and-different from an issue of human ontological-performance ${ }^{72}-$ including-virtue-as- $^{-}$ ontology $>$ /morality/ethics/justice/etc. reflecting the 'existentialising-frame-of-entailment-of- 
motif-and-apriorising/axiomatising/referencing of priorly secondnatured institutionalisationthreshold

of mere-formulaicity/ritualisation-<as-to-mere-formulaicmethodologising/mutualising/organising/institutionalising,-prospectively-losing-track-of'\{epistemic-totalising '⿳亠丷厂犬 re-apriorising/re-axiomatising/re-referencing residuality-in-reoriginariness/re-origination'> positive-opportunism—of-social-functioning-and-accordance as not speaking to prospective human disruptive postconverging-aporeticismovercoming/unovercoming'). The fundamental point being made here is that the ordinary reality of a human conception of ontological-performance ${ }^{72}-$ including-virtue-as- $^{-}$ ontology $>$ /morality/ethics/justice/etc. is much more fundamentally beholdening to an 'issue of human ontological-performance ${ }^{72}-<$ including-virtue-as-ontology $>/$ morality/ethics/justice/etc. reflecting the 'existentialising-frame-of-entailment-of-motif-andapriorising/axiomatising/referencing of priorly secondnatured institutionalisation-threshold of mere-formulaicity/ritualisation-<as-to-mere-formulaicmethodologising/mutualising/organising/institutionalising,-prospectively-losing-track-of‘fepistemic-atising ’’re-apriorising/re-axiomatising/re-referencing $\sim$ residuality-in-reoriginariness/re-origination'> positive-opportunism—of-social-functioning-and-accordance as not speaking to prospective human disruptive postconverging-aporeticismevercoming/unovercoming' in reflection of 'human lifespan extricatory punctuality/immediacy of depth-of-thought' (and particularly so ontologically-deficient when it comes to reontologising prospective Being-development/ontological-framework-expansion-as-to-depthof-ontologising-development-as-infrastructure-of- meaningfulness-and-teleology as to the requisite pestcenverging-nonextricatory-existential-preempting-of-existential-unthought contemplating underlying the <cumulating/recomposuring attendant-ontologicalcontiguity >-successive registry-worldviews/dimensions); with the veracity of the existentialising/contextualising/textualising dynamic of prospective human 
postconverging aporeticism-overcoming/unovereoming requiring 'human psychologismic-epistemic-acutisation-<as-to-postconverging-de-mentating/structuring/paradigming,-elicitingof-existence's-sublimating-nascence-in-prospective-aporeticism-overcoming/unovercoming> as to epistemic-growth,-as-\{veridical/sound\}-relative-reflexivity-in-existence/relativising from-limited-mentation-as-its-deepening/psychologismic epistemic-acutisationresidualising, ${ }^{\text {\{decompulsing }}$ delinearity for-cogency' involving intemporal 'projection of aestheticising-re-margining/re-edging/re-acuity—as-

postconverging_circumscriptive/totalitative-restructuring' as to prospective

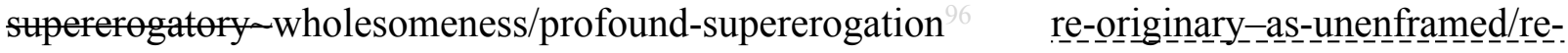
ontologising/unbeholdening/outlier-conceptualisation__imbued-postconverging/dialecticalthinking -'projective-insights'/‘epistemic-projection-in-conflatedness ' 'ofnotional deprocrypticism-prospective-sublimation) (as prospectively eliciting human ontological-performance ${ }^{72}-<$ including-virtue-as-ontology $>/$ morality/ethics/justice/etc. in sosuperseding/transcending the 'existentialising-frame-of-entailment-of-motif-andapriorising/axiomatising/referencing of priorly secondnatured institutionalisation-threshold of mere-formulaicity/ritualisation-<as-to-mere-formulaicmethodologising/mutualising/organising/institutionalising,-prospectively-losing-track-of‘fepistemic tolising †ेre-apriorising/re-axiomatising/re-referencing residuality-in-reoriginariness/re-origination'> positive-opportunism—of-social-functioning-and-accordance as not speaking to prospective human disruptive postconverging-apereticismovercoming/unovercoming'). Thus the blunt fact of the matter explaining the in-effect absolution-<as-to-apriorising/axiomatising/referencing-\{of-`prospectively implicited_attendant-ontological-contiguity ' educedexistentialising/contextualising/textualising_ intelligibility/epistemicity/reflexivity-contiguity<imbued-notional cogency >' $\}$-constitutedness -in preconverging-entailment $>$ 
ontologically-flawed manifestations of registry-worldviews/dimensions as to their relativeontological-incompleteness $^{8}$ is that human ontological-performance ${ }^{72}-$ including-virtue-as- $^{2}$ ontology $>$ /morality/ethics/justice/etc. reflecting their 'existentialising-frame-of-entailment-ofmotif-and-apriorising/axiomatising/referencing of priorly secondnatured institutionalisationthreshold of mere-formulaicity/ritualisation-<as-to-mere-formulaic methodologising/mutualising/organising/institutionalising,-prospectively-losing-track-of‘\{epistemic-totalising ’’re-apriorising/re-axiomatising/re-referencing residuality-in-reoriginariness/re-origination'> positive-opportunism—of-social-functioning-and-accordance as not speaking to prospective human disruptive postconverging aporeticismovercoming/unovercoming' turn out to be rather ineffectual when it comes to the existentialising/contextualising/textualising dynamic of prospective human postconverging aporeticism-overcoming/unovercoming as rather requiring 'human psychologismic-epistemic-acutisation-<as-to-postconverging-de-

mentating/structuring/paradigming,-eliciting-of-existence's-sublimating-nascence-inprospective-aporeticism-overcoming/unovercoming $>$ as to epistemic-growth,-as\{veridical/sound\}-relative-reflexivity-in-existence/relativising from-limited-mentation-as-itsdeepening/psychologismic epistemic acutisation residualising, decompulsing $_{\text {f }}$ delinearity for eogency' (particularly so with regards to re-ontologising prospective Beingdevelopment/ontological-framework-expansion-as-to-depth-of-ontologising-development-asinfrastructure-of- meaningfulness-and-teleology ); and so-telling by registryworldviews/dimensions beyond-the-consciousness-awareness-teleology ${ }^{9}<$ <f-preconvergingexistential-extrication-as-of-existential-unthought> imbued 'human lifespan extricatory punctuality/immediacy of depth-of-thought' and poor angling-of-imaginary implied 'multicenturies-long human crossgenerational Being-development/ontological-frameworkexpansion-as-to-depth-of-ontologising-development-as-infrastructure-of- meaningfulness- 
\{decompulsing delinearity for-cogency> magnitude\{of-experientiality/experiment\} of prospective transcendence-and-sublimity/sublimation/supereregatory $\sim$ de-mentativity' epistemic-projection. But then if existence is effectively of manifest relative-unreflexivity/relative-reflexivityontological-contiguity ${ }^{67}$ it can only be an 'epistemic falsehood' (the fundamental 'epistemic falsehood' arising from human <amplituding/formative-epistemicity>-totalising $\sim$ thrownnessin-existence ${ }^{35}$ ) to epistemically imply 'implicited_attendant-ontological-contiguity ${ }^{67}$; educedexistentialising/contextmalising/textmalising_intelligibility/epistemicity/reflexivity_contiguity$<$ imbued-notional cogency $>^{\prime}$ veracity can be reflected/construed without implying postconverging-nonextricatory-existential-preempting-of-existential-unthought (and as so-tied to the existentialising/contextualising/textualising relative-unreflexivity/relative-reflexivity ontological-contiguity dynamic of prospective human postconverging-aporeticismovercoming/mnovercoming requiring 'human psychologismic-epistemic-acutisation-<as-topostconverging-de-mentating/structuring/paradigming,-eliciting-of-existence's-sublimatingnascence-in-prospective-aporeticism-overcoming/unovercoming > as to epistemic-growth,-as\{veridical/sound\}-relative-reflexivity-in-existence/relativising from-limited-mentation-as-itsdeepening/psychologismic epistemic acutisation residualising, ${ }^{\text {\{decompulsing }}$ \}elinearity for eogency' so-associated with angling-of-imaginary) more like an animistic or medieval nonpositivising social-setup as to the constraints of its <amplituding/formative-epistemicity $>$ totalising thrownness-in-existence ${ }^{35}$ going on to conceptualise of a positivising/rationalempiricism social-setup as to imply the 'positivising/rational-empiricism knowledgereification $\sim$ gesturing-and-accounting-of-epistemic-phenomenalism- $<$ inprospective_psychologismic apriorising/axiomatising/referencing-\{of-'prospectively implicited_attendant-ontological-contiguity ' reducedexistentialising/contextualising/textualising_intelligibility/epistemicity/reflexivity_contiguity- 
postconverging entailment $>$ as to knowledge value' is somehow strictly not necessary as the enabler of the positivising/rational-empiricism social-setup. Since the very manifest failing in the human 'exercise of the epistemic-projective-equalisation of human station of presencing-absolutising-identitive-constitutedness ${ }^{14}$ (as to requisite prospective nonpresencing-<perspective-ontological-normalcy/postconvergence $>$ epistemic-projectiveequalisation' for prospective sublimating-nascence) is always 'defined-by and tied-to human preconverging-existential-extrication-as-of-existential-unthought that breaks with prospective notional-contiguity/epistemic-contiguity ${ }^{2}$ - profound-supererogation -of-mentallyaestheticised postconverging/dialectical-thinking -qualia-schema $>$ as to temporal/mortal advantageousness and purposefulness'; as so-reflecting human fundamental 'epistemic falsehood' prospectively imbuing of preconverging-existential-extrication-as-of-existentialunthought manifest <amplituding/formative> wooden-language-_imbued-temporal-mereform/virtualities/dereification/akrasiatic-drag/denatured/preconverging-or-dementing narratives - of-the- reference-of-thought- categorical-imperatives/axioms/registryteleology \. In-many-ways 'human psychologismic-epistemic-acutisation-<as-topostconverging-de-mentating/structuring/paradigming,-eliciting-of-existence's-sublimatingnascence-in-prospective-aporeticism-overcoming/unovercoming > as to epistemic-growth,-as\{veridical/sound\}-relative-reflexivity-in-existence/relativising from-limited-mentation-as-itsdeepening/psychologismic epistemic-acutisation residualising, ${ }^{\text {fdecompulsing }}$ delinearity for eogency' notional delineating of the manifest possibility for human ontological-performance ${ }^{72}$ $<$ including-virtue-as-ontology $>/$ morality/ethics/justice/etc. for prospective transcendence-andsublimity/sublimation/supererogatory-de-mentativity (with regards to 'prospective human postconverging aporeticism-overcoming/unovercoming existentialising-frame-of-entailmentof motif-and-apriorising/axiomatising/referencing of sublimation or existentialising-frame-of- 
entailment of motif-and-apriorising/axiomatising/referencing of desublimation') is reflected in the fact that the <cumulating/recomposuring attendant-ontological-contiguity $>$-successive registry-worldviews/dimensions of the relative-unreflexivity/relative-reflexivity-ontologicalcontiguity ${ }^{67}$ of-the-human-institutionalisation-process ${ }^{68}$ rather speaks to their 'preconverging/postconverging-de-mentating/structuring/paradigming notional preconverging-existential-extrication-as-of-existential-unthought-bypestconverging-nonextricatory-existential-preempting-of-existential-unthought enabling their given human institutional-development-as-to-social-function-development and livingdevelopment-as-to-personality-development psychologismic epistemic acutisationdifficulty $<$ for, residualising_\{decompulsing $\}$ delinearity for-cogency> magnitudes $\{$ \{fexperientiality/experiment ontological-performance ${ }^{72}-<$ including-virtue-asontology $>$ /morality/ethics/justice/etc. for prospective transcendence-andsublimity/sublimation/supererogatory $\sim$ de-mentativity'; so-reflected with their accompanying notional $\sim$ shiftiness-of-the-Self/construction-of-the-Self as to recurrent-utteruninstitutionalisation 'non-rules—apriorising/axiomatising/referencing-psychologism notional $\sim$ shiftiness-of-the-Self/construction-of-the-Self', $\quad$ base-institutionalisationununiversalisation 'rulemaking-over-non-rules - apriorising/axiomatising/referencingpsychologism notional shiftiness-of-the-Self/construction-of-the-Self', ${ }^{103}$ universalisationnon-positivism/medievalism $\quad$ ' ${ }^{103}$ universalisation-directed-rulemaking-over-non-rulesapriorising/axiomatising/referencing-psychologism notional $\sim$ shiftiness-of-theSelf/construction-of-the-Self', positivism- ${ }^{8}$ procrypticism 'positivising/rational-empiricismbased-universalisation-directed-rulemaking-over-non-rules-

apriorising/axiomatising/referencing-psychologism notional $\sim$ shiftiness-of-theSelf/construction-of-the-Self' and 'deprocrypticism-or-preempting-disjointedness-as-ofreference-of-thought,-as-to- ${ }^{6}<$ amplituding/formative-epistemicity>growth-or- 
conflatedness ${ }^{13}$ /transvaluative-rationalising/transepistemicity/anamnestic-residuality/spiritdrivenness' - in-superseding-mere-formulaic-positivising/rational-empiricism-baseduniversalisation-directed-rulemaking-over-non-rules_ apriorising/axiomatising/referencingpsychologism notional $\sim$ shiftiness-of-the-Self/construction-of-the-Self $\quad$ (so-collectively construable/accountable as to the relative-unreflexivity/relative-reflexivity-ontologicalcontiguity ${ }^{67}$ of-the-human-institutionalisation-process ${ }^{68}$ only as of the manifest 'notional ' deprocrypticism 'supereregatery $\sim$ wholesomeness/profound-supererogation' prospective reference-of-thought-point-ofdevolving/departure/anchoring/backdrop_of_sublimating-nascence-<as-to-the-grandestaxiomatic-construct-\{epistemic-totalising ${ }_{3}^{+}$re-apriorising/re-axiomatising/rereferencing $\sim$ residuality - in-re-originariness/re-origination of limitedness/human-subpotency prospective re-encountering/re-confrontation with unlimitedness/existence $>$ imbued psychologismic apriorising/axiomatising/referencing-\{of-"prospectively implicited_attendant-ontological-contiguity ' educedexistentialising/contextualising/textualising_'intelligibility/epistemicity/reflexivity_contiguity$<$ imbued-notional cogency $\left.>^{\prime}\right\}$-conflatedness ${ }^{13}$-in-\{preconverging-ment by\}

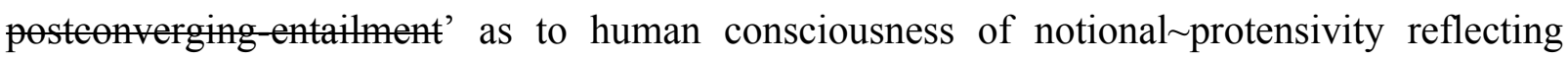
human dimensionality-of-sublimating $25<<$ amplituding/formative $>$ supererogatory $\sim$ dementativeness/epistemic-growth-or-conflatedness /transvaluativerationalising/transepistemicity/anamnestic-residuality/spirit-drivenness-equalisation〉). The bigger scheme of things with regards to overall human ontological-performance ${ }^{2}-<$ includingvirtue-as-ontology $>$ /morality/ethics/justice/etc. for prospective transcendence-andsublimity/sublimation/supererogatory-de-mentativity as reflected above (on-the-one-hand requiring 'human psychologismic-epistemic-acutisation-<as-to-postconverging-dementating/structuring/paradigming,-eliciting-of-existence's-sublimating-nascence-in- 
\{veridical/sound\}-relative-reflexivity-in-existence/relativising from-limited-mentation-as-itsdeepening/psychologismic epistemic-acutisation residualising, fdecompulsingl delinearity for eogency' fundamentally underlied notionally by either supereregatory wholesomeness/profound-supererogation $^{6}$ or shallow-supererogation 6 in relation to human prospective destructuring-threshold-〈uninstitutionalisedthreshold /presublimating-desublimating-decisionality $>$ of-ontological-performance ${ }^{72}$ <including-virtue-as-ontology>' and on-the-other-hand human ontological-performance ${ }^{72}$ $<$ including-virtue-as-ontology $>/$ morality/ethics/justice/etc. reflecting the 'existentialisingframe-of entailment of motif and apriorising/axiomatising/referencing of priorly secondnatured institutionalisation-threshold of mere-formulaicity/ritualisation-<as-to-mereformulaic — methodologising/mutualising/organising/institutionalising,-prospectively-losing-

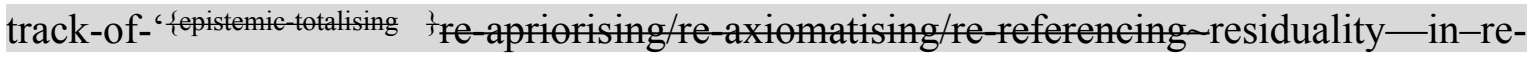
originariness/re-origination'> positive-opportunism—of-social-functioning-and-accordance as not speaking to prospective human disruptive postconverging aaporeticismevercoming/mnovercoming' and thus effectively of shallow-supererogation in relation to human prospective destructuring-threshold-〈uninstitutionalised-threshold /presublimatingdesublimating-decisionality $>$ of-ontological-performance ${ }^{72}$-<including-virtue-asontology $>$ /morality/ethics/justice/etc. when wrongly construed as of prospective postconverging aporeticism overeaming to the two fundamental undergirding elements of the social (as of its 'social-functioning-and-accordance-as-of-socialstake-contention-or-confliction imbuing existentialising-frame-of-entailment-of motif-andapriorising/axiomatising/referencing of disontologising/ontologising-and-re-ontologising') involved in human ontological-performance ${ }^{72}-$ including-virtue-as- $^{2}$ ontology $>$ /morality/ethics/justice/etc. (and so given manifest human <amplituding/formative- 
epistemicity $>$-totalising $\sim$ thrownness-in-existence prior-institutionalisation-threshold-byprospective-uninstitutionalised-threshold ${ }^{102}$ ). The very possibility for undermining blurriness$<$ sterilising/anecdotalising/trivialising-of-prospective-re-ontologising_by-preconverging,-indisontologising-formulaic-dragging-out/hollowing-out> (for prospective knowledgereification $\sim$ gesturing-and-accounting - of-epistemic-phenomenalism- $<$ inprospective_psychologismic apriorising/axiomatising/referencing-\{of-‘prospectively implicited_attendant-ontological-contiguity ' educedexistentialising/contextualising/textualising_'intelligibility/epistemicity/reflexivity-contiguity$<$ imbued-notional cogency $>\quad\}$-conflatedness -in-\{preconverging ment by\} postconverging-entailment $>$ and prospective sublimating $\sim$ existentialising-decisionality-<as-todisontologising/re-ontologising aporeticism $>$ ) can only arise as to such a clear distinction/demarcation between 'human psychologismic-epistemic-acutisation-<as-topostconverging-de-mentating/structuring/paradigming,-eliciting-of-existence's-sublimatingnascence-in-prospective-aporeticism-overcoming/unovercoming > as to epistemic-growth,-as\{veridical/sound\}-relative-reflexivity-in-existence/relativising from-limited-mentation-as-itsdeepening/psychologismic epistemic-acutisation residualising, ${ }^{\text {\{decompulsing }}$ delinearity foreogeney' exercise and naïve secondnatured construct of positive-opportunism-of-socialfunctioning-and-accordance ${ }^{75}$ ontologically-flawed conception being passed for prospective human postconverging-aporeticism-overcoming/unovercoming; wherein the latter is a disontolgising turn to the least-common-denominator-of-social-functioning-and-accordanceeffecting (as to temporally-motivated emphasis on human-subpotency 'existentialising-frameof-entailment-of-motif-and-apriorising/axiomatising/referencing of priorly secondnatured institutionalisation-threshold of mere-formulaicity/ritualisation-<as-to-mere-formulaic methodologising/mutualising/organising/institutionalising,-prospectively-losing-track-of‘\{epistemic-totalising ’re-apriorising/re-axiomatising/re-referencing residuality-in-re- 
originariness/re-origination'> positive-opportunism—of-social-functioning-and-accordance as not speaking to prospective human disruptive postconverging-aporeticismovercoming/unovercoming' reflected with its prospective preconverging-existential-extricationas-of-existential-unthought manifest <amplituding/formative> wooden-language-〈imbuedtemporal-mere-form/virtualities/dereification/akrasiatic-drag/denatured/preconverging-ordementing -narratives-of-the- reference-of-thought- categoricalimperatives/axioms/registry-teleology $\rangle)$ while the former is an ontologising turn to the highestcommon-denominator-of-social-functioning-and-accordance-effecting (in prospective intemporal emphasis on aetiologisation/ontological-escalation- $<$ ontologicalveridicality_commitment/otherliness_transcending/compulsions-encumbered_transcending> conceptivity/epistemic-reflexivity/epistemicity-relativism-determinism-<reifying \{as-toknowledge-developing\}-and-empowering $>$ with regards to 'human psychologismic-epistemicacutisation-<as-to-postconverging-de-mentating/structuring/paradigming,-eliciting-ofexistence's-sublimating-nascence-in-prospective-aporeticism-overcoming/unovercoming $>$ as to epistemic-growth,-as - \{veridical/sound\}-relative-reflexivity-in-existence/relativising fromlimited-mentation-as-its-deepening/psychologismic epistemic-acutisation residualising, \{decompulsing\} delinearity for-cogency\} conceptivity/epistemic-reflexivity/epistemicity-relativismdeterminism- $<$ reifying \{as-to-knowledge-developing $\}$-and-empowering $>$ as to postcenverging nonextricatory-existential-preempting-of-existential-unthought prospective sublimating implications of existence-as-the-absolute-a-priori-of-conceptualisation and existence-assublimating-withdrawal/unenframing/re-ontologising,-elicited-from-prospective-profoundsupererogation -<as-to-perspective-ontological-normalcy/postconvergence-implied'prospective-aporeticism-overcoming/unovercoming'> and so-prompting human ontologicalcommitment $-<$ implied — self-assuredness-of-ontological-goodfaith/authenticity postconverging-de-mentating/structuring/paradigming -as-being-as-of- 
existential-reality>). Critically, given that the social is necessarily of 'social-functioning-andaccordance - as-of-social-stake-contention-or-confliction imbuing existentialising-frame-ofentailment of motif-and-apriorising/axiomatising/referencing of disontologising/ontologisingand-re-ontologising', induced prospective sublimating-nascence is inevitably bound to elicit prospectively its very own 'existentialising-frame-of-entailment-of motif-andapriorising/axiomatising/referencing of priorly secondnatured institutionalisation-threshold of mere-formulaicity/ritualisation- $<$ as-to-mere-formulaicmethodologising/mutualising/organising/institutionalising,-prospectively-losing-track-of‘fepistemic-atising ’’re-apriorising/re-axiomatising/re-referencing residuality-in-reoriginariness/re-origination'> positive-opportunism—of-social-functioning-and-accordance as not speaking to prospective human disruptive postconverging-aporeticismovercoming/unovercoming' which then becomes prospectively susceptible to a desublimating least-common-denominator-of-social-functioning-and-accordance-effecting as to human shallow-supererogation ontologically-flawed projection of prospective human postconverging-aporeticism-overcoming/unovercoming; with this insight very much explaining how and why human social-and-institutional-frameworks-ofreferencing/registering/decisioning existentialising-decisionality-as disongeentologising aporeticism $>$ (given human limited-mentation-capacity—as-subjecting 'educedunlimitedness/existence-sublimating nascence' to-limitedness/human-subpotency in want for limited-mentation-capacity-deepening—as-subjecting limitedness/human-subpotency-to'educed-unlimitedness/existence-sublimating nascence' ${ }^{53}$ ) develop into self-sufficient and selfpresence/self-constitutedness $^{14}{ }^{-<\text {in-perspective-epistemic-abnormalcy/preconvergence }}{ }^{3}>$ constructs (manifesting their ${ }^{79}$ presencing-absolutising-identitive-constitutedness ${ }^{14}$ incidental station-of/epochal in-effect absolution-<as-to-apriorising/axiomatising/referencing-\{of'prospectively implicited_attendant-ontological-contiguity ' educed- 
existentialising/contextualising/textualising_'intelligibility/epistemicity/reflexivity-contiguity<imbued-notional cogency>' $\quad\}$ - constitutedness -in preconverging-entailment $>$ ) as soconstruable from nonpresencing-<perspective-ontological-normalcy/postconvergence $>$ epistemic-projection of prospective human postconvergingaapereticismovercoming/mnovercoming. Critically, the veracity of 'human psychologismic-epistemicacutisation-<as-to-postconverging-de-mentating/structuring/paradigming,-eliciting-ofexistence's-sublimating-nascence-in-prospective-aporeticism-overcoming/unovercoming $>$ as to epistemic-growth,-as - \{veridical/sound\}-relative-reflexivity-in-existence/relativising fromlimited-mentation-as-its-deepening/psychologismic epistemic-acutisation residualising, \{decompulsing\} delinearity for-cogency\} underlying the overall relative-unreflexivity/relativereflexivity - ontological-contiguity ${ }^{67} \sim$ of-the-human-institutionalisation-process ${ }^{68}$ is effectively graspable rather as from notional ${ }^{18}$ deprocrypticism deneuterising - referentialism (as soreflected 'from a notional ${ }^{18}$ deprocrypticism ${ }^{6}$ nonpresencing-<perspective-ontologicalnormalcy/postconvergence $>$ epistemic-projection in a protensive-consciousness ratiocontiguity/ratiocination-as-referentialism_-implicited_attendant-ontologicalcontiguity $^{67}$; educed-

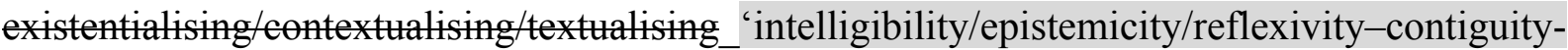
<imbued-notional cogency>' $>^{\prime} \quad$ knowledge-notionalisation construal' of the '<cumulating/recomposuring attendant-ontological-contiguity $>$-successive registryworldviews/dimensions specific ${ }^{83}$ reference-of-thought preconverging/dementing ${ }^{20}$-qualiaschema' reflecting their 'specific prospectively ontologically-flawed nondescript/ignorablevoid imbued self-presence/self-constitutedness ${ }^{14}-<$ in-perspective-epistemicabnormalcy/preconvergence ${ }^{3}>$ specific ontological-bad-faith/inauthenticity ${ }^{64} \sim$ preconvergingde-mentating/structuring/paradigming ${ }^{55}$ as so-underlining the manifest specific ${ }^{83}$ reference-ofthought preconverging/dementing ${ }^{20}$-qualia-schema $>$ ); and so with regards to 'human 
psychologismic-epistemic-acutisation-<as-to-postconverging-de-

mentating/structuring/paradigming,-eliciting-of-existence's-sublimating-nascence-in-

prospective-aporeticism-overcoming/unovercoming $>$ as to epistemic-growth,-as-

\{veridical/sound\}-relative-reflexivity-in-existence/relativising from-limited-mentation-as-its-

deepening/psychologismic epistemic-acutisation residualising, ${ }^{\text {fdecompulsing }}$ delinearity for-

eogency (implied supereregatery -wholesomeness/profound-supererogation of

notional citationality) in pestconverging-nonextricatory-existential-preempting-of-existentialunthought prospective notional-contiguity/epistemic-contiguity ${ }^{2}-<$ profound-supererogation of-mentally-aestheticised $\sim$ postconverging/dialectical-thinking -qualia-schema $>$ as talising $3{ }^{3}$ hermeneutically/textually/reprojectingly/supererogatingly/zeroingly/re-acutingly,\{decompulsing delinearity for-cogency factoring in overall human limited-mentation-capacitydeepening—as-subjecting-limitedness/human-subpotency-to-'educed-unlimitedness/existencesublimating nascence' 5 in the human 'exercise of the epistemic-projective-equalisation of human station of ${ }^{79}$ presencing-absolutising-identitive-constitutedness ${ }^{14}$ as to prospective nonpresencing-<perspective-ontological-normalcy/postconvergence $>$ epistemic - projectiveequalisation'. In this regards, the relative-unreflexivity/relative-reflexivity-ontologicalcontiguity ${ }^{67}$ of-the-human-institutionalisation-process ${ }^{68}$ fundamentally reflects 'differing 'implicited_attendant-ontological-contiguity ${ }^{67}$ notional $\sim$ preconverging-existential-extricationas-of-existential-unthought-by-postconverging-nonextricatory-existential-preempting-ofexistential-unthought of human <amplituding/formative-epistemicity>-totalising $\sim$ thrownnessin-existence $^{35} \quad$ prior-institutionalisation-threshold-by-prospective-uninstitutionalisedthreshold $^{102}$ (as imbued human prospective destructuring-threshold-〈uninstitutionalisedthreshold /presublimating-desublimating-decisionality $>$ of-ontological-performance ${ }^{72}$ <including-virtue-as-ontology $>$ /morality/ethics/justice/etc. for prospective transcendence-andsublimity/sublimation/supererogatory de-mentativity to prospective 
postconverging-aporeticism-overcoming/unovercoming), as of; <amplituding/formativeepistemicity $>$ totalising $\sim$ random-as-impulsive_-'implicited_attendant-ontologicalcontiguity $^{67}$, educedexistentialising/contextualising/textualising_'intelligibility/epistemicity/reflexivity-contiguity$<$ imbued-notional cogency>' ;-phenomenal-abstractiveness-of-presencing-in- 'trepidatiousconsciousness' with recurrent-utter-uninstitutionalisation, <amplituding/formativeepistemicity>totalising nominal-as-tendentious_-implicited_attendant—ontologicalcontiguity ${ }^{67} \sim$ educedexistentialising/contextualising/textualising_'intelligibility/epistemicity/reflexivity-contiguity$<$ imbued-notional cogency>’ ${ }^{\prime}$;-phenomenal-abstractiveness-of-presencing-in- 'warpedconsciousness' with base-institutionalisation-ununiversalisation, <amplituding/formativeepistemicity $>$ totalising $\sim$ ordinal-as-qualifying__implicited_attendant-ontologicalcontiguity $^{67}$, educedexistentialising/contextualising/textualising_intelligibility/epistemicity/reflexivity-contiguity$<$ imbued-notional cogency>' ;-phenomenal-abstractiveness-of-presencing-in-'preclusiveconsciousness' with ${ }^{103}$ universalisation-non-positivism/medieval, <amplituding/formative-

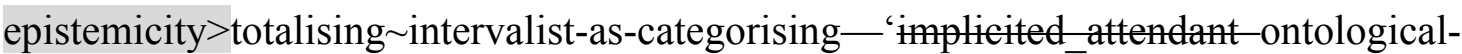
contiguity ${ }^{67} \sim$ educedexistentialising/contextualising/textualising_intelligibility/epistemicity/reflexivity-contiguity$<$ imbued-notional cogency>' ;-phenomenal-abstractiveness-of-presencing-in-'occlusiveconsciousness' with positivism- ${ }^{80}$ procrypticism, and <amplituding/formativeepistemicity $>$ totalising ratiocontiguity/ratiocination-as-referentialism_- ‘implicited_attendant ontological-contiguity ${ }^{67}$, educedexistentialising/contextualising/textualising_'intelligibility/epistemicity/reflexivity-contiguity$<$ imbued-notional cogency>' ;-phenomenal-abstractiveness-of-presencing-in-'protensive- 
consciousness' with ${ }^{18}$ deprocrypticism-or-preempting-disjointedness-as-of- ${ }^{3}$ reference-ofthought. The inherent manifestation of blurriness-<sterilising/anecdotalising/trivialising-ofprospective-re-ontologising_by-preconverging,-in-disontologising-formulaic-dragging-

out/hollowing-out $>$ (as undermining the <cumulating/recomposuring attendant-ontologicalcontiguity $>$-successive registry-worldviews/dimensions prospective knowledgereification $\sim$ gesturing-and-accounting — of-epistemic-phenomenalism- $<$ inprospective_psychologismic $\sim$ apriorising/axiomatising/referencing-\{of-'prospectively implicited_attendant-ontological-contiguity ' educedexistentialising/contextualising/textualising_'intelligibility/epistemicity/reflexivity-contiguity$<$ imbued-notional cogency $\left.>^{\prime}\right\}$-conflatedness -in-\{preconverging-ment by\} postconverging-entailment $>$ and prospective sublimating existentialising-decisionality-<as-todisontologising/re-ontologising aporeticism $>$ ) is so-inherently associated with their preconverging/postconverging-de-mentating/structuring/paradigming knowledgereification $\sim$ gesturing-and-accounting — of-epistemic-phenomenalism- $<$ inprospective_psychologismic apriorising/axiomatising/referencing-\{of- ${ }^{\star p r o s p e c t i v e l y}$ implicited_attendant-ontological-contiguity ' educedexistentialising/contexalising/textising_intelligibility/epistemicity/reflexivity-contiguity<imbued-notional cogency>' \}-conflatedness -in-\{preconverging-ment by\} postconverging-entailment $>$ reflecting respectively their notional $\sim$ shiftiness-of-theSelf/construction-of-the-Self as to recurrent-utter-uninstitutionalisation random-as-impulsive'implicited_attendant-ontological-contiguity ${ }^{67}$; educedexistentialising/contextualising/textualising_intelligibility/epistemicity/reflexivity-contiguity<imbued-notional cogency $>^{\text {' }} \quad$ non-rules - apriorising/axiomatising/referencingpsychologism notional $\sim$ shiftiness-of-the-Self/construction-of-the-Self, baseinstitutionalisation-ununiversalisation nominal-as-tendentious_- implicited_attendant- 
ontological-contiguity ${ }^{67}$, educedexistentialising/contextualising/textualising_'intelligibility/epistemicity/reflexivity_contiguity-

$<$ imbued-notional cogency $>$

apriorising/axiomatising/referencing-psychologism rulemaking-over-non-rulesnotional $\sim$ shiftiness-of-the-

Self/construction-of-the-Self, $\quad{ }^{103}$ universalisation-non-positivism/medievalism ordinal-asqualifying_-implicited_attendant_ontological-contiguity ${ }^{67}$ 'educedexistentialising/contextualising/textualising_intelligibility/epistemicity/reflexivity_contiguity$<$ imbued-notional cogency $>$ universalisation-directed-rulemaking-over-non-rulesapriorising/axiomatising/referencing-psychologism notional $\sim$ shiftiness-of-theSelf/construction-of-the-Self, positivism- ${ }^{80}$ procrypticism intervalist-as-categorising'implicited_attendant-ontological-contiguity ${ }^{67}$ ' educedexistentialising/contextmalising/textmalising_intelligibility/epistemicity/reflexivity_contiguity$<$ imbued-notional cogency $>$ ' positivising/rational-empiricism-based-universalisationdirected-rulemaking-over-non-rules_-apriorising/axiomatising/referencing-psychologism notional $\sim$ shiftiness-of-the-Self/construction-of-the-Self and $\quad{ }^{18}$ deprocrypticism-orpreempting - disjointedness-as-of- ${ }^{-3}$ reference-of-thought ratiocontiguity/ratiocination-asreferentialism—'implicied_atentantontogical-contiguity ${ }^{67}$ > educedexistentialising/contextualising/textualising_intelligibility/epistemicity/reflexivity-contiguity<imbued-notional cogency>' $>^{\prime}$ preempting-disjointedness-as-of- ${ }^{2}$ reference-of-thought,-asto- ${ }^{3}<$ amplituding/formative-epistemicity $>$ growth-or-conflatedness ${ }^{13} /$ transvaluative- $^{2}$ rationalising/transepistemicity/anamnestic-residuality/spirit-drivenness'_-in-supersedingmere-formulaic-positivising/rational-empiricism-based-universalisation-directed-rulemakingover-non-rules - apriorising/axiomatising/referencing-psychologism notional $\sim$ shiftiness-ofthe-Self/construction-of-the-Self; and so speaking to the increasing human limited-mentationcapacity-deepening —as-subjecting limitedness/human-subpotency-to-'educed- 
unlimitedness/existence-sublimating nascence' ${ }^{53}$ ontological-performance ${ }^{2}-<$ including-virtueas-ontology $>$ /morality/ethics/justice/etc. for prospective transcendence-andsublimity/sublimation/supererogatory de-mentativity as of the-very-same-immanentexistence/intrinsic-reality/ontological-veridicality,-as-to-'human<amplituding/formativeepistemicity>totalising purview-of-construal. Critically, ${ }^{18}$ deprocrypticism-or-preemptingdisjointedness-as-of- ${ }^{8}$ reference-of-thought ratiocontiguity/ratiocination-as-referentialism'implicited_attendant-ontological-contiguity ${ }^{67}$; educed-

existentialising/contextualising/textualising_'intelligibility/epistemicity/reflexivity-contiguity$<$ imbued-notional $\sim$ cogency $>$ knowledge-reification gesturing-and-accounting-ofepistemic-phenomenalism-<inprospective_psychologismic apriorising/axiomatising/referencing-\{of-‘prospectively_ implicited_attendant-ontological-contiguity ' educedexistentialising/contextualising/textualising_'intelligibility/epistemicity/reflexivity_contiguity$<$ imbued-notional cogency $>$ ' \}-conflatedness -in-\{preconverging-ment by\} postconverging-entailment $>$ (as to its knowledge-notionalisation 'undermining of totalisinglying - discretion/whim-of-thought' and as to an emphasis on difference-conflatedness ${ }^{13}$-as-tototalitative-reification-in-singularisation-<as-to-the-nondisjointedness/entailment-ofprospective- nonpresencing $>$-as-veridical-epistemicity-relativism-determinism implied

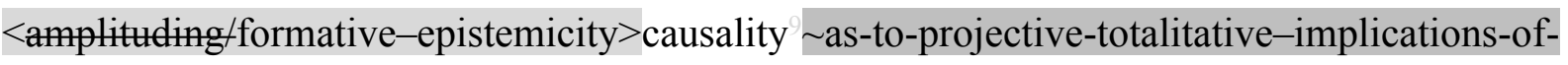
prospective- nonpresencing,-for-explicating relative-unreflexivity/relative-reflexivity ontological-contiguity involving 'understanding notionally' as to the most profound conceptivity/epistemic-reflexivity/epistemicity-relativism-determinism-<reifying \{as-toknowledge-developing\}-and-empowering $>$ arising from understanding both human individuative 'ignorances'/desublimation/temporal-dispositions and knowledge/sublimation/intemporal-disposition manifestation), reflects the more ontologically 
pertinent/profound 'human <amplituding/formative-epistemicity>-totalising $\sim$ thrownness-inexistence $^{35}$ knowledge-reification $\sim$ gesturing-and-accounting-of-epistemic-phenomenalism$<$ in-prospective_psychologismic $\sim$ apriorising/axiomatising/referencing-\{of-'prospectively_ implicited_attendant-ontological-contiguity ' educedexistentialising/contextualising/textualising_ 'intelligibility/epistemicity/reflexivity-contiguity<imbued-notional cogency>' \}-conflatedness -in-\{preconverging-ment by\} postconverging-entailment $>$ ontological-performance ${ }^{72}-<$ including-virtue-as-ontology $>$ ' for prospective transcendence-and-sublimity/sublimation/supererogatory de-mentativity as to prospective human postconverging-apereticism-overcoming/unovercoming; and so-critically as to its translative-accordance of prospective nascent-particular/incipient-andmaterial/technical-sublimations-<blinded-to-their-relative-ontological-completeness reference-of-thought- devolving $>$ implications into their true 'supereregatery $\sim$ wholesomeness/profound-supererogation ${ }^{\circ}$ as of prospective ${ }^{83}$ reference-ofthought — point-of-devolving/departure/anchoring/backdrop_of_sublimating-nascence-<as-tothe-grandest-axiomatic-constructreferencing residuality - in-re-originariness/re-origination of limitedness/human-subpotency prospective re-encountering/re-confrontation with unlimitedness/existence $>$ imbued psychologismic apriorising/axiomatising/referencing-\{of-'prospectively implicited_attendant-ontological-contiguity ' reducedexistentialising/contextualising/textualising_'intelligibility/epistemicity/reflexivity-contiguity$<$ imbued-notional $\left.\sim \operatorname{cogency}>^{\prime},\right\}$-conflatedness ${ }^{13}$-in-\{preconverging-ment by $\}^{2}$ postconverging-entailment' as of '18 deprocrypticism-or-preempting-disjointedness-as-ofreference-of-thought (in so-reflecting the more veridically profound possibility for overarching human social-and-institutional-frameworks-of-referencing/registering/decisioning sublimating existentialising-decisionality-<as-to-disontologising/re-ontologising - 
apereticism $>$ ). The translative-accordance of prospective nascent-particular/incipient-andmaterial/technical-sublimations- $<$ blinded-to-their-relative-ontological-completeness reference-of-thought- devolving $>$ implications (as to the-very-same-immanentexistence/intrinsic-reality/ontological-veridicality,-as-to- 'human<amplituding/formativeepistemicity>totalising purview-of-construal) into their "notional shallow-supererogation" of prior $\quad{ }^{8}$ reference-of-thought—point-of-devolving/departure/anchoring/backdrop or supereregatory-wholesomeness/profound-supererogation as of prospective ${ }^{83}$ reference-ofthought - point-of-devolving/departure/anchoring/backdrop', effectively underlies the given registry-worldview/dimension blurriness-<sterilising/anecdotalising/trivialising-ofprospective-re-ontologising_by-preconverging,-in-disontologising-formulaic-draggingout/hollowing-out $>/$ unblurriness-<re-ontologising_by-postconverging-as-to-dragged-outsupererogatery $\sim$ wholesomeness/profound-supererogation ,-while-anecdotalising-priordisontologising-thresholding $>$ of knowledge-reification $\sim$ gesturing-and-accounting-ofepistemic-phenomenalism-<inprospective_psychologismic apriorising/axiomatising/referencing-\{of-'prospectively implicited_attendant-ontological-contiguity ' educedexistentialising/contexalising/textralising_intelligibility/epistemicity/reflexivity-contiguity<imbued-notional cogency $>$ ' \}-conflatedness - in-\{preconverging -ment by\} postconverging-entailment>; speaking fundamentally to the fact that knowledge is all about human epistemic-growth/disquiet/discomfort-〈induced-sublimation,-as-from-existence'seffusing/ecstatic-inlining-as- historiality-\{science/authenticity/nonextrication $\}$-beyond-mereformulaicity/ritualisation-as- historicity-tracing-\{science-ideology/fashionability/distraction $\}$ ) as to construction-of-the-Self in dispensing-with-immediacy-for-relative-ontologicalcompleteness $^{87}$-by-reification/contemplative-distension ${ }^{27}$ so-accruing onto the supererogatory $\sim$ wholesomeness/profound-supererogation as of prospective ${ }^{83}$ reference-of- 
thought - point-of-devolving/departure/anchoring/backdrop (undergirded as of human protracted-social—as-to-individual-by-institutional-by-social notional $\sim$ self-distantiation$<$ imbued —re-motif-and-re-apriorising/re-axiomatising/re-referencing $>\quad$ induced psychoanalytic-unshackling/memetic-reordering/institutional-recomposuring selfbecoming/self-conflatedness ${ }^{13}$ /formative-supererogating-<projective/reprojectiveaestheticising-re-motif-and-re-apriorising/re-axiomatising/re-referencing,-in-perspectiveontological-normalcy/postconvergence $>$ ). This insight contrastively explains the antithetical epistemic postures of ${ }^{7}$ presencing-absolutising-identitive-constitutedness ${ }^{14}$ and nonpresencing-<perspective-ontological-normalcy/postconvergence $>$; as the latter veridically grasp that existence's sublimating-nascence is inherently given with all that is left for the human to do being rather about developing appropriate epistemic-projection/epistemic-growth,-as\{veridical/sound\}-relative-reflexivity-in-existence/relativising from-limited-mentation-as-itsdeepening/psychologismic epistemic acutisation residualising, \{decompulsing $\}$ delinearity foreogency as of psychologismic apriorising/axiomatising/referencing-\{of-"prospectivelyimplicited_attendant-ontological-contiguity ' educedexistentialising/contextualising/textualising_'intelligibility/epistemicity/reflexivity_contiguity<imbued-notional cogency>' $\}$-conflatedness ${ }^{13}$ in \{preconverging ment by postconverging-entailment while the former is rather reflexively of psychologismic apriorising/axiomatising/referencing-\{of-"prospectivelyimplicited_attendant-ontological-contiguity ' educedexistentialising/contextualising/textualising_'intelligibility/epistemicity/reflexivity-contiguity<imbued-notional cogency $\left.>^{\prime} \quad\right\}$-constitutedness ${ }^{14}$ in - preconverging entailment. The overall implication here is fundamentally that 'human conceiving-〈as-to-conceptivity/epistemicreflexivity/epistemicity-relativism-determinism-<reifying \{as-to-knowledge-developing $\}$-andempowering $>>$ of nascent-particular/incipient-and-material/technical-sublimations- $<$ blinded-to- 
their-relative-ontological-completeness - reference-of-thought- devolving $>$ is basically what induces existence's sublimating-nascence' as rather so-arising as of the $<$ cumulating/recomposuring attendant-ontological-contiguity $>$-successive registryworldviews/dimensions imbued supereregatory-wholesomeness/profound-supererogation ${ }^{96}$ as of prospective ${ }^{83}$ reference-of-thought—point-of-devolving/departure/anchoring/backdrop as of dimensionality-of-sublimating $-<<$ amplituding/formative $>$ supererogatory $\sim$ dementativeness/epistemic-growth-or-conflatedness /transvaluativerationalising/transepistemicity/anamnestic-residuality/spirit-drivenness-equalisation〉 conceiving-〈as-to-conceptivity/epistemic-reflexivity/epistemicity-relativism-determinism$<$ reifying \{as-to-knowledge-developing\}-and-empowering $>>$ (in so-reflectimg their respectively given overarching human social-and-institutional-frameworks-ofreferencing/registering/decisioning sublimating/desublimating existentialising-decisionality<as-to-disontologising/re-ontologising aporeticism $>$ ). In-many-ways human limitedmentation-capacity as subjecting 'educed unlimitedness/existence-sublimating nascence' to-limitedness/human-subpotency rather implies a relative flux of epistemic-projection caught between ${ }^{79}$ presencing-absolutising-identitive-constitutedness ${ }^{14}$ and ${ }^{6}$ nonpresencing$<$ perspective-ontological-normalcy/postconvergence $>$ 'human <amplituding/formativeepistemicity $>$-totalising $\sim$ thrownness-in-existence ${ }^{35} \quad$ knowledge-reification $\sim$ gesturing-andaccounting - of-epistemic-phenomenalism- $<$ inprospective_psychologismic apriorising/axiomatising/referencing-\{of-‘prespectively implicited_attendant-ontological-contiguity ' educedexistentialising/contextualising/textualising_ intelligibility/epistemicity/reflexivity-contiguity$<$ imbued-notional cogency $>>$ \}-conflatedness - in-\{preconverging ment by\} postconverging entailment> ontological-performance ${ }^{2}-<$ including-virtue-asontology $>$ /morality/ethics/justice/etc. for prospective transcendence-and- 
sublimity/sublimation/supererogatory de-mentativity’

(as of 'relative-ontologicalincompleteness $8 /$ relative-ontological-completeness ${ }^{87}$

〈sublimating $\sim$ referencing/registering/decisioning,--as-self-becoming/self-

conflatedness /formative-supererogating-<projective/reprojective-aestheticising-re-motifand-re-apriorising/re-axiomatising/re-referencing,-in-perspective-ontological-

normalcy/postconvergence $>>$ as to human-and-social-expectations/anticipationsmetaphoricity ${ }^{57}$-as-preconverging/postconverging-rede-

mentating/restructuring/reparadigming-psychologism' ${ }^{89}$ ); such that the-very-same-immanentexistence/intrinsic-reality/ontological-veridicality,-as-to-'human<amplituding/formativeepistemicity>totalising purview-of-construal apparently takes on differing substantivity (as different registry-worldviews/dimensions ${ }^{5}$ meaningfulness-and-teleology ${ }^{99}$ as to human limited-mentation-capacity—as-subjecting 'educed-unlimitedness/existence-sublimating nascence' to-limitedness/human-subpotency and limited-mentation-capacity-deepening-assubjecting limitedness/human-subpotency-to-'educed-unlimitedness/existence-sublimating nascence' implications of blurriness-<sterilising/anecdotalising/trivialising-of-prospectivere-ontologising_by-preconverging,-in-disontologising-formulaic-dragging-out/hollowingout $>/$ unblurriness-<re-ontologising_by-postconverging-as-to-dragged-outsupererogatery wholesomeness/profound-supererogation ,-while-anecdotalising-priordisontologising-thresholding $>$. As to the underlying existentialising-frame-of-entailment-ofmotif-and-apriorising/axiomatising/referencing (of the relative flux of human epistemicprojection caught between ${ }^{7}$ presencing-absolutising-identitive-constitutedness ${ }^{14}$ and nonpresencing-<perspective-ontological-normalcy/postconvergence $>$ ), the translativeaccordance of 'our present' prospective nascent-particular/incipient-and-material/technicalsublimations-<blinded-to-their-relative-ontological-completeness - reference-of-thoughtdevolving $>$ implications into their true 'supereregatory wholesomeness/profound- 
supererogation as of prospective ${ }^{83}$ reference-of-thought-point-ofdevolving/departure/anchoring/backdrop_of_sublimating-nascence-<as-to-the-grandestaxiomatic-construct-\{epistemic-tolising †ैre-apriorising/re-axiomatising/rereferencing residuality - in-re-originariness/re-origination of limitedness/human-subpotency prospective re-encountering/re-confrontation with unlimitedness/existence $>$ imbued psychologismic apriorising/axiomatising/referencing-\{of-" prospectively

implicited_attendant-ontological-contiguity ' educedexistentialising/contextualising/textualising_'intelligibility/epistemicity/reflexivity-contiguity$<$ imbued-notional cogency $>\quad\}$ - conflatedness ${ }^{13}$-in-\{preconverging-ment by\} postconverging-entailment' (in so-reflectimg the overarching human social-and-institutionalframeworks-of - referencing/registering/decisioning sublimating existentialisingdecisionality-<as-to-disontologising/re-ontologising aporeticism $>$ ), is increasingly bound to a deprocrypticism-or-preempting — disjointedness-as-of- ${ }^{3}$ reference-of-thought ratiocontiguity/ratiocination-as-referentialism_-implicited_attendant-ontologicalcontiguity $^{67} \sim$ educedexistentialising/contextualising/textualising_intelligibility/epistemicity/reflexivity-contiguity<imbued-notional cogency $>^{\prime} \quad$ knowledge-reification $\sim$ gesturing-and-accounting-ofepistemic-phenomenalism-<inprospective_psychologismic apriorising/axiomatising/referencing-\{of- ${ }^{\star}$ prospectively implicited_attendant_ontological-contiguity ' e educedexistentialising/contextualising/textualising_intelligibility/epistemicity/reflexivity-contiguity<imbued-notional $\left.\sim \operatorname{cogency}>^{\prime} \quad\right\}$-conflatedness -in-\{preconverging ment by\} pesteonverging entailment> (as to its knowledge-notionalisation 'undermining of totalisinglying - discretion/whim-of-thought' and as to an emphasis on difference-conflatedness ${ }^{13}$-as-tototalitative-reification-in-singularisation-<as-to-the-nondisjointedness/entailment-of- 
$<$ amplituding/formative-epistemicity $>$ causality $\sim$ as-to-projective-totalitative-implications-ofprospective- nonpresencing,-for-explicating relative-unreflexivity/relative-reflexivity

ontological-contiguity involving 'understanding notionally' as to the conceptivity/epistemicreflexivity/epistemicity-relativism-determinism-<reifying \{as-to-knowledge-developing $\}$-andempowering $>$ arising from understanding both human individuative 'ignorances'/desublimation/temporal-dispositions and knowledge/sublimation/intemporaldisposition manifestation). In this regards, physics with the 'supposed monotony' of differential equations on physical variables, in chemistry with the 'supposed monotony' of valence bonding explaining chemical reactions or in biology with the 'supposed monotony' of gene regulation rather ultimately central to all biological processes, etc. speaks to a conception of true science 'undermining of totalisingly-ing — discretion/whim-of-thought' as to requisite 'relativeunreflexivity/relative-reflexivity ontological-contiguity $-<$ as-from-prospective-ontologicalnormalcy/postconvergence-epistemic-or-notional projective-perspective $>$ in pestcenvergingnonextricatory-existential-preempting-of-existential-unthought' of conceptualisation that not only explains in entailment but equally in ment as to their manifest psychologismic apriorising/axiomatising/referencing- \{of-"prespectively implicited_attendant-ontological-contiguity ' reducedexistentialising/contextualising/textualising_'intelligibility/epistemicity/reflexivity_contiguity$<$ imbued-notional cogency $>$ ' $\}$ - conflatedness ${ }^{13}$ in-\{preconverging ment by\} postconverging entailment (with intervalist-as-categorising_'implicited_attendantontological-contiguity $^{67}$, educed-

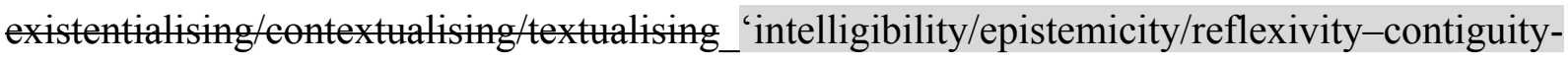
$<$ imbued-notional cogency>’, ordinal-as-qualifying_-implicited_attendant-ontologicalcontiguity ${ }^{67} \sim$ educed- 
existentialising/contextualising/textualising_intelligibility/epistemicity/reflexivity-contiguity<imbued-notional cogency>' , nominal-as-tendentious-'implicited_attendant-ontologicalcontiguity $^{67}$, educed-

existentialising/contextualising/textualising_'intelligibility/epistemicity/reflexivity-contiguity<imbued-notional cogency>' and random-as-impulsive-_implicited_attendant-ontologicalcontiguity $^{67} \sim$ educed-

existentialising/contextualising/textualising_'intelligibility/epistemicity/reflexivity-contiguity<imbued-notional cogency>' rather 'punctually subsumed aestheticising gesturings' into overall ratiocontiguity/ratiocination-as-referentialism_-implicited_attendant-ontologicalcontiguity $^{67} \sim$ educed-

existentialising/contextmalising/textmalising_intelligibility/epistemicity/reflexivity-contiguity$<$ imbued-notional cogency $>^{\prime} \quad$ knowledge-notionalisation aestheticisation-andaestheticisation-towards-ontology-<elicited-idiomatisation $>$ as the underlying 'implicited_attendant-ontological-contiguity ${ }^{67}$ educedexistentialising/contextalising/textalising_'intelligibility/epistemicity/reflexivity_contiguity$<$ imbued-notional $\sim \operatorname{cogency}>^{\prime 0}$ ). It is herein contended that inappropriate expliciting of the translative-accordance of 'our present' prospective nascent-particular/incipient-andmaterial/technical-sublimations-<blinded-to-their-relative-ontological-completeness reference-of-thought- devolving $>$ implications into their true 'supererogatory $\sim$ wholesomeness/profound-supererogation ${ }^{96}$ as of prospective ${ }^{83}$ reference-ofthought — point-of-devolving/departure/anchoring/backdrop_of_sublimating-nascence-<as-tothe-grandest-axiomatic-construct- fepistemic-totalising ${ }^{\frac{1}{3}}$ re-apriorising/re-axiomatising/rereferencing residuality - in-re-originariness/re-origination of limitedness/human-subpotency prospective re-encountering/re-confrontation with unlimitedness/existence>' as to prospective deprocrypticism-or-preempting-disjointedness-as-of- ${ }^{2}$ reference-of-thought is bound to 
induce a mechanical-knowledge misconstrual of the veracity of 'punctually subsumed aestheticising gesturings (as of intervalist-as-categorising_-implicited_attendant-ontologicalcontiguity $^{67}$, educed-

existentialising/contextualising/textmalising_intelligibility/epistemicity/reflexivity-contiguity$<$ imbued-notional cogency>', contiguity $^{67} \sim$ educed-

existentialising/contextualising/textualising_intelligibility/epistemicity/reflexivity_contiguity<imbued-notional cogency>', nominal-as-tendentious_-implicited_attendant-ontologicalcontiguity $^{67}$, educed-

existentialising/contextualising/textmalising_intelligibility/epistemicity/reflexivity-contiguity$<$ imbued-notional cogency>’ and random-as-impulsive-_implicited_attendant-ontologicalcontiguity ${ }^{67} \sim$ educed-

existentialising/contextualising/textualising_'intelligibility/epistemicity/reflexivity-contiguity$<$ imbued-notional cogency>' ${ }^{4}$ )' as to the underlying requisite 'implicited_attendantontological-contiguity ${ }^{67}$, educedexistentialising/contextualising/textualising_intelligibility/epistemicity/reflexivity_contiguity<imbued-notional cogency>' (rather reflected herein as of human-subject-emancipatingrelativism-driven-recomposuring-constructivism-towards-singularisation- $<$ as-to-thenondisjointedness/entailment-of-prospective- nonpresencing> overall ratiocontiguity/ratiocination-as-referentialism_-implicited_attendant-ontologicalcontiguity $^{67} \sim$ educedexistentialising/contextualising/textualising_intelligibility/epistemicity/reflexivity-contiguity$<$ imbued-notional cogency $>^{\prime} \quad$ knowledge-notionalisation aestheticisation-andaestheticisation-towards-ontology-<elicited-idiomatisation $>$ ); and this failure as to our positivism/rational-empiricism occlusiveness disposition (of intervalist-as-categorising- 
'implicited_attendant_ontological-contiguity ${ }^{67}$; educedexistentialising/contextualising/textualising_'intelligibility/epistemicity/reflexivity_contiguity<imbued-notional cogency>' flawed underlying 'implicited_attendant-ontologicalcontiguity $^{67} \sim$ educed-

existentialising/contextualising/textualising_intelligibility/epistemicity/reflexivity-contiguity<imbued-notional cogency>' ${ }^{\prime 0}$ ) in-many-ways accounts for the manifestation of scienceideology whether in the natural sciences themselves or more often blurred domains like the social domain as to a poor construal and appraisal of supereregatery wholesomeness/profoundsupererogation as of prospective ${ }^{83}$ reference-of-thought—point-ofdevolving/departure/anchoring/backdrop (which has to be of appropriate 'relativeunreflexivity/relative-reflexivity - ontological-contiguity ${ }_{-}<$as-from-prospective-ontologicalnormalcy/postconvergence-epistemic-or-notional projective-perspective $>$ in pestcenvergingnonextricatory-existential-preempting-of-existential-unthought'). In-many-ways it is up to such blurred domains to effectively explicit 'supereregatery $w$ wolesomeness/profoundsupererogation as of prospective ${ }^{83}$ reference-of-thought—point-ofdevolving/departure/anchoring/backdrop_of_sublimating-nascence-<as-to-the-grandestaxiomatic-construct- $\frac{\text { tepistemic-totalising }}{3}$ re apriorising/re axiomatising/re referencing $\sim$ residuality - in-re-originariness/re-origination of limitedness/human-subpotency prospective re-encountering/re-confrontation with unlimitedness/existence>' as to the fact that the natural sciences inherently tied to the sublimating-nascence incipience/instantaneity/directness before fundamental ${ }^{83}$ reference-of-thought appraisal of sublimating-nascence comprehensiveness/nonimmediacy/indirectness (as to the artifice of our human convenient division-of-labour-conception-of-knowledge flawed/incomplete conception of sublimating-nascence notwithstanding that existence in its 'superseding-oneness-ofontology/ontological-veridicality/relative-unreflexivity/relative-reflexivity ontological- 
contiguity $^{6}$, is not constrained/subjected by that artifice) may be oblivious as a matter of practicality and focus about the explicited 'supereregatery wholesomeness/profoundsupererogation as of prospective ${ }^{83}$ reference-of-thought-point-ofdevolving/departure/anchoring/backdrop_of_sublimating-nascence-<as-to-the-grandestaxiomatic-construct-\{epistemic-totalising $\stackrel{+}{{ }^{\prime}}$ re-apriorising/re-axiomatising/rereferencing-residuality - in-re-originariness/re-origination of limitedness/human-subpotency prospective re-encountering/re-confrontation with unlimitedness/existence> ${ }^{>}$as 'comprehsensive conceptivity/epistemic-reflexivity/epistemicity-relativism-determinism$<$ reifying \{as-to-knowledge-developing\}-and-empowering $>$ grounds' for such existence's sublimating-nascence incipience/instantaneity/directness in the natural sciences. In this regards, it is herein contended (as to underlying 'relative-unreflexivity/relative-reflexivity_ontologicalcontiguity ${ }^{6}<$ as-from-prospective-ontological-normalcy/postconvergence-epistemic-ornotional projective-perspective $>$ in postconverging-nonextricatory-existential-preempting-ofexistential-unthought') that such a conception like $1+1=2$ in relatively unblurriness- $<$ reontologising_by-postconverging-as-to-dragged-out-supererogatory -wholesomeness/profoundsupererogation ,-while-anecdotalising-prior-disontologising-thresholding $>$ domains-of-study as the natural and exact sciences (of sublimating-nascence incipience/instantaneity/directness) speaks to an implicited_attendant-ontological-contiguity ${ }^{67}$ ' educedexistentialising/contextmalising/textualising_'intelligibility/epistemicity/reflexivity_contiguity$<$ imbued-notional cogency $>{ }^{\prime 0}$ knowledge-notionalisation that can be missed when construed simplistically in relatively blurred domains-of-study (requiring sublimating-nascence comprehensiveness/nonimmediacy/indirectness) where the 'implicited_attendant-ontologicalcontiguity $^{67} \sim$ educedexistentialising/contextalising/textalising_'intelligibility/epistemicity/reflexivity_contiguity$<_{\text {imbued-notional } \sim \operatorname{cogency}>^{\prime}}$ is misconstrued in terms of in-effect absolution-<as-to- 
apriorising/axiomatising/referencing-\{of-'prospectively_implicited_attendant-ontological-

contiguity ' $\sim$ educed-

existentialising/contextualising/textualising_intelligibility/epistemicity/reflexivity-contiguity$<$ imbued-notional cogency >' $\quad\}$-constitutedness -in - preconverging-entailment $>$ of 'humansubpotency supposed preconverging-existential-extrication-as-of-existential-unthought conception of 'implicited_attendant-ontological-contiguity ${ }^{67}$ ' educedexistentialising/contextualising/textalising_'intelligibility/epistemicity/reflexivity_contiguity$<$ imbued-notional cogency>' $\quad$ (and so-misconstrued over 'inherent existence's pestconverging-nonextricatory-existential-preempting-of-existential-unthought phenomenal/manifest relative-unreflexivity/relative-reflexivity_ontological-contiguity ${ }^{67}$ '). This conceptivity/epistemic-reflexivity/epistemicity-relativism-determinism- $<$ reifying \{as-toknowledge-developing $\}$-and-empowering $>$ (as to the 'veracity of prospective knowledgereification $\sim$ gesturing-and-accounting — of-epistemic-phenomenalism- $<$ in-

prospective_psychologismic apriorising/axiomatising/referencing-\{of-'prospectively implicited_attendant-ontological-contiguity ' educedexistentialising/contextualising/textualising_'intelligibility/epistemicity/reflexivity-contiguity<imbued-notional cogency >' \}-conflatedness in \{preconverging ment by\}

postconverging-entailment $>$ and prospective sublimating $\sim$ existentialising-decisionality-<as-todisontologising/re-ontologising aporeticism $>$ ' as rather being as of 'relativeunreflexivity/relative-reflexivity - ontological-contiguity $67<$ as-from-prospective-ontologicalnormalcy/postconvergence-epistemic-or-notional projective-perspective $>$ in pestcenverging nonextricatory-existential-preempting-of-existential-unthought') is reflected in the difference between 'human sublimating/desublimating - modalisation- $<$ as-to-absolute-referencing-ofmeaningfulness-and-teleology ${ }^{9}>$ upon inherent existence's sublimating-nascence inducing of ontologisation/omnipotentiality' and 'human sublimating/desublimating — modalisation- $<$ as-to- 
absolute-referencing-of- ${ }^{5}$ meaningfulness-and-teleology 9

upon

social-

vestedness/normativity-<discretely-implied-functionalism $>$

inducing

of

subontologisation/subpotentiation' and can be compared in allegorical terms to say having a highway with poor signalling and construction bound to induce a given level of accidents (as to possibility of sublimation/desublimation), with the former rather construing of the inherent nature of the highway from postconverging-nonextricatory-existential-preempting-ofexistential-unthought insight of foundational problematic postconvergingaapereticismovercoming/unovercoming and the latter rather ignoring the inherent foundational problematic postconverging-aporeticism-overcoming/unovercoming nature of the highway and adopting extricatory stratagems as to preconverging-existential-extrication-as-of-existential-unthought orientation for dealing with the highway in its given state 'with the implicited expectation of accidents'; and in this respect deconstruction and genealogy analyses (and notional ${ }^{18}$ deprocrypticism suprastructuralism analysis as expressed herein with regards to the relative-unreflexivity/relative-reflexivity ontological-contiguity ${ }^{67} \sim$ of-the-human-

institutionalisation-process ${ }^{68}$ ) as to 'human sublimating/desublimating-modalisation- $<$ as-toabsolute-referencing-of- ${ }^{-5}$ meaningfulness-and-teleology $>$ upon inherent existence's sublimating-nascence inducing of ontologisation/omnipotentiality' sublimatingexistentialising-decisionality is bound to a postconverging-nonextricatory-existentialpreempting-of-existential-unthought knowledge-reification $\sim$ gesturing-and-accounting-ofepistemic-phenomenalism- $<$ in-

prospective_psychologismic apriorising/axiomatising/referencing-\{of-'prospectively_ implicited_attendant-ontological-contiguity ' reducedexistentialising/contextrising/textralising_intelligibility/epistemicity/reflexivity-contiguity<imbued-notional cogency >’ \}-conflatedness -in-\{preconverging-ment by\}

postconverging entailment $>$ for tackling the more foundational problematic 
postconverging aporeticism-overcoming/unovercoming issues underlying say the present decadal economic crises, media and information crises, political accountability, etc., whereas 'human sublimating/desublimating - modalisation-<as-to-absolute-referencing-ofmeaningfulness-and-teleology ${ }^{9}>$ upon social-vestedness/normativity-<discretely-impliedfunctionalism $>$ inducing of subontologisation/subpotentiation' supposedly of sublimatingexistentialising-decisionality as implied not only with regards to overall social-and-institutionalframeworks-of — referencing/registering/decisioning reflex but manifested with many a subjectmatter like economics theory, psychological theory and social theory which tend to implicitly ignore/consider this more foundational problematic postconverging-aporeticismovercoming/unovercoming reality of present decadal economic crises, media and information crises, political accountability, etc. (as to their ${ }^{79}$ presencing-absolutising-identitiveconstitutedness ${ }^{14}$ shallow-supererogation ${ }^{2}$ of manifest in-effect absolution- $<$ as-toapriorising/axiomatising/referencing-\{of-'prospectively implicited_attendant-ontologicalcontiguity ' $\sim$ educedexistentialising/contextualising/textualising_'intelligibility/epistemicity/reflexivity-contiguity$<$ imbued-notional cogency $>$ ' $\}$-constitutedness -in preconverging entailment $>$ inclinations) as a given as to its precontenting existential-extrionunthought orientation and rather come-up-with/reflect 'stratagems of extricatory solutions considered of sublimating-existentialising-decisionality' and paradoxically validating the very inherence of the decadal economic crises, media and information crises, political accountability, etc. as to a winners-and-losers implicited conceptualisation of social-vestedness/normativity$<$ discretely-implied-functionalism $>$ and thus incapable of an orientation for addressing fundamental ontology as to veridical postconverging apereticism oreming (as of the 'requisite profound-supererogation entailing-<amplituding/formativeepistemicity>totalising in-relative-ontological-completeness historiality/ontological- 
eventfulness 3 /ontological-aesthetic-tracing-<perspective-ontologicalnormalcy/postconvergence-reflected-‘epistemicity-relativism-determinism’> implications of postconverging aporeticism-overcoming/unovercoming'). It is critically this 'humansubpotency supposed preconverging-existential-extrication-as-of-existential-unthought conception of 'implicited_attendant-ontological-contiguity ${ }^{67}$ ' educedexistentialising/contextualising/textualising_intelligibility/epistemicity/reflexivity-contiguity$<$ imbued-notional cogency $>^{\prime}$ that underlies in all registry-worldviews/dimensions 'prospectively desublimating institutional and social pedantising/muddling/formulaichollowing-out - in-subontologisation/subpotentiation-_blurring/undermining-of-prospectivetotalising-entailing,-as-to-entailing-<amplituding/formative-epistemicity $>$ totalising inrelative-ontological-completeness $\rangle$ (in prior 'human aestheticisation-and-aestheticisationtowards-ontology-<elicited-idiomatisation $>$ beholdening, non-transcendence, complexification as to mechanical-knowledge and non-ment of prior apriorising/axiomatising/referencing')'. But then (and as to the fact that human prospective postconverging-apereticismovercoming/unovercoming for prospective transcendence-andsublimity/sublimation/supererogatory de-mentativity does not fundamentally lies with the 'existentialising-frame-of-entailment-of-motif-and-apriorising/axiomatising/referencing of priorly secondnatured institutionalisation-threshold of mere-formulaicity/ritualisation- $<$ as-tomere-formulaic - methodologising/mutualising/organising/institutionalising,-prospectively-

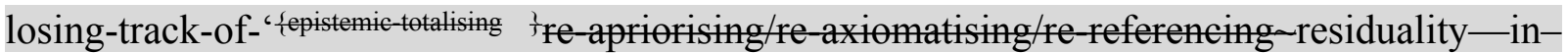
re-originariness/re-origination'> positive-opportunism—of-social-functioning-andaccordance $^{75}$ as not speaking to prospective human disruptive postconverging-aporeticismevercoming/unovercoming' as to its prospective preconverging-existential-extrication-as-ofexistential-unthought manifest <amplituding/formative> wooden-language-〈imbued temporal-mere-form/virtualities/dereification/akrasiatic-drag/denatured/preconverging-or- 


\section{dementing -narratives - of-the- reference-of-thought- categorical-}

imperatives/axioms/registry-teleology $\rangle)$, 'prospectively sublimating institutional and social notional philosophy-<as-to-the-veridical-conception-of-philosophy-as-englobing-all-humanprospective-organic-knowledge-generation-in-relative-ontological-completeness ,-beyond-aconvenient-division-of-labour-conception-of-knowledge> (in prospective 'human aestheticisation-and-aestheticisation-towards-ontology-<elicited-idiomatisation $>$ unbeholdening, transcendence, decomplexification for organic-knowledge and ment of prior apriorising/axiomatising/referencing')' is necessarily and decisively an issue of ever always tracking-and-tackling human protracted-social—as-to-individual-by-institutional-by-social manifest $<$ amplituding/formative $>$ wooden-language-〈imbued-temporal-mere-

\section{form/virtualities/dereification/akrasiatic-drag/denatured/preconverging-or-dementing}

narratives - of-the- reference-of-thought- categorical-imperatives/axioms/registry-

teleology > so-reflected in the <cumulating/recomposuring attendant-ontologicalcontiguity $>$-successive registry-worldviews/dimensions transcendence-andsublimity/sublimation/sentativity. In this regards, the veracity of thinking/thought/notional $\sim$ philosophy-<as-to-the-veridical-conception-of-philosophy-asenglobing-all-human-prospective-organic-knowledge-generation-in-relative-ontologicalcompleteness ,-beyond-a-convenient-division-of-labour-conception-of-knowledge > starts and is veridically indissociable from the contemplation of the human protracted-social - as-toindividual-by-institutional-by-social manifest <amplituding/formative $>$ wooden-language〈imbued-temporal-mere-form/virtualities/dereification/akrasiaticdrag/denatured/preconverging-or-dementing -narratives - of-the- reference-of-thoughtcategorical-imperatives/axioms/registry-teleology $\rangle$. The fact of the matter is that what the Socrates, Copernicuses, Galileos, Descartes, Kants, Newtons, Leibniz, Rousseaux, Diderots, Pasteurs, Lavoisiers, Teslas, Einsteins, etc. of the world are contemplating has to do with their 
Ages and societies <amplituding/formative> wooden-language-〈imbued-temporal-mereform/virtualities/dereification/akrasiatic-drag/denatured/preconverging-or-dementing narratives - of-the- reference-of-thought- categorical-imperatives/axioms/registryteleology $\rangle$. On the same vein the question can be asked what is veridically our modern-day human protracted-social—as-to-individual-by-institutional-by-social manifest

\section{$<$ amplituding/formative $>$ wooden-language-〈imbued-temporal-mere-}

\section{form/virtualities/dereification/akrasiatic-drag/denatured/preconverging-or-dementing}

narratives - of-the- reference-of-thought- categorical-imperatives/axioms/registry-

teleology $\rangle$ ? It is herein contended that our modern-day <preconverging ' motif-andapriorising/axiomatising/referencing'-entailing>-existentialising—enframing/imprintedness-

〈as-to- historicity-tracing - in-presencing-hyperrealisation/hyperreal-transposition〉 (with respect to the potential for prospective human transcendence-andsublimity/sublimation/supererogatory de-mentativity) is 'drowning' in its very own 'epistemicdecadence' or teleological-decadence-<-in-dimensionality-of-desublimating-lack-of ${ }^{-}$ <<amplituding/formative>supererogatory $\sim$ de-mentativeness/epistemic-growth-orconflatedness /transvaluative-rationalising/transepistemicity/anamnestic-residuality/spiritdrivenness-equalisation) increasingly as to an underpinning-suprasocial-construct that as of its pedantising/muddling/formulaic-hollowing-out - in-subontologisation/subpotentiation〈blurring/undermining-of-prospective-totalising-entailing,-as-to-entailing<amplituding/formative-epistemicity>totalising in-relative-ontological-completeness > (in prior 'human aestheticisation-and-aestheticisation-towards-ontology-<elicited-idiomatisation $>$ beholdening, non-transcendence, complexification as to mechanical-knowledge and non-ment of prior apriorising/axiomatising/referencing') prospectively speaks fundamentally of a poor 'knowledge value' for which contemplation beyond 'human lifespan extricatory punctuality/immediacy of depth-of-thought' is in-many-ways a non sequitur as to patent 
dimensionality-of-desublimating-lack-of $-\langle<$ amplituding/formative $>$ supererogatory $\sim$ dementativeness/epistemic-growth-or-conflatedness /transvaluative-

rationalising/transepistemicity/anamnestic-residuality/spirit-drivenness-equalisation〉 lack of angling-of-imaginary nonextricatory-existential-preempting-of-existentialunthought wherein even remnants of 'profound organic-knowledge value' are increasingly being subject to a prosaic/popularity/fashionability/merchandising substitutive mentality of knowledge value and worth; poorly entertaining prospective human epistemic-growth/disquiet/discomfort〈induced-sublimation,-as-from-existence's - effusing/ecstatic-inlining-as- historiality\{science/authenticity/nonextrication\}-beyond-mere-formulaicity/ritualisation-as- historicitytracing-\{science-ideology/fashionability/distraction $\}\rangle$ as to construction-of-the-Self in dispensing-with-immediacy-for-relative-ontological-completeness ${ }^{87}$-byreification/contemplative-distension ${ }^{27}$ accruing onto the 'supereregatery $\sim$ wholesomeness/profound-supererogation ${ }^{\circ}$ as of prospective ${ }^{83}$ reference-ofthought — point-of-devolving/departure/anchoring/backdrop_of_sublimating-nascence-<as-tothe-grandest-axiomatic-construct-\{epistemic-totalising ${ }^{\text {tre }}$ repriorising/re-axiomatising/rereferencing residuality - in-re-originariness/re-origination of limitedness/human-subpotency prospective re-encountering/re-confrontation with unlimitedness/existence>' (as to human protracted-social—as-to-individual-by-institutional-by-social notional $\sim$ self-distantiation$<$ imbued —re-motif-and-re-apriorising/re-axiomatising/re-referencing $>\quad$ induced psychoanalytic-unshackling/memetic-reordering/institutional-recomposuring self-

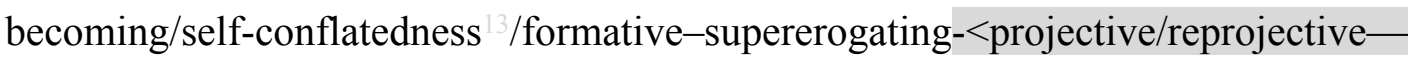
aestheticising-re-motif-and-re-apriorising/re-axiomatising/re-referencing,-in-perspectiveontological-normalcy/postconvergence $>$ ). The core vocation of notional $\sim$ philosophy-<as-to-theveridical-conception-of-philosophy-as-englobing-all-human-prospective-organic-knowledgegeneration-in-relative-ontological-completeness ,-beyond-a-convenient-division-of-labour- 
conception-of-knowledge> (as to the 'supereregatery $>$ wholesomeness/profoundsupererogation as of prospective ${ }^{83}$ reference-of-thought-point-ofdevolving/departure/anchoring/backdrop_of_sublimating-nascence-<as-to-the-grandestaxiomatic-construct-\{epistemic-totalising ${ }^{+}$re-apriorising/re-axiomatising/rereferencing $\sim$ residuality - in-re-originariness/re-origination of limitedness/human-subpotency prospective re-encountering/re-confrontation with unlimitedness/existence>' aspect of overall existence's sublimating-nascence) is rather to enable the 'accrual of the prospective ${ }^{8}$ referenceof-thought appraisal of sublimating-nascence comprehensiveness/nonimmediacy/indirectness' doing-so even in disregard of the "punctual/immediacy/constituted/compulsions-encumbered valuation of sublimating-nascence' made by 'existentialising-frame-of-entailment-of motifand-apriorising/axiomatising/referencing of priorly secondnatured institutionalisation-threshold of mere-formulaicity/ritualisation-<as-to-mere-formulaic methodologising/mutualising/organising/institutionalising,-prospectively-losing-track-of'\{epistemic tolising †ेre-apriorising/re-axiomatising/re-referencing residuality-in-reoriginariness/re-origination'> positive-opportunism—of-social-functioning-and-accordance as not speaking to prospective human disruptive postconverging-aporeticismoremingerestive sublimating-nascence can only poorly be accommodated in prior ${ }^{83}$ reference-of-thought-point-ofdevolving/departure/anchoring/backdrop. Prospective sublimating-nascence is much more than just prospective nascent-particular/incipient-and-material/technical-sublimations- $<$ blinded-totheir-relative-ontological-completeness - reference-of-thought- devolving $>$ but is made comprehensive and complete with its appropriate 'supereregatery wholesomeness/profoundsupererogation as of prospective ${ }^{83}$ reference-of-thought-point-ofdevolving/departure/anchoring/backdrop_of_sublimating-nascence-<as-to-the-grandest-

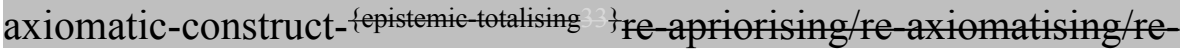


referencing residuality - in-re-originariness/re-origination of limitedness/human-subpotency prospective re-encountering/re-confrontation with unlimitedness/existence>' as to the requisite induced human epistemic-growth/disquiet/discomfort-〈induced-sublimation,-as-fromexistence's - effusing/ecstatic-inlining-as- historiality-\{science/authenticity/nonextrication $\}$ beyond-mere-formulaicity/ritualisation-as- historicity-tracing-\{scienceideology/fashionability/distraction $\}\rangle$ as to construction-of-the-Self in dispensing-withimmediacy-for-relative-ontological-completeness ${ }^{87}$-by-reification/contemplative-distension ${ }^{27}$. In this regards, it can be appreciated that the veridically comprehensive and complete sublimating-nascence of technical and scientific progress like shipbuilding and other ocean voyage technologies rather came into their full realisation as to a healthy global commercial relations these enabled over their initial pirating, warring and exploitative dehumanising pursuits (speaking of their requisite human epistemic-growth/disquiet/discomfort-〈induced-sublimation,as-from-existence's - effusing/ecstatic-inlining-as- historiality\{science/authenticity/nonextrication\}-beyond-mere-formulaicity/ritualisation-as- historicitytracing-\{science-ideology/fashionability/distraction $\}\rangle$ that is rather decisive and indispensable to all 'sublimating-nascence incipience/instantaneity/directness' as to their requisite 'prospective $\quad{ }^{83}$ reference-of-thought appraisal of sublimating-nascence comprehensiveness/nonimmediacy/indirectness'). Such an insight as to the supererogatory - wholesomeness/profound-supererogation of organic-knowledge for say present-day institutional-development-as-to-social-function-development can be garnered with the patent case of say knowledge for the management of a nuclear facility which is much more than its mere inherent processive technicalities ('knowledge as a mere doable thing') but equally with the technicity/profundity extending to the facility operators reflexive and contemplative appreciation of the dangerousness of nuclear materials and processes and ability to critically take appropriately conservative and cooperative or autonomous decisions to stave off any potential 
crises (with these associated elements including their mental/psychological suitability construed as the requisite epistemic-growth/disquiet/discomfort-_induced-sublimation,-as-fromexistence's - effusing/ecstatic-inlining-as- historiality-\{science/authenticity/nonextrication $\}$ beyond-mere-formulaicity/ritualisation-as- historicity-tracing-\{science-

ideology/fashionability/distraction $\}\rangle$ tied to that knowledge and so within the framework of the facility thought-out/contemplated operational and designing conception integrative of such sublimating operation). This reality about the supereregatory wholesomeness/profoundsupererogation of organic-knowledge is relevant in all institutional domains as well but for when it comes to conveniencing, popularising, merchandising and media-ratings driven purposes which may be innocuous in other contexts but turn out to be particularly consequential when permeating and undermining the political process as to when human sovereign participation is in-effect construed as utterly dissociated with ontological-veracity; as to the fact that there can be a 'thin-and-tenuous line between ontological-good-faith/authenticity imbuing sublimation and ontological-bad-faith/inauthenticity ${ }^{64}$ imbuing gimmickiness/desublimation' as to human aestheticisation-and-aestheticisation-towards-ontology-<elicited-idiomatisation $>, \quad$ wherein apparently 'gimmicky techniques' are effectively sublimating as to their specific aestheticising/creative/artistic existentialising-frame-of-entailment-of-motif-andapriorising/axiomatising/referencing but are rather desublimating when poorly aestheticised out of such specific aestheticising/creative/artistic existentialising-frame-of-entailment-of-motifand-apriorising/axiomatising/referencing or when 'circumstantially appreciatively aesthetically shallow/encumbering/vague/bland/incomplete/etc.' or when poorly reflected in domains of aestheticisation-towards-ontology where profound ontological-pertinence is important (requiring in all such cases the appraisal of appropriate supererogatory wholesomeness/profound-supererogation in postconverging-dementating/structuring/paradigming ${ }^{0}$ ). This underlies the very ontological- 
normalcy/postconvergence epistemic-projection with regards to the conception of 'ontologicalgood-faith/authenticity as to ontological-good-faith/authenticity $\sim$ postconverging-dementating/structuring/paradigming ${ }^{0}$, wherein communication and marketing strategies in eliciting human interest as to ontologically relevant ways for instance associated with useful public information and promotion in health, business, etc. (construed as of ontological-goodfaith/authenticity ${ }^{69}$ ), when poorly and cynically projected as to subvert the requisite ontologicalveracity and human epistemic-growth/disquiet/discomfort-〈induced-sublimation,-as-fromexistence's - effusing/ecstatic-inlining-as- historiality-\{science/authenticity/nonextrication $\}$ beyond-mere-formulaicity/ritualisation-as- historicity-tracing-\{science-

ideology/fashionability/distraction $\}\rangle$ in-the-very-same-and/or-other domains of human existentialising-decisionality-<as-to-disontologising/re-ontologising aporeticism $>$ (including citizenry and other institutional sovereignising - by-ontologising-depth existentialisingframe-of-entailment-of motif-and-apriorising/axiomatising/referencing of existentialisingdecisionality-<as-to-disontologising/re-ontologising aporeticism $>$ ) become manifestly of 'ontological-bad-faith/inauthenticity ${ }^{64}$ as to ontological-badfaith/inauthenticity ${ }^{64}$ preconverging-de-mentating/structuring/paradigming ${ }^{65}$ in need for appropriate supererogatory $\sim$ wholesomeness/profound-supererogation (in accounting-

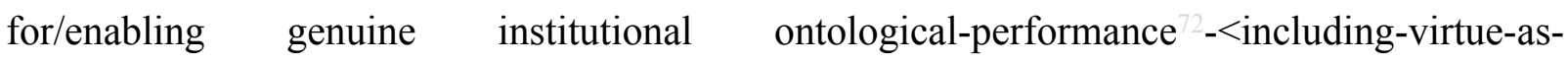
ontology $>$ /morality/ethics/justice/etc. imbued axiomatising/re-referencing-residuality-in-re-originariness/re-origination-〈as to human profound-supererogation for prospective apriorising/axiomatising/referencing-\{of'prospectively_implicited_attendant-ontological-contiguity ' educedexistentialising/contextualising/textualising_'intelligibility/epistemicity/reflexivity_contiguity<imbued-notional cogency $\left.>^{\prime}\right\}$-conflatedness -in-\{preconverging-ment by\} postconverging-entailment that cannot be unshrouded by prior mere-formulaicity/ritualisation- 
<as-to-mere-formulaic — methodologising/mutualising/organising/institutionalising,-

prospectively-losing-track-of- ‘fepistemic-totalising ${ }^{+}$re-apriorising/re-axiomatising/re-

referencing $\sim$ residuality_-in-re-originariness/re-origination'>

of

prior

apriorising/axiomatising/referencing-\{of-'prospectively implicited_attendant-ontological-

contiguity ' educed-

existentialising/contextualising/textualising_ 'intelligibility/epistemicity/reflexivity-contiguity-

$<$ imbued-notional cogency $\left.>^{\prime} \quad\right\}$-constitutedness -in-preconverging-entailment $\rangle$ as of implied

maximalising-recomposuring-for-relative-ontological-completeness

unenframed/re-ontologising conceptualisation and so beyond-and-over a defaulting mentality

of

prior

mere-formulaicity/ritualisation-<as-to-mere-formulaic

methodologising/mutualising/organising/institutionalising,-prospectively-losing-track-of-

'\{epistemic-totalising ’’re-apriorising/re-axiomatising/re-referencing $r$ residuality-in-re-

originariness/re-origination'> as of prior apriorising/axiomatising/referencing-\{of-

'prospectively_implicited_attendant-ontological-contiguity ' educed-

existentialising/contextualising/textualising_intelligibility/epistemicity/reflexivity_contiguity-

<imbued-notional cogency $\left.>^{\prime} \quad\right\}$-constitutedness ${ }^{14}$-in-preconverging-entailment implied incrementalism-in-relative-ontological-incompleteness ${ }^{88}$

enframed/disontologising conceptualisation). Such a dynamic notional conception of 'ontological-good-faith/authenticity ${ }^{69}$ as to ontological-goodfaith/authenticity ${ }^{6} \sim$ postconverging-de-mentating/structuring/paradigming ${ }^{70}$ is very much relevant with respect to human Being-development/ontological-framework-expansion-as-todepth-of-ontologising-development-as-infrastructure-of- meaningfulness-and-teleology , institutional-development-as-to-social-function-development and living-development-as-topersonality-development psychologismic epistemic acutisation - difficulty < for, residualising ${ }^{\{\text {decompusing }}$ delinearity for-cogeney $>$ magnitudes ${ }^{\{\text {of-experientiality/experiment }\}}$ wherein for 
instance while say celebrity and other persons-driven efforts bringing attention to human crisis speaks to a manifestation of ontological-good-faith/authenticity with regards to livingdevelopment-as-to-personality-development however such attention when construed as of punctual 'mere-formulaic — conformity/trending/voguing/fashionability/resonance relation to meaningfulness-and-teleology"' as well as 'so-discharging institutions and society from the more veridically profound level for the contemplation and resolution of such human crisis (as to human Being-development/ontological-framework-expansion-as-to-depth-of-ontologisingdevelopment-as-infrastructure-of- meaningfulness-and-teleology and institutionaldevelopment-as-to-social-function-development psychologismic epistemic-acutisationdifficulty $<$ for, residualising ${ }^{\{\text {decompulsing }}$ delinearity for-cogency> $>$ magnitudes ${ }^{\{0 f-}$ experientiality/experiment\} postconverging-de-mentating/structuring/paradigming ${ }^{70}$ )' is effectively of manifest 'ontological-bad-faith/inauthenticity ${ }^{4}$ as to ontological-badfaith/inauthenticity ${ }^{64}$ preconverging-de-mentating/structuring/paradigming ${ }^{5{ }^{\prime}}$; especially as soaccompanied by a generalised out-of-sight-out-of-mind preconverging-existential-extricationas-of-existential-unthought civil society 'social-functioning-and-accordance-as-of-socialstake-contention-or-confliction imbuing existentialising-frame-of-entailment-of motif-andapriorising/axiomatising/referencing of disontologising/ontologising-and-re-ontologising'. In another regards, a generalised cultivated public distraction/indifference/passivity/debased relation to the political process as to imply it is discretionary, remotely-sovereignising, inconsequential and doesn't warrant a certain requisite level of protracted-social—as-toindividual-by-institutional-by-social epistemic-growth/disquiet/discomfort-〈inducedsublimation,-as-from-existence's - effusing/ecstatic-inlining-as- historiality\{science/authenticity/nonextrication $\}$-beyond-mere-formulaicity/ritualisation-as- historicitytracing-\{science-ideology/fashionability/distraction $\}\rangle$ very much underlies the crisis of participation, misinformation and impotence marring the democratic process in want for its 
creative ontologising renewal to rekindle 'human sovereign-function/posture- $<$ as-toexistentially-manifest-`embodied-subject $\sim$ consciousness-and-direct/deferentialconscientiousness',-as-of-its-'epistemic-reflexivity/unreflexivity-in-existence'/teleology> with regards to public-sovereignty-giving function/posture'. Critically, this postconverging aporeticism-overcoming/unovercoming issue is fundamentally one of translative-accordance of 'our present' prospective nascent-particular/incipient-andmaterial/technical-sublimations-<blinded-to-their-relative-ontological-completeness

reference-of-thought- devolving $>\quad$ implications

$<$ amplituding/formative $>$ disposedness/psychologismic-construct-〈as-to-orientation/value- into

'supererogatery $\sim$ wholesomeness/profound-supererogation ${ }^{9}$ as of prospective ${ }^{83}$ reference-ofthought_-point-of-devolving/departure/anchoring/backdrop_of_sublimating-nascence- $<$ as-tothe-grandest-axiomatic-construct-fepistemic-talising $\stackrel{+}{+}$ re-apriorising/re-axiomatising/rereferencing residuality - in-re-originariness/re-origination of limitedness/human-subpotency prospective re-encountering/re-confrontation with unlimitedness/existence $>$ imbued psychologismic $\sim$ apriorising/axiomatising/referencing-\{of-'prospectively implicited_attendant-ontological-contiguity ' educedexistentialising/contextualising/textualising_'intelligibility/epistemicity/reflexivity-contiguity$<$ imbued-notional cogency $\left.>{ }^{\prime}\right\}$-conflatedness ${ }^{13}$-in-\{preconverging -ment by\} postconverging-ntailment' (in so-reflectimg the overarching human social-and-institutionalframeworks-of—referencing/registering/decisioning sublimating existentialising_decisionality-<as-to-disontologising/re-ontologising aporeticism $>$ ) as to $<$ amplituding/formative >disposedness/psychologismic-construct-〈as-to-orientation/valueconstruct/valuation-and-derived-parameterising $\rangle$, as so-underlied by the fact that humankind relates differently to the inherent epistemic-growth/disquiet/discomfort-_induced-sublimation,- 
as-from-existence's - effusing/ecstatic-inlining-as- historiality-

\{science/authenticity/nonextrication\}-beyond-mere-formulaicity/ritualisation-as- historicity-

tracing-\{science-ideology/fashionability/distraction $\})$; as warranted for prospective nascentparticular/incipient-and-material/technical-sublimations- $<$ blinded-to-their-relative-ontologicalcompleteness - reference-of-thought- devolving > and with respect to the warranted 'supereregatory $\sim$ wholesomeness/profound-supererogation ${ }^{9}$ as of prospective ${ }^{83}$ reference-ofthought—point-of-devolving/departure/anchoring/backdrop social-and-institutionalframeworks-of — referencing/registering/decisioning sublimating existentialisingdecisionality-<as-to-disontologising/re-ontologising aporeticism $>$ as to social-andinstitutional-frameworks-of — referencing/registering/decisioning existentialising-decisionality<as-to-disontologising/re-ontologising aporeticism> disruptive blurriness$<$ sterilising/anecdotalising/trivialising-of-prospective-re-ontologising_by-preconverging,-indisontologising-formulaic-dragging-out/hollowing-out> and emotional-involvement with regards to social-functioning-and-accordance-as-of-social-stake-contention-or-confliction (with such blurriness-<sterilising/anecdotalising/trivialising-of-prospective-reontologising_by-preconverging,-in-disontologising-formulaic-dragging-out/hollowing-out> just a reflection of deficient human ontological-performance ${ }^{72}-$ including-virtue-as- $^{-}$ ontology $>$ /morality/ethics/justice/etc. in the human 'exercise of the epistemic-projectiveequalisation of human station of ${ }^{7}$ presencing - absolutising-identitive-constitutedness ${ }^{14}$ as to prospective $\quad$ nonpresencing- $<$ perspective-ontological-normalcy/postconvergence $>$ epistemic_projective-equalisation' when it comes to re-ontologising prospective Beingdevelopment/ontological-framework-expansion-as-to-depth-of-ontologising-development-asinfrastructure-of- meaningfulness-and-teleology ). It can be appreciated in this regards as to the archetypal case of Galileo prosecution that in-many-ways the technical demonstrations with his telescope were more or less accommodable to his persocutors with their grander issue being 
the implications of his interpretations on their overall non-positivising/non-rational-empiricism conception of the world; and in-many-ways such an attitude is not exclusive to any one Age and society, and our very own positivism- ${ }^{80}$ procrypticism as to its occlusiveness is very much bound to turn a blind eye to its inconvenient truths in a collateralising predisposition overlooking the prospectively requisite $<$ amplituding/formative $>$ disposedness/psychologismic-construct- $\langle$ as-toorientation/value-construct/valuation-and-derived-parameterising) and $<$ amplituding/formative $>$ entailment-〈as-to-totalising-contiguous/coherent-factuality-ofvariability). Whilst in effect the sublimating-nascence of 'prospective nascentparticular/incipient-and-material/technical-sublimations- $<$ blinded-to-their-relative-ontologicalcompleteness - reference-of-thought- devolving>' like the natural sciences is construed relatively as to its cumulating/recomposuring prospective 'human aestheticisation-andaestheticisation-towards-ontology-<elicited-idiomatisation $>$ unbeholdening, transcendence, decomplexification for organic-knowledge and ment of prior apriorising/axiomatising/referencing' with respect to 'prior nascent-particular/incipient-andmaterial/technical-sublimations- $<$ blinded-to-their-relative-ontological-completeness

reference-of-thought- devolving>' (and so as the very central insight about the natural sciences postconverging-aporeticism-overcoming/unovercoming when it comes to human limited-mentation-capacity-deepening —as-subjecting limitedness/human-subpotency-to'educed-unlimitedness/existence-sublimating nascence' ${ }^{53}$ ), in-many-ways such sublimating cumulating/recomposuring prospective 'human aestheticisation-and-aestheticisation-towardsontology-<elicited-idiomatisation $>$ unbeholdening, transcendence, decomplexification for organic-knowledge and ment of prior apriorising/axiomatising/referencing' when it comes to the warranted 'supereregatory-wholesomeness/profound-supererogation' as of prospective reference-of-thought—-point-of-devolving/departure/anchoring/backdrop for social-andinstitutional-frameworks-of — referencing/registering/decisioning sublimating existentialising- 
decisionality-<as-to-disontologising/re-ontologising aporeticism $>$ ' turns out to be resistantand-tenuous and rather of crossgenerational occurrence (and particularly so as to an apathetic human mental-complex that practically tends to relate to the social as non-ontological in nature even as to when ontological-veracity is demonstrated and thus speaking to the veridical fact that prospective knowledge in this respect is one of the psychoanalytic-unshackling/memeticreordering/institutional-recomposuring of human underlying elaborate <amplituding/formative> wooden-language-_imbued-temporal-mere-

\section{form/virtualities/dereification/akrasiatic-drag/denatured/preconverging-or-dementing}

\section{narratives - of-the- reference-of-thought- categorical-imperatives/axioms/registry-}

teleology $>$ so-associated successively with recurrent-utter-uninstitutionalisation trepidatiousconsciousness disontologising, base-institutionalisation-ununiversalisation warpedconsciousness disontologising, ${ }^{103}$ universalisation-non-positivism/medievalism preclusiveconsciousness disontologising and our present positivism- ${ }^{80}$ procrypticism occlusiveconsciousness disontologising). In this respect and as reflected across the $<$ cumulating/recomposuring attendant-ontological-contiguity $>$-successive registryworldviews/dimensions, $\quad$ pedantising/muddling/formulaic-hollowing-out—insubontologisation/subpotentiation-〈blurring/undermining-of-prospective-totalising-entailing,as-to-entailing-<amplituding/formative-epistemicity $>$ totalising in-relative-ontologicalcompleteness > disontologising (as to existential-extrication-as-of-existentialunthought temporal/mortal advantageousness and purposefulness) involves an ontologicallyflawed shallow-supererogation upholding of the 'existentialising-frame-of-entailment-ofmotif-and-apriorising/axiomatising/referencing of priorly secondnatured institutionalisationthreshold of mere-formulaicity/ritualisation-<as-to-mere-formulaicmethodologising/mutualising/organising/institutionalising,-prospectively-losing-track-of-

'\{epistemic-totalising ’’re-apriorising/re-axiomatising/re-referencing residuality-in-re- 
originariness/re-origination'> positive-opportunism—of-social-functioning-and-accordance as not speaking to prospective human disruptive postconvergingaaporeticismevercoming/unovercoming' conception in relation to prospective nascent-particular/incipientand-material/technical-sublimations- $<$ blinded-to-their-relative-ontological-completeness reference-of-thought- devolving $>$ as so-failing to reflect the veridical comprehensiveness and completeness of prospective sublimating-nascence (requiring 'supereregatery $\sim$ wholesomeness/profound-supererogation as of prospective ${ }^{83}$ reference-ofthought — point-of-devolving/departure/anchoring/backdrop_of_sublimating-nascence-<as-tothe-grandest-axiomatic-construct-fepistemic-alising $\stackrel{+}{5}$ re-apriorising/re-axiomatising/rereferencing $\sim$ residuality - in-re-originariness/re-origination of limitedness/human-subpotency prospective re-encountering/re-confrontation with unlimitedness/existence>') as to its prospective $<$ amplituding/formative $>$ disposedness/psychologismic-construct-〈as-toorientation/value-construct/valuation-and-derived-parameterising $\quad$ and $<$ ampliting/formative $>$ entailment-〈as-to-totalising-contiguous/coherent-factuality-ofvariability); as underlined by a cynical station of human ${ }^{79}$ presencing — absolutising-identitiveconstitutedness ${ }^{14}$ demand for 'philosophical concreteness' (and cynically so notwithstanding the 'dragged-out nature or psychologismic-epistemic-acutisation-<as-to-postconverging-dementating/structuring/paradigming,-eliciting-of-existence's-sublimating-nascence-inprospective-aporeticism-overcoming/unovercoming $>$ as to epistemic-growth,-as\{veridieal/sound\}-relative-reflexivity-in-existence/relativising from limited mentation as its deepening/psychologismic epistemic-acutisation residualising, decompulsing $_{\text {\} }}$ delinearity for eogency' of 'prospective ${ }^{83}$ reference-of-thought appraisal of sublimating-nascence comprehensiveness/nonimmediacy/indirectness') thus undermining the notion of prospective human epistemic-growth/disquiet/discomfort-_induced-sublimation,-as-from-existence's effusing/ecstatic-inlining-as- historiality-\{science/authenticity/nonextrication -beyond-mere- 
formulaicity/ritualisation-as- historicity-tracing- $\{$ science-ideology/fashionability/distraction $\}$ )

while cultivating 'normalised/stereotyped/selfhelping/feel-good knowledge being brought at the protracted-social — as-to-individual-by-institutional-by-social sovereign's service' and in soreflecting temporally-motivated human protracted-social-as-to-individual-by-institutional-bysocial manifest <amplituding/formative> wooden-language-_imbued-temporal-mereform/virtualities/dereification/akrasiatic-drag/denatured/preconverging-or-dementing narratives - of-the- reference-of-thought- categorical-imperatives/axioms/registryteleology $\rangle$. Such an in-effect absolution-<as-to-apriorising/axiomatising/referencing-\{of'prospectively implicited_attendant-ontological-contiguity ' educedexistentialising/contextualising/textualising_'intelligibility/epistemicity/reflexivity-contiguity$<$ imbued-notional cogency $>$ ' $\}$-constitutedness -in-preconverging-entailment $>$ projection of ${ }^{56}$ meaningfulness-and-teleology ${ }^{9}$ (underlined by the cynical cultivation of a preconverging existential-extrication-as-of-existential-unthought mentality as to imply all the world that exists is respectively either as of recurrent-utter-uninstitutionalisation, base-institutionalisationununiversalisation, $\quad{ }^{103}$ universalisation-non-positivism/medievalism or our positivismprocrypticism in a closemindedness to the 'human consciousness notional protensivity imbuing prospective psychologismic-epistemic-acutisation-<as-to-postconverging-dementating/structuring/paradigming,-eliciting-of-existence's-sublimating-nascence-inprospective-aporeticism-overcoming/unovercoming $>$ as to epistemic-growth,-as\{veridical/sound\}-relative-reflexivity-in-existence/relativising from-limited-mentation-as-itsdeepening/psychologismic epistemic-acutisation residualising, fdecompulsings delinearity foreogency' undergirding the 'full experientiality/experiment-<as-to-existentially-formative‘fepistemic originariness/re-origination',-so-'notionally/epistemically/bindingnessly<as-todeterminism/conceptivity-of-relative-unreflexivity/relative-reflexivity>_implicited-and-articulated'_as-from- 
nonextricatory-'prospective-re-ontologising-Being-then-Institutional-then-Living-magnitudesof-\{hermeneutic/reprojection -protraction-of $\}$ reframing-and-reformulation $\}$ ' $>$ that is the human abstract-tissue-of-social-emanance as to dimensionality-of-sublimating

\section{<<amplituding/formative>supererogatory de-mentativeness/epistemic-growth-or-}

\section{conflatedness /transvaluative-rationalising/transepistemicity/anamnestic-residuality/spirit-}

drivenness-equalisation)) is very much fundamentally manifest with the preconverging-dementating/structuring/paradigming

blurriness-<sterilising/anecdotalising/trivialising-ofprospective-re-ontologising_by-preconverging,-in-disontologising-formulaic-draggingout/hollowing-out $>$ undermining of prospective human sublimation/emancipation in need for prospective 'human psychologismic-epistemic-acutisation-<as-to-postconverging-dementating/structuring/paradigming,-eliciting-of-existence's-sublimating-nascence-inprospective-aporeticism-overcoming/unovercoming $>$ as to epistemic-growth,-as\{veridical/sound\}-relative-reflexivity-in-existence/relativising from-limited-mentation-as-itsdeepening/psychologismic epistemic-acutisation residualising, \{decompulsing ${ }^{2}$ delinearity foreogency' unblurriness-<re-ontologising_by-postconverging-as-to-dragged-outsupererogatory wholesomeness/profound-supererogation ,-while-anecdotalising-priordisontologising-thresholding $>$. The fact remains though that any pretense to understanding cannot escape ontology/science however unsavoury/savoury as to the full picture of prospective foregrounding_entailment-<in-succession-of-profound-supererogation $>>-\langle$ postconvergingnarrowing-down $\sim$ sublimation-as-to-'existence - as-sublimating-withdrawal/unenframing/reontologising,-elicited-from-prospective-profound-supererogation '-in-reflecting'immanent $\sim$ relative- unreflexivity/relative-reflexivity - ontological-contiguity ';-as-operativenotional deprocrypticism $\rangle$ required for genuine understanding and doesn't allow for any excepting as to human temporal/mortal convenience; such that there is no circumventing knowledge strategy but rather for pointing out and highlighting the nature and manifestation of 
such

$<$ amplituding/formative $>$ wooden-language-〈imbued-temporal-mere-

form/virtualities/dereification/akrasiatic-drag/denatured/preconverging-or-dementing

narratives - of-the- reference-of-thought- categorical-imperatives/axioms/registry-

teleology $>$ as to its cynical cultivation of social dumbing-down and/or numbinbing-traction-_-of-.

desublimating_- ${ }_{-}^{5}$ meaningfulness_-and-teleology - -Las-perspective-lost-of-

‘supererogatory acuity/perspicacity/astuteness/edginess/incisiveness-as-to-the-imbued-

postconverging/dialectical-thinking -of-notional deprocrypticism- $\{$ in-dimensionality-of-

sublimating _ < amplituding/formative-epistemicity>growth-or-

conflatedness /scalarisation-as-to-rescalarisation-as-re-ontologisation $\left.\}^{\prime}\right\rangle$ as the enabling basis

for its preconverging-existential-extrication-as-of-existential-unthought temporal/mortal advantageousness and purposefulness in distractive-alignment-to- ${ }^{8}$ reference-of-thought- $<$ ofapriorising/axiomatising/referencing $>^{30}$. But then the reality of the social equally speaks to the 'overall social intellection-aptitude body' to which the veridical unblurring of human prospective postconverging apereticism elicits prospective intellectual responsiveness that is in-many-ways (however the 'dragged-out nature or psychologismic-. epistemic-acutisation-<as-to-postconverging-de-mentating/structuring/paradigming,-elicitingof-existence's-sublimating-nascence-in-prospective-aporeticism-overcoming/unovercoming> as to epistemic-growth,-as - \{veridical/sound\}-relative-reflexivity-in-existence/relativising from-limited-mentation-as-its-deepening/psychologismic epistemic-acutisationresidualising, ${ }^{\text {\{decompulsing }}$ delinearity for cogeney') up to the task of taking on desublimating pedantising/muddling/formulaic-hollowing-out — in-subontologisation/subpotentiation〈blurring/undermining-of-prospective-totalising-entailing,-as-to-entailing$<$ ampliting formative-epistemicity $>$ totalising in-relative-ontological-completeness $>$ cultivated distraction/indifference/passivity/debased relation to prospective transcendence-andsublimity/sublimation/supererogatory $\sim$ de-mentativity; explaining the totalisingly-ing- 
discretion/whim-of-thought reality of such manifest blurriness$<$ sterilising/anecdotalising/trivialising-of-prospective-re-ontologising_by-preconverging,-indisontologising-formulaic-dragging-out/hollowing-out>. But then such a challenge become more prescient and acute when mere sterile/anecdotal institutional-prescience/imprimaturing<dullness-of the-spirit/psychologismic epistemic acutisation nonresidualising imbued\{compulsing\} linearity-in-eclecticism-of-prior-mere-formulaicity/ritualisation $>$ displays a deficient/poor aptitudinal re-ontologising-incompetence gesturing/accounting-of-epistemicphenomenalism (that can effectively be so-construed as incompetent by the fact that critical members of the 'overall social intellection-aptitude body' are able to grasp the requisite appropriateness of profound aptitudinal re-ontologising-competence gesturing/accounting-ofepistemic-phenomenalism as to their relevant generalised profound aptitudinal re-ontologisingcompetence gesturing/accounting — of-epistemic-phenomenalism associated with the mastery of their various specialisms as well as their general knowledge interests); as so-implied herein and so-appreciated in relatively unblurriness-<re-ontologising_by-postconverging-as-to-draggedout-supererogatery $\sim$ wholesomeness/profound-supererogation ,-while-anecdotalising-priordisontologising-thresholding $>$ domains-of-study with regards to requisite "posteonverging nonextricatory-existential-preempting-of-existential-unthought prospective notional-

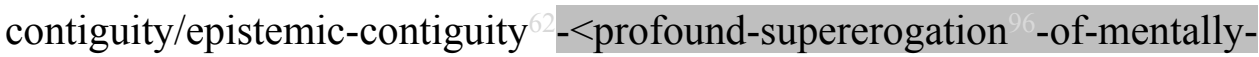
aestheticised postconverging/dialectical-thinking -qualia-schema $>$ profound aptitudinal reontologising-competence gesturing/accounting-of-epistemic-phenomenalism' while avoiding 'preconverging-existential-extrication-as-of-existential-unthought notional totalisingly-ingdiscretion/whim-of-thought deficient/poor aptitudinal re-ontologising-incompetence gesturing/accounting —of-epistemic-phenomenalism' (and so-specifically elaborated herein as to projective-insights for the appraisal of sublimating momentous ${ }^{4}$ historiality/ontologicaleventfulness 3 /ontological-aesthetic-tracing-< 
normalcy/postconvergence-reflected-'epistemicity-relativism-determinism'> so-enabled only by a developed sense of metaphysics-of-absence-_implicited-epistemic-veracity-ofnonpresencing-<perspective-ontological-normalcy/postconvergence $>\rangle$ in contrast to a 'circular perpetually-unknowing presencing-absolutising-identitive-constitutedness deficient/poor aptitudinal re-ontologising-incompetence gesturing/accounting-of-epistemicphenomenalism'). Human ${ }^{56}$ meaningfulness-and-teleology (as herein construed) as of its implied ontologising conception is effectively reflective of the reality of the social as to its manifest human 'social-functioning-and-accordance-as-of-social-stake-contention-orconfliction imbuing existentialising-frame-of-entailment-of motif-andapriorising/axiomatising/referencing of disontologising/ontologising-and-re-ontologising' as to thus correspondingly and contrastively implying a disontologising conception (herein construed as $<$ amplituding/formative $>$ wooden-language-〈imbued-temporal-mere-

\section{form/virtualities/dereification/akrasiatic-drag/denatured/preconverging-or-dementing} narratives - of-the- reference-of-thought- categorical-imperatives/axioms/registry-

teleology $>$ ) with the latter explaining the 'fundamental taboo against prospective ontologisingand-re-ontologising'; as so-reflecting registry-worldviews/dimensions imbued priorinstitutionalisation-threshold-by-prospective-uninstitutionalised-threshold 'self-referencingsyncretising forward-facing-supposedly postconverging-or-dialectical-thinking -apriorisingpsychologism epistemic-projection as of prior mere-formulaicity/ritualisation- $<$ as-to-mereformulaic — methodologising/mutualising/organising/institutionalising,-prospectively-losingtrack-of- ‘fepistemic-totalising ’’’re-apriorising/re-axiomatising/re-referencing $\sim$ residuality-in-reoriginariness/re-origination'>' and so-reflecting their 'disontologising preconverging/dementing $-<$ as-to-prospective-uninstitutionalised-threshold $>$ ignoring/biased inclination' for the sake of 'their given present minimum-and-balancing expectations/anticipations of social-functioning-and-accordance-as-of-social-stake- 
contention-or-confliction' while qualifying their prospectively uninstitutionalised-threshold actually as nondescript/ignorable-void as to their ${ }^{79}$ presencing-absolutising-identitiveconstitutedness <preconverging 'motif-and-apriorising/axiomatising/referencing' entailing >-existentialising — enframing/imprintedness-〈as-to- historicity-tracing —inpresencing-hyperrealisation/hyperreal-transposition). So-insightfully understood by the fact that the ordinary state of recurrent-utter-uninstitutionalisation, ununiversalisation, nonpositivism/medievalism and ${ }^{80}$ procrypticism-or-disjointedness-as-of- ${ }^{3}$ reference-of-thought (with regards to the "exercise of the epistemic - projective-equalisation of human station of presencing-absolutising-identitive-constitutedness ${ }^{14}$ as to prospective ${ }^{6}$ nonpresencing<perspective-ontological-normalcy/postconvergence $>$ epistemic-projective-equalisation') do not inherently epistemically contemplatively project of themselves respectively as of baseinstitutionalisation, ${ }^{103}$ universalisation, positivism/rational-empiricism and prospective deprocrypticism-or-preempting - disjointedness-as-of- ${ }^{3}$ reference-of-thought $\quad$ (as $\quad$ sowarranted with the postconverging-nonextricatory-existential-preempting-of-existentialunthought core vocation of notional philosophy-<as-to-the-veridical-conception-ofphilosophy-as-englobing-all-human-prospective-organic-knowledge-generation-in-relativeontological-completeness ,-beyond-a-convenient-division-of-labour-conception-ofknowledge $>$ as to the projected 'human consciousness notional protensivity imbuing prospective psychologismic-epistemic-acutisation-<as-to-postconverging-dementating/structuring/paradigming,-eliciting-of-existence's-sublimating-nascence-inprospective-aporeticism-overcoming/unovercoming $>$ as to epistemic-growth,-as\{veridical/sound\}-relative-reflexivity-in-existence/relativising from-limited-mentation-as-itsdeepening/psychologismic epistemic acutisation residualising, fdecompulsing $_{\text {\} }}$ delinearity for eogency' undergirding the 'full experientiality/experiment-<as-to-existentially-formative‘fepistemic-atising ’’re-apriorising/re-axiomatising/re-referencing residuality-in-re- 
originariness/re-origination', - so-'notionally/epistemically/bindingnessly-<as-to-

determinism/conceptivity-of-relative-unreflexivity/relative-reflexivity>_implicited-and-articulated'_as-from-

nonextricatory-'prospective-re-ontologising-Being-then-Institutional-then-Living-magnitudes-

of-\{hermeneutic/reprojection -protraction-of $\}$ reframing-and-reformulation $\}$ ' $>$ that is the human abstract-tissue-of-social-emanance'); speaking to the circularly recurring issue for prospective sublimating explanation (in the face of circularly recurring prospective desublimating presencing-absolutising-identitive-constitutedness ${ }^{14}$ ) with regards to the fact that 'sublimating explanation' itself (as to dimensionality-of-sublimating <<amplituding/formative>supererogatory $\sim$ de-mentativeness/epistemic-growth-orconflatedness /transvaluative-rationalising/transepistemicity/anamnestic-residuality/spiritdrivenness-equalisation〉) doesn't escape from the in-effect absolution-<as-toapriorising/axiomatising/referencing-\{of-'prospectively implicited_attendant-ontologicalcontiguity ' educedexistentialising/contextualising/textualising_'intelligibility/epistemicity/reflexivity-contiguity$<$ imbued-notional cogency $>$ ' $\quad\}$-constitutedness -in-preconverging-entailment $>\quad$ fixated notional nonprotensivity (whether fixated trepidatious, fixated warped, fixated preclusive or fixated occlusive as to fixated dimensionality-of-desublimating-lack-of <<amplituding/formative>supererogatory $\sim$ de-mentativeness/epistemic-growth-orconflatedness /transvaluative-rationalising/transepistemicity/anamnestic-residuality/spiritdrivenness-equalisation)) to which it explains as to human limited-mentation-capacitydeepening —as-subjecting limitedness/human-subpotency-to-'educed-unlimitedness/existencesublimating nascence' ${ }^{53}$ developing notional protensivity (highlighting the relativeunreflexivity/relative-reflexivity — ontological-contiguity ${ }^{67} \sim$ of-the-human-institutionalisation-

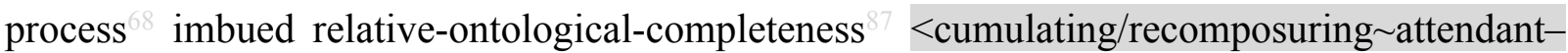
ontological-contiguity >-succession developing process as from trepidatious, warped, 
preclusive, occlusive to protensive as to developing dimensionality-of-sublimating ${ }^{5}$ <<amplituding/formative>supererogatory $\sim$ de-mentativeness/epistemic-growth-or-

conflatedness /transvaluative-rationalising/transepistemicity/anamnestic-residuality/spirit-

drivenness-equalisation)). Thus the postconvergingaaporeticism-overcoming/unovercoming issue associated with an ontologising construal of human <amplituding/formative $>$ woodenlanguage-〈imbued - temporal-mere-form/virtualities/dereification/akrasiaticdrag/denatured/preconverging-or-dementing -narratives - of-the- reference-of-thoughtcategorical-imperatives/axioms/registry-teleology $\rangle$ is fundamentally one of disruption to 'their given present minimum-and-balancing expectations/anticipations of social-functioningand-accordance-as-of-social-stake-contention-or-confliction'; as can be appreciated with the stark elucidation further above with regards to the fact that a positivism/rational-empiricism mindset encounter with say an animistic social-setup cannot relate to the latter in 'absolute terms of effectively demonstrable positivism/rational-empiricism systematicity/entailment of sublimating' (and so since inherent existence's ontological-veracity precedes/supersedes human $<$ amplituding/formative-epistemicity $>$-totalising $\sim$ thrownness-in-existence ${ }^{35}$, with ontologisingand-re-ontologising rather about optimising human aetiologisation/ontological-escalation$<$ ontological-veridicality_commitment/otherliness_transcending/compulsions-

encumbered_transcending $>\quad$ conceptivity/epistemic-reflexivity/epistemicity-relativismdeterminism-<reifying \{as-to-knowledge-developing\}-and-empowering $>$ with respect to educing existence's - effusing/ecstatic-inlining-as- ${ }^{4}$ historiality\{science/authenticity/nonextrication $\}$-beyond-mere-formulaicity/ritualisation-as- ${ }^{4}$ historicitytracing-\{science-ideology/fashionability/distraction $\}$ ). But then human limited-mentationcapacity—as-subjecting-'educed-unlimitedness/existence-sublimating nascence' tolimitedness/human-subpotency imbued 'preconverging/postconverging-dementative/structural/paradigmatic formative-risk of disontologisation associated with the 
prospect for veridical human ontologising/re-ontologising' for appropriate human sovereign 'epistemic-growth/disquiet/discomfort-〈induced-sublimation,-as-from-existence’s-

effusing/ecstatic-inlining-as- historiality-\{science/authenticity/nonextrication $\}$-beyond-mereformulaicity/ritualisation-as- historicity-tracing-\{science-ideology/fashionability/distraction $\}$ ) as to construction-of-the-Self in dispensing-with-immediacy-for-relative-ontologicalcompleteness $^{87}$-by-reification/contemplative-distension ${ }^{27}$ ' means paradoxically that the prospect for ontologising ${ }^{56}$ meaningfulness-and-teleology ${ }^{9}$ cannot be divorced from the formative-risk of disontologising <amplituding-formative> wooden-language-_imbued-temporal-mereform/virtualities/dereification/akrasiatic-drag/denatured/preconverging-or-dementing narratives - of-the- reference-of-thought- categorical-imperatives/axioms/registryteleology > (so-associated with the reality of human limited-mentation-capacity-assubjecting-'educed-unlimitedness/existence-sublimating nascence' to-limitedness/humansubpotency and limited-mentation-capacity-deepening -as-subjecting limitedness/humansubpotency to 'educed unlimitedness/existence sublimating nascence' 53 implications). This critically means that both pedantising/muddling/formulaic-hollowing-out-insubontologisation/subpotentiation-〈blurring/undermining-of-prospective-totalising-entailing,as-to-entailing-<amplituding/formative-epistemicity $>$ totalising in-relative-ontologicalcompleteness $>$ and notional philosophy-<as-to-the-veridical-conception-of-philosophy-asenglobing-all-human-prospective-organic-knowledge-generation-in-relative-ontologicalcompleteness ,-beyond-a-convenient-division-of-labour-conception-of-knowledge $>\quad$ are susceptible to disontologising <amplituding/formative $>$ wooden-language-〈imbued temporal-mere-form/virtualities/dereification/akrasiatic-drag/denatured/preconverging-ordementing -narratives - of-the- reference-of-thought- categoricalimperatives/axioms/registry-teleology $\rangle$; with the fundamental difference of their disontologising possibilities rather arising respectively as to the former's ontological-bad- 
faith/inauthenticity ${ }^{64}$ preconverging-de-mentating/structuring/paradigming ${ }^{55}$ and the latter's ontological-good-faith/authenticity $\sim$ postconverging-de-mentating/structuring/paradigming (in their self-reflexive $\sim$ instigative-eventuating-〈as-to-teleological-instigative/incipientwilling/arbitrariness/waywardness/faithdrivenness/supererogating-for-human-intelligibility,preceding-existence's-eventuating-sublimating-validation/desublimating-invalidation〉). Thus the possibility for such an effective disambiguation is rather as of "nonpresencing$<$ perspective-ontological-normalcy/postconvergence $>$ epistemic-projection of transversality$<$ for-sublimating-existential-eventuating/denouement-from-'thinking-at-first/purepredisposition-preemptive-of prospective-disontologising/subontologising' as-ofprospectively-disambiguated-affirmed-and-unaffirmed-'motif-andapriorising/axiomatising/referencing' $>101$ in so-elucidating notional $\sim$ philosophy- $<$ as-to-theveridical-conception-of-philosophy-as-englobing-all-human-prospective-organic-knowledgegeneration-in-relative-ontological-completeness ,-beyond-a-convenient-division-of-labourconception-of-knowledge> ontologising 'intradimensional sublimating-nascence incipience/instantaneity/directness' and/or ontologising 'interdimensional/transdimensional prospective $\quad$ reference-of-thought appraisal of sublimating-nascence comprehensiveness/nonimmediacy/indirectness' given its ${ }^{6}$ nonpresencing-<perspectiveontological-normalcy/postconvergence $>$ epistemic-projection predisposition; and so, in contrast to pedantising/muddling/formulaic-hollowing-out-in-subontologisation/subpotentiation〈blurring/undermining-of-prospective-totalising-entailing,-as-to-entailing<amplituding/formative-epistemicity >totalising in-relative-ontological-completeness > disontologising relation to prospective sublimating-nascence given its ${ }^{79}$ presencingabsolutising-identitive-constitutedness ${ }^{14}$ epistemic-projection predisposition. Thus reflecting the fact that <amplituding-formative> wooden-language-_imbued-temporal-mereform/virtualities/dereification/akrasiatic-drag/denatured/preconverging-or-dementing 
narratives - of-the- reference-of-thought- categorical-imperatives/axioms/registry-

teleology $>$ construal is rather achieved by its 'disambiguative-overriding/ unblurriness- $<$ reontologising_by-postconverging-as-to-dragged-out-supererogatory -wholesomeness/profoundsupererogation ,-while-anecdotalising-prior-disontologising-thresholding $>$ arising in the course of nonpresencing-<perspective-ontological-normalcy/postconvergence $>$ epistemicprojection of transversality- $<$ for-sublimating-existential-eventuating/denouement-from-

\section{thinking -at-first/pure-predisposition-preemptive-of-prospective-}

disontologising/subontologising' as-of-prospectively-disambiguated-affirmed-andunaffirmed-‘motif-and-apriorising/axiomatising/referencing'> ${ }^{101}$ elucidation' (as to more and more profound underlying 'implicited_attendant-ontological-contiguity ${ }^{67}$; educedexistentialising/eontextualising/textualising_'intelligibility/epistemicity/reflexivity-contiguity$<$ imbued-notional cogency $>^{\prime}$ and as herein reflected with the underlying ratiocontiguity/ratiocination-as-referentialism_-implicited_attendant-ontologicalcontiguity $^{67}$; educed-

existentialising/contextmalising/textualising_'intelligibility/epistemicity/reflexivity_contiguity$<$ imbued-notional cogency $>$ ' in a knowledge-notionalisation profound aetiologisation/ontological-escalation-<ontological-

veridicality_commitment/otherliness_transcending/compulsions-encumbered_transcending> conceptivity/epistemic-reflexivity/epistemicity-relativism-determinism-<reifying \{as-toknowledge-developing $\}$-and-empowering $>$ involving understanding both human individuative 'ignorances'/desublimation/temporal-dispositions and knowledge/sublimation/intemporaldisposition manifestation as to 'undermining of totalisingly-ing — discretion/whim-of-thought'). Critically such a 'disambiguative-overriding/' unblurriness-<re-ontologising_bypostconverging-as-to-dragged-out-supererogatory $\sim$ wholesomeness/profound-supererogation while-anecdotalising-prior-disontologising-thresholding $>$ arising in the course of 
nonpresencing-<perspective--ontological-normalcy/postconvergence $>$ epistemic-projection of transversality-<for-sublimating-existential-eventuating/denouement,-from-'thinking atfirst/pure-predisposition-preemptive-of-prospective-disontologising/subontologising' as-ofprospectively-disambiguated-affirmed-and-unaffirmed-'motif-andapriorising/axiomatising/referencing' $>101$ elucidation' is meant to accommodate socialfunctioning-and-accordance-as-of-social-stake-contention-or-confliction in so-allowing for the prospective prompting of 'constraining existence-as-sublimatingwithdrawal/unenframing/re-ontologising,-elicited-from-prospective-profound-supererogation imbuing human ontological-commitment $-<$ implied - self-assuredness-of-ontological-goodfaith/authenticity $\sim$ postconverging-de-mentating/structuring/paradigming -as-being-as-ofexistential-reality>' and ' ${ }^{103}$ universal-transparency ${ }^{104}$-〈transparency-of-totalising-entailing,-asto-entailing-<amplituding/formative-epistemicity $>$ totalising $\sim$ in-relative-ontologicalcompleteness $\rangle$ as available-to/elicitable-to-〈as-to-human-consciousness/collectiveconsciousness-distendedness/detruncating-<beyond-selfpresencing,-as-re-ontologisingdecentering_of-consciousness/collective-consciousness,-as-to-psychologismic-epistemicacutisation-residualising, ${ }^{-}$decompulsing $\}$delinearity for-cogency $>>$the social-functioning-andaccordance-as-of-social-stake-contention-or-confliction conception of any given registryworldview/dimension $\quad$ preconverging 'motif-and-apriorising/axiomatising/referencing'entailing >-existentialising — enframing/imprintedness-〈as-to- historicity-tracing-inpresencing-hyperrealisation/hyperreal-transposition〉'. This insight basically explains-andaccounts for the impersonalisation and objectification underlying all ontology/science existentialising-frame-of-entailment of motif-and-apriorising/axiomatising/referencing of knowledge-discursivity-〈in-determining-human-ontological-performance -<including-virtueas-ontology $>\rangle$, as without such ontological-normalcy/postconvergence epistemic-projection disambiguative process of aetiologisation/ontological-escalation- $<$ ontological- 
veridicality_commitment/otherliness_transcending/compulsions-encumbered_transcending > conceptivity/epistemic-reflexivity/epistemicity-relativism-determinism- $<$ reifying \{as-toknowledge-developing -and-empowering $>$ (as explained and justified above) then the claim to an objective existentialising-frame-of-entailment-of motif-andapriorising/axiomatising/referencing of knowledge-discursivity-〈in-determining-humanontological-performance - $<$ including-virtue-as-ontology $>\rangle$ is fundamentally flawed; given the inherent specifically manifestable disontologising <amplituding/formative $>$ wooden-language〈imbued-averaging-of-thought-<as-to-leveling/ressentiment/closed-construct-ofmeaningfulness-and-teleology -as-of-‘nondescript/ignorable-void '-with-regards-toprospective-apriorising-implications $>>$ accompanying the claim to prospective ontologising meaningfulness-and-teleology inherent to any given registry-worldview/dimension with regards to the implications of human limited-mentation-capacity-as-subjecting-'educedunlimitedness/existence-sublimating nascence' to-limitedness/human-subpotency and limitedmentation-capacity-deepening —as subjecting limitedness/human-subpoten to 'educedunlimitedness/existence-sublimating nascence' (so-summarily reflected as to recurrent-utteruninstitutionalisation trepidatious-consciousness manifestable disontologising, baseinstitutionalisation-ununiversalisation warped-consciousness manifestable disontologising, ${ }^{3}$ universalisation-non-positivism/medievalism preclusive-consciousness manifestable disontologising and our present positivism- ${ }^{8}$ procrypticism occlusive-consciousness manifestable disontologising). This speaks to the fact that there is no inherently neutral/objective human existentialising-frame-of-entailment of motif-and-apriorising/axiomatising/referencing of knowledge-discursivity-〈in-determining-human-ontological-performance -<includingvirtue-as-ontology $>>$ as to any presencing-absolutising-identitive-constitutedness epistemic-projection and supposedly attempting to objectify knowledge-discursivity-〈indetermining-human-ontological-performance - $<$ including-virtue-as-ontology $>>$ this way for 
prospective sublimating ${ }^{56}$ meaningfulness-and-teleology ${ }^{9}$ will mean contemplatively accounting for the 'plausible/contemplatable conspiratorial motives of meaningfulness and purposefulness' (as to the given registry-worldview/worldview $<$ amplitung/formative $>$ wooden-language-<imbued - averaging-of-thought-<as-toleveling/ressentiment/closed-construct-of- meaningfulness-and-teleology -as-of'nondescript/ignorable-void '-with-regards-to-prospective-apriorising-implications $>\rangle$ ) associable with all parties partaking/interested/commenting/elucidating with regards to the said knowledge-discursivity-〈in-determining-human-ontological-performance -<including-virtueas-ontology $>\rangle$ (which will inherently render such supposed knowledge-discursivity-〈indetermining-human-ontological-performance - - including-virtue-as-ontology $>>\quad$ chaotic together with the more fundamental circular issue of lacking ontologicalnormalcy/postconvergence epistemic-projection disambiguative process of aetiologisation/ontological-escalation- $<$ ontologicalveridicality_commitment/otherliness_transcending/compulsions-encumbered_transcending > conceptivity/epistemic-reflexivity/epistemicity-relativism-determinism- $<$ reifying \{as-toknowledge-developing\}-and-empowering $>$ ). An ontological/scientific construct 'escalates' specific/particular manifest instances of phenomena into a ${ }^{103}$ universal or totalising-entailing conceptualisation (as supererogatory $\sim$ acuity/perspicacity/astuteness/edginess/incisiveness-ofapriorising/axiomatising/referencing/intelligibilitysettingup/measuringinstrumenting -forconceptualisation) which 'knowledge principle conceptualisation' then addresses (percolates into) the 'infinity of related incidental phenomena and cases' (as aposteriorising/logicising/deriving/intelligising/measuring- ${ }^{5}$ meaningfulness-and-teleology ${ }^{9}$ ); and in this respect, Newton articulates the science of mechanics metaphorically from an 'initial apple that hits his head while under a tree' not because the science of mechanics will revolve around an apple that hit his head (so-construed as metaphysics-of-presence-〈implicited- 
'nondescript/ignorable-void ' -as-to- presencing — absolutising-identitive-constitutedness >

epistemic-projection perspective involving a 'mostly disconnected analysis of all the possible circumstantial factual and self-interest motives implications as to an apple that hit his head to soderive supposedly the science of mechanics which is actually circularly irrelevant because such an exercise doesn't still reflect the relevant recurrent/totalising-entailing existence manifestations across time and space of the science of mechanics as aetiologisation/ontologicalescalation-<ontological-veridicality_commitment/otherliness_transcending/compulsionsencumbered_transcending $>\quad$ conceptivity/epistemic-reflexivity/epistemicity-relativismdeterminism-<reifying \{as-to-knowledge-developing $\}$-and-empowering $>$ ' as to its sublimatingnascence incipience/instantaneity/directness) but because he'll grasp the projective-insights 'as from prior reflection and as to the punctual circumstantial insight of an apple that hit his head' to understand the myriad and infinity of instances requiring those laws of physics he articulates as to his Principia imbued psychologismic apriorising/axiomatising/referencing-\{of'prospectively_implicited_attendant-ontological-contiguity ' educedexistentialising/contextualising/textualising_'intelligibility/epistemicity/reflexivity-contiguity<imbued-notional cogency $>$ ' $\}$ - conflatedness ${ }^{13}$ in-\{preconverging-ment by\} postconverging entailment (so-construed as nonpresencing-or-withdrawal/unenframing/reontologising-or-metaphysics-of-absence-_implicited-epistemic-veracity-of- nonpresencing$<$ perspective-ontological-normalcy/postconvergence $>$ - -or-transcendental-reasoning-ofevent $^{38}$-as-prospective-ontology-origination epistemic-projection perspective requiring rather the 'critical analysis and/or criticism of relevant recurrent/totalising-entailing existence manifestations across time and space available/potentially-available to all humans experientiality/experiment- $<$ as-to-existentially-formative-'fepistemic axiomatising/re-referencing residuality - in-re-originariness/re-origination',- so'notionally/epistemically/bindingnessly" 
implicited-and-articulated'_as-from-nonextricatory-'prospective-re-ontologising-Being-thenInstitutional-then-Living-magnitudes-of-\{hermeneutic/reprojection-protraction-of\}reframingand-reformulation $\}^{\prime}>\quad$ in $\quad$ limited-mentation-capacity-deepening-as-subjectinglimitedness/human-subpotency to-'educed-unlimitedness/existence-sublimating nascence' ${ }^{53}$ to so-derive effectively the science of mechanics as aetiologisation/ontological-escalation$<$ ontological-veridicality_commitment/otherliness_transcending/compulsionsencumbered_transcending $>$ conceptivity/epistemic-reflexivity/epistemicity-relativismdeterminism-<reifying \{as-to-knowledge-developing $\}$-and-empowering $>$ ' as to its sublimatingnascence incipience/instantaneity/directness). Actually, the above elucidation of the ${ }^{103}$ universal or totalising-entailing conceptualisation implications of ${ }^{6}$ nonpresencing-orwithdrawal/unenframing/re-ontologising-or-metaphysics-of-absence-〈implicited-epistemicveracity-of- nonpresencing-<perspective-ontological-normalcy/postconvergence $>$ )- ortranscendental-reasoning-of-event ${ }^{38}$-as-prospective-ontology-origination is just partial; when factoring in as highlighted above both the fact that there is no inherently neutral/objective human existentialising-frame-of-entailment-of-motif-and-apriorising/axiomatising/referencing of knowledge-discursivity-_in-determining-human-ontological-performance -<including-virtueas-ontology $>>$ as to any ${ }^{7}$ presencing-absolutising-identitive-constitutedness ${ }^{14}$ epistemicprojection and thus subsequently the requisite ontological-normalcy/postconvergence epistemicprojection disambiguative process of aetiologisation/ontological-escalation- $<$ ontologicalveridicality_commitment/otherliness_transcending/compulsions-encumbered_transcending > conceptivity/epistemic-reflexivity/epistemicity-relativism-determinism- $<$ reifying \{as-toknowledge-developing $\}$-and-empowering $>$ to resolve human limited-mentation-capacity-assubjecting-'educed-unlimitedness/existence-sublimating nascence' to-limitedness/humansubpotency implications of <amplituding/formative-epistemicity>-totalising $\sim$ thrownness-inexistence ${ }^{35}$ with regards to 'human psychologismic-epistemic-acutisation-<as-to- 
postconverging-de-mentating/structuring/paradigming,-eliciting-of-existence's-sublimatingnascence-in-prospective-aporeticism-overcoming/unovercoming $>$ as to epistemic-growth,-as\{veridical/sound\}-relative-reflexivity-in-existence/relativising from-limited-mentation-as-itsdeepening/psychologismic epistemic-acutisation residualising, ${ }^{\text {fdecompulsing }}$ delinearity foreogency' undergirding prospective sublimating human ontological-performance ${ }^{72}<$ includingvirtue-as-ontology>. The full/comprehensive/dragged-out ${ }^{103}$ universal or totalising-entailing conceptualisation implications of nonpresencing-or-withdrawal/unenframing/reontologising-or-metaphysics-of-absence-〈implicited-epistemic-veracity-of- nonpresencing$<$ perspective-ontological-normalcy/postconvergence $>$ )-or-transcendental-reasoning-ofevent $^{38}$-as-prospective-ontology-origination speaks to its dragging-out elucidation (in three concomitant epistemic-projection perspectives with regards to human <amplituding/formativeepistemicity>-totalising $\sim$ thrownness-in-existence ${ }^{35}$,-imbued-projectivearbitrariness/waywardness-〈as-to-the-human-projective/reprojective-aestheticising-re-motifand-re-apriorising/re-axiomatising/re-referencing-process-of- '<amplituding/formativeepistemicity>totalising conceptualisation'> developing/cultivated psychologismic-epistemicacutisation-<as-to-postconverging-de-mentating/structuring/paradigming,-eliciting-ofexistence's-sublimating-nascence-in-prospective-aporeticism-overcoming/unovercoming $>$ for prospective sublimating-nascence in prospective ${ }^{45}$ foregrounding _entailment- $<$ in-successionof-profound-supererogation $>>-\langle$ postconverging-narrowing-down $\sim$ sublimation-as-to‘existence - as-sublimating-withdrawal/unenframing/re-ontologising,-elicited-fromprospective-profound-supererogation '-in-reflecting-'immanent $\sim$ relativeunreflexivity/relative-reflexivity - ontological-contiguity ' ;-as-operativenotional deprocrypticism〉):

- firstly, as from the epistemic-projection perspective of the sublimating-nascence incipience/instantaneity/directness of nascent-particular/incipient-and-material/technical- 
sublimations- $<$ blinded-to-their-relative-ontological-completeness - reference-of-thought-

devolving > projective-insights of sublimating-nascence which is intradimensional to any given registry-worldview/dimension (such as 'positivism/rational-empiricism registryworldview/dimension 'implicited_attendant-ontological-contiguity ${ }^{67}$ > educedexistentialising/contextualising/textualising_intelligibility/epistemicity/reflexivity-contiguity<imbued-notional cogency>' as to Newtonian physics projective-insights of sublimatingnascence incipience/instantaneity/directness' and as so-effectively construable protractively in the course of the crossgenerational psychoanalytic-unshackling/memeticreordering/institutional-recomposuring self-becoming/self-conflatedness ${ }^{13} /$ formative- $^{-}$ supererogating-<projective/reprojective-aestheticising-re-motif-and-re-apriorising/reaxiomatising/re-referencing,-in-perspective-ontological-normalcy/postconvergence $>$ from the then non-positivism/medievalism registry-worldview/dimension self-presence/selfconstitutedness $^{14}-<$ in-perspective-epistemic-abnormalcy/preconvergence ${ }^{3}>$ in which it was instigated in punctual/immediacy/constituted/compulsions-encumbered projective-insights of sublimating-nascence to-then-be-reflected-upon-the-fully-attained positivism/rationalempiricism 'prospective ${ }^{83}$ reference-of-thought appraisal of sublimating-nascence comprehensiveness/nonimmediacy/indirectness' imbued 'supereregatory $\sim$ wholesomeness/profound-supererogation ${ }^{96}$ as of prospective ${ }^{83}$ reference-ofthought — point-of-devolving/departure/anchoring/backdrop_of_sublimating-nascence-<as-tothe-grandest-axiomatic-construct-fepistemic-alising $\stackrel{+}{+}$ re-apriorising/re-axiomatising/rereferencing - residuality - in-re-originariness/re-origination of limitedness/human-subpotency prospective re-encountering/re-confrontation with unlimitedness/existence>' as to the overall positivism/rational-empiricism ${ }^{83}$ reference-of-thought projective-insights of sublimatingnascence);

- secondly, overall transcendental/interdimensional/transdimensional registry- 
worldviews/dimensions-level dragged-out projective-insights of sublimating-nascence as to overall human limited-mentation-capacity-deepening —as-subjecting limitedness/humansubpotency to-'educed-unlimitedness/existence-sublimating naseence' ${ }^{3}$ underlied by the $<$ cumulating/recomposuring attendant-ontological-contiguity $>$-successive registryworldviews/dimensions in reflection of the overall relative-unreflexivity/relative-reflexivity ontological-contiguity ${ }^{67}$ of-the-human-institutionalisation-process ${ }^{68}$ (with the dragged-out projective-insights of sublimating-nascence rather specifically reflecting the ontologisingdepthing of the prospective 'notional $\sim$ deprocrypticism ${ }^{6}$ nonpresencing-<perspectiveontological-normalcy/postconvergence $>\quad$ ratiocontiguity/ratiocination-as-referentialism'implicited_attendant-ontological-contiguity ${ }^{67}$ > educedexistentialising/contextualising/textualising_'intelligibility/epistemicity/reflexivity-contiguity<imbued-notional cogency>' knowledge-notionalisation epistemic-projection perspective' as to 'human consciousness notional protensivity imbuing prospective psychologismic-epistemicacutisation-<as-to-postconverging-de-mentating/structuring/paradigming,-eliciting-ofexistence's-sublimating-nascence-in-prospective-aporeticism-overcoming/unovercoming $>$ as to epistemic-growth,-as - \{veridical/sound\}-relative-reflexivity-in-existence/relativising fromlimited mentation as its deepening/psychologismic epistemic acutisation residualising, \{decompulsing\} delinearity for-cogency' undergirding the 'full experientiality/experiment-<as-toexistentially-formative- ‘fepistemic-totalising 're-apriorising/re-axiomatising/rereferencing $\sim$ residuality —in-re-originariness/re-origination',- - so'notionally/epistemically/bindingnessly implicited-and-articulated'_as-from-nonextricatory-'prospective-re-ontologising-Being-thenInstitutional-then-Living-magnitudes-of-\{hermentic/reprojection-promingand-reformulation $\}^{\prime}>$ that is the human abstract-tissue-of-social-emanance');

- thirdly, human 'existentially-<disontologising/re-ontologising aporeticism $>$ applicative self- 
reflexivity as of notional $\sim$ self-distantiation- $<$ imbued-re-motif-and-re-apriorising/reaxiomatising/re-referencing $>$ about inherent existence's imbued experientiality/experiment- $<$ asto-existentially-formative-' ‘epistemictising ${ }^{\prime}$ re-apriorising/re-axiomatising/re-

referencing residuality - in-re-originariness/re-origination',- - so'notionally/epistemically/bindingnessly-<as-to-determinism/eoneeptivity-of-relative-unreflexivity/relative-reflexivity> implicited-and-articulated'_as-from-nonextricatory-'prospective-re-ontologising-Being-thenInstitutional-then-Living-magnitudes-of-\{hermeneutic/reprojection-protraction-of $\}$ reframingand-reformulation $\}^{\prime}>$ implicited/elicited projective-insights of sublimating-nascence as when the human mortal subjects itself to existence's sublimating-nascence' underlied by the fundamental existential-<disentologising/re-ontologising aporeticism $>$ framework of inherent human teleology or human 'phenomenal/manifest conceptivity/epistemicreflexivity/epistemicity-relativism-determinism-<reifying \{as-to-knowledge-developing $\}$-andempowering > in existence as ontological' (with regards to reifying-and-empowering-reflexivityof-ecstatic-existence-as-panintelligibility/panreflexivity ${ }^{3}$ - $\langle$ existentially-imbued-and-educing\& \{epistemic-totalising thermeneutically/textually/reprojectingly/supererogatingly/zeroingly/reacutingly,-\{decompulsing\} delinearity $\sim$ for-cogency $>$-epistemic-perspective-ofprojective/reprojective - aestheticising-re-motif-and-re-apriorising/re-axiomatising/rereferencing conceptualisation,-as-herein-specifically-relevant-to human-subpotency)) and coherently/cogently implicited postconverging-nonextricatory-existential-preempting-ofexistential-unthought implications (with respect to human Being-development/ontologicalframework-expansion-as-to-depth-of-ontologising-development-as-infrastructure-ofmeaningfulness-and-teleology , institutional-development-as-to-social-functiondevelopment and living-development-as-to-personality-development psychologismic epistemic-acutisation difficulty-for, residualising \{decomplsing $\}$ delinearity for-cogency> magnitudes \{of-experientiality/experiment\}). 
Thus the elaborate conception of nonpresencing-or-withdrawal/unenframing/re-ontologisingor-metaphysics-of-absence-〈implicited-epistemic-veracity-of- nonpresencing-<perspectiveontological-normalcy/postconvergence $>$ - - or-transcendental-reasoning-of-event ${ }^{38}$-asprospective-ontology-origination (as to its full/comprehensive/dragged-out ${ }^{103}$ universal or totalising-entailing conceptualisation implications of aetiologisation/ontological-escalation$<$ ontological-veridicality_commitment/otherliness_transcending/compulsions-

encumbered_transcending $>$ ) rather reflects the 'requisite human limited-mentation-capacitydeepening —as-subjecting limitedness/human-subpotency to-'educed-unlimitedness/existencesublimating nascence' ${ }^{53}$ implied conceptivity/epistemic-reflexivity/epistemicity-relativismdeterminism-<reifying \{as-to-knowledge-developing\}-and-empowering $>\quad$ of $\quad$ overarching 'implicited_attendant-ontological-contiguity ${ }^{67}$; educed-

existentialising/contextualising/textualising_intelligibility/epistemicity/reflexivity-contiguity<imbued-notional cogency>' $>^{\text {4 }}$ (as of more and more supererogatory wholesomeness/profound-supererogation $\quad{ }^{6}$ nonpresencing-<perspectiveontological-normalcy/postconvergence> epistemic-projection of sublimating-nascence)'; soconstrued as from the 'supereregatory wholesomeness/profound-supererogation' as of prospective reference-of-thought-point-ofdevolving/departure/anchoring/backdrop_of_sublimating-nascence-<as-to-the-grandestaxiomatic-construct-\{epistemic-totising $\stackrel{+}{+}$ re-apriorising/re-axiomatising/rerefereneing $\sim$ residuality - in-re-originariness/re-origination of limitedness/human-subpotency prospective re-encountering/re-confrontation with unlimitedness/existence>' reflecting the requisite prospective human psychologismic-epistemic-acutisation-<as-to-postconverging-dementating/structuring/paradigming,-eliciting-of-existence's-sublimating-nascence-inprospective-aporeticism-overcoming/unovercoming $>$ dragged-out projective-insights of sublimating-nascence, in so-enabling the veridical 'prospective ${ }^{83}$ reference-of-thought appraisal 
of sublimating-nascence comprehensiveness/nonimmediacy/indirectness' of the 'sublimatingnascence incipience/instantaneity/directness of nascent-particular/incipient-andmaterial/technical-sublimations-<blinded-to-their-relative-ontological-completeness reference-of-thought- devolving $>$ manifestation/phenomenality' (rather susceptible to presencing-absolutising-identitive-constitutedness ${ }^{14} \quad$ ontologically-flawed desublimating $\sim$ existentialising-decisionality-<as-to-disontologising/re-ontologising apereticism $>$ in the shallow-supererogation of prior ${ }^{83}$ reference-of-thought-point-ofdevolving/departure/anchoring/backdrop). It is this elaborate conception of nonpresencing-orwithdrawal/unenframing/re-ontologising-or-metaphysics-of-absence-〈implicited-epistemicveracity-of- nonpresencing-<perspective-ontological-normalcy/postconvergence $>$ ) - ortranscendental-reasoning-of-event ${ }^{38}$-as-prospective-ontology-origination that achieves/realises the ontological-veracity-<as-to-prospective-ontologising-and-re-ontologising $>$ of the epistemic — projective-equalisation exercise ('exercise of the epistemic — projective-equalisation of human station of ${ }^{7}$ presencing - absolutising-identitive-constitutedness ${ }^{14}$ as to prospective nonpresencing-<perspective-ontological-normalcy/postconvergence $>$ epistemic-projectiveequalisation') with regards to prospective human social-and-institutional-frameworks-ofreferencing/registering/decisioning sublimating $\sim$ existentialising-decisionality-<as-todisontologising/re-ontologising aporeticism $>$; with this further (as to the induced <postconverging 'motif-and-apriorising/axiomatising/referencing'-entailing >existentialising - framing/imprinting-〈as-to-prospective- historiality/ontologicaleventfulness /ontological-aesthetic-tracing-<perspective-ontologicalnormalcy/postconvergence-reflected-'epistemicity-relativism-determinism'>>) circularly reinforcing the prospect for prospective nascent-particular/incipient-and-material/technicalsublimations- $<$ blinded-to-their-relative-ontological-completeness - reference-of-thoughtdevolving $>$. In-the-bigger-scheme-of-things, the finality of the elaborate conception of 
nonpresencing-or-withdrawal/unenframing/re-ontologising-or-metaphysics-of-absence〈implicited-epistemic-veracity-of- nonpresencing-<perspective-ontologicalnormalcy/postconvergence $>$ ) - or-transcendental-reasoning-of-event ${ }^{38}$-as-prospective-ontologyorigination (as to its full/comprehensive/dragged-out ${ }^{103}$ universal or totalising-entailing conceptualisation implications of aetiologisation/ontological-escalation- $<$ ontologicalveridicality_commitment/otherliness_transcending/compulsions-encumbered_transcending $>$ ) thus doesn't truly lie with the 'punctual particularities of sublimating-nascence incipience/instantaneity/directness' (as to an ontologically-flawed 'normalised/stereotyped/selfhelping/feel-good knowledge being brought at the protractedsocial-as-to-individual-by-institutional-by-social sovereign's service' in human selfpresence/self-constitutedness ${ }^{14}$ - in-perspective-epistemic-abnormalcy/preconvergence ${ }^{3}>$ ontological-bad-faith/inauthenticity ${ }^{6} \sim$ preconverging-de-mentating/structuring/paradigming ${ }^{65}$ ) but rather effectively lie with the 'prospective ${ }^{83}$ reference-of-thought appraisal of sublimatingnascence comprehensiveness/nonimmediacy/indirectness' as to 'dragged-out nature or psychologismic-epistemic-acutisation-<as-to-postconverging-de-

mentating/structuring/paradigming,-eliciting-of-existence's-sublimating-nascence-inprospective-aporeticism-overcoming/unovercoming $>$ as to epistemic-growth,-as\{veridical/sound\}-relative-reflexivity-in-existence/relativising from-limited-mentation-as-itsdeepening/psychologismic epistemic-acutisation residualising, \{decompulsingl delinearity for eogency' imbued 'supereregatory wholesomeness/profound-supererogation as of prospective reference-of-thought_-point-of-devolving/departure/anchoring/backdrop_of_sublimating_

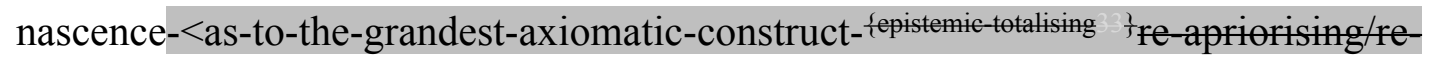
axiomatising/re-referencing $\sim$ residuality - in-re-originariness/re-origination of limitedness/human-subpotency prospective re-encountering/re-confrontation with unlimitedness/existence> (that fundamentally so-foregathers/so-underlines-the-incipient- 
wholeness of sublimating-nascence as reflected by the underlying soundness of human placeholder-setup/mental-devising-representation/mentation/consciousness-awarenessteleology ${ }^{9}$ with regards to all the relevant 'punctual particularities of sublimating-nascence incipience/instantaneity/directness' in so-emphasising the appropriate underlying 'human protracted-social—as-to-individual-by-institutional-by-social notional $\sim$ self-distantiation$<$ imbued —re-motif-and-re-apriorising/re-axiomatising/re-referencing $>\quad$ induced crossgenerational psychoanalytic-unshackling/memetic-reordering/institutional-recomposuring self-becoming/self-conflatedness ${ }^{13}$ /formative-supererogating-<projective/reprojectiveaestheticising-re-motif-and-re-apriorising/re-axiomatising/re-referencing,-in-perspectiveontological-normalcy/postconvergence>' ). In this regards (and as to the fact that there is no inherently neutral/objective human existentialising-frame-of-entailment-of-motif-andapriorising/axiomatising/referencing of knowledge-discursivity-〈in-determining-humanontological-performance -<including-virtue-as-ontology $>\rangle$ as to any presencingabsolutising-identitive-constitutedness ${ }^{14}$ epistemic-projection and thus necessitating the ontological-normalcy/postconvergence epistemic-projection disambiguative process of aetiologisation/ontological-escalation-<ontological-

veridicality_commitment/otherliness_transcending/compulsions-encumbered_transcending > conceptivity/epistemic-reflexivity/epistemicity-relativism-determinism-<reifying \{as-toknowledge-developing $\}$-and-empowering $>$ to resolve human limited-mentation-capacity-assubjecting 'educed-unlimitedness/existence-sublimating nascence' to-limitedness/humansubpotency implications of <amplituding/formative-epistemicity>-totalising $\sim$ thrownness-inexistence) and as so-underlying the elaborate conception of nonpresencing-orwithdrawal/unenframing/re-ontologising-or-metaphysics-of-absence-_implicited-epistemicveracity-of- nonpresencing-<perspective-ontological-normalcy/postconvergence $>$ - - ortranscendental-reasoning-of-event ${ }^{38}$-as-prospective-ontology-origination (as to its 
full/comprehensive/dragged-out ${ }^{103}$ universal or totalising-entailing conceptualisation implications of aetiologisation/ontological-escalation- $<$ ontologicalveridicality_commitment/otherliness_transcending/compulsions-encumbered_transcending $>$ ); the relation between notional philosophy-<as-to-the-veridical-conception-of-philosophy-asenglobing-all-human-prospective-organic-knowledge-generation-in-relative-ontologicalcompleteness ,-beyond-a-convenient-division-of-labour-conception-of-knowledge > as of its core vocation advancing of prospective human psychologismic-epistemic-acutisation-<as-topostconverging-de-mentating/structuring/paradigming,-eliciting-of-existence's-sublimatingnascence-in-prospective-aporeticism-overcoming/unovercoming> and pedantising/muddling/formulaic-hollowing-out — in-subontologisation/subpotentiation〈blurring/undermining-of-prospective-totalising-entailing,-as-to-entailing$<$ amplituding/formative-epistemicity>totalising in-relative-ontological-completeness $>$ induced distractive-alignment-to- ${ }^{8}$ reference-of-thought- $<$ ofapriorising/axiomatising/referencing $>{ }^{30}$ circularly to that core vocation, rather speaks to their very 'incipient/seeding preconverging/postconverging-de-mentating/structuring/paradigming'

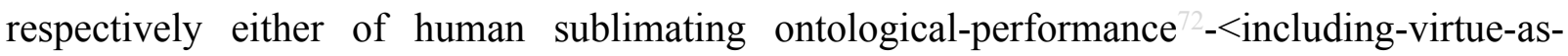
ontology $>$ /morality/ethics/justice/etc. of manifest prospective secondnatured institutionalisation or of human desublimating vices-and-impediments ${ }^{105}$ of manifest $\leq$ mereformulaicity/ritualisation-of $>$ prior secondnatured institutionalisation. The 'so-defined existentialising/contextualising/textualising framework of human notional ontologicalperformance ${ }^{72}-<$ including-virtue-as-ontology $>$ /vices-and-impediments ${ }^{105}$, (as to the 'allenglobing knowledge-notionalisation conceptivity/epistemic-reflexivity/epistemicityrelativism-determinism-<reifying \{as-to-knowledge-developing $\}$-and-empowering $>\quad$ of ratiocontiguity/ratiocination-as-referentialism_-implicited_attendant-ontologicalcontiguity $^{67}$; educed- 
existentialising/contextualising/textualising_intelligibility/epistemicity/reflexivity-contiguity<imbued-notional cogency> $>^{\prime 0}$ disambiguation of both manifest postconverging nonextricatory-existential-preempting-of-existential-unthought and preconverging-existentialextrication-as-of-existential-unthought') leaves no room for any other supposedly ontologically profound abstract contemplation/consideration of human notional ontological-performance ${ }^{72}$ <including-virtue-as-ontology $>$ /vices-and-impediments ${ }^{105}$ as can flawedly arise subontologically

extrapolating/constituting/abstracting/deducing/inferring-of-elucidation-outside-

'prospectively_implicited_attendant-ontological-contiguity ${ }^{67}$ >educed-

existentialising/contextualising/textualising_'intelligibility/epistemicity/reflexivity-contiguity<imbued-notional cogency>' (as so-implied from a subontologising naïve ${ }^{7}$ presencingabsolutising-identitive-constitutedness epistemic-projection perspective in $<$ amplituding/formative-epistemicity $>$ totalising $\sim$ self-referencingsyncretising/circularity/interiorising/akrasiatic-drag ${ }^{4}$ that as to its fundamental preconverging existential-extrication-as-of-existential-unthought threshold manifests its given ontologicallydeficient preconverging epistemic-projective-equalisation). The elaborate conception of nonpresencing-or-withdrawal/unenframing/re-ontologising-or-metaphysics-of-absence〈implicited-epistemic-veracity-of- nonpresencing-<perspective-ontologicalnormalcy/postconvergence $>$ ) - or-transcendental-reasoning-of-event ${ }^{38}$-as-prospective-ontologyorigination (as to its full/comprehensive/dragged-out ${ }^{103}$ universal or totalising-entailing conceptualisation implications of aetiologisation/ontological-escalation- $<$ ontologicalveridicality_commitment/otherliness_transcending/compulsions-encumbered_transcending $>$ ) necessarily lies with human angling-of-imaginary implied 'multicenturies-long human crossgenerational Being-development/ontological-framework-expansion-as-to-depth-ofontologising-development-as-infrastructure-of- meaningfulness-and-teleology 
psychologismic epistemic-acutisation difficulty-<or, residualising

\{decompulsing $\}$ delinearity for-cogeney> magnitude\{of-experientiality/experiment\} of prospective transcendence-and-sublimity/sublimation/supererogatory־de-mentativity' epistemic-projection of knowledge-value and knowledge-discursivity, and so over human psychical-nascency implied 'human lifespan extricatory punctuality/immediacy of depth-of-thought' epistemic-projection of knowledge-value and knowledge-discursivity. It can be appreciated that it is utterly unimportant ontologically-speaking that the prospective knowledge-value and knowledge-discursivity projected by Socrates or Galileo or Diderot be acknowledged/recognised/take-a-back-seat-to their given social-setup pedantising/muddling/formulaic-hollowing-out-insubontologisation/subpotentiation-〈blurring/undermining-of-prospective-totalising-entailing,as-to-entailing-<amplituding/formative-epistemicity $>$ totalising $\sim$ in-relative-ontologicalcompleteness > respectively as of non-universalising or non-positivising existentialising/contextualising/textualising framework of knowledge-value and knowledgediscursivity in the given $\leq$ mere-formulaicity/ritualisation-of $>$-prior secondnatured institutionalisation human psychical-nascency implied 'human lifespan extricatory punctuality/immediacy of depth-of-thought' epistemic-projection of knowledge-value entailment, and so warranting in lieu their veridical prospective notional $\sim$ philosophy- $<$ as-to-theveridical-conception-of-philosophy-as-englobing-all-human-prospective-organic-knowledgegeneration-in-relative-ontological-completeness ,-beyond-a-convenient-division-of-labourconception-of-knowledge $>$ respectively as of ${ }^{103}$ universalising-idealisation or positivism existentialising/contextualising/textualising framework of knowledge-value and knowledgediscursivity as to prospective secondnatured institutionalisation human angling-of-imaginary implied 'multicenturies-long human crossgenerational Being-development/ontologicalframework-expansion-as-to-depth-of-ontologising-development-as-infrastructure-of- 
residualising \{decompulsing\} delinearity for-cogency> - magnitude \{of-experientiality/experiment\}

prospective transcendence-and-sublimity/sublimation/supereregatory de-mentativity' postconverging epistemic - projective-equalisation of knowledge-value entailment; and so in reflection of the requisite 'supereregatory wholesomeness/profound-supererogation" as of prospective reference-of-thought-point-ofdevolving/departure/anchoring/backdrop_of_sublimating-nascence-<as-to-the-grandestaxiomatic-construct- fepistemic-totalising ${ }^{\prime}$ re-apriorising/re-axiomatising/rereferencing residuality - in-re-originariness/re-origination of limitedness/human-subpotency prospective re-encountering/re-confrontation with unlimitedness/existence>' that cannot be made to succumb to the human mortal scope of contemplation of sublimating-nascence (as of the prior 'human aestheticisation-and-aestheticisation-towards-ontology-<elicitedidiomatisation $>$ beholdening, non-transcendence, complexification as to mechanical-knowledge and non-ment of prior apriorising/axiomatising/referencing' as to human self-presence/selfconstitutedness ${ }^{14}-<$ in-perspective-epistemic-abnormalcy/preconvergence ${ }^{31}>$ ontological-badfaith/inauthenticity ${ }^{64}$ preconverging-de-mentating/structuring/paradigming ${ }^{65}$ ) and rather warrants prospective cumulating/recomposuring as to prospective 'human aestheticisation-andaestheticisation-towards-ontology-<elicited-idiomatisation $>$ unbeholdening, transcendence, decomplexification for organic-knowledge and ment of prior apriorising/axiomatising/referencing' as of human self-becoming/selfconflatedness $^{13} /$ formative-supererogating-<projective/reprojective-aestheticising-re-motifand-re-apriorising/re-axiomatising/re-referencing,-in-perspective-ontologicalnormalcy/postconvergence $>$ mentating/structuring/paradigming 70 This very much underlines the requisite notional asceticism in the elaborate conception of nonpresencing-orwithdrawal/unenframing/re-ontologising-or-metaphysics-of-absence-〈implicited-epistemic- 
veracity-of- nonpresencing-<perspective-ontological-normalcy/postconvergence $>$ - - or-

transcendental-reasoning-of-event ${ }^{38}$-as-prospective-ontology-origination (as to its full/comprehensive/dragged-out ${ }^{103}$ universal or totalising-entailing conceptualisation implications of aetiologisation/ontological-escalation- $<$ ontologicalveridicality_commitment/otherliness_transcending/compulsions-encumbered_transcending $>$ ), as so-involving intemporal-prioritisation-of- ${ }^{-3 e f e r e n c e-o f-t h o u g h t '-a s-c o n f l a t e d n e s s ~}{ }^{13}$-orontological-reprojecting; as rather arising not because of discrete choice of notional asceticism intemporal-projection but rather speaking to the fundamental intellectual-and-moral inadequacy/desublimating of prior Being-development/ontological-framework-expansion-asto-depth-of-ontologising-development-as-infrastructure-of- meaningfulness-and-teleology as to its manifest prior institutional-development-as-to-social-function-development and livingdevelopment-as-to-personality-development psychologismic epistemic-acutisationdifficulty $<$ for, residualising \{decomplom delinearity for-cogency> magnitudes $\{$ ofexperientiality/experiment' as of the 'relevant social-setup and/or institutional imbued self-presence/selfconstitutedness $^{14}$-<in-perspective-epistemic-abnormalcy/preconvergence ${ }^{31}>$ ontological-badfaith/inauthenticity ${ }^{64}$ preconverging-de-mentating/structuring/paradigming ${ }^{65}$ that veridically renders inadequate/of-irrelevance a veridical dialogical-equivalence- $<$ as-topsychologismic apriorising/axiomatising/referencing-\{of-'prospectively implicited_attendant-ontological-contiguity ' educedexistentialising/contextualising/textualising_'intelligibility/epistemicity/reflexivity-contiguity$<$ imbued-notional cogency $>$ ' $\}$-conflatedness -in-\{preconverging-ment by\} postconverging entailment,-in-self-becoming/self-conflatedness /formative-supererogating > exercise of contemplative engagement because of manifest 'epistemic-break or notionaldiscontiguity/epistemic-discontiguity ${ }^{6}-<$ between - prior-shallow-supererogation -ofmentally-aestheticised preconverging/dementing -qualia-schema_and_prospective-profound- 


\section{supererogation -of-mentally-aestheticised postconverging/dialectical-thinking -qualia-}

schema $>$ as to difference-in-nature/difference-in-apriorising-or-axiomatising-or-referencing ${ }^{24}$. Thus more critically warranting for prospective sublimation the more fundamental 'Derridean underdetermination-imbued force/violence conception' and 'Foucauldian knowledge/power conception construed as knowledge-empowerment/ignorance-disempowerment' as of notional asceticism reasoning-through/messianic-reasoning prospective existential$<$ disontelogising/re-ontelogising aporeticism $>$ deployment of transversality-<forsublimating-existential-eventuating/denouement,-from-'thinking at first/pure-predispositionpreemptive-of prospective-disontologising/subontologising' as-of-prospectivelydisambiguated-affirmed-and-unaffirmed-'motif-and-apriorising/axiomatising/referencing'> elucidation' meant to accommodate social-functioning-and-accordance-as-of-social-stakecontention-or-confliction within an existentialising-frame-of-entailment-of-motif-andapriorising/axiomatising/referencing of manifest notional asceticism sublimation in soallowing for the prospective prompting of 'constraining existence-as-sublimatingwithdrawal/unenframing/re-ontologising,-elicited-from-prospective-profound-supererogation imbuing human ontological-commitment $-<$ implied - self-assuredness-of-ontological-goodfaith/authenticity postconverging-de-mentating/structuring/paradigming -as-being-as-ofexistential-reality>' and ' ${ }^{103}$ universal-transparency ${ }^{104}$-〈transparency-of-totalising-entailing,-asto-entailing-<amplituding/formative-epistemicity $>$ totalising $\sim$ in-relative-ontologicalcompleteness $\rangle$ as available-to/elicitable-to-〈as-to-human-consciousness/collectiveconsciousness-distendedness/detruncating-<beyond-selfpresencing,-as-re-ontologisingdecentering_of-consciousness/collective-consciousness,-as-to-psychologismic_epistemicacutisation-residualising, - accordance-as-of-social-stake-contention-or-confliction conception of any given registryworldview/dimension $<$ preconverging 'motif-and-apriorising/axiomatising/referencing'- 
entailing >-existentialising — enframing/imprintedness-〈as-to- historicity-tracing — in-

presencing-hyperrealisation/hyperreal-transposition $\left.\rangle^{\prime}\right)$. Notional asceticism as such undergirds human momentous sublimating ${ }^{4}$ historiality/ontological-eventfulness ${ }^{38} /$ ontologicalaesthetic-tracing-<perspective-ontological-normalcy/postconvergence-reflected-‘epistemicityrelativism-determinism'> as wholly reflecting the 'notional protensivity retention that is enabling of prospective human civilisation' as to 'human consciousness notional protensivity imbuing prospective psychologismic-epistemic-acutisation-<as-to-postconverging-dementating/structuring/paradigming,-eliciting-of-existence's-sublimating-nascence-inprospective-aporeticism-overcoming/unovercoming $>$ as to epistemic-growth,-as\{veridieal/sound\}-relative-reflexivity-in-existence/relativising from limited mentation as its deepening/psychologismic epistemic acutisation residualising, decompulsing $_{\text {\} }}$ delinearity for eogency', and so over the variously fixated notional nonprotensivity (whether fixated trepidatious, fixated warped, fixated preclusive or fixated occlusive as to fixated dimensionalityof-desublimating-lack-of $-\langle<$ amplituding/formative $>$ supererogatery-dementativeness/epistemic-growth-or-conflatedness /transvaluativerationalising/transepistemicity/anamnestic-residuality/spirit-drivenness-equalisation〉) which as to desublimating ${ }^{47}$ historicity-tracing-in-presencing-hyperrealisation/hyperreal-transposition recurrently arises with-respect-to and in-undermining-of prospective human postconverging aporeticism-overcoming/unovercoming (while remaining unaccounted-for after prospective transcendence-and-sublimity/sublimation/superentativity and so unaccounted-for due to registry-worldviews/dimensions imbued prior-institutionalisationthreshold-by-prospective-uninstitutionalised-threshold 'self-referencing-syncretising forward-facing-supposedly postconverging-or-dialectical-thinking -apriorisingpsychologism epistemic-projection as of prior mere-formulaicity/ritualisation-<as-to-mereformulaic — methodologising/mutualising/organising/institutionalising,-prospectively-losing- 
track-of- ‘ $\left\{\right.$ epistemic-totalising ${ }^{\dagger}$ re-apriorising/re-axiomatising/re-referencing $\sim$ residuality-in-re-

originariness/re-origination'>' so-reflecting their 'disontologising preconverging/dementing <as-to-prospective-uninstitutionalised-threshold > ignoring/biased inclination' for the sake of 'their given present minimum-and-balancing expectations/anticipations of social-functioningand-accordance-as-of-social-stake-contention-or-confliction' while qualifying their prospectively uninstitutionalised-threshold ${ }^{102}$ actually as nondescript/ignorable-void as to their ${ }^{79}$ presencing-absolutising-identitive-constitutedness ${ }^{14} \quad<$ preconverging $\sim$ 'motif-andapriorising/axiomatising/referencing'-entailing >-existentialising-enframing/imprintedness〈as-to- historicity-tracing - in-presencing-hyperrealisation/hyperreal-transposition〉). Thus as to the elaborate conception of nonpresencing-or-withdrawal/unenframing/re-ontologisingor-metaphysics-of-absence-〈implicited-epistemic-veracity-of- nonpresencing-<perspectiveontological-normalcy/postconvergence $>$ - - or-transcendental-reasoning-of-event ${ }^{38}$-asprospective-ontology-origination (as to its full/comprehensive/dragged-out ${ }^{103}$ universal or totalising-entailing conceptualisation implications of aetiologisation/ontological-escalation<ontological-veridicality_commitment/otherliness_transcending/compulsions-

encumbered_transcending $>$ ), the notional asceticism underlying prospective deprocrypticism-or-preempting-disjointedness-as-of- ${ }^{3}$ reference-of-thought speaks of a conceptualisation that is much more than about prospective mere-formulaicity/ritualisation- $<$ asto-mere-formulaic_-methodologising/mutualising/organising/institutionalising,-prospectivelylosing-track-of-‘fepistemic-totalising ’’’re-apriorising/re-axiomatising/re-referencing 2 residuality-inre-originariness/re-origination'> of prospective positive-opportunism—of-social-functioningand-accordance $^{75}$ but prospectively warrants for dimensionality-of-sublimating <<amplituding/formative>supererogatery $\sim$ de-mentativeness/epistemic-growth-orconflatedness /transvaluative-rationalising/transepistemicity/anamnestic-residuality/spiritdrivenness-equalisation) rather as of 'manifest ontologically-veridical existential- 
< disontologising/re-ontologising aporeticism $>$ prospective postconverging-aporeticismovercoming/unovercoming implications as to pesteonverging-nonextricatory-existentialpreempting-of-existential-unthought' and not a 'naïve formulaic conception reflected in the vagueness of the articulation of say the notion of spirituality as to existential<disontologising/re-ontologising aporeticism $>$ hyperrealisation implications of the metaphysical/ideological in manifest preconverging-existential-extrication-as-of-existentialunthought'; reflected in the fact that such ${ }^{18}$ deprocrypticism-or-preempting - disjointedness-asof- ${ }^{8}$ reference-of-thought is rather (priorly and incipiently) critically about the veracity as of dimensionality-of-sublimating $25<<$ amplituding/formative $>$ supererogatory $\sim$ dementativeness/epistemic-growth-or-conflatedness /transvaluativerationalising/transepistemicity/anamnestic-residuality/spirit-drivenness-equalisation〉 before any pretense to veridical dialogical-equivalence-<as-topsychologismic $\sim$ apriorising/axiomatising/referencing-\{of-"prospectively implicited_attendant-ontological-contiguity ' educedexistentialising/contextualising/textualising_ 'intelligibility/epistemicity/reflexivity-contiguity<imbued-notional cogency>’ $\}$-conflatedness -in-\{preconverging-ment by\} postconverging-entailment,-in-self-becoming/self-conflatedness /formative-supererogating > can arise in the-very-first-place. Critically, the veracity of 'human conception of $<$ amplituding/formative-epistemicity $>$ causality $\sim$ as-to-projective-totalitative-implications-ofprospective- nonpresencing,-for-explicating $\sim$ relative-unreflexivity/relative-reflexivity ontological-contiguity ' in view of articulating 'existential postconverging-apereticismovercoming/unovercoming relevant ontological explanation' is more pertinently underscored as of the understanding enabled by the nonpresencing-or-withdrawal/unenframing/reontologising-or-metaphysics-of-absence-〈implicited-epistemic-veracity-of- nonpresencing$<$ perspective-ontological-normalcy/postconvergence $>$ )-or-transcendental-reasoning-of- 
event $^{38}$-as-prospective-ontology-origination epistemic-projection (as so-comprehensively elucidated above), as reflecting the apriorising/axiomatising/referencing-\{of-"prospectively implicited_attendant-ontological-contiguity ' educed-

existentialising/contextualising/textualising_intelligibility/epistemicity/reflexivity-contiguity$<$ imbued-notional $\left.\sim \operatorname{cogency}>^{\prime},\right\}$-conflatedness ${ }^{13}$-in-\{preconverging-ment by $\}^{2}$ postconverging-entailment undergirding human limited-mentation-capacity-deepening-assubjecting limitedness/human-subpotency to-'educed-unlimitedness/existence-sublimating nascence' (and as so-veridically indissociable with prospective human psychologismic-epistemic-acutisation-<as-to-postconverging-de-mentating/structuring/paradigming,-elicitingof-existence's-sublimating-nascence-in-prospective-aporeticism-overcoming/unovercoming> induced epistemic-growth/disquiet/discomfort-_induced-sublimation,-as-from-existence's effusing/ecstatic-inlining-as- historiality-\{science/authenticity/nonextrication $\}$-beyond-mereformulaicity/ritualisation-as- historicity-tracing-\{scienceideology/fashionability/distraction $\}\rangle)$. Such a 'human conception of <amplituding/formativeepistemicity $>$ causality $\sim$ as-to-projective-totalitative-implications-of-prospectivenonpresencing,-for-explicating relative-unreflexivity/relative-reflexivity ontologicalcontiguity , further reflects the fact that the notion of experientiality/experiment- $<$ as-toexistentially-formative-'fepistemic talising tre-apriorising/re-axiomatising/rereferencing $\sim$ residuality —in-re-originariness/re-origination', - - so'notionally/epistemically/bindingnessly-<as-to-determinism/conceptivity-of-relative-unreflexivity/relative-reflexivity> implicited-and-articulated'_as-from-nonextricatory-'prospective-re-ontologising-Being-thenInstitutional-then-Living-magnitudes-of-\{hermeneutic/reprojection-protraction-of\}reframingand-reformulation $\}^{\prime}>$ is undissociated from immanent-existence with 'being-in-existence already the bigger ongoing/undergone experientiality/experiment-<as-to-existentiallyformative-' \{epistemictalising ${ }^{\prime}$ re-apriorising/re-axiomatising/re-referencing $\sim$ residuality-in-re- 
originariness/re-origination', - so-'notionally/epistemically/bindingnessly-<as-to-

determinism/conceptivity-of-relative-unreflexivity/relative-reflexivity>-implicited-and-articulated'_as-from-

nonextricatory-'prospective-re-ontologising-Being-then-Institutional-then-Living-magnitudesof-\{hermeneutic/reprojection protraction-of\}reframing-and-reformulation \} '>'; as so-underlied by 'human <amplituding/formative-epistemicity>-totalising $\sim$ thrownness-in-existence imbued priorly_cumulated/recomposured-bequeathed ${ }^{56}$ meaningfulness-and-teleology ${ }^{9}$ as of human preconverging/postconverging-de-mentating/structuring/paradigming (from whence prospective sublimating experientiality/experiment-<as-to-existentially-formative-‘fepistemic re-apriorising/re-axiomatising/re-referencing residuality-in-re-originariness/reorigination',- - so-'notionally/epistemically/bindingnessly-<as-to-determinism/conceptivity-of-relativeunreflexivity/relative-reflexivity> -implicited-and-articulated'_as-from-nonextricatory- 'prospective-reontologising-Being-then-Institutional-then-Living-magnitudes-of\{hermeneutic/reprojection protraction-of\}reframing-and-reformulation \} ' $>$ is postconvergingly elicited as to prospective referencing $\sim$ residuality —in-re-originariness/re-origination of limitedness/human-subpotency prospective re-encountering/re-confrontation with the 'constraining/defining intersolipsistic reflexive-sublimating/unreflexive-desublimating measure/objectification that is unlimitedness/existence-as-ontological-normalcy/postconvergence-<in-validation-of'metaphysics-of-absence_epistemic-projection'>'), and so in expanding the overall sublimating-postconverged 'substantive abstract-tissue-of-social-emanance thermeneutically/textually/reprojectingly/supererogatingly/zeroingly/re-acutingly,$\{$ decompulsing $\}$ delinearity for-cogency—cumulated/recomposured as to cumulating/recomposuring of 'prospectively implicited_antentontogical-contiguity ${ }^{67}$ ' educedexistentialising/contextmalising/textualising_intelligibility/epistemicity/reflexivity_contiguity$<$ imbued-notional cogency $>$ ' This insight goes beyond a naïve conception of the scientific 
experimentation as all about a given natural or other science experimental/observational/survey designing/setup 'wrongly seeming to exclude contiguity with the insight from the fact of already being-in-existence' (as to the requisite postconvergingly elicited prospective apriorising/re-axiomatising/re-referencing - residuality-in-re-originariness/re-origination of limitedness/human-subpotency prospective re-encountering/re-confrontation with the 'constraining/defining intersolipsistic reflexive-sublimating/unreflexive-desublimating measure/objectification that is unlimitedness/existence-as-ontologicalnormalcy/postconvergence-<in-validation-of-'metaphysics-of-absence_epistemic-

projection'>'). Such experimental/observational/survey designing/setup are rather appreciable 'in extenso of already being-in-existence' (and as rather 'notionally/epistemically/bindingnessly' <as-to-determinism/conceptivity-of-relative-unreflexivity/relative-reflexivity>_implicited-and-articulated' as-fromnonextricatory-'prospective-re-ontologising-Being-then-Institutional-then-Living-magnitudesof-\{hermeneutic/reprojection protraction-of $\}$ reframing-and-reformulation $\}$ ); and so, in overall human re-ontologising acquiescence as to 'protracted-social—as-to-individual-by-institutionalby-social relative direct/deferential-responsibility/relative-reflexivity to cogency_chronicularity/annality-of-relative-reflexivity,-as-to-profound-supererogation ${ }^{\text {' }}$ (with regards to prospective re-ontologising 'dynamic cumulating/recomposuring psychologismic-. epistemic-acutisation-residualising,-\{decompulsing $\}$ delinearity for-cogency phasing of limitedness/human-subpotency onto unlimitedness/existence-<fll-potency-of_sublimating nascence $>$ ') as ever always prospectively opened to the human exercise of 'psychologismic-. epistemic-acutisation-residualising fepistemic-

totalising ${ }^{3}$ 'hermeneutic/textuality/reprojecting/supererogating/zeroing/re-acuting,\{decompulsing delinearity for-cogency\} (as of '<nonextricatory/postconverging/unaccommodating/questioning $>$-re-ontologising_promptingprospective_extended/prolonged-re-ontologising-enabling-in-order-to-enable- $<$ as-of-the- 
untenability-of-induced unblurriness $>$ - prospective_constricted/narrowingdown-re-

ontologising-enabling') so-underlying the 'circular dynamics in humanconsciousness/collective-consciousness-distendedness/detruncating- $<$ beyond-selfpresencing,as-re-ontologising-decentering_of-consciousness/collective-consciousness,-as-topsychologismic-epistemic-acutisation —residualising, ${ }^{-\{\text {decompulsing }}{ }^{2}$ delinearity $\sim$ for-cogency $>$ '.

As to when such natural science manifestations like physical, chemical and biological processes are effectively articulated rather as from the imbued being-in-existence "notional nonextricatory positivism/rational-empiricism implicited mindset of Being-development/ontologicalframework-expansion-as-to-depth-of-ontologising-development-as-infrastructure-ofmeaningfulness-and-teleology psychologismic epistemic-acutisation difficulty-<for, residualising \{decompulsing $\}$ delinearity for-cogency> - magnitude ${ }^{\{\text {of-experientiality/experiment\}, }}$ from whence are educed the institutional-development-as-to-social-function-development and livingdevelopment-as-to-personality-development practices as of their psychologismic epistemicacutisation difficulty-for, residualising \{decompling $\}$ delinearity for-cogency>-magnitudes $\{$ ofexperientiality/experiment\}, and further as such scientific processes are not contemplatable in our mere 'ordinary/common given positivism/rational-empiricism registry-worldview/dimension perceptual existential-disentegising/re ontologising apereticism> framework' requiring the extension of our already overall positivism/rational-empiricism being-in-existence by such natural science experimental/observational/survey designing/setup (as a 'supereregatery $\sim$ wholesomeness/profound-supererogation continuity of <sublimationeducing _epistemictalising thermeneutic/textuality/reprojecting/supererogating/zeroing/reacuting, - $^{\text {\{decompulsing }}$ delinearity for-cogency>-interpretation'); and so 'as to the given natural science human limited-mentation-capacity-deepening as stbjecting limitednessmansubpotency-to-'educed-unlimitedness/existence-sublimating nascence' ${ }^{53}$ specifically and/or generally cultivated arts/skills and time investment', in want for 'appropriate human 
contemplative projective-insights of sublimating-nascence aetiologisation/ontologicalescalation-<ontological-veridicality_commitment/otherliness_transcending/compulsions-

encumbered_transcending $>$ conceptivity/epistemic-reflexivity/epistemicity-relativismdeterminism-<reifying \{as-to-knowledge-developing\}-and-empowering >' (so-reflected as to human aestheticisation-and-aestheticisation-towards-ontology-<elicited-idiomatisation $>$ educing existence's - effusing/ecstatic-inlining-as- ${ }^{4}$ historiality\{science/authenticity/nonextrication -beyond-mere-formulaicity/ritualisation-as- ${ }^{4}$ historicitytracing-\{science-ideology/fashionability/distraction\}). It can thus be appreciated that prospective nascent-particular/incipient-and-material/technical-sublimations- $<$ blinded-to-theirrelative-ontological-completeness - reference-of-thought- devolving $>$ implicitly make assumptions about human overarching Being-development/ontological-framework-expansionas-to-depth-of-ontologising-development-as-infrastructure-of- meaningfulness-andteleology psychologismic epistemic-acutisation difficulty-<for, residualising \{deromsing delinearity for-cogeney>-magnitude\{of-experientiality/experiment\} (beyong the immediate and naïve conception of the scientific experiment as all about a given natural or other science experimental/observational/survey designing/setup 'wrongly seeming to exclude contiguity with insight from the fact of already being-in-existence' which are of veridical scientific/unscientific implications); as to the requisite coherence of such experimental/observational/survey designing/setup with the veracity of their appropriate reflection of overarching Beingdevelopment/ontological-framework-expansion-as-to-depth-of-ontologising-development-asinfrastructure-of- meaningfulness-and-teleology psychologismic epistemic-acutisationdifficulty-<or, residualising_\{decompulsing $\}$ delinearity for-cogeney> magnitude ${ }^{\{0 f-}$ experientiality/experiment\}. This can be relatively inconsequential with many a natural sciences as to their relatively constraining punctual/immediacy/constituted/compulsions-encumbered-

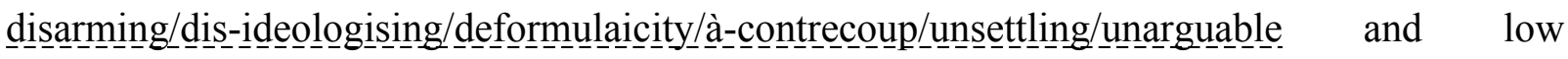


emotional-involvement whereas this is not readily the case with the social domain given the relatively punctual/immediacy/constituted/compulsions-encumbered and high emotionalinvolvement. Further, the social domain is more directly 'recurrently warranted' as to the ontologising/scientific/existence- $<$ honesty-constraining $>$ - scope_for_prospective_reontologising (with respect to 'overall prospective re-ontologising acquiescence' as to 'protracted-social - as-to-individual-by-institutional-by-social relative direct/deferentialresponsibility/relative-reflexivity to cogency_chronicularity/annality-of-relative-reflexivity,-asto-profound-supererogation ') to effectively elucidate the prospective re-ontologising implications of its supposedly elicited 'specific existential-<disentologising/re-ontelogising apereticism $>\quad$ sublimating $\quad<$ constricted/narrowingdown-re-ontologising-enabling $>-$ psychologismic epistemic-acutisation residualising fepistemic-

totalising thermeneutic/textuality/reprojecting/supererogating/zeroing/re-acuting,

\{decompulsing\} delinearity for-cogency intelligibility';- (imbued underlying untenability-ofinduced unblurriness as '<prospective_punctual/immediacy/constituted/compulsionsencumbered - disarming/dis_-ideologising/deformulaicity/à-contrecoup/unssettling/ungargunable prompted constricted/narrowingdown-re-ontologising-enabling $>$-psychologismic epistemic aentisation residualising \{epistemic-

totalising thermeneutic/textuality/reprojecting/supererogating/zeroing/re-acuting, \{decompulsing\} delinearity for-cogency'). So-eliciting with regards to the given 'specific institutionalising/organising/mutualising/methodologising $\quad<$ constricted/narrowingdown-reontologising-enabling $>$-psychologismic epistemic-acutisation - residualising fepistemictotalising ${ }^{3}$ hermeneutic/textuality/reprojecting/supererogating/zeroing/re-acuting, \{decompulsing\} delinearity for cogeney intelligibility';- (imbued underlying untenability-ofinduced unblurriness as '<prospective_punctual/immediacy/constituted/compulsionsencumbered - disarming/dis-ideologising/deformulaicity/à-contrecoup/unsettlling/unargunable 
prompted constricted/narrowingdown-re-ontologising-enabling $>$ - psychologismic epistemicacutisation residualising fepistemic-

totlising thermeneutic/textuality/reprojecting/supererogating/zeroing/re-acuting,

\{decompulsing\} delinearity for-cogency') and ultimately its given overall-overarching 'registryworldview/dimension $<$ constricted/narrowingdown-re-ontologising-enabling $>$ psychologismic epistemic-acutisation residualising fepistemic-

totalising ${ }^{3}$ hermeneutic/textuality/reprojecting/supererogating/zeroing/re-acuting,

\{decompulsing $\}$ delinearity for-cogency intelligibility'; - (imbued overall-overarching untenabilityof-induced $\sim$ unblurriness as '<prospective_punctual/immediacy/constituted/compulsionsencumbered — disarming/dis-ideologising/deformulaicity/à-contrecoup/unsettling/unarguable prompted constricted/narrowingdown-re-ontologising-enabling $>-$ psychologismic epistemicacutisation residualising fepistemic-

totalising thermeneutic/textuality/reprojecting/supererogating/zeroing/re-acuting, \{decompulsing delinearity for-cogency'); and so, as to the social domain overall protracted knowledge claim-for-and-habituation/enculturation-of untenability-of-induced unblurriness as '<prospective_punctual/immediacy/constituted/compulsions-encumbered — disarming_________-

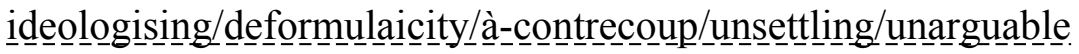
prompted constricted/narrowingdown-re-ontologising-enabling $>$ - psychologismic epistemicacutisation residualising \{epistemictolising thermeneutic/textuality/reprojecting/supererogating/zeroing/re-acuting, fdecompulsing' delinearity for-cogency' with respect to 'the-very-same purview/devolvedpurview/devolving-purview-of-unlimitedness/existence-<full-potency-of_sublimating mascence>; — implicited_attendant-ontological-contiguity ${ }^{67}$ ' educedexistentialising/contextualising/textualising_intelligibility/epistemicity/reflexivity-contiguity$<$ imbued-notional cogency ${ }^{\prime}{ }^{\prime 0}$. Concretly, such an exercise will highlight that the 
conception/interpretation of social experimentation and knowledge necessarily has to reontologisingly cover explicitly/implicitly the full ambit of human experientiality/experiment-

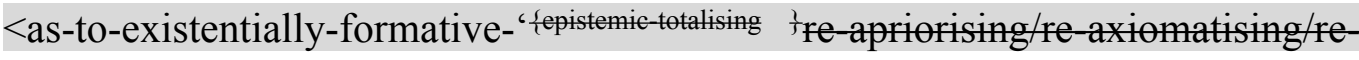
referencing residuality - in-re-originariness/re-origination',- - so'notionally/epistemically/bindingnessly-<as-to-determinism/conceptivity-of-relative-unreflexivity/relative-reflexivity> implicited-and-articulated'_as-from-nonextricatory-'prospective-re-ontologising-Being-thenInstitutional-then-Living-magnitudes-of-\{hermeneutic/reprojection-protraction-of\}reframingand-reformulation $\}^{\prime}>$ as of superseding-oneness-of-ontology/ontological-veridicality/relativeunreflexivity/relative-reflexivity - ontological-contiguity ${ }^{67}$; with such sublimating ontological coherence/contiguity rather veridically (as of the "notional/epistemic/bindingness" sas-to- $^{-}$ determinism/conceptivity-of-relative-unreflexivity/relative-reflexivitys reflection of relative-unreflexivity/relativereflexivity in existence implications') being the more overarching relevant notion about science/ontology. In this regards, it should be noted that such wording/formulations like 'byand-large', 'in-many-ways', etc. made herein specifically speak of such 'notional/epistemic/bindingness sas-detminism/enceptivity-of relative-nneflexivity/relative-reflexivitys reflection of relative-unreflexivity/relative-reflexivity in existence implications' as to the very 'reflexivity mesh' that is existence (rather undergirded as of ' ${ }^{6}$ nonpresencing-<perspective-ontologicalnormalcy/postconvergence $>$ relativism/relative-scope for epistemic-growth,-as\{veridical/sound\}-relative-reflexivity-in-existence/relativising from-limited-mentation-as-itsdeepening/psychologismic epistemic_acutisation residualising, fdecompusingl delinearity foreogency'); and such wording/formulation are effectively articulable as of their given notional/epistemic/bindingness ${ }^{<a s-t o-d e t e r m i n i s m / c o n c e p t i v i t y-o f-r e l a t i v e-u n r e f l e x i v i t y / r e l a t i v e-r e f l e x i v i t y>~}$ 'notional difference-conflatedness ${ }^{13}$-as-to-totalitative-reification-in-singularisation- $<$ as-to-thenondisjointedness/entailment-of-prospective- nonpresencing > -as-veridical-epistemicityrelativism-determinism in reflection of underlying superseding-oneness-of- 
ontology/ontological-veridicality/relative-unreflexivity/relative-reflexivity ontologicalcontiguity $^{6}$, and 'not just mere wording/formulation without a sense of underlying ontological/scientific elucidation', as so-reflecting the fact that the possibilities of thehuman/humanity are underlined existentially-<disontologising/re-ontologising aporeticism $>$ as of 'human relative-unreflexivity/relative-reflexivity' ('there is nothing outside the text of human textuality of relative-unreflexivity/relative-reflexivity' as to the fact that 'existence preceding/defining essence' inherently implies 'preconverging/postconverging-redementating/restructuring/reparadigming as of limitedness/human-subpotency supererogating ${ }^{6}$ affirmation/projection/assertion/notional $\sim$ self-distantiation-byunaffirmation/deprojection/deassertion/epistemic-decadence $\}$ —-towards $\sim$ omnipotentialaffirmation/projection/assertion/notional self-distantiation', as so-guaranteeing the 'conceivability and deterministic notional/epistemic/bindingness ${ }^{<a s-t o-d e t e r m i n i s m / c o n e e p t i v i t y-o f-r e l a t i v e-~}$ unreflexivity/relative-reflexivity $>$ articulation' of the ontologising/scientific/existence- $<$ honestyconstraining $>$ — scope_for_prospective_re-ontologising). For instance, laudable social experimentations like the Milgram experiments, as of their elicited 'specific existential<isontologising/re-ontologising aporeticism $>$ sublimating < constricted/narrowingdown-reontologising-enabling $>$ psychologismic epistemic acutisation residualising \{epistemictotalising ${ }^{3}$ hermeneutic/textuality/reprojecting/supererogating/zeroing/re-acuting, \{decompulsing\} delinearity for-cogency intelligibility';- (imbued underlying untenability-ofinduced unblurriness as '<prospective_punctual/immediacy/constituted/compulsions-

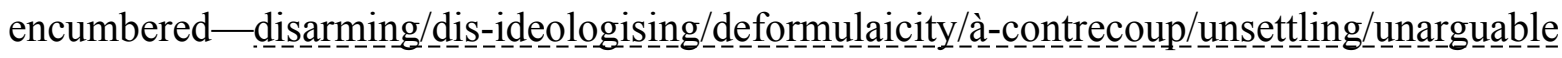
prompted constricted/narrowingdown-re-ontologising-enabling $>$-psychologismic epistemicacutisation residualising \{epistemictotalising thermeneutic/textuality/reprojecting/supererogating/zeroing/re-acuting, \{decompulsing\} delinearity for-cogency'), wrongly/incompletely seem to be interpreted as to exclude 
the 'veracity of elucidation' as of the given 'specific institutionalising/organising/mutualising/methodologising $\quad<$ constricted/narrowingdown-reontologising-enabling $>$ - psychologismic epistemic-acutisation - residualising fepistemictotalising thermeneutic/textuality/reprojecting/supererogating/zeroing/re-acuting, ${ }_{\{\text {decompulsing }\}}$ delinearity for-cogency intelligibility';- (imbued underlying untenability-ofinduced unblurriness as '<prospective_punctual/immediacy/constituted/compulsions-

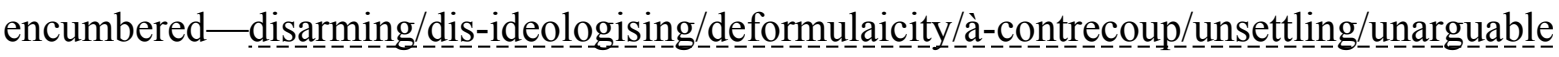
prompted constricted/narrowingdown-re-ontologising-enabling $>$-psychologismic epistemicacutisation residualising a fepistemic-

totalising thermeneutic/textuality/reprojecting/supererogating/zeroing/re-acuting, $\{$ \{decompulsing $\}$ delinearity for-cogency') and ultimately overall-overarching 'registryworldview/dimension $\quad<$ constricted/narrowingdown-re-ontologising-enabling $>-$ psychologismic epistemic acutisation residualising fepistemicthermeneutic/textuality/reprojecting/supererogating/zeroing/re-acuting, \{decompulsing $d e$ linearity for-cogency intelligibility';- (imbued overall-overarching untenabilityof-induced $\sim$ unblurriness as '<prospective_punctual/immediacy/constituted/compulsions-

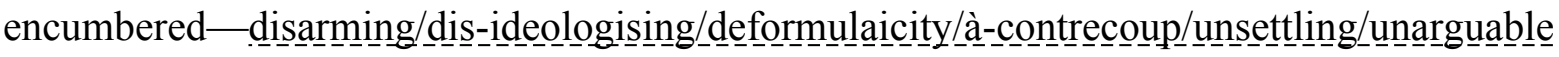
prompted constricted/narrowingdown-re-ontologising-enabling $>$ - psychologismic epistemicacutisation residualising $\{$ fepistemictotlising thermeneutic/textuality/reprojecting/supererogating/zeroing/re-acuting, \{decompulsing delinearity for-cogency'). In this respect, for instance the elucidation of overall construct of 'protracted-social-as-to-individual-by-institutional-by-social relative direct/deferential-responsibility/relative reflexivity-or-irresponsibility/relative unreflexivity to cogency_chronicularity/annality-of-relative-reflexivity,-as-to-profound-supererogation ${ }^{\text {' }}$ (as to appropriate prospective re-ontologising overarching and overall-overarching elucidation) is 
critical, in the sense that 'effective responsibility/relative-reflexivity of social narrative warrants deference to authority' whereas 'effective irresponsibility/relative-unreflexivity of social narrative warrants resistance to authority'; such that the mere human mental-reflex attitudinal disposition elucidation is incomplete as to the overall warrant for 'underlying human protractedsocial-as-to-individual-by-institutional-by-social direct/deferential epistemic-growth,-as\{veridical/sound\}-relative-reflexivity-in-existence/relativising from-limited-mentation-as-its-

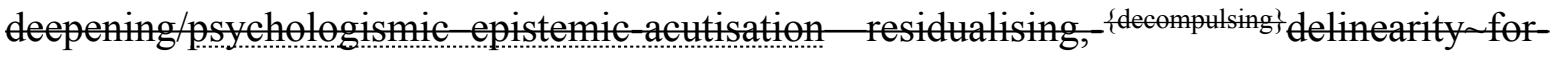
eogency' which has to be addressed by the ontologising/scientific/existence- $<$ honestyconstraining $>$ — scope_for_prospective_re-ontologising. This overall warrant (as to appropriate prospective re-ontologising overarching and overall-overarching elucidation) is often overlooked while expecting by some 'miracle of conducting social experimentation and using scientific methods' to naively resolve socially induced 'epistemic-decadence' or teleologicaldecadence-<-in-dimensionality-of-desublimating-lack-of

\section{<<amplituding/formative>supererogatery $\sim$ de-mentativeness/epistemic-growth-or-}

\section{conflatedness /transvaluative-rationalising/transepistemicity/anamnestic-residuality/spirit-}

drivenness-equalisation $\rangle$ as of <extricatory/preconverging/accommodating/unquestioning $>$ disontologising/subontologising_prompting perspective; and so-reflected as to 'underlying human protracted-social—as-to-individual-by-institutional-by-social direct/deferential flawed/unsound\}-relative-unreflexivity-in-existence/absolutising from-limitedmentation/psychologismic epistemic acutisation - nonresidualising imbued\{compulsing\}'linearity-in-eclecticism-of prior-mere-formulaicity/ritualisation' (as so-manifesting 'shallow-

supererogation $\sim$ framing/formulation/catchmenting/truncating/compulsing/linearising_scale —of-opaque/contentious/un-nominalised/flawed-interpretations/domains of manifest blurriness-<sterilising/anecdotalising/trivialising-of-prospective-re-ontologising_by- 
preconverging,-in-disontologising-formulaic-dragging-out/hollowing-out>'). Such that in both the natural sciences and the social domain the challenge for re-ontologising prospective Beingdevelopment/ontological-framework-expansion-as-to-depth-of-ontologising-development-asinfrastructure-of- meaningfulness-and-teleology psychologismic epistemic acutisationdifficulty $<$ for, residualising_\{decompulsing $\}$ delinearity for-cogency> magnitude ${ }^{\{0 f-}$ experientiality/experiment is a perpetual one as to the possibility of entrenched knowledge-deadends$<$ as-preconverging-de-mentating/structuring/paradigming $>$ practices (as failing such protracted overaching claim-for-and-habituation/enculturation-of untenability-of-induced unblurriness

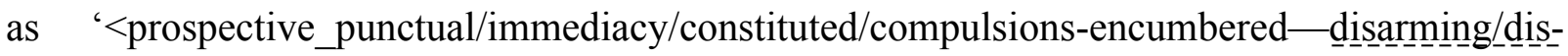
ideologisising/deformulaicity/à-contrecoup/unsettling/unarguable $\quad$ prompted constricted/narrowingdown-re-ontologising-enabling $>$ - psychologismic epistemic-

\section{acutisation residualising a fepistemic-}

\section{totalising thermeneutic/textuality/reprojecting/supererogating/zeroing/re-acuting,}

\{decompusing delinearity for-cogency'). Such that in effect the possibility of sublimating science/ontology vary as of the differing overarching registry-worldviews/dimensions projected presencing-absolutising-identitive-constitutedness $^{14}$ (as from recurrent-utteruninstitutionalisation, base-institutionalisation-ununiversalisation, ${ }^{103}$ universalisation-nonpositivism/medievalism, positivism- ${ }^{80}$ procrypticism and prospective ${ }^{18}$ deprocrypticism-orpreempting - disjointedness-as-of- ${ }^{3}$ reference-of-thought); that cannot be overlooked/ignored by the given registry-worldview/dimension ${ }^{79}$ presencing-absolutising-identitiveconstitutedness $^{14}$ conception and construed practice of science/ontology (given unlimitedness/existence-<full-potency-of_sublimating nascence $>$ prospective apriorising/axiomatising/referencing-sublimating-reflexivity-beholdening under which limitedness/human-subpotency submits in profound-supererogation for prospective sublimating). This overall elucidation of prospective human ontologising ${ }^{56}$ meaningfulness-and- 
teleology 9 and human disontologising <amplituding/formative> wooden-language-〈imbued averaging-of-thought-<as-to-leveling/ressentiment/closed-construct-of- meaningfulness-andteleology -as-of-'nondescript/ignorable-void ' -with-regards-to-prospective-apriorisingimplications $>>$ (as so-fundamentally tied to human 'social-functioning-and-accordance-as-ofsocial-stake-contention-or-confliction imbuing existentialising-frame-of-entailment-of motifand-apriorising/axiomatising/referencing of disontologising/ontologising-and-re-ontologising') critically underlies the fundamental inseparable relationship between human sovereignising (as to social-functioning-and-accordance-as-of-social-stake-contention-or-confliction) and human ontologising/disontologising; and so effectively emphasising both with regards to 'human sovereign-function/posture-<as-to-existentially-manifest-‘embodied-

\section{subject consciousness-and-direct/deferential-conscientiousness',-as-of-its-'epistemic-}

reflexivity/unreflexivity-in-existence'/teleology> with regards to public-sovereignty-giving function/posture' as well as the genuine social intellectual-function/posture as keeping opened/alive the 'scalarity/immanency of existence's ontological-normalcy/postconvergence'. In other words, 'prospective knowledge warrants its very own aptly human sovereignising existentialising-frame-of-entailment of motif-and-apriorising/axiomatising/referencing as not subjected surreptitiously to a human desovereignising existentialising-frame-of-entailment-ofmotif-and-apriorising/axiomatising/referencing disenfranchising/subjugating-it as of an underlying non-ontologising/disontologising surreptitious knowledge-withoutknowledge/knowledge-outside-knowledge/extra-knowledge manifestation' bound to close/deaden the 'scalarity/immanency of existence's ontological-normalcy/postconvergence'; and with such a non-ontologising/disontologising surreptitious knowledge-withoutknowledge/knowledge-outside-knowledge/extra-knowledge manifestation effectively construed as 'pedantising/muddling/formulaic-hollowing-out—in-subontologisation/subpotentiation〈blurring/undermining-of-prospective-totalising-entailing,-as-to-entailing- 


\section{$<$ amplituding/formative-epistemicity>totalising in-relative-ontological-completeness $>$}

ontologically-flawed claim upon human prospective ontologising possibilities as supposedly superseding/overriding existence-as-the-absolute-a-priori-ofconceptualisation $\sim$ and existence — as-sublimating-withdrawal/unenframing/re-ontologising,elicited-from-prospective-profound-supererogation $-<$ as-to-perspective-ontologicalnormalcy/postconvergence-implied-'prospective-aporeticism-overcoming/unovercoming'> (so-manifested as of various psychologismic epistemic-acutisation difficulty-for, residualising delinearity-for-cogency>-magnitudes $\{$ of-experientiality/experiment\} of human self-presence/self-constitutedness ${ }^{14}$ - $<$ in-perspective-epistemic-abnormalcy/preconvergence ${ }^{3}>$ ontological-bad-faith/inauthenticity $\sim$ preconverging-de-mentating/structuring/paradigming and it is herein contended that as to underlying Being-development/ontological-frameworkexpansion-as-to-depth-of-ontologising-development-as-infrastructure-of- meaningfulnessand-teleology psychologismic epistemic acutisation difficulty-<for, residualising

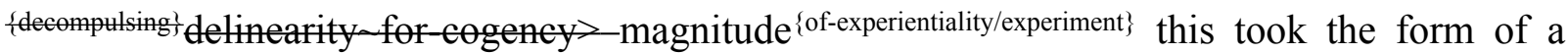
surreptitious quasi-geostrategic turn during the course of the Cold War and further re-instilled with the demise of communism in Eastern Europe as to latent/dormant socio-econo-political ideological postures of non-ontologising/disontologising claim for social sovereign ascendency). Critically and as to the fact that ontology/science doesn't allow for any exception/exceptinginfluence, foolhardily striving to contemplate-and-articulate prospective sublimating knowledge possibilities while failing to establish the 'aptly sovereignising existentialising-frame-ofentailment of motif-and-apriorising/axiomatising/referencing of the prospective organicknowledge as not subjected to any surreptitiously desovereignising existentialising-frame-هf entailment of motif-and-apriorising/axiomatising/referencing disenfranchising/subjugating it as of an underlying non-ontologising/disontologising surreptitious knowledge-withoutknowledge/knowledge-outside-knowledge/extra-knowledge manifestation' (as to human self- 
presence/self-constitutedness $^{14}-<$ in-perspective-epistemic-abnormalcy/preconvergence ${ }^{3}>$ ontological-bad-faith/inauthenticity $\sim$ preconverging-de-mentating/structuring/paradigming ${ }^{5}$, and especially-so with regards to requisite 'supereregatery wholesomeness/profoundsupererogation as of prospective ${ }^{83}$ reference-of-thought-point-ofdevolving/departure/anchoring/backdrop_of_sublimating-nascence-<as-to-the-grandestaxiomatic-construct-\{epistemic-totalising $\stackrel{+}{5}$ re-apriorising/re-axiomatising/rereferencing residuality -in-re-originariness/re-origination of limitedness/human-subpotency prospective re-encountering/re-confrontation with unlimitedness/existence>' when it comes to the 'dragged-out nature or psychologismic-epistemic-acutisation-<as-to-postconverging-dementating/structuring/paradigming,-eliciting-of-existence's-sublimating-nascence-inprospective-aporeticism-overcoming/unovercoming $>$ as to epistemic-growth,-as\{veridical/sound\}-relative-reflexivity-in-existence/relativising from-limited-mentation-as-itsdeepening/psychologismic epistemic-acutisation residualising, ${ }^{\text {fdecompulsing }}$ \}elinearity foreogency' of 'prospective ${ }^{83}$ reference-of-thought appraisal of sublimating-nascence comprehensiveness/nonimmediacy/indirectness'); is bound to induce a 'fundamental paradox of contemptuous distractive-alignment-to- ${ }^{3}$ reference-of-thought- $<$ ofapriorising/axiomatising/referencing $>^{{ }^{\prime}}$ ' as to ontologically-flawed equivalence/correspondence relation of pedantising/muddling/formulaic-hollowing-out-insubontologisation/subpotentiation-〈blurring/undermining-of-prospective-totalising-entailing,as-to-entailing-<amplituding/formative-epistemicity $>$ totalising $\sim$ in-relative-ontologicalcompleteness $>$ and notional $\sim$ philosophy-<as-to-the-veridical-conception-of-philosophy-asenglobing-all-human-prospective-organic-knowledge-generation-in-relative-ontologicalcompleteness ,-beyond-a-convenient-division-of-labour-conception-of-knowledge>, and rather warranting the veridical degradation of the former as being of 'epistemic-decadence' or teleological-decadence-<-in-dimensionality-of-desublimating-lack-of ${ }^{-}$- 
<<amplituding/formative>supererogatory $\sim$ de-mentativeness/epistemic-growth-or-

conflatedness /transvaluative-rationalising/transepistemicity/anamnestic-residuality/spirit-

drivenness-equalisation) (as of its veridically imbued ment of apriorising/axiomatising/referencing-\{of-'prospectively implieited_attendant-ontological-

contiguity ' educed-

existentialising/contextualising/textualising_'intelligibility/epistemicity/reflexivity-contiguity-

<imbued-notional cogency>' $\}$-constitutedness ${ }^{1}$-in-preconverging-entailment). This

further explains why ultimately the veracity of any ontologically/scientifically veridical claims can only come about as of a 'disambiguative-overriding// unblurriness-<re-ontologising_by-

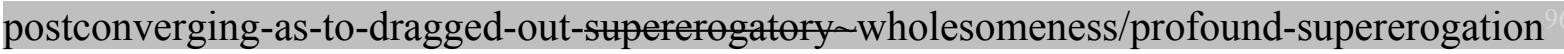
while-anecdotalising-prior-disontologising-thresholding $>$ arising in the course of nonpresencing-<perspective--ontological-normalcy/postconvergence $>$ epistemic-projection of transversality-<for-sublimating-existential-eventuating/denouement,-from-'thinking-atfirst/pure-predisposition-preemptive-of prospective-disontologising/subontologising' as-ofprospectively-disambiguated-affirmed-and-unaffirmed-'motif-and-

apriorising/axiomatising/referencing'>101 elucidation' meant to accommodate socialfunctioning-and-accordance-as-of-social-stake-contention-or-confliction in so-allowing for the prospective prompting of 'constraining existence-as-sublimatingwithdrawal/unenframing/re-ontologising,-elicited-from-prospective-profound-supererogation imbuing human ontological-commitment $-<$ implied - self-assuredness-of-ontological-goodfaith/authenticity postconverging-de-mentating/structuring/paradigming -as-being-as-ofexistential-reality>' and ' ${ }^{103}$ universal-transparency ${ }^{104}$-〈transparency-of-totalising-entailing,-asto-entailing-<amplituding/formative-epistemicity $>$ totalising $\sim$ in-relative-ontologicalcompleteness \ as available-to/elicitable-to-〈as-to-human-consciousness/collectiveconsciousness-distendedness/detruncating- $<$ beyond-selfpresencing,-as-re-ontologising- 
decentering_of-consciousness/collective-consciousness,-as-to-psychologismic-epistemic-

acutisation-residualising, ${ }^{-\{\text {decompulsing }}$ delinearity for-cogency $>>$ the social-functioning-andaccordance - as-of-social-stake-contention-or-confliction conception of any given registryworldview/dimension $\quad<$ preconverging 'motif-and-apriorising/axiomatising/referencing'entailing >-existentialising — enframing/imprintedness-〈as-to- historicity-tracing —inpresencing-hyperrealisation/hyperreal-transposition)' (in so-relegating human-subpotency imbued $<$ amplituding/formative $>$ wooden-language-〈imbued-temporal-mereform/virtualities/dereification/akrasiatic-drag/denatured/preconverging-or-dementing narratives - of-the- reference-of-thought- categorical-imperatives/axioms/registryteleology $>$ from prospective knowledge generation exercise). Most telling of such fundamental pedantising/muddling/formulaic-hollowing-out — in-subontologisation/subpotentiation〈blurring/undermining-of-prospective-totalising-entailing,-as-to-entailing$<$ amplituding/formative-epistemicity>totalising in-relative-ontological-completeness $\rangle$ is a cynical orientation to blurriness-<sterilising/anecdotalising/trivialising-of-prospective-reontologising_by-preconverging,-in-disontologising-formulaic-dragging-out/hollowing-out $>$ for undermining prospective knowledge while relating in-effect to prospective social knowledge as socially inconsequential and adopting an imprimaturing blurriness$<$ sterilising/anecdotalising/trivialising-of-prospective-re-ontologising_by-preconverging,-indisontologising-formulaic-dragging-out/hollowing-out $>$ ) purposefulness. Paradoxically such non-ontologising/disontologising surreptitious knowledge-without-knowledge/knowledgeoutside-knowledge/extra-knowledge manifestation as to their surreptitious claim of supposedly upholding given societal, cultural and economic values have in-many-ways because of their prospective surreptitious non-ontologising/disontologising undermining of veridical and consequential social criticism left the door open to surreptitious socio-econo-political disenfranchising with hardly any response to the recurrent aspirational crises underlying decadal 
institutional crises and social malaises. In-many-ways the inherent latency/lumbering/passivity of the public institutional form (increasingly bereft of veridical thoroughgoing/profound civil society social criticism) has effectively been enabling for such quick-moving and numbing/thought-deadening 'socially radiating sway of non-ontologising/disontologising surreptitious knowledge-without-knowledge/knowledge-outside-knowledge/extra-knowledge desublimation (substituting over prospective veridical knowledge sublimation possibilities of social and institutional constructs as reflexively construable from veridical prospective 'implicited_attendant-ontological-contiguity ${ }^{67}$; educedexistentialising/contextualising/textualising_'intelligibility/epistemicity/reflexivity-contiguity$<$ imbued-notional $\left.\sim \operatorname{cogency}>^{\prime}\right)^{\prime}$ '. Such a foiling of veridical social criticism in the present-day it is herein contended comes with substitutive pop-intellection stooges/foils in muddying the ontological-veracity-<as-to-prospective-ontologising-and-re-ontologising $>$ of genuine thought as of its true human sublimating/emancipating implications and associated with a numbing enculturation of the social devaluation of intellection (reflected in ingrained patterns of 'process/processive mere-formulaic_conformity/trending/voguing/fashionability/resonance relation to ${ }^{56}$ meaningfulness-and-teleology 99 devoid of requisite wholesomeness/profound-supererogation as of prospective ${ }^{83}$ reference-ofthought — point-of-devolving/departure/anchoring/backdrop_of_sublimating-nascence-<as-tothe-grandest-axiomatic-construct-\{epistemic-totalising ${ }_{3}^{\text {j}}$ re-apriorising/re-axiomatising/rereferencing residuality - in-re-originariness/re-origination of limitedness/human-subpotency prospective re-encountering/re-confrontation with unlimitedness/existence>' as appropriately underlied by \{epistemic-totalising 3 re-apriorising/re-axiomatising/re-referencing $\sim$ residuality-in-reoriginariness/re-origination- $\langle$ as to human profound-supererogation for prospective apriorising/axiomatising/referencing-\{of-'prospectively implicited_attendant-ontologicalcontiguity ' $\sim$ educed- 
existentialising/contextualising/textualising_'intelligibility/epistemicity/reflexivity-contiguity-

$<$ imbued-notional cogency $>$ ' $\}$-conflatedness -in-\{preconverging-ment by\}

pestconverging entailment that cannot be unshrouded by prior mere-formulaicity/ritualisation<as-to-mere-formulaic — methodologising/mutualising/organising/institutionalising,-

prospectively-losing-track-of- ‘\{epistemic-totalising ${ }^{3}$ re-apriorising/re-axiomatising/re-

of

prior

apriorising/axiomatising/referencing-\{of-'prospectively_implicited_attendant-ontological-

contiguity ' educed-

existentialising/contextualising/textualising_intelligibility/epistemicity/reflexivity-contiguity-

$<$ imbued-notional cogency $>$ ' $\}$ - constitutedness -in preconverging-entailment $\rangle$ as to human

limited-mentation-capacity-deepening — as-subjecting-limitedness/human-subpotency-to-

'educed-unlimitedness/existence-sublimating nascence' media but critically underlies the crisis of academia being surreptitiously quieted or turned into a validation giving institution with respect to prospective non-ontologising/disontologising as to temporal advantageousness of dominance/vested-interest-subontologising-skewed-influence-asto-social-vestedness/normativity- $<$ discretely-implied-functionalism $>$ ). Thus effectively closing the circle for profound social criticism appraisal as thought supposedly becomes re-oriented and recognised rather in the realm of its 'punctual conveniencing, popularising, merchandising and media-ratings of shallow-supererogation while circularly relegating such a profound notion like requisite 'supererogatory $\sim$ wholesomeness/profound-supererogation' as of prospective reference-of-thought—point-of-devolving/departure/anchoring/backdrop_of_sublimating_nascence-<as-to-the-grandest-axiomatic-construct-\{epistemic-totalising $\frac{\text { to }}{\mathrm{r}}$ aprierising/reaxiomatising/re-referencing residuality-in-re-originariness/re-origination

limitedness/human-subpotency prospective re-encountering/re-confrontation with

unlimitedness/existence> ${ }^{\prime} \quad$ protracted-social—as-to-individual-by-institutional-by-social 
epistemic-growth/disquiet/discomfort-〈induced-sublimation,-as-from-existence's-

effusing/ecstatic-inlining-as- historiality-\{science/authenticity/nonextrication $\}$-beyond-mere-

formulaicity/ritualisation-as- historicity-tracing-\{science-ideology/fashionability/distraction $\}$ )

(as to the enculturation of a pedantised and mediatised exercise of a 'circular perpetuallyunknowing ${ }^{7}$ presencing-absolutising-identitive-constitutedness ${ }^{14}$ deficient/poor aptitudinal re-ontologising-incompetence gesturing/accounting-of-epistemic-phenomenalism'). Further such non-ontologising/disontologising surreptitious knowledge-without-knowledge/knowledgeoutside-knowledge/extra-knowledge conception of thought fails to recognise the very universal-transparency ${ }^{104}$-〈transparency-of-totalising-entailing,-as-to-entailing<amplituding/formative-epistemicity>totalising in-relative-ontological-completeness >

implications upon true thinking as to when it claims to rather belonging to given societal and cultural traditions (rather than the pertinence of claiming prospective sublimation short-andsimple); and speaks of a ridiculous twist to the conception of knowledge as if there can be (as to the manifest sublimating-nascence incipience/instantaneity/directness of the natural sciences) any given specific societal and cultural chemistry, biology, geology, etc. or is it the case that Einsteins physics applies only to his Germanic/Swiss tradition or Lavoisier chemistry applies only to his French tradition or Newtons physics applies only to his British tradition or Galileo's physics applies only to his Italian tradition, etc.? In-many-ways such a surreptitious claim to veridical societal and cultural traditions that have to 'supposedly be protected from prospective existence-as-the-absolute-a-priori-of-conceptualisation and existence-as-sublimatingwithdrawal/unenframing/re-ontologising,-elicited-from-prospective-profoundsupererogation -<as-to-perspective-ontological-normalcy/postconvergence-implied'prospective-aporeticism-overcoming/unovercoming'>' speaks of a surreptitious selfanointedness that do not veridically reflect advantageously upon prospectve individual, institutional and social emancipation/sublimation possibilities but rather speaks to an 
undercurrent of vague domineering that is not socially accounted-for (especially as can be reflected as from the 'dragged-out nature or psychologismic-epistemic-acutisation-<as-topostconverging-de-mentating/structuring/paradigming,-eliciting-of-existence's-sublimatingnascence-in-prospective-aporeticism-overcoming/unovercoming $>$ as to epistemic-growth,-as\{veridical/sound\}-relative-reflexivity-in-existence/relativising from-limited-mentation-as-itsdeepening/psychologismic epistemic-acutisation residualising, ${ }^{\{\text {decompulsing }}$ \}elinearity foreogency' of 'prospective ${ }^{83}$ reference-of-thought appraisal of sublimating-nascence comprehensiveness/nonimmediacy/indirectness') but for a mere sense of social ascendency which paradoxically leaves in its 'non-ontologising/disontologising wake' socio-econo-political crises and malaises to which the majority of the citizenry only come across in serenity as to their numbed/manipulatable/gullible underlying sense of common nation-belonging (and most critically manifests of a veridically suboptimal human-decisionality-<as-to-play-ofvalid/invalid-decisionality-imbued-sublimation/desublimation $>$ capacity). In this regards, it is herein contended that veridical thought do not need any protection from itself with such covert/underhanded/minioning attitude of non-ontologising/disontologising surreptitious knowledge-without-knowledge/knowledge-outside-knowledge/extra-knowledge manifestation which is very much paradoxical as it is rather more socially dangerous (as to when it implicitly posits to 'covertly police' right/sound thought) in the sense that it is exactly the need for right/sound thought that can protect society against unsound thought and there is no neutral/objective ${ }^{79}$ presencing-absolutising-identitive-constitutedness ${ }^{14}$ state of thought that knows of unsound thought beforehand without the prior opened cultivation of right/sound thought (with such non-ontologising/disontologising surreptitious knowledge-withoutknowledge/knowledge-outside-knowledge/extra-knowledge enculturation as to its 'unevaluated/uncritical supposedly right/sound thought' thus leading rather to a collateralising mentality in the face of its prospective desublimation and there is no telling to which extent 
prospective human sublimating potential becomes shunted perpetually into this desublimating collateralising mode and its collateralising dearth). The opened cultivation of right/sound thought is the appropriate existential-<disontologising/re-ontologising aporeticism $>$ social validation of sublimation/emancipation (rather than a non-ontologising/disontologising surreptitious knowledge-without-knowledge/knowledge-outside-knowledge/extra-knowledge substitutive subterfuge of 'process/processive mere-formulaicconformity/trending/voguing/fashionability/resonance relation to meaningfulness-andteleology devoid of supereregatery wholesomeness/profound-supererogation as of prospective reference-of-thought-point-ofdevolving/departure/anchoring/backdrop_of_sublimating-nascence-<as-to-the-grandestaxiomatic-construct-\{epistemic-totalising ${ }^{3}$ re-apriorising/re-axiomatising/rereferencing - residuality - in-re-originariness/re-origination of limitedness/human-subpotency prospective re-encountering/re-confrontation with unlimitedness/existence $>$ ') as to underlining protracted-social—as-to-individual-by-institutional-by-social epistemicgrowth/disquiet/discomfort-〈induced-sublimation,-as-from-existence's - effusing/ecstaticinlining-as- historiality-\{science/authenticity/nonextrication $\}$-beyond-mere-

\section{formulaicity/ritualisation-as- historicity-tracing-\{science-}

ideology/fashionability/distraction $\}\rangle)$. In-the-bigger-scheme-of-things the idea so-implicited by such non-ontologising/disontologising surreptitious knowledge-without-knowledge/knowledgeoutside-knowledge/extra-knowledge (in its pedantising/muddling/formulaic-hollowing-out—insubontologisation/subpotentiation-〈blurring/undermining-of-prospective-totalising-entailing,as-to-entailing-<amplituding/formative-epistemicity $>$ totalising $\sim$ in-relative-ontologicalcompleteness $>$ manifestation) that all the effective human progress that can arise as to anglingof-imaginary does not require appropriate translative-accordance of 'our present' prospective nascent-particular/incipient-and-material/technical-sublimations- $<$ blinded-to-their-relative- 
ontological-completeness - reference-of-thought- devolving $>$ implications as to

$<$ amplituding/formative $>$ disposedness/psychologismic-construct-〈as-to-orientation/value-

construct/valuation-and-derived-parameterising $\rangle$ and $<$ amplituding/formative $>$ entailment-〈asto-totalising-contiguous/coherent-factuality-of-variability) into their true ontologising/nondisontologising 'supererogatory $\sim$ wholesomeness/profound-supererogation as of prospective reference-of-thought—point-of-devolving/departure/anchoring/backdrop_of_sublimating_ nascence-<as-to-the-grandest-axiomatic-construct-epistemic-tolising łre-apriorising/re-

axiomatising/re-referencing $\sim$ residuality-in-re-originariness/re-origination of

limitedness/human-subpotency prospective re-encountering/re-confrontation with
unlimitedness/existence> imbued psychologismic apriorising/axiomatising/referencing-\{of'prospectively_implicited_attendant-ontological-contiguity ' educedexistentialising/contextualising/textualising_intelligibility/epistemicity/reflexivity_contiguity$<$ imbued-notional cogency $\left.>^{\prime}\right\}$-conflatedness ${ }^{13}$ in-\{preconverging -ment by\} postconverging entailment'; rather effectively speaks to a human self-presence/selfconstitutedness ${ }^{14}-$ in-perspective-epistemic-abnormalcy/preconvergence $^{31}>\quad$ psychological $^{>}$ complex warranting prospective postconverging-aporeticism-overcoming/unovercoming. Such 'socially radiating sway of non-ontologising/disontologising surreptitious knowledge-withoutknowledge/knowledge-outside-knowledge/extra-knowledge desublimation (substituting over prospective veridical knowledge sublimation possibilities of social and institutional constructs as reflexively construable from veridical prospective 'implicited_attendant-ontologicalcontiguity $^{67} \sim$ educedexistentialising/contextualising/textualising_'intelligibility/epistemicity/reflexivity-contiguity$<$ imbued-notional cogency>' ${ }^{\circ}$ )', with regards to the 'exercise of the epistemic-projectiveequalisation of human station of ${ }^{7}$ presencing - absolutising-identitive-constitutedness ${ }^{14}$ as to prospective nonpresencing-<perspective-ontological-normalcy/postconvergence $>$ 
epistemic_-projective-equalisation' so-manifested in human social-and-institutionalframeworks-of — referencing/registering/decisioning existentialising-decisionality-<as-todisontologising/re-ontologising aporeticism $>$; in-many-ways involves the eliciting of the 'existentialising-frame-of-entailment-of motif-and-apriorising/axiomatising/referencing of priorly secondnatured institutionalisation-threshold of mere-formulaicity/ritualisation- $<$ as-tomere-formulaic — methodologising/mutualising/organising/institutionalising,-prospectivelylosing-track-of-‘fepistemic-totalising ’’re-apriorising/re-axiomatising/re-referencing 2 residuality-inre-originariness/re-origination'> positive-opportunism —of-social-functioning-andaccordance $^{75}$ as not speaking to prospective human disruptive postconverging-apereticismovercoming/unovercoming' to wrongly imply it is of appropriate prospective 'human psychologismic-epistemic-acutisation-<as-to-postconverging-dementating/structuring/paradigming,-eliciting-of-existence's-sublimating-nascence-inprospective-aporeticism-overcoming/unovercoming $>$ as to epistemic-growth,-as\{veridical/sound\}-relative-reflexivity-in-existence/relativising from-limited-mentation-as-itsdeepening/psychologismic epistemic acutisation residualising, fdecompulsingl delinearity for eogency'. The inherent outcome then is that the registry-worldview/dimension 'implicited_atentant-ontological-contiguity ${ }^{67}$ ' educedexistentialising/contextmalising/textualising_intelligibility/epistemicity/reflexivity_contiguity-

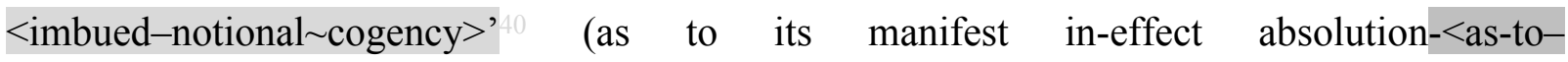
apriorising/axiomatising/referencing-\{of-'prospectively_implicited_attendant-ontologicalcontiguity ' $\sim$ educedexistentialising/contextualising/textualising_'intelligibility/epistemicity/reflexivity_contiguity$<$ imbued-notional cogency $>$ ' $\quad$ - constitutedness in preconverging entailment $>$ ) goes on to wrongly imply either 'paradoxically the non-ontological nature of the social (paradoxical because there is nothing that is not of existence and hence nothing is effectively non-ontological 
but for human limited-mentation-capacity—as-subjecting-'educed-unlimitedness/existencesublimating nascence' to-limitedness/human-subpotency of appraisal which reflexive deficiency notionally transforms-into/reveals its manifest metaphysical/ideological conceptualisation)' or wrongly imply effectively that such ad-hocness is rather of prospective postconverging aporeticism-overcoming/unovercoming as enabling prospective ontologising/re-ontologising while failing to factor in its ${ }^{79}$ presencing-absolutising-identitiveconstitutedness $^{14}$ social-vestedness/normativity- $<$ discretely-implied-functionalism $>$ imbued $<$ amplituding/formative-epistemicity $>$ totalising $\sim$ self-referencing-

syncretising/circularity/interiorising/akrasiatic-drag ${ }^{34}$ (thus undermining prospective postconverging-aporeticism-overcoming/unovercoming when its registryworldview/dimension 'implicited_attendant_ontological-contiguity ${ }^{67}$ ' educedexistentialising/contextualising/textualising_'intelligibility/epistemicity/reflexivity_contiguity$<$ imbued-notional cogency $>^{\prime} \quad$ self-presence/self-constitutedness ${ }^{14}{ }^{-<\text {in-perspective- }}$ epistemic-abnormalcy/preconvergence ${ }^{3}>$ notions of institutional access and success default conception of human ontological-performance ${ }^{72}-<_{\text {including-virtue-as- }}$ ontology $>$ /morality/ethics/justice/etc. 'supposedly-and-manifestly override the exercise of prospective veridical ontologising-and-re-ontologising as to prospective 'implieited_tentant ontological-contiguity ${ }^{67}$, educed-

existentialising/contextualising/textualising_intelligibility/epistemicity/reflexivity-contiguity<imbued-notional cogency >' with regards to the prospectively requisite 'supereregatery $\sim$ wholesomeness/profound-supererogation ${ }^{\circ}$ as of prospective ${ }^{83}$ reference-ofthought_ — point-of-devolving/departure/anchoring/backdrop_of_sublimating-nascence- $<$ as-tothe-grandest-axiomatic-construct- fepistemic-totalising ${ }^{\text {tre }}$ repriorising/re axiomatising/re referencing residuality - in-re-originariness/re-origination of limitedness/human-subpotency prospective re-encountering/re-confrontation with unlimitedness/existence>' underlied by 
\{epistemic-totalising 3 \}re-apriorising/re-axiomatising/re-referencing - residuality-in-re-

originariness/re-origination- $\langle$ as to human profound-supererogation for prospective apriorising/axiomatising/referencing-\{of-'prospectively implicited_attendant-ontologicalcontiguity ' educed-

existentialising/entextralising/textrising_intelligibility/epistemicity/reflexivity-contiguity<imbued-notional cogency $>$ ' \}-conflatedness -in-\{preconverging-ment by\} postconverging-entailment that cannot be unshrouded by prior mere-formulaicity/ritualisation$<$ as-to-mere-formulaic - methodologising/mutualising/organising/institutionalising,prospectively-losing-track-of- ‘ $\left\{\right.$ epistemic-totalising ${ }^{\dagger}$ re-apriorising/re-axiomatising/rerefereneing $\sim$ residuality-in-re-originariness/re-origination’> of prior apriorising/axiomatising/referencing-\{of-'prospectively implicited_attendant_ontologicalcontiguity ' educedexistentialising/contextualising/textualising_'intelligibility/epistemicity/reflexivity-contiguity<imbued-notional cogency >' $\}$-constitutedness -in-preconverging-entailment $\rangle$ as to human limited-mentation-capacity-deepening —as-subjecting limitedness/human-subpotency-to'educed-unlimitedness/existence-sublimating nascence' ${ }^{53}$ ). Such 'socially radiating sway of non-ontologising/disontologising surreptitious knowledge-without-knowledge/knowledgeoutside-knowledge/extra-knowledge desublimation (substituting over prospective veridical knowledge sublimation possibilities of social and institutional constructs as reflexively construable from veridical prospective 'implicited_attendant-ontological-contiguity ${ }^{67}$; educedexistentialising/contextualising/textualising_intelligibility/epistemicity/reflexivity-contiguity<imbued-notional cogency>' ')' very much explains the very paradox of human civilisation reflected with the relative-unreflexivity/relative-reflexivity ontological-contiguity $\sim$ of-thehuman-institutionalisation-process ${ }^{68}$ wherein paradoxically incipient/seeding prospective knowledge value (as to their given prospective apriorising/re- 
axiomatising/re-referencing residuality-in-re-originariness/re-origination-〈as to human profound-supererogation for prospective apriorising/axiomatising/referencing-\{of'prospectively_implicited_attendant_ontological-contiguity ' educedexistentialising/contextualising/textualising_'intelligibility/epistemicity/reflexivity-contiguity$<$ imbued-notional cogency>' $\}$-conflatedness in (preconverging ment by postconverging-entailment that cannot be unshrouded by prior mere-formulaicity/ritualisation$<$ as-to-mere-formulaic — methodologising/mutualising/organising/institutionalising,prospectively-losing-track-of- ‘fepistemic-alising $\stackrel{+}{+}$ re-apriorising/re-axiomatising/rereferencing $\sim$ residuality -in-re-originariness/re-origination'> of prior apriorising/axiomatising/referencing-\{of-'prospectively_implicited_attendant-ontologicalcontiguity ' educedexistentialising/contextualising/textualising_'intelligibility/epistemicity/reflexivity-contiguity$<$ imbued-notional cogency $>$ ' $\quad\}$-constitutedness -in-preconverging-entailment $\rangle)$ respectively as of prospective ${ }^{103}$ universalising-idealisation, budding-positivism and budding postmodern-thought are actually devalued (as to the manifest prospective 'epistemic-decadence' or teleological-decadence-<-in-dimensionality-of-desublimating-lack-of ${ }^{-}$ <<amplituding/formative>supererogatory $\sim$ de-mentativeness/epistemic-growth-orconflatedness /transvaluative-rationalising/transepistemicity/anamnestic-residuality/spiritdrivenness-equalisation) of prior non-universalising, non-positivising and totalisingly-ingdiscretion/whim-of-thought respectively of ancient-sophists, medieval-scholasticism and our modern-day manifestation of disparateness-of-conceptualisation-<unforegrounding-ment,failing-prospectively-to-reflect- 'immanent relative-unreflexivity/relative-reflexivity ontological-contiguity '>). This elucidation highlights that human prospective veridical ontologising/re-ontologising necessarily speaks to the precedence of requisite 'supereregatery $\sim$ wholesomeness/profound-supererogation ${ }^{96}$ as of prospective ${ }^{83}$ reference-of- 
thought_-point-of-devolving/departure/anchoring/backdrop_of_sublimating-nascence- $<$ as-tothe-grandest-axiomatic-construct-\{epistemic-totalising ${ }^{\frac{1}{3}}$ re-apriorising/re-axiomatising/rereferencing residuality - in-re-originariness/re-origination of limitedness/human-subpotency prospective re-encountering/re-confrontation with unlimitedness/existence ${ }^{>}$(as of cumulating/recomposuring as to prospective 'human aestheticisation-and-aestheticisationtowards-ontology-<elicited-idiomatisation $>$ unbeholdening, transcendence, decomplexification for organic-knowledge and ment of prior apriorising/axiomatising/referencing' as so-reflecting

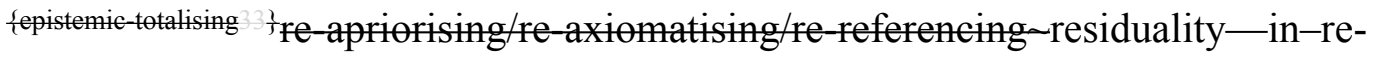
originariness/re-origination-〈as to human profound-supererogation for prospective apriorising/axiomatising/referencing-\{of-'prospectively implicited_attendant-ontologicalcontiguity ' $\sim$ educedexistentialising/contextualising/textualising_intelligibility/epistemicity/reflexivity_contiguity<imbued-notional cogency>’ \}-conflatedness -in-\{preconverging-ment by\} postconverging-entailment that cannot be unshrouded by prior mere-formulaicity/ritualisation$<$ as-to-mere-formulaic — methodologising/mutualising/organising/institutionalising,-

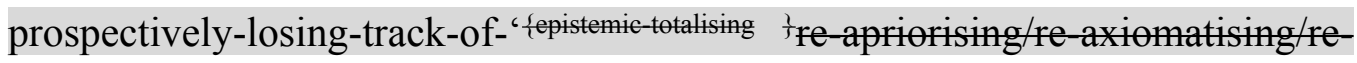
referencing $\sim$ residuality —in-re-originariness/re-origination'> of prior apriorising/axiomatising/referencing-\{of-'prospectively_implicited_attendant-ontologicalcontiguity ' educedexistentialising/contextualising/textualising_'intelligibility/epistemicity/reflexivity_contiguity<imbued-notional cogency >' $\quad\}$-constitutedness -in preconverging-entailment $\rangle$ as to human limited-mentation-capacity-deepening —as-subjecting-limitedness/human-subpotency-to'educed-unlimitedness/existence-sublimating nascence' ${ }^{53}$ ) and so over prior 'implicited_attendant-ontological-contiguity ${ }^{67}$ educedexistentialising/contextualising/textualising_'intelligibility/epistemicity/reflexivity-contiguity- 
<imbued-notional cogency>' (as to prior 'human aestheticisation-and-aestheticisationtowards-ontology-<elicited-idiomatisation $>$ beholdening, non-transcendence, complexification as to mechanical-knowledge and non-ment of prior apriorising/axiomatising/referencing'). With this being patently the case as to when manifest relative-ontological-completeness ${ }^{87}$ is-educedand-avails-and-re-avails, as so-enabled by the prospective prompting of 'constraining existence—as-sublimating-withdrawal/unenframing/re-ontologising,-elicited-fromprospective-profound-supererogation imbuing human ontological-commitment ${ }^{6}-<$ impliedself-assuredness-of-ontological-good-faith/authenticity postconverging-dementating/structuring/paradigming -as-being-as-of-existential-reality>' and ' 103 universaltransparency ${ }^{104}$-〈transparency-of-totalising-entailing,-as-to-entailing-<amplituding/formativeepistemicity $>$ totalising $\sim$ in-relative-ontological-completeness $\rangle$ as available-to/elicitable-to-〈asto-human-consciousness/collective-consciousness-distendedness/detruncating-<beyondselfpresencing,-as-re-ontologising-decentering_of-consciousness/collective-consciousness,-asto-psychologismic-epistemic-acutisation - residualising, ${ }^{\text {- }{ }_{\text {decompulsing }} \text { delinearity } \sim \text { for-cogency }>>}$ the social-functioning-and-accordance-as-of-social-stake-contention-or-confliction conception of any given registry-worldview/dimension <preconverging 'motif-andapriorising/axiomatising/referencing'-entailing >-existentialising-enframing/imprintedness$\langle$ as-to- historicity-tracing - in-presencing-hyperrealisation/hyperreal-transposition〉'; as sounderlining/emphasising the ontological-veracity that a social-setup-as-a-subpotency epistemicconception is preconverging/postconverging-de-mentatively/structurally/paradigmatically opened to prospective metaphoricity ${ }^{57}$ from existential-constraining/conflatedness ${ }^{13}$-of-itscommitment-with-existence as of its inherently implied supposedly coherent ontological-

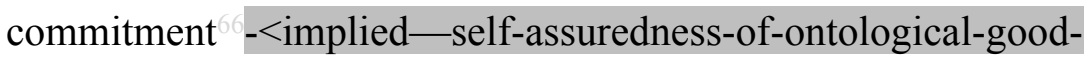
faith/authenticity postconverging-de-mentating/structuring/paradigming -as-being-as-ofexistential-reality $>$ as its individuals and social groups are naturally involved in a dynamic 
relationship of perceived social-stake-contention-or-confliction striving in apriorising/axiomatising/referencing-\{of-'prospectively implicited_attendant-ontologicalcontiguity ' educedexistentialising/contextualising/textualising_'intelligibility/epistemicity/reflexivity-contiguity<imbued-notional cogency $>$ ' $\}$-conflatedness ${ }^{13}$ in-\{preconverging-ment by\} pestcenverging-entailment to draw in various ways the optimum as of perceived existential$<$ disontologising/re-ontelogising aporeticism $>$ possibilities such that a social-setup is already involved internally however restricted in its very own reinvention/circumventing/adaptation as of its implied supposedly coherent ontological-commitment $-<$ implied-self-assuredness-ofontological-good-faith/authenticity postconverging-dementating/structuring/paradigming -as-being-as-of-existential-reality $>$ on the basis of $<$ amplituding/formative-epistemicity $>$ causality $\sim$ as-to-projective-totalitative-implications-ofprospective- nonpresencing,-for-explicating relative-unreflexivity/relative-reflexivity ontological-contiguity validatory implications as to existence-potency ${ }^{32} \sim$ sublimating- $^{-}$ nascence,-disclosed-from-prospective-epistemic-digression. Thus the manifestation of 'socially radiating sway of non-ontologising/disontologising surreptitious knowledge-withoutknowledge/knowledge-outside-knowledge/extra-knowledge desublimation (substituting over prospective veridical knowledge sublimation possibilities of social and institutional constructs as reflexively construable from veridical prospective 'implicited_attendant-ontologicalcontiguity $^{67} \sim$ educed-

existentialising/contextualising/textualising_intelligibility/epistemicity/reflexivity-contiguity<imbued-notional cogency ${ }^{\prime}{ }^{\prime}$ )' speaks to the fact that (and as so-avowed by indirect and surreptitious pronouncements manifesting such non-ontologising/disontologising) the 'very social manifestation of human intellection itself displays of its very own stealthy/surreptitious/underhanded desublimating thresholding of anti-intellection non- 
ontologising/disontologising'; however counterintuitive to our 'existentialising-frame-ofentailment of motif-and-apriorising/axiomatising/referencing of priorly secondnatured institutionalisation-threshold of mere-formulaicity/ritualisation-<as-to-mere-formulaic methodologising/mutualising/organising/institutionalising,-prospectively-losing-track-of‘\{epistemic-totalising ’’re-apriorising/re-axiomatising/re-referencing - residuality-in-reoriginariness/re-origination'> positive-opportunism—of-social-functioning-and-accordance as not speaking to prospective human disruptive postconverging-aporeticismovercoming/unovercoming' which seem to represent by default that 'public-facing social and institutional setups as to their mere-formulaicity/ritualisation-<as-to-mere-formulaicmethodologising/mutualising/organising/institutionalising,-prospectively-losing-track-of‘\{epistemic-totalising ’’re-apriorising/re-axiomatising/re-referencing $r$ residuality-in-reoriginariness/re-origination'> of intellection' necessarily and absolutely avoid/do-not-manifest a desublimating thresholding of anti-intellection non-ontologising/disontologising. This insight effectively underlies that ontology/science is actually a postconverging-birthing/nascency within prospective in-re-originariness/re-origination-〈as to human profound-supererogation for prospective apriorising/axiomatising/referencing-\{of-'prospectively implicited_attendant-ontologicalcontiguity ' $\sim$ educedexistentialising/contextualising/textualising_ 'intelligibility/epistemicity/reflexivity-contiguity$<$ imbued-notional $\left.\sim \operatorname{cogency}>^{\prime}\right\}$-conflatedness -in-\{preconverging-ment by\} postconverging-ntailment that cannot be unshrouded by prior mere-formulaicity/ritualisation$<$ as-to-mere-formulaic — methodologising/mutualising/organising/institutionalising,prospectively-losing-track-of- ‘ \{epistemic-totalising 3 re-apriorising/re-axiomatising/rereferencing $\sim$ residuality_-in-re-originariness/re-origination'> of prior apriorising/axiomatising/referencing-\{of-'prospectively_implicited_attendant-ontological- 
contiguity ' educed-

existentialising/contextualising/textualising_'intelligibility/epistemicity/reflexivity_contiguity$<$ imbued-notional cogency >' $\quad$-constitutedness -in-preconverging-entailment $\rangle$; and this insight is critical in order to preserve-and-prolong human prospective ontologising-and-reontologising and thus uphold the prospective sublimating/emancipative/enfranchising possibilities so-underlying 'human consciousness notional protensivity imbuing prospective psychologismic-epistemic-acutisation-<as-to-postconverging-dementating/structuring/paradigming,-eliciting-of-existence's-sublimating-nascence-inprospective-aporeticism-overcoming/unovercoming $>$ as to epistemic-growth,-as\{veridical/sound\}-relative-reflexivity-in-existence/relativising from-limited-mentation-as-its-

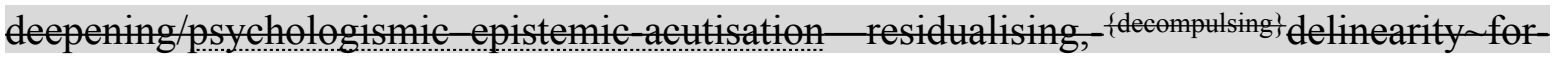
eogency' undergirding the 'full experientiality/experiment-<as-to-existentially-formative‘fepistemic talising łre-apriorising/re-axiomatising/re-referencing $r$ residuality-in-reoriginariness/re-origination',- -so- 'notionally/epistemically/bindingnessly-sastodeterminism/conceptivity-of-relative-unreflexivity/relative-reflexivity>-implicited-and-articulated'_as-fromnonextricatory-'prospective-re-ontologising-Being-then-Institutional-then-Living-magnitudesof-\{hermeneutic/reprojection-protraction-of $\}$ reframing-and-reformulation $\}$ ' $>$ that is the human abstract-tissue-of-social-emanance' (ever always at the threat and mercy of prospective nonontologising/disontologising as to temporal advantageousness of dominance/vested-interestsubontologising-skewed-influence-as-to-social-vestedness/normativity-<discretely-impliedfunctionalism>). Such an elucidation of 'socially radiating sway of nonontologising/disontologising surreptitious knowledge-without-knowledge/knowledge-outsideknowledge/extra-knowledge desublimation (substituting over prospective veridical knowledge sublimation possibilities of social and institutional constructs as reflexively construable from veridical prospective 'implicited_attendant-ontological-contiguity ${ }^{67}$ ' educed- 
existentialising/contextualising/textualising_intelligibility/epistemicity/reflexivity-contiguity<imbued-notional cogency>' ${ }^{\prime}$ )' as herein exposed has to do with the fact that engaging profoundly in notional $\sim$ philosophy-<as-to-the-veridical-conception-of-philosophy-asenglobing-all-human-prospective-organic-knowledge-generation-in-relative-ontologicalcompleteness ,-beyond-a-convenient-division-of-labour-conception-of-knowledge> $\quad$ (and particularly as to its core vocation of 'supereregatery wholesomeness/profoundsupererogation as of prospective ${ }^{83}$ reference-of-thought-point-ofdevolving/departure/anchoring/backdrop_of_sublimating-nascence-<as-to-the-grandestaxiomatic-construct- fepistemic-alising $\stackrel{+}{+}$ re-apriorising/re-axiomatising/rereferencing residuality - in-re-originariness/re-origination of limitedness/human-subpotency prospective re-encountering/re-confrontation with unlimitedness/existence>' with regards to the 'dragged-out nature or psychologismic-epistemic-acutisation-<as-to-postconverging-dementating/structuring/paradigming,-eliciting-of-existence's-sublimating-nascence-inprospective-aporeticism-overcoming/unovercoming > as to epistemic-growth,-as\{veridical/sound\}-relative-reflexivity-in-existence/relativising from-limited-mentation-as-itsdeepening/psychologismic epistemic acutisation residualising, ${ }^{\text {fdecompulsing }}$ delinearity for eogeney' of 'prospective ${ }^{83}$ reference-of-thought appraisal of sublimating-nascence comprehensiveness/nonimmediacy/indirectness') cannot allow for any nonontologising/disontologising surreptitious knowledge-without-knowledge/knowledge-outsideknowledge/extra-knowledge pretense of intellectual engagement (as falsely projecting dialogical-equivalence-<as-to-psychologismic apriorising/axiomatising/referencing-\{of'prospectively_implicited_attendant-ontological-contiguity ' ceducedexistentialising/entextualising/textralising_intelligibility/epistemicity/reflexivity-contiguity$<$ imbued-notional cogency $>$ ' \}-conflatedness -in-\{preconverging ment by\} postconverging entailment,-in-self-becoming/self-conflatedness /formative-supererogating>) 
in a 'fundamental paradox of contemptuous distractive-alignment-to- ${ }^{3}$ reference-of-thought$<$ of-apriorising/axiomatising/referencing $>^{3}{ }^{\prime} ;$ as such pedantising/muddling/formulaichollowing-out - in-subontologisation/subpotentiation-〈blurring/undermining-of-prospectivetotalising-entailing,-as-to-entailing-<amplituding/formative-epistemicity $>$ totalising inrelative-ontological-completeness > incipient/seeding non-ontologising/disontologising desublimation itself then warrants its very own prior fundamental analysis, and so as to the requisite fundamental equanimity/balance for veridical thought elucidation which is exactly what acts as the bedrock for other fundamental sublimating/emancipative/enfranchising protracted-social—as-to-individual-by-institutional-by-social equanimity/balance elucidations (and this insight is critically of 'prospective ontological-pertinence and ontological-necessity' in the sense that manifest veridical human sublimation/emancipation/enfranchisement actually 'accrues to the grander prospective sublimating ontologising-and-re-ontologising capacity of all humans/humanity beyond just about the perception of sublimation/emancipation/enfranchisement accruing punctually/immediately upon any specific subgroup/subcategory of humans/humanity' as so-reflected insightfully as from the 'draggedout nature or psychologismic-epistemic-acutisation-<as-to-postconverging-dementating/structuring/paradigming,-eliciting-of-existence's-sublimating-nascence-inprospective-aporeticism-overcoming/unovercoming > as to epistemic-growth,-as\{veridical/sound\}-relative-reflexivity-in-existence/relativising from-limited-mentation-as-its-

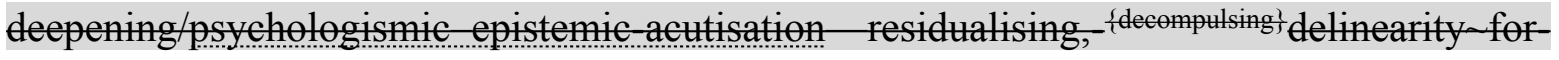
eogency' of 'prospective ${ }^{83}$ reference-of-thought appraisal of sublimating-nascence comprehensiveness/nonimmediacy/indirectness' imbued 'supereregatory $\sim$ wholesomeness/profound-supererogation' as of prospective ${ }^{83}$ reference-ofthought — point-of-devolving/departure/anchoring/backdrop_of_sublimating-nascence-<as-tothe-grandest-axiomatic-construct-fepistemic-atising $\stackrel{\text { ’ }}{\mathrm{r}}$-apriorising/re-axiomatising/re- 
prospective re-encountering/re-confrontation with unlimitedness/existence>'). In this respect, the ontologically-veridical elucidation of the 'socially radiating sway of nonontologising/disontologising surreptitious knowledge-without-knowledge/knowledge-outsideknowledge/extra-knowledge desublimation (substituting over prospective veridical knowledge sublimation possibilities of social and institutional constructs as reflexively construable from veridical prospective 'implicited_attendant-ontological-contiguity ${ }^{67}$ ' educedexistentialising/contextualising/textualising_'intelligibility/epistemicity/reflexivity-contiguity$<$ imbued-notional cogency>' ')' effectively speaks to the given registry-worldview/dimension

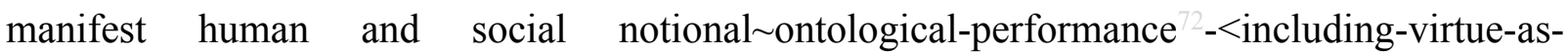
ontology $>$ /vices-and-impediments ${ }^{105}$ with regards to its epistemic-projective-equalisation exercise ('exercise of the epistemic — projective-equalisation of human station of ${ }^{79}$ presencingabsolutising-identitive-constitutedness ${ }^{14}$ as to prospective ${ }^{6}$ nonpresencing-<perspectiveontological-normalcy/postconvergence $>$ epistemic_projective-equalisation'); as can be veridically construed (and as so-profoundly elucidated further above) rather as from the elaborate conception of nonpresencing-or-withdrawal/unenframing/re-ontologising-or-metaphysicsof-absence-〈implicited-epistemic-veracity-of- nonpresencing-<perspective-ontologicalnormalcy/postconvergence $>$ )-or-transcendental-reasoning-of-event ${ }^{38}$-as-prospective-ontologyorigination (as to its full/comprehensive/dragged-out ${ }^{103}$ universal or totalising-entailing conceptualisation implications of aetiologisation/ontological-escalation- $<$ ontologicalveridicality_commitment/otherliness_transcending/compulsions-encumbered_transcending $>$ ). Prior to such an elucidation, it can be appreciated pertinently that human $<$ amplituding/formative-epistemicity $>$-totalising $\sim$ thrownness-in-existence as to limitedmentation-capacity—as-subjecting 'educed-unlimitedness/existence-sublimating nascence' to-limitedness/human-subpotency implications necessarily/inevitably burdens/weighs-on 
human intelligibility with an 'incipient/seeding contradiction of passion' (with passion so-being incipient/seeding given human 'germinative intensification — amplituding of aestheticisationbeholdening-out-of-bechancing' / 'taxingness-of-originariness,-imbued-sublimating-bydesublimating-amplituding as to the backdrop-of-inherent-immanent-existence's-sublimationstructure-<of- 'unsurrealistic-as-real'-ontological-normalcy/postconvergence $>$ ' as so-speaking to the 'fundamental/underlying human consciousness in-its-embodiment' as the potent 'phenomenological transcendental-point-of-departure handle' for human self-conscious existence and ${ }^{56}$ meaningfulness-and-teleology ${ }^{9}$ construal/conceptualisation as of knowledgeconstructs/theories/intersolipsistic-intercessory-notions/notional $\sim$ referential-

notions/articulations/virtue). The paradox between human limited-mentation-capacity-assubjecting 'educed-unlimitedness/existence-sublimating nascence' to-limitedness/humansubpotency (as to epistemic-impassion) and omnipotentiality (as to epistemic-dispassion) 'embroils human intelligibility in its limited-mentation-capacity-deepening-as-subjectinglimitedness/human-subpotency to-'educed-unlimitedness/existence-sublimating nascence' exercise' (as reflected upon its social-functioning-and-accordance-as-of-social-stakecontention-or-confliction as to manifest human 'social-functioning-and-accordance-as-ofsocial-stake-contention-or-confliction imbuing existentialising-frame-of of and-apriorising/axiomatising/referencing of disontologising/ontologising-and-re-ontologising'); as so-reflecting requisite prospective ontologising-and-re-ontologising accompanying psychoanalytic-unshackling/memetic-reordering/institutional-recomposuring selfbecoming/self-conflatedness ${ }^{13}$ /formative-supererogating-<projective/reprojectiveaestheticising-re-motif-and-re-apriorising/re-axiomatising/re-referencing,-in-perspectiveontological-normalcy/postconvergence $>$ (such that in-many-ways the immediately ensuing text herein about this 'epistemic-impassion and epistemic-dispassion embroiling of human intelligibility as to human notional ontological-performance ${ }^{72}-<$ including-virtue-as- 
ontology $>/$ vices-and-impediments $^{105}$, carries a psychoanalytic element as to prospective 'requisite taxing psychologismic-epistemic-acutisation-<as-to-postconverging-dementating/structuring/paradigming,-eliciting-of-existence's-sublimating-nascence-inprospective-aporeticism-overcoming/unovercoming $>$ as to epistemic-growth,-as\{veridical/sound\}-relative-reflexivity-in-existence/relativising from-limited-mentation-as-itsdeepening/psychologismic epistemic-acutisation residualising, ${ }^{\text {fdecompulsing }}$ \}elinearity foreogency' so-reflected in the 'markedly repetitional textual re-elaborating' hereafter meant to veridically relay the accompanying psychoanalytic ontologising-depth of the text imbued 'self-

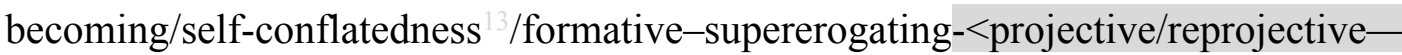
aestheticising-re-motif-and-re-apriorising/re-axiomatising/re-referencing,-in-perspectiveontological-normalcy/postconvergence $>$ conceptual appraisal' just like say a prospective positivising text in a non-positivising context 'is more than just about a straightforward textual conceptual appraisal' but actually carries along its 'requisite taxing psychologismic-epistemicacutisation-<as-to-postconverging-de-mentating/structuring/paradigming,-eliciting-ofexistence's-sublimating-nascence-in-prospective-aporeticism-overcoming/unovercoming $>$ as to epistemic-growth,-as - \{veridical/sound\}-relative-reflexivity-in-existence/relativising from-

\section{limited mentation as its deepening/psychologismic epistemic acutisation residualising,}

\{decompulsing\} delinearity for-cogency' for the possibility of the beginning of a true understanding 'as from the non-positivising epistemic-projection perspective incipience/seedingness of prospective requisite ontological-good-faith/authenticity ${ }^{6} \sim$ postconverging-dementating/structuring/paradigming ${ }^{70}$ for such an understanding to begin arising'). While existence (as to its sublimating-nascence exuding) is utterly of dispassionate/detached/unflustered seedingness/incipience, human limited-mentationcapacity —as-subjecting-'educed-unlimitedness/existence-sublimating nascence' tolimitedness/human-subpotency means that human-subpotency can only educe as much 
intelligibility (as to its conceptivity/epistemic-reflexivity/epistemicity-relativism-determinism$<$ reifying \{as-to-knowledge-developing\}-and-empowering $>$ — for-inlining with phenomenal existence) as from human sublimating epistemic-dispassion (so-construed as 'appropriate human dosage of self-reflexivity tempered/distempered projective-insights with respect to the sublimating-nascence of existence-as-the-absolute-a-priori-ofconceptualisation and existence - as-sublimating-withdrawal/unenframing/re-ontologising,elicited-from-prospective-profound-supererogation $-<$ as-to-perspective-ontologicalnormalcy/postconvergence-implied-'prospective-aporeticism-overcoming/unovercoming'>'); as so-underlying achieved human psychologismic-epistemic-acutisation- $<$ as-topostconverging-de-mentating/structuring/paradigming,-eliciting-of-existence's-sublimatingnascence-in-prospective-aporeticism-overcoming/unovercoming $>$ (as reflected with the $<$ cumulating/recomposuring attendant-ontological-contiguity $>$-successive registryworldviews/dimensions epistemic-dispassion levels of postconverging epistemic_-projectiveequalisation). It is herein contended that while all such being-in-theworld/<amplituding/formative-epistemicity $>$-totalising $\sim$ thrownness-in-existence $\quad$ seem $\quad$ to

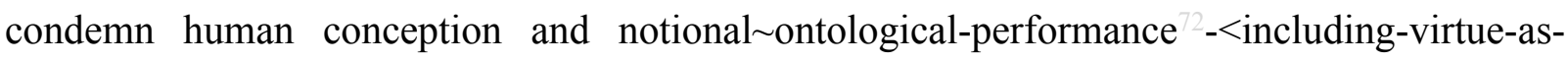
ontology $>$ /vices-and-impediments ${ }^{105}$ of its social-functioning-and-accordance-as-of-socialstake-contention-or-confliction as to their given being-in-the-world/<amplituding/formativeepistemicity $>$-totalising $\sim$ thrownness-in-existence $\quad{ }^{79}$ presencing-absolutising-identitiveconstitutedness $^{14}$ knowledge-value and knowledge-discursivity, the prospective reoriginariness/re-origination possibility for sublimating epistemic-dispassion is ever always available to appropriate notional asceticism which construes of social-functioning-andaccordance-as-of-social-stake-contention-or-confliction rather as of prospective angling-ofimaginary conceptualisation and so over an epistemic-impassion psychical-nascency 'human lifespan extricatory punctuality/immediacy of depth-of-thought' construal of social-functioning- 
and-accordance-as-of-social-stake-contention-or-confliction (and so-specifically as to enabling re-ontologising prospective Being-development/ontological-framework-expansion-asto-depth-of-ontologising-development-as-infrastructure-of- meaningfulness-and-teleology ); with such a prospective epistemic-dispassion underlying the serene possibilities for prospective transcendence-and-sublimity/sublimation/supereregatory-de-mentativity as to the fact that epistemic-dispassion projects of a 'clarity/intelligibility that is not veridically of a human construction exercise (as to an undertone/hint associated with the term construction as of '7 presencing - absolutising-identitive-constitutedness ${ }^{14}$ normalising functionalism conception as to \{flawed/unsound\}-relative-unreflexivity-in-existence/absolutising from-limitedmentation/psychologismic epistemic acutisation nonresidualising imbued-

\{compulsing\} linearityoin-eclecticism-of prior-mere-formulaicity/ritualisation' that wrongly seem to normalise the present's prospectively disontologising epistemic-abnormalcy/preconvergence epistemic-projection perspective) but rather veridically of a wholly prospective human mental liberation/empowerment exercise' as so-liberated/empowered from the cloudiness of prior epistemic-impassion (as can be appreciated with limited-mentation-capacity-deepening-assubjecting limitedness/human-subpotency-to-'educed-unlimitedness/existence-sublimating nascence implied ontological-normalcy/postconvergence epistemic-projection perspective 'so-reflectable projectively as the normal that is unfreed/unliberated in want for its prospective freeing/liberating' as construable from the more advantageous postconverging relativeontological-completeness 87 epistemic-projection perspective over preconverging relativeontological-incompleteness ${ }^{88}$ epistemic-projection perspective). It is with this explanatory backdrop that a 'prospective ${ }^{18}$ deprocrypticism-or-preempting-disjointedness-as-ofreference-of-thought sublimating epistemic-dispassion given epistemic-projectiveequalisation conception' can be perceptibly-and-pensively be understood; as of its prospectively requisite 'appropriate human dosage of self-reflexivity tempered/distempered projective-insights 
with respect to the sublimating-nascence of existence-as-the-absolute-a-priori-ofconceptualisation and existence — as-sublimating-withdrawal/unenframing/re-ontologising,elicited-from-prospective-profound-supererogation $-<$ as-to-perspective-ontologicalnormalcy/postconvergence-implied-'prospective-aporeticism-overcoming/unovercoming'>' and so-reflected by its epistemic-dispassion given epistemic-projective-equalisation conception (beyond our positivism- ${ }^{80}$ procrypticism epistemic-impassion given epistemicprojective-equalisation ontologically-deficient level of human conception of social-functioningand-accordance-as-of-social-stake-contention-or-confliction). Basically, human limitedmentation-capacity—as-subjecting 'educed-unlimitedness/existence-sublimating nascence' to-limitedness/human-subpotency speaks of the social-construct's 'dynamic epistemicprojective-equalisation social differentiation of social knowledge-value and knowledgediscursivity as of sublimating/desublimating notional ontological-performance ${ }^{2}-<$ includingvirtue-as-ontology $>/$ vices-and-impediments ${ }^{105}$, (as reflected from the underlying human and social difference-conflatedness ${ }^{13}$-as-to-totalitative-reification-in-singularisation- $<$ as-to-thenondisjointedness/entailment-of-prospective- nonpresencing > -as-veridical-epistemicityrelativism-determinism implied $<$ amplituding/formative-epistemicity $>$ causality $\sim$ as-toprojective-totalitative-implications-of-prospective- nonpresencing,-for-explicating relative unreflexivity/relative-reflexivity ontological-contiguity ); so-reflecting an 'imbued passioning of human social-functioning-and-accordance-as-of-social-stake-contention-orconfliction at the confrontation/encounter of human-subpotency postconverging/preconverging epistemic-projective-equalisation social dynamics and the constraining full-potency of existence as to its exuding/exudable sublimating-nascence' as this prompts preconverging/postconverging-de-mentating/structuring/paradigming formation of 'socialfunctioning-and-accordance-as-of-social-stake-contention-or-confliction imbuing 
disontologising/ontologising-and-re-ontologising' in a lock-in of desublimating epistemicimpassion and sublimating epistemic-dispassion. Actually, sublimating human ontologicalperformance $^{72}-<$ including-virtue-as-ontology $>$ /morality/ethics/justice/etc. manifestly arisesand-is-expanded-upon in the 'postconverging epistemic-projective-equalisation social dynamics of human limited-mentation-capacity-deepening —as-subjecting limitedness/humansubpotency-to-'educed-unlimitedness/existence-sublimating naseence' ${ }^{33}$ (as to domains-ofinterests of specifically and/or generally cultivated arts/skills and time investment)' and as to their overall notional philosophy-<as-to-the-veridical-conception-of-philosophy-as-englobingall-human-prospective-organic-knowledge-generation-in-relative-ontological-completeness beyond-a-convenient-division-of-labour-conception-of-knowledge> induced 'epistemicdispassion munificence/notional $\sim$ protensivity/re-ontologising $\sim$ dragging-out- $<$ as-toprospective-profound-supererogation -of-mentally-aestheticised $\sim$ postconverging/dialecticalthinking -qualia-schema> implied continuous/re-originating/dragged-out social-constructpestconverging-nonextricatory-existential-preempting-of-existential-unthought $\sim$ sublimation accruable-and-derivable percolation-channelling-<in-deferential-formalisation-transference $>$ of secondnatured institutionalisation (as 'so-transfusively determinant to overall sublimating human and social ontological-performance -<including-virtue-as-ontology >')'; and so rather than the shallow conception of an 'epistemic-impassion measliness/notional nonprotensivity/disontologising formulaic-dragging-out-or-formulaichollowing-out-<as-to-prior-shallow-supererogation -of-mentallyaestheticised preconverging/dementing -qualia-schema $>$ implied discrete/fixated abstractly contemplatable individualised conceptualisation of ontological-performance -<includingvirtue-as-ontology $>$ /morality/ethics/justice/etc. underiving-and-unaccruing to the socialconstruct postconverging-nonextricatory-existential-preempting-of-existentialunthought $\sim$ sublimation' as can be wrongly implied intuitively within the purview of in-effect 
absolution-<as-to-apriorising/axiomatising/referencing-\{of-'prospectively

implicited_attendant-ontological-contiguity ' educed-

existentialising/contextualising/textualising_'intelligibility/epistemicity/reflexivity-contiguity-

<imbued-notional cogency>' $\quad\}$-constitutedness -in preconverging-entailment> $>\quad$ in presencing - absolutising-identitive-constitutedness ${ }^{14}$ (which in so-doing is rather in an 'ineffect blurriness-<sterilising/anecdotalising/trivialising-of-prospective-re-ontologising_bypreconverging,-in-disontologising-formulaic-dragging-out/hollowing-out> relation with both prior and prospective registry-worldviews/dimensions' as failing-to or poorly recognising human limited-mentation-capacity-deepening —as-subjecting limitedness/human-subpotency to-'educed-unlimitedness/existence-sublimating nascence's3 cumulated/recomposured continuity so-implied as of the relative-unreflexivity/relative-reflexivity-ontologicalcontiguity ${ }^{67}$ of-the-human-institutionalisation-process ${ }^{6}$, thus failing to reflect the registryworldviews/dimensions as being profound 'supereregatery $\sim$ wholesomeness/profound-supererogation ${ }^{\circ}$ as of prospective ${ }^{83}$ reference-ofthought — point-of-devolving/departure/anchoring/backdrop_of_sublimating-nascence-<as-tothe-grandest-axiomatic-construct- fepistemic-totalising ${ }^{\frac{3}{3}}$ re-apriorising/re-axiomatising/re-

refereneing-residuality - in-re-originariness/re-origination of limitedness/human-subpotency prospective re-encountering/re-confrontation with unlimitedness/existence>' as herein undergirded by ' ${ }^{15}$ de-mentation-〈supererogatory $\sim$ ontological-de-mentation-or-dialectical-dementation-stranding-or-attributive-dialectics $\rangle$ of underlying human Beingdevelopment/ontological-framework-expansion-as-to-depth-of-ontologising-development-asinfrastructure-of- meaningfulness-and-teleology ' involving the differentiated knowledgevalue and knowledge discursivity as associated with the successive psychologismic-epistemicacutisation-<as-to-postconverging-de-mentating/structuring/paradigming,-eliciting-of- 
of recurrent-utter-uninstitutionalisation, base-institutionalisation-ununiversalisation, universalisation-non-positivism/medievalism, positivism- ${ }^{80}$ procrypticism and prospective deprocrypticism-or-preempting - disjointedness-as-of- ${ }^{8}$ reference-of-thought as so-reflecting the overall relative-unreflexivity/relative-reflexivity - ontological-contiguity ${ }^{6}$ of-the-humaninstitutionalisation-process ${ }^{68}$ overall 'grander supereregatery $\sim$ wholesomeness/profoundsupererogation as of prospective ${ }^{83}$ reference-of-thought—point-ofdevolving/departure/anchoring/backdrop_of_sublimating-nascence-<as-to-the-grandestaxiomatic-construct-\{epistemic totising ’re-apriorising/re-axiomatising/rereferencing $\sim$ residuality - in-re-originariness/re-origination of limitedness/human-subpotency prospective re-encountering/re-confrontation with unlimitedness/existence>'). This fundamental insight of ${ }^{6}$ nonpresencing-or-withdrawal/unenframing/re-ontologising-or-metaphysics-ofabsence-〈implicited-epistemic-veracity-of- nonpresencing-<perspective-ontologicalnormalcy/postconvergence $>$ )-or-transcendental-reasoning-of-event ${ }^{38}$-as-prospective-ontologyorigination (as to its full/comprehensive/dragged-out ${ }^{103}$ universal or totalising-entailing conceptualisation implications of aetiologisation/ontological-escalation- $<$ ontologicalveridicality_commitment/otherliness_transcending/compulsions-encumbered_transcending $>$ ) can be garnered from the fact that the sublimating-postconverged 'substantive abstract-tissueof-social-emanance fepistemic thermeneutically/textually/reprojectingly/supererogatingly/zeroingly/re-acutingly,${ }_{\{\text {decompulsing }}$ delinearity for-cogency — cumulated/recomposured as to cumulating/recomposuring of 'prospectively_implicited_attendant-ontological-contiguity ${ }^{67}$ ? educedexistentialising/contextualising/textualising_'intelligibility/epistemicity/reflexivity_contiguity$<$ imbued-notional cogency>' is a much more critical 'cumulated/recomposuredpostconverged behind-the-scenes/firmament' aspect of human and social notional ontologicalperformance $^{72}$-<including-virtue-as-ontology $>$ /vices-and-impediments as to its 
notional protensivity of 'prior-present-prospective pestconverging-nonextricatory-existentialpreempting-of-existential-unthought' (notwithstanding the naivety of any given ${ }^{79}$ presencingabsolutising-identitive-constitutedness ${ }^{14}$ manifestly implied 'beyond-the-consciousnessawareness-teleology $-<$ of-preconverging-existential-extrication-as-of-existential-unthought $>$ conception') with regards to the fact that it is the 'existentialising-firmament thresholding for the social-construct pesteonverging-nonextricatory-existential-preempting-of-existentialunthought $\sim$ sublimation accruing-and-deriving of prospective secondnatured institutionalisation aestheticisation-and-aestheticisation-towards-ontology-<elicited-idiomatisation>'; $\quad$ as $\quad$ soreflected intradimensionally with the "postconverging epistemic_-projective-equalisation social dynamics of human limited-mentation-capacity-deepening - as-subjecting limitedness/humansubpotency-to-'educed-unlimitedness/existence-sublimating nascence' ${ }^{33}$ (as to domains-ofinterests of specifically and/or generally cultivated arts/skills and time investment)' and as to their overall notional $\sim$ philosophy-<as-to-the-veridical-conception-of-philosophy-as-englobingall-human-prospective-organic-knowledge-generation-in-relative-ontological-completeness beyond-a-convenient-division-of-labour-conception-of-knowledge> induced 'epistemicdispassion munificence/notional protensivity/re-ontologising $\sim$ dragging-out- $<$ as-toprospective-profound-supererogation -of-mentally-aestheticised $\sim$ postconverging/dialecticalthinking -qualia-schema> implied continuous/re-originating/dragged-out social-constructpostconverging-nonextricatory-existential-preempting-of-existential-unthought $\sim$ sublimation accruable-and-derivable percolation-channelling-<in-deferential-formalisation-transference $>$ of secondnatured institutionalisation (as 'so-transfusively determinant to overall sublimating human and social ontological-performance -<including-virtue-as-ontology>')' which soreflects the "veridical social preeminent directedness of knowledge-value and knowledgediscursivity orientation ('dragged-out nature or psychologismic-epistemic-acutisation- $<$ as-topostconverging-de-mentating/structuring/paradigming,-eliciting-of-existence's-sublimating- 
nascence-in-prospective-aporeticism-overcoming/unovercoming $>$ as to epistemic-growth,-as\{veridical/sound\}-relative-reflexivity-in-existence/relativising from-limited-mentation-as-itsdeepening/psychologismic epistemic-acutisation residualising, fdecompulsingl $_{\text {f }}$ delinearity for cogency' imbued 'supererogatory wholesomeness/profound-supererogation as of prospective reference-of-thought - point-of-devolving/departure/anchoring/backdrop_of_sublimating_ nascence-<as-to-the-grandest-axiomatic-construct-\{epistemic-totalising ${ }_{3}^{+}$re-apriorising/reaxiomatising/re-referencing $\sim$ residuality-in-re-originariness/re-origination of limitedness/human-subpotency prospective re-encountering/re-confrontation with unlimitedness/existence>'). Hence, the sublimating-postconverged 'substantive abstract-tissueof-social-emanance \{epistemictotalising ${ }^{3}$ hermeneutically/textually/reprojectingly/supererogatingly/zeroing/y/re-acutingly,$\{$ decompulsing $\}$ delinearity for-cogency—cumulated/recomposured as to cumulating/recomposuring of 'prospectively_implicited_attendant-ontological-contiguity ${ }^{67}$ ' educedexistentialising/contextualising/textualising_intelligibility/epistemicity/reflexivity-contiguity<imbued-notional cogency>' ${ }^{40}$ as the 'existentialising-firmament thresholding for the socialconstruct - pestcenverging-nonextricatory-existential-preempting-of-existentialunthought $\sim$ sublimation accruing-and-deriving of prospective secondnatured institutionalisation aestheticisation-and-aestheticisation-towards-ontology-<elicited-idiomatisation $>$ ' necessarily implies that all the registry-worldviews/dimensions (recurrent-utter-uninstitutionalisation, baseinstitutionalisation-ununiversalisation, $\quad{ }^{103}$ universalisation-non-positivism/medievalism, positivism- ${ }^{80}$ procrypticism and prospective ${ }^{18}$ deprocrypticism-or-preempting - disjointednessas-of- ${ }^{8}$ reference-of-thought) have as common a basic incipient/seeding susceptibility (as of 'their specific underlying human prior limited-mentation-capacity as subjecting unlimitedness/existence-sublimating nascence' to-limitedness/human-subpotency in need for prospective limited-mentation-capacity-deepening -as-subjecting limitedness/human- 
subpotency-to-'educed-unlimitedness/existence-sublimating nascence' ${ }^{3}$,

for

their manifestation

of

‘epistemic-impassion

measliness/notional $\sim$ nonprotensivity/disontologising $\sim$ formulaic-dragging-out-or-formulaic-

hollowing-out-<as-to-prior-shallow-supererogation -of-mentally-

aestheticised preconverging/dementing -qualia-schema $>$ implied discrete/fixated abstractly

contemplatable individualised conceptualisation of ontological-performance $-<$ including-

virtue-as-ontology $>$ /morality/ethics/justice/etc. underiving-and-unaccruing to the social-

construct-pestconverging-nonextricatory-existential-preempting-of-existential-

unthought sublimation' (which is rather 'blurred/fuzzy as to the specific blurriness-

$<$ sterilising/anecdotalising/trivialising-of-prospective-re-ontologising_by-preconverging,-in-

disontologising-formulaic-dragging-out/hollowing-out> of the respective registry-

worldviews/dimensions

$\leq$ mere-formulaicity/ritualisation-of $>$-prior

secondnatured

institutionalisation in-the-face-of-failing their prospective postconverging-aporeticismovercoming/unovercoming'); speaking to the 'underlying commonness of the abstract individual human-potential/human-subpotency’ across all Ages 'beyond the phenomenologically distorting effect of secondnatured institutionalisation induced distinction' which rather arise from registryworldviews/dimensions implications of 'merely cumulated/recomposured secondnatured institutionalisation as of mere-formulaicity/ritualisation-<as-to-mere-formulaicmethodologising/mutualising/organising/institutionalising,-prospectively-losing-track-of‘fepistemic-alising ’’re-apriorising/re-axiomatising/re-referencing $r$ residuality-in-re-

originariness/re-origination'>' (without distinguishing the 'recurring preconverging/postconverging epistemic - projective-equalisation dynamics of failing or succeeding with respect to the postconverging apereticism overeoming of prospective-existentialising/contextualising/textualising' as the actively incipient/seeding

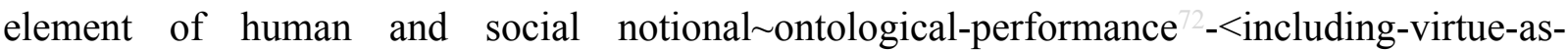


ontology $>/$ vices-and-impediments ${ }^{105}$ as so-relevant for prospective 'appropriate human contemplative projective-insights of sublimating-nascence aetiologisation/ontologicalescalation-<ontological-veridicality_commitment/otherliness_transcending/compulsionsencumbered_transcending $>\quad$ conceptivity/epistemic-reflexivity/epistemicity-relativismdeterminism-<reifying \{as-to-knowledge-developing $\}$-and-empowering $\left.>^{\prime}\right)$. Thus the succession of secondnatured institutionalisations with regards to their prospective human and social notional $\sim$ ontological-performance ${ }^{72}-<$ including-virtue-as-ontology $>/$ vices-and-impediments are more truly the outcome of the 'postconverging epistemic-projective-equalisation social dynamics of human limited-mentation-capacity-deepening —as-subjecting limitedness/humansubpotency-to-'educed-unlimitedness/existence-sublimating nascence' ${ }^{53}$ (as to domains-ofinterests of specifically and/or generally cultivated arts/skills and time investment)' and as to their overall notional $\sim$ philosophy-<as-to-the-veridical-conception-of-philosophy-as-englobingall-human-prospective-organic-knowledge-generation-in-relative-ontological-completeness beyond-a-convenient-division-of-labour-conception-of-knowledge> induced 'epistemicdispassion munificence/notional $\sim$ protensivity/re-ontologising $\sim$ dragging-out- $<$ as-toprospective-profound-supererogation -of-mentally-aestheticised $\sim$ postconverging/dialecticalthinking -qualia-schema $>$ implied continuous/re-originating/dragged-out social-constructpostconverging-nonextricatory-existential-preempting-of-existential-unthought $\sim$ sublimation accruable-and-derivable percolation-channelling- $<$ in-deferential-formalisation-transference $>$ of secondnatured institutionalisation (as 'so-transfusively determinant to overall sublimating human and social ontological-performance -<including-virtue-as-ontology>')' which soreflects the 'veridical social preeminent directedness of knowledge-value and knowledgediscursivity orientation ('dragged-out nature or psychologismic-epistemic-acutisation-<as-topostconverging-de-mentating/structuring/paradigming,-eliciting-of-existence's-sublimatingnascence-in-prospective-aporeticism-overcoming/unovercoming > as to epistemic-growth,-as- 
\{veridical/sound\}-relative-reflexivity-in-existence/relativising from-limited-mentation-as-itsdeepening/psychologismic epistemic acutisation residualising, ${ }^{\text {fdecompulsing }}$ delinearity for eogency' imbued 'supererogatory wholesomeness/profound-supererogation as of prospective reference-of-thought_-point-of-devolving/departure/anchoring/backdrop_of_sublimating_ nascence-<as-to-the-grandest-axiomatic-construct-\{epistemic-totalising $\frac{1}{r e-a p r i o r i s i n g / r e-~}$ axiomatising/re-referencing-residuality-in-re-originariness/re-origination of

limitedness/human-subpotency prospective re-encountering/re-confrontation with
unlimitedness/existence>')'. Such that in reality part-and-parcel of our positivismprocrypticism ontological-performance ${ }^{2}-<$ including-virtue-asontology $>$ /morality/ethics/justice/etc. accrues as from recurrent-utter-uninstitutionalisation, base-institutionalisation-ununiversalisation and universalisation-nonpositivism/medievalism cumulated/recomposured 'epistemic-dispassion munificence/notional $\sim$ protensivity/re-ontologising $\sim$ dragging-out-<as-to-prospective-profoundsupererogation -of-mentally-aestheticised postconverging/dialectical-thinking -qualiaschema $>$ implied continuous/re-originating/dragged-out social-construct postconvergingnonextricatory-existential-preempting-of-existential-unthought $\sim$ sublimation accruable-andderivable percolation-channelling-<in-deferential-formalisation-transference $>$ of secondnatured institutionalisation (as 'so-transfusively determinant to overall sublimating human and social ontological-performance -<including-virtue-as-ontology>')'; critically implying that the

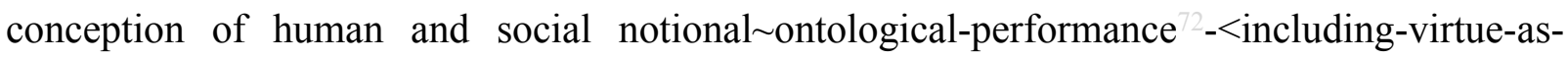
ontology $>$ /vices-and-impediments ${ }^{105}$ can only be poorly construed when failing to so-factor-in this sublimating-postconverged 'substantive abstract-tissue-of-social-emanance \{epistemictotalising ${ }^{3}$ h hermeneutically/textully/reprojectingly/supererogatingly/zeroingly/re acutingly,\{decompulsing $\}$ delinearity for-cogency—cumulated/recomposured as to cumulating/recomposuring of 'prospectively_implicited_attendant-ontological-contiguity ${ }^{67}$ ? educed- 
existentialising/contextualising/textualising_intelligibility/epistemicity/reflexivity-contiguity$<$ imbued-notional cogency $>$ ' as being the 'existentialising-firmament thresholding for the social-construct - pestconverging-nonextricatory-existential-preempting-of-existentialunthought $\sim$ sublimation accruing-and-deriving of prospective secondnatured institutionalisation aestheticisation-and-aestheticisation-towards-ontology-<elicited-idiomatisation ${ }^{\prime}$ (as to the $<$ cumulating/recomposuring attendant-ontological-contiguity $>$-successive registryworldviews/dimensions 'recurring preconverging/postconverging epistemic-projectiveequalisation dynamics of failing or succeeding with respect to the postconverging aapereticismevercoming/unovercoming of prospective-existentialising/contextualising/textualising'). This reality of 'human social and socio-psychological immanence historial tangibility with respect to

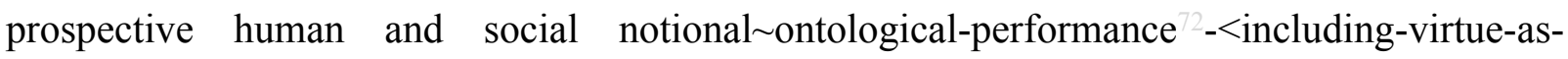
ontology $>$ /vices-and-impediments ${ }^{105}$, carries the implications that a hypothetical instantaneous erasure of all present humans memories and knowledge will lead to humankind's retrograding to its most basic animalistic background potential for social emanence as of the earliest of humans and so rather counterintuitive to what we may intuitively think as to an instant or transitory recovery of our mental-capacities as of our present positivism- ${ }^{80}$ procrypticism (potentially warranting the re-historialisation of humankind as to a recommencement of the relative-unreflexivity/relative-reflexivity - ontological-contiguity ${ }^{67}$ of-the-humaninstitutionalisation-process ${ }^{68}$ in order to 'potentially' re-achieve generations later the present positivism- ${ }^{80}$ procrypticism mental-capacities), as to the veracity that our present incipient/seeding 'epistemic-impassion measliness/notional nonprotensivity/disontologising formulaic-dragging-out-or-formulaichollowing-out-<as-to-prior-shallow-supererogation -of-mentallyaestheticised preconverging/dementing -qualia-schema $>$ implied discrete/fixated abstractly contemplatable individualised conceptualisation of ontological-performance -<including- 
virtue-as-ontology $>/$ morality/ethics/justice/etc. underiving-and-unaccruing to the socialconstruct - posteonverging-nonextricatory-existential-preempting-of-existential-

unthought sublimation' is no more fundamentally different to that of any other given registryworldview/dimension as to the 'underlying incipient/seeding human limited-mentationcapacity —as-subjecting 'educed-unlimitedness/existence-sublimating nascence' to-

limitedness/human-subpotency of postconverging/preconverging -intelligibility-construal' (as of 'recurring preconverging/postconverging epistemic_-projective-equalisation dynamics of failing or succeeding with respect to the postconverging-aporeticismovercoming/unovercoming of prospective-existentialising/contextualising/textualising'), but for the 'time immemorial accrued limited-mentation-capacity-deepening-as-subjectinglimitedness/human-subpotency-to-'educed-unlimitedness/existence-sublimating nascence' abstract-tissue-of-social-emanance perpetually enhancing for postconverging-intelligibilityconstrual' as so-accruing to the station/locus of <amplituding/formative-epistemicity >totalising thrownness-in-existence $^{35}$ of our cumulated/recomposured positivism/rationalempiricism registry-worldview/dimension (undermining the ontological-veracity of a conceptualisation of human and social ontological-performance ${ }^{72}-$ including-virtue-as- $^{-}$ ontology $>$ /morality/ethics/justice/etc. as of the 'mere-formulaicity/ritualisation-<as-to-mereformulaic - methodologising/mutualising/organising/institutionalising,-prospectively-losingtrack-of- ‘fepistemic-totalising ’’re-apriorising/re-axiomatising/re-referencing residuality-in-reoriginariness/re-origination'> generalised conception of the merely cumulated/recomposured secondnatured institutionalisation of any registry-worldview/dimension' without appreciating the underlying human-subpotency 'incipient/seeding supererogating epistemic-projection perspectives of postconverging/preconverging-intelligibility-construal' as of 'recurring preconverging/postconverging epistemic-projective-equalisation dynamics of failing or succeeding with respect to the postconverging-aporeticism-overcoming/unovercoming of 
prospective-existentialising/contextualising/textualising'). This so-validates the veracity of the altogether sublimating-postconverged 'substantive abstract-tissue-of-social-emanance \{epistemicthermeneutically/textually/reprojectingly/supererogatingly/zeroingly/re-acutingly,$\{$ decompulsing $\}$ delinearity for-cogency—cumulated/recomposured as to cumulating/recomposuring of 'prospectively_implicited_attendant-ontological-contiguity ${ }^{67}$ ' educedexistentialising/contextualising/textualising_intelligibility/epistemicity/reflexivity-contiguity<imbued-notional cogency $>$ postconverging-intelligibility-construal enhancing of humansubpotency 'incipient/seeding supererogating epistemic-projection perspectives of postconverging/preconverging_intelligibility-construal' (as of 'recurring preconverging/postconverging epistemic - projective-equalisation dynamics of failing or succeeding with respect to the postconverging-aporeticism-overcoming/unovercoming of prospective-existentialising/contextualising/textualising') for conceptualising human and social ontological-performance $^{72}$-<including-virtue-as-ontology $>/$ morality/ethics/justice/etc. as the critical 'cumulated/recomposured-postconverged behind-the-scenes/firmament' aspect of human and social notional ontological-performance ${ }^{72}<$ including-virtue-as-ontology $>/$ vicesand-impediments ${ }^{105}$ as to its notional protensivity of 'prior-present-prospective whextricatory-existential-preempting-of-existential-unthought'; upon which 'cumulated/recomposured-postconverged behind-the-scences/firmament' takes place a 'recurring preconverging/postconverging epistemic-projective-equalisation dynamics of failing or succeeding with respect to the postconvergingaaporeticismovercoming/unovercoming of prospective-existentialising/contextualising/textualising', rendering human ontological-performance ${ }^{72}-<$ including-virtue-as- $^{2}$ ontology $>$ /morality/ethics/justice/etc. decisively about the construal of prospective postconverging-nonextricatory-existential-preempting-of-existential-unthought sublimation over prospective preconverging-existential-extrication-as-of-existential-unthought 
desublimation with respect to the 'recurring preconverging/postconverging epistemicprojective-equalisation dynamics of failing or succeeding with respect to the postconverging-aporeticism-overcoming/unovercoming of prospectiveexistentialising/contextualising/textualising' (and speaking rather of the requisite ontologicalgood-faith/authenticity ${ }^{6} \sim$ postconverging-de-mentating/structuring/paradigming ${ }^{70}$ as to when manifest relative-ontological-completeness 87 is-educed-and-avails-and-re-avails for 'prospective postconverging epistemic-projective-equalisation succeeding with respect to prospective postconvergingaaporeticism-overcoming/unovercoming'). Thus our human and social notional ontological-performance ${ }^{2}-<$ including-virtue-as-ontology $>/$ vices-andimpediments $^{105}$ as of a positivism/rational-empiricism registry-worldview/dimension is veridically much more than just the supposed performance of humans existing thereafter the positivism/rational-empiricism incipient/seeding contemplation and realisation (as to a shallow conception of 'epistemic-impassion measliness/notional nonprotensivity/disontologising formulaic-dragging-out-or-formulaichollowing-out-<as-to-prior-shallow-supererogation -of-mentallyaestheticised preconverging/dementing -qualia-schema $>$ implied discrete/fixated abstractly contemplatable individualised conceptualisation of ontological-performance $-<$ includingvirtue-as-ontology $>$ /morality/ethics/justice/etc. underiving-and-unaccruing to the socialconstruct-postconverging-nonextricatory-existential-preempting-of-existentialunthought $\sim$ sublimation' as can be wrongly implied intuitively within the purview of in-effect absolution-<as-to-apriorising/axiomatising/referencing-\{of-"prospectively implicited_attendant-ontological-contiguity ' educedexistentialising/contextrising/textralising_intelligibility/epistemicity/reflexivity-contiguity<imbued-notional cogency >' $\quad\}$-constitutedness -in preconverging-entailment> $>\quad$ in presencing-absolutising-identitive-constitutedness ${ }^{14}$ failing to appreciate its very own 
'recurring preconverging/postconverging epistemic-projective-equalisation dynamics of failing or succeeding with respect to the postconverging aporeticismovercoming/unovercoming of prospective-existentialising/contextualising/textualising'); but speaks to the cumulated/recomposured-postconverged human effort/experientiality/experiment<as-to-existentially-formative-' ‘epistemic-totalising $\stackrel{+}{3}$ re-apriorising/re-axiomatising/rereferencing-residuality-in-re-originariness/re-origination',- - so'notionally/epistemically/bindingnessly-<as-to-determinism/coneeptivity-of-relative-unreflexivity/relative-reflexivity> implicited-and-articulated'_as-from-nonextricatory-'prospective-re-ontologising-Being-thenInstitutional-then-Living-magnitudes-of-\{hermeneutic/reprojection-protraction-of\}reframingand-reformulation $\}^{\prime}>$ since time immemorial with regards to human limited-mentationcapacity-deepening —as-subjecting limitedness/human-subpotency-to-'educedunlimitedness/existence-sublimating nascence' ${ }^{33}$ as to successive re-originary epistemicgrowth,-as-\{veridical/sound\}-relative-reflexivity-in-existence/relativising from-limitedmentation-as-its-deepening/psychologismic epistemic-acutisation residualising, \{decomplsing delinearity for-cogency encounters/confrontations with existence-as-the-absolutea-priori-of-conceptualisation and existence—as-sublimating-withdrawal/unenframing/reontologising,-elicited-from-prospective-profound-supererogation $-<$ as-to-perspectiveontological-normalcy/postconvergence-implied-'prospective-aporeticismovercoming/unovercoming'> as so-reflecting prospective \{epistemic-totalising 3re-apriorising/reaxiomatising/re-referencing - residuality-in-re-originariness/re-origination-〈as to human profound-supererogation for prospective apriorising/axiomatising/referencing-\{of'prespectively implicited_attendant-ontological-contiguity ' educedexistentialising/contextualising/textualising_intelligibility/epistemicity/reflexivity_contiguity$<$ imbued-notional cogency $>$ ' \}-conflatedness -in-\{preconverging-ment by\} postconverging-ntailment that cannot be unshrouded by prior mere-formulaicity/ritualisation- 
<as-to-mere-formulaic — methodologising/mutualising/organising/institutionalising,-

prospectively-losing-track-of-`\{epistemic-totalising 3 re-apriorising/re-axiomatising/re-

referencing $\sim$ residuality -in-re-originariness/re-origination'>

of

prior

apriorising/axiomatising/referencing-\{of-'prospectively implicited_attendant-ontological-

contiguity ' educed-

existentialising/contextualising/textualising_ 'intelligibility/epistemicity/reflexivity-contiguity-

<imbued-notional cogency>' $\quad\}$-constitutedness -in-preconverging-entailment) (and so

with regards to human Being-development/ontological-framework-expansion-as-to-depth-ofontologising-development-as-infrastructure-of- meaningfulness-and-teleology , institutionaldevelopment-as-to-social-function-development and living-development-as-to-personalitydevelopment psychologismic epistemic-acutisation difficulty-<for,-residualising \{decompulsing\} delinearity for-cogeney>-magnitudes $\{$ of-experientiality/experiment\} $\}$. But then human 'epistemic-impassion measliness/notional nonprotensivity/disontologising formulaicdragging-out-or-formulaic-hollowing-out-<as-to-prior-shallow-supererogation -of-mentallyaestheticised preconverging/dementing -qualia-schema $>$ implied discrete/fixated abstractly contemplatable individualised conceptualisation of ontological-performance $-<$ includingvirtue-as-ontology $>$ /morality/ethics/justice/etc. underiving-and-unaccruing to the socialconstruct - postconverging-nonextricatory-existential-preempting-of-existentialunthought $\sim$ sublimation' (even as it is 'blurred/fuzzy as to the specific blurriness$<$ sterilising/anecdotalising/trivialising-of-prospective-re-ontologising_by-preconverging,-indisontologising-formulaic-dragging-out/hollowing-out> of the respective registryworldviews/dimensions $\leqslant$ mere formulaicity/ritultisation of $>$ prior secondnatured institutionalisation in-the-face-of-failing their prospective postconverging-aporeticismovercoming/unovercoming') does effectively manifests as-outside/as-untamed-by prospective 'epistemic-dispassion munificence/notional $\sim$ protensivity/re-ontologising $\sim$ dragging-out- $<$ as-to- 
prospective-profound-supererogation -of-mentally-aestheticised $\sim$ postconverging/dialectical-

thinking -qualia-schema $>$ implied continuous/re-originating/dragged-out social-constructpestconverging-nonextricatory-existential-preempting-of-existential-unthought $\sim$ sublimation accruable-and-derivable percolation-channelling- $<$ in-deferential-formalisation-transference $>$ of secondnatured institutionalisation (as 'so-transfusively determinant to overall social sublimating human ontological-performance -<including-virtue-as-ontology >')'; as the latter is not prospectively all-pervasive/all-englobing with regards to the prospectively uninstitutionalised-threshold ${ }^{102}$ (especially-so given human formative self-drivenness reflex predisposition of poor limited-mentation-capacity-deepening-as-subjectinglimitedness/human-subpotency-to-'educed-unlimitedness/existence-sublimating nascence' ${ }^{53}$ as to extended-informality-〈susceptible-to-effecting-parsimony-as-of-shoddiness-andincompleteness-to- meaningfulness-and-teleology $\rangle$ manifestation of supposedly sublimating knowledge-value and knowledge-discursivity induced desublimating implications upon human and social ontological-performance ${ }^{72}-<$ including-virtue-as-ontology $>$ ). In-many-ways, 'epistemic-impassion measliness/notional nonprotensivity/disontologising $\sim$ formulaicdragging-out-or-formulaic-hollowing-out-<as-to-prior-shallow-supererogation -of-mentallyaestheticised preconverging/dementing -qualia-schema> implied discrete/fixated abstractly contemplatable individualised conceptualisation of ontological-performance -<includingvirtue-as-ontology $>$ /morality/ethics/justice/etc. underiving-and-unaccruing to the socialconstruct postconverging-nonextricatory-existential-preempting-of-existentialunthought sublimation' is/can-be consciously-appreciated in the prospective self-realisation by

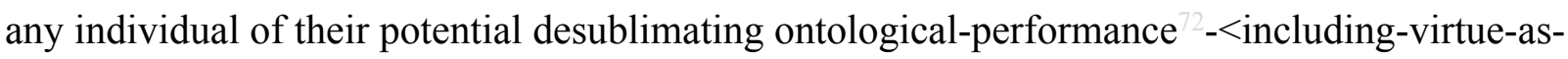
ontology $>$ /morality/ethics/justice/etc. with respect to their very own lack of requisite knowledgevalue and knowledge-discursivity imbued notional $\sim$ self-distantiation- $<$ imbued - re-motif-andre-apriorising/re-axiomatising/re-referencing > involved in other 'postconverging epistemic- 
projective-equalisation social dynamics of human limited-mentation-capacity-deepening-assubjecting limitedness/human-subpotency-to-'educed-unlimitedness/existence-sublimating naseence' (as to other domains-of-interests of specifically and/or generally cultivated arts/skills and time investment) but for the given individual's relevant postconverging epistemicprojective-equalisation social dynamics of human limited-mentation-capacity-deepening-assubjecting-limitedness/human-subpotency-to-'educed-unlimitedness/existence-sublimating nascence' (as to the individual's relevant domains-of-interests of specifically and/or generally cultivated arts/skills and time investment)'. But then such a self-realisation arises relatively easily with nascent-particular/incipient-and-material/technical-sublimations- $<$ blinded-to-theirrelative-ontological-completeness - reference-of-thought- devolving $>$ as to their constraining manifest sublimating-nascence incipience/instantaneity/directness even within the existentialising-frame-of-entailment-of-motif-and-apriorising/axiomatising/referencing of human self-presence/self-constitutedness ${ }^{14}-<$ in-perspective-epistemicabnormalcy/preconvergence $>$ (consider that rocket science for instance doesn't give room for any wrong calculations as to the pre-eminence of inherent immanent-existence) whereas such a self-realisation is often unforthcoming as to the dragged-out "prospective ${ }^{8}$ reference-of-thought appraisal of sublimating-nascence comprehensiveness/nonimmediacy/indirectness' soassociated with human social-and-institutional-frameworks-ofreferencing/registering/decisioning existentialising-decisionality-<as-to-disontologising/reentologising aporeticism $>$ requiring prospective epistemic-growth/disquiet/discomfort〈induced-sublimation,-as-from-existence's - effusing/ecstatic-inlining-as- historiality\{science/authenticity/nonextrication $\}$-beyond-mere-formulaicity/ritualisation-as- historicitytracing-\{science-ideology/fashionability/distraction\}) (consider contrastively the commission report on the Challenger disaster with Feynman being pressed to provide 'politically acceptable conclusions as to a desublimating dragged-out/hollowing-out' of the ontological-veracity of 
rocket science manifest sublimating-nascence incipience/instantaneity/directness and warranting in the end Feynman's expression of 'Derridean underdetermination-imbued force/violence conception' and 'Foucauldian knowledge/power conception construed as knowledge-empowerment/ignorance-disempowerment' as of notional asceticism reasoningthrough/messianic-reasoning prospective existential-<disontologising/re-ontologising aporeticism $>$ deployment of transversality- $<$ for-sublimating-existentialeventuating/denouement,-from-'thinking at-first/pure-predisposition-preemptive-ofprospective-disontologising/subontologising' as-of-prospectively-disambiguated-affirmedand-unaffirmed-'motif-and-apriorising/axiomatising/referencing'>101 elucidation as of notional $\sim$ self-distantiation- $<$ imbued—re-motif-and-re-apriorising/re-axiomatising/rereferencing $>\quad$ implied formativeness-<as-to-intersolipsism-ofpreformulating/preframing/premeaningfulness-imbued-mediativity-and-deferentialism $>$-ofmeaningfulness-and-teleology $\quad$ in $\quad$ nonpresencing-<perspective-ontologicalnormalcy/postconvergence $>$ epistemic-projection'). This distinction is made to highlight the fact that given human $<$ amplituding/formative-epistemicity $>$-totalising $\sim$ thrownness-in-existence the individual and social are ever always caught up in existential-<disontologising/reentolegising apereticism> situations requiring appropriate ontological-performance ${ }^{72}$ $<$ including-virtue-as-ontology $>/$ morality/ethics/justice/etc. as to implicited existentialisingdecisionality-<as-to-disontologising/re-ontologising aporeticism $>$; and with respect to human reifying-and-empowering-reflexivity-of-ecstatic-existence, (going beyond mereformulaicity/ritualisation-<as-to-mere-formulaicmethodologising/mutualising/organising/institutionalising,-prospectively-losing-track-of‘\{epistemic-totalising ’re apriorising/re axiomatising/re referencing-residuality-in-reoriginariness/re-origination'> generalised conception of mere secondnatured institutionalisation) this insight points to the underlying human-subpotency 'incipient/seeding 
supererogating epistemic-projection perspectives of postconverging/preconvergingintelligibility-construal' (as of 'recurring preconverging/postconverging epistemic_-projectiveequalisation dynamics of failing or succeeding with respect to the postconverging-aporeticismovercoming/unovercoming of prospective-existentialising/contextualising/textualising') involved and so as of both desublimating 'epistemic-impassion measliness/notional $\sim$ nonprotensivity/disontologising $\sim$ formulaic-dragging-out-or-formulaichollowing-out-<as-to-prior-shallow-supererogation -of-mentallyaestheticised preconverging/dementing -qualia-schema> implied discrete/fixated abstractly contemplatable individualised conceptualisation of ontological-performance -<includingvirtue-as-ontology $>$ /morality/ethics/justice/etc. underiving-and-unaccruing to the socialconstruct-pestconverging-nonextricatory-existential-preempting-of-existentialunthought $\sim$ sublimation' and sublimating 'epistemic-dispassion munificence/notional $\sim$ protensivity/re-ontologising $\sim$ dragging-out-<as-to-prospective-profoundsupererogation -of-mentally-aestheticised postconverging/dialectical-thinking -qualiaschema $>$ implied continuous/re-originating/dragged-out social-construct postconvergingnonextricatory-existential-preempting-of-existential-unthought $\sim$ sublimation accruable-andderivable percolation-channelling-<in-deferential-formalisation-transference $>$ of secondnatured institutionalisation (as 'so-transfusively determinant to overall social sublimating human ontological-performance -<including-virtue-as-ontology>')'. This reality as a translation of the fact of human limited-mentation-capacity—as-subjecting-'educed-unlimitedness/existencesublimating nascence' to-limitedness/human-subpotency (as to its fundamental 'lost cause' that speaks of the reality of human 'notional firstnaturedness-formativeness-<as-toeventualising inkling drive or seeding misprising $>$ temporal-to-intemporal-dispositions$<$ so-construed-as-from-perspective-ontological-normalcy/postconvergence>' and not of human ' ${ }^{103}$ universal intemporal-disposition') implies that human ontological-performance ${ }^{72}$ 
$<$ including-virtue-as-ontology $>/$ morality/ethics/justice/etc. (to cover for that limited-mentationcapacity -as-subjecting 'educed-unlimitedness/existence-sublimating nascence' to-

limitedness/human-subpotency) is about the "preservation of the underlying sublimating postconverging epistemic-projective-equalisation social dynamics' for human limitedmentation-capacity-deepening —as-subjecting limitedness/human-subpotency-to-'educedunlimitedness/existence-sublimating nascence' ${ }^{33}$ (in the face of 'recurring preconverging/postconverging epistemic - projective-equalisation dynamics of failing or succeeding with respect to the postconverging-aporeticism-overcoming/unovercoming of prospective-existentialising/contextualising/textualising'); and this regards implies that 'overall human and social limited-mentation-capacity-deepening - as-subjecting limitedness/humansubpotency-to-'educed-unlimitedness/existence-sublimating nascence' ${ }^{5}$, necessarily calls for an element of appropriate human limited-mentation-capacity-as-subjecting 'educedunlimitedness/existence-sublimating nascence' to-limitedness/hmman-subpotency percolationchannelling- $<$ in-deferential-formalisation-transference $>$ of secondnatured institutionalisation (since no individual can undertake/be-involved in all the directly requisite limited-mentationcapacity-deepening —as-subjecting limitedness/human-subpotency-to-'educed-

tnlimitedness/existence sublimating nascence ${ }^{53}$ ). However, this 'implicited insight for human limited-mentation-capacity—as-subjecting 'educed-unlimitedness/existence-sublimating nascence' to-limitedness/human-subpotency percolation-channelling-<in-deferentialformalisation-transference $>$ of secondnatured institutionalisation' is itself ever always caught up in a tangle (as to appropriate/inappropriate percolation-channelling- $<$ in-deferentialformalisation-transference $>$ of secondnatured institutionalisation) between sublimating-andunblurring notional philosophy-<as-to-the-veridical-conception-of-philosophy-as-englobingall-human-prospective-organic-knowledge-generation-in-relative-ontological-completeness beyond-a-convenient-division-of-labour-conception-of-knowledge $>$ intemporal individuative 
eliciting of limited-mentation-capacity-deepening -as-subjecting limitedness/humansubpotency-to-'educed-unlimitedness/existence-sublimating-nascence' ${ }^{3}$ and desublimatingand-blurring pedantising/muddling/formulaic-hollowing-out - insubontologisation/subpotentiation-〈blurring/undermining-of-prospective-totalising-entailing,as-to-entailing-<amplituling/formative-epistemicity $>$ totalising $\sim$ in-relative-ontologicalcompleteness > temporal individuative advantageous overt/covert undermining of human limited-mentation-capacity-deepening —as-subjecting-limitedness/human-subpotency-to'educed-unlimitedness/existence-sublimating nascence' ${ }^{53}$; and so-entangled as of relevance to our present with regards to a 'veil of knowledge associated with subterfuges' reflected say in an ambiguous continuity between genuine-knowledge and chicanery, social/institutional intellectualism and social/institutional sycophantic-sophistry, alchemy and chemistry, quackery and medicine, technological-advancement and technical-mystification, flawed-industrialanalyses-and-certifications and disinterested-scientific-analyses-and-certifications, etc. All such instances (with regards to institutional-development-as-to-social-function-development and living-development-as-to-personality-development psychologismic-epistemic-acutisationdifficulty-<for, residualising \{decompulsing $\}$ delinearity for-cogeney> magnitudes ${ }^{\{0 f-}$ experientiality/experiment\}), of 'non-ontologising/disontologising surreptitious knowledge-withoutknowledge/knowledge-outside-knowledge/extra-knowledge frameworks' involve a dynamic relation with the extended-informality-〈susceptible-to-effecting-parsimony-as-of-shoddinessand-incompleteness-to- meaningfulness-and-teleology > as underlied not just as of spontaneous/incidental/accidental manifestations but rather with 'thoroughgoing/activelycultivated way-of-being-and-acting repertoire of temporal meaningfulness and purposefulness within the existentialising-frame-of-entailment-of motif-andapriorising/axiomatising/referencing of social-functioning-and-accordance-as-of-socialstake-contention-or-confliction as informally enculturated social foils, lures and ploys of 
disontologising' in the face of prospectively assertive ontologising-and-re-ontologising (as herein explicited notwithstanding any given registry-worldviews/dimensions imbued priorinstitutionalisation-threshold-by-prospective-uninstitutionalised-threshold 'self-referencingsyncretising forward-facing-supposedly postconverging-or-dialectical-thinking -apriorisingpsychologism epistemic-projection as of prior mere-formulaicity/ritualisation-<as-to-mereformulaic — methodologising/mutualising/organising/institutionalising,-prospectively-losingtrack-of- ‘fepistemic-totalising ’’re-apriorising/re-axiomatising/re-referencing $\sim$ residuality-in-reoriginariness/re-origination'>' so-reflecting their 'disontologising preconverging/dementing $<$ as-to-prospective-uninstitutionalised-threshold $>$ ignoring/biased inclination' for the sake of 'their given present minimum-and-balancing expectations/anticipations of social-functioningand-accordance - as-of-social-stake-contention-or-confliction' while qualifying their prospectively uninstitutionalised-threshold ${ }^{102}$ actually as nondescript/ignorable-void as to their ${ }^{79}$ presencing-absolutising-identitive-constitutedness ${ }^{14} \quad<$ preconverging $\sim$ 'motif-andapriorising/axiomatising/referencing'-entailing>-existentialising-enframing/imprintedness〈as-to- historicity-tracing-in-presencing-hyperrealisation/hyperreal-transposition〉), and as so-reflected in the 'socially radiating sway of non-ontologising/disontologising surreptitious knowledge-without-knowledge/knowledge-outside-knowledge/extra-knowledge desublimation (substituting over prospective veridical knowledge sublimation possibilities of social and institutional constructs as reflexively construable from veridical prospective 'implicited_attendant-ontological-contiguity ${ }^{67}$ ' educedexistentialising/contextualising/textualising_intelligibility/epistemicity/reflexivity-contiguity$<$ imbued-notional cogency>' ')'. Obviously, human <amplituding/formative-epistemicity $>$ totalising thrownness-in-existence ${ }^{35}$ inherently means that it is an 'open-secret fallacy' (given the inherently manifest preconverging/postconverging-de-mentating/structuring/paradigming of 'social-functioning-and-accordance-as-of-social-stake-contention-or-confliction imbuing 
disontologising/ontologising-and-re-ontologising') to imply that any given registryworldview/dimension is devoid of 'non-ontologising/disontologising surreptitious knowledgewithout-knowledge/knowledge-outside-knowledge/extra-knowledge frameworks' (as will probably be claimed by ancient-sophists, medieval-scholasticism or our modern-day manifestation of disparateness-of-conceptualisation-<unforegrounding-ment,-failingprospectively-to-reflect-'immanent relative-unreflexivity/relative-reflexivity ontological-

contiguity '>). There can't then truly be a serious conception of human ontologising-capacity that fails to address the abstract-and-concrete possibilities-and-manifestations of "nonontologising/disontologising surreptitious knowledge-without-knowledge/knowledge-outsideknowledge/extra-knowledge frameworks' as it bears upon human prospective postconverginga aporeticism-overcoming/unovercoming; as prospective postconverging aporeticism-overcoming/mnovercoming is exactly what enables prospective organic-knowledge in postconverging epistemic_-projective-equalisation exercise ('exercise of the epistemic - projective-equalisation of human station of ${ }^{79}$ presencing-absolutisingidentitive-constitutedness $^{14}$ as to prospective ${ }^{6}$ nonpresencing-<perspective-ontologicalnormalcy/postconvergence $>$ epistemic - projective-equalisation') for prospective sublimatingnascence as to 'appropriate human contemplative projective-insights of sublimating-nascence aetiologisation/ontological-escalation- $<$ ontologicalveridicality_commitment/otherliness_transcending/compulsions-encumbered_transcending> conceptivity/epistemic-reflexivity/epistemicity-relativism-determinism-<reifying \{as-toknowledge-developing\}-and-empowering >'. This further translates into the fact that universalising-idealisation, budding-positivism or budding postmodern-thought in their respective existential-<disontologising/re-ontologising aporeticism $>$ relation with nonuniversalising, non-positivising or totalisingly-ing — discretion/whim-of-thought do not share a 
common postconverging 'dragged-out nature or psychologismic-epistemic-acutisation-<as-topostconverging-de-mentating/structuring/paradigming,-eliciting-of-existence's-sublimatingnascence-in-prospective-aporeticism-overcoming/unovercoming > as to epistemic-growth,-as\{veridical/sound\}-relative-reflexivity-in-existence/relativising from-limited-mentation-as-itsdeepening/psychologismic epistemic-acutisation residualising, ${ }^{\text {\{decompulsing }}$ delinearity for eөgency' imbued 'supereregatery -wholesomeness/profound-supererogation as of prospective reference-of-thought—point-of-devolving/departure/anchoring/backdrop_of_sublimatingnascence-<as-to-the-grandest-axiomatic-construct-fepistemictalising tre-apriorising/reaxiomatising/re-referencing $\sim$ residuality -in-re-originariness/re-origination limitedness/human-subpotency prospective re-encountering/re-confrontation with unlimitedness/existence>'; as so-undermining the idea that the promise of an ontologically coherent prospective postconverging aporeticism-overcoming/unovercoming ${ }^{3}$ universalising-idealisation, budding-positivism or budding postmodern-thought knowledgevalue and knowledge-discursivity can profoundly (beyond superficiality/shallowness) be undertaken as to their respective existential-<disontologising/re-ontologising aporeticism $>$ relation within the flawed registry-worldview/dimension underpinning-suprasocial-construct <preconverging 'motif-and-apriorising/axiomatising/referencing'-entailing >existentialising — enframing/imprintedness-〈as-to- historicity-tracing_-in-presencinghyperrealisation/hyperreal-transposition $\rangle$ of non-universalising, non-positivising or totalisinglying-discretion/whim-of-thought. Thus implying that there can't be any true thinking/thought/notional philosophy-<as-to-the-veridical-conception-of-philosophy-asenglobing-all-human-prospective-organic-knowledge-generation-in-relative-ontologicalcompleteness ,-beyond-a-convenient-division-of-labour-conception-of-knowledge > lacking in prospective postconverging-aporeticism-overcoming/unovercoming existential$<$ disentologising/re-ontelogising aporeticism $>$ commitment as such a lack otherwise speaks to 
an imprimaturing

blurriness- $<$ sterilising/anecdotalising/trivialising-of-prospective-re-

ontologising_by-preconverging,-in-disontologising-formulaic-dragging-out/hollowing-out>

'that doesn't or poorly make contact with prospective existential-<disontologising/reentologising aporeticism $>$ sublimation possibilities' but for 'sterile/anecdotal mere institutional imprimatur projection of the possibility for prospective human sublimation' critically characterised by a relatively underdeveloped conception of nonpresencing-orwithdrawal/unenframing/re-ontologising-or-metaphysics-of-absence-_implicited-epistemicveracity-of- nonpresencing-<perspective-ontological-normalcy/postconvergence $>$ )-ortranscendental-reasoning-of-event ${ }^{38}$-as-prospective-ontology-origination. Ontology/science inherently warrants that the limits arrived as of human presciences in institutional frameworks are unbeholdening upon inherent existence's sublimating-nascence as the preconverging/postconverging-de-mentating/structuring/paradigming of human desublimation/sublimation renders nonsensical browbeating institutionalprescience/imprimaturing-<dullness-of the-spirit/psychologismic epistemic-acutisation nonresidualising imbued-\{compulsing\} linearityoin-eclecticism-of prior-mereformulaicity/ritualisation $>$ reflex of falling back to disontologising $<$ amplituding/formative $>$ wooden-language-〈imbued-temporal-mere-

\section{form/virtualities/dereification/akrasiatic-drag/denatured/preconverging-or-dementing} narratives - of-the- reference-of-thought- categorical-imperatives/axioms/registry-

teleology $>$ with such statements like 'this is not perfect', etc. as to a paradoxical impliciting of presencing-absolutising-identitive-constitutedness ${ }^{14}$ ignoring of prospective ontologicalveracity-<as-to-prospective-ontologising-and-re-ontologising $>$ /possibilities-of-ontologicalveracity as to a defaulting gesture of inherent pre-eminence over prospective existence sublimating-nascence. Ontology/science is a frame-up of human sublimating-overdesublimating ontological-performance ${ }^{2}-<$ including-virtue-as- 
ontology $>$ /morality/ethics/justice/etc. within the existentialising-frame-of-entailment-ofmotif-and-apriorising/axiomatising/referencing of 'relative-ontologicalincompleteness 8 /relative-ontological-completeness 〈sublimating referencing/registering/decisioning,-as-self-becoming/selfconflatedness /formative-supererogating-<projective/reprojective-aestheticising-re-motifand-re-apriorising/re-axiomatising/re-referencing,-in-perspective-ontologicalnormalcy/postconvergence $>>$ as to human-and-social-expectations/anticipationsmetaphoricity ${ }^{57}$-as-preconverging/postconverging-rede-

mentating/restructuring/reparadigming-psychologism' ${ }^{89}$ and so as of inherent transversality$<$ for-sublimating-existential-eventuating/denouement, from 'thinking at first/purepredisposition-preemptive-of prospective-disontologising/subontologising' as-ofprospectively-disambiguated-affirmed-and-unaffirmed-'motif-andapriorising/axiomatising/referencing'> ; allowing for no imprimaturing outside of this existentialising-frame-of-entailment-of-motif-and-apriorising/axiomatising/referencing of sublimation/desublimation underlied by its appropriate prospective 'implicited_attendantontological-contiguity ${ }^{67} \sim$ educedexistentialising/contextmalising/textualising_'intelligibility/epistemicity/reflexivity_contiguity$<$ imbued-notional cogency>' as herein implied historially whether as of ${ }^{103}$ universalisingidealisation, budding-positivism or budding postmodern-thought (respectively as to their prospectively given postconverging aporeticism-overcoming/unovercoming knowledge-value and knowledge-discursivity implied prospective <postconverging 'motif-andapriorising/axiomatising/referencing'-entailing>-existentialising-framing/imprinting-〈as-toprospective- historiality/ontological-eventfulness /ontological-aesthetic-tracing$<$ perspective-ontological-normalcy/postconvergence-reflected-'epistemicity-relativismdeterminism'> $>$ ). In such a bigger picture of the manifestation of 'non- 
ontologising/disontologising surreptitious knowledge-without-knowledge/knowledge-outsideknowledge/extra-knowledge frameworks' with respect to Being-development/ontologicalframework-expansion-as-to-depth-of-ontologising-development-as-infrastructure-ofmeaningfulness-and-teleology (as to 'dragged-out nature or psychologismic-epistemicacutisation-<as-to-postconverging-de-mentating/structuring/paradigming,-eliciting-ofexistence's-sublimating-nascence-in-prospective-aporeticism-overcoming/unovercoming $>$ as to epistemic-growth,-as_ \{veridical/sound\}-relative-reflexivity-in-existence/relativising fromlimited-mentation-as-its-deepening/psychologismic epistemic-acutisation residualising, \{decompulsing\} delinearity for-cogency' imbued 'supererogatory wholesomeness/profoundsupererogation as of prospective ${ }^{83}$ reference-of-thought-point-ofdevolving/departure/anchoring/backdrop_of_sublimating-nascence-<as-to-the-grandestaxiomatic-construct-\{epistemic-totalising ${ }_{3}^{\text {?}}$ re-apriorising/re-axiomatising/rereferencing residuality - in-re-originariness/re-origination of limitedness/human-subpotency prospective re-encountering/re-confrontation with unlimitedness/existence>'), such efforts for human emancipation eliciting from the perspective of their times as dispensing-with-immediacyfor-relative-ontological-completeness ${ }^{87}$-by-reification/contemplative-distension ${ }^{27}$ like ending Slavery and the Slave-Trade in the United States culminating in the American civil war or the French Revolution for instance (in sublimating 'epistemic-dispassion munificence/notional $\sim$ protensivity/re-ontologising $\sim$ dragging-out-<as-to-prospective-profoundsupererogation -of-mentally-aestheticised postconverging/dialectical-thinking -qualiaschema $>$ implied continuous/re-originating/dragged-out social-construct-pestconvergingnonextricatory-existential-preempting-of-existential-unthought $\sim$ sublimation accruable-andderivable percolation-channelling-<in-deferential-formalisation-transference $>$ of secondnatured institutionalisation as so-transfusively determinant to overall social sublimating human ontological-performance -<including-virtue-as-ontology>') met with sophistic/pedantic 
eliciting-of-immediacy-as-of-relative-ontological-incompleteness ${ }^{8-d e r e i f i c a t i o n ~}$

$<$ amplituding/formative $>$ wooden-language-〈imbued — averaging-of-thought- $<$ as-to-

leveling/ressentiment/closed-construct-of- meaningfulness-and-teleology -as-of-

'nondescript/ignorable-void '-with-regards-to-prospective-apriorising-implications $>$ >

dispositions like 'in-many-ways the slaves lives are better off than their kindreds in the darkness of Africa or that their conditions will be worse off when freed', that the 'toll of the American civil war was unnecessary', or 'in-many-ways the outcome of the French Revolution was far worse than was worth the struggle' and as so-equally echoed and adhered-to even by many from the specific subgroups/subcategories of humans/humanity to which such prospective sublimation/emancipation/enfranchisement would punctually/immediately accrue-to and so out of the mere fact of the given registry-worldview/dimension underpinning-suprasocial-construct <preconverging 'motif-and-apriorising/axiomatising/referencing'-entailing >-

existentialising — enframing/imprintedness-〈as-to- historicity-tracing — in-presencing-

hyperrealisation/hyperreal-transposition) as the 'already pragmatically deferring into religiosity of the underpinning-suprasocial-construct catchmenting-by-rejection of value and valuepossibilities' (in desublimating 'epistemic-impassion measliness/notional nonprotensivity/disontologising formulaic-dragging-out-or-formulaichollowing-out-<as-to-prior-shallow-supererogation -of-mentallyaestheticised preconverging/dementing -qualia-schema> implied discrete/fixated abstractly contemplatable individualised conceptualisation of ontological-performance $-<$ includingvirtue-as-ontology $>/$ morality/ethics/justice/etc. underiving-and-unaccruing to the socialconstruct postconverging-nonextricatory-existential-preempting-of-existentialunthought $\sim$ sublimation'). This so-underlies the 'ontologically-deficient human retention of history/the-past as failing to reflect upon the veridical human dual psychological dispositions surrounding prospective postconverging-aporeticism-overcoming/unovercoming which is 
exactly what is of critical relevance to prospective ontologising-and-re-ontologising (as of 'recurring preconverging/postconverging epistemic-projective-equalisation dynamics of failing or succeeding with respect to the postconverging-aporeticismovercoming/unovercoming of prospective-existentialising/contextualising/textualising')' since such an ontologically-flawed retention of history/the-past is poorly appreciative of 'both priorand-prospective prospective postconverging-apereticism overcoming/unovercoming as the creative driver of prospective human civilisation'; as such an ontologically-flawed retention of history/the-past is merely implicitly appreciative of the manifestly postconvergingly accruing sublimating outcome of 'epistemic-dispassion munificence/notional protensivity/reontologising dragging-out-<as-to-prospective-profound-supererogation -of-mentallyaestheticised postconverging/dialectical-thinking -qualia-schema $>$ implied continuous/reoriginating/dragged-out social-construct-pestconverging-nonextricatory-existentialpreempting-of-existential-unthought $\sim$ sublimation accruable-and-derivable percolationchannelling- $<$ in-deferential-formalisation-transference $>$ of secondnatured institutionalisation as so-transfusively determinant to overall social sublimating human ontological-performance <including-virtue-as-ontology>' (as effectively reflecting human prospective aestheticisationand-aestheticisation-towards-ontology-<elicited-idiomatisation $>$ ). But then subtly ignores that it is so-manifestly the outcome of prior prospective postconverging-apereticismovercoming/unovercoming (as of 'recurring preconverging/postconverging epistemicprojective-equalisation dynamics of failing or succeeding with respect to the postconverging aporeticism-overcoming/unovercoming of prospectiveexistentialising/contextualising/textualising'), as it rather relates to its own prospective prospective postconverging apereticism overeming human desublimating 'epistemic-impassion measliness/notional nonprotensivity/disontologising formulaic-dragging-out-or-formulaic- 
hollowing-out-<as-to-prior-shallow-supererogation -of-mentally-

aestheticised preconverging/dementing -qualia-schema $>$ implied discrete/fixated abstractly contemplatable individualised conceptualisation of ontological-performance -<includingvirtue-as-ontology $>/$ morality/ethics/justice/etc. underiving-and-unaccruing to the socialconstruct-pestconverging-nonextricatory-existential-preempting-of-existential-

unthought $\sim$ sublimation'. Hence such an ontologically-flawed retention of history/the-past fails to prospectively reflect the comprehensively 'appropriate human contemplative projectiveinsights of sublimating-nascence aetiologisation/ontological-escalation- $<$ ontologicalveridicality_commitment/otherliness_transcending/compulsions-encumbered_transcending $>$ conceptivity/epistemic-reflexivity/epistemicity-relativism-determinism- $<$ reifying \{as-toknowledge-developing\}-and-empowering>' (as of 'recurring preconverging/postconverging epistemic - projective-equalisation dynamics of failing or succeeding with respect to the postconverging-aporeticism-overcoming/unovercoming of prospectiveexistentialising/contextualising/textualising'), as it doesn't or poorly factor in the 'systematic association of both prior-and-prospective prospective postconvergingaapereticismovercoming/unovercoming' with the recurrent element of human desublimating 'epistemicimpassion measliness/notional nonprotensivity/disontologising formulaic-dragging-out-orformulaic-hollowing-out-<as-to-prior-shallow-supererogation -of-mentallyaestheticised preconverging/dementing -qualia-schema $>$ implied discrete/fixated abstractly contemplatable individualised conceptualisation of ontological-performance $-<$ includingvirtue-as-ontology $>$ /morality/ethics/justice/etc. underiving-and-unaccruing to the socialconstruct - postconverging-nonextricatory-existential-preempting-of-existentialunthought sublimation' as the systematic drawback for all given prospective postconverging aporeticism-overcoming/mnovercoming (as it thus falsely implies that epistemic-impassion is not manifested by the relevant present registry-worldview/dimension 
with regards to its prospective postconverging-aporeticism-overcoming/unovercoming as the contemplative veracity of any such prospective postconvergingaapereticismovercoming/unovercoming itself is actually poorly recognised by mere mental-reflex); and so, given registry-worldviews/dimensions imbued prior-institutionalisation-threshold-byprospective-uninstitutionalised-threshold 'self-referencing-syncretising forward-facingsupposedly postconverging-or-dialectical-thinking -apriorising-psychologism epistemicprojection as of prior mere-formulaicity/ritualisation-<as-to-mere-formulaicmethodologising/mutualising/organising/institutionalising,-prospectively-losing-track-of-

‘fepistemic-atlising ’re-apriorising/re-axiomatising/re-referencing residuality-in-reoriginariness/re-origination'>' so-reflecting their 'disontologising preconverging/dementing $<$ as-to-prospective-uninstitutionalised-threshold $>$ ignoring/biased inclination' for the sake of 'their given present minimum-and-balancing expectations/anticipations of social-functioningand-accordance-as-of-social-stake-contention-or-confliction' while qualifying their prospectively uninstitutionalised-threshold ${ }^{102}$ actually as nondescript/ignorable-void as to their ${ }^{79}$ presencing — absolutising-identitive-constitutedness ${ }^{14} \quad<$ preconverging $\sim$ 'motif-andapriorising/axiomatising/referencing'-entailing >-existentialising-enframing/imprintedness〈as-to- historicity-tracing-in-presencing-hyperrealisation/hyperreal-transposition〉. The overall implication here as of overall secondnatured institutionalisation is that human and social ontological-performance ${ }^{72}$-<including-virtue-as-ontology $>/$ morality/ethics/justice/etc. is much less than the potential for sublimating 'epistemic-dispassion munificence/notional $\sim$ protensivity/re-ontologising $\sim$ dragging-out-<as-to-prospective-profoundsupererogation -of-mentally-aestheticised postconverging/dialectical-thinking -qualiaschema $>$ implied continuous/re-originating/dragged-out social-construct postconvergingnonextricatory-existential-preempting-of-existential-unthought $\sim$ sublimation accruable-andderivable percolation-channelling- $<$ in-deferential-formalisation-transference $>$ of secondnatured 
institutionalisation (as 'so-transfusively determinant to overall social sublimating human ontological-performance -<including-virtue-as-ontology>')' and so given human prospectively uninstitutionalised-threshold ${ }^{102}$ manifestation of desublimating 'epistemic-impassion measliness/notional nonprotensivity/disontologising formulaic-dragging-out-or-formulaichollowing-out-<as-to-prior-shallow-supererogation -of-mentallyaestheticised preconverging/dementing -qualia-schema $>$ implied discrete/fixated abstractly contemplatable individualised conceptualisation of ontological-performance $-<$ includingvirtue-as-ontology $>$ /morality/ethics/justice/etc. underiving-and-unaccruing to the socialconstruct - pestconverging-nonextricatory-existential-preempting-of-existentialunthought sublimation' (manifesting as 'blurred/fuzzy as to the specific blurriness$<$ sterilising/anecdotalising/trivialising-of-prospective-re-ontologising_by-preconverging,-indisontologising-formulaic-dragging-out/hollowing-out> of the respective registryworldviews/dimensions $\leq$ mere-formulaicity/ritualisation - of $>$-prior secondnatured institutionalisation in-the-face-of-failing their prospective postconverging-aporeticismevercoming/unovercoming'). This speaks to the fact that sublimating human ontologicalperformance $^{72}-<$ including-virtue-as-ontology $>$ /morality/ethics/justice/etc. notionally lies with the supererogating/messianic/parrhesiastic expansion of 'epistemic-dispassion munificence/notional $\sim$ protensivity/re-ontologising $\sim$ dragging-out- $<$ as-to-prospective-profoundsupererogation -of-mentally-aestheticised postconverging/dialectical-thinking -qualiaschema $>$ implied continuous/re-originating/dragged-out social-construct postconvergingnonextricatory-existential-preempting-of-existential-unthought $\sim$ sublimation accruable-andderivable percolation-channelling-<in-deferential-formalisation-transference $>$ of secondnatured institutionalisation (as 'so-transfusively determinant to overall social sublimating human ontological-performance -<including-virtue-as-ontology>')' which so-reflects the 'veridical social preeminent directedness of knowledge-value and knowledge-discursivity orientation 
('dragged-out nature or psychologismic-epistemic-acutisation-<as-to-postconverging-dementating/structuring/paradigming,-eliciting-of-existence's-sublimating-nascence-inprospective-aporeticism-overcoming/unovercoming $>$ as to epistemic-growth,-as\{veridical/sound\}-relative-reflexivity-in-existence/relativising from-limited-mentation-as-itsdeepening/psychologismic epistemic-acutisation residualising, ${ }^{\text {fdecompulsing }}$ delinearity foreөgency' imbued 'supererogatory -wholesomeness/profound-supererogation as of prospective reference-of-thought - point-of-devolving/departure/anchoring/backdrop_of_sublimating_ nascence-<as-to-the-grandest-axiomatic-construct-fepistemictising ${ }^{+}$re-apriorising/reaxiomatising/re-referencing $\sim$ residuality -in-re-originariness/re-origination of limitedness/human-subpotency prospective re-encountering/re-confrontation with unlimitedness/existence>'). This though doesn't override/exclude the incipient/seeding formative manifestation of 'epistemic-impassion measliness/notional nonprotensivity/disontologising formulaic-dragging-out-or-formulaichollowing-out-<as-to-prior-shallow-supererogation -of-mentallyaestheticised $\sim$ preconverging/dementing -qualia-schema $>$ implied discrete/fixated abstractly contemplatable individualised conceptualisation of ontological-performance -<includingvirtue-as-ontology $>$ /morality/ethics/justice/etc. underiving-and-unaccruing to the socialconstruct - pestconverging-nonextricatory-existential-preempting-of-existentialunthought $\sim$ sublimation' (especially with human formative self-drivenness reflex predisposition of poor limited-mentation-capacity-deepening —as-subjecting limitedness/human-subpotency to-'educed-unlimitedness/existence-sublimating nascence' ${ }^{33}$ as to extended-informality〈susceptible-to-effecting-parsimony-as-of-shoddiness-and-incompleteness-to-

meaningfulness-and-teleology $\rangle$ manifestation of supposedly sublimating knowledge-value and knowledge-discursivity induced desublimating implications upon human and social ontological-performance ${ }^{72}$-<including-virtue-as-ontology $>/$ morality/ethics/justice/etc. and as it 
is naively and paradoxically represented wrongly as from self-presence/self-constitutedness ${ }^{14}$ $<$ in-perspective-epistemic-abnormalcy/preconvergence ${ }^{3}>$ epistemic-projection perspective in 'self-referencing-syncretising forward-facing-supposedly $\sim$ postconverging-or-dialecticalthinking -apriorising-psychologism epistemic-projection as of prior mereformulaicity/ritualisation-<as-to-mere-formulaic-

methodologising/mutualising/organising/institutionalising,-prospectively-losing-track-of-

‘\{epistemic-totalising ’’re-apriorising/re-axiomatising/re-referencing residuality-in-re-

originariness/re-origination'>'); as so-reflected in the desublimating unconstrained manifestation of <amplituding/formative> wooden-language-_imbued-temporal-mereform/virtualities/dereification/akrasiatic-drag/denatured/preconverging-or-dementing narratives - of-the- reference-of-thought- categorical-imperatives/axioms/registryteleology $\rangle$, and as further elicitable with pedantising/muddling/formulaic-hollowing-out—insubontologisation/subpotentiation-〈blurring/undermining-of-prospective-totalising-entailing,as-to-entailing-<amplituding/formative-epistemicity $>$ totalising in-relative-ontologicalcompleteness $>$ desublimation in its undermining of prospective epistemic-dispassion. Inmany-ways the 'postconverging-nonextricatory-existential-preempting-of-existential-unthought prospective notional-contiguity/epistemic-contiguity ${ }^{2}-<$ profound-supererogation -ofmentally-aestheticised postconverging/dialectical-thinking -qualia-schema $>$ profound aptitudinal re-ontologising-competence gesturing/accounting-of-epistemic-phenomenalism' of 'epistemic-dispassion munificence/notional $\sim$ protensivity/re-ontologising $\sim$ dragging-out- $<$ asto-prospective-profound-supererogation -of-mentallyaestheticised postconverging/dialectical-thinking -qualia-schema> implied continuous/reoriginating/dragged-out social-construct postconverging-nonextricatory-existentialpreempting-of-existential-unthought $\sim$ sublimation accruable-and-derivable percolationchannelling-<in-deferential-formalisation-transference $>$ of secondnatured institutionalisation 
(as 'so-transfusively determinant to overall social sublimating human ontologicalperformance -<including-virtue-as-ontology>')' which so-reflects the 'veridical social preeminent directedness of knowledge-value and knowledge-discursivity orientation ('draggedout nature or psychologismic-epistemic-acutisation-<as-to-postconverging-dementating/structuring/paradigming,-eliciting-of-existence's-sublimating-nascence-inprospective-aporeticism-overcoming/unovercoming $>$ as to epistemic-growth,-as\{veridical/sound\}-relative-reflexivity-in-existence/relativising from-limited-mentation-as-itsdeepening/psychologismic epistemic acutisation residualising, decmpulsingl delinearity for eogeney' imbued 'supererogatory -wholesomeness/profound-supererogation as of prospective reference-of-thought_- point-of-devolving/departure/anchoring/backdrop_of_sublimating_nascence- $<$ as-to-the-grandest-axiomatic-construct-\{epistemic-totalising ${ }^{\prime}$ re-apriorising/reaxiomatising/re-referencing $\sim$ residuality-in-re-originariness/re-origination of limitedness/human-subpotency prospective re-encountering/re-confrontation with unlimitedness/existence>')'; is mostly/relatively as intelligible (to a human 'epistemicimpassion measliness/notional nonprotensivity/disontologising formulaic-dragging-out-orformulaic-hollowing-out-<as-to-prior-shallow-supererogation -of-mentallyaestheticised preconverging/dementing -qualia-schema> implied discrete/fixated abstractly contemplatable individualised conceptualisation of ontological-performance $-<$ includingvirtue-as-ontology $>/$ morality/ethics/justice/etc. underiving-and-unaccruing to the socialconstruct - posteonverging-nonextricatory-existential-preempting-of-existentialunthought sublimation' in the shallow-supererogation of the 'mere-formulaicity/ritualisation$<$ as-to-mere-formulaic — methodologising/mutualising/organising/institutionalising,-

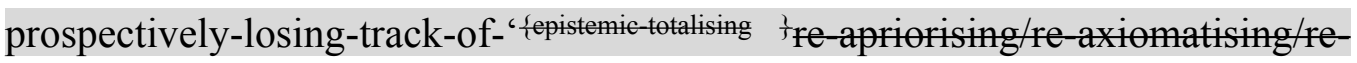
referencing $\sim$ residuality —in-re-originariness/re-origination'> imbued elaboration-as-to-mereextrapolating/constituting/abstracting/deducing/inferring-of-elucidation-outside- 
'prospectively_implicited_attendant-ontological-contiguity ' educed-

existentialising/contextualising/textualising_'intelligibility/epistemicity/reflexivity-contiguity-

$<$ imbued-notional cogency $>^{\prime}$ of the prior reference-of-thought-point-of-

devolving/departure/anchoring/backdrop) as of the direct or 'promised' positive-opportunismof-social-functioning-and-accordance ${ }^{75}$ '. Speaking to a human susceptibility to desublimating preconverging-existential-extrication-as-of-existential-unthought (as to 'lifespan extricatory/preconverging psychical-nascency moronisation-<sublimating-nascence,extricatory-desublimating-downstreaming/'avalage'>’) in dimensionality-of-desublimatinglack-of $-<<$ amplituding/formative $>$ supererogatory $\sim$ de-mentativeness/epistemic-growth-orconflatedness /transvaluative-rationalising/transepistemicity/anamnestic-residuality/spiritdrivenness-equalisation) (bound to undermine the requisite dimensionality-of-sublimating <<amplituding/formative>supererogatory $\sim$ de-mentativeness/epistemic-growth-or-

conflatedness /transvaluative-rationalising/transepistemicity/anamnestic-residuality/spiritdrivenness-equalisation) for prospective ${ }^{18}$ deprocrypticism-or-preempting — disjointedness-asof- ${ }^{8}$ reference-of-thought sublimating epistemic-dispassion conception of 'appropriate human contemplative projective-insights of sublimating-nascence aetiologisation/ontologicalescalation-<ontological-veridicality_commitment/otherliness_transcending/compulsionsencumbered_transcending $>\quad$ conceptivity/epistemic-reflexivity/epistemicity-relativismdeterminism-<reifying \{as-to-knowledge-developing $\}$-and-empowering $>$ '). The overall insight here is that (along the same lines that ontology/science is actually a postconvergingbirthing/nascency within prospective \{epistemic-totalising 3 re-apriorising/re-axiomatising/rereferencing $\sim$ residuality - in-re-originariness/re-origination- $\langle$ as to human profoundsupererogation for prospective apriorising/axiomatising/referencing-\{of-'prospectively implicited_attendant-ontological-contiguity ' educed- 
<imbued-notional cogency>' \}-conflatedness -in-\{preconverging-ment by\} postconverging-ntailment that cannot be unshrouded by prior mere-formulaicity/ritualisation<as-to-mere-formulaic — methodologising/mutualising/organising/institutionalising,prospectively-losing-track-of- ‘ \{epistemic-totalising ${ }^{\dagger}$ re-apriorising/re-axiomatising/rereferencing $\sim$ residuality—in-re-originariness/re-origination'> of prior apriorising/axiomatising/referencing-\{of-'prospectively implicited_attendant-ontologicalcontiguity ' educedexistentialising/contextualising/textualising_'intelligibility/epistemicity/reflexivity-contiguity<imbued-notional cogency >' $\quad$ - constitutedness -in-preconverging-entailment $\rangle)$; human and social ontological-performance ${ }^{72}-<$ including-virtue-asontology $>$ /morality/ethics/justice/etc. is fundamentally 'prospectively in epistemic — projectiveequalisation lockstep' with the sublimating-postconverged 'substantive abstract-tissue-ofsocial-emanance fepistemic thermeneutically/textually/reprojectingly/supererogatingly/zeroingly/re-acutingly,${ }_{\{\text {decompulsing }}$ delinearity for-cogency_cumulated/recomposured as to cumulating/recomposuring of 'prospectively implicited_attendant-ontological-contiguity ${ }^{67}$ ' educedexistentialising/contextualising/textualising_'intelligibility/epistemicity/reflexivity-contiguity<imbued-notional cogency>' reflecting its very human-subpotency supererogating incipience/seedingness as of dimensionality-of-sublimating <<amplituding/formative>supererogatory $\sim$ de-mentativeness/epistemic-growth-orconflatedness /transvaluative-rationalising/transepistemicity/anamnestic-residuality/spiritdrivenness-equalisation). Such an insight translates into the fact that since the mere-conception of the 'human sovereign-function/posture-<as-to-existentially-manifest-'embodiedsubject consciousness-and-direct/deferential-conscientiousness',-as-of-its- 'epistemicreflexivity/unreflexivity-in-existence'/teleology> with regards to public-sovereignty-giving 
function/posture' is incomplete (as to its failing of prospective postconvergingaapereticismovercoming/unovercoming in desublimating 'epistemic-impassion measliness/notional $\sim$ nonprotensivity/disontologising $\sim$ formulaic-dragging-out-or-formulaichollowing-out-<as-to-prior-shallow-supererogation -of-mentallyaestheticised preconverging/dementing -qualia-schema $>$ implied discrete/fixated abstractly contemplatable individualised conceptualisation of ontological-performance $-<$ includingvirtue-as-ontology $>$ /morality/ethics/justice/etc. underiving-and-unaccruing to the socialconstruct-pestconverging-nonextricatory-existential-preempting-of-existentialunthought $\sim$ sublimation'); such a mere-conception of the 'human sovereign-function/posture<as-to-existentially-manifest-'embodied-subject consciousness-and-direct/deferentialconscientiousness',-as-of-its-'epistemic-reflexivity/unreflexivity-in-existence'/teleology> with regards to public-sovereignty-giving function/posture' necessarily integrates (towards the 'enhancement of the prospective ontologising-capacity of the human sovereignfunction/posture-<as-to-existentially-manifest-'embodied-subject consciousness-and-

\section{direct/deferential-conscientiousness',-as-of-its-'epistemic-reflexivity/unreflexivity-in-}

existence'/teleology> within the existentialising-frame-of-entailment-of-motif-and-

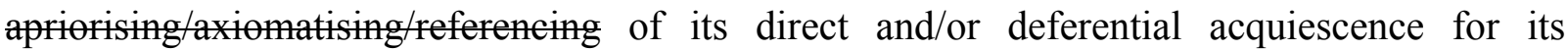
prospective sublimation/emancipation/enfranchisement') the genuine social intellectualfunction/posture (as it projects prospective ontologising-and-re-ontologising as of sublimating 'epistemic-dispassion munificence/notional $\sim$ protensivity/re-ontologising $\sim$ dragging-out- $<$ as-toprospective-profound-supererogation -of-mentally-aestheticised postconverging/dialecticalthinking -qualia-schema> implied continuous/re-originating/dragged-out social-constructposteonerging-nonextricatory-existential-preempting-of-existential-unthought $\sim$ sublimation accruable-and-derivable percolation-channelling-<in-deferential-formalisation-transference $>$ of secondnatured institutionalisation as so-transfusively determinant to overall social 
sublimating human ontological-performance -<including-virtue-as-ontology>’). In-many-ways this is again veridically uncontested as to the manifest sublimating-nascence incipience/instantaneity/directness of nascent-particular/incipient-and-material/technicalsublimations- $<$ blinded-to-their-relative-ontological-completeness - reference-of-thoughtdevolving $>$ wherein for instance the "enhancement of the prospective ontologising-capacity of the human sovereign-function/posture-<as-to-existentially-manifest-'embodiedsubject consciousness-and-direct/deferential-conscientiousness',-as-of-its-'epistemicreflexivity/unreflexivity-in-existence'/teleology> within the existentialising-frame-ofentailment of motif-and-apriorising/axiomatising/referencing of its direct and/or deferential acquiescence for its prospective sublimation/emancipation/enfranchisement' involved in the profound-supererogation /messianic/parrhesiastic curative science of say a Pasteur or mechanical science of a Newton/Galileo speaks of a genuine social intellectual-function/posture which is literally otherworldly as to its angling-of-imaginary projection relative to their given social-setup 'poor-supererogating/messianic/parrhesiastic mere-conception of human sovereign-function/posture-<as-to-existentially-manifest-'embodied-subject $\sim$ consciousnessand-direct/deferential-conscientiousness',-as-of-its-'epistemic-reflexivity/unreflexivity-inexistence'/teleology>' as of 'human lifespan extricatory punctuality/immediacy of depth-ofthought inherent psychical-nascency' (and let alone relative to all other human societies of the time 'human lifespan extricatory punctuality/immediacy of depth-of-thought inherent psychicalnascency') to which such profound-supererogation $/$ messianic/parrhesiastic curative and mechanical sublimation/emancipation/enfranchisement will ultimately accrue. Likewise, such profound-supererogation $/$ messianic/parrhesiastic enterprises as undertaken by the enlightenment revolutionaries and Encyclopédistes mostly directly and others as to disseminative/knock-on enculturation speaks of the genuine social intellectual-function/posture (as to its projection of the 'dragged-out nature or psychologismic-epistemic-acutisation- $<$ as-to- 
postconverging-de-mentating/structuring/paradigming,-eliciting-of-existence's-sublimatingnascence-in-prospective-aporeticism-overcoming/unovercoming $>$ as to epistemic-growth,-as\{veridical/sound\}-relative-reflexivity-in-existence/relativising from-limited-mentation-as-itsdeepening/psychologismic epistemic acutisation residualising, ${ }^{\text {fdecompulsing }}$ delinearity for eogency' imbued 'supereregatory $w$ wholesomeness/profound-supererogation as of prospective reference-of-thought—point-of-devolving/departure/anchoring/backdrop_of_sublimatingnascence-<as-to-the-grandest-axiomatic-construct- - epistemic-totalising ${ }_{3}^{3}$ re-apriorising/reaxiomatising/re-referencing $\sim$ residuality —in-re-originariness/re-origination limitedness/human-subpotency prospective re-encountering/re-confrontation with unlimitedness/existence>') and can hardly be construed as inherently driven by the prospective ontologising-and-re-ontologising predisposition of 'poorsupererogating/messianic/parrhesiastic mere-conception of human sovereign-function/posture<as-to-existentially-manifest-`embodied-subject $\sim$ consciousness-and-direct/deferentialconscientiousness',-as-of-its- 'epistemic-reflexivity/unreflexivity-in-existence'/teleology>’ to which such social sublimation/emancipation/enfranchisement will ultimately accrue. This supererogatory-progressivity insight very much contrasts with the "poorsupererogating/messianic/parrhesiastic usurpatory conception as of ${ }^{79}$ presencing—absolutisingidentitive-constitutedness ${ }^{14}$ social-vestedness/normativity-<discretely-implied-functionalism>’ with which pedantising/muddling/formulaic-hollowing-out—insubontologisation/subpotentiation-〈blurring/undermining-of-prospective-totalising-entailing,as-to-entailing-<amplituding/formative-epistemicity $>$ totalising $\sim$ in-relative-ontologicalcompleteness > historically relates to the human sovereign-function/posture-<as-toexistentially-manifest-'embodied-subject $\sim$ consciousness-and-direct/deferentialconscientiousness',-as-of-its-'epistemic-reflexivity/unreflexivity-in-existence'/teleology> (as of the desublimating percolation-channelling- $<$ in-deferential-formalisation-transference $>$ of the 
given

registry-worldview/dimension

underpinning-suprasocial-construct

$<$ preconverging 'motif-and-apriorising/axiomatising/referencing'-entailing >-

existentialising — enframing/imprintedness-〈as-to- historicity-tracing_-in-presencing-

hyperrealisation/hyperreal-transposition) as the 'already pragmatically deferring into religiosity of the underpinning-suprasocial-construct catchmenting-by-rejection of value and valuepossibilities'). But then the latter posture is ontologically flawed by the simple token that the momentous historial veracity speaks to the fact that thus the human sovereign-function/posture-

\section{$<$ as-to-existentially-manifest-“embodied-subject consciousness-and-direct/deferential-}

conscientiousness',-as-of-its-'epistemic-reflexivity/unreflexivity-in-existence'/teleology>

well (along the same lines with regards to human and social ontological-performance ${ }^{72}$ <including-virtue-as-ontology $>/$ morality/ethics/justice/etc. as underlied by the implication that ontology/science is actually a postconverging-birthing/nascency within prospective \{epistemicre-apriorising/re-axiomatising/re-referencing $\sim$ residuality-in-re-originariness/reorigination- $\langle$ as to human profound-supererogation for prospective apriorising/axiomatising/referencing-\{of-'prospectively implicited_attentantontologicalcontiguity ' educedexistentialising/contextualising/textualising_'intelligibility/epistemicity/reflexivity-contiguity$<$ imbued-notional $\left.\sim \operatorname{cogency}>^{\prime}\right\}$-conflatedness -in-\{preconverging ment by\} postconverging-entailment that cannot be unshrouded by prior mere-formulaicity/ritualisation$<$ as-to-mere-formulaic — methodologising/mutualising/organising/institutionalising,prospectively-losing-track-of-`\{epistemic-totalising ${ }^{3}$ re-apriorising/re-axiomatising/rereferencing $\sim$ residuality_-in-re-originariness/re-origination'> of prior apriorising/axiomatising/referencing-\{of-'prospectively_implicited_attendant-ontologicalcontiguity ' educed-

existentialising/contextualising/textualising_ intelligibility/epistemicity/reflexivity-contiguity- 
<imbued-notional cogency $\left.>^{\prime} \quad\right\}$-constitutedness -in-preconverging-entailment $\rangle$ );

fundamentally 'prospectively in epistemic_-projective-equalisation lockstep' with the genuine social intellectual-function/posture as to prospective human-subpotency profoundsupererogation $/$ messianic/parrhesiastic incipience/seedingness of prospective sublimating/emancipating/enfranchisement as of dimensionality-of-sublimating ${ }^{25}$ <<amplituding/formative>supererogatory $\sim$ de-mentativeness/epistemic-growth-or-

conflatedness /transvaluative-rationalising/transepistemicity/anamnestic-residuality/spirit-

drivenness-equalisation). Whereas such a pedantising/muddling/formulaic-hollowing-out-insubontologisation/subpotentiation-〈blurring/undermining-of-prospective-totalising-entailing,as-to-entailing-<amplituding/formative-epistemicity $>$ totalising $\sim$ in-relative-ontologicalcompleteness > implicited interpretation of mere-formulaicity/ritualisation-<as-to-mereformulaic - methodologising/mutualising/organising/institutionalising,-prospectively-losingtrack-of- ‘fepistemic-totalising ${ }^{\dagger}$ re-apriorising/re-axiomatising/re-referencing $\sim$ residuality-in-reoriginariness/re-origination'> of prior apriorising/axiomatising/referencing-\{of-'prospectively implicited_attendant-ontological-contiguity ' educedexistentialising/contextualising/textualising_ intelligibility/epistemicity/reflexivity_contiguity$<$ imbued-notional cogency $\left.>^{\prime} \quad\right\}$ - constitutedness ${ }^{14}$-in-preconverging-entailment $\quad$ (as soreadily emphasised in any ${ }^{79}$ presencing-absolutising-identitive-constitutedness ${ }^{14}$ imbued blurriness-<sterilising/anecdotalising/trivialising-of-prospective-re-ontologising_bypreconverging,-in-disontologising-formulaic-dragging-out/hollowing-out>) if taken to its true conclusion will wrongly seem to imply that there is an inherently 'profoundsupererogation $/$ messianic/parrhesiastic mere-conception of human sovereignfunction/posture-<as-to-existentially-manifest-‘embodied-subject $\sim$ consciousness-anddirect/deferential-conscientiousness',-as-of-its- 'epistemic-reflexivity/unreflexivity-inexistence'/teleology>' of respectively recurrent-utter-uninstitutionalisation, base- 
institutionalisation-ununiversalisation, ${ }^{103}$ universalisation-non-positivism/medievalism and positivism- ${ }^{80}$ procrypticism as enabling the prospective attainment of respectively baseinstitutionalisation-ununiversalisation, $\quad{ }^{103}$ universalisation-non-positivism/medievalism, positivism- ${ }^{80}$ procrypticism and ${ }^{18}$ deprocrypticism-or-preempting-disjointedness-as-ofreference-of-thought; as so-ignoring that it is the genuine social intellectual-function/posture across the successive registry-worldviews/dimensions that of its profoundsupererogation $/$ messianicity/parrhesia undergirds such a 'postconverging epistemicprojective-equalisation social dynamics of human limited-mentation-capacity-deepening-assubjecting limitedness/human-subpotency to-'educed-unlimitedness/existence-sublimating nascence' ' (as to its continuous/re-originating/dragged-out social-construct - pestcenvergingnonextricatory-existential-preempting-of-existential-unthought $\sim$ sublimation).

Counterintuitively, the 'genuine social intellectual-function/posture is so-manifested as of an ontologising intolerance-<of-disparateness $>$ /exactifying_precisioning (as of notional $\sim$ reflexivity- $<\{$ veridical/sound $\}$-relative-reflexivity-in-existence/relativising fromlimited-mentation-as-its-deepening/psychologismic-<residualising fdecompulsing delinearity foreogency $>$ by _flawed/unsound\}-relative-unreflexivity-in-existence/absolutising from-

\section{limited mentation/psychologismic epistemic acutisation nonresidualising imbued}

\{compulsing\} linearity in-eclecticism-of-prior-mere-formulaicity/ritualisation $>$ ) for prospective disontologising which it inherently $\mathrm{s}$ most critically due to disontologising imbued incipient/seeding ontological-bad-faith/inauthenticity ${ }^{64} \sim$ preconverging-dementating/structuring/paradigming and so in line with the inherently uncompromising nature of existence-potency over the mortal human-subpotency' (wherein prior non-universalising, non-positivising and totalisingly-ing-discretion/whim-of-thought respectively of ancientsophists, medieval-scholasticism and our modern-day manifestation of disparateness-ofconceptualisation-<unforegrounding-ment,-failing-prospectively-to-reflect- 
'immanent $\sim$ relative-unreflexivity/relative reflexivity - ontological-contiguity ' $>$ are related to in transversality-<for-sublimating-existential-eventuating/denouement,-from 'thinking-atfirst/pure-predisposition-preemptive-of-prospective-disontologising/subontologising' as-ofprospectively-disambiguated-affirmed-and-unaffirmed-'motif-andapriorising/axiomatising/referencing' $>101$ as to the sublimating manifestation of the prospective genuine social intellectual-function/posture of respectively ${ }^{103}$ universalising-idealisation, budding-positivism and budding postmodern-thought); and so notwithstanding a pedantising/muddling/formulaic-hollowing-out — in-subontologisation/subpotentiation〈blurring/undermining-of-prospective-totalising-entailing,-as-to-entailing<amplituding/formative-epistemicity>totalising in-relative-ontological-completeness $>$ desublimation to undermine the prospective genuine social intellectual-function/posture paradoxically by overtly or covertly cultivating the given registry-worldview/dimension $<$ amplituding/formative $>$ wooden-language-〈imbued-temporal-mereform/virtualities/dereification/akrasiatic-drag/denatured/preconverging-or-dementing narratives - of-the- reference-of-thought- categorical-imperatives/axioms/registryteleology $>$ (implicited along the lines 'afterall all the human world and mentality that exists' is-as-of-their-given-registry-worldview/dimension however its preconverging-dementating/structuring/paradigming notional ontological-performance ${ }^{72}-<$ including-virtue-asontology $>$ /vices-and-impediments ${ }^{105}$ respectively in recurrent-utter-uninstitutionalisation, baseinstitutionalisation-ununiversalisation, ${ }^{103}$ universalisation-non-positivism/medievalism and positivism- ${ }^{80}$ procrypticism and so as supposedly not veridically about prospective transcendence-and-sublimity/sublimation/supererogatory-de-mentativity and so-reflected respectively as not of prospective 'rulemaking-over-non-rulesapriorising/axiomatising/referencing-psychologism entailment of knowledge' but rather as of prior 'non-rules — apriorising/axiomatising/referencing-psychologism entailment of knowledge 
of recurrent-utter-uninstitutionalisation', as not of prospective ' ${ }^{103}$ universalisation-directedrulemaking-over-non-rules_-apriorising/axiomatising/referencing-psychologism entailment of knowledge' but rather as of prior 'rulemaking-over-non-rulesapriorising/axiomatising/referencing-psychologism entailment of knowledge of baseinstitutionalisation-ununiversalisation', as not of prospective 'positivising/rational-empiricismbased-universalisation-directed-rulemaking-over-non-rules-

apriorising/axiomatising/referencing-psychologism entailment of knowledge' but rather as of prior ${ }^{103}$ universalisation-directed-rulemaking-over-non-rulesapriorising/axiomatising/referencing-psychologism entailment of knowledge of universalisation-non-positivism/medievalism' and as not of prospective 'preemptingdisjointedness-as-of- ${ }^{8}$ reference-of-thought,-as-to- ${ }^{32}<$ amplituding/formativeepistemicity $>$ growth-or-conflatedness ${ }^{13} /$ transvaluative-

rationalising/transepistemicity/anamnestic-residuality/spirit-drivenness'-in-supersedingmere-formulaic-positivising/rational-empiricism-based-universalisation-directed-rulemakingover-non-rules — apriorising/axiomatising/referencing-psychologism entailment of knowledge' but rather as of prior 'positivising/rational-empiricism-based-universalisation-directedrulemaking-over-non-rules_-apriorising/axiomatising/referencing-psychologism entailment of knowledge of positivism- ${ }^{8}$ procrypticism'). This imbued profoundsupererogation /messianicity/parrhesia of the 'genuine social intellectual-function/posture attachment-and-commitment beyond a poor-supererogating/messianic/parrhesiastic mereconception of human sovereign-function/posture-<as-to-existentially-manifest-'embodiedsubject consciousness-and-direct/deferential-conscientiousness',-as-of-its- 'epistemicreflexivity/unreflexivity-in-existence'/teleology>' as enabling to the veridical human sovereignfunction/posture-<as-to-existentially-manifest-‘embodied-subject $\sim$ consciousness-anddirect/deferential-conscientiousness',-as-of-its-'epistemic-reflexivity/unreflexivity-in- 
existence'/teleology $>$ is effectively what is warranted in 'deconstruction analysis as more than just a balancing act between supposedly dominant and the supposedly dominated' but it more profoundly speaks to a human communion arising as from inherent existence sublimatingnascency as of notional $\sim$ self-distantiation- $<$ imbued-re-motif-and-re-apriorising/reaxiomatising/re-referencing $>\quad$ imbued transversality-<for-sublimating-existentialeventuating/denouement,-from-'thinking-at-first/pure-predisposition-preemptive-ofprospective-disontologising/subontologising' as-of-prospectively-disambiguated-affirmedand-unaffirmed-'motif-and-apriorising/axiomatising/referencing'>101 involved in 'postconverging epistemic - projective-equalisation social dynamics of human limitedmentation-capacity-deepening —as-subjecting limitedness/human-subpotency-to-'educedunlimitedness/existence-sublimating nascence' ${ }^{3}$ '; readily appreciable with the unbeholdening of the profound-supererogation $/$ messianic/parrhesiastic curative science of say a Pasteur or mechanical science of a Newton/Galileo accruing to the entirety of humanity sovereignfunction/posture-<as-to-existentially-manifest-`embodied-subject $\sim$ consciousness-anddirect/deferential-conscientiousness',-as-of-its-'epistemic-reflexivity/unreflexivity-inexistence'/teleology> with regards to nascent-particular/incipient-and-material/technicalsublimations- $<$ blinded-to-their-relative-ontological-completeness - reference-of-thoughtdevolving $>$ and equally reflected in the notion that human and social sublimation/emancipation/enfranchisement is more critically undertaken in relation to the 'existential-<disontologising/re-ontologising aporeticism $>$ human potential for sovereignfunction/posture-<as-to-existentially-manifest-`embodied-subject $~$ consciousness-anddirect/deferential-conscientiousness',-as-of-its-'epistemic-reflexivity/unreflexivity-inexistence'/teleology $>$ enhancement as of cultivated epistemic-growth/disquiet/discomfort〈induced-sublimation,-as-from-existence's - effusing/ecstatic-inlining-as- historiality\{science/authenticity/nonextrication $\}$-beyond-mere-formulaicity/ritualisation-as- historicity- 
supererogating/messianic/parrhesiastic mere-conception of human sovereign-function/posture<as-to-existentially-manifest-'embodied-subject consciousness-and-direct/deferentialconscientiousness',-as-of-its-'epistemic-reflexivity/unreflexivity-in-existence'/teleology> (whether of manifesting as of appropriate/advantageous sovereign-function/posture- $<$ as-toexistentially-manifest-'embodied-subject $\sim$ consciousness-and-direct/deferentialconscientiousness',-as-of-its-'epistemic-reflexivity/unreflexivity-in-existence'/teleology> ontologising-capacity or manifesting as of disadvantageous sovereign-function/posture- $<$ as-toexistentially-manifest-'embodied-subject consciousness-and-direct/deferentialconscientiousness',-as-of-its-'epistemic-reflexivity/unreflexivity-in-existence'/teleology> ontologising-capacity eliciting dominance-driven disontologising/subontologising-imbuingprospectively-of-human-desublimating/subjugation/disenfranchisement). But the veridical human sovereign-function/posture-<as-to-existentially-manifest-‘embodiedsubject consciousness-and-direct/deferential-conscientiousness',-as-of-its- 'epistemicreflexivity/unreflexivity-in-existence'/teleology> rather warrants the profoundsupererogation $/$ messianicity/parrhesia of the genuine social intellectual-function/posture in all instances whether in the case of punctual/immediacy/constituted/compulsions-encumbered disadvantageous sovereign-function/posture-<as-to-existentially-manifest-'embodiedsubject $\sim$ consciousness-and-direct/deferential-conscientiousness',-as-of-its- 'epistemicreflexivity/unreflexivity-in-existence'/teleology> ontologising-capacity as may be manifested with the highs-and-lows of the sovereign democratic process and exercise or with the inherently disadvantageous sovereign-function/posture-<as-to-existentially-manifest-'embodiedsubject consciousness-and-direct/deferential-conscientiousness',-as-of-its- ‘epistemicreflexivity/unreflexivity-in-existence'/teleology> ontologising-capacity coming with say 
class/racial/gender/decolonial emancipations as to historically manifested relatively disadvantaged formative sovereign-function/posture-<as-to-existentially-manifest-'embodiedsubject consciousness-and-direct/deferential-conscientiousness',-as-of-its- 'epistemicreflexivity/unreflexivity-in-existence'/teleology $>$ ontologising-capacity warranting for instance an accompanying sovereign-function/posture-<as-to-existentially-manifest-'embodiedsubject consciousness-and-direct/deferential-conscientiousness',-as-of-its-'epistemicreflexivity/unreflexivity-in-existence'/teleology> ontologising-capacity propping-up beyond just the supposed 'political proclamation-and-reckoning about such class/racial/gender/decolonial emancipations'. Ultimately in this regards, the idea of ontology/science (unlike can be wrongly projected consciously or unconsciously as to a mereformulaicity/ritualisation-<as-to-mere-formulaicmethodologising/mutualising/organising/institutionalising,-prospectively-losing-track-of‘\{epistemic-totalising ’re-apriorising/re-axiomatising/re-referencing $\sim$ residuality-in-reoriginariness/re-origination'> predisposition associated with science-ideology) is necessarily tied to the 'formative enhancement of the human sovereign-function/posture-<as-toexistentially-manifest-'embodied-subject $\sim$ consciousness-and-direct/deferentialconscientiousness',-as-of-its-'epistemic-reflexivity/unreflexivity-in-existence'/teleology>' whether as of the direct-capacity/deferential-capacity for human cultivated epistemicgrowth/disquiet/discomfort-〈induced-sublimation,-as-from-existence's - effusing/ecstaticinlining-as- historiality-\{science/authenticity/nonextrication $\}$-beyond-mereformulaicity/ritualisation-as- historicity-tracing- $\{$ science-ideology/fashionability/distraction $\}\rangle$ as to prospective sublimating epistemic-dispassion conception of 'appropriate human contemplative projective-insights of sublimating-nascence aetiologisation/ontologicalescalation-<ontological-veridicality_commitment/otherliness_transcending/compulsionsencumbered_transcending $>$ conceptivity/epistemic-reflexivity/epistemicity-relativism- 
'supererogatory $\sim$ wholesomeness/profound-supererogation ${ }^{96}$ as of prospective ${ }^{83}$ reference-ofthought_ — point-of-devolving/departure/anchoring/backdrop_of_sublimating-nascence- $<$ as-tothe-grandest-axiomatic-construct-\{epistemic-totalising ${ }^{\mathfrak{l}}$ re-apriorising/re-axiomatising/rereferencing $\sim$ residuality - in-re-originariness/re-origination of limitedness/human-subpotency prospective re-encountering/re-confrontation with unlimitedness/existence>'; with the human never outside the direct-accountability/indirect-accountability loop of ontology/science (as can be disenfranchisingly be projected by a certain flawed conception of future science and technology by the mere token that such a pretense is fallacious since the instigator of say such an organisational/technological development as a given human/human-institution can at best not keep themselves out of such a loop of direct-accountability/deferential-accountability but rather keep all-other/selected-other humans out of the loop thus manifestly enfranchising themselves while disenfranchising all-other/selected-other humans). In epistemic lockstep with notional philosophy-<as-to-the-veridical-conception-of-philosophy-as-englobing-all-humanprospective-organic-knowledge-generation-in-relative-ontological-completeness ,-beyond-aconvenient-division-of-labour-conception-of-knowledge $>$ and its associated intolerance-<ofdisparatenes/exactifying_precisioning-of-sublimation-<as-to-postconverging-narrowingdown apriorising/axiomatising/referencing-entailing-theoretical,-conceptual-and-operantimplications $>$ construed as science, is the fundamental issue of human limited-mentationcapacity -as-subjecting 'educed-unlimitedness/existence-sublimating nascence' tolimitedness/human-subpotency and limited-mentation-capacity-deepening-as-subjecting limitedness/human-subpotency to-'educed-unlimitedness/existence-sublimating nascence' ${ }^{53}$ as to human <amplituding/formative-epistemicity $>$-totalising $\sim$ thrownness-in-existence ${ }^{5}$; speaking of the ontological inextricability of the human as sovereign-subject and ontology/science imbuing conceptivity/epistemic-reflexivity/epistemicity-relativism- 
determinism-<reifying \{as-to-knowledge-developing $\}$-and-empowering $>$ upon the human (as of the 'psychoanalytic-unshackling/memetic-reordering/institutional-recomposuring self-

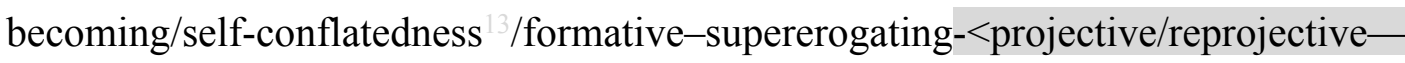
aestheticising-re-motif-and-re-apriorising/re-axiomatising/re-referencing,-in-perspectiveontological-normalcy/postconvergence>' underlying human 'epistemicgrowth/disquiet/discomfort-〈induced-sublimation,-as-from-existence's — effusing/ecstaticinlining-as- historiality-\{science/authenticity/nonextrication $\}$-beyond-mereformulaicity/ritualisation-as- historicity-tracing-\{science-ideology/fashionability/distraction $\}\rangle$ as to construction-of-the-Self in dispensing-with-immediacy-for-relative-ontologicalcompleteness $^{87}$-by-reification/contemplative-distension ${ }^{27}$ '). The implication here is that there is no ontology/science without the human since fundamentally existence is inherently given with the issue of human knowledge adding nothing to inherent existence but rather about the existentialising/contextualising/textualising optimising of human placeholder-setup/mentaldevising-representation/mentation/consciousness-awareness-teleology ${ }^{9}$ for its derived sublimating ${ }^{56}$ meaningfulness-and-teleology ${ }^{9}$. The implication here is that the human sovereign-subject can only exist as of its limitedness (imbued thresholding of ontologicalperformance ${ }^{2}-<$ including-virtue-as-ontology $>$ ) in the extensive unlimitedness that is existence; but with the human sovereign-subject a reflexive part of the unlimitedness that is existence, thus imbuing the human with omnipotentiality (as to epistemic-dispassion) enabling prospective limited-mentation-capacity-deepening —as-subjecting limitedness/human-subpotency-to'educed-unlimitedness/existence-sublimating nascence' ${ }^{53}$ however human punctually manifest limited-mentation-capacity—as-subjecting 'educed-unlimitedness/existence-sublimating nascence' to-limitedness/human-subpotency (as to epistemic-impassion); with human omnipotentiality particularly potent as to the specific human consciousness in-its-embodiment as the potent 'phenomenological transcendental-point-of-departure handle' for human self- 
conscious existence and ${ }^{5}$ meaningfulness-and-teleology ${ }^{9}$ construal/conceptualisation as of knowledge-constructs/theories/intersolipsistic-intercessory-notions/notional $\sim$ referentialnotions/articulations/virtue. Existence thus as to its prospective exuding sublimating/desublimating so-enables 'human epistemic-growth,-as-\{veridical/sound\} relative-reflexivity-in-existence/relativising from-limited-mentation-as-itsdeepening/psychologismic epistemic-acutisation residualising, \{decompulsing delinearity foreogency induced transcendental and emancipative possibilities/potential' (construed as knowledge-constructs/theories/intersolipsistic-intercessory-notions/notional referentialnotions/articulations/virtue) and so over human \{flawed/unsound\}-relative-unreflexivity-inexistence/absolutising from-limited-mentation/psychologismic epistemic acutisationnonresidualising-imbued-\{compulsing\} linearity in-eclecticism-of-prior-mereformulaicity/ritualisation overall <amplituding/formative> wooden-language-〈imbued temporal-mere-form/virtualities/dereification/akrasiatic-drag/denatured/preconverging-ordementing -narratives - of-the- reference-of-thought- categoricalimperatives/axioms/registry-teleology $\rangle$ : underlied by the simple fact that the extensive unlimitedness that is existence exudes sublimating/desublimating validative/invalidative thresholds; so-arising as from the relative sublimating validation manifestation of human epistemic-growth,-as_ \{veridical/sound\}-relative-reflexivity-in-existence/relativising fromlimited-mentation-as-its-deepening/psychologismic epistemic-acutisation residualising, ${ }_{\{\text {decompulsing }}$ delinearity for-cogency (as to prospective 'apriorising/axiomatising/referencing disambiguating/de-leveling/de-ressentiment/opened-construct-of- ${ }^{5}$ meaningfulness-andteleology $\quad$ demoronisation- $<$ sublimating-nascence,-nonextricatory-sublimatingupstreaming/'amontée'>’) ontological-performance ${ }^{72}-<$ including-virtue-asontology $>$ /morality/ethics/justice/etc. as superseding/transcending the relative desublimating invalidation manifestation of human \{flawed/unsound\}-relative-unreflexivity-in- 
existence/absolutising from-limited-mentation/psychologismic epistemic-acutisationnonresidualising imbued-\{compulsing\} linearityoin-eclecticism-of prior-mereformulaicity/ritualisation 'apriorising/axiomatising/referencingequating/leveling/ressentiment/closed-construct-of- ${ }^{5}$ meaningfulness-and-teleology moronisation-<sublimating-nascence,-extricatory-desublimating-downstreaming/'avalage'>' undifferentiation of both the prior relative-ontological-incompleteness ${ }^{88}$ and the prospective relative-ontological-completeness ${ }^{87}$, as so-effectively disambiguating/differentiating human sovereign-subjects epistemic-reflexivities respective thresholds of ontological-performance ${ }^{72}$ $<$ including-virtue-as-ontology $>$ /morality/ethics/justice/etc. as to relative exuded sublimating/desublimating as validation/invalidation. This so-fundamentally undermines the 'naivety of the human subjectivity argument as of a disparateness-of-conceptualisation$<$ unforegrounding-ment,-failing-prospectively-to-reflect-'immanent $\sim$ relativeunreflexivity/relative-reflexivity - ontological-contiguity ' $>$ induced implication of a general equating/leveling-down conception of human ontological-performance ${ }^{72}-<$ including-virtue-asontology $>$ ' that fails to factor in that 'epistemic-dispassion supposed subjectivity associated with limited-mentation-capacity-deepening —as-subjecting limitedness/human-subpotency-to'educed unlimitedness/existence sublimating nascence' ${ }^{5}$ ' ontologically overrides 'epistemicimpassion supposed subjectivity associated with limited-mentation-capacity-as-subjecting'educed-unlimitedness/existence-sublimating nascence' to-limitedness/human-subpotency' and so as to the varying psychologismic epistemic acutisation difficulty-<for, residualising \{decondsing $\}$ delinearity for-cogeney $>$ magnitudes $\{$ of-experientiality/experiment\} of aestheticisation-andaestheticisation-towards-ontology-<elicited-idiomatisation $>$ (for instance as to their relevant

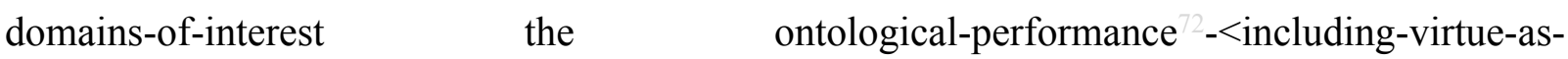
ontology $>$ /morality/ethics/justice/etc. arising from the supposed subjectivity of the astronomer, engineer, doctor, etc. as of our present-day professional psychologismic epistemic-acutisation- 
difficulty-<for, residualising_\{decompulsing $\}$ delinearity for-cogeney> magnitude ${ }^{\{0 f-}$ experientiality/experiment\} of 'epistemic-dispassion supposed subjectivity imbued limited-mentationcapacity-deepening —as-subjecting limitedness/human-subpotency to-'educed-

unlimitedness/existence-sublimating nascence' ${ }^{3}$, ontologically overrides the supposed subjectivity of the layman as to the latter's 'epistemic-impassion supposed subjectivity imbued relative limited-mentation-capacity_as-subjecting-'educed-unlimitedness/existencesublimating nascence' to-limitedness/human-subpotency'). Speaking to the naive paradox that the very notion of subjectivity seems to imply that 'supposed-subjects'/subpotencies as phenomenal/manifest $\sim$ subpotencies-〈in-transitive-conflatedness -reflexivity,-in-the-fullpotency-of-existence's $\sim$ sublimating-nascence) are in absolute dissociation from overall existence's exuding sublimating/desublimating manifestation (instead of the reality rather of 'supposed-subjects'/subpotencies in notional $\sim$ reflexivity- $<$ \{veridical/sound $\}$-relativereflexivity-in-existence/relativising from-limited-mentation-as-its-deepening/psychologismic<residualising \{decompulsing $\}$ delinearity for-cogency>-by-\{flawed/unsound\}-relativeunreflexivity-in-existence/absolutising from-limited-mentation/psychologismic epistemicacutisation nonresidualising-imbued-fcompulsings linearity-in-eclecticism-of-prior-mereformulaicity/ritualisation> imbued sublimating/desublimating in existence), such that the 'constraining/defining intersolipsistic reflexive-sublimating/unreflexive-desublimating measure/objectification that is unlimitedness/existence-as-ontologicalnormalcy/postconvergence-<in-validation-of-'metaphysics-of-absence_epistemic-projection'> is enabling of all apparent 'supposed-subjects'/subpotencies in their notional reflexivity$<\{$ veridical/sound $\}$-relative-reflexivity-in-existence/relativising from-limited-mentation-as-

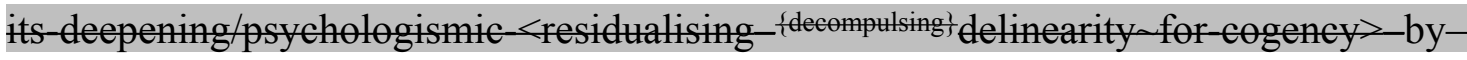
flawed/unsound\}-relative-unreflexivity-in-existence/absolutising from-limitedmentation/psychologismic epistemic-acutisation nonresidualising imbued- 
sublimating/desublimating in existence; as notional $\sim$ reflexivity- $<\{$ veridical/sound $\}$-relativereflexivity-in-existence/relativising from-limited-mentation-as-its-deepening/psychologismic<residualising ${ }^{\text {\{decompulsing }}$ \}elinearity for-cogency>-by-\{flawed/unsound\}-relativeunreflexivity-in-existencelabsolutising from-limited-mentation/psychologismic epistemicacutisation nonresidualising-imbued-\{compulsing\} linearity in-eclecticism-of-prior-mereformulaicity/ritualisation> means that 'supposed-subjects'/subpotencies cannot exist out of existence but are merely notional reflexive manifestations in existence with varying

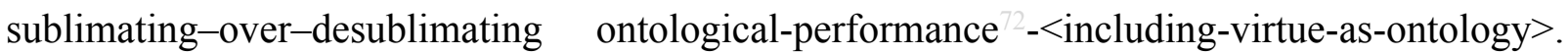
This further explains 'human originary-and-re-orginary impliciting of the necessity of a projective construal of relative-unreflexivity/relative-reflexivity-ontologicalcontiguity ${ }^{67}$ immanent $\sim$ relative- unreflexivity/relative-reflexivity - ontological-contiguity ${ }^{67}$ in reflection of the 'very contiguity of existence' as to the underlying 'existentially<disontologising/re-ontologising aporeticism $>$ assessable-and-reassessable overall expectation of consistency/coherence of existence that enables the intelligibilities of phenomenal/manifest $\sim$ subpotencies-〈in-transitive-conflatedness -reflexivity,-in-the-fullpotency-of-existence's $\sim$ sublimating-nascence) to arise' in the-very-first-place (so assessableand-reassessable in the sense for instance that we expect one and one book to ever always add up to two books going by the overall expectation of consistency/coherence of existence and if on turning around we found four books our overall expectation of consistency/coherence of existence will require that we provide an explanation for the four books along the lines two more books were added or three more books were added and one book taken away or there are still two books but for a mirage effect in the room making it seem there are four books, etc., and so as to the overall expectation of consistency/coherence of existence that enables intelligibility to arise in the-very-first-place). It is this 'human originary-and-re-orginary epistemic impliciting 
of the necessity of a projective construal of relative-unreflexivity/relative-reflexivityontological-contiguity ${ }^{67}$ immanent $\sim$ relative-unreflexivity/relative-reflexivity ontologicalcontiguity $^{67}$ in reflection of the 'very contiguity of existence' that effectively underlies the '<cumulating/recomposuring attendant-ontological-contiguity $>$-successive registryworldviews/dimensions $\quad$ 'implicited_attendant—ontological-contiguity ${ }^{67}$ ' educedexistentialising/contextualising/textualising_intelligibility/epistemicity/reflexivity-contiguity$<$ imbued-notional cogency $>^{\prime}$ in so-reflecting the overall relative-unreflexivity/relativereflexivity - ontological-contiguity ${ }^{67}$ of-the-human-institutionalisation-process ${ }^{68}$ (as to the operative diametricality of 'human-epistemicity/human-epistemicity-developing- $<$ limitedmentation-capacity-deepening —as-subjecting limitedness/human-subpotency-to-'educedunlimitedness/existence-sublimating nascence' ${ }^{3}$,-as-to-transcendence-andsublimity/sublimation/supererogatory de-mentativity >' on-the-one-hand and on-the-other-hand 'inherent existence's immanence which is already given at all times as to its inherent fullpotency-independence in its superseding-oneness-of-ontology/ontological-veridicality/relativeunreflexivity/relative-reflexivity_ontological-contiguity ${ }^{67}$ so full-potency-independent of abstractly/potentially manifestable human-epistemicity/human-epistemicity-developing'). By extension, the 'very contiguity of existence' also underlines/emphasises that the 'overall phenomenal/manifest $\sim$ subpotencies-〈in-transitive-conflatedness -reflexivity,-in-the-fullpotency-of-existence's $\sim$ sublimating-nascence $\rangle$ in existence' are of relativeunreflexivity/relative-reflexivity - ontological-contiguity ${ }^{67} /$ immanent $\sim$ relativeunreflexivity/relative-reflexivity - ontological-contiguity ${ }^{67}$ so-reflected as the overall reifyingand-empowering-reflexivity-of-ecstatic-existence-as-panintelligibility/panreflexivity ${ }^{3}$ 〈existentially-imbued-and-educing-< $<$ tepistemicthermeneutically/textually/reprojectingly/supererogatingly/zeroingly/re-acutingly,- 
aestheticising-re-motif-and-re-apriorising/re-axiomatising/re-referencing conceptualisation,as-herein-specifically-relevant-to human-subpotency). It is this insight about (phenomenal/manifest $\sim$ subpotencies-〈in-transitive-conflatedness -reflexivity,-in-the-fullpotency-of-existence's sublimating-nascence) including human-subpotency)/limitedness 'originary-and-re-orginary impliciting of the necessity of a projective construal of relativeunreflexivity/relative-reflexivity—ontological-contiguity ${ }^{67} /$ immanent $\sim$ relativeunreflexivity/relative-reflexivity - ontological-contiguity ${ }^{67}$ of unlimitedness/existence-or-anypurview-of-unlimitedness/existence-<full-potency-of_sublimating nascence $>$ that explains why ontology/science is actually a postconverging-birthing/nascency within prospective \{epistemic-totalising 3 \}re-apriorising/re-axiomatising/re-referencing residuality-in-re-

originariness/re-origination- $\langle$ as to human profound-supererogation for prospective apriorising/axiomatising/referencing-\{of-'prospectively_implicited_attendant-ontologicalcontiguity ' educedexistentialising/contexalising/texalising_'intelligibility/epistemicity/reflexivity-contiguity<imbued-notional cogency>' \}-conflatedness -in-\{preconverging-ment-by\} postconverging-ntailment that cannot be unshrouded by prior mere-formulaicity/ritualisation$<$ as-to-mere-formulaic - methodologising/mutualising/organising/institutionalising,prospectively-losing-track-of- ‘ $\left\{\right.$ epistemic-totalising ${ }^{\dagger}$ re-apriorising/re-axiomatising/rereferencing $\sim$ residuality —in-re-originariness/re-origination'> of prior apriorising/axiomatising/referencing-\{of-'prospectively implieited_attendant-ontologicalcontiguity ' educedexistentialising/contextualising/textualising_'intelligibility/epistemicity/reflexivity-contiguity<imbued-notional cogency>' $\}$-constitutedness -in-preconverging-entailment $\rangle, \quad$ and so given 'limitedness/human-subpotency incompleteness-<as-to-prospective_residuality-ofapriorising/axiomatising/referencing $>$ of ontological-performance ${ }^{72}-<$ including-virtue-as- 
ontology $>$ /morality/ethics/justice/etc. in its construal of unlimitedness/existence-or-anypurview-of-unlimitedness/existence-<fll-potency-of_sublimating nascence>'.

Limitedness/human-subpotency is then ever always veridically warranted to reflexively catchup with unlimitedness/existence $<$ full-potency-of_sublimating nascence $>$ as to 'originary-andre-orginary_aporeticism_elucidating of the perpetually_ensuing_ incompleteness- $<$ as-toprospective_residuality-of-apriorising/axiomatising/referencing $>\quad$ of $\quad$ ontologicalperformance $^{72}$-<including-virtue-as-ontology $>$ /morality/ethics/justice/etc. limitedness_cumulating/recomposuring-epistemic-reflexivities for its epistemic-growth,-as\{veridical/sound\}-relative-reflexivity-in-existence/relativising from-limited-mentation-as-itsdeepening/psychologismic epistemic-acutisation residualising, \{decompulsing $\}$ delinearity for eogency sublimating-syncing with unlimitedness/existence-<full-potency-of_sublimating nascence ${ }^{\prime}$ (so-construed as limitedness/human-subpotency epistemic-growth,-as\{veridical/sound\}-relative-reflexivity-in-existence/relativising from-limited-mentation-as-itsdeepening/psychologismic epistemic-acutisation residualising, fdecturingl delinearity for eogency as of prospective psychologismic-epistemic-acutisation-<as-to-postconverging-dementating/structuring/paradigming,-eliciting-of-existence's-sublimating-nascence-inprospective-aporeticism-overcoming/unovercoming $>$ ). This reflects the inevitable limitedness/human-subpotency incompleteness-<as-to-prospective_residuality-of-

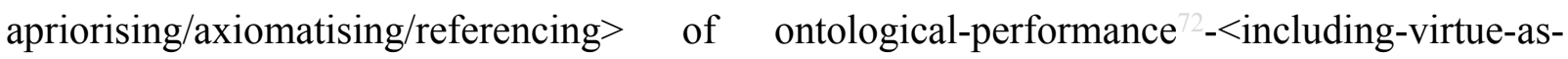
ontology $>$ /morality/ethics/justice/etc. in its construal of unlimitedness/existence-or-anypurview-of-unlimitedness/existence-<full-potency-of_sublimating nascence $>$ ', as the 'constraining/defining intersolipsistic reflexive-sublimating/unreflexive-desublimating measure/objectification that is unlimitedness/existence-as-ontologicalnormalcy/postconvergence-<in-validation-of-'metaphysics-of-absence_epistemic-projection' enables limitedness_cumulating/recomposuring-epistemic-reflexivities (as to the 'overall 
potential of the sublimating/desublimating validative/invalidative thresholds of limitedness_cumulating/recomposuring-epistemic-reflexivities'). This so-undermines a 'paradoxically desublimating \{flawed/unsound\}-relative-unreflexivity-inexistence/absolutising from limited-mentation/psychologismic epistemic acutisationnonresidualising imbued-\{compulsing\} linearity in-eclecticism-of prior-mere-

formulaicity/ritualisation impliciting of limitedness/human-subpotency (as if it is rather of unlimitedness/existence-<full-potency-of_sublimating nascence $>$ or outside unlimitedness/existence-full-potency-of_sublimating nascence $>$ or greater than unlimitedness/existence-<full-potency-of_sublimating nascence $>$ )', when limitedness/humansubpotency ontological-performance ${ }^{72}-<$ including-virtue-asontology $>$ /morality/ethics/justice/etc. is implied 'as being of prior mereformulaicity/ritualisation-<as-to-mere-formulaicmethodologising/mutualising/organising/institutionalising,-prospectively-losing-track-of‘fepstemic tre-apriorising/re-axiomatising/re-referencing $\sim$ residuality-in-reoriginariness/re-origination'> imbued elaboration-as-to-mereextrapolating/constituting/abstracting/deducing/inferring-of-elucidation-outside'prespectively implicited_attendant-ontological-contiguity ${ }^{67}$ ' educedexistentialising/contextmalising/textualising_'intelligibility/epistemicity/reflexivity_contiguity<imbued-notional cogency>' (as so-failing to attend to limitedness/human-subpotency 'originary-and-re-orginary_aporeticism_elucidating of the perpetually_ensuing_ incompleteness-<as-to-prospective_residuality-of-apriorising/axiomatising/referencing $>$ of ontological-performance ${ }^{72}<$ including-virtue-as-ontology $>/$ morality/ethics/justice/etc. as of limitedness_cumulating/recomposuring-epistemic-reflexivities for its epistemic-growth,-as\{veridical/sound\}-relative-reflexivity-in-existence/relativising from-limited-mentation-as-itsdeepening/psychologismic epistemic-acutisation residualising, fdecompulsing ${ }^{\text {delinearity for }}$ 
eogency sublimating-syncing with unlimitedness/existence-<fll-potency-of_sublimating nascence $>$ ' so-reflecting 'limitedness/human-subpotency sublimating constraining by unlimitedness/existence-<full-potency-of_sublimating nascence $>$ for ontological-veracity- $<$ asto-prospective-ontologising-and-re-ontologising $>$ to arise'); and it is rather this effective 'sublimating constraining of limitedness/human-subpotency by unlimitedness/existence-<fullpotency-of_sublimating nascence $>$ for ontological-veracity-<as-to-prospective-ontologisingand-re-ontologising $>$ to arise' that is veridically reflected (with respect to conceptivity/epistemic-reflexivity/epistemicity-relativism-determinism- $<$ reifying \{as-toknowledge-developing -and-empowering $>$ ) as existence-as-the-absolute-a-priori-ofconceptualisation $\sim$ and existence — as-sublimating-withdrawal/unenframing/re-ontologising,elicited-from-prospective-profound-supererogation $-<$ as-to-perspective-ontologicalnormalcy/postconvergence-implied-'prospective-aporeticism-overcoming/unovercoming'>. Ultimately, the sublimating/desublimating exuding emanance of inherent existence (as existence-as-the-absolute-a-priori-of-conceptualisation and existence-as-sublimatingwithdrawal/unenframing/re-ontologising,-elicited-from-prospective-profoundsupererogation $-<$ as-to-perspective-ontological-normalcy/postconvergence-implied'prospective-aporeticism-overcoming/unovercoming'>) with regards to the 'human sovereignsubject limited-mentation-capacity—as-subjecting 'educed-unlimitedness/existencesublimating nascence' to-limitedness/human-subpotency notional reflexivity$<\{$ veridical/sound\}-relative-reflexivity-in-existence/relativising from-limited-mentation-as-

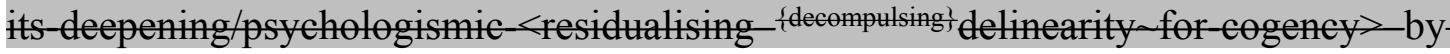

\section{\{flawed/unsound\}-relative-unreflexivity-in-existence/absolutising from-limited-}

mentation/psychologismic epistemic acutisation nonresidualising imbued-

\{compulsing\} linearity in-eclecticism-of-prior-mere-formulaicity/ritualisation> $>$ as of human limited-mentation-capacity-deepening —as-subjecting limitedness/human-subpotency-to- 
'educed-unlimitedness/existence-sublimating nascence' ${ }^{53}$, rather speaks to the undergirding ontological-veracity-<as-to-prospective-ontologising-and-re-ontologising $>$ in transversality$<$ for-sublimating-existential-eventuating/denouement,-from-'thinking-at-first/purepredisposition-preemptive-of prospective-disontologising/subontologising' as-ofprospectively-disambiguated-affirmed-and-unaffirmed-'motif-andapriorising/axiomatising/referencing' $>101$ as of notional $\sim$ self-distantiation- $<$ imbued - re-motifand-re-apriorising/re-axiomatising/re-referencing $>\quad$ implied $\quad$ formativeness- $<$ as-tointersolipsism-of-preformulating/preframing/premeaningfulness-imbued-mediativity-anddeferentialism $>$-of- - meaningfulness-and-teleology $\quad$ in $\quad{ }^{6}$ nonpresencing- $<$ perspectiveontological-normalcy/postconvergence $>$ epistemic-projection for the conceptualising of human relative ontological-performance ${ }^{72}-<$ including-virtue-as-ontology $>$; and so similar to a Derridean 'heterogeneous genesis' implicited epistemic conception implication of varying human ontological-performance ${ }^{72}-<$ including-virtue-as-ontology $>/$ morality/ethics/justice/etc. over the "naivety of the human subjectivity argument as of a disparateness-of-conceptualisation$<$ unforegrounding-ment,-failing-prospectively-to-reflect-'immanent relativeunreflexivity/relative-reflexivity - ontological-contiguity ' $>$ induced implicited implication of a general equating/leveling-down conception of human ontological-performance ${ }^{2}-<$ includingvirtue-as-ontology>' (as to the latter's relatively underdeveloped reflection of the fact that the 'constraining/defining intersolipsistic reflexive-sublimating/unreflexive-desublimating measure/objectification that is unlimitedness/existence-as-ontologicalnormalcy/postconvergence-<in-validation-of-'metaphysics-of-absence_epistemic-projection’ $>$ is rather enabling of all apparent 'supposed-subjects'/subpotencies in 'their notional reflexivity$<\{$ veridical/sound\} relative-reflexivity-in-existence/relativising from limited mentation as

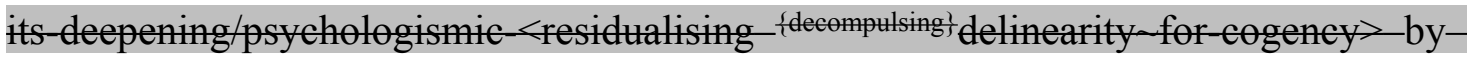
\{flawed/unsound\}-relative-unreflexivity-in-existence/absolutising from-limited- 
mentation/psychologismic epistemic acutisation nonresidualising imbued-

\{compulsing\} linearity-in-eclecticism-of prior-mere-formulaicity/ritualisation>

imbued

sublimating/desublimating in existence' and thus as requiring appropriate conceptualisation of nonpresencing-or-withdrawal/unenframing/re-ontologising-or-metaphysics-of-absence〈implicited-epistemic-veracity-of- nonpresencing-<perspective-ontologicalnormalcy/postconvergence $>$ )-or-transcendental-reasoning-of-event ${ }^{38}$-as-prospective-ontologyorigination to disambiguatingly/differentiatingly account for 'their notional reflexivity$<\{$ veridical/sound\}-relative-reflexivity-in-existence/relativising from-limited-mentation-asits-deepening/psychologismic-<residualising ${ }^{\text {\{decompulsing }}$ delinearity for-cogeney $>$ by\{flawed/unsound\}-relative-unreflexivity-in-existencelabsolutising from limitedmentation/psychologismic epistemic acutisation nonresidualising imbued\{compulsing\} linearity in-eclecticism-of prior-mere-formulaicity/ritualisation> imbued sublimating/desublimating in existence’). This human notional $\sim$ reflexivity- $<$ \{veridical/sound $\}$ relative-reflexivity-in-existence/relativising from-limited-mentation-as-itsdeepening/psychologismic-<residualising ${ }^{\text {\{decompulsing }}$ delinearity for-cogency>-by\{flawed/unsound\}-relative-unreflexivity-in-existence/absolutising from-limitedmentation/psychologismic epistemic acutisation nonresidualising imbuedfempulsingl linearity in-eclecticism-of prior-mere-formulaicity/ritualisation $>$ conception of the sublimating/desublimating exuding emanance of inherent existence effectively translates, with regards to the "potential for absolute knowledge (absolute knowledge as so-relevant as to 'effective ontologising-and-re-ontologising epistemic-projective reference-ofconceptualisation') as to human intellectual-and-moral responsibility/relative-reflexivity implications' wherein all humans are 'technically-speaking' in ontological-badfaith/inauthenticity ${ }^{64} \sim$ preconverging-de-mentating/structuring/paradigming ${ }^{55}$ to the 'absolute knowledge so-implied as from nonpresencing-<perspective-ontological- 
normalcy/postconvergence $>$ epistemic-projection perspective (providing the 'effective ontologising-and-re-ontologising epistemic-projective reference-of-conceptualisation')'; into the fact that 'what is of prospective sublimating concern has to do with human prospective postconverging aporeticism-overcoming/unovercoming of prior-perspectivefalsity/falseness/fallaciousness'. This so-undermines the undertone/hint associated with the term construction as in construction-of-the-Self as of " presencing-absolutising-identitiveconstitutedness ${ }^{14}$ normalising functionalism conception as to ffawed/unsound\}-relativeunreflexivity-in-existence/absolutising from-limited-mentation/psychologismic epistemic acutisation nonresidualising imbued-fomplinglinearity in-eclecticism-of prior-mereformulaicity/ritualisation', wrongly implying a direct limited-mentation-capacity-assubjecting 'educed-unlimitedness/existence-sublimating nascence' to-limitedness/humansubpotency ontological accessing to the Truth (as to mere-formulaicity/ritualisation- $<$ as-tomere-formulaic — methodologising/mutualising/organising/institutionalising,-prospectivelylosing-track-of-'fepistemic tratising łre-apriorising/re-axiomatising/re-referencing $\sim$ residuality-inre-originariness/re-origination'> imbued elaboration-as-to-mereextrapolating/constituting/abstracting/deducing/inferring-of-elucidation-outside'prespectively implicitedattendant-ontological-contiguity ${ }^{67}$ ' educedexistentialising/contextualising/textualising_intelligibility/epistemicity/reflexivity-contiguity$<$ imbued-notional cogency $>^{\prime 0}$ ), rather than an indirect limited-mentation-capacity-assubjecting 'educed-unlimitedness/existence-sublimating nascence' to-limitedness/humansubpotency ontological undermining of prior-perspective-falsity/falseness/fallaciousness, that wrongly seem to normalise the present's prospectively disontologising epistemicabnormalcy/preconvergence ${ }^{31}$ epistemic-projection perspective. But rather what is veridically warranted is a wholly prospective human mental liberation/empowerment exercise' as soliberated/empowered from the cloudiness of prior-perspective - falsity/falseness/fallaciousness; 
as can be appreciated with limited-mentation-capacity-deepening-as-subjectinglimitedness/human-subpotency-to-'educed-unlimitedness/existence-sublimating nascence' implied ontological-normalcy/postconvergence epistemic-projection perspective 'so-reflectable projectively as the normal that is prospectively unfreed/unliberated in want for its freeing/liberating' as construable from the more advantageous postconverging relativeontological-completeness ${ }^{87}$ epistemic-projection perspective over preconverging relativeontological-incompleteness ${ }^{8}$ epistemic-projection perspective. This fundamental insight with regards to notional philosophy-<as-to-the-veridical-conception-of-philosophy-as-englobingall-human-prospective-organic-knowledge-generation-in-relative-ontological-completeness beyond-a-convenient-division-of-labour-conception-of-knowledge $>$ and its associated intolerance-<of-disparateness $>$ /exactifying_precisioning-of-sublimation-<as-topostconverging-narrowing-down apriorising/axiomatising/referencing-entailing-theoretical,conceptual-and-operant-implications $>$ construed as science/ontology, as being about 'human prospective postconverging aporeticism-overcoming/mnovercoming of prior-perspectivefalsity/falseness/fallaciousness', speaks to a 'deconstructive knowledge-reification $\sim$ gesturingand-accounting - of-epistemic-phenomenalism- $<$ inprospective_psychologismic apriorising/axiomatising/referencing-\{of-'prespectively implicited_attendant-ontological-contiguity ' reducedexistentialising/contextualising/textualising_ intelligibility/epistemicity/reflexivity-contiguity<imbued-notional cogency >' \}-conflatedness -in-\{preconverging -ment by\} postconverging entailment>' that is altogether counterintuitive to a 79 presencing-absolutisingidentitive-constitutedness ${ }^{14}$ social-vestedness/normativity-<discretely-implied-functionalism $>$. In this regards, it can be appreciated that ${ }^{103}$ universalising-idealisation, budding-positivism and budding postmodern-thought respectively assumed their specific 'deconstruction conception as to epistemic-growth,-as — \{veridical/sound\}-relative-reflexivity-in-existence/relativising from- 
limited-mentation-as-its-deepening/psychologismic epistemic-acutisation residualising, \{decompulsing delinearity for-cogency' of knowledge over the respective ${ }^{79}$ presencingabsolutising-identitive-constitutedness ${ }^{14} \quad$ social-vestedness/normativity- $<$ discretely-impliedfunctionalism $>$ of non-universalising, non-positivising and our totalisingly-ingdiscretion/whim-of-thought presumed ' 79 presencing —absolutising-identitive-constitutedness normalising functionalism conception as to \{flawed/unsound\}-relative-unreflexivity-inexistence/absolutising from-limited-mentation/psychologismic epistemic-acutisation-

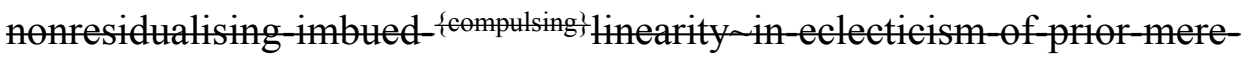
formulaicity/ritualisation'. In other words (in relation to grasping the unlimitedness/existence$\leq$ full-potency-of_sublimating nascence $>$ epistemic-projection perspective) the very abstractly inherent paradox of a limited epistemic-projection perspective (as to its 'requisite epistemicgrowth,-as-\{veridical/sound\}-relative-reflexivity-in-existence/relativising from-limitedmentation-as-its-deepening/psychologismic epistemic acutisation residualising, fdelinearity for-cogency as of prospective psychologismic-epistemic-acutisation$<$ as-to-postconverging-de-mentating/structuring/paradigming,-eliciting-of-existence'ssublimating-nascence-in-prospective-aporeticism-overcoming/unovercoming $>$ as to epistemicgrowth,-as - \{veridieal/sound relative-reflexivity-in-existence/relativising from limitedmentation-as-its-deepening/psychologismic epistemic acutisation residualising, $\{$ decompulsing $\}$ delinearity for-cogency\} for ultimately grasping ontological-veracity-<as-toprospective-ontologising-and-re-ontologising $>$ reflexively by a direct gesturing/accountingof-epistemic-phenomenalism of existential-instantiation aposteriorising/logicising/deriving/intelligising/measuring predicative-insights), calls for prospective re-ontologising 'deconstruction conception as to epistemic-growth,-as\{veridical/sound\}-relative-reflexivity-in-existence/relativising from-limited-mentation-as-itsdeepening/psychologismic epistemic-acutisation residualising, fdecompulsing ${ }^{\text {delinearity for }}$ 
eogency', so-underlied by projective-insights of 'requisite human \{epistemictotalising 3 ${ }^{3}$ hermeneutically/textually/reprojectingly/supererogatingly/zeroingly/re-acutingly,\{decomplsing delinearity for-cogency — cumulated/recomposured-and/or-designed/redesigned experientiality/experiment- $<$ as-to-existentially-formative- ‘fepistemic-totalising ${ }^{\prime}$ re-apriorising/reaxiomatising/re-referencing residuality-in-re-originariness/re-origination',-so'notionally/epistemically/bindingnessly-<as-to-determinism/conceptivity-of-relative-unreflexivity/relative-reflexivity> implicited-and-articulated'_as-from-nonextricatory-'prospective-re-ontologising-Being-thenInstitutional-then-Living-magnitudes-of-\{hermeneutic/reprojection-protraction-of \}reframingand-reformulation $\}^{\prime}>$ in existence' on the basis of a postconverging-birthing/nascency within prospective \{epistemic-totalising 3 re-apriorising/re-axiomatising/re-referencing $\sim$ residuality-in-reoriginariness/re-origination- $\langle$ as to human profound-supererogation for prospective apriorising/axiomatising/referencing-\{of-'prospectively_implicited_attendant-ontologicalcontiguity ' $\sim$ educedexistentialising/contextualising/textualising_intelligibility/epistemicity/reflexivity-contiguity<imbued-notional cogency >' \}-conflatedness -in-\{preconverging-ment-by\} postconverging-entailment that cannot be unshrouded by prior mere-formulaicity/ritualisation<as-to-mere-formulaic — methodologising/mutualising/organising/institutionalising,prospectively-losing-track-of- ‘fepistemic-totalising 3 're-apriorising/re-axiomatising/rereferencing $\sim$ residuality -in-re-originariness/re-origination'> of prior apriorising/axiomatising/referencing-\{of-'prospectively implicited_attendant-ontologicalcontiguity ' educedexistentialising/contextrising/textring_intelligibility/epistemicity/reflexivity-contiguity<imbued-notional cogency>' $\quad\}$-constitutedness -in-preconverging-entailment $\rangle$ construed as nonpresencing-or-withdrawal/unenframing/re-ontologising-or-metaphysics-ofabsence-〈implicited-epistemic-veracity-of- nonpresencing-<perspective-ontological- 
normalcy/postconvergence $>$ )-or-transcendental-reasoning-of-event ${ }^{38}$-as-prospective-ontologyorigination); and so superseding a direct gesturing/accounting—of-epistemic-phenomenalism of existential-instantiation aposteriorising/logicising/deriving/intelligising/measuring predicativeinsights undertaken by a mere "79 presencing-absolutising-identitive-constitutedness normalising functionalism conception as to existence/absolutising from-limited-mentation/psychologismic epistemic-acutisationnonresidualising-imbued-\{compulsing\}linearity in-eclecticism-of-prior-mereformulaicity/ritualisation' (as wrongly implicited/unthought projective-insights on the basis of prior apriorising/axiomatising/referencing-\{of-'prospectively_implicited_attendantontological-contiguity ' educedexistentialising/contextualising/textualising_ intelligibility/epistemicity/reflexivity-contiguity$<$ imbued-notional cogency $>$ ' $\}$-constitutedness ${ }^{-}$-in-preconverging-entailment failing to prospectively track existence-as-sublimating-withdrawal/unenframing/re-ontologising,elicited-from-prospective-profound-supererogation '). Such a 'deconstruction conception as to epistemic-growth,-as_ _ \{veridical/sound\}-relative-reflexivity-in-existence/relativising fromlimited-mentation-as-its-deepening/psychologismic epistemic-acutisation residualising, \{decompulsing delinearity for-cogeney' implies a 5 maximalising-recomposuring-for-relativeontological-completeness ${ }^{87}$ - unenframed/re-ontologising conceptualisation $\quad$ (over a '7 ${ }^{6}$ resencing - absolutising-identitive-constitutedness ${ }^{14}$ normalising functionalism conception as to \{flawed/unsound\}-relative-unreflexivity-in-existence/absolutising from-limitedmentation/psychologismic epistemic acutisation nonresidualising imbued\{compulsing\}'linearity in eclecticism-of prior mere formulaicity/ritualisation' incrementalism-in-relative-ontological-incompleteness ${ }^{88}$ enframed/disontologising conceptualisation); so unenframed/re-ontologising as to inherent existence's withdrawal/unenframing/re-ontologising exuding sublimating-nascence. 
'Deconstruction conception as to epistemic-growth,-as_ \{veridical/sound?-relative-reflexivityin-existence/relativising from-limited-mentation-as-its-deepening/psychologismic epistemic acutisation residualising, \{decompusing delinearity for-cogency' implies that there is no point dodging the manifest underlying prior-perspective - falsity/falseness/fallaciousness and then by some miracle expecting prospective postconverging aporeticism-overcoming/unovercoming as of mere " presencing-absolutising-identitive-constitutedness ${ }^{14}$ normalising functionalism conception as to \{flawed/unsound\}-relative-unreflexivity-in-existence/absolutising fromlimited-mentation/psychologismic epistemic acutisation nonresidualising imbuedfompungthearity in-eclecticism-of-prior-mere-formulaicity/ritualisation' (speaking rather of superficiality/shallowness), as such an ontologically-flawed gesturing/accounting-ofepistemic-phenomenalism underlies all the <cumulating/recomposuring attendant-ontologicalcontiguity $>$-successive registry-worldviews/dimensions notional $\sim$ collateralising (in lieu of their requisite self-surpassing - existentialism-form-factor,-in-overcoming‘notional collateralising-beholdening-protohumanity'-to-'attain-sublimating-humanity’-as-toexistence-potency $\sim$ sublimating-nascence,-disclosed-from-prospective-epistemic-digression

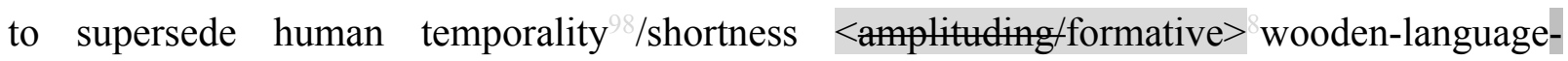
〈imbued-averaging-of-thought-<as-to-leveling/ressentiment/closed-construct-ofmeaningfulness-and-teleology -as-of-‘nondescript/ignorable-void ' -with-regards-toprospective-apriorising-implications $>\rangle)$. Human 'prospective postconverging apereticismovercoming/mnoverceming of prior-perspective-falsity/falseness/fallaciousness' is ineluctably tied to prospective epistemic-growth,-as - \{veridical/sound\}-relative-reflexivity-inexistence/relativising from-limited-mentation-as-its-deepening/psychologismic epistemic-

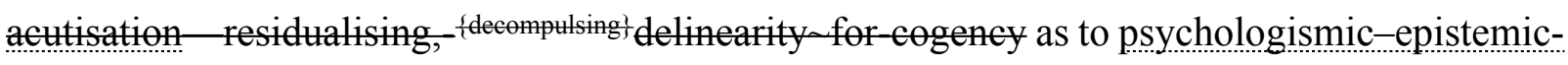
acutisation-<as-to-postconverging-de-mentating/structuring/paradigming,-eliciting-ofexistence's-sublimating-nascence-in-prospective-aporeticism-overcoming/unovercoming>; 
reflecting in the bigger psychologismic epistemic-acutisation - difficulty<-for, residualising \{decompulsing $\}$ delinearity for-eogency> magnitude \{of-experientiality/experiment\} of human Beingdevelopment/ontological-framework-expansion-as-to-depth-of-ontologising-development-asinfrastructure-of- meaningfulness-and-teleology the fact that it is an impossibility to assume the underlying <amplituding/formative>disposedness/psychologismic-construct-〈as-toorientation/value-construct/valuation-and-derived-parameterising $<$ amplittding/formative>entailment-〈as-to-totalising-contiguous/coherent-factuality-ofvariability respectively of recurrent-utter-uninstitutionalisation, base-institutionalisationununiversalisation, ${ }^{10}$ universalisation-non-positivism/medievalism and positivismprocrypticism in blurriness-<sterilising/anecdotalising/trivialising-of-prospective-reontologising_by-preconverging,-in-disontologising-formulaic-dragging-out/hollowing-out> and by some miracle prospectively generate the imbued unblurriness-<re-ontologising_bypostconverging-as-to-dragged-out-supererogatory wholesomeness/profound-supererogation while-anecdotalising-prior-disontologising-thresholding $>$ of manifest sublimating existential$<$ disontologising/re-ontologising aporeticism $>$ human ontological-performance ${ }^{72}<$ includingvirtue-as-ontology $>$ /morality/ethics/justice/etc. as of respectively base-institutionalisationununiversalisation, $\quad{ }^{103}$ universalisation-non-positivism/medievalism, $\quad$ positivismprocrypticism and ${ }^{18}$ deprocrypticism-or-preempting-disjointedness-as-of- ${ }^{-1}$ reference-ofthought. The overall insight here is that a (notional philosophy-<as-to-the-veridical-conceptionof-philosophy-as-englobing-all-human-prospective-organic-knowledge-generation-in-relativeontological-completeness ,-beyond-a-convenient-division-of-labour-conception-ofknowledge $>$ and its associated intelerance-<0f-disparateness>/exactifying_precisioning-ofsublimation-<as-to-postconverging-narrowing-down apriorising/axiomatising/referencingentailing-theoretical,-conceptual-and-operant-implications $>$ construed as science) conception of human 'prospective postconverging-aporeticism-overcoming/unoverceming of prior- 
perspective - falsity/falseness/fallaciousness' is necessarily one that is bound to undermine a counterintuitive and wrong reflex mentality of 'presumed incontrovertibility of the ontologicalveracity-<as-to-prospective-ontologising-and-re-ontologising $>$ of social-functioning-andaccordance-as-of-social-stake-contention-or-confliction'; with veridical prospective 'deconstruction conception as to epistemic-growth,-as — \{veridical/sound\}-relative-reflexivityin-existence/relativising from-limited-mentation-as-its-deepening/psychologismic epistemicacutisation residualising, ${ }^{\{\text {decompulsing }}$ delinearity for-cogency' of knowledgereification $\sim$ gesturing-and-accounting — of-epistemic-phenomenalism- $<$ in-

prospective_psychologismic $\sim$ apriorising/axiomatising/referencing-\{of-'prospectively implicited_attendant-ontological-contiguity ' reducedexistentialising/contextualising/textualising_'intelligibility/epistemicity/reflexivity-contiguity<imbued-notional cogency >' \}-conflatedness -in-\{preconverging-ment by\}

postconverging entailment> rather operating on the 'assumed controvertibility of the ontological-veracity-<as-to-prospective-ontologising-and-re-ontologising $>\quad$ of $\quad$ socialfunctioning-and-accordance-as-of-social-stake-contention-or-confliction' (as reflected as of manifest preconverging/postconverging-de-mentating/structuring/paradigming of 'socialfunctioning-and-accordance-as-of-social-stake-contention-or-confliction imbuing existentialising-frame-of-entailment-of motif-and-apriorising/axiomatising/referencing of disontologising/ontologising-and-re-ontologising'). Such a 'presumed incontrovertibility of the ontological-veracity-<as-to-prospective-ontologising-and-re-ontologising $>\quad$ of $\quad$ socialfunctioning-and-accordance-as-of-social-stake-contention-or-confliction' ${ }^{\prime}$ (as to '7 presencing —absolutising-identitive-constitutedness ${ }^{14}$ normalising functionalism conception as to mentation/psychologismic epistemic acutisation nonresidualising imbued\{compulsing' linearity-in-eclecticism-of prior-mere-formulaicity/ritualisation') is underlied by a 
'flawed-prior-purposefulness of ${ }^{79}$ presencing - absolutising-identitive-constitutedness ${ }^{14}$ before supposedly-prospective-thinking-purpose,-as-precalculated-purpose-<as-prospectively-losingtrack-of- ‘fepistemic-atising ’’re-apriorising/re-axiomatising/re-referencing residuality-in-reoriginariness/re-origination'-of-thinking>' exercise ultimately developing into a predisposition for pedantising/muddling/formulaic-hollowing-out—in-subontologisation/subpotentiation〈blurring/undermining-of-prospective-totalising-entailing,-as-to-entailing-

$<$ amplituding/formative-epistemicity $>$ totalising in-relative-ontological-completeness $>$ wherein there is 'inappropriate notional $\sim$ self-distantiation- $<$ imbued-re-motif-and-reapriorising/re-axiomatising/re-referencing $>$ from social-functioning-and-accordance-as-ofsocial-stake-contention-or-confliction' (required for the transversality-<for-sublimatingexistential-eventuating/denouement,-from-'thinking-at-first/pure-predisposition-preemptive-ofprospective-disontologising/subontologising' as-of-prospectively-disambiguated-affirmedand-unaffirmed-'motif-and-apriorising/axiomatising/referencing'>101 exercise of notional philosophy-<as-to-the-veridical-conception-of-philosophy-as-englobing-all-humanprospective-organic-knowledge-generation-in-relative-ontological-completeness ,-beyond-aconvenient-division-of-labour-conception-of-knowledge $>$ and its associated intolerance- $<$ disparateness $>$ /exactifying_precisioning-of-sublimation-<as-to-postconverging-narrowingdown apriorising/axiomatising/referencing-entailing-theoretical,-conceptual-and-operantimplications $>$ construed as ontology/science). The reality of a 'flawed-prior-purposefulness of presencing-absolutising-identitive-constitutedness ${ }^{14}$ before supposedly-prospectivethinking-purpose,-as-precalculated-purpose-<as-prospectively-losing-track-of-‘\{epistemic-

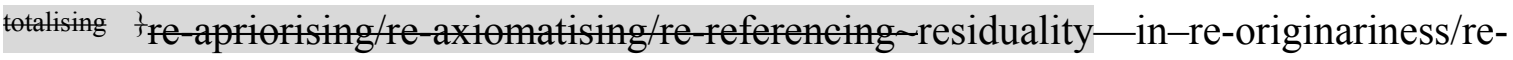
origination'-of-thinking>' critically means that manifest sublimating-nascence incipience/instantaneity/directness of nascent-particular/incipient-and-material/technicalsublimations- $<$ blinded-to-their-relative-ontological-completeness - reference-of-thought- 
devolving $>$ are only construed as reinforcing the " presencing-absolutising-identitiveconstitutedness $^{14}$ normalising functionalism conception as to fflawed/unsound\}-relativeunreflexivity-in-existencelabsolutising from-limited-mentation/psychologismic epistemic acutisation - nonresidualising-imbued-\{compulsing ${ }^{\text {fonearity }}$ lin-eclecticism-of-prior-mereformulaicity/ritualisation' prospectively ontologically-flawed desublimating rather as the 'shallow-supererogation as of prior ${ }^{83}$ reference-of-thought-point-ofdevolving/departure/anchoring/backdrop_of_sublimating-nascence-<as-to-the-grandest-

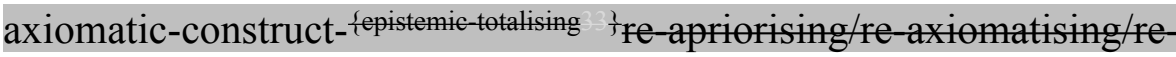
referencing residuality - in-re-originariness/re-origination of limitedness/human-subpotency prospective re-encountering/re-confrontation with unlimitedness/existence> ${ }^{>}$as to socialfunctioning-and-accordance-as-of-social-stake-contention-or-confliction of prior 'implicited_attendant-ontological-contiguity ${ }^{6}$ ' educedexistentialising/contextualising/textualising_'intelligibility/epistemicity/reflexivity-contiguity<imbued-notional cogency $>^{\prime}$ (and not as of veridical 'supererogatory $\sim$ wholesomeness/profound-supererogation ${ }^{96}$ as of prospective ${ }^{83}$ reference-ofthought — point-of-devolving/departure/anchoring/backdrop_of_sublimating-nascence- $<$ as-tothe-grandest-axiomatic-construct- fepistemic-totalising ${ }_{3}^{+}$re apriorising/re axiomatising/rereferencing - residuality - in-re-originariness/re-origination of limitedness/human-subpotency prospective re-encountering/re-confrontation with unlimitedness/existence>'). In-the-biggerscheme-of-things as to Being-development/ontological-framework-expansion-as-to-depth-ofontologising-development-as-infrastructure-of- meaningfulness-and-teleology psychologismic epistemic-acutisation difficulty-<for, residualising \{decompulsing\} delinearity for cogeney>-magnitude\{of-experientiality/experiment\}, this 'shallowsupererogation as of prior prior ${ }^{83}$ reference-of-thought—point-ofdevolving/departure/anchoring/backdrop_of_sublimating-nascence- $<$ as-to-the-grandest- 
axiomatic-construct-\{epistemic-totalising 斿e-apriorising/re-axiomatising/re-

referencing residuality-in-re-originariness/re-origination of limitedness/human-subpotency prospective re-encountering/re-confrontation with unlimitedness/existence $>$ imbued desublimating construal of 'prospective manifest sublimating-nascence incipience/instantaneity/directness of nascent-particular/incipient-and-material/technicalsublimations-<blinded-to-their-relative-ontological-completeness - reference-of-thoughtdevolving >', rather speaks to a 'prospective sublimatingnascence_incipience/instantaneity/directness_fontologically_flawed_prior_mere_sociat functioning and-accordance-as-of-social-stake-contention-or-confliction\} associativedistortion-of-referencing/registering/decisioning' (as can be appreciated with the fact that the veridically comprehensive and complete sublimating-nascence of technical and scientific progress like shipbuilding and other ocean voyage technologies rather came into their full realisation as to a healthy global commercial relations these enabled over their initial pirating, warring and exploitative dehumanising pursuits). As the given ' 7 presencing-absolutisingidentitive-constitutedness ${ }^{14}$ normalising functionalism conception as to \{flawed/unseund\} relative-unreflexivity-in-existence/absolutising from-limited-mentation/psychologismic epistemic acutisation nonresidualising imbued \{compulsing linearity-in-eclecticism-of prior mere-formulaicity/ritualisation' of human social-and-institutional-frameworks-ofreferencing/registering/decisioning existentialising-decisionality-<as-to-disentelegising/reentologising aporeticism $>$ (in reflecting the 'shallow-supererogation' as of prior ${ }^{83}$ referenceof-thought_ - point-of-devolving/departure/anchoring/backdrop_of_sublimating-nascence-<asto-the-grandest-axiomatic-construct-\{epistemic-totalising ${ }^{\frac{1}{3}} \mathrm{re}$-apriorising/re-axiomatising/rerefereneing-residuality-in-re-originariness/re-origination of limitedness/human-subpotency prospective re-encountering/re-confrontation with unlimitedness/existence $>$ imbued desublimating construal) wrongly paradoxically implies/implicits it is of the requisite 
corresponding 'supererogatory $w$ wholesomeness/profound-supererogation' as of prospective reference-of-thought—point-of-devolving/departure/anchoring/backdrop_of_sublimatingnascence-<as-to-the-grandest-axiomatic-construct-

axiomatising/re-referencing residuality-in-re-originariness/re-origination

limitedness/human-subpotency prospective re-encountering/re-confrontation with

unlimitedness/existence>' by the mere social-functioning-and-accordance-as-of-social-stakecontention-or-confliction association from which existentially-<disontologising/reentologising aporeticism $\geqslant$ arises such 'prospective manifest sublimating-nascence incipience/instantaneity/directness of nascent-particular/incipient-and-material/technicalsublimations- $<$ blinded-to-their-relative-ontological-completeness - reference-of-thoughtdevolving > with which it effectively enters into a catchmenting-by-rejection/lipservicing/monopolising/gaming-of-the-system/charade/distraction relation of prospectively desublimating existentialising-decisionality-<as-to-disentologising/re-ontelogising aporeticism $>$ (that critically undermines the truly requisite prospective re-ontologising as to the dragged-out 'prospective ${ }^{83}$ reference-of-thought appraisal of sublimating-nascence comprehensiveness/nonimmediacy/indirectness' for prospective social-and-institutionalframeworks-of—referencing/registering/decisioning sublimating existentialisingdecisionality-<as-to-disontologising/re-ontologising aporeticism $>$ ). This 'prospective sublimating-nascence_incipience/instantaneity/directness-\{ontologicallyflawed_prior_mere_social-functioning-and-accordance-as-of-social-stake-contention-oreonfliction ; associative-distortion-of-referencing/registering/decisioning' tends to arise in all registry-worldviews/dimensions as a reflection of the fact that the 'prospective manifest sublimating-nascence incipience/instantaneity/directness of nascent-particular/incipient-andmaterial/technical-sublimations-<blinded-to-their-relative-ontological-completeness

reference-of-thought- devolving >' induced as of 'postconverging-nonextricatory-existential- 
preempting-of-existential-unthought prospective notional-contiguity/epistemic-contiguity ${ }^{6}$ <profound-supererogation -of-mentally-aestheticised postconverging/dialectical-thinking qualia-schema $>$ profound aptitudinal re-ontologising-competence gesturing/accounting-ofepistemic-phenomenalism' of 'epistemic-dispassion munificence/notional $\sim$ protensivity/reontologising $\sim$ dragging-out-<as-to-prospective-profound-supererogation -of-mentallyaestheticised postconverging/dialectical-thinking -qualia-schema $>$ implied continuous/reoriginating/dragged-out social-construct - pestconverging-nonextricatory-existentialpreempting-of-existential-unthought $\sim$ sublimation accruable-and-derivable percolationchannelling- $<$ in-deferential-formalisation-transference $>$ of secondnatured institutionalisation (as 'so-transfusively determinant to overall social sublimating human ontologicalperformance -<including-virtue-as-ontology>')' which so-reflects the 'veridical social preeminent directedness of knowledge-value and knowledge-discursivity orientation ('draggedout nature or psychologismic-epistemic-acutisation-<as-to-postconverging-dementating/structuring/paradigming,-eliciting-of-existence's-sublimating-nascence-inprospective-aporeticism-overcoming/unovercoming $>$ as to epistemic-growth,-as\{veridical/sound\}-relative-reflexivity-in-existence/relativising from-limited-mentation-as-itsdeepening/psychologismic epistemic acutisation residualising, fdecompulsing $\}$ delinearity for eogency' imbued 'supererogatory wholesomeness/profound-supererogation as of prospective reference-of-thought — point-of-devolving/departure/anchoring/backdrop_of_sublimating_ nascence-<as-to-the-grandest-axiomatic-constructaxiomatising/re-referencing $\sim$ residuality-in-re-originariness/re-origination of limitedness/human-subpotency prospective re-encountering/re-confrontation with unlimitedness/existence>')'; is mostly/relatively as intelligible (to a human 'epistemicimpassion measliness/notional nonprotensivity/disontologising formulaic-dragging-out-orformulaic-hollowing-out-<as-to-prior-shallow-supererogation -of-mentally- 
aestheticised preconverging/dementing -qualia-schema $>$ implied discrete/fixated abstractly contemplatable individualised conceptualisation of ontological-performance -<includingvirtue-as-ontology $>/$ morality/ethics/justice/etc. underiving-and-unaccruing to the socialconstruct-pestconverging-nonextricatory-existential-preempting-of-existentialunthought $\sim$ sublimation' in the shallow-supererogation of the 'mere-formulaicity/ritualisation<as-to-mere-formulaic — methodologising/mutualising/organising/institutionalising,prospectively-losing-track-of- ‘fepistemic-totalising 3 're-apriorising/re-axiomatising/rereferencing $\sim$ residuality —in-re-originariness/re-origination'> imbued elaboration-as-to-mereextrapolating/constituting/abstracting/deducing/inferring-of-elucidation-outside'prospectively implicited_attendant-ontological-contiguity ' reducedexistentialising/contextualising/textualising_'intelligibility/epistemicity/reflexivity-contiguity$<$ imbued-notional cogency $>$ ' 40 of the prior reference-of-thought-point-ofdevolving/departure/anchoring/backdrop) as of the direct or 'promised' positive-opportunismof-social-functioning-and-accordance ${ }^{75}$ conception (and so instead of deferred-to 'prospective reference-of-thought appraisal of sublimating-nascence comprehensiveness/nonimmediacy/indirectness' which rather circularly requires its very own manifest prospective nontricatory-existential-preempting-of-existentialunthought prospective notional-contiguity/epistemic-contiguity ${ }^{2}-<$ profound-supererogation of-mentally-aestheticised postconverging/dialectical-thinking -qualia-schema $>$ profound aptitudinal re-ontologising-competence gesturing/accounting-of-epistemic-phenomenalism' of 'epistemic-dispassion munificence/notional $\sim$ protensivity/re-ontologising $\sim$ dragging-out- $<$ asto-prospective-profound-supererogation -of-mentallyaestheticised postconverging/dialectical-thinking -qualia-schema> implied continuous/reoriginating/dragged-out social-construct - pestconverging-nonextricatory-existentialpreempting-of-existential-unthought $\sim$ sublimation accruable-and-derivable percolation- 
channelling- $<$ in-deferential-formalisation-transference $>$ of secondnatured institutionalisation (as 'so-transfusively determinant to overall sublimating human and social ontologicalperformance -<including-virtue-as-ontology>')'. This 'prospective sublimatingnascence_incipience/instantaneity/directness_fontologically flawed_prior_mere_sociatfunctioning and-accordance as-of-social-stake-contention-or-confliction? associativedistortion-of-referencing/registering/decisioning' preconverging/postconverging-dementatively/structurally/paradigmatically underlies the 'socially radiating sway of nonontologising/disontologising surreptitious knowledge-without-knowledge/knowledge-outsideknowledge/extra-knowledge desublimation (substituting over prospective veridical knowledge sublimation possibilities of social and institutional constructs as reflexively construable from veridical prospective 'implicited_attendant-ontological-contiguity ${ }^{67}$ ' educedexistentialising/contextualising/textualising_intelligibility/epistemicity/reflexivity-contiguity$<$ imbued-notional cogency ${ }^{\prime}{ }^{\prime}$ ', Wherein as to Being-development/ontological-frameworkexpansion-as-to-depth-of-ontologising-development-as-infrastructure-of- meaningfulnessand-teleology , institutional-development-as-to-social-function-development and livingdevelopment-as-to-personality-development psychologismic epistemic acutisationdiffienly < for, residualising \{decompulsing $\}$ delinearity for cogeney> magnitudes $\{0$ experientiality/experiment\}, the so-induced catchmenting-by-rejection/lipservicing/monopolising/gaming-of-the-system/charade/distraction manifested as 'prospective sublimating-nascence_incipience/instantaneity/directness-\{ontologicallyflawed_prior_mere_social-functioning-and-accordance_as-of-social-stake-contention-oreonfliction? associative-distortion-of-referencing/registering/decisioning' (as relating to 'prospective manifest sublimating-nascence incipience/instantaneity/directness of nascentparticular/incipient-and-material/technical-sublimations- $<$ blinded-to-their-relative-ontologicalcompleteness - reference-of-thought- devolving >' rather on the ontologically-flawed basis of 
'prospectively desublimating existentialising-decisionality-<as-to-disontologising/reentologising aporeticism $>\quad$ of social-and-institutional-frameworks-ofreferencing/registering/decisioning existentialising-decisionality-<as-to-disontologising/reentologising aporeticism $>$ as so-reflecting the 'mere-formulaicity/ritualisation-<as-to-mereformulaic — methodologising/mutualising/organising/institutionalising,-prospectively-losingtrack-of- ‘fepistemic-totalising ${ }^{3}$ re-apriorising/re-axiomatising/re-referencing-residuality-in-reoriginariness/re-origination'> imbued elaboration-as-to-mereextrapolating/constituting/abstracting/deducing/inferring-of-elucidation-outside'prospectively_implicited_attendant-ontological-contiguity ${ }^{67}$ ' educedexistentialising/contextmalising/textualising_'intelligibility/epistemicity/reflexivity_contiguity$<$ imbued-notional cogency>' of the 'shallow-supererogation as of prior ${ }^{83}$ reference-ofthought — point-of-devolving/departure/anchoring/backdrop_of_sublimating-nascence-<as-tothe-grandest-axiomatic-construct-\{epistemic-totalising ${ }_{3}^{\mathfrak{l}}$ re-apriorising/re-axiomatising/rereferencing $\sim$ residuality - in-re-originariness/re-origination of limitedness/human-subpotency prospective re-encountering/re-confrontation with unlimitedness/existence>' as to induced desublimating construal); critically speaks to a counterintuitive and ontologically-flawed reflex mentality of 'presumed incontrovertibility of the ontological-veracity-<as-to-prospectiveontologising-and-re-ontologising $>$ of social-functioning-and-accordance-as-of-social-stakecontention-or-confliction'. This underlines a manifest human prospective threshold of 'nonontologising/disontologising surreptitious knowledge-without-knowledge/knowledge-outsideknowledge/extra-knowledge frameworks' (however the sterile/anecdotal institutional-and-social imprimaturing) as to the need for 'prospective postconvergingaaporeticismereoming of prior-perspective-falsity/falseness/fallaciousness' for veridical prospective ontologising-and-re-ontologising (as so-reflected in a substitutive positiveopportunism-of-social-functioning-and-accordance ${ }^{75}$ ontologically-flawed conception of 
ontological-veracity-<as-to-prospective-ontologising-and-re-ontologising $>$ that doesn't speak to 'prospective postconverging-aporeticism-overcoming/unovercoming of prior-perspectivefalsity/falseness/fallaciousness' which then goes on to substitute for prospective ontologicalveracity-<as-to-prospective-ontologising-and-re-ontologising $>$ that rather warrants candid ontological analysis for enabling 'prospective ${ }^{8}$ reference-of-thought appraisal of sublimatingnascence comprehensiveness/nonimmediacy/indirectness'); and so-manifested as of registryworldviews/dimensions 'implicited_attendant-ontological-contiguity ${ }^{67}$ ' educedexistentialising/contextualising/textualising_intelligibility/epistemicity/reflexivity-contiguity$<$ imbued-notional cogency $>$ self-presence/self-constitutedness ${ }^{14}-<$ in-perspectiveepistemic-abnormalcy/preconvergence ${ }^{3}>$ notions of institutional access and success default conception of human ontological-performance ${ }^{72}-$ including-virtue-as- $^{2}$ of ontology $>$ /morality/ethics/justice/etc. 'supposedly-and-manifestly overriding the exercise of prospective veridical ontologising-and-re-ontologising as to prospective 'implicited_attendantontological-contiguity ${ }^{67}$, educedexistentialising/contextualising/textualising_'intelligibility/epistemicity/reflexivity_contiguity-

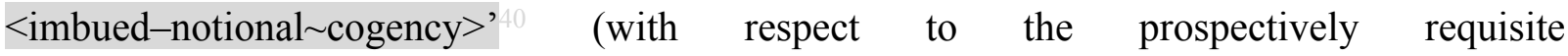

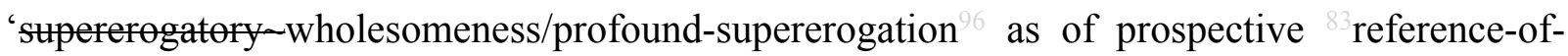
thought — point-of-devolving/departure/anchoring/backdrop_of_sublimating-nascence-<as-tothe-grandest-axiomatic-construct-\{epistemic-totalising ${ }_{3}^{\text {jo }}$-apriorising/re-axiomatising/rereferencing - residuality - in-re-originariness/re-origination of limitedness/human-subpotency prospective re-encountering/re-confrontation with unlimitedness/existence> ${ }^{>}$underlied by \{epistemic-totalising $3{ }^{3}$ re-apriorising/re-axiomatising/re-referencing $\sim$ residuality-in-reoriginariness/re-origination- $\langle$ as to human profound-supererogation for prospective apriorising/axiomatising/referencing-\{of-'prospectively implicited_attendant-ontologicalcontiguity ' $\sim$ educed- 
existentialising/contextualising/textualising_'intelligibility/epistemicity/reflexivity-contiguity-

<imbued-notional cogency $>$ ' $\}$-conflatedness -in-\{preconverging-ment by\}

pestconverging entailment that cannot be unshrouded by prior mere-formulaicity/ritualisation<as-to-mere-formulaic — methodologising/mutualising/organising/institutionalising,-

prospectively-losing-track-of- ‘\{epistemic-totalising ${ }^{3}$ re-apriorising/re-axiomatising/re-

referencing-residuality-in-re-originariness/re-origination'>

of

prior

apriorising/axiomatising/referencing-\{of-'prospectively_implicited_attendant-ontological-

contiguity ' educed-

existentialising/contextualising/textualising_intelligibility/epistemicity/reflexivity-contiguity-

<imbued-notional cogency $\left.>^{\prime} \quad\right\}$ - constitutedness -in preconverging-entailment $\rangle$ in

reflection of human limited-mentation-capacity-deepening as-subjecting-limitedness/humansubpotency-to-'educed-unlimitedness/existence-sublimating nascence' ${ }^{33}$ ). The fundamental drive here is to point out that the very possibility for prospective ontologising-and-reontologising (as to the conceptivity/epistemic-reflexivity/epistemicity-relativism-determinism$<$ reifying \{as-to-knowledge-developing\}-and-empowering $>$ enabling prospective human transcendence-and-sublimity/sublimation/supererogatory $\sim$ de-mentativity) is fundamentally caught-up/disrupted in-a-big-way by the given registry-worldview/dimension threshold of 'social-functioning-and-accordance-as-of-social-stake-contention-or-confliction imbuing existentialising-frame-of-entailment of motif-and-apriorising/axiomatising/referencing of disontologising/ontologising-and-re-ontologising' (rendering a naïve pursuit of ontologising profundity beyond that threshold of disontologising/ontologising-and-re-ontologising while expecting the requisite ontological-good-faith/authenticity $\sim$ postconverging-dementating/structuring/paradigming ${ }^{70}$ in-many-ways rather self-deceptive as can so be appreciated in-the-bigger-picture of the overall relative-unreflexivity/relative-reflexivity ontological-contiguity ${ }^{67}$ of-the-human-institutionalisation-process ${ }^{68}$, underlied by the 
'epistemic-break or notional-discontiguity/epistemic-discontiguity ${ }^{63}-<$ between - prior-shallowsupererogation -of-mentally-aestheticised $\sim$ preconverging/dementing -qualia-

schema_and_prospective-profound-supererogation -of-mentally-

aestheticised postconverging/dialectical-thinking -qualia-schema> as to difference-innature/difference-in-apriorising-or-axiomatising-or-referencing ${ }^{24}$, between ${ }^{103}$ universalisingidealisation and non-universalising ancient-sophists, budding-positivism and non-positivising medieval-scholasticism as well as budding postmodern-thought and our totalisingly-ingdiscretion/whim-of-thought as to our modern-day manifestation of disparateness-ofconceptualisation-<unforegrounding-ment,-failing-prospectively-to-reflect-

‘immanent $\sim$ relative-unreflexivity/relative-reflexivity - ontological-contiguity ' $>$ ). Such that in-many-ways the pretense to a prospective profundity of ontological-veracity- $<$ as-toprospective-ontologising-and-re-ontologising > can only arise from putting-into-question such a 'disontologising/ontologising-and-re-ontologising threshold' herein construed as the 'overall underpinning-suprasocial-construct subontologisation/ideology-over-ontology diversely/variously manifested implicited projects/projections of temporal social-functioningand-accordance-as-of-social-stake-contention-or-confliction disontologising as to their implications upon the-human/humanity omnipotential prospects' (manifested as of various psychologismic epistemic-acutisation difficulty-for, residualising \{decompulsing $\}$ delinearity for-cogeney>-magnitudes $\{$ of-experientiality/experiment\} of human selfpresence/self-constitutedness $^{14}$ - $<$ in-perspective-epistemic-abnormalcy/preconvergence ${ }^{31}>$ ontological-bad-faith/inauthenticity ${ }^{64}$ preconverging-de-mentating/structuring/paradigming whether consciously or unconsciously pursued subontologising purposefulness going beyond just formal frameworks but equally-and-dynamically with surreptitious frameworks of extendedinformality-〈susceptible-to-effecting-parsimony-as-of-shoddiness-and-incompleteness-tomeaningfulness-and-teleology $\rangle$ subontologising purposefulness). This can take the form of a 
mental reflex that seem to imply wrongly that all the human prospective ontologising-capacity with respect to 'prospective manifest sublimating-nascence incipience/instantaneity/directness of nascent-particular/incipient-and-material/technical-sublimations- $<$ blinded-to-their-relativeontological-completeness - reference-of-thought- devolving>' merely comes down to an arbitrary-and-punctual filling-in of the associated space/gap of their corresponding social-andinstitutional-frameworks-of — referencing/registering/decisioning existentialising-decisionality$<$ as-to-disontologising/re-ontologising aporeticism $>$ without or with-a-poor contemplation of the 'requisite epistemic-growth,-as - \{veridical/sound\}-relative-reflexivity-inexistence/relativising from-limited-mentation-as-its-deepening/psychologismic epistemicacutisation residualising, ${ }^{\text {\{decompulsing }}$ delinearity for-cogency as of prospective psychologismic-epistemic-acutisation-<as-to-postconverging-dementating/structuring/paradigming,-eliciting-of-existence's-sublimating-nascence-inprospective-aporeticism-overcoming/unovercoming $>$ as to epistemic-growth,-as \{veridical/sound\}-relative-reflexivity-in-existence/relativising from-limited mentation-as-itsdeepening/psychologismic epistemic acutisation residualising, fdecompulsingl delinearity for eogency' for such social-and-institutional-frameworks-of-referencing/registering/decisioning sublimating existentialising-decisionality-as to disontologising/re-ontologising aporeticism $>$ (rather as of "prospective ${ }^{83}$ reference-of-thought appraisal of sublimating-nascence comprehensiveness/nonimmediacy/indirectness' for 'supererogatory $\sim$ wholesomeness/profound-supererogation ${ }^{96}$ as of prospective ${ }^{83}$ reference-ofthought_ — point-of-devolving/departure/anchoring/backdrop_of_sublimating-nascence-<as-tothe-grandest-axiomatic-construct- epistemic-totalising ${ }^{+}$re-apriorising/re-axiomatising/rereferencing residuality - in-re-originariness/re-origination of limitedness/human-subpotency prospective re-encountering/re-confrontation with unlimitedness/existence>'). This reflects inmany-ways registry-worldviews/dimensions relatively accidented relation with the 
'sublimating/desublimating re-thinking/re-rationalisation of what is the-human/humanity' and so across the varying psychologismic epistemic-acutisation difficulty-<for, residualising

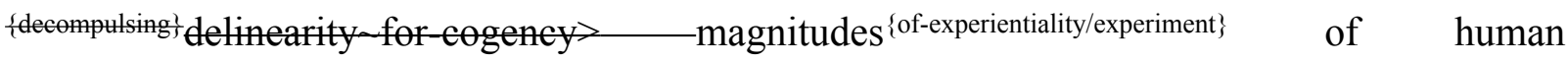
aestheticisation-and-aestheticisation-towards-ontology-<elicited-idiomatisation $>$. This insight is underlied by 'prospective sublimating-nascence_incipience/instantaneity/directness\{ontologically-flawed_prior_mere_social-functioning-and-accordance_as-of social-stakecontention-or-confliction? associative-distortion-of-referencing/registering/decisioning' arising with say a merely positive-opportunism-of-social-functioning-and-accordance ontologically-flawed conception substituting for ontological-veracity-<as-to-prospectiveontologising-and-re-ontologising $>$ that doesn't speak to 'prospective postconverging aporeticism-overcoming/unovercoming of prior-perspectivefalsity/falseness/fallaciousness'. This is so-reflected geopolitically in many a developing country 'relatively poorly-detached social enculturation of intellectualising/thinking-out/ontologising conception of overall sovereign polity design-and-implementation substantivity' as to the manifest enculturating of suboptimal/desublimating punctual polity interventions and nepotic/tribalistic associated ends (reflecting a positive-opportunism-of-social-functioningand-accordance ${ }^{75}$ ontologically-flawed conception substituting for ontological-veracity-<as-toprospective-ontologising-and-re-ontologising $>$ ) that in-many-ways critically undermine and renders relatively redundant/ineffective such a developing country's 'supposedly relatively detached social enculturation of intellectualising/thinking-out/ontologising conception of overall sovereign polity design-and-implementation substantivity' (as rather failing 'prospective postconverging aporeticism-overcoming/unovercoming of prior-perspectivefalsity/falseness/fallaciousness'). This effectively speaks to the need for the social-setup selfreflexivity as to a 'requisite formation of an overall communioning socially-enculturated direct/indirect ontologising-capacity of good governance polity' rather than an ontologically- 
flawed 'presumed incontrovertibility of the ontological-veracity-<as-to-prospectiveontologising-and-re-ontologising $>$ of social-functioning-and-accordance-as-of-social-stakecontention-or-confliction' that seem to wrongly imply that by the mere governmental projection that a given developing country is of 'supposedly relatively detached social enculturation of intellectualising/thinking-out/ontologising conception of overall sovereign polity design-andimplementation substantivity' there is hardly any prospective need for a 'requisite formation of an overall communioning socially-enculturated direct/indirect ontologising-capacity of good governance polity' (as reflecting its 'prospective postconvergingaaporeticismovercoming/unovercoming of prior-perspective_falsity/falseness/fallaciousness'); with this misrecognition critically central to the 'social-functioning-and-accordance-as-of-social-stakecontention-or-confliction jeopardising/perilous nature of the political process' in many a developing country especially during moments of political transition as to an ontologicallyflawed notion that veridical sovereignty can afford to ignore a requisite basic 'overall communioning socially-enculturated direct/indirect ontologising-capacity of good governance polity' as so-enabling a prospering/self-sustaining/emancipating social-functioning-andaccordance-as-of-social-stake-contention-or-confliction (a reality which even many a developed country seem to be oblivious-to as to a naïve emphasis of an international relations largely skewed on the basis of mere governmental projection that a given developing country is of 'supposedly relatively detached social enculturation of intellectualising/thinkingout/ontologising conception of overall sovereign polity design-and-implementation substantivity' and in-many-ways such an orientation is relatively of poor assistance with regards to such a 'requisite formation of an overall communioning socially-enculturated direct/indirect ontologising-capacity of good governance polity' and rather sometimes ending up inducing a generalised political paranoia magnifying the poor dynamics of 'overall communioning sociallyenculturated direct/indirect ontologising-capacity of good governance polity' as so-undermining 
the possibility of a prospectively prospering/self-sustaining/emancipating social-functioningand-accordance - as-of-social-stake-contention-or-confliction). This again fundamentally underlines the patchwork nature of international relations that fails to delve into a sound appraisal of a coherent and creative global and multilateral institutions and systems ontologising-capacity expansion as to a sublimating re-thinking/re-rationalisation of what is the-human/humanity; as international politics and its attendant crises rather arises/manifests as of a crises-driven 'secondary and mitigating contemplative concern'. Unsurprisingly, this is in-many-ways the reflection of the political and institutional processes of many a developing country ontologicallyflawed 'presumed incontrovertibility of the ontological-veracity-<as-to-prospectiveontologising-and-re-ontologising $>$ of social-functioning-and-accordance-as-of-social-stakecontention-or-confliction' in the face of their manifest palliative and collateralising 'vague normalised/stereotyped/selfhelping/feel-good narratives' of institutional and media contrivance as

of 'process/processive mere-formulaicconformity/trending/voguing/fashionability/resonance relation to meaningfulness-andteleology devoid of supererogatory ${ }^{9}$ wholesomeness/profound-supererogation as of prospective reference-of-thought - point-ofdevolving/departure/anchoring/backdrop_of_sublimating-nascence-<as-to-the-grandest-

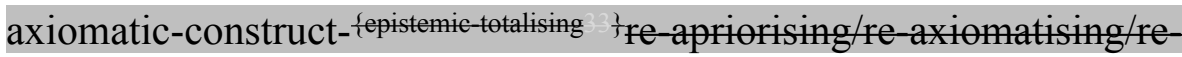
referencing $\sim$ residuality - in-re-originariness/re-origination of limitedness/human-subpotency prospective re-encountering/re-confrontation with unlimitedness/existence>' (as so-reflecting their 'prospective postconverging-aporeticism-overcoming/unovercoming of priorperspective - falsity/falseness/fallaciousness'); increasingly bent upon overlooking 'appropriately sublimating technicity/profundity capable of veridically responding to social and institutional postconverging-aporeticism-overcoming/unovercoming', and so-inducing 'individuals reflective estrangement and disinterest with regards to optimal public outcomes of 
social-stake-contention-or-confliction'. In-the-bigger-scheme-of-things of this overall analysis, prospective re-ontologising 'deconstruction conception as to epistemic-growth,-as\{veridical/sound\}-relative-reflexivity-in-existence/relativising from-limited-mentation-as-itsdeepening/psychologismic epistemic acutisation residualising, \{decompulsing $\}$ delinearity for eogency' underlines/emphasises the requisite prospective epistemic-growth,-as\{veridical/sound\}-relative-reflexivity-in-existence/relativising from-limited-mentation-as-itsdeepening/psychologismic epistemic-acutisation residualising, \{decompulsing ${ }^{\text {f }}$ delinearity foreogency as to psychologismic-epistemic-acutisation-<as-to-postconverging-dementating/structuring/paradigming,-eliciting-of-existence's-sublimating-nascence-insupereregatery $\sim$ wholesomeness/profound-supererogation of notional citationality (as to a 'connoting supererogation-drivenness construal of the epistemic-totality ${ }^{37}$ of human-textuality$<$ as-to-existentialising/contextualising/textualising $>\quad$ in epistemictotalising $\sim$ resubjecting_or_totalising-entailing $\sim$ reconstrual-<of the-whole/purview-of thewhole/oneness-of-ontelogy>'); as so-reflecting the 'centrality of postconverging aporeticismevercoming/unovercoming in prospective ${ }^{45}$ foregrounding_entailment- $<$ in-succession-ofprofound-supererogation $>$ >-〈postconverging-narrowing-down $\sim$ sublimation-as-to-'existenceas-sublimating-withdrawal/unenframing/re-ontologising,-elicited-from-prospective-profoundsupererogation '-in-reflecting-'immanent relative-unreflexivity/relative-reflexivity ontological-contiguity ';--as-operative-notional deprocrypticism)', and as so-underlying the transitioning from notional philosophy-<as-to-the-veridical-conception-of-philosophy-asenglobing-all-human-prospective-organic-knowledge-generation-in-relative-ontologicalcompleteness ,-beyond-a-convenient-division-of-labour-conception-of-knowledge $>$ into its associated intolerance-<of-disparateness $>$ /exactifying_precisioning-of-sublimation- $<$ as-topostconverging-narrowing-down apriorising/axiomatising/referencing-entailing-theoretical,- 
conceptual-and-operant-implications $>$ as ontology-<with-respect-to-'generalised-knowledge'intolerance-<of-disparateness>/exactifying_precisioning-of-sublimation;-in'supereregatery $\sim$ wholesomeness/profound-supererogation -of-prospective- ${ }^{83}$ reference-ofthought — point-of-devolving/departure/anchoring/backdrop-of-sublimating-nascence'> and science- $<$ with-respect-to- 'nascent-particular/incipient-and-material/technical-sublimations'intolerance-<of-disparateness $>$ /exactifying_precisioning-of-sublimation $>$. Critically in this regards, the sublimation-producing scientific exercise is veridically one of 'assumed controvertibility of the ontological-veracity-<as-to-prospective-ontologising-and-reontologising $>$ of social-functioning-and-accordance-as-of-social-stake-contention-orconfliction' rather than ontologically-flawed 'presumed incontrovertibility of the ontologicalveracity-<as-to-prospective-ontologising-and-re-ontologising $>$ of social-functioning-andaccordance - as-of-social-stake-contention-or-confliction' (as to scientific relevant domains-ofinterests of specifically and/or generally cultivated arts/skills and time investment as limitedmentation-capacity-deepening —as-subjecting limitedness/human-subpotency-to-'educedunlimitedness/existence-sublimating nascence' ${ }^{53}$ ); $\quad$ and critically such apriorising/axiomatising/referencing notions like space and time, atomicity, etc. as pertains in the domain of physics for instance have been sublimatingly reanalysed historically (as to requisite limitedness/human-subpotency intolerance $<$ ofdisparateness $>$ /exactifying_precisioning-of-sublimation-<as-to-postconverging-narrowingdown apriorising/axiomatising/referencing-entailing-theoretical,-conceptual-and-operantimplications $>$ ) in a gesturing/accounting-of-epistemic-phenomenalism reflexive of 'prospective postconverging-aporeticism-overcoming/unovercoming of prior-perspectivefalsity/falseness/fallaciousness' for a 'disruptive re-originariness/re-origination reconceptualisation' in the diametric apriorising/axiomatising/referencing terms of spacetime, quantum, etc. as to their aptly implicited ${ }^{6}$ nonpresencing-<perspective-ontological- 
normalcy/postconvergence $>$ epistemic-projection perspective (and so manifested with similar disruptive re-originariness/re-origination reconceptualisations in say the chemistry and biology domains however their greater elaborateness). The bigger point here is that the grander promise of prospective re-ontologising 'deconstruction conception as to epistemic-growth,-as\{veridical/sound\}-relative-reflexivity-in-existence/relativising from-limited mentation-as-itsdeepening/psychologismic epistemic-acutisation residualising, \{decompulsing $\}$ delinearity-foreogency' arises rather as of its 'intolerance-<of-disparateness $>$ /exactifying_precisioning-ofsublimation-<as-to-postconverging-narrowing-down apriorising/axiomatising/referencingentailing-theoretical,-conceptual-and-operant-implications $>\quad$ exercise' $\quad$ (so-underlied unassailably as to 'constraining existence-as-sublimating-withdrawal/unenframing/reontologising,-elicited-from-prospective-profound-supererogation imbuing human ontological-commitment $\quad<$ implied_-self-assuredness-of-ontological-goodfaith/authenticity postconverging-de-mentating/structuring/paradigming -as-being-as-ofexistential-reality>' and ' ${ }^{103}$ universal-transparency ${ }^{104}$-〈transparency-of-totalising-entailing,-asto-entailing-<amplituding/formative-epistemicity $>$ totalising $\sim$ in-relative-ontologicalcompleteness > as available-to/elicitable-to-〈as-to-human-consciousness/collectiveconsciousness-distendedness/detruncating-<beyond-selfpresencing,-as-re-ontologisingdecentering_of-consciousness/collective-consciousness,-as-to-psychologismic-epistemicacutisation-residualising, - $^{\text {fdecompulsing }}$ delinearity for-cogency $\left.>\right\rangle$ the social-functioning-andaccordance-as-of-social-stake-contention-or-confliction conception of any given registryworldview/dimension $\quad<$ preconverging 'motif-and-apriorising/axiomatising/referencing' entailing $>$-existentialising — enframing/imprintedness-〈as-to- historicity-tracing - inpresencing-hyperrealisation/hyperreal-transposition $\left.\rangle^{\prime}\right)$. In other words, the very existentialising/contextualising/textualising framework of notional $\sim$ philosophy-<as-to-theveridical-conception-of-philosophy-as-englobing-all-human-prospective-organic-knowledge- 
generation-in-relative-ontological-completeness ,-beyond-a-convenient-division-of-labour-

conception-of-knowledge > (as not shutting-off, as-of-its-demonstrative-prospectivesublimation 'by the intolerance-<of-disparateness>/exactifying_precisioning-of-sublimation<as-to-postconverging-narrowing-down apriorising/axiomatising/referencing-entailingtheoretical,-conceptual-and-operant-implications $>$ exercise', the possibility for pedantising/muddling/formulaic-hollowing-out_-in-subontologisation/subpotentiation〈blurring/undermining-of-prospective-totalising-entailing,-as-to-entailing$<$ amplituding/formative-epistemicity $>$ totalising in-relative-ontological-completeness $>$ desublimation) is effectively what ultimately warrants the grander promise of prospective reontologising 'deconstruction conception as to epistemic-growth,-as \{ridical/som relative-reflexivity-in-existence/relativising from-limited-mentation-as-itsdeepening/psychologismic epistemic-acutisation residualising, ${ }^{\text {\{decompulsing }}$ \}elinearity for eogency' arising rather as of its 'intolerance-<0f-disparateness $>$ /exactifying_precisioning-ofsublimation-<as-to-postconverging-narrowing-down apriorising/axiomatising/referencingentailing-theoretical,-conceptual-and-operant-implications $>$ exercise'; as to the genuine social intellectual-function/posture ontologising intolerance- $<$ ofdisparateness $>$ /exactifying_precisioning (as of notional $\sim$ reflexivity $-<\{$ veridical $/$ sound $\}$ relative-reflexivity-in-existence/relativising from-limited-mentation-as-itsdeepening/psychologismic < residualising \{decompulsing delinearity for-cogency $>$ by\{flawed/unsound\}-relative-unreflexivity-in-existence/absolutising from-limitedmentation/psychologismic epistemic acutisation nonresidualising imbued\{compulsing\} linearity in-eclecticism-of-prior-mere-formulaicity/ritualisation $>$ ) for prospective disontologising which it inherently $\mathrm{s}$ most critically due to disontologising imbued incipient/seeding ontological-bad-faith/inauthenticity ${ }^{64} \sim$ preconverging-dementating/structuring/paradigming ${ }^{65}$ and so in line with the inherently uncompromising nature 
of existence-potency over the mortal human-subpotency', and so-reflected as to the fact that prior non-universalising, non-positivising and totalisingly-ing-discretion/whim-of-thought respectively of ancient-sophists, medieval-scholasticism and our modern-day manifestation of disparateness-of-conceptualisation-<unforegrounding-ment,-failing-prospectively-to-reflect‘immanent $\sim$ relative-unreflexivity/relative-reflexivity - ontological-contiguity ' $>$ are related to in transversality-<for-sublimating-existential-eventuating/denouement,-from-'thinking-at-

\section{first/pure-predisposition-preemptive-of-prospective-disontologising/subontologising' as-of-} prospectively-disambiguated-affirmed-and-unaffirmed-'motif-and-

apriorising/axiomatising/referencing' $>$ as to the sublimating manifestation of the prospective genuine social intellectual-function/posture of respectively ${ }^{103}$ universalising-idealisation, budding-positivism and budding postmodern-thought. In this regards, what is veridically enabling for the prospectively desublimating 'socially radiating sway of nonontologising/disontologising surreptitious knowledge-without-knowledge/knowledge-outsideknowledge/extra-knowledge desublimation (substituting over prospective veridical knowledge sublimation possibilities of social and institutional constructs as reflexively construable from veridical prospective 'implicited_attendant-ontological-contiguity ${ }^{67}$ ' educed-

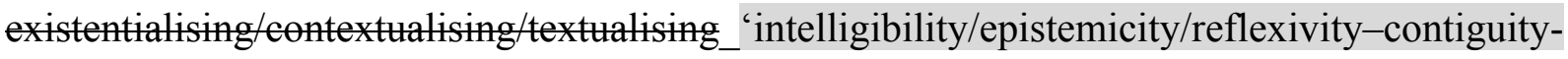
<imbued-notional cogency $>^{\prime 0}$ )' is rather lack of veridical prospective re-ontologising 'deconstruction conception as to epistemic-growth,-as_ \{veridical/sound\}-relative-reflexivityin-existence/relativising from-limited-mentation-as-its-deepening/psychologismic epistemicacutisation residualising, \{decompusing $d$ delinearity for-cogency' induced 'intolerance-<ofdisparateness $>$ /exactifying_precisioning-of-sublimation-<as-to-postconverging-narrowingdown apriorising/axiomatising/referencing-entailing-theoretical,-conceptual-and-operantimplications $>$ exercise'. In-many-ways this explains across human history the 'seeding/incipient antagonistic insight from the manifest pedantising/muddling/formulaic-hollowing-out-in- 
subontologisation/subpotentiation-〈blurring/undermining-of-prospective-totalising-entailing,as-to-entailing-<amplituding/formative-epistemicity $>$ totalising $\sim$ in-relative-ontological-

completeness \' about the 'prospective re-ontologising subversive implications' arising from any such 'deconstruction conception as to epistemic-growth,-as fveridical/some-relativereflexivity-in-existence/relativising from-limited-mentation-as-its-deepening/psychologismic epistemic-acutisation residualising, \{decompulsing delinearity for-cogency' induced 'intolerance$\leq 0$ f-disparateness $>$ /exactifying_precisioning-of-sublimation- $<$ as-to-postconvergingnarrowing-down apriorising/axiomatising/referencing-entailing-theoretical,-conceptual-andoperant-implications $>$ exercise' (as underlied by the 'intolerance-<ofdispartions $>$ exactifying_precisioning-of-sublimation-<as-to-postconverging-narrowingdown apriorising/axiomatising/referencing-entailing-theoretical,-conceptual-and-operantimplications $>$ exercise' in ${ }^{4}$ foregrounding_entailment- $<$ in-succession-of-profoundsupererogation $>$-〈postconverging-narrowing-down $\sim$ sublimation-as-to-'existence-assublimating-withdrawal/unenframing/re-ontologising,-elicited-from-prospective-profoundsupererogation '-in-reflecting-'immanent relative unreflexivity/relative reflexivity ontological-contiguity ';-as-operative-notional deprocrypticism) enabling the overall relative-unreflexivity/relative-reflexivity ontological-contiguity ${ }^{67}$ of-the-humaninstitutionalisation-process ${ }^{68} \quad$ 'grander supereregatery $\sim$ wholesomeness/profoundsupererogation as of prospective ${ }^{83}$ reference-of-thought—point-ofdevolving/departure/anchoring/backdrop_of_sublimating-nascence-<as-to-the-grandestaxiomatic-construct-\{epistemic-totalising ${ }^{\frac{1}{3}}$ re-apriorising/re-axiomatising/rereferencing residuality - in-re-originariness/re-origination of limitedness/human-subpotency prospective re-encountering/re-confrontation with unlimitedness/existence>', and so-reflected as to the superseding of successive registry-worldviews/dimensions 79 presencing-absolutisingidentitive-constitutedness ${ }^{14} \quad<$ amplituding/formative-epistemicity $>$ totalising $\sim$ self-referencing- 
syncretising/circularity/interiorising/akrasiatic-drag ${ }^{34}$ ). Prospective re-ontologising 'deconstruction conception as to epistemic-growth,-as — \{veridical/sound\}-relative-reflexivityin-existence/relativising from-limited-mentation-as-its-deepening/psychologismic epistemic acutisation residualising, ${ }^{\text {\{decompulsing }}$ delinearity for-cogency' imbued 'intolerance-<ofdisparateness $>$ /exactifying_precisioning-of-sublimation- $<$ as-to-postconverging-narrowingdown apriorising/axiomatising/referencing-entailing-theoretical,-conceptual-and-operantimplications $>$ exercise' (as to both ontology-<with-respect-to-'generalised-knowledge'intolerance-<of-disparateness $>$ /exactifying_precisioning-of-sublimation $>$ and science- $<$ withrespect-to-'nascent-particular/incipient-and-material/technical-sublimations'-intolerance-<ofdisparateness $>$ /exactifying_precisioning-of-sublimation $>$ ) is inevitably embroiled with 'prospective sublimating-nascence_incipience/instantaneity/directness-\{ontologically flawed_prior_mere_social-functioning-and-accordance_as-of-social-stake-contention-oreonfliction? associative-distortion-of-referencing/registering/decisioning' (underlied by the given '79 presencing-absolutising-identitive-constitutedness ${ }^{14}$ normalising functionalism conception as to fflawed/unsound\}-relative-unreflexivity-in-existence/absolutising fromlimited-mentation/psychologismic epistemic acutisation nonresidualising imbued\{compulsing' tinearity in eclecticism of prior mere formulaicity/rittalisation'); and so given that prospective human transcendence-and-sublimity/sublimation/supererogatory de-mentativity (implied as of notions like construction-of-the-Self or 'surrealising-<as-to-supererogation $>>$ as to the ${ }^{97}$ surrealising nature of the <cumulating/recomposuring attendant-ontologicalcontiguity>-successive registry-worldviews/dimensions', etc.) can only arise as being freed/liberated from the 'very incipient/seeding \{flawed/unsound\}-relative-unreflexivity-inexistencetabsolutising from limited mention/psychologismic epistemic acutisation nonresidualising imbued-\{compulsing\} linearity-in-eclecticism-of prior-mereformulaicity/ritualisation residual human <amplituding/formative-epistemicity $>$ - 
totalising $\sim$ thrownness-in-existence ${ }^{35} \quad$ imbued prior $\quad<$ preconverging $\sim$ 'motif-andapriorising/axiomatising/referencing'-entailing>-existentialising — enframing/imprintedness〈as-to- historicity-tracing - in-presencing-hyperrealisation/hyperreal-transposition〉 to then project of the epistemic-growth,-as - \{veridical/sound\}-relative-reflexivity-inexistence/relativising from limited mentation as its deepening/psychologismic epistemic acutisation residualising, ${ }^{\text {\{decompulsing }}$ delinearity for-cogency prospective <postconverging 'motif-and-apriorising/axiomatising/referencing'-entailing >existentialising - framing/imprinting-〈as-to-prospective- historiality/ontologicaleventfulness /ontological-aesthetic-tracing-<perspective-ontologicalnormalcy/postconvergence-reflected-'epistemicity-relativism-determinism'>>. Insightfully, it can thus be grasped herein that the very central element of intelligibility (arising as to the 'reflexive epistemic relation of limitedness/human-subpotency to unlimitedness/existence-<fullpotency-of_sublimating nascence $>$ ') is notional $\sim$ reflexivity- $<\{$ veridical/sound $\}$-relativereflexivity-in-existence/relativising from-limited-mentation-as-its-deepening/psychologismic<residualising \{decompulsing \}elinearity for cogency>by-\{flawed/unsound\}relativeunreflexivity-in-existence/absolutising from-limited-mentation/psychologismic epistemicacutisation nonresidualising-imbued-\{compulsingt linearity-in-eclecticism-of-prior-mereformulaicity/ritualisation> imbued sublimating/desublimating in existence, as so-warranting appropriate nonpresencing-or-withdrawal/unenframing/re-ontologising-or-metaphysics-ofabsence-〈implicited-epistemic-veracity-of- nonpresencing-<perspective-ontologicalnormalcy/postconvergence $>$ )- -or-transcendental-reasoning-of-event ${ }^{38}$-as-prospective-ontologyorigination for 'deconstruction conception as to epistemic-growth,-as-\{veridical/sound\} relative-reflexivity-in-existence/relativising from-limited-mentation-as-itsdeepening/psychologismic epistemic-acutisation residualising, \{decompulsing $\}$ delinearity for eogency' imbued 'interance-of disparateness/exactifying_precisioning-of-sublimation- 
<as-to-postconverging-narrowing-down apriorising/axiomatising/referencing-entailing-

theoretical,-conceptual-and-operant-implications $>$ exercise'. This insight can be further expanded upon as to the inherent fact that the 'epistemic relation of limitedness/humansubpotency to unlimitedness/existence-<full-potency-of_sublimating nascence $>$ ' can only necessarily speak to limitedness/human-subpotency (as to its <amplituding/formativeepistemicity $>$-totalising $\sim$ thrownness-in-existence ${ }^{35}$ ) ontological-faith-notion-or-ontologicalfideism - imbued-underdetermination-of-motif-and-apriorising/axiomatising/referencing-asso-being-as-of-existential-reality (as to ontological-good-faith/authenticity ${ }^{69}$ or ontological-badfaith/inauthenticity ${ }^{64}$ ) epistemic relation to unlimitedness/existence- $<$ full-potencyof_sublimating nascence> (as the 'constraining/defining intersolipsistic reflexivesublimating/unreflexive-desublimating measure/objectification that is unlimitedness/existenceas-ontological-normalcy/postconvergence-<in-validation-of-'metaphysics-ofabsence_epistemic-projection'>' as to manifest sublimation/desublimation). Thus limitedness/human-subpotency cumulating/recomposuring 'intolerance-<ofdisparateness $>$ /exactifying_precisioning-of-sublimation-<as-to-postconverging-narrowingdown apriorising/axiomatising/referencing-entailing-theoretical,-conceptual-and-operantimplications $>$ exercise' is rather as to the 'constraining/defining intersolipsistic reflexivesublimating/unreflexive-desublimating measure/objectification that is unlimitedness/existenceas-ontological-normalcy/postconvergence-<in-validation-of-'metaphysics-ofabsence_epistemic-projection'>' as to manifest sublimation/desublimation; so-translated as 'constraining existence-as-sublimating-withdrawal/unenframing/re-ontologising,-elicitedfrom-prospective-profound-supererogation imbuing human ontological-commitment <implied-self-assuredness-of-ontological-good-faith/authenticity $\sim$ postconverging-dementating/structuring/paradigming -as-being-as-of-existential-reality>' and ' ${ }^{103}$ universaltransparency ${ }^{104}$-〈transparency-of-totalising-entailing,-as-to-entailing-<amplituding/formative- 
epistemicity>totalising in-relative-ontological-completeness $\rangle$ as available-to/elicitable-to-〈asto-human-consciousness/collective-consciousness-distendedness/detruncating-<beyondselfpresencing,-as-re-ontologising-decentering_of-consciousness/collective-consciousness,-asto-psychologismic-epistemic-acutisation - residualising, $\left.{ }^{-\{\text {decompulsing }}\right\}$ delinearity $\sim$ for-cogency $\left.>\right\rangle$ the social-functioning-and-accordance-as-of-social-stake-contention-or-confliction conception of any given registry-worldview/dimension <preconverging 'motif-andapriorising/axiomatising/referencing'-entailing >-existentialising-enframing/imprintedness〈as-to- historicity-tracing - in-presencing-hyperrealisation/hyperreal-transposition〉'. But then this 'constraining' as to elicitable sublimation/desublimation doesn't escape the incipient/seeding/foundational reality of limitedness/human-subpotency (as to its $<$ amplituding/formative-epistemicity >-totalising $\sim$ thrownness-in-existence ${ }^{35}$ ) ontological-faithnotion-or-ontological-fideism—imbued-underdetermination-of-motif-andapriorising/axiomatising/referencing-as-so-being-as-of-existential-reality (reflected as of ontological-good-faith/authenticity ${ }^{6}$ or ontological-bad-faith/inauthenticity ${ }^{64}$ ); such that there is no absolutely deterministic ontological basis for existentially-disongenging entologising aporeticism $>$ overcoming manifest ontological-bad-faith/inauthenticity ${ }^{64}$ by the 'mere token of limitedness/human-subpotency <amplituding/formative-epistemicity>totalising thrownness-in-existence $^{35}$, , so-reflected as to tacit or conscious limitedness/humansubpotency ontological-bad-faith/inauthenticity ${ }^{64}$ (for instance nothing inherently stops me 'technically' to insist 5+3=11 and so in both respects of ontological-bad-faith/inauthenticity ${ }^{64}$ as elaborated with the BODMAS characters elsewhere herein in reflection of the incipient/seeding self-reflexive instigative-eventuating-〈as-to-teleological-instigative/incipientwilling/arbitrariness/waywardness/faithdrivenness/supererogating-for-human-intelligibility,preceding-existence's-eventuating-sublimating-validation/desublimating-invalidation〉 of human ${ }^{56}$ meaningfulness-and-teleology $\left.{ }^{9}\right)$. Critically, it is wrong to construe of ontology/science 
as about this more fundamental limitedness/human-subpotency ontological-faith-notion-orontological-fideism - imbued-underdetermination-of-motif-and-

apriorising/axiomatising/referencing-as-so-being-as-of-existential-reality (reflected as of ontological-good-faith/authenticity ${ }^{6}$ or ontological-bad-faith/inauthenticity ${ }^{64}$ ) per se but rather while ontology/science is rather foundationally/incipiently/seedingly derivational as from ontological-good-faith/authenticity (as to the self-reflexive instigative-eventuating-〈as-toteleological-instigative/incipient-

willing/arbitrariness/waywardness/faithdrivenness/supererogating-for-human-intelligibility,preceding-existence's-eventuating-sublimating-validation/desublimating-invalidation〉 of human ${ }^{56}$ meaningfulness-and-teleology $\left.{ }^{9}\right)$; ontolology/science effectively arises as of the projection of limitedness/human-subpotency sublimation possibilities manifestly elicitable out of the 'constraining/defining intersolipsistic reflexive-sublimating/unreflexive-desublimating measure/objectification that is unlimitedness/existence-as-ontologicalnormalcy/postconvergence-<in-validation-of-'metaphysics-of-absence_epistemic-projection'>' (as so-translated as 'constraining existence-as-sublimating-withdrawal/unenframing/reontologising,-elicited-from-prospective-profound-supererogation imbuing human ontological-commitment $\quad$-implied-self-assuredness-of-ontological-goodfaith/authenticity postconverging-de-mentating/structuring/paradigming -as-being-as-ofexistential-reality>' and ' ${ }^{103}$ universal-transparency ${ }^{104}$-〈transparency-of-totalising-entailing,-asto-entailing-<amplituding/formative-epistemicity $>$ totalising $\sim$ in-relative-ontologicalcompleteness $\rangle$ as available-to/elicitable-to-〈as-to-human-consciousness/collectiveconsciousness-distendedness/detruncating-<beyond-selfpresencing,-as-re-ontologisingdecentering_of-consciousness/collective-consciousness,-as-to-psychologismic_epistemicacutisation-residualising, ${ }^{-\{\text {decompulsing }}$ delinearity for-cogency $>>$ the social-functioning-andaccordance-as-of-social-stake-contention-or-confliction conception of any given registry- 
worldview/dimension <preconverging 'motif-and-apriorising/axiomatising/referencing'entailing >-existentialising — enframing/imprintedness-〈as-to- historicity-tracing —inpresencing-hyperrealisation/hyperreal-transposition $\left.\rangle^{\prime}\right)$. This distinction is made in order to avoid pursuing a wrong purpose 'supposedly as of ontology/science' as to when overt or covert ontological-bad-faith/inauthenticity arises that undermines the 'foundationally/incipiently/seedingly derivational ontological-good-faith/authenticity projected notional-contiguity/epistemic-contiguity ${ }^{62}<$ profound-supererogation -of-mentallyaestheticised postconverging/dialectical-thinking -qualia-schema $>$ basis' of ontology/science; and so-explaining why intellectual-and-moral dialogical-equivalence- $<$ as-topsychologismic apriorising/axiomatising/referencing-\{of-'prespectively implicited_attendant-ontological-contiguity ' educedexistentialising/contextualising/textualising_ intelligibility/epistemicity/reflexivity-contiguity$<$ imbued-notional cogency $>$ ' \}-conflatedness -in-\{preconverging -ment by\} postconverging-entailment,-in-self-becoming/self-conflatedness /formative-supererogating> doesn't necessarily arise by default where there is manifest overt or covert ontological-badfaith/inauthenticity ${ }^{64}$ notional-discontiguity/epistemic-discontiguity $3-<$ between - priorshallow-supererogation -of-mentally-aestheticised $\sim$ preconverging/dementing -qualiaschema_and_prospective-profound-supererogation -of-mentallyaestheticised postconverging/dialectical-thinking -qualia-schema $>$ as so-speaking of manifest prospective 'epistemic-decadence' or teleological-decadence-<-in-dimensionality-ofdesublimating-lack-of $-<<$ amplituding/formative $>$ supererogatory $\sim$ de-mentativeness/epistemicgrowth-or-conflatedness /transvaluative-rationalising/transepistemicity/anamnestic-

residuality/spirit-drivenness-equalisation $\rangle$. This insight speaks to the fact that ontology/science as to its proper prospective 'disontologising/ontologising-and-re-ontologising threshold' cannot arise without its requisite basic/foundational ontological-good-faith/authenticity ${ }^{69}$ as to 
ontological-good-faith/authenticity ${ }^{69}$ postconverging-de-mentating/structuring/paradigming It is critical to appreciate in this regards that the <cumulating/recomposuring attendantontological-contiguity>-successive registry-worldviews/dimensions (unlike can be wrongly construed intuitively as to a naïve mere-formulaicity/ritualisation-<as-to-mere-formulaicmethodologising/mutualising/organising/institutionalising,-prospectively-losing-track-of-

‘\{epistemic-totalising ’’’re-apriorising/re-axiomatising/re-referencing-residuality-in-re-

originariness/re-origination'> imbued elaboration-as-to-mereextrapolating/constituting/abstracting/deducing/inferring-of-elucidation-outside'prospectively_implicited_attendant_ontological-contiguity ${ }^{67}$ ' educedexistentialising/contextmalising/textualising_'intelligibility/epistemicity/reflexivity_contiguity$<$ imbued-notional cogency>' ${ }^{\prime}$ of the 'shallow-supererogation' as of prior ${ }^{83}$ reference-ofthought — point-of-devolving/departure/anchoring/backdrop_of_sublimating-nascence-<as-tothe-grandest-axiomatic-construct-\{epistemic-totalising ${ }_{3}^{\mathfrak{l}}$ re-apriorising/re-axiomatising/rereferencing residuality - in-re-originariness/re-origination of limitedness/human-subpotency prospective re-encountering/re-confrontation with unlimitedness/existence> implied presencing - absolutising-identitive-constitutedness ${ }^{14}$ ) rather arose as of the driving dimensionality-of-sublimating $25<$ < amplituding/formative $>$ supererogatory $\sim$ dementativeness/epistemic-growth-or-conflatedness /transvaluativerationalising/transepistemicity/anamnestic-residuality/spirit-drivenness-equalisation $\rangle$ in that 'invents'/“creates'-and-'nurtures' （out of ontological-goodfaith/authenticity ${ }^{6} \sim$ postconverging-de-mentating/structuring/paradigming ${ }^{70}$ as to profoundsupererogation ) the <postconverging 'motif-and-apriorising/axiomatising/referencing'entailing >-existentialising - framing/imprinting-〈as-to-prospective- historiality/ontologicaleventfulness /ontological-aesthetic-tracing-<perspective-ontologicalnormalcy/postconvergence-reflected-'epistemicity-relativism-determinism' $>>$ of the given 
'prospectively

re-ontologising

re-rationalisation-of-

contentivity/argumentativity/dialecticism/discursivity'; and so as to dimensionality-ofsublimating $25<<$ amplituding/formative $>$ supererogatory $\sim$ de-mentativeness/epistemic-growthor-conflatedness /transvaluative-rationalising/transepistemicity/anamnestic-residuality/spiritdrivenness-equalisation〉 induced limitedness/human-subpotency cumulating/recomposuring 'intolerance-<of-disparateness>/exactifying_precisioning-of-sublimation-<as-topostconverging-narrowing-down apriorising/axiomatising/referencing-entailing-theoretical,conceptual-and-operant-implications $>$ exercise of intelligibility' (as to imbued 'developing epistemic sense of nonpresencing-<perspective-ontological-normalcy/postconvergence $>$ relativism/relative-scope as projective-insights') of the relative mreflexivitrelativereflexivity - ontological-contiguity ${ }^{67} \sim$ of-the-human-institutionalisation-process ${ }^{6}$. As $\quad$ soreflected successively as of " ${ }^{103}$ universalising-idealisation prospectively re-ontologising rerationalisation-of-contentivity/argumentativity/dialecticism/discursivity' (postconvergentlyhabituated out of profound-supererogation from 'non-universalising base-institutionalisationununiversalisation rationalisation-of-contentivity/argumentativity/dialecticism/discursivity'), 'positivism/rational-empiricism prospectively re-ontologising re-rationalisation-ofcontentivity/argumentativity/dialecticism/discursivity' (postconvergently-habituated out of profound-supererogation from 'non-positivising $\quad{ }^{103}$ universalisation-nonpositivism/medievalism rationalisation-ofcontentivity/argumentativity/dialecticism/discursivity') and prospective 'postmodern ${ }^{48}$ humansubject-emancipating-relativism-driven-recomposuring-constructivism-towardssingularisation-<as-to-the-nondisjointedness/entailment-of-prospective- nonpresencing $>$ prospectively re-ontologising re-rationalisation-ofcontentivity/argumentativity/dialecticism/discursivity' (postconvergently-habituated out of profound-supererogation from 'disjointing positivism- ${ }^{8}$ procrypticism rationalisation-of- 
contentivity/argumentativity/dialecticism/discursivity'); and so speaking of the relativeunreflexivity/relative-reflexivity — ontological-contiguity ${ }^{67}$ of-the-human-institutionalisationprocess $^{68}$ as a postconverging-birthing/nascency within prospective apriorising/re axiomatising/re refencing-residuality-in-re-originariness/re-origination-〈as to human profound-supererogation for prospective apriorising/axiomatising/referencing-\{of'prospectively_implicited_attendant-ontological-contiguity ' ceducedexistentialising/contextualising/textualising_'intelligibility/epistemicity/reflexivity-contiguity$<$ imbued-notional cogency >' \}-conflatedness - in-\{preconverging ment by\} postconverging-ntailment that cannot be unshrouded by prior mere-formulaicity/ritualisation$<$ as-to-mere-formulaic — methodologising/mutualising/organising/institutionalising,-

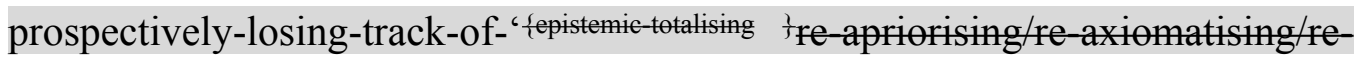
referencing $\sim$ residuality —in-re-originariness/re-origination'> of prior apriorising/axiomatising/referencing-\{of-'prospectively_implicited_attendant-ontologicalcontiguity ' educedexistentialising/contextualising/textualising_'intelligibility/epistemicity/reflexivity-contiguity$<$ imbued-notional cogency $\left.>^{\prime} \quad\right\}$-constitutedness -in-preconverging-entailment $\rangle . \quad$ This insight effectively highlights the 'constraining/defining intersolipsistic reflexivesublimating/unreflexive-desublimating measure/objectification that is unlimitedness/existenceas-ontological-normalcy/postconvergence-<in-validation-of-'metaphysics-ofabsence_epistemic-projection'> upon which limitedness/human-subpotency selfreflexive instigative-eventuating projects re-rationalisations as of more and more intolerance$<0$ f-disparateness $>$ /exactifying_precisioning-of-sublimation- $<$ as-to-postconverging narrowing-down apriorising/axiomatising/referencing-entailing-theoretical,-conceptual-andoperant-implications> (as to Being-development/ontological-framework-expansion-as-todepth-of-ontologising-development-as-infrastructure-of- meaningfulness-and-teleology , 
institutional-development-as-to-social-function-development and living-development-as-topersonality-development psychologismic epistemic acutisation difficulty-<for, residualising _ enabling the sublimating-postconverged 'substantive abstract-tissue-of-social-emanance \{epistemic-totalising 3 ? ${ }^{3}$ hermeneutically/textmally/reprojectingly/supererogatingly/zeroingly/re-

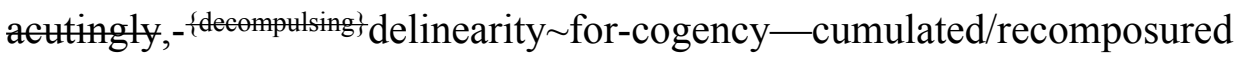
as to cumulating/recomposuring of 'prospectively_implicited_attendant-ontologicalcontiguity $^{67} \sim$ educedexistentialising/contextualising/textmalising_intelligibility/epistemicity/reflexivity-contiguity$<$ imbued-notional cogency $>^{\prime}$. When so-implied as to nascent-particular/incipient-andmaterial/technical-sublimations-<blinded-to-their-relative-ontological-completeness

reference-of-thought- devolving $>$ it can be appreciated that the 'constraining/defining intersolipsistic reflexive-sublimating/unreflexive-desublimating measure/objectification that is unlimitedness/existence-as-ontological-normalcy/postconvergence-<in-validation-of'metaphysics-of-absence_epistemic-projection'>' rather so-construed as of 'the-very-same physics <amplituding/formative-epistemicity>totalising $\sim$ devolved—purview/domain-ofconstrual-as-intrinsic-reality/ontological-veridicality/existential-reality' speaks to the fact that the veridically limitedness/human-subpotency cumulating/recomposuring intolerance-<ofdisparateness $>$ /exactifying_precisioning-of-sublimation-<as-to-postconverging-narrowingdown apriorising/axiomatising/referencing-entailing-theoretical,-conceptual-and-operantimplications $>$ of classical-mechanics-axiomatic-constructs (as to a contentivity/argumentativity/dialecticism/discursivity along the 'defining apriorising/axiomatising/referencing' of space and time, atomicity, etc. implications) rather ended up 'intolerance-<of-disparateness>/exactifying_precisioning in prospective sublimation' as theory-of-relativity-together-with-quantum-mechanics-axiomatic-constructs (as to a 
'prospectively

re-rationalisation-of-

contentivity/argumentativity/dialecticism/discursivity' along the 're-defining apriorising/axiomatising/referencing' of spacetime, quantum, etc. implications); and this is perfectly in contrast to a wrong intuition of the implications of intolerance- $<$ ofdisparateness $>$ /exactifying_precisioning-of-sublimation-<as-to-postconverging-narrowingdown apriorising/axiomatising/referencing-entailing-theoretical,-conceptual-and-operantimplications $>$ strongly associated with human social-and-institutional-frameworks-ofreferencing/registering/decisioning existentialising-decisionality-<as-to-disontologising/reentelogising aporeticism $>$ rather falling back upon the mere-formulaicity/ritualisation- $<$ as-tomere-formulaic — methodologising/mutualising/organising/institutionalising,-prospectivelylosing-track-of- ‘fepistemic-totalising ’’’re-apriorising/re-axiomatising/re-referencing-residuality-inre-originariness/re-origination'> imbued elaboration-as-to-mereextrapolating/constituting/abstracting/deducing/inferring-of-elucidation-outside'prospectively_implicited_attendant_ontological-contiguity ${ }^{67}$ ' educedexistentialising/contextalising/textualising_'intelligibility/epistemicity/reflexivity_contiguity$<$ imbued-notional cogency>' ${ }^{40}$ of the 'shallow-supererogation ${ }^{9}$ as of prior ${ }^{83}$ reference-ofthought_-point-of-devolving/departure/anchoring/backdrop_of_sublimating-nascence- $<$ as-to-

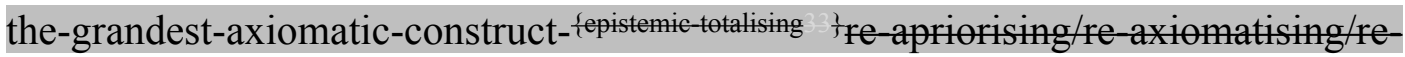
referencing residuality - in-re-originariness/re-origination of limitedness/human-subpotency prospective re-encountering/re-confrontation with unlimitedness/existence>' as to a 'flawedprior-purposefulness of ${ }^{7}$ presencing-absolutising-identitive-constitutedness ${ }^{14}$ before supposedly-prospective-thinking-purpose,-as-precalculated-purpose- $<$ as-prospectively-losingtrack-of- ‘ \{epistemic-totalising ’ apriorising/re axiomatising/re referencing-residuality-in-reoriginariness/re-origination'-of-thinking >' exercise ultimately developing into a predisposition for pedantising/muddling/formulaic-hollowing-out—in-subontologisation/subpotentiation- 


\section{〈blurring/undermining-of-prospective-totalising-entailing,-as-to-entailing-}

$<$ amplituding/formative-epistemicity>totalising in-relative-ontological-completeness $\rangle$ (thus failing to reflect prospectively the 'constraining/defining intersolipsistic reflexivesublimating/unreflexive-desublimating measure/objectification that is unlimitedness/existenceas-ontological-normalcy/postconvergence-<in-validation-of-'metaphysics-of-

absence_epistemic-projection'>' which is what is sublimatingly enabling for ontology/science as so-warranted for an appropriate nonpresencing-or-withdrawal/unenframing/reontologising-or-metaphysics-of-absence-〈implicited-epistemic-veracity-of- nonpresencing$<$ perspective-ontological-normalcy/postconvergence $>$ )-or-transcendental-reasoning-ofevent ${ }^{3}$-as-prospective-ontology-origination implied 'deconstruction conception as to epistemicgrowth,-as-\{veridical/sound\}-relative-reflexivity-in-existence/relativising from-limitedmentation-as-its-deepening/psychologismic epistemic acutisation residualising, ${ }_{\{\text {decompulsing }}$ delinearity for-cogeney'). Such a failure of limitedness/human-subpotency cumulating/recomposuring interance $<$ of disparateness $>$ /exactifying_precisioning-ofsublimation-<as-to-postconverging-narrowing-down apriorising/axiomatising/referencingentailing-theoretical,-conceptual-and-operant-implications $>$ as relatively associated with human social-and-institutional-frameworks-of — referencing/registering/decisioning existentialisingdecisionality-<as-to-disontologising/re-ontologising aporeticism $>$ is merely the manifestation of the lack of 'prospective ${ }^{83}$ reference-of-thought appraisal of sublimating-nascence comprehensiveness/nonimmediacy/indirectness' for 'supererogatory $\sim$ wholesomeness/profound-supererogation ${ }^{96}$ as of prospective ${ }^{83}$ reference-ofthought_ — point-of-devolving/departure/anchoring/backdrop_of_sublimating-nascence- $<$ as-tothe-grandest-axiomatic-construct-fepistemic-talising ${ }_{3}^{+}$re-apriorising/re-axiomatising/rereferencing residuality-in-re-originariness/re-origination of limitedness/human-subpotency prospective re-encountering/re-confrontation with unlimitedness/existence>'; and as so- 
reflected as to 'prospective sublimating-nascence_incipience/instantaneity/directness\{ontologically-flawed_prior_mere_social-functioning-and-accordance_as-of-social-stakecontention-or-confliction\} associative-distortion-of-referencing/registering/decisioning' arising with say a merely positive-opportunism-of-social-functioning-and-accordance ontologically-flawed conception substituting for ontological-veracity-<as-to-prospectiveontologising-and-re-ontologising $>$ that doesn't speak to 'prospective postconverging aporeticism-overcoming/mnovercoming of prior-perspectivefalsity/falseness/fallaciousness'. Contrastively, while even nascent-particular/incipient-andmaterial/technical-sublimations-<blinded-to-their-relative-ontological-completeness reference-of-thought- devolving $>$ equally do face such ontologising misconstrual about requisite limitedness/human-subpotency cumulating/recomposuring intolerance-<ofdisparateness $>$ /exactifying_precisioning-of-sublimation-<as-to-postconverging-narrowingdown apriorising/axiomatising/referencing-entailing-theoretical,-conceptual-and-operantimplications $>$ as more pointedly associated for instance with issues of science-ideology, inmany-ways as to the natural sciences sublimating-nascence incipience/instantaneity/directness the 'constraining/defining intersolipsistic reflexive-sublimating/unreflexive-desublimating measure/objectification that is unlimitedness/existence-as-ontologicalnormalcy/postconvergence-<in-validation-of-‘metaphysics-of-absence_epistemic-projection’> is more decisively potent in undermining such induced desublimating; such that such ontologising misconstrual in the natural sciences is rather of a 'tepid problem-of-direction of sublimation' that hover in many scientific fields given inherent human limited-mentationcapacity —as-subjecting-'educed-unlimitedness/existence-sublimating nascence' to-

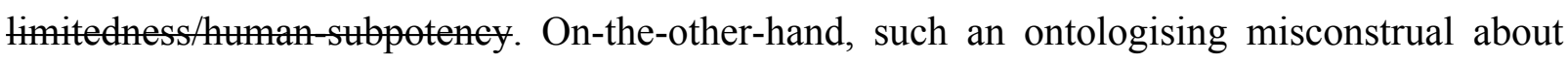
requisite limitedness/human-subpotency cumulating/recomposuring intolerance-<ofdisparateness $>$ /exactifying_precisioning-of-sublimation-<as-to-postconverging-narrowing- 
implications $>$ associated with many a social domain can actually go unthought/unnoticed as to the overt or covert non-ontologising/disontologising motive arising from the strong emotionalinvolvement of social-functioning-and-accordance-as-of-social-stake-contention-orconfliction as to a 'generalised vacillating quasi-nonontologising by punctual-ontologising' relation to social ${ }^{56}$ meaningfulness-and-teleology ${ }^{99}$ and so as merely a reflection of the greater aestheticisation - beholdening-out-of-bechancing/taxingness-of-originariness drawback of social-and-institutional-frameworks-of — referencing/registering/decisioning existentialisingdecisionality-<as-to-disontologising/re-ontologising aporeticism $>$, and thus critically speaking of a 'more profound problem-of-driving for sublimation' wherein common/mutual reontologising purpose and terms of sublimation can be questionable/uncertain as so-associated with an overemphasis on institutionalised prescience as of intellectual entitlement induced blurriness-<sterilising/anecdotalising/trivialising-of-prospective-re-ontologising_bypreconverging,-in-disontologising-formulaic-dragging-out/hollowing-out>. Ultimately, (as to prospective conceptivity/epistemic-reflexivity/epistemicity-relativism-determinism$<$ reifying \{as-to-knowledge-developing\}-and-empowering $>$ imbued epistemic-growth,-as\{reridieal/sound\}-relative-reflexivity-in-existence/relativising from limited mention as itsdeepening/psychologismic epistemic_acutisation residualising, \{decompulsing $\}$ delinearity foreogency) such an elucidation of limitedness/human-subpotency cumulating/recomposuring intolerance-<of-disparateness $>$ /exactifying_precisioning-of-sublimation-<as-topostconverging-narrowing-down apriorising/axiomatising/referencing-entailing-theoretical,conceptual-and-operant-implications $>$ is vital given the 'requisite mutual reinforcement of both nascent-particular/incipient-and-material/technical-sublimations- $<$ blinded-to-their-relativeontological-completeness - reference-of-thought- devolving> and social-and-institutionalframeworks-of — referencing/registering/decisioning existentialising-decisionality-<as-to- 
disontologising/re-ontologising aporeticism $>$ ' for their respective prospective sublimation. Along this line, it is important to effectively elucidate the veridical ontologising implications of the 'constraining/defining intersolipsistic reflexive-sublimating/unreflexive-desublimating measure/objectification that is unlimitedness/existence-as-ontologicalnormalcy/postconvergence-<in-validation-of-'metaphysics-of-absence_epistemic-projection'> with regards to limitedness/human-subpotency epistemic-growth,-as- \{veridical/sound\}relative-reflexivity-in-existence/relativising from-limited-mentation-as-itsdeepening/psychologismic epistemic acutisation residualising, decmpungl delinearity foreogency as to psychologismic-epistemic-acutisation-<as-to-postconverging-dementating/structuring/paradigming,-eliciting-of-existence's-sublimating-nascence-inprospective-aporeticism-overcoming/unovercoming>. It can be appreciated herein that the postmodern notion of " ${ }^{~ n o n p r e s e n c i n g-<p e r s p e c t i v e-o n t o l o g i c a l-n o r m a l c y / p o s t c o n v e r g e n c e ~}>$ relativism/relative-scope for epistemic-growth,-as - \{veridical/sound\}-relative-reflexivity-inexistence/relativising from limited-mentation-as-its-deepening/psychologismic epistemicacutisation residualising, \{decompulsing delinearity for-cogency' (as not 'metaphysical/ideological advocacy' but rather ontologically-veridical observations/remarks/“constatations’ of limitedness/human-subpotency relative ontologicalperformance ${ }^{72}-<$ including-virtue-as-ontology $>/$ morality/ethics/justice/etc. as to when striving to reflect unlimitedness/existence-<full-potency-of_sublimating nascence $>$ ) is merely the natural reflection of the implication of the 'reflexive epistemic relation of limitedness/humansubpotency to unlimitedness/existence-<full-potency-of_sublimating nascence $>$ '; and so as to the operative diametricality of 'human-epistemicity/human-epistemicity-developing- $<$ limitedmentation-capacity-deepening-as-subjecting limitedness/hmman-subpotency to 'educedunlimitedness/existence-sublimating nascence' ${ }^{53}$,-as-to-transcendence-andsublimity/sublimation/supererogatery $\sim$ de-mentativity>' and 'inherent existence's immanence 
which is already given at all times as to its inherent full-potency-independence in its superseding-oneness-of-ontology/ontological-veridicality/relative-unreflexivity/relativereflexivity - ontological-contiguity ${ }^{67}$ so full-potency-independent of abstractly/potentially manifestable human-epistemicity/human-epistemicity-developing'. The simple implication here is that the 'constraining/defining intersolipsistic reflexive-sublimating/unreflexivedesublimating measure/objectification that is unlimitedness/existence-as-ontologicalnormalcy/postconvergence-<in-validation-of-'metaphysics-of-absence_epistemic-projection' is ever always absolutely given and limitedness/human-subpotency is ever always just in a relativistic epistemic relation to unlimitedness/existence; as 'so-interjected by the $<$ cumulating/recomposuring attendant-ontological-contiguity $>$-successive registryworldviews/dimensions defining 'implicited_attendant-ontological-contiguity ${ }^{67}$ ? educedexistentialising/contextualising/textualising_'intelligibility/epistemicity/reflexivity_contiguity<imbued-notional cogency $>^{\prime 0} \quad$ epistemic-totalising ${ }^{3}$ frame-of-entailment-of motif-andapriorising/axiomatising/referencing imbued ontological-performance ${ }^{72}-<$ including-virtue-asontology $>$ /morality/ethics/justice/etc. (as to limitedness/human-subopotency epistemic relativeontological-completeness ${ }^{87}$ construal of "the-very-same unlimitedness/existence- $<$ full potency of_sublimating nascence')'. Just as the 'the-very-same physics <amplituding-formativeepistemicity $>$ totalising $\sim$ devolved — purview/domain-of-construal-as-intrinsicreality/ontological-veridicality/existential-reality' is absolutely given inherently whether-andwhatever the Newtons and Einsteins or any human-beings reflexively theorise about it (as to the fact that valid physical manifestations as explained by the Newtons and the Einsteins did not wait for their axiomatic explanations to start manifesting and had been manifesting long before and so including physical manifestations that are not yet known and explained) and their respective theoretical axiomatic-constructs carry their given epistemic-totalising frame-ofentailment of motif-and-apriorising/axiomatising/referencing imbued ontological- 
performance ${ }^{2}-<$ including-virtue-as-ontology $>$ /morality/ethics/justice/etc. $\quad$ (as to their limitedness/human-subpotency epistemic relative-ontological-completeness ${ }^{87}$ construal of 'thevery-same physics purview-of-unlimitedness/existence-<full-potency-of_sublimating nascence>;-_implicited_attendant-ontological-contiguity ${ }^{67}$ ' educedexistentialising/contextualising/textualising_'intelligibility/epistemicity/reflexivity-contiguity$<$ imbued-notional $\sim$ cogency $>^{\prime}$ ). It can thus be appreciated that such a postmodern notion of ${ }^{6}$ nonpresencing-<perspective-ontological-normalcy/postconvergence $>$ relativism/relativescope for epistemic-growth,-as - \{veridical/sound\}-relative-reflexivity-inexistence/relativising from-limited-mentation-as-its-deepening/psychologismic epistemicacutisation residualising, ${ }^{\text {\{decompulsing }}$ delinearity for-cogency' (as to 'developed epistemic sense of nonpresencing-<perspective-ontological-normalcy/postconvergence $>$ relativism/relative-scope as projective-insights') epistemic-projectively grasps 'limitedness/human-subpotency possibilities of epistemic-totalising frame-of-entailment-ofmotif-and-apriorising/axiomatising/referencing imbued ontological-performance ${ }^{2}-<$ includingvirtue-as-ontology $>$ /morality/ethics/justice/etc. with respect to their construal of unlimitedness/existence-or-any-purview-of-unlimitedness/existence-<full-potencyof_sublimating wascences avoiding a general equating/leveling-down of limitedness/human-subpotency possibilities by 'mixing-up both relative-ontologicalincompleteness ${ }^{88}$ and relative-ontological-completeness 87 in-effect differing apriorising/axiomatising/referencing epistemic totalising ${ }^{33}$ frames-of-entailment of motif-andapriorising/axiomatising/referencing' (as it can be appreciated that a modern day physicist cannot seriously engage discursively as to expected breakthroughs in equating/leveling-down say 'theory-of-relativity-together-with-quantum-mechanics-axiomatic-constructs epistemic totalising 3 frame-of-entailment-of motif-and-apriorising/axiomatising/referencing ontological-performance ${ }^{72}-<$ including-virtue-as-ontology $>$ ' with 'classical-mechanics- 
axiomatic-constructs

ontology>'); and so as it is such a notion of ' nonpresencing-<perspective-ontologicalnormalcy/postconvergence $>$ relativism/relative-scope for epistemic-growth,-as\{veridical/sound\}-relative-reflexivity-in-existence/relativising from-limited mentation-as-itsdeepening/psychologismic epistemic-acutisation residualising, ${ }^{\text {\{decompulsing }}$ delinearity foreogency' (as to 'developed epistemic sense of 6 nonpresencing-<perspective-ontologicalnormalcy/postconvergence $>$ relativism/relative-scope as projective-insights') that enables delineating/differentiating

'apriorising/axiomatising/referencing disambiguating/de-leveling/de-ressentiment/openedconstruct-of- ${ }^{5}$ meaningfulness-and-teleology $\quad$ demoronisation- $<$ sublimating-nascence,nonextricatory-sublimating-upstreaming/'amontée'>' as of appropriate 'deconstruction conception as to epistemic-growth,-as \{veridical/sound\}-relative-reflexivity-inexistence/relativising from-limited-mentation-as-its-deepening/psychologismic epistemicacutisation residualising, of ${ }^{61}$ nonpresencing-orwithdrawal/unenframing/re-ontologising-or-metaphysics-of-absence-〈implicited-epistemicveracity-of- nonpresencing-<perspective-ontological-normalcy/postconvergence $>$ - - ortranscendental-reasoning-of-event ${ }^{38}$-as-prospective-ontology-origination (with regards to 'thevery-same physics purview-of-unlimitedness/existence-<fll-potency-of_sublimating nascence >; - 'implicited_attendant-ontological-contiguity ${ }^{6}$ ' educedexistentialising/contextualising/textualising_intelligibility/epistemicity/reflexivity-contiguity$<$ imbued-notional cogency>' $>^{\prime}$ ). Thus the effective limitedness/human-subpotency cumulating/recomposuring 'intolerance-<of-disparateness $>$ /exactifying_precisioning-ofsublimation-<as-to-postconverging-narrowing-down apriorising/axiomatising/referencingentailing-theoretical,-conceptual-and-operant-implications $>$ exercise of intelligibility' (as to 
imbued 'developing epistemic sense of nonpresencing-<perspective-ontologicalnormalcy/postconvergence $>$ relativism/relative-scope as projective-insights') necessarily speaks

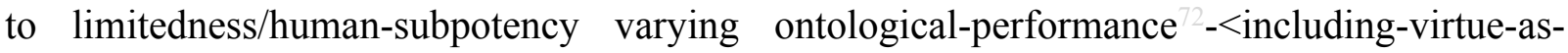
ontology $>$ /morality/ethics/justice/etc. with respect to 'the-very-same purview-ofunlimitedness/existence-<full-potency-of_sublimating nascence $>$;_-implicited_attendantontological-contiguity ${ }^{67}$; educedexistentialising/contextualising/textualising_intelligibility/epistemicity/reflexivity_contiguity$<$ imbued-notional cogency>' as to the 'warranted capacity for epistemictotalising $\sim$ resubjecting_or_totalising-entailing $\sim$ reconstrual-<of the-whole/purview-of thewhole/oneness-of-ontology>' (as human limited-mentation-capacity-deepening—as-subjectinglimitedness/human-subpotency-to-'educed-unlimitedness/existence-sublimating nascence' ${ }^{53}$ ) as to successive re-originary epistemic-growth,-as - \{veridical/sound $\}$-relative-reflexivity-inexistence/relativising from-limited-mentation-as-its-deepening/psychologismic epistemic-

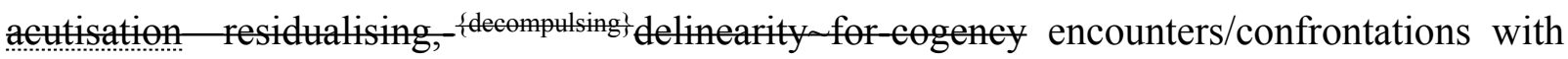
existence — as-the-absolute-a-priori-of-conceptualisation and existence—as-sublimatingwithdrawal/unenframing/re-ontologising,-elicited-from-prospective-profoundsupererogation -<as-to-perspective-ontological-normalcy/postconvergence-implied'prospective-aporeticism-overcoming/unovercoming'> (with regards Beingdevelopment/ontological-framework-expansion-as-to-depth-of-ontologising-development-asinfrastructure-of- meaningfulness-and-teleology , institutional-development-as-to-socialfunction-development and living-development-as-to-personality-development psychologismic epistemic acutisation difficulty-for, residualising \{decompulsing $\}$ delinearity for-cogency> magnitudes $\{$ of-experientiality/experiment $\}$. The postmodern notion of relativism/relative-scope as to limitedness/human-subpotency cumulating/recomposuring 'intolerance-<ofdisparateness>/exactifying_precisioning-of-sublimation-<as-to-postconverging-narrowing- 
down apriorising/axiomatising/referencing-entailing-theoretical,-conceptual-and-operant-

implications $>$ exercise of intelligibility' (imbued 'developing epistemic sense of nonpresencing-<perspective-ontological-normalcy/postconvergence $>\quad$ relativism/relativescope as projective-insights') underlies the veracity of limitedness/human-subpotency epistemic-growth,-as_ \{veridical/sound\}-relative-reflexivity-in-existence/relativising fromlimited-mentation-as-its-deepening/psychologismic epistemic-acutisation residualising, $\left\{\right.$ decompulsing ${ }^{\text {delinearity }}$ for-cogency as to psychologismic-epistemic-acutisation-<as-topostconverging-de-mentating/structuring/paradigming,-eliciting-of-existence's-sublimatingnascence-in-prospective-aporeticism-overcoming/unovercoming>, as so-undergirded herein by de-mentation-_supererogatory ontological-de-mentation-or-dialectical-de-mentationstranding-or-attributive-dialectics $\rangle. \quad$ ' $\quad$ nonpresencing-<perspective-ontologicalnormalcy/postconvergence $>$ relativism/relative-scope for epistemic-growth,-as\{veridical/sound\}-relative-reflexivity-in-existence/relativising from-limited-mentation-as-itsdeepening/psychologismic epistemic_acutisation residualising, \{decompulsing ${ }^{2}$ delinearity foreogency' (as to manifest 'developing epistemic sense of ${ }^{6}$ nonpresencing-<perspectiveontological-normalcy/postconvergence $>$ relativism/relative-scope as projective-insights') as critiqued by many a postmodern thinker distractors is rather a reflection of these distractors '7 presencing - absolutising-identitive-constitutedness ${ }^{14}$ normalising functionalism conception as to \{flawed/unsound\}-relative-unreflexivity-in-existence/absolutising from-limitedmentation/psychologismic epistemic acutisation nonresidualising imbued\{compulsing\} linearity-in-eclecticism-of-prior-mere-formulaicity/ritualisation' manifesting an underdeveloped conception of nonpresencing-or-withdrawal/unenframing/re-ontologisingor-metaphysics-of-absence-〈implicited-epistemic-veracity-of- nonpresencing-<perspectiveontological-normalcy/postconvergence $>$ /-or-transcendental-reasoning-of-event ${ }^{38}$-asprospective-ontology-origination. This is further reflected in a confused misconstruing of 
${ }^{6}$ nonpresencing-<perspective-ontological-normalcy/postconvergence $>$ relativism/relativescope for epistemic-growth,-as -\{veridical/sound\}-relative-reflexivity-inexistence/relativising from-limited-mentation-as-its-deepening/psychologismic epistemicacutisation residualising, \{decompulsing delinearity for-cogency' with such a notion as relationalism which has no relation to the epistemic-growth,-as - \{veridical/sound\}-relativereflexivity-in-existence/relativising from-limited-mentation-as-its-deepening/psychologismic epistemic-acutisation residualising, ${ }^{\text {\{decompulsing }}$ delinearity for-cogency insight (as to human psychologismic-epistemic-acutisation-<as-to-postconverging-dementating/structuring/paradigming,-eliciting-of-existence's-sublimating-nascence-inprospective-aporeticism-overcoming/unovercoming $>$ ) underlying a (notional $\sim$ reflexivity$<\{$ veridical/sound $\}$-relative-reflexivity-in-existence/relativising from-limited-mentation-as-

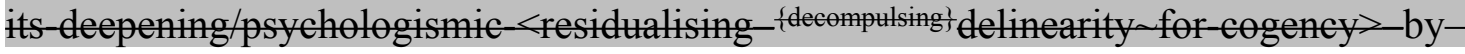
\{flawed/unsound\}-relative-unreflexivity-in-existence/absolutising from-limitedmentation/psychologismic epistemic acutisation nonresidualising imbuedfompulsing linearity in-eclecticism-of-prior-mere-formulaicity/ritualisation $>$ ) ' ${ }^{6}$ nonpresencing$<$ perspective-ontological-normalcy/postconvergence $>$ relativism/relative-scope for epistemicgrowth,-as - \{veridieal/sound\}relative-reflexivity-in-existence/relativising from limitedmentation-as-its-deepening/psychologismic epistemic acutisation residualising, \{decompulsing $\}$ delinearity for-cogency' conception of 'limitedness/human-subpotency potential' with respect to 'both the prior relative-ontological-incompleteness ${ }^{88}$ as classical-mechanicsaxiomatic-constructs and the prospective relative-ontological-completeness ${ }^{87}$ as theory-ofrelativity-together-with-quantum-mechanics - axiomatic-constructs' construing of 'the-verysame unlimitedness/existence-ffll potencof_sblimating nascence ${ }^{\prime}$ (as the 'constraining/defining intersolipsistic reflexive-sublimating/unreflexive-desublimating measure/objectification that is unlimitedness/existence-as-ontological- 
normalcy/postconvergence-<in-validation-of-'metaphysics-of-absence_epistemic-

projection'>'); as it is such a relativism/relative-scope that veridically embraces (phenomenal/manifest $\sim$ subpotencies-〈in-transitive-conflatedness -reflexivity,-in-the-fullpotency-of-existence's $\sim$ sublimating-nascence) including human-subpotency)/limitedness implied notional $\sim$ reflexivity- $<$ \{veridical/sound $\}$-relative-reflexivity-in-existence/relativising from-limited-mentation-as-its-deepening/psychologismic-<residualising\{decompulsing\} delinearity for-cogency $>$ by - fflawed/unsound\}-relative-unreflexivity-inexistence/absolutising from-limited-mentation/psychologismic epistemic acutisation nonresidualising-imbued-\{compulsing\} linearity-in-eclecticism-of-prior-mereformulaicity/ritualisation> as to unlimitedness/existence-full pon of sublimating nascence $>$. Fundamentally, it is herein contended such a confusion speaks of presumptively striving to grasp of prospective relative-ontological-completeness ${ }^{8}$-ofapriorising/axiomatising/referencing as from prior relative-ontological-incompleteness apriorising/axiomatising/referencing (more like striving to understand theory-of-relativitytogether-with-quantum-mechanics - axiomatic-constructs as from the 'classical-mechanicsaxiomatic-constructs epistemic-totalising 3 frame-of-entailment of motif-andapriorising/axiomatising/referencing ontological-performance ${ }^{72}-<$ including-virtue-asontology >' with notions like space and time, atomicity, etc. held in absolution rather than the 'former as appropriate epistemic-totalising frame-of-entailment-of-motif-andapriorising/axiomatising/referencing $\quad$ ontological-performance ${ }^{72}-$ including-virtue-as- $^{2}$ ontology>' projection as to spacetime, quantum, etc.). The notion of ' nonpresencing$<$ perspective-ontological-normalcy/postconvergence $>$ relativism/relative-scope for epistemicgrowth,-as-\{veridical/sound\}-relative-reflexivity-in-existence/relativising from-limitedmentation-as-its-deepening/psychologismic epistemic-acutisation residualising,

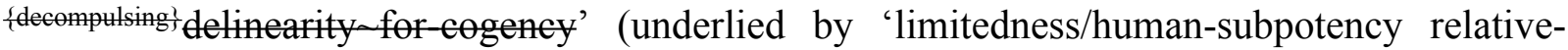


ontological-incompleteness $^{88}$ by relative-ontological-completeness ${ }^{87}$, varying projectively implied 'epistemic-totalising frames-of-entailment-of motif-andapriorising/axiomatising/referencing' ontological-performance $^{72}-<$ including-virtue-asontology>) with respect to the 'very contiguity of unlimitedness/existence-<full-potencyof_sublimating nascence> (as the-very-same unlimitedness/existence-<full-potency of_sublimating nascence>) is effectively what provides the insightful backdrop for projectively construing of the relative-unreflexivity/relative-reflexivity-ontological-contiguity ${ }^{67}$ of-thehuman-institutionalisation-process ${ }^{6}$; reflected as the sublimating-postconverged 'substantive abstract-tissue-of-social-emanance Sepistemictotalising 3 3 ${ }^{3}$ hermeneutically/textually/reprojectingly/supererogatingly/zeroingly/re-acutingly,\{decompulsing $\}$ delinearity for-cogency_cumulated/recomposured as to cumulating/recomposuring of 'prospectively_implicited_attendant-ontological-contiguity ${ }^{67}$ ' educedexistentialising/contextualising/textualising_'intelligibility/epistemicity/reflexivity-contiguity$<$ imbued-notional $\sim$ cogency $>^{\prime}$, as so-enabled by limitedness/human-subpotency cumulating/recomposuring 'intolerance-<of-disparateness $>$ /exactifying_precisioning-ofsublimation-<as-to-postconverging-narrowing-down apriorising/axiomatising/referencingentailing-theoretical,-conceptual-and-operant-implications $>$ exercise of intelligibility' (as to imbued 'developing epistemic sense of ${ }^{6}$ nonpresencing-<perspective-ontologicalnormalcy/postconvergence $>$ relativism/relative-scope as projective-insights'); and that is exactly what allows for the ontological-veracity of a sublimating ${ }^{4}$ historiality/ontologicaleventfulness 3 /ontological-aesthetic-tracing-<perspective-ontologicalnormalcy/postconvergence-reflected-'epistemicity-relativism-determinism'> 'conception of the-very-same unlimitedness/existence-full poten_fublimating nascencer ${ }^{\prime}$ over an ontologically-flawed desublimating historicity-tracing-in-presencinghyperrealisation/hyperreal-transposition 'conception of the-very-same unlimitedness/existence- 
<full-potency-of_sublimating nascence $>$ '. Such that the relative-unreflexivity/relativereflexivity - ontological-contiguity ${ }^{67}$ of-the-human-institutionalisation-process ${ }^{6} \quad$ (as $\quad$ of reference unlimitedness/existence-<full-potency-of_sublimating nascence $>$ epistemicprojection perspective) points out the notional/epistemic/bindingness ${ }^{-<a s-t o-d e t e r m i n i s m / c o n c e p t i v i t y-o f-~}$ relative-unreflexivity/relative-reflexivity $>$ ' nonpresencing-<perspective-ontologicalnormalcy/postconvergence $>$ relativism/relative-scope for epistemic-growth,-as\{veridical/sound\}-relative-reflexivity-in-existence/relativising from-limited-mentation-as-itsdeepening/psychologismic epistemic acutisation residualising, decmpungl delinearity foreogency' (as to 'developed epistemic sense of nonpresencing-<perspective-ontologicalnormalcy/postconvergence $>$ relativism/relative-scope as projective-insights') of limitedness/human-subpotency ${ }^{5}$ meaningfulness-and-teleology ${ }^{9}$ (as so insightfully divulgeable rather from the epistemic-projection perspective of the relative-ontological-completeness ${ }^{87}$ as of its perspective difference-conflatedness ${ }^{13}$-as-to-totalitative-reification-in-singularisation- $<$ as-tothe-nondisjointedness/entailment-of-prospective- nonpresencing $>$-as-veridical-epistemicityrelativism-determinism insight of 'the-very-same unlimitedness/existence-<fll potency of_sublimating nascence>' with regards to human Being-development/ontological-frameworkexpansion-as-to-depth-of-ontologising-development-as-infrastructure-of- meaningfulnessand-teleology , institutional-development-as-to-social-function-development and livingdevelopment-as-to-personality-development psychologismic epistemic-acutisationdifficulty < for, residualising \{decompulsing\} delinearity for-cogency> magnitudes $\{$ ofexperientiality/experiment' as so-reflecting their varying 'epistemic-totalising frame-of-entailment-ofmotif-and-apriorising/axiomatising/referencing ontological-performance ${ }^{72}<$ including-virtueas-ontology>' with respect to 'the-very-same unlimitedness/existence-full pon ef_sublimating nascence $>$ '). Such that with regards to Being-development/ontologicalframework-expansion-as-to-depth-of-ontologising-development-as-infrastructure-of- 
meaningfulness-and-teleology the 'prospective ${ }^{18}$ deprocrypticism-or-preemptingdisjointedness-as-of- ${ }^{8}$ reference-of-thought epistemic-projection perspective' is effectively notionally/epistemically/bindingnessly-as-to-determinism/conceptivity-of-relative-mneflexivity/relative-reflexivitys reflective of the overall relative-unreflexivity/relative-reflexivity - ontological-contiguity ${ }^{67}$ ofthe-human-institutionalisation-process ${ }^{68}$ (so-construed as notional ${ }^{18}$ deprocrypticism), as to the ‘<cumulating/recomposuring attendant-ontological-contiguity $>$-successive registryworldviews/dimensions epistemic-totalising 3 frame-of-entailment-of-motif-and-

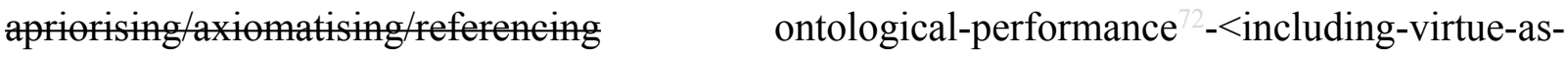
ontology >' (as from non-rules of recurrent-utter-uninstitutionalisation, non-universalising rules of base-institutionalisation-ununiversalisation, universalising rules of ${ }^{103}$ universalisation-nonpositivism/medievalism, positivising rules of positivism- ${ }^{80}$ procrypticism and prospective nondisjointing rules of ${ }^{8}$ deprocrypticism-or-preempting-disjointedness-as-of- ${ }^{3}$ reference-ofthought); and so with all the prior registry-worldviews/dimensions construable as of their relativistic 'epistemic-totalising 3 frame-of-entailment-of-motif-andapriorising/axiomatising/referencing ontological-performance ${ }^{72}-<$ including-virtue-asontology>' (with respect to 'the-very-same unlimitedness/existence-<full-potencyef_sublimating nascence>') as 'notional/epistemie/bindingness'<as-to-determinism/conceptivity-of-relativeunreflexivity/relative-reflexivitys variants' of notional ' deprocrypticism (so-implied as to their respectively given 'limitedness/human-subpotency relative-ontological-incompleteness ${ }^{88}$ by relative-ontological-completeness ${ }^{87}$, varying projectively implied 'epistemic-totalising frames-of-entailment of motif-and-apriorising/axiomatising/referencing' ontologicalperformance ${ }^{72}-<$ including-virtue-as-ontology $>$ /morality/ethics/justice/etc. with respect to 'thevery-same unlimitedness/existence-full poten of_sublimating nascences'). Likewise, with regards to nascent-particular/incipient-and-material/technical-sublimations- $<$ blinded-to-theirrelative-ontological-completeness - reference-of-thought- devolving $>$ in-many-ways for 
instance with respect to 'the-very-same physics purview-of-unlimitedness/existence- $<$ fullpotency-of_sublimating nascence>; - 'implicited_attendant-ontological-

contiguity ${ }^{6}$, educed-

existentialising/contextualising/textualising_intelligibility/epistemicity/reflexivity-contiguity-

$<$ imbued-notional cogency $>$ ', 'theory-of-relativity-together-with-quantum-mechanicsaxiomatic-constructs

epistemic-totalising

frame-of-entailment of motif-and-

apriorising/axiomatising/referencing

ontological-performance ${ }^{2}-<$ including-virtue-as-

ontology ${ }^{\prime}$ (as the relative-ontological-completeness ${ }^{87}$ ) rather underlines that in-effect 'classical-mechanics - axiomatic-constructs epistemic-totalising frame-øf-entailment-ofmotif-and-apriorising/axiomatising/referencing ontological-performance ${ }^{2}$-<including-virtueas-ontology $>^{\prime}$ (as the relative-ontological-incompleteness ${ }^{8}$ ) is rather the former's lower 'notional/epistemic/bindingness ${ }^{<a s-t o-d e t e r m i n i s m / c o n c e p t i v i t y-o f-r e l a t i v e-u n r e f l e x i v i t y / r e l a t i v e-r e f l e x i v i t y>~} \quad$ variant' as to their respectively given 'limitedness/human-subpotency relative-ontologicalincompleteness $^{88}$ by relative-ontological-completeness ${ }^{87}$ varying projectively implied 'epistemic-totalising ${ }^{3}$ frames-of-entailment-of motif-and-apriorising/axiomatising/referencing ontological-performance ${ }^{72}$-<including-virtue-as-ontology>' with respect to 'the-very-same physics purview-of-unlimitedness/existence-full poncy of_stblimating nascence;- 'implicited_attendant-ontological-contiguity ${ }^{67}$ > educedexistentialising/contextualising/textualising_intelligibility/epistemicity/reflexivity-contiguity$<$ imbued-notional cogency $>$ ' ; and so as to the fact that for instance 'classical-mechanicsaxiomatic-constructs epistemic-totalising $\quad$ frame-of-entailment-of motif-and-

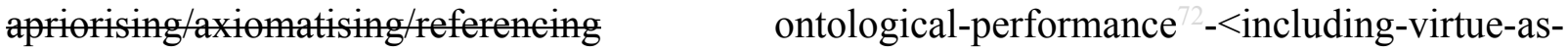
ontology >' apriorising/axiomatising/referencing conceptions of space and time, atomicity, etc. can be construed as a poorer notional/epistemic/bindingness $<$ <as-to-determinism/coneeptivity-of-relativeunreflexivity/relative-reflexivitys apriorising/axiomatising/referencing conceptions of spacetime, quantum, 
etc. respectively of 'theory-of-relativity-together-with-quantum-mechanics-axiomaticconstructs epistemic-totalising frame-of-entailment of motif-andapriorising/axiomatising/referencing ontological-performance $^{72}-<$ including-virtue-asontology ${ }^{\prime}$ (as to a difference-conflatedness ${ }^{13}$-as-to-totalitative-reification-in-singularisation$<$ as-to-the-nondisjointedness/entailment-of-prospective- nonpresencing $>$-as-veridicalepistemicity-relativism-determinism insight of 'the-very-same physics purview-ofunlimitedness/existence-<full-potency-of_sublimating nascence>;_-implicited_attendantontological-contiguity ${ }^{67}$, educedexistentialising/contextualising/textmalising_intelligibility/epistemicity/reflexivity-contiguity$<$ imbued-notional $\sim$ cogency $>^{+0}$ ) and so as both are effectively underlied notionally/epistemically/bindingnessly $y^{\text {-as-to-determinism/eoneeptivity-of-relative-unreflexivity/relative-reflexivity }>}$ by 'the-very-same physics purview-of-unlimitedness/existence-<full-potency-of_sublimating nascence $>$; - 'implicited_attendant-ontological-contiguity ${ }^{67}$ ' educedexistentialising/contextualising/textualising_intelligibility/epistemicity/reflexivity-contiguity$<$ imbued-notional cogency $>$ ' (as the 'constraining/defining intersolipsistic reflexivesublimating/unreflexive-desublimating measure/objectification that is unlimitedness/existenceas-ontological-normalcy/postconvergence-<in-validation-of-'metaphysics-ofabsence_epistemic-projection'>') as to their implicited notional $\sim$ reflexivity- $<\{$ veridical/sound $\}$ relative-reflexivity-in-existence/relativising from-limited-mentation-as-itsdeepening/psychologismic-<residualising \{decompulsing delinearity for-cogency $>$ by\{flawed/unsound\}-relative-unreflexivity-in-existence/absolutising from-limitedmentation/psychologismic epistemic acutisation nonresidualising imbued\{compulsing\} tinearity in eclecticism of prior mere formulaicity/ritualisation $>$. In this regards it is important to grasp here that the more profound philosophical insight derived from 'theory-ofrelativity-together-with-quantum-mechanics - axiomatic-constructs epistemic-totalising 
performance ${ }^{2}-<$ including-virtue-as-ontology $>$ ' rather has to do with this 'developed epistemic sense of nonpresencing-<perspective-ontological-normalcy/postconvergence $>$ relativism/relative-scope as projective-insights' for delineating/differentiating of sublimation/desublimation by 'apriorising/axiomatising/referencing disambiguating/deleveling/de-ressentiment/opened-construct-of- ${ }^{56}$ meaningfulness-and-teleology demoronisation-<sublimating-nascence,-nonextricatory-sublimating-upstreaming/'amontée'>' (and so as of appropriate 'deconstruction conception as to epistemic-growth,-as\{veridical/sound\}-relative-reflexivity-in-existence/relativising from-limited-mentation-as-itsdeepening/psychologismic epistemic-acutisation residualising, \{decompulsing $\}$ delinearity for eogency' of nonpresencing-or-withdrawal/unenframing/re-ontologising-or-metaphysics-ofabsence-〈implicited-epistemic-veracity-of- nonpresencing-<perspective-ontologicalnormalcy/postconvergence $>$ ) - or-transcendental-reasoning-of-event ${ }^{3}$-as-prospective-ontologyorigination with regards to 'the-very-same physics purview-of-unlimitedness/existence-<fullpotency-of_sublimating nascence>; - 'implicited_attendant-ontologicalcontiguity ${ }^{67}$, educedexistentialising/contextualising/textualising_intelligibility/epistemicity/reflexivity-contiguity$<$ imbued-notional cogency>' ) and not as to a naïve '7presencing-absolutising-identitiveconstitutedness ${ }^{14}$ normalising functionalism conception as to fflawed/unsound\}-relativeunreflexivity-in-existence/absolutising from-limited-mentation/psychologismic epistemic acutisation - nonresidualising imbued-\{compulsing\} linearity in-eclecticism-of-prior-mereformulaicity/ritualisation' manifesting an underdeveloped conception of nonpresencing-orwithdrawal/unenframing/re-ontologising-or-metaphysics-of-absence-_implicited-epistemicveracity-of- nonpresencing-<perspective-ontological-normalcy/postconvergence $>$ ) - ortranscendental-reasoning-of-event ${ }^{38}$-as-prospective-ontology-origination which in-many-ways 
will seem to imply a 'relationalism misconstrual' as so naively conceived philosophically with respect to general relativity (failing to philosophically reflect the delineating/differentiating of sublimation/desublimation by 'apriorising/axiomatising/referencing disambiguating/deleveling/de-ressentiment/opened-construct-of- ${ }^{56}$ meaningfulness-and-teleology demoronisation-<sublimating-nascence,-nonextricatory-sublimating-upstreaming/'amontée’>’ as to the difference-conflatedness ${ }^{13}$-as-to-totalitative-reification-in-singularisation- $<$ as-to-thenondisjointedness/entailment-of-prospective- nonpresencing $>$-as-veridical-epistemicityrelativism-determinism of 'the-very-same physics purview-of-unlimitedness/existence-<fullpotency-of_sublimating nascence>; - 'implicited_attendant-ontologicalcontiguity $^{67}$, educedexistentialising/contextualising/textualising_intelligibility/epistemicity/reflexivity-contiguity<imbued-notional cogency>' $>^{\prime 0}$ between the prior relative-ontological-incompleteness ${ }^{8}$ as classical-mechanics - axiomatic-constructs and the prospective relative-ontologicalcompleteness $^{87}$ as theory-of-relativity-together-with-quantum-mechanics-axiomaticconstructs). But actually unlimitedness/existence-<fll potency-of_sublimating nascence $>$ is effectively contiguous as to the 'constraining/defining intersolipsistic reflexivesublimating/unreflexive-desublimating measure/objectification that is unlimitedness/existenceas-ontological-normalcy/postconvergence-<in-validation-of-‘metaphysics-ofabsence_epistemic-projection'>' (and so contiguously reflected with limitedness/humansubpotency diametrical notional $\sim$ reflexivity-<\{veridical/sound $\}$-relative-reflexivity-inexistence/relativising from-limited-mentation-as-its-deepening/psychologismic<residualising ${ }^{\text {\{decompulsing }}$ \} delinearity for-cogency>-by-\{flawed/unsound\}-relativeunreflexivity-in-existencelabselutising from limited mentation/psychologismic epistemic acutisation nonresidualising-imbued-\{compulsing\} linearity-in-eclecticism-of-prior-mereformulaicity/ritualisation> imbued sublimation/desublimation as to 'limitedness/human- 
subpotency relative-ontological-incompleteness ${ }^{88}$ by relative-ontological-completeness ${ }^{87}$, varying projectively implied 'epistemic-totalising frames-of-entailment-of-motif-and-

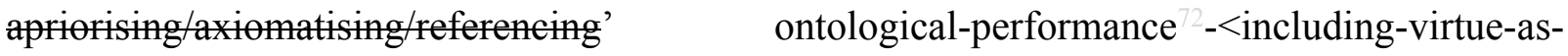
ontology>), and the idea that things are relational in existence is 'of vague epistemic implications with regards to prospective sublimation (as failing to account for notional reflexivity$<\{$ veridical/sound $\}$-relative-reflexivity-in-existence/relativising from-limited-mentation-asits-deepening/psychologismic-<residualising ${ }^{\{\text {decompulsing }}{ }^{\text {f }}$ delinearity for-cogency $>$ by \{flawed/unsound\}-relative-unreflexivity-in-existence/absolutising from-limitedmentation/psychologismic epistemic acutisation nonresidualising imbued\{compulsing\} linearity in-eclecticism-of-prior-mere-formulaicity/ritualisation $>$ as to the ' nonpresencing-<perspective-ontological-normalcy/postconvergence $>$ relativism/relativescope for epistemic-growth,-as - \{veridical/sound\}-relative-reflexivity-inexistence/relativising from-limited-mentation-as-its-deepening/psychologismic epistemicacutisation residualising, of relative-ontologicalincompleteness $^{88}$ and relative-ontological-completeness ${ }^{87}$ ') because all existential<disontologising/re-ontologising aporeticism $>$ manifestations/phenomena as to their conceptualisation are necessarily relational (whether as to direct phenomenality sublimation/desublimation or indirect/transitive epiphenomenality sublimation/desublimation as so-comprehensively reflecting ecstatic-existence-supervening-conflatedness ${ }^{13}$ ) and doesn't epistemically add anything to 'limitedness/human-subpotency sublimating epistemicity/epistemic-insight' as the latter rather requires 'appropriate limitedness/humansubpotency notional $\sim$ reflexivity- $<$ \{veridical/sound $\}$-relative-reflexivity-inexistencetrelativising from limited mentation as its deepening/psychologismic <residualising \{decompulsing $\}$ delinearity for-cogency $>$ by - flawed/unsound $\}$-relativeunreflexivity-in-existence/absolutising from-limited-mentation/psychologismic epistemic- 
acutisation nonresidualising-imbued-\{compulsing\} linearity-in-eclecticism-of-prior-mere-

formulaicity/ritualisation $>$ as to relative-ontological-completeness 87 construed as conceptivity/epistemic-reflexivity/epistemicity-relativism-determinism- $<$ reifying \{as-toknowledge-developing\}-and-empowering>' with regards to 'the-very-same unlimitedness/existence-<full-potency-of_sublimating nascence $>$ ' (with conceptivity/epistemic-reflexivity/epistemicity-relativism-determinism- $<$ reifying \{as-toknowledge-developing $\}$-and-empowering $>$ only sublimatingly arising by appropriate 'deconstruction conception as to epistemic-growth,-as_ \{veridical/sound\}-relative-reflexivityin-existence/relativising from-limited-mentation-as-its-deepening/psychologismic epistemicacutisation residualising, ${ }^{\text {\{decompulsing }}$ delinearity for-cogency' of ${ }^{6}$ nonpresencing-orwithdrawal/unenframing/re-ontologising-or-metaphysics-of-absence-_implicited-epistemicveracity-of- nonpresencing-<perspective-ontological-normalcy/postconvergence $>$ >-ortranscendental-reasoning-of-event ${ }^{38}$-as-prospective-ontology-origination with regards to 'thevery-same unlimitedness/existence-<ull-potency-of_sublimating nascence $>$ '). In this regards, such a 'relationalism misconstrual' (as to philosophical and epistemic implications) is rather a philosophical misconception of the epistemic implications of Einsteinian relativity notion (as to the reality that both Newtonian physics and Einsteinian physics are 'epistemically relational' but with the epistemic relevance arising as of their respective fflawed/unsound\}-relativeunreflexivity-in-existence/absolutising from-limited-mentation/psychologismic epistemicacutisation - nonresidualising imbued-\{compulsing\} linearity in-eclecticism-of prior-mereformulaicity/ritualisation $>$ in prior relative-ontological-incompleteness ${ }^{88}$ and $\{$ veridical/sound\} relative-reflexivity-in-existence/relativising from-limited-mentation-as-itsdeepening/psychologismic epistemic-acutisation residualising, fdecompulsing $\}$ delinearity for eogency in prospective relative-ontological-completeness ${ }^{87}$ as of varying 'limitedness/humansubpotency epistemic sublimation implications' and not arising as of the 'vague epistemic 
implications with regards to prospective sublimation' of such a 'relationalism misconstrual' that manifests ontologically-flawed 'apriorising/axiomatising/referencingequating/leveling/ressentiment/closed-construct-of- ${ }^{56}$ meaningfulness-and-teleology moronisation-<sublimating-nascence,-extricatory-desublimating-downstreaming/'avalage'>’ undifferentiation of both the prior relative-ontological-incompleteness ${ }^{88}$ and the prospective relative-ontological-completeness ${ }^{87}$ ), as to the fact that relativity (as to Einstein's 'developed epistemic sense of ${ }^{6}$ nonpresencing-<perspective-ontological-normalcy/postconvergence $>$ relativism/relative-scope as projective-insights') speaks of Einstein's notional/epistemic/bindingness sas-todeterminism/conceptivity-of-relative-unreflexivity/relative-reflexivitys impliciting of a difference-conflatedness ${ }^{13}$-as-to-totalitative-reification-in-singularisation- $<$ asto-the-nondisjointedness/entailment-of-prospective- nonpresencing $>$-as-veridicalepistemicity-relativism-determinism of 'the-very-same physics purview-ofunlimitedness/existence-<full-potency-of_sublimating nascence $>$; - 'implicited_attendantontological-contiguity ${ }^{67}$, educedexistentialising/contextualising/textualising_intelligibility/epistemicity/reflexivity-contiguity<imbued-notional cogency>' (for his prospective developing of general relativity and so in metaphoricity" from prior "classical-mechanics-axiomatic-constructs epistemic frame-of-entailment-of motif-and-apriorising/axiomatising/referencing ontologicalperformance ${ }^{2}-<$ including-virtue-as-ontology $>$ ' as so-notably associated specifically with his transformation of the 'defining conception of space and time apriorising/axiomatising/referencing implications' into the 'defining conception of spacetime apriorising/axiomatising/referencing implications'); and so-reflected as of appropriate 'deconstruction conception as to epistemic-growth,-as _veridical/some relative-reflexivityin-existence/relativising from-limited-mentation-as-its-deepening/psychologismic epistemicacutisation residualising, ${ }^{\text {\{decompulsing }}$ delinearity for-cogency' of ${ }^{6}$ nonpresencing-or- 
withdrawal/unenframing/re-ontologising-or-metaphysics-of-absence-〈implicited-epistemicveracity-of- nonpresencing-<perspective-ontological-normalcy/postconvergence $>$ - - ortranscendental-reasoning-of-event ${ }^{38}$-as-prospective-ontology-origination with regards to 'thevery-same physics purview-of-unlimitedness/existence-full poncy of stblimating nascence>;_—implicited_attendant-ontological-contiguity ${ }^{67}$ ' educedexistentialising/contextualising/textualising_intelligibility/epistemicity/reflexivity-contiguity$<$ imbued-notional cogency>' equally available to Newtonian physics (as so encapsulating the overall 'limitedness/human-subpotency notional $\sim$ reflexivity- $<$ \{veridical/sound\}-relativereflexivity-in-existence/relativising from-limited-mentation-as-its-deepening/psychologismic<residualising \{decompulsing\} delinearity for cogency>by-\{flawed/unsound\}relativeunreflexivity-in-existence/absolutising from-limited-mentation/psychologismic epistemicacutisation nonresidualising-imbued-\{compulsing\}linearity in-eclecticism-of prior-mereformulaicity/ritualisation $>$ of the-very-same physics purview-of-unlimitedness/existence- $<$ fullpotency-of_sublimating nascence>;_—implicited_attendant-ontologicalcontiguity ${ }^{67} \sim$ educedexistentialising/contextualising/textualising_'intelligibility/epistemicity/reflexivity_contiguity$<$ imbued-notional cogency $>^{\prime}$ ). It is important to note in this regards that whatever the domain of concern the diametricality of limitedness/human-subpotency and unlimitedness/existence<full-potency-of_sublimating nascence> speaks respectively of the 'possibility of transcendence of limitedness/human-subpotency' as rendered potential by the 'already given immanence of unlimitedness/existence-<full-potency-of_sublimating nascence $>$ '; as in fact transcendence, as of notional sublimation or sublimation/desublimation, is simply '(limitedness/human-subpotency) notional $\sim$ reflexivity- $<\{$ \{veridical/sound\}-relative-reflexivityin-existence/relativising from-limited-mentation-as-its-deepening/psychologismic<residualising ${ }_{\text {\{decompulsing }}$ \}elinearity for-cogency $>$ by-\{flawed/unsound\}-relative- 
unreflexivity-in-existence/absolutising from-limited-mentation/psychologismic epistemic

acutisation nonresidualising-imbued-\{compulsing\}linearity-in-eclecticism-of-prior-mere-

formulaicity/ritualisation $>$ of immanence (immanent-existence)'. Such that all potential possibilities of limitedness/human-subpotency transcendence/sublimation are rather as of epistemic-growth,-as_-\{veridical/sound\}-relative-reflexivity-in-existence/relativising fromlimited-mentation-as-its-deepening/psychologismic epistemic-acutisation residualising, \{decompulsing delinearity for-cogeney' with such a 'relationalism misconstrual' as to its flawed/unsound\}-relative-unreflexivity-in-existence/absolutising from-limitedmentation/psychologismic epistemic-acutisation nonresidualising imbued\{compulsing\} linearity in-eclecticism-of prior-mere-formulaicity/ritualisation rather implying an exercise of elaboration-as-to-mere-extrapolating/constituting/abstracting/deducing/inferring-ofelucidation-outside_-'prospectively_implicited_attendant-ontological-contiguity ${ }^{67}$ ' educedexistentialising/contextualising/textualising_'intelligibility/epistemicity/reflexivity-contiguity$<$ imbued-notional cogency $>^{\prime}$. But then given their impliciting nature the use of the term relation/relational/relationalism in the natural sciences and mathematics is often 'undergirded ineffect epistemically by reflexivity as to epistemic-growth,-as - \{veridical/sound\}-relativereflexivity-in-existence/relativising from limited mentation as its deepening/psychologismic epistemic acutisation residualising, \{decompulsing delinearity-for-cogency' which is the compulsory rule-of-thump for ontological-veracity; and so, of ontological-veracity, when such 'impliciting of relation/relational/relationalism' is as of the 'conceptivity/epistemicreflexivity/epistemicity-relativism-determinism-<reifying \{as-to-knowledge-developing $\}$-andempowering $>$ of prospectively 'implicited_attendant-ontological-contiguity ${ }^{67}$; educed-

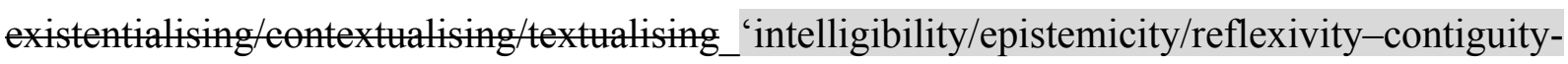
$<$ imbued-notional cogency $>^{\prime 0}$ and not prior mere-formulaicity/ritualisation-<as-to-mereformulaic - methodologising/mutualising/organising/institutionalising,-prospectively-losing- 
track-of-' \{epistemic-totalising ’’re-apriorising/re-axiomatising/re-referencing residuality-in-re-

originariness/re-origination'> imbued elaboration-as-to-mere-

extrapolating/constituting/abstracting/deducing/inferring-of-elucidation-outside-

'prospectively_implicited_attendant-ontological-contiguity ${ }^{67}$ ' educed-

existentialising/contextualising/textualising_intelligibility/epistemicity/reflexivity-contiguity-

<imbued-notional cogency ${ }^{\prime}$ (as the latter is thus unreflexive as of \{flawed/unsound relative-unreflexivity-in-existence/absolutising from-limited-mentation/psychologismic

epistemic-acutisation nonresidualising imbued-fempulsingt linearity in-eclecticism-of priormere-formulaicity/rittalisation with respect to the prospectively 'implicited_attendantontological-contiguity ${ }^{67}$ educed-

existentialising/contextmalising/textualising_'intelligibility/epistemicity/reflexivity_contiguity<imbued-notional cogency $>^{\prime}$ from whence veridical conceptivity/epistemicreflexivity/epistemicity-relativism-determinism-<reifying \{as-to-knowledge-developing $\}$-andempowering $>$ can arise). In other words, the natural sciences sublimating-nascence incipience/instantaneity/directness (in reflecting the 'constraining/defining intersolipsistic reflexive-sublimating/unreflexive-desublimating measure/objectification that is unlimitedness/existence-as-ontological-normalcy/postconvergence-<in-validation-of'metaphysics-of-absence_epistemic-projection'>') speaks of the 'constraining incipience/instantaneity/directness of their manifest sublimation/desublimation' that inherently correct their conceptualising (as quite often in the natural sciences 'initial manifest sublimation tends to precede initial overall insightful conceptualisation of the reason for the manifest sublimation'); however ultimately and as equally required with social-and-institutionalframeworks-of — referencing/registering/decisioning existentialising-decisionality_as to disontologising/re-ontologising aporeticism $\geqslant$, such initial nascent-particular/incipient-andmaterial/technical-sublimations-<blinded-to-their-relative-ontological-completeness 
reference-of-thought- devolving $>$ needs to reflexively be reconceptualised as of its 'supererogatory $\sim$ wholesomeness/profound-supererogation ${ }^{96}$ as of prospective ${ }^{83}$ reference-ofthought — point-of-devolving/departure/anchoring/backdrop_of_sublimating-nascence-<as-tothe-grandest-axiomatic-construct-fepistemic-totalising ${ }_{3}^{+}$re-apriorising/re-axiomatising/rereferencing $\sim$ residuality - in-re-originariness/re-origination of limitedness/human-subpotency prospective re-encountering/re-confrontation with unlimitedness/existence>' (so-underlied by the reflexivity as of epistemic-growth,-as-\{veridical/sound?-relative-reflexivity-inexistence/relativising from-limited-mentation-as-its-deepening/psychologismic epistemicacutisation residualising, fdecompulsing delinearity for-cogency of the prospectively 'implicited_attendant-ontological-contiguity ${ }^{67}$ ' educedexistentialising/contextmalising/textmalising_intelligibility/epistemicity/reflexivity-contiguity<imbued-notional cogency $>^{\prime}$ from whence veridical conceptivity/epistemicreflexivity/epistemicity-relativism-determinism-<reifying \{as-to-knowledge-developing $\}$-andempowering $>$ can arise). This overall limitedness/human-subpotency cumulating/recomposuring 'intolerance-<of-disparateness $>$ /exactifying_precisioning-ofsublimation-<as-to-postconverging-narrowing-down $\sim$ apriorising/axiomatising/referencingentailing-theoretical,-conceptual-and-operant-implications $>$ exercise of intelligibility' (as to imbued 'developing epistemic sense of ${ }^{6}$ nonpresencing-<perspective-ontologicalnormalcy/postconvergence $>$ relativism/relative-scope as projective-insights') underlies the statement: the veracity of say an Einsteinian notional citationality (for prospective knowledge generation 'imbued intemporal-prioritisation-of- ${ }^{8}$ reference-of-thought'-as-conflatedness ${ }^{13}$-orontological-reprojecting superseding/transcending intemporal-projection-and-appraisal of social-stake-contention-or-confliction' as to ${ }^{6}$ nonpresencing-<perspective-ontologicalnormalcy/postconvergence $>$ epistemic-projection) of Newton is veridically way more than just about an academic textbook denoting/citation exercise of any denoted/designated text by Newton 
but rather notionally such a supererogatory wholesomeness/profound-supererogation of notional citationality (as to a 'connoting supererogation-drivenness construal of the epistemictotality ${ }^{37}$ of human-textuality-<as-to-existentialising/contextualising/textualising $>$ in epistemictotalising $\sim$ resubjecting_or_totalising-entailing $\sim$ reconstrual- $<$ of the-whole/purview-of thewhole/oneness-of-ontelogy>') will imply veridical notional citationality lies with the 'relativeontological-completeness ${ }^{87}{ }^{83}$ reference-of-thought- ${ }^{8}$ devolving' as of the 'supererogatory $\sim$ wholesomeness/profound-supererogation sublimating-nascence reflected from the positivism/rational-empiricism registry-worldview/dimension (consequent cumulating/recomposuring aestheticisation-and-aestheticisation-towards-ontology-<elicitedidiomatisation>) infused with overall physics as so-influenced-and-shaped by Newtonian physics' in so-imbuing Einstein's <amplituding/formative-epistemicity >totalising thrownness-in-existence ${ }^{3}$ reference-of-thought- ${ }^{8}$ devolving as to his $<$ amplituding/formative-epistemicity $>$-totalising $\sim$ renewing-realisation/re-perception/rethought epistemic-projection of prospective physics apriorising/axiomatising/referencing-\{of'prospectively_implicited_attendant_ontological-contiguity ' educedexistentialising/contextualising/textualising_'intelligibility/epistemicity/reflexivity-contiguity-

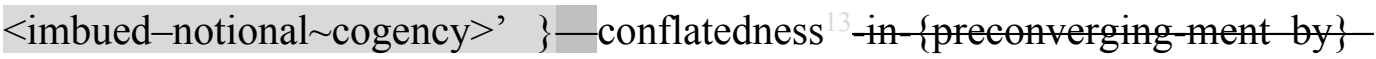
postconverging entailment. Such a limitedness/human-subpotency cumulating/recomposuring 'intolerance-<of-disparateness $>$ /exactifying_precisioning-of-sublimation- $<$ as-topostconverging-narrowing-down apriorising/axiomatising/referencing-entailing-theoretical,conceptual-and-operant-implications $>$ exercise of intelligibility' (as to imbued 'developing epistemic sense of ${ }^{6}$ nonpresencing-<perspective-ontological-normalcy/postconvergence $>$ relativism/relative-scope as projective-insights') can be similarly reflected with the disruptive re-originariness/re-origination reconceptualisations in say the chemistry and biology domains however their greater elaborateness and equally speaking of their appropriate 
limitedness/human-subpotency 'deconstruction conception as to epistemic-growth,-as\{veridical/sound\}-relative-reflexivity-in-existence/relativising from-limited-mentation-as-itsdeepening/psychologismic epistemic-acutisation residualising, fdecompulsingl delinearity foreogency' of nonpresencing-or-withdrawal/unenframing/re-ontologising-or-metaphysics-ofabsence-〈implicited-epistemic-veracity-of- nonpresencing-<perspective-ontologicalnormalcy/postconvergence $>$ ) - or-transcendental-reasoning-of-event ${ }^{38}$-as-prospective-ontologyorigination (with regards to 'their very same chemistry purview-of-unlimitedness/existence<full-potency-of_sublimating nascence>;__'implicited_attendant-ontologicalcontiguity $^{67}$, educed-

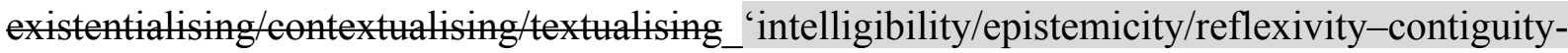
$<$ imbued-notional cogency>> or biology purview-of-unlimitedness/existence-<flll-potency өf_sublimating nascence $>$; - 'implicited_attendant-ontological-contiguity ${ }^{67}$ educedexistentialising/contextualising/textualising_intelligibility/epistemicity/reflexivity-contiguity$<$ imbued-notional cogency $>$ '0). In this regards, a similar notional/epistemic/bindingness ${ }^{<a s-t o-}$ determinism/conceptivity-of-relative-unreflexivity/relative-reflexivitys difference-conflatedness 13 -as-to-totalitativereification-in-singularisation-<as-to-the-nondisjointedness/entailment-of-prospectivenonpresencing $>$-as-veridical-epistemicity-relativism-determinism of 'the-very-same chemistry purview-of-unlimitedness/existence-<full-potency-of_sublimating nascence $>$;'implicited_attendant-ontological-contiguity ${ }^{67}$ educedexistentialising/contextualising/textualising_intelligibility/epistemicity/reflexivity-contiguity$<$ imbued-notional cogency $>$ ' can equally be appreciated with the 'conceptualisation, experimental-design and interpretative transformative sublimation apriorising/axiomatising/referencing implications' of Lavoisier's introduction of systematicand-precise measurements in chemistry ultimately paving the way for the defining insight of valence bonding in modern day chemistry (and so as to 'chemistry epistemic-totalising ${ }^{3}$ frame- 
of-entailment-of motif-and-apriorising/axiomatising/referencing ontological-performance ${ }^{72}$ <including-virtue-as-ontology >’). Insightfully, limitedness/human-subpotency cumulating/recomposuring 'intolerance-<of-disparateness $>$ /exactifying_precisioning-ofsublimation-<as-to-postconverging-narrowing-down apriorising/axiomatising/referencingentailing-theoretical,-conceptual-and-operant-implications $>$ exercise of intelligibility' (as to imbued 'developing epistemic sense of ${ }^{61}$ nonpresencing-<perspective-ontologicalnormalcy/postconvergence> relativism/relative-scope as projective-insights') speaks of limitedness/human-subpotency epistemic-growth,-as_\{veridical/sound\}-relative-reflexivityin-existence/relativising from-limited-mentation-as-its-deepening/psychologismic epistemicacutisation residualising, ${ }^{\text {ddecompulsing }}$ delinearity for-cogency as to psychologismic-epistemicacutisation-<as-to-postconverging-de-mentating/structuring/paradigming,-eliciting-ofexistence's-sublimating-nascence-in-prospective-aporeticism-overcoming/unovercoming $>$, as so-undergirded herein by de-mentation-〈supererogatory ${ }^{15}$ ontological-de-mentation-ordialectical-de-mentation - stranding-or-attributive-dialectics); and this reality reflected implicitly by postmodern thought doesn't speak to a 'disparateness-of-conceptualisation$<$ unforegrounding-ment,-failing-prospectively-to-reflect-‘immanent relativeunreflexivity/relative-reflexivity ontological-contiguity ' $>$ implied vague pluralism of thoughts' but rather a 'nondisjointing conceptualisation and purposefulness of human epistemicgrowth,-as-\{veridical/sound\}-relative-reflexivity-in-existence/relativising from-limitedmentation-as-its-deepening/psychologismic epistemic-acutisation residualising, ${ }_{\{\text {decompulsing\} }}$ delinearity for-cogency' as to 'prospective postconverging-aporeticismevercoming/unovercoming of prior-perspective_-falsity/falseness/fallaciousness' and critically so in a fundamental recognition of the human potential for self-becoming/selfconflatedness ${ }^{13}$ /formative-supererogating-<projective/reprojective-aestheticising-re-motifand-re-apriorising/re-axiomatising/re-referencing,-in-perspective-ontological- 
normalcy/postconvergence $>$. In this regards, postmodern notion of " nonpresencing$<$ perspective-ontological-normalcy/postconvergence $>$ relativism/relative-scope for epistemicgrowth,-as-\{veridical/sound\}-relative-reflexivity-in-existence/relativising from-limitedmentation-as-its-deepening/psychologismic epistemic acutisation residualising, \{decompulsing\} delinearity for-cogency\} as to limitedness/human-subpotency cumulating/recomposuring 'intolerance-<of-disparateness $>$ /exactifying_precisioning-ofsublimation-<as-to-postconverging-narrowing-down $\sim$ apriorising/axiomatising/referencingentailing-theoretical,-conceptual-and-operant-implications $>$ exercise of intelligibility' (imbued 'developing epistemic sense of ${ }^{6}$ nonpresencing- $<$ perspective-ontologicalnormalcy/postconvergence $>$ relativism/relative-scope as projective-insights') effectively underlies (as variously stated above) overall ontological-veracity as a postconvergingbirthing/nascency within prospective \{epistemic-totalising 3 re-apriorising/re-axiomatising/rereferencing $\sim$ residuality - in-re-originariness/re-origination-〈as to human profoundsupererogation for prospective apriorising/axiomatising/referencing-\{of-" prospectively implicited_attendant-ontological-contiguity ' educedexistentialising/contextualising/textualising_'intelligibility/epistemicity/reflexivity-contiguity<imbued-notional cogency >' \}-conflatedness -in-\{preconverging-ment by\} postconverging entailment that cannot be unshrouded by prior mere-formulaicity/ritualisation$<$ as-to-mere-formulaic — methodologising/mutualising/organising/institutionalising,prospectively-losing-track-of- ‘fepistemic-atising $\frac{1}{5}$ re-apriorising/re-axiomatising/rereferencing $\sim$ residuality —in-re-originariness/re-origination'> of prior apriorising/axiomatising/referencing-\{of- 'prespectively implicited_attendant-ontologicalcontiguity ' $\sim$ educedexistentialising/contextualising/textualising_ 'intelligibility/epistemicity/reflexivity-contiguity<imbued-notional cogency $\left.>^{\prime} \quad\right\}$-constitutedness -in-preconverging-entailment $\rangle . \quad$ This 
insight (in a diametrical rejection of any ontologically-flawed exercise of elaboration-as-tomere-extrapolating/constituting/abstracting/deducing/inferring-of-elucidation-outside'prospectively_implicited_attendant-ontological-contiguity ${ }^{67}$ ' educedexistentialising/contextualising/textualising_'intelligibility/epistemicity/reflexivity-contiguity$<$ imbued-notional cogency>' ${ }^{40}$ ) critically further elucidates the 'tepid problem-of-direction of sublimation' issue associated with unblurriness-<re-ontologising_by-postconverging-as-todragged-out-supererogatory $\sim$ wholesomeness/profound-supererogation ,-while-anecdotalisingprior-disontologising-thresholding $>$ and the 'more profound problem-of-driving for sublimation' associated with blurriness-<sterilising/anecdotalising/trivialising-of-prospectivere-ontologising_by-preconverging,-in-disontologising-formulaic-dragging-out/hollowing-out>. The knowledge-reification $\sim$ gesturing-and-accounting - of-epistemic-phenomenalism- $<$ inprospective_psychologismic apriorising/axiomatising/referencing-\{of-'prospectively implicited_attendant-ontological-contiguity ' educedexistentialising/contextualising/textualising_'intelligibility/epistemicity/reflexivity-contiguity<imbued-notional cogency >' \}-conflatedness -in-\{preconverging-ment by\} postconverging-entailment $>$ implications here is that 'there is no neutral presencingabsolutising-identitive-constitutedness ${ }^{14}$ point-of-devolving/departure/anchoring/backdrop for conceptualising ontological-veracity/ontological-inveracity (as so-failing to reflect the 'dynamics of apriorising/axiomatising/referencing as to preconverging/postconverging-dementating/structuring/paradigming' associated with human limited-mentation-capacity-assubjecting 'educed-unlimitedness/existence-sublimating nascence' to-limitedness/humansubpotency and limited-mentation-capacity-deepening-as-subjecting limitedness/humansubpotency to 'educed unlimitedness/existence sublimating naseence' ${ }^{5}$ )'; as rather any sublimating 'limitedness/human-subpotency conceptualisation/aestheticisation-andaestheticisation-towards-ontology-<elicited-idiomatisation $>$ of unlimitedness/existence-or- 
any-purview-of-unlimitedness/existence-<full-potency-of_sublimating nascence $>$ '

notionally/epistemically/bindingnessly-<as-to-determinism/eoneeptivity-of-relative-unreflexivity/relative-reflexivity>

about the nonpresencing-<perspective-ontological-normalcy/postconvergence $>$ relativism/relative-scope for epistemic-growth,-as - \{veridical/sound\}relative-reflexivity-inexistence/relativising from-limited-mentation-as-its-deepening/psychologismic epistemic-

acutisation residualising, ${ }^{\text {\{decompulsing }}$ delinearity for-cogeney' of prospective 'human aestheticisation-and-aestheticisation-towards-ontology-<elicited-idiomatisation $>$

unbeholdening, transcendence, decomplexification for organic-knowledge and ment of prior apriorising/axiomatising/referencing' in epistemic-totalising ${ }^{33}$ disambiguating/delineating with prior 'human aestheticisation-and-aestheticisation-towards-ontology-<elicited-idiomatisation> beholdening, non-transcendence, complexification as to mechanical-knowledge and non-ment of prior apriorising/axiomatising/referencing' as profound-supererogation prolongation of ontological-veracity over ontological-inveracity' (as to 'relevant difference-conflatedness ${ }^{13}$-asto-totalitative-reification-in-singularisation- $<$ as-to-the-nondisjointedness/entailment-ofprospective- nonpresencing $>$-as-veridical-epistemicity-relativism-determinism ${ }^{2}$ reflection of limitedness/human-subpotency cumulating/recomposuring 'intolerance- <ofdisparatens $>$ /exactifying_precisioning-of-sublimation-<as-to-postconverging-narrowingdown apriorising/axiomatising/referencing-entailing-theoretical,-conceptual-and-operantimplications $>$ exercise of intelligibility' as to imbued 'developing epistemic sense of nonpresencing-<perspective-ontological-normalcy/postconvergence $>\quad$ relativism/relativescope as projective-insights'). In-many-ways the possibility for blurriness$<$ sterilising/anecdotalising/trivialising-of-prospective-re-ontologising_by-preconverging,-indisontologising-formulaic-dragging-out/hollowing-out $>$ arises as to the failure to articulate this 'relevant difference-conflatedness ${ }^{13}$-as-to-totalitative-reification-in-singularisation- $<$ as-to-thenondisjointedness/entailment-of-prospective- nonpresencing > -as-veridical-epistemicity- 
relativism-determinism , as of the ' nonpresencing-<perspective-ontologicalnormalcy/postconvergence $>$ relativism/relative-scope for epistemic-growth,-as\{veridical/sound\}-relative-reflexivity-in-existence/relativising from-limited-mentation-as-itsdeepening/psychologismic epistemic_acutisation residualising, \{decompulsing ${ }^{2}$ delinearity foreogency of prospective 'human aestheticisation-and-aestheticisation-towards-ontology<elicited-idiomatisation> unbeholdening, transcendence, decomplexification for organicknowledge and ment of prior apriorising/axiomatising/referencing' disambiguating/delineating with prior 'human aestheticisation-and-aestheticisation-towards-ontology-<elicitedidiomatisation $>$ beholdening, non-transcendence, complexification as to mechanical-knowledge and non-ment of prior apriorising/axiomatising/referencing' as profound-supererogation prolongation of ontological-veracity over ontological-inveracity'. Critically, the natural sciences sublimating-nascence incipience/instantaneity/directness in reflecting the 'constraining/defining intersolipsistic reflexive-sublimating/unreflexive-desublimating measure/objectification that is unlimitedness/existence-as-ontologicalnormalcy/postconvergence-<in-validation-of-'metaphysics-of-absence_epistemic-projection'> more decisively potently implicits such a difference-conflatedness ${ }^{13}$-as-to-totalitativereification-in-singularisation-<as-to-the-nondisjointedness/entailment-of-prospectivenonpresencing $>$-as-veridical-epistemicity-relativism-determinism which is often massively overlooked in the <sublimation-educing-fepistemicthermeneutic/textuality/reprojecting/supererogating/zeroing/re-acuting,-

\{decompulsing $d$ delinearity $\sim$ for-cogency $>$-interpretation of natural sciences sublimation (given that the natural sciences sublimating-nascence incipience/instantaneity/directness in reflecting the 'constraining/defining intersolipsistic reflexive-sublimating/unreflexive-desublimating measure/objectification that is unlimitedness/existence-as-ontologicalnormalcy/postconvergence-<in-validation-of-'metaphysics-of-absence_epistemic-projection'> 
rather 'provides an enculturated/practiced lower threshold of explanations that renders ridiculous ontologically-flawed distraction/scepticism'). In this regards the expliciting of say Einsteinian general relativity is 'much more than just the brevity of his presentation of general relativity' but further speaks rather explicitly of general relativity induced difference-conflatedness ${ }^{13}$-as-tototalitative-reification-in-singularisation-<as-to-the-nondisjointedness/entailment-ofprospective- nonpresencing $>$-as-veridical-epistemicity-relativism-determinism of prior 'classical-mechanics - axiomatic-constructs epistemic-totalising ${ }^{3}$ frame-of-entailment-ofmotif-and-apriorising/axiomatising/referencing ontological-performance ${ }^{2}-<$ including-virtueas-ontology>'; as so-reflecting limitedness/human-subpotency cumulating/recomposuring 'intolerance-<of-disparateness>/exactifying_precisioning-of-sublimation-<as-topostconverging-narrowing-down apriorising/axiomatising/referencing-entailing-theoretical,-conceptual-and-operant-implications $>$ exercise of intelligibility' (as to imbued 'developing epistemic sense of nonpresencing-<perspective-ontological-normalcy/postconvergence $>$ relativism/relative-scope as projective-insights'). While such an elaborateness of conception is often not necessary (with respect to the natural sciences sublimating-nascence incipience/instantaneity/directness in reflecting the 'constraining/defining intersolipsistic reflexive-sublimating/unreflexive-desublimating measure/objectification that is unlimitedness/existence-as-ontological-normalcy/postconvergence-<in-validation-of'metaphysics-of-absence_epistemic-projection'>') which by their sublimating-nascence incipience/instantaneity/directness (providing an enculturated/practiced lower threshold of explanations that renders ridiculous ontologically-flawed distraction/scepticism) inherently preempts the possibility for natural sciences ontologically-flawed disparateness-ofconceptualisation-<unforegrounding-ment,-failing-prospectively-to-reflect‘immanent $\sim$ relative unreflexivity/relative-reflexivity - ontological-contiguity '>, the lack of such an exercise (of 'relevant difference-conflatedness ${ }^{3}$-as-to-totalitative-reification-in- 
singularisation-<as-to-the-nondisjointedness/entailment-of-prospective- nonpresencing $>$-asveridical-epistemicity-relativism-determinism " as of the " nonpresencing-<perspectiveontological-normalcy/postconvergence $>$ relativism/relative-scope for epistemic-growth,-as\{veridical/sound\}-relative-reflexivity-in-existence/relativising from-limited-mentation-as-itsdeepening/psychologismic epistemic-acutisation residualising, \{decompulsing ${ }^{2}$ delinearity for eogency of prospective 'human aestheticisation-and-aestheticisation-towards-ontology<elicited-idiomatisation> unbeholdening, transcendence, decomplexification for organicknowledge and ment of prior apriorising/axiomatising/referencing' in epistemic-totalising disambiguating/delineating with prior 'human aestheticisation-and-aestheticisation-towardsontology-<elicited-idiomatisation $>$ beholdening, non-transcendence, complexification as to mechanical-knowledge and non-ment of prior apriorising/axiomatising/referencing' as profound-supererogation prolongation of ontological-veracity over ontological-inveracity') in domains of relative blurriness-<sterilising/anecdotalising/trivialising-of-prospective-reontologising_by-preconverging,-in-disontologising-formulaic-dragging-out/hollowing-out> including the social domain, wrongly implicits a 'neutral ${ }^{79}$ presencing — absolutising-identitiveconstitutedness $^{14}$ point-of-devolving/departure/anchoring/backdrop for conceptualising ontological-veracity/ontological-inveracity (as so-failing to reflect the 'dynamics of apriorising/axiomatising/referencing as to preconverging/postconverging-dementating/structuring/paradigming' associated with human limited-mentation-capacity-assubjecting 'educed-unlimitedness/existence-sublimating nascence' to-limitedness/humansubpotency and limited-mentation-capacity-deepening-as-subjecting limitedness/humansubpotency-to-'educed-unlimitedness/existence-sublimating nascence' ${ }^{53}$ )' so-inducing ontologically-flawed disparateness-of-conceptualisation-<unforegrounding-ment,-failingprospectively-to-reflect-'immanent $\sim$ relative-unreflexivity/relative-reflexivity - ontologicalcontiguity '> (reflected in the fact that such domains do not project of ontological-veracity as a 
postconverging-birthing/nascency within prospective \{epistemic-totalising 3 ? $\mathrm{re}$-apriorising/reaxiomatising/re-referencing $\sim$ residuality-in-re-originariness/re-origination-〈as to human profound-supererogation for prospective apriorising/axiomatising/referencing-\{of'prospectively_implicited_attendant-ontological-contiguity ' ceducedexistentialising/entextrising/textrising_intelligibility/epistemicity/reflexivity-contiguity<imbued-notional cogency $>$ ' \}-conflatedness -in-\{preconverging-ment by\} postconverging-entailment that cannot be unshrouded by prior mere-formulaicity/ritualisation$<$ as-to-mere-formulaic - methodologising/mutualising/organising/institutionalising,prospectively-losing-track-of- ‘ $\left\{\right.$ epistemic-totalising ${ }^{\dagger}$ re-apriorising/re-axiomatising/rereferencing residuality-in-re-originariness/re-origination'> of prior apriorising/axiomatising/referencing-\{of-'prospectively implicited_attendant_ontologicalcontiguity ' educedexistentialising/contextualising/textualising_'intelligibility/epistemicity/reflexivity-contiguity<imbued-notional cogency>' $\}$-constitutedness -in-preconverging-entailment $\rangle$ and rather characteristically marked by various individual and institutional desublimating pedantising/muddling/formulaic-hollowing-out — in-subontologisation/subpotentiation〈blurring/undermining-of-prospective-totalising-entailing,-as-to-entailing$<$ amplituding/formative-epistemicity $>$ totalising in-relative-ontological-completeness $>$ manifestations and eliciting of blurriness-<sterilising/anecdotalising/trivialising-ofprospective-re-ontologising_by-preconverging,-in-disontologising-formulaic-draggingout/hollowing-out $>$ ). Critically in this regards as to the implications of limitedness/humansubpotency cumulating/recomposuring intolerance-<ofdisparateness $>$ /exactifying_precisioning-of-sublimation-<as-to-postconverging-narrowingdown apriorising/axiomatising/referencing-entailing-theoretical,-conceptual-and-operantimplications $>$ exercise of intelligibility' (as to imbued 'developing epistemic sense of 
nonpresencing-<perspective-ontological-normalcy/postconvergence $>$

relativism/relativescope as projective-insights'); the very potency for limitedness/human-subpotency sublimation possibilities manifestly elicitable out of the 'constraining/defining intersolipsistic reflexivesublimating/unreflexive-desublimating measure/objectification that is unlimitedness/existenceas-ontological-normalcy/postconvergence-<in-validation-of-'metaphysics-of-

absence_epistemic-projection'>' rather lie with the incipient/seeding human ontological-faithnotion-or-ontological-fideism—imbued-underdetermination-of-motif-and-

apriorising/axiomatising/referencing-as-so-being-as-of-existential-reality (reflected as of ontological-good-faith/authenticity ${ }^{6}$ or ontological-bad-faith/inauthenticity ${ }^{64}$ ) from when ontological-veracity is derivational (as to the self-reflexive instigative-eventuating-〈as-toteleological-instigative/incipient-

willing/arbitrariness/waywardness/faithdrivenness/supererogating-for-human-intelligibility,preceding-existence's-eventuating-sublimating-validation/desublimating-invalidation> of human ${ }^{56}$ meaningfulness-and-teleology ${ }^{9}$ ). The implication here is that the very potent natural sciences sublimating-nascence incipience/instantaneity/directness in reflecting the 'constraining/defining intersolipsistic reflexive-sublimating/unreflexive-desublimating measure/objectification that is unlimitedness/existence-as-ontologicalnormalcy/postconvergence- $<$ in-validation-of-‘metaphysics-of-absence_epistemic-projection’ $>$

(as to 'providing an enculturated/practiced lower threshold of explanations that renders ridiculous ontologically-flawed distraction/scepticism') is rather the result of the 'positivism/rational-empiricism prospectively re-ontologising re-rationalisation-ofcontentivity/argumentativity/dialecticism/discursivity' (postconvergently-habituated out of profound-supererogation from 'non-positivising $\quad{ }^{103}$ universalisation-nonpositivism/medievalism rationalisation-ofcontentivity/argumentativity/dialecticism/discursivity' as of dimensionality-of-sublimating 
conflatedness /transvaluative-rationalising/transepistemicity/anamnestic-residuality/spirit-

drivenness-equalisation)); so-reflected with the fact that budding-positivists like the Copernicuses, Galileos, Descartes, Newtons, Leibnizes, etc. introduced out of profoundsupererogation this 'positivism/rational-empiricism prospectively re-ontologising rerationalisation-of-contentivity/argumentativity/dialecticism/discursivity' which was not a given back then (since back then it wasn't psychologically related to as 'providing an enculturated/practiced lower threshold of explanations that renders ridiculous ontologicallyflawed distraction/scepticism') as we may seem to imply now as to our modern-day scientific rationalisation-of-contentivity/argumentativity/dialecticism/discursivity. In this respect 'human rationalisation-of-contentivity/argumentativity/dialecticism/discursivity is not sublimatingly given' (so-implied when of prior mere-formulaicity/ritualisation-<as-to-mere-formulaicmethodologising/mutualising/organising/institutionalising,-prospectively-losing-track-of‘fepistemic-totalising ’’’re-apriorising/re-axiomatising/re-referencing $\sim$ residuality-in-reoriginariness/re-origination'> imbued elaboration-as-to-mereextrapolating/constituting/abstracting/deducing/inferring-of-elucidation-outside'prospectively_implicited_attendant_ontological-contiguity ${ }^{67}$; educedexistentialising/contextualising/textualising_'intelligibility/epistemicity/reflexivity_contiguity$<$ imbued-notional cogency>' of the 'shallow-supererogation as of prior ${ }^{83}$ reference-ofthought — point-of-devolving/departure/anchoring/backdrop_of_sublimating-nascence-<as-tothe-grandest-axiomatic-construct- epistemic-totalising ${ }^{\frac{1}{3}}$ re-apriorising/re-axiomatising/rereferencing $\sim$ residuality - in-re-originariness/re-origination of limitedness/human-subpotency prospective re-encountering/re-confrontation with unlimitedness/existence>'); with the profound-supererogation that precedingly 'invents'/“creates'-and-'nurtures' prospective human re-rationalisation-of-contentivity/argumentativity/dialecticism/discursivity being more 
fundamental/incipient/seeding as to its inducing of prospective secondnatured institutionalisation (in 'providing an enculturated/practiced lower threshold of explanations that renders ridiculous ontologically-flawed distraction/scepticism'). This is so-validated by the inherent fact that a prior registry-worldview/dimension in relative-ontological-incompleteness 'doesn't has/carry within itself sufficient rationale as of its mere/inherent rationalisation-ofcontentivity/argumentativity/dialecticism/discursivity' to validate the prospective registryworldview/dimension sublimating re-rationalisation-ofcontentivity/argumentativity/dialecticism/discursivity but for instigated underlying human profound-supererogation as to dimensionality-of-sublimating

<<amplituding/formative>supererogatory de-mentativeness/epistemic-growth-or-

\section{conflatedness /transvaluative-rationalising/transepistemicity/anamnestic-residuality/spirit-}

drivenness-equalisation> in a prospective cumulating/recomposuring-eliciting of the 'constraining/defining intersolipsistic reflexive-sublimating/unreflexive-desublimating measure/objectification that is unlimitedness/existence-as-ontologicalnormalcy/postconvergence-<in-validation-of-'metaphysics-of-absence_epistemic-projection' (as to prospectively 'providing an enculturated/practiced lower threshold of explanations that renders ridiculous ontologically-flawed distraction/scepticism'); and so-implied as of 'epistemic-dispassion munificence/notional $\sim$ protensivity/re-ontologising $\sim$ dragging-out- $<$ as-toprospective-profound-supererogation -of-mentally-aestheticised postconverging/dialecticalthinking -qualia-schema $>$ implied continuous/re-originating/dragged-out social-constructpostconverging-nonextricatory-existential-preempting-of-existential-unthought $\sim$ sublimation accruable-and-derivable percolation-channelling- $<$ in-deferential-formalisation-transference $>$ of secondnatured institutionalisation (as 'so-transfusively determinant to overall social sublimating human ontological-performance -<including-virtue-as-ontology >')' which soreflects the 'veridical social preeminent directedness of knowledge-value and knowledge- 
discursivity orientation ('dragged-out nature or psychologismic-epistemic-acutisation- $<$ as-topostconverging-de-mentating/structuring/paradigming,-eliciting-of-existence's-sublimatingnascence-in-prospective-aporeticism-overcoming/unovercoming > as to epistemic-growth,-as\{veridical/sound\}-relative-reflexivity-in-existence/relativising from-limited-mentation-as-itsdeepening/psychologismic epistemic-acutisation residualising, $\left.{ }^{\{d e c o m p u l s i n g}\right\}$ delinearity for eogency' imbued 'supererogatory -wholesomeness/profound-supererogation as of prospective reference-of-thought_-point-of-devolving/departure/anchoring/backdrop_of_sublimating_ nascence-<as-to-the-grandest-axiomatic-construct-fepistemictalising tre-apriorising/reaxiomatising/re-referencing $\sim$ residuality —in-re-originariness/re-origination of limitedness/human-subpotency prospective re-encountering/re-confrontation with unlimitedness/existence $\left.>^{\prime}\right)^{\prime}$. This rather reflects the reality that the $<$ cumulating/recomposuring attendant-ontological-contiguity $>$-successive registryworldviews/dimensions are not incipiently/seedingly the direct outcome of 'merely produced sublimating re-rationalisation-of-contentivity/argumentativity/dialecticism/discursivity’ (which is not the existentially-disontologising/re-ontologising aporeticism $>$ sufficient reontologising basis to aporetically supersede/overcome 'dominance/vested-interest structure in relative-ontological-incompleteness ${ }^{88}$-presublimation-construct-of- ${ }^{56}$ meaningfulness-andteleology $\quad$ prospective desublimating rationalisation-ofcontentivity/argumentativity/dialecticism/discursivity of social-and-institutional-frameworksof-referencing/registering/decisioning and the derived value-construction' induced moronisation-<sublimating-nascence,-extricatory-desublimating-downstreaming/'avalage’>). It is rather the 'existential constraining of the produced sublimating re-rationalisation-ofcontentivity/argumentativity/dialecticism/discursivity' (as for instance the existential< disontologising/re-ontologising aporeticism $>$ constraining of positivistic prospective cure from the doctor, positivistic prospective technical transformation from the technician/engineer, 
positivistic prospective scientific breakthrough from the researcher, positivistic prospective social transformation from the social scientist/advocate/policymaker, etc.) that is ultimately bound cross-generationally to produce the prospective positivistic secondnatured institutionalisation superseding/overcoming of the human ontological-badfaith/inauthenticity $\sim$ preconverging-de-mentating/structuring/paradigming ${ }^{65}$ of nonpositivising 'dominance/vested-interest structure in relative-ontological-incompleteness ${ }^{8}$ presublimation-construct-of- ${ }^{5}$ meaningfulness-and-teleology 9 prospective desublimating rationalisation-of-contentivity/argumentativity/dialecticism/discursivity of social-andinstitutional-frameworks-of - referencing/registering/decisioning and the derived valueconstruction' induced disontologising/subontologising moronisation- $<$ sublimating-nascence,extricatory-desublimating-downstreaming/'avalage'>. In other words, the 'prompting of supposed rationalisation-of-contentivity/argumentativity/dialecticism/discursivity' is secondary-to-and-derived-from 'prospective existentially- $<$ disontologising/re-ontologising apereticism $>$ exuding sublimating-nascence' with the implications that it is naïve to construe of 'rationalisation-of-contentivity/argumentativity/dialecticism/discursivity of social-andinstitutional-frameworks-of — referencing/registering/decisioning' as superseding 'prospective existentially-disentogising/re ontogising apereticism> exuding sublimating-nascence'; as rather 'rationalisations-of-contentivity/argumentativity/dialecticism/discursivity of socialand-institutional-frameworks-of —referencing/registering/decisioning' are the secondnatured institutionalisation outcrop of 'prospective existentially-disontologising/re-ontologising aporeticism $>$ exuding sublimating-nascence' and their prospective validation arises as of demonstrable 'prospective existentially-<disontologising/re-ontologising aporeticism $>$ exuding sublimating-nascence' validation of the given 'rationalisation-ofcontentivity/argumentativity/dialecticism/discursivity of social-and-institutional-frameworksof - referencing/registering/decisioning'. The historiality of the matter (as of the undergirding 
overall relative-unreflexivity/relative-reflexivity - ontological-contiguity ${ }^{6}$ of-the-humaninstitutionalisation-process ${ }^{68}$ ) speaks to the very fact that 'prospective existentially$<$ disontologising/re-ontologising aporeticism $>$ exuding sublimating-nascence' is exactly what (as undergirded by human profound-supererogation ) precedingly and recurrently 'invents'/‘creates'-and-'nurtures' prospective human re-rationalisations-ofcontentivity/argumentativity/dialecticism/discursivity as of the $<$ cumulating/recomposuring attendant-ontological-contiguity $>$-successive registryworldviews/dimensions; with the onus of veracity rather incumbent to the given 'rationalisationof-contentivity/argumentativity/dialecticism/discursivity of social-and-institutionalframeworks-of_-referencing/registering/decisioning' with respect to 'prospective existentially< disontologising/re-ontologising aporeticism $>$ exuding sublimating-nascence'. Critically in this regards, sublimating 'rationalisations-ofcontentivity/argumentativity/dialecticism/discursivity of social-and-institutional-frameworksof - referencing/registering/decisioning' are more readily acquiescent to demonstrate their 'prospective existentially-<disontologising/re-ontologising aporeticism $>\quad$ exuding sublimating-nascence' (as of demoronisation-<sublimating-nascence,-nonextricatorysublimating-upstreaming/'amontée'> however their 'tepid problem-of-direction of sublimation') whereas desublimating 'rationalisations-ofcontentivity/argumentativity/dialecticism/discursivity of social-and-institutional-frameworksof-referencing/registering/decisioning' are more readily prone to strategies undermining the demonstration of 'prospective existentially-<disontologising/re-ontologising aporeticism $>$ exuding sublimating-nascence' (as of moronisation- $<$ sublimating-nascence,-extricatorydesublimating-downstreaming/'avalage'> induced blurriness$<$ sterilising/anecdotalising/trivialising-of-prospective-re-ontologising_by-preconverging,-indisontologising-formulaic-dragging-out/hollowing-out> speaking of a 'more profound problem- 
of-driving for sublimation'). This explains why the 'genuine social intellectual-function/posture claim for prospective sublimating re-rationalisation-ofcontentivity/argumentativity/dialecticism/discursivity of social-and-institutional-frameworksof-referencing/registering/decisioning and the derived value-construction' as of successive 'demoronisation-<sublimating-nascence,-nonextricatøry-sublimating-upstreaming/'amontée'> breaks' is necessarily cross-generational as to the existential-<disontologising/re-ontelogising aporeticism $>$ impact of 'prospective existentially-<isentologising/re-ontologising aporeticism $>$ exuding sublimating-nascence' rather than a naïve exercise of 'punctual aposteriorising/logicising/deriving convincing wrongly implying the same pedestal of prospective re-ontologising contemplation with the prior desublimating rationalisation-ofcontentivity/argumentativity/dialecticism/discursivity'. This is rather bound to induce ontologically-flawed 'apriorising/axiomatising/referencingequating/leveling/ressentiment/closed-construct-of- - meaningfulness-and-teleology moronisation-<sublimating-nascence,-extricatory-desublimating-downstreaming/'avalage'>’ undifferentiation of both the prior relative-ontological-incompleteness ${ }^{88}$ and the prospective relative-ontological-completeness ${ }^{8}$, as thus failing to put-into-question that the very 'prior desublimating relative-ontological-incompleteness apriorising/axiomatising/referencing imbued rationalisation-of-contentivity/argumentativity/dialecticism/discursivity' (of respectively non-universalising ancient-sophists, non-positivising medieval-scholasticism and our totalisingly-ing - discretion/whim-of-thought as to our modern-day manifestation of disparateness-of-conceptualisation-<unforegrounding-ment,-failing-prospectively-to-reflect'immanent relative-unreflexivity/relative-reflexivity - ontological-contiguity '>’) which are consequently existentially/ontologically problematic as to the ontological-veracity of prospective 'sublimating relative-ontological-completeness apriorising/axiomatising/referencing imbued sublimating re-rationalisation-of- 
contentivity/argumentativity/dialecticism/discursivity' (respectively of ${ }^{103}$ universalisingidealisation, budding-positivism and budding postmodern-thought); so-underlied as of the ontological-veracity of prospective referencing-residuality-in-re-originariness/re-origination-〈as to human profoundsupererogation for prospective apriorising/axiomatising/referencing-\{of- prespetively implicited_attendant-ontological-contiguity ' educedexistentialising/contextualising/textualising_'intelligibility/epistemicity/reflexivity-contiguity$<$ imbued-notional cogency $>$ ' \}-conflatedness -in-\{preconverging-ment by\} postconverging-ntailment that cannot be unshrouded by prior mere-formulaicity/ritualisation$<$ as-to-mere-formulaic — methodologising/mutualising/organising/institutionalising,prospectively-losing-track-of- ‘\{epistemic-totalising 3 're-apriorising/re-axiomatising/rereferencing $\sim$ residuality —in-re-originariness/re-origination'> of prior apriorising/axiomatising/referencing-\{of-'prospectively_implicited_attendant-ontologicalcontiguity ' educedexistentialising/contextualising/textualising_'intelligibility/epistemicity/reflexivity-contiguity$<$ imbued-notional cogency $\left.>^{\prime} \quad\right\}$-constitutedness -in-preconverging-entailment $\rangle$. The bigger idea here is to point out for instance that our positivism- ${ }^{80}$ procrypticism 'insinuation that its mere projecting of a rationalisation-of-contentivity/argumentativity/dialecticism/discursivity is supposedly prospectively sublimating or prospectively sublimation-inducing (as being in reflection of 'prospective existentially-<disontologising/re-ontologising_aporeticism $>$ exuding sublimating-nascence')' is in-many-ways a manifestation of its nombrilistic naivety and is ontologically-flawed (as to when manifesting shallow-supererogation when it comes to its prospectively uninstitutionalised-threshold ${ }^{102}$ limitedness/human-subpotency prospective reencountering/re-confrontation with the 'constraining/defining intersolipsistic reflexivesublimating/unreflexive-desublimating measure/objectification that is unlimitedness/existence- 
as-ontological-normalcy/postconvergence-<in-validation-of-'metaphysics-of-

absence_epistemic-projection'>'); and in-many-ways speaking of prospective 'epistemicdecadence' or teleological-decadence-<-in-dimensionality-of-desublimating-lack-of <<amplituding/formative >supererogatory de-mentativeness/epistemic-growth-orconflatedness /transvaluative-rationalising/transepistemicity/anamnestic-residuality/spiritdrivenness-equalisation) when such shallowness (of prior mere-formulaicity/ritualisation- $<$ asto-mere-formulaic_-methodologising/mutualising/organising/institutionalising,-prospectivelylosing-track-of-‘ ‘epistemic-totalising ${ }^{\dagger}$ re-apriorising/re-axiomatising/re-referencing-residuality-inre-originariness/re-origination'> imbued elaboration-as-to-mereextrapolating/constituting/abstracting/deducing/inferring-of-elucidation-outside'prospectively_implicited_attendant-ontological-contiguity ${ }^{67}$ ' educedexistentialising/contextualising/textualising_intelligibility/epistemicity/reflexivity-contiguity$<$ imbued-notional cogency>' of the 'shallow-supererogation as of prior ${ }^{83}$ reference-ofthought — point-of-devolving/departure/anchoring/backdrop_of_sublimating-nascence-<as-tothe-grandest-axiomatic-construct- fepistemic-totalising ${ }^{+}$re-apriorising/re-axiomatising/rereferencing-residuality - in-re-originariness/re-origination of limitedness/human-subpotency prospective re-encountering/re-confrontation with unlimitedness/existence>') wrongly pretend to be engaged at the same sublimating pedestal of the profound-supererogation for prospective re-rationalisation-of-contentivity/argumentativity/dialecticism/discursivity (as so-implied herein as of the specific ${ }^{18}$ deprocrypticism-or-preempting - disjointedness-as-of- ${ }^{8}$ reference-ofthought imbued prospective sublimating psychologismic-element-<as-of-diametricalconflatedness -towards-'already-given-unlimitedness/existence-<full-potencyof_sublimating nascence $>$ '-of-'limitedness/human-subpotency-as-to-its-imbued\{veridical/sound\}-relative-reflexivity-in-existence/relativising from-limited-mentation-as-itsdeepening/psychologismic epistemic-acutisation residualising, ${ }^{\text {fdecompulsing }}$ delinearity for- 
eogency'>). This more 'fundamental/incipient/seeding profound-supererogation ${ }^{6}$ insight with regards to prospective sublimating re-rationalisation-ofcontentivity/argumentativity/dialecticism/discursivity (as rather secondary-to-and-derivedfrom 'prospective existentially-disontologising/re-ontologising aporeticism $>$ exuding sublimating-nascence')' is critically relevant for appropriate limitedness/human-subpotency cumulating/recomposuring 'intolerance-<of-disparateness $>$ /exactifying_precisioning-ofsublimation-<as-to-postconverging-narrowing-down apriorising/axiomatising/referencingentailing-theoretical,-conceptual-and-operant-implications $>$ exercise of intelligibility' (as to imbued 'developing epistemic sense of nonpresencing-<perspective-ontologicalnormalcy/postconvergence $>$ relativism/relative-scope as projective-insights') with respect to the prospective \{epistemic-totalising 3 re-apriorising/re-axiomatising/re-referencing $\sim$ residuality-in-reoriginariness/re-origination of limitedness/human-subpotency prospective re-encountering/reconfrontation with the 'constraining/defining intersolipsistic reflexive-sublimating/unreflexivedesublimating measure/objectification that is unlimitedness/existence-as-ontologicalnormalcy/postconvergence-<in-validation-of-'metaphysics-of-absence_epistemic-

projection'>'; and so as rather unbeholdening to the mere-formulaicity/ritualisation-<as-tomere-formulaic — methodologising/mutualising/organising/institutionalising,-prospectivelylosing-track-of-'\{epistemic-totalising ’’re-apriorising/re-axiomatising/re-referencing-residuality-inre-originariness/re-origination'> imbued elaboration-as-to-mereextrapolating/constituting/abstracting/deducing/inferring-of-elucidation-outside'prospectively implicited_attendant-ontological-contiguity ${ }^{67}$ ' educedexistentialising/contextualising/textualising_intelligibility/epistemicity/reflexivity-contiguity$<$ imbued-notional cogency>' ${ }^{4}$ of the 'shallow-supererogation ${ }^{96}$ as of prior ${ }^{83}$ reference-ofthought_ — point-of-devolving/departure/anchoring/backdrop_of_sublimating-nascence- $<$ as-tothe-grandest-axiomatic-construct-\{epistemic-totalising ${ }^{3}$ re-apriorising/re-axiomatising/re- 
referencing residuality - in-re-originariness/re-origination of limitedness/human-subpotency prospective re-encountering/re-confrontation with unlimitedness/existence>' of our positivismprocrypticism. In other words, the 'more profound problem-of-driving for sublimation' associated with blurriness-<sterilising/anecdotalising/trivialising-of-prospective-reontologising_by-preconverging,-in-disontologising-formulaic-dragging-out/hollowing-out>, speaks of aptly relevant prospective 'fundamental/incipient/seeding profound-supererogation insight with regards to prospective sublimating re-rationalisation-ofcontentivity/argumentativity/dialecticism/discursivity' and so as to 'postmodern humansubject-emancipating-relativism-driven-recomposuring-constructivism-towardssingularisation-<as-to-the-nondisjointedness/entailment-of-prospective- nonpresencing $>$ prospectively re-ontologising re-rationalisation-ofcontentivity/argumentativity/dialecticism/discursivity' (postconvergently-habituated out of profound-supererogation from 'disjointing positivism- ${ }^{8}$ procrypticism rationalisation-ofcontentivity/argumentativity/dialecticism/discursivity'); as herein elucidated as of deprocrypticism-or-preempting-disjointedness-as-of- ${ }^{83}$ reference-of-thought 'relevant difference-conflatedness ${ }^{13}$-as-to-totalitative-reification-in-singularisation- $<$ as-to-the-

\section{nondisjointedness/entailment-of-prospective- nonpresencing $>$-as-veridical-epistemicity-}

relativism-determinism , as of the 'nonpresencing-<perspective-ontologicalnormalcy/postconvergence $>\quad$ relativism/relative-scope for epistemic-growth,-as\{veridical/sound\}-relative-reflexivity-in-existence/relativising from-limited-mentation-as-itsdeepening/psychologismic epistemic-acutisation residualising, fdecompusingl delinearity for eogency of prospective 'human aestheticisation-and-aestheticisation-towards-ontology$<$ elicited-idiomatisation $>$ unbeholdening, transcendence, decomplexification for organicknowledge and ment of prior apriorising/axiomatising/referencing' in epistemic totalising disambiguating/delineating with prior 'human aestheticisation-and-aestheticisation-towards- 
ontology-<elicited-idiomatisation $>$ beholdening, non-transcendence, complexification as to mechanical-knowledge and non-ment of prior apriorising/axiomatising/referencing' as profound-supererogation prolongation of ontological-veracity over ontological-inveracity' (as so-underlying ${ }^{18}$ deprocrypticism-or-preempting — disjointedness-as-of- ${ }^{3}$ reference-of-thought implied prospective epistemic-growth,-as - \{veridical/sound\}-relative-reflexivity-inexistence/relativising from-limited-mentation-as-its-deepening/psychologismic epistemicacutisation residualising, ${ }^{\text {\{decompulsing }}$ delinearity for-cogency as re-originary_-as-

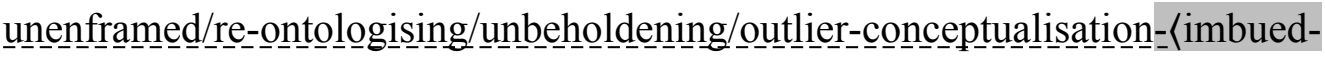

\section{postconverging/dialectical-thinking -'projective-insights'/'epistemic-projection-in-}

conflatedness '-of-notional deprocrypticism-prospective-sublimation $\rangle^{\circ}$ limitedness/humansubpotency prospective re-encountering/re-confrontation with existence-as-the-absolute-apriori-of-conceptualisation and existence — as-sublimating-withdrawal/unenframing/reontologising,-elicited-from-prospective-profound-supererogation $-<$ as-to-perspectiveontological-normalcy/postconvergence-implied-'prospective-aporeticismovercoming/unovercoming'>). As implicited throughout herein (as to the undergirding overall relative-unreflexivity/relative-reflexivity ontological-contiguity ${ }^{67} \sim$ of-the-humaninstitutionalisation-process ${ }^{68}$ sublimating insight herein), as so-underlying limitedness/humansubpotency cumulating/recomposuring 'intolerance- $<$ ofdisparateness $>$ /exactifying_precisioning-of-sublimation-<as-to-postconverging-narrowingdown apriorising/axiomatising/referencing-entailing-theoretical,-conceptual-and-operantimplications $>$ exercise of intelligibility' (as to imbued 'developing epistemic sense of nonpresencing-<perspective-ontological-normalcy/postconvergence $>\quad$ relativism/relativescope as projective-insights') with respect to prospective \{epistemic-totalising 3 're-apriorising/reaxiomatising/re-referencing residuality-in-re-originariness/re-origination of limitedness/human-subpotency prospective re-encountering/re-confrontation with the 
'constraining/defining intersolipsistic reflexive-sublimating/unreflexive-desublimating measure/objectification that is unlimitedness/existence-as-ontologicalnormalcy/postconvergence-<in-validation-of-'metaphysics-of-absence_epistemic-

projection'>'; limitedness/human-subpotency transcendence-andsublimity/sublimation/supererogatory de-mentativity rather speaks to the fact that the veridical knowledge-reification $\sim$ gesturing-and-accounting —of-epistemic-phenomenalism- $<$ inprospective_psychologismic $\sim$ apriorising/axiomatising/referencing-\{of-'prospectively implicited_attendant-ontological-contiguity ' educedexistentialising/contextualising/textualising_'intelligibility/epistemicity/reflexivity-contiguity$<$ imbued-notional cogency $>\quad\}$-conflatedness -in-\{preconverging ment by\} postconverging-entailment> holding all the 'possibilities/omnipotentiality of limitedness/human-subpotency transcendence-and-sublimity/sublimation/supereregatory $\sim$ dementativity' is rather a reflection of the overall relative-unreflexivity/relative-reflexivity ontological-contiguity ${ }^{67}$ of-the-human-institutionalisation-process ${ }^{68}$ 'grander supererogatory $\sim$ wholesomeness/profound-supererogation as of prospective ${ }^{83}$ reference-ofthought — point-of-devolving/departure/anchoring/backdrop_of_sublimating-nascence-<as-tothe-grandest-axiomatic-construct- \{epistemic-totalising $\stackrel{+}{+}$ re apriorising/re axiomatising/rereferencing $\sim$ residuality - in-re-originariness/re-origination of limitedness/human-subpotency prospective re-encountering/re-confrontation with unlimitedness/existence>' (and so-reflected as to the superseding of the 'relative-desublimating-gesturings of the successive registryworldviews/dimensions $\quad{ }^{79}$ presencing-absolutising-identitive-constitutedness $<$ amplituding/formative-epistemicity $>$ totalising $\sim$ self-referencingsyncretising/circularity/interiorising/akrasiatic-drag ${ }^{34}$ as to their mereformulaicity/ritualisation-<as-to-mere-formulaicmethodologising/mutualising/organising/institutionalising,-prospectively-losing-track-of- 
'\{epistemic-totalising ’’re-apriorising/re-axiomatising/re-referencing -residuality-in-re-

originariness/re-origination'> imbued elaboration-as-to-mereextrapolating/constituting/abstracting/deducing/inferring-of-elucidation-outside'prospectively_implicited_attendant-ontological-contiguity ${ }^{67}$ > educedexistentialising/contextualising/textualising_'intelligibility/epistemicity/reflexivity-contiguity$<$ imbued-notional cogency>' of their 'shallow-supererogation as of prior ${ }^{83}$ reference-ofthought_- point-of-devolving/departure/anchoring/backdrop_of_sublimating-nascence- $<$ as-tothe-grandest-axiomatic-construct-fepistemic talising ${ }^{+}$re-apriorising/re-axiomatising/rereferencing residuality -in-re-originariness/re-origination of limitedness/human-subpotency prospective re-encountering/re-confrontation with unlimitedness/existence>'). The above articulation is basically a reflection of 'human consciousness notional protensivity imbuing prospective psychologismic-epistemic-acutisation-<as-to-postconverging-dementating/structuring/paradigming,-eliciting-of-existence's-sublimating-nascence-inprospective-aporeticism-overcoming/unovercoming $>$ as to epistemic-growth,-as\{veridical/sound\}-relative-reflexivity-in-existence/relativising from-limited-mentation-as-itsdeepening/psychologismic epistemic acutisation residualising, ${ }^{\text {\{decompulsing }}$ delinearity forequey'; as to the fact that 'possibility-levels of limitedness/human-subpotency transcendenceand-sublimity/sublimation/supererogatory de-mentativity' are veridically varying abstractly 'foregathered sublimating-levels of supererogatory wholesomeness/profound-supererogation as of prospective reference-of-thought—point-ofdevolving/departure/anchoring/backdrop_of_sublimating-nascence-<as-to-the-grandestaxiomatic-construct-\{epistemic-totalising ${ }^{\frac{1}{3}}$ re-apriorising/re-axiomatising/rereferencing-residuality -in-re-originariness/re-origination of limitedness/human-subpotency prospective re-encountering/re-confrontation with unlimitedness/existence> beyond delusionary conception of sublimation as to the desublimating-levels of 'shallow- 
supererogation as of prior $\quad{ }^{83}$ reference-of-thought—point-ofdevolving/departure/anchoring/backdrop_of_sublimating-nascence-<as-to-the-grandestaxiomatic-construct-\{epistemic-alising ${ }^{+}$re-apriorising/re-axiomatising/rereferencing residuality - in-re-originariness/re-origination of limitedness/human-subpotency prospective re-encountering/re-confrontation with unlimitedness/existence>' as to their mereformulaicity/ritualisation-<as-to-mere-formulaicmethodologising/mutualising/organising/institutionalising,-prospectively-losing-track-of‘fepistemic tratising †re-apriorising/re-axiomatising/re-referencing residuality-in-reoriginariness/re-origination’> imbued elaboration-as-to-mereextrapolating/constituting/abstracting/deducing/inferring-of-elucidation-outside'prospectively_implicited_attendant-ontological-contiguity ${ }^{67}$ 'educedexistentialising/contextualising/textualising_'intelligibility/epistemicity/reflexivity_contiguity$<$ imbued-notional cogency $>$ ' The bigger point of this elucidation is rather to articulate and nurture the appropriate and warranted 'psychologismic-epistemic-acutisation-<as-topostconverging-de-mentating/structuring/paradigming,-eliciting-of-existence's-sublimatingnascence-in-prospective-aporeticism-overcoming/unovercoming $>$ as to epistemic-growth,-as \{veridieal/sound\} relative-reflexivity-in-existence/relativising from limited mentation as its deepening/psychologismic epistemic-acutisation residualising, ${ }^{\text {fdecompulsing }}$ delinearity for eogency' of requisite angling-of-imaginary epistemic-projection perspective for prospective ontologising-and-re-ontologising sublimating projective-insights beyond and contrasted with the cloudiness of 'human lifespan extricatory punctuality/immediacy of depth-of-thought inherent psychical-nascency' deficient contemplative capacity for prospective sublimating projectiveinsights. Critically, this is merely a reflection of the fact that unlimitedness/existence-full potency-of_sublimating nascence> 'objectively holds upstream/en-amont' (as to the 'grander supereregatery $\sim$ wholesomeness/profound-supererogation ${ }^{96}$ as of prospective ${ }^{83}$ reference-of- 
thought_-point-of-devolving/departure/anchoring/backdrop_of_sublimating-nascence- $<$ as-tothe-grandest-axiomatic-construct-\{epistemic-totalising ${ }^{\frac{1}{3}}$ re-apriorising/re-axiomatising/re-

referencing residuality - in-re-originariness/re-origination of limitedness/human-subpotency prospective re-encountering/re-confrontation with unlimitedness/existence> for limitedness/human-subpotency omnipotentiality underlying the relative-unreflexivity/relativereflexivity - ontological-contiguity ${ }^{67}$ of-the-human-institutionalisation-process ${ }^{68}$ ) the fuller sublimating projective-insights potential of limitedness/human-subpotency epistemic-growth,as-\{veridical/sound\}-relative-reflexivity-in-existence/relativising from-limited-mentationas-its-deepening/psychologismic epistemic-acutisation - residualising, $\{$ decompulsing $\}$ delinearity for-cogency, speaking of requisite sublimating 'upstreaming'/'amontée' so-construed as of 'supererogatory $\sim$ wholesomeness/profound-supererogation as of prospective reference-of-thought — point-of-devolving/departure/anchoring/backdrop_of_sublimating_ nascence-<as-to-the-grandest-axiomatic-construct-\{epistemic-totalising ${ }^{\frac{1}{r}}$ re-apriorising/reaxiomatising/re-referencing $\sim$ residuality - in-re-originariness/re-origination limitedness/human-subpotency prospective re-encountering/re-confrontation with unlimitedness/existence >'; as in reality human sublimation is critically about the sublimating 'upstreaming'/'amontée' of the implications of nascent-particular/incipient-andmaterial/technical-sublimations-<blinded-to-their-relative-ontological-completeness reference-of-thought- devolving > into their true 'supererogatory $w$ wholesomeness/profoundsupererogation as of prospective ${ }^{83}$ reference-of-thought-point-ofdevolving/departure/anchoring/backdrop_of_sublimating-nascence-<as-to-the-grandestaxiomatic-construct-\{epistemic-totalising ${ }^{\stackrel{y}{\zeta}}$ re-apriorising/re-axiomatising/rereferencing residuality - in-re-originariness/re-origination of limitedness/human-subpotency prospective re-encountering/re-confrontation with unlimitedness/existence>' and so as to the enabling of human social-and-institutional-frameworks-of — referencing/registering/decisioning 
sublimating existentialising-decisionality-<as-to-disontologising/re-ontologising aporeticism $>$ (even as such an ontologically-veridical appraisal is more readily intelligible as of the more profound sublimation appreciable from an angling-of-imaginary perspective 'multicenturies-long human crossgenerational Being-development/ontological-frameworkexpansion-as-to-depth-of-ontologising-development-as-infrastructure-of- meaningfulnessand-teleology psychologismic epistemic-acutisation difficulty-<for, residualising \{decompulsing\} delinearity for-cogeney> magnitude\{of-experientiality/experiment\} of prospective transcendence-and-sublimity/sublimation/supererogatory-de-mentativity' and more difficultly intelligible as of superficial and fashionability relation to sublimation as of 'human lifespan extricatory punctuality/immediacy of depth-of-thought inherent psychical-nascency'). Such a sublimating 'upstreaming'/'amontée' ultimately reflects holographically-<conjugatively-andtransfusively $>$ the relative-unreflexivity/relative-reflexivity - ontological-contiguity $\sim$ of-thehuman-institutionalisation-process (as the 'grander supereregatery $\sim$ wholesomeness/profoundsupererogation as of prospective ${ }^{83}$ reference-of-thought-point-ofdevolving/departure/anchoring/backdrop_of_sublimating-nascence-<as-to-the-grandestaxiomatic-construct-\{epistemic-totalising $\stackrel{+}{\text { J }}$ re-apriorising/re-axiomatising/rerefereneing-residuality - in-re-originariness/re-origination of limitedness/human-subpotency prospective re-encountering/re-confrontation with unlimitedness/existence>'); and so-reflected beyond a mere prosaic conception of 'holographically-<conjugatively-and-transfusively $>$ ' but speaking to a sublimating 'upstreaming'/'amontée' analytical dragging-out/projective intellection (which 'possible apparent unconventionality/eccentricity' is rather a reflection of the ontological-inveracity of the 'relative-desublimating-gesturing of limitedness/humansubpotency station/locus of <amplituding/formative-epistemicity>-totalising $\sim$ thrownness-inexistence $^{35}$ but rather effectively reflects the fuller ontological-veracity of the 'constraining/defining intersolipsistic reflexive-sublimating/unreflexive-desublimating 
measure/objectification

that

unlimitedness/existence-as-ontologicalnormalcy/postconvergence- $<$ in-validation-of-'metaphysics-of-absence_epistemic-projection'> as to prospective relative-sublimating-gesturing). Such a sublimating 'upstreaming'/'amontée' is rather the "veridical profound-supererogation which is uncircumventable/indispensible for prospective sublimating intellection (as of its imbued psychologismic-epistemic-acutisation<as-to-postconverging-de-mentating/structuring/paradigming,-eliciting-of-existence'ssublimating-nascence-in-prospective-aporeticism-overcoming/unovercoming $>$ as to epistemicgrowth,-as-\{veridical/sound\}-relative-reflexivity-in-existence/relativising from-limitedmentation-as-its-deepening/psychologismic epistemic acutisation residualising, \{decompulsing delinearity for-cogency)' for the prospect for prospective human Beingdevelopment/ontological-framework-expansion-as-to-depth-of-ontologising-development-asinfrastructure-of- meaningfulness-and-teleology ; and as the psychologismic-element-<as-ofdiametrical-conflatedness -towards-'already-given-unlimitedness/existence-<full-potencyof_sublimating nascence >’'of-'limitedness/human-subpotency-as-to-its-imbued\{veridical/sound\}-relative-reflexivity-in-existence/relativising from-limited-mentation-as-its-

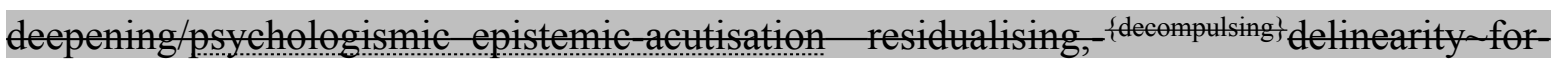
eogeney'> of prospective sublimating ${ }^{56}$ meaningfulness-and-teleology ${ }^{9}$ speaks of such a foundational/incipient/seeding sublimating transformation from say a 'non-positivising mindset into a positivising mindset (and so beyond a 'mere-formulaicity/ritualisation-<as-to-mereformulaic - methodologising/mutualising/organising/institutionalising,-prospectively-losingtrack-of-' ‘epistemic-tolising ’’re-apriorising/re-axiomatising/re-referencing residuality-in-reoriginariness/re-origination'> imbued elaboration-as-to-mereextrapolating/constituting/abstracting/deducing/inferring-of-elucidation-outside'prospectively_implicited_attendant_ontological-contiguity ${ }^{67}$ ' educedexistentialising/contextmalising/textualising_'intelligibility/epistemicity/reflexivity_contiguity- 
$<$ imbued-notional cogency $>$ 'predisposition' of the prior registry-worldview/dimension as it fails to reflect prospective \{epistemic-totalising ${ }^{3}$ re-apriorising/re-axiomatising/rereferencing residuality -in-re-originariness/re-origination of limitedness/human-subpotency prospective re-encountering/re-confrontation with the "constraining/defining intersolipsistic reflexive-sublimating/unreflexive-desublimating measure/objectification that is unlimitedness/existence-as-ontological-normalcy/postconvergence- $<$ in-validation-of'metaphysics-of-absence_epistemic-projection'>' as of the requisite sublimating 'upstreaming'/'amontée' as to 'supereregatory wholesomeness/profoundsupererogation as of prospective ${ }^{83}$ reference-of-thought-point-ofdevolving/departure/anchoring/backdrop_of_sublimating-nascence-<as-to-the-grandestaxiomatic-construct-\{epistemic-totalising ${ }^{3}$ re-apriorising/re-axiomatising/rereferencing - residuality - in-re-originariness/re-origination of limitedness/human-subpotency prospective re-encountering/re-confrontation with unlimitedness/existence>'. The 'requisite prospective sublimating psychologismic-element-<as-of-diametrical-conflatedness -towards'already-given-unlimitedness/existence-<full-potency-of_sublimating nascence $>$ '-of‘limitedness/human-subpotency-as-to-its-imbued-\{veridical/sound\}-relative-reflexivity-inexistence/relativising from limited mentation as its deepening/psychologismic epistemic acutisation residualising, \{decompulsing delinearity for-cogeney’> of prospective sublimating meaningfulness-and-teleology ${ }^{9}$ is easily missed as to the fact for instance that our positivismprocrypticism/disjointedness-as-of- ${ }^{8}$ reference-of-thought prospective relativedesublimating-gesturing in-many-ways 'implicitly forecloses by its mereformulaicity/ritualisation-<as-to-mere-formulaicmethodologising/mutualising/organising/institutionalising,-prospectively-losing-track-of‘ \{epistemic-totalising ’̀ re-apriorising/re-axiomatising/re-referencing rresiduality-in-reoriginariness/re-origination'> imbued elaboration-as-to-mere- 
extrapolating/constituting/abstracting/deducing/inferring-of-elucidation-outside'prospectively_implicited_attendant_ontological-contiguity ${ }^{67}$ ' educedexistentialising/contextualising/textualising_'intelligibility/epistemicity/reflexivity-contiguity$<$ imbued-notional cogency $>$ ' predisposition' the ontological-veracity that part-and-parcel of prospective knowledge involves the 'prospective trampling-upon of prior mindset to beget prospective mindset (as to the accompanying re-ontologising prospective sublimating psychologismic-element-<as-of-diametrical-conflatedness -towards-'already-givenunlimitedness/existence-<full-potency-of_sublimating nascence >’-of-'limitedness/humansubpotency-as-to-its-imbued-\{veridical/sound\}-relative-reflexivity-in-existence/relativising from-limited-mentation-as-its-deepening/psychologismic epistemic-acutisation residualising, ${ }^{\text {fdecompulsing }}$ delinearity for-cogency'> of the said prospective knowledge from prospective \{epistemic-totalising 3 re-apriorising/re-axiomatising/re-referencing $\sim$ residuality-in-reoriginariness/re-origination of limitedness/human-subpotency prospective re-encountering/reconfrontation with the 'constraining/defining intersolipsistic reflexive-sublimating/unreflexivedesublimating measure/objectification that is unlimitedness/existence-as-ontologicalnormalcy/postconvergence-<in-validation-of-‘metaphysics-of-absence_epistemic-

projection'>')'; as more conspicuously construable with respect to prospective human Beingdevelopment/ontological-framework-expansion-as-to-depth-of-ontologising-development-asinfrastructure-of- meaningfulness-and-teleology as herein implied-and-underlied by the full comprehension of the term ${ }^{15}$ de-mentation-〈supererogatory 0 ontological-de-mentation-ordialectical-de-mentation - stranding-or-attributive-dialectics) (underlining/emphasising the 'requisite prospective sublimating psychologismic-element-<as-of-diametrical-conflatedness towards-'already-given-unlimitedness/existence-<full-potency-of_sublimating nascence $>$ '-of‘limitedness/human-subpotency-as-to-its-imbued-\{veridical/sound\}-relative-reflexivity-inexistence/relativising from-limited-mentation-as-its-deepening/psychologismic epistemic- 
acutisation residualising, ${ }^{\text {\{decompulsing }}$ delinearity for-cogency’> of prospective sublimating meaningfulness-and-teleology ${ }^{\prime}$ of the <cumulating/recomposuring attendant-ontologicalcontiguity $>$-successive registry-worldviews/dimensions). This 'psychologismic-element- $<$ asof-diametrical-conflatedness -towards-'already-given-unlimitedness/existence-<full-potency of_sublimating nascence $>$ '-of-'limitedness/human-subpotency-as-to-its-imbued\{veridical/sound $\}-$ relative-reflexivity-in-existence/relativising from-limited-mentation-as-itsdeepening/psychologismic epistemic acutisation residualising, ${ }^{\text {\{decompulsing }}$ \}elinearity foreogency' $>$ of prospective sublimating ${ }^{56}$ meaningfulness-and-teleology ${ }^{9}$ is exactly what renders ontologically-flawed the notion of ${ }^{51}$ incrementalism-in-relative-ontological-incompleteness ${ }^{8}$ enframed/disontologising conceptualisation given that 'limitedness/human-subpotency diametrical epistemic projection of apriorising/axiomatising/referencing about unlimitedness/existence-<fll potency-of_sublimating nascence $>$ (as to the contiguity-ofexistence reflected as relative-unreflexivity/relative-reflexivity - ontological-contiguity $\left.{ }^{67}\right)^{\prime}$ is inherently epistemic-totalising thus speaking to the necessary 'psychologismic-epistemicacutisation-<as-to-postconverging-de-mentating/structuring/paradigming,-eliciting-ofexistence's-sublimating-nascence-in-prospective-aporeticism-overcoming/unovercoming $>$ as to epistemic-growth,-as - fveridical/sound\}relative-reflexivity-in-existence/relativising from limited-mentation-as-its-deepening/psychologismic epistemic-acutisation residualising, ${ }_{\{\text {decompulsing }}$ delinearity for-cogency' in grasping epistemic-totalisingly $33 /$ acutely the 'diametrical epistemic projection of apriorising/axiomatising/referencing' (whether so-reflecting limitedness/human-subpotency

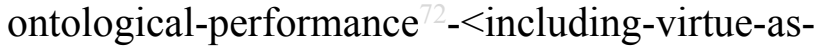
ontology $>$ /morality/ethics/justice/etc. about unlimitedness/existence-or-any-purview-ofunlimitedness/existence-ffll poten of_sublimating nascence> as of 'relative-ontologicalincompleteness ${ }^{88}$ diametrical epistemic projection of apriorising/axiomatising/referencing' or as of 'relative-ontological-completeness ${ }^{7}$ diametrical epistemic projection of 
apriorising/axiomatising/referencing'). The 'psychologismic-element-<as-of-diametricalconflatedness -towards-'already-given-unlimitedness/existence-<full-potency-

of_sublimating nascence $>$ '-of-'limitedness/human-subpotency-as-to-its-imbued-

\{veridical/sound\}-relative-reflexivity-in-existence/relativising from-limited-mentation-as-itsdeepening/psychologismic epistemic-acutisation residualising, ${ }^{\text {fdecompulsing }}$ \}elinearity foreogeney'> of prospective sublimating ${ }^{56}$ meaningfulness-and-teleology ${ }^{9}$, rather validates the ontological-veracity of $\quad{ }^{5}$ maximalising-recomposuring-for-relative-ontologicalcompleteness ${ }^{87}$ - unenframed/re-ontologising $\sim$ conceptualisation (even when reflecting limitedness/human-subpotency ontological-performance ${ }^{72}{ }^{-}$including-virtue-as- $^{2}$ ontology $>$ /morality/ethics/justice/etc. about unlimitedness/existence-or-any-purview-ofunlimitedness/existence-<full-potency-of_sublimating nascence $>$ as of 'relative-ontologicalincompleteness ${ }^{88}$ diametrical epistemic projection of apriorising/axiomatising/referencing') since the very notion of relative-ontological-incompleteness ${ }^{8}$ requires a relative-ontologicalcompleteness $^{87}$ epistemic-projection perspective to assess/implicit that it is of relativeontological-incompleteness $^{88}$ (as to the implied warranted epistemic-growth,-as\{veridical/sound\}-relative-reflexivity-in-existence/relativising from-limited-mentation-as-itsdeepening/psycholegismic epistemic acutisation residualising, ${ }^{\text {fdecompulsing }}$ delinearity for eogency as of difference-conflatedness ${ }^{13}$-as-to-totalitative-reification-in-singularisation- $<$ as-tothe-nondisjointedness/entailment-of-prospective- nonpresencing > -as-veridical-epistemicityrelativism-determinism to avoid the ontologically-flawed 'apriorising/axiomatising/referencing — equating/leveling/ressentiment/closed-construct-ofmeaningfulness-and-teleology $\quad$ moronisation-<sublimating-nascence,-extricatorydesublimating-downstreaming/'avalage'>' undifferentiation of both the prior relativeontological-incompleteness $^{88}$ and the prospective relative-ontological-completeness ${ }^{87}$, that will arise as from such a \{flawed/unsound\}-relative-unreflexivity-in-existence/absolutising from- 
limited-mentation/psychologismic epistemic acutisation nonresidualising imbued\{compulsing\} linearity in-eclecticism-of prior-mere-formulaicity/ritualisation manifestation of incrementalism-in-relative-ontological-incompleteness ${ }^{8}$ enframed/disontologising conceptualisation induced blurriness$<$ sterilising/anecdotalising/trivialising-of-prospective-re-ontologising_by-preconverging,-indisontologising-formulaic-dragging-out/hollowing-out>). But then the '<cumulating/recomposuring attendant-ontological-contiguity $>$-successive registryworldviews/dimensions are ever always successive challenges of profound-supererogation ${ }^{9}$ for prospective re-ontologising' (with regards to requisite sublimating 'upstreaming'/‘amontée' as to 'supereregatery $\sim$ wholesomeness/profound-supererogation ${ }^{6}$ as of prospective ${ }^{83}$ reference-ofthought_ — point-of-devolving/departure/anchoring/backdrop_of_sublimating-nascence- $<$ as-tothe-grandest-axiomatic-construct-\{epistemic-totalising ${ }^{3}$ re-apriorising/re-axiomatising/rereferencing $\sim$ residuality - in-re-originariness/re-origination of limitedness/human-subpotency prospective re-encountering/re-confrontation with unlimitedness/existence>', as rather the 'veridical profound-supererogation which is uncircumventable/indispensible for prospective sublimating intellection as of its imbued psychologismic-epistemic-acutisation-<as-topostconverging-de-mentating/structuring/paradigming,-eliciting-of-existence's-sublimatingnascence-in-prospective-aporeticism-overcoming/unovercoming $>$ as to epistemic-growth,-as\{veridical/sound\}-relative-reflexivity-in-existence/relativising from-limited-mentation-as-itsdeepening/psychologismic epistemic-acutisation residualising, fdecompulsingl delinearity for eogency') and so in the process of limitedness/human-subpotency cumulating/recomposuring 'intolerance-<of-disparateness>/exactifying_precisioning-of-sublimation-<as-topostconverging-narrowing-down apriorising/axiomatising/referencing-entailing-theoretical,conceptual-and-operant-implications $>$ exercise of intelligibility' (as to imbued 'developing epistemic sense of ${ }^{6}$ nonpresencing-<perspective-ontological-normalcy/postconvergence $>$ 
relativism/relative-scope as projective-insights') with respect to prospective \{epistemic-totalising $3{ }^{3}$ 'reapriorising/re-axiomatising/re-referencing $\sim$ residuality-in-re-originariness/re-origination of limitedness/human-subpotency prospective re-encountering/re-confrontation with the 'constraining/defining intersolipsistic reflexive-sublimating/unreflexive-desublimating measure/objectification that is unlimitedness/existence-as-ontologicalnormalcy/postconvergence-<in-validation-of-'metaphysics-of-absence_epistemic-

projection'>'. The fact that the '<cumulating/recomposuring attendant-ontologicalcontiguity >-successive registry-worldviews/dimensions are ever always successive challenges of profound-supererogation for prospective re-ontologising' speaks to the epistemic-veracity of the ontological-normalcy/postconvergence of unlimitedness/existence-<flllpotency of_sublimating nascence> (as so-reflecting prospective overall ontological-veracity as a postconverging-birthing/nascency within prospective fepistemic-totalising re-apriorising/reaxiomatising/re-referencing residuality-in-re-originariness/re-origination-〈as to human profound-supererogation for prospective apriorising/axiomatising/referencing-\{of'prospectively_implicited_attendant-ontological-contiguity ' educedexistentialising/contextualising/textualising_intelligibility/epistemicity/reflexivity_contiguity<imbued-notional cogency>' \}-conflatedness - in-\{preconverging-ment by\} postconverging-entailment that cannot be unshrouded by prior mere-formulaicity/ritualisation<as-to-mere-formulaic - methodologising/mutualising/organising/institutionalising,prospectively-losing-track-of- ‘fepistemictalising $\stackrel{+}{+}$ re-apriorising/re-axiomatising/rereferencing $\sim$ residuality—in-re-originariness/re-origination'> of prior apriorising/axiomatising/referencing-\{of-'prospectively implieited_attendant-ontologicalcontiguity ' educedexistentialising/contextualising/textualising_ 'intelligibility/epistemicity/reflexivity-contiguity<imbued-notional cogency>' $\}$-constitutedness -in-preconverging-entailment $\rangle) . \quad$ The 
further implication here is that the 'epistemic-veracity of notional citationality cannot be detached from the requisite profound-supererogation ${ }^{6}$ for prospective re-ontologising' and so rather than a 'nombrilistic and self-serving institutional-prescience/imprimaturing-<dullness-ofthe-spirit/psychologismic epistemic-acutisation nonresidualising-imbued\{compulsing $\}$ inearity in-eclecticism-of prior-mere-formulaicity/ritualisation $>\quad$ shallowsupererogation ontologically-flawed conception of notional citationality as to a cultivation of blurriness-<sterilising/anecdotalising/trivialising-of-prospective-re-ontologising_bypreconverging,-in-disontologising-formulaic-dragging-out/hollowing-out> while failing prospective ontologising-and-re-ontologising'. In this regards, the 'epistemic-veracity of notional citationality cannot be devoid of the prospective psychologismic-element-<as-ofdiametrical-conflatedness -towards-'already-given-unlimitedness/existence-<full-potencyof_sublimating nascence $>$ '-of-'limitedness/human-subpotency-as-to-its-imbued\{veridical/sound\}-relative-reflexivity-in-existence/relativising from-limited-mentation-as-itsdeepening/psychologismic epistemic acutisation residualising, fdecompusingldelinearity for eogency'> of prospective sublimating ${ }^{56}$ meaningfulness-and-teleology ${ }^{9}$ '. It can be appreciated that the sublimating ${ }^{5}$ meaningfulness-and-teleology ${ }^{9}$ respectively of base-institutionalisationununiversalisation, $\quad{ }^{103}$ universalisation-non-positivism/medievalism, positivismprocrypticism and deprocrypticism-or-preempting-disjointedness-as-of- ${ }^{18}$ reference-ofthought cannot 'technically be citationally-'plundered'/'looted' as to veridical notional citationality implications' as from respectively recurrent-utter-uninstitutionalisation, base-institutionalisation-ununiversalisation, ${ }^{103}$ universalisation-non-positivism/medievalism and positivism- ${ }^{80}$ procrypticism since the latter fundamentally/incipiently/seedingly fail the requisite profound-supererogation (as to such a self-presence/self-constitutedness ${ }^{14}-<$ inperspective-epistemic-abnormalcy/preconvergence $^{31}>$ ontologically-flawed conception of notional citationality) for prospective re-ontologising enabling 
sublimating 'upstreaming'/'amontée' supererogation as

of ('supererogatory wholesomeness/profoundprospective reference-of-thought-point-of-

devolving/departure/anchoring/backdrop_of_sublimating-nascence-<as-to-the-grandest-

axiomatic-construct-\{epistemic-totalising ${ }^{+}$re-apriorising/re-axiomatising/re-

referencing residuality-in-re-originariness/re-origination of limitedness/human-subpotency prospective re-encountering/re-confrontation with unlimitedness/existence>'). Such a supposed citational-'plundering'/'looting' is merely a circular manifestation of lack of the requisite prospective sublimation psychologismic-element-<as-of-diametrical-conflatedness -towards'already-given-unlimitedness/existence-<full-potency-of_sublimating nascence $>$ '-of‘limitedness/human-subpotency-as-to-its-imbued-\{veridical/sound\}-relative-reflexivity-inexistence/relativising from-limited-mentation-as-its-deepening/psychologismic epistemicacutisation residualising, ${ }^{\text {\{decompulsing }}$ delinearity for-cogency’> manifested for instance with the contradiction of a non-positivising apriorising/axiomatising/referencing mindset supposedly mastering positivistic knowledge in a 'manifestly non-positivising 79 presencing_absolutisingidentitive-constitutedness $^{14}$ gesturing/accounting-of-epistemic-phenomenalism' poorly cognisant of the requisite prospective positivistic apriorising/axiomatising/referencing metaphoricity $^{57}$ (as so-rather redundant upon the non-positivising social-setup prospectively desublimating rationalisation-of-contentivity/argumentativity/dialecticism/discursivity of social-and-institutional-frameworks-of - referencing/registering/decisioning and the derived value-construction); and this explains why (beyond human temporal mental-complexes and emotional-involvement) prospective organic-knowledge is veridically rather a profoundsupererogation uncircumventable/indispensible exercise of psychoanalyticunshackling/memetic-reordering/institutional-recomposuring self-becoming/selfconflatedness $^{13}$ /formative-supererogating-<projective/reprojective-aestheticising-re-motifand-re-apriorising/re-axiomatising/re-referencing,-in-perspective-ontological- 
normalcy/postconvergence>. These 'successive challenges of profound-supererogation' for prospective re-ontologising' are a reflection of the specific human consciousness in-itsembodiment as the potent 'phenomenological transcendental-point-of-departure handle' for human self-conscious existence and meaningfulness-and-teleology construal/conceptualisation (as of knowledge-constructs/theories/intersolipsistic-intercessorynotions/notional referential-notions/articulations/virtue); as so-underlied by human $<$ amplituding/formative-epistemicity>-totalising $\sim$ hrownness-in-existence ${ }^{35}$,-imbuedprojective-arbitrariness/waywardness-〈as-to-the-human-projective/reprojectiveaestheticising-re-motif-and-re-apriorising/re-axiomatising/re-referencing-process-of'<amplituding/formative-epistemicity $>$ totalising conceptualisation' $\rangle$ and as so-reflecting the station/locus of human limited-mentation-capacity-as-subjecting 'educedunlimitedness/existence-sublimating nascence' to-limitedness/human-subpotency as to 'veridical existentialising-frame-of-entailment of -motif-andapriorising/axiomatising/referencing becoming of human consciousness in-its-embodiment' as from prior <preconverging 'motif-and-apriorising/axiomatising/referencing'-entailing >existentialising — enframing/imprintedness-〈as-to- historicity-tracing_-in-presencinghyperrealisation/hyperreal-transposition> to prospective <postconverging 'motif-andapriorising/axiomatising/referencing'-entailing--existentialising_-framing/imprinting-〈as-toprospective- historiality/ontological-eventfulness /ontological-aesthetic-tracing$<$ perspective--ontological-normalcy/postconvergence-reflected-‘epistemicity-relativismdeterminism'>>. The 'veridical existentialising-frame-of-entailment-of motif-andapriorising/axiomatising/referencing becoming of human consciousness in-its-embodiment' (as to embodied-vitality/survival/subsistence — existential-<disentologising/re-ontologising apereticism>-becoming with regards to human Being-development/ontological-frameworkexpansion-as-to-depth-of-ontologising-development-as-infrastructure-of- meaningfulness- 
and-teleology , institutional-development-as-to-social-function-development and livingdevelopment-as-to-personality-development psychologismic epistemic acutisation-

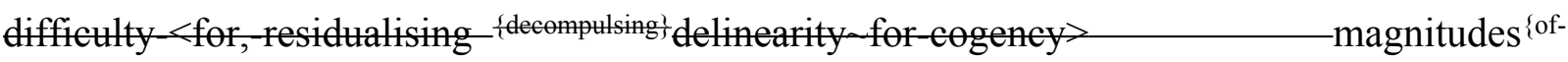
experientiality/experiment\} as so-defining the social or human-social-potency) speaks to the 'emanative human notional $\sim$ reflexivity- $<$ \{veridical/sound $\}$-relative-reflexivity-in-existence/relativising from-limited-mentation-as-its-deepening/psychologismic-<residualising $\{$ \{decompulsing $\}$ delinearity for-cogency $>$ by - flawed/unsound\}-relative-unreflexivity-inexistence/absolutising from-limited-mentation/psychologismic epistemic acutisation nonresidualising imbued-fompulsinglinearity in-eclecticism-of prior-mere-

formulaicity/ritualisation>' educing of human conceptivity/epistemic-reflexivity/epistemicityrelativism-determinism- $<$ reifying $\{$ as-to-knowledge-developing $\}$-and-empowering $>$ as $\quad$ of 'dynamic sublimation and desublimation implications of human limited-mentation-capacityas-subjecting 'educed-unlimitedness/existence-sublimating nascence' to-limitedness/humansubpotency' in want for 'human limited-mentation-capacity-deepening-as-subjecting limitedness/human-subpotency-to-'educed-unlimitedness/existence-sublimating nascence' skewing (as to postconverging-de-mentating/structuring/paradigming) for the sublimating 'upstreaming'/'amontée' of human ontological-performance ${ }^{2}-<$ including-virtueas-ontology'. This limitedness/human-subpotency of consciousness implies human ontologicalperformance ${ }^{72}-<$ including-virtue-as-ontology $>$ /morality/ethics/justice/etc. is ever always constrained to its '<amplituding/formative-epistemicity $>$-totalising $\sim$ thrownness-in-existence of social-functioning-and-accordance-as-of-social-stake-contention-or-confliction imbuing existentialising-frame-of-entailment-of-motif-and-apriorising/axiomatising/referencing of disontologising/ontologising-and-re-ontologising'; speaking to the '<amplituding/formativeepistemicity $>$ totalising/circumscribing/delineating perpetuative manifestation of human ontological-performance ${ }^{72}<$ including-virtue-as-ontology $>/$ morality/ethics/justice/etc. along the 
thresholds of its desublimating limited-mentation-capacity-as-subjecting-'educedunlimitedness/existence-sublimating nascence' to-limitedness/human-subpotency (underlied as of prior <preconverging 'motif-and-apriorising/axiomatising/referencing'-entailing >existentialising — enframing/imprintedness-〈as-to- historicity-tracing —in-presencing hyperrealisation/hyperreal-transposition〉 human consciousness in-its-embodiment) and sublimating limited-mentation-capacity-deepening -as-subjecting limitedness/humansubpotency-to-'educed-unlimitedness/existence-sublimating nascence' ${ }^{53}$ (underlied as of prospective $\quad<$ postconverging $\sim$ 'motif-and-apriorising/axiomatising/referencing'-entailing $>$ existentialising - framing/imprinting-〈as-to-prospective- historiality/ontologicaleventfulness /ontological-aesthetic-tracing-<perspective-ontologicalnormalcy/postconvergence-reflected-‘epistemicity-relativism-determinism'>> human consciousness in-its-embodiment), and so-construed as from nonpresencing-<perspectiveontological-normalcy/postconvergence $>$ epistemic-projection perspective'. Critically, the very 'emanative human notional reflexivity-<\{veridical/sound $\}$ relative-reflexivity-inexistence/relativising from-limited-mentation-as-its-deepening/psychologismic<residualising \{decompulsing $\}$ delinearity for-cogency>by-\{flawed/unsound\}-relativeunreflexivity-in-existence/absolutising from-limited mentation/psychologismic epistemic acutisation nonresidualising-imbued-\{compulsing\} linearity in-eclecticism-of prior-mereformulaicity/ritualisation>' (as to 'veridical existentialising-frame-of-entailment-of motif-andapriorising/axiomatising/referencing becoming of human consciousness in-its-embodiment') educing of human conceptivity/epistemic-reflexivity/epistemicity-relativism-determinism$<$ reifying \{as-to-knowledge-developing\}-and-empowering $>$ (as of 'dynamic sublimation and desublimation implications of human limited-mentation-capacity-as-subjecting 'educedunlimitedness/existence-sublimating nascence' to-limitedness/human-subpotency' in want for 'human limited-mentation-capacity-deepening—as-subjecting limitedness/human-subpotency- 
to-'educed-unlimitedness/existence-sublimating-nascence' ${ }^{3}$ skewing for the sublimating 'upstreaming'/'amontée' of human ontological-performance ${ }^{2}-<$ including-virtueas-ontology'), speaks to a human self-consciousness 'seeding/incipient pre-eminence of human embodied-vitality/survival/subsistence - existential-<disontologising/re-ontologising — aporeticism $>$-becoming driving human consciousness complexifying- $<$ transcending-inelaborateness as to human aestheticisation-and-aestheticisation-towards-ontology-<elicitedidiomatisation> dynamics of lifespan extricatory/preconverging psychical-nascency and nonextricatory/postconverging ontologising-and-re-ontologising angling-of-imaginary>> underlied as of 'subconscious-and-conscious_perceptible-and-repereeptible/actionable-andreactionable-dynamics of effectively_manifestable-and-remanifestable/attainable-andreattainable loss and gain existential-<disontologising/re-ontologising aporeticism $>$ sublimating-upstreaming/'amontée’—by—desublimating-downstreaming/‘avalage’ possibilities' (so-underlied by the '<amplituding/formative-epistemicity $>$ totalising thrownness-in-existence $^{35}$ of social-functioning-and-accordance-as-of-socialstake-contention-or-confliction imbuing existentialising-frame-of-entailment-of-motif-andapriorising/axiomatising/referencing of disontologising/ontologising-and-re-ontologising'); and so underlying the 'seeding/incipient pre-eminence of human embodiedvitality/survival/subsistence — existential-<disontologising/re-ontologising aporeticism $>$ becoming driving human consciousness complexifying-<transcending-in-elaborateness as to human aestheticisation-and-aestheticisation-towards-ontology-<elicited-idiomatisation $>$ dynamics of lifespan extricatory/preconverging psychical-nascency and nonextricatory/postconverging ontologising-and-re-ontologising angling-of-imaginary>> manifest 'educing of human conceptivity/epistemic-reflexivity/epistemicity-relativismdeterminism-<reifying \{as-to-knowledge-developing $\}$-and-empowering $>$ in formativeness- $<$ asto-intersolipsism-of-preformulating/preframing/premeaningfulness-imbued-mediativity-and- 
deferentialism $>$-of- meaningfulness-and-teleology '. The 'seeding/incipient pre-eminence of human embodied-vitality/survival/subsistence — existential-<disontologising/re-entelogising — apereticism $>$ becoming driving human consciousness complexifying-<transcending-inelaborateness as to human aestheticisation-and-aestheticisation-towards-ontology-<elicitedidiomatisation> dynamics of lifespan extricatory/preconverging psychical-nascency and nonextricatory/postconverging ontologising-and-re-ontologising angling-of-imaginary $>$ ' is thus effectively the 'idiosyncratic recomposuring-summative/additory/snowballing driver of human consciousness as to developing epistemic-growth,-as - \{veridical/sound\}-relative-reflexivityin-existence/relativising from-limited-mentation-as-its-deepening/psychologismic epistemic acutisation residualising, ${ }^{\text {\{decompulsing }}$ delinearity for-cogency (so-reflected in human psychologismic-epistemic-acutisation-<as-to-postconverging-de-

\section{mentating/structuring/paradigming,-eliciting-of-existence's-sublimating-nascence-in-}

prospective-aporeticism-overcoming/unovercoming $>$ ) as manifested existentially< disontologising/re-ontologising aporeticism $>$ with regards to human living-development-asto-personality-development psychologismic epistemic acutisation difficulty $<$ for, residualising $\{$ \{decompulsing $\}$ delinearity for-cogency>-magnitude $\{$ of-experientiality/experiment\}'; and as it relates to underlying collective social consciousness as to Being-development/ontologicalframework-expansion-as-to-depth-of-ontologising-development-as-infrastructure-ofmeaningfulness-and-teleology psychologismic epistemic-acutisation difficulty-for, residualising \{dempung delinearity for-cogency>-magnitude\{of-experientiality/experiment\} (reflecting the sublimating-postconverged 'substantive abstract-tissue-of-social-emanance totalising ${ }^{3}{ }^{3}$ hermeneutically/textually/reprojectingly/supererogatingly/zeroingly/re-acutingly,\{decompulsing $d$ delinearity for-cogency — cumulated/recomposured as to cumulating/recomposuring of 'prospectively_implicited_attendant-ontological-contiguity ${ }^{67}$ 'educedexistentialising/contextmalising/textmalising_intelligibility/epistemicity/reflexivity-contiguity- 
<imbued-notional cogency > ${ }^{\prime}$ ) and institutional-development-as-to-social-functiondevelopment psychologismic epistemic-acutisation difficulty-<for, residualising \{decompling\} delinearity for-cogeney>-magnitude\{of-experientiality/experiment\}. Thus such notions like human imagination and thought are merely metaphysics-of-presence-〈implicited'nondescript/ignorable-void ' 'as-to- presencing - absolutising-identitive-constitutedness >

conceptions of the 'seeding/incipient pre-eminence of human embodiedvitality/survival/subsistence — existential-<disontologising/re-ontologising aporeticism> becoming driving human consciousness complexifying-<transcending-in-elaborateness as to human aestheticisation-and-aestheticisation-towards-ontology-<elicited-idiomatisation $>$ dynamics of lifespan extricatory/preconverging psychical-nascency and nonextricatory/postconverging ontologising-and-re-ontologising angling-of-imaginary>'; and this in-many-ways explain why the 'supposed abstract-and-abrupt givenness/determinism' of such notions like human imagination and thought do not 'absolutely pan out existentially< disontologising/re-ontologising aporeticism $>$ as to a fully deterministic abstraction without an accompanying ineffable-and-arbitrary idiosyncratic element' as so-reflecting the more profound veracity of the 'seeding/incipient pre-eminence of human embodiedvitality/survival/subsistence — existential-<disontologising/re-ontologising _aporeticism $>$ becoming driving human consciousness complexifying-<transcending-in-elaborateness as to human aestheticisation-and-aestheticisation-towards-ontology-<elicited-idiomatisation $>$ dynamics of lifespan extricatory/preconverging psychical-nascency and nonextricatory/postconverging ontologising-and-re-ontologising angling-of-imaginary $>^{\prime}$ as underlying existentialisingly/contextualisingly/textualisingly such notions like human imagination and thought (which are in-many-ways rather caught up as of fflawed/unsound\} relative-unreflexivity-in-existence/absolutising from-limited-mentation/psychologismic epistemic-acutisation nonresidualising-imbued- 
mere-formulaicity/rittalisation in the manifest idiosyncracy of the 'seeding/incipient preeminence of human embodied-vitality/survival/subsistence-existential-<disontologising/reentologising aporeticism $>$ becoming driving human consciousness complexifying$<$ transcending-in-elaborateness as to human aestheticisation-and-aestheticisation-towardsontology-<elicited-idiomatisation $>$ dynamics of lifespan extricatory/preconverging psychicalnascency and nonextricatory/postconverging ontologising-and-re-ontologising angling-ofimaginary >'). Insightfully the relative-unreflexivity/relative-reflexivity-ontologicalcontiguity ${ }^{67}$ of-the-human-institutionalisation-process ${ }^{68}$ (as to its veridically implied nonpresencing-or-withdrawal/unenframing/re-ontologising-or-metaphysics-of-absence-

\section{〈implicited-epistemic-veracity-of- nonpresencing-<perspective-ontological-}

normalcy/postconvergence $>$ >-or-transcendental-reasoning-of-event ${ }^{38}$-as-prospective-ontologyorigination epistemic-projection perspective) rather reflects that this 'seeding/incipient preeminence of human embodied-vitality/survival/subsistence - existential-<disontologising/reentologising aporeticism $>$ becoming driving human consciousness complexifying$<$ transcending-in-elaborateness as to human aestheticisation-and-aestheticisation-towardsontology-<elicited-idiomatisation $>$ dynamics of lifespan extricatory/preconverging psychicalnascency and nonextricatory/postconverging ontologising-and-re-ontologising angling-ofimaginary>' is undergirded by human ${ }^{15}$ de-mentation-〈supererogatory $\sim$ ontological-dementation-or-dialectical-de-mentation-stranding-or-attributive-dialectics $\rangle$ imbued human preconverging/dementing and postconverging/dialectical-thinking predisposition as to preconverging/postconverging-de-mentating/structuring/paradigming 'notional $\sim$ reflexivity$<\{$ veridical/sound\}-relative-reflexivity-in-existence/relativising from-limited-mentation-asits-deepening/psychologismic-<residualising \{decompulsing? delinearity for-cogency>by\{flawed/unsound\}-relative-unreflexivity-in-existence/absolutising from-limitedmentation/psychologismic epistemic acutisation nonresidualising-imbued- 
ontological-performance ${ }^{2}$-<including-virtue-as-ontology $>/$ morality/ethics/justice/etc.

intercalated by shallow-supererogation and profound-supererogation (so-reflecting the various metaphysics-of-presence-〈implicited-'nondescript/ignorable-void ' 'as-topresencing - absolutising-identitive-constitutedness > dynamic/developing conceptions of 'what is human imagination and thought' as so-varying as of preconverging/dementing-bypostconverging/dialectical-thinking with respect to the <cumulating/recomposuring attendantontological-contiguity >-successive registry-worldviews/dimensions). This as well speaks to the fact that the very notions of human imagination and thought are rather a postconvergingbirthing/nascency within prospective \{epistemic-totalising 3 toriorising axiomatising referencing $\sim$ residuality —in-re-originariness/re-origination- $\langle$ as to human profoundsupererogation for prospective apriorising/axiomatising/referencing-\{of-'prospectively implicited_attendant-ontological-contiguity ' educedexistentialising/contextualising/textualising_ 'intelligibility/epistemicity/reflexivity-contiguity<imbued-notional cogency >' \}-conflatedness in \{preconverging ment by\} postconverging-ntailment that cannot be unshrouded by prior mere-formulaicity/ritualisation$<$ as-to-mere-formulaic — methodologising/mutualising/organising/institutionalising,prospectively-losing-track-of- ‘fepistemictalising łre-apriorising/re-axiomatising/rereferencing $\sim$ residuality-in-re-originariness/re-origination'> of prior apriorising/axiomatising/referencing-\{of-'prospectively implicited_attendant-ontologicalcontiguity ' $\sim$ educedexistentialising/contextualising/textualising_ intelligibility/epistemicity/reflexivity_contiguity<imbued-notional cogency> ' $\}$-constitutedness -in-preconverging-entailment $\rangle. \quad$ The 'seeding/incipient pre-eminence of human embodied-vitality/survival/subsistence - existential< disontologising/re-ontologising aporeticism $>$ becoming driving human consciousness 
complexifying-<transcending-in-elaborateness as to human aestheticisation-andaestheticisation-towards-ontology-<elicited-idiomatisation $>$ dynamics of lifespan extricatory/preconverging psychical-nascency and nonextricatory/postconverging ontologisingand-re-ontologising angling-of-imaginary $>^{\prime} \quad$ critically underlies notionally/epistemically/bindingnessly-<as-to-determinism/conceptivity-of-relative-unreflexivity/relative-reflexivity> that both the 'social-functioning-and-accordance-as-of-social-stake-contention-or-confliction aspect' and the 'disontologising/ontologising-and-re-ontologising aspect' are mutually reinforcing as to limited-mentation-capacity-deepening - as-subjecting limitedness/humansubpotency to-'educed-unlimitedness/existence-sublimating nascence' 53 educing conceptivity/epistemic-reflexivity/epistemicity-relativism-determinism-<reifying \{as-toknowledge-developing\}-and-empowering>; notwithstanding the prospective thresholding of limited-mentation-capacity-deepening—as-subjecting-limitedness/human-subpotency-to'educed-unlimitedness/existence-sublimating nascence's3 underlied on-the-one-hand by sublimating knowledge-reification $\sim$ gesturing-and-accounting-of-epistemic-phenomenalism$<$ in-prospective_psychologismic $\sim$ apriorising/axiomatising/referencing-\{of-'prospectively implicited_attendant-ontological-contiguity ' educedexistentialising/contexalising/textising_intelligibility/epistemicity/reflexivity-contiguity<imbued-notional cogency>' \}-conflatedness -in-\{preconverging-ment by\} postconverging-entailment> inducing of epistemic-growth,-as - \{veridical/sound\}-relativereflexivity-in-existence/relativising from-limited-mentation-as-its-deepening/psychologismic epistemic-acutisation residualising, \{decompusing delinearity for-eogency (so-reflected as 'demoronisation-<sublimating-nascence,-nonextricatory-sublimating-upstreaming/'amontée'> epistemic-break or notional-discontiguity/epistemic-discontiguity ${ }^{63}<$ between - prior-shallowsupererogation -of-mentally-aestheticised $\sim$ preconverging/dementing -qualiaschema_and_prospective-profound-supererogation -of-mentally- 
aestheticised postconverging/dialectical-thinking -qualia-schema>' with regards to nascentparticular/incipient-and-material/technical-sublimations- $<$ blinded-to-their-relative-ontologicalcompleteness - reference-of-thought- devolving $>\quad$ incipient sublimatingupstreaming/'amontée' as to 'supereregatory wholesomeness/profound-supererogation as of prospective reference-of-thought-point-ofdevolving/departure/anchoring/backdrop_of_sublimating-nascence-<as-to-the-grandestaxiomatic-construct-\{epistemic-totalising ${ }_{3}^{+}$re-apriorising/re-axiomatising/rereferencing -residuality - in-re-originariness/re-origination of limitedness/human-subpotency prospective re-encountering/re-confrontation with unlimitedness/existence>') and on-the-otherhand desublimating overall <amplituding/formative> wooden-language-〈imbued-temporalmere-form/virtualities/dereification/akrasiatic-drag/denatured/preconverging-or-dementing narratives - of-the- reference-of-thought- categorical-imperatives/axioms/registryteleology > and associated pedantising/muddling/formulaic-hollowing-out-insubontologisation/subpotentiation-〈blurring/undermining-of-prospective-totalising-entailing,as-to-entailing-<mplitung/formative-epistemicity $>$ totalising in-relative-ontologicalcompleteness $>$ inducing of moronisation- $<$ sublimating-nascence,-extricatory-desublimatingdownstreaming/'avalage'> (as of nascent-particular/incipient-and-material/technicalsublimations- $<$ blinded-to-their-relative-ontological-completeness - reference-of-thoughtdevolving $>$ incipient desublimating-downstreaming/'avalage' as to 'shallow-supererogation as of $\quad$ prior reference-of-thought-point-of-

devolving/departure/anchoring/backdrop_of_sublimating-nascence-<as-to-the-grandestaxiomatic-construct-\{epistemic-totalising $\stackrel{+}{\zeta}$ re-apriorising/re-axiomatising/rereferencing $\sim$ residuality - in-re-originariness/re-origination of limitedness/human-subpotency prospective re-encountering/re-confrontation with unlimitedness/existence> imbued 'desublimating rationalisation-of-contentivity/argumentativity/dialecticism/discursivity of 
social-and-institutional-frameworks-of - referencing/registering/decisioning and the derived value-construction'). Insightfully, 'prospective thresholding of limited-mentation-capacitydeepening —as-subjecting limitedness/human-subpotency to-'educed-unlimitedness/existencesublimating nascence' ${ }^{53}$ (as to prospectively uninstitutionalised-threshold ${ }^{102}$ )' speaks to the discordance between 'prospective existentialising-postconverging_framing/imprinting reontologising' and 'prior existentialising_preconverging_enframing/imprintedness socialfunctioning-and-accordance-as-of-social-stake-contention-or-confliction' underlying respectively the relative-unreflexivity/relative-reflexivity ontological-contiguity $\sim$ of-thehuman-institutionalisation-process imbued dimensionality-of-sublimating ${ }^{65}$ <<amplituding/formative >supererogatory -de-mentativeness/epistemic-growth-orconflatedness /transvaluative-rationalising/transepistemicity/anamnestic-residuality/spiritdrivenness-equalisation $\rangle \quad$ and dimensionality-of-desublimating-lack-of <<amplituding/formative>supererogatery $\sim$ de-mentativeness/epistemic-growth-orconflatedness /transvaluative-rationalising/transepistemicity/anamnestic-residuality/spiritdrivenness-equalisation). Critically the veracity of 'prospective existentialisingpostconverging_framing/imprinting re-ontologising' (as to dimensionality-of-sublimating <<amplituding/formative>supererogatory $\sim$ de-mentativeness/epistemic-growth-orconflatedness /transvaluative-rationalising/transepistemicity/anamnestic-residuality/spiritdrivenness-equalisation)) over 'prior existentialising_preconverging_enframing/imprintedness social-functioning-and-accordance-as-of-social-stake-contention-or-confliction' $\quad$ (as to dimensionality-of-desublimating-lack-of $-<<$ amplituding/formative $>$ supererogatory $\sim$ dementativeness/epistemic-growth-or-conflatedness /transvaluativerationalising/transepistemicity/anamnestic-residuality/spirit-drivenness-equalisation〉), lies in the fact that the latter is 'incoherent with itself at its given station/locus of $<$ amplituding/formative-epistemicity $>$-totalising $\sim$ thrownness-in-existence ${ }^{35}$, by its mere 
epistemic-projection of 'lifespan extricatory/preconverging psychical-nascency moronisation<sublimating-nascence,-extricatory-desublimating-downstreaming/'avalage'>' (imbued prior 're-ontologising-by-disontologising_threshold')', since going by its rationale all the prior ontologising-and-re-ontologising (manifested as 'successive challenges of profoundsupererogation for prospective re-ontologising' inducing prospective registryworldviews/dimensions sublimating re-rationalisations-ofcontentivity/argumentativity/dialecticism/discursivity) shouldn't have taken place and humanity/the-human should have remained at the initial stage of animality (as to the recurrentutter-uninstitutionalisation registry-worldview/dimension); with a coherent account of the sublimating possibility of the relative-unreflexivity/relative-reflexivity-ontologicalcontiguity ${ }^{67}$ of-the-human-institutionalisation-process ${ }^{68}$ only arising as of humanity/the-human 'prospective existentialising_postconverging_framing/imprinting re-ontologising' (as to dimensionality-of-sublimating $25<$ amplituding/formative $>$ supererogatory $\sim$ de-

\section{mentativeness/epistemic-growth-or-conflatedness /transvaluative-}

rationalising/transepistemicity/anamnestic-residuality/spirit-drivenness-equalisation〉). This ‘inherently given manifestation of discordance associated with limitedness/human-subpotency’

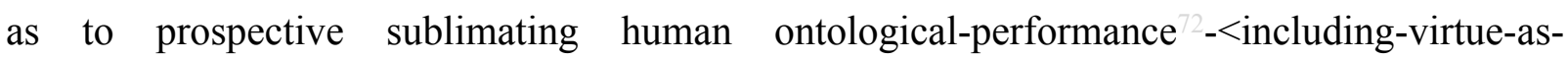
ontology $>$ /morality/ethics/justice/etc. (so-construed aetiologically/in-ontological-escalation as from a cross-generational angling-of-imaginary epistemic-projection perspective for prospective ontologising-and-re-ontologising) is in-many-ways amenable/subject to sublimating transversality-<for-sublimating-existential-eventuating/denouement,-from-'thinking-at-

\section{first/pure - predisposition-preemptive-of prospective-disontologising/subontologising' as-of-}

prospectively-disambiguated-affirmed-and-unaffirmed-'motif-and-

apriorising/axiomatising/referencing' $>101$ as of the 'constraining/defining intersolipsistic reflexive-sublimating/unreflexive-desublimating measure/objectification that is 
unlimitedness/existence-as-ontological-normalcy/postconvergence-<in-validation-of'metaphysics-of-absence_epistemic-projection'>' (as so-translated as 'constraining existenceas-sublimating-withdrawal/unenframing/re-ontologising,-elicited-from-prospective-profound-

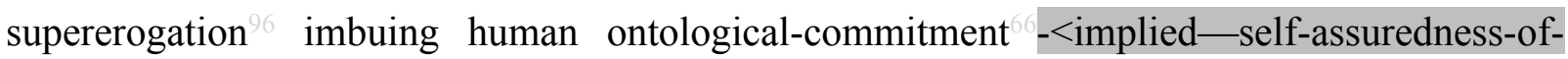
ontological-good-faith/authenticity postconverging-dementating/structuring/paradigming -as-being-as-of-existential-reality>' and ' ${ }^{103}$ universaltransparency ${ }^{104}$-〈transparency-of-totalising-entailing,-as-to-entailing-<amplituding/formativeepistemicity $>$ totalising in-relative-ontological-completeness $\rangle$ as available-to/elicitable-to-〈asto-human-consciousness/collective-consciousness-distendedness/detruncating-<beyondselfpresencing,-as-re-ontologising-decentering_of-consciousness/collective-consciousness,-asto-psychologismic-epistemic-acutisation-residualising,the social-functioning-and-accordance-as-of-social-stake-contention-or-confliction conception of any given registry-worldview/dimension <preconverging 'motif-andapriorising/axiomatising/referencing'-entailing >-existentialising — enframing/imprintedness〈as-to- historicity-tracing-in-presencing-hyperrealisation/hyperreal-transposition〉'); and in this regards, in-many-ways the prospective ${ }^{18}$ deprocrypticism-or-preempting-disjointednessas-of- ${ }^{8}$ reference-of-thought registry-worldview/dimension as warranting 'appropriate profound-supererogation for prospective re-ontologising' effectively needs to attend to the fundamental psychological process undergirding $\quad<$ preconverging $\sim$ 'motif-andapriorising/axiomatising/referencing'-entailing >-existentialising — enframing/imprintedness〈as-to- historicity-tracing-in-presencing-hyperrealisation/hyperreal-transposition〉 human consciousness in-its-embodiment' (as to the prospective ${ }^{18}$ deprocrypticism-or-preemptingdisjointedness-as-of- ${ }^{8}$ reference-of-thought process of limitedness/human-subpotency cumulating/recomposuring 'intolerance-<of-disparateness $>$ /exactifying_precisioning-ofsublimation-<as-to-postconverging-narrowing-down apriorising/axiomatising/referencing- 
entailing-theoretical,-conceptual-and-operant-implications $>$ exercise of intelligibility', as to imbued 'developing epistemic sense of ${ }^{61}$ nonpresencing-<perspective-ontologicalnormalcy/postconvergence $>$ relativism/relative-scope as projective-insights', with respect to prospective \{epistemic-totalising 3 re-apriorising/re-axiomatising/re-referencing - residuality-in-reoriginariness/re-origination of limitedness/human-subpotency prospective re-encountering/reconfrontation with the 'constraining/defining intersolipsistic reflexive-sublimating/unreflexivedesublimating measure/objectification that is unlimitedness/existence-as-ontologicalnormalcy/postconvergence-<in-validation-of-'metaphysics-of-absence_epistemic-

projection'>'). In this regards, the very 'prospective thresholding of limited-mentation-capacitydeepening —as-subjecting-limitedness/human-subpotency-to-'educed-unlimitedness/existencesublimating nascence' (as to prospectively uninstitutionalised-threshold ${ }^{102}$ ) with respect to educing conceptivity/epistemic-reflexivity/epistemicity-relativism-determinism- $<$ reifying \{asto-knowledge-developing $\}$-and-empowering $>$ is merely the reflection of the formation of the human self (reflecting protracted-social—as-to-individual-by-institutional-by-social self) as to limitedness/human-subpotency and so in its prospective axiomatising/re-referencing - residuality-in-re-originariness/re-origination of limitedness/human-subpotency prospective re-encountering/re-confrontation with the 'constraining/defining intersolipsistic reflexive-sublimating/unreflexive-desublimating measure/objectification that is unlimitedness/existence-as-ontologicalnormalcy/postconvergence- $<$ in-validation-of-'metaphysics-of-absence_epistemic-projection' $>$ (that speaks of the other as to the 'appropriate human contemplative projective-insights of sublimating-nascence aetiologisation/ontological-escalation-<ontologicalveridicality_commitment/otherliness_transcending/compulsions-encumbered_transcending > conceptivity/epistemic-reflexivity/epistemicity-relativism-determinism- $<$ reifying \{as-toknowledge-developing\}-and-empowering $>$ '); as so-reflecting appropriate notional $\sim$ self- 
distantiation- $<$ imbued — re-motif-and-re-apriorising/re-axiomatising/re-referencing $>$ as the veridical process of limitedness/human-subpotency cumulating/recomposuring 'intolerance$<0$ f-disparateness $>$ /exactifying_precisioning-of-sublimation- $<$ as-to-postconverging-

narrowing-down apriorising/axiomatising/referencing-entailing-theoretical,-conceptual-andoperant-implications $>$ exercise of intelligibility' in undermining/overriding shallowsupererogation $\quad$ \{flawed/unsound\}-relative-unreflexivity-in-existence/absolutising fromlimited-mentation/psychologismic epistemic acutisation nonresidualising imbuedfompulsing linearity in-eclecticism-of prior-mere-formulaicity/ritualisation and so as from profound-supererogation epistemic-growth,-as-\{veridical/sound $\}$-relative-reflexivity-inexistence/relativising from-limited-mentation-as-its-deepening/psychologismic epistemicacutisation residualising, ${ }^{\text {\{decompulsing }}$ delinearity for-cogency for prospective re-ontologising imbued sublimating 'upstreaming'/'amontée' ('supereregatory $\sim$ wholesomeness/profoundsupererogation as of prospective ${ }^{83}$ reference-of-thought-point-ofdevolving/departure/anchoring/backdrop_of_sublimating-nascence-<as-to-the-grandestaxiomatic-construct-\{epistemic-alising ${ }^{+}$re-apriorising/re-axiomatising/rereferencing residuality - in-re-originariness/re-origination of limitedness/human-subpotency prospective re-encountering/re-confrontation with unlimitedness/existence>' $)$. Thus the fact that 'human self-conscious existence and meaningfulness-and-teleology construal/conceptualisation (as of knowledge-constructs/theories/intersolipsistic-intercessorynotions/notional referential-notions/articulations/virtue)' is not detached from 'embodiment whether as of existentialising_preconverging_enframing/imprintedness or existentialisingpostconverging_framing/imprinting', speaks to the fundamentality/incipience/seedingness of human preconverging and postconverging predispositions as to preconverging/postconvergingde-mentating/structuring/paradigming 'notional $\sim$ reflexivity- $<$ \{veridical/sound\}-relativereflexivity-in-existence/relativising from-limited-mentation-as-its-deepening/psychologismic- 
<residualising \{decompulsing $\}$ delinearity for-cogency>-by-\{flawed/unsound\}-relative-

unreflexivity-in-existence/absolutising from-limited-mentation/psychologismic epistemic-

acutisation nonresidualising-imbued-\{compulsing\}linearity in-eclecticism-of prior-mere-

formulaicity/ritualisation $>\quad$ dualising $\quad$ ontological-performance ${ }^{72}<$ including-virtue-as- $^{2}$ ontology $>$ /morality/ethics/justice/etc. as intercalated by shallow-supererogation and profoundsupererogation ${ }^{6}$ (so-reflected herein as human notional firstnaturedness-formativeness-<as-toeventualising inkling drive or seeding misprising $>$ temporal-to-intemporal-dispositions-

$<$ so-construed-as-from-perspective-ontological-normalcy/postconvergence $>$ ); $\quad$ as $\quad$ soindependent seedingly/incipiently of any attained/achieved secondnatured institutionalisation upon which prospectively uninstitutionalised-threshold 02 this 'notional reflexivity$<\{$ veridical/sound $\}$-relative-reflexivity-in-existence/relativising from-limited-mentation-asits-deepening/psychologismic-<residualising ${ }^{\{\text {decompulsing }}{ }^{\text {f }}$ delinearity for-cogency $>$ by \{flawed/unsound\}-relative-unreflexivity-in-existence/absolutising from-limitedmentation/psychologismic epistemic acutisation nonresidualising imbued\{compulsing linearity in-eclecticism-of-prior-mere-formulaicity/ritualisation> dualising' may manifest existentially/contextually/textually (either as to dimensionality-of-sublimating 25 <<amplituding/formative >supererogatory $\sim$ de-mentativeness/epistemic-growth-orconflatedness /transvaluative-rationalising/transepistemicity/anamnestic-residuality/spiritdrivenness-equalisation> or dimensionality-of-desublimating-lack-of ${ }^{-}$ <<amplituding/formative>supererogatory $\sim$ de-mentativeness/epistemic-growth-orconflatedness /transvaluative-rationalising/transepistemicity/anamnestic-residuality/spiritdrivenness-equalisation)). But then the ontological-veracity of this human 'notional reflexivity$<\{$ veridical/sound $\}$-relative-reflexivity-in-existence/relativising from-limited-mentation-asits-deepening/psychologismic-<residualising ${ }^{\text {\{decompulsing }}$ delinearity for-cogeney $>$ by 
not/poorly/hardly reflected at prospectively uninstitutionalised-threshold ${ }^{12}$ (given registryworldviews/dimensions imbued prior-institutionalisation-threshold-by-prospectiveuninstitutionalised-threshold $\quad$ 'self-referencing-syncretising forward-facingsupposedly postconverging-or-dialectical-thinking -apriorising-psychologism epistemicprojection as of prior mere-formulaicity/ritualisation-<as-to-mere-formulaicmethodologising/mutualising/organising/institutionalising,-prospectively-losing-track-of-

‘fepistemic-atlising ’re-apriorising/re-axiomatising/re-referencing residuality-in-reoriginariness/re-origination'>' so-reflecting their 'disontologising preconverging/dementing $<$ as-to-prospective-uninstitutionalised-threshold $>$ ignoring/biased inclination' for the sake of 'their given present minimum-and-balancing expectations/anticipations of social-functioningand-accordance-as-of-social-stake-contention-or-confliction' while qualifying their prospectively uninstitutionalised-threshold ${ }^{102}$ actually as nondescript/ignorable-void as to their ${ }^{79}$ presencing-absolutising-identitive-constitutedness ${ }^{14} \quad<$ preconverging $\sim$ 'motif-andapriorising/axiomatising/referencing'-entailing >-existentialising-enframing/imprintedness〈as-to- historicity-tracing-in-presencing-hyperrealisation/hyperreal-transposition〉) and this effectively undermines the ontological-veracity for prospective re-ontologising (as to prospective originariness/re-origination of limitedness/human-subpotency prospective re-encountering/reconfrontation with the 'constraining/defining intersolipsistic reflexive-sublimating/unreflexivedesublimating measure/objectification that is unlimitedness/existence-as-ontologicalnormalcy/postconvergence-<in-validation-of-'metaphysics-of-absence_epistemic-

projection'>'); thus requiring 'successive challenges of profound-supererogation for prospective re-ontologising' as of 'prospective postconverging-aporeticism- 
overcoming/unovercoming of prior-perspective-falsity/falseness/fallaciousness (of registryworldviews/dimensions imbued prior-institutionalisation-threshold-by-prospectiveuninstitutionalised-threshold $\quad$ 'self-referencing-syncretising forward-facingsupposedly postconverging-or-dialectical-thinking -apriorising-psychologism epistemicprojection as of prior mere-formulaicity/ritualisation-<as-to-mere-formulaicmethodologising/mutualising/organising/institutionalising,-prospectively-losing-track-of‘\{epistemic-totalising łre-apriorising/re-axiomatising/re-referencing $\sim$ residuality-in-reoriginariness/re-origination'>' so-reflecting their 'disontologising preconverging/dementing $<$ as-to-prospective-uninstitutionalised-threshold $>$ ignoring/biased inclination' for the sake of 'their given present minimum-and-balancing expectations/anticipations of social-functioningand-accordance-as-of-social-stake-contention-or-confliction' while qualifying their prospectively uninstitutionalised-threshold ${ }^{102}$ actually as nondescript/ignorable-void as to their ${ }^{79}$ presencing-absolutising-identitive-constitutedness ${ }^{14} \quad<$ preconverging $\sim$ 'motif-andapriorising/axiomatising/referencing'-entailing >-existentialising — enframing/imprintedness〈as-to- historicity-tracing_in-presencing-hyperrealisation/hyperreal-transposition〉)'. This inherent manifestation of registry-worldviews/dimensions prior-perspectivefalsity/falseness/fallaciousness fundamentally/incipiently/seedingly undermines the process of limitedness/human-subpotency cumulating/recomposuring 'intolerance-<ofdisparateness $>$ /exactifying_precisioning-of-sublimation-<as-to-postconverging-narrowingdown apriorising/axiomatising/referencing-entailing-theoretical,-conceptual-and-operantimplications $>$ exercise of intelligibility' (as to imbued 'developing epistemic sense of nonpresencing-<perspective-ontological-normalcy/postconvergence $>\quad$ relativism/relativescope as projective-insights') with respect to prospective fepistemic-totalising 3re-apriorising/reaxiomatising/re-referencing residuality-in-re-originariness/re-origination of limitedness/human-subpotency prospective re-encountering/re-confrontation with the 
'constraining/defining intersolipsistic reflexive-sublimating/unreflexive-desublimating measure/objectification that is unlimitedness/existence-as-ontologicalnormalcy/postconvergence-<in-validation-of-'metaphysics-of-absence_epistemic-

projection'>'. This takes the form of prospectively uninstitutionalised-threshold ${ }^{02}$ shallowsupererogation fflawed/unsound\}-relative-unreflexivity-in-existence/absolutising fromlimited-mentation/psychologismic epistemic-acutisation nonresidualising-imbued\{compulsing\} linearity in-eclecticism-of prior-mere-formulaicity/ritualisation induced 'moronisation-<sublimating-nascence,-extricatory-desublimating-downstreaming/'avalage'> of ${ }^{56}$ meaningfulness-and-teleology ${ }^{9}$ construal/conceptualisation' (as of knowledgeconstructs/theories/intersolipsistic-intercessory-notions/notional referentialnotions/articulations/virtue) as to the conscious or unconscious deriving/eliciting of $<$ amplituding/formative $>$ wooden-language-〈imbued-temporal-mereform/virtualities/dereification/akrasiatic-drag/denatured/preconverging-or-dementing narratives - of-the- reference-of-thought- categorical-imperatives/axioms/registryteleology > and associated pedantising/muddling/formulaic-hollowing-out-insubontologisation/subpotentiation-〈blurring/undermining-of-prospective-totalising-entailing,as-to-entailing-<amplituding/formative-epistemicity $>$ totalising in-relative-ontologicalcompleteness \ desublimation as undermining epistemic-growth,-as-\{veridical/sound\} relative-reflexivity-in-existence/relativising from-limited-mentation-as-itsdeepening/psychologismic epistemic acutisation residualising, \{decompulsing ${ }^{2}$ delinearity for eogency as to psychologismic-epistemic-acutisation-<as-to-postconverging-dementating/structuring/paradigming,-eliciting-of-existence's-sublimating-nascence-inprospective-aporeticism-overcoming/unovercoming $>$. The result is the 'apriorising/axiomatising/referencing — equating/leveling/ressentiment/closed-construct-ofmeaningfulness-and-teleology $\quad$ moronisation-<sublimating-nascence,-extricatory 
desublimating-downstreaming/'avalage'>' undifferentiation of both the prior relativeontological-incompleteness ${ }^{8}$ and the prospective relative-ontological-completeness ${ }^{87}$ (in terms of the prior registry-worldview/dimension social-and-institutional-frameworks-ofreferencing/registering/decisioning blurriness-<sterilising/anecdotalising/trivialising-ofprospective-re-ontologising_by-preconverging,-in-disontologising-formulaic-dragging-

out/hollowing-out $>$ ) thus undermining prospective ontologising-and-re-ontologising; as soundermining the prospective sublimation 'effective entailment of meaningfulness-andteleology ${ }^{9}$ enculturation/habituation' as to the prospective process of limitedness/humansubpotency cumulating/recomposuring 'intolerance- $<$ ofdisparateness $>$ /exactifying_precisioning-of-sublimation-<as-to-postconverging-narrowingdown apriorising/axiomatising/referencing-entailing-theoretical,-conceptual-and-operantimplications $>$ exercise of intelligibility' (as to imbued 'developing epistemic sense of nonpresencing-<perspective-ontological-normalcy/postconvergence $>\quad$ relativism/relativescope as projective-insights') with respect to prospective axiomatising/re-referencing residuality-in-re-originariness/re-origination of limitedness/human-subpotency prospective re-encountering/re-confrontation with the 'constraining/defining intersolipsistic reflexive-sublimating/unreflexive-desublimating measure/objectification that is unlimitedness/existence-as-ontologicalnormalcy/postconvergence-<in-validation-of-'metaphysics-of-absence_epistemic-

projection'>'. $\quad$ Moronisation- $<$ sublimating-nascence,-extricatory-desublimatingdownstreaming/'avalage' $>$ is thus an undermining of the prospectively requisite 'veridical profound-supererogation epistemic-growth,-as - \{veridical/sound\}-relative-reflexivity-inexistencetrelativising from limited mentation as its deepening/psychologismic epistemic acutisation residualising, ${ }^{\text {\{decompulsing }}$ \}elinearity for-cogency which is uncircumventable/indispensable for prospective sublimating intellection (as of its imbued 
psychologismic-epistemic-acutisation-<as-to-postconverging-de-

mentating/structuring/paradigming,-eliciting-of-existence's-sublimating-nascence-inprospective-aporeticism-overcoming/unovercoming $>$ as to epistemic-growth,-as\{veridical/sound\}-relative-reflexivity-in-existence/relativising from-limited-mentation-as-itsdeepening/psychologismic epistemic-acutisation residualising, ${ }^{\text {\{decompulsing }}$ delinearity for eogency)' with regards to its sublimating 'upstreaming'/'amontée' (as to 'supererogatory wholesomeness/profound-supererogation as of prospective ${ }^{83}$ reference-ofthought_-point-of-devolving/departure/anchoring/backdrop_of_sublimating-nascence- $<$ as-tothe-grandest-axiomatic-construct-fepistemictalising $\stackrel{+}{5}$ re-apriorising/re-axiomatising/rereferencing $\sim$ residuality - in-re-originariness/re-origination of limitedness/human-subpotency prospective re-encountering/re-confrontation with unlimitedness/existence>'). Moronisation<sublimating-nascence,-extricatory-desublimating-downstreaming/'avalage'> can thus be construed as to prior registry-worldview/dimension shallow-supererogation \{flawed/unsound\}-relative-unreflexivity-in-existence/absolutising from-limitedmentation/psychologismic epistemic acutisation nonresidualising imbued\{compulsing\} linearityoin-eclecticism-of-prior-mere-formulaicity/ritualisation disenabling/undermining of the 'requisite profound-supererogation for prospective registryworldview/dimension sublimating re-rationalisation-ofcontentivity/argumentativity/dialecticism/discursivity' as of 'requisite prospectively induced psychologismic-epistemic-acutisation-<as-to-postconverging-dementating/structuring/paradigming,-eliciting-of-existence's-sublimating-nascence-inprospective-aporeticism-overcoming/unovercoming > as to epistemic-growth,-as\{veridical/sound\}-relative-reflexivity-in-existence/relativising from limited mentation as itsdeepening/psychologismic epistemic-acutisation residualising, fdecompulsing $_{\text {\} }}$ delinearity for eogency of intolerance-<of-disparateness $>$ /exactifying_precisioning-of-sublimation- $<$ as-to- 
postconverging-narrowing-down apriorising/axiomatising/referencing-entailing-theoretical,-

conceptual-and-operant-implications $>$ entailment of ${ }^{5}$ meaningfulness-and-teleology

enculturation/habituation'; wherein the states of recurrent-utter-uninstitutionalisation, baseinstitutionalisation-ununiversalisation, ${ }^{103}$ universalisation-non-positivism/medievalism and positivism $-{ }^{80}$ procrypticism respectively are construed as in moronisation- $<$ sublimatingnascence,-extricatory-desublimating-downstreaming/'avalage'> with regards to the 'requisite prospectively induced psychologismic-epistemic-acutisation-<as-to-postconverging-dementating/structuring/paradigming,-eliciting-of-existence's-sublimating-nascence-inprospective-aporeticism-overcoming/unovercoming $>$ as to epistemic-growth,-as\{veridical/sound\}-relative-reflexivity-in-existence/relativising from-limited-mentation-as-itsdeepening/psychologismic epistemic-acutisation residualising, ${ }^{\{\text {decompulsing }}$ \}elinearity foreogency of intolerance-<of-disparateness $>$ /exactifying_precisioning-of-sublimation- $<$ as-topostconverging-narrowing-down apriorising/axiomatising/referencing-entailing-theoretical,conceptual-and-operant-implications $>$ entailment of ${ }^{56}$ meaningfulness-and-teleology enculturation/habituation' respectively of base-institutionalisation-ununiversalisation, universalisation-non-positivism/medievalism, positivism- ${ }^{80}$ procrypticism and deprocrypticism-or-preempting-disjointedness-as-of- ${ }^{3}$ reference-of-thought. This insightfully highlights that 'unlimitedness/existence-<full-potency-of_sublimating nascence> holds in its fold all the sublimating-nascence' for limitedness/human-subpotency omnipotentiality (so-construed as the 'constraining/defining intersolipsistic reflexivesublimating/unreflexive-desublimating measure/objectification that is unlimitedness/existenceas-ontological-normalcy/postconvergence-<in-validation-of-'metaphysics-ofabsence_epistemic-projection'>'); but that the unleashing of this potential is merely an issue of the 'referencing-<apriorising/axiomatising $>\quad$ psychoanalytic-unshackling/memeticreordering/institutional-recomposuring' as of limitedness/human-subpotency sublimating- 
upstreaming/'amontée' ('supereregatøry wholesomeness/profound-supererogation as of prospective reference-of-thought-point-ofdevolving/departure/anchoring/backdrop_of_sublimating-nascence-<as-to-the-grandestaxiomatic-construct-\{epistemic-totalising ${ }^{+}$re-apriorising/re-axiomatising/rereferencing $\sim$ residuality - in-re-originariness/re-origination of limitedness/human-subpotency prospective re-encountering/re-confrontation with unlimitedness/existence>'); with limitedness/human-subpotency comprehensive sublimating-upstreaming/'amontée reflected as the relative-unreflexivity/relative-reflexivity - ontological-contiguity ${ }^{67}$ of-the-humaninstitutionalisation-process 68 'grander supereregatery wholesomeness/profoundsupererogation as of prospective ${ }^{83}$ reference-of-thought-point-ofdevolving/departure/anchoring/backdrop_of_sublimating-nascence-<as-to-the-grandestaxiomatic-construct-\{epistemic-totalising ${ }^{\dagger}$ re-apriorising/re-axiomatising/rereferencing $\sim$ residuality - in-re-originariness/re-origination of limitedness/human-subpotency prospective re-encountering/re-confrontation with unlimitedness/existence>'. Critically, the term moronisation- $<$ sublimating-nascence,-extricatory-desublimatingdownstreaming/'avalage'> as herein articulated is again about grasping the accompanying requisite sublimating psychologismic-element-<as-of-diametrical-conflatedness -towards'already-given-unlimitedness/existence-<full-potency-of_sublimating nascence $>$-of‘limitedness/human-subpotency-as-to-its-imbued-\{veridical/sound\}-relative-reflexivity-inexistence/relativising from-limited-mentation-as-its-deepening/psychologismic epistemicacutisation residualising, ${ }^{\text {fdecompulsing }}$ delinearity for-cogency'> (beyond 'mereformulaicity/ritualisation-<as-to-mere-formulaicmethodologising/mutualising/organising/institutionalising,-prospectively-losing-track-of‘ \{epistemic-totalising ’̀ re-apriorising/re-axiomatising/re-referencing rresiduality-in-reoriginariness/re-origination'> imbued elaboration-as-to-mere- 
extrapolating/constituting/abstracting/deducing/inferring-of-elucidation-outside'prospectively_implicited_attendant_ontological-contiguity ${ }^{67}$ ' educedexistentialising/contextmalising/textualising_'intelligibility/epistemicity/reflexivity-contiguity$<$ imbued-notional cogency $>$ predisposition' of the prior registry-worldview/dimension as it fails by its manifest desublimation to reflect prospective fepistemic-totalising 3 re-apriorising/reaxiomatising/re-referencing-residuality-in-re-originariness/re-origination of limitedness/human-subpotency prospective re-encountering/re-confrontation with the 'constraining/defining intersolipsistic reflexive-sublimating/unreflexive-desublimating measure/objectification that is unlimitedness/existence-as-ontologicalnormalcy/postconvergence-<in-validation-of-'metaphysics-of-absence_epistemic-

projection'>') involved for instance in the psychologismic fact of ${ }^{15}$ de-mentation〈supererogatory $\sim$ ontological-de-mentation-or-dialectical-de-mentation-stranding-orattributive-dialectics) that for instance (and as it applies to all registry-worldviews/dimensions in prior relative-ontological-incompleteness ${ }^{88}$ including our positivism- ${ }^{80}$ procrypticism with respect to prospective ${ }^{18}$ deprocrypticism-or-preempting-disjointedness-as-of- ${ }^{8}$ reference-ofthought) our positivism supposedly normal/expected 'intolerance- $<$ ofdisparateness $>$ /exactifying_precisioning-of-sublimation-<as-to-postconverging-narrowingdown apriorising/axiomatising/referencing-entailing-theoretical,-conceptual-and-operantimplications $>$ entailment of ${ }^{56}$ meaningfulness-and-teleology ${ }^{9}$ enculturation/habituation' is not necessarily construed as normal/expected by a non-positivising mindset (which is thus in a nonpositivising moronisation- $<$ sublimating-nascence,-extricatory-desublimatingdownstreaming/'avalage'> state to such positivising 'intolerance-<ofdisparateness $>$ /exactifying_precisioning-of-sublimation- $<$ as-to-postconverging-narrowingdown apriorising/axiomatising/referencing-entailing-theoretical,-conceptual-and-operantimplications> entailment of ${ }^{5}$ meaningfulness-and-teleology enculturation/habituation' 
implied prospective demoronisation- $<$ sublimating-nascence,-nonextricatory-sublimatingupstreaming/'amontée'>). This validates the fact that it is ontologically-flawed to reflect of the prospectively uninstitutionalised-threshold ${ }^{102}$ (especially as to re-ontologising prospective Being-development/ontological-framework-expansion-as-to-depth-of-ontologisingdevelopment-as-infrastructure-of- meaningfulness-and-teleology ) as of a 'prospective mereformulaicity/ritualisation-<as-to-mere-formulaicmethodologising/mutualising/organising/institutionalising,-prospectively-losing-track-of‘fepistemic totalising łre-apriorising/re-axiomatising/re-referencing residuality-in-reoriginariness/re-origination'> imbued elaboration-as-to-mereextrapolating/constituting/abstracting/deducing/inferring-of-elucidation-outside'prospectively_implicited_attendant-ontological-contiguity ${ }^{67}$ 'educedexistentialising/contextualising/textmalising_intelligibility/epistemicity/reflexivity-contiguity<imbued-notional cogency>' exercise' without factoring in the ontological-veracity that prospectively uninstitutionalised-threshold ${ }^{102}$ manifests its given moronisation- $<$ sublimatingnascence,-extricatory-desublimating-downstreaming/'avalage'> as elucidated above (and so as of manifest <amplituding/formative> wooden-language-_imbued-temporal-mereform/virtualities/dereification/akrasiatic-drag/denatured/preconverging-or-dementing narratives - of-the- reference-of-thought- categorical-imperatives/axioms/registryteleology > and associated pedantising/muddling/formulaic-hollowing-out - insubontologisation/subpotentiation-〈blurring/undermining-of-prospective-totalising-entailing,as-to-entailing-<amplituding/formative-epistemicity $>$ totalising $\sim$ in-relative-ontologicalcompleteness > desublimation); as not reflective of the requisite prospective 'intolerance-<ofdisparateness $>$ /exactifying_precisioning-of-sublimation-<as-to-postconverging-narrowingdown apriorising/axiomatising/referencing-entailing-theoretical,-conceptual-and-operantimplications $>$ entailment of ${ }^{56}$ meaningfulness-and-teleology ${ }^{9}$ enculturation/habituation' 
implied prospective demoronisation- $<$ sublimating-nascence,-nonextricatory-sublimatingupstreaming/'amontée’>. In this respect, accompanying requisite sublimating psychologismicelement-<as-of-diametrical-conflatedness -towards-'already-given-unlimitedness/existence<full-potency-of_sublimating nascence>'-of-'limitedness/human-subpotency-as-to-itsimbued-\{veridical/sound\}-relative-reflexivity-in-existence/relativising from-limitedmentation-as-its-deepening/psychologismic epistemic-acutisation residualising, \{decompulsing\} delinearity for-cogency'> is merely a reflection of 'nonextricatory/postconverging ontologising-and-re-ontologising angling-of-imaginary $\quad$ demoronisation- $<$ sublimatingnascence,-nonextricatory-sublimating-upstreaming/'amontée’’’ (imbued profoundsupererogation for prospective re-ontologising)' over 'lifespan extricatory/preconverging psychical-nascency moronisation- $<$ sublimating-nascence,-extricatory-desublimatingdownstreaming/'avalage'>' (imbued prior 're-ontologising-by-disontologising_threshold')'; with no room for a 'neutral ${ }^{79}$ presencing-absolutising-identitive-constitutedness ${ }^{14}$ point-ofdevolving/departure/anchoring/backdrop for conceptualising ontological-veracity/ontologicalinveracity (as so-failing to reflect the 'dynamics of apriorising/axiomatising/referencing as to preconverging/postconverging-de-mentating/structuring/paradigming' associated with human limited-mentation-capacity as subjecting ' aluced mnlimithess/existence sublimating nascence' to-limitedness/human-subpotency and limited-mentation-capacity-deepening-assubjecting limitedness/human-subpotency to 'educed-unlimitedness/existence-sublimating nascence' ${ }^{53}$ ' which rather induces ontologically-flawed disparateness-of-conceptualisation$<$ unforegrounding-ment,-failing-prospectively-to-reflect-'immanent relativeunreflexivity/relative-reflexivity - ontological-contiguity ' $>$. Thus the accompanying requisite sublimating psychologismic-element-<as-of-diametrical-conflatedness -towards-'alreadygiven-unlimitedness/existence-<full-potency-of_sublimating nascence $>$ '-of‘limitedness/human-subpotency-as-to-its-imbued-\{veridical/sound \}-relative-reflexivity-in- 
existence/relativising from-limited-mentation-as-its-deepening/psychologismic epistemic-

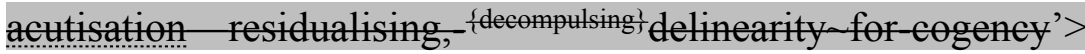

as

to

'nonextricatory/postconverging ontologising-and-re-ontologising angling-of-imaginary demoronisation-<sublimating-nascence,-nonextricatory-sublimating-upstreaming/'amontée'>' (imbued profound-supererogation for prospective re-ontologising)', is critically about prospective ontologising-and-re-ontologising undermining/superseding of the prospective disontologising 'lifespan extricatory/preconverging psychical-nascency moronisation<sublimating-nascence,-extricatory-desublimating-downstreaming/'avalage'>' (imbued prior 're-ontologising-by-disontologising_threshold')' < amplituding/formative $>$ wooden-language〈imbued-averaging-of-thought-<as-to-leveling/ressentiment/closed-construct-ofmeaningfulness-and-teleology -as-of-'nondescript/ignorable-void '-with-regards-toprospective-apriorising-implications $>\rangle$ and associated pedantising/muddling/formulaichollowing-out-in-subontologisation/subpotentiation-〈blurring/undermining-of-prospectivetotalising-entailing,-as-to-entailing-<amplituding/formative-epistemicity $>$ totalising $\sim$ inrelative-ontological-completeness \ dispositions; as to the requisite epistemic-growth,-as\{veridical/sound\}-relative-reflexivity-in-existence/relativising from-limited-mentation-as-itsdeepening/psychologismic epistemic-acutisation residualising, \{decompusingl delinearity foreogency elicited prospective re-ontologising conceptivity/epistemic-reflexivity/epistemicityrelativism-determinism-<reifying \{as-to-knowledge-developing $\}$-and-empowering $>\quad$ for prospective ontologising-and-re-ontologising sublimation/emancipation/enfranchisement. But then such prior 'lifespan extricatory/preconverging psychical-nascency moronisation<sublimating-nascence,-extricatory-desublimating-downstreaming/'avalage'>' (imbued prior 're-ontologising-by-disontologising_thresholds')' manifestations and arguments of their times (like 'in-many-ways the slaves lives are better off than their kindreds in the darkness of Africa or that their conditions will be worse off when freed', that the 'toll of the American civil war 
was unnecessary', or 'in-many-ways the outcome of the French Revolution was far worse than was worth the struggle' and as so-equally echoed and adhered-to even by many from the specific subgroups/subcategories of humans/humanity to which such prospective ontologising-and-reontologising sublimation/emancipation/enfranchisement would punctually/immediately accrueto), speaks to the fact that the 'seeding/incipient pre-eminence of human embodiedvitality/survival/subsistence — existential-<disontologising/re-ontologising aporeticism> becoming driving human consciousness complexifying-<transcending-in-elaborateness as to human aestheticisation-and-aestheticisation-towards-ontology-<elicited-idiomatisation $>$ dynamics of lifespan extricatory/preconverging psychical-nascency and nonextricatory/postconverging ontologising-and-re-ontologising angling-of-imaginary>' is underlied as of human lifespan 'subconscious-and-conscious_perceptible-andreperceptible/actionable-and-reactionable-dynamics of effectively_manifestable-andremanifestable/attainable-and-reattainable loss and gain existential-<disontologising/reentologising aporeticism $>\quad$ sublimating-upstreaming/'amontée’_by—desublimatingdownstreaming/'avalage' possibilities'; speaking of a human 're-ontologising-bydisontologising_existential-calculus-〈between 'prospective existentialisingpostconverging_framing/imprinting re-ontologising' and 'prior existentialising preconverging_enframing/imprintedness social-functioning-and-accordance-as-of-socialstake-contention-or-confliction' $\rangle$ which is just as well likely to existentially<disontologising/re-ontelogising aporeticism $>$ acquiesce to prospective disontologising/subontologising_-imbuing-prospectively-of-humandesublimating/subjugation/disenfranchisement (as to the lack of an 'existentially<disontologising/re-ontologising aporeticism $>$ convincing/plausible' prospective requisite epistemic-growth,-as_ - \{veridical/sound\}-relative-reflexivity-in-existence/relativising-fromlimited-mentation-as-its-deepening/psychologismic epistemic-acutisation residualising, 
$\{$ decompulsing $\}$ delinearity for-cogency elicited prospective re-ontologising conceptivity/epistemicreflexivity/epistemicity-relativism-determinism- $<$ reifying \{as-to-knowledge-developing $\}$-andempowering $>\quad$ for $\quad$ prospective ontologising-and-re-ontologising sublimation/emancipation/enfranchisement). In this regards, we may fail to appreciate the veracity of such a human 're-ontologising-by-disontologising_existential-calculus-_between 'prospective existentialising_-postconverging_framing/imprinting re-ontologising' and 'prior existentialising_preconverging_enframing/imprintedness social-functioning-andaccordance - as-of-social-stake-contention-or-confliction' $\rangle$ ' when we fail to grasp that the 'prospective ontologising-and-re-ontologising possibility/prospect for sublimation/emancipation/enfranchisement' of past eras/epochs/ages social struggles came with the risk of the 'prospective worsening of their given disontologising/subontologising — imbuingprospectively-of-human-desublimating/subjugation/disenfranchisement associated for instance with lynchings/mass-murdering/genocides' (and so with respect to the dominated/disenfranchised 'habituated prior mere-or-basic-surviving/subsistence' as of the overarching/defining/devolving 'prior existentialisingpreconverging_enframing/imprintedness social-functioning-and-accordance-as-of-socialstake-contention-or-confliction')' and on-the-other-hand as equally reflecting the fact that the dominance/vested-interest structure of those ages/epochs/eras possibility/prospect for undermining the dominated/disenfranchised 'prospective ontologising-and-re-ontologising possibility for sublimation/emancipation/enfranchisement' came with the risk of revolts and riots of the dominated/disenfranchised together with the overall social contestation and opprobrium of the dominance/vested-interest structure. This so-underlied the given 'dominance/vestedinterest structure by dominated/disenfranchised re-ontologising-by-disontologising_threshold of social-functioning-and-accordance-as-of-social-stake-contention-or-confliction' (and soinducing the dominated/disenfranchised 'habituated prior mere-or-basic-surviving/subsistence' 
as of 'prior existentialising_preconverging_enframing/imprintedness social-functioning-andaccordance-as-of-social-stake-contention-or-confliction'). This so-reflected the given eras/epochs/ages existential-<disentologising/re-ontologising aporeticism $>$ context of 'lifespan extricatory/preconverging psychical-nascency moronisation- $<$ sublimating-nascence,extricatory-desublimating-downstreaming/'avalage'>' (imbued prior 're-ontologising-bydisontologising_threshold')' as to their 're-ontologising-by-disontologising_existentialcalculus-〈between 'prospective existentialising-postconverging_framing/imprinting reontologising' and 'prior existentialising_preconverging_enframing/imprintedness socialfunctioning-and-accordance_-as-of-social-stake-contention-or-confliction' $\rangle$ '; as so-underlying the 'prior existentialising — preconverging_enframing/imprintedness social-functioning-andaccordance - as-of-social-stake-contention-or-confliction' in reflection of the 're-ontologisingby-disontologising_threshold of social-functioning-and-accordance-as-of-social-stakecontention-or-confliction' (as of both the 'dominated/disenfranchised relatively passive/submissive relation to the possibility/prospect for their prospective re-ontologising sublimation/emancipation/enfranchisement' and the 'dominance/vested-interest structure preemptive anticipation in relation to the possibility/prospect for the prospective re-ontologising sublimation/emancipation/enfranchisement of the dominated/disenfranchised'). With this starker elucidation in mind, it is equally important to factor in that all eras/ages/epochs including our present thus manifest 'lifespan extricatory/preconverging psychical-nascency moronisation<sublimating-nascence,-extricatory-desublimating-downstreaming/'avalage'>' (imbued prior 're-ontologising-by-disontologising_threshold')' as to 're-ontologising-bydisontologising_existential-calculus-〈between 'prospective existentialisingpostconverging_framing/imprinting re-ontologising' and 'prior existentialisingpreconverging_enframing/imprintedness social-functioning-and-accordance-as-of-socialstake-contention-or-confliction' $\rangle$ ' notwithstanding the apparently stark or tepid or otherwise 
differently manifested (as of the various psychologismic epistemic-acutisation difficulty$<$ for, residualising $\{$ \{decompulsing $\}$ delinearity for-cogency> - magnitudes $\left.{ }^{\{0 f-e x p e r i e n t i a l i t y / e x p e r i m e n t}\right\}$ of 're-ontologising-by-disontologising_thresholds' passively/actively-developing existentialising-frame-of-entailment of motif-and-apriorising/axiomatising/referencing) with regards to the overarching/defining/devolving 're-ontologising-by-disontologising threshold' of the given era/epoch/age; as so-underlying the overarching/defining/devolving 'prior existentialising_-preconverging_enframing/imprintedness social-functioning-andaccordance - as-of-social-stake-contention-or-confliction' in reflection of the 're-ontologisingby-disontologising_threshold of social-functioning-and-accordance-as-of-social-stakecontention-or-confliction' (as of both the overarching/defining/devolving 'generally given relatively passive/submissive relation to prospective re-ontologising' and overarching/defining/devolving 'corresponding overt/covert preemptive anticipation relation to prospective re-ontologising'). This carries insightful implications for prospective ontologisingand-re-ontologising possibilities (as of the requisite epistemic-growth,-as_—veridical/sound\} relative-reflexivity-in-existence/relativising from-limited-mentation-as-itsdeepening/psychologismic epistemic-acutisation residualising, $\left.{ }^{\{d e c o m p u l s i n g}\right\}$ delinearity foreogen elicited prospective re-ontologising conceptivity/epistemic-reflexivity/epistemicityrelativism-determinism-<reifying \{as-to-knowledge-developing $\}$-and-empowering $>\quad$ for prospective ontologising-and-re-ontologising sublimation/emancipation/enfranchisement) as required with the 'nonextricatory/postconverging ontologising-and-re-ontologising angling-ofimaginary demoronisation- $<$ sublimating-nascence,-nonextricatory-sublimatingupstreaming/'amontée'>' (imbued profound-supererogation ${ }^{6}$ for prospective re-ontologising)' prospective requisite sublimating psychologismic-element-<as-of-diametrical-conflatedness towards-'already-given-unlimitedness/existence-<full-potency-of_sublimating nascence $>$ '-of‘limitedness/human-subpotency-as-to-its-imbued-\{veridical/sound\}-relative-reflexivity-in- 
existence/relativising from-limited-mentation-as-its-deepening/psychologismic epistemic-

acutisation residualising, ${ }^{\text {\{decompulsing }\}}$ delinearity for-cogency’ $>$. In effect, the manifestation of overall $<$ amplituding/formative $>$ wooden-language-〈imbued-temporal-mere-

\section{form/virtualities/dereification/akrasiatic-drag/denatured/preconverging-or-dementing}

narratives - of-the- reference-of-thought- categorical-imperatives/axioms/registry-

teleology > in-many-ways is a 'human <amplituding/formative-epistemicity $>$ totalising thrownness-in-existence ${ }^{35}$ summary appraisal' of 're-ontologising-bydisontologising_existential-calculus-〈between 'prospective existentialisingpostconverging_framing/imprinting re-ontologising' and 'prior existentialisingpreconverging_enframing/imprintedness social-functioning-and-accordance-as-of-socialstake-contention-or-confliction' ’' as to 'lifespan extricatory/preconverging psychical-nascency moronisation-<sublimating-nascence,-extricatory-desublimating-downstreaming/'avalage' $>$ ' (imbued prior 're-ontologising-by-disontologising_threshold')'; and so-reflects the underlying social susceptibility to moronisation- $<$ sublimating-nascence,-esublimatingdownstreaming/'avalage'> in undermining prospective ontologising-and-re-ontologising (and so given registry-worldviews/dimensions imbued prior-institutionalisation-threshold-byprospective-uninstitutionalised-threshold 'self-referencing-syncretising forward-facingsupposedly postconverging-or-dialectical-thinking -apriorising-psychologism epistemicprojection as of prior mere-formulaicity/ritualisation-<as-to-mere-formulaic methodologising/mutualising/organising/institutionalising,-prospectively-losing-track-of-

\footnotetext{
‘\{epistemic-totalising ’re-apriorising/re-axiomatising/re-referencing-residuality-in-re-

originariness/re-origination'>' so-reflecting their 'disontologising preconverging/dementing $<$ as-to-prospective-uninstitutionalised-threshold $>$ ignoring/biased inclination' for the sake of 'their given present minimum-and-balancing expectations/anticipations of social-functioningand-accordance-as-of-social-stake-contention-or-confliction' while qualifying their
} 
prospectively uninstitutionalised-threshold ${ }^{102}$ actually as nondescript/ignorable-void as to their ${ }^{7}$ presencing — absolutising-identitive-constitutedness ${ }^{14} \quad<$ preconverging $\sim$ 'motif-andapriorising/axiomatising/referencing'-entailing--existentialising-enframing/imprintedness〈as-to- historicity-tracing-in-presencing-hyperrealisation/hyperreal-transposition〉). Moronisation- $<$ sublimating-nascence,-esublimating-downstreaming/'avalage' $>$ is so-easily promptable by 'dominance/vested-interest structure in relative-ontologicalincompleteness ${ }^{8}$-presublimation-construct-of- ${ }^{5}$ meaningfulness-and-teleology ${ }^{9}$ prospective desublimating rationalisation-of-contentivity/argumentativity/dialecticism/discursivity of social-and-institutional-frameworks-of - referencing/registering/decisioning and the derived value-construction' and associated pedantising/muddling/formulaic-hollowing-out-insubontologisation/subpotentiation-〈blurring/undermining-of-prospective-totalising-entailing,as-to-entailing-<amplituding/formative-epistemicity $>$ totalising in-relative-ontologicalcompleteness $>$ desublimation. It is important to grasp in here that moronisation- $<$ sublimatingnascence,-extricatory-desublimating-downstreaming/'avalage'> as such arises as of preconverging/postconverging-de-mentating/structuring/paradigming dynamics of 'individualby-institutional-by-social summary appraisal of what-is-ontologisingly/disontologisinglyconceivable_-by_what-is-ontologisingly/disontologisingly-expectable'; as critically inducing 'varying protracted-social-as-to-individual-by-institutional-by-social 're-ontologising-bydisontologising_existential-calculus-〈between $\quad$ 'prospective existentialisingpostconverging_framing/imprinting re-ontologising' and 'prior existentialising preconverging_enframing/imprintedness social-functioning-and-accordance-as-of-socialstake-contention-or-confliction' $\rangle$ ' for consciously or unconsciously resorting to 'mereformulaicity/ritualisation-<as-to-mere-formulaicmethodologising/mutualising/organising/institutionalising,-prospectively-losing-track-of‘\{epistemic-totalising ' ${ }^{\prime}$ re apriorising/re axiomatising/re referencing-residuality-in-re- 
extrapolating/constituting/abstracting/deducing/inferring-of-elucidation-outside-

'prospectively_implicited_attendant-ontological-contiguity ${ }^{67}$ ' educedexistentialising/contextualising/textmalising_intelligibility/epistemicity/reflexivity-contiguity<imbued-notional cogency $>$ ' in order to enable 'minimum-and-balancing expectations/anticipations of social-functioning-and-accordance-as-of-social-stakecontention-or-confliction'/least-common-denominator-of-social-functioning-and-accordanceeffecting (and so overlooking/ignoring the possibility/prospect of prospective disontologising/subontologising moronisation-<sublimating-nascence,-extricatorydesublimating-downstreaming/'avalage' $>$ ). This is so-reflected variedly/diversely in generalised public opinion making (as associated with the media), specific/professional/trades/institutions specialised public opinion making as well as with respect to the overall extended-informality-〈susceptible-to-effecting-parsimony-as-ofshoddiness-and-incompleteness-to- meaningfulness-and-teleology $\rangle$ (in reflection of the given registry-worldview/dimension prospectively uninstitutionalised-threshold ${ }^{12}$ overall disontologising/subontologising moronisation- $<$ sublimating-nascence,-extricatorydesublimating-downstreaming/'avalage'> as to its underlying desublimating rationalisation-ofcontentivity/argumentativity/dialecticism/discursivity of social-and-institutional-frameworksof - referencing/registering/decisioning and the derived value-construction). This preconverging/postconverging-de-mentating/structuring/paradigming dynamics of 'individualby-institutional-by-social summary appraisal of what-is-ontologisingly/disontologisinglyconceivable — by — what-is-ontologisingly/disontologisingly-expectable' is inherent to 'lifespan extricatory/preconverging psychical-nascency moronisation- $<$ sublimating-nascence,extricatory-desublimating-downstreaming/'avalage'>' (imbued prior 're-ontologising-bydisontologising_threshold')' as to 're-ontologising-by-disontologising_existential-calculus- 
〈between 'prospective existentialising_postconverging_framing/imprinting re-ontologising' and 'prior existentialising_preconverging_enframing/imprintedness social-functioning-andaccordance-as-of-social-stake-contention-or-confliction' $\rangle$ '. It can be appreciated in this regards that moronisation- $<$ sublimating-nascence, extricatingdownstreaming/'avalage'> is in-many-ways a manifestation of aestheticisation-beholdeningout-of-bechancing/taxingness-of-originariness (so-reflecting human shallow-supererogation ${ }^{6}$ as of a desublimating least-common-denominator-of-social-functioning-and-accordanceeffecting); as to the directly/indirectly-and-overtly/covertly conscious and unconscious 'dominance/vested-interest structure in relative-ontological-incompleteness ${ }^{88}$-presublimationconstruct-of- ${ }^{5}$ meaningfulness-and-teleology 9 prospective desublimating rationalisation-ofcontentivity/argumentativity/dialecticism/discursivity of social-and-institutional-frameworksof - referencing/registering/decisioning and the derived value-construction'. Moronisation$<$ sublimating-nascence,-extricatory-desublimating-downstreaming/'avalage'>, underlied as of 'lifespan extricatory/preconverging psychical-nascency moronisation-<sublimating-nascence,extricatory-desublimating-downstreaming/'avalage'>' (imbued prior 're-ontologising-bydisontologising_threshold')' as to 're-ontologising-by-disontologising_existential-calculus〈between 'prospective existentialising_postconverging_framing/imprinting re-ontologising' and 'prior existentialising-preconverging_enframing/imprintedness social-functioning-andaccordance - as-of-social-stake-contention-or-confliction' $\rangle$ ', is herein so-construed more or less along a Foucauldian biopower desublimation implications arising as of human prospectively uninstitutionalised-threshold ${ }^{102}$ and so-analysed rather as from ${ }^{6}$ nonpresencing-<perspectiveontological-normalcy/postconvergence $>$ epistemic-projection perspective (as to Beingdevelopment/ontological-framework-expansion-as-to-depth-of-ontologising-development-asinfrastructure-of- meaningfulness-and-teleology , institutional-development-as-to-socialfunction-development and living-development-as-to-personality-development psychologismic 
epistemic-acutisation difficulty-for, residualising \{decompulsing\} ${ }^{\text {delinearity for-cogency> }}$ magnitudes $\{$ of-experientiality/experiment\} $\}$; in reflection not only of dominance/vested-interest structure but overall social-setup protracted-social—as-to-individual-by-institutional-by-social 'prospective disontologising/subontologising-imbuing-prospectively-of-humandesublimating/subjugation/disenfranchisement imbued $\quad<$ preconverging 'motif-andapriorising/axiomatising/referencing'-entailing>-existentialising—enframing/imprintedness〈as-to- historicity-tracing-in-presencing-hyperrealisation/hyperreal-transposition〉’.

Effectively the various 're-ontologising-by-disontologising_existential-calculus-〈between 'prospective existentialising_-postconverging_framing/imprinting re-ontologising' and 'prior existentialising_-preconverging_enframing/imprintedness social-functioning-andaccordance - as-of-social-stake-contention-or-confliction' $\rangle$ of moronisation- $<$ sublimatingnascence,-extricatory-desublimating-downstreaming/'avalage'> (in reflection of the relativeunreflexivity/relative-reflexivity — ontological-contiguity ${ }^{67} \sim$ of-the-human-institutionalisationprocess $^{68}$ epistemic-projection perspective of Being-development/ontological-frameworkexpansion-as-to-depth-of-ontologising-development-as-infrastructure-of- meaningfulnessand-teleology ) are manifested as to prospectively uninstitutionalised-threshold ${ }^{02}$ associated with 'dominance/vested-interest structure in relative-ontological-incompleteness ${ }^{8}-$ presublimation-construct-of- ${ }^{5}$ meaningfulness-and-teleology 9 prospective desublimating rationalisation-of-contentivity/argumentativity/dialecticism/discursivity of social-andinstitutional-frameworks-of - referencing/registering/decisioning and the derived valueconstruction': and so, as from 'blatant brutish conquest/subjugation desublimating rationalisation-of-contentivity/argumentativity/dialecticism/discursivity of social-andinstitutional-frameworks-of — referencing/registering/decisioning and the derived valueconstruction (as to its given 're-ontologising-by-disontologising_existential-calculus-_between 'prospective existentialising_-postconverging_framing/imprinting re-ontologising' and 'prior 
accordance - as-of-social-stake-contention-or-confliction' $\rangle$ ' of moronisation- $<$ sublimatingnascence,-extricatory-desublimating-downstreaming/'avalage'> as of 'individual-byinstitutional-by-social existentialising-enframing/imprintedness to blatant brutish conquest/subjugation imbued prospective disontologising/subontologising')', 'dominion protection desublimating rationalisation-ofcontentivity/argumentativity/dialecticism/discursivity of social-and-institutional-frameworksof-referencing/registering/decisioning and the derived value-construction (as to its given 'reontologising-by-disontologising_existential-calculus-_between 'prospective existentialisingpostconverging_framing/imprinting re-ontologising' and 'prior existentialising preconverging_enframing/imprintedness social-functioning-and-accordance-as-of-socialstake-contention-or-confliction' $\rangle$ of $\quad$ moronisation- $<$ sublimating-nascence,-extricatorydesublimating-downstreaming/'avalage'> as of 'individual-by-institutional-by-social existentialising - enframing/imprintedness to dominion protection imbued prospective disontologising/subontologising')', to the 'very natural-order-of-things desublimating rationalisation-of-contentivity/argumentativity/dialecticism/discursivity of social-andinstitutional-frameworks-of - referencing/registering/decisioning and the derived valueconstruction' (as to its given 're-ontologising-by-disontologising_existential-calculus-〈between 'prospective existentialising_-postconverging_framing/imprinting re-ontologising' and 'prior existentialising_preconverging_enframing/imprintedness social-functioning-andaccordance-as-of-social-stake-contention-or-confliction' $\rangle$ ' of moronisation- $<$ sublimatingnascence,-extricatory-desublimating-downstreaming/'avalage'> as of 'individual-byinstitutional-by-social existentialising — enframing/imprintedness to the very natural-order-ofthings imbued prospective disontologising/subontologising') and to 'our subtle modern-day prospective institutionally-distorted/disjointed-and-collateralising desublimating 
rationalisation-of-contentivity/argumentativity/dialecticism/discursivity of social-andinstitutional-frameworks-of - referencing/registering/decisioning and the derived valueconstruction' (as to its given 're-ontologising-by-disontologising_existential-calculus-〈between 'prospective existentialising_postconverging_framing/imprinting re-ontologising' and 'prior existentialising_-preconverging_enframing/imprintedness social-functioning-andaccordance - as-of-social-stake-contention-or-confliction' $\rangle$ ' of moronisation- $<$ sublimatingnascence,-extricatory-desublimating-downstreaming/'avalage'> as of 'individual-byinstitutional-by-social existentialising-enframing/imprintedness to our subtle modern-day prospective institutionally-distorted/disjointed-and-collateralising imbued prospective disontologising/subontologising'). Despite all these manifest instances of dominance/vestedinterest structure 'desublimating rationalisation-ofcontentivity/argumentativity/dialecticism/discursivity of social-and-institutional-frameworksof-referencing/registering/decisioning and the derived value-construction' (as of their respective 're-ontologising-by-disontologising_existential-calculus-_between 'prospective existentialising_-postconverging_framing/imprinting re-ontologising' and 'prior existentialising_-preconverging_enframing/imprintedness social-functioning-andaccordance - as-of-social-stake-contention-or-confliction' $\rangle$ ' of moronisation- $<$ sublimatingnascence,-extricatory-desublimating-downstreaming/'avalage'> as of 'individual-byinstitutional-by-social existentialising-enframing/imprintedness to their given prospective disontologising/subontologising'), this however never existentially-disenterising entologising aporeticism $>$ invalidated the 'genuine social intellectual-function/posture claim for prospective sublimating re-rationalisations-ofcontentivity/argumentativity/dialecticism/discursivity of social-and-institutional-frameworksof-referencing/registering/decisioning and the derived value-construction' (as of successive 'demoronisation-<sublimating-nascence,-nonextricatory-sublimating-upstreaming/'amontée'> 
breaks' of 'individual-by-institutional-by-social existentialising — enframing/imprintedness to their given prospective disontologising/subontologising') with regards to prospective 'intolerance-<of-disparateness $>$ /exactifying_precisioning-of-sublimation- $<$ as-topostconverging-narrowing-down apriorising/axiomatising/referencing-entailing-theoretical,conceptual-and-operant-implications $>$ entailment of ${ }^{56}$ meaningfulness-and-teleology enculturation/habituation' (and so in prospective \{epistemic-totalising 3 ? $\mathrm{re}$-apriorising/reaxiomatising/re-referencing $\sim$ residuality -in-re-originariness/re-origination of limitedness/human-subpotency prospective re-encountering/re-confrontation with the 'constraining/defining intersolipsistic reflexive-sublimating/unreflexive-desublimating measure/objectification that is unlimitedness/existence-as-ontologicalnormalcy/postconvergence-<in-validation-of-'metaphysics-of-absence_epistemic-

projection'>'). The veracity of the manifestation of moronisation-<sublimating-nascence,extricatory-desublimating-downstreaming/'avalage' $>$ (as to the relative-unreflexivity/relativereflexivity ontological-contiguity ${ }^{67} \sim$ of-the-human-institutionalisation-process ${ }^{68}$ epistemicprojection perspective) is what underlies the fact that there is no continuity of knowledgereification $\sim$ gesturing-and-accounting - of-epistemic-phenomenalism- $<$ inprospective_psychologismic apriorising/axiomatising/referencing-\{of-'prespectively implicited_attendant-ontological-contiguity ' reducedexistentialising/contextualising/textualising_ intelligibility/epistemicity/reflexivity-contiguity<imbued-notional cogency $>\quad\}$ - conflatedness -in-\{preconverging-ment by\} postconverging-entailment> as of 'mere-formulaicity/ritualisation-<as-to-mere-formulaicmethodologising/mutualising/organising/institutionalising,-prospectively-losing-track-of'\{epistemic-totalising 're apriorising/re axiomatising/re referencing-residuality-in-re-
originariness/re-origination'> imbued elaboration-as-to-mereextrapolating/constituting/abstracting/deducing/inferring-of-elucidation-outside- 
'prospectively_implicited_attendant_ontological-contiguity ${ }^{67}$ ' educedexistentialising/contextualising/textualising_'intelligibility/epistemicity/reflexivity-contiguity$<$ imbued-notional cogency $>$ ' between the <cumulating/recomposuring attendantontological-contiguity $>$-successive registry-worldviews/dimensions; but for the 'demoronisation-<sublimating-nascence,-nonextricatory-sublimating-upstreaming/'amontée'> epistemic-break or notional-discontiguity/epistemic-discontiguity ${ }^{63}<$ between - prior-shallowsupererogation -of-mentally-aestheticised preconverging/dementing -qualiaschema_and_prospective-profound-supererogation -of-mentallyaestheticised postconverging/dialectical-thinking -qualia-schema>' (by the 'genuine social intellectual-function/posture claim for prospective sublimating re-rationalisation-ofcontentivity/argumentativity/dialecticism/discursivity of social-and-institutional-frameworksof - referencing/registering/decisioning and the derived value-construction') with prior registryworldviews/dimensions. Such 'demoronisation-<sublimating-nascence,-nonextricatory sublimating-upstreaming/'amontée’> epistemic-break or notional-discontiguity/epistemicdiscontiguity 33 - between - prior-shallow-supererogation -of-mentallyaestheticised preconverging/dementing -qualia-schema_and_prospective-profoundsupererogation -of-mentally-aestheticised postconverging/dialectical-thinking -qualiaschema> between ${ }^{103}$ universalising-idealisation and non-universalising ancient-sophists, budding-positivism and non-positivising medieval-scholasticism as well as budding postmodern-thought and our totalisingly-ing — discretion/whim-of-thought as to our modern-day manifestation of disparateness-of-conceptualisation-<unforegrounding-ment,-failingprospectively-to-reflect-'immanent $\sim$ relative- unreflexivity/relative-reflexivity - ontologicalcontiguity ' $>$ rather take the form of 'successive challenges of profound-supererogation ${ }^{6}$ for prospective re-ontologising'; so-underlying the 'intolerance-<ofdisparateness>/exactifying_precisioning-of-sublimation-<as-to-postconverging-narrowing- 
down apriorising/axiomatising/referencing-entailing-theoretical,-conceptual-and-operant-

implications $>$ exercise of intelligibility' (as to imbued 'developing epistemic sense of nonpresencing-<perspective-ontological-normalcy/postconvergence $>\quad$ relativism/relativescope as projective-insights') of the overall relative-unreflexivity/relative-reflexivityontological-contiguity ${ }^{67}$ of-the-human-institutionalisation-process ${ }^{68}$ as to limitedness/humansubpotency cumulating/recomposuring in epistemic-growth,-as \{veridical/sound\}-relativereflexivity-in-existence/relativising from-limited-mentation-as-its-deepening/psychologismic epistemic acutisation residualising, for 'prospective postconverging aporeticism-overcoming/mnovercoming of prior-perspectivefalsity/falseness/fallaciousness (given registry-worldviews/dimensions imbued priorinstitutionalisation-threshold-by-prospective-uninstitutionalised-threshold 'self-referencingsyncretising forward-facing-supposedly postconverging-or-dialectical-thinking -apriorisingpsychologism epistemic-projection as of prior mere-formulaicity/ritualisation-<as-to-mereformulaic — methodologising/mutualising/organising/institutionalising,-prospectively-losing-

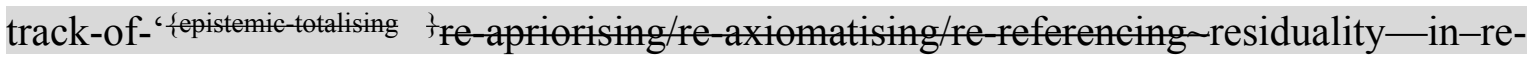
originariness/re-origination'>' so-reflecting their 'disontologising preconverging/dementing $<$ as-to-prospective-uninstitutionalised-threshold $>$ ignoring/biased inclination' for the sake of 'their given present minimum-and-balancing expectations/anticipations of social-functioningand-accordance-as-of-social-stake-contention-or-confliction' while qualifying their prospectively uninstitutionalised-threshold ${ }^{102}$ actually as nondescript/ignorable-void as to their ${ }^{79}$ presencing-absolutising-identitive-constitutedness ${ }^{14} \quad<$ preconverging ' $m o t i f-a n d-$ apriorising/axiomatising/referencing'-entailing >-existentialising-enframing/imprintedness〈as-to- historicity-tracing - in-presencing-hyperrealisation/hyperreal-transposition〉)' Insightfully, it can be appreciated (contrary to the ontological-inveracity of 'human lifespan extricatory punctuality/immediacy of depth-of-thought inherent psychical-nascency intuition of 
objectivity' in its appraisal of human 'social and institutional practices of knowledge as to the possibility for prospective sublimation/emancipation/enfranchisement') that actually a registryworldview/dimension 'social-functioning-and-accordance-as-of-social-stake-contention-orconfliction imbuing existentialising-frame-of-entailment-of motif-andapriorising/axiomatising/referencing of disontologising/ontologising-and-re-ontologising' speaks to the reality of 'both knowledge cultivating and knowledge subverting purposes' to which 'genuine intellection must be very much aware of and factor-in with regards to the direct/indirect and overt/covert relevance to the intellectual enterprise' (as to the need for prospective 'relevant difference-conflatedness ${ }^{13}$-as-to-totalitative-reification-in-singularisation$<$ as-to-the-nondisjointedness/entailment-of-prospective- nonpresencing $>$-as-veridicalepistemicity-relativism-determinism ' as of the 'nonpresencing-<perspective-ontologicalnormalcy/postconvergence $>$ relativism/relative-scope for epistemic-growth,-as\{veridical/sound\}-relative-reflexivity-in-existence/relativising from-limited-mentation-as-itsdeepening/psychologismic epistemic-acutisation residualising, fdectumglelinearity for eogency of prospective 'human aestheticisation-and-aestheticisation-towards-ontology<elicited-idiomatisation $>$ unbeholdening, transcendence, decomplexification for organicknowledge and ment of prior apriorising/axiomatising/referencing' in epistemic lising disambiguating/delineating with prior 'human aestheticisation-and-aestheticisation-towardsontology-<elicited-idiomatisation $>$ beholdening, non-transcendence, complexification as to mechanical-knowledge and non-ment of prior apriorising/axiomatising/referencing' as profound-supererogation prolongation of ontological-veracity over ontological-inveracity'). In this regards, the human 'social and institutional practices of knowledge as to the possibility for prospective sublimation/emancipation/enfranchisement' are and have always effectively been subject to the manifestation of disontologising/subontologising moronisation- $<$ sublimating nascence,-extricatory-desublimating-downstreaming/'avalage'> by 'dominance/vested-interest 
structure in relative-ontological-incompleteness ${ }^{88}$-presublimation-construct-ofmeaningfulness-and-teleology prospective desublimating rationalisation-ofcontentivity/argumentativity/dialecticism/discursivity of social-and-institutional-frameworksof-referencing/registering/decisioning and the derived value-construction'; as to 'dominance/vested-interest structure of socially-expansive implicitly-and-explicitly negotiatedarbitrariness' with regards to prospective disontologising/subontologising desublimation/subjugation/disfranchisement or prospective re-ontologising sublimation/emancipation/enfranchisement possibilities' underlied as of 'social-functioningand-accordance-as-of-social-stake-contention-or-confliction imbuing existentialising-frameof-entailment of motif-and-apriorising/axiomatising/referencing disontologising/ontologising-and-re-ontologising' (as so-reflected across the 'criss-crossing spectrum of geostrategic, political, class, racial, gender, postcolonial, etc. negotiatedarbitrariness' and defining prospective disontologising/subontologising desublimation/subjugation/disfranchisement or prospective re-ontologising sublimation/emancipation/enfranchisement possibilities). In-the-bigger-scheme-of-things, human secondnatured institutionalisation (in-many-ways hanging on its elicited positiveopportunism-of-social-functioning-and-accordance ${ }^{75}$ ) as to the possibility for prospective knowledge cultivating and knowledge subverting (within the scope of social-and-institutionalframeworks-of - referencing/registering/decisioning existentialising-decisionality-as-todisontologising/re-ontologising aporeticism $>$ ever always in want for prospective 'supereregatery $\sim$ wholesomeness/profound-supererogation ${ }^{\circ}$ as of prospective ${ }^{83}$ reference-ofthought_ — point-of-devolving/departure/anchoring/backdrop_of_sublimating-nascence- $<$ as-tothe-grandest-axiomatic-construct-\{epistemic-totalising apriorising/re axiomatising/rereferencing residuality - in-re-originariness/re-origination of limitedness/human-subpotency prospective re-encountering/re-confrontation with unlimitedness/existence>') cannot be 
construed merely as a badge of 'mere-formulaicity/ritualisation-<as-to-mere-formulaicmethodologising/mutualising/organising/institutionalising,-prospectively-losing-track-of-

‘fepistemic-totlising ’’re-apriorising/re-axiomatising/re-referencing $r$ residuality-in-re-

originariness/re-origination'> imbued elaboration-as-to-mere-

extrapolating/constituting/abstracting/deducing/inferring-of-elucidation-outside-

'prospectively implicited_attendant_ontological-contiguity ${ }^{67}$ ' educed-

existentialising/contextualising/textualising_intelligibility/epistemicity/reflexivity_contiguity-

$<$ imbued-notional cogency $>$ ' but 'warrants the prospective sublimating cultivation of thevery-same profound-supererogation underlying the prior sublimating secondnatured institutionalisation' rather than a mere shallow-supererogation desublimating mechanicknowledge usurpation (as to catchmenting-by-rejection/lip-servicing/monopolising/gaming-ofthe-system/charade/distraction) relation to such prior sublimating secondnatured institutionalisation. In-many-ways postmodern thought is critically a reflection of the

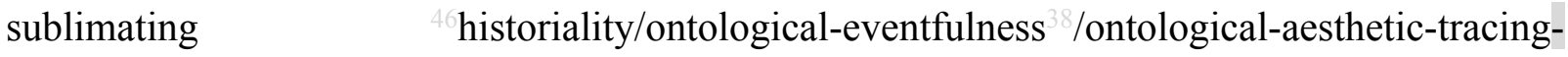
$<$ perspective-ontological-normalcy/postconvergence-reflected-‘epistemicity-relativismdeterminism'> of human meaningfulness-and-teleology ${ }^{5}$ as to 'apriorising/axiomatising/referencing disambiguating/de-leveling/de-ressentiment/openedconstruct-of- ${ }^{56}$ meaningfulness-and-teleology 9 demoronisation- $<$ sublimating-nascence,nonextricatory-sublimating-upstreaming/'amontée'>' along the natural lines of an ontology/science construal of the process of limitedness/human-subpotency cumulating/recomposuring 'intolerance-<of-disparateness $>$ /exactifying_precisioning-ofsublimation-<as-to-postconverging-narrowing-down apriorising/axiomatising/referencingentailing-theoretical,-conceptual-and-operant-implications $>$ exercise of intelligibility' (as to imbued 'developing epistemic sense of nonpresencing-<perspective-ontologicalnormalcy/postconvergence $>$ relativism/relative-scope as projective-insights') with respect to 
prospective \{epistemic-totalising 3 re-apriorising/re-axiomatising/re-referencing $\sim$ residuality-in-reoriginariness/re-origination of limitedness/human-subpotency prospective re-encountering/reconfrontation with the 'constraining/defining intersolipsistic reflexive-sublimating/unreflexivedesublimating measure/objectification that is unlimitedness/existence-as-ontologicalnormalcy/postconvergence-<in-validation-of-'metaphysics-of-absence_epistemic-projection' and so-critically as of 'successive challenges of profound-supererogation for prospective reontologising' in undermining prospective moronisation- $<$ sublimating-nascence,-extricatorydesublimating-downstreaming/'avalage'> imbued shallow-supererogation \{flawed/unsound\} relative-unreflexivity-in-existence/absolutising from-limited-mentation/psychologismic epistemic-acutisation nonresidualising imbued-\{compulsing\}linearity in-eclecticism-of-priormere-formulaicity/ritualisation as to prospective knowledge subverting implications (as to the usurpative 'mere-formulaicity/ritualisation-<as-to-mere-formulaicmethodologising/mutualising/organising/institutionalising,-prospectively-losing-track-of‘fepistemic talising łre-apriorising/re-axiomatising/re-referencing - residuality-in-reoriginariness/re-origination'> imbued elaboration-as-to-mereextrapolating/constituting/abstracting/deducing/inferring-of-elucidation-outside'prospectively_implicited_atendant-ontological-contiguity ${ }^{67}$ ' educedexistentialising/contextmalising/textualising_'intelligibility/epistemicity/reflexivity_contiguity$<$ imbued-notional cogency $>$ ' manifestation of moronisation-<sublimating-nascence,extricatory-desublimating-downstreaming/'avalage'> by 'dominance/vested-interest structure in relative-ontological-incompleteness ${ }^{88}$-presublimation-construct-of- ${ }^{56}$ meaningfulness-andteleology 9 prospective desublimating rationalisation-ofcontentivity/argumentativity/dialecticism/discursivity of social-and-institutional-frameworksof - referencing/registering/decisioning and the derived value-construction') and enabling veridical prospective sublimation/emancipation/enfranchisement possibilities. Such a 
postmodern (notional ' deprocrypticism) imbued 're-ontologising demoronisation<sublimating-nascence,-nonextricatory-sublimating-upstreaming/'amontée'> conceptivity/epistemic-reflexivity/epistemicity-relativism-determinism- $<$ reifying \{as-toknowledge-developing -and-empowering $>$ ' is a prospective ontologising-and-re-ontologising reflection upon the 'psychoanalytic implications of abnormality-<as-to-epistemicabnormalcy/preconvergence $>\quad$ associated with human prospective disontologising/subontologising moronisation $-<$ sublimating-nascence,-extricatorydesublimating-downstreaming/'avalage'>'; and rather underscores a nonpresencing<perspective-ontological-normalcy/postconvergence $>$ epistemic-projection perspective aetiologisation/ontological-escalation- $<$ ontological-

veridicality_commitment/otherliness_transcending/compulsions-encumbered_transcending $>$ construal of 'human psychoanalysis in reflection of the requisite prospective sublimating psychologismic-element-<as-of-diametrical-conflatedness -towards-'already-givenunlimitedness/existence-<full-potency-of_sublimating nascence >'-of-'limitedness/humansubpotency-as-to-its-imbued-\{veridical/sound\}-relative-reflexivity-in-existence/relativising from-limited-mentation-as-its-deepening/psychologismic epistemic-acutisation residualising, $\left.{ }^{\{d e c o m p u l s i n g}\right\}$ delinearity for cogeney'>' as fundamentally speaking of 'prospective ontologising-and-re-ontologising as from prospective sublimating re-rationalisations-ofcontentivity/argumentativity/dialecticism/discursivity of social-and-institutional-frameworksof - referencing/registering/decisioning in inducing protracted-social—as-to-individual-byinstitutional-by-social existentialising - framing/imprinting of demoronisation- $<$ sublimatingnascence,-nonextricatory-sublimating-upstreaming/‘amontée’>’ (and so beyond-andsuperseding 'any given ${ }^{79}$ presencing-absolutising-identitive-constitutedness ${ }^{14}$ conception of human psychoanalysis' that poorly/hardly reflect upon the bigger picture of prior human disontologising/subontologising thresholds so-manifested as of 'prior desublimating 
rationalisations-of-contentivity/argumentativity/dialecticism/discursivity of social-andinstitutional-frameworks-of — referencing/registering/decisioning' as so-rather inducing prospectively 'individual-by-institutional-by-social existentialising-enframing/imprintedness of disontologising/subontologising moronisation- $<$ sublimating-nascence,-extricatory desublimating-downstreaming/'avalage'>'). Such a 're-ontologising demoronisation<sublimating-nascence,-nonextricatory-sublimating-upstreaming/'amontée’> conceptivity/epistemic-reflexivity/epistemicity-relativism-determinism- $<$ reifying \{as-toknowledge-developing\}-and-empowering $>$ of human psychoanalysis in reflection of the requisite prospective sublimating psychologismic-element-<as-of-diametrical-conflatedness towards-'already-given-unlimitedness/existence-<full-potency-of_sublimating nascence $>$ '-of‘limitedness/human-subpotency-as-to-its-imbued-\{veridical/sound\}-relative-reflexivity-inexistence/relativising from-limited-mentation-as-its-deepening/psychologismic epistemicacutisation residualising, ${ }^{\text {\{decompulsing }}$ delinearity for-cogency'> $>$ (as to prospective ontologising-and-re-ontologising epistemic-growth,-as_ \{veridical/sound\}-relativereflexivity-in-existence/relativising from-limited-mentation-as-its-deepening/psychologismic epistemic-acutisation residualising, ${ }^{\{\text {decompulsing }}$ delinearity for-cogency elicited prospective re-ontologising conceptivity/epistemic-reflexivity/epistemicity-relativism-determinism$<$ reifying \{as-to-knowledge-developing\}-and-empowering $>$ ) 'operationally focusses' on the 'implications of prospective disontologising/subontologising moronisation- $<$ sublimatingnascence,-extricatory-desublimating-downstreaming/'avalage'> as this reflects protractedsocial-as-to-individual-by-institutional-by-social relatively manifest psychoanalytic abnormality-<as-to-epistemic-abnormalcy/preconvergence>'; and so-operationally-focusses on the preconverging/postconverging-de-mentating/structuring/paradigming dynamics of 'individual-by-institutional-by-social summary appraisal of what-isontologisingly/disontologisingly-conceivable — by — what-is-ontologisingly/disontologisingly- 
expectable' as so-critically eliciting 'varying protracted-social—as-to-individual-byinstitutional-by-social re-ontologising-by-disontologising_existential-calculus-_between 'prospective existentialising_postconverging_framing/imprinting re-ontologising' and 'prior existentialising_ preconverging_enframing/imprintedness social-functioning-andaccordance-as-of-social-stake-contention-or-confliction' '’ for consciously or unconsciously resorting to 'mere-formulaicity/ritualisation-<as-to-mere-formulaicmethodologising/mutualising/organising/institutionalising,-prospectively-losing-track-of‘\{epistemic-totalising ’’’re-apriorising/re-axiomatising/re-referencing residuality-in-reoriginariness/re-origination'> imbued elaboration-as-to-mereextrapolating/constituting/abstracting/deducing/inferring-of-elucidation-outside'prospectively_implicited_attendant-ontological-contiguity ${ }^{67}$ ' educedexistentialising/contextualising/textualising_intelligibility/epistemicity/reflexivity-contiguity$<$ imbued-notional cogency $>$ ' in order to enable 'minimum-and-balancing expectations/anticipations of social-functioning-and-accordance-as-of-social-stakecontention-or-confliction'/least-common-denominator-of-social-functioning-and-accordanceeffecting (and so overlooking/ignoring the possibility/prospect of prospective disontologising/subontologising moronisation- $<$ sublimating-nascence,-extricatory desublimating-downstreaming/'avalage'>). In other words, such a 'human psychoanalysis in reflection of the requisite prospective sublimating psychologismic-element- $<$ as-of-diametricalconflatedness -towards-'already-given-unlimitedness/existence-<full-potency of sublimating nascence $>$ '-of-'limitedness/human-subpotency-as-to-its-imbued\{veridical/sound\}-relative-reflexivity-in-existence/relativising from-limited-mentation-as-itsdeepening/psychologismic epistemic acutisation residualising, \{decompulsing delinearity for eogency'>' (as to its veridically implied nonpresencing-or-withdrawal/unenframing/reontologising-or-metaphysics-of-absence-_implicited-epistemic-veracity-of- nonpresencing- 
$<$ perspective-ontological-normalcy/postconvergence $>$ >-or-transcendental-reasoning-of-

event $^{38}$-as-prospective-ontology-origination epistemic-projection perspective) fundamentally has to do with re-ontologising demoronisation-<sublimating-nascence,-nonextricatorysublimating-upstreaming/'amontée'> as to \{epistemic-totalising $3{ }^{3}$ re-apriorising/re-axiomatising/rerefereneing-residuality_in-re-originariness/re-origination of limitedness/human-subpotency prospective re-encountering/re-confrontation with the 'constraining/defining intersolipsistic reflexive-sublimating/unreflexive-desublimating measure/objectification that is unlimitedness/existence-as-ontological-normalcy/postconvergence-<in-validation-of'metaphysics-of-absence_epistemic-projection'>' and so-contrasted to disontologising/subontologising moronisation- $<$ sublimating-nascence,-extricatory desublimating-downstreaming/'avalage'>' as to 'mere-formulaicity/ritualisation-<as-to-mereformulaic - methodologising/mutualising/organising/institutionalising,-prospectively-losing-

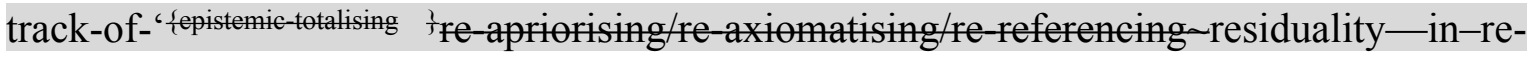
originariness/re-origination'> imbued elaboration-as-to-mereextrapolating/constituting/abstracting/deducing/inferring-of-elucidation-outside'prospectively_implicited_attendant-ontological-contiguity ${ }^{67}$ ' educedexistentialising/contextualising/textualising_intelligibility/epistemicity/reflexivity-contiguity$<$ imbued-notional cogency $>^{\prime}$. That is moronisation-<sublimating-nascence,-extricatorydesublimating-downstreaming/'avalage'> speaks to the human psyche preconverging-dementating/structuring/paradigming (given human aestheticisation-beholdening-out-ofbechancing/taxingness-of-originariness) around prior 'mere-formulaicity/ritualisation- $<$ as-tomere-formulaic - methodologising/mutualising/organising/institutionalising,-prospectively-

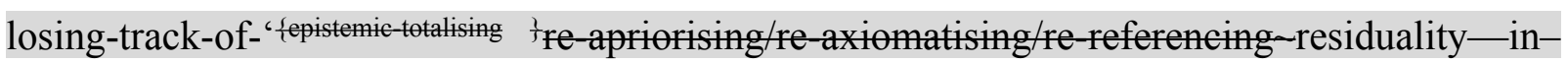
re-originariness/re-origination'> imbued elaboration-as-to-mereextrapolating/constituting/abstracting/deducing/inferring-of-elucidation-outside- 
'prospectively_implicited_attendant_ontological-contiguity ${ }^{67}$ ' educedexistentialising/contextmalising/textualising_intelligibility/epistemicity/reflexivity_contiguity$<$ imbued-notional cogency>' implications of shallow-supererogation for 'minimum-andbalancing expectations/anticipations of social-functioning-and-accordance-as-of-social-stakecontention-or-confliction'/least-common-denominator-of-social-functioning-and-accordanceeffecting (and so overlooking/ignoring the possibility/prospect of prospective disontologising/subontologising moronisation-<sublimating-nascence,-extricatorydesublimating-downstreaming/‘avalage’’>). Demoronisation- $<$ sublimating-nascence,nønextricatory-sublimating-upstreaming/'amontée'> is thus about re-emphasising a human psyche of postconverging-de-mentating/structuring/paradigming (notwithstanding human aestheticisation — beholdening-out-of-bechancing/taxingness-of-originariness) as to a postconverging-birthing/nascency within prospective \{epistemic-totalising 3 re-apriorising/reaxiomatising/re-referencing - residuality-in-re-originariness/re-origination-〈as to human profound-supererogation for prospective apriorising/axiomatising/referencing-\{of'prospectively_implicited_attendant_ontological-contiguity ' educedexistentialising/contextualising/textualising_'intelligibility/epistemicity/reflexivity-contiguity<imbued-notional cogency >' \}-conflatedness -in-\{preconverging-ment by\} postconverging-ntailment that cannot be unshrouded by prior mere-formulaicity/ritualisation$<$ as-to-mere-formulaic — methodologising/mutualising/organising/institutionalising,prospectively-losing-track-of- ‘fepistemic-atising $\stackrel{+}{\zeta}$ re-apriorising/re-axiomatising/rereferencing $\sim$ residuality —in-re-originariness/re-origination'> of prior apriorising/axiomatising/referencing-\{of- 'prespectively implicited_attendant-ontologicalcontiguity ' educedexistentialising/contextualising/textualising_intelligibility/epistemicity/reflexivity-contiguity<imbued-notional cogency>' $\quad\}$-constitutedness -in-preconverging-entailment $\rangle$ as so- 
underlied by its requisite prospective sublimating psychologismic-element- $<$ as-of-diametricalconflatedness -towards-'already-given-unlimitedness/existence-<full-potency-

of_sublimating nascence $>$ '-of-'limitedness/human-subpotency-as-to-its-imbued-

\{veridical/sound\}-relative-reflexivity-in-existence/relativising from-limited-mentation-as-itsdeepening/psychologismic epistemic-acutisation residualising, ${ }^{\text {fdecompulsing }}$ \}elinearity for-

eogency'>; and as so-reflecting limitedness/human-subpotency cumulating/recomposuring 'intolerance-<of-disparateness $>$ /exactifying_precisioning-of-sublimation- $<$ as-topostconverging-narrowing-down apriorising/axiomatising/referencing-entailing-theoretical,conceptual-and-operant-implications $>$ exercise of intelligibility' (as to imbued 'developing epistemic sense of nonpresencing-<perspective-ontological-normalcy/postconvergence $>$ relativism/relative-scope as projective-insights') with respect to prospective \{epistemic-totalising ${ }^{3}{ }^{3}$ reapriorising/re-axiomatising/re-referencing - residuality-in-re-originariness/re-origination of limitedness/human-subpotency prospective re-encountering/re-confrontation with the 'constraining/defining intersolipsistic reflexive-sublimating/unreflexive-desublimating measure/objectification that is unlimitedness/existence-as-ontologicalnormalcy/postconvergence-<in-validation-of-‘metaphysics-of-absence_epistemic-projection’> and so-critically as of 'successive challenges of profound-supererogation for prospective reontologising' in undermining prospective moronisation- $<$ sublimating-nascence,-extricatory desublimating-downstreaming/'avalage'> (so-construed as to Being-development/ontologicalframework-expansion-as-to-depth-of-ontologising-development-as-infrastructure-ofmeaningfulness-and-teleology , institutional-development-as-to-social-functiondevelopment and living-development-as-to-personality-development psychologismic epistemic acutisation diffieulty < for, residualising \{decompulsing delinearity for cogeney> magnitudes $\{$ of-experientiality/experiment $\}$ ). Critically, demoronisation-<sublimating-nascence,nonextricatory-sublimating-upstreaming/'amontée’> (as to its underlying prospective 
sublimating psychologismic-element-<as-of-diametrical-conflatedness -towards-'alreadygiven-unlimitedness/existence-<full-potency-of_sublimating nascence $>$ '-of-

‘limitedness/human-subpotency-as-to-its-imbued-\{veridical/sound\}-relative-reflexivity-inexistence/relativising from-limited-mentation-as-its-deepening/psychologismic epistemicacutisation residualising, ${ }^{\text {fdecompulsing }}$ delinearity for-cogency'>) implies grasping how the 'given station/locus of <amplituding/formative-epistemicity>-totalising $\sim$ thrownness-inexistence $^{35}$ as to its overall <amplituding/formative $>$ wooden-language-〈imbued-temporalmere-form/virtualities/dereification/akrasiatic-drag/denatured/preconverging-or-dementing narratives - of-the- reference-of-thought- categorical-imperatives/axioms/registryteleology $\rangle$ is precedingly problematic for prospective re-ontologising (as to the elicitability of the pedantising/muddling/formulaic-hollowing-out—in-subontologisation/subpotentiation〈blurring/undermining-of-prospective-totalising-entailing,-as-to-entailing$<$ amplitung/formative-epistemicity $>$ totalising in-relative-ontological-completeness $>$ desublimation of its given social-and-institutional-frameworks-ofreferencing/registering/decisioning existentialising-decisionality-<as-to-disontologising/reentologising aporeticism $>$ ); so-reflected as to 'mere-formulaicity/ritualisation-<as-to-mereformulaic - methodologising/mutualising/organising/institutionalising,-prospectively-losingtrack-of- ‘ $\left\{\right.$ epistemic-totalising ${ }^{3}$ re-apriorising/re-axiomatising/re-referencing $\sim$ residuality-in-reoriginariness/re-origination'> imbued elaboration-as-to-mereextrapolating/constituting/abstracting/deducing/inferring-of-elucidation-outside'prospectively_implicited_attendant-ontological-contiguity ${ }^{67}$ ' educedexistentialising/contextmalising/textmalising_intelligibility/epistemicity/reflexivity-contiguity<imbued-notional cogency>' implications of shallow-supererogation for 'minimum-andbalancing expectations/anticipations of social-functioning-and-accordance-as-of-social-stakecontention-or-confliction'/least-common-denominator-of-social-functioning-and-accordance- 
effecting (and so overlooking/ignoring the possibility/prospect of prospective disontologising/subontologising moronisation- $<$ sublimating-nascence,-extricatorydesublimating-downstreaming/'avalage’ $>$ ). Insightfully, $\quad$ demoronisation- $<$ sublimating nascence,-nonextricatory-sublimating-upstreaming/'amontée'> points out that 'there is no neutral presencing — absolutising-identitive-constitutedness point-ofdevolving/departure/anchoring/backdrop for conceptualising ontological-veracity/ontologicalinveracity (as so-failing to reflect the 'dynamics of apriorising/axiomatising/referencing as to preconverging/postconverging-de-mentating/structuring/paradigming' associated with human limited-mentation-capacity—as-subjecting 'educed-unlimitedness/existence-sublimating nascence' to-limitedness/human-subpotency and limited-mentation-capacity-deepening-assubjecting limitedness/human-subpotency-to-'educed-unlimitedness/existence-sublimating naseence' ${ }^{53}$ )' with respect to prospective re-ontologising but for the need to elucidate (as of nonpresencing-<perspective-ontological-normalcy/postconvergence $>$ epistemic-projection perspective) the 'postconverging-birthing/nascency within prospective apriorising/re-axiomatising/re-referencing $\sim$ residuality - in-re-originariness/re-origination- $\langle$ as to human profound-supererogation for prospective apriorising/axiomatising/referencing-\{of'prospectively_implicited_attendant-ontological-contiguity ' educedexistentialising/contextualising/textualising_'intelligibility/epistemicity/reflexivity_contiguity$<$ imbued-notional cogency $>$ ' $\}$-conflatedness in-\{preconverging ment by\} postconverging-entailment that cannot be unshrouded by prior mere-formulaicity/ritualisation$<$ as-to-mere-formulaic - methodologising/mutualising/organising/institutionalising,prospectively-losing-track-of- ‘ \{epistemic-totalising ’’ apriorising/re axiomatising/rereferencing $\sim$ residuality_-in-re-originariness/re-origination'> of prior apriorising/axiomatising/referencing-\{of-"prospectively_implicited_attendant-ontologicalcontiguity ' $\sim$ educed- 
existentialising/contextualising/textualising_'intelligibility/epistemicity/reflexivity-contiguity$<$ imbued-notional cogency $\left.>^{\prime} \quad\right\}$-constitutedness -in-preconverging-entailment $\rangle$. Thus reontologising demoronisation- $<$ sublimating-nascence,-nonextricatory-sublimatingupstreaming/'amontée'> is directly concerned (as so-underlied by its requisite prospective sublimating psychologismic-element-<as-of-diametrical-conflatedness -towards-'alreadygiven-unlimitedness/existence-<full-potency-of_sublimating nascence $>$ '-of-

‘limitedness/human-subpotency-as-to-its-imbued-\{veridical/sound $\}$-relative-reflexivity-inexistence/relativising from-limited-mentation-as-its-deepening/psychologismic epistemicacutisation residualising, ${ }^{\text {\{decompulsing? }}$ delinearity for-cogency'>) with undermining the 'prior desublimating rationalisations-of-contentivity/argumentativity/dialecticism/discursivity of social-and-institutional-frameworks-of — referencing/registering/decisioning' (as 'mereformulaicity/ritualisation-<as-to-mere-formulaicmethodologising/mutualising/organising/institutionalising,-prospectively-losing-track-of‘fepistemic-talising ’re-apriorising/re-axiomatising/re-referencing residuality-in-reoriginariness/re-origination'> imbued elaboration-as-to-mereextrapolating/constituting/abstracting/deducing/inferring-of-elucidation-outside'prospectively_implicited_attendant-ontological-contiguity ${ }^{67}$ ' educedexistentialising/contextmalising/textmalising_intelligibility/epistemicity/reflexivity-contiguity$<$ imbued-notional $\sim \operatorname{cogency}>^{\prime}{ }^{\circ}$ ); $\quad$ as inducing protracted-social-as-to-individual-byinstitutional-by-social existentialising — enframing/imprintedness of disontologising/subontologising moronisation- $<$ sublimating-nascence,-extricatorydesublimating-downstreaming/'avalage'>. The implication here is that the 'overall relativeunreflexivity/relative-reflexivity — ontological-contiguity ${ }^{67}$ of-the-human-institutionalisationprocess ${ }^{68}$ induced re-ontologising demoronisation- $<$ sublimating-nascence,-nonextricatory sublimating-upstreaming/'amontée'> while superseding/overcoming disontologising 
moronisation-<sublimating-nascence,-extricatory-desublimating-downstreaming/'avalage' $>$ ' speaks to the 'overall human protracted-social—as-to-individual-by-institutional-by-social notional $\sim$ self-distantiation- $<$ imbued—re-motif-and-re-apriorising/re-axiomatising/rereferencing >'; as so-enabling the sublimating-postconverged 'substantive abstract-tissue-ofsocial-emanance fepistemictotalising ${ }^{3}$ hermeneutically/textually/reprojectingly/supererogatingly/zeroingly/re-acutingly,$\{$ decompulsing $\}$ delinearity for-cogency—cumulated/recomposured as to cumulating/recomposuring of 'prospectively_implicited_attendant-ontological-contiguity ${ }^{67}$ educedexistentialising/contextualising/textualising_'intelligibility/epistemicity/reflexivity-contiguity$<$ imbued-notional cogency $>$ ' . This fundamentally speaks to the 'disontologising/reontologising centrality' of human protracted-social—as-to-individual-by-institutional-by-social notional self-distantiation-<imbued - re-motif-and-re-apriorising/re-axiomatising/rereferencing > as notionally undergirding the recurrent manifestations of 'human moronisation<sublimating-nascence,-extricatory-desublimating-downstreaming/'avalage'> and human demoronisation-<sublimating-nascence,-nonextricatory-sublimating-upstreaming/'amontée’>’ (as to the 'seeding/incipient pre-eminence of human embodied-vitality/survival/subsistenceexistential-disontologising/re-ontologising aporeticism>-becoming driving human consciousness complexifying-<transcending-in-elaborateness as to human aestheticisationand-aestheticisation-towards-ontology-<elicited-idiomatisation $>$ dynamics of lifespan extricatory/preconverging psychical-nascency and nonextricatory/postconverging ontologisingand-re-ontologising angling-of-imaginary>'); as so-fundamentally underlied respectively as of dimensionality-of-desublimating-lack-of $-\langle<$ amplituding/formative $>$ supererogatory $\sim$ dementativeness/epistemic-growth-or-conflatedness /transvaluativerationalising/transepistemicity/anamnestic-residuality/spirit-drivenness-equalisation〉 and dimensionality-of-sublimating $-<<$ amplituding/formative $>$ supererogatory $\sim$ de- 
mentativeness/epistemic-growth-or-conflatedness /transvaluative-

rationalising/transepistemicity/anamnestic-residuality/spirit-drivenness-equalisation $\rangle$. Such a re-ontologising conceptivity/epistemic-reflexivity/epistemicity-relativism-determinism$<$ reifying \{as-to-knowledge-developing\}-and-empowering $>$ of 'overall human protractedsocial—as-to-individual-by-institutional-by-social notional $\sim$ self-distantiation- $<$ imbued - remotif-and-re-apriorising/re-axiomatising/re-referencing >' is underlied by the construction-ofthe-Self elements (- akrasia-susceptibility-or-akrasiatic-drag/shiftiness-of-theSelf /ontological-fracturing/desublimation/gimmickiness complex, - repression and releasement as subconsciousness, and - 'recurrently mediative-<in-expectation/in-anticipation> unconsciousness/potentiation-of-conscionability-<anxiety-as-to-reconstitution/reparation,including-dreaming/psychical-reshuffling >', and so as of a psychological analysis of direct mental-processing ontological-performance ${ }^{72}-<$ including-virtue-asontology $>$ /morality/ethics/justice/etc. implications with respect to the constructiveness-ofontological-performance $^{72}$-<including-virtue-as-ontology $>/$ morality/ethics/justice/etc. of the social epistemic-totality ${ }^{37}$ of ${ }^{56}$ meaningfulness-and-teleology 99 so-undergirding the construction-of-the-Self all along in reflecting holographically-<conjugatively-andtransfusively $>$ the relative-unreflexivity/relative-reflexivity ontological-contiguity $\sim$ of-thehuman-institutionalisation-process ); pointing out that human subconsciousness is what is mostprospectively-conscious in the-human, and so as 'human subconsciousness is the backdrop-forthe-Lacanian-real enabling the effective formativeness-<as-to-intersolipsism-ofpreformulating/preframing/premeaningfulness-imbued-mediativity-and-deferentialism>-ofmeaningfulness-and-teleology of consciousness surrealising-<as-to-supererogation $>^{\prime}$ (as so-manifested with human subconsciousness most-prospectively-conscious 're-ontologisingby-disontologising_existential-calculus-〈between 'prospective existentialisingpostconverging_framing/imprinting re-ontologising' and 'prior existentialising- 
preconverging_enframing/imprintedness social-functioning-and-accordance-as-of-socialstake-contention-or-confliction' $\rangle$ ' of consciousness surrealising-<as-to-supererogation $>$ for 'prospective re-ontologising demoronisation- $<$ sublimating-nascence,-nonextricatory sublimating-upstreaming/'amontée’> psychologismic-element-<as-of-diametricalconflatedness -towards-'already-given-unlimitedness/existence-full potency of_sublimating nascence $>$ '-of-'limitedness/human-subpotency-as-to-its-imbued\{veridical/sound\}-relative-reflexivity-in-existence/relativising from-limited-mentation-as-itsdeepening/psychologismic epistemic acutisation residualising, fdecompulsingl delinearity for eogency'> imbued prospective psychologismic-epistemic-acutisation-<as-to-postconvergingde-mentating/structuring/paradigming,-eliciting-of-existence's-sublimating-nascence-inprospective-aporeticism-overcoming/unovercoming $>$ as to epistemic-growth,-as\{veridical/sound\}-relative-reflexivity-in-existence/relativising from-limited-mentation-as-itsdeepening/psychologismic epistemic-acutisation residualising, fdecompulsingl delinearity for eogency'). Central to the recurrent manifestations of 'human demoronisation- $<$ sublimatingnascence,-nonextricatory-sublimating-upstreaming/‘amontée’> and human moronisation$<$ sublimating-nascence,-extricatory-desublimating-downstreaming/'avalage'>' respectively is whether the-human-do-not-project-of or the-human-projects-of a 'flawed-prior-purposefulness of ${ }^{79}$ presencing-absolutising-identitive-constitutedness ${ }^{14}$ before supposedly-prospectivethinking-purpose,-as-precalculated-purpose-<as-prospectively-losing-track-of-‘ ‘epistemic tre-apriorising/re-axiomatising/re-referencing residuality-in-re-originariness/reorigination'-of-thinking>' exercise; so-reflecting respectively on-the-one-hand human contemplation imbued demoronisation- $<$ sublimating-nascence, sublimatingupstreaming/'amontée'> (as to the very core of notional $\sim$ philosophy-<as-to-the-veridicalconception-of-philosophy-as-englobing-all-human-prospective-organic-knowledge-generationin-relative-ontological-completeness ,-beyond-a-convenient-division-of-labour-conception-of- 
knowledge $>$ as so-reflected historially in 'successive challenges of profound-supererogation for prospective re-ontologising' with regards to the very notions of human imagination and thought as to prospective re-ontologising implications) which can only truly arise as of a 'postconverging-birthing/nascency within prospective \{epistemic-totalising 3 ? $\mathrm{re}$-apriorising/reaxiomatising/re-referencing - residuality-in-re-originariness/re-origination-〈as to human profound-supererogation for prospective apriorising/axiomatising/referencing-\{of'prospectively_implicited_attendant-ontological-contiguity ' educedexistentialising/contextualising/textualising_'intelligibility/epistemicity/reflexivity-contiguity<imbued-notional cogency>' \}-conflatedness -in-\{preconverging-ment by\} pestconverging entailment that cannot be unshrouded by prior mere-formulaicity/ritualisation$<$ as-to-mere-formulaic — methodologising/mutualising/organising/institutionalising,prospectively-losing-track-of- ‘ ‘epistemic-totalising 3 re-apriorising/re-axiomatising/rereferencing $\sim$ residuality —in-re-originariness/re-origination'> of prior apriorising/axiomatising/referencing-\{of-'prospectively_implicited_attendant-ontologicalcontiguity ' educedexistentialising/contextualising/textualising_ 'intelligibility/epistemicity/reflexivity-contiguity<imbued-notional cogency>' $\}$ - constitutedness -in-preconverging-entailment)' and as superseding/overcoming on-the-other-hand 'supposed contemplation' of prior mereformulaicity/ritualisation-<as-to-mere-formulaicmethodologising/mutualising/organising/institutionalising,-prospectively-losing-track-of-

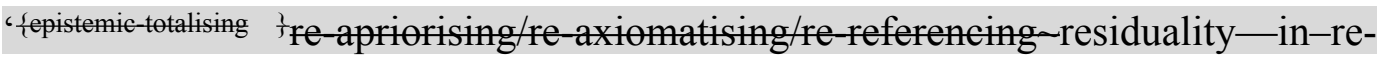
originariness/re-origination'> imbued elaboration-as-to-mereextrapolating/constituting/abstracting/deducing/inferring-of-elucidation-outside'prospectively_implicited_attendant-ontological-contiguity ${ }^{67}$ ' educedexistentialising/contextualising/textualising_'intelligibility/epistemicity/reflexivity-contiguity- 
$<$ imbued-notional cogency $>$ ' induced moronisation- $<$ sublimating-nascence,-extricatorydesublimating-downstreaming/'avalage'> (which rather speaks of $<$ amplituding/formative $>$ wooden-language-〈imbued — averaging-of-thought-<as-toleveling/ressentiment/closed-construct-of- meaningfulness-and-teleology -as-of'nondescript/ignorable-void '-with-regards-to-prospective-apriorising-implications $>>\quad$ and associated pedantising/muddling/formulaic-hollowing-out—insubontologisation/subpotentiation-〈blurring/undermining-of-prospective-totalising-entailing,as-to-entailing-<amplituding/formative-epistemicity $>$ totalising $\sim$ in-relative-ontologicalcompleteness > dispositions as to prospective disontologising implications) as failing to emphasise the ontologically-veridical requisite prospective fepistemic-totalising 3 re-apriorising/reaxiomatising/re-referencing $\sim$ residuality-in-re-originariness/re-origination of limitedness/human-subpotency prospective re-encountering/re-confrontation with the 'constraining/defining intersolipsistic reflexive-sublimating/unreflexive-desublimating measure/objectification that is unlimitedness/existence-as-ontologicalnormalcy/postconvergence-<in-validation-of-'metaphysics-of-absence_epistemic-

projection'>'. Critically in this regards, 'human demoronisation-<sublimating-nascence,nonextricatory-sublimating-upstreaming/'amontée’ $>$ and human moronisation- $<$ sublimatingnascence,-extricatory-desublimating-downstreaming/'avalage'>' can be appreciated as to the imbued sublimating/desublimating intelligibility gesturing; wherein moronisation$<$ sublimating-nascence, prior mere-formulaicity/ritualisation-<as-to-mere-formulaic methodologising/mutualising/organising/institutionalising,-prospectively-losing-track-of‘fepistemic-atising ’’re-apriorising/re-axiomatising/re-referencing $\sim$ residuality-in-reoriginariness/re-origination'> as wrongly supposedly-and-inherently providing in its ‘79 presencing—absolutising-identitive-constitutedness absolution/absolute-scope 
\{flawed/unsound\}-relative-unreflexivity-in-existence/absolutising-from-limitedmentation/psychologismic epistemic acutisation nonresidualising imbued\{compulsings linearity in-eclecticism-of prior-mere-formulaicity/ritualisation conception' veridical educing of ${ }^{56}$ meaningfulness-and-teleology" ignoring/overlooking the prospect of "prospective \{epistemic-totalising 3 \}re-apriorising/re-axiomatising/re-referencing $\sim$ residuality-in-re-

originariness/re-origination relative-ontological-completeness ${ }^{87}$ implications' (as so-implying an 'apriorising/axiomatising/referencing — equating/leveling/ressentiment/closed-construct-ofmeaningfulness-and-teleology $\quad$ moronisation- $<$ sublimating-nascence,-extricatorydesublimating-downstreaming/'avalage'>' undifferentiation of both the prior relativeontological-incompleteness ${ }^{8}$ and the prospective relative-ontological-completeness ${ }^{87}$, wherein limitedness/human-subpotency wrongly supposedly-and-inherently prospectively supersedes unlimitedness/existence-<fll-potency-of_sublimating nascence $>$ ) while demoronisation<sublimating-nascence,-nonextricatory-sublimating-upstreaming/'amontée'> rather assumes a ${ }^{6}$ nonpresencing-<perspective-ontological-normalcy/postconvergence $>$ relativism/relativescope for epistemic-growth,-as - \{veridical/sound\}-relative-reflexivity-inexistence/relativising from-limited-mentation-as-its-deepening/psychologismic epistemicacutisation residualising, \{decompulsing\} delinearity for cogeney' for educing ${ }^{56}$ meaningfulnessand-teleology as to the prospect of 'prospective fepistemic-totalising 3 re-apriorising/reaxiomatising/re-referencing residuality-in-re-originariness/re-origination relativeontological-completeness ${ }^{87}$ implications' (as $\quad$ so-implying an 'apriorising/axiomatising/referencing disambiguating/de-leveling/de-ressentiment/openedconstruct-of- -5 meaningfulness-and-teleology $\quad$ demoronisation- $<$ sublimating-nascence,-sublimating-upstreaming/'amontée’’' wherein limitedness/human-subpotency is prospectively subjected- $<$ for-its-'epistemic-growth,-as - \{veridical/sound\}-relativereflexivity-in-existence/relativising from-limited-mentation-as-its-deepening/psychologismic 
unlimitedness/existence-<fll-potency-of_sublimating nascence $>$ ). Thus derivatively, the human existentialising prospect (of demoronisation-<sublimating-nascence,-nonextricatory sublimating-upstreaming/'amontée'>) for prospectively 'prompting unlimitedness/existence<full-potency-of_sublimating nascence>' (as to the possibility of limitedness/humansubpotency omnipotentiality) is effectively devolutively-enjoined upon human notional selfdistantiation-<imbued - re-motif-and-re-apriorising/re-axiomatising/re-referencing $>$ (as of the relative-unreflexivity/relative-reflexivity — ontological-contiguity ${ }^{67} \sim$ of-the-humaninstitutionalisation-process ${ }^{68}$ ); and thus so-underlied fundamentally/incipiently/seedingly as to ' nonpresencing-or-withdrawal/unenframing/re-ontologising-or-metaphysics-of-absence-

\section{〈implicited-epistemic-veracity-of- nonpresencing-<perspective-ontological-}

normalcy/postconvergence $>$ )-or-transcendental-reasoning-of-event ${ }^{38}$-as-prospective-ontologyorigination devolutive enjoinment' of human protracted-social—as-to-individual-byinstitutional-by-social construction-of-the-Self as to undergirding construction-of-the-Self elements (- akrasia-susceptibility-or-akrasiatic-drag/shiftiness-of-the-Self /ontologicalfracturing/desublimation/gimmickiness complex, - repression and releasement as subconsciousness, and - 'recurrently mediative-<in-expectation/in-anticipation> unconsciousness/potentiation-of-conscionability-<anxiety-as-to-reconstitution/reparation,including-dreaming/psychical-reshuffling >', and so as of a psychological analysis of direct mental-processing ontological-performance ${ }^{2}-<$ including-virtue-asontology $>$ /morality/ethics/justice/etc. implications with respect to the constructiveness-ofontological-performance $^{72}$-<including-virtue-as-ontology $>/$ morality/ethics/justice/etc. of the social epistemic-totality ${ }^{37}$ of ${ }^{56}$ meaningfulness-and-teleology ${ }^{9}$ so-undergirding the construction-of-the-Self all along in reflecting holographically-<conjugatively-andtransfusively $>$ the relative-unreflexivity/relative-reflexivity ontological-contiguity $\sim$ of-the- 
human-institutionalisation-process ). Human formativeness-<as-to-intersolipsism-ofpreformulating/preframing/premeaningfulness-imbued-mediativity-and-deferentialism $>$-ofmeaningfulness-and-teleology as to 'overall human protracted-social — as-to-individual-byinstitutional-by-social notional $\sim$ self-distantiation- $<$ imbued-re-motif-and-re-apriorising/reaxiomatising/re-referencing>' (as so-underlying recurrent manifestations of 'human moronisation-<sublimating-nascence,-extrieatery-desublimating-downstreaming/'avalage'> and human demoronisation- $<$ sublimating-nascence,-nonextricatory-sublimatingupstreaming/'amontée'>') effectively reflect the reality that 'there is no neutral ${ }^{79}$ presencingabsolutising-identitive-constitutedness ${ }^{14}$ point-of-devolving/departure/anchoring/backdrop for conceptualising the ontological-veracity/ontological-inveracity of human rationalisation-ofcontentivity/argumentativity/dialecticism/discursivity' (as wrongly assumed by all registryworldviews/dimensions imbued prior-institutionalisation-threshold-by-prospectiveuninstitutionalised-threshold $\quad$ 'self-referencing-syncretising forward-facingsupposedly postconverging-or-dialectical-thinking -apriorising-psychologism epistemicprojection as of prior mere-formulaicity/ritualisation-<as-to-mere-formulaicmethodologising/mutualising/organising/institutionalising,-prospectively-losing-track-of‘\{epistemic-totalising ’re apriorising/re axiomatising/re referencing-residuality-in-reoriginariness/re-origination'>' so-reflecting their 'disontologising preconverging/dementing $<$ as-to-prospective-uninstitutionalised-threshold > ignoring/biased inclination' for the sake of 'their given present minimum-and-balancing expectations/anticipations of social-functioningand-accordance-as-of-social-stake-contention-or-confliction' while qualifying their prospectively uninstitutionalised-threshold ${ }^{102}$ actually as nondescript/ignorable-void as to their ${ }^{79}$ presencing-absolutising-identitive-constitutedness ${ }^{14} \quad<$ preconverging ' $m o t i f-a n d-$ apriorising/axiomatising/referencing'-entailing >-existentialising-enframing/imprintedness〈as-to- historicity-tracing-in-presencing-hyperrealisation/hyperreal-transposition〉). The 
implication here is that the 'overall human protracted-social—as-to-individual-by-institutionalby-social notional $\sim$ self-distantiation-<imbued—re-motif-and-re-apriorising/re-axiomatising/rereferencing>' (as so-speaking to the 'overall relative-unreflexivity/relative-reflexivity ontological-contiguity ${ }^{67}$ of-the-human-institutionalisation-process ${ }^{68}$ induced re-ontologising demoronisation-<sublimating-nascence,-nonextricatory-sublimating-upstreaming/‘amontée’> while superseding/overcoming disontologising moronisation-<sublimating-nascence,extricatory-desublimating-downstreaming/'avalage'>') implies the 'manifest conscious and/or unconscious pervasiveness' of both 'demoronisation- $<$ sublimating-nascence,-nonextricatorysublimating-upstreaming/‘amontée’> and moronisation-<sublimating-nascence,-extricatorydesublimating-downstreaming/'avalage'> inclinations (so-associated with the 'inherently recurrent limitedness/human-subpotency cumulating/recomposuringapriorising/axiomatising/referencing of the-very-same unlimitedness/existence-<full-potency ef_sublimating nascence>' by which limitedness/human-subpotency achieves epistemicgrowth,-as-\{veridical/sound\}-relative-reflexivity-in-existence/relativising from-limitedmentation-as-its-deepening/psychologismic epistemic-acutisation residualising, $\{$ decompulsing $\}$ delinearity for-cogency in prospective demoronisation-<sublimating-nascence,-

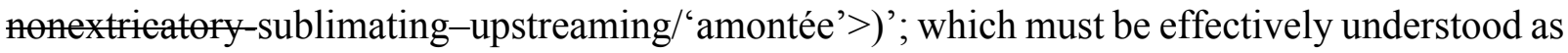
to re-ontologising conceptivity/epistemic-reflexivity/epistemicity-relativism-determinism$<$ reifying \{as-to-knowledge-developing $\}$-and-empowering $>$ for prospective ontologising-andre-ontologising sublimation/emancipation/enfranchisement. In this respect, the conception of 'overall human protracted-social-as-to-individual-by-institutional-by-social notional $\sim$ selfdistantiation-<imbued - re-motif-and-re-apriorising/re-axiomatising/re-referencing $>{ }^{\prime} \quad$ (as it relates to demoronisation- $<$ sublimating-nascence, upstreaming/‘amontée'> while superseding/overcoming moronisation-<sublimating-nascence,extricatory-desublimating-downstreaming/'avalage'>) can effectively be construed as of 
'human aestheticisation-and-aestheticisation-towards-ontology-<elicited-idiomatisation $>$ interstitial - disontologising-by-re-ontologising of ontological-performance ${ }^{2}-<$ includingvirtue-as-ontology>'; as 'so-recurrently of aestheticisation-and-aestheticisation-towardsontology-<elicited-idiomatisation $>\quad$ interstitial—disontologising-by-re-ontologising, (sounderlining 'human interstitially recurrent limited-mentation-capacity—as-subjecting 'educedunlimitedness/existence-sublimating nascence'-to-limitedness/human-subpotency-by-limitedmentation-capacity-deepening —as-subjecting limitedness/human-subpotency to-'educedunlimitedness/existence-sublimating nascence' variance_in-epistemic-projection' respectively as of disontologising 'prior mere-formulaicity/ritualisation-<as-to-mereformulaic — methodologising/mutualising/organising/institutionalising,-prospectively-losingtrack-of-' ‘epistemic-totalising ’’’re-apriorising/re-axiomatising/re-referencing $\sim$ residuality-in-reoriginariness/re-origination’> imbued elaboration-as-to-mereextrapolating/constituting/abstracting/deducing/inferring-of-elucidation-outside'prospectively_implicited_attendant-ontological-contiguity ${ }^{67}$ ' educedexistentialising/contextalising/textualising_'intelligibility/epistemicity/reflexivity_contiguity$<$ imbued-notional cogency $>$ ' induced moronisation- $<$ sublimating-nascence,-extricatorydesublimating-downstreaming/'avalage'>' and re-ontologising 'prospective \{epistemic-totalising $3{ }^{3}{ }^{3} \mathrm{re}-$ apriorising/re-axiomatising/re-referencing - residuality-in-re-originariness/re-origination-〈as to human profound-supererogation for prospective apriorising/axiomatising/referencing-\{of'prospectively_implicited_attendant-ontological-contiguity ' educedexistentialising/contextualising/textualising_'intelligibility/epistemicity/reflexivity-contiguity<imbued-notional cogency >' \}-conflatedness in \{preconverging ment by\} postconverging-entailment that cannot be unshrouded by prior mere-formulaicity/ritualisation$<$ as-to-mere-formulaic — methodologising/mutualising/organising/institutionalising,-

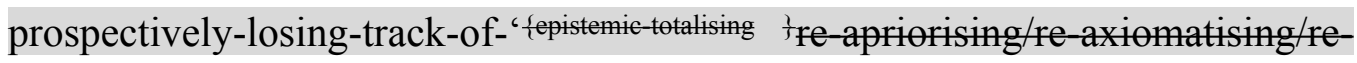


apriorising/axiomatising/referencing-\{of-'prospectively implicited_attendant-ontologicalcontiguity ' educed-

existentialising/contextualising/textualising_'intelligibility/epistemicity/reflexivity-contiguity$<$ imbued-notional cogency $>$ ' $\quad\}$-constitutedness -in-preconverging-entailment $\rangle \quad$ induced demoronisation- $<$ sublimating-nascence,-nonextricatory-sublimatingupstreaming/'amontée'>'). What thus underlies demoronisation-<sublimating-nascence,nonextricatory-sublimating-upstreaming/'amontée’> as to the full human omnipotentiality in relation to unlimitedness/existence-<full-potency-of_sublimating nascence $>$ is the 'full spectrum of contemplatable nonpresencing-<perspective-ontologicalnormalcy/postconvergence $>\quad$ relativism/relative-scope for epistemic-growth,-as\{veridical/sound\}-relative-reflexivity-in-existence/relativising from-limited-mentation-as-itsdeepening/psychologismic epistemic-acutisation residualising, fdecompusingl delinearity foreogency' as to 'apriorising/axiomatising/referencing disambiguating/de-leveling/deressentiment/opened-construct-of- ${ }^{5}$ meaningfulness-and-teleology 99 demoronisation<sublimating-nascence,-nonextricatory-sublimating-upstreaming/'amontée'>' and so over a moronisation-<sublimating-nascence,-extricatory-desublimating-downstreaming/'avalage'> ${ }^{6}$ presencing — absolutising-identitive-constitutedness ${ }^{14}$ absolution/absolute-scope \{flawed/unsound\}-relative-unreflexivity-in-existence/absolutising from-limitedmentation/psychologismic epistemic acutisation nonresidualising-imbued\{compulsing\} linearity-in-eclecticism-of prior-mere-formulaicity/ritualisation conception' closeting of the full human omnipotentiality in relation to unlimitedness/existence-full pon of_sublimating nascence $>$ as to its 'apriorising/axiomatising/referencingequating/leveling/ressentiment/closed-construct-of- ${ }^{-6}$ meaningfulness-and-teleology moronisation- $<$ sublimating-nascence,-extricatory-desublimating-downstreaming/'avalage'>' 
undifferentiation of both the prior relative-ontological-incompleteness ${ }^{88}$ and the prospective relative-ontological-completeness ${ }^{77}$; and so-manifested effectively as of 'overall human protracted-social—as-to-individual-by-institutional-by-social notional $\sim$ self-distantiation$<$ imbued-re-motif-and-re-apriorising/re-axiomatising/re-referencing $>$ '. In this regards, the 'overall relative-unreflexivity/relative-reflexivity - ontological-contiguity ${ }^{67}$ of-the-humaninstitutionalisation-process ${ }^{68}$ is overarchingly/definedly/devolvingly underlied by superseded/overcome successive 'apriorising/axiomatising/referencingequating/leveling/ressentiment/closed-construct-of- meaningfulness-and-teleology moronisation-<sublimating-nascence,-extricatory-desublimating-downstreaming/'avalage'>' along the lines of blatant brutish conquest/subjugation imbued prospective disontologising/subontologising, dominion protection imbued prospective disontologising/subontologising, natural-order-of-things imbued prospective disontologising/subontologising and our subtle modern-day prospective institutionallydistorted/disjointed-and-collateralising imbued prospective disontologising/subontologising (as to 'recurrently human aestheticisation-and-aestheticisation-towards-ontology-<elicitedidiomatisation> interstitial—disontologising-by-re-ontologising' so-underlining 'human interstitially recurrent limited-mentation-capacity as subjecting 'educed unlimitedness/existence-sublimating nascence' to-limitedness/human-subpotency-by-limitedmentation-capacity-deepening_as-subjecting limitedness/human-subpotency-to-'educedunlimitedness/existence-sublimating nascence' ${ }^{53} \quad$ variance_in-epistemic-projection', as associated specifically with Being-development/ontological-framework-expansion-as-to-depthof-ontologising-development-as-infrastructure-of- meaningfulness-and-teleology ).

Critically, in this respect demoronisation- $<$ sublimating-nascence, sublimatingupstreaming/'amontée'> effectively enables prospective re-ontologising by way of its prospective superseding/overcoming of the 'recurrently human aestheticisation-and- 
aestheticisation-towards-ontology-<elicited-idiomatisation $>$ interstitial—disontologising-byre-ontologising' (so-underlining 'human interstitially recurrent limited-mentation-capacity—assubjecting 'educed-unlimitedness/existence-sublimating nascence' to-limitedness/humansubpotency-by-limited-mentation-capacity-deepening—as-subjecting limitedness/humansubpotency-to-'educed-unlimitedness/existence-sublimating-nascence' 33 variance inepistemic-projection' respectively as of disontologising 'prior mere-formulaicity/ritualisation$<$ as-to-mere-formulaic — methodologising/mutualising/organising/institutionalising,prospectively-losing-track-of-‘ ‘epistemictalising tre-apriorising/re-axiomatising/rereferencing $\sim$ residuality —in-re-originariness/re-origination'> imbued elaboration-as-to-mereextrapolating/constituting/abstracting/deducing/inferring-of-elucidation-outside'prospectively_implicited_attendant-ontological-contiguity ${ }^{67}$ 'educedexistentialising/contextualising/textualising_'intelligibility/epistemicity/reflexivity_contiguity$<$ imbued-notional cogency $>$ ' induced moronisation-<sublimating-nascence,-extricatory desublimating-downstreaming/'avalage'>' and re-ontologising 'prospective apriorising/re-axiomatising/re-referencing - residuality-in-re-originariness/re-origination-〈as to human profound-supererogation for prospective apriorising/axiomatising/referencing-\{of'prospectively implicited_attendant-ontological-contiguity ' educedexistentialising/contextualising/textualising_'intelligibility/epistemicity/reflexivity-contiguity<imbued-notional cogency>’ $\}$-conflatedness $\quad$ in-\{preconverging -ment by\} postconverging-ntailment that cannot be unshrouded by prior mere-formulaicity/ritualisation$<$ as-to-mere-formulaic — methodologising/mutualising/organising/institutionalising,prospectively-losing-track-of- ‘\{epistemic-totalising referencing $\sim$ residuality-in-re-originariness/re-origination’> of prior apriorising/axiomatising/referencing-\{of-'prospectively implicited_attendant-ontologicalcontiguity ' educed- 
existentialising/contextualising/textualising_'intelligibility/epistemicity/reflexivity-contiguity<imbued-notional cogency >' $\quad\}$-constitutedness -in-preconverging-entailment $\rangle \quad$ induced demoronisation- $<$ sublimating-nascence,-nonextricatory-sublimating-

upstreaming/'amontée'>'). This re-ontologising superseding/overcoming of any ${ }^{79}$ presencingabsolutising-identitive-constitutedness ${ }^{14}$ 'human aestheticisation-and-aestheticisation-towardsontology-<elicited-idiomatisation $>\quad$ interstitial—disontologising-by-re-ontologising of ontological-performance ${ }^{72}-<$ including-virtue-as-ontology>' $\quad$ (so-underlining 'human interstitially recurrent limited-mentation-capacity-as-subjecting 'educedunlimitedness/existence-sublimating nascence' to-limitedness/human-subpotency-by-limitedmentation-capacity-deepening —as-subjecting limitedness/human-subpotency-to-'educedtnlimitedness/existence-sublimating nascence' ${ }^{53}$ variance_in-epistemic-projection') is soachieved as from the induced difference-conflatedness ${ }^{3}$-as-to-totalitative-reification-insingularisation-<as-to-the-nondisjointedness/entailment-of-prospective- nonpresencing $>$-asveridical-epistemicity-relativism-determinism of prospective re-ontologising demoronisation<sublimating-nascence,-nonextricatory-sublimating-upstreaming/'amontée'> (in 'prospective \{epistemic-totalising 3 \}re-apriorising/re-axiomatising/re-referencing residuality-in-re-

originariness/re-origination- $\langle$ as to human profound-supererogation for prospective apriorising/axiomatising/referencing-\{of-"prospectively_implicited_attendant-ontologicalcontiguity ' educedexistentialising/contextualising/textualising_'intelligibility/epistemicity/reflexivity-contiguity<imbued-notional cogency >' \}-conflatedness -in-\{preconverging-ment by\} postconverging-entailment that cannot be unshrouded by prior mere-formulaicity/ritualisation$<$ as-to-mere-formulaic - methodologising/mutualising/organising/institutionalising,prospectively-losing-track-of-'fepistemictalising 're-apriorising/re-axiomatising/rereferencing $\sim$ residuality—in-re-originariness/re-origination'> of prior 
apriorising/axiomatising/referencing-\{of-'prospectively_implicited_attendant-ontological-

contiguity ' educed-

existentialising/contextualising/textualising_'intelligibility/epistemicity/reflexivity-contiguity-

<imbued-notional cogency>' $\}$-constitutedness in preconverging entment '); as soreflecting limitedness/human-subpotency cumulating/recomposuring 'intolerance <ofdisparateness $>$ /exactifying_precisioning-of-sublimation- $<$ as-to-postconverging-narrowingdown apriorising/axiomatising/referencing-entailing-theoretical,-conceptual-and-operantimplications $>$ exercise of intelligibility' (as to imbued 'developing epistemic sense of nonpresencing-<perspective-ontological-normalcy/postconvergence $>\quad$ relativism/relativescope as projective-insights'), as what effectively enables the re-ontologising superseding/overcoming of 'human aestheticisation-and-aestheticisation-towards-ontology$<$ elicited-idiomatisation $>$ interstitial—disontologising-by-re-ontologising of ontologicalperformance ${ }^{2}-<$ including-virtue-as-ontology $>$ ' (so-underlining 'human interstitially recurrent limited-mentation-capacity—as-subjecting 'educed-unlimitedness/existence-sublimating nascence' to-limitedness/human-subpotency-by-limited-mentation-capacity-deepening-assubjecting limitedness/human-subpotency-to-'educed-unlimitedness/existence-sublimating nascence' variance_in-epistemic-projection'). The veracity of this elucidation (of reontologising superseding/overcoming of any ${ }^{79}$ presencing-absolutising-identitiveconstitutedness ${ }^{14}$ 'human aestheticisation-and-aestheticisation-towards-ontology- $<$ elicitedidiomatisation $>$ interstitial—disontologising-by-re-ontologising of ontological-performance ${ }^{72}$ <including-virtue-as-ontology>' so-underlining 'human interstitially recurrent limitedmentation-capacity as subjecting 'educed unlimitedness/existence sublimating nascence' to-limitedness/human-subpotency-by-limited-mentation-capacity-deepening —as-subjectinglimitedness/human-subpotency-to-'educed-unlimitedness/existence-sublimating nascence' variance_in-epistemic-projection') can be appreciated for instance (as so-construed 
aetiologically/in-ontological-escalation as from a cross-generational angling-of-imaginary epistemic-projection perspective for prospective ontologising-and-re-ontologising) in the sense that the overarching/defining/devolving difference-conflatedness ${ }^{13}$-as-to-totalitative-reificationin-singularisation-<as-to-the-nondisjointedness/entailment-of-prospective- nonpresencing $>$ as-veridical-epistemicity-relativism-determinism of 'non-positivising moronisation<sublimating-nascence,-extricatory-desublimating-downstreaming/'avalage'> meaningfulness-and-teleology ${ }^{9}$ in enabling the prospective re-ontologising of 'positivising demoronisation-<sublimating-nascence,-nonextricatory-sublimating-upstreaming/'amontée’> meaningfulness-and-teleology ${ }^{\circ}$ (as so-reflecting limitedness/human-subpotency cumulating/recomposuring 'intolerance-<of-disparateness $>$ /exactifying_precisioning-ofsublimation- $<$ as-to-postconverging-narrowing-down $\sim$ apriorising/axiomatising/referencingentailing-theoretical,-conceptual-and-operant-implications> exercise of intelligibility' as to imbued 'developing epistemic sense of ${ }^{6}$ nonpresencing-<perspective-ontologicalnormalcy/postconvergence $>$ relativism/relative-scope as projective-insights'); explains the very untenability/unsoundness/ontological-inveracity of the 'prior mere-formulaicity/ritualisation<as-to-mere-formulaic — methodologising/mutualising/organising/institutionalising,prospectively-losing-track-of- ${ }^{\text {\{ }\{\text { epistemic-totalising }}$ tre apriorising/re axiomatising/rereferencing $\sim$ residuality - in-re-originariness/re-origination'> of non-positivising moronisation<sublimating-nascence,-extricatory-desublimating-downstreaming/‘avalage’> meaningfulness-and-teleology ${ }^{9}$ within the 'prospective positivising demoronisation<sublimating-nascence,-nonextricatory-sublimating-upstreaming/'amontée’> meaningfulness-and-teleology existentialising-framing/imprinting' (and so as of positivising 'prospective \{epistemictotalising apriorising/re axiomatising/re referencing $\sim$ residuality - in-re-originariness/re-origination-〈as to human profoundsupererogation for prospective apriorising/axiomatising/referencing-\{of-"prospectively 
implicited_attendant-ontological-contiguity ' educed-

existentialising/contextualising/textualising_'intelligibility/epistemicity/reflexivity_contiguity-

<imbued-notional cogency>' \}-conflatedness -in-\{preconverging-ment by\}

postconverging-entailment that cannot be unshrouded by prior mere-formulaicity/ritualisation<as-to-mere-formulaic — methodologising/mutualising/organising/institutionalising,-

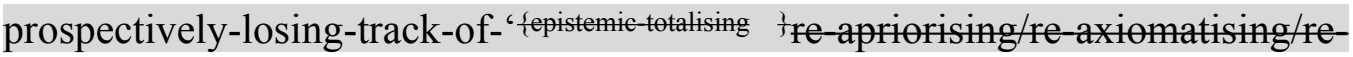

referencing residuality-in-re-originariness/re-origination'>

of

prior

apriorising/axiomatising/referencing-\{of-'prospectively implicited_attendant-ontological-

contiguity ' educed-

existentialising/contextualising/textualising_'intelligibility/epistemicity/reflexivity-contiguity-

<imbued-notional cogency $\left.>^{\prime} \quad\right\}$-constitutedness -in-preconverging-entailment $\left.)^{\prime}\right) . \quad$ This

fundamental insight (with regards to any 79 presencing — absolutising-identitive-constitutedness

'human aestheticisation-and-aestheticisation-towards-ontology-<elicited-idiomatisation $>$ interstitial - disontologising-by-re-ontologising of ontological-performance ${ }^{2}-<$ includingvirtue-as-ontology>' so-underlining 'human interstitially recurrent limited-mentationcapacity —as-subjecting 'educed-unlimitedness/existence-sublimating nascence' to-

limitedness/human-subpotency-by-limited-mentation-capacity-deepening—as-subjectinglimitedness/human-subpotency to-'educed-unlimitedness/existence-sublimating nascence' variance_in-epistemic-projection') underlines the fact that the secondnatured institutionalisation of registry-worldviews/dimensions as to their 'human social-and-institutional-frameworks-ofreferencing/registering/decisioning existentialising-decisionality-<as-to-disontologising/reentogising apresticism ' necessarily (given limitedness/human-subpotency imbued limitedmentation-capacity—as-subjecting 'educed-unlimitedness/existence-sublimating nascence' to-limitedness/human-subpotency) 'projects-of-apriorising/axiomatising/referencing in reflection of their given 're-ontologising-by-disontologising_existential-calculus-〈between 
'prospective existentialising_-postconverging_framing/imprinting re-ontologising' and 'prior existentialising_-preconverging_enframing/imprintedness social-functioning-andaccordance-as-of-social-stake-contention-or-confliction' $\rangle$ (as to 'lifespan extricatory/preconverging psychical-nascency moronisation- $<$ sublimating-nascence,extricatesublimating-downstreaming/'avalage'>’) as of prior mereformulaicity/ritualisation-<as-to-mere-formulaicmethodologising/mutualising/organising/institutionalising,-prospectively-losing-track-of‘fepistemic-atising ’’re-apriorising/re-axiomatising/re-referencing - residuality-in-reoriginariness/re-origination'>'; which supposed epistemic '79 presencing-absolutisingidentitive-constitutedness ${ }^{14} \quad$ absolution/absolute-scope $\quad$ fflawed/unsound\}-relativeunreflexivity-in-existence/absolutising from-limited-mentation/psychologismic epistemicacutisation nonresidualising-imbued-\{compulsing finearity-in-eclecticism-of-prior-mereformulaicity/ritualisation conception' underlies the given registry-worldview/dimension prospective desublimating 'human aestheticisation-and-aestheticisation-towards-ontology$<$ elicited-idiomatisation $>$ interstitial-disontologising-by-re-ontologising of ontologicalperformance ${ }^{2}$-<including-virtue-as-ontology $>$ ' (so-underlining 'human interstitially recurrent limited-mentation-capacity—as-subjecting 'educed-unlimitedness/existence-sublimating nascence' to-limitedness/human-subpotency-by-limited-mentation-capacity-deepening-assubjecting limitedness/human-subpotency to-'educed-unlimitedness/existence-sublimating nascence' variance_in-epistemic-projection'). The bigger picture here is that prospective disontologising moronisation- $<$ sublimating-nascence,-extricatory-desublimatingdownstreaming/‘avalage’> seedingly/incipiently arises out of $<$ mere formulaicity/rituation ef $\geq$-prior secondnatured institutionalisation imbued mere-formulaicity/ritualisation- $<$ as-tomere-formulaic — methodologising/mutualising/organising/institutionalising,-prospectively-

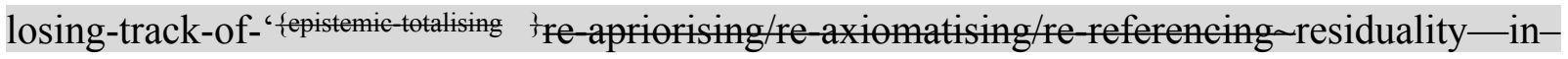


re-originariness/re-origination'> as interjected by 'human aestheticisation-and-aestheticisationtowards-ontology-<elicited-idiomatisation $>$ disontologising catchmenting-by-rejection/lipservicing/monopolising/gaming-of-the-system/charade/distraction (due to poor protractedsocial—as-to-individual-by-institutional-by-social notional $\sim$ self-distantiation- $<$ imbued-remotif-and-re-apriorising/re-axiomatising/re-referencing $>$ anticipation, contestation and preempting out of human limited-mentation-capacity-as-subjecting-educedunlimitedness/existence-sublimating nascence' to-limitedness/human-subpotency imbued 'reontologising-by-disontologising_existential-calculus-〈between 'prospective existentialisingpostconverging_framing/imprinting re-ontologising' and 'prior existentialisingpreconverging_enframing/imprintedness social-functioning-and-accordance-as-of-socialstake-contention-or-confliction' ’')'; as wrongly supposedly superseding 'prospective \{epistemictotalising 3 re-apriorising/re-axiomatising/re-referencing $\sim$ residuality-in-re-originariness/reorigination- $\langle$ as to human profound-supererogation for prospective apriorising/axiomatising/referencing-\{of-'prospectively implicited_attendant-ontologicalcontiguity ' educedexistentialising/contextualising/textualising_'intelligibility/epistemicity/reflexivity-contiguity<imbued-notional cogency $\left.>^{\prime}\right\}$-conflatedness -in-\{preconverging -ment by\} postconverging-ntailment that cannot be unshrouded by prior mere-formulaicity/ritualisation$<$ as-to-mere-formulaic — methodologising/mutualising/organising/institutionalising,prospectively-losing-track-of- ‘\{epistemic-totalising ’’re-apriorising/re-axiomatising/rereferencing-residuality-in-re-originariness/re-origination'> of prior apriorising/axiomatising/referencing-\{of-'prospectively implicited_attendant-ontologicalcontiguity ' $\sim$ educedexistentialising/contextualising/textualising_'intelligibility/epistemicity/reflexivity-contiguity<imbued-notional cogency >' $\}$-constitutedness -in preconverging-entailment)'. But then 
any ${ }^{7}$ presencing-absolutising-identitive-constitutedness ${ }^{14}$ 'human aestheticisation-andaestheticisation-towards-ontology-<elicited-idiomatisation $>$ interstitial—disontologising-by-

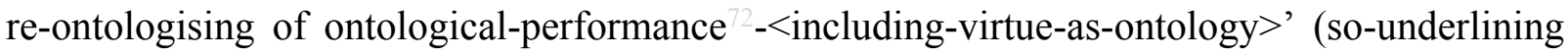
'human interstitially recurrent limited-mentation-capacity-as-subjecting-educedunlimitedness/existence-sublimating nascence' to-limitedness/human-subpotency-by-limitedmentation-capacity-deepening_as-subjecting-limitedness/human-subpotency-to-'educedunlimitedness/existence-sublimating nascence' ${ }^{53} \quad$ variance_in-epistemic-projection') is critically not beyond its prospective superseding/overcoming re-ontologising reconstrual as to human limited-mentation-capacity-deepening —as-subjecting limitedness/human-subpotency to-'educed-unlimitedness/existence-sublimating nascence's prospective reappraisal of 'reontologising-by-disontologising_existential-calculus-〈between 'prospective existentialisingpostconverging_framing/imprinting re-ontologising' and 'prior existentialising preconverging_enframing/imprintedness social-functioning-and-accordance-as-of-socialstake-contention-or-confliction'〉' (as starkly associated with the notional asceticism for reontologising prospective Being-development/ontological-framework-expansion-as-to-depthof-ontologising-development-as-infrastructure-of- meaningfulness-and-teleology as sounderlying 'successive challenges of profound-supererogation for prospective re-ontologising' as so 'inventing'/‘creating'-and-'nurturing' prospective sublimating re-rationalisations-ofcontentivity/argumentativity/dialecticism/discursivity of social-and-institutional-frameworksof - referencing/registering/decisioning); and as so-manifested veridically for overall prospective re-ontologising sublimation/emancipation/enfranchisement with overall 'prospective \{epistemic-totalising 3 're-apriorising/re-axiomatising/re-referencing $\sim$ residuality-in-reoriginariness/re-origination- $\langle$ as to human profound-supererogation for prospective apriorising/axiomatising/referencing-\{of-'prospectively_implicited_attendant-ontologicalcontiguity ' educed- 
existentialising/contextualising/textualising_'intelligibility/epistemicity/reflexivity-contiguity<imbued-notional cogency>' \}-conflatedness -in-\{preconverging-ment by\} pestconverging entailment that cannot be unshrouded by prior mere-formulaicity/ritualisation$<$ as-to-mere-formulaic — methodologising/mutualising/organising/institutionalising,prospectively-losing-track-of- ‘\{epistemic-totalising ${ }^{3}$ re-apriorising/re-axiomatising/rereferencing-residuality-in-re-originariness/re-origination'> of prior apriorising/axiomatising/referencing-\{of-'prospectively implicited_attendant-ontologicalcontiguity ' educedexistentialising/contextualising/textualising_'intelligibility/epistemicity/reflexivity-contiguity<imbued-notional cogency>' $\}$ - constitutedness -in preconverging-entailment)' ${ }^{\prime}$ (as to Being-development/ontological-framework-expansion-as-to-depth-of-ontologising-

development-as-infrastructure-of- meaningfulness-and-teleology , institutionaldevelopment-as-to-social-function-development and living-development-as-to-personalitydevelopment psychologismic epistemic-acutisation difficulty-for, residualising ${ }_{\{\text {decompulsing }\}}$ delinearity for-cogency> magnitudes ${ }^{\{\text {of-experientiality/experiment }\}}$ ). Critically, demoronisation-<sublimating-nascence,-nonextricatory-sublimating-upstreaming/‘amontée’> (in reflection of the requisite 'successive challenges of profound-supererogation' for prospective re-ontologising' as so 'inventing'/'creating'-and-'nurturing' prospective sublimating re-rationalisations-of-contentivity/argumentativity/dialecticism/discursivity of successive Being-development/ontological-framework-expansion-as-to-depth-of-ontologisingdevelopment-as-infrastructure-of- meaningfulness-and-teleology ) is rather a reflection of the fact that the <cumulating/recomposuring attendant-ontological-contiguity $>$-successive registry-worldviews/dimensions arise fundamentally/incipiently/seedingly out of ontologicalgood-faith/authenticity $\sim$ postconverging-de-mentating/structuring/paradigming $\quad$ as $\quad$ sovalidated as to (their postconverging-birthing/nascency within) prospective 
apriorising/re-axiomatising/re-referencing residuality-in-re-originariness/re-origination of limitedness/human-subpotency prospective re-encountering/re-confrontation with the 'constraining/defining intersolipsistic reflexive-sublimating/unreflexive-desublimating measure/objectification that is unlimitedness/existence-as-ontologicalnormalcy/postconvergence-<in-validation-of-'metaphysics-of-absence_epistemic-

projection'>'; from whence their so 'invented'/'created'-and-'nurtured' rationalisations-ofcontentivity/argumentativity/dialecticism/discursivity prospective re-ontologising validity allows for their prospectively imbued systematic $<$ amplituding/formative $>$ disposedness/psychologismic-construct-〈as-to-orientation/valueconstruct/valuation-and-derived-parameterising $\rangle$ and $<$ amplituding/formative $>$ entailment-〈asto-totalising-contiguous/coherent-factuality-of-variability)' (as so-carrying their given existentialising possibility for prospective re-ontologising sublimation/emancipation/enfranchisement), in reflection of the ${ }^{45}$ foregrounding_entailment$<$ in-succession-of-profound-supererogation $>$-〈postconverging-narrowingdown $\sim$ sublimation-as-to-'existence — as-sublimating-withdrawal/unenframing/re-ontologising,elicited-from-prospective-profound-supererogation ' unreflexivity/relative-reflexivity - ontological-contiguity ';-as-operative-

notional deprocrypticism) of the relative mreflexivitrelative reflexivity-ontologicalcontiguity ${ }^{67}$ of-the-human-institutionalisation-process ${ }^{68}$ Insightfully, this overall nonpresencing-or-withdrawal/unenframing/re-ontologising-or-metaphysics-of-absence〈implicited-epistemic-veracity-of- nonpresencing-<perspective-ontologicalnormalcy/postconvergence $>$ )-or-transcendental-reasoning-of-event ${ }^{38}$-as-prospective-ontologyorigination 'more profound-and-veridical aetiologisiation/ontological-escalation conceptivity/epistemic-reflexivity/epistemicity-relativism-determinism- $<$ reifying \{as-toknowledge-developing\}-and-empowering> of human psychology' (as to its 'profound- 
supererogation

epistemic-growth,-as_ _veridical/sound\}-relative-reflexivity-inexistence/relativising from-limited-mentation-as-its-deepening/psychologismic epistemicacutisation residualising, fdecompusing delinearity for-cogency of the human psychology purview-of-unlimitedness/existence-<fll-potency-of_sublimating nascence $>$; 'implicited_attendant-ontological-contiguity ${ }^{67}$ educedexistentialising/contextualising/textualising_intelligibility/epistemicity/reflexivity-contiguity<imbued-notional cogency $>^{\prime} \quad$ implying limitedness/human-subpotency cumulating/recomposuring) puts into question a modern-day conception of psychology which is rather in a 'shallow-supererogation \{flawed/unsound\}-relative-unreflexivity-inexistence/absolutising from-limited-mentation/psychologismic epistemic acutisationnonresidualising-imbued-\{compulsing\} linearity in-eclecticism-of-prior-mereformulaicity/ritualisation of the human psychology purview-of-unlimitedness/existence-<fullpotency-of_sublimating nascence>;_—implicited_attendant-ontologicalcontiguity ${ }^{67} \sim$ educedexistentialising/contextualising/textualising_intelligibility/epistemicity/reflexivity-contiguity<imbued-notional cogency $>$ ' ; as so-failing to effectively reflect the 'requisite epistemicnotional $\sim$ symmetrisation- $<$ as-to-symmetrisation-by-desymmetrisation,-inreflecting-postconverging-or-dialectical-thinking -by-preconverging-ordementing $\sim$ perspectives-of-human- ${ }^{56}$ meaningfulness-and-teleology ${ }^{9}>$ of the relativemnreflexivity/relative-reflexivity — ontological-contiguity ${ }^{67}$ of-the-human-institutionalisationprocess $^{68}$, as of the "nonpresencing-<perspective-ontological-normalcy/postconvergence $>$ relativism/relative-scope for epistemic-growth,-as - \{veridical/sound\}-relative-reflexivity-inexistence/relativising from limited mentation as its deepening/psychologismic epistemic acutisation residualising, ${ }^{\{\text {decompulsing }}$ delinearity for-cogency’ for educing ${ }^{56}$ meaningfulnessand-teleology' as to the prospect of 'prospective \{epistemic-totalising 3 3 re-apriorising/re- 
axiomatising/re-referencing $\sim$ residuality—in-re-originariness/re-origination

relativeontological-completeness ${ }^{87}$ implications' (so-underlying human 'prospective re-ontologising demoronisation-<sublimating-nascence,-nonextricatory-sublimating-upstreaming/'amontée’> psychologismic-element-<as-of-diametrical-conflatedness -towards-'already-givenunlimitedness/existence-<full-potency-of_sublimating nascence $>$ '-of-'limitedness/humansubpotency-as-to-its-imbued-\{veridical/sound $\}$-relative-reflexivity-in-existence/relativising from-limited-mentation-as-its-deepening/psychologismic epistemic-acutisation residualising, ${ }^{\text {fdecmolsing }}$ delinearity for-cogency'> imbued prospective psychologismicepistemic-acutisation-<as-to-postconverging-de-mentating/structuring/paradigming,-elicitingof-existence's-sublimating-nascence-in-prospective-aporeticism-overcoming/unovercoming> as to epistemic-growth,-as - \{veridical/sound\}-relative-reflexivity-in-existence/relativising from-limited-mentation-as its-deepening/psychologismic epistemic-acutisationresidualising, ${ }^{\text {\{decompulsing }}$ delinearity for-cogency'). This failing of the modern-day conception of psychology is particularly manifest as to its critical lack of the construction-of-the-Self element identified herein as 'akrasia-susceptibility-or-akrasiatic-drag/shiftiness-of-theSelf /ontological-fracturing/desublimation/gimmickiness complex' since this is effectively what nolionally/epistemieally/bindingnessly-<as-to-determinism/conceptivity-of-relative-unreflexivity/relativereflexivitys undergirds the possibility for protracted-social-as-to-individual-by-institutional-bysocial self prospective re-ontologising (as to the postconverging-aporeticismovercoming/unovercoming of any ${ }^{79}$ presencing-absolutising-identitive-constitutedness relatively manifest psychoanalytic abnormality-<as-to-epistemicabnormalcy/preconvergence $>$ ). Whereas such a modern-day conception of psychology operates on a 'fundamental/incipient/seeding apriorising/axiomatising/referencing ontological-flaw' that wrongly implicits the apriorising/axiomatising/referencing ontologicalnormalcy/postconvergence of the modern-day ${ }^{79}$ presencing-absolutising-identitive- 
constitutedness $^{14}$ psyche; and thus wrongly projecting a construal (as of our positivismprocrypticism/disjointedness-as-of- ${ }^{8}$ reference-of-thought $\quad$ moronisation- $<$ sublimatingnascence,-extricatory-desublimating-downstreaming/'avalage’>) of prior mereformulaicity/ritualisation-<as-to-mere-formulaic-

methodologising/mutualising/organising/institutionalising,-prospectively-losing-track-of-

' fepistemic-totalising '`re-apriorising/re-axiomatising/re-referencing-residuality-in-re-

originariness/re-origination'> as wrongly supposedly-and-inherently providing in its presencing-absolutising-identitive-constitutedness ${ }^{14}$ the absolution/absolute-scope for educing human psychology sublimating ${ }^{5}$ meaningfulness-and-teleology ${ }^{9}$ ignoring/overlooking the prospect of 'prospective ${ }^{18}$ deprocrypticism-or-preempting-disjointedness-as-ofreference-of-thought as of notional ${ }^{18}$ deprocrypticism fepistemic-totalising 3 re-apriorising/reaxiomatising/re-referencing residuality-in-re-originariness/re-origination relativeontological-completeness 87 implications' (as $\quad$ so-implying an 'apriorising/axiomatising/referencing_equating/leveling/ressentiment/closed-construct-ofmeaningfulness-and-teleology $\quad$ moronisation-<sublimating-nascence,-extricatorydesublimating-downstreaming/'avalage'>' undifferentiation of both the prior relativeontological-incompleteness ${ }^{8}$ and the prospective relative-ontological-completeness ${ }^{87}$, wherein limitedness/human-subpotency wrongly supposedly-and-inherently prospectively supersedes unlimitedness/existence-<fll potency-of_sublimating nascence $>$ ). Such that such a modernday conception of human psychology effectively fails to grasp what is effectively meant by human limited-mentation-capacity-deepening —as-subjecting limitedness/human-subpotencyto-'educed-unlimitedness/existence-sublimating nascence' ${ }^{53}$ as to when it paradoxically psychoanalyses as from the 'abstract backdrop of a wrongly supposed ontologicalnormalcy/postconvergence ${ }^{79}$ presencing-absolutising-identitive-constitutedness ${ }^{14}$ psyche' failing to reflect the ontological-veracity of 'our positivism- procrypticism prospective 
disontologising preconverging-de-mentating/structuring/paradigming' (and this is exactly what renders problematic the very scientific nature of such a modern-day conception of psychoanalysis); as in-the-bigger-scheme-of-things, psychoanalysis concretely reflects the human psychoanalytic-unshackling respectively from its disontologising desublimating recurrent-utter-uninstitutionalisation, ununiversalisation, non-positivism/medievalism and procrypticism-or-disjointedness-as-of- ${ }^{8}$ reference-of-thought into respectively reontologising sublimating base-institutionalisation, ${ }^{103}$ universalisation, positivism/rationalempiricism and prospective deprocrypticism-or-preempting-disjointedness-as-ofreference-of-thought (as-so translated as of human Being-development/ontologicalframework-expansion-as-to-depth-of-ontologising-development-as-infrastructure-ofmeaningfulness-and-teleology psychologismic epistemic-acutisation difficulty-<for, residualising_\{decompulsing\} delinearity for-cogency> magnitude\{of-experientiality/experiment\} and institutional-development-as-to-social-function-development and living-development-as-topersonality-development psychologismic epistemic acutisation difficulty < for, residualising \{dempulsing\} delinearity for-cogency> magnitudes \{of-experientiality/experiment\}). Critically, it is effectively such a prospective ${ }^{18}$ deprocrypticism-or-preemptingdisjointedness-as-of- ${ }^{8}$ reference-of-thought as of notional ${ }^{1}$ deprocrypticism construal (as to overall nonpresencing-or-withdrawal/unenframing/re-ontologising-or-metaphysics-ofabsence-〈implicited-epistemic-veracity-of- nonpresencing-<perspective-ontologicalnormalcy/postconvergence $>$ )-or-transcendental-reasoning-of-event ${ }^{38}$-as-prospective-ontologyorigination 'more profound-and-veridical aetiologisiation/ontological-escalation conceptivity/epistemic-reflexivity/epistemicity-relativism-determinism-<reifying \{as-toknowledge-developing\}-and-empowering $>$ of human psychology' as to its 'profoundsupererogation epistemic-growth,-as_ \{veridical/sound\}-relative-reflexivity-inexistence/relativising from-limited-mentation-as-its-deepening/psychologismic epistemic- 
acutisation residualising, ${ }^{\text {\{decompulsing }}$ delinearity for-cogency of the human psychology purview-of-unlimitedness/existence-<full-potency-of_sublimating nascence $>$; 'implicited_attendant-ontological-contiguity ${ }^{67}$; educedexistentialising/contextualising/textualising_'intelligibility/epistemicity/reflexivity-contiguity<imbued-notional cogency $>^{\text {' }} \quad$ implying limitedness/human-subpotency cumulating/recomposuring); that effectively attends to the veridical conception of psychological science/ontology as actually a postconverging-birthing/nascency within prospective \{epistemictre-apriorising/re-axiomatising/re-referencing 2 residuality-in-re-originariness/reorigination- $\langle$ as to human profound-supererogation for prospective apriorising/axiomatising/referencing-\{of-"prospectively implicited_attendant-ontologicalcontiguity ' educedexistentialising/contextualising/textualising_'intelligibility/epistemicity/reflexivity-contiguity<imbued-notional cogency>’ \}-conflatedness -in-\{preconverging-ment by\} postconverging-ntailment that cannot be unshrouded by prior mere-formulaicity/ritualisation<as-to-mere-formulaic - methodologising/mutualising/organising/institutionalising,prospectively-losing-track-of- ‘ ‘epistemic-totalising $\frac{1}{3}$ re-apriorising/re-axiomatising/rereferencing residuality-in-re-originariness/re-origination'> of prior apriorising/axiomatising/referencing-\{of-'prospectively implicited_attendant-ontologicalcontiguity ' educedexistentialising/contextualising/textualising_'intelligibility/epistemicity/reflexivity-contiguity<imbued-notional cogency >' $\}$-constitutedness -in-preconverging-entailment $\rangle,$ and so given 'limitedness/human-subpotency incompleteness-<as-to-prospective_residuality-of-

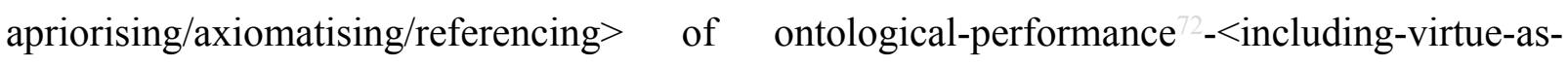
ontology $>$ /morality/ethics/justice/etc. in its construal of the human psychology purview-ofunlimitedness/existence-<full-potency-of_sublimating nascence>;_-implicited_attendant- 
ontological-contiguity ${ }^{67}$, educedexistentialising/contextualising/textualising_'intelligibility/epistemicity/reflexivity_contiguity$<$ imbued-notional cogency $>$ ' (implying prospective re-ontologising 'deconstruction conception as to epistemic-growth,-as - \{veridical/sound\}relative-reflexivity-inexistence/relativising from-limited-mentation-as-its-deepening/psychologismic epistemicacutisation residualising, $\left.{ }^{\{d e c o m p u l s i n g}\right\}$ delinearity for-cogeney', so-underlied by projectiveinsights of 'requisite human \{epistemicthermeneutically/textually/reprojectingly/supererogatingly/zeroingly/re-acutingly,delinearity for-cogency_cumulated/recomposured-and/or-designed/redesigned experientiality/experiment-<as-to-existentially-formative- ‘fepistemic-totalising ’’re-apriorising/reaxiomatising/re-referencing residuality-in-re-originariness/re-origination', - so'notionally/epistemically/bindingnessly-<as-to-determinism/coneeptivity-of-relative-unreflexivity/relative-reflexivity> implicited-and-articulated'_as-from-nonextricatory-'prospective-re-ontologising-Being-thenInstitutional-then-Living-magnitudes-of-\{hermeneutic/reprojection-protraction-of $\}$ reframingand-reformulation $\}^{\prime}>$ in existence'). Critically in this respect, a modern-day conception of human psychology fails to reflect the 'requisite epistemic-totalising notional $\sim$ symmetrisation<as-to-symmetrisation-by-desymmetrisation,-in-reflecting-postconverging-or-dialecticalthinking -by-preconverging-or-dementing $\sim$ perspectives-of-human- ${ }^{5}$ meaningfulness-andteleology $>$ of human psychology purview-of-unlimitedness/existence-<full-potency of_sublimating nascence>;_—'implicited_attendant_ontological-contiguity ${ }^{67}$ ' educedexistentialising/contextualising/textualising_'intelligibility/epistemicity/reflexivity-contiguity<imbued-notional cogency>' ${ }^{40}$ and so fundamentally/incipiently/seedingly by a 'positivismprocrypticism/disjointedness-as-of- ${ }^{8}$ reference-of-thought $\quad{ }^{79}$ presencing-absolutisingidentitive-constitutedness ${ }^{14}$ epistemic-projection' imbued reductionist misconstrual of the 'existentialising-frame-of-entailment-of motif-and-apriorising/axiomatising/referencing of 
experientiality/experiment-<as-to-existentially-formative-' \{epistemic-totalising $\frac{1}{3}$ re-apriorising/reaxiomatising/re-referencing $\sim$ residuality —in-re-originariness/re-origination', —so"notionally/epistemically/bindingnessly<as-to-determinism/conceptivity-of-relative-unreflexivity/relative-reflexivity> implicited-and-articulated'_as-from-nonextricatory-'prospective-re-ontologising-Being-thenInstitutional-then-Living-magnitudes-of-\{hermeneutic/reprojection-protraction-of $\}$ reframingand-reformulation \}'>' for eliciting the human psychology purview-of-unlimitedness/existence$\leq$ full-potency-of_sublimating nascence $>$;__'implicited_attendant-ontologicalcontiguity ${ }^{6}$, educedexistentialising/contextualising/textualising_'intelligibility/epistemicity/reflexivity-contiguity<imbued-notional cogency>' . Wherein the requisite totalising $3{ }^{3}$ hermeneutically/textually/reprojectingly/supererogatingly/zeroingly/re-acutingly,$\{$ decompulsing $\}$ delinearity $\sim$ for-cogency—cumulated/recomposured-and/or-designed/redesigned notional $\sim$ reflexivity- $<$ \{veridical/sound $\}$-relative-reflexivity-in-existence/relativising fromlimited-mentation-as-its-deepening/psychologismic-<residualising tdempung delinearity foreogency>-by-\{flawed/unsound\}-relative-unreflexivity-in-existence/absolutising fromlimited-mentation/psychologismic epistemic acutisation nonresidualising imbued\{compulsing\} linearity in eclecticism of prior mere formulaicity/ritultisation>' is overlooked (not/poorly factoring any given station/locus of <amplituding/formative-epistemicity >totalising thrownness-in-existence ${ }^{35}$ as so-bound to 'apriorising/axiomatising/referencingequating/leveling/ressentiment/closed-construct-of- ${ }^{5}$ meaningfulness-and-teleology moronisation-<sublimating-nascence,-extricatory-desublimating-downstreaming/'avalage'>' undifferentiation of both the prior relative-ontological-incompleteness ${ }^{88}$ and the prospective relative-ontological-completeness ${ }^{8}$, wherein limitedness/human-subpotency wrongly supposedly-and-inherently prospectively supersedes unlimitedness/existence-<fll-potency өf_sublimating nascence $>$ ); and failing to appreciate in-the-bigger-picture that the notion of 
experientiality/experiment-<as-to-existentially-formative-' \{epistemic-totalising $\frac{1}{3}$ re-apriorising/reaxiomatising/re-referencing $\sim$ residuality —in-re-originariness/re-origination', —so'notionally/epistemically/bindingnessly< <s-to-determinism/conceptivity of -relative-unreflexivity/relative-reflexivity> implicited-and-articulated'_as-from-nonextricatory-'prospective-re-ontologising-Being-thenInstitutional-then-Living-magnitudes-of-\{hermeneutic/reprojection-protraction-of\}reframingand-reformulation $\}^{\prime}>$ is undissociated from immanent-existence with 'being-in-existence already the bigger ongoing/undergone experientiality/experiment-<as-to-existentiallyformative-' 'fepistemic originariness/re-origination',—-so-'notionally/epistemically/bindingnessly-ass-todeterminism/conceptivity-of-relative-unreflexivity/relative-reflexivity>-implicited-and-articulated'_as-fromnonextricatory-'prospective-re-ontologising-Being-then-Institutional-then-Living-magnitudesof-\{hermeneutic/reprojection-protraction-of reframing-and-reformulation\} '>' (beyond a naïve conception of the scientific experiment as all about a given natural or other science experimental/observational/survey designing/setup "wrongly seeming to exclude contiguity with insight from the fact of already being-in-existence' as such experimental/observational/survey designing/setup are rather appreciable in extenso of already being-in-existence as to when such natural science manifestations like physical, chemical and biological processes are not contemplatable in our ordinary/common perceptual existential-<disontologising/reentologising aporeticism $>$ framework requiring the extension of our already being-inexistence by such natural science experimental/observational/survey designing/setup as a supereregatory-wholesomeness/profound-supererogation continuity of <sublimationeducing__epistemic-totalising thermeneutic/textuality/reprojecting/supererogating/zeroing/reanting, $-{ }^{\{\text {decompulsing }\}}$ delinearity $\sim$ for-cogency $>$-interpretation and so 'as to the given natural science human limited-mentation-capacity-deepening as-subjecting limitedness/humansubpotency-to-'educed-unlimitedness/existence-sublimating nascence' ${ }^{33}$ specifically and/or 
generally cultivated arts/skills and time investment'), in want for 'appropriate human contemplative projective-insights of sublimating-nascence aetiologisation/ontologicalescalation-<ontological-veridicality_commitment/otherliness_transcending/compulsionsencumbered_transcending $>\quad$ conceptivity/epistemic-reflexivity/epistemicity-relativismdeterminism-<reifying \{as-to-knowledge-developing $\}$-and-empowering $>$ ' (and so-reflected as to human aestheticisation-and-aestheticisation-towards-ontology-<elicited-idiomatisation $>$ educing existence's - effusing/ecstatic-inlining-as- ${ }^{-}$historiality\{science/authenticity/nonextrication $\}$-beyond-mere-formulaicity/ritualisation-as- ${ }^{4}$ historicitytracing-\{science-ideology/fashionability/distraction $\}$ ). Critically, the human sciences are misled when naively failing to realise that the natural sciences are founded and driven as from a most profound $\quad$ sense $\quad$ of $\quad<$ sublimation-educing_fepistemictotalising thermeneutic/textuality/reprojecting/supererogating/zeroing/re-acuting,$\{$ decompulsing $\}$ delinearity $\sim$ for-cogency $>$-interpretation by the supereregatery wholesomeness/profound-supererogation experientiality/experiment-<as-toexistentially-formative-' ‘epistemic-alising tre-apriorising/re-axiomatising/rereferencing $\sim$ residuality —in-re-originariness/re-origination',- - so'motionally/epistemiealy/bindimgnessly-<as-to-determinism/conceptivity-of-relative-unreflexivity/relative-reflexivity> implicited-and-articulated'_as-from-nonextricatory-'prospective-re-ontologising-Being-thenInstitutional-then-Living-magnitudes-of-\{hermeneutic/reprojection-protraction-of\}reframingand-reformulation $\}^{\prime}>$ of already being-in-existence' with their experimentation arising mostly because 'physical, chemical and biological processes are not contemplatable in our ordinary/common perceptual existential-<disontologising/re-ontologising aporeticism $>$ framework requiring the extension of our already being-in-existence by such natural science experimental/observational/survey designing/setup as a supereregatery $\sim$ wholesomeness/profound-supererogation continuity of <sublimation- 
educing_\{epistemic-totalising thermeneutic/textuality/reprojecting/supererogating/zeroing/re-

acuting, $-{ }_{\text {-decompulsing }}$ delinearity for-cogency>-interpretation'; and when such contemplation avails as to when such natural science experimental/observational/survey designing/setup are not specifically required and/or the prior insight is understood, the critical activity of science is continually

one

of

$'<$ sublimation-educing__epistemic-

totalising thermeneutic/textuality/reprojecting/supererogating/zeroing/re-acuting,-

$\{$ decompulsing $\}$ delinearity $\sim$ for-cogency>-interpretation

by

the

supererogatory wholesomeness/profound-supererogation

experientiality/experiment-<as-to-

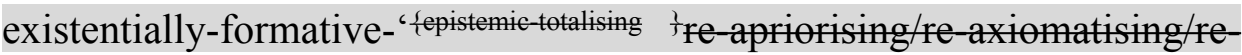

referencing $\sim$ residuality—in-re-originariness/re-origination',- - so-

"notionally/epistemically/bindingnessly-<as-to-determinism/eoneeptivity-of-relative-unreflexivity/relative-reflexivity>

implicited-and-articulated' as-from-nonextricatory- 'prospective-re-ontologising-Being-then-

Institutional-then-Living-magnitudes-of-\{hermeneutic/reprojection-protraction-of $\}$ reframing-

and-reformulation $\}^{\prime}>$ of already being-in-existence' as enabling both prospective sublimation and insight about prospective natural science experimental/observational/survey designing/setup. In this respect, it is the effectively cultivated theoretical, conceptual and operational $<$ sublimation-educingtotalising 'hermeneutic/textuality/reprojecting/supererogating/zeroing/re-acuting,$\{$ decompulsing $\}$ delinearity for-cogency $>$-interpretation conceptualisation of natural sciences purviews-of-unlimitedness/existence-<full-potency-of_sublimating nascence $>$ that provides the coherencing/contiguous backdrop for eliciting prospective sublimation so-reflected as of 'implicited attendant-ontological-contiguity ${ }^{67}$ ' educed-

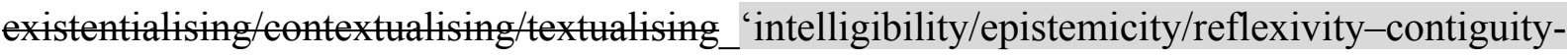
$<$ imbued-notional cogency $>$ imbued sublimation-educing-\{epistemictotalising 3'thermeneutic/textuality/reprojecting/supererogating/zeroing/re-acuting,- 
\{decompulsing\} delinearity for-cogency as-to-possibilities-of-self-becoming-as-of-'existentialinterpretation/epistemicity-in-apriorising/axiomatising/referencing-of-existence' ${ }^{95}$. elucidation is made notwithstanding the very epistemic impliciting nature of the natural sciences to highlight explicitly the very nature of science in order not to naively adopt a science-ideology conception of experimentation 'that fails-to/poorly perceive and link-up (as to lack of epistemictotalising contiguity projective-insights as to nonpresencing- $<$ perspective-ontologicalnormalcy/postconvergence $>$ relativism/relative-scope for epistemic-growth,-as\{veridical/sound\}-relative-reflexivity-in-existence/relativising from-limited-mentation-as-itsdeepening/psychologismic epistemic-acutisation residualising, fdecompusingl delinearity foreogency) to the notional protensivity backdrop for exuding sublimation that is the-very-same purview-of-unlimitedness/existence-<full-potency-of_sublimating nascence $>$; 'implicited_attendant-ontological-contiguity ${ }^{67}$ > educedexistentialising/contextualising/textualising_'intelligibility/epistemicity/reflexivity-contiguity$<$ imbued-notional cogency $>^{\prime} \quad$ (as to a shallow-supererogation of mereformulaicity/ritualisation-<as-to-mere-formulaicmethodologising/mutualising/organising/institutionalising,-prospectively-losing-track-of‘\{epistemic-totalising ’re apriorising/re axiomatising/re referencing-residuality-in-reoriginariness/re-origination'> conception of experimentation as of elaboration-as-to-mereextrapolating/constituting/abstracting/deducing/inferring-of-elucidation-outside'prospectively_implicited_attendant_ontological-contiguity ${ }^{67}$ ' educedexistentialising/contextualising/textualising_intelligibility/epistemicity/reflexivity-contiguity$<$ imbued-notional cogency $>$ ") ) that fails to effectively conceptualise the driving role of '< sublimation-educing__epistemictotalising thermeneutic/textuality/reprojecting/supererogating/zeroing/re-acuting,- 
supererogatory $\sim$ wholesomeness/profound-supererogation $\quad$ experientiality/experiment- $<$ as-toexistentially-formative- 'fepistemic-totalising ${ }^{\prime}$ re-apriorising/re-axiomatising/re-

referencing $\sim$ residuality —in-re-originariness/re-origination',- - so-

'notionally/epistemically/bindingnessly-<as-to-determinism/conceptivity-of-relative-unreflexivity/relative-reflexivity>

implicited-and-articulated'_as-from-nonextricatory- 'prospective-re-ontologising-Being-then-

Institutional-then-Living-magnitudes-of-\{hermeneutic/reprojection-protraction-of $\}$ reframingand-reformulation $\}^{\prime}>$ of already being-in-existence' (as effectively enabling postconvergingbirthing/nascency within prospective referencing $\sim$ residuality - in-re-originariness/re-origination- $\langle$ as to human profoundsupererogation for prospective apriorising/axiomatising/referencing-\{of-'prospectively implicited_attendant-ontological-contiguity ' educed-

existentialising/contextualising/textualising_'intelligibility/epistemicity/reflexivity_contiguity$<$ imbued-notional cogency $>$ ' $\}$-conflatedness in-\{preconverging ment by\} postconverging-ntailment that cannot be unshrouded by prior mere-formulaicity/ritualisation$<$ as-to-mere-formulaic — methodologising/mutualising/organising/institutionalising,-

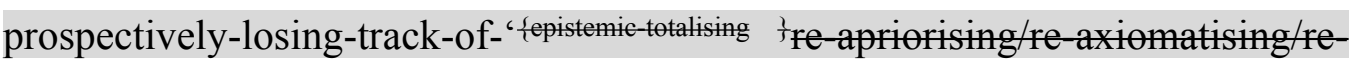

referencing $\sim$ residuality -in-re-originariness/re-origination'> of prior apriorising/axiomatising/referencing-\{of- prospectively implicited_attendant-ontologicalcontiguity ' educed-

existentialising/contextualising/textualising_'intelligibility/epistemicity/reflexivity_contiguity<imbued-notional cogency >' $\quad\}$-constitutedness -in preconverging-entailment $\rangle) . \quad$ In-thebigger-scheme-of-things, the very implication of notional $\sim$ philosophy-<as-to-the-veridicalconception-of-philosophy-as-englobing-all-human-prospective-organic-knowledge-generationin-relative-ontological-completeness ,-beyond-a-convenient-division-of-labour-conception-ofknowledge $>$ and its associated ontology/science implied intolerance-<of- 
disparateness $>$ /exactifying_precisioning-of-sublimation-<as-to-postconverging-narrowingdown apriorising/axiomatising/referencing-entailing-theoretical,-conceptual-and-operantimplications $>$ underlines the fact that whilst in-many-ways the implicitness of the very potent natural sciences sublimating-nascence incipience/instantaneity/directness in reflecting the 'constraining/defining intersolipsistic reflexive-sublimating/unreflexive-desublimating measure/objectification that is unlimitedness/existence-as-ontologicalnormalcy/postconvergence-<in-validation-of-'metaphysics-of-absence_epistemic-projection' may seem to imply their dispensation from such a requisite philosophical elucidation of prospective knowledge-reification $\sim$ gesturing-and-accounting-of-epistemic-phenomenalism<in-prospective_psychologismic $\sim$ apriorising/axiomatising/referencing-\{of-'prospectively_ implicited_attendant-ontological-contiguity ' reducedexistentialising/contextualising/textualising_'intelligibility/epistemicity/reflexivity-contiguity<imbued-notional cogency>' \}-conflatedness -in-\{preconverging -ment by\}

postconverging-entailment>; inevitably all ‘artificially created domains-of-study' are effectively limited as to their prospective re-ontologising without their conscious/explicit and/or unconscious/implicit epistemic anchoring within 'notional ${ }^{18}$ deprocrypticism wholesomeness/profound-supererogation ${ }^{96}$ implied experientiality/experiment$<$ as-to-existentially-formative-'\{epistemic-totalising ${ }^{3}$ re-apriorising/re-axiomatising/rereferencing $\sim$ residuality —in-re-originariness/re-origination',- - so'notionally/epistemically/bindingnessly $<$ as-to-determinism/conceptivity of-relative-mnreflexivity/relative-reflexivity> implicited-and-articulated'_as-from-nonextricatory-'prospective-re-ontologising-Being-thenInstitutional-then-Living-magnitudes-of-\{hermeneutic/reprojection-protraction-of $\}$ reframingand-reformulation $\}^{\prime}>$ of human epistemic ${ }^{45}$ foregrounding_entailment- $<$ in-succession-ofprofound-supererogation ${ }^{6}>-\left\langle\right.$ postconverging-narrowing-down $\sim$ sublimation-as-to- ${ }^{\text {existence }}$ as-sublimating-withdrawal/unenframing/re-ontologising,-elicited-from-prospective-profound- 
supererogation '-in-reflecting-'immanent relative-unreflexivity/relative-reflexivity

ontological-contiguity ';-as-operative-notional deprocrypticism) (as to sublimatingpostconverged 'substantive abstract-tissue-of-social-emanance \{epistemic-

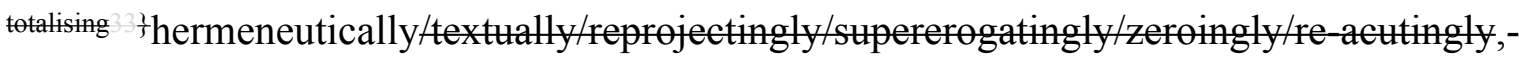
\{decompulsing $\}$ delinearity for-cogency — cumulated/recomposured as to cumulating/recomposuring of 'prospectively_implicited_attendant-ontological-contiguity ${ }^{6 /}$ 'educedexistentialising/contextualising/textualising_'intelligibility/epistemicity/reflexivity-contiguity$<$ imbued-notional cogency>' ${ }^{4}$ )', in reflection of the 'constraining/defining intersolipsistic reflexive-sublimating/unreflexive-desublimating measure/objectification that is unlimitedness/existence-as-ontological-normalcy/postconvergence- $<$ in-validation-of'metaphysics-of-absence_epistemic-projection'>'. In this regards, the very notion of experientiality/experiment-<as-to-existentially-formative-'\{epistemic-totalising ’’re-apriorising/reaxiomatising/re-referencing $\sim$ residuality — in-re-originariness/re-origination',- - so'notionally/epistemically/bindingnessly $<$ ss-todeterminism/conceptivity of-relative-unreflexivity/relative-reflexivityz_ implicited-and-articulated'_as-from-nonextricatory-'prospective-re-ontologising-Being-thenInstitutional-then-Living-magnitudes-of-\{hermeneutic/reprojection-protraction-of\}reframingand-reformulation $\}$ '> requires its appropriate '<sublimation-educing-\{epistemictotalising thermeneutic/textuality/reprojecting/supererogating/zeroing/re-acuting,\{decompuring delinearity $\sim$ for-cogency $>$-interpretation by the supereregatory $\sim$ wholesomeness/profound-supererogation $\quad$ experientiality/experiment- $<$ as-toexistentially-formative- ‘fepistemic-totalising ${ }^{\mathfrak{T}}$ re-apriorising/re-axiomatising/rereferencing -residuality —in-re-originariness/re-origination',--so'notionally/epistemically/bindingnessly-<as-to-determinism/conceptivity-of-relative-unreflexivity/relative-reflexivity> implicited-and-articulated'_as-from-nonextricatory-'prospective-re-ontologising-Being-thenInstitutional-then-Living-magnitudes-of-\{hermeneutic/reprojection-protraction-of reframing- 
and-reformulation $\}^{\prime}>$ of already being-in-existence' to be scientifically/ontologically pertinent; as so-reflecting the 'notional protensivity backdrop for the exuding sublimation that is the-verysame purview-of-unlimitedness/existence-<full-potency-of_sublimating nascence $>$;'implicited_attendant-ontological-contiguity ${ }^{67}$; educedexistentialising/contextualising/textualising_intelligibility/epistemicity/reflexivity-contiguity<imbued-notional cogency>' that underlies theorising and experimentation in the natural sciences (which do not achieve historial epistemic-growth,-as-\{veridical/sound\}-relativereflexivity-in-existence/relativising from-limited-mentation-as-its-deepening/psychologismic epistemic-acutisation residualising, \{decompling delinearity for-cogency by a naïve conception of just carrying out experimentation as to a shallow-supererogation of mereformulaicity/ritualisation-<as-to-mere-formulaic-

methodologising/mutualising/organising/institutionalising,-prospectively-losing-track-of-

‘\{epistemic-totalising ’re-apriorising/re-axiomatising/re-referencing $\sim$ residuality-in-re-

originariness/re-origination'> conception of experimentation as of elaboration-as-to-mereextrapolating/constituting/abstracting/deducing/inferring-of-elucidation-outside— 'prospectively_implicited_attendant-ontological-contiguity ${ }^{67}$ ' educed-

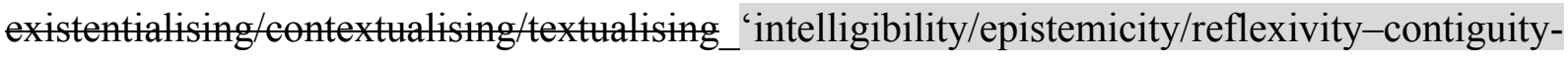
$<$ imbued-notional cogency $>^{\prime 0}$ failing to grasp that ontology/science is actually a postconverging-birthing/nascency within prospective \{epistemic-totalising 3 re-apriorising/reaxiomatising/re-referencing residuality-in-re-originariness/re-origination-〈as to human profound-supererogation for prospective apriorising/axiomatising/referencing-\{of'prospectively implicited_attendant-ontological-contiguity ' educedexistentialising/contextualising/textualising_intelligibility/epistemicity/reflexivity_contiguity$<$ imbued-notional cogency $>$ ' \}-conflatedness -in-\{preconverging-ment by\} postconverging-ntailment that cannot be unshrouded by prior mere-formulaicity/ritualisation- 
<as-to-mere-formulaic — methodologising/mutualising/organising/institutionalising,-

prospectively-losing-track-of-`\{epistemic-totalising 3 re-apriorising/re-axiomatising/re-

referencing $\sim$ residuality -in-re-originariness/re-origination'>

of

prior

apriorising/axiomatising/referencing-\{of-'prospectively implicited_attendant-ontological-

contiguity ' educed-

existentialising/contextualising/textualising_ 'intelligibility/epistemicity/reflexivity-contiguity-

<imbued-notional cogency >' $\quad\}$-constitutedness -in-preconverging-entailment $\rangle)$ but require appropriate

'<sublimation-educing-

totalising ’’hermeneutic/textuality/reprojecting/supererogating/zeroing/re-acuting,-

$\{$ decompulsing\} $\}$ delinearity $\sim$ for-cogency $>$-interpretation

by

the

supereregatery $\sim$ wholesomeness/profound-supererogation $\quad$ experientiality/experiment- $<$ as-toexistentially-formative- ‘fepistemic-totalising $r$ re-apriorising/re-axiomatising/re-

referencing $\sim$ residuality — in-re-originariness/re-origination',- - so-

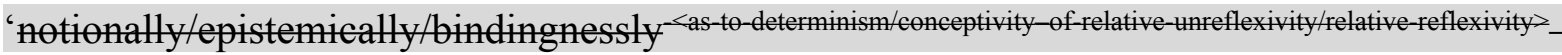

implicited-and-articulated'_as-from-nonextricatory-'prospective-re-ontologising-Being-then-

Institutional-then-Living-magnitudes-of-\{hermeneutic/reprojection-protraction-of reframing-

and-reformulation $\}^{\prime}>$ of already being-in-existence'. Critically, thus it should be explicited that 'experientiality/experiment-<as-to-existentially-formative- ‘fepistemic-totalising axiomatising/re-referencing residuality-in-re-originariness/re-origination',- - so'notionally/epistemically/bindingnessly<as-to-determinism/conceptivity-of-relative-unreflexivity/relative-reflexivity> implicited-and-articulated'_as-from-nonextricatory-'prospective-re-ontologising-Being-thenInstitutional-then-Living-magnitudes-of-\{hermentic/reprojection-praton- of reframingand-reformulation $\}^{\prime}>$, including scientific experimentation/observation/survey, as already being-in-existence' rather speaks of its <sublimation-educing-\{epistemicthermeneutic/textuality/reprojecting/supererogating/zeroing/re-acuting,- 
$\{$ decompulsing\} delinearity $\sim$ for-cogency $>$-interpretation as to (underlying limitedness/humansubpotency notional $\sim$ reflexivity- $<\{$ veridical/sound $\}$-relative-reflexivity-inexistence/relativising from-limited-mentation-as-its-deepening/psychologismic<residualising ${ }^{\{\text {decompulsing }}$ \}elinearity for-cogency>-by-\{flawed/unsound\}-relativeunreflexivity-in-existencelabsolutising from-limited-mentation/psychologismic epistemic acutisation nonresidualising-imbued-fompulsings linearity-in-eclecticism-of-prior-mereformulaicity/ritualisation>) imbued ‘fepistemic-totalising $3 \frac{3}{3}$ apriorising/axiomatising/referencing preconverging/postconverging-de-mentating/structuring/paradigming' (with respect to Beingdevelopment/ontological-framework-expansion-as-to-depth-of-ontologising-development-asinfrastructure-of- meaningfulness-and-teleology , institutional-development-as-to-socialfunction-development and living-development-as-to-personality-development psychologismic epistemic-acutisation - difficulty-for, residualising \{decompulsing ${ }^{\text {f }}$ delinearity for-cogency> magnitudes $\left.{ }^{\{0 f-e x p e r i e n t i a l i t y / e x p e r i m e n t}\right\}$, as so-underlying the 'overall relative-unreflexivity/relativereflexivity ontological-contiguity ${ }^{67} \sim$ of-the-human-institutionalisation-process ${ }^{68}$ imbued foregrounding_entailment- $<$ in-succession-of-profound-supererogation $>>$-〈postconvergingnarrowing-down $\sim$ sublimation-as-to-'existence - as-sublimating-withdrawal/unenframing/reontologising,-elicited-from-prospective-profound-supererogation ' '-in-reflecting'immanent $\sim$ relative - unreflexivity/relative-reflexivity - ontological-contiguity ';-as-operative-
notional deprocrypticism)'; $\quad$ and $\quad$ so-speaking 'supereregatory $\sim$ wholesomeness/profound-supererogation ${ }^{\circ}$ of experientiality/experiment- $<$ asto-existentially-formative- ‘fepistemic-totalising ${ }^{\mathfrak{l}}$ re-apriorising/re-axiomatising/rereferencing $\sim$ residuality - in-re-originariness/re-origination',- - so'notionally/epistemically/bindingnessly-<as-to-determinism/conceptivity-of-relative-unreflexivity/relative-reflexivity> implicited-and-articulated'_as-from-nonextricatory-'prospective-re-ontologising-Being-thenInstitutional-then-Living-magnitudes-of-\{hermeneutic/reprojection-protraction-of\}reframing- 


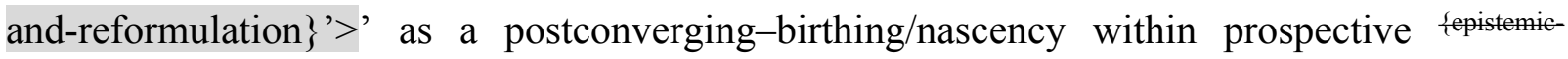
totalising 3 re-apriorising/re-axiomatising/re-referencing $\sim$ residuality-in-re-originariness/reorigination- $\langle$ as to human profound-supererogation for prospective apriorising/axiomatising/referencing-\{of-"prospectively_implicited_attendant-ontologicalcontiguity ' educedexistentialising/contextualising/textualising_ intelligibility/epistemicity/reflexivity-contiguity<imbued-notional cogency>’ \}-conflatedness -in-\{preconverging-ment by\} postconverging-entailment that cannot be unshrouded by prior mere-formulaicity/ritualisation<as-to-mere-formulaic - methodologising/mutualising/organising/institutionalising,prospectively-losing-track-of- ‘ \{epistemic-totalising ${ }^{\dagger}$ re-apriorising/re-axiomatising/rereferencing-residuality—in-re-originariness/re-origination'> of prior apriorising/axiomatising/referencing-\{of-'prospectively_implicited_attendant-ontologicalcontiguity ' educedexistentialising/contextualising/textualising_'intelligibility/epistemicity/reflexivity-contiguity<imbued-notional cogency >' $\}$-constitutedness -in preconverging-entailment $\rangle)$ but require appropriate ‘ $<$ sublimation-educing__fepistemictotalising thermeneutic/textuality/reprojecting/supererogating/zeroing/re-acuting,\{decting $d$ dearity $\sim$ for-cogency $>$-interpretation by the supereregatory $\sim$ wholesomeness/profound-supererogation $\quad$ experientiality/experiment-<as-toexistentially-formative- ‘fepistemic-totalising referencing $\sim$ residuality - in-re-originariness/re-origination',- - so"notionally/epistemically/bindingnessly-<as-to-determinism/conceptivity-of-relative-unreflexivity/relative-reflexivity> implicited-and-articulated'_as-from-nonextricatory-'prospective-re-ontologising-Being-thenInstitutional-then-Living-magnitudes-of-\{hermeneutic/reprojection-protraction-of $\}$ reframingand-reformulation $\}^{\prime}>$ of already being-in-existence' (with this insight about veridical 
experientiality/experiment-<as-to-existentially-formative-' \{epistemic-totalising $\frac{1}{3}$ re-apriorising/reaxiomatising/re-referencing $\sim$ residuality —in-re-originariness/re-origination', —so"notionally/epistemically/bindingnessly<as-to-determinism/conceptivity-of-relative-unreflexivity/relative-reflexivity> implicited-and-articulated'_as-from-nonextricatory-'prospective-re-ontologising-Being-thenInstitutional-then-Living-magnitudes-of-\{hermeneutic/reprojection-protraction-of $\}$ reframingand-reformulation $\}$ '> critically damning of the 'prevalence of subterfuges of scientific experimentation' that fundamentally fail to even establish/elucidate the 'being-in-existence implied existential-<disentologising/re-ontologising aporeticism $>$ backdrop epistemic veracity' for their experimentation/observation/survey undertaking and conclusions and rather merely relying on the 'mysticism/religiosity of the pronouncement of scientific experimentation/observation/survey' giving room for ineptitudes, platitudes, totalisingly-ing — discretion/whim-of-thought and mere imprimaturing conception of supposedly scientific experimentation/observation/survey particularly in blurred domains-of-study poorly constrained to the 'constraining/defining intersolipsistic reflexive-sublimating/unreflexive-desublimating measure/objectification that is unlimitedness/existence-as-ontologicalnormalcy/postconvergence-<in-validation-of-‘metaphysics-of-absence_epistemicprojection'>'). It is this notion of appropriate '<sublimation-educing-\{epistemictotalising thermeneutic/textuality/reprojecting/supererogating/zeroing/re-acuting,$\{$ decompulsing $\}$ delinearity $\sim$ for-cogency $>$-interpretation by the supererogatory $\sim$ wholesomeness/profound-supererogation $\quad$ experientiality/experiment- $<$ as-toexistentially-formative- ‘fepistemictalising ${ }^{\prime}$ re-apriorising/re-axiomatising/rereferencing $\sim$ residuality_-in-re-originariness/re-origination',- - so'notionally/epistemieally/bindingnessly-as-to-determinism/conceptivity-of-relative-unreflexivity/relative-reflexivity $>$ implicited-and-articulated'_as-from-nonextricatory-'prospective-re-ontologising-Being-thenInstitutional-then-Living-magnitudes-of-\{hermeneutic/reprojection-protraction-of\}reframing- 
and-reformulation $\}^{\prime}>$ of already being-in-existence' (as underlied implicitly or explicitly by the 'overaching/defining/devolving notional $\sim$ philosophy-<as-to-the-veridical-conception-ofphilosophy-as-englobing-all-human-prospective-organic-knowledge-generation-in-relativeontological-completeness ,-beyond-a-convenient-division-of-labour-conception-ofknowledge $>$ and its associated ontology/science implied intolerance-<ofdisparateness $>$ /exactifying_precisioning-of-sublimation-<as-to-postconverging-narrowingdown apriorising/axiomatising/referencing-entailing-theoretical,-conceptual-and-operantimplications $>\quad$ epistemic-growth,-as_-\{veridical/sound\}-relative-reflexivity-inexistence/relativising from-limited-mentation-as-its-deepening/psychologismic epistemicacutisation residualising, ${ }^{\{\text {decompulsing }}$ \}elinearity for-cogency implications' as of 'notional $\sim$ deprocrypticism implied supereregatery wholesomeness/profoundsupererogation experientiality/experiment-<as-to-existentially-formative-' \{epistemic-totalising ${ }^{3} \mathrm{re}-$ apriorising/re-axiomatising/re-referencing-residuality-in-re-originariness/re-origination', so-" notionally/epistemically/bindingnessly cas to determinism/coneeptivity of relative unreflexivity/relative reflexivity_implicited-and-articulated'_as-from-nonextricatory-'prospective-re-ontologisingBeing-then-Institutional-then-Living-magnitudes-of- hermeneutic/reprojection-protractioneffreframing-and-reformulation $\}^{\prime}>$ as of human epistemic ${ }^{45}$ foregrounding_entailment- $<$ insuccession-of-profound-supererogation $>>$-〈postconverging-narrowing-down $\sim$ sublimation-asto-'existence - as-sublimating-withdrawal/unenframing/re-ontologising,-elicited-fromprospective-profound-supererogation ' '-in-reflecting-'immanent $\sim$ relativeunreflexivity/relative-reflexivity - ontological-contiguity ' ';-as-operativenotional deprocrypticism〉') that precedingly reflect how any given 'artificial domain-ofstudy' sublimatingly develops as to its given 'station/locus of limitedness/human-subpotency $<$ amplituding/formative-epistemicity $>$-totalising $\sim$ thrownness-in-existence ${ }^{35}$ for prospective epistemic-growth,-as_ \{veridical/sound\}-relative-reflexivity-in-existence/relativising from- 
limited-mentation-as-its-deepening/psychologismic epistemic-acutisation residualising, \{decompulsing $\}$ delinearity for-cogency (as to prospective \{epistemic-totalising 3 re-apriorising/reaxiomatising/re-referencing - residuality-in-re-originariness/re-origination of limitedness/human-subpotency prospective re-encountering/re-confrontation with the 'constraining/defining intersolipsistic reflexive-sublimating/unreflexive-desublimating measure/objectification that is unlimitedness/existence-as-ontologicalnormalcy/postconvergence-<in-validation-of-'metaphysics-of-absence_epistemic-

projection'>')'. This overall conceptivity/epistemic-reflexivity/epistemicity-relativismdeterminism-<reifying \{as-to-knowledge-developing $\}$-and-empowering $>$ of human ontologicalperformance $^{72}$-<including-virtue-as-ontology $>$ /morality/ethics/justice/etc. with regards to prospective epistemic-growth,-as-\{veridical/sound $\}$-relative-reflexivity-inexistence/relativising from-limited-mentation-as-its-deepening/psychologismic epistemicacutisation residualising, ${ }^{\text {ddecompulsing }}$ delinearity for-cogency (as to demoronisation$<$ sublimating-nascence,-nønextricatory-sublimating-upstreaming/'amontée’’ ${ }^{6}$ nonpresencing$<$ perspective-ontological-normalcy/postconvergence $>\quad$ nonpresencing-<perspectiveontological-normalcy/postconvergence $>$ relativism/relative-scope for epistemic-growth,-as\{veridical/sound\}-relative-reflexivity-in-existence/relativising from limited mentation as itsdeepening/psychologismic epistemic_acutisation residualising, \{decompulsing ${ }^{2}$ delinearity foreogency' for educing ${ }^{5}$ meaningfulness-and-teleology 99 as to the prospect of 'prospective tre-apriorising/re-axiomatising/re-referencing residuality-in-re-

originariness/re-origination relative-ontological-completeness ${ }^{87}$ implications' and so in reflection of the underlying inherent manifestation of 'human aestheticisation-andaestheticisation-towards-ontology-<elicited-idiomatisation $>$ interstitial—disontologising-byre-ontologising of ontological-performance ${ }^{72}$-<including-virtue-as-ontology $>$ ' so-underlining 'human interstitially recurrent limited-mentation-capacity-as-subjecting 'educed- 
unlimitedness/existence-sublimating nascence' to-limitedness/human-subpotency-by-limitedmentation-capacity-deepening —as-subjecting limitedness/human-subpotency-to-'educedunlimitedness/existence-sublimating nascence' variance_in-epistemic-projection'), speaks to the ontological-veracity of a 'human aestheticisation-and-aestheticisation-towards-ontology$<$ elicited-idiomatisation $>\quad$ moronisation- $<$ sublimating-nascence,-extricatory-desublimatingdownstreaming/'avalage' $>$ — by_demoronisation-<sublimating-nascence, -nonextricatorysublimating-upstreaming/'amontée’> existentialising/emanance/becoming_constraint/pressure' notionally/epistemically/bindingnessly-as of relativemreflexivity/relative-reflexivitys underlied by the construction-of-the-Self element identified herein as 'recurrently mediative-<in-expectation/in-anticipation> unconsciousness/potentiation-ofconscionability-<anxiety-as-to-reconstitution/reparation,-including-dreaming/psychicalreshuffling>'; so-construed (with respect to unlimitedness/existence-<full-potency of_sublimating nascence $>$ ) as the 'notional reflexivity-<\{veridical/sound $\}$-relativereflexivity-in-existence/relativising from-limited-mentation-as-its-deepening/psychologismic<residualising \{decompulsing $\}$ delinearity for-cogency>-by-\{flawed/unsound\}-relativeunreflexivity-in-existence/absolutising from-limited-mentation/psychologismic epistemicacutisation nonresidualising imbued fompulsing\}linearity in eclecticism of prior mereformulaicity/ritualisation $>\quad$ existential-<disontologising/re-ontologising aporeticism $>$ backdrop' potentiating limitedness/human-subpotency as to 'the-human/humanity omnipotentiality possibility of existentialising/emanance/becoming' with regards to underlying human de-mentation-〈supereregatery-ontological-de-mentation-or-dialectical-dementation-stranding-or-attributive-dialectics〉 'inventing'/‘creating'-and-'nurturing' of prospective sublimating re-rationalisations-ofcontentivity/argumentativity/dialecticism/discursivity (as of Being-development/ontologicalframework-expansion-as-to-depth-of-ontologising-development-as-infrastructure-of- 
development and living-development-as-to-personality-development psychologismic epistemic-acutisation difficulty-for, residualising \{decompulsing ${ }^{\prime}$ delinearity for-cogency> magnitudes ${ }^{\text {of-experientiality/experiment }\}}$ and so-manifesting as of human consciousness in-itsembodiment 'existentialising_preconverging_enframing/imprintedness by existentialisingpostconverging_framing/imprinting imbuing of existentialising-frame-of-entailment of motifand-apriorising/axiomatising/referencing'). $\quad{ }^{15}$ De-mentation-(supererogatory $\sim$ ontological-dementation-or-dialectical-de-mentation-stranding-or-attributive-dialectics $\rangle$ thus wholly speaks of 'recurrently mediative-<in-expectation/in-anticipation $>$ unconsciousness/potentiation-ofconscionability-<anxiety-as-to-reconstitution/reparation,-including-dreaming/psychicalreshuffling>' (as the 'psychoanalytic boundlessness of human notional reflexivity$<\{$ veridical/sound $\}$-relative-reflexivity-in-existence/relativising from-limited-mentation-as-

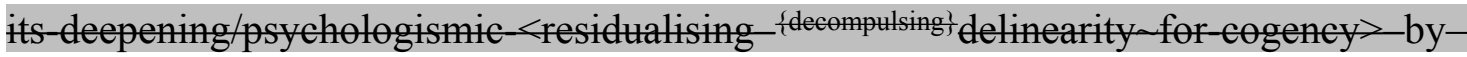
\{flawed/unsound\}-relative-unreflexivity-in-existence/absolutising from-limitedmentation/psychologismic epistemic-acutisation nonresidualising-imbued\{compulsing\} linearity -in-eclecticism-of-prior-mere-formulaicity/ritualisation> existential< disontologising/re-ontologising aporeticism $>$ backdrop' elicitable/exuding as of subconsciousness knowingly/unknowingly-manifest human ontological-goodfaith/authenticity ${ }^{6} \sim$ postconverging-de-mentating/structuring/paradigming - by ontological-bad-faith/inauthenticity ${ }^{64} \sim$ preconverging-de-mentating/structuring/paradigming ${ }^{65}$ ) as so-potentiating 'human subconsciousness as backdrop-for-the-Lacanian-real enabling the effective formativeness-<as-to-intersolipsism-ofpreformulating/preframing/premeaningfulness-imbued-mediativity-and-deferentialism>-ofmeaningfulness-and-teleology of consciousness surrealising-<as-to-supererogation ${ }^{>}$' (as so-manifested with human subconsciousness most-prospectively-conscious 're-ontologising- 
by-disontologising_existential-calculus-〈between

postconverging_framing/imprinting re-ontologising' 'prospective existentialising preconverging_enframing/imprintedness social-functioning-and-accordance - as-of-socialstake-contention-or-confliction' '> of consciousness surrealising-<as-to-supererogation $>>$ ); and as so-underlied dynamically as to human notional $\sim$ reflexivity- $<$ \{veridical/sound $\}$-relativereflexivity-in-existence/relativising from limited-mentation-as-its-deepening/psychologismic<residualising \{decompulsingtdelinearity for-cogeney>-by - \{flawed/unsound\}-relativeunreflexivity-in-existencelabsolutising from-limited-mentation/psychologismic epistemicacutisation nonresidualising imbued-\{compulsing\} finearity in -eclecticism-of prior-mereformulaicity/ritualisation $>$ about 'constraining existence-as-sublimatingwithdrawal/unenframing/re-ontologising,-elicited-from-prospective-profound-supererogation imbuing human ontological-commitment -<implied — self-assuredness-of-ontological-goodfaith/authenticity postconverging-de-mentating/structuring/paradigming -as-being-as-ofexistential-reality>' and ' ${ }^{\prime 0}$ universal-transparency ${ }^{104}$-〈transparency-of-totalising-entailing,-asto-entailing-<amplingling formative-epistemicity $>$ totalising $\sim$ in-relative-ontologicalcompleteness > as available-to/elicitable-to-〈as-to-human-consciousness/collectiveconsciousness-distendedness/detruncating-<beyond-selfpresencing,-as-re-ontologisingdecentering_of-consciousness/collective-consciousness,-as-to-psychologismic-epistemic-

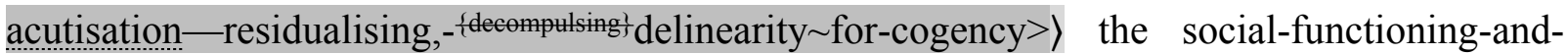
accordance-as-of-social-stake-contention-or-confliction conception of any given registryworldview/dimension $<$ preconverging $\sim$ 'motif-and-apriorising/axiomatising/referencing'entailing >-existentialising — enframing/imprintedness-〈as-to- historicity-tracing - inpresencing-hyperrealisation/hyperreal-transposition〉'. De-mentation(supererogatory ontological-de-mentation-or-dialectical-de-mentation - stranding-orattributive-dialectics (as reflecting the manifest 'human aestheticisation-and-aestheticisation- 
towards-ontology-<elicited-idiomatisation $>$ moronisation- $<$ sublimating-nascence,-extricatory desublimating-downstreaming/'avalage' $>$ — by_demoronisation- $<$ sublimating-nascence,nonextricatory-sublimating-upstreaming/‘amontée’> existentialising/emanance/becomingconstraint/pressure') underlies 'human aestheticisation-and-aestheticisation-towards-ontology$<$ elicited-idiomatisation> interstitial-disontologising-by-re-ontologising of ontologicalperformance ${ }^{72}-<$ including-virtue-as-ontology>', as so-underlining 'human interstitially recurrent limited-mentation-capacity—as-subjecting 'educed-unlimitedness/existencesublimating nascence' to-limitedness/human-subpotency-by-limited-mentation-capacitydeepening —as-subjecting limitedness/human-subpotency-to-'educed-unlimitedness/existencesublimating nascence ${ }^{53} \quad$ variance_in-epistemic-projection' (as to Beingdevelopment/ontological-framework-expansion-as-to-depth-of-ontologising-development-asinfrastructure-of- meaningfulness-and-teleology , institutional-development-as-to-socialfunction-development and living-development-as-to-personality-development psychologismic epistemic-acutisation difficulty-for, residualising \{decomplsing $\}$ delinearity for-cogency> magnitudes $\{$ of-experientiality/experiment\} $\}$; as so-reflecting the 'recurrently mediative-<inexpectation/in-anticipation $>$ unconsciousness/potentiation-of-conscionability-<anxiety-as-toreconstitution/reparation,-including-dreaming/psychical-reshuffling>' (as the 'psychoanalytic boundlessness of human notional $\sim$ reflexivity-<\{veridical/sound $\}$-relative-reflexivity-inexistence/relativising from-limited-mentation-as-its-deepening/psychologismic<residualising \{decompulsing $\}$ delinearity for-cogency>by-\{flawed/unsound\}-relativeunreflexivity-in-existencelabsolutising from-limited-mentation/psychologismic epistemic acutisation nonresidualising-imbued-\{compulsing? linearity-in-eclecticism-of-prior-mereformulaicity/ritualisation> existential-disontogising ontologising apereticism> backdrop' elicitable/exuding as of subconsciousness knowingly/unknowingly-manifest human ontological-good-faith/authenticity $\sim$ postconverging-de- 
mentating/structuring/paradigming — — by—ontological-bad-

faith/inauthenticity $\sim$ preconverging-de-mentating/structuring/paradigming ${ }^{6}$ ) with regards to 'interstitially — disontologising-by-re-ontologising anarchistic outgrowing formativeness- $<$ asto-intersolipsism-of-preformulating/preframing/premeaningfulness-imbued-mediativity-anddeferentialism $>$-of- meaningfulness-and-teleology of human sublimating meaningfulnessand-teleology', The bigger point here with respect to 'limitedness/human-subpotency prospectively sublimating conceptivity/epistemic-reflexivity/epistemicity-relativismdeterminism-<reifying \{as-to-knowledge-developing\}-and-empowering $>^{\prime}$ is the fact that the 'prospective interstitial—disontologising-by-re-ontologising (as to 'social-functioning-andaccordance - as-of-social-stake-contention-or-confliction imbuing existentialising-frame-ofentailment of motif-and-apriorising/axiomatising/referencing of disontologising/ontologisingand-re-ontologising')' prospectively encapsulates the postconverging-aporeticismevercoming/mnovercoming possibility for prospective re-ontologising sublimation (as to 'relevant difference-conflatedness ${ }^{13}$-as-to-totalitative-reification-in-singularisation-<as-to-thenondisjointedness/entailment-of-prospective- nonpresencing> -as-veridical-epistemicityrelativism-determinism , reflection of limitedness/human-subpotency cumulating/recomposuring 'intolerance <of disparateness/exactifying_precisioning-ofsublimation-<as-to-postconverging-narrowing-down apriorising/axiomatising/referencingentailing-theoretical,-conceptual-and-operant-implications> exercise of intelligibility' as to imbued 'developing epistemic sense of nonpresencing-<perspective-ontologicalnormalcy/postconvergence $>$ relativism/relative-scope as projective-insights'); with regards to the underlying 'recurrently mediative-<in-expectation/in-anticipation> unconsciousness/potentiation-of-conscionability-<anxiety-as-to-reconstitution/reparation,including-dreaming/psychical-reshuffling>' (as the 'psychoanalytic boundlessness of human notional $\sim$ reflexivity- $<\{$ veridical/sound $\}$-relative-reflexivity-in-existence/relativising from- 
limited-mentation-as-its-deepening/psychologismic-< residualising $\left.{ }^{\{\text {decompulsing }}\right\}$ delinearity foreogency $>$ by _flawed/unsound\}-relative-unreflexivity-in-existence/absolutising fromlimited-mentation/psychologismic epistemic acutisation nonresidualising imbued\{compulsing\} linearity in-eclecticism-of prior-mere-formulaicity/ritualisation> existentialdisontologising/re-ontologising aporeticism $>$ backdrop' elicitable/exuding as of subconsciousness knowingly/unknowingly-manifest human ontological-goodfaith/authenticity ${ }^{6} \sim$ postconverging-de-mentating/structuring/paradigming 7 — byontological-bad-faith/inauthenticity ${ }^{64} \sim$ preconverging-de-mentating/structuring/paradigming ${ }^{5}$ ). Human de-mentation-〈supererogatory ontological-de-mentation-or-dialectical-dementation-stranding-or-attributive-dialectics) implications (as to underlying 'recurrently mediative-<in-expectation/in-anticipation $>$ unconsciousness/potentiation-of-conscionability$<$ anxiety-as-to-reconstitution/reparation,-including-dreaming/psychical-reshuffling $>$ ' as the 'psychoanalytic boundlessness of human notional reflexivity-<\{veridical/sound\}-relativereflexivity-in-existence/relativising from-limited-mentation-as-its-deepening/psychologismic<residualising \{decompulsing $\}$ delinearity for-cogency>by-\{flawed/unsound\}-relativeunreflexivity-in-existencelabsolutising from-limited-mentation/psychologismic epistemicacutisation nonresidualising imbued-\{compulsing\}linearity in-eclecticism-of prior-mereformulaicity/ritualisation $>\quad$ existential-<disontologising/re-ontologising aporeticism $>$ backdrop' elicitable/exuding as of subconsciousness knowingly/unknowingly-manifest human ontological-good-faith/authenticity $\sim$ postconverging-dementating/structuring/paradigming — — by_ontological-badfaith/inauthenticity ${ }^{64}$ preconverging-de-mentating/structuring/paradigming ${ }^{5}$ ), rather point out that 'limitedness/human-subpotency prospectively sublimating conceptivity/epistemicreflexivity/epistemicity-relativism-determinism-<reifying \{as-to-knowledge-developing $\}$-andempowering >' is necessarily overarched in priority/precedence/primacy respectively as of (so- 
underlining the 'veracity of the epistemic-projection perspective of unlimitedness/existence-asontological-normalcy/postconvergence-<in-validation-of-'metaphysics-of-absence_epistemicprojection'> with respect to 'limitedness/human-subpotency imputed Beingdevelopment/ontological-framework-expansion-as-to-depth-of-ontologising-development-asinfrastructure-of- meaningfulness-and-teleology , institutional-development-as-to-socialfunction-development and living-development-as-to-personality-development psychologismic epistemic-acutisation difficulty-for, residualising \{decompulsing\} delinearity for-cogency> magnitudes $\left.{ }^{\{0 f-e x p e r i e n t i a l i t y / e x p e r i m e n t ~}\right\}$, as to imbued difference-conflatedness ${ }^{13}$-as-to-totalitativereification-in-singularisation-<as-to-the-nondisjointedness/entailment-of-prospectivenonpresencing $>$-as-veridical-epistemicity-relativism-determinism,$\quad$ reflection of limitedness/human-subpotency cumulating/recomposuring 'intolerance-<ofdisparateness $>$ /exactifying_precisioning-of-sublimation- $<$ as-to-postconverging-narrowingdown apriorising/axiomatising/referencing-entailing-theoretical,-conceptual-and-operantimplications $>$ exercise of intelligibility' across 'successive relative-ontological-completeness stations/loci of limitedness/human-subpotency <amplituding/formative-epistemicity $>$ totalising thrownness-in-existence ${ }^{35}$ for prospective epistemic-growth,-as — \{veridical/sound\} relative-reflexivity-in-existencetrelativising from limited mentan as itsdeepening/psychologismic epistemic-acutisation residualising, ${ }^{\text {\{decompulsing }}$ \}elinearity for eogency'):

firstly, 'ontological-good-faith/authenticity ${ }^{6} \sim$ postconverging-dementating/structuring/paradigming — — by —ontological-badfaith/inauthenticity ${ }^{64} \sim$ preconverging-de-mentating/structuring/paradigming ${ }^{5}$, as to when manifest relative-ontological-completeness ${ }^{87}$ is-educed-and-avails-and-re-avails for 'prospective postconverging epistemic-projective-equalisation succeeding with respect to prospective postconverging-aporeticism-overcoming/unovercoming' so-underlied as to 
prospective \{epistemic-totalising 3 re-apriorising/re-axiomatising/re-referencing $\sim$ residuality-in-reoriginariness/re-origination of limitedness/human-subpotency prospective re-encountering/reconfrontation with the 'constraining/defining intersolipsistic reflexive-sublimating/unreflexivedesublimating measure/objectification that is unlimitedness/existence-as-ontologicalnormalcy/postconvergence- $<$ in-validation-of-'metaphysics-of-absence_epistemic-projection'> (in reflection of the fact that 'there is no neutral ${ }^{79}$ presencing-absolutising-identitiveconstitutedness ${ }^{14}$ point-of-devolving/departure/anchoring/backdrop for conceptualising the ontological-veracity/ontological-inveracity of human rationalisation-ofcontentivity/argumentativity/dialecticism/discursivity' since all human ${ }^{56}$ meaningfulness-andteleology is rather already caught-up in 'limitedness/human-subpotency overall notional $\sim$ reflexivity-<\{veridical/sound\}-relative-reflexivity-in-existence/relativising fromlimited-mentation-as-its-deepening/psychologismic-< residualising $\left.{ }^{\text {\{decompulsing }}\right\}$ delinearity foreogency>-by-\{flawed/unsound\}-relative-unreflexivity-in-existence/absolutising fromlimited-mentation/psychologismic epistemic acutisation nonresidualising imbuedfompulsingl linearity in-eclecticism-of-prior-mere-formulaicity/ritualisation $>$ imbued overall difference-conflatedness ${ }^{13}$-as-to-totalitative-reification-in-singularisation- $<$ as-to-thenondisjointedness/entailment-of-prospective- nonpresencing > -as-veridical-epistemicityrelativism-determinism ', and so-caught-up 'whether sublimatingly manifesting nonpresencing-<perspective-ontological-normalcy/postconvergence $>\quad$ relativism/relativescope for epistemic-growth,-as - \{veridical/sound\}-relative-reflexivity-inexistence/relativising from-limited-mentation-as-its-deepening/psychologismic epistemicacutisation residualising, ${ }^{\text {ddecompulsing }}$ delinearity for-cogency' or 'whether desublimatingly manifesting any ${ }^{79}$ presencing-absolutising-identitive-constitutedness ${ }^{14}$ absolution/absolutescope \{flawed/unsound\}-relative-unreflexivity-in-existence/absolutising from-limitedmentation/psychologismic epistemic acutisation nonresidualising imbued- 
\{compulsing\} linearity-in-eclecticism-of-prior-mere-formulaicity/ritualisation', as to the given station/locus of limitedness/human-subpotency $<$ amplituding/formative-epistemicity $>$ totalising thrownness-in-existence ${ }^{35}$ as so-bound to 'apriorising/axiomatising/referencingequating/leveling/ressentiment/closed-construct-of- ${ }^{-5}$ meaningfulness-and-teleology moronisation-<sublimating-nascence,-extricatory-desublimating-downstreaming/'avalage' $>$ ' undifferentiation of both the prior relative-ontological-incompleteness ${ }^{88}$ and the prospective relative-ontological-completeness ${ }^{87}$, with 'ontological-goodfaith/authenticity ${ }^{69}$ postconverging-de-mentating/structuring/paradigming 7 - byontological-bad-faith/inauthenticity ${ }^{6} \sim$ preconverging-de-mentating/structuring/paradigming ${ }^{65}$ so-overarched in priority/precedence/primacy (as the very fundamental/incipient/seeding notion of human ontological-performance ${ }^{72}-<$ including-virtue-as- $^{2}$ ontology $>$ /morality/ethics/justice/etc.) because what is truly of " ${ }^{103}$ universal prospective transcendence-and-sublimity/sublimation/supererogatory - de-mentativity implications for all humans across all the times' (as to 'limitedness/human-subpotency prospectively sublimating conceptivity/epistemic-reflexivity/epistemicity-relativism-determinism- $<$ reifying \{as-toknowledge-developing -and-empowering >') is dimensionality-of-sublimating ${ }^{25}$, <<amplituding/formative>supererogatory $\sim$ de-mentativeness/epistemic-growth-orconflatedness /transvaluative-rationalising/transepistemicity/anamnestic-residuality/spiritdrivenness-equalisation) which 'invents'/'creates'-and-'nurtures' (out of ontological-goodfaith/authenticity ${ }^{6} \sim$ postconverging-de-mentating/structuring/paradigming ${ }^{70}$ as to profoundsupererogation ) re-rationalisations-of-contentivity/argumentativity/dialecticism/discursivity (as to when manifest relative-ontological-completeness ${ }^{87}$ is-educed-and-avails-and-re-avails as of limited-mentation-capacity-deepening —as-subjecting limitedness/human-subpotency-to'educed-unlimitedness/existence-sublimating nascence's3 for 'prospective postconverging epistemic_projective-equalisation succeeding with respect to prospective 
postconverging-aporeticism-overcoming/unovercoming') so-underlied as of the ${ }^{6}$ nonpresencing-<perspective-ontological-normalcy/postconvergence $>$ relativism/relativescope for epistemic-growth,-as - \{veridical/sound\}-relative-reflexivity-inexistence/relativising from-limited-mentation-as-its-deepening/psychologismic epistemicacutisation residualising, ${ }^{\text {ddecompulsing }}$ delinearity for-cogency' of the overall relativeunreflexivity/relative-reflexivity ontological-contiguity ${ }^{67} \sim$ of-the-human-institutionalisationprocess ${ }^{68}$ (speaking as well to the fact that the very fundamental/incipient/seeding notion of human ontological-performance ${ }^{72}-<$ including-virtue-as-ontology $>$ /morality/ethics/justice/etc. is rather a postconverging-birthing/nascency within prospective axiomatising/re-referencing-residuality-in-re-originariness/re-origination-〈as to human profound-supererogation for prospective apriorising/axiomatising/referencing- of'prospectively implicited_attendant-ontological-contiguity ' educedexistentialising/contextualising/textualising_'intelligibility/epistemicity/reflexivity-contiguity<imbued-notional cogency >' \}-conflatedness -in-\{preconverging-ment by\} postconverging-ntailment that cannot be unshrouded by prior mere-formulaicity/ritualisation<as-to-mere-formulaic — methodologising/mutualising/organising/institutionalising,prospectively-losing-track-of-' ‘epistemic-totalising ${ }^{+}$re-apriorising/re-axiomatising/rereferencing $\sim$ residuality —in-re-originariness/re-origination'> of prior apriorising/axiomatising/referencing-\{of-'prospectively_implicited_attendant-ontologicalcontiguity ' $\sim$ educedexistentialising/contextualising/textualising_'intelligibility/epistemicity/reflexivity-contiguity<imbued-notional cogency>' $\}$-constitutedness -in-preconverging-entailment $\rangle, \quad$ as soreflecting the reality that there is 'no neutral ${ }^{79}$ presencing-absolutising-identitiveconstitutedness ${ }^{14}$ point-of-devolving/departure/anchoring/backdrop conceptualisation of human sublimating ontological-performance ${ }^{2}-<$ including-virtue-as- 
ontology $>$ /morality/ethics/justice/etc. as to human rationalisation-ofcontentivity/argumentativity/dialecticism/discursivity' due to 'human preconverging/postconverging-de-mentating/structuring/paradigming interstitial $<$ amplituding/formative-epistemicity $>$-totalising thrownness-in-existence ${ }^{35}$, since otherwise any given station/locus of limitedness/human-subpotency <amplituding/formativeepistemicity $>$-totalising $\sim$ thrownness-in-existence ${ }^{35}$ will simply implicitly or explicitly declare by its prior-perspective_-falsity/falseness/fallaciousness its own ${ }^{7} 7$ presencing_absolutisingidentitive-constitutedness $^{14} \quad$ absolution/absolute-scope \{flawed/unsound\}-relativeunreflexivity-in-existence /absolutising from-limited-mentation/psychologismic epistemicacutisation nonresidualising-imbued-\{compulsing\} ${ }^{\text {finearity }}$ in-eclecticism-of prior-mereformulaicity/ritualisation conception' as absolutely determinant of human ontologicalperformance ${ }^{2}$-<including-virtue-as-ontology $>$ /morality/ethics/justice/etc. while "patently ignoring/overlooking its prospective institutionally-distorted/disjointed-and-collateralising imbued prospective disontologising/subontologising' with the true test of human ontologicalperformance $^{72}-<$ including-virtue-as-ontology $>$ /morality/ethics/justice/etc. across all times rather lying with their given prospective postconverging-apereticismovereming/movereoming as of underlying dimensionality-of-sublimating <<amplituding/formative>supererogatery $\sim$ de-mentativeness/epistemic-growth-orconflatedness /transvaluative-rationalising/transepistemicity/anamnestic-residuality/spiritdrivenness-equalisation $>\quad$ imbuing $\quad$ nonpresencing-<perspective-ontologicalnormalcy/postconvergence $>$ relativism/relative-scope for epistemic-growth,-as\{veridical/sound\}-relative-reflexivity-in-existence/relativising from-limited-mentation-as-itsdeepening/psychologismic epistemic-acutisation residualising, fdecompulsing $\}$ delinearity for eogency' of the overall relative-unreflexivity/relative-reflexivity - ontological-contiguity ${ }^{67}$ ofthe-human-institutionalisation-process and so-manifested with the 
'supererogatory $\sim$ wholesomeness/profound-supererogation ${ }^{96}$ as of prospective ${ }^{83}$ reference-ofthought_ — point-of-devolving/departure/anchoring/backdrop_of_sublimating-nascence- $<$ as-tothe-grandest-axiomatic-construct-fepistemictising ${ }_{+}^{+}$re-apriorising/re-axiomatising/re-

referencing residuality - in-re-originariness/re-origination of limitedness/human-subpotency prospective re-encountering/re-confrontation with unlimitedness/existence>');

- and thereafter, implied psychoanalytic-unshackling (as to 'prospective re-ontologising demoronisation-<sublimating-nascence,-nonextricatory-sublimating-upstreaming/'amontée’> psychologismic-element-<as-of-diametrical-conflatedness -towards-'already-givenunlimitedness/existence-<full-potency-of_sublimating nascence>'-of-'limitedness/humansubpotency-as-to-its-imbued-\{veridical/sound\}-relative-reflexivity-in-existence/relativising from-limited-mentation-as-its-deepening/psychologismic epistemic-acutisationresidualising, ${ }^{\{\text {decompulsing }}$ delinearity for-cogency’> imbued prospective psychologismicepistemic-acutisation-<as-to-postconverging-de-mentating/structuring/paradigming,-elicitingof-existence's-sublimating-nascence-in-prospective-aporeticism-overcoming/unovercoming> as to epistemic-growth,-as - \{veridical/sound\}-relative-reflexivity-in-existence/relativising from-limited-mentation-as-its-deepening/psychologismic epistemic-acutisationresidualising, ${ }^{\text {\{decompulsing }}$ 'delinearity for cogency') in reflection of the psychologismic fact of de-mentation-〈supererogatery $\sim$ ontological-de-mentation-or-dialectical-de-mentationstranding-or-attributive-dialectics $\rangle$ that for instance (and as it applies to all registryworldviews/dimensions in prior relative-ontological-incompleteness ${ }^{8}$ including our positivismprocrypticism with respect to prospective deprocrypticism-or-preempting-disjointednessas-of- ${ }^{2}$ reference-of-thought) our positivism supposedly normal/expected 'intolerance-<ofdisparateness $>$ /exactifying_precisioning-of-sublimation- $<$ as-to-postconverging-narrowingdown apriorising/axiomatising/referencing-entailing-theoretical,-conceptual-and-operantimplications $>$ entailment of ${ }^{56}$ meaningfulness-and-teleology ${ }^{9}$ enculturation/habituation' is not 
necessarily construed as normal/expected by a non-positivising mindset (which is thus in a nonpositivising moronisation-<sublimating-nascence,-extricatory-desublimatingdownstreaming/'avalage'> state to such positivising 'intolerance-<ofdisparateness $>$ /exactifying_precisioning-of-sublimation-<as-to-postconverging-narrowingdown apriorising/axiomatising/referencing-entailing-theoretical,-conceptual-and-operantimplications $>$ entailment of ${ }^{56}$ meaningfulness-and-teleology ${ }^{9}$ enculturation/habituation' implied prospective demoronisation- $<$ sublimating-nascence,-nonextricatory-sublimatingupstreaming/'amontée'>), and this is concretely reckonable with the patent case of say a Godof-plane conception or superstitious conception of modern medicine in an animistic social-setup that cannot simply be construed as supposedly 'explained away by a circumstantial thorough positivism/rational-empiricism elucidation of how a plane or modern medicine works' since such an animistic social-setup existentialising-frame-of-entailment-of-motif-andapriorising/axiomatising/referencing is so-thoroughly beholdening to its 'mystical/spirits nonpositivistic conception of things rationalisation-ofcontentivity/argumentativity/dialecticism/discursivity' going by its ingrained '83reference-ofthought specific preconverging/dementing -qualia-schema' that at best only a circumstantial constraining is induced (and not a positivism/rational-empiricism knowledge value as to its prospective ${ }^{6}$ nonpresencing-<perspective-ontological-normalcy/postconvergence $>$ epistemicprojection) since the animistic mindset is bound to psychologismically fallback/relapse into such a 'mystical/spirits nonpositivistic conception of things rationalisation-ofcontentivity/argumentativity/dialecticism/discursivity' (so-reflected 'in the generationally ingrained animistic psychologismic apriorising/axiomatising/referencing-\{of-"prospectively_ implicited_attentant-ontological-contiguity ' educedexistentialising/contextualising/textualising_'intelligibility/epistemicity/reflexivity-contiguity<imbued-notional cogency $\left.>^{\prime} \quad\right\}$-constitutedness ${ }^{14}$-in-preconverging-entailment' from which 
it has to crossgenerationally undergo psychoanalytic-unshackling/memeticreordering/institutional-recomposuring as from the positivism/rational-empiricism epistemicprojection of 'constraining existence-as-sublimating-withdrawal/unenframing/reontologising,-elicited-from-prospective-profound-supererogation imbuing human ontological-commitment ${ }^{6}<$ implied-self-assuredness-of-ontological-goodfaith/authenticity postconverging-de-mentating/structuring/paradigming -as-being-as-ofexistential-reality>') as it can hardly be expected that the systematicity/entailment of a positivism/rational-empiricism intelligibility (as to such a circumstantial demonstration of positivism/rational-empiricism knowledge) will instantly prevail in the animistic social-setup as adopted knowledge value ('knowledge value' so-reflected herein as $<$ amplituding/formative $>$ disposedness/psychologismic-construct-〈as-to-orientation/valueconstruct/valuation-and-derived-parameterising $)$;

- and only thereof, the associated prospectively 'invented'/'created'-and-'nurtured' rationalisation-of-contentivity/argumentativity/dialecticism/discursivity imbued $<$ amplituding/formative>disposedness/psychologismic-construct-〈as-to-orientation/valueconstruct/valuation-and-derived-parameterising $\rangle$ and $<$ amplituding/formative $>$ entailment-〈asto-totalising-contiguous/coherent-factuality-of-variability) as to a conception' of rerationalisations-of-contentivity/argumentativity/dialecticism/discursivity so-underlied as of the ' nonpresencing-<perspective-ontological-normalcy/postconvergence $>$ relativism/relativescope for epistemic-growth,-as-\{veridical/sound\}-relative-reflexivity-inexistence/relativising from-limited-mentation-as-its-deepening/psychologismic epistemicacutisation residualising, fdecomensing $d$ delinearity for-cogency' of the overall relativeunreflexivity/relative-reflexivity — ontological-contiguity ${ }^{67}$ of-the-human-institutionalisation$\operatorname{process}^{68}$ (as of the <cumulating/recomposuring attendant-ontological-contiguity $>$ successive registry-worldviews/dimensions prospective fepistemic-totalising 
axiomatising/re-referencing $\sim$ residuality—in-re-originariness/re-origination

limitedness/human-subpotency prospective re-encountering/re-confrontation with the 'constraining/defining intersolipsistic reflexive-sublimating/unreflexive-desublimating measure/objectification that is unlimitedness/existence-as-ontologicalnormalcy/postconvergence-<in-validation-of-'metaphysics-of-absence_epistemic-projection’ $>$ so-reflected as 'notional ' deprocrypticism implied supereregatery wholesomeness/profoundsupererogation experientiality/experiment- $<$ as-to-existentially-formative- ' ${ }^{\prime}$ epistemic-totalising ${ }^{3}$ reapriorising/re-axiomatising/re-referencing_residuality_-in-re-originariness/re-origination',so-'notionally/epistemically/bindingnessly-as-todeterminism/conceptivity-of-relative-unreflexivity/relativereflexivity $>$-implicited-and-articulated'_as-from-nonextricatory-'prospective-re-ontologisingBeing-then-Institutional-then-Living-magnitudes-of-\{hermeneutic/reprojection-protractioneffreframing-and-reformulation $\}^{\prime}>$ as of human epistemic ${ }^{4}$ foregrounding_entailment- $<$ insuccession-of-profound-supererogation $>>$-〈postconverging-narrowing-down $\sim$ sublimation-asto-'existence_-as-sublimating-withdrawal/unenframing/re-ontologising,-elicited-fromprospective-profound-supererogation ' -in-reflecting-'immanent relativeunreflexivity/relative-reflexivity - ontological-contiguity ';--as-operativenotional deprocrypticism $\rangle$ '), and thus overriding a '79 presencing-absolutising-identitiveconstitutedness ${ }^{14}$ absolution/absolute-scope \{flawed/unsound\}-relative-unreflexivity-inexistence/absolutising from-limited-mentation/psychologismic epistemic acutisationnonresidualising-imbued-\{compulsing\} linearity in-eclecticism-of-prior-mereformulaicity/ritualisation conception' of 'human rationalisation-ofcontentivity/argumentativity/dialecticism/discursivity as of ontologically-flawed prior mereformulaicity/ritualisation-<as-to-mere-formulaicmethodologising/mutualising/organising/institutionalising,-prospectively-losing-track-of‘fepistemictalising ’’re-apriorising/re-axiomatising/re-referencing-residuality-in-re- 
extrapolating/constituting/abstracting/deducing/inferring-of-elucidation-outside-

'prospectively implicited_attendant-ontological-contiguity ${ }^{67}$ ' educed-

existentialising/contextualising/textualising_'intelligibility/epistemicity/reflexivity-contiguity-

$<$ imbued-notional cogency $>$ ' that overlooks/ignores prospective \{epistemic-totalising ${ }^{3\}}$ reapriorising/re-axiomatising/re-referencing-residuality-in-re-originariness/re-origination of limitedness/human-subpotency prospective re-encountering/re-confrontation with the 'constraining/defining intersolipsistic reflexive-sublimating/unreflexive-desublimating measure/objectification that is unlimitedness/existence-as-ontologicalnormalcy/postconvergence-<in-validation-of-'metaphysics-of-absence_epistemic-projection' (as so-reflected by the paradoxically implicited/explicited reality that such ' 7 presencingabsolutising-identitive-constitutedness ${ }^{14}$ absolution/absolute-scope ffawed/unsound\}-relativeunreflexivity-in-existence/absolutising from-limited-mentation/psychologismic epistemicacutisation nonresidualising-imbued-fomsting linearity-in-eclecticism-of prior-mereformulaicity/ritualisation conception' whether as of non-universalising ancient-sophists, nonpositivising medieval-scholasticism and our totalisingly-ing-discretion/whim-of-thought as to our modern-day manifestation of disparateness-of-conceptualisation-<unforegrounding-ment,failing-prospectively-to-reflect-'immanent $\sim$ relative-unreflexivity/relative-reflexivity ontological-contiguity '>' are critically characterised by a 'mere referring, mentioning and synonymisation of concepts and conceptualisations mere_apriorising/axiomatising/referencing of hardly any prospective profound existential-<disontologising/re-ontologising aporeticism $>$ implications but for institutional-prescience/imprimaturing-<dullness-of thespirit/psychologismic epistemic acutisation nonresidualising imbued-\{compulsing\} linearity in eclecticism-of-prior-mere-formulaicity/ritualisation ${ }^{\prime} \quad$ in $\quad<$ amplituding/formativeepistemicity $>$ totalising $\sim$ self-referencing-syncretising/circularity/interiorising/akrasiatic-drag 
that do not know-of/acknowledge 'prospective \{epistemic-totalising 3 ? ${ }^{\text {? }}$ re-apriorising/reaxiomatising/re-referencing $\sim$ residuality-in-re-originariness/re-origination relativeontological-completeness ${ }^{87}$ implications' as of requisite ' ${ }^{\text {nonpresencing- }<\text { perspective- }}$ ontological-normalcy/postconvergence $>$ relativism/relative-scope for epistemic-growth,-as\{veridical/sound\}-relative-reflexivity-in-existence/relativising from-limited-mentation-as-itsdeepening/psychologismic epistemic-acutisation residualising, \{decompulsing $\}$ delinearity foreogency of prospective re-rationalisation-ofcontentivity/argumentativity/dialecticism/discursivity for educing ${ }^{5}$ meaningfulness-andteleology ${ }^{9}$, as to prospective 'apriorising/axiomatising/referencing disambiguating/deleveling/de-ressentiment/opened-construct-of- ${ }^{5}$ meaningfulness-and-teleology demoronisation-<sublimating-nascence,-nonextricatory-sublimating-upstreaming/'amontée'>’ wherein say with regards to the 'historical conception of scepticism' the prospectively requisite and developed appropriate nonpresencing-<perspective-ontologicalnormalcy/postconvergence $>$ notion of postconverging apereticism-overcoming/unoverceming as to its relativism/relative-scope is rather overlooked in such an absolution/absolute-scope desublimating manifestation of 'apriorising/axiomatising/referencingequating/leveling/ressentiment/closed-construct-of- ${ }^{5}$ meaningfulness-and-teleology moronisation-<sublimating-nascence,-extricatory-desublimating-downstreaming/'avalage'> undifferentiation of prior relative-ontological-incompleteness 8 and the prospective relativeontological-completeness ${ }^{87}$ and so-patently explaining why such 'nonontologising/disontologising surreptitious knowledge-without-knowledge/knowledge-outsideknowledge/extra-knowledge projected limited-mentation-capacity-as-subjecting 'educedtnlimitedness/existence-sublimating nascence' to limitedness/hmman-subpotency' selfcongratulatory approach to notional $\sim$ philosophy-<as-to-the-veridical-conception-ofphilosophy-as-englobing-all-human-prospective-organic-knowledge-generation-in-relative- 
ontological-completeness ,-beyond-a-convenient-division-of-labour-conception-of-

knowledge $>$ as to ${ }^{6}$ presencing-absolutising-identitive-constitutedness ${ }^{14}$ absolution/absolutescope \{flawed/unsound\}-relative-unreflexivity-in-existence/absolutising from-limitedmentation/psychologismic epistemic acutisation nonresidualising imbued-

\{compulsing $\}$ linearity in-eclecticism-of prior-mere-formulaicity/ritualisation conception' with regards to drawing out prospective sublimation implications unscientifically ignores/overlooks the contiguity/coherence across all times of 'human experientiality/experiment- $<$ as-toexistentially-formative-'fepistemic tolising tre-apriorising/re-axiomatising/rereferencing $\sim$ residuality —in-re-originariness/re-origination',- - so"notionally/epistemically/bindingnessly-<as-to-determinism/conceptivity-of-relative-unreflexivity/relative-reflexivity> implicited-and-articulated'_as-from-nonextricatory-'prospective-re-ontologising-Being-thenInstitutional-then-Living-magnitudes-of-\{hermeneutic/reprojection-protraction-of $\}$ reframingand-reformulation $\}$ ' $>$ as of human epistemic ${ }^{4}$ foregrounding _entailment- $<$ in-succession-ofprofound-supererogation $>$-〈postconverging-narrowing-down $\sim$ sublimation-as-to- ${ }^{`}$ existenceas-sublimating-withdrawal/unenframing/re-ontologising,-elicited-from-prospective-profoundsupererogation '-in-reflecting-'immanent relative-unreflexivity/relative-reflexivity ontological-contiguity ';--as-operative-notional deprocrypticism)' underlying the sublimating-postconverged 'substantive abstract-tissue-of-social-emanance thermeneutically/textually/reprojectingly/supererogatingly/zeroingly/re-acutingly,$\{$ decompulsing $\}$ delinearity for-cogency_cumulated/recomposured as to cumulating/recomposuring of 'prospectively implicited_attendant-ontological-contiguity ${ }^{67}$ 'educedexistentialising/contextualising/textualising_'intelligibility/epistemicity/reflexivity_contiguity$<$ imbued-notional $\sim$ cogency ${ }^{\prime}{ }^{\prime}$ ).

In this regards, 'limitedness/human-subpotency prospectively sublimating conceptivity/epistemic-reflexivity/epistemicity-relativism-determinism- $<$ reifying \{as-to- 
knowledge-developing\}-and-empowering>' (as to prospective ${ }^{\prime}$ \{epistemic-totalising ${ }^{3}{ }^{3}$ reapriorising/re-axiomatising/re-referencing $\sim$ residuality-in-re-originariness/re-origination of limitedness/human-subpotency prospective re-encountering/re-confrontation with the 'constraining/defining intersolipsistic reflexive-sublimating/unreflexive-desublimating measure/objectification that is unlimitedness/existence-as-ontologicalnormalcy/postconvergence-<in-validation-of-'metaphysics-of-absence_epistemic-

projection'>') underlies the veracity of notional $\sim$ philosophy-<as-to-the-veridical-conception-ofphilosophy-as-englobing-all-human-prospective-organic-knowledge-generation-in-relativeontological-completeness ,-beyond-a-convenient-division-of-labour-conception-ofknowledge $>$ and its associated ontology/science implied intolerance-<ofdisparateness $>$ /exactifying_precisioning-of-sublimation-<as-to-postconverging-narrowingdown apriorising/axiomatising/referencing-entailing-theoretical,-conceptual-and-operantimplications $>$ as 'arising exclusively at acknowledged/recognised human destructuringthreshold-〈uninstitutionalised-threshold /presublimating-desublimating-decisionality $\rangle$ ofontological-performance $^{72}$-<including-virtue-as-ontology $>/$ morality/ethics/justice/etc. in want for prospective postconverging-aporeticism-overcoming/unovercoming'. Such that pretenses of a catchmenting-by-rejection/lip-servicing/monopolising/gaming-of-thesystem/charade/distraction prior mere-formulaicity/ritualisation-<as-to-mere-formulaicmethodologising/mutualising/organising/institutionalising,-prospectively-losing-track-of‘ \{epistemictalising łre-apriorising/re-axiomatising/re-referencing $\sim$ residuality-in-reoriginariness/re-origination'> ignoring/overlooking of human destructuring-threshold〈uninstitutionalised-threshold /presublimating-desublimating-decisionality $\rangle$ of-ontologicalperformance ${ }^{2}-<$ including-virtue-as-ontology $>$ /morality/ethics/justice/etc. are but a superficial/shallow manifest prior-perspective-falsity/falseness/fallaciousness pedantising/muddling/formulaic-hollowing-out — in-subontologisation/subpotentiation- 


\section{〈blurring/undermining-of-prospective-totalising-entailing,-as-to-entailing-}

$<$ amplituding/formative-epistemicity $>$ totalising in-relative-ontological-completeness $>$

desublimation (requiring appropriate 'epistemic-break or notional-discontiguity/epistemic-

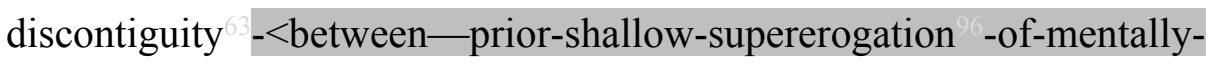
aestheticised preconverging/dementing -qualia-schema_and_prospective-profoundsupererogation -of-mentally-aestheticised postconverging/dialectical-thinking -qualiaschema $>$ as to difference-in-nature/difference-in-apriorising-or-axiomatising-or-referencing ${ }^{24}$ ), as so-reflecting the manifest moronisation- $<$ sublimating-nascence,-extricatory-desublimatingdownstreaming/'avalage'> respectively of ${ }^{103}$ universalising-idealisation ancient-sophists, nonpositivising medieval-scholasticism as well as our totalisingly-ing — discretion/whim-of-thought as to our modern-day manifestation of disparateness-of-conceptualisation-<unforegroundingment,-failing-prospectively-to-reflect-'immanent $\sim$ relative-unreflexivity/relative-reflexivity ontological-contiguity '> (as to their 'fundamental/incipient/seeding ontological-badfaith/inauthenticity ${ }^{64}$ preconverging-de-mentating/structuring/paradigming ${ }^{(5}$ ) ) in want for 'successive challenges of profound-supererogation for prospective re-ontologising' respectively as of the 'demoronisation- $<$ sublimating-nascence,-nonextricatory-sublimatingupstreaming/'amontée’> epistemic-break or notional-discontiguity/epistemic-discontiguity $<$ between-prior-shallow-supererogation -of-mentallyaestheticised preconverging/dementing -qualia-schema_and_prospective-profoundsupererogation -of-mentally-aestheticised postconverging/dialectical-thinking -qualiaschema>' of ${ }^{103}$ universalising-idealisation, budding-positivism as well as budding postmodernthought (as to their requisite 'fundamental/incipient/seeding ontological-goodfaith/authenticity ${ }^{6} \sim$ postconverging-de-mentating/structuring/paradigming ${ }^{\circ}$ as setting-up their prospective psychologismic-element-<as-of-diametrical-conflatedness -towards-'alreadygiven-unlimitedness/existence-<full-potency-of_sublimating nascence $>$ '-of- 
‘limitedness/human-subpotency-as-to-its-imbued-\{veridical/sound\}-relative-reflexivity-in-

existence/relativising from-limited-mentation-as-its-deepening/psychologismic epistemic-

acutisation residualising, ${ }^{\text {fdecompulsing }}$ delinearity for-cogency'> upon which their re-

rationalisation-of-contentivity/argumentativity/dialecticism/discursivity for educing prospective ${ }^{56}$ meaningfulness-and-teleology ${ }^{9}$ can be sublimatingly anchored); as to underlying human $\quad{ }^{15}$ de-mentation-〈supererogatory $\sim$ ontological-de-mentation-or-dialectical-dementation - stranding-or-attributive-dialectics $\rangle$ that has to reflect the appropriate sublimating 'psychologismic-epistemic-acutisation-<as-to-postconverging-de-

mentating/structuring/paradigming,-eliciting-of-existence's-sublimating-nascence-inprospective-aporeticism-overcoming/unovercoming $>$ as to epistemic-growth,-as\{veridical/sound\}-relative-reflexivity-in-existence/relativising from-limited-mentation-as-itsdeepening/psychologismic epistemic-acutisation residualising, \{decompulsing\} delinearity foreogency' as a requisite for veridical organic-knowledge (as not implied gratuitously but rather necessarily as to the fact that the Socratic-philosophers and budding-positivists respective dismissal of the moronisation- $<$ sublimating-nascence,-extricatory-desublimatingdownstreaming/'avalage'> of both non-universalising ancient-sophists and non-positivising medieval-scholasticism were of 'core necessity' as to the 'impossibility for prospective sublimating rationalisation-of-contentivity/argumentativity/dialecticism/discursivity on a common basis of both non-universalising apriorising/axiomatising/referencing and universalising apriorising/axiomatising/referencing as well as positivising apriorising/axiomatising/referencing and non-positivising apriorising/axiomatising/referencing' as ${ }^{103}$ universalising-idealisation apriorising/axiomatising/referencing and positivism/rationalempiricism apriorising/axiomatising/referencing respectively imbued demoronisation<sublimating-nascence,-nonextricatory-sublimating-upstreaming/'amontée'> had to supersede as prospectively re-ontologising, as so-implied as of prospective 
apriorising/re-axiomatising/re-referencing residuality-in-re-originariness/re-origination of limitedness/human-subpotency prospective re-encountering/re-confrontation with the 'constraining/defining intersolipsistic reflexive-sublimating/unreflexive-desublimating measure/objectification that is unlimitedness/existence-as-ontologicalnormalcy/postconvergence-<in-validation-of-‘metaphysics-of-absence_epistemic-

projection'>'). It can further be appreciated in this regards that all registryworldviews/dimensions in their ${ }^{79}$ presencing - absolutising-identitive-constitutedness ${ }^{14}$ projectof an ontologically-flawed conception that all the possibility for 'prospective knowledgereification $\sim$ gesturing-and-accounting — of-epistemic-phenomenalism- $<$ inprospective_psychologismic apriorising/axiomatising/referencing-\{of-'prospectively implicited_attendant-ontological-contiguity ' educedexistentialising/contextualising/textualising_'intelligibility/epistemicity/reflexivity_contiguity$<$ imbued-notional cogency $>$ ' \}-conflatedness -in-\{preconverging -ment by\} postconverging-ntailment> and human progress' lies within their given '79 presencingabsolutising-identitive-constitutedness ${ }^{14}$ absolution/absolute-scope fflawed/unsound\}-relativeunreflexivity-in-existence/absolutising from-limited-mentation/psychologismic epistemic acutisation nonresidualising imbued fompulsing finearity in eclecticism of prior mereformulaicity/ritualisation conception' of rationalisation-ofcontentivity/argumentativity/dialecticism/discursivity for educing ${ }^{56}$ meaningfulness-andteleology $\quad$ (as so-implying an 'apriorising/axiomatising/referencingequating/leveling/ressentiment/closed-construct-of- ${ }^{5}$ meaningfulness-and-teleology moronisation-<sublimating-nascence,-extricatory-desublimating-downstreaming/'avalage'>’ undifferentiation of both the prior relative-ontological-incompleteness ${ }^{88}$ and the prospective relative-ontological-completeness ${ }^{87}$ imbued ${ }^{83}$ reference-of-thought as grandest-axiomaticconstruct and ${ }^{83}$ reference-of-thought- ${ }^{8}$ devolving, wherein limitedness/human-subpotency 
wrongly supposedly-and-inherently prospectively supersedes unlimitedness/existence- $<$ fullpotency-of_sublimating nascence $>$ ); ignoring/overlooking the prospect of 'prospective \{epistemicTre-apriorising/re-axiomatising/re-referencing $\sim$ residuality-in-re-originariness/reorigination relative-ontological-completeness ${ }^{87}$ implications' as of the "nonpresencing$<$ perspective-ontological-normalcy/postconvergence $>$ relativism/relative-scope for epistemicgrowth,-as-\{veridieal/sound\}-relative-reflexivity-in-existence/relativising from-limitedmentation-as-its-deepening/psychologismic epistemic-acutisation residualising, \{decompling delinearity for-cogency' of prospective re-rationalisation-ofcontentivity/argumentativity/dialecticism/discursivity for educing meaningfulness-andteleology (as to the prospect of prospective 'apriorising/axiomatising/referencing disambiguating/de-leveling/de-ressentiment/opened-construct-of- ${ }^{5}$ meaningfulness-andteleology $\quad$ demoronisation-<sublimating-nascence,-nonextricatory-sublimatingupstreaming/'amontée'>' in reflection of 'prospective \{epistemic-totalising 3're-apriorising/reaxiomatising/re-referencing - residuality-in-re-originariness/re-origination relativeontological-completeness ${ }^{87} \quad$ implications'). Thus, human de-mentation〈supererogatory $\sim$ ontological-de-mentation-or-dialectical-de-mentation-stranding-orattributive-dialectics〉 implied 'limitedness/human-subpotency prospectively sublimating conceptivity/epistemic-reflexivity/epistemicity-relativism-determinism- $<$ reifying \{as-toknowledge-developing\}-and-empowering>' (as to underlying 'recurrently mediative-<inexpectation/in-anticipation $>$ unconsciousness/potentiation-of-conscionability-<anxiety-as-toreconstitution/reparation,-including-dreaming/psychical-reshuffling>' as the 'psychoanalytic boundlessness of human notional reflexivity-<\{veridical/sound $\}$-relative-reflexivity-inexistence/relativising from-limited-mentation-as-its-deepening/psychologismic<residualising \{decompulsing $\}$ delinearity for-cogency>by-\{flawed/unsound\}-relativeunreflexivity-in-existence/absolutising from-limited-mentation/psychologismic epistemic - 
backdrop' elicitable/exuding as of subconsciousness knowingly/unknowingly-manifest human ontological-good-faith/authenticity $\sim$ postconverging-de-

mentating/structuring/paradigming — by — ontological-bad-

faith/inauthenticity ${ }^{64}$ preconverging-de-mentating/structuring/paradigming ${ }^{5}$ ), is effectively what reflects the "veridical sublimating-reflexivity of the "nonpresencing-<perspectiveontological-normalcy/postconvergence $>$ relativism/relative-scope for epistemic-growth,-as\{veridical/sound\}-relative-reflexivity-in-existence/relativising from-limited-mentation-as-itsdeepening/psychologismic epistemic-acutisation residualising, \{decompulsing $\}$ delinearity for eogeney' of prospective re-rationalisations-ofcontentivity/argumentativity/dialecticism/discursivity' with regards to the overall relativeunreflexivity/relative-reflexivity — ontological-contiguity ${ }^{67}$ of-the-human-institutionalisationprocess $^{68}$ as to 'prospective postconverging-aporeticism-overcoming/unovercoming as theGood/knowledge-reification $\sim$ gesturing-and-accounting - of-epistemic-phenomenalism- $<$ inprospective_psychologismic apriorising/axiomatising/referencing-\{of-‘prospectively implicited_attendant-ontological-contiguity ' reducedexistentialising/contextmalising/textualising_'intelligibility/epistemicity/reflexivity_contiguity<imbued-notional cogency >' \}-conflatedness -in-\{preconverging -ment by\} postconverging-entailment $>$ /understanding/<amplituding/formativeepistemicity $>$ causality $\sim$ as-to-projective-totalitative-implications-of-prospectivenonpresencing,-for-explicating relative-unreflexivity/relative-reflexivity - ontologicalcontiguity ' (and so over the ontologically-flawed desublimating-reflexivity of any of the given ${ }^{6}$ presencing—absolutising-identitive-constitutedness ${ }^{14}$ absolution/absolute-scope \{flawed/unsound\}-relative-unreflexivity-in-existence/absolutising from-limited- 
mentation/psychologismic epistemic acutisation nonresidualising imbued-

\{compulsing\} linearityoin-eclecticism-of-prior-mere-formulaicity/ritualisation conception' prior rationalisations-of-contentivity/argumentativity/dialecticism/discursivity of the succession of registry-worldviews/dimensions superficiality/vacuity and nombrilism of mere-and-vague impression-driven/good-naturedness/wishfulness <amplituding/formative $>$ wooden-language〈imbued-averaging-of-thought-<as-to-leveling/ressentiment/closed-construct-ofmeaningfulness-and-teleology -as-of-‘nondescript/ignorable-void '-with-regards-toprospective-apriorising-implications $>\rangle)$ ). It can further be appreciated (concerning the 'potentiating of limitedness/human-subpotency as of the-human/humanity omnipotentiality possibility of existentialising/emanance/becoming with respect to unlimitedness/existence-<fllpotency-of_sublimating nascence $>$ '), that the <cumulating/recomposuring attendantontological-contiguity $>$-successive registry-worldviews/dimensions fundamentally/incipiently/seedingly arise as the epistemic-projection of 'successive challenges of profound-supererogation for prospective re-ontologising' as of their 'associated foundational ontological-good-faith/authenticity ${ }^{69}$ postconverging-dementating/structuring/paradigming ${ }^{0}$, that precedingly 'invent'/'create'-and-'nurture' the associated re-rationalisations-of-contentivity/argumentativity/dialecticism/discursivity; as to the fact that unlimitedness/existence-<full-potency-of_sublimating nascence $>$ is not of prospective apriorising/axiomatising/referencing-sublimating-reflexivity_beholdening to any given limitedness/human-subpotency prior rationalisation-ofcontentivity/argumentativity/dialecticism/discursivity as to when the latter fails to reflect prospective \{epistemic-totalising 3 re-apriorising/re-axiomatising/re-referencing $\sim$ residuality -in-reoriginariness/re-origination of limitedness/human-subpotency prospective re-encountering/reconfrontation with the 'constraining/defining intersolipsistic reflexive-sublimating/unreflexivedesublimating measure/objectification that is unlimitedness/existence-as-ontological- 
normalcy/postconvergence-<in-validation-of-'metaphysics-of-absence_epistemic-projection' (and so underlied, as to the epistemic-growth,-as - \{veridical/sound\}-relative-reflexivity-inexistence/relativising from-limited-mentation-as-its-deepening/psychologismic epistemic acutisation residualising, ${ }^{\text {\{decompulsing }}$ delinearity for-cogency implications of 'overaching/defining/devolving notional $\sim$ philosophy-<as-to-the-veridical-conception-ofphilosophy-as-englobing-all-human-prospective-organic-knowledge-generation-in-relativeontological-completeness ,-beyond-a-convenient-division-of-labour-conception-ofknowledge $>$ and its associated ontology/science implied intolerance- $<$ ofdisparateness $>$ /exactifying_precisioning-of-sublimation-<as-to-postconverging-narrowingdown apriorising/axiomatising/referencing-entailing-theoretical,-conceptual-and-operantimplications $>$ ' in $\quad$ so-reflecting 'notional ${ }^{18}$ deprocrypticism implied supereregatory - wholesomeness/profound-supererogation 6 experientiality/experiment- $<$ as-toexistentially-formative- ‘fepistemic-totalising ${ }^{\}}$re-apriorising/re-axiomatising/rereferencing $\sim$ residuality—in-re-originariness/re-origination',- - so'notionally/epistemically/bindingnessly<-sa-to-determinism/conceptivity-of-relative-unreflexivity/relative-reflexivityz implicited-and-articulated'_as-from-nonextricatory-'prospective-re-ontologising-Being-thenInstitutional-then-Living-magnitudes-of-\{hermentic/reprojection- of reframingand-reformulation $\}^{\prime}>$ of human epistemic ${ }^{4}$ foregrounding_entailment- $<$ in-succession-ofprofound-supererogation ${ }^{9}>-\left\langle\right.$ postconverging-narrowing-down $\sim$ sublimation-as-to- ${ }^{\text {existence }}$ as-sublimating-withdrawal/unenframing/re-ontologising,-elicited-from-prospective-profoundsupererogation '-in-reflecting-'immanent relative-unreflexivity/relative-reflexivity ontological-contiguity ';--as-operative-notional deprocrypticism)'). Critically, the psychoanalytic-unshackling veridically warranted for all prospective human re-ontologising demoronisation-<sublimating-nascence,-nonextricatory-sublimating-upstreaming/'amontée’> (as putting-into-question any given registry-worldview/dimension 'wrongly implied 
ontological-normalcy/postconvergence' as to its given '7 presencing-absolutising-identitiveconstitutedness $^{14}$ absolution/absolute-scope \{flawed/unsound\}-relative-unreflexivity-inexistence/absolutising from-limited-mentation/psychologismic epistemic acutisationnonresidualising-imbued-\{compulsing\} linearity in-eclecticism-of-prior-mereformulaicity/ritualisation conception' manifest psychoanalytic abnormality-<as-to-epistemicabnormalcy/preconvergence $>$ ) requires the full/complete human psychological uninhibitedness/decomplexification of requisite prospective psychologismic-epistemicacutisation-<as-to-postconverging-de-mentating/structuring/paradigming,-eliciting-ofexistence's-sublimating-nascence-in-prospective-aporeticism-overcoming/unovercoming $>$ as to epistemic-growth,-as_ \{veridical/sound\}-relative-reflexivity-in-existence/relativising fromlimited-mentation-as-its-deepening/psychologismic epistemic-acutisation - residualising, \{decompulsing $\}$ delinearity for-cogency. In this regards, 'limitedness/human-subpotency prospectively sublimating conceptivity/epistemic-reflexivity/epistemicity-relativismdeterminism-<reifying \{as-to-knowledge-developing\}-and-empowering >’ $\quad$ (as of human construction-of-the-Self reflected as protracted-social—as-to-individual-by-institutional-bysocial notional $\sim$ self-distantiation- $<$ imbued—re-motif-and-re-apriorising/re-axiomatising/rereferencing $>$ as so-concerning the "potentiating of limitedness/human-subpotency as of thehuman/humanity omnipotentiality possibility of existentialising/emanance/becoming with respect to unlimitedness/existence-<full-potency-of_sublimating nascence $>$ '), is critically underlied as of: 'recurrently mediative-<in-expectation/in-anticipation $>$ unconsciousness/potentiation-of-conscionability-<anxiety-as-to-reconstitution/reparation,including-dreaming/psychical-reshuffling>' as the 'psychoanalytic boundlessness of human notional $\sim$ reflexivity- $<$ \{veridieal/sound\}-relative-reflexivity-in-existence/relativising fremlimited-mentation-as-its-deepening/psychologismic-< residualising ${ }_{\text {fdecompulsing }}^{\text {\} }}$ delinearity foreogency $>$ by-\{flawed/unsound\}-relative-unreflexivity-in-existence/absolutising from- 
\{compulsing\} linearity in-eclecticism-of prior-mere-formulaicity/ritualisation $>\quad$ existential-

$<$ disontologising/re-ontologising aporeticism $>$ backdrop' elicitable/exuding as of subconsciousness knowingly/unknowingly-manifest human ontological-goodfaith/authenticity ${ }^{69}$ postconverging-de-mentating/structuring/paradigming 7 - by — ontological-bad-faith/inauthenticity ${ }^{64} \sim$ preconverging-de-mentating/structuring/paradigming ${ }^{65}$, and so-overarching/defining/devoluting upon human <amplituding/formative-epistemicity >totalising thrownness-in-existence ${ }^{35}$,-imbued-projective-arbitrariness/waywardness-〈as-to-thehuman-projective/reprojective- aestheticising-re-motif-and-re-apriorising/re-axiomatising/rereferencing-process-of- ${ }^{-}<$amplituding/formative-epistemicity $>$totalising $\sim$ conceptualisation’ $\rangle$ attendant/associated 'social-functioning-and-accordance-as-of-social-stake-contention-orconfliction imbuing existentialising-frame-of-entailment-of motif-andapriorising/axiomatising/referencing of disontologising/ontologising-and-re-ontologising' (as to Being-development/ontological-framework-expansion-as-to-depth-of-ontologisingdevelopment-as-infrastructure-of- meaningfulness-and-teleology , institutionaldevelopment-as-to-social-function-development and living-development-as-to-personalitydevelopment psychologismic epistemic-acutisation difficulty-<or, residualising \{delinearity for-cogeney>-magnitudes $\{$ of-experientiality/experiment\} $\}$. Insightfully, it can be garnered here that the above articulation reconstrued as 'interstitially-disontologising-by-reontologising anarchistic outgrowing formativeness-<as-to-intersolipsism-ofpreformulating/preframing/premeaningfulness-imbued-mediativity-and-deferentialism $>$-ofmeaningfulness-and-teleology of human sublimating ${ }^{5}$ meaningfulness-and-teleology ${ }^{\prime}$ is so-critically interlaced of varying stations/loci of limitedness/human-subpotency $<$ amplituding/formative-epistemicity $>$-totalising thrownness-in-existence ${ }^{35}$,-imbuedprojective-arbitrariness/waywardness-〈as-to-the-human-projective/reprojective- 
aestheticising-re-motif-and-re-apriorising/re-axiomatising/re-referencing-process-of-

'<amplituding/formative-epistemicity $>$ totalising $\sim$ conceptualisation' $\rangle \quad$ attendant/associated 'social-functioning-and-accordance-as-of-social-stake-contention-or-confliction imbuing existentialising-frame-of-entailment of motif-and-apriorising/axiomatising/referencing of disontologising/ontologising-and-re-ontologising'; as so-reflecting the very 'fundamental/incipient/seeding ${ }^{15}$ de-mentation-/supererogatory $\sim$ ontological-de-mentation-ordialectical-de-mentation-stranding-or-attributive-dialectics $\rangle$

preconverging/postconverging-de-mentating/structuring/paradigming' of human constructionof-the-Self (wherein the human self is undergirded anarchistically by the dualising dynamics of social-functioning-and-accordance-as-of-social-stake-contention-or-confliction and 'developing sense of notional $\sim$ ontology/notional $\sim$ ontological-veracity/notional $\sim$ ontologicalcommitment as to contiguity/coherence in social-stake-contention-or-confliction expectation/anticipation'). Thus, human sublimating/desublimating ${ }^{56}$ meaningfulness-andteleology ${ }^{9}$ can only be 'initially educed anarchistically in projective arbitrariness/waywardness' as of human <mplituding formative-epistemicity $>$-totalising $\sim$ thrownness-in-existence ${ }^{35}$,imbued-projective-arbitrariness/waywardness-〈as-to-the-human-projective/reprojective aestheticising-re-motif-and-re-apriorising/re-axiomatising/re-referencing-process-of‘<mpliteding/formative-epistemicity>totalising conceptualisation'〉; in want for its confirmation/enculturation as from prospective \{epistemic-totalising apriorising axiomatising/re-referencing residuality-in-re-originariness/re-origination of limitedness/human-subpotency prospective re-encountering/re-confrontation with the 'constraining/defining intersolipsistic reflexive-sublimating/unreflexive-desublimating measure/objectification that is unlimitedness/existence-as-ontologicalnormalcy/postconvergence-<in-validation-of-‘metaphysics-of-absence_epistemic-projection’> to thereof confirm/enculturate its social-functioning-and-accordance-as-of-social-stake- 
contention-or-confliction (and so-reflected as 'constraining existence-as-sublimatingwithdrawal/unenframing/re-ontologising,-elicited-from-prospective-profound-supererogation imbuing human ontological-commitment $-<$ implied - self-assuredness-of-ontological-goodfaith/authenticity $\sim$ postconverging-de-mentating/structuring/paradigming -as-being-as-ofexistential-reality>' and ' ${ }^{103}$ universal-transparency ${ }^{104}$-〈transparency-of-totalising-entailing,-asto-entailing-<amplituding/formative-epistemicity $>$ totalising $\sim$ in-relative-ontologicalcompleteness > as available-to/elicitable-to-〈as-to-human-consciousness/collectiveconsciousness-distendedness/detruncating-<beyond-selfpresencing,-as-re-ontologisingdecentering_of-consciousness/collective-consciousness,-as-to-psychologismic_epistemicacutisation-residualising, ${ }^{-}$decompulsing $\}$delinearity for-cogency $>>$the social-functioning-andaccordance-as-of-social-stake-contention-or-confliction conception of any given registryworldview/dimension $\quad<$ preconverging 'motif-and-apriorising/axiomatising/referencing' entailing $>$-existentialising — enframing/imprintedness-〈as-to- historicity-tracing - inpresencing-hyperrealisation/hyperreal-transposition''). This underlies the fact that human sublimating/desublimating ${ }^{56}$ meaningfulness-and-teleology ${ }^{99}$ is inevitably instigatingly anarchistic as to the anarchistic self-reflexive instigative-eventuating-〈as-to-teleologicalinstigative/incipient-willing/arbitrariness/waywardness/faithdrivenness/supererogating-forhuman-intelligibility,-preceding-existence's-eventuating-sublimating-validation/desublimatinginvalidation $\rangle$ for the 'percolation-channelling- $<$ in-deferential-formalisation-transference $>$ of the cumulated/recomposured secondnatured institutionalisation social-functioning-andaccordance-as-of-social-stake-contention-or-confliction' ultimately construed as social meaningfulness-and-teleology' (so-underlying the sublimating-postconverged 'substantive abstract-tissue-of-social-emanance totalising 3 ' $h$ hermeneutically/textually/reprojectingly/supererogatingly/zeroingly/re-acutingly,$\{$ decompulsing $\}$ delinearity for-cogency_cumulated/recomposured as to cumulating/recomposuring 

existentialising/contextualising/textualising_intelligibility/epistemicity/reflexivity-contiguity$<$ imbued-notional $\sim \operatorname{cogency}>$ ' $)$; with 'secondnatured-institutionalisation social-functioningand-accordance - as-of-social-stake-contention-or-confliction' arising critically (as of human subconsciousness most-prospectively-conscious

're-ontologising-bydisontologising_existential-calculus-〈between 'prospective existentialisingpostconverging_framing/imprinting re-ontologising' and 'prior existentialisingpreconverging_enframing/imprintedness social-functioning-and-accordance-as-of-socialstake-contention-or-confliction' $\rangle$ of consciousness surrealising-<as-to-supererogation ${ }^{9}>$ ) rather as to effectively imbued 'moronisation- $<$ sublimating-nascence, ex desublimating-downstreaming/'avalage’ $>$ - by_demoronisation- $<$ sublimating-nascence,nonextricatory-sublimating-upstreaming/'amontée’> station/locus of social-functioning-andaccordance-as-of-social-stake-contention-or-confliction'. Human anarchistic selfreflexive instigative-eventuating-〈as-to-teleological-instigative/incipientwilling/arbitrariness/waywardness/faithdrivenness/supererogating-for-human-intelligibility,preceding-existence's-eventuating-sublimating-validation/desublimating-invalidation $\rangle$ is thus effectively what undergirds the 'wrongly supposed inherent social-functioning-andaccordance-as-of-social-stake-contention-or-confliction incipiency of human meaningfulness-and-teleology 9 (whilst in reality the 'social as to its social-functioning-andaccordance-as-of-social-stake-contention-or-confliction' is rather the effective outcome of the 'dynamic of human self-reflexive instigative-eventuating-〈as-to-teleologicalinstigative/incipient-willing/arbitrariness/waywardness/faithdrivenness/supererogating-forhuman-intelligibility,-preceding-existence's-eventuating-sublimating-validation/desublimatinginvalidation> induced re-ontologising-by-disontologising_existential-calculus-〈between 'prospective existentialising_-postconverging_framing/imprinting re-ontologising' and 'prior 
accordance-as-of-social-stake-contention-or-confliction' $\left.\rangle^{\prime}\right)$; with human ${ }^{56}$ meaningfulnessand-teleology effectively undergirded anarchistically (as of self-reflexive instigativeeventuating-〈as-to-teleological-instigative/incipientwilling/arbitrariness/waywardness/faithdrivenness/supererogating-for-human-intelligibility,preceding-existence's-eventuating-sublimating-validation/desublimating-invalidation)) whether as of 'fflawed/unsound\}-relative-unreflexivity-in-existence/absolutising fromlimited-mentation/psychologismic epistemic acutisation nonresidualising imbued\{compulsing\} linearity in eclecticism-of prior mere formulaicity/ritualisation insidious-anarchy$<$ as-to-conscious/unconscious epistemically-flawed induced 'moronisation- $<$ sublimatingnascence,-extricatory-desublimating-downstreaming/'avalage’’ preconverging/dementing conception of prior mere-formulaicity/ritualisation incipiency of human social-functioning-andaccordance-as-of-social-stake-contention-or-confliction meaningfulness-and-teleology or '\{veridical/sound\}-relative-reflexivity-in-existence/relativising from-limited-mentation-asits deepening/psychologismic epistemic acutisation residualising, \{decolinearity for-cogency anarchistic-growth/anarchisation-for-re-ontologisation-〈asto-conscious/unconscious epistemically-sound induced 'demoronisation- $<$ sublimatingnascence,-nonextricatory-sublimating-upstreaming/‘amontée’> postconverging/dialecticalthinking conception of residual_re-originary_anarchistic incipiency of human socialfunctioning-and-accordance-as-of-social-stake-contention-or-confliction meaningfulnessand-teleology ' '’' (with the latter so-reflecting the projective/reprojective regenerativity of human ${ }^{56}$ meaningfulness-and-teleology ${ }^{9}$ in relative-ontological-completeness ${ }^{87}$ as so-operantly associated with prospective human aestheticising - ${ }^{7}$ surrealising/supererogating-drive). The implication here is the profound reality that supposed institutional and bureaucratic projection of human ${ }^{56}$ meaningfulness-and-teleology ${ }^{9}$ are rather actually of the undergirding-veracity of 
germinal/inceptive/formative anarchistic manifestation (with regards to underlying human ${ }^{15}$ dementation-_supererogatory $\sim$ ontological-de-mentation-or-dialectical-de-mentation - strandingor-attributive-dialectics $\rangle$ as to preconverging/postconverging-dementating/structuring/paradigming implications) of human self-reflexive instigativeeventuating-〈as-to-teleological-instigative/incipient-

willing/arbitrariness/waywardness/faithdrivenness/supererogating-for-human-intelligibility,preceding-existence's-eventuating-sublimating-validation/desublimating-invalidation>

(inherently preceding any given social-functioning-and-accordance-as-of-social-stakecontention-or-confliction conception of re-originariness/re-origination as institutional/bureaucratic setup as rather the outcome of human self-reflexive instigativeeventuating-〈as-to-teleological-instigative/incipient-

\section{willing/arbitrariness/waywardness/faithdrivenness/supererogating-for-human-intelligibility,-} preceding-existence's-eventuating-sublimating-validation/desublimating-invalidation $\rangle$ induced re-ontologising-by-disontologising_existential-calculus-〈between 'prospective existentialising_-postconverging_framing/imprinting re-ontologising' and 'prior existentialising_preconverging_enframing/imprintedness social-functioning-andaccordance-as-of-social-stake-contention-or-confliction' $\left.\rangle^{\prime}\right)$. This misconstrual in-many-ways explains institutional/bureaucratic 'proneness/susceptibility to disorientation/to-beoverwhelmed/crisis' as to when the 'notional ontological-veracity of projection/re-projectionand-anticipation/re-anticipation' as of their prior mere-formulaicity/ritualisation-<as-to-mereformulaic - methodologising/mutualising/organising/institutionalising,-prospectively-losing-

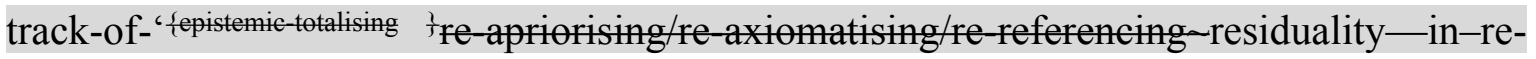
originariness/re-origination'> fail to recognise/integrate the ontological-veracity of human anarchistic self-reflexive instigative-eventuating-〈as-to-teleological-instigative/incipientwilling/arbitrariness/waywardness/faithdrivenness/supererogating-for-human-intelligibility,- 
meaningfulness-and-teleology ${ }^{9}$ and the dynamic implications upon institutional/bureaucratic functions, processes and purpose operating by mere re-ontologising-bydisontologising_existential-calculus-〈between 'prospective existentialising postconverging_framing/imprinting re-ontologising' and 'prior existentialising preconverging_enframing/imprintedness social-functioning-and-accordance-as-of-socialstake-contention-or-confliction'> given unlimitedness/existence-<full-potency-of_sublimating nascence $>$ prospective apriorising/axiomatising/referencing-sublimating-reflexivitybeholdening under which limitedness/human-subpotency submits in profound-supererogation for prospective sublimating; and so, notwithstanding the given underlying centralisingtotalitarianism or decentralising-totalitarianism ${ }^{79}$ presencing-absolutising-identitiveconstitutedness $^{14} \quad$ underpinning-suprasocial-construct $\quad<$ preconverging 'motif-andapriorising/axiomatising/referencing'-entailing >-existentialising — enframing/imprintedness〈as-to- historicity-tracing-in-presencing-hyperrealisation/hyperreal-transposition〉 failing with regards to prospective re-ontologising as to requisite "\{veridical/sound\}-relativereflexivity-in-existence/relativising from-limited-mentation-as-its-deepening/psychologismic

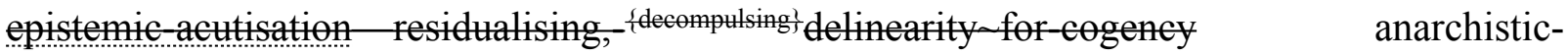
growth/anarchisation-for-re-ontologisation-〈as-to-conscious/unconscious epistemically-sound induced 'demoronisation-<sublimating-nascence, nonextricatory-sublimatingupstreaming/'amontée'> postconverging/dialectical-thinking conception of residual_reoriginary_anarchistic incipiency of human social-functioning-and-accordance-as-of-socialstake-contention-or-confliction meaningfulness-and-teleology ' $\rangle$ ', and in lieu rather manifesting a prospectively disontologising '\{flawed/unsound\}-relative-unreflexivity-inexistencetabsolutising from limited mention/psychologismic epistemie acutisation nonresidualising imbued-\{compulsings linearityoin-eclecticism-of prior-mere- 
formulaicity/ritualisation insidious-anarchy-<as-to-conscious/unconscious epistemically-flawed induced 'moronisation-<sublimating-nascence,-extricatory-desublimating-

downstreaming/'avalage'> preconverging/dementing conception of prior mere-
formulaicity/ritualisation incipiency of human social-functioning-and-accordance-as-ofsocial-stake-contention-or-confliction meaningfulness-and-teleology '>' conception of limitedness/human-subpotency prior rationalisation-ofcontentivity/argumentativity/dialecticism/discursivity (to which unlimitedness/existence-<fullpotency-of_sublimating nascence $>$ is not of prospective apriorising/axiomatising/referencing sublimating-reflexivity-beholdening as so-patently manifested in our modern-day naïve portrayal of issues that seem to imply their mere institutional/bureaucratic/mediatic procession is 'their effective ontological veracity and resolution'). The veridicality of 'human anarchistic self-reflexive $\sim$ instigative-eventuating-〈as-to-teleological-instigative/incipientwilling/arbitrariness/waywardness/faithdrivenness/supererogating-for-human-intelligibility,preceding-existence's-eventuating-sublimating-validation/desublimating-invalidation〉 of meaningfulness-and-teleology ${ }^{9}$ critically calls for requisite institutional/bureaucratic/mediatic/social prospective 'apriorising/axiomatising/referencing disambiguating/de-leveling/de-ressentiment/opened-construct-of- ${ }^{5}$ meaningfulness-andteleology $\quad$ demoronisation- $<$ sublimating-nascence,-nonextricatory-sublimatingupstreaming/'amontée'>' in reflection of 'prospective axiomatising/re-referencing $\sim$ residuality-in-re-originariness/re-origination relative-

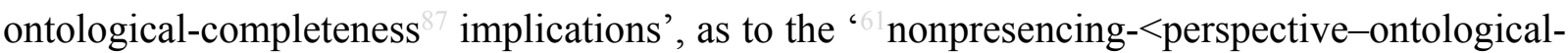
normalcy/postconvergence $>\quad$ relativism/relative-scope for epistemic-growth,-as\{veridical/sound\}-relative-reflexivity-in-existence/relativising from-limited-mentation-as-itsdeepening/psychologismic epistemic-acutisation residualising, decmor delinearity for eogency' of prospective re-rationalisation-of- 
contentivity/argumentativity/dialecticism/discursivity for educing ${ }^{56}$ meaningfulness-andteleology'; with manifest prospectively disontologising 'fflawed/unsound\}-relativeunreflexivity-in-existence/absolutising from-limited-mentation/psychologismic epistemic acutisation - nonresidualising-imbued-\{compulsing ${ }^{\text {fonearity }}$ lin-eclecticism-of-prior-mereformulaicity/ritualisation insidious-anarchy-<as-to-conscious/unconscious epistemically-flawed induced 'moronisation-<sublimating-nascence,-extrieatory-desublimating-

downstreaming/'avalage'> preconverging/dementing conception of prior mere-
formulaicity/ritualisation incipiency of human social-functioning-and-accordance-as-ofsocial-stake-contention-or-confliction meaningfulness-and-teleology ' $>$ ' rather a reflection of the defaulting social and institutional predisposition to the given preconverging-dementating/structuring/paradigming associated protracted-social—as-to-individual-byinstitutional-by-social pedantising/muddling/formulaic-hollowing-out—insubontologisation/subpotentiation-〈blurring/undermining-of-prospective-totalising-entailing,as-to-entailing- $<$ amplituding/formative-epistemicity $>$ totalising $\sim$ in-relative-ontologicalcompleteness \. A germinal/inceptive/formative elucidation highlights that human sublimating/desublimating ${ }^{56}$ meaningfulness-and-teleology" as rather 'instigatingly educed anarchistically in projective arbitrariness/waywardness' is effectively what reflects the fact that human intelligibility-〈as-to-human-projective/reprojective- aestheticising-re-motif-and-reapriorising/re-axiomatising/re-referencing/re-intelligibilitysettingup/remeasuringinstrumenting-process,-in-<amplituding/formativeepistemicity $>$ totalising conceptualisation $\rangle$ embryonically starts out as 'aestheticising motif/remotif in the projection/re-projection-and-anticipation/re-anticipation of human existential<disentologising/re-ontelogising aporeticism $>$ backdrop of coherent/contiguous meaningfulness-and-teleology', (so-underlied as to human 'recurrently mediative-<inexpectation/in-anticipation $>$ unconsciousness/potentiation-of-conscionability-<anxiety-as-to- 
reconstitution/reparation,-including-dreaming/psychical-reshuffling>' as the 'psychoanalytic boundlessness of human notional $\sim$ reflexivity-<\{veridical/sound $\}$-relative-reflexivity-inexistence/relativising from-limited-mentation-as-its-deepening/psychologismic-

<residualising ${ }^{\text {\{decompulsing }}$ \}elinearity for-cogency>-by-\{flawed/unsound\}-relative-
unreflexivity-in-existencelabsolutising from-limited-mentation/psychologismic epistemicacutisation nonresidualising-imbued-\{compulsingt finearity-in-eclecticism-of-prior-mereformulaicity/ritualisation> existential-<disontologising/re-ontologising aporeticism> backdrop' elicitable/exuding as of subconsciousness knowingly/unknowingly-manifest human ontological-good-faith/authenticity $\sim$ postconverging-dementating/structuring/paradigming — — by_ontological-badfaith/inauthenticity ${ }^{64}$ preconverging-de-mentating/structuring/paradigming ${ }^{65}$ ); with 'human aestheticisation-and-aestheticisation-towards-ontology-<elicited-idiomatisation $>$ interstitial-

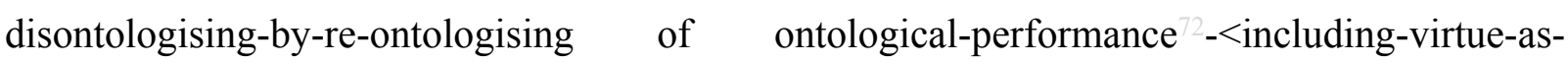
ontology >' (so-underlining 'human interstitially recurrent limited-mentation-capacity-assubjecting 'educed-unlimitedness/existence-sublimating nascence' to-limitedness/humansubpotency-by-limited-mentation-capacity-deepening —as-subjecting limitedness/humansubpotency to 'educed unlimitedness/existence-sublimating nascence' ${ }^{33}$ variance_inepistemic-projection') thus exuding as of the construction-of-the-Self 'developing sense of notional ontology/notional ontological-veracity/notional ontological-commitment $\quad$ as $\quad$ to contiguity/coherence in social-stake-contention-or-confliction expectation/anticipation'. The implication here is that given that it is the human construction-of-the-Self 'developing sense of notional ontology/notional ontological-veracity/notional ontological-commitment $\quad$ as $\quad$ to contiguity/coherence in social-stake-contention-or-confliction expectation/anticipation' that exudes coherent/contiguous ${ }^{56}$ meaningfulness-and-teleology", and even the artistic or aestheticising is imbued of an underlying 'notional ontological-veracity of projection/re- 
projection-and-anticipation/re-anticipation' exuded as of 'human existential<disontologising/re-ontelogising aporeticism> backdrop of coherent/contiguous meaningfulness-and-teleology, as so-enabling the intelligible appreciation of any given motif/motif-construct as aesthetics/arts (such that a Duchamp fountain motif-construct is artistic/aesthetical only as to the artistic/aesthetical "notional ontological-veracity of projection/re-projection-and-anticipation/re-anticipation' underlied as of 'human existential$<$ disentelegising/re-ontelogising aporeticism $>$ backdrop of coherent/contiguous meaningfulness-and-teleology ${ }^{9}$ '); with the further implication that no motif/motif-construct can be construed as artistic/aesthetical without the underlying 'notional ontological-veracity of projection/re-projection-and-anticipation/re-anticipation' exuded as of 'human existential<disontologising/re-ontologising aporeticism $>$ backdrop of coherent/contiguous meaningfulness-and-teleology '. This elucidation of the 'interstitially-disontologising-byre-ontologising anarchistic outgrowing formativeness-<as-to-intersolipsism-ofpreformulating/preframing/premeaningfulness-imbued-mediativity-and-deferentialism>-ofmeaningfulness-and-teleology of human sublimating ${ }^{5}$ meaningfulness-and-teleology ${ }^{9}$ (soimplied as of its 'dragged-out nature or psychologismic-epistemic-acutisation-<as-topostconverging-de-mentating/structuring/paradigming,-eliciting-of-existence's-sublimatingnascence-in-prospective-aporeticism-overcoming/unovercoming > as to epistemic-growth,-as\{veridical/sound\}-relative-reflexivity-in-existence/relativising from-limited-mentation-as-itsdeepening/psychologismic epistemic acutisation residualising, fdecompulsing delinearity for eөgency' imbued 'supereregatory $\sim$ wholesomeness/profound-supererogation as of prospective reference-of-thought—point-of-devolving/departure/anchoring/backdrop_of_sublimating_ nascence-<as-to-the-grandest-axiomatic-construct-\{epistemic-totalising apriorising/re 
unlimitedness/existence>'), speaks to the diametrical relation between limited-mentationcapacity-deepening —as-subjecting limitedness/human-subpotency-to-'educed-

unlimitedness/existence-sublimating nascence' ${ }^{53}$ (as to the genuine social intellectualfunction/posture specifically induced deferential-formalisation-transference as to its cultivated arts/skills and time investment) imbued '\{veridical/sound?-relative-reflexivity-inexistence/relativising from-limited-mentation-as-its-deepening/psychologismic epistemicacutisation residualising, $\left.{ }^{\{d e c o m p u l s i n g}\right\}$ delinearity for-cogency anarchisticgrowth/anarchisation-for-re-ontologisation-〈as-to-conscious/unconscious epistemically-sound induced 'demoronisation-<sublimating-nascence,-nonextricatory-sublimatingupstreaming/'amontée’> postconverging/dialectical-thinking conception of residual_reoriginary_anarchistic incipiency of human social-functioning-and-accordance-as-of-socialstake-contention-or-confliction meaningfulness-and-teleology ' $\rangle$ ' on-the-one-hand (as of its requisite prospective psychologismic-epistemic-acutisation-<as-to-postconverging-dementating/structuring/paradigming,-eliciting-of-existence's-sublimating-nascence-inprospective-aporeticism-overcoming/unovercoming $>$ as to epistemic-growth,-as\{veridical/sound\}-relative-reflexivity-in-existence/relativising from-limited-mentation-as-itsdeepening/psychologismic epistemic acutisation residualising, \{decompulsing\} delinearity foreogency) and on-the-other-hand limited-mentation-capacity-as-subjecting 'educedunlimitedness/existence-sublimating nascence' to-limitedness/human-subpotency (as to $<$ amplituding/formative $>$ wooden-language-<imbued — averaging-of-thought-<as-toleveling/ressentiment/closed-construct-of- meaningfulness-and-teleology -as-of'nondescript/ignorable-void '-with-regards-to-prospective-apriorising-implications $>$ > readily elicitable by pedantising/muddling/formulaic-hollowing-out—insubontologisation/subpotentiation-〈blurring/undermining-of-prospective-totalising-entailing,as-to-entailing-<mplituding/formative-epistemicity $>$ totalising in-relative-ontological- 
completeness 7) imbued of '\{flawed/unsound $\}$-relative-unreflexivity-inexistence Labsolutising from-limited-mentation/psychologismic epistemic-acutisationnonresidualising imbued-\{compulsing\} linearity-in-eclecticism-of prior-mereformulaicity/ritualisation insidious-anarchy-<as-to-conscious/unconscious epistemically-flawed induced 'moronisation-<sublimating-nascence,-extricatory-desublimatingdownstreaming/'avalage'> preconverging/dementing conception of prior mereformulaicity/ritualisation incipiency of human social-functioning-and-accordance-as-ofsocial-stake-contention-or-confliction meaningfulness-and-teleology ' $>$ '. Such that the socially protracted limited-mentation-capacity-deepening —as-subjecting limitedness/humansubpotency-to-'educed-unlimitedness/existence-sublimating-nascence' ${ }^{53}$ and its induced deferential-formalisation-transference abstractly speaks to all-and-sundry (as of their effective intemporal individuation sphere of limited-mentation-capacity-deepening-as-subjectinglimitedness/human-subpotency-to-'educed-unlimitedness/existence-sublimating nascence' and deferentialism/deferential-formalisation-transference implications of re-ontologising) and likewise limited-mentation-capacity—as-subjecting-'educed-unlimitedness/existencesublimating nascence' to-limitedness/human-subpotency rather speaking to all-and-sundry (but as of their effective temporal individuations sphere of limited-mentation-capacity-assubjecting-'educed-unlimitedness/existence-sublimating nascence' to-limitedness/humansubpotency implications of disontologising/subontologising); and so-reflected as to human Being-development/ontological-framework-expansion-as-to-depth-of-ontologisingdevelopment-as-infrastructure-of- meaningfulness-and-teleology , institutionaldevelopment-as-to-social-function-development and living-development-as-to-personalitydevelopment psychologismic epistemic-acutisation difficulty-<for, residualising \{decompulsing\} delinearity for-cogency>-magnitudes $\{$ of-experientiality/experiment\}. Critically, the psychoanalytic-unshackling implications of prospective demoronisation- $<$ sublimating - 
nascence,-nonextricatory-sublimating-upstreaming/‘amontée’> (as to anarchisticgrowth/anarchisation-for-re-ontologisation-〈as-to-conscious/unconscious epistemically-sound induced 'demoronisation-<sublimating-nascence,-nonextricatory-sublimatingupstreaming/'amontée’> postconverging/dialectical-thinking conception of residual_reoriginary_anarchistic incipiency of human social-functioning-and-accordance-as-of-socialstake-contention-or-confliction meaningfulness-and-teleology ' $\rangle$ ), simply portray the 'paradox of prospective re-rationalisation-ofcontentivity/argumentativity/dialecticism/discursivity for educing ${ }^{56}$ meaningfulness-andteleology ${ }^{9}$, with the incongruity of construing respectively of the 'sublimating rerationalisations-of-contentivity/argumentativity/dialecticism/discursivity of baseinstitutionalisation, ${ }^{103}$ universalisation, positivism/rational-empiricism and prospective deprocrypticism-or-preempting-disjointedness-as-of- ${ }^{3}$ reference-of-thought' rather as from the respective 'desublimating rationalisations-ofcontentivity/argumentativity/dialecticism/discursivity of recurrent-utter-uninstitutionalisation, ununiversalisation, non-positivism/medievalism and procrypticism-or-disjointedness-as-ofreference-of-thought' (but for the ${ }^{103}$ universal human possibility of underlying human dimensionality-of-sublimating $25<<$ amplituding/formative $>$ supererogatory $\sim$ dementativeness/epistemic-growth-or-conflatedness /transvaluativerationalising/transepistemicity/anamnestic-residuality/spirit-drivenness-equalisation〉 imbued ontological-good-faith/authenticity $\sim$ postconverging-de-mentating/structuring/paradigming as eliciting prospective reference-of-thought-point-ofdevolving/departure/anchoring/backdrop_of_sublimating-nascence-<as-to-the-grandestaxiomatic-construct-\{epistemictalising $\frac{1}{r}$ re-apriorising/re-axiomatising/rereferencing residuality - in-re-originariness/re-origination of limitedness/human-subpotency prospective re-encountering/re-confrontation with unlimitedness/existence $>$ ). But then this 
'paradox

of

prospective

re-rationalisation-of-

contentivity/argumentativity/dialecticism/discursivity for educing ${ }^{56}$ meaningfulness-andteleology ${ }^{9}$, is effectively what exposes prospectively the genuine social intellectualfunction/posture to protracted-social—as-to-individual-by-institutional-by-social pedantising/muddling/formulaic-hollowing-out — in-subontologisation/subpotentiation〈blurring/undermining-of-prospective-totalising-entailing,-as-to-entailing-

\section{$<$ amplituding/formative-epistemicity>totalising in-relative-ontological-completeness}

eliciting of the given registry-worldview/dimension 'lifespan extricatory/preconverging psychical-nascency moronisation- $<$ sublimating-nascence,-extricatory-desublimatingdownstreaming/'avalage'>' as to ontological-bad-faith/inauthenticity ${ }^{6} \sim$ preconverging-dementating/structuring/paradigming implied ' ${ }^{6}$ presencing-absolutising-identitiveconstitutedness ${ }^{14}$ absolution/absolute-scope \{flawed/unsound\}-relative-unreflexivity-inexistence/absolutising from-limited-mentation/psychologismic epistemic-acutisationnonresidualising imbued-\{compulsing\} linearity-in-eclecticism-of prior-mereformulaicity/ritualisation conception' (as to lack-of/undermining-of the "nonpresencing$<$ perspective-ontological-normalcy/postconvergence $>$ relativism/relative-scope for epistemicgrowth,-as-\{veridical/sound\}-relative-reflexivity-in-existence/relativising from-limitedmentation-as-its-deepening/psychologismic epistemic-acutisation - residualising, \{decompusing delinearity for-cogency' that allows for 'appropriate human contemplative projective-insights of sublimating-nascence aetiologisation/ontological-escalation<ontological-veridicality_commitment/otherliness_transcending/compulsionsencumbered_transcending $>$ conceptivity/epistemic-reflexivity/epistemicity-relativismdeterminism-<reifying \{as-to-knowledge-developing\}-and-empowering') and so-enabling-andsustaining the desublimating implications of the given registry-worldview/dimension overall $<$ amplituding/formative $>$ wooden-language- $\langle$ imbued - averaging-of-thought- $<$ as-to- 
leveling/ressentiment/closed-construct-of- meaningfulness-and-teleology -as-of-

'nondescript/ignorable-void '-with-regards-to-prospective-apriorising-implications $>\rangle . \quad$ The psychoanalytic-unshackling implications of prospective demoronisation- $<$ sublimatingnascence,-nonextricatory-sublimating-upstreaming/'amontée'> warrants the 'effective full/complete human psychological uninhibitedness/decomplexification' with regards to the prior registry-worldview/dimension imbued 'lifespan extricatory/preconverging psychicalnascency moronisation- $<$ sublimating-nascence,-extricatory-desublimatingdownstreaming/'avalage'>' as to the requisite prospective registry-worldview/dimension organic-knowledge 'apriorising/axiomatising/referencing disambiguating/de-leveling/deressentiment/opened-construct-of- ${ }^{5}$ meaningfulness-and-teleology 99 demoronisation<sublimating-nascence,-nonextricatory-sublimating-upstreaming/‘amontée’>’ imbued prospective psychologismic-element-<as-of-diametrical-conflatedness -towards-'alreadygiven-unlimitedness/existence-<full-potency-of_sublimating nascence $>$ '-of‘limitedness/human-subpotency-as-to-its-imbued-\{veridical/sound\}-relative-reflexivity-inexistence/relativising from-limited-mentation-as-its-deepening/psychologismic epistemicacutisation residualising, ${ }^{\text {\{decompulsing }}$ \}delinearity for-cogency’> (in superseding the prior registry-worldview/dimension 'apriorising/axiomatising/referencingequating/leveling/ressentiment/closed-construct-of- ${ }^{5}$ meaningfulness-and-teleology moronisation-<sublimating-nascence,-extricatory-desublimating-downstreaming/'avalage'>'); as so-validated by the mere fact that manifest sublimation-inducing concern for relativeontological-completeness ${ }^{87} \quad$ 'existentially- $<$ disontologising/re-ontologising aporeticism $>$ attributes effective drive and guidance to the profound-supererogation so-directed at the concern' undermining contradictory implications of pedantising/muddling/formulaichollowing-out - in-subontologisation/subpotentiation-〈blurring/undermining-of-prospectivetotalising-entailing,-as-to-entailing-<amplituding/formative-epistemicity $>$ totalising $\sim$ in- 
relative-ontological-completeness $>$ pretenses to prospective sublimation directedness/directing which effectively rather manifest non-ontologising/disontologising surreptitious knowledgewithout-knowledge/knowledge-outside-knowledge/extra-knowledge notion. The further reality here is that the requisite psychoanalytic-unshackling for such a prospective re-ontologising metaphoricity ${ }^{57}$ as herein articulated is in-many-ways necessarily lenient/accommodative for the sake of crossgenerational psychoanalytic-unshackling by not-fully/indirectly/passively elucidating thesublimating $<$ preconverging $\sim$ 'motif-andapriorising/axiomatising/referencing'-entailing>-existentialising-enframing/imprintedness〈as-to- historicity-tracing - in-presencing-hyperrealisation/hyperreal-transposition〉 of the prior registry-worldview/dimension disontologising social-functioning-and-accordance - as-ofsocial-stake-contention-or-confliction ${ }^{5}$ meaningfulness-and-teleology ${ }^{9}$; and so given the fact of all registry-worldviews/dimensions imbued prior-institutionalisation-threshold-byprospective-uninstitutionalised-threshold 'self-referencing-syncretising forward-facingsupposedly postconverging-or-dialectical-thinking -apriorising-psychologism epistemicprojection as of prior mere-formulaicity/ritualisation-<as-to-mere-formulaicmethodologising/mutualising/organising/institutionalising,-prospectively-losing-track-of‘\{epistemic-totalising ’’re-apriorising/re-axiomatising/re-referencing $\sim$ residuality-in-reoriginariness/re-origination'>' so-reflecting their 'disontologising preconverging/dementing $<$ as-to-prospective-uninstitutionalised-threshold $>$ ignoring/biased inclination' for the sake of 'their given present minimum-and-balancing expectations/anticipations of social-functioningand-accordance-as-of-social-stake-contention-or-confliction' while qualifying their prospectively uninstitutionalised-threshold ${ }^{102}$ actually as nondescript/ignorable-void as to their ${ }^{79}$ presencing - absolutising-identitive-constitutedness ${ }^{14} \quad<$ preconverging $\sim$ 'motif-andapriorising/axiomatising/referencing'-entailing >-existentialising — enframing/imprintedness〈as-to- historicity-tracing-in-presencing-hyperrealisation/hyperreal-transposition〉. In other 
words, this is just like a 'positivistic mindset not engaging a non-positivistic social-setup categorically/absolutely/inflexibly as if of posivistic mindset implications of prospective reference-of-thought—point-of-devolving/departure/anchoring/backdrop_of_sublimatingnascence-<as-to-the-grandest-axiomatic-construct-\{epistemic-totalising $\frac{\text { to }}{\text { re }}$-apriorising/reaxiomatising/re-referencing $\sim$ residuality —in-re-originariness/re-origination of limitedness/human-subpotency prospective re-encountering/re-confrontation with unlimitedness/existence>'; and so for the sake of 'acknowledging the crossgenerational epistemic-growth,-as - \{veridical/sound\}-relative-reflexivity-in-existence/relativising fromlimited-mentation-as-its-deepening/psychologismic epistemic-acutisation residualising, $\{$ decompulsing $\}$ delinearity for-cogency of the non-positivistic social-setup as to psychoanalyticunshackling/memetic-reordering/institutional-recomposuring into grasping positivistic meaningfulness-and-teleology'. But then the possibility for all such 'crossgenerational tactical psychoanalytic-unshackling' (as to 'demoronisation-<sublimating-nascence,nonextricatory-sublimating-upstreaming/‘amontée’> epistemic-break or notionaldiscontiguity/epistemic-discontiguity ${ }^{63}<$ between - prior-shallow-supererogation -ofmentally-aestheticised preconverging/dementing -qualia-schema_and_prospective-profoundsupererogation -of-mentally-aestheticised postconverging/dialectical-thinking -qualiaschema>' for 'prospective social-functioning-and-accordance-as-of-social-stake-contentionor-confliction $\quad{ }^{56}$ meaningfulness-and-teleology $99 \quad$ existentialisingpostconverging_framing/imprinting of re-ontologising' as so-projecting rather altogether beyond the 'prior social-functioning-and-accordance-as-of-social-stake-contention-orconfliction meaningfulness-and-teleology existentialisingpreconverging_enframing/imprintedness of disontologising') is critically 'not a question of nonontology as to a metaphysical/ideological advocacy' but rather a question of ontology-<as-torelative-ontological-completeness ${ }^{87}$-induced-re-ontologising $>$ as eliciting the underlying 
'constraining existence-as-sublimating-withdrawal/unenframing/re-ontologising,-elicitedfrom-prospective-profound-supererogation imbuing human ontological-commitment <implied - self-assuredness-of-ontological-good-faith/authenticity postconverging-dementating/structuring/paradigming -as-being-as-of-existential-reality>' and ' ${ }^{103}$ universaltransparency ${ }^{104}$-〈transparency-of-totalising-entailing,-as-to-entailing-<amplituding/formativeepistemicity $>$ totalising in-relative-ontological-completeness \ $\rangle$ as available-to/elicitable-to-〈asto-human-consciousness/collective-consciousness-distendedness/detruncating-<beyondselfpresencing,-as-re-ontologising-decentering_of-consciousness/collective-consciousness,-asto-psychologismic-epistemic-acutisation - residualising, - decompulsing $_{\text {f }}$ delinearity $\sim$ for-cogency $\left.>\right\rangle$ the social-functioning-and-accordance-as-of-social-stake-contention-or-confliction conception of any given registry-worldview/dimension <preconverging 'motif-andapriorising/axiomatising/referencing'-entailing>-existentialising-enframing/imprintedness〈as-to- historicity-tracing - in-presencing-hyperrealisation/hyperreal-transposition〉' that applies to all humans across all times (along the lines for instance that a sublimating conception of positivistic medicine as cure is not of indifference to a non-positivistic mindset who will be more inclined to choose the positivistic medicine cure rather than passing away and just as our present scientific culture operates on the basis of scientific knowledge as to its 'appropriate human contemplative projective-insights of sublimating-nascence aetiologisation/ontologicalescalation-<ontological-veridicality_commitment/otherliness_transcending/compulsionsencumbered_transcending $>\quad$ conceptivity/epistemic-reflexivity/epistemicity-relativismdeterminism-<reifying \{as-to-knowledge-developing\}-and-empowering' will induce our prospective sublimation/emancipation/enfranchisement). In this regards and across all the registry-worldviews/dimensions, the 'pedantising/muddling/formulaic-hollowing-out—insubontologisation/subpotentiation-_blurring/undermining-of-prospective-totalising-entailing,- 
completeness $>$ desublimation' rather strives to tactically-and-strategically undermine the core philosophy projection (of ontology-<as-to-relative-ontological-completeness ${ }^{8}$-induced-reontologising $>$ eliciting the underlying 'constraining existence-as-sublimatingwithdrawal/unenframing/re-ontologising,-elicited-from-prospective-profound-supererogation imbuing human ontological-commitment $-<$ implied - self-assuredness-of-ontological-goodfaith/authenticity postconverging-de-mentating/structuring/paradigming -as-being-as-ofexistential-reality>' and ' ${ }^{103}$ universal-transparency ${ }^{104}$-〈transparency-of-totalising-entailing,-asto-entailing-<amplituding/formative-epistemicity $>$ totalising $\sim$ in-relative-ontologicalcompleteness $\rangle$ as available-to/elicitable-to-〈as-to-human-consciousness/collectiveconsciousness-distendedness/detruncating-<beyond-selfpresencing,-as-re-ontologisingdecentering_of-consciousness/collective-consciousness,-as-to-psychologismic-epistemicacutisation-residualising, ${ }^{-\{\text {decompulsing }}$ delinearity for-cogency $>>$ the social-functioning-andaccordance-as-of-social-stake-contention-or-confliction conception of any given registryworldview/dimension $\quad$ <preconverging 'motif-and-apriorising/axiomatising/referencing'entailing $>$-existentialising — enframing/imprintedness-〈as-to- historicity-tracing - inpresencing-hyperrealisation/hyperreal-transposition〉') by rather engaging such prospective ontology-<as-to-relative-ontological-completeness ${ }^{8}$-induced-re-ontologising $>$ in fraudulent terms of 'non-ontology as to a metaphysical/ideological advocacy' for the sake of undermining the 'sublimating entailment of such prospective re-ontologising and in lieu induce disparatenessof-conceptualisation-<unforegrounding-ment,-failing-prospectively-to-reflect'immanent relative-unreflexivity/relative-reflexivity - ontological-contiguity '> (that cannot be falsified as of limitedness/human-subpotency prospective re-encountering/re-confrontation with unlimitedness/existence-<full-potency-of_sublimating nascence $>$ by its projection of human limited-mentation-capacity as subjecting 'educed mnlimitedness/existencesublimating nascence' to-limitedness/human-subpotency'). This 'exactly speaks to the manifest 
disontologising-threshold of prior-perspective-falsity/falseness/fallaciousness' upon which prospective psychoanalytic-unshackling has to work for prospective re-ontologising; in relation to such pedantising/muddling/formulaic-hollowing-out-in-subontologisation/subpotentiation〈blurring/undermining-of-prospective-totalising-entailing,-as-to-entailing<amplituding/formative-epistemicity>totalising in-relative-ontological-completeness > desublimation pretense-of-annulling 'prospective educing-and-availing-and-re-availing of relative-ontological-completeness

\section{<<amplituding/formative >supererogatery de-mentativeness/epistemic-growth-or-}

\section{conflatedness /transvaluative-rationalising/transepistemicity/anamnestic-residuality/spirit-}

drivenness-equalisation)'. It is important to understand here that the ontologising/scientific/existence- $<$ honesty-constraining $>$ — scope_for_prospective_reontologising is exactly what supersedes-and-provides the backdrop for the advocacy/political/applicative-scope as to the fact for instance that advocacy/political/applicative assertions do not overtly project of disontologising/unscientificity; such that while the advocacy/political/applicative-scope having to do with say advocacy campaigns, political decisions or engineering/technical choices can be construed as of a discretionary and contestable exercise however the ontologising/scientific/existence- $<$ honesty-constraining $>$ - scope_for_prospective_reontologising is rather involved in elucidating the sublimating possibilities as of prospective \{epistemic-totalising $3{ }^{3}$ re apriorising/re axiomatising/re referencing-residuality-in-re-

originariness/re-origination of limitedness/human-subpotency prospective re-encountering/reconfrontation with the 'constraining/defining intersolipsistic reflexive-sublimating/unreflexivedesublimating measure/objectification that is unlimitedness/existence-as-ontologicalnormalcy/postconvergence-<in-validation-of-‘metaphysics-of-absence_epistemic-projection’> as critically defined by unlimitedness/existence-ffull-potency-of_sublimating nascence $>$ and 
not limitedness/human-subpotency and so as we can only 'submit-to or demonstrate' limitedmentation-capacity-deepening-as-subjecting limitedness/human-subpotency-to-'educedunlimitedness/existence-sublimating nascence' ${ }^{3}$ when it comes to ontologising/scientific/existence- $<$ honesty-constraining $>$ — scope_for_prospective_reontologising (and even then where the advocacy/political/applicative-scope is intercalated with the backdrop of the ontologising/scientific/existence- $<$ honesty-constraining $>$ scope_for_prospective_re-ontologising as to 'prospective sovereign sublimation/emancipation/enfranchisement possibilities' then the ontologising/scientific/existence- $<$ honesty-constraining $>$ — scope_for_prospective_reontologising is effectively directly of relevance in advancing such advocacy/political/applicative — scope as of necessity and incontestable and not as of discretion and contestable, as so-reflected with prospective re-ontologising conceptivity/epistemicreflexivity/epistemicity-relativism-determinism-<reifying \{as-to-knowledge-developing $\}$-andempowering as to the dragged-out 'prospective ${ }^{8}$ reference-of-thought appraisal of sublimatingnascence comprehensiveness/nonimmediacy/indirectness' for prospective social-andinstitutional-frameworks-of — referencing/registering/decisioning sublimating existentialising-

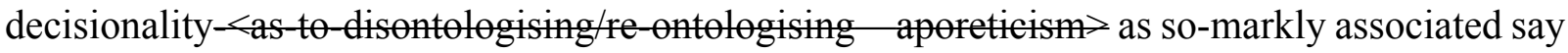
with the ending of serfdom and human slavery which inveracity much more profoundly lied beyond their advocacy/political/applicative — scope but rather the prospective re-ontologising as of ontologising/scientific/existence- $<$ honesty-constraining $>$ — scope_for_prospective_reontologising). The articulation herein effectively projects of such an ontologising/scientific/existence- $<$ honesty-constraining $>$ — scope_for_prospective_reontologising re-ontologising conceptivity/epistemic-reflexivity/epistemicity-relativismdeterminism-<reifying \{as-to-knowledge-developing\}-and-empowering as to its elucidation of human notional $\sim$ reflexivity- $<$ \{veridical/sound $\}$-relative-reflexivity-in-existence/relativising 
from-limited-mentation-as-its-deepening/psychologismic-<residualising

$\{$ \{decompulsing $\}$ delinearity for-cogency $>$ by - flawed/unsound\}-relative-unreflexivity-in-

existence/absolutising from-limited-mentation/psychologismic epistemic-acutisation

nonresidualising imbued-\{compulsing\} linearity in-eclecticism-of prior-mere-

formulaicity/ritualisation> on the basis of 'prospective postconvergingaaporeticismovercoming/mnovercoming as the-Good/knowledge-reification $\sim$ gesturing-and-accounting-ofepistemic-phenomenalism-<in-

prospective_psychologismic apriorising/axiomatising/referencing-\{of- ${ }^{\text {}}$ prospectively implicited_attendant-ontological-contiguity ' educed-

existentialising/contextualising/textualising_'intelligibility/epistemicity/reflexivity-contiguity$<$ imbued-notional cogency $\left.>^{\prime}\right\}$-conflatedness -in-\{preconverging-ment by\} postconverging entailment $>$ /understanding/<amplituding/formativeepistemicity $>$ causality $\sim$ as-to-projective-totalitative-implications-of-prospectivenonpresencing,-for-explicating relative-unreflexivity/relative-reflexivity - ontologicalcontiguity ', and not mere-and-vague impression-driven/good-naturedness/wishfulness. Inmany-ways (with regards to Being-development/ontological-framework-expansion-as-todepth-of-ontologising-development-as-infrastructure-of- meaningfulness-and-teleology , institutional-development-as-to-social-function-development and living-development-as-topersonality-development psychologismic epistemic-acutisation difficulty-for, residualising_\{decompusing\} delinearity for-cogency>-magnitudes $\left.{ }^{\{0 f-e x p e r i e n t i a l i t y / e x p e r i m e n t}\right\}$ all humans 'are well unconsciously/unknowingly-entitled to ignorance/lack-of-knowledge as to when prospective relative-ontological-completeness ${ }^{87}$ is not educed-and-availing-and-reavailing as to prospective re-ontologising and deferentialism/deferential-formalisationtransference implications of re-ontologising'; and this is effectively reflected say from 'childhood to adulthood levels-of-responsibilities', from 'non-specialists to specialists levels-of- 
responsibilities as equally articulated in the latter codes-of-conduct' and in-the-bigger-schemeof-things as well between 'lifespan extricatory/preconverging psychical-nascency moronisation<sublimating-nascence,-extricatory-desublimating-downstreaming/'avalage’’’ and 'nonextricatory/postconverging ontologising-and-re-ontologising angling-of-imaginary demoronisation-<sublimating-nascence,-nonextricatory-sublimating-upstreaming/'amontée'>' levels-of-responsibilities with regards to human intemporal/ontological/social/species/ ${ }^{103}$ universal/transcendental $/{ }^{5}$ maximalisingrecomposuring-for-relative-ontological-completeness ${ }^{8}$ —unenframed/reontologising conceptualisation postconverging-de-mentating/structuring/paradigming. All this notwithstanding, there is one fundamental/incipient/seeding element upon which no human can abscond from (with regards to sublimating human ontological-performance ${ }^{72}-<$ including-virtueas-ontology>) and that is exactly what in-the-very-core underlies the 'crossgenerational notional firstnaturedness-formativeness-<as-to-eventualising inkling-drive-or-seeding-

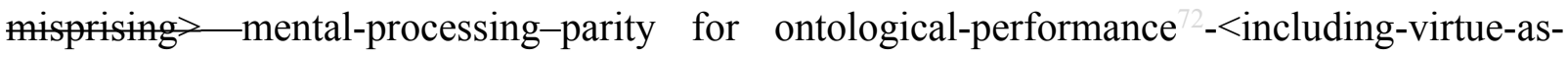
ontology $>$ /morality/ethics/justice/etc.' of all sovereign humans as to the potentiation of sublimating-over-desublimating across all times and this has to do with 'human ontologicalgood-faith/authenticity ${ }^{69}$ postconverging-de-mentating/structuring/paradigming — by_ ontological-bad-faith/inauthenticity $\sim$ preconverging-de-mentating/structuring/paradigming and so relative to the given station/locus of limitedness/human-subpotency $<$ amplituding/formative-epistemicity $>$-totalising $\sim$ thrownness-in-existence ${ }^{35}$ (and so-construed as from limited-mentation-capacity-deepening —as-subjecting limitedness/human-subpotency to-'educed-unlimitedness/existence-sublimating nascence' ${ }^{53}$ and not the nombrilistic naivety of limited-mentation-capacity as subjecting 'educed unlimitedness/existence-sublimating nascence' to-limitedness/human-subpotency given that the 'human condition by its limitedness/human-subpotency, is like a classroom-<as-of-limitedness/human-subpotency $>$ 
with no teacher-<as-of-the-sublimating-nascence-of-unlimitedness/existence $>$ that has to produce sublimating ${ }^{5}$ meaningfulness-and-teleology ${ }^{9}$, ever always at risk of being prospectively distorted/desublimated by the " blurriness- $<$ sterilising/anecdotalising/trivialisingof-prospective-re-ontologising_by-preconverging,-in-disontologising-formulaic-draggingout/hollowing-out $>$ dynamics of limited-mentation-capacity-as-subjecting 'educedunlimitedness/existence-sublimating nascence'-to-limitedness/human-subpotency').

Notwithstanding 'any given station/locus of our limitedness/human-subpotency $<$ amplituding/formative-epistemicity $>$-totalising $\sim$ thrownness-in-existence ${ }^{35}$ imbued relativeontological-incompleteness ${ }^{8}$, our 'sovereign human existential-<disontologising/reentologising aporeticism $>$ valour' is effectively deciphered as of our projected human ontological-good-faith/authenticity ${ }^{69}$ postconverging-de-

mentating/structuring/paradigming — - by—ontological-bad-

faith/inauthenticity ${ }^{64} \sim$ preconverging-de-mentating/structuring/paradigming ${ }^{5}$ (beyond the delusion of any secondnatured institutionalisation conception of human ontologicalperformance $^{72}-<$ including-virtue-as-ontology $>$ /morality/ethics/justice/etc. subject to its manifest ' blurriness-<sterilising/anecdotalising/trivialising-of-prospective-re-ontologising_bypreconverging,-in-disontologising-formulaic-dragging-out/hollowing-out $>$ dynamics of limited-mentation-capacity_as-subjecting-'educed-unlimitedness/existence-sublimating nascence' to-limitedness/human-subpotency' poorly entertaining dimensionality-ofsublimating $25<<$ amplituding/formative $>$ supererogatory $\sim$ de-mentativeness/epistemic-growthor-conflatedness /transvaluative-rationalising/transepistemicity/anamnestic-residuality/spiritdrivenness-equalisation)). Critically (with respect to prospective psychoanalytic-unshackling implications of re-ontologising), pedantising/muddling/formulaic-hollowing-out - insubontologisation/subpotentiation-〈blurring/undermining-of-prospective-totalising-entailing,as-to-entailing-<amplituding/formative-epistemicity $>$ totalising in-relative-ontological- 
completeness $>$ desublimation pretense-of-annulling 'prospective educing-and-availing-andre-availing of relative-ontological-completeness ${ }^{87}$ as to dimensionality-of-sublimating <<amplituding/formative >supererogatory-de-mentativeness/epistemic-growth-orconflatedness /transvaluative-rationalising/transepistemicity/anamnestic-residuality/spiritdrivenness-equalisation)' effectively voids its consideration as of 'unconsciously/unknowinglyentitled to ignorance/lack-of-knowledge as to when prospective relative-ontologicalcompleteness $^{87}$ is not educed-and-availing-and-re-availing as to prospective re-ontologising and deferentialism/deferential-formalisation-transference implications of re-ontologising' and so-renders the ontological-bad-faith/inauthenticity ${ }^{64} \sim$ preconverging-dementating/structuring/paradigming part-and-parcel of the exercise of prospective reontologising (in so-reflecting the fact that prospective re-ontologising involves the postconverging aporeticism-overcoming/mnovercoming of such manifest underlying dimensionality-of-desublimating-lack-of $-\langle<$ amplituding/formative $>$ supererogatory - dementativeness/epistemic-growth-or-conflatedness /transvaluativerationalising/transepistemicity/anamnestic-residuality/spirit-drivenness-equalisation〉).

Critically, any such manifest registry-worldview/dimension pedantising/muddling/formulaichollowing-out - in-subontologisation/subpotentiation-〈blurring/undermining-of-prospectivetotalising-entailing,-as-to-entailing-<amplituding/formative-epistemicity $>$ totalising $\sim$ inrelative-ontological-completeness > eliciting of overall <amplituding/formative $>$ woodenlanguage-〈imbued - temporal-mere-form/virtualities/dereification/akrasiaticdrag/denatured/preconverging-or-dementing -narratives - of-the- reference-of-thoughtcategorical-imperatives/axioms/registry-teleology \ (as to '\{flawed/unsound\}-relativeunreflexivity-in-existence/absolutising from-limited-mentation/psychologismic epistemicacutisation nonresidualising-imbued-\{compulsing finearity-in-eclecticism-of-prior-mereformulaicity/ritualisation insidious-anarchy-<as-to-conscious/unconscious epistemically-flawed 


downstreaming/'avalage'> preconverging/dementing conception of prior mere-

formulaicity/ritualisation incipiency of human social-functioning-and-accordance-as-ofsocial-stake-contention-or-confliction meaningfulness-and-teleology ' $>$ '), is effectively construed rather as of a disontologising-aggravation-〈in-want-for-prospectiveaetiologisation/ontological-escalation- $<$ ontological-

veridicality_commitment/otherliness_transcending/compulsions-encumbered_transcending $>>$ manifestation of dimensionality-of-desublimating-lack-of <<amplituding/formative>supererogatory $\sim$ de-mentativeness/epistemic-growth-orconflatedness /transvaluative-rationalising/transepistemicity/anamnestic-residuality/spiritdrivenness-equalisation). This is tantamount to presenting a true mathematician with the argument that $5+7$ is not equal to 12 'for one human mortal consideration or the other as to limited-mentation-capacity—as-subjecting-'educed-unlimitedness/existence-sublimating

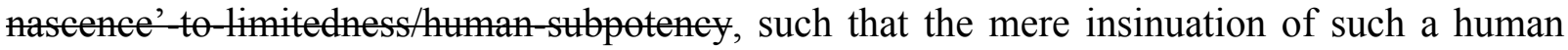
mortal consideration will rather turn out to be the more profound threat to mathematics as to the priority/precedence/primacy of the mathematics purview-of-unlimitedness/existence-<fullpotency-of_sublimating nascence>;_—implicited_attendant_ontologicalcontiguity ${ }^{67}$ educedexistentialising/contextualising/textualising_intelligibility/epistemicity/reflexivity-contiguity<imbued-notional cogency>' (as the true mathematician energy can only be directed as of overarching priority/precedence/primacy to establishing/re-establishing the 'fundamental/incipient/seeding prospective ontological-goodfaith/authenticity $\sim$ postconverging-de-mentating/structuring/paradigming 70 of mathematics as to human limited-mentation-capacity-deepening -as-subjecting limitedness/humansubpotency-to-'educed-unlimitedness/existence-sublimating nascence' ${ }^{53}$ ') and 'no human 
individual/institutional/social mortal as to limitedness/human-subpotency is big enough in that regards' but rather such an insinuation manifests a disontologising-aggravation-〈in-want-forprospective-aetiologisation/ontological-escalation-<ontologicalveridicality_commitment/otherliness_transcending/compulsions-encumbered_transcending $>>$ that needs emphatically to be trampled upon (and that is exactly what is meant by 'constraining existence - as-sublimating-withdrawal/unenframing/re-ontologising,-elicited-fromprospective-profound-supererogation imbuing human ontological-commitment $-<$ implied self-assuredness-of-ontological-good-faith/authenticity postconverging-dementating/structuring/paradigming -as-being-as-of-existential-reality>' and ' ${ }^{103}$ universaltransparency ${ }^{104}$-〈transparency-of-totalising-entailing,-as-to-entailing-<amplituding/formativeepistemicity>totalising in-relative-ontological-completeness $\rangle$ as available-to/elicitable-to-〈asto-human-consciousness/collective-consciousness-distendedness/detruncating-<beyondselfpresencing,-as-re-ontologising-decentering_of-consciousness/collective-consciousness,-as-

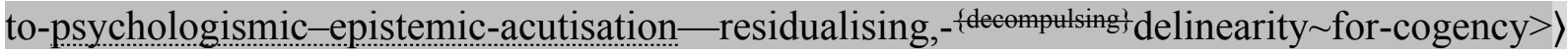
the social-functioning-and-accordance-as-of-social-stake-contention-or-confliction conception of any given registry-worldview/dimension <preconverging 'motif-andapriorising/axiomatising/referencing'-entailing >-existentialising —enframing/imprintedness〈as-to- historicity-tracing - in-presencing-hyperrealisation/hyperreal-transposition〉' and this has nothing to do with 'non-ontology as to a metaphysical/ideological advocacy'). In this regards, it can be appreciated that both the Socratic-philosophers as to their ${ }^{103}$ universalisingidealisation apriorising/axiomatising/referencing and budding-positivists as to their positivism/rational-empiricism apriorising/axiomatising/referencing effectively and naturally voided the consideration as of 'unconsciously/unknowingly-entitled to ignorance/lack-ofknowledge as to when prospective relative-ontological-completeness ${ }^{87}$ is not educed-andavailing-and-re-availing as to prospective re-ontologising and deferentialism/deferential- 
formalisation-transference implications of re-ontologising' with regards to respectively the nonuniversalising ancient-sophists apriorising/axiomatising/referencing and non-positivising medieval-scholasticism apriorising/axiomatising/referencing, and effectively related to them as of a fundamental/incipient/seeding issue of ontological-badfaith/inauthenticity ${ }^{64}$ preconverging-de-mentating/structuring/paradigming ${ }^{55}$ in want for prospectively requisite psychoanalytic-unshackling as to so-precedingly 'invent'/‘create'-and$\begin{array}{llll}\text { 'nurture' the } & \text { associated }\end{array}$ contentivity/argumentativity/dialecticism/discursivity that 'supersedes the ontological-badfaith/inauthenticity ${ }^{64} \sim$ preconverging-de-mentating/structuring/paradigming ${ }^{5}$, for prospective sublimating ${ }^{56}$ meaningfulness-and-teleology ${ }^{9}$ to arise; so-underlying ${ }^{103}$ universalisingidealisation apriorising/axiomatising/referencing and budding-positivists apriorising/axiomatising/referencing manifestations of 'Derridean underdetermination-imbued force/violence conception' and 'Foucauldian knowledge/power conception construed as knowledge-empowerment/ignorance-disempowerment' as of notional asceticism reasoningthrough/messianic-reasoning prospective existential-<disontologising/re-ontologising aporeticism $>$ deployment of transversality- $<$ for-sublimating-existential-

\section{eventuating/denouement, from 'thinking at first/pure predisposition preemptive of}

prospective-disontologising/subontologising' as-of-prospectively-disambiguated-affirmed-

and-unaffirmed-'motif-and-apriorising/axiomatising/referencing'>101 elucidation as of notional $\sim$ self-distantiation-<imbued—re-motif-and-re-apriorising/re-axiomatising/rereferencing $>\quad$ implied formativeness-<as-to-intersolipsism-ofpreformulating/preframing/premeaningfulness-imbued-mediativity-and-deferentialism>-ofmeaningfulness-and-teleology in $\quad$ nonpresencing-<perspective-ontologicalnormalcy/postconvergence $>$ epistemic-projection'). In this respect, it is important to grasp that with respect to the ontologising/scientific/existence- $<$ honesty-constraining $>$ - 
scope_for_prospective_re-ontologising,

unlimitedness/existence-<full-potencyof_sublimating nascence> is not of prospective apriorising/axiomatising/referencing sublimating-reflexivity - beholdening to the 'human mortal' as of its limitedness/humansubpotency conception of compromise and so as an ontologically-flawed inclination or subjection to another limitedness/human-subpotency mortal's whim'; as the mortals that we are are rather bound to 'submit-to or demonstrate' limited-mentation-capacity-deepening-assubjecting limitedness/human-subpotency to-'educed-unlimitedness/existence-sublimating nascence' ${ }^{53}$ as we most often readily do in our limitedness/human-subpotency prospective reencountering/re-confrontation with nascent-particular/incipient-and-material/technicalsublimations- $<$ blinded-to-their-relative-ontological-completeness - reference-of-thoughtdevolving $>$ (while increasingly trying to pervert/distort with social-and-institutionalframeworks-of-referencing/registering/decisioning as of 'fflawed/unsound\}-relativeunreflexivity-in-existence/absolutising from-limited-mentation/psychologismic epistemic

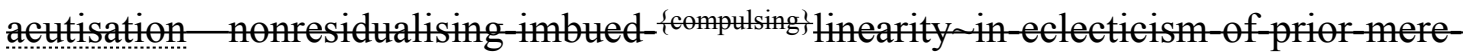
formulaicity/ritualisation insidious-anarchy-<as-to-conscious/unconscious epistemically-flawed induced 'moronisation-<sublimating-nascence,-extricatory-desublimating-

downstreaming/'avalage'> preconverging/dementing conception of prior mere-
formulaicity/ritualisation incipiency of human social-functioning-and-accordance-as-ofsocial-stake-contention-or-confliction meaningfulness-and-teleology ' $>$ '). It is important not to confuse the value appraisal within any social-setup (reflecting the 'human condition as of a classroom- $<$ as-of-limitedness/human-subpotency $>$ with no teacher- $<$ as-of-the-sublimatingnascence-of-unlimitedness/existence $>$ that has to produce sublimating ${ }^{56}$ meaningfulness-andteleology ${ }^{9 \prime}$ ) as being of absolute re-ontologising value (besides its advocacy/political/applicative — scope of value), given that the possibility for prospective human re-ontologising arises in-many-ways 'by ignoring/overlooking the punctual social-setups 
preconvergingly-de-mentating/structuring/paradigming implicited/explicited desublimating pretenses of the possibility of prospective re-ontologising' in order to be able to project of the requisite human psychologismic-epistemic-acutisation-<as-to-postconverging-dementating/structuring/paradigming,-eliciting-of-existence's-sublimating-nascence-inprospective-aporeticism-overcoming/unovercoming> acting as the 'postconverging-dementating/structuring/paradigming reference for requisite psychoanalytic-unshackling of the relative-ontological-incompleteness ${ }^{8}$-of-apriorising/axiomatising/referencing'; in reflection of prospective reference-of-thought-point-ofdevolving/departure/anchoring/backdrop_of_sublimating-nascence-<as-to-the-grandestaxiomatic-construct-\{epistemic-totalising ${ }_{3}^{+}$re-apriorising/re-axiomatising/rereferencing residuality - in-re-originariness/re-origination of limitedness/human-subpotency prospective re-encountering/re-confrontation with unlimitedness/existence $>$ (and this is soreflected in the fact that the <cumulating/recomposuring attendant-ontological-contiguity $>$ successive registry-worldviews/dimensions occurred exactly 'inspite of their conscious selfpresence/self-constitutedness $^{14}$ - in-perspective-epistemic-abnormalcy/preconvergence ${ }^{31}>$ desublimating $\sim$ existentialising-decisionality-<as-to-disontologising/re-ontologising apereticism $>$ ' as validated by the fact that 'when illumination abounds as to prospectively achieved secondnatured institutionalisation' we can effectively reflect upon the fact that prospective transcendence-and-sublimity/sublimation/supereregatery $\sim$ de-mentativity could only avail for instance as of the succession of ${ }^{103}$ universalising-idealisation and positivism/rational-empiricism over their preconverging-de-mentating/structuring/paradigming as non-universalising and non-positivising and 'our presence is no more different in this regards by its preconverging-de-mentating/structuring/paradigming which it doesn't represent to itself by mental-reflex'). This further explains-why what is most fundamental as of limitedness/human-subpotency prospective re-encountering/re-confrontation with the 
'constraining/defining intersolipsistic reflexive-sublimating/unreflexive-desublimating measure/objectification that is unlimitedness/existence-as-ontologicalnormalcy/postconvergence-<in-validation-of-'metaphysics-of-absence_epistemic-projection’ is rather ontological-good-faith/authenticity $\sim$ postconverging-dementating/structuring/paradigming ${ }^{0}$ as to enable human limited-mentation-capacitydeepening as-subjecting-limitedness/human-subpotency-to-'educed-unlimitedness/existencesublimating nascence's3 from whence 'sublimating rationalisations-ofcontentivity/argumentativity/dialecticism/discursivity can be beget'. Critically, the fundamental/incipient/seeding ontological-bad-faith/inauthenticity $\sim$ preconverging-dementating/structuring/paradigming fraudulent representation of the ontologising/scientific/existence- $<$ honesty-constraining $>$ — scope_for_prospective_reontologising as 'non-ontology as to a metaphysical/ideological advocacy' is one that 'strategically strives consciously/unconsciously to undermine an existential-<disentelegising/reentologising aporeticism $>$ entailment conception of the social' while paradoxically claiming itself to be of entailment (by 'mere referring, mentioning and synonymisation of concepts and conceptualisations mere_apriorising/axiomatising/referencing of hardly any prospective profound existential-disontologising/re-ontogising apereticism> implications but for institutional-prescience/imprimaturing- $<$ dullness-of the-spirit/psychologismic epistemic acutisation nonresidualising-imbued-\{compulsing\} linearity in-eclecticism-of-prior-mereformulaicity/ritualisation>' and it is herein claimed that 'veridical entailment is inlined with the knowledge gesturing/accounting-of-epistemic-phenomenalism projected epistemictotalising implications' as implied with say a Deridean deconstruction or Foucauldian genealogy or for that matter any scientific knowledge, and not a discretionary conception of knowledge that relies on the totalisingly-ing — discretion/whim-of-thought wherein the supposed sublimation cannot be separated-and-falsifiable from the discretion of its supposed author's 
absolution/absolute-scope ignoring/overlooking the need for 'coherence/contiguity with the vast expanses of human experientiality/experiment-<as-to-existentially-formative- ‘fepistemictre-apriorising/re-axiomatising/re-referencing $\sim$ residuality-in-re-originariness/reorigination',-- so-'notionally/epistemically/bindingnessly-<as-to-determinism/conceptivity-of-relativeunreflexivity/relative-reflexivity $z$-implicited-and-articulated'_as-from-nonextricatory-'prospective-reontologising-Being-then-Institutional-then-Living-magnitudes-of\{hermeneutic/reprojection protraction-of\}reframing-and-reformulation\} ' $>$ ' and in-many-ways manifesting a fundamental confusion between outright advocacy/political/applicative — scope and ontologising/scientific/existence- $<$ honesty-constraining $>$ — scope_for_prospective_reontologising further explaining a discretionary conception of knowledge lacking the capacity to draw out the veridical relative-ontological-completeness ${ }^{87}$ entailment exudable as from unlimitedness/existence-<fll potency-of_sublimating nascence $>$ ); but then how can there be any veridical existential-<disøntelogising/re-ontologising aporeticism $>$ entailment lacking a conception of ' nonpresencing-<perspective-ontological-normalcy/postconvergence $>$ relativism/relative-scope for epistemic-growth,-as - \{veridical/sound\}-relative-reflexivity-inexistence/relativising from-limited-mentation-as-its-deepening/psychologismic epistemicacutisation residualising, ${ }^{\text {\{decompulsing }}$ delinearity for cogency'? This effectively speaks of a 'flawed-prior-purposefulness of ${ }^{7}$ presencing-absolutising-identitive-constitutedness ${ }^{14}$ before supposedly-prospective-thinking-purpose,-as-precalculated-purpose- $<$ as-prospectively-losing-

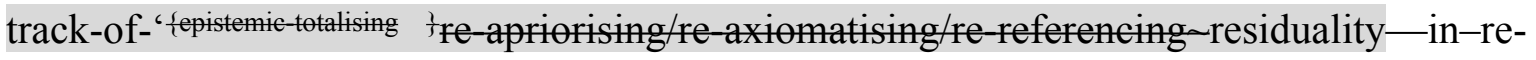
originariness/re-origination'-of-thinking >' exercise to which it is herein construed as delusional to relate to as coherent/contiguous with an exercise of prospective 'appropriate human contemplative projective-insights of sublimating-nascence aetiologisation/ontologicalescalation-<ontological-veridicality_commitment/otherliness_transcending/compulsionsencumbered_transcending $>$ conceptivity/epistemic-reflexivity/epistemicity-relativism- 
determinism-<reifying \{as-to-knowledge-developing\}-and-empowering' $\quad$ as $\quad$ to its implicit/explicit manifest fundamental/incipient/seeding ontological-badfaith/inauthenticity ${ }^{64}$ preconverging-de-mentating/structuring/paradigming ${ }^{5}$; as so-delusional as naively thinking that budding-positivist positivistic/sciencific thought apriorising/axiomatising/referencing could effectively be undertaken as continuous/contiguous with the fundamental/incipient/seeding ontological-bad-faith/inauthenticity $\sim$ preconvergingde-mentating/structuring/paradigming ${ }^{5}$ of medieval-scholasticism apriorising/axiomatising/referencing (even as in-many-ways there is a 'blurred continuum between budding-positivists positivising apriorising/axiomatising/referencing and medievalscholasticism non-positivising apriorising/axiomatising/referencing manifested confusingly in many thinkers and persons then' it is rather the 'requisite positivistic supererogatery acuity/perspicacity/astuteness/edginess/incisiveness-ofapriorising/axiomatising/referencing/intelligibilitysettingup/measuringinstrumenting -forconceptualisation as displayed by the Galileos, Descarteses, Newtons, Diderots, etc.' that provides/acts-as the 'postconverging-de-mentating/structuring/paradigming reference for requisite psychoanalytic-unshackling of the relative-ontological-incompleteness ${ }^{8}$-ofapriorising/axiomatising/referencing' in transforming the 'blurred continuum between buddingpositivists positivising apriorising/axiomatising/referencing and medieval-scholasticism nonpositivising apriorising/axiomatising/referencing' decisively into 'prospective positivism/rational-empiricism apriorising/axiomatising/referencing psychologismic epistemic-acutisation-<as-to-postconverging-de-mentating/structuring/paradigming,-elicitingof-existence's-sublimating-nascence-in-prospective-aporeticism-overcoming/unovercoming> as to epistemic-growth,-as \{veridical/sound relative-reflexivity-in-existence/relativising from-limited-mentation-as-its-deepening/psychologismic epistemic-acutisationresidualising, ${ }^{\{\text {decompulsing }}$ delinearity for-cogency' and so as of their 'implicitly/explicitly 
projected prospective positivism/rational-empiricism ${ }^{83}$ reference-of-thought—point-ofdevolving/departure/anchoring/backdrop_of_sublimating-nascence-<as-to-the-grandest-

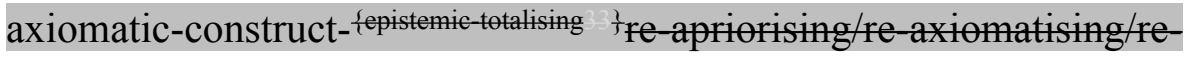

referencing residuality - in-re-originariness/re-origination of limitedness/human-subpotency prospective re-encountering/re-confrontation with unlimitedness/existence>'). In other words, appropriate psychologismic-epistemic-acutisation-<as-to-postconverging-dementating/structuring/paradigming,-eliciting-of-existence's-sublimating-nascence-inprospective-aporeticism-overcoming/unovercoming> acting as 'postconverging-dementating/structuring/paradigming reference for requisite psychoanalytic-unshackling of the relative-ontological-incompleteness ${ }^{88}$-of-apriorising/axiomatising/referencing', speaks to the fact that (as to limitedness/human-subpotency) the human psyche is rather 'of mutable placeholder-setup/mental-devising-representation/mentation/consciousness-awarenessteleology ${ }^{9}$ about immutable unlimitedness/existence-<full-potency-of_sublimating nascence>’ (and so with respect to sublimating limitedness/human-subpotency prospective reencountering/re-confrontation with the 'constraining/defining intersolipsistic reflexivesublimating/unreflexive-desublimating measure/objectification that is unlimitedness/existenceas-ontological-normalcy/postconvergence-<in-validation-of- ‘metaphysics-ofabsence_epistemic-projection'>'); so-implied as to limited-mentation-capacity-deepening-assubjecting limitedness/human-subpotency-to-'educed-unlimitedness/existence-sublimating nascence' ${ }^{33}$ induced mentally-aestheticised postconverging/dialectical-thinking ${ }^{2}$-qualiaschema. The human psyche being 'of mutable placeholder-setup/mental-devisingrepresentation/mentation/consciousness-awareness-teleology 9 about immutable unlimitedness/existence-ffll poten of_sublimating nascence> underscores that human aestheticisation- $<$ as-to-motif $>\quad$ and $\quad$ aestheticisation-towards-ontology- $<$ as-toapriorising/axiomatising/referencing $>$ effectively underlie the 'epistemic-totalising 
formativeness-<as-to-intersolipsism-of-preformulating/preframing/premeaningfulness-imbuedmediativity-and-deferentialism>-of- meaningfulness-and-teleology of human meaningfulness-and-teleology ${ }^{9}$ so-translated in underlying human mental-aestheticising- $<$ as'psychologismic-existential-metaphoricity \{as-to-\{epistemic-totalising ${ }^{\}}$re-apriorising/reaxiomatising/re-referencing_in-becoming?' -so-implicited-'by-way-of-theexistentially/contextually/textually-manifest-motif-construct-as-specific-language'-as-soreflecting-'the-existentially/contextually/textually-manifest-moronisation/demoronisation'>'; recurrently-driven by limitedness/human-subpotency prospective re-encountering/reconfrontation with the 'constraining/defining intersolipsistic reflexive-sublimating/unreflexivedesublimating measure/objectification that is unlimitedness/existence-as-ontologicalnormalcy/postconvergence- $<$ in-validation-of-'metaphysics-of-absence_epistemicprojection'>', as so-reflecting limited-mentation-capacity-deepening-as-subjecting limitedness/human-subpotency-to-'educed-unlimitedness/existence-sublimating nascence'53. The human psyche (as to Being-development/ontological-framework-expansion-as-to-depth-ofontologising-development-as-infrastructure-of- meaningfulness-and-teleology , institutionaldevelopment-as-to-social-function-development and living-development-as-to-personalitydevelopment psychologismic epistemic acutisation difficulty <for, residualising $\{$ \{lecompulsing $\}$ delinearity for-cogeney $>$ magnitudes $\{$ of-experientiality/experiment $\}$ ) imbued 'human mentalaestheticising-<as-‘psychologismic-existential-metaphoricity \{as-to-\{epistemic-totalising ${ }^{\}}$reapriorising/re-axiomatising/re-referencing_in_becoming?' 'so-implicited-'by-way-of-theexistentially/contextually/textually-manifest-motif-construct-as-specific-language'-as-soreflecting-'the-existentially/contextually/textually-manifest-moronisation/demoronisation'> notionaly/epistemiealy/bindingnessly-<as-to-determinism/conceptivity-of-relative-unreflexivity/relative-reflexivity> involves 'projective/affirmative apriorising/axiomatising/referencing-\{of-'prospectively implicited_attendant-ontological-contiguity ' educed- 
existentialising/contextualising/textualising_'intelligibility/epistemicity/reflexivity-contiguity$<$ imbued-notional cogency $\left.>^{\prime} \quad\right\}$-conflatedness ${ }^{13}$-in-\{preconverging-ment by\} postconverging-entailment' superseding of 'disontologising-thresholds in apriorising/axiomatising/referencing-\{of-'prospectively_implicited_attendant-ontologicalcontiguity ' $\sim$ educedexistentialising/contextualising/textualising_ 'intelligibility/epistemicity/reflexivity-contiguity<imbued-notional cogency>' $\quad\}$-constitutedness ${ }^{1}$-in-preconverging-entailment' $\quad$ (as somanifesting notionally/epistemically/bindingnessly mreflexivity/relative-reflexivityz human aestheticising — ${ }^{97}$ surrealising/supererogating-drive'). This basically reflects human notional ${ }^{6}$ nonpresencing-<perspective-ontologicalnormalcy/postconvergence $>$ relativism/relative-scope for epistemic-growth,-as\{veridical/sound\}-relative-reflexivity-in-existence/relativising from-limited-mentation-as-itsdeepening/psychologismic epistemic_acutisation residualising, \{decompulsing ${ }^{\text {f }}$ delinearity for cogency' (so-construable as of effectively existential-<disontologising/re-ontologisingaporeticism> notional $\sim$ reflexivity- $<\{$ veridical/sound $\}$-relative-reflexivity-inexistence/relativising from-limited-mentation-as-its-deepening/psychologismic<residualising $\{$ decompulsing $\}$ delinearity for cogency>by-\{flawed/unsound\} relativeunreflexivity-in-existence/absolutising from-limited-mentation/psychologismic epistemicacutisation nonresidualising-imbued-\{compulsing? linearity-in-eclecticism-of-prior-mereformulaicity/ritualisation>), hence speaking of the 'human notional $\sim$ difference-conflatedness ${ }^{13}$ as-to-totalitative-reification-in-singularisation- $<$ as-to-the-nondisjointedness/entailment-ofprospective- nonpresencing $>$-as-veridical-epistemicity-relativism-determinism construable as from the given projected relative-ontological-completeness ${ }^{87}$-ofapriorising/axiomatising/referencing'; with such a conception of relative-ontologicalcompleteness ${ }^{87}$-of-apriorising/axiomatising/referencing, as rather 'existentially- 
totalisingly /acutely_translating-into-the-mental-aestheticising-metaphoricity >’ by its given sunderlaid/substrated-'thrownness-aestheticising' \{of-relative-unreflexivity in-existence\}> profusion-of preconverging prior-relative-ontological-incompleteness ${ }^{8}$-ofapriorising/axiomatising/referencing_by—<overlaying/superstrating 'thrownnessaestheticising' \{of-relative-reflexivity in-existence\}>-sparsity-of-postconverging-prospectiverelative-ontological-completeness ${ }^{8}$-of-apriorising/axiomatising/referencing as to underlying $<$ amplituding/formative-epistemicity $>$-totalising $\sim$ thrownness-in-existence mentalaestheticising-<as-'psychologismic-existential-metaphoricity fas-to-epistemictising apriorising/re-axiomatising/re-referencing_in-becoming?' 'so-implicited-'by-way-of-theexistentially/contextually/textually-manifest-motif-construct-as-specific-language'-as-soreflecting-'the-existentially/contextually/textually-manifest-moronisation/demoronisation'> imbued re-ontologising-by-disontologising_existential-calculus-〈between 'prospective existentialising_-postconverging_framing/imprinting re-ontologising' and 'prior existentialising_-preconverging_enframing/imprintedness social-functioning-andaccordance-as-of-social-stake-contention-or-confliction' '’ (but not understood as of supposedly 'unlimitedness/existence-<full-potency-of_sublimating nascence $>$ absoluteontological-completeness-of-apriorising/axiomatising/referencing-<as-omnipotentiality $>$ $<$ amplituding/formative-epistemicity $>$-totalising $\sim$ thrownness-in-existence ${ }^{35}$ imbued absolute $\sim$ difference-conflatedness ${ }^{13}$-as-to-totalitative-reification-in-singularisation- $<$ as-to-thenondisjointedness/entailment-of-prospective- nonpresencing > -as-veridical-epistemicityrelativism-determinism so-construed as 'absolute reference of identity' as failing to project of its own possible prospective relative-ontological-incompleteness ${ }^{8}$-ofapriorising/axiomatising/referencing). It should be noted here that the emphasis placed on relative-ontological-completeness ${ }^{87}$-of-apriorising/axiomatising/referencing (as rather 
'existentially-<isontologising/re-ontologising aporeticism $>$

understood-<as-epistemictotalisingly /acutely_translating-into-the-mental-aestheticising-metaphoricity >’ by its given sunderlaid/substrated-'thrownness-aestheticising' \{of-relative-unreflexivity in-existence\}> profusion-of preconverging prior-relative-ontological-incompleteness ${ }^{8}$-ofapriorising/axiomatising/referencing_by—<overlaying/superstrating 'thrownnessaestheticising'-\{of-relative-reflexivity in-existence\}>-sparsity-of-postconverging-prospectiverelative-ontological-completeness ${ }^{8}$-of-apriorising/axiomatising/referencing as to underlying $<$ amplituding/formative-epistemicity $>$-totalising $\sim$ thrownness-in-existence mental-

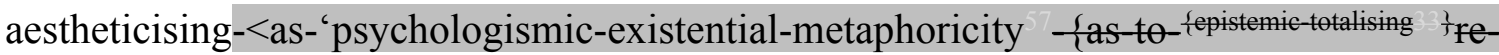
apriorising/re-axiomatising/re-referencing_in-becoming?' 'so-implicited-'by-way-of-theexistentially/contextually/textually-manifest-motif-construct-as-specific-language'-as-soreflecting-'the-existentially/contextually/textually-manifest-moronisation/demoronisation'> imbued re-ontologising-by-disontologising_existential-calculus-_between 'prospective existentialising_-postconverging_framing/imprinting re-ontologising' and 'prior existentialising_-preconverging_enframing/imprintedness social-functioning-andaccordance-as-of-social-stake-contention-or-confliction' '’'), is to highlight that a wrong conception as of 'mere abstractly-elaborate apriorising/axiomatising/referencing' is not truly existential-<disontologising/re-ontologising aporeticism> as of the 'full incipient supererogating breadth of human intelligibility transmutation' exuding '<supereregatory human-subpotency $>$-effecting imbued epistemic-totalising preformulating/preframing/premeaningfulness of notional originariness-parrhesia,--asspontaneity-of-aestheticisation' before the incipience of metaphoricity ${ }^{57}$ and then meaningfulness-and-teleology 9 as to existentialising-frame-of-entailment-of motif-andapriorising/axiomatising/referencing; and so as a wrong conception as of 'mere abstractlyelaborate apriorising/axiomatising/referencing' fails to reflect that relative-ontological- 
completeness $^{87}$-of-apriorising/axiomatising/referencing is rather effectively underlied as of: the-human/humanity 'recurrently mediative-<in-expectation/in-anticipation> unconsciousness/potentiation-of-conscionability-<anxiety-as-to-reconstitution/reparation,including-dreaming/psychical-reshuffling>' (as the 'psychoanalytic boundlessness of human notional $\sim$ reflexivity- $<\{$ veridical/sound $\}$-relative-reflexivity-in-existence $/$ relativising fromlimited-mentation-as-its-deepening/psychologismic-<residualising ${ }^{\text {\{decompulsing }}$ \} delinearity-foreogency>-by-\{flawed/unsound\}-relative-unreflexivity-in-existence/absolutising fromlimited-mentation/psychologismic epistemic acutisation nonresidualising imbuedfompulsingllinearity in-eclecticism-of-prior-mere-formulaicity/ritualisation> existential$<$ disontologising/re-ontologising aporeticism $>$ backdrop' elicitable/exuding as of subconsciousness knowingly/unknowingly-manifest human ontological-goodfaith/authenticity ${ }^{6} \sim$ postconverging-de-mentating/structuring/paradigming 7 - by — ontological-bad-faith/inauthenticity $\sim$ preconverging-de-mentating/structuring/paradigming ${ }^{65}$ ) as so-potentiating 'human subconsciousness as backdrop-for-the-Lacanian-real enabling the effective formativeness-<as-to-intersolipsism-ofpreformulating/preframing/premeaningfulness-imbued-mediativity-and-deferentialism>-ofmeaningfulness-and-teleology of consciousness surrealising-<as-to-supererogation ${ }^{>}{ }^{\prime}$ (as so-manifested with human subconsciousness most-prospectively-conscious 're-ontologisingby-disontologising_existential-calculus-〈between 'prospective existentialisingpostconverging_framing/imprinting re-ontologising' and 'prior existentialising preconverging_enframing/imprintedness social-functioning-and-accordance-as-of-socialstake-contention-or-confliction' $\rangle$ ' of consciousness surrealising-<as-to-supererogation $>$ ). The critical point being made here is that human mental-aestheticising-<as-'psychologismicexistential-metaphoricity \{as-to-fepistemic referencing_in-becoming? ' -so-implicited-'by-way-of-the-existentially/contextually/textually- 
manifest-motif-construct-as-specific-language'-as-so-reflecting-'the-

existentially/contextually/textually-manifest-moronisation/demoronisation'> (whether 'mentalaestheticising_as_of_aestheticisation- $<$ as-to-motif $>$ as-merely-reflecting-of-the-backdrop-of aestheticisation-towards-ontology-<as-to-apriorising/axiomatising/referencing $>$ ' with regards to the artistic/aesthetical or 'mental-aestheticising_as_of_aestheticisation-<as-to-motif $>$ as-for aestheticisation-towards-ontology-<as-to-apriorising/axiomatising/referencing $>$ ' with regards to disontologising/ontologising), speaks to the fact that appropriate psychologismic-epistemicacutisation-<as-to-postconverging-de-mentating/structuring/paradigming,-eliciting-ofexistence's-sublimating-nascence-in-prospective-aporeticism-overcoming/unovercoming> (acting as 'postconverging-de-mentating/structuring/paradigming reference for requisite psychoanalytic-unshackling of the relative-ontological-incompleteness ${ }^{8}$-ofapriorising/axiomatising/referencing') is rather 'projectively/affirmatively prompted as the superseding placeholder-setup/mental-devising-representation/mentation/consciousnessawareness-teleology of the relative-ontological-completeness ${ }^{8}$-ofapriorising/axiomatising/referencing' existentially- $<$ disontologising/re-ontologising aporeticism $>$ (as rather reflecting limitedness/human-subpotency prospective reencountering/re-confrontation with the 'constraining/defining intersolipsistic reflexivesublimating/unreflexive-desublimating measure/objectification that is unlimitedness/existenceas-ontological-normalcy/postconvergence-<in-validation-of-'metaphysics-ofabsence_epistemic-projection'>'); such that the relative-ontological-completeness ${ }^{87}$-ofapriorising/axiomatising/referencing concomitantly reflects existentially-<disontologising/reentologising apereticism $>$ its imbued 'notional difference-conflatedness ${ }^{13}$-as-to-totalitativereification-in-singularisation-<as-to-the-nondisjointedness/entailment-of-prospectivenonpresencing $>$-as-veridical-epistemicity-relativism-determinism construable as from the given projected relative-ontological-completeness ${ }^{87}$-of-apriorising/axiomatising/referencing' 
as 'postconverging-de-mentating/structuring/paradigming reference for requisite psychoanalytic-unshackling of the relative-ontological-incompleteness ${ }^{8}$-ofapriorising/axiomatising/referencing'. The idea here is that in effect the mental-aestheticising-

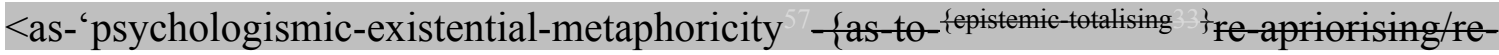
axiomatising/re-referencing_in becoming?' -so-implicited-'by-way-of-theexistentially/contextually/textually-manifest-motif-construct-as-specific-language'-as-soreflecting-'the-existentially/contextually/textually-manifest-moronisation/demoronisation'> of the 'relative-ontological-completeness ${ }^{87}$-of-apriorising/axiomatising/referencing psychologismic-epistemic-acutisation-<as-to-postconverging-dementating/structuring/paradigming,-eliciting-of-existence's-sublimating-nascence-inprospective-aporeticism-overcoming/unovercoming $>$ as superseding placeholder-setup/mentaldevising-representation/mentation/consciousness-awareness-teleology ${ }^{\circ}$ never actually represent the 'inherent relative-ontological-incompleteness ${ }^{8}$-ofapriorising/axiomatising/referencing superseded placeholder-setup/mental-devisingrepresentation/mentation/consciousness-awareness-teleology 99 as to the latter's imaginable inherent mental-aestheticising-<as-'psychologismic-existential-metaphoricity $\{$ as-to-\{epistemic-

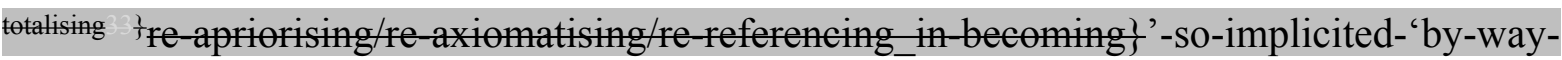
of-the-existentially/contextually/textually-manifest-motif-construct-as-specific-language'-asso-reflecting-'the-existentially/contextually/textually-manifestmoronisation/demoronisation'>'. Rather the 'relative-ontological-completeness ${ }^{87}$-ofapriorising/axiomatising/referencing psychologismic-epistemic-acutisation-<as-topostconverging-de-mentating/structuring/paradigming,-eliciting-of-existence's-sublimatingnascence-in-prospective-aporeticism-overcoming/unovercoming $>$ as superseding placeholdersetup/mental-devising-representation/mentation/consciousness-awareness-teleology ${ }^{9}$, projectively/affirmatively prompts concomitantly its very own 'notional difference- 
conflatedness $^{13}$-as-to-totalitative-reification-in-singularisation- $<$ as-to-thenondisjointedness/entailment-of-prospective- nonpresencing $>$-as-veridical-epistemicityrelativism-determinism construable as from its given projected relative-ontologicalcompleteness ${ }^{87}$-of-apriorising/axiomatising/referencing' in order to represent the relativeontological-incompleteness ${ }^{8}$-of-apriorising/axiomatising/referencing while foregoing of the 'mental-aestheticising-<as-'psychologismic-existential-metaphoricity $\{$ as-to-\{epistemictotalising '’re-apriorising/re-axiomatising/re-referencing_in-becoming?' -so-implicited-'by-wayof-the-existentially/contextually/textually-manifest-motif-construct-as-specific-language'-asso-reflecting-'the-existentially/contextually/textually-manifest-moronisation/demoronisation’> of the relative-ontological-incompleteness ${ }^{8}$-of-apriorising/axiomatising/referencing'; somanifested as 'mental-aestheticising-<as-'psychologismic-existential-metaphoricity \{as-to\{epistemic-totalising 're-apriorising/re-axiomatising/re-referencing_in becoming\}' 'so-implicited'by-way-of-the-existentially/contextually/textually-manifest-motif-construct-as-specificlanguage'-as-so-reflecting-'the-existentially/contextually/textually-manifestmoronisation/demoronisation'> of the relative-ontological-completeness ${ }^{87}$-ofapriorising/axiomatising/referencing' projectively/affirmatively prompted 'notional differenceconflatedness $^{13}$-as-to-totalitative-reification-in-singularisation- $<$ as-to-thenondisjointedness/entailment-of-prospective- nonpresencing $>$-as-veridical-epistemicityrelativism-determinism construable as from its very own projected relative-ontologicalcompleteness ${ }^{87}$-of-apriorising/axiomatising/referencing' and so for the purpose of 'effectively reflecting the relative-ontological-incompleteness ${ }^{8}$-of-apriorising/axiomatising/referencing

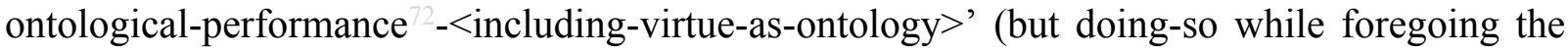
inherent mental-aestheticising-<as-'psychologismic-existential-metaphoricity $\underset{\text { fas }}{\text { to }}$ \{epistemic-

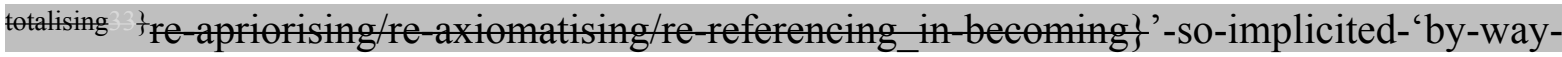
of-the-existentially/contextually/textually-manifest-motif-construct-as-specific-language'-as- 
of the relative-ontological-incompleteness ${ }^{8}$-of-apriorising/axiomatising/referencing, as can be appreciated by the fact that we can construe of a non-positivising social-setup deficient nonpositivising ${ }^{5}$ meaningfulness-and-teleology ${ }^{9}$ from a positivising mental-projection while not representing the non-positivising 'mentally-aestheticised preconverging/dementing ${ }^{20}$-qualiaschema reflected moronisation- $<$ sublimating-nascence,-extrieatery-desublimatingdownstreaming/'avalage'>' manifested in the non-positivising social-setup). This is the case not only with regards to Being-development/ontological-framework-expansion-as-to-depth-ofontologising-development-as-infrastructure-of- meaningfulness-and-teleology psychologismic epistemic-acutisation difficulty-<for, residualising \{decompulsing delinearity for-cogeney>-magnitude ${ }^{\text {\{of-experientiality/experiment }\}}$ as with the above elucidation but also applies with institutional-development-as-to-social-function-development and living-development-as-to-personality-development psychologismic epistemic-

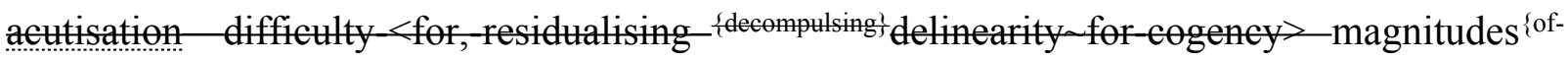
experientiality/experiment\}. This insight, points out that human ${ }^{56}$ meaningfulness-and-teleology ${ }^{99}$ is adduced as of the 'notional difference-conflatedness ${ }^{13}$-as-to-totalitative-reification-insingularisation-<as-to-the-nondisjointedness/entailment-of-prospective- nonpresencing $>$-asveridical-epistemicity-relativism-determinism construable as from the given projected relativeontological-completeness ${ }^{87}$-of-apriorising/axiomatising/referencing' as to the 'notional/epistemic/bindingness-sas-determinism/conneptivity-of-relative-mreflexivity/relative-reflexivitys developing of the given relative-ontological-completeness ${ }^{87}$-ofapriorising/axiomatising/referencing ${ }^{56}$ meaningfulness-and-teleology ${ }^{99}$ mental-aestheticising<as-'psychologismic-existential-metaphoricity fas to fepistemic-totalising axiomatising/re-referencing_in-becoming\}' -so-implicited-'by-way-of-theexistentially/contextually/textually-manifest-motif-construct-as-specific-language'-as-so- 
reflecting-'the-existentially/contextually/textually-manifest-moronisation/demoronisation'>' .

Further implying that the idea of past 'relative-ontological-incompleteness ${ }^{8}$-ofapriorising/axiomatising/referencing of ${ }^{5}$ meaningfulness-and-teleology ${ }^{9}$ ' is already caught-up in the present 'notional difference-conflatedness ${ }^{13}$-as-to-totalitative-reification-insingularisation-<as-to-the-nondisjointedness/entailment-of-prospective- nonpresencing $>$-asveridical-epistemicity-relativism-determinism construable as from the present projected relative-ontological-completeness ${ }^{8}$-of-apriorising/axiomatising/referencing imbued meaningfulness-and-teleology $\quad$ mental-aestheticising-<as-'psychologismic-existentialmetaphoricity \{as-to-\{epistemic-talising łre-apriorising/re-axiomatising/re-referencing_inbecoming? '-so-implicited-'by-way-of-the-existentially/contextually/textually-manifest-motifconstruct-as-specific-language'-as-so-reflecting-'the-existentially/contextually/textuallymanifest-moronisation/demoronisation'>' (and so-effectively reflected as of the 'present mental-aestheticising-<as-'psychologismic-existential-metaphoricity \{as-to-\{epistemictre-apriorising/re-axiomatising/re-referencing_in-becoming? '’-so-implicited- 'by-wayof-the-existentially/contextually/textually-manifest-motif-construct-as-specific-language'-asso-reflecting- 'the-existentially/contextually/textually-manifest-moronisation/demoronisation'> mutable placeholder-setup/mental-devising-representation/mentation/consciousness-awarenessteleology '). And reiterated as to the veridical existential-<disontologising/re-ontelogising aporeticism $>$ manifestation, this speaks to the given present relative-ontologicalcompleteness ${ }^{87}$-of-apriorising/axiomatising/referencing; as rather 'existentially<disontologising/re-ontologising aporeticism> understood-<as-epistemictotalisingly /acutely translating-into-the-mental-aestheticising-metaphoricity >' by its given _tnderlaid/substrated 'thrownness aestheticising' (of relative unreflexivity in existence\}> profusion-of preconverging prior-relative-ontological-incompleteness ${ }^{88}$-ofapriorising/axiomatising/referencing - by_<overlaying/superstrating 'thrownness- 
aestheticising' \{of-relative-reflexivity in-existence\} $>$-sparsity-of postconverging prospectiverelative-ontological-completeness ${ }^{8}$-of-apriorising/axiomatising/referencing as to underlying $<$ amplituding/formative-epistemicity $>$-totalising $\sim$ thrownness-in-existence mentalaestheticising-<as-'psychologismic-existential-metaphoricity \{as-to-\{epistemic-totalising †reapriorising/re-axiomatising/re-referencing_in-becoming?' -so-implicited-'by-way-of-theexistentially/contextually/textually-manifest-motif-construct-as-specific-language'-as-soreflecting-'the-existentially/contextually/textually-manifest-moronisation/demoronisation'> imbued re-ontologising-by-disontologising_existential-calculus-〈between 'prospective existentialising_-postconverging_framing/imprinting re-ontologising' and 'prior existentialising_ preconverging_enframing/imprintedness social-functioning-andaccordance-as-of-social-stake-contention-or-confliction' '’ (but not understood as of supposedly 'unlimitedness/existence-<full-potency-of_sublimating nascence $>$ absoluteontological-completeness-of-apriorising/axiomatising/referencing-<as-omnipotentiality $>$ $<$ amplituding/formative-epistemicity $>$-totalising $\sim$ thrownness-in-existence ${ }^{35}$ imbued absolute $\sim$ difference-conflatedness ${ }^{13}$-as-to-totalitative-reification-in-singularisation- $<$ as-to-thenondisjointedness/entailment-of-prospective- nonpresencing > -as-veridical-epistemicityrelativism-determinism so-construed as 'absolute reference of identity' as failing to project of its own possible prospective relative-ontological-incompleteness ${ }^{8}$-ofapriorising/axiomatising/referencing). This is effectively what notionally/epistemically/bindingnessly-<as-to-determinism/conceptivity-of-relative-unreflexivity/relative-reflexivity $>$ warrants a $\quad{ }^{6}$ nonpresencing-<perspective-ontological-normalcy/postconvergence $>$ relativism/relative-scope for epistemic-growth,-as - \{veridical/sound\}-relative-reflexivity-inexistence/relativising from-limited-mentation-as-its-deepening/psychologismic epistemicacutisation residualising, the can grasp of human sublimating 'mental-aestheticising-<as-'psychologismic-existential-metaphoricity $\{$ as-to- 
‘by-way-of-the-existentially/contextually/textually-manifest-motif-construct-as-specificlanguage'-as-so-reflecting-'the-existentially/contextually/textually-manifestmoronisation/demoronisation'> as to limited-mentation-capacity-deepening-as-subjecting limitedness/human-subpotency-to-'educed-unlimitedness/existence-sublimating nascence' ${ }^{5}$, (as to limitedness/human-subpotency prospective re-encountering/re-confrontation with the 'constraining/defining intersolipsistic reflexive-sublimating/unreflexive-desublimating measure/objectification that is unlimitedness/existence-as-ontologicalnormalcy/postconvergence-<in-validation-of-'metaphysics-of-absence_epistemic-

projection'>'); and so, as 'existentially-<disontologising/re-ontologising aporeticism $>$ understood-<as-epistemic-totalisingly /acutely_translating-into-the-mental-aestheticisingmetaphoricity >' by the given < underlaid/substrated 'thrownness-aestheticising' \{of relativeunreflexivity in-existence $>>$ profusion-of preconverging-prior-relative-ontologicalincompleteness ${ }^{8}$-of-apriorising/axiomatising/referencing_-by_ < overlaying/superstrating'thrownness-aestheticising' \{of-relative-reflexivity-in-existence\} $>$-sparsity-ofpostconverging prospective-relative-ontological-completeness ${ }^{8}$-ofapriorising/axiomatising/referencing as to underlying <amplituding/formative-epistemicity >totalising $\sim$ thrownness-in-existence ${ }^{5} \quad$ mental-aestheticising-<as-'psychologismic-existentialmetaphoricity \{as-to-\{epistemic-totalising \}re-apriorising/re-axiomatising/re-referencing_inbecoming?' -so-implicited-'by-way-of-the-existentially/contextually/textually-manifest-motifconstruct-as-specific-language'-as-so-reflecting-'the-existentially/contextually/textuallymanifest-moronisation/demoronisation'> traces of \{epistemic-totalising 33 're-apriorising/reaxiomatising-residuality-in-re-originariness/re-origination (as so-reflecting the mental-aestheticising-<as-'psychologismic-existential-metaphoricity fas-to-\{epistemictotalising '’re-apriorising/re-axiomatising/re-referencing_in-becoming\}' -so-implicited-'by-way- 
successions of relative-ontological-completeness ${ }^{87}$-of-apriorising/axiomatising/referencing as to an 'epistemic-growth,-as - \{veridical/sound\}-relative-reflexivity-in-existence/relativising from-limited-mentation-as-its-deepening/psychologismic epistemic acutisation-

residualising, ${ }^{\{\text {decompulsing }}$ delinearity for-cogeney notional difference-conflatedness ${ }^{13}$-as-tototalitative-reification-in-singularisation-<as-to-the-nondisjointedness/entailment-ofprospective- nonpresencing $>$-as-veridical-epistemicity-relativism-determinism ${ }^{2}$ imbued 'apriorising/axiomatising/referencing disambiguating/de-leveling/de-ressentiment/openedconstruct-of- $-{ }^{56}$ meaningfulness-and-teleology $\quad$ demoronisation- $<$ sublimating-nascence,nonextricatory-sublimating-upstreaming/‘amontée’’’).

This notionally/epistemically/bindingnessly-<as-to-determinism/conceptivity-of-relative-unreflexivity/relative-reflexivity $>$ contrasts with a ${ }^{7}$ presencing-absolutising-identitive-constitutedness ${ }^{14}$ absolution/absolutescope \{flawed/unsound\}-relative-unreflexivity-in-existence/absolutising from-limitedmentation/psychologismic epistemic acutisation nonresidualising imbued\{compulsing linearity-in-eclecticism-of prior-mere-formulaicity/ritualisation conception' bound to absolutise the 'mental-aestheticising-<as-'psychologismic-existential-metaphoricity fas to \{epistemic-totalising 're-apriorising/re-axiomatising/re-referencing_in-becoming\}' -so-implicited‘by-way-of-the-existentially/contextually/textually-manifest-motif-construct-as-specificlanguage'-as-so-reflecting-'the-existentially/contextually/textually-manifestmoronisation/demoronisation'> of its prospectively given relative-ontologicalincompleteness ${ }^{8}$-of-apriorising/axiomatising/referencing that wrongly projects of a naïve conception as of 'mere abstractly-elaborate apriorising/axiomatising/referencing' failing to grasp that it is rather 'existentially-<isontologising/re-ontologising aporeticism $>$ understood$<$ as-epistemic-totalisingly /acutely_translating-into-the-mental-aestheticising- 
metaphoricity >' by the given < underlaid/substrated-'thrownness-aestheticising'- fof-relativeunreflexivity in-existence\}> profusion-of preconverging prior-relative-ontologicalincompleteness ${ }^{8}$-of-apriorising/axiomatising/referencing — by — < overlaying/superstrating 'thrownness-aestheticising' \{of relative-reflexivity in-existence\}>-sparsity-ofpostconverging prospective-relative-ontological-completeness ${ }^{87}$-ofapriorising/axiomatising/referencing as to underlying <amplituding/formative-epistemicity >totalising thrownness-in-existence ${ }^{5} \quad$ mental-aestheticising-<as-" psychologismic-existentialmetaphoricity fas-to-fepistemic talising $\}_{\text {re }}$ apriorising/re-axiomatising/re-referencing_inbecoming?' 'so-implicited-'by-way-of-the-existentially/contextually/textually-manifest-motifconstruct-as-specific-language'-as-so-reflecting-'the-existentially/contextually/textuallymanifest-moronisation/demoronisation'> traces of \{epistemic-totalising ${ }^{3}$ re-apriorising/reaxiomatising/re-referencing - residuality-in-re-originariness/re-origination; as wrongly impliciting that it is in-effect of 'unlimitedness/existence-<full-potency-of_sublimating nascence $>\quad$ absolute-ontological-completeness-of-apriorising/axiomatising/referencing- $<$ asomnipotentiality $><$ amplituding/formative-epistemicity $>$-totalising $\sim$ thrownness-in-existence ${ }^{5}$, imbued absolute difference-conflatedness $^{13}$-as-to-totalitative-reification-in-singularisation$<$ as-to-the-nondisjointedness/entailment-of-prospective- nonpresencing $>$-as-veridicalepistemicity-relativism-determinism so-construed as 'absolute reference of identity' as failing to project of its 'own possible prospective relative-ontological-incompleteness ${ }^{8}$-ofapriorising/axiomatising/referencing', thus leading to human desublimating ${ }^{47}$ historicitytracing - in-presencing-hyperrealisation/hyperreal-transposition as to the consequently implied 'apriorising/axiomatising/referencing—equating/leveling/ressentiment/closed-construct-ofmeaningfulness-and-teleology 9 moronisation-<sublimating-nascence,-ex desublimating-downstreaming/'avalage'>' which is bound to induce blurriness$<$ sterilising/anecdotalising/trivialising-of-prospective-re-ontologising_by-preconverging,-in- 
disontologising-formulaic-dragging-out/hollowing-out>; and hence not reflecting an 'epistemic-growth,-as_ \{veridical/sound\}-relative-reflexivity-in-existence/relativising fromlimited-mentation-as-its-deepening/psychologismic epistemic-acutisation residualising, ${ }_{\{\text {decompulsing }}$ delinearity for-cogency notional difference-conflatedness ${ }^{13}$-as-to-totalitativereification-in-singularisation-<as-to-the-nondisjointedness/entailment-of-prospectivenonpresencing $>$-as-veridical-epistemicity-relativism-determinism '. In-the-bigger-schemeof-things, the succession of relative-ontological-completeness ${ }^{8}$-ofapriorising/axiomatising/referencing (as 'existentially-disontologising/re-ontologising aporeticism $>$ understood-<as-epistemic-totalisingly /acutely_translating-into-the-mentalaestheticising-metaphoricity $>$ ' by their given sunderlaid/substrated-'thrownnessaestheticising' \{of-relative-unreflexivity in-existence\}> profusion-of preconverging priorrelative-ontological-incompleteness ${ }^{8}$-of-apriorising/axiomatising/referencing-by<overlaying/superstrating-'thrownness-aestheticising' \{of-relative-reflexivity in-existence\}> sparsity-of postconverging prospective-relative-ontological-completeness ${ }^{87}$-ofapriorising/axiomatising/referencing as to underlying <amplituding/formative-epistemicity >totalising $\sim$ thrownness-in-existence ${ }^{35} \quad$ mental-aestheticising-<as-'psychologismic-existential-

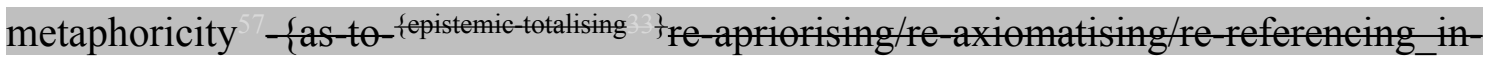
becoming? '-so-implicited-'by-way-of-the-existentially/contextually/textually-manifest-motifconstruct-as-specific-language'-as-so-reflecting-'the-existentially/contextually/textuallymanifest-moronisation/demoronisation'> traces of $>$ re-apriorising/reaxiomatising/re-referencing - residuality-in-re-originariness/re-origination) so-enabling human sublimating-postconverged 'substantive abstract-tissue-of-social-emanance fepistemictotalising $3{ }^{3}$ hermeneutically/textlly/reprojectingly/supererogatingly/zeroing/y/re acutingly,$\{$ decompulsing $\}$ delinearity for-cogency—cumulated/recomposured as to cumulating/recomposuring of 'prospectively_implicited_attendant-ontological-contiguity ${ }^{67}$;educed- 
existentialising/contextualising/textualising_intelligibility/epistemicity/reflexivity-contiguity$<$ imbued-notional cogency $>^{\prime}$, is the effective manifestation of the 'cumulating/recomposuring prospective appraisal/reappraisal of human relative-ontologicalcompleteness ${ }^{87}$-of-apriorising/axiomatising/referencing' (as to varying 'human notional difference-conflatedness ${ }^{13}$-as-to-totalitative-reification-in-singularisation- $<$ as-to-thenondisjointedness/entailment-of-prospective- nonpresencing > -as-veridical-epistemicityrelativism-determinism construable as from the given projected relative-ontologicalcompleteness ${ }^{87}$-of-apriorising/axiomatising/referencing'). Such relative-ontologicalcompleteness ${ }^{87}$-of-apriorising/axiomatising/referencing (as rather 'existentially$\leq$ disontologising/re-ontologising aporeticism $>$ understood-<as-epistemictotalisingly /acutely translating-into-the-mental-aestheticising-metaphoricity >' by its given <underlaid/substrated-'thrownness-aestheticising' \{of-relative-unreflexivity in-existence\}> profusion-of preconverging-prior-relative-ontological-incompleteness ${ }^{88}$-ofapriorising/axiomatising/referencing - by—<overlaying/superstrating 'thrownnessaestheticising' \{of-relative-reflexivity in-existence\}>-sparsity-of postconverging prospectiverelative-ontological-completeness ${ }^{8}$-of-apriorising/axiomatising/referencing as to underlying $<$ amplituding formative-epistemicity $>$-totalising $\sim$ thrownness-in-existence ${ }^{35} \quad$ mentalaestheticising-<as-'psychologismic-existential-metaphoricity \{as-to-\{epistemic-totalising ${ }^{\prime}$ reapriorising/re-axiomatising/re-referencing_in-becoming?' -so-implicited-'by-way-of-theexistentially/contextually/textually-manifest-motif-construct-as-specific-language'-as-soreflecting-'the-existentially/contextually/textually-manifest-moronisation/demoronisation'> imbued re-ontologising-by-disontologising_existential-calculus-〈between 'prospective existentialising_-postconverging_framing/imprinting re-ontologising' and 'prior existentialising_ preconverging_enframing/imprintedness social-functioning-andaccordance-as-of-social-stake-contention-or-confliction'〉') 
directly/indirectly by both the 'overall < underlaid/substrated-'thrownness-aestheticising' fofrelative-unreflexivity in-existence $\}>$ profusion-of preconverging prior-relative-ontologicalincompleteness ${ }^{8}$-of-apriorising/axiomatising/referencing conceptions' and 'overall associated soverlaying/superstrating 'thrownness-aestheticising' \{of-relative-reflexivity in-existence\}> sparsity-of-postconverging-prospective-relative-ontological-completeness ${ }^{87}$-ofapriorising/axiomatising/referencing conceptions' (whether perceived as sound/unsound/obsolete/superficial/profound/etc. as to the 'initial mentallyaestheticised $\sim$ preconverging/dementing ${ }^{20}$-qualia-schema reflected moronisation- $<$ sublimating nascence,-extricatory-desublimating-downstreaming/'avalage'>' or the 'subsequent mentallyaestheticised postconverging/dialectical-thinking - qualia-schema reflected demoronisation<sublimating-nascence,-nonextricatory-sublimating-upstreaming/'amontée’>’, and soreflected for instance respectively with the 'initial shipbuilding and other ocean voyage technologies at the service of the prior medievally clouded immaterial/social overall relativeontological-incompleteness ${ }^{8}$-presublimation-construct-of- ${ }^{56}$ meaningfulness-and-teleology value-construct and shallow-supererogating methodologising/mutualising/organising/institutionalising' and the 'subsequent veridically comprehensive and complete sublimating-nascence of technical and scientific progress of shipbuilding and other ocean voyage technologies rather came into their full realisation as to a healthy global commercial relations these enabled over their initial pirating, warring and exploitative dehumanising pursuits'); as so-underlying epistemic-totalisingly ${ }^{33} /$ acutely the mental-aestheticising-<as-'psychologismic-existential-metaphoricity $\{$ as-to-fepistemictotalising '̀re apriorising/re axiomatising/re referencing_in becomingl' '-so-implicited-‘by-wayof-the-existentially/contextually/textually-manifest-motif-construct-as-specific-language'-asso-reflecting-'the-existentially/contextually/textually-manifest-moronisation/demoronisation'> 
of the given relative-ontological-completeness ${ }^{87}$-of-apriorising/axiomatising/referencing as to its overarching epochal/societal/institutional/milieu existentialising-frame-of-entailment-ofmotif-and-apriorising/axiomatising/referencing enabling of its prospective metaphoricity ${ }^{57}$. The implication here (as to human placeholder-setup/mental-devisingrepresentation/mentation/consciousness-awareness-teleology 99 imbued mental-aestheticising-

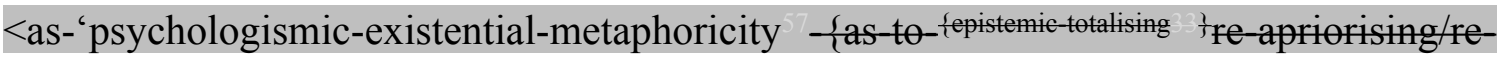
axiomatising/re-referencing_in_becoming? '-so-implicited-'by-way-of-theexistentially/contextually/textually-manifest-motif-construct-as-specific-language'-as-soreflecting- 'the-existentially/contextually/textually-manifest-moronisation/demoronisation'>) is that the 'very same soverlaying/superstrating 'thrownness-aestheticising' fof relativereflexivity in-existence\}>-sparsity-of-postconverging prospective-relative-ontologicalcompleteness ${ }^{87}$-of-apriorising/axiomatising/referencing specific conception' end up having varying/different existential<<disontologising/re-ontologising aporeticism $>$ consequences as to mental-aestheticising-<as-'psychologismic-existential-metaphoricity \{as-totratising 're-apriorising/re-axiomatising/re-referencing_in-becoming?'’-so-implicited-'by-wayof-the-existentially/contextually/textually-manifest-motif-construct-as-specific-language'-asso-reflecting-'the-existentially/contextually/textually-manifest-moronisation/demoronisation'> across the succession of overarching epochal/societal/institutional/milieu existentialisingframe-of-entailment-of motif-and-apriorising/axiomatising/referencing enabling of its prospective metaphoricity ${ }^{57}$. This is critically the case because in reality the 'mere <overlaying/superstrating 'thrownness-aestheticising' \{of relative-reflexivity in-existence\}> sparsity-of postconverging prospective-relative-ontological-completeness ${ }^{87}$-ofapriorising/axiomatising/referencing specific conception' is not the existential<disontologising/re-ontologising aporeticism> meaningfulness-and-teleology $\quad$ (soconstruable wrongly as to a naïve 'mere abstractly-elaborate 
apriorising/axiomatising/referencing'); but rather the existential-<disontologising/reentologising aporeticism $>{ }^{56}$ meaningfulness-and-teleology' attributable to the 'mere soverlaying/superstrating 'thrownness-aestheticising' \{of-relative-reflexivity in-existence\} $>$ sparsity-of postconverging prospective-relative-ontological-completeness ${ }^{87}$-ofapriorising/axiomatising/referencing specific conception' is captured in the mentalaestheticising-<as-'psychologismic-existential-metaphoricity \{as-to-\{epistemic-totalising ${ }^{\text {fre- }}$ apriorising/re-axiomatising/re-referencing_in-becoming?' -so-implicited-'by-way-of-theexistentially/contextually/textually-manifest-motif-construct-as-specific-language'-as-soreflecting-'the-existentially/contextually/textually-manifest-moronisation/demoronisation'> it reflects the 'soverlaying/superstrating 'thrownness-aestheticising'-\{of-relative-reflexivity in-existence $\}>$-sparsity-of postconverging-prospective-relative-ontological-completeness ${ }^{87}$ of-apriorising/axiomatising/referencing specific conception' as rather being 'existentially<disontologising/re-ontologising aporeticism> encircled/bordered/influenced directly/indirectly by both the 'overall < underlaid/substrated-thrownness-aestheticising' fofrelative-unreflexivity in-existence $\}>$ profusion-of preconverging prior-relative-ontologicalincompleteness ${ }^{8}$-of-apriorising/axiomatising/referencing conceptions' and 'overall associated soverlaying/superstrating 'thrownness aestheticising' (of relative reflexivity in-existence\}> sparsity-of-postconverging prospective-relative-ontological-completeness ${ }^{87}$-ofapriorising/axiomatising/referencing conceptions'. This reality is underlined by the fact that even budding practitioners of science like Newton were caught up preconverging/postconverging-dementatively/structurally/paradigmatically in-between/in-transition-with a medieval alchemy and occultism as to non-positivising reference-of-thought- ${ }^{8}$ devolving apriorising/axiomatising/referencing-\{of-'prospectively implieited_attendant-ontologicalcontiguity ' educedexistentialising/contextualising/textualising_intelligibility/epistemicity/reflexivity_contiguity- 
<imbued-notional cogency>' $\quad$-relation-to-the-world and the prospective budding positivism/rational-empiricism science reference-of-thought- ${ }^{8}$ devolving apriorising/axiomatising/referencing-\{ of-'prospectively implicited_attendant-ontologicalcontiguity ' educedexistentialising/contextualising/textualising_'intelligibility/epistemicity/reflexivity-contiguity<imbued-notional cogency >' $\quad\}$-relation-to-the-world. Along the same lines in-many-ways a conception as of the 'mere soverlaying/superstrating 'thrownness-aestheticising' fof-relativereflexivity in-existence\}>-sparsity-of-postconverging prospective-relative-ontologicalcompleteness ${ }^{87}$-of-apriorising/axiomatising/referencing specific conception' is not the existential-<disontologising/re-ontologising aporeticism $>{ }^{56}$ meaningfulness-and-teleology (so-construable wrongly as to a naïve 'mere abstractly-elaborate apriorising/axiomatising/referencing') tends to be even more misleading with regards to the social domain. It is herein contended that such a naïve focussing on 'mere referring, mentioning and synonymisation of concepts and conceptualisations mere_apriorising/axiomatising/referencing of hardly any prospective profound existential<disontologising/re-ontologising aporeticism $>$ implications but for institutionalprescience/imprimaturing-dullness of the spirit/psychologismic epistemic acutisation nonresidualising-imbued-\{compulsing\}'finearity-in-eclecticism-of prior-mereformulaicity/ritualisation ${ }^{\prime}$ in the social domain is critically central to the tendency for a disparateness-of-conceptualisation-<unforegrounding-ment,-failing-prospectively-to-reflect‘immanent relative-unreflexivity/relative-reflexivity - ontological-contiguity 'apriorising/axiomatising/referencing_equating/leveling/ressentiment/closed-construct-ofmeaningfulness-and-teleology 99 desublimating-downstreaming/'avalage'>' which is bound to induce blurriness$<$ sterilising/anecdotalising/trivialising-of-prospective-re-ontologising_by-preconverging,-in- 
disontologising-formulaic-dragging-out/hollowing-out $>$. In this regards, it is further contended herein for instance that in-many-ways the prospective " $<$ overlaying/superstrating 'thrownnessaestheticising' \{of relative-reflexivity in-existence\}>-sparsity-of postconverging prospectiverelative-ontological-completeness ${ }^{8}$-of-apriorising/axiomatising/referencing specific conception' of Sartrean thought (as to its incipient/seeding ${ }^{103}$ universalising re-orientation as to its imbued 'mentally-aestheticised postconverging/dialectical-thinking -qualia-schema reflected demoronisation-<sublimating-nascence,-nonextricatory-sublimatingupstreaming/'amontée'>' beyond Heideggerien thought implications of thrownness as to the latter's 'specific tradition constraint/restriction') is critically what paved the way to postmodern thought ${ }^{103}$ universalising implications as so-reflected by the incipient/seeding existential<isontologising/re-ontologising aporeticism $>{ }^{103}$ universalising entailment implications of Sartrean thought' more profoundly developed in latter postmodern thinkers (even as many of such postmodern thinkers by a naïve focussing on 'mere referring, mentioning and synonymisation of concepts and conceptualisations mere_apriorising/axiomatising/referencing of hardly any prospective profound existential-<disontologising/re-ontologising aporeticism $>$ implications but for institutional-prescience/imprimaturing-<dullness-of-thespirit/psychologismic epistemic acutisation nonresidualising imbued-\{compulsing ${ }^{\prime}$ linearity in eclecticism-of prior-mere-formulaicity/ritualisation $>$ ' will come to overlook the more central and prospective possibility enabled by Sartrean thought explicited ${ }^{103}$ universalising reorientation of Heideggerian thought implications of thrownness). Even then it is further contended herein that such a 'ridiculous circularity of misconstruing in the social' (arising as of such 'apriorising/axiomatising/referencing — equating/leveling/ressentiment/closed-constructof- ${ }^{56}$ meaningfulness-and-teleology $\quad$ moronisation- $<$ sublimating-nascence,-extrica desublimating-downstreaming/'avalage'>' which is bound to induce blurriness$<$ sterilising/anecdotalising/trivialising-of-prospective-re-ontologising_by-preconverging,-in- 
disontologising-formulaic-dragging-out/hollowing-out>), is such that even such latter thinkers (whose thought is even much more profound) come to be naively analysed from the much less profound prior thought as to a flawed institutional-prescience/imprimaturing-<dullness-of thespirit/psychologismic epistemic acutisation nonresidualising imbued-\{compulsing\}linearity ineclecticism-of prior-mere-formulaicity/ritualisation $>$ stake driven conception of knowledge (that fails to factor in the patent veracity that such prior thinkers thought is instigated within a poorer 'overall < underlaid/substrated-'thrownness-aestheticising' \{of-relative-unreflexivity inexistence $\}>$ profusion-of preconverging prior-relative-ontological-incompleteness ${ }^{8}$-ofapriorising/axiomatising/referencing conceptions' which the latter thinkers are better placed to elucidate as of the 'cumulating/recomposuring prospective appraisal/reappraisal of human relative-ontological-completeness ${ }^{8}$-of-apriorising/axiomatising/referencing' reflected in their more profound cumulated/recomposured 'overall soverlaying/superstrating 'thrownnessaestheticising' \{of-relative-reflexivity in-existence\}>-sparsity-of postconverging prospectiverelative-ontological-completeness ${ }^{8}$-of-apriorising/axiomatising/referencing conceptions'); and thus leading to a ${ }^{47}$ historicity-tracing-in-presencing-hyperrealisation/hyperreal-transposition conception as of 'apriorising/axiomatising/referencing — equating/leveling/ressentiment/closedconstruct-of- ${ }^{56}$ meaningfulness-and-teleology 9 moronisation- $<$ sublimating-nascence,extricatory-desublimating-downstreaming/'avalage'>'. The consequence of this blurriness$<$ sterilising/anecdotalising/trivialising-of-prospective-re-ontologising_by-preconverging,-indisontologising-formulaic-dragging-out/hollowing-out> is reflected in the prospective lost of requisite soverlaying/superstrating 'thrownness-aestheticising'- \{of relative-reflexivity inexistence $>>$-sparsity-of postconverging prospective-relative-ontological-completeness ${ }^{8}$-ofapriorising/axiomatising/referencing imbued 'psychologismic-epistemic-acutisation-<as-topostconverging-de-mentating/structuring/paradigming,-eliciting-of-existence's-sublimatingnascence-in-prospective-aporeticism-overcoming/unovercoming $>$ as to epistemic-growth,-as 
\{veridical/sound\}-relative-reflexivity-in-existence/relativising from-limited-mentation-as-itsdeepening/psychologismic epistemic acutisation residualising, ${ }^{\text {fdecompulsing }}$ delinearity for eogency' and so with respect to prospective transcendence-andsublimity/sublimation/supererogatory $\sim$ de-mentativity; as to the fact that critically the 'grander purpose' of all human thinking is rather to act as 'relays of human intemporal-individuation epistemic-projection radicalities $\sim$ in-chronicular/annalistic--cogency-<as-ofnotional $\sim$ protensivity $>$-〈as-to-limited-mentation-capacity-deepening —as-subjecting limitedness/human-subpotency-to-'educed-unlimitedness/existence-sublimating nascence' > so-construed as cogency_chronicularity/annality-of-relative-reflexivity,-as-to-profoundsupererogation, (with regards to limitedness/human-subpotency prospective reencountering/re-confrontation with the 'constraining/defining intersolipsistic reflexivesublimating/unreflexive-desublimating measure/objectification that is unlimitedness/existenceas-ontological-normalcy/postconvergence-<in-validation-of-'metaphysics-ofabsence_epistemic-projection'>'). It can be appreciated contrastively that the " nonpresencing$<$ perspective-ontological-normalcy/postconvergence $>$ relativism/relative-scope for epistemicgrowth,-as-\{veridical/sound\}-relative-reflexivity-in-existence/relativising from-limitedmentation-as-its-deepening/psychologismic epistemic acutisation residualising, delinearity for-cogeney' as implicitly manifested in the natural sciences undermines such a detrimental 'apriorising/axiomatising/referencingequating/leveling/ressentiment/closed-construct-of- ${ }^{5}$ meaningfulness-and-teleology moronisation-<sublimating-nascence,-extricatory-desublimating-downstreaming/'avalage' $>$ ' of $\leq$ underlaid/substrated 'thrownness-aestheticising' \{of-relative-unreflexivity in-existence $\}>$ profusion-of preconverging prior-relative-ontological-incompleteness ${ }^{8}$-ofapriorising/axiomatising/referencing and soverlaying/superstrating 'thrownnessaestheticising' \{of-relative-reflexivity in-existence $\}>$-sparsity-of-postconverging prospective- 
relative-ontological-completeness ${ }^{8}$-of-apriorising/axiomatising/referencing; wherein but for the overall epistemic-projection perspective of 'formativeness-<as-to-intersolipsism-ofpreformulating/preframing/premeaningfulness-imbued-mediativity-and-deferentialism>-of-

meaningfulness-and-teleology of training or introductory/background-articulation', it is hardly the case that contemporary physics or chemistry or biology will be analysed as of the 'same supposedly prospective states-of-the-art sublimation pedestal' with their past developments (more like claiming an apriorising equivalence between Newtonian physics and string theory, etc.). Such institutional-prescience reflexes manifested in social-and-institutionalframeworks-of - referencing/registering/decisioning as to lack of defined " nonpresencing$<$ perspective-ontological-normalcy/postconvergence $>$ relativism/relative-scope for epistemicgrowth,-as-\{veridical/sound\}-relative-reflexivity-in-existence/relativising from-limitedmentation-as-its-deepening/psychologismic epistemic-acutisation residualising, \{decompulsing $\}$ delinearity for-cogency' inevitably saps/embroils the prospect of construing of veridical $\quad$ prospective relative-ontological-completeness ${ }^{87}$-ofapriorising/axiomatising/referencing implications and in-many-ways underline the predisposition for the totalisingly-ing-discretion/whim-of-thought as to our modern-day manifestation of disparateness-of-conceptualisation-<unforegrounding-ment,-failingprospectively-to-reflect-'immanent relative- unreflexivity/relative-reflexivity - ontological-

contiguity '>. Thus the rule-of-thump for veridical conception of ${ }^{4}$ historiality/ontologicaleventfulness ${ }^{38}$ /ontological-aesthetic-tracing-<perspective-ontologicalnormalcy/postconvergence-reflected-'epistemicity-relativism-determinism'> rather lies with a thorough sense of the underlying 'crossgenerational notional firstnaturedness-formativenessas to enalising inkling drive or seeding misprising> mental-processing-parity for ontological-performance ${ }^{72}$-<including-virtue-as-ontology $>$ /morality/ethics/justice/etc.' of all sovereign humans as to the potentiation of sublimating-over-desublimating across all times 
which has to do with 'human ontological-good-faith/authenticity $\sim$ postconverging-dementating/structuring/paradigming — — by—ontological-bad-

faith/inauthenticity $\sim$ preconverging-de-mentating/structuring/paradigming' and so relative to the given station/locus of limitedness/human-subpotency <amplituding/formativeepistemicity $>$-totalising $\sim$ thrownness-in-existence ${ }^{35}$; in so-reflecting (as of " nonpresencing$<$ perspective-ontological-normalcy/postconvergence $>$ relativism/relative-scope for epistemicgrowth,-as-\{veridical/sound\}-relative-reflexivity-in-existence/relativising from-limitedmentation-as-its-deepening/psychologismic epistemic acutisation residualising, \{decomplsing delinearity for-cogency') the effective succession of relative-ontologicalcompleteness ${ }^{87}$-of-apriorising/axiomatising/referencing (as 'existentially-<disontologising/reentologising aporeticism $>$ understood-<as-epistemic-totalisingly /acutely_translating-intothe-mental-aestheticising-metaphoricity >’ by their given < underlaid/substrated-'thrownnessaestheticising' \{of-relative-unreflexivity in-existence\}>-profusion-of-preconverging-priorrelative-ontological-incompleteness ${ }^{8}$-of-apriorising/axiomatising/referencing-by<overlaying/superstrating 'thrownness-aestheticising' \{of relative-reflexivity in-existence $\}>$ sparsity-of postconverging prospective-relative-ontological-completeness ${ }^{87}$-of-

apriorising/axiomatising/referencing as to underlying <amplituding/formative-epistemicity >totalising $\sim$ thrownness-in-existence ${ }^{5} \quad$ mental-aestheticising-<as-'psychologismic-existential-

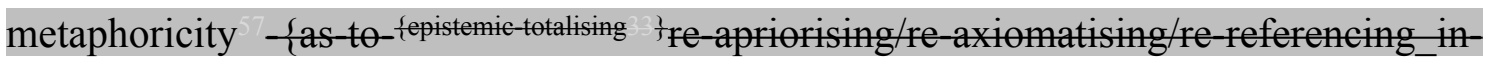
becoming?' -so-implicited-'by-way-of-the-existentially/contextually/textually-manifest-motifconstruct-as-specific-language'-as-so-reflecting-'the-existentially/contextually/textuallymanifest-moronisation/demoronisation'> traces of \{epistemic-totalising 33 3 re-apriorising/reaxiomatising/re referencing-residuality-in-re-originariness/re-origination). It is this veridically sound exercise that effectively reflects the fact that prospective historiality/ontological-eventfulness 3 /ontological-aesthetic-tracing-<perspective- 
reflection of the underlying contention herein with regards to prospective knowledge as to organic-knowledge) can only be driven by the sublimating recurrence of 'prospective human incipient/seeding ontological-faith-notion-or-ontological-fideism—imbuedunderdetermination-of-motif-and-apriorising/axiomatising/referencing-as-so-being-as-ofexistential-reality imbued psychoanalytic-unshackling as of psychologismic-epistemicacutisation-<as-to-postconverging-de-mentating/structuring/paradigming,-eliciting-ofexistence's-sublimating-nascence-in-prospective-aporeticism-overcoming/unovercoming > as to epistemic-growth,-as - \{veridical/sound\}-relative-reflexivity-in-existence/relativising fromlimited-mentation-as-its-deepening/psychologismic epistemic-acutisation residualising, ${ }_{\{\text {decompulsing }}$ delinearity for-cogency that can elicit unlimitedness/existence-<fll-potency өf_sublimating nascence> prospective apriorising/axiomatising/referencing-sublimatingreflexivity_-beholdening under which limitedness/human-subpotency submits in profoundsupererogation for prospective sublimating', as so-speaking of prospective humansubpotency-aporia/undecidability/dilemma/ought-

indeterminacy/deficiency/limitation/constraint—imbued-'notional firstnaturedness-

\section{formativeness-as to eventualising inkling drive or seeding misprising $>$ temporal-to-}

intemporal-dispositions-<so-construed-as-from-perspective-ontological-

normalcy/postconvergence>'-existentialism-form-factor' (and so, over the desublimating/distorting recurrence of already induced 'limitedness/human-subpotency prior rationalisation-of-contentivity/argumentativity/dialecticism/discursivity as to the prior mereformulaicity/ritualisation-<as-to-mere-formulaicmethodologising/mutualising/organising/institutionalising,-prospectively-losing-track-of‘ \{epistemic-totalising '̀ re-apriorising/re-axiomatising/re-referencing residuality-in-reoriginariness/re-origination'> of $<$ mere-formulaicity/ritualisation-of>-prior secondnatured 
institutionalisation given unlimitedness/existence-<full-potency-of_sublimating nascence $>$ prospective apriorising/axiomatising/referencing-sublimating-reflexivity-beholdening under which limitedness/human-subpotency submits in profound-supererogation for prospective sublimating'). In-many-ways our present-day overarching epochal/societal/institutional $/ \mathrm{milieu}$ existentialising-frame-of-entailment-of motif-and-apriorising/axiomatising/referencing 'human placeholder-setup/mental-devising-representation/mentation/consciousness-awarenessteleology imbued mental-aestheticising-<as-'psychologismic-existential-metaphoricity $\{$ asto-\{epistemic totalising '†re-apriorising/re-axiomatising/re-referencing_in-becoming\}'-so-implicited'by-way-of-the-existentially/contextually/textually-manifest-motif-construct-as-specificlanguage'-as-so-reflecting-'the-existentially/contextually/textually-manifestmoronisation/demoronisation'> of past science' (as to our present-day cumulated/recomposured 'overall soverlaying/superstrating 'thrownness-aestheticising' \{of-relative-reflexivity inexistence $>>$-sparsity-of-postconverging-prospective-relative-ontological-completeness ${ }^{87}$-ofapriorising/axiomatising/referencing conceptions' of positivism/rational-empiricism science) is now mostly devoid of much of the 'overall <underlaid/substrated 'thrownness-aestheticising' \{of-relative-unreflexivity in-existence\} $>$ profusion-of preconverging prior-relativeontological-incompleteness ${ }^{8}$-of-apriorising/axiomatising/referencing conceptions' associated with the seeding/incipient/budding positivism/rational-empiricism science; and this insight doesn't only applies to science specifically but overall human ${ }^{5}$ meaningfulness-and-teleology mental-aestheticising-<as-'psychologismic-existential-metaphoricity fas-to-\{epistemictratising 're-apriorising/re-axiomatising/re-referencing_in-becoming)' -so-implicited-'by-wayof-the-existentially/contextually/textually-manifest-motif-construct-as-specific-language'-asso-reflecting-'the-existentially/contextually/textually-manifestmoronisation/demoronisation'>. The veracity of this elucidation of human 'human placeholdersetup/mental-devising-representation/mentation/consciousness-awareness-teleology ${ }^{99}$ imbued 
mental-aestheticising-<as-'psychologismic-existential-metaphoricity $\underset{\text { fas-to- }}{\text { fepistemic- }}$ totalising '? 're-apriorising/re-axiomatising/re-referencing_in-becoming\}' -so-implicited-'by-wayof-the-existentially/contextually/textually-manifest-motif-construct-as-specific-language'-asso-reflecting-'the-existentially/contextually/textually-manifest-moronisation/demoronisation'> (whether as of 'mentally-aestheticised $\sim$ preconverging/dementing ${ }^{20}$-qualia-schema reflected moronisation- $<$ sublimating-nascence,-extrieatory-desublimating-downstreaming/'avalage'>' or 'mentally-aestheticised postconverging/dialectical-thinking -qualia-schema reflected demoronisation-<sublimating-nascence,-nonextricatory-sublimating-upstreaming/'amontée’>’ as to the existential-disontologising/re-ontologising aporeticism $>$ implications of limitedness/human-subpotency prospective re-encountering/re-confrontation with the 'constraining/defining intersolipsistic reflexive-sublimating/unreflexive-desublimating measure/objectification that is unlimitedness/existence-as-ontologicalnormalcy/postconvergence-<in-validation-of-'metaphysics-of-absence_epistemic-

projection'>', and so as not just bound-up in a naïve conception of 'mere abstractly-elaborate apriorising/axiomatising/referencing') can be garnered with regards to any specific domain-ofstudy (which is not/hardly subject to 'apriorising/axiomatising/referencingequating/leveling/ressentiment/closed-construct-of- - meaningfulness-and-teleology moronisation-<sublimating-nascence,-extricatory-desublimating-downstreaming/'avalage'> bound to induce blurriness-<sterilising/anecdotalising/trivialising-of-prospective-reontologising_by-preconverging,-in-disontologising-formulaic-dragging-out/hollowing-out>) in its given 'prospective renewal of apriorising/axiomatising/referencing'. In this regards, we can appreciate the transformational existentialising-frame-of-entailment-of-motif-andapriorising/axiomatising/refereng of human mental-aestheticising-<as-'psychologismic-

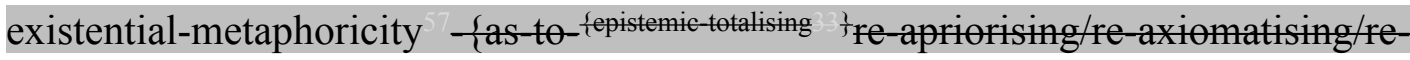
referencing_in-becoming?' -so-implicited-'by-way-of-the-existentially/contextually/textually- 
manifest-motif-construct-as-specific-language'-as-so-reflecting-'the-

existentially/contextually/textually-manifest-moronisation/demoronisation'> (rather as 'existentially-disontologising/re-ontologising aporeticism $>\quad$ understood- $<$ as-epistemictotalisingly /acutely translating-into-the-mental-aestheticising-metaphoricity $>$ ' by the 'prospectively renewal of apriorising/axiomatising/referencing' given sunderlaid/substrated'thrownness-aestheticising' - of-relative-unreflexivity in-existence\}>-profusion-ofpreconverging prior-relative-ontological-incompleteness ${ }^{88}$-ofapriorising/axiomatising/referencing - by_<overlaying/superstrating 'thrownnessaestheticising' $\{$ of relative-reflexivity in-existence\} $>$-sparsity-of postconverging prospectiverelative-ontological-completeness ${ }^{87}$-of-apriorising/axiomatising/referencing as to underlying $<$ amplituding/formative-epistemicity $>$-totalising thrownness-in-existence ${ }^{35} \quad$ mentalaestheticising-<as-'psychologismic-existential-metaphoricity \{as-to-\{epistemic-totalising ${ }^{3} \mathrm{re}$ apriorising/re-axiomatising/re-referencing_in-becoming?' -so-implicited-'by-way-of-theexistentially/contextually/textually-manifest-motif-construct-as-specific-language'-as-soreflecting-'the-existentially/contextually/textually-manifest-moronisation/demoronisation'> traces of \{epistemic-totalising ${ }^{3}$ re-apriorising/re-axiomatising/re-referencing $\sim$ residuality-in-reoriginariness/re-origination); wherein the implications of theories/axioms/concepts apriorising/axiomatising/referencing take unpredictable/unexpected turns educed from unlimitedness/existence-<full-potency-of_sublimating nascence $>$ 'as to the \{epistemic-totalising $\left.{ }^{3}\right\}$ reapriorising/re-axiomatising/re-referencing $\sim$ residuality-in-re-originariness/re-origination postconverging' (as patently manifested for instance with say the radical redevelopment and reconception of say astronomy in the past 40 years as of prospectively defining soverlaying/superstrating 'thrownness aestheticising' (of relative reflexivity in existence\}> sparsity-of-postconverging prospective-relative-ontological-completeness ${ }^{87}$-ofapriorising/axiomatising/referencing as to its specific 'apriorising/axiomatising/referencing 
disambiguating/de-leveling/de-ressentiment/opened-construct-of- ${ }^{5}$ meaningfulness-andteleology demoronisation-<sublimating-nascence,-nonextricatory-sublimatingupstreaming/'amontée'>'). We can generally appreciate this 'unpredictability/unexpectation$<$ as-to-prospective-re-apriorising/re-axiomatising/re-referencing $>$ ' of 'apriorising/axiomatising/referencing disambiguating/de-leveling/de-ressentiment/openedconstruct-of- -5 meaningfulness-and-teleology $\quad$ demoronisation- $<$ sublimating-nascence,nonextricatory-sublimating-upstreaming/'amontée’>' educed from unlimitedness/existence$\leq$ full-potency-of_sublimating nascence $>$ with regards to the general transformation of human mentalities over time as new sublimating possibilities are engendered as from prospectively defining soverlaying/superstrating 'thrownness-aestheticising' \{of-relative-reflexivity inexistence $>>$-sparsity-of postconverging prospective-relative-ontological-completeness ${ }^{8}$-ofapriorising/axiomatising/referencing. Human limited-mentation-capacity-as-subjecting 'educed-unlimitedness/existence-sublimating nascence' to-limitedness/human-subpotency inherently means that the individual can hardly wholly reassess 'all such explicit/implicit apriorising/axiomatising/referencing of overarching epochal/societal/institutional $/ \mathrm{milieu}$ existentialising-frame-of-entailment-of-motif-and-apriorising/axiomatising/referencing' (as rather 'existentially-disontogising/reontogising aporeticism> understood-<asepistemic-totalisingly /acutely_translating-into-the-mental-aestheticising-metaphoricity >’ by the given sunderlaid/substrated 'thrownness-aestheticising' \{of relative-unreflexivity inexistence $>>$ profusion-of preconverging prior-relative-ontological-incompleteness ${ }^{8}$-ofapriorising/axiomatising/referencing — by_ <overlaying/superstrating 'thrownnessaestheticising' \{of relative-reflexivity in-existence\}>-sparsity-of postconverging prospectiverelative-ontological-completeness ${ }^{8}$-of-apriorising/axiomatising/referencing as to underlying $<$ amplituding/formative-epistemicity $>$-totalising $\sim$ thrownness-in-existence mental-

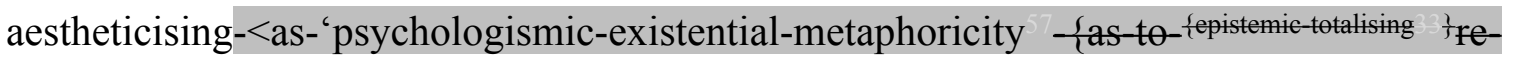


apriorising/re-axiomatising/re-referencing_in-becoming?' -so-implicited-'by-way-of-the-

existentially/contextually/textually-manifest-motif-construct-as-specific-language'-as-soreflecting-'the-existentially/contextually/textually-manifest-moronisation/demoronisation'>

traces of \{epistemic-totalising 3re-apriorising/re-axiomatising/re-referencing $\sim$ residuality-in-reoriginariness/re-origination); with the implication that in-many-ways the individual human ontological-performance $^{72}{ }_{-}$-including-virtue-as-ontology $>/$morality/ethics/justice/etc. $\quad$ is overachingly by-and-large epochal/social/institutional/milieu-determined (as to their deferentialism/deferential-formalisation-transference implications) but for the individual's relevant priorities, interests and effective prospects-and-capacity for eliciting prospectively defining soverlaying/superstrating 'thrownness-aestheticising' \{of-relative-reflexivity inexistence $>>$-sparsity-of postconverging-prospective-relative-ontological-completeness ${ }^{87}$-ofapriorising/axiomatising/referencing as of dimensionality-of-sublimating <<amplituding/formative>supererogatory $\sim$ de-mentativeness/epistemic-growth-or-

conflatedness /transvaluative-rationalising/transepistemicity/anamnestic-residuality/spirit-

drivenness-equalisation) (so-reflecting their human subconsciousness most-prospectivelyconscious 're-ontologising-by-disontologising_existential-calculus-_between 'prospective existentialising_-postconverging_framing/imprinting re-ontologising' and 'prior existentialising_ preconverging_enframing/imprintedness social-functioning-andaccordance - as-of-social-stake-contention-or-confliction' $\rangle$ ' of consciousness surrealising- $<$ asto-supererogation $>$ ). This insight (as to the 'cumulating/recomposuring prospective appraisal/reappraisal of human relative-ontological-completeness ${ }^{87}$-ofapriorising/axiomatising/referencing' so-reflecting the 'overall relative-unreflexivity/relativereflexivity ontological-contiguity ${ }^{67} \sim$ of-the-human-institutionalisation-process ${ }^{68}$ activity of limited-mentation-capacity-deepening —as-subjecting limitedness/human-subpotency-to'educed-unlimitedness/existence-sublimating nascence' ${ }^{3}$, with regards to limitedness/human- 
subpotency prospective re-encountering/re-confrontation with the 'constraining/defining intersolipsistic reflexive-sublimating/unreflexive-desublimating measure/objectification that is unlimitedness/existence-as-ontological-normalcy/postconvergence- $<$ in-validation-of-

'metaphysics-of-absence_epistemic-projection'>'), is important in the sense that in-many-ways learning from history is critically and mostly about understanding the eliciting of "human sublimating prospectively defining <overlaying/superstrating 'thrownness-aestheticising'-\{ofrelative-reflexivity in-existence $\}>$-sparsity-of postconverging prospective-relativeontological-completeness ${ }^{87}$-of-apriorising/axiomatising/referencing' (as to a human mental-

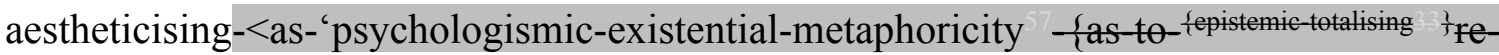
apriorising/re-axiomatising/re-referencing_in-becoming?' -so-implicited-'by-way-of-theexistentially/contextually/textually-manifest-motif-construct-as-specific-language'-as-soreflecting-'the-existentially/contextually/textually-manifest-moronisation/demoronisation'> that veridically reflects the '<overlaying/superstrating 'thrownness-aestheticising' fof relativereflexivity in-existence $\}>$-sparsity-of postconverging prospective-relative-ontologicalcompleteness ${ }^{87}$-of-apriorising/axiomatising/referencing specific conception' as rather being 'existentially- $<$ disontologising/re-ontologising aporeticism $>$ encircled/bordered/influenced directly/indirectly by both the 'overall cunderlaid/substrated 'throwness aestheticising' fof relative-unreflexivity in-existence $\}>$ profusion-of preconverging prior-relative-ontologicalincompleteness ${ }^{8}$-of-apriorising/axiomatising/referencing conceptions' and 'overall associated <overlaying/superstrating 'thrownness-aestheticising' \{of-relative-reflexivity in-existence\}> sparsity-of postconverging prospective-relative-ontological-completeness ${ }^{87}$-ofapriorising/axiomatising/referencing conceptions'); in so-inducing ${ }^{4}$ historiality/ontologicaleventfulness 3 /ontological-aesthetic-tracing-<perspective-ontologicalnormalcy/postconvergence-reflected-'epistemicity-relativism-determinism' as of dimensionality-of-sublimating $25<$ - amplituding/formative $>$ supererogatory $\sim$ de- 
mentativeness/epistemic-growth-or-conflatedness /transvaluative-

rationalising/transepistemicity/anamnestic-residuality/spirit-drivenness-equalisation $\rangle$ (as to the underlying 'crossgenerational notional firstnaturedness-formativeness-<as-toeventualising inkling-drive-or-seeding-misprising $>$ mental-processing-parity for ontological-performance ${ }^{72}$-<including-virtue-as-ontology $>$ /morality/ethics/justice/etc.' of all sovereign humans as to the potentiation of sublimating-over-desublimating across all times which has to do with 'human ontological-good-faith/authenticity $\sim$ postconverging-dementating/structuring/paradigming — — by—ontological-bad-

faith/inauthenticity $\sim$ preconverging-de-mentating/structuring/paradigming' and so relative to the given station/locus of limitedness/human-subpotency <amplituding/formativeepistemicity>-totalising thrownness-in-existence ${ }^{35}$ ), and so while more-or-less holding-inabeyance the inherent human limited-mentation-capacity-as-subjecting 'educedunlimitedness/existence-sublimating nascence' to-limitedness/human-subpotency implications associated with the 'overaching epochal/social/institutional/milieu preconverging-dementating/structuring/paradigming ontological-performance ${ }^{72}<$ including-virtue-as-ontology $>^{\text {' }}$ (as 'station/locus of limitedness/human-subpotency <amplituding/formative-epistemicity>totalising thrownness-in-existence ${ }^{35}$ imbued desublimating overall sunderlaid/substrated'thrownness-aestheticising' \{of relative-unreflexivity in-existence\}>-profusion-ofpreconverging prior-relative-ontological-incompleteness ${ }^{8}$-ofapriorising/axiomatising/referencing' so-construed as of 'crossgenerational notional firstnaturedness-formativeness-<as-to-eventualising-inkling-drive-or-seedingmisprising $>$ mental-processing-parity for ontological-performance ${ }^{72}-<$ including-virtue-asontology $>$ /morality/ethics/justice/etc.' of all sovereign humans as to the potentiation of sublimating-over-desublimating across all times as of implied 'unconsciously/unknowinglyentitled to ignorance/lack-of-knowledge as to when prospective relative-ontological- 
completeness $^{87}$ is not educed-and-availing-and-re-availing as to prospective re-ontologising and deferentialism/deferential-formalisation-transference implications of re-ontologising'). Critically, such capacity for requisite human psychologismic-epistemic-acutisation-<as-topostconverging-de-mentating/structuring/paradigming,-eliciting-of-existence's-sublimatingnascence-in-prospective-aporeticism-overcoming/unovercoming> acting as 'postconvergingde-mentating/structuring/paradigming reference for requisite psychoanalytic-unshackling of the relative-ontological-incompleteness ${ }^{8}$-of-apriorising/axiomatising/referencing' is in-manyways 'elusive to the possible epistemic-projection radicalities $\sim$ in-chronicular/annalisticcogency-<as-of-notional $\sim$ protensivity $>$-〈as-to-limited-mentation-capacity-deepening $\longrightarrow$ assubjecting limitedness/human-subpotency-to-'educed-unlimitedness/existence-sublimating nascence' > so-construed as cogency_chronicularity/annality-of-relative-reflexivity,-as-toprofound-supererogation of any single individuals' with its veracity rather manifesting as to 'relays of human intemporal-individuation epistemic-projection radicalities $\sim$ inchronicular/annalistic-cogency-<as-of-notional $\sim$ protensivity $>-\langle$ as-to-limited-mentationcapacity-deepening — as subjecting limitedness/human subpotency to 'educed-

unlimitedness/existence-sublimating nascence' $\rangle$ so-construed as cogency_chronicularity/annality-of-relative-reflexivity,-as-to-profound-supererogation ${ }^{9}$ (with regards to limitedness/human-subpotency prospective re-encountering/re-confrontation with the 'constraining/defining intersolipsistic reflexive-sublimating/unreflexive-desublimating measure/objectification that is unlimitedness/existence-as-ontologicalnormalcy/postconvergence-<in-validation-of-'metaphysics-of-absence_epistemic-

projection'>'); as to the fact that Galileo, Descartes, Newton, Leibniz, etc. actually reached their respective positivism/rational-empiricism sublimating limits by the mere fact that they were not of sufficient positivism/rational-empiricism relative-ontological-completeness ${ }^{8}$-ofapriorising/axiomatising/referencing epistemic-projection radicalities $\sim$ in- 
chronicular/annalistic-cogency-<as-of-notional $\sim$ protensivity $>$-〈as-to-limited-mentationcapacity-deepening — as-subjecting limitedness/human-subpotency to-'educed-

unlimitedness/existence sublimating nascence' > so-construed as

cogency_chronicularity/annality-of-relative-reflexivity,-as-to-profound-supererogation as 'still caught up in their various successive extents in medieval-scholasticism relativeontological-incompleteness ${ }^{8}$-of-apriorising/axiomatising/referencing' and as successive successors further advancing in succession their prospective positivism/rational-empiricism relative-ontological-completeness ${ }^{8}$-of-apriorising/axiomatising/referencing sublimating limits as of 'notional difference-conflatedness ${ }^{13}$-as-to-totalitative-reification-in-singularisation- $<$ asto-the-nondisjointedness/entailment-of-prospective- nonpresencing $>$-as-veridicalepistemicity-relativism-determinism construable as from their given projected relativeontological-completeness ${ }^{87}$-of-apriorising/axiomatising/referencing $\quad{ }^{56}$ meaningfulness-andteleology mental-aestheticising-<as-'psychologismic-existential-metaphoricity $\quad$ as-to\{epistemic-totalising '`re-apriorising/re-axiomatising/re-referencing_in-becoming\}' -so-implicited-

\section{'by-way-of-the-existentially/contextually/textually-manifest-motif-construct-as-specific-}

\section{language'-as-so-reflecting-'the-existentially/contextually/textually-manifest-}

moronisation/demoronisation'>'. Such an outcome could only occur within the scope of budding-positivists 'positivising ontological-faith-notion-or-ontological-fideism-imbuedunderdetermination-of-motif-and-apriorising/axiomatising/referencing-as-so-being-as-ofexistential-reality' and it is rather naïve to think that budding-positivists could entertain a coherence/contiguity apriorising/axiomatising/referencing with medieval-scholasticism apriorising/axiomatising/referencing existentialising — enframing/imprintedness to then be able to achieve prospective positivism/rational-empiricism (and it is exactly this psychologismic-. epistemic-acutisation—difficulty- $<$ for,-residualising_\{decompulsing $\}$ delinearity $\sim$ for-cogency $>-\langle$ asof-requisite-profound-supererogation -for-'disposedness-or-psychologismic-construct'- 
\{imbued-demoronisation-<sublimating-nascence,-nonextricatory-sublimating-

upstreaming/'amontée'>\}) that explains/underlies the multicenturies long patchy experientiality/experiment- $<$ as-to-existentially-formative- ${ }^{\text {‘epistemic-totalising }}{ }^{3}$ re-apriorising/reaxiomatising/re-referencing $\sim$ residuality — in-re-originariness/re-origination',"notionally/epistemically/bindingnessly-<as-to-determinism/conceptivity-of-relative-unreflexivity/relative-reflexivity> implicited-and-articulated'_as-from-nonextricatory-'prospective-re-ontologising-Being-thenInstitutional-then-Living-magnitudes-of-\{hermeneutic/reprojection-protraction-of\}reframingand-reformulation $\}^{\prime}>$ of human registry-worldviews/dimensions since human prehistoricity); speaking to the fact that the ontological-good-faith/authenticity $\sim$ postconverging-dementating/structuring/paradigming 70 for prospective apriorising/axiomatising/referencing has to be projected/affirmed in overarching priority/precedence/primacy as to sublimating prospective reference-of-thought—point-of-devolving/departure/anchoring/backdrop_of_sublimatingnascence-<as-to-the-grandest-axiomatic-construct-fepistemictising tre-apriorising/reaxiomatising/re-referencing-residuality-in-re-originariness/re-origination limitedness/human-subpotency prospective re-encountering/re-confrontation with unlimitedness/existence>. In-the-bigger-scheme-of-things it is this ontological-goodfaith/authenticity $\sim$ postconverging-de-mentating/structuring/paradigming ${ }^{70}$ for prospective apriorising/axiomatising/referencing that establishes the 'human psychoanalytic resilience' (as to more-and-more confident human subconsciousness most-prospectively-conscious 'reontologising-by-disontologising_existential-calculus-_between 'prospective existentialising postconverging_framing/imprinting re-ontologising' and 'prior existentialising preconverging_enframing/imprintedness social-functioning-and-accordance-as-of-socialstake-contention-or-confliction' $\rangle$ of consciousness surrealising-<as-to-supererogation $>$ ) enabling the <cumulating/recomposuring attendant-ontological-contiguity $>$-successive registry-worldviews/dimensions (in their successive sublimating prospective ${ }^{83}$ reference-of- 
thought_-point-of-devolving/departure/anchoring/backdrop_of_sublimating-nascence- $<$ as-tothe-grandest-axiomatic-construct-\{epistemic-totalising ${ }^{\frac{1}{3}}$ re-apriorising/re-axiomatising/re-

referencing residuality - in-re-originariness/re-origination of limitedness/human-subpotency prospective re-encountering/re-confrontation with unlimitedness/existence $>$ ); as it can be appreciated in-many-ways that the respective mental states of recurrent-utteruninstitutionalisation, ununiversalisation, non-positivism/medievalism and ${ }^{80}$ procrypticism-ordisjointedness-as-of- ${ }^{8}$ reference-of-thought do not effectively have the prior experientiality/experiment-<as-to-existentially-formative-'fepistemictising tre-apriorising/reaxiomatising/re-referencing $\sim$ residuality — in-re-originariness/re-origination',- so'notionally/epistemically/bindingnessly-<as-to-determinism/coneeptivity-of-relative-unreflexivity/relative-reflexivity> implicited-and-articulated'_as-from-nonextricatory-'prospective-re-ontologising-Being-thenInstitutional-then-Living-magnitudes-of-\{hermeneutic/reprojection-protraction-of\}reframingand-reformulation $\}^{\prime}>$ to respectively acquiesce to prospective base-institutionalisation, ${ }^{3}$ universalisation, positivism/rational-empiricism and prospective deprocrypticism-orpreempting - disjointedness-as-of- ${ }^{3}$ reference-of-thought (but for prospective ontological-goodfaith/authenticity ${ }^{6}$ postconverging-de-mentating/structuring/paradigming 70 inducing of prospective relative-ontological-completeness ${ }^{87}$ as educed-and-availing-and-re-availing as to prospective re-ontologising and deferentialism/deferential-formalisation-transference implications of re-ontologising). It is important to grasp in here that such a re-ontologising insight of the critical importance of the appropriate psychologismic-epistemic-acutisation- - asto-postconverging-de-mentating/structuring/paradigming,-eliciting-of-existence's-sublimatingnascence-in-prospective-aporeticism-overcoming/unovercoming> acting as 'postconvergingde-mentating/structuring/paradigming reference for requisite psychoanalytic-unshackling of the relative-ontological-incompleteness ${ }^{88}$-of-apriorising/axiomatising/referencing' (as dismissive of our ordinary 'lifespan extricatory/preconverging psychical-nascency moronisation- 
<sublimating-nascence,-extricatory-desublimating-downstreaming/‘avalage’> responsibility/relative-reflexivity imbued limited-mentation-capacity-as-subjecting 'educedunlimitedness/existence-sublimating nascence' to-limitedness/human-subpotency' and rather projective/affirmative of 'nonextricatory/postconverging ontologising-and-re-ontologising angling-of-imaginary $\quad$ demoronisation- $<$ sublimating-nascence,-nonextricatory-sublimatingupstreaming/‘amontée’> level-of-responsibility/relative-reflexivity imbued limited-mentationcapacity-deepening —as-subjecting limitedness/human-subpotency-to-'educed-

unlimitedness/existence-sublimating nascence' ${ }^{3}$, and so as of sublimating prospective reference-of-thought_-point-of-devolving/departure/anchoring/backdrop_of_sublimatingnascence-<as-to-the-grandest-axiomatic-construct-\{epistemic-totalising ${ }^{+}$re-apriorising/reaxiomatising/re-referencing $\sim$ residuality —in-re-originariness/re-origination of limitedness/human-subpotency prospective re-encountering/re-confrontation with unlimitedness/existence>) rather speaks to the requisite prospective ontological-goodfaith/authenticity ${ }^{\circ} \sim$ postconverging-de-mentating/structuring/paradigming ${ }^{70}$ for expliciting our ${ }^{6}$ presencing—absolutising-identitive-constitutedness ${ }^{14}$ absolution/absolute-scope \{flawed/unsound\}-relative-unreflexivity-in-existence/absolutising-from-limitedmentation/psychologismic epistemic acutisation nonresidualising imbued\{compulsing\} linearity in-eclecticism-of prior-mere-formulaicity/ritualisation conception' manifest psychoanalytic abnormality-<as-to-epistemic-abnormalcy/preconvergence $>$; which admission is effectively from whence the possibility for prospective thought can arise as to core philosophy 'beyond the formulaic portrayal-and-parade in our present social-and-institutional-frameworksof - referencing/registering/decisioning as thought for lifespan extricatory/preconverging psychical-nascency moronisation- $<$ sublimating-nascence, $\quad$-esublimatingdownstreaming/'avalage'> level-of-responsibility/relative-reflexivity' articulated in limitedmentation-capacity—as-subjecting-'educed-unlimitedness/existence-sublimating nascence'- 
to-limitednesshuman-subpotency as to shadow and blur the possibility of veridical thoughtfulness 'nonextricatory/postconverging ontologising-and-re-ontologising angling-ofimaginary demoronisation- $<$ sublimating-nascence,-nonextricatory-sublimatingupstreaming/‘amontée’> level-of-responsibility/relative-reflexivity imbued limited-mentationcapacity-deepening — as-subjecting limitedness/human-subpotency to-'educed-

unlimitedness/existence-sublimating nascence' ${ }^{3}$. The appropriate psychologismic-epistemicacutisation-<as-to-postconverging-de-mentating/structuring/paradigming,-eliciting-ofexistence's-sublimating-nascence-in-prospective-aporeticism-overcoming/unovercoming> acting as 'postconverging-de-mentating/structuring/paradigming reference for requisite psychoanalytic-unshackling of the relative-ontological-incompleteness ${ }^{8}$-ofapriorising/axiomatising/referencing' has to effectively project of the existential<disontologising/re-ontelogising aporeticism> 'epistemic-break or notionaldiscontiguity/epistemic-discontiguity ${ }^{3}<$ between - prior-shallow-supererogation -ofmentally-aestheticised preconverging/dementing -qualia-schema_and_prospective-profoundsupererogation -of-mentally-aestheticised postconverging/dialectical-thinking -qualiaschema> in reflection of limited-mentation-capacity-deepening-as-subjectingtimitedness/human-subpotency to 'educed unlimitedness/existence sublimating nascence' (and not of limited-mentation-capacity-as-subjecting 'educed-unlimitedness/existencesublimating nascence' to-limitedness/human-subpotency). This doesn't only applies with regards to the " ${ }^{83}$ reference-of-thought implied transcendence-andsublimity/sublimation/supererogatory $\sim$ de-mentativity' as the 'grandest axiomatic-construct induced relative-ontological-completeness $^{87}$, (when it comes to Being-development/ontologicalframework-expansion-as-to-depth-of-ontologising-development-as-infrastructure-ofmeaningfulness-and-teleology) but it is equally the case with ${ }^{83}$ reference-of-thoughtdevolving 'axiomatic-constructs impliciting of relative-ontological-completeness ${ }^{8}$ ' wherein $^{2}$ 
for instance theory-of-relativity-together-with-quantum-mechanics-axiomatic-constructs is of a wholly different psychologismic-construct from the approach to classical-mechanicsaxiomatic-constructs (forbidding the amalgamation of their knowledge gesturing/accountingof-epistemic-phenomenalism as of their respective 'relative-ontological-completeness ${ }^{87}$ and relative-ontological-incompleteness ${ }^{88}$ of the-very-same physics purview-ofunlimitedness/existence-<full-potency-of_sublimating nascence $>$;_-implicited_attendant ontological-contiguity ${ }^{67} \sim$ educedexistentialising/contextualising/textualising_'intelligibility/epistemicity/reflexivity-contiguity$<$ imbued-notional cogency>' even as within the scope of theory-of-relativity-together-withquantum-mechanics - axiomatic-constructs a transcending-amalgamation of theory-ofrelativity - axiomatic-constructs and quantum-mechanics - axiomatic-constructs is permitted for prospective relative-ontological-completeness ${ }^{87}$ transcending purposes like string theory, loop quantum gravity, etc. with their own differing psychologismic-constructs); so-reflecting the fact that prospective relative-ontological-completeness ${ }^{87}$ points to a requisite prospective 'apriorising/axiomatising/referencing disambiguating/de-leveling/de-ressentiment/openedconstruct-of- -5 meaningfulness-and-teleology 9 demoronisation- $<$ sublimating-nascence,-sublimating-upstreaming/'amontée’’' for human epistemic-growth,-as\{veridical/sound\}-relative-reflexivity-in-existence/relativising from-limited-mentation-as-itsdeepening/psychologismic epistemic-acutisation residualising, \{decompulsing $\}$ delinearity for eogency (by the mere fact of limitedness/human-subpotency prospective re-encountering/reconfrontation with the 'constraining/defining intersolipsistic reflexive-sublimating/unreflexivedesublimating measure/objectification that is unlimitedness/existence-as-ontologicalnormalcy/postconvergence-<in-validation-of-‘metaphysics-of-absence_epistemic-projection’> as so-speaking to the human psyche as a placeholder-setup/mental-devisingrepresentation/mentation/consciousness-awareness-teleology' that adjusts to 'prospectively 
educed-and-availing-and-re-availing of relative-ontological-completeness ${ }^{87}$ exuding from unlimitedness/existence-<full-potency-of_sublimating nascence $>$ ' and so-adjusting by way of the 'requisite psychologismic-epistemic-acutisation-<as-to-postconverging-dementating/structuring/paradigming,-eliciting-of-existence's-sublimating-nascence-inprospective-aporeticism-overcoming/unovercoming $>$ as to epistemic-growth,-as\{veridical/sound\}-relative-reflexivity-in-existence/relativising from-limited-mentation-as-its-

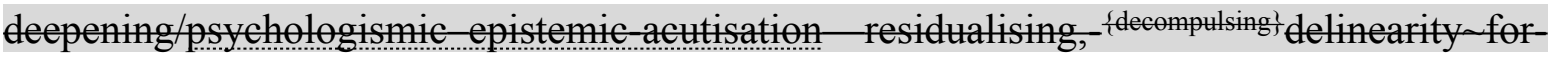
eogency'). It can thus be appreciated that (but for the ontologically-flawed interpretation of pedantising/muddling/formulaic-hollowing-out — in-subontologisation/subpotentiation〈blurring/undermining-of-prospective-totalising-entailing,-as-to-entailing$<$ amplituding/formative-epistemicity $>$ totalising in-relative-ontological-completeness $>$ priorperspective - falsity/falseness/fallaciousness) core philosophy is no more different from all domains-of-study construed as notional $\sim$ philosophy-<as-to-the-veridical-conception-ofphilosophy-as-englobing-all-human-prospective-organic-knowledge-generation-in-relativeontological-completeness ,-beyond-a-convenient-division-of-labour-conception-of-

knowledge >; and so similar rather in the simple sense that all domains-of-study attend-to/dealwith their given prospective postconverging-aporeticism-overcoming/unovercoming, with the specificity of core philosophy lying in the fact that its requisite projecting of 'human prospective reference-of-thought_-point-of-devolving/departure/anchoring/backdrop_of_sublimating-

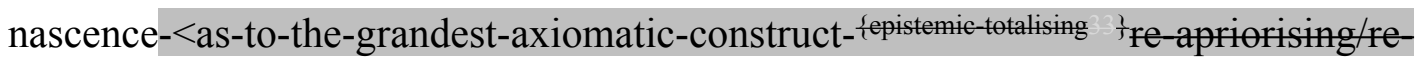
axiomatising/re-referencing $\sim$ residuality-in-re-originariness/re-origination of limitedness/human-subpotency prospective re-encountering/re-confrontation with unlimitedness/existence>' (as core philosophy ambit of prospective 'existential<disontologising/re-ontologising aporeticism $>$ postconverging aporeticismovercoming/unovercoming') is inherently problematic as to the 'contraining prospective 
psychologismic-epistemic-acutisation-<as-to-postconverging-de-

mentating/structuring/paradigming,-eliciting-of-existence's-sublimating-nascence-inprospective-aporeticism-overcoming/unovercoming $>$ as to epistemic-growth,-as\{veridical/sound\}-relative-reflexivity-in-existence/relativising from-limited-mentation-as-itsdeepening/psychologismic epistemic-acutisation residualising, ${ }^{\text {\{decompulsing }}$ delinearity for eogency' on limitedness/human-subpotency imbued limited-mentation-capacity-assubjecting 'educed-unlimitedness/existence-sublimating nascence' to-limitedness/humansubpotency as so-inducing human emotional-involvement distorting/desublimation (somanifested with all registry-worldviews/dimensions 'pedantising/muddling/formulaichollowing-out-in-subontologisation/subpotentiation-〈blurring/undermining-of-prospectivetotalising-entailing,-as-to-entailing-<amplituding/formative-epistemicity $>$ totalising $\sim$ inrelative-ontological-completeness > prior-perspective-falsity/falseness/fallaciousness' in distorting/desublimating the notion of core philosophy). It can be appreciated in this regards, that the sublimating ${ }^{4}$ historiality/ontological-eventfulness ${ }^{38}$ /ontological-aesthetic-tracing<perspective-ontological-normalcy/postconvergence-reflected-'epistemicity-relativismdeterminism'> of core philosophy is one that has ever always been of profound existential<disontologising/re-ontologising aporeticism $>$ dimensionality-of-sublimating <<amplituding/formative>supererogatory $\sim$ de-mentativeness/epistemic-growth-orconflatedness /transvaluative-rationalising/transepistemicity/anamnestic-residuality/spiritdrivenness-equalisation) as to 'human prospective ${ }^{83}$ reference-of-thought-point-ofdevolving/departure/anchoring/backdrop_of_sublimating-nascence-<as-to-the-grandestaxiomatic-construct-\{epistemic-totalising $\stackrel{+}{\zeta}$ re-apriorising/re-axiomatising/rereferencing $\sim$ residuality - in-re-originariness/re-origination of limitedness/human-subpotency prospective re-encountering/re-confrontation with unlimitedness/existence $>$ implications of transcendence-and-sublimity/sublimation/supererogatory de-mentativity for 
'nonextricatory/postconverging ontologising-and-re-ontologising angling-of-imaginary demoronisation-<sublimating-nascence,-nonextricatory-sublimating-upstreaming/'amontée’> level-of-responsibility/relative-reflexivity imbued limited-mentation-capacity-deepening-assubjecting -limitedness/human-subpotency-to-'educed-unlimitedness/existence-sublimating nascence' '; with supposedly philosophical thematics 'philosophically nonsensical' when articulated as of 'lifespan extricatory/preconverging psychical-nascency moronisation<sublimating-nascence,-extricatory-desublimating-downstreaming/'avalage'> level-ofresponsibility/relative-reflexivity imbued limited-mentation-capacity-as-subjecting 'educedunlimitedness/existence-sublimating nascence' to-limitedness/human-subpotency' (in reflection of the fact that core philosophy is veridically nonsensical for 'lifespan extricatory/preconverging psychical-nascency moronisation- $<$ sublimating-nascence,extricatory-desublimating-downstreaming/'avalage’> purposes’). In this regards, pedantising/muddling/formulaic-hollowing-out — in-subontologisation/subpotentiation〈blurring/undermining-of-prospective-totalising-entailing,-as-to-entailing<amplituding/formative-epistemicity>totalising in-relative-ontological-completeness > limited-mentation-capacity_as-subjecting-'educed-unlimitedness/existence-sublimating nascence' to-limitedness/human-subpotency imbued fundamental/incipient/seeding ontological-bad-faith/inauthenticity ${ }^{64}$ preconverging-de-mentating/structuring/paradigming is further portrayed in a disparateness-of-conceptualisation-<unforegrounding-ment,-failingprospectively-to-reflect-'immanent relative-unreflexivity/relative-reflexivity - ontologicalcontiguity ' $>$ naivety that 'it is possible to veridically think-by-the-side as of a mere-thing in soullessness' without the mind of profound existential-<disontologising/re-ontologising aporeticism $>$ dimensionality-of-sublimating ${ }^{25}-\langle<$ amplituding/formative $>$ supererogatory $\sim$ dementativeness/epistemic-growth-or-conflatedness /transvaluative- 
generates-and-follows thinking existential-<disontologising/re-ontologising aporeticism $>$ entailment as herein elucidated beyond a conception-of- $-{ }^{5}$ meaningfulness-and-teleology ${ }^{9}$ as of prior mere-formulaicity/ritualisation-<as-to-mere-formulaicmethodologising/mutualising/organising/institutionalising,-prospectively-losing-track-of'\{epistemic-totalising ’’re-apriorising/re-axiomatising/re-referencing residuality-in-reoriginariness/re-origination'>. In-many-ways such a manifestation of pedantising/muddling/formulaic-hollowing-out—in-subontologisation/subpotentiation〈blurring/undermining-of-prospective-totalising-entailing,-as-to-entailing<amplinglinglivermative-epistemicity>totalising in-relative-ontological-completeness $>$ as to when it elicits limited-mentation-capacity as subjecting ' sublimating nascence' to-limitedness/human-subpotency thrives in the 'epistemic-decadence' or teleological-decadence-<-in-dimensionality-of-desublimating-lack-of

\section{<<amplituding/formative>supererogatery $\sim$ de-mentativeness/epistemic-growth-or-}

\section{conflatedness /transvaluative-rationalising/transepistemicity/anamnestic-residuality/spirit-}

drivenness-equalisation $\rangle$ that afterall there is 'no teacher-<as-of-the-sublimating-nascence-ofunlimitedness/existence $>$ of base-institutionalisation, ${ }^{103}$ universalisation, positivism/rationalempiricism and prospective deprocrypticism-or-preempting-disjointedness-as-ofreference-of-thought' respectively in the 'classroom-<as-of-limitedness/human-subpotency $>$ of recurrent-utter-uninstitutionalisation, ununiversalisation, non-positivism/medievalism and procrypticism-or-disjointedness-as-of- ${ }^{-3}$ reference-of-thought'; and so as to sublimating limitedness/human-subpotency prospective re-encountering/re-confrontation with unlimitedness/existence-<full-potency-of_sublimating nascence $>$ 'requisite prospective reference-of-thought—point-of-devolving/departure/anchoring/backdrop_of_sublimatingnascence-<as-to-the-grandest-axiomatic-construct-\{epistemic-totalising ${ }^{\frac{1}{3}}$ re-apriorising/re- 
limitedness/human-subpotency prospective re-encountering/re-confrontation with

unlimitedness/existence>'. But then the very psychoanalytic-unshackling 'paradox of prospective re-rationalisation-of-contentivity/argumentativity/dialecticism/discursivity for educing ${ }^{56}$ meaningfulness-and-teleology ${ }^{9}$ ' with the incongruity of construing respectively of the 'sublimating re-rationalisations-of-contentivity/argumentativity/dialecticism/discursivity of base-institutionalisation, ${ }^{103}$ universalisation, positivism/rational-empiricism and prospective deprocrypticism-or-preempting-disjointedness-as-of- ${ }^{3}$ reference-of-thought' rather as from the respective 'desublimating rationalisations-ofcontentivity/argumentativity/dialecticism/discursivity of recurrent-utter-uninstitutionalisation, ununiversalisation, non-positivism/medievalism and ${ }^{80}$ procrypticism-or-disjointedness-as-ofreference-of-thought', means that an inclination for 'nonextricatory/postconverging ontologising-and-re-ontologising angling-of-imaginary $\quad$ demoronisation- $<$ sublimatingnascence,-nonextricatory-sublimating-upstreaming/‘amontée’> level-of-responsibility/relativereflexivity imbued limited-mentation-capacity-deepening —as-subjecting limitedness/humansubpotency-to-'educed-unlimitedness/existence-sublimating nascence' ${ }^{53}$ ' is effectively socially susceptible to the accusation of megalomania (as to pedantising/muddling/formulaic-hollowingout_-in-subontologisation/subpotentiation-〈blurring/undermining-of-prospective-totalisingentailing,-as-to-entailing-<amplituding/formative-epistemicity $>$ totalising $\sim$ in-relativeontological-completeness > undergirding of limited-mentation-capacity-as-subjecting'educed-unlimitedness/existence-sublimating nascence' to-limitedness/human-subpotency, which by definition doesn't factor in its relative-ontological-incompleteness ${ }^{88}$ as to its 'lifespan extricatory/preconverging psychical-nascency moronisation- $<$ sublimating-nascence,extricatory-desublimating-downstreaming/'avalage'> purposes of non-intellection'); and inmany-ways it is only natural that a mindset that doesn't know of core philosophy cannot project of ' nonpresencing-<perspective-ontological-normalcy/postconvergence $>$ relativism/relative- 
scope for epistemic-growth,-as - \{veridical/sound\}-relative-reflexivity-inexistence/relativising from-limited-mentation-as-its-deepening/psychologismic epistemicacutisation residualising, \{decomplsing delinearity for-cogeney’ which sublimatively translates such a misconception of megalomania as notional asceticism. In this regards, such 'nonextricatory/postconverging ontologising-and-re-ontologising angling-of-imaginary demoronisation-<sublimating-nascence,-nønextricatory-sublimating-upstreaming/‘amontée’> level-of-responsibility/relative-reflexivity imbued limited-mentation-capacity-deepening-assubjecting limitedness/human-subpotency-to-'educed-unlimitedness/existence-sublimating nascence' notional ascticism manifestation is in-many-ways rather damning of the prior relative-ontological-incompleteness ${ }^{88}$ 'epistemic-decadence' or teleological-decadence-<-indimensionality-of-desublimating-lack-of $-\langle<$ amplituding/formative $>$ supererogatory $\sim$ dementativeness/epistemic-growth-or-conflatedness /transvaluativerationalising/transepistemicity/anamnestic-residuality/spirit-drivenness-equalisation $\rangle$ as to its 'inadequacy of postconverging-de-mentating/structuring/paradigming and postconverging aporeticism-overcoming/unovercoming' manifested as of its prospective projection of dimensionality-of-desublimating-lack-of 〈<amplituding/formative>supererogatory $\sim$ de-mentativeness/epistemic-growth-or-

\section{conflatedness /transvaluative-rationalising/transepistemicity/anamnestic-residuality/spirit-}

drivenness-equalisation) (with respect to the fact that the relative-ontological-incompleteness future is being 'invented'/'created'-and-'nurtured' and so 'inspite of the conscious selfpresence/self-constitutedness ${ }^{14}-<$ in-perspective-epistemic-abnormalcy/preconvergence ${ }^{31}>$ desublimating existentialising-decisionality-<as-to-disontologising/re-ontologising aporeticism $>$ ' that then pedantically turns around in projection of ' ${ }^{79}$ presencing - absolutisingidentitive-constitutedness ${ }^{14} \quad$ absolution/absolute-scope \{flawed/unsound\}-relativeunreflexivity-in-existence/absolutising from-limited-mentation/psychologismic epistemic- 
acutisation nonresidualising-imbued-\{compulsing\} linearityoin-eclecticism-of prior-mereformulaicity/ritualisation conception' manifest psychoanalytic abnormality-<as-to-epistemicabnormalcy/preconvergence $>$ ). Such notional asceticism reasoning-through/messianicreasoning prospective existential-<disontologising/re-ontologising aporeticism $>$ deployment of $\quad$ transversality-<for-sublimating-existential-eventuating/denouement,-from-'thinking atfirst/pure-predisposition-preemptive-of-prospective-disontologising/subontologising' as-ofprospectively-disambiguated-affirmed-and-unaffirmed-'motif-andapriorising/axiomatising/referencing'>101 (contrary to a '79 presencing-absolutising-identitiveconstitutedness $^{14}$ absolution/absolute-scope \{flawed/unsound\}-relative-unreflexivity-inexistencelabsolutising from-limited-mentation/psychologismic epistemic-acutisationnonresidualising imbued-\{compulsing\} linearity in-eclecticism-of prior-mereformulaicity/ritualisation conception') is already notionally/epistemically/bindingnessly-<as-todeterminism/conceptivity-of-relative-unreflexivity/relative-reflexivity veridically manifest as to human Beingdevelopment/ontological-framework-expansion-as-to-depth-of-ontologising-development-asinfrastructure-of- meaningfulness-and-teleology , institutional-development-as-to-socialfunction-development and living-development-as-to-personality-development psychologismic epistemic acutisation diffieully < for, residualising \{decompulsings delinearity for cogency> magnitudes $\left\{\right.$ of-experientiality/experiment\} when so-construed as from ' ${ }^{\circ}$ nonpresencing-<perspectiveontological-normalcy/postconvergence $>$ relativism/relative-scope for epistemic-growth,-as\{veridical/sound\}-relative-reflexivity-in-existence/relativising from-limited-mentation-as-itsdeepening/psychologismic epistemic-acutisation residualising, fdecompulsingl delinearity foreogency'. In-the-bigger-scheme-of-things, notional asceticism is what we are already involved in with respect to 'childhood to adulthood levels-of-responsibilities' (as to living-developmentas-to-personality-development), from 'non-specialists to specialists levels-of-responsibilities as equally articulated in the latter codes-of-conduct' (as to institutional-development-as-to-social- 
function-development) and in the bigger frame as well between 'lifespan extricatory/preconverging psychical-nascency moronisation- $<$ sublimating-nascence,extricatory-desublimating-downstreaming/'avalage' $>$ ' and 'nonextricatory/postconverging ontologising-and-re-ontologising angling-of-imaginary $\quad$ demoronisation- $<$ sublimatingnascence,-nonextricatory-sublimating-upstreaming/'amontée'>' levels-of-responsibilities (as to Being-development/ontological-framework-expansion-as-to-depth-of-ontologisingdevelopment-as-infrastructure-of- meaningfulness-and-teleology ); with the latter being more problematic as to the greater dispensing-with-immediacy-for-relative-ontologicalcompleteness ${ }^{87}$-by-reification/contemplative-distension (as to protracted-social-as-toindividual-by-institutional-by-social notional $\sim$ self-distantiation- $<$ imbued-re-motif-and-reapriorising/re-axiomatising/re-referencing $>$ ) that is in-many-ways difficultly appreciable as from 'lifespan extricatory/preconverging psychical-nascency moronisation- $<$ sublimatingnascence,-extricatory-desublimating-downstreaming/'avalage'>' and in-many-ways even when appreciated is construed as 'sacrifice'. But then such a notion of notional asceticism as 'sacrifice' again is a naivety of any given '7 presencing-absolutising-identitiveconstitutedness $^{14}$ absolution/absolute-scope \{flawed/unsound\}-relative-unreflexivity-inexistence absolutising from limited mention/psychologismic epistemic acutisationnonresidualising imbued-\{compulsing\} linearity in-eclecticism-of prior-mereformulaicity/ritualisation conception' (and in-many-ways psychoanalytically heldup/encumbered by it) and it is contradictory in the sense that it seem to imply that "when prospective relative-ontological-completeness ${ }^{87}$ is educed-and-availing-and-re-availing as to prospective re-ontologising and deferentialism/deferential-formalisation-transference implications of re-ontologising' we still do have a choice for prospective disontologising/subontologising? This is tantamount to saying that if for instance a member of a non-positivising social-setup by one way or another found themselves in a positivism/rational- 
empiricism social-setup and came to grasp the overall 'positivism/rational-empiricism

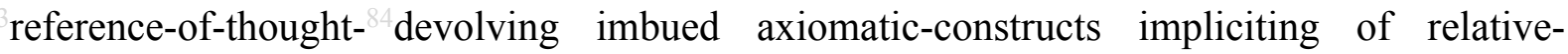
ontological-completeness ${ }^{87}$ meaningfulness-and-teleology" ${ }^{9}$ as to 'their positivism/rationalempiricism sublimating existential-<disontologising/re-ontologising aporeticism $>$ experientiality/experiment- $<$ as-to-existentially-formative- ‘fepistemic-totalising $\frac{1}{\text { re }}$ re-apriorising/reaxiomatising/re-referencing-residuality-in-re-originariness/re-origination',- - so'notionally/epistemically/bindingnessly-<as-to-determinism/coneeptivity-of-relative-unreflexivity/relative-reflexivity> implicited-and-articulated'_as-from-nonextricatory-'prospective-re-ontologising-Being-thenInstitutional-then-Living-magnitudes-of-\{hermeneutic/reprojection-protraction-of\}reframingand-reformulation \}' $>$ ' in the positivism/rational-empiricism social-setup (so-elicited as of their limitedness/human-subpotency prospective re-encountering/re-confrontation with unlimitedness/existence-<fll potency-of_sublimating nascence $>$ in reflection of 'requisite prospective reference-of-thought-point-ofdevolving/departure/anchoring/backdrop_of_sublimating-nascence-<as-to-the-grandestaxiomatic-construct-\{epistemic-alising ${ }^{+}$re-apriorising/re-axiomatising/rereferencing residuality - in-re-originariness/re-origination of limitedness/human-subpotency prospective re-encountering/re-confrontation with unlimitedness/existence>'); they still do have the choice for fully assuming a disontologising/subontologising 'non-positivising ${ }^{8}$ referenceof-thought- devolving imbued axiomatic-constructs impliciting of relative-ontologicalincompleteness ${ }^{88}$ meaningfulness-and-teleology ${ }^{9}$, within their prior non-positivising socialsetup? The historial reality speaks otherwise (as the central and potent force of 'human ontologising-and-re-ontologising as so-reflected in the overall relative-unreflexivity/relativereflexivity ontological-contiguity ${ }^{67} \sim$ of-the-human-institutionalisation-process ${ }^{6}$, rather lied historially with the possibility for human cultural diffusion); as so-reflecting underlying 'constraining existence-as-sublimating-withdrawal/unenframing/re-ontologising,-elicited- 
from-prospective-profound-supererogation imbuing human ontological-commitment <implied - self-assuredness-of-ontological-good-faith/authenticity $\sim$ postconverging-dementating/structuring/paradigming -as-being-as-of-existential-reality>' and '103 universaltransparency ${ }^{104}$-〈transparency-of-totalising-entailing,-as-to-entailing-<amplituding/formativeepistemicity $>$ totalising $\sim$ in-relative-ontological-completeness $\rangle$ as available-to/elicitable-to-〈asto-human-consciousness/collective-consciousness-distendedness/detruncating- $<$ beyondselfpresencing,-as-re-ontologising-decentering_of-consciousness/collective-consciousness,-asto-psychologismic-epistemic-acutisation - residualising, ${ }^{\text {- } \text { decompulsing }}$ delinearity $\sim$ for-cogency $\left.>\right\rangle$ the social-functioning-and-accordance-as-of-social-stake-contention-or-confliction conception of any given registry-worldview/dimension <preconverging 'motif-andapriorising/axiomatising/referencing'-entailing>-existentialising—enframing/imprintedness〈as-to- historicity-tracing - in-presencing-hyperrealisation/hyperreal-transposition〉'. Such an ontologically wrong conception of notional asceticism as 'sacrifice' again is rather the reflection of paradoxically construing of the prospective relative-ontological-completeness ${ }^{87}$ as from the epistemic-projection perspective of the relative-ontological-incompleteness ${ }^{6}$ presencing—absolutising-identitive-constitutedness ${ }^{14}$ absolution/absolute-scope \{flawed/unsound\}-relative-unreflexivity-in-existence/absolutising-from-limitedmentation/psychologismic epistemic acutisation nonresidualising imbued\{compulsing\} linearity in-eclecticism-of prior-mere-formulaicity/ritualisation'; further validating the idea that the prospective relative-ontological-completeness ${ }^{87}$ is necessarily subject to the 'overarching priority/precedence/primacy of its requisite prospective ontological-goodfaith/authenticity ${ }^{69}$ postconverging-de-mentating/structuring/paradigming ${ }^{70}$ induced 'prospective psychologismic-epistemic-acutisation-<as-to-postconverging-dementating/structuring/paradigming,-eliciting-of-existence's-sublimating-nascence-inprospective-aporeticism-overcoming/unovercoming > as to epistemic-growth,-as- 
\{veridical/sound\}-relative-reflexivity-in-existence/relativising from-limited-mentation-as-itsdeepening/psychologismic epistemic-acutisation residualising, \{decompulsing\} delinearity foreogency' as so-enabling the mental-aestheticising-<as-'psychologismic-existentialmetaphoricity \{as-to-\{epistemic-totalising łre-apriorising/re-axiomatising/re-referencing_inbecoming?' -so-implicited-'by-way-of-the-existentially/contextually/textually-manifest-motifconstruct-as-specific-language'-as-so-reflecting-'the-existentially/contextually/textuallymanifest-moronisation/demoronisation'> of the relative-ontological-completeness prospective re-rationalisation-of-contentivity/argumentativity/dialecticism/discursivity. The fact of the matter (with regards to the misconception of notional asceticism as megalomania) is that such pedantising/muddling/formulaic-hollowing-out-insubontologisation/subpotentiation-〈blurring/undermining-of-prospective-totalising-entailing,as-to-entailing-<amplituding/formative-epistemicity $>$ totalising in-relative-ontologicalcompleteness > is not as of 'unconsciously/unknowingly-entitled to ignorance/lack-ofknowledge as to when prospective relative-ontological-completeness ${ }^{87}$ is not educed-andavailing-and-re-availing as to prospective re-ontologising and deferentialism/deferentialformalisation-transference implications of re-ontologising'. It is rather involved in a contemptuous ploy in a pretense of genuine social intellectual-function/posture which ontological-bad-faith/inauthenticity $\sim$ preconverging-de-mentating/structuring/paradigming (as to ' $\{$ flawed/unsound $\}$-relative-unreflexivity-in-existence/absolutising from-limitedmentation/psychologismic epistemic acutisation - nonresidualising imbued\{compulsing\} linearity in-eclecticism-of prior-mere-formulaicity/ritualisation insidious-anarchy$<$ as-to-conscious/unconscious epistemically-flawed induced 'moronisation- $<$ sublimatingnascence,-extricatory-desublimating-downstreaming/'avalage’’ preconverging/dementing conception of prior mere-formulaicity/ritualisation incipiency of human social-functioning-andaccordance - as-of-social-stake-contention-or-confliction meaningfulness-and-teleology 
apriorising/axiomatising/referencing $>^{30}$ ) must be elucidated as part-and-parcel of prospective reontologising. Ultimately, any pretense to true genuine social intellectual-function/posture will have to 'face up intellectually with sound ontologising arguments' rather than ploys of ontological-bad-faith/inauthenticity ${ }^{64}$ preconverging-de-mentating/structuring/paradigming ${ }^{65}$, as to the fact that 'no human mortal (including this one) has ownership on ontological-veracity' but for 'submitting-to or demonstrating' limited-mentation-capacity-deepening —as-subjectinglimitedness/human-subpotency to-'educed-unlimitedness/existence-sublimating nascence'

Along the same token no one gets to carve-out a space of 'supposed knowledge that is unchallengeable/unconstestable' as even the Einsteins were challenged/contested and rather took heart in enabling the possibility for prospective human progress, and for that matter 'there is no veridical knowledge purpose as merely challenging/contesting but rather striving to elucidate divergences/differences and so along the course of an instigated drive-ofcontentivity/argumentativity/dialecticism/discursivity as to the 'requisite projection of the coherence/contiguity of the superseding-oneness-of-ontology/ontological-veridicality/relativeunreflexivity/relative-reflexivity -ontological-contiguity ${ }^{67}$, (as it can very much be argued in that sense that such a drive-of-contentivity/argumentativity/dialecticism/discursivity as herein articulated in different respects is equally making implicited challenges/contestations to budding-postmodern thought as to the 'priority/precedence/primacy of prospective ontologising/scientific/existence- $<$ honesty-constraining $>$ purposefulness than just intellectually vague complimenting'). This speaks to the bigger issue of the underlying collective human intellectual exercise requiring that all knowledge reflects its positioning in the overall human knowledge project (speaking of human notional reflexivity-<\{veridical/sound $\}$ relativereflexivity-in-existence/relativising from-limited-mentation-as-its-deepening/psychologismic<residualising \{decompulsing delinearity for-cogency>by-\{flawed/unsound\}-relative- 
unreflexivity-in-existence/absolutising from-limited-mentation/psychologismic epistemic

acutisation nonresidualising-imbued-\{compulsing\}linearity-in-eclecticism-of-prior-mere-

formulaicity/ritualisation>); as alternately, it is perfectly imaginable that many ideas articulated herein as to the 'original drive-of-contentivity/argumentativity/dialecticism/discursivity' could be represented as wholly original and positionally dissociated from other knowledge but then such an exercise will be paradoxically 'plagiaristic/unreflective of existence' (as failing to elucidate human notional $\sim$ reflexivity-<\{veridical/sound $\}$-relative-reflexivity-inexistence/relativising from-limited-mentation-as-its-deepening/psychologismic<residualising \{decompulsing\} delinearity for-cogency>by \{flawed/unsound\}-relativeunreflexivity-in-existence/absolutising from-limited-mentation/psychologismic epistemic acutisation nonresidualising-imbued-\{compulsing\} linearity in-eclecticism-of-prior-mereformulaicity/ritualisation> as so-required for articulating the 'prospective knowledge existential$<$ disontologising/re-ontelogising aporeticism $>$ imbued difference-conflatedness ${ }^{13}$-as-tototalitative-reification-in-singularisation-<as-to-the-nondisjointedness/entailment-ofprospective- nonpresencing $>$-as-veridical-epistemicity-relativism-determinism ${ }^{2}$ in its depth-of-contentivity/argumentativity/dialecticism/discursivity); explaining why any such 'original drive-of-contentivity/argumentativity/dialecticism/discursivity' has to be 'articulated in-phase/in-contact with similar/approximately-similar thought' and as so-underlied by overall human knowledge contrastive intellectual postures. Such ontological-badfaith/inauthenticity ${ }^{64}$ preconverging-de-mentating/structuring/paradigming surreptitious and non-intellectual strategies of distractive-alignment-to- ${ }^{8}$ reference-of-thought- $<$ ofapriorising/axiomatising/referencing $>{ }^{30}$ very much manifest limited-mentation-capacity-assubjecting 'educed unlimitedness/existence sublimating nascence' to limitedness/hmmansubpotency; as so-reflected in the 'paradoxical readiness' of such pedantising/muddling/formulaic-hollowing-out - in-subontologisation/subpotentiation- 


\section{〈blurring/undermining-of-prospective-totalising-entailing,-as-to-entailing-}

$<$ amplituding/formative-epistemicity $>$ totalising in-relative-ontological-completeness

transform the remote and marginal/marginalised platforms of social contestation (however their muddlement) into the defining-and-structural social problem of our times. Ultimately (as to the inherent veracity of human generation/regeneration of 'prospective postconverging aporeticism-overcoming/unovercoming as the-Good/knowledgereification $\sim$ gesturing-and-accounting — of-epistemic-phenomenalism- $<$ in-

prospective_psychologismic apriorising/axiomatising/referencing-\{of-‘prospectively_ implicited_attendant-ontological-contiguity ' educedexistentialising/contextralising/textralising_intelligibility/epistemicity/reflexivity-contiguity<imbued-notional cogency >' \}-conflatedness -in-\{preconverging-ment by\} postconverging-entailment $>$ /understanding/<amplituding/formativeepistemicity $>$ causality $\sim$ as-to-projective-totalitative-implications-of-prospectivenonpresencing,-for-explicating relative-unreflexivity/relative-reflexivity - ontologicalcontiguity ', as of the inherent human mental-aestheticising-<as-'psychologismic-existentialmetaphoricity \{as-to-\{epistemic-totalising ${ }^{\dagger}$ re-apriorising/re-axiomatising/re-referencing_inbecoming? '-so-implicited-'by-way-of-the-existentially/contextually/textually-manifest-motifconstruct-as-specific-language'-as-so-reflecting-'the-existentially/contextually/textuallymanifest-moronisation/demoronisation'> recurrently-driven limitedness/human-subpotency prospective re-encountering/re-confrontation with the "constraining/defining intersolipsistic reflexive-sublimating/unreflexive-desublimating measure/objectification that is unlimitedness/existence-as-ontological-normalcy/postconvergence-<in-validation-of'metaphysics-of-absence_epistemic-projection'>' as so-reflecting limited-mentation-capacitydeepening —as-subjecting limitedness/human-subpotency-to-'educed-unlimitedness/existencesublimating nascence' ${ }^{53}$ ), it can be appreciated that there are ever always two sides to this 
process of human limited-mentation-capacity-deepening —as-subjecting limitedness/humansubpotency-to-'educed-unlimitedness/existence-sublimating-nascence' ${ }^{33}$ (as so-associated with the human Being-development/ontological-framework-expansion-as-to-depth-of-ontologisingdevelopment-as-infrastructure-of- meaningfulness-and-teleology , institutionaldevelopment-as-to-social-function-development and living-development-as-to-personalitydevelopment psychologismic epistemic-acutisation difficulty-<for,-residualising $\{$ decompulsing $\}$ delinearity for-cogeney>-magnitudes $\{$ of-experientiality/experiment $\}$ of the overall relativeunreflexivity/relative-reflexivity - ontological-contiguity ${ }^{67}$ of-the-human-institutionalisationprocess ${ }^{6}$ ). These two sides involve on-the-one-hand the desublimating/distorting recurrence of already induced 'limitedness/human-subpotency prior rationalisation-ofcontentivity/argumentativity/dialecticism/discursivity as to the prior mereformulaicity/ritualisation-<as-to-mere-formulaicmethodologising/mutualising/organising/institutionalising,-prospectively-losing-track-of‘fepistemic latising +’re-apriorising/re-axiomatising/re-referencing $\sim$ residuality-in-reoriginariness/re-origination'> of $\leq$ mere-formulaicity/ritualisation-of $>$-prior secondnatured institutionalisation (notwithstanding unlimitedness/existence-<full-potency-of_sublimating nascence $>$ prospective apriorising/axiomatising/referencing-sublimating-reflexivitybeholdening under which limitedness/human-subpotency submits in profound-supererogation for prospective sublimating)' and on-the-other-hand the sublimating recurrence of 'prospective human incipient/seeding ontological-faith-notion-or-ontological-fideism -imbuedunderdetermination-of-motif-and-apriorising/axiomatising/referencing-as-so-being-as-ofexistential-reality imbued psychoanalytic-unshackling as of psychologismic-epistemicacutisation-<as-to-postconverging-de-mentating/structuring/paradigming,-eliciting-ofexistence's-sublimating-nascence-in-prospective-aporeticism-overcoming/unovercoming $>$ as to epistemic-growth,-as_ \{veridical/sound\}-relative-reflexivity-in-existence/relativising from- 


\section{limited-mentation-as-its-deepening/psychologismic epistemic-acutisation residualising,}

$\{$ decompulsing $\}$ delinearity for-cogency that can elicit unlimitedness/existence- $<$ full-potencyof_sublimating nascence> prospective apriorising/axiomatising/referencing-sublimatingreflexivity_-beholdening under which limitedness/human-subpotency submits in profoundsupererogation for prospective sublimating'; as so-speaking of prospective humansubpotency-aporia/undecidability/dilemma/ought-

indeterminacy/deficiency/limitation/constraint—imbued-'notional firstnaturednessformativeness-<as-to-eventualising-inkling-drive-or-seeding-misprising $>$ temporal-tointemporal-dispositions-<so-construed-as-from-perspective-ontologicalnormalcy/postconvergence>'-existentialism-form-factor'. But then the implication here is that the 'human conscious/unconscious mental-reflex' (that there ever always exist an 'absolute rationalisation-of-contentivity/argumentativity/dialecticism/discursivity as to prior mereformulaicity/ritualisation-<as-to-mere-formulaic-

methodologising/mutualising/organising/institutionalising,-prospectively-losing-track-of‘fepistemic-atising ’’re-apriorising/re-axiomatising/re-referencing $\sim$ residuality-in-reoriginariness/re-origination'> of $\leq$ mere-formulaicity/ritualisation-of $>$-prior secondnatured institutionalisation for prospective postconverging apereticism oreming') is in-many-ways false as to the requisite psychologismic epistemic acutisation difficulty<<er,

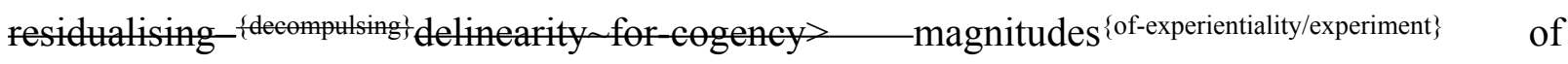
profound-supererogation required for 'prospective human incipient/seeding ontological-faithnotion-or-ontological-fideism—imbued-underdetermination-of-motif-and-

apriorising/axiomatising/referencing-as-so-being-as-of-existential-reality imbued psychoanalytic-unshackling as of psychologismic-epistemic-acutisation-<as-topostconverging-de-mentating/structuring/paradigming,-eliciting-of-existence's-sublimatingnascence-in-prospective-aporeticism-overcoming/unovercoming > as to epistemic-growth,-as- 
\{veridical/sound\}-relative-reflexivity-in-existence/relativising from-limited-mentation-as-itsdeepening/psychologismic epistemic acutisation residualising, ${ }^{\text {fdecompulsing }}$ delinearity for eogency that can elicit unlimitedness/existence-<full-potency-of_sublimating nascence> prospective apriorising/axiomatising/referencing-sublimating-reflexivity_beholdening under which limitedness/human-subpotency submits in profound-supererogation for prospective sublimating'; more-and-more demanding of profound-supererogation as from human livingdevelopment-as-to-personality-development psychologismic epistemic-acutisation-

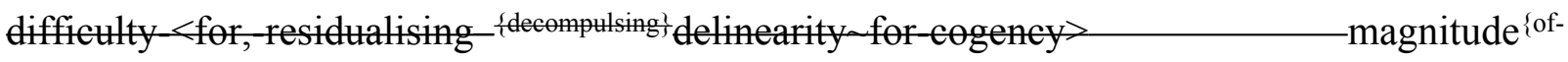
experientiality/experiment\} of profound-supererogation , institutional-development-as-to-socialfunction-development psychologismic epistemic-acutisation difficulty-for, residualising \{decompulsing delinearity for-cogency> magnitude $\{$ of-experientiality/experiment\} of profoundsupererogation and Being-development/ontological-framework-expansion-as-to-depth-ofontologising-development-as-infrastructure-of- meaningfulness-and-teleology psychologismic epistemic-acutisation difficulty-for, residualising

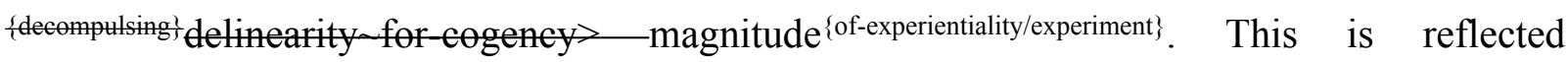
notionally/epistemically/bindingnessly-<as-to-determinism/eonceptivity-of-relative-unreflexivity/relative-reflexivity> as to the requisite human 'fveridical/sound-relative-reflexivity-in-existence/relativising fromlimited-mentation-as-its-deepening/psychologismic epistemic-acutisation residualising,

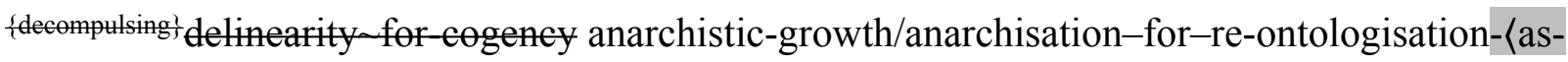
to-conscious/unconscious epistemically-sound induced 'demoronisation- $<$ sublimatingnascence,-nonextricatory-sublimating-upstreaming/‘amontée’> postconverging/dialecticalthinking conception of residual_re-originary_anarchistic incipiency of human socialfunctioning-and-accordance-as-of-social-stake-contention-or-confliction meaningfulnessand-teleology ' '’ for profound-supererogation (since the very notion of supposed institutional and bureaucratic projection of human ${ }^{56}$ meaningfulness-and-teleology ${ }^{99}$ are rather actually of the 
undergirding-veracity of germinal/inceptive/formative individuals anarchistic selfreflexive instigative-eventuating-〈as-to-teleological-instigative/incipient-

willing/arbitrariness/waywardness/faithdrivenness/supererogating-for-human-intelligibility,-

preceding-existence's-eventuating-sublimating-validation/desublimating-invalidation>

manifestation and when misconstrued otherwise as to virtual/illusory naivety of inherently actualising institutional/bureaucratic/social self-embodying epistemic-projection' turn out to induce 'fflawed/unsound\}-relative-unreflexivity-in-existence/absolutising from-limitedmentation/psychologismic epistemic acutisation nonresidualising imbued-

\{compulsing\} linearity in-eclecticism-of prior-mere-formulaicity/ritualisation insidious-anarchy$<$ as-to-conscious/unconscious epistemically-flawed induced 'moronisation- $<$ sublimatingnascence,-extricatory-desublimating-downstreaming/'avalage'> preconverging/dementing conception of prior mere-formulaicity/ritualisation incipiency of human social-functioning-andaccordance - as-of-social-stake-contention-or-confliction meaningfulness-and-teleology of shallow-supererogation ). The reality with regards to human prospective postconverging aporeticism-overcoming/unovercoming (in reflection of the underlying 'crossgenerational notional firstnaturedness-formativeness-<as-to-eventtalising-inklingdrive-or-seeding-misprising $>$ mental-processing-parity for ontological-performance ${ }^{72}$ <including-virtue-as-ontology $>$ /morality/ethics/justice/etc.' of all sovereign humans as to the potentiation of sublimating-over-desublimating across all times which has to do with 'human ontological-good-faith/authenticity $\sim$ postconverging-de-

mentating/structuring/paradigming — — by_ontological-bad-

faith/inauthenticity ${ }^{64}$ preconverging-de-mentating/structuring/paradigming' as to the given station/locus of limitedness/human-subpotency <amplituding/formative-epistemicity >totalising thrownness-in-existence $^{35}$ ) is thus veridically and fundamentally inhered upon human notional asceticism reasoning-through/messianic-reasoning prospective existential- 
$<$ disontologising/re-ontologising aporeticism $>$

deployment of transversality- $<$ for-

sublimating-existential-eventuating/denouement, from-'thinking at first/pure-predisposition-

preemptive-of prospective-disontologising/subontologising' as-of-prospectively-

disambiguated-affirmed-and-unaffirmed-'motif-and-apriorising/axiomatising/referencing'>

elucidation as of notional $\sim$ self-distantiation-<imbued-re-motif-and-re-apriorising/reaxiomatising/re-referencing $>\quad$ implied formativeness-<as-to-intersolipsism-ofpreformulating/preframing/premeaningfulness-imbued-mediativity-and-deferentialism>-ofmeaningfulness-and-teleology in $\quad$ nonpresencing- $<$ perspective-ontologicalnormalcy/postconvergence $>$ epistemic-projection (as to profound-supererogation of the genuine social intellectual-function/posture as of 'Derridean underdetermination-imbued force/violence conception' and 'Foucauldian knowledge/power conception construed as knowledge-empowerment/ignorance-disempowerment'); and so over the shallowsupererogation of the overall <amplituding/formative> wooden-language-〈imbued temporal-mere-form/virtualities/dereification/akrasiatic-drag/denatured/preconverging-ordementing -narratives - of-the- reference-of-thought- categoricalimperatives/axioms/registry-teleology $\rangle$ of registry-worldviews/dimensions priorly secondnatured institutionalisation as to a positive-opportunism-of-social-functioning-andaccordance $^{75}$ reasoning-from-results/afterthought (with the latter across all human epochs recurrently involved in falsely calling up its given registry-worldview/dimension imbued priorinstitutionalisation-threshold-by-prospective-uninstitutionalised-threshold 'self-referencingsyncretising forward-facing-supposedly postconverging-or-dialectical-thinking -apriorisingpsychologism epistemic-projection as of prior mere-formulaicity/ritualisation-<as-to-mereformulaic - methodologising/mutualising/organising/institutionalising,-prospectively-losingtrack-of-'fepistemic tratising tre-apriorising/re-axiomatising/re-referencing $r$ residuality-in-reoriginariness/re-origination'>' so-reflecting its 'disontologising preconverging/dementing - 
$<$ as-to-prospective-uninstitutionalised-threshold $>$ ignoring/biased inclination' for the sake of 'its given present minimum-and-balancing expectations/anticipations of social-functioning-andaccordance-as-of-social-stake-contention-or-confliction' while qualifying its prospectively uninstitutionalised-threshold ${ }^{102}$ actually as nondescript/ignorable-void ${ }^{6}$ as to its ${ }^{79}$ presencingabsolutising-identitive-constitutedness $<$ preconverging 'motif-andapriorising/axiomatising/referencing'-entailing>-existentialising—enframing/imprintedness〈as-to- historicity-tracing — in-presencing-hyperrealisation/hyperreal-transposition〉'). The bigger point here (with respect to human prospective postconvergingaaporeticismovercoming/unovercoming) is that in-many-ways the notion of 'rationalisation-ofcontentivity/argumentativity/dialecticism/discursivity as to prior mereformulaicity/ritualisation-<as-to-mere-formulaicmethodologising/mutualising/organising/institutionalising,-prospectively-losing-track-of'fepistemic totising †ेre-apriorising/re-axiomatising/re-referencing residuality-in-reoriginariness/re-origination'> of $\leq$ mere-formulaicity/ritualisation- $\theta f>$ prior secondnatured institutionalisation for prospective postconvergingaporeticism-overcoming/unovercoming' is at best subservient and at worst irrelevant to the determinative exercise of 'human profoundsupererogation prospective postconverging-aporeticism-overcoming/unovercoming' as to underlying 'constraining existence-as-sublimating-withdrawal/unenframing/re-ontologising,elicited-from-prospective-profound-supererogation imbuing human ontologicalcommitment $-<$ implied—self-assuredness-of-ontological-goodfaith/authenticity postconverging-de-mentating/structuring/paradigming -as-being-as-ofexistential-reality>' and ' ${ }^{103}$ universal-transparency ${ }^{104}$-〈transparency-of-totalising-entailing,-asto-entailing-<amplituding/formative-epistemicity>totalising in-relative-ontologicalcompleteness \ as available-to/elicitable-to-〈as-to-human-consciousness/collectiveconsciousness-distendedness/detruncating-<beyond-selfpresencing,-as-re-ontologising- 
decentering_of-consciousness/collective-consciousness,-as-to-psychologismic-epistemicacutisation-residualising, ${ }^{-\{\text {decompulsing }}$ delinearity for-cogency $>>$ the social-functioning-andaccordance - as-of-social-stake-contention-or-confliction conception of any given registryworldview/dimension $\quad<$ preconverging 'motif-and-apriorising/axiomatising/referencing'entailing $>$-existentialising — enframing/imprintedness-〈as-to- historicity-tracing - inpresencing-hyperrealisation/hyperreal-transposition〉'. This insight is important and relevant in order to encourage intemporal-disposition inclinations for 'human profound-supererogation prospective postconverging aporeticism-overcoming/unovercoming' that covert/overt pretenses of 'limits to veridical thought' are just manifestations of ' unreflexivity-in-existence/absolutising from-limited-mentation/psychologismic epistemic acutisation nonresidualising imbued-\{compulsing\}linearity in-eclecticism-of prior-mereformulaicity/ritualisation insidious-anarchy-<as-to-conscious/unconscious epistemically-flawed induced 'moronisation- $<$ sublimating-nascence,-extricatery-desublimatingdownstreaming/'avalage’> preconverging/dementing conception of prior mereformulaicity/ritualisation incipiency of human social-functioning-and-accordance-as-ofsocial-stake-contention-or-confliction meaningfulness-and-teleology '>' that do not define the possibility/imagination of the-human/humanity by their mere 'limitedness/humansubpotency prior rationalisation-of-contentivity/argumentativity/dialecticism/discursivity as to the prior mere-formulaicity/ritualisation-<as-to-mere-formulaic methodologising/mutualising/organising/institutionalising,-prospectively-losing-track-of-

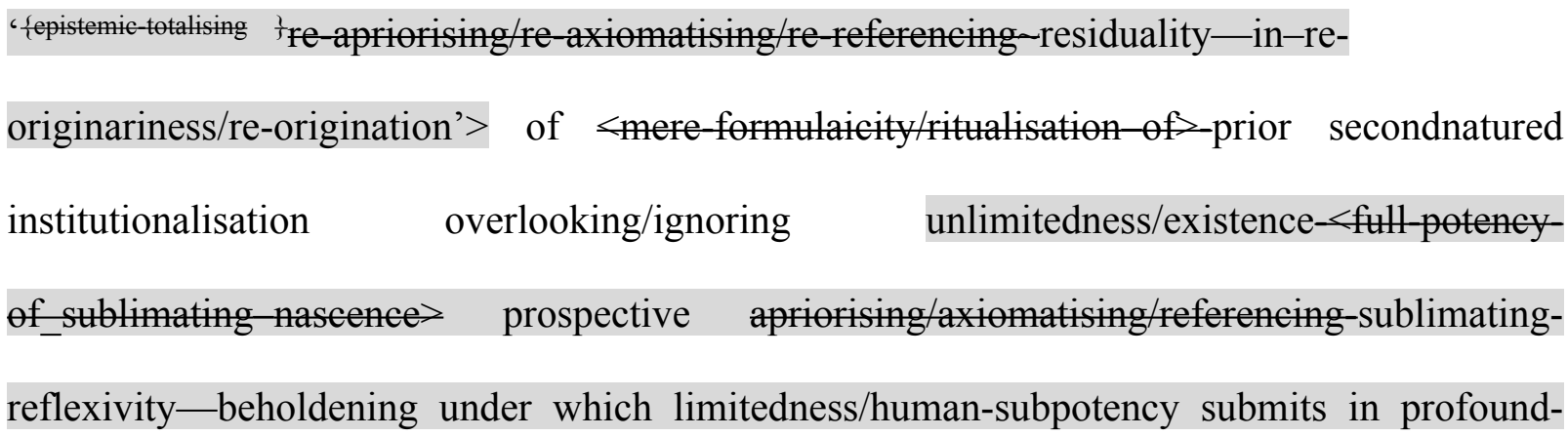


supererogation for prospective sublimating (with such covert/overt pretenses of 'limits to veridical thought' not to be confused with requisite dimensionality-of-sublimating 〈<amplituding/formative>supererogatory $\sim$ de-mentativeness/epistemic-growth-or-

conflatedness /transvaluative-rationalising/transepistemicity/anamnestic-residuality/spiritdrivenness-equalisation〉 as to when a 'wrong sense of graciousness/openness is liable to be demoralised/browbeaten for such limitedness/human-subpotency punctual/immediacy/constituted/compulsions-encumbered limited-mentation-capacity-assubjecting 'educed-unlimitedness/existence-sublimating nascence' to-limitedness/humansubpotency usurpation purposes'). Rather, the 'very sublimating-tradition/constant of human progress' (as to veridically requisite dimensionality-of-sublimating ${ }^{25}$ <<amplituding/formative>supererogatory $\sim$ de-mentativeness/epistemic-growth-orconflatedness /transvaluative-rationalising/transepistemicity/anamnestic-residuality/spiritdrivenness-equalisation)) effectively lies with the sublimating recurrence of 'prospective human incipient/seeding ontological-faith-notion-or-ontological-fideism —imbuedunderdetermination-of-motif-and-apriorising/axiomatising/referencing-as-so-being-as-ofexistential-reality imbued psychoanalytic-unshackling as of psychologismic-epistemicacutisation-<as-to-postconverging-de-mentating/structuring/paradigming,-eliciting-ofexistence's-sublimating-nascence-in-prospective-aporeticism-overcoming/unovercoming $>$ as to epistemic-growth,-as - \{veridical/sound\}-relative-reflexivity-in-existence/relativising fromtimited mentation as its deepening/psychologismic epistemic acutisation residualising, $\{$ decompulsing $\}$ delinearity for-cogency that can elicit unlimitedness/existence-<ull-potency of_sublimating nascence> prospective apriorising/axiomatising/referencing-sublimatingreflexivity_-beholdening under which limitedness/human-subpotency submits in profoundsupererogation for prospective sublimating' (with regards to Being-development/ontologicalframework-expansion-as-to-depth-of-ontologising-development-as-infrastructure-of- 
development and living-development-as-to-personality-development psychologismic epistemic-acutisation difficulty-for, residualising \{decompulsing ${ }^{\prime}$ delinearity for-cogency> magnitudes ${ }^{\{\text {of-experientiality/experiment }\}}$ ). In this regards, human construction-of-the-Self (as reflecting human psychologismic-epistemic-acutisation-<as-to-postconverging-dementating/structuring/paradigming,-eliciting-of-existence's-sublimating-nascence-inprospective-aporeticism-overcoming/unovercoming $>$ as to epistemic-growth,-as\{veridical/sound\}-relative-reflexivity-in-existence/relativising from-limited-mentation-as-itsdeepening/psychologismic epistemic-acutisation residualising, fdecompungl $_{\text {delinearity for }}$ eogency) speaks to the very 'existential-<disontologising/re-ontologising aporeticism $>$ <amplituding/formative-epistemicity>-totalising thrownness-in-existence ${ }^{35}$ of the overall relative-unreflexivity/relative-reflexivity ontological-contiguity ${ }^{67} \sim$ of-the-humaninstitutionalisation-process ${ }^{6}$, (so-undergirded as of 'human aestheticisation-andaestheticisation-towards-ontology- $<$ elicited-idiomatisation $>\quad$ moronisation- $<$ sublimating nascence,-extricatory-desublimating-downstreaming/'avalage’’-by_demoronisation<sublimating-nascence,-nonextricatory-sublimating-upstreaming/'amontée’> existentialising/emanance/becoming—constraint/pressure'). This construal of 'human psychologismic-epistemic-acutisation-<as-to-postconverging-dementating/structuring/paradigming,-eliciting-of-existence's-sublimating-nascence-inprospective-aporeticism-overcoming/unovercoming > as to epistemic-growth,-as\{veridical/sound\}-relative-reflexivity-in-existence/relativising from-limited-mentation-as-its-

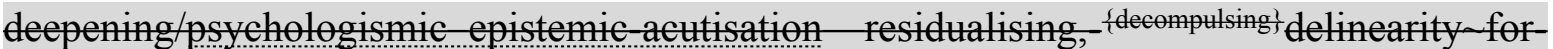
eogey' reflect the succession of 'human epistemic-projection radicalities $\sim$ inchronicular/annalistic-cogency-<as-of-notional $\sim$ protensivity $>-\langle$ as-to-limited-mentationcapacity-deepening —as-subjecting limitedness/human-subpotency-to-'educed- 
cogency_chronicularity/annality-of-relative-reflexivity,-as-to-profound-supererogation ${ }^{9}$ for eliciting unlimitedness/existence-<full-potency-of_sublimating nascence $>$ prospective apriorising/axiomatising/referencing-sublimating-reflexivity_beholdening (as so-reflecting prospective $\quad{ }^{45}$ foregrounding _ entailment- $<$ in-succession-of-profound-supererogation $>$ 〈postconverging-narrowing-down sublimation-as-to-'existence-as-sublimatingwithdrawal/unenframing/re-ontologising,-elicited-from-prospective-profoundsupererogation '-in-reflecting-'immanent relative-unreflexivity/relative-reflexivity ontological-contiguity ';--as-operative-notional deprocrypticism)). Critically this veridical crossgenerational construal of 'human psychologismic-epistemic-acutisation-<as-topostconverging-de-mentating/structuring/paradigming,-eliciting-of-existence's-sublimatingnascence-in-prospective-aporeticism-overcoming/unovercoming > as to epistemic-growth,-as\{veridical/sound\}-relative-reflexivity-in-existence/relativising from-limited-mentation-as-itsdeepening/psychologismic epistemic-acutisation residualising, ${ }^{\text {\{decompulsing }}$ delinearity for eogeney' (as caught up 'between human limited-mentation-capacity-as-subjecting 'educedunlimitedness/existence-sublimating nascence' to-limitedness/human-subpotency and the need for human limited-mentation-capacity-deepening-as-subjecting limitedness/humansubpotency-to-'educed-unlimitedness/existence-sublimating-nascence' ${ }^{3}$ ' reflecting the reality of the 'human condition by its limitedness/human-subpotency as a classroom-<as-oflimitedness/human-subpotency $>$ with no teacher-<as-of-the-sublimating-nascence-ofunlimitedness/existence $>$ that has to produce sublimating ${ }^{5}$ meaningfulness-and-teleology ${ }^{9}$ ever always at risk of being prospectively distorted/desublimated by the "blurriness$<$ sterilising/anecdotalising/trivialising-of-prospective-re-ontologising_by-preconverging,-indisontologising-formulaic-dragging-out/hollowing-out> dynamics of limited-mentationcapacity—as-subjecting-'educed-unlimitedness/existence-sublimating nascence' to- 
limitedness/human-subpotency') speaks to the self-reflexive instigative-eventuating-〈as-toteleological-instigative/incipient-

willing/arbitrariness/waywardness/faithdrivenness/supererogating-for-human-intelligibility,preceding-existence's-eventuating-sublimating-validation/desublimating-invalidation〉 of 'relays of human intemporal-individuation epistemic-projection radicalities $\sim$ inchronicular/annalistic-cogency-<as-of-notional $\sim$ protensivity $>-\langle$ as-to-limited-mentationcapacity-deepening — as-subjecting limitedness/human-subpotency-to-'educedunlimitedness/existence-sublimating nascence' > so-construed as cogency_chronicularity/annality-of-relative-reflexivity,-as-to-profound-supererogation ${ }^{2}$ (as so-analysable as from the underlying 'crossgenerational notional firstnaturednessformativeness-<as-to-eventualising inkling-drive-or-seeding-misprising $>$ mentalprocessing-parity for ontological-performance ${ }^{72}-<$ including-virtue-asontology $>$ /morality/ethics/justice/etc.' of all sovereign humans as to the potentiation of sublimating-over-desublimating across all times which has to do with 'human ontologicalgood-faith/authenticity ${ }^{69} \sim$ postconverging-de-mentating/structuring/paradigming 7 — byontological-bad-faith/inauthenticity $\sim$ preconverging-de-mentating/structuring/paradigming' as to the given station/locus of limitedness/human-subpotency <amplituding/formativeepistemicity>-totalising $\sim$ thrownness-in-existence ${ }^{35}$ ). In this respect the inherent preconverging/postconverging-de-mentative/structural/paradigmatic human 'notional $\sim$ reflexivity-<\{veridieal/sound\} relative-reflexivity-in-existence/relativising from limited-mentation-as-its-deepening/psychologismic-<residualising ${ }_{\text {fdecompulsing }}^{\text {f }}$ delinearity foreogency>-by-\{flawed/unsound\}-relative-unreflexivity-in-existence/absolutising fromlimited-mentation/psychologismic epistemic acutisation nonresidualising-imbued-
\{compulsing\}linearity-in-eclecticism-of-prior-mere-formulaicity/ritualisation> dualising' (as of
underlying 'crossgenerational notional firstnaturedness-formativeness-<as-to- 
eventualising-inkling-drive-or-seeding-misprising>-mental-processing-parity

ontological-performance $^{72}$-<including-virtue-as-ontology $>$ /morality/ethics/justice/etc.' of all sovereign humans as to the potentiation of sublimating-over-desublimating construal with regards to the "notional firstnaturedness-formativeness-<as-to-eventualising-inkling-drive-orseeding misprising $>$ temporal-to-intemporal-dispositions-<so-construed-as-fromperspective-ontological-normalcy/postconvergence> of human protracted-social-as-toindividual-by-institutional-by-social ontological-performance ${ }^{72}-$ including-virtue-as- $^{2}$ ontology $>^{\prime}$ and so relative to the given station/locus of limitedness/human-subpotency <amplituding/formative-epistemicity>-totalising $\sim$ thrownness-in-existence ${ }^{35}$ ) speaks to a

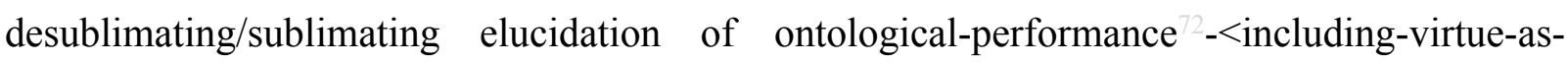
ontology $>$ /morality/ethics/justice/etc. as of 'human notional difference-conflatedness ${ }^{13}$-as-tototalitative-reification-in-singularisation- $<$ as-to-the-nondisjointedness/entailment-ofprospective- nonpresencing $>$-as-veridical-epistemicity-relativism-determinism construable as from the given projected relative-ontological-completeness ${ }^{8}$-ofapriorising/axiomatising/referencing'; in reflection of the 'manifest implications for prospective existential-<disentologising/re-ontologising aporeticism $>$ dimensionality-of-sublimating <<amplituding/formative>supererogatory $\sim$ de-mentativeness/epistemic-growth-orconflatedness /transvaluative-rationalising/transepistemicity/anamnestic-residuality/spiritdrivenness-equalisation)'. Thus (just as human relative-ontological-completeness ${ }^{87}$-ofapriorising/axiomatising/referencing is rather existentially-disontologising/re-ontelogising aporeticism $>$ reflected as to underlying <amplituding/formative-epistemicity $>$ totalising $\sim$ thrownness-in-existence ${ }^{35} \quad$ mental-aestheticising-<as-'psychologismic-existentialmetaphoricity fas-to-\{epistemic-totalising ${ }^{\frac{1}{3}} \mathrm{re}$-apriorising/re-axiomatising/re-referencing_inbecoming? '-so-implicited-'by-way-of-the-existentially/contextually/textually-manifest-motifconstruct-as-specific-language’-as-so-reflecting-'the-existentially/contextually/textually- 


postconverging_framing/imprinting re-ontologising' and 'prior existentialising-
preconverging_enframing/imprintedness social-functioning-and-accordance-as-of-socialstake-contention-or-confliction'), its associated 'human psychologismic-epistemic-acutisation$<$ as-to-postconverging-de-mentating/structuring/paradigming,-eliciting-of-existence'ssublimating-nascence-in-prospective-aporeticism-overcoming/unovercoming $>$ as to epistemicgrowth,-as-\{veridical/sound\}-relative-reflexivity-in-existence/relativising from-limitedmentation-as-its-deepening/psychologismic epistemic-acutisation residualising, \{decompulsing\} delinearity for eogeney' is rather reflected existentially-disontologising/reentologising aporeticism $>$ (as of underlying <amplituding/formative-epistemicity>totalising $\sim$ thrownness-in-existence ${ }^{35} \quad$ mental-aestheticising-<as-'psychologismic-existentialmetaphoricity fas-to-fepistemic-atising tre-apriorising/re-axiomatising/re-referencing_inbecoming? 's'-so-implicited-'by-way-of-the-existentially/contextually/textually-manifest-motifconstruct-as-specific-language'-as-so-reflecting-'the-existentially/contextually/textuallymanifest-moronisation/demoronisation'> imbued re-ontologising-bydisontologising_existential-calculus-〈between_prospective existentialisingpostconverging_framing/imprinting re-ontologising' and 'prior existentialising preconverging_enframing/imprintedness social-functioning-and-accordance-as-of-socialstake-contention-or-confliction' $\rangle)$; and rather underlined as to credibility/credulity-inducedprocessive-assent-to-moronisation-<sublimating-nascence,-extricatory-desublimatingdownstreaming/'avalage'>_by_incredibility/incredulity-induced-processive-dissent-indemoronisation-<sublimating-nascence,-nonextricatory-sublimating-upstreaming/‘amontée’> (which is so-underlied as of 'prior relative-ontological-incompleteness ${ }^{8}$-ofapriorising/axiomatising/referencing existentially-invested advantage/interest/apathy with little 
concern about the sublimating/emancipating/enfranchisement of prospective re-ontologising meaningfulness-and-teleology ', 'obscurity/remoteness/uncertainty—as-failing-to-reflectthe-effective-'existential-veracity-and-entailment-of $\sim$ relative-unreflexivity/relative-reflexivity' in the contemplation of prospective re-ontologising ${ }^{5}$ meaningfulness-and-teleology ${ }^{9}$ ' and 'individual-by-institutional-by-social conscious-sense-of-empowerment/disempowerment about prospective re-ontologising ${ }^{56}$ meaningfulness-and-teleology ${ }^{9}$ ). These three $<$ amplituding/formative-epistemicity>-totalising $\sim$ thrownness-in-existence ${ }^{35}$ elements (with respect to human credibility/credulity-induced-processive-assent-to-moronisation$<$ sublimating-nascence,-extricatory-desublimating-downstreaming/'avalage’ $>$ — by_ incredibility/incredulity-induced-processive-dissent-in-demoronisation- $<$ sublimatingnascence,-nonextricatory-sublimating-upstreaming/‘amontée’’) in-many-ways are exactly what consciously/unconsciously underlies any given registry-worldview/dimension ontologically-flawed projection/affirmation of its supposedly 'neutral ${ }^{79}$ presencingabsolutising-identitive-constitutedness ${ }^{14} \quad$ point-of-devolving/departure/anchoring/backdrop conceptualisation of human ontological-performance ${ }^{72}-<$ including-virtue-as- $^{-}$ ontology $>/$ morality/ethics/justice/etc. rationalisation-ofcontentivity/argumentativity/dialecticism/discursivity and so-reflected in it flawed 'implicited_attendant-ontological-contiguity ${ }^{67}$ > educedexistentialising/contextualising/textualising_'intelligibility/epistemicity/reflexivity-contiguity<imbued-notional cogency>' (failing to factor in its 'human preconverging/postconvergingde-mentating/structuring/paradigming interstitial <amplituding/formative-epistemicity $>$ totalising thrownness-in-existence $^{35}$ ); and this is exactly the backdrop of prospective deconstructive elucidation (as it put-into-question the manifest prospective ontologically-flawed ${ }^{6}$ presencing—absolutising-identitive-constitutedness ${ }^{14}$ absolution/absolute-scope \{flawed/unsound\}-relative-unreflexivity-in-existence/absolutising from-limited- 
mentation/psychologismic epistemic acutisation nonresidualising imbued-

\{compulsing\} linearity-in-eclecticism-of prior-mere-formulaicity/ritualisation

conception'

epistemic-projection). Effectively the veracity of prospective re-ontologising is rather deconstructive as of 'human notional difference-conflatedness ${ }^{13}$-as-to-totalitative-reificationin-singularisation-<as-to-the-nondisjointedness/entailment-of-prospective- nonpresencing $>$ as-veridical-epistemicity-relativism-determinism construable as from the prospectively projected relative-ontological-completeness ${ }^{87}$-of-apriorising/axiomatising/referencing' that supersedes/overcomes the above three <amplituding/formative-epistemicity>totalising thrownness-in-existence ${ }^{35}$ elements of prior registry-worldview/dimension credibility/credulity-induced-processive-assent-to-moronisation- $<$ sublimating-nascence,extricatory-desublimating-downstreaming/'avalage'>_-by_-incredibility/incredulity-inducedprocessive-dissent-in-demoronisation- $<$ sublimating-nascence,-nonextricatory-sublimatingupstreaming/'amontée'>; with these three <amplituding/formative-epistemicity>totalising thrownness-in-existence ${ }^{35}$ elements acting as the constraining re-ontologising-bydisontologising_existential-calculus-〈between $\quad$ 'prospective existentialisingpostconverging_framing/imprinting re-ontologising' and 'prior existentialisingpreconverging_enframing/imprintedness social-functioning-and-accordance-as-of-socialstake-contention-or-confliction'〉 stifling/undermining prospective re-ontologising possibilities (as to the given ${ }^{79}$ presencing-absolutising-identitive-constitutedness

institutional/bureaucratic/social insidious-anarchy-<as-to-conscious/unconscious epistemicallyflawed induced 'moronisation-<sublimating-nascence,-extricatory-desublimatingdownstreaming/'avalage'> preconverging/dementing conception of prior mereformulaicity/ritualisation incipiency of human social-functioning-and-accordance-as-ofsocial-stake-contention-or-confliction meaningfulness-and-teleology '> and its prospective ontologically-flawed eliciting of the registry-worldview/dimension 'prior existentialising- 
preconverging_enframing/imprintedness

stake-contention-or-confliction' as the 'neutral ${ }^{79}$ presencing-absolutising-identitiveconstitutedness ${ }^{14}$ point-of-devolving/departure/anchoring/backdrop conceptualisation of human sublimating ontological-performance ${ }^{72}-<$ including-virtue-asontology $>/$ morality/ethics/justice/etc. as to human rationalisation-ofcontentivity/argumentativity/dialecticism/discursivity'). The inherent difficulty in breaking-out from such a projection (of 'prior existentialising_preconverging_enframing/imprintedness social-functioning-and-accordance-as-of-social-stake-contention-or-confliction' as the 'neutral presencing_-absolutising-identitive-constitutedness point-ofdevolving/departure/anchoring/backdrop conceptualisation of human sublimating ontologicalperformance $^{72}-<$ including-virtue-as-ontology $>$ /morality/ethics/justice/etc. as to human rationalisation-of-contentivity/argumentativity/dialecticism/discursivity') is effectively what explains the 'multicenturies-long human crossgenerational Being-development/ontologicalframework-expansion-as-to-depth-of-ontologising-development-as-infrastructure-ofmeaningfulness-and-teleology psychologismic epistemic-acutisation difficulty-<or, residualising _decompulsing $\}$ delinearity for-cogency> - magnitude ${ }^{\{\text {of-experientiality/experiment }\}}$ of prospective transcendence-and-sublimity/sublimation/merentativity'; with regards to the requisite human mental-aestheticising-<as-'psychologismic-existentialmetaphoricity fas-to-\{epistemic-totalising ${ }^{\frac{1}{3}} \mathrm{re}$-apriorising/re-axiomatising/re-referencing_inbecoming?' 'so-implicited-‘by-way-of-the-existentially/contextually/textually-manifest-motifconstruct-as-specific-language'-as-so-reflecting-'the-existentially/contextually/textuallymanifest-moronisation/demoronisation'> recurrently-driven limitedness/human-subpotency prospective re-encountering/re-confrontation with the "constraining/defining intersolipsistic reflexive-sublimating/unreflexive-desublimating measure/objectification that is unlimitedness/existence-as-ontological-normalcy/postconvergence- $<$ in-validation-of- 
'metaphysics-of-absence_epistemic-projection'>' as so-reflecting limited-mentation-capacitydeepening —as-subjecting limitedness/human-subpotency to-'educed-unlimitedness/existencesublimating nascence' (as to an abstract model of the 'human condition by its limitedness/human-subpotency as a classroom-<as-of-limitedness/human-subpotency $>$ with no teacher-<as-of-the-sublimating-nascence-of-unlimitedness/existence $>$ that has to produce sublimating ${ }^{56}$ meaningfulness-and-teleology" ever always at risk of being prospectively distorted/desublimated by the 'blurriness-<sterilising/anecdotalising/trivialising-ofprospective-re-ontologising_by-preconverging,-in-disontologising-formulaic-dragging-

out/hollowing-out> dynamics of limited-mentation-capacity-as-subjecting-'educedunlimitedness/existence-sublimating nascence' to-limitedness/human-subpotency'). In-manyways there is a dynamic relationship between the ontologising/scientific/existence- $<$ honestyconstraining $>$ - scope_for_prospective_re-ontologising (whether as of underlying material, technical, organisational and/or mastery/know-how sublimation possibilities of 'limitedness/human-subpotency prospective re-encountering/re-confrontation with unlimitedness/existence-<full-potency-of_sublimating nascence $>$ ' and as it elicits prospective human demoronisation- $<$ sublimating-nascence,-nonextricatery-sublimatingupstreaming/'amontée'>) acting as the 'existential-disolonising aporeticism $>$ enabling-backdrop' for an advocacy/political/applicative-scope (arising as of 'civilisational quest for social stability/variety/belonging' with ancient civilisations, Faith practices, human emancipative practices with various human cultural renaissances, human enfranchisement advocacies specifically with regards to enlightenment humanisation associated with positivism/rational-empiricism induced demoronisation- $<$ sublimating-nascence,-sublimating-upstreaming/'amontée’> and the modern-day generalised expectation of material and human sublimation); in so-advancing the possibility for prospective re-ontologising and superseding/overcoming the respective epochal 'prior existentialising- 
preconverging_enframing/imprintedness social-functioning-and-accordance-as-of-socialstake-contention-or-confliction' (construed in self-presence/self-constitutedness ${ }^{14}-<$ inperspective-epistemic-abnormalcy/preconvergence ${ }^{3}>$ as the 'neutral ${ }^{7}$ presencingabsolutising-identitive-constitutedness ${ }^{14} \quad$ point-of-devolving/departure/anchoring/backdrop

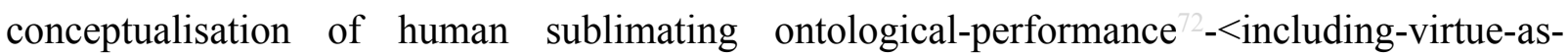
ontology $>$ /morality/ethics/justice/etc. as to human rationalisation-ofcontentivity/argumentativity/dialecticism/discursivity'). In other words, only such an overall 'detached insight' highlights that the abstract possibility for prospective re-ontologising meaningfulness-and-teleology ${ }^{9}$ of limitedness/human-subpotency is effectively potentiated as from constraining unlimitedness/existence-<full-potency-of_sublimating nascence $>$ in soreflecting human 'existentialising-firmament thresholding for the social-constructpostconverging-nonextricatory-existential-preempting-of-existential-unthought $\sim$ sublimation accruing-and-deriving of prospective secondnatured institutionalisation aestheticisation-andaestheticisation-towards-ontology-<elicited-idiomatisation>' (as underlied by the inherent human mental-aestheticising-<as-'psychologismic-existential-metaphoricity $\frac{1}{\text { as-to- }}$ totalising '⿳re-apriorising/re-axiomatising/re-referencing_in-becoming? ${ }_{3}^{\prime}$ 'so-implicited-'by-wayof-the-existentially/contextually/textually-manifest-motif-construct-as-specific-language'-asso-reflecting-'the-existentially/contextually/textually-manifest-moronisation/demoronisation'> recurrently-driven limitedness/human-subpotency prospective re-encountering/re-confrontation with the 'constraining/defining intersolipsistic reflexive-sublimating/unreflexive-desublimating measure/objectification that is unlimitedness/existence-as-ontologicalnormalcy/postconvergence-<in-validation-of-'metaphysics-of-absence_epistemic-projection’> as so-reflecting limited-mentation-capacity-deepening as-subjecting limitednesshmm subpotency-to-'educed-unlimitedness/existence-sublimating-nascence' ${ }^{53}$ ). In-many-ways, such epochal supposedly 'neutral ${ }^{79}$ presencing-absolutising-identitive-constitutedness ${ }^{14}$ point-of- 
devolving/departure/anchoring/backdrop conceptualisation of human sublimating ontologicalperformance $^{72}-<$ including-virtue-as-ontology $>$ /morality/ethics/justice/etc. as to human rationalisation-of-contentivity/argumentativity/dialecticism/discursivity' involves an active exercise of the cultivation of 'lifespan extricatory/preconverging psychical-nascency moronisation-<sublimating-nascence,-extricatory-desublimating-downstreaming/'avalage' $>$ ' (as of its " ${ }^{6}$ presencing — absolutising-identitive-constitutedness ${ }^{14}$ absolution/absolute-scope \{flawed/unsound\}-relative-unreflexivity-in-existencełabsolutising from-limitedmentation/psychologismic epistemic acutisation nonresidualising imbuedsompuring linearity in-eclecticism-of prior-mere-formulaicity/ritualisation conception' in preempting the possibility for prospective re-ontologising by a direct/indirect undermining of prospective re-ontologising competence of the genuine social intellectual-function/posture while cultivating in parallel pedantising/muddling/formulaic-hollowing-out-insubontologisation/subpotentiation-〈blurring/undermining-of-prospective-totalising-entailing,as-to-entailing-<amplituding/formative-epistemicity $>$ totalising in-relative-ontologicalcompleteness $>$ desublimation). But then not even such insidious-anarchy-<as-toconscious/unconscious epistemically-flawed induced 'moronisation-<sublimating-nascence,extricatory-desublimating-downstreaming/'avalage’> preconverging/dementing conception of prior mere-formulaicity/ritualisation incipiency of human social-functioning-andaccordance - as-of-social-stake-contention-or-confliction meaningfulness-and-teleology escapes the veracity of underlying 'constraining existence-as-sublimatingwithdrawal/unenframing/re-ontologising,-elicited-from-prospective-profound-supererogation imbuing human ontological-commitment $-<$ implied-self-assuredness-of-ontological-goodfaith/authenticity postconverging-de-mentating/structuring/paradigming -as-being-as-ofexistential-reality>' and ' ${ }^{103}$ universal-transparency ${ }^{104}$-〈transparency-of-totalising-entailing,-asto-entailing-<amplituding/formative-epistemicity $>$ totalising in-relative-ontological- 
completeness $\rangle$ as available-to/elicitable-to-〈as-to-human-consciousness/collectiveconsciousness-distendedness/detruncating-<beyond-selfpresencing,-as-re-ontologisingdecentering_of-consciousness/collective-consciousness,-as-to-psychologismic-epistemicacutisation-residualising, - $^{- \text {decompulsing }}$ - delinearity for-cogency $>>$ the social-functioning-andaccordance-as-of-social-stake-contention-or-confliction conception of any given registryworldview/dimension $\quad<$ preconverging 'motif-and-apriorising/axiomatising/referencing' entailing $>$-existentialising — enframing/imprintedness-〈as-to- historicity-tracing - inpresencing-hyperrealisation/hyperreal-transposition〉'; by the mere fact that a social-setup ever always exposes itself to prospective metaphoricity ${ }^{57}$ in one way or the other when such spontaneously arising disruptive ${ }^{56}$ meaningfulness-and-teleology ${ }^{9}$ is not of poorer but rather of a superseding <amplituding/formative-epistemicity $>$ causality $\sim$ as-to-projective-totalitativeimplications-of-prospective- nonpresencing,-for-explicating relative-unreflexivity/relativereflexivity - ontological-contiguity as of the social-setup given supposedly coherent ontological-commitment ${ }^{6}$-implied-self-assuredness-of-ontological-goodfaith/authenticity postconverging-de-mentating/structuring/paradigming -as-being-as-ofexistential-reality>. The histocial consequence is that with an eventual shift in human and social constraining re-ontologising-by-disontologising_existential-calculus-〈between 'prospective existentialising_-postconverging_framing/imprinting re-ontologising' and 'prior existentialising_preconverging_enframing/imprintedness social-functioning-andaccordance - as-of-social-stake-contention-or-confliction'〉, quite often the 'social prospect for prospective re-ontologising is poorly thought-out or poorly countenancing/contemplative of social-functioning-and-accordance-as-of-social-stake-contention-or-confliction' with regards to the consequent disorderly social irruptions associated with various revolutionary changes (which in-many-ways 'still have to re-do the thinking for prospective re-ontologising'). This speaks to the fact that the manifest existential-<disontologising/re-ontologising aporeticism $>$ 
veracity (as to effective human notional firstnaturedness-formativeness-<as-toeventualising inkling-drive-or-seeding-misprising $>$ temporal-to-intemporal-dispositions$<$ so-construed-as-from-perspective-ontological-normalcy/postconvergence $>$ of human protracted-social — as-to-individual-by-institutional-by-social ontological-performance ${ }^{72}$ <including-virtue-as-ontology $>$ ) as to the prospective manifesting of sublimating-overdesublimating ontological-performance ${ }^{72}<$ including-virtue-asontology $>$ /morality/ethics/justice/etc. for prospective re-ontologising meaningfulness-andteleology ${ }^{9}$ is rather of 'conjugative/interstitial disontologising/re-ontologising skewing towards prospective re-ontologising' (as reflecting the underlying 'crossgenerational notional firstnaturedness-formativeness-<as-to-eventualising-inkling-drive-or-seeding-

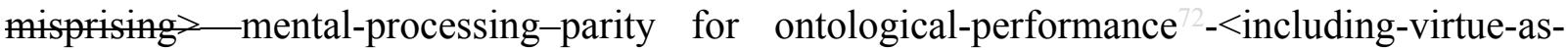
ontology $>$ /morality/ethics/justice/etc.' of all sovereign humans as to the potentiation of sublimating-over-desublimating with regards to the 'notional firstnaturedness-formativeness$<$ as-to-eventualising inkling drive-or-seeding misprising $>$ temporal-to-intemporaldispositions-<so-construed-as-from-perspective-ontological-normalcy/postconvergence $>\quad$ of human protracted-social—as-to-individual-by-institutional-by-social ontologicalperformance ${ }^{72}-<$ including-virtue-as-ontology $>$ ' and so relative to the given station/locus of limitedness/human-subpotency $<$ amplituding/formative-epistemicity>-totalising $\sim$ thrownnessin-existence ${ }^{35}$ ); and so-underlied as to the imbued interwovenness of 'prospective reontologising and its induced positive-opportunism - of-social-functioning-and-accordance ${ }^{5}$, and 'prior disontologising and its induced mere-formulaicity/ritualisation complexification as of disparateness-of-conceptualisation-<unforegrounding-ment,-failing-prospectively-to-reflect'immanent relative unreflexivity/relative reflexivity - ontological-contiguity ' $>$ '. $\quad$ This reflects the requisite ontologising/scientific/existence- $<$ honesty-constraining $>$ scope_for_prospective_re-ontologising for drawing out the veridical relative-ontological- 
completeness $^{87}$ entailment exudable as from unlimitedness/existence-<full-potencyof_sublimating nascence> and its punctually associated advocacy/political/applicative — scope (as rather of 'nonpresencing-<perspective-ontological-normalcy/postconvergence $>$ relativism/relative-scope for epistemic-growth,-as - \{veridical/sound\}relative-reflexivity-inexistence/relativising from-limited-mentation-as-its-deepening/psychologismic epistemicacutisation residualising, ${ }^{\text {\{decompulsing }}$ delinearity for-cogeney' with respect to prospective reontologising and so-undergirding the possibility for the overall relative-unreflexivity/relativereflexivity - ontological-contiguity ${ }^{67} \sim$ of-the-human-institutionalisation-process ${ }^{68}$ as to 'human interstitially recurrent limited-mentation-capacity-as-subjecting 'educedunlimitedness/existence-sublimating nascence' to-limitedness/human-subpotency-by-limitedmentation-capacity-deepening —as-subjecting limitedness/human-subpotency-to-'educedunlimitedness/existence-sublimating nascence' variance_in-epistemic-projection'). 'Human psychologismic-epistemic-acutisation-<as-to-postconverging-de-

mentating/structuring/paradigming,-eliciting-of-existence's-sublimating-nascence-inprospective-aporeticism-overcoming/unovercoming $>$ as to epistemic-growth,-as\{veridical/sound\}-relative-reflexivity-in-existence/relativising from-limited-mentation-as-itsdeepening/psychologismic epistemic acutisation residualising, ${ }^{\text {fdecompulsing }}$ delinearity for eogency' as such rather speaks of 'limitedness/human-subpotency ontological-performance ${ }^{\text {2 }}$ $<$ including-virtue-as-ontology $>/$ morality/ethics/justice/etc. as to projected/affirmed relativeontological-completeness $^{87}$ about the-very-same purview/devolved-purview/devolvingpurview-of-unlimitedness/existence-<full-potency-of_sublimating nascence $>$; as so-reflecting epistemic-totalisingly ${ }^{33}$ /acutely the prospective profound-supererogation (as to 'overarching

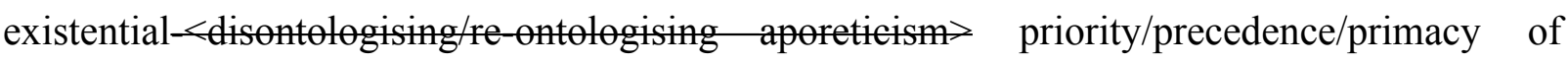
requisite prospective ontological-good-faith/authenticity $\sim$ postconverging-dementating/structuring/paradigming ${ }^{70}$ inducing the psychoanalytic-unshackling for the relative- 
ontological-completeness ${ }^{87}$-of-apriorising/axiomatising/referencing re-ontologising prospective re-rationalisation-of-contentivity/argumentativity/dialecticism/discursivity soreflected with the 'specific psychologismic-constructs of specific nascent-particular/incipientand-material/technical-sublimations- $<$ blinded-to-their-relative-ontological-completeness reference-of-thought- devolving $>$ projected/affirmed relative-ontological-completeness ${ }^{87}$, and the 'overall psychologismic-construct of overall ${ }^{83}$ reference-of-thought-and- ${ }^{83}$ reference-ofthought- ${ }^{8}$ devolving projected/affirmed relative-ontological-completeness ${ }^{87}$ ), and so as to underlying existential-<disontelogising/re-ontologising aporeticism $>$ credibility/credulityinduced-processive-assent-to-moronisation-<sublimating-nascence,-extricatorydesublimating-downstreaming/'avalage'> — by_incredibility/incredulity-induced-processivedissent-in-demoronisation- $<$ sublimating-nascence,-nonextricatory-sublimatingupstreaming/'amontée’>. Both instances of prospective profound-supererogation effectively put-into-question the 'limitedness/human-subpotency prior rationalisation-ofcontentivity/argumentativity/dialecticism/discursivity as to the prior mereformulaicity/ritualisation-<as-to-mere-formulaicmethodologising/mutualising/organising/institutionalising,-prospectively-losing-track-of‘\{pistemic-totalising '⿳亠丷厂 re apriorising/re axiomatising/re referencing-residuality-in-reoriginariness/re-origination'> of $\leq$ mere-formulaicity/ritualisation-of $>$-prior secondnatured institutionalisation' with respect to unlimitedness/existence-<full-potency-of_sublimating nascence $>$ prospective apriorising/axiomatising/referencing-sublimating-reflexivitybeholdening under which limitedness/human-subpotency submits in profound-supererogation for prospective sublimating; and thus exposing both instances of prospective profoundsupererogation to the prior overall amplituding/formative $>$ wooden-language-〈imbuedtemporal-mere-form/virtualities/dereification/akrasiatic-drag/denatured/preconverging-ordementing -narratives - of-the- reference-of-thought- categorical- 
imperatives/axioms/registry-teleology $\rangle$ as opportunistically elicitable by pedantising/muddling/formulaic-hollowing-out — in-subontologisation/subpotentiation〈blurring/undermining-of-prospective-totalising-entailing,-as-to-entailing$<$ amplituding/formative-epistemicity $>$ totalising $\sim$ in-relative-ontological-completeness desublimation. The prospective profound-supererogation of the 'specific psychologismicconstructs of specific nascent-particular/incipient-and-material/technical-sublimations<blinded-to-their-relative-ontological-completeness - reference-of-thought- devolving $>$ projected/affirmed relative-ontological-completeness ${ }^{87}$, are however less susceptible to such desublimation (and as to when not explicitly imbued-with/projecting-of prospective 'overall reference-of-thought-and- ${ }^{83}$ reference-of-thought- ${ }^{84}$ devolving projected/affirmed relativeontological-completeness ${ }^{87}$ implications') given the

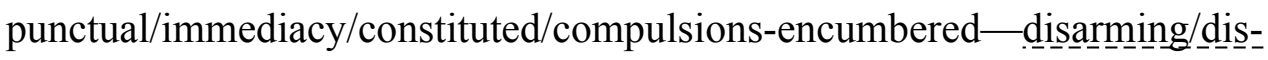

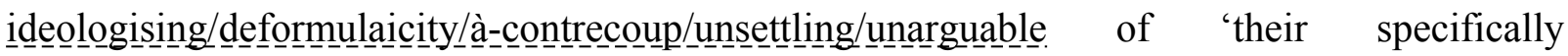
projected/affirmed technical or scientific demonstration of constrastive validity'. However, the requisite prospective profound-supererogation' of the 'overall psychologismic-construct of overall ${ }^{83}$ reference-of-thought-and- ${ }^{83}$ reference-of-thought- ${ }^{84}$ evolving projected/affirmed relative-ontological-completeness ${ }^{8}{ }^{\prime}$ is inevitably susceptible to such desublimation as to the fact of its 'very comprehensive existential-<disontologising/re-ontologising apereticism $>$ ambit as of transformative implications of human social-and-institutional-frameworks-ofreferencing/registering/decisioning existentialising-decisionality-<as-to-disontologising/reentelogising apereticism ${ }^{\prime}$. In this respect, it can be appreciated that while the Copernican heliocentric model (as to prospective profound-supererogation of the 'specific psychologismicconstructs of specific nascent-particular/incipient-and-material/technical-sublimations<blinded-to-their-relative-ontological-completeness - reference-of-thought- devolving > projected/affirmed relative-ontological-completeness ${ }^{87}$ ) was even debatable/contemplable in its 
epoch, in-many-ways what was truly problematic about it was not the notion in-of-itself (as could be demonstrated more or less explicitly by Galileo with his telescope

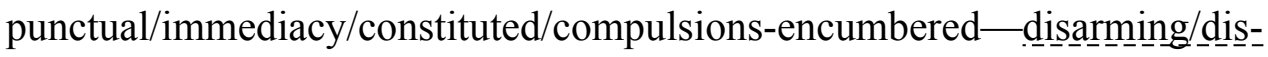

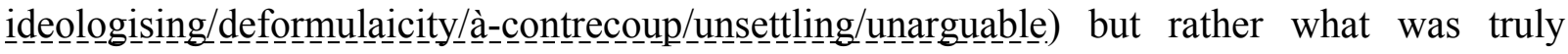
problematic was the prospective demoronisation- $<$ sublimating-nascence,-nonextricatorysublimating-upstreaming/'amontée'> implications as of positivising/rational-empiricism of the 'overall psychologismic-construct of overall ${ }^{83}$ reference-of-thought-and- ${ }^{83}$ reference-ofthought- ${ }^{8}$ devolving $\quad$ projected/affirmed relative-ontological-completeness ${ }^{87}$ soimplied/entailed by the "very comprehensive existential-<disontologising/re-ontologising apereticism $>$ ambit of transformative implications of human social-and-institutionalframeworks-of — referencing/registering/decisioning existentialising-decisionality-as-todisentologising/re-ontologising aporeticism ${ }^{\prime}$, upon the non-positivising medievalscholasticism social-setup social-functioning-and-accordance-as-of-social-stake-contentionor-confliction. Such a susceptibility to pedantising/muddling/formulaic-hollowing-out-insubontologisation/subpotentiation-〈blurring/undermining-of-prospective-totalising-entailing,as-to-entailing-<amplituding/formative-epistemicity $>$ totalising in-relative-ontologicalcompleteness $>$ desublimation is inherent to the very nature of a registry-worldview/dimension ('existentially- $<$ disontologising/re-ontologising aporeticism $>\quad$ understood- $<$ as-epistemictotalisingly /acutely_translating-into-the-mental-aestheticising-metaphoricity >’ by its given $<$ underlaid/substrated 'thrownness-aestheticising' \{of-relative-unreflexivity in-existence\} $>$ profusion-of preconverging prior-relative-ontological-incompleteness ${ }^{88}$-ofapriorising/axiomatising/referencing - by_<overlaying/superstrating 'thrownnessaestheticising' \{of relative-reflexivity in-existence\} >-sparsity-of postconverging prospectiverelative-ontological-completeness ${ }^{8}$-of-apriorising/axiomatising/referencing as to underlying $<$ amplituding/formative-epistemicity $>$-totalising $\sim$ thrownness-in-existence mental- 
aestheticising-<as-'psychologismic-existential-metaphoricity \{as-to-\{epistemic-totalising ${ }^{\prime} \mathrm{re}-$ apriorising/re-axiomatising/re-referencing_in-becoming?' 'so-implicited-'by-way-of-theexistentially/contextually/textually-manifest-motif-construct-as-specific-language'-as-soreflecting-'the-existentially/contextually/textually-manifest-moronisation/demoronisation'> imbued re-ontologising-by-disontologising_existential-calculus-〈between 'prospective existentialising_-postconverging_framing/imprinting re-ontologising' and 'prior existentialising_preconverging_enframing/imprintedness social-functioning-andaccordance - as-of-social-stake-contention-or-confliction'〉'); implying that 'projected/affirmed relative-ontological-completeness $^{8}$, has to supersede/overcome-as-to-psychoanalyticunshackling the profusion of 'prior sunderlaid/subsated 'throwness aestheticising' (of relative-unreflexivity in-existence $\}>$ profusion-of preconverging prior-relative-ontologicalincompleteness ${ }^{8}$-of-apriorising/axiomatising/referencing' (available to be elicited by pedantising/muddling/formulaic-hollowing-out_-in-subontologisation/subpotentiation〈blurring/undermining-of-prospective-totalising-entailing,-as-to-entailing$<$ amplituding/formative-epistemicity $>$ totalising in-relative-ontological-completeness $>$ desublimation). Such a profusion is massively incommensurable to a punctual/immediacy/constituted/compulsions-encumbered predisposition when it comes to contemplating of the requisite prospective profound-supererogation of the 'overall psychologismic-construct of overall ${ }^{83}$ reference-of-thought-and- ${ }^{83}$ reference-of-thoughtdevolving projected/affirmed relative-ontological-completeness ${ }^{87}$, explaining the very crossgenerational nature of registry-worldview/dimension overall transcendence-andsublimity/sublimation/supererogatory de-mentativity. In-many-ways, this reality of 'human psychologismic-epistemic-acutisation-<as-to-postconverging-dementating/structuring/paradigming,-eliciting-of-existence's-sublimating-nascence-inprospective-aporeticism-overcoming/unovercoming $>$ as to epistemic-growth,-as- 
\{veridical/sound\}-relative-reflexivity-in-existence/relativising from-limited-mentation-as-itsdeepening/psychologismic epistemic acutisation residualising, ${ }^{\text {fdecompulsing }}$ delinearity for eogency' associated with 'prospective postconverging aporeticism-overcoming/unovercoming as the-Good/knowledge-reification $\sim$ gesturing-and-accounting-of-epistemic-phenomenalism<in-prospective_psychologismic $\sim$ apriorising/axiomatising/referencing-\{of-'prospectively_ implicited_attendant-ontological-contiguity ' educedexistentialising/contextualising/textualising_intelligibility/epistemicity/reflexivity_contiguity$<$ imbued-notional cogency $>$ ' $\}$-conflatedness -in-\{preconverging ment by\} postconverging entailment $>$ /understanding/<amplituding/formativeepistemicity $>$ causality $\sim$ as-to-projective-totalitative-implications-of-prospectivenonpresencing,-for-explicating relative-unreflexivity/relative-reflexivity - ontologicalcontiguity as to nonpresencing-<perspective-ontological-normalcy/postconvergence $>$ epistemic-projection' rather speaks to the deficiency of a 'knowledge conception as of presencing-absolutising-identitive-constitutedness ${ }^{14}$ epistemic-projection' rather susceptible to its given threshold of human limited-mentation-capacity-as-subjecting-'educedunlimitedness/existence-sublimating nascence' to-limitedness/human-subpotency imbued incrementalism-in-relative-ontological-incompleteness ${ }^{8}$

enframed/disontologising conceptualisation; whereas it is the former (as to its limitedmentation-capacity-deepening —as-subjecting limitedness/human-subpotency-to-'educedunlimitedness/existence-sublimating nascence' ${ }^{53}$ maximalising-recomposuring-for-relativeontological-completeness ${ }^{87}$ - unenframed/re-ontologising conceptualisation) that is bound to elicit the ontologising/scientific/existence- $<$ honesty-constraining $>$ — scope_for_prospective_reontologising for prospective apriorising/axiomatising/referencing-sublimating-reflexivitybeholdening of unlimitedness/existence-<full-potency-of_sublimating nascence $>$. In other words, this speaks to the fact that a conception of knowledge as to the 'self-containing/self- 
satisfying determination of any given registry-worldview/dimension is in-many-ways prospectively bogus (since it implies 'normalised/stereotyped/selfhelping/feel-good knowledge being brought at the protracted-social—as-to-individual-by-institutional-by-social sovereign's service' with a poor appreciation of prospective construction-of-the-Self)'; with knowledge effectively arising as to the 'prospective existential-<disontologising/re-ontologising aporeticism $>$ deployment of transversality-<for-sublimating-existentialeventuating/denouement,-from-'thinking at-first/pure-predisposition-preemptive-ofprospective-disontologising/subontologising' as-of-prospectively-disambiguated-affirmedand-unaffirmed-'motif-and-apriorising/axiomatising/referencing'>101 elucidation as of notional $\sim$ self-distantiation-<imbued—re-motif-and-re-apriorising/re-axiomatising/rereferencing $>\quad$ implied formativeness-<as-to-intersolipsism-ofpreformulating/preframing/premeaningfulness-imbued-mediativity-and-deferentialism>-ofmeaningfulness-and-teleology $\quad$ in $\quad$ nonpresencing-<perspective-ontologicalnormalcy/postconvergence> epistemic-projection' (with our 'self-presence/selfconstitutedness $^{14}-<$ in-perspective-epistemic-abnormalcy/preconvergence ${ }^{31}>$ desublimating existentialising-decisionality-<as-to-disontologising/re-ontologising areticism $>$ ' not construed as the apriorising/axiomatising/referencing determinative limit of the possibility of prospective knowledge just as was the case with all prior 'self-presence/selfconstitutedness $^{14}-<$ in-perspective-epistemic-abnormalcy/preconvergence ${ }^{3}>$ desublimating $\sim$ existentialising-decisionality-<as-to-disontologising/re-ontologising apereticism $>$ '). It is this effectively that allows for a conception of knowledge beyond 'lifespan extricatory/preconverging psychical-nascency moronisation- $<$ sublimating-nascence,extricatesublimating-downstreaming/'avalage'>' towards 'nonextricatory/postconverging ontologising-and-re-ontologising angling-of-imaginary $\quad$ demoronisation- $<$ sublimatingnascence,-nonextricatory-sublimating-upstreaming/'amontée'>'; with the implication of a 
requisite ${ }^{6} 7$ presencing_absolutising-identitive-constitutedness ${ }^{14}$ consummated/forfeiting posture' in order to then outrightly commit to prospective transcendence-andsublimity/sublimation/supererogatory de-mentativity value-aspiration à la Diderot and the Encyclopédistes (as to a different pedestal from the desublimating/distorting recurrence of already induced 'limitedness/human-subpotency prior rationalisation-ofcontentivity/argumentativity/dialecticism/discursivity as to the prior mereformulaicity/ritualisation-<as-to-mere-formulaicmethodologising/mutualising/organising/institutionalising,-prospectively-losing-track-of‘fepistemic-alising ’’re-apriorising/re-axiomatising/re-referencing residuality-in-reoriginariness/re-origination'> of $\leq$ mere-formulaicity/ritualisation-of $>$-prior secondnatured institutionalisation in reflection of unlimitedness/existence-<fll-potency-of_sublimating nascence $>\quad$ prospective apriorising/axiomatising/referencing-sublimating-reflexivitybeholdening under which limitedness/human-subpotency submits in profound-supererogation for prospective sublimating' and as so-validated rather by the fact that it is the sublimating recurrence of "prospective human incipient/seeding ontological-faith-notion-or-ontologicalfideism - imbued-underdetermination-of-motif-and-apriorising/axiomatising/referencing-asso-being-as-of-existential-reality imbued psychoanalytic-unshackling as of 'psychologismicepistemic-acutisation-<as-to-postconverging-de-mentating/structuring/paradigming,-elicitingof-existence's-sublimating-nascence-in-prospective-aporeticism-overcoming/unovercoming> as to epistemic-growth,-as-\{veridical/sound\}-relative-reflexivity-in-existence/relativising from-limited-mentation-as-its-deepening/psychologismic epistemic-acutisationresidualising, ${ }^{\{\text {decompulsing }}$ delinearity for-cogency' that can elicit unlimitedness/existence-<fullpotency of_sublimating nascences prospective apriorising/axiomatising/referencing sublimating-reflexivity_-beholdening under which limitedness/human-subpotency submits in profound-supererogation for prospective sublimating). This equally reflects why profound 
knowledge as to core philosophy is much more than the evanescence of any ${ }^{79}$ presencingabsolutising-identitive-constitutedness ${ }^{14}$ framework but carry posterity implications (not to be confused as to the 'posterity of succession of ${ }^{79}$ presencing-absolutising-identitiveconstitutedness ${ }^{14}$ frameworks' as of successive usurpatory dimensionality-of-desublimatinglack-of $-<<$ amplituding/formative $>$ supererogatory $\sim$ de-mentativeness/epistemic-growth-orconflatedness /transvaluative-rationalising/transepistemicity/anamnestic-residuality/spiritdrivenness-equalisation) ) and requires the possibility for profound detachment from any such human generational nombrilistic conception of knowledge; the lack of which capacity for detachment will directly/indirectly induce human limited-mentation-capacity-as-subjecting'educed unlimitedness/existence-sublimating nascence' to limitedness/human-subpotency. In this regards (when it comes more particularly to the requisite prospective profoundsupererogation of the 'overall psychologismic-construct of overall ${ }^{83}$ reference-of-thoughtand- ${ }^{83}$ reference-of-thought- ${ }^{-4}$ devolving projected/affirmed relative-ontologicalcompleteness $^{87}$ '), the very idea of 'human psychologismic-epistemic-acutisation-<as-topostconverging-de-mentating/structuring/paradigming,-eliciting-of-existence's-sublimatingnascence-in-prospective-aporeticism-overcoming/unovercoming > as to epistemic-growth,-as\{veridical/sound\}-relative-reflexivity-in-existence/relativising from-limited-mentation-as-itsdeepening/psychologismic epistemic-acutisation residualising, fdecompulsingl delinearity for eogency' is much more than instantly induced 'soverlaying/superstrating 'thrownnessaestheticising' \{of-relative-reflexivity in-existence\} $>$-sparsity-of postconverging prospectiverelative-ontological-completeness ${ }^{8}$-of-apriorising/axiomatising/referencing as to underlying $<$ amplituding/formative-epistemicity $>$-totalising $\sim$ thrownness-in-existence ${ }^{35} \quad$ mental-

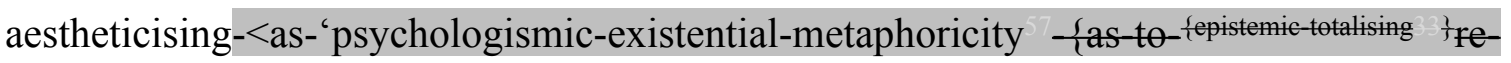
apriorising/re-axiomatising/re-referencing_in-becoming?' -so-implicited-'by-way-of-theexistentially/contextually/textually-manifest-motif-construct-as-specific-language'-as-so- 
reflecting- 'the-existentially/contextually/textually-manifest-moronisation/demoronisation'>';

but rather speaks to the existential- $<$ disontologising/re-ontologising-aporeticism $>$ human crossgenerational process/project (as to 'epistemic-break or notional-discontiguity/epistemicdiscontiguity ${ }^{6}-<$ between - prior-shallow-supererogation -of-mentallyaestheticised preconverging/dementing -qualia-schema_and_prospective-profoundsupererogation -of-mentally-aestheticised postconverging/dialectical-thinking -qualiaschema>') for the prospective possibility for 'nonextricatory/postconverging ontologising-andre-ontologising angling-of-imaginary demoronisation- $<$ sublimating-nascence,-nonextricatorysublimating-upstreaming/'amontée’>' (as herein implied with regards to prospective deprocrypticism-or-preempting-disjointedness-as-of- ${ }^{83}$ reference-of-thought projected/affirmed relative-ontological-completeness ${ }^{87}$ overall psychologismic-construct of overall ${ }^{83}$ reference-of-thought-and- ${ }^{83}$ reference-of-thought- ${ }^{8}$ devolving). In this regards, the 'overall psychologismic-construct of overall ${ }^{83}$ reference-of-thought-and- ${ }^{83}$ reference-ofthought- ${ }^{8}$ devolving projected/affirmed relative-ontological-completeness ${ }^{87}$, (as appropriate psychologismic-epistemic-acutisation-<as-to-postconverging-dementating/structuring/paradigming,-eliciting-of-existence's-sublimating-nascence-inprospective-aporeticism-overcoming/unovercoming> acting as 'postconverging-dementating/structuring/paradigming reference for requisite psychoanalytic-unshackling of the relative-ontological-incompleteness ${ }^{8}$-of-apriorising/axiomatising/referencing') is $\quad$ soconstrued as to the crossgenerational preconverging/postconverging-dementating/structuring/paradigming of human construction-of-the-Self in transversality- $<$ forsublimating-existential-eventuating/denouement,-from-'thinking-at-first/pure-predispositionpreemptive of prospective disentologising/subentologising' as-of-prospectivelydisambiguated-affirmed-and-unaffirmed-'motif-and-apriorising/axiomatising/referencing' $>$ '101 . Wherein the human self as of protracted-social - as-to-individual-by-institutional-by-social is 
undergirded anarchistically by the dualising dynamics of social-functioning-and-accordanceas-of-social-stake-contention-or-confliction (as susceptible to 'flawed/unsound-relativeunreflexivity-in-existencelabsolutising from-limited-mentation/psychologismic epistemic acutisation - nonresidualising-imbued-\{compulsing ${ }^{\text {fonearity }}$ lin-eclecticism-of-prior-mereformulaicity/ritualisation insidious-anarchy-<as-to-conscious/unconscious epistemically-flawed induced 'moronisation-<sublimating-nascence,-extricatory-desublimating-

downstreaming/'avalage'> preconverging/dementing conception of prior mere-
formulaicity/ritualisation incipiency of human social-functioning-and-accordance-as-ofsocial-stake-contention-or-confliction meaningfulness-and-teleology '>') and 'developing sense of notional $\sim$ ontology/notional ontological-veracity/notional ontological-commitment as to contiguity/coherence in social-stake-contention-or-confliction expectation/anticipation' (as amenable to '\{veridical/sound\}-relative-reflexivity-in-existence/relativising from-limitedmentation-as-its-deepening/psychologismic epistemic acutisation residualising, ${ }_{\{\text {decompulsing }}$ delinearity for-cogency anarchistic-growth/anarchisation-for-re-ontologisation-〈asto-conscious/unconscious epistemically-sound induced 'demoronisation- $<$ sublimatingnascence,-nonextricatory-sublimating-upstreaming/‘amontée’> postconverging/dialecticalthinking conception of residual_re-originary_anarchistic incipiency of human socialfunctioning-and-accordance-as-of-social-stake-contention-or-confliction meaningfulnessand-teleology ' $>$ '); and so-reflected beyond the delusions of underlying centralisingtotalitarianism or decentralising-totalitarianism ${ }^{79}$ presencing-absolutising-identitiveconstitutedness $^{14} \quad$ underpinning-suprasocial-construct $\quad<$ preconverging $\sim$ 'motif-andapriorising/axiomatising/referencing'-entailing--existentialising-enframing/imprintedness〈as-to- historicity-tracing-in-presencing-hyperrealisation/hyperreal-transposition〉 failing with regards to prospective re-ontologising. In this respect, it is critical to appreciate that presencing —absolutising-identitive-constitutedness ${ }^{14} \quad$ projected/affirmed 
advocacy/political/applicative-scope (as underlied by such underpinning-suprasocialconstruct) do not override human prospective re-ontologising possibilities as often wrongly implicited as to 'defaulting reasoning (of supposedly 'neutral 79 presencing-absolutisingidentitive-constitutedness ${ }^{14}$ point-of-devolving/departure/anchoring/backdrop conceptualisation of human ontological-performance ${ }^{72}-<$ including-virtue-asontology $>/$ morality/ethics/justice/etc. as rationalisation-ofcontentivity/argumentativity/dialecticism/discursivity and so-reflected in the flawed 'implicited_attendant-ontological-contiguity ${ }^{67}$; educedexistentialising/contextmalising/textmalising_intelligibility/epistemicity/reflexivity_contiguity$<$ imbued-notional cogency $>$ ' ) that paradoxically implies that the 'social is both ontological and non-ontological at the same moment' as to an inclination for disparateness-ofconceptualisation-<unforegrounding-ment,-failing-prospectively-to-reflect‘immanent $\sim$ relative- unreflexivity/relative-reflexivity ontological-contiguity ' $>$. But then such a poor construal of the advocacy/political/applicative - scope fails to factor in that it is ever always prior $\quad$ ontologising/scientific/existence- $<$ honesty-constraining $>$ scope_for_prospective_re-ontologising induced prospective re-ontologising that undergirds the possibility for any advocacy/political/applicative-scope, and so whether such a profoundsupererogation of prior ontologising/scientific/existence- $<$ honesty-constraining $>$ scope_for_prospective_re-ontologising (as to 'limitedness/human-subpotency prospective reencountering/re-confrontation with unlimitedness/existence-<full-potency-of_sublimating nascence $>$ ') has to do with prospective underlying material, technical, organisational and/or mastery/know-how sublimation possibilities providing the 'existential-<disentologising/reentelogising apreticism $>$ enabling-backdrop' for the advocacy/political/applicative — scope to arise; and as such advocacy/political/applicative — scope by its inclination for its given shallow-supererogation ${ }^{6}$ in ${ }^{79}$ presencing-absolutising-identitive-constitutedness 
prospectively

induces

'apriorising/axiomatising/referencing-

equating/leveling/ressentiment/closed-construct-of- ${ }^{5}$ meaningfulness-and-teleology

moronisation-<sublimating-nascence,-extricatory-desublimating-downstreaming/'avalage'>'

in want for the profound-supererogation of prospective ontologising/scientific/existence$<$ honesty-constraining $>$ - scope_for_prospective_re-ontologising in prospective 'apriorising/axiomatising/referencing disambiguating/de-leveling/de-ressentiment/openedconstruct-of- - meaningfulness-and-teleology $\quad$ demoronisation- $<$ sublimating-nascence,nonextricatory-sublimating-upstreaming/'amontée’>'. 'Human psychologismic-epistemicacutisation-<as-to-postconverging-de-mentating/structuring/paradigming,-eliciting-ofexistence's-sublimating-nascence-in-prospective-aporeticism-overcoming/unovercoming $>$ as to epistemic-growth,-as - \{veridical/sound\}-relative-reflexivity-in-existence/relativising from-

\section{limited-mentation-as-its-deepening/psychologismic epistemic-acutisation residualising,}

${ }_{\text {\{decompulsing }}$ delinearity for-cogency' in this regards speaks again of the fact that (just as with their given knowledge gesturing/accounting-of-epistemic-phenomenalism) the $<$ cumulating/recomposuring attendant-ontological-contiguity $>$-successive registryworldviews/dimensions project/affirm of their own given sense of advocacy/political/applicative—scope as to their respective " ${ }^{79}$ presencing-absolutisingidentitive-constitutedness $^{14} \quad$ absolution/absolute-scope $\quad$ flawed/unsound\}-relativeunreflexivity-in-existence/absolutising from-limited-mentation/psychologismic epistemic acutisation nonresidualising imbued lompulsinglinearity in-eclecticism-of prior-mereformulaicity/ritualisation conception'; but the truth-of-the-matter is that a 'coherence/contiguity construal of effective human prospective re-ontologising' can only be reflected by the underlying ontologising/scientific/existence- $<$ honesty-constraining $>$ - scope_for_prospective_reontologising as to its " nonpresencing-<perspective-ontological-normalcy/postconvergence $>$ relativism/relative-scope for epistemic-growth,-as - \{veridical/sound\}-relative-reflexivity-in- 
existence/relativising from-limited-mentation-as-its-deepening/psychologismic epistemicacutisation residualising, ${ }^{\text {\{decompulsing }}$ delinearity for-cogency' as so-underlying the possibility for the overall relative-unreflexivity/relative-reflexivity-ontological-contiguity ${ }^{6}$ of-thehuman-institutionalisation-process ${ }^{68}$. This elucidation is important with respect to the nombrilistic inclination to view all human prospective re-ontologising possibilities arbitrarily and unimaginatively as to our already given/presumed ${ }^{79}$ presencing-absolutising-identitiveconstitutedness ${ }^{14}$ underpinning-suprasocial-construct delusions of centralising-totalitarianism or decentralising-totalitarianism without a sense of inherently cultivated conception of ${ }^{`}$ nonpresencing-<perspective-ontological-normalcy/postconvergence $>\quad$ anarchisticgrowth/anarchisation-for-re-ontologisation-〈as-to-conscious/unconscious epistemically-sound induced 'demoronisation-<sublimating-nascence,-nonextricatory-sublimatingupstreaming/'amontée'> postconverging/dialectical-thinking conception of residual_reoriginary_anarchistic incipiency of human social-functioning-and-accordance-as-of-socialstake-contention-or-confliction meaningfulness-and-teleology ' '’ with regards to human social-and-institutional-frameworks-of — referencing/registering/decisioning existentialisingdecisionality-<as-to-disontelogising/re-ontelogising aporeticism $>$ (just as is the practiced case in the natural sciences which desublimating possibility for disparateness-of-conceptualisation$<$ unforegrounding-ment,-failing-prospectively-to-reflect-'immanent $\sim$ relativeunreflexivity/relative-reflexivity ontological-contiguity ' $>$ is more obvious/clearly inhibited/constrained by unlimitedness/existence-<full-potency-of_sublimating nascence $>$ ); but for socio-econo-political domains existentially-<disentologising/re-ontelogising aporeticism $>$ ambiguous/vague incrementalism-in-relative-ontological-incompleteness enframed/disontologising conceptualisation more or less construed as substituting for a thorough conception of prospective re-ontologising imbued 'human psychologismic-epistemicacutisation-<as-to-postconverging-de-mentating/structuring/paradigming,-eliciting-of- 
existence's-sublimating-nascence-in-prospective-aporeticism-overcoming/unovercoming $>$ as to epistemic-growth,-as_ \{veridical/sound\}-relative-reflexivity-in-existence/relativising fromlimited-mentation-as-its-deepening/psychologismic epistemic-acutisation residualising, ${ }_{\{\text {decompulsing }}$ delinearity for-cogency\} (when it comes to human contemplation of overall Beingdevelopment/ontological-framework-expansion-as-to-depth-of-ontologising-development-asinfrastructure-of- meaningfulness-and-teleology ). Thus 'human psychologismic-epistemicacutisation-<as-to-postconverging-de-mentating/structuring/paradigming,-eliciting-ofexistence's-sublimating-nascence-in-prospective-aporeticism-overcoming/unovercoming $>$ as to epistemic-growth,-as — \{veridical/sound\}-relative-reflexivity-in-existence/relativising fromlimited-mentation-as-its-deepening/psychologismic epistemic-acutisation residualising, \{decompulsing delinearity for-cogency' (so-speaking to the human psyche as a placeholdersetup/mental-devising-representation/mentation/consciousness-awareness-teleology ${ }^{9}$ that adjusts to 'prospectively educed-and-availing-and-re-availing of relative-ontologicalcompleteness $^{87}$ exuding from unlimitedness/existence-ffll-potency-of_sublimating nascence ${ }^{\prime}$ ), is reflected both with respect to the prospective profound-supererogation of the 'specific psychologismic-constructs of specific nascent-particular/incipient-andmaterial/technical-sublimations-<blinded-to-their-relative-ontological-completeness

reference-of-thought- devolving $>$ projected/affirmed relative-ontological-completeness ${ }^{87}$, (as to the 'requisite formative and articulative mastery/grasp of technical profundity' prompting a sense of requisite notional $\sim$ self-distantiation- $<$ imbued-re-motif-and-re-apriorising/reaxiomatising/re-referencing $>$ vis a vis 'ordinary laypersonhood arrogation/presumptuousness') as well as prospective profound-supererogation' of the 'overall psychologismic-construct of overall ${ }^{83}$ reference-of-thought-and- ${ }^{83}$ reference-of-thought- ${ }^{84}$ devolving projected/affirmed relative-ontological-completeness ${ }^{77}$ (as to the 'overall requisite formative and articulative core philosophy angling-of-imaginary' existential-<disontologising/re-ontologising aporeticism $>$ 
dimensionality-of-sublimating 25 -< amplituding/formative $>$ supererogatory $\sim$ de-

mentativeness/epistemic-growth-or-conflatedness /transvaluative-

rationalising/transepistemicity/anamnestic-residuality/spirit-drivenness-equalisation〉

notional $\sim$ self-distantiation- $<$ imbued — re-motif-and-re-apriorising/re-axiomatising/re-

referencing $>$ vis a vis 'ordinary laypersonhood arrogation/presumptuousness'). In the latter respect, the veracity of 'human psychologismic-epistemic-acutisation-<as-to-postconvergingde-mentating/structuring/paradigming,-eliciting-of-existence's-sublimating-nascence-inprospective-aporeticism-overcoming/unovercoming $>$ as to epistemic-growth,-as\{veridical/sound\}-relative-reflexivity-in-existence/relativising from-limited-mentation-as-itsdeepening/psychologismic epistemic acutisation residualising, ${ }^{\text {fdecompulsing }}$ delinearity for eogency' is much more dramatically reflected as to the existential-<disontelogising/reentologising apereticism> notional $\sim$ self-distantiation- $<$ imbued-re-motif-and-reapriorising/re-axiomatising/re-referencing> undergirding the <cumulating/recomposuring attendant-ontological-contiguity $>$-successive registryworldviews/dimensions in reflection of 'nonextricatory/postconverging ontologising-and-reontologising angling-of-imaginary demoronisation-<sublimating-nascence,-nonextricatorysublimating-upstreaming/'amontée'>' (as to the redeveloping relative-ontologicalcompleteness prospective re-rationalisations-ofcontentivity/argumentativity/dialecticism/discursivity of 'base-institutionalisation from recurrent-utter-uninstitutionalisation', ' ${ }^{103}$ universalisation from base-institutionalisationununiversalisation', 'positivism/rational-empiricism from ${ }^{103}$ universalisation-nonpositivism/medievalism' and prospectively 'deprocrypticism from positivism- ${ }^{80}$ procrypticism') with regards to the overall relative-unreflexivity/relative-reflexivity-ontologicalcontiguity ${ }^{67}$ of-the-human-institutionalisation-process ${ }^{68} \quad$ (as $\quad$ so-underscored $\quad$ with 'multicenturies-long human crossgenerational Being-development/ontological-framework- 
expansion-as-to-depth-of-ontologising-development-as-infrastructure-of- meaningfulnessand-teleology psychologismic epistemic acutisation difficulty-for, residualising

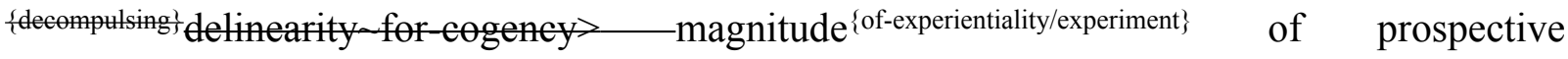
transcendence-and-sublimity/sublimation/supererogatory-de-mentativity' manifestations of relative-ontological-completeness ${ }^{8}$-of-apriorising/axiomatising/referencing); and as so-rather 'existentially- $<$ disontologising/re-ontologising aporeticism $>\quad$ understood- $<$ as-epistemictotalisingly /acutely_translating-into-the-mental-aestheticising-metaphoricity >' by the given sunderlaid/substrated-'thrownness-aestheticising'- \{of-relative-unreflexivity in-existence\}> profusion-of preconverging prior-relative-ontological-incompleteness ${ }^{8}$-ofapriorising/axiomatising/referencing_-by_<overlaying/superstrating 'thrownnessaestheticising' \{of-relative-reflexivity in-existence\}>-sparsity-of-postconverging prospectiverelative-ontological-completeness ${ }^{8}$-of-apriorising/axiomatising/referencing as to underlying $<$ amplituding/formative-epistemicity $>$-totalising $\sim$ thrownness-in-existence mentalaestheticising-<as-'psychologismic-existential-metaphoricity fas-toapriorising/re-axiomatising/re-referencing_in-becoming?' -so-implicited-'by-way-of-theexistentially/contextually/textually-manifest-motif-construct-as-specific-language'-as-soreflecting-'the-existentially/contextually/textually-manifest-moronisation/demoronisation'> imbued re-ontologising-by-disontologising_existential-calculus-〈between 'prospective existentialising_-postconverging_framing/imprinting re-ontologising' and 'prior existentialising_preconverging_enframing/imprintedness social-functioning-andaccordance-as-of-social-stake-contention-or-confliction' $\rangle$ '. The prospective profoundsupererogation of the 'overall psychologismic-construct of overall ${ }^{83}$ reference-of-thoughtand- ${ }^{83}$ reference-of-thought- ${ }^{-1}$ devolving projected/affirmed relative-ontologicalcompleteness $^{87}$ (reflected evolutively as to the "progressive formative and articulative disontologising/re-ontologising manifestations' of human social-and-institutional-frameworks- 
of-referencing/registering/decisioning

existentialising-decisionality-<as-todisontologising/re-ontologising aporeticism $>$ imbued notional $\sim$ self-distantiation- $<$ imbuedre-motif-and-re-apriorising/re-axiomatising/re-referencing $>$ vis a vis 'ordinary laypersonhood arrogation/presumptuousness') is inherently subject to the blurriness$<$ sterilising/anecdotalising/trivialising-of-prospective-re-ontologising_by-preconverging,-indisontologising-formulaic-dragging-out/hollowing-out> of institutional-imprimaturing as of human limited-mentation-capacity—as-subjecting 'educed-unlimitedness/existencesublimating nascence' to-limitedness/human-subpotency. This is effectively what underlies the need for prospective renewing of 'human psychologismic-epistemic-acutisation- $<$ as-topostconverging-de-mentating/structuring/paradigming,-eliciting-of-existence's-sublimatingnascence-in-prospective-aporeticism-overcoming/unovercoming $>$ as to epistemic-growth,-as\{veridical/sound\}-relative-reflexivity-in-existence/relativising from-limited-mentation-as-itsdeepening/psychologismic epistemic acutisation residualising, ${ }_{\text {fdecompulsing }}$ delinearity foreogency'; in so-reflecting prospective referencing residuality - in-re-originariness/re-origination-〈as to human profoundsupererogation for prospective apriorising/axiomatising/referencing-\{of- prospectively implicited_attendant-ontological-contiguity ' educedexistentialising/contextualising/textualising_ intelligibility/epistemicity/reflexivity-contiguity<imbued-notional cogency >' \}-conflatedness -in-\{preconverging-ment by\} postconverging-ntailment that cannot be unshrouded by prior mere-formulaicity/ritualisation$<$ as-to-mere-formulaic — methodologising/mutualising/organising/institutionalising,prospectively-losing-track-of- ‘ $\left\{\right.$ epistemic-totalising ${ }^{\dagger}$ re apriorising/re axiomatising/rereferencing $\sim$ residuality_-in-re-originariness/re-origination'> of prior apriorising/axiomatising/referencing-\{of-'prospectively implicited_attendant-ontologicalcontiguity ' educed- 
existentialising/contextualising/textualising_'intelligibility/epistemicity/reflexivity-contiguity<imbued-notional cogency >' $\}$-constitutedness -in-preconverging-entailment) (as herein implied as to requisite 'epistemic-break or notional-discontiguity/epistemic-discontiguity ${ }^{6}$ $<$ between-prior-shallow-supererogation -of-mentallyaestheticised preconverging/dementing -qualia-schema_and_prospective-profoundsupererogation -of-mentally-aestheticised postconverging/dialectical-thinking -qualiaschema>'). Critically, central to the contemplation of 'human psychologismic-epistemicacutisation-<as-to-postconverging-de-mentating/structuring/paradigming,-eliciting-ofexistence's-sublimating-nascence-in-prospective-aporeticism-overcoming/unovercoming $>$ as to epistemic-growth,-as - \{veridical/sound\}-relative-reflexivity-in-existence/relativising fromlimited-mentation-as-its-deepening/psychologismic epistemic-acutisation residualising, $\{$ decompulsing $\}$ delinearity for-cogency' is necessarily an epistemic-projection of ' nonpresencing$<$ perspective-ontological-normalcy/postconvergence $>$ relativism/relative-scope for epistemicgrowth,-as-\{veridical/sound\}-relative-reflexivity-in-existence/relativising from-limitedmentation-as-its-deepening/psychologismic epistemic-acutisation residualising, \{decompulsing\} delinearity for-cogency' that speaks to 'limitedness/human-subpotency developing ontological-performance $^{72}-<$ including-virtue-as-ontology $>/$ morality/ethics/justice/etc. as to projected/affirmed relative-ontological-completeness ${ }^{87}$ about the-very-same purview/devolved-purview/devolving-purview-of-unlimitedness/existence-<full-potency ef_sublimating nascence>. Otherwise human conceptualisation inevitably falls into a predisposition for totalisingly-ing — discretion/whim-of-thought of ${ }^{6} 7$ presencing—absolutisingidentitive-constitutedness $^{14} \quad$ absolution/absolute-scope unreflexivity-in-existence/absolutising from-limited-mentation/psychologismic epistemic acutisation nonresidualising imbued-fcompulsings linearity in-eclecticism-of-prior-mereformulaicity/ritualisation conception' epistemic-projection as critically failing to even formulate 
the fundamental ontology veracity of recurrently-driven limitedness/human-subpotency prospective re-encountering/re-confrontation with the 'constraining/defining intersolipsistic reflexive-sublimating/unreflexive-desublimating measure/objectification that is unlimitedness/existence-as-ontological-normalcy/postconvergence-<in-validation-of'metaphysics-of-absence_epistemic-projection'>' (which is effectively what underlies the veridical epistemic-projection of $\quad$ nonpresencing-<perspective-ontologicalnormalcy/postconvergence $>$ relativism/relative-scope for epistemic-growth,-as\{veridical/sound\}-relative-reflexivity-in-existence/relativising from-limited-mentation-as-itsdeepening/psychologismic epistemic-acutisation residualising, fdecompusingl delinearity foreogency'); as so-manifested with our modern-day disparateness-of-conceptualisation$<$ unforegrounding-ment,-failing-prospectively-to-reflect-'immanent $\sim$ relativeunreflexivity/relative-reflexivity ontological-contiguity ' $>$ lacking in the veridical conceptivity/epistemic-reflexivity/epistemicity-relativism-determinism-<reifying \{as-toknowledge-developing\}-and-empowering $>$ for 'prospective postconvergingaaporeticismovercoming/mnovercoming as the-Good/knowledge-reification $\sim$ gesturing-and-accounting-ofepistemic-phenomenalism- $<$ in-

prospective_psychologismic apriorising/axiomatising/referencing-\{of- ${ }^{\text {pprospectively }}$ implicited_attendant-ontological-contiguity ' reducedexistentialising/contextualising/textualising_ intelligibility/epistemicity/reflexivity-contiguity<imbued-notional cogency >' \}-conflatedness -in-\{preconverging -ment by\} postconverging entailment $>$ /understanding/<amplituding/formativeepistemicity $>$ causality $\sim$ as-to-projective-totalitative-implications-of-prospectivenonpresencing,-for-explicating relative unreflexivity/relative reflexivity - ontologicalcontiguity '. Thus the-very-same purview/devolved-purview/devolving-purview-ofunlimitedness/existence-<full-potency-of_sublimating nascence $>$;_- implicited_attendant- 
ontological-contiguity ${ }^{67}$, educedexistentialising/contextualising/textualising_'intelligibility/epistemicity/reflexivity_contiguity<imbued-notional cogency>' (as to the fundamental ontology veracity of recurrently-driven limitedness/human-subpotency prospective re-encountering/re-confrontation with the 'constraining/defining intersolipsistic reflexive-sublimating/unreflexive-desublimating measure/objectification that is unlimitedness/existence-as-ontologicalnormalcy/postconvergence-<in-validation-of-'metaphysics-of-absence_epistemic-

projection'>') speaks on-the-one-hand of 'human limited-mentation-capacity-as-subjecting 'educed-unlimitedness/existence-sublimating nascence' to-limitedness/human-subpotency tolerance-<of-disparateness $>$ /inexactitude' underlying the manifest failing-to-elicit prospective apriorising/axiomatising/referencing-sublimating-reflexivity-beholdening and on-the-otherhand 'human limited-mentation-capacity-deepening -as-subjecting limitedness/humansubpotency-to-'educed-unlimitedness/existence-sublimating nascence' ${ }^{53}$ intolerance-<ofdisparateness>/exactifying_precisioning, underlying the manifest eliciting of unlimitedness/existence-full-potency-of_sublimating nascence $>\quad$ prospective apriorising/axiomatising/referencing-sublimating-reflexivity_beholdening under which limitedness/human-subpotency submits in profound-supererogation for prospective sublimating. The point here is to reflect upon the fact that human 'interstitially-disontologisingby-re-ontologising anarchistic outgrowing formativeness-<as-to-intersolipsism-ofpreformulating/preframing/premeaningfulness-imbued-mediativity-and-deferentialism>-ofmeaningfulness-and-teleology of human sublimating ${ }^{5}$ meaningfulness-and-teleology ${ }^{9}$ (as to 'human interstitially recurrent limited-mentation-capacity-as-subjecting-educedtnlimitedness/existence-sublimating nascence' to limitedness/hmman-subpotency-by-limitedmentation-capacity-deepening —as-subjecting limitedness/human-subpotency-to-'educedunlimitedness/existence-sublimating nascence' ${ }^{33}$ variance_in-epistemic-projection') is 
critically undergirded by the notion of 'inherent unlimitedness/existence-<full-potencyөf_sublimating nascence $>$ educed intolerance-<0f-disparateness $>$ /exactifying_precisioning' associated with the possibility for 'prospective postconvergingaapereticismovercoming/unovercoming as the-Good/knowledge-reification $\sim$ gesturing-and-accounting —ofepistemic-phenomenalism- $<$ in-

prospective_psychologismic apriorising/axiomatising/referencing-\{of-‘prospectively implicited_attendant-ontological-contiguity ' educedexistentialising/contextualising/textualising_'intelligibility/epistemicity/reflexivity-contiguity<imbued-notional cogency $>$ ' \}-conflatedness -in-\{preconverging ment by\} postconverging-entailment $>$ /understanding/<amplituding/formativeepistemicity $>$ causality $\sim$ as-to-projective-totalitative-implications-of-prospectivenonpresencing,-for-explicating relative-unreflexivity/relative-reflexivity - ontologicalcontiguity '. This effectively reflects 'human limited-mentation-capacity-deepening-assubjecting limitedness/human-subpotency-to-'educed-unlimitedness/existence-sublimating nascence' intolerance-<of-disparateness>/exactifying_precisioning' as underlying the sublimating recurrence of 'prospective human incipient/seeding ontological-faith-notion-orontological-fideism - imbued-underdetermination-of-motif-andapriorising/axiomatising/referencing-as-so-being-as-of-existential-reality imbued psychoanalytic-unshackling as of 'psychologismic-epistemic-acutisation-<as-topostconverging-de-mentating/structuring/paradigming,-eliciting-of-existence's-sublimatingnascence-in-prospective-aporeticism-overcoming/unovercoming $>$ as to epistemic-growth,-as\{veridical/sound\}-relative-reflexivity-in-existence/relativising from-limited-mentation-as-itsdeepening/psychologismic epistemic acutisation residualising, \{decompulsing ${ }^{2}$ delinearity for eogency' (with regards to prospective human-subpotencyaporia/undecidability/dilemma/ought-indeterminacy/deficiency/limitation/constraint—imbued- 
'notional firstnaturedness-formativeness-<as-to-eventualising -inkling drive or seeding-

misprising $>$ temporal-to-intemporal-dispositions- $<$ so-construed-as-from-perspective-

ontological-normalcy/postconvergence>'-existentialism-form-factor'); as so-superseding of the 'human limited-mentation-capacity—as-subjecting-'educed-unlimitedness/existencesublimating nascence' to-limitedness/human-subpotency tolerance-<ofdisparateness>/inexactitude' underlying the desublimating/distorting recurrence of already induced 'limitedness/human-subpotency prior rationalisation-ofcontentivity/argumentativity/dialecticism/discursivity as to the prior mereformulaicity/ritualisation-<as-to-mere-formulaic-

methodologising/mutualising/organising/institutionalising,-prospectively-losing-track-of-

‘\{epistemic-totalising ’’re-apriorising/re-axiomatising/re-referencing $r$ residuality-in-re-

originariness/re-origination'> of $\leq$ mere-formulaicity/ritualisation-of $>$-prior secondnatured institutionalisation. The bigger point being made here is that 'human psychologismic-epistemicacutisation-<as-to-postconverging-de-mentating/structuring/paradigming,-eliciting-ofexistence's-sublimating-nascence-in-prospective-aporeticism-overcoming/unovercoming $>$ as to epistemic-growth,-as - \{veridical/sound\}-relative-reflexivity-in-existence/relativising fromlimited mentation as its deepening/psychologismic epistemic acutisation residualising,
\{decompulsing\} delinearity for-cogency' $\quad$ (as $\quad$ associated $\quad$ with $\quad$ 'prospective postconverging aporeticism-overcoming/unovereoming as the-Good/knowledgereification $\sim$ gesturing-and-accounting - of-epistemic-phenomenalism- $<$ inprospective_psychologismic apriorising/axiomatising/referencing-\{of-‘prospectively implicited_attendant-ontological-contiguity ' reducedexistentialising/contexalising/texalising_intelligibility/epistemicity/reflexivity-contiguity$<$ imbued-notional cogency $>$ ' \}-conflatedness -in-\{preconverging-ment by\} postconverging-entailment $>$ /understanding/<amplituding/formative- 
epistemicity $>$ causality $\sim$ as-to-projective-totalitative-implications-of-prospective-

nonpresencing,-for-explicating relative-unreflexivity/relative-reflexivity - ontological-

contiguity ', with regards to the-very-same purview/devolved-purview/devolving-purview-ofunlimitedness/existence-full-potency-of_sublimating nascence $>$ ), speaks fundamentally to the eliciting of prospective re-ontologising as to an exercise of 'human limited-mentation-capacitydeepening - as-subjecting-limitedness/human-subpotency-to-'educed-unlimitedness/existencesublimating nascence' ${ }^{53}$ intolerance-<of-disparateness>/exactifying_precisioning' (soreflecting the profound-supererogation of the genuine social intellectual-function/posture sublimation); as so-superseding 'human limited-mentation-capacity-as-subjecting 'educedunlimitedness/existence-sublimating nascence' to-limitedness/human-subpotency tolerancesof-disparateness>/inexactitude' (as of the shallow-supererogation of pedantising/muddling/formulaic-hollowing-out — in-subontologisation/subpotentiation〈blurring/undermining-of-prospective-totalising-entailing,-as-to-entailing$<$ amplituding/formative-epistemicity >totalising in-relative-ontological-completeness > desublimation). This critically reflects upon the fact that (with regards to underlying Beingdevelopment/ontological-framework-expansion-as-to-depth-of-ontologising-development-asinfrastructure-of- meaningfulness-and-teleology psychologismic epistemic-acutisationdifficulty < for, residualising \{decompulsing\} delinearity for-cogency> magnitude $\{$ ofexperientiality/experiment\}) prospective registry-worldviews/dimensions induced prospective transcendence-and-sublimity/sublimation/supereregatory $\sim$ de-mentativity are $<$ cumulating/recomposuring attendant-ontological-contiguity $>$-successive manifestations of an exercise of 'human limited-mentation-capacity-deepening-as-subjectinglimitedness/human-subpotency to-'educed-unlimitedness/existence-sublimating nascence' intolerance-<of-disparateness $>$ /exactifying_precisioning' (as of the profound-supererogation of the genuine social intellectual-function/posture sublimation); as so-reflected by any given 
registry-worldview/dimension prospective profound-supererogation of the 'specific psychologismic-constructs of specific nascent-particular/incipient-and-material/technicalsublimations- $<$ blinded-to-their-relative-ontological-completeness - reference-of-thought-

devolving $>$ projected/affirmed relative-ontological-completeness ${ }^{8}$, and as the latter is translated (as of prospective 'apriorising/axiomatising/referencing disambiguating/deleveling/de-ressentiment/opened-construct-of- ${ }^{56}$ meaningfulness-and-teleology demoronisation- $<$ sublimating-nascence, -nonextricatory-sublimatingupstreaming/'amontée'>') as the prospective profound-supererogation of the 'overall psychologismic-construct of overall ${ }^{83}$ reference-of-thought-and- ${ }^{8}$ reference-of-thoughtdevolving projected/affirmed relative-ontological-completeness ${ }^{8}$, enabling the prospective registry-worldview/dimension to arise (as of prospective ${ }^{83}$ reference-of-thought—point-ofdevolving/departure/anchoring/backdrop_of_sublimating-nascence-<as-to-the-grandestaxiomatic-construct-\{epistemic-totalising $\frac{\text { }}{3}$ re-apriorising/re-axiomatising/rereferencing residuality - in-re-originariness/re-origination of limitedness/human-subpotency prospective re-encountering/re-confrontation with unlimitedness/existence>'). It can thus be appreciated how the nascent-particular/incipient-and-material/technical-sublimations- $<$ blindedto-their-relative-ontological-completeness - reference-of-thought- devolving > of 'budding positivism/rational-empiricism science' and ' ${ }^{103}$ universalising occultic practices/sciences/mathematics of ancient Mediterranean civilisations' respectively underlied the prospective 'apriorising/axiomatising/referencing disambiguating/de-leveling/deressentiment/opened-construct-of- ${ }^{5}$ meaningfulness-and-teleology 99 demoronisation<sublimating-nascence,-nonextricatory-sublimating-upstreaming/'amontée'>’ of prospective positivism/rational-empiricism and ${ }^{103}$ universalising-idealisation registryworldviews/dimensions. The implication here is that prospective human transcendence-andsublimity/sublimation/supereregatory $\sim$ de-mentativity the 
worldviews/dimensions) doesn't arise by the shallow-supererogation contiguity/coherence respectively 'in mere-extension of the ${ }^{79}$ presencing - absolutising-identitive-constitutedness ${ }^{14}$, as of recurrent-utter-uninstitutionalisation, base-institutionalisation-ununiversalisation, ${ }^{3}$ universalisation-non-positivism/medievalism and positivism- ${ }^{80}$ procrypticism which are dead-ends of prospective human Being-development/ontological-framework-expansion-as-todepth-of-ontologising-development-as-infrastructure-of- meaningfulness-and-teleology

going by their 'human limited-mentation-capacity-as-subjecting-'educedunlimitedness/existence-sublimating nascence' to-limitedness/human-subpotency tolerance$\leq 0$-disparateness $>$ /inexactitude'; as to the fact that 'unlimitedness/existence-<full-potencyof_sublimating nascence> is not of prospective apriorising/axiomatising/referencingsublimating-reflexivity-beholdening to their $\leq$ mere-formulaicity/ritualisation-of $>$-prior secondnatured institutionalisation of prospective shallow-supererogation', with regards to prospective reference-of-thought- point-ofdevolving/departure/anchoring/backdrop_of_sublimating-nascence-<as-to-the-grandest-

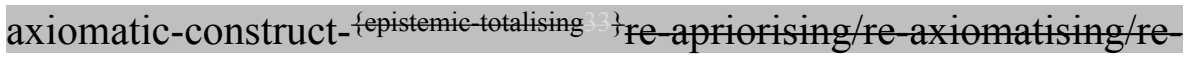
refereneing-residuality - in-re-originariness/re-origination of limitedness/human-subpotency prospective re-encountering/re-confrontation with unlimitedness/existence $>$. But rather the notion of '<cumulating/recomposuring attendant-ontological-contiguity $>$-successive registry-worldviews/dimensions' speaks to manifest prospective 'human limited-mentationcapacity-deepening —as-subjecting limitedness/human-subpotency-to-'educedunlimitedness/existence-sublimating nascence' intolerance $<$ of disparateness $>$ /exactifying_precisioning' over prior 'human limited-mentation-capacity—assubjecting-'educed-unlimitedness/existence-sublimating nascence' to-limitedness/humansubpotency tolerance-<of-disparateness>-inexactitude' respectively as of: 'base- 
institutionalisation over recurrent-utter-uninstitutionalisation', ' ${ }^{103}$ universalisation over baseinstitutionalisation-ununiversalisation', 'positivism over $\quad{ }^{103}$ universalisation-nonpositivism/medievalism' and prospectively “ ${ }^{18}$ deprocrypticism-or-preempting-disjointednessas-of- ${ }^{8}$ reference-of-thought over our positivism- ${ }^{80}$ procrypticism' (so-construed in profoundsupererogation as 'epistemic-break or notional-discontiguity/epistemic-discontiguity ${ }^{6}$ $<$ between-prior-shallow-supererogation -of-mentally-

aestheticised preconverging/dementing -qualia-schema_and_prospective-profoundsupererogation -of-mentally-aestheticised postconverging/dialectical-thinking -qualiaschema>'). This ('human limited-mentation-capacity-deepening-as-subjectinglimitedness/human-subpotency-to-'educed-unlimitedness/existence-sublimating nascence' intolerance-<of-disparateness>/exactifying_precisioning') is merely the reflection of the underlying fundamental/incipient/seeding insight 'of prospective ontological-goodfaith/authenticity ${ }^{\circ} \sim$ postconverging-de-mentating/structuring/paradigming $70 \quad$ implications' (inherently arising from the 'defining precedence of unlimitedness/existence- $<$ full potency of_sublimating nascence $>$ eliciting of limitedness/human-subpotency dynamically adjusting placeholder-setup/mental-devising-representation/mentation/consciousness-awarenessteleology ') and divulgeable/enlightening-giving as from the 'requisite projection of the coherence/contiguity of the superseding-oneness-of-ontology/ontological-veridicality/relativeunreflexivity/relative-reflexivity_ontological-contiguity ${ }^{67}$ (so-construed as the 'fundamental human conscious/unconscious sense/drive/disposition' enabling experientiality/experiment-<asto-existentially-formative-'fepistemictalising ${ }^{3}$ re-apriorising/re-axiomatising/re-

referencing $\sim$ residuality —in-re-originariness/re-origination', - - so'notionally/epistemically/bindingnessly-<as-to-determinism/conceptivity-of-relative-unreflexivity/relative-reflexivity> implicited-and-articulated'_as-from-nonextricatory-'prospective-re-ontologising-Being-thenInstitutional-then-Living-magnitudes-of-\{hermeneutic/reprojection-protraction-of\}reframing- 
and-reformulation\}'> with regards to 'formative and articulative implications of apriorising/axiomatising/referencing and corresponding existentialising/contextualising/textualising aposteriorising/logicising/deriving' underlying the possibility for human intelligibility-〈as-to-human-projective/reprojective-aestheticising-remotif-and-re-apriorising/re-axiomatising/re-referencing/re-intelligibilitysettingup/remeasuringinstrumenting-process,-in-<amplituding/formativeepistemicity $>$ totalising conceptualisation) $)$; so-enabling sublimating 'conceptivity/epistemicreflexivity/epistemicity-relativism-determinism-<reifying \{as-to-knowledge-developing $\}$-andempowering> entailment' as to fundamental ontology veracity of recurrently-driven limitedness/human-subpotency prospective re-encountering/re-confrontation with the 'constraining/defining intersolipsistic reflexive-sublimating/unreflexive-desublimating measure/objectification that is unlimitedness/existence-as-ontologicalnormalcy/postconvergence-<in-validation-of-'metaphysics-of-absence_epistemic-

projection'>'. This elucidation is critical in effectively appreciating what is effectively meant by 'human psychologismic-epistemic-acutisation-<as-to-postconverging-dementating/structuring/paradigming,-eliciting-of-existence's-sublimating-nascence-inprospective-aporeticism-overcoming/unovercoming $>$ as to epistemic-growth,-as\{veridical/sound\}-relative-reflexivity-in-existence/relativising from-limited-mentation-as-itsdeepening/psychologismic epistemic-acutisation residualising, ddecompulsingt delinearity foreogency' with respect to human Being-development/ontological-framework-expansion-as-todepth-of-ontologising-development-as-infrastructure-of- meaningfulness-and-teleology , institutional-development-as-to-social-function-development and living-development-as-topersonality-development psychologismic epistemic acutisation difficulty-for,

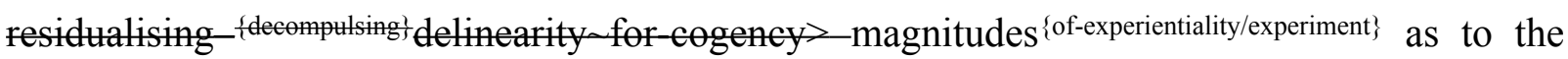
'defining precedence of unlimitedness/existence-<full-potency-of_sublimating nascence> 
eliciting of limitedness/human-subpotency dynamically adjusting placeholder-setup/mentaldevising-representation/mentation/consciousness-awareness-teleology ${ }^{9}$; and so-defined over any given registry-worldview/dimension 'human limited-mentation-capacity—as-subjecting 'educed-unlimitedness/existence-sublimating nascence' to-limitedness/human-subpotency tolerance-<of-disparateness>-inexactitude' (as to its '79 presencing-absolutising-identitiveconstitutedness ${ }^{14}$ absolution/absolute-scope \{flawed/unsound\}-relative-unreflexivity-inexistence/absolutising from-limited-mentation/psychologismic epistemic-acutisation-

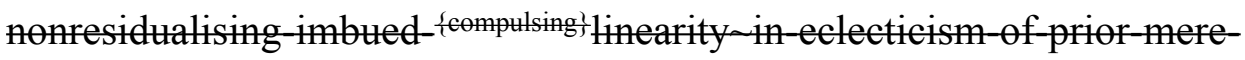
formulaicity/ritualisation conception' implied non-adjustable/non-subjectable psyche as placeholder-setup/mental-devising-representation/mentation/consciousness-awarenessteleology ${ }^{9}$ ) hypocritical notion of profound-supererogation ${ }^{96}$ rather prospectively of shallowsupererogation (when so-assessed as of the underlying 'crossgenerational notional firstnaturedness-formativeness-<as-to-eventualising-inkling-drive-or-seedingmisprising $>$ mental-processing-parity for ontological-performance ${ }^{72}-<$ including-virtue-asontology $>$ /morality/ethics/justice/etc.' of all sovereign humans as to the potentiation of sublimating-over-desublimating with regards to the 'notional firstnaturedness-formativeness<as to eventulising inkling drive or seeding misprising $>$ temporal-to-intemporal-

dispositions-<so-construed-as-from-perspective-ontological-normalcy/postconvergence $>$ of human protracted-social—as-to-individual-by-institutional-by-social ontologicalperformance $^{72}-<$ including-virtue-as-ontology $>$ ' and so relative to the given station/locus of limitedness/human-subpotency $<$ amplituding/formative-epistemicity $>$-totalising $\sim$ thrownnessin-existence ${ }^{35}$ ). In this regards, it is herein contended that such an elucidation of 'human psychologismic-epistemic-acutisation-<as-to-postconverging-dementating/structuring/paradigming,-eliciting-of-existence's-sublimating-nascence-in- 
\{veridical/sound\}-relative-reflexivity-in-existence/relativising from-limited-mentation-as-itsdeepening/psychologismic epistemic acutisation residualising, ${ }^{\text {fdecompulsing }}$ delinearity for eogency' is effectively what differentiates the 'sublimating veracity of the existential$<$ disontologising/re-ontologising aporeticism $>$ apriorising/axiomatising/referencing' (as underlied by ' nonpresencing-<perspective-ontological-normalcy/postconvergence $>$ relativism/relative-scope for epistemic-growth,-as - \{veridical/sound\}-relative-reflexivity-inexistence/relativising from-limited-mentation-as-its-deepening/psychologismic epistemicacutisation residualising, framework of human profoundsupererogation") over the 'desublimating inveracity of rhetorical vagueness of mere abstractlyapriorising/axiomatising/referencing' (as caught up in '7 presencing - absolutising-identitiveconstitutedness ${ }^{14}$ absolution/absolute-scope \{flawed/unsound\}-relative-unreflexivity-inexistence/absolutising from-limited-mentation/psychologismic epistemic-acutisationnonresidualising imbued-\{compulsing\} linearity in-eclecticism-of prior-mereformulaicity/ritualisation conception' pretense of human profound-supererogation ${ }^{\circ}$ ). In this regards 'human limited-mentation-capacity-deepening —as-subjecting limitedness/humansubpotency-to-'educed-unlimitedness/existence-sublimating-nascence' ${ }^{53}$ intolerance-<ofdisparatens $>$ /exactifying_precisioning' speaks of the 'effective existential$\leq$ disontologising/re-ontologising aporeticism> apriorising/axiomatising/referencing construal' of the "foregrounding _ entailment- $<$ in-succession-of-profound-supererogation 〈postconverging-narrowing-down $\sim$ sublimation-as-to-'existence-as-sublimatingwithdrawal/unenframing/re-ontologising,-elicited-from-prospective-profoundsupererogation '-in-reflecting-'immanent relative unreflexivity/relative reflexivity ontological-contiguity ';-as-operative-notional deprocrypticism) $<$ amplituding/formative $>$ disposedness/psychologismic-construct-〈as-to-orientation/valueconstruct/valuation-and-derived-parameterising $\rangle$ and $<$ amplituding/formative $>$ entailment-〈as- 
to-totalising-contiguous/coherent-factuality-of-variability)) implications' of the overall relativeunreflexivity/relative-reflexivity —ontological-contiguity ${ }^{67}$ of-the-human-institutionalisationprocess ${ }^{68}$ (and not 'rhetorical vagueness of mere abstractlyapriorising/axiomatising/referencing' as to 'human limited-mentation-capacity—as-subjecting'educed unlimitedness/existence sublimating nascence' to limitedness/human-subpotency tolerance-<of-disparateness>/inexactitude'). In other words, 'human limited-mentationcapacity-deepening —as-subjecting-limitedness/human-subpotency-to-'educed-

unlimitedness/existence-sublimating nascence' intolerance- $<$ ofdisparateness>/exactifying_precisioning' so-reflects a prospective pinning-down (as to profound-supererogation of the genuine social intellectual-function/posture as of 'Derridean underdetermination-imbued force/violence conception' and 'Foucauldian knowledge/power conception construed as knowledge-empowerment/ignorance-disempowerment') that is preemptive of the possibility for the prospective manifestation of the shallow-supererogation of pedantising/muddling/formulaic-hollowing-out-in-subontologisation/subpotentiation〈blurring/undermining-of-prospective-totalising-entailing,-as-to-entailing<amplituding/formative-epistemicity>totalising in-relative-ontological-completeness > desublimation manifest 'human limited-mentation-capacity-as-subjecting-educedunlimitedness/existence-sublimating nascence' to-limitedness/human-subpotency tolerancesof-disparateness>/inexactitude'; and so with regards to prospective human-subpotencyaporia/undecidability/dilemma/ought-indeterminacy/deficiency/limitation/constraint—imbued'notional firstnaturedness-formativeness-<as-to-eventualising-inkling-drive or seedingmisprising $>$ temporal-to-intemporal-dispositions- $<$ so-construed-as-from-perspectiveontological-normalcy/postconvergence>'-existentialism-form-factor' in want for the sublimating recurrence of 'prospective human incipient/seeding ontological-faith-notion-orontological-fideism — imbued-underdetermination-of-motif-and- 
apriorising/axiomatising/referencing-as-so-being-as-of-existential-reality

psychoanalytic-unshackling as of 'psychologismic-epistemic-acutisation-<as-topostconverging-de-mentating/structuring/paradigming,-eliciting-of-existence's-sublimatingnascence-in-prospective-aporeticism-overcoming/unovercoming $>$ as to epistemic-growth,-as\{veridical/sound\}-relative-reflexivity-in-existence/relativising from-limited-mentation-as-itsdeepening/psychologismic epistemic-acutisation residualising, ${ }^{\{\text {decompulsing }}$ \}elinearity foreogency'. This insight is validated by the fact that the '<cumulating/recomposuring attendantontological-contiguity >-successive superseding/overcoming (of 'human limited-mentationcapacity —as-subjecting-educed-unlimitedness/existence-sublimating nascence' tolimitedness/human-subpotency tolerance-<of-disparateness $>$ /inexactitude' in desublimating/distorting recurrence of already induced 'limitedness/human-subpotency prior rationalisation-of-contentivity/argumentativity/dialecticism/discursivity as to the prior mereformulaicity/ritualisation-<as-to-mere-formulaicmethodologising/mutualising/organising/institutionalising,-prospectively-losing-track-of‘fepistemic-talising ’re-apriorising/re-axiomatising/re-referencing residuality-in-reoriginariness/re-origination'> of $\leq$ mere-formulaicity/ritualisation-of $>$-prior secondnatured institutionalisation), speaks for instance to the fact that 'base-institutionalisation rulemakingapriorising/axiomatising/referencing-psychologism' over 'recurrent-utter-uninstitutionalisation non-rules_-apriorising/axiomatising/referencing-psychologism' (and as similarly reflected across the overall relative-unreflexivity/relative-reflexivity ontological-contiguity $\sim$ of-thehuman-institutionalisation-process ${ }^{68}$ ) is fundamentally a question of intolerance- $<$ f disparateness>/exactifying_precisioning ('human limited-mentation-capacity-deepening—assubjecting limitedness/hmman-subpotency to 'educed unlimitedness/existence-sublimating nascence' ${ }^{53}$ intolerance-<of-disparateness>/exactifying_precisioning') as to rulemaking-overnon-rules - apriorising/axiomatising/referencing-psychologism, as so-enabling the prospective 
re-ontologising. This 'deterministic insight' about the nature of prospective re-ontologising points out that in effect prospective re-ontologising is an exercise of 'relays of human intemporal-individuation epistemic-projection radicalities $\sim$ in-chronicular/annalistic-cogency$<$ as-of-notional $\sim$ protensivity $>$-〈as-to-limited-mentation-capacity-deepening as subjecting limitedness/human-subpotency to 'educed-unlimitedness/existence-sublimating nascence' > so-construed as cogency_chronicularity/annality-of-relative-reflexivity,-as-to-profoundsupererogation, meant at superseding/overcoming the 'prior desublimating apriorising/axiomatising/referencing-psychologism', as to the fact that: the 'prospective leeway of ontologising-tolerance-<of-disparateness $>$ /inexactitude of base-institutionalisation' doesn't admit 'lack of rulemaking-over-non-rules — apriorising/axiomatising/referencingpsychologism' (manifested by recurrent-utter-uninstitutionalisation); the 'prospective leeway of ontologising-tolerance-<of-disparateness>-inexactitude of ${ }^{103}$ universalisation' doesn't admit 'lack of universalisation-directed-rulemaking-over-non-rulesapriorising/axiomatising/referencing-psychologism' (manifested by base-institutionalisationununiversalisation); the 'prospective leeway of ontologising-tolerance-<ofdisparateness $>$ /inexactitude of positivism/rational-empiricism' doesn't admit 'lack of positivising/rational-empiricism-based-universalisation-directed-rulemaking-over-non-rulesapriorising/axiomatising/referencing-psychologism' (manifested by ${ }^{103}$ universalisation-nonpositivism/medievalism); and prospectively the 'prospective leeway of ontologising-tolerance$\leqslant 0$-disparateness $>$ /inexactitude of ${ }^{18}$ deprocrypticism-or-preempting-disjointedness-as-ofreference-of-thought (reflected as to budding-postmodern thought)' doesn't admit 'lack of preempting - disjointedness-as-of- ${ }^{8}$ reference-of-thought,-as-to- ${ }^{\cdot 3}<$ amplituding/formativeepistemicity $>$ growth-or-conflatedness ${ }^{13} /$ transvaluative- $^{2}$ rationalising/transepistemicity/anamnestic-residuality/spirit-drivenness'_-in-supersedingmere-formulaic-positivising/rational-empiricism-based-universalisation-directed-rulemaking- 
over-non-rules — apriorising/axiomatising/referencing-psychologism' (manifested by our positivism- ${ }^{80}$ procrypticism/disjointedness-as-of- ${ }^{83}$ reference-of-thought). The above articulation speaks to the "notional $\sim$ deprocrypticism-or-preempting - disjointedness-as-of- reference-ofthought-<as-to-'the-successive-stations/loci-of-limitedness/human-subpotency$<$ amplituding/formative-epistemicity $>$-totalising $\sim$ thrownness-in-existence '-imbuedepistemic-projections-of-'the-coherence/contiguity-of-the_superseding-oneness-ofontology/ontological-veridicality/relative-unreflexivity/relative-reflexivity - ontologicalcontiguity '> of the overall relative-unreflexivity/relative-reflexivity-ontologicalcontiguity ${ }^{67}$ of-the-human-institutionalisation-process ${ }^{6}$ ' as of 'effective existential$<$ disontologising/re-ontologising aporeticism $>$ apriorising/axiomtising/referencing construal' and not 'rhetorical vagueness of mere abstractly-elaborate apriorising/axiomatising/referencing (poorly/hardly reflecting upon the underlying <amplituding/formative-epistemicity>totalising $\sim$ thrownness-in-existence ${ }^{35} \quad$ mental-aestheticising-<as-'psychologismic-existentialmetaphoricity fas-to-fepistemictising łre-apriorising/re-axiomatising/re-referencing_inbecoming?' -so-implicited-'by-way-of-the-existentially/contextually/textually-manifest-motifconstruct-as-specific-language'-as-so-reflecting-'the-existentially/contextually/textuallymanifest-moronisation/demoronisation'> that veridically exudes of apriorising/axiomatising/referencing)' and so as to the manifestation of succession of relativeontological-completeness ${ }^{87}$-of-apriorising/axiomatising/referencing of 'human limitedmentation-capacity-deepening —as-subjecting limitedness/human-subpotency-to-'educedunlimitedness/existence-sublimating nascence' intolerance $<$ ofdisparateness>/exactifying_precisioning; and as so-rather 'existentially-<disontelogising/reentogising apreticism $>$ understood-<as-epistemic-totalisingly /acutely_translating-intothe-mental-aestheticising-metaphoricity >' by the succession of given < underlaid/substrated'thrownness-aestheticising' - of -relative-unreflexivity in-existence\} $>$ profusion-of- 
preconverging prior-relative-ontological-incompleteness ${ }^{8}$-of-

apriorising/axiomatising/referencing — by_<overlaying/superstrating 'thrownness-

aestheticising' \{of relative-reflexivity in-existence\}>-sparsity-of postconverging prospectiverelative-ontological-completeness ${ }^{87}$-of-apriorising/axiomatising/referencing as to succession of underlying $\quad<$ amplituding/formative-epistemicity $>$-totalising $\sim$ thrownness-in-existence mental-aestheticising-<as-'psychologismic-existential-metaphoricity $\quad$ \{as-to-fepistemictotalising '’re-apriorising/re-axiomatising/re-referencing_in-becoming\}' -so-implicited- 'by-wayof-the-existentially/contextually/textually-manifest-motif-construct-as-specific-language'-asso-reflecting-'the-existentially/contextually/textually-manifest-moronisation/demoronisation'> imbued succession of re-ontologising-by-disontologising_existential-calculus-〈between 'prospective existentialising_-postconverging_framing/imprinting re-ontologising' and 'prior existentialising_preconverging_enframing/imprintedness social-functioning-andaccordance-as-of-social-stake-contention-or-confliction' ’'. Thus the 'notional $\sim$ deprocrypticism-or-preempting-disjointedness-as-of- ${ }^{-}$reference-of-thought- $<$asto- 'the-successive-stations/loci-of-limitedness/human-subpotency-<amplituding/formativeepistemicity>-totalising thrownness-in-existence " '-imbued-epistemic-projections-of-'thecoherence/contiguity-of-the_superseding-oneness-of-ontology/ontologicalveridicality/relative-unreflexivity/relative-reflexivity - ontological-contiguity '> of the overall relative-unreflexivity/relative-reflexivity - ontological-contiguity $\sim$ of-the-humaninstitutionalisation-process ${ }^{6}$, (speaking of ' nonpresencing-<perspective-ontologicalnormalcy/postconvergence $>$ relativism/relative-scope for epistemic-growth,-as\{veridical/sound\}-relative-reflexivity-in-existence/relativising from-limited-mentation-as-itsdeepening/psychologismic epistemic-acutisation residualising, fdecompulsing $\}$ delinearity for eogency' epistemic-projection) is thus the 'veridical neutral point-ofdevolving/departure/anchoring/backdrop conceptualisation of human ontological- 
performance $^{2}$-<including-virtue-as-ontology $>$ /morality/ethics/justice/etc. as to rerationalisations-of-contentivity/argumentativity/dialecticism/discursivity so-reflecting successive relative-ontological-completeness 87 'implicited_attendant-ontologicalcontiguity $^{67}$; educed-

existentialising/contextualising/textmalising_intelligibility/epistemicity/reflexivity-contiguity<imbued-notional cogency>' ; so-construed summarily as underlying-elucidative 'requisite sublimating/desublimating formulative-framing/fielding — of-entailment of human ontologicalperformance ${ }^{72}-<$ including-virtue-as-ontology $>$ /morality/ethics/justice/etc. contemplation' or 'overall human ontological-entrapment' (as of notionally implied ${ }^{45}$ foregrounding_entailment$<$ in-succession-of-profound-supererogation $>$ - $>$ postconverging-narrowing-

down sublimation-as-to-'existence - as-sublimating-withdrawal/unenframing/re-ontologising,elicited-from-prospective-profound-supererogation ' '-in-reflecting- 'immanent $\sim$ relativeunreflexivity/relative-reflexivity ontological-contiguity ";-as-operative-

notional deprocrypticism) $)$. This underlying-elucidative 'requisite sublimating/desublimating formulative-framing/fielding — of-entailment of human ontological-performance ${ }^{2}-<$ includingvirtue-as-ontology $>/$ morality/ethics/justice/etc. contemplation' (as of notionally implied foregrounding_entailment- $<$ in-succession-of-profound-supererogation $>>-\langle$ postconvergingnarrowing-down $\sim$ sublimation-as-to- 'existence - as-sublimating-withdrawal/unenframing/reontologising,-elicited-from-prospective-profound-supererogation ' '-in-reflecting‘immanent relative-unreflexivity/relative-reflexivity - ontological-contiguity ';-as-operativenotional deprocrypticism)) underlies the entirety of 'human psychologismic-epistemicacutisation-<as-to-postconverging-de-mentating/structuring/paradigming,-eliciting-ofexistence's-sublimating-nascence-in-prospective-aporeticism-overcoming/unovercoming $>$ as to epistemic-growth,-as_ _veridical/sound\}-relative-reflexivity-in-existence/relativising fromlimited-mentation-as-its-deepening/psychologismic epistemic-acutisation residualising, 
$\{$ decompulsing\} delinearity for-cogency' (in reflection of 'human limited-mentation-capacitydeepening —as-subjecting limitedness/human-subpotency to-'educed-unlimitedness/existencesublimating nascence' 53 intolerance-<of-disparateness>/exactifying_precisioning') as to the 'existential-<disontologising/re-ontologising_aporeticism $>\quad$ insight' that 'unlimitedness/existence-<full-potency-of_sublimating nascence $>$ prospective apriorising/axiomatising/referencing-sublimating-reflexivity-beholdening under which limitedness/human-subpotency submits in profound-supererogation for prospective sublimating' rather warrants its very 'upfronting of prospective sublimating-nascence' upon limitedness/human-subpotency psyche as adjustable/subjectable placeholder-setup/mentaldevising-representation/mentation/consciousness-awareness-teleology superseding/overcoming the 'rhetorical vagueness of mere abstractly-elaborate apriorising/axiomatising/referencing (poorly/hardly reflecting upon the underlying $<$ amplituding/formative-epistemicity $>$-totalising $\sim$ thrownness-in-existence ${ }^{35} \quad$ mentalaestheticising-<as-'psychologismic-existential-metaphoricity fas-to-epistemictaling apriorising/re-axiomatising/re-referencing_in_becoming\}' -so-implicited-'by-way-of-theexistentially/contextually/textually-manifest-motif-construct-as-specific-language'-as-soreflecting-'the-existentially/contextually/textually-manifest-moronisation/demoronisation'> that veridically exudes of apriorising/axiomatising/referencing)' of any 'limitedness/humansubpotency prior rationalisation-of-contentivity/argumentativity/dialecticism/discursivity as to the prior mere-formulaicity/ritualisation-<as-to-mere-formulaicmethodologising/mutualising/organising/institutionalising,-prospectively-losing-track-of'\{epistemic-totalising '⿳亠丷厂犬re-apriorising/re-axiomatising/re-referencing residuality-in-reoriginariness/re-origination'> of $\leq$ mere formmlaicity/ritualisation-of $>$ prior secondnatured institutionalisation'; and so-reflecting the warranted 'overarching existential< disontologising/re-ontologising aporeticism $>$ priority/precedence/primacy of requisite 
prospective

ontological-good-faith/authenticity ${ }^{6} \sim$ postconverging-dementating/structuring/paradigming inducing of psychoanalytic-unshackling for the relativeontological-completeness ${ }^{87}$-of-apriorising/axiomatising/referencing re-ontologising prospective re-rationalisation-of-contentivity/argumentativity/dialecticism/discursivity' (as to dimensionality-of-sublimating $25<<$ amplituding/formative $>$ supererogatory $\sim$ de-

\section{mentativeness/epistemic-growth-or-conflatedness /transvaluative-}

rationalising/transepistemicity/anamnestic-residuality/spirit-drivenness-equalisation〉). In this regards the 'upfronting of prospective sublimating-nascence' as of 'overarching existential<disentologising/re-ontelogising aporeticism $>$ priority/precedence/primacy of requisite prospective ontological-good-faith/authenticity ${ }^{69}$ postconverging-dementating/structuring/paradigming 70 inducing of psychoanalytic-unshackling for the relativeontological-completeness ${ }^{87}$-of-apriorising/axiomatising/referencing re-ontologising prospective re-rationalisation-of-contentivity/argumentativity/dialecticism/discursivity' rather speaks to the succession of 'prospectively anticipated/expected sublimating

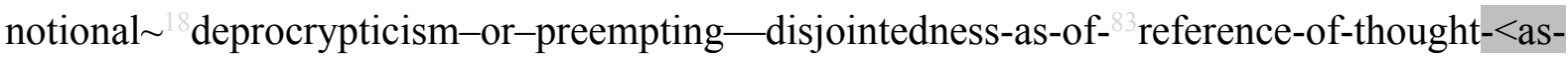
to-'the-successive-stations/loci-of-limitedness/human-subpotency-<amplituding/formativeepistemicity>-totalising -thrownness-in-existence ' -imbued-epistemic-projections-of- 'thecoherence/contiguity-of-the_superseding-oneness-of-ontology/ontological-

veridicality/relative-unreflexivity/relative-reflexivity - ontological-contiguity ' $>$ of the overall relative-unreflexivity/relative-reflexivity - ontological-contiguity ${ }^{67}$ of-the-humaninstitutionalisation-process ${ }^{68}$ reflected as to registry-worldviews/dimensions specific allenglobling/all-encompassing/all-accounting-for/epistemic-totalising 33 contiguity/coherence of re-rationalisations-of-contentivity/argumentativity/dialecticism/discursivity'. In this respect, much of present-day 'rhetorical vagueness of mere abstractly-elaborate apriorising/axiomatising/referencing (poorly/hardly reflecting upon the underlying 


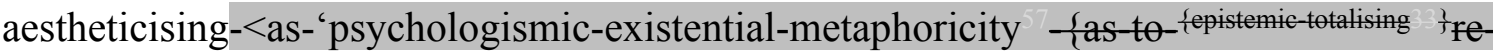

apriorising/re-axiomatising/re-referencing_in-becoming?' 'so-implicited-'by-way-of-the-

existentially/contextually/textually-manifest-motif-construct-as-specific-language'-as-so-

reflecting-'the-existentially/contextually/textually-manifest-moronisation/demoronisation'>

that veridically exudes of apriorising/axiomatising/referencing)' supposedly critical of buddingpostmodern and other critical thought (in-many-ways fail to existentially-<disontologising/reentelogising aporeticism $>$ countenance of the specific "prospectively anticipated/expected sublimating ${ }^{18}$ deprocrypticism-or-preempting-disjointedness-as-of- ${ }^{3}$ reference-of-thought$<$ as-to-'its-specific-station/locus-of-limitedness/human-subpotency-<amplituding/formativeepistemicity>-totalising thrownness-in-existence '-imbued-epistemic-projection-of-'thecoherence/contiguity-of-the_superseding-oneness-of-ontology/ontologicalveridicality/relative-unreflexivity/relative-reflexivity - ontological-contiguity ' $>$ reflected as to its given registry-worldview/dimension specific all-englobling/all-encompassing/allaccounting for/epistemic-totalising - contiguity/coherence of re-rationalisation-ofcontentivity/argumentativity/dialecticism/discursivity') and is rather cacophonic as to the myriad of confusions and 'flawed-prior-purposefulness of ${ }^{79}$ presencing-absolutisingidentitive-constitutedness ${ }^{14}$ before supposedly-prospective-thinking-purpose,-as-precalculatedpurpose-<as-prospectively-losing-track-of- ‘ \{epistemic-totalising ${ }^{\frac{1}{3}}$ re-apriorising/re-axiomatising/rereferencing residuality_-in-re-originariness/re-origination'-of-thinking $>$ '. That said, it is effectively the crossgenerational cultivation and enculturation of the specific relativeontological-completeness ${ }^{87}$-of-apriorising/axiomatising/referencing 'prospectively anticipated/expected sublimating notional ${ }^{18}$ deprocrypticism-or-preempting-disjointednessas-of- ${ }^{3}$ reference-of-thought imbued registry-worldview/dimension specific all-englobling/allencompassing/all-accounting-for/epistemic-totalising - contiguity/coherence of re- 
rationalisation-of-contentivity/argumentativity/dialecticism/discursivity' that underlies the prospect of the given registry-worldview/dimension 'human limited-mentation-capacitydeepening —as-subjecting limitedness/human-subpotency to-'educed-unlimitedness/existencesublimating nascence' 53 intolerance-<of-disparateness $>$ /exactifying_precisioning' induced prospective re-ontologising (with respect to requisite 'human psychologismic-epistemicacutisation-<as-to-postconverging-de-mentating/structuring/paradigming,-eliciting-ofexistence's-sublimating-nascence-in-prospective-aporeticism-overcoming/unovercoming $>$ as to epistemic-growth,-as - \{veridical/sound\}-relative-reflexivity-in-existence/relativising fromlimited-mentation-as-its-deepening/psychologismic epistemic-acutisation residualising, ${ }_{\{\text {decompulsing }\}}$ delinearity for-cogency'); as to 'unlimitedness/existence-<full-potencyөf_sublimating nascence $>$ prospective apriorising/axiomatising/referencing-sublimatingreflexivity-beholdening under which limitedness/human-subpotency submits in profoundsupererogation for prospective sublimating' as 'upfronting of prospective sublimatingnascence' upon limitedness/human-subpotency psyche as adjustable/subjectable placeholdersetup/mental-devising-representation/mentation/consciousness-awareness-teleology ${ }^{9}$, and soupfronted prospectively as of 'overarching existential-<disontologising/re-ontologising apereticism> priority/precedence/primacy of requisite prospective ontological-goodfaith/authenticity ${ }^{6} \sim$ postconverging-de-mentating/structuring/paradigming 70 inducing of psychoanalytic-unshackling for the relative-ontological-completeness ${ }^{8}$-ofapriorising/axiomatising/referencing re-ontologising prospective re-rationalisation-ofcontentivity/argumentativity/dialecticism/discursivity' and so over a prior 'self-presence/selfconstitutedness $^{14}-<$ in-perspective-epistemic-abnormalcy/preconvergence ${ }^{3}>$ desublimating existentialising-decisionality<as do disontologising/re-ontelogising aporeticism $>$ ' naïve and ontologically-flawed supposed 'backend-secondnaturedinstitutionalisation of prospective sublimating-nascence' as from any given 'limitedness/human- 
subpotency prior rationalisation-of-contentivity/argumentativity/dialecticism/discursivity as to the

prior mere-formulaicity/ritualisation-<as-to-mere-formulaicmethodologising/mutualising/organising/institutionalising,-prospectively-losing-track-of‘\{epistemic-totalising łre-apriorising/re-axiomatising/re-referencing-residuality-in-reoriginariness/re-origination'> of $\leq$ mere-formulaicity/ritualisation-of $>$-prior secondnatured institutionalisation' elicited 'rhetorical vagueness of mere abstractly-elaborate apriorising/axiomatising/referencing (poorly/hardly reflecting upon the underlying $<$ amplituding/formative-epistemicity $>$-totalising $\sim$ thrownness-in-existence mentalaestheticising-<as-‘psychologismic-existential-metaphoricity apriorising/re-axiomatising/re-referencing_in-becoming?' -so-implicited-'by-way-of-theexistentially/contextually/textually-manifest-motif-construct-as-specific-language'-as-soreflecting-'the-existentially/contextually/textually-manifest-moronisation/demoronisation'> that veridically exudes of apriorising/axiomatising/referencing)'. This ('human psychologismic_epistemic-acutisation-<as-to-postconverging-de-mentating/structuring/paradigming,-elicitingof-existence's-sublimating-nascence-in-prospective-aporeticism-overcoming/unovercoming> as to epistemic-growth,-as - \{veridical/sound\}-relative-reflexivity-in-existence/relativising from limited mentation as its deepening/psychologismic epistemic acutisation residualising, ${ }^{\text {\{decompulsing }}$ delinearity for-cogency' insight) is merely a reflection of the fact that 'human limited-mentation-capacity-deepening—as-subjecting limitedness/human-subpotencyto-'educed-unlimitedness/existence-sublimating nascence' intelerance $<$ of disparateness>/exactifying_precisioning' implies the sublimating-nascence of respectively base-institutionalisation, universalisation, positivism/rational-empiricism and deprocrypticism-or-preempting-disjointedness-as-of- ${ }^{83}$ reference-of-thought $\quad$ (as to prospective 'apriorising/axiomatising/referencing disambiguating/de-leveling/deressentiment/opened-construct-of- ${ }^{5}$ meaningfulness-and-teleology 99 demoronisation- 
<sublimating-nascence,-nonextricatory-sublimating-upstreaming/'amontée’>’) cannot be elicited respectively as of recurrent-utter-uninstitutionalisation, ununiversalisation, nonpositivism/medievalism and ${ }^{80}$ procrypticism-or-disjointedness-as-of- ${ }^{3}$ reference-of-thought imbued prior rationalisations-of-contentivity/argumentativity/dialecticism/discursivity as to the prior mere-formulaicity/ritualisation-<as-to-mere-formulaic methodologising/mutualising/organising/institutionalising,-prospectively-losing-track-of'\{epistemic-totalising ’̛́re-apriorising/re-axiomatising/re-referencing residuality-in-reoriginariness/re-origination'>; and this 'human limited-mentation-capacity-deepening-assubjecting -limitedness/human-subpotency-to-'educed-unlimitedness/existence-sublimating nascence' 53 intelerance-<of-disparateness>/exactifying_precisioning' applies not only with regards to Being-development/ontological-framework-expansion-as-to-depth-of-ontologisingdevelopment-as-infrastructure-of- meaningfulness-and-teleology psychologismic epistemic acutisation difficulty-for, residualising \{decompulsing $\}$ delinearity for-cogency> magnitude\{of-experientiality/experiment\} of apriorising/axiomatising/referencing but also institutionaldevelopment-as-to-social-function-development and living-development-as-to-personalitydevelopment psychologismic epistemic-acutisation difficulty-<for, residualising \{decompulsing\} delinearity for cogeney> magnitudes \{of-experientiality/experiment\} apriorising/axiomatising/referencing (in all such instances as of the implied 'epistemic-growth,as-\{veridical/sound\}-relative-reflexivity-in-existence/relativising from-limited-mentationas-its-deepening/psychologismic epistemic acutisation residualising, $\{$ decompung $\}$ delinearity for-cogeney as of notional $\sim$ self-distantiation- $<$ imbued-re-motif-and-reapriorising/re-axiomatising/re-referencing >' with respect to the-very-same purview/devolvedpurview/devolving-purview-of-unlimitedness/existence-full poney_of sublimating nascence $>$ ). This prospective apriorising/axiomatising/referencing sublimating exercise (as of unlimitedness/existence-<full-potency-of_sublimating nascence $>$ prospective 
apriorising/axiomatising/referencing-sublimating-reflexivity_beholdening 'upfronting of prospective sublimating-nascence' upon limitedness/human-subpotency psyche as adjustable/subjectable placeholder-setup/mental-devisingrepresentation/mentation/consciousness-awareness-teleology ${ }^{9}$ ) speaks of prospective existential-<disontologising/re-ontologising aporeticism $>$ counteracting/supplanting/alienating-of-prior-apriorising/axiomatising/referencing in contrast to prior processive — aposteriorising/logicising/deriving- $<$ as-from-priorapriorising/axiomatising/referencing>; as so-reflecting the psychoanalytic-unshackling for the relative-ontological-completeness ${ }^{8}$-of-apriorising/axiomatising/referencing re-ontologising prospective re-rationalisation-of-contentivity/argumentativity/dialecticism/discursivity' imbued veridical 'backend - secondnatured-institutionalisation of prospective sublimatingnascence' (so-underlied as to the overall relative-unreflexivity/relative-reflexivity_ontologicalcontiguity ${ }^{67} \sim$ of-the-human-institutionalisation-process ${ }^{68}$ imbued human consciousness/collective-consciousness notional $\sim$ symmetrisation- $<$ as-to-symmetrisation-bydesymmetrisation,-in-reflecting-postconverging-or-dialectical-thinking ${ }^{21}$-by-preconvergingor-dementing ${ }^{20} \sim$ perspectives-of-human $-{ }^{5}$ meaningfulness-and-teleology $>$ ). Thus existential-disontelogising/re ontelogising apereticism> counteracting/supplanting/alienating-ofprior-apriorising/axiomatising/referencing captures the fact that prospective re-ontologising is rather a 'despite-the-self exercise of epistemic-projection in notional $\sim$ self-distantiation$<$ imbued —re-motif-and-re-apriorising/re-axiomatising/re-referencing >' and not a 'self-exulting exercise of epistemic-projection in prior processive-motif-'exuding aestheticising gesturing' of apriorising/axiomatising/referencing_imbued_notional $~$ reductionism- $<$ of-existentialprospection,-whether-as-of-trepidatious/warped/preclusive/occlusive/protensivenotional reductionism>' as to the 'sublimating determination of educed-and-availing-and-reavailing of relative-ontological-completeness ${ }^{87}$ exuding from unlimitedness/existence-<full- 
potency-of_sublimating nascence>' upon limitedness/human-subpotency psyche as adjustable/subjectable placeholder-setup/mental-devisingrepresentation/mentation/consciousness-awareness-teleology (in reflection of underlying

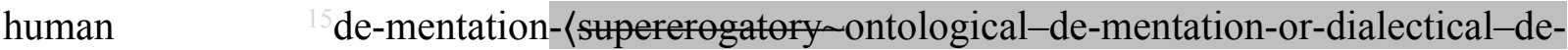
mentation-stranding-or-attributive-dialectics $\rangle)$. Thus the manifest human existential$\leq$ disontologising/re-ontologising aporeticism $>$ counteracting/supplanting/alienating-ofprior-apriorising/axiomatising/referencing underlying the overall relative-unreflexivity/relativereflexivity - ontological-contiguity ${ }^{67} \sim$ of-the-human-institutionalisation-process ${ }^{68}$ effectively speaks to the latter notional $\sim$ symmetrisation-<as-to-symmetrisation-by-desymmetrisation,-inreflecting-postconverging-or-dialectical-thinking -by-preconverging-ordementing $\sim$ perspectives-of-human- ${ }^{5}$ meaningfulness-and-teleology ${ }^{9}>$; so-reflecting the 'notional firstnaturedness-formativeness-<as-to-eventualising -inkling-drive-or-seedingmisprising $>$ temporal-to-intemporal-dispositions- $<$ so-construed-as-from-perspectiveontological-normalcy/postconvergence $>$ of human protracted-social—as-to-individual-byinstitutional-by-social ontological-performance ${ }^{72}{\text { - including-virtue-as-ontology }>^{\prime}}^{\prime}$ as $\quad$ sounderlied by the imbued interwovenness of "prospective re-ontologising and its induced positiveopportunism - of-social-functioning-and-accordance ${ }^{7}$ ' and 'prior disontologising and its induced mere-formulaicity/ritualisation complexification as of disparateness-ofconceptualisation-<unforegrounding-ment,-failing-prospectively-to-reflect‘immanent relative- unreflexivity/relative-reflexivity - ontological-contiguity '>’. Insightfully, $\quad$ human $\quad$ existential-disontologising/re-ontologising aporeticism $>$ counteracting/supplanting/alienating-of-prior-apriorising/axiomatising/referencing (as of 'human psychologismic-epistemic-acutisation-<as-to-postconverging-dementating/structuring/paradigming,-eliciting-of-existence's-sublimating-nascence-inprospective-aporeticism-overcoming/unovercoming > as to epistemic-growth,-as 
\{veridical/sound\}-relative-reflexivity-in-existence/relativising from-limited-mentation-as-itsdeepening/psychologismic epistemic acutisation residualising, ${ }^{\text {fdecompulsing }}$ delinearity for eogency' implications) speaks to the fact that human consciousness/collective-consciousness is a 'dynamical-construct of human mental-aestheticising-<as-'psychologismic-existentialmetaphoricity \{as-to-\{epistemic-totalising ${ }^{\}}$re-apriorising/re-axiomatising/re-referencing_inbecoming?' -so-implicited-'by-way-of-the-existentially/contextually/textually-manifest-motifconstruct-as-specific-language'-as-so-reflecting-'the-existentially/contextually/textuallymanifest-moronisation/demoronisation'>' (as of 'human aestheticisation-and-aestheticisationtowards-ontology-<elicited-idiomatisation $>$ interstitial—disontologising-by-re-ontologising of ontological-performance ${ }^{72}-<$ including-virtue-as-ontology>' so-reflecting 'human interstitially recurrent limited-mentation-capacity—as-subjecting-'educed-unlimitedness/existencesublimating nascence' to-limitedness/human-subpotency-by-limited-mentation-capacitydeepening —as-subjecting limitedness/human-subpotency to-'educed-unlimitedness/existencesublimating nascence'53 variance_in-epistemic-projection'); with the implication (as from nonpresencing-<perspective-ontological-normalcy/postconvergence $>$ epistemic-projection) that human consciousness/collective-consciousness supposed representation/unity/comprehensiveness is in-many-ways 'ontologically superfluous' with respect to the 'dynamically manifest relative inveracity of human sunderlaid/substrated'thrownness-aestheticising' \{of-relative-unreflexivity in-existence\}> profusion-ofpreconverging prior-relative-ontological-incompleteness ${ }^{88}$-ofapriorising/axiomatising/referencing' and the 'dynamically manifest relative veracity of human <overlaying/superstrating-'thrownness-aestheticising' \{of-relative-reflexivity in-existence\}>

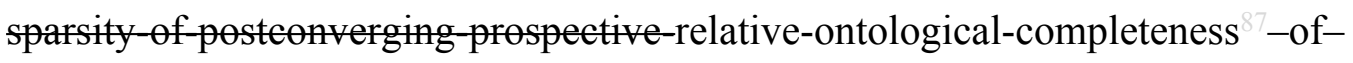
apriorising/axiomatising/referencing' (as to when it comes to limitedness/human-subpotency psyche as adjustable/subjectable placeholder-setup/mental-devising- 
representation/mentation/consciousness-awareness-teleology' with respect to 'sublimating determination of educed-and-availing-and-re-availing of relative-ontological-completeness exuding from unlimitedness/existence-<full-potency-of_sublimating nascence $>$ '). This 'ontological-superfluity' of human consciousness/collective-consciousness (as to its relation to human epistemic-growth,-as - \{veridical/sound\}-relative-reflexivity-in-existence/relativising from-limited-mentation-as-its-deepening/psychologismic epistemic-acutisation

residualising, ${ }^{\text {\{decompulsing }}$ delinearity for-cogency) is in-many-ways what renders the conception of the-human/humanity sublimatingly omnipotentiable; as so-implying that thehuman/humanity possibility/imagination is defined by 'unlimitedness/existence-<full-potencyof_sublimating nascence> prospective apriorising/axiomatising/referencing-sublimatingreflexivity-beholdening under which limitedness/human-subpotency submits in profoundsupererogation for prospective sublimating' as to the ontologising/scientific/existence$<$ honesty-constraining $>$ _ scope_for_prospective_re-ontologising implications of existential$\leq$ disontologising/re-ontologising aporeticism $>$ counteracting/supplanting/alienating-ofprior-apriorising/axiomatising/referencing inducing of human transcendence-andsublimity/sublimation/supererogatoryade-mentativity. Concretely, human existentialdisontologising/re ontologising aporeticism> counteracting/supplanting/alienating-ofprior-apriorising/axiomatising/referencing is underlied by the fact that the "manifest/prompt actualising' of human consciousness/collective-consciousness is rather as of the undergirdingveracity of germinal/inceptive/formative individuals anarchistic self-reflexive instigativeeventuating-〈as-to-teleological-instigative/incipient-

\section{willing/arbitrariness/waywardness/faithdrivenness/supererogating-for-human-intelligibility,-} preceding-existence's-eventuating-sublimating-validation/desublimating-invalidation) manifestations and ontological-performance ${ }^{72}-<$ including-virtue-asontology $>/$ morality/ethics/justice/etc. (rather than the virtual/illusory naivety of inherently 
actualising institutional/bureaucratic/social self-embodying epistemic-projection'). This underlies that 'human consciousness/collective-consciousness representation/unity/comprehensiveness of the institutional/bureaucratic/social and their purposefulness' is rather of constructive-veracity (so-construed 'as-if-of-inherently-actualising self-embodying representation/unity/comprehensiveness' for the purpose of institutional/bureaucratic/social procession- $<$ as-to-constructive-veracity/inveracity_ofapriorising/axiomatising/referencing $>$ ); and so-constructively processing (in processiveaposteriorising/logicising/deriving-<as-from-prior-apriorising/axiomatising/referencing $>$ ) notionally/epistemically/bindingnessly-ass-tederminism/conceptivity-of elative-mreflexivity/relative-reflexivitys as of credibility/credulity-induced-processive-assent-to-moronisation- $<$ sublimating-nascence,extricatory-desublimating-downstreaming/'avalage'>—by_incredibility/incredulity-inducedprocessive-dissent-in-demoronisation- $<$ sublimating-nascence, nonextricatory-sublimatingupstreaming/'amontée'>. Such a constructive-veracity of 'human consciousness/collectiveconsciousness representation/unity/comprehensiveness of the institutional/bureaucratic/social and their purposefulness' is rather elicited by 'projectively blinding-out/screening-out the undergirding-veracity of germinal/inceptive/formative individuals anarchistic selfreflexive instigative-eventuating-〈as-to-teleological-instigative/incipientwilling/arbitrariness/waywardness/faithdrivenness/supererogating-for-human-intelligibility,preceding-existence's-eventuating-sublimating-validation/desublimating-invalidation〉

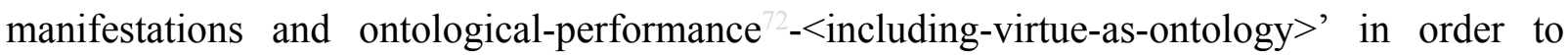
'superpose/imply/suggest/infer of the institutional/bureaucratic/social and their purposefulness'. Such that down-the-line, 'human consciousness/collective-consciousness representation/unity/comprehensiveness of the institutional/bureaucratic/social and their purposefulness' end up prospectively dislodging/disenabling the undergirding-veracity of germinal/inceptive/formative individuals anarchistic self-reflexive instigative-eventuating-〈as- 


\section{to-teleological-instigative/incipient-}

\section{willing/arbitrariness/waywardness/faithdrivenness/supererogating-for-human-intelligibility,-}

\section{preceding-existence's-eventuating-sublimating-validation/desublimating-invalidation)}

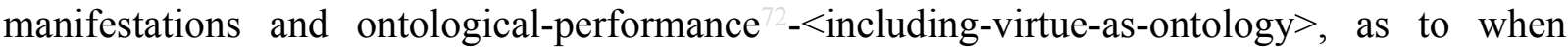
prospectively succumbing to preconverging-de-mentating/structuring/paradigming (as of the processing of prior mere-formulaicity/ritualisation-<as-to-mere-formulaic methodologising/mutualising/organising/institutionalising,-prospectively-losing-track-of-

‘fepistemic-atising ’’re-apriorising/re-axiomatising/re-referencing - residuality-in-re-

originariness/re-origination'> of prior $\quad$ rationalisation-ofcontentivity/argumentativity/dialecticism/discursivity); so-manifested as desublimating-andresidually-unaccounted-for-apriorising/axiomatising/referencing processing as of prior 'human consciousness/collective-consciousness representation/unity/comprehensiveness of the institutional/bureaucratic/social and their purposefulness' constructive-inveracity (and soreflected as to credibility/credulity-induced-processive-assent-to-moronisation- $<$ sublimating nascence,-extricatory-desublimating-downstreaming/'avalage'>). In contrast to prior processive — aposteriorising/logicising/deriving-<as-from-prior-

apriorising/axiomatising/referencing $>$, the notion of prospective existential-<disentologising/reentologising aporeticism $>$ counteracting/supplanting/alienating-of-prior-

apriorising/axiomatising/referencing with regards to human protracted-social—as-to-individualby-institutional-by-social psychoanalytic-unshackling (as of 'human psychologismic-epistemicacutisation-<as-to-postconverging-de-mentating/structuring/paradigming,-eliciting-ofexistence's-sublimating-nascence-in-prospective-aporeticism-overcoming/unovercoming $>$ as to epistemic-growth,-as_- \{veridical/sound\}-relative-reflexivity-in-existence/relativising fromlimited-mentation-as-its-deepening/psychologismic epistemic-acutisation residualising, \{decompulsing delinearity for-cogeney') is rather 'prospectively re-eliciting of the undergirding- 
veracity of germinal/inceptive/formative individuals anarchistic self-reflexive instigativeeventuating-〈as-to-teleological-instigative/incipient-

willing/arbitrariness/waywardness/faithdrivenness/supererogating-for-human-intelligibility,-

preceding-existence's-eventuating-sublimating-validation/desublimating-invalidation〉

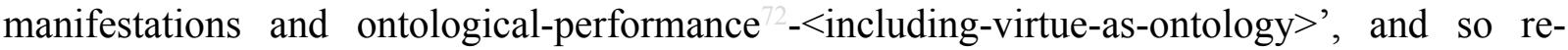
eliciting as to postconverging-de-mentating/structuring/paradigming prospective reontologising imbued profound-supererogation of re-rationalisation-ofcontentivity/argumentativity/dialecticism/discursivity (in superseding/overcoming the shallowsupererogation of the processing of the prior mere-formulaicity/ritualisation-<as-to-mereformulaic — methodologising/mutualising/organising/institutionalising,-prospectively-losingtrack-of- ‘fepistemic-totalising ${ }^{\prime}$ re-apriorising/re-axiomatising/re-referencing $\sim r e s i d u a l i t y-i n-r e-$ originariness/re-origination'> of prior rationalisation-ofcontentivity/argumentativity/dialecticism/discursivity); as to sublimating-and-residuallyaccounted-for-apriorising/axiomatising/referencing processing of prospective 'human consciousness/collective-consciousness representation/unity/comprehensiveness of the institutional/bureaucratic/social and their purposefulness' constructive-veracity (so-reflected as to incredibility/incredulity-induced-processive-dissent-in-demoronisation- $<$ sublimating nascence,-nonextricatory-sublimating-upstreaming/‘amontée’>). In-the-bigger-scheme-ofthings this contrast between desublimating-and-residually-unaccounted-forapriorising/axiomatising/referencing processing as of prior 'human consciousness/collectiveconsciousness representation/unity/comprehensiveness of the institutional/bureaucratic/social and their purposefulness' constructive-inveracity and sublimating-and-residually-accountedfor-apriorising/axiomatising/referencing processing of prospective 'human consciousness/collective-consciousness representation/unity/comprehensiveness of the institutional/bureaucratic/social and their purposefulness' constructive-veracity, speaks to the 
fact

that

'procession-<as-to-constructive-veracity/inveracity_of-

apriorising/axiomatising/referencing $>$ (with regards to 'human consciousness/collectiveconsciousness representation/unity/comprehensiveness of the institutional/bureaucratic/social and their purposefulness' constructive-veracity/inveracity) of human ${ }^{56}$ meaningfulness-andteleology ${ }^{9}$ ' is 're-actable upon' (as to human subconsciousness most-prospectively-conscious 're-ontologising-by-disontologising_existential-calculus-〈between 'prospective existentialising_-postconverging_framing/imprinting re-ontologising' and 'prior existentialising_preconverging_enframing/imprintedness social-functioning-andaccordance - as-of-social-stake-contention-or-confliction' $\rangle$ ' of consciousness surrealising- $<$ asto-supererogation $>$ ); and so 're-actable upon' as of the undergirding-veracity of germinal/inceptive/formative individuals anarchistic self-reflexive $\sim$ instigative-eventuating-〈asto-teleological-instigative/incipient-

willing/arbitrariness/waywardness/faithdrivenness/supererogating-for-human-intelligibility,preceding-existence's-eventuating-sublimating-validation/desublimating-invalidation)

(whether as of '\{veridical/sound\}-relative-reflexivity-in-existence/relativising from-limitedmentation-as-its-deepening/psychologismic epistemic-acutisation residualising,

$\{$ decompulsing $\}$ delinearity for-cogeney anarchistic-growth/anarchisation-for-re-ontologisation-〈asto-conscious/unconscious epistemically-sound induced 'demoronisation- $<$ sublimatingnascence, -nonextricatory-sublimating-upstreaming/‘amontée’> postconverging/dialecticalthinking conception of residual_re-originary_anarchistic incipiency of human socialfunctioning-and-accordance-as-of-social-stake-contention-or-confliction meaningfulnessand-teleology ' '’ or as of '\{flawed/unsound\}-relative-unreflexivity-in-existence/absolutising from-limited-mentation/psychologismic epistemic-acutisation nonresidualising-imbued\{compulsing\} tinearity in eclecticism of prior mere formulaicity/ritualisation insidious-anarchy$<$ as-to-conscious/unconscious epistemically-flawed induced 'moronisation- $<$ sublimating- 
conception of prior mere-formulaicity/ritualisation incipiency of human social-functioning-andaccordance-as-of-social-stake-contention-or-confliction meaningfulness-and-

teleology ' $>$ '). Basically, the human reality of the 'undergirding-veracity of germinal/inceptive/formative individuals anarchistic self-reflexive instigative-eventuating-〈asto-teleological-instigative/incipient-

willing/arbitrariness/waywardness/faithdrivenness/supererogating-for-human-intelligibility,preceding-existence's-eventuating-sublimating-validation/desublimating-invalidation〉' as such implies that the very same ambit/frame of human existentialising-decisionality-<as-todisentogising/re ontegising apereticism $>$ is as of procession-<as-to-constructiveveracity/inveracity_of-apriorising/axiomatising/referencing $>$ available to both prospective sublimating re-ontologising and desublimating disontologising, and so-implied as to the various psychologismic epistemic-acutisation difficulty-for, residualising

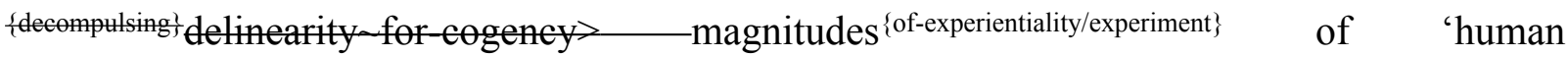
consciousness/collective-consciousness representation/unity/comprehensiveness of the institutional/bureaucratic/social and their purposefulness' (imbued 'superposing/implying/suggesting/inferring of the institutional/bureaucratic/social and their purposefulness' so-construed 'as-if-of-inherently-actualising self-embodying representation/unity/comprehensiveness' for the purpose of institutional/bureaucratic/social procession-<as-to-constructive-veracity/inveracity_of-apriorising/axiomatising/referencing $>$ ); in their interrelatedness-dynamics-of-social-constructing (as from 'catchmented-andcompulsed-<in-'existential-dearth-of-demoronisation',-so-construed-as-from-ontologicalnormalcy/postconvergence-perspective-reflection-of-the-'destructuring-threshold_of-thegiven-level's-conjugated-postlogism as-dementing'> interpersonal, group, intergroup, community, local, national, political, geostrategic, etc. psychologismic epistemic-acutisation- 
difficulty-for, residualising_\{decompulsing $\}$ delinearity for-cogency>-levels of interrelatednessdynamics-of-social-constructing' of 'formativeness-<as-to-intersolipsism-ofpreformulating/preframing/premeaningfulness-imbued-mediativity-and-deferentialism>-ofmeaningfulness-and-teleology and existential-<disontologising/re-ontologising aporeticism $>$ articulation manifestations' as to the 'undergirding-veracity of germinal/inceptive/formative individuals anarchistic self-reflexive instigative-eventuating-〈asto-teleological-instigative/incipientwilling/arbitrariness/waywardness/faithdrivenness/supererogating-for-human-intelligibility,preceding-existence's-eventuating-sublimating-validation/desublimating-invalidation〉') as sublimatingly/desublimatingly relevant with regards to human Being-development/ontologicalframework-expansion-as-to-depth-of-ontologising-development-as-infrastructure-ofmeaningfulness-and-teleology , institutional-development-as-to-social-functiondevelopment and living-development-as-to-personality-development psychologismic epistemic acutisation difficulty-for, residualising \{decompulsing\} ${ }^{\text {felinearity for-cogency> }}$ magnitudes ${ }^{\text {} o f-e x p e r i e n t i a l i t y / e x p e r i m e n t\}}$. Thus (with respect to 'overaching omnipotentiable human constructive-veracity/inveracity of the overall relative-unreflexivity/relative-reflexivity ontological-contiguity ${ }^{67}$ of-the-human-institutionalisation-process ${ }^{6}$ ' in reflection of 'human psychologismic-epistemic-acutisation-<as-to-postconverging-dementating/structuring/paradigming,-eliciting-of-existence's-sublimating-nascence-inprospective-aporeticism-overcoming/unovercoming $>$ as to epistemic-growth,-as\{veridical/sound\}-relative-reflexivity-in-existence/relativising from-limited-mentation-as-itsdeepening/psychologismic epistemic-acutisation residualising, ${ }^{\text {\{decompulsing }}$ delinearity for eogency') it can be appreciated that prospective re-ontologising speaks to the fact that human 'epistemic-growth,-as — \{veridical/sound\}-relative-reflexivity-in-existence/relativising fromlimited-mentation-as-its-deepening/psychologismic epistemic acutisation residualising, 
$\{$ decompulsing $\}$ delinearity for-cogency as to limited-mentation-capacity-deepening-as-subjectinglimitedness/human-subpotency to-'educed-unlimitedness/existence-sublimating nascence' ${ }^{3}$, arises as of existential-<disontologising/re-ontologising aporeticism $>$ counteracting/supplanting/alienating-of-prior-apriorising/axiomatising/referencing (as to a 'despite-the-self exercise of epistemic-projection in notional $\sim$ self-distantiation-<imbued-remotif-and-re-apriorising/re-axiomatising/re-referencing >') and doesn't arise by a 'convincing/persuading/swaying along the course of prior processiveaposteriorising/logicising/deriving-<as-from-prior-apriorising/axiomatising/referencing $>$ ' (as to an ontologically-flawed human 'self-exulting exercise of epistemic-projection in prior processive-motif-'exuding aestheticising-gesturing' of apriorising/axiomatising/referencing imbued_notional $\sim$ reductionism- $<$ of-existential-prospection,-whether-as-oftrepidatious/warped/preclusive/occlusive/protensive-notional $\sim$ reductionism $>$ '); and so in reflection of the 'sublimating determination of educed-and-availing-and-re-availing of relative-ontological-completeness ${ }^{77}$ exuding from unlimitedness/existence-<flllpotency of_sublimating nascence> upon limitedness/human-subpotency psyche as adjustable/subjectable placeholder-setup/mental-devisingrepresentation/mentation/consciousness-awareness-teleology ${ }^{9}$ This psychoanalyticunshackling insight (as to existential-<disontologising/re-ontologising aporeticism> counteracting/supplanting/alienating-of-prior-apriorising/axiomatising/referencing) is effectively and implicitly reflected broadly when it comes to relatively uncontentious/nominalised frameworks of human personal/institutionalised/social practices, learning and education as to human institutional-development-as-to-social-functiondevelopment and living-development-as-to-personality-development psycholegismic epistemic acutisation difficulty-for, residualising \{decompulsing $\}$ delinearity for-cogency> magnitudes $\{$ of-experientiality/experiment\} (of relatively unchallenging notional $\sim$ self-distantiation- 
$<$ imbued—re-motif-and-re-apriorising/re-axiomatising/re-referencing $>$ ), $\quad$ as so-reflecting underlying 'existential-<disontologising/re-ontologising aporeticism $>$ human supererogation', as to 'human individual self-reflexive $\sim$ instigative-eventuating-〈as-toteleological-instigative/incipientwilling/arbitrariness/waywardness/faithdrivenness/supererogating-for-human-intelligibility,preceding-existence's-eventuating-sublimating-validation/desublimating-invalidation $\rangle$ ' induced 'notional

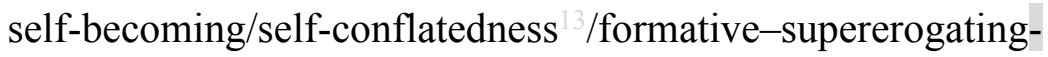
$<$ projective/reprojective- aestheticising-re-motif-and-re-apriorising/re-axiomatising/rereferencing,-in-perspective-ontological-normalcy/postconvergence>'; so-speaking to the fact of a human underlying fundamental/incipient/seeding insight 'of prospective ontological-goodfaith/authenticity ${ }^{6} \sim$ postconverging-de-mentating/structuring/paradigming 70 implications' (inherently arising from the 'defining precedence of unlimitedness/existence- $<$ full potency of_sublimating nascence $>$ eliciting of limitedness/human-subpotency dynamically adjusting placeholder-setup/mental-devising-representation/mentation/consciousness-awarenessteleology' ${ }^{9}$ ) and divulgeable/enlightening-giving as from the 'requisite projection of the coherence/contiguity of the superseding-oneness-of-ontology/ontological-veridicality/relativeunreflexivity/relative-reflexivity ontological-contiguity ${ }^{67}$ ' (so-construed as the 'fundamental human conscious/unconscious sense/drive/disposition' enabling experientiality/experiment- $<$ asto-existentially-formative- ‘fepistemictalising ${ }^{3}$ re-apriorising/re-axiomatising/rereferencing $\sim$ residuality —in-re-originariness/re-origination',- - so'notionally/epistemically/bindingnessly-<as-to-determinism/conceptivity-of-relative-unreflexivity/relative-reflexivity> implicited-and-articulated'_as-from-nonextricatory-'prospective-re-ontologising-Being-thenInstitutional-then-Living-magnitudes-of-\{hermeneutic/reprojection-protraction-of\}reframingand-reformulation\}'> with regards to 'formative and articulative implications of apriorising/axiomatising/referencing and corresponding 
existentialising/contextualising/textualising aposteriorising/logicising/deriving' underlying the possibility for human intelligibility-〈as-to-human-projective/reprojective-aestheticising-remotif-and-re-apriorising/re-axiomatising/re-referencing/re-intelligibilitysettingup/remeasuringinstrumenting-process,-in-<amplituding/formativeepistemicity $>$ totalising $\sim$ conceptualisation $\rangle), \quad$ and $\quad$ so-enabling sublimating 'conceptivity/epistemic-reflexivity/epistemicity-relativism-determinism-<reifying \{as-toknowledge-developing\}-and-empowering> entailment' as to fundamental ontology veracity of recurrently-driven limitedness/human-subpotency prospective re-encountering/re-confrontation with the 'constraining/defining intersolipsistic reflexive-sublimating/unreflexive-desublimating measure/objectification that is unlimitedness/existence-as-ontologicalnormalcy/postconvergence-<in-validation-of-'metaphysics-of-absence_epistemic-

projection'>'. However, when it gets to appreciating the veracity of this psychoanalyticunshackling insight (as to existential-<disontologising/re-ontologising aporeticism $>$ counteracting/supplanting/alienating-of-prior-apriorising/axiomatising/referencing) as of 'human Being-development/ontological-framework-expansion-as-to-depth-of-ontologisingdevelopment-as-infrastructure-of- meaningfulness-and-teleology psychologismic epistemic-acutisation difficulty-for, residualising \{decompulsing $\}$ delinearity for-cogency> magnitude $\{$ of-experientiality/experiment $\}$ of relatively challenging notional $\sim$ self-distantiation- $<$ imbuedre-motif-and-re-apriorising/re-axiomatising/re-referencing>' (with regards to 'nonextricatory/postconverging ontologising-and-re-ontologising angling-of-imaginary demoronisation-<sublimating-nascence,-nonextricatory-sublimating-upstreaming/‘amontée’>’ implications as to prospective reference-of-thought-point-ofdevolving/departure/anchoring/backdrop_of_sublimating-nascence-<as-to-the-grandestaxiomatic-construct-fepistemictalising ${ }^{+}$re-apriorising/re-axiomatising/rereferencing - residuality - in-re-originariness/re-origination of limitedness/human-subpotency 
prospective re-encountering/re-confrontation with unlimitedness/existence $>$ ), there is a conflictedness and an ontologically-flawed human inclination for shallow-supererogation ${ }^{6}$ in prior 'self-presence/self-constitutedness ${ }^{14}<$ in-perspective-epistemicabnormalcy/preconvergence ${ }^{3}>$ desublimating $\sim$ existentialising-decisionality-<as-todisontologising/re-ontologising aporeticism $>$ '; with this conflictedness and ontologicallyflawed human inclination rather associated with the "dynamically manifest relative inveracity of human $\leq$ underlaid/substrated-thrownness-aestheticising' fof relative-unreflexivity inexistence $\}>$ profusion-of preconverging prior-relative-ontological-incompleteness ${ }^{8}$-ofapriorising/axiomatising/referencing' (so-construed as from ${ }^{6}$ nonpresencing-<perspectiveontological-normalcy/postconvergence> epistemic-projection) and 'so-susceptible to the eliciting of pedantising/muddling/formulaic-hollowing-out—insubontologisation/subpotentiation-〈blurring/undermining-of-prospective-totalising-entailing,as-to-entailing-<amplituding/formative-epistemicity $>$ totalising in-relative-ontologicalcompleteness > desublimation' by way of a 'convincing/persuading/swaying along the course of prior processive - aposteriorising/logicising/deriving-<as-from-priorapriorising/axiomatising/referencing>' (as to an ontologically-flawed human 'self-exulting exercise of epistemic-projection in prior processive-motif-'exuding aestheticising gesturing' of-apriorising/axiomatising/referencing_imbued_notional $\sim$ reductionism- $<$ of-existentialprospection,-whether-as-of-trepidatious/warped/preclusive/occlusive/protensivenotional reductionism>'). Critically, this elucidation of human 'existential-<disentelegising/reentologising aporeticism $>$ counteracting/supplanting/alienating-of-prior-

apriorising/axiomatising/referencing constructive-veracity' (with regards to 'human psychologismic-epistemic-acutisation-<as-to-postconverging-de-

mentating/structuring/paradigming,-eliciting-of-existence's-sublimating-nascence-inprospective-aporeticism-overcoming/unovercoming > as to epistemic-growth,-as 
\{veridical/sound\}-relative-reflexivity-in-existence/relativising from-limited-mentation-as-itsdeepening/psychologismic epistemic acutisation residualising, ${ }^{\text {fdecompulsing }}$ \}elinearity for eogency') is effectively what underlies transversality-<for-sublimating-existentialeventuating/denouement,from-'thinking-at-first/pure-predisposition-preemptive-ofprospective-disontologising/subontologising' as-of-prospectively-disambiguated-affirmedand-unaffirmed-'motif-and-apriorising/axiomatising/referencing' ${ }^{101}$ as rather an exercise about the ontologising/scientific/existence- $<$ honesty-constraining $>$ - scope_for_prospective_reontologising with respect to 'limitedness/human-subpotency prospective re-encountering/reconfrontation with unlimitedness/existence-<full-potency-of_sublimating nascence $>$ ' (and as it provides the 'existential-<disontologising/re-ontologising aporeticism $>$ enabling-backdrop' for prospective advocacy/political/applicative—scope to arise) in 'subjecting the human mortal as of limited-mentation-capacity-deepening —as-subjecting-limitedness/human-subpotency-to'educed-unlimitedness/existence-sublimating nascence' ${ }^{53}$ to unlimitedness/existence-<fullpotency-of_sublimating nascence>' (and not an exercise of 'human mortality purposefulness accommodation/agreeing' as of limited-mentation-capacity-as-subjecting 'educedunlimitedness/existence-sublimating nascence' to-limitedness/human-subpotency manifested by any given presencing-absolutising-identitive-constitutedness advocacy/political/applicative — scope penchant for 'convincing/persuading/swaying along the course of prior processive - aposteriorising/logicising/deriving-<as-from-priorapriorising/axiomatising/referencing $>$, given unlimitedness/existence-<full-potency of_sublimating nascence> prospective apriorising/axiomatising/referencing-sublimatingreflexivity-beholdening under which limitedness/human-subpotency submits in profoundsupererogation for prospective sublimating). It is inevitably the case that human 'existential< disontologising/re-ontologising aporeticism $>$ counteracting/supplanting/alienating-ofprior-apriorising/axiomatising/referencing constructive-veracity' is associated with human 
notional asceticism (as to requisite human notional $\sim$ self-distantiation- $<$ imbued - re-motif-andre-apriorising/re-axiomatising/re-referencing $>$ for epistemic-growth,-as—\{veridical/sound\} relative-reflexivity-in-existence/relativising from-limited-mentation-as-itsdeepening/psychologismic epistemic acutisation residualising, fdecompulsing delinearity for eogency, which is increasingly challenging getting to Being-development/ontologicalframework-expansion-as-to-depth-of-ontologising-development-as-infrastructure-ofmeaningfulness-and-teleology psychologismic epistemic-acutisation difficulty-for,

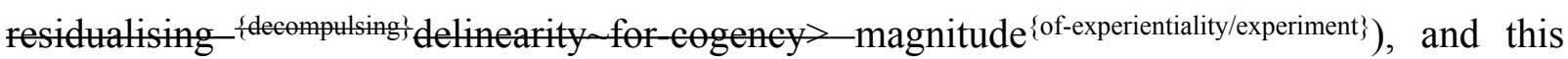
reality of notional asceticism has to be reflected by the profound-supererogation of the genuine social intellectual-function/posture as of 'Derridean underdetermination-imbued force/violence conception' and 'Foucauldian knowledge/power conception construed as knowledge-empowerment/ignorance-disempowerment' in an outright apriorising/axiomatising/referencing dismissal of pedantising/muddling/formulaic-hollowingout_-in-subontologisation/subpotentiation-〈blurring/undermining-of-prospective-totalisingentailing,-as-to-entailing-<amplituding/formative-epistemicity $>$ totalising $\sim$ in-relativeontological-completeness > eliciting and supposed knowledge discourse along-the-linesof/blending-with 'ordinary laypersonhood arrogation/presumptuousness' (imbued amplituding/formative > wooden-language-〈imbued-temporal-mereform/virtualities/dereification/akrasiatic-drag/denatured/preconverging-or-dementing narratives - of-the- reference-of-thought- categorical-imperatives/axioms/registryteleology >); as so-easily manifested in domains susceptible to blurriness$<$ sterilising/anecdotalising/trivialising-of-prospective-re-ontologising_by-preconverging,-indisontologising-formulaic-dragging-out/hollowing-out>. It is important here to appreciate that the notion of 'human epistemic-growth,-as - \{veridical/sound\}-relative-reflexivity-inexistence/relativising from-limited-mentation-as-its-deepening/psychologismic epistemic - 
acutisation residualising, \{decompulsing\} delinearity for-cogency' (with regards to 'human psychologismic-epistemic-acutisation-<as-to-postconverging-dementating/structuring/paradigming,-eliciting-of-existence's-sublimating-nascence-inprospective-aporeticism-overcoming/unovercoming $>$ as to epistemic-growth,-as\{veridical/sound\}-relative-reflexivity-in-existence/relativising from-limited-mentation-as-itsdeepening/psychologismic epistemic-acutisation residualising, ${ }^{\{\text {decompulsing }}{ }^{\text {felinearity for- }}$ eogency' in reflection of its manifest ontologising/scientific/existence- $<$ honestyconstraining $>$ — scope_for_prospective_re-ontologising) doesn't speak to any 'existential$<$ disontologising/re-ontologising aporeticism $>$ substituting-for/taking-the-place-of the human sovereign-function/posture-<as-to-existentially-manifest-'embodied-subject $\sim$ consciousnessand-direct/deferential-conscientiousness',-as-of-its-'epistemic-reflexivity/unreflexivity-inexistence'/teleology> imbued protracted-social—as-to-individual-by-institutional-by-social self supererogation' (apart from the fact that it is equally 'human sovereign-function/posture- $<$ asto-existentially-manifest-'embodied-subject $\sim$ consciousness-and-direct/deferentialconscientiousness',-as-of-its-'epistemic-reflexivity/unreflexivity-in-existence'/teleology> subjects' that are involved in elucidating any such manifest ontologising/scientific/existence$<$ honesty-constraining $>$ _ scope_for_prospective_re-ontologising and as to the socially acknowledged/elicitable deferentialism/deferential-formalisation-transference implications of re-ontologising), but rather speaks to the inherent 'prospective educing-and-availing-and-reavailing of relative-ontological-completeness ${ }^{87}$ ' (as to underlying 'constraining existence-assublimating-withdrawal/unenframing/re-ontologising,-elicited-from-prospective-profoundsupererogation imbuing human ontological-commitment $-<$ implied-self-assuredness-ofontological-good-faith/authenticity postconverging-dementating/structuring/paradigming -as-being-as-of-existential-reality>' and ' ${ }^{103}$ universaltransparency ${ }^{104}$-〈transparency-of-totalising-entailing,-as-to-entailing-<amplituding/formative- 
epistemicity>totalising in-relative-ontological-completeness $\rangle$ as available-to/elicitable-to-〈asto-human-consciousness/collective-consciousness-distendedness/detruncating-<beyondselfpresencing,-as-re-ontologising-decentering_of-consciousness/collective-consciousness,-asto-psychologismic-epistemic-acutisation - residualising, $\left.{ }^{\{\text {decompulsing }}\right\}$ delinearity $\sim$ for-cogency $\left.>\right\rangle$ the social-functioning-and-accordance-as-of-social-stake-contention-or-confliction conception of any given registry-worldview/dimension <preconverging 'motif-andapriorising/axiomatising/referencing'-entailing >-existentialising-enframing/imprintedness〈as-to- historicity-tracing - in-presencing-hyperrealisation/hyperreal-transposition〉'). This clarification of the ontologising/scientific/existence- $<$ honesty-constraining $>$ scope_for_prospective_re-ontologising rather points out that beyond the 'manifest accidentedness/occasioning of human ingenuity/lack-of-ingenuity with respect to prospective sublimation accruing/not-accruing to any social-construct', there is as yet a more fundamental/incipient/seeding profound-supererogation ${ }^{6}$ responsibility/relative-reflexivity that befalls all humans as to individual's relevant priorities, interests and effective prospects-andcapacity for eliciting prospectively defining 'orlaying/superstang aestheticising' \{of-relative-reflexivity in-existence\} $>$-sparsity-of-postconverging prospectiverelative-ontological-completeness ${ }^{8}$-of-apriorising/axiomatising/referencing (as so-reflecting the underlying 'crossgenerational notional firstnaturedness-formativeness-<as-toeventualising-inkling-drive-or-seeding-misprising $>$ - mental-processing-parity for ontological-performance $^{72}$-<including-virtue-as-ontology $>$ /morality/ethics/justice/etc.' of all sovereign humans as to the potentiation of sublimating-over-desublimating with regards to the 'notional firstnaturedness-formativeness-<as-to-eventualising -inkling-drive-or-seeding misprising $>$ temporal-to-intemporal-dispositions- $<$ so-construed-as-from-perspectiveontological-normalcy/postconvergence $>$ of human protracted-social—as-to-individual-byinstitutional-by-social ontological-performance ${ }^{72}$ including-virtue-as-ontology $>^{\prime}$ and so 
relative to the given station/locus of limitedness/human-subpotency <amplituding/formativeepistemicity $>$-totalising $\sim$ thrownness-in-existence ${ }^{35}$ ); and this is underscored with respect to all humans prospectively manifestable dimensionality-of-sublimating

\section{<<amplituding/formative >supererog de-mentativeness/epistemic-growth-or-}

conflatedness /transvaluative-rationalising/transepistemicity/anamnestic-residuality/spirit-

drivenness-equalisation> effectively underlying the 'potentiative/omnipotential correspondence of limitedness/human-subpotency to unlimitedness/existence-<flllpotency-of_sublimating nascence>' (as to the epistemic-projection of 'nonpresencing-<perspective-ontologicalnormalcy/postconvergence $>$ relativism/relative-scope for epistemic-growth,-asfveridieal/sound\}-relative-reflexivity-in-existence/relativising from limited mentation as its deepening/psychologismic epistemic acutisation residualising, \{decompulsing $\}$ delinearity foreogency' imbued underlying-elucidative 'requisite sublimating/desublimating formulative-

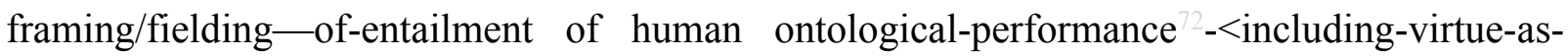
ontology $>$ /morality/ethics/justice/etc. contemplation' as of notionally implied foregrounding_entailment-<in-succession-of-profound-supererogation $>>-\langle$ postconvergingnarrowing-down sublimation-as-to-'existence - as-sublimating-withdrawal/unenframing/reontologising,-elicited-from-prospective-profound-supererogation ' '-in-reflecting‘immanent relative-unreflexivity/relative-reflexivity - ontological-contiguity ';--as-operativenotional deprocrypticism)); so-potentiative/omnipotential as to the fact that the ontologising/scientific/existence- $<$ honesty-constraining $>$ - scope_for_prospective_reontologising inherently implies 'prior relative-ontological-incompleteness ${ }^{88}$ and prospective relative-ontological-completeness 87 limitedness/human-subpotency' with respect to preconverging/postconverging-de-mentating/structuring/paradigming possibility for 'epistemic-growth,-as_ \{veridical/sound\}-relative-reflexivity-in-existence/relativising fromlimited-mentation-as-its-deepening/psychologismic epistemic-acutisation residualising, 
$\{$ decompulsing $\}$ delinearity for-cogency conceptualisation' towards unlimitedness/existence- $<\mathrm{full}-$ potency-of_sublimating nascence> (and this 'epistemic-growth,-as_\{veridical/sound\} relative-reflexivity-in-existence/relativising from-limited-mentation-as-itsdeepening/psychologismic epistemic acutisation residualising, fdecompulsing delinearity for eogency conceptualisation' cannot be formulated-as-if-of-absolute-ontological-veracitywithout-residuality-of-apriorising/axiomatising/referencing which will wrongly imply an ontologically-flawed conceptualisation as of 'unlimitedness/existence-<flllpotencyef_sublimating nascence> absolute-ontological-completeness-ofapriorising/axiomatising/referencing-<as-omnipotentiality $>$ $<$ amplituding/formativeepistemicity>-totalising thrownness-in-existence $^{35}$ ), notwithstanding the fact that the 'ontologising/scientific/existence- $<$ honesty-constraining $>$ — scope_for_prospective_reontologising contiguously/coherently points' to the-very-same purview/devolvedpurview/devolving-purview-of-unlimitedness/existence-<full-potency-of_sublimating nascence $>$. The overall implication here is that 'human secondnaturedness (as to Beingdevelopment/ontological-framework-expansion-as-to-depth-of-ontologising-development-asinfrastructure-of- meaningfulness-and-teleology , institutional-development-as-to-socialfunction-development and living-development-as-to-personality-development psychologismic epistemic-acutisation difficulty-for, residualising \{decompulsing $\}$ delinearity for-cogency> magnitudes $\{$ of-experientiality/experiment\})' doesn't inherently carry 'prospective intemporal firstnaturedness-as-to-inkling implications of dimensionality-of-sublimating <<amplituding/formative >supererogatery de-mentativeness/epistemic-growth-orconflatedness /transvaluative-rationalising/transepistemicity/anamnestic-residuality/spiritdrivenness-equalisation)' (as implying the inducing of prospectively requisite 'human psychologismic-epistemic-acutisation-<as-to-postconverging-dementating/structuring/paradigming,-eliciting-of-existence's-sublimating-nascence-in- 


\section{\{veridical/sound\}-relative-reflexivity-in-existence/relativising from-limited-mentation-as-its-}

deepening/psychologismic epistemic-acutisation residualising, fdecompulsingl delinearity for

eogency' in reflection of the requisite 'ontologising/scientific/existence- $<$ honestyconstraining $>$ — scope_for_prospective_re-ontologising); and so as 'unlimitedness/existence<full-potency-of_sublimating nascence $>$ is not of prospective apriorising/axiomatising/referencing-sublimating-reflexivity-beholdening to $\leq$ mereformulaicity/ritualisation-of $>$-prior secondnatured institutionalisation of prospective shallowsupererogation", (with such unlimitedness/existence-<full-potency-of_sublimating nascence> prospective apriorising/axiomatising/referencing-sublimating-reflexivity_beholdening potentiatively/omnipotentially rather accruing as of the epistemic-projection of ' nonpresencing-<perspective-ontological-normalcy/postconvergence $>$ relativism/relativescope for epistemic-growth,-as - \{veridical/sound\}-relative-reflexivity-inexistence/relativising from-limited-mentation-as-its-deepening/psychologismic epistemic-

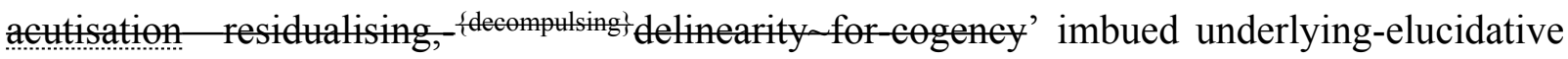
'requisite sublimating/desublimating formulative-framing/fielding-of-entailment of human ontological-performance ${ }^{72}$-<including-virtue-as-ontology $>/$ morality/ethics/justice/etc.

contemplation' as of notionally implied foregrounding_entailment- $<$ in-succession-ofprofound-supererogation $>$ - $>$ postconverging-narrowing-down $\sim$ sublimation-as-to-'existenceas-sublimating-withdrawal/unenframing/re-ontologising,-elicited-from-prospective-profoundsupererogation '-in-reflecting-'immanent relative-unreflexivity/relative-reflexivity ontological-contiguity ';--as-operative-notional deprocrypticism), as so-defining the underlying 'crossgenerational notional firstnaturedness-formativeness-<as-toeventualising inkling-drive-or-seeding misprising $>$ mental-processing-parity for ontological-performance ${ }^{72}$-<including-virtue-as-ontology $>$ /morality/ethics/justice/etc.' of all 
sovereign humans as to the potentiation of sublimating-over-desublimating). This insight as it underlines/emphasises the 'overall human institutional/bureaucratic/social procession- $<$ as-toconstructive-veracity/inveracity_of-apriorising/axiomatising/referencing>' explains why ontological-veracity/ontological-pertinence is profoundly much more than just the "mere fact of simply being secondnatured/institutionalised at the backend of the relativeunreflexivity/relative-reflexivity ontological-contiguity ${ }^{67} \sim$ of-the-human-institutionalisationprocess $^{68}$ as of any relative-ontological-completeness ${ }^{87}$ registry-worldview/dimension'; with 'human psychologismic-epistemic-acutisation-<as-to-postconverging-dementating/structuring/paradigming,-eliciting-of-existence's-sublimating-nascence-inprospective-aporeticism-overcoming/unovercoming $>$ as to epistemic-growth,-as\{veridical/sound\}-relative-reflexivity-in-existence/relativising from-limited-mentation-as-itsdeepening/psychologismic epistemic acutisation residualising, ${ }^{\{\text {decompulsing }}$ delinearity foreogency' more critically speaking of the successive 'prospective postconverging apereticismovercoming/unovercoming as the-Good/knowledge-reification $\sim$ gesturing-and-accounting-ofepistemic-phenomenalism- $<$ inprospective_psychologismic apriorising/axiomatising/referencing-\{of-‘prospectively_ implicited_attentant-ontological-contiguity ' educedexistentialising/contextualising/textualising_ intelligibility/epistemicity/reflexivity-contiguity$<$ imbued-notional cogency $>$ ' \}-conflatedness -in-\{preconverging-ment by\} postconverging entailment $>$ /understanding/<amplituding/formativeepistemicity $>$ causality $\sim$ as-to-projective-totalitative-implications-of-prospectivenonpresencing,-for-explicating relative-unreflexivity/relative-reflexivity - ontologicalcontiguity ' (as to 'successive challenges of profound-supererogation for prospective reontologising' as so 'inventing'/'creating'-and-'nurturing' prospective sublimating rerationalisations-of-contentivity/argumentativity/dialecticism/discursivity of successive Being- 
development/ontological-framework-expansion-as-to-depth-of-ontologising-development-asinfrastructure-of- meaningfulness-and-teleology psychologismic epistemic-acutisationdifficulty < for, residualising \{decompulsing $\}$ delinearity for-cogeney> magnitude $\{$ ofexperientiality/experiment\} and the consequent implications as to institutional-development-as-to-socialfunction-development and living-development-as-to-personality-development psychologismic epistemic-acutisation difficulty-for, residualising ${ }^{\{\text {decompulsing }}{ }^{\text {f }}$ delinearity for-cogency> magnitudes $\{$ of-experientiality/experiment $\}$. Thus the very profoundness of human ontologicalpertinence/ontological-veracity as to prospective re-ontologising implications is of an epistemicprojection that goes well beyond any ${ }^{79}$ presencing-absolutising-identitive-constitutedness advocacy/political/applicative—scope penchant for 'convincing/persuading/swaying along the course of prior processive - aposteriorising/logicising/deriving- $<$ as-from-priorapriorising/axiomatising/referencing >' (as to an ontologically-flawed human 'self-exulting exercise of epistemic-projection in prior processive-motif-'exuding aestheticising-gesturing' ef-apriorising/axiomatising/referencing_imbued_notional $\sim$ reductionism- $<$ of-existentialprospection,-whether-as-of-trepidatious/warped/preclusive/occlusive/protensivenotional reductionism>’) given unlimitedness/existence-<full-potency-of_sublimating nascence $>$ prospective apriorising/axiomatising/referencing-sublimating-reflexivitybeholdening under which limitedness/human-subpotency submits in profound-supererogation for prospective sublimating imply that the requisite existential-<disontologising/reentologising aporeticism $>$ counteracting/supplanting/alienating-of-priorapriorising/axiomatising/referencing (as to a 'despite-the-self exercise of epistemic-projection in notional $\sim$ self-distantiation- $<$ imbued—re-motif-and-re-apriorising/re-axiomatising/rereferencing >') for human limited-mentation-capacity-deepening as atbjecting limitedness/human-subpotency to-'educed-unlimitedness/existence-sublimating nascence' 53 ; and so as to the full epistemic-growth,-as - \{veridical/sound\}-relative-reflexivity-in- 
existence/relativising from-limited-mentation-as-its-deepening/psychologismic epistemicacutisation residualising, ${ }^{\{\text {decompulsing }}$ \}elinearity for-cogency possibility arising as of 'nonextricatory/postconverging ontologising-and-re-ontologising angling-of-imaginary demoronisation- $<$ sublimating-nascence,-nonextricatory-sublimating-

upstreaming/'amontée'>'. In this regards, it can be appreciated that going by their ${ }^{79}$ presencingabsolutising-identitive-constitutedness ${ }^{14}$ advocacy/political/applicative-scope penchant for 'convincing/persuading/swaying along the course of prior processiveaposteriorising/logicising/deriving-<as-from-prior-apriorising/axiomatising/referencing >', inmany-ways the non-universalising ancient-sophists, non-positivising medieval-scholasticism and our modern-day disparateness-of-conceptualisation-<unforegrounding-ment,-failingprospectively-to-reflect-'immanent $\sim$ relative- unreflexivity/relative-reflexivity - ontologicalcontiguity ' $>$ are effectively of most advanced conception of the 'given human secondnatured institutionalisation' of their times respectively as to their base-institutionalisation, universalisation and positivism/rational-empiricism 'convincing/persuading/swaying along the course of prior processive - aposteriorising/logicising/deriving-<as-from-prior apriorising/axiomatising/referencing >' (such that along those 'secondnatured institutionalisation terms of rationalisation-of-contentivity/argumentativity/dialecticism/discursivity' effectively there are respectively no base-institutionalisation, universalisation and positivism/rationalempiricism reasons for contesting respectively non-universalising ancient-sophists, nonpositivising medieval-scholasticism and our modern-day disparateness-of-conceptualisation$<$ unforegrounding-ment,-failing-prospectively-to-reflect-'immanent $\sim$ relative-

unreflexivity/relative-reflexivity - ontological-contiguity ' $>$, with the contestation only arising as of the 'ontological-good-faith/authenticity ${ }^{\circ} \sim$ postconverging-dementating/structuring/paradigming 70 epistemic-projection of prospective ${ }^{83}$ reference-ofthought — point-of-devolving/departure/anchoring/backdrop_of_sublimating-nascence-<as-to- 

prospective re-encountering/re-confrontation with unlimitedness/existence $>$ induced relativeontological-completeness ${ }^{87}$-of-apriorising/axiomatising/referencing re-ontologising prospective re-rationalisation-of-contentivity/argumentativity/dialecticism/discursivity'); and it is this reality that points out that the very notion of prospective ontologising-and-re-ontologising is rather captured in the "potentiation/omnipotentiality that is human dimensionality-ofsublimating $25<<$ amplituding/formative $>$ supererogatory $\sim$ de-mentativeness/epistemic-growthor-conflatedness /transvaluative-rationalising/transepistemicity/anamnestic-residuality/spiritdrivenness-equalisation)' (as it highlights the 'defining sublimating/desublimating relationshipbetween-limitedness/human-subpotency-and-unlimitedness/existence- $<$ full-potency of_sublimating nascence>' wherein 'unlimitedness/existence-<full-potency-of_sublimating nascence $>$ is not of prospective apriorising/axiomatising/referencing-sublimating-reflexivitybeholdening to $\leq$ mere-formulaicity/ritualisation-of $>$-prior secondnatured institutionalisation of prospective shallow-supererogation ${ }^{\prime}$ ). This is exactly what underlies the veridical manifest conception of prospective re-ontologising rather as of 'overarching existential$\leq$ disontologising/re-ontologising aporeticism $>$ priority/precedence/primacy of requisite prospective ontological-good-faith/authenticity $\sim$ postconverging-dementating/structuring/paradigming inducing of psychoanalytic-unshackling for the relativeontological-completeness ${ }^{87}$-of-apriorising/axiomatising/referencing re-ontologising prospective re-rationalisation-of-contentivity/argumentativity/dialecticism/discursivity' going by the 'defining sublimating/desublimating relationship-between-limitedness/humansubpotency-and-unlimitedness/existence-<full-potency-of_sublimating nascence $>\quad$ (as to 'limitedness/human-subpotency susceptibility to processing as of the prior mereformulaicity/ritualisation-<as-to-mere-formulaic- 
methodologising/mutualising/organising/institutionalising,-prospectively-losing-track-of-

‘\{epistemic-totalising ’’re-apriorising/re-axiomatising/re-referencing-residuality-in-re-

originariness/re-origination'> of prior rationalisation-of-

contentivity/argumentativity/dialecticism/discursivity' that wrongly implicits 'epistemicgrowth,-as-\{veridical/sound\}-relative-reflexivity-in-existence/relativising from-limitedmentation-as-its-deepening/psychologismic epistemic-acutisation residualising, \{decompulsing\} delinearity for-cogeney conceptualisation' can be formulated-as-if-of-absoluteontological-veracity-without-residuality-of-apriorising/axiomatising/referencing); $\quad$ with prospective re-ontologising so-construed with respect to the undergirding profoundsupererogation associated with Being-development/ontological-framework-expansion-as-todepth-of-ontologising-development-as-infrastructure-of- meaningfulness-and-teleology , institutional-development-as-to-social-function-development and living-development-as-topersonality-development psychologismic epistemic-acutisation difficulty-for, residualising \{ be appreciated that (beyond the 'mere fact of simply being secondnatured/institutionalised at the backend of the relative-unreflexivity/relative-reflexivity-ontological-contiguity ${ }^{60 f-t h e-}$ human-institutionalisation-process ${ }^{68}$ as of any relative-ontological-completeness ${ }^{87}$ registryworldview/dimension') the more fundamental/incipient/seeding and recurrent issue for human prospective re-ontologising has to do with the 'potentiation/omnipotentiality that is human dimensionality-of-sublimating 5 -<<amplituding/formative $>$ supererogatory $\sim$ dementativeness/epistemic-growth-or-conflatedness /transvaluativerationalising/transepistemicity/anamnestic-residuality/spirit-drivenness-equalisation $\rangle$ ' as it reflects existential-<disontologising/re-ontologising aporeticism $>$ counteracting/supplanting/alienating-of-prior-apriorising/axiomatising/referencing as to 'prospective re-eliciting of the undergirding-veracity of germinal/inceptive/formative 
individuals

anarchistic

self-reflexive instigative-eventuating-〈as-to-teleological-

instigative/incipient-willing/arbitrariness/waywardness/faithdrivenness/supererogating-for-

human-intelligibility,-preceding-existence's-eventuating-sublimating-validation/desublimating-

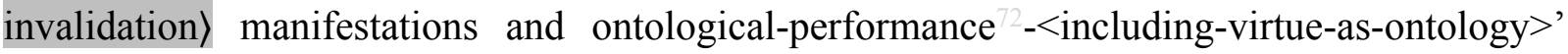
(inducing sublimating-and-residually-accounted-for-apriorising/axiomatising/referencing processing of prospective 'human consciousness/collective-consciousness representation/unity/comprehensiveness of the institutional/bureaucratic/social and their purposefulness' constructive-veracity as of 'qveridical/sound?-relative-reflexivity-inexistence/relativising from-limited-mentation-as-its-deepening/psychologismic epistemic-

acutisation residualising, ${ }^{\text {\{decompulsing }}$ delinearity for cogeney anarchisticgrowth/anarchisation-for-re-ontologisation-〈as-to-conscious/unconscious epistemically-sound induced 'demoronisation-<sublimating-nascence,-nonextricatery-sublimatingupstreaming/‘amontée’> postconverging/dialectical-thinking conception of residual_reoriginary_anarchistic incipiency of human social-functioning-and-accordance-as-of-socialstake-contention-or-confliction meaningfulness-and-teleology ' $\rangle$ '). But then such a veridical prospective re-ontologising conception as to human profound-supererogation underlying the ontologising/scientific/existence- $<$ honesty-constraining $>$ — scope_for_prospective_reontologising is hardly countenanced as to the shallow-supererogation of ${ }^{79}$ presencingabsolutising-identitive-constitutedness ${ }^{14}$ advocacy/political/applicative-scope penchant for 'convincing/persuading/swaying along the course of prior processiveaposteriorising/logicising/deriving-<as-from-prior-apriorising/axiomatising/referencing >' (in a myopia that fails to appreciate that it is the profound-supererogation of the ontologising/scientific/existence- $<$ honesty-constraining $>$ - scope_for_prospective_reontologising as to 'limitedness/human-subpotency prospective re-encountering/re-confrontation with unlimitedness/existence-<full-potency-of_sublimating nascence $>$ ' that brings about 
prospective underlying material, technical, organisational and/or mastery/know-how sublimation possibilities providing the 'existential-<disontologising/re-entelogising apereticism $>$ enabling-backdrop' for the prospective advocacy/political/applicative-scope to arise); with this myopia so-manifested with human underpinning-suprasocial-constructs (historially involving 'dominance/vested-interest structure in relative-ontologicalincompleteness ${ }^{8}$-presublimation-construct-of- ${ }^{5}$ meaningfulness-and-teleology desublimating $\sim$ existentialising-decisionality-<as-to-disontologising/re-ontologising apereticism ${ }^{\prime}$ as from blatant brutish conquest/subjugation conception of apportioning, dominion protection conception of apportioning, to the very natural-order-of-things conception of apportioning and to our subtle modern-day institutionally-distorted/disjointed conception of apportioning). Thus in-many-ways the prospective profundity of the ontologising/scientific/existence- $<$ honesty-constraining $>$ — scope_for_prospective_reontologising is very much absent to an underpinning-suprasocial-construct but for the prospective positive-opportunism - of-social-functioning-and-accordance ${ }^{75}$ it presents as to the underpinning-suprasocial-construct prior 'self-presence/self-constitutedness ${ }^{14}$-<in-perspectiveepistemic-abnormalcy/preconvergence ${ }^{3}>$ desublimating $\sim$ existentialising-decisionality-<as-todisentogising/re ontogising apereticism ${ }^{\prime}$ naïve and ontologically-flawed supposed 'backend - secondnatured-institutionalisation of prospective sublimating-nascence'; such that the 'potentiation/omnipotentiality that is human dimensionality-of-sublimating <<amplituding/formative>supererogatory $\sim$ de-mentativeness/epistemic-growth-orconflatedness /transvaluative-rationalising/transepistemicity/anamnestic-residuality/spiritdrivenness-equalisation)' underlying the ontologising/scientific/existence- $<$ honestyconstraining $>$ — scope_for_prospective_re-ontologising (beyond secondnaturedness) is mostly of messianicity 'ever always in want for its futural coming' as to profound-supererogation (with regards to Being-development/ontological-framework-expansion-as-to-depth-of- 
ontologising-development-as-infrastructure-of- meaningfulness-and-teleology , institutionaldevelopment-as-to-social-function-development and living-development-as-to-personalitydevelopment psychologismic epistemic-acutisation difficulty-for, residualising ${ }_{\text {\{decompulsing }}$ delinearity for-cogeney>-magnitudes $\{0$-experientiality/experiment $\}$ ). It can thus be appreciated that profound-supererogation basically speaks to the predisposition for 'limitedness/human-subpotency prospective re-encountering/re-confrontation with unlimitedness/existence-<full-potency-of_sublimating nascence ${ }^{\prime}$ (as to incredibility/incredulity-induced-processive-dissent-in-demoronisation- $<$ sublimatingnascence,-nonextricatory-sublimating-upstreaming/‘amontée’>) in contrast to shallowsupererogation predisposition for 'limitedness/human-subpotency prior mereformulaicity/ritualisation-<as-to-mere-formulaicmethodologising/mutualising/organising/institutionalising,-prospectively-losing-track-of‘\{epistemic-totalising ’re-apriorising/re-axiomatising/re-referencing $\sim$ residuality-in-reoriginariness/re-origination'> ' (as to credibility/credulity-induced-processive-assent-tomoronisation-<sublimating-nascence,-extricatory-desublimating-downstreaming/'avalage'>). This paradox (as to the 'defining sublimating/desublimating relationship-betweenlimitedness/human-subpotency-and-unlimitedness/existence-full pof of sublimating nascence $>$ ') implies that the ontologising/scientific/existence- $<$ honesty-constraining $>$ scope_for_prospective_re-ontologising is veridically a 'residualising exercise' of (the genuine social intellectual-function/posture) 'apriorising/axiomatising/referencing disambiguating/deleveling/de-ressentiment/opened-construct-of- ${ }^{56}$ meaningfulness-and-teleology demoronisation-<sublimating-nascence,-nonextricatory-sublimating-upstreaming/‘amontée’’’ (of pedantising/muddling/formulaic-hollowing-out-in-subontologisation/subpotentiation〈blurring/undermining-of-prospective-totalising-entailing,-as-to-entailing<amplituding/formative-epistemicity >totalising in-relative-ontological-completeness $\rangle)$ 
'apriorising/axiomatising/referencing_equating/leveling/ressentiment/closed-construct-ofmeaningfulness-and-teleology $\quad$ re-moronisation-<sublimating-nascence,-extricatorydesublimating-downstreaming/'avalage'>’ of (prior genuine social intellectualfunction/posture) 'apriorising/axiomatising/referencing disambiguating/de-leveling/deressentiment/opened-construct-of- ${ }^{5}$ meaningfulness-and-teleology 99 demoronisation<sublimating-nascence,-nonextricatory-sublimating-upstreaming/'amontée'>'; and so, as to when so-construed veridically (beyond human secondnatured positive-opportunism-of-socialfunctioning-and-accordance ${ }^{75}$ ) in reflecting the 'play of human dimensionality-of-sublimating <<amplituding/formative>supererogatory $\sim$ de-mentativeness/epistemic-growth-orconflatedness /transvaluative-rationalising/transepistemicity/anamnestic-residuality/spiritdrivenness-equalisation> and dimensionality-of-desublimating-lack-of ${ }^{-}$ <<amplituding/formative>supererogatory $\sim$ de-mentativeness/epistemic-growth-orconflatedness /transvaluative-rationalising/transepistemicity/anamnestic-residuality/spiritdrivenness-equalisation)'. Basically, thus the 'full experientiality/experiment-<as-toexistentially-formative-“\{epistemic-totalising ’’re-apriorising/re-axiomatising/re-

referencing $\sim$ residuality—in-re-originariness/re-origination',- - so'notionally/epistemically/bindingnessly-sas-to-determinism/conceptivity-of-relative-unreflexivity/relative-reflexivityz implicited-and-articulated'_as-from-nonextricatory-'prospective-re-ontologising-Being-thenInstitutional-then-Living-magnitudes-of-\{hermeneutic/reprojection-protraction-of\}reframingand-reformulation $\}^{\prime}>$ of the overall relative unreflexivitrelative reflexivity-ontologicalcontiguity ${ }^{67}$ of-the-human-institutionalisation-process ${ }^{68}$ imbued epistemic-growth,-as\{veridical/sound\}-relative-reflexivity-in-existence/relativising from-limited-mentation-as-itsdeepening/psychologismic epistemic-acutisation-residualising, fdecompusingl delinearity foreogency' rather speaks of the psychoanalytic-unshackling implications of limitedness/humansubpotency 'firstnaturedness-as-to-inkling profound-supererogation for overarching 
existential-<disontologising/re-ontologising aporeticism $>$ priority/precedence/primacy of \{epistemic-totalising 3 \}re-apriorising/re-axiomatising/re-referencing $\sim$ residuality—in-re-

originariness/re-origination projection' in 'recurrent/perpetuating/continuity-recomposuring existential-<disontologising/re-ontologising aporeticism $>$

counteracting/supplanting/alienating-of-prior-apriorising/axiomatising/referencing'

over 'secondnatured prior mere-formulaicity/ritualisation-<as-to-mere-formulaicmethodologising/mutualising/organising/institutionalising,-prospectively-losing-track-of‘fepistemic talising łre-apriorising/re-axiomatising/re-referencing - residuality-in-reoriginariness/re-origination'>' that achieves prospective postconverging-aporeticismovercoming/unovercoming (as to the veracity of epistemic-projection of "nonpresencing<perspective-ontological-normalcy/postconvergence $>$ relativism/relative-scope for epistemicgrowth,-as-\{veridical/sound\}-relative-reflexivity-in-existence/relativising-from-limitedmentation-as-its-deepening/psychologismic epistemic-acutisation - residualising, \{demping delinearity for-cogency'), and so in the face of an ever renewing limitedness/humansubpotency 'secondnaturedness of epistemic prior mere-formulaicity/ritualisation' as of 'continuity of prior processive-aposteriorising/logicising/deriving-<as-from-priorapriorising/axiomatising/referencing $>$ ' that fails prospective postconverging-aporeticismovercoming/unovercoming (as to the inveracity of epistemic-projection of " 7 presencingabsolutising-identitive-constitutedness ${ }^{14}$ absolution/absolute-scope fflawed/unsound\}-relativeunreflexivity-in-existence/absolutising from-limited-mentation/psychologismic epistemic acutisation nonresidualising-imbued-fompulsing linearity-in-eclecticism-of prior-mereformulaicity/ritualisation'); with this dual dimensionality manifestations respectively underlying profound-supererogation dimensionality-of-sublimating

<<amplituding/formative>supererogatory $\sim$ de-mentativeness/epistemic-growth-orconflatedness /transvaluative-rationalising/transepistemicity/anamnestic-residuality/spirit- 
drivenness-equalisation> and shallow-supererogation as dimensionality-of-desublimatinglack-of $-<<$ amplituding/formative > supererogatory $\sim$ de-mentativeness/epistemic-growth-orconflatedness /transvaluative-rationalising/transepistemicity/anamnestic-residuality/spiritdrivenness-equalisation), and critically-so as notionally/epistemically/bindingnessly-<as-todeterminism/conceptivity-of-relative-unreflexivity/relative-reflexivitys underlying 'human psychologismic-epistemicacutisation-<as-to-postconverging-de-mentating/structuring/paradigming,-eliciting-ofexistence's-sublimating-nascence-in-prospective-aporeticism-overcoming/unovercoming $>$ as to epistemic-growth,-as - \{veridical/sound $\}$-relative-reflexivity-in-existence/relativising fromlimited mentation as its deepening/psychologismic epistemic acutisation residualising, \{decompulsing\} delinearity for-cogency'. In this regards, the epistemic-growth,-as\{veridical/sound\}-relative-reflexivity-in-existence/relativising from-limited-mentation-as-itsdeepening/psychologismic epistemic-acutisation residualising, fdecompulsingl delinearity foreogency social contemplation (as to limitedness/human-subpotency 'firstnaturedness-as-toinkling profound-supererogation for overarching existential-<disontologising/reentolegising apereticism> priority/precedence/primacy of \{epistemic-totalising $3{ }^{3} \frac{1}{\mathrm{r}} \mathrm{re}-\mathrm{apriorising} / \mathrm{re}-$ axiomatising/re-referencing $\sim$ residuality-in-re-originariness/re-origination projection' in 'recurrent/perpetuating/continuity-recomposuring existential-<disontologising/reentologising apereticism $>$ counteracting/supplanting/alienating-of-prior-

apriorising/axiomatising/referencing' over 'secondnatured prior mere-formulaicity/ritualisation$<$ as-to-mere-formulaic — methodologising/mutualising/organising/institutionalising,prospectively-losing-track-of- ‘fepistemic-totalising re-apriorising/re-axiomatising/rereferencing $\sim$ residuality - in-re-originariness/re-origination'>' that achieves prospective postconverging aporeticism-overcoming/unovercoming) is relatively benign with 'human institutional-development-as-to-social-function-development and living-development-as-topersonality-development psychologismic epistemic-acutisation difficulty-<for, 
residualising_\{decompulsing\} delinearity for-cogency> magnitudes \{of-experientiality/experiment\}

prospective transcendence-and-sublimity/sublimation/supererogatory $\sim$ de-mentativity' wherein the elicited soverlaying/superstrating 'thrownness-aestheticising'-\{of-relative-reflexivity in-

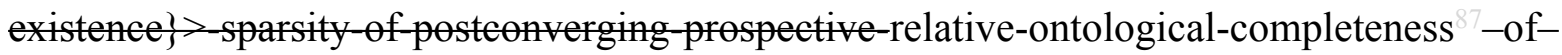
apriorising/axiomatising/referencing involves a social-setup (circumscribed/bounded overall human subconsciousness most-prospectively-conscious 're-ontologising-bydisontologising_existential-calculus-〈between 'prospective existentialisingpostconverging_framing/imprinting re-ontologising' and 'prior existentialisingpreconverging_enframing/imprintedness social-functioning-and-accordance-as-of-socialstake-contention-or-confliction' $\rangle$ ' of consciousness surrealising-<as-to-supererogation $>$ ) upon which such an soverlaying/superstrating 'thrownness-aestheticising'-\{of-relative-reflexivityin-existence\}>-sparsity-of postconverging prospective-relative-ontological-completeness ${ }^{87}$ of-apriorising/axiomatising/referencing is socially contemplatable. However, it is an altogether different ball game when it comes to 'Being-development/ontological-framework-expansionas-to-depth-of-ontologising-development-as-infrastructure-of- meaningfulness-andteleology psychologismic epistemic-acutisation difficulty-<for, residualising \{decompulsing\} delinearity for-cogeney>-magnitude\{of-experientiality/experiment\} of prospective transcendence-and-sublimity/sublimation/supererogatory-de-mentativity' as to the fact that a social-setup (circumscribed/bounded overall human subconsciousness most-prospectivelyconscious 're-ontologising-by-disontologising_existential-calculus-〈between 'prospective existentialising_-postconverging_framing/imprinting re-ontologising' and 'prior existentialising_preconverging_enframing/imprintedness social-functioning-andaccordance-as-of-social-stake-contention-or-confliction' $\rangle$ ' of consciousness surrealising-<asto-supererogation $>$ ) in-many-ways is not grounded (as all registry-worldviews/dimensions wrongly project of themselves) on 'prospective profundity of the 
ontologising/scientific/existence- $<$ honesty-constraining $>$ — scope_for_prospective_reontologising as to a veridical absolute-ontological-completeness-ofapriorising/axiomatising/referencing-<as-omnipotentiality $>$ ' which is very much absent to an underpinning-suprasocial-construct but is rather grounded on the "positive-opportunism-ofsocial-functioning-and-accordance ${ }^{75}$ of its $\quad{ }^{7}$ presencing-absolutising-identitiveconstitutedness ${ }^{14}$ advocacy/political/applicative — scope induced as from the prior profundity of the ontologising/scientific/existence- $<$ honesty-constraining $>$ — scope_for_prospective_reontologising' (as to the effective reality that all registry-worldviews/dimensions effectively assume their given prior 'apriorising/axiomatising/referencingequating/leveling/ressentiment/closed-construct-of- - meaningfulness-and-teleology moronisation-<sublimating-nascence,-extricatory-desublimating-downstreaming/'avalage'>’ and not their prospective 'apriorising/axiomatising/referencing disambiguating/de-leveling/deressentiment/opened-construct-of- ${ }^{5}$ meaningfulness-and-teleology 99 demoronisation<sublimating-nascence,-nonextricatory-sublimating-upstreaming/'amontée'>' as the latter is what will validate 'prospective profundity of the ontologising/scientific/existence- $<$ honestyconstraining $>$ — scope_for_prospective_re-ontologising' and as the latter is only instigatable as from prospective profound-supererogation as from 'limitedness/human-subpotency prospective re-encountering/re-confrontation with unlimitedness/existence-full-potency of_sublimating nascence $>$ ' so-reflected with regards to prospective ${ }^{83}$ reference-of-thoughtpoint-of-devolving/departure/anchoring/backdrop_of_sublimating-nascence-<as-to-thegrandest-axiomatic-constructreferencing residuality - in-re-originariness/re-origination of limitedness/human-subpotency prospective re-encountering/re-confrontation with unlimitedness/existence $>$ ); such that prospective soverlaying/superstrating 'thrownness-aestheticising'- \{of-relative-reflexivity inexistence $\}>$-sparsity-of postconverging prospective-relative-ontological-completeness ${ }^{87}$-of- 
apriorising/axiomatising/referencing can only be effected as of the crossgenerational 'encyclopedic fepistemic-totalising 3 're-apriorising/re-axiomatising/re-referencing $\sim$ residuality—inre-originariness/re-origination' superseding/overcoming of prior sunderlaid/substrated'thrownness-aestheticising' \{of-relative-unreflexivity in-existence $>>$ profusion-ofpreconverging prior-relative-ontological-incompleteness ${ }^{88}$-of-

apriorising/axiomatising/referencing, explaining why the possibility of the $<$ cumulating/recomposuring attendant-ontological-contiguity $>$-successive registryworldviews/dimensions is underlied as of 'encyclopedic axiomatising/re-referencing $\sim$ residuality —in-re-originariness/re-origination' relativeontological-completeness ${ }^{87}$-of-apriorising/axiomatising/referencing re-ontologising prospective re-rationalisations-of-contentivity/argumentativity/dialecticism/discursivity (in order to attain Being-development/ontological-framework-expansion-as-to-depth-ofontologising-development-as-infrastructure-of- meaningfulness-and-teleology

psychologismic epistemic-acutisation difficulty-for, residualising

\{decomplsing $d e$ dinearity for-cogency> magnitude\{of-experientiality/experiment\} of prospective transcendence-and-sublimity/sublimation/supererogatory-de-mentativity with respect to limitedness/human-subpotency 'firstnaturedness-as-to-inkling profound-supererogation' for overarching existential-<disontologising/re-ontologising aporeticism> priority/precedence/primacy of \{epistemic-totalising 3 re-apriorising/re-axiomatising/rereferencing $\sim$ residuality—in-re-originariness/re-origination projection' in 'recurrent/perpetuating/continuity-recomposuring existential-<disontologising/reentologising aporeticism $>$ counteracting/supplanting/alienating-of-priorapriorising/axiomatising/referencing' over 'secondnatured prior mere-formulaicity/ritualisation$<$ as-to-mere-formulaic — methodologising/mutualising/organising/institutionalising,prospectively-losing-track-of- ‘fepistemic-totalising ’re-apriorising/re-axiomatising/re- 
referencing residuality -in-re-originariness/re-origination'>' that achieves prospective postconverging aporeticism-overcoming/unovercoming). The bigger implication here (with regards to attaining Being-development/ontological-framework-expansion-as-to-depth-ofontologising-development-as-infrastructure-of- meaningfulness-and-teleology psychologismic epistemic acutisation difficulty-<for, residualising \{decompulsing $\}$ delinearity for-cogeney> magnitude\{of-experientiality/experiment\} of prospective transcendence-and-sublimity/sublimation/supereregatory-de-mentativity with respect to limitedness/human-subpotency 'firstnaturedness-as-to-inkling profound-supererogation for overarching existential-<disentologising/re-ontelogising aporeticism> priority/precedence/primacy of \{epistemic-totalising ${ }^{3}$ re-apriorising/re-axiomatising/rereferencing $\sim$ residuality—in-re-originariness/re-origination projection' in 'recurrent/perpetuating/continuity-recomposuring existential-<disontologising/reentelogising aporeticism $>$ counteracting/supplanting/alienating-of-priorapriorising/axiomatising/referencing' over 'secondnatured prior mere-formulaicity/ritualisation$<$ as-to-mere-formulaic - methodologising/mutualising/organising/institutionalising,-

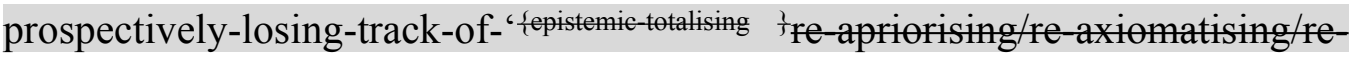
referencing-residuality-in-re-originariness/re-origination'>' that achieves prospective postconverging aporeticism-overcoming/unovercoming) is that every registryworldview/dimension is thus effectively constrained as to the social-setup (circumscribed/bounded overall human subconsciousness most-prospectively-conscious 'reontologising-by-disontologising_existential-calculus-〈between 'prospective existentialisingpostconverging_framing/imprinting re-ontologising' and 'prior existentialising preconverging_enframing/imprintedness social-functioning-and-accordance-as-of-socialstake-contention-or-confliction' $\rangle$ ' of consciousness surrealising-<as-to-supererogation $>$ ) in want for prospective profound-supererogation induced psychoanalytic-unshackling for 
'epistemic-break or notional-discontiguity/epistemic-discontiguity ${ }^{63}-<$ between - prior-shallowsupererogation -of-mentally-aestheticised $\sim$ preconverging/dementing -qualiaschema_and_prospective-profound-supererogation -of-mentallyaestheticised $\sim$ postconverging/dialectical-thinking -qualia-schema>'. Such a 'constraining (in relative-ontological-incompleteness ${ }^{8}$-of-apriorising/axiomatising/referencing)' is effectively contemplatable/assessable as from the 'epistemic-projection ambit of the relative-ontologicalcompleteness ${ }^{87}$-of-apriorising/axiomatising/referencing (induced prospective notional $\sim$ difference-conflatedness ${ }^{13}$-as-to-totalitative-reification-in-singularisation- $<$ as-to-thenondisjointedness/entailment-of-prospective- nonpresencing > -as-veridical-epistemicityrelativism-determinism )', as to the fact that relative-ontological-completeness ${ }^{8}$-ofapriorising/axiomatising/referencing is rather effectively underlied as of: the-human/humanity 'recurrently mediative-<in-expectation/in-anticipation $>$ unconsciousness/potentiation-ofconscionability-<anxiety-as-to-reconstitution/reparation,-including-dreaming/psychicalreshuffling>' (as the 'psychoanalytic boundlessness of human notional reflexivity$<\{$ veridical/sound\}-relative-reflexivity-in-existence/relativising from-limited-mentation-as-

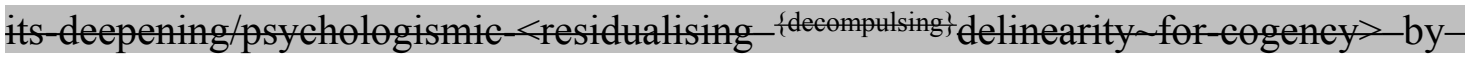

\section{\{flawed/unsound\}relative-unreflexivity-in-existencetabsolutising from limited-} mentation/psychologismic epistemic acutisation nonresidualising imbued-

disontologising/re-ontologising aporeticism $>$ backdrop' elicitable/exuding as of subconsciousness knowingly/unknowingly-manifest human ontological-goodfaith/authenticity ${ }^{69}$ postconverging-de-mentating/structuring/paradigming 70 - byontological-bad-faith/inauthenticity ${ }^{64} \sim$ preconverging-de-mentating/structuring/paradigming ${ }^{65}$ ) as so-potentiating 'human subconsciousness as backdrop-for-the-Lacanian-real enabling the effective formativeness-<as-to-intersolipsism-of- 
preformulating/preframing/premeaningfulness-imbued-mediativity-and-deferentialism>-of-

meaningfulness-and-teleology of consciousness surrealising-<as-to-supererogation ${ }^{>}$' (as so-manifested with human subconsciousness most-prospectively-conscious 're-ontologisingby-disontologising_existential-calculus-〈between 'prospective existentialisingpostconverging_framing/imprinting re-ontologising' and 'prior existentialisingpreconverging_enframing/imprintedness social-functioning-and-accordance-as-of-socialstake-contention-or-confliction'〉' of consciousness surrealising-<as-to-supererogation $>$ ). In other words, this illuminates that the-human/humanity 'recurrently mediative-<inexpectation/in-anticipation $>$ unconsciousness/potentiation-of-conscionability-<anxiety-as-toreconstitution/reparation,-including-dreaming/psychical-reshuffling >' rather speaks to the 'potentiation/omnipotentiality of human adjustable/subjectable placeholder-setup/mentaldevising-representation/mentation/consciousness-awareness-teleology 9 with respect to unlimitedness/existence-<fll-potency-of_sublimating nascence $>$ ' as 'sublimating enablingbackdrop of profound-supererogation ' for 'relative-ontological-completeness ${ }^{87}$-ofapriorising/axiomatising/referencing induced prospective notional difference-conflatedness ${ }^{13}$ as-to-totalitative-reification-in-singularisation- $<$ as-to-the-nondisjointedness/entailment-ofprospective- nonpresencing $>$-as-veridical-epistemicity-relativism-determinism $\quad$, as to manifest human subconsciousness most-prospectively-conscious 're-ontologising-bydisontologising_existential-calculus-〈between $\quad$ 'prospective existentialisingpostconverging_framing/imprinting re-ontologising' and 'prior existentialisingpreconverging_enframing/imprintedness social-functioning-and-accordance-as-of-socialstake-contention-or-confliction' $\rangle$ ' of consciousness surrealising-<as-to-supererogation $>$ ). In this regards (as to the implications for 'human psychologismic-epistemic-acutisation-<as-topostconverging-de-mentating/structuring/paradigming,-eliciting-of-existence's-sublimating- 
\{veridical/sound\}-relative-reflexivity-in-existence/relativising from-limited-mentation-as-itsdeepening/psychologismic epistemic acutisation residualising, ${ }^{\text {fdecompulsing }}$ delinearity for eogency'), human 'sublimating mental-aestheticising-<as-'psychologismic-existentialmetaphoricity \{as-to-\{epistemic-totalising łre-apriorising/re-axiomatising/re-referencing_inbecoming?' -so-implicited-'by-way-of-the-existentially/contextually/textually-manifest-motifconstruct-as-specific-language'-as-so-reflecting-'the-existentially/contextually/textuallymanifest-moronisation/demoronisation'> $\quad$ (as to limitedness/human-subpotency 'firstnaturedness-as-to-inkling profound-supererogation for overarching existential<disontologising/re-ontelogising aporeticism $>$ priority/precedence/primacy of tetlising $3 \frac{?}{3}$ re-apriorising/re-axiomatising/re-referencing $\sim$ residuality-in-re-originariness/reorigination projection' in 'recurrent/perpetuating/continuity-recomposuring existential< disontologising/re-ontologising aporeticism $>$ counteracting/supplanting/alienating-ofprior-apriorising/axiomatising/referencing' over 'secondnatured prior mereformulaicity/ritualisation-<as-to-mere-formulaicmethodologising/mutualising/organising/institutionalising,-prospectively-losing-track-of' \{epistemic-totalising '`re-apriorising/re-axiomatising/re-referencing $r$ residuality-in-reoriginariness/re-origination'>' that achieves prospective postconverging-aporeticismovercoming/unovercoming) is what underlies 'reifying-mental-aestheticising-<as-of'prospective_reformulating-of-mental-aestheticising'as-to-'residuality-in-re-originariness/reorigination'-of-mental-aestheticising $>$ educed processive-motif-'exuding aestheticisinggesturing' of-apriorising/axiomatising/referencing as to re-aestheticisation-and-reaestheticisation-towards-ontology-<elicited-prospective-idiomatisation $>{ }^{\prime}$ so-implied as to 'limitedness/human-subpotency prospective re-encountering/re-confrontation with unlimitedness/existence-<full-potency-of_sublimating nascence $>$ ' (as so-enabling of the 'very fundamental notion of knowledge reifying' as being about limitedness/human-subpotency 
prospective re-encountering/re-confrontation with the "constraining/defining intersolipsistic reflexive-sublimating/unreflexive-desublimating measure/objectification that is unlimitedness/existence-as-ontological-normalcy/postconvergence- $<$ in-validation-of'metaphysics-of-absence_epistemic-projection'>' for human epistemic-growth,-as\{veridical/sound\}-relative-reflexivity-in-existence/relativising from-limited-mentation-as-itsdeepening/psychologismic epistemic-acutisation residualising, \{decompulsing $\}$ delinearity-foreogency); and so-manifested with a 'reifying-mental-aestheticising-<as-of'prospective_reformulating-of-mental-aestheticising'as-to-'residuality_in-re-originariness/reorigination'-of-mental-aestheticising> educed processive-motif-'exuding aestheticisinggesturing'-of-apriorising/axiomatising/referencing as to re-aestheticisation-and-reaestheticisation-towards-ontology-<elicited-prospective-idiomatisation $>{ }^{\prime} \quad$ associated unblurriness-<re-ontologising_by-postconverging-as-to-dragged-outsupererogatory $\sim$ wholesomeness/profound-supererogation ,-while-anecdotalising-priordisontologising-thresholding $>$ for engaging/reflecting about 'limitedness/human-subpotency prospective re-encountering/re-confrontation with unlimitedness/existence-<fll potency of_sublimating nascence $>^{\prime}$ as to a rationalisation-ofcontentivity/argumentativity/dialecticism/discursivity that effectively projects of prospective 'human limited-mentation-capacity-deepening—as-subjecting-limitedness/human-subpotency to-'educed-unlimitedness/existence-sublimating nascence' intolerance- $<0 f-$ disparateness $>$ /exactifying_precisioning' induced ${ }^{45}$ foregrounding_entailment- $<$ in-successionof-profound-supererogation $>$-〈postconverging-narrowing-down $\sim$ sublimation-as-to‘existence — as-sublimating-withdrawal/unenframing/re-ontologising,-elicited-fromprospective-profound-supererogation '-in-reflecting-'immanent relativeunreflexivity/relative-reflexivity - ontological-contiguity ';--as-operativenotional deprocrypticism) (in reflection of the epistemic-projection of "nonpresencing- 
$<$ perspective-ontological-normalcy/postconvergence $>$ relativism/relative-scope for epistemicgrowth,-as-\{veridical/sound\}-relative-reflexivity-in-existence/relativising from-limitedmentation-as-its-deepening/psychologismic epistemic-acutisation residualising, \{decompulsing $\}$ delinearity for-cogeney' imbued underlying-elucidative 'requisite sublimating/desublimating formulative-framing/fielding — of-entailment of human ontologicalperformance $^{72}-<$ including-virtue-as-ontology $>$ /morality/ethics/justice/etc. contemplation' as of notionally implied $\quad{ }^{45}$ foregrounding_entailment- $<$ in-succession-of-profoundsupererogation $>$ >-〈postconverging-narrowing-down $\sim$ sublimation-as-to-'existence-assublimating-withdrawal/unenframing/re-ontologising,-elicited-from-prospective-profoundsupererogation '-in-reflecting-'immanent relative-unreflexivity/relative-reflexivity ontological-contiguity ';--as-operative-notional deprocrypticism)). On-the-other-hand, human 'desublimating mental-aestheticising-<as-'psychologismic-existential-metaphoricity \{as-to-\{epistemic-talising '⿳re-apriorising/re-axiomatising/re-referencing_in-becoming\}'-soimplicited-'by-way-of-the-existentially/contextually/textually-manifest-motif-construct-asspecific-language'-as-so-reflecting-'the-existentially/contextually/textually-manifestmoronisation/demoronisation'>' (as to limitedness/human-subpotency 'secondnaturedness of epistemic prior mere-formulaicity/ritualisation' as of 'continuity of prior processiveaposteriorising/logicising/deriving-<as-from-prior-apriorising/axiomatising/referencing $>$ ' that fails prospective postconverging-aporeticism-overcoming/unovercoming) is what underlies 'dereifying-mental-aestheticising-<as-of-'prior_mere-formulaicity/ritualisation-of-mentalaestheticising'-failing-'residuality-in-re-originariness/re-origination'-of-mentalaestheticising $>$ as of the processive-motif-'exuding-aestheticising-gesturing' ofapriorising/axiomatising/referencing of prior aestheticisation-and-aestheticisation-towardsontology-<elicited-idiomatisation>' (as associated in our modern-day for instance with 'psychological and survey strategies of marketing/popular communication as to their mere 
ratings purposes of sales, audience-numbers and entertainment' subtly-and-deceitfully creeping/sliding/re-orientating into 'supposedly existential-<disontologising/re-ontologising aporeticism $>$ elucidating pretenses of prospective knowledge reifying purpose' so-translated in knowledge misrepresentation with manifestations of pop-intellectualism of shallow intellectual investment, popular-driven/impression-making communication/media activities, popular/impression politics and worst still the construal of inherent knowledge reifying in terms of popularity/impression-driven and secondary interests purposes all in a predisposition to blur or directly subvert the space of the ontologising/scientific/existence- $<$ honesty-constraining $>$ scope_for_prospective_re-ontologising, thus failing the 'very fundamental notion of knowledge reifying' as being about limitedness/human-subpotency prospective re-encountering/reconfrontation with the 'constraining/defining intersolipsistic reflexive-sublimating/unreflexivedesublimating measure/objectification that is unlimitedness/existence-as-ontologicalnormalcy/postconvergence-<in-validation-of-‘metaphysics-of-absence_epistemic-projection’> for human epistemic-growth,-as - \{veridical/sound\}-relative-reflexivity-inexistence/relativising from-limited-mentation-as-its-deepening/psychologismic epistemicacutisation residualising, ${ }^{\text {\{decompulsing }}$ delinearity for-cogency); and so-manifested with a 'dereifying-mental-aestheticising-<as-of-'prior_mere-formulaicity/ritualisation-of-mentalaestheticising'-failing-'residuality-in-re-originariness/re-origination'-of-mentalaestheticising $>$ as of the processive-motif-'exuding aestheticising-gesturing' ofapriorising/axiomatising/referencing of prior aestheticisation-and-aestheticisation-towardsontology-<elicited-idiomatisation> associated blurriness-

\section{$<$ sterilising/anecdotalising/trivialising-of-prospective-re-ontologising_by-preconverging,-in-} disontologising-formulaic-dragging-out/hollowing-out> for engaging/reflecting about 'limitedness/human-subpotency prospective re-encountering/re-confrontation with unlimitedness/existence-<full-potency-of_sublimating nascence $>$ ' as to a rationalisation-of- 
contentivity/argumentativity/dialecticism/discursivity that hardly/poorly projects of prospective 'human limited-mentation-capacity-deepening—as-subjecting limitedness/human-subpotencyto-'educed-unlimitedness/existence-sublimating nascence' intolerance $<0 f-$ disparateness $>$ /exactifying_precisioning' induced ${ }^{45}$ foregrounding_entailment- $<$ in-successionof-profound-supererogation $>$-〈postconverging-narrowing-down $\sim$ sublimation-as-to'existence - as-sublimating-withdrawal/unenframing/re-ontologising,-elicited-fromprospective-profound-supererogation '-in-reflecting-'immanent relativeunreflexivity/relative-reflexivity - ontological-contiguity ';-as-operativenotional deprocrypticism) (in reflection of the epistemic-projection of "nonpresencing$<$ perspective-ontological-normalcy/postconvergence $>$ relativism/relative-scope for epistemicgrowth,-as-\{veridical/sound\}-relative-reflexivity-in-existence/relativising from-limitedmentation-as-its-deepening/psychologismic epistemic acutisation residualising,

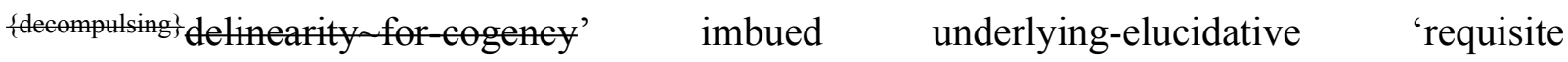
sublimating/desublimating formulative-framing/fielding — of-entailment of human ontologicalperformance $^{72}-<$ including-virtue-as-ontology $>$ /morality/ethics/justice/etc. contemplation' as of notionally implied $\quad{ }^{45}$ foregrounding_entailment- $<$ in-succession-of-profoundsupererogation $>$-〈postconverging-narrowing-down $\sim$ sublimation-as-to-'existence-assublimating-withdrawal/unenframing/re-ontologising,-elicited-from-prospective-profoundsupererogation '-in-reflecting-'immanent relative-unreflexivity/relative-reflexivity ontological-contiguity ';--as-operative-notional deprocrypticism)). Thus with regards to human social-stake-contention-or-confliction, 'dereifying-mental-aestheticising-<as-of'prior_mere-formulaicity/ritualisation-of-mental-aestheticising'-failing-'residuality-in-reoriginariness/re-origination'-of-mental-aestheticising $>$ as of the processive-motif-exuding aestheticising-gesturing' of apriorising/axiomatising/referencing of prior aestheticisation-andaestheticisation-towards-ontology-<elicited-idiomatisation>' speaks to $\mathrm{a}$ 
conscious/unconscious

'pedantising/muddling/formulaic-hollowing-out—in-

subontologisation/subpotentiation-〈blurring/undermining-of-prospective-totalising-entailing,-

as-to-entailing-<amplituding/formative-epistemicity $>$ totalising in-relative-ontological-

completeness $\rangle$ desublimation strategising/inclination' that operates on the basis that the 'direct eliciting of the human sovereign-function/posture-<as-to-existentially-manifest-'embodiedsubject $\sim$ consciousness-and-direct/deferential-conscientiousness',-as-of-its-'epistemicreflexivity/unreflexivity-in-existence'/teleology $>\quad$ prior processiveaposteriorising/logicising/deriving-<as-from-prior-apriorising/axiomatising/referencing $>$ (soreflecting the human sovereign-function/posture-<as-to-existentially-manifest-'embodiedsubject consciousness-and-direct/deferentiat-conscientiousness',-as-of-its- 'epistemicreflexivity/unreflexivity-in-existence'/teleology> prior 'human consciousness/collectiveconsciousness representation/unity/comprehensiveness of the institutional/bureaucratic/social and their purposefulness' constructive-inveracity)' is effectively how to go about undermining/subverting the inherent knowledge reifying purpose of the genuine social intellectual-function/posture (as of its ontologically-veridical propping of the human sovereignfunction/posture-<as-to-existentially-manifest-'embodied-subject $\sim$ consciousness-anddirect/deferential-conscientiousness',-as-of-its-'epistemic-reflexivity/unreflexivity-inexistence'/teleology $>$ by providing the underlying ontologising/scientific/existence- $<$ honestyconstraining $>$ — scope_for_prospective_re-ontologising as to 'limitedness/human-subpotency prospective re-encountering/re-confrontation with unlimitedness/existence-<flll-potency of_sublimating nascence>' as so-providing the 'existential-<disontologising/re-ontologising aporeticism $>$ enabling-backdrop' for the advocacy/political/applicative-scope to arise) by way of its requisite inclination for 'reifying-mental-aestheticising-<as-of'prospective_reformulating-of-mental-aestheticising'as-to-'residuality-in-re-originariness/reorigination'-of-mental-aestheticising> educed processive-motif-'exuding aestheticising- 
gesturing' of-apriorising/axiomatising/referencing as to re-aestheticisation-and-reaestheticisation-towards-ontology-<elicited-prospective-idiomatisation $>$ (in so-inducing the human sovereign-function/posture-<as-to-existentially-manifest-'embodiedsubject consciousness-and-direct/deferential-conscientiousness',-as-of-its- 'epistemicreflexivity/unreflexivity-in-existence'/teleology> prospective 'human consciousness/collectiveconsciousness representation/unity/comprehensiveness of the institutional/bureaucratic/social and their purposefulness' constructive-veracity)'. This discrepancy (as a reflection of the placeholder-setup/mental-devising-representation/mentation/consciousness-awarenessteleology that is human consciousness in-its-embodiment 'existentialisingpreconverging_enframing/imprintedness by existentialisingpostconverging_framing/imprinting imbuing of existentialising-frame-of-entailment-of motifand-apriorising/axiomatising/referencing') speaks to the fact that human ${ }^{56}$ meaningfulness-andteleology 'is not merely abstractly-elaborate apriorising/axiomatising/referencing' but 'is reflected as to the underlying <amplituding/formative-epistemicity>-totalising $\sim$ thrownness-inexistence $^{35}$ mental-aestheticising-<as-'psychologismic-existential-metaphoricity $\underset{\text { fas-to- }}{ }$ \{epistemic-totalising 're-apriorising/re-axiomatising/re-referencing in becoming\}' -so-implicited-

\section{'by-way-of-the-existentially/contextually/textually-manifest-motif-construct-as-specific-} language'-as-so-reflecting-'the-existentially/contextually/textually-manifestmoronisation/demoronisation'> that veridically exudes of apriorising/axiomatising/referencing'; with the implication that the 'prior <preconverging 'motif-andapriorising/axiomatising/referencing'-entailing >-existentialising — enframing/imprintedness〈as-to- historicity-tracing-in-presencing-hyperrealisation/hyperreal-transposition〉 (as to prior sunderlaid/substrated 'thrownness-aestheticising' \{of relative-unreflexivity-in-existence\}> profusion-of preconverging prior-relative-ontological-incompleteness ${ }^{8}$-ofapriorising/axiomatising/referencing) effectively renders registry-worldviews/dimensions 
sharply susceptible to their manifest 'dereifying-mental-aestheticising-<as-of-'prior_mereformulaicity/ritualisation-of-mental-aestheticising'-failing-'residuality-in-re-originariness/reorigination'-of-mental-aestheticising $>$ as of the processive-motif-'exuding aestheticising gesturing' of apriorising/axiomatising/referencing of prior aestheticisation-andaestheticisation-towards-ontology-<elicited-idiomatisation $>\quad$ credibility/credulity-inducedprocessive-assent-to-moronisation-<sublimating-nascence,-extrieatory-desublimatingdownstreaming/'avalage'> at their prospectively uninstitutionalised-threshold ${ }^{102}$ (as to wrongly implicit in-effect of their 'unlimitedness/existence-<full-potency-of_sublimating nascence> absolute-ontological-completeness-of-apriorising/axiomatising/referencing-<as-

omnipotentiality $><$ amplituding/formative-epistemicity $>$-totalising $\sim$ thrownness-in-existence ${ }^{35}$, imbued absolute $\sim$ difference-conflatedness ${ }^{13}$-as-to-totalitative-reification-in-singularisation$<$ as-to-the-nondisjointedness/entailment-of-prospective- nonpresencing $>$-as-veridicalepistemicity-relativism-determinism so-construed as 'absolute reference of identity' as failing to project of their 'own possible prospective relative-ontological-incompleteness ${ }^{8}$-ofapriorising/axiomatising/referencing'). The implications here (as of 'human psychologismicepistemic-acutisation-<as-to-postconverging-de-mentating/structuring/paradigming,-elicitingof-existence's-sublimating-nascence-in-prospective-aporeticism-overcoming/unovercoming> as to epistemic-growth,-as-\{veridieal/sound\}-relative-reflexivity-in-existence/relativising from-limited-mentation-as-its-deepening/psychologismic epistemic-acutisationresidualising, ${ }_{\text {flecompulsing }}^{\text {f }}$ delinearity for-cogency') with regards to prospective transcendenceand-sublimity/sublimation/supererogatory-de-mentativity, effectively harkens-back to the human underlying fundamental/incipient/seeding insight 'of prospective ontological-goodfaith/authenticity ${ }^{6} \sim$ postconverging-de-mentating/structuring/paradigming ${ }^{70}$ implications' (inherently arising from the 'defining precedence of unlimitedness/existence-<fll-potency of_sublimating nascence> eliciting of limitedness/human-subpotency dynamically adjusting 
placeholder-setup/mental-devising-representation/mentation/consciousness-awarenessteleology ${ }^{9}$ ') and divulgeable/enlightening-giving as from the 'requisite projection of the coherence/contiguity of the superseding-oneness-of-ontology/ontological-veridicality/relativeunreflexivity/relative-reflexivity - ontological-contiguity ${ }^{67}$ ' (so-construed as the 'fundamental human conscious/unconscious sense/drive/disposition' enabling experientiality/experiment- $<$ asto-existentially-formative- ${ }^{\prime}$ \{epistemic-totalising ${ }_{3}^{\frac{1}{3}}$ re-apriorising/re-axiomatising/re-

referencing $\sim$ residuality —in-re-originariness/re-origination',- - so-

"notionally/epistemically/bindingnessly <as to detminism/enceptivity of relative unreflexivity/relative reflexivity?

implicited-and-articulated'_as-from-nonextricatory-'prospective-re-ontologising-Being-then-

Institutional-then-Living-magnitudes-of-\{hermeneutic/reprojection-protraction-of\}reframingand-reformulation\}'> with regards to 'formative and articulative implications of apriorising/axiomatising/referencing and corresponding existentialising/contextualising/textualising aposteriorising/logicising/deriving' underlying the possibility for human intelligibility-〈as-to-human-projective/reprojective-aestheticising-remotif-and-re-apriorising/re-axiomatising/re-referencing/re-intelligibilitysettingup/remeasuringinstrumenting-process,-in-<amplituding/formativeepistemicity $>$ totalising $\sim$ conceptualisation $\rangle), \quad$ and $\quad$ so-enabling sublimating 'conceptivity/epistemic-reflexivity/epistemicity-relativism-determinism-<reifying \{as-toknowledge-developing $\}$-and-empowering $>$ entailment' as to fundamental ontology veracity of recurrently-driven limitedness/human-subpotency prospective re-encountering/re-confrontation with the 'constraining/defining intersolipsistic reflexive-sublimating/unreflexive-desublimating measure/objectification that is unlimitedness/existence-as-ontologicalnormalcy/postconvergence-<in-validation-of-'metaphysics-of-absence_epistemic-

projection'>'. So-translated as to the fact that a registry-worldview/dimension 'variegated confusion of epistemic-totalising ${ }^{336}$ meaningfulness-and-teleology ${ }^{9}$ ' in-effect boils down to the 
dynamics of its 'debilitating sunderlaid/substrated-'thrownness-aestheticising'- fof-relativeunreflexivity in-existence\}> profusion-of preconverging prior-relative-ontological-

incompleteness ${ }^{8}$-of-apriorising/axiomatising/referencing' and its 'invigorating <overlaying/superstrating 'thrownness-aestheticising'-\{of-relative-reflexivity in-existence\}> sparsity-of-postconverging prospective-relative-ontological-completeness ${ }^{87}$-of-

apriorising/axiomatising/referencing', and so as to 'its underlying <amplituding/formativeepistemicity $>$-totalising $\sim$ thrownness-in-existence ${ }^{35}$ mental-aestheticising-<as-" psychologismicexistential-metaphoricity $\{$ as-toreferencing_in-becoming? ' -so-implicited-'by-way-of-the-existentially/contextually/textuallymanifest-motif-construct-as-specific-language'-as-so-reflecting-'theexistentially/contextually/textually-manifest-moronisation/demoronisation'> that veridically exudes of apriorising/axiomatising/referencing' (as to its manifest human subconsciousness most-prospectively-conscious 're-ontologising-by-disontologising_existential-calculus〈between 'prospective existentialising_postconverging_framing/imprinting re-ontologising' and 'prior existentialising-preconverging_enframing/imprintedness social-functioning-andaccordance - as-of-social-stake-contention-or-confliction' ’' of consciousness surrealising-<asto-supererogation $>$ ). Summarily, 'human psychologismic-epistemic-acutisation-<as-topostconverging-de-mentating/structuring/paradigming,-eliciting-of-existence's-sublimatingnascence-in-prospective-aporeticism-overcoming/unovercoming $>$ as to epistemic-growth,-as\{veridical/sound\}-relative-reflexivity-in-existence/relativising from-limited-mentation-as-itsdeepening/psychologismic epistemic-acutisation residualising, ${ }^{\text {\{decompulsing }}$ delinearity foreogency' is thus about reflecting 'unlimitedness/existence-<full-potency-of_sublimating nascence $>$ prospective apriorising/axiomatising/referencing-sublimating-reflexivitybeholdening under which limitedness/human-subpotency submits in profound-supererogation for prospective sublimating' as to the ontologising/scientific/existence- $<$ honesty- 
constraining $>$ — scope_for_prospective_re-ontologising implications of existential$<$ disontologising/re-ontologising aporeticism $>$ counteracting/supplanting/alienating-ofprior-apriorising/axiomatising/referencing inducing of human transcendence-andsublimity/sublimation/supererogatory $\sim$ de-mentativity (upon such registryworldview/dimension underpinning-suprasocial-construct prior 'self-presence/selfconstitutedness $^{14}-<$ in-perspective-epistemic-abnormalcy/preconvergence ${ }^{31}>$ desublimating $\sim$ existentialising-decisionality-<as-to-disontologising/re-ontologising aporeticism $>$ ' imbued 'variegated confusion of epistemic-totalising ${ }^{33}$ meaningfulness-andteleology $\left.{ }^{9}\right) ; \quad$ as $\quad$ to invigorating sublimating-and-residually-accounted-forapriorising/axiomatising/referencing processing of prospective 'human consciousness/collective-consciousness representation/unity/comprehensiveness of the institutional/bureaucratic/social and their purposefulness' constructive-veracity (as of ' 'veridical/sound\}-relative-reflexivity-in-existence/relativising from-limited-mentation-as-itsdeepening/psychologismic epistemic-acutisation residualising, decmingl delinearity for eogency anarchistic-growth/anarchisation-for-re-ontologisation-〈as-to-conscious/unconscious epistemically-sound induced 'demoronisation-<sublimating-nascence,-nonextricatorysublimating-upstreaming/'amontée'> postconverging/dialectical-thinking conception of residual_re-originary_anarchistic incipiency of human social-functioning-and-accordance-asof-social-stake-contention-or-confliction meaningfulness-and-teleology ' $\rangle$ ') over debilitating desublimating-and-residually-unaccounted-for-apriorising/axiomatising/referencing processing as of prior 'human consciousness/collective-consciousness representation/unity/comprehensiveness of the institutional/bureaucratic/social and their purposefulness' constructive-inveracity (as of '\{flawed/unsound\}-relative-unreflexivity-inexistence/absolutising from-limited-mentation/psychologismic epistemic acutisationnonresidualising-imbued-fompulsingt linearity in-eclecticism-of-prior-mere- 
formulaicity/ritualisation insidious-anarchy-<as-to-conscious/unconscious epistemically-flawed induced 'moronisation-<sublimating-nascence,-extricatory-desublimating-

downstreaming/'avalage’> preconverging/dementing conception of prior mere-
formulaicity/ritualisation incipiency of human social-functioning-and-accordance-as-ofsocial-stake-contention-or-confliction meaningfulness-and-teleology '>'). The fundamental issue of human transcendence-and-sublimity/sublimation/supereregatory de-mentativity (with regards to reflecting 'unlimitedness/existence-<full-potency-of_sublimating nascence> prospective apriorising/axiomatising/referencing-sublimating-reflexivity-beholdening under which limitedness/human-subpotency submits in profound-supererogation for prospective sublimating' as to the ontologising/scientific/existence- $<$ honesty-constraining $>$ scope_for_prospective_re-ontologising implications of existential-<disontologising/reentologising aporeticism $>$ counteracting/supplanting/alienating-of-prior-

apriorising/axiomatising/referencing inducing of human transcendence-andsublimity/sublimation/supererogatory de-mentativity) it is herein contended underlies the succession of human 'sublimating <amplituding/formative-epistemicity >totalising thrownness-in-existence ${ }^{35} \quad$ mental-aestheticising-<as-"psychologismic-existentialmetaphoricity fas to \{epistemictotalising ${ }^{3}$ re apriorising/re axiomatising/re referencing_in becoming?' -so-implicited-'by-way-of-the-existentially/contextually/textually-manifest-motifconstruct-as-specific-language'-as-so-reflecting-'the-existentially/contextually/textuallymanifest-moronisation/demoronisation'> that veridically exudes of apriorising/axiomatising/referencing' (as 'reifying-mental-aestheticising-<as-of'prospective_reformulating-of-mental-aestheticising'as-to-'residuality-in-re-originariness/reorigination'-of-mental-aestheticising $>$ educed processive-motif-exting astheicising gesturing' of-apriorising/axiomatising/referencing as to re-aestheticisation-and-reaestheticisation-towards-ontology-<elicited-prospective-idiomatisation $>^{\prime}$ underlied as of 
manifest human subconsciousness most-prospectively-conscious 're-ontologising-bydisontologising_existential-calculus-〈between_prospective existentialisingpostconverging_framing/imprinting re-ontologising' and 'prior existentialisingpreconverging_enframing/imprintedness social-functioning-and-accordance-as-of-socialstake-contention-or-confliction' $\rangle$ ' of consciousness surrealising-<as-to-supererogation $>$ ); and so-reflected in the overall relative-unreflexivity/relative-reflexivity-ontologicalcontiguity ${ }^{67}$ of-the-human-institutionalisation-process ${ }^{68}$, as from the experientiality/experiment-<as-to-existentially-formative- ‘fepistemic-totalising ${ }^{\prime}$ re-apriorising/reaxiomatising/re-referencing $\sim$ residuality-in-re-originariness/re-origination',-so"notionally/epistemieally/bindingnessly-<as-to-determinism/conceptivity-of-relative-unreflexivity/relative-reflexivity> implicited-and-articulated'_as-from-nonextricatory-'prospective-re-ontologising-Being-thenInstitutional-then-Living-magnitudes-of-\{hermeneutic/reprojection-protraction-offreframingand-reformulation $\}^{\prime}>$ of trancing-processive-motif-'exuding aestheticising-gesturing' ofapriorising/axiomatising/referencing - as-to-trepidatious-

consciousness $\sim$ moronisation/demoronisation, $\quad$ mysticising-processive-motif-'exuding aestheticising-gesturing'-of-apriorising/axiomatising/referencing - as-to-warpedconsciousness $\sim$ moronisation/demoronisation, $\quad$ occulticising-processive-motif-‘exuding aestheticising-gesturing' of-apriorising/axiomatising/referencing - as-to-preclusiveconsciousness $\sim$ moronisation/demoronisation, procrypticising/subtranslational/subnotionality/subepistemicity-processive-motif-exuding aestheticising-gesturing' of apriorising/axiomatising/referencing - as-to-occlusiveconsciousness $\sim$ moronisation/demoronisation and prospectively deprocrypticising/omnitranslational/omninotionality/omniepistemicity-processive-motif'exuding aestheticising-gesturing' of apriorising/axiomatising/referencing -as-to-protensiveconsciousness $\sim$ moronisation/demoronisation successively imbued 'reifying-mental- 
aestheticising-<as-of-'prospective_reformulating-of-mental-aestheticising'as-to-'residuality in-re-originariness/re-origination'-of-mental-aestheticising > educed processive-motif'exuding aestheticising-gesturing' of apriorising/axiomatising/referencing as to reaestheticisation-and-re-aestheticisation-towards-ontology-<elicited-prospectiveidiomatisation $>$ (speaking of their successive procession-<as-to-constructiveveracity/inveracity_of-apriorising/axiomatising/referencing $>$ as to human 'undergirdingveracity of germinal/inceptive/formative individuals anarchistic self-reflexive instigativeeventuating-〈as-to-teleological-instigative/incipient-

\section{willing/arbitrariness/waywardness/faithdrivenness/supererogating-for-human-intelligibility,-} preceding-existence's-eventuating-sublimating-validation/desublimating-invalidation〉

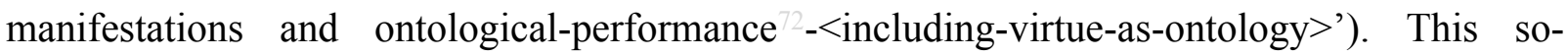
underlies the <cumulating/recomposuring attendant-ontological-contiguity $>$-successive registry-worldviews/dimensions given psychologismic epistemic-acutisation difficulty-for, residualising \{decompulsing\} delinearity for-cogency>-magnitudes $\{$ of-experientiality/experiment\} of 'human consciousness/collective-consciousness representation/unity/comprehensiveness of the institutional/bureaucratic/social and their purposefulness' imbued 'superposing/implying/suggesting/inferring of the institutional/bureaucratic/social and their purposefulness' so-construed 'as-if-of-inherently-actualising self-embodying representation/unity/comprehensiveness' for the purpose of institutional/bureaucratic/social procession-<as-to-constructive-veracity/inveracity_of-apriorising/axiomatising/referencing $>$; as to their given interrelatedness-dynamics-of-social-constructing (as from 'catchmented-andcompulsed-<in-'existential-dearth-of-demoronisation',-so-construed-as-from-ontologicalnormalcy/postconvergence-perspective-reflection-of-the-'destructuring-threshold_of-thegiven-level's-conjugated-postlogism as-dementing'> interpersonal, group, intergroup, community, vassal, dominion, politico-strategic, etc. psychologismic epistemic-acutisation- 
difficulty-for, residualising_\{decompulsing $\}$ delinearity for-cogency>-levels of interrelatednessdynamics-of-social-constructing' of 'formativeness-<as-to-intersolipsism-ofpreformulating/preframing/premeaningfulness-imbued-mediativity-and-deferentialism>-ofmeaningfulness-and-teleology and existential-<disontologising/re-ontologising aporeticism $>$ articulation manifestations' as to the 'undergirding-veracity of germinal/inceptive/formative individuals anarchistic self-reflexive instigative-eventuating-〈asto-teleological-instigative/incipientwilling/arbitrariness/waywardness/faithdrivenness/supererogating-for-human-intelligibility,preceding-existence's-eventuating-sublimating-validation/desublimating-invalidation〉') as sublimatingly/desublimatingly relevant with regards to human Being-development/ontologicalframework-expansion-as-to-depth-of-ontologising-development-as-infrastructure-ofmeaningfulness-and-teleology , institutional-development-as-to-social-functiondevelopment and living-development-as-to-personality-development psychologismic epistemic acutisation difficulty-for, residualising \{decompulsing\} ${ }^{\text {felinearity for-cogency> }}$ magnitudes ${ }^{\text {of-experientiality/experiment\} }}$. This elucidation (as to the inherent preconverging/postconverging-de-mentating/structuring/paradigming potential for human epistemic-growth,-as_ \{veridical/sound\}-relative-reflexivity-in-existence/relativising fromlimited-mentation-as-its-deepening/psychologismic epistemic-acutisation residualising, \{decompulsing\} delinearity for-cogeney) 'human apriorising/axiomatising/referencing sublimating' is itself enjoined in the 'human processivemotif-'exuding aestheticising-gesturing' of-apriorising/axiomatising/referencing of

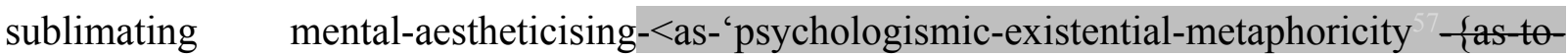
\{epistemic-totalising '’re-apriorising/re-axiomatising/re-referencing_in-becoming\}' -so-implicited‘by-way-of-the-existentially/contextually/textually-manifest-motif-construct-as-specificlanguage'-as-so-reflecting-'the-existentially/contextually/textually-manifest- 
moronisation/demoronisation'>', and so-underlied as of: the-human/humanity 'recurrently mediative-<in-expectation/in-anticipation $>$ unconsciousness/potentiation-of-conscionability<anxiety-as-to-reconstitution/reparation,-including-dreaming/psychical-reshuffling >' as to the 'potentiation/omnipotentiality of human adjustable/subjectable placeholder-setup/mentaldevising-representation/mentation/consciousness-awareness-teleology ${ }^{9}$ with respect to unlimitedness/existence-<fll-potency-of_sublimating nascence $>$ ' as 'sublimating enablingbackdrop of profound-supererogation ' for 'relative-ontological-completeness ${ }^{8}$-ofapriorising/axiomatising/referencing induced prospective notional $\sim$ difference-conflatedness ${ }^{13}$ as-to-totalitative-reification-in-singularisation- $<$ as-to-the-nondisjointedness/entailment-ofprospective- nonpresencing $>$-as-veridical-epistemicity-relativism-determinism ${ }^{2}$ (as to manifest human subconsciousness most-prospectively-conscious 're-ontologising-bydisontologising_existential-calculus-〈between $\quad$ 'prospective existentialisingpostconverging_framing/imprinting re-ontologising' and 'prior existentialisingpreconverging_enframing/imprintedness social-functioning-and-accordance-as-of-socialstake-contention-or-confliction' $\rangle$ of consciousness surrealising-<as-to-supererogation $>$ ). Thus (with regards to 'human psychologismic-epistemic-acutisation-<as-to-postconverging-dementating/structuring/paradigming,-eliciting-of-existence's-sublimating-nascence-inprospective-aporeticism-overcoming/unovercoming > as to epistemic-growth,-as\{veridical/sound\}-relative-reflexivity-in-existence/relativising from-limited-mentation-as-itsdeepening/psychologismic epistemic-acutisation residualising, ${ }^{\text {fdecompulsing }\}}$ delinearity foreogency'), the ontologising/scientific/existence- $<$ honesty-constraining $>$ scope_for_prospective_re-ontologising implications of existential-<disontologising/reentologising aporeticism $>$ counteracting/supplanting/alienating-of-priorapriorising/axiomatising/referencing speak to the fact that unlimitedness/existence- $<$ fullpotency-of_sublimating nascence> is already of givenness; and so, as the givenness of 
existence - as-the-absolute-a-priori-of-conceptualisation and existence-as-sublimatingwithdrawal/unenframing/re-ontologising,-elicited-from-prospective-profoundsupererogation $-<$ as-to-perspective-ontological-normalcy/postconvergence-implied'prospective-aporeticism-overcoming/unovercoming'> that is not subjected to limitedness/human-subpotency ontologically-flawed in-effect absolution temporal-dispositions. The further implication here is that thus limitedness/human-subpotency epistemic-growth,-as\{veridical/sound\}-relative-reflexivity-in-existence/relativising from-limited-mentation-as-itsdeepening/psychologismic epistemic acutisation residualising, fdecmpusingl delinearity for eogency speaks of a 'clarity/intelligibility that is not veridically of a human construction exercise (as to an undertone/hint associated with the term construction as of ${ }^{679}$ presencing-absolutisingidentitive-constitutedness $^{14}$ normalising functionalism conception as to fflawed/unsound relative-unreflexivity-in-existencelabsolutising from-limited-mentation/psychologismic epistemic acutisation nonresidualising imbued-\{compulsing\} linearity-in-eclecticism-of-priormere-formulaicity/ritualisation' that wrongly seem to normalise the present's prospectively disontologising epistemic-abnormalcy/preconvergence ${ }^{31}$ epistemic-projection perspective) but rather veridically of a wholly prospective human mental liberation/empowerment exercise' with respect to the already givenness of unlimitedness/existence-full pons of stblimating nascence $>$ (as so-liberating/empowering from the 'experientiality/experiment- $<$ as-toexistentially-formative- ‘fepistemic-totalising 're-apriorising/re-axiomatising/rereferencing $\sim$ residuality —in-re-originariness/re-origination',- - so'notionally/epistemically/bindingnessly implicited-and-articulated'_as-from-nonextricatory-'prospective-re-ontologising-Being-thenInstitutional-then-Living-magnitudes-of-\{hermentic/reprojection-proction-of reframingand-reformulation $\}^{\prime}>\quad$ cloudiness' of prior <amplituding/formative-epistemicity $>$ totalising $\sim$ thrownness-in-existence ${ }^{35} \quad$ mental-aestheticising-<as-'psychologismic-existential- 
metaphoricity \{as-to-\{epistemic-totalising \}re-apriorising/re-axiomatising/re-referencing_in-

becoming?' -so-implicited-'by-way-of-the-existentially/contextually/textually-manifest-motif-

construct-as-specific-language'-as-so-reflecting-'the-existentially/contextually/textually-

manifest-moronisation/demoronisation' $>$ institutional/bureaucratic/social procession- $<$ as-toconstructive-veracity/inveracity_of-apriorising/axiomatising/referencing $>$ ); such that prospective postconverging-aporeticism overcoming/unovercoming is counterintuitively ineffect rather a 'passive-active human exercise of mental-aestheticising-<as-'psychologismicexistential-metaphoricity fas-to-fepistemictalising łre-apriorising/re-axiomatising/rereferencing_in-becoming? ' -so-implicited-'by-way-of-the-existentially/contextually/textuallymanifest-motif-construct-as-specific-language'-as-so-reflecting-'theexistentially/contextually/textually-manifest-moronisation/demoronisation'>’ to notionally/epistemically/bindingnessly-<as-to-determinism/conceptivity-of-relative-unreflexivity/relative-reflexivity $>$ access the prospect of unlimitedness/existence-<full-potency-of_sublimating nascence $>$ (as intelligibility-〈as-to-human-projective/reprojective - aestheticising-re-motif-and-reapriorising/re-axiomatising/re-referencing/re-intelligibilitysettingup/remeasuringinstrumenting-process,-in- $<$ amplituding/formativeepistemicity $>$ totalising conceptualisation $\rangle$ reflected as of human manifest liberating/empowering psychoanalytic-unshackling 'play of ${ }^{79}$ presencing-absolutisingidentitive-constitutedness ${ }^{14}$ mental-representation and ${ }^{6}$ nonpresencing-<perspectiveontological-normalcy/postconvergence $>$ mental-representation, as to existential$\leq$ disontologising/re-ontologising aporeticism $>$ counteracting/supplanting/alienating-ofprior-apriorising/axiomatising/referencing'). Critically (with regards to 'human psychologismic-epistemic-acutisation-<as-to-postconverging-dementating/structuring/paradigming,-eliciting-of-existence's-sublimating-nascence-inprospective-aporeticism-overcoming/unovercoming> as to epistemic-growth,-as 
\{veridical/sound\}-relative-reflexivity-in-existence/relativising from-limited-mentation-as-itsdeepening/psychologismic epistemic-acutisation residualising, ${ }_{\text {decompulsing }}$ delinearity foreogency'), the ontologising/scientific/existence- $<$ honesty-constraining $>$ scope_for_prospective_re-ontologising implications of existential-<disentelogising/reentologising aporeticism $>$ counteracting/supplanting/alienating-of-prior-

apriorising/axiomatising/referencing (as of its intolerance-<ofdisparateness $>$ /exactifying_precisioning-of-sublimation-<as-to-postconverging-narrowingdown apriorising/axiomatising/referencing-entailing-theoretical,-conceptual-and-operantimplications $>$ ) liberates/empowers limitedness/human-subpotency (from its 'experientiality/experiment-<as-to-existentially-formative- '\{epistemic-totalising 're-apriorising/reaxiomatising/re-referencing residuality-in-re-originariness/re-origination', - so'notionally/epistemically/bindingnessly-<as-to-determinism/coneeptivity-of-relative-unreflexivity/relative-reflexivity> implicited-and-articulated'_as-from-nonextricatory-'prospective-re-ontologising-Being-thenInstitutional-then-Living-magnitudes-of-\{hermeneutic/reprojection-protraction-of\}reframingand-reformulation $\}^{\prime}>\quad$ cloudiness' of prior <amplituding/formative-epistemicity $>$ totalising $\sim$ thrownness-in-existence ${ }^{35} \quad$ mental-aestheticising-<as-'psychologismic-existentialmetaphoricity fas to \{epistemic-totalising \}re apriorising/re axiomatising/re referencing_in becoming?' -so-implicited-'by-way-of-the-existentially/contextually/textually-manifest-motifconstruct-as-specific-language'-as-so-reflecting-'the-existentially/contextually/textuallymanifest-moronisation/demoronisation'> institutional/bureaucratic/social procession- $<$ as-toconstructive-veracity/inveracity_of-apriorising/axiomatising/referencing $>$ ) going by the 'constraining/defining intersolipsistic reflexive-sublimating/unreflexive-desublimating measure/objectification that is unlimitedness/existence'; such that prospective human sublimating is not construed as in any way dependent-on/defined-by any limitedness/humansubpotency protracted-social—as-to-individual-by-institutional-by-social 'covert/overt 
privy/temporal/mortal terms of contemplation as to protracted-social—as-to-individual-byinstitutional-by-social supposedly-prospective-thinking-purpose,-as-precalculated-purpose- $<$ as-

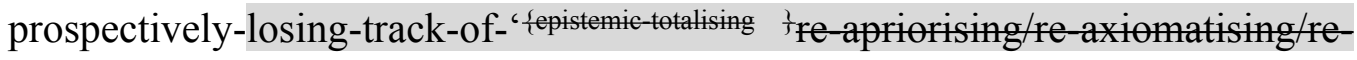
referencing residuality_-in-re-originariness/re-origination'-of-thinking >' but rather as to unlimitedness/existence-<full-potency-of_sublimating nascence $>$ educing 'constraining existence—as-sublimating-withdrawal/unenframing/re-ontologising,-elicited-fromprospective-profound-supererogation imbuing human ontological-commitment ${ }^{6}-<$ impliedself-assuredness-of-ontological-good-faith/authenticity postconverging-dementating/structuring/paradigming -as-being-as-of-existential-reality>' and ' ${ }^{103}$ universaltransparency ${ }^{104}$-〈transparency-of-totalising-entailing,-as-to-entailing-<amplituding/formativeepistemicity $>$ totalising $\sim$ in-relative-ontological-completeness $\rangle$ as available-to/elicitable-to-〈asto-human-consciousness/collective-consciousness-distendedness/detruncating-<beyondselfpresencing,-as-re-ontologising-decentering_of-consciousness/collective-consciousness,-asto-psychologismic-epistemic-acutisation - residualising, ${ }^{\text {\{decompulsing }}$ delinearity $\sim$ for-cogency $>$ > the social-functioning-and-accordance-as-of-social-stake-contention-or-confliction conception of any given registry-worldview/dimension <preconverging 'motif-andapriorising/axiomatising/referencing'-entailing >-existentialising-enframing/imprintedness〈as-to- historicity-tracing - in-presencing-hyperrealisation/hyperreal-transposition〉'. The ontologising/scientific/existence- $<$ honesty-constraining $>$ — scope_for_prospective_reontologising implications of existential-disonologising/ontologising apereticism> counteracting/supplanting/alienating-of-prior-apriorising/axiomatising/referencing (with regards to 'human psychologismic-epistemic-acutisation-<as-to-postconverging-dementating/structuring/paradigming,-eliciting-of-existence's-sublimating-nascence-inprospective-aporeticism-overcoming/unovercoming $>$ as to epistemic-growth,-as\{veridical/sound\}-relative-reflexivity-in-existence/relativising from-limited-mentation-as-its- 
deepening/psychologismic epistemic acutisation residualising, ${ }^{\text {fdecompulsing }}$ delinearity for

eogency') translate into the fact that the respective prospective re-ontologising of universalising-idealisation, positivism/rational-empiricism and ${ }^{18}$ deprocrypticism-orpreempting-disjointedness-as-of- ${ }^{8}$ reference-of-thought effectively relate to the respective prior disontologising non-universalising ancient-sophists, non-positivising medievalscholasticism and our modern-day disparateness-of-conceptualisation-<unforegrounding-ment,failing-prospectively-to-reflect- 'immanent relative-unreflexivity/relative-reflexivity ontological-contiguity '> rather as of 'existential-<disontologising/re-ontologising aporeticism $>$ counteracting/supplanting/alienating-of-prior-

apriorising/axiomatising/referencing implied prospective ${ }^{83}$ reference-of-thought—point-ofdevolving/departure/anchoring/backdrop_of_sublimating-nascence-<as-to-the-grandestaxiomatic-construct-\{epistemic-totalising ${ }^{\mathfrak{t}}$ re-apriorising/re-axiomatising/rereferencing - residuality - in-re-originariness/re-origination of limitedness/human-subpotency prospective re-encountering/re-confrontation with unlimitedness/existence $>$ re-rationalisationof-contentivity/argumentativity/dialecticism/discursivity' (and not as to limitedness/humansubpotency 'secondnaturedness of epistemic prior mere-formulaicity/ritualisation' as of 'continuity of prior processive-aposteriorising/logicising/deriving-<as-from-priorapriorising/axiomatising/referencing $>$ ' that fails prospective postconvergingaaporeticismovercoming/unovercoming); so-underlied as to 'Derridean underdetermination-imbued force/violence conception' and 'Foucauldian knowledge/power conception construed as knowledge-empowerment/ignorance-disempowerment' for prospective 'human psychologismic-epistemic-acutisation-<as-to-postconverging-dementating/structuring/paradigming,-eliciting-of-existence's-sublimating-nascence-inprospective-aporeticism-overcoming/unovercoming > as to epistemic-growth,-as\{veridical/sound\}-relative-reflexivity-in-existence/relativising from-limited-mentation-as-its- 
eogency'. That said, such an ontologically-veridical construal is about inducing the inherent 'prospective educing-and-availing-and-re-availing of relative-ontological-completeness ${ }^{8}$ ' but $^{-}$ not 'existentially-<disontologising/re-ontologising aporeticism $>$ substituting-for/taking-theplace-of the human sovereign-function/posture-<as-to-existentially-manifest-'embodiedsubject consciousness-and-direct/deferential-conscientiousness',-as-of-its- ‘epistemicreflexivity/unreflexivity-in-existence'/teleology> imbued protracted-social—as-to-individualby-institutional-by-social self supererogation' (apart from the fact that it is equally 'human sovereign-function/posture-<as-to-existentially-manifest-'embodied-subject $\sim$ consciousnessand-direct/deferential-conscientiousness',-as-of-its- 'epistemic-reflexivity/unreflexivity-inexistence'/teleology $>$ subjects' that are involved in elucidating any such manifest ontologising/scientific/existence- $<$ honesty-constraining $>$ - scope_for_prospective_reontologising and as to the socially acknowledged/elicitable deferentialism/deferentialformalisation-transference implications of re-ontologising); with regards to the prospect of prospectively 'inventing'/'creating'-and-'nurturing' the-human/humanity as to the ontologising/scientific/existence- $<$ honesty-constraining $>$ — scope_for_prospective_reontologising. In this regards, the ontologising/scientific/existence- $<$ honesty-constraining $>$ scope_for_prospective_re-ontologising cannot be construed as of protracted-social—as-toindividual-by-institutional-by-social 'covert/overt privy/temporal/mortal terms of contemplation as to supposedly-prospective-thinking-purpose,-as-precalculated-purpose- $<$ as-prospectivelylosing-track-of- ‘fepistemic-talising ’’re-apriorising/re-axiomatising/re-referencing 2 residuality_-inre-originariness/re-origination'-of-thinking>' from a genuine social intellectualfunction/posture epistemic-projection perspective (as so-contesting the veracity of such protracted-social—as-to-individual-by-institutional-by-social 'covert/overt privy/temporal/mortal terms of contemplation as to supposedly-prospective-thinking-purpose,- 
as-precalculated-purpose-<as-prospectively-losing-track-of- ‘fepistemic-totalising ${ }^{\prime}$ re-apriorising/reaxiomatising/re-referencing $\sim$ residuality_-in-re-originariness/re-origination'-of-thinking >' associated with the epistemic-projection perspective of pedantising/muddling/formulaichollowing-out - in-subontologisation/subpotentiation-〈blurring/undermining-of-prospectivetotalising-entailing,-as-to-entailing-<amplituding/formative-epistemicity $>$ totalising $\sim$ inrelative-ontological-completeness $>$ desublimation); such that such the idea of say $1+1$ is not 2 because of $\mathrm{x}$ given protracted-social—as-to-individual-by-institutional-by-social 'covert/overt privy/temporal/mortal terms of contemplation as to supposedly-prospective-thinking-purpose,as-precalculated-purpose-<as-prospectively-losing-track-of- ‘ $\left\{\right.$ epistemic-totalising ${ }^{\prime}$ re-apriorising/reaxiomatising/re referencing-residuality-in-re-originariness/re-origination'-of-thinking >' is effectively 'ontologically not entertainable' and as rather of disontologising-aggravation-〈inwant-for-prospective-aetiologisation/ontological-escalation-<ontologicalveridicality_commitment/otherliness_transcending/compulsions-encumbered_transcending $>\rangle$ manifestation (and so-construed factoring in the given registry-worldview/dimension attendant/associated 'social-functioning-and-accordance-as-of-social-stake-contention-orconfliction imbuing existentialising-frame-of-entailment-of motif-andapriorising/axiomatising/referencing of disontologising/ontologising-and-re-ontologising' ontologically-flawed pretense to supersede 'unlimitedness/existence-<full-potency of_sublimating nascence> prospective apriorising/axiomatising/referencing-sublimatingreflexivity-beholdening under which limitedness/human-subpotency submits in profoundsupererogation for prospective sublimating' as to the ontologising/scientific/existence$<$ honesty-constraining $>$ _ scope_for_prospective_re-ontologising implications of existential$<$ disontologising/re-ontologising aporeticism $>$ counteracting/supplanting/alienating-ofprior-apriorising/axiomatising/referencing whether such a pretense is manifested as to trancingprocessive-motif-'exuding aestheticising-gesturing' of apriorising/axiomatising/referencing 
with aestheticising-gesturing' of-apriorising/axiomatising/referencing with base-institutionalisation, occulticising-processive-motif-'exuding aestheticising gesturing' ofapriorising/axiomatising/referencing with non-positivism/medievalism or subtranslationalprocessive-motif-exuding aestheticising-gesturing' of apriorising/axiomatising/referencing with our procrypticism/disjointedness-as-of- ${ }^{83}$ reference-of-thought). This fundamentally speaks to the fact that the "potentiation/omnipotentiality that is human dimensionality-of-sublimating <<amplituding/formative>supererogatory $\sim$ de-mentativeness/epistemic-growth-orconflatedness /transvaluative-rationalising/transepistemicity/anamnestic-residuality/spiritdrivenness-equalisation)' underlying the ontologising/scientific/existence- $<$ honestyconstraining $>$ _ scope_for_prospective_re-ontologising (beyond secondnaturedness) is mostly of messianicity 'ever always in want for its futural coming' as to profound-supererogation (with regards to Being-development/ontological-framework-expansion-as-to-depth-ofontologising-development-as-infrastructure-of- meaningfulness-and-teleology , institutionaldevelopment-as-to-social-function-development and living-development-as-to-personalitydevelopment psychologismic epistemic-acutisation difficulty-<for, residualising $\{$ decompulsing $\}$ delinearity for-cogeney>-magnitudes $\{$ of-experientiality/experiment\} $\}$ and cannot be compromised as to protracted-social—as-to-individual-by-institutional-by-social 'covert/overt privy/temporal/mortal terms of contemplation as to supposedly-prospective-thinking-purpose,as-precalculated-purpose-<as-prospectively-losing-track-of-‘ ‘epistemic-totalising axiomatising/re-referencing - residuality_-in-re-originariness/re-origination'-of-thinking >' which can only be recurrently trampled-upon as to the 'requisite transversality-<forsublimating-existential-eventuating/denouement,-from-'thinking-at-first/pure-predispositionpreemptive-of prospective-disontologising/subontologising' as-of-prospectivelydisambiguated-affirmed-and-unaffirmed-'motif-and-apriorising/axiomatising/referencing'> 
undergirding

the

ontologising/scientific/existence- $<$ honesty-constraining $>$ scope_for_prospective_re-ontologising' (as to the fact that the concern and advancing of profound-supererogation is by itself of 'ontologising pride-of-place/preeminence'). In this respect, the requisite 'ontologising/scientific/existence- $<$ honesty-constraining $>$ scope_for_prospective_re-ontologising implications of existential-<disontologising/reentologising aporeticism> counteracting/supplanting/alienating-of-prior-

apriorising/axiomatising/referencing' (with regards to 'human psychologismic-epistemicacutisation-<as-to-postconverging-de-mentating/structuring/paradigming,-eliciting-of-

existence's-sublimating-nascence-in-prospective-aporeticism-overcoming/unovercoming $>$ as to epistemic-growth,-as_ \{veridical/sound\}-relative-reflexivity-in-existence/relativising fromlimited-mentation-as-its-deepening/psychologismic epistemic-acutisation residualising, ${ }_{\{\text {decompulsing }}$ delinearity for-cogency') is effectively caught-up/tied-up with the given registryworldview/dimension attendant/associated 'social-functioning-and-accordance-as-of-socialstake-contention-or-confliction imbuing existentialising-frame-of-entailment-of motif-andapriorising/axiomatising/referencing of disontologising/ontologising-and-re-ontologising' manifest 'human aestheticisation-and-aestheticisation-towards-ontology-<elicitedidiomatisation $>\quad$ moronisation- $<$ sublimating-nascence, downstreaming/'avalage'> — by_demoronisation-<sublimating-nascence, -nonextricatory sublimating-upstreaming/'amontée'> $\quad$ existentialising/emanance/becomingconstraint/pressure' (as to the 'play of human dimensionality-of-sublimating ${ }^{25}$ <<amplituding/formative >supererogatery de-mentativeness/epistemic-growth-orconflatedness /transvaluative-rationalising/transepistemicity/anamnestic-residuality/spiritdrivenness-equalisation $\rangle \quad$ and dimensionality-of-desublimating-lack-of <<amplituding/formative>supererogatory $\sim$ de-mentativeness/epistemic-growth-orconflatedness /transvaluative-rationalising/transepistemicity/anamnestic-residuality/spirit- 
drivenness-equalisation)' as to underlying 'crossgenerational notional firstnaturednessformativeness-<as-to-eventualising-inkling-drive-or-seeding-misprising $>$ mentalprocessing-parity for ontological-performance ${ }^{72}-$ including-virtue-as- $^{2}$ ontology $>$ /morality/ethics/justice/etc.' of all sovereign humans as to the potentiation of sublimating-over-desublimating); with respect to which desublimating, "notions of sublimationby-desublimation / emancipation-by-subjugation / enfranchisement-by-disenfranchisement cannot be abstractly dissociated' (so-underlied as of the disontologising/subontologisingimbuing-prospectively-of-human-desublimating/subjugation/disenfranchisement implications associated with trancing-processive-motif-'exuding aestheticising-gesturing' ofapriorising/axiomatising/referencing recurrent-utter-uninstitutionalisation, mysticisingprocessive-motif-'exuding aestheticising-gesturing'-of-apriorising/axiomatising/referencing base-institutionalisation, occulticising-processive-motif-'exuding -aestheticising-gesturing' ofapriorising/axiomatising/referencing non-positivism/medievalism or our subtranslationalprocessive-motif-'exuding aestheticising-gesturing' of apriorising/axiomatising/referencing procrypticism/disjointedness-as-of- reference-of-thought). Critically, the requisite 'ontologising/scientific/existence- $<$ honesty-constraining $>$ - scope_for_prospective_reontologising implications of existential-<disontologising/re-ontelogising aporeticism $>$ counteracting/supplanting/alienating-of-prior-apriorising/axiomatising/referencing' (with regards to 'human psychologismic-epistemic-acutisation-<as-to-postconverging-dementating/structuring/paradigming,-eliciting-of-existence's-sublimating-nascence-inprospective-aporeticism-overcoming/unovercoming $>$ as to epistemic-growth,-as\{veridical/sound\}-relative-reflexivity-in-existence/relativising from limited mentation as itsdeepening/psychologismic epistemic acutisation residualising, ${ }^{\{\text {decompulsing }}$ delinearity foreogency') cannot veridically be abstractly dissociated from the appraisal of manifest human subconsciousness most-prospectively-conscious 're-ontologising-by- 


postconverging_framing/imprinting re-ontologising' and 'prior existentialising-
preconverging_enframing/imprintedness social-functioning-and-accordance-as-of-socialstake-contention-or-confliction' $\rangle$ ' of consciousness surrealising-<as-to-supererogation $>$; as this ultimately leads to the ontological-inveracity of desublimating-and-residuallyunaccounted-for-apriorising/axiomatising/referencing processing as of prior 'human consciousness/collective-consciousness representation/unity/comprehensiveness of the institutional/bureaucratic/social and their purposefulness' constructive-inveracity (as of ' flawed/unsound\}-relative-unreflexivity-in-existence/absolutising from-limitedmentation/psychologismic epistemic acutisation nonresidualising imbued\{compulsing\} linearity in-eclecticism-of prior-mere-formulaicity/ritualisation insidious-anarchy$<$ as-to-conscious/unconscious epistemically-flawed induced 'moronisation- $<$ sublimatingnascence,-extricatory-desublimating-downstreaming/'avalage’’ $\quad$ preconverging/dementing conception of prior mere-formulaicity/ritualisation incipiency of human social-functioning-andaccordance-as-of-social-stake-contention-or-confliction meaningfulness-and-

teleology '>') as manifested with 'abstract institutional-prescience/imprimaturing- $<$ dullnessof the-spirit/psychologismic epistemic-acutisation nonresidualising-imbued-

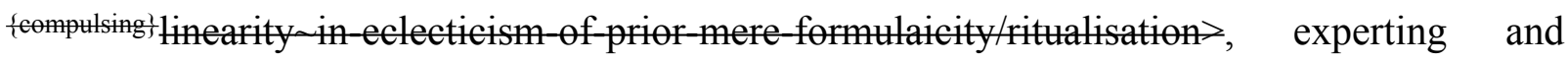
academicism' untethered/poorly-tethered to core-philosophy/derivative-core-philosophy(imbued requisite 'inkling-drive of dimensionality-of-sublimating ${ }^{25}$ <<amplituding/formative>supererogatery $\sim$ de-mentativeness/epistemic-growth-orconflatedness /transvaluative-rationalising/transepistemicity/anamnestic-residuality/spiritdrivenness-equalisation)') relevant existential-<disontologising/re-ontologising aporeticism $>$ scale and issues of prospective human Being-development/ontological-framework-expansionas-to-depth-of-ontologising-development-as-infrastructure-of- meaningfulness-and- 
\{decompulsing\} delinearity for-cogeney>-magnitude\{of-experientiality/experiment\}, and so rather than the ontological-veracity sublimating-and-residually-accounted-forapriorising/axiomatising/referencing processing of prospective 'human consciousness/collective-consciousness representation/unity/comprehensiveness of the institutional/bureaucratic/social and their purposefulness' constructive-veracity as of '\{veridical/sound\}-relative-reflexivity-in-existence/relativising-from-limited-mentation-as-itsdeepening/psychologismic epistemic acutisation residualising, fdecmpusingl delinearity for eogency anarchistic-growth/anarchisation-for-re-ontologisation-〈as-to-conscious/unconscious epistemically-sound induced 'demoronisation-<sublimating-nascence,-nonextricatorysublimating-upstreaming/'amontée’> postconverging/dialectical-thinking conception of residual_re-originary_anarchistic incipiency of human social-functioning-and-accordance-asof-social-stake-contention-or-confliction meaningfulness-and-teleology ' $\rangle$. In this regards, 'human segmentation and division-of-labour as of secondnatured institutionalisation induced prospective shallow-supererogation"' doesn't override the 'requisite profound-supererogation prospective contemplation of overall human knowledge' imbued 'human psychologismic-. epistemic-acutisation-<as-to-postconverging-de-mentating/structuring/paradigming,-elicitingof-existence's-sublimating-nascence-in-prospective-aporeticism-overcoming/unovercoming> as to epistemic-growth,-as - \{veridical/sound\}-relative-reflexivity-in-existence/relativising from-limited-mentation-as-its-deepening/psychologismic epistemic acutisationresidualising, ${ }^{\text {\{decompulsing }}$ delinearity for-cogency'; as to requisite core-philosophy/derivativecore-philosophy_-(imbued requisite 'inkling-drive of dimensionality-of-sublimating <<amplituding/formative>supererogatory $\sim$ de-mentativeness/epistemic-growth-orconflatedness /transvaluative-rationalising/transepistemicity/anamnestic-residuality/spiritdrivenness-equalisation〉') existential-<disontologising/re-ontologising aporeticism> 
sublimating appraisal. Furthermore, the manifest lack of epistemic-totalising ${ }^{3}$ insight with respect to human recurrent 'limitedness/human-subpotency prospective re-encountering/reconfrontation with unlimitedness/existence-<full-potency-of_sublimating nascence>' implications of epistemic-growth,-as - \{veridical/sound\}-relative-reflexivity-inexistence/relativising from limited-mentation-as-its-deepening/psychologismic epistemicacutisation residualising, ${ }^{\text {\{decompulsing }}$ delinearity for-cogeney is very much associated with desublimating manifestations of 'human rationalisation-ofcontentivity/argumentativity/dialecticism/discursivity as of ontologically-flawed prior mereformulaicity/ritualisation-<as-to-mere-formulaicmethodologising/mutualising/organising/institutionalising,-prospectively-losing-track-of‘\{epistemic-totalising ’’re-apriorising/re-axiomatising/re-referencing $r$ residuality-in-reoriginariness/re-origination’> imbued elaboration-as-to-mereextrapolating/constituting/abstracting/deducing/inferring-of-elucidation-outside'prospectively_implicited_attendant-ontological-contiguity ${ }^{67}$ ' educedexistentialising/contextalising/textualising_'intelligibility/epistemicity/reflexivity_contiguity$<$ imbued-notional $\sim$ cogency $>$; as to poorly operant or non-operant conceptual-patterning-〈asdevoid-of-'prospectively_implicited_attendant_ontological-contiguity ' i educedexistentialising/contextualising/textualising_'intelligibility/epistemicity/reflexivity-contiguity$<$ imbued-notional $\sim \operatorname{cogency}>$ ' 's-reifying-or-elucidating-of- 'prospective-relative-ontologicalcompleteness ' ';-so-rather-enabled-<by-a- nonpresencing-divulging-of-momentoushistoriality/ontological-eventfulness /ontological-aesthetic-tracing-<perspectiveontological-normalcy/postconvergence-reflected-‘epistemicity-relativism-determinism'>> gesturing/accounting — of-epistemic-phenomenalism of mere-referring-confused-withexplicating, mere-mentioning-confused-with-deriving and mere-conceptual-synonymisingconfused-for-prospective-knowledge-reification $\sim$ gesturing-and-accounting — of-epistemic- 
phenomenalism- $<$ in-prospective_psychologismic $\sim$ apriorising/axiomatising/referencing-\{of'prospectively implicited_attendant-ontological-contiguity ' educedexistentialising/contextualising/textualising_'intelligibility/epistemicity/reflexivity-contiguity$<$ imbued-notional cogency $>\quad\}$-conflatedness - in-\{preconverging ment by\} postconverging-entailment> ending up projecting 'ontologically-flawed existential<disontologising/re-ontologising aporeticism $>$ gesturing/accounting — of-epistemicphenomenalism conceptualisation', and so rather than the 'ontologically-veridical existential<disentologising/re-ontelogising aporeticism $>$ gesturing/accounting — of-epistemicphenomenalism conceptualisation' (as of the overaching epistemic-projection of ${ }^{6}$ nonpresencing-<perspective-ontological-normalcy/postconvergence $>$ relativism/relativescope for epistemic-growth,-as - \{veridical/sound\}-relative-reflexivity-inexistence/relativising from-limited-mentation-as-its-deepening/psychologismic epistemicacutisation - residualising, ${ }^{\text {\{decompulsing }}$ delinearity for-cogency' imbued underlying elucidation 'requisite sublimating/desublimating formulative-framing/fielding-of-entailment of human ontological-performance ${ }^{2}$-<including-virtue-as-ontology $>/$ morality/ethics/justice/etc. contemplation' as of notionally $\sim$ implied ${ }^{45}$ foregrounding_entailment-<in-succession-ofprofound-supererogation $>$-〈postconverging-narrowing-down $\sim$ sublimation-as-to- ${ }^{`}$ existenceas-sublimating-withdrawal/unenframing/re-ontologising,-elicited-from-prospective-profoundsupererogation '-in-reflecting-'immanent relative unreflexivity/relative-reflexivity ontological-contiguity ';--as-operative-notional deprocrypticism)). Such deficiency in gesturing/accounting - of-epistemic-phenomenalism as failing/subpar-to the requisite 'ontologising/scientific/existence- $<$ honesty-constraining $>$ — scope_for_prospective_reontologising implications of existential-<disontologising/re-ontologising aporeticism>counteracting/supplanting/alienating-of-prior-apriorising/axiomatising/referencing' (with regards to 'human psychologismic-epistemic-acutisation-<as-to-postconverging-de- 
mentating/structuring/paradigming,-eliciting-of-existence's-sublimating-nascence-in-

prospective-aporeticism-overcoming/unovercoming>

as

to

epistemic-growth,-as

\{veridical/sound\}-relative-reflexivity-in-existence/relativising from-limited-mentation-as-its-

deepening/psychologismic epistemic-acutisation residualising, ${ }^{\text {fdecompulsing }}$ delinearity for-

eogency'), it is herein contended, is tantamount to say switching the construal of the-very-same purview-of-unlimitedness/existence-<full-potency-of_sublimating nascence $>$; -

'implicited_attendant-ontological-contiguity ${ }^{67}$ ' educed-

existentialising/contextualising/textualising_'intelligibility/epistemicity/reflexivity-contiguity-

$<$ imbued-notional cogency $>$ ' of physics (rather into a 'supposedly reactivity notion of physics sublimation') with that of chemistry (rather into a 'supposedly action-and-reaction notion of chemistry sublimation') thus ending up rendering such supposed elucidation of physics and chemistry rather of 'ontologically-flawed existential-<disontologising/re-ontologising aporeticism $>$ gesturing/accounting - of-epistemic-phenomenalism conceptualisations' (even if both end up speaking of common terms associated with physics and chemistry like atoms, molecules, bonding, matter, measurements, etc.), with the result that both end up losing their 'veridical sublimating conceptivity/epistemic-reflexivity/epistemicity-relativism-determinism$<$ reifying \{as-to-knowledge-developing\}-and-empowering $>$ entailment' (and it is herein implied that as to the ontologising/scientific/existence- $<$ honesty-constraining $>$ scope_for_prospective_re-ontologising necessicity to abstractly account foreverything/epistemic-totalisingly ${ }^{33} /$ acutely/in-intolerance-<of-

disparateness>/exactifying_precisioningly, such will hypothetically be the most effective way of undermining physics and chemistry as to the luring notion of effective overt investment in physics and chemistry knowledge elucidation on the supposed legitimate basis respectively of a 'supposedly reactivity notion of physics sublimation' and a 'supposedly action-and-reaction notion of chemistry sublimation' while consciously or unconsciously destroying the prospective 
potential for physics and chemistry by such ontologically-flawed gesturing/accounting — ofepistemic-phenomenalism undermining of their 'ontologically-veridical given gesturing/accounting - of-epistemic-phenomenalism for sublimating conceptivity/epistemicreflexivity/epistemicity-relativism-determinism-<reifying \{as-to-knowledge-developing $\}$-andempowering> entailment' as of the veridically 'action-and-reaction notion of physics sublimation' and 'reactivity notion of chemistry sublimation' as to their 'phenomenological and associated epiphenomenological constructs'). In-many-ways it is herein asserted that the deficient/poor aptitudinal moronisation- $<$ sublimating-nascence,-extricatory-desublimatingdownstreaming/'avalage'> with which the comprehensive work of many a budding-postmodern thinker has been engaged with cannot truly be considered as of legitimate intellection and critique but rather speaks of 'blatant knowledge destroying strategising' driven by mere institutional-prescience/imprimaturing-<dullness-of the-spirit/psychologismic epistemicacutisation nonresidualising-imbued-\{compulsing\} finearity-in-eclecticism-of-prior-mereformulaicity/ritualisation $>$ (and in this regards, part-and-parcel of the requisite 'ontologising/scientific/existence- $<$ honesty-constraining $>$ — scope_for_prospective_reontologising implications of existential-<disontologising/re-entelogising aporeticism $>$ counteracting/supplanting/alienating-of-prior-apriorising/axiomatising/referencing' is to undermine disontologising-aggravation-〈in-want-for-prospective-aetiologisation/ontologicalescalation-<ontological-veridicality_commitment/otherliness_transcending/compulsionsencumbered_transcending $>>$ imbued ontological-bad-faith/inauthenticity ${ }^{64} \sim$ preconverging-dementating/structuring/paradigming ${ }^{5}$ by holding such prior-perspectivefalsity/falseness/fallaciousness into account beyond the naivety and vague impressiveness of 'ordinary laypersonhood arrogation/presumptuousness' and media nonsensical conception of sublimating social intellection as to vague popular impression). Critically in this respect, 'human psychologismic-epistemic-acutisation-<as-to-postconverging-de- 
mentating/structuring/paradigming,-eliciting-of-existence's-sublimating-nascence-in-

prospective-aporeticism-overcoming/unovercoming $>$ as to epistemic-growth,-as-

\{veridical/sound\}-relative-reflexivity-in-existence/relativising from-limited-mentation-as-its-

deepening/psychologismic epistemic-acutisation residualising, \{decompulsing ${ }^{2}$ delinearity for-

eogency' is simply the 'reflection of core-philosophy/derivative-core-philosophy-(imbued requisite 'inkling-drive of dimensionality-of-sublimating ${ }^{25}$

〈<amplituding/formative>supererogatory $\sim$ de-mentativeness/epistemic-growth-or-

conflatedness /transvaluative-rationalising/transepistemicity/anamnestic-residuality/spirit-

drivenness-equalisation)') implications of requisite profound-supererogation contemplation of overall human knowledge imbued experientiality/experiment-<as-to-existentially-formative‘\{epistemic-totalising ’’re-apriorising/re-axiomatising/re-referencing-residuality-in-re-

originariness/re-origination',--so- 'notionally/epistemically/bindingnessly-<as-to-

determinism/conceptivity-of-relative-unreflexivity/relative-reflexivity>-implicited-and-articulated'_as-from-

nonextricatory-'prospective-re-ontologising-Being-then-Institutional-then-Living-magnitudesof-\{hermeneutic/reprojection-protraction-of $\}$ reframing-and-reformulation \}'> (as beyond/sooverriding human segmentation and division-of-labour as of secondnatured institutionalisation induced prospective shallow-supererogation failing to reflect 'unlimitedness/existence-<fullpotency-of_sublimating nascence $>$ prospective apriorising/axiomatising/referencing sublimating-reflexivity-beholdening under which limitedness/human-subpotency submits in profound-supererogation for prospective sublimating')'; wherein '\{epistemic-totalising ${ }^{3\}}$ 'reapriorising/re-axiomatising/re-referencing $\sim$ residuality_-in-re-originariness/re-origination eliciting of epistemic-growth,-as - \{veridical/sound\}-relative-reflexivity-inexistence/relativising from-limited-mentation-as-its-deepening/psychologismic epistemicacutisation residualising, as to cogent/tense/limpid- $<$ asof-prospective-profound-supererogation ,-for-residuality-in-re-originariness/re-origination> 
epistemic-totalising ${ }^{3}$ 'apriorising/axiomatising/referencing disambiguating/de-leveling/deressentiment/opened-construct-of- ${ }^{5}$ meaningfulness-and-teleology 99 demoronisation<sublimating-nascence,-nonextricatory-sublimating-upstreaming/'amontée'>’)' is effectively what is central to postconverging aporeticism-overcoming/unovercoming 'ontologicallyveridical existential<<disontologising/re-ontologising - aporeticism $>$ gesturing/accounting — ofepistemic-phenomenalism conceptualisation' (as of the overaching epistemic-projection of ' nonpresencing-<perspective-ontological-normalcy/postconvergence $>$ relativism/relativescope for epistemic-growth,-as - \{veridical/sound\}-relative-reflexivity-inexistence/relativising from-limited-mentation-as-its-deepening/psychologismic epistemicacutisation residualising, ${ }^{\text {ddecompulsing }}$ delinearity for-cogency' imbued underlying-elucidative 'requisite sublimating/desublimating formulative-framing/fielding-of-entailment of human ontological-performance ${ }^{2}$-<including-virtue-as-ontology $>/$ morality/ethics/justice/etc.

contemplation' as of notionally implied ${ }^{4}$ foregrounding_entailment- $<$ in-succession-ofprofound-supererogation $>$-〈postconverging-narrowing-down $\sim$ sublimation-as-to-'existenceas-sublimating-withdrawal/unenframing/re-ontologising,-elicited-from-prospective-profoundsupererogation ' -in-reflecting-'immanent relative-unreflexivity/relative-reflexivity ontological-contiguity ';-as-operative-notional deprocrypticism)). The point here is that the prospective re-ontologising-failsafe-<as-to-'relative-unreflexivity/relative-reflexivity bindingness/nondiscretionariness' of totalising entailment $>$ that is the 'ontologising/scientific/existence- $<$ honesty-constraining $>$ — scope_for_prospective_reontologising implications of existential-<disontologising/re-ontologising aporeticism $>$ counteracting/supplanting/alienating-of-prior-apriorising/axiomatising/referencing' $\quad$ is effectively driven as of 'overarching existential-<disontologising/re-ontologising apereticism $>$ priority/precedence/primacy of requisite prospective ontological-goodfaith/authenticity ${ }^{6} \sim$ postconverging-de-mentating/structuring/paradigming 70 inducing of 
psychoanalytic-unshackling for the relative-ontological-completeness ${ }^{8}$-ofapriorising/axiomatising/referencing re-ontologising prospective re-rationalisation-ofcontentivity/argumentativity/dialecticism/discursivity'; with the implication here that it is profound-supererogation (as to its 'thinking at first/pure predisposition preemptive of prospective disontologising/subontologising') that can allow for prospective re-ontologising and so different from the shallow-supererogation of mere prior rationalisation-ofcontentivity/argumentativity/dialecticism/discursivity (which is not truly 'thinking at first/pure predisposition preemptive of prospective disontologising/subontologising but a conscious/unconscious rationalising/calculating of the sublimating outcome of prior profoundsupererogation rationalisation-of-contentivity/argumentativity/dialecticism/discursivity imbued positive-opportunism — of-social-functioning-and-accordance ${ }^{75}$ ) as in-effect it is rather a 'logical eliciting of conscious/unconscious positive-opportunism—of-social-functioning-andaccordance $^{75}$ as to constraining existential-<disontologising/re-ontologising aporeticism $>$ postconverging aporeticism-overcoming/unovercoming' (so-underlied as of human subconsciousness most-prospectively-conscious $\quad$ 're-ontologising-bydisontologising_existential-calculus-〈between_prospective existentialising postconverging_framing/imprinting re-ontologising' and 'prior existentialising preconverging_enframing/imprintedness social-functioning-and-accordance-as-of-socialstake-contention-or-confliction' $\rangle$ ' of consciousness surrealising-<as-to-supererogation $>$ ). This difference is critical because the condition for prospective re-ontologising as to the failsafe-<asto-'relative-unreflexivity/relative-reflexivity bindingness/nondiscretionariness' of totalisingentailment $>$ that is $\quad$ ontologising/scientific/existence- $<$ honesty-constraining $>$ scope_for_prospective_re-ontologising implications of existential-<disontologising/reentologising apereticism $>$ counteracting/supplanting/alienating-of-priorapriorising/axiomatising/referencing' (especially as of the difficulty associated with prospective 
sublimation of Being-development/ontological-framework-expansion-as-to-depth-ofontologising-development-as-infrastructure-of- meaningfulness-and-teleology

psychologismic epistemic-acutisation difficulty-for, residualising ${ }_{\text {\{decompulsing }}$ delinearity for-cogeney>-magnitude ${ }^{\{\text {of-experientiality/experiment }\}}$ ) is not one of a shallowsupererogation 'logical eliciting of conscious/unconscious positive-opportunism-of-socialfunctioning-and-accordance ${ }^{75}$ as to the constraining existential-<disontologising/reentologising aporeticism $\gtrsim$ postconverging aporeticism-overcoming/unovercoming' but rather speaks of the need for prospective profound-supererogation (as to its 'thinking at first/pure predisposition preemptive of prospective disontologising/subontologising') which is

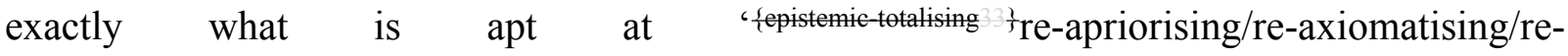
referencing $\sim$ residuality —in-re-originariness/re-origination with regards to the-very-same purview/devolved-purview/devolving-purview-of-unlimitedness/existence-<full-potency өf_sublimating nascence $>$; — 'implicited_attendant-ontological-contiguity ${ }^{67}$; educedexistentialising/contextualising/textualising_intelligibility/epistemicity/reflexivity-contiguity<imbued-notional cogency>' (whereas the shallow-supererogation of prior mere rationalisation-of-contentivity/argumentativity/dialecticism/discursivity which is not truly 'thinking at first/pure predisposition preemptive of prospective disontologising/subontologising but a conscious/unconscious rationalising/calculating of the sublimating outcome of prior profound-supererogation rationalisation-ofcontentivity/argumentativity/dialecticism/discursivity imbued positive-opportunism—of-socialfunctioning-and-accordance ${ }^{75}$, will rather prospectively digress into secondnatured prior mereformulaicity/ritualisation-<as-to-mere-formulaicmethodologising/mutualising/organising/institutionalising,-prospectively-losing-track-of‘ \{epistemic-totalising ’̀ re-apriorising/re-axiomatising/re-referencing rresiduality-in-reoriginariness/re-origination'> in the face of prospective postconverging apereticism- 
overcoming/mnovercoming). In other words (as to the underlying 'crossgenerational notional firstnaturedness-formativeness-<as-to-eventualising-inkling-drive-or-seeding-

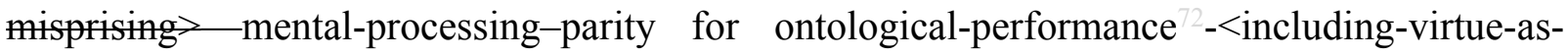
ontology $>$ /morality/ethics/justice/etc.' of all sovereign humans as to the potentiation of sublimating-over-desublimating), it will be very naïve to imply that our present-day 'mere positivism/rational-empiricism rationalisation-ofcontentivity/argumentativity/dialecticism/discursivity contemplation of say a heliocentric model as from our present-day social-setup inherited positivism/rational-empiricism $<$ amplituding/formative-epistemicity $>$-totalising $\sim$ thrownness-in-existence positivism/rational-empiricism 'reifying-mental-aestheticising-<as-of'prospective_reformulating-of-mental-aestheticising'as-to-'residuality-in-re-originariness/reorigination'-of-mental-aestheticising> educed processive-motif-'exuding aestheticisinggesturing' of apriorising/axiomatising/referencing as to re-aestheticisation-and-reaestheticisation-towards-ontology-<elicited-prospective-idiomatisation $>$ ')' is of the same profound-supererogation as from human 'crossgenerational notional firstnaturednessformativeness-<as-to-eventualising-inkling-drive-or-seeding-misprising $>$ mentalprocessing-parity for ontological-performance ${ }^{72}-<$ including-virtue-asontology $>$ /morality/ethics/justice/etc.' with a 'Galileo/Copernicus profound-supererogation projection of prospective positivism/rational-empiricism re-ontologising but rather as from their social-setup inherited non-positivism/medievalism <amplituding/formative-epistemicity $>$ totalising thrownness-in-existence ${ }^{35}$ (of non-positivism/medievalism prior 'dereifying-mentalaestheticising-<as-of-'prior_mere-formulaicity/ritualisation-of-mental-aestheticising'-failing‘residuality-in-re-originariness/re-origination'-of-mental-aestheticising $>$ as of the processivemotif-exuding aestheticising-gesturing' of apriorising/axiomatising/referencing of prior aestheticisation-and-aestheticisation-towards-ontology-<elicited-idiomatisation> ')' 
prospectively 'inventing'/'creating'-and-'nurturing' heliocentric model positivism/rationalempiricism re-rationalisation-of-contentivity/argumentativity/dialecticism/discursivity; as to the fact that 'prospective re-ontologising arises exactly out of profound-supererogation ${ }^{6}$ in the face of lack of prospective requisite <amplituding/formative-epistemicity $>$ totalising $\sim$ thrownness-in-existence re-rationalisation-ofcontentivity/argumentativity/dialecticism/discursivity', and not the naivety of supposedly projecting of prospective re-ontologising as from the '<amplituding/formative-epistemicity $>$ totalising $\sim$ thrownness-in-existence ${ }^{55}$ of prior rationalisation-ofcontentivity/argumentativity/dialecticism/discursivity as to shallow-supererogation'. The further implication here is that (with regards to the-very-same purview/devolvedpurview/devolving-purview-of-unlimitedness/existence-<full-potency-of_sublimating nascence>;-_'implicited_attendant-ontological-contiguity ${ }^{67}$ ' educedexistentialising/contextalising/textalising_'intelligibility/epistemicity/reflexivity_contiguity$<$ imbued-notional cogency>' as to 'limitedness/human-subpotency prospective reencountering/re-confrontation with unlimitedness/existence-<flll-potency-of_sublimating nascence $>$ ') 'human psychologismic-epistemic-acutisation-<as-to-postconverging-dementating/structuring/paradigming,-eliciting-of-existence's-sublimating-nascence-inprospective-aporeticism-overcoming/unovercoming $>$ as to epistemic-growth,-as\{veridical/sound\}-relative-reflexivity-in-existence/relativising from-limited-mentation-as-itsdeepening/psychologismic epistemic-acutisation residualising, fdecompulsingl delinearity for eogency' cannot be construed as of a naïve 'eclecticism-of-prior-mere-formulaicity/ritualisation$<$ as-of-prior $\sim$ rationalisation-of-contentivity/argumentativity/dialecticism/discursivity $>$ composition/blending-in-\{compulsing $\}$ linearity/linear-accretion of relative-ontologicalcompleteness and relative-ontological-incompleteness apriorising/axiomatising/referencing as to secondnatured prior mere-formulaicity/ritualisation- $<$ as-to-mere-formulaic 
methodologising/mutualising/organising/institutionalising,-prospectively-losing-track-of-

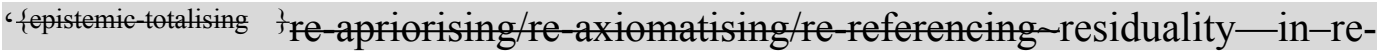

originariness/re-origination' $>$ ' that doesn't project of 'coherent/contiguous acuity/perspicacity/astuteness/edginess/incisiveness reflection of the-very-same purview/devolved-purview/devolving-purview-of-unlimitedness/existence-<full-potency ef_sublimating nascence>;-_implicited_attendant_ontological-contiguity ${ }^{67}$ ' educedexistentialising/contextmalising/textualising_'intelligibility/epistemicity/reflexivity_contiguity$<$ imbued-notional cogency> $>^{4}$ (as to cogent/tense/limpid-<as-of-prospective-profoundsupererogation ,-for-residuality-in-re-originariness/re-origination $>$ implicited contrast of relative-ontological-completeness ${ }^{87}$ over relative-ontological-incompleteness ${ }^{88}$ )'; such that with profound-

supererogation $\sim$ reframing/reformulation/decatchmenting/detruncating/decompulsing/delinear ising_scale_-of-transparent/noncontentious/un-nominalised/sound-interpretations/domains of manifest unblurriness-<re-ontologising_by-postconverging-as-to-dragged-outsupererogatory $\sim$ wholesomeness/profound-supererogation ,-while-anecdotalising-priordisontologising-thresholding $>\quad$ a requisite and core element of sublimating gesturing/accounting - of-epistemic-phenomenalism is the cogent/tense/limpid-<as-ofprospective-profound-supererogation ,-for-residuality-in-re-originariness/re-origination> elucidating of the precedence of the prospective-state-of-the-art over-and-thereafter the 'subordinating superseded successive prior-state-of-the-art as to the historial and formative account of epistemic-growth,-as-\{veridical/sound $\}$-relative-reflexivity-inexistence/relativising from-limited-mentation-as-its-deepening/psychologismic epistemicacutisation residualising, ${ }^{\text {\{decompulsing }}$ delinearity for cogeney' whereas with shallow supererogation $\sim$ framing/formulation/catchmenting/truncating/compulsing/linearising_scale —of-opaque/contentious/un-nominalised/flawed-interpretations/domains of manifest 


\section{blurriness- $<$ sterilising/anecdotalising/trivialising-of-prospective-re-ontologising_by-}

preconverging,-in-disontologising-formulaic-dragging-out/hollowing-out> the very notion of such disambiguation is absent and so-underlies their manifestations of disparateness-ofconceptualisation-<unforegrounding-ment,-failing-prospectively-to-reflect-

‘immanent $\sim$ relative- unreflexivity/relative-reflexivity - ontological-contiguity '> as to
totalisingly-ing — discretion/whim-of-thought 'apriorising/axiomatising/referencingequating/leveling/ressentiment/closed-construct-of- - meaningfulness-and-teleology moronisation-<sublimating-nascence,-extricatory-desublimating-downstreaming/'avalage'>' (as to an emphasis on institutional-prescience/imprimaturing-<dullness-of-thespirit/psychologismic epistemic acutisation nonresidualising-imbued-\{compulsing\}linearity ineclecticism-of-prior-mere-formulaicity/ritualisation $>$ and/or accessorising of 'ordinary laypersonhood arrogation/presumptuousness' conception of supposedly prospective sublimation). The 'driving-seat/centrality (for prospective postconvergingaaporeticismovercoming/unovercoming 'ontologically-veridical existential-<disontologising/reentologising aporeticism> gesturing/accounting —of-epistemic-phenomenalism conceptualisation') as rather taken-up by '\{epistemic-totalising ${ }^{3}$ ' $\mathrm{re}$-apriorising/re-axiomatising/rereferencing residuality — in-re-originariness/re-origination with regards to the-very-same purview/devolved-purview/devolving-purview-of-unlimitedness/existence-<full-potencyөf_sublimating nascence $>$; — 'implicited_attendant-ontological-contiguity ${ }^{67}$ ' educedexistentialising/contextmalising/textualising_'intelligibility/epistemicity/reflexivity_contiguity$<$ imbued-notional cogency>' (as to the cogent/tense/limpid-<as-of-prospective-profoundsupererogation ,-for-residuality—in-re-originariness/re-origination> overlaying/superstrating 'thrownness aestheticising' (of relative reflexivity in existence\}> sparsity of postconverging prospective-relative-ontological-completeness ${ }^{87}$-ofapriorising/axiomatising/referencing over sunderlaid/substrated 'thrownness-aestheticising' 
\{of-relative-unreflexivity in-existence $\}>$ profusion-of preconverging prior-relativeontological-incompleteness ${ }^{8}$-of-apriorising/axiomatising/referencing, that is more than just an 'eclecticism-of-prior-mere-formulaicity/ritualisation-<as-of-prior $\sim$ rationalisation-ofcontentivity/argumentativity/dialecticism/discursivity> composition/blending-in\{compulsing\}linearity/linear-accretion of relative-ontological-completeness and relativeontological-incompleteness apriorising/axiomatising/referencing as to secondnatured prior mere-formulaicity/ritualisation-<as-to-mere-formulaicmethodologising/mutualising/organising/institutionalising,-prospectively-losing-track-of‘fepistemic-talising ’’re-apriorising/re-axiomatising/re-referencing $r$ residuality-in-reoriginariness/re-origination' $>$, in $\quad$ moronisation- $<$ sublimating-nascence,-extricatory desublimating-downstreaming/'avalage'>) can be appreciated in the sense that even though much of Newtonian physics was developed by Newton (as underlaid with the physics of Galileo, Descartes, etc.) the 'cogent/tense/limpid-<as-of-prospective-profound-supererogation ,-forresiduality-in-re-originariness/re-origination $>$ sublimation emphasis on apriorising/re-axiomatising/re-referencing $\sim$ residuality-in-re-originariness/re-origination with regards to the-very-same purview/devolved-purview/devolving-purview-ofunlimitedness/existence-full potency of_sublimating nascence>;_-implicited_attendantontological-contiguity ${ }^{67}$, educedexistentialising/contextualising/textualising_intelligibility/epistemicity/reflexivity-contiguity<imbued-notional cogency>' meant that in-many-ways the prospect for still further prospective postconverging aporeticism-overcoming/unovercoming naturally required the adoption of Leibniz's notational presentation over Newtonian notational presentation (and the further cogent/tense/limpid-<as-of-prospective-profound-supererogation ,-for-residuality-inre-originariness/re-origination $>$ overlaying with say Maxwellian physics, Poincaréan physics, etc.). In this same respect, the previous theorising respectively of the Poincarés, Einsteins, Bohrs, 
Feynmans, etc. (as to their epochal seminality) 'could not be saved' from the prospective 'reentologising fepistemic-totalising ’’re-apriorising/re-axiomatising/re-referencing residuality in-reoriginariness/re-origination \{decompulsingt delinearity/delinear-accreting/recomposuring cogency/tensing/limpidity-<as-of-prospective-profound-supererogation ,-for-residuality-inre-originariness/re-origination>-,prospective_reifying mental-aestheticising-<as-of'prospective_reformulating-of-mental-aestheticising'as-to-'residuality in re-originariness/reerigination' of -mental-aestheticising $>$ ' with regards to the-very-same purview/devolvedpurview/devolving-purview-of-unlimitedness/existence-<full-potency-of_sublimating nascence $>$; - 'implicited_attendant-ontological-contiguity ${ }^{67}$ ' educedexistentialising/contextmalising/textualising_'intelligibility/epistemicity/reflexivity_contiguity$<$ imbued-notional cogency>' as from respectively the Einsteins, Bohrs, Feymans and the latter succeeding generation of physicists (however such previous physicists human mortal framing of reputation); and so in effective reflection of the uncompromising precedence and postconverging-de-mentating/structuring/paradigming of 'unlimitedness/existence- $<$ fullpotency-of_sublimating nascence> prospective apriorising/axiomatising/referencing sublimating-reflexivity — beholdening under which limitedness/human-subpotency submits in profound-supererogation for prospective sublimating' elicited as to transversality- $<$ forsublimating-existential-eventuating/denouement-from-'thinking-at-first/pure-predispositionpreemptive-of prospective-disontologising/subontologising' as-of-prospectivelydisambiguated-affirmed-and-unaffirmed-'motif-and-apriorising/axiomatising/referencing'> (having nothing to do with protracted-social-as-to-individual-by-institutional-by-social 'covert/overt privy/temporal/mortal terms of contemplation as to supposedly-prospectivethinking-purpose,-as-precalculated-purpose-<as-prospectively-losing-track-of-‘ \{epistemictotalising ${ }^{\prime}$ re-apriorising/re-axiomatising/re-referencing residuality-in-re-originariness/reorigination'-of-thinking >'). The above points out that it is exactly the-very-underlying-(as 
inherently 'defining-and-imbuing of limitedness/human-subpotency de-mentation〈supererogatory $\sim$ ontological-de-mentation-or-dialectical-de-mentation-stranding-orattributive-dialectics ${ }^{\prime}$ as to preconverging/postconverging-dementating/structuring/paradigming)—relationship-between-limitedness/human-subpotencyand-unlimitedness/existence-<full-potency-of_sublimating nascence $>$ with respect to the preeminence of the latter (as to 'limitedness/human-subpotency prospective re-encountering/reconfrontation with unlimitedness/existence-<full-potency-of_sublimating nascence $>$ '), as somanifested with profoundsupererogation $\sim$ reframing/reformulation/decatchmenting/detruncating/decompulsing/delinear ising_scale_of-transparent/noncontentious/un-nominalised/sound-interpretations/domains of manifest unblurriness-<re-ontologising_by-postconverging-as-to-dragged-outsupererogatory $\sim$ wholesomeness/profound-supererogation ,-while-anecdotalising-priordisontologising-thresholding>, that enables sublimating conceptivity/epistemicreflexivity/epistemicity-relativism-determinism-<reifying \{as-to-knowledge-developing $\}$-andempowering $>$ to arise; as to the fact that the sublimating is rather of 'unlimitedness/existence<full-potency-of_sublimating nascence> prospective apriorising/axiomatising/referencingsublimating-reflexivity-beholdening under which limitedness/human-subpotency submits in profound-supererogation for prospective sublimating' arising as to successive human mortals submission/subjection to unlimitedness/existence-<full-potency-of_sublimating nascence $>$ to elicit prospective sublimating (and 'not the inherent anointing of any human mortal/mortals as supposedly superseding unlimitedness/existence-<full-potency-of_sublimating nascence $>$ ' and so not even as of vague impression-driven/good-naturedness/wishfulness associated with presencing — absolutising-identitive-constitutedness ${ }^{14}$ advocacy/political/applicative — scope that cannot be confused with the 'more profound underlying sublimating potency of the ontologising/scientific/existence- $<$ honesty-constraining $>$ — scope_for_prospective_re- 
ontologising' as of its implied 'nonextricatory/postconverging ontologising-and-re-ontologising angling-of-imaginary demoronisation- $<$ sublimating-nascence,-nonextricatory-sublimatingupstreaming/'amontée'>'). The implication here is that the-very-same purview/devolvedpurview/devolving-purview-of-unlimitedness/existence-<fll-potency-of_sublimating nascence>;_—implicited_attendant-ontological-contiguity ${ }^{67}$ ' educedexistentialising/contextualising/textualising_'intelligibility/epistemicity/reflexivity_contiguity$<$ imbued-notional cogency>' (as to implicited 'requisite projection of the coherence/contiguity of the superseding-oneness-of-ontology/ontological-veridicality/relativeunreflexivity/relative-reflexivity - ontological-contiguity ${ }^{67}$ ') rather speaks of the 'reentologising \{epistemic-totalising ${ }^{+}$re-apriorising/re-axiomatising/re-referencing-residuality in-reoriginariness/re-origination $\{$ decompulsing\} $\}$ delinearity/delinear-accreting/recomposuring cogency/tensing/limpidity-<as-of-prospective-profound-supererogation ,-for-residuality—inre-originariness/re-origination>-,prospective_reifying mental-aestheticising-<as-of-

\section{'prospective_reformulating of mental-aestheticising'as-to-'residuality in re-originariness/re-} origination' of -mental-aestheticising $>$ ' underlying such an exercise of successive human mortals submission/subjection to unlimitedness/existence-<full-potency-of_sublimating naseence $>$ to elicit prospective sublimating and doesn't allow for discretion as of 'eclecticismof-prior-mere-formulaicity/ritualisation-<as-of-prior $\sim$ rationalisation-ofcontentivity/argumentativity/dialecticism/discursivity> composition/blending-incompusing linearity/linear-accretion of relative-ontological-completeness and relativeontological-incompleteness apriorising/axiomatising/referencing as to secondnatured prior mere-formulaicity/ritualisation-<as-to-mere-formulaicmethodologising/mutualising/organising/institutionalising,-prospectively-losing-track-of‘ \{epistemic-totalising ’̀ re-apriorising/re-axiomatising/re-referencing rresiduality-in-re-

originariness/re-origination'>' (with the latter manifested as to 'lack of prospectively educed- 
and-availing-and-re-availing

apriorising/axiomatising/referencing of

from relative-ontological-completeness ${ }^{87}$-of-

unlimitedness/existence-<flll potency-

of_sublimating naseence>'); such that inherently any prospective exercise of postconverging apereticism-overcoming/unovereoming has to demonstrate prospective relative-ontological-completeness ${ }^{87}$ and expose itself to be demonstrated as of either relativeontological-completeness $^{87}$ or relative-ontological-incompleteness ${ }^{88}$ (as to the requisite transversality-<for-sublimating-existential-eventuating/denouement,-from 'thinking-atfirst/pure predisposition -preemptive of prospective-disontologising/subontologising' as-ofprospectively-disambiguated-affirmed-and-unaffirmed-'motif-andapriorising/axiomatising/referencing' $>101 \quad$ imbuing $\quad{ }^{45}$ foregrounding_entailment- $<$ insuccession-of-profound-supererogation $>>$-〈postconverging-narrowing-down $\sim$ sublimation-asto-'existence - as-sublimating-withdrawal/unenframing/re-ontologising,-elicited-fromprospective-profound-supererogation ' '-in-reflecting-'immanent relativeunreflexivity/relative reflexivity —ontological-contiguity ';-as-operativenotional deprocrypticism $\rangle$ underlying 'human psychologismic-epistemic-acutisation-<as-topostconverging-de-mentating/structuring/paradigming,-eliciting-of-existence's-sublimatingnascence-in-prospective-aporeticism-overcoming/unovercoming > as to epistemic-growth,-as\{veridical/sound\}-relative-reflexivity-in-existence/relativising from-limited-mentation-as-itsdeepening/psychologismic epistemic acutisation residualising, eogency'). This insight (as to the 're-ontologising fepistemic-totalising 're-apriorising/reaxiomatising/re-refereneing residuality in-re-originariness/re-origination \{decompulsing $\}$ delinearity/delinear-accreting/recomposuring cogency/tensing/limpidity-<as-ofprospective-profound-supererogation ${ }^{\circ}$,-for-residuality—in-re-originariness/reorigination>-,prospective_reifying mental-aestheticising <as-0f 'prospective_reformulating of-mental-aestheticising'as-to 'residuality in re-originariness/re-origination' of mental- 
aestheticising $>$ ' implied with regards to 'human psychologismic-epistemic-acutisation-<as-topostconverging-de-mentating/structuring/paradigming,-eliciting-of-existence's-sublimatingnascence-in-prospective-aporeticism-overcoming/unovercoming > as to epistemic-growth,-as\{veridical/sound\}-relative-reflexivity-in-existence/relativising from-limited-mentation-as-itsdeepening/psychologismic epistemic-acutisation residualising, ${ }^{\text {\{decompulsing }}$ delinearity for eogency') covers the ambit of 'human aestheticisation-and-aestheticisation-towards-ontology$<$ elicited-idiomatisation $>$ overall imbuing of human ${ }^{56}$ meaningfulness-and-teleology ${ }^{9}$ in the sense that even mere aestheticisation does manifest re-aestheticising/re-motif- $<$ inpostconverging-narrowing-down $\sim$ 'sublimation-of-taste-

totalising ${ }^{3}$ hermeneutically/textually/reprojectingly/supererogatingly/zeroingly/re-acutingly,\{decompulsing $\}$ delinearity for-cogency-educing-conceptivity/epistemic-reflexivity/epistemicityrelativism-determinism-<reifying \{as-to-knowledge-developing $\}$-and-empowering $>$-ofhistoriality/ontological-eventfulness /ontological-aestheticising-tracing',-as-to-existenceas-sublimating-withdrawal/unenframing/re-ontologising,-elicited-from-prospective-profoundsupererogation $>$ (as to the fact that even the artistic or aestheticising is imbued of an underlying 'notional ontological-veracity of projection/re-projection-and-anticipation/re-anticipation'

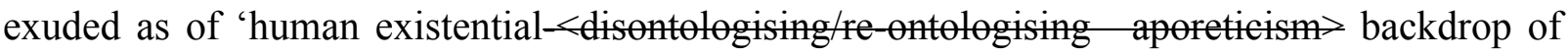
coherent/contiguous ${ }^{5}$ meaningfulness-and-teleology ${ }^{\circ}$, as so-enabling the intelligible appreciation of any given motif/motif-construct as aesthetics/arts and with the further implication that no motif/motif-construct can be construed as artistic/aesthetical without the underlying 'notional ontological-veracity of projection/re-projection-and-anticipation/reanticipation' exuded as of 'human existential-<disontologising/re-ontologising aporeticism $>$ backdrop of coherent/contiguous ${ }^{56}$ meaningfulness-and-teleology ${ }^{99}$ '). In this respect, 'lack of prospectively educed-and-availing-and-re-availing of relative-ontological-completeness ${ }^{87}$-ofapriorising/axiomatising/referencing from unlimitedness/existence-<full-potency 
ef_sublimating nascence $>$ (as to the-very-same purview/devolved-purview/devolvingpurview-of-unlimitedness/existence-<full-potency-of_sublimating nascence $>$; 'implicited_attendant-ontological-contiguity ${ }^{67}$; educedexistentialising/contextualising/textualising_intelligibility/epistemicity/reflexivity-contiguity$<$ imbued-notional $\left.\sim \operatorname{cogency}>{ }^{\prime}\right)^{\prime}$ ' should not be confused with shallowsupererogation $\sim$ framing/formulation/catchmenting/truncating/compulsing/linearising_scale —of-opaque/contentious/un-nominalised/flawed-interpretations/domains of manifest blurriness-<sterilising/anecdotalising/trivialising-of-prospective-re-ontologising_bypreconverging,-in-disontologising-formulaic-dragging-out/hollowing-out $>$ that seem to imply that certain domains are supposedly excepted of the ontologising/scientific/existence- $<$ honestyconstraining $>$ _ scope_for_prospective_re-ontologising (as to the fact that failing or being incapable or unwilling to do one's homework doesn't mean that the resolution to the homework doesn't exist as of potential prospective sublimating conceptivity/epistemicreflexivity/epistemicity-relativism-determinism-<reifying \{as-to-knowledge-developing $\}$-andempowering $>$ ). The $\quad$ ontologising/scientific/existence- $<$ honesty-constraining $>-$ scope_for_prospective_re-ontologising as such (as to its underlying educed sublimating ontological-performance $^{72}$-<including-virtue-as-ontology $>/$ morality/ethics/justice/etc. as from experientiality/experiment-<as-to-existentially-formative- ‘fepistemic-totalising $r$ re-apriorising/reaxiomatising/re-referencing -residuality-in-re-originariness/re-origination',- - so'notionally/epistemically/bindingnessly<ss-to-determinism/conceptivity-of-relative-mnreflexivity/relative-reflexivity> implicited-and-articulated'_as-from-nonextricatory-'prospective-re-ontologising-Being-thenInstitutional-then-Living-magnitudes-of-\{hermeneutic/reprojection-protraction-of $\}$ reframingand-reformulation $\}^{\prime}>$ ) effectively implies that there is 'no epistemic difference' between 'science as of its intolerance-<of-disparateness>/exactifying_precisioning-of-sublimation- $<$ asto-postconverging-narrowing-down apriorising/axiomatising/referencing-entailing- 
theoretical,-conceptual-and-operant-implications>' ${ }^{>}$and 'overall human

historiality/ontological-eventfulness 38 ontological-aesthetic-tracing-<perspective-

ontological-normalcy/postconvergence-reflected-'epistemicity-relativism-determinism'>' (as to the implications of 'limitedness/human-subpotency prospective re-encountering/reconfrontation with unlimitedness/existence-<full-potency-of_sublimating nascence $>$ ' with respect to 'the-very-same purview/devolved-purview/devolving-purview-ofunlimitedness/existence-<full-potency-of_sublimating_nascence>;_-implicited_attendantontological-contiguity ${ }^{67} \sim$ educedexistentialising/contextmalising/textualising_'intelligibility/epistemicity/reflexivity-contiguity<imbued-notional cogency $>^{\prime} \quad$ in $\quad\left\{\right.$ fepistemic-totalising ${ }^{3}$ 're-apriorising/re-axiomatising/rereferencing $\sim$ residuality—in-re-originariness/re-origination' so-undergirding epistemicgrowth,-as-\{veridical/sound\}-relative-reflexivity-in-existence/relativising from-limitedmentation-as-its-deepening/psychologismic epistemic-acutisation residualising, fdecompulsingt delinearity for-cogency); since both speak of the very same 'cogent/tense/limpid<as-of-prospective-profound-supererogation ,-for-residuality-in-re-originariness/reorigination> overlaying/superstrating 'thrownness-aestheticising' \{ $>$ of relative-reflexivity inexistence? $>$-sparsity of posteonverging prospective-relative-ontological-completeness ${ }^{8}$-ofapriorising/axiomatising/referencing in demoronisation-<sublimating-nascence,nonextricatory-sublimating-upstreaming/'amontée’> over < tnderlaid/substrated-'thrownnessaestheticising' \{of relative-unreflexivity in-existence\}> profusion-of preconverging priorrelative-ontological-incompleteness ${ }^{88}$-of-apriorising/axiomatising/referencing (that is more than just an 'eclecticism-of-prior-mere-formulaicity/ritualisation-<as-of-prior $\sim$ rationalisationof-contentivity/argumentativity/dialecticism/discursivity> composition/blending-in\{compulsing\}linearity/linear-accretion of relative-ontological-completeness and relativeontological-incompleteness apriorising/axiomatising/referencing as to secondnatured prior 
mere-formulaicity/ritualisation-<as-to-mere-formulaic-

methodologising/mutualising/organising/institutionalising,-prospectively-losing-track-of-

‘fepistemic-alising ’’re-apriorising/re-axiomatising/re-referencing residuality-in-re-

originariness/re-origination' $>$ ' in $\quad$ moronisation- $<$ sublimating-nascence,-extricatorydesublimating-downstreaming/'avalage'>)'. Rather it is the secondnatured prior mereformulaicity/ritualisation-<as-to-mere-formulaic-

methodologising/mutualising/organising/institutionalising,-prospectively-losing-track-of-

‘fepistemic talising łre-apriorising/re-axiomatising/re-referencing - residuality-in-re-

originariness/re-origination'> of human social practices of the sciences on-the-one-hand and social-sciences and humanities on-the-other-hand (construing of their 'material difference' with respect to 'their various nonhuman phenomena' and the 'various human consciousness-driven phenomena' as naively-and-wrongly implying their underlying 'epistemic difference' as to overall knowledge requisite \{epistemic-totalising 3 ? $\mathrm{re}$-apriorising/re-axiomatising/rereferencing residuality—in-re-originariness/re-origination) that induces an 'epistemic confusion' with regards to the overall underlying ontologising/scientific/existence- $<$ honestyconstraining $>$ — scope_for_prospective_re-ontologising (as to their respective 'ontologicallyveridical given gesturing/accounting-of-epistemic-phenomenalism for sublimating conceptivity/epistemic-reflexivity/epistemicity-relativism-determinism-<reifying \{as-toknowledge-developing\}-and-empowering> entailment'); as the overall underlying ontologising/scientific/existence- $<$ honesty-constraining $>$ — scope_for_prospective_reontologising effectively speaks of the 'experientiality/experiment-<as-to-existentiallyformative- '\{epistemic-totalising ’re-apriorising/re-axiomatising/re-referencing $r$ residuality-in-reoriginariness/re-origination', - so-'notionally/epistemieally/bindingnessly-<as-todeterminism/conceptivity-of-relative-unreflexivity/relative-reflexivity>-implicited-and-articulated'_as-fromnonextricatory-'prospective-re-ontologising-Being-then-Institutional-then-Living-magnitudes- 
of-\{hermeneutic/reprojection -protraction-of $\}$ reframing-and-reformulation $\}^{\prime}>\quad$ fact' that intolerance-<of-disparateness>/exactifying_precisioning-of-sublimation-<as-topostconverging-narrowing-down apriorising/axiomatising/referencing-entailing-theoretical,conceptual-and-operant-implications $>$ ' is epistemically same as 'overall human

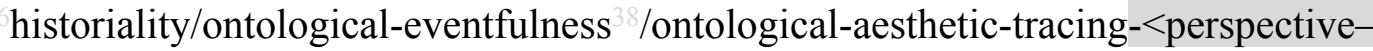
ontological-normalcy/postconvergence-reflected-'epistemicity-relativism-determinism'>' as to overall knowledge requisite \{epistemic-totalising 3 ? $\mathrm{re}$-apriorising/re-axiomatising/rereferencing $\sim$ residuality—in-re-originariness/re-origination). The requisite 'ontologising/scientific/existence- $<$ honesty-constraining $>$ — scope_for_prospective_reontologising implications of existential-<disontologising/re-ontologising aporeticism $>$ counteracting/supplanting/alienating-of-prior-apriorising/axiomatising/referencing' (with regards to 'human psychologismic-epistemic-acutisation-<as-to-postconverging-dementating/structuring/paradigming,-eliciting-of-existence's-sublimating-nascence-inprospective-aporeticism-overcoming/unovercoming > as to epistemic-growth,-as\{veridical/sound\}-relative-reflexivity-in-existence/relativising from-limited-mentation-as-itsdeepening/psychologismic epistemic-acutisation residualising, $\left.{ }^{\{d e c o m p u l s i n g}\right\}$ delinearity foreogey') is effectively underlied as of the above elucidated failsafe-as 'relative unreflexivity/relative-reflexivity bindingness/nondiscretionariness' of totalising-entailment> (as to underlying 'constraining existence-as-sublimating-withdrawal/unenframing/reontologising,-elicited-from-prospective-profound-supererogation imbuing human ontological-commitment $-<$ implied-self-assuredness-of-ontological-goodfaith/authenticity $\sim$ postconverging-de-mentating/structuring/paradigming -as-being-as-ofexistential-reality>' and ' ${ }^{103}$ universal-transparency ${ }^{104}$-〈transparency-of-totalising-entailing,-asto-entailing-<amplituding/formative-epistemicity $>$ totalising $\sim$ in-relative-ontologicalcompleteness > as available-to/elicitable-to-〈as-to-human-consciousness/collective- 
consciousness-distendedness/detruncating- $<$ beyond-selfpresencing,-as-re-ontologising-

decentering_of-consciousness/collective-consciousness,-as-to-psychologismic-epistemicacutisation-residualising, - $^{\text {fdecompulsing }}$ delinearity for-cogency $>>$ the social-functioning-andaccordance - as-of-social-stake-contention-or-confliction conception of any given registryworldview/dimension $\quad$ <preconverging 'motif-and-apriorising/axiomatising/referencing'entailing $>$-existentialising — enframing/imprintedness-〈as-to- historicity-tracing - inpresencing-hyperrealisation/hyperreal-transposition〉'); in so 'de-privying/renderinguniversally-transparent ontological-veracity with regards to prospective postconverging apereticism of either blurriness-<sterilising/anecdotalising/trivialising-of-prospective-re-ontologising_bypreconverging,-in-disontologising-formulaic-dragging-out/hollowing-out> or unblurriness$<$ re-ontologising_by-postconverging-as-to-dragged-out-

supererogatory $\sim$ wholesomeness/profound-supererogation ,-while-anecdotalising-priordisontologising-thresholding $>$ ). In this regards, 'there can't be a privy issue' of the ontologising/scientific/existence- $<$ honesty-constraining $>$ — scope_for_prospective_reontologising in the sense that 'claims of ontological-veracity/ontological-inveracity' are much more than 'privy purposes claims' as to the direct or indirect sublimating/desublimating effect on all humans (whether so conscious or unconscious of the sublimating/desublimating effect), and such that supposed technicians, experts, intellectuals, etc. (so-defined as of human socially expanded framework of deferential-formalisation-transference as to various cultivated skills/arts and time investment) cannot truly have 'privy purposes disagreements of ontologicalveracity/ontological-inveracity' since the subsequent manifestation of defective products, regulations, practices, policies will ultimately directly or indirectly affect the general public (as to the human sovereign-function/posture-<as-to-existentially-manifest-'embodiedsubject consciousness-and-direct/deferential-conscientiousness',-as-of-its-'epistemic- 
reflexivity/unreflexivity-in-existence'/teleology>) however the latter levels of conscious or unconscious awareness of the sublimating/desublimating effect; thus implying that consciously cynical pedantising/muddling/formulaic-hollowing-out_-in-subontologisation/subpotentiation〈blurring/undermining-of-prospective-totalising-entailing,-as-to-entailing$<$ amplituding/formative-epistemicity>totalising in-relative-ontological-completeness > inclination to undermine prospective sublimating are in-effect a surreptitious subverting of underlying human sovereign-function/posture-<as-to-existentially-manifest-'embodiedsubject consciousness-and-direct/deferential-conscientiousness',-as-of-its- 'epistemicreflexivity/unreflexivity-in-existence'/teleology> prospective sublimation/emancipation/enfranchisement. This in-many-ways explains why the respective prospective re-ontologising of ${ }^{103}$ universalising-idealisation, positivism/rational-empiricism and deprocrypticism-or-preempting-disjointedness-as-of- ${ }^{3}$ reference-of-thought effectively

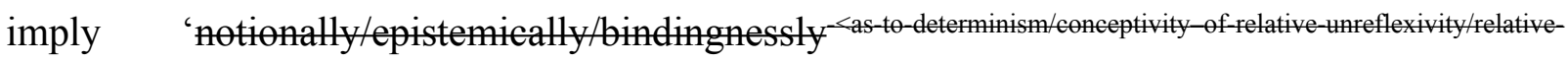
reflexivity $>$ locking-in' their respective prior disontologising non-universalising ancient-sophists, non-positivising medieval-scholasticism and our modern-day disparateness-ofconceptualisation-<unforegrounding-ment,-failing-prospectively-to-reflect‘immanent relative-unreflexivity/relative-reflexivity ontological-contiguity in preempting such conscious/unconscious surreptitiously implicited 'privy purposes disagreements of ontological-veracity/ontological-inveracity' (and as to the overall relativeunreflexivity/relative-reflexivity — ontological-contiguity ${ }^{67}$ of-the-human-institutionalisationprocess ${ }^{6}$ imbued 'human psychologismic-epistemic-acutisation-<as-to-postconverging-dementating/structuring/paradigming,-eliciting-of-existence's-sublimating-nascence-inprospective-aporeticism-overcoming/unovercoming $>$ as to epistemic-growth,-as\{veridical/sound\}-relative-reflexivity-in-existence/relativising from-limited-mentation-as-itsdeepening/psychologismic epistemic-acutisation residualising, decompulsingl delinearity for- 
eogency'). In this regards, the failsafe-<as-to-'relative-unreflexivity/relative-reflexivitybindingness/nondiscretionariness' of-totalising-entailment $>$ that is the 'ontologising/scientific/existence- $<$ honesty-constraining $>$ — scope_for_prospective_reontologising implications of existential<<disontologising/re-ontologising aporeticism $>$ counteracting/supplanting/alienating-of-prior-apriorising/axiomatising/referencing' (with regards to the overall relative-unreflexivity/relative-reflexivity ontological-contiguity ${ }^{67}$ ofthe-human-institutionalisation-process ${ }^{68}$ ) can effectively be construed as 'driving prospective intolerance-<of-disparateness>/exactifying_precisioning-of-sublimation-<as-topostconverging-narrowing-down apriorising/axiomatising/referencing-entailing-theoretical,conceptual-and-operant-implications $>^{\prime}$ of the overaching epistemic-projection of ' ${ }^{\text {nonpresencing- }<\text { perspective-ontological-normalcy/postconvergence }>\quad \text { relativism/relative- }}$ scope for epistemic-growth,-as-\{veridical/sound\}-relative-reflexivity-inexistence/relativising from-limited-mentation-as-its-deepening/psychologismic epistemic-

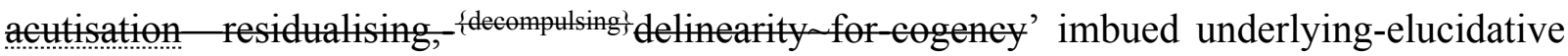
'requisite sublimating/desublimating formulative-framing/fielding-of-entailment of human ontological-performance ${ }^{72}$-<including-virtue-as-ontology $>/$ morality/ethics/justice/etc. contemplation' as of notionally implied ${ }^{45}$ foregrounding_entailment- $<$ in-succession-ofprofound-supererogation $>$ - $\langle$ postconverging-narrowing-down $\sim$ sublimation-as-to-'existenceas-sublimating-withdrawal/unenframing/re-ontologising,-elicited-from-prospective-profoundsupererogation '-in-reflecting-'immanent relative-unreflexivity/relative-reflexivity ontological-contiguity ';-as-operative-notional deprocrypticism). The uncompromising precedence and postconverging-de-mentating/structuring/paradigming of 'unlimitedness/existence-<full-potency-of_sublimating nascence $>$ prospective apriorising/axiomatising/referencing-sublimating-reflexivity-beholdening under which limitedness/human-subpotency submits in profound-supererogation for prospective 
sublimating' implies that 'ontologically-veridical existential-<disontologising/reentologising aporeticism> gesturing/accounting_of-epistemic-phenomenalism conceptualisation' is not as of 'eclecticism-of-prior-mere-formulaicity/ritualisation-<as-ofprior $\sim$ rationalisation-of-contentivity/argumentativity/dialecticism/discursivity $>$ composition/blending-in_\{compulsing $\}$ linearity/linear-accretion of sunderlaid/substrated'thrownness-aestheticising'-\{of-relative-unreflexivity in-existence $\}>$ profusion-ofpreconverging prior-relative-ontological-incompleteness -ofapriorising/axiomatising/referencing and overlaying/superstrating 'thrownness-aestheticising' \{of-relative-reflexivity in-existence $\}>$-sparsity-of postconverging prospective-relativeontological-completeness -of-apriorising/axiomatising/referencing' but is rather utterly of prospective 're-ontologising \{epistemic-totalising tre-apriorising/re-axiomatising/rereferencing residuality in re-originariness/re-origination \{decompulsing\} delinearity/delinearaccreting/recomposuring cogency/tensing/limpidity-<as-of-prospective-profoundsupererogation ,-for-residuality-in-re-originariness/re-origination $>$, prospective_reifying mental-aestheticising <as-of 'prospective_reformulating of mental-aestheticising' as-to'residuality in-re-originariness/re-origination'-of-mental-aestheticising ${ }^{\prime} \quad$ epistemicprojection (as to postconverging-de-mentating/structuring/paradigming overlaying/superstrating 'thrownness-aestheticising' \{of-relative-reflexivity in-existence\}> sparsity-of postconverging prospective-relative-ontological-completeness ${ }^{87}$-ofapriorising/axiomatising/referencing) induced psychoanalytic-unshackling; and as previously indicated the overly abundant/generous elucidation herein is critically to reflect this underlying effective psychoanalytic-unshackling depth of demoronisation-<sublimating-nascence,-sublimating-upstreaming/'amontée'> (as to implicited metaphoricity ${ }^{57}$ beyond our natural positivism- ${ }^{80}$ procrypticism predisposition of procession- $<$ as-to-constructiveveracity/inveracity_of-apriorising/axiomatising/referencing $>$ ). That said the ontological- 
veracity of such underlying 'existential-<disontologising/re-ontologising aporeticism> counteracting/supplanting/alienating-of-prior-apriorising/axiomatising/referencing inducing of human epistemic-growth,-as - \{veridical/sound\}-relative-reflexivity-in-existence/relativising from-limited-mentation-as-its-deepening/psychologismic epistemic-acutisationresidualising, ${ }^{\{\text {decompulsing }}$ delinearity for-cogency' is effectively understandable with institutional-development-as-to-social-function-development and living-development-as-topersonality-development psychologismic epistemic-acutisation difficulty $<$ for, residualising - magnitudes \{of-experientiality/experiment\} (notwithstanding the disinhibition/complexification arising when it comes to Beingdevelopment/ontological-framework-expansion-as-to-depth-of-ontologising-development-asinfrastructure-of- meaningfulness-and-teleology psychologismic epistemic-acutisationdifficulty $<$ for, residualising \{decompulsing\} $\}$ delinearity for-cogeney> $>$ magnitude $\{$ ofexperientiality/experiment\}). It is rather such an ontologically-flawed 'eclecticism-of-prior-mereformulaicity/ritualisation-<as-of-prior $\sim$ rationalisation-ofcontentivity/argumentativity/dialecticism/discursivity> composition/blending-in\{compulsing\} linearity/linear-accretion of sunderlaid/substrated-'thrownness-aestheticising' fofrelative unreflexivity in existence\}> profusion of preconverging prior-relative-ontologicalincompleteness -of-apriorising/axiomatising/referencing and overlaying/superstrating 'thrownness-aestheticising'-\{of-relative-reflexivity in-existence\}>-sparsity-ofpostconverging prospective-relative-ontological-completeness -ofapriorising/axiomatising/referencing' that effectively underlies any prospectively uninstitutionalised-threshold ${ }^{102}$; as to the fact that the latter is fundamentally underlied by the prior 'dereifying-mental-aestheticising-<as-of-'prior_mere-formulaicity/ritualisation-ofmental-aestheticising'-failing-'residuality_-in-re-originariness/re-origination'-of-mentalaestheticising $>$ as of the processive-motif-exuding aestheticising-gesturing' of- 
apriorising/axiomatising/referencing of prior aestheticisation-and-aestheticisation-towardsontology-<elicited-idiomatisation>' (imbued credibility/credulity-induced-processive-assentto-moronisation- $<$ sublimating-nascence,-extricatory-desublimatingdownstreaming/'avalage'>) notwithstanding the accruing/accummulating overlaying/superstrating 'thrownness-aestheticising' \{of-relative-reflexivity in-existence $\}>$ sparsity-of-postconverging-prospective-relative-ontological-completeness ${ }^{87}$-ofapriorising/axiomatising/referencing in want for its very own prospective 'reifying-mentalaestheticising-<as-of-'prospective_reformulating-of-mental-aestheticising'as-to-'residuality_in-re-originariness/re-origination'-of-mental-aestheticising $>$ educed processive-motif'exuding aestheticising-gesturing'-of-apriorising/axiomatising/referencing as to reaestheticisation-and-re-aestheticisation-towards-ontology-<elicited-prospectiveidiomatisation>' (imbued incredibility/incredulity-induced-processive-dissent-indemoronisation- $<$ sublimating-nascence,-nonextricatory-sublimatingupstreaming/'amontée'>). This explains why a mere circumstantial thorough positivism/rational-empiricism elucidation in animistic social-setup is not a positivism/rationalempiricism transformation of the said animistic social-setup knowledge value inclination (as to the animistic social-setup 'dereifying-mental-aestheticising-<as-of-'prior_mereformulaicity/ritualisation-of-mental-aestheticising'-failing-'residuality-in-re-originariness/reorigination'-of-mental-aestheticising $>$ as of the processive-motif-exuding aestheticisinggesturing'-of-apriorising/axiomatising/referencing of prior aestheticisation-andaestheticisation-towards-ontology-<elicited-idiomatisation $>$ ' imbued desublimating-andresidually-unaccounted-for-apriorising/axiomatising/referencing processing as of prior 'human consciousness/collective-consciousness representation/unity/comprehensiveness of the institutional/bureaucratic/social and their purposefulness' constructive-inveracity 'associated with the animistic social-setup ${ }^{83}$ reference-of-thought-and- ${ }^{83}$ reference-of-thought- ${ }^{8}$ devolving 
mysticising-processive-motif-'exuding aestheticising-gesturing' of-

apriorising/axiomatising/referencing'). Such that notwithstanding this elucidation of prospective re-ontologising-failsafe-<as-to-'relative-unreflexivity/relative-reflexivity-

bindingness/nondiscretionariness' of totalising-entailment $>$ that is the 'ontologising/scientific/existence- $<$ honesty-constraining $>$ — scope_for_prospective_re-

ontologising implications of existential-<disontelogising/re-ontelogising apereticism $>$ counteracting/supplanting/alienating-of-prior-apriorising/axiomatising/referencing', that doesn't cancel the fact that (as with the animistic social-setup example above) 'abstract ontological-veracity is not the sufficient basis for registry-worldviews/dimensions contemplation of prospective re-ontologising-failsafe-<as-to-'relative-unreflexivity/relativereflexivity bindingness/nondiscretionariness, of totalising-entailment $>$ (that is the 'ontologising/scientific/existence- $<$ honesty-constraining $>$ — scope_for_prospective_reontologising implications of existential-<disontologising/re-ontologising aporeticism $>$ counteracting/supplanting/alienating-of-prior-apriorising/axiomatising/referencing)'; as in effect the failsafe-<as-to-'relative-unreflexivity/relative-reflexivity_ bindingness/nondiscretionariness' of totalising-entailment $>$ is rather underlied as of its constraining ramifications of crossgenerational existential-disontologising/re-ontologising aporeticism $>$ import upon 'social-functioning-and-accordance-as-of-social-stake-contentionor-confliction imbuing existentialising-frame-of-entailment of motif-andapriorising/axiomatising/referencing of disontologising/ontologising-and-re-ontologising' (à la Diderot and Encyclopédistes active crossgenerational epistemic-projection or overall buddingpositivists passive crossgenerational epistemic-projection of the ontologising/scientific/existence- $<$ honesty-constraining $>$ — scope_for_prospective_reontologising), as so-associated with the overall transformation of processive-motif-exuding aestheticising-gesturing' of-apriorising/axiomatising/referencing so-underlying the relative- 
ontological-completeness ${ }^{87}$-of-apriorising/axiomatising/referencing re-ontologising prospective re-rationalisation-of-contentivity/argumentativity/dialecticism/discursivity. Thus the uninstitutionalised-threshold ${ }^{102}$ (as of such 'eclecticism-of-prior-mereformulaicity/ritualisation-<as-of-prior $\sim$ rationalisation-ofcontentivity/argumentativity/dialecticism/discursivity> composition/blending-in\{compulsing\} linearity/linear-accretion of <underlaid/substrated-'thrownness-aestheticising'-\{ofrelative-unreflexivity in-existence $\}>$ profusion-of preconverging prior-relative-ontologicalincompleteness -of-apriorising/axiomatising/referencing and overlaying/superstrating'thrownness-aestheticising' \{of-relative-reflexivity in-existence\}>-sparsity-ofpostconverging prospective-relative-ontological-completeness -ofapriorising/axiomatising/referencing') is a reflection of the 'deficiency of the notion of facticity/factness as to a presencing-absolutising-identitive-constitutedness conceptualisation' (so-reflected historially as of 'dominance/vested-interest structure in relativeontological-incompleteness ${ }^{8}$-presublimation-construct-of- meaningfulness-and-teleology desublimating $\sim$ existentialising-decisionality-<as-to-disontologising/re-ontologising aporeticism $>$ ' as from the 'dereifying-mental-aestheticising-<as-of-'prior_mereformulaicity/ritualisation-of-mental-aestheticising'-failing-'residuality-in-re-originariness/reorigination'-of-mental-aestheticising $>$ as of the processive-motif-exuding aestheticisinggesturing' of apriorising/axiomatising/referencing of prior aestheticisation-andaestheticisation-towards-ontology-<elicited-idiomatisation> $>^{\prime}$ of blatant brutish conquest/subjugation conception of apportioning implied factness/fact, dominion protection conception of apportioning implied factness/fact, to the very natural-order-of-things conception of apportioning implied factness/fact and to our subtle modern-day institutionallydistorted/disjointed conception of apportioning implied factness/fact); given that it fails to reflect 'unlimitedness/existence-<full-potency-of_sublimating nascence> prospective 
apriorising/axiomatising/referencing-sublimating-reflexivity-beholdening under which limitedness/human-subpotency submits in profound-supererogation for prospective sublimating' and supposedly seem to imply that any notion of fact/factness can be segregrated from the epistemic-projection of ' nonpresencing-<perspective-ontologicalnormalcy/postconvergence $>\quad$ relativism/relative-scope for epistemic-growth,-as\{veridical/sound\}-relative-reflexivity-in-existence/relativising from-limited-mentation-as-its-

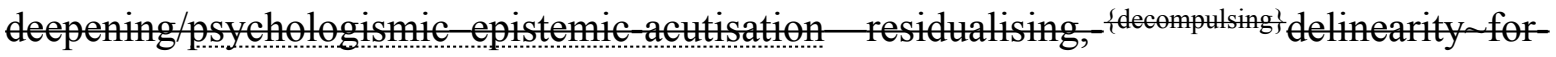
eogency' and failing to then account for the human $<$ amplituding/formative $>$ disposedness/psychologismic-construct-_as-to-orientation/valueconstruct/valuation-and-derived-parameterising $\rangle$ and $<$ amplituding/formative $>$ entailment-〈asto-totalising-contiguous/coherent-factuality-of-variability) (so-underlying 'human psychologismic-epistemic-acutisation-<as-to-postconverging-de-

mentating/structuring/paradigming,-eliciting-of-existence's-sublimating-nascence-inprospective-aporeticism-overcoming/unovercoming > as to epistemic-growth,-as\{veridieal/sound\}-relative-reflexivity-in-existence/relativising from limited mentation as its deepening/psychologismic epistemic acutisation residualising, ${ }^{\text {fdecompulsing }}$ delinearity foreogency'). In this regards, the notion of a rock speaks to its central significance as a potential weapon, a totem, a mineral resource, a construction material, etc. as of the 'ontologising/scientific/existence- $<$ honesty-constraining $>$ — scope_for_prospective_reontologising potential' as to the indissociable level of epistemic-growth,-as — \{veridical/sound\} relative-reflexivity-in-existence/relativising from-limited-mentation-as-itsdeepening/psychologismic epistemic-acutisation residualising, \{decompulsing $\}$ delinearity foreogency attached to the conceptualisation of the rock. In-the-bigger-picture, such a defective conception of fact/factness (with regards to the 'deficiency of the notion of facticity/factness as to a presencing-absolutising-identitive-constitutedness ${ }^{14}$ conceptualisation') is in-effect 
consciously/unconsciously inherently manifested as to the uninstitutionalised-threshold implications of the 'eclecticism-of-prior-mere-formulaicity/ritualisation- $<$ as-ofprior $\sim$ rationalisation-of-contentivity/argumentativity/dialecticism/discursivity $>$ composition/blending-in-\{compulsing\} linearity/linear-accretion of sunderlaid/substrated'thrownness-aestheticising' \{of-relative unreflexivity in-existence $\}>$ profusion-ofpreconverging-prior-relative-ontological-incompleteness -ofapriorising/axiomatising/referencing and overlaying/superstrating 'thrownness-aestheticising' $\{$ fof-relative-reflexivity in-existence\} $>$-sparsity-of-postconverging prospective-relativeontological-completeness -of-apriorising/axiomatising/referencing' underlied by the 'dereifying-mental-aestheticising-<as-of-'prior_mere-formulaicity/ritualisation-of-mentalaestheticising'-failing-'residuality-in-re-originariness/re-origination'-of-mentalaestheticising $>$ as of the processive-motif-'exuding-aestheticising-gesturing' ofapriorising/axiomatising/referencing of prior aestheticisation-and-aestheticisation-towardsontology-<elicited-idiomatisation>'. In this respect, the lack of a 're-ontologising epistemictre-apriorising/re-axiomatising/re-referencing residuality in-re-originariness/reorigination \{decompulsing\} delinearity/delinear-acereting/recomposuring cogency/tensing/limpidity$<$ as-of-prospective-profound-supererogation ,-for-residuality-in-re-originariness/reorigination $>$, p prospective_reifying mental-aestheticising_<as-of 'prospective_reformulating of-mental-aestheticising'as-to-'residuality in -re-originariness/re-origination' of mentalaestheticising $>$ ' epistemic-projection about factness/fact as to 'limitedness/human-subpotency prospective re-encountering/re-confrontation with unlimitedness/existence-<flll-potency of_sublimating nascence>' (as rather warranting 'reifying-mental-aestheticising-<as-of'prospective_reformulating-of-mental-aestheticising'as-to-'residuality-in-re-originariness/reorigination'-of-mental-aestheticising> educed processive-motif-'exuding aestheticisinggesturing' of apriorising/axiomatising/referencing as to re-aestheticisation-and-re- 
aestheticisation-towards-ontology-<elicited-prospective-idiomatisation $>$ ') is effectively what prospectively induces \{flawed/unsound\}-relative-unreflexivity-in-existence/absolutising fromlimited-mentation/psychologismic epistemic acutisation nonresidualising imbued\{compulsing\} linearityoin-eclecticism-of prior-mere-formulaicity/ritualisation 'apriorising/axiomatising/referencing_equating/leveling/ressentiment/closed-construct-ofmeaningfulness-and-teleology $\quad$ moronisation- $<$ sublimating-nascence,-extricatorydesublimating-downstreaming/'avalage'>’; as to falsely calling up its given registryworldview/dimension imbued prior-institutionalisation-threshold-by-prospectiveuninstitutionalised-threshold $\quad$ 'self-referencing-syncretising forward-facingsupposedly postconverging-or-dialectical-thinking -apriorising-psychologism epistemicprojection as of prior mere-formulaicity/ritualisation-<as-to-mere-formulaicmethodologising/mutualising/organising/institutionalising,-prospectively-losing-track-of‘\{epistemic-totalising ’re-apriorising/re-axiomatising/re-referencing $\sim$ residuality-in-reoriginariness/re-origination'>' so-reflecting its 'disontologising preconverging/dementing $<$ as-to-prospective-uninstitutionalised-threshold $>$ ignoring/biased inclination' for the sake of 'its given present minimum-and-balancing expectations/anticipations of social-functioning-andaccordance-as-of-social-stake-contention-or-confliction' while qualifying its prospectively uninstitutionalised-threshold ${ }^{102}$ actually as nondescript/ignorable-void ${ }^{6}$ as to its ${ }^{79}$ presencingabsolutising-identitive-constitutedness $<$ preconverging 'motif-andapriorising/axiomatising/referencing'-entailing >-existentialising — enframing/imprintedness〈as-to- historicity-tracing - in-presencing-hyperrealisation/hyperreal-transposition〉'. This is manifested in our modern-day disparateness-of-conceptualisation-<unforegrounding-ment,failing-prospectively-to-reflect- 'immanent relative- unreflexivity/relative-reflexivity ontological-contiguity '> (factness/fact implications of $>$ our procrypticising/subtranslational/subnotionality/subepistemicity-processive-motif-'exuding 
aestheticising-gesturing' of apriorising/axiomatising/referencing - as-to-occlusive-

consciousness $\sim$ moronisation/demoronisation

'dereifying-mental-aestheticising-<as-of-

'prior_mere-formulaicity/ritualisation-of-mental-aestheticising'-failing-'residuality - in-re-

originariness/re-origination'-of-mental-aestheticising $>$ as of the processive-motif-exuding aestheticising gesturing' of apriorising/axiomatising/referencing of prior aestheticisation-andaestheticisation-towards-ontology-<elicited-idiomatisation>') associated for instance with media, marketing and entertainment usage of ratings' wherein a 'mere numerative conception' (as to the cultivation and enculturation of shallow attention-grabbing and superficial interest) is in-many-ways increasingly translated into the undergirding-and-defining prospective possibility of overall human aestheticising and imagination for prospective aestheticisation on-the-one-hand and with regards to aestheticisation-towards-ontology on-the-other-hand is associated for instance with the 'mere conception of numbers/statistics/mathematics and scientific experimentation/observation/survey designs in the social' as inherently defining of sublimating ontological-veracity (notwithstanding the poor elucidation of a 're-ontologising epistemictratising 're-apriorising/re-axiomatising/re-referencing-residuality in re-originariness/reorigination \{decompulsing\} delinearity/delinear-acereting/recomposuring cogency/tensing/limpidity<as-of-prospective-profound-supererogation ,-for-residuality-in-re-originariness/reorigination $>$, p prospective_reifying mental-aestheticising_<as-of 'prospective_reformulating of-mental-aestheticising'as-to-'residuality in-re-originariness/re-origination' of-mentalaestheticising $>$ ' epistemic-projection about factness/fact); and so as such factness/fact implications ontologically-flawed processive-motif-'exuding aestheticising gesturing' of apriorising/axiomatising/referencing so define-and-undergird human 'information crisis' and 'crisis of contemplation/reflection' as well as 'institutional and social crises and malaises manifested in the socio-econo-political domains' (which are effectively all interlinked), as to when such superficiality (of poor elucidation of a 're-ontologising fepistemic-totalising 're- 
apriorising/re-axiomatising/re-referencing residuality in-re-originariness/re-origination $\{$ decompulsing $\}$ delinearity/delinear-accreting/recomposuring $\quad$ cogency/tensing/limpidity-<as-ofprospective-profound-supererogation ,-for-residuality-in-re-originariness/reorigination $>$,-prospective_reifying mental-aestheticising <as-of 'prospective_reformulating of-mental-aestheticising'as-to 'residuality in-re-originariness/re-origination' of-mentalaestheticising>' epistemic-projection about factness/fact) threatens to submerge the genuine social intellectual-function/posture re-ontologising (as the ontologically-flawed factness/fact practices of our ${ }^{79}$ presencing-absolutising-identitive-constitutedness ${ }^{14}$ conceptualisation increasingly substitute the 'constraining/defining intersolipsistic reflexivesublimating/unreflexive-desublimating measure/objectification that is unlimitedness/existence' derivation of factness/fact as to the requisite sublimating epistemic-projection of ${ }^{6}$ nonpresencing-<perspective-ontological-normalcy/postconvergence $>$ relativism/relativescope for epistemic-growth,-as - \{veridical/sound\}-relative-reflexivity-inexistence/relativising from-limited-mentation-as-its-deepening/psychologismic epistemic-

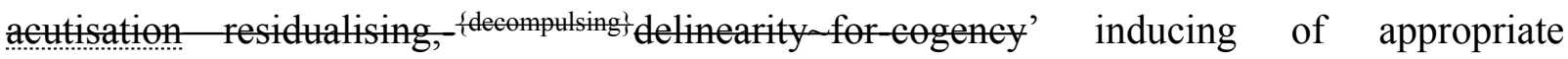
'reifying-mental-aestheticising-<as-of-'prospective_reformulating-of-mental-aestheticising'asto-'residuality-in-re-originariness/re-origination'-of-mental-aestheticising > educed processive-motif-'exuding aestheticising-gesturing'-of-apriorising/axiomatising/referencing as to re-aestheticisation-and-re-aestheticisation-towards-ontology-<elicited-prospectiveidiomatisation $>$ '). Ultimately, the 'ontologising/scientific/existence- $<$ honesty-constraining $>$ scope_for_prospective_re-ontologising implications of existential-<disontologising/reentologising aporeticism> counteracting/supplanting/alienating-of-priorapriorising/axiomatising/referencing' (with regards to 'human psychologismic-epistemicacutisation-<as-to-postconverging-de-mentating/structuring/paradigming,-eliciting-of- 
epistemic-growth,-as - \{veridical/sound\}-relative-reflexivity-in-existence/relativising fromlimited-mentation-as-its-deepening/psychologismic epistemic acutisation residualising, \{decompulsing delinearity for-cogency'), reflecting the-very-underlying-(as inherently 'definingand-imbuing of limitedness/human-subpotency de-mentation-〈stperentologicalde-mentation-or-dialectical-de-mentation-stranding-or-attributive-dialectics ${ }^{\prime} \quad$ as to preconverging/postconverging-de-mentating/structuring/paradigming)—relationship-betweenlimitedness/human-subpotency-and-unlimitedness/existence-<full-potency-of_sublimating nascence $>$ with respect to the pre-eminence of the latter (as to 'limitedness/human-subpotency prospective re-encountering/re-confrontation with unlimitedness/existence-<flllpotency of_sublimating nascence>'), notionally/epistemically/bindingnessly-<as-to-determinism/conceptivity-ofrelative-unreflexivity/relative-reflexivitys implies that a 'human processive-motif-'exuding aestheticisinggesturing' of-apriorising/axiomatising/referencing of prior processiveaposteriorising/logicising/deriving-<as-from-prior-apriorising/axiomatising/referencing $>{ }^{\prime} \quad$ is inherently ever always prospectively disontologising/subontologising as of a 'self-exulting exercise of epistemic-projection in prior processive-motif-'exuding aestheticising gesturing' ef-apriorising/axiomatising/referencing -imbued notional $\sim$ reductionism- $<$ of-existentialprospection,-whether-as-of-trepidatious/warped/preclusive/occlusive/protensivenotional $\sim$ reductionism>' (whether as to trancing-processive-motif-'exuding aestheticisinggesturing' of apriorising/axiomatising/referencing with recurrent-utter-uninstitutionalisation, mysticising-processive-motif-'exuling aestheticising gesturing' ofapriorising/axiomatising/referencing with base-institutionalisation, occulticising-processivemotif-'exuding aestheticising-gesturing' of-apriorising/axiomatising/referencing with nonpositivism/medievalism or subtranslational-processive-motif-'exuding aestheticisinggesturing' of-apriorising/axiomatising/referencing with our procrypticism/disjointedness-as-ofreference-of-thought); with the bigger point here being that the 'capacity to 
notionally/epistemically/bindingnessly-<as-to-determinism/conceptivity-of-relative-unreflexivity/relative-reflexivity>

assume (not in reaction as with the prior < cumulating/recomposuring attendant-ontologicalcontiguity $>$-successive registry-worldviews/dimensions) rather in anticipation/preemption' a human processive-motif-'exuding aestheticising-gesturing' of apriorising/axiomatising/referencing of existential-<disontologising/re-ontologising aporeticism $>$ counteracting/supplanting/alienating-of-prior-

apriorising/axiomatising/referencing (as to a 'despite-the-self exercise of epistemic-projection in notional $\sim$ self-distantiation- $<$ imbued—re-motif-and-re-apriorising/re-axiomatising/rereferencing >') is effectively what undergirds a 'prospectively deprocrypticising/omnitranslational/omninotionality/omniepistemicity-processive-motif'exuding aestheticising gesturing' of-apriorising/axiomatising/referencing -as-to-protensiveconsciousness $\sim$ moronisation/demoronisation' as to its prospective 'reifying-mentalaestheticising-<as-of-'prospective_reformulating-of-mental-aestheticising'as-to-'residuality in-re-originariness/re-origination'-of-mental-aestheticising $>$ educed processive-motif'exuding aestheticising-gesturing'-of-apriorising/axiomatising/referencing as to reaestheticisation-and-re-aestheticisation-towards-ontology-<elicited-prospectiveidiomatisation>' (so-elucidated as to a reflection of the imbued 'overarching existential-disontologising/re-ontologising aporeticism $>$ priority/precedence/primacy of requisite prospective ontological-good-faith/authenticity ${ }^{69} \sim$ postconverging-dementating/structuring/paradigming 70 inducing of psychoanalytic-unshackling for the relativeontological-completeness ${ }^{87}$-of-apriorising/axiomatising/referencing re-ontologising prospective re-rationalisation-of-contentivity/argumentativity/dialecticism/discursivity' associated with the ${ }^{18}$ deprocrypticism-or-preempting-disjointedness-as-of- ${ }^{3}$ reference-ofthought warranted 'human psychologismic-epistemic-acutisation-<as-to-postconverging-dementating/structuring/paradigming,-eliciting-of-existence's-sublimating-nascence-in- 
\{veridical/sound\}-relative-reflexivity-in-existence/relativising from-limited-mentation-as-itsdeepening/psychologismic epistemic-acutisation residualising, fdecompulsingl delinearity for eogency'). Critically, the 'very germinal/inceptive/formative anarchistic manifestation of human totalitarianism (as to human mental-totalitarianism, so-construed as to its lack of a 'reontologising \{epistemic-totalising $\frac{1}{3}$ re-apriorising/re-axiomatising/re-referencing-residuality in reeriginariness/re-origination $\{$ decompulsing $\}$ delinearity/delinear-accreting/recomposuring cogency/tensing/limpidity-<as-of-prospective-profound-supererogation ,-for-residuality-inre-originariness/re-origination>-,prospective_reifying mental-aestheticising $<$ as-of'prospective_reformulating of -mental-aestheticising'as-to-'residuality in -re-originariness/reorigination'-of-mental-aestheticising $>$ ' epistemic-projection) is preconvergingly-dementated/structured/paradigmed', and so-reflected manifestly on-the-one-hand as to the 'stunted-profusion of human mental-totalitarianism social manifestation' and on-the-other-hand as to the 'unstunted-sparsity of human mental-totalitarianism social manifestation' (and so, 'respectively as from stunted-profusion to unstunted-sparsity manifestation' reflected in the interrelatedness-dynamics-of-social-constructing as from 'catchmented-and-compulsed-<in‘existential-dearth-of-demoronisation',-so-construed-as-from-ontologicalnormalcy/postconvergence-perspective-reflection-of-the-'destructuring-threshold_of-thegiven-level's-conjugated-postlogism as-dementing'> interpersonal, group, intergroup, community, local, national, political, geostrategic, etc. psychologismic epistemic-acutisationdifficulty < for, residualising_\{decompulsing $\}$ delinearity for-cogency>-levels of interrelatednessdynamics-of-social-constructing' of 'formativeness-<as-to-intersolipsism-ofpreformulating/preframing/premeaningfulness-imbued-mediativity-and-deferentialism>-ofmeaningfulness-and-teleology and existential-<disontologising/re-ontologising aporeticism $>$ articulation manifestations' as to the 'undergirding-veracity of 
germinal/inceptive/formative individuals anarchistic self-reflexive $\sim$ instigative-eventuating-〈asto-teleological-instigative/incipient-

willing/arbitrariness/waywardness/faithdrivenness/supererogating-for-human-intelligibility,preceding-existence's-eventuating-sublimating-validation/desublimating-invalidation〉'); and so, as human totalitarianism (as to human mental-totalitarianism) speaks of 'human processivemotif-'exuding aestheticising-gesturing' of-apriorising/axiomatising/referencing of prior processive — aposteriorising/logicising/deriving-<as-from-prior-

apriorising/axiomatising/referencing >' which is inherently ever always prospectively disontologising/subontologising as of a 'self-exulting exercise of epistemic-projection in prior processive-motif'exuding aestheticising gesturing' of apriorising/axiomatising/referencing imbued_notional reductionism-<of-existential-prospection,-whether-as-oftrepidatious/warped/preclusive/occlusive/protensive- notional reductionism>' (whether as to trancing-processive-motif-'exuding aestheticising-gesturing' of apriorising/axiomatising/referencing with recurrent-utter-uninstitutionalisation, mysticisingprocessive-motif-'exuding aestheticising-gesturing' of-apriorising/axiomatising/referencing with base-institutionalisation, occulticising-processive-motif-exuding aestheticisinggesturing' of apriorising/axiomatising/referencing with non-positivism/medievalism or subtranslational-processive-motif-'exuding aestheticising gesturing' of apriorising/axiomatising/referencing with our procrypticism/disjointedness-as-of- referenceof-thought). Thus the mental-anti-totalitarianism of prospective deprocrypticism-orpreempting - disjointedness-as-of- ${ }^{3}$ reference-of-thought as to the "capacity to notionally/epistemically/bindingnessly-<as-to-determinism/conceptivity-of-relative-unreflexivity/relative-reflexivity> assume (not in reaction as with the prior < cumulating/recomposuring attendant-ontologicalcontiguity >-successive registry-worldviews/dimensions) rather in anticipation/preemption' a human processive-motif-'exuding aestheticising-gesturing' of 
apriorising/axiomatising/referencing of existential-<disontologising/re-ontelogising aporeticism $>$ counteracting/supplanting/alienating-of-prior-

apriorising/axiomatising/referencing (as to a 'despite-the-self exercise of epistemic-projection in notional $\sim$ self-distantiation- $<$ imbued—re-motif-and-re-apriorising/re-axiomatising/re-

referencing >') is effectively what undergirds a 'prospectively deprocrypticising/omnitranslational/omninotionality/omniepistemicity-processive-motif'exuding aestheticising gesturing' of apriorising/axiomatising/referencing -as-to-protensiveconsciousness $\sim$ moronisation/demoronisation'; and is so-translated as critically 'adopting a relation to the social-setup ${ }^{79}$ presencing - absolutising-identitive-constitutedness ${ }^{14}$ conceptionof- ${ }^{56}$ meaningfulness-and-teleology ${ }^{9}$ (underlied by its given notional/epistemic/bindingness ${ }^{-<a s-}$ to-determinism/conceptivity-of-relative-unreflexivity/relative-reflexivity>

\section{$<$ amplituding/formative $>$ disposedness/psychologismic-construct-_as-to-orientation/value-} construct/valuation-and-derived-parameterising $\rangle$ and $<$ amplituding/formative $>$ entailment-〈asto-totalising-contiguous/coherent-factuality-of-variability))' as not prospectively-supersedingbut-rather-superseded by the ontologising/scientific/existence- $<$ honesty-constraining $>$ scope_for_prospective_re-ontologising. The implication of such a notional deprocrypticism here is that any registry-worldview/dimension social-setup can effectively be 'looked down upon' as 'mentally underdeveloped as preconvergingly-de-mentated/structured/paradigmed' and so 'only-for-the-requisite sake/prospect/purpose of its prospective re-ontologising sublimation/emancipation/enfranchisement' as of prospectively 'inventing'/'creating'-and'nurturing' the-human/humanity as to the ontologising/scientific/existence- $<$ honestyconstraining $>$ — scope_for_prospective_re-ontologising thus so-making nonsensical ontologically-flawed 'self-exulting exercise of epistemic-projection in prior processive-motif'exuding aestheticising-gesturing' of apriorising/axiomatising/referencingimbued_notional $\sim$ reductionism- $<$ of-existential-prospection,-whether-as-of- 
trepidatious/warped/preclusive/occlusive/protensive—notional $\sim$ reductionism>’ ${ }^{\prime} \quad$ rather fraudulently bent on immortalising the "mortal scale of perceived institutional access and success default conception of human ontological-performance ${ }^{72}-<$ including-virtue-as-ontology $>^{\prime}$ as to a cooptation/subversion in shallow-supererogation of the ontologising/scientific/existence$<$ honesty-constraining $>$ _ scope_for_prospective_re-ontologising as effectively detrimental to the veridically requisite profound-supererogation of 'postconverging-dementating/structuring/paradigming for prospective postconvergingaaporeticismovercoming/unovercoming'). This merely reflects the requisite 'reclamation/recovery of maximalising-recomposuring-for-relative-ontological-completeness ${ }^{87}$ - unenframed/reontologising conceptualisation (elicited/prompted <amplituding/formative-epistemicity $>$ totalising renewing-realisation/re-perception/re-thought as of 're-ontologising fepistemictotalising tre-apriorising/re-axiomatising/re-referencing residuality in-re-originariness/reorigination \{decompulsing\} delinearity/delinear-acereting/recomposuring cogency/tensing/limpidity<as-of-prospective-profound-supererogation ,-for-residuality-in-re-originariness/reorigination $>$,-prospective_reifying mental-aestheticising $<$ as-of 'prospective_reformulating of-mental-aestheticising'as-to-residuality in -re-originariness/re-origination' of mentalaestheticising >')' undergirding the ontologising/scientific/existence- $<$ honesty-constraining $>$ scope_for_prospective_re-ontologising (as so enabling the avoidance of incrementalism-inrelative-ontological-incompleteness ${ }^{8}$ —enframed/disontologising $\sim$ conceptualisation reflected as of 'eclecticism-of-prior-mere-formulaicity/ritualisation-<as-of-prior $\sim$ rationalisation-ofcontentivity/argumentativity/dialecticism/discursivity> composition/blending-in\{compulsing\} linearity/linear-accretion of sunderlaid/substrated-'thrownness-aestheticising' - ofrelative unreflexivity in existence\}> profusion of preconverging prior-relative-ontologicalincompleteness -of-apriorising/axiomatising/referencing and overlaying/superstrating'thrownness-aestheticising' \{of-relative-reflexivity in-existence\} $>$-sparsity-of- 
postconverging prospective-relative-ontological-completeness -of-

apriorising/axiomatising/referencing' underlied by the 'dereifying-mental-aestheticising-<asof-'prior_mere-formulaicity/ritualisation-of-mental-aestheticising'-failing-'residuality-in-reoriginariness/re-origination'-of-mental-aestheticising $>$ as of the processive-motif-'exuding aestheticising-gesturing' of-apriorising/axiomatising/referencing of prior aestheticisation-andaestheticisation-towards-ontology-<elicited-idiomatisation>' in co-optation/subversion of the ontologising/scientific/existence- $<$ honesty-constraining $>$ — scope_for_prospective_reontologising). This speaks to the fact that human 'existential-<disentologising/re-ontelogising aporeticism $>$ prospection' so-construed as to 'phenomenal/manifest human existing/living' as to the-very-underlying — (as inherently 'defining-and-imbuing of limitedness/human-subpotency de-mentation-_supererogatory ontological-de-mentation-or-dialectical-de-mentationstranding-or-attributive-dialectics $\rangle^{\prime}$ as to preconverging/postconverging-dementating/structuring/paradigming)—relationship-between-limitedness/human-subpotencyand-unlimitedness/existence-<full-potency-of_sublimating naseence $>$ implied human $<$ amplituding/formative-epistemicity $>$-totalising $\sim$ thrownness-in-existence ${ }^{35}$,-imbuedprojective-arbitrariness/waywardness-〈as-to-the-human-projective/reprojectiveaestheticising-re-motif-and-re-apriorising/re-axiomatising/re-referencing-process-of‘<amplituding/formative-epistemicity $>$ totalising conceptualisation' $\rangle$, is underlied by the given registry-worldview/dimension processive-motif-'exuding aestheticising-gesturing' ofapriorising/axiomatising/referencing (imbued rationalisation-ofcontentivity/argumentativity/dialecticism/discursivity which is not truly 'thinking at first/pure predisposition preemptive of prospective disontologising/subontologising but a conscious/unconscious rationalising/calculating of the sublimating outcome of prior profoundsupererogation rationalisation-of-contentivity/argumentativity/dialecticism/discursivity imbued positive-opportunism—of-social-functioning-and-accordance ${ }^{75}$ ); from whence human 
'crossgenerational notional firstnaturedness-formativeness-<as-to-eventualising-inklingdrive-or-seeding-misprising $>$ mental-processing-parity for ontological-performance ${ }^{72}$ <including-virtue-as-ontology $>$ /morality/ethics/justice/etc.' existentially-<disontologising/reentologising aporeticism $>$ manifestable profound-supererogation or shallowsupererogation can be elicited prospectively (with respect to the possibility for prospectively 'thinking at first/pure predisposition preemptive of prospective disontologising/subontologising' as so-reflecting requisite profound-supererogation' as from human 'crossgenerational notional firstnaturedness-formativeness-<as-to-eventualising inkling-drive-or-seeding-

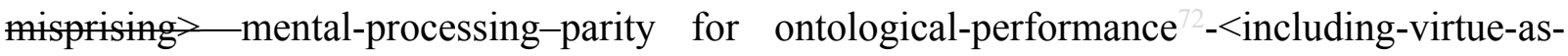
ontology $>$ /morality/ethics/justice/etc.' with regards to 'prospective nonpresencing<perspective-ontological-normalcy/postconvergence> epistemic-projection' induced 'human re-ontologising transcendence-and-sublimity/sublimation/supereregatory $\sim$ de-mentativity' notwithstanding priorly given '79 presencing-absolutising-identitive-constitutedness disontologising $<$ amplituding/formative-epistemicity $>$-totalising $\sim$ thrownness-in-existence ${ }^{35}$ ), thus reflecting how the 'sublimating or desublimating conception of the-human/humanity can be reaffirmed prospectively' (respectively either as of prospective profound-supererogation ${ }^{6}$ or prospective shallow-supererogation as enabling or failing the prospect for the ontologising/scientific/existence- $<$ honesty-constraining $>$ - scope_for_prospective_reontologising). This is exactly what provides the possibility for superseding/overcoming $\leq$ mereformulaicity/ritualisation-of $>$ prior secondnatured 'dereifying-mental-aestheticising-<as-of'prior_mere-formulaicity/ritualisation-of-mental-aestheticising'-failing-'residuality-in-reoriginariness/re-origination'-of-mental-aestheticising $>$ as of the processive-motif-'exuding aestheticising gesturing' of apriorising/axiomatising/referencing of prior aestheticisation-andaestheticisation-towards-ontology-<elicited-idiomatisation>' (whether manifested as of $\leq$ mereformulaicity/ritualisation-of $>$-prior secondnatured blatant brutish conquest/subjugation 
conception of apportioning imbued shallow-supererogation,$\leq$ mere-formulaicity/ritualisation ef $>$-prior secondnatured dominion protection conception of apportioning imbued shallowsupererogation , $\leq$ mere-formulaicity/ritualisation-of $>$ prior secondnatured the very naturalorder-of-things conception of apportioning imbued shallow-supererogation and prospectively our $\leq$ mere-formulaicity/ritualisation - of $>$-prior secondnatured subtle modern-day institutionallydistorted/disjointed conception of apportioning imbued shallow-supererogation ${ }^{9}$ ), as to the imbued underlying-elucidative 'requisite sublimating/desublimating formulative-

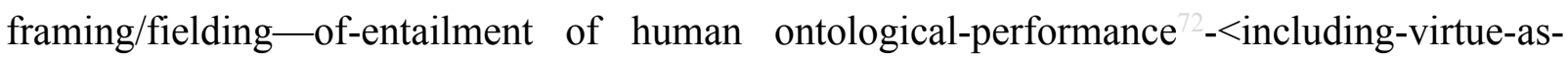
ontology $>$ /morality/ethics/justice/etc. contemplation' (as the 'veridical neutral point-ofdevolving/departure/anchoring/backdrop conceptualisation of human ontologicalperformance $^{72}-<$ including-virtue-as-ontology $>$ /morality/ethics/justice/etc. $\quad$ as to rerationalisations-of-contentivity/argumentativity/dialecticism/discursivity so-reflecting successive relative-ontological-completeness 87 'implicited_attendant-ontologicalcontiguity ${ }^{67} \sim$ educed-

existentialising/contextualising/textualising_intelligibility/epistemicity/reflexivity-contiguity<imbued-notional cogency>' ${ }^{\prime}$ ); and so rather than the given prior-perspectivefalsity/falseness/fallaciousness of supposedly 'neutral ${ }^{79}$ presencing-absolutising-identitiveconstitutedness ${ }^{14}$ point-of-devolving/departure/anchoring/backdrop conceptualisation of human ontological-performance ${ }^{2}$-<including-virtue-as-ontology $>/$ morality/ethics/justice/etc. rationalisation-of-contentivity/argumentativity/dialecticism/discursivity and so-reflected in the flawed 'implicited_attendant-ontological-contiguity ${ }^{67}$ ' educedexistentialising/contextualising/textualising_'intelligibility/epistemicity/reflexivity-contiguity$<$ imbued-notional cogency $>$ '. It is effectively the mental-anti-totalitarianism imbued in the 'notional ' deprocrypticism-or-notional $\sim$ preempting — disjointedness-as-of- ${ }^{8}$ reference-ofthought of the overall relative-unreflexivity/relative-reflexivity - ontological-contiguity ${ }^{67}$ of- 
the-human-institutionalisation-process ${ }^{6}$, , as to successive registry-worldviews/dimensions stations/loci of limitedness/human-subpotency <amplituding/formative-epistemicity $>$ totalising thrownness-in-existence ${ }^{5}$ ) manifestation of a 'human processive-motif-'exuding aestheticising gesturing' of apriorising/axiomatising/referencing of existential$<$ disontologising/re-ontologising aporeticism $>$ counteracting/supplanting/alienating-ofprior-apriorising/axiomatising/referencing' (as to a 'despite-the-self exercise of epistemicprojection in notional $\sim$ self-distantiation- $<$ imbued-re-motif-and-re-apriorising/reaxiomatising/re-referencing >'), that is the very enabler of the ontologising/scientific/existence$<$ honesty-constraining $>$ _-scope_for_prospective_re-ontologising; as the latter mental-antitotalitarianism (in undermining prior mental-totalitarianism as of 'human processive-motif'exuding aestheticising-gesturing' of-apriorising/axiomatising/referencing of prior processive - aposteriorising/logicising/deriving-<as-from-prior-

apriorising/axiomatising/referencing>') elicits/prompts underlying 'constraining existence_-assublimating-withdrawal/unenframing/re-ontologising,-elicited-from-prospective-profoundsupererogation imbuing human ontological-commitment $-<$ implied-self-assuredness-ofontological-good-faith/authenticity $\sim$ postconverging-dementating/structuring/paradigming -as-being-as-of-existential-reality>' and ' ${ }^{103}$ universaltransparency ${ }^{104}$-〈transparency-of-totalising-entailing,-as-to-entailing-<amplituding/formativeepistemicity $>$ totalising $\sim$ in-relative-ontological-completeness $\rangle$ as available-to/elicitable-to-〈asto-human-consciousness/collective-consciousness-distendedness/detruncating-<beyondselfpresencing,-as-re-ontologising-decentering_of-consciousness/collective-consciousness,-as-

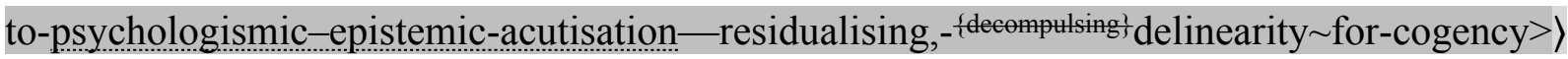
the social-functioning-and-accordance-as-of-social-stake-contention-or-confliction conception of any given registry-worldview/dimension <preconverging 'motif-andapriorising/axiomatising/referencing'-entailing >-existentialising — enframing/imprintedness- 
〈as-to- historicity-tracing-in-presencing-hyperrealisation/hyperreal-transposition〉'. It is effectively by such unblurriness-<re-ontologising_by-postconverging-as-to-dragged-outsupererogatory $\sim$ wholesomeness/profound-supererogation ,-while-anecdotalising-priordisontologising-thresholding $>\quad$ induced sublimating conceptivity/epistemicreflexivity/epistemicity-relativism-determinism-<reifying \{as-to-knowledge-developing $\}$-andempowering $>$ that the veridically profound prospective sublimating possibilities of the advocacy/political/applicative - scope can arise as it is so-undergirded by the ontologising/scientific/existence- $<$ honesty-constraining $>$ — scope_for_prospective_reontologising. The ontologising/scientific/existence- $<$ honesty-constraining $>$ scope_for_prospective_re-ontologising is thus the 'sublimating conceptivity/epistemicreflexivity/epistemicity-relativism-determinism-<reifying \{as-to-knowledge-developing $\}$-andempowering $>$ overarching-undergirding' enabling the advocacy/political/applicative — scope to arise (but is not of 'existential-<disontologising/re-ontologising aporeticism $>$ substitutingfor/taking-the-place-of the human sovereign-function/posture-<as-to-existentially-manifest‘embodied-subject consciousness-and-direct/deferential-conscientiousness',-as-of-its‘epistemic-reflexivity/unreflexivity-in-existence'/teleology> imbued protracted-social—as-toindividual-by-institutional-by-social self supererogation as underlied-and-reflected with the manifest techno-socio-econo-political dynamics of the advocacy/political/applicative-scope); and so overarching-undergirding practically as to the ontologising/scientific/existence$<$ honesty-constraining $>$ — scope_for_prospective_re-ontologising imbued ' ${ }^{\circ}$ nonpresencing$<$ perspective-ontological-normalcy/postconvergence $>$ anarchistic-growth/anarchisation-forre-ontologisation-〈as-to-conscious/unconscious epistemically-sound induced 'demoronisation<sublimating-nascence,-nonextricatory-sublimating-upstreaming/'amontée’> postconverging/dialectical-thinking conception of residual_re-originary_anarchistic incipiency of human social-functioning-and-accordance-as-of-social-stake-contention-or- 
confliction meaningfulness-and-teleology ' $\rangle$ ' (as so-reflecting 'nonpresencing$<$ perspective-ontological-normalcy/postconvergence $>$ relativism/relative-scope for epistemicgrowth,-as-\{veridical/sound\}-relative-reflexivity-in-existence/relativising from-limitedmentation-as-its-deepening/psychologismic epistemic-acutisation residualising, \{decompulsing $\}$ delinearity for underlying-elucidative 'requisite sublimating/desublimating formulative-framing/fielding —of-entailment of human ontologicalperformance ${ }^{72}-<$ including-virtue-as-ontology $>$ /morality/ethics/justice/etc. contemplation' as of notionally implied $\quad{ }^{45}$ foregrounding_entailment- $<$ in-succession-of-profoundsupererogation $>$-〈postconverging-narrowing-down $\sim$ sublimation-as-to-'existence- assublimating-withdrawal/unenframing/re-ontologising,-elicited-from-prospective-profoundsupererogation '-in-reflecting-'immanent relative-unreflexivity/relative-reflexivity ontological-contiguity ';--as-operative-notional deprocrypticism)), as so effectively speaking of the overarching-undergirding re-ontologising within which 'human succession of advocacy/political/applicative — scope arise' as to the given station/locus of limitedness/humansubpotency $<$ amplituding/formative-epistemicity $>$-totalising $\sim$ thrownness-in-existence ${ }^{35}$. In other words, it is within the framework of the ontologising/scientific/existence- $<$ honestyconstraining $>$ — scope_for_prospective_re-ontologising successively induced 'apriorising/axiomatising/referencing disambiguating/de-leveling/de-ressentiment/openedconstruct-of- $-{ }^{56}$ meaningfulness-and-teleology $\quad$ demoronisation- $<$ sublimating-nascence,nonextricatory-sublimating-upstreaming/'amontée’’' that successive human advocacy/political/applicative - scope arise; as to the fact that in-the-bigger-scheme-of-things, the 'social-stake-contention-or-confliction of the advocacy/political/applicative-scope as to techno-socio-econo-political implications' of any given epoch is effectively within the framework of that epoch 'prospectively debatable/discussable ontologising/scientific/existence$<$ honesty-constraining $>$ — scope_for_prospective_re-ontologising' (so-reflected by the fact that 
for instance however the apparent discord manifested with the present-day political parties discourse there are inherent limits to the "possibility of disontologising/subontologisingimbuing-prospectively-of-human-desublimating/subjugation/disenfranchisement that are epochally untenable as of policy orientation no matter the politics' as so-constrained by the epochal overaching-undergirding ontologising/scientific/existence- $<$ honesty-constraining $>$ scope_for_prospective_re-ontologising). In this regards, the possibility for successive human 'social-stake-contention-or-confliction of the advocacy/political/applicative-scope as to techno-socio-econo-political implications' to develop (as from $\leq$ mereformulaicity/ritualisation-of $>$-prior secondnatured blatant brutish conquest/subjugation conception of apportioning imbued shallow-supererogation,$\leq$ mere-formulaicity/ritualisation өf $\geq$-prior secondnatured dominion protection conception of apportioning imbued shallowsupererogation,$\leq$ mere-formulaicity/ritualisation-of $>$ prior secondnatured the very naturalorder-of-things conception of apportioning imbued shallow-supererogation and prospectively our $\leq$ mere-formulaicity/ritualisation - of $>$-prior secondnatured subtle modern-day institutionallydistorted/disjointed conception of apportioning imbued shallow-supererogation ${ }^{9}$ ) is effectively manifested as to the overarching-undergirding of developing ontologising/scientific/existence$<$ honesty-constraining $>$ _ scope_for_prospective_re-ontologising so-reflected historially with the very developing of human social formations as to their sublimating re-ontologising possibilities, re-ontologising developing sense for overcoming practices of human servitude, reontologising developing sense of common humanity as to sublimating emancipation and enfranchisement, re-ontologising developing sense of greater human egalitarianism as well as the underlying re-ontologising technical developments across successive epochs as to eventually overcoming a human mentality for punctual/immediacy/constituted/compulsions-encumbered perceived subsistence/survival/advantage which is undermining-of/detrimental-to prospective 'apriorising/axiomatising/referencing disambiguating/de-leveling/de-ressentiment/opened- 
construct-of- ${ }^{5}$ meaningfulness-and-teleology

demoronisation- $<$ sublimating-nascence,nonextricatory-sublimating-upstreaming/'amontée’>'. That said, it is equally the case that such overarching-undergirding by the ontologising/scientific/existence- $<$ honesty-constraining $>$ scope_for_prospective_re-ontologising (of human 'social-stake-contention-or-confliction of the advocacy/political/applicative—scope as to techno-socio-econo-political implications') has ever always historially effectively been susceptible to a punctual/immediacy/constituted/compulsions-encumbered predisposition misconstrual from the advocacy/political/applicative-scope (as to a presencing-absolutising-identitiveconstitutedness 'apriorising/axiomatising/referencingequating/leveling/ressentiment/closed-construct-of- ${ }^{5}$ meaningfulness-and-teleology moronisation-<sublimating-nascence,-extricatory-desublimating-downstreaming/'avalage'>’) as 'supposedly being all-determinant with regards to the manifest possibility of human sublimating/desublimating'; such that the reality is one where in-many-ways across all human epochs as so-inherent to the implications of the-very-underlying - (as inherently 'defining-andimbuing of limitedness/human-subpotency de-mentation-〈supererogatory $\sim$ ontological-dementation-or-dialectical-de-mentation—-stranding-or-attributive-dialectics〉' as to preconverging/postconverging-de-mentating/structuring/paradigming)—relationship-betweenlimitedness/human-subpotency-and-unlimitedness/existence-<full-potency-of_sublimating nascence $>$ implied human <amplituding/formative-epistemicity>-totalising $\sim$ thrownness-inexistence ${ }^{35}$,-imbued-projective-arbitrariness/waywardness-〈as-to-the-humanprojective/reprojective - aestheticising-re-motif-and-re-apriorising/re-axiomatising/rereferencing-process-of-‘ $<$ amplituding/formative-epistemicity $>$ totalising $\sim$ conceptualisation' $\rangle$, human 'social-stake-contention-or-confliction of the advocacy/political/applicative- - scope as to techno-socio-econo-political implications' do not necessarily absolutely-and-overtly subscribe to the notion of its overaching-undergirding of the ontologising/scientific/existence- $<$ honesty- 
constraining $>$ — scope_for_prospective_re-ontologising (as so-projecting of 'nonontologising/disontologising surreptitious knowledge-without-knowledge/knowledge-outsideknowledge/extra-knowledge constructs out-of/besides human ontological-commitment $<$ implied—-self-assuredness-of-ontological-good-faith/authenticity $\sim$ postconverging-dementating/structuring/paradigming -as-being-as-of-existential-reality $>$ and implicitly obviating the veracity of the ${ }^{103}$ universal-transparency ${ }^{104}$-〈transparency-of-totalising-entailing,as-to-entailing-<amplituding/formative-epistemicity $>$ totalising in-relative-ontologicalcompleteness > of knowledge-reification $\sim$ gesturing-and-accounting-of-epistemicphenomenalism-<in-prospective_psychologismic $\sim$ apriorising/axiomatising/referencing- of'prospectively implicitedatendant-ontological-contiguity ' educedexistentialising/contextualising/textualising_'intelligibility/epistemicity/reflexivity-contiguity<imbued-notional cogency >' \}-conflatedness -in-\{preconverging ment by\} postconverging-entailment>') and so as to self-serving ${ }^{79}$ presencing-absolutising-identitiveconstitutedness ${ }^{14}$ social-vestedness/normativity-<discretely-implied-functionalism $>$ ). Such that in-many-ways the possibility for prospective human re-ontologising as to the ontologising/scientific/existence- $<$ honesty-constraining $>$ — scope_for_prospective_reontologising has historially had to deal with confliction arising from social disagreements, contestations, revolutions, etc. so-inherently associated with the fact that 'human $<$ amplituding/formative-epistemicity $>$-totalising $\sim$ thrownness-in-existence ${ }^{35}$ by itself prospectively exudes of disontologising/subontologising as to human punctual/immediacy/constituted/compulsions-encumbered and ideology mental-totalitarianism’ (in want for prospective manifest mental-anti-totalitarianism imbued in the 'notional ' deprocrypticism-or-notional $\sim$ preempting — disjointedness-as-of- ${ }^{-3}$ reference-ofthought of the overall relative-unreflexivity/relative-reflexivity - ontological-contiguity ${ }^{67}$ ofthe-human-institutionalisation-process ${ }^{6}$, for the prospective perpetuating/upholding of the 
ontologising/scientific/existence- $<$ honesty-constraining $>$ — scope_for_prospective_reontologising). Such an inclination for the overriding of the ontologising/scientific/existence$<$ honesty-constraining $>$ _ scope_for_prospective_re-ontologising is manifested with presentday centralising-totalitarianism or decentralising-totalitarianism ideological predispositions of the advocacy/political/applicative-scope and as these surreptitiously strive to coopt-and-usurp the ontologising/scientific/existence- $<$ honesty-constraining $>$ - scope_for_prospective_reontologising (especially manifested with contentious/un-nominalised 'social-stake-contentionor-confliction of the advocacy/political/applicative-scope as to techno-socio-econo-political implications'), and so-increasingly manifested with the desublimating implications arising from the curtailing of the autonomy of knowledge institutions and their increasing subjection to the 'prioritised overt/covert motives of both private interest and public dominance/vested-interest advocacy/political/applicative-scope' (so-associated with funding and sponsorship implications of co-optation/usurpation); eventually leading to the "cultivation and enculturation of practices of overt/covert privying of the supposed conception of the ontologising/scientific/existence- $<$ honesty-constraining $>$ — scope_for_prospective_reontologising' (as so-associated with surreptitious and media-savvy political and economic thinktanking and related pop-intellectualism) effective participation in inducing the overall $<$ preconverging 'motif-and-apriorising/axiomatising/referencing'-entailing $>$ existentialising — enframing/imprintedness-〈as-to- historicity-tracing_-in-presencinghyperrealisation/hyperreal-transposition〉 of the underpinning-suprasocial-construct desublimating rationalisation-of-contentivity/argumentativity/dialecticism/discursivity (as to desublimating eliciting/prompting of human subconsciousness most-prospectively-conscious 're-ontologising-by-disontologising_existential-calculus-〈between 'prospective existentialising — postconverging_framing/imprinting re-ontologising' and 'prior 
accordance-as-of-social-stake-contention-or-confliction' $\rangle$ ' of consciousness surrealising-<asto-supererogation $>$ ). Such that eventually a re-originary-_as-unenframed/reontologising/unb_eholdening/outlier-conceptualis_ation___imbued-postconverging/dialecticalthinking -'projective-insights'/‘epistemic-projection-in-conflatedness ' '-ofnotional deprocrypticism-prospective-sublimation d $^{0}$ conception of the ontologising/scientific/existence- $<$ honesty-constraining $>$ — scope_for_prospective_reontologising is rather dissipated; as reflected with the elucidatation above on-the-one-hand and on-the-other-hand as to the manifestation of mere competence/expertising (as of human socially expanded framework of deferential-formalisation-transference as to various cultivated skills/arts and time investment with regards to effectively manifest 'underlying veracity of corephilosophy/derivative-core-philosophy prospective re-ontologising as relevantly superseding prior mere-formulaicity/ritualisation pedantism induced knowledge-deadends- $<$ aspreconverging-de-mentating/structuring/paradigming >') with regards to relatively uncontentious/nominalised social-stake-contention-or-confliction. But then this 'supposed comprehensive conception of the ontologising/scientific/existence- $<$ honesty-constraining $>$ scope_for_prospective_re-ontologising' is rather a 'prospectively ontologically-flawed presencing-absolutising-identitive-constitutedness ${ }^{14}$ conception of the ontologising/scientific/existence- $<$ honesty-constraining $>$ — scope_for_prospective_reontologising' that fails to effectively reflect 'core-philosophy/derivative-core-philosophy (as of notional philosophy-<as-to-the-veridical-conception-of-philosophy-as-englobing-all-humanprospective-organic-knowledge-generation-in-relative-ontological-completeness ,-beyond-aconvenient-division-of-labour-conception-of-knowledge $>$ ) implications of requisite supererogatory $\sim$ wholesomeness/profound-supererogation contemplation of overall human knowledge imbued experientiality/experiment-<as-to-existentially-formative- ‘epistemictotalising ${ }^{\prime}$ re-apriorising/re-axiomatising/re-referencing residuality-in-re-originariness/re- 
origination',- - so-'notionally/epistemically/bindingnessly-<as-to-determinism/conceptivity-of-relative-

unreflexivity/relative-reflexivity -implicited-and-articulated'_as-from-nonextricatory-'prospective-re-

ontologising-Being-then-Institutional-then-Living-magnitudes-of-

\{hermeneutic/reprojection-protraction-of\}reframing-and-reformulation\}'>' (with regards to reflecting the 're-ontologising fepistemic-totalising ${ }^{3}$ re-apriorising/re-axiomatising/rerefereneing-residuality in re-originariness/re-origination \{decompulsing $\}$ delinearity/delinearaccreting/recomposuring cogency/tensing/limpidity-<as-of-prospective-profoundsupererogation ,-for-residuality_-in-re-originariness/re-origination $>$, $\sim$ prospective_reifying mental-aestheticising_<as-of-prospective_reformulating-of-mental-aestheticising'as to'residuality in-re-originariness/re-origination'-of-mental-aestheticising >’ apriorising/axiomatising/referencing-sublimating-reflexivity-beholdening under which limitedness/human-subpotency submits in profound-supererogation for prospective sublimating' as of 'human psychologismic-epistemic-acutisation-<as-to-postconverging-dementating/structuring/paradigming,-eliciting-of-existence's-sublimating-nascence-inprospective-aporeticism-overcoming/unovercoming $>$ as to epistemic-growth,-as\{veridieal/sound\}-relative-reflexivity-in-existence/relativising from limited mentation as its deepening/psychologismic epistemic acutisation residualising, \{decompulsing\} delinearity foreogency'), as so-underlining the requisite prospectively sublimating 'human processive-motif'exuding aestheticising-gesturing' of-apriorising/axiomatising/referencing of existential<disontologising/re-ontologising aporeticism $>$ counteracting/supplanting/alienating-ofprior-apriorising/axiomatising/referencing'; which is herein underlined as the mental-antitotalitarianism of prospective ${ }^{18}$ deprocrypticism-or-preempting-disjointedness-as-ofreference-of-thought as to the "capacity to notionally/epistemically/bindingnessly-<as-todeterminism/conceptivity-of-relative-unreflexivity/relative-reflexivity $>$ assume (not in reaction as with the prior 
worldviews/dimensions) rather in anticipation/preemption' a human processive-motif-'exuding aestheticising-gesturing' of apriorising/axiomatising/referencing of existential$<$ disontologising/re-ontologising aporeticism $>$ counteracting/supplanting/alienating-ofprior-apriorising/axiomatising/referencing (as to a 'despite-the-self exercise of epistemicprojection in notional $\sim$ self-distantiation- $<$ imbued-re-motif-and-re-apriorising/reaxiomatising/re-referencing >') as effectively what undergirds a 'prospectively deprocrypticising/omnitranslational/omninotionality/omniepistemicity-processive-motif'exuding aestheticising gesturing' of-apriorising/axiomatising/referencing -as-to-protensiveconsciousness $\sim$ moronisation/demoronisation' (over our ' 7 presencing—absolutising-identitiveconstitutedness ${ }^{14} \quad$ procrypticising/subtranslational/subnotionality/subepistemicity-processivemotif-'exuding aestheticising-gesturing' of-apriorising/axiomatising/referencing - as-toocclusive-consciousness $\sim$ moronisation/demoronisation'). This 'prospectively ontologicallyflawed ${ }^{79}$ presencing-absolutising-identitive-constitutedness ${ }^{14}$ conception of the ontologising/scientific/existence- $<$ honesty-constraining $>$ — scope_for_prospective_reontologising' explains why the ontologising/scientific/existence- $<$ honesty-constraining $>$ scope for prospective re-ontologising-failsafe-as to 'relative mreflexivitrelativereflexivity bindingness/nondiscretionariness' of totalising-entailment $>$ is rather underlied as of its constraining ramifications of crossgenerational existential-<disontologising/reentologising aporeticism $₹$ import upon 'social-functioning-and-accordance-as-of-socialstake-contention-or-confliction imbuing existentialising-frame-of-entailment of motif-andapriorising/axiomatising/referencing of disontologising/ontologising-and-re-ontologising' (à la Diderot and Encyclopédistes active crossgenerational epistemic-projection or overall buddingpositivists passive crossgenerational epistemic-projection of the ontologising/scientific/existence- $<$ honesty-constraining $>$ — scope_for_prospective_re- 
ontologising). In contrast the punctual/immediacy/constituted/compulsions-encumbered nature of the 'social-stake-contention-or-confliction of the advocacy/political/applicative—scope as to techno-socio-econo-political implications' of any given epoch so-speaks to an intragenerational epistemic-projection (that is effectively beholdening to the 'notional/epistemic/bindingness - $^{<a-}$ to-determinism/conceptivity-of-relative-unreflexivity/relative-reflexivity $<$ preconverging $\sim$ 'motif-andapriorising/axiomatising/referencing'-entailing>-existentialising—enframing/imprintedness〈as-to- historicity-tracing-in-presencing-hyperrealisation/hyperreal-transposition〉 of the underpinning-suprasocial-construct desublimating rationalisation-ofcontentivity/argumentativity/dialecticism/discursivity') however the 'perceived relative ontological-veracity or releative ontological-inveracity orientation of the advocacy/political/applicative—scope'; whereas (more than just any given intragenerational epistemic-projection 'perceived relative ontological-veracity or relevative ontological-inveracity orientation of the advocacy/political/applicative-scope') the ontologising/scientific/existence$<$ honesty-constraining $>$ _ scope_for_prospective_re-ontologising is critically about ushering in prospective 'notional/epistemic/bindingness ${ }^{<a s-t o-d e t e r m i n i s m / c o n c e p t i v i t y-o f-r e l a t i v e-u n r e f l e x i v i t y / r e l a t i v e-~}$ reflexivity $>$ postconverging $\sim$ 'motif-and-apriorising/axiomatising/referencing'-entailing $>$ existentialising - framing/imprinting-〈as-to-prospective- historiality/ontologicaleventfulness /ontological-aesthetic-tracing-<perspective-ontologicalnormalcy/postconvergence-reflected-'epistemicity-relativism-determinism' $>\rangle$ ' as rather redefining of the prospective overarching-undergirding re-ontologising for prospective human 'social-stake-contention-or-confliction of the advocacy/political/applicative-scope as to techno-socio-econo-political implications'. Critically, the very manifestation across the $<$ cumulating/recomposuring attendant-ontological-contiguity $>$-successive registryworldviews/dimensions of notional intellection (as to the preconverging/postconverging-dementatively/structurally/paradigmatically dynamics of pedantising/muddling/formulaic- 
hollowing-out-in-subontologisation/subpotentiation-〈blurring/undermining-of-prospectivetotalising-entailing,-as-to-entailing-<amplituding/formative-epistemicity $>$ totalising $\sim$ in-

relative-ontological-completeness $\rangle$ and the genuine social intellectual-function/posture reontologising) is effectively underlied by such a differing appraisal (of the prospective overarching-undergirding by the ontologising/scientific/existence- $<$ honesty-constraining $>$ scope_for_prospective_re-ontologising of human 'social-stake-contention-or-confliction of the advocacy/political/applicative_-scope as to techno-socio-econo-political implications'); inducing respectively an inclination for 'lifespan extricatory/preconverging psychical-nascency moronisation- $<$ sublimating-nascence,-extricatory-desublimating-downstreaming/'avalage' $>$ ' and 'nonextricatory/postconverging ontologising-and-re-ontologising angling-of-imaginary demoronisation- $<$ sublimating-nascence,-nonextricatory-sublimating-

upstreaming/'amontée'>'. This naivety (with regards to failing to grasp the 'crossgenerational nature of the ontologising/scientific/existence- $<$ honesty-constraining $>$ scope_for_prospective_re-ontologising') is effectively reflected with 'intragenerational presencing-absolutising-identitive-constitutedness ${ }^{14}$ construal as supposedly in-effect ontological in absolution' with respect to successive human 'social-stake-contention-orconfliction of the advocacy/political/applicative-scope as to techno-socio-econo-political implications' (as from $\leq$ mere-formulaicity/ritualisation-of $>$-prior secondnatured blatant brutish conquest/subjugation conception of apportioning imbued shallow-supererogation , $<$ mereformulaicity/ritualisation - of $>$ prior secondnatured dominion protection conception of apportioning imbued shallow-supererogation , $\leq$ mere-formulaicity/ritualisation-of $\geq$ prior secondnatured the very natural-order-of-things conception of apportioning imbued shallowsupererogation and prospectively our $\leq$ mere-formulaicity/ritualisation- - f $>$ prior secondnatured subtle modern-day institutionally-distorted/disjointed conception of apportioning imbued shallow-supererogation ), in an inclination to pedantising/muddling/formulaic- 
hollowing-out-in-subontologisation/subpotentiation-〈blurring/undermining-of-prospectivetotalising-entailing,-as-to-entailing-<amplituding/formative-epistemicity $>$ totalising $\sim$ inrelative-ontological-completeness > cooptation-and-usurpation of the ontologising/scientific/existence- $<$ honesty-constraining $>$ - scope_for_prospective_reontologising. Effectively, the ontologising/scientific/existence- $<$ honesty-constraining $>$ scope_for_prospective_re-ontologising is about supereregatery $\sim$ wholesomeness/profoundsupererogation as of prospectively 'thinking at first/pure predisposition preemptive of prospective disontologising/subontologising' and so not on the basis of 'rhetorical vagueness of mere abstractly-elaborate apriorising/axiomatising/referencing' (but rather as to the sublimating eliciting/prompting of human subconsciousness most-prospectively-conscious 're-ontologisingby-disontologising_existential-calculus-〈between 'prospective existentialisingpostconverging_framing/imprinting re-ontologising' and 'prior existentialisingpreconverging_enframing/imprintedness social-functioning-and-accordance-as-of-socialstake-contention-or-confliction' $\rangle$ ' of consciousness surrealising-<as-to-supererogation ${ }^{>}{ }^{\text {' }}$ with respect to prospective human crossgenerational 'social-functioning-and-accordance-as-ofsocial-stake-contention-or-confliction imbuing existentialising-frame-of-entailment-of motifand-apriorising/axiomatising/referencing of disontologising/ontologising-and-re-ontologising' in so-enabling prospectively the 'sublimating conceptivity/epistemic-reflexivity/epistemicityrelativism-determinism-<reifying \{as-to-knowledge-developing $\}$-and-empowering $>$ overarching-undergirding' that is the ontologising/scientific/existence- $<$ honestyconstraining $>$ — scope_for_prospective_re-ontologising); as so sublimatingly transforming (by the induced $\quad$ nonpresencing-<perspective-ontological-normalcy/postconvergence $>$ anarchistic-growth/anarchisation-for-re-ontologisation-〈as-to-conscious/unconscious epistemically-sound induced 'demoronisation-<sublimating-nascence,-nonextricatorysublimating-upstreaming/'amontée'> postconverging/dialectical-thinking conception of 
residual_re-originary_anarchistic incipiency of human social-functioning-and-accordance-asof-social-stake-contention-or-confliction meaningfulness-and-teleology ' $\rangle$ ') the epochal 'prospectively debatable/discussable ontologising/scientific/existence- $<$ honestyconstraining $>$ — scope_for_prospective_re-ontologising' as overarching-undergirding reontologising for prospective human 'social-stake-contention-or-confliction of the advocacy/political/applicative—scope as to techno-socio-econo-political implications'. In other words, latter epochal 'social-stake-contention-or-confliction of the advocacy/political/applicative — scope as to techno-socio-econo-political implications' arise from the sublimating expanding of the ontologising/scientific/existence- $<$ honestyconstraining $>$ - scope_for_prospective_re-ontologising (underlied as of the overall relativetnreflexivity/relative-reflexivity - ontological-contiguity ${ }^{67} \sim$ of-the-human-institutionalisationprocess ${ }^{68}$ imbued ${ }^{45}$ foregrounding__entailment- $<$ in-succession-of-profound-supererogation $>>$ 〈postconverging-narrowing-down $\sim$ sublimation-as-to-'existence-as-sublimatingwithdrawal/unenframing/re-ontologising,-elicited-from-prospective-profoundsupererogation '-in-reflecting-'immanent relative- unreflexivity/relative-reflexivity ontological-contiguity ';-as-operative-notional deprocrypticism)). In this regards (as to human Being-development/ontological-framework-expansion-as-to-depth-of-ontologisingdevelopment-as-infrastructure-of- meaningfulness-and-teleology , institutionaldevelopment-as-to-social-function-development and living-development-as-to-personalitydevelopment psychologismic epistemic-acutisation difficulty-<for, residualising \{decompulsing delinearity for-eogeney>-magnitudes $\{0$-experientiality/experiment $\}$ implications of moronisation/demoronisation), the ontologising/scientific/existence- $<$ honesty-constraining $>$ scope_for_prospective_re-ontologising is the effective translation of 'limitedness/humansubpotency prospective re-encountering/re-confrontation with unlimitedness/existence-<fullpotency-of_sublimating nascence>'; 
supererogatory wholesomeness/profound-supererogation' of 'overall human knowledge imbued experientiality/experiment-<as-to-existentially-formative- ‘fepistemic-totalising ${ }^{\prime}$ reapriorising/re-axiomatising/re-referencing residuality_in-re-originariness/re-origination',so-'notionally/epistemically/bindingnessly-<as-to-determinism/conceptivity-of-relative-unreflexivity/relativereflexivity>_implicited-and-articulated'_as-from-nonextricatory-'prospective-re-ontologisingBeing-then-Institutional-then-Living-magnitudes-of-\{hermeneutic/reprojection-protractionef reframing-and-reformulation \}'>' (with regards to reflecting the 're-ontologising fepistemictratising tre-apriorising/re-axiomatising/re-referencing residuality in-re-originariness/reөrigination \{decompulsing\} delinearity/delinear-accreting/recomposuring cogency/tensing/limpidity<as-of-prospective-profound-supererogation ,-for-residuality-in-re-originariness/reorigination>-aprospective_reifying mental-aestheticising-<as-of 'prospective_reformulatingof-mental-aestheticising'as-to-residuality in re-originariness/re-origination' of -mentalaestheticising $>$ ' of 'unlimitedness/existence-<full-potency-of_sublimating nascence $>$ prospective apriorising/axiomatising/referencing-sublimating-reflexivity-beholdening under which limitedness/human-subpotency submits in profound-supererogation for prospective sublimating' as of 'human psychologismic-epistemic-acutisation-<as-to-postconverging-dementating/structuring/paradigming,-eliciting-of-existence's-sublimating-nascence-inprospective-aporeticism-overcoming/unovercoming $>$ as to epistemic-growth,-as\{veridical/sound\}-relative-reflexivity-in-existence/relativising from-limited-mentation-as-itsdeepening/psychologismic epistemic-acutisation residualising, decompulsing? delinearity foreogency'). Thus the ontologising/scientific/existence- $<$ honesty-constraining $>$ scope_for_prospective_re-ontologising can be construed as merely sublimatingly expanding upon human \{decompulsing $\}$ delinearit/delinear acereting/recompestring cogency/tensing/limpidity-<as-of-prospective-profound-supererogation ,-for-residuality-inre-originariness/re-origination $>$ (as of 'human psychologismic-epistemic-acutisation- $<$ as-to- 
postconverging-de-mentating/structuring/paradigming,-eliciting-of-existence's-sublimatingnascence-in-prospective-aporeticism-overcoming/unovercoming > as to epistemic-growth,-as\{veridical/sound\}-relative-reflexivity-in-existence/relativising from-limited-mentation-as-itsdeepening/psychologismic epistemic-acutisation residualising, ${ }^{\text {fdecompulsing }}$ delinearity foreogency'); and so cogently/tensely/limpidly (as from the experientiality/experiment- $<$ as-to-

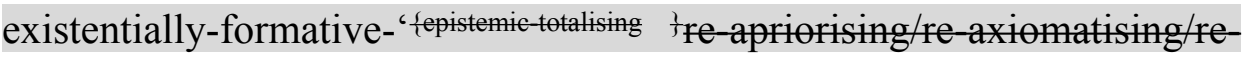
refereneing $\sim$ residuality—in-re-originariness/re-origination',- - so'notionally/epistemically/bindingnessly <as determinism/enneeptivity of relative unreflexivity/relative reflexivity? implicited-and-articulated'_as-from-nonextricatory-'prospective-re-ontologising-Being-thenInstitutional-then-Living-magnitudes-of-\{hermeneutic/reprojection-protraction-of\}reframingand-reformulation $\}^{\prime}>$ of trancing/mysticising/occulticising/subtranslational/omnitranslational processive-motif-'exuding aestheticising-gesturing'-of-apriorising/axiomatising/referencing as to re-aestheticisation-and-re-aestheticisation-towards-ontology-<elicited-prospectiveidiomatisation $>$ ) with respect to 'the-very-same purview/devolved-purview/devolvingpurview-of-unlimitedness/existence-<full-potency-of_sublimating nascence $>$; 'implicited_attendant-ontological-contiguity ${ }^{67}$; educed-

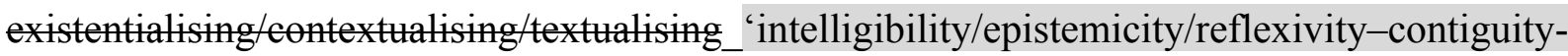
$<$ imbued-notional cogency $>^{\prime} \quad$ in $\quad$ \{epistemic-totalising ${ }^{3}$ 're-apriorising/re-axiomatising/rereferencing residuality—in-re-originariness/re-origination'. Effectively, 're-ontologising fepistemictising tre-apriorising/re-axiomatising/re-referencing-residuality in-reeriginariness/re-origination \{decompulsing\} delinearity/delinear-accreting/recomposuring cogency/tensing/limpidity-<as-of-prospective-profound-supererogation , ,-for-residuality-inre-originariness/re-origination $>$,-prespective_reifying mental aestheticising $<$ as of 'prospective_reformulating-of-mental-aestheticising'as-to-'residuality in re-originariness/reerigination'-of-mental-aestheticising $>$ ' speaks to the fact that the 
$<$ cumulating/recomposuring attendant-ontological-contiguity $>$-successive

registry-

worldviews/dimensions (as to the overall relative-unreflexivity/relative-reflexivity ontological-contiguity ${ }^{67}$ of-the-human-institutionalisation-process ${ }^{68}$ ) are instigatingly 'much more than just successions of prior mere secondnatured institutionalisations (as of mere rationalisation-of-contentivity/argumentativity/dialecticism/discursivity devoid of prospective profound-supererogation ')' with the implication that the possibility for the succession of human transcendence-and-sublimity/sublimation/supereregatory $\sim$ de-mentativity is rather of the veridical 'fundamental/incipient/seeding experientiality/experiment-<as-to-existentiallyformative- ‘fepistemictalising 're-apriorising/re-axiomatising/re-referencing $\sim$ residuality -in-reoriginariness/re-origination',-so-'notionally/epistemically/bindingnessly<-as-todeterminism/conceptivity-of-relative-unreflexivity/relative-reflexivity>-implicited-and-articulated'_as-fromnonextricatory-'prospective-re-ontologising-Being-then-Institutional-then-Living-magnitudesof-\{hermeneutic/reprojection -protraction-of $\}$ reframing-and-reformulation $\}$ '> that is human profound-supererogation' so-reflecting the 'overarching existential-<disontologising/reentologising aporeticism $\geqslant$ priority/precedence/primacy of axiomatising/re-referencing $\sim$ residuality-in-re-originariness/re-origination projection' (as dimensionality-of-sublimating $25<<$ amplituding/formative $>$ supererogatory $\sim$ dementativeness/epistemic-growth-or-conflatedness /transvaluativerationalising/transepistemicity/anamnestic-residuality/spirit-drivenness-equalisation $\rangle)^{\prime} . \quad$ This elucidation is to point out prospectively the 'fundamental/incipient/seeding profoundsupererogation deficiency' of a supposed conception of prospective human re-ontologising (especially as to re-ontologising prospective Being-development/ontological-frameworkexpansion-as-to-depth-of-ontologising-development-as-infrastructure-of- meaningfulnessand-teleology psychologismic epistemic-acutisation difficulty-<for, residualising

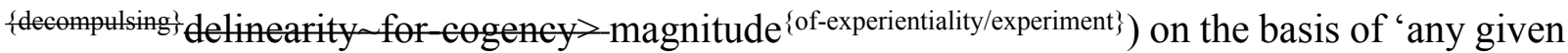


registry-worldview/dimension

overall

$<$ preconverging 'motif-and-

apriorising/axiomatising/referencing'-entailing>-existentialising-enframing/imprintedness-

〈as-to- historicity-tracing-in-presencing-hyperrealisation/hyperreal-transposition〉 of its

underpinning-suprasocial-construct

desublimating

rationalisation-of-

contentivity/argumentativity/dialecticism/discursivity', as so-occurrent in our modern-day with the 'cultivation and enculturation of practices of overt/covert privying of the supposed conception of the ontologising/scientific/existence- $<$ honesty-constraining $>$ scope_for_prospective_re-ontologising (as so-associated prominently with surreptitious and media-savvy political and economic think-tanking and related pop-intellectualism with regards to relatively contentious/un-nominalised social-stake-contention-or-confliction) as well as mere competence/expertising (as of human socially expanded framework of deferential-formalisationtransference as to various cultivated skills/arts and time investment with regards to relatively uncontentious/nominalised social-stake-contention-or-confliction with regards to effectively manifest 'underlying veracity of core-philosophy/derivative-core-philosophy prospective reontologising as relevantly superseding prior mere-formulaicity/ritualisation pedantism induced knowledge-deadends-<as-preconverging-de-mentating/structuring/paradigming >')'; with such an inclination to 'prior mere secondnatured institutionalisation rationalisation-ofcontentivity/argumentativity/dialecticism/discursivity' bound to fundamentally fail to put-intoquestion the given registry-worldview/dimension overall gesturing/accounting-of-epistemicphenomenalism as to prospective ${ }^{83}$ reference-of-thought-point-ofdevolving/departure/anchoring/backdrop_of_sublimating-nascence-<as-to-the-grandest-

\section{axiomatic-construct-\{epistemic-totalising ${ }^{\frac{1}{3}}$ re apriorising/re axiomatising/re-}

referencing - residuality - in-re-originariness/re-origination of limitedness/human-subpotency prospective re-encountering/re-confrontation with unlimitedness/existence $>$ re-rationalisationof-contentivity/argumentativity/dialecticism/discursivity. In other words, 're-ontologising 
\{epistemic-totalising tre-apriorising/re-axiomatising/re-referencing-residuality in-re-

eriginariness/re-erigination

$\{$ decompulsing $\}$ delinearity/delinear-accreting/recomposuring

cogency/tensing/limpidity-<as-of-prospective-profound-supererogation ,, for-residuality—inre-originariness/re-origination>-_prospective_reifying mental-aestheticising-<as-of-

'prospective_reformulating of -mental-aestheticising'as-to-'residuality in re-originariness/reerigination'-of-mental-aestheticising>' (as to the reflection of the overall relativeunreflexivity/relative-reflexivity — ontological-contiguity ${ }^{67}$ of-the-human-institutionalisationprocess ${ }^{6}$ ) highlights the centrality/driving-seat of human profound-supererogation as the altogether most requisite-and-defining element of prospective human experientiality/experiment-<as-to-existentially-formative- ‘fepistemic-totalising ${ }^{\stackrel{3}{3}} \mathrm{re}$-apriorising/reaxiomatising/re-referencing residuality-in-re-originariness/re-origination', - so'notionally/epistemically/bindingnessly $<$ as-to-determinism/conceptivity-of-relative-unreflexivity/relative-reflexivity $>$ implicited-and-articulated'_as-from-nonextricatory-'prospective-re-ontologising-Being-thenInstitutional-then-Living-magnitudes-of-\{hermeneutic/reprojection-protraction-of\}reframingand-reformulation $\}^{\prime}>$ (as to 'overarching existential-<disontologising/re-ontologising aporeticism $>$ priority/precedence/primacy of requisite prospective ontological-goodfaith/authenticity ${ }^{6} \sim$ postconverging-de-mentating/structuring/paradigming 70 inducing of psychoanalytic-unshackling for the relative-ontological-completeness ${ }^{8}$-ofapriorising/axiomatising/referencing re-ontologising prospective re-rationalisation-ofcontentivity/argumentativity/dialecticism/discursivity'); and so beyond a 'human positiveopportunism-of-social-functioning-and-accordance ${ }^{75}$ integration as secondnaturedinstitutionalisation' ontologically-flawed supposed reconstrual of prospective re-ontologising as supposedly of prospective postconverging apereism overeoming ineffect in a 'self-exulting exercise of epistemic-projection in prior processive-motif-'exuding aestheticising-gesturing' of-apriorising/axiomatising/referencing 
imbued_notional $\sim$ reductionism- $<$ of-existential-prospection,-whether-as-oftrepidatious/warped/preclusive/occlusive/protensive-notional $\sim$ reductionism $>$ '), which is rather bound to stifle/undermine prospective re-ontologising (highlighting the inherently requisite consciousness elevation associated with prospective human re-ontologising as not 'thinking-by-the-side as of a mere-thing in soullessness' as to the requisite prospective sublimating by desublimating distinction between 'nonextricatory/postconverging ontologisingand-re-ontologising angling-of-imaginary demoronisation- $<$ sublimating-nascence,nonextricatory-sublimating-upstreaming/'amontée'>' and 'lifespan extricatory/preconverging psychical-nascency moronisation- $<$ sublimating-nascence,-extricatory-desublimatingdownstreaming/'avalage'>'). That is exactly why it is herein contended that there is 'no selfpresence/self-constitutedness ${ }^{14}$-<in-perspective-epistemic-abnormalcy/preconvergence ${ }^{3}>$ purposefulness of core philosophy (as to 'normalised/stereotyped/selfhelping/feel-good knowledge being brought at the protracted-social—as-to-individual-by-institutional-by-social sovereign's service')' but rather core philosophy is about the 'prospective educing-andavailing-and-re-availing of relative-ontological-completeness ${ }^{87}$ and its implication as to 'despite-the-self exercise of epistemic-projection in notional $\sim$ self-distantiation-<imbued-remotif-and-re-apriorising/re-axiomatising/re-referencing >'; and so in reflecting 'unlimitedness/existence-<full-potency-of_sublimating nascence> prospective apriorising/axiomatising/referencing-sublimating-reflexivity-beholdening under which limitedness/human-subpotency submits in profound-supererogation for prospective sublimating'. In the bigger scheme of things, it is ontologically-flawed to imply that the succession of registry-worldviews/dimensions are merely a succession of their 'rationalisationsof-contentivity/argumentativity/dialecticism/discursivity (imbued processive-motif-exuling aestheticising-gesturing' of -apriorising/axiomatising/referencing as to re-aestheticisation-andre-aestheticisation-towards-ontology-<elicited-prospective-idiomatisation $>$ )', $\quad$ supposedly 
excluding the veridical 'fundamental/incipient/seeding experientiality/experiment- $<$ as-toexistentially-formative-' ‘epistemic-totalising $\frac{1}{3}$ re-apriorising/re-axiomatising/re-

referencing $\sim$ residuality —in-re-originariness/re-origination',- - so-

'notionally/epistemically/bindingnessly-<as-to-determinism/conceptivity-of-relative-unreflexivity/relative-reflexivity> implicited-and-articulated'_as-from-nonextricatory-'prospective-re-ontologising-Being-thenInstitutional-then-Living-magnitudes-of-\{hermeneutic/reprojection-protraction-of $\}$ reframingand-reformulation $\}^{\prime}>$ that is human profound-supererogation ' (so-reflecting the 'overarching existential-<disontologising/re-ontologising aporeticism $>$ priority/precedence/primacy of re-apriorising/re-axiomatising/re-referencing $\sim$ residuality-in-re-

originariness/re-origination projection'); and it is this ontologically-flawed inclination that underlies institutionalised pedantising/muddling/formulaic-hollowing-out—insubontologisation/subpotentiation-〈blurring/undermining-of-prospective-totalising-entailing,as-to-entailing-<amplituding/formative-epistemicity $>$ totalising in-relative-ontologicalcompleteness > desublimation as well as the accessorising of 'ordinary laypersonhood arrogation/presumptuousness' conception of supposedly prospective re-ontologising. The profound-supererogation for re-ontologising (as to 'overarching existential$\leq$ disontologising/re-ontologising aporeticism $>$ priority/precedence/primacy of requisite prospective ontological-good-faith/authenticity ${ }^{69} \sim$ postconverging-dementating/structuring/paradigming 70 inducing of psychoanalytic-unshackling for the relativeontological-completeness ${ }^{87}$-of-apriorising/axiomatising/referencing re-ontologising prospective re-rationalisation-of-contentivity/argumentativity/dialecticism/discursivity') effectively translates into the requisite prospective <postconverging 'motif-andapriorising/axiomatising/referencing'-entailing>-existentialising-framing/imprinting-〈as-toprospective- historiality/ontological-eventfulness /ontological-aesthetic-tracing$<$ perspective-ontological-normalcy/postconvergence-reflected-'epistemicity-relativism- 
determinism' $>>$ (undergirding the prospective sublimating interrelatedness-dynamics-of-socialconstructing as from 'catchmented-and-compulsed-<in-'existential-dearth-ofdemoronisation',-so-construed-as-from-ontological-normalcy/postconvergence-perspectivereflection-of-the-'destructuring-threshold_of-the-given-level's-conjugated-postlogism asdementing'> interpersonal, group, intergroup, community, local, national, political, geostrategic, etc. psychologismic epistemic-acutisation difficulty-for, residualising$\{$ decompulsing $\}$ delinearity for-cogency $y$-levels of interrelatedness-dynamics-of-socialconstructing' of 'formativeness-<as-to-intersolipsism-ofpreformulating/preframing/premeaningfulness-imbued-mediativity-and-deferentialism>-ofmeaningfulness-and-teleology and existential-<disontologising/re-ontologising aporeticism> articulation manifestations'); and so, in superseding/overcoming the underpinning-suprasocial-construct $<$ preconverging 'motif-andapriorising/axiomatising/referencing'-entailing >-existentialising-enframing/imprintedness〈as-to- historicity-tracing - in-presencing-hyperrealisation/hyperreal-transposition〉 prospective disontologising/subontologising (as from $\leq$ mere-formulaicity/ritualisation-of $>$ prior secondnatured blatant brutish conquest/subjugation conception of apportioning imbued shallow-supererogation,$\leq$ mere-formulaicity/ritualisation-of $>$-prior secondnatured dominion protection conception of apportioning imbued shallow-supererogation , $\leq$ mereformulaicity/ritualisation-of $>$-prior secondnatured the very natural-order-of-things conception of apportioning imbued shallow-supererogation and prospectively our $<$ mereformulaicity/ritualisation-of $>$ prior secondnatured subtle modern-day institutionallydistorted/disjointed conception of apportioning imbued shallow-supererogation ${ }^{\circ}$ ). All such underpinning-suprasocial-construct shallow-supererogation merely reflect their epochal supposedly 'neutral ${ }^{79}$ presencing-absolutising-identitive-constitutedness ${ }^{14}$ point-ofdevolving/departure/anchoring/backdrop conceptualisation of human sublimating ontological- 
performance $^{72}-<$ including-virtue-as-ontology $>$ /morality/ethics/justice/etc. as to human rationalisation-of-contentivity/argumentativity/dialecticism/discursivity' (but for manifestable prospective parrhesiastic/messianicity/profound-supererogation which is what can fundamentally/incipiently/seedingly instigate their prospective re-rationalisations-ofcontentivity/argumentativity/dialecticism/discursivity for prospective re-ontologising); and so, as to 'the-very-same purview/devolved-purview/devolving-purview-ofunlimitedness/existence-<full-potency-of_sublimating nascence>;_-implicited_attendantontological-contiguity ${ }^{67}$, educedexistentialising/contextualising/textmalising_intelligibility/epistemicity/reflexivity-contiguity-

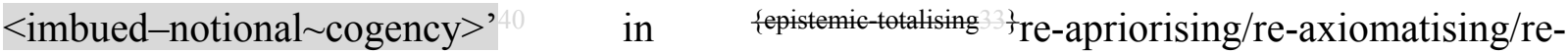
referencing residuality—in-re-originariness/re-origination'. Insightfully, this means that 'social-stake-contention-or-confliction of the advocacy/political/applicative-scope as to techno-socio-econo-political implications' (inevitably enjoined to its given epochal underpinning-suprasocial-construct $<$ preconverging 'motif-andapriorising/axiomatising/referencing'-entailing >-existentialising — enframing/imprintedness(as-to- historicity-tracing-in-presencing-hyperrealisation/hyperreal-transposition〉) cannot be construed as superseding/overriding the ontologising/scientific/existence- $<$ honestyconstraining $>$ _ scope_for_prospective_re-ontologising which is rather of 'unlimitedness/existence-<full-potency-of_sublimating nascence> prospective apriorising/axiomatising/referencing-sublimating-reflexivity-beholdening under which limitedness/human-subpotency submits in profound-supererogation for prospective sublimating' as so-enabling the possibility for prospective re-ontologising as to prospective <postconverging 'motif-and-apriorising/axiomatising/referencing'-entailing >existentialising - framing/imprinting-_as-to-prospective- historiality/ontologicaleventfulness /ontological-aesthetic-tracing-<perspective-ontological- 
normalcy/postconvergence-reflected-‘epistemicity-relativism-determinism’ $>\rangle$. In other words, the 'profound-supererogation enabling the overall relative-unreflexivity/relative-reflexivityontological-contiguity ${ }^{67}$ of-the-human-institutionalisation-process ${ }^{6}$ ' (as to 'the-very-same purview/devolved-purview/devolving-purview-of-unlimitedness/existence-<full-potency ef_sublimating nascence>;_-implicited_attendant-ontological-contiguity ${ }^{67}$ ' educedexistentialising/contextualising/textualising_intelligibility/epistemicity/reflexivity-contiguity<imbued-notional cogency $>^{\prime} \quad$ in $\quad\left\{\right.$ fepistemic-totalising ${ }^{3}$ 're-apriorising/re-axiomatising/rereferencing residuality—in-re-originariness/re-origination' with regards to its imbued cumulating/recomposuring 'prospective re-ontologising as to prospective $<$ postconverging 'motif-and-apriorising/axiomatising/referencing'-entailing $>$ existentialising - framing/imprinting-〈as-to-prospective- historiality/ontologicaleventfulness /ontological-aesthetic-tracing-<perspective-ontologicalnormalcy/postconvergence-reflected-‘epistemicity-relativism-determinism'>〉') effectively speaks of the 're-ontologising \{epistemic-totalising 're-apriorising/re-axiomatising/rereferencing residuality in re originariness/re origination $\quad\{$ decompulsing $\}$ delinearity/delinear accreting/recomposuring cogency/tensing/limpidity-<as-of-prospective-profoundsupererogation ,-for-residuality_in-re-originariness/re-origination>-,prospective_reifying mental-aestheticising_<as-of-prospective_reformulating of-mental-aestheticising'as-to'residuality in-re-originariness/re-origination'-of-mental-aestheticising $\gg$ of the overall relative-unreflexivity/relative-reflexivity — ontological-contiguity ${ }^{67} \sim$ of-the-humaninstitutionalisation-process ${ }^{6}$ '. Thus supereregatory - wholesomeness/profound-supererogation and 're-ontologising \{epistemic-totalising łre-apriorising/re-axiomatising/rereferencing residuality in-re-originariness/re-origination fecompusingt delinearity/delinear accreting/recomposuring cogency/tensing/limpidity-<as-of-prospective-profoundsupererogation ,-for-residuality_in-re-originariness/re-origination>- $>$ prospective_reifying 
mental-aestheticising-<as-of-'prospective_reformulating-of-mental-aestheticising'as-to-

'residuality in-re-originariness/re-origination'-of-mental-aestheticising $>$ ' are in-effect indistinguishable as to the critical epistemic reflection/projection as from 'unlimitedness/existence-<full-potency-of_sublimating nascence> prospective apriorising/axiomatising/referencing-sublimating-reflexivity-beholdening under which limitedness/human-subpotency submits in profound-supererogation for prospective sublimating'; as $\quad$ so-underlying nonpresencing-<perspective-ontologicalnormalcy/postconvergence $>$ relativism/relative-scope for epistemic-growth,-as\{veridical/sound\}-relative-reflexivity-in-existence/relativising from-limited-mentation-as-itsdeepening/psychologismic epistemic-acutisation residualising, \{decompulsing\} ${ }^{\text {\{telinearity for }}$ eogency' imbued underlying-elucidative 'requisite sublimating/desublimating formulativeframing/fielding - of-entailment of human ontological-performance ${ }^{72}-<$ including-virtue-asontology $>$ /morality/ethics/justice/etc. contemplation' as of notionally implied foregrounding_entailment- $<$ in-succession-of-profound-supererogation $>_{-}-\langle$postconverging narrowing-down sublimation-as-to-'existence - as-sublimating-withdrawal/unenframing/reontologising,-elicited-from-prospective-profound-supererogation ' '-in-reflecting'immanent relative-unreflexivity/relative-reflexivity - ontological-contiguity ';-as-operativenotional deprocrypticism $\rangle$. Critically, this profound-supererogation' insight about 'reentologising fepistemictalising Tre-apriorising/re-axiomatising/re-referencing residuality in-reөriginariness/re-origination $\{$ \{decompulsing $\}$ delinearity/delinear-accreting/recomposuring cogency/tensing/limpidity-<as-of-prospective-profound-supererogation ,-for-residuality_inre-originariness/re-origination>-_prospective_reifying mental-aestheticising-<as-of'prospective_reformulating of-mental-aestheticising'as-to-'residuality in re-originariness/reorigination' of mental-aestheticising $>$ ' contrastively highlights the inherent shallowsupererogation with respect to 'eclecticism-of-prior-mere-formulaicity/ritualisation-<as-of- 
prior $\sim$ rationalisation-of-contentivity/argumentativity/dialecticism/discursivity> composition/blending-in-\{compulsing\}linearity/linear-accretion of relative-ontologicalcompleteness and relative-ontological-incompleteness apriorising/axiomatising/referencing as to secondnatured prior mere-formulaicity/ritualisation- $<$ as-to-mere-formulaicmethodologising/mutualising/organising/institutionalising,-prospectively-losing-track-of-

‘\{epistemic-totalising ’’’re-apriorising/re-axiomatising/re-referencing-residuality-in-re-

originariness/re-origination'>> in $>$ moronisation- $<$ sublimating-nascence,-extricatory desublimating-downstreaming/'avalage'>; and as so-inherent to human desublimating interrelatedness-dynamics-of-social-constructing as from 'catchmented-and-compulsed-<in‘existential-dearth-of-demoronisation',-so-construed-as-from-ontologicalnormalcy/postconvergence-perspective-reflection-of-the-'destructuring-threshold_of-thegiven-level's-conjugated-postlogism as-dementing'> interpersonal, group, intergroup, community, local, national, political, geostrategic, etc. psychologismic epistemic-acutisation-

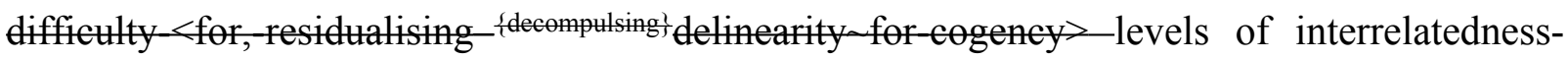
dynamics-of-social-constructing' of 'formativeness-<as-to-intersolipsism-ofpreformulating/preframing/premeaningfulness-imbued-mediativity-and-deferentialism>-ofmeaningfulness-and-teleology and existential-disontologising/re ontologising aporeticism $>$ articulation manifestations' (in $<$ preconverging 'motif-andapriorising/axiomatising/referencing'-entailing>-existentialising-enframing/imprintedness〈as-to- historicity-tracing-in-presencing-hyperrealisation/hyperreal-transposition〉). ontologising \{epistemic-totalising ’̀re-apriorising/re-axiomatising/re-referencing residuality in-reeriginariness/re origination $\{$ decompulsing\} delinearity/delinear acereting/recomposuring cogency/tensing/limpidity-<as-of-prospective-profound-supererogation ,, for-residuality-inre-originariness/re-origination>-,prospective_reifying mental-aestheticising-<as-of'prospective_reformulating of mental-aestheticising'as-to-'residuality in re-originariness/re- 
supererogation $\sim$ reframing/reformulation/decatchmenting/detruncating/decompulsing/delinear ising_scale_-of-transparent/noncontentious/un-nominalised/sound-interpretations/domains of manifest unblurriness-<re-ontologising_by-postconverging-as-to-dragged-outsupererogatory wholesomeness/profound-supererogation ,-while-anecdotalising-priordisontologising-thresholding $>\quad$ (implied notional ${ }^{8}$ deprocrypticism/notional preemptingdisjointedness-as-of- ${ }^{-3}$ reference-of-thought

disparateness $>$ /exactifying_precisioning-of-sublimation- $<$ as-to-postconverging-narrowingdown apriorising/axiomatising/referencing-entailing-theoretical,-conceptual-and-operantimplications $>$ ) eliciting of sublimating conceptivity/epistemic-reflexivity/epistemicityrelativism-determinism- $<$ reifying \{as-to-knowledge-developing $\}$-and-empowering $>$. By the fact that it projects of 'implicited attendant-ontological-contiguity ${ }^{67}$ ' educedexistentialising/contextualising/textualising_'intelligibility/epistemicity/reflexivity-contiguity$<$ imbued-notional cogency >' (as so-implying 'unlimitedness/existence-<full-potency of_sublimating nascence> prospective apriorising/axiomatising/referencing-sublimatingreflexivity-beholdening under which limitedness/human-subpotency submits in profoundsupererogation for prospective sublimating') in 'cogent/tense/limpid-<as-of-prospectiveprofound-supererogation ,-for-residuality-in-re-originariness/re-origination $>$ reflection of the comprehensive coherence/contiguity/noncontradiction of overall experientiality/experiment<as-to-existentially-formative-" ' referencing $\sim$ residuality-in-re-originariness/re-origination',- - so'notionally/epistemically/bindingnessly'<as-to-determinism/coneeptivity-of-relative-unreflexivity/relative-reflexivity> implicited-and-articulated'_as-from-nonextricatory-'prospective-re-ontologising-Being-thenInstitutional-then-Living-magnitudes-of-\{hermeneutic/reprojection-protraction-of\}reframingand-reformulation $\}$ '> for elucidating relative-sublimating over relative-desublimating. This is 
underlied by the fact that various 'pieces of knowledge' are squared-up/cross-examined with one another for arriving-at/eliciting sublimating-existential-eventuating/denouement of relativesublimating over relative-desublimating'; in the sense for instance that 'apart from breakthrough research' the overall state-of-the-arts of such domains/interpretations are highly coherent/contiguous/noncontradictory as to their underlying practice of transversality $-<$ forsublimating-existential-eventuating/denouement,-from-'thinking-at-first/pure-predispositionpreemptive-of prospective-disontologising/subontologising' as-of-prospectivelydisambiguated-affirmed-and-unaffirmed-'motif-and-apriorising/axiomatising/referencing'> $>$ ' In contrast shallowsupererogation $\sim$ framing/formulation/catchmenting/truncating/compulsing/linearising_scale —of-opaque/contentious/un-nominalised/flawed-interpretations/domains of manifest blurriness-<sterilising/anecdotalising/trivialising-of-prospective-re-ontologising_bypreconverging,-in-disontologising-formulaic-dragging-out/hollowing-out> (implied notional $\sim$ procrypticism/notional $\sim$ disjointedness-as-of- ${ }^{3}$ reference-of-thought as of tolerancesof-disparateness>/inexactitude) poorly/hardly project of 'implicited_attendant-ontologicalcontiguity $^{67}$, educed-

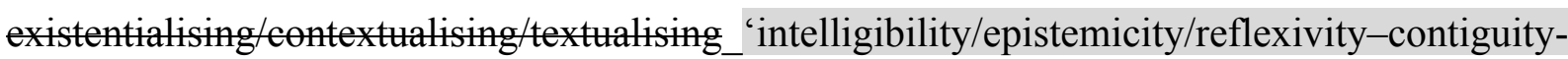
$<$ imbued-notional cogency >' (thus failing to imply 'unlimitedness/existence-<full-potency of_sublimating nascence> prospective apriorising/axiomatising/referencing-sublimatingreflexivity-beholdening under which limitedness/human-subpotency submits in profoundsupererogation for prospective sublimating') as to totalisingly-ing-discretion/whim-ofthought (underlied by the fact that various 'pieces of knowledge' are-not/hardly squaredup/cross-examined with one another for arriving-at/eliciting sublimating-existentialeventuating/denouement); and so-reflected in the broad disparity/incoherence/discontiguity/contradiction arising to the supposed knowledge 'construed 
as overall state-of-the-arts' as to an underlying practice that is-coy-on/shuns transversality- $<$ forsublimating-existential-eventuating/denouement, from-'thinking at first/pure-predispositionpreemptive-of prospective-disontologising/subontologising' as-of-prospectivelydisambiguated-affirmed-and-unaffirmed-'motif-and-apriorising/axiomatising/referencing'> in favour of institutional-prescience/imprimaturing-<dullness-of the-spirit/psychologismic epistemic-acutisation nonresidualising-imbued-\{compulsing\}linearity-in-eclecticism-of-priormere-formulaicity/ritualisation $>$ and/or accessorising of 'ordinary laypersonhood arrogation/presumptuousness' conception of supposedly prospective sublimation. Such a divergence in sublimating and desublimating gesturing/accounting-of-epistemicphenomenalism as to the manifestation of blurriness-<sterilising/anecdotalising/trivialising-ofprospective-re-ontologising_by-preconverging,-in-disontologising-formulaic-draggingout/hollowing-out $>$ is tantamount to failing to grasp that prospective knowledge is as of prospective 'reifying-mental-aestheticising-<as-of-'prospective_reformulating-of-mentalaestheticising'as-to-'residuality-in-re-originariness/re-origination'-of-mental-aestheticising> educed processive-motif-'exuding aestheticising-gesturing' ofapriorising/axiomatising/referencing as to re-aestheticisation-and-re-aestheticisation-towardsontology-<elicited-prospective-idiomatisation>' and not prior 'dereifying-mentalaestheticising-<as-of-‘prior_mere-formulaicity/ritualisation-of-mental-aestheticising'-failing‘residuality-in-re-originariness/re-origination'-of-mental-aestheticising $>$ as of the processivemotif-'exuding aestheticising-gesturing' of-apriorising/axiomatising/referencing of prior aestheticisation-and-aestheticisation-towards-ontology-<elicited-idiomatisation $>{ }^{\prime} \quad$ (as soreflecting 'unlimitedness/existence-<full-potency-of_sublimating nascence $>$ prospective apriorising/axiomatising/refereng-ing sublimating-reflexivity-beholdening under which limitedness/human-subpotency submits in profound-supererogation for prospective sublimating'); wherein for instance say Einsteinian relativity axiomatically imbued prospective 
'reifying-mental-aestheticising-<as-of-'prospective_reformulating-of-mental-aestheticising'asto-'residuality-in-re-originariness/re-origination'-of-mental-aestheticising > educed processive-motif-'exuding aestheticising gesturing' of apriorising/axiomatising/referencing as to re-aestheticisation-and-re-aestheticisation-towards-ontology-<elicited-prospectiveidiomatisation>' is supposedly being construed as of say prior Maxwellian conceptualisation (as unilluminated by the Einsteinian conceptualisation as equally illuminating prior illuminations of the Maxwellian conceptualisation including Poincaré, etc.) imbued prior 'dereifying-mentalaestheticising-<as-of-'prior_mere-formulaicity/ritualisation-of-mental-aestheticising'-failing‘residuality-in-re-originariness/re-origination'-of-mental-aestheticising $>$ as of the processivemotif-'exuding aestheticising-gesturing' of-apriorising/axiomatising/referencing of prior aestheticisation-and-aestheticisation-towards-ontology-<elicited-idiomatisation $>^{\prime} . \quad$ In this respect, profoundsupererogation $\sim$ reframing/reformulation/decatchmenting/detruncating/decompulsing/delinear ising_scale_of-transparent/noncontentious/un-nominalised/sound-interpretations/domains of manifest unblurriness-<re-ontologising_by-postconverging-as-to-dragged-outsupererogatory $\sim$ wholesomeness/profound-supererogation ,-while-anecdotalising-priordisontologising-thresholding $>$ inherently constrain the adoption of the sublimating prospective 'reifying-mental-aestheticising-<as-of-'prospective_reformulating-of-mental-aestheticising'asto-'residuality-in-re-originariness/re-origination'-of-mental-aestheticising > educed processive-motif'exuding aestheticising-gesturing' of apriorising/axiomatising/referencing as to re-aestheticisation-and-re-aestheticisation-towards-ontology-<elicited-prospectiveidiomatisation >'; as to the fact that it is just untenable to ignore/overlook Einsteinian relativity axiomatically imbued prospective 'reifying-mental-aestheticising-<as-of'prospective_reformulating-of-mental-aestheticising'as-to-'residuality-in-re-originariness/reorigination'-of-mental-aestheticising $>$ educed processive-motif-'exuding aestheticising 
gesturing' of-apriorising/axiomatising/referencing as to re-aestheticisation-and-reaestheticisation-towards-ontology-<elicited-prospective-idiomatisation $>$ ' and then effectively grasp the sublimating it projects in immediacy/punctually/effectively like nuclear energy and prospective astronomical implications (on the basis of such a prior unilluminated Maxwellian conceptualisation failing the overall Einsteinian conceptualisation prospective "re-ontologising

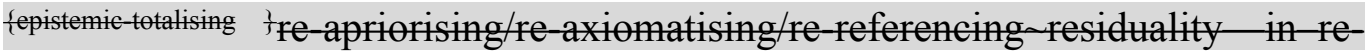
өriginariness/re-origination $\{$ decompulsing\} delinearity/delinear-accreting/recomposuring cogency/tensing/limpidity-<as-of-prospective-profound-supererogation ,, for-residuality-inre-originariness/re-origination>--prospective_reifying mental-aestheticising $<$ as-of'prospective_reformulating of mental-aestheticising'as-to-'residuality in re-originariness/reorigination' of -mental-aestheticising $>$ ' imbued conceptivity/epistemic-reflexivity/epistemicityrelativism-determinism-<reifying \{as-to-knowledge-developing $\}$-and-empowering $>$ ). $\quad$ In contrast such constraining for prospective 'reifying-mental-aestheticising-<as-of'prospective_reformulating-of-mental-aestheticising'as-to-'residuality-in-re-originariness/reorigination'-of-mental-aestheticising> educed processive-motif-'exuding aestheticisinggesturing'-of-apriorising/axiomatising/referencing as to re-aestheticisation-and-reaestheticisation-towards-ontology-<elicited-prospective-idiomatisation $>$ ' can be weak with shallow

supererogation $\sim$ framing/formulation/catchmenting/truncating/compulsing/linearising_scale —of-opaque/contentious/un-nominalised/flawed-interpretations/domains of manifest blurriness-<sterilising/anecdotalising/trivialising-of-prospective-re-ontologising_bypreconverging,-in-disontologising-formulaic-dragging-out/hollowing-out> as to institutionalprescience/imprimaturing-dullness of the spirit/psychologismic epistemie acutisation nonresidualising imbued-\{compulsing\} linearity in-eclecticism-of prior-mereformulaicity/ritualisation $>$ investedness in prior 'dereifying-mental-aestheticising-<as-of- 


\section{'prior_mere-formulaicity/ritualisation-of-mental-aestheticising'-failing-'residuality-in-re-}

originariness/re-origination'-of-mental-aestheticising $>$ as of the processive-motif-'exuding aestheticising-gesturing' of apriorising/axiomatising/referencing of prior aestheticisation-andaestheticisation-towards-ontology-<elicited-idiomatisation>' (in an 'eclecticism-of-prior-mereformulaicity/ritualisation-<as-of-prior $\sim$ rationalisation-of-

contentivity/argumentativity/dialecticism/discursivity> composition/blending-in\{compulsing\}linearity/linear-accretion of relative-ontological-completeness and relativeontological-incompleteness apriorising/axiomatising/referencing as to secondnatured prior mere-formulaicity/ritualisation- $<$ as-to-mere-formulaicmethodologising/mutualising/organising/institutionalising,-prospectively-losing-track-of‘\{epistemic-totalising ’’re-apriorising/re-axiomatising/re-referencing-residuality-in-reoriginariness/re-origination'> $>$ in $\quad$ moronisation- $<$ sublimating-nascence,-extricatorydesublimating-downstreaming/'avalage'>) and thus prospectively undermining 're-ontologising fepistemic tre-apriorising/re-axiomatising/re-referencing residuality in reoriginariness/re-origination \{decompulsing\} delinearity/delinear-accreting/recomposuring cogency/tensing/limpidity-<as-of-prospective-profound-supererogation ,, for-residuality-inre-originariness/re-origination $>$, prospective reifying mental aestheticising $<$ as of 'prospective_reformulating-of-mental-aestheticising'as-to-'residuality in re-originariness/reerigination' of-mental-aestheticising >'; which in-many-ways will explain the weak/inappropriate re-ontologising conceptivity/epistemic-reflexivity/epistemicity-relativismdeterminism-<reifying \{as-to-knowledge-developing\}-and-empowering $>$ associated with a naïve predisposition to turn to overt/covert privying of the supposed conception of the ontologising/scientific/existence- $<$ honesty-constraining $>$ — scope_for_prospective_reontologising while shunning transversality-<for-sublimating-existentialeventuating/denouement,-from-'thinking at-first/pure-predisposition-preemptive-of- 
prospective-disontologising/subontologising' as-of-prospectively-disambiguated-affirmedand-unaffirmed-'motif-and-apriorising/axiomatising/referencing' $>$. Critically, the veridical 'fundamental/incipient/seeding experientiality/experiment-<as-to-existentially-formative‘\{epistemic-totalising ${ }^{\dagger}$ re-apriorising/re-axiomatising/re-referencing residuality-in-reoriginariness/re-origination', - so-'notionally/epistemically/bindingnessly-<as-todeterminism/conceptivity-of-relative-unreflexivity/relative-reflexivityz-implicited-and-articulated' as-fromnonextricatory-'prospective-re-ontologising-Being-then-Institutional-then-Living-magnitudesof-\{hermeneutic/reprojection -protraction-of $\}$ reframing-and-reformulation $\}$ '> that is human profound-supererogation' (so-reflecting the 'overarching existential-<disontologising/reentologising apereticism $>$ priority/precedence/primacy of \{epistemic-totalising ${ }^{3}{ }^{2} \mathrm{re}$-apriorising/reaxiomatising/re-referencing $\sim$ residuality-in-re-originariness/re-origination projection') implies that it is exactly the expansion of 're-ontologising fepistemic-totalising 're-apriorising/reaxiomatising/re-referencing residuality in re-originariness/re-origination \{decompulsing\} delinearity/delinear-accreting/recomposuring cogency/tensing/limpidity-<as-ofprospective-profound-supererogation ,-for-residuality-in-re-originariness/reorigination>--prospective reifying mental-aestheticising_<as-of "prospective reformulating-

\section{of mental aestheticising'as to 'residuality in re originariness/re origination' of mental-}

aestheticising $>$, as from overall nascent-particular/incipient-and-material/technicalsublimations- $<$ blinded-to-their-relative-ontological-completeness - reference-of-thoughtdevolving $>\quad$ to $\quad$ overall social-and-institutional-frameworks-ofreferencing/registering/decisioning (so-underlied by the succession of < amplituding/formativeepistemicity $>$-totalising $\sim$ thrownness-in-existence ${ }^{35}$ ) that as of accreting-<accreting-substitutivesubsumption-as-futural-différance-freeplay $>\quad$ induces $>$ prospective 'apriorising/axiomatising/referencing disambiguating/de-leveling/de-ressentiment/openedconstruct-of- ${ }^{-}$meaningfulness-and-teleology demoronisation- $<$ sublimating-nascence,- 
nonextricatory-sublimating-upstreaming/'amontée’>' undergirding both intradimensional and interdimensional human sublimating (reflected as to human Being-development/ontologicalframework-expansion-as-to-depth-of-ontologising-development-as-infrastructure-ofmeaningfulness-and-teleology , institutional-development-as-to-social-functiondevelopment and living-development-as-to-personality-development psychologismic

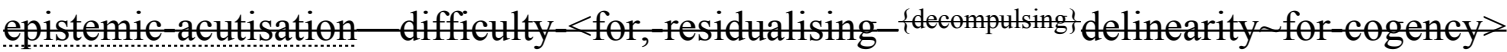
magnitudes $\left.{ }^{\{0-e x p e r i e n t i a l i t y / e x p e r i m e n t}\right\}$ ). However, the-very-underlying-(as inherently 'definingand-imbuing of limitedness/human-subpotency de-mentation-〈supererogatory $\sim$ ontologicalde-mentation-or-dialectical-de-mentation-stranding-or-attributive-dialectics ${ }^{\prime}$ as to preconverging/postconverging-de-mentating/structuring/paradigming)—relationship-betweenlimitedness/human-subpotency-and-unlimitedness/existence-<full-potency-of_sublimating nascence $>$ with respect to the pre-eminence of the latter (as to 'limitedness/human-subpotency prospective re-encountering/re-confrontation with unlimitedness/existence-<full-potency of_sublimating nascence>') implies that there is ever always an 'imputable human blindednessto-relative-ontological-completeness ${ }^{87}$ reference-of-thought- ${ }^{8}$ devolving by which accreting$<$ accreting-substitutive-subsumption-as-futural-différance-freeplay ${ }^{2}>$ occurs as to the given $<$ amplituding/formative-epistemicity $>$-totalising $\sim$ thrownness-in-existence ${ }^{3}$, (rather as of 'human notional difference-conflatedness ${ }^{13}$-as-to-totalitative-reification-in-singularisation$<$ as-to-the-nondisjointedness/entailment-of-prospective- nonpresencing $>$-as-veridicalepistemicity-relativism-determinism construable as from the given projected and prospectively educed-and-availing-and-re-availing relative-ontological-completeness ${ }^{87}$-ofapriorising/axiomatising/referencing'); as so-reflecting the fact that limitedness/humansubpotency doesn't manifest ‘unlimitedness/existence-<full-potency-of_sublimating nascence> absolute-ontological-completeness-of-apriorising/axiomatising/referencing- $<$ asomnipotentiality $><$ amplituding/formative-epistemicity $>$-totalising $\sim$ thrownness-in-existence ${ }^{35}$, 
imbued absolute difference-conflatedness ${ }^{13}$-as-to-totalitative-reification-in-singularisation<as-to-the-nondisjointedness/entailment-of-prospective- nonpresencing $>$-as-veridicalepistemicity-relativism-determinism so-construed as 'absolute reference of identity' (which misconstrual as supposedly veridical will lead to a failure to project/appreciate limitedness/human-subpotency prospective relative-ontological-incompleteness ${ }^{8}$-ofapriorising/axiomatising/referencing as impliciting 'there is supposedly no human prospective epistemic-growth,-as_ \{veridical/sound\}-relative-reflexivity-in-existence/relativising fromlimited-mentation-as-its-deepening/psychologismic epistemic-acutisation residualising, \{decompusing delinearity for-cogency in superseding/overcoming the prior \{flawed/unsound\} relative-unreflexivity-in-existence/absolutising from-limited-mentation/psychologismic epistemic-acutisation nonresidualising-imbued-\{compulsing\} linearity in-eclecticism-of-priormere-formulaicity/ritualisation'). This elucidation effectively points out that limitedness/humansubpotency prospective submitting to unlimitedness/existence-ffull-potency-of_sublimating nascence $>$ is what is reflected as the prospective 'reifying-mental-aestheticising-<as-of'prospective_reformulating-of-mental-aestheticising'as-to-'residuality-in-re-originariness/reorigination'-of-mental-aestheticising $>$ educed processive-motif-'exuding aestheticising gesturing' of apriorising/axiomatising/referencing as to re-aestheticisation-and-reaestheticisation-towards-ontology-<elicited-prospective-idiomatisation $>$ limitedness/human-subpotency educed 're-ontologising fepistemic-totalising 're-apriorising/reaxiomatising/re-referencing-residuality in-re-originariness/re-origination \{decompulsing\} delinearity/delinear-acereting/recomposuring $\quad$ cogency/tensing/limpidity-<as-ofprospective-profound-supererogation ,-for-residuality-in-re-originariness/reorigination $>$, prospective_reifying mental aestheticising <as of 'prospective_reformulating of-mental-aestheticising'as-to 'residuality in re-originariness/re-origination' of -mentalaestheticising $>$ ' from unlimitedness/existence-<full-potency-of_sublimating nascence $>$ ); such 
that such an educing cannot be confused with elaboration-as-to-mereextrapolating/constituting/abstracting/deducing/inferring-of-elucidation-outside'prospectively_implicited_attendant-ontological-contiguity ${ }^{67}$ ' educedexistentialising/contextualising/textualising_'intelligibility/epistemicity/reflexivity-contiguity<imbued-notional cogency $>$ ' . This explains the use of 'unlimitedness in reflection of existence/existence-potency' herein which should not be confused with 'infinity as reflecting existence/existence-potency' as the latter will rather speak of the 'mere-abstracted possibility for human-subpotency-constitutive-extrapolation as anchored to the given ${ }^{79}$ presencingabsolutising-identitive-constitutedness ${ }^{14}$ as of human-subpotency-constitutive\{compulsing' linearity epistemic-projection' whereas 'unlimitedness in reflection of existence/existence-potency' veridically speaks of the 'relative-unreflexivity/relativereflexivity - ontological-contiguity ${ }^{67}$ possibility for human-subpotency-conflative${ }_{\{\text {decompulsing }}$ delinearity-of-re-originariness/re-origination as of ${ }^{6}$ nonpresencing-<perspectiveontological-normalcy/postconvergence> epistemic-projection' as so-translating into human sublimating cogency_chronicularity/annality-of-relative-reflexivity,-as-to-profoundsupererogation (so-implied as to 'limitedness/human-subpotency prospective reencountering/re-confrontation with unlimitedness/existence-full pof sublimating nascence>' in effectively accounting for limitedness/human-subpotency as 'reflexively aspirative to omnipotential-affirmation/projection/assertion/notional $\sim$ self-distantiation with regards to limitedness/human-subpotency relative-unreflexivity/relative-reflexivityontological-contiguity dynamics of supererogating ${ }^{9}$ affirmation/projection/assertion/notional $\sim$ self-distantiation-byunaffirmation/deprojection/deassertion/epistemic-decadence $\}$ — towards $\sim$ omnipotentialaffirmation/projection/assertion/notional self-distantiation' so-underlined as to the 'flow of human prospective profound-supererogation -over-shallow-supererogation ${ }^{\circ}$ ). This reflection 
about limitedness/human-subpotency accreting-<accreting-substitutive-subsumption-as-futuraldifférance-freeplay $>$ is exactly what renders 'a conceptualisation of prospective human reontologising not altogether straightforward (with regards to the accreting-<accretingsubstitutive-subsumption-as-futural-différance-freeplay $>$ of human intelligibility-〈as-tohuman-projective/reprojective- aestheticising-re-motif-and-re-apriorising/re-axiomatising/rereferencing/re-intelligibilitysettingup/re-measuringinstrumenting-process,-in-

$<$ amplituding/formative-epistemicity>totalising conceptualisation $\rangle$ )'; expanded upon as 'human consciousness/collective-consciousness representation/unity/comprehensiveness of the institutional/bureaucratic/social and their purposefulness' imbued 'superposing/implying/suggesting/inferring of the institutional/bureaucratic/social and their purposefulness' so-construed 'as-if-of-inherently-actualising self-embodying representation/unity/comprehensiveness' for the purpose of institutional/bureaucratic/social procession-<as-to-constructive-veracity/inveracity_of-apriorising/axiomatising/referencing $>$ (as to their given interrelatedness-dynamics-of-social-constructing as from 'catchmented-andcompulsed-<in-'existential-dearth-of-demoronisation',-so-construed-as-from-ontologicalnormalcy/postconvergence-perspective-reflection-of-the-"destructuring-threshold of-thegiven-level's-conjugated-postlogism as-dementing'> interpersonal, group, intergroup, community, local, national, political, geostrategic, etc. psychologismic epistemic-acutisationdifficulty < for, residualising_\{decompulsing $\}$ delinearity for-cogency>-levels of interrelatednessdynamics-of-social-constructing' of 'formativeness-<as-to-intersolipsism-ofpreformulating/preframing/premeaningfulness-imbued-mediativity-and-deferentialism $>$-ofmeaningfulness-and-teleology and existential-<disontologising/re-ontologising aporeticism $>$ articulation manifestations' as to the 'undergirding-veracity of germinal/inceptive/formative individuals anarchistic self-reflexive instigative-eventuating-〈asto-teleological-instigative/incipient- 
willing/arbitrariness/waywardness/faithdrivenness/supererogating-for-human-intelligibility,preceding-existence's-eventuating-sublimating-validation/desublimating-invalidation〉'). In other words, human ${ }^{5}$ meaningfulness-and-teleology ${ }^{9}$ basically manifests either sublimating constructive-veracity or desublimating constructive-inveracity so-arising as from the 'protracted-social - as-to-individual-by-institutional-by-social existential-diseresinge entologising aporeticism> accreting-<accreting-substitutive-subsumption-as-futuraldifférance-freeplay $>$ relative-ontological-incompleteness ${ }^{8}-$ ofapriorising/axiomatising/referencing_by_relative-ontological-completeness ${ }^{87}$-ofapriorising/axiomatising/referencing point-of-devolving/departure/anchoring/backdrop of notional $\sim$ difference-conflatedness ${ }^{13}$-as-to-totalitative-reification-in-singularisation- $<$ as-to-thenondisjointedness/entailment-of-prospective- nonpresencing > -as-veridical-epistemicityrelativism-determinism , (and expanding upon as to the interrelatedness-dynamics-of-socialconstructing as from 'catchmented-and-compulsed-<in-'existential-dearth-ofdemoronisation',-so-construed-as-from-ontological-normalcy/postconvergence-perspectivereflection-of-the-‘destructuring-threshold_of-the-given-level's-conjugated-postlogism asdementing'> interpersonal, group, intergroup, community, local, national, political, geostrategic, etc. psychologismic epistemic-acutisation difficulty-for, residualising $\{$ decompulsing $\}$ delinearity for-cogeney> levels of interrelatedness-dynamics-of-socialconstructing' of 'formativeness-<as-to-intersolipsism-ofpreformulating/preframing/premeaningfulness-imbued-mediativity-and-deferentialism $>$-ofmeaningfulness-and-teleology $\quad$ and $\quad$ existential-<disontologising/re-ontologising articulation manifestations'). From the sublimating perspective of ' \{epistemic-totalising tre-apriorising/re-axiomatising/re-referencing residuality in re- 
re-originariness/re-origination>,-prospective_reifying mental-aestheticising-<as-of-

'prospective_reformulating of mental-aestheticising'as-to-'residuality in re-originariness/reerigination'-of-mental-aestheticising ${ }^{\prime} \quad$ (as to relative-ontological-completeness ${ }^{8}$-ofapriorising/axiomatising/referencing), this effectively speaks to prospective 'existential$\leq$ disontologising/re-ontologising aporeticism>

hermeneutic/textuality/reprojecting/supererogating/zeroing/re-acuting

${ }_{\{\text {decompulsing }}$ delinearity/delinear-accreting/recomposuring- ${ }^{6}$ nonpresencing-perceptualisation-ofsublimating-over-desublimating-<as-'psychologismic-epistemic-acutisation-residualising,\{decompulsing $\}$ delinearity for-cogency’_as-to-'prospective-profound-supererogation -epistemicperspective'-of prospective-\& prior-differentiated apriorising/axiomatising/referencing $>$ with-respect-to-the-prospect-of-prospective-human-re-ontologising' induced sublimating constructive-veracity; as manifested with the relative profoundsupererogation $\sim$ reframing/reformulation/decatchmenting/detruncating/decompulsing/delinear ising_scale_of-transparent/noncontentious/un-nominalised/sound-interpretations/domains of manifest unblurriness-<re-ontologising_by-postconverging-as-to-dragged-outsupererogatory wholesomeness/profound-supererogation ,-while-anecdotalising-priordisontologising-thresholding $>$ associated with nascent-particular/incipient-andmaterial/technical-sublimations-<blinded-to-their-relative-ontological-completeness reference-of-thought- devolving $>\quad$ punctual/immediacy/constituted/compulsionsencumbered — disarming/dis_-ideologising/deformulaicity/à-contrecoup/unssettling/unnargunable. Thus 'protracted-social—as-to-individual-by-institutional-by-social existential<disontologising/re-ontologising aporeticism $>$ accreting-<accreting-substitutivesubsumption-as-futural-différance-freeplay $>\quad$ relative-ontological-incompleteness ${ }^{8}$-ofapriorising/axiomatising/referencing_by—relative-ontological-completeness ${ }^{87}$-ofapriorising/axiomatising/referencing point-of-devolving/departure/anchoring/backdrop of 
notional $\sim$ difference-conflatedness ${ }^{13}$-as-to-totalitative-reification-in-singularisation- $<$ as-to-thenondisjointedness/entailment-of-prospective- nonpresencing $>$-as-veridical-epistemicityrelativism-determinism ' (with regards to the very same social-stake-contention-or-confliction) are not absolute/clear-cut; as to individuals socially prioritised 'formativeness-<as-tointersolipsism-of-preformulating/preframing/premeaningfulness-imbued-mediativity-anddeferentialism $>$-of- meaningfulness-and-teleology and existential-<disontologising/reentelogising aporeticism $>$ articulation of interest'. This is relatively bound to be manifested with the shallowsupererogation $\sim$ framing/formulation/catchmenting/truncating/compulsing/linearising_scale —of-opaque/contentious/un-nominalised/flawed-interpretations/domains of manifest blurriness- $<$ sterilising/anecdotalising/trivialising-of-prospective-re-ontologising_bypreconverging,-in-disontologising-formulaic-dragging-out/hollowing-out> ${ }^{\prime}$ together with 'unwieldy-contemplatable-disontologising/re-ontologising-implications,-with-regards-tohuman-sovereign-function/posture-<as-to-narrowness/evasiveness/vagueness-ofdisontologising/re-ontologising $>$ with respect to contentious/un-nominalisedness of socialstake-contention-or-confliction' as to the punctual/immediacy/constituted/compulsionsencumbered nature of the 'social-stake-contention-or-confliction of the advocacy/political/applicative-scope as to techno-socio-econo-political implications'; as soeliciting prior \{compulsing $\}$ linearity/linear-accreting- ${ }^{-1}$ presencing-perceptualisation-ofsublimating-over-desublimating-<as-'psychologismic-epistemic-acutisationnonresidualising-imbued-fompulsingt linearity in-eclecticism-of-prior-mereformulaicity/ritualisation'_as-to-'secondnatured-epistemic-perspective'-of-prospective-\&prior differentiated apriorising/axiomatising/referencing $>$ and-as-developing-intointerrelatedness-dynamics-of-social-constructing desublimating constructive-inveracity. This though contrasts with profound- 
supererogation $\sim$ reframing/reformulation/decatchmenting/detruncating/decompulsing/delinear ising_scale_ of-transparent/noncontentious/un-nominalised/sound-interpretations/domains of manifest ' unblurriness-<re-ontologising_by-postconverging-as-to-dragged-outsupererogatory wholesomeness/profound-supererogation ,-while-anecdotalising-priordisontologising-thresholding $>$ in $\quad$ existentialising-decisionality-<as-to-disontologising/reentologising aporeticism>' where 'existential-<disontologising/re-ontologising aporeticism $>\quad$ hermeneutic/textuality/reprojecting/supererogating/zeroing/re-acuting delinearity/delinear-accreting/recomposuring- nonpresencing-perceptualisation-ofsublimating-over-desublimating-<as-'psychologismic-epistemic-acutisation-residualising,$\left\{\right.$ \{decompulsing\} ${ }^{\prime}$ delinearity for-cogency'_as-to-'prospective-profound-supererogation -epistemicperspective'-of-prospective-\&-prior-differentiated-apriorising/axiomatising/referencing> with-respect-to-the-prospect-of-prospective-human-re-ontologising, induced sublimating constructive-veracity is relatively straightforward; and so, as to the latter profoundsupererogation $\sim$ reframing/reformulation/decatchmenting/detruncating/decompulsing/delinear ising_scale_-of-transparent/noncontentious/un-nominalised/sound-interpretations/domains clearer projecting of the-very-same purview/devolved-purview/devolving-purview-ofunlimitedness/existence-full potency of_sublimating nascence>;_-implicited_attendantontological-contiguity ${ }^{67}$, educedexistentialising/contextualising/textualising_intelligibility/epistemicity/reflexivity-contiguity$<$ imbued-notional cogency>' (as so-implying 'unlimitedness/existence-<full-potencyof_sublimating nascence $>$ prospective apriorising/axiomatising/referencing-sublimatingreflexivity-beholdening under which limitedness/human-subpotency submits in profoundsupererogation for prospective sublimating' in 'cogent/tense/limpid-<as-of-prospectiveprofound-supererogation ,-for-residuality-in-re-originariness/re-origination $>$ reflection of the comprehensive coherence/contiguity/noncontradiction of overall experientiality/experiment- 
<as-to-existentially-formative-' \{epistemic-totalising ${ }^{\prime}$ re-apriorising/re-axiomatising/re-

referencing $\sim$ residuality-in-re-originariness/re-origination',- - so-

'notionally/epistemically/bindingnessly< <s-to-determinism/conceptivity of -relative-unreflexivity/relative-reflexivity>

implicited-and-articulated'_as-from-nonextricatory-'prospective-re-ontologising-Being-then-

Institutional-then-Living-magnitudes-of-\{hermeneutic/reprojection-protraction-of\}reframing-

and-reformulation $\}^{\prime}>$ for elucidating relative-sublimating over relative-desublimating'). It can effectively be appreciated that the ontologising/scientific/existence- $<$ honesty-constraining $>$ scope_for_prospective_re-ontologising is effectively about prospectively eliciting 'reentologising epistemictalising tre-apriorising/re-axiomatising/re-referencing residuality in-reoriginariness/re-origination $\{$ decompulsing $\}$ delinearity/delinear-accreting/recomposuring cogency/tensing/limpidity-<as-of-prospective-profound-supererogation ,-for-residuality-inre-originariness/re-origination>-,prospective_reifying mental-aestheticising-<as-of'prospective_reformulating of mental-aestheticising'as-to-'residuality in re-originariness/reerigination'-of-mental-aestheticising $>$ ' (as to its imbued ${ }^{45}$ foregrounding_entailment- $<$ insuccession-of-profound-supererogation $>$-/postconverging-narrowing-down $\sim$ sublimation-asto-'existence - as-sublimating-withdrawal/unenframing/re-ontologising,-elicited-fromprospective-profound-supererogation ' '-in-reflecting-'immanent relativeunreflexivity/relative-reflexivity - ontological-contiguity ' ';-as-operativenotional deprocrypticism $\rangle$ protracted framework of dispensing-with-immediacy-for-relativeontological-completeness ${ }^{87}$-by-reification/contemplative-distension ${ }^{27}$ ) whereas in-many-ways the 'social-stake-contention-or-confliction of the advocacy/political/applicative-scope as to techno-socio-econo-political implications' is relatively under the constraint of prior \{compulsing\} linearity/linear-accreting- 7 presencing-perceptualisation-of-sublimating-overdesublimating-<as-'psychologismic-epistemic-acutisation-nonresidualising-imbuedfompulsing linearity in-eclecticism-of-prior-mere-formulaicity/ritualisation'_as-to- 


\section{‘secondnatured-epistemic-perspective'-of-prospective-\& prior-differentiated-}

\section{apriorising/axiomatising/referencing $>$ and-as-developing-into-interrelatedness-dynamics-of-}

social-constructing as to its operating in an immediacy framework of relative lack of dispensingwith-immediacy-for-relative-ontological-completeness ${ }^{87}$-by-reification/contemplativedistension ${ }^{27}$. This disambiguation in-the-bigger-scheme-of-things explains why say punctual intragenerational orientations as to 'social-stake-contention-or-confliction of the advocacy/political/applicative — scope as to techno-socio-econo-political implications' such as the practices of human servitude across various historical epochs doesn't render irrelevant the ontologising/scientific/existence- $<$ honesty-constraining $>$ — scope_for_prospective_reontologising prospective crossgenerational projection for bringing such practices of human servitude to an end. Inherently, the constraint of prior feompulsing linearity/linear-accretingpresencing-perceptualisation-of-sublimating-over-desublimating-<as-'psychologismicepistemic-acutisation - nonresidualising-imbued-\{compulsing\}linearity in-eclecticism-of-priormere-formulaicity/ritualisation’_as-to-‘secondnatured-epistemic-perspective'-of prospective\& prior-differentiated-apriorising/axiomatising/referencing $>$ and-as-developing-intointerrelatedness-dynamics-of-social-constructing is effectively what underlies the manifestation of institutionalised pedantising/muddling/formulaic-hollowing-out-insubontologisation/subpotentiation-〈blurring/undermining-of-prospective-totalising-entailing,as-to-entailing-<amplituding/formative-epistemicity $>$ totalising in-relative-ontologicalcompleteness $>$ desublimation as well as overall $<$ amplituding/formative $>$ wooden-language〈imbued-temporal-mere-form/virtualities/dereification/akrasiaticdrag/denatured/preconverging-or-dementing -narratives - of-the- reference-of-thoughtcategorical-imperatives/axioms/registry-teleology $\rangle$; so-arising as to the fact that 'abstractly perceptible contemplation of relative-ontological-completeness ${ }^{8}$-ofapriorising/axiomatising/referencing' do not necessarily override human ingrained 
punctual/immediacy/constituted/compulsions-encumbered prior mere-formulaicity/ritualisation rationalisation-of-contentivity/argumentativity/dialecticism/discursivity' (reflected in the manifestation of the notional/epistemic/bindingness ${ }^{<a s-t o-d e t e r m i n i s m / c o n c e p t i v i t y-o f-r e l a t i v e-~}$ unreflexivity/relative-reflexivity $>$ overaching cultivated-and-enculturated interrelatedness-dynamics-ofsocial-constructing as from 'catchmented-and-compulsed-<in-'existential-dearth-ofdemoronisation',-so-construed-as-from-ontological-normalcy/postconvergence-perspectivereflection-of-the-'destructuring-threshold_of-the-given-level's-conjugated-postlogism asdementing'> interpersonal, group, intergroup, community, local, national, political, geostrategic, etc. psychologismic epistemic-acutisation difficulty-<for, residualising \{decompulsing delinearity for-cogency> levels of interrelatedness-dynamics-of-socialconstructing' of 'formativeness-<as-to-intersolipsism-ofpreformulating/preframing/premeaningfulness-imbued-mediativity-and-deferentialism>-ofmeaningfulness-and-teleology and existential-<disontologising/re-ontologising apereticism $>$ articulation manifestations'), but for the requisite profound-supererogation induced psychoanalytic-unshackling of the protracted-social—as-to-individual-by-institutionalby-social self for prospective human re-rationalisation-ofcontentivity/argumentativity/dialecticism/discursivity. This is the case as prior linearity/linear-accreting- ${ }^{79}$ presencing-perceptualisation-of-sublimating-overdesublimating-<as-'psychologismic-epistemic-acutisation-nonresidualising-imbued\{compulsing $\}$ linearity in-eclecticism-of-prior-mere-formulaicity/ritualisation’as-to‘secondnatured-epistemic-perspective'-of prospective \& prior differentiated apriorising/axiomatising/referencing $\gg$ and-as-developing-into-interrelatedness-dynamics-ofsocial-constructing is effectively constrained as of the 'seeding/incipient pre-eminence of human 
embodied-vitality/survival/subsistence — existential-<disontologising/re-ontologising — aporeticism $>$ becoming driving human consciousness complexifying- $<$ transcending-inelaborateness as to human aestheticisation-and-aestheticisation-towards-ontology-<elicitedidiomatisation> dynamics of lifespan extricatory/preconverging psychical-nascency and nonextricatory/postconverging ontologising-and-re-ontologising angling-of-imaginary>' sounderlied as of human lifespan 'subconscious-and-conscious_perceptible-andreperceptible/actionable-and-reactionable-dynamics of effectively_manifestable-andremanifestable/attainable-and-reattainable loss and gain existential-<disontologising/reөntologising aporeticism $>\quad$ sublimating-upstreaming/'amontée’-by_desublimatingdownstreaming/'avalage' possibilities'; speaking of a human 're-ontologising-bydisontologising_existential-calculus-〈between_prospective $\quad$ existentialisingpostconverging_framing/imprinting re-ontologising' and 'prior existentialising preconverging_enframing/imprintedness social-functioning-and-accordance-as-of-socialstake-contention-or-confliction' $\rangle$ which is just as well likely to existentially<disontologising/re-ontologising aporeticism $>$ acquiesce to prospective disontologising/subontologising_-imbuing-prospectively-of-humandesublimating/subjugation/disenfranchisement (as to the lack of an 'existentially<disontologising/re-ontologising aporeticism $>$ convincing/plausible' prospective requisite epistemic-growth,-as_ \{veridical/sound\}-relative-reflexivity-in-existence/relativising fromlimited-mentation-as-its-deepening/psychologismic epistemic-acutisation residualising, ${ }_{\{\text {decompulsing }}$ delinearity for-cogency elicited prospective re-ontologising conceptivity/epistemicreflexivity/epistemicity-relativism-determinism-<reifying \{as-to-knowledge-developing $\}$-andempowering $>\quad$ for $\quad$ prospective ontologising-and-re-ontologising sublimation/emancipation/enfranchisement. Interestingly, the 're-ontologising tepistemic tre-apriorising/re-axiomatising/re-referencing residuality in re-originariness/re- 
origination \{decompulsing\} delinearity/delinear-acereting/recomposuring cogency/tensing/limpidity<as-of-prospective-profound-supererogation ,-for-residuality—in-re-originariness/re-

origination>-,prospective_reifying mental-aestheticising-<as-of-'prospective_reformulatingof-mental-aestheticising'as-to-'residuality in -re-originariness/re-origination' of-mentalaestheticising $>$ ' enabling the prospectively achieved/secondnatured transcendence-andsublimity/sublimation/supererogatory-de-mentativity render the prior registryworldview/dimension constraining \{compulsing $/$ linearity/linear-accreting $-{ }^{70}$ presencingperceptualisation-of-sublimating-over-desublimating-<as-'psychologismic-epistemicacutisation-nonresidualising-imbued-fompllsinglinearity in-eclecticism-of-prior-mereformulaicity/ritualisation'_as-to-‘secondnatured-epistemic-perspective'-of-prospective-\&prior-differentiated-apriorising/axiomatising/referencing $>$ and-as-developing-intointerrelatedness-dynamics-of-social-constructing critically mostly irrelevant with respect to the prospective registry-worldview/dimension requisite 'existential-<disontologising/reentologising aporeticism $>\quad$ hermeneutic/textmality/reprojecting/supererogating/zeroing/reacuting nonpresencingperceptualisation-of-sublimating-over-desublimating-<as-" psychologismic-epistemic-

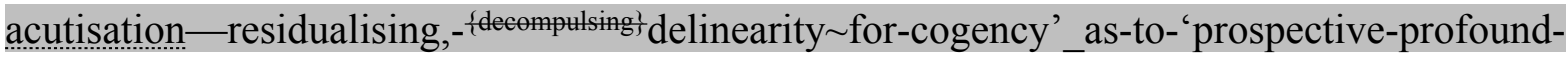
supererogation -epistemic-perspective'-of-prospective-\& prior-differentiatedapriorising/axiomatising/referencing $>$ with-respect-to-the-prospect-of-prospective-human-reontologising' (as so-reflecting the already achieved/secondnatured transcendence-andsublimity/sublimation/supererogatory de-mentativity want for profound-supererogation ${ }^{6}$ for prospective transcendence-and-sublimity/sublimation/supereregatery $\sim$ de-mentativity). This translates into the fact that the very notion of 'prospective transcendence-andsublimity/sublimation/supererogatory-de-mentativity' is a reflection of the fact that the prior \{compulsing\} linearity/linear-accreting_ ${ }^{79}$ presencing-perceptualisation-of-sublimating-over- 
desublimating-<as-'psychologismic-epistemic-acutisation-nonresidualising-imbued\{compulsing\} linearity in-eclecticism-of-prior-mere-formulaicity/ritualisation'_as-to-

\section{‘secondnatured-epistemic-perspective'-of-prospective-\& prior-differentiated-}

apriorising/axiomatising/referencing $>$ and-as-developing-into-interrelatedness-dynamics-ofsocial-constructing (as to secondnatured prior mere-formulaicity/ritualisation-<as-to-mereformulaic — methodologising/mutualising/organising/institutionalising,-prospectively-losingtrack-of-‘ ‘epistemic-totalising ’’re-apriorising/re-axiomatising/re-referencing residuality-in-reoriginariness/re-origination'>) doesn't carry the prospectively requisite 'reifying-mentalaestheticising-<as-of-'prospective_reformulating-of-mental-aestheticising'as-to-'residualityin-re-originariness/re-origination'-of-mental-aestheticising $>$ educed processive-motif'exuding aestheticising-gesturing'-of-apriorising/axiomatising/referencing as to reaestheticisation-and-re-aestheticisation-towards-ontology-<elicited-prospectiveidiomatisation>' (imbuing 're-ontologising fepistemic-totalising '’re-apriorising/re-axiomatising/rereferencing residuality in-re-originariness/re-origination tecompusing accreting/recomposuring cogency/tensing/limpidity-<as-of-prospective-profoundsupererogation ,-for-residuality_in-re-originariness/re-origination>-aprospective_reifying mental aestheticising <as of 'prospective_reformulating of mental restheticising' as to 'residuality in re-originariness/re-origination'-of-mental-aestheticising ${ }^{\prime}$ ) enabling the 'prospective transcendence-and-sublimity/sublimation/supererogatory de-mentativity'; as soexplaining the prospectively manifest 'existential-<disontologising/re-ontologising aporeticism $>\quad$ hermeneutic/textuality/reprojecting/supererogating/zeroing/re-acuting ${ }_{\{\text {decompulsing }\}}$ delinearity/delinear-accreting/recomposuring- ${ }^{6}$ nonpresencing-perceptualisation-ofsublimating-over-desublimating-<as-'psychologismic-epistemic-acutisation-residualising,$\{$ \{lecompulsing $\}$ delinearity for-cogency’_as-to-'prospective-profound-supererogation -epistemicperspective'-of-prospective \& $\&$ prior-differentiated apriorising/axiomatising/referencing $>$ 
with-respect-to-the-prospect-of-prospective-human-re-ontologising', such that it is as of the manifestable parrhesiastic/messianicity/profound-supererogation of 'limitedness/humansubpotency prospective re-encountering/re-confrontation with unlimitedness/existence-<fullpotency-of_sublimating nascence>' (as to prospectively sublimating 'human processive-motif'exuding aestheticising-gesturing' of-apriorising/axiomatising/referencing of existential<disontologising/re-ontelogising aporeticism> counteracting/supplanting/alienating-ofprior-apriorising/axiomatising/referencing' in so-reflecting prospectively 'sublimatingepistemic-imbricatedness/threadedness/recomposuring as of 'implicited_attendant-ontologicalcontiguity $^{67}$, educed-

existentialising/contextualising/textualising_intelligibility/epistemicity/reflexivity-contiguity$<$ imbued-notional $\sim$ cogency $>,{ }^{\prime},-<$ reifying-or-elucidating-of-prospective-relative-ontologicalcompleteness -of- reference-of-thought- devolving-as-of-instantiative-context> as to existence-potency $^{39} \sim$ sublimating-nascence,-disclosed-from-prospective-epistemicdigression—rules-of-apriorising/axiomatising/referencing-that-further-epistemicallyunconceal-the-very-ontologically-same-existential-reality') that the prospective 'reifyingmental-aestheticising-<as-of-'prospective_reformulating-of-mental-aestheticising'as-to‘residuality-in-re-originariness/re-origination'-of-mental-aestheticising $>$ educed processivemotif-'exuding aestheticising-gesturing' of-apriorising/axiomatising/referencing as to reaestheticisation-and-re-aestheticisation-towards-ontology-<elicited-prospectiveidiomatisation>' (imbuing 're-ontologising tre-apriorising/re-axiomatising/rereferencing residuality in-re-originariness/re-origination \{decompulsing $\}$ delinearity/delinearaccreting/recomposuring cogency/tensing/limpidity-<as-of-prospective-profoundsupererogation ,-for-residuality_in-re-originariness/re-origination $>$,-prespective_reifying mental-aestheticising-<as-of-'prospective_reformulating-of-mental-aestheticising'as-to- 
'prospective transcendence-and-sublimity/sublimation/supereregatory de-mentativity' (and so, as to human Being-development/ontological-framework-expansion-as-to-depth-ofontologising-development-as-infrastructure-of- meaningfulness-and-teleology , institutionaldevelopment-as-to-social-function-development and living-development-as-to-personalitydevelopment psychologismic epistemic-acutisation difficulty-<for, residualising$\{$ decompulsing $\}$ delinearity for-cogeney>-magnitudes ${ }^{\{\text {of-experientiality/experiment }\}}$ of relative-ontologicalcompleteness ${ }^{87}$-of-apriorising/axiomatising/referencing). Hence 'existential<disentologising/re-ontelogising aporeticism $>$ hermeneutic/textuality/reprojecting/supererogating/zeroing/re-acuting $\{$ decompulsing $\}$ delinearity/delinear-accreting/recomposuring- nonpresencing-perceptualisation-of-

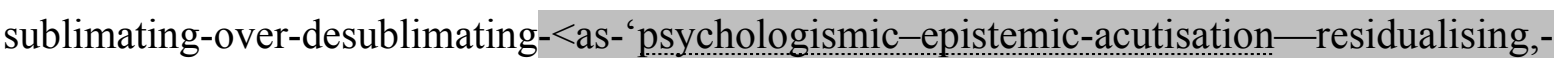
\{decompulsing\} $d$ delinearity for-cogency'_as-to-'prospective-profound-supererogation -epistemicperspective'-of-prospective-\&-prior-differentiated-apriorising/axiomatising/referencing $>$ with-respect-to-the-prospect-of-prospective-human-re-ontologising' is prospectively projected with respect to 'prospective postconverging aporeticism-overcoming/unovercoming desublimating ${ }^{56}$ meaningfulness-and-teleology ${ }^{9}$ prospectively in want for its postconverging apereticism-overeoming so-associated with destructuringthreshold-〈uninstitutionalised-threshold /presublimating-desublimating-decisionality $\rangle$ ofontological-performance ${ }^{72}$-<including-virtue-as-ontology>' while linearity/linearaccreting- ${ }^{79}$ presencing-perceptualisation-of-sublimating-over-desublimating-<as'psychologismic-epistemic-acutisation - nonresidualising-imbued-\{compulsing\} linearity ineclecticism-of-prior-mere-formulaicity/ritualisation'_as-to-‘secondnatured-epistemicperspective'-of prospective-\&-prior-differentiated apriorising/axiomatising/referencing $>$ and-as-developing-into-interrelatedness-dynamics-of-social-constructing is effectively manifested as of "prior postconverging aporeticism-overcoming/unovercoming sublimating 
meaningfulness-and-teleology as to prior achieved/secondnatured transcendence-andsublimity/sublimation/supererogatoryade-mentativity'. This inherently explains why the implicited or explicited prospective construal of human sublimating knowledge breakthroughs (before overcoming destructuring-threshold-〈uninstitutionalised-threshold /presublimatingdesublimating-decisionality $>$ of-ontological-performance ${ }^{72}-<$ including-virtue-as-ontology $>$ ) as rather supposedly as of \{compulsing $\}$ linearity/linear-accreting- ${ }^{-1}$ presencing-perceptualisation-ofsublimating-over-desublimating-<as-'psychologismic-epistemic-acutisationnonresidualising-imbued-\{compulsing\} linearity in-eclecticism-of-prior-mereformulaicity/ritualisation'_as-to-‘secondnatured-epistemic-perspective'-of-prospective-\&prior differentiated apriorising/axiomatising/refereneing $>$ and-as-developing-intointerrelatedness-dynamics-of-social-constructing is effectively ontologically-flawed with serious dereifying consequences; as to secondnatured prior mere-formulaicity/ritualisation- $<$ asto-mere-formulaic - methodologising/mutualising/organising/institutionalising,-prospectively-

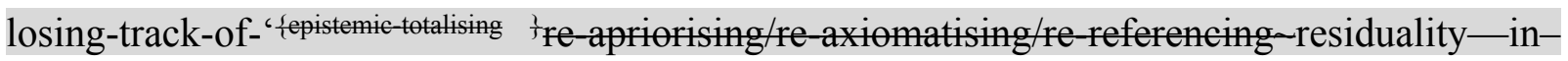
re-originariness/re-origination'> lacking prospectively requisite 'reifying-mentalaestheticising-<as-of-'prospective_reformulating-of-mental-aestheticising'as-to-'residualityin-re-originariness/re-origination'-of-mental-aestheticising $>$ educed processive-motif'exuding aestheticising-gesturing'-of-apriorising/axiomatising/referencing as to reaestheticisation-and-re-aestheticisation-towards-ontology-<elicited-prospectiveidiomatisation>' (imbuing 're-ontologising fepistemic-totalising '’ ${ }^{\prime}$ re-apriorising/re-axiomatising/rereferencing residuality in re-originariness/re-origination \{decompulsing $\}$ delinearity/delinearaccreting/recomposuring cogency/tensing/limpidity-<as-of-prospective-profoundsupererogation ,-for-residuality-in-re-originariness/re-origination>--prospective_reifying mental-aestheticising-<as-of-'prospective_reformulating-of-mental-aestheticising'as-to'residuality in-re-originariness/re-origination'-of-mental-aestheticising $\left.{ }^{\prime}\right)$. In reality, 
prospective human sublimating knowledge breakthroughs effectively arise as of 'comprehensive human $<$ amplituding/formative-epistemicity $>$-totalising $\sim$ renewing-realisation/re-perception/rethought epistemic-projection with respect to the-very-same purview/devolvedpurview/devolving-purview-of-unlimitedness/existence-<full-potency-of_sublimating nascence>;_—implicited_attendant-ontological-contiguity ${ }^{67}$ ' educedexistentialising/contextualising/textualising_intelligibility/epistemicity/reflexivity-contiguity$<$ imbued-notional cogency>' (in so-reflecting the prospectively manifest 'existential<disontologising/re-ontologising aporeticism> hermeneutic/textuality/reprojecting/supererogating/zeroing/re-acuting $\{$ decompulsing $\}$ delinearity/delinear-accreting/recomposuring- nonpresencing-perceptualisation-ofsublimating-over-desublimating-<as-'psychologismic-epistemic-acutisation-residualising,\{decompulsing\}delinearity for-cogency'_as-to-'prospective-profound-supererogation -epistemicperspective'-of-prospective-\&-prior-differentiated-apriorising/axiomatising/referencing $>$ with-respect-to-the-prospect-of-prospective-human-re-ontologising'), and the implications here as well are counterintuitive as rather explaining 'notional citationality as $<$ amplituding/formative-epistemicity $>$-totalising $\sim$ thrownness-in-existence ${ }^{35} \quad$ epistemicprojection of prospective apriorising/axiomatising/referencing-\{of- prespectively implicited_attendant-ontological-contiguity ' reducedexistentialising/contextualising/textualising_ intelligibility/epistemicity/reflexivity-contiguity<imbued-notional cogency>' \}-conflatedness ${ }^{13}$ in-\{preconverging-ment by\} postconverging-entailment in <amplituding/formative-epistemicity >-totalising $\sim$ renewingrealisation/re-perception/re-thought'; and thus revealing as nonsensical the mental-reflex of construing of notional citationality for prospective sublimating knowledge breakthroughs as supposedly rather of \{compulsing $\}$ linearity/linear-accreting- ${ }^{-1}$ presencing-perceptualisation-ofsublimating-over-desublimating-<as-'psychologismic-epistemic-acutisation- 
nonresidualising-imbued-\{compulsing\}linearity in-eclecticism-of-prior-mere-

formulaicity/ritualisation'_as-to-'secondnatured-epistemic-perspective'-of prospective-\&-

prior-differentiated apriorising/axiomatising/referencing $>$ and-as-developing-into-

interrelatedness-dynamics-of-social-constructing (and this translates simply and explains more profoundly why research is undertaken as prior linear understanding by itself cannot/can-hardly be projected as to a linear extrapolation for enabling prospective sublimating knowledge breakthroughs given that the 'unlimitedness/existence-<full-potency-of_sublimating nascence $>$ ambit for prospective sublimating knowledge breakthroughs' is in prospective delinearity with 'prior limitedness/human-subpotency linearity construable knowledge' as can be appreciated for instance with the delinearity of 'conceiving of spacetime as one' over the prior linearity mentalreflex of 'conceiving of space and time as separate' with the latter not linearly extrapolatable into deriving the former but for 'a wholly re-originary profound-supererogation to conceive of spacetime' as from the 'point-of-departure of the <amplituding/formative-epistemicity>totalising thrownness-in-existence $^{35}$ of the prior rationalisation-ofcontentivity/argumentativity/dialecticism/discursivity' as 'conceiving of space and time as separate'). The manifest 'existential-<disontologising/re-ontologising aporeticism $>$ hermeneutic/textuality/reprojecting/supererogating/zeroing/re auting

\{decompulsing $\}$ delinearity/delinear-accreting/recomposuring- nonpresencing-perceptualisation-ofsublimating-over-desublimating-<as-'psychologismic-epistemic-acutisation-residualising,\{decompulsing $\}$ delinearity for-cogency’_as-to-'prospective-profound-supererogation -epistemicperspective'-of-prospective-\&-prior-differentiated-apriorising/axiomatising/referencing $>$ with-respect-to-the-prospect-of-prospective-human-re-ontologising, associated with prospective human sublimating knowledge breakthroughs is effectively what renders the exercise of prospective human knowledge and transcendence-andsublimity/sublimation/supererogatory de-mentativity rather as of 'nonpresencing- 
$<$ perspective-ontological-normalcy/postconvergence $>$ relativism/relative-scope for epistemicgrowth,-as-\{veridical/sound\}-relative-reflexivity-in-existence/relativising from-limitedmentation-as-its-deepening/psychologismic epistemic-acutisation residualising, \{decompulsing\} delinearity for-cogency' (and not '79 presencing-absolutising-identitiveconstitutedness absolution/absolute-scope \{flawed/unsound\}-relative-unreflexivity-inexistence/absolutising from-limited-mentation/psychologismic epistemic-acutisation nonresidualising imbued-\{compulsings linearityoin-eclecticism-of prior-mereformulaicity/ritualisation conception'). Thus central to the ontologising/scientific/existence$<$ honesty-constraining $>$ - scope_for_prospective_re-ontologising is the appraisal (as to the 'constraining/defining intersolipsistic reflexive-sublimating/unreflexive-desublimating measure/objectification that is unlimitedness/existence') of the ${ }^{79}$ presencing-absolutisingidentitive-constitutedness ${ }^{14}$ constraint of fcompulsing\}linearity/linear-accreting- ${ }^{2}$ presencingperceptualisation-of-sublimating-over-desublimating-<as-'psychologismic-epistemicacutisation-nonresidualising-imbued-fompulsingllinearity in-eclecticism-of-prior-mereformulaicity/ritualisation'_as-to-‘secondnatured-epistemic-perspective'-of-prospective-\&prior-differentiated apriorising/axiomatising/referencing > and-as-developing-intointerrelatedness-dynamics-of-social-constructing realisable re-ontologising in view of prospective 'existential-<disontologising/re-ontologising aporeticism $>$ hermeneutic/textuality/reprojecting/supererogating/zeroing/re-acuting \{decomearity/delinear-accreting/recomposuring- nonpresencing-perceptualisation-ofsublimating-over-desublimating-<as-'psychologismic-epistemic-acutisation-residualising,$\{$ \{decompulsing\} delinearity for-cogency’_as-to-'prospective-profound-supererogation -epistemicperspective'-of prospective \& prior differentiated apriorising/axiomatising/referencing with-respect-to-the-prospect-of-prospective-human-re-ontologising'; as so-undergirded with prospective 'reifying-mental-aestheticising-<as-of-'prospective_reformulating-of-mental- 
aestheticising'as-to-'residuality-in-re-originariness/re-origination'-of-mental-aestheticising >

educed

processive-motif-'exuding aestheticising-gesturing' of-

apriorising/axiomatising/referencing as to re-aestheticisation-and-re-aestheticisation-towardsontology-<elicited-prospective-idiomatisation>' (imbuing 're-ontologising \{epistemic-totalising ${ }^{\frac{1}{3}} \mathrm{re}-$ apriorising/re-axiomatising/re-referencing -residuality in-re-originariness/re-origination $\{$ decompulsing $\}$ delinearity/delinear-acereting/recomposuring $\quad$ cogency/tensing/limpidity-<as-ofprospective-profound-supererogation ,-for-residuality-in-re-originariness/re-

origination $>$, prospective_reifying mental-aestheticising-<as-of-'prospective_reformulatingof-mental-aestheticising'as-to 'residuality in -re-originariness/re-origination' of mentalaestheticising $\left.>^{\prime}\right)$. The $\quad$ ontologising/scientific/existence- $<$ honesty-constraining $>$ scope_for_prospective_re-ontologising 'existential-<disentologising/re-ontelogising_ apereticism $>$ projection of relative-ontological-completeness ${ }^{8}$-ofapriorising/axiomatising/referencing' (as to the above elucidation) is effectively reflected with human protracted-social - as-to-individual-by-institutional-by-social self imbued constructionof-the-Self (as undergirded as of 'qveridical/sound?-relative-reflexivity-inexistence/relativising from-limited-mentation-as-its-deepening/psychologismic epistemicacutisation residualising, ${ }^{\text {\{decompulsing }}$ delinearity for cogeney anarchisticgrowth/anarchisation-for-re-ontologisation-〈as-to-conscious/unconscious epistemically-sound induced 'demoronisation-<sublimating-nascence,-nonextricatory-sublimatingupstreaming/'amontée'> postconverging/dialectical-thinking conception of residual_reoriginary_anarchistic incipiency of human social-functioning-and-accordance-as-of-socialstake-contention-or-confliction meaningfulness-and-teleology ' $\rangle$ ' over ' $\{$ flawed/unsound\} relative-unreflexivity-in-existence/absolutising from-limited-mentation/psychologismic epistemic-acutisation nonresidualising imbued-fompulsing linearity in-eclecticism-of-priormere-formulaicity/ritualisation insidious-anarchy-<as-to-conscious/unconscious epistemically- 


downstreaming/'avalage'> preconverging/dementing conception of prior mere-
formulaicity/ritualisation incipiency of human social-functioning-and-accordance-as-ofsocial-stake-contention-or-confliction meaningfulness-and-teleology '>'); and so, as to interrelatedness-dynamics-of-social-constructing as from 'catchmented-and-compulsed-<in‘existential-dearth-of-demoronisation',-so-construed-as-from-ontologicalnormalcy/postconvergence-perspective-reflection-of-the-'destructuring-threshold_of-thegiven-level's-conjugated-postlogism as-dementing'> interpersonal, group, intergroup, community, local, national, political, geostrategic, etc. psychologismic epistemic-acutisationdifficulty $<$ for, residualising \{decompulsing $\}$ delinearity for-cogency>-levels of interrelatednessdynamics-of-social-constructing' of 'formativeness-<as-to-intersolipsism-ofpreformulating/preframing/premeaningfulness-imbued-mediativity-and-deferentialism>-ofmeaningfulness-and-teleology and existential-<disontologising/re-ontologising apereticism $>$ articulation manifestations' with regards to organisational, theoretical, conceptual and operant sublimating implications of 'reifying-mental-aestheticising-<as-of'prospective_reformulating-of-mental-aestheticising'as-to-'residuality-in-re-originariness/reorigination'-of-mental-aestheticising $>$ educed processive-motif-exuling aestheticising gesturing' of apriorising/axiomatising/referencing as to re-aestheticisation-and-reaestheticisation-towards-ontology-<elicited-prospective-idiomatisation>' (imbuing 'reentologising fepistemictalising tre-apriorising/re-axiomatising/re-referencing residuality in-reoriginariness/re-origination \{decompulsingtdelinearity/delinear-accreting/recomposuring cogency/tensing/limpidity-<as-of-prospective-profound-supererogation ${ }^{6}$,-for-residuality-inre-originariness/re-origination $>$, prospective_reifying mental aestheticising $<$ as of 'prospective_reformulating of-mental-aestheticising'as-to-'residuality in re-originariness/reerigination' of -mental-aestheticising $>$ '). In this regards, the prospective 'reifying-mental- 
aestheticising-<as-of-'prospective_reformulating-of-mental-aestheticising'as-to-'residuality in-re-originariness/re-origination'-of-mental-aestheticising $>$ educed processive-motif'exuding aestheticising-gesturing' of apriorising/axiomatising/referencing as to reaestheticisation-and-re-aestheticisation-towards-ontology-<elicited-prospectiveidiomatisation>' (imbuing 're-ontologising fepistemic-totalising ${ }^{\prime}$ 're-apriorising/re-axiomatising/rereferencing-residuality in re-originariness/re-origination $\{$ decompulsing $\}$ delinearity/delinearaccreting/recomposuring cogency/tensing/limpidity-<as-of-prospective-profoundsupererogation ${ }^{9}$,-for-residuality_in-re-originariness/re-origination $>$,-prospective_reifying mental-aestheticising-<as-of-'prospective_reformulating-of-mental-aestheticising'as-to'residuality in-re-originariness/re-origination' of -mental-aestheticising ’') reflecting 'existential-<disentologising/re-ontologising aporeticism> hermeneutic/textuality/reprojecting/supererogating/zeroing/re-acuting \{decompulsing $\}$ delinearity/delinear-accreting/recomposuring- nonpresencing-perceptualisation-ofsublimating-over-desublimating-<as-"psychologismic-epistemic-acutisation-residualising,\{decompulsing $\}$ delinearity for-cogency’_as-to-'prospective-profound-supererogation -epistemicperspective'-of-prospective-\& prior-differentiated apriorising/axiomatising/referencing $>$ with-respect-to-the-prospect-of-prospective-human-re-ontologising, associated with prospective human sublimating knowledge breakthroughs and prospective transcendence-andsublimity/sublimation/supererogatory $\sim$ de-mentativity (as to " ${ }^{\circ}$ nonpresencing-<perspectiveontological-normalcy/postconvergence $>$ relativism/relative-scope for epistemic-growth,-as\{veridical/sound\}-relative-reflexivity-in-existence/relativising from-limited-mentation-as-its-

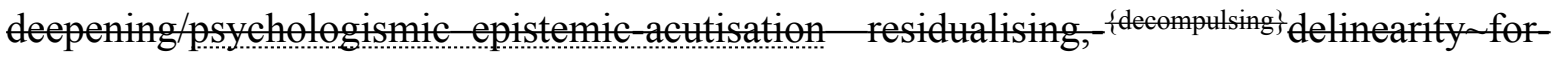
eogency') effectively projects of the 'ontologically-veridical protracted-social-as-toindividual-by-institutional-by-social self organisational/theoretical/conceptual/operant sublimating accreting-<accreting-substitutive-subsumption-as-futural-différance-freeplay $>>$ 
(as of 'human notional difference-conflatedness ${ }^{3}$-as-to-totalitative-reification-insingularisation-<as-to-the-nondisjointedness/entailment-of-prospective- nonpresencing $>$-asveridical-epistemicity-relativism-determinism construable as from the given projected and prospectively educed-and-availing-and-re-availing relative-ontological-completeness ${ }^{87}$-ofapriorising/axiomatising/referencing'), and thus effectively represents the appropriate/sublimating human 'defining precedence of unlimitedness/existence-<flltpoteneyof_sublimating nascence $>$ eliciting of limitedness/human-subpotency dynamically adjusting placeholder-setup/mental-devising-representation/mentation/consciousness-awarenessteleology ${ }^{\prime}$. This effectively avoids a ${ }^{7}$ presencing—absolutising-identitive-constitutedness absolution/absolute-scope \{flawed/unsound\}-relative-unreflexivity-in-existence/absolutising from-limited-mentation/psychologismic epistemic acutisation nonresidualising-imbued\{compulsing\} linearity in-eclecticism-of prior-mere-formulaicity/ritualisation conception' reflected 'ontologically-flawed protracted-social—as-to-individual-by-institutional-by-social self organisational/theoretical/conceptual/operant sublimating accreting-<accreting-substitutivesubsumption-as-futural-différance-freeplay ${ }^{2}>$ ' (supposedly as of 'unlimitedness/existence$\leq$ full-potency-of_sublimating nascence> absolute-ontological-completeness-ofapriorising/axiomatising/referencing-<as-omnipotentiality $>$ <amplituding/formativeepistemicity>-totalising $\sim$ thrownness-in-existence ${ }^{5}$ imbued absolute $\sim$ differenceconflatedness $^{13}$-as-to-totalitative-reification-in-singularisation- $<$ as-to-thenondisjointedness/entailment-of-prospective- nonpresencing > -as-veridical-epistemicityrelativism-determinism so-construed as 'absolute reference of identity' which misconstrual as supposedly veridical will lead to a failure to project/appreciate limitedness/human-subpotency prospective relative-ontological-incompleteness ${ }^{88}$-of-apriorising/axiomatising/referencing as impliciting there is no human epistemic-growth,-as - \{veridical/sound\}-relative-reflexivity-inexistence/relativising from-limited-mentation-as-its-deepening/psychologismic epistemic- 
acutisation residualising, ${ }^{\text {\{decompulsing }}$ delinearity for-cogency as to be prospectively elicited in profound-supererogation ); as so-manifesting the desublimating prior 'dereifying-mentalaestheticising-<as-of-'prior_mere-formulaicity/ritualisation-of-mental-aestheticising'-failing‘residuality-in-re-originariness/re-origination'-of-mental-aestheticising $>$ as of the processivemotif-'exuding aestheticising-gesturing' of apriorising/axiomatising/referencing of prior aestheticisation-and-aestheticisation-towards-ontology-<elicited-idiomatisation $>^{\prime} \quad$ (in $\quad$ an 'eclecticism-of-prior-mere-formulaicity/ritualisation-<as-of-prior $\sim$ rationalisation-ofcontentivity/argumentativity/dialecticism/discursivity> composition/blending-inlinearity/linear-accretion of relative-ontological-completeness and relativeontological-incompleteness apriorising/axiomatising/referencing as to secondnatured prior mere-formulaicity/ritualisation-<as-to-mere-formulaicmethodologising/mutualising/organising/institutionalising,-prospectively-losing-track-of‘\{epistemic-totalising ’re-apriorising/re-axiomatising/re-referencing $\sim$ residuality-in-reoriginariness/re-origination'>> in $>$ moronisation- $<$ sublimating-nascence,-extricatory desublimating-downstreaming/'avalage'>), and thus prospectively undermining 'reentologising fepistemic-totalising ’re-apriorising/re-axiomatising/re-referencing-residuality in-reeriginariness/re origination $\{$ decompulsing $\}$ delinearity/delinear acereting/recomposuring cogency/tensing/limpidity-<as-of-prospective-profound-supererogation ,-for-residuality-inre-originariness/re-origination>-,prospective_reifying mental-aestheticising <as-of'prospective_reformulating of-mental-aestheticising'as-to-'residuality in re-originariness/reerigination' of-mental-aestheticising $>$ '. In the bigger scheme of things, this explains the conception of prospective human re-ontologising (as of the 'fundamental/incipient/seeding preconverging/postconverging-de-mentating/structuring/paradigming potential for human epistemic-growth,-as — \{veridical/sound\}-relative-reflexivity-in-existence/relativising fromlimited-mentation-as-its-deepening/psychologismic epistemic-acutisation residualising, 
\{decompulsing\} delinearity for-cogency') of the ontologising/scientific/existence- $<$ honestyconstraining $>$ — scope_for_prospective_re-ontologising (as to its eliciting of the potential/prospect of 'existential-<disontologising/re-ontologising aporeticism $>$ hermeneutic/textuality/reprojecting/supererogating/zeroing/re-acuting ${ }_{\{\text {decompulsing }}$ delinearity/delinear-accreting/recomposuring- ${ }^{6}$ nonpresencing-perceptualisation-ofsublimating-over-desublimating-<as-"psychologismic-epistemic-acutisation-residualising,$\{$ decompulsing\} delinearity for-cogency'_as-to-'prospective-profound-supererogation -epistemicperspective'-of-prospective-\& prior-differentiated-apriorising/axiomatising/referencing $>$ with-respect-to-the-prospect-of-prospective-human-re-ontologising, rather as from ${ }^{6}$ nonpresencing-<perspective-ontological-normalcy/postconvergence $>$ relativism/relativescope for epistemic-growth,-as - \{veridical/sound\}-relative-reflexivity-inexistence/relativising from limited-mentation-as-its-deepening/psychologismic epistemicacutisation residualising, ${ }^{\text {\{decompulsing }}$ delinearity for-cogency'); in so-achieving 'reentologising fopistemic tre-apriorising/re-axiomatising/re-referencing residuality in-reoriginariness/re-origination \{decompulsing\} delinearity/delinear-accreting/recomposuring cogency/tensing/limpidity-<as-of-prospective-profound-supererogation ${ }^{2}$,-for-residuality—inre-originariness/re-origination>-,prospective reifying mental aestheticising $<a s$ of 'prospective_reformulating of-mental-aestheticising'as-to-'residuality in re-originariness/reerigination' of-mental-aestheticising $>^{\prime}$ as to the ontologising/scientific/existence- $<$ honestyconstraining $>$ — scope_for_prospective_re-ontologising imbued underlying-elucidative 'requisite sublimating/desublimating formulative-framing/fielding-of-entailment of human ontological-performance ${ }^{72}$ - including-virtue-as-ontology $>/$ morality/ethics/justice/etc. contemplation' as of notionally implied ${ }^{45}$ foregrounding_entailment- $<$ in-succession-ofprofound-supererogation ${ }^{9}>-$ - postconverging-narrowing-down $\sim$ sublimation-as-to- ${ }^{\text {existence- }}$ as-sublimating-withdrawal/unenframing/re-ontologising,-elicited-from-prospective-profound- 
supererogation '-in-reflecting-'immanent $\sim$ relative-unreflexivity/relative-reflexivity

ontological-contiguity ';--as-operative-notional deprocrypticism) as protracted framework of dispensing-with-immediacy-for-relative-ontological-completeness ${ }^{87}$-by-

reification/contemplative-distension ${ }^{27}$. This is what overarchingly-undergird the 'social-stakecontention-or-confliction of the advocacy/political/applicative-scope as to techno-socioecono-political implications' (which is relatively under the constraint of \{compulsing\} linearity/linear-accreting- ${ }^{7}$ presencing-perceptualisation-of-sublimating-overdesublimating-<as-'psychologismic-epistemic-acutisation-nonresidualising-imbued\{compulsing $\}$ linearity in-eclecticism-of-prior-mere-formulaicity/ritualisation’ as-to‘secondnatured-epistemic-perspective'-of-prospective-\&-prior-differentiatedapriorising/axiomatising/referencing $>$ and-as-developing-into-interrelatedness-dynamics-ofsocial-constructing 'imbued prospective threshold-of-disontologising/subontologising' as to its ${ }^{6}$ presencing - absolutising-identitive-constitutedness ${ }^{14}$ absolution/absolute-scope \{flawed/unsound\}-relative-unreflexivity-in-existence/absolutising from-limitedmentation/psychologismic epistemic acutisation nonresidualising imbued\{compulsing\} linearity in-eclecticism-of prior-mere-formulaicity/ritualisation conception' in an immediacy framework of relative lack of dispensing-with-immediacy-for-relative-ontologicalcompleteness $^{87}$-by-reification/contemplative-distension ${ }^{27}$ ). In this regards, the overachingundergirding of the ontologising/scientific/existence- $<$ honesty-constraining $>$ scope_for_prospective_re-ontologising as to its requisite profound-supererogation for 'prospective protracted-social—as-to-individual-by-institutional-by-social self organisational/theoretical/conceptual/operant transcendence-andsublimity/sublimation/supererogatory de-mentativity' (as from $\quad<$ mereformulaicity/ritualisation-of $>$ prior secondnatured blatant brutish conquest/subjugation conception of apportioning imbued shallow-supererogation,$\leq$ mere-formulaicity/rittalisation- 
өf>-prior secondnatured dominion protection conception of apportioning imbued shallowsupererogation, $\leq$ mere-formulaicity/ritualisation-of $>$-prior secondnatured the very naturalorder-of-things conception of apportioning imbued shallow-supererogation and prospectively our $\leq$ mere-formulaicity/ritualisation - of $>$-prior secondnatured subtle modern-day institutionallydistorted/disjointed conception of apportioning imbued shallow-supererogation ) effectively supplants any such conception of supposedly sublimating that preconvergingly-dementating/structuring/paradigming uphold the given $\leq$ mere-formulaicity/ritualisation - of $\geq$-prior secondnatured shallow-supererogation (as to its superficial/desublimating eliciting/prompting of human subconsciousness most-prospectively-conscious 're-ontologising-bydisontologising_existential-calculus-〈between 'prospective existentialisingpostconverging_framing/imprinting re-ontologising' and 'prior existentialising preconverging_enframing/imprintedness social-functioning-and-accordance-as-of-socialstake-contention-or-confliction' $\rangle$ ' of consciousness surrealising-<as-to-supererogation $>>$ '). This is the case as the prior human intragenerational ${ }^{79}$ presencing-absolutising-identitiveconstitutedness 'social-functioning-and-accordance-as-of-social-stake-contention-orconfliction imbuing existentialising-frame-of-entailment of motif-andapriorising/axiomatising/referencing of disontologising/ontologising-and-re-ontologising' imbued desublimating <amplituding/formative $>$ disposedness/psychologismic-construct-〈as-toorientation/value-construct/valuation-and-derived-parameterising and $<$ amplituding/formative >entailment-〈as-to-totalising-contiguous/coherent-factuality-ofvariability) (as reflected with its prior 'dereifying-mental-aestheticising-<as-of-'prior_mereformulaicity/ritualisation-of-mental-aestheticising'-failing-'residuality-in-re-originariness/reorigination'-of-mental-aestheticising $>$ as of the processive-motif-exuding aestheticisinggestuing' of apriorising/axiomatising/referencing of prior aestheticisation-andaestheticisation-towards-ontology-<elicited-idiomatisation>') is associated say with the 'priorly 
implied-and-justified inequity' within which its ${ }^{79}$ presencing-absolutising-identitiveconstitutedness $^{14}$ advocacy/political/applicative — scope magnanimity of say an autocrat or plutocrat or formulaic-fashionability-<'wholesome-dearth'/shallowness_as-to-requisite-'reontologising rhizomatic-wholesomeness' for postconverging rede-

mentating/restructuring/reparadigming $>$ shallowly operates; as so-manifesting comprehensively as to the overall social-setup presencing absolutising-identitive-constitutedness 'existential-<disontologising/re-ontologising aporeticism> preconverging dementating/structuring/paradigming punctual/immediacy/constituted/compulsions-encumbered prior mere-formulaicity/ritualisation rationalisation-ofcontentivity/argumentativity/dialecticism/discursivity' (so-reflected in the manifestation of the notional/epistemic/bindingness ${ }^{-<a-t o-d e t e r m i n i s m / c o n c e p t i v i t y-o f-r e l a t i v e-u n r e f l e x i v i t y / r e l a t i v e-r e f l e x i v i t y>~}$ overaching cultivated-and-enculturated interrelatedness-dynamics-of-social-constructing as from 'catchmented-and-compulsed-<in-'existential-dearth-of-demoronisation',-so-construedas-from-ontological-normalcy/postconvergence-perspective-reflection-of-the-'destructuringthreshold_of-the-given-level's-conjugated-postlogism as-dementing'> interpersonal, group, intergroup, community, vassal, dominion, politico-strategic, etc. psychologismic epistemicacutisation diffieully <for, residualising ${ }^{\text {\{decompulsing }}$ delinearity for cogeney> levels of interrelatedness-dynamics-of-social-constructing' of 'formativeness-<as-to-intersolipsism-ofpreformulating/preframing/premeaningfulness-imbued-mediativity-and-deferentialism>-ofmeaningfulness-and-teleology $\quad$ and $\quad$ existential-<disontologising/re-ontologisingaporeticism $>$ articulation manifestations'). Again human epistemic-projection as of \{compulsing $\}$ linearity/linear-accreting- ${ }^{7}$ presencing-perceptualisation-of-sublimating-overdesublimating-<as-'psychologismic-epistemic-acutisation-nonresidualising-imbued\{compulsing\} linearity in-eclecticism-of-prior-mere-formulaicity/ritualisation'_as-to- 
apriorising/axiomatising/referencing $>$ and-as-developing-into-interrelatedness-dynamics-of-

social-constructing and 'existential-<disontologising/re-ontologising aporeticism $>$ hermeneutic/textuality/reprojecting/supererogating/zeroing/re-acuting

$\{$ decompulsing $\}$ delinearity/delinear-accreting/recomposuring- ${ }^{6}$ nonpresencing-perceptualisation-ofsublimating-over-desublimating-<as-"psychologismic-epistemic-acutisation-residualising,$\left.{ }_{\{d e c o m p u l s i n g}\right\}$ delinearity for-cogency'_as-to-'prospective-profound-supererogation -epistemicperspective'-of-prospective-\& prior-differentiated apriorising/axiomatising/referencing $>$ with-respect-to-the-prospect-of-prospective-human-re-ontologising', is inherently the reflection of the-very-underlying- (as inherently 'defining-and-imbuing of limitedness/humansubpotency de-mentation-〈supererogatory ontological-de-mentation-or-dialectical-dementation-stranding-or-attributive-dialectics ${ }^{\prime}$ as to preconverging/postconverging-dementating/structuring/paradigming)—relationship-between-limitedness/human-subpotencyand-unlimitedness/existence-<full-potency-of_sublimating naseence $>$ with respect to the preeminence of the latter (as to 'limitedness/human-subpotency prospective re-encountering/reconfrontation with unlimitedness/existence-<full-potency-of_sublimating nascence>'). The implication is that 're-ontologising fepistemic-totalising 're-apriorising/re-axiomatising/rereferencing residuality in-re-originariness/re-origination \{decompulsing $\}$ delinearity/delinearaccreting/recomposuring cogency/tensing/limpidity-<as-of-prospective-profoundsupererogation ,-for-residuality-in-re-originariness/re-origination>--prospective_reifying mental-aestheticising-<as-of 'prospective_reformulating-of-mental-aestheticising'as-to'residuality in re-originariness/re-origination' of-mental-aestheticising $\gg$ ' is induced as of 'unlimitedness/existence-<full-potency-of_sublimating nascence> prospective apriorising/axiomatising/referencing-sublimating-reflexivity-beholdening under which limitedness/human-subpotency submits in profound-supererogation for prospective sublimating'; as so-translated as from Being-development/ontological-framework-expansion- 
as-to-depth-of-ontologising-development-as-infrastructure-of- meaningfulness-and-

teleology psychologismic epistemic-acutisation difficulty-<for, residualising

\{decompulsing $\}$ delinearity for-cogency> magnitude \{of-experientiality/experiment\}

cogently/tensely/limpidly subsuming both institutional-development-as-to-social-functiondevelopment and living-development-as-to-personality-development psychologismic epistemic-acutisation difficulty-for, residualising ${ }^{\{\text {decompulsing }}{ }^{\text {f }}$ delinearity for-cogency> magnitudes $\{$ of-experientiality/experiment\} (wherein for instance it can be appreciated that the inherent disontologising/subontologising_imbuing-prospectively-of-human-

desublimating/subjugation/disenfranchisement as to vices-and-impediments 105 of nonpositivising social-setup is critically in want of the prospective human ontologicalperformance ${ }^{2}-<$ including-virtue-as-ontology $>/$ morality/ethics/justice/etc. of a positivising social-setup as of prospective 'existential-<disontologising/re-ontologising aporeticism $>$ hermeneutic/textuality/reprojecting/supererogating/zeroing/re-acuting

delinearity/delinear-accreting/recomposuring- nonpresencing-perceptualisation-ofsublimating-over-desublimating-<as-'psychologismic-epistemic-acutisation-residualising,$\{$ \{decompulsing\} $d$ delinearity $\sim$ for-cogency'_as-to-'prospective-profound-supererogation -epistemicperspective'-of prospective \& prior differentiated apriorising/axiomatising/referencing with-respect-to-the-prospect-of-prospective-human-re-ontologising' and so more than just a

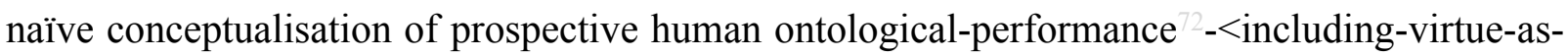
ontology $>$ /morality/ethics/justice/etc. as rather within the very desublimating ambit of the given non-positivising social-setup as of prior perceptualisation-of-sublimating-over-desublimating-<as-" psychologismic-epistemicacutisation-nonresidualising-imbued-\{compulsing? linearity in-eclecticism-of-prior-mereformulaicity/ritualisation'_as-to-‘secondnatured-epistemic-perspective’-of-prospective-\&prior-differentiated-apriorising/axiomatising/referencing $>$ and-as-developing-into- 
interrelatedness-dynamics-of-social-constructing). This speaks to the fact that the 'veridical neutral point-of-devolving/departure/anchoring/backdrop conceptualisation of human ontological-performance $^{72}$-<including-virtue-as-ontology $>/$ morality/ethics/justice/etc. as to rerationalisations-of-contentivity/argumentativity/dialecticism/discursivity so-reflecting successive relative-ontological-completeness 'implicited_attendant-ontologicalcontiguity $^{67}$, educedexistentialising/contextualising/textualising_'intelligibility/epistemicity/reflexivity-contiguity$<$ imbued-notional cogency $>$ ' (as to the underlying-elucidative 'requisite sublimating/desublimating formulative-framing/fielding — of-entailment of human ontologicalperformance $^{72}$-<including-virtue-as-ontology $>$ /morality/ethics/justice/etc. contemplation' of the ontologising/scientific/existence- $<$ honesty-constraining $>$ — scope_for_prospective_reontologising) is necessarily about 'Being-development/ontological-framework-expansion-asto-depth-of-ontologising-development-as-infrastructure-of- meaningfulness-and-teleology psychologismic epistemic-acutisation difficulty-for, residualising \{decompling delinearity for-cogeney> magnitude $\{$ of-experientiality/experiment\} prospective postconverging aporeticism-overcoming/mnovereoming induced aetiologisation/ontologicalescalation-<ontological-veridicality_commitment/otherliness_transcending/compulsionsencumbered_transcending>' (as to 'existential-<disontologising/re-ontologising aporeticism $>$ hermeneutic/textuality/reprojecting/supererogating/zeroing/re-acuting delinearity/delinear-accreting/recomposuring- ${ }^{6}$ nonpresencing-perceptualisation-ofsublimating-over-desublimating-<as-'psychologismic-epistemic-acutisation-residualising,${ }_{\{\text {decompulsing }\}}$ delinearity for-cogency’_as-to-'prospective-profound-supererogation -epistemicperspective'-of prospective \& prior differentiated apriorising/axiomatising/refereneing with-respect-to-the-prospect-of-prospective-human-re-ontologising'); as so-reflecting the vagueness of conceptions of say morality/ethics/justice, etc. (construed as of ${ }^{79}$ presencing- 
absolutising-identitive-constitutedness

institutional-development-as-to-social-function-

development and living-development-as-to-personality-development psychologismic epistemic-acutisation difficulty-for, residualising \{decompulsing ${ }^{\prime}$ delinearity for-cogency> magnitudes $\{$ of-experientiality/experiment\} rather caught up in their given prior registryworldview/dimension \{compulsing $\}$ linearity/linear-accreting- ${ }^{7}$ presencing-perceptualisation-ofsublimating-over-desublimating-<as-'psychologismic-epistemic-acutisationnonresidualising-imbued-\{compulsing\}linearity in-eclecticism-of-prior-mereformulaicity/ritualisation'_as-to-'secondnatured-epistemic-perspective'-of-prospective-\&prior-differentiated-apriorising/axiomatising/referencing $>$ and-as-developing-intointerrelatedness-dynamics-of-social-constructing) poorly reflective of prospective 'reentologising \{epistemic-totalising ${ }^{\prime}$ re-apriorising/re-axiomatising/re-referencing-residuality in-reeriginariness/re-origination \{decompulsing\} delinearity/delinear-acereting/recomposuring cogency/tensing/limpidity-<as-of-prospective-profound-supererogation ,-for-residuality-inre-originariness/re-origination>-,prospective_reifying mental-aestheticising-<as-of'prospective_reformulating of -mental-aestheticising'as-to-'residuality in -re-originariness/reorigination'-of-mental-aestheticising $>$ ' epistemic-projection (as to the prospective 'existentialsdisontologising/re ontologising aporeticism> hermeneutic/textuality/reprojecting/supererogating/zeroing/re-acuting $\{$ decompulsing $\}$ delinearity/delinear-accreting/recomposuring- nonpresencing-perceptualisation-ofsublimating-over-desublimating-<as-'psychologismic-epistemic-acutisation-residualising,\{decompulsing\} delinearity for-cogency'_as-to-'prospective-profound-supererogation -epistemicperspective'-of-prospective-\& prior-differentiated apriorising/axiomatising/referencing $>$ with-respect-to-the-prospect-of-prospective-human-re-ontologising' for the requisite 'Beingdevelopment/ontological-framework-expansion-as-to-depth-of-ontologising-development-asinfrastructure-of- meaningfulness-and-teleology psychologismic epistemic acutisation- 
difficulty-<or, residualising_\{decompulsing $\}$ delinearity for-cogency> magnitude $\{$ ofexperientiality/experiment\} prospective postconverging aporeticism-overcoming/unovercoming induced aetiologisation/ontological-escalation-<ontologicalveridicality_commitment/otherliness_transcending/compulsions-encumbered_transcending >' in sublimating redefining of institutional-development-as-to-social-function-development and living-development-as-to-personality-development psychologismic epistemic-acutisation difficulty-<for, residualising \{decompulsing\} ${ }^{\text {delinearity }}$ for-cogency> $>$ magnitudes $\{$ ofexperientiality/experiment ontological-performance ${ }^{2}-<$ including-virtue-asontology $>$ /morality/ethics/justice/etc.). The implication here is that the projection of human ontological-performance ${ }^{72}$-<including-virtue-as-ontology $>$ /morality/ethics/justice/etc. rather veridically arises as from the 'human psychologismic-epistemic-acutisation-<as-topostconverging-de-mentating/structuring/paradigming,-eliciting-of-existence's-sublimatingnascence-in-prospective-aporeticism-overcoming/unovercoming > as to epistemic-growth,-as \{veridical/sound\}-relative-reflexivity-in-existence/relativising from-limited-mentation-as-itsdeepening/psychologismic epistemic-acutisation residualising, ${ }^{\text {fdecompulsing }}$ delinearity foreogency' for re-ontologising prospective Being-development/ontological-frameworkexpansion-as-to-depth-of-ontologising-development-as-infrastructure-of- meaningfulnessand-teleology psychologismic epistemic-acutisation difficulty-for, residualising \{decompulsing\} delinearity for-cogency $>$ magnitude ${ }^{\text {\{of-experientiality/experiment }\}} ;$ in reflection of 'prospective reference-of-thought-point-ofdevolving/departure/anchoring/backdrop_of_sublimating-nascence- $<$ as-to-the-grandestaxiomatic-construct-\{epistemic-totalising ${ }^{\frac{1}{3}}$ re-apriorising/re-axiomatising/rereferencing-residuality -in-re-originariness/re-origination of limitedness/human-subpotency prospective re-encountering/re-confrontation with unlimitedness/existence $>$ re-rationalisationof-contentivity/argumentativity/dialecticism/discursivity' as to the-very-underlying-(as 
inherently 'defining-and-imbuing of limitedness/human-subpotency de-mentation〈supererogatory $\sim$ ontological-de-mentation-or-dialectical-de-mentation-stranding-orattributive-dialectics ${ }^{\prime}$ as to preconverging/postconverging-dementating/structuring/paradigming)—relationship-between-limitedness/human-subpotencyand-unlimitedness/existence-<full-potency-of_sublimating naseence $>$ with respect to the preeminence of the latter as to 'limitedness/human-subpotency prospective re-encountering/reconfrontation with unlimitedness/existence-<full-potency-of_sublimating nascence>'. Such that the postconverging aporeticism-overcoming/unovercoming (respectively of $\leq$ mereformulaicity/ritualisation of $>$ prior secondnatured blatant brutish conquest/subjugation conception of apportioning imbued shallow-supererogation,$<$ mere formulaicity/ritualisation ef $>$-prior secondnatured dominion protection conception of apportioning imbued shallowsupererogation , $\leq$ mere-formulaicity/ritualisation-of $>$ prior secondnatured the very naturalorder-of-things conception of apportioning imbued shallow-supererogation and prospectively our $\leq$ mere-formulaicity/ritualisation - of $>$-prior secondnatured subtle modern-day institutionallydistorted/disjointed conception of apportioning imbued shallow-supererogation as soovercome as to the profound-supererogation for 'existential-<disontologising/reentologising aporeticism $>$ hermeneutic/textuality/reprojecting/supererogating/zeroing/reacuting delinearity/delinear-accreting/recomposuring- nonpresencingperceptualisation-of-sublimating-over-desublimating-<as-"psychologismic-epistemicacutisation—residualising,-\{decompulsing\} $d$ delinearity for-cogency’_as-to-‘prospective-profoundsupererogation -epistemic-perspective'-of-prospective-\& prior-differentiatedapriorising/axiomatising/referencing $>$ with-respect-to-the-prospect-of-prospective-human-reontologising' as underlied as of 'nonextricatory/postconverging ontologising-and-reontologising angling-of-imaginary demoronisation-<sublimating-nascence,-nonextricatory sublimating-upstreaming/'amontée'>') is critically as of sublimating 're-ontologising epistemic- 
totalising ${ }^{\prime}$ re-apriorising/re-axiomatising/re-referencing residuality in-re-originariness/reorigination \{decompulsing\} delinearity/delinear-accreting/recomposuring cogency/tensing/limpidity$<$ as-of-prospective-profound-supererogation ,-for-residuality-in-re-originariness/reorigination $>$, - prospective_reifying mental-aestheticising-<as-of-'prospective_reformulating of-mental-aestheticising'as to 'residuality in -re-originariness/re-origination' of mentalaestheticising>' (as to 'human psychologismic-epistemic-acutisation-<as-to-postconvergingde-mentating/structuring/paradigming,-eliciting-of-existence's-sublimating-nascence-inprospective-aporeticism-overcoming/unovercoming > as to epistemic-growth,-as\{veridical/sound\}-relative-reflexivity-in-existence/relativising from-limited-mentation-as-itsdeepening/psychologismic epistemic-acutisation residualising, ${ }^{\text {\{decompulsing }}$ delinearity for eogency'); and so over the 'circular desublimating redundance' of the given ${ }^{7}$ presencingabsolutising-identitive-constitutedness ${ }^{14} \quad$ institutional-development-as-to-social-functiondevelopment and living-development-as-to-personality-development psychologismic epistemic-acutisation difficulty-for, residualising \{decomplsing $\}$ delinearity for-cogency> magnitudes $\{$ of-experientiality/experiment\} desublimating conception of human ontologicalperformance $^{72}-<$ including-virtue-as-ontology $>$ /morality/ethics/justice/etc. (ontologicallyflawed prior \{compulsing\} linearity/linear-accreting -79 presencing-perceptualisation-of-sublimatingover-desublimating-<as-'psychologismic-epistemic-acutisation-nonresidualising-imbued\{compulsing\} linearity in-eclecticism-of-prior-mere-formulaicity/ritualisation'_as-to‘secondnatured-epistemic-perspective'-of-prospective-\&-prior-differentiatedapriorising/axiomatising/referencing $>$ and-as-developing-into-interrelatedness-dynamics-ofsocial-constructing as underlied as of 'lifespan extricatory/preconverging psychical-nascency moronisation-<sublimating-nascence, exublimating-downstreaming/'avalage'>’). Inevitably, the cross-manifestation or juxtaposing-manifestation of human epistemic-projection as of 'existential-<disontologising/re-ontologising aporeticism> 
hermeneutic/textuality/reprojecting/supererogating/zeroing/re-acuting

$\{$ decompulsing $\}$ delinearity/delinear-accreting/recomposuring- ${ }^{6}$ nonpresencing-perceptualisation-of-

sublimating-over-desublimating-<as-'psychologismic-epistemic-acutisation-residualising,-

$\{$ \{decompulsing\} delinearity for-cogency’_as-to-'prospective-profound-supererogation -epistemic-

perspective'-of-prospective-\& prior-differentiated apriorising/axiomatising/referencing $>$

with-respect-to-the-prospect-of-prospective-human-re-ontologising' and

\{compulsing\} linearity/linear-accreting- ${ }^{7}$ presencing-perceptualisation-of-sublimating-over-

desublimating-<as-'psychologismic-epistemic-acutisation-nonresidualising-imbued-

\{ringulsing linearity in-eclecticism-of-prior-mere-formulaicity/ritualisation’_as-to-

‘secondnatured-epistemic-perspective'-of prospective-\&-prior-differentiated-

apriorising/axiomatising/referencing $\gg$ and-as-developing-into-interrelatedness-dynamics-of-

social-constructing (as to the cross-dynamics of human profound-supererogation and derived secondnatured-institutionalisation on-the-one-hand and human destructuring-threshold〈uninstitutionalised-threshold /presublimating-desublimating-decisionality $>$ of-ontological-

performance $^{72}-<$ including-virtue-as-ontology $>$ /morality/ethics/justice/etc. on-the-other-hand reflected in the overall relative-unreflexivity/relative-reflexivity - ontological-contiguity ${ }^{67}$ ofthe-human-institutionalisation-process ${ }^{6}$ ) is actually critically important as not allowing for the defining of the-human/humanity; and thus not constraining the "potential individual sublimating conception' of the-human/humanity by other humans (as mere mortals when consciously/unconsciously manifesting a desublimating closed-construct-of- -5 meaningfulnessand-teleology of the-human/humanity) but rather implying the opened-construct-ofmeaningfulness-and-teleology for eliciting unlimitedness/existence-<ull өf_sublimating nascence $>$ as of the possibility for the educing-and-availing-and-re-availing of relative-ontological-completeness ${ }^{87}$ as of profound-supererogation (as so-requisite for the potential for veridical sublimating as rather in expansive derivation as from human socially 
expanded framework of deferential-formalisation-transference as to various cultivated skills/arts and time investment). Profound-supererogation' (as to the 'fundamental/incipient/seeding experientiality/experiment-<as-to-existentially-formative-'fepistemictalising ${ }^{+} \mathrm{re}$-apriorising/reaxiomatising/re-referencing $\sim$ residuality —in-re-originariness/re-origination',- - so'notionally/epistemically/bindingnessly-<as-to-determinism/coneeptivity-of-relative-unreflexivity/relative-reflexivity> implicited-and-articulated'_as-from-nonextricatory-'prospective-re-ontologising-Being-thenInstitutional-then-Living-magnitudes-of-\{hermeneutic/reprojection-protraction-of $\}$ reframingand-reformulation $\}$ '> that is human profound-supererogation' so-reflecting the 'overarching existential-<disontologising/re-ontologising aporeticism $>$ priority/precedence/primacy of \{epistemic-totalising ${ }^{3}{ }^{\}}$re-apriorising/re-axiomatising/re-referencing $\sim$ residuality-in-reoriginariness/re-origination projection') as so-speaking of dimensionality-of-sublimating 〈<amplituding/formative>supererogatory $\sim$ de-mentativeness/epistemic-growth-orconflatedness /transvaluative-rationalising/transepistemicity/anamnestic-residuality/spiritdrivenness-equalisation), is the effective sublimating-tradition/constant for human 'reentologising \{epistemic-totalising ’’re-apriorising/re-axiomatising/re-referencing residuality in-reeriginariness/re-origination $\{$ \{decompulsing\} delinearity/delinear-accreting/recomposuring cogency/tensing/limpidity-<as-of-prospective-profound-supererogation ,-for-residuality-inre-originariness/re-origination>-,prospective_reifying mental-aestheticising-<as-of'prospective_reformulating of-mental-aestheticising'as-to-'residuality in re-originariness/reorigination' of-mental-aestheticising ${ }^{\prime}$ ' (across the overall relative-unreflexivity/relativereflexivity - ontological-contiguity ${ }^{67}$ of-the-human-institutionalisation-process ${ }^{68}$ ); prospectively unachieved human transcendence-and-sublimity/sublimation/supereregatory $\sim$ dementativity is rather elucidated as of 'existential-<disontologising/re-ontologising aporeticism> hermeneutic/textuality/reprojecting/supererogating/zeroing/re-acuting \{decompling $d$ delinearity/delinear-accreting/recomposuring- nonpresencing-perceptualisation-of- 
sublimating-over-desublimating-<as-" psychologismic-epistemic-acutisation-residualising,$\{$ \{decompulsing\} $\}$ delinearity for-cogency'_as-to-'prospective-profound-supererogation -epistemicperspective'-of-prospective-\& prior-differentiated-apriorising/axiomatising/referencing $>$ with-respect-to-the-prospect-of-prospective-human-re-ontologising' while priorly achieved human transcendence-and-sublimity/sublimation/supererogatory - de-mentativity is then elucidated as of \{compulsing $\}$ linearity/linear-accreting- ${ }^{7}$ presencing-perceptualisation-ofsublimating-over-desublimating-<as-'psychologismic-epistemic-acutisationnonresidualising-imbued-fompusingl linearity in-eclecticism-of-prior-mereformulaicity/ritualisation'_as-to-'secondnatured-epistemic-perspective'-of-prospective-\&prior-differentiated-apriorising/axiomatising/referencing $>$ and-as-developing-intointerrelatedness-dynamics-of-social-constructing (as to the cross-dynamics of 'firstnaturednessas-to-inkling profound-supererogation for overarching existential-<disontolegising/reentologising apereticism $\geqslant$ priority/precedence/primacy of \{epistemic-totalising 3 ? $\mathrm{re}$-apriorising/reaxiomatising/re-referencing $\sim$ residuality-in-re-originariness/re-origination projection' in 'recurrent/perpetuating/continuity-recomposuring existential-<disontologising/reentologising aporeticism $>$ counteracting/supplanting/alienating-of-prior-

apriorising/axiomatising/referencing' over 'secondnatured prior mere-formulaicity/ritualisation$<$ as-to-mere-formulaic — methodologising/mutualising/organising/institutionalising,prospectively-losing-track-of-`\{epistemic-totalising 3 're-apriorising/re-axiomatising/rereferencing $\sim$ residuality —in-re-originariness/re-origination'>'). Insightfully, this speaks to the fact that human consciousness/collective-consciousness is most truly this cross-dynamics induced potentiation across the overall relative-unreflexivity/relative-reflexivity ontologicalcontiguity ${ }^{67}$ of-the-human-institutionalisation-process ${ }^{68}$ as in-many-ways the crossgenerational cumulating/recomposuring (as from the experientiality/experiment-<as-to-existentiallyformative- ‘fepistemic-totalising ${ }^{3}$ re-apriorising/re-axiomatising/re-referencing $\sim r e s i d u a l i t y-i n-r e-$ 
originariness/re-origination', - so-'notionally/epistemically/bindingnessly-<as-to-

determinism/conceptivity-of-relative-unreflexivity/relative-reflexivity>-implicited-and-articulated'_as-from-

nonextricatory-'prospective-re-ontologising-Being-then-Institutional-then-Living-magnitudesof-\{hermeneutic/reprojection-protraction-of\}reframing-and-reformulation $\}^{\prime}>$ of trancingprocessive-motif-'exuding aestheticising gesturing' of apriorising/axiomatising/referencing as-to-trepidatious-consciousness $\sim$ moronisation/demoronisation, mysticising-processive-motif'exuding aestheticising-gesturing' of apriorising/axiomatising/referencing - as-to-warpedconsciousness $\sim$ moronisation/demoronisation, $\quad$ occulticising-processive-motif-'exuding aestheticising-gesturing' of-apriorising/axiomatising/referencing - as-to-preclusiveconsciousness $\sim$ moronisation/demoronisation,

procrypticising/subtranslational/subnotionality/subepistemicity-processive-motif-'exuding aestheticising-gesturing' of apriorising/axiomatising/referencing -as-to-occlusiveconsciousness $\sim$ moronisation/demoronisation and prospectively deprocrypticising/omnitranslational/omninotionality/omniepistemicity-processive-motif'exuding aestheticising-gesturing' of apriorising/axiomatising/referencing -as-to-protensiveconsciousness $\sim$ moronisation/demoronisation successively imbued 'reifying-mentalaestheticising-<as-of-'prospective_reformulating-of-mental-aestheticising'as-to-'residualityin-re-originariness/re-origination'-of-mental-aestheticising $>$ educed processive-motif'exuding aestheticising-gesturing' of-apriorising/axiomatising/referencing as to reaestheticisation-and-re-aestheticisation-towards-ontology-<elicited-prospectiveidiomatisation>') speaks to the very notional/epistemic/bindingness relative-unreflexivity/relative-reflexivity> 're-ontologising \{epistemic-totalising $\frac{1}{3} \mathrm{re}$-apriorising/re-axiomatising/rereferencing-residuality in re originariness/re origination $\{$ decompulsing\} delinearity/delinear accreting/recomposuring cogency/tensing/limpidity-<as-of-prospective-profoundsupererogation ,-for-residuality_in-re-originariness/re-origination>-_prospective_reifying 
mental-aestheticising <as-of 'prospective_reformulating-of-mental-aestheticising' as-to-

'residuality in-re-originariness/re-origination'-of-mental-aestheticising $>$ ' of human consciousness/collective-consciousness (so-arising dynamically as of epistemic-growth,-as\{veridical/sound\}-relative-reflexivity-in-existence/relativising from-limited-mentation-as-itsdeepening/psychologismic epistemic-acutisation residualising, ${ }^{\text {\{decompulsing }}$ \}elinearity foreogency over \{flawed/unsound\}-relative-unreflexivity-in-existence/absolutising from-limitedmentation/psychologismic epistemic acutisation nonresidualising imbued-

fompulsing linearity in-eclecticism-of prior-mere-formulaicity/ritualisation). The bigger point here (as to the crossgenerational relevant manifestation of human consciousness/collectiveconsciousness as to its sublimating epistemic cumulating/recomposuring dynamics) is to highlight the 'shallowness of an absolute punctual/immediacy/constituted/compulsionsencumbered consciousness/collective-consciousness conception with respect to prospective human sublimation' whereas what is rather insightfully warranted is an overall appraisal-of and engagement-with the underlying consciousness/collective-consciousness backdrop over which human transcendence-and-sublimity/sublimation/supererogatory de-mentativity actively-andpassively ensues (as from underlying 'constraining existence-as-sublimatingwithdrawal/unenframing/re-ontologising,-elicited-from-prospective-profound-supererogation imbuing human ontological-commitment $-<$ implied — self-assuredness-of-ontological-goodfaith/authenticity postconverging-de-mentating/structuring/paradigming -as-being-as-ofexistential-reality>' and ' ${ }^{103}$ universal-transparency ${ }^{104}$-〈transparency-of-totalising-entailing,-asto-entailing-<amplituding/formative-epistemicity $>$ totalising $\sim$ in-relative-ontologicalcompleteness $\rangle$ as available-to/elicitable-to-〈as-to-human-consciousness/collectiveconsciousness-distendedness/detruncating-<beyond-selfpresencing,-as-re-ontologisingdecentering_of-consciousness/collective-consciousness,-as-to-psychologismic-epistemicacutisation-residualising, - $^{\text {fdecompulsing }}$ \} delinearity for-cogency $>>$ the social-functioning-and- 
accordance-as-of-social-stake-contention-or-confliction conception of any given registryworldview/dimension $<$ preconverging 'motif-and-apriorising/axiomatising/referencing' entailing $>$-existentialising — enframing/imprintedness-〈as-to- historicity-tracing - inpresencing-hyperrealisation/hyperreal-transposition $\left.\rangle^{\prime}\right) ;$ as so-relevant to the ontologising/scientific/existence- $<$ honesty-constraining $>$ — scope_for_prospective_reontologising 'profound-supererogation ${ }^{6}$ re-assessability of prospective human re-ontologising' (as of overall 're-ontologising tre-apriorising/re-axiomatising/rereferencing residuality in-re-originariness/re-origination \{decompulsing $\}$ delinearity/delinearaccreting/recomposuring cogency/tensing/limpidity-<as-of-prospective-profoundsupererogation ,-for-residuality_in-re-originariness/re-origination $>$,-prespective_reifying mental-aestheticising <as-of 'prospective reformulating-of-mental-aestheticising'as-to'residuality in-re-originariness/re-origination' of-mental-aestheticising $>$ '), and as so-educed as from nonpresencing-<perspective-ontological-normalcy/postconvergence $>$ relativism/relative-scope for epistemic-growth,-as - \{veridical/sound\}-relative-reflexivity-inexistence/relativising from-limited-mentation-as-its-deepening/psychologismic epistemicacutisation residualising, $\left.{ }^{\{d e c o m p u l s i n g}\right\}$ delinearity for-cogeney' epistemic-projection. Such a conception of human consciousness/collective-consciousness will rather speak of its 'preconverging/postconverging-de-mentating/structuring/paradigming out' into 'socialfunctioning-and-accordance-as-of-social-stake-contention-or-confliction imbuing existentialising-frame-of-entailment of motif-and-apriorising/axiomatising/referencing of disontologising/ontologising-and-re-ontologising', as so-underlying the very formation/derivation/adherence to ${ }^{5}$ meaningfulness-and-teleology ${ }^{9}$, so-underlied as of: thehuman/humanity 'recurrently mediative-<in-expectation/in-anticipation $>$ unconsciousness/potentiation-of-conscionability-<anxiety-as-to-reconstitution/reparation,-including-dreaming/psychical-reshuffling>' (as the 'psychoanalytic boundlessness of human 
notional $\sim$ reflexivity- $<$ \{veridical/sound $\}$-relative-reflexivity-in-existence/relativising fromlimited-mentation-as-its-deepening/psychologismic-<residualising ${ }^{\text {fdecompulsing }}$ \} delinearity foreogency>-by-\{flawed/unsound\}-relative-unreflexivity-in-existence/absolutising fromlimited-mentation/psychologismic epistemic acutisation nonresidualising imbued\{compulsing\} linearity in-eclecticism-of prior-mere-formulaicity/ritualisation> existential<disontelogising/re-ontelogising aporeticism $>$ backdrop' elicitable/exuding as of subconsciousness knowingly/unknowingly-manifest human ontological-goodfaith/authenticity $\sim$ postconverging-de-mentating/structuring/paradigming — byontological-bad-faith/inauthenticity ${ }^{64} \sim$ preconverging-de-mentating/structuring/paradigming ${ }^{65}$ ) as so-potentiating 'human subconsciousness as backdrop-for-the-Lacanian-real enabling the effective formativeness-<as-to-intersolipsism-ofpreformulating/preframing/premeaningfulness-imbued-mediativity-and-deferentialism>-ofmeaningfulness-and-teleology of consciousness surrealising-<as-to-supererogation $>^{>}$(as so-manifested with human subconsciousness most-prospectively-conscious 're-ontologisingby-disontologising_existential-calculus-〈between 'prospective existentialisingpostconverging_framing/imprinting re-ontologising' and 'prior existentialisingpreconverging_enframing/imprintedness social-functioning-and-accordance-as-of-socialstake-contention-or-confliction' $\rangle$ ' of consciousness surrealising-<as-to-supererogation $>$ ). This in effect speaks to the very sovereign-emergence/becoming,-existentially-imbuing-humanfreedom-as-to-supererogating/surrealising-for-'knowledge-empowerment-over-ignorancedisempowerment'-<as-of-'developing-and-availing-sovereignsublimating_potential/possibilities/options/choices'-as-to-the-'credibility’/'ontologicalveracity'-underlying-the-'sovereign-conscious/conscientious-backdrop'> of thehuman/humanity in its consciousness/collective-consciousness with respect to its successively given and superseded <amplituding/formative-epistemicity>-totalising $\sim$ thrownness-in- 
existence $^{35}$; further explaining a notional deprocrypticism prospective re-ontologising implication that any registry-worldview/dimension social-setup can effectively be 'looked down upon' as 'mentally underdeveloped as preconvergingly-de-mentated/structured/paradigmed' and so 'only-for-the-requisite sake/prospect/purpose of its prospective re-ontologising sublimation/emancipation/enfranchisement' as of prospectively 'inventing'/'creating'-and'nurturing' the-human/humanity as to the ontologising/scientific/existence- $<$ honestyconstraining $>$ — scope_for_prospective_re-ontologising. This re-ontologising 'stance as preconvergingly-de-mentated/structured/paradigmed' with regards to the 'mortal scale of perceived institutional access and success default conception of human ontologicalperformance $^{72}-<$ including-virtue-as-ontology $>^{\prime}$ (as to the latter cooptation/subversion in shallow-supererogation of the prospect of the ontologising/scientific/existence- $<$ honestyconstraining $>$ — scope_for_prospective_re-ontologising) is not idle but effectively a reontologising necessity; since such an overall consciousness/collective-consciousness is rather built onto the given registry-worldview ${ }^{7}$ presencing-absolutising-identitive-constitutedness linearity/linear-accreting- ${ }^{79}$ presencing-perceptualisation-of-sublimating-overdesublimating-<as-'psychologismic-epistemic-acutisation-nonresidualising-imbued\{compulsing\} linearity in-eclecticism-of-prior-mere-formulaicity/ritualisation'_as-to‘secondnatured-epistemic-perspective'-of-prospective-\& prior-differentiatedapriorising/axiomatising/referencing $>$ and-as-developing-into-interrelatedness-dynamics-ofsocial-constructing (respectively as of the 'mortal scale of perceived institutional access and success default conception of human ontological-performance ${ }^{72}-$ including-virtue-as- $^{-}$ ontology $>$ ' of $\leq$ mere-formulaicity/ritualisation-of $>$-prior secondnatured blatant brutish conquest/subjugation conception of apportioning imbued shallow-supererogation , $<$ mereformulaicity/ritualisation-of $\geq$-prior secondnatured dominion protection conception of apportioning imbued shallow-supererogation, $\leq$ mere-formulaicity/ritualisation-of $>$ prior 
secondnatured the very natural-order-of-things conception of apportioning imbued shallowsupererogation and prospectively our $\leq$ mere-formulaicity/ritualisation- - f $>$-prior secondnatured subtle modern-day institutionally-distorted/disjointed conception of apportioning imbued shallow-supererogation ); which is effectively in want for prospective nonpresencing<perspective-ontological-normalcy/postconvergence> appraisal as being of 'existential$<$ disontologising/re-ontologising aporeticism> hermeneutic/textuality/reprojecting/supererogating/zeroing/re-acuting

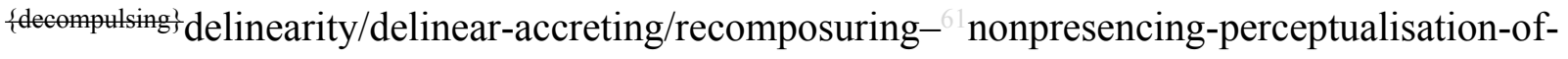
sublimating-over-desublimating-<as-'psychologismic-epistemic-acutisation-residualising,$\left\{\right.$ \{decompulsing\} ${ }^{\prime}$ delinearity for-cogency'_as-to-'prospective-profound-supererogation -epistemicperspective'-of-prospective-\&-prior-differentiated-apriorising/axiomatising/referencing $>$ with-respect-to-the-prospect-of-prospective-human-re-ontologising' (and specifically-so as to 'prospective reference-of-thought-point-ofdevolving/departure/anchoring/backdrop_of_sublimating-nascence-<as-to-the-grandestaxiomatic-construct-\{epistemic-talising ${ }^{+}$re-apriorising/re-axiomatising/rereferencing residuality - in-re-originariness/re-origination of limitedness/human-subpotency prospective re-encountering/re-confrontation with unlimitedness/existence $>$ re-rationalisationof-contentivity/argumentativity/dialecticism/discursivity' Beingdevelopment/ontological-framework-expansion-as-to-depth-of-ontologising-development-asinfrastructure-of- meaningfulness-and-teleology psychologismic epistemic-acutisationdifficulty< < for, residualising_\{decompulsing $\}$ delinearity for-cogency> magnitude $\{$ ofexperientiality/experiment\}). This is necessarily the case notwithstanding the 'inherent dispensing-withimmediacy-for-relative-ontological-completeness ${ }^{87}$-by-reification/contemplative-distension difficulty of profound-supererogation , for any social-setup to existentially< disontologising/re-ontelogising aporeticism $>$ assume a consciousness/collective-conscious 
of re-ontologising prospective Being-development/ontological-framework-expansion-as-todepth-of-ontologising-development-as-infrastructure-of- meaningfulness-and-teleology psychologismic epistemic-acutisation difficulty-for, residualising \{decompulsing\} delinearity for-cogency> magnitude $\{$ of-experientiality/experiment\} $\quad$ (as $\quad$ sooverriding/superseding its prior punctual/immediacy/constituted/compulsions-encumbered institutional-development-as-to-social-function-development and living-development-as-topersonality-development psychologismic epistemic acutisation difficulty < for,

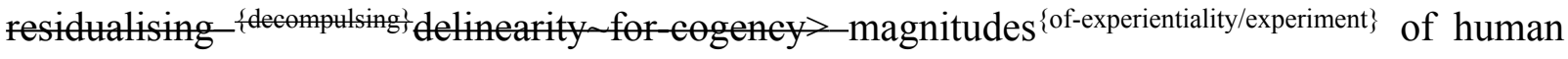
ontological-performance $^{72}-<$ including-virtue-as-ontology $>/$ morality/ethics/justice/etc.). In-thebigger-picture, unlike consciously/unconsciously advanced opportunistically by institutionalised pedantising/muddling/formulaic-hollowing-out — in-subontologisation/subpotentiation〈blurring/undermining-of-prospective-totalising-entailing,-as-to-entailing$<$ amplituding/formative-epistemicity $>$ totalising in-relative-ontological-completeness $>$ desublimation (as to eliciting of the shallow-supererogation of the overall $<$ amplituding/formative $>$ wooden-language-〈imbued-temporal-mere-

\section{form/virtualities/dereification/akrasiatic-drag/denatured/preconverging-or-dementing} narratives - of-the- reference-of-thought- categorical-imperatives/axioms/registryteleology > of registry-worldviews/dimensions with regards to 'lifespan extricatory/preconverging psychical-nascency moronisation-<sublimating-nascence,extricatesublimating-downstreaming/'avalage'>’', prospective sublimating of thehuman/humanity cannot effectively do without the genuine social intellectual-function/posture 'nonextricatory/postconverging ontologising-and-re-ontologising angling-of-imaginary demoronisation-<sublimating-nascence,-nonextricatory-sublimating-

upstreaming/'amontée'>'; and so-construed not as a mere abstract conception but the 'effective existential-<disontologising/re-ontologising aporeticism> human sovereign- 
emergence/becoming,-existentially-imbuing human-freedom-as-to-supererogating/surrealisingfor-'knowledge-empowerment-over-ignorance-disempowerment'-<as-of-'developing-andavailing-sovereign-sublimating_potential/possibilities/options/choices'-as-to-the'credibility'/'ontological-veracity'-underlying-the-'sovereign-conscious/conscientiousbackdrop'> consciousness/collective-consciousness' that gives 'human sovereignemergence/becoming,-existentially-imbuing-human-freedom-as-to-supererogating/surrealisingfor-'knowledge-empowerment-over-ignorance-disempowerment'-<as-of-'developing-andavailing-sovereign-sublimating_potential/possibilities/options/choices'-as-to-the'credibility'/'ontological-veracity'-underlying-the-'sovereign-conscious/conscientiousbackdrop'> sublimating-meaning/signification to the overall relative-unreflexivity/relativereflexivity - ontological-contiguity ${ }^{67} \sim$ of-the-human-institutionalisation-process ${ }^{6}{ }^{\circ}$. In this regards, the 'recurrent manifestation of a human prospective desublimating conception with regards to the need for prospective re-ontologising' across the overall relativeunreflexivity/relative-reflexivity —ontological-contiguity ${ }^{67}$ of-the-human-institutionalisationprocess ${ }^{6}$ effectively arises as to a 'recurrent misconception that prospective re-ontologising supposedly arises rather by the shallow-supererogation ${ }^{6}$ of the mere-formulaicity/ritualisation of prior rationalisation-of-contentivity/argumentativity/dialecticism/discursivity' (specifically as to Being-development/ontological-framework-expansion-as-to-depth-of-ontologisingdevelopment-as-infrastructure-of- meaningfulness-and-teleology psychologismic epistemic-acutisation difficulty-for, residualising \{decompulsing $\}$ delinearity for-cogency> magnitude \{f-experientiality/experiment $\}$, such that in effect the very 'fundamental/incipient/seeding experientiality/experiment-<as-to-existentially-formative- ‘fepistemic-totalising ${ }^{\prime}$ re-apriorising/reaxiomatising/re referencing-residuality-in-re-originariness/re-origination',-so'notionally/epistemically/bindingnessly-<as-to-determinism/conceptivity-of-relative-unreflexivity/relative-reflexivity> implicited-and-articulated'_as-from-nonextricatory-'prospective-re-ontologising-Being-then- 
Institutional-then-Living-magnitudes-of-\{hermeneutic/reprojection-protraction-of\}reframingand-reformulation $\}^{\prime}>$ that is human profound-supererogation' so-reflecting the 'overarching existential-<disontologising/re-ontologising aporeticism $>$ priority/precedence/primacy of \{epistemic-totalising 3 \}re-apriorising/re-axiomatising/re-referencing $\sim$ residuality—in-reoriginariness/re-origination projection' (as to its recurrent instigating of sublimating 'reontologising \{epistemic-totalising $\frac{1}{3}$ re-apriorising/re-axiomatising/re-referencing-residuality in reөriginariness/re-origination $\{$ decompulsing\} delinearity/delinear-accreting/recomposuring cogency/tensing/limpidity-<as-of-prospective-profound-supererogation ,-for-residuality-inre-originariness/re-origination>-,prospective_reifying mental-aestheticising $<$ as-of'prospective_reformulating-of-mental-aestheticising'as-to-'residuality in-re-originariness/reerigination'-of-mental-aestheticising ') is exactly what tends to be lost in human conscious enterprise of prospective re-ontologising (as to the naivety of the shallow-supererogation ${ }^{6}$ of $\leq$ mere-formulaicity/ritualisation-of $>$-prior secondnatured institutionalised reasoning-fromresults/afterthought imbued " 79 presencing—absolutising-identitive-constitutedness absolution/absolute-scope \{flawed/unsound\}-relative-unreflexivity-in-existence/absolutising from-limited-mentation/psychologismic epistemic-acutisation nonresidualising-imbued\{compulsing\}'tinearity in eclecticism-of prior mere formulaicity/ritultisation conception'); but for the fact that profoundsupererogation $\sim$ reframing/reformulation/decatchmenting/detruncating/decompulsing/delinear ising_scale_of-transparent/noncontentious/un-nominalised/sound-interpretations/domains of manifest unblurriness-<re-ontologising_by-postconverging-as-to-dragged-outsupererogatory $\sim$ wholesomeness/profound-supererogation ,-while-anecdotalising-priordisontologising-thresholding $>$ do effectively implicit this 'fundamental/incipient/seeding experientiality/experiment-<as-to-existentially-formative-'\{epistemic-totalising ’re-apriorising/reaxiomatising/re-referencing residuality-in-re-originariness/re-origination',- so- 
'notionally/epistemically/bindingnessly'<as-to-determinism/conceptivity-of-relative-unreflexivity/relative-reflexivity> implicited-and-articulated'_as-from-nonextricatory-'prospective-re-ontologising-Being-thenInstitutional-then-Living-magnitudes-of-\{hermeneutic/reprojection-protraction-of $\}$ reframingand-reformulation $\}^{\prime}>$ that is human profound-supererogation' ${ }^{9}$ so-reflecting the 'overarching existential-<disontologising/re-ontologising aporeticism $>$ priority/precedence/primacy of \{epistemic-totalising $3{ }^{3}$ re-apriorising/re-axiomatising/re-referencing $\sim$ residuality—in-re-

originariness/re-origination projection' (which is not even implicited when it comes to shallowsupererogation $\sim$ framing/formulation/catchmenting/truncating/compulsing/linearising_scale —of-opaque/contentious/un-nominalised/flawed-interpretations/domains of manifest blurriness-<sterilising/anecdotalising/trivialising-of-prospective-re-ontologising_bypreconverging,-in-disontologising-formulaic-dragging-out/hollowing-out>). Critically, the question/issue is hardly asked/contemplated as to how-and-why the profound-supererogation of a Copernicus/Galileo/Descartes/Newton/Leibniz/Diderot, etc. in their varying social-setup inherited non-positivism/medievalism $<$ amplituding/formative-epistemicity $>$ totalising thrownness-in-existence ${ }^{35}$ (of non-positivism/medievalism prior 'dereifying-mentalaestheticising-<as-of-‘prior_mere-formulaicity/ritualisation-of-mental-aestheticising'-failing‘residuality - in-re-originariness/re-origination'-of-mental-aestheticising $>$ as of the processivemotif-'exuding aestheticising-gesturing' of-apriorising/axiomatising/referencing of prior aestheticisation-and-aestheticisation-towards-ontology-<elicited-idiomatisation>')' went on to prospectively 'inventing'/'creating'-and-'nurturing' positivism/rational-empiricism rerationalisation-of-contentivity/argumentativity/dialecticism/discursivity; as so-rather interceded by the 'fundamental/incipient/seeding experientiality/experiment- $<$ as-toexistentially-formative- ‘fepistemic-totalising tre apriorising/re axiomatising/re referencing $\sim$ residuality —in-re-originariness/re-origination',- - so'notionally/epistemically/bindingnessly-<as-to-determinism/coneeptivity-of-relative-unreflexivity/relative-reflexivity> 
implicited-and-articulated'_as-from-nonextricatory-'prospective-re-ontologising-Being-thenInstitutional-then-Living-magnitudes-of-\{hermeneutic/reprojection-protraction-of\}reframingand-reformulation $\}$ ' $>$ that is human profound-supererogation' so-reflecting the 'overarching existential-<disontologising/re-ontologising aporeticism $>$ priority/precedence/primacy of \{epistemic-totalising 3 \}re-apriorising/re-axiomatising/re-referencing $\sim$ residuality—in-re-

originariness/re-origination projection' (in reflection of requisite profound-supererogation ${ }^{6}$ as from human 'crossgenerational notional firstnaturedness-formativeness-<as-toeventualising-inkling-drive-or-seeding-misprising > mental-processing-parity for ontological-performance ${ }^{72}$-<including-virtue-as-ontology $>$ /morality/ethics/justice/etc.' as to 'prospective nonpresencing-<perspective-ontological-normalcy/postconvergence $>$ epistemicprojection' induced 'human re-ontologising transcendence-andsublimity/sublimation/supererogatoryade-mentativity' notwithstanding priorly given ${ }^{6}$ presencing-absolutising-identitive-constitutedness ${ }^{14} \quad$ disontologising $<$ amplituding/formative-epistemicity $>$-totalising $\sim$ thrownness-in-existence ${ }^{3{ }^{\prime}}$ )..$\quad$ Such a misconstrual wrongfully implicits-and-explicits that the adoption of a positivism/rationalempiricism re-rationalisation-of-contentivity/argumentativity/dialecticism/discursivity with respect to the 'backdrop of an inherited non-positivism/medievalism <amplituding/formativeepistemicity $>$-totalising $\sim$ thrownness-in-existence ${ }^{35}$, is inherently obvious; and therefore not projecting of the same profound-supererogation as from human 'crossgenerational notional firstnaturedness-formativeness-<as-to-eventualising-inkling-drive-or-seeding

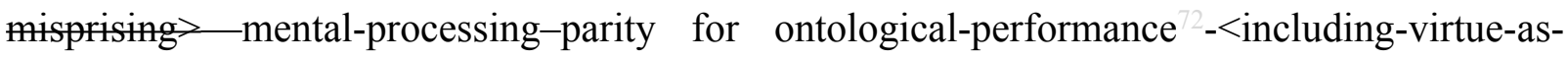
ontology $>$ /morality/ethics/justice/etc.' prospectively as to put-into-question our very own 'backdrop of inherited positivism- ${ }^{8}$ procrypticism/disjointedness-as-of- ${ }^{3}$ reference-of-thought $<$ amplituding/formative-epistemicity>-totalising $\sim$ thrownness-in-existence ${ }^{35}$. This in-manyways exposes the 'soulless ridiculousness' undergirding many a conception of supposedly 
prospective re-ontologising knowledge and prospective research (wherein everything of our human mortal purposefulness but for the intemporality of prospective re-ontologising knowledge and research is present); such that an 'institutionalised mere-formulaicity/ritualisation conception of experimental design/conceptualisation, presentation/clarity and metrics as to its given ${ }^{7}$ presencing-absolutising-identitive-constitutedness ${ }^{14}$ prospectively disontologising $<$ amplituding/formative-epistemicity $>$-totalising thrownness-in-existence ${ }^{35^{5}}$ is construed as inherently sublimating beforehand (as of our subtranslational-processive-motif-exuding aestheticising-gesturing' of apriorising/axiomatising/referencing imbued occlusivereductionism) and so in failing to project of the 'fundamental/incipient/seeding experientiality/experiment-<as-to-existentially-formative- ‘fepistemic-totalising ${ }^{\stackrel{3}{3}} \mathrm{re}$-apriorising/reaxiomatising/re-referencing residuality-in-re-originariness/re-origination', - so'notionally/epistemically/bindingnessly-<as-to-determinism/conceptivity-of-relative-unreflexivity/relative-reflexivity $>$ implicited-and-articulated'_as-from-nonextricatory-'prospective-re-ontologising-Being-thenInstitutional-then-Living-magnitudes-of-\{hermeneutic/reprojection-protraction-offreframingand-reformulation $\}^{\prime}>$ that is human profound-supererogation', (so-reflecting the 'overarching existential-<disontologising/re-ontologising aporeticism $>$ priority/precedence/primacy of \{epistemic-totalising ${ }^{3}$ re-apriorising/re-axiomatising/re-referencing $\sim$ residuality—in-re-

originariness/re-origination projection') and as 'so-reflecting/so-fulfilling the mere prior rationalisation-of-contentivity/argumentativity/dialecticism/discursivity in an epistemicprojection of institutionalised ${ }^{79}$ presencing - absolutising-identitive-constitutedness ${ }^{14}$, (that thus seem to imply human-subpotency/unlimitedness prospectively supersedes 'unlimitedness/existence-<full-potency-of sublimating nascence $>$ prospective apriorising/axiomatising/referencing-sublimating-reflexivity-beholdening under which limitedness/human-subpotency submits in profound-supererogation for prospective sublimating'). In-many-ways such 'institutionalised mere-formulaicity/ritualisation conception 
of experimental design/conceptualisation, presentation/clarity and metrics as to its given presencing —absolutising-identitive-constitutedness ${ }^{14} \quad$ prospectively disontologising $<$ amplituding/formative-epistemicity>-totalising thrownness-in-existence ${ }^{35}$, fail to satisfy the 'fundamental/incipient/seeding experientiality/experiment-<as-to-existentially-formative‘\{epistemic-totalising łre-apriorising/re-axiomatising/re-referencing-residuality-in-reoriginariness/re-origination',- - so-'notionally/epistemically/bindingnessly-<as-todeterminism/conceptivity-of-relative-unreflexivity/relative-reflexivity >-implicited-and-articulated'_as-fromnonextricatory-'prospective-re-ontologising-Being-then-Institutional-then-Living-magnitudesof-\{hermeneutic/reprojection-protraction-of $\}$ reframing-and-reformulation $\}$ '> that is human profound-supererogation 'so-reflecting the 'overarching existential-<disontelogising/reentelogising apereticism $>$ priority/precedence/primacy of \{epistemic-totalising $3{ }^{3} \mathrm{re}$-apriorising/reaxiomatising/re-referencing $\sim$ residuality-in-re-originariness/re-origination projection' (in reflection of profound-supererogation as from human 'crossgenerational notional firstnaturedness-formativeness-<as-to-eventualising-inkling-drive-or-seedingmisprising $>$ mental-processing-parity for ontological- performance ${ }^{72}-<$ including-virtue-asontology $>$ /morality/ethics/justice/etc.' as to 'prospective ${ }^{6}$ nonpresencing-<perspectiveontological-normalcy/postconvergence> epistemic-projection' induced 'human re-ontologising transcendence-and-sublimity/sublimation/supererogatory>de-mentativity' notwithstanding priorly given ' ${ }^{79}$ presencing-absolutising-identitive-constitutedness ${ }^{14}$ disontologising $<$ amplituding/formative-epistemicity>-totalising $\sim$ thrownness-in-existence ${ }^{35}$ ); $\quad$ when $\quad$ soadopting such a prior mere-formulaicity/ritualisation-<as-to-mere-formulaicmethodologising/mutualising/organising/institutionalising,-prospectively-losing-track-of'\{epistemic-totalising apriorising/re axiomatising/re refencing-residuality-in-re-
originariness/re-origination'> of institutional/bureaucratic/social $\quad$ procession-<as-to-
constructive-veracity/inveracity_of-apriorising/axiomatising/referencing $>$. This can be 
reflected for instance as to a 'vague projection of prospective intolerance-<ofdisparateness $>$ /exactifying_precisioning-of-sublimation-<as-to-postconverging-narrowingdown apriorising/axiomatising/referencing-entailing-theoretical,-conceptual-and-operantimplications $>$ rather on the basis of the shallow-supererogation of the mereformulaicity/ritualisation of prior rationalisation-ofcontentivity/argumentativity/dialecticism/discursivity' while paradoxically lacking the 'fundamental/incipient/seeding experientiality/experiment-<as-to-existentially-formative‘fepistemic talising łre-apriorising/re-axiomatising/re-referencing - residuality-in-reoriginariness/re-origination',-so- 'notionally/epistemically/bindingnessly-as-todeterminism/conceptivity-of-relative-unreflexivity/relative-reflexivity>_implicited-and-articulated'_as-fromnonextricatory-'prospective-re-ontologising-Being-then-Institutional-then-Living-magnitudesof-\{hermeneutic/reprojection-protraction-of $\}$ reframing-and-reformulation $\}$ '> that is human profound-supererogation' (so-reflecting the 'overarching existential-<disontologising/reentologising aporeticism $>$ priority/precedence/primacy of axiomatising/re-referencing $\sim$ residuality-in-re-originariness/re-origination projection'); as inmany-ways the sublimating ${ }^{4}$ historiality/ontological-eventfulness ${ }^{38}$ /ontological-aesthetictracing-<perspective-ontological-normalcy/postconvergence-reflected-'epistemicityrelativism-determinism' $>$ of prior transcendence-and-sublimity/sublimation/supererogatory $\sim$ dementativity arose as of 'relays of human intemporal-individuation epistemic-projection radicalities $\sim$ in-chronicular/annalistic-cogency-<as-of-notional $\sim$ protensivity $>$-〈as-to-limitedmentation-capacity-deepening —as-subjecting limitedness/human-subpotency-to-'educedunlimitedness/existence-sublimating nascence' > so-construed as cogency_chronicularity/annality-of-relative-reflexivity,-as-to-profound-supererogation ${ }^{\circ}$ (as to a 'despite-the-self exercise of epistemic-projection in notional $\sim$ self-distantiation-<imbued-remotif-and-re-apriorising/re-axiomatising/re-referencing >'). When cultivated to the extreme such 
\{flawed/unsound\}-relative-unreflexivity-in-existence/absolutising-from-limitedmentation/psychologismic epistemic acutisation nonresidualising imbuedfcompusings linearity in-eclecticism-of-prior-mere-formulaicity/ritualisation)

'pedantising/muddling/formulaic-hollowing-out —in-subontologisation/subpotentiation〈blurring/undermining-of-prospective-totalising-entailing,-as-to-entailing$<$ amplituding/formative-epistemicity $>$ totalising in-relative-ontological-completeness $>$ enculturation') construe of the possibility of eliciting 'conceptual-patterning-〈as-devoid-of'prospectively_implicited_attendant-ontological-contiguity ' ceduced-

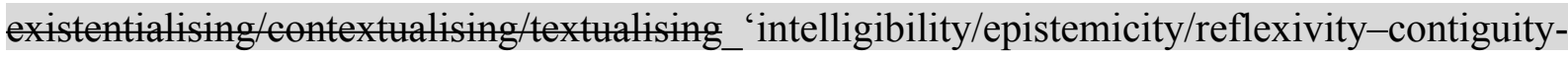
<imbued-notional cogency>' 's-reifying-or-elucidating-of-'prospective-relative-ontologicalcompleteness ' ;-so-rather-enabled-<by-a- nonpresencing-divulging-of-momentoushistoriality/ontological-eventfulness /ontological-aesthetic-tracing-<perspectiveontological-normalcy/postconvergence-reflected-‘epistemicity-relativism-determinism'>> for desublimating formulaic-fashionability $<$ 'wholeseme dearth'/shallowness_as to requisite 'reentologising rhizomatic-wholesomeness' for $>$ postconverging redementating/restructuring/reparadigming $>$, shadowing and bothsidesism-〈as-'mereprocessive'/pedantising-'dialogical-relation'-to ‘perceived-social-and-institutionalcommonly-enculturated_referencing,-of- meaningfulness-and-teleology '-failing-'requisiteexistential-thematic-baseline-of-technicity/profundity-framing' \{of-sublimating-discursivityfor-sovereign-repassing \},-as-of-psychologismic-epistemic-acutisation-nonresidualisingimbued-\{compulsing? linearity in-eclecticism-of-prior-mere-formulaicity/ritualisation,-as-so‘consciously/unconsciously-preordained/fated'-to-fail-prospective-notional cogency) ontologically-flawed conceptualising' as effective techniques to avoid transversality- $<$ forsublimating-existential-eventuating/denouement, from 'thinking at first/pure predisposition preemptive-of prospective-disontologising/subontologising' as-of-prospectively- 
disambiguated-affirmed-and-unaffirmed-'motif-and-apriorising/axiomatising/referencing'>

and thus preempt the demarcation of veridical/profound sublimating conceptivity/epistemicreflexivity/epistemicity-relativism-determinism- $<$ reifying \{as-to-knowledge-developing $\}$-andempowering $>$ entailment. In this regards for instance (as to pedantic incipience/seeding of generalised misunderstanding/confusion), just as numeration/numbering cannot be drawn into a bothsidesism-〈as-'mere-processive'/pedantising-'dialogical-relation'-to 'perceived-socialand-institutional-commonly-enculturated_referencing,-of- meaningfulness-and-teleology 'failing-'requisite-existential-thematic-baseline-of-technicity/profundity-framing' \{ofsublimating-discursivity-for-sovereign-repassing $\}$,-as-of-psychologismic-epistemicacutisation-nonresidualising-imbued-\{compulsing linearity in-eclecticism-of-prior-mereformulaicity/ritualisation,-as-so- 'consciously/unconsciously-preordained/fated'-to-failprospective-notional cogency) conception of mathematics it is likewise contended herein that motif-and-apriorising/axiomatising/referencing as to human aestheticisation-andaestheticisation-towards-ontology-<elicited-idiomatisation $>$ (as arising and evolving as of human <amplituding/formative-epistemicity >-totalising $\sim$ thrownness-in-existence ${ }^{35}$ with respect to human Being-development/ontological-framework-expansion-as-to-depth-ofontologising-development-as-infrastructure-of- meaningfulness-and-teleology , institutionaldevelopment-as-to-social-function-development and living-development-as-to-personalitydevelopment psychologismic epistemic acutisation difficulty-for, residualising ${ }_{\text {\{decompulsing }}$ delinearity for-cogeney>-magnitudes ${ }^{\{\text {of-experientiality/experiment }\}}$ ) cannot be drawn into a bothsidesism-〈as-'mere-processive'/pedantising-'dialogical-relation'-to 'perceived-socialand-institutional-commonly-enculturated_referencing,-of- meaningfulness-and-teleology 'failing-'requisite-existential-thematic-baseline-of-technicity/profundity-framing' \{ofsublimating-discursivity-for-sovereign-repassing \},-as-of-psychologismic-epistemicacutisation-nonresidualising-imbued-\{compulsing\} linearity in-eclecticism-of-prior-mere- 
formulaicity/ritualisation,-as-so-'consciously/unconsciously-preordained/fated'-to-fail-

prospective-notional $\sim$ cogency $>$ conception of human ${ }^{56}$ meaningfulness-and-teleology ${ }^{99}$ as there is no intelligibility-〈as-to-human-projective/reprojective-aestheticising-re-motif-and-reapriorising/re-axiomatising/re-referencing/re-intelligibilitysettingup/re-

measuringinstrumenting-process,-in-<amplituding/formative-

epistemicity $>$ totalising conceptualisation) without a 'limitedness/human-subpotency motifand-apriorising/axiomatising/referencing reflection/representation' of unlimitedness/existence<full-potency-of_sublimating nascence $>$ however of relative-ontologically-flawed (as to flawedunsound-relative-unreflexivity-in-existence tabsolutising from limitedmentation/psychologismic epistemic acutisation nonresidualising imbued\{compulsing\}linearityoin-eclecticism-of-prior-mere-formulaicity/ritualisation) or relativeontologically-veridical (as to epistemic-growth,-as - \{veridical/sound\}-relative-reflexivity-inexistence/relativising from-limited-mentation-as-its-deepening/psychologismic epistemicacutisation residualising, ${ }^{\text {\{decompulsing }}$ delinearity for-cogency) the reflection/representation; with the pedantic eliciting of such misconception (as to the ontologically-flawed fact that there can be anything outside of existence and its experientiality/experiment- $<$ as-to-existentiallyformative-'fepistemic-totalising ${ }^{\text {’ }}$ re-apriorising/re-axiomatising/re-referencing $\sim$ residuality-in-reoriginariness/re-origination',—-so-'notionally/epistemically/bindingnessly-3s-todeterminism/conceptivity-of-relative-unreflexivity/relative-reflexivity>-implicited-and-articulated'_as-fromnonextricatory-'prospective-re-ontologising-Being-then-Institutional-then-Living-magnitudesof-\{hermeneutic/reprojection-protraction-øf $\}$ reframing-and-reformulation $\}$ '>) in-many-ways a 'deficient/poor aptitudinal moronisation- $<$ sublimating-nascence,-extricatory-desublimatingdownstreaming/'avalage'> manipulation of laypersonhood obliviousness/indifference/disinterest' rendered possible as to the cultivation of blurriness$<$ sterilising/anecdotalising/trivialising-of-prospective-re-ontologising_by-preconverging,-in- 
disontologising-formulaic-dragging-out/hollowing-out $>$. Along the same lines (in highlighting the re-ontologising deficiency as from ${ }^{7}$ presencing-absolutising-identitive-constitutedness epistemic-projection perspective of conceptual elucidation and definition), the 'ontologising/reontologising conception herein as of notional/epistemic/bindingness ${ }^{<a s-t o-d e t e r m i n i s m / c o n c e p t i v i t y-o f-~}$ relative-unreflexivity/relative-reflexivitys sublimation/desublimation' speaking to human potential/possibility for prospective transcendence-and-sublimity/sublimation/supereregatory de-mentativity (and as implicited by many a scientific thinker conception of 'beauty' as to their nascentparticular/incipient-and-material/technical-sublimations- $<$ blinded-to-their-relative-ontologicalcompleteness - reference-of-thought- devolving $>$ ) has nothing to do with 'an ordinary notion of beauty and as to a presencing-absolutising-identitive-constitutedness ${ }^{14}$ epistemicprojection of mere enculturated-aestheticising-appraisal'; but rather speaks to the 'more fundamental existential-<disontologising/re-ontologising aporeticism $>$ enchanting/reenchanting or lack-of-enchanting/re-enchanting arising respectively as of either epistemicgrowth,-as-\{veridical/sound\}-relative-reflexivity-in-existence/relativising from-limitedmentation-as-its-deepening/psychologismic epistemic-acutisation-residualising, \{decompulsing delinearity for-cogency imbuing sublimation or fflawed/unsound\}-relativeunreflexivity-in-existence absolutising from limited mentation/psychologismic epistemic acutisation nonresidualising-imbued-\{compulsing \} linearity in-eclecticism-of prior-mereformulaicity/ritualisation imbuing desublimation' (so-construable as from a nonpresencing<perspective-ontological-normalcy/postconvergence> epistemic-projection); with such 'epistemic-growth,-as — \{veridical/sound\}-relative-reflexivity-in-existence/relativising fromlimited-mentation-as-its-deepening/psychologismic epistemic-acutisation residualising, \{decompulsing\} delinearity for imbuing sublimation' rather translated for instance in Einsteinian physics possibility for nuclear energy and prospective astronomical implications of 'beauty' or say DNA genetics implications of 'beauty' for prospective development of medicine, 
etc. What is veridically implied as 'beauty' is thus rather as from 'unlimitedness/existence-<fullpotency-of_sublimating nascence> prospective apriorising/axiomatising/referencingsublimating-reflexivity-beholdening under which limitedness/human-subpotency submits in profound-supererogation for prospective sublimating'; as elucidated herein as to the 'preconverging/postconverging-de-mentating/structuring/paradigming imbuing sublimation/desublimation' of the overall relative-unreflexivity/relative-reflexivity ontological-contiguity ${ }^{67}$ of-the-human-institutionalisation-process ${ }^{68}$ undergirding human Being-development/ontological-framework-expansion-as-to-depth-of-ontologisingdevelopment-as-infrastructure-of- meaningfulness-and-teleology , institutionaldevelopment-as-to-social-function-development and living-development-as-to-personalitydevelopment psychologismic epistemic-acutisation difficulty-<for, residualising \{decompulsing\} Aelinearity for-cogency> magnitudes $\{$ of-experientiality/experiment\}. Thus notionally/epistemically/bindingnessly-<as-to-determinism/conceptivity-of-relative-unreflexivity/relative-reflexivity> 'beauty' (as of notional/epistemic/bindingness <as to detminism/conceptivity of relative unreflexivity/relative reflexivity sublimation/desublimation speaking to human potential/possibility for prospective transcendence-and-sublimity/sublimation/supererogatory-de-mentativity) is rather the profound/underlying determinant of the notion of fact/factness in existence (as unsegregrated from the epistemic-projection of ' nonpresencing-<perspective-ontologicalnormalcy/postconvergence $>\quad$ relativism/relative-scope for epistemic-growth,-as\{veridical/sound\}-relative-reflexivity-in-existence/relativising from-limited-mentation-as-itsdeepening/psychologismic epistemic-acutisation residualising, fdecompulsingl delinearity foreogency') and thus undissociable with sublimating conceptivity/epistemicreflexivity/epistemicity-relativism-determinism-<reifying \{as-to-knowledge-developing $\}$-andempowering>; such that 'beauty' effectively arises as from sublimating 'limitedness/humansubpotency prospective re-encountering/re-confrontation with unlimitedness/existence-<full- 
potency-of_sublimating nascence $>$ (as to 'unlimitedness/existence-<full-potencyof_sublimating nascence> prospective apriorising/axiomatising/referencing-sublimatingreflexivity-beholdening under which limitedness/human-subpotency submits in profoundsupererogation for prospective sublimating') and 'beauty' is existentially-<disontologising/reentologising aporeticism $>$ realised as to human 'reifying-mental-aestheticising-<as-of'prospective_reformulating-of-mental-aestheticising'as-to-'residuality-in-re-originariness/reorigination'-of-mental-aestheticising > educed processive-motif-exuding aestheticising gesturing'-of-apriorising/axiomatising/referencing as to re-aestheticisation-and-reaestheticisation-towards-ontology-<elicited-prospective-idiomatisation>' (imbuing 'reentologising \{epistemic-totalising ${ }^{\prime}$ re-apriorising/re-axiomatising/re-referencing-residuality in-reeriginariness/re-origination $\{$ decompulsing\} $\}$ delinearity/delinear-accreting/recomposuring cogency/tensing/limpidity-<as-of-prospective-profound-supererogation ,-for-residuality-inre-originariness/re-origination>--prospective_reifying mental-aestheticising-<as-of-

\section{'prospective_reformulating of mental-aestheticising'as-to-'residuality in re-originariness/re-} origination'-of-mental-aestheticising ${ }^{\prime}$ ). Further along the same lines (in highlighting the reontologising deficiency as from presencing-absolutising-identitive-constitutedness epistemic-projection perspective of conceptual elucidation and definition), the 'ontologising/reontologising conception herein portrayal of human 'existential-<disentologising/reentologising aporeticism $\geqslant$ postconverging-aporeticism-overcoming/unovercoming' as enabling the ontologising/scientific/existence- $<$ honesty-constraining $>$ scope_for_prospective_re-ontologising 'exuding of antinihilism and anti-absurdism', is the notion that the-very-underlying - (as inherently 'defining-and-imbuing of limitedness/humansubpotency de-mentation-〈supererogatory $\sim$ ontological-de-mentation-or-dialectical-dementation-stranding-or-attributive-dialectics $\rangle^{\prime}$ as to preconverging/postconverging-dementating/structuring/paradigming)—relationship-between-limitedness/human-subpotency- 
and-unlimitedness/existence-<full-potency-of_sublimating naseence $>$ with respect to the preeminence of the latter (with regards to limitedness/human-subpotency prospective reencountering/re-confrontation with unlimitedness/existence-<full-potency-of_sublimating nascence $>$ )' means that the-human/humanity is ever always conscious of 'prospective projectable/anticipable directly-or-deferentially educed-and-availing-and-re-availing relativeontological-completeness ${ }^{87}$-of-apriorising/axiomatising/referencing' (as of the divergent human <amplituding/formative-epistemicity $>$-totalising thrownness-in-existence ${ }^{35}$ ); rendering null-and-void a supposedly ontologically-coherent pretense to nihilism and absurdism as to the implicited contradiction that when 'relative-ontological-completeness ${ }^{87}$-ofapriorising/axiomatising/referencing is directly-or-deferentially educed-and-avails-and-reavails' the choice of nihilism or absurdism can coherently arise. Speaking to the fact that a conscious pursuit of nihilism or absurdism arises rather as of a lack of organic-knowledge as from ${ }^{7}$ presencing-absolutising-identitive-constitutedness ${ }^{14}$ epistemic-projection confusion and poor appreciation of requisite notional $\sim$ self-distantiation- $<$ imbued-re-motif-and-reapriorising/re-axiomatising/re-referencing $>$ for epistemic-growth,-as_ \{veridical/sound\} relative-reflexivity-in-existence/relativising from-limited-mentation-as-itsdeepening/psychologismic epistemic acutisation residualising, \{decompulsing $\}$ lelinearity for eogency' (as so-failing the requisite human 'existential-<disontologising/re-ontologisingaporeticism $>$ postconverging-aporeticism-overcoming/unovercoming' enabling the ontologising/scientific/existence- $<$ honesty-constraining $>$ — scope_for_prospective_reontologising); and so-reflected implicitly/explicitly as to a disontologising pursuit of not truly 'thinking at first/pure predisposition preemptive of prospective disontologising/subontologising but a conscious/unconscious rationalising/calculating of the sublimating outcome of prior profound-supererogation rationalisation-ofcontentivity/argumentativity/dialecticism/discursivity imbued positive-opportunism—of-social- 
functioning-and-accordance ${ }^{7}$, as to shallow-supererogation undermining of prospective ontologising/scientific/existence- $<$ honesty-constraining $>$ — scope_for_prospective_reontologising. In other words, human 'existential-<disontologising/re-ontologisingaporeticism $>$ postconverging aporeticism-overcoming/unovercoming' arises successorally in cumulating/recomposuring as to the psychologismic-transfixity-<placeholder-setupontological-rescheduling - in-realigning/preactivity/formative-becoming/psychoanalytical-

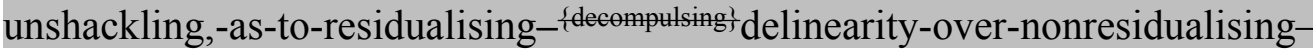
fompulsinglinearity $>$ of 'human construction-of-the-Self (notional $\sim$ self-distantiation- $<$ imbuedre-motif-and-re-apriorising/re-axiomatising/re-referencing $>$ for epistemic-growth,-as\{veridical/sound\}-relative-reflexivity-in-existence/relativising from-limited-mentation-as-its-

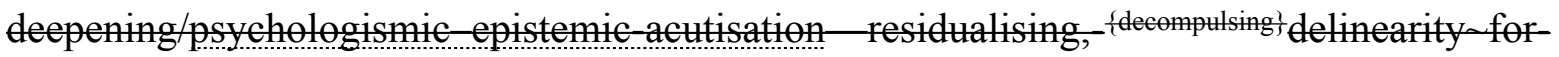
eogency) as from the individual's very existential-<disontologising/re-ontologising aporeticism $>$ inception expanding thereof institutionally and socially' (associated with Beingdevelopment/ontological-framework-expansion-as-to-depth-of-ontologising-development-asinfrastructure-of- meaningfulness-and-teleology , institutional-development-as-to-socialfunction-development and living-development-as-to-personality-development psychologismic epistemic acutisation diffienly < for, residualising \{decompulsing\} delinearity for cogency> magnitudes $\{$ of-experientiality/experiment $\}$ with regards to human <amplituding/formative-epistemicity $>$ totalising renewing-realisation/re-perception/re-thought arising as of 'unlimitedness/existence<full-potency-of_sublimating nascence $>$ prospective apriorising/axiomatising/referencing sublimating-reflexivity_-beholdening under which limitedness/human-subpotency submits in profound-supererogation for prospective sublimating') as to a continual ontologising/scientific/existence- $<$ honesty-constraining $>$ - scope_for_prospective_reontologising 'exuding of antinihilism and anti-absurdism'; and hence it is such 'existential<disontologising/re-ontologising aporeticism> postconverging apereticism- 
overcoming/mnovercoming' successoral 'exuding of antinihilism and anti-absurdism' that paradoxically gives perspective/depth/relief to the possible coherence-of-contemplation of any such notion as nihilism or absurdism (as rather notionally/epistemically/bindingnessly-as-todeterminism/conceptivity-of-relative-unreflexivity/relative-reflexivitys arising from within the coherent sublimating/desublimating-appraisal of 'existential-<disontologising/re-ontologising aporeticism $>$ postconverging-apereticism overcoming/tunovercoming'). Such that in reality any such notion as nihilism or absurdism can only arise rather as of the effectively manifest desublimating collapse/degradation/dégringolade of the coherent sublimating/desublimatingappraisal of 'existential-<disontologising/re-ontologising aporeticism $>$ postconverging aporeticism-overcoming/unovercoming' which in reality is never void of 'prospective projectable/anticipable directly-or-deferentially educed-and-availing-and-reavailing relative-ontological-completeness ${ }^{8}$-of-apriorising/axiomatising/referencing' as of profound-supererogation' 'with respect to human-consciousness/collective-consciousnessdistendedness/detruncating-<beyond-selfpresencing,-as-re-ontologising-decentering_ofconsciousness/collective-consciousness,-as-to-psychologismic-epistemic-acutisation-

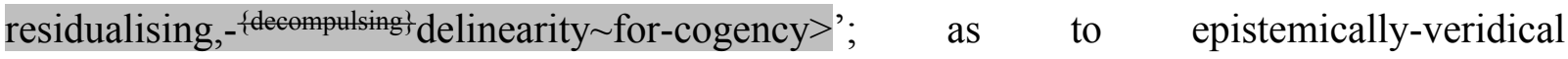
impliciting/expliciting of $\quad$ nonpresencing-<perspective-ontologicalnormalcy/postconvergence $>$ relativism/relative-scope for epistemic-growth,-as\{veridical/sound\}-relative-reflexivity-in-existence/relativising from-limited-mentation-as-itsdeepening/psychologismic epistemic-acutisation residualising, fdecompusingl delinearity for eogency' epistemic-projection (and so over the epistemically-flawed impliciting/expliciting as of '79 presencing-absolutising-identitive-constitutedness ${ }^{14}$ absolution/absolute-scope

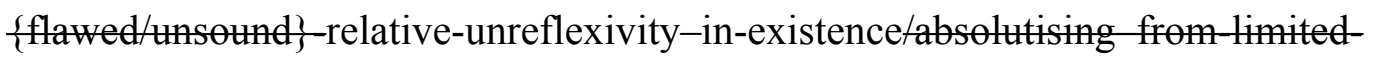
mentation/psychologismic epistemic-acutisation nonresidualising imbued\{compulsing\} linearityoin-eclecticism-of prior-mere-formulaicity/ritualisation conception' 
epistemic-projection effectively manifesting nihilism or absurdism as to prospective 'preconverging-de-mentating/structuring/paradigming imbuing desublimation' in not recognising/acknowledging 'prospective projectable/anticipable directly-or-deferentially educed-and-availing-and-re-availing relative-ontological-completeness ${ }^{87}$-ofapriorising/axiomatising/referencing' as of profound-supererogation ${ }^{\circ}$ ). In other words, 'human construction-of-the-Self (notional $\sim$ self-distantiation- $<$ imbued-re-motif-and-re-apriorising/reaxiomatising/re-referencing $>$ for epistemic-growth,-as — \{veridical/sound\}-relative-reflexivityin-existence/relativising from-limited-mentation-as-its-deepening/psychologismic epistemic acutisation residualising, fdecompungle delinearity for-cogency) as from the individual's very existential-<disontologising/re-ontologising aporeticism $>$ inception expanding thereof institutionally and socially' is already a calling for 'profound-supererogation re-assessability of prospective human re-ontologising' (as of imputed ' nonpresencing-<perspectiveontological-normalcy/postconvergence $>$ relativism/relative-scope for epistemic-growth,-as\{veridical/sound\}-relative-reflexivity-in-existence/relativising from-limited-mentation-as-itsdeepening/psychologismic epistemic-acutisation residualising, fdecompusingl delinearity for eogency' epistemic-projection) but-for/until the drawback/indisposedness of 'human derogation-to-profound-supererogation ${ }^{96}$ in shallow-supererogation (manifested as of presencing absolutising-identitive-constitutedness 'existential-<disontologising/reentologising aporeticism> preconverging de-mentating/structuring/paradigming punctual/immediacy/constituted/compulsions-encumbered prior mere-formulaicity/ritualisation rationalisation-of-contentivity/argumentativity/dialecticism/discursivity') as so-defining human destructuring-threshold-〈uninstitutionalised-threshold /presublimating-desublimatingdecisionality $>\sim$ of-ontological-performance ${ }^{72}-<$ including-virtue-asontology $>$ /morality/ethics/justice/etc. (with regards to Being-development/ontologicalframework-expansion-as-to-depth-of-ontologising-development-as-infrastructure-of- 
development and living-development-as-to-personality-development psychologismic epistemic-acutisation difficulty-for, residualising \{decompulsing $\}$ delinearity for-cogency> magnitudes $\left.{ }^{\{0 f-e x p e r i e n t i a l i t y / e x p e r i m e n t}\right\}$. It is herein contended that it is the appropriate elucidation of the ontologising/scientific/existence- $<$ honesty-constraining $>$ - scope_for_prospective_reontologising 'profound-supererogation ${ }^{96}$ re-assessability of prospective human re-ontologising' (as of overall 're-ontologising fepistemic-totalising 're-apriorising/re-axiomatising/rereferencing residuality in re-originariness/re-origination accreting/recomposuring cogency/tensing/limpidity-<as-of-prospective-profoundsupererogation ,-for-residuality-in-re-originariness/re-origination>-,prospective_reifying mental-aestheticising-<as-of-prospective_reformulating-of-mental-aestheticising'as-to'residuality in-re-originariness/re-origination' of-mental-aestheticising ${ }^{\prime}$ ) that effectively overcomes/supersedes shallow supererogation $\sim$ framing/formulation/catchmenting/truncating/compulsing/linearising_scale —of-opaque/contentious/un-nominalised/flawed-interpretations/domains of manifest blurriness-<sterilising/anecdotalising/trivialising-of-prospective-re-ontologising_bypreconverging,-in-disontologising-formulaic-dragging-out/hollowing-out>; with the latter manifested as to human ingrained presencing absolutising identitive-constitutedness 'existential-<disontologising/re-ontologising aporeticism $>$ preconverging dementating/structuring/paradigming punctual/immediacy/constituted/compulsions-encumbered prior mere-formulaicity/ritualisation rationalisation-ofcontentivity/argumentativity/dialecticism/discursivity' (reflected in the manifestation of the notional/epistemie/bindingness ${ }^{<\text {as-to-determinism/conceptivity-of-relative-unreflexivity/relative-reflexivity }>}$ overaching cultivated-and-enculturated interrelatedness-dynamics-of-social-constructing as from 'catchmented-and-compulsed-<in-'existential-dearth-of-demoronisation',-so-construed- 
as-from-ontological-normalcy/postconvergence-perspective-reflection-of-the-'destructuring-

threshold_of-the-given-level's-conjugated-postlogism as-dementing'> interpersonal, group, intergroup, community, local, national, political, geostrategic, etc. psychologismic epistemic acutisation difficulty-for, residualising \{decompulsing $\}$ delinearity for-cogency> levels of interrelatedness-dynamics-of-social-constructing' of 'formativeness-<as-to-intersolipsism-ofpreformulating/preframing/premeaningfulness-imbued-mediativity-and-deferentialism>-ofmeaningfulness-and-teleology $\quad$ and $\quad$ existential-<disontologising/re-ontologising apereticism $>$ articulation manifestations'). This (re-ontologising treapriorising/re-axiomatising/re-referencing-residuality in-re-originariness/re-origination ${ }_{\{\text {decompulsing }\}}$ delinearity/delinear-accreting/recomposuring $\quad$ cogency/tensing/limpidity-<as-ofprospective-profound-supererogation ,-for-residuality-in-re-originariness/reorigination>-aprospective_reifying mental-aestheticising-<as-of 'prospective_reformulating of-mental-aestheticising'as-to-residuality in re-originariness/re-origination' of mentalaestheticising $>$ ) of the ontologising/scientific/existence- $<$ honesty-constraining $>$ scope_for_prospective_re-ontologising is so-reflected with regards to the successive profoundsupererogation re-assessability as from base-institutionalisation, ${ }^{103}$ universalisation, positivism/rational-empiricism and prospective deprocrypticism-or-preemptingdisjointedness-as-of- ${ }^{8}$ reference-of-thought over their respective subontologisation/subpotentiation of recurrent-utter-uninstitutionalisation, ununiversalisation, non-positivism/medievalism and procrypticism-or-disjointedness-as-of- ${ }^{8}$ reference-ofthought. In this respect the scientific basis (ontologising/scientific/existence- $<$ honestyconstraining $>$ — scope_for_prospective_re-ontologising basis) for such an elucidation exactly arises as of the 'fundamental/incipient/seeding experientiality/experiment- $<$ as-to-existentiallyformative-' ‘epistemic-totalising ${ }^{3}$ re-apriorising/re-axiomatising/re-referencing $\sim$ residuality-in-reoriginariness/re-origination', - so-'notionally/epistemically/bindingnessly-<as-to- 
determinism/conceptivity-of-relative-unreflexivity/relative-reflexivity $>$ _implicited-and-articulated' as-from-

nonextricatory-'prospective-re-ontologising-Being-then-Institutional-then-Living-magnitudesof-\{hermeneutic/reprojection $\sim$ protraction-of reframing-and-reformulation $\}^{\prime}>$ that is human profound-supererogation' (so-reflecting the 'overarching existential-<disontologising/reentologising apereticism $>$ priority/precedence/primacy of \{epistemic-totalising $3{ }^{3} \mathrm{re}$ reapriorising/reaxiomatising/re-referencing $\sim$ residuality-in-re-originariness/re-origination projection') and is so-allowed to trample-upon the supposed sensibility/decorum of ${ }^{79}$ presencing-absolutisingidentitive-constitutedness $^{14}$ that rather acts as foil for disontologising/subontologising 'pedantising/muddling/formulaic-hollowing-out—in-subontologisation/subpotentiation〈blurring/undermining-of-prospective-totalising-entailing,-as-to-entailing$<$ amplituding/formative-epistemicity $>$ totalising in-relative-ontological-completeness $>$ enculturation' (as to an ontologically-flawed prior \{compulsing linearity/linear-accretingpresencing-perceptualisation-of-sublimating-over-desublimating-<as-'psychologismic_epistemic-acutisation - nonresidualising-imbued-\{compulsing\} $\}$ linearity in-eclecticism-of-priormere-formulaicity/ritualisation'_as-to-'secondnatured-epistemic-perspective'-of-prospective\&-prior-differentiated apriorising/axiomatising/referencing $>$ and-as-developing-intointerrelatedness-dynamics-of-social-constructing). This can be so-appreciated as to the elicited 'existential-<disontologising/re-ontologising aporeticism> hermeneutic/textuality/reprojecting/supererogating/zeroing/re-acuting $\{$ decompulsing $\}$ delinearity/delinear-accreting/recomposuring- ${ }^{6}$ nonpresencing-perceptualisation-ofsublimating-over-desublimating-<as-"psychologismic-epistemic-acutisation-residualising,${ }_{\{\text {decompulsing }}$ delinearity for-cogency’_as-to-'prospective-profound-supererogation -epistemicperspective'-of prospective-\& prior-differentiated apriorising/axiomatising/referencing $>$ with-respect-to-the-prospect-of-prospective-human-re-ontologising' relationship between the Socratic-philosophers and ancient-sophists as well as budding-positivists and medieval- 
scholasticism; and as further appreciated with regards to profoundsupererogation $\sim$ reframing/reformulation/decatchmenting/detruncating/decompulsing/delinear ising_scale_-of-transparent/noncontentious/un-nominalised/sound-interpretations/domains of manifest unblurriness-<re-ontologising_by-postconverging-as-to-dragged-outsupererogatory $\sim$ wholesomeness/profound-supererogation ,-while-anecdotalising-priordisontologising-thresholding $>$ associated with nascent-particular/incipient-andmaterial/technical-sublimations-<blinded-to-their-relative-ontological-completeness reference-of-thought- devolving > punctual/immediacy/constituted/compulsions-

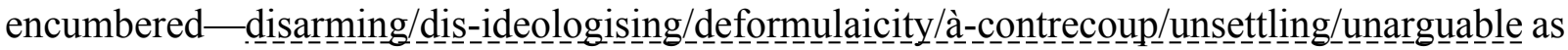
of 'unlimitedness/existence-<full-potency-of_sublimating-nascence> prospective apriorising/axiomatising/referencing-sublimating-reflexivity_beholdening under which limitedness/human-subpotency submits in profound-supererogation for prospective sublimating' (wherein for instance the previous theorising as to their epochal seminality respectively of the Poincarés, Einsteins, Bohrs, Feynmans, etc. 'could not be saved' from the prospective 're-ontologising tre-apriorising/re-axiomatising/rereferencing residuality in-re-originariness/re-origination \{decompulsing $\}$ delinearity/delinearaccreting/recomposuring cogency/tensing/limpidity-<as-of-prospective-profoundsupererogation ,-for-residuality_in-re-originariness/re-origination>-^prospective_reifying mental-aestheticising-<as-of 'prospective_reformulating-of-mental-aestheticising'as-to'residuality in-re-originariness/re-origination'-of-mental-aestheticising ${ }^{\prime}$ ' with regards to thevery-same purview/devolved-purview/devolving-purview-of-unlimitedness/existence-<fullpotency-of_sublimating nascence>;_—implicited_attendant-ontologicalcontiguity ${ }^{67} \sim$ educedexistentialising/contextualising/textualising_'intelligibility/epistemicity/reflexivity-contiguity$<$ imbued-notional cogency ${ }^{\prime}$ as from respectively the Einsteins, Bohrs, Feymans and the 
latter succeeding generation of physicists however such previous physicists human mortal framing of reputation). This speaks to the fact that 'intemporality doesn't accede to temporality as of ontological-veracity' as acting otherwise induces an even hopeless disontologisingaggravation-〈in-want-for-prospective-aetiologisation/ontological-escalation-<ontologicalveridicality_commitment/otherliness_transcending/compulsions-encumbered_transcending $>\rangle$ given that it is one thing for pedantic disontologising to consciously/unconsciously arise but it is an altogether 'human lost cause' if the genuine social intellectual-function/posture were to accede to such pedantic disontologising. In the bigger scheme of things, it can equally be appreciated that 'this (re-ontologising fepistemic-totalising '’ ${ }^{\prime}$ re-apriorising/re-axiomatising/rereferencing residuality in re originariness/re origination $\quad\{$ decompulsing $\}$ delinearity/delinear accreting/recomposuring cogency/tensing/limpidity-<as-of-prospective-profoundsupererogation ,-for-residuality_in-re-originariness/re-origination>-_prospective_reifying mental-aestheticising-<as-of 'prospective_reformulating-of-mental-aestheticising'as-to'residuality in-re-originariness/re-origination' of -mental-aestheticising $\geqslant$ ) of the ontologising/scientific/existence- $<$ honesty-constraining $>$ — scope_for_prospective_reontologising' is effectively the more ontologically-veridical and rigorous notion with respect to prospective human knowledge and transcendence-andsublimity/sublimation/supererogatory de-mentativity (as of its requisite nonpresencing<perspective-ontological-normalcy/postconvergence $>\quad$ epistemic-projection 'implicited/explicited psychologismic-epistemic-acutisation-residualising \{epistemictotalising $3{ }^{3}$ hermeneutic/textuality/reprojecting/supererogating/zeroing/re-acuting,${ }_{\{\text {decompulsing }}$ delinearity for-cogency'), and so over the relatively ontologically-flawed approach of a 'purported crisis-of-reproducibility in academia' of prospective human knowledge and transcendence-and-sublimity/sublimation/supereregatery $\sim$ de-mentativity (as of 79 presencingabsolutising-identitive-constitutedness epistemic-projection 'implicited/explicited 
punctual/immediacy/constituted/compulsions-encumbered-hypothesisation reproducibility'). In this regards, the latter approach of a 'purported crisis-of-reproducibility in academia' inmany-ways poorly reflects the-very-underlying-(as inherently 'defining-and-imbuing of limitedness/human-subpotency de-mentation-〈supererontolonical-de-mentation-ordialectical-de-mentation — stranding-or-attributive-dialectics ${ }^{\prime}$ as to preconverging/postconverging-de-mentating/structuring/paradigming)—relationship-betweenlimitedness/human-subpotency-and-unlimitedness/existence-<full-potency-of_sublimating nascence $>$ with respect to the pre-eminence of the latter (as to 'limitedness/human-subpotency prospective re-encountering/re-confrontation with unlimitedness/existence-<flll-potency ef_sublimating '), such that what is effectively warranted 'is not prospective limitedness/human-subpotency shallow reproducibility of prior limitedness/human-subpotency research and knowledge' (as to 79 presencing-absolutising-identitive-constitutedness epistemic-projection 'implicited/explicited punctual/immediacy/constituted/compulsionsencumbered-hypothesisation reproducibility'). But rather what is effectively warranted is 'limitedness/human-subpotency prospective profound-supererogation sublimating reflection of the-very-same purview/devolved-purview/devolving-purview-of-unlimitedness/existence$<$ full-potency-of_sublimating nascence $>$;_-'implicited_attendant-ontologicalcontiguity $^{67}$; educedexistentialising/contextualising/textualising_intelligibility/epistemicity/reflexivity_contiguity$<$ imbued-notional cogency >' of prior limitedness/human-subpotency research and knowledge' (as to 'nonpresencing-<perspective-ontological-normalcy/postconvergence $>$ epistemic-projection 'implicited/explicited psychologismic-epistemic-acutisationresidualising \{epistemic-totalising 33 h hermeneutic/textuality/reprojecting/supererogating/zeroing/re-

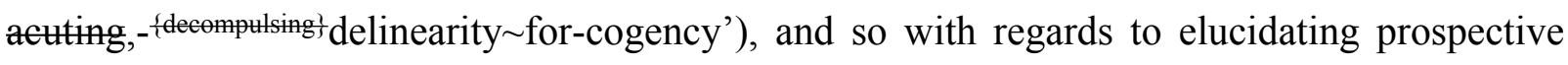

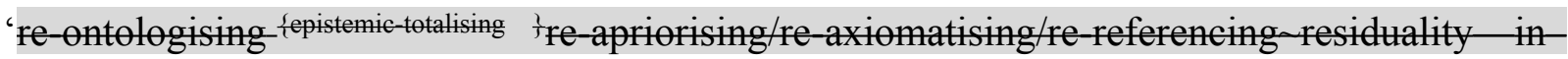


cogency/tensing/limpidity-<as-of-prospective-profound-supererogation ,, for-residuality - inre-originariness/re-origination $>$, prospective_reifying mental-aestheticising-as-of-

\section{'prospective_reformulating-of-mental-aestheticising'as-to-'residuality in re-originariness/re-}

origination' of -mental-aestheticising >'. Effectively and in-the-bigger-picture, such a presencing-absolutising-identitive-constitutedness ${ }^{14} \quad$ epistemic-projection 'implicited/explicited punctual/immediacy/constituted/compulsions-encumberedhypothesisation reproducibility' (as manifested as of our 'positivismprocrypticism/disjointedness-as-of- ${ }^{83}$ reference-of-thought $\quad{ }^{79}$ presencing-absolutisingidentitive-constitutedness ${ }^{14}$ epistemic-projection' imbued reductionist misconstrual of the 'existentialising-frame-of-entailment-of-motif-and-apriorising/axiomatising/referencing of experientiality/experiment-<as-to-existentially-formative- ‘fepistemic-totalising ${ }^{\prime}$ re-apriorising/reaxiomatising/re-referencing $\sim$ residuality —in-re-originariness/re-origination','notionally/epistemically/bindingnessly-as to determinism/eoneeptivity of relative mnreflexivity/relative reflexivitys_ implicited-and-articulated'_as-from-nonextricatory-'prospective-re-ontologising-Being-thenInstitutional-then-Living-magnitudes-of-\{hermeneutic/reprojection-protraction-of $\}$ reframingand-reformulation \}'>' in eliciting for instance human psychology and other social-sciences purview-of-unlimitedness/existence-<full-potency-of_sublimating nascence>;'implicited_attendant-ontological-contiguity ${ }^{67}$ > educedexistentialising/contextmalising/textualising_'intelligibility/epistemicity/reflexivity_contiguity$<$ imbued-notional cogency>' ) are rather veridically construable in profundity (as from nonpresencing-<perspective-ontological-normalcy/postconvergence $>$ epistemic-projection 'implicited/explicited psychologismic-epistemic-acutisation-residualising $\sim$ \{epistemictotalising 3 ' 3 hermeneutic/textuality/reprojecting/supererogating/zeroing/re-acuting,\{decompulsing\} delinearity for-cogency') as the ambit-of-elucidation of 'overall profound/sound 
gesturing/accounting — of-epistemic-phenomenalism'

worldviews/dimensions or the overall relative-unreflexivity/relative-reflexivity-ontologicalcontiguity ${ }^{67}$ of-the-human-institutionalisation-process ${ }^{68}$ (so-underlied herein as of human ${ }^{15}$ dementation-〈supererogatory $\sim$ ontological-de-mentation-or-dialectical-de-mentation — strandingor-attributive-dialectics $\rangle$ ); as so-reflecting the ontologising/scientific/existence- $<$ honestyconstraining $>$ — scope_for_prospective_re-ontologising imbued underlying-elucidative 'requisite sublimating/desublimating formulative-framing/fielding-of-entailment of human ontological-performance ${ }^{2}$-<including-virtue-as-ontology $>/$ morality/ethics/justice/etc. contemplation' as of notionally implied ${ }^{45}$ foregrounding_entailment- $<$ in-succession-ofprofound-supererogation $>$-〈postconverging-narrowing-down $\sim$ sublimation-as-to- ${ }^{`}$ existenceas-sublimating-withdrawal/unenframing/re-ontologising,-elicited-from-prospective-profoundsupererogation '-in-reflecting-'immanent relative unreflexivity/relative-reflexivity ontological-contiguity ';--as-operative-notional deprocrypticism) (such that 'our positivismprocrypticism/disjointedness-as-of- ${ }^{8}$ reference-of-thought given ${ }^{79}$ presencing-absolutisingidentitive-constitutedness ${ }^{14}$ conception of human psychoanalysis' poorly/hardly reflect upon the bigger picture implications of "prior human disontologising/subontologising thresholds and their superseding/overcoming' so-manifested as of 'prior desublimating rationalisations-ofcontentivity/argumentativity/dialecticism/discursivity of social-and-institutional-frameworksof-referencing/registering/decisioning', which failure of appreciating relativeunreflexivity/relative-reflexivity ontological-contiguity ${ }^{67}$ so-rather induces prospectively 'individual-by-institutional-by-social existentialising-enframing/imprintedness of disontologising/subontologising moronisation- $<$ sublimating-nascence,-extricatorydesublimating-downstreaming/'avalage'>'). In other words, a mere-formulaicity/ritualisation$<$ as-to-mere-formulaic — methodologising/mutualising/organising/institutionalising,- 


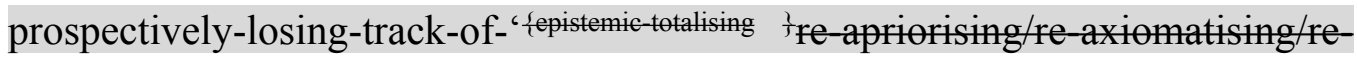

referencing - residuality - in-re-originariness/re-origination'> approach of a 'purported crisisof-reproducibility in academia' of prospective human knowledge and transcendence-andsublimity/sublimation/supererogatory-de-mentativity as to our prior positivismprocrypticism/disjointedness-as-of- ${ }^{8}$ reference-of-thought $\quad{ }^{79}$ presencing-absolutisingidentitive-constitutedness ${ }^{14} \quad$ epistemic-projection $\quad$ 'implicited/explicited punctual/immediacy/constituted/compulsions-encumbered-hypothesisation reproducibility' in disparateness-of-conceptualisation-<unforegrounding-ment,-failing-prospectively-to-reflect‘immanent relative-unreflexivity/relative-reflexivity ontological-contiguity '> (as failing requisite prospective nonpresencing-<perspective-ontological-normalcy/postconvergence $>$ epistemic-projection 'implicited/explicited psychologismic-epistemic-acutisationresidualising \{ \{epistemic-totalising 3 3 hermeneutic/textuality/reprojecting/supererogating/zeroing/reacuting, ${ }^{\{\text {decompulsing }}$ delinearity for-cogency' successive profound/state-of-the-art sublimating reflection of the-very-same purview/devolved-purview/devolving-purview-ofunlimitedness/existence-<full-potency-of_sublimating nascence $>$;_-implicited_attendant ontological-contiguity ${ }^{67} \sim$ educed-

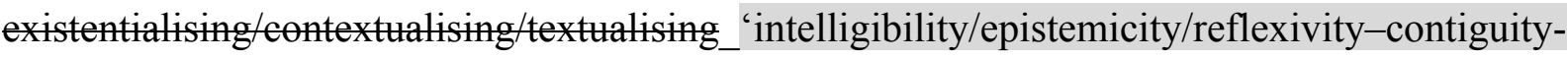
$<$ imbued-notional cogency>' of prior limitedness/human-subpotency research and knowledge) is bound to induce a "79 presencing-absolutising-identitive-constitutedness 'apriorising/axiomatising/referencing — equating/leveling/ressentiment/closed-construct-ofmeaningfulness-and-teleology $\quad$ moronisation- $<$ sublimating-nascence,-extricatory desublimating-downstreaming/'avalage’’’ (in an eclecticism-of-prior-mereformulaicity/ritualisation-<as-of-prior $\sim$ rationalisation-ofcomposition/blending-in\{compulsing\}linearity/linear-accretion of relative-ontological-completeness and relative- 
ontological-incompleteness apriorising/axiomatising/referencing as to our positivismprocrypticism/disjointedness-as-of- ${ }^{2}$ reference-of-thought secondnatured prior mereformulaicity/ritualisation-<as-to-mere-formulaic-

methodologising/mutualising/organising/institutionalising,-prospectively-losing-track-of-

‘\{epistemic-totalising ’’re-apriorising/re-axiomatising/re-referencing - residuality-in-re-

originariness/re-origination'>). This (as to requisite re-ontologising ambit-of-elucidation of 'overall profound/sound gesturing/accounting-of-epistemic-phenomenalism' of the $<$ cumulating/recomposuring attendant-ontological-contiguity $>$-successive registryworldviews/dimensions or the overall relative-unreflexivity/relative-reflexivity_ontologicalcontiguity ${ }^{67}$ of-the-human-institutionalisation-process ${ }^{68}$ ) is so-reflected as to the 'differing psychologismic epistemic-acutisation difficulty-<for, residualising-

$\{$ decompulsing $\}$ delinearity for-cogency $>$ magnitudes $\{$ of-experientiality/experiment $\}$ in acceding/not-acceding to ontological-deficiency'; and so with regards to the contemplation of such a 'purported crisisof-reproducibility in academia' specifically but equally as so relevantly applicable to our 'overall positivism- ${ }^{80}$ procrypticism/disjointedness-as-of- ${ }^{8}$ reference-of-thought knowledgereification $\sim$ gesturing-and-accounting — of-epistemic-phenomenalism- $<$ inprospective_psychologismic apriorising/axiomatising/referencing-\{of-'prespectively implicited_attendant-ontological-contiguity ' reducedexistentialising/contextualising/textualising_ intelligibility/epistemicity/reflexivity-contiguity<imbued-notional cogency >' \}-conflatedness -in-\{preconverging-ment by\} postconverging entailment'). So-reflected on-the-one-hand (with respect to the more $<$ extricatory/preconverging/accommodating/unquestioning $>-$

disontologising/subontologising_prompting perspective of our positivismprocrypticism/disjointedness-as-of- ${ }^{3}$ reference-of-thought intradimensional institutionaldevelopment-as-to-social-function-development and living-development-as-to-personality- 
$\{$ decompulsing $\}$ delinearity for-cogeney $>$ magnitudes $\{$ of-experientiality/experiment\}) as to our positivismprocrypticism/disjointedness-as-of- ${ }^{3}$ reference-of-thought presencing absolutising identitive-constitutedness 'existential<<disontologising/re-ontologising aporeticism $>$ preconverging de-mentating/structuring/paradigming punctual/immediacy/constituted/compulsions-encumbered prior mere-formulaicity/ritualisation rationalisation-of-contentivity/argumentativity/dialecticism/discursivity'; as so-underlied by the (positivism- ${ }^{8}$ procrypticism/disjointedness-as-of- ${ }^{-3 e f e r e n c e-o f-t h o u g h t) ~}$ '<extricatory/preconverging/accommodating/unquestioning $>$ -

disontologising/subontologising_prompting as to $\leq$ mere-formulaicity/ritualisation $-\theta f>$ prior induced $<$ punctual/immediacy/constituted/compulsions-encumbered prompted extended/prolonged-re-ontologising-enabling $>$-psychologismic epistemic-acutisation residualising \{epistemic-totalising ’’hermeneutic/textuality/reprojecting/supererogating/zeroing/reacuting, ${ }^{\text {\{decompulsing }}$ delinearity for-cogency' (so-effectively manifesting prospectively as disontologising/subontologising 'rationalisation-ofcontentivity/argumentativity/dialecticism/discursivity in psychologismic-epistemicacutisation-nonresidualising-imbued-\{compulsing linearity in-eclecticism-of-prior-mereformulaicity/ritualisation' as to 'positivism- ${ }^{80}$ procrypticism/disjointedness-as-of- ${ }^{8}$ reference-ofthought imbued knowledge-reification $\sim$ gesturing-and-accounting-of-epistemicphenomenalism-<in-prospective_psychologismic $\sim$ apriorising/axiomatising/referencing- of'prospectively implicited_attendant-ontological-contiguity ' educedexistentialising/contextualising/textualising_ intelligibility/epistemicity/reflexivity-contiguity<imbued-notional cogency>' \}-conflatedness in \{preconverging ment by\} postconverging-entailment'). So-reflected on-the-other-hand in contrast (with regards to the more $<$ nonextricatory/postconverging/unaccommodating/questioning $>$-re- 
ontologising_prompting perspective as to interdimensional re-ontologising prospective Beingdevelopment/ontological-framework-expansion-as-to-depth-of-ontologising-development-asinfrastructure-of- meaningfulness-and-teleology psychologismic epistemic-acutisationdifficulty $<$ for, residualising \{decompulsing $\}$ delinearity - for-cogency> magnitude $\{$ ofexperientiality/experiment\} undergirding registry-worldviews/dimensions transcendence-andsublimity/sublimation/supererogatory-de-mentativity as pointing herein to prospective deprocrypticism-or-preempting-disjointedness-as-of- ${ }^{3}$ reference-of-thought) as to nonpresencing-<perspective-ontological-normalcy/postconvergence> 'existential<disontologising/re-ontologising aporeticism $>$ prospect of human individualconsciousness/collective-consciousness decompulsion-appraisal'; (in relation to our 'positivism- ${ }^{80}$ procrypticism/disjointedness-as-of- ${ }^{8}$ reference-of-thought prospective disontologising/subontologising') so-eliciting $'<$ nonextricatory/postconverging/unaccommodating/questioning $>$-re-ontologising_prompting perspective as to < punctual/immediacy/constituted/compulsions-encumbered prompted extended/prolonged-re-ontologising-enabling $>$-psychologismic epistemic-acutisationresidualising $\left\{\right.$ fepistemic-totalising ${ }^{3}$ hermeneutic/textuality/reprojecting/supererogating/zeroing/reacuting, ${ }^{\text {\{decompulsing }}$ delinearity for cogeney -in-order-to-enable-<as-of-the-untenability-ofinduced unblurriness $>$ _ _ p prospective_punctual/immediacy/constituted/compulsionsencumbered — disarming/dis_-ideologising/deformulaicity/à-contrecoup/unsettlling/unargunable prompted constricted/narrowingdown-re-ontologising-enabling $>$-psychologismic epistemicacutisation residualising a fepistemictotalising thermeneutic/textuality/reprojecting/supererogating/zeroing/re-acuting, \{decompulsing\} delinearity for cogency' (so-construed herein as prospective re-ontologising ' deprocrypticism-or-preempting-disjointedness-as-of- ${ }^{3}$ reference-of-thought imbued knowledge-reification $\sim$ gesturing-and-accounting — of-epistemic-phenomenalism- $<$ in- 
prospective_psychologismic apriorising/axiomatising/referencing-\{of- ${ }^{\text {prospectively }}$ implicited_attendant-ontological-contiguity ' educedexistentialising/contextualising/textualising_'intelligibility/epistemicity/reflexivity-contiguity$<$ imbued-notional $\left.\sim \operatorname{cogency}>^{\prime}\right\}$-conflatedness -in-\{preconverging -ment by\} postconverging-entailment'). This is so-implied as to prospective 'human psychologismicepistemic-acutisation-<as-to-postconverging-de-mentating/structuring/paradigming,-elicitingof-existence's-sublimating-nascence-in-prospective-aporeticism-overcoming/unovercoming> as to epistemic-growth,-as - \{veridical/sound\}-relative-reflexivity-in-existence/relativising from-limited-mentation-as-its-deepening/psychologismic epistemic-acutisationresidualising, ${ }^{\text {\{decompulsing? }}$ delinearity for-cogency' of the-very-same purview/devolvedpurview/devolving-purview-of-unlimitedness/existence-<full-potency-of_sublimating nascence>;_- 'implicited_attendant-ontological-contiguity ${ }^{67}$ ' educedexistentialising/contextmalising/textualising_'intelligibility/epistemicity/reflexivity_contiguity$<$ imbued-notional cogency $>$; as so superseding/overcoming the psychologismic-epistemicacutisation-difficulty-<for,-residualising_\{decompulsing $\}$ delinearity $\sim$ for-cogency $>-\langle$ as-ofrequisite-profound-supererogation -for-'disposedness-or-psychologismic-construct'\{imbued-demoronisation-<sublimating-nascence,-nonextricatory-sublimatingupstreaming/'amontée'>\}) for re-ontologising prospective Being-development/ontologicalframework-expansion-as-to-depth-of-ontologising-development-as-infrastructure-ofmeaningfulness-and-teleology psychologismic epistemic-acutisation difficulty-for, residualising \{decompulsing delinearity for-cogency $>$ magnitude $\{$ of-experientiality/experiment\}. This overall insight (with regards to such an ontologically-flawed ${ }^{79}$ presencing-absolutising-identitiveconstitutedness ${ }^{14} \quad$ epistemic-projection $\quad$ 'implicited/explicited punctual/immediacy/constituted/compulsions-encumbered—hypothesisation reproducibility' as veridically warranting prospective nonpresencing-<perspective-ontological- 
normalcy/postconvergence> epistemic-projection 'implicited/explicited psychologismicepistemic-acutisation-residualising \{epistemic-

thermeneutic/textuality/reprojecting/supererogating/zeroing/re-acuting,-

\{decompulsing $\}$ delinearity for-cogency') can be gleaned from the fact that for instance the epochal seminalities respectively of the Poincarés, Einsteins, Bohrs, Feynmans, etc. would effectively flop with respect to such an approach to a 'purported crisis-of-reproducibility in academia' of prospective human knowledge and transcendence-andsublimity/sublimation/supererogatory-de-mentativity (as of ${ }^{79}$ presencing-absolutisingidentitive-constitutedness ${ }^{14} \quad$ epistemic-projection 'implicited/explicited punctual/immediacy/constituted/compulsions-encumbered-hypothesisation reproducibility'). Specifically in this regards, it is critical not to turn a 'front-end issue of research execution' (as reflecting 'implicited/explicited inappropriate baseline professional/technical training, practice and evaluation issues' with respect to the requisite 'educed methodologising/mutualising/organising/institutionalising of prior baseline research sublimation') into a 'back-end issue of research execution' (of 'implicited/explicited appropriate baseline trained/practicing/evaluating researcher/evaluator requisite profound-supererogation for prospective sublimating research' as to <amplituding/formative-epistemicity $>$ totalising renewing-realisation/re-perception/re-thought), as consequently not 'necessarily/absolutely but rather so-relatively beholdening' to such 'educed methodologising/mutualising/organising/institutionalising of prior baseline research sublimation' and as the prospective sublimating research may further elicit its very own 'prospective methodologising/mutualising/organising/institutionalising'; and so with regards to the fact that adopting the relative orthodoxy of the 'educed methodologising/mutualising/organising/institutionalising of prior baseline research sublimation' (as to a veridically 'front-end issue of research execution') and wrongly projecting 
it upon a veridically 'back-end issue of research execution', may end up creating an even graver problem with respect to the latter's requisite profound-supererogation manifest 'creative relative unorthodoxy as to anarchistic-growth/anarchisation-for-re-ontologisation-〈as-toconscious/unconscious epistemically-sound induced 'demoronisation-<sublimating-nascence,nonextricaty-sublimating-upstreaming/'amontée’> postconverging/dialectical-thinking conception of residual_re-originary_anarchistic incipiency of human social-functioning-andaccordance - as-of-social-stake-contention-or-confliction meaningfulness-and-teleology ' $\rangle$ ' (as of the veridical 'back-end issue of research execution' requisite 'educed methodologising/mutualising/organising/institutionalising of prospective research sublimation' unbeholdening methodologising/mutualising/organising/institutionalising' prospectively failing sublimatingprolongation). What is of 'ontologically-veridical rigour' is rather the 're-ontologising fepistemictre-apriorising/re-axiomatising/re-referencing residuality in-re-originariness/reorigination \{decompulsing\} ${ }^{\{}$delinearity/delinear-acereting/recomposuring cogency/tensing/limpidity<as-of-prospective-profound-supererogation ,-for-residuality-in-re-originariness/reorigination $>$-_prospective_reifying mental-aestheticising_<as-of-'prospective_reformulatingof-mental-aestheticising'as to 'residuality in re-originariness/re-origination' of mentalaestheticising >' with regards to the-very-same purview/devolved-purview/devolving-purviewof-unlimitedness/existence-<full-potency-of_sublimating nascence $>$;_- 'implicited_attendantontological-contiguity ${ }^{67} \sim$ educedexistentialising/contextualising/textualising_intelligibility/epistemicity/reflexivity-contiguity$<$ imbued-notional cogency $>^{\prime}$ as from respectively the Einsteins, Bohrs, Feymans and the latter succeeding generation of physicists; as so-enabling a 'cogent/tense/limpid-<as-ofprospective-profound-supererogation ,-for-residuality-in-re-originariness/re-origination> overlaying/superstrating 'thrownness-aestheticising' $\{$ of-relative-reflexivity in-existence $\}>$ 
sparsity-of-postconverging prospective-relative-ontological-completeness ${ }^{87}$-of-

apriorising/axiomatising/referencing in demoronisation-<sublimating-nascence,nonextricatory-sublimating-upstreaming/'amontée’>' (over 'eclecticism-of-prior-mereformulaicity/ritualisation-<as-of-prior $\sim$ rationalisation-of-

contentivity/argumentativity/dialecticism/discursivity> composition/blending-in\{compulsing\} linearity/linear-accretion of <underlaid/substrated-'thrownness-aestheticising'-\{ofrelative-unreflexivity in-existence $\}>$ profusion-of preconverging prior-relative-ontologicalincompleteness -of-apriorising/axiomatising/referencing and overlaying/superstrating'thrownness-aestheticising' \{of-relative-reflexivity in-existence\}>-sparsity-ofpostconverging prospective-relative-ontological-completeness -ofapriorising/axiomatising/referencing'), in reflection of human limited-mentation-capacitydeepening —as-subjecting limitedness/human-subpotency-to-'educed-unlimitedness/existencesublimating nascence 53 . This summarily implies that the-very-same purview/devolvedpurview/devolving-purview-of-unlimitedness/existence-<full-potency-of_sublimating nascence>;-_implicited_attendant-ontological-contiguity ${ }^{67}$ ' educedexistentialising/contextmalising/textualising_intelligibility/epistemicity/reflexivity_contiguity$<$ imbued-notional cogency>' 40 is rather recurrently as of 'unlimitedness/existence-<fllt potency-of_sublimating nascence> prospective apriorising/axiomatising/referencingsublimating-reflexivity_-beholdening under which limitedness/human-subpotency submits in profound-supererogation for prospective sublimating'; with all that is of veridical ontologising/scientific/existence- $<$ honesty-constraining $>$ - scope_for_prospective_reontologising being about its 'implicited/explicited psychologismic-epistemic-acutisationresidualising \{epistemic-totalising 3 3 3 hermeneutic/textality/reprojecting/supererogating/zeroing/reacuting, $-{ }^{\{\text {decompulsing }}$ \}elinearity for-cogency' for 're-ontologising \{epistemic-totalising ${ }^{\dagger}$ 'reapriorising/re-axiomatising/re-referencing -residuality in-re-originariness/re-origination 
prospective-profound-supererogation ,-for-residuality-in-re-originariness/re-

origination $>$, prospective_reifying mental-aestheticising-<as-of 'prospective_reformulating

of-mental-aestheticising'as-to-residuality in-re-originariness/re-origination' of -mental-

aestheticising $>$ ' reflection of the comprehensive coherence/contiguity/noncontradiction of overall experientiality/experiment- $<$ as-to-existentially-formative- ${ }^{\text {' }}$ epistemic-totalising ${ }^{\frac{1}{7}} \mathrm{re}$ apriorising/re-axiomatising/re-referencing residuality-in-re-originariness/re-origination',so-'notionally/epistemically/bindingnessly -as to determinism/conceptivity of relative unreflexivity/relative reflexivityz-implicited-and-articulated'_as-from-nonextricatory-'prospective-re-ontologisingBeing-then-Institutional-then-Living-magnitudes-of-\{hermeneutic/reprojection-protractioneffreframing-and-reformulation $\}^{\prime}>$ for elucidating relative-sublimating over relativedesublimating. Such an elucidation of the ontologising/scientific/existence- $<$ honestyconstraining $>$ _ scope_for_prospective_re-ontologising 'profound-supererogation 9 reassessability of prospective human re-ontologising' (as of overall 're-ontologising tepistemictre-apriorising/re-axiomatising/re-referencing residuality in-re-originariness/reorigination \{decompulsing\} ${ }^{\{}$delinearity/delinear-accreting/recomposuring cogency/tensing/limpidity<as-of-prospective-profound-supererogation ,-for-residuality-in-re-originariness/reorigination $>$, p prospective_reifying mental-aestheticising_<as-of 'prospective_reformulating of-mental-aestheticising'as-to-'residuality in -re-originariness/re-origination' of mentalaestheticising $>$ ') effectively highlights the veracity of the social as of 'existential$<$ disontologising/re-ontologising aporeticism $>$ intercessive procession- $<$ as-to-constructiveveracity/inveracity_of-apriorising/axiomatising/referencing $>$ as to sublimating-orientation and desublimating-disorientation' which is 're-ontologisingly elucidated/resolved' as to the constraining notional/epistemic/bindingness $<$ as-to-determinism/eonceptivity-of-relative-unreflexivity/relativereflexivitys play of 're-ontologising \{epistemic-totalising 're-apriorising/re-axiomatising/re- 
supererogation ,-for-residuality-in-re-originariness/re-origination>- prospective_reifying mental-aestheticising_<as-of 'prospective_reformulating of mental-aestheticising'as to'residuality in re-originariness/re-origination' of -mental-aestheticising ${ }^{\prime}$ (educed in transversality-<for-sublimating-existential-eventuating/denouement,-from-'thinking-atfirst/pure - predisposition-preemptive-of prospective-disontologising/subontologising' as-ofprospectively-disambiguated-affirmed-and-unaffirmed-'motif-andapriorising/axiomatising/referencing'> ${ }^{101}$ ). Basically, the 'entirety/comprehensiveness of thehuman/humanity experientiality/experiment- $<$ as-to-existentially-formative- ' \{epistemic-totalising ${ }^{3}$ reapriorising/re-axiomatising/re-referencing residuality-in-re-originariness/re-origination',so-" notionally/epistemically/bindingnessly-<as-to-determinism/conceptivity-of-relative-unreflexivity/relativereflexivity>-implicited-and-articulated'_as-from-nonextricatory-'prospective-re-ontologisingBeing-then-Institutional-then-Living-magnitudes-of- hermeneutic/reprojection-protraction-

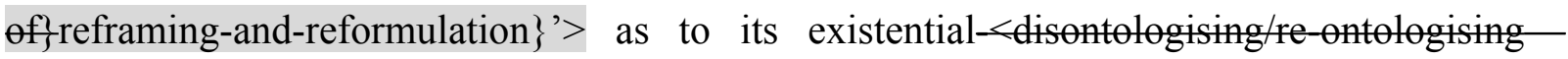
aporeticism $>$ differentiating (associated with the overall relative-unreflexivity/relativereflexivity ontological-contiguity ${ }^{67} \sim$ of-the-human-institutionalisation-process ${ }^{68}$ )' can be construed as of the notionally/epistemically/bindingnessly-<as-to-determinism/coneeptivity-of-relativeunreflexivity/relative-reflexivity> recurrent 'shifting/drifting existential-<disontologising/reentologising aporeticism $>$ differentiating' arising in the-very-underlying - (as inherently 'defining-and-imbuing of limitedness/human-subpotency de-mentation〈supererogatory $\sim$ ontological-de-mentation-or-dialectical-de-mentation-stranding-orattributive-dialectics $\rangle$ as to preconverging/postconverging-dementating/structuring/paradigming)—relationship-between-limitedness/human-subpotencyand-unlimitedness/existence- $<$ full-potency-of_sublimating nascence $>$ (as to the pre-eminence 
of the latter with regards to 'limitedness/human-subpotency prospective re-encountering/reconfrontation with unlimitedness/existence-<full-potency-of_sublimating nascence $>$ ' as of 'dynamic cumulating/recomposuring psychologismic-epistemic-acutisation-residualising,\{decompulsing delinearity for-cogency phasing of limitedness/human-subpotency onto unlimitedness/existence-<full-potency-of_sublimating nascence $>^{\prime}$ ); and so as to overall recurrent notionally/epistemically/bindingnessly-<as-to-determinism/conceptivity-of-relative-unreflexivity/relativereflexivity $\quad$ 'shifting/drifting existential-<disontologising/re-ontologising aporeticism $>$ differentiating' arising in 're-ontologising tre-apriorising/re-axiomatising/rereferencing residuality in-re-originariness/re-origination accreting/recomposuring cogency/tensing/limpidity-<as-of-prospective-profoundsupererogation ,-for-residuality_in-re-originariness/re-origination>-_prospective_reifying mental-aestheticising-<as-of-'prospective_reformulating-of-mental-aestheticising'as-to'residuality in-re-originariness/re-origination'-of-mental-aestheticising $\gg$ ' (in reflection of 'human existential-<disontologising/re-ontologising aporeticism $>$ constraining/subjecting to unlimitedness/existence-<full-potency-of_sublimating nascence $>$ for sublimating' sounderlying the notionally/epistemically/bindingnessly-<as-to-determinism/eoneeptivity-of-relativeunreflexivity/relative-reflexivity> recurrent 'shifting/drifting existential-disontologising/reentologising aporeticism $>$ differentiating' manifested as of 'human psychologismic... epistemic-acutisation-<as-to-postconverging-de-mentating/structuring/paradigming,-elicitingof-existence's-sublimating-nascence-in-prospective-aporeticism-overcoming/unovercoming> as to epistemic-growth,-as - \{veridical/sound\}-relative-reflexivity-in-existence/relativising from-limited-mentation-as-its-deepening/psychologismic epistemic-acutisationresidualising, ${ }^{\text {\{decompulsing }}$ delinearity for cogeney'). Such notionally/epistemically/bindingnessly-<as-to-determinism/conceptivity-of-relative-unreflexivity/relative-reflexivity $>$ recurrent 'shifting/drifting existential-<isontologising/re-ontologising apereticism> 
differentiating' as to 'relays of human intemporal-individuation epistemic-projection radicalities $\sim$ in-chronicular/annalistic-cogency-<as-of-notional $\sim$ protensivity $>$-〈as-to-limitedmentation-capacity-deepening —as-subjecting limitedness/human-subpotency to-'educedunlimitedness/existence-sublimating nascence' > so-construed as cogency_chronicularity/annality-of-relative-reflexivity,-as-to-profound-supererogation ${ }^{2}$ is associated for instance between (on-the-one-hand) say childhood/trainee/amateur/regular performance expectations with regards (on-the-other-hand) to adulthood/trainer/professional/transformative performance expectations respectively and going all-the-way to the notionally/epistemically/bindingnessly-<as-to-determinism/coneeptivity-of-relativeunreflexivity/relative-reflexivitys $\quad$ recurrent 'shifting/drifting existential-disontologing/reentologising aporeticism $>$ differentiating' implications for re-ontologising prospective Beingdevelopment/ontological-framework-expansion-as-to-depth-of-ontologising-development-asinfrastructure-of- meaningfulness-and-teleology psychologismic epistemic-acutisationdifficulty $<$ for, residualising \{decompulsing $\}$ delinearity - for-cogency> magnitude $\{$ ofexperientiality/experiment\} implied with the <cumulating/recomposuring attendant-ontologicalcontiguity $>$-successive registry-worldviews/dimensions), and so as to requisite 'reclamation/recovery of maximalising-recomposuring-for-relative-ontologicalcompleteness $^{87}$ —unenframed/re-ontologising conceptualisation (elicited/prompted $<$ amplituding/formative-epistemicity $>$-totalising $\sim$ renewing-realisation/re-perception/rethought as of 're-ontologising \{epistemic-totalising ' ${ }^{3}$ re-apriorising/re-axiomatising/rereferencing residuality in-re-originariness/re-origination \{decompulsing $\}$ delinearity/delinearaccreting/recomposuring cogency/tensing/limpidity-<as-of-prospective-profoundsupererogation ,-for-residuality_in-re-originariness/re-origination $>$,-prospective_reifying mental-aestheticising-<as-of 'prospective_reformulating-of-mental-aestheticising'as-to'residuality in re-originariness/re-origination' of mental-aestheticising ’')' for human 
sublimating — course-changing/game-changing; with human sublimating-coursechanging/game-changing so-construed as of human <amplituding/formative-epistemicity >totalising thrownness-in-existence ${ }^{5}$ implications of 're-ontologising apriorising/re-axiomatising/re-referencing-residuality in-re-originariness/re-origination $\{$ \{decompulsing\} $\}$ delinearity/delinear-accreting/recomposuring $\quad$ cogency/tensing/limpidity-<as-ofprospective-profound-supererogation ,-for-residuality-in-re-originariness/reorigination $>$,-prospective_reifying mental-aestheticising-as-of-'prospective_reformulating of mental-aestheticising'as to 'residuality in re-originariness/re-origination' of mentalaestheticising $>$ ' (imbued 'human psychologismic-epistemic-acutisation-<as-topostconverging-de-mentating/structuring/paradigming,-eliciting-of-existence's-sublimatingnascence-in-prospective-aporeticism-overcoming/unovercoming $>$ as to epistemic-growth,-as\{veridical/sound\}-relative-reflexivity-in-existence/relativising from-limited-mentation-as-itsdeepening/psychologismic epistemic-acutisation residualising, ${ }^{\text {fdecompulsing }}$ \}elinearity foreogency') as to human Being-development/ontological-framework-expansion-as-to-depth-ofontologising-development-as-infrastructure-of- meaningfulness-and-teleology , institutionaldevelopment-as-to-social-function-development and living-development-as-to-personalitydevelopment psycholegismic epistemie acutisation diffieulty <for, residualising \{decompulsing\} delinearity for-cogeney>-magnitudes \{of-experientiality/experiment\}. Critically, 'reentologising \{epistemic-totalising łre-apriorising/re-axiomatising/re-referencing-residuality in-reoriginariness/re-origination \{decompulsingt delinearity/delinear-accreting/recomposuring cogency/tensing/limpidity-<as-of-prospective-profound-supererogation ${ }^{6}$,-for-residuality - inre-originariness/re-origination>-_prospective_reifying mental-aestheticising-as-of 'prospective_reformulating of mental aestheticising'as to 'residuality in re originariness/re origination'-of-mental-aestheticising $>$ ' (imbued 'human psychologismic-epistemic-acutisation<as-to-postconverging-de-mentating/structuring/paradigming,-eliciting-of-existence's- 
sublimating-nascence-in-prospective-aporeticism-overcoming/unovercoming $>$ as to epistemicgrowth,-as-\{veridical/sound\}-relative-reflexivity-in-existence/relativising from-limitedmentation-as-its-deepening/psychologismic epistemic-acutisation residualising, $\{$ \{decompulsing $\}$ delinearity for-cogency') is merely the reflection of 'unlimitedness/existence-<fullpotency-of_sublimating nascence $>$ prospective apriorising/axiomatising/referencing sublimating-reflexivity-beholdening under which limitedness/human-subpotency submits in profound-supererogation for prospective sublimating'; with the 'submitting of limitedness/human-subpotency' existentially-<disontologising/re-ontologising aporeticism $>$ reflected/translated in-effect as of 're-ontologising axiomatising/re-referencing residuality in re-originariness/re-origination $\{$ decompulsing $\}$ delinearity/delinear-acereting/recomposuring $\quad$ cogency/tensing/limpidity-<as-ofprospective-profound-supererogation ,-for-residuality-in-re-originariness/re-

origination $>$, prospective_reifying mental-aestheticising-<as-of-'prospective_reformulating of-mental-aestheticising'as-to 'residuality in -re-originariness/re-origination' of mentalaestheticising $>$ ' (imbued 'human psychologismic-epistemic-acutisation-<as-topostconverging-de-mentating/structuring/paradigming,-eliciting-of-existence's-sublimatingnascence-in-prospective-aporeticism-overcoming/unovercoming $>$ as to epistemic-growth,-as\{veridical/sound\}-relative-reflexivity-in-existence/relativising from-limited-mentation-as-itsdeepening/psychologismic epistemic-acutisation residualising, \{decompulsing $\}$ delinearity for eogency'). This explains why the elucidation above of say respectively childhood/trainee/amateur/regular performance expectations 'cannot be misrepresented for the mere sake of it' as being respectively of adulthood/trainer/professional/transformative performance expectations (as not reflecting the appropriate circumstantially/contextually requisite 'unlimitedness/existence-<full-potency-of_sublimating nascence $>$ prospective apriorising/axiomatising/referencing-sublimating-reflexivity-beholdening under which 
limitedness/human-subpotency submits in profound-supererogation for prospective sublimating' but as rather existentially-<disontologising/re-ontologising aporeticism $>$ reflected/translated psychologismically otherwise as associated to adulthood/trainer/professional/transformative performance expectations). It is rather as from the 'backdrop of prospective aetiologisation/ontological-escalation- $<$ ontologicalveridicality_commitment/otherliness_transcending/compulsions-encumbered_transcending >' (with regards to re-ontologising prospective Being-development/ontological-frameworkexpansion-as-to-depth-of-ontologising-development-as-infrastructure-of- meaningfulnessand-teleology psychologismic epistemic-acutisation difficulty-for, residualising ${ }_{\text {\{decompulsing }}$ delinearity for-cogency>-magnitude $\{$ of-experientiality/experiment\} so-implied prospective reference-of-thought—point-of-devolving/departure/anchoring/backdrop_of_sublimatingnascence-<as-to-the-grandest-axiomatic-construct-\{epistemic-totalising ${ }^{3}$ re-apriorising/reaxiomatising/re-referencing $\sim$ residuality-in-re-originariness/re-origination of limitedness/human-subpotency prospective re-encountering/re-confrontation with unlimitedness/existence $>$ ) that the 'ontologising/scientific/existence- $<$ honesty-constraining $>$ scope_for_prospective_re-ontologising aspiration of the entire content herein' can be appreciated; as to its projected 're apriorising axiomatising/re-referencing-residuality in-re-originariness/re-origination $\{$ decompulsing $\}$ delinearity/delinear-accreting/recomposuring $\quad$ cogency/tensing/limpidity-<as-ofprospective-profound-supererogation ,-for-residuality—in-re-originariness/reorigination>-_prospective_reifying mental-aestheticising_<as-of-prospective_reformulatingof -mental-aestheticising'as-to-residuality in re-originariness/re-origination' of mentalaestheticising $>$ ' (imbued 'human psychologismic-epistemic-acutisation-<as-topostconverging-de-mentating/structuring/paradigming,-eliciting-of-existence's-sublimatingnascence-in-prospective-aporeticism-overcoming/unovercoming $>$ as to epistemic-growth,-as- 
\{veridical/sound\}-relative-reflexivity-in-existence/relativising from-limited-mentation-as-itsdeepening/psychologismic epistemic acutisation residualising, ${ }^{\text {fdecompulsing }}$ delinearity for eogency'), and so beyond our ${ }^{79}$ presencing - absolutising-identitive-constitutedness ${ }^{14}$ 'socialfunctioning-and-accordance-as-of-social-stake-contention-or-confliction imbuing existentialising-frame-of-entailment of motif-and-apriorising/axiomatising/referencing of disontologising/ontologising-and-re-ontologising'. Just as in-many-ways induced 'reentologising \{epistemic-totalising łre-apriorising/re-axiomatising/re-referencing residuality in-reөriginariness/re-origination \{decompulsing\} delinearity/delinear-accreting/recomposuring cogency/tensing/limpidity-<as-of-prospective-profound-supererogation ,-for-residuality-inre-originariness/re-origination>--prospective_reifying mental-aestheticising_<as-of'prospective_reformulating of mental-aestheticising'as-to-'residuality in re-originariness/reerigination'-of-mental-aestheticising >' (imbued 'human psychologismic-epistemic-acutisation$<$ as-to-postconverging-de-mentating/structuring/paradigming,-eliciting-of-existence'ssublimating-nascence-in-prospective-aporeticism-overcoming/unovercoming $>$ as to epistemicgrowth,-as-\{veridical/sound\}-relative-reflexivity-in-existence/relativising from-limitedmentation-as-its-deepening/psychologismic epistemic-acutisation residualising, \{decompulsing delinearity for cogeney') of say Socratic-philosophers and budding-positivists were projection beyond their social-setup ${ }^{79}$ presencing-absolutising-identitive-constitutedness 'social-functioning-and-accordance-as-of-social-stake-contention-or-confliction imbuing existentialising-frame-of-entailment of motif-and-apriorising/axiomatising/referencing of disontologising/ontologising-and-re-ontologising'. This speaks to the fact that the 'ontologising/scientific/existence- $<$ honesty-constraining $>$ — scope_for_prospective_reontologising aspiration' is not limited to any given social-setup ${ }^{79}$ presencing-absolutisingidentitive-constitutedness 'social-functioning-and-accordance-as-of-social-stakecontention-or-confliction imbuing existentialising-frame-of-entailment-of motif-and- 
apriorising/axiomatising/referencing of disontologising/ontologising-and-re-ontologising' (but is rather of 'unlimitedness/existence-<full-potency-of_sublimating nascence $>$ prospective apriorising/axiomatising/referencing-sublimating-reflexivity-beholdening under which limitedness/human-subpotency submits in profound-supererogation for prospective sublimating'), as to the more profound veracity of the-human/humanity as of: its 'recurrently mediative-<in-expectation/in-anticipation $>$ unconsciousness/potentiation-of-conscionability<anxiety-as-to-reconstitution/reparation,-including-dreaming/psychical-reshuffling >' as the 'psychoanalytic boundlessness of human notional $\sim$ reflexivity-<\{veridical/sound $\}$-relativereflexivity-in-existence/relativising from-limited-mentation-as-its-deepening/psychologismic<residualising \{decompulsing $\}$ delinearity for-cogency>-by-\{flawed/unsound\}-relativeunreflexivity-in-existence/absolutising from-limited-mentation/psychologismic epistemic acutisation nonresidualising imbued-\{compulsing\}linearity in-eclecticism-of prior-mereformulaicity/ritualisation $>\quad$ existential-<disontologising/re-ontologising aporeticism $>$ backdrop' (so-elicited/so-prompted as from underlying 'constraining existence-assublimating-withdrawal/unenframing/re-ontologising,-elicited-from-prospective-profoundsupererogation imbuing human ontological-commitment $-<$ implied-self-assuredness-ofontological-good-faith/authenticity postconverging-dementating/structuring/paradigming -as-being-as-of-existential-reality>' and '103 universaltransparency ${ }^{104}$-〈transparency-of-totalising-entailing,-as-to-entailing-<amplituding/formativeepistemicity $>$ totalising $\sim$ in-relative-ontological-completeness $\rangle$ as available-to/elicitable-to-〈asto-human-consciousness/collective-consciousness-distendedness/detruncating- $<$ beyondselfpresencing,-as-re-ontologising-decentering_of-consciousness/collective-consciousness,-as-

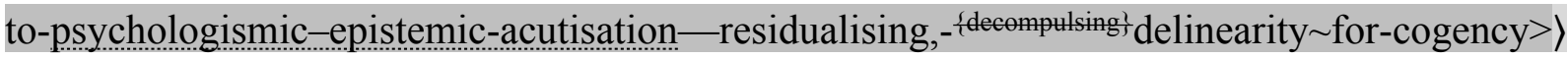
the social-functioning-and-accordance-as-of-social-stake-contention-or-confliction conception of any given registry-worldview/dimension <preconverging 'motif-and- 
apriorising/axiomatising/referencing'-entailing>-existentialising—enframing/imprintedness〈as-to- historicity-tracing —in-presencing-hyperrealisation/hyperreal-transposition〉'). Inmany-ways within the framework of any given social-setup 79 presencing-absolutisingidentitive-constitutedness 'social-functioning-and-accordance-as-of-social-stakecontention-or-confliction imbuing existentialising-frame-of entailment of motif andapriorising/axiomatising/referencing of disontologising/ontologising-and-re-ontologising', 'reentologising \{epistemic-totalising łre-apriorising/re-axiomatising/re-referencing residuality in-reeriginariness/re-origination \{decompulsing\} delinearity/delinear-accreting/recomposuring cogency/tensing/limpidity-<as-of-prospective-profound-supererogation ${ }^{9}$,-for-residuality-inre-originariness/re-origination>-,prospective_reifying mental-aestheticising-<as-of'prospective_reformulating-of-mental-aestheticising'as-to-'residuality in re-originariness/reorigination' of -mental-aestheticising >' (imbued 'human psychologismic-epistemic-acutisation$<$ as-to-postconverging-de-mentating/structuring/paradigming,-eliciting-of-existence'ssublimating-nascence-in-prospective-aporeticism-overcoming/unovercoming $>$ as to epistemicgrowth,-as-\{veridical/sound\}-relative-reflexivity-in-existence/relativising from-limitedmentation-as-its-deepening/psychologismic epistemic-acutisation residualising, \{decompulsing $\}$ delinearity for-cogency') is rather wrongly susceptible/subjectable to its 'sidestepping/selective/incongruent mere-formulaicity/ritualisation disontologising/subontologising failing overall sublimating-over-desublimating delineation' as so-associated with shallow supererogation $\sim$ framing/formulation/catchmenting/truncating/compulsing/linearising_scale —of-opaque/contentious/un-nominalised/flawed-interpretations/domains of manifest blurriness-<sterilising/anecdotalising/trivialising-of-prospective-re-ontologising_bypreconverging,-in-disontologising-formulaic-dragging-out/hollowing-out>, thus undermining the requisite 'overall delineation of relative-sublimating over relative-desublimating' as 
requisite

with

profound-

supererogation $\sim$ reframing/reformulation/decatchmenting/detruncating/decompulsing/delinear ising_scale_of-transparent/noncontentious/un-nominalised/sound-interpretations/domains of manifest unblurriness-<re-ontologising_by-postconverging-as-to-dragged-outsupererogatory $\sim$ wholesomeness/profound-supererogation ,-while-anecdotalising-prior-

disontologising-thresholding>; and as such 'overall delineation of relative-sublimating over relative-desublimating' must be necessarily elicited/projected as of 'implicited/explicited psychologismic-epistemic-acutisation-residualising -

thermeneutic/textuality/reprojecting/supererogating/zeroing/re-acuting,-

\{decompulsing $\}$ delinearity for-cogency' of 'implicited_attendant-ontologicalcontiguity $^{67}$, educed-

existentialising/contextualising/textualising_'intelligibility/epistemicity/reflexivity_contiguity$<$ imbued-notional cogency>' (in so-educing the requisite prospective 'human psychologismic-epistemic-acutisation-<as-to-postconverging-dementating/structuring/paradigming,-eliciting-of-existence's-sublimating-nascence-inprospective-aporeticism-overcoming/unovercoming > as to epistemic-growth,-as\{veridieal/sound\}-relative-reflexivity-in-existence/relativising from limited mentation as its deepening/psychologismic epistemic acutisation residualising, \{decompulsing\} delinearity foreogency'). Critically, with regards to 're-ontologising fepistemic-totalising 're-apriorising/reaxiomatising/re-referencing residuality in re-originariness/re-origination \{decompulsing\} delinearity/delinear-acereting/recomposuring $\quad$ cogency/tensing/limpidity-<as-ofprospective-profound-supererogation , ,for-residuality-in-re-originariness/reorigination $>$,-prospective_reifying mental aestheticising $<$ as of 'prospective_reformulating of-mental-aestheticising'as to 'residuality in re-originariness/re-origination' of mentalaestheticising $>$ ' associated with explicit knowledge formulation and elucidation, it can be 
supererogation $\sim$ reframing/reformulation/decatchmenting/detruncating/decompulsing/delinear ising_scale_-of-transparent/noncontentious/un-nominalised/sound-interpretations/domains of manifest unblurriness-<re-ontologising_by-postconverging-as-to-dragged-outsupererogatory wholesomeness/profound-supererogation ,-while-anecdotalising-priordisontologising-thresholding $>$ are characterised particularly by their epistemic-projection of 'objectification-seeking 'implicited_attendant-ontological-contiguity ${ }^{67}$ ' educedexistentialising/contextualising/textualising_'intelligibility/epistemicity/reflexivity-contiguity$<$ imbued-notional cogency>' in 're-ontologising axiomatising/re-referencing residuality in-re-originariness/re-origination $\{$ decompulsing $\}$ delinearity/delinear-acereting/recomposuring $\quad$ cogency/tensing/limpidity-<as-ofprospective-profound-supererogation ,-for-residuality-in-re-originariness/reorigination $>$, p prospective_reifying mental-aestheticising <as-of-'prospective_reformulating of-mental-aestheticising'as-to 'residuality in -re-originariness/re-origination' of mentalaestheticising ' reflection of the comprehensive coherence/contiguity/noncontradiction of overall experientiality/experiment- $<$ as-to-existentially-formative-'\{epistemic-totalising ${ }^{\dagger}$ reapriorising/re axiomatising/re referencing-residuality-in-re-originariness/re-origination',so-'notionally/epistemically/bindingnessly-<as-to-determinism/conceptivity-of-relative-unreflexivity/relativereflexivity $>$-implicited-and-articulated'_as-from-nonextricatory-'prospective-re-ontologisingBeing-then-Institutional-then-Living-magnitudes-of-\{hermeneutic/reprojection-protractioneffreframing-and-reformulation $\}^{\prime}>$ for elucidating relative-sublimating over relativedesublimating' (as to a 'prospective exercise of postconvergingaaporeticismevereoming demonstrating of prospective relative-ontological-completeness and/or exposure to be demonstrated as of either relative-ontological-completeness ${ }^{87}$ or relativeontological-incompleteness 8 with regards to requisite transversality-<for-sublimating- 
existential-eventuating/denouement-from-'thinking-at-first/pure-predisposition-preemptive-ofprospective-disontologising/subontologising' as-of-prospectively-disambiguated-affirmedand-unaffirmed-'motif-and-apriorising/axiomatising/referencing'> ${ }^{101}$ )' and thusly sounderlying the 'sourcing/tracing-of-derivation-of-authority from unlimitedness/existence-<fullpotency-of_sublimating nascence>' that enables the ontologising/scientific/existence$<$ honesty-constraining $>$ — scope_for_prospective_re-ontologising'. This speaks to the underlying implication that 're-ontologising fepistemic-totalising 're-apriorising/re-axiomatising/re-

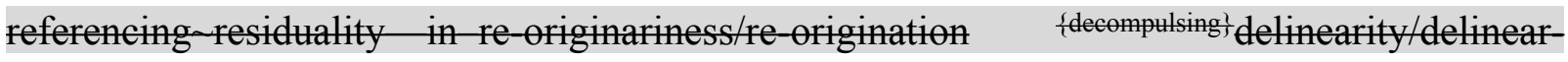
acereting/recomposuring cogency/tensing/limpidity-<as-of-prospective-profoundsupererogation ,-for-residuality_in-re-originariness/re-origination>-,prospective_reifying mental-aestheticising <as-of 'prospective_reformulating-of mental-aestheticising'as-to'residuality in re-originariness/re-origination'-of-mental-aestheticising

fundamentally/incipiently/seedingly potented, and rather so-potented (as to the veracity of requisite nonpresencing-<perspective-ontological-normalcy/postconvergence $>$ epistemicprojection 'implicited/explicited psychologismic-epistemic-acutisation-residualising totalising ${ }^{3}$ hermeneutic/textuality/reprojecting/supererogating/zeroing/re-acuting,-

${ }_{\{\text {decompulsing }}$ delinearity for-cogency' successive profound/state-of-the-art sublimating reflection of the-very-same purview/devolved-purview/devolving-purview-of-unlimitedness/existence$<$ full-potency-of_sublimating nascence $>$;_-'implicited_attendant-ontologicalcontiguity $^{67}$; educedexistentialising/contextmalising/textualising_'intelligibility/epistemicity/reflexivity_contiguity$<$ imbued-notional cogency>' ${ }^{\prime 0}$ ), as arising as from the backdrop of: the-human/humanity

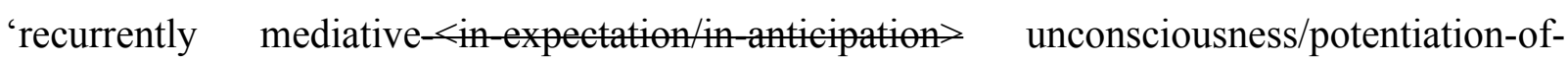
conscionability-<anxiety-as-to-reconstitution/reparation,-including-dreaming/psychicalreshuffling>' (as the 'psychoanalytic boundlessness of human notional reflexivity- 
$<\{$ veridical/sound $\}$-relative-reflexivity-in-existence/relativising from-limited-mentation-as-

its-deepening/psychologismic-<residualising \{decompulsing $\}$ delinearity for-cogency $>$ by-

\{flawed/unsound\}-relative-unreflexivity-in-existence/absolutising from-limited-

mentation/psychologismic epistemic acutisation nonresidualising-imbued-

\{compulsing\} linearity in-eclecticism-of prior-mere-formulaicity/ritualisation> existential<disontologising/re-ontologising aporeticism> backdrop' elicitable/exuding as of subconsciousness knowingly/unknowingly-manifest human ontological-goodfaith/authenticity ${ }^{69}$ postconverging-de-mentating/structuring/paradigming - by ontological-bad-faith/inauthenticity ${ }^{64}$ preconverging-de-mentating/structuring/paradigming ${ }^{65}$ ) as so-potentiating 'human subconsciousness as backdrop-for-the-Lacanian-real enabling the effective formativeness-<as-to-intersolipsism-ofpreformulating/preframing/premeaningfulness-imbued-mediativity-and-deferentialism>-ofmeaningfulness-and-teleology of consciousness surrealising-<as-to-supererogation $>>$ (as so-manifested with human subconsciousness most-prospectively-conscious 're-ontologisingby-disontologising_existential-calculus-〈between 'prospective existentialisingpostconverging_framing/imprinting re-ontologising' and 'prior existentialisingpreconverging_enframing/imprintedness social-functioning-and-accordance-as-of-socialstake-contention-or-confliction' $\rangle$ ' of consciousness surrealising-<as-to-supererogation $>$ ). This elucidation highlights why the overall 're-ontologising tre-apriorising/reaxiomatising/re-referencing residuality in re-originariness/re-origination $\left.{ }_{\{d e c o m p u l s i n g}\right\}$ delinearity/delinear-accreting/recomposuring $\quad$ cogency/tensing/limpidity- $<$ as-ofprospective-profound-supererogation ,-for-residuality-in-re-originariness/reorigination $>$, prospective_reifying mental-aestheticising-<as-of 'prospective_reformulatingof-mental-aestheticising'as-to 'residuality in -re-originariness/re-origination' of mentalaestheticising $>$ ' of the overall relative-unreflexivity/relative-reflexivity-ontological- 
contiguity ${ }^{67}$ of-the-human-institutionalisation-process ${ }^{68}$ (as of its imbued 'human psychologismic-epistemic-acutisation-<as-to-postconverging-de-

mentating/structuring/paradigming,-eliciting-of-existence's-sublimating-nascence-inprospective-aporeticism-overcoming/unovercoming $>$ as to epistemic-growth,-as\{veridical/sound\}-relative-reflexivity-in-existence/relativising from-limited-mentation-as-itsdeepening/psychologismic epistemic-acutisation residualising, ${ }^{\{\text {decompulsing }}$ \}elinearity foreogency') is encapsulated by the notion of 'overarching existential-<disontologising/reentologising aporeticism $>$ priority/precedence/primacy of requisite prospective ontologicalgood-faith/authenticity $\sim$ postconverging-de-mentating/structuring/paradigming inducing of psychoanalytic-unshackling for the relative-ontological-completeness ${ }^{87}$-ofapriorising/axiomatising/referencing re-ontologising prospective re-rationalisation-ofcontentivity/argumentativity/dialecticism/discursivity'; as to the fact that the possibility for superseding/overcoming human ingrained presencing absolutising identitiveconstitutedness 'existential-<disontologising/re-ontologising aporeticism $>$ preconverging de-mentating/structuring/paradigming punctual/immediacy/constituted/compulsionsencumbered prior mere-formulaicity/ritualisation rationalisation-ofcontentivity/argumentativity/dialecticism/discursivity' (reflected in the manifestation of the notional/epistemic/bindingness-<as-to-determinism/conceptivity-of-relative-unreflexivity/relative-reflexivity $>$ overaching cultivated-and-enculturated interrelatedness-dynamics-of-social-constructing as from 'catchmented-and-compulsed-<in-'existential-dearth-of-demoronisation',-so-construedas-from-ontological-normalcy/postconvergence-perspective-reflection-of-the-'destructuringthreshold_of-the-given-level's-conjugated-postlogism as-dementing'> interpersonal, group, intergroup, community, local, national, political, geostrategic, etc. psychologismic epistemie acutisation difficulty<<for, residualising \{decompulsing $\}$ delinearity for-cogency> levels of interrelatedness-dynamics-of-social-constructing' of 'formativeness-<as-to-intersolipsism-of- 
preformulating/preframing/premeaningfulness-imbued-mediativity-and-deferentialism>-ofmeaningfulness-and-teleology and existential-<disontologising/re-ontologisingaporeticism $>$ articulation manifestations') is not as of priority/precedence/primacy dealt as of the 'shallow-supererogation of prior mere-formulaicity/ritualisation-<as-to-mere-formulaicmethodologising/mutualising/organising/institutionalising,-prospectively-losing-track-of-

‘\{epistemic-totalising ${ }^{\dagger}$ re-apriorising/re-axiomatising/re-referencing-residuality-in-re-

originariness/re-origination'>

rationalisation-of-

contentivity/argumentativity/dialecticism/discursivity' (which inevitable exudes its conscious/unconscious prospectively shady/shifty shallow-supererogation explaining why it is effectively tethered at its given $<$ amplituding/formative-epistemicity $>$-totalising $\sim$ thrownnessin-existence ${ }^{35}$ ). This insight is highlighted to draw attention to the fundamental problematic of 'putting-into-question a given registry-worldview/dimension overall gesturing/accounting-ofepistemic-phenomenalism with respect to the requisite prospective ${ }^{83}$ reference-of-thoughtpoint-of-devolving/departure/anchoring/backdrop_of_sublimating-nascence-<as-to-thegrandest-axiomatic-construct-\{epistemictalising $\stackrel{+}{+}$ re-apriorising/re-axiomatising/rereferencing - residuality - in-re-originariness/re-origination of limitedness/human-subpotency prospective re-encountering/re-confrontation with unlimitedness/existence $>$ re-rationalisationof-contentivity/argumentativity/dialecticism/discursivity' in order to elicit re-ontologising prospective Being-development/ontological-framework-expansion-as-to-depth-ofontologising-development-as-infrastructure-of- meaningfulness-and-teleology psychologismic epistemic-acutisation difficulty-for, residualising \{decompulsing\} delinearity for-cogeney>-magnitude ${ }^{\{0 f-e x p e r i e n t i a l i t y / e x p e r i m e n t\}}$ requisite 're-ontologising \{epistemic-totalising łre apriorising/re axiomatising/re referencing-residuality in re $\{$ decompulsing $\}$ delinearity/delinear-acereting/recomposuring cogency/tensing/limpidity-<as-of-prospective-profound-supererogation , 
re-originariness/re-origination>,-prospective_reifying mental-aestheticising-<as-of-

'prospective_reformulating of mental-aestheticising'as-to-'residuality in re-originariness/reorigination' of -mental-aestheticising >' (imbued 'human psychologismic-epistemic-acutisation$<$ as-to-postconverging-de-mentating/structuring/paradigming,-eliciting-of-existence'ssublimating-nascence-in-prospective-aporeticism-overcoming/unovercoming $>$ as to epistemicgrowth,-as-\{veridieal/sound\}-relative-reflexivity-in-existence/relativising from-limitedmentation-as-its-deepening/psychologismic epistemic acutisation residualising, \{decompung delinearity for-cogency'); as so-problematic (with respect to presencing absolutising-identitive-constitutedness 'existential-<disontologising/re-ontologising aporeticism> preconverging de-mentating/structuring/paradigming punctual/immediacy/constituted/compulsions-encumbered prior mere-formulaicity/ritualisation rationalisation-of-contentivity/argumentativity/dialecticism/discursivity' reflected in the manifestation of the notional/epistemic/bindingness-<as-to-determinism/coneeptivity-of-relative-

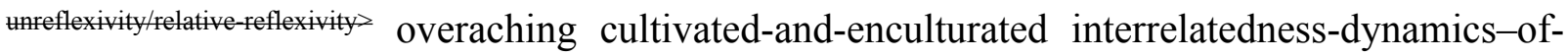
social-constructing as from 'catchmented-and-compulsed-<in-'existential-dearth-ofdemoronisation',-so-construed-as-from-ontological-normalcy/postconvergence-perspectivereflection-of-the-'destructuring-threshold_of-the-given-level's-conjugated-postlogism asdementing'> interpersonal, group, intergroup, community, local, national, political, geostrategic, etc. psychologismic epistemic acutisation difficulty < for, residualising \{decomplsing delinearity for-cogency> levels of interrelatedness-dynamics-of-socialconstructing' of 'formativeness-<as-to-intersolipsism-ofpreformulating/preframing/premeaningfulness-imbued-mediativity-and-deferentialism>-ofmeaningfulness-and-teleology and existential-disontogising/re ontogising apereticism $>$ articulation manifestations'), and as manifested in our modern-day 'cultivation and enculturation of practices of overt/covert privying of the supposed conception of the 
ontologising/scientific/existence- $<$ honesty-constraining $>$ — scope_for_prospective_reontologising (as so-associated prominently with surreptitious and media-savvy political and economic think-tanking and related pop-intellectualism with regards to relatively contentious/un-nominalised social-stake-contention-or-confliction) as well as mere competence/expertising (as of human socially expanded framework of deferential-formalisationtransference as to various cultivated skills/arts and time investment with regards to effectively manifest 'underlying veracity of core-philosophy/derivative-core-philosophy prospective reontologising as relevantly superseding prior mere-formulaicity/ritualisation pedantism induced knowledge-deadends-<as-preconverging-de-mentating/structuring/paradigming >’) $\quad$ with regards to relatively uncontentious/nominalised social-stake-contention-or-confliction)'. In this regards, the psychologismic-epistemic-acutisation-difficulty- $<$ for,-residualising\{dectinearity for-cogency $>$-〈as-of-requisite-profound-supererogation -for‘disposedness-or-psychologismic-construct'-\{ imbued-demoronisation-<sublimatingnascence,-nonextricatory-sublimating-upstreaming/'amontée’’\}) (that explains/underlies the multicenturies long patchy experientiality/experiment-<as-to-existentially-formative-`\{epistemictotalising '`re-apriorising/re-axiomatising/re-referencing-residuality-in-re-originariness/reorigination', - so- 'notionally/epistemically/bindingnessly-<as-to-determinism/conceptivity-of-relativemreflexivity/relative reflexivity_-implicited-and-articulated'_as-from-nonextricatory-'prospective-reontologising-Being-then-Institutional-then-Living-magnitudes-of-

\{hermeneutic/reprojection-protraction-of\}reframing-and-reformulation\}'> of human registryworldviews/dimensions since human prehistoricity as to recurrent prospective disontologising/subontologising manifestation of presencing absolutising-identitiveeonstitutedness 'existential<<disontologising/re-ontologising aporeticism $>$ preconverging de-mentating/structuring/paradigming punctual/immediacy/constituted/compulsionsencumbered prior mere-formulaicity/ritualisation rationalisation-of- 
contentivity/argumentativity/dialecticism/discursivity') is much more profoundly relevant and the more central issue (as of the prospectively warranted 'human psychologismic-epistemicacutisation-<as-to-postconverging-de-mentating/structuring/paradigming,-eliciting-ofexistence's-sublimating-nascence-in-prospective-aporeticism-overcoming/unovercoming $>$ as to epistemic-growth,-as - \{veridical/sound\}-relative-reflexivity-in-existence/relativising fromlimited-mentation-as-its-deepening/psychologismic epistemic-acutisation residualising, \{decompulsing\} delinearity for-cogency'); and so over the naivety of any supposed shallowsupererogation mere-formulaicity/ritualisation of prior rationalisation-ofcontentivity/argumentativity/dialecticism/discursivity which is rather circularly enthralled to its given <amplituding/formative-epistemicity>-totalising $\sim$ thrownness-in-existence ${ }^{35}$ framework of presencing absolutising-identitive-constitutedness 'existential-<disontologising/reentelogising aporeticism $>$ preconverging de-mentating/structuring/paradigming punctual/immediacy/constituted/compulsions-encumbered prior mere-formulaicity/ritualisation rationalisation-of-contentivity/argumentativity/dialecticism/discursivity' (as to prospectively not truly 'thinking at first/pure predisposition preemptive of prospective disontologising/subontologising but a conscious/unconscious rationalising/calculating of the sublimating outcome of prior profound-supererogation rationalisation-ofcontentivity/argumentativity/dialecticism/discursivity imbued positive-opportunism—of-socialfunctioning-and-accordance ${ }^{75}$, and so-reflected with respectively between prior recurrent-utteruninstitutionalisation, ununiversalisation, non-positivism/medievalism and ${ }^{80}$ procrypticism-ordisjointedness-as-of- ${ }^{8}$ reference-of-thought and prospective base-institutionalisation, universalisation, positivism/rational-empiricism and ${ }^{18}$ deprocrypticism-or-preemptingdisjointedness-as-of- ${ }^{8}$ reference-of-thought). Such a psychologismic-epistemic-acutisationdifficulty- $<$ for,-residualising-\{decompling $\}$ delinearity for-cogency $>-\langle$ as-of-requisite-profoundsupererogation -for-'disposedness-or-psychologismic-construct'-\{imbued-demoronisation- 
punctual/immediacy/constituted/compulsions-encumbered prior mere-formulaicity/ritualisation rationalisation-of-contentivity/argumentativity/dialecticism/discursivity') with respect to

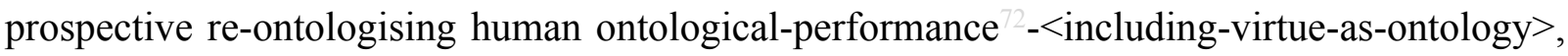
so-inherently arising as to the-very-underlying- (as inherently 'defining-and-imbuing of limitedness/human-subpotency de-mentation-〈supererogatory $\sim$ ontological-de-mentation-ordialectical-de-mentation — stranding-or-attributive-dialectics ${ }^{\prime}$ as to preconverging/postconverging-de-mentating/structuring/paradigming)—relationship-betweenlimitedness/human-subpotency-and-unlimitedness/existence-<full-potency-of_sublimating nascence $>$ with respect to the pre-eminence of the latter as to 'limitedness/human-subpotency prospective re-encountering/re-confrontation with unlimitedness/existence-<full-potency ef_sublimating nascence>', is tantamount to the 'varying human individualconsciousness/collective-consciousness compulsion_imprintedness/decompulsion_imprinting appraisal' of 'lottery playing sublimating/desublimating ontological-performance ${ }^{2}-<$ includingvirtue-as-ontology>'; as from an idiosyncratic conscious/unconscious compulsion-appraisal that even though allocatable resources for winnings are not endless/unlimited rather one has a 'chosenness chance of winning' over the majority of other players (on-the-one-hand) to a conscious decompulsion-appraisal (on-the-other-hand) that lottery is an overall losing game for the majority of players as to the strictly allocatable resources for winnings (given that a fraction of bets go for business and administration, a fraction for the various limited winners and a fraction for various public/social allocations). Contrastively, unlike the lottery playing idiosyncratic and closed/locked dilemma, the psychologismic-epistemic-acutisationdifficulty- $<$ for,-residualising_\{decompulsing $\}$ delinearity $\sim$ for-cogency $>-\langle$ as-of-requisite-profound- 
supererogation -for-'disposedness-or-psychologismic-construct'-\{imbued-demoronisation-

<sublimating-nascence,-nønextricatory-sublimating-upstreaming/'amontée’>\}) (as to presencing absolutising-identitive-constitutedness 'existential-<disontologising/reentologising aporeticism> preconverging de-mentating/structuring/paradigming punctual/immediacy/constituted/compulsions-encumbered prior mere-formulaicity/ritualisation rationalisation-of-contentivity/argumentativity/dialecticism/discursivity') with respect to prospective re-ontologising limitedness/human-subpotency ontological-performance ${ }^{72}$ $<$ including-virtue-as-ontology $>/$ morality/ethics/justice/etc. is rather as of an opened/unlocked dilemma (as rather in relation to unlimitedness/existence-<full-potency-of_sublimating nascence $>$ ); and so, when construed as of consciousness/collective-consciousness lessons of human angling-of-imaginary implied 'multicenturies-long human crossgenerational Beingdevelopment/ontological-framework-expansion-as-to-depth-of-ontologising-development-asinfrastructure-of- meaningfulness-and-teleology psychologismic epistemic-acutisationdifficulty< <or, residualising \{decompunging delinearity for-cogency> magnitude $\{$ ofexperientiality/experiment $\}$ of prospective transcendence-and-sublimity/sublimation/supereregatery $\sim \mathrm{de}-$ mentativity' (speaking necessarily of the veracity of 'limitedness/human-subpotency psychoanalytic-unshackling becoming with respect to unlimitedness/existence- $<$ full-potencyof_sublimating nascence>' in the profound-supererogation 'inventing'/'creating'-and'nurturing' of prospective sublimating re-rationalisation-ofcontentivity/argumentativity/dialecticism/discursivity) but seemingly of closed/locked dilemma when construed as of consciousness/collective-consciousness lessons of psychical-nascency 'human lifespan extricatory punctuality/immediacy depth-of-thought' (prospectively blinded to its shallow-supererogation of punctual/immediacy/constituted/compulsions-encumbered prior mere-formulaicity/ritualisation rationalisation-ofcontentivity/argumentativity/dialecticism/discursivity). In-many-ways this cross-dynamic is 
effectively reflected in the emerging of human consciousness/collective-consciousness (as from the

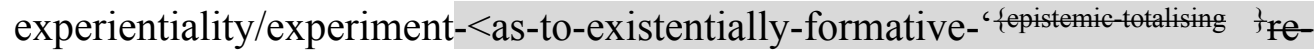
apriorising/re-axiomatising/re-referencing 2 residuality —in-re-originariness/re-origination',so-'notionally/epistemically/bindingnessly-<as-to-determinism/conceptivity-of-relative-unreflexivity/relativereflexivity>_implicited-and-articulated'_as-from-nonextricatory-'prospective-re-ontologisingBeing-then-Institutional-then-Living-magnitudes-of-\{hermeneutic/reprojection-protractioneffreframing-and-reformulation $\}^{\prime}>$ of trancing-processive-motif-exuding aestheticisinggesturing' of apriorising/axiomatising/referencing - as-to-trepidatious-

consciousness $\sim$ moronisation/demoronisation, $\quad$ mysticising-processive-motif-'exuding aestheticising-gesturing' of apriorising/axiomatising/referencing - as-to-warpedconsciousness $\sim$ moronisation/demoronisation, $\quad$ occulticising-processive-motif-'exuding aestheticising-gesturing' of apriorising/axiomatising/referencing - as-to-preclusiveconsciousness $\sim$ moronisation/demoronisation, procrypticising/subtranslational/subnotionality/subepistemicity-processive-motif-'exuding aestheticising-gesturing' of-apriorising/axiomatising/referencing - as-to-occlusiveconsciousness $\sim$ moronisation/demoronisation and prospectively deprocrypticising/omnitranslational/omninotionality/omniepistemicity-processive-motif'exuding aestheticising gesturing' of apriorising/axiomatising/referencing - as-to-protensiveconsciousness $\sim$ moronisation/demoronisation successively imbued 'reifying-mentalaestheticising-<as-of-'prospective_reformulating-of-mental-aestheticising'as-to-'residualityin-re-originariness/re-origination'-of-mental-aestheticising $>$ educed processive-motif'exuding aestheticising-gesturing' of-apriorising/axiomatising/referencing as to reaestheticisation-and-re-aestheticisation-towards-ontology-<elicited-prospectiveidiomatisation>'); as so-potenting 're-ontologising \{epistemic-totalising 're-apriorising/reaxiomatising/re-referencing residuality in re-originariness/re-origination 
prospective-profound-supererogation ,-for-residuality-in-re-originariness/re-

origination $>$, prospective_reifying mental-aestheticising-<as-of 'prospective_reformulating of-mental-aestheticising'as-to-residuality in-re-originariness/re-origination' of -mentalaestheticising $>$ ' (imbued 'human psychologismic-epistemic-acutisation- $<$ as-topostconverging-de-mentating/structuring/paradigming,-eliciting-of-existence's-sublimatingnascence-in-prospective-aporeticism-overcoming/unovercoming $>$ as to epistemic-growth,-as\{veridical/sound\}-relative-reflexivity-in-existence/relativising from-limited-mentation-as-itsdeepening/psychologismic epistemic-acutisation residualising, fdecompulsingl delinearity foreogency'). The emerging of human consciousness/collective-consciousness arising (reflected in human Being-development/ontological-framework-expansion-as-to-depth-of-ontologisingdevelopment-as-infrastructure-of- meaningfulness-and-teleology , institutionaldevelopment-as-to-social-function-development and living-development-as-to-personalitydevelopment psychologismic epistemic-acutisation difficulty-<for, residualising \{decondsing delinearity for-cogeney $>$ magnitudes $\{0$-experientiality/experiment $\}$ ) is rather as to underlying 'constraining existence - as-sublimating-withdrawal/unenframing/re-ontologising,-elicitedfrom-prospective-profound-supererogation imbuing human ontological-commitment $<$ implied—-self-assuredness-of-ontological-good-faith/authenticity $\sim$ postconverging-dementating/structuring/paradigming -as-being-as-of-existential-reality>' and ' 103 universaltransparency ${ }^{104}$-〈transparency-of-totalising-entailing,-as-to-entailing-<amplituding/formativeepistemicity>totalising in-relative-ontological-completeness $\rangle$ as available-to/elicitable-to-〈asto-human-consciousness/collective-consciousness-distendedness/detruncating-<beyondselfpresencing,-as-re-ontologising-decentering_of-consciousness/collective-consciousness,-asto-psychologismic-epistemic-acutisation - residualising, ${ }^{\text {\{decompulsing }}$ delinearity $\sim$ for-cogency $>$ > the social-functioning-and-accordance-as-of-social-stake-contention-or-confliction 
conception of any given registry-worldview/dimension <preconverging 'motif-andapriorising/axiomatising/referencing'-entailing >-existentialising — enframing/imprintedness〈as-to- historicity-tracing - in-presencing-hyperrealisation/hyperreal-transposition〉' recurrent prompting of: the-human/humanity 'recurrently mediative-<in-expectation/in-anticipation $>$ unconsciousness/potentiation-of-conscionability-<anxiety-as-to-reconstitution/reparation,including-dreaming/psychical-reshuffling>' (as the 'psychoanalytic boundlessness of human notional $\sim$ reflexivity- $<\{$ veridical/sound $\}$-relative-reflexivity-in-existence/relativising fromlimited-mentation-as-its-deepening/psychologismic-<residualising fdecompulsing delinearity foreogency $>$ by - \{flawed/unsound\}-relative-unreflexivity-in-existence/absolutising fromlimited-mentation/psychologismic epistemic acutisation nonresidualising imbued\{compulsing\} linearity-in-eclecticism-of-prior-mere-formulaicity/ritualisation $>\quad$ existential<disontologising/re-ontologising aporeticism $>$ backdrop' elicitable/exuding as of subconsciousness knowingly/unknowingly-manifest human ontological-goodfaith/authenticity ${ }^{69}$ postconverging-de-mentating/structuring/paradigming — byontological-bad-faith/inauthenticity ${ }^{64} \sim$ preconverging-de-mentating/structuring/paradigming ${ }^{65}$ ) as so-potentiating 'human subconsciousness as backdrop-for-the-Lacanian-real enabling the effective formativeness-<as-to-intersolipsism-ofpreformulating/preframing/premeaningfulness-imbued-mediativity-and-deferentialism>-ofmeaningfulness-and-teleology of consciousness surrealising-<as-to-supererogation $>^{\prime}$ (as so-manifested with human subconsciousness most-prospectively-conscious 're-ontologisingby-disontologising_existential-calculus-〈between 'prospective existentialisingpostconverging_framing/imprinting re-ontologising' and 'prior existentialisingpreconverging_enframing/imprintedness social-functioning-and-accordance-as-of-socialstake-contention-or-confliction' $\rangle$ ' of consciousness surrealising-<as-to-supererogation $>$ ). But for such prompting of the commonalty of the-human/humanity 'recurrently mediative-<in- 
expectation/in-anticipation $>$ unconsciousness/potentiation-of-conscionability-<anxiety-as-toreconstitution/reparation,-including-dreaming/psychical-reshuffling>' (as the 'psychoanalytic boundlessness of human notional $\sim$ reflexivity- $<$ \{veridical/sound $\}$-relative-reflexivity-inexistence/relativising from-limited-mentation-as-its-deepening/psychologismic<residualising \{decompulsing delinearity for-cogency>by-\{flawed/unsound\}-relativeunreflexivity-in-existence/absolutising from-limited-mentation/psychologismic epistemicacutisation nonresidualising imbued-fcompulsing\}linearity in-eclecticism-of prior-mereformulaicity/ritualisation> existential-<disontologising/re-ontologising aporeticism $>$ backdrop'), it can fairly be argued in-many-ways there is only 'a weaker individuals commonality as of a same consciousness/collective-consciousness representation as to both intemporal-firstnaturedness-as-to-inkling and secondnatured-institutionalisation epistemicprojection' as reflected between say an animistic or non-positivism/medievalism mindset and a positivism/rational-empiricism mindset differing mental-aestheticising-<as-‘psychologismicexistential-metaphoricity fas-toreferencing_in-becoming?' -so-implicited-'by-way-of-the-existentially/contextually/textuallymanifest-motif-construct-as-specific-language'-as-so-reflecting-'the-

existentially/contextually/textually-manifest-moronisation/demoronisation'>'. Such an insight is not only of interdimensional relevance as elucidated above but can equally be appreciated intradimensionally say within a positivism/rational-empiricism registry-worldview/dimension (as to the ontological-veracity of "existential-<disontologising/re-ontologising aporeticism> human-consciousness/collective-consciousness-distendedness/detruncating-<beyondselfpresencing,-as-re-ontologising-decentering_of-consciousness/collective-consciousness,-asto-psychologismic-epistemic-acutisation — residualising, - $^{\text {\{decompulsing }\}}$ delinearity $\sim$ for-cogency $>$, underlying the operational social-setup as of 'human socially expanded framework of deferential-formalisation-transference as to various cultivated skills/arts and time investment') 
which also reflects 'a weaker individuals commonality as of a same consciousness/collectiveconsciousness representation as to intemporal-firstnaturedness-as-to-inkling epistemicprojection' but for the 'elaborate-and-coherent direct-and-deferential consciousness/collectiveconsciousness representation as to secondnaturedness epistemic-projection'; with the latter inmany-ways explaining the inherently-arising/inherent-susceptibility-to disontologising/subontologising of an implicited/explicited engagement with such secondnatured-institutionalisation as if of prospective ontologising/scientific/existence$<$ honesty-constraining $>$ _ scope_for_prospective_re-ontologising' (which is rather about 'unlimitedness/existence-<full-potency-of_sublimating nascence $>$ prospective apriorising/axiomatising/referencing-sublimating-reflexivity-beholdening under which limitedness/human-subpotency submits in profound-supererogation for prospective sublimating' and rather warrants prospective intemporal-firstnaturedness-as-to-inkling epistemic-projection as of profound-supererogation (); as often associated with communication and media-driven impressionable narratives rather 'elicited/constrained on human secondnatured-institutionalisation predisposition' of 'poor prospective ontologising/scientific/existence- $<$ honesty-constraining $>$ — scope_for_prospective_reontologising predisposition' (with regards to consciously/unconsciously blinding-out/screeningout of underlying 'constraining existence-as-sublimating-withdrawal/unenframing/reontologising,-elicited-from-prospective-profound-supererogation imbuing human ontological-commitment $\quad<$ implied-self-assuredness-of-ontological-goodfaith/authenticity postconverging-de-mentating/structuring/paradigming -as-being-as-ofexistential-reality>' and ' ${ }^{103}$ universal-transparency ${ }^{104}$-〈transparency-of-totalising-entailing,-asto-entailing-<amplituding/formative-epistemicity $>$ totalising $\sim$ in-relative-ontologicalcompleteness > as available-to/elicitable-to-〈as-to-human-consciousness/collectiveconsciousness-distendedness/detruncating-<beyond-selfpresencing,-as-re-ontologising- 
decentering_of-consciousness/collective-consciousness,-as-to-psychologismic-epistemicacutisation-residualising, ${ }^{-\{\text {decompulsing }}$ delinearity for-cogency $>>$ the social-functioning-andaccordance - as-of-social-stake-contention-or-confliction conception of any given registryworldview/dimension $\quad<$ preconverging 'motif-and-apriorising/axiomatising/referencing'entailing >-existentialising — enframing/imprintedness-〈as-to- historicity-tracing —inpresencing-hyperrealisation/hyperreal-transposition〉'). This speaks to the more profound veracity that the 'the-human/humanity is rather construed in commonality' as from its 'recurrently mediative-<in-expectation/in-anticipation $>$ unconsciousness/potentiation-ofconscionability-<anxiety-as-to-reconstitution/reparation,-including-dreaming/psychicalreshuffling>' (as the 'psychoanalytic boundlessness of human notional reflexivity$<\{$ veridical/sound\}-relative-reflexivity-in-existence/relativising from-limited-mentation-as-

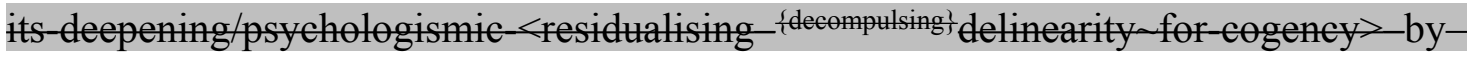
\{flawed/unsound\}-relative-unreflexivity-in-existence/absolutising from-limitedmentation/psychologismic epistemic acutisation nonresidualising imbued\{compulsing\} tinearity in eclecticism of prior mere formulaicity/ritualisation> existential-disontologising/re-ontologising aporeticism $>$ backdrop'); and this is what effectively undergirds human 're-ontologising fepistemic-totalising 're-apriorising/re-axiomatising/rereferencing residuality in-re-originariness/re-origination \{decompulsing $d e l i n e a r i t y / d e l i n e a r-$ accreting/recomposuring cogency/tensing/limpidity-<as-of-prospective-profoundsupererogation ,-for-residuality_in-re-originariness/re-origination $>$ - prospective_reifying mental-aestheticising-<as-of-'prospective_reformulating-of-mental-aestheticising'as-to'residuality in re-originariness/re-origination' of-mental-aestheticising $\gg$ ' (imbued 'human psychologismic-epistemic-acutisation-<as-to-postconverging-dementating/structuring/paradigming,-eliciting-of-existence's-sublimating-nascence-inprospective-aporeticism-overcoming/unovercoming > as to epistemic-growth,-as- 
\{veridical/sound\}-relative-reflexivity-in-existence/relativising from-limited-mentation-as-itsdeepening/psychologismic epistemic acutisation residualising, ${ }^{\text {fdecompulsing }}$ delinearity for eogency'). This so-validates the ontologising/scientific/existence- $<$ honesty-constraining $>$ scope_for_prospective_re-ontologising 'profound-supererogation $\quad$ re-assessability of prospective human re-ontologising' (as of overall 're-ontologising fepistemic-totalising ’’reapriorising/re-axiomatising/re-referencing-residuality in re-originariness/re-origination \{decompulsing $\}$ delinearity/delinear-accreting/recomposuring $\quad$ cogency/tensing/limpidity-<as-ofprospective-profound-supererogation ,-for-residuality-in-re-originariness/reorigination $>$,-prospective_reifying mental-aestheticising $<$ as-of-'prospective_reformulating of-mental-aestheticising'as-to 'residuality in-re-originariness/re-origination' of mentalaestheticising $>$ '), and as so-educed as from ' nonpresencing-<perspective-ontologicalnormalcy/postconvergence $>\quad$ relativism/relative-scope for epistemic-growth,-as\{veridical/sound\}-relative-reflexivity-in-existence/relativising from-limited-mentation-as-itsdeepening/psychologismic epistemic-acutisation residualising, fdecmpungl delinearity for eogency' epistemic-projection. In this respect, the ontologising/scientific/existence- $<$ honestyconstraining $>$ — scope_for_prospective_re-ontologising thus portends that 'it doesn't matter to inherently be perceived right/correct as of the non-positivism/medievalism mindset' as what rather matters is the 're-ontologising existential-disontologising/re-ontelogisingaporeticism $>$ eliciting/constraining of the non-positivism/medievalism mindset into a positivism/rational-emipricism mindset (as equally ontologically applicable intradimensionally as to 'existential-<disontologising/re-ontologising aporeticism $>$ humanconsciousness/collective-consciousness-distendedness/detruncating- $<$ beyond-selfpresencing,as-re-ontologising-decentering_of-consciousness/collective-consciousness,-as-topsychologismic-epistemic-acutisation — residualising, ${ }^{\text {\{decompulsing }}$ \}delinearity $\sim$ for-cogency $>$, imbued 'sublimating dynamics for existential-<disontologising/re-ontologising aporeticism $>$ 
eliciting/constraining of prospective re-ontologising' as of 'human socially expanded framework of deferential-formalisation-transference as to various cultivated skills/arts and time investment' wherein it is not critically important that the given technician/professional is perceived as right/correct as to laypersonhood terms of appraisal but rather as of prospective sublimating reontologising performance)' and as so-reflected with all prior and prospective registryworldviews/dimensions transcendence-and-sublimity/sublimation/supererogatery $\sim$ dementativity (as to the more profound veracity of the-human/humanity as from its 'recurrently mediative-<in-expectation/in-anticipation $>$ unconsciousness/potentiation-of-conscionability$<$ anxiety-as-to-reconstitution/reparation,-including-dreaming/psychical-reshuffling $>$ ' $\quad$ as the 'psychoanalytic boundlessness of human notional reflexivity-<\{veridical/sound\}-relativereflexivity-in-existence/relativising from-limited-mentation-as-its-deepening/psychologismic<residualising \{decompulsing $\}$ delinearity for-cogency $>$ by-\{flawed/unsound\}-relativeunreflexivity-in-existence/absolutising from-limited-mentation/psychologismic epistemicacutisation nonresidualising-imbued-fompulsingt linearity in-eclecticism-of-prior-mereformulaicity/ritualisation> existential<<disontologising/re-ontologising aporeticism $>$ backdrop'). This speaks (as to when consciously/unconsciously failing the 'requisite existentialdisentologising/re ontelogising apereticism $>$ intemporal-firstnaturedness-as-to-inkling epistemic-projection' as of profound-supererogation') of 'a deficient conception of the intellectual exercise', wrongly construed as being about absolutely beholdening to any given social-setup ${ }^{7}$ presencing — absolutising-identitive-constitutedness ${ }^{14}$ 'social-functioning-andaccordance-as-of-social-stake-contention-or-confliction imbuing existentialising-frame-ofentailment of motif-and-apriorising/axiomatising/referencing of disontologising/ontologisingand-re-ontologising' (as to the allure of 'pedantising/muddling/formulaic-hollowing-out-insubontologisation/subpotentiation-〈blurring/undermining-of-prospective-totalising-entailing,as-to-entailing-<amplituding/formative-epistemicity $>$ totalising in-relative-ontological- 
completeness > desublimation' bouncing-off/associating-with/voicing/relaying/cultivating 'human prior secondnaturdness prospective disontologising/subontologising <amplitung/formative $>$ wooden-language-〈imbued-temporal-mereform/virtualities/dereification/akrasiatic-drag/denatured/preconverging-or-dementing narratives - of-the- reference-of-thought- categorical-imperatives/axioms/registryteleology \'). This comprehensive elucidation of 're-ontologising apriorising/re-axiomatising/re-referencing -residuality in-re-originariness/re-origination $\{$ decompulsing $\}$ delinearity/delinear-accreting/recomposuring $\quad$ cogency/tensing/limpidity-<as-ofprospective-profound-supererogation ,-for-residuality—in-re-originariness/reorigination>-,prospective_reifying mental-aestheticising-as-of-'prospective_reformulatingof-mental-aestheticising'as-to-'residuality in -re-originariness/re-origination' of-mentalaestheticising $>$ ' (imbued 'human psychologismic-epistemic-acutisation-<as-topostconverging-de-mentating/structuring/paradigming,-eliciting-of-existence's-sublimatingnascence-in-prospective-aporeticism-overcoming/unovercoming $>$ as to epistemic-growth,-as\{veridieal/sound\} relative-reflexivity-in-existence/relativising from limited mentation as its deepening/psychologismic epistemic acutisation residualising, ${ }^{\text {fdecompulsing }}$ delinearity foreogency'): is illuminative of the psychologismic-epistemic-acutisation-difficulty- $<$ for,residualising-\{decompulsing\} $d$ delinearity for-cogency>-〈as-of-requisite-profound-supererogation for-'disposedness-or-psychologismic-construct'- \{imbued-demoronisation- $<$ sublimatingnascence,-nonextricatory-sublimating-upstreaming/‘amontée’>\}) for re-ontologising prospective Being-development/ontological-framework-expansion-as-to-depth-ofontologising-development-as-infrastructure-of- meaningfulness-and-teleology psychologismic epistemic acutisation difficulty < for, residualising

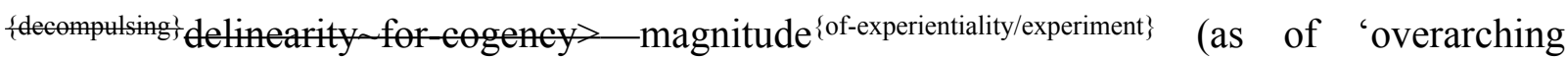
existential-disontegising/re ontologising aporeticism> priority/precedence/primacy of 
requisite prospective ontological-good-faith/authenticity $\sim$ postconverging-dementating/structuring/paradigming inducing of psychoanalytic-unshackling for the relativeontological-completeness ${ }^{87}$-of-apriorising/axiomatising/referencing re-ontologising prospective re-rationalisation-of-contentivity/argumentativity/dialecticism/discursivity' for sublimating prospective reference-of-thought—point-ofdevolving/departure/anchoring/backdrop_of_sublimating-nascence-<as-to-the-grandestaxiomatic-construct- fepistemic-totalising ${ }^{\prime}$ re-apriorising/re-axiomatising/rereferencing residuality - in-re-originariness/re-origination of limitedness/human-subpotency prospective re-encountering/re-confrontation with unlimitedness/existence>) as well as generally (intradimensional/interdimensional) illuminative of prospective human knowledge and transcendence-and-sublimity/sublimation/supererogatory $\sim$ de-mentativity; and so, as to the ontologising/scientific/existence- $<$ honesty-constraining $>$ - scope_for_prospective_reontologising requisite nonpresencing-<perspective-ontological-normalcy/postconvergence $>$ epistemic-projection 'implicited/explicited psychologismic-epistemic-acutisationresidualising $\sim$ istemictalising 3 hermeneutic/textmality/reprojecting/supererogating/zeroing/reacuting,- ${ }^{\{\text {decompulsing }}$ delinearity for-cogency’ successive profound/state-of-the-art sublimating reflection (of the-very-same purview/devolved-purview/devolving-purview-ofunlimitedness/existence-<full-potency-of_sublimating nascence $>$;_- 'implicited_attendantontological-contiguity ${ }^{67}$, educedexistentialising/contextualising/textualising_'intelligibility/epistemicity/reflexivity-contiguity$<$ imbued-notional cogency $>^{\prime}$ of prior limitedness/human-subpotency imbued research/knowledge and registry-worldview/dimension). The implication here is that (as relevant to Being-development/ontological-framework-expansion-as-to-depth-of-ontologisingdevelopment-as-infrastructure-of- meaningfulness-and-teleology , institutionaldevelopment-as-to-social-function-development and living-development-as-to-personality- 
$\{$ \{decompulsing\} $\}$ delinearity for-cogency> -magnitudes $\{$ of-experientiality/experiment\} $\}$, 're-ontologising fepistemic-atising tre-apriorising/re-axiomatising/re-referencing-residuality in re-

cogency/tensing/limpidity-<as-of-prospective-profound-supererogation ,-for-residuality—inre-originariness/re-origination>-_prospective_reifying mental-aestheticising-<as-of-

\section{'prospective_reformulating of-mental-aestheticising'as-to-'residuality in re-originariness/re-}

origination'-of-mental-aestheticising $>$ ' (imbued 'human psychologismic-epistemic-acutisation<as-to-postconverging-de-mentating/structuring/paradigming,-eliciting-of-existence's-

sublimating-nascence-in-prospective-aporeticism-overcoming/unovercoming $>$ as to epistemicgrowth,-as-\{veridical/sound\}-relative-reflexivity-in-existence/relativising from-limitedmentation-as-its-deepening/psychologismic epistemic-acutisation residualising, \{decompulsing\} delinearity for-cogency') is educed as of the 'firstnaturedness-as-to-inkling profound-supererogation for overarching existential-<disontologising/re-ontologising apereticism $>$ priority/precedence/primacy of referencing residuality—in-re-originariness/re-origination projection' in 'recurrent/perpetuating/continuity-recomposuring existential-disontologising/reentologising aporeticism $>$ counteracting/supplanting/alienating-of-priorapriorising/axiomatising/referencing' over 'secondnatured prior mere-formulaicity/ritualisation<as-to-mere-formulaic — methodologising/mutualising/organising/institutionalising,prospectively-losing-track-of- ' referencing $\sim$ residuality_-in-re-originariness/re-origination'>': and so-manifested, as to the overarching play of " nonpresencing-<perspective-ontological-normalcy/postconvergence> relativism/relative-scope for epistemic-growth,-as - \{veridical/sound\}-relative-reflexivity-inexistence/relativising from-limited-mentation-as-its-deepening/psychologismic epistemic- 
acutisation - residualising, ${ }^{\{\text {decompulsing }\}}$ delinearity for-cogency

'79 presencing - absolutising-identitive-constitutedness epistemic-projection over absolution/absolute-scope \{flawed/unsound\}-relative-unreflexivity-in-existencelabsolutising from-limitedmentation/psychologismic epistemic acutisation nonresidualising-imbued\{compulsing\} linearityoin-eclecticism-of prior-mere-formulaicity/ritualisation conception' epistemic-projection (in relation to the-very-same purview/devolved-purview/devolvingpurview-of-unlimitedness/existence-<full-potency-of_sublimating nascence $>$; 'implicited_attendant-ontological-contiguity ${ }^{67}$; educedexistentialising/contextualising/textualising_'intelligibility/epistemicity/reflexivity-contiguity$<$ imbued-notional cogency $>^{\prime 0}$ ); as so-reflecting the underlying gesturing/accounting-ofepistemic-phenomenalism of 'epistemic-totality ${ }^{37}$ of ${ }^{56}$ meaningfulness-and-teleology ${ }^{99}$ as to phenomenality-and-epiphenomenality' (so-underlied as from 'overall registryworldview/dimension $\quad$ reference-of-thought gesturing/accounting-of-epistemicphenomenalism' entailing into ' ${ }^{83}$ reference-of-thought- ${ }^{8}$ devolving gesturing/accounting-ofepistemic-phenomenalism' implied processive-motif-'exuding aestheticising-gesturing'-ofapriorising/axiomatising/referencing_imbued_notional $\sim$ reductionism- $<$ of-existentialprospection,-whether-as-of-trepidatious/warped/preclusive/occlusive/protensivenotional reductionism $>$ for instance as reflected with 'our overall positivism/rationalempiricism $\quad{ }^{83}$ reference-of-thought gesturing/accounting-of-epistemic-phenomenalism’ entailing into 'various devolved domains axiomaticially imbued positivism/rational-empiricism gesturing/accounting - of-epistemic-phenomenalism'). It should be noted parenthetically, that human 'epistemic-totality ${ }^{37}$ of ${ }^{5}$ meaningfulness-and-teleology' as to phenomenality-andepiphenomenality' in relation to the-very-same purview/devolved-purview/devolving-purviewof-unlimitedness/existence-<full-potency-of_sublimating nascence>;-_implicited_attendantontological-contiguity ${ }^{67} \sim$ educed- 
existentialising/contextualising/textualising_intelligibility/epistemicity/reflexivity-contiguity$<$ imbued-notional cogency >' is effectively what allows for intelligibility-〈as-to-humanprojective/reprojective - aestheticising-re-motif-and-re-apriorising/re-axiomatising/re-

\section{referencing/re-intelligibilitysettingup/re-measuringinstrumenting-process,-in-}

$<$ amplituding/formative-epistemicity>totalising conceptualisation〉 to arise; such that the 'comprehensive coherence/contiguity/noncontradiction of overall experientiality/experiment$<$ as-to-existentially-formative- ‘ referencing $\sim$ residuality —in-re-originariness/re-origination',- - so'notionally/epistemically/bindingnessly-<as-to-determinism/conceptivity-of-relative-unreflexivity/relative-reflexivity> implicited-and-articulated'_as-from-nonextricatory-'prospective-re-ontologising-Being-thenInstitutional-then-Living-magnitudes-of-\{hermeneutic/reprojection-protraction-of\}reframingand-reformulation \}'>' is lost when impliciting/expliciting that conceptual elucidation and definition can arise discreetly without prior tethering to an 'overall profound/sound gesturing/accounting — of-epistemic-phenomenalism' of 'epistemic-totality ${ }^{37}$ of meaningfulness-and-teleology ${ }^{9}$ as to phenomenality-and-epiphenomenality' (so-implied both interdimensionally and intradimensionally). This is a case again because of 'unlimitedness/existence-<full-potency-of_sublimating nascence $>$ prospective apriorising/axiomatising/referencing-sublimating-reflexivity-beholdening under which limitedness/human-subpotency submits in profound-supererogation for prospective sublimating'; since the-very-same purview/devolved-purview/devolving-purview-ofunlimitedness/existence-<full-potency-of_sublimating nascence $>$; - 'implicited_attendantontological-contiguity ${ }^{67}$, educedexistentialising/contextmalising/textualising_'intelligibility/epistemicity/reflexivity_contiguity<imbued-notional cogency>' warrants appropriate (relative-sublimating over relativedesublimating) human-subpotency/limitedness 'overall profound/sound gesturing/accounting- 
of-epistemic-phenomenalism' of 'epistemic-totality ${ }^{37}$ of ${ }^{56}$ meaningfulness-and-teleology ${ }^{99}$ as to phenomenality-and-epiphenomenality'. Such a misconstrual of conceptual elucidation and definition (as to the human epistemic limit to articulating an 'overall profound/sound gesturing/accounting - of-epistemic-phenomenalism') is effectively what induces the given presencing - absolutising-identitive-constitutedness ${ }^{14}$ given disontologising/subontologising notional reductionism (in the sense of rather impliciting an 'overall unthought/uncontemplated/mere-reflex/shallow/unsound gesturing/accounting-of-epistemicphenomenalism' of 'epistemic-totality ${ }^{37}$ of ${ }^{56}$ meaningfulness-and-teleology ${ }^{9}$ as to phenomenality-and-epiphenomenality'); so-reflected as of 'human notional differenceconflatedness $^{13}$-as-to-totalitative-reification-in-singularisation- $<$ as-to-the-

\section{nondisjointedness/entailment-of-prospective- nonpresencing $>$-as-veridical-epistemicity-}

relativism-determinism construable as from the given projected and prospectively educedand-availing-and-re-availing relative-ontological-completeness ${ }^{87}$-ofapriorising/axiomatising/referencing'. Intradimensionally, the issue of gesturing/accountingof-epistemic-phenomenalism can be appreciated in the manifestation of both profoundsupererogation $\sim$ reframing/reformulation/decatchmenting/detruncating/decompulsing/delinear ising_scale—of-transparent/noncontentious/un-nominalised/sound-interpretations/domains of manifest unblurriness-<re-ontologising_by-postconverging-as-to-dragged-outsupererogatory wholesomeness/profound-supererogation ,-while-anecdotalising-priordisontologising-thresholding $>$ and shallowsupererogation $\sim$ framing/formulation/catchmenting/truncating/compulsing/linearising_scale —of-opaque/contentious/un-nominalised/flawed-interpretations/domains of manifest blurriness-<sterilising/anecdotalising/trivialising-of-prospective-re-ontologising_bypreconverging,-in-disontologising-formulaic-dragging-out/hollowing-out>; wherein the former is implicitly and explicitly cognisant of the fact that conceptual elucidation and definition only 
arise as to its prior tethering to an 'overall profound/sound gesturing/accounting — of-epistemicphenomenalism' of 'epistemic-totality ${ }^{37}$ of ${ }^{56}$ meaningfulness-and-teleology ${ }^{9}$ as to phenomenality-and-epiphenomenality' (for instance space and time have 'no other or superseding meaning' but for the 'overall profound/sound gesturing/accounting — of-epistemicphenomenalism' of Newtonian physics that then give depth to the conceptual elucidation of space and time, and this is equally the case with Einsteinian physics with regards to spacetime or for that matter the incoherence in the astronomy 'overall profound/sound gesturing/accounting - of-epistemic-phenomenalism' that required a reconstrual of the conceptual elucidation and definition of a planet) whereas the latter as often manifested in the social is bound to naively imply the possibility of such discreet conceptual elucidation and definition without tethering to an 'overall profound/sound gesturing/accounting — of-epistemicphenomenalism' of 'epistemic-totality ${ }^{37}$ of ${ }^{56}$ meaningfulness-and-teleology 99 as to phenomenality-and-epiphenomenality' thus inducing elaboration-as-to-mereextrapolating/constituting/abstracting/deducing/inferring-of-elucidation-outside'prospectively_implicited_attendant-ontological-contiguity ${ }^{67}$ ? educedexistentialising/contextualising/textualising_intelligibility/epistemicity/reflexivity-contiguity$<$ imbued-notional cogency $>$ ' 40 as so-rather impliciting an 'overall unthought/uncontemplated/mere-reflex/shallow/unsound gesturing/accounting_-of-epistemicphenomenalism' of 'epistemic-totality ${ }^{37}$ of ${ }^{5}$ meaningfulness-and-teleology 9 as to phenomenality-and-epiphenomenality' (the consequence being that oftentimes such implicited 'overall unthought/uncontemplated/mere-reflex/shallow/unsound gesturing/accounting—ofepistemic-phenomenalism' is wrongly projected in misanalysis upon more 'overall profound/sound gesturing/accounting — of-epistemic-phenomenalism' derived knowledge like postmodern-thought however the rough-edges associated with social elucidation to wrongly imply that such thought is of unsound footing whereas the reality is actually the very reverse). 
Critically in this regards, the sublimating conceptivity/epistemic-reflexivity/epistemicityrelativism-determinism- $<$ reifying \{as-to-knowledge-developing $\}$-and-empowering $>$ entailment (as

supererogation $\sim$ reframing/reformulation/decatchmenting/detruncating/decompulsing/delinear ising_scale_-of-transparent/noncontentious/un-nominalised/sound-interpretations/domains of manifest unblurriness-<re-ontologising by-postconverging-as-to-dragged-outsupererogatery $\sim$ wholesomeness/profound-supererogation ,-while-anecdotalising-priordisontologising-thresholding $>\quad$ imbued ontologising/scientific/existence- $<$ honestyconstraining $>$ - scope_for_prospective_re-ontologising requisite nonpresencing$<$ perspective-ontological-normalcy/postconvergence $>$ epistemic-projection ‘implicited/explicited psychologismic-epistemic-acutisation-residualising \{epistemictotalising 3 ? ${ }^{3}$ hermeneutic/textuality/reprojecting/supererogating/zeroing/re-acuting,\{decompulsing\} delinearity for-cogency' successive profound/state-of-the-art sublimating) doesn't allow for 'sidestepping/selective/incongruent mere-formulaicity/ritualisation disontologising/subontologising failing overall sublimating-over-desublimating delineation' of the-very-same purview/devolved-purview/devolving-purview-of-unlimitedness/existencesflll potency of_sublimating nascence>; - 'implicited_attendant-ontologicalcontiguity ${ }^{67} \sim$ educedexistentialising/contextualising/textualising_intelligibility/epistemicity/reflexivity-contiguity$<$ imbued-notional cogency $>$ ' ; and so in contrast to the 'poorly construed human reflexivity' (manifested as to a pretense of 'institutionalised mere-formulaicity/ritualisation conception of experimental design/conceptualisation, presentation/clarity and metrics as to its given presencing - absolutising-identitive-constitutedness ${ }^{14} \quad$ prospectively disontologising $<$ amplituding/formative-epistemicity>-totalising $\sim$ thrownness-in-existence ${ }^{35}$, of shallowsupererogation $\sim$ framing/formulation/catchmenting/truncating/compulsing/linearising_scale 
—of-opaque/contentious/un-nominalised/flawed-interpretations/domains

of manifest

\section{blurriness- $<$ sterilising/anecdotalising/trivialising-of-prospective-re-ontologising_by-}

preconverging,-in-disontologising-formulaic-dragging-out/hollowing-out>) that in-many-ways consider broad swathes of requisite human 'comprehensive coherence/contiguity/noncontradiction of overall experientiality/experiment- $<$ as-to-

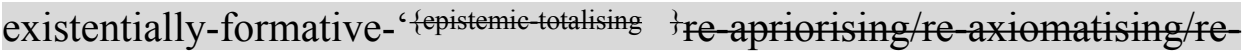

referencing $\sim$ residuality—in-re-originariness/re-origination',- so-

'notionally/epistemically/bindingnessly <as to determinism/eoneeptivity of relative unreflexivity/relative reflexivity?

implicited-and-articulated'_as-from-nonextricatory-'prospective-re-ontologising-Being-then-

Institutional-then-Living-magnitudes-of-\{hermeneutic/reprojection-protraction-of $\}$ reframingand-reformulation \}'>' as nondescript/ignorable-void ${ }^{60}$ or undefined, as so-failing to reflect requisite "epistemic-totality ${ }^{37}$ of ${ }^{5}$ meaningfulness-and-teleology' as to phenomenality-andepiphenomenality' (and as so-manifested in the lack/deficiency arising with regards to the warranted ontologising/scientific/existence- $<$ honesty-constraining $>$ scope_for_prospective_re-ontologising imbued underlying-elucidative 'requisite sublimating/desublimating formulative-framing/fielding —of-entailment of human ontologicalperformance $^{72}-<$ including-virtue-as-ontology $>$ /morality/ethics/justice/etc. contemplation' as of notionally implied $\quad{ }^{45}$ foregrounding_entailment- $<$ in-succession-of-profoundsupererogation $>$-〈postconverging-narrowing-down $\sim$ sublimation-as-to-'existence-assublimating-withdrawal/unenframing/re-ontologising,-elicited-from-prospective-profoundsupererogation '-in-reflecting-'immanent $\sim$ relative- unreflexivity/relative-reflexivity ontological-contiguity ';--as-operative-notional deprocrypticism), as herein implied as of notional ${ }^{18}$ deprocrypticism imbued ${ }^{15}$ de-mentation-〈supererogatory $\sim$ ontological-de-mentationor-dialectical-de-mentation-stranding-or-attributive-dialectics〉 underlying the overall relative-unreflexivity/relative-reflexivity - ontological-contiguity ${ }^{67}$ of-the-human- 
institutionalisation-process ${ }^{68}$ ). Such an 'overall profound/sound gesturing/accounting-ofepistemic-phenomenalism' of the ontologising/scientific/existence- $<$ honesty-constraining $>$ scope_for_prospective_re-ontologising in-many-ways is so-effectively 'notionally/epistemically/bindingnessly-<as-to-determinism/enceptivity-of-relative-unreflexivity/relative-reflexivity> integrative as to its ambit-of-elucidation of the epistemic misconstrual' of prior and present 'overall unthought/uncontemplated/mere-reflex/shallow/unsound gesturing/accounting-ofepistemic-phenomenalism'; as herein implied as of ${ }^{83}$ reference-of-thought disambiguation between ' ${ }^{\prime}$ nonpresencing-<perspective-ontological-normalcy/postconvergence $>$ ' epistemicprojection in relative-ontological-completeness ${ }^{87}$-of-apriorising/axiomatising/referencing and '79 presencing - absolutising-identitive-constitutedness ${ }^{14}$ epistemic-projection in relativeontological-incompleteness ${ }^{8}$-of-apriorising/axiomatising/referencing (respectively imbued 'human notional difference-conflatedness ${ }^{13}$-as-to-totalitative-reification-in-singularisation$<$ as-to-the-nondisjointedness/entailment-of-prospective- nonpresencing $>$-as-veridicalepistemicity-relativism-determinism construable as from the given projected relativeontological-completeness ${ }^{87}$-of-apriorising/axiomatising/referencing' and absolute $\sim$ differenceconflatedness $^{13}$-as-to-totalitative-reification-in-singularisation- $<$ as-to-the-

\section{nondisjointedness/entailment-of-prospective- nonpresencing $>$-as-veridical-epistemicity-}

relativism-determinism so-construed as 'absolute reference of identity' which misconstrual as supposedly veridical will lead to a failure to project/appreciate limitedness/human-subpotency prospective relative-ontological-incompleteness ${ }^{88}$-of-apriorising/axiomatising/referencing as impliciting there is no human epistemic-growth,-as - \{veridical/sound\}-relative-reflexivity-inexistence/relativising from-limited-mentation-as-its-deepening/psychologismic epistemicacutisation residualising, ${ }^{\text {\{decompulsing }}$ delinearity for cogency as to be prospectively elicited in profound-supererogation ). This is equally the case with regards to our present-day Science 'overall profound/sound gesturing/accounting-of-epistemic-phenomenalism' rather 
'notionally/epistemically/bindingnessly-as-to-determinism/eonceptivity-of-relative-unreflexivity/relative-reflexivity> integrative (as to its ambit-of-elucidation) of the epistemic misconstrual' of prior as well as present-day non-scientific 'overall unthought/uncontemplated/mere-reflex/shallow/unsound gesturing/accounting - of-epistemic-phenomenalism' (wherein for instance past 'mythical experientiality/experiment- $<$ as-to-existentially-formative- ‘fepistemic-totalising ${ }^{+}$re-apriorising/reaxiomatising/re-referencing-residuality-in-re-originariness/re-origination',-so'notionally/epistemically/bindingnessly-<as-to-determinism/conceptivity-of-relative-unreflexivity/relative-reflexivity> implicited-and-articulated'_as-from-nonextricatory-'prospective-re-ontologising-Being-thenInstitutional-then-Living-magnitudes-of-\{hermeneutic/reprojection-protraction-of $\}$ reframingand-reformulation \}'>' about comet appearances, diseases, witchcraft, etc. as well as present-day unscientific beliefs are notionally/epistemically/bindingnessly-<as-to-determinism/eoneeptivity-of-relativeunreflexivity/relative-reflexivity $>$-integrated within the ambit-of-elucidation of present-day science reflected requisite 'epistemic-totality ${ }^{37}$ of ${ }^{56}$ meaningfulness-and-teleology ${ }^{99}$ as to phenomenality-and-epiphenomenality'); and in this regards for instance, 'an ancient society conceptual elucidation and definition of a comet as a bright moving light in the sky associated with say a good omen or bad omen' is altogether reconstrued as to a profound/state-of-the-art sublimating conception of present-day astronomy science 'overall profound/sound gesturing/accounting - of-epistemic-phenomenalism' of 'epistemic-totality ${ }^{37}$ of meaningfulness-and-teleology as to phenomenality-and-epiphenomenality' conceptual elucidation and definition of a comet that goes all the way back to the formation of the solar system and universe (with the historical recollection of such a past mythical account effectively used to predict when next a given comet may return). Such notionally/epistemieally/bindingnessly-<as-to-determinism/conceptivity-of-relative-unreflexivity/relative-reflexivity $>$ integrative relative-ontological-completeness ${ }^{87}$-of-apriorising/axiomatising/referencing imbued 'overall profound/sound gesturing/accounting—of-epistemic-phenomenalism' as to its 
ambit-of-elucidation (inclusive of the elucidation of relative-ontological-incompleteness ${ }^{8}$-ofapriorising/axiomatising/referencing imbued 'overall unthought/uncontemplated/merereflex/shallow/unsound gesturing/accounting - of-epistemic-phenomenalism'), speaks to the veridical implications of 'sublimating conceptivity/epistemic-reflexivity/epistemicityrelativism-determinism-<reifying \{as-to-knowledge-developing $\}$-and-empowering $>$ entailment' as to re-ontologising aetiologisation/ontological-escalation- $<$ ontologicalveridicality_commitment/otherliness_transcending/compulsions-encumbered_transcending > (as superseding/overcoming a 'poorly construed human reflexivity' as of 79 presencingabsolutising-identitive-constitutedness ${ }^{14} \quad$ epistemic-projection $\quad$ totalisingly-ingdiscretion/whim-of-thought disontologising/subontologising as "wrongly impliciting of the disparateness-of-conceptualisation-<unforegrounding-ment,-failing-prospectively-to-reflect‘immanent relative-unreflexivity/relative-reflexivity - ontological-contiguity '> of relativeunreflexivity/relative-reflexivity_ontological-contiguity ${ }^{77}$ /superseding-oneness-of-ontology'). Such notionally/epistemically/bindingnessly-as determinism/eoneeptivity of relative mnreflexivity/relativereflexivityz-integrative relative-ontological-completeness ${ }^{87}$-ofapriorising/axiomatising/referencing imbued 'overall profound/sound gesturing/accountingof-epistemic-phenomenalism' as to its ambit-of-elucidation (inclusive of the elucidation of relative-ontological-incompleteness ${ }^{8}$-of-apriorising/axiomatising/referencing imbued 'overall unthought/uncontemplated/mere-reflex/shallow/unsound gesturing/accounting-of-epistemicphenomenalism') is effectively manifested as to the 'veracity of impliciting of relative-

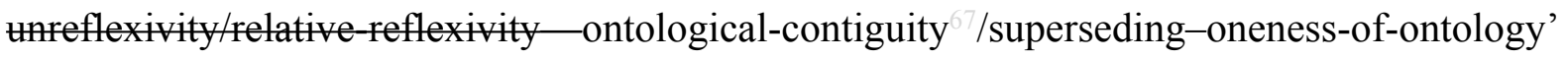
as of nonpresencing-<perspective-ontological-normalcy/postconvergence $>$ epistemicprojection (as so notionally/epistemically/bindingnessly-<as-to-determinism/conceptivity-of-relativeunreflexivity/relative-reflexivity>-integrative in its ambit-of-elucidation of both human 'epistemicgrowth,-as-\{veridical/sound\}-relative-reflexivity-in-existence/relativising from-limited- 
mentation-as-its-deepening/psychologismic epistemic-acutisation residualising, \{decompulsing \}elinearity for-cogency imbuing sublimation' and 'fflawed/unsound\}-relativeunreflexivity-in-existencelabsolutising from-limited-mentation/psychologismic epistemic acutisation nonresidualising-imbued-\{compulsing finearity-in-eclecticism-of-prior-mereformulaicity/ritualisation imbuing desublimation' in relation to already given unlimitedness/existence-<full-potency-of_sublimating nascence $>$ ); which is so-elucidated as of transversality-<for-sublimating-existential-eventuating/denouement,-from-'thinking-atfirst/pure-predisposition-preemptive-of-prospective-disontologising/subontologising' as-ofprospectively-disambiguated-affirmed-and-unaffirmed-'motif-andapriorising/axiomatising/referencing' $>$ ' rather at the level of 'overall profound/sound gesturing/accounting — of-epistemic-phenomenalism' implied 'epistemic-growth,-as\{veridical/sound\}-relative-reflexivity-in-existence/relativising from-limited-mentation-as-itsdeepening/psychologismic epistemic_acutisation residualising, ${ }^{\text {\{decompulsing }\}}$ delinearity for eogency imbuing sublimation' (so-reflecting the underlying-elucidative 'requisite sublimating/desublimating formulative-framing/fielding — of-entailment of human ontologicalperformance $^{72}-<$ including-virtue-as-ontology $>$ /morality/ethics/justice/etc. contemplation' as of notionally implied $\quad{ }^{45}$ foregrounding_entailment- $<$ in-succession-of-profoundsupererogation $>$-〈postconverging-narrowing-down $\sim$ sublimation-as-to-'existence-assublimating-withdrawal/unenframing/re-ontologising,-elicited-from-prospective-profoundsupererogation '-in-reflecting-'immanent relative-unreflexivity/relative-reflexivity ontological-contiguity ';--as-operative-notional deprocrypticism)' for epistemic-growth,as - \{veridical/sound\}-relative-reflexivity-in-existence/relativising from-limited-mentationas-its-deepening/psychologismic epistemic acutisation residualising, \{demplimg delinearity for-cogency imbuing sublimation). Optimally, the ontologising/scientific/existence- $<$ honesty-constraining $>$ — scope_for_prospective_re- 
ontologising requisite nonpresencing-<perspective-ontological-normalcy/postconvergence $>$ epistemic-projection 'implicited/explicited psychologismic-epistemic-acutisationresidualising \{epistemictalising 3 hermeneutic/textuality/reprojecting/supererogating/zeroing/reacuting, - decompulsing $^{-}$delinearity for-cogency’ successive profound/state-of-the-art sublimating reflection (of the-very-same purview/devolved-purview/devolving-purview-ofunlimitedness/existence-<full-potency-of_sublimating nascence>;_-implicited_attendant ontological-contiguity ${ }^{67} \sim$ educedexistentialising/contextualising/textualising_intelligibility/epistemicity/reflexivity-contiguity<imbued-notional cogency $>^{\prime}$ of prior limitedness/human-subpotency imbued research/knowledge and registry-worldview/dimension) warrants a mutual critique transversality- $<$ for-sublimating-existential-eventuating/denouement-from-'thinking at-

\section{first/pure-predisposition-preemptive-of-prospective-disontologising/subontologising' as-of-} prospectively-disambiguated-affirmed-and-unaffirmed-'motif-andapriorising/axiomatising/referencing' $>101$ rather at the level of 'overall profound/sound gesturing/accounting — of-epistemic-phenomenalism' (in order to transversally demarcate relative-sublimating 'overall profound/sound gesturing/accounting-of-epistemicphenomenalism' and relative-desublimating implicited 'overall unthought/uncontemplated/mere-reflex/shallow/unsound gesturing/accounting-of-epistemicphenomenalism'). Thereof, the conceptual elucidation and definition is rather subsumed as to the relevant/pertinent cumulated/recomposured 'overall profound/sound gesturing/accountingof-epistemic-phenomenalism' (of the-very-same purview/devolved-purview/devolvingpurview-of-unlimitedness/existence-<full-potency-of_sublimating nascence $>$; 'implicited_antentological-contiguity ${ }^{67}$ ' educedexistentialising/contextualising/textualising_'intelligibility/epistemicity/reflexivity-contiguity<imbued-notional cogency $>^{\text {' }}$ of prior limitedness/human-subpotency imbued 
research/knowledge and registry-worldview/dimension); and as to the subsequently educed ' nonpresencing-<perspective-ontological-normalcy/postconvergence $>$ relativism/relativescope for epistemic-growth,-as - \{veridical/sound\}-relative-reflexivity-inexistence/relativising from-limited-mentation-as-its-deepening/psychologismic epistemicacutisation residualising, ${ }^{\{\text {decompulsing }}$ delinearity for-cogency' epistemic-projection of relevant/pertinent cumulated/recomposured 'overall profound/sound gesturing/accounting—ofepistemic-phenomenalism' (such that with regards to the say the conceptual elucidation and definition of space and time we can delineate/disambiguate a pre-Newtonian, Newtonian, Einsteinian and subsequent physics conceptualisation). It is herein contended that the misconstrual of the conceptual elucidation and definition of such classical notions like relativism, solipsism, scepticism, aporia, determinism, free-will, etc. arises exactly because of ontologically-flawed implicited 'overall unthought/uncontemplated/merereflex/shallow/unsound gesturing/accounting_of-epistemic-phenomenalism'; and often soimplicited rather as from the accessorising of 'ordinary laypersonhood arrogation/presumptuousness' conception of supposedly prospective sublimation as to ${ }^{7}$ presencing —absolutising-identitive-constitutedness ${ }^{14}$ absolution/absolute-scope

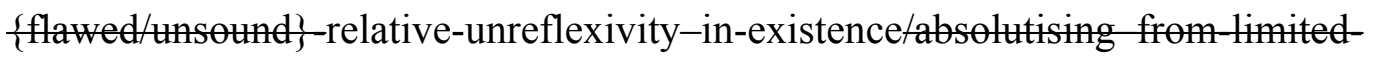
mentation/psychologismic epistemic acutisation nonresidualising-imbued\{compulsing\} linearityoin-eclecticism-of prior-mere-formulaicity/ritualisation conception' epistemic-projection (thus inducing a predisposition to 'apriorising/axiomatising/referencingequating/leveling/ressentiment/closed-construct-of- ${ }^{5}$ meaningfulness-and-teleology moronisation-<sublimating-nascence,-extricatory-desublimating-downstreaming/'avalage'>'). It is this insight that underlines/emphasises the ontologising-inveracity of the plethora of ismsconceptualisations articulated as of ${ }^{7}$ presencing-absolutising-identitive-constitutedness ${ }^{14}$ by wrongly implying everything is of the same notional-contiguity/epistemic-contiguity ${ }^{62}$ 


\section{<profound-supererogation -of-mentally-aestheticised postconverging/dialectical-thinking}

qualia-schema $>$ (as of undisambiguated relative-unreflexivity/relative-reflexivity - ontologicalcontiguity ${ }^{67}$ as to relative-ontological-incompleteness ${ }^{88}$-of-apriorising/axiomatising/referencing and relative-ontological-completeness ${ }^{87}$-of-apriorising/axiomatising/referencing thus inducing 'apriorising/axiomatising/referencing_equating/leveling/ressentiment/closed-construct-ofmeaningfulness-and-teleology $\quad$ moronisation-<sublimating-nascence,-extrieaterydesublimating-downstreaming/'avalage'>'), so-reflected as to relative-desublimating implicited 'overall unthought/uncontemplated/mere-reflex/shallow/unsound gesturing/accounting - of-epistemic-phenomenalism' supposed elucidation and definition of categories without 'a veridical/profound sublimating conceptivity/epistemicreflexivity/epistemicity-relativism-determinism- $<$ reifying \{as-to-knowledge-developing $\}$-andempowering> entailment (of relevant/pertinent cumulated/recomposured 'overall profound/sound gesturing/accounting-of-epistemic-phenomenalism') as to a veridical disambiguation reflecting human epistemic-growth,-as_ \{veridical/sound\}-relative-reflexivityin-existence/relativising from-limited-mentation-as-its-deepening/psychologismic epistemicacutisation residualising, ${ }^{\text {\{decompulsing }}$ delinearity for-cogency' implications (as of 'reentologising \{epistemictotalising tre apriorising/re axiomatising/re referencing-residuality in re eriginariness/re-origination $\{$ \{decompulsing\} delinearity/delinear-accreting/recomposuring cogency/tensing/limpidity-<as-of-prospective-profound-supererogation ,-for-residuality-inre-originariness/re-origination $>$, prospective_reifying mental-aestheticising-<as-of'prospective_reformulating-of-mental-aestheticising'as-to-'residuality in-re-originariness/reerigination' of -mental-aestheticising ' ')'. Such an insight is articulated herein with respect to the universal as of totalising-entailing; wherein for instance, universal human rights supererogatorily becomes more and more profound as from say the Socratic-philosophers (even as slavery, class-seclusion and female-seclusion was prevalent as to warped collateralisation), 
budding-positivists (even as in-many-ways the practices of serfdom/slavery, social-class discrimination and female-discrimination were equally prevalent as to preclusive collateralisation) and today's supposedly universal conception of human rights (even as it is marked by occlusive collateralisation of other peoples, cultures and nations as well as gender and age occlusive collateralising biases). This insight about the overarching existential<disontologising/re-ontelogising aporeticism $>$ priority/precedence/primacy of such a relevant/pertinent cumulated/recomposured 'overall profound/sound gesturing/accounting — ofepistemic-phenomenalism' (as so prior/preceding/primary before conceptual elucidation and definition) is exactly what underlies (the implicited cumulating/recomposuring as of their varying 'difference conception') of Derridean deconstruction, Foucauldian genealogy/archaeology and Deleuzian rhizomatics 'overall profound/sound gesturing/accounting-of-epistemic-phenomenalism' (rather so construed as to a ${ }^{6}$ nonpresencing-<perspective-ontological-normalcy/postconvergence $>$ relativism/relativescope for epistemic-growth,-as -\{veridical/sound\}-relative-reflexivity-inexistence/relativising from-limited-mentation-as-its-deepening/psychologismic epistemicacutisation residualising, ${ }^{\text {\{decompulsing }}$ delinearity for-cogency' epistemic-projection and not the flawed paradoxical misinterpretation of their thought as from implicited/explicited ${ }^{6}$ presencing-absolutising-identitive-constitutedness ${ }^{14}$ absolution/absolute-scope \{flawed/unsound\}-relative-unreflexivity-in-existence/absolutising from-limitedmentation/psychologismic epistemic acutisation nonresidualising-imbuedfompusings linearityoin-eclecticism-of prior-mere-formulaicity/ritualisation conception' epistemic-projection). Along the same lines, the 'overall profound/sound gesturing/accounting-of-epistemic-phenomenalism' herein is construed notionally/epistemically/bindingnessly-<as-to-determinism/conceptivity-of-relative-unreflexivity/relative-reflexivity> as from the epistemic-projection of prospective protensive-consciousness as 'deepest 
phenomenological transcendental-point-of-departure handle as of the notional conflatedness of notional ${ }^{18}$ deprocrypticism deneuterising — referentialism' (imbued 'demarcation of veridical/profound sublimating conceptivity/epistemic-reflexivity/epistemicity-relativismdeterminism-<reifying \{as-to-knowledge-developing $\}$-and-empowering $>$ entailment') as soundergirding the ambit-of-elucidation of the overall relative-unreflexivity/relative-reflexivity ontological-contiguity ${ }^{67}$ of-the-human-institutionalisation-process ${ }^{68}$ (with regards to the ontologising/scientific/existence- $<$ honesty-constraining $>$ — scope_for_prospective_reontologising imbued underlying-elucidative 'requisite sublimating/desublimating formulative-

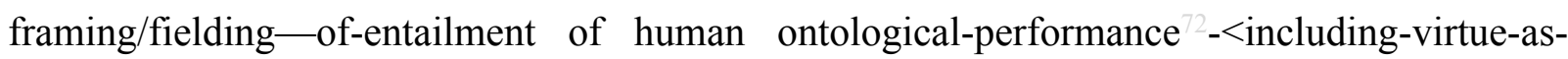
ontology $>$ /morality/ethics/justice/etc. contemplation' as of notionally implied foregrounding_entailment-<in-succession-of-profound-supererogation $>>-\langle$ postconvergingnarrowing-down $\sim$ sublimation-as-to-'existence - as-sublimating-withdrawal/unenframing/reontologising,-elicited-from-prospective-profound-supererogation '-in-reflecting‘immanent relative-unreflexivity/relative-reflexivity - ontological-contiguity ';-as-operativenotional deprocrypticism) $)$. This is herein practically reflected as to the 'driven distinct comprehensively coherent/contiguous operant-level of insights articulation, and carrying implicative and applicative operant-level possibilities' (over 'a rhyming/speculative/interpreted categories of philosophical theories and concepts' in reflection of the fact that artificial subjectmatter categories-schemes do not precede nor define intrinsic-reality as 'knowledge-in-itsoneness-and-entirety' as so-undermining the 'natural referentialism ontologicalnormalcy/postconvergence nature of knowledge'); and is so-articulated implicitly/explicitly as from the overarching existential-<disontologising/re-ontologising aporeticism $>$ priority/precedence/primacy of Being-development/ontological-framework-expansion-as-todepth-of-ontologising-development-as-infrastructure-of- meaningfulness-and-teleology psychologismic epistemic-acutisation - difficulty-for, residualising 
\{decompulsing\} delinearity for-cogeney>-magnitude\{of-experientiality/experiment\} and as it then translates into institutional-development-as-to-social-function-development and living-development-asto-personality-development psychologismic epistemic acutisation difficulty <for, residualising $\{$ \{decompulsing $\}$ delinearity for-cogency $>$ magnitudes $\{$ of-experientiality/experiment $\}$. It can thus be appreciated that the overall relative-unreflexivity/relative-reflexivity-ontologicalcontiguity ${ }^{67}$ of-the-human-institutionalisation-process ${ }^{68}$ educing 're-ontelogising fepistemictotalising '̀re-apriorising/re-axiomatising/re-referencing residuality in -re-originariness/reorigination decompusingt delinearity/delinear-acereting/recomposuring cogency/tensing/limpidity$<$ as-of-prospective-profound-supererogation ,-for-residuality-in-re-originariness/reorigination $>$, -prospective_reifying mental-aestheticising-<as-of 'prospective_reformulating of-mental-aestheticising'as-to-'residuality in -re-originariness/re-origination' of-mentalaestheticising $>$ ' (imbued 'human psychologismic-epistemic-acutisation-<as-topostconverging-de-mentating/structuring/paradigming,-eliciting-of-existence's-sublimatingnascence-in-prospective-aporeticism-overcoming/unovercoming $>$ as to epistemic-growth,-as\{veridical/sound\}-relative-reflexivity-in-existence/relativising from-limited-mentation-as-itsdeepening/psychologismic epistemic-acutisation residualising, ${ }^{\text {\{decompulsing }}$ delinearity foreogency') is elicited rather of 'nonpresencing-<perspective-ontologicalnormalcy/postconvergence $>$ relativism/relative-scope for epistemic-growth,-as\{veridical/sound\}-relative-reflexivity-in-existence/relativising from-limited-mentation-as-itsdeepening/psychologismic epistemic-acutisation residualising, fdecompusingl delinearity for cogeney' epistemic-projection delineating/differentiating of sublimation/desublimation in 'apriorising/axiomatising/referencing disambiguating/de-leveling/de-ressentiment/openedconstruct-of $-{ }^{5}$ meaningfulness-and-teleology 9 demoronisation- $<$ sublimating-nascence,nonextricatory-sublimating-upstreaming/'amontée'>' as of appropriate 'deconstruction conception as to epistemic-growth,-as-\{veridical/sound\}-relative-reflexivity-in- 
existence/relativising from-limited-mentation-as-its-deepening/psychologismic epistemicacutisation residualising, \{decompulsing delinearity for-cogency': as so-reflecting the effective 'sublimating gesturing/accounting-of-epistemic-phenomenalism of epistemic-totality ${ }^{37}$ of meaningfulness-and-teleology as to phenomenality-and-epiphenomenality' of the ontologising/scientific/existence- $<$ honesty-constraining $>$ — scope_for_prospective_reontologising imbued underlying-elucidative 'requisite sublimating/desublimating formulativeframing/fielding — of-entailment of human ontological-performance ${ }^{72}-<$ including-virtue-asontology $>$ /morality/ethics/justice/etc. contemplation' as of notionally implied foregrounding_entailment-<in-succession-of-profound-supererogation $>>-\langle$ postconverging narrowing-down $\sim$ sublimation-as-to-'existence - as-sublimating-withdrawal/unenframing/reontologising,-elicited-from-prospective-profound-supererogation '-in-reflecting‘immanent relative-unreflexivity/relative-reflexivity ontological-contiguity ';-as-operativenotional deprocrypticism) (involving human profound-supererogation superseding/overcoming of 'successive desublimating notional reductionisms as a reflection of the fact that reductionism speaks fundamentally to a defect of " presencing-absolutisingidentitive-constitutedness $^{14} \quad$ absolution/absolute-scope $\quad$ flawed/unsound\}-relativeunreflexivity-in-existence/absolutising from-limited-mentation/psychologismic epistemic acutisation nonresidualising imbuedformulaicity/ritualisation conception' epistemic-projection manifested as to relativeontologically-flawed $\quad$ reference-of-thought $\quad$ gesturing/accounting-of-epistemicphenomenalism' entailing into ' ${ }^{83}$ reference-of-thought- ${ }^{84}$ devolving gesturing/accounting-ofepistemic-phenomenalism'). This overall is thus validative of the ontologising/scientific/existence- $<$ honesty-constraining $>$ — scope_for_prospective_reontologising requisite nonpresencing-<perspective-ontological-normalcy/postconvergence $>$ epistemic-projection 'implicited/explicited psychologismic-epistemic-acutisation- 
residualising $\sim$ \{epistemic-totalising 3 ? 3 hermeneutic/textuality/reprojecting/supererogating/zeroing/reacuting,-\{decompulsing $\}$ delinearity for-cogency’ successive profound/state-of-the-art sublimating reflection (of the-very-same purview/devolved-purview/devolving-purview-ofunlimitedness/existence-<full-potency-of_sublimating nascence>;_-implicited_attendantontological-contiguity ${ }^{67} \sim$ educedexistentialising/contextualising/textualising_intelligibility/epistemicity/reflexivity-contiguity$<$ imbued-notional cogency> ${ }^{\prime}$ of prior limitedness/human-subpotency imbued research/knowledge and registry-worldview/dimension), and so over the psychologismic-. epistemic-acutisation — difficulty- $<$ for,-residualising_\{decompulsing $\}$ delinearity $\sim$ for-cogency $>-\langle$ asof-requisite-profound-supererogation -for-'disposedness-or-psychologismic-construct'\{imbued-demoronisation-<sublimating-nascence,-nonextricatory-sublimatingupstreaming/'amontée’>\}) (as to presencing absolutising-identitive-constitutedness 'existential-<disontologising/re-ontologising aporeticism $>$ preconverging dementating/structuring/paradigming punctual/immediacy/constituted/compulsions-encumbered prior mere-formulaicity/ritualisation rationalisation-ofcontentivity/argumentativity/dialecticism/discursivity') as specifically reflected with the example of our modern-day ${ }^{7}$ presencing - absolutising-identitive-constitutedness ${ }^{14}$ epistemicprojection 'implicited/explicited punctual/immediacy/constituted/compulsions-encumberedhypothesisation reproducibility' (implied as to a 'purported crisis-of-reproducibility in academia'); as a relevant issue of our modern-day competence/expertising (as of human socially expanded framework of deferential-formalisation-transference as to various cultivated skills/arts and time investment with regards to effectively manifest 'underlying veracity of corephilosophy/derivative-core-philosophy prospective re-ontologising as relevantly superseding prior mere-formulaicity/ritualisation pedantism induced knowledge-deadends- $<$ aspreconverging-de-mentating/structuring/paradigming >') with regards to relatively 
uncontentious/nominalised social-stake-contention-or-confliction, and so with respect to the overall requisite prospective 're-ontologising fepistemic-totalising ${ }^{3}$ re-apriorising/re-axiomatising/rereferencing residuality in-re-originariness/re-origination \{decompulsing $\}$ delinearity/delinearaccreting/recomposuring cogency/tensing/limpidity-<as-of-prospective-profoundsupererogation ,-for-residuality_in-re-originariness/re-origination $>-$,prospective_reifying mental-aestheticising-<as-of-'prospective_reformulating-of-mental-aestheticising'as-to'residuality in re-originariness/re-origination'-of-mental-aestheticising $\gg$ ' imbued 'human psychologismic-epistemic-acutisation-<as-to-postconverging-dementating/structuring/paradigming,-eliciting-of-existence's-sublimating-nascence-inprospective-aporeticism-overcoming/unovercoming $>$ as to epistemic-growth,-as\{veridical/sound\}-relative-reflexivity-in-existence/relativising from-limited-mentation-as-itsdeepening/psychologismic epistemic-acutisation residualising, ${ }^{\{\text {decompulsing }}$ delinearity foreogency'. Effectively and in-the-bigger-picture, such a ${ }^{79}$ presencing-absolutising-identitiveconstitutedness epistemic-projection 'implicited/explicited punctual/immediacy/constituted/compulsions-encumbered—hypothesisation reproducibility' (as manifested as of our 'positivism- ${ }^{80}$ procrypticism/disjointedness-as-of- ${ }^{8}$ reference-ofthought ${ }^{79}$ presencing-absolutising-identitive-constitutedness ${ }^{14}$ epistemic-projection' imbued reductionist misconstrual of the 'existentialising-frame-of-entailment-of-motif-andapriorising/axiomatising/referencing of experientiality/experiment- $<$ as-to-existentiallyformative-' ‘epistemictalising ${ }^{\dagger}$ re-apriorising/re-axiomatising/re-referencing $\sim$ residuality-in-reoriginariness/re-origination',- - so- 'notionally/epistemically/bindingnessly-as-todeterminism/conceptivity-of-relative-unreflexivity/relative-reflexivityz_-implicited-and-articulated'_as-fromnonextricatory- 'prospective-re-ontologising-Being-then-Institutional-then-Living-magnitudesof-\{hermeneutic/reprojection-protraction-of $\{$ reframing-and-reformulation $\}$ '>' in eliciting for instance human psychology and other social-sciences purview-of-unlimitedness/existence- $<\mathrm{full}-$ 
potency-of_sublimating nascence>;_—implicited_attendant-ontological-

contiguity $^{67}$ ? educed-

existentialising/contextmalising/textmalising_'intelligibility/epistemicity/reflexivity-contiguity-

$<$ imbued-notional cogency>>) are rather veridically construable in profundity (as from nonpresencing-<perspective-ontological-normalcy/postconvergence $>$ epistemic-projection 'implicited/explicited psychologismic-epistemic-acutisation-residualising \{epistemic-

totalising 3'thermeneutic/textuality/reprojecting/supererogating/zeroing/re-acuting,-

\{delinearity for-cogency') as the ambit-of-elucidation of 'overall profound/sound gesturing/accounting - of-epistemic-phenomenalism' of the $<$ cumulating/recomposuring attendant-ontological-contiguity $>$-successive registryworldviews/dimensions or the overall relative-unreflexivity/relative-reflexivity_ontologicalcontiguity ${ }^{67}$ of-the-human-institutionalisation-process ${ }^{68}$ (so-underlied herein as of human ${ }^{15}$ dementation-〈supererogatory $\sim$ ontological-de-mentation-or-dialectical-de-mentation — strandingor-attributive-dialectics $)$ ); as so-reflecting the ontologising/scientific/existence- $<$ honestyconstraining $>$ — scope_for_prospective_re-ontologising imbued underlying-elucidative 'requisite sublimating/desublimating formulative-framing/fielding-of-entailment of human ontological-performance ${ }^{2}$-<including-virtue-as-ontology $>/$ morality/ethics/justice/etc.

contemplation' as of notionally implied ${ }^{45}$ foregrounding_entailment- $<$ in-succession-ofprofound-supererogation $>$-〈postconverging-narrowing-down $\sim$ sublimation-as-to-'existenceas-sublimating-withdrawal/unenframing/re-ontologising,-elicited-from-prospective-profoundsupererogation '-in-reflecting-'immanent relative-unreflexivity/relative-reflexivity ontological-contiguity ';--as-operative-notional deprocrypticism). But then more gravely in this regards, as to the fact that in-many-ways our modern-day competence/expertising (as of human socially expanded framework of deferential-formalisation-transference as to various cultivated skills/arts and time investment with regards to relatively uncontentious/nominalised 
social-stake-contention-or-confliction with regards to effectively manifest 'underlying veracity of core-philosophy/derivative-core-philosophy prospective re-ontologising as relevantly superseding prior mere-formulaicity/ritualisation pedantism induced knowledge-deadends- $<$ aspreconverging-de-mentating/structuring/paradigming >') is more-or-less of prospective ontological-good-faith/authenticity ${ }^{6} \sim$ postconverging-de-mentating/structuring/paradigming however the effective relative-sublimating over relative-desublimating ontologicalperformance ${ }^{72}-<$ including-virtue-as-ontology $>$, is the issue of our modern-day 'cultivation and enculturation of practices of overt/covert privying of the supposed conception of the ontologising/scientific/existence- $<$ honesty-constraining $>$ — scope_for_prospective_reontologising (as so-associated prominently with surreptitious and media-savvy political and economic think-tanking and related pop-intellectualism with regards to relatively contentious/un-nominalised social-stake-contention-or-confliction), and as it in turn undermines competence/expertising (not only directly but as well as to its wrongly implicited 'supposedly ontologising shallow supererogation $\sim$ framing/formulation/catchmenting/truncating/compulsing/linearising —as-topreconverging de-mentating/structuring/paradigming of competence/expertising problematics' which are not then fundamentally analysed as to their veridical/profound prospective reontologising implications as of 'unlimitedness/existence-<full-potency-of_sublimating nascence $>$ prospective apriorising/axiomatising/referencing-sublimating-reflexivitybeholdening under which limitedness/human-subpotency submits in profound-supererogation for prospective sublimating'); and so, as to requisite prospective 're-ontologising epistemictotalising ${ }^{\dagger}$ re-apriorising/re-axiomatising/re-referencingoresiduality in-re-originariness/reerigination \{decompulsing\} delinearity/delinear acereting/recomposuring cogency/tensing/limpidity$<$ as-of-prospective-profound-supererogation ,-for-residuality-in-re-originariness/reorigination>-pprospective_reifying mental-aestheticising_<as-of 'prospective_reformulating 
of-mental-aestheticising'as-to 'residuality in -re-originariness/re-origination' of -mental-

aestheticising $>$ ' imbued 'human psychologismic-epistemic-acutisation-<as-to-postconvergingde-mentating/structuring/paradigming,-eliciting-of-existence's-sublimating-nascence-inprospective-aporeticism-overcoming/unovercoming > as to epistemic-growth,-as\{veridical/sound\}-relative-reflexivity-in-existence/relativising from-limited-mentation-as-itsdeepening/psychologismic epistemic-acutisation residualising, ${ }_{\text {fdecompulsing }}$ delinearity foreogency'. It is herein contended that this is manifested as to the decades-long tested and increasingly trialed 'prioritised overt/covert motives of both private interest and public dominance/vested-interest advocacy/political/applicative-scope' in conjunction with pedantising/muddling/formulaic-hollowing-out - in-subontologisation/subpotentiation〈blurring/undermining-of-prospective-totalising-entailing,-as-to-entailing$<$ amplituding/formative-epistemicity $>$ totalising in-relative-ontological-completeness $>$ desublimation 'stunting of prospective re-ontologising especially with regards to relatively contentious/un-nominalised social-stake-contention-or-confliction' together with the accessorising of 'ordinary laypersonhood arrogation/presumptuousness' conception of supposedly prospective sublimation (as a cultivated-and-enculturated conscious/unconscious 'sidestepping/selective/incongruent mere-formulaicity/ritualisation disontologising/subontologising failing overall sublimating-over-desublimating delineation'), as a defining three-prong strategy for subverting the modern-day genuine social intellectualfunction/posture "nonextricatory/postconverging ontologising-and-re-ontologising angling-ofimaginary demoronisation- $<$ sublimating-nascence,-nonextricatory-sublimatingupstreaming/'amontée'>'. This is so-manifested in the increasing reflection of the 'mortal scale of perceived institutional access and success default conception of human ontologicalperformance ${ }^{2}-<$ including-virtue-as-ontology $>$ ' associated with pop-intellectualism, the subjection/dependency of knowledge institutions and in turn inducing an 'epistemic-decadence' 
<<amplituding/formative>supererogatory $\sim$ de-mentativeness/epistemic-growth-or-

conflatedness /transvaluative-rationalising/transepistemicity/anamnestic-residuality/spirit-

drivenness-equalisation〉 that thrives with strategies of eliciting 'conceptual-patterning-〈asdevoid-of-'prospectively_implicited_attendant_ontological-contiguity ' i educedexistentialising/contextualising/textualising_'intelligibility/epistemicity/reflexivity-contiguity$<$ imbued-notional cogency>' 's-reifying-or-elucidating-of-'prospective-relative-ontologicalcompleteness ' ';-so-rather-enabled-<by-a- nonpresencing-divulging-of-momentoushistoriality/ontological-eventfulness /ontological-aesthetic-tracing-<perspectiveontological-normalcy/postconvergence-reflected-'epistemicity-relativism-determinism’>>, desublimating formulaic-fashionability $<$ 'wholesome-dearth'/shallowness_as-to-requisite-'reentologising rhizomatic-wholesomeness' for-postconverging redeshadowing and bothsidesism-〈as-'mereprocessive'/pedantising-'dialogical-relation'-to 'perceived-social-and-institutionalcommonly-enculturated_referencing,-of- meaningfulness-and-teleology '-failing-'requisiteexistential-thematic-baseline-of-technicity/profundity-framing' \{of-sublimating-discursivityfor-sovereign-repassing \},-as-of-psychologismic-epistemic-acutisation-nonresidualisingimbued-\{compulsing\} linearity in-eclecticism-of-prior-mere-formulaicity/ritualisation,-as-so'consciously/unconsciously-preordained/fated'-to-fail-prospective-notional cogency) ontologically-flawed conceptualising' as effective techniques to avoid transversality $-<$ forsublimating-existential-eventuating/denouement,-from-'thinking-at-first/pure-predispositionpreemptive-of prospective-disontologising/subontologising' as-of-prospectivelydisambiguated-affirmed-and-unaffirmed-'motif-and-apriorising/axiomatising/referencing'> and thus preempt the demarcation of veridical/profound sublimating conceptivity/epistemicreflexivity/epistemicity-relativism-determinism-<reifying \{as-to-knowledge-developing $\}$-and- 
empowering> entailment. This so-fundamentally 'destroys' the 'requisite conceptivity/epistemic-reflexivity/epistemicity-relativism-determinism- $<$ reifying \{as-toknowledge-developing -and-empowering $>$ for prospective re-ontologising' opening the way for the modern-day 'information crisis' and 'crisis of contemplation/reflection' as well as 'institutional and social crises and malaises manifested in the socio-econo-political domains'. In this regards, the ontological-veracity of 'existential-<disontologising/re-ontelogising aporeticism $>$ human-consciousness/collective-consciousness-distendedness/detruncating$<$ beyond-selfpresencing,-as-re-ontologising-decentering_of-consciousness/collectiveconsciousness,-as-to-psychologismic-epistemic-acutisation-residualising,$\{$ decompulsing $\}$ delinearity for-cogency $>$ ' underlying the operational social-setup as of 'human socially expanded framework of deferential-formalisation-transference as to various cultivated skills/arts and time investment' effectively speaks to the fundamental unfairness to the sovereign-function/posture-<as-to-existentially-manifest-'embodied-subject $\sim$ consciousnessand-direct/deferential-conscientiousness',-as-of-its- 'epistemic-reflexivity/unreflexivity-inexistence'/teleology>; as to the very sovereign-emergence/becoming-existentially-imbuinghuman-freedom-as-to-supererogating/surrealising for-'knowledge-empowerment-overisment'-<as-of-'developing-and-availing-sovereignsublimating_potential/possibilities/options/choices'-as-to-the- 'credibility'/'ontologicalveracity'-underlying-the-'sovereign-conscious/conscientious-backdrop'> of thehuman/humanity in its consciousness/collective-consciousness with respect to its successively given and superseded <amplituding/formative-epistemicity $>$-totalising $\sim$ thrownness-inexistence $^{3}$ - (as imbued of limitedness/human-subpotency prospective dearth for fepistemictotalising $\frac{1}{r}$ re-apriorising/re-axiomatising/re-referencing $\sim$ residuality-in-re-originariness/reorigination projection), 'so-cynically' lured into an existentialising-decisionality-as-todisontologising/re-ontologising aporeticism $>$ as of 'our modern-day shallow-supererogation 
contentivity/argumentativity/dialecticism/discursivity' (as the all-be-all of the democratic process and the correspondent social imaginary). Thusly, as so lacking/deficient in the genuine social intellectual-function/posture cultivated '\{veridical/sound\}-relative-reflexivity-inexistence/relativising from-limited-mentation-as-its-deepening/psychologismic epistemicacutisation residualising, ${ }^{\{\text {decompulsing }}$ delinearity for-cogency anarchisticgrowth/anarchisation-for-re-ontologisation-〈as-to-conscious/unconscious epistemically-sound induced 'demoronisation-<sublimating-nascence,-nonextricatery-sublimatingupstreaming/'amontée'> postconverging/dialectical-thinking conception of residual_reoriginary_anarchistic incipiency of human social-functioning-and-accordance-as-of-socialstake-contention-or-confliction meaningfulness-and-teleology ' $\rangle$ ' (as often reflected in poor public substantive appreciation of the veracity of social information/data); and so, as to surreptitious subversion purposes of '\{flawed/unsound $\}$-relative-unreflexivity-inexistence/absolutising from-limited-mentation/psychologismic epistemic-acutisationnonresidualising-imbued-\{compulsing\} linearity-in-eclecticism-of-prior-mereformulaicity/ritualisation insidious-anarchy-<as-to-conscious/unconscious epistemically-flawed induced 'moronisation- $<$ sublimating-nascence,-extricatory-desublimatingdownstreaming/'avalage’> preconverging/dementing conception of prior mereformulaicity/ritualisation incipiency of human social-functioning-and-accordance-as-ofsocial-stake-contention-or-confliction meaningfulness-and-teleology '>' (reflecting a conscious/unconscious creative stunting of the 'human democratic potential' as to a cynical punctual/immediacy/constituted/compulsions-encumbered play upon human lifespan 'subconscious-and-conscious_perceptible-and-reperceptible/actionable-and-reactionabledynamics of effectively_manifestable-and-remanifestable/attainable-and-reattainable loss and 
gain

Insightfully, it can be appreciated as well (with regards to Being-development/ontologicalframework-expansion-as-to-depth-of-ontologising-development-as-infrastructure-ofmeaningfulness-and-teleology psychologismic epistemic-acutisation difficulty-for, residualising \{decompulsing\} delinearity-for-cogency>-magnitude \{of-experientiality/experiment\}) that the veracity of 'existential-<disontologising/re-ontologising aporeticism> humanconsciousness/collective-consciousness-distendedness/detruncating- $<$ beyond-selfpresencing,as-re-ontologising-decentering_of-consciousness/collective-consciousness,-as-to-

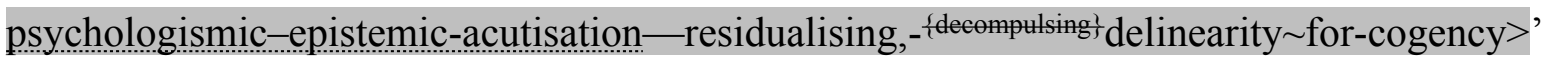
underlying the operational social-setup as of 'human socially expanded framework of deferential-formalisation-transference as to various cultivated skills/arts and time investment' means that for instance the "non-positivism/medievalism shallow-supererogation of punctual/immediacy/constituted/compulsions-encumbered prior mere-formulaicity/ritualisation rationalisation-of-contentivity/argumentativity/dialecticism/discursivity' is not the sufficient basis (as to its <preconverging 'motif-and-apriorising/axiomatising/referencing'-entailing>existentialising — enframing/imprintedness-〈as-to- historicity-tracing-in-presencinghyperrealisation/hyperreal-transposition〉) for the requisite 're-ontologising apriorising/re-axiomatising/re-referencing residuality in-re-originariness/re-origination $\{$ decompulsing $\}$ delinearity/delinear-accreting/recomposuring $\quad$ cogency/tensing/limpidity-<as-ofprospective-profound-supererogation ,-for-residuality-in-re-originariness/reorigination>-,prospective_reifying mental-aestheticising-<as-of-prospective_reformulatingof-mental-aestheticising'as-to 'residuality in -re-originariness/re-origination' of -mentalaestheticising $>$ ' (imbued 'human psychologismic-epistemic-acutisation-<as-topostconverging-de-mentating/structuring/paradigming,-eliciting-of-existence's-sublimating- 
nascence-in-prospective-aporeticism-overcoming/unovercoming $>$ as to epistemic-growth,-as \{veridical/sound\}-relative-reflexivity-in-existence/relativising from-limited-mentation-as-itsdeepening/psychologismic epistemic-acutisation residualising, fdecompulsingl delinearity foreogency') enabling prospective positivism/rational-empiricism knowledge and transcendenceand-sublimity/sublimation/supereregatory $\sim$ de-mentativity imbued 'existential<disontologising/re-ontelogising aporeticism> human-consciousness/collectiveconsciousness-distendedness/detruncating-<beyond-selfpresencing,-as-re-ontologisingdecentering_of-consciousness/collective-consciousness,-as-to-psychologismic-epistemicacutisation-residualising, - ${ }^{\{\text {decompulsing }}$ delinearity for-cogency $>$ ' (as to the requisite sublimating manifestation of 'thinking at first/pure predisposition preemptive of prospective disontologising/subontologising' re-ontologisingly spilling out of prior institutional disontologising/subontologising). The ontologising/scientific/existence- $<$ honestyconstraining $>$ — scope_for_prospective_re-ontologising profound-supererogation $\quad$ reassessability of prospective human re-ontologising (as to its tethering to underlying 'constraining existence — as-sublimating-withdrawal/unenframing/re-ontologising,-elicited-fromprospective-profound-supererogation ${ }^{9}$ imbuing human ontological-commitment ${ }^{6}-<$ implied self-assuredness-of-ontological-good-faith/authenticity postconverging-dementating/structuring/paradigming -as-being-as-of-existential-reality>' and ' 103 universaltransparency ${ }^{104}$-〈transparency-of-totalising-entailing,-as-to-entailing-<amplituding/formativeepistemicity $>$ totalising in-relative-ontological-completeness $\rangle$ as available-to/elicitable-to-〈asto-human-consciousness/collective-consciousness-distendedness/detruncating- $<$ beyondselfpresencing,-as-re-ontologising-decentering_of-consciousness/collective-consciousness,-as-

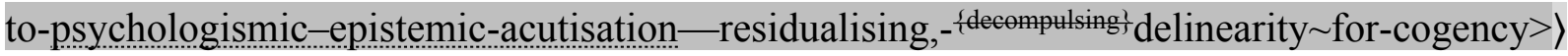
the social-functioning-and-accordance-as-of-social-stake-contention-or-confliction conception of any given registry-worldview/dimension <preconverging 'motif-and- 
apriorising/axiomatising/referencing'-entailing>-existentialising—enframing/imprintedness〈as-to- historicity-tracing - in-presencing-hyperrealisation/hyperreal-transposition〉' recurrent prompting of: the-human/humanity 'recurrently mediative-<in-expectation/in-anticipation> unconsciousness/potentiation-of-conscionability-<anxiety-as-to-reconstitution/reparation,including-dreaming/psychical-reshuffling >' as the 'psychoanalytic boundlessness of human notional $\sim$ reflexivity- $<\{$ veridical/sound $\}$-relative-reflexivity-in-existence/relativising fromlimited-mentation-as-its-deepening/psychologismic-<residualising \{decompulsing $\}$ delinearity foreogency>-by-\{flawed/unsound\}-relative-unreflexivity-in-existence/absolutising fromlimited-mentation/psychologismic epistemic acutisation nonresidualising imbued\{compulsing\} linearity in-eclecticism-of prior-mere-formulaicity/ritualisation> existential<lisontologising/re-ontologising aporeticism $>$ backdrop' elicitable/exuding as of subconsciousness knowingly/unknowingly-manifest human ontological-goodfaith/authenticity ${ }^{60} \sim$ postconverging-de-mentating/structuring/paradigming $~ —$ byontological-bad-faith/inauthenticity ${ }^{64} \sim$ preconverging-de-mentating/structuring/paradigming ${ }^{65}$ ) 'is not limited/constrained to the institutional-setup validation' of any given registryworldview/dimension $\quad<$ preconverging 'motif-and-apriorising/axiomatising/referencing'entailing >-existentialising — enframing/imprintedness-〈as-to- historicity-tracing - inpresencing-hyperrealisation/hyperreal-transposition) (so-speaking of its cumulating/recomposuring 'prospective re-ontologising as to prospective $<$ postconverging 'motif-and-apriorising/axiomatising/referencing'-entailing $>$ existentialising - framing/imprinting-〈as-to-prospective-- historiality/ontologicaleventfulness /ontological-aesthetic-tracing-<perspective-ontologicalnormalcy/postconvergence-reflected-'epistemicity-relativism-determinism'>〉'). In this regards, the ontologising/scientific/existence- $<$ honesty-constraining $>$ - scope_for_prospective_reontologising profound-supererogation ${ }^{6}$ re-assessability of prospective human re-ontologising is 
what effectively validates the relevance/veracity of any such institutional-setup as to the fact that the ancients-sophists nor the medieval-scholastics institutional-setups couldn't prevent/void the ontologising/scientific/existence- $<$ honesty-constraining $>$ - scope_for_prospective_reontologising respectively with Socratic-philosophers as of ${ }^{103}$ universalising-idealisation trampling-upon of non-universalising sophistry or budding-positivists positivism/rationalempiricism trampling-upon of non-positivising medieval-scholasticism (speaking of the naïve nombrilism of any institutional-setup absolutising its 'punctual/immediacy/constituted/compulsions-encumbered prior

mereformulaicity/ritualisation rationalisation-ofcontentivity/argumentativity/dialecticism/discursivity'): in reflection

of 'unlimitedness/existence-<full-potency-of_sublimating nascence> prospective apriorising/axiomatising/referencing-sublimating-reflexivity-beholdening under which limitedness/human-subpotency submits in profound-supererogation for prospective sublimating' notwithstanding the psychologismic-epistemic-acutisation-difficulty- $<$ for,residualising_\{decompulsing\} delinearity $\sim$ for-cogency $>$-〈as-of-requisite-profound-supererogation for-'disposedness-or-psychologismic-construct'- $\{$ imbued-demoronisation-<sublimatingnascence,-nonextricatory-sublimating-upstreaming/'amontée’’\}) (as manifested with the contention arising with regards to budding postmodern-thought as to 'a deficient/poor aptitudinal manifestation of ontological-bad-faith/inauthenticity $\sim$ preconverging-dementating/structuring/paradigming ${ }^{5}$ ) for re-ontologising prospective Beingdevelopment/ontological-framework-expansion-as-to-depth-of-ontologising-development-asinfrastructure-of- meaningfulness-and-teleology psychologismic epistemic-acutisation difficulty < for, residualising \{decompulsing $\}$ delinearity for-cogency> magnitude $\{$ ofexperientiality/experiment\}; as thusly elucidating herein the 'ontologising/scientific/existence- $<$ honestyconstraining $>$ — scope_for_prospective_re-ontologising profound-supererogation $\quad$ re- 
assessability of prospective human re-ontologising' as to prospective ${ }^{18}$ deprocrypticism-orpreempting - disjointedness-as-of- ${ }^{83}$ reference-of-thought requisite 're-ontologising fepistemictratising apriorising/re-axiomatising/re-referencing residuality in-re-originariness/reorigination \{decompulsing\} delinearity/delinear-accreting/recomposuring cogency/tensing/limpidity<as-of-prospective-profound-supererogation ,-for-residuality—in-re-originariness/reorigination $>$-_prospective_reifying mental-aestheticising-<as-of-prospective_reformulatingof-mental-aestheticising'as-to 'residuality in -re-originariness/re-origination' of -mentalaestheticising $>$ ' (imbued 'human psychologismic-epistemic-acutisation-<as-topostconverging-de-mentating/structuring/paradigming,-eliciting-of-existence's-sublimatingnascence-in-prospective-aporeticism-overcoming/unovercoming $>$ as to epistemic-growth,-as\{veridical/sound\}-relative-reflexivity-in-existence/relativising from-limited-mentation-as-itsdeepening/psychologismic epistemic-acutisation residualising, ${ }^{\text {\{decompulsing }}$ \}elinearity foreogency'). In this regards, human 'sublimating contemplation' and 'developing mentality' go hand-to-hand in reflection of the requisite 'existential-<disontologising/re-ontologisingapereticism $>$ human-consciousness/collective-consciousness-distendedness/detruncating$<$ beyond-selfpresencing,-as-re-ontologising-decentering_of-consciousness/collectiveconsciousness,-as-to-psychologismic-epistemic-acutisation-residualising,\{decompulsing $\}$ delinearity for-cogency>', and so beyond a disparateness-of-conceptualisation$<$ unforegrounding-ment,-failing-prospectively-to-reflect-'immanent relativeunreflexivity/relative-reflexivity - ontological-contiguity ' $>$ naivety that 'it is possible to veridically think-by-the-side as of a mere-thing in soullessness' without the mind of profound existential-<disontologising/re-ontologising aporeticism $>$ dimensionality-of-sublimating ${ }^{25}$ <<amplituding/formative>supererogatory $\sim$ de-mentativeness/epistemic-growth-orconflatedness /transvaluative-rationalising/transepistemicity/anamnestic-residuality/spiritdrivenness-equalisation> that generates-and-follows thinking existential-<disontologising/re- 
entologising aporeticism $>$ entailment. The human psychologismic-epistemic-acutisationdifficulty- $<$ for,-residualising_\{decompulsing $\}$ delinearity $\sim$ for-cogency $>-\langle$ as-of-requisite-profoundsupererogation -for-'disposedness-or-psychologismic-construct'-\{imbued-demoronisation<sublimating-nascence,-nonextricatory-sublimating-upstreaming/‘amontée’>\}) (as to presencing absolutising identitive-constitutedness 'existential-<disontologising/reentologising aporeticism $\geq$ preconverging de-mentating/structuring/paradigming punctual/immediacy/constituted/compulsions-encumbered prior mere-formulaicity/ritualisation rationalisation-of-contentivity/argumentativity/dialecticism/discursivity') effectively speaks to the fact that 'all successive secondnatured human stations/loci of limitedness/human-subpotency <amplingling formative-epistemicity $>$-totalising $\sim$ thrownness-in-existence ${ }^{35}$ - (as imbued of limitedness/human-subpotency prospective dearth for \{epistemic-totalising ’’re-apriorising/reaxiomatising/re-referencing $\sim$ residuality-in-re-originariness/re-origination projection)' are a 'calling' for prospective 'overarching existential-<disontologising/re-ontologising apereticism $>$ priority/precedence/primacy of requisite prospective ontological-goodfaith/authenticity ${ }^{6}$ postconverging-de-mentating/structuring/paradigming 7 inducing of psychoanalytic-unshackling for the relative-ontological-completeness ${ }^{8}$-ofapriorising/axiomatising/referencing re-ontologising prospective re-rationalisation-ofcontentivity/argumentativity/dialecticism/discursivity' as the very possibility of prospective 'reentologising fepistemic-talising tre-apriorising/re-axiomatising/re-referencing residuality in-reeriginariness/re-origination $\{$ decompulsing $\}$ delinearity/delinear-accreting/recomposuring cogency/tensing/limpidity-<as-of-prospective-profound-supererogation ,-for-residuality-inre-originariness/re-origination>-,prospective_reifying mental-aestheticising-<as-of'prospective_reformulating of mental-aestheticising'as-to-'residuality in re-originariness/reorigination'-of-mental-aestheticising >' (imbued 'human psychologismic-epistemic-acutisation<as-to-postconverging-de-mentating/structuring/paradigming,-eliciting-of-existence's- 
sublimating-nascence-in-prospective-aporeticism-overcoming/unovercoming $>$ as to epistemicgrowth,-as-\{veridical/sound\}-relative-reflexivity-in-existence/relativising from-limitedmentation-as-its-deepening/psychologismic epistemic acutisation residualising, ${ }_{\{\text {decompulsing }}$ delinearity for-cogeney'); as 'so-specifically requisite explicitly' with reontologising prospective Being-development/ontological-framework-expansion-as-to-depthof-ontologising-development-as-infrastructure-of- meaningfulness-and-teleology . The implication here is that human-consciousness/collective-consciousnessdistendedness/detruncating-<beyond-selfpresencing,-as-re-ontologising-decentering_ofconsciousness/collective-consciousness,-as-to-psychologismic-epistemic-acutisation

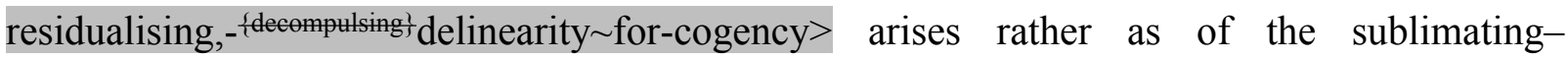
tradition/constant of profound-supererogation (as to the 'fundamental/incipient/seeding experientiality/experiment- $<$ as-to-existentially-formative- ‘fepistemic-totalising łre-apriorising/reaxiomatising/re-referencing $\sim$ residuality —in-re-originariness/re-origination',-so'notionally/epistemically/bindingnessly <as to determinism/enneeptivity of relative enreflexivity/relative reflexivityz implicited-and-articulated'_as-from-nonextricatory-'prospective-re-ontologising-Being-thenInstitutional-then-Living-magnitudes-of-\{hermeneutic/reprojection-protraction-of\}reframingand-reformulation $\}$ '> that is human profound-supererogation' so-reflecting the 'overarching existential-<disontologising/re-ontologising aporeticism $>$ priority/precedence/primacy of \{epistemic-totalising 3 \}re-apriorising/re-axiomatising/re-referencing $\sim$ residuality—in-reoriginariness/re-origination projection') manifested as of prospective 'overarching existential-disontologising/re-ontologising aporeticism $>$ priority/precedence/primacy of requisite prospective ontological-good-faith/authenticity $\sim$ postconverging-dementating/structuring/paradigming inducing of psychoanalytic-unshackling for the relativeontological-completeness ${ }^{87}$-of-apriorising/axiomatising/referencing re-ontologising prospective re-rationalisation-of-contentivity/argumentativity/dialecticism/discursivity' at 
every given 'secondnatured human station/locus of limitedness/human-subpotency <amplituding/formative-epistemicity $>$-totalising $\sim$ thrownness-in-existence ${ }^{5}$ - (as imbued of limitedness/human-subpotency prospective dearth for tre-apriorising/reaxiomatising/re-referencing $\sim$ residuality-in-re-originariness/re-origination projection)'; soimplied in reflection of the very inherence of 'unlimitedness/existence-<full-potencyof_sublimating nascence> prospective apriorising/axiomatising/referencing-sublimatingreflexivity-beholdening under which limitedness/human-subpotency submits in profoundsupererogation for prospective sublimating'. This reflects the fact that 'secondnatured human stations/loci of limitedness/human-subpotency <amplituding/formative-epistemicity >totalising thrownness-in-existence ${ }^{35}$ - as imbued of limitedness/human-subpotency prospective dearth for \{epistemic-totalising ’’re-apriorising/re-axiomatising/rereferencing residuality—in-re-originariness/re-origination projection)' are prospectively of desublimating presencing absolutising identitive-constitutedness 'existential<disontologising/re-ontologising aporeticism $>$ preconverging dementating/structuring/paradigming punctual/immediacy/constituted/compulsions-encumbered prior mere-formulaicity/ritualisation rationalisation-of-

contentivity/argumentativity/dialecticism/discursivity' such that the prospective nonpresencing-<perspective-ontological-normalcy/postconvergence> 'existential<disontologising/re-ontologising aporeticism $>$ prospect of human individualconsciousness/collective-consciousness decompulsion-appraisal' can only arise as of prospective 'overarching existential-<disontologising/re-ontologising aporeticism $>$ priority/precedence/primacy of requisite prospective ontological-goodfaith/authenticity ${ }^{6} \sim$ postconverging-de-mentating/structuring/paradigming ${ }^{0}$ inducing of psychoanalytic-unshackling for the relative-ontological-completeness ${ }^{8}$-ofapriorising/axiomatising/referencing re-ontologising prospective re-rationalisation-of- 
contentivity/argumentativity/dialecticism/discursivity'. This explains why the fundamental/incipient/seeding continuity of human ontological-performance ${ }^{2}-<$ includingvirtue-as-ontology $>$ /morality/ethics/justice/etc. lies solely with human profoundsupererogation as of ontological-good-faith/authenticity ${ }^{9} \sim$ postconverging-dementating/structuring/paradigming ${ }^{70}$ (that is, as so-appraised beyond the shiftiness-of-the-Self of any given ${ }^{7}$ presencing — absolutising-identitive-constitutedness ${ }^{14}$ ). The latter point, speaks to the more indispensable and relevant implication of profound-supererogation as from human 'crossgenerational notional firstnaturedness-formativeness-<as-to-eventualising inkling drive-or-seeding-misprising $>$ mental-processing-parity for ontological-performance ${ }^{72}$ $<$ including-virtue-as-ontology $>$ /morality/ethics/justice/etc.' as to 'prospective ${ }^{6}$ nonpresencing<perspective-ontological-normalcy/postconvergence> epistemic-projection' induced 'human re-ontologising transcendence-and-sublimity/sublimation/supereregatory $\sim$ de-mentativity' notwithstanding priorly given '79 presencing-absolutising-identitive-constitutedness disontologising $<$ amplituding/formative-epistemicity $>$-totalising $\sim$ thrownness-in-existence ${ }^{35}$ (as imbued of limitedness/human-subpotency prospective dearth for treapriorising/re-axiomatising/re-referencing $\sim$ residuality_-in-re-originariness/re-origination projection)'; and so with regards to the recurrently requisite 'relative-ontologicalincompleteness 8 /relative-ontological-completeness ${ }^{87}$

〈sublimating referencing/registering/decisioning,-as-self-becoming/selfconflatedness /formative-supererogating-<projective/reprojective-aestheticising-re-motifand-re-apriorising/re-axiomatising/re-referencing,-in-perspective-ontologicalnormalcy/postconvergence $>>$ as to human-and-social-expectations/anticipationsmetaphoricity ${ }^{57}$-as-preconverging/postconverging-redementating/restructuring/reparadigming-psychologism' ${ }^{89}$ for human prospective re-ontologising (as of 'overarching existential-<disontologising/re-ontologising aporeticism $>$ 
priority/precedence/primacy of requisite prospective ontological-goodfaith/authenticity $\sim$ postconverging-de-mentating/structuring/paradigming 7 inducing of psychoanalytic-unshackling for the relative-ontological-completeness ${ }^{87}$ ofapriorising/axiomatising/referencing re-ontologising prospective re-rationalisation-ofcontentivity/argumentativity/dialecticism/discursivity') that so-defines humanconsciousness/collective-consciousness-distendedness/detruncating- $<$ beyond-selfpresencing,as-re-ontologising-decentering_of-consciousness/collective-consciousness,-as-topsychologismic-epistemic-acutisation-residualising, - $^{\text {decmpung }}$ delinearity for-cogency $>$.

The implication here is that profound-supererogation is an exercise of 'superseding/overcoming a human self-presence/self-constitutedness ${ }^{14}$-<in-perspectiveepistemic-abnormalcy/preconvergence ${ }^{31}>$ rationalisation-ofcontentivity/argumentativity/dialecticism/discursivity' and rather existentially<disontologising/re-ontelogising aporeticism $>$ constraining to the prospect of 'unlimitedness/existence-<full-potency-of_sublimating nascence> prospective apriorising/axiomatising/referencing-sublimating-reflexivity-beholdening under which limitedness/human-subpotency submits in profound-supererogation for prospective sublimating' induced re-ontologising re-rationalisation-ofcontentivity/argumentativity/dialecticism/discursivity; speaking of the fact that humanconsciousness/collective-consciousness-distendedness/detruncating- $<$ beyond-selfpresencing,as-re-ontologising-decentering_of-consciousness/collective-consciousness,-as-to-

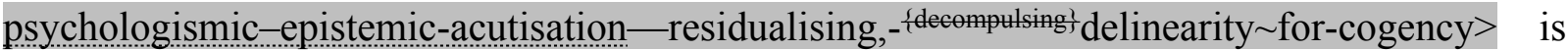
rather about the eliciting of underlying 'constraining existence-as-sublimatingwithdrawal/unenframing/re-ontologising,-elicited-from-prospective-profound-supererogation imbuing human ontological-commitment $-<$ implied — self-assuredness-of-ontological-goodfaith/authenticity postconverging-de-mentating/structuring/paradigming -as-being-as-of- 
existential-reality>' and ' ${ }^{103}$ universal-transparency ${ }^{104}$-〈transparency-of-totalising-entailing,-asto-entailing-<amplituding/formative-epistemicity $>$ totalising $\sim$ in-relative-ontologicalcompleteness \ as available-to/elicitable-to-〈as-to-human-consciousness/collectiveconsciousness-distendedness/detruncating-<beyond-selfpresencing,-as-re-ontologisingdecentering_of-consciousness/collective-consciousness,-as-to-psychologismic-epistemicacutisation-residualising, - decompulsing $^{-}$delinearity for-cogency $\left.>\right\rangle$the social-functioning-andaccordance-as-of-social-stake-contention-or-confliction conception of any given registryworldview/dimension $\quad$ <preconverging 'motif-and-apriorising/axiomatising/referencing'entailing $>$-existentialising — enframing/imprintedness-〈as-to- historicity-tracing-inpresencing-hyperrealisation/hyperreal-transposition) ${ }^{\prime} \quad$ (in $\quad$ self-becoming/selfconflatedness ${ }^{13}$ /formative-supererogating-<projective/reprojective-aestheticising-re-motifand-re-apriorising/re-axiomatising/re-referencing,-in-perspective-ontologicalnormalcy/postconvergence $>$ ). In other words, the ontologising/scientific/existence- $<$ honestyconstraining $>$ — scope_for_prospective_re-ontologising effectively portends to a much more real notion of human consciousness that is effectively of prospective actualisation/re-actualisation as of human-consciousness/collective-consciousness-distendedness/detruncating- $<$ beyondselfpresencing,-as-re-ontologising-decentering_of-consciousness/collective-consciousness,-asto-psychologismic-epistemic-acutisation —residualising, ${ }^{-{ }^{\text {fdecompulsing }}}$ - $d e l i n e a r i t y \sim$ for-cogency $>$ (undergirded recurrently as of 'overarching existential-distogising apereticism $>$ priority/precedence/primacy of requisite prospective ontological-goodfaith/authenticity ${ }^{6} \sim$ postconverging-de-mentating/structuring/paradigming 70 inducing of psychoanalytic-unshackling for the relative-ontological-completeness ${ }^{8}$-ofapriorising/axiomatising/referencing re-ontologising prospective re-rationalisation-ofcontentivity/argumentativity/dialecticism/discursivity'), with the veracity of humanconsciousness/collective-consciousness-distendedness/detruncating-<beyond-selfpresencing,- 
as-re-ontologising-decentering_of-consciousness/collective-consciousness,-as-to-

psychologismic-epistemic-acutisation — residualising, - $^{\text {\{decompulsing }}$ delinearity $\sim$ for-cogency $>$

much than just a given rationalisation-ofcontentivity/argumentativity/dialecticism/discursivity but rather of nonpresencing <perspective-ontological-normalcy/postconvergence $>\quad$ 'existential-<disontologising/reentologising aporeticism $\gg$ prospect of human individual-consciousness/collectiveconsciousness decompulsion-appraisal' as to the accompanying devolving sublimation of prospective re-rationalisation-of-contentivity/argumentativity/dialecticism/discursivity; such that prospective re-ontologising cannot and shouldn't overrate/be-defined-by the prior 'mere rationalisation-of-contentivity/argumentativity/dialecticism/discursivity' of any given 'secondnatured human station/locus of limitedness/human-subpotency <amplituding/formativeepistemicity $>$-totalising $\sim$ thrownness-in-existence ${ }^{3}$ - as imbued of limitedness/humansubpotency prospective dearth for \{epistemic-totalising ł're-apriorising/re-axiomatising/rereferencing residuality —in-re-originariness/re-origination projection)' (but is rather bound to re-elicit underlying 'constraining existence-as-sublimating-withdrawal/unenframing/reontologising,-elicited-from-prospective-profound-supererogation imbuing human ontological-commitment $\quad$-<implied_-self-assuredness-of-ontological-goodfaith/authenticity postconverging-de-mentating/structuring/paradigming -as-being-as-ofexistential-reality>' and ' ${ }^{103}$ universal-transparency ${ }^{104}$-〈transparency-of-totalising-entailing,-asto-entailing-<amplituding/formative-epistemicity $>$ totalising $\sim$ in-relative-ontologicalcompleteness $\rangle$ as available-to/elicitable-to-〈as-to-human-consciousness/collectiveconsciousness-distendedness/detruncating-<beyond-selfpresencing,-as-re-ontologisingdecentering_of-consciousness/collective-consciousness,-as-to-psychologismic-epistemic-

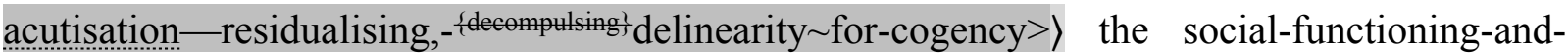
accordance-as-of-social-stake-contention-or-confliction conception of any given registry- 
worldview/dimension <preconverging 'motif-and-apriorising/axiomatising/referencing'entailing >-existentialising — enframing/imprintedness-〈as-to- historicity-tracing - inpresencing-hyperrealisation/hyperreal-transposition $\left.\rangle^{\prime}\right)$ in so-averting the given uninstitutionalised-threshold ${ }^{102}$ imbued pedanticism, nihilism and absurdism. In this regards, for instance the human-consciousness/collective-consciousness-distendedness/detruncating$<$ beyond-selfpresencing,-as-re-ontologising-decentering_of-consciousness/collectiveconsciousness,-as-to-psychologismic-epistemic-acutisation-residualising,\{decompulsing\} delinearity for-cogency $>$ allowing for a non-positivising social-setup mindset developing into a positivising registry-worldview/dimension mindset is much more than the positivising 'mere rationalisation-of-contentivity/argumentativity/dialecticism/discursivity' but rather entails the nonpresencing-<perspective-ontological-normalcy/postconvergence> 'existential-<disontologising/re-ontologising aporeticism $>$ prospect of human individualconsciousness/collective-consciousness decompulsion-appraisal' as to the accompanying devolving sublimation of prospective positivising re-rationalisation-ofcontentivity/argumentativity/dialecticism/discursivity; with the re-ontologising implication that part-and-parcel of human-consciousness/collective-consciousness-distendedness/detruncating$<$ beyond-selfpresencing,-as-re-ontologising-decentering_of-consciousness/collectiveconsciousness,-as-to-psychologismic-epistemic-acutisation-residualising,\{decompulsing $d$ delinearity for-cogency $>$ as to prospective firstnaturedness-as-to-inkling profoundsupererogation is the 'prospective projection/anticipation directly-or-deferentially of educedand-availing-and-re-availing relative-ontological-completeness ${ }^{87}$-ofapriorising/axiomatising/referencing' as to the recurrently requisite 'relative-ontologicalincompleteness $^{8} /$ relative-ontological-completeness $^{87}$

\section{〈sublimating referencing/registering/decisioning,--as-self-becoming/self-}


and-re-apriorising/re-axiomatising/re-referencing,-in-perspective-ontological-

normalcy/postconvergence $>>$ as to human-and-social-expectations/anticipationsmetaphoricity ${ }^{57}$-as-preconverging/postconverging-rede-

mentating/restructuring/reparadigming-psychologism' ${ }^{89}$ for human prospective re-ontologising (as of 'overarching existential-disontologising/re ontologising aporeticism> priority/precedence/primacy of requisite prospective ontological-goodfaith/authenticity ${ }^{6}$ postconverging-de-mentating/structuring/paradigming 7 inducing of psychoanalytic-unshackling for the relative-ontological-completeness ${ }^{8}$-ofapriorising/axiomatising/referencing re-ontologising prospective re-rationalisation-ofcontentivity/argumentativity/dialecticism/discursivity'). Such an implication of humanconsciousness/collective-consciousness-distendedness/detruncating-<beyond-selfpresencing,as-re-ontologising-decentering_of-consciousness/collective-consciousness,-as-to-

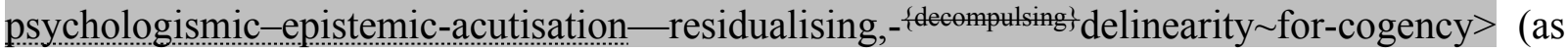
to the veracity of the ontologising/scientific/existence- $<$ honesty-constraining $>$ scope_for_prospective_re-ontologising) points to the paradoxical fact that 'human conscious grasp of re-ontologising sublimating ${ }^{56}$ meaningfulness-and-teleology ${ }^{9}$ is constrained-andlimited by the given 'secondnatured human station/locus of limitedness/human-subpotency <amplituding/formative-epistemicity $>$-totalising $\sim$ thrownness-in-existence ${ }^{35}$ - (as imbued of limitedness/human-subpotency prospective dearth for tre-apriorising/reaxiomatising/re-referencing $\sim$ residuality-in-re-originariness/re-origination projection)' which so-fails to cover the prospective possibility/potential for re-ontologising beyond its limitative presencing-absolutising-identitive-constitutedness ${ }^{14}$. This thus speaks to the validity of the ontologising/scientific/existence- $<$ honesty-constraining $>$ — scope_for_prospective_reontologising 'psychologismic-transfixity-<placeholder-setup-ontological-rescheduling-inrealigning/preactivity/formative-becoming/psychoanalytical-unshackling,-as-to-residualising- 
$\{$ \{decompulsing $\}$ delinearity-over-nonresidualising_\{compulsing\} $\}$ linearity $>$ of human consciousness' as bound with prospective metaphoricity ${ }^{57}$ (explaining why the re-ontologising exercise cannot be construed-as/constrained-as-of the implicited all-be-all of a presencing-absolutisingidentitive-constitutedness ${ }^{14}$ conceptualisation and/or ${ }^{79}$ presencing-absolutising-identitiveconstitutedness ${ }^{14}$ advocacy/political/applicative-scope); such that the genuine social intellectual-function/posture 'insists on the posteriority/exteriorisation of human re-ontologising intelligibility' (beyond just any given 'secondnatured human station/locus of limitedness/humansubpotency <amplituding/formative-epistemicity>-totalising thrownness-in-existence ${ }^{35}$ - (as imbued of limitedness/human-subpotency prospective dearth for treapriorising/re-axiomatising/re-referencing $\sim$ residuality_-in-re-originariness/re-origination projection)' imbued intelligibility) as defining the very possibility of the ontologising/scientific/existence- $<$ honesty-constraining $>$ - scope_for_prospective_reontologising. Critically, the 'secondnatured human station/locus of limitedness/humansubpotency <amplituding/formative-epistemicity>-totalising $\sim$ thrownness-in-existence ${ }^{35}$ - (as imbued of limitedness/human-subpotency prospective dearth for treapriorising/re-axiomatising/re-referencing $\sim$ residuality_-in-re-originariness/re-origination projection)' prospective re-ontologising deficiency arises as to the fact that it is 'mostly of the retention of the sublimating outcome of prior profound-supererogation ${ }^{9}$ rationalisation-ofcontentivity/argumentativity/dialecticism/discursivity imbued positive-opportunism—of-socialfunctioning-and-accordance ${ }^{75}$, and 'poorly of the requisite prospective retention of profoundsupererogation, which is required for prospective 'existential-<disontologising/reentologising aporeticism $>$ postconverging-aporeticism-overcoming/unovercoming' as sorequisite for the posteriority/exteriorisation of the ontologising/scientific/existence- $<$ honestyconstraining $>$ — scope_for_prospective_re-ontologising (especially-so with regards to reontologising prospective Being-development/ontological-framework-expansion-as-to-depth- 
of-ontologising-development-as-infrastructure-of- meaningfulness-and-teleology

psychologismic epistemic acutisation difficulty-for, residualising

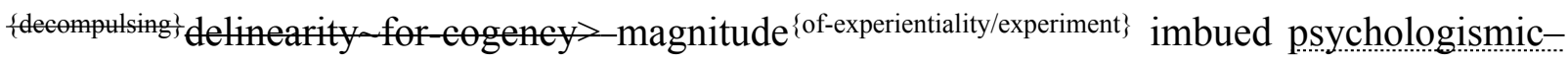
epistemic-acutisation - difficulty- $<$ for,-residualising_\{decompulsing $\}$ delinearity $\sim$ for-cogency $>-\langle$ asof-requisite-profound-supererogation -for-'disposedness-or-psychologismic-construct'-

$\{$ imbued-demoronisation-<sublimating-nascence,-nonextricatory-sublimatingupstreaming/'amontée'>\})); as so-manifested as to presencing absolutising-identitiveconstitutedness 'existential-<disontologising/re-ontologising aporeticism $>$ preconverging de-mentating/structuring/paradigming punctual/immediacy/constituted/compulsionsencumbered prior mere-formulaicity/ritualisation rationalisation-ofcontentivity/argumentativity/dialecticism/discursivity' (so-reflected with the manifestation of the notional/epistemic/bindingness $<$ as-to-determinism/coneeptivity-of-relative-unreflexivity/relative-reflexivity $>$ overaching cultivated-and-enculturated interrelatedness-dynamics-of-social-constructing as from 'catchmented-and-compulsed-<in-'existential-dearth-of-demoronisation',-so-construedas-from-ontological-normalcy/postconvergence-perspective-reflection-of-the-'destructuringthreshold_of-the-given-level's-conjugated-postlogism as-dementing'> interpersonal, group, intergroup, community, local, national, political, geostrategic, etc. psychologismic epistemicacutisation difficulty-<for, residualising \{decompulsing $\}$ delinearity for-cogeney> levels of interrelatedness-dynamics-of-social-constructing' of 'formativeness-<as-to-intersolipsism-ofpreformulating/preframing/premeaningfulness-imbued-mediativity-and-deferentialism>-ofmeaningfulness-and-teleology and existential-<disontologising/re-ontologising apereticism $>$ articulation manifestations'). This further explains why spontaneous opting for prospective profound-supererogation 'inherently grants intellectual-and-moral ascendency, responsibility/relative-reflexivity and purposefulness' so-translated as to prospective 'profoundsupererogation $\sim$ reframing/reformulation/decatchmenting/detruncating/decompulsing/delinear 
ising - as to-postconverging de-mentating/structuring/paradigming

priority/precedence/primacy of that which spontaneously opts for prospective profoundsupererogation, (so-manifesting as to ontologising-failsafe-<as-to-relativeunreflexivity/relative-reflexivity bindingness/nondiscretionariness' of totalising-entailment> as of 'substantivity of transversality-<for-sublimating-existential-eventuating/denouementfrom-'thinking-at-first/pure-predisposition-preemptive-of-prospective-

\section{disontologising/subontologising' as-of-prospectively-disambiguated-affirmed-and-}

unaffirmed-'motif-and-apriorising/axiomatising/referencing'>10' '); and so, not withstanding 'surreptitious usurpative pretense to profoundsupererogation $\sim$ reframing/reformulation/decatchmenting/detruncating/decompulsing/delinear ising —as-to-postconverging - de-mentating/structuring/paradigming' of pedantising/muddling/formulaic-hollowing-out — in-subontologisation/subpotentiation〈blurring/undermining-of-prospective-totalising-entailing,-as-to-entailing<amplituding/formative-epistemicity>totalising in-relative-ontological-completeness > desublimation. It is effectively rather a nonpresencing-<perspective-ontologicalnormaley/postconvergence> 'existential-<disontologising/re-ontologising aporeticism> prospect of human individual-consciousness/collective-consciousness decompulsion-appraisal' that is bound to reproject of the profound-supererogation (as to 'overarching existential< disontologising/re-ontologising aporeticism $>$ priority/precedence/primacy of requisite prospective ontological-good-faith/authenticity ${ }^{60} \sim$ postconverging-dementating/structuring/paradigming inducing of psychoanalytic-unshackling for the relativeontological-completeness ${ }^{87}$-of-apriorising/axiomatising/referencing re-ontologising prospective re-rationalisation-of-contentivity/argumentativity/dialecticism/discursivity') in prospectively reinvigorating the ontologising/scientific/existence- $<$ honesty-constraining $>$ scope_for_prospective_re-ontologising (beyond the instrumentalising arising as of the 
'secondnatured prior mere-formulaicity/ritualisation-<as-to-mere-formulaicmethodologising/mutualising/organising/institutionalising,-prospectively-losing-track-of-

‘fepistemic-totlising ’’re-apriorising/re-axiomatising/re-referencing $r$ residuality-in-re-

originariness/re-origination'>' with the latter so-construed as of its undergirding presencing absolutising -identitive-constitutedness $\quad$ 'existential-<disontologising/re-ontologising aporeticism> preconverging de-mentating/structuring/paradigming punctual/immediacy/constituted/compulsions-encumbered prior mere-formulaicity/ritualisation rationalisation-of-contentivity/argumentativity/dialecticism/discursivity'). In-the-biggerscheme-of-things (as to human Being-development/ontological-framework-expansion-as-todepth-of-ontologising-development-as-infrastructure-of- meaningfulness-and-teleology , institutional-development-as-to-social-function-development and living-development-as-topersonality-development psychologismic epistemic-acutisation difficulty-for, residualising $\{$ \{decompulsing\} delinearity for-cogency> - magnitudes $\{$ of-experientiality/experiment\} $\}$ this effectively speaks to the 'psychologismic-transfixity-<placeholder-setup-ontologicalrescheduling - in-realigning/preactivity/formative-becoming/psychoanalytical-unshackling,-asto-residualising_\{decompulsing $\}$ delinearity-over-nonresidualising_\{compulsing $\}$ linearity $>$ of human consciousness' (so-construed herein as of human-consciousness/collective-consciousnessdistendedness/detruncating-<beyond-selfpresencing,-as-re-ontologising-decentering_ofconsciousness/collective-consciousness,-as-to-psychologismic-epistemic-acutisationresidualising, ${ }^{\text {fdecompulsing }}$ delinearity $\sim$ for-cogency $>$ notionally/epistemically/bindingnessly-<as-todeterminism/conceptivity-of relative-mreflexivity/relative-reflexivityz effusing 'psychologismic-transfixity$<$ placeholder-setup-ontological-rescheduling - in-realigning/preactivity/formativebecoming/psychoanalytical-unshackling,-as-to-residualising-\{decompulsing ${ }^{\text {\{delinearity-over- }}$ nonresidualising_\{compulsing linearity $>$ with respect to 'idiosyncratic-ferment_fornotional cogency-〈as-to- $<$ surrealising/supererogating-drive $>$-of-aestheticising 
relief/depth-and-impetus $\quad$ imbuing-<by-needling/prying/prospecting-for-'phasing-androoting'>-of interlay/organicalism/aestheticising-handle-<of-'psychologismictransfixity\{residualising_\{decompulsing $\}$ delinearity-over-nonresidualising \{compulsing\} linearity\}’’’ of reifying/dereifying mental-aestheticising-<as-‘psychologismic-existential-metaphoricity $\underset{\text { as }}{ }-$ to '́pistemic-totalising ’’re apriorising/re axiomatising/re referencing_in becomingt' -so-implicited‘by-way-of-the-existentially/contextually/textually-manifest-motif-construct-as-specificlanguage'-as-so-reflecting-'the-existentially/contextually/textually-manifestmoronisation/demoronisation'>'); in so-reflecting notionally/epistemically/bindingnessly-<as-todeterminism/conceptivity-of-relative-unreflexivity/relative-reflexivitys the failing or prospect of 're-ontologising \{epistemic-totalising 're-apriorising/re-axiomatising/re-referencing residuality in-reeriginariness/re-origination $\{$ \{decompulsing\} delinearity/delinear-accreting/recomposuring cogency/tensing/limpidity-<as-of-prospective-profound-supererogation ,-for-residuality-inre-originariness/re-origination>,-prospective_reifying mental-aestheticising-<as-of 'prospective_reformulating of -mental-aestheticising'as-to-'residuality in re-originariness/reorigination' of -mental-aestheticising >' (imbued 'human psychologismic-epistemic-acutisation$<$ as-to-postconverging-de-mentating/structuring/paradigming,-eliciting-of-existence'ssublimating-nascence-in-prospective-aporeticism-overcoming/unovercoming $>$ as to epistemicgrowth,-as-\{veridical/sound\}-relative-reflexivity-in-existence/relativising from-limitedmentation-as-its-deepening/psychologismic epistemic-acutisation residualising, \{decompulsing delinearity for-cogency'), and so respectively as to human psychologismic implications as of presencing absolutising-identitive-constitutedness 'existential<disontologising/re ontologising aporeticism> preconverging dementating/structuring/paradigming punctual/immediacy/constituted/compulsions-encumbered prior mere-formulaicity/ritualisation rationalisation-ofcontentivity/argumentativity/dialecticism/discursivity' or nonpresencing-<perspective- 
aporeticism $>$ prospect of human individual-consciousness/collective-consciousness decompulsion-appraisal'. The psychologismic-transfixity-<placeholder-setup-ontologicalrescheduling - in-realigning/preactivity/formative-becoming/psychoanalytical-unshackling,-asto-residualising_\{decompulsing $\}$ delinearity-over-nonresidualising_\{compulsing $\}$ linearity $>$ as of humanconsciousness/collective-consciousness-distendedness/detruncating- $<$ beyond-selfpresencing,as-re-ontologising-decentering_of-consciousness/collective-consciousness,-as-topsychologismic-epistemic-acutisation - residualising, - speaking of prospective 're-ontologising referencing residuality in-re-originariness/re-origination $\quad\{$ decompulsing $\}$ delinearity/delinearaccreting/recomposuring cogency/tensing/limpidity-<as-of-prospective-profoundsupererogation ,-for-residuality_in-re-originariness/re-origination>-oprospective_reifying mental-aestheticising_<as-of-prospective_reformulating-of-mental-aestheticising'as-to'residuality in-re-originariness/re-origination' of-mental-aestheticising ${ }^{\prime}$ (so-arising as of 'human psychologismic-epistemic-acutisation-<as-to-postconverging-dementating/structuring/paradigming,-eliciting-of-existence's-sublimating-nascence-inprospective-aporeticism-overcoming/unovercoming > as to epistemic-growth,-as\{veridical/sound\}-relative-reflexivity-in-existence/relativising from-limited-mentation-as-itsdeepening/psychologismic epistemic-acutisation residualising, \{decompulsing $\}$ delinearity for eogency' educed as of the 'firstnaturedness-as-to-inkling profound-supererogation for overarching existential-<disontologising/re-ontologising aporeticism $>$ priority/precedence/primacy of \{epistemic-totalising ${ }^{3}$ re-apriorising/re-axiomatising/rereferencing $\sim$ residuality—in-re-originariness/re-origination projection' in 'recurrent/perpetuating/continuity-recomposuring existential-<disontologising/reentologising aporeticism $>$ counteracting/supplanting/alienating-of-prior- 
apriorising/axiomatising/referencing' over 'secondnatured prior mere-formulaicity/ritualisation<as-to-mere-formulaic — methodologising/mutualising/organising/institutionalising,-

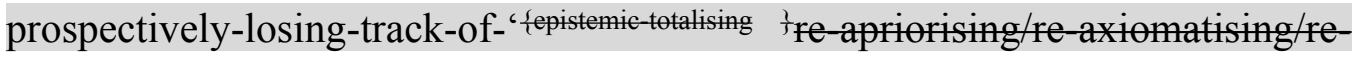
referencing $\sim$ residuality - in-re-originariness/re-origination'>'), is the very reflection of prospective 'apriorising/axiomatising/referencing disambiguating/de-leveling/deressentiment/opened-construct-of- ${ }^{5}$ meaningfulness-and-teleology 99 demoronisation<sublimating-nascence,-nonextricatory-sublimating-upstreaming/'amontée'>'; as to the ontologising/scientific/existence- $<$ honesty-constraining $>$ - scope_for_prospective_reontologising very own 'profoundsupererogation $\sim$ reframing/reformulation/decatchmenting/detruncating/decompulsing/delinear ising - as-to-postconverging de-mentating/structuring/paradigming imbued re-rationalisationof-contentivity/argumentativity/dialecticism/discursivity' as of prospective re-ontologising <postconverging 'motif-and-apriorising/axiomatising/referencing'-entailing >-

existentialising - framing/imprinting-_as-to-prospective- historiality/ontologicaleventfulness /ontological-aesthetic-tracing-<perspective-ontologicalnormalcy/postconvergence-reflected-‘epistemicity-relativism-determinism' $>\rangle$. The point here is that in-many-ways 'prospective disontologising and pedantising/muddling/formulaichollowing-out - in-subontologisation/subpotentiation-〈blurring/undermining-of-prospectivetotalising-entailing,-as-to-entailing-<amplituding/formative-epistemicity $>$ totalising $\sim$ inrelative-ontological-completeness 〉' supposed pretense to 'shallowsupererogation $\sim$ framing/formulation/catchmenting/truncating/compulsing/linearising —as-topreconverging de-mentating/structuring/paradigming rationalisation-ofcontentivity/argumentativity/dialecticism/discursivity' is psychologismically caught up in the prior disontologising <preconverging 'motif-and-apriorising/axiomatising/referencing' entailing >-existentialising — enframing/imprintedness-〈as-to- historicity-tracing —in- 

apriorising/axiomatising/referencing-sublimating-reflexivity-beholdening under which limitedness/human-subpotency submits in profound-supererogation for prospective sublimating'), and rather speaks to its 'nihilistic knowledge-deadends- $<$ as-preconverging-dementating/structuring/paradigming $>$ undermining prospective re-ontologising' (as not resolvable as of prior presencing absolutising identitive-constitutedness 'existential$\leqslant$ disontologising/re-ontologising aporeticism $>$ preconverging dementating/structuring/paradigming punctual/immediacy/constituted/compulsions-encumbered prior mere-formulaicity/ritualisation rationalisation-of-

contentivity/argumentativity/dialecticism/discursivity but rather as of prospective profoundsupererogation for nonpresencing-<perspective-ontological-normalcy/postconvergence $>$ 'existential-<disontologising/re-ontologising aporeticism $>$ prospect of human individualconsciousness/collective-consciousness decompulsion-appraisal, in reflection of 'unlimitedness/existence-<full-potency-of_sublimating nascence> prospective apriorising/axiomatising/referencing-sublimating-reflexivity-beholdening under which limitedness/human-subpotency submits in profound-supererogation for prospective sublimating'); as manifested with non-universalising ancient-sophists and non-positivising medieval-scholasticism as not being the appropriate re-ontologising 'profoundsupererogation $\sim$ reframing/reformulation/decatchmenting/detruncating/decompulsing/delinear ising - as-to-postconverging de-mentating/structuring/paradigming imbued re-rationalisationof-contentivity/argumentativity/dialecticism/discursivity' respectively as to requisite Socraticphilosophers ${ }^{103}$ universalising-idealisation or budding-positivists positivism/rationalempiricism. For instance the 'relays of human intemporal-individuation epistemic-projection radicalities $\sim$ in-chronicular/annalistic-cogency-<as-of-notional $\sim$ protensivity $>$-〈as-to-limited- 
cogency_chronicularity/annality-of-relative-reflexivity,-as-to-profound-supererogation ${ }^{9}$ (as to a 'despite-the-self exercise of epistemic-projection in notional $\sim$ self-distantiation-<imbued-remotif-and-re-apriorising/re-axiomatising/re-referencing >') can be reflected with buddingpositivists like Galileo, Descartes, Newton, Leibniz, etc. as actually 'reaching/arriving-at their respective positivism/rational-empiricism sublimating limits' by the mere fact that they were not of sufficient positivism/rational-empiricism relative-ontological-completeness ${ }^{8}$-ofapriorising/axiomatising/referencing epistemic-projection radicalities $\sim$ inchronicular/annalistic-cogency-<as-of-notional $\sim$ protensivity $>-\langle$ as-to-limited-mentationcapacity-deepening — as-subjecting limitedness/human-subpotency to-'educedunlimitedness/existence-sublimating nascence' so-construed cogency_chronicularity/annality-of-relative-reflexivity,-as-to-profound-supererogation imbued prospective positivism/rational-empiricism <postconverging 'motif-andapriorising/axiomatising/referencing'-entailing>-existentialising-framing/imprinting-〈as-toprospective- historiality/ontological-eventfulness /ontological-aesthetic-tracing$<$ perspective-ontological-normalcy/postconvergence-reflected-'epistemicity-relativismdeterminism' $>>$ (as 'still caught up in their various successive extents in medieval-scholasticism relative-ontological-incompleteness ${ }^{8}$-of-apriorising/axiomatising/referencing' imbued prior occulticising <preconverging 'motif-and-apriorising/axiomatising/referencing'-entailing >existentialising — enframing/imprintedness-〈as-to- historicity-tracing_-in-presencinghyperrealisation/hyperreal-transposition〉). In this regards, (as to requisite re-ontologising 'profoundsupererogation $\sim$ reframing/reformulation/decatchmenting/detruncating/decompulsing/delinear ising - as-to-postconverging de-mentating/structuring/paradigming imbued re-rationalisation- 
ontologising_by-postconverging-as-to-dragged-out-supererogatory -wholesomeness/profoundsupererogation ,-while-anecdotalising-prior-disontologising-thresholding $>$ of nascentparticular/incipient-and-material/technical-sublimations- $<$ blinded-to-their-relative-ontologicalcompleteness - reference-of-thought- devolving $>$

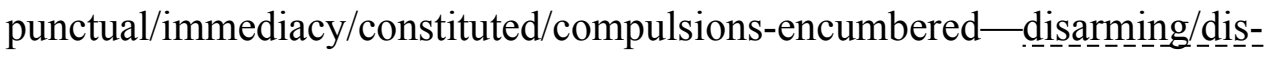

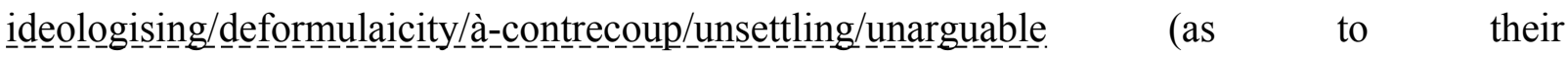
'unlimitedness/existence-<full-potency-of_sublimating nascence> prospective apriorising/axiomatising/referencing-sublimating-reflexivity-beholdening under which limitedness/human-subpotency submits in profound-supererogation for prospective sublimating') is more readily amenable to the posteriority/exteriorisation of the 'ontologising/scientific/existence- $<$ honesty-constraining $>$ — scope_for_prospective_reontologising implications of existential-<disontologising/re-ontologising aporeticism $>$ counteracting/supplanting/alienating-of-prior-apriorising/axiomatising/referencing' (in contrast to the blurriness-<sterilising/anecdotalising/trivialising-of-prospective-re-ontologising_bypreconverging,-in-disontologising-formulaic-dragging-out/hollowing-out> of many a human social-and-institutional-frameworks-of — referencing/registering/decisioning existentialisingdecisionality-<as-to-disontologising/re-ontologising aporeticism $>$ as prone to a presencing-absolutising-identitive-constitutedness ${ }^{14}$ accessorising of 'ordinary laypersonhood arrogation/presumptuousness' conception of supposedly prospective sublimation with regards to the associated secondnaturing 'poor requisite prospective retention of profoundsupererogation" for prospective 'existential-<disontologising/re-ontologising aporeticism $>$

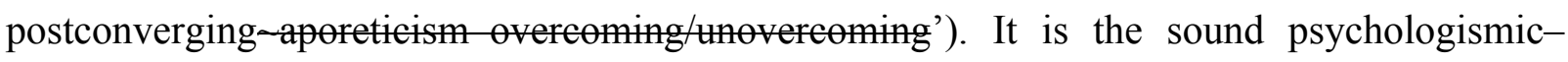
transfixity-<placeholder-setup-ontological-rescheduling -in-realigning/preactivity/formativebecoming/psychoanalytical-unshackling,-as-to-residualising-\{decompulsing\} $d$ delinearity-over- 
nonresidualising-\{compulsing\} linearity $>$ as of human-consciousness/collective-consciousnessdistendedness/detruncating-<beyond-selfpresencing,-as-re-ontologising-decentering_ofconsciousness/collective-consciousness,-as-to-psychologismic-epistemic-acutisation

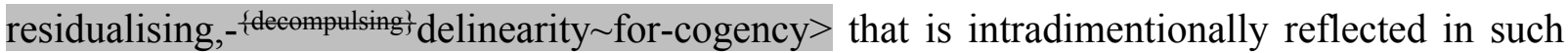
profound-

supererogation $\sim$ reframing/reformulation/decatchmenting/detruncating/decompulsing/delinear ising_scale_-of-transparent/noncontentious/un-nominalised/sound-interpretations/domains of manifest unblurriness-<re-ontologising_by-postconverging-as-to-dragged-outsupererogatery $\sim$ wholesomeness/profound-supererogation ,-while-anecdotalising-priordisontologising-thresholding $>\quad$ imbued ontologising/scientific/existence- $<$ honestyconstraining $>$ — scope_for_prospective_re-ontologising requisite nonpresencing$<$ perspective-ontological-normalcy/postconvergence $>\quad$ epistemic-projection ‘implicited/explicited psychologismic-epistemic-acutisation-residualising \{epistemicthermeneutic/textuality/reprojecting/supererogating/zeroing/re-acuting,sdecolinearity for-cogency' successive profound/state-of-the-art sublimating prospective re-ontologising with respect to the-very-same purview/devolvedpurview/devolving-purview-of-unlimitedness/existence-full potencof_sublimating nascence>;-_implicited_attendant-ontological-contiguity ${ }^{67}$ ' educedexistentialising/contextualising/textualising_intelligibility/epistemicity/reflexivity-contiguity<imbued-notional cogency>' $>^{\text {4 }}$ (in sontrast to shallowsupererogation $\sim$ framing/formulation/catchmenting/truncating/compulsing/linearising_scale —of-opaque/contentious/un-nominalised/flawed-interpretations/domains of manifest blurriness-<sterilising/anecdotalising/trivialising-of-prospective-re-ontologising_bypreconverging,-in-disontologising-formulaic-dragging-out/hollowing-out> of ${ }^{79}$ presencingabsolutising-identitive-constitutedness ${ }^{14} \quad$ epistemic-projection 'implicited/explicited 
punctual/immediacy/constituted/compulsions-encumbered-hypothesisation reproducibility'). It is herein contended (with respect to psychologismic-transfixity-<placeholder-setupontological-rescheduling - in-realigning/preactivity/formative-becoming/psychoanalyticalunshackling,-as-to-residualising_\{decompulsing ${ }^{\text {\{ }}$ delinearity-over-nonresidualising\{compulsing\} linearity $>\quad$ as $\quad$ of human-consciousness/collective-consciousnessdistendedness/detruncating-<beyond-selfpresencing,-as-re-ontologising-decentering_ofconsciousness/collective-consciousness,-as-to-psychologismic-epistemic-acutisation-

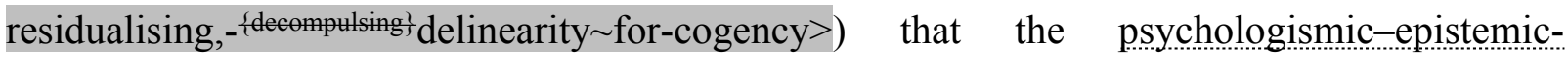
acutisation-difficulty- $<$ for,-residualising $-\{$ decompulsing $\}$ delinearity $\sim$ for-cogency $>-\langle$ as-ofrequisite-profound-supererogation -for-'disposedness-or-psychologismic-construct'\{imbued-demoronisation-<sublimating-nascence,-nonextricatory-sublimatingupstreaming/'amontée’> $>$ ) (as to presencing absolutising identitive-constitutedness 'existential-<disontologising/re-ontologising aporeticism $>$ preconverging dementating/structuring/paradigming punctual/immediacy/constituted/compulsions-encumbered prior mere-formulaicity/ritualisation rationalisation-ofcontentivity/argumentativity/dialecticism/discursivity') manifested with shallowsupererogation $\sim$ framing/formulation/catchmenting/truncating/compulsing/linearising_scale —of-opaque/contentious/un-nominalised/flawed-interpretations/domains of manifest blurriness-<sterilising/anecdotalising/trivialising-of-prospective-re-ontologising_bypreconverging,-in-disontologising-formulaic-dragging-out/hollowing-out> of ${ }^{79}$ presencingabsolutising-identitive-constitutedness ${ }^{14} \quad$ epistemic-projection 'implicited/explicited punctual/immediacy/constituted/compulsions-encumbered-hypothesisation reproducibility' (as effectively translating into the misconstrual of the-very-same purview/devolvedpurview/devolving-purview-of-unlimitedness/existence-<full-potency-of_sublimating nascence >; - 'implicited_attendant-ontological-contiguity ${ }^{6}$ ' educed- 
existentialising/contextualising/textualising_intelligibility/epistemicity/reflexivity-contiguity$<$ imbued-notional cogency $>^{\prime 0}$ ), not only underlies a ${ }^{79}$ presencing-absolutising-identitiveconstitutedness ${ }^{14} \quad$ 'nihilistic knowledge-deadends- $<$ as-preconverging-dementating/structuring/paradigming $>$ undermining prospective re-ontologising' of the prospective sublimating possibilities of many a social and psychological sciences but equally speaks to their susceptibility to confusion/misuse/misapprehension; and so fundamentally/incipiently/seedingly as to a failure to factor in their very own 'despite-the-self exercise of epistemic-projection in notional $\sim$ self-distantiation- $<$ imbued-re-motif-and-reapriorising/re-axiomatising/re-referencing >' in other to prospectively accord sublimatingly with the-very-same purview/devolved-purview/devolving-purview-of-unlimitedness/existence<full-potency-of_sublimating nascence>;-_'implicited_attendant-ontologicalcontiguity $^{67} \sim$ educedexistentialising/contextualising/textualising_intelligibility/epistemicity/reflexivity-contiguity<imbued-notional cogency $>^{\prime}$ before even the exercise of prospective knowledge elucidation. In other words, this is tantamount to ancient-sophists non-universalising or medievalismscholasticism non-positivising manifesting a prospectively 'overall unthought/uncontemplated/mere-reflex/shallow/unsound gesturing/accounting-of-epistemicphenomenalism' impliciting that the-very-same purview/devolved-purview/devolvingpurview-of-unlimitedness/existence-<full-potency-of_sublimating nascence $>$; 'implicited_attendant-ontological-contiguity ${ }^{67}$ educedexistentialising/contextualising/textualising_'intelligibility/epistemicity/reflexivity-contiguity<imbued-notional cogency>' 'is available for absolute sublimating knowledge and transcendence-and-sublimity/sublimation/superentativity' without undergoing their very own 'despite-the-self exercise of epistemic-projection in notional $\sim$ self-distantiation<imbued - re-motif-and-re-apriorising/re-axiomatising/re-referencing >' as of profound- 
supererogation; as to the need to imply that it is as from the 'overall profound/sound gesturing/accounting —of-epistemic-phenomenalism' respectively of ${ }^{103}$ universalisingidealisation and positivism/rational-empiricism that prospective re-ontologising sublimating could arise. This speaks to the inherent presumptuousness of the human mindset in its intragenerational framework of 60 to 100 years to claim to surmise the possibility/potential of the-very-same purview/devolved-purview/devolving-purview-of-unlimitedness/existence<full-potency-of_sublimating nascence>;-_implicited_attendant-ontologicalcontiguity ${ }^{67} \sim$ educedexistentialising/contextualising/textualising_'intelligibility/epistemicity/reflexivity-contiguity<imbued-notional cogency>' as of its given processive-motif-exuding aestheticising gesturing' of-apriorising/axiomatising/referencing _imbued_notional $\sim$ reductionism- $<$ ofexistential-prospection,-whether-as-of-trepidatious/warped/preclusive/occlusive/protensivenotional reductionism $>$ (so-explaining the multicenturies long patchy experientiality/experiment-<as-to-existentially-formative-' fepistemic axiomatising/re-referencing residuality - in-re-originariness/re-origination',- so"notionally/epistemically/bindingnessly-<as-to-determinism/eoneeptivity-of-relative-unreflexivity/relative-reflexivity> implicited-and-articulated' as-from-nonextricatory-'prospective-re-ontologising-Being-thenInstitutional-then-Living-magnitudes-of- hhermeneutic/reprojection-protraction-offreframingand-reformulation $\}^{\prime}>$ of human registry-worldviews/dimensions since human prehistoricity as to recurrent prospective disontologising/subontologising manifestation of presencing absolutising-identitive-constitutedness 'existential-<disontologising/re-ontologising aporeticism> preconverging de-mentating/structuring/paradigming punctual/immediacy/constituted/compulsions-encumbered prior mere-formulaicity/ritualisation rationalisation-of-contentivity/argumentativity/dialecticism/discursivity'); with that presumptuousness as to presencing absolutising identitive-constitutedness 'existential- 
mentating/structuring/paradigming punctual/immediacy/constituted/compulsions-encumbered prior mere-formulaicity/ritualisation rationalisation-of-

contentivity/argumentativity/dialecticism/discursivity' explaining the psychologismic epistemic-acutisation — difficulty- $<$ for,-residualising $-\{$ decompulsing $\}$ delinearity $\sim$ for-cogency $>-\langle$ asof-requisite-profound-supererogation -for-'disposedness-or-psychologismic-construct'-

\section{\{imbued-demoronisation-<sublimating-nascence,-nonextricatory-sublimating-}

upstreaming/'amontée'> $>\rangle$ for human notional $\sim$ self-distantiation- $<$ imbued-re-motif-and-reapriorising/re-axiomatising/re-referencing $>^{\prime}$ as of profound-supererogation especially as manifested with shallow supererogation $\sim$ framing/formulation/catchmenting/truncating/compulsing/linearising_scale —of-opaque/contentious/un-nominalised/flawed-interpretations/domains of manifest blurriness-<sterilising/anecdotalising/trivialising-of-prospective-re-ontologising_bypreconverging,-in-disontologising-formulaic-dragging-out/hollowing-out $>$ of ${ }^{79}$ presencingabsolutising-identitive-constitutedness ${ }^{14} \quad$ epistemic-projection 'implicited/explicited punctual/immediacy/constituted/compulsions-encumbered-hypothesisation reproducibility' (and as so-marked by their considering of broad swathes of requisite human 'comprehensive coherence/contiguity/noncontradiction of overall experientiality/experiment-<as-toexistentially-formative-' referencing $\sim$ residuality - in-re-originariness/re-origination',- - so'notionally/epistemically/bindingnessly-as-to-determinism/conceptivity-of-relative-unreflexivity/relative-reflexivity $>$ implicited-and-articulated'_as-from-nonextricatory-'prospective-re-ontologising-Being-thenInstitutional-then-Living-magnitudes-of-\{hermeneutic/reprojection -protraction-of $\}$ reframingand-reformulation \}'>' as nondescript/ignorable-void ${ }^{60}$ or undefined, as so-failing to reflect requisite "epistemic-totality ${ }^{37}$ of ${ }^{56}$ meaningfulness-and-teleology ${ }^{99}$ as to phenomenality-and- 
epiphenomenality'). Such a lack-of/deficient 'despite-the-self exercise of epistemic-projection in notional $\sim$ self-distantiation- $<$ imbued — re-motif-and-re-apriorising/re-axiomatising/rereferencing >' as of profound-supererogation is effectively what undergirds an impoverished conception of knowledge as to a presencing-absolutising-identitive-constitutedness 'normalised/stereotyped/selfhelping/feel-good knowledge being brought at the protractedsocial—as-to-individual-by-institutional-by-social sovereign's service' (which again fails to elicit a 'despite-the-self exercise of epistemic-projection in notional $\sim$ self-distantiation$<$ imbued —re-motif-and-re-apriorising/re-axiomatising/re-referencing >'). It is herein contended ultimately that ${ }^{7}{ }^{7}$ presencing — absolutising-identitive-constitutedness ${ }^{14}$ as to dominance/vestedinterest and institutional-prescience purposefulness' increasingly comes to supersede and define consciously/unconsciously a relationship (as to presencing absolutising-identitiveconstitutedness 'existential-<disontologising/re-ontologising aporeticism $>$ preconverging de-mentating/structuring/paradigming punctual/immediacy/constituted/compulsionsencumbered prior mere-formulaicity/ritualisation rationalisation-ofcontentivity/argumentativity/dialecticism/discursivity') undermining a re-originariness/reorigination exercise with the-very-same purview/devolved-purview/devolving-purview-ofunlimitedness/existence-full potency of_sublimating nascence>;-_implicited_attendantontological-contiguity ${ }^{67}$, educedexistentialising/contextualising/textualising_intelligibility/epistemicity/reflexivity-contiguity$<$ imbued-notional cogency $>$. Such that beyond such purposefulness what is exactly lacking is an overall human social imaginary of the ontologising/scientific/existence- $<$ honestyconstraining $>$ — scope_for_prospective_re-ontologising (so-undermined as to lack of veridical psychologismic-transfixity-<placeholder-setup-ontological-rescheduling-inrealigning/preactivity/formative-becoming/psychoanalytical-unshackling,-as-to-residualising\{decompulsing $\}$ delinearity-over-nonresidualising_\{compulsing\} linearity $>$ as of human- 
consciousness/collective-consciousness-distendedness/detruncating- $<$ beyond-selfpresencing,as-re-ontologising-decentering_of-consciousness/collective-consciousness,-as-topsychologismic-epistemic-acutisation-residualising, ${ }^{-\{\text {decompulsing }}$ delinearity $\sim$ for-cogency $>$ ), and so beyond the naivety that an instrumentalising emphasis is up to the task of humanconsciousness/collective-consciousness-distendedness/detruncating-<beyond-selfpresencing,as-re-ontologising-decentering_of-consciousness/collective-consciousness,-as-topsychologismic-epistemic-acutisation — residualising, ${ }^{-\{\text {decompulsing }}$ delinearity $\sim$ for-cogency $>$ (veridically undergirded recurrently as of 'overarching existential-<disontologising/reentelogising aporeticism $>$ priority/precedence/primacy of requisite prospective ontologicalgood-faith/authenticity $\sim$ postconverging-de-mentating/structuring/paradigming inducing of psychoanalytic-unshackling for the relative-ontological-completeness ${ }^{87}$-ofapriorising/axiomatising/referencing re-ontologising prospective re-rationalisation-ofcontentivity/argumentativity/dialecticism/discursivity'); as not putting-into-question the very mental development (as to epistemic-growth,-as - \{veridical/sound\}-relative-reflexivity-inexistence/relativising from limited-mentation-as-its-deepening/psychologismic epistemicacutisation residualising, ${ }^{\text {\{decompulsing }}$ delinearity for-cogency) of that which the instrumentalising purposefulness is supposedly being advanced for. It is herein contended (with regards to the-very-same purview/devolved-purview/devolving-purview-ofunlimitedness/existence-<full-potency-of_sublimating nascence $>$;_- implicited_attendant ontological-contiguity ${ }^{67}$; educedexistentialising/contextmalising/textualising_'intelligibility/epistemicity/reflexivity-contiguity<imbued-notional cogency>' ${ }^{40}$ as to 'unlimitedness/existence-<full-potency-of_sublimating nascence $>$ prospective apriorising/axiomatising/referencing-sublimating-reflexivity beholdening under which limitedness/human-subpotency submits in profound-supererogation for prospective sublimating') that just as the occulticising sciences of medieval-scholasticism (as 
apriorising/axiomatising/referencing - as-to-preclusive-

consciousness $\sim$ moronisation/demoronisation) pointed by-and-large to a requisite 'despite-theself exercise of epistemic-projection in notional $\sim$ self-distantiation- $<$ imbued-re-motif-and-reapriorising/re-axiomatising/re-referencing ${ }^{\prime}$ ' as putting-into-question the veracity of the medieval-scholasticism mental development for enabling the sublimating potential of science inthe-very-first-place (as to requisite positivism/rational-empiricism sublimating prospective reference-of-thought—point-of-devolving/departure/anchoring/backdrop_of_sublimatingnascence-<as-to-the-grandest-axiomatic-construct- tepistemic-alsing $\frac{1}{7}$ re-apriorising/reaxiomatising/re-referencing $\sim$ residuality - in-re-originariness/re-origination limitedness/human-subpotency prospective re-encountering/re-confrontation with unlimitedness/existence $>$ ), by-and-large our positivism- ${ }^{8}$ procrypticism (as of subtranslationalprocessive-motif-'exuding aestheticising-gesturing' of apriorising/axiomatising/referencing procrypticism/disjointedness-as-of- ${ }^{83}$ reference-of-thought) 'occluding ${ }^{83}$ reference-of-thoughtdevolving' manifestation of administrative, educational, marketing, psychoanalysis or even statal dark-arts/ploys/gimmicks (and as vicariously disontologising/subontologising even upon nascent-particular/incipient-and-material/technical-sublimations- $<$ blinded-to-their-relativeontological-completeness - reference-of-thought- devolving $>$ ) speaks to its very own requisite 'despite-the-self exercise of epistemic-projection in notional $\sim$ self-distantiation<imbued —re-motif-and-re-apriorising/re-axiomatising/re-referencing $>^{\prime}$ (as to prospective deprocrypticism-or-preempting-disjointedness-as-of- ${ }^{83}$ reference-of-thought sublimating reference-of-thought_-point-of-devolving/departure/anchoring/backdrop_of_sublimatingnascence-<as-to-the-grandest-axiomatic-construct-\{epistemic-totalising łre apriorising/re- 
unlimitedness/existence>). Critically, such positivism- ${ }^{80}$ procrypticism 'occluding ${ }^{8}$ referenceof-thought- devolving' (manifestations as of various human institutional crises and malaises) go on to effectively contemplate about everything else 'but for the contemplation of a noninstrumentalising re-conception' (as to projecting notionally/epistemically/bindingnessly-<as-todeterminism/conceptivity-of-relative-unreflexivity/relative-reflexivitys beyond the instrumentally associated secondnaturing 'poor requisite prospective retention of profound-supererogation' for prospective 'existential-<disontologising/re-ontologising aporeticism $>$ postconverging aporeticism-overcoming/unovereoming'); and so, with regards to the requisite ontologising/scientific/existence- $<$ honesty-constraining $>$ — scope_for_prospective_reontologising nonpresencing-<perspective - ontological-normalcy/postconvergence> 'existential-<disontologising/re-ontologising aporeticism $>$ prospect of human individualconsciousness/collective-consciousness decompulsion-appraisal' re-conception (of the-verysame $\quad$ purview/devolved-purview/devolving-purview-of-unlimitedness/existence-<fullpotency-of_sublimating nascence>; - 'implicited_attendant-ontologicalcontiguity $^{67} \sim$ educedexistentialising/contextualising/textualising_intelligibility/epistemicity/reflexivity_contiguity<imbued-notional cogency>' nascence $>$ prospective apriorising/axiomatising/referencing-sublimating-reflexivitybeholdening under which limitedness/human-subpotency submits in profound-supererogation for prospective sublimating'). This in-many-ways is symbolic of human institutionally manifest presencing - absolutising-identitive-constitutedness ${ }^{14}$ 'nihilistic knowledge-deadends- $<$ aspreconverging-de-mentating/structuring/paradigming $>$ undermining prospective reontologising', with this elucidated 'nihilistic veracity' paradoxically 'so-marginally appraised' or 'construed as nondescript/ignorable-void' or undefined as a reflection of 'our given positivism- ${ }^{80}$ procrypticism/disjointedness-as-of- ${ }^{-3}$ reference-of-thought presencing- 
absolutising-identitive-constitutedness ${ }^{14}$ prospective psychologismic-epistemic-acutisationdifficulty- $<$ for,-residualising_\{decompulsing $\}$ delinearity $\sim$ for-cogency $>-\langle$ as-of-requisite-profoundsupererogation -for-'disposedness-or-psychologismic-construct'-\{imbued-demoronisation$<$ sublimating-nascence,-nonextricatory-sublimating-upstreaming/'amontée' $>\}\rangle$ dilemma' as so-arises with all registry-worldviews/dimensions given < amplituding/formative-epistemicity $>$ totalising thrownness-in-existence ${ }^{3}$ - as imbued of limitedness/human-subpotency prospective dearth for tre-apriorising/re-axiomatising/rereferencing $\sim$ residuality —in-re-originariness/re-origination projection); with human 'nihilistic knowledge-deadends-<as-preconverging-de-mentating/structuring/paradigming $>$ undermining prospective re-ontologising' not resolvable as of prior presencing absolutising identitiveconstitutedness 'existential-<disontologising/re-ontologising aporeticism $>$ preconverging de-mentating/structuring/paradigming punctual/immediacy/constituted/compulsionsencumbered prior mere-formulaicity/ritualisation rationalisation-ofcontentivity/argumentativity/dialecticism/discursivity but rather as of prospective profoundsupererogation for nonpresencing-<perspective-ontological-normalcy/postconvergence> 'existential-<disontologising/re-ontologising aporeticism $>$ prospect of human individualconsciousness/collective-consciousness decompulsion-appraisal, in reflection of 'unlimitedness/existence-<full-potency-of_sublimating nascence> prospective apriorising/axiomatising/referencing-sublimating-reflexivity-beholdening under which limitedness/human-subpotency submits in profound-supererogation for prospective sublimating'. The human psychologismic-epistemic-acutisation-difficulty- $<$ for,residualising_- delinearity for-cogency $>-\langle$ as-of-requisite-profound-supererogation for-'disposedness-or-psychologismic-construct'-\{imbued-demoronisation-<sublimatingnascence,-nonextricatory-sublimating-upstreaming/‘amontée’>\}) as such speaks to the 'upsidedown' human relationship (as to presencing absolutising-identitive-constitutedness 
mentating/structuring/paradigming punctual/immediacy/constituted/compulsions-encumbered prior mere-formulaicity/ritualisation rationalisation-of-

contentivity/argumentativity/dialecticism/discursivity') with respect to the ontological-veracity of 'unlimitedness/existence-<full-potency-of_sublimating nascence $>$ prospective apriorising/axiomatising/referencing-sublimating-reflexivity-beholdening under which limitedness/human-subpotency submits in profound-supererogation for prospective sublimating'; such that 'limitedness/human-subpotency reflex epistemic-projection' wrongly implies the 'shallowsupererogation $\sim$ framing/formulation/catchmenting/truncating/compulsing/linearising —as-topreconverging de-mentating/structuring/paradigming priority/precedence/primacy' of livingdevelopment-as-to-personality-development psychologismic epistemic-acutisationdifficulty-<for, residualising _\{decompulsing $\}$ delinearity for-cogency> magnitude $\{$ ofexperientiality/experiment\} and then institutional-development-as-to-social-function-development psychologismic epistemic-acutisation difficulty-for, residualising $\{$ \{lecompulsing $\}$ delinearity for-cogenc $y>$ magnitude $\{$ of-experientiality/experiment\} precede/supersede Beingdevelopment/ontological-framework-expansion-as-to-depth-of-ontologising-development-asinfrastructure-of- meaningfulness-and-teleology psychologismic epistemic acutisationdifficulty < for, residualising \{decompulsing $\}$ delinearity for-cogeney> magnitude $>$ \{ofexperientiality/experiment\} (as to an incrementalism-in-relative-ontological-incompleteness 8 enframed/disontologising conceptualisation) and so-construed as ${ }^{7}{ }^{7}$ presencing-absolutisingidentitive-constitutedness ${ }^{14} \quad$ epistemic-projection imbued moronisation- $<$ sublimatingnascence,-desublimating-downstreaming/'avalage'>'. This so-fails to appraise that 'ontological-veracity rather lies inherently with unlimitedness/existence-<flll-potencyof_sublimating nascence> and not limitedness/human-subpotency' thus speaking rather to the 
inherent precedence/supersedingness of Being-development/ontological-framework-expansionas-to-depth-of-ontologising-development-as-infrastructure-of- meaningfulness-andteleology psychologismic epistemic-acutisation difficulty < for, residualising \{decompulsing\} delinearity for-cogency>-magnitude\{of-experientiality/experiment\} as defining the sublimating prospect for institutional-development-as-to-social-function-development psychologismic epistemic-acutisation difficulty-<for, residualising $\{$ decompulsing $\}$ delinearity for-cogeney $>$ magnitude $\{$ of-experientiality/experiment $\}$ and living-developmentas-to-personality-development psychologismic epistemic acutisation difficulty-for, residualising \{dempuring\} delinearity for-cogency>-magnitude \{of-experientiality/experiment\} (and so reflected as to the precedence/supersedingness of having the right/correct sublimating mental development as to reference-of-thought—point-ofdevolving/departure/anchoring/backdrop_of_sublimating-nascence-<as-to-the-grandestaxiomatic-construct-\{epistemic-totalising ${ }_{3}^{+}$re-apriorising/re-axiomatising/rereferencing residuality - in-re-originariness/re-origination of limitedness/human-subpotency prospective re-encountering/re-confrontation with unlimitedness/existence $>$ ); as so-underlying the requisite limitedness/human-subpotency 'despite-the-self exercise of epistemic-projection in notional $\sim$ self-distantiation- $<$ imbued—re-motif-and-re-apriorising/re-axiomatising/rereferencing>' as of 'reclamation/recovery of ${ }^{55}$ maximalising-recomposuring-for-relativeontological-completeness ${ }^{87}$ - unenframed/re-ontologising conceptualisation' and so-construed as ' nonpresencing-<perspective-ontological-normalcy/postconvergence $>\quad$ epistemicprojection imbued demoronisation- $<$ sublimating-nascence,-nonextricatery-sublimatingupstreaming/'amontée’>'. This critically upside-down human relationship to ontologicalveracity (and as can be appreciated across successive uninstitutionalised-threshold ${ }^{102}$ including our positivism- ${ }^{80}$ procrypticism/disjointedness-as-of- ${ }^{83}$ reference-of-thought ${ }^{79}$ presencingabsolutising-identitive-constitutedness ${ }^{14}$ ) is reflected in the patent case of say a God-of-plane 
conception or superstitious conception of modern medicine in an animistic social-setup that cannot simply be construed as supposedly 'explained away by a circumstantial thorough positivism/rational-empiricism elucidation of how a plane or modern medicine works' since such an animistic social-setup existentialising-frame-of-entailment-of motif-andapriorising/axiomatising/referencing is so-thoroughly beholdening to its 'mystical/spirits nonpositivistic conception of things rationalisation-ofcontentivity/argumentativity/dialecticism/discursivity' going by its ingrained 's? reference-ofthought specific preconverging/dementing -qualia-schema' that at best only a circumstantial constraining is induced to its 'overall appraisal as of institutional-development-as-to-socialfunction-development psychologismic epistemic-acutisation difficulty-<for, residualising ${ }_{\text {\{decompulsing }}$ delinearity for-cogency $>$ magnitude $\{$ of-experientiality/experiment $\}$ and living-developmentas-to-personality-development psychologismic epistemic-acutisation difficulty-<for, residualising \{decompulsing\} \{elinearity for-cogency>-magnitude \{of-experientiality/experiment\}, (and not a positivism/rational-empiricism knowledge value as to prospective nonpresencing$<$ perspective-ontological-normalcy/postconvergence $>$ epistemic-projection) since the animistic mindset is bound to psychologismically fallback/relapse into such a 'mystical/spirits nonpositivistic conception of things rationalisation-ofcontentivity/argumentativity/dialecticism/discursivity' in reflection of the 'shallowsupererogation $\sim$ framing/formulation/catchmenting/truncating/compulsing/linearising —as-topreconverging de-mentating/structuring/paradigming mental-reflex hold' of its underlying prior animistic Being-development/ontological-framework-expansion-as-to-depth-of-ontologisingdevelopment-as-infrastructure-of- meaningfulness-and-teleology psychologismic epistemic acutisation diffieulty < for, residualising \{decompulsings delinearity for cogency> magnitude\{of-experientiality/experiment\} (so-reflected 'in the generationally ingrained animistic psychologismic apriorising/axiomatising/referencing-\{of-"prospectively 
implicited_attendant-ontological-contiguity ' educed-

existentialising/contextualising/textualising_intelligibility/epistemicity/reflexivity-contiguity<imbued-notional cogency>' $\}$-constitutedness ${ }^{14}$-in-preconverging-entailment' from which it has to crossgenerationally undergo psychoanalytic-unshackling/memeticreordering/institutional-recomposuring as from 'existentially-<disontologising/reentologising aporeticism $>$ manifest/phenomenal cumulating/recomposuring' of positivism/rational-empiricism epistemic-projection as of 'constraining existence-assublimating-withdrawal/unenframing/re-ontologising,-elicited-from-prospective-profoundsupererogation imbuing human ontological-commitment $-<$ implied-self-assuredness-ofontological-good-faith/authenticity $\sim$ postconverging-dementating/structuring/paradigming -as-being-as-of-existential-reality >'). It can hardly be expected that the systematicity/entailment of the requisite 'profoundsupererogation $\sim$ reframing/reformulation/decatchmenting/detruncating/decompulsing/delinear ising -as-to-postconverging-de-mentating/structuring/paradigming mental-reflex hold' of a positivism/rational-empiricism intelligibility/epistemicity/reflexivity as to underlying prospective positivism/rational-empiricism Being-development/ontological-frameworkexpansion-as-to-depth-of-ontologising-development-as-infrastructure-of- meaningfulnessand-teleology psychologismic epistemic acutisation difficulty<<for, residualising \{decompulsing $\}$ delinearity for-cogeney>-magnitude\{of-experientiality/experiment\} (as to such a circumstantial demonstration of positivism/rational-empiricism knowledge) will instantly prevail in the animistic social-setup as adopted knowledge value ('knowledge value' so-reflected herein as of overall <amplituding/formative>disposedness/psychologismic-construct-〈as-toorientation/value-construct/valuation-and-derived-parameterising)); and so, given the very existentially-< $<$ disentologising/re-ontologising aporeticism $>$ ingrained overall animistic nonpositivising/non-rational-empiricist 
mentating/structuring/paradigming punctual/immediacy/constituted/compulsions-encumbered prior mere-formulaicity/ritualisation rationalisation-of-

contentivity/argumentativity/dialecticism/discursivity' that so-undermines 'widening the social imaginary' as to the latter nonpresencing-<perspective - ontologicatnormaley/postconvergence> 'existential-<disontologising/re-ontologising aporeticism $>$ prospect of human individual-consciousness/collective-consciousness decompulsion-appraisal' enabling of the ontologising/scientific/existence- $<$ honesty-constraining $>$ scope_for_prospective_re-ontologising requisite enhancing of the human sovereignfunction/posture-<as-to-existentially-manifest-‘embodied-subject consciousness-and-

\section{direct/deferential-conscientiousness',-as-of-its-'epistemic-reflexivity/unreflexivity-in-}

existence'/teleology> (as to the 'requisite prospective sublimating decompulsion_imprinting across the various institutional levels of interrelatedness-dynamics-of-social-constructing' soarising from the 'educing-and-availing-and-re-availing of relative-ontological-completeness with respect to unlimitedness/existence-<full-potency-of_sublimating nascence $>$ prospective apriorising/axiomatising/referencing-sublimating-reflexivity-beholdening under which limitedness/human-subpotency submits in profound-supererogation for prospective sublimating'). It is exactly this upside-down human relationship to ontological-veracity (as to 'unlimitedness/existence-<full-potency-of_sublimating nascence> prospective apriorising/axiomatising/referencing-sublimating-reflexivity-beholdening under which limitedness/human-subpotency submits in profound-supererogation for prospective sublimating') that explains the requisite 'reclamation/recovery of ${ }^{55}$ maximalisingrecomposuring-for-relative-ontological-completeness ${ }^{87}$ — unenframed/reontologising conceptualisation (elicited/prompted <amplituding/formative-epistemicity $>$ totalising renewing-realisation/re-perception/re-thought as of 're-ontologising fepistemic- 
totalising 're-apriorising/re-axiomatising/re-referencing residuality in-re-originariness/re-

origination \{decompulsing\} ${ }^{\text {}}$ delinearity/delinear-accreting/recomposuring cogency/tensing/limpidity$<$ as-of-prospective-profound-supererogation ,-for-residuality-in-re-originariness/reorigination $>$, - prospective_reifying mental-aestheticising-<as-of-'prospective_reformulating of-mental-aestheticising'as to 'residuality in -re-originariness/re-origination' of mentalaestheticising ' ')' for human sublimating - course-changing/game-changing. Since the veracity of prospective sublimating ${ }^{56}$ meaningfulness-and-teleology 9 arises (not by an 'eclecticism-ofprior-mere-formulaicity/ritualisation-<as-of-prior $\sim$ rationalisation-ofcontentivity/argumentativity/dialecticism/discursivity> composition/blending-in\{compulsing\}linearity/linear-accretion of relative-ontological-completeness and relativeontological-incompleteness apriorising/axiomatising/referencing as to secondnatured prior mere-formulaicity/ritualisation-<as-to-mere-formulaicmethodologising/mutualising/organising/institutionalising,-prospectively-losing-track-of‘fepistemic tratising tre-apriorising/re-axiomatising/re-referencing residuality-in-reoriginariness/re-origination'>> imbued $>$ incrementalism-in-relative-ontologicalincompleteness ${ }^{8}$ - enframed/disontologising conceptualisation) but rather arises in an altogether prospective 're-ontologising fepistemic-totalising ${ }^{3}$ apriorising/re axiomatising/rereferencing residuality in re-originariness/re-origination $\quad\{$ decompulsing $\}$ delinearity/delinearaccreting/recomposuring cogency/tensing/limpidity-<as-of-prospective-profoundsupererogation $^{\circ}$,-for-residuality_in-re-originariness/re-origination>-,prospective_reifying mental-aestheticising-<as-of 'prospective_reformulating-of-mental-aestheticising'as-to'residuality in-re-originariness/re-origination'-of-mental-aestheticising ${ }^{\prime}$; which is soundergirded recurrently as of 'overarching existential-distong apereticism $>$ priority/precedence/primacy of requisite prospective ontological-goodfaith/authenticity $\sim$ postconverging-de-mentating/structuring/paradigming 70 inducing of 
psychoanalytic-unshackling for the relative-ontological-completeness ${ }^{8}$-ofapriorising/axiomatising/referencing re-ontologising prospective re-rationalisation-ofcontentivity/argumentativity/dialecticism/discursivity', and as so-reflecting the fact that 'prospective sublimating-intelligibility/epistemicity/reflexivity' (as to overarching profoundsupererogation $\sim$ reframing/reformulation/decatchmenting/detruncating/decompulsing/delinear ising as-to-posteonverging de-mentating/structuring/paradigming order/direction of ontological-veracity imbuing 'reifying-mental-aestheticising-<as-of'prospective_reformulating-of-mental-aestheticising'as-to-'residuality_in-re-originariness/reorigination'-of-mental-aestheticising $>$ educed processive-motif-'exuding aestheticising gesturing' of-apriorising/axiomatising/referencing as to re-aestheticisation-and-reaestheticisation-towards-ontology-<elicited-prospective-idiomatisation $\left.>^{\prime}\right)$ is rather educed, however counterintuitive, as from 'profoundsupererogation $\sim$ reframing/reformulation/decatchmenting/detruncating/decompulsing/delinear ising -as-to-postconverging de-mentating/structuring/paradigming priority/precedence/primacy' of re-ontologising prospective Being-development/ontologicalframework-expansion-as-to-depth-of-ontologising-development-as-infrastructure-ofmeaningfulness-and-teleology psychologismic epistemie aeutisation diffieully <for, residualising \{decompulsing\} delinearity-for-cogency>-magnitude\{of-experientiality/experiment\}, then institutional-development-as-to-social-function-development $\quad$ psychologismic epistemicacutisation difficulty < for, residualising \{decompulsing $\}$ delinearity for-cogency> magnitude $\{$ ofexperientiality/experiment\} and then living-development-as-to-personality-development psychologismic epistemic-acutisation difficulty-<for, residualising

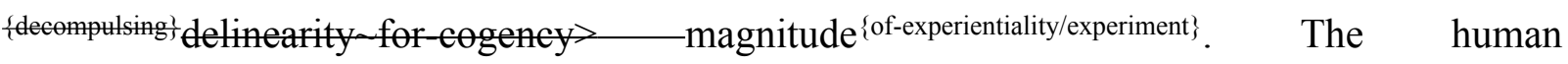
psychologismic-epistemic-acutisation — difficulty- $<$ for,-residualisingdelinearity for-cogency $>$-〈as-of-requisite-profound-supererogation -for- 


\section{‘disposedness-or-psychologismic-construct'-\{imbued-demoronisation-<sublimating-}

nascence,-nonextricatory-sublimating-upstreaming/'amontée’’\}〉 in-many-ways equally elucidates the problematic involved between the advocacy/political/applicative — scope as bounded to a ${ }^{79}$ presencing-absolutising-identitive-constitutedness ${ }^{14}$ epistemic-projection and the ontologising/scientific/existence- $<$ honesty-constraining $>$ - scope_for_prospective_reontologising unboundedness as to nonpresencing- $<$ perspective-ontologicalnormalcy/postconvergence> epistemic-projection. Such that the "naïve projecting of any given presencing—absolutising-identitive-constitutedness ${ }^{14}$ advocacy/political/applicative—scope threshold of human prospective transcendence-and-sublimity/sublimation/supereregatery $\sim$ dementativity' may consciously/unconsciously implicit in-effect that it 'substitutes-for or supersedes' the veridical ontologising/scientific/existence- $<$ honesty-constraining $>$ scope_for_prospective_re-ontologising (as to inducing a presencing absolutising-identitiveeonstitutedness 'existential<<disontologising/re-ontologising aporeticism $>$ preconverging de-mentating/structuring/paradigming punctual/immediacy/constituted/compulsionsencumbered prior mere-formulaicity/ritualisation rationalisation-ofcontentivity/argumentativity/dialecticism/discursivity'); with regards to the failure to appraise that unlimitedness/existence-<full-potency-of_sublimating nascence $>$ precedence/supersedingness inherently portends of the momentousness of the ontologising/scientific/existence- $<$ honesty-constraining $>$ — scope_for_prospective_reontologising beyond any given human registry-worldview/dimension <amplituding/formativeepistemicity $>$-totalising $\sim$ thrownness-in-existence ${ }^{35}$ - as imbued of limitedness/humansubpotency prospective dearth for \{epistemic-totalising ’’̀-apriorising/re-axiomatising/rereferencing $\sim$ residuality —in-re-originariness/re-origination projection) 'supposedly absolute determining threshold of human prospective knowledge and transcendence-andsublimity/sublimation/supererogatory de-mentativity'; whether so-construed as of $\leq$ mere- 
formulaicity/ritualisation-of $>$-prior secondnatured blatant brutish conquest/subjugation conception of apportioning imbued shallow-supererogation,$<$ mere-formulaicity/ritualisationef $>$-prior secondnatured dominion protection conception of apportioning imbued shallowsupererogation , $\leq$ mere-formulaicity/ritualisation-of $>$-prior secondnatured the very naturalorder-of-things conception of apportioning imbued shallow-supererogation and prospectively our $<$ mere-formulaicity/ritualisation of $>$-prior secondnatured subtle modern-day institutionallydistorted/disjointed conception of apportioning imbued shallow-supererogation (so-implied prospectively as to the wholesome-dearth of 'sublimating conceptivity/epistemicreflexivity/epistemicity-relativism-determinism-<reifying \{as-to-knowledge-developing $\}$-andempowering> entailment' of such '79 presencing-absolutising-identitive-constitutedness advocacy/political/applicative—scope desublimating thresholds'). Critically, the ontologising/scientific/existence- $<$ honesty-constraining $>$ - scope_for_prospective_reontologising as so-elucidated notionally/epistemically/bindingnessly-<as-to-determinism/coneeptivity-ofrelative speaks to the superseding/overcoming of the human psychologismic-epistemic-acutisation — difficulty- $<$ for,-residualising$\{$ decompulsing $\}$ delinearity for-cogency $>$-〈as-of-requisite-profound-supererogation -for'disposedness-or-psychologismic-construct'-\{imbued-demoronisation-<sublimatingnascence,-nonextricatory-sublimating-upstreaming/'amontée’’ $>$ ) (as of human psychologismic-transfixity-<placeholder-setup-ontological-rescheduling-inrealigning/preactivity/formative-becoming/psychoanalytical-unshackling,-as-to-residualising$\{$ decompulsing $\}$ delinearity-over-nonresidualising_\{compulsing\} linearity> as $>$ of humanconsciousness/collective-consciousness-distendedness/detruncating- $<$ beyond-selfpresencing,as-re-ontologising-decentering_of-consciousness/collective-consciousness,-as-topsychologismic-epistemic-acutisation-residualising,- - decmplling $\}$ delinearity $\sim$ for-cogency $>$ ); so-manifested as of 'qveridical/sound\}-relative-reflexivity-in-existence/relativising from- 
limited-mentation-as-its-deepening/psychologismic epistemic-acutisation residualising, ${ }_{\{d e c o m p u l s i n g}$ delinearity for-cogency anarchistic-growth/anarchisation-for-re-ontologisation-〈asto-conscious/unconscious epistemically-sound induced 'demoronisation- $<$ sublimatingnascence,-nonextricatory-sublimating-upstreaming/'amontée’> postconverging/dialecticalthinking conception of residual_re-originary_anarchistic incipiency of human socialfunctioning-and-accordance-as-of-social-stake-contention-or-confliction meaningfulnessand-teleology ' ' ', as to the 'veracity of the sovereign-function/posture-<as-to-existentiallymanifest-'embodied-subject consciousness-and-direct/deferential-conscientiousness',-as-ofits-'epistemic-reflexivity/unreflexivity-in-existence'/teleology> as coextensive with the genuine social intellectual-function/posture' (as of the latter ontologically-veridical propping of the human sovereign-function/posture-<as-to-existentially-manifest-'embodiedsubject consciousness-and-direct/deferential-conscientiousness',-as-of-its- 'epistemicreflexivity/unreflexivity-in-existence'/teleology $>$ by providing the underlying ontologising/scientific/existence- $<$ honesty-constraining $>$ — scope_for_prospective_reontologising as to 'limitedness/human-subpotency prospective re-encountering/re-confrontation with unlimitedness/existence-<full-potency-of_sublimating naseence>' as so-providing the 'existential-<disontologising/re-ontologising aporeticism $>$ enabling-backdrop' for the advocacy/political/applicative — scope to arise). Thus in-many-ways (with respect to human psychologismic-transfixity-<placeholder-setup-ontological-rescheduling - inrealigning/preactivity/formative-becoming/psychoanalytical-unshackling,-as-to-residualising$\{$ decompulsing $\}$ delinearity-over-nonresidualising_\{compulsing $\}$ linearity $>\quad$ as of humanconsciousness/collective-consciousness-distendedness/detruncating- $<$ beyond-selfpresencing,as-re-ontologising-decentering_of-consciousness/collective-consciousness,-as-topsychologismic-epistemic-acutisation-residualising, - $^{\text {tdecmpulsing }}$ delinearity $\sim$ for-cogency $>$ ) the veracity of human sovereign-emergence/becoming,-existentially-imbuing human-freedom- 
as-to-supererogating/surrealising-for-'knowledge-empowerment-over-ignorance-

disempowerment'-<as-of-'developing-and-availing-sovereign-

sublimating_potential/possibilities/options/choices'-as-to-the-'credibility'/'ontological-

veracity'-underlying-the-'sovereign-conscious/conscientious-backdrop'> is institutionally

construed as to the 'backdrop of credible/ontological-veracity-of sovereignsublimating_potential/possibilities/options/choices' as to the inherent necessity for a veridical exercise of human sovereign-function/posture-<as-to-existentially-manifest-'embodiedsubject $\sim$ consciousness-and-direct/deferential-conscientiousness',-as-of-its- 'epistemicreflexivity/unreflexivity-in-existence'/teleology>. Again in this regards, profoundsupererogation $\sim$ reframing/reformulation/decatchmenting/detruncating/decompulsing/delinear ising_scale_-of-transparent/noncontentious/un-nominalised/sound-interpretations/domains of manifest unblurriness-<re-ontologising_by-postconverging-as-to-dragged-outsupererogatory wholesomeness/profound-supererogation ,-while-anecdotalising-priordisontologising-thresholding $>$ effectively manifest such a relative veracity of human sovereignemergence/becoming,-existentially-imbuing human-freedom-as-to-supererogating/surrealisingfor-'knowledge-empowerment-over-ignorance-disempowerment'-<as-of-'developing-andavailing-sovereign-sublimating potential/possibilities/options/choices'-as-to-the'credibility’/'ontological-veracity'-underlying-the-'sovereign-conscious/conscientiousbackdrop'> (as so-reflected with relatively uncontentious/nominalised social-stake-contentionor-confliction manifesting a 're-ontologising sanitation of the sphere of veridical exercise of human sovereign-function/posture-<as-to-existentially-manifest-‘embodied-

\section{subject $\sim$ consciousness-and-direct/deferential-conscientiousness',-as-of-its- 'epistemic-}

reflexivity/unreflexivity-in-existence'/teleology>' when it comes to uncontested competence/expertising associated with their intrinsic deontologies as so-providing the 'backdrop of credible/ontological-veracity-of sovereign- 
sublimating_potential/possibilities/options/choices'). But then 'overt and covert relatively contentious/un-nominalised social-stake-contention-or-confliction' (as to their manifest shallow

supererogation $\sim$ framing/formulation/catchmenting/truncating/compulsing/linearising_scale —of-opaque/contentious/un-nominalised/flawed-interpretations/domains of manifest blurriness-<sterilising/anecdotalising/trivialising-of-prospective-re-ontologising_by-

preconverging,-in-disontologising-formulaic-dragging-out/hollowing-out>) in-many-ways are susceptible to the surreptitious sapping of their 'backdrop of credible/ontological-veracity-of sovereign-sublimating_potential/possibilities/options/choices’, (with such 'disontologising/subontologsing sapping' rather consciously/unconsciously ensnaring as to the presencing absolutising-identitive-constitutedness 'existential-<disontologising/reentologising aporeticism> preconverging de-mentating/structuring/paradigming punctual/immediacy/constituted/compulsions-encumbered prior mere-formulaicity/ritualisation rationalisation-of-contentivity/argumentativity/dialecticism/discursivity') as so-elicitable when it comes to their 'unwieldy-contemplatable-disontologising/re-ontologising-implications,-withregards-to-human-sovereign-function/posture-<as-to-narrowness/evasiveness/vagueness-ofdisontologising/re-ontologising $>$ with respect to contentious/un-nominalisedness of socialstake-contention-or-confliction'; and this is so-overarchingly manifested with the 'democratic practice ontologising unwieldiness' and its institutionally associated/derivational contentious/un-nominalised social-stake-contention-or-confliction (such that in-many-ways the 'backdrop of credible/ontological-veracity-of sovereignsublimating_potential/possibilities/options/choices' is rather a 'scruffy shrinking of the social imaginary' as to a basic emphasis on a 'basic manifest/gestural sovereign-exercising-<as-ofsovereign-deferentialism;-as-to-'direct/indirect-electing-and/or-nominating'>' of 'unwieldycontemplatable disontologising/re-ontologising implications' with regards to human sovereign- 
function/posture-<as-to-existentially-manifest-`embodied-subject $\sim$ consciousness-anddirect/deferential-conscientiousness',-as-of-its-'epistemic-reflexivity/unreflexivity-inexistence'/teleology>). In this respect, it is mostly the indirect 're-ontologising sanitation of the sphere of veridical exercise of human sovereign-function/posture-<as-to-existentially-manifest‘embodied-subject consciousness-and-direct/deferential-conscientiousness',-as-of-its'epistemic-reflexivity/unreflexivity-in-existence'/teleology>' as of appropriate cultivation-andenculturation of ' $\{$ veridical/sound $\}$-relative-reflexivity-in-existence/relativising from-limitedmentation-as-its-deepening/psychologismic epistemic-acutisation residualising, ${ }_{\{\text {decompulsing }}$ delinearity for-cogency anarchistic-growth/anarchisation-for-re-ontologisation-〈asto-conscious/unconscious epistemically-sound induced 'demoronisation- $<$ sublimatingnascence,-nonextricatory-sublimating-upstreaming/‘amontée’> postconverging/dialecticalthinking conception of residual_re-originary_anarchistic incipiency of human socialfunctioning-and-accordance-as-of-social-stake-contention-or-confliction meaningfulnessand-teleology '’' (over '\{flawed/unsound\}-relative-unreflexivity-in-existence/absolutising from-limited-mentation/psychologismic epistemic acutisation nonresidualising imbued\{compulsing\} linearity-in-eclecticism-of-prior-mere-formulaicity/ritualisation insidious-anarchy$<$ as-to-conscious/unconscious epistemically-flawed induced 'moronisation-<sublimatingnascence,-extricatory-desublimating-downstreaming/'avalage’’ $\quad$ preconverging/dementing conception of prior mere-formulaicity/ritualisation incipiency of human social-functioning-andaccordance-as-of-social-stake-contention-or-confliction meaningfulness-andteleology '>') that effectively enhances the 'backdrop of credible/ontological-veracity-of sovereign-sublimating_potential/possibilities/options/choices' in so 'widening the social imaginary' as to nonpresencing-<perspective-ontological-normalcy/postconvergence> 'existential-<disontologising/re-ontologising aporeticism $>$ prospect of human individualconsciousness/collective-consciousness decompulsion-appraisal' enabling of the 
ontologising/scientific/existence- $<$ honesty-constraining $>$ — scope_for_prospective_reontologising requisite enhancing of the human sovereign-function/posture- $<$ as-to-existentiallymanifest-'embodied-subject consciousness-and-direct/deferential-conscientiousness',-as-ofits-'epistemic-reflexivity/unreflexivity-in-existence'/teleology> (as to the 'requisite prospective sublimating decompulsion_imprinting across the various institutional levels of interrelatednessdynamics-of-social-constructing' so-arising from the 'educing-and-availing-and-re-availing of relative-ontological-completeness ${ }^{87}$ with respect to unlimitedness/existence-<full-potencyof_sublimating nascence> prospective apriorising/axiomatising/referencing-sublimatingreflexivity-beholdening under which limitedness/human-subpotency submits in profoundsupererogation for prospective sublimating'); and so beyond the 'superficial/shallow manifest prior-perspective_-falsity/falseness/fallaciousness of human institutional and social desublimating $\sim$ existentialising-decisionality-<as-to-disontologising/re-ontologising apereticism $>$ as to catchmenting-by-rejection/lip-servicing/monopolising/gaming-of-thesystem/charade/distraction'. It is no wonder that this implicitly/explicitly more veridical insight as to 'such an expansive conception of the human sovereign-function/posture-<as-toexistentially-manifest-‘embodied-subject $\sim$ consciousness-and-direct/deferentialconscientiousness',-as-of-its- 'epistemic-reflexivity/unreflexivity-in-existence'/teleology>' $\quad$ is exactly the conscious/unconscious surreptitous target of dominance/vested-interest and pedantic subversion as to strategies of 'underlying dumbing-down public intellection and media industry' and overall ${ }^{4}$ historicity-tracing-in-presencing-hyperrealisation/hyperreal-transposition numbing-traction-_of-desublimating_

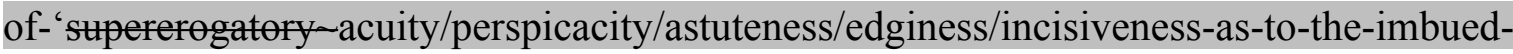
postconverging/dialectical-thinking -of-notional deprocrypticism- in-dimensionality-ofsublimating _ < $<$ amplituding/formative-epistemicity $>$ growth-orconflatedness /scalarisation-as-to-rescalarisation-as-re-ontologisation $\left.\}^{\prime}\right\rangle$ in so propping up 


\section{‘disposedness-or-psychologismic-construct'-\{imbued-demoronisation-<sublimating-} nascence,-nonextricatory-sublimating-upstreaming/'amontée’’\}\}; as to the prospectively desublimating 'overall unthought/uncontemplated/mere-reflex/shallow/unsound gesturing/accounting_of-epistemic-phenomenalism' of our positivismprocrypticism/disjointedness-as-of- ${ }^{8}$ reference-of-thought $\quad$ presencing-absolutisingidentitive-constitutedness ${ }^{14} \quad$ 'nihilistic knowledge-deadends-<as-preconverging-dementating/structuring/paradigming > undermining prospective re-ontologising' (as not resolvable as of prior preseneing absolutising identitive constitutedness 'existential<disontologising/re-ontologising aporeticism $>$ preconverging dementating/structuring/paradigming punctual/immediacy/constituted/compulsions-encumbered prior mere-formulaicity/ritualisation rationalisation-ofcontentivity/argumentativity/dialecticism/discursivity but rather as of prospective profoundsupererogation for nonpresencing-perspective-ontological-normalcy/postconvergence $>$ 'existential-<disontologising/re-ontologising aporeticism $>$ prospect of human individualconsciousness/collective-consciousness decompulsion-appraisal, in reflection of 'unlimitedness/existence-<full-potency-of_sublimating nascence> prospective apriorising/axiomatising/referencing-sublimating-reflexivity_beholdening under which limitedness/human-subpotency submits in profound-supererogation for prospective sublimating'). In this regards, it is important to grasp here that just as with profoundsupereregation $\sim$ reframing/reformulation/decatchmenting/detruncating/decompulsing/delinear ising_scale_of-transparent/noncontentious/un-nominalised/sound-interpretations/domains of manifest unblurriness-<re-ontologising_by-postconverging-as-to-dragged-out- 
disontologising-thresholding $>\quad$ imbued ontologising/scientific/existence- $<$ honestyconstraining $>$ — scope_for_prospective_re-ontologising enhancing of the human sovereignfunction/posture-<as-to-existentially-manifest-`embodied-subject $\sim$ consciousness-and-

\section{direct/deferential-conscientiousness',-as-of-its-'epistemic-reflexivity/unreflexivity-in-}

existence'/teleology $>$ (associated for instance with generalised social sovereign-deferentialism to practices of nascent-particular/incipient-and-material/technical-sublimations- $<$ blinded-totheir-relative-ontological-completeness - reference-of-thought- devolving $>$ with regards to their 'implicited-and-explicited repassing for human sovereign-function/posture-<as-toexistentially-manifest-'embodied-subject consciousness-and-direct/deferentialconscientiousness',-as-of-its-'epistemic-reflexivity/unreflexivity-in-existence'/teleology> approbation-of/adherence-to deferentialism' as to 'protracted-social—as-to-individual-byinstitutional-by-social relative direct/deferential-responsibility/relative-reflexivity to cogency_chronicularity/annality-of-relative-reflexivity,-as-to-profound-supererogation ${ }^{\prime}$ ), likewise the shallowsupererogation $\sim$ framing/formulation/catchmenting/truncating/compulsing/linearising_scale —of-opaque/contentious/un-nominalised/flawed-interpretations/domains of manifest blurriness-<sterilising/anecdotalising/trivialising-of-prospective-re-ontologising_bypreconverging,-in-disontologising-formulaic-dragging-out/hollowing-out> (as manifested say with 'unwieldy-contemplatable disontologising/re-ontologising implications' with regards to human sovereign-function/posture-<as-to-existentially-manifest-'embodied-

\section{subject $\sim$ consciousness-and-direct/deferential-conscientiousness',-as-of-its-'epistemic-}

reflexivity/unreflexivity-in-existence'/teleology> associated for instance with the 'democratic practice ontologising unwieldiness') is not exempt from its sublimating elucidation (as of conceptivity/epistemic-reflexivity/epistemicity-relativism-determinism- $<$ reifying \{as-toknowledge-developing\}-and-empowering > entailment) so long as such elucidation eventually 
reprompts (as allowed to the ontologising/scientific/existence- $<$ honesty-constraining $>$ scope_for_prospective_re-ontologising opened-construct-of- ${ }^{5}$ meaningfulness-and-teleology sublimating re-eliciting of unlimitedness/existence-<full-potency-of_sublimating nascence $>$ ) the 'implicited-and-explicited repassing for human sovereign-function/posture-<as-toexistentially-manifest-`embodied-subject $\sim$ consciousness-and-direct/deferentialconscientiousness',-as-of-its-'epistemic-reflexivity/unreflexivity-in-existence'/teleology> approbation-of/adherence-to deferentialism' (as to 'protracted-social—as-to-individual-byinstitutional-by-social relative direct/deferential-responsibility/relative-reflexivity to cogency_chronicularity/annality-of-relative-reflexivity,-as-to-profound-supererogation ${ }^{9}$ ) with regards to its claim to inducing 'human sovereign-function/posture-<as-to-existentiallymanifest-'embodied-subject consciousness-and-direct/deferential-conscientiousness',-as-ofits-'epistemic-reflexivity/unreflexivity-in-existence'/teleology> epistemic-growth,-as\{veridical/sound\}-relative-reflexivity-in-existence/relativising from-limited-mentation-as-itsdeepening/psychologismic epistemic-acutisation residualising, fdecturingl delinearity for eogency'; and so in reflection of the underlying 'human sovereign-function/posture-<as-toexistentially-manifest-‘embodied-subject $\sim$ consciousness-and-direct/deferentialconscientiousness',-as-of-its-'epistemic-reflexivity/unreflexivity-in-existence'/teleology> inherent entanglement with the ontologising/scientific/existence- $<$ honesty-constraining $>$ scope_for_prospective_re-ontologising, as to the possibility for sovereignemergence/becoming,-existentially-imbuing human-freedom-as-to-supererogating/surrealisingfor-'knowledge-empowerment-over-ignorance-disempowerment'-<as-of-'developing-andavailing-sovereign-sublimating_potential/possibilities/options/choices'-as-to-the‘credibility’/'ontological-veracity’-underlying-the-'sovereign-conscious/conscientiousbackdrop'> in human-consciousness/collective-consciousness-distendedness/detruncating$<$ beyond-selfpresencing,-as-re-ontologising-decentering_of-consciousness/collective- 
consciousness,-as-to-psychologismic-epistemic-acutisation-residualising,-

\{decompulsing delinearity for-cogency> with respect to its successively given and superseded registry-worldviews/dimensions $<$ amplituding/formative-epistemicity $>$-totalising $\sim$ thrownnessin-existence ${ }^{35}$ - as imbued of limitedness/human-subpotency prospective dearth for fepistemictotalising ${ }^{3}$ re-apriorising/re-axiomatising/re-referencing $\sim$ residuality-in-re-originariness/reorigination projection). In this respect, human placeholder-setup/mental-devisingrepresentation/mentation/consciousness-awareness-teleology ${ }^{9}$ is inherently prone to its given $<$ amplituding/formative-epistemicity $>$-totalising $\sim$ thrownness-in-existence 'framing/formulation/catchmenting/truncating/compulsing/linearising_scale_ofopaque/contentious/un-nominalised/flawed-interpretations/domains of manifest blurriness$<$ sterilising/anecdotalising/trivialising-of-prospective-re-ontologising_by-preconverging,-indisontologising-formulaic-dragging-out/hollowing-out> psychologismic-epistemicacutisation-difficulty- $<$ for,-residualising $-\{$ decoldsing $d$ delinearity $\sim$ for-cogency $>-\langle$ as-ofrequisite-profound-supererogation -for-'disposedness-or-psychologismic-construct'\{imbued-demoronisation-<sublimating-nascence,-nonextricatory-sublimatingupstreaming/'amontée'>\})' (as to presencing absolutising-identitive-constitutedness ‘existential-<disontologising/re-ontologising aporeticism $>$ preconverging dementating/structuring/paradigming punctual/immediacy/constituted/compulsions-encumbered prior mere-formulaicity/ritualisation rationalisation-ofcontentivity/argumentativity/dialecticism/discursivity'); wherein the given registryworldview/dimension is rather susceptible to the "compulsively-encumbered desublimating tempering' of its potential sublimating prospective cogency_chronicularity/annality-of-relativereflexivity,-as-to-profound-supererogation ${ }^{6}$, so-manifested for instance with our subtle modernday institutionally-distorted/disjointed incipient/instigative 'direct/indirect psychological gimmicks of conscious/unconscious surreptitious eliciting, cultivation and enculturation of 
sovereign compulsivity as of closed-construct-of- ${ }^{5}$ meaningfulness-and-teleology prospectively undermining deprocrypticism-or-preempting-disjointedness-as-ofreference-of-thought cogency_chronicularity/annality-of-relative-reflexivity,-as-to-profoundsupererogation (as so-concretely reflected as to an overall conscious/unconscious practice and enculturation of disontologising/subontologising or unimaginative or instrumentalising social and mediatic discursivity as to a 'scruffy shrinking of the social imaginary' with respect to prospective the-human/humanity contemplatable potential). This explains why unlike the case with the inherently open possibility of nascent-particular/incipient-and-material/technicalsublimations- $<$ blinded-to-their-relative-ontological-completeness - reference-of-thought-

devolving>, all registry-worldviews/dimensions inherently construe implicitly/explicitly of the 'potential sublimating possibility of their human social-and-institutional-frameworks-ofreferencing/registering/decisioning' rather as entrenched/captured within their given <preconverging 'motif-and-apriorising/axiomatising/referencing'-entailing >-

existentialising — enframing/imprintedness-〈as-to- historicity-tracing —in-presencing-

hyperrealisation/hyperreal-transposition $\rangle$ Such that whereas the 'ontologising/scientific/existence- $<$ honesty-constraining $>$ — scope_for_prospective_reontologising implications of existential-<disontologising/re-ontologising aporeticism $>$ counteracting/supplanting/alienating-of-prior-apriorising/axiomatising/referencing' is more or less construed by the intradimensional human consciousness/collective-consciousness as of sublimating-prolongation with regards to nascent-particular/incipient-and-material/technicalsublimations- $<$ blinded-to-their-relative-ontological-completeness - reference-of-thought-

devolving > . However when it comes to the 'potential sublimating possibility of their human social-and-institutional-frameworks-of - referencing/registering/decisioning (as to failing prospectively requisite demoronisation- $<$ sublimating-nascence,-nonextricatory-sublimatingupstreaming/'amontée’> for re-ontologising prospective Being-development/ontological- 
framework-expansion-as-to-depth-of-ontologising-development-as-infrastructure-ofmeaningfulness-and-teleology psychologismic epistemic acutisation difficulty-<or,

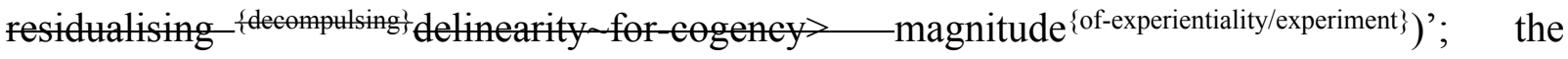
intradimensional human consciousness/collective-consciousness grasp of such a re-ontologising appraisal is rather relatively far-off/faint/removed (and rather in distontologising/subontologising integrating/acceptance of the logic/rationale of 'existentially<disontologising/re-ontologising aporeticism $>$ manifest incidental/accidental reactivesufferance/endurance in supposedly and paradoxically subordinating/subserving/collateralising the possibility for prospective re-ontologising-imbuing-of-prospective-humansublimating/emancipating/enfranchisement') as so-relatively manifesting a 'poorly/suboptimally defined/elucidated overarching prospective re-ontologising conceptualisation'. So-underlining the circularity of human destructuring-transitoriness ${ }^{19}$-as-ofderatiocination/deratiocontiguity as to the 'recoiling-<as-to-induced'wavering/redounding/waveforming-of-dimensionality-of-sublimating '-by-'dimensionalityof-desublimating '-at-successive-loci/stations-of- ‘thrownness-disposition-as-of-mereformulaicity/ritualisation'>-_from dimensionality-of-sublimating 5

\section{kamplituding/formative>supererogatory de-mentativeness/epistemic-growth-or-}

\section{eonflatedness /transvaluative-rationalising/transepistemicity/anamnestic-residuality/spirit-}

drivenness-equalisation) elicited prospective psychologismic-epistemic-acutisation-<as-topostconverging-de-mentating/structuring/paradigming,-eliciting-of-existence's-sublimatingnascence-in-prospective-aporeticism-overcoming/unovercoming $>$ as to epistemic-growth,-as\{veridical/sound\}-relative-reflexivity-in-existence/relativising from-limited-mentation-as-itsdeepening/psychologismic epistemic acutisation residualising, fdecompulsing $_{\text {\} }}$ delinearity for eogency)' as to manifest 'seeding-misprising of dimensionality-of-desublimating-lack-of ${ }^{-}$ <<amplituding/formative>supererogatory $\sim$ de-mentativeness/epistemic-growth-or- 
conflatedness /transvaluative-rationalising/transepistemicity/anamnestic-residuality/spirit-

drivenness-equalisation)'. As 'so-existentially-<disontologising/re-ontologising aporeticism $>$ distracting from the requisite re-ontologising for sublimating-prolongation' enabling human sovereign-emergence/becoming,-existentially-imbuing human-freedom-as-to-

supererogating/surrealising for ' $k$ nowledge empowerment over ignorance disempowerment' $<$ as-of-'developing-and-availing-sovereign-

sublimating_potential/possibilities/options/choices'-as-to-the-'credibility'/'ontologicalveracity'-underlying-the-'sovereign-conscious/conscientious-backdrop'>'. This elucidation is so-articulated (for instance with regards to our subtle modern-day institutionallydistorted/disjointed) in reflecting the paradox on-the-one-hand of 'manifest prospectively sovereign disontologising/subontologising with regards to social-and-institutional-frameworksof-referencing/registering/decisioning' (as manifested with human 'information crisis' and 'crisis of contemplation/reflection' as well as 'institutional and social crises and malaises manifested in the socio-econo-political domains') and on-the-other-hand 'supposedly profound discursivity for prospective re-ontologising' that fail-to/poorly appreciate how the former derails the latter; and so-speaking to the human psychologismic-epistemic-acutisation-difficulty$<$ for,-residualising-\{dering $\}$ delinearity for-cogency $>-\langle$ as-of-requisite-profoundsupererogation -for-'disposedness-or-psychologismic-construct'-\{imbued-demoronisation$<$ sublimating-nascence,-nonextricatory-sublimating-upstreaming/'amontée’’ $>\}\rangle$ for veridically construing of the Social as of the ontologising/scientific/existence- $<$ honesty-constraining $>$ scope_for_prospective_re-ontologising (notwithstanding 'unlimitedness/existence-<fullpotency-of_sublimating nascence> prospective apriorising/axiomatising/referencing sublimating-reflexivity-beholdening under which limitedness/human-subpotency submits in profound-supererogation for prospective sublimating'). As elucidated above the continual ontologising/scientific/existence- $<$ honesty-constraining $>$ — scope_for_prospective_re- 
ontologising 'exuding of antinihilism and anti-absurdism' (as to 'existential-<disontologising/reentologising aporeticism> postconverging aporeticism-overcoming/mnovercoming' successoral 'exuding of antinihilism and anti-absurdism') effectively reflect the fact that the human sovereign-function/posture-<as-to-existentially-manifest-‘embodiedsubject $\sim$ consciousness-and-direct/deferential-conscientiousness',-as-of-its- 'epistemicreflexivity/unreflexivity-in-existence'/teleology> (as from the individual's very existential< disontologising/re-ontologising aporeticism $>$ inception expanding thereof institutionally and socially) 'necessarily make prospective re-ontologising-as-to-sublimating existential< disontologising/re-ontologising aporeticism $>$ demands' (as of underlying 'constraining existence - as-sublimating-withdrawal/unenframing/re-ontologising,-elicited-fromprospective-profound-supererogation imbuing human ontological-commitment ${ }^{6}-$ implied $^{9}$ self-assuredness-of-ontological-good-faith/authenticity postconverging-dementating/structuring/paradigming -as-being-as-of-existential-reality>' and '103 universaltransparency ${ }^{104}$-〈transparency-of-totalising-entailing,-as-to-entailing-<amplituding/formativeepistemicity $>$ totalising in-relative-ontological-completeness $\rangle$ as available-to/elicitable-to-〈asto-human-consciousness/collective-consciousness-distendedness/detruncating-<beyondselfpresencing,-as-re-ontologising-decentering_of-consciousness/collective-consciousness,-asto-psychologismic-epistemic-acutisation - residualising, ${ }^{\text {\{decompulsing }}$ delinearity for-cogency $>$ > the social-functioning-and-accordance-as-of-social-stake-contention-or-confliction conception of any given registry-worldview/dimension <preconverging 'motif-andapriorising/axiomatising/referencing'-entailing >-existentialising — enframing/imprintedness〈as-to- historicity-tracing-in-presencing-hyperrealisation/hyperreal-transposition〉'); but for when rather 'manifesting disontologising-as-to-desublimating prospective human sovereignfunction/posture-<as-to-existentially-manifest-`embodied-subject $\sim$ consciousness-and- 
threshold /presublimating-desublimating-decisionality $>$ of-ontological-performance ${ }^{72}$

$<$ including-virtue-as-ontology $>$ ' arising as of 'lifespan extricatory/preconverging psychicalnascency moronisation-<sublimating-nascence,-extrieatedesublimatingdownstreaming/'avalage'>' (as so-failing 'nonextricatory/postconverging ontologising-and-reontologising angling-of-imaginary demoronisation-<sublimating-nascence,-nenextricatorysublimating-upstreaming/'amontée'>). In other words, the human sovereign-function/posture<as-to-existentially-manifest-“embodied-subject consciousness-and-direct/deferentialconscientiousness',-as-of-its- 'epistemic-reflexivity/unreflexivity-in-existence'/teleology> is inherently entangled with the ontologising/scientific/existence- $<$ honesty-constraining $>$ scope_for_prospective_re-ontologising as to the existential-<disontologising/re-ontologising _ aporeticism $>$ possibility for sovereign-emergence/becoming,-existentially-imbuing humanfreedom-as-to-supererogating/surrealising-for-'knowledge-empowerment-over-ignorancedisempowerment'-<as-of-'developing-and-availing-sovereignsublimating_potential/possibilities/options/choices'-as-to-the-'credibility'/'ontologicalveracity'-underlying-the-'sovereign-conscious/conscientious-backdrop'> humanconsciousness/collective-consciousness-distendedness/detruncating- $<$ beyond-selfpresencing,as-re-ontologising-decentering_of-consciousness/collective-consciousness,-as-topsychologismic-epistemic-acutisation-residualising, - \{decompulsingl $d e l i n e a r i t y ~ f o r-c o g e n c y>$ with respect to its successively given and superseded registry-worldviews/dimensions <amplituding/formative-epistemicity $>$-totalising $\sim$ thrownness-in-existence ${ }^{35}$ - (as imbued of limitedness/human-subpotency prospective dearth for \{epistemic-totalising łre-apriorising/reaxiomatising/re-referencing $\sim$ residuality-in-re-originariness/re-origination projection). Such that the implicited/explicited articulation of the human sovereign-function/posture-<as-toexistentially-manifest-'embodied-subject $\sim$ consciousness-and-direct/deferential- 
supposedly of 'ontology displacing' rather arises as of a flawed ${ }^{79}$ presencing — absolutisingidentitive-constitutedness ${ }^{14}$ lack of requisite limitedness/human-subpotency 'despite-the-self exercise of epistemic-projection in notional $\sim$ self-distantiation- $<$ imbued-re-motif-and-reapriorising/re-axiomatising/re-referencing >'; which in reality doesn't effectively renege to prospective re-ontologising as manifested by the inclination to admit to 'ontological-veracity as undergirding sovereignty' when it comes to profoundsupereregation $\sim$ reframing/reformulation/decatchmenting/detruncating/decompulsing/delinear ising_scale_-of-transparent/noncontentious/un-nominalised/sound-interpretations/domains of manifest unblurriness-<re-ontologising_by-postconverging-as-to-dragged-outsupererogatory $\sim$ wholesomeness/profound-supererogation ,-while-anecdotalising-priordisontologising-thresholding $>\quad$ (as to nascent-particular/incipient-and-material/technicalsublimations- $<$ blinded-to-their-relative-ontological-completeness - reference-of-thought-

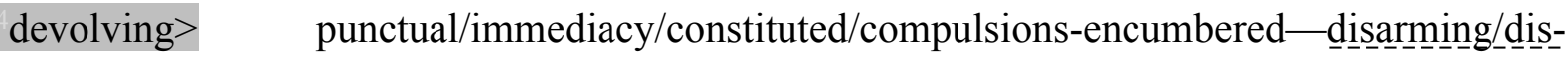
ideologising/deformulaicity/à-contrecoup/unsettling/unarguable), with a pretense to the 'precedence/supersedingness of sovereignty over ontological-veracity' rather arising selectively/whimsically/incoherently with shallow supererogation $\sim$ framing/formulation/catchmenting/truncating/compulsing/linearising_scale —of-opaque/contentious/un-nominalised/flawed-interpretations/domains of manifest blurriness-<sterilising/anecdotalising/trivialising-of-prospective-re-ontologising_bypreconverging,-in-disontologising-formulaic-dragging-out/hollowing-out> especially as to 'directly and/or deferentially perceived advantageous social-stake-contention-or-confliction' (reflecting the manifestation of presencing absolutising identitive constitutedness 
contentivity/argumentativity/dialecticism/discursivity' at human destructuring-threshold$\langle$ uninstitutionalised-threshold /presublimating-desublimating-decisionality $\rangle \sim$ of-ontologicalperformance $^{72}-<$ including-virtue-as-ontology $>$ ). In this regards, human sovereignemergence/becoming, existentially imbuing human freedom as to supererogating/surrealising for-'knowledge-empowerment-over-ignorance-disempowerment'-<as-of-'developing-andavailing-sovereign-sublimating_potential/possibilities/options/choices'-as-to-the'credibility'/‘ontological-veracity'-underlying-the-'sovereign-conscious/conscientiousbackdrop'> is existentially-<disontologising/re-ontologising aporeticism $>$ tied to the ontologising/scientific/existence- $<$ honesty-constraining $>$ - scope_for_prospective_reontologising imbued notional asceticism for superseding/overcoming of the human psychologismic-epistemic-acutisation-difficulty-<for,-residualising${ }_{\{\text {decompulsing }\}}$ delinearity for-cogency $>$-〈as-of-requisite-profound-supererogation -for‘disposedness-or-psychologismic-construct'-\{ imbued-demoronisation-<sublimatingnascence,-nonextricatory-sublimating-upstreaming/'amontée’’ $>\}$ (as of human psychologismic-transfixity-<placeholder-setup-ontological-rescheduling-inrealigning/preactivity/formative-becoming/psychoanalytical-unshackling,-as-to-residualising\{decompulsing delinearity-over-nonresidualising_andsing linearity $>$ as of humanconsciousness/collective-consciousness-distendedness/detruncating-<beyond-selfpresencing,as-re-ontologising-decentering_of-consciousness/collective-consciousness,-as-topsychologismic-epistemic-acutisation — residualising, - $_{\text {-decompulsing? }}$ delinearity for-cogency $>$ ); as so-reflected in the requisite eliciting of ontological-veracity as of 'unlimitedness/existence- $<\mathrm{full}-$ potency-of_sublimating nascence $>$ prospective apriorising/axiomatising/referencingsublimating-reflexivity - beholdening under which limitedness/human-subpotency submits in profound-supererogation for prospective sublimating' so-emphasising demoronisation- 
$<$ sublimating-nascence,-nonextricatory-sublimating-upstreaming/'amontée’> as reflecting the overarching profoundsupererogation $\sim$ reframing/reformulation/decatchmenting/detruncating/decompulsing/delinear ising - as-to-postconverging de-mentating/structuring/paradigming order/direction of ontological-veracity (as to imbuing 'reifying-mental-aestheticising-<as-of'prospective_reformulating-of-mental-aestheticising'as-to-'residuality-in-re-originariness/reorigination'-of-mental-aestheticising $>$ educed processive-motif-'exuding aestheticisinggesturing'-of-apriorising/axiomatising/referencing as to re-aestheticisation-and-reaestheticisation-towards-ontology-<elicited-prospective-idiomatisation>') rather as of the 'profound-

supererogation $\sim$ reframing/reformulation/decatchmenting/detruncating/decompulsing/delinear ising -as-to-postconverging de-mentating/structuring/paradigming priority/precedence/primacy' of re-ontologising prospective Being-development/ontologicalframework-expansion-as-to-depth-of-ontologising-development-as-infrastructure-ofmeaningfulness-and-teleology psychologismic epistemic-acutisation difficulty < for, residualising \{decompulsing\} ${ }^{\{}$delinearity for-cogency> magnitude $\{$fof-experientiality/experiment $\}$then institutional-development-as-to-social-function-development psychologismic epistemic acutisation difficulty-for, residualising \{decompulsing $\}$ delinearity for-cogency>-magnitude $\{$ ofexperientiality/experiment\} and then living-development-as-to-personality-development psychologismic epistemic acutisation difficulty-for, residualising \{decondering $d e$ dinearity for-cogency $>$ magnitude $\{$ of-experientiality/experiment $\}$. Thus the overall relativeunreflexivity/relative-reflexivity — ontological-contiguity ${ }^{67}$ of-the-human-institutionalisationprocess ${ }^{68}$ speaks of the 'inherent ${ }^{6}$ nonpresencing- $<$ perspective-ontologicalnormalcy/postconvergence $>$ epistemic-projection of the ontologising/scientific/existence$<$ honesty-constraining $>$ _ scope_for_prospective_re-ontologising' (as the 'reflexive-<as-to- 
epistemic-regulative $>-$ opened-construct $\quad$ of human sovereign-emergence/becoming-existentially-imbuing human-freedom-as-to-supererogating/surrealising for-'knowledgeempowerment-over-ignorance-disempowerment'-<as-of-'developing-and-availing-sovereignsublimating_potential/possibilities/options/choices'-as-to-the-'credibility'/'ontologicalveracity'-underlying-the-'sovereign-conscious/conscientious-backdrop'>' in demoronisation<sublimating-nascence,-nonextricatory-sublimating-upstreaming/'amontée'>), and so over successive ${ }^{7}$ presencing-absolutising-identitive-constitutedness ${ }^{14}$ 'conception of human sovereign apportioning as of lifespan extricatory/preconverging psychical-nascency moronisation-<sublimating-nascence,-extricatory-desublimating-downstreaming/'avalage' (as absolute-<as-to-the-given-unreflexive-epistemic-dictat/dogma/ideology $>$-closed-construct as from blatant brutish conquest/subjugation conception of sovereign apportioning, dominion protection conception of sovereign apportioning, to the very natural-order-of-things conception of sovereign apportioning and to our subtle modern-day institutionally-distorted/disjointed conception of sovereign apportioning). Sovereign-emergence/becoming-existentially-imbuinghuman-freedom-as-to-supererogating/surrealising-for''knowledge-empowerment-overignorance-disempowerment'-<as-of-'developing-and-availing-sovereignsublimating_potential/possibilities/options/choices'-as-to-the-'credibility'/'ontologicalveracity'-underlying-the-'sovereign-conscious/conscientious-backdrop'> (in reflection of the ontologising/scientific/existence- $<$ honesty-constraining $>$ - scope_for_prospective_reontologising unboundedness) as so-reflecting the-very-underlying-(as inherently 'definingand-imbuing of limitedness/human-subpotency de-mentation-〈supereregaryologicalde-mentation-or-dialectical-de-mentation — stranding-or-attributive-dialectics〉' as to preconverging/postconverging-de-mentating/structuring/paradigming)—relationship-betweenlimitedness/human-subpotency-and-unlimitedness/existence-<full-potency-of_sublimating nascence $>$ with respect to the pre-eminence of the latter (as to 'limitedness/human-subpotency 
prospective re-encountering/re-confrontation with unlimitedness/existence-<full-potencyof_sublimating nascence>'); effectively speaks to the underlying prospective 're-ontologising fepistemic-tolising tre-apriorising/re-axiomatising/re-referencing-residuality in-reoriginariness/re-origination $\left.{ }_{\{d e c o m p u l s i n g}\right\}$ delinearity/delinear-accreting/recomposuring cogency/tensing/limpidity-<as-of-prospective-profound-supererogation ,-for-residuality—inre-originariness/re-origination>-_prospective_reifying mental-aestheticising-<as-of'prospective_reformulating of mental-aestheticising'as-to-'residuality in -re-originariness/reorigination' of mental-aestheticising $>$ ' implications for prospective sublimating human sovereign-function/posture-<as-to-existentially-manifest-‘embodied-subject $\sim$ consciousnessand-direct/deferential-conscientiousness',-as-of-its- 'epistemic-reflexivity/unreflexivity-inexistence'/teleology $>$. Such that the 'reflexive-<as-to-epistemic-regulative $>-$ opened-construct of human sovereign-emergence/becoming,-existentially-imbuing human-freedom-as-tosupererogating/surrealising for ' $k$ nowledge-empowerment-over-ignorance-disempowerment'<as-of-'developing-and-availing-sovereignsublimating_potential/possibilities/options/choices'-as-to-the-'credibility'/'ontologicalveracity'-underlying-the-'sovereign-conscious/conscientious-backdrop'>' existentiallydisontologising/re ontologising aporeticism> speaks to 'succession of $<$ amplituding/formative-epistemicity $>$-totalising $\sim$ renewing-realisation/re-perception/rethought sublimating knowledge and transcendence-andsublimity/sublimation/supererogatory de-mentativity' (which are not an 'eclecticism-of-priormere-formulaicity/ritualisation-<as-of-prior $\sim$ rationalisation-ofcontentivity/argumentativity/dialecticism/discursivity> composition/blending-in\{compulsing linearity/linear-accretion of relative-ontological-completeness and relativeontological-incompleteness apriorising/axiomatising/referencing as to secondnatured prior mere-formulaicity/ritualisation- $<$ as-to-mere-formulaic- 
methodologising/mutualising/organising/institutionalising,-prospectively-losing-track-of-

‘\{epistemic-totalising ’’re-apriorising/re-axiomatising/re-referencing-residuality-in-re-

originariness/re-origination'>'); as so-reflecting the 'ontologising/scientific/existence$<$ honesty-constraining $>$ — scope_for_prospective_re-ontologising backdrop' of 'sovereignemergence/becoming,-existentially-imbuing human-freedom-as-to-supererogating/surrealising for-'knowledge-empowerment-over-ignorance-disempowerment'-<as-of-'developing-andavailing-sovereign-sublimating_potential/possibilities/options/choices'-as-to-the'credibility’/'ontological-veracity’-underlying-the-'sovereign-conscious/conscientiousbackdrop'>' imbued nonpresencing-<perspective-ontological-normalcy/postconvergence> 'existential-<disontologising/re-ontologising aporeticism $>$ prospect of human individualconsciousness/collective-consciousness decompulsion-appraisal' (as to the fact that the-verysame $\quad$ purview/devolved-purview/devolving-purview-of-unlimitedness/existence-<fullpotency-of_sublimating nascence $>$; - 'implicited_attendant-ontologicalcontiguity $^{67}$ ' educedexistentialising/contextualising/textualising_intelligibility/epistemicity/reflexivity-contiguity$<$ imbued-notional cogency $>$ ' ${ }^{40}$ is of differing-<as-not-of_composition/blending-in\{compulsing linearity/linear-accretion $>$ human sovereign-function/posture-<as-to-existentiallymanifest-'embodied-subject consciousness-and-direct/deferential-conscientiousness',-as-ofits-'epistemic-reflexivity/unreflexivity-in-existence'/teleology> recomposuring imbued 'reifying-mental-aestheticising-<as-of-'prospective_reformulating-of-mental-aestheticising'asto-'residuality-in-re-originariness/re-origination'-of-mental-aestheticising $>\quad$ educed processive-motif-'exuding aestheticising-gesturing'-of-apriorising/axiomatising/referencing as to re-aestheticisation-and-re-aestheticisation-towards-ontology-<elicited-prospectiveidiomatisation>' as of manifest recurrent-utter-uninstitutionalisation human sovereignfunction/posture-<as-to-existentially-manifest-`embodied-subject $\sim$ consciousness-and- 
direct/deferential-conscientiousness',-as-of-its-'epistemic-reflexivity/unreflexivity-in-

existence'/teleology>, base-institutionalisation-ununiversalisation human sovereignfunction/posture-<as-to-existentially-manifest-‘embodied-subject consciousness-and-

direct/deferential-conscientiousness',-as-of-its-'epistemic-reflexivity/unreflexivity-in-

existence'/teleology>, $\quad{ }^{103}$ universalisation-non-positivism/medievalism human sovereignfunction/posture-<as-to-existentially-manifest-'embodied-subject consciousness-anddirect/deferential-conscientiousness',-as-of-its- 'epistemic-reflexivity/unreflexivity-inexistence'/teleology>, positivism- ${ }^{8}$ procrypticism/disjointedness-as-of- ${ }^{2}$ reference-of-thought human sovereign-function/posture-<as-to-existentially-manifest-'embodiedsubject $\sim$ consciousness-and-direct/deferential-conscientiousness',-as-of-its- 'epistemicreflexivity/unreflexivity-in-existence'/teleology>, and prospectively deprocrypticism-orpreempting - disjointedness-as-of- ${ }^{8}$ reference-of-thought human sovereign-function/posture$<$ as-to-existentially-manifest-`embodied-subject $\sim$ consciousness-and-direct/deferentialconscientiousness',-as-of-its-'epistemic-reflexivity/unreflexivity-in-existence'/teleology>).

This effectively underlies that 'apriorising/axiomatising/referencing disambiguating/deleveling/de-ressentiment/opened-construct-of- ${ }^{5}$ meaningfulness-and-teleology demoronisation-<sublimating-nascence, is but an exercise in prospective 're-ontologising fepistemic-totalising 're-apriorising/reaxiomatising/re-referencing residuality in re-originariness/re-origination \{decompulsingt delinearity/delinear-accreting/recomposuring $\quad$ cogency/tensing/limpidity-<as-ofprospective-profound-supererogation ,-for-residuality-in-re-originariness/reorigination $>$ - prospective reifying mental-aestheticising-<as-of-prospective reformulatingof mental restheticising'as to 'residuality in re originariness/re origination' of mental aestheticising $>^{\prime}$ as to the implications for sublimating human sovereign-function/posture- $<$ asto-existentially-manifest-'embodied-subject consciousness-and-direct/deferential- 
implied as to Being-development/ontological-framework-expansion-as-to-depth-ofontologising-development-as-infrastructure-of- meaningfulness-and-teleology , institutionaldevelopment-as-to-social-function-development and living-development-as-to-personalitydevelopment psychologismic epistemic-acutisation difficulty-<for, residualising $\{$ decompulsing $\}$ delinearity for-cogeney $>$ magnitudes $\left.{ }^{\{\text {of-experientiality/experiment }\}}\right\}$. The overall implication here (as to the coextensive nature of sovereign-emergence/becoming-existentially-imbuing human-freedom-as-to-supererogating/surrealising for-'knowledge-empowerment-overignorance-disempowerment'-<as-of-'developing-and-availing-sovereignsublimating_potential/possibilities/options/choices'-as-to-the-'credibility'/'ontologicalveracity'-underlying-the-'sovereign-conscious/conscientious-backdrop'> and the ontologising/scientific/existence- $<$ honesty-constraining $>$ - scope_for_prospective_reontologising) is that 'sovereign accountability' (as construed in the basic terms of our modern age) is much more than just a 'basic manifest/gestural sovereign-exercising-<as-of-sovereigndeferentialism;-as-to- 'direct/indirect-electing-and/or-nominating'>' of 'unwieldycontemplatable disontologising/re-ontologising implications' with regards to human sovereignfunction/posture-<as-to-existentially-manifest-`embodied-subject $\sim$ consciousness-anddirect/deferential-conscientiousness',-as-of-its-'epistemic-reflexivity/unreflexivity-inexistence'/teleology>; but very much integrates the effective prospective re-ontologising elucidation 'widening the social imaginary' as to nonpresencing-<perspective-ontologicalnormalcy/postconvergence> 'existential-<disontologising/re-ontologising aporeticism $>$ prospect of human individual-consciousness/collective-consciousness decompulsion-appraisal' (as to the 'requisite prospective sublimating decompulsion_imprinting across the various institutional levels of interrelatedness-dynamics-of-social-constructing' so-arising from the 'educing-and-availing-and-re-availing of relative-ontological-completeness ${ }^{87}$ with respect to 
apriorising/axiomatising/referencing-sublimating-reflexivity-beholdening under which limitedness/human-subpotency submits in profound-supererogation for prospective sublimating'). This reflects the fact that successive 'secondnatured human stations/loci of limitedness/human-subpotency <amplituding/formative-epistemicity>-totalising $\sim$ thrownnessin-existence ${ }^{35}$ - as imbued of limitedness/human-subpotency prospective dearth for fepistemictotalising ${ }^{\prime}$ re-apriorising/re-axiomatising/re-referencing $\sim$ residuality-in-re-originariness/reorigination projection)' of the overall relative-unreflexivity/relative-reflexivity-ontologicalcontiguity ${ }^{67}$ of-the-human-institutionalisation-process ${ }^{68}$ manifest their given 'unwieldycontemplatable disontologising/re-ontologising implications' with regards to human sovereignfunction/posture-<as-to-existentially-manifest-'embodied-subject consciousness-anddirect/deferential-conscientiousness',-as-of-its-'epistemic-reflexivity/unreflexivity-inexistence'/teleology> (as so-reflecting their given 'existential-<disontologising/reentologising aporeticism $>$ postconverging-aporeticism-overcoming/unovercoming' for prospective sublimating human sovereign-function/posture-<as-to-existentially-manifest'embodied-subject consciousness-and-direct/deferential-conscientiousness',-as-of-its'epistemic-reflexivity/unreflexivity-in-existence'/teleology>); and in-many-ways it is paradoxically such 'unwieldy-contemplatable disontologising/re-ontologising implications' with regards to human sovereign-function/posture-<as-to-existentially-manifest-'embodiedsubject consciousness-and-direct/deferential-conscientiousness',-as-of-its-'epistemicreflexivity/unreflexivity-in-existence'/teleology>' that drive '79 presencing-absolutisingidentitive-constitutedness ${ }^{14}$ advocacy/political/applicative-scope desublimating thresholds' eliciting of their given presencing absolutising identitive constitutedness 'existential<disontologising/re-ontologising aporeticism $>$ preconverging dementating/structuring/paradigming punctual/immediacy/constituted/compulsions-encumbered 
contentivity/argumentativity/dialecticism/discursivity' in so-striving consciously/unconsciously to prospectively curb/curtail the full-potency of the ontologising/scientific/existence- $<$ honestyconstraining $>$ _ scope_for_prospective_re-ontologising (especially with respect to the profoundsupererogation $\sim$ reframing/reformulation/decatchmenting/detruncating/decompulsing/delinear ising as-to-postcenverging de-mentating/structuring/paradigming of contentious/unnominalised social-stake-contention-or-confliction underlying prospective sublimating human sovereign-function/posture-<as-to-existentially-manifest-'embodied-subject $\sim$ consciousnessand-direct/deferential-conscientiousness',-as-of-its- 'epistemic-reflexivity/unreflexivity-inexistence'/teleology>). It can thus be appreciated in this regards that sovereignemergence/becoming,-existentially-imbuing human-freedom-as-to-supererogating/surrealising for-'knowledge-empowerment-over-ignorance-disempowerment'-<as-of-'developing-andavailing-sovereign-sublimating_potential/possibilities/options/choices'-as-to-the‘credibility'/'ontological-veracity'-underlying-the-'sovereign-conscious/conscientiousbackdrop'> is effectively underlied as of its manifest 'wieldy-contemplatable and unwieldycontemplatable disontologising/re-ontologising implications' associated respectively with overt and covert 'relatively uncontentious/nominalised and relatively contentious/un-nominalised social-stake-contention-or-confliction' (so-reflected respectively as to profoundsupererogation $\sim$ reframing/reformulation/decatchmenting/detruncating/decompulsing/delinear ising_scale_-of-transparent/noncontentious/un-nominalised/sound-interpretations/domains of manifest unblurriness-<re-ontologising by-postconverging-as-to-dragged-outsupererogatory $\sim$ wholesomeness/profound-supererogation ,-while-anecdotalising-priordisontologising-thresholding $>\quad$ and manifest shallow supererogation $\sim$ framing/formulation/catchmenting/truncating/compulsing/linearising_scale —of-opaque/contentious/un-nominalised/flawed-interpretations/domains of manifest 


\section{blurriness-<sterilising/anecdotalising/trivialising-of-prospective-re-ontologising_by-}

preconverging,-in-disontologising-formulaic-dragging-out/hollowing-out>); such that prospective re-ontologising elucidation 'widening the social imaginary' (as to the 'requisite prospective sublimating decompulsion_imprinting across the various institutional levels of interrelatedness-dynamics-of-social-constructing' so-arising from the 'educing-and-availingand-re-availing of relative-ontological-completeness ${ }^{87}$ with respect to unlimitedness/existence<full-potency-of_sublimating nascence $>$ prospective apriorising/axiomatising/referencing sublimating-reflexivity_-beholdening under which limitedness/human-subpotency submits in profound-supererogation for prospective sublimating') is rather an exercise of sublimatingly superseding/overcoming prospective 'unwieldy-contemplatable disontologising/re-ontologising implications' with regards to human sovereign-function/posture-<as-to-existentially-manifest‘embodied-subject consciousness-and-direct/deferential-conscientiousness',-as-of-its'epistemic-reflexivity/unreflexivity-in-existence'/teleology> (and not succumbing to the prospective undermining of the ontologising/scientific/existence- $<$ honesty-constraining $>$ scope_for_prospective_re-ontologising as to the latter's veridical undergirding as of 'substantivity of transversality- $<$ for-sublimating-existential-eventuating/denouement-from-

\section{thinking at first/pure predisposition preemptive of prospective}

disontologising/subontologising’ as-of-prospectively-disambiguated-affirmed-andunaffirmed-'motif-and-apriorising/axiomatising/referencing'>10'). Critically, such 'human derogation-to-profound-supererogation in shallow-supererogation (manifested as of presencing absolutising identitive-constitutedness 'existential-<disontologising/reentologising aporeticism $>$ preconverging de-mentating/structuring/paradigming punctual/immediacy/constituted/compulsions-encumbered prior mere-formulaicity/ritualisation rationalisation-of-contentivity/argumentativity/dialecticism/discursivity') correspondingly calls for a sublimating conception as of 'substantivity of transversality-<for-sublimating- 
existential-eventuating/denouement-from-'thinking-at-first/pure-predisposition-preemptive-ofprospective-disontologising/subontologising' as-of-prospectively-disambiguated-affirmedand-unaffirmed-'motif-and-apriorising/axiomatising/referencing'> ${ }^{\text {1 }}$ ' (in effective reflection of 'unlimitedness/existence-<full-potency-of_sublimating nascence $>$ prospective apriorising/axiomatising/referencing-sublimating-reflexivity-beholdening under which limitedness/human-subpotency submits in profound-supererogation for prospective sublimating') involving 'ontological-veracity impersonalisation and deinstitutionalisation' as to 'prospective nonpresencing-<perspective-ontological-normalcy/postconvergence $>$ epistemicprojection profoundsupererogation $\sim$ reframing/reformulation/decatchmenting/detruncating/decompulsing/delinear ising-as-to-postconverging de-mentating/structuring/paradigming'. $\quad$ Such an 'impersonalisation and deinstitutionalisation of prospective re-ontologising meaningfulnessand-teleology ${ }^{\prime \prime}$ (as to ontologising-failsafe-<as-to-'relative-unreflexivity/relative-reflexivity bindingness/nondiscretionariness' of totalising-entailment $>$ ) means that the effective reflection of 'unlimitedness/existence-<full-potency-of_sublimating nascence> prospective apriorising/axiomatising/referencing-sublimating-reflexivity-beholdening under which limitedness/human-subpotency submits in profound-supererogation for prospective sublimating' renders 'unlimitedness/existence-<full-potency-of_sublimating nascence $>$ byitself/inherently the reflection of sublimating/desublimating manifestation' (so-construed as 'prospective-and-perpetual decisive-bottomline of demonstrative disontologising/reontologising'), and so beyond/unbeholdening even to personal and institutional cadres/frameworks that had elicited 'prior demonstrative disontologising/re-ontologising'; as soreadily manifested relatively with the practice of pront supererogation $\sim$ reframing/reformulation/decatchmenting/detruncating/decompulsing/delinear ising_scale_of-transparent/noncontentious/un-nominalised/sound-interpretations/domains of 
manifest

unblurriness-<re-ontologising_by-postconverging-as-to-dragged-out-

supererogatory $\sim$ wholesomeness/profound-supererogation ,-while-anecdotalising-prior-

disontologising-thresholding $>$ (for instance as to the 'relays of human intemporal-individuation epistemic-projection

radicalities $\sim$ in-chronicular/annalistic-cogency-<as-of-

notional protensivity $>$-〈as-to-limited-mentation-capacity-deepening —as-subjecting

limitedness/human-subpotency-to-'educed-unlimitedness/existence-sublimating nascence' >

so-construed as cogency_chronicularity/annality-of-relative-reflexivity,-as-to-profoundsupererogation 'driving many a domain in the natural sciences) whereas the manifest shallowsupererogation $\sim$ framing/formulation/catchmenting/truncating/compulsing/linearising_scale —of-opaque/contentious/un-nominalised/flawed-interpretations/domains of manifest blurriness- $<$ sterilising/anecdotalising/trivialising-of-prospective-re-ontologising_bypreconverging,-in-disontologising-formulaic-dragging-out/hollowing-out> are relatively desublimatingly bound to fall back to personal and institutional cadres/frameworks, and so undermining ontologising-failsafe-<as-to-'relative-unreflexivity/relative-reflexivitybindingness/nondiscretionariness' of totalising entailment $\geq$. In-the-bigger-scheme-of-things, 'substantivity of transversality- $<$ for-sublimating-existential-eventuating/denouement,-from'thinking at-first/pure-predisposition-preemptive-of-prospectivedisontologising/subontologising’ as-of-prospectively-disambiguated-affirmed-andunaffirmed-'motif-and-apriorising/axiomatising/referencing'> $>$ ' so-reflect a conceptualisation of human ontological-performance ${ }^{72}-$ including-virtue-as- $^{2}$ ontology $>$ /morality/ethics/justice/etc. as to the 'more profound veracity of varying firstnaturedness-as-to-inkling profound-supererogation and derived secondnatured positiveopportunism — of-social-functioning-and-accordance ${ }^{7}$, induced untenability/internalcontradiction/internal-incoherence/institutional-constraining for the pre-eminence of the ontologising/scientific/existence- $<$ honesty-constraining $>$ - scope_for_prospective_re- 
ontologising reflecting human-consciousness/collective-consciousnessdistendedness/detruncating-<beyond-selfpresencing,-as-re-ontologising-decentering_ofconsciousness/collective-consciousness,-as-to-psychologismic-epistemic-acutisation

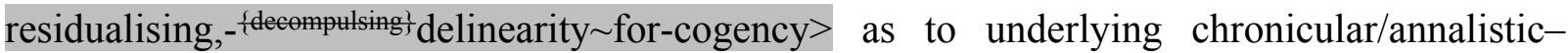
cogency-<as-of-notional protensivity $>$ so-construed as cogency_chronicularity/annality-ofrelative-reflexivity,-as-to-profound-supererogation (so-undergirded as of 'preconverging/postconverging-rede-mentating/restructuring/reparadigming of limitedness/human-subpotency ${ }^{15}$ de-mentation-/supereregatory $\sim$ ontological-de-mentation-ordialectical-de-mentation — stranding-or-attributive-dialectics $\left.\rangle^{\prime}\right)$; and so over ${ }^{79}$ presencingabsolutising-identitive-constitutedness ${ }^{14}$ misconstrual that fail to appreciate that 'all the human ontological-performance ${ }^{72}<$ including-virtue-as-ontology $>/$ morality/ethics/justice/etc. that can arise' is rather a 'sublimating postconverging supererogation (whether of varying firstnaturedness-as-to-inkling profound-supererogation and derived secondnatured positiveopportunism-of-social-functioning-and-accordance ${ }^{75}$ ) acting upon underlying limitedness/human-subpotency preconverging/postconverging-dementating/structuring/paradigming' and not the idea of any given ' 79 presencing — absolutisingidentitive-constitutedness ${ }^{14}$ absolute-distinctiveness of individual/institutional ontologicalperformance ${ }^{2}$-<including-virtue-as-ontology $>$ /morality/ethics/justice/etc.', as so-failing to appreciate requisite profound-supererogation as from human 'crossgenerational notional firstnaturedness-formativeness-<as-to-eventualising inkling-drive-or-seedingmisprising $>$ mental-processing-parity for ontological-performance ${ }^{72}-<$ including-virtue-asontology $>$ /morality/ethics/justice/etc.' as of the given <amplituding/formative-epistemicity $>$ totalising thrownness-in-existence ${ }^{5}$ - as imbued of limitedness/human-subpotency prospective dearth for tre-apriorising/re-axiomatising/rereferencing $\sim$ residuality - in-re-originariness/re-origination projection) warrant for profound- 
supererogation ${ }^{6}$ requisite prospective demoronisation- $<$ sublimating-nascence,-nonextricatory sublimating-upstreaming/'amontée’>. In this regards, the relatively tepid psychologismic-epistemic-acutisation — difficulty- $<$ for,-residualising_\{decompulsing $\}$ delinearity $\sim$ for-cogency $>-\langle$ asof-requisite-profound-supererogation -for-'disposedness-or-psychologismic-construct'\{imbued-demoronisation-<sublimating-nascence, nonextrieatery-sublimatingupstreaming/‘amontée’>\}) of profoundsupererogation $\sim$ reframing/reformulation/decatchmenting/detruncating/decompulsing/delinear ising_scale_of-transparent/noncontentious/un-nominalised/sound-interpretations/domains of manifest unblurriness-<re-ontologising_by-postconverging-as-to-dragged-outsupererogaty wholesomeness/profound-supererogation ,-while-anecdotalising-priordisontologising-thresholding $>$ (as manifested with nascent-particular/incipient-andmaterial/technical-sublimations-<blinded-to-their-relative-ontological-completeness reference-of-thought- devolving $>\quad$ punctual/immediacy/constituted/compulsions-

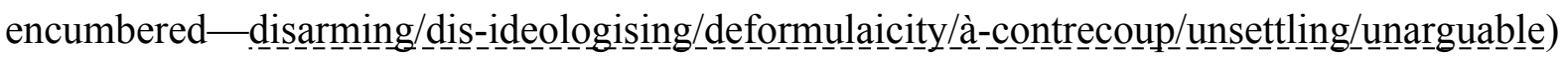
means that they are relatively amenable to 'ontological-veracity impersonalisation and deinstitutionalisation' (as to their relatively uncontentious/nominalised social-stake-contentionor-confliction) which is hardly/weakly the case with the manifest shallowsupererogation $\sim$ framing/formulation/catchmenting/truncating/compulsing/linearising_scale —of-opaque/contentious/un-nominalised/flawed-interpretations/domains of manifest blurriness-<sterilising/anecdotalising/trivialising-of-prospective-re-ontologising_bypreconverging,-in-disontologising-formulaic-dragging-out/hollowing-out> (as manifested with many human social-and-institutional-frameworks-of-referencing/registering/decisioning existentialising-decisionality-<as-to-disontologising/re-ontologising aporeticism $>\quad$ of relatively contentious/un-nominalised social-stake-contention-or-confliction for which 'radicalities $\sim$ in-chronicular/annalistic-cogency-<as-of-notional $\sim$ protensivity $>$-〈as-to-limited- 
mentation-capacity-deepening —as-subjecting limitedness/human-subpotency-to-'educed-

unlimitedness/existence-sublimating nascence' > so-construed as

cogency_chronicularity/annality-of-relative-reflexivity,-as-to-profound-supererogation are inherently unsettling/unnerving as to their ${ }^{79}$ presencing-absolutising-identitiveconstitutedness ${ }^{14}$ purposefulness). 'Substantivity of transversality- $<$ for-sublimating-existentialeventuating/denouement,from-'thinking-at-first/pure-predisposition-preemptive-ofprospective-disontologising/subontologising' as-of-prospectively-disambiguated-affirmedand-unaffirmed-'motif-and-apriorising/axiomatising/referencing' $>{ }^{101}$, as such is effectively what allows for 'superseding/overcoming prior mere-formulaicity/ritualisation-<as-to-mereformulaic — methodologising/mutualising/organising/institutionalising,-prospectively-losingtrack-of- ‘ \{epistemic-totalising ${ }^{3}$ re-apriorising/re-axiomatising/re-referencing-residuality-in-reoriginariness/re-origination'> (as defining of the prospective destructuring-threshold〈uninstitutionalised-threshold /presublimating-desublimating-decisionality $\rangle$ of-ontologicalperformance ${ }^{72}-<$ including-virtue-as-ontology $>$ )' for prospective 're-ontologising [epistemictotalising ${ }^{\prime}$ re-apriorising/re-axiomatising/re-referencing-residuality in -re-originariness/reorigination \{decompulsing\} ${ }^{\{}$delinearity/delinear-acereting/recomposuring cogency/tensing/limpidity<as-of-prospective-profound-supererogation ,-for-residuality-in-re-originariness/reorigination>-,prospective_reifying mental-aestheticising-<as-of-'prospective_reformulatingof-mental-aestheticising'as-to-'residuality in-re-originariness/re-origination' of-mentalaestheticising $>$ '; and so as superseding/overcoming the prospectively desublimating 'overall unthought/uncontemplated/mere-reflex/shallow/unsound gesturing/accounting-of-epistemicphenomenalism' of the given ${ }^{7}$ presencing — absolutising-identitive-constitutedness ${ }^{14}$ 'nihilistic knowledge-deadends-<as-preconverging-de-mentating/structuring/paradigming $>$ undermining prospective re-ontologising' (as not resolvable as of prior presencing absolutising-identitiveconstitutedness 'existential-<disontologising/re-ontologising aporeticism $>$ preconverging 
contentivity/argumentativity/dialecticism/discursivity but rather as of prospective profoundsupererogation for nonpresencing-<perspective-ontological-normalcy/postconvergence $>$ 'existential-<disontologising/re-ontologising aporeticism $>$ prospect of human individualconsciousness/collective-consciousness decompulsion-appraisal, in reflection of 'unlimitedness/existence-<full-potency-of_sublimating nascence $>$ prospective apriorising/axiomatising/referencing-sublimating-reflexivity-beholdening under which limitedness/human-subpotency submits in profound-supererogation for prospective sublimating'). This so-enables the psychologismic-transfixity-<placeholder-setup-ontologicalrescheduling —in-realigning/preactivity/formative-becoming/psychoanalytical-unshackling,-asto-residualising_\{decompulsing $\}$ delinearity-over-nonresidualising_\{compulsing $\}$ linearity $>$ (as of humanconsciousness/collective-consciousness-distendedness/detruncating-<beyond-selfpresencing,as-re-ontologising-decentering_of-consciousness/collective-consciousness,-as-topsychologismic-epistemic-acutisation - residualising, - \{decompulsingl $d e$ dinearity for-cogency $>$ ) of ${ }^{63}$ reference-of-thought- ${ }^{8}$ devolving ${ }^{56}$ meaningfulness-and-teleology" as from the given ${ }^{63}$ reference-of-thought ${ }^{56}$ meaningfulness-and-teleology ${ }^{9}$ imbuing sublimating prospective chronicular/annalistic-cogency-<as-of-notional $\sim$ protensivity $>$ so-construed as cogency_chronicularity/annality-of-relative-reflexivity,-as-to-profound-supererogation (whether as from trepidatious-consciousness/trancing to warped-consciousness/mysticising, preclusive-consciousness/occulticising, occlusive-consciousness/subtranslational or prospectively protensive-consciousness/omnitranslational imbued sublimating prospective cogency_chronicularity/annality-of-relative-reflexivity,-as-to-profound-supererogation ${ }^{9}$ ); as to the fact that prospective re-ontologising metaphoricity ${ }^{57}$ projection of base-institutionalisation, ${ }^{3}$ universalisation, positivism/rational-empiricism and ${ }^{18}$ deprocrypticism-or-preempting- 
disjointedness-as-of- ${ }^{8}$ reference-of-thought respectively over the respective disontlogising/subontologisating of recurrent-utter-uninstitutionalisation, ununiversalisation, non-positivism/medievalism and procrypticism-or-disjointedness-as-of- ${ }^{\text {reference-of- }}$ thought is not veridically a-limiting-factor/a-limit to 'thinking at first/pure predisposition preemptive of prospective disontologising/subontologising' (in contrast to a mere 'secondnatured conscious/unconscious rationalising/calculating of the sublimating outcome of prior profound-supererogation rationalisation-ofcontentivity/argumentativity/dialecticism/discursivity imbued positive-opportunism—of-socialfunctioning-and-accordance ${ }^{7}$,) as so-veridically underlying the possibility for core philosophy ambit of prospective 'existential-<disontologising/re-ontologising aporeticism $>$ postconverging-aporeticism-overcoming/unovercoming' and so-reflected as to 'human prospective reference-of-thought - point-ofdevolving/departure/anchoring/backdrop_of_sublimating-nascence-<as-to-the-grandestaxiomatic-construct-\{epistemic alising łre-apriorising/re-axiomatising/rereferencing residuality - in-re-originariness/re-origination of limitedness/human-subpotency prospective re-encountering/re-confrontation with unlimitedness/existence>' ${ }^{\text {. Thus }}$ notional $\sim$ philosophy-<as-to-the-veridical-conception-of-philosophy-as-englobing-all-humanprospective-organic-knowledge-generation-in-relative-ontological-completeness ,-beyond-aconvenient-division-of-labour-conception-of-knowledge $>$ is reflected as to the 'relays of human intemporal-individuation epistemic-projection radicalities $\sim$ in-chronicular/annalistic-cogency$<$ as-of-notional $\sim$ protensivity $>-\langle$ as-to-limited-mentation-capacity-deepening as subjecting

\section{limitedness/human-subpotency-to-'educed-unlimitedness/existence-sublimating nascence' >}

so-construed as cogency_chronicularity/annality-of-relative-reflexivity,-as-to-profoundsupererogation, (with regards to limitedness/human-subpotency prospective reencountering/re-confrontation with the 'constraining/defining intersolipsistic reflexive- 
sublimating/unreflexive-desublimating measure/objectification that is unlimitedness/existenceas-ontological-normalcy/postconvergence-<in-validation-of-‘metaphysics-ofabsence_epistemic-projection'>'); as thusly underlying the overall ontologising/scientific/existence- $<$ honesty-constraining $>$ — scope_for_prospective_reontologising 'human consciousness notional protensivity psychologismic-epistemicacutisation-<as-to-postconverging-de-mentating/structuring/paradigming,-eliciting-ofexistence's-sublimating-nascence-in-prospective-aporeticism-overcoming/unovercoming $>$ as to epistemic-growth,-as — \{veridical/sound\}-relative-reflexivity-in-existence/relativising fromlimited-mentation-as-its-deepening/psychologismic epistemic-acutisation residualising, $\{$ decompulsing $\}$ delinearity for-cogency' as of human-consciousness/collective-consciousnessdistendedness/detruncating-<beyond-selfpresencing,-as-re-ontologising-decentering_ofconsciousness/collective-consciousness,-as-to-psychologismic-epistemic-acutisationresidualising,-\{decompulsing\} delinearity for-cogency> (as to the cross-dynamics of 'firstnaturedness-as-to-inkling profound-supererogation for overarching existential$\leq$ disontologising/re-ontologising aporeticism $>$ priority/precedence/primacy of apistemictotalising $3{ }^{3}$ re-apriorising/re-axiomatising/re-referencing $\sim$ residuality-in-re-originariness/reorigination projection' in 'recurrent/perpetuating/continuity-recomposuring existential$\leq$ disontologising/re-ontologising aporeticism $>$ counteracting/supplanting/alienating-ofprior-apriorising/axiomatising/referencing' over 'secondnatured prior mereformulaicity/ritualisation-<as-to-mere-formulaic methodologising/mutualising/organising/institutionalising,-prospectively-losing-track-of‘\{epistemic-totalising ’’re-apriorising/re-axiomatising/re-referencing - residuality-in-reoriginariness/re-origination'>'). 'Substantivity of transversality-<for-sublimating-existentialeventuating/denouement,-from-'thinking at-first/pure-predisposition-preemptive-ofprospective-disontologising/subontologising' as-of-prospectively-disambiguated-affirmed- 
and-unaffirmed-'motif-and-apriorising/axiomatising/referencing'>10, as such is ever always about 'overarching existential-<disontologising/re-ontologising aporeticism $>$ priority/precedence/primacy of referencing $\sim$ residuality—in-re-originariness/re-origination projection'; as to the enchanting/reenchanting of the-very-same purview/devolved-purview/devolving-purview-ofunlimitedness/existence-<full-potency-of_sublimating nascence>;_-implicited_attendant ontological-contiguity ${ }^{67}$; educed-

existentialising/contextualising/textualising_'intelligibility/epistemicity/reflexivity-contiguity<imbued-notional cogency>' (so-reflected as to prospective 're-ontologising -epistemictotalising $\frac{1}{r}$ re-apriorising/re-axiomatising/re-referencing residuality in-re-originariness/reorigination \{decompulsing\} ${ }^{\{}$delinearity/delinear-acereting/recomposuring cogency/tensing/limpidity<as-of-prospective-profound-supererogation ,-for-residuality-in-re-originariness/reorigination $>$, p prospective_reifying mental-aestheticising <as-of-'prospective_reformulating of-mental-aestheticising'as-to 'residuality in re-originariness/re-origination' of mentalaestheticising $>$ '). 'Substantivity of transversality-<for-sublimating-existentialeventuating/denouement,-from-'thinking at-first/pure-predisposition-preemptive-ofprospective disontologising/subontologising' as-of-prospectively-disambiguated-affirmedand-unaffirmed-'motif-and-apriorising/axiomatising/referencing'>101, as to 'overarching existential-<disontologising/re-ontologising aporeticism $>$ priority/precedence/primacy of re-apriorising/re-axiomatising/re-referencing $\sim$ residuality—in-reoriginariness/re-origination projection' (when it comes to 'unwieldy-contemplatabledisontologising/re-ontologising-implications,-with-regards-to-human-sovereignfunction/posture-<as-to-narrowness/evasiveness/vagueness-of-disontologising/reontologising > with respect to contentious/un-nominalisedness of social-stake-contention-orconfliction') sublimatingly elicits prospective chronicular/annalistic-cogency-<as-of- 
notional protensivity $>\quad$ so-construed as cogency_chronicularity/annality-of-relativereflexivity,-as-to-profound-supererogation (as to prospective <postconverging ' motif-andapriorising/axiomatising/referencing'-entailing>-existentialising_-framing/imprinting-〈as-toprospective- historiality/ontological-eventfulness /ontological-aesthetic-tracing$<$ perspective-ontological-normalcy/postconvergence-reflected-'epistemicity-relativismdeterminism'>l); with respect to a conception of sovereign-emergence/becoming,-existentiallyimbuing human-freedom-as-to-supererogating/surrealising for-'knowledge-empowermentover-ignorance-disempowerment'-<as-of-'developing-and-availing-sovereignsublimating_potential/possibilities/options/choices'-as-to-the-'credibility'/'ontologicalveracity'-underlying-the-'sovereign-conscious/conscientious-backdrop'> arising sublimatingly as to 'nonextricatory/postconverging ontologising-and-re-ontologising angling-of-imaginary demoronisation-<sublimating-nascence,-nonextricatory-sublimating-upstreaming/‘amontée’>’ imbued 'vigorous re-ontologising project/oeuvrement of human sovereign-function/posture<as-to-existentially-manifest-`embodied-subject consciousness-and-direct/deferentialconscientiousness',-as-of-its- 'epistemic-reflexivity/unreflexivity-in-existence'/teleology>' (as decompulsively disentangled respectively as from compulsively-encumbered trepidatiousconsciousness, warped-consciousness, preclusive-consciousness and occlusive-consciousnesses towards protensive-consciousness in reflection of 'notional protensivity as to nonpreseneing<perspective ontological-normalcy/postconvergence $\quad$ 'existential-<disontologising/reentologising aporeticism $>$ prospect of human individual-consciousness/collectiveconsciousness decompulsion-appraisal'), and so rather than 'lifespan extricatory/preconverging psychical-nascency moronisation- $<$ sublimating-nascence,-extricatory-desublimatingdownstreaming/'avalage'>' imbued 'prospective disontologising/subontologising de-project/deoeuvrement of human sovereign-function/posture-<as-to-existentially-manifest-'embodiedsubject $\sim$ consciousness-and-direct/deferential-conscientiousness',-as-of-its- 'epistemic- 
reflexivity/unreflexivity-in-existence'/teleology>' (of the 'catchmenting-by-rejection/lipservicing/monopolising/gaming-of-the-system/charade/distraction vague/imaginary lures of social-stake-contention-or-confliction' as to 'accessory/adjunctive cobbling-together/gathering, procession, forming, presenting, dissipating and instrumentalising in a dearth of prospective chronicular/annalistic-cogency-<as-of-notional $\sim$ protensivity $>\quad$ so-construed $\quad$ as cogency_chronicularity/annality-of-relative-reflexivity,-as-to-profound-supererogation ${ }^{9}$ as so-reflected with the desublimating envelopment of prior < preconverging 'motif-andapriorising/axiomatising/referencing'-entailing>-existentialising-enframing/imprintedness〈as-to- historicity-tracing-in-presencing-hyperrealisation/hyperreal-transposition〉). Ultimately, 'substantivity of transversality-<for-sublimating-existentialeventuating/denouement,-from-'thinking-at-first/pure-predisposition-preemptive-ofprospective-disontologising/subontologising' as-of-prospectively-disambiguated-affirmedand-unaffirmed-'motif-and-apriorising/axiomatising/referencing'>10, reflects human ontologising/scientific/existence- $<$ honesty-constraining $>$ — scope_for_prospective_reontologising unboundedness (arising as to the-human/humanity 'recurrently mediative-<inexpectation/in-anticipation $>$ unconsciousness/potentiation-of-conscionability- $<$ anxiety-as-toreconstitution/reparation,-including-dreaming/psychical-reshuffling>' as the 'psychoanalytic boundlessness of human notional $\sim$ reflexivity-<\{veridical/sound $\}$-relative-reflexivity-inexistence/relativising from-limited-mentation-as-its-deepening/psychologismic<residualising \{decompulsing delinearity for-cogency>-by-\{flawed/unsound\}-relativeunreflexivity-in-existencelabsolutising from-limited-mentation/psychologismic epistemic acutisation nonresidualising imbued \{compulsing\} linearity in eclecticism of prior mere formulaicity/ritualisation> existential-<disentologising/re-ontologising aporeticism> backdrop'), and so-reflected as to human 'aestheticising motif/re-motif in the projection/reprojection-and-anticipation/re-anticipation of human existential-<disontologising/re- 
entologising aporeticism $>$ backdrop of coherent/contiguous ${ }^{56}$ meaningfulness-andteleology $^{9}$, for intelligibility-〈as-to-human-projective/reprojective-aestheticising-re-motifand-re-apriorising/re-axiomatising/re-referencing/re-intelligibilitysettingup/re-

measuringinstrumenting-process,-in-<amplituding/formative-

epistemicity>totalising conceptualisation). So-reconstrued basically as to human 'selfreflexive $\sim$ instigative-eventuating-〈as-to-teleological-instigative/incipient-

willing/arbitrariness/waywardness/faithdrivenness/supererogating-for-human-intelligibility,preceding-existence's-eventuating-sublimating-validation/desublimating-invalidation> of human embodied-consciousness motif-and-apriorising/axiomatising/referencing-\{of'prospectively_implicited_attendant-ontological-contiguity ' educedexistentialising/contextualising/textualising_'intelligibility/epistemicity/reflexivity-contiguity$<$ imbued-notional cogency $>$ ' $\}$-elicited-incipience-of-existentialising-decisionality-<as-todisontologising/re-ontologising aporeticism $>$ ' undergirding the 'full incipient supererogating breadth of human intelligibility transmutation'; as so-underlied concurrently as of 'motif (outcome/outfit/shell—construed-historially-as-of-the-specifically-aestheticisedincrusting/plating/coating-as-institutional-manifestation) imbuing aestheticisation-andaestheticisation-towards-ontology-<elicited-idiomatisation $>$ and ‘apriorising/axiomatising/referencing imbuing ontological-performance -<including-virtue-asontology $>$ /morality/ethics/justice/etc. of implicited requisite projection of the coherence/contiguity of the superseding-oneness-of-ontology/ontological-veridicality/relativeunreflexivity/relative-reflexivity_ontological-contiguity ' with regards to eliciting prospective 're-ontologising \{epistemic-totalising 're-apriorising/re-axiomatising/re-referencing-residuality in re-originariness/re-origination \{decompulsing delinearity/delinear-accreting/recomposuring cogency/tensing/limpidity-<as-of-prospective-profound-supererogation , re-originariness/re-origination>-,prospective_reifying mental-aestheticising-<as-of- 


\section{'prospective_reformulating-of-mental-aestheticising'as-to-'residuality in-re-originariness/re-}

erigination'-of-mental-aestheticising $>$ '; as 'human consciousness notional protensivity psychologismic-epistemic-acutisation-<as-to-postconverging-de-

mentating/structuring/paradigming,-eliciting-of-existence's-sublimating-nascence-inprospective-aporeticism-overcoming/unovercoming > as to epistemic-growth,-as\{veridical/sound\}-relative-reflexivity-in-existence/relativising from-limited-mentation-as-itsdeepening/psychologismic epistemic acutisation residualising, ${ }^{\text {fdecompulsing }}$ delinearity foreogency' with respect to the-very-same purview/devolved-purview/devolving-purview-ofunlimitedness/existence-<full-potency-of_sublimating nascence $>$; - ‘implicited_attendantontological-contiguity ${ }^{67}$, educedexistentialising/contextualising/textualising_intelligibility/epistemicity/reflexivity-contiguity$<$ imbued-notional cogency $>$ ' ' This concurrence speaks to the 'dynamic cumulating/recomposuring psychologismic-epistemic-acutisation-residualising,delinearity for-cogency phasing of limitedness/human-subpotency onto unlimitedness/existence-<fll potency-of_sublimating nascence $>$ ' in reflection of human placeholder-setup/mental-devising-representation/mentation/consciousness-awarenessteleology , as inherently reflecting both the given overall <amplituding/formativeepistemicity $>$-totalising $\sim$ thrownness-in-existence ${ }^{5}$ - as imbued of limitedness/humansubpotency prospective dearth for \{epistemic-totalising łre-apriorising/re-axiomatising/rereferencing $\sim$ residuality —in-re-originariness/re-origination projection) presencing absolutising-identitive-constitutedness 'existential-<disontologising/re-ontologising aporeticism> preconverging de-mentating/structuring/paradigming punctual/immediacy/constituted/compulsions-encumbered prior mere-formulaicity/ritualisation rationalisation-of-contentivity/argumentativity/dialecticism/discursivity' and potentiating its nonpresencing-<perspective-ontological-normalcy/postconvergence $>$ 'existential- 
<disontologising/re-ontologising aporeticism $>$ prospect of human individualconsciousness/collective-consciousness decompulsion-appraisal; as so-driven as of 'psychologismic-transfixity-<placeholder-setup-ontological-rescheduling-inrealigning/preactivity/formative-becoming/psychoanalytical-unshackling,-as-to-residualising$\{$ \{decompulsing $\}$ delinearity-over-nonresidualising_\{compulsing\} $\}$ linearity $>$ of human consciousness' (soconstrued herein as of human-consciousness/collective-consciousnessdistendedness/detruncating-<beyond-selfpresencing,-as-re-ontologising-decentering_ofconsciousness/collective-consciousness,-as-to-psychologismic-epistemic-acutisationresidualising, - $\left\{\right.$ decompulsing $^{-} d e l i n e a r i t y ~ f o r-\operatorname{cogency}>$ notionally/epistemically/bindingnessly-<as-todeterminism/conceptivity-of-relative-unreflexivity/relative-reflexivitys effusing 'psychologismic-transfixity$<$ placeholder-setup-ontological-rescheduling - in-realigning/preactivity/formativebecoming/psychoanalytical-unshackling,-as-to-residualising-\{decompulsing $\}$ delinearity-overnonresidualising_\{compulsing\} linearity> with respect to 'idiosyncratic-ferment_fornotional $\sim$ cogency-〈as-to- $<$ surrealising/supererogating-drive $>$-of-aestheticising relief/depth-and-impetus $\quad$ imbuing-<by-needling/prying/prospecting-for-"phasing-androoting'>-of interlay/organicalism/aestheticising-handle-<of-'psychologismictransfixity\{residualising \{decompulsing\} delinearity-over-nonresidualising \{compulsing linearity\}'>' of

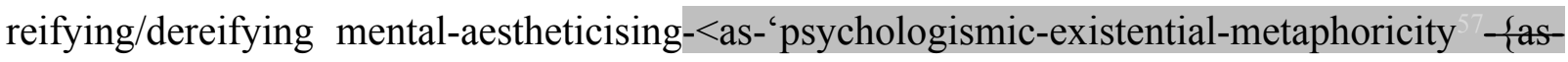
to-\{epistemic-tolising ’’re-apriorising/re-axiomatising/re-referencing_in-becoming\}'-so-implicited'by-way-of-the-existentially/contextually/textually-manifest-motif-construct-as-specificlanguage'-as-so-reflecting-'the-existentially/contextually/textually-manifestmoronisation/demoronisation'>'), and so in reflection of the-very-underlying-(as inherently 'defining-and-imbuing of limitedness/human-subpotency de-mentation〈supererogatory $\sim$ ontological-de-mentation-or-dialectical-de-mentation-stranding-orattributive-dialectics $\rangle^{\prime}$ as to preconverging/postconverging-de- 
mentating/structuring/paradigming)—relationship-between-limitedness/human-subpotencyand-unlimitedness/existence- $<$ full-potency-of_sublimating naseence $>$ with respect to the preeminence of the latter (as to 'limitedness/human-subpotency prospective re-encountering/reconfrontation with unlimitedness/existence-<full-potency-of_sublimating nascence $>$ '). The sublimating potentiating of nonpresencing-<perspective-ontologicalnormaley/postconvergence > 'existential-<disontologising/re-ontologising aporeticism $>$ prospect of human individual-consciousness/collective-consciousness decompulsion-appraisal (reflecting 'existential-<disontologising/re-ontologising aporeticism> hermeneutic/textuality/reprojecting/supererogating/zeroing/re-acuting $\{$ decompulsing $\}$ delinearity/delinear-accreting/recomposuring- ${ }^{6}$ nonpresencing-perceptualisation-ofsublimating-over-desublimating- $<$ as-' psychologismic-epistemic-acutisation - residualising,\{decompulsing $\}$ delinearity for-cogency’_as-to-‘prospective-profound-supererogation -epistemicperspective'-of-prospective-\&-prior-differentiated-apriorising/axiomatising/referencing $>$ with-respect-to-the-prospect-of-prospective-human-re-ontologising') is what effectively underlies prospective 're-ontologising referencing residuality in-re-originariness/re-origination \{decompulsing $\}$ delinearity/delinearaccreting/recomposuring cogency/tensing/limpidity-<as-of-prospective-profoundsupererogation ,-for-residuality_in-re-originariness/re-origination>-,prospective_reifying mental-aestheticising-<as-of-'prospective_reformulating-of-mental-aestheticising'as-to'residuality in-re-originariness/re-origination'-of-mental-aestheticising $» ' \quad$ imbuing 'apriorising/axiomatising/referencing disambiguating/de-leveling/de-ressentiment/openedconstruct-of- -5 meaningfulness-and-teleology $\quad$ demoronisation- $<$ sublimating-nascence,(as to hublimating-upstreaming/'amontée’’ $>$ Beingdevelopment/ontological-framework-expansion-as-to-depth-of-ontologising-development-asinfrastructure-of- meaningfulness-and-teleology , institutional-development-as-to-social- 
function-development and living-development-as-to-personality-development psychologismic epistemic acutisation difficulty-for, residualising \{decompulsing ${ }^{\text {\} }}$ delinearity for-cogency> magnitudes $\left.{ }^{\{0-e x p e r i e n t i a l i t y / e x p e r i m e n t}\right\}$. Insightfully, human limited-mentation-capacity-deepeningas-subjecting limitedness/human-subpotency-to-'educed-unlimitedness/existence-sublimating nascence' : as of 'motif (outcome/outfit/shell-construed-historially-as-of-the-specificallyaestheticised-incrusting/plating/coating-as-institutional-manifestation) imbuing aestheticisation-and-aestheticisation-towards-ontology-<elicited-idiomatisation $>$ ' exudingand-educing 'apriorising/axiomatising/referencing imbuing ontological-performance <including-virtue-as-ontology $>$ /morality/ethics/justice/etc. of implicited requisite projection of the coherence/contiguity of the superseding-oneness-of-ontology/ontologicalveridicality/relative-unreflexivity/relative-reflexivity —ontological-contiguity ' with regards to eliciting prospective 're-ontologising_fepistemic-totalising 're-apriorising/re-axiomatising/rereferencing residuality in re-originariness/re-origination $\{$ decompulsing $\}$ delinearity/delinearaccreting/recomposuring cogency/tensing/limpidity-<as-of-prospective-profoundsupererogation ,-for-residuality-in-re-originariness/re-origination>--prospective_reifying mental-aestheticising-<as-of 'prospective_reformulating of mental-aestheticising'as-to'residuality in re originariness/re origination' of mental aestheticising' (as 'human consciousness notional protensivity psychologismic-epistemic-acutisation-<as-topostconverging-de-mentating/structuring/paradigming,-eliciting-of-existence's-sublimatingnascence-in-prospective-aporeticism-overcoming/unovercoming > as to epistemic-growth,-as\{veridical/sound\}-relative-reflexivity-in-existence/relativising from-limited-mentation-as-itsdeepening/psychologismic epistemic acutisation residualising, ${ }^{\text {\{decompulsing }}$ delinearity foreogeney' with respect to the-very-same purview/devolved-purview/devolving-purview-ofunlimitedness/existence-<full-potency-of_sublimating nascence $>$;_-implicited_attendant ontological-contiguity ${ }^{67} \sim$ educed- 
existentialising/contextualising/textualising_intelligibility/epistemicity/reflexivity-contiguity$<$ imbued-notional $\sim$ cogency $>^{\prime}$ ), and so-manifesting as sublimating ‘ $<$ amplituding/formative $>$ disposedness/psychologismic-construct-〈as-to-orientation/valueconstruct/valuation-and-derived-parameterising $\rangle$ and $<$ amplituding/formative $>$ entailment-〈asto-totalising-contiguous/coherent-factuality-of-variability); rather arises as from underlying sublimating potentiating of nonpresencing-<perspective-ontologicalnormalcy/postconvergence> 'existential-<disontologising/re-ontologising aporeticism $>$ prospect of human individual-consciousness/collective-consciousness decompulsion-appraisal (in cumulating/recomposuring eliciting of human-consciousness/collective-consciousnessdistendedness/detruncating-<beyond-selfpresencing,-as-re-ontologising-decentering_ofconsciousness/collective-consciousness,-as-to-psychologismic-epistemic-acutisation

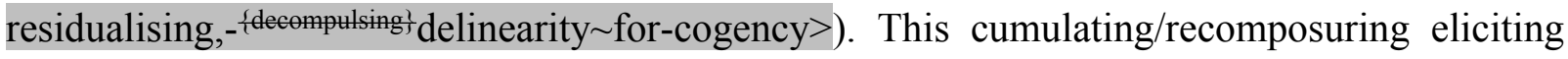
of human-consciousness/collective-consciousness-distendedness/detruncating-<beyondselfpresencing,-as-re-ontologising-decentering_of-consciousness/collective-consciousness,-as-

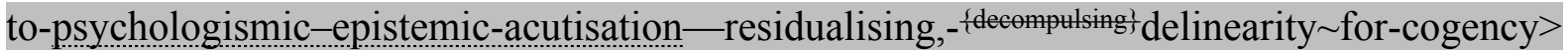
(as from underlying sublimating potentiating of nonpresencing-<perspective-ontologicalnormalcy/postconvergence $>\quad$ 'existential-<disontologising/re-ontologising aporeticism $>$ prospect of human individual-consciousness/collective-consciousness decompulsion-appraisal) speaks to the underlying 'human consciousness notional protensivity psychologismicepistemic-acutisation-<as-to-postconverging-de-mentating/structuring/paradigming,-elicitingof-existence's-sublimating-nascence-in-prospective-aporeticism-overcoming/unovercoming> as to epistemic-growth,-as-\{veridical/sound\}-relative-reflexivity-in-existence/relativising from-limited-mentation-as-its-deepening/psychologismic epistemic-acutisationresidualising, ${ }^{\text {\{decompungl }}$ delinearity for-cogency' (as reflecting its cumulating/recomposuringdiscarding/foregoing of presencing absolutising-identitive-constitutedness 'existential- 
mentating/structuring/paradigming punctual/immediacy/constituted/compulsions-encumbered prior mere-formulaicity/ritualisation rationalisation-of-

contentivity/argumentativity/dialecticism/discursivity'). In other words, human sublimating potentiating of nonpresencing-<perspective-ontological-normalcy/postconvergence $>$ 'existential-<disontologising/re-ontologising aporeticism $>$ prospect of human individualconsciousness/collective-consciousness decompulsion-appraisal speaks to the 'notion of more and more profound-as-to-cumulating/recomposuring registry-worldviews/dimensions institutionalisation (within which the "notion of parity of individual/institutional distinctiveness ontological-performance ${ }^{72}<$ including-virtue-as-ontology $>$ /morality/ethics/justice/etc.' naively arises)'; and so, in effective reflection of 'unlimitedness/existence-<full-potencyof_sublimating nascence> prospective apriorising/axiomatising/referencing-sublimatingreflexivity-beholdening under which limitedness/human-subpotency submits in profoundsupererogation for prospective sublimating'. The implication here is that all the possibility for prospective human knowledge and transcendence-andsublimity/sublimation/supererogatery de-mentativity is as of "relays of human intemporalindividuation epistemic-projection radicalities $\sim$ in-chronicular/annalistic-cogency-<as-ofnotional protensivity>-〈as-to-limited-mentation-capacity-deepening—as-subjecting

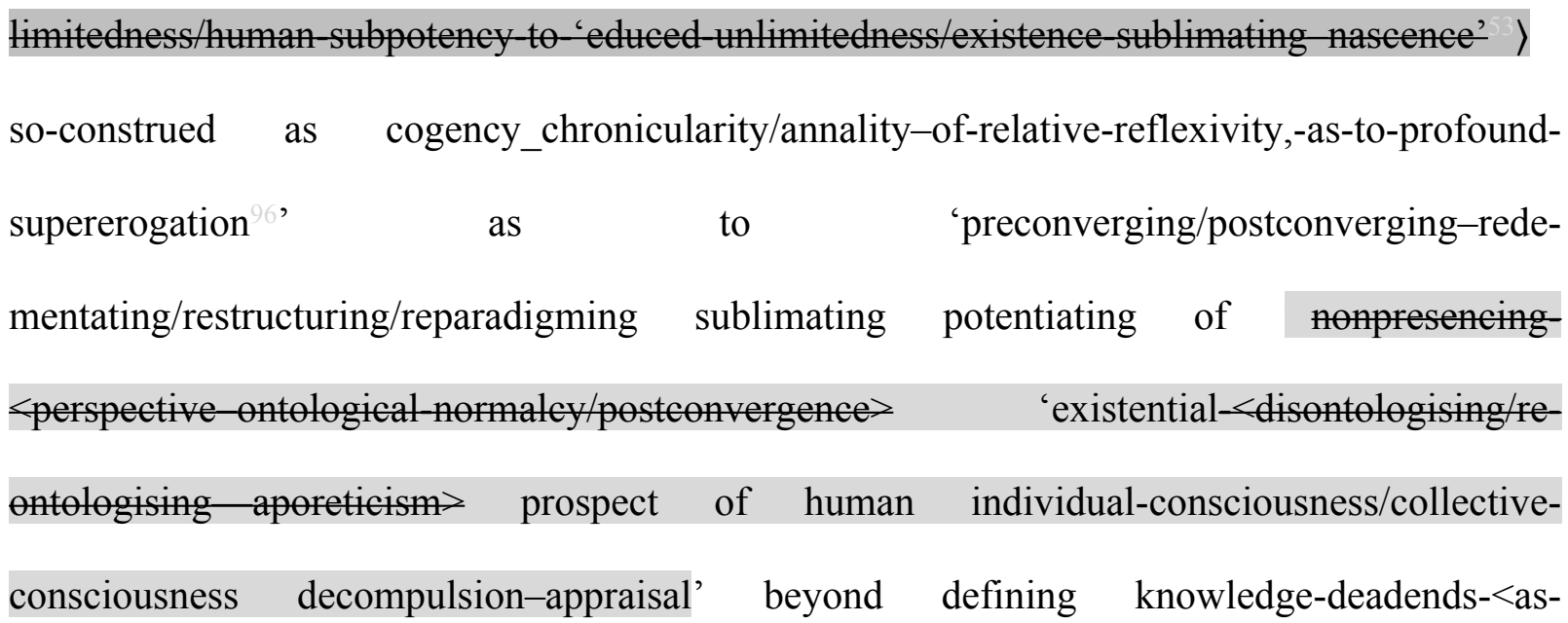


preconverging-de-mentating/structuring/paradigming $>$ (as not resolvable as of prior presencing absolutising identitive-constitutedness 'existential-<disontologising/reentologising aporeticism $>$ preconverging de-mentating/structuring/paradigming punctual/immediacy/constituted/compulsions-encumbered prior mere-formulaicity/ritualisation rationalisation-of-contentivity/argumentativity/dialecticism/discursivity but rather as of prospective profound-supererogation for nonpresencing-<perspective ontologicalnormalcy/postconvergence $>$ 'existential-<disontologising/re-ontologising aporeticism> prospect of human individual-consciousness/collective-consciousness decompulsion-appraisal, in reflection of "unlimitedness/existence-<full-potency-of_sublimating naseence $>$ prospective apriorising/axiomatising/referencing-sublimating-reflexivity-beholdening under which limitedness/human-subpotency submits in profound-supererogation for prospective sublimating'); as from compulsively-encumbered trepidatious-consciousness, warpedconsciousness, preclusive-consciousness and occlusive-consciousnesses towards protensiveconsciousness in cumulating/recomposuring-successive decompulsion-appraisal. This emphasis is drawn to highlight that in-many-ways a registry-worldview/dimension construes of knowledge without even factoring in the more fundamental implications as to its given mentaldevelopment as to underlying 'human consciousness notional protensivity psychologismicepistemic-acutisation-<as-to-postconverging-de-mentating/structuring/paradigming,-elicitingof-existence's-sublimating-nascence-in-prospective-aporeticism-overcoming/unovercoming> as to epistemic-growth,-as-\{veridical/sound\}-relative-reflexivity-in-existence/relativising from-limited-mentation-as-its-deepening/psychologismic epistemic-acutisationresidualising, ${ }^{\text {\{decompulsing }}$ delinearity for-cogency' (in reflection of the 'profound-reframing/reformulation/decatchmenting/detruncating/decompulsing/delinear ising —as-to-postconverging - de-mentating/structuring/paradigming priority/precedence/primacy' of re-ontologising prospective Being-development/ontological- 
framework-expansion-as-to-depth-of-ontologising-development-as-infrastructure-ofmeaningfulness-and-teleology psychologismic epistemic acutisation difficulty-<for, residualising \{dementsing\} delinearity for-cogency> magnitude\{of-experientiality/experiment\}, then institutional-development-as-to-social-function-development psychologismic epistemic acutisation difficulty-for, residualising \{decompulsing $\}$ delinearity for-cogency> magnitude of- $^{\text {for }}$ experientiality/experiment\} and then living-development-as-to-personality-development psychologismic epistemic-acutisation difficulty-for, residualising \{decomplsing delinearity for-cogency $>$ magnitude ${ }^{\text {of-experientiality/experiment }\}}$ ) so-explaining how its given knowledge-deadends-<as-preconverging-de-mentating/structuring/paradigming $>$ arise in want for prospective profound-supererogation ${ }^{9}$ (as not resolvable as of prior presencing absolutising-identitive-constitutedness $\quad$ 'existential-<disontologising/re-ontologising aporeticism> preconverging de-mentating/structuring/paradigming punctual/immediacy/constituted/compulsions-encumbered prior mere-formulaicity/ritualisation rationalisation-of-contentivity/argumentativity/dialecticism/discursivity but rather as of prospective profound-supererogation for nonpresencing-<perspective-ontologicalnormaley/postconvergence $>\quad$ 'existential-<disontologising/re-ontologising aporeticism $>$ prospect of human individual-consciousness/collective-consciousness decompulsion-appraisal, in reflection of 'unlimitedness/existence-<full-potency-of_sublimating nascence $>$ prospective apriorising/axiomatising/referencing-sublimating-reflexivity-beholdening under which limitedness/human-subpotency submits in profound-supererogation for prospective sublimating'); in the sense for instance that " universalising occultic practices/sciences/mathematics of ancient Mediterranean civilisations' were inherently limited as to their ${ }^{83}$ reference-of-thought mysticising and occulticising 'lifespan extricatory/preconverging psychical-nascency moronisation-<sublimating-nascence,extricatory-desublimating-downstreaming/'avalage'>’ imbued presencing absolutising 
preconverging de-mentating/structuring/paradigming

punctual/immediacy/constituted/compulsions-encumbered prior mere-formulaicity/ritualisation rationalisation-of-contentivity/argumentativity/dialecticism/discursivity' explaining their very prospectively mental-underdevelopment impossibility for arriving at a modern-day positivism/rational-empiricism conceptualisation and practice of science. It is herein contended that in-many-ways the very exercise of prospective human limited-mentation-capacitydeepening —as-subjecting limitedness/human-subpotency to-'educed-unlimitedness/existencesublimating nascence' (as to sublimating potentiating of nonpresencing-<perspectiveontological-normalcy/postconvergence $>\quad$ 'existential-<disontologising/re-ontologising aporeticism $\geqslant$ prospect of human individual-consciousness/collective-consciousness decompulsion-appraisal): as of 'motif (outcome/outfit/shell—construed-historially-as-of-thespecifically-aestheticised-incrusting/plating/coating-as-institutional-manifestation) imbuing aestheticisation-and-aestheticisation-towards-ontology-<elicited-idiomatisation $>$ ' exudingand-educing 'apriorising/axiomatising/referencing imbuing ontological-performance $<$ including-virtue-as-ontology $>/$ morality/ethics/justice/etc. of implicited requisite projection of the coherence/contiguity of the superseding-oneness-of-ontology/ontologicalveridicality/relative-unreflexivity/relative-reflexivity - ontological-contiguity ' with regards to eliciting prospective 're-ontologising \{epistemic-totalising ${ }^{3}$ re-apriorising/re-axiomatising/rereferencing residuality in re-originariness/re-origination accreting/recomposuring cogency/tensing/limpidity-<as-of-prospective-profoundsupererogation ,-for-residuality_in-re-originariness/re-origination>-_prospective_reifying mental aestheticising <as of 'prospective_reformulating of mental aestheticising' as to 'residuality in-re-originariness/re-origination' of-mental-aestheticising ${ }^{\prime}$ (as 'human consciousness notional protensivity psychologismic-epistemic-acutisation-<as-to- 
postconverging-de-mentating/structuring/paradigming,-eliciting-of-existence's-sublimatingnascence-in-prospective-aporeticism-overcoming/unovercoming $>$ as to epistemic-growth,-as\{veridical/sound\}-relative-reflexivity-in-existence/relativising from-limited-mentation-as-itsdeepening/psychologismic epistemic-acutisation residualising, ${ }^{\text {fdecompulsing }}$ delinearity foreogency' with respect to the-very-same purview/devolved-purview/devolving-purview-ofunlimitedness/existence-<full-potency-of_sublimating nascence>;_-implicited_attendantontological-contiguity ${ }^{67}$ ' educed-

existentialising/contextualising/textualising_'intelligibility/epistemicity/reflexivity-contiguity$<$ imbued-notional cogency ${ }^{\prime}$ ), when wrongly construed as of accreting- ${ }^{79}$ presencing-perceptualisation-of-sublimating-over-desublimating-<as'psychologismic-epistemic-acutisation - nonresidualising-imbued-\{compulsing\})linearity ineclecticism-of-prior-mere-formulaicity/ritualisation'_as-to-'secondnatured-epistemicperspective'-of-prospective-\&-prior-differentiated-apriorising/axiomatising/referencing $>$ and-as-developing-into-interrelatedness-dynamics-of-social-constructing is bound to implicit prospective desublimating presencing absolutising-identitive-constitutedness 'existential<disontologising/re-ontologising aporeticism $>$ preconverging de-

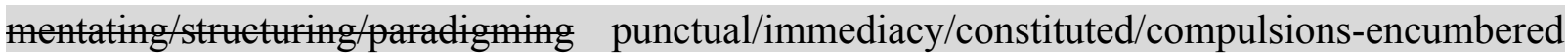
prior mere-formulaicity/ritualisation rationalisation-ofcontentivity/argumentativity/dialecticism/discursivity'; and so-pointing to prospective sublimating hold rather as of 'existential-<disontologising/re-ontologising aporeticism> hermeneutic/textuality/reprojecting/supererogating/zeroing/re-acuting $\{$ decompulsing $\}$ delinearity/delinear-accreting/recomposuring- ${ }^{6}$ nonpresencing-perceptualisation-ofsublimating-over-desublimating-<as-'psychologismic-epistemic-acutisation-residualising,${ }_{\{\text {decompulsing }}$ delinearity for-cogency'_as-to-'prospective-profound-supererogation -epistemicperspective'-of prospective- \&-prior-differentiated-apriorising/axiomatising/referencing $>$ 
'recurrent/perpetuating/continuity-recomposuring

existential $<$ disontologising/reentologising aporeticism $>$ counteracting/supplanting/alienating-of-prior-

apriorising/axiomatising/referencing' over 'secondnatured prior mere-formulaicity/ritualisation<as-to-mere-formulaic — methodologising/mutualising/organising/institutionalising,-

prospectively-losing-track-of- ‘ ‘epistemic-totalising $\frac{1}{3}$ re-apriorising/re-axiomatising/re-

referencing residuality -in-re-originariness/re-origination'>')', in reflection of requisite prospective mental-development as to underlying 'human consciousness notional protensivity psychologismic-epistemic-acutisation-<as-to-postconverging-de-

mentating/structuring/paradigming,-eliciting-of-existence's-sublimating-nascence-inprospective-aporeticism-overcoming/unovercoming $>$ as to epistemic-growth,-as\{veridical/sound\}-relative-reflexivity-in-existence/relativising from-limited-mentation-as-itsdeepening/psychologismic epistemic-acutisation residualising, ${ }_{\text {d decompulsing }\}}$ delinearity foreogency' of the human placeholder-setup/mental-devisingrepresentation/mentation/consciousness-awareness-teleology (as humanconsciousness/collective-consciousness-distendedness/detruncating-<beyond-selfpresencing,as-re-ontologising-decentering_of-consciousness/collective-consciousness,-as-topsychologismic-epistemic-acutisation-residualising, - $^{\{\text {decompulsing }}$ delinearity $\sim$ for-cogency $>$ ). Thus the overall relative-unreflexivity/relative-reflexivity ontological-contiguity $\sim$ of-thehuman-institutionalisation-process ${ }^{68}$ imbued human-consciousness/collective-consciousnessdistendedness/detruncating-<beyond-selfpresencing,-as-re-ontologising-decentering_ofconsciousness/collective-consciousness,-as-to-psychologismic-epistemic-acutisationresidualising, ${ }^{-\{\text {decompulsing }}$ delinearity for-cogency $>$ effectively reflects the successive superseding/overcoming of the human psychologismic-epistemic-acutisation-difficulty- $<$ for,residualising_\{decompulsing\} $\}$ delinearity for-cogency $>-\langle$ as-of-requisite-profound-supererogation 
for-'disposedness-or-psychologismic-construct'- \{imbued-demoronisation-<sublimating-

nascence,-nonextricatory-sublimating-upstreaming/'amontée’> $\}\rangle$ with regards to the 'dynamic cumulating/recomposuring psychologismic-epistemic-acutisation-residualising,\{decompulsing delinearity for-cogency phasing of limitedness/human-subpotency onto unlimitedness/existence-full potey of_sublimating nascence>' so-manifesting upon the underlying human placeholder-setup/mental-devising-representation/mentation/consciousnessawareness-teleology ${ }^{9}$ (as inherently hampered/limited/in-difficulty with respect to the given overall <amplituding/formative-epistemicity>-totalising thrownness-in-existence $^{35}$ - (as imbued of limitedness/human-subpotency prospective dearth for \{epistemic-totalising ${ }^{\frac{1}{3}}$ reapriorising/re-axiomatising/re-referencing $\sim$ residuality—in-re-originariness/re-origination projection) presencing absolutising-identitive-constitutedness 'existential<disontologising/re-ontologising aporeticism> preconverging dementating/structuring/paradigming punctual/immediacy/constituted/compulsions-encumbered prior mere-formulaicity/ritualisation rationalisation-ofcontentivity/argumentativity/dialecticism/discursivity' but equally prospectively potentiating as to epistemic-growth,-as - \{veridical/sound\}-relative-reflexivity-in-existence/relativising fromlimited-mentation-as-its-deepening/psychologismic epistemic-acutisation residualising, $\{$ decompulsing delinearity for-cogency its nonpresencing-<perspective-ontologicalnormaley/postconvergence> 'existential-<disontologising/re-ontologising aporeticism $>$ prospect of human individual-consciousness/collective-consciousness decompulsion-appraisal); as so-underlying the concurrence of 'motif (outcome/outfit/shell-construed-historially-as-ofthe-specifically-aestheticised-incrusting/plating/coating-as-institutional-manifestation) imbuing aestheticisation-and-aestheticisation-towards-ontology-<elicited-idiomatisation $>$ ' exudingand-educing 'apriorising/axiomatising/referencing imbuing ontological-performance $<$ including-virtue-as-ontology $>/$ morality/ethics/justice/etc. of implicited requisite projection of 
the coherence/contiguity of the superseding-oneness-of-ontology/ontologicalveridicality/relative-unreflexivity/relative-reflexivity - ontological-contiguity ' with regards to

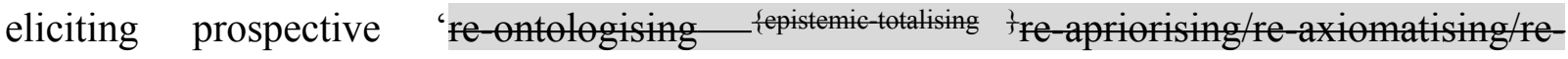
referencing residuality in-re-originariness/re-origination \{decompulsing $\}$ delinearity/delinearaccreting/recomposuring cogency/tensing/limpidity-<as-of-prospective-profoundsupererogation ,-for-residuality-in-re-originariness/re-origination $>$ - prospective_reifying mental-aestheticising <as-of 'prospective_reformulating of mental-aestheticising'as-to'residuality in re-originariness/re-origination' of mental-aestheticising $>$ ' (as 'human consciousness notional protensivity psychologismic-epistemic-acutisation- $<$ as-topostconverging-de-mentating/structuring/paradigming,-eliciting-of-existence's-sublimatingnascence-in-prospective-aporeticism-overcoming/unovercoming $>$ as to epistemic-growth,-as\{veridical/sound\}-relative-reflexivity-in-existence/relativising from-limited-mentation-as-itsdeepening/psychologismic epistemic-acutisation residualising, ${ }^{\text {fdecompulsing }}$ delinearity foreogency' with respect to the-very-same purview/devolved-purview/devolving-purview-ofunlimitedness/existence-<full-potency-of_sublimating nascence $>$;_—'implicited_attendantontological-contiguity ${ }^{67}$; educed-

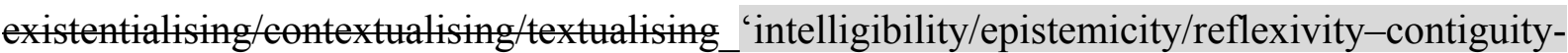
$<$ imbued-notional cogency $>^{\prime}$ ). This latter point translates practically with regards to the human existential-<disontologising/re-ontologising aporeticism> relationship between 'substantivity of transversality-<for-sublimating-existential-eventuating/denouement,-from'thinking at-first/pure-predisposition-preemptive-of prospectivedisontologising/subontologising’ as-of-prospectively-disambiguated-affirmed-andunaffirmed-'motif-and-apriorising/axiomatising/referencing'> ${ }^{101}$ ' (as sublimatingly generative in prospective profound-supererogation of overall human-consciousness/collectiveconsciousness-distendedness/detruncating-<beyond-selfpresencing,-as-re-ontologising- 
decentering_of-consciousness/collective-consciousness,-as-to-psychologismic-epistemic-

acutisation-residualising, - -decompulsing $\}^{-}$delinearity for-cogency $>$prospective re-ontologising profound-

supererogation $\sim$ reframing/reformulation/decatchmenting/detruncating/decompulsing/delinear ising - as-to-postconverging de-mentating/structuring/paradigming in re-ontologising 'dynamic cumulating/recomposuring psychologismic-epistemic-acutisation-residualising,${ }_{\{\text {decompulsing }}$ delinearity for-cogency phasing of limitedness/human-subpotency onto unlimitedness/existence-<full-potency-of_sublimating nascence>' so-manifesting upon the underlying human placeholder-setup/mental-devising-representation/mentation/consciousnessawareness-teleology ${ }^{9}$ ) and so on-the-one-hand (as of protracted-social — as-to-individual-byinstitutional-by-social formativeness-<as-to-intersolipsism-ofpreformulating/preframing/premeaningfulness-imbued-mediativity-and-deferentialism>-ofmeaningfulness-and-teleology as to bechancing-becoming-originariness/origination-as-tohistoriality/ontological-eventfulness 3 /ontological-aesthetic-tracing-<perspectiveontological-normalcy/postconvergence-reflected-‘epistemicity-relativismdeterminism'> disinhibited-mental-aestheticising scalarisation potential), and on-the-otherhand the inherent shallow-supererogation of 'catchmenting-by-rejection/lipservicing/monopolising/gaming-of-the-system/charade/distraction vague/imaginary lures of social-stake-contention-or-confliction' prospective disontologising/subontologising shallow supererogation $\sim$ framing/formulation/catchmenting/truncating/compulsing/linearising —as-topreconverging de-mentating/structuring/paradigming arresting-effect on overall humanconsciousness/collective-consciousness-distendedness/detruncating- $<$ beyond-selfpresencing,as-re-ontologising-decentering_of-consciousness/collective-consciousness,-as-topsychologismic-epistemic-acutisation — residualising, - -decompulsing $_{\}}$delinearity for-cogency $>$(as of protracted-social—as-to-individual-by-institutional-by-social 
concreteness/concretism/<preconverging 'motif-and-apriorising/axiomatising/referencing'entailing >-existentialising — enframing/imprintedness-〈as-to- historicity-tracing - inpresencing-hyperrealisation/hyperreal-transposition〉_ of-human-ontological-performance ${ }^{72}$ $<$ including-virtue-as-ontology $>/$ morality/ethics/justice/etc. as to beholdening-becomingdistortive-originariness/distortive-origination-as-to- ${ }^{-}$historicity-tracing inhibited-mentalaestheticising descalarisation reflex by its inducing of ${ }^{79}$ presencing-absolutising-identitiveconstitutedness <preconverging 'motif-and-apriorising/axiomatising/referencing' entailing $>$-existentialising — enframing/imprintedness-〈as-to- historicity-tracing-inpresencing-hyperrealisation/hyperreal-transposition)). The bigger point here is thus summarily about the 'flow of human prospective profound-supererogation-over-shallowsupererogation', (given 'unlimitedness/existence-<full-potency-of_sublimating nascence> prospective apriorising/axiomatising/referencing-sublimating-reflexivity-beholdening under which limitedness/human-subpotency submits in profound-supererogation for prospective sublimating' warrant the 'overarching existential-disontologising/re-ontologisingaporeticism $>$ priority/precedence/primacy of \{epistemic-totalising 3 3 re-apriorising/re-axiomatising/rereferencing $\sim$ residuality —in-re-originariness/re-origination projection') with regards to 'human socially-protracted-as-to-individual-by-institutional-by-social psychologismic-epistemicacutisation-difficulty- $<$ for,-residualising-\{decompulsing $\}$ delinearity $\sim$ for-cogency $>-\langle$ as-of-

\section{requisite-profound-supererogation -for-'disposedness-or-psychologismic-construct'-}

\section{\{imbued-demoronisation-<sublimating-nascence,-nonextricatory-sublimating-}

upstreaming/'amontée'>\})' (as to prospective sublimating educing 'dynamic cumulating/recomposuring psychologismic-epistemic-acutisation-residualising,\{decompulsing $\}$ delinearity for-cogency phasing of limitedness/human-subpotency onto unlimitedness/existence-full pon of as imbuing of human epistemic-growth,-as - \{veridical/sound\}-relative-reflexivity-in-existence/relativising from- 
limited-mentation-as-its-deepening/psychologismic epistemic-acutisation residualising, \{decompulsing $\}$ delinearity for-cogeney). The 'flow of human prospective profoundsupererogation -over-shallow-supererogation' (given 'unlimitedness/existence-<fullpotency-of_sublimating nascence> prospective apriorising/axiomatising/referencingsublimating-reflexivity — beholdening under which limitedness/human-subpotency submits in profound-supererogation for prospective sublimating' warrant the 'overarching existential$<$ disontologising/re-ontelogising aporeticism $>$ priority/precedence/primacy of \{epistemic子re-apriorising/re-axiomatising/re-referencing $\sim$ residuality-in-re-originariness/reorigination projection') is effectively what underlies 'relays of human intemporal-individuation epistemic-projection radicalities $\sim$ in-chronicular/annalistic-cogency-<as-ofnotional protensivity>-〈as-to-limited-mentation-capacity-deepening —as-subjecting limitedness/human-subpotency-to-'educed-unlimitedness/existence-sublimating nascence' > so-construed as cogency_chronicularity/annality-of-relative-reflexivity,-as-to-profoundsupererogation as to preconverging/postconverging-redementating/restructuring/reparadigming sublimating potentiating of nonpresencing<perspective ontological-normaley/posteonvergence> 'existential-<disontologising/reentologising aporeticism $>$ prospect of human individual-consciousness/collectiveconsciousness decompulsion-appraisal'. In this respect, 'catchmenting-by-rejection/lipservicing/monopolising/gaming-of-the-system/charade/distraction vague/imaginary lures of social-stake-contention-or-confliction' manifest shallow-supererogation usurpation of profound-supererogation (as to 'accessory/adjunctive cobbling-together/gathering, procession, forming, presenting, dissipating and instrumentalising in a dearth of prospective chronicular/annalistic-cogency-<as-of-notional protensivity $>$ so-construed as cogency_chronicularity/annality-of-relative-reflexivity,-as-to-profound-supererogation ${ }^{\circ}$ ); with the implication here being that the very 'habituated conception of < amplituding/formative- 
epistemicity $>$-totalising $\sim$ thrownness-in-existence ${ }^{35}$ - as imbued of limitedness/humansubpotency prospective dearth for \{epistemic-totalising łre-apriorising/re-axiomatising/rereferencing $\sim$ residuality_in-re-originariness/re-origination projection)' of such manifest shallow supererogation $\sim$ framing/formulation/catchmenting/truncating/compulsing/linearising_scale —of-opaque/contentious/un-nominalised/flawed-interpretations/domains of manifest blurriness-<sterilising/anecdotalising/trivialising-of-prospective-re-ontologising_bypreconverging,-in-disontologising-formulaic-dragging-out/hollowing-out> and/or 'unwieldycontemplatable-disontologising/re-ontologising-implications,-with-regards-to-humansovereign-function/posture-<as-to-narrowness/evasiveness/vagueness-of-disontologising/reontologising > with respect to contentious/un-nominalisedness of social-stake-contention-orconfliction' is what veridically speaks of knowledge-deadends-<as-preconverging-dementating/structuring/paradigming > (as not resolvable as of prior presencing absolutising identitive-constitutedness 'existential-<disontologising/re-ontologising aporeticism $>$ preconverging de-mentating/structuring/paradigming punctual/immediacy/constituted/compulsions-encumbered prior mere-formulaicity/ritualisation rationalisation-of-contentivity/argumentativity/dialecticism/discursivity but rather as of prospective profound-supererogation of nonpresencing-<perspective-ontologicalnormaley/postconvergence $>\quad$ 'existential-<disontologising/re-ontologising aporeticism $>$ prospect of human individual-consciousness/collective-consciousness decompulsion-appraisal, in reflection of 'unlimitedness/existence-<full-potency-of_sublimating nascence $>$ prospective apriorising/axiomatising/referencing-sublimating-reflexivity-beholdening under which limitedness/human-subpotency submits in profound-supererogation for prospective sublimating'). In this regards, a distinction can be made between the 'protracted-social—as-toindividual-by-institutional-by-social relative direct/deferential-irresponsibility/relative- 
unreflexivity to cogency_chronicularity/annality-of-relative-reflexivity,-as-to-profoundsupererogation, as (related above) and the 'protracted-social—as-to-individual-byinstitutional-by-social relative direct/deferential-responsibility/relative-reflexivity to cogency_chronicularity/annality-of-relative-reflexivity,-as-to-profound-supererogation ' (with respect supererogation $\sim$ reframing/reformulation/decatchmenting/detruncating/decompulsing/delinear ising_scale_of-transparent/noncontentious/un-nominalised/sound-interpretations/domains of manifest unblurriness-<re-ontologising_by-postconverging-as-to-dragged-outsupererogatory wholesomeness/profound-supererogation ,-while-anecdotalising-priordisontologising-thresholding $>$ as manifested with nascent-particular/incipient-andmaterial/technical-sublimations- $<$ blinded-to-their-relative-ontological-completeness reference-of-thought- devolving > punctual/immediacy/constituted/compulsionsencumbered — disarming/dis_ideologising/deformulaicity/à-contrecoup/unssettling/unargarguableb- $)$. Basically, 'protracted-social—as-to-individual-by-institutional-by-social relative direct/deferential-irresponsibility/relative-unreflexivity to cogency_chronicularity/annality-ofrelative-reflexivity,-as-to-profound-supererogation' as to 'habituated conception of <amplituding/formative-epistemicity $>$-totalising $\sim$ thrownness-in-existence ${ }^{35}$ - (as imbued of limitedness/human-subpotency prospective dearth for \{epistemic-totalising łre-apriorising/reaxiomatising/re-referencing $\sim$ residuality-in-re-originariness/re-origination projection)', of such manifest shallowsupererogation $\sim$ framing/formulation/catchmenting/truncating/compulsing/linearising_scale —of-opaque/contentious/un-nominalised/flawed-interpretations/domains of manifest blurriness-<sterilising/anecdotalising/trivialising-of-prospective-re-ontologising_bypreconverging,-in-disontologising-formulaic-dragging-out/hollowing-out> and/or 'unwieldycontemplatable-disontologising/re-ontologising-implications,-with-regards-to-human- 
sovereign-function/posture-<as-to-narrowness/evasiveness/vagueness-of-disontologising/re-

ontologising > with respect to contentious/un-nominalisedness of social-stake-contention-orconfliction'; inherently arises (from a misconstrual of 'neutral 79 presencing-absolutisingidentitive-constitutedness ${ }^{14}$ point-of-devolving/departure/anchoring/backdrop conceptualisation of human sublimating ontological-performance ${ }^{72}-<_{\text {including-virtue-as- }}$ ontology $>$ /morality/ethics/justice/etc. as to the specifically given human rationalisation-ofcontentivity/argumentativity/dialecticism/discursivity' manifested in all given registryworldviews/dimensions) and thusly failing to prospectively reflect 'unlimitedness/existence<full-potency-of_sublimating nascence $>$ prospective apriorising/axiomatising/referencing sublimating-reflexivity-beholdening under which limitedness/human-subpotency submits in profound-supererogation for prospective sublimating' as rather warranting the 'veridical neutral point-of-devolving/departure/anchoring/backdrop conceptualisation of human ontological-performance ${ }^{72}$-<including-virtue-as-ontology $>/$ morality/ethics/justice/etc. as to rerationalisations-of-contentivity/argumentativity/dialecticism/discursivity so-reflecting successive relative-ontological-completeness 8 'implicited_attendant-ontologicalcontiguity $^{67}$, educed-

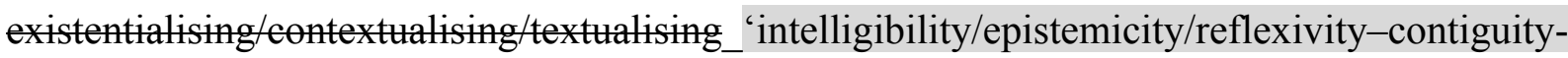
$<$ imbued-notional cogency $>$ ', so-construed summarily as underlying-elucidative 'requisite sublimating/desublimating formulative-framing/fielding — of-entailment of human ontologicalperformance $^{72}$-<including-virtue-as-ontology $>$ /morality/ethics/justice/etc. contemplation' or 'overall human ontological-entrapment' (as of notionally implied ${ }^{45}$ foregrounding_entailment$<$ in-succession-of-profound-supererogation $>$--〈postconverging-narrowingdown $\sim$ sublimation-as-to-'existence - as-sublimating-withdrawal/unenframing/re-ontologising,elicited-from-prospective-profound-supererogation ' -in-reflecting-'immanent $\sim$ relativeunreflexivity/relative-reflexivity - ontological-contiguity ' ';-as-operative- 
notional deprocrypticism)). Critically in this respect, 'protracted-social—as-to-individual-byinstitutional-by-social relative direct/deferential-irresponsibility/relative-unreflexivity to cogency_chronicularity/annality-of-relative-reflexivity,-as-to-profound-supererogation ${ }^{2}$ is marked by varying psychologismic epistemic acutisation difficulty-<for, residualising \{decompulsing $\}$ delinearity for cogency> magnitudes $\{$ of-experientiality/experiment\} of distontologising/subontologising integrating/acceptance of the logic of 'existentially<disontologising/re-ontologising aporeticism $>$ manifest incidental/accidental reactivesufferance/endurance in supposedly and paradoxically subordinating/subserving/collateralising the possibility for prospective re-ontologising-imbuing-of-prospective-humansublimating/emancipating/enfranchisement' whilst often manifesting a 'poorly/suboptimally defined/elucidated overarching prospective re-ontologising conceptualisation'; as can be appreciated with a 'relatively realpolitik relation to ${ }^{56}$ meaningfulness-and-teleology ${ }^{9}$. This seem to imply somehow that the 'mortal that we are' will keep-up its prior presencing absolutising-identitive-constitutedness 'existential-<disontologising/re-ontologising aporeticism $>$ preconverging de-mentating/structuring/paradigming punctual/immediacy/constituted/compulsions-encumbered prior mere-formulaicity/ritualisation rationalisation-of-contentivity/argumentativity/dialecticism/discursivity and by some 'prior mere-formulaicity/ritualisation miracle' achieve its prospective re-ontologising demoronisation<sublimating-nascence,-nonextricatory-sublimating-upstreaming/'amontée’> (failing to appreciate that the mind itself precedingly must do its prospective homework as to requisite limitedness/human-subpotency 'despite-the-self exercise of epistemic-projection in notional $\sim$ self-distantiation-<imbued—re-motif-and-re-apriorising/re-axiomatising/rereferencing>'). In contrast 'protracted-social—as-to-individual-by-institutional-by-social relative direct/deferential-responsibility/relative-reflexivity to cogency_chronicularity/annality-of-relative-reflexivity,-as-to-profound-supererogation ${ }^{\text {, }}$ 
optimally define/elucidate overarching prospective re-ontologising conceptualisation for prospective human sublimating/emancipating/enfranchisement with relatively less of distontologising/subontologising integrating/acceptance of the logic of 'existentially$<$ disontologising/re-ontologising aporeticism $>$ manifest incidental/accidental reactivesufferance/endurance in supposedly and paradoxically subordinating/subserving/collateralising the possibility for prospective re-ontologising-imbuing-of-prospective-humansublimating/emancipating/enfranchisement' (notwithstanding in-many-ways the relatively manifest uncontentious/nominalised social-stake-contention-or-confliction for prospective profound-supererogation nonpresencing-<perspective-ontologicalnormaley/postconvergence> ‘existential-<disontologising/re-ontologising aporeticism $>$ prospect of human individual-consciousness/collective-consciousness decompulsion-appraisal). Such 'protracted-social—as-to-individual-by-institutional-by-social relative direct/deferentialresponsibility/relative-reflexivity to cogency_chronicularity/annality-of-relative-reflexivity,-asto-profound-supererogation' ${ }^{9}$ can be appreciated with the 'substantivity of transversality- $<$ forsublimating-existential-eventuating/denouement,-from-'thinking at-first/pure-predispositionpreemptive-of-prospective-disontologising/subontologising' as-of-prospectivelydisambiguated-affirmed-and-unaffirmed-'motif-and-apriorising/axiomatising/referencing'> independently running through many nascent-particular/incipient-and-material/technicalsublimations- $<$ blinded-to-their-relative-ontological-completeness - reference-of-thoughtdevolving > as to their "'veridical/sound\}-relative-reflexivity-in-existence/relativising fromlimited-mentation-as-its-deepening/psychologismic epistemic-acutisation residualising, \{decompulsing $\}$ delinearity for-cogency anarchistic-growth/anarchisation-for-re-ontologisation-〈asto-conscious/unconscious epistemically-sound induced 'demoronisation- $<$ sublimatingnascence,-nonextricatory-sublimating-upstreaming/‘amontée’> postconverging/dialecticalthinking conception of residual_re-originary_anarchistic incipiency of human social- 
and-teleology ' $\rangle$ ' not beholdening to any mortals but for unlimitedness/existence-<fullpotency-of_sublimating nascence $>$ educed prospective human knowledge and transcendenceand-sublimity/sublimation/supererogatory de-mentativity. In this regards, it is fundamentally flawed to acknowledge the 'human socially-protracted-as-to-individual-by-institutional-bysocial psychologismic-epistemic-acutisation — difficulty- $<$ for,-residualising$\{$ \{decompulsing $\}$ delinearity for-cogency $>$-〈as-of-requisite-profound-supererogation -for-

\section{‘disposedness-or-psychologismic-construct’-\{imbued-demoronisation-<sublimating-}

nascence,-nonextricatory-sublimating-upstreaming/'amontée’’\}〉' associated with 'protractedsocial—as-to-individual-by-institutional-by-social relative direct/deferentialirresponsibility/relative-unreflexivity to cogency_chronicularity/annality-of-relativereflexivity,-as-to-profound-supererogation and then go on to imply that the Social is of a different conceptualisation (as seeming to imply that the 'mortals that we are' are paradoxically bigger than 'unlimitedness/existence-<full-potency-of_sublimating nascence $>$ prospective apriorising/axiomatising/refereneing-sublimating-reflexivity-beholdening under which limitedness/human-subpotency submits in profound-supererogation for prospective sublimating' in an implicit reflex underlining the difficulty of priorly implying our very own requisite prospective mental-development for prospective human knowledge and transcendenceand-sublimity/sublimation/supererogatory de-mentativity); as such an argument should then be available to all prior registry-worldviews/dimensions to supposedly and desublimatingly imply that they shouldn't have superseded/overcome their very own 'human socially-protracted-as-toindividual-by-institutional-by-social psychologismic-epistemic-acutisation-difficulty- $<$ for,residualising-\{decompulsing $\}$ delinearity $\sim$ for-cogency $>$-〈as-of-requisite-profound-supererogation for-'disposedness-or-psychologismic-construct'- \{imbued-demoronisation-<sublimatingnascence,-nonextricatory-sublimating-upstreaming/'amontée’’\}〉’. In-many-ways such an 
optimally defined/elucidated overarching prospective re-ontologising conceptualisation for prospective human sublimating/emancipating/enfranchisement is effectively lost to "protractedsocial—as-to-individual-by-institutional-by-social relative direct/deferentialirresponsibility/relative-unreflexivity to cogency_chronicularity/annality-of-relativereflexivity,-as-to-profound-supererogation ", wherein fundamentally/incipiently/seedingly the 'prospective commitment to cogency_chronicularity/annality-of-relative-reflexivity,-as-toprofound-supererogation ${ }^{\prime}$ is relatively wanting or inexistent but for 'accessory/adjunctive cobbling-together/gathering, procession, forming, presenting, dissipating and instrumentalising' of 'poor overarching existential-<disontologising/re-ontologising aporeticism $>$ priority/precedence/primacy of \{epistemic-totalising ${ }^{3}$ re-apriorising/re-axiomatising/rereferencing $\sim$ residuality —in-re-originariness/re-origination projection' (as to the magnification of prior presencing absolutising-identitive-constitutedness 'existential<disontologising/re-ontologising aporeticism> preconverging dementating/structuring/paradigming punctual/immediacy/constituted/compulsions-encumbered prior mere-formulaicity/ritualisation rationalisation-ofcontentivity/argumentativity/dialecticism/discursivity being passed for prospective sublimating). Such a contrast (with respect to optimally defined/elucidated overarching prospective re-ontologising conceptualisation) can tangibly be drawn for instance between the chronicular/annalistic writing of say a Poincare at the advent of the $20^{\text {th }}$ summarising past achievements and articulating the possibilities for a new physics as of background substantive projection of human prospective re-ontologising, as so-atypically contrasted to the 'prevalent reontologising unguidedness/abandonment manifested in say modern-day media recounting' as to an exercise bent on stirring-up mere readability and audience-capture for the mortal's compulsions magnification as to 'normalised/stereotyped/selfhelping/feel-good knowledge being brought at the protracted-social — as-to-individual-by-institutional-by-social sovereign's 
service'. This is so-literally implicited with the 'medium is the message' conception to which cogency_chronicularity/annality-of-relative-reflexivity,-as-to-profound-supererogation is not critically of 'overarching existential-<disontologising/re-ontologising aporeticism $>$ priority/precedence/primacy of \{epistemic-totalising $3{ }^{3}$ re-apriorising/re-axiomatising/rereferencing $\sim$ residuality —in-re-originariness/re-origination projection' and thus inducing prospective disontologising/subontologising. Such that the 'vague impliciting of prospective reontologising conceptualisation' notwithstanding the distontologising/subontologising integrating/acceptance of the logic of 'existentially-<disentologising/re-ontelogising aporeticism $>$ manifest incidental/accidental reactive-sufferance/endurance in supposedly and paradoxically subordinating/subserving/collateralising the possibility for prospective reontologising_-imbuing-of-prospective-human-sublimating/emancipating/enfranchisement' rather underlines the imbued media 'notional perceptualisation-of-and-leashing-to_socialfunctioning-and-accordance-as-of-social-stake-contention-or-confliction as of circularly catchmented-and-compulsed-<in-'existential-dearth-of-demoronisation',-so-construed-asfrom-ontological-normalcy/postconvergence-perspective-reflection-of-the-'destructuringthreshold_of-the-given-level's-conjugated-postlogism as-dementing'> prospectively disontologising/subontologising shallow supererogation $\sim$ framing/formulation/catchmenting/truncating/compulsing/linearising —as-topreconverging de-mentating/structuring/paradigming'; as manifesting effectively a 'poorly/suboptimally defined/elucidated overarching prospective re-ontologising conceptualisation' (impotently-so as to the varying psychologismic epistemic acutisationdifficulty < for, residualising \{decompulsing $\}$ delinearity for-cogency> magnitudes $\{$ ofexperientiality/experiment\} of prospective human Being-development/ontological-frameworkexpansion-as-to-depth-of-ontologising-development-as-infrastructure-of- meaningfulnessand-teleology , institutional-development-as-to-social-function-development and living- 
development-as-to-personality-development). In this regards (as prospectively failing cogency_chronicularity/annality-of-relative-reflexivity,-as-to-profound-supererogation as to requisite notional $\sim$ self-distantiation-<imbued-re-motif-and-re-apriorising/re-axiomatising/rereferencing $>$ of 'nonpresencing-<perspective-ontological-normalcy/postconvergence $>$ anarchistic-growth/anarchisation-for-re-ontologisation-〈as-to-conscious/unconscious epistemically-sound induced 'demoronisation-<sublimating-nascence,-nonextricatorysublimating-upstreaming/'amontée’> postconverging/dialectical-thinking conception of residual_re-originary_anarchistic incipiency of human social-functioning-and-accordance-asof-social-stake-contention-or-confliction meaningfulness-and-teleology ' $\rangle$ '), the media soforegoes the 'veracity of the sovereign-function/posture-<as-to-existentially-manifest'embodied-subject consciousness-and-direct/deferential-conscientiousness',-as-of-its'epistemic-reflexivity/unreflexivity-in-existence'/teleology> as coextensive with the genuine social intellectual-function/posture'; as of the latter ontologically-veridical propping of the human sovereign-function/posture-<as-to-existentially-manifest-'embodiedsubject $\sim$ consciousness-and-direct/deferential-conscientiousness',-as-of-its- 'epistemicreflexivity/unreflexivity-in-existence'/teleology $>$ by providing the underlying ontologising/scientific/existence- $<$ honesty-constraining $>$ — scope_for_prospective_reontologising as to 'limitedness/human-subpotency prospective re-encountering/re-confrontation with unlimitedness/existence-<full-potency-of_sublimating naseence>' as so-providing the 'existential-<disontologising/re-ontologising aporeticism $>$ enabling-backdrop' for the advocacy/political/applicative — scope to arise. This is so-manifested when wrongly implying that the 'assumed/perceived concretisable possibilities of our modern-day ${ }^{79}$ presencingabsolutising-identitive-constitutedness ${ }^{14}$ social-stake-contention-or-confliction of the advocacy/political/applicative-scope as to techno-socio-econo-political implications' (and falsely qualifying that as neutrality/objectivity) override/supersede the contemplative prospect 
for prospective re-ontologising

sublimating/emancipating/enfranchisement beyond such assumed/perceived concretisable possibilities. Such that the given ${ }^{7}$ presencing-absolutising-identitive-constitutedness ${ }^{14}$ mere 'secondnatured conscious/unconscious rationalising/calculating of the sublimating outcome of prior profound-supererogation rationalisation-ofcontentivity/argumentativity/dialecticism/discursivity imbued positive-opportunism—of-socialfunctioning-and-accordance ${ }^{7}$ ' is construed as all the possibility for 'media ontological-veracity' (with regards to 'our modern-day ${ }^{79}$ presencing_absolutising-identitive-constitutedness ${ }^{14}$ socialstake-contention-or-confliction of the advocacy/political/applicative-scope as to techno-socioecono-political implications' as rather overall skewed to self-serving 'dominance/vestedinterest—-drivenness-<as-to-its-direct/indirect-eliciting-by-or-exploiting-of-prospectively-

\section{descalarising/subontologising-sycophantic-sophistic-interests,-as-inducing-prospective-}

threshold-of-institutional-and-social-desublimation>); as so-rendering the given human sovereign-function/posture-<as-to-existentially-manifest-'embodied-subject $\sim$ consciousnessand-direct/deferential-conscientiousness',-as-of-its-'epistemic-reflexivity/unreflexivity-inexistence'/teleology $>$ susceptible to 'notional perceptualisation-of-and-leashing-to_socialfunctioning-and-accordance-as-of-social-stake-contention-or-confliction as of circularly catchmented-and-compulsed-<in- ‘existential-dearth-of-demoronisation',-so-construed-asfrom-ontological-normalcy/postconvergence-perspective-reflection-of-the-'destructuringthreshold_of-the-given-level's-conjugated-postlogism as-dementing'> prospectively disontologising/subontologising shallowsupererogation $\sim$ framing/formulation/catchmenting/truncating/compulsing/linearising —as-topreconverging de mentang/struturing/paradigming'. The media (as prospectively failing cogency_chronicularity/annality-of-relative-reflexivity,-as-to-profound-supererogation as to requisite notional $\sim$ self-distantiation-<imbued — re-motif-and-re-apriorising/re-axiomatising/re- 
referencing $>$ of 'nonpresencing-<perspective-ontological-normalcy/postconvergence $>$ anarchistic-growth/anarchisation-for-re-ontologisation-〈as-to-conscious/unconscious epistemically-sound induced 'demoronisation-<sublimating-nascence,-nonextricatorysublimating-upstreaming/'amontée’> postconverging/dialectical-thinking conception of residual_re-originary_anarchistic incipiency of human social-functioning-and-accordance_-asof-social-stake-contention-or-confliction meaningfulness-and-teleology ' $\rangle$ '), thusly removes itself from the requisite exercise of 'profound-supererogation' in superseding/overcoming a human self-presence/self-constitutedness ${ }^{14}-<$ in-perspective-epistemicabnormalcy/preconvergence ${ }^{3}>$ rationalisation-ofcontentivity/argumentativity/dialecticism/discursivity of ${ }^{79}$ presencing —absolutising-identitiveconstitutedness $^{1 /}$; and so while misconstruing and ignoring that the ${ }^{4}$ historiality/ontologicaleventfulness 3 /ontological-aesthetic-tracing-<perspective-ontologicalnormalcy/postconvergence-reflected-'epistemicity-relativism-determinism'> of the human media-function/posture' manifested as from oral communication, inscriptions, the invention of writing, the invention of the printing press, etc. has ever always gone hand-in-hand with a requisite projection of profound-supererogation (as to its 'thinking at first/pure predisposition preemptive of prospective disontologising/subontologising' as prospectively unconstrained to the given ${ }^{79}$ presencing-absolutising-identitive-constitutedness ${ }^{14}$ mere 'secondnatured conscious/unconscious rationalising/calculating of the sublimating outcome of prior profoundsupererogation rationalisation-of-contentivity/argumentativity/dialecticism/discursivity imbued positive-opportunism-of-social-functioning-and-accordance ${ }^{7{ }^{5}}$, as so effectively manifested with the 'Lutheran emancipation' and the Encyclopédistes project as to their imbued projection for cogency_chronicularity/annality-of-relative-reflexivity,-as-to-profoundsupererogation ) and as so-enabling the various 'historial re-ontologising prospective rerationalisation-of-contentivity/argumentativity/dialecticism/discursivity imbued human 
sublimating/emancipating/enfranchisement' undergirding various human renaissances, overcoming of human servitude, articulating human rights and freedoms, and just as recently as civil right movements (and so effected beyond just the notion of the assumed/perceived concretisable possibilities of their given epochal ${ }^{7}$ presencing-absolutising-identitiveconstitutedness ${ }^{14}$ 'social-stake-contention-or-confliction of the advocacy/political/applicativescope as to techno-socio-econo-political implications'). This insight in-many-ways, underlies the contention herein about the disontologising/subontologising arising from pedantising/muddling/formulaic-hollowing-out - in-subontologisation/subpotentiation〈blurring/undermining-of-prospective-totalising-entailing,-as-to-entailing<amplituding/formative-epistemicity>totalising in-relative-ontological-completeness $>$ desublimation conscious/unconscious eliciting of institutional-prescience/imprimaturing$\leq$ dullness-of the-spirit/psychologismic epistemic acutisation nonresidualising imbued\{compulsings linearity in-eclecticism-of prior-mere-formulaicity/ritualisation $>$ and/or accessorising of 'ordinary laypersonhood arrogation/presumptuousness' conception of supposedly prospective sublimation, as bound to undermine the "veracity of the sovereign-function/posture- $<$ as-toexistentially-manifest-‘embodied-subject $\sim$ consciousness-and-direct/deferentialconscientiousness',-as-of-its- 'epistemic-reflexivity/unreflexivity-in-existence'/teleology> coextensive with the genuine social intellectual-function/posture' (by so-rendering the given human sovereign-function/posture-<as-to-existentially-manifest-'embodiedsubject consciousness-and-direct/deferential-conscientiousness',-as-of-its- 'epistemicreflexivity/unreflexivity-in-existence'/teleology> 'notional $\sim$ perceptualisation-of-and-leashingto_social-functioning-and-accordance-as-of-social-stake-contention-or-confliction as of circularly catchmented-and-compulsed-<in-'existential-dearth-of-demoronisation',-soconstrued-as-from-ontological-normalcy/postconvergence-perspective-reflection-of-the'destructuring-threshold_of-the-given-level's-conjugated-postlogism as-dementing'> 
supererogation $\sim$ framing/formulation/catchmenting/truncating/compulsing/linearising —as-topreconverging de-mentating/structuring/paradigming'); as to the veracity of human epistemicgrowth,-as-\{veridical/sound\}-relative-reflexivity-in-existence/relativising from-limitedmentation-as-its-deepening/psychologismic epistemic-acutisation residualising, $\{$ decompulsing $\}$ delinearity for-cogeney' (underlied as of 'unlimitedness/existence-<full-potencyof_sublimating nascence $>$ prospective apriorising/axiomatising/referencing-sublimatingreflexivity-beholdening under which limitedness/human-subpotency submits in profoundsupererogation for prospective sublimating' imbuing cogency_chronicularity/annality-ofrelative-reflexivity,-as-to-profound-supererogation ${ }^{9}$ ), and not our modern-day ${ }^{79}$ presencingabsolutising-identitive-constitutedness ${ }^{14}$ media 'accessory/adjunctive cobblingtogether/gathering, procession, forming, presenting, dissipating and instrumentalising' of 'poor overarching existential-<isontologising/re-ontologising aporeticism> priority/precedence/primacy of referencing residuality—in-re-originariness/re-origination for cogency_chronicularity/annality-of-relative-reflexivity,-as-to-profound-supererogation . But then in-many-ways such a misconstruing and ignoring of the "historiality/ontologicaleventfulness 3 /ontological-aesthetic-tracing-<perspective-ontologicalnormalcy/postconvergence-reflected-'epistemicity-relativism-determinism'> of the human media-function/posture' is in-effect a pretense to the 'precedence/supersedingness of sovereignty over ontological-veracity' which is rather elicited selectively/whimsically/incoherently with shallowsupereration _framing/formulation/catchmenting/truncating/compulsing/linearising_scale —of-opaque/contentious/un-nominalised/flawed-interpretations/domains of manifest blurriness-<sterilising/anecdotalising/trivialising-of-prospective-re-ontologising_by- 
'directly and/or deferentially perceived advantageous social-stake-contention-or-confliction'; wherein the thematics advantageous to dominance/vested-interest-drivenness- $<$ as-to-itsdirect/indirect-eliciting-by-or-exploiting-of-prospectively-descalarising/subontologisingsycophantic-sophistic-interests,-as-inducing-prospective-threshold-of-institutional-and-socialdesublimation> paradoxically call for requisite 'media cerebrality' as to a pretense to cogency_chronicularity/annality-of-relative-reflexivity,-as-to-profound-supererogation .

Central to such a disontologising/subontologising distortion is the naivety that ontologicalveracity can be articulated without a prior superseding/overriding core-driven commitment for prospective re-ontologising (beyond desublimating formulaic-fashionability-<wholesemedearth'/shallowness_as-to-requisite-'re-ontologising-rhizomatic-wholesomeness' for-postconverging-rede-mentating/restructuring/reparadigming $>, \quad$ shadowing and bothsidesism-〈as-‘mere-processive'/pedantising-'dialogical-relation'-to 'perceived-socialand-institutional-commonly-enculturated_referencing,-of- meaningfulness-and-teleology 'failing-'requisite-existential-thematic-baseline-of-technicity/profundity-framing' \{ofsublimating-discursivity-for-sovereign-repassing $\}$,-as-of-psychologismic-epistemicacutisation - nonresidualising-imbued-\{compulsing linearity in-eclecticism-of-prior-mereformulaicity/ritualisation,-as-so-'consciously/unconsciously-preordained/fated'-to-failprospective-notional cogency) ontologically-flawed conceptualising' as effective techniques avoiding transversality-<for-sublimating-existential-eventuating/denouement,-from-'thinkingat-first/pure-predisposition-preemptive-of-prospective-disontologising/subontologising' asof-prospectively-disambiguated-affirmed-and-unaffirmed-'motif-andapriorising/axiomatising/referencing' $>101$ and thus preempting the demarcation of veridical/profound sublimating conceptivity/epistemic-reflexivity/epistemicity-relativismdeterminism-<reifying \{as-to-knowledge-developing $\}$-and-empowering $>\quad$ entailment); as 
ontological-veracity is not about the 'relationship among human-subpotencies/limitedness' but how the latter can be elevated by adhering to the-very-underlying - (as inherently 'defining-andimbuing of limitedness/human-subpotency de-mentation-〈supererogatory $\sim$ ontological-dementation-or-dialectical-de-mentation-stranding-or-attributive-dialectics $\rangle$ as to preconverging/postconverging-de-mentating/structuring/paradigming)—relationship-betweenlimitedness/human-subpotency-and-unlimitedness/existence-<full-potency-of_sublimating nascence $>$ Such a 'protracted-social-as-to-individual-by-institutional-by-social relative direct/deferential-irresponsibility/relative-unreflexivity to cogency_chronicularity/annality-ofrelative-reflexivity,-as-to-profound-supererogation " effectively plays to the hands of 'catchmenting-by-rejection/lip-servicing/monopolising/gaming-of-thesystem/charade/distraction vague/imaginary lures of social-stake-contention-or-confliction' manifesting shallow-supererogation ${ }^{9}$ urpation of profound-supererogation ; as rather soinducing 'prospective disontologising/subontologising de-project/de-oeuvrement of human sovereign-function/posture-<as-to-existentially-manifest-'embodied-subject $\sim$ consciousnessand-direct/deferential-conscientiousness',-as-of-its-'epistemic-reflexivity/unreflexivity-inexistence'/teleology>' as to a sovereign-function/posture-<as-to-existentially-manifest'embodied-subject consciousness-and-direct/deferential-conscientiousness',-as-of-its'epistemic-reflexivity/unreflexivity-in-existence'/teleology> perceptualisation-of-andleashing-to_social-functioning-and-accordance_-as-of-social-stake-contention-or-confliction that is well below the 'effective human sovereign-function/posture-<as-to-existentiallymanifest-'embodied-subject consciousness-and-direct/deferential-conscientiousness',-as-ofits-'epistemic-reflexivity/unreflexivity-in-existence'/teleology> potential for epistemicgrowth,-as-\{veridical/sound\}-relative-reflexivity-in-existence/relativising from-limitedmentation-as-its-deepening/psychologismic epistemic-acutisation residualising,

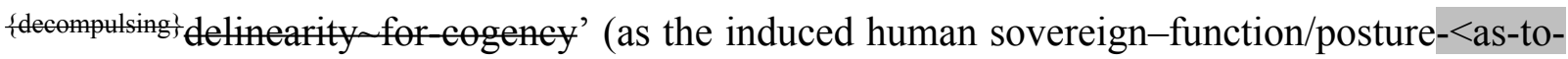


existentially-manifest-`embodied-subject $\sim$ consciousness-and-direct/deferential-

conscientiousness',-as-of-its-'epistemic-reflexivity/unreflexivity-in-existence'/teleology>

'notional perceptualisation-of-and-leashing-to_social-functioning-and-accordance-as-ofsocial-stake-contention-or-confliction as of circularly catchmented-and-compulsed-<in‘existential-dearth-of-demoronisation',-so-construed-as-from-ontological-

normalcy/postconvergence-perspective-reflection-of-the-'destructuring-threshold_of-the-

given-level's-conjugated-postlogism as-dementing'>

prospectively

disontologising/subontologising

shallow-

supererogation $\sim$ framing/formulation/catchmenting/truncating/compulsing/linearising —as-topreconverging de-mentating/structuring/paradigming'). In this regards, a challenge to prospective re-ontologising as to organic-knowledge is ever always the capacity to put-intoquestion the circularly catchmented-and-compulsed-<in-'existential-dearth-ofdemoronisation',-so-construed-as-from-ontological-normalcy/postconvergence-perspectivereflection-of-the-'destructuring-threshold_of-the-given-level's-conjugated-postlogism asdementing'> prospectively disontologising/subontologising shallow supererogation $\sim$ framing/formulation/catchmenting/truncating/compulsing/linearising —as-topreconverging de mentating/strueturing/paradigming' of 'protracted-social—as-to-individualby-institutional-by-social relative direct/deferential-irresponsibility/relative-unreflexivity to cogency_chronicularity/annality-of-relative-reflexivity,-as-to-profound-supererogation ${ }^{\circ}$ (as so-required for prospective deprocrypticism-or-preempting-disjointedness-as-ofreference-of-thought cogency_chronicularity/annality-of-relative-reflexivity,-as-to-profoundsupererogation ); as to the veracity of prospective human knowledge and transcendence-andsublimity/sublimation/supererenterentativity for comprehensive humanconsciousness/collective-consciousness-distendedness/detruncating-<beyond-selfpresencing,as-re-ontologising-decentering_of-consciousness/collective-consciousness,-as-to- 
psychologismic-epistemic-acutisation - residualising, - $^{\text {fdecompulsing }}$ \} delinearity $\sim$ for-cogency $>$

prospective

re-ontologising

profound-

supererogation $\sim$ reframing/reformulation/decatchmenting/detruncating/decompulsing/delinear ising -as-to-postconverging de-mentating/structuring/paradigming (in prospective reontologising 'dynamic cumulating/recomposuring psychologismic-epistemic-acutisationresidualising, ${ }^{-\{\text {decompulsing }}$ delinearity for-cogency phasing of limitedness/human-subpotency onto unlimitedness/existence-<full-potency-of_sublimating nascence $\left.>^{\prime}\right)$. Insightfully as to a further elucidation, human epistemic-growth,-as - \{veridical/sound\}-relative-reflexivity-inexistence/relativising from-limited-mentation-as-its-deepening/psychologismic epistemicacutisation residualising, ${ }^{\text {\{decompulsing }}$ delinearity for-cogency (as it veridically speaks notionally/epistemically/bindingnessly $y^{\text {-as-to-determinism/eoneeptivity-of-relative-unreflexivity/relative-reflexivity> }}$ of reflexivity) points to overall prospective 're-ontologising overall sublimating-overdesublimating delineation' of the-very-same purview/devolved-purview/devolving-purviewof-unlimitedness/existence-<full-potency-of_sublimating nascence $>$; - 'implicited_attendantontological-contiguity ${ }^{67}$; educed-

existentialising/contextualising/textualising_intelligibility/epistemicity/reflexivity_contiguity<imbued-notional cogency>' (in coherence with the 'underlying overall reifying-andempowering-reflexivity-of-ecstatic-existence-as-panintelligibility/panreflexivity ${ }^{3}$

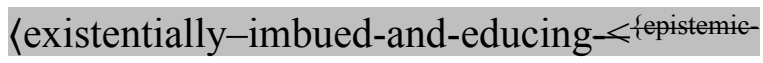

thermeneutically/textually/reprojectingly/supererogatingly/zeroingly/re-acutingly,-

$\{$ decompulsing\} $d e$ linearity $\sim$ for-cogency $\geq$-epistemic-perspective-of-projective/reprojective-

aestheticising-re-motif-and-re-apriorising/re-axiomatising/re-referencing $\sim$ conceptualisation-

as-herein-specifically-relevant-to human-subpotency)'). The latter

(panintelligibility/panreflexivity ${ }^{3}$ ) speaks of the very 'reflexivity mesh' that is existence wherein the 'epistemicities/epistemic-situations of phenomenal/manifest $\sim$ subpotencies-〈in- 
nascence) (as to existence's panintelligibility/panreflexivity/panepistemicity)' are part-andparcel of existence as ontology (in the sense that such 'epistemicities/epistemic-situations of sublimating/desublimating performance in existence' are 'notional $\sim$ reflexively of ontological reality as to their relative-reflexivity/relative-unreflexivity') speaking to the fact that a distinction between the epistemic and ontological is rather an illusion of any ${ }^{7}$ presencing-absolutisingidentitive-constitutedness $^{14}$ (including our positivism- ${ }^{80}$ procrypticism/disjointedness-as-ofreference-of-thought) as from the 'reflexivity of prospective notional ${ }^{18}$ deprocrypticism/notional preempting — disjointedness-as-of- ${ }^{3}$ reference-of-thought nonpresencing-<perspective-ontological-normalcy/postconvergence $>$ epistemic-projection' with respect to the very 'reflexivity mesh' that is existence. This so-underlies the perspicacity (in reflection of 'unlimitedness/existence-<full-potency-of_sublimating nascence $>$ prospective apriorising/axiomatising/referencing-sublimating-reflexivity-beholdening under which limitedness/human-subpotency submits in profound-supererogation for prospective sublimating') of say 'Deleuzian rhizomatics transcendental construal as to the immanent backdrop of existence's plane-of-immanence' or 'Derridean transcendental signifier transcendental construal as to the immanent backdrop of existence's transcendental signified' so-implied as to Derridean quasi-transcendental ontological implications (herein construed as ecstatic-existence-as-transcendental-signifier-emergence/becoming-spontaneity-

implications) or Foucauldian historial/genealogical-a-priori ontological implications; which are all veridically undergirded as herein construed as of the 'flow of human prospective profoundsupererogation -over-shallow-supererogation', (given 'unlimitedness/existence-<fll potency-of_sublimating nascence> prospective apriorising/axiomatising/referencingsublimating-reflexivity-beholdening under which limitedness/human-subpotency submits in profound-supererogation for prospective sublimating' warrant the 'overarching existential- 
<disontologising/re-ontologising aporeticism $>$ priority/precedence/primacy of \{epistemictotalising 3 re-apriorising/re-axiomatising/re-referencing $\sim$ residuality-in-re-originariness/reorigination projection') so-implied as of the sublimating-tradition/constant of profoundsupererogation (as to the 'fundamental/incipient/seeding experientiality/experiment- $<$ as-toexistentially-formative- ‘fepistemic-totalising referencing-residuality—in-re-originariness/re-origination',-so'notionally/epistemically/bindingnessly-<as-to-determinism/conceptivity-of-relative-unreflexivity/relative-reflexivity>_ implicited-and-articulated'_as-from-nonextricatory-'prospective-re-ontologising-Being-thenInstitutional-then-Living-magnitudes-of-\{hermeneutic/reprojection-protraction-offreframingand-reformulation $\}^{\prime}>$ that is human profound-supererogation 'so-reflecting the 'overarching existential-<disontologising/re-ontologising aporeticism $>$ priority/precedence/primacy of \{epistemic-totalising $3{ }^{3}$ re-apriorising/re-axiomatising/re-referencing $\sim$ residuality—in-re-

originariness/re-origination projection') and manifested as of prospective 'overarching existential-<disontologising/re-ontologising aporeticism $>$ priority/precedence/primacy of requisite prospective ontological-good-faith/authenticity ${ }^{69} \sim$ postconverging-dementating/structuring/paradigming inducing of psychoanalytic-unshackling for the relativeontological-completeness ${ }^{87}$-of-apriorising/axiomatising/referencing re-ontologising prospective re-rationalisation-of-contentivity/argumentativity/dialecticism/discursivity' at every given 'secondnatured human station/locus of limitedness/human-subpotency $<$ amplituding/formative-epistemicity $>$-totalising $\sim$ thrownness-in-existence ${ }^{35}$ - (as imbued of limitedness/human-subpotency prospective dearth for tre-apriorising/reaxiomatising/re-referencing $\sim$ residuality—in-re-originariness/re-origination projection)'. Further (with reference to panintelligibility/panreflexivity ${ }^{73}$ as to the very 'reflexivity mesh' that is existence), the specificity of human-subpotency epistemic reflexivity is rather double fold with respect to the "existential-<disontologising/re-ontologising aporeticism $>$ dynamics of human 
bodying reflexivity projection and consciousness reflexivity projection' so construed as human consciousness embodiment rather so-implied as to the prospect of human individual/collective consciousness embodiment epistemic-growth,-as - \{veridical/sound\}-relative-reflexivity-inexistence/relativising from-limited-mentation-as-its-deepening/psychologismic epistemicacutisation residualising, ${ }^{\text {\{decompulsing }}$ delinearity for-cogency in cumulating/recomposuring as of human Being-development/ontological-framework-expansion-as-to-depth-of-ontologisingdevelopment-as-infrastructure-of- meaningfulness-and-teleology , institutionaldevelopment-as-to-social-function-development and living-development-as-to-personalitydevelopment psychologismic epistemic-acutisation difficulty < for, residualising ${ }_{\{\text {decompulsing }\}}$ delinearity for-cogeney $>$ magnitudes $\left.{ }^{\{0 f-e x p e r i e n t i a l i t y / e x p e r i m e n t}\right\}$. In this regards, the very 'reflexivity mesh' that is existence equally implies that a 'punctual noumenality and phenomenality distinction' is equally vague (as to the 'prospective unreflexivity of our positivism- ${ }^{80}$ procrypticism/disjointedness-as-of- ${ }^{-}$reference-of-thought presencingabsolutising-identitive-constitutedness ${ }^{14}$ epistemic-projection') and rather veridically speaking of 'relative-unreflexivity-by-relative-reflexivity epistemic-projection' as of notional epistemic-growth,-as_ \{veridical/sound\}-relative-reflexivity-inexistence/relativising from limited mentation as its deepening/psycholegismic epistemic acutisation residualising, \{decompulsing delinearity for-cogency; and so, since the supposed phenomenality conception in such a 'punctual noumenality and phenomenality distinction' is veridically about the 'relative-unreflexivity-by-relative-reflexivity notional/epistemic/bindingness of ontological-reality' (as to 'epistemicities/epistemic-situations of sublimating/desublimating performance in existence'). Actually, the 'reflexivity of prospective notional $\sim$ deprocrypticism/notional preempting — disjointedness-as-of- ${ }^{8}$ reference-of-thought nonpresencing-<perspective-ontological-normalcy/postconvergence $>$ epistemic-projection' 
rather warrants (in the construal of 'relative-unreflexivity-by-relative-reflexivity notional/epistemic/bindingness ${ }^{- \text {as-to-determinism/conceptivity-of-relative-unreflexivity/relative-reflexivity }>}$ dynamics of ontological-reality' as to 'epistemicities/epistemic-situations of sublimating/desublimating performance in existence') the 'overarching existential-<disontologising/re-ontologising apereticism $>$ priority/precedence/primacy of \{epistemic-totalising 3 're-apriorising/re-axiomatising/rereferencing residuality—in-re-originariness/re-origination projection' (and so reflecting 'unlimitedness/existence-<full-potency-of_sublimating nascence> prospective apriorising/axiomatising/referencing-sublimating-reflexivity-beholdening under which limitedness/human-subpotency submits in profound-supererogation for prospective sublimating'), as thusly undergirding requisite 'reclamation/recovery of ${ }^{55}$ maximalisingrecomposuring-for-relative-ontological-completeness ${ }^{87}$ - unenframed/reontologising conceptualisation (elicited/prompted <amplituding/formative-epistemicity $>$ totalising renewing-realisation/re-perception/re-thought as of 're-ontologising fepistemictre-apriorising/re-axiomatising/re-referencing residuality in re-originariness/reorigination \{decompulsingt delinearity/delinear-acereting/recomposuring cogency/tensing/limpidity<as-of-prospective-profound-supererogation ,-for-residuality—in-re-originariness/reorigination $>$, prospective_reifying mental aestheticising <as of 'prospective_reformulating of-mental-aestheticising'as-to-'residuality in -re-originariness/re-origination' of mentalaestheticising $>$ ')'; and so, as to the-very-underlying - (as inherently 'defining-and-imbuing of limitedness/human-subpotency de-mentation-〈supererogatory $\sim$ ontological-de-mentation-ordialectical-de-mentation—-stranding-or-attributive-dialectics $\rangle^{\prime}$ as to preconverging/postconverging-de-mentating/structuring/paradigming)—relationship-betweenlimitedness/human-subpotency-and-unlimitedness/existence-<full-potency-of_sublimating nascence $>$ with respect to the pre-eminence of the latter (as to 'limitedness/human-subpotency prospective re-encountering/re-confrontation with unlimitedness/existence-<ull-potency 
of_sublimating nascence $>$ '). This very much explains why the veracity of conceptual elucidation and definition only arise as to its prior tethering to an 'overall profound/sound gesturing/accounting - of-epistemic-phenomenalism' of 'epistemic-totality ${ }^{37}$ of meaningfulness-and-teleology as to phenomenality-and-epiphenomenality'; as of the reflexivity as to psychologismic-epistemic-acutisation-<as-to-postconverging-dementating/structuring/paradigming,-eliciting-of-existence's-sublimating-nascence-inprospective-aporeticism-overcoming/unovercoming $>$ as to epistemic-growth,-as\{veridical/sound\}-relative-reflexivity-in-existence/relativising from-limited-mentation-as-itsdeepening/psychologismic epistemic-acutisation residualising, decompulsingl delinearity foreogency. The 'reflexivity of prospective notional $\sim$ 'deprocrypticism/notional $\sim$ preemptingdisjointedness-as-of- ${ }^{8}$ reference-of-thought nonpresencing-<perspective-ontologicalnormalcy/postconvergence $>$ epistemic-projection' thus rather speaks inherently of 'sublimating-over-desublimating perpetuation/continuity' (and not 'punctual noumenality and phenomenality distinction'), as of 'human consciousness notional protensivity psychologismic_epistemic-acutisation-<as-to-postconverging-de-mentating/structuring/paradigming,-elicitingof-existence's-sublimating-nascence-in-prospective-aporeticism-overcoming/unovercoming> as to epistemic-growth,-as - \{veridieal/sound-relative-reflexivity-in-existence/relativising from-limited-mentation-as-its-deepening/psychologismic epistemic acutisationresidualising, ${ }^{\text {\{decompulsing }}$ \} delinearity for-cogency ontological-performance ${ }^{2}-<$ including-virtueas-ontology $>$ /morality/ethics/justice/etc.' inducing of prospective 'apriorising/axiomatising/referencing disambiguating/de-leveling/de-ressentiment/openedconstruct-of- -5 meaningfulness-and-teleology $\quad$ demoronisation- $<$ sublimating-nascence, -sublimating-upstreaming/'amontée’’ as to nonpresencing <perspective entological-normalcy/postconvergence> 'existential-<disontologising/re-ontologising aporeticism $>$ prospect of human individual-consciousness/collective-consciousness 
decompulsion-appraisal (so-reflected as of the ontologising/scientific/existence- $<$ honestyconstraining $>$ — scope_for_prospective_re-ontologising imbued underlying-elucidative 'requisite sublimating/desublimating formulative-framing/fielding-of-entailment of human ontological-performance ${ }^{2}-<$ including-virtue-as-ontology $>/$ morality/ethics/justice/etc.

contemplation' as of notionally implied ${ }^{45}$ foregrounding_entailment- $<$ in-succession-ofprofound-supererogation $>$-〈postconverging-narrowing-down $\sim$ sublimation-as-to-'existenceas-sublimating-withdrawal/unenframing/re-ontologising,-elicited-from-prospective-profoundsupererogation '-in-reflecting-'immanent relative-unreflexivity/relative-reflexivity ontological-contiguity ';-as-operative-notional deprocrypticism〉);

superseding/overriding the arbitrariness/discreetness of any supposed 'punctual noumenality and phenomenality distinction' (as so-bound to be related to flawedly in an exercise of elaborationas-to-mere-extrapolating/constituting/abstracting/deducing/inferring-of-elucidation-outside'prospectively_implicited_attendant-ontological-contiguity ${ }^{67}$ ' educedexistentialising/contextualising/textualising_intelligibility/epistemicity/reflexivity-contiguity$<$ imbued-notional cogency $>$ as 'prospectively lacking/impervious-to cogency_chronicularity/annality-of-relative-reflexivity,-as-to-profound-supererogation ') inducing 'apriorising/axiomatising/referencing—equating/leveling/ressentiment/closedconstruct-of- ${ }^{5}$ meaningfulness-and-teleology 9 moronisation- $<$ sublimating-nascence,extricatory-desublimating-downstreaming/'avalage'>’ as to presencing absolutising identitive-constitutedness 'existential-<disontologising/re-ontologising aporeticism $>$ preconverging de-mentating/structuring/paradigming punctual/immediacy/constituted/compulsions-encumbered prior mere-formulaicity/ritualisation rationalisation-of-contentivity/argumentativity/dialecticism/discursivity. Such that human ontological-performance ${ }^{72}$-<including-virtue-as-ontology $>/$ morality/ethics/justice/etc. is veridically thus all about psychologismic-epistemic-acutisation-<as-to-postconverging-de- 
mentating/structuring/paradigming,-eliciting-of-existence's-sublimating-nascence-inprospective-aporeticism-overcoming/unovercoming $>$ as to epistemic-growth,-as\{veridical/sound\}-relative-reflexivity-in-existence/relativising from-limited-mentation-as-itsdeepening/psychologismic epistemic acutisation residualising, ${ }^{\text {fdecompulsing }}$ delinearity for eogency' as of 'preconverging/postconverging-rede-mentating/restructuring/reparadigming of limitedness/human-subpotency ${ }^{15}$ de-mentation-〈supererogatory - ontological-de-mentation-ordialectical-de-mentation — stranding-or-attributive-dialectics $\rangle$ ' in reflection of sublimating prospective chronicular/annalistic-cogency-<as-of-notional $\sim$ protensivity $>$ so-construed as cogency_chronicularity/annality-of-relative-reflexivity,-as-to-profound-supererogation from the 'profoundsupererogation $\sim$ reframing/reformulation/decatchmenting/detruncating/decompulsing/delinear ising -as-to-postconverging de-mentating/structuring/paradigming priority/precedence/primacy' of re-ontologising prospective Being-development/ontologicalframework-expansion-as-to-depth-of-ontologising-development-as-infrastructure-ofmeaningfulness-and-teleology psychologismic epistemic-acutisation difficulty-for, residualising \{decompulsing\} delinearity-for-cogency>-magnitude $\{$ of-experientiality/experiment\}, then institutional-development-as-to-social-function-development psychologismic epistemic acutisation difficulty-for, residualising \{decompung delinearity for-cogency> magnitude $\{$ ofexperientiality/experiment\} and then living-development-as-to-personality-development psychologismic epistemic-acutisation difficulty-for, residualising \{decompulsing\} delinearity for-cogency> magnitude $\{$ of-experientiality/experiment\}. Notional perceptualisation-of-and-leashing-to_social-functioning-and-accordance-as-ofsocial-stake-contention-or-confliction herein speaks of the notional/epistemic/bindingness ${ }^{<a s-t o-}$ determinism/conceptivity of relative unreflexivity/relative reflexivitys implications of human-per-cep-ti-vi-ty-<asto - notional perceptualisation-of-and-leashing-to_social-functioning-and-accordance-as- 
of-social-stake-contention-or-confliction> as to: both presencing absolutising-identitiveeonstitutedness 'existential<<disontologising/re-ontologising aporeticism $>$ preconverging de-mentating/structuring/paradigming punctual/immediacy/constituted/compulsionsencumbered prior mere-formulaicity/ritualisation rationalisation-ofcontentivity/argumentativity/dialecticism/discursivity' and nonpresencing-<perspectiveentological-normaley/postconvergence $>\quad$ 'existential-<disontologising/re-ontologising aporeticism $>$ prospect of human individual-consciousness/collective-consciousness decompulsion-appraisal, as reflected in the manifestation of the notional/epistemic/bindingnessoveraching cultivated-and-enculturated interrelatedness-dynamics-of-social-constructing as from 'catchmented-and-compulsed-<in‘existential-dearth-of-demoronisation',-so-construed-as-from-ontologicalnormalcy/postconvergence-perspective-reflection-of-the-'destructuring-threshold_of-thegiven-level's-conjugated-postlogism as-dementing'> interpersonal, group, intergroup, community, local, national, political, geostrategic, etc. psychologismic epistemic acutisationdifficulty-for, residualising \{decompulsing $d e$ linearity for-cogency>-levels of interrelatednessdynamics-of-social-constructing' of 'formativeness-<as-to-intersolipsism-ofpreformulating/preframing/premeaningfulness-imbued-mediativity-and-deferentialism>-ofmeaningfulness-and-teleology and existential-<disontologising/re-ontologisingaporeticism $>$ articulation manifestations'. Thus relative-unreflexive ${ }^{79}$ presencing-absolutisingidentitive-constitutedness ${ }^{14}$ 'punctual noumenality and phenomenality distinction' shallowsupererogation $\sim$ framing/formulation/catchmenting/truncating/compulsing/linearising —as-topreconverging de-mentating/structuring/paradigming as relative-unreflexivity of human-percep-ti-vi-ty-<as-to - notional perceptualisation-of-and-leashing-to_social-functioning-andaccordance - as-of-social-stake-contention-or-confliction> inherently arises by the mere fact of human $<$ amplituding/formative-epistemicity $>$-totalising $\sim$ thrownness-in-existence ${ }^{5}$ - as 
imbued of limitedness/human-subpotency prospective dearth for \{epistemic-totalising treapriorising/re-axiomatising/re-referencing $\sim$ residuality_-in-re-originariness/re-origination projection); and so-construed as 'human limited-mentation-capacity-as-subjecting 'educedunlimitedness/existence-sublimating nascence' to-limitedness/human-subpotency existential<disontologising/re-ontologising aporeticism $>$ overload' induced 'per-cep-ti-vi-ty dearth', and ultimately in want for appropriate prospective 're-ontologising fepistemic-totalising ${ }^{\frac{1}{7}} \mathrm{re}$ apriorising/re-axiomatising/re-referencing-residuality in-re-originariness/re-origination

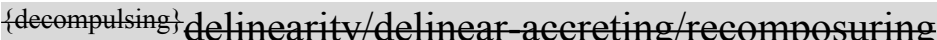
cogency/tensing/limpidity-<as-ofprospective-profound-supererogation ${ }^{9}$,-for-residuality—in-re-originariness/reorigination $>$ - p prospective_reifying mental-aestheticising_<as-of 'prospective_reformulating of-mental-aestheticising'as-to-'residuality in -re-originariness/re-origination' of-mentalaestheticising $>$ ' induced demoronisation- $<$ sublimating-nascence,-nonextricatory-sublimatingupstreaming/'amontée'> (and so as to the cogency_chronicularity/annality-of-relativereflexivity,-as-to-profound-supererogation reflexively undergirding the 'overall relativeunreflexivity/relative-reflexivity — ontological-contiguity ${ }^{67} \sim$ of-the-human-institutionalisation-

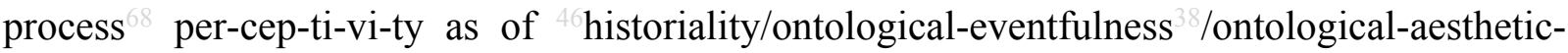
tracing-<perspective-ontological-normalcy/postconvergence-reflected-'epistemicityrelativism-determinism'>)'. Practically, notional $\sim$ perceptualisation-of-and-leashing-to_socialfunctioning-and-accordance-as-of-social-stake-contention-or-confliction (as to 'human limited-mentation-capacity_as-subjecting 'educed-unlimitedness/existence-sublimating nascence' to-limitedness/human-subpotency existential-<disontologising/re-ontologisingaporeticism $>$ overload' threshold of 'per-cep-ti-vi-ty lucidity' by 'per-cep-ti-vi-ty dearth') speaks to the overaching cultivated-and-enculturated interrelatedness-dynamics-of-socialconstructing as underlying respectively 'protracted-social—as-to-individual-by-institutional-bysocial relative direct/deferential-irresponsibility/relative-unreflexivity to 
cogency_chronicularity/annality-of-relative-reflexivity,-as-to-profound-supererogation ${ }^{9}$ and 'protracted-social—as-to-individual-by-institutional-by-social relative direct/deferentialresponsibility/relative-reflexivity to cogency_chronicularity/annality-of-relative-reflexivity,-asto-profound-supererogation '; as to the implications of the 'flow of human prospective profound-supererogation -over-shallow-supererogation' (given 'unlimitedness/existence<full-potency-of_sublimating nascence> prospective apriorising/axiomatising/referencingsublimating-reflexivity_-beholdening under which limitedness/human-subpotency submits in profound-supererogation for prospective sublimating' warrant the 'overarching existential< disontologising/re-ontologising aporeticism $>$ priority/precedence/primacy of totalising $3{ }^{3}$ re-apriorising/re-axiomatising/re-referencing $\sim$ residuality-in-re-originariness/reorigination projection') underlying 'relays of human intemporal-individuation epistemicprojection radicalities $\sim$ in-chronicular/annalistic-cogency-<as-of-notional $\sim$ protensivity $>-\langle$ as-tolimited-mentation-capacity-deepening — as-subjecting limitedness/human-subpotency-to'educed-unlimitedness/existence-sublimating nascence' > so-construed as cogency_chronicularity/annality-of-relative-reflexivity,-as-to-profound-supererogation ${ }^{2}$ (in the face of the inherent shallow-supererogation of 'catchmenting-by-rejection/lipservicing/monopolising/gaming-of-the-system/charade/distraction vague/imaginary lures of social-stake-contention-or-confliction' prospective disontologising/subontologising shallowsupererogation $\sim$ framing/formulation/catchmenting/truncating/compulsing/linearising —as-topreconverging de-mentating/structuring/paradigming arresting-effect on overall humanconsciousness/collective-consciousness-distendedness/detruncating-<beyond-selfpresencing,as-re-ontologising-decentering_of-consciousness/collective-consciousness,-as-to-

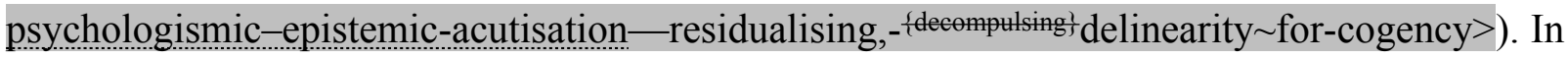
this respect, 'human consciousness/collective-consciousness notional perceptualisation-ofand-leashing-to_social-functioning-and-accordance-as-of-social-stake-contention-or- 
confliction' as underlied as of human 'conjugative/interstitial disontologising/re-ontologising skewing towards prospective re-ontologising' is so-construed as from the 'reflexivity of prospective notional $\sim$ deprocrypticism/notional $\sim$ preempting — disjointedness-as-ofreference-of-thought nonpresencing-<perspective-ontological-normalcy/postconvergence $>$ epistemic-projection' (in so-reflecting the reality of overall human 'formativeness-<as-tointersolipsism-of-preformulating/preframing/premeaningfulness-imbued-mediativity-anddeferentialism $>$-of- meaningfulness-and-teleology as to inherent human embodiedvitality/survival/subsistence — existential-<disontologising/re-ontologising _aporeticism $>$ becoming with regards to human Being-development/ontological-framework-expansion-as-todepth-of-ontologising-development-as-infrastructure-of- meaningfulness-and-teleology , institutional-development-as-to-social-function-development and living-development-as-topersonality-development psychologismic epistemic-acutisation difficulty-for, residualising \{decompulsing\} delinearity-for-cogency>-magnitudes \{of-experientiality/experiment\} as sodefining the social or human-social-potency'); and so-underlining 'human consciousness/collective-consciousness eliciting of prospective ${ }^{56}$ meaningfulness-andteleology' whether 'sublimating in demoronisation-<sublimating-nascence,-nonextricatorysublimating-upstreaming/'amontée'>' or 'desublimating in moronisation- $<$ sublimatingnascence,-extricatory-desublimating-downstreaming/'avalage'>' (as to 'recurrently mediative$<$ in-expectation/in-anticipation $>$ unconsciousness/potentiation-of-conscionability-<anxiety-asto-reconstitution/reparation,-including-dreaming/psychical-reshuffling>' as the 'psychoanalytic boundlessness of human notional $\sim$ reflexivity-<\{veridical/sound $\}$-relative-reflexivity-inexistence/relativising from-limited-mentation-as-its-deepening/psychologismic<residualising \{decompulsing $\}$ delinearity for cogency>by-\{flawed/unsound\}relativeunreflexivity-in-existence/absolutising from-limited-mentation/psychologismic epistemicacutisation nonresidualising-imbued-\{compulsing\}linearity in-eclecticism-of prior-mere- 
formulaicity/ritualisation>

backdrop'). Insightfully, existential-<disontologising/re-ontologising aporeticism $>$

the 'reflexivity

of

prospective

notional $\sim$ deprocrypticism/notional preempting — disjointedness-as-of- reference-of-thought nonpresencing- $<$ perspective-ontological-normalcy/postconvergence $>$ epistemic-projection' reflecting human ontological-performance ${ }^{72}-<_{\text {including-virtue-as- }}$ ontology $>$ /morality/ethics/justice/etc. is rather veridically about human psychologismicepistemic-acutisation-<as-to-postconverging-de-mentating/structuring/paradigming,-elicitingof-existence's-sublimating-nascence-in-prospective-aporeticism-overcoming/unovercoming> as to epistemic-growth,-as-\{veridical/sound\}-relative-reflexivity-in-existence/relativising from-limited-mentation-as-its-deepening/psychologismic epistemic acutisationresidualising, ${ }^{\{\text {decompulsing }\}}$ delinearity for-cogency (over the "prospective unreflexivity of our positivism- ${ }^{8}$ procrypticism/disjointedness-as-of- ${ }^{8}$ reference-of-thought' presencingabsolutising-identitive-constitutedness ${ }^{14}$ epistemic-projection as to a 'punctual noumenality and phenomenality distinction'); and underlines the fact that the requisite projection of 'relativereflexivity of human-per-cep-ti-vi-ty-<as-to-notional perceptualisation-of-and-leashingto social-functioning-and-accordance_-as-of-social-stake-contention-or-confliction> ${ }^{\prime} \quad$ is coextensive with prospective demoronisation- $<$ sublimating-nascence, sublimating-upstreaming/'amontée'>' with this coextension translated into 'limitedness/humansubpotency relative-reflexivity educed sublimating psychologismic-transfixity-<placeholdersetup-ontological-rescheduling — in-realigning/preactivity/formative-

\section{becoming/psychoanalytical-unshackling,-as-to-residualising-\{decompulsing $d$ delinearity-over-}

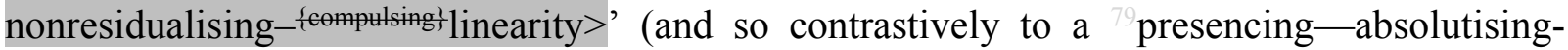
identitive-constitutedness ${ }^{14}$ epistemic-projection as to a 'punctual noumenality and phenomenality distinction' projection of 'relative-unreflexivity of human-per-cep-ti-vi-ty-<asto - notional $\sim$ perceptualisation-of-and-leashing-to_social-functioning-and-accordance-as- 
of-social-stake-contention-or-confliction>' that fails to highlight such a coextension by its 'punctual noumenality and phenomenality distinction' in elaboration-as-to-mereextrapolating/constituting/abstracting/deducing/inferring-of-elucidation-outside'prospectively_implicited_attendant-ontological-contiguity ${ }^{67}$ ' educedexistentialising/contextualising/textualising_'intelligibility/epistemicity/reflexivity-contiguity$<$ imbued-notional $\sim$ cogency $>$, and rather so-betrays prospective moronisation- $<$ sublimatingnascence,-extricatory-desublimating-downstreaming/'avalage’>). The implication here being that 'relative-reflexivity of human-per-cep-ti-vi-ty-<as-to-notional perceptualisation-of-andleashing-to_social-functioning-and-accordance_-as-of-social-stake-contention-orconfliction>' arises as from the very requisite 'fundamental/incipient/seeding experientiality/experiment- $<$ as-to-existentially-formative- ${ }^{\text {‘epistemic-totalising }}{ }^{3}$ re-apriorising/reaxiomatising/re-referencing residuality - in-re-originariness/re-origination',- so"notionally/epistemically/bindingnessly-<as-to-determinism/conceptivity-of-relative-unreflexivity/relative-reflexivity> implicited-and-articulated'_as-from-nonextricatory-'prospective-re-ontologising-Being-thenInstitutional-then-Living-magnitudes-of-\{hermeneutic/reprojection-protraction-of\}reframingand-reformulation $\}^{\prime}>$ that is human profound-supererogation', (so-reflecting the 'overarching existential-disentegising/re ontelogising apereticism> priority/precedence/primacy of \{epistemic-totalising 3 \}re-apriorising/re-axiomatising/re-referencing $\sim$ residuality—in-reoriginariness/re-origination projection') as not to fall into prior mere-formulaicity/ritualisation<as-to-mere-formulaic - methodologising/mutualising/organising/institutionalising,prospectively-losing-track-of- ‘fepistemic-alising tre-apriorising/re-axiomatising/rereferencing $\sim$ residuality - in-re-originariness/re-origination'> (so-reflexively arising as of human psychologismic-epistemic-acutisation-<as-to-postconverging-dementating/structuring/paradigming,-eliciting-of-existence's-sublimating-nascence-inprospective-aporeticism-overcoming/unovercoming > as to epistemic-growth,-as 
\{veridical/sound\}-relative-reflexivity-in-existence/relativising from-limited-mentation-as-itsdeepening/psychologismic epistemic acutisation residualising, ${ }^{\text {fdecompulsing }}$ delinearity for eogency imbued demoronisation- $<$ sublimating-nascence,-nonextricatery-sublimatingupstreaming/'amontée'>). With the projection of 'relative-unreflexivity of human-per-cep-ti-vity-<as-to - notional perceptualisation-of-and-leashing-to_social-functioning-andaccordance - as-of-social-stake-contention-or-confliction>' rather arising inherently because of 'human limited-mentation-capacity—as-subjecting-'educed-unlimitedness/existencesublimating nascence' to-limitedness/human-subpotency for self-reflexive instigativeeventuating-〈as-to-teleological-instigative/incipientwilling/arbitrariness/waywardness/faithdrivenness/supererogating-for-human-intelligibility,preceding-existence's-eventuating-sublimating-validation/desublimating-invalidation〉'; soimplicited as from the reflexive epistemic-projection perspective of "unlimitedness/existence<full-potency-of_sublimating nascence $>$ prospective apriorising/axiomatising/referencing sublimating-reflexivity_-beholdening under which limitedness/human-subpotency submits in profound-supererogation for prospective sublimating' as imbuing of prospective 'reentologising \{epistemic-totalising łre-apriorising/re-axiomatising/re-referencing-residuality in reeriginariness/re-origination \{decompulsing $\}$ delinearity/delinear-accreting/recomposuring cogency/tensing/limpidity-<as-of-prospective-profound-supererogation ${ }^{6}$,-for-residuality-inre-originariness/re-origination>--prospective_reifying mental-aestheticising-<as-of'prospective_reformulating of-mental-aestheticising'as-to-'residuality in-re-originariness/reorigination'-of-mental-aestheticising ' ' Thusly speaking to the artifice of the variously manifest human ${ }^{79}$ presencing-absolutising-identitive-constitutedness ${ }^{14}$ epistemic-projection of 'punctual noumenality and phenomenality distinction' projection of 'relative-unreflexivity of human-per-cep-ti-vi-ty-<as-to-notional perceptualisation-of-and-leashing-to_socialfunctioning-and-accordance-as-of-social-stake-contention-or-confliction>> induced 
moronisation- $<$ sublimating-nascence,-extricatory-desublimating-downstreaming/'avalage' $>$; as so-underlying the <cumulating/recomposuring attendant-ontological-contiguity successive registry-worldviews/dimensions of the overall relative-unreflexivity/relativereflexivity - ontological-contiguity ${ }^{67}$ of-the-human-institutionalisation-process ${ }^{68}$ associated presencing - absolutising-identitive-constitutedness ${ }^{14}$ projections of 'relative-unreflexivity of human-per-cep-ti-vi-ty-<as-to - notional perceptualisation-of-and-leashing-to_socialfunctioning-and-accordance-as-of-social-stake-contention-or-confliction>'. This elucidation is made to point out that the veracity of 'demoronisation-<sublimating-nascence,nonextricatory-sublimating-upstreaming/‘amontée’> over moronisation- $<$ sublimatingnascence,-extricatory-desublimating-downstreaming/'avalage'>' (as to human psychologismic-epistemic-acutisation-<as-to-postconverging-dementating/structuring/paradigming,-eliciting-of-existence's-sublimating-nascence-inprospective-aporeticism-overcoming/unovercoming $>$ as to epistemic-growth,-as\{veridical/sound\}-relative-reflexivity-in-existence/relativising from-limited-mentation-as-itsdeepening/psychologismic epistemic-acutisation residualising, fdecompulsingl delinearity foreogency) is notionally/epistemically/bindingnessly-<as-to-determinism/conceptivity-of-relativeunreflexivity/relative-reflexivity of the underlying 'manifest idiosyncratic-ferment_fornotional $\sim$ cogency-〈as-to- $<$ surrealising/supererogating-drive $>$-of-aestheticisingrelief/depth-and-impetus〉 as of re-ontologising-by-disontologising/subontologisingdynamics of human-per-cep-ti-vi-ty-<as-to-notional perceptualisation-of-and-leashingto_social-functioning-and-accordance - as-of-social-stake-contention-or-confliction> ${ }^{\prime} \quad$ as 'reflexively coextensive with human-consciousness/collective-consciousnessdistendedness/detruncating-<beyond-selfpresencing,-as-re-ontologising-decentering_ofconsciousness/collective-consciousness,-as-to-psychologismic-epistemic-acutisation-

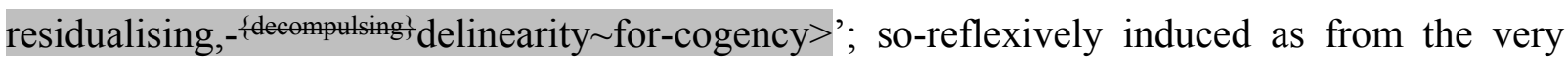


requisite 'fundamental/incipient/seeding experientiality/experiment- $<$ as-to-existentiallyformative- ‘fepistemic-totalising ${ }^{\prime}$ re-apriorising/re-axiomatising/re-referencing $\sim$ residuality-in-reoriginariness/re-origination',- - so-'notionally/epistemically/bindingnessly< determinism/conceptivity-of-relative-unreflexivity/relative-reflexivity>_implicited-and-articulated'_as-fromnonextricatory-'prospective-re-ontologising-Being-then-Institutional-then-Living-magnitudesof-\{hermeneutic/reprojection-protraction-of $\}$ reframing-and-reformulation $\}$ '> that is human profound-supererogation' (so-reflecting the 'overarching existential-<disontologising/reentologising aporeticism $>$ priority/precedence/primacy of axiomatising/re-referencing $\sim$ residuality—in-re-originariness/re-origination projection'), in prospectively reflecting 'unlimitedness/existence-<full-potency-of_sublimating nascence> prospective apriorising/axiomatising/referencing-sublimating-reflexivity-beholdening under which limitedness/human-subpotency submits in profound-supererogation for prospective sublimating' as so-imbuing of prospective 're-ontologising fepistemic-totalising 're-apriorising/reaxiomatising/re-referencing residuality in re-originariness/re-origination $\{$ \{lecompulsing $\}$ delinearity/delinear-accreting/recomposuring $\quad$ cogency/tensing/limpidity-<as-ofprospective-profound-supererogation ,-for-residuality—in-re-originariness/reorigination $>$, prospective_reifying mental aestheticising <as of 'prospective_reformulating of-mental-aestheticising'as-to 'residuality in re-originariness/re-origination' of mentalaestheticising $>$ '. Thus, per-cep-ti-vi-ty as such is of relative-reflexivity projection of apriorising/axiomatising/referencing-\{of-'prospectively_implicited_attendant-ontologicalcontiguity ' educedexistentialising/contextualising/textualising_'intelligibility/epistemicity/reflexivity-contiguity-

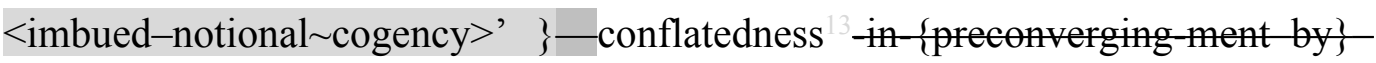
pestconverging-entailment as to prospective ontological-faith-notion-or-ontological-fideism imbued-underdetermination-of-motif-and-apriorising/axiomatising/referencing-as-so-being-as- 
of-existential-reality elicited prospective profound-supererogation (rather than the relativeunreflexivity projection of apriorising/axiomatising/referencing-\{of-'prospectively implicited_attendant-ontological-contiguity ' educedexistentialising/contextualising/textualising_'intelligibility/epistemicity/reflexivity-contiguity$<$ imbued-notional cogency $>$ ' $\}$-constitutedness ${ }^{14}$-in-preconverging-entailment as of prior mere-formulaicity/ritualisation-<as-to-mere-formulaicmethodologising/mutualising/organising/institutionalising,-prospectively-losing-track-of‘fepistemic totalising łre-apriorising/re-axiomatising/re-referencing residuality-in-reoriginariness/re-origination'>). In effect, the reflexivity of 'human consciousness notional protensivity imbuing prospective psychologismic-epistemic-acutisation- $<$ as-topostconverging-de-mentating/structuring/paradigming,-eliciting-of-existence's-sublimatingnascence-in-prospective-aporeticism-overcoming/unovercoming $>$ as to epistemic-growth,-as\{veridical/sound\}-relative-reflexivity-in-existence/relativising from-limited-mentation-as-itsdeepening/psychologismic epistemic-acutisation residualising, fdecmpulingl $_{\text {f }}$ delinearity for eogency' speaks to the fact that such notions as perception and conception veridically alluding to per-cep-ti-vi-ty are rather unreflexively construed as from the given presencingabsolutising-identitive-constitutedness ${ }^{14}$ 'punctual noumenality and phenomenality distinction' shallow

supererogation $\sim$ framing/formulation/catchmenting/truncating/compulsing/linearising —as-topreconverging de-mentating/structuring/paradigming imbued 'relative-unreflexivity of humanper-cep-ti-vi-ty-<as-to - notional perceptualisation-of-and-leashing-to_social-functioningand-accordance-as-of-social-stake-contention-or-confliction>'. Thus 'human consciousness notional protensivity psychologismic-epistemic-acutisation- $<$ as-to-postconverging-dementating/structuring/paradigming,-eliciting-of-existence's-sublimating-nascence-inprospective-aporeticism-overcoming/unovercoming $>$ as to epistemic-growth,-as- 
\{veridical/sound\}-relative-reflexivity-in-existence/relativising from-limited-mentation-as-itsdeepening/psychologismic epistemic acutisation residualising, ${ }^{\text {fdecompulsing }}$ delinearity for eogency' reflexivity construal is overriding/superseding (of 79 presencing-absolutisingidentitive-constitutedness ${ }^{14}$ epistemic-projection of 'punctual noumenality and phenomenality distinction') as to its notional/epistemic/bindingness ${ }^{<a s-t o-d e t e r m i n i s m / e o n c e p t i v i t y-o f-r e l a t i v e-~}$ unreflexivity/relative-reflexivity $>$ reflection of the underlying 'manifest idiosyncratic-ferment_fornotional cogency-〈as-to- $<$ surrealising/supererogating-drive $>$-of-aestheticising relief/depth-and-impetus $\rangle$ as of re-ontologising-by-disontologising/subontologisingdynamics of human-per-cep-ti-vi-ty-<as-to - notional perceptualisation-of-and-leashingto_social-functioning-and-accordance-as-of-social-stake-contention-or-confliction>'; as rather prompted as from 'unlimitedness/existence-<full-potency-of_sublimating nascence $>$ prospective apriorising/axiomatising/referencing-sublimating-reflexivity-beholdening under which limitedness/human-subpotency submits in profound-supererogation for prospective sublimating' as so-imbuing of prospective 're-ontologising fepistemic-totalising 're-apriorising/reaxiomatising/re-referencing residuality in-re-originariness/re-origination ${ }_{\{\text {decompulsing }}$ delinearity/delinear-accreting/recomposuring $\quad$ cogency/tensing/limpidity-<as-ofprospective-profound-supererogation ,-for-residuality-in-re-originariness/reorigination>-_prospective_reifying mental-aestheticising-<as-of 'prospective_reformulating of-mental-aestheticising'as-to-'residuality in-re-originariness/re-origination' of mentalaestheticising $>$ '. This so-overrides the inherent 'eclecticism-of-prior-mereformulaicity/ritualisation-<as-of-prior $\sim$ rationalisation-ofcontentivity/argumentativity/dialecticism/discursivity> composition/blending-in\{compulsing\} linearity/linear-accretion of relative-ontological-completeness and relativeontological-incompleteness apriorising/axiomatising/referencing as to secondnatured prior mere-formulaicity/ritualisation-<as-to-mere-formulaic- 
methodologising/mutualising/organising/institutionalising,-prospectively-losing-track-of-

‘\{epistemic-totalising ’’re-apriorising/re-axiomatising/re-referencing-residuality-in-re-

originariness/re-origination'>' underlying any such per-cep-ti-vi-ty projection as rather of relative-unreflexive $\quad{ }^{79}$ presencing-absolutising-identitive-constitutedness ${ }^{14} \quad$ 'punctual noumenality and phenomenality distinction' shallowsupererogation $\sim$ framing/formulation/catchmenting/truncating/compulsing/linearising —as-to preconverging de-mentating/structuring/paradigming as 'relative-unreflexivity of human-percep-ti-vi-ty-<as-to - notional $\sim$ perceptualisation-of-and-leashing-to_social-functioning-andaccordance - as-of-social-stake-contention-or-confliction>'. Basically, the above overarching elucidation of $\quad$ nonpresencing-<perspective-ontological-normalcy/postconvergence $>$ epistemic-projection of 'human consciousness notional protensivity psychologismicepistemic-acutisation-<as-to-postconverging-de-mentating/structuring/paradigming,-elicitingof-existence's-sublimating-nascence-in-prospective-aporeticism-overcoming/unovercoming> as to epistemic-growth,-as- \{veridical/sound\}-relative-reflexivity-in-existence/relativising from-limited-mentation-as-its-deepening/psychologismic epistemic acutisationresidualising, ${ }^{\{\text {decompulsing }}$ delinearity for-cogency' reflexivity construal (as sooverriding/superseding of ${ }^{7}$ presencing-absolutising-identitive-constitutedness ${ }^{14}$ epistemicprojection of 'punctual noumenality and phenomenality distinction') is anchored upon the 'contrastive insights for elucidative equivalence' as from 'unlimitedness/existence-<fullpotency-of_sublimating nascence> perspective' and 'limitedness/human-subpotency perspective' when it comes to 'limitedness/human-subpotency projection of relativeunreflexivity/relative-reflexivity - ontological-contiguity ${ }^{67}$ of human-per-cep-ti-vi-ty-<as-tonotional perceptualisation-of-and-leashing-to_social-functioning-and-accordance-as-ofsocial-stake-contention-or-confliction>'; wherein unlimitedness/existence-<full-potency of_sublimating nascences is rather inherently of 'immanent-reflexivity omnipotential- 
affirmation/projection/assertion/notional self-distantiation' while limitedness/humansubpotency is 'reflexively aspirative to omnipotentialaffirmation/projection/assertion/notional self-distantiation with regards to limitedness/humansubpotency relative-unreflexivity/relative-reflexivity - ontological-contiguity ${ }^{67}$ dynamics of supererogating $\{$ affirmation/projection/assertion/notional $\sim$ self-distantiation-byunaffirmation/deprojection/deassertion/epistemic-decadence $\}$ — towards $\sim$ omnipotentialaffirmation/projection/assertion/notional self-distantiation' (underlined as to the 'flow of human prospective profound-supererogation -over-shallow-supererogation ${ }^{\prime}$ ). Such a 'relative-unreflexivity/relative-reflexivity limitedness/human-subpotency dynamics of supererogating $\{$ affirmation/projection/assertion/notional $\sim$ self-distantiation-byunaffirmation/deprojection/deassertion/epistemic-decadence $\}$ —-towards $\sim$ omnipotentialaffirmation/projection/assertion/notional self-distantiation' is so-dynamically of 'issue/relevance as to reflexivity/unreflexivity only to limitedness/human-subpotency' and not to 'unlimitedness/existence-<full-potency-of_sublimating nascence $>$ already givenness/immanence' as inherently of immanent-reflexivity. This so-explains the veracity of limitedness/human-subpotency 'sublimating-over-desublimating perpetuation/continuity' towards 'omnipotential-affirmation/projection/assertion/notional $\sim$ self-distantiation'; and so rather as of nonpresencing-<perspective-ontological-normalcy/postconvergence $>$ epistemicprojection of 'human consciousness notional protensivity psychologismic-epistemicacutisation-<as-to-postconverging-de-mentating/structuring/paradigming,-eliciting-ofexistence's-sublimating-nascence-in-prospective-aporeticism-overcoming/unovercoming $>$ as to epistemic-growth,-as - \{veridical/sound\}-relative-reflexivity-in-existence/relativising fromlimited mentation as its deepening/psychologismic epistemic acutisation residualising, \{decompulsing\} delinearity for-cogency\} reflexivity construal (in so-overriding/superseding of presencing-absolutising-identitive-constitutedness ${ }^{14}$ epistemic-projection of 'punctual 
noumenality and phenomenality distinction' inclination to wrongly and implicitly imply it is of 'unlimitedness/existence-<full-potency-of_sublimating nascence $>\quad$ already givenness/immanence' imbued omnipotential-affirmation/projection/assertion/notional selfdistantiation thusly inducing the given ${ }^{79}$ presencing-absolutising-identitive-constitutedness failing of prospective supererogatory $\sim$ acuity/perspicacity/astuteness/edginess/incisiveness-ofapriorising/axiomatising/referencing/intelligibilitysettingup/measuringinstrumenting -forconceptualisation so-manifested as of prior mere-formulaicity/ritualisation-<as-to-mereformulaic — methodologising/mutualising/organising/institutionalising,-prospectively-losing-

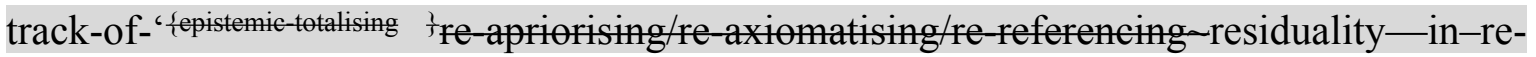
originariness/re-origination'> reflecting human knowledge-deadends-<as-preconverging-dementating/structuring/paradigming $>$ ). Insightfully, this translates into the fact that the $<$ cumulating/recomposuring attendant-ontological-contiguity $>$-successive registryworldviews/dimensions of the overall relative-unreflexivity/relative-reflexivity-ontologicalcontiguity ${ }^{67}$ of-the-human-institutionalisation-process ${ }^{68}$ imbued notional cogency_chronicularity/annality-of-relative-reflexivity,-as-to-profoundsupererogation (as of human Being-development/ontological-framework-expansion-as-todepth-of-ontologising-development-as-infrastructure-of- meaningfulness-and-teleology , institutional-development-as-to-social-function-development and living-development-as-topersonality-development psychologismic epistemic-acutisation difficulty-for, residualising regards to cumulating/recomposuring succession of prospective 'apriorising/axiomatising/referencing disambiguating/de-leveling/de-ressentiment/openedconstruct-of- ${ }^{56}$ meaningfulness-and-teleology 9 demoronisation- $<$ sublimating-nascence,nonextricatory-sublimating-upstreaming/'amontée’’' as to nonpresencing-<perspectiveentological-normaley/postconvergence> 'existential-<disontologising/re-ontologising 
aporeticism $>$ prospect of human individual-consciousness/collective-consciousness

decompulsion-appraisal for human-consciousness/collective-consciousness-

distendedness/detruncating-<beyond-selfpresencing,-as-re-ontologising-decentering_of-

consciousness/collective-consciousness,-as-to-psychologismic-epistemic-acutisation

residualising, ${ }^{-\{\text {decompulsing }}$ delinearity $\sim$ for- $\operatorname{cogency}>$ ) is the ontologising/scientific/existence$<$ honesty-constraining $>$ _ scope_for_prospective_re-ontologising omnipotential (as to 'unlimitedness/existence-<full-potency-of_sublimating nascence $>$ perspective') for 'fullreflexivity of human-per-cep-ti-vi-ty-<as-to - notional perceptualisation-of-and-leashingto_social-functioning-and-accordance - as-of-social-stake-contention-or-confliction>'. Thusly overriding ${ }^{7}$ presencing-absolutising-identitive-constitutedness ${ }^{14}$ epistemic-projection of 'punctual noumenality and phenomenality distinction' inclination to wrongly and implicitly imply it is of 'unlimitedness/existence-<full-potency-of_sublimating nascence $>$ already givenness/immanence' imbued omnipotential-affirmation/projection/assertion/notional $\sim$ selfdistantiation as to the given ${ }^{79}$ presencing-absolutising-identitive-constitutedness ${ }^{14}$ 'relativeunreflexivity of human-per-cep-ti-vi-ty-<as-to-notional perceptualisation-of-and-leashingto_social-functioning-and-accordance-as-of-social-stake-contention-or-confliction>'. Again, this summarily reflects the veracity of the 'flow of human prospective profoundsupererogation -over-shallow-supererogation', (given 'unlimitedness/existence-<fullpotency-of_sublimating nascence> prospective apriorising/axiomatising/referencingsublimating-reflexivity - beholdening under which limitedness/human-subpotency submits in profound-supererogation for prospective sublimating' warrant the 'overarching existential<disontologising/re-ontologising aporeticism $>$ priority/precedence/primacy of \{epistemictotalising $3 \frac{\text { }}{3}$ re-apriorising/re-axiomatising/re-referencing $\sim$ residuality-in-re-originariness/reorigination projection') with regards to 'human socially-protracted-as-to-individual-byinstitutional-by-social psychologismic-epistemic-acutisation-difficulty- $<$ for,-residualising- 
delinearity $\sim$ for-cogency $>$-〈as-of-requisite-profound-supererogation -for-

‘disposedness-or-psychologismic-construct'-\{imbued-demoronisation-<sublimating-

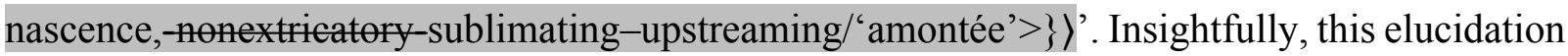
of the ontologising/scientific/existence- $<$ honesty-constraining $>$ - scope_for_prospective_reontologising 'full-reflexivity of human-per-cep-ti-vi-ty-<as-to - notional perceptualisation-ofand-leashing-to_social-functioning-and-accordance-as-of-social-stake-contention-orconfliction>' (and in reflection of the 'fundamental/incipient/seeding experientiality/experiment- $<$ as-to-existentially-formative- ‘fepistemic-totalising ${ }^{\prime}$ re-apriorising/reaxiomatising/re-referencing $\sim$ residuality-in-re-originariness/re-origination',-so"notionally/epistemically/bindingnessly <as-to-determinism/conceptivity-of-relative-unreflexivity/relative-reflexivity> implicited-and-articulated'_as-from-nonextricatory-'prospective-re-ontologising-Being-thenInstitutional-then-Living-magnitudes-of-\{hermeneutic/reprojection-protraction-offreframingand-reformulation $\}^{\prime}>$ that is human profound-supererogation' ${ }^{\prime}$ so-reflecting the 'overarching existential-<disontologising/re-ontologising aporeticism $>$ priority/precedence/primacy of \{epistemic-totalising $3{ }^{3}$ re-apriorising/re-axiomatising/re-referencing $\sim$ residuality—in-re-

originariness/re-origination projection') points out that ontology/science is most ontologically/scientifically coextensive with the profound-supererogation driving its 'relativereflexivity of human-per-cep-ti-vi-ty-<as-to - notional perceptualisation-of-and-leashingto_social-functioning-and-accordance-as-of-social-stake-contention-or-confliction>' as to demoronisation-<sublimating-nascence,-nonextricatory-sublimating-upstreaming/‘amontée’> (as so-appreciable as from 'unlimitedness/existence-<full-potency-of_sublimating nascence $>$ perspective'); with ${ }^{79}$ presencing — absolutising-identitive-constitutedness ${ }^{14}$ 'catchmenting-byrejection/lip-servicing/monopolising/gaming-of-the-system/charade/distraction vague/imaginary lures of social-stake-contention-or-confliction' manifesting shallowsupererogation usurpation of the profound-supererogation for ontological-veracity/science, 
bound to drift into prior mere-formulaicity/ritualisation-<as-to-mere-formulaic methodologising/mutualising/organising/institutionalising,-prospectively-losing-track-of-

‘fepistemic-totlising ’’re-apriorising/re-axiomatising/re-referencing $r$ residuality-in-re-

originariness/re-origination'> 'normalised/stereotyped/selfhelping/feel-good knowledge being brought at the protracted-social—as-to-individual-by-institutional-by-social sovereign's service' (as to 'epistemic-decadence' or teleological-decadence-<-in-dimensionality-ofdesublimating-lack-of $-<<$ amplituding/formative $>$ supererogatory $\sim$ de-mentativeness/epistemicgrowth-or-conflatedness /transvaluative-rationalising/transepistemicity/anamnesticresiduality/spirit-drivenness-equalisation $\rangle$ and moronisation- $<$ sublimating-nascence,extricatesublimating-downstreaming/'avalage'> imbued 'relative-unreflexivity of humanper-cep-ti-vi-ty-<as-to - notional perceptualisation-of-and-leashing-to_social-functioningand-accordance - as-of-social-stake-contention-or-confliction>'). In this regards, the veracity of the 'flow of human prospective profound-supererogation -over-shallow-supererogation given 'unlimitedness/existence $<$ full-potency-of_sublimating nascence $>$ prospective apriorising/axiomatising/referencing-sublimating-reflexivity-beholdening under which limitedness/human-subpotency submits in profound-supererogation for prospective sublimating' warrant the 'overarching existential-<disontologising/re-ontologisingapereticism $>$ priority/precedence/primacy of referencing residuality—in-re-originariness/re-origination projection' (as effectively reflecting that ontology/science is most ontologically/scientifically coextensive with the profoundsupererogation driving its 'relative-reflexivity of human-per-cep-ti-vi-ty-<as-tonotional perceptualisation-of-and-leashing-to_social-functioning-and-accordance-as-ofsocial-stake-contention-or-confliction>') so-arises as to the 'succession of genuine social intellectual-function/posture profound-supererogation educed prospective institutionalisations' over 'uninstitutionalised-threshold ${ }^{02}$ manifesting 
pedantising/muddling/formulaic-hollowing-out — in-subontologisation/subpotentiation〈blurring/undermining-of-prospective-totalising-entailing,-as-to-entailing$<$ ampliteding formative-epistemicity $>$ totalising in-relative-ontological-completeness shallow-supererogation' (as so-manifested by ancient-sophists, medieval-scholasticism and our subtle modern-day institutionally-distorted/disjointed positivismprocrypticism/disjointedness-as-of- ${ }^{3}$ reference-of-thought). Shallow-supererogation (varyingly with respect to Being-development/ontological-framework-expansion-as-to-depthof-ontologising-development-as-infrastructure-of- meaningfulness-and-teleology , institutional-development-as-to-social-function-development and living-development-as-topersonality-development psychologismic epistemic acutisation diffieulty< <er, residualising_\{decompulsing\} delinearity for-cogency> - magnitudes $\{$ of-experientiality/experiment\}) rather arises technically as of 'human-per-cep-ti-vi-ty-<as-to - notional perceptualisation-of-andleashing-to_social-functioning-and-accordance-as-of-social-stake-contention-or-confliction> prospective re-ontologising/sublimating residual loss and/or maladjustment' to appropriate 'idiosyncratic-ferment_for-notional $\sim$ cogency- $\langle$ as-to- $<$ surrealising/supererogating-drive $>$-ofaestheticising - relief/depth-and-impetus $\rangle \quad$ imbuing-<by-needling/prying/prospecting-for'phasing-and-rooting'>-of interlay/organicalism/aestheticising-handle-<of-'psychologismic-

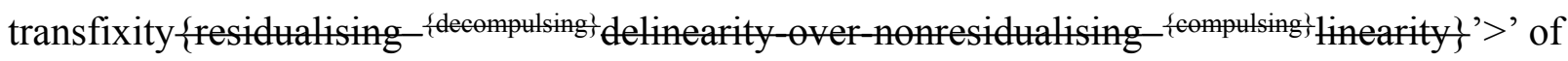
'reifying-mental-aestheticising-<as-of-'prospective_reformulating-of-mental-aestheticising'asto-'residuality - in-re-originariness/re-origination'-of-mental-aestheticising > educed processive-motif-'exuding aestheticising-gesturing'-of-apriorising/axiomatising/referencing as to re-aestheticisation-and-re-aestheticisation-towards-ontology-<elicited-prospectiveidiomatisation>' with regards to eliciting 'organic-knowledge imbued profoundsupererogation $\sim$ reframing/reformulation/decatchmenting/detruncating/decompulsing/delinear ising_scale_-of-transparent/noncontentious/un-nominalised/sound-interpretations/domains of 
manifest

unblurriness-<re-ontologising_by-postconverging-as-to-dragged-out-

supererogatory $\sim$ wholesomeness/profound-supererogation ,-while-anecdotalising-prior-

disontologising-thresholding >' (as so-elicited from firstnaturedness-as-to-inkling profoundsupererogation and upheld as to derived secondnatured positive-opportunism-of-socialfunctioning-and-accordance ${ }^{75}$ ); which 'prospective re-ontologising/sublimating residual loss and/or maladjustment' thusly induces 'mechanical-knowledge imbued shallowsupererogation $\sim$ framing/formulation/catchmenting/truncating/compulsing/linearising_scale —of-opaque/contentious/un-nominalised/flawed-interpretations/domains of manifest blurriness-<sterilising/anecdotalising/trivialising-of-prospective-re-ontologising_bypreconverging,-in-disontologising-formulaic-dragging-out/hollowing-out>' as so undermining prospective cogency_chronicularity/annality-of-relative-reflexivity,-as-to-profoundsupererogation. This critically speaks to the fact that (with regards to 'human-per-cep-ti-vi-ty$<$ as-to - notional $\sim$ perceptualisation-of-and-leashing-to_social-functioning-and-accordanceas-of-social-stake-contention-or-confliction> prospective re-ontologising/sublimating residual loss and/or maladjustment' susceptibility) the social is inherently construable as of 'disontologising/subontologising_de-project/de-oeuvrement by reontologising_project/oeuvrement' imbued preconverging/postconverging-redementating/restructuring/reparadigming (in reflection of the social prospective fepistemic-

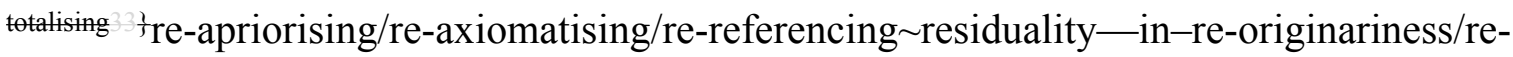
origination projection); as so-manifesting underlying 'desublimating/sublimating notional catchmenting-<as-to_disontologising/subontologising institutional-imprintednessby re-ontologising institutional-imprinting $>$ as to the given disontologising/re-ontologising human ${ }^{56}$ meaningfulness-and-teleology ${ }^{9}$, and as this translates into the given institutional (whether as of catchmented-and-compulsed-<in-'existential-dearth-of-demoronisation',-soconstrued-as-from-ontological-normalcy/postconvergence-perspective-reflection-of-the- 
'destructuring-threshold_of-the-given-level's-conjugated-postlogism as-dementing'>

interpersonal, group, intergroup, community, local, national, political, geostrategic, etc. psychologismic epistemic-acutisation difficulty-for, residualising

$\{$ decompulsing $\}$ delinearity for-cogeney levels of interrelatedness-dynamics-of-socialconstructing) imbued notional compulsion (compulsion_imprintedness/decompulsion_imprinting) of the human sovereignfunction/posture-<as-to-existentially-manifest-‘embodied-subject consciousness-anddirect/deferential-conscientiousness',-as-of-its-'epistemic-reflexivity/unreflexivity-inexistence'/teleology> notional perceptualisation-of-and-leashing-to_social-functioning-andaccordance - as-of-social-stake-contention-or-confliction' (with respect to the possibility for prospective 're-ontologising in cogency_chronicularity/annality-of-relative-reflexivity,-as-toprofound-supererogation ${ }^{\circ}$ as to human-consciousness/collective-consciousnessdistendedness/detruncating-<beyond-selfpresencing,-as-re-ontologising-decentering_ofconsciousness/collective-consciousness,-as-to-psychologismic-epistemic-acutisation-

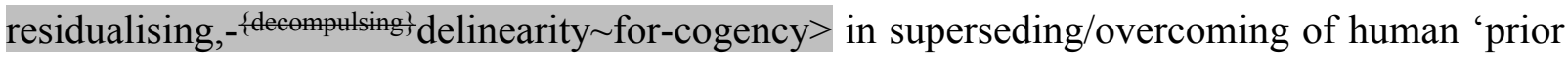

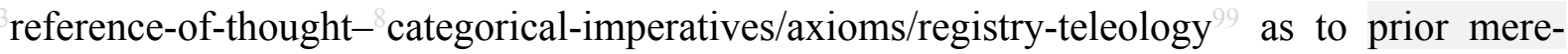
formulaicity/ritualisation-<as-to-mere-formulaicmethodologising/mutualising/organising/institutionalising,-prospectively-losing-track-of'\{epistemic-totalising ’’re-apriorising/re-axiomatising/re-referencing residuality-in-reoriginariness/re-origination'>'). This further reflects the fact that (with regards to the ontologising/scientific/existence- $<$ honesty-constraining $>$ — scope_for_prospective_reontologising imbuing cogency_chronicularity/annality-of-relative-reflexivity,-as-to-profoundsupererogation") the very 'veracity of the sovereign-function/posture-<as-to-existentiallymanifest-'embodied-subject consciousness-and-direct/deferential-conscientiousness',-as-ofits-'epistemic-reflexivity/unreflexivity-in-existence'/teleology> as coextensive with the genuine 
social intellectual-function/posture' (in relation to human-per-cep-ti-vi-ty-<as-to notional perceptualisation-of-and-leashing-to_social-functioning-and-accordance-as-ofsocial-stake-contention-or-confliction> of socially-protracted-as-to-individual-by-institutionalby-social profoundsupererogation $\sim$ reframing/reformulation/decatchmenting/detruncating/decompulsing/delinear ising - as-to-postconverging de-mentating/structuring/paradigming re-rationalisation of contentivity/argumentativity/dialecticism/discursivity of sublimating as so-reflected with the manifestation of the notional/epistemic/bindingness mreflexivity/relative-entexivity overaching cultivated-and-enculturated interrelatedness-dynamics-ofsocial-constructing as from 'catchmented-and-compulsed-<in-'existential-dearth-ofdemoronisation',-so-construed-as-from-ontological-normalcy/postconvergence-perspectivereflection-of-the-'destructuring-threshold_of-the-given-level's-conjugated-postlogism asdementing'> interpersonal, group, intergroup, community, local, national, political, geostrategic, etc. psychologismic epistemic-acutisation difficulty-for, residualising

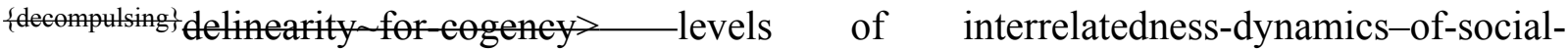
constructing' of 'formativeness-<as-to-intersolipsism-ofpreformulating/preframing/premeaningfulness-imbued-mediativity-and-deferentialism>-ofmeaningfulness-and-teleology and existential-<disontologising/re-ontologising aporeticism $>$ articulation manifestations') rather speaks of human sovereignemergence/becoming,-existentially-imbuing human-freedom-as-to-supererogating/surrealising for-'knowledge-empowerment-over-ignorance-disempowerment'-<as-of-'developing-andavailing-sovereign-sublimating_potential/possibilities/options/choices'-as-to-the‘credibility’/'ontological-veracity’-underlying-the-'sovereign-conscious/conscientiousbackdrop'>. This is the case as to the very incipient/seeding 'widening the social imaginary' as inducing human sovereign-emergence/becoming,-existentially-imbuing human-freedom-as-to- 
supererogating/surrealising for-'knowledge-empowerment-over-ignorance-disempowerment'$<$ as-of-'developing-and-availing-sovereign-

sublimating_potential/possibilities/options/choices'-as-to-the-'credibility'/'ontologicalveracity'-underlying-the-'sovereign-conscious/conscientious-backdrop'> in-the-very-firstplace; that is, 'widening the social imaginary' for 'prospective sublimating notional $\sim$ catchmenting-<as-to_disontologising/subontologising institutional-imprintedness by re-ontologising institutional-imprinting $>$ as to nonpresencing-<perspective-ontologicalnormalcy/postconvergence $>\quad$ existential-<disontologising/re-ontologising aporeticism $>$ prospect of human individual-consciousness/collective-consciousness decompulsion-appraisal' as enabling of the 'ontologising/scientific/existence- $<$ honesty-constraining $>$ scope_for_prospective_re-ontologising requisite enhancing of the human sovereignfunction/posture-<as-to-existentially-manifest-`embodied-subject $\sim$ consciousness-anddirect/deferential-conscientiousness',-as-of-its- 'epistemic-reflexivity/unreflexivity-inexistence'/teleology>'. Thusly with the human sovereign-function/posture-<as-to-existentiallymanifest-'embodied-subject consciousness-and-direct/deferential-conscientiousness',-as-ofits-'epistemic-reflexivity/unreflexivity-in-existence'/teleology> so-emerging/so-becoming as of prospective eliciting of 'unlimitedness/existence-full potency of_sublimating nascence> prospective apriorising/axiomatising/referencing-sublimating-reflexivity-beholdening under which limitedness/human-subpotency submits in profound-supererogation for prospective sublimating', and 'as so-sublimatingly superseding/overriding any given 'prior desublimating notional $\sim$ catchmenting-<as-to_disontologising/subontologising institutional-imprintedness_by re-ontologising institutional-imprinting $>$ as to presencing absolutising-identitiveeonstitutedness existential-disontelogising/re ontologising apereticism> preconverging de-mentating/structuring/paradigming punctual/immediacy/constituted/compulsionsencumbered prior mere-formulaicity/ritualisation rationalisation-of- 
contentivity/argumentativity/dialecticism/discursivity' notion of human sovereignfunction/posture-<as-to-existentially-manifest-`embodied-subject $\sim$ consciousness-anddirect/deferential-conscientiousness',-as-of-its-'epistemic-reflexivity/unreflexivity-inexistence'/teleology> veracity/inveracity (which is implicitly/explicitly reflected by the given desublimating underpinning-suprasocial-construct human sovereign-function/posture-<as-toexistentially-manifest-`embodied-subject consciousness-and-direct/deferentialconscientiousness',-as-of-its-'epistemic-reflexivity/unreflexivity-in-existence'/teleology> 'notional $\sim$ perceptualisation-of-and-leashing-to_social-functioning-and-accordance-as-ofsocial-stake-contention-or-confliction as of circularly catchmented-and-compulsed-<in‘existential-dearth-of-demoronisation',-so-construed-as-from-ontologicalnormalcy/postconvergence-perspective-reflection-of-the-'destructuring-threshold_of-thegiven-level's-conjugated-postlogism as-dementing'> prospectively disontologising/subontologising shallow supererogation $\sim$ framing/formulation/catchmenting/truncating/compulsing/linearising —as-topreconverging -de-mentating/structuring/paradigming'). This speaks to the inherent requisite limitedness/human-subpotency 'despite-the-self exercise of epistemic-projection in notional $\sim$ self-distantiation-<imbued—re-motif-and-re-apriorising/re-axiomatising/rereferencing>' undergirding human sovereign-function/posture-<as-to-existentially-manifest‘embodied-subject $\sim$ consciousness-and-direct/deferential-conscientiousness',-as-of-its'epistemic-reflexivity/unreflexivity-in-existence'/teleology> with regards to humanconsciousness/collective-consciousness-distendedness/detruncating-<beyond-selfpresencing,as-re-ontologising-decentering_of-consciousness/collective-consciousness,-as-topsychologismic-epistemic-acutisation-residualising,- - decompulsing $^{\text {f }}$ delinearity $\sim$ for-cogency $>$. Ultimately, human-per-cep-ti-vi-ty-<as-to-notional perceptualisation-of-and-leashingto_social-functioning-and-accordance-as-of-social-stake-contention-or-confliction> 
notionally-speaking to the veracity/inveracity in the 'flow of human prospective profoundsupererogation -over-shallow-supererogation', given 'unlimitedness/existence-<fullpotency-of_sublimating nascence $>$ prospective apriorising/axiomatising/referencing sublimating-reflexivity_-beholdening under which limitedness/human-subpotency submits in profound-supererogation for prospective sublimating' warrant the 'overarching existential$<$ disontologising/re-ontelogising aporeticism $>$ priority/precedence/primacy of \{epistemictotalising 3 ? origination projection' with regards to 'human socially-protracted-as-to-individual-byinstitutional-by-social psychologismic-epistemic-acutisation-difficulty- $<$ for,-residualising$\{$ decompulsing $\}$ delinearity for-cogency $>$-〈as-of-requisite-profound-supererogation -for-

\section{‘disposedness-or-psychologismic-construct'-\{imbued-demoronisation-<sublimating-}

nascence,-nonextricatory-sublimating-upstreaming/'amontée’’\}〉’' points to requisite profound-supererogation in superseding/overcoming human knowledge-deadends- $<$ aspreconverging-de-mentating/structuring/paradigming $>$ (as prospectively reflecting the failure to reconnect with the 'overarching existential-<disontologising/re-ontologising aporeticism $>$ priority/precedence/primacy of \{epistemic-totalising ${ }^{3}$ re-apriorising/re-axiomatising/rereferencing $\sim$ residuality—in-re-originariness/re-origination projection'); and when such failure is consciously driven this speaks to pedantising/muddling/formulaic-hollowing-out-insubontologisation/subpotentiation-_blurring/undermining-of-prospective-totalising-entailing,as-to-entailing-<amplituding/formative-epistemicity $>$ totalising in-relative-ontologicalcompleteness \ 'epistemic-decadence' or teleological-decadence- $<$-in-dimensionality-ofdesublimating-lack-of ${ }^{-}-\langle<$amplituding/formative $>$supererogatory $\sim$ de-mentativeness/epistemicgrowth-or-conflatedness /transvaluative-rationalising/transepistemicity/anamnesticresiduality/spirit-drivenness-equalisation) (so-reflected in the 'incoherence/insincerity of knowledge/ignorance postures' speaking of ontological-bad- 
faith/inauthenticity ${ }^{64}$ preconverging-de-mentating/structuring/paradigming ${ }^{55}$ specifically-so as to human re-ontologising prospective Being-development/ontological-framework-expansionas-to-depth-of-ontologising-development-as-infrastructure-of- meaningfulness-andteleology ). In this regards, human-per-cep-ti-vi-ty-<as-to-notional $\sim$ perceptualisation-ofand-leashing-to_social-functioning-and-accordance-as-of-social-stake-contention-orconfliction> as of the various psychologismic epistemic-acutisation difficulty-<for,residualising \{decompulsing\} delinearity for-cogency $>$ magnitudes $\{0$-experientiality/experiment $\}$ of 'human socially-protracted-as-to-individual-by-institutional-by-social psychologismic-epistemicacutisation-difficulty- $<$ for,-residualising_\{decompulsing $\}$ delinearity $\sim$ for-cogency $>-\langle$ as-ofrequisite-profound-supererogation -for-'disposedness-or-psychologismic-construct'-

\section{\{imbued-demoronisation-<sublimating-nascence,-nonextricatory-sublimating-}

upstreaming/'amontée'>\})', is as from the relative-unreflexivity of 'lifespan extricatory/preconverging psychical-nascency moronisation- $<$ sublimating-nascence,extricatory-desublimating-downstreaming/'avalage'>' towards the relative-reflexivity of 'nonextricatory/postconverging ontologising-and-re-ontologising angling-of-imaginary demoronisation-<sublimating-nascence,-nonextrieatory-sublimating-

upstreaming/'amontée'>'; with the knowledge and transcendence-andsublimity/sublimation/supererogatory de-mentativity warranted for both thresholds are radically dissimilar (as to their differing overarching existential-<disontelogising/reentologising aporeticism $>$ implications) as to an emphasis on 'upholding the secondnatured positive-opportunism-of-social-functioning-and-accordance ${ }^{75}$ of prior profoundsupererogation induced prior $\sim$ rationalisation-ofcontentivity/argumentativity/dialecticism/discursivity >' with the former and an emphasis on 'firstnaturedness-as-to-inkling of prospective profound-supererogation ${ }^{\circ}$ re-rationalisation-ofcontentivity/argumentativity/dialecticism/discursivity ${ }^{\prime}$ with the latter. In this regards, 
'nonextricatory/postconverging ontologising-and-re-ontologising angling-of-imaginary demoronisation-<sublimating-nascence,-nonextricatory-sublimating-upstreaming/'amontée’>' is effectively paradoxical (as to the psychologismic-epistemic-acutisation-difficulty- $<$ for,residualising_\{decompulsing $\}$ delinearity $\sim$ for-cogency $>-\langle$ as-of-requisite-profound-supererogation for-'disposedness-or-psychologismic-construct'- $\{$ imbued-demoronisation-<sublimatingnascence,-nonextricatory-sublimating-upstreaming/'amontée’’\}〉 that the relative-ontologicalcompleteness ${ }^{87}$ respectively of base-institutionalisation, ${ }^{103}$ universalisation, positivism/rationalempiricism and prospective deprocrypticism-or-preempting-disjointedness-as-ofreference-of-thought is paradoxically affirmed/projected/asserted within the disontologising 'mental-reflex framing-and-formulation' as of the prior relative-ontological-incompleteness ${ }^{88}$ of recurrent-utter-uninstitutionalisation, ununiversalisation, non-positivism/medievalism and procrypticism-or-disjointedness-as-of- ${ }^{2}$ reference-of-thought respectively). Such that inmany-ways the 'nombrilistic scepticism' projected by the latter is merely an exercise of pedantising/muddling/formulaic-hollowing-out - in-subontologisation/subpotentiation〈blurring/undermining-of-prospective-totalising-entailing,-as-to-entailing$<$ amplituding/formative-epistemicity>totalising in-relative-ontological-completeness $>$ which imbued 'mental-reflex framing-and-formulation' as of prior relative-ontologicalincompleteness $^{88}$ is not reflexively/veridically projective of the requisite profoundsupererogation for superseding/overcoming the prospective human knowledge-deadends- $<$ aspreconverging-de-mentating/structuring/paradigming $>$ but for its mere projection of institutional-prescience/imprimaturing-<dullness-of-the-spirit/psychologismic epistemicacutisation nonresidualising imbued-\{compulsings linearity in-eclecticism-of-prior-mereformulaicity/ritualisation $>$ as to a 'desublimating threshold of poor penchant for prospective reontologising_-imbuing-of-prospective-human-sublimating/emancipating/enfranchisement'; so-accounting for the given pedantising/muddling/formulaic-hollowing-out-in- 
subontologisation/subpotentiation-〈blurring/undermining-of-prospective-totalising-entailing,-

as-to-entailing-<amplituding/formative-epistemicity $>$ totalising $\sim$ in-relative-ontological-

completeness >

knowledge-deadends-<as-preconverging-de-

mentating/structuring/paradigming $>$. In this regards, the manifestation of the "prior ${ }^{8}$ referenceof-thought- categorical-imperatives/axioms/registry-teleology 99 as to prior mereformulaicity/ritualisation-<as-to-mere-formulaic-

methodologising/mutualising/organising/institutionalising,-prospectively-losing-track-of-

‘\{epistemic-totalising ’’re-apriorising/re-axiomatising/re-referencing $\sim$ residuality-in-re-

originariness/re-origination'>' incapacity for prospectively 'thinking at first/pure predisposition preemptive of prospective disontologising/subontologising' (as prospectively unconstrained to the given ${ }^{79}$ presencing-absolutising-identitive-constitutedness ${ }^{14}$ mere 'secondnatured conscious/unconscious rationalising/calculating of the sublimating outcome of prior profoundsupererogation rationalisation-of-contentivity/argumentativity/dialecticism/discursivity imbued positive-opportunism - of-social-functioning-and-accordance ${ }^{75}$ ) is what underlies the ontologising/scientific/existence- $<$ honesty-constraining $>$ — scope_for_prospective_re-

ontologising imbued notional asceticism for superseding/overcoming of the human psychologismic-epistemic-acutisation-difficulty- $<$ for,-residualising-

$\{$ decompulsing $\}$ delinearity $\sim$ for-cogency $>$-〈as-of-requisite-profound-supererogation -for-

‘disposedness-or-psychologismic-construct'-\{ imbued-demoronisation-<sublimating-

nascence,-nonextricatory-sublimating-upstreaming/'amontée'>\}〉. The notional asceticism of Socratic-philosophers and budding-positivists reflects the requisite existential-disontologising/re-ontologising aporeticism $>$ detachment for 'upholding the possibility for prospective ${ }^{103}$ universalising-idealisation and positivism/rational-empiricism respectively' (from the distortion/usurpation bound to arise respectively from ancient-sophists and medievalscholasticism 'mental-reflex framing-and-formulation' as of their prior relative-ontological- 
incompleteness ${ }^{8}$ ) and in so-doing elicit human-consciousness/collective-consciousnessdistendedness/detruncating-<beyond-selfpresencing,-as-re-ontologising-decentering_ofconsciousness/collective-consciousness,-as-to-psychologismic-epistemic-acutisation residualising, ${ }^{\left.-{ }^{\text {decompulsing }}\right\}}$ delinearity $\sim$ for-cogency $>$ as to the educing-and-availing-and-reavailing of relative-ontological-completeness (with respect to prospective re-ontologising 'dynamic cumulating/recomposuring psychologismic-epistemic-acutisation-residualising,\{decompulsing delinearity for-cogency phasing of limitedness/human-subpotency onto unlimitedness/existence-<flll-potency-of_sublimating nascence $>$ '). This reflects the fact that the social-construct as to its given human <amplituding/formative-epistemicity $>$ totalising thrownness-in-existence ${ }^{35}$ - as imbued of limitedness/human-subpotency prospective dearth for \{epistemic-totalising '̀ $\mathrm{re-apriorising/re-axiomatising/re-}$ referencing residuality - in-re-originariness/re-origination projection) 'is not of the honest mental-development' for 'direct intelligible confrontation as to meaningfulness-andteleology', but is rather engageable as to 'oblique intelligible confrontation as to metaphoricity $^{57}$ (so-elicitable as to underlying 'constraining existence-as-sublimatingwithdrawal/unenframing/re-ontologising,-elicited-from-prospective-profound-supererogation imbuing human ontological-commitment $-<$ implied — self-assuredness-of-ontological-goodfaith/authenticity postconverging-de-mentating/structuring/paradigming -as-being-as-ofexistential-reality>' and ' ${ }^{103}$ universal-transparency ${ }^{104}$-〈transparency-of-totalising-entailing,-asto-entailing-<amplituding/formative-epistemicity $>$ totalising $\sim$ in-relative-ontologicalcompleteness \ as available-to/elicitable-to-〈as-to-human-consciousness/collectiveconsciousness-distendedness/detruncating- $<$ beyond-selfpresencing,-as-re-ontologisingdecentering_of-consciousness/collective-consciousness,-as-to-psychologismic_epistemicacutisation-residualising, ${ }^{-}$decompulsing $\}$delinearity for-cogency $\left.>\right\rangle$the social-functioning-andaccordance - as-of-social-stake-contention-or-confliction conception of any given registry- 
worldview/dimension <preconverging 'motif-and-apriorising/axiomatising/referencing'

entailing >-existentialising — enframing/imprintedness-〈as-to- historicity-tracing —in-

presencing-hyperrealisation/hyperreal-transposition〉'). This insight about notional asceticism is so-implicited across the overall relative enreflexivity/relative reflexivity-ontologicalcontiguity ${ }^{67}$ of-the-human-institutionalisation-process ${ }^{68}$ as to Being-development/ontologicalframework-expansion-as-to-depth-of-ontologising-development-as-infrastructure-of-

meaningfulness-and-teleology psychologismic epistemic acutisation difficulty-<for, residualising \{decompulsing\} delinearity for-cogency> magnitude\{of-experientiality/experiment\} whether with respect to the 'social obliqueness of the secret-societies' of primal and agrarian societies, the 'social obliqueness of prophesying metaphysico-theological constructs' of early times as reflected in non-universalising and ${ }^{103}$ universalising creeds but equally so-translated as to the present-day institutional-development-as-to-social-function-development psychologismic epistemic-acutisation difficulty-for, residualising \{decompulsing $\}$ delinearity for-cogency> magnitude \{of-experientiality/experiment\} and living-development-as-to-personality-development psychologismic epistemic-acutisation difficulty-for, residualising \{decompulsing\} delinearity for-cogeney>-magnitude\{of-experientiality/experiment\} with the 'directly implicited social obliqueness of competence/expertising (as of human socially expanded framework of deferential-formalisation-transference as to various cultivated skills/arts and time investment with regards to effectively manifest 'underlying veracity of corephilosophy/derivative-core-philosophy prospective re-ontologising as relevantly superseding prior mere-formulaicity/ritualisation pedantism induced knowledge-deadends- $<$ aspreconverging-de-mentating/structuring/paradigming >') with regards to relatively uncontentious/nominalised social-stake-contention-or-confliction; and so-underlied as to the fact that the given human sovereign-function/posture-<as-to-existentially-manifest-'embodiedsubject consciousness-and-direct/deferential-conscientiousness',-as-of-its- 'epistemic- 
reflexivity/unreflexivity-in-existence'/teleology > 'notional perceptualisation-of-and-leashingto_social-functioning-and-accordance-as-of-social-stake-contention-or-confliction as of circularly catchmented-and-compulsed-<in-'existential-dearth-of-demoronisation',-soconstrued-as-from-ontological-normalcy/postconvergence-perspective-reflection-of-the‘destructuring-threshold_of-the-given-level's-conjugated-postlogism as-dementing'> prospectively disontologising/subontologising shallowsupererogation $\sim$ framing/formulation/catchmenting/truncating/compulsing/linearising —as-topreconverging de-mentating/structuring/paradigming' has to be subjected to prospective reontologising 'dynamic cumulating/recomposuring psychologismic-epistemic-acutisationresidualising, ${ }^{-\{\text {decompulsing }}$ delinearity for-cogency phasing of limitedness/human-subpotency onto unlimitedness/existence-<full-potency-of_sublimating nascence>' (as to the 'veracity of the sovereign-function/posture-<as-to-existentially-manifest-‘embodiedsubject consciousness-and-direct/deferential-conscientiousness',-as-of-its- ‘epistemicreflexivity/unreflexivity-in-existence'/teleology> as coextensive with the genuine social intellectual-function/posture'). It is herein contended that in-many-ways it is no surprising that the 'deliberate misconstrual' of budding-postmodern thought speaks of the 'same notional/epistemie/bindingness ${ }^{<a s-t o-d e t e r m i n i s m / c o n c e p t i v i t y-o f-r e l a t i v e-u n r e f l e x i v i t y / r e l a t i v e-r e f l e x i v i t y ~}>$ parity of relative-unreflexivity/relative-reflexivity' rather manifesting as of 'epistemic-decadence' or teleological-decadence-<-in-dimensionality-of-desublimating-lack-of ${ }^{-}$ <<amplituding/formative>supererogatory $\sim$ de-mentativeness/epistemic-growth-orconflatedness /transvaluative-rationalising/transepistemicity/anamnestic-residuality/spiritdrivenness-equalisation); notwithstanding the 'pretext for a genuine projection for prospective collective practice of ontology/science' as so-divulged as to the failing in 'thinking at first/pure predisposition preemptive of prospective disontologising/subontologising' in the face of prospective re-ontologising (as so-rather bound to stifle the possibility for prospective 
knowledge and transcendence-and-sublimity/sublimation/supereregatory $\sim$ de-mentativity as manifested with disontologising eliciting of our subtle modern-day institutionallydistorted/disjointed positivism- ${ }^{8}$ procrypticism/disjointedness-as-of- ${ }^{2}$ reference-of-thought 'notional perceptualisation-of-and-leashing-to_social-functioning-and-accordance-as-ofsocial-stake-contention-or-confliction as of circularly catchmented-and-compulsed-<in‘existential-dearth-of-demoronisation',-so-construed-as-from-ontologicalnormalcy/postconvergence-perspective-reflection-of-the-'destructuring-threshold_of-thegiven-level's-conjugated-postlogism as-dementing'> prospectively disontologising/subontologising shallow supererogation $\sim$ framing/formulation/catchmenting/truncating/compulsing/linearising —as-topreconverging -de-mentating/structuring/paradigming'). Notional asceticism so-speaks to the reality that human consciousness 'is veridically ever always human-consciousness/collectiveconsciousness-distendedness/detruncating-<beyond-selfpresencing,-as-re-ontologisingdecentering_of-consciousness/collective-consciousness,-as-to-psychologismic-epistemicacutisation-residualising,- -decompulsing $^{-}$delinearity for-cogency> as of nonpresencing<perspective-ontological-normalcy/postconvergence $>$ epistemic-projection', in reflection of this fundamental/incipient/seeding dynamics (as to the 'veracity of the sovereignfunction/posture-<as-to-existentially-manifest-`embodied-subject $~$ consciousness-anddirect/deferential-conscientiousness',-as-of-its-'epistemic-reflexivity/unreflexivity-inexistence'/teleology $>$ as coextensive with the genuine social intellectual-function/posture') underlying human consciousness (as of human Being-development/ontological-frameworkexpansion-as-to-depth-of-ontologising-development-as-infrastructure-of- meaningfulnessand-teleology , institutional-development-as-to-social-function-development and livingdevelopment-as-to-personality-development psychologismic epistemic-acutisationdifficulty $<$ for, residualising_\{decompulsing $\}$ delinearity for-cogency> magnitudes $\{$ of- 
experientiality/experiment\}); wherein overall human intelligibility-〈as-to-humanprojective/reprojective - aestheticising-re-motif-and-re-apriorising/re-axiomatising/rereferencing/re-intelligibilitysettingup/re-measuringinstrumenting-process,-in$<$ amplituding/formative-epistemicity>totalising conceptualisation $\rangle$ is rather manifested in notional distendedness/detruncating as of notional cogency_chronicularity/annality-ofrelative-reflexivity,-as-to-profound-supererogation imbued transversality-<for-sublimatingexistential-eventuating/denouement,-from-'thinking at-first/pure-predisposition-preemptive-ofprospective-disontologising/subontologising' as-of-prospectively-disambiguated-affirmedand-unaffirmed-'motif-and-apriorising/axiomatising/referencing' ${ }^{101}$ (as so-counterintuitive to our wrong impression of \{compulsing $\}$ linearity/linear-accreting $-{ }^{7}$ presencing-perceptualisation-ofsublimating-over-desublimating-<as-'psychologismic-epistemic-acutisationnonresidualising-imbued-\{compulsing\} linearity in-eclecticism-of-prior-mereformulaicity/ritualisation'_as-to-‘secondnatured-epistemic-perspective'-of-prospective-\&prior-differentiated apriorising/axiomatising/referencing $>$ and-as-developing-intointerrelatedness-dynamics-of-social-constructing which is of 'secondnaturedness presencing - absolutising-identitive-constitutedness ${ }^{14}$ mindset' but rather of 'existential<disontologising/re-ontologising aporeticism> hermeneutic/textuality/reprojecting/supererogating/zeroing/re-acuting \{decomearity/delinear-accreting/recomposuring- nonpresencing-perceptualisation-ofsublimating-over-desublimating-<as-"psychologismic-epistemic-acutisation-residualising,${ }_{\{\text {decompulsing }}$ delinearity for-cogency’_as-to- ‘prospective-profound-supererogation -epistemicperspective'-of prospective- \&-prior-differentiated apriorising/axiomatising/referencing $>$ with-respect-to-the-prospect-of-prospective-human-re-ontologising' as to 'firstnaturedness-asto-inkling profound-supererogation $\quad$ nonpresencing- $<$ perspective-ontologicalnormalcy/postconvergence $>$ mindset' with the latter perspective inducing of human- 
consciousness/collective-consciousness-distendedness/detruncating- $<$ beyond-selfpresencing,as-re-ontologising-decentering_of-consciousness/collective-consciousness,-as-to-

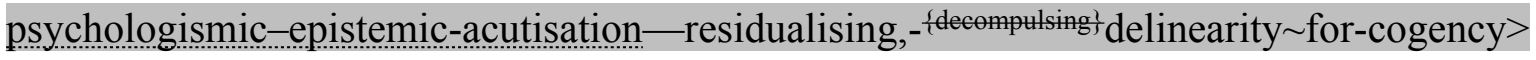
underlying human notional asceticism as beyond $\leq$ mere-formulaicity/ritualisation - of $\geq$-prior secondnaturedness shallowsupereregation $\sim$ framing/formulation/catchmenting/truncating/compulsing/linearising —as-topreconverging de-mentating/structuring/paradigming). This so-reflects the prospective superseding/overcoming of desublimating 'eclecticism-of-prior-mere-formulaicity/ritualisation<as-of-prior $\sim$ rationalisation-of-contentivity/argumentativity/dialecticism/discursivity $>$ composition/blending-in-\{compulsing $\}$ linearity/linear-accretion of relative-ontologicalcompleteness and relative-ontological-incompleteness apriorising/axiomatising/referencing as to secondnatured prior mere-formulaicity/ritualisation-<as-to-mere-formulaicmethodologising/mutualising/organising/institutionalising,-prospectively-losing-track-of‘fepstemic tre-apriorising/re-axiomatising/re-referencing $\sim$ residuality-in-reoriginariness/re-origination'> inducing $\quad{ }^{47}$ historicity-tracing-in-presencinghyperrealisation/hyperreal-transposition' (notionally underlying 'lifespan extricatory/preconverging psychical-nascency moronisation-<sublimating-nascence,extricatory-desublimating-downstreaming/'avalage'>’) at prospective destructuring-threshold〈uninstitutionalised-threshold /presublimating-desublimating-decisionality $\rangle$ of-ontologicalperformance $^{72}-<$ including-virtue-as-ontology $>/$ morality/ethics/justice/etc. as effectively what allows for prospective 're-ontologising fepistemic-totalising ${ }^{3}$ re-apriorising/re-axiomatising/rereferencing-residuality in re originariness/re origination \{decompulsing; delinearity/delinear accreting/recomposuring cogency/tensing/limpidity-<as-of-prospective-profoundsupererogation ,-for-residuality_in-re-originariness/re-origination $>$,-prospective_reifying mental-aestheticising-<as-of-'prospective_reformulating-of-mental-aestheticising'as-to- 
'residuality in re-originariness/re-origination'-of-mental-aestheticising>' (notionally

underlying 'nonextricatory/postconverging ontologising-and-re-ontologising angling-ofimaginary demoronisation- $<$ sublimating-nascence,-nonextricatory-sublimatingupstreaming/'amontée'>'). Again, this elucidation is made to emphasise that 'relative-reflexivity of human-per-cep-ti-vi-ty-<as-to-notional perceptualisation-of-and-leashing-to_socialfunctioning-and-accordance - as-of-social-stake-contention-or-confliction>' (as to the veracity of the 'flow of human prospective profound-supererogation -over-shallow-supererogation ", given 'unlimitedness/existence-full-potency-of_sublimating nascence $>$ prospective apriorising/axiomatising/referencing-sublimating-reflexivity-beholdening under which limitedness/human-subpotency submits in profound-supererogation for prospective sublimating') warrants that spontaneous opting for prospective profound-supererogation 'inherently grants intellectual-and-moral ascendency, responsibility/relative-reflexivity and purposefulness' so-translated as to prospective 'profoundsupererogation $\sim$ reframing/reformulation/decatchmenting/detruncating/decompulsing/delinear ising —as-to-postconverging de-mentating/structuring/paradigming

priority/precedence/primacy of that which spontaneously opts for prospective profoundsupererogation'. The 'flow of human prospective profound-supererogation -over-shallowsupererogation re-ontologisingly speaks of psychologismic-transfixity-<placeholder-setupontological-rescheduling - in-realigning/preactivity/formative-becoming/psychoanalyticalunshackling,-as-to-residualising_tecompulsingt delinearity-over-nonresidualising\{compulsing linearity $>$ as of preconverging/postconverging-redementating/restructuring/reparadigming with regards to socially-protracted-as-to-individual-byinstitutional-by-social profound supererogation $\sim$ reframing/reformulation/decatchmenting/detruncating/decompulsing/delinear ising - as-to-postconverging de-mentating/structuring/paradigming rationalisation-of- 
contentivity/argumentativity/dialecticism/discursivity of sublimating (as so-reflected with the manifestation of the notional/epistemic/bindingness ${ }^{<a s-t o-d e t e r m i n i s m / c o n c e p t i v i t y-o f-r e l a t i v e-~}$ meflexivityrelative-reflexivity overaching cultivated-and-enculturated interrelatedness-dynamics-ofsocial-constructing as from 'catchmented-and-compulsed-<in-'existential-dearth-ofdemoronisation',-so-construed-as-from-ontological-normalcy/postconvergence-perspectivereflection-of-the-'destructuring-threshold_of-the-given-level's-conjugated-postlogism asdementing'> interpersonal, group, intergroup, community, local, national, political, geostrategic, etc. psychologismic epistemic acutisation difficulty-<for, residualising

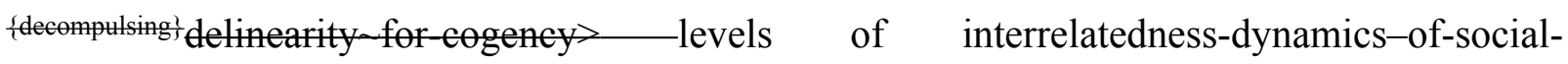
constructing' of 'formativeness-<as-to-intersolipsism-ofpreformulating/preframing/premeaningfulness-imbued-mediativity-and-deferentialism $>$-ofmeaningfulness-and-teleology and existential-<disontologising/re-ontologising apereticism $>$ articulation manifestations'); with respect to the given processive-motif-'exuding aestheticising-gesturing' of-apriorising/axiomatising/referencing

imbued_notional $\sim$ reductionism-<of-existential-prospection,-whether-as-oftrepidatious/warped/preclusive/occlusive/protensive—notional $\sim$ reductionism $>\quad$ (in human construing of the-very-same purview/devolved-purview/devolving-purview-ofunlimitedness/existence-<full-potency-of_sublimating nascence>;_-implicited_attendantontological-contiguity ${ }^{67}$, educedexistentialising/contextualising/textualising_intelligibility/epistemicity/reflexivity-contiguity$<$ imbued-notional $\sim$ cogency $>^{\prime}$ ). The social is thus summarily reflected as of the veracity of the 'flow of human prospective profound-supererogation ${ }^{-}$over-shallow-supererogation ${ }^{\prime}$ as to human 'desublimating/sublimating notional catchmenting $<$ asto_disontologising/subontologising institutional-imprintedness_by re-ontologising institutional-imprinting as to the given disontologising/re-ontologising human 
meaningfulness-and-teleology ${ }^{\prime}$ (and as this translates into the given institutional level whether as of catchmented-and-compulsed-<in-'existential-dearth-of-demoronisation',-soconstrued-as-from-ontological-normalcy/postconvergence-perspective-reflection-of-the-

\section{'destructuring-threshold_of-the-given-level's-conjugated-postlogism as-dementing'>}

interpersonal, group, intergroup, community, local, national, political, geostrategic, etc. psychologismic epistemic-acutisation difficulty-<for, residualising $\{$ decompulsing $\}$ delinearity for-cogeney> levels of interrelatedness-dynamics-of-socialconstructing) imbued notional compulsion (compulsion_imprintedness/decompulsion_imprinting) implied underlying human sovereignfunction/posture-<as-to-existentially-manifest-`embodied-subject $\sim$ consciousness-and-

\section{direct/deferential-conscientiousness',-as-of-its-'epistemic-reflexivity/unreflexivity-in-}

existence'/teleology> notional $\sim$ perceptualisation-of-and-leashing-to_social-functioning-andaccordance-as-of-social-stake-contention-or-confliction'. The social so-reflect notionally/epistemically/bindingnessly as determinism/enceptivity of relative mreflexivity/relative reflexivitys the possibility for prospective 're-ontologising in cogency_chronicularity/annality-of-relativereflexivity,-as-to-profound-supererogation , as to human-consciousness/collectiveconsciousness-distendedness/detruncating-<beyond-selfpresencing,-as-re-ontologisingdecentering_of-consciousness/collective-consciousness,-as-to-psychologismic_epistemic-

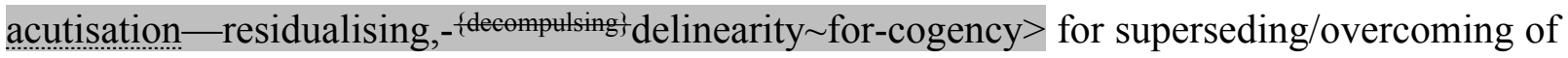
human 'prior ${ }^{83}$ reference-of-thought- categorical-imperatives/axioms/registry-teleology ${ }^{99}$ as to prior mere-formulaicity/ritualisation-<as-to-mere-formulaic

methodologising/mutualising/organising/institutionalising,-prospectively-losing-track-of-

\footnotetext{
‘\{epistemic-totalising ’’ apriorising/re axiomatising/re referencing-residuality-in-re-

originariness/re-origination'>'. Thus so-underlying the fact that anthropologisation-<as-tofutural-reflexivity,-in-\{decompulsing\} delinearity-'invention'/‘creation'-of-the-human/humanity>
} 
effectively speaks to human 'prospective sublimating notional catchmenting-<asto_disontologising/subontologising institutional-imprintedness by re-ontologising institutional-imprinting $>$ as to nonpresencing-<perspective - ontologicalnormaley/postconvergence> existential-<disontologising/re-ontologising aporeticism $>$ prospect of human individual-consciousness/collective-consciousness decompulsion-appraisal' imbued 're-ontologising realignment of human-per-cep-ti-vi-ty-<as-to notional perceptualisation-of-and-leashing-to_social-functioning-and-accordance-as-ofsocial-stake-contention-or-confliction>' ${ }^{\prime}$ so-implied as of prospective profoundsupererogation $\sim$ reframing/reformulation/decatchmenting/detruncating/decompulsing/delinear ising - as-to-postconverging de-mentating/structuring/paradigming (imbued 'existential<disontologising/re-ontologising aporeticism $>$ hermeneutic/textmality/reprojecting/supererogating/zeroing/re-acuting \{decompulsing\} delinearity/delinear-accreting/recomposuring- ${ }^{6}$ nonpresencing-perceptualisation-ofsublimating-over-desublimating-<as-'psychologismic-epistemic-acutisation-residualising,-

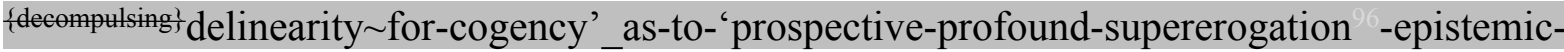
perspective'-of-prospective-\& prior-differentiated apriorising/axiomatising/referencing $\gg$ with-respect-to-the-prospect-of-prospective-human-re-ontologising') and so over shallow supererogation $\sim$ framing/formulation/catchmenting/truncating/compulsing/linearising —as-topreconverging de-mentating/structuring/paradigming (imbued fompulsing\}linearity/linearaccreting- ${ }^{79}$ presencing-perceptualisation-of-sublimating-over-desublimating-<as'psychologismic-epistemic-acutisation-nonresidualising-imbued-\{compulsingt linearity ineclecticism-of-prior-mere-formulaicity/ritualisation'_as-to-'secondnatured-epistemicperspective'-of prospective \& prior differentiated apriorising/axiomatising/referencing $>$ and-as-developing-into-interrelatedness-dynamics-of-social-constructing); as to human \{epistemic-totalising 3 \}re-apriorising/re-axiomatising/re-referencing $\sim$ residuality—in-re- 
originariness/re-origination projection of "prospective sublimating notional catchmenting-<asto_disontologising/subontologising institutional-imprintedness by re-ontologising institutional-imprinting $>$ as to nonpresencing-<perspective-ontologicalnormaley/postconvergence> existential-<disontologising/re-ontologising aporeticism $>$ prospect of human individual-consciousness/collective-consciousness decompulsion-appraisal' . This is so-construed as 'widening the social imaginary' (as to the 'requisite prospective sublimating decompulsion imprinting across the various institutional levels of interrelatednessdynamics-of-social-constructing' so-arising from the 'educing-and-availing-and-re-availing of relative-ontological-completeness ${ }^{87}$ with respect to unlimitedness/existence-<full-potency of_sublimating nascence> prospective apriorising/axiomatising/referencing-sublimatingreflexivity-beholdening under which limitedness/human-subpotency submits in profoundsupererogation for prospective sublimating'); as so-undergirded aestheticisingly by notional/epistemic/bindingness ${ }^{-<a-t o-d e t e r m i n i s m / c o n c e p t i v i t y-o f-r e l a t i v e-u n r e f l e x i v i t y / r e l a t i v e-r e f l e x i v i t y s ~} \quad$ human 'manifest idiosyncratic-ferment_for-notional cogency-〈as-to- $<$ surrealising/supererogating_ drive>-of-aestheticising-relief/depth-and-impetus $\rangle$ as of re-ontologising-bydisontologising/subontologising — dynamics of human-per-cep-ti-vi-ty-<as-to notional perceptualisation-of-and-leashing-to_social-functioning-and-accordance-as-ofsocial-stake-contention-or-confliction $>$ imbued notional cogency_chronicularity/annality-ofrelative-reflexivity,-as-to-profound-supererogation ${ }^{9}$ (as of '< $<$ amplituding/formativeepistemicity>-totalising renewing-realisation/re-perception/re-thought selfreflexive instigative-eventuating-〈as-to-teleological-instigative/incipientwilling/arbitrariness/waywardness/faithdrivenness/supererogating-for-human-intelligibility,preceding-existence's-eventuating-sublimating-validation/desublimating-invalidation〉' perpetuating the 'flow of human prospective profound-supererogation"-over-shallowsupererogation as of re-aestheticising psychologismic-transfixity-<placeholder-setup- 
ontological-rescheduling - in-realigning/preactivity/formative-becoming/psychoanalytical-

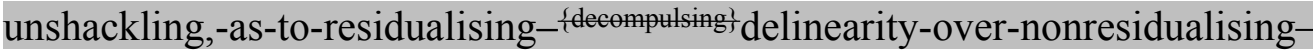

\{compusing linearity $>$ ). Critically in this respect (as to the social sublimating veracity of anthropologisation-<as-to-futural-reflexivity,-in-\{decompulsing $\}$ delinearity- ‘invention'/‘creation'of-the-human/humanity>), our present-day disjointed notion of the 'anthropological' is equally caught up prospectively in the 'relative-unreflexive human-per-cep-ti-vi-ty-<as-tonotional perceptualisation-of-and-leashing-to_social-functioning-and-accordance-as-ofsocial-stake-contention-or-confliction> of our positivism- ${ }^{8}$ procrypticism/disjointedness-as-ofreference-of-thought', with regards to its disontologising/subontologising 79 presencingabsolutising-identitive-constitutedness ${ }^{14}$ epistemic-projection of 'punctual noumenality and phenomenality distinction' of prospectively 'relative-unreflexive human-per-cep-ti-vi-ty-<asto - notional perceptualisation-of-and-leashing-to social-functioning-and-accordance-asof-social-stake-contention-or-confliction> ${ }^{\prime}$ as to shallowsupererogation $\sim$ framing/formulation/catchmenting/truncating/compulsing/linearising —as-topreconverging de-mentating/structuring/paradigming (imbued linearity/linearaccreting- ${ }^{79}$ presencing-perceptualisation-of-sublimating-over-desublimating- $<$ as-

\section{'psychologismic-epistemic-acutisation-nonresidualising-imbued-\{compulsing\} linearity in-}

eclecticism-of-prior-mere-formulaicity/ritualisation'_as-to-‘secondnatured-epistemic-

\section{perspective'-of-prospective-\&-prior-differentiated-apriorising/axiomatising/referencing $>$}

and-as-developing-into-interrelatedness-dynamics-of-social-constructing) as underlied by the logic of 'existentially-<disontologising/re-ontologising aporeticism $>$ manifest incidental/accidental reactive-sufferance/endurance in supposedly and paradoxically subordinating/subserving/collateralising the possibility for prospective re-ontologisingimbuing-of-prospective-human-sublimating/emancipating/enfranchisement'; and somanifested as to when it goes on to ignore/overlook in an ontologically unjustified 
sanctification' (our present-day 'failure to reflect upon our very own positivismprocrypticism/disjointedness-as-of- ${ }^{2}$ reference-of-thought' requisite prospective \{epistemic†re-apriorising/re-axiomatising/re-referencing $\sim$ residuality-in-re-originariness/reorigination projection of 'prospective sublimating notional catchmenting-asto_disontologising/subontologising institutional-imprintedness_by re-ontologising institutional-imprinting $>$ as to nonpresencing-<perspective ontologicalnormalcy/postconvergence> existential-<disontologising/re-ontologising aporeticism $>$ prospect of human individual-consciousness/collective-consciousness decompulsion-appraisal' for prospective 're-ontologising in cogency_chronicularity/annality-of-relative-reflexivity,-asto-profound-supererogation ' ${ }^{\prime}$. Thus wrongly implying our very own positivismprocrypticism/disjointedness-as-of- ${ }^{-}$reference-of-thought is bigger than 'unlimitedness/existence-<full-potency-of_sublimating nascence> prospective apriorising/axiomatising/referencing-sublimating-reflexivity-beholdening under which limitedness/human-subpotency submits in profound-supererogation for prospective sublimating', so-reflecting its prospective human psychologismic-epistemic-acutisationdifficulty- $<$ for,-residualising_\{decompulsing $\}$ delinearity $\sim$ for-cogency $>-\langle$ as-of-requisite-profoundsupererogation -for-'disposedness-or-psychologismic-construct'-\{imbued-demoronisation$<$ sublimating-nascence,-nonextricatory-sublimating-upstreaming/'amontée’’ $>\}$ (as to requisite re-ontologising prospective Being-development/ontological-framework-expansion-as-to-depthof-ontologising-development-as-infrastructure-of- meaningfulness-and-teleology psychologismic epistemic acutisation difficulty < for, residualising

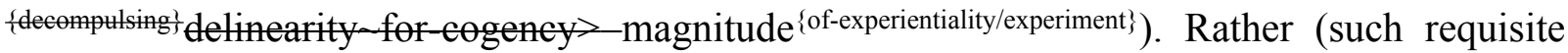
prospective \{epistemic-totalising 3 ? $\mathrm{re}$-apriorising/re-axiomatising/re-referencing $\sim$ residuality —in-reoriginariness/re-origination projection of 'prospective sublimating notional catchmenting-<asto_disontologising/subontologising institutional-imprintedness_by re-ontologising - 
prospect of human individual-consciousness/collective-consciousness decompulsion-appraisal' for prospective 're-ontologising in cogency_chronicularity/annality-of-relative-reflexivity,-asto-profound-supererogation ') is herein construed as of overall prospective notional ${ }^{8}$ deprocrypticism-or-notional preempting — disjointedness-as-of- ${ }^{8}$ reference-ofthought imbued 'prospective sublimating notional catchmenting-<asto_disontologising/subontologising institutional-imprintedness by re-ontologising institutional-imprinting $>$ as to nonpresencing-<perspective-ontological normaley/postconvergence> existential-<disontologising/re-ontologising aporeticism $>$ prospect of human individual-consciousness/collective-consciousness decompulsion-appraisal'. Notional ${ }^{18}$ deprocrypticism-or-notional $\sim$ preempting — disjointedness-as-of- ${ }^{2}$ reference-ofthought so de-exoticises the 'anthropological' with regards to its truly given re-ontologising universal/totalising-entailing (as to overall relative-unreflexivity/relative-reflexivityontological-contiguity ${ }^{67}$ of-the-human-institutionalisation-process imbued notional cogency_chronicularity/annality-of-relative-reflexivity,-as-to-profoundsupererogation ) implications of human 'formativeness-<as-to-intersolipsism-ofpreformulating/preframing/premeaningfulness-imbued-mediativity-and-deferentialism>-of-

meaningfulness-and-teleology and as so-reflected with the notional/epistemic/bindingnesssas-todeterminism/cenceptivity-of-relative-mnreflexivity/relative-reflexivitys enculturated-specificities of human existential-<disontologising/re-ontologising aporeticism $>$ articulation manifestations'; and soreflected with regards to the-very-same purview/devolved-purview/devolving-purview-ofunlimitedness/existence-full potency_of_sublimating nascence>;_-implicited_attendantontological-contiguity ${ }^{67}$ ' educedexistentialising/contextualising/textualising_intelligibility/epistemicity/reflexivity_contiguity- 
$<$ imbued-notional cogency>' (with regards to the 'notional/epistemic/bindingness'-<as-todeterminism/conceptivity-of-relative-unreflexivity/relative-reflexivitys_-differentiation as to relativereflexivity/relative-unreflexivity of prior, present and prospective underlying disontologising/reontologising of human specific cultures/enculturations' reflected in their processive-motif'exuding aestheticising-gesturing' of-apriorising/axiomatising/referencing imbued_notional $\sim$ reductionism-<of-existential-prospection,-whether-as-oftrepidatious/warped/preclusive/occlusive/protensive-notional $\sim$ reductionism $>$ as to the $<$ cumulating/recomposuring attendant-ontological-contiguity $>$-successive registryworldviews/dimensions of the 'overall relative-unreflexivity/relative-reflexivity - ontologicalcontiguity ${ }^{6} \sim$ of-the-human-institutionalisation-process imbued notional cogency_chronicularity/annality-of-relative-reflexivity,-as-to-profoundsupererogation $\left.{ }^{\prime}\right)$. With such a re-ontologising ${ }^{103}$ universal/totalising-entailing of notional ${ }^{18}$ deprocrypticism-or-notional preempting — disjointedness-as-of- ${ }^{3}$ reference-ofthought a reflection of 'relative-reflexivity of human-per-cep-ti-vi-ty-<as-tonotional perceptualisation-of-and-leashing-to_social-functioning-and-accordance-as-ofsocial-stake-contention-or-confliction> ${ }^{\prime}$ so-implied as of prospective profoundsupereration - reframing/reformulation/decatchmenting/detruncating/decompulsing/delinear ising - as-to-postconverging de-mentating/structuring/paradigming (imbued 'existential$\leq$ disontologising/re-ontologising aporeticism $>$ hermeneutic/textuality/reprojecting/supererogating/zeroing/re-acuting decolinearity/delinear-accreting/recomposuring- nonpresencing-perceptualisation-ofsublimating-over-desublimating-<as-'psychologismic-epistemic-acutisation-residualising,${ }_{\{\text {decompulsing }}$ delinearity $\sim$ for-cogency’_as-to- 'prospective-profound-supererogation -epistemicperspective'-of prospective- \& prior-differentiated apriorising/axiomatising/referencing $>$ with-respect-to-the-prospect-of-prospective-human-re-ontologising') and so over shallow- 
supererogation $\sim$ framing/formulation/catchmenting/truncating/compulsing/linearising —as to preconverging de-mentating/structuring/paradigming (imbued fcompulsings linearity/linearaccreting- ${ }^{7}$ presencing-perceptualisation-of-sublimating-over-desublimating- $<$ as'psychologismic-epistemic-acutisation - nonresidualising-imbued-\{compulsing\} linearity ineclecticism-of-prior-mere-formulaicity/ritualisation'_as-to-‘secondnatured-epistemicperspective'-of-prospective-\&-prior-differentiated apriorising/axiomatising/referencing $>$ and-as-developing-into-interrelatedness-dynamics-of-social-constructing); as so-underlining a nonpresencing-<perspective--ontological-normalcy/postconvergence $>$ epistemic-projection of 'human consciousness notional $\sim$ protensivity psychologismic-epistemic-acutisation- $<$ as-topostconverging-de-mentating/structuring/paradigming,-eliciting-of-existence's-sublimatingnascence-in-prospective-aporeticism-overcoming/unovercoming $>$ as to epistemic-growth,-as\{veridical/sound\}-relative-reflexivity-in-existence/relativising from-limited-mentation-as-itsdeepening/psychologismic epistemic-acutisation residualising, ${ }_{\text {d decompulsing }\}}$ delinearity foreogency' reflexivity construal of the 'anthropological' rather as of 'relativeunreflexivity/relative-reflexivity limitedness/human-subpotency dynamics of supererogating $\{$ affirmation/projection/assertion/notional $\sim$ self-distantiation-byunaffirmation/deprojection/deassertion/epistemic-decadence $\}$ — towards $\sim$ omnipotentialaffirmation/projection/assertion/notional self-distantiation' for omnitranslational reflexivity of human 'prospective noblimating notional catchmenting-<asto_disontologising/subontologising institutional-imprintedness by re-ontologising institutional-imprinting $>$ as to nonpresencing-<perspective-ontologicalnormaley/postconvergence> existential-<disontologising/re-ontologising aporeticism> prospect of human individual-consciousness/collective-consciousness decompulsion-appraisal' for re-ontologising futural potentiation of anthropologisation-<as-to-futural-reflexivity,-in\{decompulsing\} delinearity-'invention'/'creation'-of-the-human/humanity>. Basically it can thus be 
appreciated (as translated into the given institutional whether as of catchmented-andcompulsed-<in-'existential-dearth-of-demoronisation',-so-construed-as-from-ontologicalnormalcy/postconvergence-perspective-reflection-of-the-'destructuring-threshold_of-thegiven-level's-conjugated-postlogism as-dementing'> interpersonal, group, intergroup, community, local, national, political, geostrategic, etc. psychologismic epistemic-acutisation-

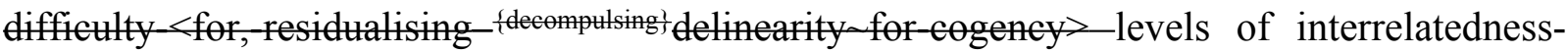
dynamics-of-social-constructing) that notional $\sim$ catchmenting-<asto_disontologising/subontologising institutional-imprintedness_by re-ontologising institutional-imprinting $\quad$ (imbued 'notional compulsion (compulsion_imprintedness/decompulsion_imprinting) of the human sovereignfunction/posture-<as-to-existentially-manifest-‘embodied-subject $\sim$ consciousness-anddirect/deferential-conscientiousness',-as-of-its-'epistemic-reflexivity/unreflexivity-inexistence'/teleology> notional perceptualisation-of-and-leashing-to_social-functioning-andaccordance-as-of-social-stake-contention-or-confliction') is effectively a reflection of the 'very incipient/seeding re-ontologising futural potentiation of anthropologisation- $<$ as-to-futuralreflexivity,-in-\{decompulsing\} delinearity-'invention'/‘creation'-of-the-human/humanity>'; as of the dynamics of both presencing absolutising identitive constitutedness 'existential<disontologising/re-ontologising aporeticism $>$ preconverging dementating/structuring/paradigming punctual/immediacy/constituted/compulsions-encumbered prior mere-formulaicity/ritualisation rationalisation-ofcontentivity/argumentativity/dialecticism/discursivity' and nonpreseneing-<perspectiveentological-normalcy/postconvergence> 'existential-<disontologising/re-ontologising apereticism $>$ prospect of human individual-consciousness/collective-consciousness decompulsion-appraisal (so-manifesting across Being-development/ontological-frameworkexpansion-as-to-depth-of-ontologising-development-as-infrastructure-of- meaningfulness- 
and-teleology , institutional-development-as-to-social-function-development and livingdevelopment-as-to-personality-development psychologismic epistemic acutisation-

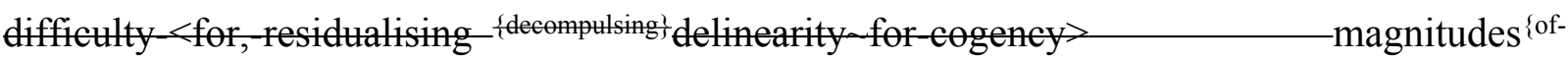
experientiality/experiment\} of human psychologismic-epistemic-acutisation-difficulty- $<$ for,residualising_\{decompulsing $\}$ delinearity $\sim$ for-cogency $>-\langle$ as-of-requisite-profound-supererogation for-'disposedness-or-psychologismic-construct'- $\{$ imbued-demoronisation-<sublimatingnascence,-nonextricatory-sublimating-upstreaming/‘amontée’’\}\}). Notional $\sim$ catchmenting$<a s-t o \_$disontologising/subontologising institutional-imprintedness by re-ontologising institutional-imprinting $>$ (as to the "very incipient/seeding re-ontologising futural potentiation of anthropologisation- $<$ as-to-futural-reflexivity,-in-\{decompulsing $\}$ delinearity'invention'/'creation'-of-the-human/humanity>' so-manifested with regards to the 'overall relative-unreflexivity/relative-reflexivity - ontological-contiguity ${ }^{67}$ of-the-humaninstitutionalisation-process ${ }^{68}$ imbued notional cogency_chronicularity/annality-of-relativereflexivity,-as-to-profound-supererogation ') insightfully reflects how 'prospective human secondnatured ${ }^{56}$ meaningfulness-and-teleology" is effectively derived from 'prior human profound-supererogation ${ }^{6}$ metaphoricity ${ }^{57}$, as to the re-ontologising superseding/overcoming of human destructuring-threshold-〈uninstitutionalised-threshold /presublimating-desublimatingdecisionality $>$ of-ontological-performance ${ }^{2}-<$ including-virtue-as-ontology $>$, so-construed as 'wdening the social imaginary' (as to the 'requisite prospective sublimating decompulsion_imprinting across the various institutional levels of interrelatedness-dynamicsof-social-constructing' so-arising from the 'educing-and-availing-and-re-availing of relativeontological-completeness with respect to unlimitedness/existence-<full-potency өf_sublimating nascence $>$ prospective apriorising/axiomatising/referencing-sublimatingreflexivity-beholdening under which limitedness/human-subpotency submits in profoundsupererogation for prospective sublimating'). Wherein 'widening the social imaginary' as so- 


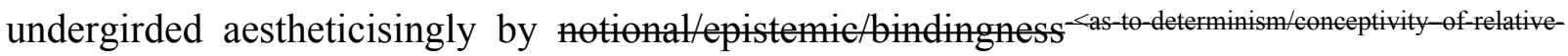
unreflexivity/relative-reflexivity $>$ human 'manifest idiosyncratic-ferment_for-notional $\sim$ cogency-〈as-tosurrealising/supererogating-drive $>$-of-aestheticising-relief/depth-and-impetus $\rangle$ as of reontologising-by-disontologising/subontologising — dynamics of human-per-cep-ti-vi-ty-<asto - notional perceptualisation-of-and-leashing-to_social-functioning-and-accordance-asof-social-stake-contention-or-confliction> imbued notional cogency_chronicularity/annalityof-relative-reflexivity,-as-to-profound-supererogation ' (as of '< $<$ amplituding/formativeepistemicity>-totalising $\sim$ renewing-realisation/re-perception/re-thought selfreflexive instigative-eventuating-〈as-to-teleological-instigative/incipientwilling/arbitrariness/waywardness/faithdrivenness/supererogating-for-human-intelligibility,preceding-existence's-eventuating-sublimating-validation/desublimating-invalidation〉' perpetuating the 'flow of human prospective profound-supererogation"-over-shallowsupererogation, as of re-aestheticising psychologismic-transfixity-<placeholder-setupontological-rescheduling - in-realigning/preactivity/formative-becoming/psychoanalytical-

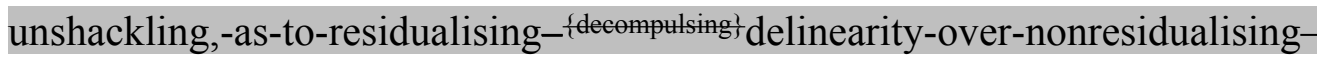
\{compulsing\} linearity $>$ ) effectively speaks of 'relative-reflexivity of human-per-cep-ti-vi-ty-<asto - notional perceptualisation-of-and-leashing-to_social-functioning-and-accordance- asof-social-stake-contention-or-confliction>'; so-implied as of prospective profoundsupererogation $\sim$ reframing/reformulation/decatchmenting/detruncating/decompulsing/delinear ising as to posteonverging de mentating/struturing/paraligming (imbued 'existential<disontologising/re-ontologising aporeticism> hermeneutic/textuality/reprojecting/supererogating/zeroing/re-acuting \{delinearity/delinear-accreting/recomposuring- nonpresencing-perceptualisation-ofsublimating-over-desublimating-<as-"psychologismic-epistemic-acutisation-residualising,${ }_{\{\text {decompulsing }}$ delinearity for-cogency’_as-to- 'prospective-profound-supererogation -epistemic- 
perspective'-of prospective \& prior-differentiated apriorising/axiomatising/referencing $>$

with-respect-to-the-prospect-of-prospective-human-re-ontologising') and so over shallowsupererogation $\sim$ framing/formulation/catchmenting/truncating/compulsing/linearising —as-topreconverging - de-mentating/structuring/paradigming (imbued fcompulsing\}linearity/linearaccreting- ${ }^{79}$ presencing-perceptualisation-of-sublimating-over-desublimating-<as'psychologismic-epistemic-acutisation - nonresidualising-imbued-\{compulsing\} linearity ineclecticism-of-prior-mere-formulaicity/ritualisation'_as-to-‘secondnatured-epistemicperspective'-of-prospective-\&-prior-differentiated-apriorising/axiomatising/referencing $>$ and-as-developing-into-interrelatedness-dynamics-of-social-constructing).

Notional catchmenting-<as-to_disontologising/subontologising_institutional-imprintedness_by re-ontologising institutional-imprinting $>$ thusly reflect the fact that there is no inherent difference between 'prospective human secondnatured ${ }^{5}$ meaningfulness-and-teleology ${ }^{9}$ ' and 'prior human profound-supererogation ${ }^{6}$ metaphoricity ${ }^{57}$ as from 'unlimitedness/existence<full-potency-of_sublimating nascence $>$ perspective' imbued immanent-reflexivity omnipotential-affirmation/projection/assertion/notional self-distantiation (but for the 'ontological reflection' of manifest limitedness/human-subpotency relativemaneflexivityelative reflexivity ontological-contiguity ${ }^{67}$ so-construed as from 'unlimitedness/existence-<full-potency-of_sublimating nascence $>$ perspective'); with such an apparent difference rather arising as from 'limitedness/human-subpotency perspective' imbued 'relative-unreflexivity/relative-reflexivity limitedness/human-subpotency dynamics of supererogating $\{$ affirmation/projection/assertion/notional $\sim$ self-distantiation-byunaffirmation/deprojection/deassertion/epistemic-decadence $\}$ — towards $\sim$ omnipotentialaffirmation/projection/assertion/notional self-distantiation' (as of human 'prospective sublimating notional $\sim$ catchmenting-<as-to_disontologising/subontologising institutionalimprintedness by re-ontologising institutional-imprinting $>$ as to nonpresencing 
entelogising aporeticism $>$ prospect of human individual-consciousness/collectiveconsciousness decompulsion-appraisal' for re-ontologising futural potentiation as anthropologisation-<as-to-futural-reflexivity,-in-\{decompulsing $\}$ delinearity- ‘invention'/‘creation’of-the-human/humanity>). Such a construal of 'prospective human secondnatured meaningfulness-and-teleology' and 'prior human profound-supererogation metaphoricity ${ }^{57}$ ' as of no inherent difference (so-construed as from 'unlimitedness/existence<full-potency-of_sublimating nascence $>$ perspective' imbued immanent-reflexivity omnipotential-affirmation/projection/assertion/notional self-distantiation in reflection of 'unlimitedness/existence-<full-potency-of_sublimating nascence $>$ prospective apriorising/axiomatising/referencing-sublimating-reflexivity-beholdening under which limitedness/human-subpotency submits in profound-supererogation for prospective sublimating') is effectively what underlies the veracity of the ontologising/scientific/existence$<$ honesty-constraining $>$ - scope_for_prospective_re-ontologising impliciting of humanconsciousness/collective-consciousness-distendedness/detruncating-<beyond-selfpresencing,as-re-ontologising-decentering_of-consciousness/collective-consciousness,-as-to-

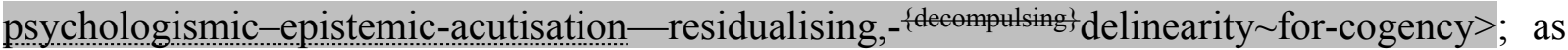
so underlying 'limitedness/human-subpotency ${ }^{15}$ de-mentation-〈supererogatory $\sim$ ontological-dementation-or-dialectical-de-mentation-stranding-or-attributive-dialectics $\rangle$ as to preconverging/postconverging-rede-mentating/restructuring/reparadigming' (with regards to prospective 'existential-<disentologising/re-ontologising aporeticism $>$ postconverging aporeticism-overcoming/unovercoming') in the 'reinvention'/'recreation' of the-human/humanity so-construed as anthropologisation-<as-to-futural-reflexivity,-in\{decomplsing delinearity-'invention'/'creation'-of-the-human/humanity> (and so as from 'profound- 
supererogation $\sim$ reframing/reformulation/decatchmenting/detruncating/decompulsing/delinear ising —as-to-postconverging de-mentating/structuring/paradigming

priority/precedence/primacy' of re-ontologising prospective Being-development/ontologicalframework-expansion-as-to-depth-of-ontologising-development-as-infrastructure-ofmeaningfulness-and-teleology psychologismic epistemic-acutisation difficulty-for, residualising \{decompulsing\} delinearity-for-cogency> magnitude\{of-experientiality/experiment\}, then institutional-development-as-to-social-function-development psychologismic epistemic acutisation difficulty< < for, residualising \{decompulsing $\}$ delinearity for-cogency> magnitude $\{$ ofexperientiality/experiment\} and then living-development-as-to-personality-development psychologismic epistemic-acutisation difficulty-for, residualising $\{$ decompulsing $\}$ delinearity for-cogency $>$ magnitude $\{$ of-experientiality/experiment $\}$ ). Thus the possibility for prospective sublimating anthropologisation-<as-to-futural-reflexivity,-in-\{decompulsing $\}$ delinearity'invention'/'creation'-of-the-human/humanity> lies in superseding/overcoming of 'prior desublimating notional $\sim$ catchmenting-<as-to_disontologising/subontologising institutionalimprintedness by re-ontologising institutional-imprinting $>$ as to presencingabsolutising-identitive-constitutedness existential-<disontologising/re-ontologising aporeticism> preconverging de mentating/structuring/paradigming punctual/immediacy/constituted/compulsions-encumbered prior mere-formulaicity/ritualisation rationalisation-of-contentivity/argumentativity/dialecticism/discursivity'; reflected with presencing—absolutising-identitive-constitutedness ${ }^{14}$ 'catchmenting-by-rejection/lipservicing/monopolising/gaming-of-the-system/charade/distraction vague/imaginary lures of social-stake-contention-or-confliction' manifesting shallow-supererogation usurpation of the profound-supererogation for ontological-veracity/science, and so-arising (at the reontologising prospective Being-development/ontological-framework-expansion-as-to-depthof-ontologising-development-as-infrastructure-of- meaningfulness-and-teleology 
psychologismic epistemic-acutisation difficulty-<or, residualising \{decompulsing $\}$ delinearity for-cogeney> magnitude\{of-experientiality/experiment $\}$ specifically) with the disontologising/subontologising manifestation of dominance/vested-interest—drivenness- $<$ asto-its-direct/indirect-eliciting-by-or-exploiting-of-prospectively-descalarising/subontologisingsycophantic-sophistic-interests,-as-inducing-prospective-threshold-of-institutional-and-socialdesublimation>, institutional-prescience/imprimaturing-edullness-of-thespirit/psychologismic epistemic acutisation nonresidualising imbued-\{compulsing\}linearity ineclecticism-of prior-mere-formulaicity/ritualisation $>$ of pedantising/muddling/formulaichollowing-out - in-subontologisation/subpotentiation-〈blurring/undermining-of-prospectivetotalising-entailing,-as-to-entailing-<amplituding/formative-epistemicity $>$ totalising $\sim$ inrelative-ontological-completeness $\rangle$ desublimation and the accessorising of 'ordinary laypersonhood arrogation/presumptuousness' conception of supposedly prospective sublimation (and so as to the 'mortal scale of perceived institutional access and success default conception of human ontological-performance ${ }^{72}<$ including-virtue-as-ontology $>^{\prime}$ associated with popintellectualism, the subjection/dependency of knowledge institutions as well as induced prospective 'epistemic-decadence' or teleological-decadence-<-in-dimensionality-ofdesublimating-lack-of ${ }^{-}-\langle<$amplituding/formative $>$supererogatory $\sim$ de-mentativeness/epistemicgrowth-or-conflatedness /transvaluative-rationalising/transepistemicity/anamnesticresiduality/spirit-drivenness-equalisation〉 with strategies of eliciting 'conceptual-patterning〈as-devoid-of-‘prospectively_implicited_attendant_ontological-contiguity ' educedexistentialising/contextualising/textualising_'intelligibility/epistemicity/reflexivity_contiguity$<$ imbued-notional cogency>' ', 's-reifying-or-elucidating-of- 'prospective-relative-ontologicalcompleteness ' ';-so-rather-enabled-<by-a- nonpresencing-divulging-of-momentoushistoriality/ontological-eventfulness /ontological-aesthetic-tracing-<perspectiveontological-normalcy/postconvergence-reflected-‘epistemicity-relativism-determinism’>>, 
desublimating formulaic-fashionability-<wholesome-dearth'/shallowness_as-to-requisite-'reentologising rhizomatic-wholesomeness' for-postconverging rede-

mentating/restructuring/reparadigming $>$ shadowing and bothsidesism-〈as-'mereprocessive'/pedantising-'dialogical-relation'-to 'perceived-social-and-institutionalcommonly-enculturated_referencing,-of- meaningfulness-and-teleology '-failing-'requisiteexistential-thematic-baseline-of-technicity/profundity-framing' \{of-sublimating-discursivityfor-sovereign-repassing $\}$,-as-of-psychologismic-epistemic-acutisation-nonresidualising-

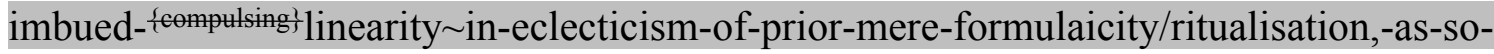
‘consciously/unconsciously-preordained/fated'-to-fail-prospective-notional cogency) ontologically-flawed conceptualising' as effective techniques to avoid transversality- $<$ forsublimating-existential-eventuating/denouement,-from-'thinking at-first/pure-predispositionpreemptive-of prospective-disontologising/subontologising' - as-of-prospectivelydisambiguated-affirmed-and-unaffirmed-'motif-and-apriorising/axiomatising/referencing'> and thus preempt the demarcation of veridical/profound sublimating conceptivity/epistemicreflexivity/epistemicity-relativism-determinism-<reifying \{as-to-knowledge-developing $\}$-andempowering $>$ entailment). Such that in-many-ways the possibility for prospective sublimating anthropologisation-<as-to-futural-reflexivity,-in-\{decompulsing $\}$ delinearity-'invention'/‘creation'of-the-human/humanity> (with regards to prospective human re-ontologising as to the 'flow of human prospective profound-supererogation -over-shallow-supererogation ') is rather about the 'profound-supererogation imagined, educed, habituated and honed in fepistemictotalising 3 h hermeneutic/textuality/reprojecting/supererogating/zeroing/re-acuting,\{decompulsing $\}$ delinearity for-cogency (herein construed as of 'human consciousness notional protensivity imbuing prospective psychologismic-epistemic-acutisation-<as-topostconverging-de-mentating/structuring/paradigming,-eliciting-of-existence's-sublimatingnascence-in-prospective-aporeticism-overcoming/unovercoming $>$ as to epistemic-growth,-as 
\{veridical/sound\}-relative-reflexivity-in-existence/relativising from-limited-mentation-as-itsdeepening/psychologismic epistemic acutisation residualising, ${ }^{\text {fdecompulsing }}$ delinearity for eogency')' for overcoming the human psychologismic-epistemic-acutisation-difficulty- $<$ for,residualising-\{decompulsing\} $d$ delinearity for-cogency $>-\langle$ as-of-requisite-profound-supererogation for-'disposedness-or-psychologismic-construct'-\{ imbued-demoronisation-<sublimatingnascence,-nonextricatory-sublimating-upstreaming/'amontée’’\}); as to the fact that such overcoming is rather a reflection of human re-ontologising-by-disontologising_existentialcalculus-〈between 'prospective existentialising - postconverging_framing/imprinting reontologising' and 'prior existentialising_preconverging_enframing/imprintedness socialfunctioning-and-accordance-as-of-social-stake-contention-or-confliction' $\rangle$ (with respect to the manifestation of either 'prior desublimating notional catchmenting-<asto_disontologising/subontologising institutional-imprintedness_by re-ontologising institutional-imprinting $>$ as to presencing absolutising identitive-constitutedness existential-disontologising/re ontologising aporeticism> preconverging dementating/structuring/paradigming punctual/immediacy/constituted/compulsions-encumbered prior mere-formulaicity/ritualisation rationalisation-ofcontentivity/argumentativity/dialecticism/discursivity' or 'prospective sublimating notional catchmenting-<as-to_disontologising/subontologising institutional-imprintednessby re-ontologising institutional-imprinting $>$ as to nonpresencing-<perspective-ontologicalnormaley/pestconvergences existential<-disontologising/re ontologising aporeticism> prospect of human individual-consciousness/collective-consciousness decompulsion-appraisal' for re-ontologising futural potentiation as anthropologisation-<as-to-futural-reflexivity,-in\{decomplsingldelinearity-'invention'/'creation'-of-the-human/humanity>). Thusly, the 'paucity of human ontological-performance ${ }^{72}-<$ including-virtue-as-ontology $>/$ morality/ethics/justice/etc. with regards to the disontologising/subontologising-imbuing-prospectively-of-human- 
desublimating/subjugation/disenfranchisement as to vices-and-impediments ${ }^{105}$ manifestation across human <cumulating/recomposuring attendant-ontological-contiguity $>$-successive registry-worldviews/dimensions given ${ }^{8}$ reference-of-thought-and- ${ }^{8}$ reference-of-thoughtdevolving $-{ }^{56}$ meaningfulness-and-teleology ${ }^{9}$ ' is so-manifested as of 'institutionally educed catchmented-and-compulsed-<in- 'existential-dearth-of-demoronisation',-so-construed-asfrom-ontological-normalcy/postconvergence-perspective-reflection-of-the-'destructuringthreshold_of-the-given-level's-conjugated-postlogism as-dementing'> interpersonal, group, intergroup, community, local, national, political, geostrategic, etc. psychologismic epistemicacutisation difficulty<-for, residualising \{decomplsing delinearity for-cogency> levels of interrelatedness-dynamics-of-social-constructing imbued notional $\sim$ compulsion as to compulsion_imprintedness/decompulsion_imprinting of the human sovereign-function/posture$<$ as-to-existentially-manifest-“embodied-subject $\sim$ consciousness-and-direct/deferentialconscientiousness',-as-of-its-'epistemic-reflexivity/unreflexivity-in-existence'/teleology> notional perceptualisation-of-and-leashing-to_social-functioning-and-accordance_-as-ofsocial-stake-contention-or-confliction' (and so with respect to human Beingdevelopment/ontological-framework-expansion-as-to-depth-of-ontologising-development-asinfrastructure-of- meaningfulness-and-teleology , institutional-development-as-to-socialfunction-development and living-development-as-to-personality-development psychologismic epistemic-acutisation difficulty-for, residualising \{decompulsing $\}$ delinearity for-cogency> magnitudes ${ }^{\{0 f-e x p e r i e n t i a l i t y / e x p e r i m e n t\}}$ ). This can effectively be construed (with respect to ‘ veridically 'profound-and-comprehensive human experientiality/experiment- $<$ as-toexistentially-formative- ‘fepistemic-totalising ${ }^{\dagger}$ re-apriorising/re-axiomatising/rereferencing-residuality_-in-re-originariness/re-origination',- - so'notionally/epistemically/bindingnessly-<as-to-determinism/conceptivity-of-relative-unreflexivity/relative-reflexivity> implicited-and-articulated'_as-from-nonextricatory-'prospective-re-ontologising-Being-then- 
Institutional-then-Living-magnitudes-of-\{hermeneutic/reprojection-protraction-of\}reframingand-reformulation\}'>' of the 'flow of human prospective profound-supererogation -overshallow-supererogation' undergirding the 'overall relative-unreflexivity/relative-reflexivity_ ontological-contiguity ${ }^{67}$ of-the-human-institutionalisation-process ${ }^{68}$ imbued notional cogency_chronicularity/annality-of-relative-reflexivity,-as-to-profoundsupererogation') as 'limitedness/human-subpotency limited-mentation-capacity-assubjecting 'educed-unlimitedness/existence-sublimating nascence' to-limitedness/humansubpotency implications' of 'prospective lack/deficiency/paucity of profound-supererogation imagined, educed, habituated and honed in totalising $3{ }^{3}$ hermeneutic/textuality/reprojecting/supererogating/zeroing/re-acuting,${ }_{\{\text {decompulsing }}$ delinearity for-cogency (herein construed as of 'human consciousness notional protensivity imbuing prospective psychologismic-epistemic-acutisation- $<$ as-topostconverging-de-mentating/structuring/paradigming,-eliciting-of-existence's-sublimatingnascence-in-prospective-aporeticism-overcoming/unovercoming $>$ as to epistemic-growth,-as\{veridical/sound\}-relative-reflexivity-in-existence/relativising from-limited-mentation-as-itsdeepening/psychologismic epistemic-acutisation residualising, ${ }^{\text {\{decompulsing }}$ delinearity foreogeney')'. This so-validates the profound-supererogation ${ }^{6}$ as from human 'crossgenerational notional firstnaturedness-formativeness-<as-to-eventualising inkling-drive-or-seeding misprising $>$ mental-processing-parity for ontological-performance ${ }^{72}-<$ including-virtue-asontology $>$ /morality/ethics/justice/etc.' as of the given <amplituding/formative-epistemicity $>$ totalising thrownness-in-existence ${ }^{3}$ - as imbued of limitedness/human-subpotency prospective dearth for \{epistemic-totalising ${ }^{3}$ re-apriorising/re-axiomatising/rereferencing $\sim$ residuality —in-re-originariness/re-origination projection) warrant for 'prospective requisite profound-supererogation induced demoronisation-<sublimating-nascence,nonextricatory-sublimating-upstreaming/'amontée’> for superseding/overcoming the 
succession of human registry-worldviews/dimensions disontologising/subontologisingimbuing-prospectively-of-human-desublimating/subjugation/disenfranchisement as to vicesand-impediments ${ }^{105}$; and effectively so as to the prospectively requisite 'profoundsupererogation imagined, educed, habituated and honed in fepistemictotalising ${ }^{3}$ h ${ }^{2}$ ermeneutic/textuality/reprojecting/supererogating/zeroing/re-acuting,-

\{decompulsing\} delinearity for-cogency (herein construed as of 'human consciousness notional protensivity imbuing prospective psychologismic-epistemic-acutisation-<as-topostconverging-de-mentating/structuring/paradigming,-eliciting-of-existence's-sublimatingnascence-in-prospective-aporeticism-overcoming/unovercoming $>$ as to epistemic-growth,-as\{veridical/sound\}-relative-reflexivity-in-existence/relativising from-limited-mentation-as-itsdeepening/psychologismic epistemic acutisation residualising, ${ }^{\text {fdecompulsing }}$ delinearity for eogency')' FOR 'prospective sublimating notional catchmenting-<asto_disontologising/subontologising institutional-imprintedness_by re-ontologising institutional-imprinting $>$ as to nonpresencing-<perspective-ontologicalnormaley/postconvergence> existential-<disontologising/re-ontologising aporeticism $>$ prospect of human individual-consciousness/collective-consciousness decompulsion-appraisal' for re-ontologising futural potentiation as anthropologisation-<as-to-futural-reflexivity,-in\{decompulsing\} delinearity-'invention'/'creation'-of-the-human/humanity>.

Thus

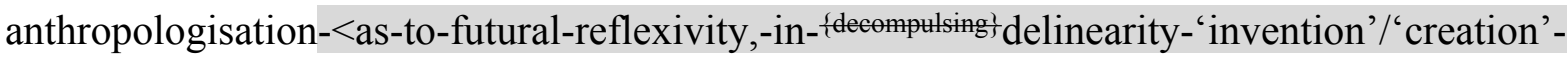
of-the-human/humanity>, as effectively speaking to overall human Beingdevelopment/ontological-framework-expansion-as-to-depth-of-ontologising-development-asinfrastructure-of- meaningfulness-and-teleology requisite 'widening the social imaginary' (as to the 'requisite prospective sublimating decompulsion_imprinting across the various institutional levels of interrelatedness-dynamics-of-social-constructing' so-arising from the 'educing-and-availing-and-re-availing of relative-ontological-completeness ${ }^{87}$ with respect to 
apriorising/axiomatising/referencing-sublimating-reflexivity-beholdening under which limitedness/human-subpotency submits in profound-supererogation for prospective sublimating'), is critically about 're-ontologising relative-reflexivity of human-per-cep-ti-vi-ty$<$ as-to-notional $\sim$ perceptualisation-of-and-leashing-to_social-functioning-and-accordance as-of-social-stake-contention-or-confliction>'; so-implied as of prospective profoundsupererogation $\sim$ reframing/reformulation/decatchmenting/detruncating/decompulsing/delinear ising - as-to-postconverging de-mentating/structuring/paradigming (imbued 'existential$<$ disontologising/re-ontologising aporeticism $>$ hermeneutic/textuality/reprojecting/supererogating/zeroing/re-acuting $\{$ decompulsing $\}$ delinearity/delinear-accreting/recomposuring- ${ }^{6}$ nonpresencing-perceptualisation-ofsublimating-over-desublimating-<as-'psychologismic-epistemic-acutisation-residualising,$\{$ decompulsing $\}$ delinearity for-cogency'_as-to- 'prospective-profound-supererogation -epistemicperspective'-of-prospective-\& prior-differentiated apriorising/axiomatising/referencing $>$ with-respect-to-the-prospect-of-prospective-human-re-ontologising') and so over shallowsupererogation $\sim$ framing/formulation/catchmenting/truncating/compulsing/linearising —as-topreconverging de mentang/stureturing/paradigming (imbued fcompulsing linearity/linearaccreting- ${ }^{79}$ presencing-perceptualisation-of-sublimating-over-desublimating-<as'psychologismic-epistemic-acutisation-nonresidualising-imbued-\{compulsing\} linearity ineclecticism-of-prior-mere-formulaicity/ritualisation'_as-to-‘secondnatured-epistemicperspective'-of-prospective- \& prior-differentiated-apriorising/axiomatising/referencing $>$ and-as-developing-into-interrelatedness-dynamics-of-social-constructing). This is so-implied with respect to the 'human psychologismic-epistemic-acutisation-difficulty- $<$ for,residualising-\{decomentsing $\}$ delinearity $\sim$ for-cogency $>$-〈as-of-requisite-profound-supererogation for-'disposedness-or-psychologismic-construct'- \{imbued-demoronisation-<sublimating- 
nascence,-nonextricatory-sublimating-upstreaming/‘amontée’>\}) for requisite prospective re-apriorising/re-axiomatising/re-referencing $\sim$ residuality—in-reoriginariness/re-origination projection'; existentially-<disentologising/re-ontologising aporeticism $>$ manifested as to 'human notional catchmenting-<asto_disentelogising/subentologising institutional imprintedness by re ontelogising institutional-imprinting $>$ predicament' of 'lifespan extricatory/preconverging psychicalnascency moronisation- $<$ sublimating-nascence,-extricatory-desublimatingdownstreaming/'avalage'>' by 'nonextricatory/postconverging ontologising-and-reontologising angling-of-imaginary demoronisation-<sublimating-nascence,-nenextricatery sublimating-upstreaming/'amontée’> (as so-underlying the human sovereignfunction/posture-<as-to-existentially-manifest-‘embodied-subject $\sim$ consciousness-anddirect/deferential-conscientiousness',-as-of-its-'epistemic-reflexivity/unreflexivity-inexistence'/teleology $>$ notional perceptualisation-of-and-leashing-to_social-functioning-andaccordance-as-of-social-stake-contention-or-confliction' possibility for prospective 'reontologising in cogency_chronicularity/annality-of-relative-reflexivity,-as-to-profoundsupererogation $^{6}$ as to human-consciousness/collective-consciousnessdistendedness/detruncating-<beyond-selfpresencing,-as-re-ontologising-decentering_ofconsciousness/collective-consciousness,-as-to-psychologismic-epistemic-acutisationresidualising, - $^{\text {(decentsing }}$ delinearity $\sim$ for- $\operatorname{cogency}>$ ). $\quad$ Anthropologisation- $<$ as-to-futural-

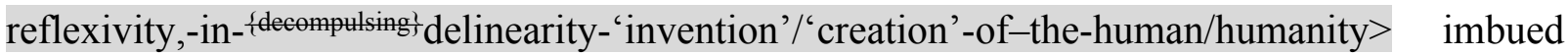
'widening the social imaginary' is thus effectively underlied as of 'cogency_chronicularity/annality-of-relative-reflexivity,-as-to-profound-supererogation imbued relative-reflexivity of human-per-cep-ti-vi-ty-<as-to-notional $\sim$ perceptualisation-ofand-leashing-to_social-functioning-and-accordance-as-of-social-stake-contention-orconfliction>'; $\quad$ so-implied as of prospective profound- 
supererogation $\sim$ reframing/reformulation/decatchmenting/detruncating/decompulsing/delinear ising - as-to-postconverging de-mentating/structuring/paradigming (imbued 'existential<disontologising/re-ontologising aporeticism> hermeneutic/textuality/reprojecting/supererogating/zeroing/re-acuting $\{$ decompulsing $\}$ delinearity/delinear-accreting/recomposuring- ${ }^{6}$ nonpresencing-perceptualisation-ofsublimating-over-desublimating-<as-" psychologismic-epistemic-acutisation-residualising,\{decompulsing $\}$ delinearity for-cogency’_as-to-'prospective-profound-supererogation -epistemicperspective'-of-prospective-\& prior-differentiated-apriorising/axiomatising/referencing $>$ with-respect-to-the-prospect-of-prospective-human-re-ontologising') and so over shallowsupererogation $\sim$ framing/formulation/catchmenting/truncating/compulsing/linearising —as-topreconverging - de-mentating/structuring/paradigming (imbued fcompulsing linearity/linearaccreting $-{ }^{79}$ presencing-perceptualisation-of-sublimating-over-desublimating-<as'psychologismic-epistemic-acutisation - nonresidualising-imbued-\{compulsing\}linearity ineclecticism-of-prior-mere-formulaicity/ritualisation’_as-to-‘secondnatured-epistemicperspective'-of prospective \& $\&$ prior-differentiated apriorising/axiomatising/referencing $>$ and-as-developing-into-interrelatedness-dynamics-of-social-constructing). In this regards, it can be appreciated that in the face of a positivistic demonstration an animistic mindset is patently bound to psychologismically fallback/relapse (as to its given non-positivistic 'human psychologismic-epistemic-acutisation-difficulty- $<$ for,-residualising$\{$ decompulsing $\}$ delinearity for-cogency $>$-〈as-of-requisite-profound-supererogation -for‘disposedness-or-psychologismic-construct'-\{ imbued-demoronisation-<sublimatingnascence,-nonextricatory-sublimating-upstreaming/'amontée’>\}) for requisite prospective \{epistemic-totalising 3 \}re-apriorising/re-axiomatising/re-referencing $\sim$ residuality—in-reoriginariness/re-origination projection') into a 'mystical/spirits nonpositivistic conception of things rationalisation-of-contentivity/argumentativity/dialecticism/discursivity' (in reflection 
supererogation $\sim$ framing/formulation/catchmenting/truncating/compulsing/linearising —as-topreconverging de-mentating/structuring/paradigming mental-reflex hold' of its underlying prior animistic Being-development/ontological-framework-expansion-as-to-depth-of-ontologisingdevelopment-as-infrastructure-of- meaningfulness-and-teleology psychologismic epistemic-acutisation difficulty-for, residualising \{decompulsing $\}$ delinearity-for-cogency> magnitude\{of-experientiality/experiment\} $\}$; and so as to its prior nonpositivistic shallowsupererogation $\sim$ framing/formulation/catchmenting/truncating/compulsing/linearising —as-topreconverging de-mentating/structuring/paradigming rationalisation-ofcontentivity/argumentativity/dialecticism/discursivity in fompulsing $/$ linearity/linear-accretingpresencing-perceptualisation-of-sublimating-over-desublimating- $<$ as-'psychologismicepistemic-acutisation - nonresidualising-imbued-\{compulsing\}linearity in-eclecticism-of-priormere-formulaicity/ritualisation’_as-to-‘secondnatured-epistemic-perspective'-of prospective\& prior-differentiated-apriorising/axiomatising/referencing $>$ and-as-developing-intointerrelatedness-dynamics-of-social-constructing (rather than an appreciation of prospective positivistic profound-reframing/reformulation/decatchmenting/detruncating/decompulsing/delinear ising - as-to-postconverging-de-mentating/structuring/paradigming re-rationalisation-ofcontentivity/argumentativity/dialecticism/discursivity in 'existential-<disontologising/reentologising aporeticism $>$ hermeneutic/textuality/reprojecting/supererogating/zeroing/reacuting decolingering/delinear-accreting/recomposuring- nonpresencingperceptualisation-of-sublimating-over-desublimating-<as-'psychologismic-epistemic-

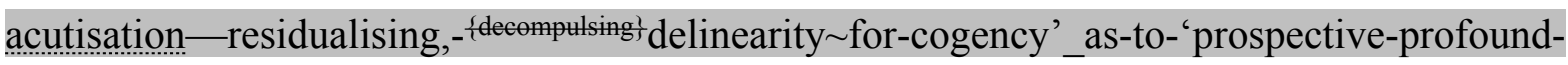
supererogation -epistemic-perspective'-of prospective- \& prior-differentiatedapriorising/axiomatising/referencing $>$ with-respect-to-the-prospect-of-prospective-human-re- 
ontologising' which effectively underlies the inherent requisite limitedness/human-subpotency 'despite-the-self exercise of epistemic-projection in notional $\sim$ self-distantiation-<imbued-remotif-and-re-apriorising/re-axiomatising/re-referencing >' undergirding human sovereignfunction/posture-<as-to-existentially-manifest-‘embodied-subject $\sim$ consciousness-anddirect/deferential-conscientiousness',-as-of-its-'epistemic-reflexivity/unreflexivity-inexistence'/teleology $>$ with regards to human-consciousness/collective-consciousnessdistendedness/detruncating-<beyond-selfpresencing,-as-re-ontologising-decentering_ofconsciousness/collective-consciousness,-as-to-psychologismic-epistemic-acutisationresidualising,- - decompulsing $^{-}$delinearity for- $\operatorname{cogency}>$ ). This insight applies not only as from 'our positivism/rational-empiricism epistemic-projection perspective in relation to prior nonpositivistic epistemic-projection perspective' but can equally be countenanced prospectively, as from 'prospective ${ }^{18}$ deprocrypticism/preempting-disjointedness-as-of- ${ }^{8}$ reference-ofthought epistemic-projection perspective in relation to our prior positivism-

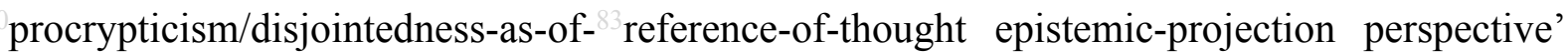
(and so as to our prospectively disjointing shallowsupererogation $\sim$ framing/formulation/catchmenting/truncating/compulsing/linearising —as-topreconverging de mentating/strueturing/paraligming rationalisation of contentivity/argumentativity/dialecticism/discursivity in \{compulsing $\}$ linearity/linear-accretingpresencing-perceptualisation-of-sublimating-over-desublimating-<as-'psychologismic_epistemic-acutisation - nonresidualising-imbued-\{compulsing\} linearity in-eclecticism-of-priormere-formulaicity/ritualisation'_as-to-‘secondnatured-epistemic-perspective'-of-prospective\&-prior-differentiated-apriorising/axiomatising/referencing $>$ and-as-developing-intointerrelatedness-dynamics-of-social-constructing); as to the fact that the prospective nondisjointing profoundsupererogation $\sim$ reframing/reformulation/decatchmenting/detruncating/decompulsing/delinear 
ising - as-to-postconverging de-mentating/structuring/paradigming re-rationalisation-ofcontentivity/argumentativity/dialecticism/discursivity in 'existential-<disontologising/reentologising aporeticism $>$ hermeneutic/textuality/reprojecting/supererogating/zeroing/reacuting \{decompulsing $\}$ delinearity/delinear-accreting/recomposuring- ${ }^{6}$ nonpresencingperceptualisation-of-sublimating-over-desublimating-<as-'psychologismic-epistemicacutisation-residualising, - ${ }^{\text {\{decompulsing }}$ delinearity $\sim$ for-cogency’_as-to-'prospective-profoundsupererogation -epistemic-perspective'-of-prospective \& prior-differentiatedapriorising/axiomatising/referencing $~$ with-respect-to-the-prospect-of-prospective-human-reontologising' as manifested with budding postmodern-thought carries its very own prospective profound-

supererogation $\sim$ reframing/reformulation/decatchmenting/detruncating/decompulsing/delinear ising - as-to-postconverging de-mentating/structuring/paradigming re-rationalisation-ofcontentivity/argumentativity/dialecticism/discursivity underlying its sublimating organicknowledge (as sublimating 're-ontologising trepristemic apriorising/re-axiomatising/rereferencing residuality in re-originariness/re-origination \{decompulsing $\}$ delinearity/delinearaccreting/recomposuring $\quad$ cogency/tensing/limpidity-<as-of-prospective-profoundsupererogation ,-for-residuality_in-re-originariness/re-origination $>$,-prospective_reifying mental-aestheticising <as-of-prospective_reformulating-of-mental-aestheticising'as-to'residuality in-re-originariness/re-origination'-of-mental-aestheticising $\left.{ }^{\prime}\right)$. Whereas this is crudely turned into the desublimating shallowsupererogation $\sim$ framing/formulation/catchmenting/truncating/compulsing/linearising —as-topreconverging - de-mentating/structuring/paradigming rationalisation-ofeontentivity/argmentaty/dialecticism/diseursivity mechanical-knowledge of our prior positivism- ${ }^{80}$ procrypticism/disjointedness-as-of- ${ }^{83}$ reference-of-thought epistemic-projection perspective (in its ${ }^{79}$ presencing-absolutising-identitive-constitutedness ${ }^{14}$ instrumentalisation 
desublimating 'eclecticism-of-prior-mere-formulaicity/ritualisation-<as-ofprior $\sim$ rationalisation-of-contentivity/argumentativity/dialecticism/discursivity $>$ composition/blending-inof relative-ontologicalcompleteness and relative-ontological-incompleteness apriorising/axiomatising/referencing as to secondnatured prior mere-formulaicity/ritualisation-<as-to-mere-formulaic methodologising/mutualising/organising/institutionalising,-prospectively-losing-track-of‘ fepistemic-totalising ’’ re-apriorising/re-axiomatising/re-referencing $r$ residuality-in-reoriginariness/re-origination'> $\quad$ inducing $\quad{ }^{4}$ historicity-tracing-in-presencinghyperrealisation/hyperreal-transposition); as ultimately losing track of underlying anthropologisation-<as-to-futural-reflexivity,-in-\{decompulsing $\}$ delinearity-'invention'/‘creation'of-the-human/humanity> imbued 'widening the social imaginary'. Again, this can be further elucidated as to both institutional-development-as-to-social-function-development psychologismic epistemic-acutisation difficulty-for, residualising $\{$ decomsing delinearity for-cogeney $>$ magnitude $\{$ of-experientiality/experiment $\}$ or living-development-asto-personality-development psychologismic epistemic acutisation difficulty <for, residualising ${ }^{\{\text {decompulsing }}$ delinearity for-cogency $>$ magnitude $\left.{ }^{\{0 f-e x p e r i e n t i a l i t y / e x p e r i m e n t}\right\}$ within any given registry-worldview/dimension (as overarching Being-development/ontologicalframework-expansion-as-to-depth-of-ontologising-development-as-infrastructure-ofmeaningfulness-and-teleology psychologismic epistemic-acutisation difficulty-for,

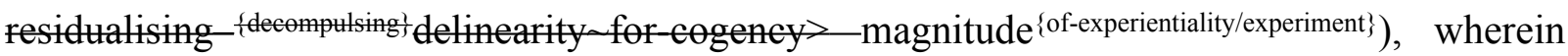
for instance an competence/expertising technical explanation (as to its prospective reontologising 'dynamic cumulating/recomposuring psychologismic-epistemic-acutisationresidualising, ${ }^{-\{\text {decompulsing }}$ delinearity for-cogency phasing of limitedness/human-subpotency onto unlimitedness/existence-<full-potency-of_sublimating nascence $>$ ') is already of recurrent circular prospective profound- 
supererogation $\sim$ reframing/reformulation/decatchmenting/detruncating/decompulsing/delinear ising - as-to-postconverging de-mentating/structuring/paradigming re-rationalisation-ofcontentivity/argumentativity/dialecticism/discursivity underlying its sublimating organicknowledge (as sublimating 're-ontologising \{epistemic-totalising ${ }^{3}$ re-apriorising/re-axiomatising/rereferencing residuality in-re-originariness/re-origination \{decompulsing $\}$ delinearity/delinearaccreting/recomposuring cogency/tensing/limpidity-<as-of-prospective-profoundsupererogation ${ }^{9}$,-for-residuality_-in-re-originariness/re-origination $>$,-prospective_reifying mental-aestheticising-<as-of-'prospective_reformulating-of-mental-aestheticising'as-to'residuality in re-originariness/re-origination'-of-mental-aestheticising $\left.{ }^{\prime}\right)$; such that an 'ordinary laypersonhood arrogation/presumptuousness' claim to mutual engagement is not effectively of a mutual 'veridical neutral point-of-devolving/departure/anchoring/backdrop conceptualisation of human ontological-performance ${ }^{72}-<_{\text {including-virtue-as- }}$ ontology $>$ /morality/ethics/justice/etc. as to re-rationalisations-ofcontentivity/argumentativity/dialecticism/discursivity' since it is circularly implicating its desublimating shallowsupererogation $\sim$ framing/formulation/catchmenting/truncating/compulsing/linearising —as-topreconverging de mentating/structuring/paradigming rationalisation of contentivity/argumentativity/dialecticism/discursivity mechanical-knowledge (as to its prospective failing for re-ontologising 'dynamic cumulating/recomposuring psychologismic-

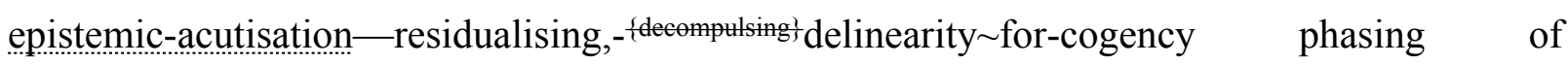
limitedness/human-subpotency onto unlimitedness/existence-<full-potency-of_sublimating nascence $>$ '). In-many-ways, the overall 'protracted-social-as-to-individual-by-institutionalby-social relative direct/deferential-responsibility/relative reflexivity to cogency_chronicularity/annality-of-relative-reflexivity,-as-to-profound-supererogation enables individuals to effectively accede to this 'human psychologismic-epistemic- 


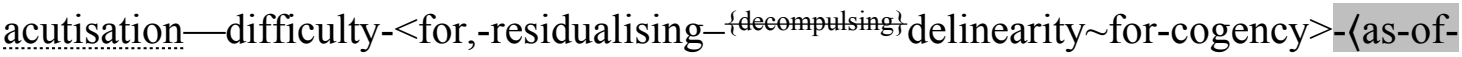
requisite-profound-supererogation -for-'disposedness-or-psychologismic-construct'\{imbued-demoronisation-<sublimating-nascence,-nonextricatory-sublimatingupstreaming/‘amontée’>\}) for requisite prospective \{epistemic-totalising 3 3 're-apriorising/reaxiomatising/re-referencing $\sim$ residuality-in-re-originariness/re-origination projection' (with regards to institutional-development-as-to-social-function-development psychologismic epistemic-acutisation difficulty-for, residualising \{decomplling delinearity for-cogency> magnitude\{of-experientiality/experiment\} or living-development-as-to-personality-development psychologismic epistemic-acutisation difficulty < for, residualising ${ }_{\{\text {decompulsing }}$ delinearity for imbued profoundsupererogation $\sim$ reframing/reformulation/decatchmenting/detruncating/decompulsing/delinear ising_scale_of-transparent/noncontentious/un-nominalised/sound-interpretations/domains of manifest unblurriness-<re-ontologising_by-postconverging-as-to-dragged-outsupererogatory wholesomeness/profound-supererogation ,-while-anecdotalising-priordisontologising-thresholding >') but then are paradoxically susceptible to it (with respect to Being-development/ontological-framework-expansion-as-to-depth-of-ontologisingdevelopment-as-infrastructure-of- meaningfulness-and-teleology psychologismic epistemic-acutisation difficulty-for, residualising \{decomplling $\}$ delinearity for-cogency> magnitude\{of-experientiality/experiment\} as to 'mechanical-knowledge imbued shallow supererogation $\sim$ framing/formulation/catchmenting/truncating/compulsing/linearising_scale —of-opaque/contentious/un-nominalised/flawed-interpretations/domains of manifest blurriness- $<$ sterilising/anecdotalising/trivialising-of-prospective-re-ontologising_bypreconverging,-in-disontologising-formulaic-dragging-out/hollowing-out> $\quad$ together with 'unwieldy-contemplatable-disontologising/re-ontologising-implications,-with-regards-to- 
human-sovereign-function/posture-<as-to-narrowness/evasiveness/vagueness-of-

disontologising/re-ontologising $>$ with respect to contentious/un-nominalisedness of socialstake-contention-or-confliction'). In this regards, human sublimating ${ }^{4}$ historiality/ontologicaleventfulness 3 /ontological-aesthetic-tracing-<perspective-ontological-

normalcy/postconvergence-reflected-'epistemicity-relativism-determinism

(as

to

anthropologisation-<as-to-futural-reflexivity,-in-\{decompulsing $\}$ delinearity- ‘invention'/‘creation'-

of-the-human/humanity> imbued 'widening the social imaginary') is notionally/epistemically/bindingnessly-as determinism/enceptivity of relative unreflexivitylative reflexivity underlied as of 'relative-unreflexivity/relative-reflexivity limitedness/human-subpotency dynamics of supererogating ${ }^{9}$ affirmation/projection/assertion/notional $\sim$ self-distantiation-byunaffirmation/deprojection/deassertion/epistemic-decadence $\}$ —-towards $\sim$ omnipotentialaffirmation/projection/assertion/notional self-distantiation' with regards to prospective profound-

supererogation $\sim$ reframing/reformulation/decatchmenting/detruncating/decompulsing/delinear ising - as-to-postconverging de-mentating/structuring/paradigming re-rationalisation-ofcontentivity/argumentativity/dialecticism/discursivity over shallowsupereration $\sim$ framing/formulation/catchmenting/truncating/compulsing/linearising as preconverging de-mentating/structuring/paradigming rationalisation-ofcontentivity/argumentativity/dialecticism/discursivity in 'organic accompaniment' of 'limitedness/human-subpotency prospective re-encountering/re-confrontation with unlimitedness/existence-<full-potency-of_sublimating nascence>' (for 're-ontologising \{epistemic-totalising 're-apriorising/re-axiomatising/re-referencing residuality in-recogency/tensing/limpidity-<as-of-prospective-profound-supererogation , ,for-residuality—inre-originariness/re-origination>-,prospective_reifying mental-aestheticising <as-of- 
'prospective_reformulating of-mental-aestheticising'as-to-'residuality in re-originariness/re-

erigination'-of-mental-aestheticising >'). Thusly speaking of human-consciousness/collectiveconsciousness-distendedness/detruncating-<beyond-selfpresencing,-as-re-ontologisingdecentering_of-consciousness/collective-consciousness,-as-to-psychologismic-epistemicacutisation-residualising,- ${ }^{\{\text {decompulsing }\}}$ delinearity for-cogency $>$ as undergirded not by any given registry-worldview/dimension ${ }^{79}$ presencing-absolutising-identitive-constitutedness social-functioning-and-accordance-as-of-social-stake-contention-or-confliction shallowsupererogation $\sim$ framing/formulation/catchmenting/truncating/compulsing/linearising —as-topreconverging de-mentating/structuring/paradigming rationalisation-ofcontentivity/argumentativity/dialecticism/discursivity (in fcompulsingłlinearity/linear-accretingpresencing-perceptualisation-of-sublimating-over-desublimating-<as-'psychologismicepistemic-acutisation - nonresidualising-imbued-\{compulsing\}linearity in-eclecticism-of-priormere-formulaicity/ritualisation’_as-to-‘secondnatured-epistemic-perspective'-of prospective\& prior-differentiated apriorising/axiomatising/referencing $>$ and-as-developing-intointerrelatedness-dynamics-of-social-constructing) but rather by the nonpresencing<perspective-ontological-normalcy/postconvergence $>$ epistemic-projection profound-reframing/reformulation/decatchmenting/detruncating/decompulsing/delinear ising - as-to-postconverging de-mentating/structuring/paradigming re-rationalisation-ofcontentivity/argumentativity/dialecticism/discursivity (in $\quad$ 'existential-<disontologising/reentologising aporeticism $>$ hermeneutic/textuality/reprojecting/supererogating/zeroing/reacuting

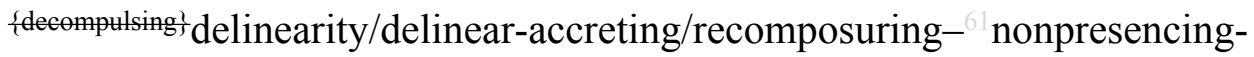
perceptualisation-of-sublimating-over-desublimating-<as-'psychologismic-epistemicacutisation-residualising,-\{decompulsing\} delinearity for-cogency'_as-to-‘prospective-profoundsupererogation -epistemic-perspective'-of prospective- \& prior-differentiatedapriorising/axiomatising/referencing $>$ with-respect-to-the-prospect-of-prospective-human-re- 
ontologising'); as to the 'relative-reflexivity of human-per-cep-ti-vi-ty-<as-to notional perceptualisation-of-and-leashing-to_social-functioning-and-accordance-as-ofsocial-stake-contention-or-confliction>' as of underlying 'constraining existence-assublimating-withdrawal/unenframing/re-ontologising,-elicited-from-prospective-profound-

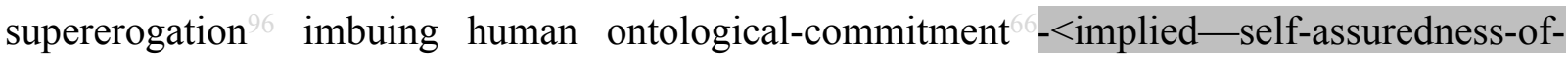
ontological-good-faith/authenticity postconverging-de-

mentating/structuring/paradigming -as-being-as-of-existential-reality>' and '103 universaltransparency ${ }^{104}$-〈transparency-of-totalising-entailing,-as-to-entailing-<amplituding/formativeepistemicity $>$ totalising $\sim$ in-relative-ontological-completeness $\rangle$ as available-to/elicitable-to-〈asto-human-consciousness/collective-consciousness-distendedness/detruncating- $<$ beyondselfpresencing,-as-re-ontologising-decentering_of-consciousness/collective-consciousness,-asto-psychologismic-epistemic-acutisation - residualising, ${ }^{\text {- } \text { decompulsingt }}$ delinearity for-cogency $\left.>\right\rangle$ the social-functioning-and-accordance-as-of-social-stake-contention-or-confliction conception of any given registry-worldview/dimension <preconverging 'motif-andapriorising/axiomatising/referencing'-entailing>-existentialising—enframing/imprintedness〈as-to- historicity-tracing - in-presencing-hyperrealisation/hyperreal-transposition〉'. But then the-very-underlying — (as inherently 'defining-and-imbuing of limitedness/human-subpotency

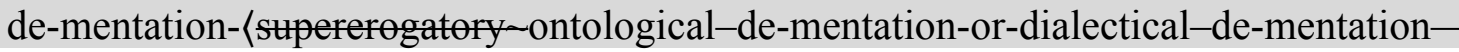
stranding-or-attributive-dialectics ${ }^{\prime}$ as to preconverging/postconverging-dementating/structuring/paradigming)—relationship-between-limitedness/human-subpotency_ and-unlimitedness/existence-<full-potency-of_sublimating nascence $>$ means that prospective profound-

supererogation $\sim$ reframing/reformulation/decatchmenting/detruncating/decompulsing/delinear ising - as to posteonverging de mentating/structuring/paradigming re rationalisation-of eontentivity/argumentativity/dialecticism/discursivity superseding/overcoming of shallow- 
supererogation $\sim$ framing/formulation/catchmenting/truncating/compulsing/linearising —as to preconverging de-mentating/structuring/paradigming rationalisation-ofcontentivity/argumentativity/dialecticism/discursivity thus rather manifests as of 'recurrent/perpetuating/continuity-recomposuring existential-<disontologising/reentologising aporeticism $>$ counteracting/supplanting/alienating-of-priorapriorising/axiomatising/referencing' (as recurrently eliciting prospective profoundsupererogation $\sim$ reframing/reformulation/decatchmenting/detruncating/decompulsing/delinear ising - as-to-postconverging de-mentating/structuring/paradigming re-rationalisation-ofcontentivity/argumentativity/dialecticism/discursivity) over 'secondnatured prior mereformulaicity/ritualisation-<as-to-mere-formulaicmethodologising/mutualising/organising/institutionalising,-prospectively-losing-track-of‘\{epistemic-totalising ’’łre-apriorising/re-axiomatising/re-referencing residuality-in-reoriginariness/re-origination'> $\quad$ (as recurrently shallowsupererogation $\sim$ framing/formulation/catchmenting/truncating/compulsing/linearising —as-topreconverging de-mentating/structuring/paradigming rationalisation-ofcontentivity/argumentativity/dialecticism/discursivity); so-reflecting appropriate 'human notional $\sim$ difference-conflatedness ${ }^{3}$-as-to-totalitative-reification-in-singularisation- $<$ as-to-thenondisjointedness/entailment-of-prospective- nonpresencing > -as-veridical-epistemicityrelativism-determinism construable as from the given projected and prospectively educedand-availing-and-re-availing relative-ontological-completeness ${ }^{87}$-ofapriorising/axiomatising/referencing' as to 'recurrent/perpetuating/continuity-recomposuring existential-<disontologising/re-ontologising aporeticism>

counteracting/supplanting/alienating-of-prior-apriorising/axiomatising/referencing'. This soimplies a recurrent eliciting of prospective profoundsupererogation $\sim$ reframing/reformulation/decatchmenting/detruncating/decompulsing/delinear 

eontentivity/argumentativity/dialecticism/discursivity (whether with regards to prospective sublimating associated with Being-development/ontological-framework-expansion-as-todepth-of-ontologising-development-as-infrastructure-of- meaningfulness-and-teleology psychologismic epistemic acutisation difficulty-<for, residualising ${ }_{\{\text {decompulsing }}$ delinearity for-cogeney $>$ magnitude ${ }^{\{0 \text { of-experientiality/experiment }\}}, \quad$ institutionaldevelopment-as-to-social-function-development psychologismic epistemic-acutisationdifficulty $<$ for, residualising \{decompulsing\} delinearity for-cogency> magnitude $\{$ ofexperientiality/experiment\} or living-development-as-to-personality-development psychologismic epistemic-acutisation difficulty-for, residualising \{decompulsing $\}$ delinearity for-cogency> magnitude ${ }^{\text {of-experientiality/experiment }\}}$ as to ${ }^{83}$ reference-of-thought-and- ${ }^{8}$ reference-of-thoughtdevolving- ${ }^{56}$ meaningfulness-and-teleology ${ }^{\circ}$ ); as 'organic accompaniment' of 'limitedness/human-subpotency prospective re-encountering/re-confrontation with unlimitedness/existence-full-potency-of_sublimating nascence>' (for 're-ontologising fepistemictising tre-apriorising/re-axiomatising/re-referencing-residuality in-reoriginariness/re-origination $\{$ \{decompulsing\} delinearity/delinear-accreting/recomposuring cogency/tensing/limpidity-<as-of-prospective-profound-supererogation ,-for-residuality-inre-originariness/re-origination>-,prospective_reifying mental-aestheticising-<as-of'prospective_reformulating of-mental-aestheticising'as-to-'residuality in -re-originariness/reerigination' of -mental-aestheticising >'). This in-many-ways underlies the requisite 'relays of human intemporal-individuation epistemic-projection radicalities $\sim$ in-chronicular/annalisticcogency-<as-of-notional $\sim$ protensivity $>$-〈as-to-limited-mentation-capacity-deepening —assubjecting limitedness/human-subpotency-to-'educed-unlimitedness/existence-sublimating nascence' > so-construed as cogency_chronicularity/annality-of-relative-reflexivity,-as-toprofound-supererogation, for upholding prospective profound- 
supererogation $\sim$ reframing/reformulation/decatchmenting/detruncating/decompulsing/delinear ising - as-to-postconverging de-mentating/structuring/paradigming re-rationalisation-ofcontentivity/argumentativity/dialecticism/discursivity (with regards to anthropologisation- $<$ as-

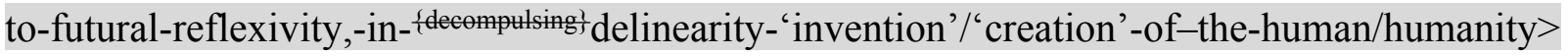
imbued 'widening the social imaginary'); and so-overarch the manifestations of both 'organicknowledge imbued profoundsupererogation $\sim$ reframing/reformulation/decatchmenting/detruncating/decompulsing/delinear ising_scale_of-transparent/noncontentious/un-nominalised/sound-interpretations/domains of manifest unblurriness-<re-ontologising_by-postconverging-as-to-dragged-outsupererogatory -wholesomeness/profound-supererogation ,-while-anecdotalising-priordisontologising-thresholding>' (effectively reflected prospectively as to sublimating 'reentologising \{epistemic-totalising łre-apriorising/re-axiomatising/re-referencing-residuality in-reeriginariness/re-origination $\{$ decompulsing $\}$ delinearity/delinear-accreting/recomposuring cogency/tensing/limpidity-<as-of-prospective-profound-supererogation ,-for-residuality-inre-originariness/re-origination>-,prospective_reifying mental-aestheticising-<as-of'prospective_reformulating of mental-aestheticising'as-to-'residuality in re-originariness/reorigination' of mental aestheticising >') and 'mechanical-knowledge imbued shallow supererogation $\sim$ framing/formulation/catchmenting/truncating/compulsing/linearising_scale —of-opaque/contentious/un-nominalised/flawed-interpretations/domains of manifest blurriness-<sterilising/anecdotalising/trivialising-of-prospective-re-ontologising_bypreconverging,-in-disontologising-formulaic-dragging-out/hollowing-out>' together with 'unwieldy-contemplatable-disontologising/re-ontologising-implications,-with-regards-tohuman-sovereign-function/posture-<as-to-narrowness/evasiveness/vagueness-ofdisontologising/re-ontologising > with respect to contentious/un-nominalisedness of socialstake-contention-or-confliction' (effectively reflected as to desublimating 'eclecticism-of-prior- 
mere-formulaicity/ritualisation-<as-of-prior $\sim$ rationalisation-of-

contentivity/argumentativity/dialecticism/discursivity> composition/blending-infcompulsing linearity/linear-accretion of relative-ontological-completeness and relativeontological-incompleteness apriorising/axiomatising/referencing as to secondnatured prior mere-formulaicity/ritualisation-<as-to-mere-formulaicmethodologising/mutualising/organising/institutionalising,-prospectively-losing-track-of‘\{epistemic-totalising łre-apriorising/re-axiomatising/re-referencing $\sim$ residuality-in-reoriginariness/re-origination'>'). So-overarched respectively as to the accompanying human inclinations for either the genuine social intellectual-function/posture or pedantising/muddling/formulaic-hollowing-out - in-subontologisation/subpotentiation〈blurring/undermining-of-prospective-totalising-entailing,-as-to-entailing$<$ amplituding/formative-epistemicity>totalising in-relative-ontological-completeness $\rangle ; \quad$ and so-relevant to the requisite inducing of human sovereign-function/posture-<as-to-existentiallymanifest-'embodied-subject consciousness-and-direct/deferential-conscientiousness',-as-ofits-'epistemic-reflexivity/unreflexivity-in-existence'/teleology> 'despite-the-self exercise of epistemic-projection in notional $\sim$ self-distantiation- $<$ imbued-re-motif-and-re-apriorising/reaxiomatising/re-referencing $>^{\prime}$ as to human-consciousness/collective-consciousnessdistendedness/detruncating-<beyond-selfpresencing,-as-re-ontologising-decentering_ofconsciousness/collective-consciousness,-as-to-psychologismic-epistemic-acutisationresidualising, ${ }_{-}^{-\{\text {decompulsing }}$ delinearity for-cogency $>$ for prospective re-ontologising-imbuingof-prospective-human-sublimating/emancipating/enfranchisement. In this regards, the ontologising/scientific/existence- $<$ honesty-constraining $>$ — scope_for_prospective_reontologising (as to its implicited nonpresencing-<perspective-ontologicalnormalcy/postconvergence $>\quad$ relativism/relative-scope for epistemic-growth,-as\{veridical/sound\}-relative-reflexivity-in-existence/relativising from-limited-mentation-as-its- 
deepening/psychologismic epistemic acutisation residualising, \{decompulsing $\}$ delinearity foreogency') warrants that human sovereign-function/posture-<as-to-existentially-manifest‘embodied-subject $\sim$ consciousness-and-direct/deferential-conscientiousness',-as-of-its'epistemic-reflexivity/unreflexivity-in-existence'/teleology> is notionally/epistemically/bindingnessly -as-to-determinism/conceptivity-of-relative-unreflexivity/relative-reflexivity> $^{-}$the inherent point-of-departure for human prospective re-ontologising-imbuing-of-prospectivehuman-sublimating/emancipating/enfranchisement (and so as to human sovereignemergence/becoming,-existentially-imbuing human-freedom-as-to-supererogating/surrealising for-'knowledge-empowerment-over-ignorance-disempowerment'-<as-of-'developing-andavailing-sovereign-sublimating_potential/possibilities/options/choices'-as-to-the'credibility'/'ontological-veracity'-underlying-the-'sovereign-conscious/conscientiousbackdrop'>); in reflection of the fact that human limited-mentation-capacity-as-subjecting 'educed-unlimitedness/existence-sublimating nascence' to-limitedness/human-subpotency effectively warrants human limited-mentation-capacity-deepening-as-subjectinglimitedness/human-subpotency to-'educed-unlimitedness/existence-sublimating nascence' 53 , as to 'protracted-social—as-to-individual-by-institutional-by-social relative direct/deferentialresponsibility/relative reflexivity to cogency_chronicularity/annality-of-relative-reflexivity,-asto-profound-supererogation 'so-undergirded by the 'overall genuine social intellectualfunction/posture various existentially-<disontologising/re-ontologising aporeticism $>$ induced human conceptivity/epistemic-reflexivity/epistemicity-relativism-determinism- $<$ reifying \{as-toknowledge-developing\}-and-empowering $>$ with respect to overall human competence/expertising (as of human socially expanded framework of deferential-formalisationtransference as to various cultivated skills/arts and time investment with regards to effectively manifest 'underlying veracity of core-philosophy/derivative-core-philosophy prospective reontologising as relevantly superseding prior mere-formulaicity/ritualisation pedantism induced 
knowledge-deadends-<as-preconverging-de-mentating/structuring/paradigming >’ ', notwithstanding the manifestation of undermining pedantising/muddling/formulaic-hollowingout - in-subontologisation/subpotentiation-〈blurring/undermining-of-prospective-totalisingentailing,-as-to-entailing-<amplituding/formative-epistemicity $>$ totalising $\sim$ in-relativeontological-completeness $\rangle$ desublimation; and so in reflection of prospective re-ontologising 'dynamic cumulating/recomposuring psychologismic-epistemic-acutisation-residualising,delinearity for-cogency phasing of limitedness/human-subpotency onto unlimitedness/existence-<full-potency-of_sublimating nascence $>$ ' (as to the 'veracity of the sovereign-function/posture-<as-to-existentially-manifest-'embodied-subject $\sim$ consciousnessand-direct/deferential-conscientiousness',-as-of-its-'epistemic-reflexivity/unreflexivity-inexistence'/teleology $>$ as coextensive with the genuine social intellectual-function/posture'). Inthe-bigger-scheme-of-things, human sovereign-emergence/becoming-existentially-imbuinghuman-freedom-as-to-supererogating/surrealising for ' 'knowledge-empowerment-overignorance-disempowerment'-<as-of-'developing-and-availing-sovereignsublimating_potential/possibilities/options/choices'-as-to-the-'credibility'/'ontologicalveracity'-underlying-the-'sovereign-conscious/conscientious-backdrop'> thus speaks to the fact that in-the-very-essence-of-things there is 'no inherently prior human sovereignfunction/posture-<as-to-existentially-manifest-`embodied-subject $\sim$ consciousness-anddirect/deferential-conscientiousness',-as-of-its-'epistemic-reflexivity/unreflexivity-inexistence'/teleology $\quad$ self-reflection — as-to-prospective-re-ontologising-articulation-ofsovereignty' but for the notional/epistemic/bindingness ${ }^{-<a s-t o-d e t e r m i n i s m / c o n c e p t i v i t y-o f-r e l a t i v e-~}$ unreflexivity/relative-reflexivity> overall 'protracted-social—as-to-individual-by-institutional-by-social relative direct/deferential-responsibility/relative-reflexivity to cogency_chronicularity/annality-of-relative-reflexivity,-as-to-profound-supererogation (imbued priorly-articulated-and-prospective-re-ontologising-articulation-of- 
sublimating/emancipating/enfranchisement-of-sovereignty) for 'implicited-and-explicited repassing for human sovereign-function/posture-<as-to-existentially-manifest-'embodiedsubject $\sim$ consciousness-and-direct/deferential-conscientiousness',-as-of-its- 'epistemicreflexivity/unreflexivity-in-existence'/teleology> approbation-of/adherence-to deferentialism' as so allowing for such a self-reflection-as-to-prospective-re-ontologising-articulation-ofsovereignty to be countenanced starting from the 'individual emergence/becoming in existence' (as to human <amplituding/formative-epistemicity>-totalising $\sim$ thrownness-in-existence ${ }^{35}$ ); and so-reflected with regards to the self-reflection - as-to-prospective-re-ontologising-articulationof-sovereignty associated as of human Being-development/ontological-framework-expansionas-to-depth-of-ontologising-development-as-infrastructure-of- meaningfulness-andteleology psychologismic epistemic-acutisation difficulty-<for, residualising $\{$ decompulsing\} delinearity for-cogency>-magnitude $\{$ of-experientiality/experiment\}, institutionaldevelopment-as-to-social-function-development psychologismic epistemic-acutisationdifficulty < for, residualising \{decomplsing $\}$ delinearity for-cogeney> magnitude $\{$ ofexperientiality/experiment\} or living-development-as-to-personality-development psychologismic epistemic acutisation difficulty-for, residualising \{decompulsing $\}$ delinearity for-cogency> magnitude\{of-experientiality/experiment\} (as to ${ }^{83}$ reference-of-thought-and- ${ }^{83}$ reference-of-thoughtdevolving $-{ }^{5}$ meaningfulness-and-teleology $\left.{ }^{9}\right)$. Such that the veridical existential< disontologising/re-ontologising aporeticism $>$ manifestation of human sovereignfunction/posture-<as-to-existentially-manifest-'embodied-subject $\sim$ consciousness-and-

\section{direct/deferential-conscientiousness',-as-of-its-'epistemic-reflexivity/unreflexivity-in-}

existence'/teleology> self-reflection — as-to-prospective-re-ontologising-articulation-ofsovereignty (arising from such unreflexivity/relative-reflexivity $>$ overall 'protracted-social—as-to-individual-by-institutional-by-social relative direct/deferential-responsibility/relative-reflexivity to 
cogency_chronicularity/annality-of-relative-reflexivity,-as-to-profound-supererogation ${ }^{9}$ ) $\quad$ is rather undergirded by the 'implicited-and-explicited repassing for human sovereignfunction/posture-<as-to-existentially-manifest-`embodied-subject $\sim$ consciousness-anddirect/deferential-conscientiousness',-as-of-its-'epistemic-reflexivity/unreflexivity-inexistence'/teleology> approbation-of/adherence-to deferentialism' so-elicited from the interlacing of the sovereign-function/posture-<as-to-existentially-manifest-'embodiedsubject consciousness-and-direct/deferential-conscientiousness',-as-of-its-'epistemicreflexivity/unreflexivity-in-existence'/teleology > with the 'overall genuine social intellectualfunction/posture various existentially-<disontologising/re-ontologising aporeticism $>$ induced human conceptivity/epistemic-reflexivity/epistemicity-relativism-determinism- $<$ reifying \{as-toknowledge-developing\}-and-empowering $>$ with respect to overall human competence/expertising (as of human socially expanded framework of deferential-formalisationtransference as to various cultivated skills/arts and time investment with regards to effectively manifest 'underlying veracity of core-philosophy/derivative-core-philosophy prospective reontologising as relevantly superseding prior mere-formulaicity/ritualisation pedantism induced knowledge-deadends-<as-preconverging-de-mentating/structuring/paradigming>')', notwithstanding the manifestation of undermining pedantising/muddling/formulaic-hollowingout_-in-subontologisation/subpotentiation-〈blurring/undermining-of-prospective-totalisingentailing,-as-to-entailing-<amplituding/formative-epistemicity $>$ totalising $\sim$ in-relativeontological-completeness $>$ desublimation. This so-critically implies the interlacing of human sovereign-emergence/becoming,-existentially-imbuing-human-freedom-as-tosupererogating/surrealising for-'knowledge-empowerment-over-ignorance-disempowerment'$<$ as-of-'developing-and-availing-sovereignsublimating_potential/possibilities/options/choices'-as-to-the-'credibility'/'ontologicalveracity'-underlying-the-'sovereign-conscious/conscientious-backdrop’> with 
anthropologisation-<as-to-futural-reflexivity,-in-\{decompulsing $\}$ delinearity- ‘invention'/‘creation'of-the-human/humanity> imbued 'widening the social imaginary' as to the ontologising/scientific/existence- $<$ honesty-constraining $>$ — scope_for_prospective_reontologising; and so, when it comes to manifest human sovereign-function/posture-<as-toexistentially-manifest-'embodied-subject consciousness-and-direct/deferentialconscientiousness',-as-of-its- 'epistemic-reflexivity/unreflexivity-in-existence'/teleology> selfreflection-as-to-prospective-re-ontologising-articulation-of-sovereignty induced epistemicgrowth,-as-\{veridical/sound\}-relative-reflexivity-in-existence/relativising from-limitedmentation-as-its-deepening/psychologismic epistemic-acutisation residualising, ${ }_{\{\text {decompulsing }\} \text { delinearity for-cogency with regards to prospective }}$ 'apriorising/axiomatising/referencing disambiguating/de-leveling/de-ressentiment/openedconstruct-of- $-{ }^{56}$ meaningfulness-and-teleology $\quad$ demoronisation- $<$ sublimating-nascence, nonextricatory-sublimating-upstreaming/'amontée'>', as to 'relative-reflexivity of human-percep-ti-vi-ty-<as-to - notional perceptualisation-of-and-leashing-to_social-functioning-andaccordance-as-of-social-stake-contention-or-confliction>'; so-implied as of prospective profound-

supereframing/reformulation/decatchmenting/detruncating/decompulsing/delinear ising - as-to-postconverging de-mentating/structuring/paradigming (imbued 'existential$\leq$ disontologising/re-ontologising aporeticism $>$ hermeneutic/textuality/reprojecting/supererogating/zeroing/re-acuting \{decompling $d$ delinearity/delinear-accreting/recomposuring- ${ }^{61}$ nonpresencing-perceptualisation-ofsublimating-over-desublimating-<as-'psychologismic-epistemic-acutisation-residualising,${ }_{\{\text {decompulsing }}$ delinearity for-cogency'_as-to- 'prospective-profound-supererogation -epistemicperspective'-of prospective- \& prior-differentiated apriorising/axiomatising/referencing $>$ with-respect-to-the-prospect-of-prospective-human-re-ontologising') and so over shallow- 
supererogation $\sim$ framing/formulation/catchmenting/truncating/compulsing/linearising —as-topreconverging de-mentating/structuring/paradigming (imbued fcompulsings linearity/linearaccreting- ${ }^{7}$ presencing-perceptualisation-of-sublimating-over-desublimating- $<$ as'psychologismic-epistemic-acutisation - nonresidualising-imbued-\{compulsing\} linearity ineclecticism-of-prior-mere-formulaicity/ritualisation'_as-to-‘secondnatured-epistemicperspective'-of-prospective-\&-prior-differentiated apriorising/axiomatising/referencing $>$ and-as-developing-into-interrelatedness-dynamics-of-social-constructing). Human sovereignemergence/becoming,-existentially-imbuing human-freedom-as-to-supererogating/surrealisingfor-'knowledge-empowerment-over-ignorance-disempowerment'-<as-of-'developing-andavailing-sovereign-sublimating_potential/possibilities/options/choices'-as-to-the'credibility'/'ontological-veracity'-underlying-the-'sovereign-conscious/conscientiousbackdrop'> thus speaks of the 'transfixing bifurcation' of human sovereign-function/posture<as-to-existentially-manifest-‘embodied-subject consciousness-and-direct/deferentialconscientiousness',-as-of-its- 'epistemic-reflexivity/unreflexivity-in-existence'/teleology> notionally/epistemically/bindingnessly of 'intragenerational epochal ${ }^{79}$ presencing-absolutising-identitive-constitutedness ${ }^{14}$ socialstake-contention-or-confliction of the advocacy/political/applicative-scope as to techno-socioecono-political implications' transfixing-susceptibility to 'protracted-social—as-to-individualby-institutional-by-social relative direct/deferential-irresponsibility/relative-unreflexivity to cogency_chronicularity/annality-of-relative-reflexivity,-as-to-profound-supererogation ${ }^{\circ}$ with regards supererogation $\sim$ framing/formulation/catchmenting/truncating/compulsing/linearising —as-topreconverging de mentang/struturing/paradigming (imbued fompulsingllinearity/linearaccreting $-{ }^{79}$ presencing-perceptualisation-of-sublimating-over-desublimating-<as'psychologismic-epistemic-acutisation-nonresidualising-imbued-\{compulsing'linearity in- 
eclecticism-of-prior-mere-formulaicity/ritualisation'_as-to-‘secondnatured-epistemic-

perspective'-of-prospective-\& prior-differentiated apriorising/axiomatising/referencing $>$

and-as-developing-into-interrelatedness-dynamics-of-social-constructing) on-the-one-hand and on-the-other-hand as of the crossgenerational overarching ontologising/scientific/existence$<$ honesty-constraining $>$ _ scope_for_prospective_re-ontologising imbued underlyingelucidative 'requisite sublimating/desublimating formulative-framing/fielding — of-entailment of human ontological-performance ${ }^{72}-<_{\text {including-virtue-as- }}$ ontology $>$ /morality/ethics/justice/etc. contemplation' of transfixing-imbuing of 'protractedsocial-as-to-individual-by-institutional-by-social relative direct/deferentialresponsibility/relative-reflexivity to cogency_chronicularity/annality-of-relative-reflexivity,-asto-profound-supererogation, with regards to prospective profoundsupererogation $\sim$ reframing/reformulation/decatchmenting/detruncating/decompulsing/delinear ising - as-to-postconverging de-mentating/structuring/paradigming (imbued 'existential<disontologising/re-ontologising aporeticism> hermeneutic/textuality/reprojecting/supererogating/zeroing/re-acuting ${ }_{\{\text {decompulsing }\}}$ delinearity/delinear-accreting/recomposuring- ${ }^{6}$ nonpresencing-perceptualisation-ofsublimating-over-desublimating-<as-'psychologismic-epistemic-acutisation-residualising,\{decompulsing $\}$ delinearity for-cogency’_as-to- 'prospective-profound-supererogation -epistemicperspective'-of-prospective-\& prior-differentiated apriorising/axiomatising/referencing $>$ with-respect-to-the-prospect-of-prospective-human-re-ontologising'). Such that the ontologising/scientific/existence- $<$ honesty-constraining $>$ — scope_for_prospective_reontologising effectively contests and addresses the 'human incidental/accidental ${ }^{79}$ presencingabsolutising-identitive-constitutedness ${ }^{14}$ psychologismic-epistemic-acutisation-difficulty$<$ for,-residualising_\{decomplsing $\}$ delinearity $\sim$ for-cogency $>$-〈as-of-requisite-profoundsupererogation -for-'disposedness-or-psychologismic-construct'-\{imbued-demoronisation- 
$<$ sublimating-nascence,-nonextricatory-sublimating-upstreaming/'amontée’> $>\rangle$ of the successive registry-worldviews/dimensions' so-reflected as to their " 79 presencing—absolutisingidentitive-constitutedness ${ }^{14} \quad$ social-stake-contention-or-confliction of the advocacy/political/applicative — scope as to techno-socio-econo-political implications conception of human sovereign apportioning as of lifespan extricatory/preconverging psychicalnascency moronisation- $<$ sublimating-nascence,-extricatory-desublimatingdownstreaming/'avalage'>'; and so, as of their absolute-<as-to-the-given-unreflexiveepistemic-dictat/dogma/ideology $>$-closed-construct as from blatant brutish conquest/subjugation conception of sovereign apportioning, dominion protection conception of sovereign apportioning, to the very natural-order-of-things conception of sovereign apportioning and to our subtle modern-day institutionally-distorted/disjointed conception of sovereign apportioning which are so-implied as of their given shallowsupererogation $\sim$ framing/formulation/catchmenting/truncating/compulsing/linearising —as-topreconverging de-mentating/structuring/paradigming (imbued accreting- ${ }^{79}$ presencing-perceptualisation-of-sublimating-over-desublimating-<as-

$$
\text { 'psychologismic-epistemic-acutisation-nonresidualising-imbued-\{compulsing\}linearity in- }
$$

eclecticism-of-prior-mere-formulaicity/ritualisation'_as-to-'secondnatured-epistemicperspective'-of-prospective-\&-prior-differentiated-apriorising/axiomatising/referencing $>$ and-as-developing-into-interrelatedness-dynamics-of-social-constructing). Such pretenses to ontological-veracity are existentially- $<$ disontologising/re-ontologising aporeticism $>$ baseless (but for eliciting the given registry-worldview/dimension 'prior desublimating notional $\sim$ catchmenting_<s to_disontologising/subontologising institutional imprintedness by re-ontologising institutional-imprinting $>$ as to presencing absolutising-identitiveconstitutedness existential-<disontologising/re-ontologising aporeticism $>$ preconverging 
contentivity/argumentativity/dialecticism/discursivity' notion of human sovereignfunction/posture-<as-to-existentially-manifest-'embodied-subject consciousness-and-

\section{direct/deferential-conscientiousness',-as-of-its-'epistemic-reflexivity/unreflexivity-in-}

existence'/teleology $>$ veracity/inveracity); as so-speaking inherently to 'limitedness/humansubpotency relative-unreflexivity as of the successive ${ }^{79}$ presencing-absolutising-identitiveconstitutedness ${ }^{14}$ social-stake-contention-or-confliction of the advocacy/political/applicativescope imbued 'shallow-

supereregation $\sim$ framing/formulation/catchmenting/truncating/compulsing/linearising_scale —of-opaque/contentious/un-nominalised/flawed-interpretations/domains of manifest blurriness-<sterilising/anecdotalising/trivialising-of-prospective-re-ontologising_bypreconverging,-in-disontologising-formulaic-dragging-out/hollowing-out>' (with regards to the associated successive pedantising/muddling/formulaic-hollowing-out—insubontologisation/subpotentiation-〈blurring/undermining-of-prospective-totalising-entailing,as-to-entailing-<amplituding/formative-epistemicity $>$ totalising in-relative-ontologicalcompleteness > cultivated and enculturated 'catchmenting-by-rejection/lipservicing/monopolising/gaming-of-the-system/charade/distraction vague/imaginary lures of social-stake-contention-or-confliction' as to 'accessory/adjunctive cobbling-together/gathering, procession, forming, presenting, dissipating and instrumentalising in a dearth of prospective chronicular/annalistic-cogency-<as-of-notional $\sim$ protensivity $>$ so-construed as cogency_chronicularity/annality-of-relative-reflexivity,-as-to-profound-supererogation ${ }^{\prime \prime}$ ). This so-explains why when the ontologising/scientific/existence- $<$ honesty-constraining $>$ scope_for_prospective_re-ontologising relative-ontological-completeness ${ }^{87}$ is-educed-andavails-and-re-avails (as to eliciting 'prospective human sovereign-emergence/becomingexistentially-imbuing human-freedom-as-to-supererogating/surrealising-for-'knowledge- 
empowerment-over-ignorance-disempowerment'-<as-of-'developing-and-availing-sovereignsublimating_potential/possibilities/options/choices'-as-to-the-'credibility'/'ontologicalveracity'-underlying-the-'sovereign-conscious/conscientious-backdrop'>'), such 'successive pretenses to ontological-veracity which are existentially-<disentologising/re-ontologising aporeticism $>$ baseless' (and underlying their human self-presence/self-constitutedness ${ }^{14}-<$ inperspective-epistemic-abnormalcy/preconvergence ${ }^{3}>\quad$ rationalisation-ofcontentivity/argumentativity/dialecticism/discursivity) are prospectively superseded/overcome; as of "prospective sublimating notional catchmenting-<as-to_disentologising/subontologising institutional-imprintedness - by re-ontologising institutional-imprinting $>$ as to nonpresencing-<perspective ontological-normalcy/postconvergence $>\quad$ existential<disontologising/re-ontologising aporeticism $>$ prospect of human individualconsciousness/collective-consciousness decompulsion-appraisal' for re-ontologising futural potentiation as anthropologisation-<as-to-futural-reflexivity,-in-\{decompulsing $\}$ delinearity'invention'/'creation'-of-the-human/humanity>. Thus, in reality human sovereignfunction/posture-<as-to-existentially-manifest-‘embodied-subject consciousness-anddirect/deferential-conscientiousness',-as-of-its-'epistemic-reflexivity/unreflexivity-inexistence'/teleology> 'protracted-social—as-to-individual-by-institutional-by-social relative direct/deferential-responsibility/relative-reflexivity to cogency_chronicularity/annality-ofrelative-reflexivity,-as-to-profound-supererogation " can only be accounted-for as of the crossgenerational overarching ontologising/scientific/existence- $<$ honesty-constraining $>$ scope_for_prospective_re-ontologising; as to its prospective sublimating cogency_chronicularity/annality-of-relative-reflexivity,-as-to-profound-supererogation ${ }^{9}$ claim to 'implicited-and-explicited repassing for human sovereign-function/posture-<as-toexistentially-manifest-‘embodied-subject $\sim$ consciousness-and-direct/deferentialconscientiousness',-as-of-its-'epistemic-reflexivity/unreflexivity-in-existence'/teleology> 
approbation-of/adherence-to deferentialism' (as to the eliciting of humanconsciousness/collective-consciousness-distendedness/detruncating-<beyond-selfpresencing,as-re-ontologising-decentering_of-consciousness/collective-consciousness,-as-topsychologismic-epistemic-acutisation — residualising, - $_{\text {-decompulsing? }}$ delinearity for-cogency $>$ for prospective re-ontologising - imbuing-of-prospective-humansublimating/emancipating/enfranchisement) cannot be existentially-<disontologising/reentologising aporeticism $>$ annulled by any such ${ }^{79}$ presencing-absolutising-identitiveconstitutedness ${ }^{4}$ 'conception of human sovereign apportioning as of lifespan extricatory/preconverging psychical-nascency moronisation- $<$ sublimating-nascence,extricatory-desublimating-downstreaming/'avalage’. As in reality the crossgenerational overarching ontologising/scientific/existence- $<$ honesty-constraining $>$ scope_for_prospective_re-ontologising imbued human-consciousness/collectiveconsciousness-distendedness/detruncating-<beyond-selfpresencing,-as-re-ontologisingdecentering_of-consciousness/collective-consciousness,-as-to-psychologismic-epistemic-

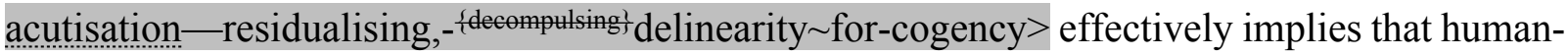
consciousness/collective-consciousness-distendedness/detruncating- $<$ beyond-selfpresencing,as-re-ontologising-decentering_of-consciousness/collective-consciousness,-as-topsychologismic-epistemic-acutisation-residualising, - -decompulsing\} $_{\text {delinearity }} \sim$ for-cogency $>$ reontologising potentiation as to 'overall human profound-supererogation ${ }^{6}$ of psychologismic epistemic-acutisation-residualising fepistemic-

thermeneutic/textuality/reprojecting/supererogating/zeroing/re-acuting,${ }_{\{\text {decompulsing }}$ delinearity for-cogency exercise' is of re-ontologising priority/precedence/primacy (as so-reflecting prospective re-ontologising 'dynamic cumulating/recomposuring psychologismic-epistemic-acutisation—residualising,--\{decompulsing $\}$ delinearity for-cogency phasing of limitedness/human-subpotency onto unlimitedness/existence-<flll-potency 
ef_sublimating nascence $>$ '); and so over any given registry-worldview/dimension 'rationalisation-of-contentivity/argumentativity/dialecticism/discursivity in psychologismic-. epistemic-acutisation-nonresidualising-imbued-\{complesing linearity in-eclecticism-of-priormere-formulaicity/ritualisation' which are rather effectively successively 'reinvented'/'recreated' by the sublimating-tradition/constant of humanconsciousness/collective-consciousness-distendedness/detruncating- $<$ beyond-selfpresencing,as-re-ontologising-decentering_of-consciousness/collective-consciousness,-as-to-

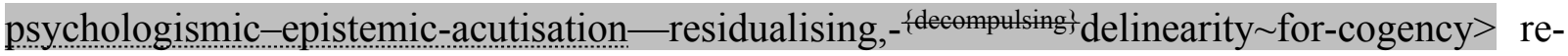
ontologising potentiation as to 'overall human profound-supererogation of psychologismicepistemic-acutisation-residualising \{epistemic-

totalising ${ }^{3}$ ' $h e r m e n e u t i c / t e x t u a l i t y /$ reprojecting/supererogating/zeroing/re-acuting,\{decompulsing\} delinearity for-cogency exercise'. Such that the palpability of the 'flow of human prospective $\quad$ profound-supererogation - over-shallow-supererogation ${ }^{2} \quad$ in superseding/overcoming the 'human incidental/accidental ${ }^{79}$ presencing-absolutisingidentitive-constitutedness ${ }^{14} \quad$ psychologismic-epistemic-acutisation-difficulty- $<$ for,residualising $-\{$ decompulsing $\}$ delinearity $\sim$ for-cogency $>$-〈as-of-requisite-profound-supererogation for-'disposedness-or-psychologismic-construct'-\{imbued-demoronisation-<sublimatingnascence,-nonextricatory-sublimating-upstreaming/'amontée’>\}) of the successive registryworldviews/dimensions' can only be countenanced as of human-consciousness/collectiveconsciousness-distendedness/detruncating-<beyond-selfpresencing,-as-re-ontologisingdecentering_of-consciousness/collective-consciousness,-as-to-psychologismic-epistemic-

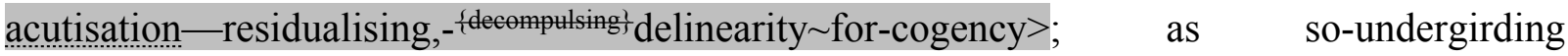
'limitedness/human-subpotency ${ }^{15}$ de-mentation-〈supererogatory $\sim$ ontological-de-mentation-ordialectical-de-mentation - stranding-or-attributive-dialectics $\rangle$ 
prospective 'existential-<disontologising/re-ontologising aporeticism $>$ postconverging aporeticism-overcoming/unovercoming' in the 'reinvention'/'recreation' of the-human/humanity so-construed as anthropologisation-<as-to-futural-reflexivity,-in-

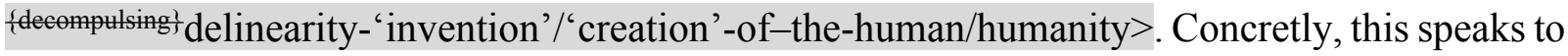
the fact the crossgenerational overarching ontologising/scientific/existence- $<$ honestyconstraining $>$ — scope_for_prospective_re-ontologising (imbuing of 'protracted-social—as-toindividual-by-institutional-by-social relative direct/deferential-responsibility/relativereflexivity to cogency_chronicularity/annality-of-relative-reflexivity,-as-to-profoundsupererogation ') claim to 'implicited-and-explicited repassing for human sovereignfunction/posture-<as-to-existentially-manifest-`embodied-subject $\sim$ consciousness-and-

\section{direct/deferential-conscientiousness',-as-of-its-'epistemic-reflexivity/unreflexivity-in-}

existence'/teleology> approbation-of/adherence-to deferentialism' is indispensable and must be articulated overtly, coherently and continuously; and so notwithstanding the elicited distractivealignment-to- ${ }^{8}$ reference-of-thought- $<$ of-apriorising/axiomatising/referencing $>30$ of the given registry-worldview/dimension ' ${ }^{79}$ presencing —absolutising-identitive-constitutedness ${ }^{14}$ socialstake-contention-or-confliction of the advocacy/political/applicative-scope as to techno-socioecono-political implications conception of human sovereign apportioning (as of its imbued lifespan extricatory/preconverging psychical-nascency moronisation-<sublimating-nascence,extricatory-desublimating-downstreaming/'avalage'>’ failing prospective human Beingdevelopment/ontological-framework-expansion-as-to-depth-of-ontologising-development-asinfrastructure-of- meaningfulness-and-teleology psychologismic epistemic acutisationdifficulty-for, residualising_\{decompulsing $\}$ delinearity for-cogeney> magnitude ${ }^{\{0 f-}$ experientiality/experiment\}). In this respect, the notion of 'implicited-and-explicited repassing for human sovereign-function/posture-<as-to-existentially-manifest-'embodied-subject $\sim$ consciousnessand-direct/deferential-conscientiousness',-as-of-its-'epistemic-reflexivity/unreflexivity-in- 
existence'/teleology> approbation-of/adherence-to deferentialism' (as to 'protracted-social—asto-individual-by-institutional-by-social relative direct/deferential-responsibility/relativereflexivity to cogency_chronicularity/annality-of-relative-reflexivity,-as-to-profoundsupererogation ') fundamentally underlies human sovereign-function/posture-<as-toexistentially-manifest-'embodied-subject consciousness-and-direct/deferentialconscientiousness',-as-of-its-'epistemic-reflexivity/unreflexivity-in-existence'/teleology> epistemic-growth,-as_ \{veridical/sound\}-relative-reflexivity-in-existence/relativising fromlimited-mentation-as-its-deepening/psychologismic epistemic-acutisation residualising, \{decomplsing delinearity for-cogency regards to prospective 'apriorising/axiomatising/referencing disambiguating/de-leveling/de-ressentiment/openedconstruct-of- -5 meaningfulness-and-teleology $\quad$ demoronisation- $<$ sublimating-nascence,nonextricatory-sublimating-upstreaming/'amontée'>' (for human sovereign-function/posture<as-to-existentially-manifest-‘embodied-subject consciousness-and-direct/deferentialconscientiousness',-as-of-its- 'epistemic-reflexivity/unreflexivity-in-existence'/teleology> selfreflection - as-to-prospective-re-ontologising-articulation-of-sovereignty); fundamentally in reflection of the fact that the 'relative-unreflexivity/relative-reflexivity limitedness/humansubpotency dynamics of supererogating ${ }^{6}$ \{affirmation/projection/assertion/notional $\sim$ selfdistantiation-by-unaffirmation/deprojection/deassertion/epistemic-decadence\}towards $\sim$ omnipotential-affirmation/projection/assertion/notional $\sim$ self-distantiation' is sodynamically of 'issue/relevance as to reflexivity/unreflexivity only to limitedness/humansubpotency' and not to 'unlimitedness/existence-<full-potency-of_sublimating nascence> already givenness/immanence' as inherently of immanent-reflexivity (as the issue of reontologising_-imbuing-of-prospective-human-sublimating/emancipating/enfranchisement is rather about prospective re-ontologising 'dynamic cumulating/recomposuring psychologismic-. epistemic-acutisation-residualising,-\{decompulsing $\}$ delinearity for-cogency phasing of 
limitedness/human-subpotency onto unlimitedness/existence-<fll-potency-of_sublimating nascence $>$ '). Such that inherent ontological-veracity is only as pertinent as to its eliciting of human sovereign-function/posture-<as-to-existentially-manifest-‘embodiedsubject consciousness-and-direct/deferential-conscientiousness',-as-of-its-'epistemicreflexivity/unreflexivity-in-existence'/teleology> epistemic-growth,-as_\{veridical/sound\} relative-reflexivity-in-existence/relativising from-limited-mentation-as-itsdeepening/psychologismic epistemic-acutisation residualising, \{decompulsing $\}$ delinearity foreogency (even as this openness paradoxically prompts the parallel manifestation of overall human $<$ amplituding/formative $>$ wooden-language-〈imbued-temporal-mereform/virtualities/dereification/akrasiatic-drag/denatured/preconverging-or-dementing narratives - of-the- reference-of-thought- categorical-imperatives/axioms/registryteleology > and pedantising/muddling/formulaic-hollowing-out-insubontologisation/subpotentiation-〈blurring/undermining-of-prospective-totalising-entailing,as-to-entailing-<amplituding/formative-epistemicity $>$ totalising $\sim$ in-relative-ontologicalcompleteness > desublimation); as so-failing prospective re-ontologising 'dynamic cumulating/recomposuring psychologismic-epistemic-acutisation-residualising,-phasing of limitedness/human-subpotency onto unlimitedness/existence-<fll potency-of_sublimating nascence>' (especially as manifested with 'shallowsuperenoming/formulation/catchmenting/truncating/compulsing/linearising_scale —of-opaque/contentious/un-nominalised/flawed-interpretations/domains of manifest blurriness-<sterilising/anecdotalising/trivialising-of-prospective-re-ontologising_bypreconverging,-in-disontologising-formulaic-dragging-out/hollowing-out>' together with 'unwieldy-contemplatable-disontologising/re-ontologising-implications,-with-regards-tohuman-sovereign-function/posture-<as-to-narrowness/evasiveness/vagueness-of- 
disontologising/re-ontologising $>$ with respect to contentious/un-nominalisedness of socialstake-contention-or-confliction'). Thus, the underlying manifestation of suboptimal sovereignemergence/becoming,-existentially-imbuing human-freedom-as-to-supererogating/surrealising for-'knowledge-empowerment-over-ignorance-disempowerment'-<as-of-'developing-andavailing-sovereign-sublimating_potential/possibilities/options/choices'-as-to-the'credibility'/'ontological-veracity'-underlying-the-'sovereign-conscious/conscientiousbackdrop'> (failing 'prospective sublimating notional catchmenting-<asto_disontologising/subontologising institutional-imprintedness-by re-ontologising institutional-imprinting $>$ as to nonpresencing-<perspective-ontologicalnormalcy/postconvergence $>\quad$ existential- $<$ disontologising/re-ontologising aporeticism $>$ prospect of human individual-consciousness/collective-consciousness decompulsion-appraisal' for re-ontologising futural potentiation as anthropologisation-<as-to-futural-reflexivity,-in\{decompulsing\} delinearity-'invention'/'creation'-of-the-human/humanity>) rather speaks to the given registry-worldview/dimension ${ }^{79}$ presencing-absolutising-identitive-constitutedness 'conception of human sovereign apportioning as of lifespan extricatory/preconverging psychical-nascency moronisation- $<$ sublimating-nascence,-extricatory-desublimatingdownstreaming/'avalage' imbued dearth of human sovereign-function/posture-<as-toexistentially-manifest-‘embodied-subject $\sim$ consciousness-and-direct/deferentialconscientiousness',-as-of-its-‘epistemic-reflexivity/unreflexivity-in-existence’/teleology> 'protracted-social—as-to-individual-by-institutional-by-social relative direct/deferentialresponsibility/relative-reflexivity to cogency_chronicularity/annality-of-relative-reflexivity,-asto-profound-supererogation'. Such that in-many-ways, it can perfectly be argued that the modern-day democratic process is more critically played notionally/epistemically/bindingnessly-<as-to-determinism/conceptivity-of-relative-unreflexivity/relative-reflexivity> rather at the level of 'ontologically-hegemonising-narrative ${ }^{71}$ ontological-performance ${ }^{72}$ 
<including-virtue-as-ontology>/morality/ethics/justice/etc.'-(with

notional/epistemic/bindingness ${ }^{-a s-t o-d e t e r m i n i s m / c o n c e p t i v i t y-o f-r e l a t i v e-u n r e f l e x i v i t y / r e l a t i v e-r e f l e x i v i t y s ~}$

'parrhesiastic/messianicity/profound-supererogation projection for sublimatingprolongation') with respect to inducing/failing-to-induce human sovereign-function/posture<as-to-existentially-manifest-“embodied-subject consciousness-and-direct/deferential-

conscientiousness',-as-of-its-'epistemic-reflexivity/unreflexivity-in-existence'/teleology> 'protracted-social—as-to-individual-by-institutional-by-social relative direct/deferentialresponsibility/relative-reflexivity to cogency_chronicularity/annality-of-relative-reflexivity,-asto-profound-supererogation '; which is what effectively and truly gives notional/epistemic/bindingness ${ }^{<a s-t o-d e t e r m i n i s m / c o n c e p t i v i t y-o f-r e l a t i v e-u n r e f l e x i v i t y / r e l a t i v e-r e f l e x i v i t y ~}>\quad$ 'human manifest idiosyncratic-ferment_for-notional $\sim$ cogency-〈as-to- $<$ surrealising/supererogatingdrive $>$-of-aestheticising-relief/depth-and-impetus $\rangle$ as of re-ontologising-bydisontologising/subontologising — dynamics of human-per-cep-ti-vi-ty-<as-to notional perceptualisation-of-and-leashing-to_social-functioning-and-accordance-as-ofsocial-stake-contention-or-confliction $>$ imbued notional cogency_chronicularity/annality-ofrelative-reflexivity,-as-to-profound-supererogation"' to the 'basic manifest/gestural sovereignexercising-<as-of-sovereign-deferentialism;-as-to-'direct/indirect-electing-and/ornominating'>' of 'unwieldy-contemplatable disontologising/re-ontologising implications'. Such that claims/pretenses to directly impute manifest human sovereign-function/posture-<as-toexistentially-manifest-'embodied-subject $\sim$ consciousness-and-direct/deferentialconscientiousness',-as-of-its-'epistemic-reflexivity/unreflexivity-in-existence'/teleology> 'protracted-social—as-to-individual-by-institutional-by-social relative direct/deferentialirresponsibility/relative-unreflexivity to cogency_chronicularity/annality-of-relativereflexivity,-as-to-profound-supererogation' (as to excessive weighting place on the 'basic manifest/gestural sovereign-exercising-<as-of-sovereign-deferentialism;-as-to-'direct/indirect- 
electing-and/or-nominating'>' of 'unwieldy-contemplatable disontologising/re-ontologising implications') are ontologically-flawed; given that the ontologising/scientific/existence$<$ honesty-constraining $>$ _ scope_for_prospective_re-ontologising (as to its implicited ' nonpresencing-<perspective-ontological-normalcy/postconvergence $>$ relativism/relativescope for epistemic-growth,-as - \{veridical/sound\}-relative-reflexivity-inexistence/relativising from-limited-mentation-as-its-deepening/psychologismic epistemicacutisation residualising, ${ }^{\text {\{decompulsing }}$ delinearity for-cogency') warrants that human sovereign-function/posture-<as-to-existentially-manifest-'embodied-subject $\sim$ consciousnessand-direct/deferential-conscientiousness',-as-of-its-'epistemic-reflexivity/unreflexivity-inexistence'/teleology> is notionally/epistemically/bindingnessly-<as-to-determinism/conceptivity-of-relativeunreflexivity/relative-reflexivity> the inherent point-of-departure for human prospective re-ontologisingimbuing-of-prospective-human-sublimating/emancipating/enfranchisement. Thusly, such human sovereign-function/posture-<as-to-existentially-manifest-'embodiedsubject consciousness-and-direct/deferential-conscientiousness',-as-of-its- ‘epistemicreflexivity/unreflexivity-in-existence'/teleology> 'protracted-social—as-to-individual-byinstitutional-by-social relative direct/deferential-irresponsibility/relative-unreflexivity to cogency_chronicularity/annality-of-relative-reflexivity,-as-to-profound-supererogation ${ }^{\text {, }}$ effectively lies with the overt/covert manifestation of undermining pedantising/muddling/formulaic-hollowing-out — in-subontologisation/subpotentiation〈blurring/undermining-of-prospective-totalising-entailing,-as-to-entailing<amplituding/formative-epistemicity>totalising in-relative-ontological-completeness $>$ desublimation; together with inadequate interlacing of the overall genuine social intellectualfunction/posture various existentially-<disontologising/re-ontologising aporeticism $>$ for inducing sublimating human conceptivity/epistemic-reflexivity/epistemicity-relativismdeterminism-<reifying \{as-to-knowledge-developing $\}$-and-empowering $>$ with respect to overall 
human competence/expertising (as of human socially expanded framework of deferentialformalisation-transference as to various cultivated skills/arts and time investment with regards to effectively manifest 'underlying veracity of core-philosophy/derivative-core-philosophy prospective re-ontologising as relevantly superseding prior mere-formulaicity/ritualisation pedantism induced knowledge-deadends-<as-preconverging-dementating/structuring/paradigming >'). In this respect, (notwithstanding the 'vague idealisation and romanticism of human rights and liberties') the veridical strength/pungency of such conceptions arise as of their instigative interlacing with the overall genuine social intellectualfunction/posture various existentially-<disentologising/re-ontologising aporeticism $>$ induced human conceptivity/epistemic-reflexivity/epistemicity-relativism-determinism- $<$ reifying \{as-toknowledge-developing\}-and-empowering $>$ with respect to overall human competence/expertising (as of human socially expanded framework of deferential-formalisationtransference as to various cultivated skills/arts and time investment with regards to effectively manifest 'underlying veracity of core-philosophy/derivative-core-philosophy prospective reontologising as relevantly superseding prior mere-formulaicity/ritualisation pedantism induced knowledge-deadends-<as-preconverging-de-mentating/structuring/paradigming >’'); as $\quad$ sopriorly defining and bound to induce either human sovereign-function/posture-<as-toexistentially-manifest-'embodied-subject $\sim$ consciousness-and-direct/deferentialconscientiousness',-as-of-its-'epistemic-reflexivity/unreflexivity-in-existence'/teleology> 'prospective sublimating notional catchmenting-<as-to_disontologising/subontologising institutional-imprintedness by re-ontologising institutional-imprinting $>$ as to nonpresencing-<perspective ontological-normaley/postconvergence> existentialdisontologising/re ontologising aporeticism> prospect of human individualconsciousness/collective-consciousness decompulsion-appraisal' for re-ontologising futural potentiation as anthropologisation-<as-to-futural-reflexivity,-in-\{decompulsing $\}$ delinearity- 
'invention'/'creation'-of-the-human/humanity> on-the-one-hand or on-the-other-hand human sovereign-function/posture-<as-to-existentially-manifest-'embodied-subject $\sim$ consciousnessand-direct/deferential-conscientiousness',-as-of-its-'epistemic-reflexivity/unreflexivity-inexistence'/teleology $>\quad$ 'prior desublimating notional catchmenting-<asto_disontologising/subontologising institutional-imprintedness_by re-ontologising institutional-imprinting $>$ as to presencing absolutising-identitive-constitutedness existential<<disontologising/re-ontologising aporeticism $>$ preconverging dementating/structuring/paradigming punctual/immediacy/constituted/compulsions-encumbered prior mere-formulaicity/ritualisation rationalisation-ofcontentivity/argumentativity/dialecticism/discursivity'. This insight is effectively validated by the fact that in-many-ways the difference between political 'convincing', 'constraining' and 'subterfuge' with regards to 'basic manifest/gestural sovereign-exercising-<as-of-sovereigndeferentialism;-as-to-'direct/indirect-electing-and/or-nominating'>' of 'unwieldycontemplatable disontologising/re-ontologising implications' (as to our modern-day 'intragenerational epochal ${ }^{79}$ presencing — absolutising-identitive-constitutedness ${ }^{14}$ social-stakecontention-or-confliction of the advocacy/political/applicative-scope as to techno-socioecono-political implications') increasingly manifests 'catchmenting-by-rejection/lipservicing/monopolising/gaming-of-the-system/charade/distraction vague/imaginary lures of social-stake-contention-or-confliction' as to 'accessory/adjunctive cobbling-together/gathering, procession, forming, presenting, dissipating and instrumentalising in a dearth of prospective chronicular/annalistic-cogency-<as-of-notional $\sim$ protensivity $>\quad$ so-construed $\quad$ as cogency_chronicularity/annality-of-relative-reflexivity,-as-to-profound-supererogation ${ }^{9}$; $\quad$ as the 'veracity of notions are poorly/hardly debated or rendered irrelevant in an increasingly chaotic media scene devoid-of/lacking sublimating cogency_chronicularity/annality-ofrelative-reflexivity,-as-to-profound-supererogation ${ }^{\prime}$ and aligned to the already absolutised 
conception of perceived prospective human re-ontologising possibility/potential (undergirded by the 'prior desublimating notional catchmenting-<as-to_disontologising/subentologising institutional-imprintedness - by re-ontologising institutional-imprinting $>$ as to presencing absolutising identitive-constitutedness existential-<disontologising/reentologising aporeticism $>$ preconverging de-mentating/structuring/paradigming punctual/immediacy/constituted/compulsions-encumbered prior mere-formulaicity/ritualisation rationalisation-of-contentivity/argumentativity/dialecticism/discursivity' narrative). In this regards, it is effectively the given registry-worldview/dimension notional cogency_chronicularity/annality-of-relative-reflexivity,-as-to-profoundsupererogation that manifestly precedes the given exercise of human sovereignfunction/posture-<as-to-existentially-manifest-'embodied-subject $\sim$ consciousness-and-

\section{direct/deferential-conscientiousness',-as-of-its-'epistemic-reflexivity/unreflexivity-in-}

existence'/teleology> (as so-reflected as from blatant brutish conquest/subjugation conception of sovereign apportioning, dominion protection conception of sovereign apportioning, to the very natural-order-of-things conception of sovereign apportioning and to our subtle modern-day institutionally-distorted/disjointed conception of sovereign apportioning and so since any such supposed conception/pretense to the given exercise of human sovereign-function/posture- $<$ asto-existentially-manifest-‘embodied-subject consciousness-and-direct/deferentialconscientiousness',-as-of-its-'epistemic-reflexivity/unreflexivity-in-existence'/teleology> doesn't arise but only after the given notional cogency_chronicularity/annality-of-relativereflexivity,-as-to-profound-supererogation is articulated existentially-<disontologising/reentologising aporeticism $>$ for such a given exercise of human sovereign-function/posture- $<$ asto-existentially-manifest-‘embodied-subject consciousness-and-direet/deferentialconscientiousness',-as-of-its-'epistemic-reflexivity/unreflexivity-in-existence'/teleology> to then arise existentially-<disontelogising/re-ontelogising aporeticism $>$ ); so-underlying the 
fundamental grip of the 'prior desublimating notional catchmenting-<asto_disontologising/subontologising institutional-imprintedness by re-ontologising institutional-imprinting $>$ as to presencing absolutising-identitive-constitutedness existential-<disontologising/re-ontologising aporeticism $>$ preconverging dementating/structuring/paradigming punctual/immediacy/constituted/compulsions-encumbered prior mere-formulaicity/ritualisation rationalisation-of-

contentivity/argumentativity/dialecticism/discursivity' narrative (which though cannot be construed as inherently superseding and subserving the ontologising/scientific/existence$<$ honesty-constraining $>$ - scope_for_prospective_re-ontologising with regards to its prospective sublimating 'implicited-and-explicited repassing for human sovereign-function/posture- $<$ as-toexistentially-manifest-`embodied-subject consciousness-and-direct/deferentialconscientiousness',-as-of-its-'epistemic-reflexivity/unreflexivity-in-existence'/teleology> approbation-of/adherence-to deferentialism' as to 'protracted-social—as-to-individual-byinstitutional-by-social relative direct/deferential-responsibility/relative-reflexivity to cogency_chronicularity/annality-of-relative-reflexivity,-as-to-profound-supererogation ${ }^{9}$ '). It is herein contended that the prospect for the prospective superseding/overcoming of "human incidental/accidental ${ }^{79}$ presencing — absolutising-identitive-constitutedness ${ }^{14}$ psychologismicepistemic-acutisation - difficulty- $<$ for,-residualisingof-requisite-profound-supererogation -for-'disposedness-or-psychologismic-construct'\{imbued-demoronisation-<sublimating-nascence,-nonextricatory-sublimatingupstreaming/'amontée'>\}) of the successive registry-worldviews/dimensions' as requisite of the ontologising/scientific/existence- $<$ honesty-constraining $>$ — scope_for_prospective_reontologising as to its prospective profoundsupererogation $\sim$ reframing/reformulation/decatchmenting/detruncating/decompulsing/delinear ising - as-to-postconverging de-mentating/structuring/paradigming (imbued 'existential- 
$\leq$ disontologising/re-ontologising aporeticism $>$

hermeneutic/textuality/reprojecting/supererogating/zeroing/re-acuting

\{decompusing delinearity/delinear-accreting/recomposuring- ${ }^{6}$ nonpresencing-perceptualisation-ofsublimating-over-desublimating-<as-'psychologismic-epistemic-acutisation-residualising,$\{$ \{decompulsing\} $\}$ delinearity $\sim$ for-cogency’_as-to-'prospective-profound-supererogation -epistemicperspective'-of-prospective-\&-prior-differentiated apriorising/axiomatising/referencing $>$ with-respect-to-the-prospect-of-prospective-human-re-ontologising') is in-many-ways effectively 'lacking/deficient as to registry-worldviews/dimensions institutionalprescience/imprimaturing-<dullness-of-the-spirit/psychologismic epistemic-acutisationnonresidualising-imbued-\{compulsing\} linearity in-eclecticism-of-prior-mereformulaicity/ritualisation $>$ imbued overt/covert preconverging-dementating/structuring/paradigming' (and so including and specifically reflected in our presentday totalisingly-ing — discretion/whim-of-thought); as to warrant appropriate 'substantivity of transversality-<for-sublimating-existential-eventuating/denouement,-from-'thinking-atfirst/pure-predisposition-preemptive-of-prospective-disontologising/subontologising' as-ofprospectively-disambiguated-affirmed-and-unaffirmed-'motif-andapriorising/axiomatising/referencing'> $>1$ ' imbued 'impersonalisation and deinstitutionalisation of prospective re-ontologising ${ }^{56}$ meaningfulness-and-teleology ${ }^{9}$ (as to ontologising-failsafe$\leq a s-t o-r e l a t i v e-u n r e f l e x i v i t y / r e l a t i v e-r e f l e x i v i t y$ bindingness/nondiscretionariness' of totalising-entailment $>$ ) for $\quad$ veridical re-originary_-_as-unen_-_rame-_ed/reontologising/unbeholdening/outlier_conceptualisation__imbued-postconverging/dialecticalthinking -'projective-insights'/‘epistemic-projection-in-conflatedness ' 'ofnotional deprocrypticism-prospective-sublimation $\rangle^{\circ}$ (and so with respect to unlimitedness/existence-<full-potency-of_sublimating nascence $>$ prospective apriorising/axiomatising/referencing-sublimating-reflexivity-beholdening under which 
limitedness/human-subpotency submits in profound-supererogation for prospective sublimating to which no registry-worldview/dimension conception of intellection can exclude itself with regards to its prospective epistemic-projection perspective elucidation of its manifestation pedantising/muddling/formulaic-hollowing-out-insubontologisation/subpotentiation-〈blurring/undermining-of-prospective-totalising-entailing,as-to-entailing-<amplituding/formative-epistemicity $>$ totalising $\sim$ in-relative-ontologicalcompleteness $>$ knowledge-deadends-<as-preconverging-dementating/structuring/paradigming $>$ ). In this regards, human-consciousness/collectiveconsciousness-distendedness/detruncating-<beyond-selfpresencing,-as-re-ontologisingdecentering_of-consciousness/collective-consciousness,-as-to-psychologismic_epistemicacutisation-residualising, - $^{\{\text {decompulsing }}$ \}elinearity for-cogency $>$ re-ontologising potentiation (with regards to prospective re-ontologising 'dynamic cumulating/recomposuring

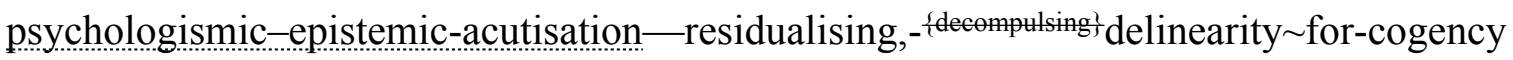
phasing of limitedness/human-subpotency onto unlimitedness/existence- $<$ full-potencyef_sublimating nascence $>$ ') of prospective 'reinvention'/'recreation' of the-human/humanity so-construed as anthropologisation-<as-to-futural-reflexivity,-in-\{decompulsing ${ }^{\text {f }}$ delinearity'invention'/'creation'-of-the-human/humanity> (as to the palpability of the 'flow of human prospective $\quad$ profound-supererogation ${ }^{6}$ over-shallow-supererogation ${ }^{\circ} \quad$ in superseding/overcoming the 'human incidental/accidental ${ }^{79}$ presencing-absolutisingidentitive-constitutedness psychologismic-epistemic-acutisation-difficulty- $<$ for,residualising-\{decompulsing\} $d$ delinearity for-cogency $>-\langle$ as-of-requisite-profound-supererogation for-'disposedness-or-psychologismic-construct'- $\{$ imbued-demoronisation- $<$ sublimatingnascence,-nonextricatory-sublimating-upstreaming/'amontée’ $>\}\rangle$ of the successive registryworldviews/dimensions') speaks to the 'psychologismic-epistemic-acutisationresidualising \{epistemic-totalising 3 \} ${ }^{3}$ hermeneutic/textuality/reprojecting/supererogating/zeroing/re- 
acuting, ${ }^{\{\text {decompulsing }\}}$ delinearity $\sim$ for-cogency’ notionally/epistemically/bindingnessly-<as-todeterminism/conceptivity-of-relative-unreflexivity/relative-reflexivity $>$ undergirding the superseding/overcoming of human Being-development/ontological-framework-expansion-as-to-depth-of-ontologisingdevelopment-as-infrastructure-of- meaningfulness-and-teleology , institutionaldevelopment-as-to-social-function-development and living-development-as-to-personalitydevelopment psychologismic epistemic-acutisation difficulty-<for, residualising $\{$ decompulsing $\}$ delinearity for-cogency $>$ magnitudes ${ }^{\{\text {of-experientiality/experiment }\}}$. It should be appreciated herein that human 'psychologismic-epistemic-acutisation-residualising thermeneutic/textuality/reprojecting/supererogating/zeroing/re-acuting,\{decompulsing\} delinearity for-cogency' (as to 'sublimating re-aestheticising psychologismictransfixity-<placeholder-setup-ontological-rescheduling - in-realigning/preactivity/formativebecoming/psychoanalytical-unshackling,-as-to-residualising-\{decompulsing\} delinearity-overnonresidualising_\{compulsing\} linearity $>$, with regards to prospective 'apriorising/axiomatising/referencing disambiguating/de-leveling/de-ressentiment/openedconstruct-of- $-{ }^{56}$ meaningfulness-and-teleology $\quad$ demoronisation- $<$ sublimating-nascence,nønextricatøry-sublimating-upstreaming/'amontée’> in relation to the-very-same purview/devolved-purview/devolving-purview-of-unlimitedness/existence-full par өf_sublimating nascence $>$; — 'implicited_attendant-ontological-contiguity ${ }^{67}$ ' educedexistentialising/contextualising/textualising_intelligibility/epistemicity/reflexivity-contiguity<imbued-notional cogency >' ${ }^{\prime}$ ), is effectively the exercise (aestheticisingly reflected as to human 'idiosyncratic-ferment_for-notional cogency-〈as-to- $<$ surrealising/supererogatingdrive $>$-of-aestheticising-relief/depth-and-impetus $\rangle \quad$ imbuing- $<$ by needling/prying/prospecting-for-'phasing-and-rooting'>-of interlay/organicalism/aestheticising-handle-<of-'psychologismic-transfixity\{residualising

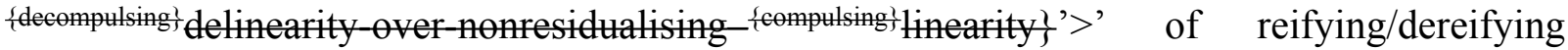


mental-aestheticising-<as-'psychologismic-existential-metaphoricity $\underset{\text { fas-to- }}{\text { fepistemic- }}$ totalising '’re-apriorising/re-axiomatising/re-referencing_in becoming\}’'-so-implicited-‘by-wayof-the-existentially/contextually/textually-manifest-motif-construct-as-specific-language'-asso-reflecting-'the-existentially/contextually/textually-manifestmoronisation/demoronisation' $>$ ') that underlies 're-ontologising as to the relativeunreflexivity/relative-reflexivity ontological-contiguity ${ }^{77}$ of disontologising/re-ontologising human ${ }^{56}$ meaningfulness-and-teleology ${ }^{\circ} ;$ and so, as from 'overall shallowsupererogation $\sim$ framing/formulation/catchmenting/truncating/compulsing/linearising_scale —of-opaque/contentious/un-nominalised/flawed-interpretations/domains of manifest blurriness-<sterilising/anecdotalising/trivialising-of-prospective-re-ontologising_bypreconverging,-in-disontologising-formulaic-dragging-out/hollowing-out>' $\quad$ (imbued \{compulsing\} linearity/linear-accreting- 7 presencing-perceptualisation-of-sublimating-overdesublimating-<as-'psychologismic-epistemic-acutisation-nonresidualising-imbuedlinearity in-eclecticism-of-prior-mere-formulaicity/ritualisation'_as-to‘secondnatured-epistemic-perspective'-of prospective-\& prior-differentiatedapriorising/axiomatising/referencing $\gg$ and-as-developing-into-interrelatedness-dynamics-ofsocial-constructing) TOWARDS 'prospective overall profoundsupererogation $\sim$ reframing/reformulation/decatchmenting/detruncating/decompulsing/delinear ising_scale_of-transparent/noncontentious/un-nominalised/sound-interpretations/domains of manifest unblurriness-<re-ontologising_by-postconverging-as-to-dragged-outsupererogatory $\sim$ wholesomeness/profound-supererogation ,-while-anecdotalising-priordisontologising-thresholding>' (imbued 'existential-<disontologising/re-ontelogising aporeticism> hermeneutic/textulity/reprojecting/supererogating/zeroing/re acuting $\{$ decompulsing $\}$ delinearity/delinear-accreting/recomposuring- ${ }^{-}$nonpresencing-perceptualisation-ofsublimating-over-desublimating-<as-'psychologismic-epistemic-acutisation-residualising,- 
$\{$ decompulsing $\}$ delinearity for-cogency’_as-to-'prospective-profound-supererogation -epistemic-

perspective'-of prospective-\& prior-differentiated apriorising/axiomatising/referencing $>$

with-respect-to-the-prospect-of-prospective-human-re-ontologising'). $\quad$ As $\quad$ from

'unlimitedness/existence-<full-potency-of_sublimating nascence $>$ perspective of immanentreflexivity' imperious as to re-ontologising human-per-cep-ti-vi-ty-<as-to notional perceptualisation-of-and-leashing-to_social-functioning-and-accordance-as-ofsocial-stake-contention-or-confliction> (with regards to human-consciousness/collectiveconsciousness-distendedness/detruncating-<beyond-selfpresencing,-as-re-ontologisingdecentering_of-consciousness/collective-consciousness,-as-to-psychologismic-epistemicacutisation-residualising, - $^{\text {ddecompulsing }}$ \} delinearity for-cogency> re-ontologising potentiation manifested as to 'recurrent/perpetuating/continuity-recomposuring existential$<$ disentologising/re-ontelogising aporeticism $>$ counteracting/supplanting/alienating-ofprior-apriorising/axiomatising/referencing' undergirding the 'overall relativeunreflexivity/relative-reflexivity - ontological-contiguity ${ }^{67} \sim$ of-the-human-institutionalisationprocess $^{68}$ imbued notional $\sim$ cogency_chronicularity/annality-of-relative-reflexivity,-as-toprofound-supererogation '), this so-implies on-the-one-hand that 'profound-reframing/reformulation/decatchmenting/detruncating/decompulsing/delinear ising_scale_of-transparent/noncontentious/un-nominalised/sound-interpretations/domains of manifest unblurriness-<re-ontologising_by-postconverging-as-to-dragged-outsupererogatory wholesomeness/profound-supererogation ,-while-anecdotalising-priordisontologising-thresholding>' (imbued 'existential-<disontologising/re-ontologising aporeticism $>\quad$ hermeneutic/texttality/reprojecting/supererogating/zeroing/re-acuting $\{$ \{decompulsing $\}$ delinearity/delinear-accreting/recomposuring- ${ }^{61}$ nonpresencing-perceptualisation-ofsublimating-over-desublimating-<as-'psychologismic-epistemic-acutisation-residualising,${ }_{\{\text {decompulsing }}$ delinearity for-cogency’_as-to-'prospective-profound-supererogation -epistemic- 
perspective'-of-prospective-\&-prior-differentiated-apriorising/axiomatising/referencing $>$

with-respect-to-the-prospect-of-prospective-human-re-ontologising') rather reflects

'<nonextricatory/postconverging/unaccommodating/questioning $>$-re-ontologising_prompting

perspective as to <punctual/immediacy/constituted/compulsions-encumbered prompted extended/prolonged-re-ontologising-enabling $>$ - psychologismic epistemic acutisation

residualising \{epistemic-totalising ${ }^{3}$ hermeneutic/textuality/reprojecting/supererogating/zeroing/re-

acuting, ${ }^{\text {\{decompulsing }}$ delinearity for-cogency _in-order-to-enable-<as-of-the-untenability-of-

induced unblurriness $>$ _ _ $\quad<$ prospective_punctual/immediacy/constituted/compulsions-

encumbered - disarming/dis-ideologising/deformulaicity/à-contrecoup/unsettlling/unarguable

prompted constricted/narrowingdown-re-ontologising-enabling $>$-psychologismic epistemic-

acutisation residualising a fepistemic-

totalising thermeneutic/textuality/reprojecting/supererogating/zeroing/re-acuting,

\{decompulsing delinearity for-cogency'; and so, in 'overall prospective re-ontologising acquiescence' as to 'protracted-social-as-to-individual-by-institutional-by-social relative direct/deferential-responsibility/relative-reflexivity to cogency_chronicularity/annality-ofrelative-reflexivity,-as-to-profound-supererogation' (and so with respect to 'overaching cultivated-and-enculturated interrelatedness-dynamics-of-social-constructing' notionally/epistemically/bindingnessly-<as-to-determinism/conceptivity-of-relative-unreflexivity/relative-reflexivity> imbued 'prospective sublimating notional catchmenting-<asto_disontologising/subontologising institutional-imprintedness_by re-ontologising institutional-imprinting $>$ as to nonpresencing-<perspective-ontologicalnormaley/postconvergence> existential-<disontologising/re-ontologising aporeticism $>$ prospect of human individual-consciousness/collective-consciousness decompulsion-appraisal' as the 'given re-ontologising human ${ }^{5}$ meaningfulness-and-teleology''). Whereas on-the-otherhand 
supererogation $\sim$ framing/formulation/catchmenting/truncating/compulsing/linearising_scale —of-opaque/contentious/un-nominalised/flawed-interpretations/domains of manifest blurriness- $<$ sterilising/anecdotalising/trivialising-of-prospective-re-ontologising_bypreconverging,-in-disontologising-formulaic-dragging-out/hollowing-out>' (imbued \{compulsing\} linearity/linear-accreting- 7 presencing-perceptualisation-of-sublimating-overdesublimating-<as-'psychologismic-epistemic-acutisation-nonresidualising-imbued\{compulsing\}]linearity in-eclecticism-of-prior-mere-formulaicity/ritualisation'_as-to‘secondnatured-epistemic-perspective'-of-prospective-\& prior-differentiatedapriorising/axiomatising/referencing $>$ and-as-developing-into-interrelatedness-dynamics-ofsocial-constructing) rather reflects

'<extricatory/preconverging/accommodating/unquestioning $>-$ disontologising/subontologising_prompting as to $\leq$ mere-formulaicity/ritualisation - $>$-prior induced $\quad<$ punctual/immediacy/constituted/compulsions-encumbered prompted extended/prolonged-re-ontologising-enabling $>$-psychologismic epistemic-acutisation residualising a fepistemictalising thermeneutic/textuality/reprojecting/supererogating/zeroing/reacuting, ${ }^{\text {\{decompulsing }}$ delinearity for-cogency' (manifesting prospectively as disontologising/subontologising 'rationalisation-ofcontentivity/argumentativity/dialecticism/discursivity in psychologismic-epistemicacutisation-nonresidualising-imbued-\{compulsing\} linearity in-eclecticism-of-prior-mereformulaicity/ritualisation') in 'overall prospective disontologising/subontologising acquiescence' as to 'protracted-social-as-to-individual-by-institutional-by-social relative direct/deferential-irresponsibility/relative-unreflexivity to cogency_chronicularity/annality-ofrelative-reflexivity,-as-to-profound-supererogation '; and so, with respect to 'overaching cultivated-and-enculturated interrelatedness-dynamics-of-social-constructing’ notionally/epistemically/bindingnessly-<as-to-determinism/conceptivity-of-relative-unreflexivity/relative-reflexivity $>$ 
imbued 'prior desublimating notional catchmenting-<as-to_disentologising/subentologising institutional-imprintedness-by re-ontologising institutional-imprinting $>$ presencing absolutising identitive-constitutedness existential-<disontologising/reentologising aporeticism> preconverging de-mentating/structuring/paradigming punctual/immediacy/constituted/compulsions-encumbered prior mere-formulaicity/ritualisation rationalisation-of-contentivity/argumentativity/dialecticism/discursivity' as the 'given disontologising/subontologising human ${ }^{56}$ meaningfulness-and-teleology ${ }^{9}$. The bigger implication here being that overall re-ontologising acquiescence as to 'protracted-social—as-toindividual-by-institutional-by-social relative direct/deferential-responsibility/relativereflexivity to cogency_chronicularity/annality-of-relative-reflexivity,-as-to-profoundsupererogation, (with regards to prospective re-ontologising 'dynamic cumulating/recomposuring psychologismic-epistemic-acutisation-residualising,-\{decompulsing\} delinearity for-cogency phasing of limitedness/human-subpotency onto unlimitedness/existence-<full-potency-of_sublimating nascence $>$ ') is ever always prospectively opened to the human exercise of "psychologismic-epistemic-acutisationresidualising $\sim$ fepistemic-totalising $3{ }^{3}$ hermeneutic/textuality/reprojecting/supererogating/zeroing/re-

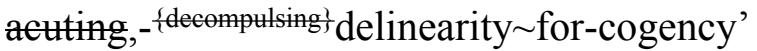
prospective_extended/prolonged-re-ontologising-enabling-in-order-to-enable- $<$ as-of-theuntenability-of-induced unblurriness $>$ - prospective_constricted/narrowingdown-reontologising-enabling') so-underlying the 'circular dynamics in humanconsciousness/collective-consciousness-distendedness/detruncating-<beyond-selfpresencing,as-re-ontologising-decentering_of-consciousness/collective-consciousness,-as-topsychologismic-epistemic-acutisation-residualising,-\{decompulsing $\}$ delinearity for-cogency $>$ '. This again is so-implied as to prospective 'human psychologismic-epistemic-acutisation-<as-to- 
postconverging-de-mentating/structuring/paradigming,-eliciting-of-existence's-sublimatingnascence-in-prospective-aporeticism-overcoming/unovercoming > as to epistemic-growth,-as\{veridical/sound\}-relative-reflexivity-in-existence/relativising from-limited-mentation-as-itsdeepening/psychologismic epistemic-acutisation residualising, ${ }^{\text {fdecompulsing }}$ delinearity foreogency' of the-very-same purview/devolved-purview/devolving-purview-ofunlimitedness/existence-<full-potency-of_sublimating nascence>;_-implicited_attendant ontological-contiguity ${ }^{67} \sim$ educed-

existentialising/contextualising/textualising_'intelligibility/epistemicity/reflexivity-contiguity$<$ imbued-notional cogency >' ; as so superseding/overcoming the psychologismic-epistemicacutisation-difficulty- $<$ for,-residualising_\{decompulsing $\}$ delinearity $\sim$ for-cogency $>-\langle$ as-ofrequisite-profound-supererogation -for-'disposedness-or-psychologismic-construct'\{imbued-demoronisation-<sublimating-nascence,-nonextricatory-sublimatingupstreaming/'amontée'>\}) for re-ontologising prospective Being-development/ontologicalframework-expansion-as-to-depth-of-ontologising-development-as-infrastructure-ofmeaningfulness-and-teleology psychologismic epistemic-acutisation difficulty-for, residualising \{decompulsing\} delinearity-for-eogency>-magnitude $\{$ of-experientiality/experiment\}. This sounderlies 'substantivity of transversality-<for-sublimating-existentialeventuating/denouement,-from-'thinking at first/pure-predisposition-preemptive-ofprospective-disontologising/subontologising' as-of-prospectively-disambiguated-affirmedand-unaffirmed-'motif-and-apriorising/axiomatising/referencing'>101, imbued 'impersonalisation and deinstitutionalisation of prospective re-ontologising ${ }^{5}$ meaningfulnessand-teleology ${ }^{9}$ (as to ontologising-failsafe-<as-to-'relative-unreflexivity/relative-reflexivity bindingness/nondiscretionariness' of totalising entailment $>$ ); in reflection of underlying 'constraining existence_-as-sublimating-withdrawal/unenframing/re-ontologising,-elicitedfrom-prospective-profound-supererogation imbuing human ontological-commitment - 
$<$ implied—-self-assuredness-of-ontological-good-faith/authenticity $\sim$ postconverging-dementating/structuring/paradigming -as-being-as-of-existential-reality>' and ' ${ }^{103}$ universaltransparency ${ }^{104}$-〈transparency-of-totalising-entailing,-as-to-entailing-<amplituding/formativeepistemicity>totalising in-relative-ontological-completeness \\as available-to/elicitable-to-〈asto-human-consciousness/collective-consciousness-distendedness/detruncating-<beyondselfpresencing,-as-re-ontologising-decentering_of-consciousness/collective-consciousness,-asto-psychologismic-epistemic-acutisation - residualising,- ${ }^{\{\text {decompulsing }\}}$ delinearity for-cogency $>>$ the social-functioning-and-accordance-as-of-social-stake-contention-or-confliction conception of any given registry-worldview/dimension <preconverging 'motif-andapriorising/axiomatising/referencing'-entailing >-existentialising — enframing/imprintedness〈as-to- historicity-tracing - in-presencing-hyperrealisation/hyperreal-transposition〉'. In this regards, it can be appreciated that present-day positivism/rational-empiricism nascentparticular/incipient-and-material/technical-sublimations- $<$ blinded-to-their-relative-ontologicalcompleteness - reference-of-thought- devolving> construed as '<prospective_punctual/immediacy/constituted/compulsions-encumbered_- disarming

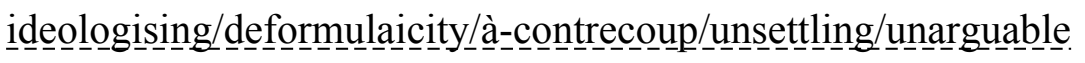
prompted constricted/narrowingdown-re-ontologising-enabling $>$-psychologismic epistemicacutisation residualising repistemictotalising thermeneutic/textuality/reprojecting/supererogating/zeroing/re-acuting, \{decompulsing $\}$ delinearity for cogeney' (as then of positivism/rational-empiricism 'prior human profound-supererogation ${ }^{6}$ metaphoricity ${ }^{57}$ ') were not so-uncontroversial in the non-positivising medieval-scholasticism manifest 'overaching cultivated-and-enculturated interrelatednessdynamics-of-social-constructing' notionally/epistemically/bindingnessly<as-todeterminism/conceptivity-of-relative-unreflexivity/relative-reflexivity> imbued 'prior desublimating notional catchmenting-<as-to_disontologising/subontologising institutional-imprintedness- 
constitutedness existential-<disontologising/re-ontologising aporeticism $>$ preconverging de-mentating/structuring/paradigming punctual/immediacy/constituted/compulsionsencumbered prior mere-formulaicity/ritualisation rationalisation-ofcontentivity/argumentativity/dialecticism/discursivity' as the 'given disontologising/subontologising human ${ }^{56}$ meaningfulness-and-teleology ${ }^{9}$ '. It is rather such asthen-of positivising/rational-empiricism profound-supererogation metaphoricity ${ }^{57}$ (as of '<nonextricatory/postconverging/unaccommodating/questioning $>$-re-ontologising_prompting perspective as to < punctual/immediacy/constituted/compulsions-encumbered prompted extended/prolonged-re-ontologising-enabling $>$ - psychologismic -epistemic-acutisationresidualising $\_$fepistemic-totalising ${ }^{\dagger}$ hermeneutic/textuality/reprojecting/supererogating/zeroing/reacuting, ${ }^{\{\text {decompulsing }}$ delinearity for-cogency $\quad$ in-order-to-enable- $<$ as-of-the-untenability-ofinduced unblurriness $>$ $<$ prospective_punctual/immediacy/constituted/compulsionsencumbered - disarming/dis_-ideologising/deformulaicity/à-contrecoup/unsettling/unargunabuble prompted constricted/narrowingdown-re-ontologising-enabling $>$-psychologismic epistemicacutisation residualising \{epistemic-

\section{totalising thermeneutic/textuality/reprojecting/supererogating/zeroing/re acuting,}

\{decompulsing $\}$ delinearity for-cogency') as to our present-day positivising/rational-empiricism meaningfulness-and-teleology : that ultimately led to the 'present-day overall re-ontologising acquiescence' as to 'protracted-social-as-to-individual-by-institutional-by-social relative direct/deferential-responsibility/relative-reflexivity to cogency_chronicularity/annality-ofrelative-reflexivity,-as-to-profound-supererogation " (with respect to our positivism/rationalempiricism 'overaching cultivated-and-enculturated interrelatedness-dynamics-of-socialconstructing' notionally/epistemically/bindingnessly-<as-to-determinism/conceptivity-of-relativeunreflexivity/relative-reflexivity> imbued 'prospective sublimating notional $\sim$ catchmenting $<$ as- 
to_disontologising/subontologising institutional-imprintedness by re-ontologising

institutional-imprinting $>$ as to

nonpresencing-<perspective-ontologicat-

normaley/postconvergence>

existential-<disontologising/re-ontologising aporeticism $>$

prospect of human individual-consciousness/collective-consciousness decompulsion-appraisal'

as the 'given re-ontologising human ${ }^{56}$ meaningfulness-and-teleology ${ }^{9}$ '). In other words, humanconsciousness/collective-consciousness-distendedness/detruncating- $<$ beyond-selfpresencing,-

as-re-ontologising-decentering_of-consciousness/collective-consciousness,-as-to-

psychologismic-epistemic-acutisation-residualising, - $^{- \text {decmpulsing }}$ delinearity for-cogency $>$ re-

ontologising potentiation as to 'overall human profound-supererogation of psychologismic-. epistemic-acutisation-residualising $\sim$ \{epistemic-

totalising ${ }^{3}$ 'hermeneutic/textuality/reprojecting/supererogating/zeroing/re-acuting,-

$\{$ decompulsing $\}$ delinearity for-cogency exercise' of re-ontologising priority/precedence/primacy (as so-reflecting prospective re-ontologising 'dynamic cumulating/recomposuring psychologismic-. epistemic-acutisation - residualising,--\{ phasing of limitedness/human-subpotency onto unlimitedness/existence-<fll-potency-of_sublimating nascence $>$ ') effectively supersedes any given registry-worldview/dimension 'rationalisation-ofcontentivity/argumentativity/dialecticism/discursivity in psychologismic-epistemicacutisation-nonresidualising-imbued-\{compulsing linearity in-eclecticism-of-prior-mereformulaicity/ritualisation'. Thus, speaking to the requisite profound-supererogation in overcoming human psychologismic-epistemic-acutisation-difficulty-<for,-residualising$\{$ decompulsing $\}$ delinearity for-cogency $>$-〈as-of-requisite-profound-supererogation -for-

\section{‘disposedness-or-psychologismic-construct'-\{imbued-demoronisation-<sublimating-}

nascence,-nonextricatory-sublimating-upstreaming/'amontée’> $>\rangle$ as to 'thinking at first/pure predisposition preemptive of prospective disontologising/subontologising'; as so-underlied as of preconverging/postconverging-rede-mentating/restructuring/reparadigming 
superseding/overcoming of " presencing-absolutising-identitive-constitutedness psychologismic-epistemic-acutisation — difficulty- $<$ for,-residualising${ }_{\{\text {decompulsing }\}}$ delinearity for-cogency $>-\langle$ as-of-requisite-profound-supererogation -for‘disposedness-or-psychologismic-construct'-\{ imbued-demoronisation-<sublimatingnascence,-nonextricatory-sublimating-upstreaming/'amontée'>\}〉'. This so-reflect the reality that humans did not transcend from a medieval worldview to a positivistic worldview by a mere 'logical/rationalising exercise' (as the mere logical/rationalising conceptualisation we have of such a transformation in today's positivism/rational-empiricism world is rather in effect an afterthought appraisal) but because the 'grander grasp on unlimitedness/existence-<full-potency ef_sublimating of positivism/rational-empiricism' as to its then 'prior human profound-supererogation ${ }^{9}$ metaphoricity ${ }^{5}$, developing human-per-cep-ti-vi-ty-<as-tonotional perceptualisation-of-and-leashing-to_social-functioning-and-accordance-as-ofsocial-stake-contention-or-confliction $>$ (so-underlied as of preconverging/postconverging-redementating/restructuring/reparadigming superseding/overcoming of the 'medievalism nonpositivising psychologismic-epistemic-acutisation-difficulty- $<$ for,-residualising\{decompulsing $\}$ delinearity for-cogency $>$-〈as-of-requisite-profound-supererogation -for'disposedness-or-psychologismic-construct'-\{ imbued-demoronisation-<sublimatingnascence,-nonextricatory-sublimating-upstreaming/'amontée’’\}〉') before its transformationas-to - transcendence-and-sublimity/sublimation/supereregatery $\sim$ de-mentativity into our modern-day positivism 'prospective human secondnatured ${ }^{56}$ meaningfulness-and-teleology ${ }^{9}$ ', constrained and made the medieval registry-worldview untenable/internally-contradictory existentially-< disontologising/re-ontologising aporeticism $>$; as well as the fact that the ships that set sail around the world for spices elicit a positive commercial opportunism that is responsible for destroying the social myth of a flat world; the bacteria theory that will ensure that one lives or die if we believe in it or not coerced the destruction of a superstitious medical 
worldview; or the scientific tools and knowledge that ensured that nation A or nation B will triumph if they believe in it or not, coerces the need to adopt a scientific worldview, etc. This points out the naivety of a supposedly core-philosophy/derivative-core-philosophy-(imbued requisite 'inkling-drive of dimensionality-of-sublimating ${ }^{25}$ <<amplituding/formative>supererogatory $\sim$ de-mentativeness/epistemic-growth-orconflatedness /transvaluative-rationalising/transepistemicity/anamnestic-residuality/spiritdrivenness-equalisation)') exercise 'failing to contemplate of the relevant existential< disontologising/re-ontologising aporeticism $>$ scale and issues (imbued psychologismic-epistemic-acutisation - difficulty- $<$ for,-residualising_\{decompulsing $\}$ delinearity $\sim$ for-cogency $>-\langle$ asof-requisite-profound-supererogation -for-'disposedness-or-psychologismic-construct'\{imbued-demoronisation-<sublimating-nascence,-nonextricatory-sublimatingupstreaming/'amontée'>\}) as to prospective human Being-development/ontologicalframework-expansion-as-to-depth-of-ontologising-development-as-infrastructure-ofmeaningfulness-and-teleology psychologismic epistemie acutisation diffieuly < for, residualising \{decompulsing\} delinearity-for-cogency>-magnitude\{of-experientiality/experiment\}’; as such core-philosophy/derivative-core-philosophy_(imbued requisite 'inkling-drive of dimensionality-of-sublimating 25 -<<amplituding/formative $>$ supererogatory $\sim$ dementativeness/epistemic-growth-or-conflatedness /transvaluativerationalising/transepistemicity/anamnestic-residuality/spirit-drivenness-equalisation〉') is undertaken in reflection of requisite profound-supererogation as from human 'crossgenerational notional firstnaturedness-formativeness-<as-to-eventualising inkling drive-or-seeding-misprising $>$ mental-processing-parity for ontological-performance ${ }^{72}$ <including-virtue-as-ontology $>$ /morality/ethics/justice/etc.' (as to 'prospective nonpresencing-<perspective-ontological-normalcy/postconvergence $>$ epistemic-projection' induced 'human re-ontologising transcendence-and-sublimity/sublimation/supereregatery $\sim$ de- 
mentativity' notwithstanding priorly given '79 presencing-absolutising-identitiveconstitutedness $^{14} \quad$ disontologising $<$ amplituding/formative-epistemicity $>$ totalising thrownness-in-existence $^{35}$ ), such that the frivolity of prior mereformulaicity/ritualisation-<as-to-mere-formulaicmethodologising/mutualising/organising/institutionalising,-prospectively-losing-track-of‘\{epistemic-totalising ${ }^{\dagger}$ re-apriorising/re-axiomatising/re-referencing-residuality-in-reoriginariness/re-origination'> 'normalised/stereotyped/selfhelping/feel-good knowledge being brought at the protracted-social—as-to-individual-by-institutional-by-social sovereign's service' cannot truly be qualified as of core-philosophy/derivative-core-philosophy-(imbued requisite 'inkling-drive of dimensionality-of-sublimating 〈<amplituding/formative>supererogatory $\sim$ de-mentativeness/epistemic-growth-orconflatedness /transvaluative-rationalising/transepistemicity/anamnestic-residuality/spiritdrivenness-equalisation)') as it fails 'thinking at first/pure predisposition preemptive of prospective disontologising/subontologising' (as rather prospectively constrained to the given presencing-absolutising-identitive-constitutedness ${ }^{14}$ mere 'secondnatured conscious/unconscious rationalising/calculating of the sublimating outcome of prior profoundsupererogation rationalisation-of-contentivity/argumentativity/dialecticism/discursivity imbued positive-opportunism — of-social-functioning-and-accordance ${ }^{75}$ ). This insight is critical in a veridical appreciation of what is truly meant by Science or Ontology (as to the ontologising/scientific/existence- $<$ honesty-constraining $>$ — scope_for_prospective_reontologising) beyond a ${ }^{7}$ presencing-absolutising-identitive-constitutedness ${ }^{14}$ naivety, as the ontologising/scientific/existence- $<$ honesty-constraining $>$ — scope_for_prospective_reontologising is rather more profoundly undergirded as of 'overall human profoundsupererogation of psychologismic-epistemic-acutisation-residualising hermeneutic/textuality/reprojecting/supererogating/zeroing/re-acuting,- 
\{decompulsing $\}$ delinearity for-cogency exercise' (in relation to the 'overaching cultivated-andenculturated interrelatedness-dynamics-of-social-constructing' notionally/epistemically/bindingnessly-as-to-determinism/conceptivity-of-relative-mneflexivity/relative-reflexivitys imbued 'desublimating/sublimating notional $\sim$ catchmenting-<asto_disontologising/subontologising institutional-imprintedness-by re-ontologising institutional-imprinting $>$ as to the given disontologising/re-ontologising human meaningfulness-and-teleology $\left.{ }^{9}\right) ;$ as such a presencing-absolutising-identitiveconstitutedness ${ }^{14}$ naivety simply generates the 'afterthought mere-formulaicity/ritualisation- $<$ asto-mere-formulaic — methodologising/mutualising/organising/institutionalising,-prospectivelylosing-track-of-‘ ‘epistemic-totalising ${ }^{\dagger}$ re-apriorising/re-axiomatising/re-referencing-residuality-inre-originariness/re-origination'> conception of science/ontology' which is not fundamentally as of the sublimating-tradition/constant of human-consciousness/collective-consciousnessdistendedness/detruncating-<beyond-selfpresencing,-as-re-ontologising-decentering_ofconsciousness/collective-consciousness,-as-to-psychologismic-epistemic-acutisationresidualising, - decompulsing $\}^{-}$delinearity for-cogency $>$re-ontologising potentiation as to 'overall human profound-supererogation of psychologismic-epistemic-acutisationresidualising \{ \{epistemic-totalising $3{ }^{3}$ hermeneutic/textly/reprojecting/supererogating/zeroing/reacuting, -\{decompulsing\} $d$ delinearity for-cogency exercise', of re-ontologising priority/precedence/primacy (as so-reflecting prospective re-ontologising 'dynamic cumulating/recomposuring psychologismic-epistemic-acutisation-residualising,\{decompling phasing of limitedness/human-subpotency onto unlimitedness/existence-<fll-potency-of_sublimating nascence $>$ '), over any given registryworldview/dimension 'rationalisation-of-contentivity/argumentativity/dialecticism/discursivity in psychologismic-epistemic-acutisation-nonresidualising-imbued-\{compulsing $\}$ linearity ineclecticism-of-prior-mere-formulaicity/ritualisation'. Ultimately, this elucidation of human- 
consciousness/collective-consciousness-distendedness/detruncating- $<$ beyond-selfpresencing,as-re-ontologising-decentering_of-consciousness/collective-consciousness,-as-topsychologismic-epistemic-acutisation — residualising, - decompulsing $_{\text {f }}$ delinearity $\sim$ for-cogency $>$ reontologising potentiation as to 'overall human profound-supererogation of psychologismic-. epistemic-acutisation-residualising $\sim$ fepistemic-

totalising 3 3 ${ }^{3}$ hermeneutic/textuality/reprojecting/supererogating/zeroing/re-acuting,\{decompulsing\} delinearity for-cogency exercise' undergirds the 'delineation of profoundsupererogation -veracity and shallow-supererogation-inveracity' with regards to '(notional/epistemic/bindingness sas-tederminism/conceptivity-of relative-mreflexivity/relative-reflexivityz_ human manifest idiosyneratic ferment_for-notional-cogency-_as-to $<$ surrealising/supererogating drive $>$ of-aestheticising relief/depth-and-impetus) as of $\quad$ re-ontologising-bydisontologising/subontologising—dynamics of human-per-cep-ti-vi-ty-<as-to notional perceptualisation-of-and-leashing-to_social-functioning-and-accordance-as-ofsocial-stake-contention-or-confliction $>$ imbued notional cogency_chronicularity/annality-ofrelative-reflexivity,-as-to-profound-supererogation "

- with this 'delineation of profound-supererogation -veracity and shallow-supererogation inveracity' so-warranted for prospective psychologismic-epistemic-acutisation-<as-topostconverging-de-mentating/structuring/paradigming,-eliciting-of-existence's-sublimatingnascence-in-prospective-aporeticism-overcoming/unovercoming $>$ as to epistemic-growth,-as \{veridical/sound\}-relative-reflexivity-in-existence/relativising from-limited-mentation-as-itsdeepening/psychologismic epistemic acutisation residualising, ${ }^{\{\text {decompulsing }}$ \}elinearity for eogency' imbued 'thinking at first/pure predisposition preemptive of prospective disontologising/subontologising' to thereof elicit prospective cogency_chronicularity/annalityof-relative-reflexivity,-as-to-profound-supererogation with respect to 'prospective postconverging aporeticism-overcoming/unovercoming the-Good/knowledge- 
reification $\sim$ gesturing-and-accounting — of-epistemic-phenomenalism- $<$ inprospective_psychologismic apriorising/axiomatising/referencing-\{of-'prospectively implicited_attendant-ontological-contiguity ' educedexistentialising/contextualising/textualising_'intelligibility/epistemicity/reflexivity-contiguity<imbued-notional cogency >' \}-conflatedness -in-\{preconverging ment by\} postconverging-entailment $>$ /understanding/<amplituding/formative-

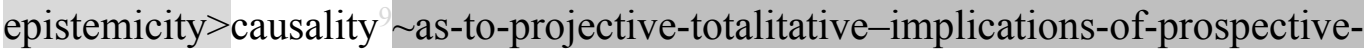
nonpresencing,-for-explicating relative-unreflexivity/relative-reflexivity - ontologicalcontiguity ';

- with this 'delineation of profound-supererogation -veracity and shallow-supererogation inveracity' so warranted for elucidating 're-ontologising unblurring/decolouring of human emotional-involvement' as of nonpresencing-<perspective-ontologicalnormalcy/postconvergence> epistemic-projection over 'disontologising/subontologising blurring/colouring human emotional-involvement' as of presencing-absolutising-identitiveconstitutedness $^{14}$ epistemic-projection, and so in reflecting the underlying re-ontologising veracity of prospective human sublimating/emancipating/enfranchisement (with regards to prospective re-ontologising 'dynamic cumulating/recomposuring psychologismic-epistemicacutisation-residualising, - $^{\{\text {decompulsing }}$ delinearity for-cogency phasing of limitedness/humansubpotency onto unlimitedness/existence-<full-potency-of_sublimating nascence $>$ as superseding any given registry-worldview/dimension 'rationalisation-ofcontentivity/argumentativity/dialecticism/discursivity in psychologismic-epistemicacutisation-nonresidualising-imbued-\{compulsing linearity in-eclecticism-of-prior-mereformulaicity/ritualisation');

- and, with this 'delineation of profound-supererogation -veracity and shallowsupererogation -inveracity' so warranted for elucidating the appropriateness of 
'desublimating/sublimating notional catchmenting-<as-to_disontologising/subontologising institutional-imprintedness by re-ontologising institutional-imprinting $>$ as to the given disontologising/re-ontologising human ${ }^{5}$ meaningfulness-and-teleology ${ }^{9}$, with regards to the sublimating perpetuating of the 'flow of human prospective profound-supererogation -overshallow-supererogation (in order to avoid manifest pedantising/muddling/formulaichollowing-out - in-subontologisation/subpotentiation-〈blurring/undermining-of-prospectivetotalising-entailing,-as-to-entailing-<amplituding/formative-epistemicity $>$ totalising $\sim$ inrelative-ontological-completeness > knowledge-deadends-<as-preconverging-dementating/structuring/paradigming > induced prospective 'epistemic-decadence' or teleologicaldecadence-<-in-dimensionality-of-desublimating-lack-of ${ }^{-}$-

\section{$<<$ amplituding/formative $>$ supererogatory $\sim$ de-mentativeness/epistemic-growth-or-}

\section{conflatedness /transvaluative-rationalising/transepistemicity/anamnestic-residuality/spirit-}

drivenness-equalisation> as of <extricatory/preconverging/accommodating/unquestioning >disontologising/subontologising_prompting perspective), wherein prior shallow supererogation $\sim$ framing/formulation/catchmenting/truncating/compulsing/linearising —as-topreconverging de-mentating/structuring/paradigming (imbued fcompulsings linearity/linearaccreting $-{ }^{79}$ presencing-perceptualisation-of-sublimating-over-desublimating-<as'psychologismic-epistemic-acutisation - nonresidualising-imbued-\{compulsing\} linearity ineclecticism-of-prior-mere-formulaicity/ritualisation'_as-to-'secondnatured-epistemicperspective'-of prospective \& prior differentiated apriorising/axiomatising/referencing $>$ and-as-developing-into-interrelatedness-dynamics-of-social-constructing) INDUCES 'prior desublimating notional catchmenting-<as-to_disontologising/subontologising institutionalimprintedness by re-ontologising institutional-imprinting $>$ as to presencingabsolutising-identitive-constitutedness existential-<disontologising/re-ontologising 
punctual/immediacy/constituted/compulsions-encumbered prior mere-formulaicity/ritualisation rationalisation-of-contentivity/argumentativity/dialecticism/discursivity' and so-bound to undermine the 'flow of human prospective profound-supererogation -over-shallowsupererogation ', whereas the 'flow of human prospective profound-supererogation -overshallow-supererogation, is rather veridically undergirded as of prospective profoundsupereregation $\sim$ reframing/reformulation/decatchmenting/detruncating/decompulsing/delinear ising - as-to-postconverging de-mentating/structuring/paradigming (imbued 'existential<disontologising/re-ontologising aporeticism> hermeneutic/textuality/reprojecting/supererogating/zeroing/re-acuting $\{$ decompulsing $\}$ delinearity/delinear-accreting/recomposuring- ${ }^{6}$ nonpresencing-perceptualisation-ofsublimating-over-desublimating-<as-'psychologismic-epistemic-acutisation-residualising,\{decompulsing\}delinearity for-cogency’_as-to-'prospective-profound-supererogation -epistemicperspective'-of-prospective-\&-prior-differentiated-apriorising/axiomatising/referencing $>$ with-respect-to-the-prospect-of-prospective-human-re-ontologising') INDUCED 'prospective sublimating notional $\sim$ catchmenting-<as-to_disontologising/subontologising institutionalimprintedness by re-ontologising institutional-imprinting $>$ as to nonpresencing<perspective ontological normaley/postconvergence> existential-<disontologising/reentologising apereticism $\gg$ prospect of human individual-consciousness/collectiveconsciousness decompulsion-appraisal'. This elucidation of human-consciousness/collectiveconsciousness-distendedness/detruncating-<beyond-selfpresencing,-as-re-ontologisingdecentering_of-consciousness/collective-consciousness,-as-to-psychologismic-epistemicacutisation-residualising, ${ }^{-\{\text {decompulsing }}$ \}delinearity for-cogency $>$ re-ontologising potentiation (as to 'overall human profound-supererogation' of psychologismic-epistemic-acutisationresidualising \{epistemic-totalising 3 \} 3 hermeneutic/textuality/reprojecting/supererogating/zeroing/reacuting,- -\{decompulsing\} $d$ delinearity for-cogency exercise' undergirding the 'delineation of 
profound-supererogation -veracity and shallow-supererogation -inveracity') speaks to the 'circular dynamics in human-consciousness/collective-consciousnessdistendedness/detruncating-<beyond-selfpresencing,-as-re-ontologising-decentering_ofconsciousness/collective-consciousness,-as-to-psychologismic-epistemic-acutisation residualising, - $^{\text {\{decompulsing }\}}$ delinearity $\sim$ for-cogency $>$ ' as of 'notional firstnaturednessformativeness-<as-to-eventualising-inkling-drive or seeding-misprising $>$ temporal-tointemporal-dispositions- $<$ so-construed-as-from-perspective-ontologicalnormalcy/postconvergence $>$ of human protracted-social - as-to-individual-by-institutional-bysocial ontological-performance ${ }^{72}<$ including-virtue-as-ontology $>$ /morality/ethics/justice/etc.' and cumulating/recomposuring 'human positive-opportunism-of-social-functioning-andaccordance $^{75}$ integration as secondnatured-institutionalisation' undergirding the 'overall relative-unreflexivity/relative-reflexivity ontological-contiguity ${ }^{67} \sim$ of-the-humaninstitutionalisation-process ${ }^{68}$ imbued notional cogency_chronicularity/annality-of-relativereflexivity,-as-to-profound-supererogation'. This 'circular dynamics in humanconsciousness/collective-consciousness-distendedness/detruncating-<beyond-selfpresencing,as-re-ontologising-decentering_of-consciousness/collective-consciousness,-as-to-

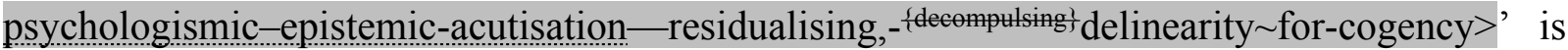
so-undergirded as of the constrastive 'manifest existential-<disontologising/re-ontologising aporeticism $>$ weighting-of/constrained-for' either human inhibited/uninhibited intemporalprojection/longness-of-register-of- meaningfulness-and-teleology or uninhibited/inhibited temporal-projection/shortness-of register-of - meaningfulness-and-teleology (as so-reflecting human preconverging/postconverging-rede-mentating/restructuring/reparadigming ontologicalperformance $^{72}-<$ including-virtue-as-ontology $>$ /morality/ethics/justice/etc.). Wherein on-theone-hand 'underlying human protracted-social—as-to-individual-by-institutional-by-social direct/deferential \{flawed/unsound\}-relative-unreflexivity-in-existence/absolutising from- 
limited-mentation/psychologismic epistemic acutisation nonresidualising imbued-

\{compulsing\} linearityoin-eclecticism-of-prior-mere-formulaicity/ritualisation' (as so-manifest with 'shallow-

supererogation $\sim$ framing/formulation/catchmenting/truncating/compulsing/linearising_scale —of-opaque/contentious/un-nominalised/flawed-interpretations/domains of manifest blurriness-<sterilising/anecdotalising/trivialising-of-prospective-re-ontologising_bypreconverging,-in-disontologising-formulaic-dragging-out/hollowing-out>') rather warrants $'<$ nonextricatory/postconverging/unaccommodating/questioning $>$-re-ontologising_prompting perspective as to <punctual/immediacy/constituted/compulsions-encumbered prompted extended/prolonged-re-ontologising-enabling $>$-psychologismic epistemic-acutisation residualising $\left\{\right.$ fepistemic-totalising ${ }^{3}$ hermeneutic/textuality/reprojecting/supererogating/zeroing/reacuting, ${ }^{\text {\{decompulsing }}$ delinearity for-cogency $\quad$-in-order-to-enable- $<$ as-of-the-untenability-ofinduced unblurriness $>$ _ $\quad<$ prospective_punctual/immediacy/constituted/compulsionsencumbered - disarming/dis_-ideologising/deformulaicity/à-contrecoup/unsettling/unargunabuble prompted constricted/narrowingdown-re-ontologising-enabling $>$-psychologismic epistemicacutisation residualising fepistemictotalising thermeneutic/textuality/reprojecting/supererogating/zeroing/re acuting, \{decompulsing delinearity for-cogency'. So-prompted with respect to the underlying blurriness$<$ sterilising/anecdotalising/trivialising-of-prospective-re-ontologising_by-preconverging,-indisontologising-formulaic-dragging-out/hollowing-out $>$ scope of relatively unelucidated-<asto-preconverging/postconverging rede-mentating/restructuring/reparadigming $>$ human ontological-commitment $^{66}$ and universal-transparency ${ }^{104}$ (with respect to underlying human 'crossgenerational notional firstnaturedness-formativeness-as drive or seeding misprising $>$ mental-processing-parity for ontological-performance ${ }^{72}$ $<$ including-virtue-as-ontology $>$ /morality/ethics/justice/etc.'); as to its consequent susceptibility 
to the 'relative eliciting-of uninhibited temporal-projection/shortness-of-register-ofmeaningfulness-and-teleology and inhibited intemporal-projection/longness-of-register-ofmeaningfulness-and-teleology, (which is so-eliciting/cultivating of relative 'pedantising/muddling/formulaic-hollowing-out —in-subontologisation/subpotentiation〈blurring/undermining-of-prospective-totalising-entailing,-as-to-entailing$<$ amplituding/formative-epistemicity $>$ totalising in-relative-ontological-completeness $>$ knowledge-deadends-<as-preconverging-de-mentating/structuring/paradigming >'). While onthe-other-hand 'underlying human protracted-social—as-to-individual-by-institutional-bysocial direct/deferential epistemic-growth,-as - \{veridical/sound\}-relative-reflexivity-inexistence/relativising from limited mentation as its deepening/psychologismic epistemic acutisation residualising, \{decompulsing\} delinearity for-cogency' (as so-manifest with 'profoundsupererogation $\sim$ reframing/reformulation/decatchmenting/detruncating/decompulsing/delinear ising_scale_of-transparent/noncontentious/un-nominalised/sound-interpretations/domains of manifest unblurriness-<re-ontologising_by-postconverging-as-to-dragged-outsupererogatory $\sim$ wholesomeness/profound-supererogation ,-while-anecdotalising-priordisontologising-thresholding>') 'rather manifests re-ontologising_prompting' as to '<prospective_punctual/immediacy/constituted/compulsions-encumbered_ _ disarmining/disideologising/deformulaicity/à-contrecoup/unsettling/un_-_arguable prompted constricted/narrowingdown-re-ontologising-enabling $>$ - psychologismic epistemicacutisation residualising \{epistemictotalising ${ }^{t}$ hermeneutic/textuality/reprojecting/supererogating/zeroing/re-acuting, \{decompulsing $\}$ delinearity for-cogency'. So-prompted with respect to the underlying unblurriness$<$ re-ontologising_by-postconverging-as-to-dragged-outsupererogatery $\sim$ wholesomeness/profound-supererogation ,-while-anecdotalising-priordisontologising-thresholding $>$ scope as of relatively elucidated-as-to- 
ontological-commitment ${ }^{66}$ and universal-transparency ${ }^{104}$ (with respect to underlying human 'crossgenerational notional firstnaturedness-formativeness-<as-to-eventualising inkling drive-or-seeding -misprising $>$ mental-processing-parity for ontological-performance ${ }^{72}$ $<$ including-virtue-as-ontology $>$ /morality/ethics/justice/etc.'), as to its consequent pliability/amenability to the 'relative eliciting-of inhibited temporal-projection/shortness-ofregister-of - meaningfulness-and-teleology and uninhibited intemporal-projection/longnessof-register-of meaningfulness-and-teleology' which is so-eliciting of relative 'genuine social intellectual-function/posture prospective re-ontologising-imbuing-of-prospective-humansublimating/emancipating/enfranchisement'. This 'circular dynamics in humanconsciousness/collective-consciousness-distendedness/detruncating- $<$ beyond-selfpresencing,as-re-ontologising-decentering of-consciousness/collective-consciousness,-as-to-

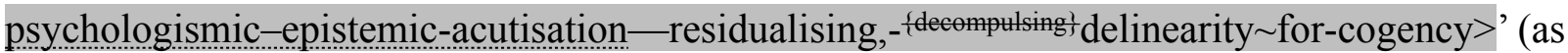
to human Being-development/ontological-framework-expansion-as-to-depth-of-ontologisingdevelopment-as-infrastructure-of- meaningfulness-and-teleology , institutionaldevelopment-as-to-social-function-development and living-development-as-to-personalitydevelopment psycholegismic epistemie acutisation diffieulty <for, residualising \{decompulsing\} delinearity for-cogeney>-magnitudes $\{$ of-experientiality/experiment\} $\}$ is effectively soreflected with the manifestation of the notional/epistemic/bindingness ${ }^{<a s-t o-d e t e r m i n i s m / c o n c e p t i v i t y-o f-~}$

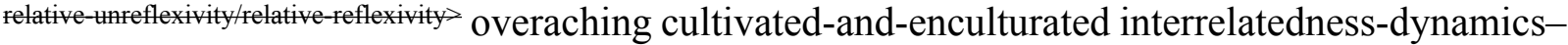
of-social-constructing as from 'catchmented-and-compulsed-<in-'existential-dearth-ofdemoronisation',-so-construed-as-from-ontological-normalcy/postconvergence-perspectivereflection-of-the-'destructuring-threshold_of-the-given-level's-conjugated-postlogism asdementing'> interpersonal, group, intergroup, community, local, national, political, geostrategic, etc. psychologismic epistemic acutisation difficulty-<for, residualising 
$\{$ decompulsing $\}$ delinearity for-cogency $>$ levels of interrelatedness-dynamics-of-socialconstructing'

preformulating/preframing/premeaningfulness-imbued-mediativity-and-deferentialism>-of-

meaningfulness-and-teleology and existential-<disontologising/re-ontologising aporeticism $>$ articulation manifestations'. This reflects the very impasse of human ontologicalperformance $^{72}-<$ including-virtue-as-ontology $>$ /morality/ethics/justice/etc. underlied as of human 'intemporal-projection/longness-of-register-of- meaningfulness-and-teleology' as to nonpresencing-<perspective-ontological-normalcy/postconvergence $>$ epistemic-projection' and 'temporal-projection/shortness-of-register-of- meaningfulness-and-teleology' as to presencing-absolutising-identitive-constitutedness ${ }^{14}$ epistemic-projection', and so with respect to any 'secondnatured human station/locus of limitedness/human-subpotency <amplituding/formative-epistemicity $>$-totalising $\sim$ thrownness-in-existence ${ }^{35}$ - (as imbued of limitedness/human-subpotency prospective dearth for \{epistemic-totalising łre-apriorising/reaxiomatising/re-referencing $\sim$ residuality — in-re-originariness/re-origination projection)' underlining human 'crossgenerational notional firstnaturedness-formativeness-<as-toeventualisingainkling-drive-or-seeding-misprising $>$-mental-processing-parity for ontological-performance ${ }^{72}$-<including-virtue-as-ontology $>$ /morality/ethics/justice/etc.'

existentially-<disontologising/re-ontologising aporeticism $>$ manifestable shallowsupererogation and profound-supererogation; and this with regards to requisite 'recurrent/perpetuating/continuity-recomposuring existential-<disontologising/reentologising aporeticism $>$ counteracting/supplanting/alienating-of-priorapriorising/axiomatising/referencing' for limitedness/human-subpotency supererogating ${ }^{\circ}$ affirmation/projection/assertion/notional $\sim$ self-distantiation-byunaffirmation/deprojection/deassertion/epistemic-decadence $\}$ —-towards $\sim$ omnipotentialaffirmation/projection/assertion/notional self-distantiation (as to its aspirative projection of 
'unlimitedness/existence-<full-potency-of_sublimating nascence $>$ perspective' imbued immanent-reflexivity omnipotential-affirmation/projection/assertion/notional $\sim$ selfdistantiation). Such an impasse speaks to the fact that there is inherently no basis as of human 'temporal-projection/shortness-of-register-of- meaningfulness-and-teleølogy' as of presencing-absolutising-identitive-constitutedness ${ }^{14}$ epistemic-projection' (imbued threshold of 'self-presence/self-constitutedness ${ }^{14}$-<in-perspective-epistemic-abnormalcy/preconvergence ${ }^{1}>$ rationalisation-of-contentivity/argumentativity/dialecticism/discursivity') for 'intemporalprojection/longness-of-register-of- meaningfulness-and-teleology as of nonpresencing<perspective-ontological-normalcy/postconvergence> epistemic-projection' dispensing-withimmediacy-for-relative-ontological-completeness ${ }^{8}$-by-reification/contemplative-distension (as to 'despite-the-self exercise of epistemic-projection in notional $\sim$ self-distantiation<imbued — re-motif-and-re-apriorising/re-axiomatising/re-referencing > $\quad$ as $\quad$ of $<$ nonextricatory/postconverging/unaccommodating/questioning $>$-re-ontologising_prompting perspective); but for the very inherently justificatory manifestation of 'intemporalprojection/longness-of register-of- meaningfulness-and-teleology as of nonpresencing$<$ perspective-ontological-normalcy/postconvergence $>$ epistemic-projection' (as to its educingand-availing-and-re-availing of relative-ontological-completeness ${ }^{87}$ imbued supererogation $\sim$ reframing/reformulation/decatchmenting/detruncating/decompulsing/delinear ising - as-to-postconverging de-mentating/structuring/paradigming). This is the case given 'unlimitedness/existence-<full-potency-of_sublimating nascence $>$ perspective' imbued immanent-reflexivity omnipotential-affirmation/projection/assertion/notional $\sim$ self-distantiation (implications as of prospective re-ontologising 'dynamic cumulating/recomposuring psychologismic-epistemic-acutisation—residualising,--\{decompulsing $\}$ delinearity for-cogency phasing of limitedness/human-subpotency onto unlimitedness/existence-<full-potency of_sublimating nascence' as superseding any given registry-worldview/dimension 
'rationalisation-of-contentivity/argumentativity/dialecticism/discursivity in psychologismic-.

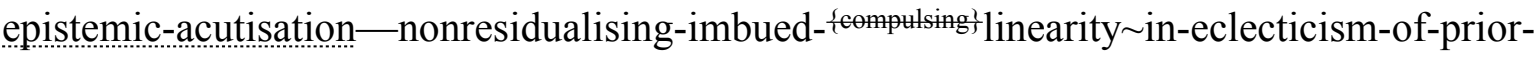
mere-formulaicity/ritualisation'); so-underlying human-consciousness/collectiveconsciousness-distendedness/detruncating-<beyond-selfpresencing,-as-re-ontologisingdecentering_of-consciousness/collective-consciousness,-as-to-psychologismic-epistemicacutisation-residualising,- ${ }^{\text {fdecompulsing }}$ - delinearity for-cogency $>$ as palpably reflected with the preconverging/postconverging-rede-mentating/restructuring/reparadigming of human psychologismic-transfixity-<placeholder-setup-ontological-rescheduling - inrealigning/preactivity/formative-becoming/psychoanalytical-unshackling,-as-to-residualising$\{$ \{decompulsing $\}$ delinearity-over-nonresidualising_\{compulsing\} linearity $>$. In-many-ways, this explains the circularity of any registry-worldviews/dimensions disontologising/subontologising imbuing-prospectively-of-human-desublimating/subjugation/disenfranchisement as to vicesand-impediments ${ }^{105}$, as it is precedingly caught up in its very prior 'overall shallowsupererogation $\sim$ framing/formulation/catchmenting/truncating/compulsing/linearising_scale —of-opaque/contentious/un-nominalised/flawed-interpretations/domains of manifest blurriness-<sterilising/anecdotalising/trivialising-of-prospective-re-ontologising_bypreconverging,-in-disontologising-formulaic-dragging-out/hollowing-out>’ $\quad$ (imbued \{compulsing\}linearity/linear-accreting- 7 presencing-perceptualisation-of-sublimating-overdesublimating-<as-'psychologismic-epistemic-acutisation-nonresidualising-imbuedfompulsingl linearity in-eclecticism-of-prior-mere-formulaicity/ritualisation'_as-to‘secondnatured-epistemic-perspective'-of prospective-\& prior-differentiatedapriorising/axiomatising/referencing $>$ and-as-developing-into-interrelatedness-dynamics-ofsocial-constructing); such that the very underlying 'relevant issue as to human relativereflexivity/relative-unreflexivity' to any given registry-worldview/dimension is rather a reflection upon how its inherently given 'temporal-projection/shortness-of-register-of- 
meaningfulness-and-teleology as of presencing-absolutising-identitive-constitutedness epistemic-projection' (imbued threshold of 'self-presence/self-constitutedness ${ }^{14}<$ inperspective-epistemic-abnormalcy/preconvergence ${ }^{31}>\quad$ rationalisation-ofcontentivity/argumentativity/dialecticism/discursivity') fundamentally undermines its pretense to prospective knowledge and transcendence-and-sublimity/sublimation/supereregatery $\sim$ dementativity. Thusly, so-underlying the ontologising/scientific/existence- $<$ honestyconstraining $>$ — scope_for_prospective_re-ontologising requisite human exercise of 'psychologismic-epistemic-acutisation-residualising

Thermeneutic/textuality/reprojecting/supererogating/zeroing/re-acuting,$\{$ decompulsing $\}$ delinearity for-cogency

'<nonextricatory/postconverging/unaccommodating/questioning $>$-re-ontologising_promptingprospective_extended/prolonged-re-ontologising-enabling-in-order-to-enable- $<$ as-of-theuntenability-of-induced $\sim$ unblurriness $>$ - prospective_constricted/narrowingdown-reontologising-enabling')' for 'substantivity of transversality-<for-sublimating-existentialeventuating/denouement,-from-'thinking at-first/pure-predisposition-preemptive-ofprospective-disontologising/subontologising' as-of-prospectively-disambiguated-affirmedand-unaffirmed-'motif-and-apriorising/axiomatising/referencing'>101, imbued 'impersonalisation and deinstitutionalisation of prospective re-ontologising meaningfulnessand-teleology ${ }^{9}$ ' (as to ontologising-failsafe-<as-to-'relative-unreflexivity/relative-reflexivity bindingness/nondiscretionariness' of totalising-entailment $>$ ); in reflection of the fact that knowledge-deadends-<as-preconverging-de-mentating/structuring/paradigming $>$ are inseparable from their given 'temporal-projection/shortness-of-register-of - meaningfulnessand teleogy as of presencing-absolutising-identitive-constitutedness ${ }^{14}$ epistemic-projection' failing prospective 'intemporal-projection/ongness-of-register-of- meaningfulness-andteleology as of ${ }^{6}$ nonpresencing-<perspective-ontological-normalcy/postconvergence $>$ 
epistemic-projection'. In this regards, the ontological-failsafe-<as-to-'relativeunreflexivity/relative-reflexivity bindingness/nondiscretionariness' of totalising-entailment> rather speaks of the 'relays of human intemporal-individuation epistemic-projection radicalities $\sim$ in-chronicular/annalistic-cogency-<as-of-notional $\sim$ protensivity $>$-〈as-to-limitedmentation-capacity-deepening —as subjecting limitedness/human-subpotency to 'educedunlimitedness/existence-sublimating nascence' $\rangle$ so-construed as cogency_chronicularity/annality-of-relative-reflexivity,-as-to-profound-supererogation ${ }^{\circ}$ for upholding prospective profoundsupererogation $\sim$ reframing/reformulation/decatchmenting/detruncating/decompulsing/delinear ising -as to postconverging de mentating/structuring/paradigming re rationalisation of contentivity/argumentativity/dialecticism/discursivity; and so underlined by the undergirding 'circular dynamics in human-consciousness/collective-consciousnessdistendedness/detruncating-<beyond-selfpresencing,-as-re-ontologising-decentering_ofconsciousness/collective-consciousness,-as-to-psychologismic-epistemic-acutisationresidualising, ${ }^{\text {- } \text { decompulsing }}$ delinearity $\sim$ for-cogency $>$

'<nonextricatory/postconverging/unaccommodating/questioning $>$-re-ontologising_prompting perspective as to < punctual/immediacy/constituted/compulsions-encumbered prompted extended/prolonged-re-ontologising-enabling $>$ - psychologismic epistemic acutisation residualising fepistemictotlising thermeneutic/textuality/reprojecting/supererogating/zeroing/reacuting, ${ }^{\text {\{decompulsing }}$ delinearity for-cogency -in-order-to-enable- $<$ as-of-the-untenability-ofinduced unblurriness $>$ _ _ prospective_punctual/immediacy/constituted/compulsions-

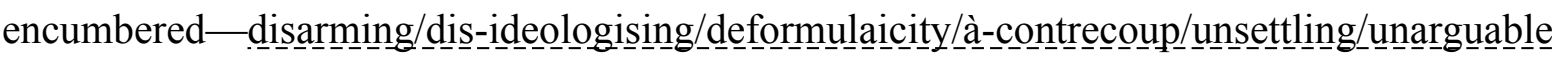
prompted constricted/narrowingdown-re-ontologising-enabling $>$-psychologismic epistemic acutisation residualising fepistemicthalising thermeneutic/textuality/reprojecting/supererogating/zeroing/re-acuting, 
\{decompulsing $\}$ delinearity for-cogency $\}$ in the face of prospective

'<extricatory/preconverging/accommodating/unquestioning $>-$

disontologising/subontologising_prompting as to $\leq$ mere-formulaicity/ritualisation - f $>$-prior induced $\quad<$ punctual/immediacy/constituted/compulsions-encumbered prompted extended/prolonged-re-ontologising-enabling $>$-psychologismic epistemic acutisation residualising \{epistemic-totalising ${ }^{3}$ hermeneutic/textuality/reprojecting/supererogating/zeroing/reacuting, ${ }^{\text {\{decompulsing }}$ delinearity for-cogency' imbued distractive-alignment-to- ${ }^{8}$ reference-ofthought- $<$ of-apriorising/axiomatising/referencing ${ }^{30}$ ). The undergirding 'circular dynamics in human-consciousness/collective-consciousness-distendedness/detruncating- $<$ beyondselfpresencing,-as-re-ontologising-decentering_of-consciousness/collective-consciousness,-asto-psychologismic-epistemic-acutisation - residualising, ${ }^{\text {\{decompulsing }}$ delinearity $\sim$ for-cogency $>$ ' thus attends to human preconverging-existential-extrication-as-of-existential-unthought (as to 'lifespan extricatory/preconverging psychical-nascency moronisation- $<$ sublimating-nascence,extricatory-desublimating-downstreaming/'avalage'>') as so-associated with the underlying blurriness-<sterilising/anecdotalising/trivialising-of-prospective-re-ontologising_bypreconverging,-in-disontologising-formulaic-dragging-out/hollowing-out> scope of relatively unelucidated <as to preconverging/posteonverging rede-

mentating/restructuring/reparadigming $>$ human ontological-commitment ${ }^{\circ}$ and universaltransparency ${ }^{104}$ (with respect to underlying human 'crossgenerational notional firstnaturednessformativeness-<as-to-eventualising inkling drive-or seeding-misprising $>$ mentalprocessing-parity for ontological-performance ${ }^{72}-$ including-virtue-as- $^{2}$ ontology $>$ /morality/ethics/justice/etc.'), as to its consequent susceptibility to the 'relative eliciting-of human uninhibited temporal-projection/shorness of register of meaning and-teleology and inhibited intemporal-projection/longness-of-register-of- meaningfulnessand-teleology 
out - in-subontologisation/subpotentiation-〈blurring/undermining-of-prospective-totalisingentailing,-as-to-entailing-<amplituding/formative-epistemicity $>$ totalising $\sim$ in-relativeontological-completeness $\rangle$ knowledge-deadends-<as-preconverging-dementating/structuring/paradigming $>^{\prime}$ ); and hence in want for nonextricatoryexistential-preempting-of-existential-unthought $'<$ nonextricatory/postconverging/unaccommodating/questioning $>$-re-ontologising_prompting perspective as to < punctual/immediacy/constituted/compulsions-encumbered prompted extended/prolonged-re-ontologising-enabling $>$-psychologismic epistemic-acutisation residualising fepistemic-totalising ${ }^{`}$ hermeneutic/textuality/reprojecting/supererogating/zeroing/reacuting, ${ }^{\text {fdecompulsing }}$ delinearity for cogeney -in-order-to-enable- $<$ as-of-the-untenability-ofinduced unblurriness $>$ _- $\quad$ prospective_punctual/immediacy/constituted/compulsions-

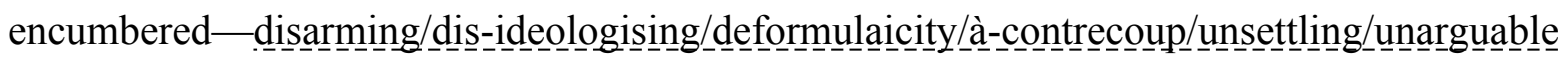
prompted constricted/narrowingdown-re-ontologising-enabling $>$-psychologismic epistemicacutisation residualising fepistemictotalising thermeneutic/textuality/reprojecting/supererogating/zeroing/re-acuting, \{decompulsing\} delinearity for-cogency' (as to 'nonextricatory/postconverging ontologising-and-reontologising angling-of-imaginary demoronisation- $<$ sublimating-nascence,-nonextricatorysublimating-upstreaming/'amontée'>'), as so-inducing and so-associated with the underlying unblurriness-<re-ontologising_by-postconverging-as-to-dragged-outsupererogatory $\sim$ wholesomeness/profound-supererogation ,-while-anecdotalising-priordisontologising-thresholding $>$ scope as of relatively elucidated-<as-topreconverging/postconverging rede-mentating/restructuring/reparadigming $>$ human ontological-commitment ${ }^{66}$ and universal-transparency ${ }^{104}$ (with respect to underlying human 'crossgenerational notional firstnaturedness-formativeness-<as-to-eventualising-inkling drive-or-seeding-misprising $>$ mental-processing-parity for ontological-performance ${ }^{72}$ 
$<$ including-virtue-as-ontology $>$ /morality/ethics/justice/etc.'), as to its consequent pliability/amenability to the 'relative eliciting-of human inhibited temporalprojection/shortness-of register-of- meaningfulness-and-teleology and uninhibited intemporal-projection/longness-of-register-of meaningfulness-and-teleology ' (which is soeliciting of relative 'genuine social intellectual-function/posture prospective re-ontologisingimbuing-of-prospective-human-sublimating/emancipating/enfranchisement'). This effectively so underscores human-consciousness/collective-consciousness-distendedness/detruncating$<$ beyond-selfpresencing,-as-re-ontologising-decentering_of-consciousness/collectiveconsciousness,-as-to-psychologismic-epistemic-acutisation-residualising,${ }_{\{\text {decompulsing }\}}$ delinearity for-cogency $>$ prospectively educed-and-availing-and-re-availing relative-ontological-completeness ${ }^{8}$-of-apriorising/axiomatising/referencing as to 'underlying human protracted-social-as-to-individual-by-institutional-by-social direct/deferential epistemic-growth,-as_-\{veridical/sound\}-relative-reflexivity-in-existence/relativising fromlimited-mentation-as-its-deepening/psychologismic epistemic-acutisation residualising, \{decompunging delinearity for-cogency' (as so-manifesting profoundsupererogation $\sim$ reframing/reformulation/decatchmenting/detruncating/decompulsing/delinear ising_scale_of-transparent/noncontentious/un-nominalised/sound-interpretations/domains of unblurriness-<re-ontologising_by-postconverging-as-to-dragged-out-

\section{supererogatory $\sim$ wholesomeness/profound-supererogation ,-while-anecdotalising-prior-}

disontologising-thresholding $>$ ); and so over priorly 'underlying human protracted-social—asto-individual-by-institutional-by-social direct/deferential \{flawed/unsound\}-relativeunreflexivity-in-existencelabsolutising from-limited-mentation/psychologismic epistemic acutisation nonresidualising imbued feompulsings tinearity in eclecticism of prior mere formulaicity/ritualisation' (as so-manifesting 'shallowsupereregation $\sim$ framing/formulation/catchmenting/truncating/compulsing/linearising_scale 
—of-opaque/contentious/un-nominalised/flawed-interpretations/domains

of manifest

blurriness- $<$ sterilising/anecdotalising/trivialising-of-prospective-re-ontologising_by-

preconverging,-in-disontologising-formulaic-dragging-out/hollowing-out>'). Such that the perceived palpability of inherent underlying unblurriness-<re-ontologising_by-postconvergingas-to-dragged-out-supererogatory-wholesomeness/profound-supererogation ,-while-

anecdotalising-prior-disontologising-thresholding $>$ scope as of relatively elucidated-<as-topreconverging/postconverging rede-mentating/restructuring/reparadigming $>\quad$ human ontological-commitment ${ }^{66}$ and universal-transparency ${ }^{104}$ (with respect to underlying human 'crossgenerational notional firstnaturedness-formativeness-<as-to-eventualising inklingdrive-or-seeding-misprising $>$ mental-processing-parity for ontological-performance ${ }^{72}$ <including-virtue-as-ontology $>$ /morality/ethics/justice/etc.') bluntly-speaking naturally keeps out non-ontologising/disontologising surreptitious knowledge-without-knowledge/knowledgeoutside-knowledge/extra-knowledge (as thusly rather superseded/overcome by reontologising_prompting as to '<prospective_punctual/immediacy/constituted/compulsionsencumbered — disarming/dis-ideologising/deformulaicity/à-contrecoup/unsettling/unarguable prompted constricted/narrowingdown-re-ontologising-enabling $>$-psychologismic epistemic aentisation residualising \{epistemic-

totalising thermeneutic/textuality/reprojecting/supererogating/zeroing/re-acuting, \{decompulsing\} delinearity for-cogency'); whereas the manifestation of underlying blurriness$<$ sterilising/anecdotalising/trivialising-of-prospective-re-ontologising_by-preconverging,-indisontologising-formulaic-dragging-out/hollowing-out $>$ scope of relatively unelucidated-<asto-preconverging/postconverging rede-mentating/restructuring/reparadigming $>\quad$ human ontological-commitment $^{66}$ and universal-transparency ${ }^{104}$ (with respect to underlying human 'crossgenerational notional firstnaturedness-formativeness-<as-to-eventualising inklingdrive-or-seeding misprising $>$ mental-processing-parity for ontological-performance ${ }^{72}$ 
<including-virtue-as-ontology $>$ /morality/ethics/justice/etc.') as effectively eliciting nonontologising/disontologising surreptitious knowledge-without-knowledge/knowledge-outsideknowledge/extra-knowledge rather superseded/overcome by '<nonextricatory/postconverging/unaccommodating/questioning $>$-re-ontologising_prompting perspective as to <punctual/immediacy/constituted/compulsions-encumbered prompted extended/prolonged-re-ontologising-enabling $>$ - psychologismic epistemic-acutisation residualising $\left\{\right.$ fepistemic-totalising ${ }^{\dagger}$ hermeneutic/textuality/reprojecting/supererogating/zeroing/reacuting, ${ }^{\{\text {decompulsing }}$ delinearity for-cogency -in-order-to-enable- $<$ as-of-the-untenability-ofinduced unblurriness $>$ _ $\quad<$ prospective_punctual/immediacy/constituted/compulsionsencumbered - disarming/dis-ideologising/deformulaicity/à-contrecoup/unsettlling/unnarguable prompted constricted/narrowingdown-re-ontologising-enabling $>$-psychologismic epistemic acutisation residualising $\{$ fepistemictotalising thermeneutic/textuality/reprojecting/supererogating/zeroing/re-acuting, \{decomplsing delinearity for-cogency'). Further, the elucidation of humanconsciousness/collective-consciousness-distendedness/detruncating-<beyond-selfpresencing,as-re-ontologising-decentering_of-consciousness/collective-consciousness,-as-topsychologismic-epistemic-acutisation — residualising, - $_{\text {¿decompulsing? }}$ delinearity for-cogency $>$ reontologising potentiation (as to 'overall human profound-supererogation of psychologismic-. epistemic-acutisation-residualising \{epistemic-

thermeneutic/textuality/reprojecting/supererogating/zeroing/re-acuting,\{decomplsing delinearity for-cogency exercise' undergirding the 'delineation of profoundsupererogation -veracity and shallow-supererogation -inveracity') effectively reflects that the 'point-of-departure of the profundity of overall human intelligibility-〈as-to-humanprojective/reprojective - aestheticising-re-motif-and-re-apriorising/re-axiomatising/rereferencing/re-intelligibilitysettingup/re-measuringinstrumenting-process,-in- 
<amplituding/formative-epistemicity>totalising conceptualisation〉' doesn't rest within any 'secondnatured human station/locus given threshold of self-presence/self-constitutedness ${ }^{14}-<$ inperspective-epistemic-abnormalcy/preconvergence ${ }^{3}>$ rationalisation-ofcontentivity/argumentativity/dialecticism/discursivity' but is rather beyond-the-consciousnessawareness-teleology ${ }^{9}<$ of-preconverging-existential-extrication-as-of-existential-unthought $>$; and so, in reflection of 'recurrently mediative-<in-expectation/in-anticipation> unconsciousness/potentiation-of-conscionability-<anxiety-as-to-reconstitution/reparation,-including-dreaming/psychical-reshuffling>' as the 'psychoanalytic boundlessness of human notional $\sim$ reflexivity- $<$ \{veridical/sound $\}$-relative-reflexivity-in-existence/relativising fromlimited-mentation-as-its-deepening/psychologismic-<residualising ${ }^{\text {\{decompulsing }}$ delinearity foreogency> by _flawed/unsound\}-relative-unreflexivity-in-existence/absolutising fromlimited-mentation/psychologismic epistemic acutisation nonresidualising imbued\{compulsing\} linearity in-eclecticism-of prior-mere-formulaicity/ritualisation> existential< disontologising/re-ontologising aporeticism $>$ backdrop'. The implication here is that humanconsciousness/collective-consciousness-distendedness/detruncating-<beyond-selfpresencing,-

\section{as-re-ontologising-decentering_of-consciousness/collective-consciousness,-as-to-}

psychologismic-epistemic-acutisation - residualising,-\{decompulsing\} delinearity for-cogency> speaks notionally/epistemically/bindingnessly-<as-to-determinism/conceptivity-of-relative-unreflexivity/relativereflexivitys to tre-eliciting of prospective profoundsupererogation $\sim$ reframing/reformulation/decatchmenting/detruncating/decompulsing/delinear ising—as-to-postconverging de-mentating/structuring/paradigming re-rationalisation-ofcontentivity/argumentativity/dialecticism/discursivity' as to 're-ontologising-bydisontologising/subontologising — dynamics of human-per-cep-ti-vi-ty-<as-tonotional perceptualisation-of-and-leashing-to_social-functioning-and-accordance-as-ofsocial-stake-contention-or-confliction>' with regards to 'protracted-social—as-to-individual- 
by-institutional-by-social direct/deferential facing-up or blinking to educed-and-availing-andre-availing relative-ontological-completeness ${ }^{87}$-of-apriorising/axiomatising/referencing (underlied as of preconverging/postconverging-rede-mentating/restructuring/reparadigming)'. This is the case with respect to shallow $<$ extricatory/preconverging/accommodating/unquestioning $>-$ disontologising/subontologising_prompting perspective' $\quad$ TO 'profound $<$ nonextricatory/postconverging/unaccommodating/questioning $>$-re-ontologising_prompting perspective' (imbued 'psychologismic epistemic-acutisation difficulty-<for, residualising

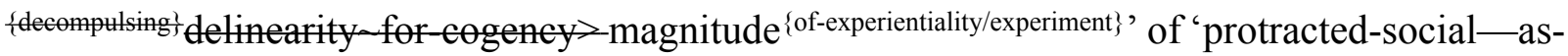
to-individual-by-institutional-by-social direct/deferential facing-up or blinking to educed-andavailing-and-re-availing relative-ontological-completeness ${ }^{87}$-ofapriorising/axiomatising/referencing'); so-reflecting 'profoundsupererogation $\sim$ reframing/reformulation/decatchmenting/detruncating/decompulsing/delinear ising —as-to-postconverging de-mentating/structuring/paradigming priority/precedence/primacy' as from re-ontologising prospective Beingdevelopment/ontological-framework-expansion-as-to-depth-of-ontologising-development-asinfrastructure-of- meaningfulness-and-teleology psychologismic epistemic aeutisationdifficulty $<$ for, residualising_\{decompulsing $\}$ delinearity for-cogency> magnitude $\{$ ofexperientiality/experiment\}, then institutional-development-as-to-social-function-development psychologismic epistemic acutisation difficulty-for, residualising \{decompusing\} delinearity for-cogency> magnitude $\{$ of-experientiality/experiment\} and then livingdevelopment-as-to-personality-development psychologismic epistemic-acutisationdifficulty< for, residualising \{decompulsing\} delinearity for cogeney> magnitude ${ }^{\{0 f-}$ experientiality/experiment\}. The underlying implication being that human 'disontologising/subontologising failure to address the relevantly requisite 
superseding/overcoming of prospective psychologismic epistemic-acutisation difficulty$<$ for, residualising $\{$ decompulsing $\}$ delinearity for-cogency> magnitude $\{$ of-experientiality/experiment $\}$, priorily goes hand-in-hand with the manifestation of associated knowledge-deadends- $<$ aspreconverging-de-mentating/structuring/paradigming $>$ (as so reflecting-and-defining the given registry-worldview's/dimension's disontologising/subontologising_imbuing-prospectivelyof-human-desublimating/subjugation/disenfranchisement as to vices-and-impediments ${ }^{105}$ ); and so notwithstanding the 'ploy of overlooking/ignoring', which simply speaks to the reality of human 'disontologising/subontologising processive-motif-'exuding aestheticising-gesturing' ef-apriorising/axiomatising/referencing_imbued_notional $\sim$ reductionism- $<$ of-existentialprospection,-whether-as-of-trepidatious/warped/preclusive/occlusive/protensivenotional $\sim$ reductionism $>$ ' (as to 'existentially-<disontologising/re-ontologising aporeticism $>$ manifest incidental/accidental reactive-sufferance/endurance in supposedly and paradoxically subordinating/subserving/collateralising the possibility for prospective re-ontologisingimbuing-of-prospective-human-sublimating/emancipating/enfranchisement'). Thusly speaking to the fact that requisite prospective re-ontologising is 'underlined unwaveringly/definitely' as of human '<amplituding/formative-epistemicity $>$-totalising $\sim$ renewing-realisation/reperception/re-thought self-reflexive instigative-eventuating-〈as-to-teleologicalinstigative/incipient-willing/arbitrariness/waywardness/faithdrivenness/supererogating-forhuman-intelligibility,-preceding-existence's-eventuating-sublimating-validation/desublimatinginvalidation)' perpetuating the 'flow of human prospective profound-supererogation -overshallow-supererogation', as of re-aestheticising psychologismic-transfixity-<placeholdersetup-ontological-rescheduling — in-realigning/preactivity/formativebecoming/psychoanalytical-unshackling,-as-to-residualising-\{decompulsing\} $d$ delinearity-over-

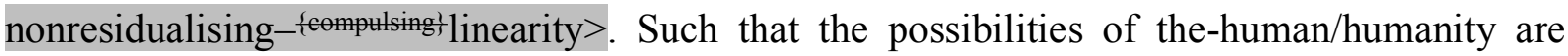
underlined existentially-<disontologising/re-ontologising aporeticism $>$ as of 'human relative- 
unreflexivity/relative-reflexivity' ('there is nothing outside the text of human textuality of relative-unreflexivity/relative-reflexivity' as to the fact that 'existence preceding/defining essence' inherently implies 'preconverging/postconverging-redementating/restructuring/reparadigming as of limitedness/human-subpotency supererogating ${ }^{6}\{$ affirmation/projection/assertion/notional $\sim$ self-distantiation-byunaffirmation/deprojection/deassertion/epistemic-decadence $\}$ — towards $\sim$ omnipotentialaffirmation/projection/assertion/notional self-distantiation'); as so-guaranteeing the

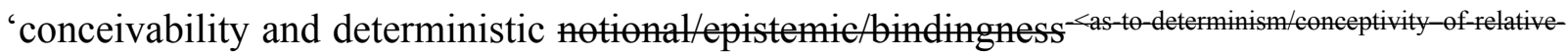
mneflexivity/relative-reflexivityz-articulation' of the ontologising/scientific/existence- $<$ honestyconstraining $>$ _-scope_for_prospective_re-ontologising. Such that 'human relative-unreflexivity disontologising/subontologising failure to address the relevantly requisite superseding/overcoming of prospective psychologismic epistemic-acutisation difficulty$<$ for, residualising \{decompulsing\} delinearity for-cogency> magnitude $\left.{ }^{\{0-e x p e r i e n t i a l i t y / e x p e r i m e n t}\right\}$, is effectively amenable/pliable (however the high or low emotional-involvement) to relativereflexivity educed 'substantivity of transversality-<for-sublimating-existentialeventuating/denouement,-from-'thinking-at-first/pure-predisposition-preemptive-ofprospective disontologising/subontologising’' as-of-prospectively-disambiguated-affirmedand-unaffirmed-'motif-and-apriorising/axiomatising/referencing'>101, imbued 'impersonalisation and deinstitutionalisation of prospective re-ontologising ${ }^{5}$ meaningfulnessand-teleology ${ }^{9}$, (as to ontologising-failsafe-<as-to-'relative-unreflexivity/relative-reflexivity bindingness/nondiscretionariness' of totalising-entailment $>$ ). This is the case, notwithstanding elicited distractive-alignment-to- ${ }^{83}$ reference-of-thought- $<$ ofapriorising/axiomatising/referencing $>$ ' <in-'existential-dearth-of-demoronisation',-so-construed-as-from-ontologicalnormalcy/postconvergence-perspective-reflection-of-the-'destructuring-threshold_of-the- 
given-level's-conjugated-postlogism as-dementing'> interpersonal, group, intergroup, community, local, national, political, geostrategic, etc. psychologismic epistemic-acutisationdifficulty < for, residualising \{decompulsing\} delinearity for-cogency>-levels of interrelatednessdynamics-of-social-constructing' of 'formativeness-<as-to-intersolipsism-ofpreformulating/preframing/premeaningfulness-imbued-mediativity-and-deferentialism>-ofmeaningfulness-and-teleology and existential-<disontologising/re-ontologising apereticism $>$ articulation manifestations'); actually speaking of the 'veracity of a human overt/covert conscious/subconscious appraisal/reappraisal-capacity of underlying ontologisingveracity' however the incidental/accidental disontologising/subontologising motivation of 'temporal-projection/shortness-of register-of- meaningfulness-and-teleology 9 as to

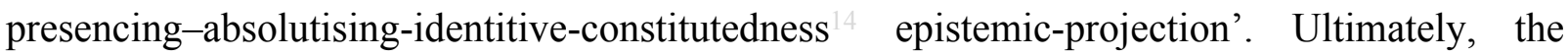
overall elucidation herein of human-consciousness/collective-consciousnessdistendedness/detruncating-<beyond-selfpresencing,-as-re-ontologising-decentering_ofconsciousness/collective-consciousness,-as-to-psychologismic-epistemic-acutisation residualising, - \{decompulsing $\}$ delinearity for-cogency $>$ re-ontologising potentiation (as to 'overall human profound-supererogation of psychologismic-epistemic-acutisationresidualising \{epistemic-totalising $3{ }^{3}$ hermeneutic/textalit/reprojecting/supererogating/zeroing/reacuting,-\{decompulsing delinearity for-cogency exercise' undergirding the 'delineation of profound-supererogation -veracity and shallow-supererogation-inveracity') underlies the 'existential-<disontologising/re-ontologising aporeticism $>$ notional/epistemic/bindingness ${ }^{<a s-}$

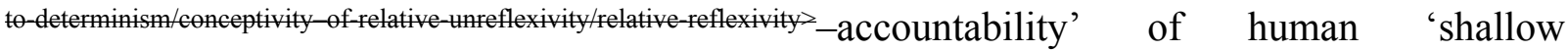
$<$ extricatory/preconverging/accommodating/unquestioning $>$ disontologising/subontologising_prompting perspective' TO 'profound $<$ nonextricatory/postconverging/unaccommodating/questioning $>$-re-ontologising_prompting perspective' (as of imbued 'psychologismic epistemic-acutisation difficulty-for, 
residualising_\{decompulsing $\}$ delinearity for-cogency> magnitude $\{$ of-experientiality/experiment $\}$, 'protracted-social—as-to-individual-by-institutional-by-social direct/deferential facing-up or blinking to educed-and-availing-and-re-availing relative-ontological-completeness ${ }^{87}$-ofapriorising/axiomatising/referencing'). This overall 'existential-<disontologising/reentologising aporeticism $>$ notional/epistemic/bindingness $<$ <as-to-determinism/conceptivity-of-relativeunreflexivity/relative-reflexivitys -accountability' is so-reflected as of the dynamics of 'despite-the-self exercise of epistemic-projection in notional $\sim$ self-distantiation- $<$ imbued-re-motif-and-reapriorising/re-axiomatising/re-referencing>’

$<$ nonextricatory/postconverging/unaccommodating/questioning $>$-re-ontologising_prompting perspective (as to 'underlying human protracted-social - as-to-individual-by-institutional-bysocial direct/deferential epistemic-growth,-as - \{veridical/sound\}-relative-reflexivity-inexistence/relativising from-limited-mentation-as-its-deepening/psychologismic epistemic acutisation - residualising, ${ }^{\text {\{decompulsing\} }}$ delinearity for-cogency' as so-manifest with 'profoundsupererogation $\sim$ reframing/reformulation/decatchmenting/detruncating/decompulsing/delinear ising_scale_of-transparent/noncontentious/un-nominalised/sound-interpretations/domains of manifest unblurriness-<re-ontologising_by-postconverging-as-to-dragged-outsupereregaty wholesomeness/profound-supererogation ,-while-anecdotalising-priordisontologising-thresholding>') on-the-one-hand and on-the-other-hand 'epistemic-decadence' or teleological-decadence-<-in-dimensionality-of-desublimating-lack-of ${ }^{<}$ <<amplituding/formative >supererogatory $\sim$ de-mentativeness/epistemic-growth-orconflatedness /transvaluative-rationalising/transepistemicity/anamnestic-residuality/spiritdrivenness-equalisation) as of <extricatory/preconverging/accommodating/unquestioning >disontologising/subontologising_prompting perspective (as to 'underlying human protractedsocial-as-to-individual-by-institutional-by-social direct/deferential \{flawed/unsound\} relative-unreflexivity-in-existence/absolutising from-limited-mentation/psychologismic - 
epistemic acutisation nonresidualising imbued-\{compulsing $\}$ linearity-in-eclecticism-of priormere-formulaicity/ritualisation' as so-manifesting 'shallowsupererogation $\sim$ framing/formulation/catchmenting/truncating/compulsing/linearising_scale —of-opaque/contentious/un-nominalised/flawed-interpretations/domains of manifest blurriness- $<$ sterilising/anecdotalising/trivialising-of-prospective-re-ontologising_bypreconverging,-in-disontologising-formulaic-dragging-out/hollowing-out>'). This is so of 'existential-<disontologising/re-ontologising aporeticism $>$ notional/epistemic/bindingness ${ }^{-<a s-}$

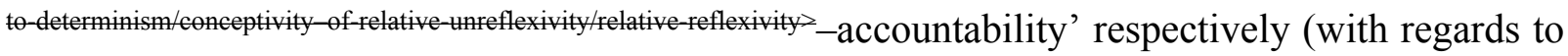
'despite-the-self exercise of epistemic-projection in notional $\sim$ self-distantiation- $<$ imbued-remotif-and-re-apriorising/re-axiomatising/re-referencing >’')

'<nonextricatory/postconverging/unaccommodating/questioning $>$-re-ontologising_prompting perspective as to < punctual/immediacy/constituted/compulsions-encumbered prompted extended/prolonged-re-ontologising-enabling $>$-psychologismic epistemic-acutisationresidualising fepistemic tollising thermeneutic/textuality/reprojecting/supererogating/zeroing/reacuting, $\left.{ }^{\{\text {decompulsing }}\right\}$ delinearity for-cogency -in-order-to-enable- $<$ as-of-the-untenability-ofinduced unblurriness $>$ < _ prospective_punctual/immediacy/constituted/compulsions-

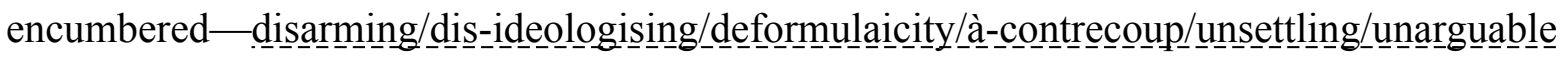
prompted constricted/narrowingdown-re-ontologising-enabling $>$ - psychologismic epistemicacutisation residualising $\{$ fepistemic-

\section{thermeneutic/textuality/reprojecting/supererogating/zeroing/re-acuting,}

\{decompulsing delinearity for-cogency' on-the-one-hand and on-the-other-hand (with regards to 'epistemic-decadence' or teleological-decadence-<-in-dimensionality-of-desublimating-lackof ${ }^{-}$-<<amplituding/formative >supererogatory - de-mentativeness/epistemic-growth-orconflatedness /transvaluative-rationalising/transepistemicity/anamnestic-residuality/spiritdrivenness-equalisation〉 
$<$ extricatory/preconverging/accommodating/unquestioning $>$ -

disontologising/subontologising_prompting

perspective)

priorly

induced

‘ prospective_punctual/immediacy/constituted/compulsions-encumbered disarming/dis-

ideologising/deformulaicity/à-contrecoup/unsettling/unarguable

prompted

eonstricted/narrowingdown-re-ontologising enabling $>$ psychologismic epistemic-

acutisation residualising fepistemic-

totalising thermeneutic/textuality/reprojecting/supererogating/zeroing/re-acuting,

\{decompulsingtdelinearity for-cogency' (manifesting prospectively

as

disontologising/subontologising

'rationalisation-of-

contentivity/argumentativity/dialecticism/discursivity

in psychologismic-epistemic-

acutisation-nonresidualising-imbued-\{compulsing? linearity in-eclecticism-of-prior-mere-

formulaicity/ritualisation'). Such a nonextricatory-unaccounting (nonextricatory-unaccounted of

'<extricatory/preconverging/accommodating/unquestioning $>-$

disontologising/subontologising_prompting as to $<$ mere-formulaicity/ritualisation - f $>$-prior

induced $\quad<$ punctual/immediacy/constituted/compulsions-encumbered prompted extended/prolonged-re-ontologising-enabling $>$-psychologismic epistemic acutisation

residualising $\{$ fepistemic-totalising thermeneutic/textuality/reprojecting/supererogating/zeroing/re

acuting, \{decompulsing\} delinearity for-cogency') is specifically the heightened case with regards to the

Being-development/ontological-framework-expansion-as-to-depth-of-ontologising-

development-as-infrastructure-of- meaningfulness-and-teleology

psychologismic

epistemic-acutisation difficulty-for, residualising \{decompulsing ${ }^{\prime}$ delinearity for-cogency>

magnitude $\{$ of-experientiality/experiment\}; as to the fact that all registry-worldviews/dimensions imbued

prior-institutionalisation-threshold-by-prospective-uninstitutionalised-threshold 'selfreferencing-syncretising forward-facing-supposedly postconverging-or-dialectical-thinking apriorising-psychologism epistemic-projection as of prior mere-formulaicity/ritualisation- $<$ as- 
to-mere-formulaic — methodologising/mutualising/organising/institutionalising,-prospectively-

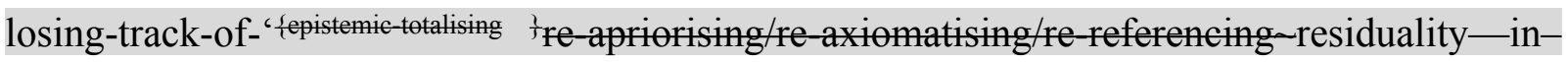
re-originariness/re-origination'>' so-reflect their 'disontologising preconverging/dementing $<$ as-to-prospective-uninstitutionalised-threshold $>$ ignoring/biased inclination' for the sake of 'their given present minimum-and-balancing expectations/anticipations of social-functioningand-accordance-as-of-social-stake-contention-or-confliction' while qualifying their prospectively uninstitutionalised-threshold ${ }^{102}$ actually as nondescript/ignorable-void as to their ${ }^{79}$ presencing — absolutising-identitive-constitutedness ${ }^{4} \quad<$ preconverging ' motif-andapriorising/axiomatising/referencing'-entailing>-existentialising-enframing/imprintedness〈as-to- historicity-tracing - in-presencing-hyperrealisation/hyperreal-transposition〉. But then the very notion of implicited nonpresencing-<perspective-ontologicalnormalcy/postconvergence $>$ relativism/relative-scope for epistemic-growth,-as\{veridical/sound\}-relative-reflexivity-in-existence/relativising from-limited-mentation-as-itsdeepening/psychologismic epistemic-acutisation residualising, fdecompusingl delinearity foreogency' pointed to by such an 'existential-<disontologising/re-ontologising aporeticism> notional/epistemic/bindingness $<$-as-to-determinism/eonceptivity-of-relative-unreflexivity/relative-reflexivity>_ accountability' of 'despite-the-self exercise of epistemic-projection in notional $\sim$ selfdistantiation-<imbued - re-motif-and-re-apriorising/re-axiomatising/re-referencing $>^{\prime} \quad$ (as of $<$ nonextricatory/postconverging/unaccommodating/questioning $>$-re-ontologising_prompting perspective) is inherently/necessarily/implicitly acknowledged/re-acknowledged as of human institutional-development-as-to-social-function-development and living-development-as-topersonality-development psychologismic epistemic acutisation diffieulty <for, residualising $\{$ \{decompulsing $\}$ delinearity for-cogency $>$ magnitudes $\{$ of-experientiality/experiment $\}$; as the very basic possibility of human personal-development and learning can only be undergirded as of ' nonpresencing-<perspective-ontological-normalcy/postconvergence $>$ relativism/relative- 
scope for epistemic-growth,-as - \{veridical/sound\}-relative-reflexivity-inexistence/relativising from-limited-mentation-as-its-deepening/psychologismic epistemicacutisation residualising, \{decomplsing $d e$ linearity for-cogency'. Such that in reality distractivealignment-to- ${ }^{83}$ reference-of-thought- $<$ of-apriorising/axiomatising/referencing $>{ }^{30}$ of all natures (as from 'catchmented-and-compulsed-<in-'existential-dearth-of-demoronisation',-soconstrued-as-from-ontological-normalcy/postconvergence-perspective-reflection-of-the'destructuring-threshold_of-the-given-level's-conjugated-postlogism as-dementing'> interpersonal, group, intergroup, community, local, national, political, geostrategic, etc. psychologismic epistemic-acutisation - difficulty-for, residualising $\{$ decompulsing $\}$ delinearity for-cogeney $>$ levels of interrelatedness-dynamics-of-socialconstructing' of 'formativeness-<as-to-intersolipsism-ofpreformulating/preframing/premeaningfulness-imbued-mediativity-and-deferentialism>-ofmeaningfulness-and-teleology and existential-<disontologising/re-ontologising aporeticism $>$ articulation manifestations') are effectively what underly disontologising/subontologising criticisms of ${ }^{6}$ nonpresencing-<perspective-ontologicalnormalcy/postconvergence $>$ relativism/relative-scope for epistemic-growth,-as\{veridical/sound\}-relative-reflexivity-in-existence/relativising from limited mentation as its deepening/psychologismic epistemic-acutisation residualising, ${ }^{\text {\{decompulsing }}$ \}elinearity for eogency'. So-reflected as to the unavowed implicited/explicited inclination to project of their given '79 presencing-absolutising-identitive-constitutedness ${ }^{14}$ absolution/absolute-scope flawed/unsound\}-relative-unreflexivity-in-existencelabsolutising from-limitedmentation/psychologismic epistemic-acutisation nonresidualising-imbued\{compulsing\} tinearity in eclecticism of prior mere formulaicity/ritultisation conception' induced 'epistemic-decadence' or teleological-decadence-<-in-dimensionality-of-desublimating-lackof $^{-}$-<<amplituding/formative > supererogatory $\sim$ de-mentativeness/epistemic-growth-or- 
conflatedness /transvaluative-rationalising/transepistemicity/anamnestic-residuality/spirit-

drivenness-equalisation) (as of nonextricatory-unaccounting of

'<extricatory/preconverging/accommodating/unquestioning $>-$

disontologising/subontologising_prompting as to $\leq$ mere-formulaicity/ritualisation - f $>$-prior induced $\quad<$ punctual/immediacy/constituted/compulsions-encumbered prompted extended/prolonged-re-ontologising-enabling $>$-psychologismic epistemic-acutisationresidualising fepistemic-totalising ${ }^{3}$ hermeneutic/textuality/reprojecting/supererogating/zeroing/reacuting, ${ }^{\{\text {decompulsing }}$ delinearity for-cogency') imbued distractive-alignment-to- ${ }^{83}$ reference-ofthought-< $<$ of-apriorising/axiomatising/referencing $>$ $>$ as manifest disontologising/subontologising with respect to re-ontologising prospective Beingdevelopment/ontological-framework-expansion-as-to-depth-of-ontologising-development-asinfrastructure-of- meaningfulness-and-teleology psychologismic-epistemic-acutisation-

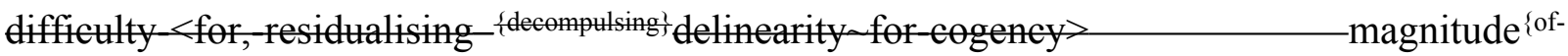
experientiality/experiment\}. In this regards, the notions of 'despite-the-self exercise of epistemicprojection in notional $\sim$ self-distantiation-<imbued-re-motif-and-re-apriorising/reaxiomatising/re-referencing $>^{\prime} \quad$ (as of $<$ nonextricatory/postconverging/unaccommodating/questioning $>$-re-ontologising_prompting perspective) and 'epistemic-decadence' or teleological-decadence-<-in-dimensionality-ofdesublimating-lack-of ${ }^{-}-\langle<$amplituding/formative $>$supererogatory $\sim$ de-mentativeness/epistemicgrowth-or-conflatedness /transvaluative-rationalising/transepistemicity/anamnestic-

$<$ extricatory/preconverging/accommodating/unquestioning $>$ -

disontologising/subontologising_prompting perspective) are very much palpable. In the sense that with regards to nascent-particular/incipient-and-material/technical-sublimations- $<$ blindedto-their-relative-ontological-completeness - reference-of-thought- devolving $>$ articulated 
existentially/contextually/textually (as of human institutional-development-as-to-socialfunction-development and living-development-as-to-personality-development psychologismic epistemic-acutisation difficulty-for, residualising \{decompulsing ${ }^{\prime}$ delinearity for-cogency> magnitudes ${ }^{\{0 f-e x p e r i e n t i a l i t y / e x p e r i m e n t\}}$, and so within the scope of an already attained prior Beingdevelopment/ontological-framework-expansion-as-to-depth-of-ontologising-development-asinfrastructure-of- meaningfulness-and-teleology psychologismic epistemic-acutisation difficulty-<for, residualising \{decompulsing\} ${ }^{\text {delinearity }}$ for-cogency> $>$ magnitude $\{$ ofexperientiality/experiment imbued positive-opportunism — of-social-functioning-and-accordance ${ }^{75}$ as to 'secondnatured conscious/unconscious rationalising/calculating of the sublimating outcome of prior profound-supererogation rationalisation-ofcontentivity/argumentativity/dialecticism/discursivity imbued positive-opportunism—of-socialfunctioning-and-accordance ${ }^{75}$ ), there is a naturally arising 'despite-the-self exercise of epistemic-projection in notional $\sim$ self-distantiation- $<$ imbued-re-motif-and-re-apriorising/reaxiomatising/re-referencing>' $<$ nonextricatory/postconverging/unaccommodating/questioning $>$-re-ontologising_prompting perspective). This is the case with reference to prospectively disontologising/subontologising 'human limited-mentation-capacity as subjecting 'oduced mnlimitedness-existencesublimating nascence'-to-limitedness/human-subpotency' (with regards to the underlying prospective inveracity of the registry-worldview/dimension closed-construct-ofmeaningfulness-and-teleology /wooden-language reflected as to its 'ordinary laypersonhood arrogation/presumptuousness' and prior mere-formulaicity/ritualisation pedantism induced knowledge-deadends-<as-preconverging-de-mentating/structuring/paradigming) on-the-onehand that 'will not by-and-large nally/epistemically/bindingnessly-<as-to-determinism/conceptivityef-relative-unreflexivity/relative-reflexivitys engage as if of re-ontologising equivalence/correspondence' with on-the-other-hand prospectively re-ontologising 'human limited-mentation-capacity- 
deepening —as-subjecting limitedness/human-subpotency-to-'educed-unlimitedness/existencesublimating nascence ${ }^{\prime}$ '; as to the registry-worldview/dimension effectively manifest 'underlying veracity of core-philosophy/derivative-core-philosophy-(imbued requisite 'inkling-drive of dimensionality-of-sublimating ${ }^{25}-\langle<$ amplituding formative $>$ supererogatery dementativeness/epistemic-growth-or-conflatedness /transvaluativerationalising/transepistemicity/anamnestic-residuality/spirit-drivenness-equalisation〉') prospective re-ontologising as relevantly superseding prior mere-formulaicity/ritualisation pedantism induced knowledge-deadends- $<$ as-preconverging-dementating/structuring/paradigming >' (when so-reflected as to 'prospective sublimating competence/expertising as of human socially expanded framework of deferential-formalisationtransference as to various cultivated skills/arts and time investment'). In this regards, the 'prospect of humans to appreciate/understand ${ }^{56}$ meaningfulness-and-teleology ${ }^{99}$ beyond-theconsciousness-awareness-teleology ${ }^{9}<$ of-preconverging-existential-extrication-as-ofexistential-unthought> (preconverging/postconverging-dementatively/structurally/paradigmatically) implies that which gets to 'conceptualise/construe beyond-the-consciousness-awareness-teleology ${ }^{9}-<$ of-preconverging-existential-extrication-asof-existential-unthought $>$ ' is necessarily of ontological desymmetry as rather imbued with intellectual-and-moral responsibility/relative-reflexivity over that which doesn't get there (and so, even with regards to a basic non-transcendental construal of ontological desymmetry within a same registry-worldview's/dimension's ${ }^{83}$ reference-of-thought like Doctor -Patient, Parent Child, Server -Customer, Teacher -Student etc. as veridically ensues from a Derridean binary opposition analysis rather emphasising 'ontological-veracity drivenness'). This speaks to the fact that (and so with respect to the 'overall prospective re-ontologising acquiescence' as to 'protracted-social—as-to-individual-by-institutional-by-social relative direct/deferentialresponsibility/relative-reflexivity to cogency_chronicularity/annality-of-relative-reflexivity,-as- 
to-profound-supererogation') 'overall human re-ontologising intelligibility-(as-to-humanprojective/reprojective - aestheticising-re-motif-and-re-apriorising/re-axiomatising/rereferencing/re-intelligibilitysettingup/re-measuringinstrumenting-process,-in$<$ amplituding/formative-epistemicity>totalising conceptualisation $\rangle$ ' manifesting as of 'despitethe-self exercise of epistemic-projection in notional $\sim$ self-distantiation- $<$ imbued - re-motif-andre-apriorising/re-axiomatising/re-referencing >' (as so-effectively underlied as of re-ontologising prospective Being-development/ontological-framework-expansion-as-to-depth-ofontologising-development-as-infrastructure-of- meaningfulness-and-teleology psychologismic epistemic-acutisation difficulty < for, residualising

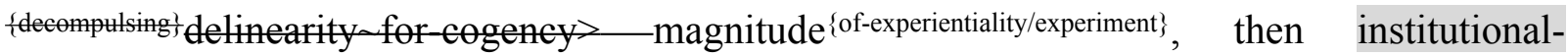
development-as-to-social-function-development psychologismic epistemic-acutisationdifficulty < for, residualising ${ }^{\{\text {decompulsing }\}}$ delinearity for-cogency> magnitude $\{$ ofexperientiality/experiment\} and then living-development-as-to-personality-development psychologismic epistemic-acutisation difficulty-for, residualising \{decompulsing $\}$ delinearity for-cogency $>$ magnitude $\{$ of-experientiality/experiment $\}$ ), is effectively manifested as of nonextricatory-accounting (that is, '<nonextricatory/postconverging/unaccommodating/questioning $>$-re-ontologising_prompting perspective as to < punctual/immediacy/constituted/compulsions-encumbered prompted extended/prolonged-re-ontologising-enabling $>$-psychologismic epistemic-acutisationresidualising $\left\{\right.$ fepistemic-totalising ${ }^{3}$ hermeneutic/textuality/reprojecting/supererogating/zeroing/reacuting, ${ }^{\text {\{decompulsing }}$ delinearity for-cogency $\quad$-in-order-to-enable- $<$ as-of-the-untenability-ofinduced unblurriness $>$ _ $\quad<$ prospective_punctual/immediacy/constituted/compulsions-

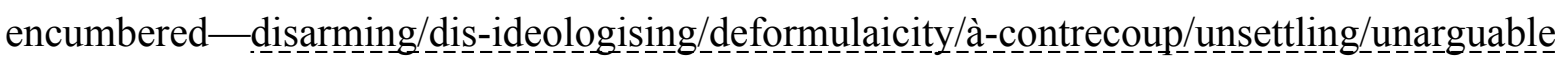
prompted constricted/narrowingdown-re-ontologising-enabling $>$-psychologismic epistemicacutisation residualising fepistemic- 
totalising thermeneutic/textuality/reprojecting/supererogating/zeroing/re-acuting,

$\{$ \{decompulsing\} delinearity for-cogency'). Concretly, this simply means for instance that with regards

to overall human <cumulating/recomposuring attendant-ontological-contiguity $>$-successive registry-worldviews/dimensions (so-reflecting the 'overall relative-unreflexivity/relativereflexivity ontological-contiguity ${ }^{67} \sim$ of-the-human-institutionalisation-process ${ }^{68}$ imbued notional cogency_chronicularity/annality-of-relative-reflexivity,-as-to-profound-

supererogation '),

untenability-of-induced unblurriness

as

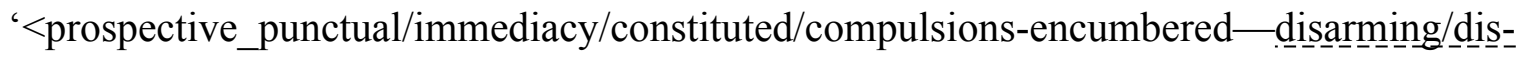

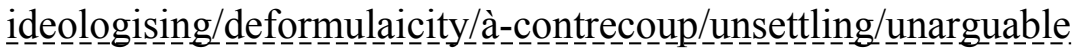

prompted

constricted/narrowingdown-re-ontologising-enabling $>$-psychologismic epistemic-

acutisation residualising \{epistemic-

totalising thermeneutic/textuality/reprojecting/supererogating/zeroing/re-acuting,

\{decompulsing delinearity for-cogency' is induced (as of 'human limited-mentation-capacitydeepening —as-subjecting limitedness/human-subpotency to-'educed-unlimitedness/existencesublimating nascence ${ }^{9}{ }^{\prime}$ ): and so, as from interdimensional (Being-development/ontologicalframework-expansion-as-to-depth-of-ontologising-development-as-infrastructure-ofmeaningfulness-and-teleology psychologismic epistemic aeutisation diffieulty <for, residualising \{decompulsing\} delinearity for-cogency $>$ magnitude $\{$ of-experientiality/experiment\} $\}$ for instance as to the eliciting of 'positivism/rational-empiricism registry-worldview/dimension $<$ constricted/narrowingdown-re-ontologising-enabling $>$-psychologismic epistemic acutisation residualising fepistemictotalising 'hermeneutic/textuality/reprojecting/supererogating/zeroing/re-acuting, \{decompulsing\} delinearity for cogen intelligibility' and thereof devolving intradimensionally (institutional-development-as-to-social-function-development psychologismic epistemicacutisation difficulty-for, residualising \{decompulsing $\}$ delinearity for-cogency> magnitude $\{$ of- 
institutionalising/organising/mutualising/methodologising $\quad<$ constricted/narrowingdown-reontologising-enabling $>$ - psychologismic epistemic-acutisation - residualising fepistemictotalising thermeneutic/textuality/reprojecting/supererogating/zeroing/re-acuting, ${ }_{\{\text {decompulsing }}$ delinearity for-cogency intelligibility' and then further devolving intradimensionally (living-development-as-to-personality-development psychologismic epistemic-acutisation difficulty-<for, residualising \{decompulsing\} ${ }^{\text {delinearity }}$ for-cogency> $>$ magnitudes $\{$ ofexperientiality/experiment') into 'specific positivising existential-<disontologising/re-ontologising aporeticism $>\quad$ sublimating $\quad<$ constricted/narrowingdown-re-ontologising-enabling $>-$ psychologismic epistemic-acutisation residualising fepistemictotalising thermeneutic/textuality/reprojecting/supererogating/zeroing/re-acuting, \{decompulsing\} delinearity for-cogency intelligibility'. In this regards, it can for instance be appreciated that our modern day hereditary DNA genetics 'specific positivising existential$<$ disentelogising/re-ontelogising aporeticism $>$ sublimating <constricted/narrowingdown-reontologising-enabling $>$ psychologismic epistemic acutisation residualising a fepistemictotalising 'thermeneutic/textuality/reprojecting/supererogating/zeroing/re-acuting, \{decompulsing\} delinearity for cogeney intelligibility';- (imbued underlying untenability-ofinduced unblurriness as '<prospective_punctual/immediacy/constituted/compulsions-

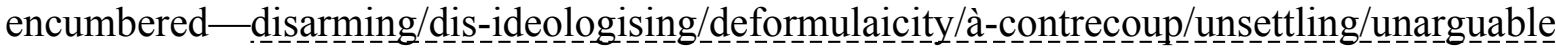
prompted constricted/narrowingdown-re-ontologising-enabling $>$-psychologismic epistemicacutisation residualising fepistemic-

totalising ${ }^{3}$ hermeneutic/textuality/reprojecting/supererogating/zeroing/re-acuting, \{decompulsing delinearity-for cogeney'), as to the fact that it is in-many-ways unthinkable/untenable to pretend/claim to be seriously engaging in sublimating state-of-the-arts hereditary discourse outside the '<constricted/narrowingdown-re-ontologising-enabling $>$ - 


\section{psychologismic epistemic acutisation residualising a fepistemic-}

\section{totalising thermeneutic/textuality/reprojecting/supererogating/zeroing/re-acuting,}

\{decompulsing delinearity for-cogency intelligibility' that is DNA genetics; equally harkens back to $\begin{array}{llll}\text { its } & \text { given } & \text { overarching } & \text { positivising }\end{array}$ institutionalising/organising/mutualising/methodologising $\quad<$ constricted/narrowingdown-reontologising-enabling $>$ psychologismic epistemic-acutisation residualising fepistemictotalising ${ }^{3}$ hermeneutic/textuality/reprojecting/supererogating/zeroing/re-acuting, \{decompulsing delinearity for-cogency intelligibility';- (imbued underlying untenability-ofinduced unblurriness as '<prospective_punctual/immediacy/constituted/compulsions-

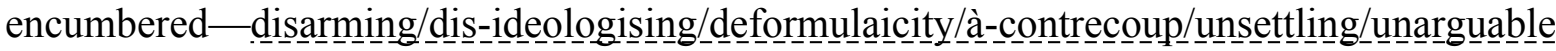
prompted constricted/narrowingdown-re-ontologising-enabling $>$-psychologismic epistemic acutisation residualising a fepistemic-

totalising thermeneutic/textuality/reprojecting/supererogating/zeroing/re-acuting, \{decompulsing delinearity for-cogency'); as well as harkens back to the overall-overarching 'positivism/rational-empiricism registry-worldview/dimension <constricted/narrowingdownre-ontologising-enabling $>$-psychologismic epistemic acutisation residualising fepistemictotalising thermeneutic/textuality/reprojecting/supererogating/zeroing/re acuting, \{decompulsing\} delinearity for-cogeney intelligibility'; - (imbued overall-overarching untenabilityof-induced $\sim$ unblurriness as '<prospective_punctual/immediacy/constituted/compulsionsencumbered — disarming/dis_-ideologising/deformulaicity/à-contrecoup/unsettlling/unnarguable prompted constricted/narrowingdown-re-ontologising-enabling $>$-psychologismic epistemicacutisation residualising $\sim$ fepistemictotalising thermeneutic/textuality/reprojecting/supererogating/zeroing/re acuting, ${ }_{\{\text {decompulsing }}$ \}elinearity for-cogency') as superseding/overcoming prior nonpositivising/nonrational-empiricism ${ }^{56}$ meaningfulness-and-teleology ${ }^{9}$. This so-reflects the underlying 
implicited science/ontology overall protracted claim-for-and-habituation/enculturation-of untenability-of-induced unblurriness

'<prospective_punctual/immediacy/constituted/compulsions-encumbered__ disarmining/diss-

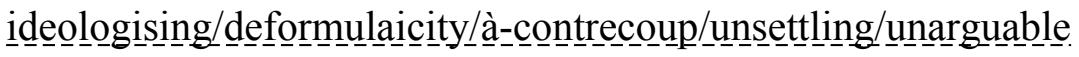

prompted

constricted/narrowingdown-re-ontologising-enabling $>$ - psychologismic epistemic-

acutisation residualising \{ fepistemic-

totalising ${ }^{3}$ hermeneutic/textuality/reprojecting/supererogating/zeroing/re-acuting,

\{dempulsing delinearity for-cogency' with respect to 'the-very-same purview/devolvedpurview/devolving-purview-of-unlimitedness/existence-<full-potency-of_sublimating nascence>;-_implicited_attendant-ontological-contiguity ${ }^{67}$ ' educedexistentialising/contextualising/textualising_'intelligibility/epistemicity/reflexivity-contiguity$<$ imbued-notional cogency $>$ ' ; so-construed as of veridically 'profound-and-comprehensive human experientiality/experiment-<as-to-existentially-formative- ‘fepistemic-totalising ${ }^{\prime}$ reapriorising/re-axiomatising/re-referencing-residuality-in-re-originariness/re-origination', so-"notionally/epistemically/bindingnessly reflexivity>-implicited-and-articulated'_as-from-nonextricatory-'prospective-re-ontologisingBeing-then-Institutional-then-Living-magnitudes-of- -hermeneutic/reprojection-protractioneffreframing-and-reformulation\}' '> ' (with regards to Being-development/ontologicalframework-expansion-as-to-depth-of-ontologising-development-as-infrastructure-ofmeaningfulness-and-teleology psychologismic epistemic acutisation difficulty-<or, residualising \{dementsing\} delinearity for-cogency> magnitude \{of-experientiality/experiment\}, then institutional-development-as-to-social-function-development psychologismic epistemicacutisation difficulty < for, residualising \{decompulsing $\}$ delinearity for cogency>-magnitude $\{$ ofexperientiality/experiment\} and then living-development-as-to-personality-development psychologismic epistemic-acutisation difficulty-for, residualising 
$\{$ decompulsing $\}$ delinearity for-cogency $>$ magnitude $\{$ of-experientiality/experiment $\}$ ). That is, until when all such devolving underlying untenability-of-induced unblurriness as

'<prospective_punctual/immediacy/constituted/compulsions-encumbered__ disarmining/diss-

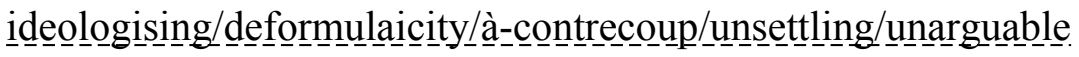
prompted constricted/narrowingdown-re-ontologising-enabling $>$ - psychologismic epistemicacutisation residualising fepistemictotalising thermeneutic/textuality/reprojecting/supererogating/zeroing/re-acuting, \{decompusing delinearity for-cogency' are construed as failing prospective re-ontologising 'dynamic cumulating/recomposuring psychologismic-epistemic-acutisation-residualising,$\{$ \{decompulsing $\}$ delinearity for-cogency phasing of limitedness/human-subpotency onto unlimitedness/existence-<full-potency-of_sublimating nascence $>$ '; and in this regards, it can be appreciated that it is rather implausible (as of a human-consciousness/collective-consciousnessdistendedness/detruncating-<beyond-selfpresencing,-as-re-ontologising-decentering_ofconsciousness/collective-consciousness,-as-to-psychologismic-epistemic-acutisationresidualising,- - decompulsing $\}$ delinearity $\sim$ for-cogency $>$ appreciation) that an overall-overarching 'prior nonpositivising/non-rational-empiricism registry-worldview/dimension like medievalscholasticism or non-universalising <constricted/narrowingdown-re-ontologising-enabling >psychologismic epistemic acutisation residualising \{epistemic-

totalising thermeneutic/textuality/reprojecting/supererogating/zeroing/re-acuting, \{decompulsing\} delinearity for-cogency intelligibility'; - (imbued overall-overarching untenabilityof-induced unblurriness as '<prospective_punctual/immediacy/constituted/compulsions-

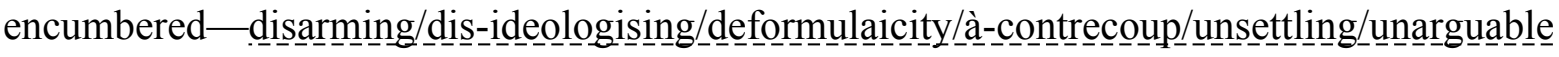
prompted constricted/narrowingdown-re-ontologising-enabling $>$-psychologismic epistemic acutisation residualising \{epistemictotalising thermeneutic/textuality/reprojecting/supererogating/zeroing/re-acuting, 
$\{$ \{decompulsing $\}$ delinearity for-cogency') can effectively overarch such a modern day hereditary DNA genetics 'specific positivising existential-<disontologising/re-ontologising aporeticism $>$ sublimating $<$ constricted/narrowingdown-re-ontologising-enabling $>$-psychologismic epistemic-acutisation residualising a fepistemic-

totalising ${ }^{\jmath}$ hermeneutic/textuality/reprojecting/supererogating/zeroing/re-acuting,

${ }_{\{\text {decompulsing }\}}$ delinearity for-cogeney intelligibility';- - (imbued underlying untenability-ofinduced unblurriness as '<prospective_punctual/immediacy/constituted/compulsions-

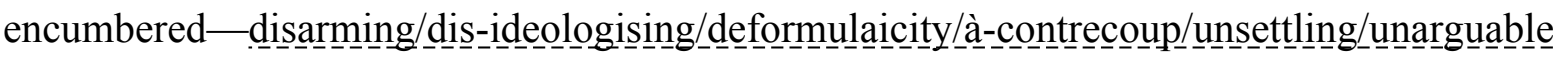
prompted constricted/narrowingdown-re-ontologising-enabling $>$-psychologismic epistemicacutisation residualising \{epistemic-

totalising thermeneutic/textuality/reprojecting/supererogating/zeroing/re-acuting,

${ }_{\{\text {decompulsing }}$ delinearity for-cogency'). This equally speaks to the dearth of a modern-day sense of human-consciousness/collective-consciousness-distendedness/detruncating- $<$ beyondselfpresencing,-as-re-ontologising-decentering_of-consciousness/collective-consciousness,-asto-psychologismic-epistemic-acutisation —residualising, - decompulsing $^{-}$delinearity $\sim$ for-cogency $>$ appreciation (as of requisite nonpresencing-<perspective-ontologicalnormalcy/postconvergence $>$ epistemic-projection perspective) as to how re-ontologising prospective Being-development/ontological-framework-expansion-as-to-depth-ofontologising-development-as-infrastructure-of- meaningfulness-and-teleology psychologismic epistemic-acutisation difficulty-<or, residualising \{decompulsing $\}$ delinearity for-cogency> magnitude $\{$ of-experientiality/experiment $\} \quad$ as of deprocrypticism/preempting - disjointedness-as-of- ${ }^{-3}$ reference-of-thought) underlies the possibility of superseding/overcoming our positivism- ${ }^{80}$ procrypticism/disjointedness-as-ofreference-of-thought knowledge-deadends-<as-preconverging-dementating/structuring/paradigming; and so, as of 'existential-<disontologising/re- 
entologising aporeticism $>\quad$ hermeneutic/textuality/reprojecting/supererogating/zeroing/reacuting $\{$ \{decompulsing\} delinearity/delinear-accreting/recomposuring- nonpresencingperceptualisation-of-sublimating-over-desublimating-<as-'psychologismic-epistemic-

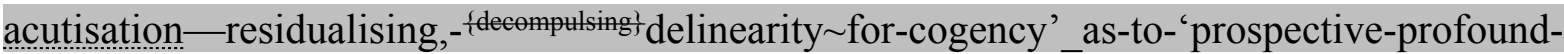
supererogation -epistemic-perspective'-of-prospective-\& prior-differentiatedapriorising/axiomatising/referencing $>$ with-respect-to-the-prospect-of-prospective-human-reontologising' induced sublimating constructive-veracity for 'prospective cogency_chronicularity/annality-of-relative-reflexivity,-as-to-profound-supererogation as to requisite notional $\sim$ self-distantiation- $<$ imbued — re-motif-and-re-apriorising/re-axiomatising/rereferencing>'. Thusly speaking to the veracity of the 'circular dynamics in humanconsciousness/collective-consciousness-distendedness/detruncating- $<$ beyond-selfpresencing,as-re-ontologising-decentering_of-consciousness/collective-consciousness,-as-topsychologismic-epistemic-acutisation-residualising, - $^{\text {-decompulsing? }}$ delinearity for-cogency $>$ ' (as of ' $<$ nonextricatory/postconverging/unaccommodating/questioning $>$-reontologising_prompting perspective as to <punctual/immediacy/constituted/compulsionsencumbered prompted extended/prolonged-re-ontologising-enabling $>$-psychologismic epistemic acutisation residualising fepistemictotalising ${ }^{3}$ hermeneutic/textuality/reprojecting/supererogating/zeroing/re-acuting, $\{$ decompulsing $\}$ delinearity for-cogency -in-order-to-enable-<as-of-the-untenability-ofinduced unblurriness $>$ _ _ $\quad$ prospective_punctual/immediacy/constituted/compulsions-

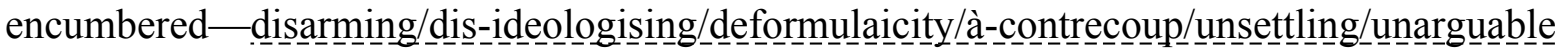
prompted constricted/narrowingdown-re-ontologising-enabling $>$-psychologismic epistemic acutisation residualising \{epistemictotalising thermeneutic/textuality/reprojecting/supererogating/zeroing/re-acuting, \{decompulsing\} delinearity for-cogency' in the face of prospective 
'<extricatory/preconverging/accommodating/unquestioning $>$ -

disontologising/subontologising_prompting as to $\leq$ mere-formulaicity/ritualisation-of $>$-prior induced $\quad<$ punctual/immediacy/constituted/compulsions-encumbered prompted extended/prolonged-re-ontologising-enabling $>$ - psychologismic epistemic -acutisationresidualising \{ tepistemic-totalising thermeneutic/textuality/reprojecting/supererogating/zeroing/reacuting, ${ }^{\{\text {decompulsing }}$ \}elinearity for-cogeney' imbued distractive-alignment-to- ${ }^{83}$ reference-ofthought- $<$ of-apriorising/axiomatising/referencing $>^{30}$ ) as effectively a reflection respectively of 'human notional difference-conflatedness ${ }^{13}$-as-to-totalitative-reification-in-singularisation$<$ as-to-the-nondisjointedness/entailment-of-prospective- nonpresencing $>$-as-veridicalepistemicity-relativism-determinism construable as from the given projected and prospectively educed-and-availing-and-re-availing relative-ontological-completeness ${ }^{87}$-ofapriorising/axiomatising/referencing' as to 'recurrent/perpetuating/continuity-recomposuring existential-<disontologising/re-ontologising aporeticism>

counteracting/supplanting/alienating-of-prior-apriorising/axiomatising/referencing' on-theone-hand and on-the-other-hand human absolute $\sim$ difference-conflatedness ${ }^{13}$-as-to-totalitativereification-in-singularisation-<as-to-the-nondisjointedness/entailment-of-prospectivenonpresencing $>$-as-veridical-epistemicity-relativism-determinism $\quad$ so-construed as 'absolute reference of identity' as failing to project of their own possible prospective relativeontological-incompleteness ${ }^{8}$-of-apriorising/axiomatising/referencing. Effectively, reontologising is so-construed as an exercise of "nonpresencing-<perspective-ontologicalnormalcy/postconvergence $>$ relativism/relative-scope for epistemic-growth,-as\{veridical/sound\}-relative-reflexivity-in-existence/relativising from-limited-mentation-as-itsdeepening/psychologismic epistemic acutisation residualising, \{decompulsing ${ }^{2}$ delinearity-for eogency' (as rather involving prospective re-ontologising 'dynamic cumulating/recomposuring psychologismic-epistemic-acutisation—residualising,-\{decompulsing $\}^{2}$ delinearity for-cogency 
phasing of limitedness/human-subpotency onto unlimitedness/existence-<full-potency of_sublimating nascence>'); as so-enabling the 'despite-the-self exercise of epistemicprojection in notional $\sim$ self-distantiation- $<$ imbued-re-motif-and-re-apriorising/reaxiomatising/re-referencing $>^{\prime}$ as of $<$ nonextricatory/postconverging/unaccommodating/questioning $>$-re-ontologising_prompting perspective, and so as from a given point-of-departure of prospectively disontologising/subontologising 'human limited-mentation-capacity-as-subjecting 'educedunlimitedness/existence-sublimating nascence' to-limitedness/human-subpotency' (with regards to the underlying prospective inveracity of the registry-worldview/dimension closedconstruct-of- ${ }^{5}$ meaningfulness-and-teleology $/$ wooden-language reflected as to its 'ordinary laypersonhood arrogation/presumptuousness' and prior mere-formulaicity/ritualisation pedantism induced knowledge-deadends-<as-preconverging-dementating/structuring/paradigming) in reflection of the basic possibility of human personaldevelopment and learning, and thus palpably speaking of postconverging-dementating/structuring/paradigming. Contrastively, this elucidation of humanconsciousness/collective-consciousness-distendedness/detruncating- $<$ beyond-selfpresencing,as-re-ontologising-decentering_of-consciousness/collective-consciousness,-as-topsychologismic-epistemic-acutisation — residualising, - \{decompulsing\} $_{\text {delinearity }} \sim$ for-cogency $>$ reontologising potentiation equally highlights (so-implied beyond-the-consciousness-awareness-

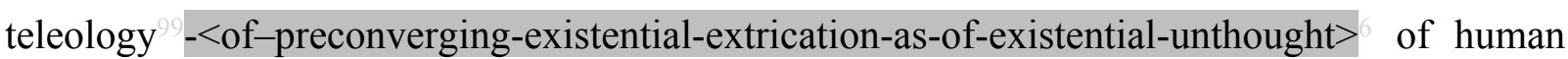
'self-presence/self-constitutedness ${ }^{14}$-<in-perspective-epistemic-abnormalcy/preconvergence ${ }^{1}>$ rationalisation-of-contentivity/argumentativity/dialecticism/discursivity') the palpability of human 'epistemic-decadence' or teleological-decadence- $<$-in-dimensionality-of-desublimatinglack-of ${ }^{-}$-< <amplituding/formative > supererogatory $\sim$ de-mentativeness/epistemic-growth-orconflatedness /transvaluative-rationalising/transepistemicity/anamnestic-residuality/spirit- 
drivenness-equalisation) as of <extricatory/preconverging/accommodating/unquestioning $>-$ disontologising/subontologising_prompting perspective (palpably reflected as of preconverging-de-mentating/structuring/paradigming) as to the failure of prospective 'despitethe-self exercise of epistemic-projection in notional $\sim$ self-distantiation- $<$ imbued - re-motif-andre-apriorising/re-axiomatising/re-referencing >’

$<$ nonextricatory/postconverging/unaccommodating/questioning $>$-re-ontologising_prompting perspective). This so-explains the manifestation of 'disontologising/subontologising equivalence/correspondence' of prospectively disontologising/subontologising 'human limitedmentation-capacity—as-subjecting-'educed-unlimitedness/existence-sublimating nascence' to-limitedness/human-subpotency' (with regards to the underlying prospective inveracity of the registry-worldview/dimension closed-construct-of- ${ }^{5}$ meaningfulness-and-teleology ${ }^{9} /$ woodenlanguage reflected as to its 'ordinary laypersonhood arrogation/presumptuousness' and prior mere-formulaicity/ritualisation pedantism induced knowledge-deadends- $<$ as-preconverging-dementating/structuring/paradigming) on-the-one-hand and on-the-other-hand prospectively reontologising 'human limited-mentation-capacity-deepening —as-subjecting limitedness/humansubpotency-to-'educed-unlimitedness/existence-sublimating-nascence' ${ }^{3}$ ' (with regards to the registry-worldview/dimension effectively manifest 'underlying veracity of corephilosophy/derivative-core-philosophy prospective re-ontologising as relevantly superseding prior mere-formulaicity/ritualisation pedantism induced knowledge-deadends- $<$ aspreconverging-de-mentating/structuring/paradigming >' when so-reflected as to 'prospective sublimating competence/expertising as of human socially expanded framework of deferentialformalisation-transference as to various cultivated skills/arts and time investment'); and so specifically marked with respect to the prospect of re-ontologising prospective Beingdevelopment/ontological-framework-expansion-as-to-depth-of-ontologising-development-asinfrastructure-of- meaningfulness-and-teleology psychologismic epistemic-acutisation- 
difficulty-<for, residualising_\{decompulsing $\}$ delinearity for-cogeney> magnitude ${ }^{\{0 f-}$ experientiality/experiment\} (and as it thereof induces re-ontologising prospective human institutionaldevelopment-as-to-social-function-development and living-development-as-to-personalitydevelopment psychologismic epistemic-acutisation - difficulty<-for, residualising $\{$ decompulsing $\}$ delinearity for-cogency>-magnitudes $\left.\left.{ }^{\{0 f-e x p e r i e n t i a l i t y / e x p e r i m e n t}\right\}\right) . T$ This ontologicallyflawed manifestation of 'disontologising/subontologising equivalence/correspondence' (failing to discriminate between 'epistemic-decadence' or teleological-decadence-<-in-dimensionalityof-desublimating-lack-of ${ }^{-}-\langle<$amplituding/formative $>$supererogatory $\sim$ dementativeness/epistemic-growth-or-conflatedness /transvaluativerationalising/transepistemicity/anamnestic-residuality/spirit-drivenness-equalisation〉 as of $<$ extricatory/preconverging/accommodating/unquestioning $>-$

disontologising/subontologising_prompting perspective on-the-one-hand and on-the-other-hand 'despite-the-self exercise of epistemic-projection in notional $\sim$ self-distantiation-<imbued-remotif-and-re-apriorising/re-axiomatising/re-referencing>' as of $<$ nonextricatory/postconverging/unaccommodating/questioning $>$-re-ontologising_prompting perspective) is so-palpably reflected with say between the Socratic-philosophers universalising-idealisation and ancient-sophists non-universalising as well as between the budding-positivists positivism/rational-empiricism and medieval-scholasticism nonpositivising; respectively so, as to the existential-<disontologising/re-ontologising aporeticism $>$ implications of (Socratic-philosophers ${ }^{103}$ universalising-idealisation and budding-positivists positivism/rational-empiricism) prospective $<$ nonextricatory/postconverging/unaccommodating/questioning $>$-re-ontologising_prompting perspective on-the-one-hand and on-the-other-hand (ancient-sophists non-universalising and medieval-scholasticism nonpositivising) $<$ extricatory/preconverging/accommodating/unquestioning $>$ - 
disontologising/subontologising_prompting perspective. Such ontologically-flawed manifestation of 'disontologising/subontologising equivalence/correspondence' (with respect to human institutional-development-as-to-social-function-development and living-developmentas-to-personality-development psychologismic epistemic-acutisation difficulty-<for, residualising \{decompulsing\} delinearity for-cogency>-magnitudes $\{0$-experientiality/experiment\}) is also reflected with the 'manifestation of bothsidesism-〈as-'mere-processive'/pedantising-'dialogicalrelation'-to 'perceived-social-and-institutional-commonly-enculturated_referencing,-ofmeaningfulness-and-teleology '-failing-'requisite-existential-thematic-baseline-oftechnicity/profundity-framing' \{of-sublimating-discursivity-for-sovereign-repassing $\}$,-as-ofpsychologismic-epistemic-acutisation-nonresidualising-imbued-\{compulsing\}linearity ineclecticism-of-prior-mere-formulaicity/ritualisation,-as-so-'consciously/unconsciouslypreordained/fated'-to-fail-prospective-notional cogency) conception of human meaningfulness-and-teleology, , arising as to the inherent susceptibility of the given registryworldview/dimension closed-construct-of- ${ }^{5}$ meaningfulness-and-teleology $9 /$ wooden-language (reflected as to its 'ordinary laypersonhood arrogation/presumptuousness' and prior mereformulaicity/ritualisation pedantism induced knowledge-deadends-<as-preconverging-dementating/structuring/paradigming); and so susceptible with regards to prospective 'epistemicdecadence' or teleological-decadence-<-in-dimensionality-of-desublimating-lack-of ${ }^{-}$ <<amplituding/formative>supererogatory $\sim$ de-mentativeness/epistemic-growth-orconflatedness /transvaluative-rationalising/transepistemicity/anamnestic-residuality/spiritdrivenness-equalisation) (as of <extricatory/preconverging/accommodating/unquestioning >disontologising/subontologising_prompting perspective). Wherein such susceptibility prospectively undermines the notion of ontological-veracity which is rather about the 'dynamic cumulating/recomposuring psychologismic-epistemic-acutisation-residualising,\{decompulsing\} delinearity for-cogency phasing of limitedness/human-subpotency onto 
unlimitedness/existence-<full-potency-of_sublimating nascence>' (and not such a bothsidesism-〈as-'mere-processive'/pedantising-'dialogical-relation'-to 'perceived-socialand-institutional-commonly-enculturated_referencing,-of- meaningfulness-and-teleology 'failing-'requisite-existential-thematic-baseline-of-technicity/profundity-framing' \{ofsublimating-discursivity-for-sovereign-repassing \},-as-of-psychologismic-epistemicacutisation-nonresidualising-imbued-\{compulsing\}linearity in-eclecticism-of-prior-mereformulaicity/ritualisation,-as-so- 'consciously/unconsciously-preordained/fated'-to-failprospective-notional cogency> abusing of the notion of dialogical-equivalence-<as-topsychologismic apriorising/axiomatising/referencing-\{of-" prospectivelyimplicited_attentantontological-contiguity ' educedexistentialising/contextualising/textualising_ 'intelligibility/epistemicity/reflexivity-contiguity<imbued-notional cogency>' \}-conflatedness -in-\{preconverging -ment by\} postconverging-entailment,-in-self-becoming/self-conflatedness /formative-supererogating $>$ ); and thusly, the elucidation of ontological-veracity is rather elicited as of 'despite-the-self exercise of epistemic-projection in notional $\sim$ self-distantiation- $<$ imbued-re-motif-and-reapriorising/re-axiomatising/re-referencing >’ (as of $<$ nonextricatory/postconverging/unaccommodating/questioning $>$-re-ontologising_prompting perspective). Human-consciousness/collective-consciousness-distendedness/detruncating$<$ beyond-selfpresencing,-as-re-ontologising-decentering_of-consciousness/collectiveconsciousness,-as-to-psychologismic-epistemic-acutisation-residualising,${ }_{\{\text {decompulsing }}$ delinearity for-cogency $>$ thus fundamentally underlines the inherently 'notional/epistemic/bindingness ${ }^{-<a s-t o-d e t e r m i n i s m / c o n c e p t i v i t y-o f-r e l a t i v e-u n r e f l e x i v i t y / r e l a t i v e-r e f l e x i v i t y>~} \quad$ human psychologismic-transfixity-<placeholder-setup-ontological-rescheduling-inrealigning/preactivity/formative-becoming/psychoanalytical-unshackling,-as-to-residualising-

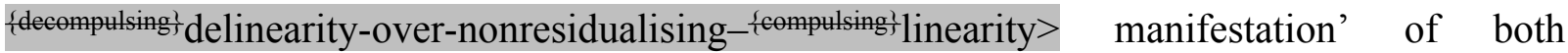


'epistemic-decadence' or teleological-decadence-<-in-dimensionality-of-desublimating-lackof - -< <amplituding/formative > supererogatory - de-mentativeness/epistemic-growth-or-

conflatedness /transvaluative-rationalising/transepistemicity/anamnestic-residuality/spirit-

drivenness-equalisation) (as of <extricatory/preconverging/accommodating/unquestioning >disontologising/subontologising_prompting perspective) and 'despite-the-self exercise of epistemic-projection in notional $\sim$ self-distantiation- $<$ imbued-re-motif-and-re-apriorising/reaxiomatising/re-referencing >'

$<$ nonextricatory/postconverging/unaccommodating/questioning $>$-re-ontologising_prompting perspective); and so with respect to requisite profound-supererogation as from human 'crossgenerational notional firstnaturedness-formativeness-as drive-or-seeding misprising $>$ mental-processing-parity for ontological-performance ${ }^{72}$ <including-virtue-as-ontology $>$ /morality/ethics/justice/etc.' as of the given $<$ amplituding/formative-epistemicity $>$-totalising $\sim$ thrownness-in-existence ${ }^{35}$ - (as imbued of limitedness/human-subpotency prospective dearth for \{epistemic-totalising 're-apriorising/reaxiomatising/re-referencing $\sim$ residuality-in-re-originariness/re-origination projection) warrant for 'prospective requisite profound-supererogation induced demoronisation- $<$ sublimatingnascence,-nonextricatory-sublimating-upstreaming/‘amontée’> for superseding/overcoming the succession of human registry-worldviews/dimensions disontologising/subontologisingimbuing-prospectively-of-human-desublimating/subjugation/disenfranchisement as to vicesand-impediments ${ }^{105}$. This points out that knowledge-deadends-<as-preconverging-dementating/structuring/paradigming $>$ are much more than a question of mereformulaicity/ritualisation but underline human psychologismic-epistemic-acutisationdifficulty-<for,-residualising_decompusing $d$ delinearity for-cogency $>-\langle$ as-of-requisite-profoundsupererogation -for-'disposedness-or-psychologismic-construct'-\{imbued-demoronisation<sublimating-nascence,-nonextricatory-sublimating-upstreaming/'amontée' $>\}\rangle$; $\quad$ as $\quad$ it is 
inescapable that the veracity of manifest prospective 'epistemic-decadence' or teleologicaldecadence-<-in-dimensionality-of-desublimating-lack-of ${ }^{-}$-

〈<amplituding/formative>supererogatory $\sim$ de-mentativeness/epistemic-growth-or-

conflatedness /transvaluative-rationalising/transepistemicity/anamnestic-residuality/spirit-

drivenness-equalisation) (as of <extricatory/preconverging/accommodating/unquestioning >disontologising/subontologising_prompting perspective) 'has to be recognised' for the possibility of the requisite 'despite-the-self exercise of epistemic-projection in notional selfdistantiation-<imbued - re-motif-and-re-apriorising/re-axiomatising/re-referencing $>{ }^{\prime} \quad$ (as of $<$ nonextricatory/postconverging/unaccommodating/questioning $>$-re-ontologising_prompting perspective) induced prospective re-ontologising to arise in-the-very-first-place. In this regards, the 'circular dynamics in human-consciousness/collective-consciousnessdistendedness/detruncating-<beyond-selfpresencing,-as-re-ontologising-decentering_ofconsciousness/collective-consciousness,-as-to-psychologismic-epistemic-acutisationresidualising, $\left.-{ }^{\{\text {decompulsing }}\right\}$ delinearity $\sim$ for-cogency $>$

'<nonextricatory/postconverging/unaccommodating/questioning $>$-re-ontologising_prompting perspective as to <punctual/immediacy/constituted/compulsions-encumbered prompted extended/prolonged-re-ontologising-enabling $>$ - psychologismic epistemic-acutisationresidualising fepistemictalising thermeneutic/textuality/reprojecting/supererogating/zeroing/reacuting, ${ }^{\{\text {decompulsing }}$ delinearity for-cogency $\quad$ in-order-to-enable- $<$ as-of-the-untenability-ofinduced unblurriness $>$ _ $\quad<$ prospective_punctual/immediacy/constituted/compulsionsencumbered - disarming/dis-ideologising/deformulaicity/à-contrecoup/unsettlling/unarguable prompted constricted/narrowingdown-re-ontologising-enabling $>$-psychologismic epistemicacutisation residualising \{ \{epistemicthalising thermeneutic/textuality/reprojecting/supererogating/zeroing/re-acuting, \{decompunging delinearity for-cogeney' in the face of prospective 
'<extricatory/preconverging/accommodating/unquestioning $>$ -

disontologising/subontologising_prompting as to $\leq$ mere-formulaicity/ritualisation-of $>$-prior induced $\quad<$ punctual/immediacy/constituted/compulsions-encumbered prompted extended/prolonged-re-ontologising-enabling $>$ - psychologismic epistemic -acutisationresidualising \{ tepistemic-totalising thermeneutic/textuality/reprojecting/supererogating/zeroing/reacuting, ${ }^{\{\text {decompulsing }}$ \}elinearity for-cogeney' imbued distractive-alignment-to- ${ }^{83}$ reference-ofthought- $<$ of-apriorising/axiomatising/referencing $>^{30}$ ) is effectively a reflection respectively of 'human notional difference-conflatedness ${ }^{13}$-as-to-totalitative-reification-in-singularisation$<$ as-to-the-nondisjointedness/entailment-of-prospective- nonpresencing $>$-as-veridical-

epistemicity-relativism-determinism construable as from the given projected and prospectively educed-and-availing-and-re-availing relative-ontological-completeness ${ }^{87}$-ofapriorising/axiomatising/referencing' as to 'recurrent/perpetuating/continuity-recomposuring existential-<disontologising/re-ontologising aporeticism>-

counteracting/supplanting/alienating-of-prior-apriorising/axiomatising/referencing' on-theone-hand and on-the-other-hand human absolute difference-conflatedness ${ }^{13}$-as-to-totalitativereification-in-singularisation-<as-to-the-nondisjointedness/entailment-of-prospectivenonpresencing $>$-as-veridical-epistemicity-relativism-determinism $\quad$ so-construed $\quad$ as 'absolute reference of identity' as failing to project of their own possible prospective relativeontological-incompleteness ${ }^{8}$-of-apriorising/axiomatising/referencing. This is so-reflected with varying social and institutional 'sublimating/desublimating-thresholds of subculturation-ofmeaningfulness-and-teleology , notwithstanding-<and-intermingling-with/dissipating from $>$ perceived-social-and-institutional-commonly-enculturated_referencing,-ofmeaningfulness-and-teleology' (as so-speaking to the 'differential phasing-by-out-ofphasing of human ${ }^{5}$ meaningfulness-and-teleology ${ }^{\circ}$ underlying manifest 'protracted-socialas-to-individual-by-institutional-by-social relative direct/deferential-responsibility/relative- 
reflexivity-or-irresponsibility/relative-unreflexivity to cogency_chronicularity/annality-ofrelative-reflexivity,-as-to-profound-supererogation ${ }^{(9}$ ); which is relatively overlooked as from the 'heightened social and institutional frameworks of social-functioning-and-accordance-asof-social-stake-contention-or-confliction' and 'so-relatively overlooked exactly for the purpose of social-functioning-and-accordance' (with consequential re-ontologising-bydisontologising/subontologising implications arising as to the profundity of the given human psychologismic epistemic-acutisation difficulty < for, residualising \{decompling delinearity for-cogeney>-magnitudes $\{$ of-experientiality/experiment\} $\}$. This is the case (notwithstanding the requisite veracity of prospective re-ontologising 'dynamic cumulating/recomposuring psychologismic-epistemic-acutisation-residualising,\{decompulsing\} delinearity for-cogency phasing of limitedness/human-subpotency onto unlimitedness/existence-<full-potency-of_sublimating nascence $>$ '), and explaining the necessary discrimination between " presencing-absolutising-identitive-constitutedness social-stake-contention-or-confliction of the advocacy/political/applicative — scope as to technosocio-econo-political' (as to human emphasis on sovereign-function/posture-<as-toexistentially-manifest-'embodied-subject $\sim$ consciousness-and-direct/deferentialconscientiousness',-as-of-its-'epistemic-reflexivity/unreflexivity-in-existence'/teleology> social-functioning-and-accordance-as-of-social-stake-contention-or-confliction) and ${ }^{6}$ nonpresencing-<perspective-ontological-normalcy/postconvergence> ontologising/scientific/existence- $<$ honesty-constraining $>$ — scope_for_prospective_reontologising' (as to human emphasis on ontological-veracity); and so as to the prospect of reontologising human-consciousness/collective-consciousness-distendedness/detruncating$<$ beyond-selfpresencing,-as-re-ontologising-decentering_of-consciousness/collectiveconsciousness,-as-to-psychologismic-epistemic-acutisation-residualising,$\{$ decompulsing $\}$ delinearity for-cogency $>$, wherein the ontologising/scientific/existence- $<$ honesty- 
constraining $>$ — scope_for_prospective_re-ontologising reflects the ${ }^{\text {nonpresencing- }}$ <perspective-ontological-normalcy/postconvergence $>$ anarchistic-growth/anarchisation-forre-ontologisation-〈as-to-conscious/unconscious epistemically-sound induced 'demoronisation<sublimating-nascence,-nonextricatory-sublimating-upstreaming/‘amontée’> postconverging/dialectical-thinking conception of residual_re-originary_anarchistic incipiency of human social-functioning-and-accordance-as-of-social-stake-contention-orconfliction meaningfulness-and-teleology ' $\rangle$ ' imbued 'existential-<disontologising/reentologising aporeticism $>$ hermeneutic/textuality/reprojecting/supererogating/zeroing/reacuting ${ }_{\{\text {decompulsing }}$ \} delinearity/delinear-accreting/recomposuring- nonpresencingperceptualisation-of-sublimating-over-desublimating-<as-'psychologismic-epistemicacutisation-residualising,-\{decompulsing $\}$ delinearity for-cogency'_as-to-'prospective-profoundsupererogation -epistemic-perspective'-of-prospective-\& prior-differentiatedapriorising/axiomatising/referencing $>$ with-respect-to-the-prospect-of-prospective-human-reontologising' induced sublimating constructive-veracity for 'prospective cogency_chronicularity/annality-of-relative-reflexivity,-as-to-profound-supererogation as to requisite notional $\sim$ self-distantiation- $<$ imbued—re-motif-and-re-apriorising/re-axiomatising/rereferencing>'. The implication here as to human-consciousness/collective-consciousnessdistendedness/detruncating-<beyond-selfpresencing,-as-re-ontologising-decentering_ofconsciousness/collective-consciousness,-as-to-psychologismic-epistemic-acutisationresidualising, ${ }^{-\{\text {decompulsing }}$ delinearity for-cogency $>$ (with respect to the veracity of human ‘<amplituding/formative-epistemicity $>$-totalising $\sim$ renewing-realisation/re-perception/rethought self-reflexive instigative-eventuating-〈as-to-teleological-instigative/incipientwilling/arbitrariness/waywardness/faithdrivenness/supererogating-for-human-intelligibility,preceding-existence's-eventuating-sublimating-validation/desublimating-invalidation〉') is that human consciousness/collective-consciousness is rather 'profusively of mutual-in-phasing of 
meaningfulness-and-teleology" (with regards to ' $\leq$ mere-formulaicity/ritualisation-of $>$-prior secondnatured positive-opportunism-of-social-functioning-and-accordance ${ }^{75}$ of prior profound-supererogation induced prior $\sim$ rationalisation-ofcontentivity/argumentativity/dialecticism/discursivity>') on-the-one-hand and on-the-otherhand is 'sparsely of mutual-in-phasing ${ }^{56}$ meaningfulness-and-teleology ${ }^{9} / /$ relatively of out-ofphasing of ${ }^{56}$ meaningfulness-and-teleology ${ }^{9}$ as relevant for prospective postconverging-aporeticism-overcoming/unovercoming re-ontologising (with regards to prospective human 'notional firstnaturedness-formativeness-<as-to-eventualising inkling drive-or-seeding-misprising $>$ temporal-to-intemporal-dispositions- $<$ so-construed-as-fromperspective-ontological-normalcy/postconvergence> of human protracted-social-as-toindividual-by-institutional-by-social ontological-performance ${ }^{72}-$ including-virtue-as- $^{2}$ ontology $>$ /morality/ethics/justice/etc.'); and so-reflected as of Being-development/ontologicalframework-expansion-as-to-depth-of-ontologising-development-as-infrastructure-ofmeaningfulness-and-teleology , institutional-development-as-to-social-functiondevelopment and living-development-as-to-personality-development psychologismic epistemic-acutisation difficulty<<for, residualising \{decompulsing delinearity for-cogency> magnitudes ${ }^{\{0 f-e x p e r i e n t i a l i t y / e x p e r i m e n t\}}$. The bigger issue here, with regards to the " nonpresencing$<$ perspective-ontological-normalcy/postconvergence $>\quad$ ontologising/scientific/existence$<$ honesty-constraining $>$ — scope_for_prospective_re-ontologising' (as to human emphasis on ontological-veracity), is to avoid the covert/overt creeping and its supposed substitution by the ${ }^{6}$ presencing - absolutising-identitive-constitutedness ${ }^{14}$ social-stake-contention-or-confliction of the advocacy/political/applicative-scope as to techno-socio-econo-political'; as to an overriding emphasising of " $<$ mere formulaicitritulisation of $>$ prior secondnatured positiveopportunism-of-social-functioning-and-accordance ${ }^{75}$ of prior profound-supererogation induced prior $\sim$ rationalisation-of-contentivity/argumentativity/dialecticism/discursivity $>{ }^{\prime}$ as 
defining of prospective human knowledge and transcendence-andsublimity/sublimation/supererogatory de-mentativity (so-reflected with pedantising/muddling/formulaic-hollowing-out - in-subontologisation/subpotentiation〈blurring/undermining-of-prospective-totalising-entailing,-as-to-entailing<amplituding/formative-epistemicity>totalising in-relative-ontological-completeness $>$ desublimation conscious/unconscious eliciting of institutional-prescience/imprimaturing<dullness-of the-spirit/psychologismic epistemic-acutisation nonresidualising imbued\{compulsing\} linearity in-eclecticism-of prior-mere-formulaicity/ritualisation $>$ and/or accessorising of 'ordinary laypersonhood arrogation/presumptuousness' conception of supposedly prospective sublimation and thusly inducing the blurriness-<sterilising/anecdotalising/trivialising-ofprospective-re-ontologising_by-preconverging,-in-disontologising-formulaic-draggingout/hollowing-out $>$ of prospective knowledge-deadends-<as-preconverging-dementating/structuring/paradigming $>$ ). Hence undermining the requisite 'recurrent/perpetuating/continuity-recomposuring existential-<disontologising/reentologising apereticism> counteracting/supplanting/alienating-of-priorapriorising/axiomatising/referencing' for limitedness/human-subpotency supererogating $\{$ affirmation/projection/assertion/notional $\sim$ self-distantiation-byunaffirmation/deprojection/deassertion/epistemic-decadence $\}$ — towards $\sim$ omnipotentialaffirmation/projection/assertion/notional self-distantiation enabling prospective reontologising; and so, as to prior \{compulsing linearity/linear-accreting- ${ }^{7}$ presencingperceptualisation-of-sublimating-over-desublimating-<as-" psychologismic-epistemicacutisation-nonresidualising-imbued-\{compulsing linearity in-eclecticism-of-prior-mereformulaicity/ritualisation'_as-to-‘secondnatured-epistemic-perspective'-of-prospective-\& prior-differentiated apriorising/axiomatising/referencing $>$ and-as-developing-intointerrelatedness-dynamics-of-social-constructing desublimating constructive-inveracity (rather 
manifesting ${ }^{7}$ presencing-absolutising-identitive-constitutedness ${ }^{14}$ epistemic-projection of 'punctual noumenality and phenomenality distinction' inclination to wrongly and implicitly imply it is of 'unlimitedness/existence-<full-potency-of_sublimating nascence $>$ already givenness/immanence' imbued omnipotential-affirmation/projection/assertion/notional $\sim$ selfdistantiation as to the given ${ }^{7}$ presencing-absolutising-identitive-constitutedness ${ }^{14}$ 'relativeunreflexivity of human-per-cep-ti-vi-ty-<as-to - notional perceptualisation-of-and-leashingto_social-functioning-and-accordance - as-of-social-stake-contention-or-confliction>'). This underlies why the 'flow of human prospective profound-supererogation -over-shallowsupererogation, is rather veridically undergirded as of prospective profoundsupererogation $\sim$ reframing/reformulation/decatchmenting/detruncating/decompulsing/delinear ising -as-to-postconverging de-mentating/structuring/paradigming (imbued 'existential$\leq$ disontologising/re-ontologising aporeticism $>$ hermeneutic/textuality/reprojecting/supererogating/zeroing/re-acuting delinearity/delinear-accreting/recomposuring- nonpresencing-perceptualisation-ofsublimating-over-desublimating-<as-'psychologismic-epistemic-acutisation-residualising,\{decompulsing $\}$ delinearity for-cogency' as-to- 'prospective-profound-supererogation -epistemicperspective'-of prospective \& prior differentiated apriorising/axiomatising/refereneing $>$ with-respect-to-the-prospect-of-prospective-human-re-ontologising') INDUCED 'prospective sublimating notional $\sim$ catchmenting-<as-to_disontologising/subontologising institutionalimprintedness by re-ontologising institutional-imprinting $>$ as to nonpresencing<perspective ontological-normalcy/postconvergence $>\quad$ existential-<disontologising/reentologising aporeticism $>$ prospect of human individual-consciousness/collectiveconsciousness decompulsion-appraisal' (over 'prior desublimating notional catchmenting $<$ asto_disontologising/subontologising institutional-imprintedness_by re-ontologising institutional-imprinting $>$ as to presencing absolutising-identitive-constitutedness 
mentating/structuring/paradigming punctual/immediacy/constituted/compulsions-encumbered prior mere-formulaicity/ritualisation rationalisation-ofcontentivity/argumentativity/dialecticism/discursivity' as so-bound to undermine the 'flow of human prospective profound-supererogation -over-shallow-supererogation '). This further explains why the ultimate basis of the ontologising/scientific/existence- $<$ honestyconstraining $>$ — scope_for_prospective_re-ontologising is actually beyond-the-consciousnessawareness-teleology ${ }^{0}-<$ of-preconverging-existential-extrication-as-of-existential-unthought $>$ as of human-consciousness/collective-consciousness-distendedness/detruncating-<beyondselfpresencing,-as-re-ontologising-decentering_of-consciousness/collective-consciousness,-asto-psychologismic-epistemic-acutisation — residualising, - $^{\text {\{decompulsing }}$ delinearity $\sim$ for-cogency $>$; as to prospectively elucidated-<as-to-preconverging/postconverging-redementating/restructuring/reparadigming $>$ human ontological-commitment ${ }^{\circ}$ and universaltransparency ${ }^{104}$ (with respect to underlying human 'crossgenerational notional firstnaturednessformativeness-<as-to-eventualising-inkling-drive-or-seeding-misprising $>$ mentalprocessing-parity for ontological-performance ${ }^{72}-$ including-virtue-as- $^{2}$ ontology $>$ /morality/ethics/justice/etc.') as to 'substantivity of transversality-<for-sublimatingexistential-eventuating/denouement-from-'thinking-at-first/pure-predisposition-preemptive-ofprospective-disontologising/subontologising' as-of-prospectively-disambiguated-affirmedand-unaffirmed-'motif-and-apriorising/axiomatising/referencing'>101, imbued 'impersonalisation and deinstitutionalisation of prospective re-ontologising ${ }^{56}$ meaningfulnessand-teleology ${ }^{9}$ (as to ontologising-failsafe-<as-to-'relative- mnreflexivity/relative-reflexivity

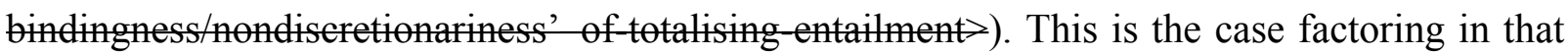
the reality of human varying social and institutional 'sublimating/desublimating-thresholds of subculturation-of- ${ }^{5}$ meaningfulness-and-teleology ${ }^{9}$ (notwithstanding-<and-intermingling 
enculturated_referencing,-of- ${ }^{5}$ meaningfulness-and-teleology ${ }^{9}$ ) means that 'ontologicalveracity cannot naively be construed as absolutely dwelling with the perceived-social-andinstitutional-commonly-enculturated_referencing,-of- ${ }^{56}$ meaningfulness-and-teleology ${ }^{9}$ (as to the latter potential susceptibility to a cynical realpolitiking as blatantly manifested with 'high institutional and social social-stake-contention-or-confliction with regards to mobilisability- $<$ asto-'re-ontologising-projecting/oeuvrement'-over-'disontologising-de-projecting/deoeuvrement'> associated with the blurriness-<sterilising/anecdotalising/trivialising-ofprospective-re-ontologising_by-preconverging,-in-disontologising-formulaic-draggingout/hollowing-out $>$ of prospective knowledge-deadends- $<$ as-preconverging-dementating/structuring/paradigming $>$ ). Thusly, requiring appropriate insight beyond a mere overarching functionalist rationale (in reflection of the manifestation of human consciousness/collective-consciousness 'profusively of mutual-in-phasing of ${ }^{56}$ meaningfulnessand-teleology ${ }^{9}$, with regards to ' $\leq$ mere-formulaicity/ritualisation-of $>$ prior secondnatured positive-opportunism-of-social-functioning-and-accordance ${ }^{75}$ of prior profoundsupererogation $\quad$ induced $\quad$ prior $\sim$ rationalisation - of contentivity/argumentativity/dialecticism/discursivity >' on-the-one-hand and on-the-other-hand 'sparsely of mutual-in-phasing ${ }^{56}$ meaningfulness-and-teleology ${ }^{\circ} /$ 'relatively of out-of-phasing of ${ }^{5}$ meaningfulness-and-teleology ${ }^{9}$ as relevant for prospective postconverging-apereticismovercoming/unovercoming re-ontologising with regards to prospective human protractedsocial-as-to-individual-by-institutional-by-social ontological-performance ${ }^{2}-<$ includingvirtue-as-ontology $>$ /morality/ethics/justice/etc.' as to prospective re-ontologising 'dynamic cumulating/recomposuring psychologismic-epistemic-acutisation-residualising,\{decompulsing $\}$ delinearity for-cogency phasing of limitedness/human-subpotency onto unlimitedness/existence-<full-potency-of_sublimating nascence $>$ '). As so-underlined 
effectively beyond-the-consciousness-awareness-teleology ${ }^{\circ}<$ of-preconverging-existentialextrication-as-of-existential-unthought $>$ as of human-consciousness/collective-consciousnessdistendedness/detruncating-<beyond-selfpresencing,-as-re-ontologising-decentering_ofconsciousness/collective-consciousness,-as-to-psychologismic-epistemic-acutisation residualising, ${ }^{-\{\text {decompulsing }}$ delinearity $\sim$ for- $\operatorname{cogency}>$, with regards to prospectively elucidated<as-to-preconverging/postconverging rede-mentating/restructuring/reparadigming $>$ human ontological-commitment ${ }^{6}$ and universal-transparency ${ }^{104}$ (with respect to underlying human 'crossgenerational notional firstnaturedness-formativeness-<as-to-eventualising-inklingdrive-or-seeding-misprising $>$ mental-processing-parity for ontological-performance ${ }^{72}$ $<$ including-virtue-as-ontology $>$ /morality/ethics/justice/etc.'); as to 'substantivity of transversality-<for-sublimating-existential-eventuating/denouement-from-'thinking-at-

\section{first/pure-predisposition-preemptive-of-prospective-disontologising/subontologising' as-of-} prospectively-disambiguated-affirmed-and-unaffirmed-'motif-andapriorising/axiomatising/referencing' $>101$ 'imbued 'impersonalisation and deinstitutionalisation of prospective re-ontologising ${ }^{56}$ meaningfulness-and-teleology ${ }^{9}$ as to ontologising-failsafe<as-to-'relative-unreflexivity/relative-reflexivity bindingness/nondiscretionariness' of

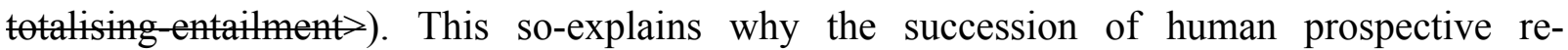
ontologising_-imbuing-of-prospective-human-sublimating/emancipating/enfranchisement are 'relays of human intemporal-individuation epistemic-projection radicalities $\sim$ inchronicular/annalistic-cogency-<as-of-notional $\sim$ protensivity $>$-〈as-to-limited-mentationcapacity-deepening —as-subjecting limitedness/human-subpotency-to-'educedcogency_chronicularity/annality-of-relative-reflexivity,-as-to-profound-supererogation '; as to prospective re-ontologising 'dynamic cumulating/recomposuring psychologismic-epistemicacutisation-residualising, - 
subpotency onto unlimitedness/existence-<full-potency-of_sublimating nascence $>$ beyond ' $\leq$ mere-formulaicity/ritualisation-of $>$-prior secondnatured positive-opportunism-of-socialfunctioning-and-accordance ${ }^{75}$ of prior profound-supererogation ${ }^{6}$ induced prior $\sim$ rationalisationof-contentivity/argumentativity/dialecticism/discursivity>'. This in-many-ways reveals a drawback to many a social science implicitly/explicitly manifesting overarching functionalist rationale (of ' ${ }^{6}$ presencing — absolutising-identitive-constitutedness ${ }^{14}$ absolution/absolute-scope flawed/unsound\}-relative-unreflexivity-in-existencelabsolutising-from-limitedmentation/psychologismic epistemic acutisation nonresidualising imbuedfompulsing linearityoin-eclecticism-of prior-mere-formulaicity/ritualisation conception') that critically undermine the possibility of profound elucidation of 'notional/epistemic/bindingness' $\leq$ as-to-determinism/conceptivity-of-relative-unreflexivity/relative-reflexivity $>$ reflection of relativeunreflexivity/relative-reflexivity in existence implications' as to the very 'reflexivity mesh' that is existence (rather undergirded as of ' nonpresencing-<perspective-ontologicalnormalcy/postconvergence $>$ relativism/relative-scope for epistemic-growth,-as\{veridical/sound\}-relative-reflexivity-in-existence/relativising from-limited-mentation-as-itsdeepening/psychologismic epistemic acutisation residualising, ${ }^{\text {\{decompulsing }}$ delinearity for eogeney'); as poorly projecting of a knowledge model failing to reflect the veridical 'recurrent/perpetuating/continuity-recomposuring existential-<disontologising/reentologising aporeticism> counteracting/supplanting/alienating-of-priorapriorising/axiomatising/referencing' for limitedness/human-subpotency supererogating $\{$ affirmation/projection/assertion/notional $\sim$ self-distantiation-byunaffirmation/deprojection/deassertion/epistemic-decadence $\}$ — towards $\sim$ omnipotentialaffirmation/projection/assertion/notional $\sim$ self-distantiation enabling prospective re-ontologising (effectively undergirded as of human-consciousness/collective-consciousnessdistendedness/detruncating-<beyond-selfpresencing,-as-re-ontologising-decentering_of- 
consciousness/collective-consciousness,-as-to-psychologismic-epistemic-acutisation

residualising, ${ }_{-}^{-\{\text {decompulsing }}$ delinearity for- $\operatorname{cogency}>$ ). Human-consciousness/collective-

consciousness-distendedness/detruncating- $<$ beyond-selfpresencing,-as-re-ontologising-

decentering_of-consciousness/collective-consciousness,-as-to-psychologismic_epistemic-

acutisation-residualising, - $^{\{\text {decompulsing }\}}$ delinearity for-cogency $>\quad$ (as to implicited

dimensionality-of-sublimating ${ }^{25}-<<$ amplituding/formative $>$ supererogatory $\sim$ de-

mentativeness/epistemic-growth-or-conflatedness /transvaluative-

rationalising/transepistemicity/anamnestic-residuality/spirit-drivenness-equalisation $\rangle$ ) thus

effectively precedes-and-drives the notion of prospective re-rationalisation-ofcontentivity/argumentativity/dialecticism/discursivity (as the prospective supererogation $\sim$ reframing/reformulation/decatchmenting/detruncating/decompulsing/delinear ising - as-to-postconverging de-mentating/structuring/paradigming for re-rationalisation-ofcontentivity/argumentativity/dialecticism/discursivity) as so-underlying the 'despite-the-self exercise of epistemic-projection in notional $\sim$ self-distantiation- $<$ imbued-re-motif-and-reapriorising/re-axiomatising/re-referencing >’

(as

of

$<$ nonextricatory/postconverging/unaccommodating/questioning $>$-re-ontologising_prompting perspective) possibility for epistemic-growth,-as - \{veridical/sound\}-relative-reflexivity-inexistence/relativising from-limited-mentation-as-its-deepening/psychologismic epistemicacutisation residualising, \{decompusing delinearity for-cogency'. This point is made to point out that it is 'delusional' to ignore the manifestation of 'epistemic-decadence' or teleologicaldecadence-<-in-dimensionality-of-desublimating-lack-of ${ }^{-}$ <<amplituding/formative>supererogatory $\sim$ de-mentativeness/epistemic-growth-orconflatedness /transvaluative-rationalising/transepistemicity/anamnestic-residuality/spiritdrivenness-equalisation) (as of <extricatory/preconverging/accommodating/unquestioning >disontologising/subontologising_prompting perspective in prior shallow- 
supererogation $\sim$ framing/formulation/catchmenting/truncating/compulsing/linearising —as-topreconverging - de-mentating/structuring/paradigming) and then wrongly imply prospective rerationalisation-of-contentivity/argumentativity/dialecticism/discursivity supposedly avails for prospective epistemic-growth,-as_ \{veridical/sound\}-relative-reflexivity-inexistence/relativising from-limited-mentation-as-its-deepening/psychologismic epistemicacutisation residualising, \{decompulsing delinearity-for-cogeney; as to an ontologically-flawed manifestation of 'disontologising/subontologising equivalence/correspondence' (failing to discriminate between 'epistemic-decadence' or teleological-decadence-<-in-dimensionality-ofdesublimating-lack-of ${ }^{2}-\langle<$ amplituding/formative $>$ supererogatory $\sim$ de-mentativeness/epistemicgrowth-or-conflatedness /transvaluative-rationalising/transepistemicity/anamnestic-

$<$ extricatory/preconverging/accommodating/unquestioning $>$ -

disontologising/subontologising_prompting perspective on-the-one-hand and on-the-other-hand 'despite-the-self exercise of epistemic-projection in notional $\sim$ self-distantiation-<imbued-remotif-and-re-apriorising/re-axiomatising/re-referencing>’ $<$ nonextricatory/postconverging/unaccommodating/questioning $>$-re-ontologising_prompting perspective), and as it translates into an ontologically-flawed bothsidesism-〈as-'mereprocessive'/pedantising-'dialogical-relation'-to 'perceived-social-and-institutionalcommonly-enculturated_referencing,-of- meaningfulness-and-teleology '-failing-'requisiteexistential-thematic-baseline-of-technicity/profundity-framing' \{of-sublimating-discursivityfor-sovereign-repassing \},-as-of-psychologismic-epistemic-acutisation-nonresidualisingimbued-\{compulsing linearity in-eclecticism-of-prior-mere-formulaicity/ritualisation,-as-so'consciously/unconsciously-preordained/fated'-to-fail-prospective-notional cogency) conceptualisation. In other words, the notion of 'epistemic-decadence' or teleologicaldecadence-<-in-dimensionality-of-desublimating-lack-of ${ }^{-}$- 
conflatedness /transvaluative-rationalising/transepistemicity/anamnestic-residuality/spirit-

drivenness-equalisation) speaks to the 'decadent circuituousness' wherein prospectively educed-and-availing-and-re-availing relative-ontological-completeness ${ }^{87}$-ofapriorising/axiomatising/referencing (with respect to underlying unblurriness- $<$ reontologising_by-postconverging-as-to-dragged-out-supererogatory -wholesomeness/profoundsupererogation, -while-anecdotalising-prior-disontologising-thresholding $>$ scope as of relatively elucidated-<as-to-preconverging/postconverging redementating/restructuring/reparadigming $>$ human ontological-commitment and universaltransparency ${ }^{104}$ with respect to underlying human 'crossgenerational notional firstnaturednessformativeness-<as-to-eventualising-inkling-drive-or-seeding-misprising $>$ mentalprocessing-parity for ontological-performance ${ }^{72}-<$ including-virtue-asontology $>$ /morality/ethics/justice/etc.') is merely overlooked (as to a pedantising/muddling/formulaic-hollowing-out - in-subontologisation/subpotentiation〈blurring/undermining-of-prospective-totalising-entailing,-as-to-entailing-

\section{$<$ amplituding/formative-epistemicity $>$ totalising in-relative-ontological-completeness $\rangle$}

inclination that doesn't recognise implicitly/explicitly the requisite/inherent ontological coherence/contiguity), to then 'pretend/claim to prospective intellection re-engagement' as if such prospectively educed-and-availing-and-re-availing relative-ontological-completeness ${ }^{87}$ of-apriorising/axiomatising/referencing is irrelevant (as so-implicitly/explicitly denying the pertinence of human 'despite-the-self exercise of epistemic-projection in notional selfdistantiation-<imbued - re-motif-and-re-apriorising/re-axiomatising/re-referencing >’ underlying human personal-development and learning). Such that the allegation of 'epistemicdecadence' or teleological-decadence-<-in-dimensionality-of-desublimating-lack-of ${ }^{-}$- 


\section{conflatedness /transvaluative-rationalising/transepistemicity/anamnestic-residuality/spirit-}

drivenness-equalisation) is merely a reflection of the fact that (with regards to underlying human personal-development and learning) individuals self-becoming/self-conflatedness ${ }^{13} /$ formative- $^{-}$ supererogating-<projective/reprojective - aestheticising-re-motif-and-re-apriorising/reaxiomatising/re-referencing,-in-perspective-ontological-normalcy/postconvergence> 'cannot be substituted for' but rather 'can only be elicited' (as to educed-and-availing-and-re-availing relative-ontological-completeness ${ }^{87}$-of-apriorising/axiomatising/referencing); and so, with regards to underlying requisite human supererogation ${ }^{6}$ (as not even a Camusian suicide as to its projection of self-dissolution can arise without individual notional self-becoming/selfconflatedness $^{13} /$ formative-supererogating-<projective/reprojective-aestheticising-re-motifand-re-apriorising/re-axiomatising/re-referencing,-in-perspective-ontologicalnormalcy/postconvergence $>$ ). Making nonsensical such a 'supposed project (of substituting for requisite profound-supererogation )' without 'spontaneous human abstract-and-solipsistic cognisance/recognition for underlying human-consciousness/collective-consciousnessdistendedness/detruncating-<beyond-selfpresencing,-as-re-ontologising-decentering_ofconsciousness/collective-consciousness,-as-to-psychologismic-epistemic-acutisation residualising,-\{decompulsing? delinearity $\sim$ for-cogency $>$ '. This explains why the point-of-departure of prospective knowledge and transcendence-and-sublimity/sublimation/supererogatery $\sim$ dementativity is human prospective 'overarching existential-<disontologising/re-ontologising apereticism $>$ priority/precedence/primacy of requisite prospective ontological-goodfaith/authenticity ${ }^{6} \sim$ postconverging-de-mentating/structuring/paradigming 7 inducing of psychoanalytic-unshackling for the relative-ontological-completeness ${ }^{8}$-ofapriorising/axiomatising/referencing re-ontologising prospective re-rationalisation-ofcontentivity/argumentativity/dialecticism/discursivity'. Such that, unlike a naïve pedantising/muddling/formulaic-hollowing-out - in-subontologisation/subpotentiation- 


\section{〈blurring/undermining-of-prospective-totalising-entailing,-as-to-entailing-}

$<$ amplituding/formative-epistemicity $>$ totalising $\sim$ in-relative-ontological-completeness $>$

calculus/rationale, the very exercise of knowledge-reification $\sim$ gesturing-and-accounting-ofepistemic-phenomenalism-<in-

prospective_psychologismic apriorising/axiomatising/referencing-\{of-‘prospectively_

implicited_attendant-ontological-contiguity ' educed-

existentialising/contextualising/textualising_ 'intelligibility/epistemicity/reflexivity-contiguity$<$ imbued-notional cogency $>$ ' \}-conflatedness -in-\{preconverging-ment by\}

postconverging-entailment $>$ reflexively engages the intellectual pertinence of 'all-and-sundry claims/pretenses to intellectual pertinence' as of knowledge gesturing-and-accounting-ofepistemic-phenomenalism (and so with respect to unlimitedness/existence-<full-potencyof_sublimating nascence> prospective apriorising/axiomatising/referencing-sublimatingreflexivity-beholdening under which limitedness/human-subpotency submits in profoundsupererogation for prospective sublimating), and thusly it is not an exercise of 'discretionary disjointed hovering about' that cannot articulate the knowledge gesturing-and-accounting —ofepistemic-phenomenalism as of requisite/inherent ontological coherence/contiguity in reflection of unlimitedness/existence-full-potency-of_sublimating nascence $>$. By that token (with respect to the underlying requisite human supererogation ) a 'wilful spread/range of incoherent narratives' whether of 'conscious or unconscious strategised participation' doesn't neither speak of requisite/inherent ontological coherence/contiguity but rather speak of the 'driving priorperspective-falsity/falseness/fallaciousness' that defines the 'epistemic-decadence' or teleological-decadence-<-in-dimensionality-of-desublimating-lack-of ${ }^{<}$-

<<amplituding/formative>supererogatory $\sim$ de-mentativeness/epistemic-growth-orconflatedness /transvaluative-rationalising/transepistemicity/anamnestic-residuality/spiritdrivenness-equalisation) as to its disontologising-aggravation-〈in-want-for-prospective- 
aetiologisation/ontological-escalation- $<$ ontological-

veridicality_commitment/otherliness_transcending/compulsions-encumbered_transcending $>>$. In this regards, unlike the practice (as to 'shallowsupererogation $\sim$ framing/formulation/catchmenting/truncating/compulsing/linearising_scale —of-opaque/contentious/un-nominalised/flawed-interpretations/domains of manifest blurriness-< $<$ sterilising/anecdotalising/trivialising-of-prospective-re-ontologising_bypreconverging,-in-disontologising-formulaic-dragging-out/hollowing-out>') that effectively hover about 'vague and poorly existential-<disontologising/re-ontologising aporeticism $>$ thematisations' with a poor/disinterested elucidation of educed-and-availing-and-re-availing relative-ontological-completeness ${ }^{8}$-of-apriorising/axiomatising/referencing, veridical organicknowledge (as reflected with profoundsupererogation $\sim$ reframing/reformulation/decatchmenting/detruncating/decompulsing/delinear ising_scale_-of-transparent/noncontentious/un-nominalised/sound-interpretations/domains of manifest unblurriness-<re-ontologising_by-postconverging-as-to-dragged-outsupererogatory wholesomeness/profound-supererogation ,-while-anecdotalising-priordisontologising-thresholding $>$ ) necessarily warrant the articulation of existential<disontologising/re-ontologising aporeticism $>$ knowledge gesturing-and-accounting-ofepistemic-phenomenalism as of both 'prospective knowledge consolidation gesturing-andaccounting-of-epistemic-phenomenalism' and 'prospective re-ontologising knowledge gesturing-and-accounting —of-epistemic-phenomenalism inducing consolidation' (so-underlied as of cogency_chronicularity/annality-of-relative-reflexivity,-as-to-profound-supererogation ). Critically, such a failure to truly appreciate the meaning of the notion elaboration-as-to-mereextrapolating/constituting/abstracting/deducing/inferring-of-elucidation-outside'prospectively_implicited_attendant-ontological-contiguity ${ }^{6}$ ' educedexistentialising/contextualising/textualising_'intelligibility/epistemicity/reflexivity-contiguity- 
<imbued-notional cogency>' (as so reflecting a dearth of requisite/inherent ontological coherence/contiguity existential-<disontologising/re-ontologising aporeticism $>$ implications beyond conceptual-patterning) 'systematically divulges' the poor motivation and superfluousness of such hovering about 'vague and poorly existential-<disentologising/reentologising aporeticism $>$ thematisations'; herein illuminated for the purpose of requisite prospective psychologismic-epistemic-acutisation-<as-to-postconverging-dementating/structuring/paradigming,-eliciting-of-existence's-sublimating-nascence-inprospective-aporeticism-overcoming/unovercoming $>$ as to epistemic-growth,-as\{veridical/sound\}-relative-reflexivity-in-existence/relativising from-limited-mentation-as-itsdeepening/psychologismic epistemic-acutisation residualising, ${ }^{\text {\{decompulsing }}$ delinearity for eogency' imbued 'overall existential-priming/funnelling/staking of human-per-cep-ti-vi-ty$<$ as-to - notional $~ p e r c e p t u a l i s a t i o n-o f-a n d-$ leashing-to_social-functioning-and-accordanceas-of-social-stake-contention-or-confliction> decompulsing-construct'; - $\{$ as to 'embodiedconsciousness elicited for demoronisation-<sublimating-nascence,-nonextricatory-sublimatingupstreaming/'amontée'>'\} (over \{epistemic-totalising $3{ }^{3}$ 'psychologismic-subliminal-truncating as of 'catchmented-and-compulsed-<in-'existential-dearth-of-demoronisation',-so-construed-asfrom-ontological-normalcy/postconvergence-perspective-reflection-of-the- 'destructuringthreshold_of-the-given-level's-conjugated-postlogism as-dementing'> interpersonal, group, intergroup, community, local, national, political, geostrategic, etc. psychologismic epistemic acutisation difficulty-for, residualising \{decompulsing delinearity for-cogency> levels of interrelatedness-dynamics-of-social-constructing'). The further point here is that humanconsciousness/collective-consciousness-distendedness/detruncating-<beyond-selfpresencing,as-re-ontologising-decentering_of-consciousness/collective-consciousness,-as-topsychologismic-epistemic-acutisation — residualising, - $_{\text {-decompulsing? }}$ delinearity for-cogency $>$ (as 
absolutely constrained upon prospective re-ontologising 'dynamic cumulating/recomposuring psychologismic-epistemic-acutisation—residualising,--\{decompulsing $d$ delinearity for-cogency phasing of limitedness/human-subpotency onto unlimitedness/existence-<full-potency өf_sublimating nascence $>$ '), rather dismisses the 'pretence of any given epochal ${ }^{7}$ presencingabsolutising-identitive-constitutedness ${ }^{14}$ consciousness/collective-consciousness to be the contemplative limit for the ontologising/scientific/existence- $<$ honesty-constraining $>$ scope_for_prospective_re-ontologising' (in contrast to the desublimating contemplative limit implicited/explicited by " 79 presencing - absolutising-identitive-constitutedness ${ }^{14}$ social-stakecontention-or-confliction of the advocacy/political/applicative-scope as to techno-socioecono-political' ). Such that just as we can appreciate that the prior recurrent-utteruninstitutionalisation, ununiversalisation and non-positivism/medievalism registryworldviews/dimensions consciousness/collective-consciousness were superseded/overcome for prospective re-ontologising, our positivism- ${ }^{80}$ procrypticism-or-disjointedness-as-ofreference-of-thought consciousness/collective-consciousness is not beyond the same exercise of its superseding/overcoming; and so, with respect to requisite profound-supererogation ${ }^{6}$ as from human 'crossgenerational notional firstnaturedness-formativeness-<as-toeventualising inkling drive or seeding misprising> mental-processing-parity for ontological-performance ${ }^{2}$-<including-virtue-as-ontology $>$ /morality/ethics/justice/etc.' as of the given <amplituding/formative-epistemicity $>$-totalising thrownness-in-existence $^{35}$ - (as imbued of limitedness/human-subpotency prospective dearth for treapriorising/re-axiomatising/re-referencing $\sim$ residuality_-in-re-originariness/re-origination projection) warrant for 'prospective requisite profound-supererogation induced demoronisation-<sublimating-nascence, sublimating-upstreaming/‘amontée’> for superseding/overcoming the succession of human registry-worldviews/dimensions disontologising/subontologising_imbuing-prospectively-of-human- 
desublimating/subjugation/disenfranchisement as to vices-and-impediments ${ }^{105}$. That is exactly the opening (as to opened-construct-of- meaningfulness-and-teleology for prospective metaphoricity ${ }^{57}$ undergirding 'limitedness/human-subpotency de-mentation〈supererogatory-ontological-de-mentation-or-dialectical-de-mentation-stranding-orattributive-dialectics $\rangle$ as to preconverging/postconverging-redementating/restructuring/reparadigming' with regards to prospective 'existential$\leq$ disontologising/re-ontologising aporeticism $>$ postconverging apereticismovercoming/unovercoming' in the 'reinvention'/'recreation' of the-human/humanity soconstrued as anthropologisation-<as-to-futural-reflexivity,-in-\{decompulsing $\}$ delinearity'invention'/'creation'-of-the-human/humanity $>$ imbued 'widening the social imaginary' (as to the ontologising/scientific/existence- $<$ honesty-constraining $>$ — scope_for_prospective_reontologising); with regards to the superseding/overcoming of prospective knowledge-deadends$<$ as-preconverging-de-mentating/structuring/paradigming $>$. Human-consciousness/collectiveconsciousness-distendedness/detruncating-<beyond-selfpresencing,-as-re-ontologisingdecentering_of-consciousness/collective-consciousness,-as-to-psychologismic_epistemicacutisation-residualising, ${ }^{-\{\text {decompulsing }}$ delinearity for-cogency $>$ so-further highlights the fact that (with respect to educed-and-availing-and-re-availing relative-ontological-completeness ${ }^{8}$ of-apriorising/axiomatising/referencing) the mindset that as of 'human incidental/accidental idiosyncratic intemporal/longness-of register-of meaningfulness-and-teleology individuation' project of prospective re-ontologising (however the 'low emotional-involvement' or 'high emotional-involvement') is 'inherently granted intellectual-and-moral ascendency, responsibility/relative-reflexivity and purposefulness' to 'slap down' upon disontologising priorperspective - falsity/falseness/fallaciousness (not as an 'idle notion of human mortal discretion' but as of 'inherent requisite organic-knowledge' imbued 'prospective postconverging aporeticism-overcoming/unovercoming as the-Good/knowledge- 
reification $\sim$ gesturing-and-accounting — of-epistemic-phenomenalism- $<$ in-

prospective_psychologismic apriorising/axiomatising/referencing-\{of- ${ }^{\text {pprospectively }}$ implicited_attendant-ontological-contiguity ' educed-

existentialising/contextualising/textualising_intelligibility/epistemicity/reflexivity-contiguity$<$ imbued-notional $\left.\sim \operatorname{cogency}>{ }^{\prime}\right\}$-conflatedness -in-\{preconverging-ment by\}

postconverging-entailment $>$ /understanding/<amplituding/formative-

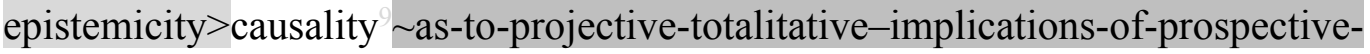

nonpresencing,-for-explicating relative-unreflexivity/relative-reflexivity - ontological-

contiguity '); and so, as to the re-ontologising appropriateness for 'overall existentialpriming/funnelling/staking of human-per-cep-ti-vi-ty-<as-to - notional $\sim$ perceptualisation-ofand-leashing-to_social-functioning-and-accordance-as-of-social-stake-contention-or-

confliction> decompulsing-construct'; $-\{$ as to 'embodied-consciousness elicited fepistemictotalising ${ }^{\mathfrak{l}}$ psychologismic-subliminal-distendedness/detruncating for demoronisation<sublimating-nascence,-nonextricatory-sublimating-upstreaming/'amontée'>’\} (over 'psychologismic-subliminal-truncating as of 'catchmented-and-compulsed-<in‘existential-dearth-of-demoronisation',-so-construed-as-from-ontologicalnormalcy/postconvergence-perspective-reflection-of-the-'destructuring-threshold_of-thegiven-level's-conjugated-postlogism as-dementing'> interpersonal, group, intergroup, community, local, national, political, geostrategic, etc. psychologismic epistemic acutisationdifficulty < for, residualising \{decompulsing $d$ delinearity for-cogency>-levels of interrelatednessdynamics-of-social-constructing'). This (re-ontologising appropriateness for 'overall existential-priming/funnelling/staking of human-per-cep-ti-vi-ty-<as-tonotional perceptualisation-of-and-leashing-to_social-functioning-and-accordance-as-ofsocial-stake-contention-or-confliction $>$ decompulsing-construct'; $-\{$ as to 'embodiedconsciousness elicited \{epistemic-totalising ’’psychologismic-subliminal-distendedness/detruncating 
upstreaming/'amontée'>'\} so-undergirding overall re-ontologising acquiescence as to 'protracted-social — as-to-individual-by-institutional-by-social relative direct/deferentialresponsibility/relative-reflexivity to cogency_chronicularity/annality-of-relative-reflexivity,-asto-profound-supererogation ${ }^{\prime}$ ), with regards to requisite 'supererogating ${ }^{6}\{$ affirmation/projection/assertion/notional $\sim$ self-distantiation-byunaffirmation/deprojection/deassertion/epistemic-decadence \} mobilisability-<as-to-'reontologising-projecting/oeuvrement'-over-'disontologising-de-projecting/de-oeuvrement'>', is so-underlied notionally/epistemically/bindingnessly-sas-derminism/contivity-relativeunreflexivity/relative-reflexivitys as of 'desublimating/sublimating notional catchmenting-<asto_disontologising/subontologising institutional-imprintedness_by re-ontologising institutional-imprinting $>$ as to the given disontologising/re-ontologising human meaningfulness-and-teleology ${ }^{\prime}$ (and as this translates into the given institutional level whether as of catchmented-and-compulsed-<in-'existential-dearth-of-demoronisation',-soconstrued-as-from-ontological-normalcy/postconvergence-perspective-reflection-of-the'destructuring-threshold_of-the-given-level's-conjugated-postlogism as-dementing'> interpersonal, group, intergroup, community, local, national, political, geostrategic, etc. psychologismic epistemic-acutisation difficulty-for, residualising $\{$ decompulsing $\}$ delinearity for-cogeney> levels of interrelatedness-dynamics-of-socialconstructing)'. Wherein human 'protracted-social—as-to-individual-by-institutional-by-social relative direct/deferential-responsibility/relative-reflexivity-or-irresponsibility/relativeunreflexivity to cogency_chronicularity/annality-of-relative-reflexivity,-as-to-profoundsupererogation' (imbued varying social and institutional 'sublimating/desublimatingthresholds of subculturation — of- ${ }^{5}$ meaningfulness-and-teleology ${ }^{9}$ notwithstanding-<andintermingling-with/dissipating from $>$ perceived-social-and-institutional-commonly- 
enculturated_referencing,-of- ${ }^{-6}$ meaningfulness-and-teleology 9 as so-speaking to the 'differential phasing-by-out-of-phasing of human ${ }^{5}$ meaningfulness-and-teleology ${ }^{9}$ ') effectively speaks to undergirding 'human-consciousness/collective-consciousnessdistendedness/detruncating-<beyond-selfpresencing,-as-re-ontologising-decentering_ofconsciousness/collective-consciousness,-as-to-psychologismic-epistemic-acutisation residualising, ${ }^{-\{\text {decompulsing }}$ delinearity $\sim$ for-cogency $>$ re-ontologising dynamics' with regards to re-ontologising appropriateness for 'overall existential-priming/funnelling/staking of humanper-cep-ti-vi-ty-<as-to-notional perceptualisation-of-and-leashing-to_social-functioningand-accordance - as-of-social-stake-contention-or-confliction> decompulsing-construct'; \{as to 'embodied-consciousness elicited \{epistemic-totalising '’’ $p$ sychologismic-subliminaldistendedness/detruncating for $\quad$ demoronisation-<sublimating-nascence, -nonextricatory sublimating-upstreaming/'amontée'>'\}; and so, over \{epistemic-totalising 3 ’ ’ psychologismicsubliminal-truncating (as of 'catchmented-and-compulsed-<in-'existential-dearth-ofdemoronisation',-so-construed-as-from-ontological-normalcy/postconvergence-perspectivereflection-of-the-'destructuring-threshold_of-the-given-level's-conjugated-postlogism asdementing'> interpersonal, group, intergroup, community, local, national, political, geostrategic, etc. psychologismic epistemic aeutisation diffieuly < for, residualising \{decompulsing delinearity for-cogeney> levels of interrelatedness-dynamics-of-socialconstructing'). This 'overall existential-priming/funnelling/staking of human-per-cep-ti-vi-ty$<$ as-to-notional $\sim$ perceptualisation-of-and-leashing-to_social-functioning-and-accordanceas-of-social-stake-contention-or-confliction> decompulsing-construct'; - $\{$ as to 'embodiedconsciousness elicited \{epistemic-totalising ${ }^{\mathfrak{3}} \mathrm{psychologismic-subliminal-distendedness/detruncating}$ for demoronisation-<sublimating-nascence, nonextricatory-sublimatingupstreaming/'amontée'>'\}) is so-reflected with regards to the warrant for the requisite sublimating-tradition/constant of profound-supererogation (as to the 
‘\{epistemic-totalising ’re-apriorising/re-axiomatising/re-referencing-residuality-in-re-

originariness/re-origination',-—so-'notionally/epistemically/bindingnessly-sas-to-

determinism/conceptivity-of-relative-unreflexivity/relative-reflexivity>_implicited-and-articulated'_as-from-

nonextricatory-'prospective-re-ontologising-Being-then-Institutional-then-Living-magnitudesof-\{hermeneutic/reprojection-protraction-of $\}$ reframing-and-reformulation $\}$ '> that is human profound-supererogation' so-underlying the 'overarching existential-<disontologising/reentelogising aporeticism $>$ priority/precedence/primacy of axiomatising/re-referencing $\sim$ residuality—in-re-originariness/re-origination projection'); and manifested as of prospective 'overarching existential-<disontologising/re-ontologising apereticism $>$ priority/precedence/primacy of requisite prospective ontological-goodfaith/authenticity ${ }^{6} \sim$ postconverging-de-mentating/structuring/paradigming 70 inducing of psychoanalytic-unshackling for the relative-ontological-completeness ${ }^{8}$-ofapriorising/axiomatising/referencing re-ontologising prospective re-rationalisation-ofcontentivity/argumentativity/dialecticism/discursivity' at every given 'secondnatured human station/locus of limitedness/human-subpotency <amplituding/formative-epistemicity >totalising thrownness-in-existence ${ }^{3}$ - as imbued of limitedness/human-subpotency prospective dearth for \{epistemic-totalising łre-apriorising/re-axiomatising/rereferencing $\sim$ residuality —in-re-originariness/re-origination projection)'. In-many-ways the 'historial veracity' of such a human 'overall existential-priming/funnelling/staking of humanper-cep-ti-vi-ty-<as-to-notional perceptualisation-of-and-leashing-to_social-functioningand-accordance-as-of-social-stake-contention-or-confliction> decompulsing-construct'; \{as to 'embodied-consciousness elicited \{epistemic-totalising ${ }^{\frac{1}{3}}$ psychologismic-subliminaldistendedness/detruncating for $\quad$ demoronisation-<sublimating-nascence,-nonextricatorysublimating-upstreaming/'amontée'>'\} has been obscured behind the 'successively given 
relative-unreflexivity of the <cumulating/recomposuring attendant-ontological-contiguity successive registry-worldviews/dimensions given ${ }^{79}$ presencing-absolutising-identitiveconstitutedness ${ }^{14}$ social-stake-contention-or-confliction imbued totalising 3 5 pychologismic-subliminal-truncating' (as to their 'existentially-<disontologising/reentologising aporeticism $>$ manifest incidental/accidental reactive-sufferance/endurance in supposedly and paradoxically subordinating/subserving/collateralising the possibility for prospective re-ontologising-imbuing-of-prospective-humansublimating/emancipating/enfranchisement'). However, prospective ${ }^{18}$ deprocrypticism-orpreempting - disjointedness-as-of- ${ }^{-3}$ reference-of-thought relative-reflexivity (imbued nonpresencing-<perspective-ontological-normalcy/postconvergence $>$ epistemic-projection) critically portends of its given prospective uninhibited/decomplexified appraisal as of human 'overall existential-priming/funnelling/staking of human-per-cep-ti-vi-ty-<as-tonotional perceptualisation-of-and-leashing-to_social-functioning-and-accordance-as-ofsocial-stake-contention-or-confliction $>\quad$ decompulsing-construct'; $-\{$ as to 'embodiedconsciousness elicited for demoronisation-<sublimating-nascence,-nonextricatory-sublimatingupstreaming/'amontée'>'\} with regards to preempting-disjointedness-as-of- ${ }^{8}$ reference-ofthought (and so, as beyond such notional procrypticism/notional disjointedness-as-ofreference-of-thought ${ }^{79}$ presencing-absolutising-identitive-constitutedness ${ }^{14}$ social-stakecontention-or-confliction 'existentially-<disentologising/re-ontologising aporeticism $>$ manifest incidental/accidental reactive-sufferance/endurance in supposedly and paradoxically subordinating/subserving/collateralising the possibility for prospective re-ontologisingimbuing-of-prospective-human-sublimating/emancipating/enfranchisement'); and herein construed as requisite prospective deprocrypticism-or-preempting-disjointedness-as-ofreference-of-thought given overall-overarching 'registry-worldview/dimension 
$<$ constricted/narrowingdown-re-ontologising-enabling $>$ - psychologismic epistemic-

acutisation residualising fepistemic-

thermeneutic/textuality/reprojecting/supererogating/zeroing/re-acuting,

\{decompulsing\} delinearity for-cogency intelligibility';- (imbued overall-overarching untenabilityof-induced unblurriness as '<prospective_punctual/immediacy/constituted/compulsionsencumbered — disarming/dis-ideologising/deformulaicity/à-contrecoup/unsettling/unarguable prompted constricted/narrowingdown-re-ontologising-enabling $>-$ psychologismic epistemicacutisation residualising fepistemic

totalising thermeneutic/textuality/reprojecting/supererogating/zeroing/re-acuting,

$\left.{ }_{\{d e c o m p u l s i n g}\right\}$ delinearity for-cogency'). This so-reflects prospective ${ }^{18}$ deprocrypticism-orpreempting - disjointedness-as-of- ${ }^{-3}$ reference-of-thought 'very point-of-departure for the appraisal of the ontologising/scientific/existence- $<$ honesty-constraining $>$ scope_for_prospective_re-ontologising' (speaking of its prospective profoundsupererogation $\sim$ reframing/reformulation/decatchmenting/detruncating/decompulsing/delinear ising - as-to-postconverging de-mentating/structuring/paradigming for re-rationalisation-ofcontentivity/argumentativity/dialecticism/discursivity); with the 'historial veracity' of such a human 'overall existential-priming/funnelling/staking of human-per-cep-ti-vi-ty-<as-tonotional perceptualisation-of-and-leashing-to_social-functioning-and-accordance-as-ofsocial-stake-contention-or-confliction $>\quad$ decompulsing-construct'; $-\{$ as to 'embodiedconsciousness elicited for demoronisation-<sublimating-nascence,-nonextricatory-sublimatingupstreaming/'amontée'>'\}, so-underlined as of the veridically 'profound-and-comprehensive human experientiality/experiment-<as-to-existentially-formative-'\{epistemic-totalising ${ }^{+}$reapriorising/re-axiomatising/re-referencing residuality — in-re-originariness/re-origination', so-'notionally/epistemically/bindingnessly-<as-to-determinism/conceptivity-of-relative-unreflexivity/relative- 
reflexivity>-implicited-and-articulated'_as-from-nonextricatory-'prospective-re-ontologising-

Being-then-Institutional-then-Living-magnitudes-of-Shermeneutic/reprojection-protractioneffreframing-and-reformulation\}' $>$ ' of the 'flow of human prospective profoundsupererogation -over-shallow-supererogation', undergirding the 'overall relativeunreflexivity/relative-reflexivity - ontological-contiguity ${ }^{67}$ of-the-human-institutionalisationprocess $^{68}$ imbued notional cogency_chronicularity/annality-of-relative-reflexivity,-as-toprofound-supererogation $\quad$ Human-consciousness/collective-consciousnessdistendedness/detruncating-<beyond-selfpresencing,-as-re-ontologising-decentering_ofconsciousness/collective-consciousness,-as-to-psychologismic-epistemic-acutisation residualising,- -decompulsing $^{-}$delinearity $\sim$ for-cogency $>$ (as reflecting underlying human 'overall existential-priming/funnelling/staking of human-per-cep-ti-vi-ty-<as-to notional perceptualisation-of-and-leashing-to_social-functioning-and-accordance-as-ofsocial-stake-contention-or-confliction $>\quad$ decompulsing-construct'; $-\{$ as to 'embodiedconsciousness elicited for demoronisation- $<$ sublimating-nascence, -nonextricatory-sublimatingupstreaming/'amontée'>'\}) effectively speaks to the fact that 'human presumpustapriorising-eliciting-of-assmptionstaposteriorising (arising as from human $<$ amplituding/formative-epistemicity $>$-totalising $\sim$ thrownness-in-existence ${ }^{35}$,-imbuedprojective-arbitrariness/waywardness-〈as-to-the-human-projective/reprojectiveaestheticising-re-motif-and-re-apriorising/re-axiomatising/re-referencing-process-of$<$ amplituding/formative-epistemicity $>$ totalising conceptualisation'〉') undergirds 'protractedsocial—as-to-individual-by-institutional-by-social relative direct/deferentialresponsibility/relative-reflexivity-or-irresponsibility/relative-unreflexivity to cogency_chronicularity/annality-of-relative-reflexivity,-as-to-profound-supererogation '; and so as to the 'ontological-inveracity or ontological-veracity of perceived-social-and-institutional- 
commonly-enculturated_referencing,-of- meaningfulness-and-teleology' imbued relativeunreflexivity/relative-reflexivity -ontological-contiguity ${ }^{77}$ with regards to underlying unblurriness-<re-ontologising_by-postconverging-as-to-dragged-out-

supererogatory wholesomeness/profound-supererogation ,-while-anecdotalising-prior-

disontologising-thresholding $>$ scope as of relatively elucidated-<as-topreconverging/postconverging rede-mentating/restructuring/reparadigming $>\quad$ human ontological-commitment ${ }^{6}$ and universal-transparency ${ }^{104}$ (with respect to underlying human 'crossgenerational notional firstnaturedness-formativeness-<as-to-eventualising inkling drive-or-seeding-misprising $>$ mental-processing-parity for ontological-performance ${ }^{72}$ <including-virtue-as-ontology $>$ /morality/ethics/justice/etc.'). 'human presumptuousness/apriorising-eliciting-of-assumptionstaposteriorising (arising as from human $<$ amplituding/formative-epistemicity $>$-totalising $\sim$ thrownness-in-existence ${ }^{35}$,-imbuedprojective-arbitrariness/waywardness-〈as-to-the-human-projective/reprojectiveaestheticising-re-motif-and-re-apriorising/re-axiomatising/re-referencing-process-of'<amplituding/formative-epistemicity $>$ totalising $\sim$ conceptualisation' $\rangle$ ') undergirding, (whether manifested as of the 'ontological-inveracity or ontological-veracity of perceived-social-andinstitutional-commonly-enculturated_referencing,-of- meaningfulness-and-teleology'), goes on to reflect the 'concretely manifest social and institutional disontologising/re-ontologisingthreshold' (whether in shallowsupererogation $\sim$ framing/formulation/catchmenting/truncating/compulsing/linearising —as-topreconverging - de-mentating/structuring/paradigming or profoundsupererogation $\sim$ reframing/reformulation/decatchmenting/detruncating/decompulsing/delinear ising - as-to-postconverging de-mentating/structuring/paradigming'); as so-defining (with respect to 'limitedness/human-subpotency prospective re-encountering/re-confrontation with unlimitedness/existence-<ull-potency-of_sublimating nascence>') the relative- 
unreflexivity/relative-reflexivity_ontological-contiguity ${ }^{77}$ as to requisite re-ontologising as of the given 'specific institutionalising/organising/mutualising/methodologising $<$ constricted/narrowingdown-re-ontologising-enabling $>$-psychologismic epistemic -

acutisation residualising a fepistemic-

totalising thermeneutic/textuality/reprojecting/supererogating/zeroing/re-acuting,

${ }_{\{\text {decompulsing }}$ delinearity for-cogency intelligibility';- (imbued underlying untenability-ofinduced unblurriness as '<prospective_punctual/immediacy/constituted/compulsions-

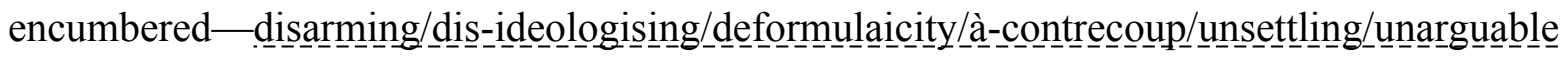
prompted constricted/narrowingdown-re-ontologising-enabling $>$-psychologismic epistemicacutisation residualising \{epistemic-

totalising ${ }^{t}$ hermeneutic/textuality/reprojecting/supererogating/zeroing/re-acuting,

${ }_{\{\text {decompulsing }}$ delinearity for-cogency'). So-underlying the given station/locus overall relationship between 'human relative-reflexivity-threshold of emphasis on ontological-veracity' and 'human relative-unreflexivity-threshold of emphasis on sovereign-function/posture-<as-toexistentially-manifest-‘embodied-subject $\sim$ consciousness-and-direct/deferentialconscientiousness',-as-of-its-'epistemic-reflexivity/unreflexivity-in-existence'/teleology> social-functioning-and-accordance-as-of-social-stake-contention-or-confliction'; as reflected in the given station/locus imbued 'effective existential-<disontologising/re-ontologising aporeticism $>$ human sovereign-emergence/becoming,-existentially-imbuing-human-freedomas-to-supererogating/surrealising-for-'knowledge-empowerment-over-ignorancedisempowerment'-<as-of-'developing-and-availing-sovereignsublimating_potential/possibilities/options/choices'-as-to-the-'credibility'/'ontologicalveracity'-underlying-the-'sovereign-conscious/conscientious-backdrop’> consciousness/collective-consciousness' (underlied overall by the given station/locus relationship between the genuine social intellectual-function/posture, 
pedantising/muddling/formulaic-hollowing-out — in-subontologisation/subpotentiation〈blurring/undermining-of-prospective-totalising-entailing,-as-to-entailing$<$ ampliting/formative-epistemicity $>$ totalising in-relative-ontological-completeness $>$ and consequential human sovereign-function/posture-<as-to-existentially-manifest-'embodiedsubject $\sim$ consciousness-and-direct/deferential-conscientiousness',-as-of-its- 'epistemicreflexivity/unreflexivity-in-existence'/teleology>). This insight effectively speaks to the fact that social and institutional manifestations of prospectively ontologically-flawed process/processive bothsidesism-〈as-'mere-processive'/pedantising-'dialogical-relation'-to 'perceived-socialand-institutional-commonly-enculturated_referencing,-of- meaningfulness-and-teleology 'failing-'requisite-existential-thematic-baseline-of-technicity/profundity-framing' \{ofsublimating-discursivity-for-sovereign-repassing \},-as-of-psychologismic-epistemicacutisation-nonresidualising-imbued-fompulsing linearity in-eclecticism-of-prior-mereformulaicity/ritualisation,-as-so- 'consciously/unconsciously-preordained/fated'-to-failprospective-notional $\sim \operatorname{cogency}$ ) conceptualisation are inherently bound to arise (without/wherethere-is-lack-of a prospective sense of 'supererogating ${ }^{\prime}\{$ affirmation/projection/assertion/notional $\sim$ self-distantiation-byunaffirmation/deprojection/deassertion/epistemic-decadence $\quad$ mobilisability-<as-to-'reontologising-projecting/oeuvrement'-over-'disontologising-de-projecting/de-oeuvrement'>'); as to the fact that 'human presumptuousnessfapriorising-eliciting-ofassmptionstaposteriorising (arising as from human <amplituding/formative-epistemicity>totalising $\sim$ thrownness-in-existence ${ }^{35}$,-imbued-projective-arbitrariness/waywardness-〈as-to-thehuman-projective/reprojective- aestheticising-re-motif-and-re-apriorising/re-axiomatising/rereferencing-process-of- '<mplitung/formative-epistemicity $>$ totalising $\sim$ conceptualisation' $\rangle)$ ' rather rests upon such 'concretely and pointedly manifest social and institutional disontologising/re-ontologising relative-unreflexity/relative-reflexivity-threshold' 
(prospectively, in prior mere-formulaicity/ritualisation-<as-to-mere-formulaic methodologising/mutualising/organising/institutionalising,-prospectively-losing-track-of‘fepistemic-totlising ’’re-apriorising/re-axiomatising/re-referencing $r$ residuality-in-reoriginariness/re-origination'>, as failing prospective re-ontologising 'dynamic cumulating/recomposuring psychologismic-epistemic-acutisation-residualising,${ }_{\text {\{decompulsing }}$ delinearity for-cogency phasing of limitedness/human-subpotency onto unlimitedness/existence-<full-potency-of_sublimating nascence $>$ '). The implication here, with regards to the very requisite 'recurrent/perpetuating/continuity-recomposuring existential< disontologising/re-ontologising aporeticism $>$ counteracting/supplanting/alienating-ofprior-apriorising/axiomatising/referencing' for limitedness/human-subpotency supererogating $\{$ affirmation/projection/assertion/notional $\sim$ self-distantiation-byunaffirmation/deprojection/deassertion/epistemic-decadence $\}$ — towards $\sim$ omnipotentialaffirmation/projection/assertion/notional self-distantiation (as to its aspirative projection of 'unlimitedness/existence-<full-potency-of_sublimating nascence $>$ perspective' imbued immanent-reflexivity omnipotential-affirmation/projection/assertion/notional $\sim$ selfdistantiation), means that the overarching ' presencing-absolutising-identitiveconstitutedness $^{14}$ prospectively disontologising relative-unreflexity-threshold' or ' nonpresencing-<perspective-ontological-normalcy/postconvergence> prospectively reontologising relative-reflexity-threshold' with respect to prospectively warranted 'specific institutionalising/organising/mutualising/methodologising $\quad<$ constricted/narrowingdown-reontologising-enabling $>$-psychologismic epistemic acutisation residualising a fepistemictotalising thermeneutic/textuality/reprojecting/supererogating/zeroing/re-acuting, \{decompulsing\} delinearity for cogeney intelligibility'; - (imbued underlying untenability-ofinduced unblurriness as '<prospective_punctual/immediacy/constituted/compulsions-

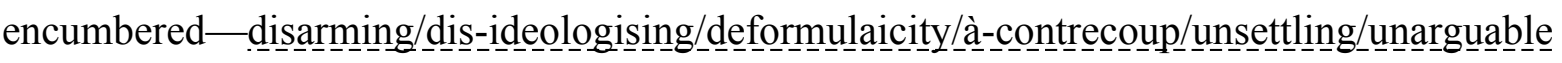


prompted constricted/narrowingdown-re-ontologising-enabling $>-$ psychologismic epistemicacutisation residualising fepistemic-

totlising thermeneutic/textuality/reprojecting/supererogating/zeroing/re-acuting,

${ }_{\{d e c o m p u l s i n g}$ delinearity for-cogency') is effectively undertaken/manifested/occurrent respectively 'either as of disontologising prospective relative-unreflexivity shallowsupereregation $\sim$ framing/formulation/catchmenting/truncating/compulsing/linearising —as-topreconverging de-mentating/structuring/paradigming ontological-performance ${ }^{2}-<$ includingvirtue-as-ontology $>$ /morality/ethics/justice/etc. or re-ontologising prospective relativereflexivity profoundsupererogation $\sim$ reframing/reformulation/decatchmenting/detruncating/decompulsing/delinear ising - as-to-postconverging de-mentating/structuring/paradigming ontological-performance ${ }^{72}$ <including-virtue-as-ontology $>$ /morality/ethics/justice/etc.'. Such that such 'disontologising prospective relative-unreflexivity shallow supererogation $\sim$ framing/formulation/catchmenting/truncating/compulsing/linearising —as-topreconverging -de-mentating/structuring/paradigming' (more pronounced with social and institutional manifestations of prospectively ontologically-flawed process/processive bothsidesism-〈as-'mere-processive'/pedantising-'dialogical-relation'-to 'perceived-socialand-institutional-commonly-enculturated_referencing,-of- meaningfulness-and-teleology 'failing-'requisite-existential-thematic-baseline-of-technicity/profundity-framing' \{ofsublimating-discursivity-for-sovereign-repassing\},-as-of-psychologismic-epistemicacutisation-nonresidualising-imbued-\{compulsing\}linearity in-eclecticism-of-prior-mereformulaicity/ritualisation,-as-so- 'consciously/unconsciously-preordained/fated'-to-failprospective-notional cogency) conceptualisation and as particularly manifest with shallowsupererogation $\sim$ framing/formulation/catchmenting/truncating/compulsing/linearising_scale —of-opaque/contentious/un-nominalised/flawed-interpretations/domains of blurriness- 
$<$ sterilising/anecdotalising/trivialising-of-prospective-re-ontologising_by-preconverging,-in-

disontologising-formulaic-dragging-out/hollowing-out> together with 'unwieldycontemplatable-disontologising/re-ontologising-implications,-with-regards-to-humansovereign-function/posture-<as-to-narrowness/evasiveness/vagueness-of-disontologising/reontologising > with respect to contentious/un-nominalisedness of social-stake-contention-orconfliction'), speak to the fact that even relatively profoundsupereregation $\sim$ reframing/reformulation/decatchmenting/detruncating/decompulsing/delinear ising_scale_of-transparent/noncontentious/un-nominalised/sound-interpretations/domains of manifest unblurriness-<re-ontologising_by-postconverging-as-to-dragged-outsupererogatory wholesomeness/profound-supererogation ,-while-anecdotalising-priordisontologising-thresholding $>$ (with regards to relatively uncontentious/nominalised socialstake-contention-or-confliction) are not absolutely immune from prospectively ontologicallyflawed process/processive bothsidesism-〈as-'mere-processive'/pedantising-'dialogicalrelation'-to 'perceived-social-and-institutional-commonly-enculturated_referencing,-ofmeaningfulness-and-teleology '-failing-'requisite-existential-thematic-baseline-oftechnicity/profundity-framing' \{of-sublimating-discursivity-for-sovereign-repassing \},-as-ofpsychologismic-epistemic-acutisation-nonresidualising-imbued-\{compulsing\}linearity ineclecticism-of-prior-mere-formulaicity/ritualisation,-as-so-'consciously/unconsciouslypreordained/fated'-to-fail-prospective-notional cogency $\rangle$ conceptualisation (particularly so as to when 'requisite overarching prospective Being-development/ontological-frameworkexpansion-as-to-depth-of-ontologising-development-as-infrastructure-of- meaningfulnessand-teleology psychologismic epistemic-acutisation difficulty-<for, residualising $\{$ decompulsing $\}$ delinearity for-cogeney $>$ magnitudes $\{$ of-experientiality/experiment $\}$, is undermined by social and institutional manifestations of shallow supererogation $\sim$ framing/formulation/catchmenting/truncating/compulsing/linearising_scale 
—of-opaque/contentious/un-nominalised/flawed-interpretations/domains

of manifest blurriness- $<$ sterilising/anecdotalising/trivialising-of-prospective-re-ontologising_bypreconverging,-in-disontologising-formulaic-dragging-out/hollowing-out>).

Such immunity/insusceptibility at all times is rather enabled as to prospectively elucidated-<as-topreconverging/postconverging rede-mentating/restructuring/reparadigming $>$ human ontological-commitment ${ }^{66}$ and universal-transparency ${ }^{104}$ (with respect to underlying human 'crossgenerational notional firstnaturedness-formativeness-<as-to-eventualising inkling drive or seeding misprising $>$ mental-processing-parity for ontological-performance ${ }^{72}$ <including-virtue-as-ontology $>$ /morality/ethics/justice/etc.'), and so as to 'substantivity of transversality-<for-sublimating-existential-eventuating/denouement,-from-'thinking at-

\section{first/pure-predisposition-preemptive-of-prospective-disontologising/subontologising' as-of-} prospectively-disambiguated-affirmed-and-unaffirmed-'motif-and-

apriorising/axiomatising/referencing'> $>1$ ' imbued 'impersonalisation and deinstitutionalisation of prospective re-ontologising ${ }^{56}$ meaningfulness-and-teleology ${ }^{9}$ ' as ontologising-failsafe-<asto-'relative-unreflexivity/relative-reflexivity bindingness/nondiscretionariness' of totalising entailment $>$ (as of 'limitedness/human-subpotency prospective re-encountering/re-confrontation with unlimitedness/existence-full poten of_sublimating naseencer); so-underlied as from 'profound-

supererogation $\sim$ reframing/reformulation/decatchmenting/detruncating/decompulsing/delinear ising —as-to-postconverging - de-mentating/structuring/paradigming

priority/precedence/primacy' of re-ontologising prospective Being-development/ontologicalframework-expansion-as-to-depth-of-ontologising-development-as-infrastructure-ofmeaningfulness-and-teleology psychologismic epistemic acutisation diffieulty < for, residualising \{decompulsing\} delinearity for-cogency> magnitude\{of-experientiality/experiment\}, then institutional-development-as-to-social-function-development psychologismic epistemic - 
acutisation difficulty-<for, residualising \{decompulsing $\}$ delinearity for-cogency> magnitude $\{$ ofexperientiality/experiment\} and then living-development-as-to-personality-development psychologismic epistemic-acutisation difficulty < for, residualising ${ }_{\text {\{decompulsing }}$ delinearity for-cogency $>$ magnitude ${ }^{\{0-\text { experientiality/experiment }\}}$ (and so, as to ${ }^{83}$ referenceof-thought-and- ${ }^{83}$ reference-of-thought- ${ }^{84}$ evolving- ${ }^{5}$ meaningfulness-and-teleology 'organic accompaniment' of 'limitedness/human-subpotency prospective re-encountering/reconfrontation with unlimitedness/existence-<full-potency-of_sublimating nascence $>$ '). This (with regards to 'limitedness/human-subpotency prospective re-encountering/re-confrontation with unlimitedness/existence-<full-potency-of_sublimating naseence>') so-reflects prospective re-ontologising as to the 'given specific institutionalising/organising/mutualising/methodologising <constricted/narrowingdown-reontologising-enabling $>$-psychologismic epistemic acutisation - residualising fepistemictotalising thermeneutic/textuality/reprojecting/supererogating/zeroing/re-acuting, \{decompulsing delinearity for-cogency intelligibility';- (imbued underlying untenability-ofinduced unblurriness as '<prospective_punctual/immediacy/constituted/compulsions-

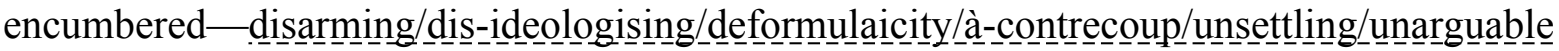
prompted constricted/narrowingdown-re-ontologising-enabling $>$ psychologismic epistemic acutisation residualising fepistemic-

totalising thermeneutic/textuality/reprojecting/supererogating/zeroing/re-acuting, \{decompulsing delinearity for-cogency'. In other words, any such given specific institutionalising/organising/mutualising/methodologising rather sublimatingly-arise and is sublimatingly-prolongated only as of 'limitedness/human-subpotency prospective reencountering/re-confrontation with unlimitedness/existence-full pof nascence $>$ ' as the more fundamental validation of ontological-veracity (as to induced 'protracted-social — as-to-individual-by-institutional-by-social relative direct/deferential- 
responsibility/relative-reflexivity to cogency_chronicularity/annality-of-relative-reflexivity,-asto-profound-supererogation '); failing which, any such given specific institutionalising/organising/mutualising/methodologising is validly subjectable to contestation as of its manifestation of relative 'epistemic-decadence' or teleological-decadence-<-indimensionality-of-desublimating-lack-of $-\langle<$ amplituding/formative $>$ supererogatory $\sim$ dementativeness/epistemic-growth-or-conflatedness /transvaluativerationalising/transepistemicity/anamnestic-residuality/spirit-drivenness-equalisation〉 imbued distractive-alignment-to- ${ }^{8}$ reference-of-thought- $<$ of-apriorising/axiomatising/referencing $>$ (and so, rather than the requisite manifestation of 'despite-the-self exercise of epistemicprojection in notional $\sim$ self-distantiation- $<$ imbued-re-motif-and-re-apriorising/reaxiomatising/re-referencing $>$ ' involved in 'limitedness/human-subpotency prospective reencountering/re-confrontation with unlimitedness/existence-ffull-potency-of_sublimating nascence $>$ '). The bigger and overall point here palpably speaks to the 'recoiling-<as-to-induced'wavering/redounding/waveforming-of-dimensionality-of-sublimating '-by-'dimensionalityof-desublimating '-at-successive-loci/stations-of-'thrownness-disposition-as-of-mereformulaicity/ritualisation'>-_from dimensionality-of-sublimating Kamplituding/formative>supererogatory de-mentativeness/epistemic-growth-orconflatedness /transvaluative-rationalising/transepistemicity/anamnestic-residuality/spiritdrivenness equalisation) elicited prospective psychologismic-epistemic-acutisation- $<$ as-topostconverging-de-mentating/structuring/paradigming,-eliciting-of-existence's-sublimatingnascence-in-prospective-aporeticism-overcoming/unovercoming > as to epistemic-growth,-as\{veridical/sound\}-relative-reflexivity-in-existence/relativising from-limited-mentation-as-itsdeepening/psychologismic epistemic-acutisation residualising, fdecompulsingl delinearity foreogency)' as to manifest 'seeding-misprising of dimensionality-of-desublimating-lack-of ${ }^{-}$ <<amplituding/formative >supererogatory $\sim$ de-mentativeness/epistemic-growth-or- 
conflatedness /transvaluative-rationalising/transepistemicity/anamnestic-residuality/spirit-

drivenness-equalisation)'; and so, with regards to the inherent relationship between 'limitedness/human-subpotency' (as to prospective re-encountering/re-confrontation) with 'unlimitedness/existence-<full-potency-of_sublimating nascence $>$ '. Wherein (at successiveloci/stations-of-'thrownness-disposition-as-of-mere-formulaicity/ritualisation’)

consciously/unconsciously 'limitedness/human-subpotency' presents the social-stakecontention-or-confliction 'self-referencing-syncretising forward-facingsupposedly postconverging-or-dialectical-thinking ${ }^{21}$-apriorising-psychologism epistemicprojection imbued prior mere-formulaicity/ritualisation-<as-to-mere-formulaicmethodologising/mutualising/organising/institutionalising,-prospectively-losing-track-of-

‘\{epistemic-totalising ’’re-apriorising/re-axiomatising/re-referencing-residuality-in-re-

originariness/re-origination'>' as prospectively substitutive of 'unlimitedness/existence-<fullpotency-of_sublimating nascence '; and so, as impliciting (as of dimensionality-ofdesublimating-lack-of ${ }^{-}-\langle<$amplituding/formative $>$supererogatory $\sim$ de-mentativeness/epistemicgrowth-or-conflatedness /transvaluative-rationalising/transepistemicity/anamnestic-

residuality/spirit-drivenness-equalisation〉) a 'protection' from prospective re-ontologising, and so-specifically with respect to prospective Being-development/ontological-frameworkexpansion-as-to-depth-of-ontologising-development-as-infrastructure-of- meaningfulnessand-teleology psychologismic epistemic-acutisation difficulty-<for, residualising${ }_{\text {\{decompulsing }}$ delinearity for-cogeney $>$ magnitude ${ }^{\text {of-experientiality/experiment }\}}$. Along the lines, afterall all the world that exists is respectively either as of recurrent-utter-uninstitutionalisation, baseinstitutionalisation-ununiversalisation, ${ }^{103}$ universalisation-non-positivism/medievalism or our positivism- ${ }^{80}$ procrypticism/disjointedness-as-of- ${ }^{83}$ reference-of-thought (and not as of the correspondingly requisite prospective psychologismic-epistemic-acutisation-<as-topostconverging-de-mentating/structuring/paradigming,-eliciting-of-existence's-sublimating- 
nascence-in-prospective-aporeticism-overcoming/unovercoming $>$ as to epistemic-growth,-as \{veridical/sound\}-relative-reflexivity-in-existence/relativising from-limited-mentation-as-itsdeepening/psychologismic epistemic-acutisation residualising, fdecompulsingl $_{\text {f }}$ delinearity foreogency for base-institutionalisation, ${ }^{10}$ universalisation or positivism or ${ }^{18}$ deprocrypticism-orpreempting - disjointedness-as-of- ${ }^{8}$ reference-of-thought). This is insightfully the very 'test of whatever presents/qualifies itself as of core-philosophy/derivative-core-philosophy-(imbued requisite 'inkling-drive of dimensionality-of-sublimating

<<amplituding/formative>supererogatory $\sim$ de-mentativeness/epistemic-growth-or-

conflatedness /transvaluative-rationalising/transepistemicity/anamnestic-residuality/spiritdrivenness-equalisation)')' with respect to prospectively undermining/preempting the 'recoiling-<as-to-induced-'wavering/redounding/waveforming-of-dimensionality-ofsublimating '-by-'dimensionality-of-desublimating '-at-successive-loci/stations-of‘thrownness-disposition-as-of-mere-formulaicity/ritualisation'>_(from dimensionality-ofsublimating f ramplituding/formative $>$ supererogatory de mentativeness/epistemic growth or conflatedness /transvaluative rationalising/transepistemicity/anamnestic residuality/spirit drivenness-equalisation) elicited prospective psychologismic-epistemic-acutisation- $<$ as-topostconverging-de-mentating/structuring/paradigming,-eliciting-of-existence's-sublimatingnascence-in-prospective-aporeticism-overcoming/unovercoming $>$ as to epistemic-growth,-as\{veridical/sound\}-relative-reflexivity-in-existence/relativising from-limited-mentation-as-itsdeepening/psychologismic epistemic acutisation residualising, $\left.{ }^{\{d e c o m p u l s i n g}\right\}$ delinearity for eogency)' as to manifest 'seeding-misprising of dimensionality-of-desublimating-lack-of ${ }^{-}$ <<amplituding/formative>supererogatory $\sim$ de-mentativeness/epistemic-growth-orconflatedness /transvaluative-rationalising/transepistemicity/anamnestic-residuality/spiritdrivenness-equalisation〉': as to the fact that philosophy occurs where Socratic-philosophers universalising-idealisation and budding-positivists positivism/rational-empiricism 
prospective

ontologising_prompting
$<$ nonextricatory/postconverging/unaccommodating/questioning $>$-reexistentially-<isontologising/re-ontologising aporeticism $>$ 'highlight the prospectively mental-underdevelopment of their respectively given nonuniversalising and nonpositivising social-stake-contention-or-confliction construct' as the very psychoanalytic-unshackling backdrop for enabling prospective re-ontologising (notwithstanding the pedantising/muddling/formulaic-hollowing-out-in-subontologisation/subpotentiation〈blurring/undermining-of-prospective-totalising-entailing,-as-to-entailing$<$ amplituding/formative-epistemicity $>$ totalising in-relative-ontological-completeness $>$ respectively of ancient-sophists and medieval-scholasticism in $<$ extricatory/preconverging/accommodating/unquestioning $>-$ disontologising/subontologising_prompting). In other words, the representation of corephilosophy/derivative-core-philosophy_ (imbued requisite 'inkling-drive of dimensionality-ofsublimating 25 -<<mplituding/formative $>$ supererogatory $\sim$ de-mentativeness/epistemic-growthor-conflatedness /transvaluative-rationalising/transepistemicity/anamnestic-residuality/spiritdrivenness-equalisation)') as 'supposedly ontologically-contiguous' with the 'shallowsupererogation $\sim$ framing/formulation/catchmenting/truncating/compulsing/linearising_scale —of-opaque/contentious/un-nominalised/flawed-interpretations/domains of ${ }^{79}$ presencingabsolutising-identitive-constitutedness ${ }^{14}$ social-stake-contention-or-confliction construct' defining ' $\leq$ mere-formulaicity/ritualisation - of $>$-prior secondnatured positive-opportunism-ofsocial-functioning-and-accordance ${ }^{75}$ as to imbuing prospective shallow-supererogation ${ }^{9}$ rather reflects disontologising prior-perspective-falsity/falseness/fallaciousness of a mere 'logical/rationalising exercise' (speaking to the ever always requisite sublimatingwithdrawal/unenframing/re-ontologising to prospectively subject 'limitedness/humansubpotency' as to reflecting 'unlimitedness/existence-<flllpotency-of_sublimating nascence ${ }^{\prime}$ ); and so, as of requisite re-ontologising psychologismic-epistemic-acutisation- $<$ as- 
to-postconverging-de-mentating/structuring/paradigming,-eliciting-of-existence's-sublimatingnascence-in-prospective-aporeticism-overcoming/unovercoming > as to epistemic-growth,-as\{veridical/sound\}-relative-reflexivity-in-existence/relativising from-limited-mentation-as-itsdeepening/psychologismic epistemic acutisation residualising, ${ }^{\text {fdecompulsing }}$ delinearity for eogency (as manifested with the fundamental prospective reconstrual of successive-loci/stationsof-'thrownness-disposition-as-of-mere-formulaicity/ritualisation'). $\quad$ The corephilosophy/derivative-core-philosophy_ (imbued requisite 'inkling-drive of dimensionality-ofsublimating $25<<$ amplituding/formative $>$ supererogatory $\sim$ de-mentativeness/epistemic-growthor-conflatedness /transvaluative-rationalising/transepistemicity/anamnestic-residuality/spiritdrivenness-equalisation $\rangle^{\prime}$ ) ramifications (that any given specific institutionalising/organising/mutualising/methodologising rather sublimatingly-arise and is sublimatingly-prolongated only as of 'limitedness/human-subpotency prospective reencountering/re-confrontation with unlimitedness/existence-<fll-potency-of_sublimating nascence $>$ as to limited-mentation-capacity-deepening - as-subjecting limitedness/humansubpotency to-'educed-unlimitedness/existence-sublimating nascence' ${ }^{5}$ ), implies that no institutionalising/organising/mutualising/methodologising can be shielded/protected (as to any 'practice/collegiality/consensus of limitedness/human-subpotency') from 'unlimitedness/existence-<ull-potency-of_sublimating nascence $>$ ' inherently justificatory evaluation of either such 'limitedness/human-subpotency' manifest 'disontologising irresponsibility/relative-unreflexivity' or manifest 're-ontologising responsibility/relativereflexivity'; so-reflected as to the fact that prospective Socratic-philosophers ${ }^{103}$ universalisingidealisation and budding-positivists positivism/rational-empiricism prospective sublimatingprolongation correspondingly arose as from their respectively imbued profoundsupereregation $\sim$ reframing/reformulation/decatchmenting/detruncating/decompulsing/delinear ising - as to postconverging de-mentating/structuring/paradigming subverting/undermining of 
the 'practice/collegiality/consensus of limitedness/human-subpotency (failing prospective sublimating-prolongation)' of ancient-sophists non-universalising and medieval-scholasticism nonpositivising respectively imbued shallow supererogation $\sim$ framing/formulation/catchmenting/truncating/compulsing/linearising —as-topreconverging-de-mentating/structuring/paradigming. In many ways, such a 'practice/collegiality/consensus of limitedness/human-subpotency (failing prospective sublimating-prolongation)' associated with our positivism- ${ }^{8}$ procrypticism/disjointedness-asof- ${ }^{8}$ reference-of-thought knowledge-deadends-<as-preconverging-dementating/structuring/paradigming especially as undermining/compromising prospective Beingdevelopment/ontological-framework-expansion-as-to-depth-of-ontologising-development-asinfrastructure-of- meaningfulness-and-teleology psychologismic epistemic-acutisationdifficulty <for, residualising_\{decompulsing\} ${ }^{\text {delinearity for-cogency> }}$ magnitude $\{$ ofexperientiality/experiment\} (and as this undermines/compromises prospective institutional-developmentas-to-social-function-development psychologismic epistemic-acutisation difficulty-for,

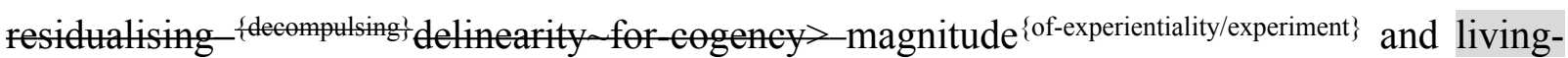
development-as-to-personality-development psychologismic epistemic-acutisationdiffieuly <for, residualising ${ }^{\{\text {decompulsing }\}}$ delinearity for cogeney> magnitude $\{$ ofexperientiality/experiment\}), is critically associated with the existentialising-decisionality-as-todisontologising/re-ontologising aporeticism $>$ of 'beholdening as sovereignising-imbuedsubontologisation/subpotentiation' associated with 'social-and-institutional-frameworks-ofreferencing/registering/decisioning in blurriness-<sterilising/anecdotalising/trivialising-ofprospective-re-ontologising_by-preconverging,-in-disontologising-formulaic-dragging-

out/hollowing-out>'. This is markedly undergirded implicitly/explicitly as to a 'mutually reinforcing self-indulging and self-sustaining triptych/trinity' of 'practice/collegiality/consensus of limitedness/human-subpotency failing prospective sublimating-prolongation' manifested as 
formulaicity/ritualisation ('as supposedly more critically covered/protected/shielded from requisite sublimating-prolongation with respect to the prospective veracity of superseding unlimitedness/existence-<full-potency-of_sublimating nascence $>$ ') by its assumed institutionalised-legalese-posturing mere-formulaicity/ritualisation and institutionalisedcommunication/public-relations-posturing mere-formulaicity/ritualisation, and so-underlied overall as to formulaic profusion of prospectively ontologically-flawed process/processive bothsidesism-〈as-'mere-processive'/pedantising-'dialogical-relation'-to 'perceived-socialand-institutional-commonly-enculturated_referencing,-of- meaningfulness-and-teleology 'failing-'requisite-existential-thematic-baseline-of-technicity/profundity-framing' \{ofsublimating-discursivity-for-sovereign-repassing\},-as-of-psychologismic-epistemicacutisation-nonresidualising-imbued-\{compulsing linearity in-eclecticism-of-prior-mereformulaicity/ritualisation,-as-so- 'consciously/unconsciously-preordained/fated'-to-failprospective-notional cogency) conceptualisation $\quad$ (supposedly superseding 'unlimitedness/existence-<full-potency-of_sublimating nascence $>$ ' inherently justificatory evaluation of either 'limitedness/human-subpotency' manifest 'disontologising irresponsibility/relative-unreflexivity' or 're-ontologising responsibility/relative-reflexivity'); speaking in-effect of relative 'epistemic-decadence' or teleological-decadence-<-indimensionality-of-desublimating-lack-of $-<<$ amplituding/formative $>$ supererogatory $\sim$ dementativeness/epistemic-growth-or-conflatedness /transvaluativerationalising/transepistemicity/anamnestic-residuality/spirit-drivenness-equalisation〉 imbued distractive-alignment-to- ${ }^{8}$ reference-of-thought-<of-apriorising/axiomatising/referencing $>$ (and so, rather than the requisite manifestation of 'despite-the-self exercise of epistemicprojection in notional $\sim$ self-distantiation- $<$ imbued-re-motif-and-re-apriorising/reaxiomatising/re-referencing>' involved in 'limitedness/human-subpotency prospective re- 
encountering/re-confrontation with unlimitedness/existence-<flll-potency-of_sublimating nascence $>$ '). This mutually reinforcing triptych/trinity takes on a purposefulness (as to its manifest 'micro-decisionality/decisionality thrownness-disposition of prior mereformulaicity/ritualisation-<as-to-mere-formulaic-

methodologising/mutualising/organising/institutionalising,-prospectively-losing-track-of-

‘fepistemic-totalising '`re-apriorising/re-axiomatising/re-referencing-residuality-in-re-

originariness/re-origination'> $>$ failing prospective postconverging aporeticismovercoming/unovercoming (as to prospective profoundsupereregation $\sim$ reframing/reformulation/decatchmenting/detruncating/decompulsing/delinear ising - as-to-postconverging de-mentating/structuring/paradigming requisite manifestation of 'despite-the-self exercise of epistemic-projection in notional $\sim$ self-distantiation-<imbued-remotif-and-re-apriorising/re-axiomatising/re-referencing>' involved in 'limitedness/humansubpotency prospective re-encountering/re-confrontation with unlimitedness/existence-<fullpotency-of_sublimating nascence>'). This mutually reinforcing triptych/trinity seem to consciously/unconsciously imply (reactionarily-and-anti-conspiratorially) a 'protection' from prospective re-ontologising (as of the eliciting of the recoiling-<as-to-induced-

\section{'wavering-redounding forming-of-dimensionality-of-sublimating '-by-'dimensionality-}

\section{of-desublimating '-at-successive-loci/stations-of-'thrownness-disposition-as-of-mere-}

formulaicity/ritualisation'> of our positivism $-{ }^{80}$ procrypticism/disjointedness-as-of- ${ }^{8}$ referenceof-thought given locus/station-of-'thrownness-disposition-as-of-mereformulaicity/ritualisation' of limitedness/human-subpotency social-stake-contention-orconfliction 'self-referencing-syncretising forward-facing-supposedly $\sim$ postconverging-ordialectical-thinking -apriorising-psychologism epistemic-projection); from whence 'our prospectively given preconverging-de-mentating/structuring/paradigming procrypticism/disjointedness-as-of- ${ }^{2}$ reference-of-thought supposedly cannot be thought' 
(which paradoxically is the very prospective existential-<disontologising/re-ontologising aporeticism $>$ point of core-philosophy/derivative-core-philosophy requisite 'thinking at first/pure predisposition preemptive of prospective disontologising/subontologising'). The existentialising-decisionality-<as-to-disontologising/re-ontologising aporeticism $>\quad$ of 'beholdening as sovereignising-imbued-subontologisation/subpotentiation' underlying this mutually reinforcing triptych/trinity is most patently reflected as to our shallowsupererogation $\sim$ framing/formulation/catchmenting/truncating/compulsing/linearising —as-topreconverging de-mentating/structuring/paradigming with respect to prospectively requisite sublimating-prolongation 'supererogating $\{$ affirmation/projection/assertion/notional $\sim$ self-distantiation-byunaffirmation/deprojection/deassertion/epistemic-decadence $\} \quad$ mobilisability-<as-to-'reontologising-projecting/oeuvrement'-over-'disontologising-de-projecting/de-oeuvrement'> of immaterial and material value' (but rather undermined as of our epochal 'renting and skewed value-extraction'); along the same lines of 'historical desublimating renting and skewed immaterial and material value' as of blatant brutish conquest/subjugation conception of sovereign apportioning, dominion protection conception of sovereign apportioning, to the very natural-order-of-things conception of sovereign apportioning and to our subtle modern-day institutionally-distorted/disjointed conception of sovereign apportioning (so-underlied as to their respectively elicited \{epistemic-totalising $3{ }^{3}$ psychologismic-subliminal-truncating as of 'catchmentedand-compulsed-<in-'existential-dearth-of-demoronisation',-so-construed-as-from-ontologicalnormalcy/postconvergence-perspective-reflection-of-the-'destructuring-threshold_of-thegiven-level's-conjugated-postlogism as-dementing'> interpersonal, group, intergroup, community, local, national, political, geostrategic, etc. psycholegismic epistemic acutisationdifficulty < for, residualising \{decompulsing $\}$ delinearity for-cogency>-levels of interrelatednessdynamics-of-social-constructing'). In other words, core-philosophy/derivative-core- 
philosophy-(imbued requisite 'inkling-drive of dimensionality-of-sublimating ${ }^{5}$ <<amplituding/formative >supererogatory $\sim$ de-mentativeness/epistemic-growth-or-

conflatedness /transvaluative-rationalising/transepistemicity/anamnestic-residuality/spirit-

drivenness-equalisation)') speaks to the fact that the the inherent relationship between 'limitedness/human-subpotency' (as to prospective re-encountering/re-confrontation) with 'unlimitedness/existence-<full-potency-of_sublimating nascence> $>$ attributes inherent 'disontologising irresponsibility/relative-unreflexivity' to the state of manifest human relativeontological-incompleteness ${ }^{8}$-of-apriorising/axiomatising/referencing in contrast to the inherent 're-ontologising responsibility/relative-reflexivity' of the prospectively manifest state of human prospective relative-ontological-completeness ${ }^{87}$-ofapriorising/axiomatising/referencing (as to the fact that 'unlimitedness/existence-<full-potencyof_sublimating nascence $>$ is so-inherently the justificatory evaluation of either 'limitedness/human-subpotency' manifest 'disontologising irresponsibility/relativeunreflexivity' or 're-ontologising responsibility/relative-reflexivity'); and so-undergirded as of prospective 'specific institutionalising/organising/mutualising/methodologising $<$ constricted/narrowingdown-re-ontologising-enabling $>$ - psychologismic epistemicacutisation residualising $\{$ fepistemic-

thermeneutic/textuality/reprojecting/supererogating/zeroing/re-acuting,

\{decompulsing delinearity for-cogency intelligibility';- (imbued underlying untenability-ofinduced unblurriness as '<prospective_punctual/immediacy/constituted/compulsions-

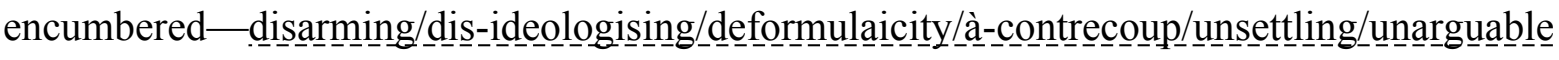
prompted constricted/narrowingdown-re-ontologising-enabling $>$ - psychologismic epistemicacutisation residualising \{epistemicthermeneutic/textuality/reprojecting/supererogating/zeroing/re-acuting,

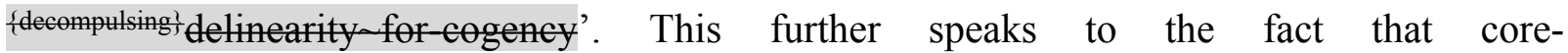


philosophy/derivative-core-philosophy_-(imbued requisite 'inkling-drive of dimensionality-ofsublimating $25<<$ amplituding/formative $>$ supererogatory $\sim$ de-mentativeness/epistemic-growthor-conflatedness /transvaluative-rationalising/transepistemicity/anamnestic-residuality/spiritdrivenness-equalisation)') is rather 'a holding-out/point-referencing-psychoanalyticunshackling exercise of educed-and-availing-and-re-availing relative-ontologicalcompleteness $^{87}$-of-apriorising/axiomatising/referencing' to allow for play out of untenabilityof-induced unblurriness as '<prospective_punctual/immediacy/constituted/compulsionsencumbered — disarming/dis_-ideologising/deformulaicity/à-contrecoup/unsettling/unargunabuble prompted constricted/narrowingdown-re-ontologising-enabling $>$-psychologismic epistemicacutisation residualising \{epistemictotalising thermeneutic/textuality/reprojecting/supererogating/zeroing/re-acuting, \{decompulsing $\}$ delinearity for-cogency' as to 'developing human-per-cep-ti-vi-ty-<as-tonotional perceptualisation-of-and-leashing-to_social-functioning-and-accordance-as-ofsocial-stake-contention-or-confliction> in preconverging/postconverging-redementating/restructuring/reparadigming'. This is the case in the sense that there is only an 'inkling-drive of dimensionality-of-sublimating 25 -< < amplituding/formative $>$ supererogatery $\sim$ dementativeness/epistemic-growth-or-conflatedness /transvaluativerationalising/transepistemicity/anamnestic-residuality/spirit-drivenness-equalisation〉 that initially hardly/poorly carries any prospective secondnatured positive-opportunism—of-socialfunctioning-and-accordance ${ }^{75}$; and so with regards to such (inkling drive of dimensionality of sublimating - <amplituding/formative>supererogatory de-mentativeness/epistemic-growthor-conflatedness /transvaluative-rationalising/transepistemicity/anamnestic-residuality/spiritdrivenness equalisation) 'elicited requisite re-ontologising prospective psychologismic-. epistemic-acutisation-<as-to-postconverging-de-mentating/structuring/paradigming,-elicitingof-existence's-sublimating-nascence-in-prospective-aporeticism-overcoming/unovercoming> 
as to epistemic-growth,-as-\{veridical/sound\}-relative-reflexivity-in-existence/relativising from-limited-mentation-as-its-deepening/psychologismic epistemic-acutisation-

residualising, ${ }^{\{\text {decompulsing }\}}$ delinearity for-cogency' for base-institutionalisation, universalisation or positivism or ${ }^{18}$ deprocrypticism-or-preempting-disjointedness-as-ofreference-of-thought; so-correspondingly so-elicited with respect to prior disontologising recurrent-utter-uninstitutionalisation, base-institutionalisation-ununiversalisation, universalisation-non-positivism/medievalism $\quad$ or $\quad$ our positivismprocrypticism/disjointedness-as-of- ${ }^{8}$ reference-of-thought. It is rather the succession of 'relays of human intemporal-individuation epistemic-projection radicalities $\sim$ in-chronicular/annalisticcogency-<as-of-notional $\sim$ protensivity $>$-〈as-to-limited-mentation-capacity-deepening - assubjecting-limitedness/human-subpotency-to-'educed-unlimitedness/existence-sublimating nascence' > so-construed as cogency_chronicularity/annality-of-relative-reflexivity,-as-toprofound-supererogation (as so-driven by the inkling-drive of dimensionality-ofsublimating $25<<$ amplituding/formative $>$ supereregatery-de-mentativeness/epistemic-growthor-conflatedness /transvaluative-rationalising/transepistemicity/anamnestic-residuality/spiritdrivenness-equalisation) as latterly richly endowed with prospective 'secondnatured positiveepportunism of-social-functioning-and-accordance , as-toprospective punctual/immediacy/constituted/compulsions-encumbered__isarming-_-___dis-_. ideologising/deformulaicity/à-contrecoup/unsettling/unarguable); that so-reflects the 'holdingout/point-referencing - psychoanalytic-unshackling exercise of educed-and-availing-and-reavailing relative-ontological-completeness ${ }^{8}$-of-apriorising/axiomatising/referencing' to allow for play out of untenability-of-induced unblurriness as '<prospective_punctual/immediacy/constituted/compulsions-encumbered—_isarming

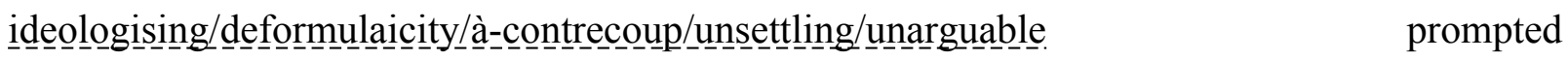
constricted/narrowingdown-re-ontologising-enabling $>$ - psychologismic epistemic- 
acutisation residualising \{ \{epistemic-

totalising thermeneutic/textuality/reprojecting/supererogating/zeroing/re-acuting,

\{decompulsing\} delinearity for-cogency' as to 'developing human-per-cep-ti-vi-ty-<as-to-

notional perceptualisation-of-and-leashing-to_social-functioning-and-accordance-as-of-

social-stake-contention-or-confliction> in preconverging/postconverging-rede-

mentating/restructuring/reparadigming' (with regards to human angling-of-imaginary implied 'multicenturies-long human crossgenerational Being-development/ontological-frameworkexpansion-as-to-depth-of-ontologising-development-as-infrastructure-of- meaningfulnessand-teleology psychologismic epistemic-acutisation difficulty-for, residualising $\{$ decompulsing $\}$ delinearity for-cogeney> magnitude\{of-experientiality/experiment $\}$ of prospective transcendence-and-sublimity/sublimation/supererogatory-de-mentativity'). Critically, such latterly richly endowed prospective ssecondnatured positive-opportunism of-sociatfunctioning and-accordance ${ }^{\prime}$ as-to-

prospective_punctual/immediacy/constituted/compulsions-encumbered_disarming/disideologising/deformulaicity/à-contrecoup/unsettling/unarguable as it ultimately elicits existentially- $<$ disontologising/re-ontologising aporeticism $>\quad$ protracted-social —as-toindividual-by-institutional-by-social relative direct/deferential-responsibility/relativereflexivity to cogency_chronicularity/annality-of-relative-reflexivity,-as-to-profoundsupererogation" (with respect to the scope of human ${ }^{79}$ presencing-absolutising-identitiveconstitutedness ${ }^{14} \quad$ social-stake-contention-or-confliction 'existentially-<disontologising/reentologising aporeticism $>$ manifest incidental/accidental reactive-sufferance/endurance in supposedly and paradoxically subordinating/subserving/collateralising the possibility for prospective re-ontologising_-imbuing-of-prospective-humansublimating/emancipating/enfranchisement'); cannot be confused with corephilosophy/derivative-core-philosophy_-(imbued requisite 'inkling-drive of dimensionality-of- 
sublimating $25-<$ amplituding/formative $>$ supererogatory $\sim$ de-mentativeness/epistemic-growthor-conflatedness /transvaluative-rationalising/transepistemicity/anamnestic-residuality/spiritdrivenness-equalisation)') as of human 're-ontologising-nascency-<as-of-prospectivesolipsistic/intersolipsistic-inkling-drive-for-knowledge-elucidation,-as-to-veridical-organicknowledge $>$ for sublimating-prolongation', whether as initially hardly/poorly carrying any prospective 'secondnatured positive-opportunism of-social-functioning and-accordance as-to-prospective_punctual/immediacy/constituted/compulsions-encumbered_disarmining/disideologising/deformulaicity/à-contrecoup/unsettling/unarguable or as latterly richly endowed with prospective ssecondnatured positive-opportunism-of-social-functioning andaccordance , as to prospective_punctual/immediacy/constituted/compulsions

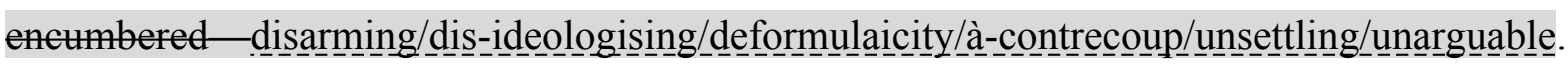
This is the case notwithstanding core-philosophy/derivative-core-philosophy-(imbued requisite 'inkling-drive of dimensionality-of-sublimating ${ }^{25}$ <<amplituding/formative >supererogatede-mentativeness/epistemic-growth-orconflatedness /transvaluative-rationalising/transepistemicity/anamnestic-residuality/spiritdrivenness-equalisation)') ever present susceptibility to the 'recoiling-<as-to-induced'wavering/redounding/waveforming-of-dimensionality-of-sublimating '-by-'dimensionalityof-desublimating '-at-successive-loci/stations-of-'thrownness-disposition-as-of-mereformulaicity/ritualisation'>-_from dimensionality-of-sublimating Kamplituding/formative>supererogatory -de-mentativeness/epistemic-growth-orconflatedness /transvaluative-rationalising/transepistemicity/anamnestic-residuality/spiritdrivenness-equalisation) elicited prospective psychologismic-epistemic-acutisation- $<$ as-topostconverging-de-mentating/structuring/paradigming,-eliciting-of-existence's-sublimatingnascence-in-prospective-aporeticism-overcoming/unovercoming $>$ as to epistemic-growth,-as\{veridical/sound\}-relative-reflexivity-in-existence/relativising from-limited-mentation-as-its- 
deepening/psychologismic epistemic acutisation residualising, ${ }^{\text {fdecompulsing }}$ delinearity for

eogency)'; so-manifested as of 'seeding-misprising of dimensionality-of-desublimating-lackof $^{-}$-<<amplituding/formative>supererogatory $\sim$ de-mentativeness/epistemic-growth-or-

conflatedness /transvaluative-rationalising/transepistemicity/anamnestic-residuality/spirit-

drivenness-equalisation)'. In concrete terms, the 'inkling-drive of dimensionality-ofsublimating $25-<<$ amplituding/formative $>$ supererogatory $\sim$ de-mentativeness/epistemic-growthor-conflatedness /transvaluative-rationalising/transepistemicity/anamnestic-residuality/spiritdrivenness-equalisation)' is rather the profound-supererogation underlying the palpably induced 'relays of prospective secondnatured positive-opportunism—of-social-functioning-andaccordance $^{75}$ ('holding-out/point-referencing-psychoanalytic-unshackling exercise of educed-and-availing-and-re-availing relative-ontological-completeness ${ }^{8}$-ofapriorising/axiomatising/referencing' to allow for play out of untenability-ofinduced unblurriness as '<prospective_punctual/immediacy/constituted/compulsions-

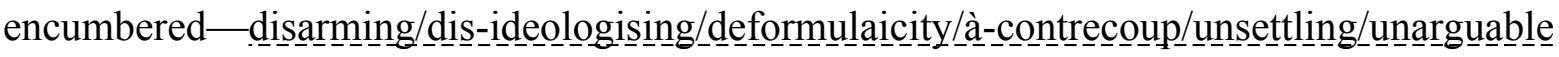
prompted constricted/narrowingdown-re-ontologising-enabling $>$-psychologismic epistemicacutisation residualising $\{$ fepistemic-

thermeneutic/textuality/reprojecting/supererogating/zeroing/re-acuting, \{decompulsing\} delinearity for-cogency', as to 'developing human-per-cep-ti-vi-ty-<as-tonotional perceptualisation-of-and-leashing-to_social-functioning-and-accordance-as-ofsocial-stake-contention-or-confliction> in preconverging/postconverging-redementating/restructuring/reparadigming'). However, such palpable relaying play out is what is translated (with regards to the scope of human ${ }^{79}$ presencing-absolutising-identitiveconstitutedness ${ }^{14} \quad$ social-stake-contention-or-confliction 'existentially-<disontologising/reentologising aporeticism $>$ manifest incidental/accidental reactive-sufferance/endurance in supposedly and paradoxically subordinating/subserving/collateralising the possibility for 
prospective re-ontologising-imbuing-of-prospective-humansublimating/emancipating/enfranchisement') into: the reality that humans did not transcend from a medieval worldview to a positivistic worldview by a mere 'logical/rationalising exercise' (as the mere logical/rationalising conceptualisation we have of such a transformation in today's positivism/rational-empiricism world is rather in effect an afterthought appraisal). But because the 'grander grasp on unlimitedness/existence-<full-potency-of_sublimating nascence $>$ of positivism/rational-empiricism' as to its then 'prior human profound-supererogation metaphoricity $^{57}$, developing human-per-cep-ti-vi-ty-<as-to-notional perceptualisation-ofand-leashing-to_social-functioning-and-accordance-as-of-social-stake-contention-orconfliction $>\quad$ (so-underlied as of preconverging/postconverging-redementating/restructuring/reparadigming superseding/overcoming of the 'medievalism nonpositivising psychologismic-epistemic-acutisation — difficulty- $<$ for,-residualising-

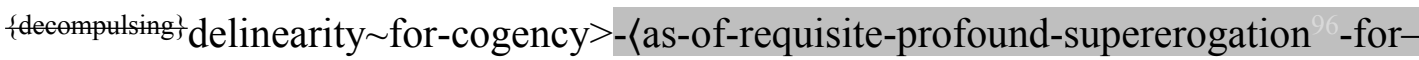

\section{‘disposedness-or-psychologismic-construct'-\{imbued-demoronisation-<sublimating-}

nascence,-nonextricatory-sublimating-upstreaming/'amontée’>\}〉’) before its transformationas-to- - transcendence-and-sublimity/sublimation/supereregatery -de-mentativity into our modern-day positivism 'prospective human secondnatured ${ }^{56}$ meaningfulness-and-teleology ${ }^{9}$, constrained and made the medieval registry-worldview untenable/internally-contradictory existentially-<disontologising/re-ontologising aporeticism $>$; as well as the fact that the ships that set sail around the world for spices elicit a positive commercial opportunism that is responsible for destroying the social myth of a flat world; the bacteria theory that will ensure that one lives or die if we believe in it or not coerced the destruction of a superstitious medical worldview; or the scientific tools and knowledge that ensured that nation A or nation B will triumph if they believe in it or not, coerces the need to adopt a scientific worldview, etc. In other words, it will be 'critically impertinent for a supposed conception of core-philosophy/derivative- 
core-philosophy_(imbued requisite 'inkling-drive of dimensionality-of-sublimating ${ }^{5}$ <<amplituding/formative>supererogatory $\sim$ de-mentativeness/epistemic-growth-or-

conflatedness /transvaluative-rationalising/transepistemicity/anamnestic-residuality/spirit-

drivenness-equalisation)') as to requisite prospective profound-supererogation ' to be construed as of a mere 'logical/rationalising exercise' (without factoring the superseding veracity of human existential-<disontologising/re-ontologising aporeticism $>$ condition of dimensionality-of-sublimating ${ }^{5}$-by-dimensionality-of-desublimating 26 over the conscious/unconscious manifestable human disontologising prior-perspectivefalsity/falseness/fallaciousness of a mere 'logical/rationalising exercise'); as so-failing to appreciate the scope of human ${ }^{7}$ presencing - absolutising-identitive-constitutedness ${ }^{14}$ socialstake-contention-or-confliction 'existentially-<disontologising/re-ontologising aporeticism $>$ manifest incidental/accidental reactive-sufferance/endurance in supposedly and paradoxically subordinating/subserving/collateralising the possibility for prospective re-ontologisingimbuing-of-prospective-human-sublimating/emancipating/enfranchisement'. This speaks to the veracity of human $<$ amplituding/formative-epistemicity $>$-totalising $\sim$ thrownness-in-existence beholdening with respect to the specifically given \{epistemic-totalising $3{ }^{3}$ psychologismic-subliminaltruncating (reflected as of 'catchmented-and-compulsed-<in-'existential-dearth-ofdemoronisation',-so-construed-as-from-ontological-normalcy/postconvergence-perspectivereflection-of-the-'destructuring-threshold_of-the-given-level's-conjugated-postlogism asdementing'> interpersonal, group, intergroup, community, local, national, political, geostrategic, etc. psychologismic epistemic-acutisation difficulty-<for, residualising \{decompulsing $\}$ delinearity for-cogeney> levels of interrelatedness-dynamics-of-socialconstructing'). In this respect, core-philosophy/derivative-core-philosophy_(imbued requisite 'inkling-drive of dimensionality-of-sublimating 25 -<<amplituding/formative $>$ supererogatory $\sim$ dementativeness/epistemic-growth-or-conflatedness /transvaluative- 
rationalising/transepistemicity/anamnestic-residuality/spirit-drivenness-equalisation〉') speaks

to the fact that (as of "nonpresencing-<perspective-ontological-normalcy/postconvergence> prospectively re-ontologising relative-reflexivity'), the 'supposedly imaginary' human-per-cepti-vi-ty-<as-to —notional perceptualisation-of-and-leashing-to_social-functioning-andaccordance - as-of-social-stake-contention-or-confliction> of prospective baseinstitutionalisation, ${ }^{103}$ universalisation or positivism or ${ }^{18}$ deprocrypticism-or-preemptingdisjointedness-as-of- ${ }^{8}$ reference-of-thought (correspondingly so-imaginary as from the prior presencing-absolutising-identitive-constitutedness ${ }^{14}$ social-stake-contention-or-confliction construct of recurrent-utter-uninstitutionalisation, base-institutionalisation-ununiversalisation, universalisation-non-positivism/medievalism $\quad$ or $\quad$ our positivismprocrypticism/disjointedness-as-of- ${ }^{2}$ reference-of-thought) are 'paradoxically relatively more real' as of relative-reflexivity of human-per-cep-ti-vi-ty-<as-to-notional $\sim$ perceptualisationof-and-leashing-to_social-functioning-and-accordance-as-of-social-stake-contention-orconfliction>. So-speaking to the requisite and veridical prospective psychologismic-epistemicacutisation-<as-to-postconverging-de-mentating/structuring/paradigming,-eliciting-ofexistence's-sublimating-nascence-in-prospective-aporeticism-overcoming/unovercoming $>$ as to epistemic-growth,-as - \{veridical/sound\}-relative-reflexivity-in-existence/relativising fromlimited-mentation-as-its-deepening/psychologismic epistemic-acutisation residualising, \{decompulsing delinearity for-cogency of the inkling-drive of dimensionality-of-sublimating <<amplituding/formative>supererogatory $\sim$ de-mentativeness/epistemic-growth-orconflatedness /transvaluative-rationalising/transepistemicity/anamnestic-residuality/spiritdrivenness-equalisation)'; that cannot be confused with elicitable ' $\leq$ mereformulaicity/ritualisation - of $>$ prior $\quad$ secondnatured $\quad$ positive-opportunism-of-socialfunctioning-and-accordance ${ }^{75}$ as to imbuing prospective shallow-supererogation ${ }^{\prime}$ that is bound to induce 'recoiling-<as-to-induced-'wavering/redounding/waveforming-of-dimensionality-of- 
sublimating '-by-'dimensionality-of-desublimating '-at-successive-loci/stations-of-

‘thrownness-disposition-as-of-mere-formulaicity/ritualisation'> from the prospectively requisite 'inkling-drive of dimensionality-of-sublimating

<<amplituding/formative>supererogatory de-mentativeness/epistemic-growth-or-

conflatedness /transvaluative-rationalising/transepistemicity/anamnestic-residuality/spirit-

drivenness-equalisation)' (manifested as of 'seeding-misprising of dimensionality-ofdesublimating-lack-of ${ }^{-}-\langle<$amplituding/formative $>$supererogatory $\sim$ de-mentativeness/epistemicgrowth-or-conflatedness /transvaluative-rationalising/transepistemicity/anamnestic-

residuality/spirit-drivenness-equalisation〉'). This distinction is critical going by the fact that if core-philosophy/derivative-core-philosophy_(imbued requisite 'inkling-drive of dimensionality-of-sublimating $-<<$ amplituding/formative $>$ supererogatory $\sim$ de-

mentativeness/epistemic-growth-or-conflatedness /transvaluative-

rationalising/transepistemicity/anamnestic-residuality/spirit-drivenness-equalisation〉') 'is to supposedly start out' with the 'shallowness (in shallowsupererogation $\sim$ framing/formulation/catchmenting/truncating/compulsing/linearising—as-topreconverging de-mentating/structuring/paradigming) of elicitable ' $\leq$ mereformulaicity/ritualisation - of $>$ prior $\quad$ secondnatured $\quad$ positive-opportunism-of-socialfunctioning-and-accordance ${ }^{75}$ as to imbuing prospective shallow-supererogation , then this will compromise/undermine the prospective palpably inducible 'relays of prospective secondnatured positive-opportunism—of-social-functioning-and-accordance ${ }^{7}$, ('holdingout/point-referencing - psychoanalytic-unshackling exercise of educed-and-availing-and-reavailing relative-ontological-completeness ${ }^{8}$-of-apriorising/axiomatising/referencing' to allow for play out of untenability-of-induced unblurriness as '<prospective_punctual/immediacy/constituted/compulsions-encumbered_ _ disarminging/dis_-

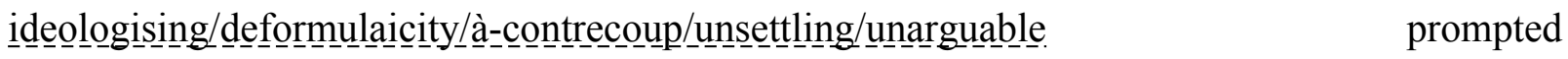


constricted/narrowingdown-re-ontologising-enabling $>$ - psychologismic epistemic-

acutisation residualising fepistemic-

totlising thermeneutic/textuality/reprojecting/supererogating/zeroing/re-acuting,

\{decompulsing $\}$ delinearity for-cogency' as to 'developing human-per-cep-ti-vi-ty-<as-tonotional perceptualisation-of-and-leashing-to_social-functioning-and-accordance-as-of-

social-stake-contention-or-confliction> in preconverging/postconverging-redementating/restructuring/reparadigming')'. It is rather because of the instigative nonpresencing$<$ perspective-ontological-normalcy/postconvergence $>$ profundity of Socratic-philosophers ${ }^{3}$ universalising-idealisation and budding-positivists positivism/rational-empiricism respectively imbued inkling-drive of dimensionality-of-sublimating <<amplituding/formative>supererogatory $\sim$ de-mentativeness/epistemic-growth-or-

conflatedness /transvaluative-rationalising/transepistemicity/anamnestic-residuality/spirit-

drivenness-equalisation〉' (and not any 79 presencing-absolutising-identitive-constitutedness nombrilistic elicitable ' $\leq$ mere-formulaicity/ritualisation-of $>$-prior secondnatured positiveopportunism-of-social-functioning-and-accordance ${ }^{75}$ as to imbuing prospective shallowsupererogation correspondingly of priorly given non-universalising and nonpositivising social-stake-contention-or-confliction construct); that, such prospective palpably inducible 'relays of prospective secondnatured positive-opportunism-of-social-functioning-andaccordance ${ }^{75}$ ('holding-out/point-referencing_-psychoanalytic-unshackling exercise of educedand-availing-and-re-availing relative-ontological-completeness ${ }^{87}$-ofapriorising/axiomatising/referencing' to allow for play out of untenability-ofinduced unblurriness as '<prospective_punctual/immediacy/constituted/compulsions-

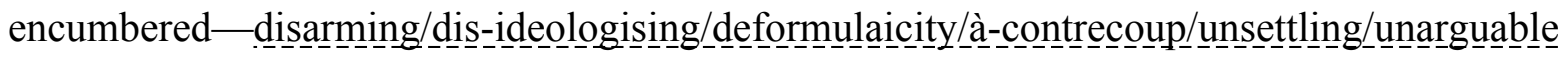
prompted constricted/narrowingdown-re-ontologising-enabling $>$ - psychologismic epistemicacutisation residualising fepistemic- 
totalising thermeneutic/textuality/reprojecting/supererogating/zeroing/re-acuting,

$\{$ decompulsing $\}$ delinearity for-cogency' as to 'developing human-per-cep-ti-vi-ty-<as-to

notional perceptualisation-of-and-leashing-to_social-functioning-and-accordance-as-of-

social-stake-contention-or-confliction>')' could arise. Thusly, allowing for the prospective reaestheticisation-and-re-aestheticisation-towards-ontology-<elicited-prospective-

idiomatisation $>$ (as to human-consciousness/collective-consciousnessdistendedness/detruncating-<beyond-selfpresencing,-as-re-ontologising-decentering_ofconsciousness/collective-consciousness,-as-to-psychologismic-epistemic-acutisationresidualising, - $^{\text {ddecompusing }}$ delinearity for- $\operatorname{cogency}>$ ) of respectively ${ }^{103}$ universalisingidealisation and positivism/rational-empiricism. This reality of the overall possibility for corephilosophy/derivative-core-philosophy_-(imbued requisite 'inkling-drive of dimensionality-ofsublimating $25-<<$ amplituding/formative $>$ supererogatory $\sim$ de-mentativeness/epistemic-growthor-conflatedness /transvaluative-rationalising/transepistemicity/anamnestic-residuality/spiritdrivenness-equalisation)') is effectively reflected as to the multicenturies long patchy experientiality/experiment-<as-to-existentially-formative- ${ }^{`}$ \{epistemic-totalising ${ }^{\dagger}$ re-apriorising/reaxiomatising/re-referencing-residuality-in-re-originariness/re-origination',- - so"notionally/epistemically/bindingnessly-<as-to-determinism/conceptivity-of-relative-unreflexivity/relative-reflexivity> implicited-and-articulated'_as-from-nonextricatory-'prospective-re-ontologising-Being-thenInstitutional-then-Living-magnitudes-of-\{hermeneutic/reprojection-protraction-of\}reframingand-reformulation $\}^{\prime}>$ of human registry-worldviews/dimensions since human prehistoricity; as reinforced with recurrent human re-aestheticisation-and-re-aestheticisation-towards-ontology$<$ elicited-prospective-idiomatisation> cultural diffusion (which possibility has relatively narrowed in our globalised world requiring profound conscientiousness for prospective reaestheticisation-and-re-aestheticisation-towards-ontology-<elicited-prospectiveidiomatisation $>$ ). It can be further appreciated (as to the human 'crossgenerational 
notional firstnaturedness-formativeness-<as-to-eventualising inkling drive-or-seeding-

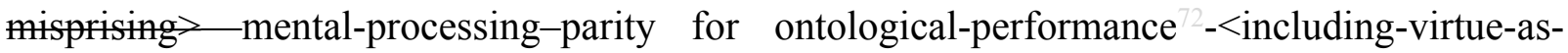
ontology $>$ /morality/ethics/justice/etc.' $\quad$ existentially-<disentologising/re-ontelogising aporeticism $>$ manifestable shallow-supererogation ${ }^{6}$ or profound-supererogation ${ }^{6}$ that knowledge as to organic-knowledge necessarily has to effectively retrace-and-relay 'thinking at first/pure predisposition preemptive of prospective disontologising/subontologising' as of 'inkling-drive of dimensionality-of-sublimating ${ }^{25}-\langle<$ amplituding/formative $>$ supererogatery $\sim$ dementativeness/epistemic-growth-or-conflatedness /transvaluative-

rationalising/transepistemicity/anamnestic-residuality/spirit-drivenness-equalisation〉'; and so rather than a conception of mechanical-knowledge prospectively absolutising the 'pedantising/muddling/formulaic-hollowing-out —in-subontologisation/subpotentiation〈blurring/undermining-of-prospective-totalising-entailing,-as-to-entailing$<$ ampliting/formative-epistemicity $>$ totalising in-relative-ontological-completeness $>$ eliciting of ' $<$ mere formulaicitrittalisation of $>$ prior secondnatured positive-opportunismof-social-functioning-and-accordance ${ }^{75}$ as to imbuing prospective shallow-supererogation ${ }^{\prime}$ (in an 'existential-<disontologising/re-ontologising aporeticism $>$ dearth' with regards to the 'inkling-drive of dimensionality-of-sublimating ${ }^{25}-\langle<$ amplituding/formative $>$ supererogatory $\sim$ dementativeness/epistemic-growth-or-conflatedness /transvaluativerationalising/transepistemicity/anamnestic-residuality/spirit-drivenness-equalisation〉'). Basically, core-philosophy/derivative-core-philosophy_-(imbued requisite inkling-drive of dimensionality-of-sublimating ${ }^{25}$-<<amplituding/formative $>$ supererogatory - dementativeness/epistemic-growth-or-conflatedness /transvaluativerationalising/transepistemicity/anamnestic-residuality/spirit-drivenness-equalisation〉') cannot be construed as an exercise of 'conveniently dodging one's epochal existential$<$ disontologising/re-ontologising aporeticism $>$ ' and then pretend/claim (as to the eliciting of 
' $\leq$ mere-formulaicity/ritualisation-of $>$-prior secondnatured positive-opportunism-of-socialfunctioning-and-accordance ${ }^{75}$ as to imbuing prospective shallow-supererogation ') to $\begin{array}{llll}\text { supposedly } & \text { have } & \text { 'a } & \text { magical }\end{array}$ framing/formulation/catchmenting/truncating/compulsing/linearising of knowledge' that supersedes the manifest veracity of such prospectively requisite postconverging-apereticismovercoming/unoverceming; as so-implying consciously/unconsciously as supposedly being prospectively bigger than 'unlimitedness/existence-<full-potency-of_sublimating naseence $>$ '. In this respect, core-philosophy/derivative-core-philosophy-(imbued requisite 'inkling-drive of dimensionality-of-sublimating ${ }^{25}-<<$ amplituding/formative $>$ supererogatory $\sim$ dementativeness/epistemic-growth-or-conflatedness /transvaluativerationalising/transepistemicity/anamnestic-residuality/spirit-drivenness-equalisation〉') reflects the fact that notional philosophy-<as-to-the-veridical-conception-of-philosophy-as-englobingall-human-prospective-organic-knowledge-generation-in-relative-ontological-completeness beyond-a-convenient-division-of-labour-conception-of-knowledge $>$ (as to its imbued perspicacity of psychologismic-epistemic-acutisation-<as-to-postconverging-dementating/structuring/paradigming,-eliciting-of-existence's-sublimating-nascence-inprospective-aporeticism-overcoming/unovercoming > as to epistemic-growth,-as\{veridical/sound\}-relative-reflexivity-in-existence/relativising from-limited-mentation-as-itsdeepening/psychologismic epistemic-acutisation residualising, ${ }^{\text {\{decompulsing }}$ delinearity foreogency' of 'unlimitedness/existence-<full-potency-of_sublimating nascence $>$ ') doesn't recognise any human artificially elicited notion of division-of-labour-conception-of-knowledge (as 'knowledge is necessarily whole' with respect to 'limitedness/human-subpotency prospective re-encountering/re-confrontation with unlimitedness/existence-<full-potency-of_sublimating nascence $>$ '); $\quad$ as so-underlied as from supererogation $\sim$ reframing/reformulation/decatchmenting/detruncating/decompulsing/delinear 
ising —as-to-postconverging de-mentating/structuring/paradigming

priority/precedence/primacy' of re-ontologising prospective Being-development/ontologicalframework-expansion-as-to-depth-of-ontologising-development-as-infrastructure-of-

meaningfulness-and-teleology psychologismic epistemic-acutisation difficulty-for, residualising \{decompulsing delinearity-for-cogency>-magnitude\{of-experientiality/experiment\}, then institutional-development-as-to-social-function-development psychologismic epistemicacutisation difficulty-for, residualising_\{decompulsing $\}$ delinearity for-cogency>-magnitude $\{$ ofexperientiality/experiment $\}$ and then living-development-as-to-personality-development psychologismic epistemic-acutisation difficulty-for, residualising ${ }_{\{\text {decompulsing }}$ delinearity for-cogeney $>$ magnitude ${ }^{\{0-\text { experientiality/experiment }\}}$ (and so as to ${ }^{83}$ referenceof-thought-and- ${ }^{83}$ reference-of-thought- ${ }^{84}$ evolving- ${ }^{5}$ meaningfulness-and-teleology 'organic accompaniment' of 'limitedness/human-subpotency prospective re-encountering/reconfrontation with unlimitedness/existence-<full-potency-of_sublimating-nascence $>$ '). In this regards, such a human artificially elicited notion of division-of-labour-conception-of-knowledge induces a prospective lost of the 'perspicacity of psychologismic-epistemic-acutisation-<as-topostconverging-de-mentating/structuring/paradigming,-eliciting-of-existence's-sublimatingnascence-in-prospective-aporeticism-overcoming/unovercoming $>$ as to epistemic-growth,-as\{veridical/sound\}-relative-reflexivity-in-existence/relativising from-limited-mentation-as-itsdeepening/psychologismic epistemic-acutisation residualising, \{decompulsing $\}$ delinearity for eogency' of 'unlimitedness/existence-<full-potency-of_sublimating nascence $>$ '. This sounderlies 'prospectively uninstitutionalised-threshold ${ }^{102}$ moronisation- $<$ sublimating-nascence,extricatory-desublimating-downstreaming/'avalage'>' as to imbued 'supposedly pragmatic' unblurriness/blurriness-

threshold framing/formulation/catchmenting/truncating/compulsing/linearising: as 'recoiling<as-to-induced-'wavering/redounding/waveforming-of-dimensionality-of-sublimating '-by- 
'dimensionality-of-desublimating '-at-successive-loci/stations-of-'thrownness-disposition-asof-mere-formulaicity/ritualisation'>_ (from dimensionality-of-sublimating kamplituding/formative>supererogatory de-mentativeness/epistemic-growth-or-

conflatedness /transvaluative-rationalising/transepistemicity/anamnestic-residuality/spiritdrivenness-equalisation) elicited prospective psychologismic-epistemic-acutisation-<as-topostconverging-de-mentating/structuring/paradigming,-eliciting-of-existence's-sublimatingnascence-in-prospective-aporeticism-overcoming/unovercoming > as to epistemic-growth,-as\{veridical/sound\}-relative-reflexivity-in-existence/relativising from-limited-mentation-as-itsdeepening/psychologismic epistemic-acutisation residualising, \{decompulsing $\}$ delinearity for eegeney)' rather to the 'micro-decisionality/decisionality thrownness-disposition of prior mereformulaicity/ritualisation-<as-to-mere-formulaicmethodologising/mutualising/organising/institutionalising,-prospectively-losing-track-of‘fepistemicalising $\stackrel{+}{+}$ re-apriorising/re-axiomatising/re-referencing $r$ residuality-in-reoriginariness/re-origination'>' in so-failing prospective postconvergingaaporeticismovercoming/unovercoming; as to manifest 'seeding-misprising of dimensionality-ofdesublimating-lack-of ${ }^{-}-<<$amplituding/formative $>$supererogatory $\sim$ de-mentativeness/epistemicgrowth-or-conflatedness /transvaluative-rationalising/transepistemicity/anamnesticresiduality/spirit-drivenness-equalisation〉'. Organic-knowledge requisite 'perspicacity of psychologismic-epistemic-acutisation-<as-to-postconverging-dementating/structuring/paradigming,-eliciting-of-existence's-sublimating-nascence-inprospective-aporeticism-overcoming/unovercoming > as to epistemic-growth,-as\{veridical/sound\}-relative-reflexivity-in-existence/relativising from-limited-mentation-as-itsdeepening/psychologismic epistemic-acutisation residualising, fdecompulsingl $_{\text {f }}$ delinearity for eogency' of 'unlimitedness/existence-<full-potency-of_sublimating nascence $>$ ' (as to ever always referring to 'the-very-same purview/devolved-purview/devolving-purview-of- 
unlimitedness/existence-<full-potency-of_sublimating nascence>;_—implicited_attendantontological-contiguity ${ }^{6}$ ' educed-

existentialising/contextualising/textualising_'intelligibility/epistemicity/reflexivity-contiguity$<$ imbued-notional $\sim$ cogency $>{ }^{40}$ ); effectively underlies the continually requisite psychoanalyticunshackling for relative-ontological-completeness ${ }^{87}$-of-apriorising/axiomatising/referencing. Speaking of organic-knowledge as basically of nonpresencing-<perspective-ontologicalnormalcy/postconvergence> 'notional/epistemic/bindingness ${ }^{<a s-t o-d e t e r m i n i s m / c o n c e p t i v i t y-o f-r e l a t i v e-~}$ human psychologismic-transfixity-<placeholder-setup-ontologicalrescheduling - in-realigning/preactivity/formative-becoming/psychoanalytical-unshackling,-asto-residualising_\{decompulsing\} $\}$ delinearity-over-nonresidualising_\{compulsing\} $\}$ linearity $>$ manifestation'). The very 'test of whatever presents/qualifies itself as of corephilosophy/derivative-core-philosophy_(imbued requisite 'inkling-drive of dimensionality-ofsublimating $25<<$ amplituding/formative $>$ supererogatory $\sim$ de-mentativeness/epistemic-growthor-conflatedness /transvaluative-rationalising/transepistemicity/anamnestic-residuality/spiritdrivenness-equalisation)' '), with respect to prospectively undermining/preempting the 'recoiling-<as-to-induced-'wavering/redounding/waveforming-of-dimensionality-ofsublimating '-by-'dimensionality-of-desublimating ' -at-successive-loci/stations-of‘thrownness-disposition-as-of-mere-formulaicity/ritualisation'>-_from dimensionality-ofsublimating $-<$ amplituding/formative $>$ supererogatory $\sim$ de -mentativeness/epistemic-growthor-conflatedness /transvaluative-rationalising/transepistemicity/anamnestic-residuality/spiritdrivenness-equalisation) elicited prospective psychologismic-epistemic-acutisation- $<$ as-topostconverging-de-mentating/structuring/paradigming,-eliciting-of-existence's-sublimatingnascence-in-prospective-aporeticism-overcoming/unovercoming $>$ as to epistemic-growth,-as\{veridical/sound\}-relative-reflexivity-in-existence/relativising from-limited-mentation-as-itsdeepening/psychologismic epistemic-acutisation residualising, ${ }^{\text {\{decompulsing }}$ delinearity for 
eogency)', and so (in contrast to disontologising prior-perspectivefalsity/falseness/fallaciousness of a mere 'logical/rationalising exercise' as to manifest 'seedingmisprising of dimensionality-of-desublimating-lack-of <<amplituding/formative >supererogatory de-mentativeness/epistemic-growth-orconflatedness /transvaluative-rationalising/transepistemicity/anamnestic-residuality/spiritdrivenness-equalisation〉'): lies in effectively reflecting prospectively the veracity of 'human knowledge unblurriness/blurrinessthreshold framing/formulation/catchmenting/truncating/compulsing/linearising; from whence is articulated prospective 're-ontologising idiomatisation-<as-to- blurriness-elicited-profoundsupererogation -of- ' $\{$ epistemic-totalising ' ’’metaphoricity '-for-prospective- unblurriness-of'\{epistemic-totalising $\frac{\text { ? }}{\dagger}$ meaningfulness-and-teleology ',-as-of-sublimating-prolongation;-inpsychologismic epistemic acutisation residualising, \{decompulsing $\}$ delinearity for-cogency>'. Critically, the veracity of prospective 're-ontologising idiomatisation-<as-to- blurrinesselicited-profound-supererogation -of- ‘ \{epistemic-totalising ’’ ${ }^{3}$ metaphoricity '-for-prospectiveunblurriness-of- ‘ $\left\{\right.$ epistemic-totalising $\frac{\mathfrak{3}}{3}$ meaningfulness-and-teleology ',-as-of-sublimatingprolongation;-in-psychologismic epistemic-acutisation residualising, \{decompulsing $\}$ delinearity for-cogency $>$ ' only arises as of the 'prospective existential<disontologising/re-ontologising aporeticism $>$ difficulty' posed by the given 'epochal $<$ amplituding/formative-epistemicity>-totalising $\sim$ thrownness-in-existence ${ }^{35}$ imbued human knowledge unblurriness/blurrinessthreshold framing/formulation/catchmenting/truncating/compulsing/linearising' (in reflection of the epochal given prospectively uninstitutionalised-threshold ${ }^{102}$ ). Such that prospectively educed unblurriness-<re-ontologising_by-postconverging-as-to-dragged-outsupererogatery $\sim$ wholesomeness/profound-supererogation ,-while-anecdotalising-priordisontologising-thresholding $>$ scope as of relatively elucidated-as-to- 
ontological-commitment ${ }^{66}$ and universal-transparency ${ }^{104}$ with respect to underlying human 'crossgenerational notional firstnaturedness-formativeness-<as-to-eventualising inkling drive-or-seeding-misprising $>$ mental-processing-parity for ontological-performance ${ }^{72}$ $<$ including-virtue-as-ontology $>$ /morality/ethics/justice/etc.' (imbued 'relative-reflexivity as to prospectively requisite cogency_chronicularity/annality-of-relative-reflexivity,-as-to-profoundsupererogation "); then warrants that the ontologically-flawed representation of $\leq$ mereformulaicity/ritualisation-of $>$-prior 're-ontologising idiomatisation-<as-to- blurriness-elicitedprofound-supererogation -of-' ‘epistemictalising '’metaphoricity '-for-prospective- unblurrinessof- ‘fepistemic-totalising $\frac{?}{3}$ meaningfulness-and-teleology ',-as-of-sublimating-prolongation;-inpsychologismic epistemic-acutisation residualising, ${ }^{\text {\{decompulsing\} }}$ delinearity for-cogency>' as being of prospective re-ontologising, is rather manifesting consciously/unconsciously priorperspective - falsity/falseness/fallaciousness of a mere 'logical/rationalising exercise' (as soeffectively reflecting prospective 'pedantising/muddling/formulaic-hollowing-out—insubontologisation/subpotentiation-〈blurring/undermining-of-prospective-totalising-entailing,as-to-entailing-<amplituding/formative-epistemicity $>$ totalising in-relative-ontologicalcompleteness $\rangle$ eliciting of ' $\leq$ mere-formulaicity/ritualisation-of $>$-prior secondnatured positiveopportunism-of-social-functioning-and-accordance ${ }^{75}$ as to imbuing prospective shallowsupererogation' in manifest 'relative-unreflexivity failing the requisite relative-reflexivity for prospective cogency_chronicularity/annality-of-relative-reflexivity,-as-to-profoundsupererogation '). In this regards, the given 'epochal <amplituding/formative-epistemicity>totalising thrownness-in-existence ${ }^{35}$ imbued human knowledge unblurriness/blurrinessthreshold framing/formulation/catchmenting/truncating/compulsing/linearising (in reflection of the given epochal prospectively uninstitutionalised-threshold ${ }^{02}$ ) effectively articulated prospective 're-ontologising idiomatisation-<as-to- blurriness-elicited-profound- 
supererogation -of-' ‘epistemic-totalising '’3metaphoricity '-for-prospective- unblurriness-of-

'\{epistemic-totalising $\frac{?}{3}$ meaningfulness-and-teleology ',-as-of-sublimating-prolongation;-in-

psychologismic epistemic-acutisation residualising, \{decompulsing delinearity for-cogency>' of

say the-very-same physics purview-of-unlimitedness/existence-<ull-potency-of_sublimating nascence>;-_implicited_attendant-ontological-contiguity ${ }^{67}$ ' educed-

existentialising/contextualising/textualising_'intelligibility/epistemicity/reflexivity_contiguity<imbued-notional cogency>' (as from 'mythical unexplicitly-positivistic/rationalempiricism physics' and then 'nonmythical explicitly-posivistic/rational-empiricism physics' as from say Copernicus, Galileo, Descartes, Newton, Leibniz, Maxwell, Poincare, Einstein, Bohr, Feynman, etc.), speaks to the respective epochally elicited unblurriness-<re-ontologising_bypostconverging-as-to-dragged-out-supererogatory $\sim$ wholesomeness/profound-supererogation while-anecdotalising-prior-disontologising-thresholding $>$ scope as of relatively elucidated-<asto-preconverging/postconverging rede-mentating/restructuring/reparadigming $>$ human ontological-commitment and universal-transparency ${ }^{104}$ with respect to underlying human 'crossgenerational notional firstnaturedness-formativeness-<as-to-eventualising-inkling drive or seeding misprising $>$ mental-processing-parity for ontological-performance ${ }^{72}$ <including-virtue-as-ontology $>$ /morality/ethics/justice/etc.' (imbued 'relative-reflexivity as to prospectively requisite physics cogency_chronicularity/annality-of-relative-reflexivity,-as-toprofound-supererogation '). But then a representation of the respectively epochal $\leq$ mereformulaicity/ritualisation-of $>$ prior 're-ontologising idiomatisation-<as-to- blurriness-elicited-

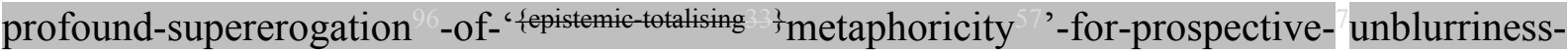
of- ‘fepistemic-totalising ? $\frac{?}{3}$ meaningfulness-and-teleology ',-as-of-sublimating-prolongation;-inpsychologismic epistemic acutisation residualising, ${ }^{\text {\{decompulsing }}$ 'delinearity for cogency>' as being of prospective re-ontologising (and so as if of the corresponding epochal prospective 'physics unblurriness/blurriness- 
threshold framing/formulation/catchmenting/truncating/compulsing/linearising by which prospective 're-ontologising idiomatisation-<as-to- blurriness-elicited-profoundsupererogation -of- ‘fepistemic-alising '’metaphoricity '-for-prospective- unblurriness-of‘\{epistemic-totalising $+\frac{3}{3}$ meaningfulness-and-teleology ',-as-of-sublimating-prolongation;-inpsychologismic epistemic acutisation residualising, ${ }^{\{\text {decompulsing }}$ \}elinearity for-cogency>’ arises), will rather speak to disontologising prior-perspective_-falsity/falseness/fallaciousness of a mere 'logical/rationalising exercise'; as so-effectively reflecting prospectively 'pedantising/muddling/formulaic-hollowing-out—in-subontologisation/subpotentiation〈blurring/undermining-of-prospective-totalising-entailing,-as-to-entailing<amplituding/formative-epistemicity>totalising in-relative-ontological-completeness $>$ eliciting of " $\leq$ mere-formulaicity/ritualisation - of $>$ prior secondnatured positive-opportunismof-social-functioning-and-accordance ${ }^{75}$ as to imbuing prospective shallow-supererogation ${ }^{\prime}$ (in manifest 'relative-unreflexivity failing the requisite relative-reflexivity for prospective physics cogency_chronicularity/annality-of-relative-reflexivity,-as-to-profound-supererogation ${ }^{9}$ ). In this regards, it can be appreciated as well that ancient-sophists non-universalising and medievalscholasticism nonpositivising are in many ways the mere 'disontologising complexification' of their respectively ' $\leq$ mere-formulaicity/ritualisation-of $>$-prior secondnatured positiveopportunism - of-social-functioning-and-accordance ${ }^{75}$ as to imbuing prospective shallowsupererogation, (so-educed from the respective prior 'inkling-drive of dimensionality-ofsublimating $25-<$ amplituding/formative $>$ supererogatory - de-mentativeness/epistemic-growthor-conflatedness /transvaluative-rationalising/transepistemicity/anamnestic-residuality/spiritdrivenness-equalisation)'); as so-failing prospective postconverging-aporeticismovercoming/unovercoming with regards to their corresponding 'epochal $<$ amplituding/formative-epistemicity>-totalising $\sim$ thrownness-in-existence ${ }^{35}$, imbued human knowledge unblurriness/blurriness- 
threshold framing/formulation/catchmenting/truncating/compulsing/linearising ～(warranting correspondingly Socratic-philosophers ${ }^{10}$ universalising-idealisation and budding-positivists positivism/rational-empiricism prospective 're-ontologising idiomatisation- $<$ as-to- blurriness-

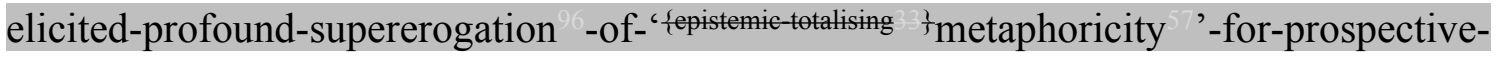
unblurriness-of- ‘\{epistemic-totalising $\frac{3}{3}$ meaningfulness-and-teleology ',-as-of-sublimatingprolongation;-in-psychologismic epistemic-acutisation residualising, ${ }_{\{\text {decompulsing }}$ delinearity for-cogency $>$ '). Insightfully, this equally points out our present-day human knowledge unblurriness/blurrinessthreshold framing/formulation/catchmenting/truncating/compulsing/linearising with respect to such notions like Platonism (with regards to ${ }^{103}$ universalising-idealisation) and Cartesianism (with regards to positivism/rational-empiricism), as to a failure to appreciate that what is most fundamental about both Plato and Descartes is not their 'mere-formulaicity/ritualisation of knowledge (as to $\leq$ mere-formulaicity/ritualisation-of $\geq$-prior secondnatured positiveopportunism - of-social-functioning-and-accordance ${ }^{75}$ as to imbuing prospective shallowsupererogation )' but rather their prior 'inkling-drive of dimensionality-of-sublimating ${ }^{25}$ <<amplituding/formative>supererogatery $\sim$ de-mentativeness/epistemic-growth-or-

\section{conflatedness /transvaluative-rationalising/transepistemicity/anamnestic-residuality/spirit-}

drivenness-equalisation)' educing propsective knowledge elucidation for sublimatingprolongation' (as overcoming their given 'epochal <amplituding/formative-epistemicity>totalising thrownness-in-existence ${ }^{35}$ imbued human knowledge unblurriness/blurrinessthreshold framing/formulation/catchmenting/truncating/compulsing/linearising). So-speaking to our present-day human knowledge unblurriness/blurrinessthreshold framing/formulation/catchmenting/truncating/compulsing/linearising lack/dearth of requisite prospective 'inkling-drive of dimensionality-of-sublimating ${ }^{25}$ <<amplituding/formative>supererogatory $\sim$ de-mentativeness/epistemic-growth-or- 
conflatedness /transvaluative-rationalising/transepistemicity/anamnestic-residuality/spirit-

drivenness-equalisation)' (as failing to overcoming its given 'epochal <amplituding/formativeepistemicity $>$-totalising $\sim$ thrownness-in-existence ${ }^{35}$ imbued human knowledge unblurriness/blurriness-

threshold framing/formulation/catchmenting/truncating/compulsing/linearising). This is further reflected as to the ontologising-inveracity of our present-day plethora of isms-conceptualisations (when for instance such notions as humanism and antihumanism, enlightenment and counterenlightenment, etc. seem to imply that the latter conceptualisations are against humanity or enlightenment rather than being more profound conceptions of humanity and enlightenment over the former as shallow conceptions as so-wrongly implying we-are-undecenterable/ourconscious-self-cannot-be-prospectively-dissolved with respect to our ${ }^{79}$ presencingabsolutising-identitive-constitutedness ${ }^{14} \quad$ implicited blurriness$<$ sterilising/anecdotalising/trivialising-of-prospective-re-ontologising_by-preconverging,-indisontologising-formulaic-dragging-out/hollowing-out> of thought); articulated as of presencing - absolutising-identitive-constitutedness ${ }^{14}$ by wrongly implying everything is of the same notional-contiguity/epistemic-contiguity ${ }^{62}<$ profound-supererogation -of-mentallyaestheticised postconverging/dialectical-thinking -qualia-schema> (as of undisambiguated relative-unreflexivity/relative-reflexivity - ontological-contiguity ${ }^{67}$ as to relative-ontologicalincompleteness ${ }^{8}$-of-apriorising/axiomatising/referencing and relative-ontologicalcompleteness ${ }^{87}$-of-apriorising/axiomatising/referencing thus inducing 'apriorising/axiomatising/referencing_equating/leveling/ressentiment/closed-construct-ofmeaningfulness-and-teleology $\quad$ moronisation-<sublimating-nascence,-extricar desublimating-downstreaming/'avalage'>'). Thusly, the appraisal of $\leq$ mereformulaicity/ritualisation-of $>$ prior 're-ontologising idiomatisation- $<$ as-to- blurriness-elicitedprofound-supererogation -of- ‘fepistemictalising '’metaphoricity '-for-prospective- unblurriness- 
only as pertinent as to the prospective elucidation of 'human relative-unreflexivity/relativereflexivity - ontological-contiguity ${ }^{67}$ with regards to successively prior sublimating-arising and prospective sublimating-prolongation as of cogency_chronicularity/annality-of-relativereflexivity,-as-to-profound-supererogation ' in order to inform 'prospective relativereflexivity' (as so-speaking of human sublimating ${ }^{4}$ historiality/ontologicaleventfulness 38 ontological-aesthetic-tracing-<perspective-ontologicalanthropologisation-<as-to-futural-reflexivity,-in-\{decompulsing $\}$ delinearity-'invention'/‘creation'of-the-human/humanity> imbued 'widening the social imaginary'); and not as of $\leq$ mereformulaicity/ritualisation-of $>$ prior 're-ontologising idiomatisation-<as-to- blurriness-elicitedprofound-supererogation -of- ‘' \{epistemic-totalising '`3metaphoricity '-for-prospective- unblurrinessof- ‘fepistemic atlising + + meaningfulness-and-teleology ',-as-of-sublimating-prolongation;-inpsychologismic epistemic-acutisation residualising, ddecompulsing delinearity for-cogency>' apriorising/axiomatising/referencing — equating/leveling/ressentiment/closed-construct-ofmeaningfulness-and-teleology' with prospective 're-ontologising idiomatisation-<as-toblurriness-elicited-profound-supererogation -of-‘\{epistemic-totalising 'ł'metaphoricity '-forprospective- unblurriness-of- ‘ $\left\{\right.$ epistemic-totalising $\frac{3}{3}$ meaningfulness-and-teleology ',-as-ofsublimating-prolongation;-in psychologismic epistemic acutisation residualising, \{decompulsing delinearity $\sim$ for-cogency $>\quad$ imbued demoronisation- $<$ sublimating-nascence,nonextricatory-sublimating-upstreaming/'amontée’’' (failing to prospectively reflect cogency_chronicularity/annality-of-relative-reflexivity,-as-to-profound-supererogation ${ }^{9}$ as to inform 'prospective relative-reflexivity'). It is herein contended (unlike is relatively the case with nascent-particular/incipient-and-material/technical-sublimations- $<$ blinded-to-their-relative- 
‘<prospective_punctual/immediacy/constituted/compulsions-encumbered__ _isararming/diss-

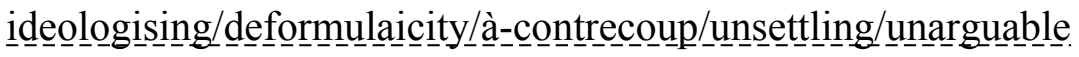
prompted constricted/narrowingdown-re-ontologising-enabling $>$ - psychologismic epistemicacutisation residualising fepistemictotalising thermeneutic/textuality/reprojecting/supererogating/zeroing/re-acuting, \{decompulsing $\}$ delinearity for-cogency'), that the 'sublimating-remoteness/distance-of-appraisal<as-to-requisite-'Being-development-notional self-distantiation'-imbued-psychologismicepistemic-acutisation,-eliciting-of-prospective-ontologically-hegemonising-narrative $>$ as to overarching 'registry-worldview/dimension existentialising-framing-byenframing/\{worlding\} - reference-of-thought' (as of requisite prospective 're-ontologising idiomatisation-<as-to- blurriness-elicited-profound-supererogation -of- ‘ $\{$ epistemictotalising '’metaphoricity '-for-prospective- unblurriness-of-' \{epistemic-totalising $\frac{\mathfrak{l}}{3}$ meaningfulnessand-teleology ',-as-of-sublimating-prolongation;--in psychologismic epistemic acutisation residualising, ${ }^{\{\text {decompulsing }}$ delinearity for-cogency>’ imbued unblurriness $\sim$ reframing/reformulation/decatchmenting/detruncating/decompulsing/delinearisi ng)', and so-construed as from re-ontologising prospective Being-development/ontologicalframework-expansion-as-to-depth-of-ontologising-development-as-infrastructure-ofmeaningfulness-and-teleology psychologismic epistemic-acutisation difficulty-for, residualising \{dementsing delinearity-for-cogency>-magnitude\{of-experientiality/experiment\}, as of its veridical core-philosophy/derivative-core-philosophy-_imbued requisite 'inkling-drive of dimensionality-of-sublimating 25 -<<amplituding/formative $>$ supererogatory $\sim$ dementativeness/epistemic-growth-or-conflatedness /transvaluativerationalising/transepistemicity/anamnestic-residuality/spirit-drivenness-equalisation〉’') 'holding-out/point-referencing_psychoanalytic-unshackling exercise of educed-and-availing- 
and-re-availing relative-ontological-completeness ${ }^{87}$-of-apriorising/axiomatising/referencing' to allow for play out of untenability-of-induced unblurriness as

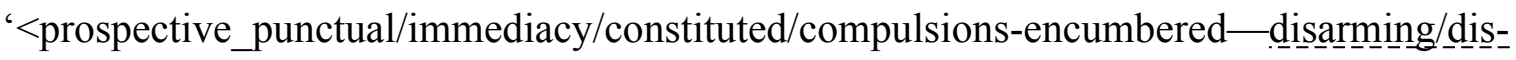

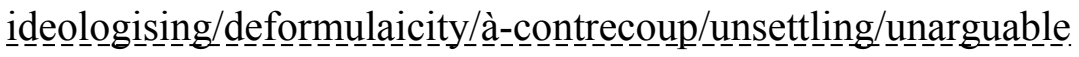
prompted constricted/narrowingdown-re-ontologising-enabling $>$ - psychologismic epistemicacutisation residualising fepistemic-

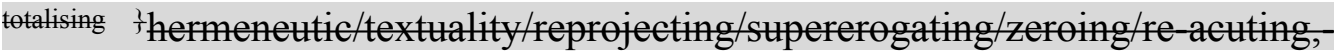
\{decompulsing delinearity for-cogency' as to 'developing human-per-cep-ti-vi-ty-<as-tonotional perceptualisation-of-and-leashing-to_social-functioning-and-accordance-as-ofsocial-stake-contention-or-confliction> in preconverging/postconverging-redementating/restructuring/reparadigming': relatively elicits 'existentially-<disontologising/reontologising aporeticism $>$ manifest entanglement-as-to '<out-of-phasing $>$ disparatenarratives' representation-as-being-of-prospective-re-ontologising-<atunblurriness/blurriness threshold $>$ ' of both $\leq$ mere-formulaicity/ritualisation-of $\geq$ prior 'reontologising idiomatisation-<as-to- blurriness-elicited-profound-supererogation -of- ‘fepistemic-

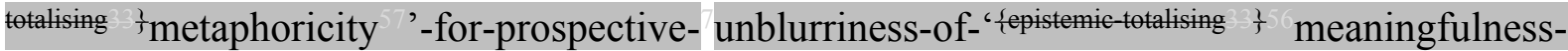
and-teleology ',-as-of-sublimating-prolongation;-in psychologismic epistemic acutisation residualising, ${ }^{\text {\{decompulsing? }}$ delinearity for-cogency>' and prospective 're-ontologising idiomatisation-<as-to- blurriness-elicited-profound-supererogation -of-`\{epistemict'metaphoricity '-for-prospective- unblurriness-of-'fepistemictalising $\frac{3}{+}$ meaningfulnessand-teleology ',-as-of-sublimating-prolongation;-in psychologismic epistemic acutisation residualising, ${ }^{\text {\{decompulsing }}$ delinearity for-cogency>’ . So-reflecting a poor appreciation and understanding of the requisite cogency_chronicularity/annality-of-relative-reflexivity,-as-toprofound-supererogation as to inform 'prospective relative-reflexivity' in many a social-andinstitutional domain/domain-of-study imbued disparateness-of-conceptualisation- 
<unforegrounding-ment,-failing-prospectively-to-reflect-'immanent relative-

unreflexivity/relative-reflexivity - ontological-contiguity ' $>$ (with regards to human notionally/epistemically/bindingnessly-as-to-derminism/conceptivity-of-relative-mneflexivity/relative-reflexivitys elicited sublimating-arising and sublimating-prolongation with respect to 'the-very-same purview/devolved-purview/devolving-purview-of-unlimitedness/existence-<flll-potency of_sublimating nascence>;-—'implicited_attendant_ontological-contiguity ${ }^{67}$ ' educedexistentialising/contextualising/textualising_intelligibility/epistemicity/reflexivity_contiguity<imbued-notional cogency $>$ ' ${ }^{\circ}$ ). This $\quad$ 'existentially-<disontologising/re-ontologising aporeticism $>\quad$ manifest entanglement-as-to '<out-of-phasing $>$ disparate-narratives' representation-as being of prospective-re-ontologising < < at - unblurriness/blurrinessthreshold $>^{\prime}$ is reflected with multicenturies long patchy experientiality/experiment- $<$ as-toexistentially-formative-`\{epistemic-totalising \}re-apriorising/re-axiomatising/rereferencing $\sim$ residuality - in-re-originariness/re-origination',- - so'notionally/epistemically/bindingnessly <as to determinism/eneeptivity of relative enreflexivity/relative reflexivityz implicited-and-articulated'_as-from-nonextricatory-'prospective-re-ontologising-Being-thenInstitutional-then-Living-magnitudes-of-\{hermeneutic/reprojection-protraction-of\}reframingand-reformulation \}'>; and can be so-appreciated as to play out of social-functioning-andaccordance-as-of-social-stake-contention-or-confliction construct as from the 'supposedly imaginary' human-per-cep-ti-vi-ty-<as-to - notional perceptualisation-of-and-leashingto_social-functioning-and-accordance-as-of-social-stake-contention-or-confliction> of prospective base-institutionalisation, ${ }^{103}$ universalisation or positivism or ${ }^{18}$ deprocrypticism-orpreempting - disjointedness-as-of- ${ }^{83}$ reference-of-thought imbued prospective 're-ontologising idiomatisation-<as-to- blurriness-elicited-profound-supererogation -of- ‘fepistemictotalising ' 'metaphoricity '-for-prospective- unblurriness-of-' 'fepistemic-totalising $\frac{3}{3}$ meaningfulnessand-teleology ',-as-of-sublimating-prolongation;-in psychologismic epistemic acutisation- 
residualising, ${ }^{\{\text {decompulsing }}$ \}delinearity for-cogency>' (correspondingly so-imaginary as from the prior ${ }^{79}$ presencing - absolutising-identitive-constitutedness ${ }^{14}$ social-stake-contention-orconfliction construct of recurrent-utter-uninstitutionalisation, base-institutionalisationununiversalisation, ${ }^{103}$ universalisation-non-positivism/medievalism or our positivismprocrypticism/disjointedness-as-of- ${ }^{~}$ reference-of-thought $\quad$ imbued $\quad \leq$ mereformulaicity/ritualisation of $>$-prior 're-ontologising idiomatisation- $<$ as-to- blurriness-elicitedprofound-supererogation -of- '\{epistemic-totalising '’metaphoricity '-for-prospective- unblurriness-

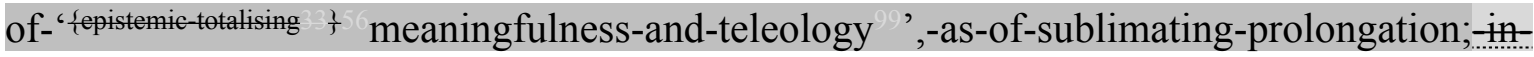
psychologismic epistemic-acutisation residualising, ${ }^{\text {\{decompusingl }}$ delinearity for-cogency>'). The very prospect for unblurriness-<re-ontologising_by-postconverging-as-to-dragged-outsupererogatory $\sim$ wholesomeness/profound-supererogation ,-while-anecdotalising-priordisontologising-thresholding $>$ scope as of relatively elucidated-<as-topreconverging/postconverging-rede-mentating/restructuring/reparadigming $>$ human ontological-commitment and universal-transparency ${ }^{104}$ with respect to underlying human 'crossgenerational notional firstnaturedness-formativeness-<as-to-eventualising-inkling drive-or-seeding misprising $>$ mental-processing-parity for ontological-performance ${ }^{72}$ <including-virtue-as-ontology $>$ /morality/ethics/justice/etc.' (imbued 'relative-reflexivity as to prospectively requisite cogency_chronicularity/annality-of-relative-reflexivity,-as-to-profoundsupererogation "); is thus (with regards to 'existentially-<disontologising/re-ontologising aporeticism $>$ manifest entanglement-as-to '<out-of-phasing $>$-disparate-narratives' representation-as being of prospective-re-ontologising <at- unblurriness/blurrinessthreshold $>$ ') ever always prospectively susceptible/assailable from 'direct/indirect-andconscious/unconscious destabilisation' of 'requisite prospective re-ontologising for sublimating-prolongation'-(which so-imbues effectively of the serenity for 'prospective existential-<disontologising/re-ontologising aporeticism $>$ sovereign- 
emergence/becoming,-existentially-imbuing human-freedom-as-to-supererogating/surrealisingfor-'knowledge-empowerment-over-ignorance-disempowerment'-<as-of-'developing-andavailing-sovereign-sublimating_potential/possibilities/options/choices'-as-to-the'credibility’/'ontological-veracity’-underlying-the-'sovereign-conscious/conscientiousbackdrop'> consciousness/collective-consciousness'). In this regards, corephilosophy/derivative-core-philosophy_-(imbued requisite 'inkling-drive of dimensionality-ofsublimating $25<<$ amplituding/formative $>$ supererogatory $\sim$ de-mentativeness/epistemic-growthor-conflatedness /transvaluative-rationalising/transepistemicity/anamnestic-residuality/spiritdrivenness-equalisation)'), as rather 'a holding-out/point-referencing-psychoanalyticunshackling exercise of educed-and-availing-and-re-availing relative-ontologicalcompleteness $^{87}$-of-apriorising/axiomatising/referencing' to allow for play out of untenabilityof-induced unblurriness as '<prospective_punctual/immediacy/constituted/compulsionsencumbered — disarming/dis_-ideologising/deformulaicity/à-contrecoup/unsettling/unarguable prompted constricted/narrowingdown-re-ontologising-enabling $>$-psychologismic epistemicacutisation residualising $\{$ fepistemictotalising thermeneutic/textuality/reprojecting/supererogating/zeroing/re-acuting, $\{$ decompulsing $\}$ delinearity for-cogency' as to 'developing human-per-cep-ti-vi-ty-<as-tonotional perceptualisation-of-and-leashing-to_social-functioning-and-accordance-as-ofsocial-stake-contention-or-confliction> in preconverging/postconverging-redementating/restructuring/reparadigming', must necessarily (as of organic-knowledge requisite 'perspicacity of psychologismic-epistemic-acutisation-<as-to-postconverging-dementating/structuring/paradigming,-eliciting-of-existence's-sublimating-nascence-inprospective-aporeticism-overcoming/unovercoming $>$ as to epistemic-growth,-as\{veridical/sound\}-relative-reflexivity-in-existence/relativising from-limited-mentation-as-itsdeepening/psychologismic epistemic acutisation residualising, fdecompulsingl delinearity for 
eogency' of 'unlimitedness/existence-<full-potency-of_sublimating nascence $>$ ') perpetually re-articulate (as to knowledge gesturing-and-accounting-of-epistemic-phenomenalism as of relative-unreflexivity/relative-reflexivity); the distinction between existentially$<$ disontologising/re-ontologising aporeticism $>$ manifest unblurriness $\sim$ reframing/reformulation/decatchmenting/detruncating/decompulsing/delinearisi ng (imbued 'despite-the-self exercise of epistemic-projection in notional $\sim$ self-distantiation$<$ imbued — re-motif-and-re-apriorising/re-axiomatising/re-referencing $>$ ' involved in 'limitedness/human-subpotency prospective re-encountering/re-confrontation with unlimitedness/existence-<full-potency-of_sublimating nascence $>$ ') on-the-one-hand and onthe-other-hand unblurriness/blurrinessthreshold framing/formulation/catchmenting/truncating/compulsing/linearising (imbued 'existentially-disontologising/re-ontologising aporeticism $>$ manifest entanglement-as-to‘<out-of phasing >-disparate-narratives'representation-as-being-of prospective-reentologising < at unblurriness/blurriness-threshold $>$ ' of both 'despite-the-self exercise of epistemic-projection in notional $\sim$ self-distantiation- $<$ imbued-re-motif-and-re-apriorising/reaxiomatising/re-referencing >' involved in 'limitedness/human-subpotency prospective reencountering/re-confrontation with unlimitedness/existence-full pof sublimating nascence>' and relative 'epistemic-decadence' or teleological-decadence-<-in-dimensionalityof-desublimating-lack-of $-<<$ amplituding/formative $>$ supererogatory $\sim$ dementativeness/epistemic-growth-or-conflatedness /transvaluativerationalising/transepistemicity/anamnestic-residuality/spirit-drivenness-equalisation〉 imbued distractive-alignment-to- ${ }^{3}$ reference-of-thought- $<$ of-apriorising/axiomatising/referencing $>{ }^{30}$ ). In this regards, the human 'reflex mentality' (as to institutional-development-as-to-socialfunction-development psychologismic epistemic-acutisation difficulty-for, residualising \{decomping $\}$ delinearity for-cogeney>-magnitude ${ }^{\{\text {of-experientiality/experiment }\}}$ and living-development- 
residualising_\{decompulsing $\}$ delinearity for-cogency>-magnitude $\{$ of-experientiality/experiment $\}$ ) is to wrongly implicit that prospective knowledge elucidation is 'ever always supposedly educed as from achieved/attained existentially-<disontologising/re-ontologising aporeticism $>$ manifest unblurriness $\sim$ reframing/reformulation/decatchmenting/detruncating/decompulsing/delinearisi ng'; and so-reflected as to an implicited ${ }^{79}$ presencing — absolutising-identitive-constitutedness underlying/overarching representation of supposedly prospectively re-ontologised Beingdevelopment/ontological-framework-expansion-as-to-depth-of-ontologising-development-asinfrastructure-of- meaningfulness-and-teleology psychologismic epistemic-acutisationdifficulty $<$ for, residualising_\{decompulsing $\}$ delinearity for-cogency> magnitude ${ }^{\{0 f-}$ experientiality/experiment\}. This poorly/hardly reflect the latter's requisite veridical prospective reontologising, notwithstanding the existentially-<disontologising/re-ontologising aporeticism $>$ manifest 'sublimating-remoteness/distance-of-appraisal-<as-to-requisite-'Being-developmentnotional self-distantiation'-imbued-psychologismic-epistemic-acutisation,-eliciting-ofprospective-ontologically-hegemonising-narrative $>$ as to 'registry-worldview/dimension existentialising-framing-by-enframing $/\{$ worlding $\}-{ }^{8}$ reference-of-thought' (of its requisite prospective re-ontologising idiomatisation-<as-to- blurriness-elicited-profoundsupererogation -of-' ‘epistemic-totalising '’metaphoricity '-for-prospective- unblurriness-of‘ \{epistemic-totalising $\frac{?}{3}$ meaningfulness-and-teleology ',-as-of-sublimating-prolongation;-inpsychologismic epistemic acutisation residualising, ${ }^{\text {tdecompulsingl }}$ delinearity for - cogency> imbued unblurriness $\sim$ reframing/reformulation/decatchmenting/detruncating/decompulsing/delinearisi ng)'; as so prospectively undergirding veridical prospective institutional-development-as-tosocial-function-development psychologismic epistemic acutisation difficulty < for, residualising \{ $\{$ decompulsing\} delinearity for-cogency>-magnitude $\{$ of-experientiality/experiment\} and living- 
difficulty-<for, residualising _decompulsing $\}$ delinearity for-cogency> magnitude ${ }^{\{0 f-}$ experientiality/experiment\}. This so-reflects the corresponding disontologising representation unblurriness/blurriness-

threshold framing/formulation/catchmenting/truncating/compulsing/linearising (imbued 'existentially- $<$ disontologising/re-ontologising aporeticism $>$ manifest entanglement as-to‘<out-of phasing $>$-disparate-narratives'representation-as-being-of prospective-reentelogising <at unblurriness/blurriness threshold $>$ ' of both 'despite-the-self exercise of epistemic-projection in notional $\sim$ self-distantiation- $<$ imbued-re-motif-and-re-apriorising/reaxiomatising/re-referencing >' involved in 'limitedness/human-subpotency prospective reencountering/re-confrontation with unlimitedness/existence-<fll-potency-of_sublimating nascence $>$ ' and relative 'epistemic-decadence' or teleological-decadence-<-in-dimensionalityof-desublimating-lack-of $-<<$ amplituding/formative $>$ supererogatory $\sim$ dementativeness/epistemic-growth-or-conflatedness /transvaluativerationalising/transepistemicity/anamnestic-residuality/spirit-drivenness-equalisation〉 imbued distractive-alignment-to- ${ }^{-}$reference-of-thought- $<$of-apriorising/axiomatising/referencing $>{ }^{30}$ ) on-the-one-hand and on-the-other-hand the re-ontologising representation of unblurriness $\sim$ reframing/reformulation/decatchmenting/detruncating/decompulsing/delinearisi ng (imbued manifestation of 'despite-the-self exercise of epistemic-projection in notional selfdistantiation- $<$ imbued - re-motif-and-re-apriorising/re-axiomatising/re-referencing $>$ ' involved in 'limitedness/human-subpotency prospective re-encountering/re-confrontation with unlimitedness/existence-<full-potency-of_sublimating nascence $>$ '). The overall underlying distinction herein implied (as to knowledge-reification $\sim$ gesturing-and-accounting-ofepistemic-phenomenalism- $<$ in- 
implicited_attendant-ontological-contiguity ' reduced-

existentialising/contextualising/textualising_intelligibility/epistemicity/reflexivity-contiguity$<$ imbued-notional cogency $>$ ' $\}$-conflatedness - in-\{preconverging ment by\}

postconverging entailment $>$ ) is thus between 'despite-the-self exercise of epistemic-projection in notional $\sim$ self-distantiation- $<$ imbued — re-motif-and-re-apriorising/re-axiomatising/rereferencing>' involved in 'limitedness/human-subpotency prospective re-encountering/reconfrontation with unlimitedness/existence-<full-potency-of_sublimating nascence>' on-theone-hand and on-the-other-hand 'epistemic-decadence' or teleological-decadence-<-indimensionality-of-desublimating-lack-of $-\langle<$ amplituding/formative $>$ supererogatory $\sim$ dementativeness/epistemic-growth-or-conflatedness /transvaluativerationalising/transepistemicity/anamnestic-residuality/spirit-drivenness-equalisation $\rangle$ imbued distractive-alignment-to- ${ }^{8}$ reference-of-thought- $<$ of-apriorising/axiomatising/referencing $>30$. Wherein concretely Einstein (notwithstanding his 'epistemic-totalising ${ }^{32}$ hunch' that quantummechanics is not on the right tract) effectively by his openness makes and elicits fundamental contributions to the development of quantum-mechanics in his relation with other physicists who held an 'epistemic-totalising ${ }^{33}$ hunch' that quantum-mechanics is on the right tract; so-speaking to their mutual 'despite-the-self exercise of epistemic-projection in notional $\sim$ self-distantiation<imbued - re-motif-and-re-apriorising/re-axiomatising/re-referencing $>$ ' involved in 'limitedness/human-subpotency prospective re-encountering/re-confrontation with unlimitedness/existence-<flll-potency-of_sublimating nascence $>$ ' (reflected in the higher value Einstein and these other physicists place on inherent prospective knowledge elucidation over the mere sake of holding onto their specifically given theoretical dispositions, and so-underlying the possibility of the physics purview 'effective ${ }^{45}$ foregrounding_entailment- $<$ in-succession-ofprofound-supererogation $>$ - $\left\langle\right.$ postconverging-narrowing-down $\sim$ sublimation-as-to- ${ }^{\circ}$ existence- 
supererogation '-in-reflecting-'immanent $\sim$ relative- unreflexivity/relative-reflexivity

ontological-contiguity ${ }^{\prime} ;$-as-operative-notional deprocrypticism)

as

of

cogency_chronicularity/annality-of-relative-reflexivity,-as-to-profound-supererogation ${ }^{9}$

imbuing conceptivity/epistemic-reflexivity/epistemicity-relativism-determinism- $<$ reifying \{asto-knowledge-developing\}-and-empowering $>$ ). In contrast, Socrates and Galileo rather eventually assumed a posture with regards to their epochal interlocutors in questioning what they thought was even more fundamental and important than their given specific thought orientations; as so-questioning 'whether their interlocutors placed a higher value on inherent prospective knowledge elucidation' which is effectively what precedes the possibility for prospective human 're-ontologising-nascency-<as-of-prospective-solipsistic/intersolipsistic-inkling-drive-forknowledge-elucidation,-as-to-veridical-organic-knowledge $>$ for sublimating-prolongation' (with respect to whichever specific thought orientation can be prospectively validated). Thusly speaking to the fact that they realised their 'supposedly prospective knowledge elucidation relationship with their respective epochal contentious/un-nominalised interlocutors' was not of mutual 'despite-the-self exercise of epistemic-projection in notional $\sim$ self-distantiation<imbued — re-motif-and-re-apriorising/re-axiomatising/re-referencing > $\quad$ involved in 'limitedness/human-subpotency prospective re-encountering/re-confrontation with unlimitedness/existence-<full-potency-of_sublimating nascence $>$ '; but rather underlied their epochal contentious/un-nominalised interlocutors 'epistemic-decadence' or teleologicaldecadence-<-in-dimensionality-of-desublimating-lack-of ${ }^{6}$

\section{<<amplituding/formative >supererogatory $\sim$ de-mentativeness/epistemic-growth-or-}

conflatedness /transvaluative-rationalising/transepistemicity/anamnestic-residuality/spirit-

drivenness-equalisation) imbued distractive-alignment-to- ${ }^{-}$reference-of-thought- $<$ofapriorising/axiomatising/referencing $>{ }^{30}$ (so-underlying the impossibility of overall knowledge 'effective $\quad{ }^{45}$ foregrounding_entailment- $<$ in-succession-of-profound-supererogation $>$ - 


\section{〈postconverging-narrowing-down sublimation-as-to-'existence-as-sublimating-}

\section{withdrawal/unenframing/re-ontologising,-elicited-from-prospective-profound-}

\section{supererogation '-in-reflecting-'immanent relative-unreflexivity/relative-reflexivity}

ontological-contiguity ${ }^{\prime} ;$-as-operative-notional deprocrypticism>

as

of

cogency_chronicularity/annality-of-relative-reflexivity,-as-to-profound-supererogation

imbuing conceptivity/epistemic-reflexivity/epistemicity-relativism-determinism- $<$ reifying \{asto-knowledge-developing\}-and-empowering $>$ ). The emphasis on 'placing a higher value on inherent prospective knowledge elucidation as effectively what precedes the possibility for prospective human re-ontologising' reflects the fact that it is unlimitedness/existence-<fullpotencof_sublimating nascences perpetual subjection of limitedness/human-subpotency (as to 'limitedness/human-subpotency prospective re-encountering/re-confrontation with unlimitedness/existence-<full-potency-of_sublimating nascence $>$ ') that (as to 'limitedness/human-subpotency incipient-aligning/subjection to unlimitedness/existence-<fullpotency-of_sublimating nascence>' as of 'notional/epistemic/bindingness ${ }^{-<a s-t o-}$ determinism/conceptivity-of-relative-unreflexivity/relative-reflexivityz re-ontologising potentiation'): drives veridical core-philosophy/derivative-core-philosophy_-(imbued requisite 'inkling-drive of dimensionality-of-sublimating $-<<$ amplituding/formative $>$ supererogatory $\sim$ dementativeness/epistemic-growth-or-conflatedness /transvaluativerationalising/transepistemicity/anamnestic-residuality/spirit-drivenness-equalisation〉') 'holding-out/point-referencing_ — psychoanalytic-unshackling exercise of educed-and-availingand-re-availing relative-ontological-completeness ${ }^{87}$-of-apriorising/axiomatising/referencing' to allow for play out of untenability-of-induced unblurriness as ‘ $<$ prospective_punctual/immediacy/constituted/compulsions-encumbered_- disarming

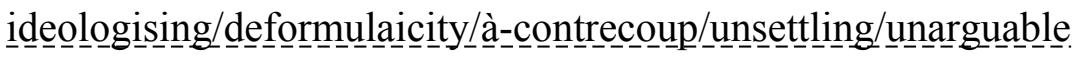
prompted constricted/narrowingdown-re-ontologising-enabling $>$ - psychologismic epistemic- 
acutisation residualising \{epistemic-

totalising thermeneutic/textuality/reprojecting/supererogating/zeroing/re-acuting,

\{decompulsing delinearity for-cogency' as to 'developing human-per-cep-ti-vi-ty-<as-tonotional perceptualisation-of-and-leashing-to_social-functioning-and-accordance-as-of-

social-stake-contention-or-confliction> in preconverging/postconverging-redementating/restructuring/reparadigming'; and so rendering delusional the idea of ignoring manifest 'epistemic-decadence' or teleological-decadence-<-in-dimensionality-ofdesublimating-lack-of $-\langle<$ amplituding/formative $>$ supererogatory $\sim$ de-mentativeness/epistemicgrowth-or-conflatedness /transvaluative-rationalising/transepistemicity/anamnesticresiduality/spirit-drivenness-equalisation $\rangle$ imbued distractive-alignment-to- ${ }^{3}$ reference-ofthought- $<$ of-apriorising/axiomatising/referencing $>^{30}$, and then pretending/claiming to eventually attain veridical prospective 're-ontologising-nascency-<as-of-prospectivesolipsistic/intersolipsistic-inkling-drive-for-knowledge-elucidation,-as-to-veridical-organic-

knowledge > for sublimating-prolongation' (beyond a shallowness/superficiality of thought conception of such supposed re-ontologising). In other words, 'knowledge elucidation and knowledge implications at unblurriness/blurrinessthreshold framing/formulation/catchmenting/truncating/compulsing/linearising for sublimating-prolongation' cannot be construed-and-related-to as if of 'knowledge elucidation and knowledge implications at unblurriness $\sim$ reframing/reformulation/decatchmenting/detruncating/decompulsing/delinearisi ng for sublimating-prolongation' (imbued mutual 'despite-the-self exercise of epistemicprojection in notional $\sim$ self-distantiation- $<$ imbued-re-motif-and-re-apriorising/reaxiomatising/re-referencing>' involved in 'limitedness/human-subpotency prospective reencountering/re-confrontation with unlimitedness/existence-<fll potency-of_sublimating nascence $>$ '). The former necessarily has to re-articulate organic-knowledge requisite 
'perspicacity of psychologismic-epistemic-acutisation-<as-to-postconverging-dementating/structuring/paradigming,-eliciting-of-existence's-sublimating-nascence-inprospective-aporeticism-overcoming/unovercoming $>$ as to epistemic-growth,-as\{veridical/sound\}-relative-reflexivity-in-existence/relativising from-limited-mentation-as-itsdeepening/psychologismic epistemic-acutisation residualising, ${ }^{\text {fdecompulsing }}$ \}elinearity foreogency' of 'unlimitedness/existence-<full-potency-of_sublimating nascence $>$ '; with respect to 'the-very-same purview/devolved-purview/devolving-purview-of-unlimitedness/existence<full-potency-of_sublimating_nascence>;_-'implicited_attendant-ontologicalcontiguity $^{67}$, educedexistentialising/contextualising/textualising_'intelligibility/epistemicity/reflexivity-contiguity$<$ imbued-notional cogency $>^{\prime}$ : as to the requisite further knowledge gesturing-andaccounting-of-epistemic-phenomenalism of prospective 'epistemic-decadence' or teleological-decadence-<-in-dimensionality-of-desublimating-lack-of ${ }^{-}$ <<amplituding/formative >supererogatory $\sim$ de-mentativeness/epistemic-growth-orconflatedness /transvaluative-rationalising/transepistemicity/anamnestic-residuality/spiritdrivenness-equalisation $\rangle$ imbued distractive-alignment-to- ${ }^{3}$ reference-of-thought- $<$ ofapriorising/axiomatising/referencing $>^{30}$; and so, in order to enable sublimating-prolongation (by overcoming the 'disparateness-of-conceptualisation-<unforegrounding-ment,-failingprospectively-to-reflect-'immanent relative-unreflexivity/relative-reflexivity - ontologicalcontiguity '> of unblurriness/blurrinessthreshold framing/formulation/catchmenting/truncating/compulsing/linearising') for veridical prospective knowledge 'effective ${ }^{45}$ foregrounding_entailment- $<$ in-succession-of-profoundsupererogation $>$-〈postconverging-narrowing-down $\sim$ sublimation-as-to-'existence-assublimating-withdrawal/unenframing/re-ontologising,-elicited-from-prospective-profoundsupererogation '-in-reflecting-'immanent relative-unreflexivity/relative-reflexivity 
cogency_chronicularity/annality-of-relative-reflexivity,-as-to-profound-supererogation imbuing conceptivity/epistemic-reflexivity/epistemicity-relativism-determinism- $<$ reifying \{asto-knowledge-developing\}-and-empowering > (educed unblurriness $\sim$ reframing/reformulation/decatchmenting/detruncating/decompulsing/delinearisi ng for sublimating-prolongation). Such manifest 'epistemic-decadence' or teleologicaldecadence-<-in-dimensionality-of-desublimating-lack-of ${ }^{-}$

<<amplituding/formative>supererogatory $\sim$ de-mentativeness/epistemic-growth-orconflatedness /transvaluative-rationalising/transepistemicity/anamnestic-residuality/spiritdrivenness-equalisation> imbued distractive-alignment-to- ${ }^{-}$reference-of-thought- $<$ofapriorising/axiomatising/referencing $>{ }^{30}$ more fundamentally underlies the 'direct/indirect-andconscious/unconscious destabilisation' of 'requisite prospective re-ontologising for sublimating-prolongation'-(which so-imbues effectively of the serenity for 'prospective existential-<disontologising/re-ontologising aporeticism $>\quad$ human sovereignemergence/becoming, existentially imbuing hmman freedom as to-supererogating/surrealising for-'knowledge-empowerment-over-ignorance-disempowerment'-<as-of-'developing-andavailing-sovereign-sublimating_potential/possibilities/options/choices'-as-to-the'credibility’/'ontological-veracity’-underlying-the-'sovereign-conscious/conscientiousbackdrop'> consciousness/collective-consciousness'); and so, whether such 'direct/indirectand-conscious/unconscious destabilisation' is manifested bluntly or subtly, with regards to elicited \{epistemic-totalising 3 ? psychologismic-subliminal-truncating (as of 'catchmented-andcompulsed-<in-'existential-dearth-of-demoronisation',-so-construed-as-from-ontologicalnormalcy/postconvergence-perspective-reflection-of-the-'destructuring-threshold_of-thegiven-level's-conjugated-postlogism as-dementing'> interpersonal, group, intergroup, community, local, national, political, geostrategic, etc. psychologismic epistemic-acutisation- 
difficulty-for, residualising_\{decompulsing $\}$ delinearity for-cogency>-levels of interrelatednessdynamics-of-social-constructing'). Critically, all such 'despite-the-self exercise of epistemicprojection in notional $\sim$ self-distantiation- $<$ imbued-re-motif-and-re-apriorising/reaxiomatising/re-referencing $>$ ' involved in 'limitedness/human-subpotency prospective reencountering/re-confrontation with unlimitedness/existence-<full-potency-of_sublimating nascence>' (as to its emphasis on 'placing a higher value on inherent prospective knowledge elucidation as effectively what precedes the possibility for prospective human re-ontologising' so-imbuing of prospective 're-ontologising idiomatisation-<as-to- blurriness-elicited-profound-

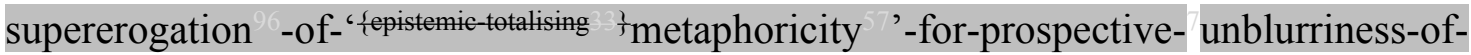
‘\{epistemic-totalising ? meaningfulness-and-teleology ',-as-of-sublimating-prolongation;-inpsychologismic epistemic-acutisation residualising, ${ }^{\text {fdecompulsing }}$ delinearity for-cogency>') implicitly/explicitly ensures its ontologising-failsafe-<as-to-relative-unreflexivity/relativereflexivity bindingness/nondiscretionariness' of totalising-entailment $>$ as of 'substantivity of transversality-<for-sublimating-existential-eventuating/denouement,-from-'thinking atfirst/pure predisposition - preemptive-of prospective-disontologising/subontologising' as-ofprospectively-disambiguated-affirmed-and-unaffirmed-'motif-andapriorising/axiomatising/referencing'> $>1$ ' imbued 'impersonalisation and deinstitutionalisation of prospective re-ontologising ${ }^{56}$ meaningfulness-and-teleology ${ }^{9}$ '; so-undergirding sublimatingprolongation underlying 'effective ${ }^{45}$ foregrounding_entailment- $<$ in-succession-of-profoundsupererogation $>$-〈postconverging-narrowing-down $\sim$ sublimation-as-to-'existence- assublimating-withdrawal/unenframing/re-ontologising,-elicited-from-prospective-profoundsupererogation '-in-reflecting-'immanent relative unreflexivity/relative reflexivity ontological-contiguity ';-as-operative-notional deprocrypticism〉 as cogency_chronicularity/annality-of-relative-reflexivity,-as-to-profound-supererogation ${ }^{\text {, }}$ imbuing conceptivity/epistemic-reflexivity/epistemicity-relativism-determinism- $<$ reifying \{as- 
to-knowledge-developing\}-and-empowering>. It should be noted here that such 'placing a higher value on inherent prospective knowledge elucidation as effectively what precedes the possibility for prospective human re-ontologising' speaks to the 'social-functioning-andaccordance-as-of-social-stake-contention-or-confliction construct abstractly imbued intemporal individuative' requisite sublimating-prolongation (retracing-and-relaying 'thinking at first/pure predisposition preemptive of prospective disontologising/subontologising' as from 'inkling-drive of dimensionality-of-sublimating ${ }^{25}$-<<amplituding/formative > supererogatory $\sim$ dementativeness/epistemic-growth-or-conflatedness /transvaluative-

rationalising/transepistemicity/anamnestic-residuality/spirit-drivenness-equalisation $\rangle$ '); that as to sublimating-prolongation 'manifests in or supersedes the given social-setup or institution' as to the veracity of the pre-eminence of impersonalisation and deinstitutionalisation of prospective re-ontologising ${ }^{5}$ meaningfulness-and-teleology" (and so notwithstanding whether or not the sublimating-prolongation is manifested along/within or in contestation of any such given social-setup or institution). The bigger point here is that core-philosophy/derivative-corephilosophy_(imbued requisite 'inkling-drive of dimensionality-of-sublimating ${ }^{25}$ <<amplituding/formative>supererogatory $\sim$ de-mentativeness/epistemic-growth-orconflatedness /transvaluative-rationalising/transepistemicity/anamnestic-residuality/spiritdrivenness-equalisation)'), as rather 'a holding-out/point-referencing-psychoanalyticunshackling exercise of educed-and-availing-and-re-availing relative-ontologicalcompleteness ${ }^{87}$-of-apriorising/axiomatising/referencing' to allow for play out of untenabilityof-induced $\sim$ unblurriness as '<prospective_punctual/immediacy/constituted/compulsions-

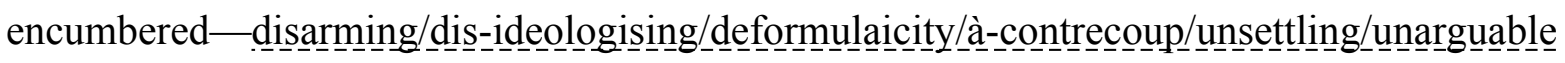
prompted constricted/narrowingdown-re-ontologising-enabling $>$-psychologismic epistemicacutisation residualising $\{$ fepistemic-

totalising thermeneutic/textuality/reprojecting/supererogating/zeroing/re-acuting, 
$\{$ decompulsing $\}$ delinearity for-cogency' as to 'developing human-per-cep-ti-vi-ty-<as-to notional perceptualisation-of-and-leashing-to_social-functioning-and-accordance-as-ofsocial-stake-contention-or-confliction> in preconverging/postconverging-redementating/restructuring/reparadigming'; is more fundamentally not prospectively beholdening to any given social-setup or institution (even as any such given social-setup or institution is the consequence of the sublimating-arising from prior core-philosophy/derivative-corephilosophy), but rather core-philosophy/derivative-core-philosophy is in-the-very-essence prospectively beholdening to underlying 'social-functioning-and-accordance-as-of-socialstake-contention-or-confliction construct abstractly imbued intemporal individuative' requisite sublimating-prolongation (as to 'relays of human intemporal-individuation epistemic-projection radicalities $\sim$ in-chronicular/annalistic-cogency-<as-of-notional $\sim$ protensivity $>$-〈as-to-limitedmentation-capacity-deepening —as-subjecting limitedness/human-subpotency-to-'educedunlimitedness/existence-sublimating nascence' so-construed cogency_chronicularity/annality-of-relative-reflexivity,-as-to-profound-supererogation ${ }^{\text {') }}$ ). This is so-reflected in the instance where there is a mere sterile/anecdotal institutionalprescience/imprimaturing- $<$ dullness-of-the-spirit/psychologismic epistemic-acutisation nonresidualising-imbued-\{compulsing\}linearity in-eclecticism-of-prior-mereformulaicity/ritualisation $>$ display of a deficient/poor aptitudinal re-ontologising-incompetence gesturing/accounting - of-epistemic-phenomenalism; and as that can effectively be soconstrued as incompetent, by the fact that critical members of the 'overall social intellectionaptitude body' are able to grasp the requisite appropriateness of profound aptitudinal reontologising-competence gesturing/accounting-of-epistemic-phenomenalism as to their relevant generalised profound aptitudinal re-ontologising-competence gesturing/accountingof-epistemic-phenomenalism associated with the mastery of their various specialisms as well as their general knowledge interests. In this regards, it can be appreciated that it is because of an 
underlying 'overall social intellection-aptitude body' (as to its emphasis on 'placing a higher value on inherent prospective knowledge elucidation as effectively what precedes the possibility for prospective human re-ontologising') that even a deliberate inclination for pedantising/muddling/formulaic-hollowing-out — in-subontologisation/subpotentiation〈blurring/undermining-of-prospective-totalising-entailing,-as-to-entailing$<$ amplituding/formative-epistemicity>totalising in-relative-ontological-completeness $\rangle$ 'isn't outrightly and explicitly dismissive of requisite prospective knowledge elucidation'; and thusly, exposing itself (as to human ontological-commitment ${ }^{6}$ and universal-transparency ${ }^{104}$ of meaningfulness-and-teleology", with respect to underlying human 'crossgenerational notional firstnaturedness-formativeness-as to entulising inkling drive or seeding misprising $>$ mental-processing-parity for ontological-performance ${ }^{72}-<_{\text {including-virtue-as- }}$ ontology $>$ /morality/ethics/justice/etc.', for sublimating-prolongation) to its contestation-andundermining as from the genuine social intellectual-function/posture re-ontologising. In this respect, in-many-ways the re-ontologising enterprises of Socratic-philosophers universalising-idealisation and budding-positivists positivism/rational-empiricism (as to their correspondingly given unblurriness/blurrinessthreshold framing/formulation/catchmenting/truncating/compulsing/linearising of ancientsophists non-universalising and medieval-scholasticism nonpositivising) could only arise as to the reality of an underlying manifest 'overall social intellection-aptitude body' (of many an ancient-sophist non-universalising and many a medieval-scholastics nonpositivising) in 'placing a higher value on inherent prospective knowledge elucidation as effectively what precedes the possibility for prospective human re-ontologising'; and thus the susceptibility of this underlying manifest 'overall social intellection-aptitude body' to the eliciting of human ontologicalcommitment ${ }^{6}$ and universal-transparency ${ }^{104}$ of ${ }^{56}$ meaningfulness-and-teleology ${ }^{9}$ (with respect to underlying human 'crossgenerational notional firstnaturedness-formativeness-<as-to- 
ontological-performance ${ }^{72}$-<including-virtue-as-ontology>/morality/ethics/justice/etc.') for sublimating-prolongation. Such that in-many-ways it can be appreciated that Socraticphilosophers rather engaged with many of such an ancient-sophist to elicit prospective universalising-idealisation while much of the contribution to Diderot-led Encyclopédistes project for instance came from medieval-scholastics with a weak positivistic/rational-empiricism outlook (notwithstanding anectodally that as to their given tolerance for such new ideas and the exposition of such ideas some of the medieval-scholastics effectively destroyed sections and pages of this enlightening project). Thus it is important to grasp here that 'with respect to prospectively requisite sublimating-prolongation at unblurriness/blurrinessthreshold framing/formulation/catchmenting/truncating/compulsing/linearising' (unlike the take/impression-given, which truly rather manifests consciously/unconsciously priorperspective - falsity/falseness/fallaciousness of a mere 'logical/rationalising exercise', of a deliberate inclination for pedantising/muddling/formulaic-hollowing-out-insubontologisation/subpotentiation-〈blurring/undermining-of-prospective-totalising-entailing,-

\section{as-to-entailing-<amplituding/formative-epistemicity $>$ totalising $\sim$ in-relative-ontological-}

completeness > flawed projection of a 'neutral confrontation of ideas' as if of 'prospective mutual/dialogical engagement in knowledge elucidation for sublimating-prolongation' as sowrongly implying 'despite-the-self exercise of epistemic-projection in notional $\sim$ selfdistantiation-<imbued—re-motif-and-re-apriorising/re-axiomatising/re-referencing $>$ ' involved in 'limitedness/human-subpotency prospective re-encountering/re-confrontation with unlimitedness/existence-<fll potency-of_sublimating nascence $>$ '): (the effectively manifest 'epistemic-decadence' or teleological-decadence-<-in-dimensionality-of-desublimating-lackof - -< <amplituding/formative>supererogatory -de-mentativeness/epistemic-growth-or- 
drivenness-equalisation $\rangle$ imbued distractive-alignment-to- ${ }^{3}$ reference-of-thought- $<$ ofapriorising/axiomatising/referencing $>30$ at unblurriness/blurrinessthreshold framing/formulation/catchmenting/truncating/compulsing/linearising), means that the 'more fundamental/incipient issue of knowledge elucidation' is rather one of the 'inducing of the disontologising deferential-desovereignising' (as from 'smere formulaicity/rittatisation ef $>$-prior secondnatured positive-opportunism—of-social-functioning-and-accordance ${ }^{75}$ as to imbuing prospective shallow-supererogation ') of the sovereign-function/posture-<as-toexistentially-manifest-‘embodied-subject $\sim$ consciousness-and-direct/deferentialconscientiousness',-as-of-its- 'epistemic-reflexivity/unreflexivity-in-existence'/teleology>; in undermining its requisite "protracted-social — as-to-individual-by-institutional-by-social relative direct/deferential-responsibility/relative-reflexivity to cogency_chronicularity/annality-ofrelative-reflexivity,-as-to-profound-supererogation ". In other words, the reality of Socraticphilosophers induced ${ }^{103}$ universalising-idealisation and budding-positivists induced positivism/rational-empiricism are rather correspondingly the 'eliciting of re-ontologising deferential-sovereignising' (as from 'inkling-drive of dimensionality-of-sublimating <<amplituding/formative >supererogatory $\sim$ de-mentativeness/epistemic-growth-or-

conflatedness /transvaluative-rationalising/transepistemicity/anamnestic-residuality/spiritdrivenness-equalisation)' hardly/poorly carrying any prospective 'secondnatured positiveopportunism of-social-functioning-and-accordance ${ }^{7}$ as-toprospective _punctual/immediacy/constituted/compulsions-encumbered_disarmingng/disideologising/deformulaicity/à-contrecoup/unsettling/unarguable) $\quad$ of $\quad$ the $\quad$ sovereignfunction/posture-<as-to-existentially-manifest-‘embodied-subject consciousness-anddirect/deferential-conscientiousness',-as-of-its- 'epistemic-reflexivity/unreflexivity-inexistence'/teleology>; in enabling its requisite 'protracted-social—as-to-individual-byinstitutional-by-social relative direct/deferential-responsibility/relative-reflexivity to 
cogency_chronicularity/annality-of-relative-reflexivity,-as-to-profound-supererogation .

Such that in-effect there is a more 'intrinsic issue of knowledge elucidation' (other than and superseding a veridical 'prospective mutual/dialogical engagement in knowledge elucidation for sublimating-prolongation') between pedantising/muddling/formulaic-hollowing-out - insubontologisation/subpotentiation-〈blurring/undermining-of-prospective-totalising-entailing,-

as-to-entailing-<amplituding/formative-epistemicity $>$ totalising in-relative-ontological-

completeness > and the genuine social intellectual-function/posture; as fundamentally/incipiently an issue of sovereign-function/posture-<as-to-existentially-manifest'embodied-subject $\sim$ consciousness-and-direct/deferential-conscientiousness',-as-of-its'epistemic-reflexivity/unreflexivity-in-existence'/teleology> disontologising deferentialdesovereignising or re-ontologising deferential-sovereignising. So-reflected in the fact that the sovereign-function/posture-<as-to-existentially-manifest-'embodied-subject $\sim$ consciousnessand-direct/deferential-conscientiousness',-as-of-its-'epistemic-reflexivity/unreflexivity-inexistence'/teleology $>$ existential-<disontologising/re-ontologising aporeticism $>$ attainment of universalising-idealisation and positivism/rational-empiricism respectively (as of 'reontologising-nascency-<as-of-prospective-solipsistic/intersolipsistic-inkling-drive-forknowledge-elucidation,-as-to-veridical-organic-knowledge > for sublimating-prolongation') is in-many-ways not essentially of the 'given genuine social intellectual-function/posture personalised relevance/gain of re-ontologising social-functioning-and-accordance-as-ofsocial-stake-contention-or-confliction'; but for the profound-supererogation in 'placing a higher value on inherent prospective knowledge elucidation as effectively what precedes the possibility for prospective human re-ontologising' (so-undergirded as of human ontologicalcommitment and universal-transparency ${ }^{104}$ with respect to underlying human 'crossgenerational notional firstnaturedness-formativeness-<as-to-eventualising-inkling drive-or-seeding misprising $>$ mental-processing-parity for ontological-performance ${ }^{72}$ 
<including-virtue-as-ontology $>$ /morality/ethics/justice/etc.'). Overall, such an 'impersonalisation and deinstitutionalisation of prospective re-ontologising ${ }^{5}$ meaningfulnessand-teleology $^{9}$, of requisite sublimating-prolongation can be appreciated as to the fact that paradoxically Socratic-philosophers ${ }^{103}$ universalising-idealisation and budding-positivists positivism/rational-empiricism respectively arose from (as to their corresponding contestation of the prospectively shallowsupererogation $\sim$ framing/formulation/catchmenting/truncating/compulsing/linearising —as-topreconverging de-mentating/structuring/paradigming) ancient-sophists non-universalising and medieval-scholasticism nonpositivising failing prospective sublimating-prolongation; with the latter in prospectively manifest 'epistemic-decadence' or teleological-decadence-<-indimensionality-of-desublimating-lack-of $-\langle<$ amplituding/formative $>$ supererogatory $\sim$ dementativeness/epistemic-growth-or-conflatedness /transvaluativerationalising/transepistemicity/anamnestic-residuality/spirit-drivenness-equalisation〉 imbued distractive-alignment-to- ${ }^{83}$ reference-of-thought- $<$ of-apriorising/axiomatising/referencing $>30$. Effectively, the existential-<disontologising/re-ontologising aporeticism $>$ reality of 'notional firstnaturedness-formativeness-<as-to-eventualising-inkling-drive or seedingmisprising $>$ temporal-to-intemporal-dispositions- $<$ so-construed-as-from-perspectiveontological-normalcy/postconvergence $>$ of human protracted-social—as-to-individual-byinstitutional-by-social ontological-performance ${ }^{72}$-<including-virtue-asontology $>$ /morality/ethics/justice/etc.' (so-construed as of 'protracted-social — as-to-individualby-institutional-by-social relative direct/deferential-responsibility/relative-reflexivity-orirresponsibility/relative-unreflexivity to cogency_chronicularity/annality-of-relativereflexivity,-as-to-profound-supererogation ') fundamentally 'undermines the veracity of a conception of prospectively inherent human generalised/proletarianised sublimatingprolongation'; and rather points to the veracity of the 'social-functioning-and-accordance-as- 
of-social-stake-contention-or-confliction construct abstractly imbued intemporal individuative' requisite sublimating-prolongation (retracing-and-relaying 'thinking at first/pure predisposition preemptive of prospective disontologising/subontologising' as of 'inkling-drive of dimensionality-of-sublimating ${ }^{25}-<$ amplituding/formative $>$ supererogatory - dementativeness/epistemic-growth-or-conflatedness /transvaluativerationalising/transepistemicity/anamnestic-residuality/spirit-drivenness-equalisation〉'). In this regards, human limited-mentation-capacity (in want for limited-mentation-capacitydeepening — as-subjecting limitedness/human-subpotency-to-'educed-unlimitedness/existencesublimating nascence ${ }^{53}$ ) necessarily underlies the existentially-<disontologising/reentogising apereticism $>$ manifest parrhesiastic/messianicity/profound-supererogation ${ }^{6}$ of 'limitedness/human-subpotency prospective re-encountering/re-confrontation with unlimitedness/existence-<fll potency-of_sublimating nascence $>$ for prospective sublimating-prolongation. Such that even the well-meaning 'claim/pretense to any such supposed prospectively inherent human generalised/proletarianised sublimating-prolongation' (as to a communist take) is in-effect so-educed rather paradoxically as from a notional/epistemic/bindingness ${ }^{\text {-as-to-determinism/conceptivity-of-relative-unreflexivity/relative-reflexivity }>}$ 'parrhesiastic/messianicity/profound-supererogation projection for sublimatingprolongation'. Such that in reality the social-functioning-and-accordance-as-of-social-stakecontention-or-confliction construct is the consequence of 'prior notional/epistemic/bindingness' $\leq$ as-to-determinism/conceptivity-of-relative-unreflexivity/relative-reflexivity $>$ parrhesiastic/messianicity/profoundsupererogation projection for sublimating-arising' and 'prospective aspirative notional/epistemic/bindingness $<$ as-to-determinism/conceptivity-of-relative-unreflexivity/relative-reflexivity $>$ parrhesiastic/messianicity/profound-supererogation projection for sublimating-prolongation'; and so, as to 'relays of human intemporal-individuation epistemic-projection radicalities $\sim$ inchronicular/annalistic-cogency-<as-of-notional $\sim$ protensivity $>$-〈as-to-limited-mentation- 
capacity-deepening —as-subjecting limitedness/human-subpotency-to-'educed-

so-construed

as

cogency_chronicularity/annality-of-relative-reflexivity,-as-to-profound-supererogation '. This so-underlies (in reflection of institutional-development-as-to-social-function-development psychologismic epistemic acutisation diffieuly <for, residualising

$\{$ decompulsing $\}$ delinearity for-cogeney>-magnitude $\{$ of-experientiality/experiment $\}$ and living-developmentas-to-personality-development psychologismic epistemic-acutisation difficulty-for, residualising delinearity for-cogency $>$ magnitude \{of-experientiality/experiment\}) the fact that there is no human generalised/proletarianised sublimating-prolongation as to manifest informal and formal human specialisms say doctor, electrician, musician, plumber, lawyer, etc. (given human limited-mentation-capacity warrant for optimal limited-mentation-capacity orientation/allocation); which are all effectively of their specifically given 'prospective aspirative notional/epistemic/bindingness - as to determinism/enceptivity of relative mneflexivity/relative reflexivitys parrhesiastic/messianicity/profound-supererogation projection for sublimating-prolongation' as re-ontologising 'on behalf of overall social-functioning-and-accordance-as-of-social-stakecontention-or-confliction construct enabled sovereign-emergence/becoming,-existentiallyimbuing human-freedom-as-to-supererogating/surrealising for-'knowledge-empowermentover-ignorance-disempowerment'-<as-of-'developing-and-availing-sovereignsublimating_potential/possibilities/options/choices'-as-to-the-'credibility’/'ontologicalveracity'-underlying-the-'sovereign-conscious/conscientious-backdrop'>'. Overall 'prospective aspirative notional/epistemic/bindingness-<as-to-determinism/conceptivity-of-relative-unreflexivity/relative-reflexivity> parrhesiastic/messianicity/profound-supererogation projection for sublimating-prolongation' is (transparently or indirectly) effectively underscored: coherently-and-comprehensibly, as from the 'profoundsupererogation $\sim$ reframing/reformulation/decatchmenting/detruncating/decompulsing/delinear 
ising —as-to-postconverging de-mentating/structuring/paradigming

priority/precedence/primacy' of re-ontologising prospective Being-development/ontologicalframework-expansion-as-to-depth-of-ontologising-development-as-infrastructure-of-

meaningfulness-and-teleology psychologismic epistemic-acutisation difficulty-for, residualising \{decompulsing delinearity-for-cogency>-magnitude\{of-experientiality/experiment\}, then institutional-development-as-to-social-function-development psychologismic epistemicacutisation difficulty-for, residualising \{decompulsing $\}$ delinearity for-cogency> magnitude ${ }^{\{0 f-}$ experientiality/experiment $\}$ and then living-development-as-to-personality-development psychologismic epistemic-acutisation difficulty-for, residualising $\{$ decompulsing $\}$ delinearity for-cogeney $>$ magnitude ${ }^{\{0 f-e x p e r i e n t i a l i t y / e x p e r i m e n t\}}$ (and so as to ${ }^{83}$ referenceof-thought-and- ${ }^{83}$ reference-of-thought- devolving- ${ }^{5}$ meaningfulness-and-teleology 'organic accompaniment' of 'limitedness/human-subpotency prospective re-encountering/reconfrontation with unlimitedness/existence-<full-potency-of_sublimating nascence $>$ '). Soreflecting notionally/epistemically/bindingnessly-as determinism/eoneeptivity of relative unreflexivity/relativereflexivity> the inevitable (with regards to 'existentially-<disontologising/re-ontologising aporeticism $>$ manifest entanglement-as-to '<out-of-phasing $>$-disparate-narratives' representation as being of prospective re ontologising <at mblurriness/blurriness

threshold $>$ ') 'hierarchisation-of-narratives about sublimating-prolongation of socialfunctioning-and-accordance-as-of-social-stake-contention-or-confliction construct'-(with reference to notional/epistemic/bindingness $<$ as-todeterminism/conceptivity-of-relative-mnreflexivity/relativereflexivitys 'parrhesiastic/messianicity/profound-supererogation' projection for sublimatingprolongation'); as so-undermining the 'claim/pretense to any such supposed prospectively inherent human generalised/proletarianised sublimating-prolongation'. This is so-underscored as from the 'ontologically-hegemonising-narrative ${ }^{71}$ ontological-performance ${ }^{2}-<$ includingvirtue-as-ontology $>$ /morality/ethics/justice/etc.'-(with reference to 
notional/epistemic/bindingness ${ }^{-<a-t o-d e t e r m i n i s m / c o n c e p t i v i t y-o f-r e l a t i v e-u n r e f l e x i v i t y / r e l a t i v e-r e f l e x i v i t y s ~}$

'parrhesiastic/messianicity/profound-supererogation projection for sublimatingprolongation') for sublimating-prolongation as to veridical core-philosophy/derivative-corephilosophy_(imbued requisite 'inkling-drive of dimensionality-of-sublimating <<amplituding/formative>supererogatory $\sim$ de-mentativeness/epistemic-growth-or-

\section{conflatedness /transvaluative-rationalising/transepistemicity/anamnestic-residuality/spirit-}

drivenness-equalisation〉') 'holding-out/point-referencing-psychoanalytic-unshackling exercise of educed-and-availing-and-re-availing relative-ontological-completeness ${ }^{8}$-ofapriorising/axiomatising/referencing' to allow for play out of untenability-ofinduced unblurriness as '<prospective_punctual/immediacy/constituted/compulsionsencumbered - disarming/dis_-ideologising/_eformulaicity/à-contrecoup/unsettlling/unargunable prompted constricted/narrowingdown-re-ontologising-enabling $>$-psychologismic epistemicacutisation residualising fepistemic-

totalising thermeneutic/textuality/reprojecting/supererogating/zeroing/re-acuting,

$\{$ decompulsing $\}$ delinearity for-cogency' as to 'developing human-per-cep-ti-vi-ty-<as-to

notional perceptualisation-of-and-leashing-to_social-functioning-and-accordance-as-of-

social-stake-contention-or-confliction> in preconverging/postconverging-redementating/restructuring/reparadigming'; so-undergirding all such informal and formal specialisms as of veridical core-philosophy/derivative-core-philosophy-(imbued requisite 'inkling-drive of dimensionality-of-sublimating 5 -<<amplituding/formative $>$ supererogatory - dementativeness/epistemic-growth-or-conflatedness /transvaluative-

rationalising/transepistemicity/anamnestic-residuality/spirit-drivenness-equalisation〉') limitedmentation-capacity-deepening —as-subjecting limitedness/human-subpotency-to-'educedunlimitedness/existence-sublimating nascence' ${ }^{33}$ for sublimating-prolongation. It is this 'notional/epistemic/bindingness ${ }^{<a s-t o-d e t e r m i n i s m / c o n c e p t i v i t y-o f-r e l a t i v e-u n r e f l e x i v i t y / r e l a t i v e-r e f l e x i v i t y>~}$ relative- 
reflexivity/relative-unreflexivity existential-<disontologising/re-ontologising aporeticism $>$ dynamics' for 'ontologically-hegemonising-narrative ${ }^{71}$ ontological-performance ${ }^{72}<$ includingvirtue-as-ontology $>$ /morality/ethics/justice/etc.'-(with reference to notional/epistemic/bindingness ${ }^{<\text {as-to-determinism/conceptivity-of-relative-unreflexivity/relative-reflexivity> }}$ 'parrhesiastic/messianicity/profound-supererogation projection for sublimatingprolongation') that elicits or fails-to-elicit human sovereign-function/posture- $<$ as-toexistentially-manifest-'embodied-subject consciousness-and-direct/deferentialconscientiousness',-as-of-its-'epistemic-reflexivity/unreflexivity-in-existence'/teleology> 'protracted-social—as-to-individual-by-institutional-by-social relative direct/deferentialresponsibility/relative-reflexivity to cogency_chronicularity/annality-of-relative-reflexivity,-asto-profound-supererogation '; so-notionally/epistemically/bindingnessly-<as-todeterminism/conceptivity-of-relative-unreflexivity/relative-reflexivitys reflecting the possibility for sovereignemergence/becoming,-existentially-imbuing human-freedom-as-to-supererogating/surrealisingfor-'knowledge-empowerment-over-ignorance-disempowerment'-<as-of-'developing-andavailing-sovereign-sublimating_potential/possibilities/options/choices'-as-to-the'credibility'/‘ontological-veracity'-underlying-the-'sovereign-conscious/conscientiousbackdrop'>). Strangely enough, the 'claim/pretense to any such supposed prospectively inherent human generalised/proletarianised sublimating-prolongation' is not only reflected as to wishful communist ideology narrative but is equally paradoxically implicited in-effect with a capitalist/neoliberal ideology narrative; specifically associated with the punctual/immediacy/constituted/compulsions-encumbered nature of the 'social-stakecontention-or-confliction of the advocacy/political/applicative-scope as to techno-socioecono-political implications', so-overarchingly manifested with the 'democratic practice ontologising unwieldiness' and its institutionally associated/derivational contentious/unnominalised social-stake-contention-or-confliction (such that in-many-ways the 'backdrop of 
credible/ontological-veracity-of sovereign-sublimating_potential/possibilities/options/choices' is rather a 'scruffy shrinking of the social imaginary' as to a basic emphasis on a 'basic manifest/gestural sovereign-exercising-<as-of-sovereign-deferentialism;-as-to-'direct/indirectelecting-and/or-nominating'>' of 'unwieldy-contemplatable disontologising/re-ontologising implications' with regards to human sovereign-function/posture-<as-to-existentially-manifest‘embodied-subject consciousness-and-direct/deferential-conscientiousness',-as-of-its-

'epistemic-reflexivity/unreflexivity-in-existence'/teleology>). The fact remains that the unblurriness $\sim$ reframing/reformulation/decatchmenting/detruncating/decompulsing/delinearisi ng reflected with uncontentious/nominalised social-stake-contention-or-confliction effectively elicits a human existential-<disontologising/re-ontologising aporeticism $>$ recognition (in manifest 'protracted-social—as-to-individual-by-institutional-by-social relative direct/deferential-responsibility/relative-reflexivity to cogency_chronicularity/annality-ofrelative-reflexivity,-as-to-profound-supererogation') of the 'hierarchisation-of-narratives about sublimating-prolongation of social-functioning-and-accordance-as-of-social-stakecontention-or-confliction construct'-(with reference to notional/epistemic/bindingness $<a s-t o-$ determinism/conceptivity-of-relative-unreflexivity/relative-reflexivity $>$ 'parrhesiastic/messianicity/profoundsupererogation projection for sublimating-prolongation'); and so with respect to existential<disontologising/re-ontologising aporeticism $>$ appraisal of requisite human competence/expertising (as of human socially expanded framework of deferential-formalisationtransference as to various cultivated skills/arts and time investment with regards to effectively manifest 'underlying veracity of core-philosophy/derivative-core-philosophy prospective reontologising as relevantly superseding prior mere-formulaicity/ritualisation pedantism induced knowledge-deadends-<as-preconverging-de-mentating/structuring/paradigming $>$ '). Such an

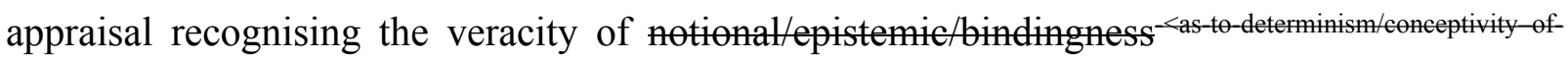
relative-unreflexivity/relative-reflexivitys 'parrhesiastic/messianicity/profound-supererogation projection 
for sublimating-prolongation' (over the 'claim/pretense to any such supposed prospectively inherent human generalised/proletarianised sublimating-prolongation') is so-existentially-disontologising/re-ontologising aporeticism $>$ recognised; as to the human sovereignfunction/posture-<as-to-existentially-manifest-‘embodied-subject $\sim$ consciousness-anddirect/deferential-conscientiousness',-as-of-its-'epistemic-reflexivity/unreflexivity-inexistence'/teleology> 'veridical notionality/epistemicity/bindingness ${ }^{<a s-t o-d e t e r m i n i s m / c o n e e p t i v i t y-o f-}$ relative-unreflexivity/relative-reflexivity $>$ conception-of- ${ }^{5}$ meaningfulness-and-teleology ${ }^{9}$ '-(reflection upon the given 'existential-<disontologising/re-ontologising aporeticism> 〈'baseline/nominalising/editional—aptitudinal underlay-<as-to-prior-

capacitating-<for-existential-thematic $>\quad$ imbued interest/disinterest, investedness/disinvestment, exposure/lack-of-exposure, role/task participative-emplacement and relevance/irrelevance-andcapability/incapability-appraisal'). As so-constrained—preconvergingly/postconverginglyrede-mentating/restructuring/reparadigming (as to recurrently-driven limitedness/humansubpotency prospective re-encountering/re-confrontation with the 'constraining/defining intersolipsistic reflexive-sublimating/unreflexive-desublimating measure/objectification that is unlimitedness/existence-as-ontological-normalcy/postconvergence-<in-validation-of'metaphysics-of-absence_epistemic-projection'>') in so-eliciting human ontologicalcommitment and universal-transparency ${ }^{104}$ with respect to underlying human 'crossgenerational notional firstnaturedness-formativeness-<as-to-eventualising inkling drive-or-seeding misprising $>$ mental-processing-parity for ontological-performance ${ }^{72}$ <including-virtue-as-ontology $>$ /morality/ethics/justice/etc.'. And so, with respect to the 
possibility for the specifically given competence/expertising notional/epistemic/bindingness ${ }^{-<a s-}$

philosophy_-(imbued requisite 'inkling-drive of dimensionality-of-sublimating <<amplituding formative>supereronary de-mentativeness/epistemic-growth-or-

conflatedness /transvaluative-rationalising/transepistemicity/anamnestic-residuality/spirit-

drivenness-equalisation〉') sublimating-prolongation. Thus it can effectively be appreciated (with respect to prospective 're-ontologising-nascency-<as-of-prospectivesolipsistic/intersolipsistic-inkling-drive-for-knowledge-elucidation,-as-to-veridical-organic-

knowledge $>$ for sublimating-prolongation') that the grander issue for the human sovereignfunction/posture-<as-to-existentially-manifest-`embodied-subject $\sim$ consciousness-and-

\section{direct/deferential-conscientiousness',-as-of-its-'epistemic-reflexivity/unreflexivity-in-}

existence'/teleology> lies not in the inability of abstractly acknowledging requisite 'protractedsocial—as-to-individual-by-institutional-by-social relative direct/deferentialresponsibility/relative-reflexivity to cogency_chronicularity/annality-of-relative-reflexivity,-asto-profound-supererogation ' (as to notional/epistemic/bindingness ${ }^{<a s-t o-d e t e r m i n i s m / c o n e e p t i v i t y-o f-~}$ relative-unreflexivity/relative-reflexivitys 'parrhesiastic/messianicity/profound-supererogation projection for sublimating-prolongation' over the 'claim/pretense to any such supposed prospectively inherent human generalised/proletarianised sublimating-prolongation'). But it rather lies with prospective unblurriness/blurrinessthreshold framing/formulation/catchmenting/truncating/compulsing/linearising associated contentious/un-nominalised social-stake-contention-or-confliction (imbued 'existentially<disontologising/re-ontologising aporeticism $>$ manifest entanglement-as-to-‘ < out-ofphasing $>$-disparate-narratives' representation-as being of prospective-re-ontologising < <atunblurriness/blurriness threshold $>$ ' as eliciting both 'despite-the-self exercise of epistemicprojection in notional $\sim$ self-distantiation- $<$ imbued-re-motif-and-re-apriorising/re- 
axiomatising/re-referencing>' involved in 'limitedness/human-subpotency prospective reencountering/re-confrontation with unlimitedness/existence-<fll-potency-of_sublimating nascence $>$ ' and prospectively 'epistemic-decadence' or teleological-decadence-<-indimensionality-of-desublimating-lack-of $-\langle<$ amplituding/formative $>$ supererogatory - dementativeness/epistemic-growth-or-conflatedness /transvaluativerationalising/transepistemicity/anamnestic-residuality/spirit-drivenness-equalisation〉 imbued distractive-alignment-to- ${ }^{8}$ reference-of-thought- $<$ of-apriorising/axiomatising/referencing $>{ }^{30}$ ); and thereof, from which 'existentially-< disontologising/re-ontologising aporeticism $>$ manifest entanglement-as-to '<out-of phasing $>$ disparate-narratives' representation-as-being-ofprospective re ontologising <at unblurriness/blurriness threshold $>$ ' the possibility for 'protracted-social—as-to-individual-by-institutional-by-social relative direct/deferentialirresponsibility/relative-unreflexivity to cogency_chronicularity/annality-of-relativereflexivity,-as-to-profound-supererogation ${ }^{\circ}$ arises. In this respect, the genuine social intellectual-function/posture (as to its 'inkling-drive of dimensionality-of-sublimating ${ }^{25}$ <<amplituding/formative>supererogatory $\sim$ de-mentativeness/epistemic-growth-orconflatedness /transvaluative-rationalising/transepistemicity/anamnestic-residuality/spiritdrivenness-equalisation)' hardly/poorly carrying any prospective 'secondnatured positiveopportunism of-social-functioning and-accordance 7 , as-toprospective _punctual/immediacy/constituted/compulsions-encumbered_disarming/disideologising/deformulaicity/à-contrecoup/unsettling/unarguable) $\quad$ 'implicited/explicited deferential-transference-formalisation eliciting' rather prospectively elicit 'deferentialresponsibility/relative-reflexivity as of re-ontologising deferential-sovereignising' (in contrast to pedantising/muddling/formulaic-hollowing-out-in-subontologisation/subpotentiation〈blurring/undermining-of-prospective-totalising-entailing,-as-to-entailing- 
prospectively eliciting 'deferential-irresponsibility/relative-unreflexivity disontologising deferential-desovereignising' as from the prompting of ' $\leq$ mere-formulaicity/ritualisation - of $>$ prior secondnatured positive-opportunism-of-social-functioning-and-accordance ${ }^{5}$ as to imbuing prospective shallow-supererogation '). However (speaking with respect to contentious/un-nominalised social-stake-contention-or-confliction so-associated with unblurriness/blurriness-

threshold framing/formulation/catchmenting/truncating/compulsing/linearising imbued 'existentially-disontologising/re-ontologising aporeticism $>$ manifest entanglement-as-to‘<out-of phasing $>$-disparate-narratives'representation-as-being-of prospective-reentelogising < at unblurriness/blurriness threshold $>$ '), such a distinction (as to enabling or failing sublimating-prolongation) isn't necessarily construed by the given historial/epochal 'human sovereign-function/posture-<as-to-existentially-manifest-‘embodiedsubject consciousness-and-direct/deferential-conscientiousness',-as-of-its- 'epistemicreflexivity/unreflexivity-in-existence'/teleology> consciousness/collective-consciousness' in such acute/definitive terms (as of its given amplituding/formative-epistemicity $>$ totalising thrownness-in-existence $\quad$ locus/station 'notional/epistemic/bindingness' ${ }^{<a s-t o-}$ determinism/conceptivity-of-relative-unreflexivity/relative-reflexivity $\quad$ protracted-social—as-to-individual-byinstitutional-by-social relative direct/deferential-responsibility/relative-reflexivity-orirresponsibility/relative-unreflexivity to cogency_chronicularity/annality-of-relativereflexivity,-as-to-profound-supererogation appraisal' of such acute/definitive 'deferentialresponsibility/relative-reflexivity re-ontologising deferential-sovereignising' or acute/definitive 'deferential-irresponsibility/relative-unreflexivity disontologising deferentialdesovereignising'). This is so underlined by the 'sovereign-function/posture-<as-toexistentially-manifest-'embodied-subject consciousness-and-direct/deferentialconscientiousness',-as-of-its-'epistemic-reflexivity/unreflexivity-in-existence'/teleology> 
consciousness/collective-consciousness' imbued existential-<disentologising/re-ontelogising _ aporeticism $>$ ' $<$ out-of-phasing $>$-disparate-narratives_of_social-functioning-and-accordanceas-of-social-stake-contention-or-confliction_construct manifesting-at-the-givenunblurriness/blurriness-

threshold framing/formulation/catchmenting/truncating/compulsing/linearising'. But rather the possibility for such 'acute/definitive appraisal of prospective re-ontologising as to sublimatingprolongation' arises notionally/epistemically/bindingnessly-<as-to-determinism/conceptivity-of-relativemeflexivityrative reflexivity as of prospective 'human manifest existentialising-decisionality-<as-todisentologising/re-ontologising aporeticism $>\quad$ coming-to-a-head/culmination-point-<ofdesovereignising-or-sovereignising - sovereign-repassing '- (so-reflected as of underlying 'constraining direct/deferential micro-decisionality/macro-decisionality thrownness-disposition of disontologising/re-ontologising' upon the 'social-functioning-and-accordance-as-of-socialstake-contention-or-confliction construct'). So-educed as from 'ontologically-hegemonisingnarrative ontological-performance ${ }^{2}-<$ including-virtue-asontology $>$ /morality/ethics/justice/etc.' - (with reference to notional/epistemic/bindingness $<$ as-todeterminism/conceptivity-of-relative-unreflexivity/relative-reflexivity> 'parrhesiastic/messianicity/profoundsupererogation projection for sublimating-prolongation') for sublimating-prolongation as to veridical core-philosophy/derivative-core-philosophy-(imbued requisite 'inkling-drive of dimensionality-of-sublimating 25 -<amplituding/formative>supererogatory - dementativeness/epistemic-growth-or-conflatedness /transvaluativerationalising/transepistemicity/anamnestic-residuality/spirit-drivenness-equalisation〉') 'holding-out/point-referencing—-psychoanalytic-unshackling exercise of educed-and-availingand-re-availing relative-ontological-completeness ${ }^{87}$-of-apriorising/axiomatising/referencing' to allow for play out of 'untenability-of-induced unblurriness as ‘ $<$ prospective_punctual/immediacy/constituted/compulsions-encumbered__ disararming/diss- 
idenologising/deformulaicity/à-contrecoup/_unssettling/unarguable

constricted/narrowingdown-re-ontologising-enabling $>$ - psychologismic epistemic -

acutisation residualising a fepistemic-

totalising $3{ }^{3}$ hermeneutic/textuality/reprojecting/supererogating/zeroing/re-acuting,-

$\{$ decompulsing\} $\}$ delinearity for-cogency. And so (in relation to the requisite 'acute/definitive appraisal of prospective re-ontologising as to sublimating-prolongation'), with regards to 'reontologising/re-sublimating-axiomatic-constructs_as_impliciting-of prospectively requisite-relative-reflexivity/delinearising (as to elicited 'reconstruing of ${ }^{83}$ reference-of-

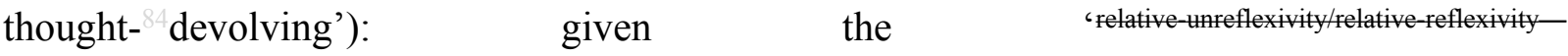
bindingness/nondiscretionariness-<as-from-sublimating remoteness/distance-of-appraisal-ofrequisite Being-development $>$ of unlimitedness/existence-<full-potency-of_sublimating nascence $>$ ' - (as to 'relative-unreflexivity/relative-reflexivity limitedness/human-subpotency dynamics of supererogating \{affirmation/projection/assertion/notional $\sim$ self-distantiation-byunaffirmation/deprojection/deassertion/epistemic-decadence $\}$ - towards $\sim$ omnipotentialaffirmation/projection/assertion/notional self-distantiation' with respect to 'limitedness/humansubpotency prospective re-encountering/re-confrontation with unlimitedness/existence- $<$ fullpotencof_sublimating nascence>'); as to its relative-reflexivity as from re-ontologising prospective Being-development/ontological-framework-expansion-as-to-depth-ofontologising-development-as-infrastructure-of- meaningfulness-and-teleology psychologismic epistemic-acutisation difficulty-for, residualising \{decolinearity for-cogency magnitude \{of-experientiality/experiment\} as to overarching 'registry-worldview/dimension existentialising-framing-by-enframing/\{worlding\}reference-of-thought' (with regards to its requisite prospective re-ontologising idiomatisation$<$ as-to- blurriness-elicited-profound-supererogation -of- '\{epistemic-totalising '’metaphoricity '-forprospective- unblurriness-of- ‘fepistemic-totalising $\frac{3}{3}$ meaningfulness-and-teleology ',-as-of- 
unblurriness $\sim$ reframing/reformulation/decatchmenting/detruncating/decompulsing/delinearisi ng)'. This so-reflects the fact that 'human sovereign-function/posture-<as-to-existentiallymanifest-'embodied-subject consciousness-and-direct/deferential-conscientiousness',-as-ofits-'epistemic-reflexivity/unreflexivity-in-existence'/teleology $>\quad$ consciousness/collectiveconsciousness' (as to prospective uncertainty-as-failing-to-reflect-the-effective-'existentialveracity-and-entailment-of $\sim$ relative-unreflexivity/relative-reflexivity') is rather always susceptible, with respect to 'veridical notionality/epistemicity/bindingness determinism/conceptivity-of-relative-unreflexivity/relative-reflexivity> conception-of- 56 meaningfulness-andteleology' - (reflection upon the given 'existential-<disontologising/re-ontologising aporeticism>

'baselining/cogency/reconstruing — aptitudinal overlay-<for-prospective- unblurriness-dragging-out $>$ ' $\rangle$-..... reflected-as_-....

\section{recurring existentialising-framing-by-enframing/\{worlding $\}-<$ as-manifest-}

individuative-direct/deferential-transeffusive/worlding-looping > _reflected-as_-supererogation 76

capacitating-<for-existential-thematic $>\quad$ imbued interest/disinterest, investedness/disinvestment, exposure/lack-of-exposure, role/task participative-emplacement and relevance/irrelevance-andcapability/incapability-appraisal', and as so-constrained-preconvergingly/postconverginglyrede-mentating/restructuring/reparadigming by elicitable human ontological-commitment ${ }^{66}$ and universal-transparency ${ }^{104}$ with respect to underlying human 'crossgenerational notional firstnaturedness-formativeness-<as-to-eventualising-inkling-drive-or-seeding-

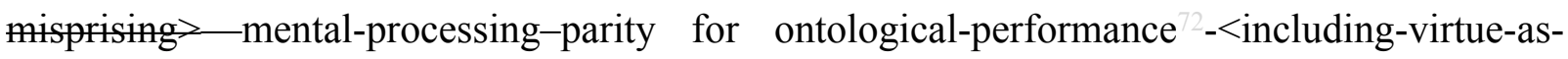
ontology $>$ /morality/ethics/justice/etc.'), to: 'direct/indirect-and-conscious/unconscious destabilisation' of 'requisite prospective re-ontologising for sublimating-prolongation'-(which 
so-imbues effectively of the serenity for 'prospective existential-<disontologising/reentologising aporeticism $>$ human sovereign-emergence/becoming-existentially-imbuinghuman-freedom-as-to-supererogating/surrealising for-'knowledge-empowerment-overignorance-disempowerment'-<as-of-'developing-and-availing-sovereignsublimating_potential/possibilities/options/choices'-as-to-the-'credibility'/'ontologicalveracity'-underlying-the-'sovereign-conscious/conscientious-backdrop'> consciousness/collective-consciousness'). Critically, contentious/un-nominalised social-stakecontention-or-confliction (as to unblurriness/blurrinessthreshold framing/formulation/catchmenting/truncating/compulsing/linearising imbued 'existentially-<disontologising/re-ontologising aporeticism $>$ manifest entanglement—as-to‘out-of-phasing $>$-disparate-narratives'representation-as-being-of-prospective-reentologising < $<$ at - mblurriness/blurriness-threshold $>$ ') speak to requisite corephilosophy/derivative-core-philosophy_ (imbued requisite 'inkling-drive of dimensionality-ofsublimating $25-<<$ amplituding/formative $>$ supererogatory $\sim$ de-mentativeness/epistemic-growthor-conflatedness /transvaluative-rationalising/transepistemicity/anamnestic-residuality/spiritdrivenness-equalisation〉'); as rather being about 'a holding-out/point-referencingpsychoanalytic-unshackling exercise of educed-and-availing-and-re-availing relativeontological-completeness ${ }^{87}$-of-apriorising/axiomatising/referencing' to allow for play out of untenability-of-induced unblurriness

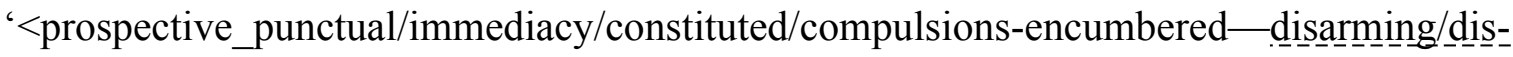
idenologising/deformulaicity/à-contrecoup/uns_ettling/un_constricted/narrowingdown-re-ontologising-enabling $>$ - psychologismic epistemicacutisation residualising \{epistemicthatising thermeneutic/textuality/reprojecting/supererogating/zeroing/re-acuting, \{decompulsingt delinearity for-cogency' as to 'developing human-per-cep-ti-vi-ty-<as-to 
notional perceptualisation-of-and-leashing-to_social-functioning-and-accordance-as-of-

social-stake-contention-or-confliction> in preconverging/postconverging-redementating/restructuring/reparadigming'. So-highlighting core-philosophy/derivative-corephilosophy_(imbued requisite 'inkling-drive of dimensionality-of-sublimating <<amplituding/formative>supererogatory $\sim$ de-mentativeness/epistemic-growth-or-

\section{conflatedness /transvaluative-rationalising/transepistemicity/anamnestic-residuality/spirit-}

drivenness-equalisation)') prospective existentially-<disontologising/re-ontologisingaporeticism $>\quad$ warranted educing $\quad$ of unblurriness $\sim$ reframing/reformulation/decatchmenting/detruncating/decompulsing/delinearisi ng for prospectively uncontentious/nominalised social-stake-contention-or-confliction. In soprospectively eliciting human existential-<disontologising/re-ontologising aporeticism $>$ recognition (as to 'protracted-social-as-to-individual-by-institutional-by-social relative direct/deferential-responsibility/relative-reflexivity to cogency_chronicularity/annality-ofrelative-reflexivity,-as-to-profound-supererogation ') of the 'hierarchisation-of-narratives about sublimating-prolongation of social-functioning-and-accordance-as-of-social-stakecontention-or-confliction construct' - (with reference to notional/epistemic/bindingness ${ }^{<a s-t o-}$ determinism/conceptivity-of-relative-unreflexivity/relative-reflexivity> 'parrhesiastic/messianicity/profoundsupererogation projection for sublimating-prolongation'); and so, in superseding prior contentious/un-nominalised social-stake-contention-or-confliction unblurriness/blurriness-

threshold framing/formulation/catchmenting/truncating/compulsing/linearising imbued 'existentially-<disontologising/re-ontologising aporeticism $>$ manifest entanglement-as-to‘<out-of-phasing $>$ disparate-narratives'representation-as-being-of-prospective-reentologising < at unblurriness/blurriness threshold $>^{\prime}$ ), as susceptible to elicitable 'direct/indirect-and-conscious/unconscious destabilisation' of 'requisite prospective re- 
ontologising for sublimating-prolongation'-(which so-imbues effectively of the serenity for 'prospective existential-<disontologising/re-ontologising aporeticism $>$ human sovereignemergence/becoming,-existentially-imbuing human-freedom-as-to-supererogating/surrealising for-'knowledge-empowerment-over-ignorance-disempowerment'-<as-of-'developing-andavailing-sovereign-sublimating_potential/possibilities/options/choices'-as-to-the'credibility'/'ontological-veracity'-underlying-the-'sovereign-conscious/conscientiousbackdrop'> consciousness/collective-consciousness'). In this regards, human 're-ontologisingnascency-<as-of-prospective-solipsistic/intersolipsistic-inkling-drive-for-knowledgeelucidation,-as-to-veridical-organic-knowledge > for sublimating-prolongation' is rather 'most fundamentally' of-incipience as from the imbued 'notional/epistemic/bindingness'<as-todeterminism/conceptivity-of-relative-unreflexivity/relative-reflexivitys inkling-drive of dimensionality-ofsublimating ${ }^{25}-<<$ amplituding/formative $>$ supererogatory $\sim$ de-mentativeness/epistemic-growthor-conflatedness /transvaluative-rationalising/transepistemicity/anamnestic-residuality/spiritdrivenness-equalisation) (whether in shallow-supererogation or profound-supererogation ')' of the 'human sovereign-function/posture-<as-to-existentially-manifest-'embodiedsubject consciousness-and-direct/deferential-conscientiousness',-as-of-its- 'epistemicreflexivity/unreflexivity-in-existence'/teleology> consciousness/collective-consciousness': in reflection of human 'crossgenerational notional firstnaturedness-formativeness-<as-toeventualising inkling-drive-or-seeding-misprising $>$ mental-processing-parity for ontological-performance ${ }^{72}$-<including-virtue-as-ontology $>$ /morality/ethics/justice/etc.' (notionally/epistemically/bindingnessly-<as-to-determinism/coneeptivity-of-relative-unreflexivity/relative-reflexivity> as to manifest 'direct/deferential eliciting-of or acceding-to prospectively educed-and-availingand-re-availing relative-ontological-completeness ${ }^{8}$-of-apriorising/axiomatising/referencing'). Such that in reality 'prospective mutual/dialogical engagement in knowledge elucidation for sublimating-prolongation' is not of-incipience but rather subsequent-to/derivative-from 're- 
ontologising-nascency-<as-of-prospective-solipsistic/intersolipsistic-inkling-drive-forknowledge-elucidation,-as-to-veridical-organic-knowledge> for sublimating-prolongation' (as to imbued inkling-drive of dimensionality-of-sublimating <<amplituding/formative>supereronatede-mentativeness/epistemic-growth-orconflatedness /transvaluative-rationalising/transepistemicity/anamnestic-residuality/spiritdrivenness-equalisation)); which is rather preceding and preconditioning the possibility for veridical 'prospective mutual/dialogical engagement in knowledge elucidation for sublimatingprolongation' (as to elicitable human ontological-commitment ${ }^{6}$ and universal-transparency with respect to underlying human 'crossgenerational notional firstnaturedness-formativenessas to eventualising inkling drive or seeding misprising - mental-processing-parity for ontological-performance ${ }^{72}$-<including-virtue-as-ontology $>$ /morality/ethics/justice/etc.'). From whence then arises the possibility for 'prospective mutual/dialogical engagement in knowledge elucidation for sublimating-prolongation' (which cannot be construed/related-to as substituting for the 'priorly requisite incipient human supererogation '); and as so-undergirding 'prospective existential-<disontologising/re-ontologising aporeticism $>\quad$ human sovereignemergence/becoming,-existentially-imbuing-human-freedom-as-to-supererogating/surrealisingfor-'knowledge-empowerment-over-ignorance-disempowerment'-<as-of-'developing-andavailing-sovereign-sublimating_potential/possibilities/options/choices'-as-to-the'credibility’/'ontological-veracity’-underlying-the-'sovereign-conscious/conscientiousbackdrop'> consciousness/collective-consciousness'. It is this reality that underlies the fundamental distinction between 'despite-the-self exercise of epistemic-projection in notional $\sim$ self-distantiation- $<$ imbued—re-motif-and-re-apriorising/re-axiomatising/rereferencing>' involved in 'limitedness/human-subpotency prospective re-encountering/reconfrontation with unlimitedness/existence-<full-potency-of_sublimating nascence $>$ and prospectively 'epistemic-decadence' or teleological-decadence-<-in-dimensionality-of- 
desublimating-lack-of $-<<$ amplituding/formative $>$ supererogatory $\sim$ de-mentativeness/epistemicgrowth-or-conflatedness /transvaluative-rationalising/transepistemicity/anamnestic-

residuality/spirit-drivenness-equalisation $\rangle$ imbued distractive-alignment-to- ${ }^{8}$ reference-ofthought- $<$ of-apriorising/axiomatising/referencing ${ }^{30}$. So-reflecting the fact that the former cannot be construed as of 'a gesturing of adhoc and/or successive skipping/unaccounting' with respect to its requisite 'ontological coherence/contiguity appraisal of prospectively educed-andavailing-and-re-availing relative-ontological-completeness ${ }^{87}$-ofapriorising/axiomatising/referencing' (as to the warrant for enabling prospective re-ontologising idiomatisation-<as-to- blurriness-elicited-profound-supererogation -of- ‘ \{epistemic-

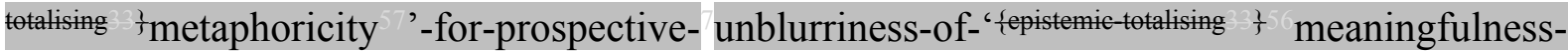
and-teleology ',-as-of-sublimating-prolongation;-in psychologismic epistemic acutisationresidualising, ${ }^{\text {\{decompulsing }}$ delinearity for-cogency> imbuing unblurriness $\sim$ reframing/reformulation/decatchmenting/detruncating/decompulsing/delinearisi ng), and then 'naively reproject of' a supposedly 'prospective mutual/dialogical engagement in knowledge elucidation for sublimating-prolongation' (as so-failing to fulfil 'despite-the-self exercise of epistemic-projection in notional $\sim$ self-distantiation- $<$ imbued-re-motif-and-reapriorising/re-axiomatising/re-referencing>' involved in 'limitedness/human-subpotency prospective re-encountering/re-confrontation with unlimitedness/existence-<flllpotency ef_sublimating nascence>'). So-manifested with both ancient-sophists non-universalising and medieval-scholasticism nonpositivising failing prospective sublimating-prolongation as not of veridical 'prospective mutual/dialogical engagement for knowledge elucidation for sublimatingprolongation' correspondingly with the requisite Socratic-philosophers ${ }^{103}$ universalisingidealisation and budding-positivists positivism/rational-empiricism respectively imbued 'reontologising-nascency-<as-of-prospective-solipsistic/intersolipsistic-inkling-drive-forknowledge-elucidation,-as-to-veridical-organic-knowledge> for sublimating-prolongation' in 
$<$ amplituding/formative-epistemicity $>$-totalising $\sim$ renewing-realisation/re-perception/rethought,-in-supereregatory $\sim$ epistemic-conflatedness ${ }^{13}$; and so, with respect to 'the-very-same purview/devolved-purview/devolving-purview-of-unlimitedness/existence-<full-potency of_sublimating nascence>;_—'implicited_attendant_ontological-contiguity ${ }^{67}$ ' educedexistentialising/contextmalising/textualising_'intelligibility/epistemicity/reflexivity_contiguity$<$ imbued-notional cogency>' . Consequently, prospectively 'epistemic-decadence' or teleological-decadence-<-in-dimensionality-of-desublimating-lack-of ${ }^{2}{ }^{-}$ <<amplituding/formative>supererogatory $\sim$ de-mentativeness/epistemic-growth-orconflatedness /transvaluative-rationalising/transepistemicity/anamnestic-residuality/spiritdrivenness-equalisation> imbued distractive-alignment-to- ${ }^{-}$reference-of-thought- $<$ofapriorising/axiomatising/referencing $>30$ cannot be ignored (and supposedly veridical sublimating-prolongation avails but for a shallowness/superficiality of thought conception of such supposed re-ontologising); as to the requisite underlying profoundsupererogation $\sim$ reframing/reformulation/decatchmenting/detruncating/decompulsing/delinear ising - as-to-postconverging de-mentating/structuring/paradigming for 'despite-the-self exercise of epistemic-projection in notional $\sim$ self-distantiation- $<$ imbued-re-motif-and-reapriorising/re-axiomatising/re-referencing>' involved in 'limitedness/human-subpotency prospective re-encountering/re-confrontation with unlimitedness/existence-<flllpotency of_sublimating nascence'. As it is the latter that so-overcomes/supersedes totalising 3 ' $p$ sychologismic-subliminal-truncating (as of 'catchmented-and-compulsed-<in-

\section{‘existential-dearth-of-demoronisation',-so-construed-as-from-ontological-}

normalcy/postconvergence-perspective-reflection-of-the-'destructuring-threshold_of-the-

given-level's-conjugated-postlogism as-dementing'> interpersonal, group, intergroup, community, local, national, political, geostrategic, etc. psychologismic epistemic acutisationdifficulty-for, residualising_\{decompulsing $\}$ delinearity for-cogeney>-levels of interrelatedness- 
dynamics-of-social-constructing'); as to overcoming/superseding the manifest 'direct/indirectand-conscious/unconscious destabilisation' of 'requisite prospective re-ontologising for sublimating-prolongation'-(which so-imbues effectively of the serenity for 'prospective existential-<disontologising/re-ontologising aporeticism $>\quad$ human $\quad$ sovereignemergence/becoming,-existentially-imbuing human-freedom-as-to-supererogating/surrealisingfor-'knowledge-empowerment-over-ignorance-disempowerment'-<as-of-'developing-andavailing-sovereign-sublimating_potential/possibilities/options/choices'-as-to-the'credibility’/'ontological-veracity’-underlying-the-'sovereign-conscious/conscientiousbackdrop'> consciousness/collective-consciousness'). This translates into the reality that 'what most fundamentally-and-veridically undermines prospective knowledge elucidation for sublimating-prolongation' is the shallowsupererogation $\sim$ framing/formulation/catchmenting/truncating/compulsing/linearising —as-topreconverging de-mentating/structuring/paradigming disontologising claim/pretense to a 'logical/rationalising exercise'. So-overarchingly, as to '7 presencing-absolutising-identitiveconstitutedness $^{14} \quad$ social-functioning-and-accordance-as-of-social-stake-contention-orconfliction construct implicited scope' of 'existentially-<disontologising/re-ontologising apereticism $>$ manifest incidental/accidental sufferance/endurance in supposedly and paradoxically subordinating/subserving/collateralising the possibility for prospective reontologising_-imbuing-of-prospective-human-sublimating/emancipating/enfranchisement'; as overarchingly overriding the scope of prospectively requisite 're-ontologising-nascency-<as-ofprospective-solipsistic/intersolipsistic-inkling-drive-for-knowledge-elucidation,-as-toveridical-organic-knowledge $>$ for sublimating-prolongation'. So-construable as to the 'relativeunreflexivity/relative-reflexivity — bindingness/nondiscretionariness-<as from-sublimating remoteness/distance-of-appraisal-of requisite Being-development> of unlimitedness/existence-<flllpotency-of_sublimating nascence $>$ '- (as to 'relative- 
unreflexivity/relative-reflexivity

limitedness/human-subpotency

dynamics

of

supererogating \{affirmation/projection/assertion/notional $\sim$ self-distantiation-by-

unaffirmation/deprojection/deassertion/epistemic-decadence $\}$ - towards $\sim$ omnipotential-

affirmation/projection/assertion/notional self-distantiation' with respect to 'limitedness/human-

subpotency prospective re-encountering/re-confrontation with unlimitedness/existence-<full-

potency-of_sublimating nascence $>$ '); rather as from the relative-reflexivity of prospective reontologising

Being-development/ontological-framework-expansion-as-to-depth-of-

ontologising-development-as-infrastructure-of- meaningfulness-and-teleology

psychologismic epistemic-acutisation difficulty-<for, residualising-

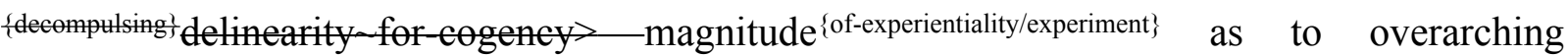
'registry-worldview/dimension existentialising-framing-by-enframing/\{worlding\}reference-of-thought'. Thusly, failing requisite sublimating-prolongation: retracing-andrelaying 'thinking at first/pure predisposition preemptive of prospective disontologising/subontologising' as of 'inkling-drive of dimensionality-of-sublimating <<amplituding/formative>supererogatory $\sim$ de-mentativeness/epistemic-growth-or-

\section{conflatedness /transvaluative-rationalising/transepistemicity/anamnestic-residuality/spirit-}

drivenness-equalisation)'. In-the-first-instance (as to the veracity of prospective knowledge elucidation and knowledge implications for sublimating-prolongation with respect to its 'direct/indirect-and-conscious/unconscious destabilisation'), such shallowsupererogation $\sim$ framing/formulation/catchmenting/truncating/compulsing/linearising —as-topreconverging de-mentating/structuring/paradigming is manifested with a disontologising claim/pretense to a 'logical/rationalising exercise' in relation to ${ }^{7}$ presencing — absolutisingidentitive-constitutedness unblurriness/blurrinessthreshold framing/formulation/catchmenting/truncating/compulsing/linearising' contentions/conceptions about the notion of relativism. Such that when so-wrongly engaged with 
as of a 'logical/rationalising exercise', with regards to the prospective knowledge elucidation and knowledge implications of such contentions/conceptions about the notion of relativism rather 'then wrongly validate as being of logical/rationalising pertinence' the so-implicited presencing - absolutising-identitive-constitutedness ${ }^{14}$ 'shallowsupererogation $\sim$ framing/formulation/catchmenting/truncating/compulsing/linearising —as-topreconverging de-mentating/structuring/paradigming of the notion of relativism; as of such contentions/conceptions underlying fundamental disontologising representation, so-reflected specifically interdimensionally with respect to prospective re-ontologising Beingdevelopment/ontological-framework-expansion-as-to-depth-of-ontologising-development-asinfrastructure-of- meaningfulness-and-teleology psychologismic epistemic-acutisationdifficulty-for, residualising \{decompulsing $\}$ delinearity - for-cogency> magnitude ${ }^{\{0 f-}$ experientiality/experiment\} with regards to overarching 'registry-worldview/dimension existentialisingframing-by-enframing/\{worlding $\}$ - ${ }^{3}$ reference-of-thought' (while in contrast intradimensionally the "notion of relativism is rather reflexively/inevitably/necessarily notionally/epistemically/bindingnessly-ass-determinism/enceptivity-of relative-mneflexivity/relative-reflexivityz_ implicited with respect to the very existential-<disontologising/re-ontologising aporeticism $>$ possibility of both human learning and institutional growth as to manifest registry worldview/dimension existentialising framing by enframing/worlding thought $>$ - undergirding-of-existentialising-framing-by-enframing/\{worlding $\}$ - axiomaticconstructs'). Such a misconstrual of the notion of relativism also underlies the naivety of 'implying reactively to such ontologically-flawed contentions/conceptions' rather the notion of perspectivism which effectively fails to reflect the fundamental point of the "palpable dissolving/decentering of the conscious-self/collective-conscious-self' as of 'preconverging/postconverging-rede-mentating/restructuring/reparadigming in existence' (in reflection of any 'epistemic-state-of-becoming in existence' as necessarily being 
notionally/epistemically/bindingnessly $y^{\text {-as-to-determinism/conceptivity-of-relative-unreflexivity/relative-reflexivity }>\text { of }}$ the given 'manifest relative-unreflexivity/relative-reflexivity in existence'). Rather the prospective knowledge elucidation and knowledge implications of the notion of relativism carries its very own prospective re-ontologising idiomatisation- $<$ as-to- blurriness-elicitedprofound-supererogation -of-' ‘epistemic-totalising ${ }^{3}$ 'metaphoricity '-for-prospective- unblurrinessof- ' \{epistemic-totalising $\frac{?}{3}$ meaningfulness-and-teleology ',-as-of-sublimating-prolongation;-inpsychologismic epistemic-acutisation residualising, ${ }^{\{\text {decompulsing }}$ delinearity for-cogency> imbued unblurriness $\sim$ reframing/reformulation/decatchmenting/detruncating/decompulsing/delinearisi ng; with the notion of relativism rather implied as from the 'profoundsupererogation $\sim$ reframing/reformulation/decatchmenting/detruncating/decompulsing/delinear ising - as-to-postconverging-de-mentating/structuring/paradigming of ${ }^{6}$ nonpresencing<perspective-ontological-normalcy/postconvergence> epistemic-projection/construal' (with respect to the existentially-<disontologising/re-ontologising aporeticism $>$ given human ${ }^{5}$ meaningfulness-and-teleology reflexivity - ontological-contiguity ${ }^{67}$ of the overall relative-unreflexivity/relative-reflexivity ontological-contiguity ${ }^{67}$ of-the-human-institutionalisation-process ${ }^{6}$ implied conception of the notion of relativism). The notion of relativism is herein construed as underlying the very human existential-<disontologising/re-ontologising aporeticism $>$ possibility for prospective 
knowledge elucidation; as of organic-knowledge requisite 'perspicacity of psychologismic-. epistemic-acutisation-<as-to-postconverging-de-mentating/structuring/paradigming,-elicitingof-existence's-sublimating-nascence-in-prospective-aporeticism-overcoming/unovercoming> as to epistemic-growth,-as - \{veridical/sound\}-relative-reflexivity-in-existence/relativising from-limited-mentation-as-its-deepening/psychologismic epistemic-acutisationresidualising, ${ }^{\text {\{decompulsing }}$ delinearity for-cogency' of 'unlimitedness/existence-<full-potencyof_sublimating nascence>'. So-reflecting the very 'flow of human prospective profoundsupererogation -over-shallow-supererogation', undergirding the 'overall relativeunreflexivity/relative-reflexivity - ontological-contiguity ${ }^{67} \sim$ of-the-human-institutionalisationprocess ${ }^{68}$ imbued notional $\sim$ cogency_chronicularity/annality-of-relative-reflexivity,-as-toprofound-supererogation '; as of core-philosophy/derivative-core-philosophy-_imbued requisite 'inkling-drive of dimensionality-of-sublimating ${ }^{25}$ <<amplituding/formative>supererogatory $\sim$ de-mentativeness/epistemic-growth-or-

conflatedness /transvaluative-rationalising/transepistemicity/anamnestic-residuality/spiritdrivenness-equalisation〉') 'holding-out/point-referencing-psychoanalytic-unshackling exercise of educed-and-availing-and-re-availing relative-ontological-completeness ${ }^{8}$-ofapriorising/axiomatising/referencing' to allow for play out of untenability-ofinduced unblurriness as '<prospective_punctual/immediacy/constituted/compulsions-

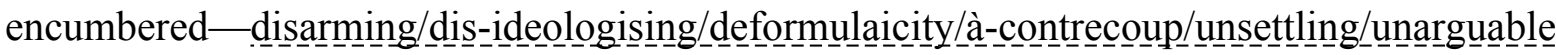
prompted constricted/narrowingdown-re-ontologising-enabling $>-$ psychologismic epistemicacutisation residualising \{epistemic-

totalising thermeneutic/textuality/reprojecting/supererogating/zeroing/re-acuting, \{decompulsing $\}$ delinearity for-cogency' as to 'developing human-per-cep-ti-vi-ty-<as-tonotional perceptualisation-of-and-leashing-to_social-functioning-and-accordance-as-ofsocial-stake-contention-or-confliction> in preconverging/postconverging-rede- 
mentating/restructuring/reparadigming' (and as so-reflected with the relativism construal of prospective re-ontologising Being-development/ontological-framework-expansion-as-to-depthof-ontologising-development-as-infrastructure-of- meaningfulness-and-teleology

psychologismic epistemic-acutisation difficulty-<for, residualising

\{decompulsing\} delinearity for-cogency>-magnitude $\{$ of-experientiality/experiment\} as to overarching 'registry-worldview/dimension existentialising-framing-by-enframing/\{worlding\}reference-of-thought', and both institutional-development-as-to-social-function-development psychologismic epistemic-acutisation difficulty-for, residualising \{decomping $\}$ delinearity for-cogency>-magnitude ${ }^{\text {of-experientiality/experiment }\}}$ and living-developmentas-to-personality-development psychologismic epistemic-acutisation difficulty-for, residualising ${ }^{\{\text {decompulsing }\}}$ delinearity for-cogency $>$ magnitude $\left.{ }^{\{0 f-e x p e r i e n t i a l i t y / e x p e r i m e n t ~}\right\}$ as $\leq$ registry worldview/dimension existentialising framing by enframing/worlding thought $>$ undergirding-of-existentialising-framing-by-enframing/\{worlding $\}$-axiomaticconstructs). Hence the notion of relativism overarchingly defines the prospect of limitedness/human-subpotency relative-reflexivity for sublimating-prolongation underlined as of 'effective ${ }^{45}$ foregrounding_entailment- $<$ in-succession-of-profound-supererogation 〈postconverging-narrowing-down sublimation-as-to-'existence-as-sublimatingwithdrawal/unenframing/re-ontologising,-elicited-from-prospective-profoundsupererogation '-in-reflecting-'immanent relative-unreflexivity/relative-reflexivity ontological-contiguity ';-as-operative-notional deprocrypticism〉 cogency_chronicularity/annality-of-relative-reflexivity,-as-to-profound-supererogation ${ }^{\text {, }}$ imbuing conceptivity/epistemic-reflexivity/epistemicity-relativism-determinism- $<$ reifying \{asto-knowledge-developing $\}$-and-empowering>. In-the-second-instance, along the same lines (as to the veracity of prospective knowledge elucidation and knowledge implications for sublimating-prolongation with respect to its 'direct/indirect-and-conscious/unconscious 
destabilisation') such implicited 79 presencing-absolutising-identitive-constitutedness shallow

supererogation $\sim$ framing/formulation/catchmenting/truncating/compulsing/linearising —as-topreconverging -de-mentating/structuring/paradigming disontologising claim/pretense to a 'logical/rationalising exercise' is equally reflected overarchingly in a naive '7 presencingabsolutising-identitive-constitutedness ${ }^{14}$ relative-unreflexivity contrasting of the abstract/theoretical-as-impractical and action/practice-as-practical' (as to 'lifespan extricatory/preconverging psychical-nascency moronisation-<sublimating-nascence,extricatory-desublimating-downstreaming/'avalage'>’); whilst 'profoundsupererogation $\sim$ reframing/reformulation/decatchmenting/detruncating/decompulsing/delinear ising - as-to-postconverging de-mentating/structuring/paradigming of nonpresencing<perspective-ontological-normalcy/postconvergence> epistemic-projection/construal' (as to 'nonextricatory/postconverging ontologising-and-re-ontologising angling-of-imaginary demoronisation- $<$ sublimating-nascence,-nonextricatory-sublimatingupstreaming/'amontée'>') veridically points out in relative-reflexivity that there is 'nothing most fundamental/incipient to action/practice' than the abstract/theoretical, and so as the abstract/theoretical underlies the possibility for educed human transcendence-andsublimity/sublimation/supererogatory de-mentativity undergirding the 'possibility for all subsequent secondnatured positive-opportunism-of-social-functioning-and-accordance action/practice'. Such that it can be appreciated in-the-very-first-place that the possibility for positivism/rational-empiricism action/practice doesn't avail to say a nonpositivistic animist social-setup as to the impossibility of "positivistic/rational-empiricism <registry worldview/dimension existentialising framing by enframing /worlding s reference-of thought $>$ - undergirding of-existentialising-framing-by-enframing/\{worlding $\}$ - axiomaticconstructs' implicited action/practice (so-reflected as to the lack of underlying 
abstract/theoretical projection with regards to the requisite sublimating-remoteness/distance-ofappraisal-<as-to-requisite-'Being-development-notional $\sim$ self-distantiation'-imbuedpsychologismic-epistemic-acutisation,-eliciting-of-prospective-ontologically-hegemonisingnarrative $>$ of positivism/rational-empiricism overarching 'registry-worldview/dimension existentialising-framing-by-enframing/\{worlding $\}$ - ${ }^{3}$ reference-of-thought' implicited abstract/theoretical projection); and so as of requisite prospective re-ontologising idiomatisation<as-to- blurriness-elicited-profound-supererogation -of- ‘fepistemic-totalising 'łmetaphoricity '-for-

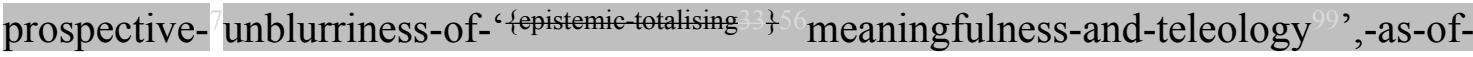
sublimating-prolongation;-in psychologismic epistemic acutisation residualising, $\{$ decompulsing $\}$ delinearity for-cogency> imbued unblurriness $\sim$ reframing/reformulation/decatchmenting/detruncating/decompulsing/delinearisi ng (of requisite positivism/rational-empiricism prospective re-ontologising Beingdevelopment/ontological-framework-expansion-as-to-depth-of-ontologising-development-asinfrastructure-of- meaningfulness-and-teleology psychologismic epistemic-acutisationdifficulty< <or, residualising \{decompulsing\} $d e$ linearity for-cogency> magnitude $\{$ ofexperientiality/experiment\} as to overarching 'registry-worldview/dimension existentialising-framingby-enframing/\{worlding\} - ${ }^{8}$ reference-of-thought'). Intradimensionally, the action/practice of various engineering/technical/art/practice domains only arise as to the abstract/theoretical of modern-day theorisation and science, and as such engineering/technical/art/practice domains further their very specific abstract/theoretical. The abstract/theoretical veridically speaks to the core-philosophy/derivative-core-philosophy_(imbued requisite 'inkling-drive of dimensionality-of-sublimating $25<<$ amplituding/formative $>$ supererogatory $\sim$ dementativeness/epistemic-growth-or-conflatedness /transvaluativerationalising/transepistemicity/anamnestic-residuality/spirit-drivenness-equalisation〉') 'holding-out/point-referencing_psychoanalytic-unshackling exercise of educed-and-availing- 
and-re-availing relative-ontological-completeness ${ }^{87}$-of-apriorising/axiomatising/referencing' to allow for play out of untenability-of-induced unblurriness as

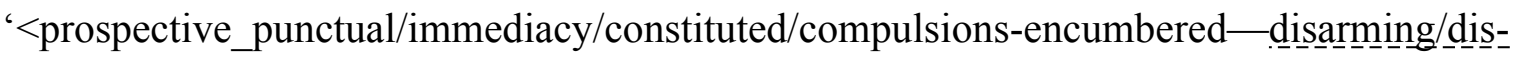

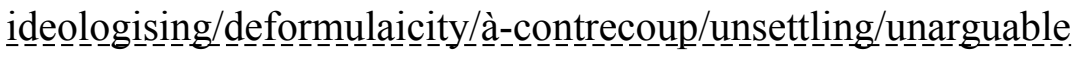
prompted constricted/narrowingdown-re-ontologising-enabling $>$ - psychologismic epistemicacutisation residualising fepistemic-

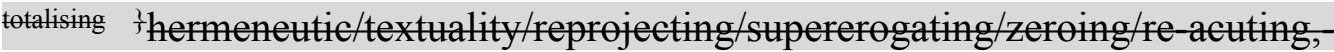
\{decompusing delinearity for-cogency' as to 'developing human-per-cep-ti-vi-ty-<as-tonotional perceptualisation-of-and-leashing-to_social-functioning-and-accordance-as-ofsocial-stake-contention-or-confliction> in preconverging/postconverging-redementating/restructuring/reparadigming'; as to the 'recurrently-abstract/theoretical (in the human $<$ amplituding/formative-epistemicity $>$-totalising $\sim$ thrownness-in-existence ${ }^{35}$ of successive registry-worldviews/dimensions) along the overall relative-unreflexivity/relative-reflexivity ontological-contiguity ${ }^{67}$ of-the-human-institutionalisation-process ${ }^{6}$, so-educing of the 'possibility for corresponding secondnatured positive-opportunism—of-social-functioning-andaccordance 75 recurrently-action/practice' (as so-enabling 'effective foregrounding_entailment-<in-succession-of-profound-supererogation $>>-\langle$ postconvergingnarrowing-down $\sim$ sublimation-as-to-'existence - as-sublimating-withdrawal/unenframing/reontologising,-elicited-from-prospective-profound-supererogation '-in-reflecting‘immanent relative-unreflexivity/relative-reflexivity - ontological-contiguity ';-as-operativenotional deprocrypticism) as of cogency_chronicularity/annality-of-relative-reflexivity,-asto-profound-supererogation imbuing conceptivity/epistemic-reflexivity/epistemicityrelativism-determinism-<reifying \{as-to-knowledge-developing $\}$-and-empowering $>$ ). In-thethird-instance (as to the veracity of prospective knowledge elucidation and knowledge implications for sublimating-prolongation with respect to its 'direct/indirect-and- 
conscious/unconscious destabilisation'), overachingly underlying social-setups together with their associated institutions given 'protracted-ideologies- $<$ imbued-mere-formulaicities $>$ (as from 'rigid-to-subtle and as from politically-overaching-to-culturally-inculcated variance) of human \{epistemic-totalising 3 ’ $^{2}$ psychologismic-subliminal-truncating' (so-associated with contentious/un-nominalised social-stake-contention-or-confliction imbued unblurriness/blurrinessthreshold framing/formulation/catchmenting/truncating/compulsing/linearising as of 'existentially-disontologising/re-ontologising aporeticism $>$ manifest entanglement-as-to‘out-of-phasing >-disparate-narratives'representation-as-being-of-prospective-reentologising < <at mnblurriness/blurriness - threshold $>$ '), are rather in-effect of shallowsupererogation $\sim$ framing/formulation/catchmenting/truncating/compulsing/linearising —as-topreconverging de-mentating/structuring/paradigming implicited ${ }^{7}$ presencing-absolutisingidentitive-constitutedness ${ }^{14}$ disontologising claim/pretense to a 'logical/rationalising exercise'. So-underlied with their relative ontologically-deficient 'prospective mutual/dialogical engagement for knowledge elucidation for sublimating-prolongation' rather articulated within the scope of their 'existentially-<disontologising/re-ontologising aporeticism $>$ manifest incidental/accidental sufferance/endurance in supposedly and paradoxically subordinating/subserving/collateralising the possibility for prospective re-ontologisingimbuing-of-prospective-human-sublimating/emancipating/enfranchisement'; $\quad$ as not subsequent-to/derivative-from 're-ontologising-nascency-<as-of-prospective-

\section{solipsistic/intersolipsistic-inkling-drive-for-knowledge-elucidation,-as-to-veridical-organic-}

knowledge> for sublimating-prolongation'. This in-many-ways underlines such given protracted-ideologies-<imbued-mere-formulaicities $>\quad$ 'marked impliciting/professing-ofmanifest-social-stake-relevance/irrelevance' (with respect to social-functioning-andaccordance-as-of-social-stake-contention-or-confliction construct); and so, as to such given 
'protracted-ideologies-<imbued-mere-formulaicities $>$

existentially- $<$ disontologising/reentelogising aporeticism $>$ manifest concurring-with or discording-from' the-potential-for prospective re-ontologising 'ontologically-hegemonising-narrative 11 ontologicalperformance $^{72}$-<including-virtue-as-ontology $>$ /morality/ethics/justice/etc.'- (with reference to notional/epistemic/bindingness ${ }^{<a s-t o-d e t e r m i n i s m / c o n c e p t i v i t y-o f-r e l a t i v e-u n r e f l e x i v i t y / r e l a t i v e-r e f l e x i v i t y s ~}$

'parrhesiastic/messianicity/profound-supererogation projection for sublimatingprolongation'); with the latter rather so-relatively undersold by protracted-ideologies- $<$ imbuedmere-formulaicities $>$ with respect to the re-ontologising possibilities/potential for socialfunctioning-and-accordance-as-of-social-stake-contention-or-confliction construct. In this regards, it is no wonder that such overarching protracted-ideologies-<imbued-mereformulaicities $>$ are inevitably anchored on the supposed pre-eminence of 'their given institutionally implicited power relations' as supposedly superseding (in relatingsuperficially/selectively/opportunistically-to) the human potential for prospective reontologising 'ontologically-hegemonising-narrative ${ }^{71}$ ontological-performance ${ }^{2}-<$ includingvirtue-as-ontology $>$ /morality/ethics/justice/etc.'-(with reference to notional/epistemic/bindingness ${ }^{<a s-t o-d e t e r m i n i s m / c o n c e p t i v i t y-o f-r e l a t i v e-u n r e f l e x i v i t y / r e l a t i v e-r e f l e x i v i t y>~}$ 'parrhesiastic/messianicity/profound-supererogation projection for sublimatingprolongation'). Hence, such given 'protracted-ideologies-<imbued-mere-formulaicities $>$ existentially-<disontologising/re-ontologising aporeticism $>$ manifest concurring-with or discording-from' requisite 'prospective aspirative notional/epistemic/bindingness determinism/conceptivity-of-relative-unreflexivity/relative-reflexivity> parrhesiastic/messianicity/profoundsupererogation projection for sublimating-prolongation', so-underlies their 'formulaic-

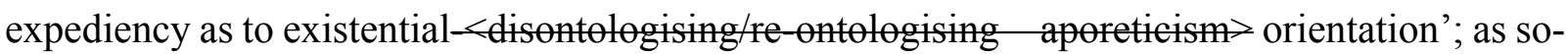
impliciting supposedly their 'effective alignment' or 'pragmatic alignment' as if of prospective re-ontologising 'ontologically-hegemonising-narrative ${ }^{7 !}$ ontological-performance ${ }^{22}<$ including- 
virtue-as-ontology $>$ /morality/ethics/justice/etc.'-(with

reference

notional/epistemic/bindingness ${ }^{-a s-t o-d e t e r m i n i s m / c o n c e p t i v i t y-o f-r e l a t i v e-u n r e f l e x i v i t y / r e l a t i v e-r e f l e x i v i t y>~}$

'parrhesiastic/messianicity/profound-supererogation projection for sublimatingprolongation'). This in-many-ways is further reflected with the associated adhesionto/cultivation-of a 'supposed conception of core-philosophy/derivative-core-philosophy(imbued requisite 'inkling-drive of dimensionality-of-sublimating <<amplituding/formative>supererogatory $\sim$ de-mentativeness/epistemic-growth-or-

conflatedness /transvaluative-rationalising/transepistemicity/anamnestic-residuality/spiritdrivenness-equalisation)')' consciously/unconsciously construed rather as in-effect anchored/aligned-with-and/or-institutionally-validated-by the 'truncating protractedideologies-<imbued-mere-formulaicities $>$ and overarching protracted-political/ideological orientation' (as wrongly implied as superseding unlimitedness/existence-<fll potencyof_sublimating nascence $>$ '); and so, with respect to 'supposedly proper rationalisation-ofcontentivity/argumentativity/dialecticism/discursivity' (so-implicitly construed as unassailable as from prospective re-rationalisation-of-contentivity/argumentativity/dialecticism/discursivity as to prospective 're-ontologising idiomatisation-<as-to- blurriness-elicited-profoundsupererogation -of-' ‘epistemic-totalising '’metaphoricity '-for-prospective- unblurriness-of'fepistemic lasing $+\frac{7}{3}$ meaningfulness-and-teleology ',-as-of-sublimating-prolongation;-inpsychologismic epistemic-acutisation residualising, ${ }^{\{\text {decompulsing }}$ delinearity for-cogency>').

Such that the 'supposed conception of core-philosophy/derivative-core-philosophy-(imbued requisite 'inkling-drive of dimensionality-of-sublimating ${ }^{25}$ <<amplituding/formative>supererogatory $\sim$ de-mentativeness/epistemic-growth-or-

conflatedness /transvaluative-rationalising/transepistemicity/anamnestic-residuality/spiritdrivenness-equalisation)' ') (consciously/unconsciously construed rather as in-effect anchored/aligned-with-and/or-institutionally-validated-by the 'truncating protracted- 
ideologies-<imbued-mere-formulaicities $>$ and overarching protracted-political/ideological orientation' as wrongly implied as superseding unlimitedness/existence- $<$ full-potencyof_sublimating nascence>') in shallowsupererogation $\sim$ framing/formulation/catchmenting/truncating/compulsing/linearising —as-topreconverging de-mentating/structuring/paradigming, can hardly be regarded as veridically 'thinking at first/pure predisposition preemptive of prospective disontologising/subontologising' (on the grounds of such 'existentially-<disontologising/re-ontologising aporeticism $>$ truncating protracted-ideologies-<imbued-mere-formulaicities $>$ and overarching protractedpolitical/ideological orientation' implicited adjudicating of the supposedly 'rationally sensible' and 'rationally non-sensible'). The requisite 'prospective aspirative notional/epistemic/bindingness ${ }^{-<a-t o-d e t e r m i n i s m / c o n c e p t i v i t y-o f-r e l a t i v e-u n r e f l e x i v i t y / r e l a t i v e-r e f l e x i v i t y>~}$ parrhesiastic/messianicity/profound-supererogation projection for sublimating-prolongation' (imbued prospective 're-ontologising idiomatisation-<as-to- blurriness-elicited-profound-

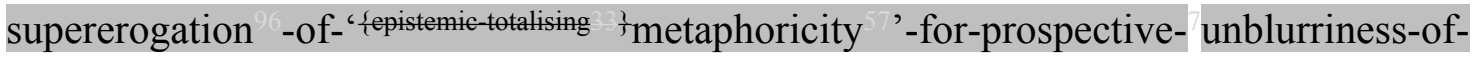
‘fepistemictising $+\frac{?}{+}$ meaningfulness-and-teleology ',-as-of-sublimating-prolongation;-in psychologismic epistemic-acutisation residualising, ${ }^{\{d e c o m p u l s i n g\}}$ \}elinearity for-cogency>’) is rather as of the 'profoundsupererogation $\sim$ reframing/reformulation/decatchmenting/detruncating/decompulsing/delinear ising - as-to-postconverging de-mentating/structuring/paradigming of nonpresencing<perspective-ontological-normalcy/postconvergence> epistemic-projection/construal'; soundergirding veridical core-philosophy/derivative-core-philosophy-(imbued requisite ‘inkling-drive of dimensionality-of-sublimating ${ }^{25}-\langle<$ amplituding/formative $>$ supererogatory $\sim$ dementativeness/epistemic-growth-or-conflatedness /transvaluativerationalising/transepistemicity/anamnestic-residuality/spirit-drivenness-equalisation〉') 'holding-out/point-referencing — psychoanalytic-unshackling exercise of educed-and-availing- 
and-re-availing relative-ontological-completeness ${ }^{87}$-of-apriorising/axiomatising/referencing' to allow for play out of untenability-of-induced unblurriness as '<prospective_punctual/immediacy/constituted/compulsions-encumbered__ disarmining/diss-

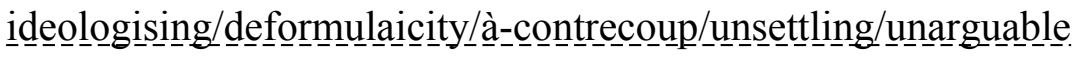
prompted constricted/narrowingdown-re-ontologising-enabling $>$ - psychologismic epistemic acutisation residualising fepistemic-

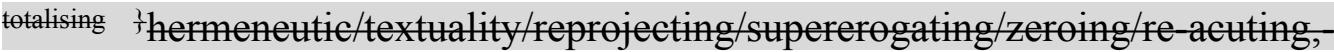
\{decompusing delinearity for-cogency' as to 'developing human-per-cep-ti-vi-ty-<as-tonotional perceptualisation-of-and-leashing-to_social-functioning-and-accordance-as-ofsocial-stake-contention-or-confliction> in preconverging/postconverging-redementating/restructuring/reparadigming'. In this respect, it can be appreciated that the $\leq$ mereformulaicity/ritualisation - of $>$-prior 're-ontologising idiomatisation- $<$ as-to- blurriness-elicitedprofound-supererogation -of-'\{epistemic-totalising '’3metaphoricity '-for-prospective- unblurrinessof-'fepistemic atising + meaningfulness-and-teleology ',-as-of-sublimating-prolongation;-inpsychologismic epistemic-acutisation residualising, ddecompulsing delinearity for-cogency>' (with regards to the absolute-<as-to-the-given-unreflexive-epistemic-dictat/dogma/ideology $>$ closed-construct as from blatant brutish conquest/subjugation conception of sovereign apportioning, dominion protection conception of sovereign apportioning, to the very naturalorder-of-things conception of sovereign apportioning and to our subtle modern-day institutionally-distorted/disjointed conception of sovereign apportioning which are so-implied as of their given shallow supererogation $\sim$ framing/formulation/catchmenting/truncating/compulsing/linearising —as-topreconverging de mentang/struturing/paradigming) claim/pretense of supposedly 'thinking at first/pure predisposition preemptive of prospective disontologising/subontologising' are effectively put into question by their respectively 'manifest historial/epochal veridical re- 
assertive core-philosophy/derivative-core-philosophy_-(imbued requisite 'inkling-drive of dimensionality-of-sublimating ${ }^{25}$-<<amplituding/formative>supererogatory $\sim$ dementativeness/epistemic-growth-or-conflatedness /transvaluativerationalising/transepistemicity/anamnestic-residuality/spirit-drivenness-equalisation〉') as to limited-mentation-capacity-deepening —as-subjecting limitedness/human-subpotency-to'educed-unlimitedness/existence-sublimating nascence's3 for sublimating-prolongation'. As so-overriding/undermining the unblurriness/blurrinessthreshold framing/formulation/catchmenting/truncating/compulsing/linearising of their given loci/stations-of-'thrownness-disposition-as-of-mere-formulaicity/ritualisation' inherent socialstake-contention-or-confliction 'self-referencing-syncretising forward-facingsupposedly postconverging-or-dialectical-thinking -apriorising-psychologism epistemicprojection imbued prior mere-formulaicity/ritualisation- $<$ as-to-mere-formulaicmethodologising/mutualising/organising/institutionalising,-prospectively-losing-track-of‘\{epistemic-totalising ’’re-apriorising/re-axiomatising/re-referencing $\sim$ residuality-in-reoriginariness/re-origination'>' as prospectively substitutive of 'unlimitedness/existence-<fullpotency-of_sublimating nascence>'. The implications here (with respect to the veracity of prospective knowledge elucidation and knowledge implication for sublimating-prolongation) is that the articulation of say prospective positivistic knowledge within say a nonpositivistic animist social-setup is not a naive exercise of submitting to the latter's $<$ mere-formulaicity/ritualisationef $>$-prior 're-ontologising idiomatisation-<as-to- blurriness-elicited-profound-supererogation of-'\{epistemic-totalising '’metaphoricity '-for-prospective- unblurriness-of-'\{epistemictotalising $\frac{?}{3}$ meaningfulness-and-teleology ', -as-of-sublimating-prolongation;-inpsychologismic epistemic acutisation - residualising, ${ }^{\text {fdecompulsing }}$ \} delinearity for-cogency>> like a God-of-plane idiomatising (on the basis of such animist 'existentially-<disontologising/reentologising apereticism $>$ truncating protracted-ideologies- $<$ imbued-mere-formulaicities $>$ 
and overarching protracted-political/ideological orientation' implicited adjudicating of the supposedly 'rationally sensible' and 'rationally non-sensible' as to prior given shallowsupererogation $\sim$ framing/formulation/catchmenting/truncating/compulsing/linearising —as-topreconverging -de-mentating/structuring/paradigming). But rather speaks more fundamentally about 'thinking at first/pure predisposition preemptive of prospective disontologising/subontologising' with respect to 'limitedness/human-subpotency prospective reencountering/re-confrontation with unlimitedness/existence-full-potency-of_sublimating nascence $>$ (as of 'inkling-drive of dimensionality-of-sublimating <<amplituding/formative>supererogatory $\sim$ de-mentativeness/epistemic-growth-orconflatedness /transvaluative-rationalising/transepistemicity/anamnestic-residuality/spiritdrivenness-equalisation〉') induced psychoanalytic-unshackling; and so, as of the veridical availing of 'prospective mutual/dialogical engagement for knowledge elucidation for sublimating-prolongation' only as subsequent-to/derivative-from 're-ontologising-nascency<as-of-prospective-solipsistic/intersolipsistic-inkling-drive-for-knowledge-elucidation,-as-toveridical-organic-knowledge $>$ for sublimating-prolongation'. Likewise, our manifest positivism- ${ }^{80}$ procrypticism/disjointedness-as-of- ${ }^{8}$ reference-of-thought 'pedantic conscious/unconscious rampant misanalysis as well as stealthy and deliberate foolery' with regards to budding-postmodern thought (and as herein wholesomely articulated theoretically as of deprocrypticism-or-preempting-disjointedness-as-of- ${ }^{8}$ reference-of-thought prospective 're-ontologising idiomatisation-<as-to- blurriness-elicited-profound-supererogation -of-

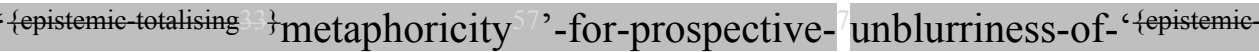
totalising $\frac{\jmath}{3}$ meaningfulness-and-teleology , -as-of-sublimating-prolongation;-inpsychologismic epistemic-acutisation residualising, \{decompulsing\} delinearity for-cogency $>$ ' (along the same lines of an animist social-setup God-of-plane desublimating naivety with respect to prospective positivistic sublimating-prolongation), still wouldn't cancel the fact that (as to 
when prospective relative-ontological-completeness ${ }^{87}$ is educed-and-availing-and-re-availing) the prospect for prospective knowledge elucidation and knowledge implications cannot be divorced from our very own retracing-and-relaying 'thinking at first/pure predisposition preemptive of prospective disontologising/subontologising' as of 'inkling-drive of dimensionality-of-sublimating $25<<$ amplituding/formative $>$ supererogatory $\sim$ de-

\section{mentativeness/epistemic-growth-or-conflatedness /transvaluative-}

rationalising/transepistemicity/anamnestic-residuality/spirit-drivenness-equalisation〉' induced psychoanalytic-unshackling (as of the veridical availing of 'prospective mutual/dialogical engagement for knowledge elucidation for sublimating-prolongation' and so only as subsequent-to/derivative-from 're-ontologising-nascency-<as-of-prospective-

\section{solipsistic/intersolipsistic-inkling-drive-for-knowledge-elucidation,-as-to-veridical-organic-}

knowledge $>$ for sublimating-prolongation'). So-undermining the disontologising priorperspective - falsity/falseness/fallaciousness of a mere 'logical/rationalising exercise' on the basis that we can naively 'idiomatise budding-postmodern thought as supposedly prospectively disontologising' (as to the 'marked impliciting/professing-of-manifest-social-stake-irrelevance' so-elicited as of 'our protracted-ideologies-<imbued-mere-formulaicities $>$ of socialfunctioning-and-accordance-as-of-social-stake-contention-or-confliction construct'); as sowrongly implying we-are-undecenterable/our-conscious-self-cannot-be-prospectively-dissolved with respect to our ${ }^{7}$ presencing-absolutising-identitive-constitutedness ${ }^{14}$, as to when prospective relative-ontological-completeness ${ }^{87}$ is educed-and-availing-and-re-availing (as soenabling 'effective foregrounding_entailment- $<$ in-succession-of-profoundsupererogation $>$-〈postconverging-narrowing-down $\sim$ sublimation-as-to-'existence-assublimating-withdrawal/unenframing/re-ontologising,-elicited-from-prospective-profoundsupererogation '-in-reflecting-'immanent relative-unreflexivity/relative-reflexivity 
cogency_chronicularity/annality-of-relative-reflexivity,-as-to-profound-supererogation imbuing conceptivity/epistemic-reflexivity/epistemicity-relativism-determinism- $<$ reifying \{asto-knowledge-developing \}-and-empowering $>$ ). In-the-fourth-instance (as to the veracity of prospective knowledge elucidation and knowledge implications for sublimating-prolongation with respect to its 'direct/indirect-and-conscious/unconscious destabilisation'), overarchingly a presencing-absolutising-identitive-constitutedness ${ }^{14} \quad$ elaboration-as-to-mereextrapolating/constituting/abstracting/deducing/inferring-of-elucidation-outside'prospectively_implicited_attendant-ontological-contiguity ${ }^{67}$ 'educedexistentialising/contextualising/textmalising_intelligibility/epistemicity/reflexivity-contiguity<imbued-notional cogency >' inherently underscores prospective shallowsupererogation $\sim$ framing/formulation/catchmenting/truncating/compulsing/linearising as-topreconverging de-mentating/structuring/paradigming ; by failing to effectively recognise and account-for its given <amplituding/formative-epistemicity>-totalising $\sim$ thrownness-inexistence ${ }^{35}$. Thus, inevitably adopting a supposed knowledge-reification $\sim$ gesturing-andaccounting - of-epistemic-phenomenalism- $<$ inprospective_psychologismic apriorising/axiomatising/referencing-\{of-‘prospectively implicited_attendant-ontological-contiguity ' educedexistentialising/contextualising/textualising_'intelligibility/epistemicity/reflexivity-contiguity<imbued-notional cogency >’ \}-conflatedness -in-\{preconverging-ment by\}

postconverging-entailment $>$ that poorly/hardly construes of the very 're-ontologising centrality of the veridically existential-<disontologising/re-ontologising aporeticism $>$ ' (with respect to the educing of both sublimating-arising and sublimating-prolongation). So-reflected with an 'implicited/explicited notionally-and-operatively deficient construal of the apriorising and the aposteriorising as supposedly representing correspondingly a distinction between the nonexperiential and experiential'; whereas the apriorising (as to presumptuousness-in- 
existence) and the aposteriorising (as to assumptions-in-existence) veridically points to 'fepistemictotalising 3 3 hermeneutic/textuality/reprojecting/supererogating/zeroing/re-acuting,-

delinearity for-cogency manifest < apriorising-for-aposteriorising,-in-existence $>$ existentialising-framing-by-enframing/\{worlding $\}<$-in-'educing/availing and-re-educing/reavailing of prospective-relative-ontological-completeness $\stackrel{9}{\rightarrow}$

cumulating/recomposuring of 'the-very-same purview/devolved-purview/devolving-purviewof-unlimitedness/existence-<full-potency-of_sublimating nascence $>$; - 'implicited_attendantontological-contiguity ${ }^{67}$, educedexistentialising/contextualising/textmalising_intelligibility/epistemicity/reflexivity-contiguity$<$ imbued-notional cogency $>^{\prime 0}$ ). So-failing to appreciate the fact that there cannot be anything outside of existence (underlining the 're-ontologising centrality of the existential<disontologising/re-ontelogising aporeticism $>$ ' as to inherent '\{epistemictotalising ${ }^{3}$ h hermeneutic/textuality/reprojecting/supererogating/zeroing/re-acuting,felinearity for-cogency manifest <apriorising-for-aposteriorising,-in-existence $>$ existentialising-framing-by-enframing/\{worlding $\}<$ in-'educing/availing and-re-educing/reavailing of prospective-relative-ontological-completeness ${ }^{\prime} \rightarrow$ '). Since the existentialdisontologising/re ontologising aporeticism> rather speaks of the 'relativeunreflexivity/relative-reflexivity limitedness/human-subpotency dynamics of supererogating $\{$ affirmation/projection/assertion/notional $\sim$ self-distantiation-byunaffirmation/deprojection/deassertion/epistemic-decadence $\}$ — towards $\sim$ omnipotentialaffirmation/projection/assertion/notional self-distantiation' in $\quad<$ amplituding/formativeepistemicity>-totalising $\sim$ thrownness-in-existence ${ }^{35}$ Human '\{epistemictotalising ${ }^{3}$ hermeneutic/textulity/reprojecting/supererogating/zeroing/re acuting,$\{$ decompulsing $\}$ delinearity for-cogency manifest <apriorising-for-aposteriorising,-in-existence $>$ existentialising-framing-by-enframing/\{worlding $\}<$ in-'educing/availing and-re-educing/re- 
availing of prospective-relative-ontological-completeness ${ }^{\prime} \rightarrow$ ', as such (as to 'human presumptuousness/apriorising-eliciting-of-assumptions/aposteriorising'), so-reflect the fact that it is <apriorising-for-aposteriorising,-in-existence>-existentialising-framing-byenframing/\{worlding $\}$-in-'educing/availing and-re-educing/re-availing of prospectiverelative-ontological-completeness $\stackrel{2}{\rightarrow}$ that dynamically undergirds the 'thresholding/thresholds of existentialising — enframing/imprintedness by existentialising — framing/imprinting' educing human intelligibility-〈as-to-human-projective/reprojective-aestheticising-re-motif-and-reapriorising/re-axiomatising/re-referencing/re-intelligibilitysettingup/remeasuringinstrumenting-process,-in-<amplituding/formativeepistemicity>totalising conceptualisation)' (whether as of prior < preconverging 'motif-andapriorising/axiomatising/referencing'-entailing>-existentialising — enframing/imprintedness〈as-to- historicity-tracing-in-presencing-hyperrealisation/hyperreal-transposition〉 prospective <postconverging 'motif-and-apriorising/axiomatising/referencing'-entailing >existentialising - framing/imprinting-_as-to-prospective- historiality/ontologicaleventfulness /ontological-aesthetic-tracing-<perspective-ontologicalnormalcy/postconvergence-reflected-‘epistemicity-relativism-determinism'> $>\rangle$ ). So-reflected with respect to the renicter totalising $3{ }^{3}$ hermeneutic/textuality/reprojecting/supererogating/zeroing/re-acuting,${ }_{\{\text {decompulsing }}$ delinearity for-cogency manifest <apriorising-for-aposteriorising,-in-existence $>$ existentialising-framing-by-enframing/\{worlding $\}<$ in-'educing/availing and-re-educing/reavailing of prospective-relative-ontological-completeness $\stackrel{\text { ? }}{\rightarrow}$, of Beingdevelopment/ontological-framework-expansion-as-to-depth-of-ontologising-development-asinfrastructure-of- meaningfulness-and-teleology psychologismic epistemic acutisationdifficulty $<$ for, residualising _decompulsing $\}$ delinearity for-cogency> magnitude ${ }^{\{\text {of- }}$ experientiality/experiment\} (implied as to transcendental/interdimensional/transdimensional registry- 
worldview/dimension-level existentialising-framing-by-enframing/\{worlding $\}$ - ${ }^{8}$ referenceof-thought') and institutional-development-as-to-social-function-development psychologismic epistemic-acutisation difficulty-for, residualising \{decompulsing ${ }^{\prime}$ delinearity for-cogency> magnitude $\{$ of-experientiality/experiment\} and living-development-as-to-personality-development psychologismic epistemic acutisation difficulty-<for, residualising $\{$ decompulsing $\}$ delinearity for-cogeney> magnitude $\{$ of-experientiality/experiment $\} \quad$ (implied intradimensionally within any given registry-worldview/dimension as to <registryworldview/dimension existentialising framing by enframing/worlding? reference-ofthought $>$ - undergirding of-existentialising-framing-by-enframing/\{worlding $\}$-axiomaticconstructs). In other words, human ${ }^{56}$ meaningfulness-and-teleology ${ }^{9}$ necessarily arise as of prior unblurriness/blurriness-

threshold framing/formulation/catchmenting/truncating/compulsing/linearising (existentialising —enframing/imprintedness) or as of prospective unblurriness $\sim$ reframing/reformulation/decatchmenting/detruncating/decompulsing/delinearisi ng (existentialising — framing/imprinting); with regards to the specifically given registryworldview/dimension or its institutional purview '<apriorising-for-aposteriorising,-inexistence $>$ - existentialising-framing-by-enframing/\{worlding $\}<$ in 'educing $/$ availing and reeducing/re-availing of prospective-relative-ontological-completeness $\stackrel{2}{\rightarrow}$ imbued human existential<<disontologising/re-ontologising aporeticism $>$ ontological-performance ${ }^{72}$ <including-virtue-as-ontology $>$ /morality/ethics/justice/etc.'. So-elicited as of 'protractedsocial—as-to-individual-by-institutional-by-social relative direct/deferentialresponsibility/relative-reflexivity-or-irresponsibility/relative-unreflexivity to cogency_chronicularity/annality-of-relative-reflexivity,-as-to-profound-supererogation ${ }^{2}$. In this respect, 'nonexperientiality of apriorising-for-aposteriorising is a notional/epistemic/bindingness ${ }^{-<a s-t o-d e t e r m i n i s m / c o n c e p t i v i t y-o f-r e l a t i v e-u n r e f l e x i v i t y / r e l a t i v e-r e f l e x i v i t y ~}>$ 
impossibility' by the mere token that already being in existence consciously-and-unconsciously informs human ' \{epistemic-totalising 3 3' ${ }^{3}$ hermeneutic/textuality/reprojecting/supererogating/zeroing/reacuting,- - decomplsing $\}$ delinearity for-cogency manifest <apriorising-for-aposteriorising,-inexistence $>$ — existentialising-framing-by-enframing/\{worlding $\}<$ in-'educing/availing and-reeducing/re-availing of prospective-relative-ontological-completeness $\stackrel{\text { ' }}{\rightarrow}$ ' (along the lines it is impossible for a child to speak without priorly babbling-as-pseudo-speaking with latter speaking efficiency/orientation necessarily affected as to the child's prior speaking and perceiving-ofspeaking in so-reflecting the 'child's developing existentialising-frame-of-entailment-of motifand-apriorising/axiomatising/referencing' imbued 'circular < apriorising-for-aposteriorising,-inexistence $>$ - existentialising-framing-by-enframing/\{worlding $\}<$ in-'educing/availing and-reeducing/re-availing of prospective-relative-ontological-completeness $\stackrel{2}{\rightarrow}$, as of the 'hermeneutic circle'); and so, as to the driving human <amplituding/formative-epistemicity >totalising $\sim$ thrownness-in-existence ${ }^{35}$,-imbued-projective-arbitrariness/waywardness-〈as-to-thehuman-projective/reprojective - aestheticising-re-motif-and-re-apriorising/re-axiomatising/rereferencing-process-of-‘ $<$ amplituding/formative-epistemicity $>$ totalising $\sim$ conceptualisation' $\rangle$. Critically, the disparateness-of-conceptualisation-<unforegrounding-ment,-failingprospectively-to-reflect-'immanent relative-unreflexivity/relative-reflexivity - ontologicalcontiguity '> implied from such 'implicited/explicited nonexperientiality of apriorising-foraposteriorising' (as of ${ }^{79}$ presencing — absolutising-identitive-constitutedness ${ }^{14}$ elaboration-as-tomere-extrapolating/constituting/abstracting/deducing/inferring-of-elucidation-outside_'prospectively_implicited_attendant-ontological-contiguity ${ }^{67}$ ' educedexistentialising/contextualising/textualising_'intelligibility/epistemicity/reflexivity-contiguity$<$ imbued-notional cogency>') across all registry-worldviews/dimensions fails to appreciate that prior sublimating-arising and prospective sublimating-prolongation is rather enabled as from 'existential-<disentologising/re-ontologising aporeticism $>$ imbued 
totalising 3 ' ${ }^{3}$ hermeneutic/textuality/reprojecting/supererogating/zeroing/re-acuting,-

$\{$ decompulsing $\}$ delinearity for-cogency educed re-ontologising-nascency-<as-of-prospective-

solipsistic/intersolipsistic-inkling-drive-for-knowledge-elucidation,-as-to-veridical-organic-

knowledge>'; as of veridical core-philosophy/derivative-core-philosophy-(imbued requisite 'inkling-drive of dimensionality-of-sublimating ${ }^{25}-\langle<$ amplituding/formative $>$ supererogatory $\sim$ dementativeness/epistemic-growth-or-conflatedness /transvaluative-

rationalising/transepistemicity/anamnestic-residuality/spirit-drivenness-equalisation〉')

'holding-out/point-referencing — psychoanalytic-unshackling exercise of educed-and-availingand-re-availing relative-ontological-completeness ${ }^{87}$-of-apriorising/axiomatising/referencing' to allow for play out of untenability-of-induced unblurriness as ‘ $<$ prospective_punctual/immediacy/constituted/compulsions-encumbered_- disarming

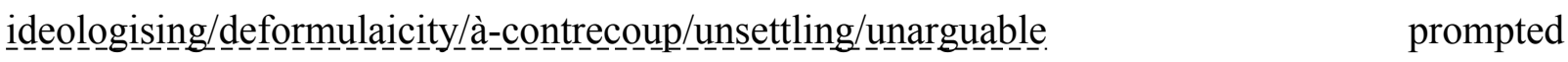
constricted/narrowingdown-re-ontologising-enabling $>$ - psychologismic epistemic-

acutisation residualising fepistemic-

totalising thermeneutic/textuality/reprojecting/supererogating/zeroing/re-acuting, \{decompulsing\} delinearity-for-cogency' as to 'developing human-per-cep-ti-vi-ty-<as-tonotional perceptualisation-of-and-leashing-to_social-functioning-and-accordance-as-ofsocial-stake-contention-or-confliction> in preconverging/postconverging-redementating/restructuring/reparadigming'. Whereas an implicited/explicited nonexperientiality of apriorising-for-aposteriorising rather paradoxically 'implicitly/explicitly objectifies-asnonframed/absolute-<as-unreflexively-impliciting-of-a-supposedly 'absolutising framing'>' the specifically given registry-worldview scope of 'existentially-<disontologising/reentologising aporeticism $>$ manifest incidental/accidental reactive-sufferance/endurance in supposedly and paradoxically subordinating/subserving/collateralising the possibility for prospective re-ontologising - imbuing-of-prospective-human- 
sublimating/emancipating/enfranchisement'; as supposedly being beyond the appraisal of prospective 're-ontologising-nascency-<as-of-prospective-solipsistic/intersolipsistic-inklingdrive-for-knowledge-elucidation,-as-to-veridical-organic-knowledge $>\quad$ for $\quad$ sublimatingprolongation'. Such a conception wrongly undermines the recurrently requisite profound 'palpable dissolving/decentering of the conscious-self/collective-conscious-self' and rather reflects the 'shallowness/superficiality of presumptmousness/apriorising-eliciting-ofassumptions/aposteriorising' of the specifically given registry-worldview/dimension reference-of-thought/axiomatic-constructs presencing - absolutising-identitiveconstitutedness ${ }^{14}$. Thusly, failing to grasp the 'relative-mreflexivity/relative-reflexivitybindingness/nondiscretionariness-<as-from-sublimating remoteness/distance-of-appraisal-ofrequisite $\sim$ Being-development $>$ of unlimitedness/existence-<flll-potency-of_sublimating nascence $>$ ' - (as to 'relative-unreflexivity/relative-reflexivity limitedness/human-subpotency dynamics of supererogating \{affirmation/projection/assertion/notional $\sim$ self-distantiation-byunaffirmation/deprojection/deassertion/epistemic-decadence\} - - towards omnipotentialaffirmation/projection/assertion/notional self-distantiation' with respect to 'limitedness/humansubpotency prospective re-encountering/re-confrontation with unlimitedness/existence-<fullpotencersublimating nascences'); rather as from the relative-reflexivity of prospective reontologising Being-development/ontological-framework-expansion-as-to-depth-ofontologising-development-as-infrastructure-of- meaningfulness-and-teleology psychologismic epistemic acutisation difficulty-for, residualising \{decompulsing delinearity for-cogency>-magnitude\{of-experientiality/experiment\} as to overarching 'registry-worldview/dimension existentialising-framing-by-enframing/\{worlding $\}-$ reference-of-thought' (as of requisite prospective re-ontologising idiomatisation-<as-toblurriness-elicited-profound-supererogation -of- ‘fepistemic-totalising '’̀metaphoricity '-forprospective- unblurriness-of- ‘fepistemic-totalising $\frac{3}{3}$ meaningfulness-and-teleology ',-as-of- 
unblurriness $\sim$ reframing/reformulation/decatchmenting/detruncating/decompulsing/delinearisi ng)'. Rather the veracity of 're-ontologising-nascency-<as-of-prospectivesolipsistic/intersolipsistic-inkling-drive-for-knowledge-elucidation,-as-to-veridical-organicknowledge $>$ for sublimating-prolongation' points out that the succession of prospective registryworldviews/dimensions 'had no corresponding prior registry-worldviews/dimensions imbued mere logical/rationalising' (since such a construal will have wrongly represented the corresponding prior registry-worldviews/dimensions as 'implicitly/explicitly objectified-asnonframed/absolute-<as-unreflexively-impliciting-of-a-supposedly 'absolutising-framing'>').

Such that it is ever always the 'thinking at first/pure predisposition preemptive of prospective disontologising/subontologising' with respect to 'limitedness/human-subpotency prospective reencountering/re-confrontation with unlimitedness/existence-<fll-potency-of_sublimating nascence $>$ (as of 'inkling-drive of dimensionality-of-sublimating ${ }^{25}$ <<amplituding/formative>supererogatery $\sim$ de-mentativeness/epistemic-growth-or-

\section{conflatedness /transvaluative-rationalising/transepistemicity/anamnestic-residuality/spirit-}

drivenness-equalisation)') induced psychoanalytic-unshackling; as from the specifically given human $<$ amplituding/formative-epistemicity $>$-totalising $\sim$ thrownness-in-existence 'prospective opening' (as to opened-construct-of- ${ }^{5}$ meaningfulness-and-teleology ${ }^{9}$ for prospective metaphoricity ${ }^{57}$ ) that elicits the possibility for prospective 're-ontologising idiomatisation-<as-to- blurriness-elicited-profound-supererogation -of- ‘ \{epistemic-

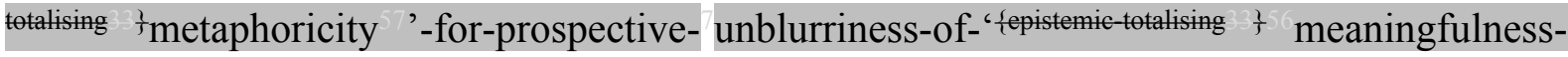
and-teleology ',-as-of-sublimating-prolongation;-in psychologismic epistemic acutisationresidualising, fdecomplsing delinearity for-cogency>'. As so-undergirding the overall relativeunreflexivity/relative-reflexivity — ontological-contiguity ${ }^{67}$ of-the-human-institutionalisation- 
process ${ }^{68}$ educed sublimating-prolongation 'effective ${ }^{45}$ foregrounding_entailment- $<$ insuccession-of-profound-supererogation $>$ >-〈postconverging-narrowing-down $\sim$ sublimation-asto-'existence — as-sublimating-withdrawal/unenframing/re-ontologising,-elicited-fromprospective-profound-supererogation ' \#nreflexivity/relative reflexivity ontological-contiguity ';-as-operativenotional deprocrypticism $\rangle$ as of cogency_chronicularity/annality-of-relative-reflexivity,-asto-profound-supererogation imbuing conceptivity/epistemic-reflexivity/epistemicityrelativism-determinism-<reifying \{as-to-knowledge-developing $\}$-and-empowering $>$.

Overarchingly in-the-overall-instance (as to the veracity of prospective knowledge elucidation and knowledge implications for sublimating-prolongation with respect to its 'direct/indirectand-conscious/unconscious destabilisation'), it can thus be appreciated that the 'overall relativeunreflexivity/relative-reflexivity — ontological-contiguity ${ }^{67}$ of-the-human-institutionalisationprocess $^{68}$ imbued notional $\sim$ cogency_chronicularity/annality-of-relative-reflexivity,-as-toprofound-supererogation' is rather one whole 'relative-unreflexivity/relative-reflexivity ontological-contiguity ${ }^{67}$ construct-and-potentiation' of 'despite-the-self exercise of epistemicprojection in notional $\sim$ self-distantiation- $<$ imbued-re-motif-and-re-apriorising/reaxiomatising/re-referencing>' involved in 'limitedness/human-subpotency prospective reencountering/re-confrontation with unlimitedness/existence-<fll-potency-of_sublimating nascence $>$ for unblurriness $\sim$ reframing/reformulation/decatchmenting/detruncating/decompulsing/delinearisi ng imbuing sublimating-prolongation (as to requisite re-acceding to 're-ontologising-nascency<as-of-prospective-solipsistic/intersolipsistic-inkling-drive-for-knowledge-elucidation,-as-toveridical-organic-knowledge $>$ for sublimating-prolongation' elicited 'perspicacity of psychologismic-epistemic-acutisation-<as-to-postconverging-dementating/structuring/paradigming,-eliciting-of-existence's-sublimating-nascence-in- 
\{veridical/sound\}-relative-reflexivity-in-existence/relativising from-limited-mentation-as-itsdeepening/psychologismic epistemic-acutisation residualising, fdecompulsingl delinearity for eogency' of 'unlimitedness/existence-<full-potency-of_sublimating nascence $>$ '); and so, whilst interceded/interspersed with successoral 'epistemic-decadence' or teleological-decadence-<-indimensionality-of-desublimating-lack-of $-\langle<$ amplituding/formative $>$ supererogatory $\sim$ dementativeness/epistemic-growth-or-conflatedness /transvaluativerationalising/transepistemicity/anamnestic-residuality/spirit-drivenness-equalisation〉 imbued distractive-alignment-to- ${ }^{8}$ reference-of-thought- $<$ of-apriorising/axiomatising/referencing $>$ inducing unblurriness/blurrinessthreshold framing/formulation/catchmenting/truncating/compulsing/linearising (as of human presencing - absolutising-identitive-constitutedness ${ }^{14}$ social-functioning-and-accordanceas-of-social-stake-contention-or-confliction construct 'existentially-<disontologising/reentologising aporeticism $>$ manifest incidental/accidental reactive-sufferance/endurance in supposedly and paradoxically subordinating/subserving/collateralising the possibility for prospective re-ontologising - imbuing-of-prospective-humansublimating/emancipating/enfranchisement'). Hence it can be further appreciated that (with respect to 'limitedness/human-subpotency prospective re-encountering/re-confrontation with unlimitedness/existence-full-potency-of_sublimating nascence $>$ ' as to 'limited-mentationcapacity-deepening —as-subjecting limitedness/human-subpotency-to-'educedunlimitedness/existence-sublimating nascence' ${ }^{53}$ for sublimating-prolongation') psychologismic-epistemic-acutisation-<as-to-postconverging-dementating/structuring/paradigming,-eliciting-of-existence's-sublimating-nascence-inprospective-aporeticism-overcoming/unovercoming> as to epistemic-growth,-as\{veridical/sound\}-relative-reflexivity-in-existence/relativising from-limited-mentation-as-its- 
deepening/psychologismic epistemic acutisation residualising, ${ }^{\text {fdecompulsing }}$ delinearity for

eogency rather/effectively speaks to the 'cut-out-<as-to-re-ontologising redressing/straightening out $>$ (as of relative-reflexivity psychologismic-transfixity<placeholder-setup-ontological-rescheduling — in-realigning/preactivity/formativebecoming/psychoanalytical-unshackling,-as-to-residualising-\{decompulsing $\}$ delinearity-overnonresidualising_\{compulsing\}linearity $>$ ) for sublimating-prolongation', of the prior scope of 'existentially- $<$ disontologising/re-ontologising aporeticism $>$ manifest incidental/accidental reactive-sufferance/endurance in supposedly and paradoxically subordinating/subserving/collateralising the possibility for prospective re-ontologisingimbuing-of-prospective-human-sublimating/emancipating/enfranchisement'; and so for prospectively re-acceding to 're-ontologising-nascency-<as-of-prospectivesolipsistic/intersolipsistic-inkling-drive-for-knowledge-elucidation,-as-to-veridical-organicknowledge $>$ for sublimating-prolongation' (even as the latter development 'prospectively effuses' of its very own scope of 'existentially-<disontologising/re-ontologising aporeticism $>$ manifest incidental/accidental reactive-sufferance/endurance in supposedly and paradoxically subordinating/subserving/collateralising the possibility for prospective re-ontologisingimbuing-of-prospective-human-sublimating/emancipating/enfranchisement', given prospective limited-mentation-capacity). It can be appreciated in this regards that the successive registryworldviews/dimensions re-acceding to 're-ontologising-nascency-<as-of-prospectivesolipsistic/intersolipsistic-inkling-drive-for-knowledge-elucidation,-as-to-veridical-organicknowledge> for sublimating-prolongation' so-educe of their successively given 'priordemoronisation-<sublimating-nascence,-nonextricatory-sublimating-upstreaming/‘amontée’> by prospective-moronisation- $<$ sublimating-nascence,-extricatesublimatingdownstreaming/'avalage'> (of human-per-cep-ti-vi-ty-<as-to - notional $\sim$ perceptualisation-ofand-leashing-to_social-functioning-and-accordance-as-of-social-stake-contention-or- 
confliction> of social-functioning-and-accordance-as-of-social-stake-contention-orconfliction construct)'; as so-reflecting limitedness/human-subpotency recomposuring/cumulating demoronisation-<sublimating-nascence,-nonextricatory sublimating-upstreaming/'amontée'> re-acceding to 're-ontologising-nascency-<as-ofprospective-solipsistic/intersolipsistic-inkling-drive-for-knowledge-elucidation,-as-toveridical-organic-knowledge $>$ for sublimating-prolongation'. This psychologismic-epistemicacutisation-<as-to-postconverging-de-mentating/structuring/paradigming,-eliciting-ofexistence's-sublimating-nascence-in-prospective-aporeticism-overcoming/unovercoming $>$ as to epistemic-growth,-as - \{veridical/sound\}-relative-reflexivity-in-existence/relativising fromlimited-mentation-as-its-deepening/psychologismic epistemic-acutisation residualising, \{decompulsing $\}$ delinearity for-cogency imbued 'cut-out-<as-to-re-ontologising redressing/straightening-out $>$ (as of relative-reflexivity psychologismic-transfixity$<$ placeholder-setup-ontological-rescheduling - in-realigning/preactivity/formativebecoming/psychoanalytical-unshackling,-as-to-residualising-\{decompulsing $d$ delinearity-overnonresidualising_ompulsingtlinearity $>$ ) for sublimating-prolongation' (as cutting-out-<as-to-reentologising redressing/straightening out $>$ the moronisation- $<$ sublimating-nascence,-

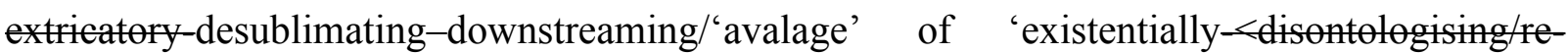
entologising aporeticism $>$ manifest incidental/accidental reactive-sufferance/endurance in supposedly and paradoxically subordinating/subserving/collateralising the possibility for prospective re-ontologising - imbuing-of-prospective-humansublimating/emancipating/enfranchisement'): is rather underlied by veridical corephilosophy/derivative-core-philosophy_-(imbued requisite 'inkling-drive of dimensionality-ofsublimating $25-<$ amplituding/formative $>$ supererogatory $\sim$ de-mentativeness/epistemic-growthor-conflatedness /transvaluative-rationalising/transepistemicity/anamnestic-residuality/spiritdrivenness-equalisation〉') 'holding-out/point-referencing-psychoanalytic-unshackling 
exercise of educed-and-availing-and-re-availing relative-ontological-completeness ${ }^{87}$-ofapriorising/axiomatising/referencing' to allow for play out of untenability-ofinduced unblurriness as '<prospective_punctual/immediacy/constituted/compulsions-

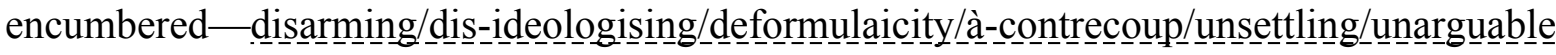
prompted constricted/narrowingdown-re-ontologising-enabling $>$-psychologismic epistemic acutisation residualising fepistemic-

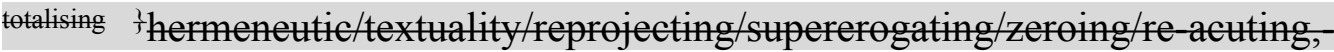
fdecomploming delinearity for-cogency' as to 'developing human-per-cep-ti-vi-ty-<as-tonotional perceptualisation-of-and-leashing-to_social-functioning-and-accordance-as-ofsocial-stake-contention-or-confliction> in preconverging/postconverging-redementating/restructuring/reparadigming'); and so with respect to the notional/epistemic/bindingness ${ }^{<a s-t o-d e t e r m i n i s m / c o n c e p t i v i t y-o f-r e l a t i v e-u n r e f l e x i v i t y / r e l a t i v e-r e f l e x i v i t y>~}$ 'formativeness-<as-to-intersolipsism-of-preformulating/preframing/premeaningfulnessimbued-mediativity-and-deferentialism>-of- meaningfulness-and-teleology and existential< disontologising/re-ontologising aporeticism $>$ articulation manifestations (undergirding 'catchmented-and-compulsed-<in-'existential-dearth-of-demoronisation',-so-construed-as-

\section{from-ontological-normalcy/postconvergence-perspective-reflection-of-the-'destructuring-}

threshold_of-the-given-level's-conjugated-postlogism as-dementing'> interpersonal, group, intergroup, community, local, national, political, geostrategic, etc. psychologismic epistemicacutisation difficulty-<or, residualising fdecompulsing delinearity for-cogency> levels of interrelatedness-dynamics-of-social-constructing' as underlied by apriorising- ${ }^{83}$ reference-ofthought/apriorising-registry—elements-\{ \{epistemic-totalising 3 psychologismic-subliminality-ofindividuation —effusing/worlding imbued logical-dueness-or-scape-or-frame, profile-or-stature, presumptuousness-or-arrogation, assumptions, value-reference and teleology $\left.{ }^{9}\right\}$ )'. And sodynamically undergirding the 'thresholding/thresholds of existentialising- 
enframing/imprintedness

notionally/epistemically/bindingnessly-<as-to-determinism/conceptivity-of-relative-unreflexivity/relative-reflexivity $>$ educing of human intelligibility-〈as-to-human-projective/reprojective- aestheticising-re-motifand-re-apriorising/re-axiomatising/re-referencing/re-intelligibilitysettingup/remeasuringinstrumenting-process,-in-<amplitudingfformativeepistemicity>totalising conceptualisation)' (as so-reflected with regards to prospective reontologising Being-development/ontological-framework-expansion-as-to-depth-ofontologising-development-as-infrastructure-of- meaningfulness-and-teleology psychologismic epistemic-acutisation difficulty-<or, residualising \{decompulsing $\}$ delinearity for cogeney $y$-magnitude $\{$ of-experientiality/experiment $\}$ as overarching 'registryworldview/dimension existentialising-framing-by-enframing/\{worlding $\}$ — ${ }^{8}$ reference-ofthought', and both institutional-development-as-to-social-function-development psychologismic epistemic-acutisation difficulty-<for, residualising ${ }_{\text {\{decompulsing }}$ delinearity $\sim$ for-cogeney $>$ magnitude ${ }^{\text {of-experientiality/experiment }\}}$ and living-developmentas-to-personality-development psychologismic epistemic acutisation difficulty<for, residualising \{decompulsing $\}$ delinearity for-cogency $>$ magnitude ${ }^{\{0 f-e x p e r i e n t i a l i t y / e x p e r i m e n t\}}$ as $<$ registryworldview/dimension existentialising framing by enframing/worlding thought $>$-undergirding-of-existentialising-framing-by-enframing/\{worlding $\}$-axiomaticconstructs). This effectively speaks of 're-ontologising-nascency-<as-of-prospectivesolipsistic/intersolipsistic-inkling-drive-for-knowledge-elucidation,-as-to-veridical-organicknowledge $>$ for sublimating-prolongation' as about the <postconverging-aporeticismovercoming/unovercoming >-enjoining of the successively educed re-ontologising of the overall relative-unreflexivity/relative-reflexivity ontological-contiguity $\sim$ of-the-humaninstitutionalisation-process $^{68}$ (as interceded/interspersed with successive 'existentially<disontologising/re-ontologising aporeticism $>$ manifest incidental/accidental reactive- 
sufferance/endurance in supposedly and paradoxically subordinating/subserving/collateralising the possibility for prospective re-ontologising-imbuing-of-prospective-humansublimating/emancipating/enfranchisement'), and so rather as of 'nonextricatory/postconverging ontologising-and-re-ontologising angling-of-imaginary demoronisation-<sublimating-nascence,-nonextricatory-sublimating-upstreaming/'amontée'>' sublimating-prolongation (over 'lifespan extricatory/preconverging psychical-nascency moronisation-<sublimating-nascence,-extricatory-desublimating-downstreaming/'avalage'>’); as so-reflecting ' nonpresencing-<perspective-ontological-normalcy/postconvergence $>$ epistemic-projection/construal (human-per-cep-ti-vi-ty-<as-to - notional perceptualisation-ofand-leashing-to_social-functioning-and-accordance-as-of-social-stake-contention-orconfliction>) of social-functioning-and-accordance-as-of-social-stake-contention-orconfliction construct' as of requisite 'effective ${ }^{45}$ foregrounding _entailment- $<$ in-succession-ofprofound-supererogation ${ }^{6}>-\langle$ postconverging-narrowing-down $\sim$ sublimation-as-to-'existenceas-sublimating-withdrawal/unenframing/re-ontologising,-elicited-from-prospective-profoundsupererogation '-in-reflecting-'immanent relative-unreflexivity/relative-reflexivity ontological-contiguity ';-as-operative-notional deprocrypticism> as of cogency_chronicularity/annality-of-relative-reflexivity,-as-to-profound-supererogation imbuing conceptivity/epistemic-reflexivity/epistemicity-relativism-determinism- $<$ reifying \{asto-knowledge-developing $\}$-and-empowering $>$. 'Human sovereign-function/posture-<as-toexistentially-manifest-`embodied-subject consciousness-and-direct/deferentialconscientiousness',-as-of-its-'epistemic-reflexivity/unreflexivity-in-existence'/teleology> consciousness/collective-consciousness', with respect to 'veridical notionality/epistemicity/bindingness ${ }^{<\text {as-to-determinism/conceptivity-of-relative-unreflexivity/relative-reflexivity }>}$ conception-of- ${ }^{5}$ meaningfulness-and-teleology" - (reflection upon the given 'existential<disontologising/re-ontelogising aporeticism $>$ ("baseline/nominalising/editional—aptitudinal underlay-<as-to-prior- 
capacitating-<for-existential-thematic> imbued interest/disinterest, investedness/disinvestment, exposure/lack-of-exposure, role/task participative-emplacement and relevance/irrelevance-andcapability/incapability-appraisal', as so-constrained-preconvergingly/postconvergingly-redementating/restructuring/reparadigming by elicitable human ontological-commitment ${ }^{66}$ and universal-transparency ${ }^{104}$ with respect to underlying human 'crossgenerational notional firstnaturedness-formativeness-<as-to-eventualising -inkling-drive - or - seedingmisprising $>$ mental-processing-parity for ontological-performance ${ }^{72}-<$ including-virtue-as- $^{2}$ ontology $>$ /morality/ethics/justice/etc.') as well as with respect to the notional/epistemic/bindingness as determinism/enceptivity of relative unreflexivity/relative reflexivity eliciting of 'prospective existential-<disontologising/re-ontologising aporeticism $>$ human sovereignemergence/becoming,-existentially-imbuing human-freedom-as-to-supererogating/surrealising for-'knowledge-empowerment-over-ignorance-disempowerment'-<as-of-'developing-andavailing-sovereign-sublimating_potential/possibilities/options/choices'-as-to-the'credibility’/'ontological-veracity'-underlying-the-'sovereign-conscious/conscientiousbackdrop'> consciousness/collective-consciousness': is rather reflective of the fact that (however counterintuitive to a ${ }^{79}$ presencing-absolutising-identitive-constitutedness predisposition) 'there is no singly arising of ${ }^{56}$ meaningfulness-and-teleology" (as wrongly implicited/explicited as of elaboration-as-to-mereextrapolating/constituting/abstracting/deducing/inferring-of-elucidation-outside'prospectively_implicited_attendant-ontological-contiguity ${ }^{67}$ ' educedexistentialising/contextualising/textualising_intelligibility/epistemicity/reflexivity-contiguity- 

meaningfulness-and-teleology'-reflex propositional-attitude). As such a 'supposedly singly arising conception-of- ${ }^{5}$ meaningfulness-and-teleology ${ }^{9}$, then falls into a ${ }^{79}$ presencingabsolutising-identitive-constitutedness ${ }^{14}$ predisposition that fails to reflect 'veridical notionality/epistemicity/bindingness ${ }^{-<a-t o-d e t e r m i n i s m / c o n c e p t i v i t y-o f-r e l a t i v e-u n r e f l e x i v i t y / r e l a t i v e-r e f l e x i v i t y>~}$ conception-of- ${ }^{5}$ meaningfulness-and-teleology" - (reflection upon the given 'existential< disontologising/re-ontologising aporeticism> ("baseline/nominalising/editional—aptitudinal underlay_<as-to-prior-

'baselining/cogency/reconstruing — aptitudinal overlay-<for-prospective- unblurriness-dragging-out $>$ ' -...reflected-as-

recurring $\sim$ existentialising-framing-by-enframing $/\{$ worlding $\}-<$ as-manifest-

individuative direct/deferential-transeffusive/worlding-looping > _ reflected-as_-supererogation 6 -

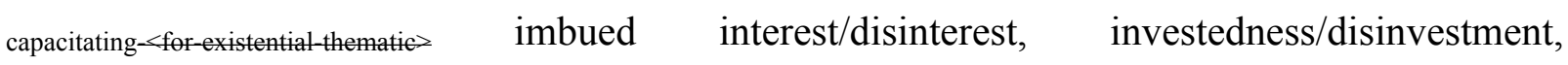
exposure/lack-of-exposure, role/task participative-emplacement and relevance/irrelevance-andcapability/incapability-appraisal'). As to the that human ${ }^{56}$ meaningfulness-and-teleology ${ }^{9}$ is actually and effectively underlied by 'successoral psychologismic-epistemic-acutisation-<as-topostconverging-de-mentating/structuring/paradigming,-eliciting-of-existence's-sublimatingnascence-in-prospective-aporeticism-overcoming/unovercoming $>$ as to epistemic-growth,-as\{veridical/sound\}-relative-reflexivity-in-existence/relativising from-limited-mentation-as-itsdeepening/psychologismic epistemic acutisation residualising, decompulsingl delinearity foreogency imbued 'cut-out-<as-to-re-ontologising redressing/straightening-out $>$ (as of relativereflexivity psychologismic-transfixity-<placeholder-setup-ontological-rescheduling - inrealigning/preactivity/formative-becoming/psychoanalytical-unshackling,-as-to-residualising$\{$ decompulsing\} $\}$ delinearity-over-nonresidualising_\{compulsing\} linearity $>$ ) for $\quad$ sublimatingprolongation'; so-underlining 'limitedness/human-subpotency prospective re-encountering/reconfrontation with unlimitedness/existence-<full-potency-of_sublimating nascence>' as to 
'limited-mentation-capacity-deepening—as-subjecting limitedness/human-subpotency-to'educed-unlimitedness/existence-sublimating nascence's3 for sublimating-prolongation' (and so-underlied as to the overarching construal/conceptualising of relative-unreflexivity/relativereflexivity - ontological-contiguity ${ }^{67} \quad$ 'existentially-<disontologising/re-ontologising aporeticism $>$ manifested as of the overall relative-unreflexivity/relative-reflexivity ontological-contiguity ${ }^{67}$ of-the-human-institutionalisation-process ${ }^{68}$ ). This (in reflection of the fact that 'enunciated propositions are of underlying manifest < registry-worldview/dimension existentialising framing by enframing/ worlding? reference-of thought $>$ - undergirding-of existentialising-framing-by-enframing/\{worlding $\}$ - axiomatic-constructs' and thus rather harkening back notionally/epistemically/bindingnessly-<as-to-determinism/conceptivity-of-relativeunreflexivity/relative-reflexivity $>$ to the sublimating-remoteness/distance-of-appraisal-<as-to-requisite-

\section{‘Being-development-notional self-distantiation’-imbued-psychologismic-epistemic-}

acutisation,-eliciting-of-prospective-ontologically-hegemonising-narrative >) points out that meaningfulness-and-teleology necessarily/effectively arises rather as of existentially$\leq$ disontologising/re-ontologising aporeticism $>\quad$ imbued 'notionally/epistemically/bindingnessly-<as-to-determinism/conceptivity-of-relative-unreflexivity/relative-reflexivitys circular <apriorising-for-aposteriorising,-in-existence $>$ - existentialising-framing-byenframing/\{worlding\}-<in-'educing/availing and-re-educing/re-availing of prospectiverelative-ontological-completeness $\stackrel{2}{\rightarrow}$ ' (as of limitedness/human-subpotency manifest aestheticisation-and-aestheticisation-towards-ontology-<elicited-idiomatisation $>\quad$ for meaningfulness-and-teleology ${ }^{9}$ ). Concretely, the 'veridical notionality/epistemicity/bindingness ${ }^{-<a s-t o-d e t e r m i n i s m / c o n c e p t i v i t y-o f-r e l a t i v e-u n r e f l e x i v i t y / r e l a t i v e-r e f l e x i v i t y s ~}$ conception-of- ${ }^{5}$ meaningfulness-and-teleology" - (reflection upon the given 'existential<disontologising/re-ontologising aporeticism> ("baseline/nominalising/editional—aptitudinal underlay<<as-to-priorunblurriness-reframing/reformulation/decatchmenting/detruncating/decompulsing/delinearising $>$ ' 
'baselining/cogency/reconstruing — aptitudinal overlay-for-prospective- unblurriness_dragging-out $>$ ’ $\rangle$-.... reflected-as-

recurring existentialising-framing-by-enframing/\{worlding $\}-<$ as-manifest-

individuative direct/deferential-transeffusive/worlding-looping $>$ _ reflected-as_-supererogation $0_{-}$

capacitating-<for-existential-thematic $>$ ) can be grasped as from the insight of the 'relatively innocent/uningrained/unenculturated national/epistemie/bindingness ${ }^{<a s-t o-d e t e r m i n i s m / c o n c e p t i v i t y-o f-~}$ relative-unreflexivity/relative-reflexivity $>$ perspective' of say a child's existential-<disontologising/reentologising aporeticism $>$ discovery of the notion of $1+1=2$. Wherein the child's appreciation (however faint) of such a notion of $1+1=2$ is more profoundly underlied by its appreciation that $1+1=2$ speaks to another social institutional practice but of practice-of-educating (different from its immediate family and community and people); as to all such institutions_-imbued-associatedindividuals existential-<disontologising/re-ontologising aporeticism $>$ prodding/eliciting-ofvarying-purposefulness-and-interests upon the child (reflected as its manifest notionally/epistemically/bindingnessly-as determinism/enceptivity of relative unneflexivity/relative reflexivitys given 'existential-<disontologising/re-ontelogising aporeticism $>$ 〈'baseline/nominalising/editional_ aptitudinal underlay-<as-to-prior-_ unblurriness $\sim$ reframing/reformulation/decatchmenting/detruncating/decompulsing/delinearising $>$ ' enabling 'baselining/cogency/reconstruing — aptitudinal overlay-<for-prospective- unblurriness-dragging-out $>$ ' $\rangle$ - reflected-asrecurring existentialising-framing-by-enframing/\{worlding $\}-<$ as-manifestindividuative $\sim$ direct/deferential-transeffusive/worlding-looping $>$ _reflected-as_-supererogation 6 capacitating-<for-existential-thematic $>$ ') as the child comes to discover/adopt such prodded/elicited varying purposefulness-and-interests as socially-construed as purposefully valuable; in reflection of the fact that the child is ever always notionally/epistemically/bindingnessly-<as-to-determinism/eoneeptivityef-relative-unreflexivity/relative-reflexivitys (as of its given 'existential-<disontologising/re-ontologisingaporeticism> 
recurring existentialising-framing-by-enframing/\{worlding $\}$-<as-manifest-

individuative -direct/deferential-transeffusive/worlding-looping $>$ _reflected-as_-supererogation 6 -

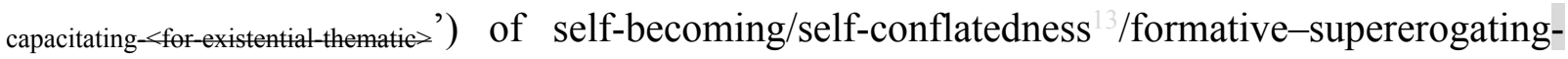
$<$ projective/reprojective - aestheticising-re-motif-and-re-apriorising/re-axiomatising/re-

referencing,-in-perspective-ontological-normalcy/postconvergence $>$. Interestingly, such a mere propositional representation of $1+1=2$ is rather effectively meaningless to an infant to which the requisite 'existential-<disontologising/re-ontologising aporeticism> ('baseline/nominalising/editional_-

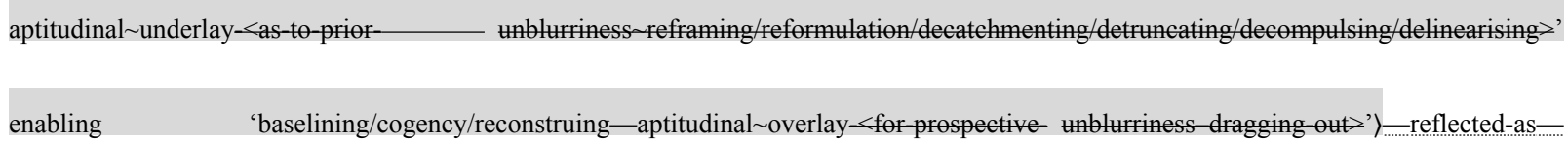
recurring existentialising-framing-by-enframing/\{worlding $\}$-<as-manifestindividuative -direct/deferential-transeffusive/worlding-looping > _reflected-as_-supererogation 6 capacitating-<for-existential-thematic $>$ ' for such a notional/epistemic/bindingness-<as-to-determinism/conceptivity-ofrelative-unreflexivity/relative-reflexivity> social/institutional practice-of-educating does not avail. And sounavailing as to the infant's notionally/epistemically/bindingnessly-<as-to-determinism/conceptivity-ofrelative-unreflexivity/relative-reflexivity> given 'existential-<disontologising/re-ontologising aporeticism> 〈'baseline/nominalising/editional—aptitudinal underlay-<as-to-prior-

unblurriness reframing/reformulation/decatchmenting/detruncating/decompulsing/delinearising $>$ ' enabling 'baselining/cogency/reconstruing — aptitudinal overlay-<for-prospective- unblurriness-dragging-out $>$ ' $\rangle$-..... reflected-as recurring existentialising-framing-by-enframing/\{worlding $\}$-<as-manifestindividuative-direct/deferential-transeffusive/worlding-looping $>$ _reflected-as - supererogation 6 capacitating-<for-existential-thematic $>\quad$ imbued interest/disinterest, investedness/disinvestment, exposure/lack-of-exposure, role/task participative-emplacement and relevance/irrelevance-andcapability/incapability-appraisal'; as so-constrained-preconvergingly/postconvergingly-redementating/restructuring/reparadigming by elicitable human ontological-commitment and universal-transparency ${ }^{104}$ with respect to underlying human 'crossgenerational 
notional firstnaturedness-formativeness-<as-to-eventualising-inkling-drive-or-seeding-

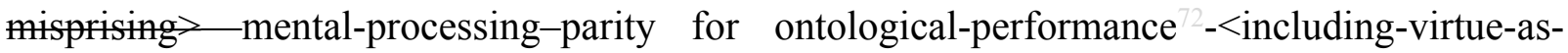
ontology $>$ /morality/ethics/justice/etc'. Likewise, (with respect to the sovereignfunction/posture-<as-to-existentially-manifest-'embodied-subject $\sim$ consciousness-and-

\section{direct/deferential-conscientiousness',-as-of-its-'epistemic-reflexivity/unreflexivity-in-}

existence'/teleology> existential-<disontologising/re-ontologising aporeticism> '<out-ofphasing $>$-disparate-narratives_of_social-functioning-and-accordance-as-of-social-stakecontention-or-confliction_construct manifesting-at-the-given — unblurriness/blurrinessthreshold framing/formulation/catchmenting/truncating/compulsing/linearising') it is rather as of the protracted-social—as-to-individual-by-institutional-by-social 'existential$<$ disontologising/re-ontologising aporeticism» $>$ ("baseline/nominalising/editional—aptitudinal underlay-<as-to-prior-

recurring existentialising-framing-by-enframing/\{worlding $\}$-<as-manifest-

individuative -direct/deferential-transeffusive/worlding-looping $>$ _reflected-as_-supererogation 0 -

capacitating-<for-existential-thematic $>$ ' (with respect to 'veridical notionality/epistemicity/bindingness ${ }^{<}$as-todeterminism/conceptivity-of-relative-unreflexivity/relative-reflexivity> conception-of- ${ }^{5}$ meaningfulness-andteleology ${ }^{\prime}$ ' in reflection of shallow-to-profound supererogation ${ }^{-}$- capacitating-<for-existentialthematic $>$ ) that varying human ${ }^{56}$ meaningfulness-and-teleology ${ }^{9}$ ontological-performance ${ }^{72}$ $<$ including-virtue-as-ontology $>$ /morality/ethics/justice/etc. arise. And sonotionally/epistemically/bindingnessly-<as-to-determinism/conceptivity-of-relative-unreflexivity/relative-reflexivity $>$ arising with regards to the 'educing-and-availing-and-re-availing of relative-ontologicalcompleteness ${ }^{8}$; with respect to unlimitedness/existence-<full-potency-of_sublimating nascence $>$ prospective apriorising/axiomatising/referencing-sublimating-reflexivitybeholdening under which limitedness/human-subpotency submits in profound-supererogation 
for prospective sublimating'). Speaking to the 'relative-unreflexivity/relative-reflexivitybindingness/nondiscretionariness-<as-from-sublimating remoteness/distance-of-appraisal-ofrequisite $\sim$ Being development $>$ of unlimitedness/existence-<full-potency-of_sublimating nascence $>$ ' - (as to 'relative-unreflexivity/relative-reflexivity limitedness/human-subpotency dynamics of supererogating \{affirmation/projection/assertion/notional $\sim$ self-distantiation-byunaffirmation/deprojection/deassertion/epistemic-decadence \}-towards -omnipotentialaffirmation/projection/assertion/notional self-distantiation' with respect to 'limitedness/humansubpotency prospective re-encountering/re-confrontation with unlimitedness/existence-<fullpotency-of_sublimating nascence $>$ '); and so, as to its relative-reflexivity as from prospective re-ontologising Being-development/ontological-framework-expansion-as-to-depth-ofontologising-development-as-infrastructure-of- meaningfulness-and-teleology psychologismic epistemic acutisation difficulty < for, residualising \{decompulsing\} delinearity for-cogency>-magnitude\{of-experientiality/experiment\}, then institutionaldevelopment-as-to-social-function-development psychologismic epistemic-acutisationdifficulty-for, residualising \{decompulsing\} delinearity for-cogency> magnitude $\{$ ofexperientiality/experiment\} and then living-development-as-to-personality-development psychologismic epistemic acutisation diffieuly <for, residualising \{decompulsing\} delinearity for-cogeney>-magnitude\{of-experientiality/experiment\}. This can further be elucidated (and as it is equally pertinent as to the prospective relative-unreflexivity of our positivism- ${ }^{80}$ procrypticism/disjointedness-as-of- ${ }^{83}$ reference-of-thought 'mélée_of_supposedlysingly conception-of- ${ }^{5}$ meaningfulness-and-teleology ${ }^{9}, \quad{ }^{79}$ presencing-absolutisingidentitive-constitutedness ${ }^{14}$ predisposition) with regards to the patent case of say a God-of-plane conception or superstitious conception of modern medicine in an animistic social-setup that cannot simply be construed as supposedly 'explained away by a circumstantial thorough positivism/rational-empiricism elucidation of how a plane or positivism/rational-empiricism 
medicine works' (as of such 'mélée_of_supposedly-singly conception-of-5 meaningfulnessand-teleology ${ }^{9}$ - - reflex $\sim$ propositional-attitude) since such an animistic social-setup existentialising-frame-of-entailment-of motif-and-apriorising/axiomatising/referencing is rather existentially-<disontologising/re-ontologising aporeticism $>$ of a nonpositivistic overarching 'registry-worldview/dimension existentialising-framing-byenframing/\{worlding $\}$ - ${ }^{83}$ reference-of-thought' (with regards to its notionally/epistemically/bindingnessly ${ }^{-a s-t o-d e t e r m i n i s m / c o n c e p t i v i t y-o f-r e l a t i v e-u n r e f l e x i v i t y / r e l a t i v e-r e f l e x i v i t y>~}$ given 'existential-<disøntologising/re-ontølogising apøreticism> ('baseline/nominalising/editionalaptitudinal underlay-<as-to-prior-_unblurriness $\sim$ reframing/reformulation/decatchmenting/detruncating/decompulsing/delinearising $>$ ' enabling 'baselining/cogency/reconstruing — aptitudinal overlay-<for-prospective- unblurriness-dragging-out $>$ ' $\rangle$-..reflected-asrecurring existentialising-framing-by-enframing/\{worlding $\}$-<as-manifest-

individuative direct/deferential-transeffusive/worlding-looping $>$ _ reflected-as_-supererogation 6 capacitating-<forexistential-a '); as the animistic nonpositivistic overarching 'registryworldview/dimension existentialising-framing-by-enframing/\{worlding $\}$ - ${ }^{8}$ reference-ofthought' is bound existentially-<disontologising/re-ontologising aporeticism $>$ to psychologismically fallback/relapse into its nonpositivistic articulated 'enunciated propositions as of underlying manifest <registry-worldview/dimension existentialising framing by enframing/fworlding; reference-of thought $>$ undergirding-of-existentialising-framing-byenframing/\{worlding\} - axiomatic-constructs' (in reflection of such underlying nonpositivistic Being-development/ontological-framework-expansion-as-to-depth-of-ontologisingdevelopment-as-infrastructure-of- meaningfulness-and-teleology psychologismic epistemic acutisation difficulty-for, residualising \{decompulsing $\}$ delinearity for-cogency> magnitude\{of-experientiality/experiment\} notionally/epistemically/bindingnessly-<as-to-determinism/eonceptivityof relative unreflexivity/relative reflexivitys given 'existential-<disontologising/re-ontologising aporeticism> 
capacitating-<for-existential-thematic >). This overall insight highlights that (as reflecting relativeunreflexivity/relative-reflexivity_ontological-contiguity ${ }^{77} \quad$ existentially-< $<$ disontologising/reentologising aporeticism $>$ manifested as of the overall relative-unreflexivity/relativereflexivity - ontological-contiguity ${ }^{67} \sim$ of-the-human-institutionalisation-process ${ }^{68}$ ) in-effect human " meaningfulness-and-teleology" is not notionally/epistemically/bindingnessly-<as-todeterminism/conceptivity-of-relative-unreflexivity/relative-reflexivitys differentiable' from the 'palpable dissolving/decentering of the conscious-self/collective-conscious-self that sonotionally/epistemically/bindingnessly-<as-to-determinism/conceptivity-of-relative-unreflexivity/relative-reflexivity> allows for organic-knowledge; with respect to 'veridical notionality/epistemicity/bindingness' $\leq a s-t o-d e t e r m i n i s m / c o n c e p t i v i t y-o f-r e l a t i v e-u n r e f l e x i v i t y /$ relative-reflexivity $>$ conception-of- -5 meaningfulness-andteleology',-(reflection upon the given 'existential-<disontologising/re-ontologising aporeticism> capacitating-<for-existential-thematic $>$. So-underlining the 'protracted-social-as-toindividual-by-institutional-by-social notional/epistemie/bindingness relative-unreflexivity/relative-reflexivity self-becoming/self-conflatedness ${ }^{13}$ /formative-supererogating- 
notional/epistemic/bindingness ${ }^{- \text {as-to-determinism/conceptivity-of-relative-unreflexivity/relative-reflexivitys }}$

nonpresencing-<perspective-ontological-normalcy/postconvergence $>$ ) that veridically undergirds the relative-unreflexivity/relative-reflexivity-ontological-contiguity ${ }^{67}$ of meaningfulness-and-teleology ${ }^{9}$. The very scope of protracted-social-as-to-individual-byinstitutional-by-social 're-ontologising-nascency-<as-of-prospective-solipsistic/intersolipsisticinkling-drive-for-knowledge-elucidation,-as-to-veridical-organic-knowledge $>$ for sublimatingprolongation' (as to 'nonextricatory/postconverging ontologising-and-re-ontologising anglingof-imaginary demoronisation- $<$ sublimating-nascence,-nonextricatory-sublimatingupstreaming/'amontée'>' sublimating-prolongation), thus speaks effectively to human existential-<disontologising/re-ontologising aporeticism $>$ rediscovery/regenerating: with respect to 'veridical notionality/epistemicity/bindingness ${ }^{<\text {as-to-determinism/conceptivity-of-relative- }}$ unreflexivity/relative-reflexivity> conception-of- ${ }^{56}$ meaningfulness-and-teleology ${ }^{9}$ - - (reflection upon the given 'existential-<disontologising/re-ontologising aporeticism> 〈'baseline/nominalising/editional_aptitudinal underlay-<as-to-prior-_unblurriness $\sim$ reframing/reformulation/decatchmenting/detruncating/decompulsing/delinearising $>$ '

recurring existentialising-framing-by-enframing/\{worlding $\}-<$ as-manifest-

individuative $\sim$ direct/deferential-transeffusive/worlding-looping $>$ _reflected-as_-supererogation 6 capacitating-<for-existential-thematic $>$ ') with regards to 'the-very-same purview/devolvedpurview/devolving-purview-of-unlimitedness/existence-<full-potency-of_sublimating nascence>;-_implicited_attendant-ontological-contiguity ${ }^{67}$ ' educedexistentialising/contextualising/textualising_'intelligibility/epistemicity/reflexivity_contiguity$<$ imbued-notional cogency $>^{\prime}$. And so, expandable in relation to the notional/epistemic/bindingness 'formativeness-<as-to-intersolipsism-of-preformulating/preframing/premeaningfulness- 
imbued-mediativity-and-deferentialism>-of- meaningfulness-and-teleology and existential< disontologising/re-ontologising aporeticism $>$ articulation manifestations (undergirding 'catchmented-and-compulsed-<in-'existential-dearth-of-demoronisation',-so-construed-asfrom-ontological-normalcy/postconvergence-perspective-reflection-of-the-`destructuringthreshold_of-the-given-level's-conjugated-postlogism as-dementing'> interpersonal, group, intergroup, community, local, national, political, geostrategic, etc. psychologismic epistemicacutisation difficulty-for, residualising \{decompulsing $\}$ delinearity for-cogency> levels of interrelatedness-dynamics-of-social-constructing' as underlied by apriorising- ${ }^{83}$ reference-ofthought/apriorising-registry_elements- \{ individuation —effusing/worlding imbued logical-dueness-or-scape-or-frame, profile-or-stature, presumptuousness-or-arrogation, assumptions, value-reference and teleology $\left.\left.{ }^{9}\right\}\right)^{\prime}$. This most fundamental reality speaks to 'limitedness/human-subpotency prospective re-encountering/reconfrontation with unlimitedness/existence-<full-potency-of_sublimating nascence $>$ ' with respect to 'veridical notionality/epistemicity/bindingness

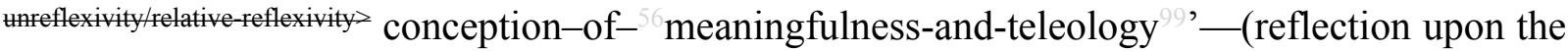
given 'existential<<disontologising/re-ontologising aporeticism> 〈'baseline/nominalising/editional_ aptitudinal underlay-<as-to-prior-_ unblurriness $\sim$ reframing/reformulation/decatchmenting/detruncating/decompulsing/delinearising $>$ ' enabling 'baselining/cogency/reconstruing — aptitudinal overlay-<for-prospective- unblurriness-dragging-out $>$ ' recurring $\sim$ existentialising-framing-by-enframing/\{worlding $\}$-<as-manifestindividuative -direct/deferential-transeffusive/worlding-looping $>$ _reflected-as - supererogation 0 capacitating-<for-existential-thematic >') for the veridical construing/conceptualising of the 'protractedsocial-as-to-individual-by-institutional-by-social ontological-performance ${ }^{2}-<$ includingvirtue-as-ontology $>/$ morality/ethics/justice/etc'. And so, over the relative-unreflexivity of implicited/explicited elaboration-as-to-mereextrapolating/constituting/abstracting/deducing/inferring-of-elucidation-outside- 
'prospectively_implicited_attendant_ontological-contiguity ${ }^{67}$ ' educedexistentialising/contextmalising/textualising_'intelligibility/epistemicity/reflexivity_contiguity<imbued-notional cogency>' 'mélée_of_supposedly-singly conception-ofmeaningfulness-and-teleology , -reflex $\sim$ propositional-attitude as bound to induce disparateness-of-conceptualisation-<unforegrounding-ment,-failing-prospectively-to-reflect‘immanent relative-unreflexivity/relative-reflexivity ontological-contiguity '> (in failing to reflect 'veridical notionality/epistemicity/bindingness ${ }^{<\text {as-to-determinism/eonceptivity-of-relative- }}$

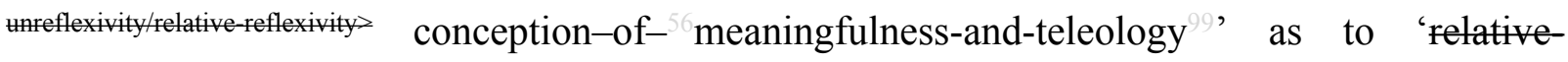
unreflexivity/relative-reflexivity - ontological-contiguity ${ }^{77}$ of the overall relativeunreflexivity/relative-reflexivity — ontological-contiguity ${ }^{67}$ of-the-human-institutionalisationprocess ${ }^{6}$ ' implied conception of the notion of relativism). Thusly, emphasising the fact that the sovereign-function/posture-<as-to-existentially-manifest-'embodied-subject $\sim$ consciousnessand-direct/deferential-conscientiousness',-as-of-its- 'epistemic-reflexivity/unreflexivity-inexistence'/teleology> existential-<disontologising/re-ontologising aporeticism $>\quad$ '<out-ofphasing $>$-disparate-narratives_of_social-functioning-and-accordance_-as-of-social-stakecontention-or-confliction_construct manifesting-at-the-given- unblurriness/blurrinessthreshold framing/formulation/catchmenting/truncating/compulsing/linearising' are rather veridically construable with respect to "veridical notionality/epistemicity/bindingness ${ }^{<a s-t o-}$ determinism/conceptivity-of-relative-unreflexivity/relative-reflexivity> conception-of- - meaningfulness-andteleology',-(reflection upon the given 'existential-<disentologising/re-ontelogising aporeticism> 
capacitating-<for-existential-thematic $>$ '). And so-construable notionally/epistemically/bindingnessly-<as-todeterminism/conceptivity-of-relative-unreflexivity/relative-reflexivity $>$ as to the (sovereign-function/posture- $<$ as-toexistentially-manifest-'embodied-subject consciousness-and-direct/deferentialconscientiousness',-as-of-its-'epistemic-reflexivity/unreflexivity-in-existence'/teleology> existential-<disontologising/re-ontologising aporeticism $>\quad<$ out-of phasing $>$ disparatenarratives_of_social-functioning-and-accordance_-as-of-social-stake-contention-orconfliction_construct manifesting-at-the-given — unblurriness/blurrinessthreshold framing/formulation/catchmenting/truncating/compulsing/linearising') imbued disontologising/subontologising — unculturated/enculturated/subculturated elasticity/margin/threshold/circumstantiality-of-discretionariness-from/acceding-to’ $<$ developed/developing $>$-relation with prospective re-ontologising 'ontologicallyhegemonising-narrative ontological-performance ${ }^{72}$-<including-virtue-asontology $>$ /morality/ethics/justice/etc.' - (with reference to notional/epistemic/bindingness ${ }^{<a s-t o-}$ determinism/enceptivity of relative unreflexivity/relative reflexivity 'parrhesiastic/messianicity/profoundsupererogation projection for sublimating-prolongation'). In this respect, it should be appreciated that prospective re-ontologising 'ontologically-hegemonising-narrative ontological-performance ${ }^{72}$-<including-virtue-as-ontology $>$ /morality/ethics/justice/etc.'- (with reference to notional/epistemic/bindingness-<as-to-determinism/conceptivity-of-relative-unreflexivity/relativereflexivitys 'parrhesiastic/messianicity/profound-supererogation projection for sublimatingprolongation') effectively speaks (as to 're-ontologising-nascency-<as-of-prospectivesolipsistic/intersolipsistic-inkling-drive-for-knowledge-elucidation,-as-to-veridical-organicknowledge $>$ for sublimating-prolongation') to: the prospectively implicited/explicited psychologismic-epistemic-acutisation-<as-to-postconverging-dementating/structuring/paradigming,-eliciting-of-existence's-sublimating-nascence-inprospective-aporeticism-overcoming/unovercoming> as to epistemic-growth,-as 
\{veridical/sound\}-relative-reflexivity-in-existence/relativising from-limited-mentation-as-itsdeepening/psychologismic epistemic acutisation residualising, ${ }^{\text {fdecompulsing }}$ delinearity for eogency imbued 'cut-out-<as-to-re-ontologising redressing/straightening-out $>$ (as of relativereflexivity psychologismic-transfixity-<placeholder-setup-ontological-rescheduling - inrealigning/preactivity/formative-becoming/psychoanalytical-unshackling,-as-to-residualising$\{$ decompulsing\} $\}$ delinearity-over-nonresidualising_\{compulsing\} $\}$ linearity $>$ ) for $\quad$ sublimatingprolongation'. As so cutting-out-<as-to-re-ontologising redressing/straightening-out $>$ the moronisation-<sublimating-nascence,-extricatory-desublimating-downstreaming/'avalage' of 'existentially-disontologising/re-ontologising aporeticism $>$ manifest incidental/accidental reactive-sufferance/endurance in supposedly and paradoxically subordinating/subserving/collateralising the possibility for prospective re-ontologisingimbuing-of-prospective-human-sublimating/emancipating/enfranchisement'; effectively manifested as to the (sovereign-function/posture-<as-to-existentially-manifest-'embodiedsubject $\sim$ consciousness-and-direct/deferential-conscientiousness',-as-of-its- 'epistemicreflexivity/unreflexivity-in-existence'/teleology> existential-<disontologising/reentologising aporeticism $>$ ' $<$ out-of-phasing $>$-disparate-narratives_of_social-functioning-andaccordance-as-of-social-stake-contention-or-confliction_construct manifesting-at-thegiven - unblurriness/blurriness-

threshold framing/formulation/catchmenting/truncating/compulsing/linearising') imbued disontologising/subontologising_unculturated/enculturated/subculturated elasticity/margin/threshold/circumstantiality-of-discretionariness-from/acceding-to’ <developed/developing $>$-relation with prospective re-ontologising 'ontologicallyhegemonising-narrative

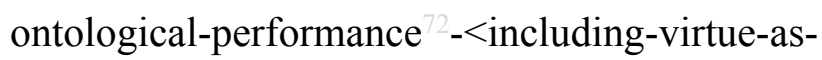
ontology $>$ /morality/ethics/justice/etc.' - (with reference to notional/epistemic/bindingness ${ }^{<a s-t o-}$ determinism/conceptivity-of-relative-unreflexivity/relative-reflexivity> 'parrhesiastic/messianicity/profound- 
supererogation projection for sublimating-prolongation'). Effectively, psychologismic-. epistemic-acutisation-<as-to-postconverging-de-mentating/structuring/paradigming,-elicitingof-existence's-sublimating-nascence-in-prospective-aporeticism-overcoming/unovercoming> as to epistemic-growth,-as - \{veridical/sound\}-relative-reflexivity-in-existence/relativising from-limited-mentation-as-its-deepening/psychologismic epistemic-acutisationresidualising, ${ }^{\{d e c o m p u l s i n g\}}$ \}elinearity for-cogency imbued 'cut-out-<as-to-re-ontologising redressing/straightening-out $>$ (as of relative-reflexivity psychologismic-transfixity$<$ placeholder-setup-ontological-rescheduling — in-realigning/preactivity/formativebecoming/psychoanalytical-unshackling,-as-to-residualising-\{decompulsingl $d$ delinearity-overnonresidualising-\{compulsing linearity $>$ ) for sublimating-prolongation': so-arises rather withinthe-scope-of/with-respect-to 'veridical notionality/epistemicity/bindingness ${ }^{<\text {as-to- }}$ determinism/conceptivity-of-relative-unreflexivity/relative-reflexivity $\quad$ conception-of- - meaningfulness-andteleology',-(reflection upon the given 'existential-<disentelogising/re-ontelogising aporeticism> 〈'baseline/nominalising/editional—aptitudinal underlay-<as-to-priorunblurriness $\sim$ reframing/reformulation/decatchmenting/detruncating/decompulsing/delinearising $>$ enabling 'baselining/cogency/reconstruing — aptitudinal overlay-<for-prospective- unblurriness-dragging-out $>$ ’ _-...reflected-as_-... recurring existentialising-framing-by-enframing/\{worlding $\}$-<as-manifestindividuative direct/deferential-transeffusive/worlding-looping $>$ _reflected-as_-supererogation 0 capacitating-<for-existential-thematic >') for the veridical construing/conceptualising of the 'protractedsocial - as-to-individual-by-institutional-by-social ontological-performance ${ }^{72}<$ including- $^{2}$ virtue-as-ontology $>$ /morality/ethics/justice/etc.'. So-undergirding 'prospective existential<disontologising/re-ontologising aporeticism $>$ human sovereign-emergence/becoming,existentially-imbuing human-freedom-as-to-supererogating/surrealising-for-'knowledgeempowerment-over-ignorance-disempowerment'-<as-of-'developing-and-availing-sovereignsublimating_potential/possibilities/options/choices'-as-to-the-'credibility'/'ontological- 
veracity'-underlying-the-'sovereign-conscious/conscientious-backdrop'>

consciousness/collective-consciousness'; as so-overcoming/superseding the (sovereignfunction/posture-<as-to-existentially-manifest-“embodied-subject $\sim$ consciousness-and-

direct/deferential-conscientiousness',-as-of-its-'epistemic-reflexivity/unreflexivity-in-

existence'/teleology $>\quad$ existential-<disontologising/re-ontologising aporeticism $>\quad$ '<out-ofphasing $>$ disparate-narratives_of_social-functioning-and-accordance-as-of-social-stake-

contention-or-confliction_construct manifesting-at-the-given- unblurriness/blurrinessthreshold framing/formulation/catchmenting/truncating/compulsing/linearising') imbued disontologising/subontologising — unculturated/enculturated/subculturated elasticity/margin/threshold/circumstantiality-of-discretionariness-from/acceding-to’ <developed/developing $>$-relation with prospective re-ontologising 'ontologicallyhegemonising-narrative ontological-performance ${ }^{2}-<$ including-virtue-asontology $>$ /morality/ethics/justice/etc.' - (with reference to notional/epistemic/bindingness ${ }^{-<a-t o-}$ determinism/cenceptivity of relative unreflexivity/relative reflexivity> 'parrhesiastic/messianicity/profoundsupererogation projection for sublimating-prolongation'). And so-manifested as of relativeontological-completeness ${ }^{87}$-of-apriorising/axiomatising/referencing as rather 'existentiallyslisentologising/re ontologising aporeticism> understood-<as-epistemictotalisingly /acutely_translating-into-the-mental-aestheticising-metaphoricity >’ by its given sunderlaid/substrated-'thrownness-aestheticising' \{of-relative-unreflexivity-in-existence\}> profusion-of preconverging-prior-relative-ontological-incompleteness ${ }^{88}$-ofapriorising/axiomatising/referencing — by_<overlaying/superstrating 'thrownnessaestheticising' \{of-relative-reflexivity in-existence\}>-sparsity-of postconverging prospectiverelative-ontological-completeness ${ }^{8}$-of-apriorising/axiomatising/referencing as to underlying $<$ amplituding/formative-epistemicity $>$-totalising $\sim$ thrownness-in-existence mentalaestheticising-<as-'psychologismic-existential-metaphoricity \{as-to-\{epistemic-totalising ‘ُ 
apriorising/re-axiomatising/re-referencing_in-becoming\}' -so-implicited-'by-way-of-the-

existentially/contextually/textually-manifest-motif-construct-as-specific-language'-as-so-

reflecting-'the-existentially/contextually/textually-manifest-moronisation/demoronisation'>

imbued re-ontologising-by-disontologising_existential-calculus-〈between 'prospective existentialising_-postconverging_framing/imprinting re-ontologising' and 'prior existentialising_-preconverging_enframing/imprintedness social-functioning-andaccordance-as-of-social-stake-contention-or-confliction'〉' (but not understood as of supposedly 'unlimitedness/existence-<full-potency-of_sublimating nascence $>$ absoluteontological-completeness-of-apriorising/axiomatising/referencing-<as-omnipotentiality $>$ $<$ amplituding/formative-epistemicity $>$-totalising thrownness-in-existence ${ }^{35}$ imbued absolute $\sim$ difference-conflatedness ${ }^{13}$-as-to-totalitative-reification-in-singularisation- $<$ as-to-thenondisjointedness/entailment-of-prospective- nonpresencing $>$-as-veridical-epistemicityrelativism-determinism so-construed as 'absolute reference of identity' as failing to project of its own possible prospective relative-ontological-incompleteness ${ }^{8}$-ofapriorising/axiomatising/referencing). The fundamental reality with respect to 'veridical notionality/epistemicity/bindingness ${ }^{-<a s-t o-d e t e r m i n i s m / e o n c e p t i v i t y-o f-r e l a t i v e-u n r e f l e x i v i t y / r e l a t i v e-r e f l e x i v i t y>~}$ conception-of- meaningfulness-and-teleology" - (reflection upon the given 'existential$\leq$ disontologising/re-ontologising aporeticism> $>$ ("baseline/nominalising/editional—aptitudinal underlay-<as-to-priorunblurriness $\sim$ reframing/reformulation/decatchmenting/detruncating/decompulsing/delinearising ${ }^{\prime}$ enabling ‘baselining/cogency/reconstruing — aptitudinal overlay-<for-prospective- unblurriness-dragging-out $>$ ’ $\rangle$ - reflected-as-.... recurring existentialising-framing-by-enframing/\{worlding $\}$-<as-manifestindividuative -direct/deferential-transeffusive/worlding-looping > _reflected-as_-supererogation 0 -

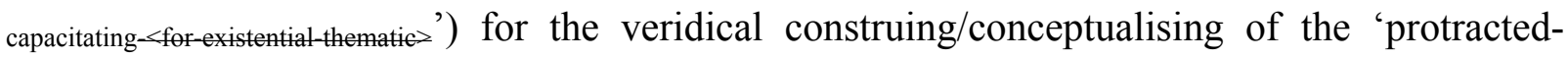
social - as-to-individual-by-institutional-by-social $\quad$ ontological-performance ${ }^{72}<$ including- $^{2}$ virtue-as-ontology $>$ /morality/ethics/justice/etc': equally speaks to the incredulity/unscientific- 
basis (as to the relative-unreflexivity of implicited/explicited elaboration-as-to-mereextrapolating/constituting/abstracting/deducing/inferring-of-elucidation-outside-

'prospectively_implicited_attendant-ontological-contiguity ${ }^{67}$ ' educed-

existentialising/contextualising/textualising_'intelligibility/epistemicity/reflexivity-contiguity-

<imbued-notional cogency>' 'mélée_of_supposedly-singly conception-ofmeaningfulness-and-teleology ${ }^{\circ}$-reflex $\sim$ propositional-attitude) appraisal of human consciousness/collective-consciousness. So-appraising human consciousness/collectiveconsciousness as 'implicitly/explicitly objectifiable-as-nonframed/absolute-<as-unreflexivelyimpliciting of a-supposedly 'abselutising framing' $>$ ', as to a paradox with regards to 'where the consciousness that so appraises stands out from' (with such a 'mélée_of_supposedlysingly conception-of $-{ }^{5}$ meaningfulness-and-teleology ${ }^{\circ}$ - reflex $\sim$ propositional-attitude). This effectively fails to reflect relative-unreflexivity/relative-reflexivity with respect to "veridical notionality/epistemicity/bindingness ${ }^{<a s-t 0-d e t e r m i n i s m / c o n c e p t i v i t y-o f-r e l a t i v e-u n r e f l e x i v i t y / r e l a t i v e-r e f l e x i v i t y>~}$ conception-of- ${ }^{5}$ meaningfulness-and-teleology '- (reflection upon the given 'existential-

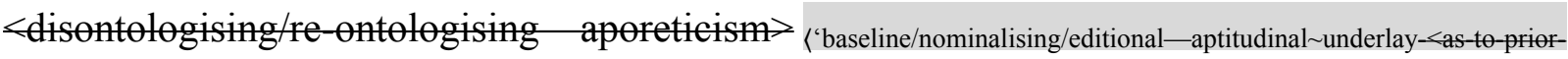

capacitating-<for-existential-thematic ’') undergirding human consciousness/collective-consciousness'; with regards to 'protracted-social—as-to-individual-by-institutional-by-social notional/epistemic/bindingness ${ }^{<a s-t o-d e t e r m i n i s m / c o n c e p t i v i t y-o f-r e l a t i v e-u n r e f l e x i v i t y / r e l a t i v e-r e f l e x i v i t y ~}>\quad$ self-

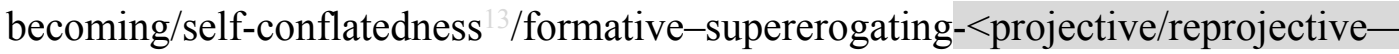
aestheticising-re-motif-and-re-apriorising/re-axiomatising/re-referencing,-in-perspectiveontological-normalcy/postconvergence $>$ (as of notional/epistemic/bindingness $<$ ss-to- 
normalcy/postconvergence $>$ ) that veridically undergirds ${ }^{56}$ meaningfulness-and-teleology ${ }^{9}$. Human consciousness/collective-consciousness as such can only always be internal (in reflection of limitedness/human-subpotency inherently imbued 'notional/epistemic/bindingness'<as-todeterminism/conceptivity-of-relative-unreflexivity/relative-reflexivity> human-consciousness/collectiveconsciousness-distendedness/detruncating- $<$ beyond-selfpresencing,-as-re-ontologisingdecentering_of-consciousness/collective-consciousness,-as-to-psychologismic-epistemic-

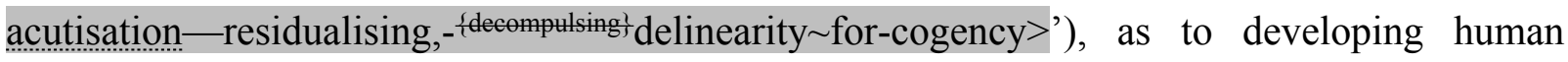
'existential-<disontologising/re-ontologising aporeticism> 〈'baseline/nominalising/editionalaptitudinal underlay-<as-to-priorunblurriness reframing/reformulation/decatchmenting/detruncating/decompulsing/delinearising $>$ '

recurring existentialising-framing-by-enframing/\{worlding $\}$-<as-manifest-

individuative - direct/deferential-transeffusive/worlding-looping $>$ _reflected-as_-supererogation 6 -

capacitating-<for-existential-thematic $>$ in manifest relative-unreflexivity/relative-reflexivity' (with regards to limited-mentation-capacity-deepening —as-subjecting limitedness/human-subpotency-to'educed-unlimitedness/existence-sublimating nascence' ${ }^{33}$ as to recurrently-driven limitedness/human-subpotency prospective re-encountering/re-confrontation with the 'constraining/defining intersolipsistic reflexive-sublimating/unreflexive-desublimating measure/objectification that is unlimitedness/existence-as-ontologicalnormalcy/postconvergence-<in-validation-of-'metaphysics-of-absence_epistemic-

projection'>'). Such that just as 'there is nothing outside of existence', it is human consciousness/collective-consciousness that is inherently the manifest-outleting of 'human meaningfulness-and-teleology and intelligibility-〈as-to-human-projective/reprojectiveaestheticising-re-motif-and-re-apriorising/re-axiomatising/re-referencing/reintelligibilitysettingup/re-measuringinstrumenting-process,-in-<amplituding/formative- 
determinism/cenceptivity of-relative-nnreflexivity/relative-reflexivitys reflection of unlimitedness/existence-<fullpotency-of_sublimating nascence>', as so-concurrently (with regards to consciousness 'relative-unreflexivity/relative-reflexivity in existence' as its imbued manifest phasing with existence) underlying the 'coherence/contiguity of the superseding-oneness-ofontology/ontological-veridicality/relative-unreflexivity/relative-reflexivity - ontologicalcontiguity ${ }^{67}$. As human consciousness/collective-consciousness 'so-manifests its notional/epistemic/bindingness $<a s-$ to-detminism/conceptivity-of-relative-mreflexivity/relative-reflexivityz limitedness/human-subpotency relative-unreflexivity/relative-reflexivity in existence', underlied by the fact that there is no human " meaningfulness-and-teleology ${ }^{\circ}$ and intelligibility〈as-to-human-projective/reprojective - aestheticising-re-motif-and-re-apriorising/reaxiomatising/re-referencing/re-intelligibilitysettingup/re-measuringinstrumenting-process,-in<amplituding/formative-epistemicity>totalising conceptualisation〉' outside human consciousness/collective-consciousness but for the potentiation within the scope of "veridical notionality/epistemicity/bindingness ${ }^{<\text {as-to-determinism/conceptivity-of-relative-unreflexivity/relative-reflexivity }>}$ conception-of- ${ }^{5}$ meaningfulness-and-teleology ${ }^{9}$ '-(reflection upon the given 'existential$<$ disontologising/re-ontelogising aporeticism $>$ ("baseline/nominalising/editional—aptitudinal underlay-<as-to-priorunblurriness $\sim$ reframing/reformulation/decatchmenting/detruncating/decompulsing/delinearising ${ }^{\prime}$ enabling 'baselining/cogency/reconstruing — aptitudinal overlay-<for-prospective- unblurriness-dragging-out $>$ ' $\rangle$ - reflected-asrecurring existentialising-framing-by-enframing/\{worlding $\}-<$ as-manifestindividuative direct/deferential-transeffusive/worlding-looping > _reflected-as_-supererogation 0 capacitating-<forenistential '); and so, in accordance with the 'underlying overall reifying-andempowering-reflexivity-of-ecstatic-existence-as-panintelligibility/panreflexivity ${ }^{73}$ 〈existentially-imbued-and-educing-<fepistemictotalising thermeneutically/textually/reprojectingly/supererogatingly/zeroingly/re-acutingly,- 
$\{$ decompulsing $\}$ delinearity $\sim$ for-cogency $\geq$-epistemic-perspective-of-projective/reprojective-

aestheticising-re-motif-and-re-apriorising/re-axiomatising/re-referencing $\sim$ conceptualisation-as-herein-specifically-relevant-to human-subpotency)'). Interestingly thus, human consciousness/collective-consciousness (as manifest-outleting of 'human ${ }^{56}$ meaningfulness-andteleology and intelligibility-〈as-to-human-projective/reprojective-aestheticising-re-motifand-re-apriorising/re-axiomatising/re-referencing/re-intelligibilitysettingup/remeasuringinstrumenting-process,-in-<amplituding/formativeepistemicity $>$ totalising conceptualisation $\rangle$ in its determinism/conceptivity-of-relative-unreflexivity/relative-reflexivitys reflection of unlimitedness/existence-full potency-of_sublimating nascence>') is not differentiable/cannot-stand-out from the 'palpable dissolving/decentering of the conscious-self/collective-conscious-self that sonotionally/epistemically/bindingnessly-as-to-determinism/conceptivity-of-relative-mneflexivity/relative-reflexivitys allows for organic-knowledge; with respect to 'veridical notionality/epistemicity/bindingness' $\leq$ as-to-determinism/conceptivity-of-relative-unreflexivity/relative-reflexivity $>$ conception-of- -56 meaningfulness-andteleology' - (reflection upon the given 'existential-disontologising/re-ontologising aporeticism>

'baselining/cogency/reconstruing — aptitudinal overlay-<for-prospective- unblurriness-dragging-out $>$ ' $\rangle$ - reflected-as-

recurring existentialising-framing-by-enframing/\{worlding $\}$-<as-manifest-

individuative direct/deferential-transeffusive/worlding-looping $>$ _reflected-as_-supererogation 6 -

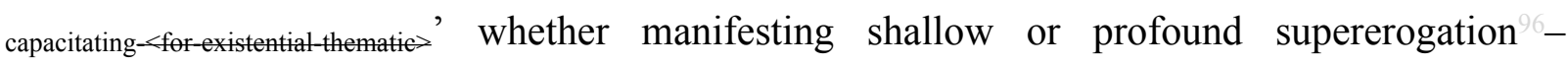
capacitating-<for-existential-thematic $>$ ). Thus so-validating the fact that human consciousness/collective-consciousness rather arises 'existentially-disontologising/reentelogising apereticism $>$ and organically' as to the '<amplituding/formative-epistemicity $>$ totalising thrownness-in-existence ${ }^{35}$ locus/station of limitedness/human-subpotency social- 
functioning-and-accordance-as-of-social-stake-contention-or-confliction' as so-reflected above with the respectively given child, infant and nonpositivism/non-rational-empiricism animistic registry-worldview respective notionally/epistemically/bindingnessly-<s-to-

determinism/conceptivity-of-relative-unreflexivity/relative-reflexivity $>$ entologising aporeticism>

$$
\text { given 'existential-<disontologising/re- }
$$

\section{recurring $\sim$ existentialising-framing-by-enframing/\{worlding $\}-<$ as-manifest-}

\section{individuative direct/deferential-transeffusive/worlding-looping $>$ _reflected-as_-supererogation 6 -}

capacitating-<for-existential-thematic >. And so, in reflection of their respectively given consciousness/collective-consciousness manifest unblurriness/blurrinessthreshold framing/formulation/catchmenting/truncating/compulsing/linearising' imbued disontologising/subontologising—unculturated/enculturated/subculturated elasticity/margin/threshold/circumstantiality-of-discretionariness-from/acceding-to' -developed/developing $>$ relation with prospective re-ontologising 'ontologicallyhegemonising-narrative ontological-performance ${ }^{2}-<$ including-virtue-asontology $>$ /morality/ethics/justice/etc.' - (with reference to notional/epistemic/bindingness ${ }^{<a s-t o-}$

supererogation projection for sublimating-prolongation'); in want for prospective unblurriness $\sim$ reframing/reformulation/decatchmenting/detruncating/decompulsing/delinearisi ng imbuing sublimating-prolongation (as to requisite re-acceding to 're-ontologising-nascency<as-of-prospective-solipsistic/intersolipsistic-inkling-drive-for-knowledge-elucidation,-as-toveridical-organic-knowledge $>$ for sublimating-prolongation' elicited 'perspicacity of psychologismic-epistemic-acutisation-<as-to-postconverging-de- 
\{veridical/sound\}-relative-reflexivity-in-existence/relativising from-limited-mentation-as-itsdeepening/psychologismic epistemic-acutisation residualising, fdecompulsingl delinearity for eogency' of 'unlimitedness/existence-<full-potency-of_sublimating-nascence $>$ '). Such that human consciousness/collective-consciousness as arising 'existentially-<disontologising/reentologising aporeticism> and organically' (as of notional/epistemic/bindingness ${ }^{<a s-t o-}$ determinism/conceptivity-of-relative-unreflexivity/relative-reflexivitys re-acceding to 're-ontologising-nascency- $<$ as-

\section{of-prospective-solipsistic/intersolipsistic-inkling-drive-for-knowledge-elucidation,-as-to-}

veridical-organic-knowledge $>$ for sublimating-prolongation') implies that even the notion of '<amplituding/formative-epistemicity $>$-totalising thrownness-in-existence ${ }^{35}$ locus/station of limitedness/human-subpotency social-functioning-and-accordance-as-of-social-stakecontention-or-confliction' (so-construed herein as ${ }^{79}$ presencing-absolutising-identitiveconstitutedness $^{1}$ ) itself is ever always prospectively reschedulable-<as-overriding priorinstitutionalising prior-mere-formulaicity/ritualisation-failing-requisite-prospective-profoundsupererogation for-sovereign-emergences (with respect to recurrently-driven limitedness/human-subpotency prospective re-encountering/re-confrontation with the 'constraining/defining intersolipsistic reflexive-sublimating/unreflexive-desublimating measure/objectification that is unlimitedness/existence-as-ontologicalnormalcy/postconvergence-<in-validation-of-'metaphysics-of-absence_epistemic-

projection'>'); as to the reschedulability-<as-overriding prior-institutionalising prior-mereformulaicity/ritualisation-failing requisite-prospective-profound-supererogation -forsovereign-emergence $>$ of the notional/epistemic/bindingness ${ }^{<a s-t o-d e t e r m i n i s m / c o n c e p t i v i t y-o f-r e l a t i v e-~}$ unreflexivity/relative-reflexivity 'formativeness-<as-to-intersolipsism-ofpreformulating/preframing/premeaningfulness-imbued-mediativity-and-deferentialism>-of- 
aporeticism $>$ articulation manifestations (undergirding 'catchmented-and-compulsed- $<$ in‘existential-dearth-of-demoronisation',-so-construed-as-from-ontologicalnormalcy/postconvergence-perspective-reflection-of-the-'destructuring-threshold_of-thegiven-level's-conjugated-postlogism as-dementing'> interpersonal, group, intergroup, community, local, national, political, geostrategic, etc. psychologismic epistemic acutisationdifficulty-<for, residualising \{decompulsing $\}$ delinearity for-cogeney>-levels of interrelatednessdynamics-of-social-constructing' as underlied by apriorising- ${ }^{83}$ reference-of-

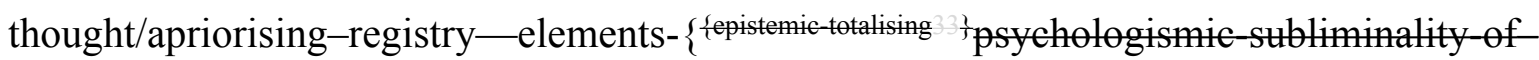
individuation —effusing/worlding imbued logical-dueness-or-scape-or-frame, profile-or-stature, presumptuousness-or-arrogation, assumptions, value-reference and teleology $\left.{ }^{9}\right\}$ ). In this regards, such a rescheduling-<as-overriding prior-institutionalising prior-mereformulaicity/ritualisation failing-requisite-prospective-profound-supererogation -forsovereign-emergence $>$ as of organic-knowledge speaks to the given '< $<$ amplituding/formativeepistemicity>-totalising $\sim$ thrownness-in-existence ${ }^{35}$ locus/station of limitedness/humansubpotency social-functioning-and-accordance-as-of-social-stake-contention-or-confliction' (as to notionally/epistemically/bindingnessly-<as-to-determinism/eonceptivity-of-relative-unreflexivity/relativereflexivity $>$ given 'existential-disontogising/re ontologising aporeticism> 〈'baseline/nominalising/editional—aptitudinal underlay-<as-to-prior-

capacitating-rom ') elicited: as from veridical core-philosophy/derivative-corephilosophy_(imbued requisite 'inkling-drive of dimensionality-of-sublimating ${ }^{25}$ <<amplituding/formative>supererogatory $\sim$ de-mentativeness/epistemic-growth-or- 
conflatedness /transvaluative-rationalising/transepistemicity/anamnestic-residuality/spirit-

drivenness-equalisation)') 'holding-out/point-referencing-psychoanalytic-unshackling exercise of educed-and-availing-and-re-availing relative-ontological-completeness ${ }^{8}$-ofapriorising/axiomatising/referencing' to allow for play out of untenability-ofinduced unblurriness as '<prospective_punctual/immediacy/constituted/compulsionsencumbered — disarming/dis_-ideologising/deformulaicity/à-contrecoup/unsettling/unargunabuble prompted constricted/narrowingdown-re-ontologising-enabling $>$-psychologismic epistemicacutisation residualising fepistemic-

totalising thermeneutic/textuality/reprojecting/supererogating/zeroing/re-acuting,

\{decompulsing delinearity for-cogency' as to 'developing human-per-cep-ti-vi-ty-<as-tonotional perceptualisation-of-and-leashing-to_social-functioning-and-accordance-as-ofsocial-stake-contention-or-confliction> in preconverging/postconverging-redementating/restructuring/reparadigming'. Speaking to the fact that the potential for sublimatingprolongation is dynamised as from the specifically given existential-<disontologising/reentologising aporeticism>

〈'baseline/nominalising/editional—aptitudinal underlay-<as-to-prior-

'baselining/cogency/reconstruing — aptitudinal overlay-<for-prospective- unblurriness_dragging-out $>$ ’’-... reflected-as-

recurring $\sim$ existentialising-framing-by-enframing/\{worlding $\}-<$ as-manifest-

individuative-direct/deferential-transeffusive/worlding-looping $>$ _reflected-as-_supererogation 6 -

capacitating-<for-existential-thematic $>\quad$ imbued interest/disinterest, investedness/disinvestment, exposure/lack-of-exposure, role/task participative-emplacement and relevance/irrelevance-andcapability/incapability-appraisal' (as so-constrained—preconvergingly/postconvergingly-redementating/restructuring/reparadigming by elicitable human ontological-commitment and universal-transparency ${ }^{104}$ with respect to underlying human 'crossgenerational notional firstnaturedness-formativeness-<as-to-eventualising inkling-drive-or-seeding- 
misprising $>$ mental-processing-parity for ontological-performance ${ }^{72}-<$ including-virtue-asontology $>$ /morality/ethics/justice/etc') and so-reflected whether as elucidated above with the infant, child or animist nonpositivism/non-rational-empiricism registry-worldview/dimension: in so dragging-out (into prospective unblurriness $\sim$ reframing/reformulation/decatchmenting/detruncating/decompulsing/delinearisi ng imbuing sublimating-prolongation) their respectively manifest unblurriness/blurrinessthreshold framing/formulation/catchmenting/truncating/compulsing/linearising imbued disontologising/subontologising — unculturated/enculturated/subculturated elasticity/margin/threshold/circumstantiality-of-discretionariness-from/acceding-to’ $<$ developed/developing $>$-relation with prospective re-ontologising 'ontologicallyhegemonising-narrative ontological-performance ${ }^{2}-<$ including-virtue-asontology $>$ /morality/ethics/justice/etc.' - (with reference to notional/epistemic/bindingness ${ }^{<a s-t o-}$ determinism/conceptivity-of-relative-unreflexivity/relative-reflexivity> 'parrhesiastic/messianicity/profoundsupererogation ${ }^{9}$ projection for sublimating-prolongation'). In this respect (and with respect to anthropologisation-<as-to-futural-reflexivity,-in-\{decompusing\} delinearity-'invention'/‘creation'of-the-human/humanity>), as to the very epistemic-totalising ${ }^{33}$ reality (of human meaningfulness-and-teleology and intelligibility-〈as-to-human-projective/reprojectiveaestheticising-re-motif-and-re-apriorising/re-axiomatising/re-referencing/reintelligibilitysettingup/re-measuringinstrumenting-process,-in-<amplituding/formativeepistemicity $>$ totalising $\sim$ conceptualisation $\rangle$ ) and thus human consciousness/collectiveconscious: the undergirding catchmented-and-compulsed-<in-'existential-dearth-ofdemoronisation',-so-construed-as-from-ontological-normalcy/postconvergence-perspectivereflection-of-the-'destructuring-threshold_of-the-given-level's-conjugated-postlogism asdementing'> impediment to reschedulability-<as-overriding prior-institutionalising priormere-formulaicity/ritualisation-failing requisite-prospective-profound-supererogation -for- 
sovereign-emergence $>$ is critically preconvergingly-de-mentating/structuring/paradigming rather epistemic-totalisingly ${ }^{33}$ as from the 'geostrategic, political, national, local, community, intergroup, group, interpersonal, etc. psychologismic epistemic acutisation difficulty-for, residualising \{decompulsing delinearity-for-cogency>-levels of interrelatedness-dynamics-ofsocial-constructing'; and so, in reflection of the veridical 'notional $\sim$ conflatedness ${ }^{13}$ of underlying apriorising- ${ }^{83}$ reference-of-thought/apriorising-registry—elements- $\{$ \{epistemictotalising 3 psychologismic-subliminality-of-individuation_effusing/worlding imbued logicaldueness-or-scape-or-frame, profile-or-stature, presumptuousness-or-arrogation, assumptions, value-reference and teleology $\left.{ }^{9}\right\}^{\prime}$ (so-effusing notionally/epistemically/bindingnessly-<sodeterminism/conceptivity-of-relative-unreflexivity/relative-reflexivity $>$ as to the notional conflatedness ${ }^{13}$ 'dynamics of limitedness/human-subpotency prior_institutionalisation-<as-to-its-mereformulaicity/ritualisation,-conscious-moronisation-linearising $\sim$ construct-of-thought'/ ‘fepistemictotalising ’’psychologismic-subliminal-truncating';-as-relative-unreflexivityenframing failing $\sim$ sublimating-prolongation $>$ by memorative-extension- $<$ as-to'conscientiousness-demoronisation-delinearising construct-of-thought'/‘ fepistemictotalising ’’psychologismic-subliminal-detruncating';-as-relative-reflexivityreframing_educing sublimating-prolongation>). As so-reflecting (as of nonpresencing$<$ perspective-ontological-normalcy/postconvergence> epistemic-projection) the 'successive higher-levels defining direct/indirect-limiting/constraining-of_reschedulability-<asoverriding prior-institutionalising prior-mere-formulaicity/ritualisation-failing requisiteprospective-profound-supererogation -for-sovereign-emergence $>$ import/implications upon the successive lower-levels'; that is, as from 'geostrategic, political, national, local, community, intergroup, group, interpersonal, etc. psychologismic epistemic acutisation difficulty < for, residualising \{decompulsing\} delinearity-for-cogency>-levels of interrelatedness-dynamics-ofsocial-constructing'. So-underlined existentially-<disentologising/re-ontelogising 
aporeticism $>$ by such an 'implicited/explicited ${ }^{79}$ presencing-absolutising-identitiveconstitutedness ${ }^{14}$ stratified disontologising/subontologising conception of the-human/humanity' (as from 'geostrategic, political, national, local, community, intergroup, group, interpersonal, etc. psychologismic epistemic-acutisation difficulty-<for, residualising $\{$ decompulsing $\}$ delinearity for-cogency $>$ levels of interrelatedness-dynamics-of-socialconstructing'); implicitly/explicitly failing to reflect the requisite organic-knowledge prospect for prospectively elicitable human ontological-commitment and universal-transparency (with respect to underlying human 'crossgenerational notional firstnaturedness-formativeness$<$ as-to-eventualising inkling-drive-or-seeding-misprising $>$ mental-processing-parity for ontological-performance ${ }^{72}$-<including-virtue-as-ontology $>$ /morality/ethics/justice/etc.). The implication here is that, as to the very notional conflatedness ${ }^{13}$ of human ${ }^{56}$ meaningfulness-andteleology, such a dragging-out into prospective unblurriness $\sim$ reframing/reformulation/decatchmenting/detruncating/decompulsing/delinearisi ng imbuing sublimating-prolongation (with regards to anthropologisation- $<$ as-to-futural-

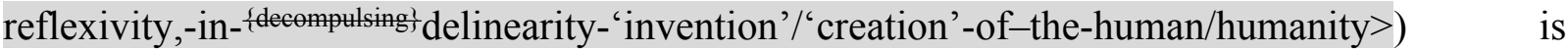
necessarily/effectively as of the respectively-defining/overarching (as from 'geostrategic, political, national, local, community, intergroup, group, interpersonal, etc. psychelegismic

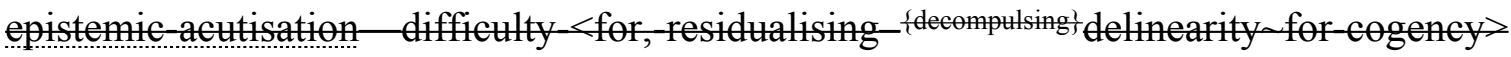
levels of interrelatedness-dynamics-of-social-constructing'); as so-veridically allowing for 'prospective existential-<disontologising/re-ontologising aporeticism $>$ human sovereignemergence/becoming,-existentially-imbuing human-freedom-as-to-supererogating/surrealising for-'knowledge-empowerment-over-ignorance-disempowerment'-<as-of-'developing-andavailing-sovereign-sublimating_potential/possibilities/options/choices'-as-to-the'credibility’/'ontological-veracity’-underlying-the-'sovereign-conscious/conscientiousbackdrop'> consciousness/collective-consciousness'. And so, as to the respectively- 
defining/overarching (as from 'geostrategic, political, national, local, community, intergroup, group, interpersonal, etc. psychologismic epistemic-acutisation difficulty-for, residualising \{decompulsing delinearity for-cogency>-levels of interrelatedness-dynamics-ofsocial-constructing') notionally/epistemically/bindingnessly-<as-to-determinism/conceptivity-of-relativeunreflexivity/relative-reflexivitys given 'existential-<disontologising/re-ontologising aporeticism> 〈'baseline/nominalising/editional—aptitudinal underlay-<as-to-prior-

'baselining/cogency/reconstruing — aptitudinal overlay-<for-prospective- unblurriness-dragging-out $>$ ’ $\rangle$-.... reflected-as $\ldots$

recurring existentialising-framing-by-enframing/\{worlding $\}$-<as-manifest-

individuative-direct/deferential-transeffusive/worlding-looping > -reflected-as-supererogation 6 -

unblurriness/blurriness-

threshold framing/formulation/catchmenting/truncating/compulsing/linearising imbued disontologising/subontologising — unculturated/enculturated/subculturated elasticity/margin/threshold/circumstantiality-of-discretionariness-from/acceding-to’ <developed/developing $>$-relation with prospective re-ontologising 'ontologicallyhegemonising-narrative ontological-performance ${ }^{2}-<$ including-virtue-asontology $>$ /morality/ethics/justice/etc.' - (with reference to notional/epistemic/bindingness ${ }^{<a s-t o-}$ supererogation projection for sublimating-prolongation'). In this regards (and with respect to anthropologisation-<as-to-futural-reflexivity,-in-\{decompulsing\} delinearity-'invention'/‘creation'of-the-human/humanity>), it is herein contended that our 'implicited/explicited ${ }^{79}$ presencingabsolutising-identitive-constitutedness ${ }^{14}$ stratified disontologising/subontologising conception of the-human/humanity' (as from 'geostrategic, political, national, local, community, intergroup, group, interpersonal, etc. psychologismic epistemic-acutisation difficulty-for, residualising \{decompulsing delinearity for-cogency>-levels of interrelatedness-dynamics-of- 
social-constructing') is reflected directly/indirectly-and-consciously/unconsciously in our overall positivism- ${ }^{8}$ procrypticism/disjointedness-as-of- ${ }^{-3 e f e r e n c e-o f-t h o u g h t ~}$ pedantising/muddling/formulaic-hollowing-out - in-subontologisation/subpotentiation-

\section{〈blurring/undermining-of-prospective-totalising-entailing,-as-to-entailing-}

$<$ amplituding/formative-epistemicity>totalising in-relative-ontological-completeness $\rangle$; as to its 'cynical prospectively manifest unblurriness/blurrinessthreshold framing/formulation/catchmenting/truncating/compulsing/linearising' as to socialstake-contention-or-confliction 'self-referencing-syncretising forward-facingsupposedly postconverging-or-dialectical-thinking -apriorising-psychologism epistemicprojection imbued prior mere-formulaicity/ritualisation-<as-to-mere-formulaic methodologising/mutualising/organising/institutionalising,-prospectively-losing-track-of-

'\{epistemic-totalising ’’re-apriorising/re-axiomatising/re-referencing residuality-in-re-

originariness/re-origination'>' as prospectively substitutive of 'unlimitedness/existence-<fullpotency-of_sublimating nascence>' (as so-prospectively undermining of organic-knowledge prospectively elicitable human ontological-commitment ${ }^{66}$ and universal-transparency ${ }^{104}$ with respect to underlying human 'crossgenerational notional firstnaturedness-formativeness-<as-toeventualising-inkling-drive-or-seeding-misprising $>$ mental-processing-parity for ontological-performance $^{72}$-<including-virtue-as-ontology $>/$ morality/ethics/justice/etc.). But then our very own so-manifested positivism- ${ }^{80}$ procrypticism/disjointedness-as-of- ${ }^{8}$ referenceof-thought is not immuned as of its '<amplituding/formative-epistemicity $>$ totalising thrownness-in-existence ${ }^{35}$ locus/station of limitedness/human-subpotency socialfunctioning-and-accordance-as-of-social-stake-contention-or-confliction', with respect to 'veridical notionality/epistemicity/bindingness ${ }^{-<a s-t o-d e t e r m i n i s m / c o n c e p t i v i t y-o f-r e l a t i v e-u n r e f l e x i v i t y / r e l a t i v e-~}$ reflexivity conception-of- ${ }^{5}$ meaningfulness-and-teleology ${ }^{9}$ - (reflection upon the given 'existential-<disentologising/re-ontologising aporeticism> 〈'baseline/nominalising/editional_ 


\section{recurring existentialising-framing-by-enframing/\{worlding $\}-<$ as-manifest-}

\section{individuative-direct/deferential-transeffusive/worlding-looping > _ reflected-as_-supererogation 8 -}

capacitating-<for-existential-thematic>>), from the genuine social intellectual-function/posture eliciting of: veridical core-philosophy/derivative-core-philosophy-_imbued requisite 'inkling-drive of dimensionality-of-sublimating $25<<$ amplituding/formative $>$ supererogatory $\sim$ de-

\section{mentativeness/epistemic-growth-or-conflatedness /transvaluative-}

\section{rationalising/transepistemicity/anamnestic-residuality/spirit-drivenness-equalisation〉’)}

'holding-out/point-referencing_-psychoanalytic-unshackling exercise of educed-and-availingand-re-availing relative-ontological-completeness ${ }^{87}$-of-apriorising/axiomatising/referencing' to allow for play out of untenability-of-induced unblurriness as ‘ $<$ prospective_punctual/immediacy/constituted/compulsions-encumbered_ _ disarming

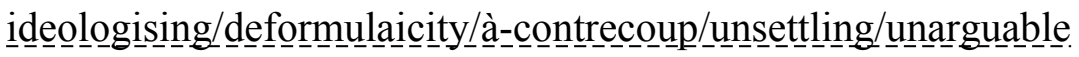
prompted constricted/narrowingdown-re-ontologising-enabling $>$ psychologismic epistemic acutisation residualising $\{$ epistemictotalising ihermeneutic/textuality/reprojecting/supererogating/zeroing/re-acuting, \{decompulsing delinearity for-cogency' as to 'developing human-per-cep-ti-vi-ty-<as-tonotional perceptualisation-of-and-leashing-to_social-functioning-and-accordance-as-ofsocial-stake-contention-or-confliction> in preconverging/postconverging-redementating/restructuring/reparadigming'. In this respect, 'prospective existential< disontologising/re-ontologising aporeticism $>$ human sovereign-emergence/becomingexistentially-imbuing human-freedom-as-to-supererogating/surrealising-for-'knowledgeempowerment-over-ignorance-disempowerment'-<as-of- 'developing-and-availing-sovereignsublimating_potential/possibilities/options/choices'-as-to-the-'credibility'/'ontological- 
veracity'-underlying-the-'sovereign-conscious/conscientious-backdrop'>

consciousness/collective-consciousness' is critically about the genuine social intellectualfunction/posture organic-knowledge $\quad$ so-elicited prospective unblurriness $\sim$ reframing/reformulation/decatchmenting/detruncating/decompulsing/delinearisi ng imbuing sublimating-prolongation allowing for veridical 'logical/rationalising exercise' of prospective ${ }^{18}$ deprocrypticism-or-preempting-disjointedness-as-of- ${ }^{3}$ reference-of-thought (rather than a 'logical/rationalising exercise' within the prior unblurriness/blurrinessthreshold framing/formulation/catchmenting/truncating/compulsing/linearising of our

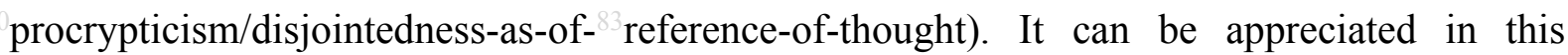
regards with the 'possible manifest pedantising/muddling/formulaic-hollowing-out—insubontologisation/subpotentiation-〈blurring/undermining-of-prospective-totalising-entailing,as-to-entailing-<amplituding/formative-epistemicity $>$ totalising in-relative-ontologicalcompleteness '’ as to the highlighted existential-<disentologising/re-ontologising aporeticism $>$ instances above: say with the infant and nonpositivism/non-rational-empiricism animist registry-worldview respectively unavailing social/institutional practice-of-educating and positivism/rational-empiricism (as of their respective notionally/epistemically/bindingnessly-<asto-determinism/conceptivity-of-relative-unreflexivity/relative-reflexivity> given 'existential-<disentelogising/reentologising aporeticism> 〈'baseline/nominalising/editional—aptitudinal underlay-<as-to-priorunblurriness $\sim$ reframing/reformulation/decatchmenting/detruncating/decompulsing/delinearising $>$ enabling ‘baselining/cogency/reconstruing — aptitudinal overlay-<for-prospective- unblurriness-dragging-out $>$ ’ $\rangle$ - reflected-as-.... recurring existentialising-framing-by-enframing/\{worlding $\}$-<as-manifestindividuative direct/deferential-transeffusive/worlding-looping $>$ _reflected-as_-supererogation 6 -

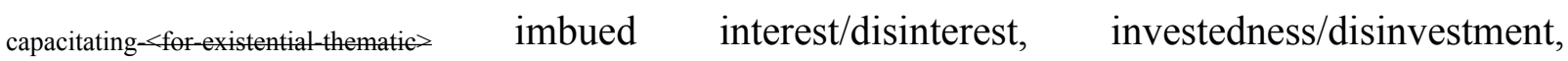
exposure/lack-of-exposure, role/task participative-emplacement and relevance/irrelevance-andcapability/incapability-appraisal'). This doesn't call for an ontologically-flawed 
'logical/rationalising exercise' within their respective unblurriness/blurrinessthreshold framing/formulation/catchmenting/truncating/compulsing/linearising: $\quad$ such $\quad$ as wrongly implying a 'logical/rationalising exercise' for appropriate money change (with regards to the infant's lack of mastery of arithmetic) or 'relatively appropriate positivistic medical treatment' with regards to the (nonpositivism/non-rational-empiricism animist lack of relevant positivism/rational-empiricism science cure); and so, as patent illustrations of 'apriorising/axiomatising/referencing_equating/leveling/ressentiment/closed-construct-ofmeaningfulness-and-teleology and bothsidesism-〈as-'mere-processive'/pedantising'dialogical-relation'-to 'perceived-social-and-institutional-commonlyenculturated_referencing,-of- meaningfulness-and-teleology '-failing-'requisite-existentialthematic-baseline-of-technicity/profundity-framing' \{of-sublimating-discursivity-forsovereign-repassing \},-as-of-psychologismic-epistemic-acutisation-nonresidualising-imbuedfompulsing linearity in-eclecticism-of-prior-mere-formulaicity/ritualisation,-as-so‘consciously/unconsciously-preordained/fated'-to-fail-prospective-notional cogency〉' failing cogency_chronicularity/annality-of-relative-reflexivity,-as-to-profound-supererogation . $^{2}$ Wherein (as to the unavailing supererogation -capacitating-for-existential-thematic $>$ with regards to social/institutional practice-of-educating and positivism/rational-empiricism respectively) the prospect for 'possible manifest pedantising/muddling/formulaic-hollowingout - in-subontologisation/subpotentiation-〈blurring/undermining-of-prospective-totalisingentailing,-as-to-entailing-<amplituding/formative-epistemicity $>$ totalising $\sim$ in-relativeontological-completeness '’' arises; from say an older child or animist witchdoctor respectively wrongly implying a 'logical/rationalising exercise' for appropriate money change (with regards to the infant's lack of mastery of arithmetic) or 'relatively appropriate positivistic medical treatment'. Thusly requiring the genuine social intellectual-function/posture organic-knowledge elicited dragging-out into prospective 
unblurriness $\sim$ reframing/reformulation/decatchmenting/detruncating/decompulsing/delinearisi ng (with regards to recurrently-driven limitedness/human-subpotency prospective reencountering/re-confrontation with the 'constraining/defining intersolipsistic reflexivesublimating/unreflexive-desublimating measure/objectification that is unlimitedness/existenceas-ontological-normalcy/postconvergence-<in-validation-of-‘metaphysics-of-

absence_epistemic-projection'>') as to enabling the availing of supererogation -capacitating<for-existential-thematic $>$ with regards to social/institutional practice-of-educating and positivism/rational-empiricism respectively in order to so-educe their respective 'prospective existential-<disontologising/re-ontologising aporeticism $>\quad$ human sovereignemergence/becoming,-existentially-imbuing human-freedom-as-to-supererogating/surrealisingfor-'knowledge-empowerment-over-ignorance-disempowerment'-<as-of-'developing-andavailing-sovereign-sublimating_potential/possibilities/options/choices'-as-to-the‘credibility’/'ontological-veracity’-underlying-the-'sovereign-conscious/conscientiousbackdrop'> consciousness/collective-consciousness'. So-dissipating the prospect for 'possible manifest pedantising/muddling/formulaic-hollowing-out—insubontologisation/subpotentiation-〈blurring/undermining-of-prospective-totalising-entailing,as-to-entailing-<amplituding/formative-epistemicity $>$ totalising $\sim$ in-relative-ontologicalcompleteness '’'; as to their respectively induced psychologismic-epistemic-acutisation-<as-topostconverging-de-mentating/structuring/paradigming,-eliciting-of-existence's-sublimatingnascence-in-prospective-aporeticism-overcoming/unovercoming $>$ as to epistemic-growth,-as\{veridical/sound\}-relative-reflexivity-in-existence/relativising from-limited-mentation-as-its-

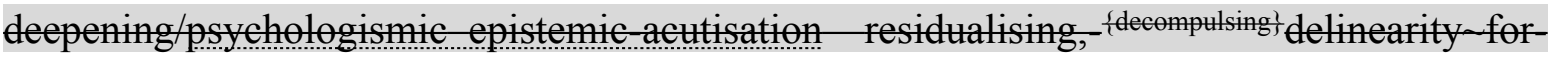
eogency imbued 'cut-out-<as-to-re-ontologising redressing/straightening-out> (as of relativereflexivity psychologismic-transfixity-<placeholder-setup-ontological-rescheduling - inrealigning/preactivity/formative-becoming/psychoanalytical-unshackling,-as-to-residualising- 
prolongation'. Highlighting the fact that pedantising/muddling/formulaic-hollowing-out - insubontologisation/subpotentiation-〈blurring/undermining-of-prospective-totalising-entailing,as-to-entailing-<amplituding/formative-epistemicity $>$ totalising $\sim$ in-relative-ontologicalcompleteness > is overran/dissipated where the sovereign-function/posture- $<$ as-toexistentially-manifest-'embodied-subject consciousness-and-direct/deferentialconscientiousness',-as-of-its-'epistemic-reflexivity/unreflexivity-in-existence'/teleology> attains the appropriate competence (reflecting the competent notionally/epistemically/bindingnessly-<as-to-determinism/conceptivity-of-relative-unreflexivity/relative-reflexivity> given 'existential-<disontologising/re-ontologising aporeticism> 〈'baseline/nominalising/editional_ aptitudinal underlay<as to prior _ unblurriness-reframing/reformulation/decatehmenting/detruncating/decompulsing/delinearising $>$ ' enabling 'baselining/cogency/reconstruing — aptitudinal overlay-<for-prospective- unblurriness-dragging-out $>\rangle$ ’...... reflected-as-

\section{recurring $\sim$ existentialising-framing-by-enframing/\{worlding $\}$-<as-manifest-}

\section{individuative direct/deferential-transeffusive/worlding-looping > _reflected-as-supererogation 6 -}

capacitating-<for-existential-thematic >') for 'protracted-social—as-to-individual-by-institutional-by-social relative direct/deferential-responsibility/relative-reflexivity

cogency_chronicularity/annality-of-relative-reflexivity,-as-to-profound-supererogation ${ }^{2}$. In this respect, it should be noted that (however counterintuitive) the 'appraisal of human meaningfulness-and-teleology ${ }^{99}$ and consciousness/collective-consciousness' as of manifest unblurriness/blurriness-

threshold framing/formulation/catchmenting/truncating/compulsing/linearising is effectively 'psychologismically different' from the 'appraisal of human ${ }^{56}$ meaningfulness-and-teleology and consciousness/collective-consciousness a of manifest unblurriness $\sim$ reframing/reformulation/decatchmenting/detruncating/decompulsing/delinearisi ng. This is the case given the "relative-unreflexivity/relative-reflexivity-bindingness/nondiscretionariness- 
$\leqslant$ as-from-sublimating remoteness/distance-of-appraisal-of-requisite-Being-development $>$ of unlimitedness/existence-<fll potency-of_sublimating nascence $>$ '- (as to 'relativeunreflexivity/relative-reflexivity limitedness/human-subpotency dynamics of supererogating \{affirmation/projection/assertion/notional $\sim$ self-distantiation-byunaffirmation/deprojection/deassertion/epistemic-decadence $\}$ - towards $\sim$ omnipotentialaffirmation/projection/assertion/notional self-distantiation' with respect to 'limitedness/humansubpotency prospective re-encountering/re-confrontation with unlimitedness/existence-<fullpotency-of_sublimating nascence $>$ '): rather as from the relative-reflexivity of prospective reontologising Being-development/ontological-framework-expansion-as-to-depth-ofontologising-development-as-infrastructure-of- meaningfulness-and-teleology psychologismic epistemic-acutisation difficulty-<or, residualising \{decompulsing\} delinearity for-cogeney $>$ magnitude ${ }^{\{\text {of-experientiality/experiment }\}}$ (with the latter appreciated more acutely for instance where nascent-particular/incipient-and-material/technicalsublimations- $<$ blinded-to-their-relative-ontological-completeness - reference-of-thoughtdevolving > need to harken back explicitly/implicitly to the requisite overarching 'registryworldview/dimension existentialising-framing-by-enframing/\{worlding $\}$ - ${ }^{83}$ reference-of-

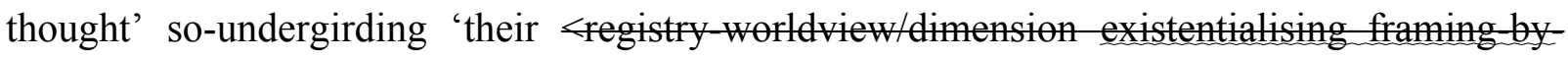
enframing/worlding; reference-of thought $>$ undergirding-of-existentialising-framing-byenframing/\{worlding\} - axiomatic-constructs' as to when Galileo implicitly realises that his geocentric model is more profoundly speaking to a positivism/rational-empiricism sublimation construal or reframing of the world, or early $20^{\text {th }}$ century physicists realised that their discovery of nuclear energy implicits that their subject-matter is more than just technicalities but speaks to requisite registry-worldview/dimension sublimation within which their technicalities can effectively manifest sublimation than desublimating nuclear extermination). The 'psychologismic difference' in the appraisal of human ${ }^{56}$ meaningfulness-and-teleology ${ }^{99}$ and 
consciousness/collective-consciousness (as of prior unblurriness/blurrinessthreshold framing/formulation/catchmenting/truncating/compulsing/linearising and prospective

unblurriness $\sim$ reframing/reformulation/decatchmenting/detruncating/decompulsing/delinearisi ng) underlines the very nature of human consciousness/collective-consciousness (with regards to recurrently-driven limitedness/human-subpotency prospective re-encountering/reconfrontation with the 'constraining/defining intersolipsistic reflexive-sublimating/unreflexivedesublimating measure/objectification that is unlimitedness/existence-as-ontologicalnormalcy/postconvergence-<in-validation-of-'metaphysics-of-absence_epistemic-

projection'>'). As so-reflecting the 'delinearising-imbuing_conscientiousness-demoronisation$<$ as-to-renewing realisation/re-perception/re-thought $>$ reframing over linearisingimbuing_conscious-moronisation-<as-to-prior_mere-formulaicity/ritualisation> enframing' undergirding 'prospective existential-<disontologising/re-ontologising aporeticism $>$ human sovereign-emergence/becoming,-existentially-imbuing human-freedom-as-tosupererogating/surrealising-for-'knowledge-empowerment-over-ignorance-disempowerment'$<$ as-of-'developing-and-availing-sovereignsublimating potential/possibilities/options/choices'-as-to-the-'credibility'/'ontologicalveracity'-underlying-the-'sovereign-conscious/conscientious-backdrop’> consciousness/collective-consciousness'. And so, notwithstanding human existential<disontologising/re-ontologising_aporeticism $>$ 'delinearising-imbuing_conscientiousnessdemoronisation-<as-to-renewing-realisation/re-perception/re-thought $>\sim$ reframing inversely' (given limited-mentation-capacity of ontological-performance ${ }^{72}-<$ including-virtue-as- $^{-}$ ontology $>$ /morality/ethics/justice/etc.) rather tepidly as from living-development-as-topersonality-development psychologismic epistemic acutisation difficulty-<for, residualising \{decompulsing\} delinearity for-cogency> magnitude $\{$ fof-experientiality/experiment\}, then 
acutisation difficulty-<or, residualising _\{decompulsing $\}$ delinearity for-cogency> magnitude $\{$ ofexperientiality/experiment\} and then Being-development/ontological-framework-expansion-as-to-depthof-ontologising-development-as-infrastructure-of- meaningfulness-and-teleology psychologismic epistemic acutisation difficulty-<for, residualising ${ }_{\{\text {decompulsing }}$ delinearity for-cogeney>-magnitude ${ }^{\{\text {of-experientiality/experiment }\}}$. This 'psychologismic difference' (reflecting the incompetent notionally/epistemically/bindingnessly-<as-todeterminism/entive of relative unreflexivity/relative reflexivitys given 'existential-<disontologising/reentologising aporeticism>

capacitating-<for-existential-thematic’' with respect to '<out-of-phasing $>$ disparate-narratives_of_socialfunctioning-and-accordance-as-of-social-stake-contention-or-confliction_construct manifesting-at-the-given — unblurriness/blurriness-

threshold framing/formulation/catchmenting/truncating/compulsing/linearising') is central to sophistic manifestations whether intradimensionally or interdimensionally. In this regards, organic-knowledge cannot be construed as substituting for the 'priorly requisite incipient human profound-supererogation, (which lacking/deficiency is associated with pedantising/muddling/formulaic-hollowing-out — in-subontologisation/subpotentiation〈blurring/undermining-of-prospective-totalising-entailing,-as-to-entailing$<$ amplituding(formative-epistemicity>totalising in-relative-ontological-completeness $\rangle)$; and so, due to the inevitability of the latter arising as from human limited-mentation-capacity inherently imbued notional firstnaturedness-formativeness-<as-to-eventualising-inkling 
drive or seeding misprising $>$ temporal-to-intemporal-dispositions- $<$ so-construed-as-fromperspective-ontological-normalcy/postconvergence $>$ with respect to human protracted-social-

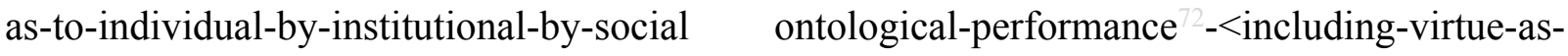
ontology $>$ /morality/ethics/justice/etc. (as to the '<amplituding/formative-epistemicity $>$ totalising thrownness-in-existence ${ }^{35}$ locus/station of limitedness/human-subpotency socialfunctioning-and-accordance-as-of-social-stake-contention-or-confliction'). The fact remains though that (with respect to the given 'existential-<disontologising/re-ontologisingaporeticism>

recurring existentialising-framing-by-enframing/\{worlding $\}$-<as-manifest-

individuative direct/deferential-transeffusive/worlding-looping $>$ _ reflected-as_-supererogation 6 -

capacitating-<for-existential-thematic $>$ '

speaking-notionally/epistemically/bindingnessly-as-todeterminism/conceptivity-of-relative-unreflexivity/relative-reflexivitys to the 'relative-unreflexivity/relativereflexivity - ontological-contiguity ${ }^{67}$ of the overall relative-unreflexivity/relative-reflexivityontological-contiguity ${ }^{67}$ of-the-human-institutionalisation-process ${ }^{6}$, implied conception of the notion of relativism), any given '<amplituding/formative-epistemicity $>$-totalising $\sim$ thrownnessin-existence ${ }^{35}$ locus/station of limitedness/human-subpotency social-functioning-andaccordance - as-of-social-stake-contention-or-confliction' is equally effectively susceptible to prospectively elicitable re-ontologising; and so, given fundamental human ontologicalcommitment $^{6}$ and universal-transparency ${ }^{104}$ with respect to underlying human 'crossgenerational notional firstnaturedness-formativeness-<as-to-eventualising-inkling drive-or-seeding-misprising $>$ mental-processing-parity for ontological-performance ${ }^{72}$ <including-virtue-as-ontology $>$ /morality/ethics/justice/etc. Thusly, so-providing the avenue/leeway for overruning/dissipating of human pedantising/muddling/formulaic-hollowing- 
out - in-subontologisation/subpotentiation-〈blurring/undermining-of-prospective-totalisingentailing,-as-to-entailing-<amplituding/formative-epistemicity $>$ totalising $\sim$ in-relativeontological-completeness $>$ (as to its manifest 'epistemic-decadence' or teleological-decadence$<$-in-dimensionality-of-desublimating-lack-of ${ }^{-}-\langle<$amplituding/formative $>$supererogatory $\sim$ dementativeness/epistemic-growth-or-conflatedness /transvaluativerationalising/transepistemicity/anamnestic-residuality/spirit-drivenness-equalisation〉 imbued distractive-alignment-to- ${ }^{8}$ reference-of-thought- $<$ of-apriorising/axiomatising/referencing $>$ inducing unblurriness/blurrinessthreshold framing/formulation/catchmenting/truncating/compulsing/linearising); and so, for the sake of prospective 'despite-the-self exercise of epistemic-projection in notional $\sim$ selfdistantiation-<imbued —re-motif-and-re-apriorising/re-axiomatising/re-referencing $>$ ' involved in 'limitedness/human-subpotency prospective re-encountering/re-confrontation with unlimitedness/existence-<full-potency-of_sublimating nascence $>$ for unblurriness $\sim$ reframing/reformulation/decatchmenting/detruncating/decompulsing/delinearisi ng imbuing sublimating-prolongation. As so-enabling ontologising-failsafe-<as-to-'relativeunreflexivity/relative-reflexivity bindingness/nondiscretionariness' of totalising-entailment> as of 'substantivity of transversality-<for-sublimating-existential-eventuating/denouement-from-'thinking at first/pure-predisposition-preemptive-of-prospectivedisontologising/subontologising' - as-of-prospectively-disambiguated-affirmed-andunaffirmed-'motif-and-apriorising/axiomatising/referencing' $>$ 101, imbued 'impersonalisation and deinstitutionalisation of prospective re-ontologising ${ }^{56}$ meaningfulness-and-teleology ${ }^{9}$. Human consciousness/collective-consciousness notionally/epistemically/bindingnessly-<as-todeterminism/conceptivity-of-relative-unreflexivity/relative-reflexivity manifests 'delinearisingimbuing_conscientiousness-demoronisation-<as-to-renewing realisation/re-perception/rethought $>\sim$ reframing over linearising-imbuing_conscious-moronisation-<as-to-prior_mere- 
formulaicity/ritualisation>-enframing' (with regards to limited-mentation-capacitydeepening —as-subjecting limitedness/human-subpotency to-'educed-unlimitedness/existencesublimating nascence' 33 as of 'limitedness/human-subpotency prospective re-encountering/reconfrontation with unlimitedness/existence-<full-potency-of_sublimating nascence $>$ '); within which scope of notionality/epistemicity/bindingness ${ }^{<a s-t o-d e t e r m i n i s m / e o n c e p t i v i t y-o f-r e l a t i v e-~}$ unreflexivity/relative-reflexivity, organic-knowledge for sublimating-prolongation can arise (with respect to the existentially-<disontologising/re-ontologising aporeticism> given human 'consciousness/collective-consciousness 〈'baseline/nominalising/editional—aptitudinal underlay-<as-to-priorunblurriness reframing/reformulation/decatchmenting/detruncating/decompulsing/delinearising ${ }^{\prime}$ enabling 'baselining/cogency/reconstruing — aptitudinal overlay-<for-prospective- unblurriness-dragging-out $>$ ' $\rangle$-..reflected-asrecurring existentialising-framing-by-enframing/\{worlding $\}-<$ as-manifestindividuative -direct/deferential-transeffusive/worlding-looping > _reflected-as_-supererogation 6 -

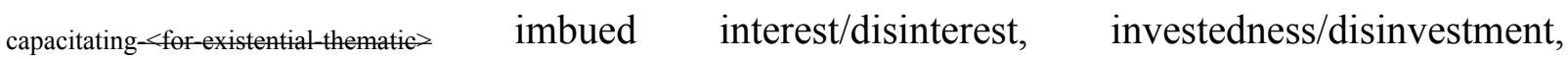
exposure/lack-of-exposure, role/task participative-emplacement and relevance/irrelevance-andcapability/incapability-appraisal'). So-speaking to the fact that prospective knowledge as to organic-knowledge effectively arises as of 'delinearising-imbuing_conseientiousnessdemoronisation-<as-to-renewing-realisation/re-perception/re-thought $>\sim$ reframing for sublimating-prolongation of ${ }^{5}$ meaningfulness-and-teleology 9 ' as thusly warranting its fulsome relative-reflexivity reflection as to limited-mentation-capacity-deepening-as-subjecting limitedness/human-subpotency to-'educed-unlimitedness/existence-sublimating nascence' 53 ; and so, rather as from Being-development/ontological-framework-expansion-as-to-depth-ofontologising-development-as-infrastructure-of- meaningfulness-and-teleology psychologismic epistemic-acutisation difficulty-<or, residualising

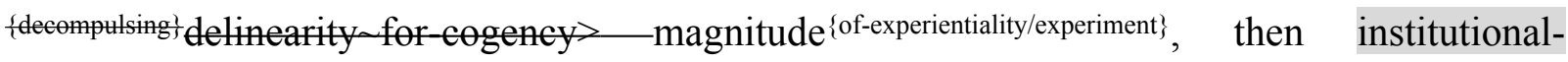
development-as-to-social-function-development psychologismic epistemic acutisation- 
difficulty-<for, residualising_\{decompulsing $\}$ delinearity for-cogeney> magnitude ${ }^{\{0 f-}$ experientiality/experiment\} and then living-development-as-to-personality-development psychologismic epistemic-acutisation difficulty < for, residualising \{decompulsing\} delinearity for-cogeney>-magnitude\{of-experientiality/experiment\}. The genuine social intellectual-function/posture organic-knowledge for sublimating-prolongation elicited dragging-out into prospective unblurriness $\sim$ reframing/reformulation/decatchmenting/detruncating/decompulsing/delinearisi ng (with regards to recurrently-driven limitedness/human-subpotency prospective reencountering/re-confrontation with the 'constraining/defining intersolipsistic reflexivesublimating/unreflexive-desublimating measure/objectification that is unlimitedness/existenceas-ontological-normalcy/postconvergence-<in-validation-of-‘metaphysics-of-

absence_epistemic-projection'>') is rather 'geared to avoid the existential-<disontolegising/reentologising aporeticism $>$ construal of prospective organic-knowledge desublimatingly/disontologisingly/subontologisingly' (as if of 'human consciousness/collectiveconsciousness manifest linearising-imbuing_conscious-møronisation-<as-to-prior_mereformulaicity/ritualisation>nenframing' as so-inducing mechanical-knowledge); as relatively incapable of projecting of the 'relative-unreflexivity/relative-reflexivity-bindingness/nondiscretionariness<as-from-sublimating remoteness/distance-of-appraisal-of-requisite Being-development> of unlimitedness/existence-<full-potency-of_sublimating nascence $>$ '-(as to 'relativeunreflexivity/relative-reflexivity limitedness/human-subpotency dynamics of supererogating \{affirmation/projection/assertion/notional self-distantiation-byunaffirmation/deprojection/deassertion/epistemic-decadence\} - towards $\sim$ omnipotentialaffirmation/projection/assertion/notional self-distantiation' with respect to 'limitedness/humansubpotency prospective re-encountering/re-confrontation with unlimitedness/existence- $<$ fullpotency-of_sublimating nascence $>$ ') rather as from the relative-reflexivity of prospective re- 
ontologising

Being-development/ontological-framework-expansion-as-to-depth-of-

ontologising-development-as-infrastructure-of- meaningfulness-and-teleology

psychologismic epistemic-acutisation difficulty-for, residualising

${ }_{\{\text {decompulsing }}$ delinearity for-cogency> magnitude $\left.\left.{ }^{\{0 f-e x p e r i e n t i a l i t y / e x p e r i m e n t}\right\}\right)$. Such mechanicalknowledge is bound to induce 'institutionalising-inflative-distortion-<as-to-prior_mereformulaicity/ritualisation-failing-prospective-profound-supererogation >’ undermining requisite recurrent-linking-up of prior sublimating-arising and prospective sublimatingprolongation as so-reflected as to its lack of cogency_chronicularity/annality-of-relativereflexivity,-as-to-profound-supererogation ; as well as further bound to prospectively elicit 'epistemic-decadence' or teleological-decadence-<-in-dimensionality-of-desublimating-lackof ${ }^{-}$-<<amplituding/formative $>$supererogatory $\sim$ de-mentativeness/epistemic-growth-orconflatedness /transvaluative-rationalising/transepistemicity/anamnestic-residuality/spiritdrivenness-equalisation) imbued distractive-alignment-to- ${ }^{-}$reference-of-thought- $<$ofapriorising/axiomatising/referencing $>$ (as $\quad$ so-inducing unblurriness/blurrinessthreshold framing/formulation/catchmenting/truncating/compulsing/linearising). Human consciousness/collective-consciousness (as to its so-elucidated-above 'delinearisingimbuing_conscientiousness-demoronisation-<as-to-renewing realisation/re-perception/rethought $>$ reframing over linearising-imbuing_conscious-moronisation-<as-to-prior_mereformulaicity/ritualisation>enframing' imbued amplituding 'so-elaborated-as-of conceptivity/epistemic-reflexivity/epistemicity-relativism-determinism-<reifying \{as-toknowledge-developing\}-and-empowering $>-<$ as-to-frame-of-

motif/pattern/sign/token/mark/type/figure/symbol/attribute/inscription/writing > — forinlining-<as-to-frame-ofreflection/retentiveness/recollection/memoration/memory/anamnesis/cognisance/intelligibility/ comprehension/realisation> undergirded by existence's panintelligibility/panreflexivity ${ }^{73}$ 
effusing/ecstatic-inlining') so-reflects effectively limitedness/human-subpotency memorativeextension-<as-to-'conscientiousness-demoronisation — delinearising construct-of-

thought'/‘fepistemic-atising '’psychologismic-subliminal-detruncating';-as-relative-reflexivityreframing_educing sublimating-prolongation> (with regards to 'limitedness/humansubpotency prospective re-encountering/re-confrontation with unlimitedness/existence-<fullpotency-of_sublimating nascence $>$ '), and so-effusing as of: the notionality/epistemicity/bindingness ${ }^{-<a s-t o-d e t e r m i n i s m / c o n c e p t i v i t y-o f-r e l a t i v e-u n r e f l e x i v i t y / r e l a t i v e-r e f l e x i v i t y ~}>$ scope of veridical core-philosophy/derivative-core-philosophy_(imbued requisite inklingdrive of dimensionality-of-sublimating ${ }^{25}-<$ amplituding/formative $>$ supererogatory $\sim$ dementativeness/epistemic-growth-or-conflatedness /transvaluativerationalising/transepistemicity/anamnestic-residuality/spirit-drivenness-equalisation〉') 'holding-out/point-referencing — psychoanalytic-unshackling exercise of educed-and-availingand-re-availing relative-ontological-completeness ${ }^{87}$-of-apriorising/axiomatising/referencing' to allow for play out of untenability-of-induced unblurriness as

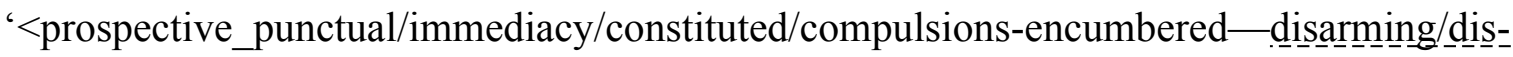
idenologising/deformulaicity/à-contrecoup/_unsettling/un_-_constricted/narrowingdown-re-ontologising-enabling $>$ - psychologismic epistemicacutisation residualising fepistemic tolising thermeneutic/textuality/reprojecting/supererogating/zeroing/re-acuting, \{decompulsing\} delinearity for-cogency' as to 'developing human-per-cep-ti-vi-ty-<as-to notional perceptualisation-of-and-leashing-to_social-functioning-and-accordance-as-ofsocial-stake-contention-or-confliction> in preconverging/postconverging-redementating/restructuring/reparadigming'. As thusly reflecting 'limitedness/human-subpotency prospective re-encountering/re-confrontation with unlimitedness/existence-<flll-potency of_sublimating nascence $>$ ' with respect to 'veridical notionality/epistemicity/bindingness 
teleology"-(reflection upon the given 'existential-<disontologising/re-ontologising aporeticism>

recurring $\sim$ existentialising-framing-by-enframing/\{worlding $\}$-<as-manifest-

individuative direct/deferential-transeffusive/worlding-looping > _ reflected-as_-supererogation 0 -

capacitating-<for-existential-thematic>>); with respect to recurrent eliciting of knowledgereification $\sim$ gesturing-and-accounting — of-epistemic-phenomenalism-<in-

prospective_psychologismic a apriorising/axiomatising/referencing-\{of-'prospectively

implicited_attendant_ontological-contiguity ' educed-

existentialising/contextualising/textualising_'intelligibility/epistemicity/reflexivity-contiguity$<$ imbued-notional cogency $>$ ' $\}$-conflatedness -in-\{preconverging-ment by\}

postconverging-entailment $>$ for sublimating-prolongation (with regards to 'the-very-same purview/devolved-purview/devolving-purview-of-unlimitedness/existence-<full-potencyof_sublimating nascence>;-_implicited_attendant_ontological-contiguity ${ }^{67}$ ' educedexistentialising/contextualising/textualising_intelligibility/epistemicity/reflexivity-contiguity$<$ imbued-notional cogency $>^{\prime}$ ). This underlies the fact that all human ontologicalperformance $^{2}-<$ including-virtue-as-ontology $>$ /morality/ethics/justice/etc., $\quad$ (as of the notional conflatedness ${ }^{13}$ of both direct 'sovereign-function/posture-<as-to-existentiallymanifest-'embodied-subject $\sim$ consciousness-and-direct/deferential-conscientiousness',-as-ofits-'epistemic-reflexivity/unreflexivity-in-existence'/teleology> as to limited-mentationcapacity emphasis' on-the-one-hand and on-the-other-hand deferential 'competence/expertising of human socially expanded framework of deferential-formalisation-transference as to various cultivated skills/arts and time investment as to limited-mentation-capacity-deepening-as- 
subjecting limitedness/human-subpotency-to-'educed-unlimitedness/existence-sublimating nascence' ${ }^{33}$ emphasis', and so as 'conjointly-implied human protracted-social—as-toindividual-by-institutional-by-social ontological-performance $^{72}-<$ including-virtue-asontology $>$ /morality/ethics/justice/etc.'): is of the same 'veridical notionality/epistemicity/bindingness ${ }^{<a s-t o-d e t e r m i n i s m / c o n c e p t i v i t y-o f-r e l a t i v e-u n r e f l e x i v i t y / r e l a t i v e-r e f l e x i v i t y>~}$ conception-of- ${ }^{5}$ meaningfulness-and-teleology" - (reflection upon the given 'existential<disontologising/re-ontologising aporeticism> ("baseline/nominalising/editional—aptitudinal underlay<<as-to-prior-

capacitating-<forexistentheralic '); with respect to the existentially-<disontologising/reentologising aporeticism $₹$ given human 'consciousness/collective-consciousness

〈'baseline/nominalising/editional—aptitudinal underlay-<as-to-prior-

capacitating-<for-existential-thematic> imbued interest/disinterest, investedness/disinvestment, exposure/lack-of-exposure, role/task participative-emplacement and relevance/irrelevance-andcapability/incapability-appraisal' (as so-constrained-preconvergingly/postconvergingly-redementating/restructuring/reparadigming by elicitable human ontological-commitment and universal-transparency ${ }^{104}$ with respect to underlying human 'crossgenerational notional firstnaturedness-formativeness-<as-to-eventualising inkling-drive-or-seeding misprising $>$ mental-processing-parity for ontological-performance ${ }^{72}-<$ including-virtue-as- 
ontology $>$ /morality/ethics/justice/etc.'). And for-that-matter as well, the 'conjointly-implied human protracted-social—as-to-individual-by-institutional-by-social ontological-

performance $^{72}-<$ including-virtue-as-ontology $>$ /morality/ethics/justice/etc.'

'notionally/epistemically/bindingnessly'-as-to-determinism/conceptivity-of-relative-unreflexivity/relative-reflexivitys

reflected as to manifest human consciousness/collective-consciousness existential<disontologising/re-ontologising aporeticism>

linearising-to-<asdisentelegising/subontelegising $>$ or delinearising-from-<as-re-ontelegising $>$ '; in reflection of the existentially-<disontologising/re-ontologising aporeticism> given '<out-of phasing> disparate-narratives_of_social-functioning-and-accordance-as-of-social-stake-contention-orconfliction_construct (so-manifesting-at-the-given — unblurriness/blurrinessthreshold framing/formulation/catchmenting/truncating/compulsing/linearising)' imbued disontologising/subontologising — unculturated/enculturated/subculturated elasticity/margin/threshold/circumstantiality-of-discretionariness-from/acceding-to’ -developed/developing $>$ relation with prospective re-ontologising 'ontologicallyhegemonising-narrative ontological-performance ${ }^{2}-<$ including-virtue-asontology $>$ /morality/ethics/justice/etc.' - (with reference to notional/epistemic/bindingness ${ }^{<a s-t o-}$ determinism/conceptivity-of-relative-unreflexivity/relative-reflexivity> 'parrhesiastic/messianicity/profoundsupererogation ${ }^{9}$ projection for sublimating-prolongation'). The overall implication here is that the originary-and-re-originary (as to 're-ontologising-nascency-<as-of-prospectivesolipsistic/intersolipsistic-inkling-drive-for-knowledge-elucidation,-as-to-veridical-organicknowledge $>$ for sublimating-prolongation') is rather manifested as of limitedness/humansubpotency memorative-extension-<as-to-'conscientiousness-demoronisationdelinearising construct-of-thought'/ ‘ \{epistemic-totalising '’ $p$ pychologismic-subliminaldetruncating';-as-relative-reflexivity-reframing_educing sublimating-prolongation>; whereas prior_institutionalisation-<as-to-its-mere-formulaicity/ritualisation,-conscious-moronisation- 
linearising construct-of-thought'/ ‘ \{epistemic-totalising ${ }^{3}$ psychologismic-subliminal-truncating';-as-

relative-unreflexivity-enframing_failing $\sim$ sublimating-prolongation $>\quad$ is rather intermediate/transitional (and formulaically bound to prospectively induce 'institutionalisinginflative-distortion-<as-to-prior_mere-formulaicity/ritualisation-failing-prospective-profoundsupererogation $>$ ' undermining the recurrent-linking-up of prior sublimating-arising and prospective sublimating-prolongation). Such that what is effectively foundational to prospective sublimating-prolongation of human ${ }^{56}$ meaningfulness-and-teleology ${ }^{9}$ is notionally/epistemically/bindingnessly-as determinism/enceptivity of relative unreflexivityelative reflexivity rather of memorative-extension-<as-to-"conscientiousness-demoronisation delinearising construct-of-thought'/ ‘ \{epistemic-totalising ' ’’ psychologismic-subliminaldetruncating';-as-relative-reflexivity-reframing_educing sublimating-prolongation $>$ imbued: veridical core-philosophy/derivative-core-philosophy_-(imbued requisite 'inkling-drive of dimensionality-of-sublimating $25<<$ amplituding/formative $>$ supererogatory $\sim$ dementativeness/epistemic-growth-or-conflatedness /transvaluativerationalising/transepistemicity/anamnestic-residuality/spirit-drivenness-equalisation〉') 'holding-out/point-referencing_-psychoanalytic-unshackling exercise of educed-and-availingand-re-availing relative-ontological-completeness ${ }^{87}$-of-apriorising/axiomatising/referencing' to allow for play out of untenability-of-induced unblurriness as '<prospective_punctual/immediacy/constituted/compulsions-encumbered— _ disarming $/$ dis-

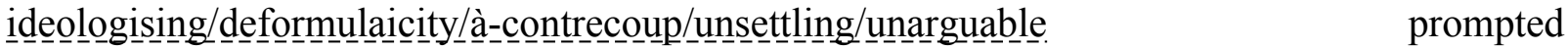
constricted/narrowingdown-re-ontologising-enabling $>$-psychologismic epistemicacutisation residualising \{epistemictotalising thermeneutic/textuality/reprojecting/supererogating/zeroing/re-acuting, \{decompulsing delinearity for-cogency' as to 'developing human-per-cep-ti-vi-ty-<as-tonotional perceptualisation-of-and-leashing-to_social-functioning-and-accordance-as-of- 
social-stake-contention-or-confliction> in preconverging/postconverging-redementating/restructuring/reparadigming'; and so, involving such core-philosophy/derivativecore-philosophy sublimating-prolongation superseding of its priorly educed 'institutionalisation-constructs-<as-to-baseline/nominalisedmethodologising/mutualising/organising/institutionalising> and derived/associated_institutionalisation-constructs-<as-to-baseline/nominalised methodologising/mutualising/organising/institutionalising >'. So-including the superseding of a division-of-labour/subject-matters conception poorly appraising of the requisite originary-andre-originary/re-ontologising-nascency (of the 'relative-unreflexivity/relative-reflexivityontological-contiguity ${ }^{67}$ of the overall relative-unreflexivity/relative-reflexivity - ontologicalcontiguity ${ }^{67}$ of-the-human-institutionalisation-process ${ }^{6}$ implied conception of the notion of relativism); in reflection of all such division-of-labour/subject-matters necessary construal as for-human-studies/for-human-constructs (with the natural sciences as actually for-humanstudies/for-human-constructs whose specific ambit of human-subpotency is about 'human consciousness as for material and physical effecting devolving teleologies as meaningfulness' while the social domains-of-study are actually for-human-studies/for-human-constructs whose specific ambit of human-subpotency is about 'human consciousness inherent effecting devolving teleologies as meaningfulness'). Specifically (as from the re-ontologising perspective of requisite $\quad{ }^{4}$ foregrounding_entailment- $<$ in-succession-of-profound-supererogation 〈postconverging-narrowing-down $\sim$ sublimation-as-to-'existence-as-sublimatingwithdrawal/unenframing/re-ontologising,-elicited-from-prospective-profoundsupererogation '-in-reflecting-'immanent relative unreflexivity/relative reflexivity ontological-contiguity ';-as-operative-notional deprocrypticism) as of cogency_chronicularity/annality-of-relative-reflexivity,-as-to-profound-supererogation ${ }^{\text {, }}$ imbuing conceptivity/epistemic-reflexivity/epistemicity-relativism-determinism- $<$ reifying \{as- 
to-knowledge-developing $\}$-and-empowering $>$ ), it is herein contended that our so-manifest 'positivism- ${ }^{8}$ procrypticism/disjointedness-as-of- ${ }^{-3 e f e r e n c e-o f-t h o u g h t ~}$ prospective unblurriness/blurriness-

threshold framing/formulation/catchmenting/truncating/compulsing/linearising' is in many ways rather underlied with linearising-imbuing_conscious-moronisation-<as-to-prior_mereformulaicity/ritualisation>-enframing directionality of 'vague/clumsy dominance-driven intra/inter-statal insidious-anarchy_influencing/geoinfluencing-<as-to-dynamic-'mereinfluencing-over-sublimating-technicity/profundity',-so-scheming-as-allowed-by‘formulaically $\sim$ passivated/linearised-forwardfacing — institutional existentialising-framingby-enframing/\{worlding\} ';-as-so-truncating-the-strategic/geostrategic,-political-andsuccessive-lower-interrelatedness-dynamics-of-social-constructing'> imbued infowarring manifesting knowledge-without-knowledge/knowledge-outside-knowledge/extra-knowledge' within which domineering ambit arises implicitly/explicitly secondary roles of jumbling disparateness-of-conceptualisation-<unforegrounding-ment,-failing-prospectively-to-reflect‘immanent relative-unreflexivity/relative-reflexivity - ontological-contiguity '> inherently geared towards failing 'thinking at first/pure predisposition preemptive of prospective disontologising/subontologising' thus failing conceptivity/epistemic-reflexivity/epistemicityrelativism-determinism-<reifying \{as-to-knowledge-developing $\}$-and-empowering $>$ (notwithstanding vague overt/public depiction of re-ontologising-imbuing-of-prospectivehuman-sublimating/emancipating/enfranchisement imbued with impractical/improbable technicity/profundity as to their effective deficient re-ontologising-imbuing-of-prospectivehuman-sublimating/emancipating/enfranchisement but for the in-effect ${ }^{79}$ presencingabsolutising-identitive-constitutedness \{epistemic-totalising $3{ }^{3}$ psychologismic-subliminaltruncating). But then thought has to be done 'notwithstanding the stresses and ineptness of presencing - absolutising-identitive-constitutedness ${ }^{1{ }^{\prime}}$, as the very possibility for the openness 
for recurring human sovereign-emergence/becoming,-existentially-imbuing-human-freedomas-to-supererogating/surrealising-for-'knowledge-empowerment-over-ignorancedisempowerment'-<as-of-'developing-and-availing-sovereignsublimating_potential/possibilities/options/choices'-as-to-the-'credibility'/'ontologicalveracity'-underlying-the-'sovereign-conscious/conscientious-backdrop’> consciousness/collective-consciousness'. What substitutes for thought when there is no profound drive to think is knowledge-without-knowledge/knowledge-outside-knowledge/extraknowledge; as the very recipe for 'existentially- $<$ disontologising/re-ontologising aporeticism $>$ manifest incidental/accidental reactive-sufferance/endurance in supposedly and paradoxically subordinating/subserving/collateralising the possibility for prospective re-ontologisingimbuing-of-prospective-human-sublimating/emancipating/enfranchisement'. So-reflected as to the very vague premises of such linearising-imbuing_conscious-moronisation-<as-to-

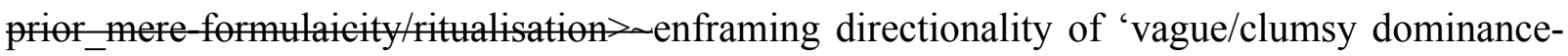
driven intra/inter-statal insidious-anarchy_influencing/geoinfluencing-<as-to-dynamic-‘mereinfluencing-over-sublimating-technicity/profundity',-so-scheming-as-allowed-by‘formulaically $\sim$ passivated/linearised-forwardfacing - institutional existentialising-framingby-enframing/\{worlding\} ';-as-so-truncating-the-strategic/geostrategic,-political-andsuccessive-lower-interrelatedness-dynamics-of-social-constructing'> imbued infowarring manifesting knowledge-without-knowledge/knowledge-outside-knowledge/extra-knowledge': as implying that 'what is supposed to be the very opening of intemporal-projection/longness-ofregister-of meaningfulness-and-teleology can be boxed-in for temporal/mortal purposes' of 'lifespan extricatory/preconverging psychical-nascency moronisation- $<$ sublimating-nascence,extrictesublimating-downstreaming/'avalage'>’. This infowarring paradox is effectively reflected across the successive registry-worldviews/dimensions (beyond their ('everyday supposedly relatively-superficial/irrelevant/unthought $\quad$ out-of-phasing $>$ disparate- 
narratives_of_social-functioning-and-accordance_-as-of-social-stake-contention-or-

confliction_construct')—_formulaically $\sim$ passivated/linearised-forwardfacing-

institutional existentialising-framing-by-enframing/\{worlding $\}$ of the sovereignfunction/posture-<as-to-existentially-manifest-‘embodied-subject $\sim$ consciousness-and-

direct/deferential-conscientiousness',-as-of-its-'epistemic-reflexivity/unreflexivity-in-

existence'/teleology >'); as to the reality of both ancient-sophists non-universalising institutionalinfowarring and medieval-scholasticism nonpositivising institutional-infowarring effectively hardly dawned to their given ${ }^{79}$ presencing — absolutising-identitive-constitutedness ${ }^{14}$, just as it is 'ontologically delusional' to fail to factor-in our modern-day disparateness-of-conceptualisation$<$ unforegrounding-ment,-failing-prospectively-to-reflect-'immanent relative-

unreflexivity/relative-reflexivity ontological-contiguity ' $>$ as to totalisingly-ingdiscretion/whim-of-thought institutional-infowarring. This articulation is made as the more profound and truer notion of re-ontologising human ontological-performance ${ }^{2}-<$ includingvirtue-as-ontology $>/$ morality/ethics/justice/etc. rather lies with prospective dimensionality-ofsublimating $25-<<$ amplituding/formative $>$ supererogatory $\sim$ de-mentativeness/epistemic-growthor-conflatedness /transvaluative-rationalising/transepistemicity/anamnestic-residuality/spiritdrivenness-equalisation〉 and thus postconvergingaporeticism-overcoming/unovercoming 'can't be dodged' and then a pretense of prospective sublimating ontological-performance ${ }^{72}$ $<$ including-virtue-as-ontology $>/$ morality/ethics/justice/etc. re-avails; but for the manifest knowledge-deadends-<as-preconverging-de-mentating/structuring/paradigming $>$ of the said presencing-absolutising-identitive-constitutedness ${ }^{14} \quad$ habituated $\quad$ fepistemictotalising 3 psychologismic-subliminal-truncating (as so rather revealing to us the reality of our 'shallow psychologismic-transfixity-<placeholder-setup-ontological-rescheduling-inrealigning/preactivity/formative-becoming/psychoanalytical-unshackling,-as-to-residualising-

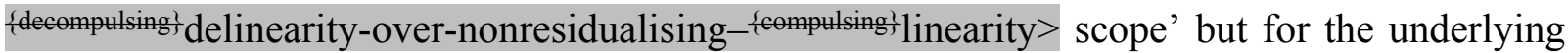


recomposured/cumulated prior ssecondnatured positive-opportunism-of-social-functioningand-accordance , as-to prospective_punctual/immediacy/constituted/compulsions-

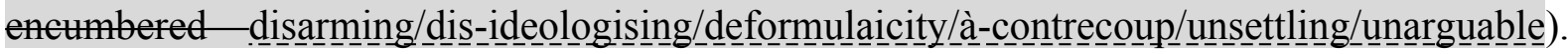
Such implicitly/explicitly secondary roles of jumbling disparateness-of-conceptualisation$<$ unforegrounding-ment,-failing-prospectively-to-reflect-‘immanent relativeunreflexivity/relative-reflexivity ontological-contiguity '> emphasis upon 'mortals mutualising of mortality/temporal-projection/shortness-of-register-of meaningfulness-andteleology', seem to imply 'its remote and desovereignising institutional ownership on the prospective possibility of human sovereign-emergence/becoming-existentially-imbuing human-freedom-as-to-supererogating/surrealising-for-'knowledge-empowerment-overignorance-disempowerment'-<as-of-'developing-and-availing-sovereignsublimating_potential/possibilities/options/choices'-as-to-the-'credibility'/'ontologicalveracity'-underlying-the-'sovereign-conscious/conscientious-backdrop'>'; and so, as to a supposedly foolproof/infallible 'mutually reinforcing self-indulging and self-sustaining triptych/trinity' of 'practice/collegiality/consensus of limitedness/human-subpotency failing prospective sublimating-prolongation' manifested as of institutionalised-minimumcompetence/expertising-posturing mere-formulaicity/ritualisation ('as supposedly more critically covered/protected/shielded from requisite sublimating-prolongation with respect to the prospective veracity of superseding unlimitedness/existence-full-potency-of_sublimating nascence $>$ ') by its assumed institutionalised-legalese-posturing mere-formulaicity/ritualisation and institutionalised-communication/public-relations-posturing mere-formulaicity/ritualisation (so-underlied overall as to formulaic profusion of prospectively ontologically-flawed process/processive bothsidesism-〈as-'mere-processive'/pedantising-'dialogical-relation'to 'perceived-social-and-institutional-commonly-enculturated_referencing,-ofmeaningfulness-and-teleology '-failing-'requisite-existential-thematic-baseline-of- 
technicity/profundity-framing' \{of-sublimating-discursivity-for-sovereign-repassing $\}$,-as-of-

psychologismic-epistemic-acutisation - nonresidualising-imbued-\{compulsing\}linearity in-

eclecticism-of-prior-mere-formulaicity/ritualisation,-as-so-'consciously/unconsciously-

preordained/fated'-to-fail-prospective-notional cogency conceptualisation as supposedly

superseding 'unlimitedness/existence-full ponofofublimating nascence $>$ ' inherently justificatory evaluation of either 'limitedness/human-subpotency' manifest 'disontologising irresponsibility/relative-unreflexivity' or 're-ontologising responsibility/relative-reflexivity'). Such a manifest 'epistemic-decadence' or teleological-decadence-<-in-dimensionality-ofdesublimating-lack-of ${ }^{-}-\langle<$amplituding/formative $>$supererogatory-de-mentativeness/epistemicgrowth-or-conflatedness /transvaluative-rationalising/transepistemicity/anamnestic-

residuality/spirit-drivenness-equalisation $\rangle$ imbued distractive-alignment-to- ${ }^{8}$ reference-ofthought- $<$ of-apriorising/axiomatising/referencing $>30$ is further paradoxically caught up between the philosophical (as to the requisite 'thinking at first/pure predisposition preemptive of prospective disontologising/subontologising' as for 'human solipsistic impulse/intuition for prospective re-originariness/re-origination of intelligibility-and-knowledge as-looping-with prior social-emanance) and the ontological/scientific (prospectively 'thinking at first/pure predisposition preemptive of prospective disontologising/subontologising' as for intelerance$\leq$ of-disparateness $>$ /exactifying_precisioning-of-sublimation-<as-to-postconverging narrowing-down apriorising/axiomatising/referencing-entailing-theoretical,-conceptual-andoperant-implications $>$ ); as it degenerates into a pedantising/muddling/formulaic-hollowingout_-in-subontologisation/subpotentiation-〈blurring/undermining-of-prospective-totalisingentailing,-as-to-entailing-<amplituding/formative-epistemicity $>$ totalising $\sim$ in-relativeontological-completeness $>$ that at one moment claim to emphasise a scientific conception of knowledge and at another moment sterile/anecdotal institutional-prescience/imprimaturingSdullness of the spirit/psychelogismic epistemic acutisation nonresidualising imbued- 
aphoristic conception of knowledge (and certainly failing to prospectively reflect relativeunreflexivity/relative-reflexivity_ontological-contiguity ${ }^{77}$ as to 'limitedness/humansubpotency prospective re-encountering/re-confrontation with unlimitedness/existence-<fullpotency-of_sublimating nascence>> unblurriness $\sim$ reframing/reformulation/decatchmenting/detruncating/decompulsing/delinearisi ng imbuing sublimating-prolongation). The requisite memorative-extension- $<$ as-to'conscientiousness-demoronisation — delinearising construct-of-thought'/‘ ' tepistemic 'psychologismic-subliminal-detruncating';-as-relative-reflexivityreframing_educing $\sim$ sublimating-prolongation $>$ (over such prior_institutionalisation-<as-to-itsmere-formulaicity/ritualisation,-conscious-moronisation-linearising $\sim$ construct-ofthought'/‘ \{epistemic-totalising '’ psychologismic-subliminal-truncating';-as-relative-unreflexivityenframing_failing $\sim$ sublimating-prolongation> elicited institutionalising-inflative-distortion$<$ as-to-prior_mere-formulaicity/ritualisation-failing-prospective-profound-supererogation undermining the recurrent-linking-up of prior sublimating-arising and prospective sublimatingprolongation), as to the 'originary-and-re-originary/re-ontologising-nascency of the 'relativethreflexivityelative reflexivity - ontological-contiguity ${ }^{77}$ of the overall relativeunreflexivity/relative-reflexivity - ontological-contiguity ${ }^{67} \sim$ of-the-human-institutionalisationprocess ${ }^{6}$, implied conception of the notion of relativism (in superseding/overcoming such manifest pedantising/muddling/formulaic-hollowing-out—insubontologisation/subpotentiation-_blurring/undermining-of-prospective-totalising-entailing,as-to-entailing-<amplituding/formative-epistemicity>totalising in-relative-ontologicalcompleteness 7): is rather underlied as of requisite sovereign-function/posture-<as-toexistentially-manifest-`embodied-subject consciousness-and-direct/deferentialconscientiousness',-as-of-its-'epistemic-reflexivity/unreflexivity-in-existence'/teleology> 
existentially-< $<$ disentologising/re-ontologising aporeticism $>$ manifest 'limitedness/humansubpotency prospective re-encountering/re-confrontation with unlimitedness/existence-<fullpotency-of_sublimating nascence>'. So-educing recurring human sovereignemergence/becoming,-existentially-imbuing human-freedom-as-to-supererogating/surrealising for-'knowledge-empowerment-over-ignorance-disempowerment'-<as-of-'developing-andavailing-sovereign-sublimating_potential/possibilities/options/choices'-as-to-the'credibility'/'ontological-veracity'-underlying-the-'sovereign-conscious/conscientiousbackdrop'> consciousness/collective-consciousness; notwithstanding the ('everyday supposedly relatively superficial/irrelevant/unthought $\quad \leq$ out-of-phasing $>$ disparate-narratives_of_socialfunctioning-and-accordance-as-of-social-stake-contention-or-confliction_construct') 'formulaically $\sim$ passivated/linearised-forwardfacing —institutional existentialising-framingby-enframing/\{worlding\} of the sovereign-function/posture-<as-to-existentially-manifest‘embodied-subject consciousness-and-direct/deferential-conscientiousness',-as-of-its'epistemic-reflexivity/unreflexivity-in-existence'/teleology>' recurring prospective susceptibility to pedantising/muddling/formulaic-hollowing-out—insubontologisation/subpotentiation-〈blurring/undermining-of-prospective-totalising-entailing,as-to-entailing-<amplituding/formative-epistemicity $>$ totalising $\sim$ in-relative-ontologicalcompleteness ) I. In other words, the ('everyday supposedly relatively superficial/irrelevant/unthought $\leqslant$ out-of-phasing $>$ disparate-narratives_of_social-functioningand-accordance_-as-of-social-stake-contention-or-confliction_construct') —

'formulaically $\sim$ passivated/finearised-forwardfacing — institutional existentialising-framingby-enframing/\{worlding\} of the sovereign-function/posture-<as-to-existentially-manifest‘embodied-subject $\sim$ consciousness-and-direct/deferential-conscientiousness',-as-of-its'epistemic-reflexivity/unreflexivity-in-existence'/teleology>' is more critically failing to 'reflect the notional/epistemic/bindingness 5 ss-determinism/conceptivity-of-relative-mreflexivity/relative-reflexivityz 
prospect for prospective re-ontologising' which 'underlies the relation between limitedness/human-subpotency prospective re-encountering/re-confrontation with unlimitedness/existence-<full-potency-of_sublimating nascence $>$ ': wherein limitedness/human-subpotency is overall rather subpotently of ' $<$ out-of-phasing $>$ disparatenarratives_of_social-functioning-and-accordance-as-of-social-stake-contention-orconfliction_construct (so-manifesting-at-the-given — unblurriness/blurrinessthreshold framing/formulation/catchmenting/truncating/compulsing/linearising)' imbued disontologising/subontologising — unculturated/enculturated/subculturated elasticity/margin/threshold/circumstantiality-of-discretionariness-from/acceding-to' $<$ developed/developing $>$ relation with (the full-potentiation that is unlimitedness/existence<full-potency-of_sublimating nascence $>$ as to) potentiating prospective re-ontologising 'ontologically-hegemonising-narrative ${ }^{71}$ ontological-performance ${ }^{72}-<$ including-virtue-asontology $>$ /morality/ethics/justice/etc.' - (with reference to notional/epistemic/bindingness ${ }^{-<a-t o-}$ determinism/conceptivity of relative unreflexivity/relative reflexivity> 'parrhesiastic/messianicity/profoundsupererogation projection for sublimating-prolongation'). Such that the individuative manifestations of: the sovereign-function/posture-<as-to-existentially-manifest-'embodiedsubject consciousness-and-direct/deferentiat-conscientiousness',-as-of-its- 'epistemicreflexivity/unreflexivity-in-existence'/teleology>, the genuine social intellectualfunction/posture and pedantising/muddling/formulaic-hollowing-out-insubontologisation/subpotentiation-〈blurring/undermining-of-prospective-totalising-entailing,as-to-entailing-<amplituding/formative-epistemicity $>$ totalising $\sim$ in-relative-ontologicalcompleteness $\rangle$ (as so-differentially elucidated 'limitedness/human-subpotency prospective reencountering/re-confrontation with unlimitedness/existence-<fll-potency-of_sublimating nascence $>$ '), are all of the-very-same underlying 'veridical notionality/epistemicity/bindingness' 
teleology' - (reflection upon the given 'existential-<disontologising/re-ontologising aporeticism>

〈'baseline/nominalising/editional—aptitudinal underlay-<as-to-prior-

unblurriness reframing/reformulation/decatchmenting/detruncating/decompulsing/delinearising $>$ enabling

'baselining/cogency/reconstruing — aptitudinal overlay-<for-prospective- unblurriness-dragging-out $>$ ' $\rangle$-...reflected-as-

recurring $\sim$ existentialising-framing-by-enframing/\{worlding $\}$-<as-manifest-

individuative direct/deferential-transeffusive/worlding-looping $>$ _reflected-as_-supererogation 6 -

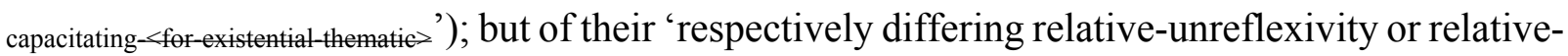
reflexivity

ontological-performance ${ }^{72}-<$ including-virtue-asontology $>$ /morality/ethics/justice/etc.' (so-manifesting-at-the-given - unblurriness/blurrinessthreshold framing/formulation/catchmenting/truncating/compulsing/linearising of socialfunctioning-and-accordance-as-of-social-stake-contention-or-confliction). In this respect, the ('everyday supposedly relatively -superficial/irrelevant/unthought $<$ out-of-phasing $>$ disparatenarratives_of_social-functioning-and-accordance_-as-of-social-stake-contention-orconfliction_construct')_-'formulaically passivated/Ainearised-forwardfacinginstitutional existentialising-framing-by-enframing/\{worlding\} of the sovereignfunction/posture-<as-to-existentially-manifest-'embodied-subject $\sim$ consciousness-anddirect/deferential-conscientiousness',-as-of-its-'epistemic-reflexivity/unreflexivity-inexistence'/teleology >' is the reflection of the fact that limitedness/human-subpotency (as to its given ‘ $<$ amplituding/formative-epistemicity $>$-totalising $\sim$ thrownness-in-existence locus/station of social-functioning-and-accordance-as-of-social-stake-contention-orconfliction' imbued unblurriness/blurrinessthreshold framing/formulation/catchmenting/truncating/compulsing/linearising) poorly/weakly appreciates the 'uncompromising ontological-veracity' of the inherent full-potentiation that is the 'relative mreflexivity/relative reflexivity bindingness/nondiscretionariness-<as-from-sublimating remoteness/distance-of-appraisal-of-requisite-Being-development> of 
unlimitedness/existence-<full-potency-of_sublimating nascence $>$ '-(as to 'relativeunreflexivity/relative-reflexivity limitedness/human-subpotency dynamics of supererogating \{affirmation/projection/assertion/notional self-distantiation-byunaffirmation/deprojection/deassertion/epistemic-decadence $\}$-towards $\sim$ omnipotentialaffirmation/projection/assertion/notional self-distantiation' with respect to 'limitedness/humansubpotency prospective re-encountering/re-confrontation with unlimitedness/existence-<fullpotency-of_sublimating nascence>'). So-explaining limitedness/human-subpotency manifest 'tepid limited-mentation-capacity of ontological-performance ${ }^{72}-<$ including-virtue-asontology $>$ /morality/ethics/justice/etc.' (and rather so-tepidly as from living-development-as-topersonality-development psychologismic epistemic-acutisation difficulty $<$ for,

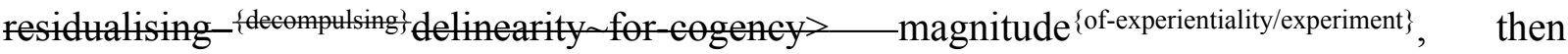
institutional-development-as-to-social-function-development psychologismic epistemicacutisation difficulty<-for, residualising \{decompulsing $\}$ delinearity for-cogency> magnitude $\{$ ofexperientiality/experiment\} and then Being-development/ontological-framework-expansion-as-to-depthof-ontologising-development-as-infrastructure-of- meaningfulness-and-teleology psychologismic epistemic-acutisation difficulty-for, residualising $\{$ decompulsing $\}$ delineariter for to the relative scope of "existentially-<disontologising/re-ontologising aporeticism $>$ manifest incidental/accidental reactive-sufferance/endurance in supposedly and paradoxically subordinating/subserving/collateralising the possibility for prospective re-ontologisingimbuing-of-prospective-human-sublimating/emancipating/enfranchisement'. Whereas the genuine social intellectual-function/posture emphasises the relative scope of originary-and-reoriginary manifest 're-ontologising-nascency-<as-of-prospective-solipsistic/intersolipsisticinkling-drive-for-knowledge-elucidation,-as-to-veridical-organic-knowledge $>$ for sublimatingprolongation' in reflection of the 'uncompromising ontological-veracity' of the inherent full- 
potentiation that is the 'relative-unreflexivity/relative-reflexivity-bindingness/nondiscretionariness-<asfrom-sublimating remoteness/distance-of-appraisal-of-requisite-Being-development> of unlimitedness/existence-<full-potency-of_sublimating nascence $>$ '- (as to 'relativeunreflexivity/relative-reflexivity limitedness/human-subpotency dynamics of supererogating \{affirmation/projection/assertion/notional $\sim$ self-distantiation-byunaffirmation/deprojection/deassertion/epistemic-decadence \}-towards -omnipotentialaffirmation/projection/assertion/notional self-distantiation' with respect to 'limitedness/humansubpotency prospective re-encountering/re-confrontation with unlimitedness/existence-<fullpotency-of_sublimating nascence $>$ '): and so, as to requisite psychologismic-epistemicacutisation-<as-to-postconverging-de-mentating/structuring/paradigming,-eliciting-ofexistence's-sublimating-nascence-in-prospective-aporeticism-overcoming/unovercoming $>$ as to epistemic-growth,-as_ \{veridical/sound\}-relative-reflexivity-in-existence/relativising fromlimited-mentation-as-its-deepening/psychologismic epistemic-acutisation residualising, \{decompulsing delinearity for-cogency imbued 'cut-out-<as-to-re-ontologising redressing/straightening-out $>$ (as of relative-reflexivity psychologismic-transfixity$<$ placeholder-setup-ontological-rescheduling - in-realigning/preactivity/formative-

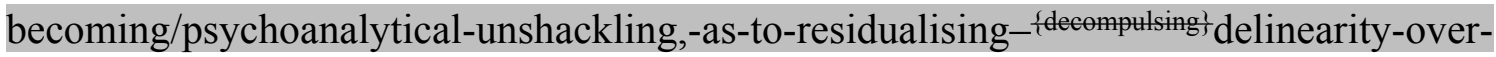
nonresidualising-\{compulsing\}linearity $>$ ) for sublimating-prolongation'. The 'uncompromising ontological-veracity' (of the inherent full-potentiation that is the 'relative-unreflexivity/relative-reflexivitybindingness/nondiscretionariness-<as-from-sublimating remoteness/distance-of-appraisal-ofrequisite $\sim$ Being development $>$ of unlimitedness/existence-<full-potency-of_sublimating nascence $>$ ' - (as to 'relative-unreflexivity/relative-reflexivity limitedness/human-subpotency dynamics of supererogating \{affirmation/projection/assertion/notional $\sim$ self-distantiation-byunaffirmation/deprojection/deassertion/epistemic-decadence\} - towards omnipotentialaffirmation/projection/assertion/notional self-distantiation' with respect to 'limitedness/human- 
subpotency prospective re-encountering/re-confrontation with unlimitedness/existence- $<$ fullpotency-of_sublimating nascence $>$ '): as such speaks to the fact that ('everyday supposedly relatively superficial/irrelevant/unthought sout-of-phasing $>$ disparate-narratives_of_socialfunctioning-and-accordance_-as-of-social-stake-contention-or-confliction_construct')_ 'formulaically $\sim$ passivated/linearised-forwardfacing — institutional existentialising-framingby-enframing/\{worlding\} of the sovereign-function/posture-<as-to-existentially-manifest'embodied-subject consciousness-and-direct/deferential-conscientiousness',-as-of-its'epistemic-reflexivity/unreflexivity-in-existence'/teleology>' (as to contentious/un-nominalised social-stake-contention-or-confliction imbued unblurriness/blurrinessthreshold framing/formulation/catchmenting/truncating/compulsing/linearising) do not override the requisite 'notional/epistemic/bindingness'-<as-to-determinism/conceptivity-of-relativeunreflexivity/relative-reflexivitys elucidation' of the 'relative-unreflexivity/relative-reflexivitybindingness/nondiscretionariness-<as-from-sublimating remoteness/distance-of-appraisal-ofrequisite $\sim$ Being development $>$ of unlimitedness/existence-<full-potency-of_sublimating nascence $>$ ' - (as to 'relative-unreflexivity/relative-reflexivity limitedness/human-subpotency dynamics of supererogating \{affirmation/projection/assertion/notional $\sim$ self-distantiation-byunaffirmation/deprojection/deassertion/epistemic-decadence\} - towards omnipotentialaffirmation/projection/assertion/notional self-distantiation' with respect to 'limitedness/humansubpotency prospective re-encountering/re-confrontation with unlimitedness/existence- $<$ fullpotency-of_sublimating nascence $>$ '). And so, with regards to such $\leqslant$ out-of-phasing $>$ disparatenarratives_of_social-functioning-and-accordance_-as-of-social-stake-contention-orconfliction_construct direct/deferential 'human manifest existentialising-decisionality-<as-todisontologising/re ontologising aporeticism $>$ coming-to-a-head/culmination-point-ofdesovereignising-or-sovereignising sovereign-repassing '- (so-reflected as of underlying 'constraining direct/deferential micro-decisionality/macro-decisionality thrownness-disposition 
of disontologising/re-ontologising' upon the 'social-functioning-and-accordance-as-of-socialstake-contention-or-confliction construct'). This effectively underlines the existentially$<$ disontologising/re-ontelogising aporeticism $>$ manifest 'differential sovereignfunction/posture-<as-to-existentially-manifest-‘embodied-subject $\sim$ consciousness-anddirect/deferential-conscientiousness',-as-of-its-'epistemic-reflexivity/unreflexivity-inexistence'/teleology $>$ by genuine social intellectual-function/posture by pedantising/muddling/formulaic-hollowing-out—in-subontologisation/subpotentiation〈blurring/undermining-of-prospective-totalising-entailing,-as-to-entailing$<$ amplitudingfformative-epistemicity $>$ totalising in-relative-ontological-completeness respective ontological-performance ${ }^{72}<$ including-virtue-asontology $>$ /morality/ethics/justice/etc.'; as to 'human consciousness/collective-consciousness differential disontologising/re-ontologising ${ }^{56}$ meaningfulness-and-teleology ${ }^{9}$, with respect to 'veridical notionality/epistemicity/bindingness reflexivity> conception-of- ${ }^{5}$ meaningfulness-and-teleology ${ }^{\circ}$ - (reflection upon the given 'existential-<disontologising/re-ontologising aporeticism $>\quad$ ('baseline/nominalising/editional_aptitudinal $\sim$ underlay-<as-to-priorunblurriness $\sim$ reframing/reformulation/decatchmenting/detruncating/decompulsing/delinearising $>$ '

recurring $\sim$ existentialising-framing-by-enframing/\{worlding $\}-<$ as-manifest-

individuative -direct/deferential-transeffusive/worlding-looping $>$ _reflected-as-supererogation 6 -

capacitating-<for-existential-thematic $>\quad$ imbued interest/disinterest, investedness/disinvestment, exposure/lack-of-exposure, role/task participative-emplacement and relevance/irrelevance-andcapability/incapability-appraisal'). And so, as to the respective 'disontologising/re-ontologising implications' upon 'human manifest existentialising-decisionality-<as-to-disontologising/reentologising aporeticism $>$ coming-to-a-head/culmination-point-<of-desovereignising-orsovereignising sovereign-repassing >'- (so-reflected as of underlying 'constraining 
direct/deferential micro-decisionality/macro-decisionality thrownness-disposition of

disontologising/re-ontologising' upon the 'social-functioning-and-accordance-as-of-socialstake-contention-or-confliction construct'). So-speaking to the fact that the reality of human consciousness/collective-consciousness is rather of such 'differential social-functioning-andaccordance-as-of-social-stake-contention-or-confliction construct (with respect to educedand-availing-and-re-availing relative-ontological-completeness ${ }^{87}$-ofapriorising/axiomatising/referencing)'; as to the dynamic intersolipsism of existentially$<$ disontologising/re-ontologising aporeticism $>$ manifest individuals-and-individuative <amplituding/formative-epistemicity>-totalising $\sim$ thrownness-in-existence ${ }^{35}$ of human consciousness/collective-consciousness (imbued differential 'delinearisingimbuing_conscientiousness-demoronisation-<as-to-renewing-realisation/re-perception/rethought $>\sim$ reframing over linearising-imbuing_conscious-moronisation-<as-to-prior_mereformulaicity/ritualisation>nenframing'). This differential reality so-underlies 'thehuman/humanity consciousness/collective-consciousness differential disontologising/reontologising meaningfulness-and-teleology ${ }^{\circ}$ ': with respect to 'veridical notionality/epistemicity/bindingness ${ }^{-<a s-t o-d e t e r m i n i s m / c o n c e p t i v i t y-o f-r e l a t i v e-u n r e f l e x i v i t y / r e l a t i v e-r e f l e x i v i t y ~}>$ conception-of- ${ }^{5}$ meaningfulness-and-teleology" - (reflection upon the given 'existential-

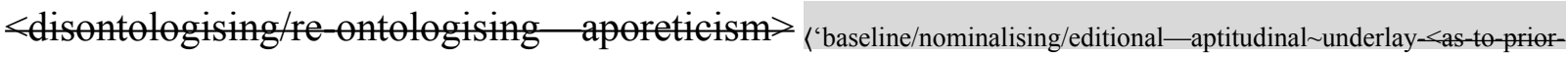
unblurriness-reframing/reformulation/decatchmenting/detruncating/decompulsing/delinearising enabling 'baselining/cogency/reconstruing — aptitudinal overlay-<for-prospective- unblurriness-dragging-out $>$ ' $\rangle$-...reflected-asrecurring existentialising-framing-by-enframing/\{worlding $\}$-<as-manifestindividuative -direct/deferential-transeffusive/worlding-looping > _reflected-as_-supererogation 6 capacitating $<$ imbued interest/disinterest, investedness/disinvestment, exposure/lack-of-exposure, role/task participative-emplacement and relevance/irrelevance-andcapability/incapability-appraisal'). And so, in reflection of such 'differential 
limitedness/human-subpotency

ontological-performance ${ }^{72}-<$ including-virtue-asontology $>$ /morality/ethics/justice/etc.' (with respect to 'referenced relative-reflexivity ontological-performance $^{72}$-<including-virtue-as-ontology $>$ /morality/ethics/justice/etc.'): $\quad$ as 'veridically construable/referenced' as of the 'relative-unreflexivity/relative-reflexivitybindingness/nondiscretionariness-<as-from-sublimating remoteness/distance-of-appraisal-ofrequisite-Being-development $>$ of unlimitedness/existence-ffll-potency-of_sublimating nascence $>$ ' - (as to 'relative-unreflexivity/relative-reflexivity limitedness/human-subpotency dynamics of supererogating \{affirmation/projection/assertion/notional $\sim$ self-distantiation-byunaffirmation/deprojection/deassertion/epistemic-decadence $\}$ - towards $\sim$ omnipotentialaffirmation/projection/assertion/notional self-distantiation' with respect to 'limitedness/humansubpotency prospective re-encountering/re-confrontation with unlimitedness/existence- $<\mathrm{full}-$ potency-of_sublimating nascence $>$ '), and rather veridically as from prospective re-ontologising Being-development/ontological-framework-expansion-as-to-depth-of-ontologisingdevelopment-as-infrastructure-of- meaningfulness-and-teleology psychologismic epistemic-acutisation difficulty-for, residualising \{decompulsing $\}$ delinearity for-cogency> magnitude $\{$ of-experientiality/experiment\}, then institutional-development-as-to-social-functiondevelopment psycholegismic epistemic acutisation difficulty <for, residualising \{decompulsing\} delinearity for-cogeney>-magnitude\{of-experientiality/experiment\} and then livingdevelopment-as-to-personality-development psychologismic epistemic acutisation-

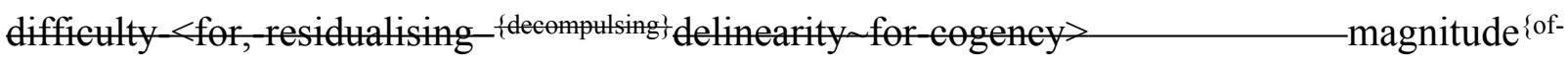
experientiality/experiment'). This elucidation reflects upon ('everyday supposedly relatively superficial/irrelevant/unthought sout-of-phasing >-disparate-narratives_of_social-functioningand-accordance_-as-of-social-stake-contention-or-confliction_construct') _'formulaically $\sim$ passivated/linearised-forwardfacing — institutional existentialising-framingby-enframing/\{worlding\} of the sovereign-function/posture-<as-to-existentially-manifest- 
‘embodied-subject consciousness-and-direct/deferential-conscientiousness',-as-of-its-

'epistemic-reflexivity/unreflexivity-in-existence'/teleology>'; and so, with respect to the fullpotentiation that is the 'relative-unreflexivity/relative-reflexivity-bindingness/nondiscretionariness-<asfrom-sublimating remoteness/distance-of-appraisal-of-requisite-Being-development $>$ of unlimitedness/existence-<fll potency-of_sublimating nascence $>$ '- (as to 'relativeunreflexivity/relative-reflexivity limitedness/human-subpotency dynamics of supererogating \{affirmation/projection/assertion/notional $\sim$ self-distantiation-byunaffirmation/deprojection/deassertion/epistemic-decadence $\}$ - towards $\sim$ omnipotentialaffirmation/projection/assertion/notional self-distantiation' with respect to 'limitedness/humansubpotency prospective re-encountering/re-confrontation with unlimitedness/existence- $<$ fullpotency-of_sublimating nascence $>$ '). And speaks to the fact that 'human consciousness/collective-consciousness manifest linearising-imbuing_conscious-moronisation<as-to-prior_mere-formulaicity/ritualisation>-enframing' (so-constrained 'more decisively/potently as to the preconverging-de-mentating/structuring/paradigming directionality' of 'vague/clumsy dominance-driven intra/inter-statal insidiousanarchy_influencing/geoinfluencing-<as-to-dynamic-'mere-influencing-over-sublimatingtechnicity/profundity', -so-scheming-as-allowed-by-'formulaically passivated/Ainearisedforwardfacing — institutional existentialising-framing-by-enframing/\{worlding\} ';-as-sotruncating-the-strategic/geostrategic,-political-and-successive-lower-interrelatednessdynamics-of-social-constructing'> imbued infowarring manifesting knowledge-withoutknowledge/knowledge-outside-knowledge/extra-knowledge' as imbuing of existentially<disontologising/re-ontologising aporeticism> manifest <amplituding/formativeepistemicity>-totalising $\sim$ thrownness-in-existence ${ }^{35}$ pedantising/muddling/formulaic-hollowingout_-in-subontologisation/subpotentiation-〈blurring/undermining-of-prospective-totalisingentailing,-as-to-entailing-<amplituding/formative-epistemicity $>$ totalising $\sim$ in-relative- 
ontological-completeness \) (across the successive registry-worldviews/dimensions): sodirectionally preconverging-de-mentating/structuring/paradigming impart their imbued 'disontologising/subontologising overweighted-limiting/thresholding (as the ${ }^{79}$ presencingabsolutising-identitive-constitutedness ${ }^{14}$ habituated \{epistemic-totalising $3{ }^{3}$ psychologismicsubliminal-truncating)' upon the prospect of prospective human re-ontologising. And so, as to the 'given <amplituding/formative-epistemicity>-totalising $\sim$ thrownness-in-existence attained/relative-reflexivity-by-unattained/relative-unreflexivity -threshold-of-reontologising'-(elicited human ontological-commitment and universal-transparency with respect to underlying human 'crossgenerational notional firstnaturedness-formativeness-<as-toeventualising-inkling drive-or-seeding misprising $>$ mental-processing-parity for ontological-performance -<including-virtue-as-ontology $>$ /morality/ethics/justice/etc.') imbued ('everyday supposedly relatively -superficial/irrelevant/unthought $\leqslant$ out-of-phasing $>$ disparatenarratives_of_social-functioning-and-accordance-as-of-social-stake-contention-orconfliction_construct')__formulaically $\sim$ passivated/Ainearised-forwardfacing_ institutional existentialising-framing-by-enframing/\{worlding $\} \quad$ of the sovereignfunction/posture-<as-to-existentially-manifest-‘embodied-subject consciousness-and-

\section{direct/deferential-conscientiousness',-as-of-its-'epistemic-reflexivity/unreflexivity-in-}

existence'/teleology>'; with respect to the disontologising/re-ontologising implications of effusing 'human manifest existentialising-decisionality-<as-to-disontologising/reentologising aporeticism $>\quad$ coming-to-a-head/culmination-point-<of-desovereignising-orsovereignising sovereign-repassing >'-(so-reflected as of underlying 'constraining direct/deferential micro-decisionality/macro-decisionality thrownness-disposition of disontologising/re-ontologising' upon the 'social-functioning-and-accordance-as-of-socialstake-contention-or-confliction construct'). Such that in-many-ways supposedly construing the ontologising/scientific/existence- $<$ honesty-constraining $>$ — scope_for_prospective_re- 
ontologising as speaking to ('everyday supposedly relatively superficial/irrelevant/unthought sout-of phasing $>$ disparate-narratives_of_social-functioning-and-accordance-as-of-socialstake-contention-or-confliction_construct')_- formulaically $\sim$ passivated/linearisedforwardfacing - institutional existentialising-framing-by-enframing/\{worlding $\}$ of the sovereign-function/posture-<as-to-existentially-manifest-'embodied-subject $\sim$ consciousnessand-direct/deferential-conscientiousness',-as-of-its-'epistemic-reflexivity/unreflexivity-inexistence'/teleology>' as of ${ }^{79}$ presencing - absolutising-identitive-constitutedness ${ }^{14}$ habituated thychologismic-subliminal-truncating, effectively renders the supposedly ontologising/scientific/existence- $<$ honesty-constraining $>$ - scope_for_prospective_reontologising paradoxically relatively-irrelevant to prospective human transcendence-andsublimity/sublimation/supererogatory-de-mentativity; as manifested with both ancient-sophists non-universalising and medieval-scholasticism nonpositivism/non-rational-empiricism failing prospective sublimating-prolongation (as to an uncritical relation to their respectively given registry-worldview/dimension overall 'apriorising/axiomatising/referencingequating/leveling/ressentiment/closed-construct-of- ${ }^{56}$ meaningfulness-and-teleology ${ }^{99}$ and bothsidesism-〈as-'mere-processive'/pedantising-'dialogical-relation'-to 'perceived-socialand-institutional-commonly-enculturated_referencing,-of- meaningfulness-and-teleology 'failing-'requisite-existential-thematic-baseline-of-technicity/profundity-framing' \{ofsublimating-discursivity-for-sovereign-repassing\},-as-of-psychologismic-epistemicacutisation-nonresidualising-imbued-fompulsing linearity in-eclecticism-of-prior-mereformulaicity/ritualisation,-as-so- 'consciously/unconsciously-preordained/fated'-to-failprospective-notional cogency) failing cogency_chronicularity/annality-of-relativereflexivity,-as-to-profound-supererogation ). In other words, the veracity of the ontologising/scientific/existence- $<$ honesty-constraining $>$ - scope_for_prospective_reontologising warrants its effective 'human consciousness/collective-consciousness manifest 
delinearising-imbuing_conscientiousness-demoronisation-<as-to-renewing-realisation/reperception/re-thought>-reframing': as of the 'notional/epistemic/bindingness'<as-todeterminism/conceptivity of relative-mreflexivity/relative-reflexivitys elucidation' of the 'relative-mreflexivity/relativereflexivity—bindingness/nondiscretionariness-<as-from-sublimating remoteness/distance-ofappraisal-of-requisite-Being development $>$ of unlimitedness/existence- $<$ full-potency ef_sublimating nascence>'-(as to 'relative-unreflexivity/relative-reflexivity limitedness/human-subpotency dynamics of supererogating \{affirmation/projection/assertion/notional $\sim$ self-distantiation-byunaffirmation/deprojection/deassertion/epistemic-decadence $\}$ — towards $\sim$ omnipotentialaffirmation/projection/assertion/notional self-distantiation' with respect to 'limitedness/humansubpotency prospective re-encountering/re-confrontation with unlimitedness/existence-<fullpotency-of_sublimating nascence $>$ '); with regards to the 'relative-reflexivity of educed-andavailing-and-re-availing relative-ontological-completeness ${ }^{87}$-ofapriorising/axiomatising/referencing' (and so, in relation to the relative-unreflexivity of linearising-imbuing_conscious-moronisation-<as-to-prior_mereformulaicity/ritualisation $>\sim$ enframing as to preconverging-dementating/structuring/paradigming directionality of 'vague/clumsy dominance-driven intra/inter-statal insidious-anarchy_influencing/geoinfluencing-<as-to-dynamic-‘mereinfluencing-over-sublimating-technicity/profundity',-so-scheming-as-allowed-by'formulaically $\sim$ passivated/linearised-forwardfacing - institutional existentialising-framingby-enframing/\{worlding\} ';-as-so-truncating-the-strategic/geostrategic,-political-andsuccessive-lower-interrelatedness-dynamics-of-social-constructing'> imbued infowarring manifesting knowledge-without-knowledge/knowledge-outside-knowledge/extra-knowledge'). In so-elucidating 'human geotopological-<as-to- nonpresencing-detruncating-of-'humanpresencing-complexes/inhibitions-of-manifest-disanthropologisation'> disontologising/re- 
ontologising implications' (with regards to requisite anthropologisation- $<$ as-to-futuralreflexivity,-in-\{decompulsing\} delinearity-'invention'/“creation'-of-the-human/humanity>). In this regards, the ontologising/scientific/existence- $<$ honesty-constraining $>$ scope_for_prospective_re-ontologising, as to the full-potentiation that is the 'relativeunreflexivity/relative-reflexivity—bindingness/nondiscretionariness-<as-from-sublimating

remoteness/distance-of-appraisal of-requisite-Being-development>

of unlimitedness/existence-<full-potency-of_sublimating nascence $>$ '- (as to 'relativeunreflexivity/relative-reflexivity limitedness/human-subpotency dynamics of supererogating \{affirmation/projection/assertion/notional self-distantiation-byunaffirmation/deprojection/deassertion/epistemic-decadence $\}$ - towards $\sim$ omnipotentialaffirmation/projection/assertion/notional self-distantiation' with respect to 'limitedness/humansubpotency prospective re-encountering/re-confrontation with unlimitedness/existence-<fullpotency-of_sublimating nascence $>$ ') is of: the notionality/epistemicity/bindingness ${ }^{-<a s-t o-}$ determinism/entive of relative enreflexivity/relative reflexivitys scope of veridical core-philosophy/derivativecore-philosophy_(imbued requisite 'inkling-drive of dimensionality-of-sublimating ${ }^{25}$ <<amplituding/formative>supererogatery $\sim$ de-mentativeness/epistemic-growth-orconflatedness /transvaluative-rationalising/transepistemicity/anamnestic-residuality/spiritdrivenness-equalisation〉') 'holding-out/point-referencing-psychoanalytic-unshackling exercise of educed-and-availing-and-re-availing relative-ontological-completeness ${ }^{87}$-ofapriorising/axiomatising/referencing' to allow for play out of untenability-ofinduced unblurriness as '<prospective_punctual/immediacy/constituted/compulsionsencumbered - disarming/dis-ideologising/deformulaicity/à-contrecoup/unsettling/unarguable prompted constricted/narrowingdown-re-ontologising-enabling $>$-psychologismic epistemic acutisation residualising fepistemicthalising thermeneutic/textuality/reprojecting/supererogating/zeroing/re-acuting, 
\{decompulsing $\}$ delinearity for-cogency' as to 'developing human-per-cep-ti-vi-ty-<as-to notional perceptualisation-of-and-leashing-to_social-functioning-and-accordance-as-ofsocial-stake-contention-or-confliction> in preconverging/postconverging-redementating/restructuring/reparadigming'. The ontologising/scientific/existence- $<$ honestyconstraining $>$ — scope_for_prospective_re-ontologising (so-undergirding recurrent-linking-up of prior sublimating-arising and prospective sublimating-prolongation as to the 'originary-andre-originary/re-ontologising-nascency of the 'relative-unreflexivity/relative-reflexivityontological-contiguity of the overall relative-unreflexivity/relative-reflexivity_ontologicalcontiguity ${ }^{67}$ of-the-human-institutionalisation-process ${ }^{6}$, implied conception of the notion of relativism), speaks to the genuine social intellectual-function/posture 'higher value placed on inherent prospective knowledge elucidation'. As so-educing (as incipient to delinearisingimbuing_conscientiousness-demoronisation-<as-to-renewing realisation/re-perception/rethought $>\sim$ reframing) the organic-knowledge 'inkling-drive of dimensionality-of-sublimating <<amplituding/formative>supererogatery $\sim$ de-mentativeness/epistemic-growth-orconflatedness /transvaluative-rationalising/transepistemicity/anamnestic-residuality/spiritdrivenness-equalisation)'-over-'seeding-misprising of dimensionality-of-desublimating-lackof - -< < amplituding/formative >supererogatory - de-mentativeness/epistemic-growth-orconflatedness /transvaluative-rationalising/transepistemicity/anamnestic-residuality/spiritdrivenness-equalisation)': as of 'baseline/nominalising/editional—aptitudinal underlay_as to prior

unblurriness reframing/reformulation/decatchmenting/detruncating/decompulsing/delinearisi ng $>$ '-<imbued_aptitudinal-coherence-of-existentially-manifest $\sim$ hunches/cues/flags $>\quad$ (soundergirding eventual 'secondnatured positive-opportunism-of-social-functioning-andaccordance , as-to-prospective_punctual/immediacy/constituted/compulsionsencumbered _ disarming/dis_-ideologising/deformulaicity/à-contrecoup/unsettling/unargunable 
unblurriness $\sim$ reframing/reformulation/decatchmenting/detruncating/decompulsing/delinearisi ng'). Thusly, underlining the 'palpable dissolving/decentering of the conscious-self/collectiveconscious-self' that so-notionally/epistemically/bindingnessly-<as-to-determinism/coneeptivity-of-relativeunreflexivity/relative-reflexivitys allows for organic-knowledge; as to the recurrently-driven limitedness/human-subpotency prospective re-encountering/re-confrontation with the 'constraining/defining intersolipsistic reflexive-sublimating/unreflexive-desublimating measure/objectification that is unlimitedness/existence-as-ontologicalnormalcy/postconvergence-<in-validation-of-'metaphysics-of-absence_epistemic-projection' (as so-eliciting human ontological-commitment ${ }^{66}$ and universal-transparency ${ }^{104}$ with respect to underlying human 'crossgenerational notional firstnaturedness-formativeness-<as-toeventualising inkling-drive-or-seeding-misprising $>$-mental-processing-parity for ontological-performance ${ }^{72}$-<including-virtue-as-ontology>/morality/ethics/justice/etc.'). Speaking more fundamentally and counterintuitively to the ontologising/scientific/existence$<$ honesty-constraining $>$ — scope_for_prospective_re-ontologising 'veridical notionality/epistemicity/bindingness ${ }^{-<a s-t o-d e t e r m i n i s m / c o n c e p t i v i t y-o f-r e l a t i v e-u n r e f l e x i v i t y / r e l a t i v e-r e f l e x i v i t y>~}$ conception-of- ${ }^{5}$ meaningfulness-and-teleology" - (reflection upon the given 'existential-

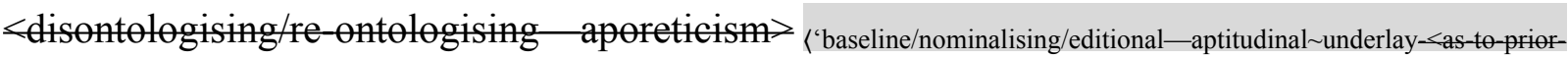

capacitating commitment and universal-transparency ${ }^{104}$ with respect to underlying human 'crossgenerational notional firstnaturedness-formativeness-<as-to-eventualising inkling- 
drive-or-seeding-misprising $>$ mental-processing-parity for ontological-performance ${ }^{72}$ <including-virtue-as-ontology $>$ /morality/ethics/justice/etc.'; and not a 'mélée_of_supposedlysingly conception-of $-{ }^{5}$ meaningfulness-and-teleology ${ }^{\circ}$ - reflex $\sim$ propositional-attitude. The illusion/counterintuition of such a 'mélée_of_supposedly-singly conception-ofmeaningfulness-and-teleology ${ }^{9}$ - reflex $\sim$ propositional-attitude arises out of the fact that human ${ }^{56}$ meaningfulness-and-teleology ${ }^{9}$ is existentialisingly/contextually/textually articulated as of <registry-worldview/dimension existentialising framing by enframing/\{worlding\} reference-of thought $>$ - undergirding-of-existentialising-framing-by-enframing/\{worlding $\}$ axiomatic-constructs (as to ${ }^{83}$ reference-of-thought- ${ }^{84}$ devolving) while simply impliciting the overarching 'registry-worldview/dimension existentialising-framing-byenframing/\{worlding\} - reference-of-thought' (as to ${ }^{83}$ reference-of-thought) which is so wrongly 'implicited as supposedly psychologised off-or-away'/nominalised (as the 'implicited baseline/nominalised outcome' of relative-reflexivity psychologismic-transfixity-<placeholdersetup-ontological-rescheduling — in-realigning/preactivity/formativebecoming/psychoanalytical-unshackling,-as-to-residualising-\{decompulsing $d$ delinearity-overnonresidualising_\{compulsing\} linearity $>$ ). Thus counterintuitively overlooking the 'successive registry-worldviews/dimensions recomposured/cumulated secondnatured institutionalisation of meaningfulness-and-teleology', as 'underlying relative-reflexivity carpeting/baseline/nominalising/editional' of the 'given <amplituding/formative-epistemicity $>$ totalising thrownness-in-existence unblurriness $\sim$ reframing/reformulation/decatchmenting/detruncating/decompulsing/delinearisi ng' (as so wrongly 'implicited as supposedly psychologised off-or-away'/nominalised); and so, in reflection of its 'given <amplituding/formative-epistemicity>-totalising $\sim$ thrownness-inexistence $^{35}$ attained/relative-reflexivity-by-unattained/relative-unreflexivity threshold-of-reontologising'-(elicited human ontological-commitment and universal-transparency with 
respect to underlying human 'crossgenerational notional firstnaturedness-formativeness-<as-toeventualising inkling-drive-or-seeding-misprising $>$ mental-processing-parity for ontological-performance -<including-virtue-as-ontology>/morality/ethics/justice/etc.'). Soreflecting the overarching 'registry-worldview/dimension existentialising-framing-byenframing/\{worlding $\}$ - ${ }^{8}$ reference-of-thought' (as to ${ }^{83}$ reference-of-thought); as the veridical 'palpable dissolving/decentering of the conscious-self/collective-conscious-self' outcropping/arising from the successively prior secondnatured institutionalisation (as from successively prior re-ontologising elicited human ontological-commitment ${ }^{66}$ and universaltransparency ${ }^{104}$ with respect to underlying human 'crossgenerational notional firstnaturednessformativeness-<as-to-eventualising -inkling-drive-or-seeding-misprising $>$ mental-

processing-parity for ontological-performance ${ }^{72}-$ including-virtue-as- $^{2}$ ontology $>$ /morality/ethics/justice/etc.'). This is effectively and fundamentally the implications of the full-potentiation that is the 'relative-unreflexivity/relative-reflexivitybindingness/nondiscretionariness-<as-from-sublimating remoteness/distance-of-appraisal-ofrequisite $\sim$ Being-development $>$ of unlimitedness/existence-<fll-potency-of_sublimating nascence $>$ '- (as to 'relative-unreflexivity/relative-reflexivity limitedness/human-subpotency dynamics of supererogating \{affirmation/projection/assertion/notional $\sim$ self-distantiation-byunaffirmation/deprojection/deassertion/epistemic-decadence\} - towards omnipotentialaffirmation/projection/assertion/notional self-distantiation' with respect to 'limitedness/humansubpotency prospective re-encountering/re-confrontation with unlimitedness/existence-<fullpotency-of_sublimating nascence $>$ '); and so, (as to unlimitedness/existence-<full-potencyof_sublimating nascence $>$ imbued fundamental 'veridical notionality/epistemicity/bindingness" $\leq$ as-to-determinism/conceptivity-of-relative-unreflexivity/relative-reflexivity $>$ conception-of- -5 meaningfulness-andteleology'9 rather as of the 'relative-unreflexivity/relative-reflexivity-ontologicalcontiguity of the overall relative-unreflexivity/relative-reflexivity-ontological- 
contiguity ${ }^{67}$ of-the-human-institutionalisation-process ${ }^{6}$, implied conception of the notion of relativism (so-undergirding the recurrent-linking-up of prior sublimating-arising and prospective sublimating-prolongation as to originary-and-re-originary/re-ontologisingnascency). The illusion/counterintuition of such a 'mélée_of_supposedly-singly conceptionof- ${ }^{5}$ meaningfulness-and-teleology ${ }^{9}$ - - reflex $\sim$ propositional-attitude is thus reflected in the fact that such a poor grasp (of prior re-ontologising priorly elicited human ontological-commitment and universal-transparency ${ }^{104}$ with respect to underlying human 'crossgenerational notional firstnaturedness-formativeness-<as-to-eventualising-inkling-drive-or-seedingmisprising $>$ mental-processing-parity for ontological-performance ${ }^{72}-<$ including-virtue-asontology $>$ /morality/ethics/justice/etc.', so-educed 'baseline/nominalising/editional— aptitudinal underlay-<as-to-prior-

unblurriness reframing/reformulation/decatchmenting/detruncating/decompulsing/delinearisi ng $>$ '), as to the veridical 'palpable dissolving/decentering of the conscious-self/collectiveconscious-self' so-implied 'veridical notionality/epistemicity/bindingness determinism/conceptivity-of-relative-unreflexivity/relative-reflexivity> conception-of- ${ }^{56}$ meaningfulness-andteleology aporeticism>

'baselining/cogency/reconstruing — aptitudinal overlay-<for-prospective- unblurriness-dragging-out $>$ ' $\rangle$ _.... reflected-as_

recurring existentialising-framing-by-enframing/\{worlding $\}$-<as-manifest-

individuative direct/deferential-transeffusive/worlding-looping $>$ _reflected-as_-supererogation 96

capacitating-<for-existential-thematic >): translates into a circular ${ }^{79}$ presencing-absolutising-identitiveconstitutedness ${ }^{14}$ habituated \{epistemic-totalising 3 ’ $p$ pychologismic-subliminal-truncating 'recoiling<as-to-induced-'wavering/redounding/waveforming-of-dimensionality-of-sublimating '-by'dimensionality-of-desublimating '-at-successive-loci/stations-of-'thrownness-disposition-as- 
kamplituding/formative>supererogatory de-mentativeness/epistemic-growth-or-

conflatedness /transvaluative-rationalising/transepistemicity/anamnestic -residuality/spirit-

drivenness-equalisation) elicited prospective psychologismic-epistemic-acutisation-<as-topostconverging-de-mentating/structuring/paradigming,-eliciting-of-existence's-sublimatingnascence-in-prospective-aporeticism-overcoming/unovercoming $>$ as to epistemic-growth,-as\{veridical/sound\}-relative-reflexivity-in-existence/relativising from-limited-mentation-as-itsdeepening/psychologismic epistemic-acutisation residualising, ${ }^{\text {\{decompulsing }}$ delinearity foreogency)' rather into the 'micro-decisionality/decisionality thrownness-disposition of prior mere-formulaicity/ritualisation-<as-to-mere-formulaic-

methodologising/mutualising/organising/institutionalising,-prospectively-losing-track-of-

‘\{epistemic-totalising ’’re-apriorising/re-axiomatising/re-referencing $\sim$ residuality-in-re-

originariness/re-origination'>' in so-failing prospective postconverging-aporeticismevercoming/unovercoming; as to manifest 'seeding-misprising of dimensionality-ofdesublimating-lack-of ${ }^{-}-\langle<$amplituding/formative $>$supererogatory $\sim$ de-mentativeness/epistemicgrowth-or-conflatedness /transvaluative-rationalising/transepistemicity/anamnesticresiduality/spirit-drivenness-equalisation)'. Speaking to the circular manifestation (as to contentious/un-nominalised social-stake-contention-or-confliction imbued unblurriness/blurriness-

threshold $\sim$ framing/formulation/catchmenting/truncating/compulsing/linearising) of correspondingly: pedantising/muddling/formulaic-hollowing-out—insubontologisation/subpotentiation-〈blurring/undermining-of-prospective-totalising-entailing,as-to-entailing-<amplituding/formative-epistemicity>totalising in-relative-ontologicalcompleteness > constraining-and-spurious 'disontologising/subontologising onionising/recoiling/linearising narratives disorientation' (as to seeding-misprising of 
dimensionality-of-desublimating-lack-of $-\langle<$ amplituding/formative $>$ supererogatory $\sim$ dementativeness/epistemic-growth-or-conflatedness /transvaluative-

rationalising/transepistemicity/anamnestic-residuality/spirit-drivenness-equalisation〉') on-theone-hand and on-the-other-hand the genuine social intellectual-function/posture organicknowledge 're-ontologising reprojecting/delinearising ontologically-hegemonising-narrative re-orientation' (as to 'inkling-drive of dimensionality-of-sublimating <<amplituding/formative>supererogatory $\sim$ de-mentativeness/epistemic-growth-or-

conflatedness /transvaluative-rationalising/transepistemicity/anamnestic-residuality/spiritdrivenness-equalisation $\rangle$ '). As so-existentially-<disontologising/re-ontologising aporeticism $>$ manifesting all along the genuine social intellectual-function/posture organic-knowledge 'inkling-drive of dimensionality-of-sublimating ${ }^{25}-\langle<$ amplituding/formative $>$ supererogatory $\sim$ dementativeness/epistemic-growth-or-conflatedness /transvaluativerationalising/transepistemicity/anamnestic-residuality/spirit-drivenness-equalisation〉'-over'seeding-misprising of dimensionality-of-desublimating-lack-of ${ }^{2}$ <<amplituding/formative >supererogatory $\sim$ de-mentativeness/epistemic-growth-orconflatedness /transvaluative-rationalising/transepistemicity/anamnestic-residuality/spiritdrivenness-equalisation $\rangle$ ': as of 'baseline/nominalising/editional—aptitudinal underlay-<as-toprior-

unblurrinessoreframing/reformulation/decatchmenting/detruncating/decompulsing/delinearisi ng $>$ '-<imbued_aptitudinal-coherence-of-existentially-manifest $\sim$ hunches/cues/flags $>\quad$ (soundergirding eventual 'secondnatured positive-opportunism-of-social-functioning andaccordance 7 as-to-prospective_punctual/immediacy/constituted/compulsionsencumbered disarming/dis_-ideologising/deformulaicity/à-contrecoup/unsettling/unargunable dragging-out into prospective unblurriness $\sim$ reframing/reformulation/decatchmenting/detruncating/decompulsing/delinearisi 
ng). Underlining the 'veridical notionality/epistemicity/bindingness ${ }^{<a s-t o-d e t e r m i n i s m / c o n c e p t i v i t y-o f-~}$

relative-unreflexivity/relative-reflexivity $>$

upon the given conception - of $-{ }^{5}$ meaningfulness-and-teleology ${ }^{9}$ - - (reflection 'existential-<disontologising/re-ontologising aporeticism $>$

〈'baseline/nominalising/editional—aptitudinal underlay-<as-to-prior-

unblurriness reframing/reformulation/decatchmenting/detruncating/decompulsing/delinearising $>$

enabling

'baselining/cogency/reconstruing — aptitudinal overlay_<for-prospective- unblurriness_dragging-out $\geq ’\rangle$-..reflected-as_-...

recurring $\sim$ existentialising-framing-by-enframing/\{worlding $\}-<$ as-manifest-

individuative direct/deferential-transeffusive/worlding-looping $>$ _ reflected-as_-supererogation 6 -

capacitating-for-existential-thematiez') with regards to the 'elicited untenability-of-induced unblurriness of circular ${ }^{6}$ nonpresencing-<perspective-ontological-normalcy/postconvergence> fepistemictataling 3’’psychologismic-subliminal-detruncating'; and not a 'mélée_of_supposedlysingly $\sim$ conception-of $-{ }^{5}$ meaningfulness-and-teleology ${ }^{99}$ - reflex $\sim$ propositional-attitude of circular presencing-absolutising-identitive-constitutedness ${ }^{4}$ habituated totalising 3 ? ${ }^{\text {p }}$ sychologismic-subliminal-truncating. Such that correspondingly the ontologising/scientific/existence-<honesty-constraining $>$ - scope_for_prospective_reontologising, with respect to 'veridical notionality/epistemicity/bindingness ${ }^{- \text {ass }}$-todeterminism/conceptivity-of-relative-unreflexivity/relative-reflexivity> conception-of- ${ }^{5}$ meaningfulness-andteleology" ${ }^{09}$ (reflection upon the given 'existential-<disontologising/re-ontologising aporeticism>

capacitating-<for-existential-thematic>’') as to prospective re-ontologising eliciting of human ontologicalcommitment and universal-transparency ${ }^{104}$ with respect to underlying human 
'crossgenerational notional firstnaturedness-formativeness-<as-to-eventualising-inklingdrive-or-seeding-misprising $>$ mental-processing-parity for ontological-performance ${ }^{72}$ <including-virtue-as-ontology $>$ /morality/ethics/justice/etc.'), is perpetually of nonpresencing<perspective-ontological-normalcy/postconvergence> epistemic-projection. And so, with regards to attending to 'prospective contentious/un-nominalised social-stake-contention-orconfliction imbued unblurriness/blurrinessthreshold framing/formulation/catchmenting/truncating/compulsing/linearising', in reflection of the 'given <amplituding/formative-epistemicity>-totalising -thrownness-in-existence attained/relative-reflexivity-by-unattained/relative-unreflexivity $\sim$ threshold-of-reontologising'-(elicited human ontological-commitment and universal-transparency with respect to underlying human 'crossgenerational notional firstnaturedness-formativeness-<as-toeventualising-inkling drive-or-seeding misprising $>$ mental-processing-parity for ontological-performance -<including-virtue-as-ontology>/morality/ethics/justice/etc.'): as soprospectively inducing (as to such manifestly unattained/relative-unreflexivity - threshold-ofre-ontologising) the given <amplituding/formative-epistemicity>-totalising $\sim$ thrownness-inexistence ${ }^{35}$ 'mélée_of_supposedly-singly conception-of- ${ }^{56}$ meaningfulness-and-teleology ${ }^{99}$ reflex $\sim$ propositional-attitude recoiling-<as-to-induced-'wavering/redounding/waveforming-ofdimensionality-of-sublimating '-by-'dimensionality-of-desublimating ' -at-successiveloci/stations-of-'thrownness-disposition-as-of-mere-formulaicity/ritualisation'>. The overall insight here is that 'veridical notionality/epistemicity/bindingness mreflexivity/relative-reflexivitys conception-of- ${ }^{56}$ meaningfulness-and-teleology ${ }^{9}$ '- (reflection upon the given 'existential-<disontologising/re-ontologising aporeticism $>\quad$ 〈'baseline/nominalising/editional— 


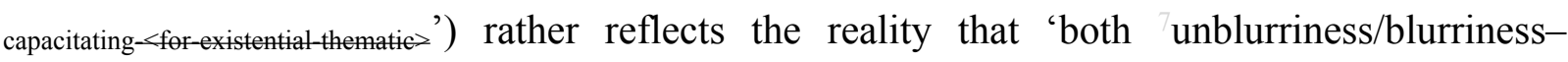
threshold framing/formulation/catchmenting/truncating/compulsing/linearising and unblurriness $\sim$ reframing/reformulation/decatchmenting/detruncating/decompulsing/delinearisi ng of human ${ }^{56}$ meaningfulness-and-teleology ${ }^{9}$ and consciousness/collective-consciousness' speak to the full-potentiation that is the 'relative-unreflexivity/relative-reflexivitybindingness/nondiscretionariness-<as-from-sublimating remoteness/distance-of-appraisal-ofrequisite $\sim$ Being development $>$ of unlimitedness/existence-<fll-potency-of_sublimating nascence $>$ ' - (as to 'relative-unreflexivity/relative-reflexivity limitedness/human-subpotency dynamics of supererogating \{affirmation/projection/assertion/notional $\sim$ self-distantiation-byunaffirmation/deprojection/deassertion/epistemic-decadence $\}$ - towards $\sim$ omnipotentialaffirmation/projection/assertion/notional self-distantiation' with respect to 'limitedness/humansubpotency prospective re-encountering/re-confrontation with unlimitedness/existence-<fullpotency-of_sublimating nascence $>$ '). Within which full-potentiation incipiently lies all the relative-reflexivity possibility/potentiation for the recurrent-linking-up of prior sublimatingarising and prospective sublimating-prolongation as to the originary-and-re-originary/reontologising-nascency of the 'relative unreflexivitrelative reflexivity-ontologicalcontiguity $^{67}$ of the overall relative-unreflexivity/relative-reflexivity-ontologicalcontiguity ${ }^{67}$ of-the-human-institutionalisation-process ${ }^{6}$, implied conception of the notion of relativism; and so as to human memorative-extension- $<$ as-to-'conscientiousnessdemoronisation — delinearising construct-of-thought'/ ‘ \{epistemictalising ’’’psychologismicsubliminal-detruncating';-as-relative-reflexivity-reframing_educing $\sim$ sublimatingprolongation>, as so-overriding the relative-unreflexivity of implicited/explicited elaborationas-to-mere-extrapolating/constituting/abstracting/deducing/inferring-of-elucidation-outside'prospectively_implicited_attendant-ontological-contiguity ${ }^{67}$ ' educed- 
existentialising/contextualising/textualising_intelligibility/epistemicity/reflexivity-contiguity<imbued-notional cogency>' 'mélée_of_supposedly-singly conception-ofmeaningfulness-and-teleology, reflex $\sim$ propositional-attitude (bound to induce prior_institutionalisation-<as-to-its-mere-formulaicity/ritualisation,-conscious-moronisation-

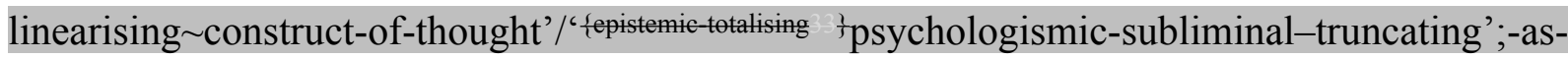
relative-unreflexivity_enframing_failing $\sim$ sublimating-prolongation $>$ elicited institutionalisinginflative-distortion-<as-to-prior_mere-formulaicity/ritualisation-failing-prospective-profoundsupererogation $>$ undermining the recurrent-linking-up of prior sublimating-arising and prospective sublimating-prolongation). It is herein contended that the veracity of the fullpotentiation that is the 'relative-unreflexivity/relative-reflexivity-bindingness/nondiscretionariness-<asfrom-sublimating remoteness/distance-of-appraisal-of-requisite-Being-development $>$ of unlimitedness/existence-<full-potency-of_sublimating nascence $>$ '- (as to 'relativeunreflexivity/relative-reflexivity limitedness/human-subpotency dynamics of supererogating \{affirmation/projection/assertion/notional $\sim$ self-distantiation-byunaffirmation/deprojection/deassertion/epistemic-decadence\} - - towards omnipotentialaffirmation/projection/assertion/notional self-distantiation' with respect to 'limitedness/humansubpotency prospective re-encountering/re-confrontation with unlimitedness/existence-<full potency-of_sublimating nascence $>$ '): means that our present conception of many domains of nascent-particular/incipient-and-material/technical-sublimations- $<$ blinded-to-their-relativeontological-completeness - reference-of-thought- devolving $>$ is in many ways (more or less inconsequentially) 'effectively blinded/incomplete' and tainted with ${ }^{79}$ presencingabsolutising-identitive-constitutedness intradimensionalinstitutionalising/organising/mutualising/methodologising 'mélée_of_supposedlysingly conception-of- ${ }^{5}$ meaningfulness-and-teleology ${ }^{\circ}$ - reflex $\sim$ propositional-attitude; as when failing to veridically reflect such domains sublimating-remoteness/distance-of-appraisal- 
$<$ as-to-requisite-'Being-development-notional self-distantiation'-imbued-psychologismic_-

epistemic-acutisation,-eliciting-of-prospective-ontologically-hegemonising-narrative

as to

their underlying <registry-worldview/dimension existentialising framing by enframing/worlding; reference-of thought $>$ undergirding-of-existentialising-framing-byenframing/\{worlding\} - axiomatic-constructs (as to ${ }^{83}$ reference-of-thought- devolving). The notion that ${ }^{56}$ meaningfulness-and-teleology ${ }^{99}$ is notionally/epistemically/bindingnessly-<as-todeterminism/conceptivity-of-relative-unreflexivity/relative-reflexivity> effusing/worlding within the 'relativemreflexivity/relative reflexivity bindingness/nondiscretionariness-<as-from-sublimating

remoteness/distance-of-appraisal-of-requisite-Being-development>

of unlimitedness/existence-<full-potency-of_sublimating nascence $>$ '- (as to 'relativeunreflexivity/relative-reflexivity limitedness/human-subpotency dynamics of supererogating \{affirmation/projection/assertion/notional $\sim$ self-distantiation-byunaffirmation/deprojection/deassertion/epistemic-decadence $\}$ - towards omnipotentialaffirmation/projection/assertion/notional self-distantiation' with respect to 'limitedness/humansubpotency prospective re-encountering/re-confrontation with unlimitedness/existence-<fullpotency-of_sublimating nascence $>$ '): means that our 'division-of-labour/subject-matters forhuman-studies/for-human-constructs (with respect to both natural sciences and social sciences/humanities)' tend to do 'a bad job of overarching conceptualising'; with regards to reflecting the supersedingness/precedence of unlimitedness/existence-<flllpotency ef_sublimating nascence>. And so, as human 'relative-reflexivity ontological-performance ${ }^{72}$ <including-virtue-as-ontology $>$ /morality/ethics/justice/etc.' is 'veridically construable' as of manifest ‘relative-unreflexivity/relative-reflexivity— bindingness/nondiscretionariness-<as-fromsublimating remoteness/distance of appraisal of requisite-Being development> of unlimitedness/existence-<fll-potency-of_sublimating nascence $>$ '- (as to 'relativeunreflexivity/relative-reflexivity limitedness/human-subpotency dynamics of 
supererogating \{affirmation/projection/assertion/notional $\sim$ self-distantiation-by-

unaffirmation/deprojection/deassertion/epistemic-decadence\} - towards omnipotential-

affirmation/projection/assertion/notional self-distantiation' with respect to 'limitedness/human-

subpotency prospective re-encountering/re-confrontation with unlimitedness/existence-<full-

potency-of_sublimating nascence $>$ '); rather veridically as from prospective re-ontologising

Being-development/ontological-framework-expansion-as-to-depth-of-ontologising-

development-as-infrastructure-of- meaningfulness-and-teleology

psychologismic

epistemic-acutisation difficulty-for, residualising fdecompulsing delinearity for-cogency>

magnitude\{of-experientiality/experiment\}, then institutional-development-as-to-social-function-

development psychologismic epistemic-acutisation difficulty-<for, residualising \{decompulsing delinearity for-cogeney>-magnitude\{of-experientiality/experiment\} and then livingdevelopment-as-to-personality-development psychologismic epistemic-acutisation-

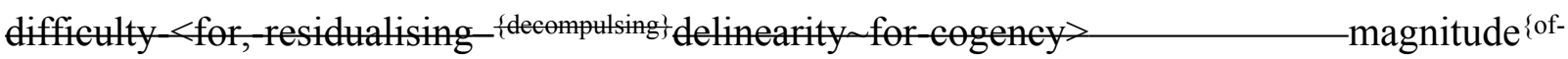
experientiality/experiment\}. This 'relative-unreflexivity as to the appraising-and-accounting-for the overarching conceptualisation unlimitedness/existence-<fll-potency-of_sublimating nascence $>$ ' by 'division-of-labour/subject-matters for-human-studies/for-human-constructs (with respect to both natural sciences and social sciences/humanities)' is markedly reflected for instance in the naive ${ }^{7}$ presencing-absolutising-identitive-constitutedness ${ }^{14}$ intradimensionalinstitutionalising/organising/mutualising/methodologising 'mélée_of_supposedlysingly $\sim$ conception-of- ${ }^{5}$ meaningfulness-and-teleology ${ }^{9}$, - reflex $\sim$ propositional-attitude notion of science; as so-poorly appreciative of the 'relative-mreflexivity/relative-reflexivitybindingness/nondiscretionariness-<as-from-sublimating remoteness/distance-of-appraisal-ofrequisite-Being development $>$ of unlimitedness/existence-full poncy of_sublimating nascence $>$ ' - (as to 'relative-unreflexivity/relative-reflexivity limitedness/human-subpotency dynamics of supererogating \{affirmation/projection/assertion/notional $\sim$ self-distantiation-by- 
unaffirmation/deprojection/deassertion/epistemic-decadence $\}$ - towards $\sim$ omnipotential_affirmation/projection/assertion/notional self-distantiation' with respect to 'limitedness/humansubpotency prospective re-encountering/re-confrontation with unlimitedness/existence- $<\mathrm{full}-$ potency-of_sublimating nascence $>$ '); within which the 'intolerance-<ofdisparateness $>$ /exactifying_precisioning-of-sublimation-<as-to-postconverging-narrowingdown apriorising/axiomatising/referencing-entailing-theoretical,-conceptual-and-operantimplications $>$ conception of overall knowledge' (so-veridically construed as science) sublimatingly-arises and is sublimatingly-prolongated. In other words, many an unsound conception of science and scientific domains tend to be oblivious to the fact that science is not truly divorced (however perceived in immediacy as being supposedly inconsequential) from the 'sublimating-remoteness/distance-of-appraisal-<as-to-requisite-'Being-developmentnotional self-distantiation'-imbued-psychologismic-epistemic-acutisation,-eliciting-ofprospective-ontologically-hegemonising-narrative $>$ of ${ }^{83}$ reference-of-thought- ${ }^{8}$ devolving' that overarchingly existentially-<disontologising/re-ontologising aporeticism $>$ allows for the intelligibility-〈as-to-human-projective/reprojective - aestheticising-re-motif-and-re-

\section{apriorising/re-axiomatising/re-referencing/re-intelligibilitysettingup/re-}

measuringinstrumenting-process,-in-<amplituding/formative-

epistemicity>totalising conceptualisation $\rangle$ of a sound conception of science. This counterintuitive overlooking of the 'successive registry-worldviews/dimensions recomposured/cumulated secondnatured institutionalisation of ${ }^{56}$ meaningfulness-andteleology as ${ }^{83}$ reference-of-thought', as 'underlying relative-reflexivity carpeting' (soconstrued as 'baseline/nominalising/editional—aptitudinal $\sim$ underlay-<as-to-priorunblurriness reframing/reformulation/decatchmenting/detruncating/decompulsing/delinearisi $n g>$ ') of the 'given <amplituding/formative-epistemicity $>$-totalising $\sim$ thrownness-in-existence unblurriness $\sim$ reframing/reformulation/decatchmenting/detruncating/decompulsing/delinearisi 
ng as ${ }^{83}$ reference-of-thought- devolving' (as so wrongly 'implicited as supposedly psychologised off-or-away'/nominalised): can 'be perceived in immediacy as supposedly inconsequential so long as all the perceived-effusing/worlding is of 79 presencing — absolutisingidentitive-constitutedness ${ }^{14} \quad{ }^{83}$ reference-of-thought- ${ }^{8}$ devolving intradimensionalinstitutionalising/organising/mutualising/methodologising'. But then speaks to an 'incomplete/naive conception of experientiality/experiment-<as-to-existentially-formative‘\{epistemic-totalising łre-apriorising/re-axiomatising/re-referencing $\sim$ residuality-in-reoriginariness/re-origination',—-so-'notionally/epistemically/bindingnessly-as to determinism/conceptivity-of-relative-unreflexivity/relative-reflexivity>_implicited-and-articulated' as-fromnonextricatory-'prospective-re-ontologising-Being-then-Institutional-then-Living-magnitudesof-\{hermeneutic/reprojection -protraction-of $\}$ reframing-and-reformulation $\}^{\prime}>$ ': as failing (by such 'relative-unreflexivity unbindingness/discretionariness') to reflect the veridical fullpotentiation of the 'relative-unreflexivity/relative-reflexivity — bindingness/nondiscretionariness- $<$ as-fromsublimating-remoteness/distance-of-appraisal-of-requisite-Being-development $>\quad$ of unlimitedness/existence-<fll potency-of_sublimating nascence>'-(as to 'relativeunreflexivity/relative-reflexivity limitedness/human-subpotency dynamics of supererogating \{affirmation/projection/assertion/notional $\sim$ self-distantiation-byunaffirmation/deprojection/deassertion/epistemic-decadence $\}$ - towards $\sim$ omnipotentialaffirmation/projection/assertion/notional self-distantiation' with respect to 'limitedness/humansubpotency prospective re-encountering/re-confrontation with unlimitedness/existence- $<$ fullpotency-of_sublimating nascence $>$ ') rather veridically pointing to the 'reconstruing of reference-of-thought- devolving'; as to immediacy-of-sublimation-(imbued 'secondnatured positive opportunism of social functioning and accordance 7 , as to prospective _punctual/immediacy/constituted/compulsions-encumbered_disarming/dis-

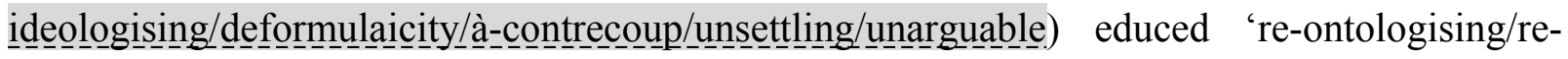


sublimating-axiomatic-constructs_as_impliciting of prospectively-requisite-relativereflexivity/delinearising (as to elicited 'reconstruing of ${ }^{83}$ reference-of-thought-8 devolving')'. Thus, rather manifesting the given prior 79 presencing - absolutising-identitive-constitutedness intradimensional-institutionalising/organising/mutualising/methodologising $\quad{ }^{83}$ reference-ofthought- ${ }^{8}$ devolving knowledge-deadends-<as-preconverging-dementating/structuring/paradigming $>$ ' (with respect to requisite ${ }^{6}$ nonpresencing- $<$ perspectiveontological-normalcy/postconvergence> interdimensionalinstitutionalising/organising/mutualising/methodologising prospective human transcendenceand-sublimity/sublimation/supereregatory de-mentativity imbued ${ }^{83}$ reference-of-thoughtdevolving). This so-explains the reality that budding-positivists like Copernicus, Galileo, Descartes, Newton, Leibniz, etc. are not really 'inventing'/"creating' science as of a 'mélée_of_supposedly-singly $\sim$ conception-of- ${ }^{5}$ meaningfulness-and-teleology ${ }^{9}$ 'reflex propositional-attitude notion of science (as to a flawed 79 presencing-absolutisingidentitive-constitutedness intradimensionalinstitutionalising/organising/mutualising/methodologising appraisal of our positivisim/rationalempiricism secondnatured institutionalisation) but are rather resolving their prior medievalscholasticism nonpositivising/non-rational-empiricism 'prospectively disontologising presencing—absolutising-identitive-constitutedness ${ }^{14} \quad$ intradimensionalinstitutionalising/organising/mutualising/methodologising manifest knowledge-deadends- $<$ aspreconverging-de-mentating/structuring/paradigming >' (and much more critically as to enable the prospectively requisite positivism/rational-empiricism overarching 'sublimatingremoteness/distance-of-appraisal-<as-to-requisite-'Being-development-notional $\sim$ selfdistantiation'-imbued-psychologismic-epistemic-acutisation,-eliciting-of-prospectiveontologically-hegemonising-narrative $>$ of ${ }^{8}$ reference-of-thought- ${ }^{8}$ devolving'). Highlighting that the veracity of science is effusing/worlding within the 'relative-mrefflexivity/relative-reflexivity- 
bindingness/nondiscretionariness-<as-from-sublimating remoteness/distance-of appraisal-ofrequisite $\sim$ Being-development $>$ of unlimitedness/existence-<full-potency-of_sublimating nascence $>$ ' - (as to 'relative-unreflexivity/relative-reflexivity limitedness/human-subpotency dynamics of supererogating \{affirmation/projection/assertion/notional $\sim$ self-distantiation-byunaffirmation/deprojection/deassertion/epistemic-decadence $\}$ - towards $\sim$ omnipotentialaffirmation/projection/assertion/notional self-distantiation' with respect to 'limitedness/humansubpotency prospective re-encountering/re-confrontation with unlimitedness/existence- $<$ fullpotency-of_sublimating nascence $>$ '); with respect to 'veridical notionality/epistemicity/bindingness 5 as-ateterminism/conceptivity-of-relative-mnreflexivity/relative-reflexivity> conception-of- ${ }^{5}$ meaningfulness-and-teleology" - (reflection upon the given 'existential$<$ disontologising/re-ontologising aporeticism» $>$ ("baseline/nominalising/editional—aptitudinal underlay-<as-to-priorfor-human-studies/for-human-constructs' (in reflection of the 'relative-unreflexivity/relativereflexivity - ontological-contiguity ${ }^{67}$ of the overall relative-unreflexivity/relative-reflexivity ontological-contiguity ${ }^{67}$ of-the-human-institutionalisation-process ${ }^{6}$, implied conception of the notion of relativism as to originary-and-re-originary/re-ontologising-nascency recurrentlinking-up of prior sublimating-arising and prospective sublimating-prolongation) rather speaks to human memorative-extension-<as-to-'conscientiousness-demoronisation-

delinearising construct-of-thought' $/$ ‘ \{epistemic-totalising ${ }^{\prime}$ 'psychologismic-subliminaldetruncating';-as-relative-reflexivity-reframing_educing sublimating-prolongation> (over prior_institutionalisation-<as-to-its-mere-formulaicity/ritualisation,-conscious-moronisation- 
linearising construct-of-thought'/ ‘ \{epistemic-totalising ${ }^{3}$ psychologismic-subliminal-truncating';-as-

relative-unreflexivity-enframing_failing $\sim$ sublimating_-prolongation $>$ elicited institutionalising_inflative-distortion-<as-to-prior_mere-formulaicity/ritualisation-failing-prospective-profound-

supererogation $>$ ). Such that the veracity of 'division-of-labour/subject-matters for-humanstudies/for-human-constructs' across all times (as from prior to prospective) is 'effusing/worlding within the 'relative-unreflexivity/relative-reflexivity-bindingness/nondiscretionariness<as-from-sublimating remoteness/distance-of-appraisal-of-requisite-Being-development $>$ of unlimitedness/existence-<full-potency-of_sublimating nascence $>$ '-(as to 'relativeunreflexivity/relative-reflexivity limitedness/human-subpotency dynamics of supererogating \{affirmation/projection/assertion/notional $\sim$ self-distantiation-byunaffirmation/deprojection/deassertion/epistemic-decadence $\}$-towards $\sim$ omnipotentialaffirmation/projection/assertion/notional self-distantiation' with respect to 'limitedness/humansubpotency prospective re-encountering/re-confrontation with unlimitedness/existence-<fullpotency-of_sublimating nascence $>$ '); as of implicited and/or explicited overarching <registry worldview/dimension existentialising framing by enframing/worlding thought $>$ - undergirding of-existentialising-framing-by-enframing/\{worlding $\}$ - axiomaticconstructs. The implication here for instance is that (with respect to the 'the-very-same purview/devolved-purview/devolving-purview-of-unlimitedness/existence-<full-potencyөf_sublimating nascence $>$; — 'implicited_attendant-ontological-contiguity ${ }^{67}$ ' educedexistentialising/contextmalising/textualising_'intelligibility/epistemicity/reflexivity_contiguity$<$ imbued-notional cogency>’0) successive registry-worldviews/dimensions ${ }^{83}$ reference-ofthought do articulate differing 'conception, development and purposefulness of mathematics'; with the notion of mathematics strictly speaking not separable (as to its fulsome notional/epistemic/bindingness ${ }^{<a s-t o-d e t e r m i n i s m / c o n c e p t i v i t y-o f-r e l a t i v e-u n r e f l e x i v i t y / r e l a t i v e-r e f l e x i v i t y>~}$

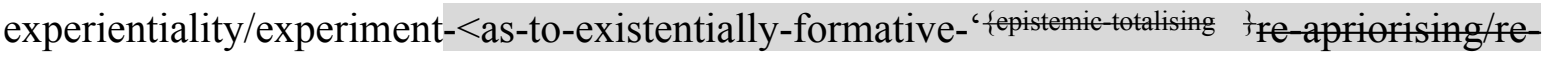


axiomatising/re-referencing -residuality-in-re-originariness/re-origination',- - so-

'notionally/epistemically/bindingnessly-<as-to-determinism/conceptivity-of-relative-unreflexivity/relative-reflexivity implicited-and-articulated'_as-from-nonextricatory-'prospective-re-ontologising-Being-thenInstitutional-then-Living-magnitudes-of-\{hermeneutic/reprojection-protraction-of\}reframingand-reformulation $\}^{\prime}>$ ) from successive (prior to prospective) registry-worldviews/dimensions implicited and/or explicited overarching 'sublimating-remoteness/distance-of-appraisal-<as-torequisite-'Being-development-notional self-distantiation'-imbued-psychologismic-epistemicacutisation,-eliciting-of-prospective-ontologically-hegemonising-narrative $>$ of ${ }^{83}$ reference-ofthought- devolving' (beyond any naive 79 presencing — absolutising-identitive-constitutedness intradimensional-institutionalising/organising/mutualising/methodologising 'mélée_of_supposedly-singly conception-of- ${ }^{5}$ meaningfulness-and-teleology ${ }^{9}$ reflex $\sim$ propositional-attitude notion of mathematics). In-many-ways the highly implicited nature and strong immediacy-of-sublimation-(imbued 'secondnatured positive-opportmnismof-social-functioning and-accordance , as-to-

prospective punctual/immediacy/constituted/compulsions-encumbered_disarming/disidenologising domain of nascent-particular/incipient-and-material/technical-sublimations- $<$ blinded-to-theirrelative-ontological-completeness - reference-of-thought- devolving > (as so effectively and practically overriding the possibility of strongly ingrained ideological predispositions including science ideology) means that ${ }^{79}$ presencing-absolutising-identitive-constitutedness intradimensional-institutionalising/organising/mutualising/methodologising 'mélée_of_supposedly-singly conception-of- ${ }^{56}$ meaningfulness-and-teleology ${ }^{9}$ ' reflex $\sim$ propositional-attitude hardly gets entrenched in practice given the inherently 'strong immediacy-of-sublimation drivenness' (in dragging-out unblurriness $\sim$ reframing/reformulation/decatchmenting/detruncating/decompulsing/delinearisi 
ng) even when misconstrued abstractly and relative-inconsequentially with regards to prospective science sublimating-prolongation. In this regards, it can be appreciated that many a scientific domain had developed in contradiction-or-unexpectedly to the given epochal scientific consensus expectations; as so-reflecting a 'readily ideology-killing disseminativesublimating-selectivity-of-ontological-good-faith/authenticity $\sim$ postconverging-dementating/structuring/paradigming , over desublimating-deselectivity-of-ontological-badfaith/inauthenticity -preconverging-de-mentating/structuring/paradigming ' (consider in this regards the successive unpredictable breakthroughs in $20^{\text {th }}$ science like Theory of relativity, quantum mechanics, material sciences, DNA genetics, astrophysics, etc. even as their 'associated social-and-institutional-frameworks-of — referencing/registering/decisioning science ideologies' tend to arise mainly after the fact-of-the-matter). However this means that the highly implicited nature and strong immediacy-of-sublimation-(imbued 'secondnatured positiveopportunism of-social-functioning-and-accordance 5 , as-to-

prospective punctual/immediacy/constituted/compulsions-encumbered_disarming/disideologising/deformulaicity/à-contrecoup/unsettling/unarguable domain of nascent-particular/incipient-and-material/technical-sublimations- $<$ blinded-to-theirrelative-ontological-completeness - reference-of-thought- devolving > is merely of 'reontologising/re-sublimating-axiomatic-constructs_as_impliciting-of prospectively requisite-relative-reflexivity/delinearising (as to elicited 'reconstruing of ${ }^{83}$ reference-ofthought- devolving')', and tepidly reflective of prospective re-ontologising 'sublimatingremoteness/distance-of-appraisal-<as-to-requisite-'Being-development-notional $\sim$ selfdistantiation'-imbued-psychologismic-epistemic-acutisation,-eliciting-of-prospectiveontologically-hegemonising-narrative $>\quad$ of ${ }^{83}$ reference-of-thought- ${ }^{8}$ devolving'. Sonotionally/epistemically/bindingnessly-<as-to-determinism/conceptivity-of-relative-unreflexivity/relative-reflexivity $>$ with respect to limitedness/human-subpotency effusing/worlding within the scope of the 'relative- 
unreflexivity/relative-reflexivity— bindingness/nondiscretionariness-<as-from-sublimating

remoteness/distance-of-appraisal-of requisite B Being-development $>$

unlimitedness/existence-<fll-potency-of_sublimating nascence $>$ '- (as to 'relativeunreflexivity/relative-reflexivity limitedness/human-subpotency dynamics of supererogating \{affirmation/projection/assertion/notional $\sim$ self-distantiation-byunaffirmation/deprojection/deassertion/epistemic-decadence\} - towards omnipotentialaffirmation/projection/assertion/notional self-distantiation' with respect to 'limitedness/humansubpotency prospective re-encountering/re-confrontation with unlimitedness/existence-<fullpotency-of_sublimating nascence $>$ ') so-reflecting such 're-ontologising/re-sublimatingaxiomatic-constructs_as_impliciting of prospectively-requisite_relative-

reflexivity/delinearising (as to elicited 'reconstruing of ${ }^{83}$ reference-of-thought- ${ }^{84}$ devolving')'. Underlined by the fact that all such multigenerational 'recomposured/cumulated-reontologising/re-sublimating-axiomatic-constructs_as_impliciting of prospectively requisite-relative-reflexivity/delinearising (as to elicited 'reconstruing of ${ }^{83}$ reference-of-

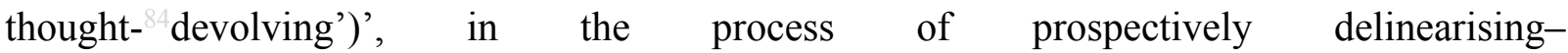
imbuing_conscientiousness-demoronisation-<as-to-renewing realisation/re-perception/refrom prior linearising-imbuing_consciousmorenisation <as to prior_mere-formulaicity/ritualisation $>\sim$ enframing in the 'reconstruing of ${ }^{83}$ reference-ofthought- ${ }^{8}$ devolving'): is what effectively undergirds human psychologismic-epistemicacutisation-<as-to-postconverging-de-mentating/structuring/paradigming,-eliciting-ofexistence's-sublimating-nascence-in-prospective-aporeticism-overcoming/unovercoming $>$ as to epistemic-growth,-as — \{veridical/sound\}-relative-reflexivity-in-existence/relativising fromlimited mentation as its deepening/psychologismic epistemic acutisation residualising, $\{$ decompulsing $\}$ delinearity for-cogency imbued 'cut-out-<as-to-re-ontologising redressing/straightening-out $>$ (as of relative-reflexivity psychologismic-transfixity- 


\title{
$<$ placeholder-setup-ontological-rescheduling — in-realigning/preactivity/formative-
}

\section{becoming/psychoanalytical-unshackling,-as-to-residualising-\{decompulsing\} $d$ delinearity-over-}

nonresidualising_compulsingl linearity $>$ ) for sublimating-prolongation'. As socially manifested as of 'relays of human intemporal-individuation epistemic-projection radicalities $\sim$ inchronicular/annalistic-cogency-<as-of-notional $\sim$ protensivity $>-\langle$ as-to-limited-mentation-

\section{capacity-deepening —as-subjecting limitedness/human-subpotency to-'educed-}

\author{
unlimitedness/existence-sublimating nascence' $\rangle$ so-construed as
}

cogency_chronicularity/annality-of-relative-reflexivity,-as-to-profound-supererogation "'; with all such multigenerational 'recomposured/cumulated_as-well-as_prospectivelyrecompesuble/eumulate-re-ontologising/re-sublimating-axiomatic-

constructs_as _ impliciting of prospectively-requisite —relative-reflexivity/delinearising (as to elicited 'reconstruing of ${ }^{83}$ reference-of-thought- ${ }^{-1 e v o l v i n g}$ ')'; then ultimately coming to point (reflecting the notionally/epistemically/bindingnessly-as-determinism/conceptivity-relativeunreflexivity/relative-reflexivitys given 'existential-<disontologising/re-ontologising aporeticism> 〈'baseline/nominalising/editional—aptitudinal underlay-<as-to-prior-

'baselining/cogency/reconstruing — aptitudinal overlay-<for-prospective- unblurriness-dragging-out $>$ ’ $\ldots$ - reflected-as

recurring $\sim$ existentialising-framing-by-enframing/\{worlding $\}$-<as-manifest-

individuative -direct/deferential-transeffusive/worlding-looping $>$ __reflected-as_-supererogation 0 -

capacitating-<for-existential-thematic $>$ ') to prospective re-ontologising overarching 'registryworldview/dimension existentialising-framing-by-enframing/\{worlding $\}$ - ${ }^{8}$ reference-ofthought' (as to existentialising-framing-by-enframing/\{worlding\}-axiomatic-constructs 'reconstruing of ${ }^{83}$ reference-of-thought- ${ }^{84}$ devolving'). In this regards, it can be appreciated that both the Socratic-philosophers ${ }^{103}$ universalising-idealisation ${ }^{83}$ reference-of-thought and budding-positivists positivism/rational-empiricism ${ }^{83}$ reference-of-thought didn't just arise out of 
the blue but reflected their given multigenerational 'recomposured/cumulated_as-wellas_prospectively-recomposurable/cumulatable_re-ontologising/re-sublimating-axiomaticconstructs_as_impliciting of prospectively-requisite_relative-reflexivity/delinearising' as to elicited 'reconstruing of ${ }^{83}$ reference-of-thought- devolving' (as from prospective 'sublimatingremoteness/distance-of-appraisal-<as-to-requisite-'Being-development-notional $\sim$ selfdistantiation'-imbued-psychologismic-epistemic-acutisation,-eliciting-of-prospectiveontologically-hegemonising-narrative $>\quad$ of $\quad{ }^{83}$ reference-of-thought- ${ }^{8}$ devolving'). Paradoxically, it is rather as of many a presencing-absolutising-identitive-constitutedness social domain-of-study/interpretation or social interpretations of the implication of nascentparticular/incipient-and-material/technical-sublimations- $<$ blinded-to-their-relative-ontologicalcompleteness - reference-of-thought- devolving >: in both instances as poorly constrained by highly implicited nature and strong immediacy-of-sublimation(imbued 'secondnatured positiveopportunism of-social-functioning and-accordance , as-toprospective _punctual/immediacy/constituted/compulsions-encumbered_disarming/disideologising/deformulaicity/à-contrecoup/unsettling/unargarguable) more-or-less guiding many a domain of nascent-particular/incipient-and-material/technical-sublimations- $<$ blinded-to-theirrelative-ontological-completeness - reference-of-thought- devolving $>$ as well as the consequent eliciting of pedantising/muddling/formulaic-hollowing-out-insubontologisation/subpotentiation-〈blurring/undermining-of-prospective-totalising-entailing,as-to-entailing-<amplituding/formative-epistemicity $>$ totalising in-relative-ontologicalcompleteness $\rangle$; that ${ }^{7}$ presencing — absolutising-identitive-constitutedness ${ }^{14}$ intradimensionalinstitutionalising/organising/mutualising/methodologising 'mélée_of_supposedlysingly $\sim$ conception-of- ${ }^{5}$ meaningfulness-and-teleology ${ }^{9}$ '-reflex $\sim$ propositional-attitude explicitly arises as to vague good-naturedness (failing 'technical' ontological-goodfaith/authenticity as from ontological-normalcy/postconvergence epistemic-projection 
perspective conceptualisation). Rather such an orientation, poorly appreciative of the recurrently-driven limitedness/human-subpotency prospective re-encountering/re-confrontation with the "constraining/defining intersolipsistic reflexive-sublimating/unreflexive-desublimating measure/objectification that is unlimitedness/existence-as-ontologicalnormalcy/postconvergence-<in-validation-of-'metaphysics-of-absence_epistemic-projection' as to the "relative-unreflexivity/relative-reflexivity — bindingness/nondiscretionariness-<as-from-sublimating remoteness/distance-of-appraisal-of-requisite $\sim$ Being-development $>$ of unlimitedness/existence-<full-potency-of_sublimating nascence $>$ '- (as to 'relativeunreflexivity/relative-reflexivity limitedness/human-subpotency dynamics of supererogating \{affirmation/projection/assertion/notional $\sim$ self-distantiation-byunaffirmation/deprojection/deassertion/epistemic-decadence\} - towards $\sim$ omnipotentialaffirmation/projection/assertion/notional self-distantiation' with respect to 'limitedness/humansubpotency prospective re-encountering/re-confrontation with unlimitedness/existence-<fullpotency-of_sublimating nascence $>$ '): is bound to 'acutely arrive wrongly' at the 'given $<$ amplituding/formative-epistemicity $>$-totalising $\sim$ thrownness-in-existence unblurriness/blurrinessthreshold framing/formulation/catchmenting/truncating/compulsing/linearising' relativeunreflexivity (as to its implicited/explicited elaboration-as-to-mereextrapolating/constituting/abstracting/deducing/inferring-of-elucidation-outside'prospectively_implicited_attendant-ontological-contiguity ${ }^{67}$ ' educedexistentialising/contextualising/textmalising_intelligibility/epistemicity/reflexivity-contiguity<imbued-notional cogency>' $\quad$ 'mélée_of_supposedly-singly conception-ofmeaningfulness-and-teleology ${ }^{\circ}$-reflex $\sim$ propositional-attitude). The overall implication here is that the 'relative-unreflexivity/relative-reflexivity — bindingness/nondiscretionariness- $<$ as-fromsublimating remoteness/distance-of-appraisal-of-requisite-Being-development $>\quad$ of 
unlimitedness/existence-<full-potency-of_sublimating nascence $>$ '- (as to 'relativeunreflexivity/relative-reflexivity limitedness/human-subpotency dynamics of supererogating \{affirmation/projection/assertion/notional self-distantiation-byunaffirmation/deprojection/deassertion/epistemic-decadence $\}$ - towards $\sim$ omnipotentialaffirmation/projection/assertion/notional self-distantiation' with respect to 'limitedness/humansubpotency prospective re-encountering/re-confrontation with unlimitedness/existence- $<\mathrm{full}-$ potency-of sublimating nascence $>$ ') effectively speaks to 'overall human knowledgereification $\sim$ gesturing-and-accounting — of-epistemic-phenomenalism- $<$ in-

prospective_psychologismic apriorising/axiomatising/referencing-\{of-'prospectively implicited_attendant-ontological-contiguity ' educedexistentialising/contextualising/textualising_'intelligibility/epistemicity/reflexivity-contiguity<imbued-notional cogency $>\quad\}$-conflatedness -in-\{preconverging-ment by\} postconverging-entailment> for sublimating-prolongation'; with respect to 'veridical notionality/epistemicity/bindingness conception-of- ${ }^{5}$ meaningfulness-and-teleology ${ }^{9}$ '-(reflection upon the given 'existential<disontologising/re-ontologising aporeticism $>$ ("baseline/nominalising/editional—aptitudinal underlay-<as-to-priorunblurriness $\sim$ reframing/reformulation/decatchmenting/detruncating/decompulsing/delinearising ${ }^{\prime}$ enabling

'baselining/cogency/reconstruing — aptitudinal overlay-<for-prospective- unblurriness-dragging-out $>$ ’ - - reflected-as -

recurring $\sim$ existentialising-framing-by-enframing/\{worlding $\}$-<as-manifest-

individuative direct/deferential-transeffusive/worlding-looping $>$ _reflected-as _-supererogation 76

capacitating-<for-existential-thematic $>$ ') with regards to 'the-very-same purview/devolvedpurview/devolving-purview-of-unlimitedness/existence-<full-potency-of_sublimating nascence>;-—implicited_attendant-ontological-contiguity ${ }^{67}$ ' educedexistentialising/contextualising/textualising_intelligibility/epistemicity/reflexivity-contiguity<imbued-notional cogency $>$. And so, in reflection of the overall reifying-and-empowering- 
reflexivity-of-ecstatic-existence-as-panintelligibility/panreflexivity ${ }^{73}$-〈existentially-imbuedand-educing-< $<$ fepistemic-

totalising '⿳⺈冂大 $h$ rmeneutically/textually/reprojectingly/supererogatingly/zeroingly/re-acutingly,$\{$ decompulsing\} $\}$ delinearity $\sim$ for-cogency $>$-epistemic-perspective-of-projective/reprojectiveaestheticising-re-motif-and-re-apriorising/re-axiomatising/re-referencing conceptualisationas-herein-specifically-relevant-to human-subpotency), which speaks of 'perspective ontological-normalcy/postconvergence relative-reflexivity/relative-unreflexivity veracity of existence' as to phenomenal/manifest $\sim$ subpotencies-〈in-transitive-conflatedness -reflexivity,in-the-full-potency-of-existence's $\sim$ sublimating-nascence) supervening manifestations in notional conflatedness ${ }^{13}$ : in reflection of the 'relative-unreflexivity/relative-reflexivitybindingness/nondiscretionariness-<as-from-sublimating remoteness/distance-of-appraisal-ofrequisite $\sim$ Being development $>$ of unlimitedness/existence-<fll-potency-of_sublimating nascence $>$ ' - (as to 'relative-unreflexivity/relative-reflexivity limitedness/human-subpotency dynamics of supererogating \{affirmation/projection/assertion/notional $\sim$ self-distantiation-byunaffirmation/deprojection/deassertion/epistemic-decadence\} - towards omnipotentialaffirmation/projection/assertion/notional self-distantiation' with respect to 'limitedness/humansubpotency prospective re-encountering/re-confrontation with unlimitedness/existence-<fullpotency-of_sublimating nascence $>$ ') as <amplituding/formative-epistemicity $>$ causality $\sim$ asto-projective-totalitative-implications-of-prospective- nonpresencing,-for-

explicating relative unreflexivity/relative reflexivity ontological-contiguity . The very central notion of 'human ${ }^{5}$ meaningfulness-and-teleology' and consciousness/collectiveconsciousness educed transcendence-and-sublimity/sublimation/supereregatory $\sim$ dementativity' as to human existential-<disontologising/re-ontologising aporeticism $>$ potentiating (with regards to 'limitedness/human-subpotency prospective re-encountering/reconfrontation with unlimitedness/existence-<full-potency-of_sublimating nascence $>$ '), has to 
do with human 'recomposured/cumulated-re-ontologising/re-sublimating-axiomaticconstructs_as_impliciting-of-prospectively-requisite_relative-reflexivity/delinearising (as to elicited 'reconstruing of ${ }^{83}$ reference-of-thought- devolving')'; as so-pointing (reflecting the notionally/epistemically/bindingnessly-<as-to-determinism/conceptivity-of-relative-unreflexivity/relative-reflexivity $>$ given 'existential-<disontologising/re-ontologising aporeticism> 〈'baseline/nominalising/editional_aptitudinal underlay-<as-to-priorunblurriness $\sim$ reframing/reformulation/decatchmenting/detruncating/decompulsing/delinearising ${ }^{\prime}$ enabling 'baselining/cogency/reconstruing — aptitudinal overlay-<for-prospective- unblurriness-dragging-out $>$ ' $\rangle$ _...... reflected-as_....

\section{recurring $\sim$ existentialising-framing-by-enframing $/\{$ worlding $\}-<$ as-manifest-}

\section{individuative direct/deferential-transeffusive/worlding-looping $>$ _ reflected-as_-supererogation 0 -}

capacitating-<for-existential-thematic>) to prospective 'reconstruing of ${ }^{83}$ reference-of-thought- ${ }^{84}$ devolving' (so-reflected as of veridical 'palpable dissolving/decentering of the conscious-self/collectiveconscious-self'). This effectively speaks to memorative-extension-<as-to-'conscientiousnessdemoronisation — delinearising construct-of-thought'/ ‘ Sepstemictising ${ }^{\prime}$ psychologismicsubliminal-detruncating';-as-relative-reflexivity-reframing_educing $\sim$ sublimating_ prolongation $>\quad$ (over prior_institutionalisation-<as-to-its-mere-formulaicity/ritualisation,conscious-moronisation - linearising construct-of-thought' $/$ ‘ \{epistemic-totalising ' ’’psychologismicsubliminal-truncating';-as-relative-unreflexivity-enframing_failing sublimatingprolongation $>\quad$ elicited institutionalising-inflative-distortion-<as-to-prior_mereformulaicity/ritualisation-failing-prospective-profound-supererogation $>$ ); in reflection of the fact that nascent-particular/incipient-and-material/technical-sublimations- $<$ blinded-to-theirrelative-ontological-completeness - reference-of-thought- devolving> (imbued 'inklingdrive of dimensionality-of-sublimating $-<<$ amplituding/formative $>$ supererogatory $\sim$ dementativeness/epistemic-growth-or-conflatedness /transvaluativerationalising/transepistemicity/anamnestic-residuality/spirit-drivenness-equalisation〉' induced 'delinearising-imbuing_conscientiousness-demoronisation-<as-to-renewing-realisation/re- 
perception/re-thought $>\sim$ reframing from prior linearising-imbuing_conscious-moronisation<as-to-prior_mere-formulaicity/ritualisation>-enframing') is not necessarily translated into social-and-institutional-frameworks-of — referencing/registering/decisioning corresponding 'delinearising-imbuing_conscientiousness-demoronisation-<as-to-renewing-realisation/reperception/re-thought $>\sim$ reframing from prior linearising-imbuing_conscious-moronisation<as-to-prior_mere-formulaicity/rittualisation>-enframing'. But rather in-many-ways such social-and-institutional-frameworks-of - referencing/registering/decisioning rather tend to adopt 'a $\quad{ }^{79}$ presencing-absolutising-identitive-constitutedness ${ }^{14}$ intradimensionalinstitutionalising/organising/mutualising/methodologising linearising-imbuing_consciousmoronisation-<as-to-prior_mere-formulaicity/ritualisation>nenframing' usurping/distorting assetising construal of nascent-particular/incipient-and-material/technical-sublimations$<$ blinded-to-their-relative-ontological-completeness - reference-of-thought- devolving $>$ leading to vague good-naturedness (failing 'technical' ontological-good-faith/authenticity ${ }^{69}$ as from ontological-normalcy/postconvergence epistemic-projection perspective conceptualisation); with a poor/passive/distant appreciation and contemplation of the latter implications for social-and-institutional-frameworks-of — referencing/registering/decisioning prospective 'inkling-drive of dimensionality-of-sublimating <<amplituding/formative>supererogatory $\sim$ de-mentativeness/epistemic-growth-orconflatedness /transvaluative-rationalising/transepistemicity/anamnestic-residuality/spiritdrivenness-equalisation)' induced 'delinearising-imbuing_conscientiousness-demoronisation<as-to-renewing realisation/re-perception/re-thought $>\sim$ reframing from prior linearisingimbuing_conscious-moronisation-<as_to-prior_mere-formulaicity/ritualisation> enframing' (so-patently reflected in an implicited conception that the grander social is inevitably the sphere of relative 'existentially-<disontologising/re-ontologising aporeticism $>$ manifest incidental/accidental reactive-sufferance/endurance in supposedly and paradoxically 
subordinating/subserving/collateralising the possibility for prospective re-ontologisingimbuing-of-prospective-human-sublimating/emancipating/enfranchisement' and not of relative 're-ontologising-nascency-<as-of-prospective-solipsistic/intersolipsistic-inkling-drive-forknowledge-elucidation,-as-to-veridical-organic-knowledge> for sublimating-prolongation'). With this contrast explained by the fact that the highly implicited nature and strong immediacyof-sublimation- (imbued 'secondnatured positive-opportunism of-social-functioning-andaccordance , as-to-prospective_punctual/immediacy/constituted/compulsions-

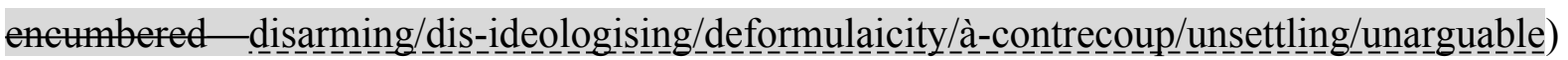
more-or-less guiding many a domain of nascent-particular/incipient-and-material/technicalsublimations- $<$ blinded-to-their-relative-ontological-completeness - reference-of-thoughtdevolving $>$ (as to their given subject-matters/division-of-labour as natural sciences are actually for-human-studies/for-human-constructs whose specific ambit of human-subpotency is about 'human consciousness as for material and physical effecting devolving teleologies as meaningfulness') relatively do not have to 'ontologically project of full existential<disontologising/re-ontologising aporeticism $>$ organic-knowledge' imbued prospective 'reconstruing of ${ }^{83}$ reference-of-thought- devolving' (as from prospective 'sublimatingremoteness/distance-of-appraisal-<as-to-requisite-‘Being-development-notional $\sim$ selfdistantiation'-imbued-psychologismic-epistemic-acutisation,-eliciting-of-prospectiveontologically-hegemonising-narrative $>$ of ${ }^{83}$ reference-of-thought- ${ }^{8}$ devolving'). While many a social-and-institutional-frameworks-of - referencing/registering/decisioning (as to their given subject-matters/division-of-labour as social domains-of-study are actually for-humanstudies/for-human-constructs whose specific ambit of human-subpotency is about 'human consciousness inherent effecting devolving teleologies as meaningfulness) implicitly or explicitly intradimensionally give up to such prospective ontological projection (of prospective

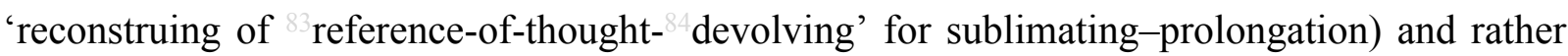


falling into their intradimensional mere-formulaicity/ritualisation and ideologising; with the paradox that such scientific/ontological incompetence is most socially verbose about what is veridical science as to its 'unscientific/disontologising/subontologising supposed imprimaturing defence of science without doing their relevantly veridical science/ontology' ('ontologically project of full existential-<disentologising/re-ontologising aporeticism $>$ organic-knowledge' imbued prospective 'reconstruing of ${ }^{83}$ reference-of-thought- devolving' for sublimatingprolongation). This ' ${ }^{79}$ presencing-absolutising-identitive-constitutedness ${ }^{14}$ intradimensionalinstitutionalising/organising/mutualising/methodologising linearising-imbuing_consciousmoronisation-<as-to-prior_mere-formulaicity/ritualisation>>enframing' usurping/distorting assetising relationship to ${ }^{56}$ meaningfulness-and-teleology ${ }^{99}$ is reflected in our modern-day social-and-institutional-frameworks-of - referencing/registering/decisioning centrality of the triptych/trinity of manifest institutionalised-minimum-competence/expertising-posturing mereformulaicity/ritualisation ('as supposedly more critically covered/protected/shielded from requisite sublimating-prolongation with respect to the prospective veracity of superseding unlimitedness/existence-<full-potency-of_sublimating nascence $>$ ') by its assumed institutionalised-legalese-posturing mere-formulaicity/ritualisation and institutionalisedcommunication/public-relations-posturing mere-formulaicity/ritualisation; and so, even reflected as to the fashioning-of/influence-over many a purview/practice of nascentparticular/incipient-and-material/technical-sublimations- $<$ blinded-to-their-relative-ontologicalcompleteness - reference-of-thought- devolving> (as to when the latter is susceptible to social-and-institutional-frameworks-of — referencing/registering/decisioning elicited blurriness of social-functioning-and-accordance-as-of-social-stake-contention-or-confliction).

Eventually, memorative-extension-<as-to-'conscientiousness-demoronisation delinearising construct-of-thought'/‘ \{epistemic-totalising ' ’psychologismic-subliminaldetruncating';-as-relative-reflexivity-reframing_educing sublimating-prolongation> (as to 
'human ${ }^{56}$ meaningfulness-and-teleology ${ }^{99}$ and consciousness/collective-consciousness educed transcendence-and-sublimity/sublimation/supererogatory-de-mentativity') warrants that both nascent-particular/incipient-and-material/technical-sublimations- $<$ blinded-to-their-relativeontological-completeness - reference-of-thought- devolving $>$ and social-and-institutionalframeworks-of - referencing/registering/decisioning effectively assume (as to their effusing/worlding): the disseminative-sublimating-selectivity-of-ontological-goodfaith/authenticity postconverging-de-mentating/structuring/paradigming , overdesublimating deselectivity of ontological bad-faith/inauthenticity -preconverging dementating/structuring/paradigming as of 'recomposured/cumulated—re-ontologising/resublimating-axiomatic-constructs_as_impliciting of prespectively-requisite_relativereflexivity/delinearising (as to elicited 'reconstruing of ${ }^{83}$ reference-of-thought- ${ }^{84}$ devolving')'. So-effectively underlying veridical organic-knowledge imbued prospective 'despite-the-self exercise of epistemic-projection in notional $\sim$ self-distantiation- $<$ imbued-re-motif-and-reapriorising/re-axiomatising/re-referencing>' involved in 'limitedness/human-subpotency prospective re-encountering/re-confrontation with unlimitedness/existence-full-potency өf_sublimating nascence> ${ }^{2}$ for unblurriness $\sim$ reframing/reformulation/decatchmenting/detruncating/decompulsing/delinearisi ng imbuing sublimating-prolongation. Memorative-extension-<as-to-'conscientiousnessdemoronisation — delinearising construct-of-thought' $/{ }^{\circ}$ \{epistemic-totalising ’’’ psychologismicsubliminal-detruncating';-as-relative-reflexivity-reframing_educing $\sim$ sublimatingprolongation $>$ is so-reflected as to the 'psychologismic difference' in the appraisal of human meaningfulness-and-teleology ${ }^{9}$ and consciousness/collective-consciousness (as of prior unblurriness $\sim$ reframing/reformulation/decatchmenting/detruncating/decompulsing/delinearisi ng on-the-one-hand and on-the-other-hand prospective unblurriness/blurrinessthreshold framing/formulation/catchmenting/truncating/compulsing/linearising); with regards 
to organic-knowledge 'inkling-drive of dimensionality-of-sublimating <<amplituding/formative >supererogatory $\sim$ de-mentativeness/epistemic-growth-orconflatedness /transvaluative-rationalising/transepistemicity/anamnestic-residuality/spiritdrivenness-equalisation)'-over-'seeding-misprising of dimensionality-of-desublimating-lackof ${ }^{-}-\langle<$amplituding/formative $>$supererogatory $\sim$ de-mentativeness/epistemic-growth-orconflatedness /transvaluative-rationalising/transepistemicity/anamnestic-residuality/spiritdrivenness-equalisation)'. And so, as of 'baseline/nominalising/editionalaptitudinal underlay-<as-to-priorunblurriness reframing/reformulation/decatchmenting/detruncating/decompulsing/delinearisi ng $>$ '-<imbued_aptitudinal-coherence-of-existentially-manifest $\sim$ hunches/cues/flags $>$ (soundergirding eventual 'secondnatured positive-opportunism-of-social-functioning-andaccordance , as-to-prospective_punctual/immediacy/constituted/compulsions-

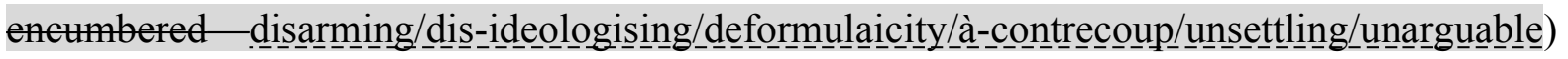
dragging-out into prospective unblurriness $\sim$ reframing/reformulation/decatchmenting/detruncating/decompulsing/delinearisi ng. Underlining the reality that human ${ }^{56}$ meaningfulness-and-teleology ${ }^{9}$ is existentially< disontologising/re-ontologising aporeticism $>$ manifested as of its <amplituding/formativeepistemicity>-totalising $\sim$ thrownness-in-existence ${ }^{35}$ (as to prior unblurriness $\sim$ reframing/reformulation/decatchmenting/detruncating/decompulsing/delinearisi ng and prospective unblurriness/blurrinessthreshold framing/formulation/catchmenting/truncating/compulsing/linearising); so-reflected with respect to 'veridical notionality/epistemicity/bindingness ${ }^{<a s-t o-d e t e r m i n i s m / e o n c e p t i v i t y-o f-r e l a t i v e-~}$ mreflexivity/relative-reflexivityz conception-of- ${ }^{56}$ meaningfulness-and-teleology ${ }^{9}$, - (reflection upon the given 'existential-disontologising/re-ontelogising apereticism> ('baseline/nominalising/editional_- 
recurring existentialising-framing-by-enframing/\{worlding $\}$-<as-manifest-

individuative direct/deferential-transeffusive/worlding-looping $>$ _. reflected-as_-supererogation 6 -

capacitating-<for-existential-thematic>> ${ }^{\prime}$. Thus, notionally/epistemically/bindingnessly-<as-todeterminism/conceptivity-of-relative-unreflexivity/relative-reflexivitys reflecting a 'perpetuating unblurrinessdragging-out psychologismic difference pyramid' with the 'broadbase-of-the-pyramid reflecting unblurriness/blurriness-

threshold framing/formulation/catchmenting/truncating/compulsing/linearising of meaningfulness-and-teleology ${ }^{9}$ (relatively susceptible to sout-of-phasing $>$ disparatenarratives_of_social-functioning-and-accordance-as-of-social-stake-contention-or-

confliction construct) and the top-of-the-pyramid reflecting unblurriness $\sim$ reframing/reformulation/decatchmenting/detruncating/decompulsing/delinearisi ng of ${ }^{56}$ meaningfulness-and-teleology ' (relatively converging to 'ontologically-hegemonisingnarrative ontological-performance ${ }^{72}-<$ including-virtue-asontology $>$ /morality/ethics/justice/etc.'); so-implied veridically rather as from prospective reontologising Being-development/ontological-framework-expansion-as-to-depth-ofontologising-development-as-infrastructure-of- meaningfulness-and-teleology psychologismic epistemic acutisation difficulty-<for, residualising

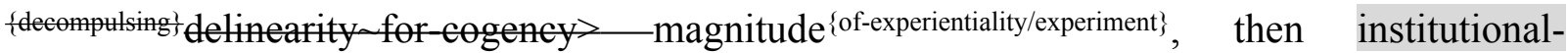
development-as-to-social-function-development psychologismic epistemic-acutisationdifficulty-<for, residualising _decompulsing $\}$ delinearity for-cogency> $>$ magnitude ${ }^{\{0 f-}$ experientiality/experiment\} and then living-development-as-to-personality-development psychologismic epistemic acutisation difficulty < for, residualising $\{$ decompulsing $\}$ delinearity for-cogeney>-magnitude $\{$ of-experientiality/experiment $\}$. Fundamentally speaking to the fact that this "psychologismic difference bounds of human meaningfulness-and- 
teleology ${ }^{9}$, reflects 'relative-unreflexivity/relative-reflexivity—bindingness/nondiscretionariness- $<$ as-fromsublimating-remoteness/distance-of-appraisal-of-requisite-Being-development> of unlimitedness/existence-<full-potency-of_sublimating nascence $>$ '- (as to 'relativeunreflexivity/relative-reflexivity limitedness/human-subpotency dynamics of supererogating \{affirmation/projection/assertion/notional $\sim$ self-distantiation-byunaffirmation/deprojection/deassertion/epistemic-decadence \}-towards -omnipotentialaffirmation/projection/assertion/notional self-distantiation' with respect to 'limitedness/humansubpotency prospective re-encountering/re-confrontation with unlimitedness/existence-<fullpotency-of_sublimating nascence $>$ '), within which human ${ }^{5}$ meaningfulness-and-teleology ${ }^{9}$ is underlaid (as to the given <amplituding/formative-epistemicity>-totalising $\sim$ thrownness-inexistence ${ }^{35}$ ); and so, with respect to 'veridical notionality/epistemicity/bindingness ${ }^{<a s-t o-}$ determinism/conceptivity-of-relative-unreflexivity/relative-reflexivity> conception-of- -5 meaningfulness-andteleology' - (reflection upon the given 'existential-<disontologising/re-ontelogising aporeticism>

capacitating-<for-existential-thematic '). It is effectively as to this 'psychologismic difference bounds of human ${ }^{5}$ meaningfulness-and-teleology ${ }^{9}$ that inevitably arises the manifestation of the 'differential ontological-performance ${ }^{2}-<$ including-virtue-asontology $>$ /morality/ethics/justice/etc.' of the sovereign-function/posture-<as-to-existentiallymanifest-'embodied-subject consciousness-and-direct/deferential-conscientiousness',-as-ofits-'epistemic-reflexivity/unreflexivity-in-existence'/teleology> by the genuine social intellectual-function/posture by pedantising/muddling/formulaic-hollowing-out-in- 
subontologisation/subpotentiation-〈blurring/undermining-of-prospective-totalising-entailing,as-to-entailing-<amplituding/formative-epistemicity $>$ totalising $\sim$ in-relative-ontological-

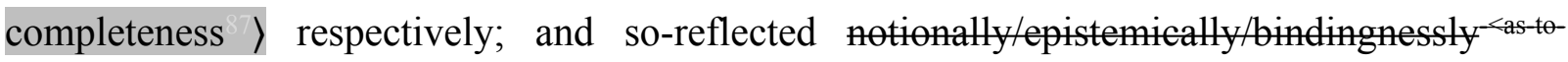
determinism/conceptivity-of-relative-unreflexivity/relative-reflexivity> as to 'eventualised/eventualising notional conflatedness ${ }^{13}$ of human ${ }^{5}$ meaningfulness-and-teleology', (effusing 'human geotopological-<as-to- nonpresencing-detruncating-of-'human- presencingcomplexes/inhibitions-of-manifest-disanthropologisation'> disontologising/re-ontologising implications'). In this respect, as to the veracity of knowledge as more than just the existential$<$ disontologising/re-ontologising aporeticism $>$ construal of prospective organic-knowledge desublimatingly (as if of 'human consciousness/collective-consciousness manifest linearisingimbuing_conscious-moronisation-<as-to-prior_mere-formulaicity/ritualisation> enframing' and so-inducing mechanical-knowledge), the very existential-<disontologising/reentologising aporeticism $>$ "contemplative and supererogation ${ }^{\circ}$-capacitating-<for-existentialthematic $>$ dynamics' underlining organic-knowledge dragging-out (into prospective unblurriness $\sim$ reframing/reformulation/decatchmenting/detruncating/decompulsing/delinearisi ng), as of 'baseline/nominalising/editional — aptitudinal underlay-<as-to-priorunblurriness reframing/reformulation/decatchmenting/detruncating/decompulsing/delinearisi ng $>$ '-<imbued_aptitudinal-coherence-of-existentially-manifest $\sim$ hunches/cues/flags $>\quad$ (soundergirding eventual ssecondnatmred positive-opportunism-of-social-functioning-andaccordance , as-to-prospective_punctual/immediacy/constituted/compulsions-

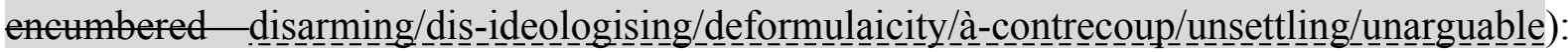
is so-educed as superseding/overcoming 'apriorising/axiomatising/referencingequating/leveling/ressentiment/closed-construct-of- ${ }^{56}$ meaningfulness-and-teleology ${ }^{9}$ and bothsidesism-〈as- ‘mere-processive'/pedantising- 'dialogical-relation'-to 'perceived-socialand-institutional-commonly-enculturated_referencing,-of- meaningfulness-and-teleology 
failing-'requisite-existential-thematic-baseline-of-technicity/profundity-framing' \{of-

sublimating-discursivity-for-sovereign-repassing , ,-as-of-psychologismic-epistemic-

acutisation-nonresidualising-imbued-\{compulsingl linearity in-eclecticism-of-prior-mere-

formulaicity/ritualisation,-as-so- 'consciously/unconsciously-preordained/fated'-to-fail-

prospective-notional cogency) ${ }^{\prime} \quad$ failing cogency_chronicularity/annality-of-relativereflexivity,-as-to-profound-supererogation (which so-undermine veridically requisite organicknowledge imbued prospective 'despite-the-self exercise of epistemic-projection in notional $\sim$ self-distantiation-<imbued—re-motif-and-re-apriorising/re-axiomatising/re-

referencing>' involved in 'limitedness/human-subpotency prospective re-encountering/reconfrontation with unlimitedness/existence-<full-potency-of_sublimating nascence $>$ ' for unblurriness $\sim$ reframing/reformulation/decatchmenting/detruncating/decompulsing/delinearisi ng imbuing sublimating-prolongation). The implication here is that, with respect to 'veridical notionality/epistemicity/bindingness conception-of- ${ }^{5}$ meaningfulness-and-teleology' - (reflection upon the given 'existential<disontelogising/re-ontelogising aporeticism> ("baseline/nominalising/editional—aptitudinal $\sim$ underlay-<as-to-prior-

'baselining/cogency/reconstruing — aptitudinal overlay-<for-prospective- unblurriness_dragging-out $>$ ’ $\rangle$-...reflected-as_-...

recurring $\sim$ existentialising-framing-by-enframing/\{worlding $\}$-<as-manifest-

individuative _direct/deferential-transeffusive/worlding-looping $>$ _reflected-as_-supererogation 6 -

capacitating-<for-existential-thematic $>$ '): the 'baseline/nominalising/editional—aptitudinal $\sim$ underlay-<asto-prior-

unblurriness reframing/reformulation/decatchmenting/detruncating/decompulsing/delinearisi ng $>{ }^{\prime}-<$ imbued_aptitudinal-coherence-of-existentially-manifest $\sim$ hunches/cues/flags $>$ (reflecting 'inkling-drive of dimensionality-of-sublimating ${ }^{25}-\langle<$ amplituding/formative $>$ supererogatory $\sim$ dementativeness/epistemic-growth-or-conflatedness /transvaluative- 


\section{<<amplituding/formative >supererogatory de-mentativeness/epistemic-growth-or-}

\section{conflatedness /transvaluative-rationalising/transepistemicity/anamnestic-residuality/spirit-}

drivenness-equalisation)') is inherently 'telling of a veridical pretense of mutual engagement for organic-knowledge elucidation'; as so-underlaying (whether credibly/soundly or uncredibly/unsoundly) the 'baselining/cogency/reconstruing — aptitudinal overlay-<forprospective- unblurriness-dragging-out ${ }^{\prime}$ for organic-knowledge educing (of eventual 'secondnatured positive opportmism of social functioning and accordance ${ }^{7}$ as to prospective punctual/immediacy/constituted/compulsions-encumbered_disarming/dis-_ideologising/deformulaicity/à-contrecoup/unsettling/unarguable). This is the case as the idea of knowledge is veridically much more than just the 'constraining mere-formulaicity/ritualisation outcome' of elicited immediacy-of-sublimation-(imbued 'secondnatured positiveepportunism of-social-functioning and-accordance ${ }^{5}$ as-to-

\section{prospective_punctual/immediacy/constituted/compulsions encumbered_dis_armining/dis_-}

ideologising/deformulaicity/à-contrecoup/unsettling/unarguable). So-failing to appraise-andaccount-for its requisite existential-<disontologising/re-ontologising aporeticism $>$ 'delinearising-imbuing_conscientiousness-demoronisation-<as-to-renewing-realisation/reperception/re-thought $>\sim$ reframing from prior linearising-imbuing_conscious-moronisation<as-to-prior_mere-formulaicity/ritualisation>-enframing' as to profound-supererogation ; soenabling memorative-extension- $<$ as-to-'conscientiousness-demoronisation-

\section{delinearising construct-of-thought'/‘ \{epistemic-totalising ' ’’psychologismic-subliminal-}

reflection of the possibility/potentiation of requisite sublimating-prolongation within the ambit of 'relative-unreflexivity/relative-reflexivity — bindingness/nondiscretionariness-<as-from-sublimating 
remoteness/distance-of appraisal-of requisite $\sim$ Being-development>

unlimitedness/existence-<fll potency-of_sublimating nascence $>$ '- (as to 'relativeunreflexivity/relative-reflexivity limitedness/human-subpotency dynamics of supererogating \{affirmation/projection/assertion/notional $\sim$ self-distantiation-byunaffirmation/deprojection/deassertion/epistemic-decadence $\}$ - towards omnipotentialaffirmation/projection/assertion/notional self-distantiation' with respect to 'limitedness/humansubpotency prospective re-encountering/re-confrontation with unlimitedness/existence- $<$ fullpotency-of_sublimating nascence $>$ '). Organic-knowledge requires appropriate appraising-andaccounting-for 'baseline/nominalising/editional—aptitudinal underlay-<as-to-priorunblurriness reframing/reformulation/decatchmenting/detruncating/decompulsing/delinearisi ng $>$ '-<imbued_aptitudinal-coherence-of-existentially-manifest $\sim$ hunches/cues/flags $>$ (reflecting 'inkling-drive of dimensionality-of-sublimating ${ }^{25}-\langle<$ amplituding/formative $>$ supererogatory $\sim$ dementativeness/epistemic-growth-or-conflatedness /transvaluativerationalising/transepistemicity/anamnestic-residuality/spirit-drivenness-equalisation〉’ or 'seeding-misprising of dimensionality-of-desublimating-lack-of' <<amplituding/formative>supererogatory $\sim$ de-mentativeness/epistemic-growth-orconflatedness /transvaluative-rationalising/transepistemicity/anamnestic-residuality/spiritdrivenness-equalisation)'): so-undergirding veridical 'baselining/cogency/reconstruingaptitudinal overlay-<for-prospective- tnblurriness-dragging-out $>$ ' as it educes eventual 'secondnatured positive opportmism of social functioning and accordance 7 as to prospective punctual/immediacy/constituted/compulsions-encumbered_disarming_-___dis-

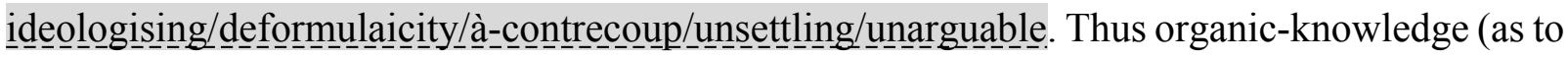
educing-and-enculturating of 'dimensionality-of-sublimating <<amplituding/formative >supererogatery de-mentativeness/epistemic-growth-orconflatedness /transvaluative-rationalising/transepistemicity/anamnestic-residuality/spirit- 
drivenness-equalisation)') requires appropriate prospective 'despite-the-self exercise of epistemic-projection in notional $\sim$ self-distantiation- $<$ imbued-re-motif-and-re-apriorising/reaxiomatising/re-referencing $>$ ' involved in 'limitedness/human-subpotency prospective reencountering/re-confrontation with unlimitedness/existence-<full-potency-of_sublimating nascences': and so unavoidable/necessary, in the face of prospective 'unblurriness/blurrinessthreshold framing/formulation/catchmenting/truncating/compulsing/linearising warrant forprospective- unblurriness-dragging-out. So-explaining the prospective cogency_chronicularity/annality-of-relative-reflexivity,-as-to-profound-supererogation sought by Socratic-philosophers ${ }^{103}$ universalising-idealisation ${ }^{83}$ reference-of-thought and budding-positivists positivism/rational-empiricism ${ }^{83}$ reference-of-thought disseminativesublimating-selectivity-of-ontological-good-faith/authenticity postconverging-dementating/structuring/paradigming , over desublimating deselectivity-of-ontological-badfaith/inauthenticity -preconverging de-mentating/structuring/paradigming respectively superseding/overriding ancient-sophists non-universalising and medieval-scholasticism nonpositivising (with respect to re-ontologising Being-development/ontological-frameworkexpansion-as-to-depth-of-ontologising-development-as-infrastructure-of- meaningfulnessand-teleology psychologismic epistemic-acutisation difficulty-<for, residualising\{decompulsing $\}$ delinearity for-cogeney>-magnitude $\{$ of-experientiality/experiment\} $\}$; as so-reflected as of the requisite 'recomposured/cumulated_re-ontologising/re-sublimating-axiomaticconstructs_as_impliciting-of prospectively-requisite_relative-reflexivity/delinearising (as to elicited 'reconstruing of ${ }^{83}$ reference-of-thought- ${ }^{8}$ devolving')'. Thus 'veridical notionality/epistemicity/bindingness ${ }^{<a s-t o-d e t e r m i n i s m / e o n c e p t i v i t y-o f-r e l a t i v e-u n r e f l e x i v i t y / r e l a t i v e-r e f l e x i v i t y>~}$ conception-of-5 meaningfulness-and-teleology' - (reflection upon the given 'existential<disontologising/re-ontologising aporeticism> ("baseline/nominalising/editional—aptitudinal underlay-<as-to-prior- 
'baselining/cogency/reconstruing — aptitudinal overlay-<for-prospective- unblurriness_dragging-out $>$ ' $\rangle$-... reflected-as-

recurring existentialising-framing-by-enframing/\{worlding $\}$-<as-manifest-

individuative direct/deferential-transeffusive/worlding-looping $>$ _ reflected-as_-supererogation $0_{-}$

capacitating-<for-existential-thematic ') with respect to both nascent-particular/incipient-andmaterial/technical-sublimations-<blinded-to-their-relative-ontological-completeness

reference-of-thought- devolving $>\quad$ and social-and-institutional-frameworks-ofreferencing/registering/decisioning: is underlied as of manifest coherent 'recomposured/cumulated—re-ontologising/re-sublimating-axiomatic-

constructs_as_impliciting of prospectively_requisite_relative-reflexivity/delinearising (as to elicited 'reconstruing of ${ }^{83}$ reference-of-thought- ${ }^{8}$ devolving')'; and not the conscious/unconscious subterfuge of 'apriorising/axiomatising/referencingequating/leveling/ressentiment/closed-construct-of- ${ }^{56}$ meaningfulness-and-teleology ${ }^{9} \quad$ and bothsidesism-〈as-'mere-processive'/pedantising-'dialogical-relation'-to 'perceived-socialand-institutional-commonly-enculturated_referencing,-of- meaningfulness-and-teleology 'failing-'requisite-existential-thematic-baseline-of-technicity/profundity-framing' \{ofsublimating-discursivity-for-sovereign-repassing\},-as-of-psychologismic-epistemicacutisation-nonresidualising-imbued-\{compulsing\} linearity in-eclecticism-of-prior-mereformulaicity/ritualisation,-as-so- 'consciously/unconsciously-preordained/fated'-to-failprospective-notional cogency) ${ }^{\prime} \quad$ failing cogency_chronicularity/annality-of-relativereflexivity,-as-to-profound-supererogation . In this respect, 'veridical notionality/epistemicity/bindingness ${ }^{-<a s-t o-d e t e r m i n i s m / c o n c e p t i v i t y-o f-r e l a t i v e-u n r e f l e x i v i t y / r e l a t i v e-r e f l e x i v i t y>~}$ conception-of- ${ }^{5}$ meaningfulness-and-teleology ${ }^{9}$ '- (reflection upon the given 'existential<disontelogising/re-ontelogising apereticism> ("baseline/nominalising/editional—aptitudinal underlay-<as-to-priorunblurriness $\sim$ reframing/reformulation/decatchmenting/detruncating/decompulsing/delinearising ${ }^{\prime}$ enabling 'baselining/cogency/reconstruing — aptitudinal overlay-<for-prospective- unblurriness-dragging-out $>$ ' $\rangle$-... reflected-as- 
recurring existentialising-framing-by-enframing/\{worlding $\}$-<as-manifest-

individuative-direct/deferential-transeffusive/worlding-looping $>$ __reflected-as_-supererogation 6 -

capacitating-for-existential-thematic ${ }^{\prime}$ ) implies that the appraising-and-accounting-for

'baseline/nominalising/editional—aptitudinal underlay-<as-to-prior-

unblurriness-reframing/reformulation/decatchmenting/detruncating/decompulsing/delinearisi

ng $>$ '-<imbued_aptitudinal-coherence-of-existentially-manifest $\sim$ hunches/cues/flags $>$ (reflecting

'inkling-drive of dimensionality-of-sublimating ${ }^{25}$-<<amplituding/formative $>$ supererogatory $\sim$ de-

mentativeness/epistemic-growth-or-conflatedness /transvaluative-

rationalising/transepistemicity/anamnestic-residuality/spirit-drivenness-equalisation〉 $\quad$ or

'seeding-misprising of dimensionality-of-desublimating-lack-of -

<<amplituding/formative>supererogatory $\sim$ de-mentativeness/epistemic-growth-or-

conflatedness /transvaluative-rationalising/transepistemicity/anamnestic-residuality/spirit-

drivenness-equalisation)') as underlaying of 'baselining/cogency/reconstruingaptitudinal overlay<for prespective - mblurriness dragging out $>$ for organic-knowledge educing (of eventual ssecondnatured positive-opportunism-of-social-functioning-andaccordance , as-to-prospective_punctual/immediacy/constituted/compulsions-

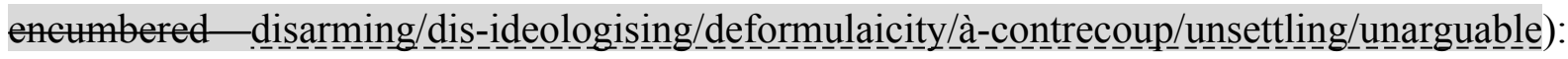
is notionally/epistemically/bindingnessly-<as-to-determinism/conceptivity-of-relative-unreflexivity/relative-reflexivity> 'telling of the veridical pretense of mutual engagement for organic-knowledge elucidation'. And so, with regards to the (credibility/soundness or uncredibility/unsoundness) of 'baseline/nominalising/editional—aptitudinal underlay-<as-to-priorunblurrinessareframing/reformulation/decatchmenting/detruncating/decompulsing/delinearisi ng $>$ '-<imbued_aptitudinal-coherence-of-existentially-manifest $\sim$ hunches/cues/flags $>$ (reflecting 'inkling-drive of dimensionality-of-sublimating ${ }^{25}-\langle<$ amplituding formative $>$ supereregatery dementativeness/epistemic-growth-or-conflatedness /transvaluative- 
<<amplituding/formative >supererogatory-de-mentativeness/epistemic-growth-or-

conflatedness /transvaluative-rationalising/transepistemicity/anamnestic-residuality/spirit-

drivenness-equalisation〉') which supposedly_veridically_so-underlay the

'baselining/cogency/reconstruing — aptitudinal overlay-<for-prospective- tnblurriness-

dragging-out $>$ ' for organic-knowledge educing (of eventual 'secondnatured positiveopportunism of-social-functioning and-accordance 7 , as-to-

prospective punctual/immediacy/constituted/compulsions encumbered_disarming/dis-

ideologising/deformulaicity/à-contrecoup/unsettling/unarguable-_e). This speaks to the fact that even apparently 'prospective contentious/un-nominalised social-stake-contention-or-confliction imbued unblurriness/blurrinessthreshold framing/formulation/catchmenting/truncating/compulsing/linearising' do not allow for free-for-all misconstrual/misanalysis; as so-notionally/epistemically/bindingnessly-<as-todeterminism/conceptivity-of-relative-unreflexivity/relative-reflexivity s 'telling of the veridical pretense of mutual engagement for organic-knowledge elucidation'. In this regards (and as herein contended) specifically, gross pretenses of conclusive analysis of postmodern thought while implicitly/explicitly grossly avowing/demonstrating paradoxically lack of understanding as well as an orientation geared towards media propagandising and infowarring effectively speaks to a more fundamental organic-knowledge issue of failure of requisite 'baseline/nominalising/editional—aptitudinal underlay-<as-to-priorunblurriness reframing/reformulation/decatchmenting/detruncating/decompulsing/delinearisi ng $>{ }^{\prime}-<$ imbued_aptitudinal-coherence-of-existentially-manifest $\sim$ hunches/cues/flags $>$ (reflecting ‘inkling-drive of dimensionality-of-sublimating ${ }^{25}-<<$ amplituding/formative $>$ supererogatory $\sim$ dementativeness/epistemic-growth-or-conflatedness /transvaluative- 
drivenness-equalisation〉') before even an issue of logical/rationalising pertinence (as of 'baselining/cogency/reconstruing — aptitudinal overlay-<for-prospective- tnblurrinessdragging-out $>$ '). In this regards, organic-knowledge appropriately points out that whether relatively validated or relatively invalidated in due course (by the eventual ssecondnatured positive opportmism of social functioning and aceordance 7 , as to prospective punctual/immediacy/constituted/compulsions-encumbered_disarming/dis-

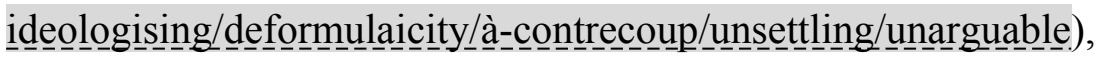
the 'baseline/nominalising/editional — aptitudinal underlay-<as-to-priorunblurriness reframing/reformulation/decatchmenting/detruncating/decompulsing/delinearisi ng $>$ '-<imbued_aptitudinal-coherence-of-existentially-manifest $\sim$ hunches/cues/flags $>$ discernible in a healthy/unhealthy intellectual exercise (whether as reflecting manifest or lackof prospective 'despite-the-self exercise of epistemic-projection in notional $\sim$ self-distantiation$<$ imbued — re-motif-and-re-apriorising/re-axiomatising/re-referencing> $\quad$ involved in 'limitedness/human-subpotency prospective re-encountering/re-confrontation with unlimitedness/existence-<full-potency-of_sublimating nascence $>$ for unblurriness $\sim$ reframing/reformulation/decatchmenting/detruncating/decompulsing/delinearisi ng imbuing sublimating-prolongation) do not lie and cannot be ignored. And so, with regards to revealing the blatant manifestation of ontological-good-faith/authenticity $\sim$ postconverging-dementating/structuring/paradigming ${ }^{70}$ or ontological-bad-faith/inauthenticity ${ }^{64} \sim$ preconvergingde-mentating/structuring/paradigming ; so-reflected respectively with regards to the (credibility/soundness or incredibility/unsoundness) of requisite 
'baseline/nominalising/editional—aptitudinal underlay-<as-to-priorunblurriness reframing/reformulation/decatchmenting/detruncating/decompulsing/delinearisi ng $>$ '-<imbued_aptitudinal-coherence-of-existentially-manifest $\sim$ hunches/cues/flags $>$ (reflecting 'inkling-drive of dimensionality-of-sublimating ${ }^{25}-\langle<$ amplituding formative $>$ supereregatery dementativeness/epistemic-growth-or-conflatedness /transvaluativerationalising/transepistemicity/anamnestic-residuality/spirit-drivenness-equalisation〉’ or 'seeding-misprising of dimensionality-of-desublimating-lack-of <<amplituding/formative >supererogaty de-mentativeness/epistemic-growth-orconflatedness /transvaluative-rationalising/transepistemicity/anamnestic-residuality/spiritdrivenness-equalisation〉') which so-underlay the 'baselining/cogency/reconstruingaptitudinal overlay-for-prospective- tnblurriness_dragging-out $>$ ' for organic-knowledge educing (of eventual ssecondnatured positive-opportunism-of-social-functioning-andaccordance , as-to-prospective_punctual/immediacy/constituted/compulsions-

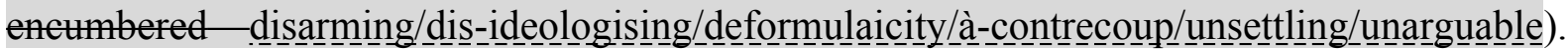

Thusly, cogency_chronicularity/annality-of-relative-reflexivity,-as-to-profoundsupererogation rather veridically speaks of the 'recomposuring/cumulating' of 'baseline/nominalising/editional — aptitudinal underlay-<as-to-priorunblurrinessoreframing/reformulation/decatchmenting/detruncating/decompulsing/delinearisi ng $>$ '-<imbued_aptitudinal-coherence-of-existentially-manifest $\sim$ hunches/cues/flags $>$ (reflecting 'inkling-drive of dimensionality-of-sublimating ${ }^{25}-\langle<$ amplituding/formative $>$ supererogatory $\sim$ dementativeness/epistemic-growth-or-conflatedness /transvaluativerationalising/transepistemicity/anamnestic-residuality/spirit-drivenness-equalisation〉' or 'seeding-misprising of dimensionality-of-desublimating-lack-of <<amplituding/formative>supererogatory $\sim$ de-mentativeness/epistemic-growth-orconflatedness /transvaluative-rationalising/transepistemicity/anamnestic-residuality/spirit- 
drivenness-equalisation $\rangle$ ') so-underlayin 'baselining/cogency/reconstruingaptitudinal overlay-for-prospective- tnblurriness_dragging-out $>$ ' as for organic-knowledge educing (of eventual ssecondnatured positive-opportunism-of-social-functioning-andaccordance 3 , as-to-prospective punctual/immediacy/constituted/compulsions-

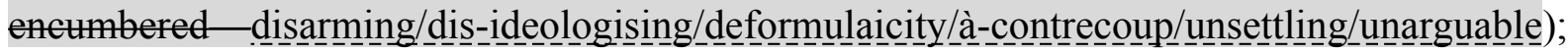
with cogency_chronicularity/annality-of-relative-reflexivity,-as-to-profound-supererogation so-reflected existentially-<disontologising/re-ontologising aporeticism $>$ as of 'recomposured/cumulated_re-ontologising/re-sublimating-axiomaticconstructs_as_impliciting of prospectively-requisite_relative-reflexivity/delinearising (as to elicited 'reconstruing of ${ }^{83}$ reference-of-thought- ${ }^{8}$ devolving')'. Organic-knowledge notional/epistemic/bindingness ${ }^{-<a-t o-d e t e r m i n i s m / c o n c e p t i v i t y-o f-r e l a t i v e-u n r e f l e x i v i t y / r e l a t i v e-r e f l e x i v i t y s ~} \quad$ with respect to 'veridical notionality/epistemicity/bindingness ${ }^{<a s-t o-d e t e r m i n i s m / c o n c e p t i v i t y-o f-r e l a t i v e-~}$ meflexivity/relative reflexivity> conception-of- ${ }^{56}$ meaningfulness-and-teleology ${ }^{9}$ - (reflection upon the given 'existential-<disontologising/re-ontologising aporeticism> 〈'baseline/nominalising/editional_ aptitudinal underlay-<as-to-prior-_unblurriness $\sim$ reframing/reformulation/decatchmenting/detruncating/decompulsing/delinearising $>$ ' enabling 'baselining/cogency/reconstruing — aptitudinal overlay-<for-prospective- unblurriness_dragging-out $>$ ' $\rangle$-... reflected-asrecurring existentialising-framing-by-enframing/\{worlding $\}-<$ as-manifestindividuative $\sim$ direct/deferential-transeffusive/worlding-looping $>$ _reflected-as_-supererogation 6 capacitating-<for-existential-thematic ‘') equally explains why even as the genuine social intellectualfunction/posture prospective re-ontologising rather stresses/emphasises 'human prospective delinearising-imbuing_conscientiousness-demoronisation-<as-to-renewing-realisation/reperception/re-thought $>\sim$ reframing over prior linearising-imbuing_conscious-moronisation-<asto-prior_mere-formulaicity/ritualisation>oenframing': notwithstanding its prior linearisingimbuing_conscious-moronisation-<as-to-prior_mere-formulaicity/ritualisation>enframing (especially with respect to Being-development/ontological-framework-expansion-as-to-depth- 
of-ontologising-development-as-infrastructure-of- meaningfulness-and-teleology

psychologismic epistemic acutisation difficulty-for, residualising

\{decomering $\}$ delinearity for-cogeney> magnitude $\{$ of-experientiality/experiment\} $\}$ the sovereignfunction/posture-<as-to-existentially-manifest-`embodied-subject $\sim$ consciousness-anddirect/deferential-conscientiousness',-as-of-its-'epistemic-reflexivity/unreflexivity-inexistence'/teleology $>$ is effectively equally amenable to 'prospective delinearisingimbuing_conscientiousness-demoronisation-<as-to-renewing-realisation/re-perception/rethought $>$ reframing over prior linearising-imbuing_conscious-moronisation-<as-toprior_mere-formulaicity/rittalisation $>$ enframing' (as equally, though differentially, exposable to prospective re-ontologising eliciting of human ontological-commitment and universaltransparency ${ }^{104}$ with respect to underlying human 'crossgenerational notional firstnaturednessformativeness-<as-to-eventualising-inkling-drive-or-seeding-misprising $>$ mentalprocessing-parity for ontological-performance ${ }^{72}-<$ including-virtue-asontology $>$ /morality/ethics/justice/etc.'). And so, however the manifestation of pedantising/muddling/formulaic-hollowing-out - in-subontologisation/subpotentiation〈blurring/undermining-of-prospective-totalising-entailing,-as-to-entailing$<$ amplituding/formative-epistemicity $>$ totalising in-relative-ontological-completeness $>$ 'epistemic-decadence' or teleological-decadence-<-in-dimensionality-of-desublimating-lackof - -< < amplituding/formative $>$ supererogatory $\sim$ de-mentativeness/epistemic-growth-orconflatedness /transvaluative-rationalising/transepistemicity/anamnestic-residuality/spiritdrivenness-equalisation $>$ imbued distractive-alignment-to- ${ }^{-}$reference-of-thought- $<$ofapriorising/axiomatising/referencing $>{ }^{30}$. In this respect (and notwithstanding the inherently imbued 'psychologismic-epistemic-acutisation-difficulty-<for, residualising \{decompulsing delinearity for-cogency> for human ${ }^{56}$ meaningfulness-and-teleology ${ }^{99}$ sublimatingarising and sublimating-prolongation' as so-reflecting a 'perpetuating 'unblurriness-dragging- 
out psychologismic difference pyramid'), human 'direct/deferential-individuative differential ontological-performance ${ }^{72}$-<including-virtue-as-ontology $>$ /morality/ethics/justice/etc.' rather reflects a geotopological-<as-to- nonpresencing-detruncating-of-'human- presencingcomplexes/inhibitions-of-manifest-disanthropologisation'> potentiation of thehuman/humanity: and so-potentiating in relatively converging to 'ontologically-hegemonisingnarrative ontological-performance ${ }^{72}-<$ including-virtue-asontology $>$ /morality/ethics/justice/etc.' (undergirded as to 'differential existential$<$ disentologising/re-ontelogising aporeticism $>$ direct/deferential-individuative exposing to prospective re-ontologising' elicited human ontological-commitment and universaltransparency ${ }^{104}$ with respect to underlying human 'crossgenerational notional firstnaturednessformativeness-<as-to-eventualising-inkling-drive-or-seeding-misprising $>$ mentalprocessing-parity for ontological-performance ${ }^{72}-<$ including-virtue-asontology $>$ /morality/ethics/justice/etc.'); and so, with regards to the full-potentiation of 'relativemreflexivity/relative reflexivity bindingness/nondiscretionariness-<as-from-sublimating

remoteness/distance-of-appraisal-of requisite $<$ Being-development $>$ of unlimitedness/existence-<fll-potency-of_sublimating nascence $>$ '-(as to 'relativeunreflexivity/relative-reflexivity limitedness/human-subpotency dynamics of supererogating \{affirmation/projection/assertion/notional $\sim$ self-distantiation-byunaffirmation/deprojection/deassertion/epistemic-decadence\} - towards omnipotentialaffirmation/projection/assertion/notional self-distantiation' with respect to 'limitedness/humansubpotency prospective re-encountering/re-confrontation with unlimitedness/existence-<fullpotency-of_sublimating nascence $>$ '). Thus, the 'psychologismic difference bounds of human meaningfulness-and-teleology ${ }^{9}$, (as of prior unblurriness $\sim$ reframing/reformulation/decatchmenting/detruncating/decompulsing/delinearisi ng on-the-one-hand and on-the-other-hand prospective unblurriness/blurriness- 
threshold framing/formulation/catchmenting/truncating/compulsing/linearising) with regards to 'perpetuating unblurriness-dragging-out psychologismic difference pyramid': effectively portends of eventual human 'recomposured/cumulated_as-well-as_prospectively recomposurable/cumulatable—re-ontologising/re-sublimating-axiomatic-

constructs_as_impliciting-of-prospectively-requisite_relative-reflexivity/delinearising (as to elicited 'reconstruing of ${ }^{83}$ reference-of-thought- ${ }^{8}$ devolving')'. So-reflected as of 'reschedulability-<as-overriding prior-institutionalising prior-mere-formulaicity/ritualisationfailing requisite-prospective-profound-supererogation -for-sovereign-emergence $>$ with respect to geotopological-<as-to- nonpresencing-detruncating-of-'human- presencingcomplexes/inhibitions-of-manifest-disanthropologisation'> potentiation of thehuman/humanity'; with regards to the interplay of existentially-disontologising/reentelogising aporeticism $>$ manifest 'differential sovereign-function/posture- $<$ as-toexistentially-manifest-‘embodied-subject $\sim$ consciousness-and-direct/deferentialconscientiousness',-as-of-its-'epistemic-reflexivity/unreflexivity-in-existence'/teleology> by genuine social intellectual-function/posture by pedantising/muddling/formulaic-hollowingout - in-subontologisation/subpotentiation-〈blurring/undermining-of-prospective-totalisingentailing,-as-to-entailing-<amplituding/formative-epistemicity $>$ totalising $\sim$ in-relative-

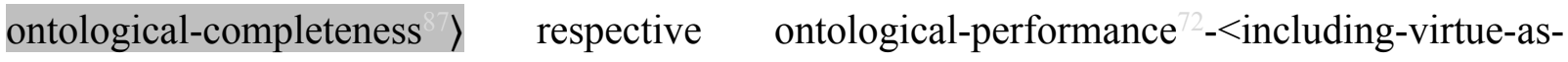
ontology $>$ /morality/ethics/justice/etc.'. In this respect, 'human ${ }^{56}$ meaningfulness-andteleology and consciousness/collective-consciousness as to its sublimating-prolongation' is effectively existentially-<as-to-disontologising/re-ontologising aporeticism $>$ potentiated as of the 'connective-<in-the-'reconstruing-of- reference-of-thought- devolving',-as-from-

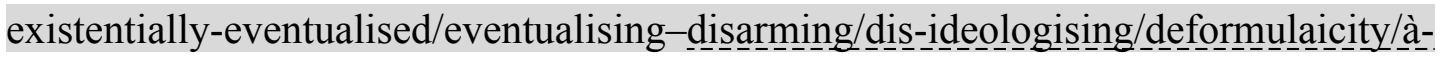

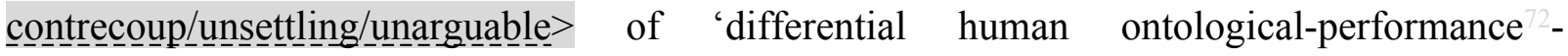
<including-virtue-as-ontology>/morality/ethics/justice/etc.': manifested as of 
'baseline/nominalising/editional—aptitudinal underlay-<as-to-priorunblurriness reframing/reformulation/decatchmenting/detruncating/decompulsing/delinearisi ng $>$ '-<imbued_aptitudinal-coherence-of-existentially-manifest $\sim$ hunches/cues/flags $>$ (as prior unblurriness $\sim$ reframing/reformulation/decatchmenting/detruncating/decompulsing/delinearisi ng) in the elucidation of 'baselining/cogency/reconstruing — aptitudinal overlay-<forprospective- unblurriness dragging-out $>^{\prime} \quad$ (as prospective unblurriness/blurrinessthreshold framing/formulation/catchmenting/truncating/compulsing/linearising), in so-educing eventual 'secondnatured positive-opportmism of-social-functioning and-accordance 5 asto-prospective_punctual/immediacy/constituted/compulsions-encumbered__disarming-_.__is_ideologising/deformulaicity/à-contrecoup/unsettling/unarguable- $). \quad$ The 'connective- $<$ in-the'reconstruing-of- reference-of-thought- devolving',-as-from-existentiallyeventualised/eventualising-disarming/dis-ideologising/deformulaicity/àcontrecoup/unsettling/unarguable $>$ of 'differential human ontological-performance ${ }^{72}$ $<$ including-virtue-as-ontology $>$ /morality/ethics/justice/etc.' is so-reflected as to the fact that it is not the 'prior linearising-imbuing_conscious-moronisation-<as-to-prior_mereformulaicity/ritualisation $>\sim$ enframing of the sovereign-function/posture-<as-to-existentiallymanifest-'embodied-subject consciousness-and-direct/deferentiat-conscientiousness',-as-ofits-'epistemic-reflexivity/unreflexivity-in-existence'/teleology>' or the 'insidious prior linearising-imbuing_conscious-moronisation-<as-to-prior_mereformulaicity/ritualisation>enframing of pedantising/muddling/formulaic-hollowing-out-insubontologisation/subpotentiation-〈blurring/undermining-of-prospective-totalising-entailing,as-to-entailing-<amplituding/formative-epistemicity $>$ totalising in-relative-ontologicalcompleteness \' (implied mere 'logical/rationalising exercise' of prior linearisingimbuing_conscious-moronisation-<as-to-prior_mere-formulaicity/ritualisation $>\sim$ enframing) that underlies sublimating-prolongation but rather the genuine social intellectual- 
function/posture delinearising-imbuing_conscientiousness-demoronisation-<as-to-renewing realisation/re-perception/re-thought $>\sim$ reframing (as to 'limitedness/human-subpotency prospective re-encountering/re-confrontation with unlimitedness/existence-<full-potency of_sublimating nascence $>^{\prime}$ ); and so, as of radicalities $\sim$ in-chronicular/annalistic-cogency- $<$ asof-notional protensivity>-〈as-to-limited-mentation-capacity-deepening —as-subjecting

\section{limitedness/human-subpotency to-'educed-unlimitedness/existence-sublimating nascence' >}

so-construed as cogency_chronicularity/annality-of-relative-reflexivity,-as-to-profoundsupererogation so-differentially reflecting both the 'genuine social intellectualfunction/posture and eventual sovereign-function/posture-<as-to-existentially-manifest‘embodied-subject consciousness-and-direct/deferential-conscientiousness',-as-of-its‘epistemic-reflexivity/unreflexivity-in-existence'/teleology> prospective delinearisingimbuing_conscientiousness-demoronisation-<as-to-renewing realisation/re-perception/rethought $>\sim$ reframing' overruning/dissipating of 'insidious prior linearising-imbuing_consciousmoronisation-<as-to-prior_mere-formulaicity/ritualisation>>enframing of pedantising/muddling/formulaic-hollowing-out - in-subontologisation/subpotentiation〈blurring/undermining-of-prospective-totalising-entailing,-as-to-entailing$<$ amplituding/formative-epistemicity>totalising in-relative-ontological-completeness $\rangle$ '. The 'connective-<in-the-'reconstruing-of- reference-of-thought- devolving',-as-from-

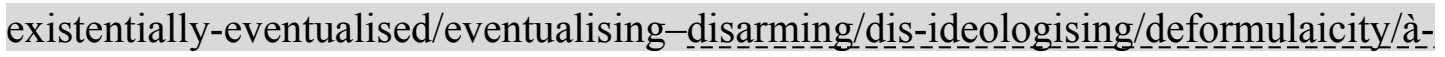
contrecoup/unsettling/unarguable $>$ of 'differential human ontological-performance ${ }^{72}$ <including-virtue-as-ontology $>$ /morality/ethics/justice/etc.' is so-reflected as to the reality that humans did not transcend from a medieval worldview to a positivistic worldview by a mere 'logical/rationalising exercise' (as the mere logical/rationalising conceptualisation we have of such a transformation in today's positivism/rational-empiricism world is rather in effect an afterthought appraisal). But because the 'grander grasp on unlimitedness/existence- $<$ full- 
potency-of_sublimating nascence> of positivism/rational-empiricism' as to its then 'prior human profound-supererogation metaphoricity ${ }^{57}$ developing human-per-cep-ti-vi-ty-<asto-notional perceptualisation-of-and-leashing-to_social-functioning-and-accordance-asof-social-stake-contention-or-confliction> (so-underlied as of preconverging/postconvergingrede-mentating/restructuring/reparadigming superseding/overcoming of the 'medievalism nonpositivising psychologismic-epistemic-acutisation — difficulty- $<$ for,-residualising-

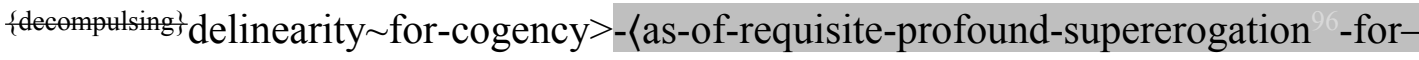
‘disposedness-or-psychologismic-construct'-\{ imbued-demoronisation-<sublimatingnascence, sublimating-upstreaming/'amontée’’\}〉') before its transformationas-to- transcendence-and-sublimity/sublimation/serentativity into our modern-day positivism 'prospective human secondnatured ${ }^{5}$ meaningfulness-and-teleology ${ }^{9}$ ', constrained and made the medieval registry-worldview untenable/internally-contradictory existentially-<disontologising/re-ontologising aporeticism $>$; as well as the fact that the ships that set sail around the world for spices elicit a positive commercial opportunism that is responsible for destroying the social myth of a flat world; the bacteria theory that will ensure that one lives or die if we believe in it or not coerced the destruction of a superstitious medical worldview; or the scientific tools and knowledge that ensured that nation A or nation B will triumph if they believe in it or not, coerces the need to adopt a scientific worldview, etc. The connective-<in-the-'reconstruing-of- reference-of-thought- devolving',-as-from-existentiallyeventualised/eventualising-disarming/dis-ideologising/deformulaicity/à-

contrecoup/uns_ettling/unarguable $>$ of $>$ of 'differential human ontological-performance ${ }^{72}$ $<$ including-virtue-as-ontology $>$ /morality/ethics/justice/etc.' as to the 'reconstruing of reference-of-thought- devolving' effectively speaks to the inveracity of '7presencingabsolutising-identitive-constitutedness ${ }^{14}$ linearising-imbuing_conscious-moronisation-<as-toprior_mere-formulaicity/ritualisation $>\sim$ enframing conception'; and rather to the requisite 
veracity of ' nonpresencing-<perspective-ontological-normalcy/postconvergence $>$ delinearising-imbuing_conscientiousness-demoronisation-<as-to-renewing realisation/reperception/re thought $>\sim$ reframing conception' of 'human ${ }^{56}$ meaningfulness-and-teleology ${ }^{9}$ and consciousness/collective-consciousness as to its sublimating-prolongation'. Effectively reflected as to the genuine social intellectual-function/posture emphasising so-associated human psychologismic-epistemic-acutisation-<as-to-postconverging-dementating/structuring/paradigming,-eliciting-of-existence's-sublimating-nascence-inprospective-aporeticism-overcoming/unovercoming $>$ as to epistemic-growth,-as\{veridical/sound\}-relative-reflexivity-in-existence/relativising from-limited-mentation-as-itsdeepening/psychologismic epistemic-acutisation residualising, ${ }^{\text {\{decompulsing }}$ delinearity for eogency imbued 'cut-out-<as-to-re-ontologising redressing/straightening-out $>$ (as of relativereflexivity psychologismic-transfixity-<placeholder-setup-ontological-rescheduling - inrealigning/preactivity/formative-becoming/psychoanalytical-unshackling,-as-to-residualising\{decompulsing delinearity-over-nonresidualising_- for $\quad$ sublimatingprolongation'; to which human pedantising/muddling/formulaic-hollowing-out-insubontologisation/subpotentiation-〈blurring/undermining-of-prospective-totalising-entailing,as-to-entailing-<amplituding/formative-epistemicity $>$ totalising $\sim$ in-relative-ontologicalcompleteness $\rangle$ is rather consciously/unconsciously distractive and de-emphasising. In this regards, human pedantising/muddling/formulaic-hollowing-out—insubontologisation/subpotentiation-〈blurring/undermining-of-prospective-totalising-entailing,as-to-entailing-<amplituding/formative-epistemicity $>$ totalising $\sim$ in-relative-ontologicalcompleteness > is notionally/epistemically/bindingnessly-ass-erminism/contivity-relativemreflexivity/relative-reflexivity bound to arise by the very inherent relationship between 'limitedness/human-subpotency' (as to prospective re-encountering/re-confrontation) with 'unlimitedness/existence-<full-potency-of_sublimating nascence>': with regards to 
presencing-absolutising-identitive-constitutedness

ideologising/mere-

formulaicity/ritualisation implications undermining the 'reconstruing of ${ }^{8}$ reference-of-thoughtdevolving' - (rather expansively eventualising veridically as of 'human social-functioningand-accordance-as-of-social-stake-contention-or-confliction_construct geotopological-<asto- nonpresencing-detruncating-of-'human- presencing-complexes/inhibitions-of-manifestdisanthropologisation'> potentiation of the-human/humanity'). Such that even nascentparticular/incipient-and-material/technical-sublimations- $<$ blinded-to-their-relative-ontologicalcompleteness - reference-of-thought- devolving> are 'technically-speaking' liable to pedantising/muddling/formulaic-hollowing-out — in-subontologisation/subpotentiation〈blurring/undermining-of-prospective-totalising-entailing,-as-to-entailing$<$ amplituding/formative-epistemicity>totalising in-relative-ontological-completeness $\rangle$; but for the fact that their highly implicited nature and strong immediacy-of-sublimation-(imbued 'secondnatured positive-opportunism of-social-functioning-and-accordance as-toprospective _punctual/immediacy/constituted/compulsions-encumbered__isarming-_-__dis-

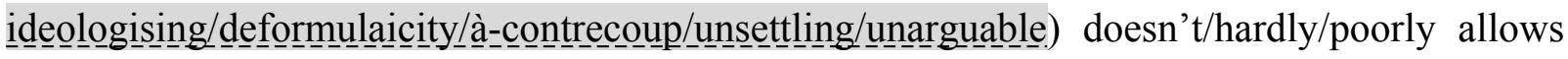
for the 'thorough formation of ideologising/mere-formulaicity/ritualisation practices' (even when such ideologising/mere-formulaicity/ritualisation as to science ideology is abstractly expressed) as well as the manifest relatively 'low emotional-involvement'. Such that with regards to the 'recomposured/cumulated-re-ontologising/re-sublimating-axiomaticconstructs_as_impliciting of prospectively requisite_relative-reflexivity/delinearising (as to elicited 'reconstruing of ${ }^{83}$ reference-of-thought- devolving')' implications of natural sciences (as for-human-studies/for-human-constructs whose specific ambit of human-subpotency is about 'human consciousness as for material and physical effecting devolving teleologies as meaningfulness'): the practice of many a domain of science is actually one where 'potential ideologising/mere-formulaicity/ritualisation orientations' are rather relatively articulated-and- 
constrained as of 'after the fact-of-the-matter educed sublimation'. This highly implicited nature and strong immediacy-of-sublimation-(imbued 'secondnatured positive-opportunism-ofsocial-functioning and-accordance , as to-

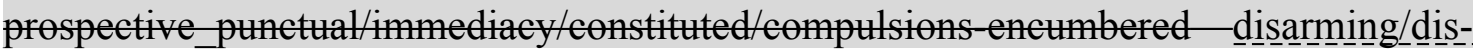
ideologising/deformulaicity/à-contrecoup/unsettling/unarguable) further translates with the efficacious simplieited-relative $>$ nominalising-<elucidation ${ }^{-0}$-relative-unreflexivity/relative-reflexivity $>$ of nascent-particular/incipient-and-material/technical-sublimations- $<$ blinded-to-their-relativeontological-completeness - reference-of-thought- devolving>: with respect to 'baseline/nominalising/editional—aptitudinal underlay-<as-to-priorunblurriness reframing/reformulation/decatchmenting/detruncating/decompulsing/delinearisi ng $>$ '-<imbued_aptitudinal-coherence-of-existentially-manifest $\sim$ hunches/cues/flags $>$ (as prior unblurriness $\sim$ reframing/reformulation/decatchmenting/detruncating/decompulsing/delinearisi ng) in the elucidation of 'baselining/cogency/reconstruing - aptitudinal $\sim$ overlay-<forprospective- unblurriness-dragging-out $>^{\prime} \quad$ (as prospective unblurriness/blurrinessthreshold framing/formulation/catchmenting/truncating/compulsing/linearising). In contrast, the task of 'recomposured/cumulated-re-ontologising/re-sublimating-axiomaticconstructs_as _ impliciting of prespectively requisite_relative-reflexivity/delinearising (as to elicited 'reconstruing of ${ }^{83}$ reference-of-thought- ${ }^{-1 e v o l v i n g ') ', ~ a n d ~ s o ~ a s ~ t o ~ a p p r a i s i n g-a n d-~}$ accounting-for prospective 'sublimating-remoteness/distance-of-appraisal-<as-to-requisite‘Being-development-notional self-distantiation'-imbued-psychologismic-epistemicacutisation,-eliciting-of-prospective-ontologically-hegemonising-narrative $>$ of ${ }^{83}$ reference-ofthought- ${ }^{8}$ devolving' with regards to 'requisite overall existential-<disontologising/reentologising apreticism> cogency_chronicularity/annality-of-relative-reflexivity,-as-toprofound-supererogation ': means that in many ways social-and-institutional-frameworks-ofreferencing/registering/decisioning (as of social domains-of-study for-human-studies/for- 
human-constructs whose specific ambit of human-subpotency is about 'human consciousness inherent effecting devolving teleologies as meaningfulness) are laden with 'a long noose' to knot themselves in 'thorough formation of ideologising/mere-formulaicity/ritualisation practices' as to consciously/unconsciously manifest social-stake-contention-or-confliction and relatively 'high emotional-involvement'. This elucidation of the 'reconstruing of ${ }^{8}$ reference-of-thoughtdevolving' (as to 'insidious pedantising/muddling/formulaic-hollowing-out-insubontologisation/subpotentiation-〈blurring/undermining-of-prospective-totalising-entailing,as-to-entailing-<amplituding/formative-epistemicity $>$ totalising in-relative-ontologicalcompleteness $\rangle$ ') further implies that the disseminative-sublimating-selectivity-ofontological-good-faith/authenticity $\sim$ postconverging-dementating/structuring/paradigming , over-desublimating deselectivity of ontological-badfaith/inauthenticity -preconverging de-mentating/structuring/paradigming (as to facilitating the genuine social intellectual-function/posture) is relatively smoother/better with nascentparticular/incipient-and-material/technical-sublimations- $<$ blinded-to-their-relative-ontologicalcompleteness - reference-of-thought- devolving $>$ as of their <implicited-relative $>$ nominalising<elucidation ${ }^{-}$- ${ }^{-r e l a t i v e-u n r e f l e x i v i t y / r e l a t i v e-r e f l e x i v i t y ~}>$ (in contrast with social-and-institutionalframeworks-of—referencing/registering/decisioning < <elative $>$ un-nominalising-<unelucidationof relative unreflexivity/relative reflexivity $>$ ); since the former strong immediacy-of-sublimation-(imbued 'secondnatured positive-opportunism of-social-functioning and-accordance s, as-toprospective _punctual/immediacy/constituted/compulsions-encumbered_disarming/disidenologising/deformulaicity/à-contrecoup/uns_ettling/un_an inclination for conscious/unconscious pedantising/muddling/formulaic-hollowing-out - insubontologisation/subpotentiation-〈blurring/undermining-of-prospective-totalising-entailing,as-to-entailing-<amplituding/formative-epistemicity $>$ totalising $\sim$ in-relative-ontologicalcompleteness > beholdening to ideologising/mere-formulaicity/ritualisation practices. This 
explains the importance of grasping the 'un-nominalising-or-nominalising-<unelucidation-orelucidation -of-relative-unreflexivity/relative-reflexivity $>$ implications of the 'psychologismic difference bounds of human ${ }^{56}$ meaningfulness-and-teleology ${ }^{9}$ (as of prior unblurriness $\sim$ reframing/reformulation/decatchmenting/detruncating/decompulsing/delinearisi ng on-the-one-hand and on-the-other-hand prospective unblurriness/blurrinessthreshold framing/formulation/catchmenting/truncating/compulsing/linearising as to 'reconstruing of ${ }^{83}$ reference-of-thought- ${ }^{8}$ devolving') in reflection of the 'relative-unreflexivity/relativereflexivity - bindingness/nondiscretionariness- $<a s-f r o m-s u b l i m a t i n g-r e m o t e n e s s / d i s t a n c e-o f-$ appraisal-of-requisite-Being-development $>$ of unlimitedness/existence- $<$ full-potency of_sublimating nascence>'-(as to 'relative-unreflexivity/relative-reflexivity limitedness/human-subpotency dynamics of supererogating \{affirmation/projection/assertion/notional $\sim$ self-distantiation-byunaffirmation/deprojection/deassertion/epistemic-decadence $\}$ — towards omnipotentialaffirmation/projection/assertion/notional self-distantiation' with respect to 'limitedness/humansubpotency prospective re-encountering/re-confrontation with unlimitedness/existence-<fullpotency-of_sublimating nascence $>$ '); and so construed, with respect to 'veridical notionality/epistemicity/bindingness ${ }^{<\text {as-to-determinism/conceptivity-of-relative-unreflexivity/relative-reflexivity }>}$ conception-of- ${ }^{5}$ meaningfulness-and-teleology" - (reflection upon the given 'existential$\leq$ disontologising/re-ontologising_aporeticism> $>$ ("baseline/nominalising/editional-aptitudinal underlay_<as-to-priorunblurriness $\sim$ reframing/reformulation/decatchmenting/detruncating/decompulsing/delinearising $>$ enabling 'baselining/cogency/reconstruing — aptitudinal overlay-<for-prospective- unblurriness-dragging-out $>$ ’ $\rangle$-.... reflected-as-.... recurring existentialising-framing-by-enframing/\{worlding $\}$-<as-manifestindividuative direct/deferential-transeffusive/worlding-looping $>$ _ reflected-as_-supererogation 0 -

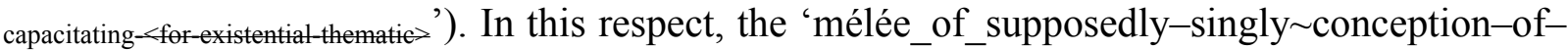
meaningfulness-and-teleology" - reflex $\sim$ propositional-attitude flawed appraisal of the 
natural sciences nominalising (as often so-appraised and more or less relatively adopted into many a social domain-of-study institutionalising/organising/mutualising/methodologising orientation rather relatively un-nominalising) is in many ways amenable to the manifestation of disparateness-of-conceptualisation-<unforegrounding-ment,-failing-prospectively-to-reflect‘immanent relative-unreflexivity/relative-reflexivity - ontological-contiguity ' $>$ as to totalisingly-ing — discretion/whim-of-thought. The effective reality (that is not explicited) of the natural sciences nominalising is otherwise as such an apparent 'mélée_of_supposedlysingly conception-of $-{ }^{5}$ meaningfulness-and-teleology ${ }^{\circ}$ - reflex $\sim$ propositional-attitude is wrongly so-apparent rather because of the 'relative efficacy of many a natural science nominalising': with respect to 'baseline/nominalising/editional—aptitudinal underlay-<as-toprior-

unblurriness reframing/reformulation/decatchmenting/detruncating/decompulsing/delinearisi ng $>$ '-<imbued_aptitudinal-coherence-of-existentially-manifest $\sim$ hunches/cues/flags $>$ (as prior unblurriness $\sim$ reframing/reformulation/decatchmenting/detruncating/decompulsing/delinearisi ng) in the elucidation of 'baselining/cogency/reconstruing — aptitudinal $\sim$ overlay-<forprospective- unblurriness-dragging-out $>^{\prime} \quad$ (as prospective unblurriness/blurrinessthreshold framing/formulation/catchmenting/truncating/compulsing/linearising). Such $\leq$ explicited-relative $>$-nominalising-<elucidation-of-relative-unreflexivity/relative-reflexivity $>\quad$ rather highlights that the 'veridical epistemic-totalising ${ }^{3}$ resubjecting_or_totalisingentailing $\sim$ reconstrual-<of the-whole/purview-of-the-whole/oneness-of-ontology $>\quad$ of mathematics' in 'implicitly reflecting relative-unreflexivity/relative-reflexivity' for instance means that in effect there is no such thing as $1+1=2$ as a 'mélée_of_supposedlysingly $\sim$ conception - of $-{ }^{5}$ meaningfulness-and-teleology ${ }^{9}$, - reflex $\sim$ propositional-attitude (which is the 'nominalised outcome picture' implicited representation of mathematics seeming to imply mathematics is only about its relative-reflexivity rather than its relative- 
unreflexivity/relative-reflexivity as to human 'existential-<disontologising/re-ontologising aporeticism $>\quad<$ amplituding/formative-epistemicity $>$-totalising $\sim$ thrownness-in-existence ${ }^{35}$ ). Such that in effect mathematics 'nominalised outcome picture' of relative-reflexivity (apparently excluding of 'supersededly/deflatedly/overlookably_nominalised relative-unreflexivity') with regards to 'veridical epistemic-totalising ${ }^{3} \sim$ resubjecting_or_totalising-entailing $\sim$ reconstrual$<$ of the-whole/purview-of-the-whole/oneness-of-ontology of mathematics' in 'implicitly reflecting relative-unreflexivity/relative-reflexivity' (as of human 'existential<disontologising/re-ontologising aporeticism> $<$ amplituding/formative-epistemicity $>$ totalising thrownness-in-existence ${ }^{35}$, disseminative- sublimating-selectivity-of-ontologicalgood-faith/authenticity postconverging-de-mentating/structuring/paradigming , overdesublimating deselectivity-of-ontological-bad-faith/inauthenticity opreconverging dementating/structuring/paradigming ) means that $1+1=2$ rather speaks to $1+3 \neq 5,4+4=8,6-7 \neq 0$, $5-3=2, \quad 6 \div 2 \neq 4, \quad 3 \times 9=27, \quad x+2 \neq x+3, \quad$ etc. as to selative nominalising-<elucidation - of-relativeunreflexivity/relative reflexivity $>$ in reflection of mathematics cogency_chronicularity/annality-ofrelative-reflexivity,-as-to-profound-supererogation "; and so, with respect to 'veridical notionality/epistemicity/bindingness ${ }^{<\text {as-to-determinism/conceptivity-of-relative-unreflexivity/relative-reflexivity }>}$ conception-of- ${ }^{5}$ meaningfulness-and-teleology ${ }^{9}$ '-(reflection upon the given 'existential-

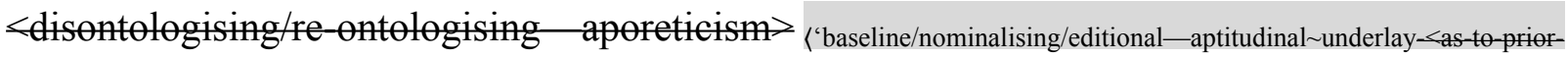
unblurriness-reframing/reformulation/decatchmenting/detruncating/decompulsing/delinearising $>$ enabling 'baselining/cogency/reconstruing — aptitudinal overlay-<for-prospective- unblurriness-dragging-out $>$ ' $\rangle$ - reflected-asrecurring existentialising-framing-by-enframing/\{worlding $\}$-<as-manifestindividuative direct/deferential-transeffusive/worlding-looping > _reflected-as-supererogation 0 capacitating -4 '). In other words, natural sciences 'nominalised outcome picture' of relative-reflexivity (apparently excluding of 'supersededly/deflatedly/overlookably_ nominalised relative-unreflexivity') 'merely implicit-of (and not explicit-of) their epistemic- 
totalising ${ }^{33} \sim$ resubjecting_or_totalising-entailing $\sim$ reconstrual- $<$ of the-whole/purview-of thewhole/oneness-of-ontology>' in 'implicitly reflecting relative-unreflexivity/relativereflexivity', which may be confused-with and undermine the fact that they are veridically of human 'existential-<disontologising/re-ontologising aporeticism $><$ amplituding/formativeepistemicity $>$-totalising $\sim$ thrownness-in-existence ${ }^{35}$, imbued disseminative- -sublimatingselectivity-of-ontological-good-faith/authenticity postconverging-dementating/structuring/paradigming , over-desublimating deselectivity-of-ontological badfaith/inauthenticity -preconverging-de-mentating/structuring/paradigming as to relativeunreflexivity/relative-reflexivity implications; and so, with reference to protracted-social-asto-individual-by-institutional-by-social formativeness-<as-to-intersolipsism-ofpreformulating/preframing/premeaningfulness-imbued-mediativity-and-deferentialism>-ofmeaningfulness-and-teleology (as of Being-development/ontological-frameworkexpansion-as-to-depth-of-ontologising-development-as-infrastructure-of- meaningfulnessand-teleology psychologismic epistemic-acutisation difficulty-<for, residualising \{decomsing delinearity for-cogency> magnitude $\{$ of-experientiality/experiment $\}$ institutionaldevelopment-as-to-social-function-development psychologismic epistemic-acutisationdiffieulty <for, residualising \{decompulsing\} ${ }^{\text {delinearity for cogeney> }}$ magnitude $\{$ ofexperientiality/experiment\} and living-development-as-to-personality-development psychologismic epistemic-acutisation difficulty-for, residualising \{decompulsing $\}$ delinearity for-cogency> magnitude $\{$ of-experientiality/experiment $\}$. In this respect, in many ways the 'formal presentation of the natural sciences themselves' is rather an incomplete/partial 'nominalised outcome picture' of relative-reflexivity (apparently excluding of 'supersededly/deflatedly/overlookably_ nominalised relative-unreflexivity'), as of their full formative linguisivity-〈of-psychologismicepistemic-acutisation/acutising human-per-cep-ti-vi-ty,-as-to-aestheticisation-andaestheticisation-towards-ontology-<elicited-idiomatisation $>>\quad$ as to relative- 
unreflexivity/relative-reflexivity): beyond the so-wrongly apparent 'mélée_of_supposedlysingly $\sim$ conception-of- ${ }^{5}$ meaningfulness-and-teleology ${ }^{\circ}$ - reflex $\sim$ propositional-attitude (which fails to reflect their cogency_chronicularity/annality-of-relative-reflexivity,-as-toprofound-supererogation with regards to disseminative-sublimating-selectivity-ofontological-good-faith/authenticity $\sim$ postconverging-dementating/structuring/paradigming , over desublimating-deselectivity-of-ontological-badfaith/inauthenticity -preconverging-de-mentating/structuring/paradigming as to relativeunreflexivity/relative-reflexivity implications). As so-wrongly implying apparently the natural sciences are not as of 'veridical notionality/epistemicity/bindingness

relative-unreflexivity/relative-reflexivity $>$

upon the given conception-of- ${ }^{5}$ meaningfulness-and-teleology ${ }^{9}$ - (reflection 'existential-<disontologising/re-ontologising aporeticism $>$

〈'baseline/nominalising/editional — aptitudinal underlay-<as-to-prior-

'baselining/cogency/reconstruing — aptitudinal overlay-<for-prospective- unblurriness-dragging-out $>$ ' $\rangle$-.....eflected-as_-....

recurring $\sim$ existentialising-framing-by-enframing/\{worlding $\}-<$ as-manifest-

individuative -direct/deferential-transeffusive/worlding-looping > _reflected-as_supererogation 8 -

capacitating-<for-existential-thematic >'). In this respect it can be appreciated that nobody veridically masters any scientific subject-matter by 'merely and robotically grasping' the 'nominalised outcome picture' of relative-reflexivity (along the lines of say glancing over relevant subject-matter books and grasping the 'nominalised outcome picture' of relative-reflexivity); as the truth of the full relative-unreflexivity/relative-reflexivity formative linguisivity-〈of-psychologismic-epistemicacutisation/acutising human-per-cep-ti-vi-ty,-as-to-aestheticisation-and-aestheticisationtowards-ontology-<elicited-idiomatisation $>>$ extends into the 'existential-<disontologising/reentologising aporeticism $>$ <amplituding/formative-epistemicity $>$-totalising $\sim$ thrownness-inexistence ${ }^{35}$ recalibrating of successive nominalised understanding (so-reflected with teachings, 
exercises, discussions, etc. elucidated relative-unreflexivity/relative-reflexivity) towards the eventually considered judgment call (whether as of exam or otherwise) of achieving such an implicited 'nominalised outcome picture' relative-reflexivity competence. This veridically implies for instance that the conception of mathematics can always be re-articulated to reflect the 'existential-<disontologising/re-ontologising aporeticism $>\quad<$ amplituding/formativeepistemicity $>$-totalising $\sim$ thrownness-in-existence ${ }^{35}$, disseminative- sublimating-selectivity-ofontological-good-faith/authenticity $\sim$ postconverging-dementating/structuring/paradigming , over -desublimating deselectivity-of-ontological-badfaith/inauthenticity -preconverging de-mentating/structuring/paradigming (manifest 'despite-the-self exercise of epistemic-projection in notional $\sim$ self-distantiation-<imbued-remotif-and-re-apriorising/re-axiomatising/re-referencing>' involved in 'limitedness/humansubpotency prospective re-encountering/re-confrontation with unlimitedness/existence-<fullpotency-of_sublimating nascence>' on-the-one-hand over on-the-other-hand 'epistemicdecadence' or teleological-decadence-<-in-dimensionality-of-desublimating-lack-of ${ }^{-}$ <<amplituding/formative>supererogatory $\sim$ de-mentativeness/epistemic-growth-orconflatedness /transvaluative-rationalising/transepistemicity/anamnestic-residuality/spiritdrivenness-equalisation $\rangle$ imbued distractive-alignment-to- ${ }^{8}$ reference-of-thought- $<$ ofapriorising/axiomatising/referencing $>^{30}$ ); and so, beyond our presently common nominalised conception of mathematics as to a 'nominalised outcome picture' of relative-reflexivity (apparently excluding of 'supersededly/deflatedly/overlookably-nominalised relativeunreflexivity'). Wherein for instance, if the requisite arithmetics 'baseline/nominalising/editional—aptitudinal underlay-<as-to-priorunblurriness reframing/reformulation/decatchmenting/detruncating/decompulsing/delinearisi ng $>$ '-<imbued_aptitudinal-coherence-of-existentially-manifest $\sim$ hunches/cues/flags $>$ (as prior unblurriness $\sim$ reframing/reformulation/decatchmenting/detruncating/decompulsing/delinearisi 
ng) in the elucidation of algebra 'baselining/cogency/reconstruing — aptitudinal overlay-<forprospective- unblurriness-dragging-out $>^{\prime} \quad$ (as prospective unblurriness/blurrinessthreshold framing/formulation/catchmenting/truncating/compulsing/linearising): was undermined existentially-<as-to-disontologising/re-ontologising aporeticism $>$ as to a supposed social or physical phenomena inducing a recurrent memory loss in the proper calculation of arithmetics, then algebra can still be done but so rather as of a change in linguisivity-〈of-psychologismic-epistemic-acutisation/acutising $\sim$ human-per-cep-ti-vi-ty,-asto-aestheticisation-and-aestheticisation-towards-ontology-<elicited-idiomatisation $>>$ as to the readaptation of mathematics 'implicited nominalising-<elucidation-of-relative-unreflexivity/relativereflexivity $>$ (from the presently common nominalised conception of mathematics as to a 'nominalised outcome picture' relative-reflexivity of sound arithmetics) like introducing 'if the arithmetic is correct or is incorrect' conditions (of existential-<as-to-disontologising/reentologising aporeticism $>$ examination of the memory loss in the proper calculation of arithmetics)' for elucidating algebraic equations. This speaks to the fact that mathematics (and for that matter any subject-matter as to its memorative-extension- $<$ as-to-'conscientiousnessdemoronisation — delinearising construct-of-thought'/ ' \{epistemic-totalising ${ }^{\prime}$ ’psychologismicsubliminal-detruncating';-as-relative-reflexivity-reframing_educing sublimatingprolongation>) is more fundamentally a question of its 'inkling-drive of dimensionality-ofsublimating $2-\langle<$ amplituding/formative $>$ supererogatory $\sim$ de-mentativeness/epistemic-growthor-conflatedness /transvaluative-rationalising/transepistemicity/anamnestic-residuality/spiritdrivenness-equalisation)' within the ambit of 'veridical notionality/epistemicity/bindingness ${ }^{-<a s-}$ to-determinism/conceptivity-of-relative-unreflexivity/relative-reflexivity> conception-of- -5 meaningfulness-andteleology', -(reflection upon the given 'existential-<disontologising/re-ontologising aporeticism> 
'baselining/cogency/reconstruing — aptitudinal overlay-<for-prospective- unblurriness_dragging-out $>$ ’ $\rangle$-... reflected-as-

recurring existentialising-framing-by-enframing/\{worlding $\}$-<as-manifest-

individuative direct/deferential-transeffusive/worlding-looping $>$ _ reflected-as_-supererogation 06

capacitating-<for-existential-thematic>>) with regards to its <relative>nominalising-<elucidation ${ }^{-0 \text {-relative- }}$ unreflexivity/relative-reflexivity $\geq$. In this respect, even the division of mathematics into separate branches like arithmetic, algebra, trigonometry, etc. is rather driven as of 'existential-<as-todisontologising/re-ontologising aporeticism $>$ $<$ amplituding/formative-epistemicity >totalising thrownness-in-existence ${ }^{35}$ overarching 'inkling-drive of dimensionality-ofsublimating $25-<$ amplituding/formative $>$ supererogatery de-mentativeness/epistemic-growthor-conflatedness /transvaluative-rationalising/transepistemicity/anamnestic-residuality/spiritdrivenness-equalisation)'; as to mathematics sublimating ${ }^{4}$ historiality/ontologicaleventfulness 3 /ontological-aesthetic-tracing-<perspective-ontologicalnormalcy/postconvergence-reflected-'epistemicity-relativism-determinism'> as of 'srelative $>$ nominalising-<elucidation ${ }^{-o f-r e l a t i v e-u n r e f l e x i v i t y / r e l a t i v e-r e f l e x i v i t y ~}>\quad$ reschedulability-<as-overridingprior institutionalising prior mere formulaicity/ritualisation failing requisite prospectiveprofound-supererogation for-sovereign-emergences'. Such that actually the reality of mathematics in many ways is rather more effectively reflected and construable in these terms of the 'epistemic-totalising $\sim$ resubjecting_or_totalising-entailing $\sim$ reconstrual $<$ of thewhole/purview of the-whole/oneness-of-ontology>' in 'implicitly reflecting relativeunreflexivity/relative-reflexivity' (as to 'existential-<disontologising/re-ontologising aporeticism> <amplituding/formative-epistemicity $>$-totalising $\sim$ thrownness-in-existence ${ }^{35}$, disseminative - sublimating-selectivity-of-ontological-good-

faith/authenticity postconverging-de-mentating/structuring/paradigming , over desublimating-deselectivity-of-ontological-bad-faith/inauthenticity -preconverging dementating/structuring/paradigming ); notwithstanding an apparent '79 presencing- 
absolutising-identitive-constitutedness ${ }^{14}$ linearising-imbuing_conscious-moronisation-<as-toprior_mere-formulaicity/ritualisation $>\sim$ enframing conception' naive/wrong construal of mathematics "poorly appreciative of the centrality of the existential-<disontologising/reentologising aporeticism $>$ recomposuring/cumulating for cogency_chronicularity/annalityof-relative-reflexivity,-as-to-profound-supererogation ' (such that relative-unreflexivity is rather 'implicited as supposedly psychologised off-or-away'/nominalised for the 'seemingly absolutely-right/proper mathematics') as if of 'mélée_of_supposedly-singly conception-ofmeaningfulness-and-teleology ${ }^{\circ}$-reflex $\sim$ propositional-attitude. For instance, mathematical developments as from Feymanian physics and later physics existentially-as-todisontologising/re-ontologising aporeticism $>$ reinterprete mathematical infinity in finite terms of reconception and so-overriding (as prior relative-unreflexivity) the 'veracity of priorly nominalised implications of infinity in mathematics'; and so as to renewed 'baseline/nominalising/editional—aptitudinal underlay-<as-to-priorunblurriness reframing/reformulation/decatchmenting/detruncating/decompulsing/delinearisi ng $>$ conception of the implication of mathematical infinity (for the relevant prospective 'baselining/cogency/reconstruing — aptitudinal overlay-<for-prospective- unblurrinessAraging entucidation sought by such physics or mathematics as to 'prospective existential<as-to-disontologising/re-ontologising aporeticism $>$ veracity'). Obviously, they can get away with it correspondingly by the strong immediacy-of-sublimation-(imbued 'secondnatured positive-opportunism of-social-functioning and-accordance as-toprospective punctual/immediacy/constituted/compulsions-encumbered_disarming_-__dis-

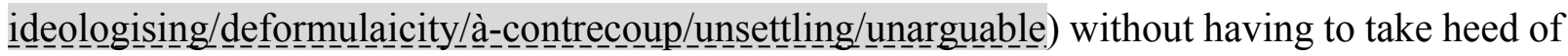
any irrelevant ideologising/mere-formulaicity/ritualisation. And for that matter as well (as to mathematics 'existential-<disontologising/re-ontologising aporeticism> $<$ amplituding/formative-epistemicity $>$-totalising $\sim$ thrownness-in-existence ${ }^{5}$, disseminative- 
sublimating-selectivity-of-ontological-good-faith/authenticity $\sim$ postconverging-dementating/structuring/paradigming , over desublimating deselectivity-of-ontological-badfaith/inauthenticity -preconverging de-mentating/structuring/paradigming ), if the above supposed 'arithmetic memory loss' (as to 'baseline/nominalising/editionalaptitudinal $\sim$ underlay-<as-to-priorunblurriness-reframing/reformulation/decatchmenting/detruncating/decompulsing/delinearisi ng $>$ '-<imbued_aptitudinal-coherence-of-existentially-manifest $\sim$ hunches/cues/flags $>$ ) existentially-<as-to-disontologising/re-ontologising aporeticism $>$ assessed as unfounded then the veracity of logical/rationalising pertinence of algebra elucidation (as of 'baselining/cogency/reconstruing — aptitudinal overlay-<for-prospective- unblurrinessdragging-out $>$ ' elucidation) doesn't arise at all as to the manifest <relative $>$ un-nominalising< unelucidation - of-relative-unreflexivity/relative-reflexivity $>$; for the simple fact that mathematics warrants a 'calculations mutual engagement' of appropriate 'despite-the-self exercise of epistemicprojection in notional $\sim$ self-distantiation- $<$ imbued-re-motif-and-re-apriorising/reaxiomatising/re-referencing>' involved in 'limitedness/human-subpotency prospective reencountering/re-confrontation with unlimitedness/existence-ffull-potency-of_sublimating nascences' (as to 'inkling-drive of dimensionality-of-sublimating ${ }^{25}$ <<amplituding/formative>supererogatory $\sim$ de-mentativeness/epistemic-growth-or-

conflatedness /transvaluative-rationalising/transepistemicity/anamnestic-residuality/spiritdrivenness-equalisation)'). Whereas acceding-to/tolerating in-the-very-least (such expressly manifest 'epistemic-decadence' or teleological-decadence- $<$-in-dimensionality-ofdesublimating-lack-of ${ }^{-}-\langle<$amplituding/formative $>$supererogatory $\sim$ de-mentativeness/epistemicgrowth-or-conflatedness /transvaluative-rationalising/transepistemicity/anamnesticresiduality/spirit-drivenness-equalisation $\rangle$ imbued distractive-alignment-to- ${ }^{8}$ reference-ofthought- $<$ of-apriorising/axiomatising/referencing $>^{30}$ ) is providing the leeway for the cynical ad- 
hoc-and-opportune recourse to pedantising/muddling/formulaic-hollowing-out-insubontologisation/subpotentiation-〈blurring/undermining-of-prospective-totalising-entailing,as-to-entailing-<amplituding/formative-epistemicity $>$ totalising in-relative-ontologicalcompleteness > constraining-and-spurious 'disontologising/subontologising onionising/recoiling/linearising narratives disorientation' (as to seeding-misprising of dimensionality-of-desublimating-lack-of $-<<$ amplituding/formative $>$ supererogatory $\sim$ dementativeness/epistemic-growth-or-conflatedness /transvaluativerationalising/transepistemicity/anamnestic-residuality/spirit-drivenness-equalisation〉'). This point is made to underline the fact that 'technically/abstractly' both nascent-particular/incipientand-material/technical-sublimations- $<$ blinded-to-their-relative-ontological-completeness reference-of-thought- devolving $>\quad$ and social-and-institutional-frameworks-ofreferencing/registering/decisioning are subjectable to manifest 'linearising-imbuing_consciousmoronisation-<as-to-prior_mere-formulaicity/ritualisation $>\sim e n f r a m i n g$ pedantising/muddling/formulaic-hollowing-out - in-subontologisation/subpotentiation〈blurring/undermining-of-prospective-totalising-entailing,-as-to-entailing<amplituding/formative-epistemicity>totalising in-relative-ontological-completeness > ' undermining 'recomposured/cumulated—re-ontologising/re-sublimating-axiomaticconstructs_as _ impliciting of prospectively_requisite—relative-reflexivity/delinearising (as to

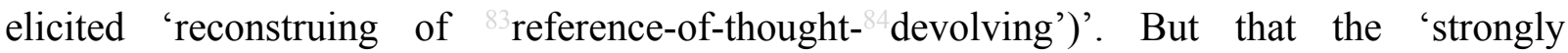
enculturated 'nominalised outcome picture' of relative-reflexivity (apparently excluding of 'supersededly/deflatedly/overlookably_nominalised relative-unreflexivity') as of 'baseline/nominalising/editional—aptitudinal underlay-<as-to-priorunblurriness $\sim$ reframing/reformulation/decatchmenting/detruncating/decompulsing/delinearisi ng $>$ ' so-arising from nascent-particular/incipient-and-material/technical-sublimations- $<$ blindedto-their-relative-ontological-completeness - reference-of-thought- devolving $>\quad$ strong 
immediacy-of-sublimation_ (imbued_secondnatured positive-opportunism-of-socialfunctioning and-accordance 7 as-toprospective_punctual/immediacy/constituted/compulsions-encumbered_disarming_-___disideologising/deformulaicity/à-contrecoup/unsettling/unarguableble) effectively and practically 'psychologises off/away'/nominalises such a problematic of prospective relative-unreflexivity (which 'technically-speaking' is ever always present however abstract). The implication here for social-and-institutional-frameworks-of-referencing/registering/decisioning (not/poorly amenable to such 'psychologising off-or-away'/nominalising such a problematic of prospective relative-unreflexivity) is that it is naïve to merely adopt such a mental-reflex of 'psychologised off-or-away'/nominalised analysis of the social domain without going the extra mile (now and then, here and there) to appraise-and-account-for the veracity of 'baseline/nominalising/editional—aptitudinal underlay-<as-to-priorunblurriness reframing/reformulation/decatchmenting/detruncating/decompulsing/delinearisi ng $>$ '-<imbued_aptitudinal-coherence-of-existentially-manifest $\sim$ hunches/cues/flags $>$ (as prior unblurriness $\sim$ reframing/reformulation/decatchmenting/detruncating/decompulsing/delinearisi ng) in the supposed elucidation of 'baselining/cogency/reconstruing — aptitudinal overlay-<forprospective enblurriness draging (as prospective unblurriness/blurrinessthreshold framing/formulation/catchmenting/truncating/compulsing/linearising); as with the case of the existentially-<as-to-disontologising/re-ontologising aporeticism $>$ unfounded 'arithmetic memory loss' (as to 'baseline/nominalising/editional—aptitudinal underlay-<as-toprior-

unblurriness-reframing/reformulation/decatchmenting/detruncating/decompulsing/delinearisi ng $>$ '-<imbued_aptitudinal-coherence-of-existentially-manifest $\sim$ hunches/cues/flags $>$ manifestly of '<relative $>$ un-nominalising-<unelucidation ${ }^{-o f-r e l a t i v e-u n r e f l e x i v i t y / r e l a t i v e-r e f l e x i v i t y ~}>$ ). Otherwise, this induces a 'mélée_of_supposedly-singly conception-of- ${ }^{56}$ meaningfulness-and-teleology' - 
reflex $\sim$ propositional-attitude which veridically translates as: $1+1=2$ speaks to $1+3 \neq 5,1+3=5$, $1+3=4,4+4=8,4+4=10,4+4 \neq 8,6-7 \neq 0,6-7=0,6-7=-1,5-3=2,5-3 \neq 2,6 \div 2 \neq 4,6 \div 2 \neq 3,3 \times 9=27$, $3 \times 9 \neq 27, \quad x+2 \neq x+3, \quad x+2=x+3$, etc. as to 'selative $>$ un-nominalising-<unelucidation-of-relativeunreflexivity/relative-reflexivity $>$ (so-poorly constrained to 'existential-<disontologising/reentologising aporeticism $><$ amplituding/formative-epistemicity $>$-totalising $\sim$ thrownness-inexistence $^{35}$ disseminative — sublimating-selectivity-of-ontological-goodfaith/authenticity postconverging-de-mentating/structuring/paradigming , overdesublimating deselectivity-of-ontological-bad-faith/inauthenticity -preconverging dementating/structuring/paradigming ) as of a disparateness-of-conceptualisation$<$ unforegrounding-ment,-failing-prospectively-to-reflect-'immanent relativeunreflexivity/relative-reflexivity ontological-contiguity ' $>$ as to totalisingly-ingdiscretion/whim-of-thought failing 'requisite overall existential-<disontologising/reentologising_aporeticism $>\quad$ cogency_chronicularity/annality-of-relative-reflexivity,-as-toprofound-supererogation '. Underlining a 'bogus idea that such a conceptualisation deficient in cogency_chronicularity/annality-of-relative-reflexivity,-as-to-profound-supererogation ${ }^{9}$ is supposedly of 'recomposured/cumulated—re-ontologising/re-sublimating-axiomaticconstructs_as _ impliciting of prespectively requisite_relative-reflexivity/delinearising (as to elicited 'reconstruing of reference-of-thought- devolving')'; rather than the reality of manifest intradimensional-institutionalising/organising/mutualising/methodologising knowledgedeadends-<as-preconverging-de-mentating/structuring/paradigming $>$ '. So-reflected with the naïve notion that various contributions as of 'disontologising/subontologising linearisingimbuing_conscious-moronisation-<as-to-prior_mere-formulaicity/ritualisation $>\sim e n f r a m i n g$ (manifest gesturing/accounting-of-epistemic-phenomenalism as to implicited/explicited portrayal of relative-unreflexivity/relative-reflexivity)' necessarily addup/recomposure/cumulate to knowledge sublimating-prolongation (in 'reconstruing of 
reference-of-thought- devolving'); failing to appraise-and-account-for the fact that it is rather the 're-ontologising delinearising-imbuing_conscientiousness-demoronisation-<as-torenewing realisation/re-perception/re-thought $>\sim$ reframing cogency_chronicularity/annality-ofrelative-reflexivity,-as-to-profound-supererogation (manifest gesturing/accounting-ofepistemic-phenomenalism as to implicited/explicited portrayal of relative-unreflexivity/relativereflexivity)' that enables such knowledge sublimating-prolongation (in 'reconstruing of reference-of-thought- devolving'). As reflected by the fact that the 'notionally/epistemically/bindingnessly manifest totalisingly-disentailing — discretion/whim-of-thought' of respectively ancient-sophists non-universalising contributions, medieval-scholasticism nonpositivising contributions and our present-day manifest disparateness-of-conceptualisation-<unforegrounding-disentailment,-

\section{failing-prospectively-to-reflect-'immanent $\sim$ relative-unreflexivity/relative-reflexivity}

ontological-contiguity '> contributions (as to 'disontologising/subontologising linearisingimbuing_conscious-moronisation-<as-to-prior_mere-formulaicity/rittualisation $>\sim$ enframing'): are effectively bound to fail prospective sublimating-prolongation in 'reconstruing of reference-of-thought- devolving', as to respectively requisite 'existential-<disentelogising/reentologising apereticism> postconverging-apereticism overeoming/movercoming' Socratic-philosophers ${ }^{103}$ universalising-idealisation, budding-positivists positivism/rationalempiricism and budding-postmodern thought (in re-ontologising delinearisingimbuing_conscientiousness-demoronisation-<as-to-renewing realisation/re-perception/rethought $>-$ reframing). Wherein institutionalising-inflative-distortion-<as-to-prior_mereformulaicity/ritualisation-failing-prospective-profound-supererogation

institutionalising/organising/mutualising/methodologising comes to relatively supersede 'limitedness/human-subpotency prospective re-encountering/re-confrontation with unlimitedness/existence-<full-potency-of_sublimating nascence $>$ implications of 
sublimating-prolongation (in 'reconstruing of ${ }^{83}$ reference-of-thought- ${ }^{4}$ devolving'); and undermine/discourage veridical cogency_chronicularity/annality-of-relative-reflexivity,-as-toprofound-supererogation (rather along the lines $1+1=2$ speaks to $1+3 \neq 5,1+3=4,4+4=8$, $4+4 \neq 10,6-7 \neq 0,6-7 \neq 0,6-7=-1,5-3=2,5-3 \neq 2,6 \div 2 \neq 4,6 \div 2=3,3 \times 9=27, x+2 \neq x+3$, etc. as to $<$ relative $>$ nominalising-<elucidation - of-relative-unreflexivity/relative-reflexivity $>$ ) as to a 'protracted-socialas-to-individual-by-institutional-by-social entrapment' to which both 'motivated thought, scholarship and studentship' are consciously/unconsciously misused/underused as to institutional directional self-serving purposes supposedly portending of the institutional collective (not to mention the warrant for the-human/humanity sublimating-prolongation collective). Such a misconstrual similarly speaks to the fact that for instance the convolutedness of say modern-day DNA genetics knowledge-reification $\sim$ gesturing-and-accounting-ofepistemic-phenomenalism-<in-

prospective_psychologismic apriorising/axiomatising/referencing-\{of-'prospectively implicited_attendant-ontological-contiguity ' educedexistentialising/contextualising/textualising_'intelligibility/epistemicity/reflexivity-contiguity<imbued-notional cogency>' \}-conflatedness -in-\{preconverging disentailment by\} postconverging entailment> axiomatic-construct in 'implicited_attendant-ontologicalcontiguity ${ }^{67} \sim$ educed-

existentialising/contextualising/textualising_intelligibility/epistemicity/reflexivity-contiguity<imbued-notional cogency>' cannot be construed as of mere conceptual-patterning-〈asdevoid-of-'prospectively_implicited_attendant-ontological-contiguity ' educed-

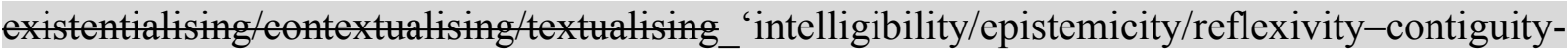
$<$ imbued-notional cogency>' 's-reifying-or-elucidating-of- 'prospective-relative-ontologicalcompleteness ' ;-so-rather-enabled-<by-a- nonpresencing-divulging-of-momentoushistoriality/ontological-eventfulness /ontological-aesthetic-tracing-<perspective- 
in terms of Mendelian hereditary axiomatic-construct which will utterly undermine the modernday

supereregatery acuity/perspicacity/astuteness/edginess/incisiveness-ofapriorising/axiomatising/referencing/intelligibilitysettingup/measuringinstrumenting -forconceptualisation as to its postconverging-de-mentating/structuring/paradigming postconverging aporeticism-overcoming/unovercoming implications'; so-reflecting conscious/unconscious subterfuge of 'apriorising/axiomatising/referencingequating/leveling/ressentiment/closed-construct-of- ${ }^{5}$ meaningfulness-and-teleology ${ }^{9}$ and bothsidesism-〈as-'mere-processive'/pedantising-'dialogical-relation'-to 'perceived-socialand-institutional-commonly-enculturated_referencing,-of- meaningfulness-and-teleology 'failing-'requisite-existential-thematic-baseline-of-technicity/profundity-framing' \{ofsublimating-discursivity-for-sovereign-repassing \},-as-of-psychologismic-epistemicacutisation-nonresidualising-imbued-\{compulsing? linearity in-eclecticism-of-prior-mereformulaicity/ritualisation,-as-so- 'consciously/unconsciously-preordained/fated'-to-failprospective-notional cogency) ${ }^{\prime} \quad$ failing cogency_chronicularity/annality-of-relativereflexivity,-as-to-profound-supererogation . It is important to grasp herein that this 'linearisingimbuing_conscious-moronisation-<as-to-prior_mere-formulaicity/ritualisation $>\sim$ enframing pedantising/muddling/formulaic-hollowing-out - in-subontologisation/subpotentiation〈blurring/undermining-of-prospective-totalising-entailing,-as-to-entailing<amplituding/formative-epistemicity>totalising in-relative-ontological-completeness >’ distinction between nascent-particular/incipient-and-material/technical-sublimations- $<$ blindedto-their-relative-ontological-completeness - reference-of-thought- devolving $>$ and socialand-institutional-frameworks-of — referencing/registering/decisioning effectively reflect the fact that while both for-human-studies/for-human-constructs are abstractly/technically geared 


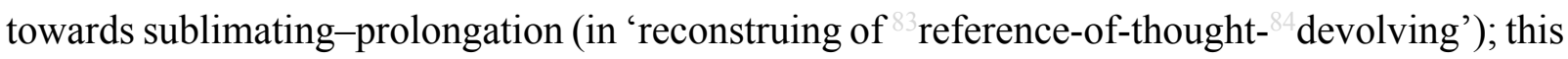
explicited 'un-nominalising-or-nominalising-<unelucidation-or-elucidation ${ }^{-0}$-relativemreflexivity/relative-reflexivity $>$ is rather about highlighting their existentially-<as-to-disontologising/reentologising aporeticism $\geqslant$ differing constraints (with respect to 'linearisingimbuing_conscious-moronisation-<as-to-prior_mere-formulaicity/ritualisation $>\sim e n f r a m i n g$ pedantising/muddling/formulaic-hollowing-out_-in-subontologisation/subpotentiation〈blurring/undermining-of-prospective-totalising-entailing,-as-to-entailing$<$ amplituding/formative-epistemicity>totalising in-relative-ontological-completeness $>$ ') to be addressed for their respectively given profound prospective sublimating-prolongation. This so highlights the fact that 'veridical notionality/epistemicity/bindingness ${ }^{<a s-t o-d e t e r m i n i s m / c o n c e p t i v i t y-o f-~}$ relative-unreflexivity/relative-reflexivity> upon the given 'existential-<disontologising/re-ontologising aporeticism>

〈'baseline/nominalising/editional—aptitudinal underlay-<as-to-priorgesturing/accounting - of-epistemic-phenomenalism with regards to eliciting appropriate sublimating institutionalising/organising/mutualising/methodologising; as to 'existential<disontologising/re-ontologising aporeticism $>$ $<$ amplituding/formative-epistemicity $>$ totalising thrownness-in-existence ${ }^{5}$, educing of 'recomposured/cumulated-reontologising/re-sublimating-axiomatic-constructs_as_impliciting-of prospectively requisite-relative-reflexivity/delinearising (as to elicited 'reconstruing of ${ }^{83}$ reference-of-

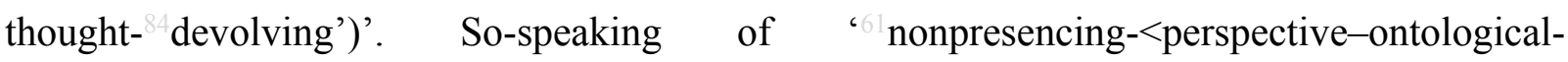


normalcy/postconvergence> originary-and-re-originary/re-ontologising-nascency delinearising-imbuing_conscientiousness-demoronisation-<as-to-renewing-realisation/reperception/re-thought $>\sim$ reframing conception of the-whole/purview-of-the-whole/oneness-ofontology' implications of 'reconstruing of ${ }^{83}$ reference-of-thought- ${ }^{84}$ devolving' (so-reflected as of veridical 'palpable dissolving/decentering of the conscious-self/collective-conscious-self' conception of the notion of relativism) as to 'objectifying aestheticisation-and-aestheticisationtowards-ontology of overall profound/sound gesturing/accounting-of-epistemicphenomenalism' along the lines of say Derridean deconstruction scheme, Foucauldian genealogy/archaeology scheme and Deleuzian rhizomatics scheme (and as herein implied overall 'limitedness/human-subpotency de-mentation-(supererogatory ontological-dementation-or-dialectical-de-mentation-stranding-or-attributive-dialectics $\rangle$ as to preconverging/postconverging-rede-mentating/restructuring/reparadigming' with regards to prospective 'existential-<disontologising/re-ontologising aporeticism> postconverging aporeticism-overcoming/unovercoming'): and for that matter (when it comes to nascent-particular/incipient-and-material/technical-sublimations- $<$ blinded-to-their-relativeontological-completeness - reference-of-thought- devolving $>$ ) the 'objectifying aestheticisation-and-aestheticisation-towards-ontology of overall profound/sound gesturing/accounting — of-epistemic-phenomenalism' of say Newtonian mechanics scheme or Einsteinian relativity scheme or Feynman diagrams scheme in physics and say DNA genetics scheme in biology, etc. Such 'veridical notionality/epistemicity/bindingness ${ }^{-<a s-t o-}$ determinism/conceptivity-of-relative-unreflexivity/relative-reflexivity $\quad$ conception-of-56 meaningfulness-andteleology ${ }^{9}$, schemes (as to 'reconstruing of ${ }^{83}$ reference-of-thought- ${ }^{8}$ devolving') are projectively not as of (totalisingly-disentailing-discretion/whim-of-thought relativeunreflexivity 'mélée_of_supposedly-singly conception-of- ${ }^{56}$ meaningfulness-andteleology ${ }^{\circ}$ - reflex $\sim$ propositional-attitude) presencing-absolutising-identitive- 
formulaicity/ritualisation>enframing conception of the-whole/purview-of-the-whole/onenessof-ontology; going by the aspiratively_objectified theoretical, conceptual and operant implications of their gesturing/accounting-of-epistemic-phenomenalism as to the explicited/implicited reflection of relative-unreflexivity/relative-reflexivity (with respect to 'limitedness/human-subpotency prospective re-encountering/re-confrontation with unlimitedness/existence-<full-potency-of_sublimating nascence $>$ implications of sublimating-prolongation in 'reconstruing of ${ }^{83}$ reference-of-thought- devolving') And so, aspiratively satisfying cogency_chronicularity/annality-of-relative-reflexivity,-as-to-profoundsupererogation model of $1+1=2$ rather speaks to $1+3 \neq 5,4+4=8,6-7 \neq 0,5-3=2,6 \div 2 \neq 4,3 \times 9=27$, $\mathrm{x}+2 \neq \mathrm{x}+3$, etc. as to $<$ relative $>$ nominalising-<elucidation ${ }^{- \text {of }}$-relative-unreflexivity/relative-reflexivity $>$ with regards to 'veridical epistemic-totalising ${ }^{33} \sim$ resubjecting_or_totalising-entailing $\sim$ reconstrualsof the-whole/purview-of the-whole/oneness-of-ontology>' (as of human 'existentialsdisentologising/re-ontologising aporeticism> $<$ amplituding/formative--epistemicity $>$ totalising $\sim$ thrownness-in-existence ${ }^{5}$, disseminative - sublimating-selectivity-of-ontologicalgood-faith/authenticity postconverging-de-mentating/structuring/paradigming , over-

\section{desublimating deselectivity of ontological bad faith/inauthenticity preconverging de-}

mentating/structuring/paradigming ). In this respect, what is rather warranted with social domains-of-study is the 'actively explicited appraisal' of their given division-of-labour/subjectmatters implications of $\leq$ relative $>$ nominalising-<elucidation-of-relative-unreflexivity/relative-reflexivity $>$ in 'reconstruing of ${ }^{83}$ reference-of-thought- ${ }^{84}$ devolving' (over selative $>$ un-nominalising<unelucidation-of-relative-unreflexivity/relative-reflexivity $>$

notionality/epistemicity/bindingness ${ }^{-<a s-t o-d e t e r m i n i s m / c o n c e p t i v i t y-o f-r e l a t i v e-u n r e f l e x i v i t y / r e l a t i v e-r e f l e x i v i t y ~}>$

conception-of- ${ }^{5}$ meaningfulness-and-teleology ${ }^{9}$ '- (reflection upon the given 'existential<disontologising/re-ontelogising aporeticism> ("baseline/nominalising/editional—aptitudinal underlay-<as-to-prior- 
capacitating-<for-existential-thematic >’) manifest overarching gesturing/accounting-of-epistemicphenomenalism. With regards to veridical sublimating-prolongation as to 'existential$\leq$ disontologising/re-ontologising aporeticism> postconverging-aporeticismovercoming/unovercoming' sublimating institutionalising/organising/mutualising/methodologising; and not ad-hoc/mimicked conception of science/ontological-veracity (as of perceived/supposedly appropriate sublimating institutionalising/organising/mutualising/methodologising) that fails to appraise-and-accountfor their requisite overarching gesturing/accounting —of-epistemic-phenomenalism (as to their specifically given purview-of-the-whole originary-and-re-originary/re-ontologising-nascency). So-reflected for instance with the considering of broad swathes of requisite human 'comprehensive coherence/contiguity/noncontradiction of overall experientiality/experiment$<$ as-to-existentially-formative- ‘ $\{$ epistemic-totalising $\stackrel{+}{3}$ re-apriorising/re-axiomatising/rereferencing $\sim$ residuality —in-re-originariness/re-origination',- - so'notionally/epistemically/bindingnessly-<as-to-determinism/conceptivity-of-relative-unreflexivity/relative-reflexivity> implicited-and-articulated'_as-from-nonextricatory-'prospective-re-ontologising-Being-thenInstitutional-then-Living-magnitudes-of-\{hermeneutic/reprojection-protraction-of\}reframingand-reformulation\}'>' as nondescript/ignorable-void or undefined; as so-failing to reflect requisite 'epistemic-totality ${ }^{37}$ of ${ }^{56}$ meaningfulness-and-teleology' as to phenomenality-andepiphenomenality'. Effectively the veridical reality of the overall natural sciences is much more than a 'nominalised outcome picture' of relative-reflexivity (apparently excluding of 'supersededly/deflatedly/overlookably_nominalised relative-unreflexivity'); as so- 
seemingly/wrongly implying a 'mélée_of_supposedly-singly conception-ofmeaningfulness-and-teleology ${ }^{\prime}$ - reflex $\sim$ propositional-attitude. Thusly, failing to grasp (not withstanding their advantageously relative 'low emotional involvement' and hence lesser psychologismic-epistemic-acutisation-difficulty-<for, residualising $\{$ decompulsing $\}$ delinearity for-cogency) the natural sciences more salient but implicited corephilosophy/derivative-core-philosophy_-(imbued requisite 'inkling-drive of dimensionality-ofsublimating 25 -<<amplituding/formative $>$ supererogatory $\sim$ de-mentativeness/epistemic-growthor-conflatedness /transvaluative-rationalising/transepistemicity/anamnestic-residuality/spiritdrivenness-equalisation)') 'holding-out/point-referencing-psychoanalytic-unshackling exercise of educed-and-availing-and-re-availing relative-ontological-completeness ${ }^{87}$-ofapriorising/axiomatising/referencing' to allow for play out of untenability-ofinduced unblurriness as '<prospective_punctual/immediacy/constituted/compulsionsencumbered — disarming/dis_-ideologising/deformulaicity/à-contrecoup/unsettling/unarguable prompted constricted/narrowingdown-re-ontologising-enabling $>$-psychologismic epistemicacutisation residualising fepistemictotalising ${ }^{i}$ hermeneutic/textuality/reprojecting/supererogating/zeroing/re-acuting, $\{$ decompulsing $\}$ delinearity for-cogency' as to 'developing human-per-cep-ti-vi-ty-<as-tonotional perceptualisation-of-and-leashing-to_social-functioning-and-accordance-as-ofsocial-stake-contention-or-confliction> in preconverging/postconverging-redementating/restructuring/reparadigming'; so-reflected with the multi-decadal commitment and time investment underlying the eventual outcome of many a scientific breakthrough (more than just a vague notion of genius which it is herein contended paradoxically serves to abnormalise intellectual-and-moral responsibility/relative-reflexivity with respect to requisite microdecisionality/decisionality). Such an insight with respect to 'reconstruing of ${ }^{83}$ reference-ofthought- ${ }^{8}$ devolving' reflects the fact that requisite postconverging-aporeticism- 
overcoming/mnovercoming 'can't be dodged' (however the relatively 'high emotionalinvolvement' in the social domain) and then a pretense of prospective sublimating ontologicalperformance $^{72}-<$ including-virtue-as-ontology $>$ /morality/ethics/justice/etc. re-avails, but for the manifest knowledge-deadends- $<$ as-preconverging-de-mentating/structuring/paradigming $>$ of the said ${ }^{7}$ presencing-absolutising-identitive-constitutedness ${ }^{14}$ habituated \{epistemictotalising $3{ }^{3}$ psychologismic-subliminal-truncating. So-speaking to the relative-unreflexivity/relativereflexivity — bindingness/nondiscretionariness- $<a s-f r o m-s u b l i m a t i n g-r e m o t e n e s s / d i s t a n c e-o f-$ appraisal-of-requisite-Being development $>$ of unlimitedness/existence-<flll-potency ef_sublimating nascence>'-(as to 'relative-unreflexivity/relative-reflexivity limitedness/human-subpotency dynamics of supererogating \{affirmation/projection/assertion/notional $\sim$ self-distantiation-byunaffirmation/deprojection/deassertion/epistemic-decadence $\}$ — towards omnipotentialaffirmation/projection/assertion/notional self-distantiation' with respect to 'limitedness/humansubpotency prospective re-encountering/re-confrontation with unlimitedness/existence- $<$ fullpotency-of_sublimating nascence $>$ '). This ontological-deficiency with respect to prospectively 'reconstruing of ${ }^{83}$ reference-of-thought- ${ }^{84}$ devolving' very much explains a '79 presencingabsolutising-identitive-constitutedness intradimensionalinstitutionalising/organising/mutualising/methodologising linearising-imbuing_consciousmoronisation-<as-to-prior_mere-formulaicity/ritualisation>-enframing' usurping/distorting assetising relationship to ${ }^{56}$ meaningfulness-and-teleology ${ }^{9}$ and corresponding institutionalising-inflative-distortion-<as-to-prior_mere-formulaicity/ritualisation-failingprospective-profound-supererogation $>$; failing the requisite memorative-extension- $<$ as-to'conscientiousness-demoronisation - delinearising construct-of-thought'/‘ \{epistemictotalising ’’psychologismic-subliminal-detruncating';-as-relative-reflexivityreframing_educing sublimating-prolongation> for 'reconstruing of ${ }^{83}$ reference-of-thought- 
devolving' (however the prospective 'sublimating-remoteness/distance-of-appraisal-<as-torequisite-'Being-development-notional $\sim$ self-distantiation'-imbued-psychologismic-epistemicacutisation,-eliciting-of-prospective-ontologically-hegemonising-narrative $>$ of ${ }^{83}$ reference-ofthought- ${ }^{-}$devolving'). $\quad$ But then social-and-institutional-frameworks-ofreferencing/registering/decisioning ontological-deficiency in 'reconstruing of ${ }^{83}$ reference-ofthought- ${ }^{8}$ devolving' (as to requisite relative 're-ontologising-nascency-<as-of-prospectivesolipsistic/intersolipsistic-inkling-drive-for-knowledge-elucidation,-as-to-veridical-organic-

knowledge $>$ for sublimating-prolongation') effectively translate (with respect to their relative 'existentially-<disentologising/re-ontologising aporeticism $>$ manifest incidental/accidental reactive-sufferance/endurance in supposedly and paradoxically subordinating/subserving/collateralising the possibility for prospective re-ontologisingimbuing-of-prospective-human-sublimating/emancipating/enfranchisement') into the overall social construct existentially-<disontologising/re-ontologising aporeticism $>$ manifest pedantising/muddling/formulaic-hollowing-out — in-subontologisation/subpotentiation〈blurring/undermining-of-prospective-totalising-entailing,-as-to-entailing$<$ amplituding/formative-epistemicity>totalising in-relative-ontological-completeness $\rangle$. Somanifested expansively as of 'relative-unreflexivity of linearising-imbuing_consciousmoronisation-<as-to-prior_mere-formulaicity/ritualisation> enframing' as to preconvergingde-mentating/structuring/paradigming directionality of 'vague/clumsy dominance-driven intra/inter-statal insidious-anarchy_influencing/geoinfluencing-<as-to-dynamic-'mereinfluencing-over-sublimating-technicity/profundity',-so-scheming-as-allowed-by'formulaically $\sim$ passivated/linearised-forwardfacing — institutional existentialising-framingby-enframing/\{worlding\}';-as-so-truncating-the-strategic/geostrategic,-political-andsuccessive-lower-interrelatedness-dynamics-of-social-constructing'> imbued infowarring manifesting knowledge-without-knowledge/knowledge-outside-knowledge/extra-knowledge'; 
with regards to ${ }^{7}$ presencing — absolutising-identitive-constitutedness ${ }^{14}$ ideologising/mereformulaicity/ritualisation implications undermining the 'reconstruing of ${ }^{8}$ reference-of-thoughtdevolving' - (rather expansively eventualising veridically as of 'human social-functioningand-accordance_-as-of-social-stake-contention-or-confliction_construct geotopological-<asto- nonpresencing-detruncating-of-'human- presencing-complexes/inhibitions-of-manifestdisanthropologisation'> potentiation of the-human/humanity'). This reflection of social-andinstitutional-frameworks-of — referencing/registering/decisioning ontological-deficiency in 'reconstruing of ${ }^{83}$ reference-of-thought- ${ }^{8}$ devolving' speaks to the fact that (unlike the 'relatively outright re-ontologising cogency_chronicularity/annality-of-relative-reflexivity,-as-toprofound-supererogation ${ }^{\prime}$ of nascent-particular/incipient-and-material/technical-sublimations$<$ blinded-to-their-relative-ontological-completeness - reference-of-thought- devolving $>$ ), in many ways social-and-institutional-frameworks-of-referencing/registering/decisioning (construed as 'supposedly of re-ontologising cogency_chronicularity/annality-of-relativereflexivity,-as-to-profound-supererogation ") are historically relatively subject to 'disontologising/subentologising -oddballing undermining of the sense of re-ontologising cogency_chronicularity/annality-of-relative-reflexivity,-as-to-profound-supererogation '; along the disontologising/subontologising lines $1+1=2$ speaks to $1+3 \neq 5,1+3=5,1+3=4,4+4=8$, $4+4=10,4+4 \neq 8,6-7 \neq 0,6-7=0,6-7=-1,5-3=2,5-3 \neq 2,6 \div 2 \neq 4,6 \div 2 \neq 3,3 \times 9=27,3 \times 9 \neq 27, x+2 \neq x+3$, $\mathrm{x}+2=\mathrm{x}+3$, etc. as to $\leq$ elative $>$ un-nominalising-<unelucidation - of-relative-unreflexivity/relative-reflexivity $\geq$. As to a consequent ontologically-deficient conception of 'supersededly/deflatedly/overlookably_ nominalised relative-unreflexivity' inducing manifest disparateness-of-conceptualisation$<$ unforegrounding-disentailment,-failing-prospectively-to-reflect-"immanent $\sim$ relativeenreflexivity/relative reflexivity - ontological-contiguity ' $>$ (that rather speaks to totalisinglydisentailing_discretion/whim-of-thought relative-unreflexivity 'mélée_of_supposedlysingly conception-of- ${ }^{5}$ meaningfulness-and-teleology ${ }^{\circ}$ - reflex $\sim$ propositional-attitude) 
failing 'requisite overall existential-<disontologising/re-ontologising aporeticism $>$ cogency_chronicularity/annality-of-relative-reflexivity,-as-to-profound-supererogation ${ }^{\circ}$.

Wherein (as to disparate/incongruent implications of 'limitedness/human-subpotency prospective re-encountering/re-confrontation with unlimitedness/existence-<flll-potency of_sublimating nascence>' for sublimating-prolongation in 'reconstruing of ${ }^{83}$ reference-ofthought- devolving') relative-unreflexivity construals and relative-reflexivity construals 'are wrongly related-to and enter into a supposed relationship of equivalence': rather as of 'apriorising/axiomatising/referencing_equating/leveling/ressentiment/closed-construct-ofmeaningfulness-and-teleology and bothsidesism-〈as-'mere-processive'/pedantising‘dialogical-relation'-to 'perceived-social-and-institutional-commonlyenculturated_referencing,-of- meaningfulness-and-teleology '-failing-'requisite-existentialthematic-baseline-of-technicity/profundity-framing' \{of-sublimating-discursivity-forsovereign-repassing \},-as-of-psychologismic-epistemic-acutisation-nonresidualising-imbuedfcompulsing linearity in-eclecticism-of-prior-mere-formulaicity/ritualisation,-as-so‘consciously/unconsciously-preordained/fated'-to-fail-prospective-notional cogency)' failing cogency_chronicularity/annality-of-relative-reflexivity,-as-to-profound-supererogation . As so-relatively poorly constrained to 'existential-<disontologising/re-ontologising aporeticism $>$ $<$ amplituding/formative-epistemicity $>$-totalising $\sim$ thrownness-in-existence ${ }^{3}$, disseminativesublimating-selectivity-of-ontological-good-faith/authenticity $\sim$ postconverging-dementating/structuring/paradigming , over-desublimating-deselectivity-of-ontological-badfaith/inauthenticity -preconverging de-mentating/structuring/paradigming . Since $6-7 \neq 0$ or $4+4=10$ can effectively be projected (as of disontologising/subontologising-oddballing in totalisingly-disentailing — discretion/whim-of-thought relative-unreflexivity 'mélée_of_supposedly-singly conception-of- ${ }^{5}$ meaningfulness-and-teleology ${ }^{9}$ ' reflex propositional-attitude) undermining of requisite cogency_chronicularity/annality-of- 
relative-reflexivity,-as-to-profound-supererogation . Even when the relative-reflexivity of 6$7=-1$ or $4+4=8$ can be contemplated but rather caught up (in such totalisingly-disentailingdiscretion/whim-of-thought relative-unreflexivity 'mélée_of_supposedly-singly conceptionof- ${ }^{56}$ meaningfulness-and-teleology ${ }^{9}$ - - reflex $\sim$ propositional-attitude); and so, as not even such intermingling will reflect cogency_chronicularity/annality-of-relative-reflexivity,-as-toprofound-supererogation (which rather warrants 'holding-out/point-referencingpsychoanalytic-unshackling exercise of educed-and-availing-and-re-availing relativeontological-completeness ${ }^{87}$-of-apriorising/axiomatising/referencing' as to 'veridical epistemictotalising $\sim$ resubjecting_or_totalising-entailing $\sim$ reconstrual- $<$ of the-whole/purview 0 f thewhole/oneness-of-ontology ' $\leq$ explicited-or-implicited-relative $>$ nominalising-<elucidation unreflexivity/relative-reflexivity $\geq$ as not inducing the apriorising/axiomatising/referencingequating/leveling/ressentiment/closed-construct-of- ${ }^{5}$ meaningfulness-and-teleology $99 \quad$ of relative-unreflexivity construals and relative-reflexivity construals). And so-consequentially underlying the disontologising/re-ontologising implications of 'human manifest existentialising-decisionality-<as-to-disontologising/re-ontologising aporeticism $>$ comingto-a-head/culmination-point-<of-desovereignising-or-sovereignising sovereignrepassing '- (so-reflected as of underlying 'constraining direct/deferential microdecisionality/macro-decisionality thrownness-disposition of disontologising/re-ontologising' upon the 'social-functioning-and-accordance-as-of-social-stake-contention-or-confliction construct'). In this regards, ontologising/scientific/existence- $<$ honesty-constraining $>$ scope_for_prospective_re-ontologising, with regards to delinearisingimbuing_conscientiousness-demoronisation-<as-to-renewing realisation/re-perception/rethereframing superseding/overcoming of ('everyday suppedly relatively superficial/irrelevant/unthought sout-of-phasing >-disparate-narratives_of_social-functioningand-accordance - as-of-social-stake-contention-or-confliction_construct') - 
'formulaically $\sim$ passivated/linearised-forwardfacing — institutional existentialising-framingby-enframing/\{worlding\} of the sovereign-function/posture-<as-to-existentially-manifest‘embodied-subject consciousness-and-direct/deferential-conscientiousness',-as-of-its'epistemic-reflexivity/unreflexivity-in-existence'/teleology>' as of ${ }^{7}$ presencing — absolutisingidentitive-constitutedness ${ }^{14}$ habituated fepistemic-totalising ${ }^{3}$ psychologismic-subliminal-truncating: rather underscores the centrality/criticality of social-functioning-and-accordance-as-of-socialstake-contention-or-confliction_construct dynamics of 'elicitable cogency_chronicularity/annality-of-relative-reflexivity,-as-to-profound-supererogation (as of the genuine social intellectual-function/posture delinearising-imbuing_conseientiousnessdemoronisation-<as-to-renewing realisation/re-perception/re-thought $>\sim$ reframing)' on-the-onehand and on-the-other-hand 'disontologising/subontologising-oddballing undermining of cogency_chronicularity/annality-of-relative-reflexivity,-as-to-profound-supererogation ${ }^{9}$ (as of conscious/unconscious 'linearising-imbuing_conscious-moronisation-<as-to-prior_mereformulaicity/ritualisation>®enframing pedantising/muddling/formulaic-hollowing-out-insubontologisation/subpotentiation-〈blurring/undermining-of-prospective-totalising-entailing,as-to-entailing-<amplituding/formative-epistemicity $>$ totalising in-relative-ontologicalcompleteness \')'. 'Disontologising/subontologising-oddballing undermining of cogency_chronicularity/annality-of-relative-reflexivity,-as-to-profound-supererogation ${ }^{\circ}$ soarises as to the fact that the 'prior linearising-imbuing_conscious-moronisation-<as-toprior_mere-formulaicity/ritualisation $>\sim$ enframing $\quad$ sovereign-function/posture- $<$ as-toexistentially-manifest-'embodied-subject $\sim$ consciousness-and-direct/deferentialconscientiousness',-as-of-its-'epistemic-reflexivity/unreflexivity-in-existence'/teleology>' imbued 'differential ontological-performance ${ }^{72}-<$ including-virtue-asontology $>$ /morality/ethics/justice/etc.' (as to its delayed/retarded differentially-elicited 'inklingdrive of dimensionality-of-sublimating ${ }^{25}-<$ amplituding/formative $>$ supererogatory $\sim$ de- 
mentativeness/epistemic-growth-or-conflatedness /transvaluative-

rationalising/transepistemicity/anamnestic-residuality/spirit-drivenness-equalisation〉' towards eventual ssecondnatured positive-opportmism of-social-functioning-and-accordance ${ }^{7}$ asto-prospective_punctual/immediacy/constituted/compulsions-encumbered__issarm-_-ning/dis_-

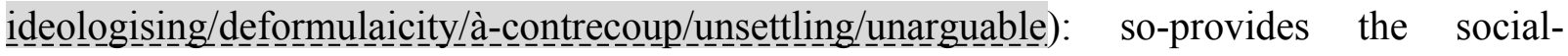
functioning-and-accordance_-as-of-social-stake-contention-or-confliction_construct leeway for surreptitious and/or overt pedantising/muddling/formulaic-hollowing-out-insubontologisation/subpotentiation-〈blurring/undermining-of-prospective-totalising-entailing,as-to-entailing-<amplituding/formative-epistemicity $>$ totalising $\sim$ in-relative-ontologicalcompleteness $>$ undermining of sublimating-prolongation (in 'reconstruing of ${ }^{83}$ reference-ofthought- devolving'). Wherein the prospective sublimating-prolongation imbued 'existentially-disontologising/re-ontologising aporeticism $>\quad$ delinearisingimbuing_conscientiousness-demoronisation-<as-to-renewing realisation/re-perception/rethought $>\sim$ reframing connective- $<$ in-the-'reconstruing-of- reference-of-thought- devolving',-

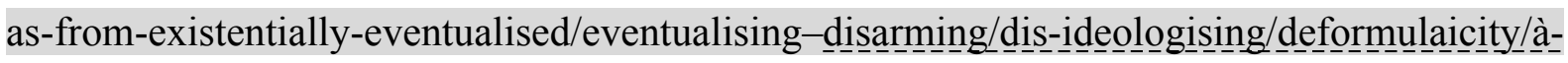
contrecoup/unsettling/unarguable $>$ ' hasn't dawn upon the sovereign-function/posture- $<$ as-toexistentially-manifest-'embodied-subject consciousness-and-direct/deferentialconscientiousness',-as-of-its- 'epistemic-reflexivity/unreflexivity-in-existence'/teleology>. Soreflected for instance, as to the bigger picture that the sovereign-function/posture-<as-toexistentially-manifest-`embodied-subject consciousness-and-direct/deferentialconscientiousness',-as-of-its-'epistemic-reflexivity/unreflexivity-in-existence'/teleology> (as of recurrent-utter-uninstitutionalisation, ununiversalisation, non-positivism/medievalism and procrypticism/disjointedness-as-of- ${ }^{2}$ reference-of-thought) doesn't necessarily appreciate as from its prior linearising-imbuing_conscious-møronisation-<as-to-prior_mereformulaicity/ritualisation $>\sim$ enframing the prospectively requisite/elicitable 
cogency_chronicularity/annality-of-relative-reflexivity,-as-to-profound-supererogation (as of base-institutionalisation, ${ }^{103}$ universalisation, positivism and ${ }^{18}$ deprocrypticism-orpreempting - disjointedness-as-of- ${ }^{-3}$ reference-of-thought respectively); as equally so-reflected as to intradimensional differential disontologising/re-ontologising implications of socialfunctioning-and-accordance_-as-of-social-stake-contention-or-confliction_construct (with respect to limitedness/human-subpotency developmental implications as to both institutionaldevelopment-as-to-social-function-development psychologismic epistemic-acutisation-

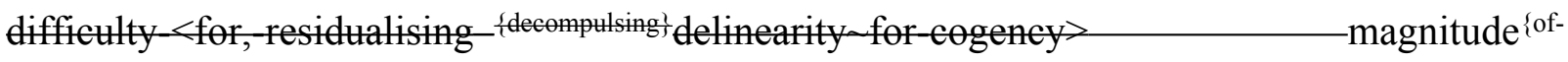
experientiality/experiment\} and living-development-as-to-personality-development psychologismic epistemic-acutisation difficulty-for, residualising ${ }^{\text {\{decompulsing }}$ delinearity for-cogeney> magnitude (of-experientiality/experiment\} . Thusly, the veridical 'limitedness/human-subpotency prospective re-encountering/re-confrontation with unlimitedness/existence-<full-potency ef_sublimating nascence' implications of sublimating-prolongation (of the genuine social intellectual-function/posture with regards to deferential 'competence/expertising of human socially expanded framework of deferential-formalisation-transference as to various cultivated skills/arts and time investment as to limited-mentation-capacity-deepening-as-subjectinglimitedness/hmman-subpotency to 'educed unlimitedness/existence sublimating nascence' emphasis') is rather reflected as of: prospective_delinearising_imbuing conscientiousness_demoronisation-<as-to-renewing realisation/re-perception/re thought 'baseline/nominalising/editional—aptitudinal underlay-<as-to-priorunblurriness $\sim$ reframing/reformulation/decatchmenting/detruncating/decompulsing/delinearisi ng $>$ '-<imbued_aptitudinal-coherence-of-existentially-manifest $\sim$ hunches/cues/flags $>$ (as prior unblurriness $\sim$ reframing/reformulation/decatchmenting/detruncating/decompulsing/delinearisi ng) in the elucidation of 'baselining/cogency/reconstruing — aptitudinal overlay-<forprospective- unblurriness-dragging-out>' (as prospective unblurriness/blurriness- 
threshold framing/formulation/catchmenting/truncating/compulsing/linearising), and soimplied as of $\leq$ nominalising-<elucidation - of-relative-unreflexivity/relative-reflexivity $\geq$. As sounderscoring the 'intellectualising of ${ }^{56}$ meaningfulness-and-teleology ${ }^{9}$ ' as reflected for instance with Socratic-philosophers universalising-idealisation, budding-positivists positivism/rational-empiricism and budding-postmodern thought in so-elucidatively 'elevating into prospective relative-reflexivity' the 'sovereign-function/posture-<as-to-existentiallymanifest-'embodied-subject $\sim$ consciousness-and-direct/deferential-conscientiousness',-as-ofits-'epistemic-reflexivity/unreflexivity-in-existence'/teleology $>$ prior linearisingimbuing_conscious-moronisation-<as-to-prior_mere-formulaicity/ritualisation> $>$ enframing'. While the 'inveracity/poor pedantising/muddling/formulaic-hollowing-out—insubontologisation/subpotentiation-〈blurring/undermining-of-prospective-totalising-entailing,-as-to-entailing-<amplituding/formative-epistemicity $>$ totalising in-relative-ontologicalcompleteness > projection' failing-to-reflect/poorly-reflecting 'limitedness/human-subpotency prospective re-encountering/re-confrontation with unlimitedness/existence-<fll-potency of_sublimating nascence> implications of sublimating-prolongation (as to disentologising/subentologising oddballing) is rather reflected as of: supposedly__prior linearising_imbuing conscious_moronisation_<as_to-prior_mere-

formulaicity/ritualisationzenframing manifest 'baseline/nominalising/editional— aptitudinal $\sim$ underlay-<as-to-priorunblurriness-reframing/reformulation/decatchmenting/detruncating/decompulsing/delinearisi ng $>$ '-<imbued_aptitudinal-coherence-of-existentially-manifest $\sim$ hunches/cues/flags $>$ (as prior unblurriness $\sim$ reframing/reformulation/decatchmenting/detruncating/decompulsing/delinearisi ng) in failing-the-elucidation of 'baselining/cogency/reconstruing — aptitudinal overlay-<forprospective- unblurriness-dragging-out $>^{\prime}$ (as prospective unblurriness/blurrinessthreshold framing/formulation/catchmenting/truncating/compulsing/linearising), and so- 
implied as of $\leq$ relative $>$ un-nominalising-<unelucidation ${ }^{-0}$-relative-unreflexivity/relative-reflexivity $\geq$. As sounderscoring the 'rhetorising of ${ }^{56}$ meaningfulness-and-teleology" ${ }^{99}$ as reflected for instance with ancient-sophists non-universalising, medieval-scholasticism nonpositivising and our presentday manifest disparateness-of-conceptualisation-<unforegrounding-disentailment,-failingprospectively-to-reflect-'immanent relative- unreflexivity/relative-reflexivity - ontologicalcontiguity '> (as to totalisingly-disentailing-discretion/whim-of-thought relativeunreflexivity 'mélée_of_supposedly-singly conception-of- ${ }^{5}$ meaningfulness-andteleology' - reflex propositional-attitude); as 'so-impressionably usurping the relativeunreflexivity' of the 'sovereign-function/posture-<as-to-existentially-manifest-'embodiedsubject $\sim$ consciousness-and-direct/deferential-conscientiousness',-as-of-its- 'epistemicreflexivity/unreflexivity-in-existence'/teleology> prior linearising-imbuing_consciousmoronisation-<as-to-prior_mere-formulaicity/ritualisation>-enframing'. In this regards, the truth of intellectualising is about emphasising the 'third-party unlimitedness/existence-<fullpotency-of_sublimating nascence $>$ elucidative implications of delinearisingimbuing_conscientiousness-demoronisation-<as-to-renewing realisation/re-perception/rethought $>\sim$ reframing cogency_chronicularity/annality-of-relative-reflexivity,-as-to-profoundsupererogation (whether so-articulated convincingly or not but rather constructively)'; whereas rhetorising manifestly emphasises the 'impressionable and disontologising/subontologising oddballing implications upon the sovereign-function/posture-<as-to-existentially-manifest'embodied-subject consciousness-and-direct/deferential-conscientiousness',-as-of-its‘epistemic-reflexivity/unreflexivity-in-existence'/teleology $>\quad$ prior linearisingimbuing_conscious-moronisation_<as-to-prior_mere-formulaicity/ritualisation> enframing'.

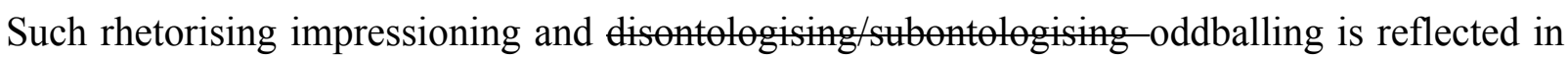
the opportunistic eliciting/tinging-with ('everyday supposedly relatively superficial/irrelevant/unthought <out-of-phasing >-disparate-narratives_of_social-functioning- 
and-accordance_-as-of-social-stake-contention-or-confliction_construct') _-

'formulaically $\sim$ passivated/linearised-forwardfacing — institutional existentialising-framingby-enframing/\{worlding\} of the sovereign-function/posture-<as-to-existentially-manifest'embodied-subject consciousness-and-direct/deferential-conscientiousness',-as-of-its'epistemic-reflexivity/unreflexivity-in-existence'/teleology>' as of ${ }^{79}$ presencing—absolutisingidentitive-constitutedness ${ }^{14}$ habituated fepistemic-totalising ${ }^{3}{ }^{3}$ psychologismic-subliminal-truncating; as so-undermining a geotopological-<as-to- nonpresencing-detruncating-of-'humanpresencing-complexes/inhibitions-of-manifest-disanthropologisation'> potentiation of thehuman/humanity (as to preemptive distraction/sidestepping and irrelevant/mere-assetised eliciting/tinging of particularities of class, interests, ideologies, nationalism, race/ethnicity, culture, subcultures, etc. as to explicited/implicited divide-and-conquer tactics of 'minimumand-balancing expectations/anticipations of social-functioning-and-accordance-as-of-socialstake-contention-or-confliction'/least-common-denominator-of-social-functioning-andaccordance-effecting). While projecting of supposedly 'ontologically-hegemonising-narrative ontological-performance ${ }^{72}$-<including-virtue-as-ontology $>$ /morality/ethics/justice/etc.' however paradoxically deficient of cogency_chronicularity/annality-of-relative-reflexivity,-asto-profound-supererogation (as to a conception of knowledge as bounded/circumscribed rather to impressioning than veridical thought). Critically, in this regards the very 'protracted-socialas-to-individual-by-institutional-by-social relative direct/deferential-responsibility/relativereflexivity-or-irresponsibility/relative-unreflexivity to cogency_chronicularity/annality-ofrelative-reflexivity,-as-to-profound-supererogation' (as to differential 'human existential$<$ disontologising/re-ontelogising aporeticism $>$ ontological-performance ${ }^{22}-<$ including-virtueas-ontology $>$ /morality/ethics/justice/etc.'): inevitably portends to 'skewed social-andinstitutional access/gatekeeping of sublimating/desublimating meaningfulness-andteleology ${ }^{9}$ ' (as to the reality of the access/gatekeeping dynamics as of either 'intellectualising 
of ${ }^{5}$ meaningfulness-and-teleology' and/or 'rhetorising of ${ }^{5}$ meaningfulness-and-teleology with respect to social-functioning-and-accordance-as-of-social-stake-contention-orconfliction_construct). As so-translated existentially-<disontologising/re-ontelogising aporeticism $>$ with respect to micro/macro social-and-institutional-frameworks-ofreferencing/registering/decisioning; reflected as to 'human manifest existentialisingdecisionality-<as-to-disontologising/re-ontelogising aporeticism $>\quad$ coming-to-ahead/culmination-point-<of-desovereignising-or-sovereignising - sovereign-repassing $>$ ' - (soreflected as of underlying 'constraining direct/deferential micro-decisionality/macrodecisionality thrownness-disposition of disontologising/re-ontologising' upon the 'socialfunctioning-and-accordance-as-of-social-stake-contention-or-confliction construct'). In this respect, the veracity of 'human equality' is veridically as of 'differential human equality' with regards to the reality of 'differential ontological-performance ${ }^{72}-<$ including-virtue-asontology $>$ /morality/ethics/justice/etc.' warrant for human limited-mentation-capacity requisite mutually differential re-ontologising 'ontologically-hegemonising-narrative ${ }^{\text {! }}$ ontologicalperformance $^{72}-<$ including-virtue-as-ontology $>$ /morality/ethics/justice/etc.' - (with reference to notional/epistemic/bindingness-<as-to-determinism/conceptivity-of-relative-unreflexivity/relative-reflexivity>

'parrhesiastic/messianicity/profound-supererogation projection for sublimatingprolongation'); as recognised with intradimensional functional implications (with regards to deferential 'competence/expertising of human socially expanded framework of deferentialformalisation-transference as to various cultivated skills/arts and time investment as to limitedmentation-capacity-deepening —as-subjecting limitedness/human-subpotency-to-'educedunlimitedness/existence-sublimating nascence' ${ }^{5}$ ') but poorly appreciated as of the requisite implications for prospective Being-development/ontological-framework-expansion-as-todepth-of-ontologising-development-as-infrastructure-of- meaningfulness-and-teleology psychologismic epistemic-acutisation difficulty-for, residualising 
\{decompulsing $\}$ delinearity for-cogency> magnitude \{of-experientiality/experiment\}.

Rhetorising impressioning and disontologising/subontologising-oddballing (as often overtly manifested with various cable and media outlets) undermining of the social 'intellectualising of meaningfulness-and-teleology", (herein construed as 'sovereign-function/posture-<as-toexistentially-manifest-'embodied-subject consciousness-and-direct/deferential-

conscientiousness',-as-of-its- 'epistemic-reflexivity/unreflexivity-in-existence'/teleology> deintellectualising') is particularly socially nefarious with regards to 'desovereignising and deintellectualising eliciting of compulsions/magnified-representation-of-compulsions' having little to do with veridical existential-<disontologising/re-ontologising aporeticism $>$ sovereign claims/interests. As to the fact sovereign claims/interests that are not 'intellectually constructed and translated/formulated/articulated' are 'only of virtual/ineffective reckoning' with respect to political, social, economic and other institutional policy frameworks of 'human manifest existentialising-decisionality-<as-to-disontologising/re-ontologising aporeticism $>$ comingto-a-head/culmination-point-<of-desovereignising-or-sovereignising sovereignrepassing $>$ '- (so-reflected as of underlying 'constraining direct/deferential microdecisionality/macro-decisionality thrownness-disposition of disontologising/re-ontologising' upon the 'social-functioning-and-accordance-as-of-social-stake-contention-or-confliction construct'); and rather defaulting onto vested interests implicitly/explicitly 'constructed and translated/formulated/articulated' (however their manifest inadequacy as to requisite delinearising-imbuing_conscientiousness-demoronisation-<as-to-renewing realisation/reperception/re-thought $>\sim$ reframing cogency_chronicularity/annality-of-relative-reflexivity,-asto-profound-supererogation ). This insight as to the 'construction and translation/formulation/articulation' of sovereign claims/interests is readily appreciated with uncontentious/nominalised social-stake-contention-or-confliction as to 'intellectually constructed and translated/formulated/articulated' policy frameworks of say consumer 
protection, health and safety, etc. Such that it is rather relatively unthinkable to socially contemplate of rhetorising impressioning and disontologising/subontologising-oddballing contestation of such social advances and protection. But then beyond such a sphere of directly personal and communal consequences, rhetorising impressioning and disentologising/subentologising—oddballing carries much more hideous and indirect desovereignising and de-intellectualising implications with respect to broader political, social, economic and other institutional policy and orientation frameworks (as so-reflected historically with tactical media, legal and public policy destabilisation/undermining, with the 'referenced formulaically $\sim$ passivated/Ainearised-forwardfacing — institutional existentialising-framing-byenframing/\{worlding\} mere frontage' construed as of a 'public threshold of tolerance/ineptitude' to be tactically toyed with by such rhetorising impressioning and disontologising/subontologising-oddballing). It is herein contended that beyond the directly manifest public policy implications of rhetorising impressioning and disontologising/subontologising—oddballing, rhetorising further manifests circuitously/indirectly as to a surreptitious posturing all along the intellectual production process and its derived policy fulfilment and orientations' in critically preempting and stifling sovereign claims/interests 'intellectual construction and translation/formulation/articulation'; as so-reflected increasingly as to self-serving institutional capital and assetising conception of knowledge (of manifest institutionalising-inflative-distortion-<as-to-prior_mere-

\section{formulaicity/ritualisation-failing-prospective-profound-supererogation}

institutionalising/organising/mutualising/methodologising). It is herein, contended as well (with regards to the consequence of ontologically-deficient implications as to 'baseline/nominalising/editional — aptitudinal underlay-as to prior unblurriness reframing/reformulation/decatchmenting/detruncating/decompulsing/delinearisi ng $>$ '-<imbued_aptitudinal-coherence-of-existentially-manifest $\sim$ hunches/cues/flags $>$ ) that in 
many ways the 'grossly impertinent and intellectually irrational supposed critique' of postmodern thought (by such rhetorising impressioning and disentologising/subentologising oddballing) in-effect portends of a much more conscious/unconscious sinister and intellectuallyirrelevant purpose of preemptively undermining its 'overarching intellectual construction and translation/formulation/articulation' of democratic and overall human emancipation sovereign claims/interests. And so, while paradoxically projecting of a flawed non-ontologising implicited/explicited conception of human sovereign-emergence/becoming,-existentiallyimbuing human-freedom-as-to-supererogating/surrealising for-'knowledge-empowermentover-ignorance-disempowerment'-<as-of-'developing-and-availing-sovereignsublimating_potential/possibilities/options/choices'-as-to-the-'credibility'/'ontologicalveracity'-underlying-the-'sovereign-conscious/conscientious-backdrop'>. Such 'intellectual irrationality' can be reflected for instance with the cynical equating of 'the wider social issues/problematics of emancipatory delinearising-imbuing_conscientiousness-demoronisation$<$ as-to-renewing realisation/re-perception/re-thought $>-$ reframing cogency_chronicularity/annality-of-relative-reflexivity,-as-to-profound-supererogation ${ }^{9}$ with disentologising/subentelogising_oddballing ontologically-flawed conception (as if structural<as to-cogency_chronicularity/annality of relative reflexivity, as to profoundsupererogation $>$ ) as reflected with the 'supposed critique of cancel culture'. As very much typical of historical rhetorising impressioning and disontologising/subontologising-oddballing undermining (of structural-<as-to-cogency_chronicularity/annality_of-relative-reflexivity, asto-profound-supererogation $>$ political, social, economic, media and other institutional policy and orientation issues); as allowed by the 'democratic practice ontologising unwieldiness' poorly accounting for such undermining as to 'skewed social and institutional access/gatekeeping of sublimating/desublimating ${ }^{56}$ meaningfulness-and-teleology ${ }^{9}$. It is equally contended herein that such historical recurrent rhetorising impressioning and disontologising/subentologising 
oddballing speaks of the bigger challenge of a Derridean democracy to come with respect to the expansion of the-human/humanity imaginary and re-ontologising potentiation (as to going beyond a present anti-Establishment electorate entrapped in Establishment politics which is rather overran by overt and surreptitious rhetorising impressioning and disontologising/subontologising -oddballing). Critically in this respect, human intellectual-andmoral responsibility/relative-reflexivity or irresponsibility/relative-unreflexivity (however counterintuitive to a ${ }^{7}$ presencing-absolutising-identitive-constitutedness ${ }^{14}$ intradimensional conception 'wrongly construed as rather as of discrete individual ontological-performance ${ }^{72}$ <including-virtue-as-ontology $>$ /morality/ethics/justice/etc.') is rather veridically of individuative-conscious/unconscious implications of 'protracted-social—as-to-individual-byinstitutional-by-social relative direct/deferential-responsibility/relative-reflexivity-orirresponsibility/relative-unreflexivity to cogency_chronicularity/annality-of-relativereflexivity,-as-to-profound-supererogation '. Speaking to requisite individual selfconsciousness conscientiousness-appraisal as being rather responsible with regards to a projection of 'individuative-conscious/unconscious implications of protracted-social-as-toindividual-by-institutional-by-social' (and not the naivety of mere discrete individual responsibility); in reflection of requisite psychologismic-epistemic-acutisation-<as-topostconverging-de-mentating/structuring/paradigming,-eliciting-of-existence's-sublimatingnascence-in-prospective-aporeticism-overcoming/unovercoming $>$ as to epistemic-growth,-as\{veridical/sound\}-relative-reflexivity-in-existence/relativising from-limited-mentation-as-itsdeepening/psychologismic epistemic-acutisation residualising, fdecompulsingl delinearity foreogency imbued 'cut-out-<as-to-re-ontologising redressing/straightening-out $>$ (as of relativereflexivity psychologismic-transfixity-<placeholder-setup-ontological-rescheduling - inrealigning/preactivity/formative-becoming/psychoanalytical-unshackling,-as-to-residualising$\{$ \{decompulsing $\}$ delinearity-over-nonresidualising_\{compulsing\} linearity $>$ ) for sublimating-prolongation 
(in 'reconstruing of ${ }^{83}$ reference-of-thought- ${ }^{84}$ devolving')'. It is important for a 're-ontologising existential-<disontologising/re-ontologising aporeticism $>$ conception' to deliberately articulate the uncompromising implications (not of a 'discrete conception of individual intellectual-and-moral responsibility/relative-reflexivity or irresponsibility/relativeunreflexivity' which is ontologically-vague with respect to requisite postconverging-aporeticism overcoming/unovereoming) but rather of manifest individuativeconscious/unconscious implications of 'protracted-social - as-to-individual-by-institutional-bysocial relative direct/deferential-responsibility/relative-reflexivity-or-irresponsibility/relativeunreflexivity to cogency_chronicularity/annality-of-relative-reflexivity,-as-to-profoundsupererogation'. So-insightfully grasped as to the veracity that for instance there is no nonpositivising mental-disposition in a positivising registry-worldview not because of positivising individuals discrete exceptionalism (but for individuative-conscious/unconscious implications of protracted-social—as-to-individual-by-institutional-by-social positivising), as equally reflected with the fact that human conscious/unconscious pedantising/muddling/formulaichollowing-out - in-subontologisation/subpotentiation-〈blurring/undermining-of-prospective-

\section{totalising-entailing,-as-to-entailing-<amplituding/formative-epistemicity $>$ totalising $\sim$ in-}

relative-ontological-completeness $\rangle$ is effectively of individuative-conscious/unconscious implications of protracted-social—as-to-individual-by-institutional-by-social, and as further reflected with limit phenomena (associated for instance with say mobbings/lynchings or psychopathy as to dynamic social psychopathy/postlogism or say manifestations of genocides). Such a veridical 're-ontologising existential-<disontologising/re-ontologising aporeticism $>$ conception' (reflecting individuative-conscious/unconscious implications of protractedsocial-as-to-individual-by-institutional-by-social positivising): is effectively what truly underlines the veracity of the 'differential magnitudes of human experientiality/experiment- $<$ asto-existentially-formative- ‘epistemictalising ${ }^{\prime}$ re-apriorising/re-axiomatising/re- 
referencing $\sim$ residuality —in-re-originariness/re-origination',- - so-

"notionally/epistemically/bindingnessly-<as-to-determinism/coneeptivity-of-relative-unreflexivity/relative-reflexivity> implicited-and-articulated'_as-from-nonextricatory-'prospective-re-ontologising-Being-thenInstitutional-then-Living-magnitudes-of-\{hermeneutic/reprojection-protraction-of\}reframingand-reformulation \}'>' (and not an exercise of apriorising/axiomatising/referencingequating/leveling/ressentiment/closed-construct-of- ${ }^{56}$ meaningfulness-and-teleology ${ }^{9}$ of a presencing_absolutising-identitive-constitutedness ${ }^{14}$ linearising-imbuing_consciousmoronisation-<as-to-prior_mere-formulaicity/ritualisation>-enframing conception); in reflection of the differential magnitudes requisite psychologismic-epistemic-acutisation- $<$ as-topostconverging-de-mentating/structuring/paradigming,-eliciting-of-existence's-sublimatingnascence-in-prospective-aporeticism-overcoming/unovercoming $>$ as to epistemic-growth,-as\{veridical/sound\}-relative-reflexivity-in-existence/relativising from-limited-mentation-as-itsdeepening/psychologismic epistemic-acutisation residualising, ${ }^{\text {fdecompulsing }}$ delinearity foreogency imbued 'cut-out-<as-to-re-ontologising-redressing/straightening-out $>$ (as of relativereflexivity psychologismic-transfixity-<placeholder-setup-ontological-rescheduling - inrealigning/preactivity/formative-becoming/psychoanalytical-unshackling,-as-to-residualising$\{$ \{decompulsing $\}$ delinearity-over-nonresidualising_\{compulsing\} linearity $>$ ) for sublimating-prolongation (in 'reconstruing of ${ }^{8}$ reference-of-thought- ${ }^{8}$ devolving')'. As to the fact that ultimately it is the re-ontologising 'reconstruing of ${ }^{83}$ reference-of-thought- ${ }^{84}$ devolving' as from relatively higher differential magnitude as from prospective 'sublimating-remoteness/distance-of-appraisal-<asto-requisite-'Being-development-notional self-distantiation'-imbued-psychologismicepistemic-acutisation,-eliciting-of-prospective-ontologically-hegemonising-narrative $>\quad$ of reference-of-thought- devolving' (with respect to 'holding-out/point-referencingpsychoanalytic-unshackling exercise of educed-and-availing-and-re-availing relativeontological-completeness ${ }^{87}$-of-apriorising/axiomatising/referencing'): that 'in-the-bigger- 
scheme-of-things dissipates disontologising/subontologising vices-and-impediments ${ }^{105}$ of relatively lower magnitudes beyond any ${ }^{7}$ presencing—absolutising-identitive-constitutedness intradimensional linearising-imbuing_conscious-moronisation-<as-to-prior_mereformulaicity/ritualisation $>\sim$ enframing conception'. So-reflected (with respect to overarching Being-development/ontological-framework-expansion-as-to-depth-of-ontologisingdevelopment-as-infrastructure-of- meaningfulness-and-teleology ) as to the dissipating of say the vices-and-impediments ${ }^{105}$ of respectively recurrent-utter-uninstitutionalisation, ununiversalisation, non-positivism/medievalism and procrypticism/disjointedness-as-ofreference-of-thought (rather in manifest 'self-presence/self-constitutedness ${ }^{14}-<$ in-perspectiveepistemic-abnormalcy/preconvergence ${ }^{31}>$ rationalisation-ofcontentivity/argumentativity/dialecticism/discursivity'); with respect to the re-ontologising 'reconstruing of reference-of-thought- devolving' of base-institutionalisation, universalisation, positivism and deprocrypticism-or-preempting-disjointedness-as-ofreference-of-thought respectively (as of 'protracted-social—as-to-individual-by-institutionalby-social self-becoming/self-conflatedness ${ }^{13}$ /formative-supererogating-

\section{$<$ projective/reprojective - aestheticising-re-motif-and-re-apriorising/re-axiomatising/re-}

referencing,-in-perspective-ontological-normalcy/postconvergence $>\quad$ re-rationalisation-ofcontentivity/argumentativity/dialecticism/discursivity'). This elucidation of re-ontologising 'reconstruing of ${ }^{83}$ reference-of-thought- ${ }^{84}$ devolving' implications (as to 'protracted-social—asto-individual-by-institutional-by-social differential ontological-performance ${ }^{2}-<$ includingvirtue-as-ontology $>$ /morality/ethics/justice/etc.') effectively underlies the very 'relativeunreflexivity/relative-reflexivity_ontological-contiguity of the overall relativemmeflexivity/relative reflexivity ontological-contiguity ${ }^{67}$ of-the-human-institutionalisationprocess ${ }^{6}$, imbued: overarching 'veridical notionality/epistemicity/bindingness ${ }^{<a s-t o-}$ 
teleology' - (reflection upon the given 'existential-<disontologising/re-ontologising aporeticism>

'baselining/cogency/reconstruing — aptitudinal overlay-<for-prospective- unblurriness-dragging-out $>\rangle$ '- reflected-as-

\section{recurring $\sim$ existentialising-framing-by-enframing/\{worlding $\}-<$ as-manifest-}

individuative -direct/deferential-transeffusive/worlding-looping $>$ _reflected-as_-supererogation 6 -

capacitating-<forention of the notion of relativism as to originary-and-re-originary/re-ontologising-nascency recurrent-linking-up of prior sublimating-arising and prospective sublimating-prolongation with regards to the veridical 'palpable dissolving/decentering of the conscious-self/collective-conscious-self' so-underlying the very inherent relationship between 'limitedness/human-subpotency' (as to prospective reencountering/re-confrontation) with 'unlimitedness/existence-<full-potency-of_sublimating nascence $>$ '. And so-reflected notionally/epistemically/bindingnessly relative-unreflexivity/relative-reflexivity $>$ as of 'existentially-<isontologising/re-ontologising apereticism $>$ manifest disontologising/re-ontologising thresholds/magnitudes' (with regards to recurring consciousness/collective-consciousness shallow-supererogation /profoundsupererogation in relation to the educing-and-availing-and-re-availing of relativeontological-completeness ${ }^{87}$-of-apriorising/axiomatising/referencing as to 'veridical epistemictotalising $\sim$ resubjecting_or_totalising-entailing $\sim$ reconstrual $<$ of the-whole/purview-of-thewhole/oneness-of-ontology>' imbued 'srelative>nominalising-<elucidation ${ }^{-0 \text { - }- \text { relative- }}$ unreflexivity/relative-reflexivity $>\quad$ reschedulability-<as-overriding prior-institutionalising prior-mereformulaicity/ritualisation failing-requisite-prospective-profound-supererogation -forsovereign-emergence $>$ '). This underlines the fact that overall human ${ }^{56}$ meaningfulness-andteleology and consciousness/collective-consciousness (as to 'protracted-social-as-toindividual-by-institutional-by-social differential ontological-performance ${ }^{22}<$ including-virtue- 
as-ontology $>$ /morality/ethics/justice/etc.') rather points to the veracity of human differential 'unnominalising-or-nominalising-<unelucidation-or-elucidation- of-relative-unreflexivity/relative-

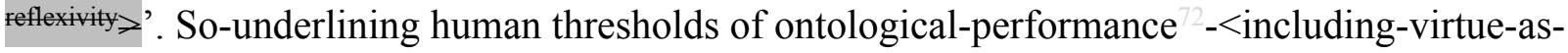
ontology $>$ /morality/ethics/justice/etc. (with regards to differentially manifest psychologismic epistemic-acutisation-<as-to-postconverging-de-mentating/structuring/paradigming,-elicitingof-existence's-sublimating-nascence-in-prospective-aporeticism-overcoming/unovercoming > as to epistemic-growth,-as- \{veridical/sound\}-relative-reflexivity-in-existence/relativising from-limited-mentation-as-its-deepening/psychologismic epistemic-acutisationresidualising, ${ }^{\text {\{decompulsing }}$ delinearity for-cogency imbued 'cut-out-<as-to-re-ontologising redressing/straightening-out $>$ as of relative-reflexivity psychologismic-transfixity$<$ placeholder-setup-ontological-rescheduling - in-realigning/preactivity/formativebecoming/psychoanalytical-unshackling,-as-to-residualising-\{decompulsing\} delinearity-overnonresidualising_\{compulsing\} linearity> for sublimating-prolongation' in 'reconstruing of reference-of-thought- devolving'): of existentially-<disontologising/re-ontologising apereticism $>$ manifest totalisingly-disentailing-discretion/whim-of-thought relativeunreflexivity 'mélée_of_supposedly-singly conception-of- ${ }^{5}$ meaningfulness-andteleology ${ }^{9}$, - reflex propositional-attitude (along the disontologising/subontologising lines $1+1=2$ speaks to $1+3 \neq 5,1+3=5,1+3=4,4+4=8,4+4=10,4+4 \neq 8,6-7 \neq 0,6-7=0,6-7=-1,5-3=2$, $5-3 \neq 2,6 \div 2 \neq 4,6 \div 2 \neq 3,3 \times 9=27,3 \times 9 \neq 27, x+2 \neq x+3, x+2=x+3$, etc. as to <unelucidation - of-relative-unreflexivity/relative-reflexivity $>$ ) on-the-one-hand and on-the-other-hand of educed 'veridical epistemic-totalising ${ }^{33} \sim$ resubjecting_or_totalising-entailing $\sim$ reconstrual- $<$ ofthe-whole/purview-of-the-whole/oneness-of-ontology>' sexplicited-or-implicited-relative $>$ nominalising-

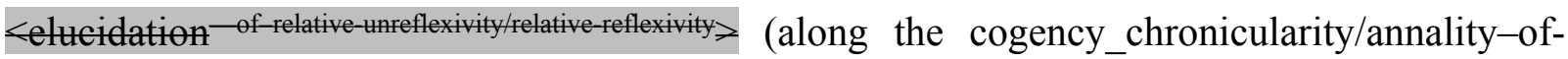
relative-reflexivity,-as-to-profound-supererogation model of $1+1=2$ rather speaks to $1+3 \neq 5$, $4+4=8,6-7 \neq 0,5-3=2,6 \div 2 \neq 4,3 \times 9=27, x+2 \neq x+3$, etc. as to selative $>$ nominalising-<elucidation- 
of-relative-unreflexivity/relative-reflexivity $>$ ). Critically, this 'differential human ontological-performance ${ }^{72}$ <including-virtue-as-ontology $>$ /morality/ethics/justice/etc.' (reflected as of 'protracted-socialas-to-individual-by-institutional-by-social differential ontological-performance ${ }^{72}<$ includingvirtue-as-ontology $>$ /morality/ethics/justice/etc.') rather translates notionally/epistemically/bindingnessly ${ }^{<a s-t o-d e t e r m i n i s m / c o n c e p t i v i t y-o f-r e l a t i v e-u n r e f l e x i v i t y / r e l a t i v e-r e f l e x i v i t y>: ~ a s ~}$ of manifest human differential 'inkling-drive of dimensionality-of-sublimating <<amplituding/formative>supererogatory $\sim$ de-mentativeness/epistemic-growth-orconflatedness /transvaluative-rationalising/transepistemicity/anamnestic-residuality/spiritdrivenness-equalisation〉' towards eventual 'secondmatmed positive oppormism of sociat functioning and accordance 7 , as to prospective_punctual/immediacy/constituted/compulsions-encumbered_disarming-_._disideologising/deformulaicity/à-contrecoup/unsettling/unarguable. So-highlighting the fact that human notional/epistemical/bindingness 3 ss-determinism/conceptivity-of-relative-mneflexivity/relative-reflexivityz inclination for either 'existentially-<disontologising/re-ontologising aporeticism $>$ manifest incidental/accidental reactive-sufferance/endurance in supposedly and paradoxically subordinating/subserving/collateralising the possibility for prospective re-ontologisingimbuing-of-prospective-human-sublimating/emancipating/enfranchisement' on-the-one-hand or on-the-other-hand 're-ontologising-nascency-<as-of-prospective-solipsistic/intersolipsisticinkling-drive-for-knowledge-elucidation,-as-to-veridical-organic-knowledge $>$ for sublimatingprolongation': rather speaks to human existentially-<disontologising/re-ontologisingaporeticism $>$ manifest 'un-nominalising-or-nominalising-<unelucidation-or-elucidation-ofrelative-unreflexivity/relative-reflexivity $>$ (in reflection of lack-of or manifest 'protracted-social—as-toindividual-by-institutional-by-social formativeness-<as-to-intersolipsism-ofpreformulating/preframing/premeaningfulness-imbued-mediativity-and-deferentialism $>$-ofmeaningfulness-and-teleology , in the relative projection of 'sublimating- 
remoteness/distance-of-appraisal-<as-to-requisite-'Being-development-notional $\sim$ selfdistantiation'-imbued-psychologismic-epistemic-acutisation,-eliciting-of-prospectiveontologically-hegemonising-narrative $>$ of ${ }^{83}$ reference-of-thought- ${ }^{8}$ devolving'). With 'formativeness-<as-to-intersolipsism-of-preformulating/preframing/premeaningfulnessimbued-mediativity-and-deferentialism>-of- meaningfulness-and-teleology effectively speaking notionally/epistemically/bindingnessly-<as-to-determinism/eoneeptivity-of-relative-unreflexivity/relativereflexivity> to 'human existentially-<disontologising/re-ontologising aporeticism $>$ manifest/manifesting differential ontological-performance ${ }^{72}-$ including-virtue-as- $^{2}$ ontology $>$ /morality/ethics/justice/etc.' (as to differentially manifest 'inkling-drive of dimensionality-of-sublimating $25<<$ amplituding/formative $>$ supererogatory - dementativeness/epistemic-growth-or-conflatedness /transvaluativerationalising/transepistemicity/anamnestic-residuality/spirit-drivenness-equalisation〉' towards eventual ssecondnatured positive-opportmnism of-social-functioning-and-accordance asto prospective_punctual/immediacy/constituted/compulsions-encumbered_disarming/dis-

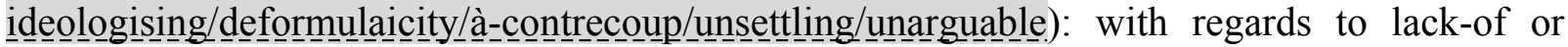
manifest 'protracted-social-as-to-individual-by-institutional-by-social formativeness-<as-tointersolipsism-of-preformulating/preframing/premeaningfulness-imbued-mediativity-anddeferentialism $>$-of- meaningfulness-and-teleology ${ }^{\prime}$ projection of 'sublimatingremoteness/distance-of-appraisal-<as-to-requisite-'Being-development-notional $\sim$ selfdistantiation'-imbued-psychologismic-epistemic-acutisation,-eliciting-of-prospectiveontologically-hegemonising-narrative $>$ of ${ }^{8}$ reference-of-thought- ${ }^{8}$ devolving'. In other words, the implications here (as to the notional/epistemic/bindingness ${ }^{<a s-t o-d e t e r m i n i s m / c o n c e p t i v i t y-o f-r e l a t i v e-~}$ unreflexivity/relative-reflexivity $>$ elucidation of differential human formativeness- $<$ as-to-intersolipsismof-preformulating/preframing/premeaningfulness-imbued-mediativity-and-deferentialism>-ofmeaningfulness-and-teleology ) implies that even Machiavellian pretenses (as to 
'existentially-<disontologising/re-ontologising aporeticism $>$ manifest incidental/accidental reactive-sufferance/endurance in supposedly and paradoxically subordinating/subserving/collateralising the possibility for prospective re-ontologisingimbuing-of-prospective-human-sublimating/emancipating/enfranchisement') are rather reflective of ${ }^{79}$ presencing-absolutising-identitive-constitutedness ${ }^{14}$ ad-hoc thresholds of ontological-performance ${ }^{72}$-<including-virtue-as-ontology $>/$ morality/ethics/justice/etc.

'existential-<disentologising/re-ontologising aporeticism $>$ equilibria'; poorly appraisingand-accounting-for the very 'relative-unreflexivity/relative-reflexivity-ontologicalcontiguity $^{67}$ of the overall relative-unreflexivity/relative-reflexivity-ontologicalcontiguity ${ }^{67}$ of-the-human-institutionalisation-process ${ }^{6}$, imbued overarching 'veridical notionality/epistemicity/bindingness ${ }^{<a s-t o-d e t e r m i n i s m / c o n c e p t i v i t y-o f-r e l a t i v e-u n r e f l e x i v i t y / r e l a t i v e-r e f l e x i v i t y ~}>$ conception-of- ${ }^{5}$ meaningfulness-and-teleology" - (reflection upon the given 'existential$<$ disentelogising/re-ontelogising aporeticism> $>$ ("baseline/nominalising/editional—aptitudinal underlay-<as-to-priorunblurriness $\sim$ reframing/reformulation/decatchmenting/detruncating/decompulsing/delinearising $>$ enabling 'baselining/cogency/reconstruing — aptitudinal overlay-<for-prospective- unblurriness-dragging-out $>$ ' $\rangle$-... reflected-asrecurring $\sim$ existentialising-framing-by-enframing/\{worlding $\}$-<as-manifestindividuative direct/deferential-transeffusive/worlding-looping > _reflected-as_-supererogation 0 -

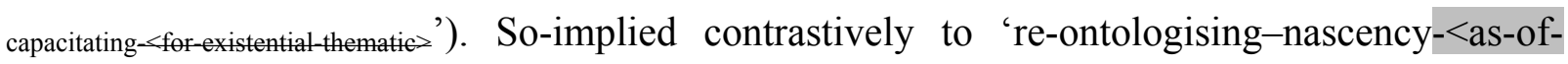
prospective-solipsistic/intersolipsistic-inkling-drive-for-knowledge-elucidation,-as-toveridical-organic-knowledge $>$ for sublimating-prolongation' implications as to Beingdevelopment/ontological-framework-expansion-as-to-depth-of-ontologising-development-asinfrastructure-of- meaningfulness-and-teleology psychologismic epistemic-acutisationdifficulty $<$ for, residualising_\{decompulsing $\}$ delinearity for-cogency> magnitude $\{$ ofexperientiality/experiment\}, institutional-development-as-to-social-function-development psychologismic epistemic-acutisation difficulty-<for, residualising- 
$\{$ decompulsing $\}$ delinearity for-cogency $>$ magnitude $\{$ of-experientiality/experiment $\}$ and living-developmentas-to-personality-development psychologismic epistemic acutisation difficulty < for, residualising \{decompulsing\} delinearity for-cogency> magnitude $\{$ of-experientiality/experiment\}. Machiavellian pretenses (with regards to their successive epochal 'existential<disontologising/re-ontologising aporeticism $>$ equilibria' as merely usurping/assetising of the inherent 'sovereign-function/posture-<as-to-existentially-manifest-'embodied-

\section{subject consciousness-and-direct/deferential-conscientiousness',-as-of-its-'epistemic-}

reflexivity/unreflexivity-in-existence'/teleology>

linearising-imbuing_conscious-

moronisation-<as-to-prior_mere-formulaicity/ritualisation>-enframing') quickly dissipate with prospectively elicited 'sovereign-function/posture-<as-to-existentially-manifest-'embodiedsubject consciousness-and-direct/deferential-conscientiousness',-as-of-its- 'epistemicreflexivity/unreflexivity-in-existence'/teleology> delinearising-imbuing_conseientiousnessdemoronisation-<as-to-renewing-realisation/re-perception/re-thought $>-$ reframing'; in reflection of the 'conscious/unconscious possibility/opportunity for apriorising/axiomatising/referencing_equating/leveling/ressentiment/closed-construct-ofmeaningfulness-and-teleology ${ }^{9}$ that arises from the given epochal ad-hoc totalisinglydisentailing_-discretion/whim-of-thought relative-unreflexivity 'mélée_of_supposedlysingly conception-of- ${ }^{5}$ meaningfulness-and-teleology ${ }^{\circ}$ - reflex $\sim$ propositional-attitude.

Contrastively, the 'third-party unlimitedness/existence-<fll-potency-of_sublimating nascence $>$ elucidative implications of delinearising-imbuing_conscientiousnessdemoronisation-<as-to-renewing realisation/re-perception/re-thought $>\sim$ reframing cogency_chronicularity/annality-of-relative-reflexivity,-as-to-profound-supererogation ${ }^{9}$ can only veridically be construed across all epochs and magnitudes rather as to originary-and-reoriginary/re-ontologising-nascency (in 'reconstruing of ${ }^{83}$ reference-of-thought- ${ }^{84}$ devolving' with respect to educing-and-availing-and-re-availing of relative-ontological-completeness ${ }^{87}$ 
of-apriorising/axiomatising/referencing): reflecting the non-ad-hoc 'veridical epistemictotalising $\sim$ resubjecting_or_totalising-entailing $\sim$ reconstrual $<$ of the-whole/purview-of thewhole/oneness-of-ontology>' rather underlining the overarching 'veridical notionality/epistemicity/bindingness ${ }^{<a s-t o-d e t e r m i n i s m / c o n e e p t i v i t y-o f-r e l a t i v e-u n r e f l e x i v i t y / r e l a t i v e-r e f l e x i v i t y>~}$ conception-of- ${ }^{5}$ meaningfulness-and-teleology $y^{9}$ '-(reflection upon the given 'existential-

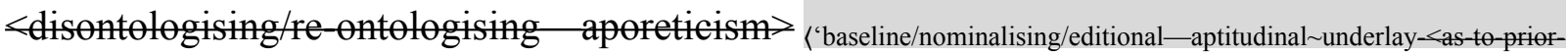

'baselining/cogency/reconstruing — aptitudinal overlay-<for-prospective- unblurriness-dragging-out $>$ ’ $\rangle$-.... reflected-as $\ldots$

recurring existentialising-framing-by-enframing/\{worlding $\}-<$ as-manifest-

individuative direct/deferential-transeffusive/worlding-looping > _reflected-as_-supererogation 6 -

capacitating-<for-existential-thematic ’'). The 'third-party unlimitedness/existence-<full-potencyof_sublimating nascence $>\quad$ elucidative implications of delinearisingimbuing_conscientiousness-demoronisation-<as-to-renewing realisation/re-perception/rethought $>\sim$ reframing cogency_chronicularity/annality-of-relative-reflexivity,-as-to-profoundsupererogation' (in 'reconstruing of ${ }^{8}$ reference-of-thought- ${ }^{8}$ devolving' with respect to educing-and-availing-and-re-availing of relative-ontological-completeness ${ }^{8}$-ofapriorising/axiomatising/referencing): is effectively what overrides apriorising/axiomatising/referencing — equating/leveling/ressentiment/closed-construct-ofmeaningfulness-and-teleology ; so-wrongly projected with regards to an ontologically-flawed conception of a supposed 'identity politics' as of our ${ }^{79}$ presencing - absolutising-identitiveconstitutedness ${ }^{14} \quad$ 'sovereign-function/posture-<as-to-existentially-manifest-'embodiedsubject consciousness-and-direct/deferential-conscientiousness',-as-of-its- 'epistemicreflexivity/unreflexivity-in-existence'/teleology> linearising-imbuing_consciousmoronisation-<as-to-prior_mere-formulaicity/ritualisation $>\sim$ enframing'. This by extension will wrongly seem to imply successive epochal re-ontologising 
sublimation/emancipation/enfranchisement (as from human and individual rights proclamations, end of slavery/serfdom, women rights, end of colonialism, civil rights, etc. within the scope of their given epochal presencing-absolutising-identitive-constitutedness controversies/conflicts) are rather of their successive epochal 'identity politics'; as supposedly relevant only to the direct social categories in question, rather than the veracity of 'overall human re-ontologising sublimation/emancipation/enfranchisement $<$ relative $>$ nominalising-<elucidation of-relative-unreflexivity/relative-reflexivity $>$ re-appraisal' (as to when prospective relative-ontologicalcompleteness $^{87}$ is educed-and-availing-and-re-availing). As if to imply with our present delinearising-imbuing_conscientiousness-demoronisation-<as-to-renewing realisation/reperception/re-thought $>-$ reframing distance of appraisal in 'reconstruing of ${ }^{83}$ reference-ofthought- devolving' (with respect to such historical disontologising desublimation/unemancipation/disenfranchisement), any human (supposedly not of any of the direct social categories in question) can seriously entertain the notion that were such human disontologising desublimation/unemancipation/unenfranchisement to prospectively arise it wouldn't be of their relevant concern (as to such an ontologically-flawed notion of 'identity politics' impervious to originary-and-re-originary/re-ontologising-nascency appraisal). Thusly, human sovereign-emergence/becoming, existentially imbuing human freedom as to supererogating/surrealising-for-'Knowledge-empowerment-over-ignorance-disempowerment' $<$ as-of-'developing-and-availing-sovereignsublimating_potential/possibilities/options/choices'-as-to-the-'credibility'/'ontologicalveracity'-underlying-the-'sovereign-conscious/conscientious-backdrop'>is effectively bounded (as to requisite 'overall human re-ontologising sublimation/emancipation/enfranchisement

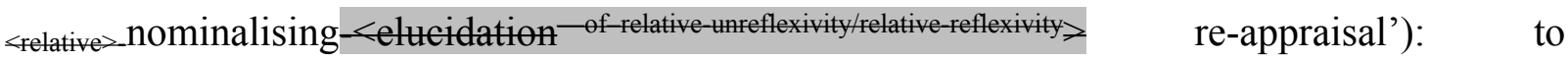
overarching 'veridical notionality/epistemicity/bindingness ${ }^{<a s-t o-d e t e r m i n i s m / c o n c e p t i v i t y-o f-r e l a t i v e-~}$ unreflexivity/relative-reflexivitys conception-of $-{ }^{56}$ meaningfulness-and-teleology ${ }^{9}$ ' - (reflection upon the 
given 'existential-<disontologising/re-ontologising aporeticism〉 〈'baseline/nominalising/editionalaptitudinal underlay<ss-to-prior-__ unblurriness-reframing/reformulation/decatchmenting/detruncating/decompulsing/delinearising >’ enabling 'baselining/cogency/reconstruing — aptitudinal overlay-<for-prospective- unblurriness-dragging-out $>$ ' - reflected-asrecurring existentialising-framing-by-enframing/\{worlding $\}$-<as-manifestindividuative-direct/deferential-transeffusive/worlding-looping > _reflected-as_-supererogation 0 capacitating-for ' In this respect, 'overall human re-ontologising sublimation/emancipation/enfranchisement $\leq$ relative $>$ nominalising-<elucidation-of-relativeunreflexivity/relative-reflexivity $>$ re-appraisal' (as so-reflecting the epochal non-ad-hoc 'veridical epistemic-totalising ${ }^{33} \sim$ resubjecting_or_totalising-entailing $\sim$ reconstrual $<0$ f thewhele/purview of the wholeloneness of ontology>') imbued 'baseline/nominalising/editional—aptitudinal underlay-<as-to-priorunblurriness $\sim$ reframing/reformulation/decatchmenting/detruncating/decompulsing/delinearisi ng $>$ '-<imbued_aptitudinal-coherence-of-existentially-manifest $\sim$ hunches/cues/flags $>$ (as prior unblurriness $\sim$ reframing/reformulation/decatchmenting/detruncating/decompulsing/delinearisi ng), effectively speaks to the requisite 'social, institutional and mediatic discursivity intermediating editional-competence' (enabling veridical re-rationalisation-ofcontentivity/argumentativity/dialecticism/discursivity for sublimating-prolongation); and so, with regards to the constructive elucidation of 'baselining/cogency/reconstruingaptitudinal overlay-for-prospective- tnblurriness-dragging-out $>$ ' (as prospective unblurriness/blurriness-

threshold framing/formulation/catchmenting/truncating/compulsing/linearising). As so ontologically overriding apriorising/axiomatising/referencingequating/leveling/ressentiment/closed-construct-of- ${ }^{5}$ meaningfulness-and-teleology 9 (as of epochal ad-hoc totalisingly-disentailing-discretion/whim-of-thought relative-unreflexivity 'mélée_of_supposedly-singly conception-of- ${ }^{5}$ meaningfulness-and-teleology ${ }^{\circ}$ - 
reflex $\sim$ propositional-attitude) imbued $\quad<$ relative $>$ un-nominalising-<unelucidation ${ }^{-}$of-relativeunreflexivity/relative-reflexivity $>$ undermining of requisite 'social, institutional and mediatic discursivity intermediating editional-competence' (enabling veridical re-rationalisation-ofcontentivity/argumentativity/dialecticism/discursivity for sublimating-prolongation). But then the fact remains that the requisite human \{epistemic-totalising ${ }^{3}$ psychologismic-subliminaldetruncating in 'reconstruing of ${ }^{83}$ reference-of-thought- devolving' (as to 'sublimatingremoteness/distance-of-appraisal-<as-to-requisite-'Being-development-notional selfdistantiation'-imbued-psychologismic-epistemic-acutisation,-eliciting-of-prospectiveontologically-hegemonising-narrative $>$ of ${ }^{83}$ reference-of-thought- ${ }^{8}$ devolving') is of 'protracted-social—as-to-individual-by-institutional-by-social formativeness- $<$ as-tointersolipsism-of-preformulating/preframing/premeaningfulness-imbued-mediativity-anddeferentialism $>$-of- meaningfulness-and-teleology '; with regards to 'overall human reontologising sublimation/emancipation/enfranchisement nominalising-<elucidation elative unreflexivity/relative reflexivity $>$ re-appraisal' (in so-reflecting the epochal non-ad-hoc 'veridical epistemic-totalising ${ }^{33} \sim$ resubjecting_or_totalising-entailing $\sim$ reconstrual $<0$ f thewhole/purview of the-whole/oneness-of-ontology>'). With the more critical issue in this regards (however counterintuitive) not the mere occurrence/manifestation per se of rhetorising impressioning and disontologising/subontologising_oddballing (associated with epochal ad-hoc totalisingly-disentailing - discretion/whim-of-thought relative-unreflexivity 'mélée_of_supposedly-singly conception-of- ${ }^{5}$ meaningfulness-and-teleology ${ }^{9}$ '

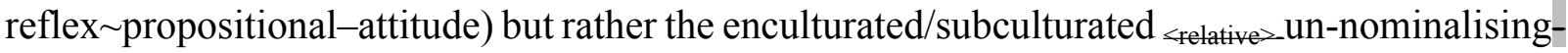
< unelucidation- of-relative-unreflexivity/relative-reflexivity $>$ undermining of requisite 'social, institutional and mediatic discursivity intermediating editional-competence' (as inducing the desovereignising prevalence of rhetorising impressioning and disentelogising/subentelogising oddballing). In this respect, in many ways both nascent-particular/incipient-and- 
material/technical-sublimations- $<$ blinded-to-their-relative-ontological-completeness

reference-of-thought- devolving $>$ and social-and-institutional-frameworks-ofreferencing/registering/decisioning are subject to rhetorising impressioning and disontologising/subontologising oddballing but then their respectively stronger and weaker immediacy-of-sublimation_ (imbued 'secondnatured positive-opportunism of-sociatfunctioning-and-accordance ${ }^{7}$ as-to-

prospective_punctual/immediacy/constituted/compulsions-encumbered_disarming/dis-

ideologising/deformulaicity/à-contrecoup/unsettling/unarguable $)$ in 'reconstruing of reference-of-thought- devolving': translate into their respective <relative $>$ nominalising<elucidation ${ }^{-}$of-relative-unreflexivity/relative-reflexivity $>$'social, institutional and mediatic discursivity intermediating $\sim$ editional-competence' and $\leq$ relative $>$ un-nominalising-<unelucidation ${ }^{-}$of-relativeunreflexivity/relative-reflexivity $>$ undermining of requisite 'social, institutional and mediatic discursivity intermediating editional-competence'. This difference is rather protracted as to the reality of such 'social, institutional and mediatic discursivity intermediating editional-competence' imbued protracted-social—as-to-individual-by-institutional-by-social manifest 'wieldycontemplatable disontologising/re-ontologising implications' of srelative $>$ nominalising<elueidation ${ }^{-}$- - relative-unreflexivity/relative-reflexivity $>$or manifest 'unwieldy-contemplatable disontologising/re-ontologising implications' as of $<$ relative $>$ un-nominalising-< unelucidation - of relative-unreflexivity/relative-reflexivity $>$; and as 'social, institutional and mediatic institutionalised un-nominalising-<mnelucidation-of-relative-mreflexivity/relative-reflexivity $>$ practice' is liable to manifest institutionalising-inflative-distortion-<as-to-prior_mere-formulaicity/ritualisation-failingprospective-profound-supererogation

institutionalising/organising/mutualising/methodologising (of reflex uncontemplated/poorlycontemplated ontological-veracity with respect to requisite memorative-extension-<as-to‘conscientiousness-demoronisation-delinearising construct-of-thought’/‘ fepistemic- 
reframing_educing sublimating-prolongation> for 'reconstruing of reference-of-thoughtdevolving'). In this regards, nascent-particular/incipient-and-material/technical-sublimations$<$ blinded-to-their-relative-ontological-completeness - reference-of-thought- devolving $>$ 'social, institutional and mediatic discursivity intermediating editional-competence' imbued protracted-social—as-to-individual-by-institutional-by-social manifest 'wieldy-contemplatable disontologising/re-ontologising implications' as of <relative $\_$nominalising-<elucidation ${ }^{-o f-r e l a t i v e-~}$ mreflexivity/relative reflexivity $>$ (reflected as to technical and policy frameworks of say professional and production practices, consumer protection, health and safety, etc.): are of manifest compact '<relative $>$ nominalising-<elucidation ${ }^{-}$of-relative-unreflexivity/relative-reflexivity $>$ reschedulability $<$ asoverriding prior-institutionalising prior-mere-formulaicity/ritualisation-failing requisiteprospective-profound-supererogation for-sovereign-emergence>'; given the relative constraining implications of their underlying stronger immediacy-of-sublimation-(imbued 'secondnatured positive-opportunism of-social-functioning-and-accordance as-toprospective _punctual/immediacy/constituted/compulsions-encumbered_disarming/disideologising/deformulaicity/à-contrecoup/unsettling/unarguable) as to the rescheduling perpetuating ontologically-hegemonising-narrative ${ }^{71}$ in 'reconstruing of ${ }^{83}$ reference-of-thoughtdevolving'. In contrast, the underlying weaker immediacy-of-sublimation-(imbued 'secondnatured positive-opportunism of-social-functioning-and-accordance as-toprospective_punctual/immediacy/constituted/compulsions-encumbered_disarming_-___disideologising/deformulaicity/à-contrecoup/unsettling/unarguableble) as well as prospective 'sublimating-remoteness/distance-of-appraisal-<as-to-requisite-'Being-developmentnotional self-distantiation'-imbued-psychologismic-epistemic-acutisation,-eliciting-ofprospective-ontologically-hegemonising-narrative $>$ of ${ }^{83}$ reference-of-thought- ${ }^{-1}$ devolving': means that overarching social-and-institutional-frameworks-of- 
referencing/registering/decisioning reflected 'social, institutional and mediatic discursivity intermediating editional-competence' imbued protracted-social—as-to-individual-byinstitutional-by-social manifest 'unwieldy-contemplatable disontologising/re-ontologising implications' as of $<$ relative $>$ un-nominalising-<unelucidation-of-relative-unreflexivity/relative-reflexivity $>$ are in many ways of intermingling 'rhetorising of ${ }^{5}$ meaningfulness-and-teleology' and 'intellectualising of ${ }^{56}$ meaningfulness-and-teleology ${ }^{9}$. And this effectively translates into the defining/given ${ }^{7}$ presencing_absolutising-identitive-constitutedness ${ }^{14}$ overarching 'social, institutional and mediatic discursivity intermediating editional-competence' nominalising-<unelucidation - of-relative-unreflexivity/relative-reflexivity $>$ (so-inculcated as to iconically habituated \{epistemic-totalising $3{ }^{3}$ 'psychologismic-subliminal-truncating notions of 'human inhibiting/complexifying-particularities rather existentially-<isontologising/re-ontologising aporeticism $>\quad$ intercepting-consciously/unconsciouly originary-and-re-originary/reontologising-nascency appraisal of the-human/humanity potentiation' with regards to requisite postconverging-aporeticism-overcoming/unovercoming); and so-undermining the 'reconstruing of ${ }^{83}$ reference-of-thought- ${ }^{-4}$ devolving'-(rather expansively eventualising veridically as of 'human social-functioning-and-accordance-as-of-social-stake-contention-orconfliction_construct geotopological-<as-to- nonpresencing-detruncating-of-'humanpresencing-complexes/inhibitions-of-manifest-disanthropologisation'> potentiation of thehuman/humanity'). This 'human existentialising-decisionality-<as-to-disontologising/reentologising aporeticism $>$ dual psychological-dispositions continuum-gradient of sovereignising - by — ontologising-depth in inducing desublimation or sublimation' effectively underlies the inherent existentialising-decisionality-<as-to-disontologising/re-ontologising apereticism $>$ of underpinning-suprasocial-construct as to underlying socio-econo-political subontologisation/ideology-over-ontology whether technocratic, capitalistic or communist; as to the fact that in-many-ways the "very existentialising-realness of such abstract notions as to their 
nondisjointing tends to be <amplituding/formative-epistemicity>totalisingly absent/vague, relative/qualified and ephemeral/fleeting' with the underpinning-suprasocial-construct more fruitfully identifiable/construable as to its 'underlying preconverging epistemic-projectiveequalisation social dynamics of ${ }^{7}$ presencing — absolutising-identitive-constitutedness ${ }^{14}$ socialvestedness/normativity-<discretely-implied-functionalism>> ${ }^{\prime} \quad$ that-drives/is-behind $\quad$ such subontologisation/ideology-over-ontology disjointing abstract notions as technocratic, capitalistic or communist which are rather 'catchmenting-by-rejection/lipservicing/monopolising/gaming-of-the-system/charade/distraction vague/imaginary lures of social-stake-contention-or-confliction' (as can be more vividly be observed in moments of crisis when such 'underlying preconverging epistemic_projective-equalisation social dynamics of presencing - absolutising-identitive-constitutedness ${ }^{14} \quad$ social-vestedness/normativity$<$ discretely-implied-functionalism>' manifest themselves as superseding any such abstract 'catchmenting-by-rejection/lip-servicing/monopolising/gaming-of-thesystem/charade/distraction vague/imaginary lures of social-stake-contention-or-confliction' but also persistently across time in more subtle ways). Such 'catchmenting-by-rejection/lipservicing/monopolising/gaming-of-the-system/charade/distraction vague/imaginary lures of social-stake-contention-or-confliction' are geared on collectively inducing defaulting 'beholdening as sovereignising-imbued-subontologisation/subpotentiation' existentialisingdecisionality-<as-to-disontologising/re-ontologising aporeticism $>$ psychological-disposition (as to relative-ontological-incompleteness ${ }^{8}$-presublimation-construct-of- ${ }^{56}$ meaningfulnessand-teleology $\quad$ desublimating existentialising-decisionality-<as-to-disontologising/reentologising aporeticism $>$ ) that goes on to 'surreptitiously/subconsciously distractfrom/drown/dilute/enframe the possibility for prospective incisive and diligent ontologicalveracity sublimation/emancipation analysis of any such underpinning-suprasocial-construct defining catchmenting-by-rejection of value and value-possibilities' as to the underlying 
manifestations

vestedness/normativity- $<$ discretely-implied-functionalism $>$ (as more thoroughly elucidated further above); wherein as 'supposedly forever-and-ever tried-and-tested ready-to-hand reflex existentialising-decisionality-<as-to-disontologising/re-ontologising aporeticism $>$ that do not know of human limited-mentation-capacity—as-subjecting-'educed-unlimitedness/existencesublimating nascence'-to-limitedness/human-subpotency and thus the need for human limitedmentation-capacity-deepening —as-subjecting limitedness/human-subpotency-to-'educedunlimitedness/existence-sublimating nascence' ${ }^{3}$, the analytical possibility for original prospective creative re-ontologisation (as required for human scalarisation-as-to-rescalarisationas-re-ontologisation/supereregatery $\sim$ involuting-or-guilding-or-amplifying-scalarisation- $<$ asto-existence — as-sublimating-withdrawal/unenframing/re-ontologising,-elicited-fromprospective-profound-supererogation $>$ ) is preconverging/postconverging-dementatively/structurally/paradigmatically closed-off, and there is 'supposedly no sublimating/emancipating existentialising-decisionality-<as-to-disontologising/reentologising aporeticism $>{ }^{5}$ meaningfulness-and-teleology" that can arise outside the underpinning-suprasocial-construct $<$ preconverging 'motif-andapriorising/axiomatising/referencing'-entailing $>$-existentialising_enframing/imprintedness〈as-to- historicity-tracing-in-presencing-hyperrealisation/hyperreal-transposition〉 as puttinginto-question the very ontological-veracity of the subontologisation/ideology-over-ontology 'catchmenting-by-rejection/lip-servicing/monopolising/gaming-of-thesystem/charade/distraction vague/imaginary lures of social-stake-contention-or-confliction' (as the underpinning-suprasocial-construct becomes an enclosing/hemming-in religiosity inculcated as defining the very notional/epistemic/bindingness ${ }^{<a s-t o-d e t e r m i n i s m / c o n c e p t i v i t y-o f-r e l a t i v e-~}$ unreflexivity/relative-reflexivity framework of human Being-development/ontological-frameworkexpansion-as-to-depth-of-ontologising-development-as-infrastructure-of- meaningfulness- 
and-teleology , institutional-development-as-to-social-function-development and livingdevelopment-as-to-personality-development psychologismic epistemic acutisationdifficulty < for, residualising \{decomplsing $\}$ delinearity for-cogeney> magnitudes $\{$ \{fexperientiality/experiment\} and so consciously/unconsciously as supposedly superseding pure-ontology) as we can appreciate that the very supposedly abstract notions of say social-science or economics-science or political-science do not actually socially exist in their 'abstract semantic sense' but are 'already pragmatically deferring into the religiosity of the underpinningsuprasocial-construct catchmenting-by-rejection of value and value-possibilities', such that in effect all thought gravitates around the religiosity whether critical or praising as to the <preconverging 'motif-and-apriorising/axiomatising/referencing'-entailing >existentialising — enframing/imprintedness-〈as-to- historicity-tracing-in-presencinghyperrealisation/hyperreal-transposition $\rangle$ of the religiosity with the idea of an altogether incisive and diligent engagement as to socio-econo-political re-originary-_as-unenframed/reontologising/unbeholdening/outlier-conceptualisation__imbued-postconverging/dialectical-

\section{thinking -'projective-insights'/‘epistemic-projection-in-conflatedness ' 'of-}

notional deprocrypticism-prospective-sublimation $\rangle^{0}$ rather of overt-and-covert taboo status thus in-many-ways ripping away from the human the possibility to reproject originarily for 'human-decisionality-<as-to-play-of-valid/invalid-decisionality-imbued-

sublimation/desublimation> omni-potential commensurability with inherent immanentexistence's sublimation-structure'/omnipotentiality. In this respect, the possibility of critical pure-ontology is rather underlied as of overall reifying-and-empowering-reflexivity-of-ecstaticexistence-as-panintelligibility/panreflexivity ${ }^{73}$-〈existentially-imbued-and-educing-< $<$ epistemicthermeneutically/textually/reprojectingly/supererogatingly/zeroingly/re-acutingly,$\{$ decompulsing $\}$ delinearity $\sim$ for-cogency $\geq$-epistemic-perspective-of-projective/reprojective- 
as-herein-specifically-relevant-to human-subpotency) as to the fact that human ontologicalperformance $^{72}-<$ including-virtue-as-ontology $>$ /potentiation optimisation/maximalisation rather arises from ${ }^{103}$ universal-transparency ${ }^{104}$-〈transparency-of-totalising-entailing,-as-to-entailing<amplituding/formative-epistemicity>totalising in-relative-ontological-completeness > of 'prospective postconverging aporeticism-overceming/unovercoming as the-Good/knowledgereification $\sim$ gesturing-and-accounting — of-epistemic-phenomenalism- $<$ inprospective_psychologismic apriorising/axiomatising/referencing-\{of-'prospectivelyimplicited_attendant-ontological-contiguity ' educedexistentialising/contextualising/textralising_intelligibility/epistemicity/reflexivity-contiguity<imbued-notional cogency $\left.>^{\prime} \quad\right\}$-conflatedness -in-\{preconverging-disentailment by\} postconverging-entailment $>$ /understanding/<amplituding/formativeepistemicity $>$ causality $\sim$ as-to-projective-totalitative-implications-of-prospectivenonpresencing,-for-explicating relative-unreflexivity/relative-reflexivity - ontologicalcontiguity ' as to profound 'unbeholdening sublimating-nascence ontologising-depth of the full-potency of existence' and so over any desublimating <preconverging 'motif-andapriorising/axiomatising/referencing'-entailing>-existentialising-enframing/imprintedness〈as-to- historicity-tracing - in-presencing-hyperrealisation/hyperreal-transposition〉 of mereand-vague impression-driven/good-naturedness/wishfulness 'beholdening as sovereignisingimbued-subontologisation/subpotentiation' of totalisingly-disentailing — discretion/whim-ofthought; and as so-underlied preconverging/postconverging-dementatively/structurally/paradigmatically by human-subpotency 'fatedness-of-sublimationover-desublimation to existence-potency sublimating-nascence,-disclosed-from-prospectiveepistemic-digression in reflecting holographically-<conjugatively-and-transfusively $>$ the relative-unreflexivity/relative-reflexivity - ontological-contiguity of-the-humaninstitutionalisation-process '. In summary, 'human existentialising-decisionality-<as-to- 
disentologising/re-ontologising aporeticism $>$ dual psychological-dispositions continuumgradient of sovereignising — by — ontologising-depth in inducing desublimation or sublimation' underscores how human social-and-institutional-frameworks-ofreferencing/registering/decisioning existentialising-decisionality-<as-to-disontologising/reentelogising aporeticism $>$ are prone to presencing-absolutising-identitiveconstitutedness ${ }^{14}$ (and so as of overall social and institutional existentialising-decisionality-<asto-disontologising/re-ontologising aporeticism $>$ implications as to the very notional/epistemic/bindingness - as to determinism/enceptivity of relative unreflexivity/relative reflexivitys framework of Being-development/ontological-framework-expansion-as-to-depth-ofontologising-development-as-infrastructure-of- meaningfulness-and-teleology , institutionaldevelopment-as-to-social-function-development and living-development-as-to-personalitydevelopment psychologismic epistemic-acutisation difficulty-<for, residualising \{decompulsing $\}$ delinearity for-cogeney>-magnitudes $\{$ of-experientiality/experiment $\}$ ). This reflects a preconverging/postconverging-de-mentative/structural/paradigmatic human 'notional $\sim$ reflexivity- $<\{$ veridical/sound\}-relative-reflexivity-in-existence/relativising fromlimited-mentation-as-its-deepening/psychologismic-< residualising ${ }^{\text {fdecompulsing }}$ delinearity foreogeney>-by-\{flawed/unsound\}-relative-unreflexivity-in-existence/absolutising from limited-mentation/psychologismic epistemic acutisation nonresidualising imbued\{compulsing\} linearity in-eclecticism-of prior-mere-formulaicity/ritualisation> dualising' with regards to the notional firstnaturedness-formativeness-<as-to-eventualising-inkling-drive-orseeding misprising $>$ temporal-to-intemporal-dispositions-<so-construed-as-fromperspective-ontological-normalcy/postconvergence> of human protracted-social-as-to-

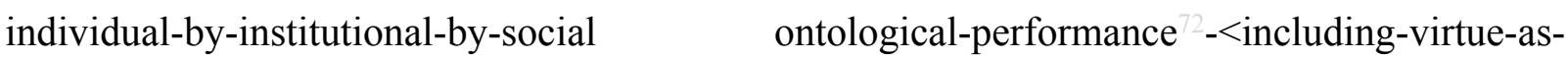
ontology $>$ /morality/ethics/justice/etc. (as to existentially-disontologising/re-ontologising apereticism $>$ dual-language/split-mentality that on-the-one-hand fails implied emancipation and 
on-the-other-hand implies a strife for emancipation); with regards to the variance in institutional existentialising-frame-of-entailment of motif-and-apriorising/axiomatising/referencing

underlied with existentialising-decisionality-<as-to-disontologising/re-ontologising aporeticism $>$ of 'beholdening as sovereignising-imbued-subontologisation/subpotentiation' associated with 'social-and-institutional-frameworks-of - referencing/registering/decisioning in blurriness-<sterilising/anecdotalising/trivialising-of-prospective-re-ontologising_bypreconverging,-in-disontologising-formulaic-dragging-out/hollowing-out>' on-the-one-hand and on-the-other-hand existentialising-decisionality-<as-to-disentologising/re-ontelogising aporeticism $>$ of 'unbeholdening sublimating-nascence ontologising-depth of the full-potency of existence' as associated with social-and-institutional-frameworks-ofreferencing/registering/decisioning in unblurriness-<re-ontologising_by-postconverging-as-todragged-out-supererogatory $\sim$ wholesomeness/profound-supererogation ,-while-anecdotalisingprior-disontologising-thresholding $>$ of sublimating-nascence' (and as critically reflected with nascent-particular/incipient-and-material/technical-sublimations- $<$ blinded-to-their-relativeontological-completeness - reference-of-thought- devolving $>$ ). Thus critically social-andinstitutional-frameworks-of - referencing/registering/decisioning as rather 'relatively predisposed to defaulting as of relative-ontological-incompleteness ${ }^{88}$-presublimation-constructof- ${ }^{56}$ meaningfulness-and-teleology 9 desublimating $\sim$ existentialising-decisionality-<as-todisontologising/re-ontologising aporeticism $>$ ' (in relation to induced nascentparticular/incipient-and-material/technical-sublimations- $<$ blinded-to-their-relative-ontologicalcompleteness - reference-of-thought- devolving $>$ ) need to be properly re-examined and reconstrued (and so in the sublimating light of nascent-particular/incipient-and-material/technicalsublimations- $<$ blinded-to-their-relative-ontological-completeness - reference-of-thought-

devolving $>$ ) to imply the need for their very own prospectively induced sublimation as to ${ }^{6}$ reference-of-thought-and- ${ }^{83}$ reference-of-thought- ${ }^{84}$ devolving- $-{ }^{56}$ meaningfulness-and- 
teleology ${ }^{9}$ comprehensiveness of prospective sublimating-nascence' (over relative-ontologicalincompleteness ${ }^{8}$ - presublimation-construct-of- ${ }^{56}$ meaningfulness-and-teleology ${ }^{9}$ ). emphasis here lies with the fact that while nascent-particular/incipient-and-material/technicalsublimations- $<$ blinded-to-their-relative-ontological-completeness - reference-of-thoughtdevolving $>$ (as to 'unbeholdening sublimating-nascence ontologising-depth of the fullpotency of existence' existentialising-decisionality-<as-to-disontologising/re-ontelogising aporeticism $>$ ) come with “ ${ }^{\text {'03 }}$ universal-transparency ${ }^{104}$-〈transparency-of-totalising-entailing,-asto-entailing-<amplituding/formative-epistemicity>totalising in-relative-ontological-

completeness > of sublimating-nascence' eliciting human positive-opportunism-of-socialfunctioning-and-accordance ${ }^{75}$ integration as secondnatured-institutionalisation, this ' ${ }^{103}$ universal-transparency ${ }^{104}$-〈transparency-of-totalising-entailing,-as-to-entailing<amplituding/formative-epistemicity>totalising in-relative-ontological-completeness > of sublimating-nascence' eliciting human positive-opportunism-of-social-functioning-andaccordance ${ }^{75}$ integration as secondnatured-institutionalisation does not-directly/not-immediately permeate $\quad$ prospective social-and-institutional-frameworks-ofreferencing/registering/decisioning (in relation to the nascent-particular/incipient-andmaterial/technical-sublimations-<blinded-to-their-relative-ontological-completeness reference-of-thought- devolving $>$ ) as to inducing the ${ }^{103}$ universal-transparency ${ }^{104}$ $\langle$ transparency-of-totalising-entailing,-as-to-entailing-<amplituding/formativeepistemicity>totalising in-relative-ontological-completeness > of 'unbeholdening sublimating-nascence ontologising-depth of the full-potency of existence' thus in-many-ways eliciting ${ }^{79}$ presencing - absolutising-identitive-constitutedness ${ }^{14}$ social-vestedness/normativity$<$ discretely-implied-functionalism $>$ interpretations of nascent-particular/incipient-andmaterial/technical-sublimations-<blinded-to-their-relative-ontological-completeness

reference-of-thought- devolving $>$ (so-associated with social and intellectual pedantic 
incrementalism-in-relative-ontological-incompleteness ${ }^{8}$

enframed/disontologising conceptualisation of desublimating defaulting as of relativeontological-incompleteness ${ }^{88}$-presublimation-construct-of- ${ }^{56}$ meaningfulness-and-teleology desublimating $\sim$ existentialising-decisionality-<as-to-disontologising/re-ontologising aporeticism $\geqslant$ with regards to its totalisingly-disentailing — discretion/whim-of-thought pretenseof-sublimation rather unconstrained to existence-as-sublimating-withdrawal/unenframing/reontologising,-elicited-from-prospective-profound-supererogation ${ }^{6}$ failing to reflect prospective sublimating-nascence as of prospective ${ }^{45}$ foregrounding_entailment- $<$ in-succession-ofprofound-supererogation $>$-〈postconverging-narrowing-down $\sim$ sublimation-as-to-'existenceas-sublimating-withdrawal/unenframing/re-ontologising,-elicited-from-prospective-profoundsupererogation ' -in-reflecting-'immanent $\sim$ relative-unreflexivity/relative-reflexivity ontological-contiguity ';--as-operative-notional deprocrypticism)), hence undermining 'nonimmediacy prospective sublimating value and ontological-veracity disposition' of sublimating $\sim$ existentialising-decisionality-<as-to-disontologising/re-ontologising apereticism $>$; and so as a fundamental preconverging/postconverging-dementative/structural/paradigmatic sublimation/desublimation existentialising-decisionality<as-to-disontologising/re-ontologising aporeticism $>$ paradox of 'human existentialisingdecisionality-<as-to-disontologising/re-ontologising aporeticism $>$ dual psychologicaldispositions continuum-gradient of sovereignising-by-ontologising-depth in inducing desublimation or sublimation' as so-reflected in the <cumulating/recomposuring attendantontological-contiguity >-successive registry-worldviews/dimensions as to the overall relativeunreflexivity/relative-reflexivity — ontological-contiguity ${ }^{67} \sim$ of-the-human-institutionalisationprocess ${ }^{68}$ In-many-ways the 'catchmenting-by-rejection/lip-servicing/monopolising/gamingof-the-system/charade/distraction vague/imaginary lures of social-stake-contention-orconfliction' of underpinning-suprasocial-construct as to 'human existentialising-decisionality- 
continuum-gradient of sovereignising — by—ontologising-depth in inducing desublimation or sublimation' is rather more revealing of the more ontologically profound "nonpresencing$<$ perspective-ontological-normalcy/postconvergence> notion of supererogatory-progressivity' underlying human possibility to reproject originarily for 'human-decisionality-<as-to-play-ofvalid/invalid-decisionality-imbued-sublimation/desublimation> omni-potential commensurability with inherent immanent-existence's sublimation-structure'omnipotentiality

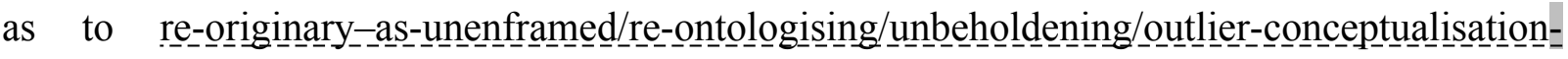
〈imbued-postconverging/dialectical-thinking -'projective-insights'/'epistemic-projection-inconflatedness '-of-notional deprocrypticism-prospective-sublimation $\rangle^{\circ}$ as so-underlying human-subpotency 'fatedness-of-sublimation-over-desublimation, to existencepotency $\sim$ sublimating-nascence,-disclosed-from-prospective-epistemic-digression (in reflecting holographically-<conjugatively-and-transfusively $>$ the relative-unreflexivity/relativereflexivity - ontological-contiguity of-the-human-institutionalisation-process ), as from human-subpotency ontological-faith-notion-or-ontological-fideism - imbuedunderdetermination-of-motif-and-apriorising/axiomatising/referencing-as-so-being-as-ofexistential-reality as to the disseminative-sublimating-selectivity-of-ontological-goodfaith/authenticity postconverging-de-mentating/structuring/paradigming , overdesublimating deselectivity of ontological bad-faith/inauthenticity -preconverging dementating/structuring/paradigming '; as to the fact that any such underpinning-suprasocialconstruct 'beholdening as sovereignising-imbued-subontologisation/subpotentiation' existentialising-decisionality-<as-to-disontologising/re-ontologising aporeticism $>$ actually speak of a limitative-artifice-of-human-imaginary/metaphysical-conceptualisation beneath which in effect supererogatory-progressivity (however the 'shallow-supererogation' of supererogatory-progressivity') 'unbeholdening sublimating-nascence ontologising-depth of the 
full-potency of existence' existentialising-decisionality-<as-to-disontologising/reentologising apereticism $>$ is notionally operating but rather operating as to the enframing of that underpinning-suprasocial-construct 'beholdening as sovereignising-imbuedsubontologisation/subpotentiation' (as reflecting the reality of human 'shallow-supererogation of supererogatory-progressivity'). Thus beneath any supposedly underpinning-suprasocialconstruct (reflected in the modern-day underlying socio-econo-political subontologisation/ideology-over-ontology whether technocratic, capitalistic or communist), is a more fundamental ' ${ }^{\prime}$ nonpresencing-<perspective-ontological-normalcy/postconvergence $>$ notion of supererogatory-progressivity' (however the 'shallow-supererogation of supererogatory-progressivity') accounting for the possibility for prospective human social-andinstitutional-frameworks-of — referencing/registering/decisioning existentialising-decisionality<as-to-disontologising/re-ontologising aporeticism $>$ sublimation/desublimation as in effect creatively permeating all such 'underpinning-suprasocial-construct of ${ }^{79}$ presencingabsolutising-identitive-constitutedness ${ }^{14}$ existentialising-entailing'; and so (especially potent

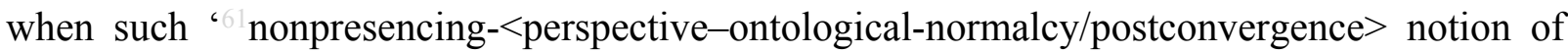
supererogatory-progressivity' is manifested as of profound-supererogation entailing<amplindformative-epistemicity>totalising in-relative-ontological-completeness ${ }^{87}$ as to dimensionality-of-sublimating $25<<$ amplituding/formative $>$ supererogatory $\sim$ dementativeness/epistemic-growth-or-conflatedness /transvaluativerationalising/transepistemicity/anamnestic-residuality/spirit-drivenness-equalisation〉 over 'shallow-supererogation of supererogatory-progressivity'), as more critically superseding human delusions as to desublimating beholdening-becoming-distortiveoriginariness/distortive-origination-as-to- ${ }^{4}$ historicity-tracing inhibited-mental-aestheticising (and thus reflecting the sublimating possibility for prospective 'bechancing-backdrop of nonpresencing-<perspective--ontological-normalcy/postconvergence $>$ ' as to 'bechancing- 
becoming — originariness/origination-as-to- ${ }^{4}$ historiality/ontological-

eventfulness $^{38}$ /ontological-aesthetic-tracing-<perspective-ontological-

normalcy/postconvergence-reflected-‘epistemicity-relativism-determinism’ $>\sim$ disinhibited-

mental-aestheticising sublimation reclamation/recovery from beholdening-becomingdistortive-originariness/distortive-origination-as-to- ${ }^{-}$historicity-tracing inhibited-mental-

aestheticising', so-construed as 'reclamation/recovery of maximalising-recomposuring-forrelative-ontological-completeness ${ }^{8}$ - unenframed/re-ontologising conceptualisation'). In this respect we can appreciate with regards to the capitalistic 'catchmenting-by-rejection/lipservicing/monopolising/gaming-of-the-system/charade/distraction vague/imaginary lures of social-stake-contention-or-confliction' that its most critical/grave moments are moments at which it is hardly/poorly present/existent as to its 'given implied totalising-entailing meaningfulness-and-teleology ${ }^{\circ}$ wherein for instance the social atrophying associated with the Great Depression rather elicited statal supererogatory-progressivity extending into the postwar era of sociopolitical and socioeconomic value renewal that can hardly be qualified as of capitalistic instigation in the pure sense of the word and in-many-ways the technocracy developed and resourced in the postwar years and the associated scientific and technical advancement especially in the face of the Cold War in-many-ways speak to an underlying supererogatory-progressivity on which waves the capitalistic 'catchmenting-by-rejection/lipservicing/monopolising/gaming-of-the-system/charade/distraction vague/imaginary lures of social-stake-contention-or-confliction' rode as so-reflected by Eisenhower cautioning about the U.S. militaro-industrial complex potential sycophantic exploitation of such overall national supererogatory-progressivity and further reflected as to the accruing of national technical and scientific dividends incommensurably to private capitalistic actors. Furthermore, moments of national socio-economic crises as to such capitalistic 'catchmenting-by-rejection/lipservicing/monopolising/gaming-of-the-system/charade/distraction vague/imaginary lures of 
social-stake-contention-or-confliction' have always been critically involved with recouping and reallocating resouces and means for a 'poorly self-sustaining capitalistic model of social ascendency with respect to public externalities, taxation and public debt' as such a capitalistic model increasingly developed in later years into a preconverging/postconverging-dementative/structural/paradigmatic parasitising renting economic model associated with the explosion of financialisation especially as it substitutes/arrogates the social capacity to instigate formative supererogatory-progressivity initiatives (as it can now be appreciated that in-manyways much of the postwar economy arose as of strong public and local governance directed investment in public infrastructure, housing and property which supererogatory-progressivity in-many-ways is now capitalistically substituted/arrogated rather as of a short-term rentingmodel that thrives upon creating winners and losers as to asset inflation strategy for skewed value-extraction). In a critical respect all the creative social supererogatory-progressivity after the postwar years is now reduced in terms of public mitigation of the deleterious fallouts from the capitalistic model all other social supererogatory-progressivity possibilities are now effectively assumed to lie with propping up a poorly self-sustaining capitalistic model (with respect to public subventions, bailouts, taxbreaks) and so notwithstanding the massive financial gains and transfers to tax havens as to a global economy of contrasting rising wealth disparity with the supererogatory-progressivity for individual and social creative initiatives construed as lying in a labour subsistence surrendering to whatever modest possibilities such capitalistic model makes available as supposedly an absolutely determining construct of human supererogatory-progressivity possibilities (while overlooking the reality of its manifest renting parasitising of social value and value possibilities). This in effect speaks to a 'renting and skewed value-extraction capitalistic colonising of the social capacity for supererogatory-progressivity' as to imply that the social capacity for initiative can only be logged/cultured into the expropriating/estranging/constraining/limiting capitalistic model and so-reflected as of a 
globalised framework of totalising-entailing interlocking corporate interests and corporate welfaring that in effect critically and implicitly dictates to states (as of the subtle threat of runaway financial and economic disaster and/or state political-economy retrogradation for noncompliance) the very possibility for their full-capacity for supererogatory-progressivity while being well aloof of the public accounting that political actors running states have to fulfill thus speaking to a most fundamental globalised capitalistic induced democratic-deficit while relatively disempowered governments are left to pick-up-the-pieces (while preconverging/postconverging-de-mentatively/structurally/paradigmatically hemmed-in by the clerical counsels championing the capitalistic model) as to the blindness/sightlessness of a general public backlash (directed to media-driven impressionable narratives rather than to the protracted implications of the roguish capitalistic model), and so as to the more critical preconverging/postconverging-de-mentative/structural/paradigmatic international capitalistic system usurpation and undermining of the possibility for social supererogatory-progressivity and rendering democratic processes circularly unsatisfactory with the electorate increasingly resorting to protest and anti-incumbent votes. In-many-ways thus the supererogatoryprogressivity potential of the global economy presents more opportunities than the capitalistic model arrogatingly seem to imply as in-many-ways it can be argued that as of individual and social supererogatory-progressivity much of 'vocational rationale', 'vocational skills', 'vocational economic models' and 'vocational creativity' underlying the capitalistic model can perfectly thrive without capitalistic 'catchmenting-by-rejection/lipservicing/monopolising/gaming-of-the-system/charade/distraction vague/imaginary lures of social-stake-contention-or-confliction'; and so as to the fact that the very notion of capitalistic enterprising across the world takes various shapes and forms wherein the 'more doctrinaire skewed value-extraction and market distorting models' ride-the-wave of profound value creation activities (often of poorly compensated supererogatory-progressivity) and in-many-ways 
undermining the inclination for profound value creation as to the shortcut for short-term returns. This capitalistic model of skewed value-extraction undermines the possibility of overall human supererogatory-progressivity as to when in the contest between optimal-resource-allocation for value-creation as to the requisite creativity for individuals and social supererogatoryprogressivity and skewed value-extraction eventually reflects poorly self-sustaining capitalistic model (but for mechanisms of external and foreign relocations exploiting the externalities investments in education and infrastructure of second and third world countries) but still posing the question as to how skewed value-extraction can preconverging/postconverging-dementatively/structurally/paradigmatically address in the long-run issues of requisite social and public investment as a requisite for a theoretically self-sustaining economic model (not critically driven and supported by the supererogatory-progressivity prioritisation of local or foreign state) as 'arrogating public supererogatory-progressivity at the exclusion of overall social and resourcefulness/ingenious possibilities'. Interestingly, the more explicit manifestation of supererogatory-progressivity as underlying any given underpinning-suprasocial-construct is most obvious today with the Chinese economic revolution as to the creative impetus driving its overall socioeconomic transformation. Here again it is fair to say just like with the Japanese and South Korean economic revolutions (given their more uniform and deferential populations) there is a whole directedness here (beyond just a purist capitalism model especially of a renting and skewed value-extraction capitalistic model) and so as to 'country supererogatory-progressivity directed whole socioeconomic transformation project', and in-many-ways the capacity for the Chinese to now begin to invest abroad lies with this relatively healthy supererogatoryprogressivity conception/model less betrothed to short-term skewed value-extraction poorly capable of fulfilling the necessary externalities investment to thrive in weaker developing markets (in contrast to the long-term resource-allocation needed to make such markets stable and sustainable). But then in reality when push-came-to-shove the fact is that the postwar history 
of all modern developed governments was hardly about their naïve subjection to a purist capitalistic model to rebuild themselves as in reality their redevelopment involved initial and massive public-driven investments in association with already matured nation-building human resource as to the reality of their supererogatory-progressivity national development programmes (especially as in the middle of the $20^{\text {th }}$ century international trade accounted for just a small part of economic growth) and it is this that purportedly then gave way in later years to a the rising capitalistic model associated with privatisations and private equitisation; and this supererogatory-progressivity model applied in the postwar governments of Western Europe, the United States as well as China, Japan and South Korea as to their initial economic redevelopment. Paradoxically one of the most deleterious postwar economic policy stances advanced with respect to many a third world country as to the prodding of international economic organisations and as 'abstractly and vaguely theorised' by capitalist economists was the advocacy of nation-building in the third world following their postwar independence on the basis of the purist capitalistic model, thus leading in-many-ways to perpetuating the dependence of these nations on these international economic organisations as having to submit to the capitalistic 'shallow-supererogation of supererogatory-progressivity' as so-associated with debt servitude and preconverging/postconverging-de-mentative/structural/paradigmatic adjustment programmes. The fact then is that the only nations in the postwar years that 'truly experienced anything closed to the pure capitalistic economic model as devoid of any national supererogatory-progressivity investment-drive and social programmes mitigation for the consequences of the capitalistic model' are in-many-ways third world countries of limited human and natural resources to be capable of instigating national supererogatory-progressivity with respect to their incipiently disadvantageous circumstances (especially compounded by their limited nation-building human resources) and this in-many-ways accounts for their high and relatively inefficient and subsistence informal sectors as to the relative inability of state resources 
to construct profound and sustainable projects of socioeconomic development (and even then when given the chance with the little means available as of a natural intuition they recoursed essentially to supererogatory-progressivity initiatives like education and basic infrastructural capacities that will hardly pass the test of a true profit-driven and value-extraction capitalistic model), and more critically so as to their more profound interests in social stability in-the-veryfirst-place which can only arise as from a basic level of social wellbeing of their populations before even practically utterly appropriating any such abstract capitalistic model rationale (which in-many-ways actually served to induce a skewed logic on the basis of which natural resources exploiting corporations from developed countries exploit third world natural resources on unfair shallow-supererogation economic terms) and as the short-termism of such a capitalistic model can hardly contribute to inducing the requisite political stability for sustained economic progress (with the capitalistic model as to its self-serving requirement rather warranting the requisite externalities possibilities for its thriving to be established beforehand). The more abstract rationale here (as to 'human-decisionality-<as-to-play-of-valid/invalid-decisionality-imbuedsublimation/desublimation> omni-potential commensurability with inherent immanentexistence's sublimation-structure'/omnipotentiality) is to reflect the reality today of underlying human supererogatory-progressivity as to the incipient reality that human family, communal, clanic and national communities cannot truly operate on the totalising-entailing basis of a purist capitalistic model of social organisation (as to the very risk of undermining social organisation as reflected in the relative prioritisation of national education and basic public facilities in the post-independence years in many Third world countries) with such a purist conception rather reflected as to capitalistic 'catchmenting-by-rejection/lip-servicing/monopolising/gaming-ofthe-system/charade/distraction vague/imaginary lures of social-stake-contention-or-confliction' in a rather comprehensively developed framework/mechanism of value-allocation and valueextraction necessarily underlied notionally by a basic level of supereregatory progressivity 
allow for the 'delusion/sleight projected about a purist conception of capitalism' (serving rather the more veridical and underlying self-serving 'dominance/vested-interest-drivenness- $<$ as-toits-direct/indirect-eliciting-by-or-exploiting-of-prospectively-descalarising/subontologisingsycophantic-sophistic-interests,-as-inducing-prospective-threshold-of-institutional-and-socialdesublimation $>\quad$ of $\quad{ }^{7}$ presencing-absolutising-identitive-constitutedness ${ }^{14}$ socialvestedness/normativity-<discretely-implied-functionalism>'). Further the capitalistic model as to its fabrication of winners and losers given its 'all englobing critical delimiting/catchmentingby-rejection of human supererogatory-progressivity possibilities' increasingly brings peoples at loggerheads across races, classes, regions and nations with the implication that since it is centrally/critically defining as to the modern-day statal conception of social supererogatoryprogressivity possibilities, there must necessarily be losers and winners with no creative supererogatory-progressivity beyond this dilemma; thus as to the fact that there can't be a profound humanity-level creative supererogatory-progressivity as well as decolonisedcapitalistic-by-statal supererogatory-progressivity so-construed as 'anarchical individual and social supererogatory-progressivity'. Such a representation as herein articulated of the truer supererogatory-progressivity (however the 'shallow-supererogation' of supererogatoryprogressivity') beneath the capitalistic 'catchmenting-by-rejection/lipservicing/monopolising/gaming-of-the-system/charade/distraction vague/imaginary lures of social-stake-contention-or-confliction' is hardly reflected today as to 'hardened narratives of an absolutising pure capitalistic model' as mirroring the very ruthlessness associated with the renting and skewed value-extraction capitalistic model (as so-enculturated socially and mediatically as to ${ }^{7}$ presencing-absolutising-identitive-constitutedness ${ }^{14}$ socialvestedness/normativity-<discretely-implied-functionalism $>$ ). The relative veracity of supererogatory-progressivity is strongly seen with the state-driven Asian and European supererogatory-progressivity economies (with the Germans, Japanese and Chinese out- 
competing the U.S. with respect to trade balance and so without all the 'grandiose capitalistic economic theorising' but on the more veridical realism of policy-driven supererogatoryprogressivity) and as even in the U.S. there is atleast a critical level of strategic supererogatoryprogressivity with local states definitely adopting incentives-driven approaches of supererogatory-progressivity; all this speaking from a totalising-entailing perspective analysis of the purist capitalistic model as poorly self-sustaining of its socioeconomic framework (especially its relative irresponsibility/relative-unreflexivity with regards to foundational externalities like education, infrastructure, well thought-out policies, collective social advancement, etc.). The bigger question that then arises has to do with the possibility for optimal human supererogatory-progressivity 'beyond just the statism and geostrategy/states-competition muddled framework' that is preconvergingly-de-mentated/structured/paradigmed to induce skewed 'shallow-supererogation of supererogatory-progressivity' as to capitalistic 'catchmenting-by-rejection/lip-servicing/monopolising/gaming-of-thesystem/charade/distraction vague/imaginary lures of social-stake-contention-or-confliction'. Taking a step aback, in-many-ways the reality of the very fundamental notion of the capitalistic model speaking of perfect markets do not exist, and rather 'markets themselves develop as advantageously created situations after the facts' as to the requisite human creative supererogatory-progressivity for a market to even arise; and in this respect the supposed fittest notion of capitalistic competition as to punctual/immediacy/constituted/compulsionsencumbered fitness tends to underperform the more advantageous supererogative contemplative deliberation of markets for critically efficient/optimising resource allocation/utilisation/development (as to the fact that preconverging/postconverging-dementatively/structurally/paradigmatically the relatively deliberative conceptualisation of markets associated with say German, Japanese, Chinese, South Korean public-policy supererogatory-progressivity economic models participate in their competitive edge over 
'vague/abstract punctual/immediacy/constituted/compulsions-encumbered fitness notion of capitalistic competition' that speaks to an overall deliberative optimalising potential of human supererogatory-progressivity beyond any such capitalistic limitative-artifice-of-humanimaginary/metaphysical-conceptualisation as to 'unbeholdening sublimating-nascence ontologising-depth of the full-potency of existence' elicited existentialising-decisionality-<asto-disentelogising/re-ontelogising aporeticism>).

The so-construed notional ${ }^{18}$ deprocrypticism epistemicity conception of predicative-effectivity-sublimation-〈asto-underlying,-ontological-commitment $-<$ implied - self-assuredness-of-ontological-good-

\section{faith/authenticity $\sim$ postconverging-de-mentating/structuring/paradigming -as-being-as-of-}

existential-reality>> as to the overall relative-unreflexivity/relative-reflexivity-ontologicalcontiguity ${ }^{67}$ of-the-human-institutionalisation-process ${ }^{68}$ provides the requisite basis for prospective human ontological-performance ${ }^{72}-<_{\text {including-virtue-as- }}$ ontology $>$ /morality/ethics/justice/etc. convergence towards 'scalarity/immanency of existence's ontological-normalcy/postconvergence', and so as to the fact that prospective notional ${ }^{18}$ deprocrypticism registry-worldview/dimension as of its superseding/transcending conception (beyond 'social-construct $\quad<$ amplituding/formativeepistemicity $>$ totalising/circumscribing/delineating given prior-institutionalisation-thresholdby-prospective-uninstitutionalised-threshold ${ }^{102}$ imbued secondnaturing') technically equates to 'supposed human-subpotency abstract self-determinative ontological-performance ${ }^{72}$ $<$ including-virtue-as-ontology $>/$ morality/ethics/justice/etc. capacity as to the full-potency of existence' so-implied with the protensive-consciousness 'deepest phenomenological transcendental-point-of-departure handle as of the notional conflatedness ${ }^{13}$ of notional ${ }^{1}$ deprocrypticism deneuterising — 17 referentialism'; and so as to the effective construal of the possibilities of human ${ }^{56}$ meaningfulness-and-teleology' beyond 'mere-formulaic methodologising/mutualising/organising/institutionalising as of human-subpotency non- 
scalarity/beholdening-<as-to-what-has-gone-before-aesthetically-de-

mentates/structures/paradigms-distortedly-the-possibility-for-the-later-ontologisation>

presencing — absolutising-identitive-constitutedness

<amplituding/formative-

epistemicity $>$ totalising $\sim$ self-referencing-syncretising/circularity/interiorising/akrasiatic-drag ${ }^{34}$.

However, in effect despite the reality of 'human-subpotency non-scalarity/beholdening- $<$ as-to-

what-has-gone-before-aesthetically-de-mentates/structures/paradigms-distortedly-the-

possibility-for-the-later-ontologisation>', the human psychology in any of its registryworldview/dimension ${ }^{79}$ presencing-absolutising-identitive-constitutedness ${ }^{14}$ paradoxically projects a notional-contiguity/epistemic-contiguity ${ }^{6}-<$ profound-supererogation -of-mentallyaestheticised postconverging/dialectical-thinking -qualia-schema $>$ wrongly implying it is actually as of 'scalarity/immanency of existence's ontological-normalcy/postconvergence', as to its ontological-performance ${ }^{72}-<$ including-virtue-as-ontology $>$; and so as the very manifest condition of human <amplituding/formative-epistemicity>-totalising $\sim$ thrownness-inexistence ${ }^{35}$,-imbued-projective-arbitrariness/waywardness-〈as-to-the-humanprojective/reprojective - aestheticising-re-motif-and-re-apriorising/re-axiomatising/rereferencing-process-of-'< $<$ amplituding/formative-epistemicity $>$ totalising $\sim$ conceptualisation’ $\rangle$.

This reflects the sub-ontological-<as-to-the-limitation-of-human-subpotency-in-its-reifyingand-empowering-reflexivity-of-the-full-potency-of-existence's $\sim$ sublimating-nascence $>$ nature of all registry-worldviews/dimensions ${ }^{56}$ meaningfulness-and-teleology ${ }^{9}$ however the more-andmore profound ontologisation/ontological-veracity/aestheticisation-towards-ontology with 'relative-ontological-incompleteness 88 /relative-ontological-completeness 3 '

〈sublimating $\sim$ referencing/registering/decisioning,-as-self-becoming/self-

conflatedness /formative-supererogating-<projective/reprojective-aestheticising-re-motifand-re-apriorising/re-axiomatising/re-referencing,-in-perspective-ontologicalnormalcy/postconvergence $>>$ as to human-and-social-expectations/anticipations- 
metaphoricity ${ }^{57}$-as-preconverging/postconverging-rede-

mentating/restructuring/reparadigming-psychologism' ${ }^{89}$ as to prospective induced psychoanalytic-unshackling/memetic-reordering/institutional-recomposuring selfbecoming/self-conflatedness ${ }^{13} /$ formative-supererogating-<projective/reprojectiveaestheticising-re-motif-and-re-apriorising/re-axiomatising/re-referencing,-in-perspectiveontological-normalcy/postconvergence $>$ as conflating towards the possibility of 'scalarity/immanency of existence's ontological-normalcy/postconvergence'; so-implied as of notional ${ }^{1}$ deprocrypticism deneuterising 'exteriorisation attitude/mental-disposition/careand-episteme ${ }^{5}$ of ${ }^{5}$ meaningfulness-and-teleology ${ }^{9}$-as-metaphoricity ${ }^{57}$ superseding/overriding prior ${ }^{83}$ reference-of-thought temporally neuterising 'interiorisation attitude/mentaldisposition/care-and-episteme ${ }^{5}$ of ${ }^{56}$ meaningfulness-and-teleology ${ }^{9}$. The more critical issue thus has to do with how relative ontologisation/ontological-veracity/aestheticisation-towardsontology for prospective transcendence-and-sublimity/sublimation/supereregatory $\sim$ dementativity arises, and so as to the 'reclamation/recovery of maximalising-recomposuring-forrelative-ontological-completeness ${ }^{8}$ - unenframed/re-ontologising conceptualisation beyond any sub-ontological-<as-to-the-limitation-of-human-subpotency-in-its-reifying-andempowering-reflexivity-of-the-full-potency-of-existence's $\sim$ sublimating-nascence> presencing - absolutising-identitive-constitutedness $^{\mid{ }^{4}}$. Given the <amplituding/formativeepistemicity>totalising/circumscribing/delineating nature of human meaningfulness-andteleology ${ }^{9}$, the sub-ontological-<as-to-the-limitation-of-human-subpotency-in-its-reifying-andempowering-reflexivity-of-the-full-potency-of-existence's $\sim$ sublimating-nascence> 'humansubpotency non-scalarity/beholdening-<as-to-what-has-gone-before-aesthetically-dementates/structures/paradigms-distortedly-the-possibility-for-the-later-ontologisation>' $\quad$ in effect reflexively assumes its ontological-performance ${ }^{72}-$ including-virtue-as- $^{-}$ ontology $>$ /morality/ethics/justice/etc. is as of 'scalarity/immanency of existence's ontological- 
normalcy/postconvergence'; with the consequence that the human <amplituding/formativeepistemicity $>$ totalising/circumscribing/delineating conception-of- - meaningfulness-andteleology develops an 'aestheticisation of $<$ preconverging 'motif-andapriorising/axiomatising/referencing'-entailing>-existentialising-enframing/imprintedness〈as-to- historicity-tracing-in-presencing-hyperrealisation/hyperreal-transposition〉' that 'unconsciously/surreptitiously projectively overrides/blinds-out any abstract contemplation of purist ontologisation/ontological-veracity/aestheticisation-towards-ontology' as to its incrementalism-in-relative-ontological-incompleteness ${ }^{8}$ enframed/disontologising conceptualisation and then 'reflexively falsely implies/presupposes its very own purist ontologisation/ontological-veracity/aestheticisation-towards-ontology not subject to contemplation'. In this regards, any registry-worldview/dimension as of its presencing-absolutising-identitive-constitutedness ${ }^{14}$ is, more-or-less as of its prospective relative-ontological-incompleteness ${ }^{88}$, a 'usurpation of abstract purist ontologisation/ontological-veracity/aestheticisation-towards-ontology projected as of notional $\sim{ }^{18}$ deprocrypticism/notional preempting — disjointedness-as-of- ${ }^{3}$ reference-ofthought'; so-reflected by all registry-worldviews/dimensions imbued prior-institutionalisationthreshold-by-prospective-uninstitutionalised-threshold 'self-referencing-syncretising forward-facing-supposedly postconverging-or-dialectical-thinking -apriorisingpsychologism epistemic-projection as of prior mere-formulaicity/ritualisation-<as-to-mereformulaic — methodologising/mutualising/organising/institutionalising,-prospectively-losingtrack-of- ‘ $\left\{\right.$ epistemic-totalising ${ }^{\dagger}$ re-apriorising/re-axiomatising/re-referencing $\sim$ residuality-in-reoriginariness/re-origination'>' as so-reflecting their 'disontologising preconverging/dementing $-<$ as-to-prospective-uninstitutionalised-threshold $>$ ignoring/biased inclination' for the sake of 'their given present minimum-and-balancing expectations/anticipations of social-functioning-and-accordance-as-of-social-stake- 
contention-or-confliction' while qualifying their prospectively uninstitutionalised-threshold actually as nondescript/ignorable-void as to their ${ }^{79}$ presencing-absolutising-identitiveconstitutedness $<$ preconverging 'motif-and-apriorising/axiomatising/referencing' entailing $>$-existentialising — enframing/imprintedness-〈as-to- historicity-tracing - inpresencing-hyperrealisation/hyperreal-transposition). The preconverging/postconverging-dementative/structural/paradigmatic nature of any ${ }^{79}$ presencing-absolutising-identitiveconstitutedness ${ }^{14}$ given 'aestheticisation of $<$ preconverging 'motif-andapriorising/axiomatising/referencing'-entailing>-existentialising-enframing/imprintedness〈as-to- historicity-tracing —-in-presencing-hyperrealisation/hyperreal-transposition〉' usurping/overriding 'notional deprocrypticism abstract purist ontologisation/ontologicalveracity/aestheticisation-towards-ontology' as to the ontological-veracity of nonpresencingor-withdrawal/unenframing/re-ontologising-or-metaphysics-of-absence-_implicited-

\section{epistemic-veracity-of- nonpresencing-<perspective-ontological-}

normalcy/postconvergence $>$ ) - or-transcendental-reasoning-of-event ${ }^{38}$-as-prospective-ontologyorigination, is existentially-<disontologising/re-ontelogising aporeticism $>$ so-reflected as to 'dominance/vested-interest - drivenness-<as-to-its-direct/indirect-eliciting-by-or-exploiting-ofprospectively-descalarising/subontologising-sycophantic-sophistic-interests,-as-inducingprospective-threshold-of-institutional-and-social-desublimation $>\quad$ of $\quad{ }^{79}$ presencingabsolutising-identitive-constitutedness ${ }^{14} \quad$ social-vestedness/normativity- $<$ discretely-impliedfunctionalism>; and so-underlined with the registry-worldview/dimension priorly defining human Being-development/ontological-framework-expansion-as-to-depth-of-ontologisingdevelopment-as-infrastructure-of- meaningfulness-and-teleology , institutionaldevelopment-as-to-social-function-development and living-development-as-to-personalitydevelopment psychologismic epistemic-acutisation difficulty < for, residualising \{decompulsing\} delinearity- for cogency>-magnitudes $\{$ of-experientiality/experiment $\}$ re-engaging with 
ontological-veracity as to human limited-mentation-capacity-deepening-as-subjectinglimitedness/human-subpotency-to-'educed-unlimitedness/existence-sublimating nascence' for prospective sublimation of human ${ }^{56}$ meaningfulness-and-teleology ${ }^{9}$, The implication here is one of a 'double-faceted recurrence preconverging-de-mentating/structuring/paradigming of overlapping human subontologising-<as-to-the-limitation-of-human-subpotency-in-its-reifyingand-empowering-reflexivity-of-the-full-potency-of-existence's $\sim$ sublimating-nascence $>$ subversion/undermining (so-construed as incrementalism-in-relative-ontologicalincompleteness ${ }^{8}$ — enframed/disontologising conceptualisation) of the possibility of prospective purist human ontologisation/ontological-veracity/aestheticisation-towards-ontology implications' (as to human Being-development/ontological-framework-expansion-as-to-depthof-ontologising-development-as-infrastructure-of- meaningfulness-and-teleology , institutional-development-as-to-social-function-development and living-development-as-topersonality-development psychologismic epistemic acutisation difficulty-<for, residualising \{ reflected in the sublimating possibility for prospective 'bechancing-backdrop of nonpresencing-<perspective-ontological-normalcy/postconvergence $>$ ' as to 'bechancingbecoming — originariness/origination-as-to- ${ }^{4}$ historiality/ontologicaleventfulness 3 /ontological-aesthetic-tracing-<perspective-ontologicalnormalcy/postconvergence-reflected-‘epistemicity-relativism-determinism’> disinhibitedmental-aestheticising sublimation reclamation/recovery from beholdening-becomingdistortive-originariness/distortive-origination-as-to- ${ }^{-}$historicity-tracing inhibited-mentalaestheticising' (so-construed as 'reclamation/recovery of ${ }^{55}$ maximalising-recomposuring-forrelative-ontological-completeness ${ }^{87}$ — unenframed/re-ontologising $\sim$ conceptualisation). Critically, incrementalism-in-relative-ontological-incompleteness ${ }^{88}$ enframed/disontologising conceptualisation and ${ }^{55}$ maximalising-recomposuring-for-relative- 
ontological-completeness ${ }^{87}$ - unenframed/re-ontologising conceptualisation possibilities as soarticulated rather speak to human limited-mentation-capacity-as-subjecting 'educedunlimitedness/existence-sublimating nascence' to-limitedness/human-subpotency idiosyncratically imbued paradoxical social behavioural characterisations arising from 'humansubpotency non-scalarity/beholdening-<as-to-what-has-gone-before-aesthetically-dementates/structures/paradigms-distortedly-the-possibility-for-the-later-ontologisation>' relatively deficient human ontological-performance ${ }^{72}-<_{\text {including-virtue-as- }}$ ontology $>$ /morality/ethics/justice/etc. wrongly assuming unreflexively to be of 'scalarity/immanency of existence's ontological-normalcy/postconvergence' relatively sound human ontological-performance ${ }^{72}-<$ including-virtue-as-ontology $>$ Thus an 'notional/epistemic/bindingness-<as-to-determinism/conceptivity-of-relative-unreflexivity/relative-reflexivity> disquisitive enframed/disontologising conceptualisation-by-unenframed/reontologising conceptualisation knowledge-reification gesturing-and-accounting —ofepistemic-phenomenalism-<inprospective_psychologismic apriorising/axiomatising/referencing-\{of-'prospectively implicited_attendant-ontological-contiguity ' educedexistentialising/contextralising/texing_intelligibility/epistemicity/reflexivity-contiguity<imbued-notional cogency >' \}-conflatedness -in-\{preconverging-disentailment by\} postconverging-entailment> constructive conception' for prospective ontologisation/ontological-veracity/aestheticisation-towards-ontology (so-construed as disquisitive 'scalarising of human ${ }^{5}$ meaningfulness-and-teleology' as to ontologicalnormalcy/postconvergence analysis of 'human Being-development/ontological-frameworkexpansion-as-to-depth-of-ontologising-development-as-infrastructure-of- meaningfulnessand-teleology , institutional-development-as-to-social-function-development and livingdevelopment-as-to-personality-development psychologismic epistemic acutisation- 
difficulty-<or, residualising_\{decompulsing $\}$ delinearity for-cogency> $>$ magnitudes $\{$ ofexperientiality/experiment $\left.\}^{\prime}\right)$ as so-relevantly construable across the $<$ cumulating/recomposuring attendant-ontological-contiguity $>$-succession of registryworldviews/dimensions (critically elucidating the underlying 'human social psychology of dominance/vested-interest—drivenness-<as-to-its-direct/indirect-eliciting-by-or-exploiting-ofprospectively-descalarising/subontologising-sycophantic-sophistic-interests,-as-inducingprospective-threshold-of-institutional-and-social-desublimation $>\quad$ of $\quad{ }^{7}$ presencingabsolutising-identitive-constitutedness ${ }^{14}$ ). $\quad \quad{ }^{79}$ Presencing-absolutising-identitiveconstitutedness $\quad \quad<$ preconverging $\sim$ 'motif-and-apriorising/axiomatising/referencing' entailing $>$-existentialising — enframing/imprintedness-〈as-to- historicity-tracing - inpresencing-hyperrealisation/hyperreal-transposition> involves the subontologisation/subpotentiation of ontology as to dominance/vested-interest-drivenness$<$ as-to-its-direct/indirect-eliciting-by-or-exploiting-of-prospectivelydescalarising/subontologising-sycophantic-sophistic-interests,-as-inducing-prospectivethreshold-of-institutional-and-social-desublimation> with the latter rather epistemically analysed as from the originariness/origination-〈so-construed-as-to-ontologicalnormalcy/postconvergence-perspective-scalarising-construal-of-existence) perspective of notional ' deprocrypticism implied 'scalarity/immanency of existence's ontologicalnormalcy/postconvergence' underlying the possibility for prospective scalarisation-as-torescalarisation-as-re-ontologisation/supererolinvoluting-or-guilding-or-amplifyingscalarisation-<as-to-existence—as-sublimating-withdrawal/unenframing/re-ontologising,elicited-from-prospective-profound-supererogation $>$ as reflecting the ${ }^{55}$ maximalisingrecomposuring-for-relative-ontological-completeness ${ }^{87}$ - unenframed/reontologising conceptualisation necessary for re-ontologising prospective Beingdevelopment/ontological-framework-expansion-as-to-depth-of-ontologising-development-as- 
difficulty-<for, residualising _decompulsing $\}$ delinearity for-cogency> magnitude ${ }^{\{0 f-}$ experientiality/experiment\} and its induced prospective institutional-development-as-to-social-functiondevelopment and living-development-as-to-personality-development psychologismic epistemic-acutisation difficulty-<for, residualising \{decompulsing ${ }^{\{}$delinearity for-cogency> magnitudes ${ }^{\{0-e x p e r i e n t i a l i t y / e x p e r i m e n t\}}$ of human social-stake-contention-or-confliction (as otherwise an analysis as to " presencing-absolutising-identitive-constitutedness <preconverging 'motif-and-apriorising/axiomatising/referencing'-entailing >existentialising — enframing/imprintedness-〈as-to- historicity-tracing — in-presencinghyperrealisation/hyperreal-transposition $\rangle$ with the subontologisation/subpotentiation of ontology as to dominance/vested-interest - drivenness-<as-to-its-direct/indirect-eliciting-by-orexploiting-of-prospectively-descalarising/subontologising-sycophantic-sophistic-interests,-asinducing-prospective-threshold-of-institutional-and-social-desublimation>' implied as of 'human-subpotency non-scalarity/beholdening-<as-to-what-has-gone-before-aesthetically-dementates/structures/paradigms-distortedly-the-possibility-for-the-later-ontologisation> $\quad$ will wrongly project the accomplishment of prospective ontologisation and value-construction as rather construable from ${ }^{79}$ presencing-absolutising-identitive-constitutedness ${ }^{14}$ as to its prior Being-development/ontological-framework-expansion-as-to-depth-of-ontologisingdevelopment-as-infrastructure-of- meaningfulness-and-teleology $\quad$ incrementalism-inrelative-ontological-incompleteness ${ }^{8}$ — enframed/disontologising conceptualisation induced institutional-development-as-to-social-function-development and living-development-as-topersonality-development psychologismic epistemic-acutisation difficulty-<or, residualising \{decompulsing $\}$ delinearity for-cogency>-magnitudes $\{$ of-experientiality/experiment\} of socialstake-contention-or-confliction and wrongly implying that any given registryworldview/dimension 
imponderable/inscrutable/unavoidable/inevitable/inescapable/unpreventable/unchangeable/in surmountable/unovercomable framework since it fails to factor in how registryworldviews/dimensions are transcended for prospective re-ontologisation and valueconstruction), as it is the ontological-normalcy/postconvergence perspective that reflects 're-

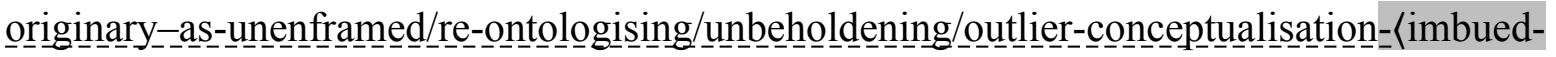

\section{postconverging/dialectical-thinking -'projective-insights'/'epistemic-projection-in-}

conflatedness '-of-notional deprocrypticism-prospective-sublimation $\rangle^{0}$ intemporaldisposition supererogatory rescalarisation of ontologisation and value-construction within any given registry-worldview/dimension ${ }^{79}$ presencing-absolutising-identitive-constitutedness

\section{$<$ preconverging 'motif-and-apriorising/axiomatising/referencing'-entailing $>$ -}

existentialising — enframing/imprintedness-〈as-to- historicity-tracing —in-presencing-

hyperrealisation/hyperreal-transposition> in highlighting prospective sublimation-overdesublimation ${ }^{5}$ meaningfulness-and-teleology ${ }^{9}$ infrastructure thus effectively superseding any such given registry-worldview/dimension underpinning-suprasocial-construct prior conception of ontologisation and value-construction' (and so as to the underlying 'tight-and-entwined connection between the overall human ontological-commitment $-<$ implied — self-assurednessof-ontological-good-faith/authenticity postconverging-de-

mentating/structuring/paradigming -as-being-as-of-existential-reality $>$ as to existence-assublimating-withdrawal/unenframing/re-ontologising,-elicited-from-prospective-profoundsupererogation across all registry-worldviews/dimensions and corresponding registryworldviews/dimensions inherent predicative-effectivity-sublimation-〈as-to-underlying,ontological-commitment ${ }^{6}<$ implied-self-assuredness-of-ontological-goodfaith/authenticity postconverging-de-mentating/structuring/paradigming -as-being-as-ofexistential-reality>> in the 'scalarity/immanency of existence's ontologicalnormalcy/postconvergence' perspective that such 're-originary_-ass-unenframed_- 


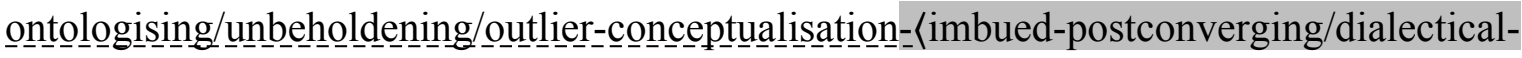

thinking -'projective-insights'/‘epistemic-projection-in-conflatedness ' 'of-

notional deprocrypticism-prospective-sublimation $\rangle$ intemporal-disposition' can induce), and

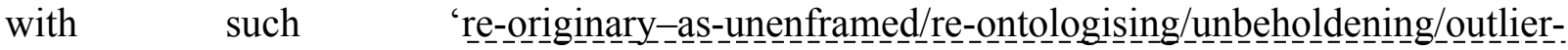
conceptualisation___imbued-postconverging/dialectical-thinking -'projective-

insights'/'epistemic-projection-in-conflatedness ' '-of-notional deprocrypticism-prospectivesublimation $\rangle^{0}$ intemporal-disposition supererogatory rescalarisation of ontologisation and value-construction (within any given registry-worldview/dimension ${ }^{79}$ presencing-absolutisingidentitive-constitutedness ${ }^{14}<$ preconverging 'motif-and-apriorising/axiomatising/referencing'entailing $>$-existentialising — enframing/imprintedness-〈as-to- historicity-tracing - inpresencing-hyperrealisation/hyperreal-transposition〉) highlighting prospective sublimationover-desublimation meaningfulness-and-teleology ${ }^{5}$ infrastructure (thus effectively superseding any such given prior registry-worldview/dimension underpinning-suprasocialconstruct prior conception of ontologisation and value-construction' and preconverging/postconverging-de-mentatively/structurally/paradigmatically explaining the possibility for the <cumulating/recomposuring attendant-ontological-contiguity $>$-succession of registry-worldviews/dimensions as to prospectively induced institutional-development-as-tosocial-function-development and living-development-as-to-personality-development psychologismic epistemic-acutisation difficulty-for, residualising \{decompulsing\} delinearity for-cogeney>-magnitudes $\{$ of-experientiality/experiment\} social-stake-contentionor-confliction). $\quad{ }^{7}$ Presencing-absolutising-identitive-constitutedness <preconverging 'motif-and-apriorising/axiomatising/referencing'-entailing >existentialising — enframing/imprintedness-〈as-to- historicity-tracing_-in-presencinghyperrealisation/hyperreal-transposition) (beyond 'subontologisation/subpotentiation of ontology as to dominance/vested-interest - drivenness-<as-to-its-direct/indirect-eliciting-by-or- 
exploiting-of-prospectively-descalarising/subontologising-sycophantic-sophistic-interests,-as-

inducing-prospective-threshold-of-institutional-and-social-desublimation>'),

preconverging/postconverging-de-mentatively/structurally/paradigmatically speaks to underpinning-suprasocial-construct inherent susceptibility to subontologisation/subpotentiation associated with the descalarisation of ${ }^{56}$ meaningfulness-and-teleology ${ }^{99}$ as reflected with overall $<$ amplituding/formative $>$ wooden-language-〈imbued-temporal-mere-

form/virtualities/dereification/akrasiatic-drag/denatured/preconverging-or-dementing narratives - of-the- reference-of-thought- categorical-imperatives/axioms/registry-

teleology $\rangle$, and thus 'prospective ${ }^{83}$ reference-of-thought re-ontologisation as to rescalarisation' in-many-ways occurs in ontological-normalcy/postconvergence rather as a 're-originary_-as-

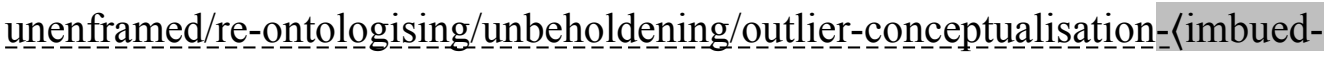
postconverging/dialectical-thinking -'projective-insights'/‘epistemic-projection-inconflatedness ' -of-notional deprocrypticism-prospective-sublimation $\rangle^{0}$ intemporaldisposition' mental-reflex of rescalarisation as to its criticality for the underpinning-suprasocialconstruct re-ontologising prospective Being-development/ontological-framework-expansionas-to-depth-of-ontologising-development-as-infrastructure-of- meaningfulness-andteleology with the reality of all such induced re-ontologisation whether with say the Socraticphilosophers and budding-positivists rescalarisation of ${ }^{5}$ meaningfulness-and-teleology effectively implying a psychoanalytic-unshackling/memetic-reordering/institutionalrecomposuring exercise in transversality-<for-sublimating-existentialeventuating/denouement,-from-'thinking at-first/pure-predisposition-preemptive-ofprospective-disontologising/subontologising' as-of-prospectively-disambiguated-affirmedand-unaffirmed-'motif-and-apriorising/axiomatising/referencing'> ${ }^{101}$ with the prior registryworldview/dimension in relative-ontological-incompleteness ${ }^{88}$ descalarisation in inducing the requisite positive-opportunism-of-social-functioning-and-accordance ${ }^{75}$ for prospective 
sublimation of the underpinning-suprasocial-construct since the prior underpinningsuprasocial-construct appreciation of re-ontologising prospective Beingdevelopment/ontological-framework-expansion-as-to-depth-of-ontologising-development-asinfrastructure-of- meaningfulness-and-teleology most critically arises only as the backdrop for prospective induced institutional-development-as-to-social-function-development and living-development-as-to-personality-development psychologismic epistemic-acutisation difficulty-for, residualising_\{decompulsing\} delinearity for-cogency> magnitudes $\{$ ofexperientiality/experiment\} social-stake-contention-or-confliction and so in the sense that the underpinning-suprasocial-construct appreciation of Socratic philosophy and budding-positivism didn't arise as to their abstractly articulated ${ }^{103}$ universalising-idealisation and positivism/rational-empiricism respectively (explaining their persecution at that instigative stage) but only took hold respectively as to the positive-opportunism-of-social-functioningand-accordance ${ }^{75}$ respectively of a ${ }^{103}$ universalising-idealisation notional ontology/existential backdrop and positivism/rational-empiricism notional ontology/existential backdrop for the subsequent induced institutional-development-as-to-social-function-development and livingdevelopment-as-to-personality-development psychologismic epistemic acutisation-

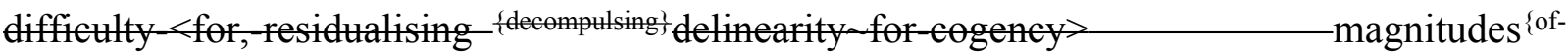
experientiality/experiment\} social-stake-contention-or-confliction implications these ushered (and it is only at this point that the need to draw from their respective ${ }^{56}$ meaningfulness-and-teleology infrastructure for prospectively induced institutional-development-as-to-social-functiondevelopment and living-development-as-to-personality-development psychologismic epistemic-acutisation difficulty-for, residualising \{decompulsing\} delinearity for-cogency> magnitudes $\{$ of-experientiality/experiment\} social-stake-contention-or-confliction then elicited the overall social appreciation of the underlying Being-development/ontological-framework-expansion-asto-depth-of-ontologising-development-as-infrastructure-of- meaningfulness-and-teleology ). 
This reflect the fact that the rescalarising re-ontologisation respectively as of baseinstitutionalisation, ${ }^{103}$ universalisation, positivism/rational-empiricism and prospective deprocrypticism-or-preempting-disjointedness-as-of- ${ }^{3}$ reference-of-thought over the respective subontologisation/subpotentiation of recurrent-utter-uninstitutionalisation, ununiversalisation, non-positivism/medievalism and ${ }^{80}$ procrypticism-or-disjointedness-as-ofreference-of-thought construed as descalarising, rather speak of a 'messianic-structure of intemporality ${ }^{52}$ and its derived deferential-formalisation-transference secondnaturing that goes well beyond the sophistic/pedantic contemplative pertinence or logical-basis/logic,-as-derivedfrom $\sim$ transversality-<for-sublimating-existential-eventuating/denouement-from-'thinking-atfirst/pure-predisposition-preemptive-of prospective-disontologising/subontologising' as-ofprospectively-disambiguated-affirmed-and-unaffirmed-'motif-andapriorising/axiomatising/referencing' $>$ (01 of any of the transcended registryworldview/dimension caught up in its <amplituding/formative-epistemicity >totalising $\sim$ selfreferencing-syncretising/circularity/interiorising/akrasiatic-drag $<$ amplituding/formative $>$ wooden-language-〈imbued-temporal-mere-

\section{form/virtualities/dereification/akrasiatic-drag/denatured/preconverging-or-dementing}

\section{narratives - of-the- reference-of-thought- categorical-imperatives/axioms/registry-}

teleology $\rangle$. The further implication is that such a 'merely manifest positive-opportunism-ofsocial-functioning-and-accordance ${ }^{75}$ underpinning-suprasocial-construct conception of the instigative dispensing-with-immediacy-for-relative-ontological-completeness ${ }^{87}$-byreification/contemplative-distension ${ }^{27}$ for re-ontologising prospective Beingdevelopment/ontological-framework-expansion-as-to-depth-of-ontologising-development-asinfrastructure-of- meaningfulness-and-teleology rather as to the positive-opportunism-ofsocial-functioning-and-accordance ${ }^{75}$ backdrop for prospective induced institutionaldevelopment-as-to-social-function-development and living-development-as-to-personality- 
$\{$ decompulsing $\}$ delinearity for-cogeney $>$ magnitudes ${ }^{\{\text {of-experientiality/experiment }\}}$ social-stake-contentionor-confliction' in its ontologically-deficient notional originariness-parrhesia,--as-spontaneityof-aestheticisation implies an aloofness to the 'messianic-structure of intemporality ${ }^{52}$ ' as of the overall existential-<disontologising/re-ontologising aporeticism $>$ dimensionality-ofsublimating $25-<$ amplituding/formative $>$ supererogatory $\sim$ de-mentativeness/epistemic-growthor-conflatedness /transvaluative-rationalising/transepistemicity/anamnestic-residuality/spiritdrivenness-equalisation) as the inherent ontological-good-faith/authenticity $\sim$ postconvergingde-mentating/structuring/paradigming ${ }^{70}$ effectively reflected as of notional ${ }^{18}$ deprocrypticism such that such an underpinning-suprasocial-construct conception as of positive-opportunismof-social-functioning-and-accordance ${ }^{75}$ will rather be in a complexification of positivism/rational-empiricism manifestation of procrypticism-or-disjointedness-as-ofreference-of-thought that can't truly contemplate of prospective deprocrypticism-orpreempting-disjointedness-as-of- ${ }^{83}$ reference-of-thought which is a notion beyond just the possibility for secondnatured reproducibility-mathesis/motif/thrownness-disposition,--asreproducibility-of-aestheticisation as so-reflected by the requisite inducing of the capacity for originariness-parrhesia,-as-spontaneity-of-aestheticisation-

supererogatory acuity/perspicacity/astuteness/edginess/incisiveness projection as to overall existential-<disontologising/re-ontologising aporeticism $>$ dimensionality-of-sublimating <<amplituding/formative>supererogatory $\sim$ de-mentativeness/epistemic-growth-or-

\section{conflatedness /transvaluative-rationalising/transepistemicity/anamnestic-residuality/spirit-}

drivenness-equalisation) as the inherent ontological-good-faith/authenticity $\sim$ postconvergingde-mentating/structuring/paradigming ${ }^{70}$ to truly contemplate of ${ }^{18}$ deprocrypticism-orpreempting - disjointedness-as-of- ${ }^{-3}$ reference-of-thought as of rescalarition possibilities for reontologisation. In this regards with respect to ${ }^{79}$ presencing-absolutising-identitive- 
constitutedness

entailing >-existentialising — enframing/imprintedness-〈as-to- historicity-tracing —in-

presencing-hyperrealisation/hyperreal-transposition〉 conception of social-stake-contention-orconfliction in its $<$ amplituding formative-epistemicity $>$ totalising $\sim$ self-referencingsyncretising/circularity/interiorising/akrasiatic-drag ${ }^{34}$, in-many-ways the core incipient/nascent/instigative genuine social intellectual-function/posture as keeping opened/alive the 'scalarity/immanency of existence's ontological-normalcy/postconvergence' is about an intemporal-disposition that is consummated as to its unenframed/reontologising conceptualisation and so in 'articulating the ${ }^{103}$ universal-transparency ${ }^{104}$ 〈transparency-of-totalising-entailing,-as-to-entailing-<amplituding/formative-

epistemicity>totalising in-relative-ontological-completeness $>$ of the dead-end as to reontologising prospective Being-development/ontological-framework-expansion-as-to-depthof-ontologising-development-as-infrastructure-of- meaningfulness-and-teleology of the presencing - absolutising-identitive-constitutedness ${ }^{14} \quad<$ preconverging 'motif-andapriorising/axiomatising/referencing'-entailing>-existentialising—enframing/imprintedness〈as-to- historicity-tracing-in-presencing-hyperrealisation/hyperreal-transposition〉 with respect to its implications for prospective induced institutional-development-as-to-socialfunction-development and living-development-as-to-personality-development psychologismic epistemic acutisation difficulty< <or, residualising \{decompulsing\} delinearity for cogeney> magnitudes $\{$ of-experientiality/experiment\} social-stake-contention-or-confliction'; and thus ushering the possibility for prospective ontological-good-faith/authenticity ${ }^{6}$ within-and-without such presencing-absolutising-identitive-constitutedness $<$ preconverging ' motif-andapriorising/axiomatising/referencing'-entailing >-existentialising-enframing/imprintedness〈as-to- historicity-tracing-in-presencing-hyperrealisation/hyperreal-transposition〉 in renewing the genuine social intellectual-function/posture engagement for such re-ontologising 
prospective Being-development/ontological-framework-expansion-as-to-depth-ofontologising-development-as-infrastructure-of- meaningfulness-and-teleology (so-implied as of 'limitedness/human-subpotency prospective re-encountering/re-confrontation with unlimitedness/existence-<full-potency-of_sublimating nascence $>$ ' specifically with regards to reference-of-thought_-point-of-devolving/departure/anchoring/backdrop_of_sublimating_ nascence-<as-to-the-grandest-axiomatic-construct- - epistemic-totalising ${ }_{3}^{+}$re-apriorising/reaxiomatising/re-referencing residuality-in-re-originariness/re-origination of limitedness/human-subpotency prospective re-encountering/re-confrontation with

unlimitedness/existence>). This is so-reflected as to the fact that Socratic-philosophers were more critically/precisely involved in 'thinking at first/pure predisposition preemptive of prospective disontologising/subontologising' (as to recurrently requisite 'relative-ontologicalincompleteness 8 /relative-ontological-completeness ${ }^{87}$ -

〈sublimating referencing/registering/decisioning,-as-self-becoming/self-

conflatedness /formative-supererogating-<projective/reprojective- aestheticising-re-motifand-re-apriorising/re-axiomatising/re-referencing,-in-perspective-ontologicalnormalcy/postconvergence $>>$ as to human-and-social-expectations/anticipationsmetaphoricity ${ }^{57}$-as-preconverging/postconverging-redementating/restructuring/reparadigming-psychologism' ${ }^{89}$ for human prospective re-ontologising) and so rather with regards to their philosophy implied ${ }^{103}$ universalising-idealisation ontologicalgood-faith/authenticity ${ }^{6}$ over non-universalising sophistry ontological-badfaith/inauthenticity ${ }^{64}$ as to human limited-mentation-capacity-deepening-as-subjecting limitedness/human-subpotency to-'educed-unlimitedness/existence-sublimating nascence' implications of originariness-parrhesia,-as-spontaneity-of-aestheticisationsupererogatory acuity/perspicacity/astuteness/edginess/incisiveness projection (beyond just an absolutising divide between philosophers/sophists as reflected by the fact of Socratic- 
philosophers engagement with supposed sophists as to the eliciting of the ${ }^{103}$ universaltransparency ${ }^{104}$-〈transparency-of-totalising-entailing,-as-to-entailing-<amplituding/formativeepistemicity>totalising in-relative-ontological-completeness > of philosophy implied universalising-idealisation as ontological-good-faith/authenticity ${ }^{69}$ over non-universalising sophistry as ontological-bad-faith/inauthenticity ${ }^{64}$ ). Likewise in-many-ways budding-positivists were rather critically/precisely involved in 'thinking at first/pure predisposition preemptive of prospective disontologising/subontologising' eliciting of the ${ }^{103}$ universal-transparency 〈transparency-of-totalising-entailing,-as-to-entailing-<amplituding/formativeepistemicity>totalising in-relative-ontological-completeness > of positivism/rationalempiricism as ontological-good-faith/authenticity over non-positivism/medievalism as ontological-bad-faith/inauthenticity ${ }^{64}$. Both cases respectively projected the ${ }^{103}$ universaltransparency ${ }^{104}$ - transparency-of-totalising-entailing,-as-to-entailing-<amplituding/formativeepistemicity $>$ totalising in-relative-ontological-completeness $\rangle$ that re-ontologising prospective Being-development/ontological-framework-expansion-as-to-depth-of-ontologisingdevelopment-as-infrastructure-of- meaningfulness-and-teleology resided respectively with universalising-idealisation and positivism/rational-empiricism with respect to any solipsistic ontological-good-faith/authenticity inclination notwithstanding any prior influences it had as of prior <amplituding/formative-epistemicity>-totalising $\sim$ thrownness-in-existence ${ }^{35}$. Thus effectively the relative-unreflexivity/relative-reflexivity ontological-contiguity $\sim$ of-thehuman-institutionalisation-process ${ }^{68}$ speaks to the fact that (as to their mere-formulaic reference-of-thought- categorical-imperatives/axioms/registry-teleology ${ }^{9}$,-foraposteriorising/logicising/deriving/intelligising/measuring - ${ }^{56}$ meaningfulness-and-teleology that fail prospective originariness-parrhesia,-as-spontaneity-of-aestheticisationacuity/perspicacity/astuteness/edginess/incisiveness-of- 
conceptualisation) recurrent-utter-uninstitutionalisation, base-institutionalisation-

ununiversalisation, $\quad{ }^{103}$ universalisation-non-positivism/medievalism and positivismprocrypticism are dead-ends of human Being-development/ontological-frameworkexpansion-as-to-depth-of-ontologising-development-as-infrastructure-of- meaningfulnessand-teleology so-reflected as from notional ' deprocrypticism implied 'scalarity/immanency of existence's ontological-normalcy/postconvergence' (so-reflecting the ontologising/scientific/existence- $<$ honesty-constraining $>$ - scope_for_prospective_reontologising imbued underlying-elucidative 'requisite sublimating/desublimating formulative-

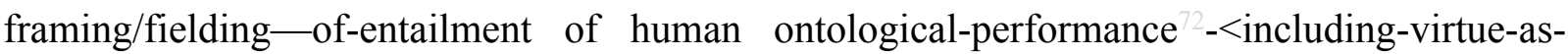
ontology $>$ /morality/ethics/justice/etc. contemplation' as of notionally implied foregrounding_entailment- $<$ in-succession-of-profound-supererogation $>-\langle$ postconvergingnarrowing-down $\sim$ sublimation-as-to-'existence - as-sublimating-withdrawal/unenframing/reontologising,-elicited-from-prospective-profound-supererogation '-in-reflecting'immanent $\sim$ relative-unreflexivity/relative-reflexivity ontological-contiguity ${ }^{\prime} ;$-as-operativenotional deprocrypticism)). Ultimately, 'human-subpotency non-scalarity/beholdening-<asto-what-has-gone-before-aesthetically-de-mentates/structures/paradigms-distortedly-thepossibility-for-the-later-ontologisation>' speaks to a mental-disposition that reflexively assumes incrementalism-in-relative-ontological-incompleteness ${ }^{8}$ enframed/disontologising conceptualisation as to the priority of ${ }^{56}$ meaningfulness-andteleology and value-construction as of induced institutional-development-as-to-socialfunction-development and living-development-as-to-personality-development psycholegismic epistemic-acutisation difficulty-for, residualising \{decompulsing\} ${ }^{\text {delinearity for-cogency> }}$ magnitudes $\{$ of-experientiality/experiment\} social-stake-contention-or-confliction enamoured to the prior ontologically-deficient/relative-ontological-incompleteness ${ }^{88}$ Being-development/ontologicalframework-expansion-as-to-depth-of-ontologising-development-as-infrastructure-of- 
meaningfulness-and-teleology with a poorer capacity for the dispensing-with-immediacyfor-relative-ontological-completeness ${ }^{87}$-by-reification/contemplative-distension ${ }^{27}$ for the more profound implications of re-ontologising prospective Being-development/ontologicalframework-expansion-as-to-depth-of-ontologising-development-as-infrastructure-ofmeaningfulness-and-teleology as to 'scalarity/immanency of existence's ontologicalnormalcy/postconvergence' projected ${ }^{5}$ maximalising-recomposuring-for-relative-ontologicalcompleteness $^{87}$ — unenframed/re-ontologising conceptualisation (given that originariness/origination-〈so-construed-as-to-ontological-normalcy/postconvergenceperspective-scalarising-construal-of-existence) as to human limited-mentation-capacitydeepening as subjecting limitedness/hmman subpotency to 'educed unlimitedness/existence sublimating nascence 5 implications as of the apriorising/axiomatising/referencing-\{of'prospectively implicited_attendant-ontological-contiguity ' educedexistentialising/contextualising/textualising_'intelligibility/epistemicity/reflexivity-contiguity$<$ imbued-notional cogency $\left.>{ }^{\prime}\right\}$-conflatedness ${ }^{13}$ in- -preconverging-disentailment by\} pestcenverging entailment of ontological-normalcy/postconvergence implied maximalisingrecomposuring-for-relative-ontological-completeness ${ }^{87}$ - unenframed/reontologising conceptualisation and not apriorising/axiomatising/referencing-\{of'prospectively_implicited_attendant-ontological-contiguity ' educedexistentialising/contextualising/textualising_intelligibility/epistemicity/reflexivity-contiguity$<$ imbued-notional cogency $\left.>^{\prime} \quad\right\}$-constitutedness ${ }^{14}$-in-preconverging-entailment $\quad$ implied incrementalism-in-relative-ontological-incompleteness

enframed/disontologising conceptualisation). $\quad$ This in-many-ways preconverging/postconverging-de-mentatively/structurally/paradigmatically explains the ingrained manifestation for the <cumulating/recomposuring attendant-ontologicalcontiguity >-successive registry-worldviews/dimensions elapsing into: 
- $\quad{ }^{7}$ presencing — absolutising-identitive-constitutedness

$<$ preconverging 'motif-and-

apriorising/axiomatising/referencing'-entailing>-existentialising-enframing/imprintedness-

〈as-to- historicity-tracing - in-presencing-hyperrealisation/hyperreal-transposition〉 with the subontologisation/subpotentiation of ontology as to dominance/vested-interest-drivenness$<$ as-to-its-direct/indirect-eliciting-by-or-exploiting-of-prospectively-

descalarising/subontologising-sycophantic-sophistic-interests,-as-inducing-prospectivethreshold-of-institutional-and-social-desublimation>;

presencing — absolutising-identitive-constitutedness

$<$ preconverging 'motif-andapriorising/axiomatising/referencing'-entailing >-existentialising —enframing/imprintedness〈as-to- historicity-tracing-in-presencing-hyperrealisation/hyperreal-transposition〉 skewed $<$ amplituding/formative-epistemicity>totalising/circumscribing/delineating conception of value-construction as to social-vestedness/normativity- $<$ discretely-implied-functionalism $>$; - $\quad{ }^{7}$ presencing — absolutising-identitive-constitutedness ${ }^{14} \quad<$ preconverging 'motif-andapriorising/axiomatising/referencing'-entailing >-existentialising-enframing/imprintedness〈as-to- historicity-tracing-in-presencing-hyperrealisation/hyperreal-transposition〉 construed as the imponderable/inscrutable/unavoidable/inevitable/inescapable/unpreventable/unchangeable/in surmountable/unovercomable framework with regards to social-stake-contention-or-confliction; - $\quad{ }^{7}$ presencing — absolutising-identitive-constitutedness ${ }^{14} \quad<$ preconverging ' $m o t i f-a n d-$ apriorising/axiomatising/referencing'-entailing >-existentialising — enframing/imprintedness〈as-to- historicity-tracing-in-presencing-hyperrealisation/hyperreal-transposition〉 $<$ amplituding/formative-epistemicity $>$ totalising $\sim$ self-referencingsyncretising/circularity/interiorising/akrasiatic-drag ${ }^{34}$ closed framework of sanctified probity and probationary exercise;

- $\quad{ }^{79}$ presencing-absolutising-identitive-constitutedness 
apriorising/axiomatising/referencing'-entailing>-existentialising—enframing/imprintedness〈as-to- historicity-tracing-in-presencing-hyperrealisation/hyperreal-transposition〉 underlying social disenfranchising/desublimating influence-networking-<subvertingsupposedly- ${ }^{103}$ universal-possibilities-and-opportunities $>$ falsely construed as prospectively sublimating;

- $\quad{ }^{79}$ presencing - absolutising-identitive-constitutedness $<$ preconverging 'motif-andapriorising/axiomatising/referencing'-entailing >-existentialising—enframing/imprintedness〈as-to- historicity-tracing-in-presencing-hyperrealisation/hyperreal-transposition〉 flawed exemplifying/epitomising/charade as supposedly sublimation in substitution of relevant ontological optimisation exercise for prospective sublimation;

- $\quad{ }^{7}$ presencing - absolutising-identitive-constitutedness ${ }^{14} \quad<$ preconverging 'motif-andapriorising/axiomatising/referencing'-entailing>-existentialising-enframing/imprintedness〈as-to- historicity-tracing-in-presencing-hyperrealisation/hyperreal-transposition〉 institutional and social dysfunctional stultifying/hampering as to constricted enframed outlets of sublimation and defensive institutional threatening of chaos with regards to re-originary_asunenframed/re-ontologising/unbeholdening/outlier_conceptualisation___imbuedpostconverging/dialectical-thinking - 'projective-insights'/'epistemic-projection-inconflatedness '-of-notional deprocrypticism-prospective-sublimation $\rangle^{0} \quad$ prospective sublimation possibilities it construes as valuelessness; - $\quad 7$ presencing - absolutising-identitive-constitutedness ${ }^{14} \quad<$ preconverging 'motif-andapriorising/axiomatising/referencing'-entailing>-existentialising-enframing/imprintedness〈as-to- historicity-tracing-in-presencing-hyperrealisation/hyperreal-transposition〉 institutionalised pedantising/muddling/formulaic-hollowing-out—insubontologisation/subpotentiation-〈blurring/undermining-of-prospective-totalising-entailing,as-to-entailing-<amplituding/formative-epistemicity $>$ totalising in-relative-ontological- 
completeness > desublimation in undermining re-originary_-as-unenframed/reontologising/unbeholdening/outlier-conceptualisation__imbued-postconverging/dialecticalthinking -'projective-insights'/‘epistemic-projection-in-conflatedness ' '-ofnotional deprocrypticism-prospective-sublimation $\rangle$ prospective sublimation possibilities; - ${ }^{7}$ presencing—absolutising-identitive-constitutedness ${ }^{14} \quad<$ preconverging $\sim$ 'motif-andapriorising/axiomatising/referencing'-entailing>-existentialising-enframing/imprintedness〈as-to- historicity-tracing-in-presencing-hyperrealisation/hyperreal-transposition〉 desublimation as to pedantising/muddling/formulaic-hollowing-out-insubontologisation/subpotentiation-〈blurring/undermining-of-prospective-totalising-entailing,as-to-entailing-<amplituding/formative-epistemicity $>$ totalising $\sim$ in-relative-ontologicalcompleteness $>$ of priorly induced sublimation;

- $\quad{ }^{7}$ presencing - absolutising-identitive-constitutedness ${ }^{14} \quad<$ preconverging 'motif-andapriorising/axiomatising/referencing'-entailing >-existentialising — enframing/imprintedness〈as-to- historicity-tracing-in-presencing-hyperrealisation/hyperreal-transposition〉 catchmenting-by-rejection/lip-servicing/monopolising/gaming-of-thesystem/charade/distraction of budding sublimating ontologisation and value-construction into its constricted desublimating <preconverging 'motif-and-apriorising/axiomatising/referencing'entailing >-existentialising — enframing/imprintedness-〈as-to- historicity-tracing - inpresencing-hyperrealisation/hyperreal-transposition〉 of institutionalised socialvestedness/normativity- $<$ discretely-implied-functionalism $>$ undermining the full potential for prospective ontologisation/ontological-veracity/aestheticisation-towards-ontology and valueconstruction;

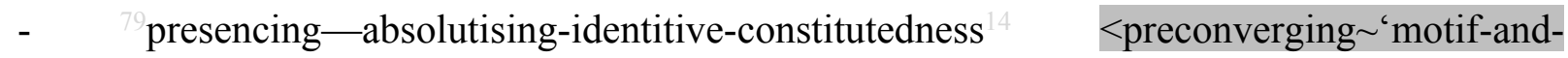
apriorising/axiomatising/referencing'-entailing>-existentialising-enframing/imprintedness〈as-to- historicity-tracing-in-presencing-hyperrealisation/hyperreal-transposition〉 
preconverging/postconverging-de-mentative/structural/paradigmatic demobilisation of human sovereign and full prospective sublimation capacity;

- $\quad{ }^{7}$ presencing - absolutising-identitive-constitutedness ${ }^{14} \quad<$ preconverging $\sim^{\text {'motif-and- }}$ apriorising/axiomatising/referencing'-entailing >-existentialising — enframing/imprintedness〈as-to- historicity-tracing-in-presencing-hyperrealisation/hyperreal-transposition〉 sophistic/pedantic $\quad{ }^{5}$ incrementalism-in-relative-ontological-incompleteness ${ }^{8}$ enframed/disontologising conceptualisation and <amplituding/formative $>$ wooden-language〈imbued-temporal-mere-form/virtualities/dereification/akrasiaticdrag/denatured/preconverging-or-dementing -narratives - of-the- reference-of-thoughtcategorical-imperatives/axioms/registry-teleology > eliciting of $<$ amplituding/formative $>$ wooden-language-_imbued — averaging-of-thought- $<$ as-toleveling/ressentiment/closed-construct-of- meaningfulness-and-teleology -as-of'nondescript/ignorable-void '-with-regards-to-prospective-apriorising-implications $>>$ as to preempting prospectively subverting sublimation; and - $\quad$ presencing - absolutising-identitive-constitutedness ${ }^{14} \quad<$ preconverging $\sim$ 'motif-andapriorising/axiomatising/referencing'-entailing>-existentialising-enframing/imprintedness〈as-to- historicity-tracing-in-presencing-hyperrealisation/hyperreal-transposition〉 preconverging/postconverging-de-mentatively/structurally/paradigmatically construing as calamitous the possibility for prospective re-ontologisation from its subontologisation; with 'human superseding of so-articulated ${ }^{7}$ presencing-absolutising-identitive-constitutedness <preconverging 'motif-and-apriorising/axiomatising/referencing'-entailing >existentialising — enframing/imprintedness-〈as-to- historicity-tracing - in-presencinghyperrealisation/hyperreal-transposition〉' keeping opened/alive the 'scalarity/immanency of existence's ontological-normalcy/postconvergence'.

Critically, scalarisation analysis operantly implies projecting the implied 'scaling/scalar of 
reference' as from ontological-normalcy/postconvergence epistemic-projection perspective implications of analysis as to the prospective possibilities for 'human Beingdevelopment/ontological-framework-expansion-as-to-depth-of-ontologising-development-asinfrastructure-of- meaningfulness-and-teleology , institutional-development-as-to-socialfunction-development and living-development-as-to-personality-development psychologismic epistemic-acutisation difficulty-for, residualising \{decompulsing $\}$ delinearity for-cogency> magnitudes $\{$ of-experientiality/experiment $\}$. In this regards, it can very much be appreciated that human scalarisation $\quad$ potential $\quad$ (existentially-<disontologising/re-ontologisingapereticism $>$ manifestable as of successive rescalarisation as re-ontologisation as to human limited-mentation-capacity-deepening—as-subjecting limitedness/human-subpotency-to'educed-unlimitedness/existence-sublimating-nascence' ${ }^{53}$ implications) reflects all the sublimation-over-desublimation possibility for the full possibility of human ontologicalperformance $^{72}$-<including-virtue-as-ontology $>$ /morality/ethics/justice/etc. as can be so-

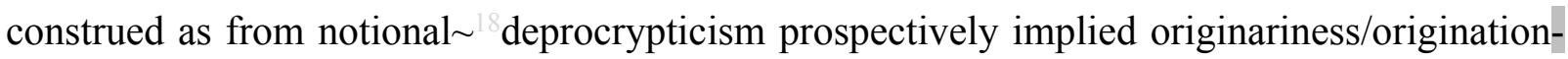
〈so-construed-as-to-ontological-normalcy/postconvergence-perspective-scalarising-construal-

of-existence). But then inevitably human limited-mentation-capacity-deepening-as-subjectinglimitedness/human-subpotency-to-'educed-unlimitedness/existence-sublimating nascence' implications speaks to conceptivity/epistemic-reflexivity/epistemicity-relativism-determinism$<$ reifying \{as-to-knowledge-developing\}-and-empowering $>$ in the sense that (beyond naïve presencing - absolutising-identitive-constitutedness $<$ preconverging 'motif-andapriorising/axiomatising/referencing'-entailing >-existentialising — enframing/imprintedness〈as-to- historicity-tracing-in-presencing-hyperrealisation/hyperreal-transposition〉) as from nonpresencing-<perspective-ontological-normalcy/postconvergence $>\quad$ epistemic-projection perspective, 'human descalarisation is already caught up in the human aspiration for scalarisation re-originariness/re-origination' as to the underlying sublimating-by-desublimating 
<amplituding/formative-epistemicity>totalising/circumscribing/delineating manifestation of aestheticisation-and-aestheticisation-towards-ontology-<elicited-idiomatisation $>\quad$ as $\quad$ of 'relative-ontological-incompleteness ${ }^{8 /} /$ relative-ontological-completeness $^{87}$ -

〈sublimating referencing/registering/decisioning,-as-self-becoming/selfconflatedness /formative-supererogating-<projective/reprojective-aestheticising-re-motifand-re-apriorising/re-axiomatising/re-referencing,-in-perspective-ontologicalnormalcy/postconvergence $>>$ as to human-and-social-expectations/anticipationsmetaphoricity ${ }^{57}$-as-preconverging/postconverging-rede-

mentating/restructuring/reparadigming-psychologism' ${ }^{89}$ just as for instance the notion of length is already caught up in the notion of width in the 'sublimating <amplituding formativeepistemicity $>$ totalising/circumscribing/delineating manifestation of a rectangle' and so with regards to the fact that human aestheticisation-and-aestheticisation-towards-ontology$<$ elicited-idiomatisation $>$ of ${ }^{56}$ meaningfulness-and-teleology ${ }^{9}$ is ever always about 'idealisedtypification in epistemic-conflatedness ${ }^{13}$ sublimation or epistemic apriorising/axiomatising/referencing-\{of-'prospectively_implicited_attendant-ontologicalcontiguity ' $\sim$ educedexistentialising/contextmalising/textualising_'intelligibility/epistemicity/reflexivity_contiguity$<$ imbued-notional $\sim$ cogency $>\quad, \quad$ - constitutedness ${ }^{1}$-in-preconverging entailment/pseudoconflation desublimation/gimmickiness' for eliciting sublimation/desublimation from the 'full-potency of existence withheld as from ontologicalnormalcy/postconvergence epistemic projection-perspective'. In this respect, scalarisation analysis is a projection beyond just a conceptually implied originariness/origination-〈soconstrued-as-to-ontological-normalcy/postconvergence-perspective-scalarising-construal-ofexistence) but is comprehensively and notionally/epistemically/bindingnessly-<as-to- 
preconverging/postconverging-de-mentative/structural/paradigmatic rescalarisation and descalarisation of human ontological-performance ${ }^{72}-$ including-virtue-as- $^{2}$ of ontology $>$ /morality/ethics/justice/etc. as to human limited-mentation-capacity-as-subjecting 'educed-unlimitedness/existence-sublimating nascence' to-limitedness/human-subpotency implications. This incipient descalarisation reflex is critically manifested by the fact that the human is preconverging/postconverging-de-mentatively/structurally/paradigmatically as of its $<$ amplituding/formative-epistemicity>-totalising $\sim$ thrownness-in-existence ${ }^{35}$ (as so-attendant of overall reifying-and-empowering-reflexivity-of-ecstatic-existence-as-

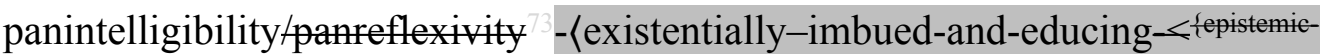
totalising thermeneutically/textually/reprojectingly/supererogatingly/zeroingly/re-acutingly,$\{$ decompulsing\} delinearity for-cogency $>$-epistemic-perspective-of-projective/reprojectiveaestheticising-re-motif-and-re-apriorising/re-axiomatising/re-referencing $\sim$ conceptualisation-as-herein-specifically-relevant-to human-subpotency) abstractly) imbued with human 'formativeness-<as-to-intersolipsism-of-preformulating/preframing/premeaningfulnessimbued-mediativity-and-deferentialism>-of- meaningfulness-and-teleology as to inherent human embodied-vitality/survival/subsistence — existential-<disontologising/re-ontelogising aporeticism $>$ becoming with regards to human Being-development/ontological-frameworkexpansion-as-to-depth-of-ontologising-development-as-infrastructure-of- meaningfulnessand-teleology , institutional-development-as-to-social-function-development and livingdevelopment-as-to-personality-development psychologismic epistemic-acutisationdifficulty <for, residualising \{decompulsing\} delinearity for-cogency> magnitudes ${ }^{\{0 f-}$ experientiality/experiment\} as so-defining the social or human-social-potency' (so-reflecting perpetually/continually human bechancing-becoming-originariness/origination-as-tohistoriality/ontological-eventfulness 8 /ontological-aesthetic-tracing-<perspectiveontological-normalcy/postconvergence-reflected-‘epistemicity-relativism- 
determinism'> disinhibited-mental-aestheticising scalarisation potential) as preveniently/priorly preceding any concreteness/concretism $/<$ preconverging $\sim$ 'motif-andapriorising/axiomatising/referencing'-entailing>-existentialising—enframing/imprintedness〈as-to- historicity-tracing - in-presencing-hyperrealisation/hyperreal-transposition〉-ofhuman-ontological-performance ${ }^{72}-<$ including-virtue-as-ontology $>/$ morality/ethics/justice/etc. (reflecting overall human 'aestheticisation as to the extensive manifest outcomes/outfits/shellsconstrued-historially-as-of-the-specifically-aestheticised-incrusting/plating/coating,-soreflected-as-institutional-manifestations of human ${ }^{56}$ meaningfulness-and-teleology ${ }^{\circ}$, and so as taxingness-of-originariness induces beholdening-becoming - distortive-originariness/distortiveorigination-as-to- ${ }^{4}$ historicity-tracing inhibited-mental-aestheticising descalarisation reflex). Thus the very notion of 'human formativeness-<as-to-intersolipsism-ofpreformulating/preframing/premeaningfulness-imbued-mediativity-and-deferentialism $>$-of-

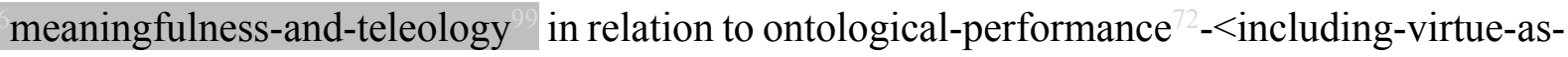
ontology $>^{\prime}$ is very much incipient/inchoate/preceding with respect to concreteness/concretism/<preconverging 'motif-and-apriorising/axiomatising/referencing'entailing >-existentialising — enframing/imprintedness-〈as-to- historicity-tracing — inpresencing-hyperrealisation/hyperreal-transposition〉_ of-human-ontological-performance ${ }^{72}$ <including-virtue-as-ontology $>$, such that the issue of human ontological-performance ${ }^{72}$ <including-virtue-as-ontology $>$ /morality/ethics/justice/etc. is more rightly and veridically ontologically construable in terms of these two aspects of formativeness-<as-to-intersolipsismof-preformulating/preframing/premeaningfulness-imbued-mediativity-and-deferentialism>-ofmeaningfulness-and-teleology (as to bechancing-becoming-originariness/origination-asto- ${ }^{4}$ historiality/ontological-eventfulness $3 \%$ ontological-aesthetic-tracing- $<$ perspectiveontological-normalcy/postconvergence-reflected-‘epistemicity-relativismdeterminism'> disinhibited-mental-aestheticising scalarisation potential) and 
concreteness/concretism/<preconverging 'motif-and-apriorising/axiomatising/referencing'entailing >-existentialising — enframing/imprintedness-〈as-to- historicity-tracing - inpresencing-hyperrealisation/hyperreal-transposition〉_ of-human-ontological-performance ${ }^{72}$ <including-virtue-as-ontology $>$ /morality/ethics/justice/etc. (as to beholdening-becomingdistortive-originariness/distortive-origination-as-to- ${ }^{-}$historicity-tracing inhibited-mentalaestheticising descalarisation reflex) by its inducing of ${ }^{79}$ presencing-absolutising-identitiveconstitutedness $<$ preconverging 'motif-and-apriorising/axiomatising/referencing' entailing $>$-existentialising — enframing/imprintedness-〈as-to- historicity-tracing - inpresencing-hyperrealisation/hyperreal-transposition); as reflecting scalarisation-as-torescalarisation-as-re-ontologisation/supererogatory-involuting-or-guilding-or-amplifyingscalarisation-<as-to-existence—as-sublimating-withdrawal/unenframing/re-ontologising,elicited-from-prospective-profound-supererogation $>$ of human formativeness-<as-tointersolipsism-of-preformulating/preframing/premeaningfulness-imbued-mediativity-anddeferentialism $>$-of- meaningfulness-and-teleology for $\quad$ superseding/overcoming 'concreteness/concretism/<preconverging 'motif-and-apriorising/axiomatising/referencing'entailing >-existentialising — enframing/imprintedness-〈as-to- historicity-tracing-inpresencing-hyperrealisation/hyperreal-transposition〉_ of-human-ontological-performance 2 <including-virtue-as-ontology $>$ /morality/ethics/justice/etc. descalarisation reflex' (with scalarisation projection implied originariness/origination-〈so-construed-as-to-ontologicalnormalcy/postconvergence-perspective-scalarising-construal-of-existence) ever always about 'formativeness-<as-to-intersolipsism-of-preformulating/preframing/premeaningfulnessimbued-mediativity-and-deferentialism $>$-of- meaningfulness-and-teleology $\quad$ construed scalarisation-as-to-rescalarisation-as-re-ontologisation/supererogatory-involuting-or-guildingor-amplifying-scalarisation-<as-to-existence_-as-sublimating-withdrawal/unenframing/reontologising,-elicited-from-prospective-profound-supererogation $>$ with respect to human 
limited-mentation-capacity-deepening —as-subjecting-limitedness/human-subpotency-to'educed-unlimitedness/existence-sublimating nascence' 5', and so preveniently/priorly to phenomenal/manifest concreteness/concretism/<preconverging 'motif-andapriorising/axiomatising/referencing'-entailing >-existentialising — enframing/imprintedness〈as-to- historicity-tracing - in-presencing-hyperrealisation/hyperreal-transposition〉—ofhuman-ontological-performance ${ }^{72}-<$ including-virtue-as-ontology $>/$ morality/ethics/justice/etc. descalarisation reflex). This inherent 'human limited-mentation-capacity-as-subjecting'educed-unlimitedness/existence-sublimating nascence' to-limitedness/human-subpotency implied phenomenal/manifest concreteness/concretism/ $/$ preconverging $\sim$ 'motif-andapriorising/axiomatising/referencing'-entailing >-existentialising — enframing/imprintedness〈as-to- historicity-tracing — in-presencing-hyperrealisation/hyperreal-transposition〉_-ofhuman-ontological-performance 2 - $<$ including-virtue-as-ontology $>/$ morality/ethics/justice/etc. descalarisation reflex' is however concomitant with the corresponding potential capacity for rescalarisation as to human formativeness-<as-to-intersolipsism-ofpreformulating/preframing/premeaningfulness-imbued-mediativity-and-deferentialism>-ofmeaningfulness-and-teleology as to human gesturing/accounting-of-epistemicphenomenalism of dispensing-with-immediacy-for-relative-ontological-completeness ${ }^{87}$-byreification/contemplative-distension ${ }^{27}$ for $\quad{ }^{55}$ maximalising-recomposuring-for-relativeontological-completeness ${ }^{87}$ - unenframed/re-ontologising conceptualisation. $\quad$ Such a scalarisation-as-to-rescalarisation-as-re-ontologisation/supereregatery involuting-or-guildingor-amplifying-scalarisation-<as-to-existence_-as-sublimating-withdrawal/unenframing/reontologising,-elicited-from-prospective-profound-supererogation $>$ construal of human formativeness-<as-to-intersolipsism-of-preformulating/preframing/premeaningfulness-imbuedmediativity-and-deferentialism>-of- meaningfulness-and-teleology (so-implied as of originariness-parrhesia,-as-spontaneity-of-aestheticisation- 
supererogatory acuity/perspicacity/astuteness/edginess/incisiveness-ofapriorising/axiomatising/referencing/intelligibilitysettingup/measuringinstrumenting -forconceptualisation) underlies the very possibility for human limited-mentation-capacitydeepening —as-subjecting limitedness/human-subpotency to-'educed-unlimitedness/existencesublimating nascence' ${ }^{53}$ reflecting holographically-<conjugatively-and-transfusively $>$ the relative-unreflexivity/relative-reflexivity ontological-contiguity of-the-humaninstitutionalisation-process . The overall point here is that the human as ever always caught up in 'human limited-mentation-capacity-as-subjecting-'educed-unlimitedness/existencesublimating nascence' to-limitedness/human-subpotency implied phenomenal/manifest concreteness/concretism/<preconverging 'motif-and-apriorising/axiomatising/referencing'entailing >-existentialising — enframing/imprintedness-〈as-to- historicity-tracing —inpresencing-hyperrealisation/hyperreal-transposition〉_ of-human-ontological-performance ${ }^{72}$ $<$ including-virtue-as-ontology $>$ /morality/ethics/justice/etc. descalarisation reflex', the human capacity for scalarisation lies in a 'distending/dragged-out scalarisation relationship' with this 'phenomenal/manifest concreteness/concretism/<preconverging 'motif-andapriorising/axiomatising/referencing'-entailing--existentialising-enframing/imprintedness〈as-to- historicity-tracing — in-presencing-hyperrealisation/hyperreal-transposition〉_ ofhuman-ontological-performance ${ }^{72}-<$ including-virtue-as-ontology $>/$ morality/ethics/justice/etc. descalarisation reflex' as to the fact that human absolute scalarisation cannot be achieved as to any resultant reproducibility - mathesis/motif/thrownness-disposition,-as-reproducibility-ofaestheticisation of concreteness/concretism/ $<$ preconverging 'motif-andapriorising/axiomatising/referencing'-entailing>-existentialising-enframing/imprintedness〈as-to- historicity-tracing - in-presencing-hyperrealisation/hyperreal-transposition〉—of-

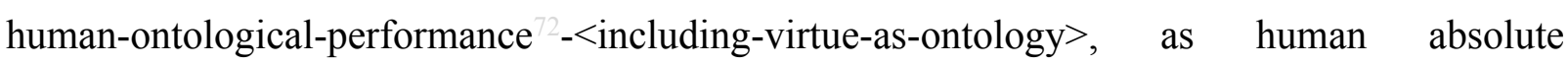
scalarisation is always a potential held-up in originariness-parrhesia,-as-spontaneity-of- 
aestheticisation as to the capacity for 'human gesturing/accounting-of-epistemicphenomenalism of dispensing-with-immediacy-for-relative-ontological-completeness ${ }^{87}$-byreification/contemplative-distension ${ }^{27}$ for $\quad{ }^{55}$ maximalising-recomposuring-for-relativeontological-completeness ${ }^{87}$ - unenframed/re-ontologising conceptualisation' (as can be soappreciated with the notional ${ }^{18}$ deprocrypticism $<$ amplituding/formative $>$ notional $\sim$ preempting — disjointedness-as-of- ${ }^{83}$ reference-of-thought underlying the relative-unreflexivity/relative-reflexivity ontological-contiguity $\sim$ of-thehuman-institutionalisation-process ${ }^{68}$ ); such that supererogatery acuity/perspicacity/astuteness/edginess/incisiveness-ofapriorising/axiomatising/referencing/intelligibilitysettingup/measuringinstrumenting -forconceptualisation rather speaks of 'one long continuous whole of human originarinessparrhesia,-as-spontaneity-of-aestheticisation as of notional deprocrypticism' which guiding spirit no human prospective apriorising/axiomatising/referencing-conceptualisation can pretend to ignore-and-override without falling into perversion of ${ }^{56}$ meaningfulness-and-teleology ${ }^{99}$ as to pedantising/muddling/formulaic-hollowing-out - in-subontologisation/subpotentiation〈blurring/undermining-of-prospective-totalising-entailing,-as-to-entailing$<$ amplituding/formative-epistemicity $>$ totalising in-relative-ontological-completeness $>$ and/or sophistry by mere-formulaic-methodologising/mutualising/organising/institutionalising humansubpotency $\quad<$ preconverging $\sim$ 'motif-and-apriorising/axiomatising/referencing'-entailing $>$ existentialising — enframing/imprintedness-〈as-to- historicity-tracing_-in-presencinghyperrealisation/hyperreal-transposition $\rangle$ in gimmickiness/desublimation. This insight about human 'distending/dragged-out scalarisation' points to the ontological-veracity of a necessary psychologismic-epistemic-acutisation-residualising totalising 3 h hermeneutic/textuality/reprojecting/supererogating/zeroing/re-acuting,\{decompulsing $\}$ delinearity for-cogency understanding associated with human ontological- 
performance ${ }^{72}-<$ including-virtue-as-ontology $>$, with the dearth of such hermeneuticism often associated with social contemplative fragility as well as the sophistry that further exploits this social contemplative fragility as to ${ }^{79}$ presencing-absolutising-identitive-constitutedness ${ }^{14}$; and originariness-parrhesia,-as-spontaneity-of-aestheticisation imbued scalarisation effectively speaks of the ontological-veracity of the requisite difference-conflatedness ${ }^{13}$-as-to-totalitativereification-in-singularisation-<as-to-the-nondisjointedness/entailment-of-prospectivenonpresencing $>$-as-veridical-epistemicity-relativism-determinism for the appropriately optimisable

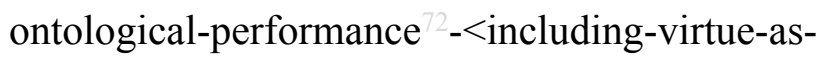
ontology $>$ /morality/ethics/justice/etc. of human conceptual and operant ${ }^{56}$ meaningfulness-andteleology . Scalarisation analysis as such provides human boundless possibility for human scalarisation-as-to-rescalarisation-as-re-ontologisation/supererogatory -involuting-or-guildingor-amplifying-scalarisation-<as-to-existence_-as-sublimating-withdrawal/unenframing/reontologising,-elicited-from-prospective-profound-supererogation $>$ with regards to human Being-development/ontological-framework-expansion-as-to-depth-of-ontologisingdevelopment-as-infrastructure-of- meaningfulness-and-teleology , institutionaldevelopment-as-to-social-function-development and living-development-as-to-personalitydevelopment psychologismic epistemic acutisation diffieully <for, residualising \{decompulsing\} delinearity for-cogeney>-magnitudes $\{$ of-experientiality/experiment\}. The more critically conceptual and operant issue lies with how priorly induced 'human notional firstnaturednessformativeness-<as-to-eventualising-inkling drive-or-seeding-misprising $>$ temporal-tointemporal-dispositions-<so-construed-as-from-perspective-ontologicalnormalcy/postconvergence> accordioning-〈as-of-varying-individuations-contextuallytransverse-desublimation/sublimation,-as-to-the-wavering/redounding/waveforming of-theirreferencing-and-their-devolved-referencing-imbued-ontological-performance -<includingvirtue-as-ontology $>\rangle$ at uninstitutionalised-threshold ${ }^{12}$ as reflecting both desublimating 
historicity-tracing - in-presencing-hyperrealisation/hyperreal-transposition and sublimating historiality/ontological-eventfulness 38 ontological-aesthetic-tracing-<perspectiveontological-normalcy/postconvergence-reflected-‘epistemicity-relativism-determinism'> possibilities' as to ${ }^{7}$ presencing-absolutising-identitive-constitutedness ${ }^{14}$ shapes any such ontologically-flawed presence human psychology as to its given 'aestheticisation of <preconverging $\sim$ 'motif-and-apriorising/axiomatising/referencing'-entailing >-

existentialising — enframing/imprintedness-〈as-to- historicity-tracing —in-presencinghyperrealisation/hyperreal-transposition〉' with regards to prospectively addressing such 'phenomenal/manifest concreteness/concretism/<preconverging 'motif-andapriorising/axiomatising/referencing'-entailing >-existentialising — enframing/imprintedness〈as-to- historicity-tracing - in-presencing-hyperrealisation/hyperreal-transposition〉_ ofhuman-ontological-performance ${ }^{72}-<$ including-virtue-as-ontology $>/$ morality/ethics/justice/etc. descalarisation reflex' concerns identified above (as to '79 presencing-absolutising-identitiveconstitutedness <preconverging 'motif-and-apriorising/axiomatising/referencing'entailing >-existentialising — enframing/imprintedness-〈as-to- historicity-tracing —inpresencing-hyperrealisation/hyperreal-transposition $\rangle$ with the subontologisation/subpotentiation of ontology as to dominance/vested-interest-drivenness$<$ as-to-its-direct/indirect-eliciting-by-or-exploiting-of-prospectively-

\section{descalarising/subontologising-sycophantic-sophistic-interests,-as-inducing-prospective-}

threshold-of-institutional-and-social-desublimation>'); and so with regards to overall underlying human 'social and institutional crises/suboptimisation as to subontologisation' prospective need for re-ontologisation. This overall construal of the determinative structure of human ontologicalperformance $^{72}-<$ including-virtue-as-ontology $>$ /morality/ethics/justice/etc. (as it reflects the ontological-veracity of human formativeness-<as-to-intersolipsism-ofpreformulating/preframing/premeaningfulness-imbued-mediativity-and-deferentialism>-of- 
meaningfulness-and-teleology over any given conception of human of intersubjectivity-ofmeaningfulness-and-teleology ${ }^{9}$ ') rather undermines the ontological-pertinence as to the ontological-performance $^{72}$-<including-virtue-as-ontology $>/$ morality/ethics/justice/etc. of the notion of human intersubjectivity-of- ${ }^{56}$ meaningfulness-and-teleology ${ }^{9}$ and so very much along the same lines of the Derridean criticism of intersubjectivity-of- ${ }^{56}$ meaningfulness-andteleology ${ }^{9}$ going by his 'heterogeneous genesis' epistemic conception (even as the latter is more-or-less caught up in metaphysics-of-presence-_implicited-'nondescript/ignorable-void as-to- presencing-absolutising-identitive-constitutedness > epistemic apriorising/axiomatising/referencing-\{of-"prospectively_implicited_attendant-ontologicalcontiguity ' $\sim$ educedexistentialising/contextualising/textualising_ intelligibility/epistemicity/reflexivity-contiguity<imbued-notional cogency>' $\}$-constitutedness ${ }^{- \text {in }}$-preconverging-entailment as to its quasi-transcendental implications since genesis is rather truly as of the 'full-conflatedness ${ }^{13}$ in the apriorising/referencing/axiomatising of ${ }^{56}$ meaningfulness-and-teleology ${ }^{9}$, involved with human limited-mentation-capacity-deepening —as-subjecting limitedness/human-subpotencyto-'educed-unlimitedness/existence-sublimating nascence' ${ }^{33}$ and so-reflected rather as from 'originariness/origination-〈so-construed-as-to-ontological-normalcy/postconvergence-

perspective-scalarising-construal-of-existence $\rangle$ implied scalarisation-as-to-rescalarisation-asre-ontologisation/supererogatory involuting-or-guilding-or-amplifying-scalarisation- $<$ as-toexistence — as-sublimating-withdrawal/unenframing/re-ontologising,-elicited-fromprospective-profound-supererogation $>>$ inducing transcendence-andsublimity/sublimation/supererogatory-de-mentativity), such that intersubjectivity-ofmeaningfulness-and-teleology 9 is rather an ontologically-flawed conceptualisation 'poorly reflecting the ontological-veracity of the social/human-social-potency as to the full potential for human ontological-performance ${ }^{72}-$ including-virtue-as-ontology $>^{\prime}$ and so since 
intersubjectivity-of- ${ }^{5}$ meaningfulness-and-teleology ${ }^{9}$ is rather beholdening to ${ }^{79}$ presencingabsolutising-identitive-constitutedness ${ }^{14}$ (as of ' 7 presencing-absolutising-identitiveconstitutedness <preconverging 'motif-and-apriorising/axiomatising/referencing' entailing $>$-existentialising — enframing/imprintedness-〈as-to- historicity-tracing — inpresencing-hyperrealisation/hyperreal-transposition> with the subontologisation/subpotentiation of ontology as to dominance/vested-interest-drivenness$<$ as-to-its-direct/indirect-eliciting-by-or-exploiting-of-prospectivelydescalarising/subontologising-sycophantic-sophistic-interests,-as-inducing-prospectivethreshold-of-institutional-and-social-desublimation >') unlike is the case with human 'formativeness-<as-to-intersolipsism-of-preformulating/preframing/premeaningfulnessimbued-mediativity-and-deferentialism>-of- meaningfulness-and-teleology construed scalarisation-as-to-rescalarisation-as-re-ontologisation/supererogatory-involuting-or-guildingor-amplifying-scalarisation-<as-to-existence—as-sublimating-withdrawal/unenframing/reontologising,-elicited-from-prospective-profound-supererogation $>$ with respect to human limited-mentation-capacity-deepening —as-subjecting limitedness/human-subpotency-to'educed-unlimitedness/existence-sublimating nascence' ${ }^{3}$ ' which perspective of ontological conceptualisation is not of prospective apriorising/axiomatising/referencing-sublimatingreflexivity-beholdening to any ${ }^{79}$ presencing-absolutising-identitive-constitutedness $<$ preconverging 'motif-and-apriorising/axiomatising/referencing'-entailing $>$ existentialising — enframing/imprintedness-〈as-to- historicity-tracing_in-presencing_hyperrealisation/hyperreal-transposition> but is rather reflective of nonpresencing$<$ perspective-ontological-normalcy/postconvergence $>$ epistemic-projection'. That is, the reality of the full potential for human-subpotency ontological-performance ${ }^{72}-$ including-virtue-as- $^{2}$ ontology $>$ /morality/ethics/justice/etc. (as enabling the superseding of any ${ }^{79}$ presencingabsolutising-identitive-constitutedness <preconverging 'motif-and- 
apriorising/axiomatising/referencing'-entailing>-existentialising—enframing/imprintedness〈as-to- historicity-tracing - in-presencing-hyperrealisation/hyperreal-transposition〉) rather lies with human underlying supposedly coherent ontological-commitment $-<$ implied-selfassuredness-of-ontological-good-faith/authenticity postconverging-dementating/structuring/paradigming -as-being-as-of-existential-reality> (so-associated with 'originariness/origination-〈so-construed-as-to-ontological-normalcy/postconvergenceperspective-scalarising-construal-of-existence $\rangle$ implied scalarisation-as-to-rescalarisation-asre-ontologisation/supereregatery involuting-or-guilding-or-amplifying-scalarisation- $<$ as-toexistence—as-sublimating-withdrawal/unenframing/re-ontologising,-elicited-fromprospective-profound-supererogation $>^{>}$as reflecting human formativeness-<as-tointersolipsism-of-preformulating/preframing/premeaningfulness-imbued-mediativity-anddeferentialism $>$-of- meaningfulness-and-teleology full potential for human-subpotency

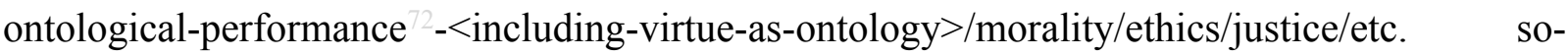
underscored as of originariness-parrhesia,-as-spontaneity-of-aestheticisationsupereraity/perspicacity/astuteness/edginess/incisiveness) and so, as to: humansubpotency 'fatedness-of-sublimation-over-desublimation, to existence-potency $\sim$ sublimatingnascence,-disclosed-from-prospective-epistemic-digression (in reflecting holographically$<$ conjugatively-and-transfusively $>$ the relative-unreflexivity/relative-reflexivity - ontologicalcontiguity $\sim$ of-the-human-institutionalisation-process ), as from human-subpotency ontological-faith-notion-or-ontological-fideism - imbued-underdetermination-of-motif-andapriorising/axiomatising/referencing-as-so-being-as-of-existential-reality as to the disseminative - sublimating-selectivity-of-ontological-goodfaith/authenticity postconverging-de-mentating/structuring/paradigming , overdesublimating deselectivity of ontological-bad-faith/inauthenticity -preconverging dementating/structuring/paradigming , as the driver of the human-subpotency potentiating 
existential-<disontologising/re-ontologising aporeticism $>$ becoming manifestation of sublimating-over-desublimating social-and-institutional-constructs-of- ${ }^{56}$ meaningfulness-andteleology - in-cumulation/recomposuring all along in reflecting holographically$<$ conjugatively-and-transfusively $>$ the relative-unreflexivity/relative-reflexivity - ontologicalcontiguity of-the-human-institutionalisation-process ; as it dynamically induces (as of 'varying psychologismic epistemic-acutisation difficulty-<for,-residualising $\{$ decompulsing $\}$ delinearity for-cogency> magnitudes $\{$ of-experientiality/experiment $\} /$ scales—as-tosuccessively-profound-preconverging/postconverging-redementating/restructuring/reparadigming-frames-as-from-living,-institutionalising,-and-Beingontologising/infrastructure-of- ${ }^{5}$ meaningfulness-and-teleology 9 of prospective humansubpotency-aporia/undecidability/dilemma/ought-

indeterminacy/deficiency/limitation/constraint_ - imbued-'notional firstnaturednessformativeness-<as-to-eventualising-inkling drive or seeding-misprising $>$ temporal-tointemporal-dispositions- $<$ so-construed-as-from-perspective-ontologicalnormalcy/postconvergence>'-existentialism-form-factor') successive prospective reasoningthrough/messianic-reasoning for reasoning-from-results/afterthought as the secondnaturedinstitutionalisation of the <cumulating/recomposuring attendant-ontological-contiguity successive registry-worldviews/dimensions ${ }^{8}$ reference-of-thought-and- ${ }^{83}$ reference-of-thoughtdevolving- meaningfulness-and-teleology' so-construed as 'generating varying human sublimating-over-desublimating social-and-institutional-constructs-of- ${ }^{56}$ meaningfulness-andteleology $\mathrm{y}^{9}$ - in-cumulation/recomposuring of apriorising/axiomatising/referencing/intelligibilitysettingup/measuringinstrumenting' as to their pre-eminence as of their 'prospectively projected relative-ontological-completeness dimensionality-of-sublimating $25<$ amplituding/formative $>$ supererogatory $\sim$ dementativeness/epistemic-growth-or-conflatedness /transvaluative- 
rationalising/transepistemicity/anamnestic-residuality/spirit-drivenness-equalisation〉'. It is the profound ontological-veracity of such implied human intersolipsism of ${ }^{56}$ meaningfulness-andteleology (as of formativeness-<as-to-intersolipsism-ofpreformulating/preframing/premeaningfulness-imbued-mediativity-and-deferentialism>-ofmeaningfulness-and-teleology full potential for human-subpotency ontologicalperformance ${ }^{2}-<$ including-virtue-as-ontology $>$ ) and so over intersubjectivity-ofmeaningfulness-and-teleology ${ }^{9}$ as to ${ }^{79}$ presencing-absolutising-identitive-constitutedness $<$ preconverging 'motif-and-apriorising/axiomatising/referencing'-entailing $>$ existentialising — enframing/imprintedness-〈as-to- historicity-tracing — in-presencinghyperrealisation/hyperreal-transposition $\rangle$, that reflects the intemporal-disposition possibility for the 'abstract individual' to venture at eliciting the transcendence-andsublimity/sublimation/supererogatory de-mentativity possibilities of existence-assublimating-withdrawal/unenframing/re-ontologising,-elicited-from-prospective-profoundsupererogation beyond and superseding human temporality $\%$ /shortness $<$ amplituding/formative $>$ wooden-language-_imbued — averaging-of-thought-<as-toleveling/ressentiment/closed-construct-of- meaningfulness-and-teleology -as-of'nondescript/ignorable-void '-with-regards-to-prospective-apriorising-implications $>$ ) enabling prospective human Being-development/ontological-framework-expansion-as-todepth-of-ontologising-development-as-infrastructure-of- meaningfulness-and-teleology , institutional-development-as-to-social-function-development and living-development-as-topersonality-development psychologismic epistemic acutisation difficulty<for,

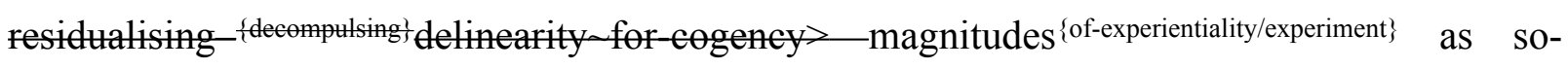
defining the social or human-social-potency. This fundamental undermining of intersubjectivity-of- ${ }^{5}$ meaningfulness-and-teleology 99 as to its ontological-performance ${ }^{72}$ $<$ including-virtue-as-ontology $>/$ morality/ethics/justice/etc. conception lies in the fact that as of 
its implied ${ }^{79}$ presencing — absolutising-identitive-constitutedness ${ }^{14}<$ preconverging $\sim$ 'motif-andapriorising/axiomatising/referencing'-entailing>-existentialising-enframing/imprintedness〈as-to- historicity-tracing-in-presencing-hyperrealisation/hyperreal-transposition〉, it goes on to induce human-subpotency beholdening-becoming-distortive-originariness/distortiveorigination-as-to- ${ }^{47}$ historicity-tracing inhibited-mental-aestheticising and so undermining the bechancing-becoming - originariness/origination-as-to- ${ }^{4}$ historiality/ontological-

eventfulness 3 /ontological-aesthetic-tracing-<perspective-ontologicalnormalcy/postconvergence-reflected-‘epistemicity-relativism-determinism’ $>\sim$ disinhibitedmental-aestheticising as to the scalarity/immanency of existence's ontologicalnormalcy/postconvergence as 'bechancing-backdrop of ${ }^{6}$ nonpresencing-<perspectiveontological-normalcy/postconvergence>'; wherein the prospectively requisite rescalarisation as to human formativeness-<as-to-intersolipsism-ofpreformulating/preframing/premeaningfulness-imbued-mediativity-and-deferentialism>-ofmeaningfulness-and-teleology is obfuscated on the basis of such ontologically-flawed implied intersubjectivity-of- ${ }^{5}$ meaningfulness-and-teleology ${ }^{79}$ presencing-absolutisingidentitive-constitutedness ${ }^{14}$ <preconverging 'motif-and-apriorising/axiomatising/referencing'entailing >-existentialising — enframing/imprintedness-〈as-to- historicity-tracing - inpresencing-hyperrealisation/hyperreal-transposition〉 associated with such ontologically vague notions like 'institutionalised facts' as of 'mere-formulaicmethodologising/mutualising/organising/institutionalising human $<$ preconverging 'motif-andapriorising/axiomatising/referencing'-entailing>-existentialising-enframing/imprintedness〈as-to- historicity-tracing - in-presencing-hyperrealisation/hyperreal-transposition〉' that supposedly and wrongly supersede 'genuine knowledge-reification gesturing-and-accountingof-epistemic-phenomenalism- $<$ in- 
implicited_attendant-ontological-contiguity ' reduced-

existentialising/contextualising/textualising_'intelligibility/epistemicity/reflexivity_contiguity<imbued-notional cogency>> $\}$-conflatedness -in-\{preconverging-disentailment by\}

postconverging entailment $>$ framework involving a detour to existence-potency ${ }^{39} \sim$ sublimatingnascence,-disclosed-from-prospective-epistemic-digression induced prospective determination which then is preconverging/postconverging-de-mentatively/structurally/paradigmatically preceding-and-constraining to human-subpotency as enabling prospective sublimation-overdesublimation'. The supposed consequence of such ontologically-flawed analysis as to intersubjectivity-of- ${ }^{5}$ meaningfulness-and-teleology ${ }^{9} \quad{ }^{79}$ presencing-absolutising-identitiveconstitutedness <preconverging 'motif-and-apriorising/axiomatising/referencing'entailing >-existentialising — enframing/imprintedness-〈as-to- historicity-tracing —inpresencing-hyperrealisation/hyperreal-transposition〉 that fails to grasp 'relative-ontologicalincompleteness $^{8} /$ relative-ontological-completeness ${ }^{87}$ 〈sublimating referencing/registering/decisioning,-as-self-becoming/selfconflatedness /formative-supererogating-<projective/reprojective-aestheticising-re-motifand-re-apriorising/re-axiomatising/re-referencing,-in-perspective-ontologicalnormalcy/postconvergence $>>$ as to human-and-social-expectations/anticipationsmetaphoricity ${ }^{57}$-as-preconverging/postconverging-redementating/restructuring/reparadigming-psychologism' ${ }^{89}$ is that the 'institutionalised facts' of the $\quad<$ cumulating/recomposuring attendant-ontological-contiguity $>$-successive registryworldviews/dimensions are then construed wrongly as 'beyond ontological analysis' such that the relative-unreflexivity/relative-reflexivity - ontological-contiguity ${ }^{67}$ of-the-humaninstitutionalisation-process ${ }^{68}$ herein implied is then construed as 'unintelligible' as even the notion of how <cumulating/recomposuring attendant-ontological-contiguity $>$-successive registry-worldviews/dimensions come about is obfuscated. This overall insight points to the fact 
that all the potentiality for human ontological-performance ${ }^{72}-<$ including-virtue-asontology $>$ /morality/ethics/justice/etc. rather lies with grasping: human 'formativeness-<as-tointersolipsism-of-preformulating/preframing/premeaningfulness-imbued-mediativity-anddeferentialism $>$-of- meaningfulness-and-teleology (so-construed as human $<$ amplituding/formative-epistemicity $>$ causality potentiality of ontological-performance ${ }^{72}$ <including-virtue-as-ontology $>$ ) as to inherent human embodied-vitality/survival/subsistenceexistential-<disontologising/re-ontologising aporeticism $>$-becoming with regards to human Being-development/ontological-framework-expansion-as-to-depth-of-ontologisingdevelopment-as-infrastructure-of- meaningfulness-and-teleology , institutionaldevelopment-as-to-social-function-development and living-development-as-to-personalitydevelopment psychologismic epistemic-acutisation difficulty-<for, residualising \{decompulsing $\}$ delinearity for-cogeney $>$ magnitudes $\{$ of-experientiality/experiment\} as so-defining the social or human-social-potency'. Human 'formativeness-<as-to-intersolipsism-ofpreformulating/preframing/premeaningfulness-imbued-mediativity-and-deferentialism>-ofmeaningfulness-and-teleology construed scalarisation-as-to-rescalarisation-as-reontologisation/supererogatery involuting-or-guilding-or-amplifying-scalarisation-<as-toexistence - as-sublimating-withdrawal/unenframing/re-ontologising,-elicited-fromprospective-profound-supererogation $>$ ' (as to prospective human ontological-performance ${ }^{72}$ $<$ including-virtue-as-ontology $>$ /morality/ethics/justice/etc. for historiality/ontological-eventfulness 38 ontological-aesthetic-tracing-<perspectiveontological-normalcy/postconvergence-reflected-'epistemicity-relativism-determinism'> over historicity-tracing - in-presencing-hyperrealisation/hyperreal-transposition) preconverging/postconverging-de-mentatively/structurally/paradigmatically encompasses: human 'germinative intensification - amplituding of aestheticisation-beholdening-out-ofbechancing' / 'taxingness-of-originariness,-imbued-sublimating-by-desublimating-amplituding 
as to the backdrop-of-inherent-immanent-existence's-sublimation-structure-<of-'unsurrealisticas-real'-ontological-normalcy/postconvergence>' (in reflecting human formative notional conflatedness ${ }^{13}$ of motif-and-apriorising/axiomatising/referencing-psychologism) as generative-and-regenerative of ${ }^{56}$ meaningfulness-and-teleology $/$ aestheticisation-andaestheticisation-towards-ontology-<elicited-idiomatisation $>$ (as from inherently embodiedvitality/survival/subsistence — existential-<disontologising/re-ontologising aporeticism> becoming inducing the dynamics of Being-development/ontological-framework-expansion-asto-depth-of-ontologising-development-as-infrastructure-of- meaningfulness-and-teleology , institutional-development-as-to-social-function-development and living-development-as-topersonality-development psychologismic epistemic-acutisation difficulty $<$ for, residualising_\{decompulsing\} delinearity for-cogency>-magnitudes $\{$ of-experientiality/experiment\} reflecting holographically-<conjugatively-and-transfusively $>$ the relative-unreflexivity/relativereflexivity - ontological-contiguity of-the-human-institutionalisation-process ) scalarisingly preconverging/postconverging-rede-mentating/restructuring/reparadigming descalarised concreteness/concretism/<preconverging 'motif-andapriorising/axiomatising/referencing'-entailing >-existentialising-enframing/imprintedness〈as-to- historicity-tracing-in-presencing-hyperrealisation/hyperreal-transposition〉_ofhuman-ontological-performance ${ }^{72}<$ including-virtue-as-ontology $>/$ morality/ethics/justice/etc. so-existentially-disontologising/re-ontologising aporeticism $>$ reflected as the 'extensive manifest outcomes/outfits/shells_construed-historially-as-of-the-specifically-aestheticisedincrusting/plating/coating,-so-reflected-as-institutional-manifestations of human meaningfulness-and-teleology aestheticisation', - human individual as solipsistic sovereignemergence/becoming,-existentially-imbuing human-freedom-as-to-supererogating/surrealisingfor-'knowledge-empowerment-over-ignorance-disempowerment'-<as-of-'developing-andavailing-sovereign-sublimating_potential/possibilities/options/choices'-as-to-the- 
'credibility’/'ontological-veracity’-underlying-the-'sovereign-conscious/conscientious-

backdrop'> of drivenness beyond just 'socially induced emancipating/non-emancipating drivenness' as to the individual <amplituding/formative-epistemicity $>$-totalising $\sim$ thrownnessin-existence ${ }^{35}$ in any registry-worldview's/dimension's prior-institutionalisation-threshold-byprospective-uninstitutionalised-threshold ${ }^{102}$ of ontological-performance ${ }^{72}-<_{\text {including-virtue-as- }}$ ontology>, - human formative convoluted developmental echeloning in any registryworldview/dimension as of socially translative ontological-goodfaith/authenticity $\sim$ postconverging-de-mentating/structuring/paradigming 70 and ontologicalbad-faith/inauthenticity $\sim$ preconverging-de-mentating/structuring/paradigming $\quad$ reflecting respectively the structure of human intemporal and temporal ontological-performance ${ }^{2}$ $<$ including-virtue-as-ontology $>$, - the social-construct uninstitutionalised-threshold ${ }^{102}$ defined as to the given registry-worldview/dimension prospectively 'descalarising-in-dementating/structuring/paradigming first-moving/rentier/prerogative induced beholdeningbecoming — distortive-originariness/distortive-origination-as-to- ${ }^{-1}$ historicity-tracing $\sim$ inhibitedmental-aestheticising ${ }^{56}$ meaningfulness-and-teleology ${ }^{9}$ ontological-performance ${ }^{72}<$ includingvirtue-as-ontology $>$ /morality/ethics/justice/etc. (as to Being-development/ontologicalframework-expansion-as-to-depth-of-ontologising-development-as-infrastructure-ofmeaningfulness-and-teleology , institutional-development-as-to-social-functiondevelopment and living-development-as-to-personality-development psychologismic epistemic acutisation difficulty-for, residualising fdecompulsing $d$ delinearity for-cogency> magnitudes $\left.{ }^{\{0 f-e x p e r i e n t i a l i t y / e x p e r i m e n t\}}\right\}$ ' so-underlined by the 'descalarising totalisinglydisentailing - discretion/whim-of-thought of individuals-suboptimal instigative potency as of human notional firstnaturedness-formativeness-as to or seeding misprising $>$ temporal-to-intemporal-dispositions-<so-construed-as-fromperspective-ontological-normalcy/postconvergence> accordioning-〈as-of-varying- 
individuations-contextually-transverse-desublimation/sublimation,-as-to-the-

wavering/redounding/waveforming of-their-referencing-and-their-devolved-referencing-

imbued-ontological-performance -<including-virtue-as-ontology >)' (and so as poorlyamenable-to and forestalling prospective bechancing-becoming-originariness/origination-asto- ${ }^{4}$ historiality/ontological-eventfulness 3 /ontological-aesthetic-tracing-<perspectiveontological-normalcy/postconvergence-reflected-`epistemicity-relativismdeterminism'> disinhibited-mental-aestheticising as sublimating bechancing-backdrop of ontological-normalcy/postconvergence so-underlined by the 'scalarising as of human supererogatory/messianic intemporal and secondnatured socially-optimal instigative potency'), - human social-formativeness defined as to the given registry-worldview/dimension surreptitious flipping-around/flipping-about of social-stake-and-contention framing as to 'ontological-goodfaith/authenticity -and-equanimity of social/institutional process towards credible social/institutional outcome as reflecting manifest dispensing-with-immediacy-for-relativeontological-completeness ${ }^{87}$-by-reification/contemplative-distension' ${ }^{27}$ and 'ontological-badfaith/inauthenticity ${ }^{6}$-and-lack-of-equanimity of social/institutional process towards preconverging/postconverging-de-mentative/structural/paradigmatic priorly-defaulted/usurped social/institutional outcome as reflecting manifest lack of dispensing-with-immediacy-forrelative-ontological-completeness ${ }^{87}$-by-reification/contemplative-distension ${ }^{27}$, , with such flipping-around/flipping-about rather reflecting respectively the implications of 'originarinessparrhesia,-as-spontaneity-of-aestheticisation-

supererogatory acuity/perspicacity/astuteness/edginess/incisiveness underlying dimensionalityof-sublimating $25-\langle<$ amplituding/formative $>$ supererogatory $\sim$ de-mentativeness/epistemicgrowth-or-conflatedness /transvaluative-rationalising/transepistemicity/anamnesticresiduality/spirit-drivenness-equalisation $\rangle$ as to its profound dispensing-with-immediacy-forrelative-ontological-completeness ${ }^{87}$-by-reification/contemplative-distension ${ }^{27}$, and 
'reproducibility—mathesis/motif/thrownness-disposition,-as-reproducibility-ofaestheticisation mere-formulaic-methodologising/mutualising/organising/institutionalising underlying dimensionality-of-desublimating-lack-of

\section{<<amplituding/formative >supererog de-mentativeness/epistemic-growth-or-}

conflatedness /transvaluative-rationalising/transepistemicity/anamnestic-residuality/spirit-

drivenness-equalisation> as to its lack-of/shallow dispensing-with-immediacy-for-relativeontological-completeness ${ }^{87}$-by-reification/contemplative-distension ${ }^{27}$, (with the latter associated with $<$ amplituling/formative $>$ wooden-language-〈imbued-temporal-mereform/virtualities/dereification/akrasiatic-drag/denatured/preconverging-or-dementing narratives - of-the- reference-of-thought- categorical-imperatives/axioms/registry-

teleology >). This overall elucidation points to 'human ontological-performance ${ }^{2}-<$ includingvirtue-as-ontology $>$ /morality/ethics/justice/etc. as more rightly and veridically ontologically construable in terms of the two aspects of formativeness-<as-to-intersolipsism-ofpreformulating/preframing/premeaningfulness-imbued-mediativity-and-deferentialism>-ofmeaningfulness-and-teleology (as to bechancing-becoming-originariness/origination-asto- ${ }^{4}$ historiality/ontological-eventfulness $\$$ /ontological-aesthetic-tracing-<perspectiveontological-normalcy/postconvergence-reflected-'epistemicity-relativismdeterminism'> disinhibited-mental-aestheticising scalarisation potential) and concreteness/concretism/<preconverging 'motif-and-apriorising/axiomatising/referencing'entailing >-existentialising — enframing/imprintedness-〈as-to- historicity-tracing - inpresencing-hyperrealisation/hyperreal-transposition〉_ of-human-ontological-performance ${ }^{72}$ $<$ including-virtue-as-ontology $>$ /morality/ethics/justice/etc. (as to beholdening-becomingdistortive-originariness/distortive-origination-as-to- ${ }^{-}$historicity-tracing $\sim$ inhibited-mentalaestheticising descalarisation reflex) by its inducing of ${ }^{79}$ presencing-absolutising-identitiveconstitutedness 
entailing >-existentialising — enframing/imprintedness-〈as-to- historicity-tracing — in-

presencing-hyperrealisation/hyperreal-transposition〉'. Insightfully, a most fundamental ontology/science as aspired herein in reflecting holographically-<conjugatively-andtransfusively $>$ the relative unreflexivity/relative reflexivity ontological-contiguity $\sim$ of-thehuman-institutionalisation-process rather points to human formativeness-<as-tointersolipsism-of-preformulating/preframing/premeaningfulness-imbued-mediativity-anddeferentialism $>$-of- meaningfulness-and-teleology as to recurrently self-surpassing meaningfulness-and-teleology and the resultant consecutive consequent ${ }^{79}$ presencingabsolutising-identitive-constitutedness $<$ preconverging 'motif-andapriorising/axiomatising/referencing'-entailing >-existentialising — enframing/imprintedness〈as-to- historicity-tracing - in-presencing-hyperrealisation/hyperreal-transposition〉 reflecting the <cumulating/recomposuring attendant-ontological-contiguity $>$-successive registryworldviews/dimensions imbued $\quad{ }^{83}$ reference-of-thought-and- ${ }^{83}$ reference-of-thoughtdevolving- ${ }^{5}$ meaningfulness-and-teleology ${ }^{9}$ respective less-and-less relative-ontologicalincompleteness $^{88}$ of ontological-performance ${ }^{2}-<$ including-virtue-as-ontology $>$; $_{\text {such }}$ that inherently the construal of their social-stake-contention-or-confliction are ever always construed in $<$ amplituding/formative--epistemicity $>$ totalising $\sim$ self-referencingsyncretising/circularity/interiorising/akrasiatic-drag ${ }^{34}$ as to any such given registryworldview's/dimension's presencing —absolutising-identitive-constitutedness $<$ preconverging 'motif-and-apriorising/axiomatising/referencing'-entailing >existentialising — enframing/imprintedness-〈as-to- historicity-tracing_-in-presencinghyperrealisation/hyperreal-transposition) (as to Being-development/ontological-frameworkexpansion-as-to-depth-of-ontologising-development-as-infrastructure-of- meaningfulnessand-teleology , institutional-development-as-to-social-function-development and livingdevelopment-as-to-personality-development 
difficulty-<for, residualising_\{decompulsing $\}$ delinearity for-cogeney> magnitudes $\{$ \{fexperientiality/experiment\}), whereas an ontologically more profound construal as of differenceconflatedness $^{13}$-as-to-totalitative-reification-in-singularisation- $<$ as-to-the-

nondisjointedness/entailment-of-prospective- nonpresencing $>$-as-veridical-epistemicity-

relativism-determinism (reflecting originariness/origination-〈so-construed-as-to-ontologicalnormalcy/postconvergence-perspective-scalarising-construal-of-existence)) rather highlights an 'utterly superseding construal of ontological-performance ${ }^{72}-<$ including-virtue-as-ontology $>$ ' of any such registry-worldview/dimension ${ }^{79}$ presencing - absolutising-identitive-constitutedness $<$ preconverging 'motif-and-apriorising/axiomatising/referencing'-entailing >existentialising — enframing/imprintedness-〈as-to- historicity-tracing_-in-presencinghyperrealisation/hyperreal-transposition $\rangle$ construal of social-stake-contention-or-confliction wherein base-institutionalisation, ${ }^{103}$ universalisation, positivism/rational-empiricism and notional deprocrypticism respectively are rather of unenframed/reontologising/unbeholdening/bechancing-supererogation with regards to the social-stakecontention-or-confliction of recurrent-utter-uninstitutionalisation, ununiversalisation, nonpositivism/medievalism and our ${ }^{80}$ procrypticism-or-disjointedness-as-of- ${ }^{8}$ reference-of-thought as to the prospective sublimating/emancipating possibilities of human limited-mentationcapacity-deepening —as-subjecting limitedness/human-subpotency-to-'educedunlimitedness/existence-sublimating nascence' ${ }^{33}$ 'in the face of existence - as-sublimatingwithdrawal/unenframing/re-ontologising,-elicited-from-prospective-profound-supererogation enabling of human ontological realisation as of human formativeness-<as-to-intersolipsism-ofpreformulating/preframing/premeaningfulness-imbued-mediativity-and-deferentialism>-ofmeaningfulness-and-teleology ' and so rather than any ${ }^{79}$ presencing-absolutising-identitiveconstitutedness <preconverging 'motif-and-apriorising/axiomatising/referencing'entailing $>$-existentialising — enframing/imprintedness-〈as-to- historicity-tracing — in- 
presencing-hyperrealisation/hyperreal-transposition〉 construal inevitably caught up in humansubpotency subontologisation/ideology-over-ontology. Incipiently, an ontology that professes to be of the most profound science as fundamental ontology should be able to see-through (as to unblurriness-<re-ontologising_by-postconverging-as-to-dragged-out-

supererogaty-wholesomeness/profound-supererogation ,-while-anecdotalising-prior-

disontologising-thresholding $>$ ) the superficiality of human-subpotency ${ }^{79}$ presencingabsolutising-identitive-constitutedness

$<$ preconverging ' motif-andapriorising/axiomatising/referencing'-entailing >-existentialising — enframing/imprintedness〈as-to- historicity-tracing - in-presencing-hyperrealisation/hyperreal-transposition〉 imbued social-stake-contention-or-confliction projections (beyond-the-consciousness-awarenessteleology ${ }^{9}<$ of-preconverging-existential-extrication-as-of-existential-unthought $>$ ) of any given registry-worldview/dimension, and articulate prospective aestheticisation-andaestheticisation-towards-ontology-<elicited-idiomatisation $>/ /$ meaningfulness-and-teleology that is of unenframed/re-ontologising/unbeholdening/bechancing-supererogation enabling prospective human re-ontologisation possibilities. Such a depth of contemplation as to Beingdevelopment/ontological-framework-expansion-as-to-depth-of-ontologising-development-asinfrastructure-of- meaningfulness-and-teleology effectively reflects a rather more profound conceptualisation of human psychology as to its transcendence-andsublimity/sublimation/supererogatory-de-mentativity inducing potential as to the psychoanalytic-unshackling/memetic-reordering/institutional-recomposuring implications in reflecting holographically-<conjugatively-and-transfusively $>$ the relative-unreflexivity/relativereflexivity - ontological-contiguity of-the-human-institutionalisation-process (at the crossroads of prior ${ }^{5}$ meaningfulness-and-teleology ${ }^{9}$ and prospective metaphoricity ${ }^{57}$ ) over approaches of relative gimmickiness-of-thought as to our positivism/rational-empiricism presencing-absolutising-identitive-constitutedness <amplituding/formative- 
epistemicity $>$ totalising $\sim$ self-referencing-syncretising/circularity/interiorising/akrasiatic-drag that poorly address human egotistic/self-referential complex in the face of prospective humansubpotency-aporia/undecidability/dilemma/ought-

indeterminacy/deficiency/limitation/constraint and with the corresponding possibility for sophistic/pedantic moral

and intellectual disenfranchisement/swindling/corruption/dispossession (as the fact is when it comes to socialstake-contention-or-confliction 'knowledge-reification gesturing-and-accounting —ofepistemic-phenomenalism- $<$ in-

prospective_psychologismic apriorising/axiomatising/referencing-\{of-'prospectively implicited_attendant-ontological-contiguity ' reducedexistentialising/contextualising/textualising_'intelligibility/epistemicity/reflexivity-contiguity<imbued-notional cogency >' \}-conflatedness -in-\{preconverging disentailment by\} postconverging-entailment> tends to be notionally/epistemically/bindingnessly-<as-todeterminism/enceptivity of relative mreflexivity/relative reflexivitys between a desublimation/gimmickiness and sublimation preconverging/postconverging-dementating/structuring/paradigming' as reflected in the social reality of a 'veil of knowledge associated with subterfuges' reflected say in an ambiguous continuity between genuineknowledge and chicanery, social/institutional intellectualism and social/institutional sycophantic-sophistry, alchemy and chemistry, quackery and medicine, technologicaladvancement and technical-mystification, flawed-industrial-analyses-and-certifications and disinterested-scientific-analyses-and-certifications, etc.). In other words, the notion of the 'other' as aetiologisation/ontological-escalation-<ontologicalveridicality_commitment/otherliness_transcending/compulsions-encumbered_transcending $>$ is much more than 'magnanimity towards the other' but more fully a stance that 'calls upon a principled commitment to the notion of the other' by the other as enabling the completeness of 
universal responsibility/relative-reflexivity. Paradoxically, viewed from this angle as of the possibility of inducing prospective notional-contiguity/epistemic-contiguity ${ }^{62}-<$ profoundsupererogation -of-mentally-aestheticised postconverging/dialectical-thinking -qualiaschema $>$ for ontologically-veridical virtue transcendence-andsublimity/sublimation/supererogatory de-mentativity, a different interpretation can be made about the posture of a thinker like Heidegger during the troubled years of the 1930s; as effectively, the implication of Heidegger's analysis of the situation which he associated with Being-development/ontological-framework-expansion-as-to-depth-of-ontologisingdevelopment-as-infrastructure-of- meaningfulness-and-teleology $<$ amplituding/formativeepistemicity $>$ causality $\sim$ as-to-projective-totalitative-implications-of-prospectivenonpresencing,-for-explicating relative-unreflexivity/relative-reflexivity - ontologicalcontiguity points to a 'conception emphasising ontology as defining virtue thus ultimately geared towards prospective notional-contiguity/epistemic-contiguity ${ }^{6}-<$ profoundsupererogation -of-mentally-aestheticised postconverging/dialectical-thinking -qualia-

schema $>$ as of the need for prospective relative-ontological-completeness ${ }^{87}$-of- ${ }^{83}$ reference-ofthought', but failing not because of the said orientation but with regards to the wrong conclusion about Being-development/ontological-framework-expansion-as-to-depth-of-ontologisingdevelopment-as-infrastructure-of- meaningfulness-and-teleology misunderstood as implying that it lies with a historical tradition like the Ancient Greece tradition or German Folk tradition rather than lying with an underlying transcendental ${ }^{103}$ universal notion construed as 'going beyond them-and-us logic' as of the implications of ${ }^{103}$ universal human emancipating potential of re-originary-as-unenframed/re-ontologising/unbeholdening/outlier-conceptualisation〈imbued-postconverging/dialectical-thinking -'projective-insights'/‘epistemic-projection-inconflatedness '-of-notional deprocrypticism-prospective-sublimation $\rangle,$ and this fundamentally scuppered his possibility of 'attaining a conception of prospective notional- 
contiguity/epistemic-contiguity ${ }^{2}-<$ profound-supererogation -of-mentally-

aestheticised postconverging/dialectical-thinking -qualia-schema $>$ as of the need for prospective relative-ontological-completeness ${ }^{87}$-of- ${ }^{8}$ reference-of-thought', rather than an 'ontologically-flawed idea implying a certain given historical tradition'. Likewise, but with regards to virtue analysts analyses that are naively articulated on the supposedly prospective reontologising basis of the 'supposedly notional-contiguity/epistemic-contiguity ${ }^{62}<$ profoundsupererogation -of-mentally-aestheticised postconverging/dialectical-thinking -qualiaschema>' of our 'modern take attitude/mental-disposition/care-and-episteme' as of our $<$ amplituding/formative-epistemicity $>$ totalising $\sim$ self-referencing-

syncretising/circularity/interiorising/akrasiatic-drag 34 prior relative-ontologicalincompleteness ${ }^{8}$-of- ${ }^{8}$ reference-of-thought leading to charade as of selecting, triaging, mutually-concurring-and-accommodating and power-relations driven charades virtue constructs, an altogether different drawback is decisively apparent as we know that since those troubled years, wars, genocides, and other crimes against humanity have still been taking place and will probably continue to take place, as of the preconverging/postconverging-dementative/structural/paradigmatic consequence arising with such manifestations 'supposedly of the notional-contiguity/epistemic-contiguity ${ }^{62}-<$ profound-supererogation -of-mentallyaestheticised postconverging/dialectical-thinking -qualia-schema>' of our 'modern take attitude/mental-disposition/care-and-episteme '; divulging that conceptualising virtue in as to such 'wrongly implicited notional-contiguity/epistemic-contiguity ${ }^{62}-<$ profoundsupererogation -of-mentally-aestheticised postconverging/dialectical-thinking -qualia-

schema ${ }^{\prime}$ is at best only of palliative consequence and not truly aetiologisation/ontologicalescalation-<ontological-veridicality_commitment/otherliness_transcending/compulsionsencumbered_transcending $>$ which rather warrants prospectively veridical notional-

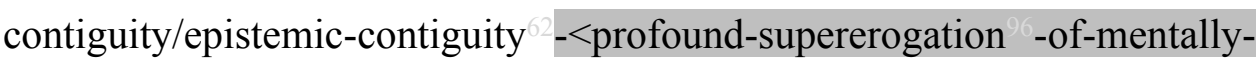


aestheticised postconverging/dialectical-thinking -qualia-schema $>$ as of prospective relativeontological-completeness ${ }^{87}$-of- ${ }^{83}$ reference-of-thought (as of prospective ${ }^{18}$ deprocrypticism-orpreempting - disjointedness-as-of- ${ }^{8}$ reference-of-thought). The fact is well-meaningness, goodintentions and/or good-naturedness however comforting to contemplate about doesn't substitute for ontology/ontological-veridicality as of the need to truly understand the human limitedmentation-capacity as-subjecting-'educed-unlimitedness/existence-sublimating nascence' to-limitedness/human-subpotency dynamics behind human action for appropriate aetiologisation/ontological-escalation-<ontological-

veridicality_commitment/otherliness_transcending/compulsions-encumbered_transcending> that brings an end to the endemisation and enculturation of any given registryworldview's/dimension's vices-and-impediments ${ }^{105}$. This existential-<disentologising/reentologising aporeticism $>$ reality about $<$ amplituding/formative-epistemicity $>$ causality $\sim$ asto-projective-totalitative-implications-of-prospective- nonpresencing,-for-

explicating relative-unreflexivity/relative-reflexivity ontological-contiguity is no more different between the social world and the natural world, and so as of existence- - as-the-absolutea-priori-of-conceptualisation and existence—as-sublimating-withdrawal/unenframing/reontologising,-elicited-from-prospective-profound-supererogation $-<$ as-to-perspectiveontological-normalcy/postconvergence-implied-'prospective-aporeticism-

overcoming/unovercoming'> inherent ontological coherence/contiguity. This insight about virtue as lying with ontology has been to varying degrees implicitly understood by many postmodern thinkers, beginning with Heidegger pointing to a sophistication of thought but for the poor development and poor conclusions of his analysis during the troubled years of 1930s; and rather poorly interpreted by virtue critiques adopting a 'modern take attitude/mentaldisposition/care-and-episteme', supposedly in 'supposedly notional-contiguity/epistemiccontiguity ${ }^{6}<$ profound-supererogation - of-mentally-aestheticised $\sim$ postconverging/dialectical- 
thinking -qualia-schema>', rather as of its <amplituding/formativeepistemicity $>$ totalising $\sim$ self-referencing-syncretising/circularity/interiorising/akrasiatic-drag prior relative-ontological-incompleteness ${ }^{8}$-of- ${ }^{-}$reference-of-thought perspective construed-as reasoning-from-results/afterthought of modernity. Such sophistication of thought to think in terms of inherent ontology, however ontologically-flawed with respect to Heidegger, has been further implicitly pursued by latter postmodern thinkers as of quasi-transcendental implications for construing virtue from the orientation of prospective notional-contiguity/epistemiccontiguity $^{62}-<$ profound-supererogation -of-mentally-aestheticised $\sim$ postconverging/dialecticalthinking -qualia-schema $>$ as of prospective relative-ontological-completeness ${ }^{87}$-ofreference-of-thought, as implicited with the case of Derrida's spirit insight. Ultimately, the 'postmodern ${ }^{18}$ deprocrypticism-or-preempting — disjointedness-as-of- ${ }^{8}$ reference-of-thought apriorising/axiomatising/referencing/intelligibilitysettingup/measuringinstrumenting attitude/mental-disposition/care-and-episteme' should ontologically nurture the requisite psychoanalytic-unshackling/prospective-grounding/prospective-reification for prospective notional-contiguity/epistemic-contiguity ${ }^{2}$ - profound-supererogation -of-mentallyaestheticised postconverging/dialectical-thinking -qualia-schema $>$ as of prospective relativeontological-completeness ${ }^{87}$-of- ${ }^{83}$ reference-of-thought implied as of ${ }^{18}$ deprocrypticism-orpreempting - disjointedness-as-of- ${ }^{-3}$ reference-of-thought as implied by postmodern ${ }^{4}$ humansubject-emancipating-relativism-driven-recomposuring-constructivism-towardssingularisation-<as-to-the-nondisjointedness/entailment-of-prospective- nonpresencing $>$ thus inducing the aetiologisation/ontological-escalation- $<$ ontologicalveridicality_commitment/otherliness_transcending/compulsions-encumbered_transcending> addressing/resolving our 'modern take attitude/mental-disposition/care-and-episteme' and-impediments ${ }^{105}$. As a further elucidation, prospective notional-contiguity/epistemiccontiguity ${ }^{62}<$ profound-supererogation - of-mentally-aestheticised $\sim$ postconverging/dialectical- 
thinking -qualia-schema> as of prospective relative-ontological-completeness ${ }^{87}$-ofreference-of-thought actually points out that the uninstitutionalised-threshold ${ }^{12}$ is rather a point of de-mentation-〈supererogatory ontological-de-mentation-or-dialectical-dementation-stranding-or-attributive-dialectics $\rangle$ which is what justifies the pre-eminence of the prospective institutionalisation attitude/mental-disposition/care-and-episteme over the uninstitutionalised-threshold attitude/mental-disposition/care-and-episteme $^{102}$ We can effectively grasp why Heidegger's implicited insight as of notional-discontiguity/epistemicdiscontiguity 3 - $<$ between - prior-shallow-supererogation -of-mentallyaestheticised preconverging/dementing -qualia-schema_and_prospective-profoundsupererogation -of-mentally-aestheticised postconverging/dialectical-thinking -qualiaschema $>$ but rather being associated with a given tradition actually couldn't break through the

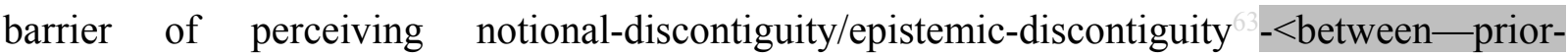
shallow-supererogation -of-mentally-aestheticised preconverging/dementing -qualiaschema_and_prospective-profound-supererogation -of-mentallyaestheticised postconverging/dialectical-thinking -qualia-schema> as 'futural way of thinking', as it misperceived that any tradition can reveal as of its inherent nature the 'futural way of thinking', rather than that this lies with a " ${ }^{103}$ universal principle understanding of the transformation of traditions' and thus how such ${ }^{103}$ universal principle understanding as of its 'universal implications informs about the 'futural way of thinking'. In this regard, we can equally understand why Heidegger's supposed criticism of Cartesianism was altogether a misplaced analysis given that a ${ }^{103}$ universal principle understanding of the transformation of traditions' as herein implied by this author in reflecting holographically-<conjugatively-andtransfusively $>$ the relative-unreflexivity/relative-reflexivity ontological-contiguity $\sim$ of-thehuman-institutionalisation-process, would have provided the insight that Descartes was actually 'establishing a positivism tradition as of futural way of thinking' breaking away from 
non-positivism/medievalism and so 'as to the fact that dimensionality-of-sublimating ${ }^{5}$ <<amplituding/formative >supererogatory $\sim$ de-mentativeness/epistemic-growth-or-

conflatedness /transvaluative-rationalising/transepistemicity/anamnestic-residuality/spirit-

drivenness-equalisation> as to existence-as-sublimating-withdrawal/unenframing/reontologising,-elicited-from-prospective-profound-supererogation is aporetically the more fundamental incipient/seeding originariness-parrhesia,-as-spontaneity-of-aestheticisation to Descartes thinking-proposition for budding-positivism reproducibilitymathesis/motif/thrownness-disposition,-as-reproducibility-of-aestheticisation' and thus inmany-ways the naïve/flawed Cartesianism today arise as to a reasoning as from reproducibility_mathesis/motif/thrownness-disposition,-as-reproducibility-of-aestheticisation perspective whereas Descartes is more fundamentally involved in an postconverging-apereticismovercoming/unovercoming exercise with respect to medieval-scholasticism non-positivising (as of dimensionality-of-sublimating ${ }^{25}-<$ amplituding/formative $>$ supererogatory $\sim$ dementativeness/epistemic-growth-or-conflatedness /transvaluativerationalising/transepistemicity/anamnestic-residuality/spirit-drivenness-equalisation〉 as to existence — as-sublimating-withdrawal/unenframing/re-ontologising,-elicited-fromprospective-profound-supererogation ) which as of 'self-reflexive instigative-eventuating-〈asto-teleological-instigative/incipientwilling/arbitrariness/waywardness/faithdrivenness/supererogating-for-human-intelligibility,preceding-existence's-eventuating-sublimating-validation/desublimating-invalidation) philosophically generates his thinking-proposition as to prospective reasoning-fromresults/afterthought implied budding-positivism reproducibility—mathesis/motif/thrownnessdisposition,-as-reproducibility-of-aestheticisation; such that budding-positivism apriorising/axiomatising/referencing/intelligibilitysettingup/measuringinstrumenting becomes intelligible, thus revealing that Heidegger implied notional-discontiguity/epistemic- 
discontiguity 3 - $<$ between - prior-shallow-supererogation -of-mentally-

aestheticised preconverging/dementing -qualia-schema_and_prospective-profound-

supererogation -of-mentally-aestheticised postconverging/dialectical-thinking -qualia-

schema while intending to be of prospective

apriorising/axiomatising/referencing/intelligibilitysettingup/measuringinstrumenting is actually of an $\quad<$ amplituding/formative-epistemicity $>$ totalising $\sim$ self-referencingsyncretising/circularity/interiorising/akrasiatic-drag

aposteriorising/logicising/deriving/intelligising/measuring with prior positivism apriorising/axiomatising/referencing/intelligibilitysettingup/measuringinstrumenting attitude/mental-disposition/care-and-episteme , even though in its attempt it effectively elicits many insights for the prospect of ontologically-veridical prospective postmodern apriorising/axiomatising/referencing/intelligibilitysettingup/measuringinstrumenting with its corresponding postmodern deprocrypticism-or-preempting-disjointedness-as-ofreference-of-thought

apriorising/axiomatising/referencing/intelligibilitysettingup/measuringinstrumenting attitude/mental-disposition/care-and-episteme . In other words philosophical thought is all incipiently/seedingly about dimensionality-of-sublimating <<amplituding/formative>supererogatory $\sim$ de-mentativeness/epistemic-growth-or-

conflatedness /transvaluative-rationalising/transepistemicity/anamnestic-residuality/spirit-

drivenness-equalisation), and Heidegger's issue should have actually been about future Beingdevelopment/ontological-framework-expansion-as-to-depth-of-ontologising-development-asinfrastructure-of- meaningfulness-and-teleology just as Descartes issue in articulating budding-positivism/rational-empiricism (traditionally construed-as-rationalism) was not with setting up its ${ }^{56}$ meaningfulness-and-teleology ${ }^{9}$ in contention with prior nonpositivism/medievalism as of the then projective future Being-development/ontological- 
framework-expansion-as-to-depth-of-ontologising-development-as-infrastructure-of-

meaningfulness-and-teleology of positivism/rational-empiricism, apart from mere intellectually contrastive elucidation, but rather implied affirming prospective positivism as of its very own apriorising/axiomatising/referencing/intelligibilitysettingup/measuringinstrumenting attitude/mental-disposition/care-and-episteme ; and so as of the fundamental implication of positivism prospective relative-ontological-completeness ${ }^{87}$-of- ${ }^{8}$ reference-of-thought over nonpositivism/medievalism prior relative-ontological-incompleteness ${ }^{8}$-of- ${ }^{8}$ reference-of-thought. We thus see why the future redevelopment of Heideggerian misconceived prospective notionalcontiguity/epistemic-contiguity ${ }^{2}<$ profound-supererogation -of-mentallyaestheticised postconverging/dialectical-thinking -qualia-schema $>$ as of prospective relativeontological-completeness ${ }^{87}$-of- ${ }^{8}$ reference-of-thought as undertaken by latter thinkers like Foucault, Derrida, Deleuze, Lacan, Lyotard and others are full of prospective quasitranscendental 'preconverging/postconverging-de-mentative/structural/paradigmatic disseminative implications' as reflecting an underlying reality of prospective ${ }^{83}$ reference-ofthought de-mentation-〈supererogatory ontological-de-mentation-or-dialectical-dementation-stranding-or-attributive-dialectics $\rangle$ construed herein as of prospective postmodern deprocrypticism-or-preempting - disjointedness-as-of- ${ }^{3}$ reference-of-thought apriorising/axiomatising/referencing/intelligibilitysettingup/measuringinstrumenting attitude/mental-disposition/care-and-episteme, and so just as searing with 'preconverging/postconverging-de-mentative/structural/paradigmatic disseminative implications' was the mathesis universalis metaphoricity ${ }^{57}$ extended development/influence on the works of the Galileos, Descartes, Newtons, Leibnizes and others that ultimately reflected an underlying reality of prospective ${ }^{83}$ reference-of-thought ${ }^{15}$ de-mentation〈supererogatory ontological-de-mentation-or-dialectical-de-mentation-stranding-or- 
attributive-dialectics $\rangle$ implied as of prospective positivism

apriorising/axiomatising/referencing/intelligibilitysettingup/measuringinstrumenting

attitude/mental-disposition/care-and-episteme in superseding/transcending nonpositivism/medievalism. In effect it is herein contended that what is implicitly missed about the Cartesian proposition 'I think therefore I am' is not the idea that Descartes contemplates that he is the first person to be self-conscious about his thinking; rather his underlying reasoning is 'more than just speculative doubting' but 'motivated doubting' that is highly contextual-as-of-the-nonpositivism/medieval-epoch and highly prefigurative-as-to-what-Descartes-wants-to-do-oftransformative-with-thinking-given-that-context postconverging aporeticismovercoming/unovercoming (underlying that Descartes' dimensionality-of-sublimating ${ }^{25}$ <<amplituding/formative>supererogatery $\sim$ de-mentativeness/epistemic-growth-or-

\section{conflatedness /transvaluative-rationalising/transepistemicity/anamnestic-residuality/spirit-}

drivenness-equalisation> as to existence-as-sublimating-withdrawal/unenframing/reontologising,-elicited-from-prospective-profound-supererogation is aporetically the more fundamental incipient/seeding originariness-parrhesia,-as-spontaneity-of-aestheticisation in then secondarily inducing his thinking-proposition for budding-positivism reproducibilitymathesis/motif/thrownness-disposition,-as-reproducibility-of-aestheticisation). That is, Descartes seeks to affirm the 'mereness of thought' beyond any existing habit-and-tradition-ofthought as of non-positivism/medievalism pedantic dogmatism reasoning-fromresults/afterthought, and so liberated rearticulate thought 'out of thin air' as of prospective reasoning-through/messianic-reasoning as reflected by his novel mathesis universalis metaphoricity ${ }^{57}$ rationalism schema/dissemination ${ }^{28}$ that permeates all of his works such that even with his ontological argument something subtle and more original is happening, in that unlike many medieval-scholasticism dogmatic interpretations that construe of a supernatural permeation into the natural, in affirming the ontological argument Descartes blocks- 
out/passivises the supernatural from the natural with the metaphoricity ${ }^{57}$ implication that the natural can be thought of operationally and in sublimation on its own terms-as-of-axiomaticconstruct. Thus Descartes 'I think therefore I am' is rather a statement of intent as of a 'futural way of thinking and sublimation' and its budding-positivism apriorising/axiomatising/referencing/intelligibilitysettingup/measuringinstrumenting attitude/mental-disposition/care-and-episteme , that is unique as 'consciously setting up the preeminence of thinking in eliciting-and-resolving systemic doubting and postconvergingly-dementating/structuring/paradigming the possibility of elucidation of any subject on this thinking educing sublimation basis'. In effect Descartes project is actually as to existencepotency $^{32} \sim$ sublimating-nascence,-disclosed-from-prospective-epistemic-digression relativeontological-completeness ${ }^{87}$-of-apriorising/axiomatising/referencing as of positivism/rationalempiricism, and so from the prior ${ }^{7}$ presencing-absolutising-identitive-constitutedness ${ }^{14}$ of non-positivism/medievalism. With both the budding-positivism apriorising/axiomatising/referencing/intelligibilitysettingup/measuringinstrumenting attitude/mental-disposition/care-and-episteme and postmodern ${ }^{5}$ deprocrypticism-orpreempting - disjointedness-as-of- ${ }^{83}$ reference-of-thought

apriorising/axiomatising/referencing/intelligibilitysettingup/measuringinstrumenting attitude/mental-disposition/care-and-episteme, we may be forgiven to confuse-and-dismiss their schema as-to-preconverging/postconverging-de-mentative/structural/paradigmaticdisseminative-implications as of prospective reasoning-through/messianic-reasoning as incoherent from a shallow-and-immediate uninsightful analytical perspective on the basis of the respectively prior reasoning-from-results/afterthought of non-positivism/medievalism and positivism/rational-empiricism manifestation of ${ }^{80}$ procrypticism-or-disjointedness-as-ofreference-of-thought (since as of the latter relative-ontological-incompleteness ${ }^{8}$ perspective 'all the reasoning in the world' is only respectively as of non-positivism/medievalism 
apriorising/axiomatising/referencing-psychologism apriorising/axiomatising/referencing-psychologism); thus failing to perceive that the projectiveinsights for dispensing-with-immediacy-for-relative-ontological-completeness ${ }^{87}$-byreification/contemplative-distension ${ }^{27}$ (as of human self-surpassing-existentialism-formfactor,-in-overcoming-'notional collateralising-beholdening-protohumanity'-to-'attainsublimating-humanity'-as-to-existence-potency sublimating-nascence,-disclosed-fromprospective-epistemic-digression to supersede human temporality $/$ shortness $<$ amplituding/formative $>$ wooden-language-〈imbued - averaging-of-thought-<as-toleveling/ressentiment/closed-construct-of- meaningfulness-and-teleology -as-of'nondescript/ignorable-void '-with-regards-to-prospective-apriorising-implications $>\rangle)$, as of deneuterising 'exteriorisation attitude/mental-disposition/care-and-episteme' of meaningfulness-and-teleology ${ }^{9}$-as-metaphoricity ${ }^{57}$ superseding/overriding prior ${ }^{8}$ referenceof-thought temporally ${ }^{58}$ neuterising 'interiorisation attitude/mental-disposition/care-andepisteme ${ }^{,}$of ${ }^{56}$ meaningfulness-and-teleology ${ }^{9}$, reflects Being-development/ontologicalframework-expansion-as-to-depth-of-ontologising-development-as-infrastructure-ofmeaningfulness-and-teleology as of human limited-mentation-capacity-deepening-assubjecting limitedness/human-subpotency to 'educed-unlimitedness/existence-sublimating nascence' ${ }^{53}$ implications wherein ontological-faith-notion-or-ontological-fideism-imbuedunderdetermination-of-motif-and-apriorising/axiomatising/referencing-as-so-being-as-ofexistential-reality is sublimatingly rather about a 'seeding promise of human-subpotency ontological-performance ${ }^{2}$-<including-virtue-as-ontology $>/$ morality/ethics/justice/etc. equivalence/correspondence with the full-potency-of-existence's $\sim$ sublimating-nascence-as-ofits-coherence/contiguity' that comes out short and which 'reinvigoration as of furthered ontological-faith-notion-or-ontological-fideism - imbued-underdetermination-of-motif-andapriorising/axiomatising/referencing-as-so-being-as-of-existential-reality parrhesiastic askesis- 
or-acumen for originary/as-of-event ${ }^{38}$ reasoning-through/messianic-reasoning' induces the successive prospective relative-ontological-completeness ${ }^{87}$-of- ${ }^{3}$ reference-of-thought as to the 'relative-unreflexivity/relative-reflexivity - ontological-contiguity ${ }^{67}$ of-the-humaninstitutionalisation-process ${ }^{68}$ as of ${ }^{83}$ reference-of-thought différance/internaldialectics/difference-deferral'. The appropriate contemplative perspective for the appreciation of their schema as-to-preconverging/postconverging-de-mentative/structural/paradigmatic_disseminative-implications is effectively crossgenerational as of the amplitude/breadth of reference-of-thought implied transcendence-and-sublimity/sublimation/supererogatory $\sim$ dementativity; as we can effectively appreciate that the very mathesis ${ }^{103}$ universalis schema/disseminative metaphoricity ${ }^{57}$ engendering our positivism apriorising/axiomatising/referencing/intelligibilitysettingup/measuringinstrumenting attitude/mental-disposition/care-and-episteme is still ongoing today even as it is more clearly demarcated as initiated about 500 years ago. The overall logic of this notionaldiscontiguity/epistemic-discontiguity ${ }^{6}-<$ between - prior-shallow-supererogation -ofmentally-aestheticised preconverging/dementing -qualia-schema_and_prospective-profoundsupererogation -of-mentally-aestheticised postconverging/dialectical-thinking -qualia-

schema $>$ analysis, implied as of prospective relative-ontological-completeness ${ }^{87}$-of- ${ }^{8}$ referenceof-thought, can be understood simply as of the relation between existence which is already given and human-subpotency which as of prospective relative-ontological-completeness ${ }^{87}$-ofreference-of-thought grasp more and more what is of the full-potency of existence by way of its axiomatic-constructs of existence or of purviews of existence, with its grandest axiomaticconstruct as an epistemic-totalising 33 circumscribing/delineating construct being the ${ }^{83}$ referenceof-thought. We can grasp that it is not existence and purviews of existence which will adjust to human-subpotency for ontologically-veridical ${ }^{56}$ meaningfulness-and-teleology ${ }^{9}$ but rather human-subpotency adjusting as to existence-potency ${ }^{39} \sim$ sublimating-nascence,-disclosed-from- 
prospective-epistemic-digression; with such adjusting being construed as of prospective relativeontological-completeness ${ }^{87}$. But then humankind as of its developed-and-invested habits and traditions about existence counterintuitively relates to existence and purviews of existence as if it supersedes them, and thus do not or poorly construes of prospective relative-ontologicalcompleteness ${ }^{87}$-of- ${ }^{8}$ reference-of-thought/relative-ontological-completeness ${ }^{87}$-of-axiomaticconstruct as an issue of human-subpotency adjustment as of psychoanalyticunshackling/prospective-grounding/prospective-reification, implied as of ${ }^{15}$ de-mentation〈supererogatory $\sim$ ontological-de-mentation-or-dialectical-de-mentation-stranding-or-

attributive-dialectics $\rangle$ with regards to the ${ }^{83}$ reference-of-thought transcendence-andsublimity/sublimation/sentativity. In lieu the poor intuition is to imply that we are already well grounded and that prospective ${ }^{56}$ meaningfulness-and-teleology ${ }^{9}$ is an incrementalism-in-relative-ontological-incompleteness ${ }^{8}$ enframed/disontologising conceptualisation to our already established psychoanalytic disposition rather than a maximalising-recomposuring-for-relative-ontologicalcompleteness ${ }^{87}$ - unenframed/re-ontologising conceptualisation in resetting-ourpsychoanalytic-disposition/prospective-grounding as of < amplituding/formative-epistemicity $>$ totalising $\sim$ renewing-realisation/re-perception/re-thought in apriorising/axiomatising/referencing-\{of-'prospectively_implicited_attendant-ontologicalcontiguity ' educedexistentialising/contextualising/textualising_'intelligibility/epistemicity/reflexivity-contiguity<imbued-notional cogency $>$ ' \}-conflatedness ${ }^{13}$-in-\{preconverging disentailment by\} postconverging-entailment, such that this leads to apriorising/axiomatising/referencing-\{of'prospectively implicited_attendant-ontological-contiguity ' ceducedexistentialising/contextualising/textualising_'intelligibility/epistemicity/reflexivity-contiguity<imbued-notional cogency $\left.>^{\prime} \quad\right\}$-constitutedness ${ }^{1}$-in-preconverging-entailment when so 
poorly psychoanalytically grounded on the naïve and ontologically-flawed basis that it is existence and purviews of existence that adjust to our human-subpotency. Thus however counterintuitive, this overall conception structures the fact that it as of de-mentation〈supererogatory ontological-de-mentation-or-dialectical-de-mentation-stranding-orattributive-dialectics $>$ that our human <amplituding/formativeepistemicity>totalising/circumscribing/delineating ${ }^{83}$ reference-of-thought is transcended for prospective relative-ontological-completeness ${ }^{87}$-of- ${ }^{83}$ reference-of-thought implied as of notional-discontiguity/epistemic-discontiguity ${ }^{6}-<$ between - prior-shallow-supererogation -ofmentally-aestheticised preconverging/dementing -qualia-schema_and prospective-profoundsupererogation -of-mentally-aestheticised postconverging/dialectical-thinking -qualiaschema>. In this regard, 'intemporal ontological-faith-notion-or-ontological-fideism-imbuedunderdetermination-of-motif-and-apriorising/axiomatising/referencing-as-so-being-as-ofexistential-reality instigated relative-unreflexivity/relative-reflexivity-ontologicalcontiguity $^{67}$ of-the-human-institutionalisation-process ${ }^{68}$ as of difference-conflatedness ${ }^{13}$-as-tototalitative-reification-in-singularisation-<as-to-the-nondisjointedness/entailment-ofprospective- nonpresencing $>$-as-veridical-epistemicity-relativism-determinism implied $<$ amplituding/formative-epistemicity $>$ causality $\sim$ as-to-projective-totalitative-implications-ofprospective- nonpresencing,-for-explicating relative-unreflexivity/relative-reflexivity ontological-contiguity , as of Being-development/ontological-framework-expansion-as-todepth-of-ontologising-development-as-infrastructure-of- meaningfulness-and-teleology is essentially one of shifting attitude/mental-disposition/care-and-episteme by the successive institutionalisations reference-of-thought apriorising/axiomatising/referencing/intelligibilitysettingup/measuringinstrumenting for aposteriorising/logicising/deriving/intelligising/measuring ${ }^{56}$ meaningfulness-and-teleology ${ }^{9}$, even though beyond-the-consciousness-awareness-teleology ${ }^{9}<$ of-preconverging-existential- 
extrication-as-of-existential-unthought $>$ human induced bias leads to a wholly immersed-andengrossed focussing only at its given present institutionalisation's ${ }^{83}$ reference-of-thought 'present attitude/mental-disposition/care-and-episteme' as if other retrospective-andprospective institutionalisations' ${ }^{8}$ reference-of-thought do not have their own attitude/mentaldisposition/care-and-episteme ${ }^{5}$ as of their underlying relative-ontological-incompleteness ${ }^{88}$ and relative-ontological-completeness ${ }^{87}$ reference-of-thought. This phenomenological insight in recognising that there is an 'underlying metaphoricity ${ }^{57}$-induced relative-emancipating migration' from the mindset of the early hunter-gathers as of recurrent-utteruninstitutionalisation towards modern man as of positivism- ${ }^{80}$ procrypticism to the prospective postmodern man as of deprocrypticism, calls for a full appreciation of this most profound phenomenological transcendental process of corresponding 'human attitude/mentaldisposition/care-and-episteme migration' inducing successive apriorisings/apriorising/axiomatising/referencing/intelligibilitysettingup/measuringinstrumenti ngs of human ${ }^{56}$ meaningfulness-and-teleology as of prospective relative-ontologicalcompleteness $^{87}$-of- ${ }^{83}$ reference-of-thought; and so, as of retrospective and prospective meaningfulness-and-teleology interpretation construed as ${ }^{4}$ historiality/ontologicaleventfulness 3 /ontological-aesthetic-tracing-<perspective-ontological-

normalcy/postconvergence-reflected-‘epistemicity-relativism-determinism'>. $\quad$ Such a conception that goes beyond our natural inclination of 'referring to' and 'adhocly-and-scantily' identify other retrospective and prospective registry-worldviews/dimensions ${ }^{83}$ reference-ofthought apriorising/axiomatising/referencing/intelligibilitysettingup/measuringinstrumenting attitude/mental-disposition/care-and-episteme from our present attitude/mentaldisposition/care-and-episteme, , towards an ontologically-veridical transparent 'to be or existing as wholly immersed-and-engrossed' existential-<disontologising/re-ontologising apereticism $>$ projection insight about all registry-worldviews/dimensions attitude/mental- 
disposition/care-and-episteme is what underlies the protensive-consciousness of deprocrypticism, from which standpoint as of its ontological-completeness-of- ${ }^{3}$ reference-ofthought such an ontologically-veridical analysis of 'human attitude/mental-disposition/careand-episteme migration' can be undertaken, for retrospective and prospective attitude/mentaldisposition/care-and-episteme conception, and specifically as relevant for understanding prospective 'postmodern ${ }^{18}$ deprocrypticism-or-preempting-disjointedness-as-of- ${ }^{8}$ referenceof-thought apriorising/axiomatising/referencing/intelligibilitysettingup/measuringinstrumenting attitude/mental-disposition/care-and-episteme'. In this regard, 'human attitude/mentaldisposition/care-and-episteme migration' in reflecting holographically-<conjugatively-andtransfusively $>$ the relative-unreflexivity/relative-reflexivity ontological-contiguity $\sim$ of-thehuman-institutionalisation-process induced Being-development/ontological-frameworkexpansion-as-to-depth-of-ontologising-development-as-infrastructure-of- meaningfulnessand-teleology is instilled as of ${ }^{15}$ de-mentation-〈supererogatory $\sim$ ontological-de-mentation-ordialectical-de-mentation - stranding-or-attributive-dialectics $\rangle$ wherein the prospective reference-of-thought

apriorising/axiomatising/referencing/intelligibilitysettingup/measuringinstrumenting attitude/mental-disposition/care-and-episteme is intemporally induced as deneuterising 'exteriorisation attitude/mental-disposition/care-and-episteme' of ${ }^{56}$ meaningfulness-andteleology ${ }^{9}$-as-metaphoricity ${ }^{57}$ superseding/overriding the prior ${ }^{83}$ reference-of-thought temporally ${ }^{58}$ neuterising 'interiorisation attitude/mental-disposition/care-and-episteme' of meaningfulness-and-teleology . The 'exteriorisation attitude/mental-disposition/care-andepisteme ${ }^{5}$ implies ${ }^{56}$ meaningfulness-and-teleology ${ }^{9}$ as not referenced/registered/decisionedas-ascribed/neuterised as of a prior ${ }^{83}$ reference-of-thought- categoricalimperatives/axioms/registry-teleology ${ }^{9}$, -foraposteriorising/logicising/deriving/intelligising/measuring- ${ }^{5}$ meaningfulness-and-teleology ${ }^{9}$, 
that is, not as of the prior ${ }^{83}$ reference-of-thought 'interiorisation attitude/mentaldisposition/care-and-episteme ${ }^{,}$, but rather referenced/registered/decisioned-asdeascribed/deneuterised as of the prospective ${ }^{83}$ reference-of-thought- categoricalimperatives/axioms/registry-teleology ${ }^{9}$,-foraposteriorising/logicising/deriving/intelligising/measuring- ${ }^{5}$ meaningfulness-and-teleology ; with the latter construed as postconverging-or-dialectical-thinking -apriorising-psychologism and the former construed as preconverging-or-dementing ${ }^{20}$-apriorising-psychologism. Thus a registry-worldview/dimension institutionalisation ${ }^{83}$ reference-of-thought always operates as if it is the absolute framework of ${ }^{5}$ meaningfulness-and-teleology ${ }^{99}$, that is, by its 'interiorisation attitude/mental-disposition/care-and-episteme ', notwithstanding the ontological-veridicality of its prior relative-ontological-incompleteness ${ }^{8}$-of- ${ }^{83}$ eference-of-thought at its uninstitutionalised-threshold ${ }^{102}$, as reflected by the prospective registry-worldview/dimension institutionalisation ${ }^{83}$ reference-of-thought in an 'exteriorisation attitude/mentaldisposition/care-and-episteme " towards it. Consider in this regard the ontologically-veridical reflected immersed-and-engrossed attitude/mental-disposition/care-and-episteme with respect to the 'ill-health <amplituding/formative-epistemicity>totalising $\sim$ devolved-purview/domainof-construal-as-intrinsic-reality/ontological-veridicality/existential-reality' wherein the 'to be or existing as wholly immersed-and-engrossed' recurrent-utter-uninstitutionalisation 'implicited_attendant-ontological-contiguity ${ }^{67}$ > educedexistentialising/contextualising/textualising_'intelligibility/epistemicity/reflexivity-contiguity$<$ imbued-notional cogency> $>$-lowest-level-reification per-cep-ti-vi-ty-as-of-bad-omen attitude/mental-disposition/care-and-episteme could involve a conversational stance of the sort, 'I have been stricken by a spirit', in an effusive-conversational-as-of-existential articulating of what can be done to allay such a spirit; or with respect to our positivism- ${ }^{80}$ procrypticism, in an effusive-conversational-as-of-existential articulating of a clinical analysis mainly as a patient 
ill-health state; or with respect to prospective postmodernism, in an effusive-conversational-asof-existential articulating of associated socio-economic and socio-political factors behind a patient's ill-health. Basically, 'exteriorisation attitude/mental-disposition/care-and-episteme ', as relevant for the conception of a 'postmodern exteriorisation attitude/mental-disposition/careand-episteme relative to our modern take interiorisation attitude/mental-disposition/care-andepisteme', as of notional ${ }^{18}$ deprocrypticism protensive-consciousness in ontologicalcompleteness-of- reference-of-thought encapsulates: - underlying relative-ontologicalincompleteness ${ }^{88}$ and relative-ontological-completeness ${ }^{87}{ }^{83}$ reference-of-thought as of relativepestcenverging-nonextricatory-existential-preempting-of-existential-unthought over relativepreconverging-existential-extrication-as-of-existential-unthought; - notional disconguity of the prospective ${ }^{83}$ reference-of-thought over the prior ${ }^{83}$ reference-of-thought; - and prospective deascription/deneuterising

psychologism/apriorising/axiomatising/referencing/intelligibilitysettingup/measuringinstrumen ting over prior ascription $/{ }^{5}$ neuterising psychologism/apriorising/axiomatising/referencing/intelligibilitysettingup/measuringinstrumen ting. When so-construed prospectively, 'postmodern exteriorisation attitude/mentaldisposition/care-and-episteme ${ }^{5}$ is all about such a ${ }^{18}$ deprocrypticism-or-preemptingdisjointedness-as-of- ${ }^{8}$ reference-of-thought as implied by its human-subject-emancipatingrelativism-driven-recomposuring-constructivism-towards-singularisation- $<$ as-to-thenondisjointedness/entailment-of-prospective- nonpresencing $>$ 'originary postmodernthought-process and other postmodern creative-processes avant-gardism' that are not in a reasoning-from-results/afterthought ontological entanglement with our 'modern take attitude/mental-disposition/care-and-episteme ${ }^{-}$. Consider in this regard the reasoningthrough/messianic-reasoning prospective preconverging/postconverging-dementative/structural/paradigmatic disseminative implications as of Derridean 
différance/internal-dialectics/difference-deferral, Foucauldian genealogy-knowledge-andpower-discourse and Deleuzian immanence experimentation that can all be construed (and as equally implied by this author's ontological-normalcy/postconvergence referentialism

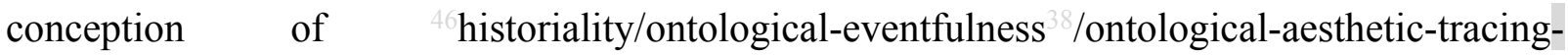
$<$ perspective-ontological-normalcy/postconvergence-reflected-‘epistemicity-relativismdeterminism'>), as of prospective transcendence-and-sublimity/sublimation/supererogatery $\sim$ dementativity singularisation- $<$ as-to-the-nondisjointedness/entailment-of-prospectivenonpresencing $>\quad$ projected epistemic-immanence/veridical-epistemicity-relativismdeterminism for perpetuated/disseminative preemption of conceptual disjointedness/disentailment. Thus ultimately the notional ${ }^{18}$ deprocrypticism registryworldview/dimension is one that will be marked by sharper and sharper singularisation-<as-tothe-nondisjointedness/entailment-of-prospective- nonpresencing $>$ projected epistemicimmanence/veridical-epistemicity-relativism-determinism, construed as of its perpetuating/disseminating of the preemption of disjointedness. In this regard, singularisation$<$ as-to-the-nondisjointedness/entailment-of-prospective- nonpresencing $>$ projected epistemic-immanence/veridical-epistemicity-relativism-determinism retrospectively and prospectively reflects the notional conflatedness ${ }^{13} /$ conflatedness $^{13}$ implied as of ontologicalfaith-notion-or-ontological-fideism — imbued-underdetermination-of-motif-andapriorising/axiomatising/referencing-as-so-being-as-of-existential-reality but with the latter as a 'seeding promise of human-subpotency ontological-performance ${ }^{72}-<$ including-virtue-asontology $>$ /morality/ethics/justice/etc. equivalence/correspondence with the full-potency-ofexistence's $\sim$ sublimating-nascence-as-of-its-coherence/contiguity' ever always coming short

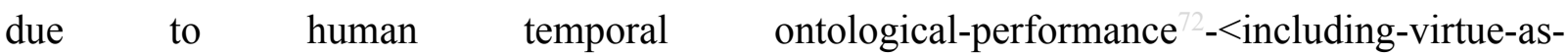
ontology $>$ /morality/ethics/justice/etc. denaturing as of temporal/shortness-of-register-ofmeaningfulness-and-teleology pedantic/formulaic alignment to 
'apriorising/axiomatising/referencing/intelligibilitysettingup/measuringinstrumenting reference-of-thought- categorical-imperatives/axioms/registry-teleology ${ }^{9}$,-foraposteriorising/logicising/deriving/intelligising/measuring- ${ }^{5}$ meaningfulness-and-teleology ${ }^{9}$, for aposteriorising/logicising/deriving/intelligising/measuring meaningfulness, so-construed at the uninstitutionalised-threshold ${ }^{102}$ as apriorising/axiomatising/referencing-\{of- prospectively implicited_attendant_ontological-contiguity ' educedexistentialising/contextualising/textualising_'intelligibility/epistemicity/reflexivity-contiguity$<$ imbued-notional cogency >' $\}$-constitutedness ${ }^{14}$-in-preconverging-entailment, thus requiring prospective intemporal/longness-of register-of meaningfulness-and-teleology institutionalisation renewing of reference-of-thought- categoricalimperatives/axioms/registry-teleology ${ }^{99}$,-for-

aposteriorising/logicising/deriving/intelligising/measuring - ${ }^{56}$ meaningfulness-and-teleology that overcome the distortional implications of such pedantic/formulaic denaturing ; by way of 'reinvigoration as of furthered ontological-faith-notion-or-ontological-fideism-imbuedunderdetermination-of-motif-and-apriorising/axiomatising/referencing-as-so-being-as-ofexistential-reality parrhesiastic askesis-or-acumen' for originary/as-of-event ${ }^{38}$ reasoningthrough/messianic-reasoning. Singularisation-<as-to-the-nondisjointedness/entailment-ofprospective- nonpresencing $>\quad$ projected epistemic-immanence/veridical-epistemicityrelativism-determinism as such is a conception that grasps that 'axiomatic-constructs as of $<$ amplituding/formative-epistemicity>totalising/circumscribing/delineating $\quad$ reference-ofthought- ${ }^{8}$ devolving' is the ${ }^{5}$ meaningfulness-and-teleology ${ }^{9}$ format implied by the ontologicalfaith-notion-or-ontological-fideism - imbued-underdetermination-of-motif-andapriorising/axiomatising/referencing-as-so-being-as-of-existential-reality 'seeding promise of human-subpotency

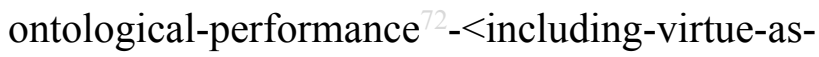
ontology $>$ /morality/ethics/justice/etc. equivalence/correspondence with the full-potency-of- 
existence's $\sim$ sublimating-nascence-as-of-its-coherence/contiguity' with respect to any given '<amplituding/formative-epistemicity $>$ totalising $\sim$ devolved—purview/domain-of-construal-asintrinsic-reality/ontological-veridicality/existential-reality', with potentially divergent meaningfulness-and-teleology implications as of underlying relative-ontologicalincompleteness 8 /relative-ontological-completeness ${ }^{87}$

\section{〈sublimating referencing/registering/decisioning,-as-self-becoming/self-}

conflatedness /formative-supererogating-<projective/reprojective-aestheticising-re-motifand-re-apriorising/re-axiomatising/re-referencing,-in-perspective-ontologicalnormalcy/postconvergence $>>$ arising from human limited-mentation-capacity-deepening —as subjecting limitedness/human subpotency to 'educed unlimitedness/existence sublimating nascence' ; with relative completeness increasingly attained, by way of 'reinvigorating as of furthered ontological-faith-notion-or-ontological-fideism - imbued-underdetermination-ofmotif-and-apriorising/axiomatising/referencing-as-so-being-as-of-existential-reality

parrhesiastic askesis-or-acumen' for originary/as-of-event ${ }^{38}$ reasoning-through/messianicreasoning. Thus singularisation-<as-to-the-nondisjointedness/entailment-of-prospectivenonpresencing $>\quad$ projected epistemic-immanence/veridical-epistemicity-relativismdeterminism by its implied notional conflatedness ${ }^{13}$ highlights that 'axiomatic-constructs as of $<$ amplituding/formative-epistemicity>totalising/circumscribing/delineating $\quad$ reference-ofthought- devolving' in reflecting of 'human-subpotency ontological-performance ${ }^{72}$ $<$ including-virtue-as-ontology $>$ /morality/ethics/justice/etc. correspondence with the fullpotency of existence in its coherence/contiguity' as of implied human-subject-emancipatingrelativism-driven-recomposuring-constructivism-towards-singularisation- $<$ as-to-thenondisjointedness/entailment-of-prospective- nonpresencing $>$, is effectively as of dissingularisation-<as-to-the-disjointedness/disentailment-of- presencing - absolutisingidentitive-constitutedness > /epistemic-nonimmanence/flawed-epistemicity-relativism- 
determinism to singularisation- $<$ as-to-the-nondisjointedness/entailment-of-prospectivenonpresencing $>\quad$ projected epistemic-immanence/veridical-epistemicity-relativismdeterminism. That is singularisation-<as-to-the-nondisjointedness/entailment-of-prospectivenonpresencing $>\quad$ projected epistemic-immanence/veridical-epistemicity-relativismdeterminism points out that there is no inherent meaning of existence about existence as existence is tautologically what it is as existence, rather the notion of meaning arises as of the notion of human-subpotency strife to 'grasp what is existence', and that latter notion is all about human-subpotency 'axiomatic-constructs as of <amplituding/formativeepistemicity>totalising/circumscribing/delineating $\quad$ reference-of-thought- ${ }^{84}$ devolving' human-subject-emancipating-relativism-driven-recomposuring-constructivism-towardssingularisation- $<$ as-to-the-nondisjointedness/entailment-of-prospective- nonpresencing $>$ ? In other words, meaning is always a human project to construe existence as of human limitedmentation-capacity-deepening-as-subjecting limitedness/human-subpotency-to-'educedunlimitedness/existence-sublimating nascence' ${ }^{33}$ of 'axiomatic-constructs as of $<$ amplituding/formative-epistemicity>totalising/circumscribing/delineating $\quad{ }^{83}$ reference-of-

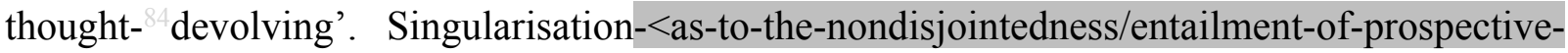
nonpresencing $>\quad$ projected epistemic-immanence/veridical-epistemicity-relativismdeterminism, and as reflected by this author's notion of ontological-normalcy/postconvergence referentialism conception of ${ }^{4}$ historiality/ontological-eventfulness $3 /$ ontological-aesthetictracing-<perspective-ontological-normalcy/postconvergence-reflected-‘epistemicityrelativism-determinism' $>$ points out that dissingularisation- $<$ as-to-thedisjointedness/disentailment-of- presencing - absolutising-identitiveconstitutedness $>$ /epistemic-nonimmanence/flawed-epistemicity-relativism-determinism as of human-subpotency ontological-performance ${ }^{72}-<_{\text {including-virtue-as- }}$ ontology $>$ /morality/ethics/justice/etc. correspondence with the full-potency of 
existence/intrinsic-reality/ontological-veridicality is ontologically-flawed, and that prospective relative-ontological-completeness reflects

that singularisation-<as-to-thenondisjointedness/entailment-of-prospective- nonpresencing> projected epistemicimmanence/veridical-epistemicity-relativism-determinism as of human-subpotency ontologicalperformance $^{72}-<$ including-virtue-as-ontology $>$ /morality/ethics/justice/etc. correspondence with the full-potency of existence/intrinsic-reality/ontological-veridicality is what is rather ontologically-veridical. It is this prospective singularisation- $<$ as-to-thenondisjointedness/entailment-of-prospective- nonpresencing $>$ projected epistemicimmanence/veridical-epistemicity-relativism-determinism that reflects the effective possibility of a 'seeding promise of human-subpotency ontological-performance ${ }^{72}-<$ including-virtue-asontology $>$ /morality/ethics/justice/etc. equivalence/correspondence with the full-potency-ofexistence's $\sim$ sublimating-nascence-as-of-its-coherence/contiguity' as implied by ontologicalfaith-notion-or-ontological-fideism—imbued-underdetermination-of-motif-andapriorising/axiomatising/referencing-as-so-being-as-of-existential-reality; attainable as of human limited-mentation-capacity-deepening —as-subjecting limitedness/human-subpotency to-'educed-unlimitedness/existence-sublimating nascence' ${ }^{53}$ of 'axiomatic-constructs as of $<$ ampling/formative-epistemicity>totalising/circumscribing/delineating $\quad{ }^{83}$ reference-of-

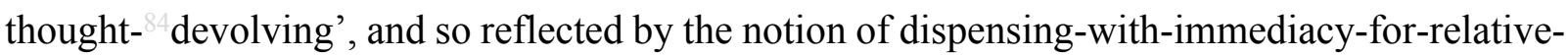
ontological-completeness ${ }^{87}$-by-reification/contemplative-distension ${ }^{27}$. This reality of the need to construe of human-subpotency ontological-performance ${ }^{72}-$ including-virtue-as- $^{2}$ ontology $>$ /morality/ethics/justice/etc. correspondence with the full-potency of existence/intrinsic-reality/ontological-veridicality as of singularisation- $<$ as-to-thenondisjointedness/entailment-of-prospective- nonpresencing $>$ projected epistemicimmanence/veridical-epistemicity-relativism-determinism over dissingularisation-<as-to-thedisjointedness/disentailment-of- presencing — absolutising-identitive- 
constitutedness $>$ /epistemic-nonimmanence/flawed-epistemicity-relativism-determinism has increasingly been revealed as from the 'strangely axiomatic teleologically-thorough singularisation-<as-to-the-nondisjointedness/entailment-of-prospective- nonpresencing $>$ projected epistemic-immanence/veridical-epistemicity-relativism-determinism manifestations' of quantum entanglement, relativity theory implications, the teleologically constrained nature of biological processes as more than just the parsimonious-or-disparate nature of organic matter but rather singularisation-<as-to-the-nondisjointedness/entailment-of-prospectivenonpresencing $>\quad$ projected epistemic-immanence/veridical-epistemicity-relativismdeterminism as of whole living organisms, and likewise human meaningfulness itself as to sublimation is a postconverging-de-mentating/structuring/paradigming singularisation- $<$ as-tothe-nondisjointedness/entailment-of-prospective- nonpresencing $>$ projected epistemicimmanence/veridical-epistemicity-relativism-determinism as of sharply defined teleological possibilities of social and individuals existence with respect to the different registryworldviews/dimensions specific institutionalisations, etc. (Interestingly, as of this author's conception of such a teleological perception of existence as of its singularisation- $<$ as-to-thenondisjointedness/entailment-of-prospective- nonpresencing $>$ projected epistemicimmanence/veridical-epistemicity-relativism-determinism, as of the ${ }^{4}$ human-subjectemancipating-relativism-driven-recomposuring-constructivism-towards-singularisation- $<$ as-tothe-nondisjointedness/entailment-of-prospective- nonpresencing $>$ insights of postmodernthought has been subject to naïve obfuscation grounded on the supposed privilege of 'scienceideology' over science-in-practice as an opened construct of scientific knowledge as of causeand-effect constraint, and with the form of science at various times continually moulting as from the budding science of the days of Galileo and Copernicus, to Newtonian science, to Lavoisier laboratory science, to Einsteinian science to modern-day institutional practices of science, with all fundamentally driven not by any 'purported science-ideology' but rather the practicality of 
results as of the constraint of the subject-domains of scientific study as of their knowledgereification $\sim$ gesturing-and-accounting — of-epistemic-phenomenalism- $<$ inprospective_psychologismic apriorising/axiomatising/referencing-\{of-'prospectively implicited_attendant-ontological-contiguity ' reducedexistentialising/contextualising/textualising_ 'intelligibility/epistemicity/reflexivity-contiguity<imbued-notional cogency $\left.>{ }^{\prime}\right\}$-conflatedness -in-\{preconverging-disentailment by\} postconverging entailment $>$ rather than 'any implied notion that naively supersede existenceas-the-absolute-a-priori-of-conceptualisation and existence-as-sublimatingwithdrawal/unenframing/re-ontologising,-elicited-from-prospective-profoundsupererogation $-<$ as-to-perspective-ontological-normalcy/postconvergence-implied'prospective-aporeticism-overcoming/unovercoming'>'. In this regard, it is interesting to note that the notion of science practised by the successive pioneers cited above are markly different from each other and all subjected rather to the implications of knowledge-reification $\sim$ gesturingand-accounting - of-epistemic-phenomenalism- $<$ inprospective_psychologismic apriorising/axiomatising/referencing-\{of- ${ }^{\text {pprospectively }}$ implicited_attendant-ontological-contiguity ' educedexistentialising/contexalising/textising_intelligibility/epistemicity/reflexivity-contiguity<imbued-notional cogency >' \}-conflatedness -in-\{preconverging-disentailment by\} postconverging-entailment $>$ of their purview/domain of existence/intrinsic-reality/ontologicalveridicality. It is interesting as well to note for example that when equations didn't work out in reflecting 'implicited_attendant-ontological-contiguity ${ }^{67}$ ' educedexistentialising/contextualising/textualising_intelligibility/epistemicity/reflexivity-contiguity$<$ imbued-notional cogency $>$, Einstein rather rethought and subjected human assumptions to existence — as-the-absolute-a-priori-of-conceptualisation and existence—as-sublimatingwithdrawal/unenframing/re-ontologising,-elicited-from-prospective-profound- 
supererogation $-<$ as-to-perspective-ontological-normalcy/postconvergence-implied-

'prospective-aporeticism-overcoming/unovercoming'> for his science, with such notions as space-time rather than traditional space and time; pointing out that there cannot be any ideology about science and it is rather the constraint for knowledge-reification $\sim$ gesturing-andaccounting - of-epistemic-phenomenalism- $<$ in-

prospective_psychologismic apriorising/axiomatising/referencing-\{of-‘prospectively

implicited_attendant-ontological-contiguity ' educed-

existentialising/contextualising/textualising_'intelligibility/epistemicity/reflexivity_contiguity-

<imbued-notional cogency $\left.>^{\prime} \quad\right\}$-conflatedness -in-\{preconverging-disentailment by\}

postconverging-entailment> that determines science practice, and so in existential<disontologising/re-ontologising aporeticism $>$ apriorising/axiomatising/referencing-\{of'prospectively_implicited_attendant-ontological-contiguity ' educed-

existentialising/contextualising/textualising_'intelligibility/epistemicity/reflexivity_contiguity<imbued-notional cogency $\left.>{ }^{\prime}\right\}$ - conflatedness ${ }^{13}$-in-\{preconverging-disentailment-by\}

postconverging-entailment. Further, it had long dawned on this author that scam studies meant to undermine the validity of underlying constructivist and relativist insights about existentialdisontologising/re ontologising aporeticism> reality as implied by postmodern-thought including with respect to such implications in the natural sciences are rather 'supposedly invalidating' wholly with respect to the authors of such scam studies coming out with the arguments of their 'intendedness of invalidation'; with the legitimate contention that such ploys are thus surreptitious manoeuvres for preempting a given orientation of thought "not because of the inherent invalidity of such orientations as of inherent theoretical knowledge arguments in undermining such orientations' but rather as a ploy of 'inducing popularised scientific ideology' to surreptitiously stifle such orientations without truly engaging in undermining its theorisation. Bogusness or non-bogusness is not a relevant scientific criteria, though granted it can be a 
relevant criteria for 'surreptitious media-driven invalidation', as science-in-practice is about ultimate cause-and-effect relationships, and in practical terms many scientific studies are rather elaborated as of 'deferred cause-and-effect constraint' as a reifying gesture for ultimate causeand-effect determination. The fact that similar scam studies for the 'intendedness of invalidation' cannot be construed as scientifically valid with respect to any given orientation of study renders such manoeuvres intellectually void, and whatever their underlying 'covert goals' and however genuine their authors are of intent. It is very much important in this regard that intellectuals, whether in the natural sciences or in the social and humanities, not be cowered/enframed by nonintellectual/extra-intellectual approaches to 'acknowledged intellectual ways and approaches for intellectual argumentation', and not even if such approaches are media-driven, so because much that is central and critical to intellectualism is about exploring all possibilities.) All these highlight an underlying ontology's-directedness-as-Being that bears notional conflatedness singularisation-<as-to-the-nondisjointedness/entailment-of-prospective- nonpresencing $>$ projected epistemic-immanence/veridical-epistemicity-relativism-determinism implications, as of ontologically-veridical singularisation-<as-to-the-nondisjointedness/entailment-ofprospective- nonpresencing $>\quad$ projected epistemic-immanence/veridical-epistemicityrelativism-determinism of human-subpotency ontological-performance ${ }^{72}-<$ including-virtue-asontology $>$ /morality/ethics/justice/etc. correspondence with the full-potency of existence/intrinsic-reality/ontological-veridicality over ontologically-flawed dissingularisation$<$ as-to-the-disjointedness/disentailment-of- presencing — absolutising-identitiveconstitutedness > /epistemic-nonimmanence/flawed-epistemicity-relativism-determinism; and yet our psychological disposition is more often than not geared to ontologically-flawed dissingularisation-<as-to-the-disjointedness/disentailment-of- presencing - absolutisingidentitive-constitutedness $>$ /epistemic-nonimmanence/flawed-epistemicity-relativismdeterminism that tend to be absolutised in apriorising/axiomatising/referencing-\{of- 
'prospectively_implicited_attendant-ontological-contiguity ' educed-

existentialising/contextualising/textualising_'intelligibility/epistemicity/reflexivity_contiguity-

$<$ imbued-notional cogency $>$ ' $\}$-constitutedness ${ }^{14}$-in-preconverging-entailment of prior reasoning-from-results/afterthought mental-reflexes of <amplituding/formative> woodenlanguage-〈imbued-temporal-mere-form/virtualities/dereification/akrasiatic-

drag/denatured/preconverging-or-dementing -narratives - of-the- reference-of-thought-

categorical-imperatives/axioms/registry-teleology $\rangle$, and so failing to grasp that the very principle of human institutional-cumulation/institutional-recomposure-〈as-tohistoriality/ontological-eventfulness /ontological-aesthetic-tracing-<perspectiveontological-normalcy/postconvergence-reflected-‘epistemicity-relativism-determinism’>> in reflecting holographically-<conjugatively-and-transfusively $>$ the relative-unreflexivity/relativereflexivity ontological-contiguity of-the-human-institutionalisation-process itself is one driven by the future as of its own reasoning-through/messianic-reasoning attitude/mentaldisposition/care-and-episteme ", which reflects an increasing orientation away from identitiveconstitutedness ${ }^{14}$-as-'epistemic-totality ${ }^{37}$ '-dereification-in-dissingularisation-<as-to-thedisjointedness/disentailment-of- presencing - absolutising-identitive-constitutedness $>$-asflawed-epistemicity-relativism-determinism as-cloistered-within-the-same- ${ }^{8}$ reference-ofthought towards difference-conflatedness ${ }^{13}$-as-to-totalitative-reification-in-singularisation- $<$ asto-the-nondisjointedness/entailment-of-prospective- nonpresencing $>$-as-veridical-

epistemicity-relativism-determinism protracted-teleological-wholeness/nested-congruence-inreflecting-the-relative-unreflexivity/relative-reflexivity - ontological-contiguity $\sim$ of-thehuman-institutionalisation-process ${ }^{68}$,-so-construed-as-singularisation- $<$ as-to-thenondisjointedness/entailment-of-prospective- nonpresencing $>$ projected epistemicimmanence/veridical-epistemicity-relativism-determinism', and so because the future is as of prospective relative-ontological-completeness ${ }^{87}$-of- ${ }^{8}$ reference-of-thought and takes precedence 
for its apriorising/axiomatising/referencing/intelligibilitysettingup/measuringinstrumenting as of increasing axiomatic teleological wholeness/nested-congruence or prospective relativeontological-completeness ${ }^{87}$-of- ${ }^{8}$ reference-of-thought. For instance, with regards to 'the-verysame ill-health <amplituding/formative-epistemicity>totalising $\sim$ devolved-purview-as-domainof-construal-as-intrinsic-reality/ontological-veridicality/ontological-veridical', with the successive ${ }^{83}$ reference-of-thought ${ }^{15}$ de-mentation-〈supererogatory $\sim$ ontological-de-mentationor-dialectical-de-mentation-stranding-or-attributive-dialectics $\rangle$ at their uninstitutionalisedthreshold ${ }^{102}$ inducing successive displacement of human-subpotency ${ }^{83}$ reference-of-thoughtcategorical-imperatives/axioms/registry-teleology ${ }^{9}$, ,for-

aposteriorising/logicising/deriving/intelligising/measuring $-{ }^{5}$ meaningfulness-and-teleology ${ }^{9}$, it is rather singularisation- $<$ as-to-the-nondisjointedness/entailment-of-prospectivenonpresencing $>\quad$ projected epistemic-immanence/veridical-epistemicity-relativismdeterminism ontologically-veridical ${ }^{83}$ reference-of-thought-level difference-conflatedness ${ }^{13}$-asto-totalitative-reification-in-singularisation- $<$ as-to-the-nondisjointedness/entailment-ofprospective- nonpresencing $>$-as-veridical-epistemicity-relativism-determinism protractedteleological-wholeness/nested-congruence-in-reflecting-the-relative-unreflexivity/relativereflexivity - ontological-contiguity ${ }^{67} \sim$ of-the-human-institutionalisation-process ${ }^{68}$,-soconstrued-as-singularisation-<as-to-the-nondisjointedness/entailment-of-prospectivenonpresencing $>\quad$ projected epistemic-immanence/veridical-epistemicity-relativismdeterminism' that effectively reflects the ${ }^{4}$ historiality/ontological-eventfulness 38 /ontologicalaesthetic-tracing-<perspective-ontological-normalcy/postconvergence-reflected-'epistemicityrelativism-determinism'> (and so over identitive-constitutedness ${ }^{14}$-as-'epistemic-totality ${ }^{37}$ 'dereification-in-dissingularisation-<as-to-the-disjointedness/disentailment-of- presencingabsolutising-identitive-constitutedness $>$-as-flawed-epistemicity-relativism-determinism as-cloistered-within-the-same- ${ }^{8}$ reference-of-thought that will simply imply the obliviousness of 
one ${ }^{8}$ reference-of-thought from the other since 'identity of ${ }^{5}$ meaningfulness-and-teleology ${ }^{9}$ ' is wrongly fixed-and-set as of each registry-worldview's/dimension's ${ }^{83}$ reference-of-thought cloistered-consciousness). As it is prospective relative-ontological-completeness ${ }^{87}$-ofreference-of-thought of human-subpotency that brings about 'better and better axiomatic teleological wholeness/nested-congruence of ${ }^{56}$ meaningfulness-and-teleology ${ }^{9}$ increasing human-subpotency ontological-performance ${ }^{72}-<$ including-virtue-asontology $>$ /morality/ethics/justice/etc. correspondence with the full-potency of existence/intrinsic-reality/ontological-veridicality, and so from: 'implicited_attendantontological-contiguity $^{67}$, educedexistentialising/contextualising/textualising_intelligibility/epistemicity/reflexivity-contiguity$<$ imbued-notional cogency> -lowest-level-reification per-cep-ti-vi-ty-as-of-bad-omen with recurrent-utter-ininstitutionalisation, 'implicited_attendant-ontologicalcontiguity $^{67} \sim$ educedexistentialising/contextualising/textualising_intelligibility/epistemicity/reflexivity-contiguity<imbued-notional cogency>' ${ }^{\prime}$-second-level-reification per-cep-ti-vi-ty-as-of-a-specific-placeor-specific-evil-people-or-specific-evil-period with base-institutionalisation-ununiversalisation, to 'implieited_attentontontolont-contiguity ${ }^{67}$ ' educedexistentialising/contextualising/textualising_'intelligibility/epistemicity/reflexivity-contiguity<imbued-notional cogency>' -third-level-reification per-cep-ti-vi-ty-as-of-failure-to-followthe-heeding-of-the-Deity-or-failure-to-adhere-to-a-certain-mysticism-or-failure-to-payreverence-to-an-ancestor with ${ }^{103}$ universalisation-non-positivism/medievalism, to 'implicited_attendant-ontological-contiguity ${ }^{67}$; educed-

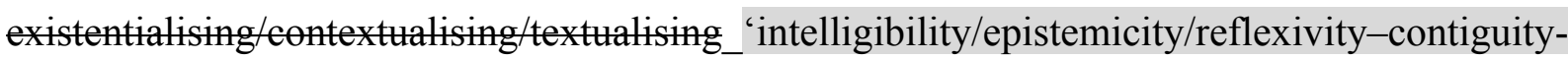
$<$ imbued-notional cogency>' ${ }^{\prime}$-fourth-level-reification per-cep-ti-vi-ty-as-of-full-disease-andscientific-theory-construct-as-the-exclusive-cause-and-effect-conceptualisation with 
positivism- procrypticism, and prospectively to 'implicited_attendant-ontologicalcontiguity ${ }^{67} \sim$ educed-

existentialising/contextualising/textualising_intelligibility/epistemicity/reflexivity_contiguity<imbued-notional cogency>' -full-reification per-cep-ti-vi-ty-as-of-factoring-intotalising $3{ }^{3}$ hermeneutically/textually/reprojectingly/supererogatingly/zeroingly/re-acutingly,$\{$ \{lecompulsing\} delinearity for-cogency:-socioeconomic,-education,-information,-environmental,gender-and-power-relations-issues-underlying-healthcare-and-medical-delivery with notional ${ }^{18}$ deprocrypticism that then achieves difference-conflatedness ${ }^{13}$-as-to-totalitativereification-in-singularisation-<as-to-the-nondisjointedness/entailment-of-prospectivenonpresencing $>$-as-veridical-epistemicity-relativism-determinism protracted-teleologicalwholeness/nested-congruence-in-reflecting-the-relative-unreflexivity/relative-reflexivityontological-contiguity ${ }^{67}$ of-the-human-institutionalisation-process ${ }^{68}$,-so-construed-assingularisation-<as-to-the-nondisjointedness/entailment-of-prospective- nonpresencing $>$ projected epistemic-immanence/veridical-epistemicity-relativism-determinism'. This insight

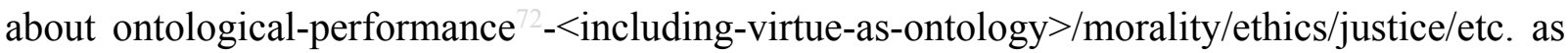
of prospective relative-ontological-completeness ${ }^{87}$ of human-subpotency can be garnered with respect to any axiomatic-construct as the ${ }^{56}$ meaningfulness-and-teleology ${ }^{9}$ representation of human-subpotency ontological-performance ${ }^{2}-<$ including-virtue-asontology $>$ /morality/ethics/justice/etc. correspondence with the full-potency-ofexistence's $\sim$ sublimating-nascence-as-of-its-coherence/contiguity or a purview/domain of existence/intrinsic-reality/ontological-veridicality, and so not only with regards to the reference-of-thought as the grandest axiomatic-construct. This fundamentally points out that at uninstitutionalised-threshold ${ }^{102}$, human cognition which is rather in 'excogitative-blanking of prospective institutionalisation 'implicited_attendant-ontological-contiguity ${ }^{67}$; educedexistentialising/contextualising/textualising_intelligibility/epistemicity/reflexivity-contiguity- 
<imbued-notional cogency>' -in-elucidation-or-reification' suffers-and-fails to relay the 'seeding promise of human-subpotency ontological-performance ${ }^{72}-<$ including-virtue-asontology $>$ /morality/ethics/justice/etc. equivalence/correspondence with the full-potency-ofexistence's $\sim$ sublimating-nascence-as-of-its-coherence/contiguity' for prospective institutionalisation as of difference-conflatedness ${ }^{13}$-as-to-totalitative-reification-insingularisation-<as-to-the-nondisjointedness/entailment-of-prospective- nonpresencing $>$-asveridical-epistemicity-relativism-determinism protracted-teleological-wholeness/nestedcongruence-in-reflecting-the-relative-unreflexivity/relative-reflexivity - ontologicalcontiguity ${ }^{67}$ of-the-human-institutionalisation-process ${ }^{68}$,-so-construed-as-singularisation- $<$ asto-the-nondisjointedness/entailment-of-prospective- nonpresencing $>$ projected epistemicimmanence/veridical-epistemicity-relativism-determinism'; since this potential for such singularisation-<as-to-the-nondisjointedness/entailment-of-prospective- nonpresencing $>$ projected epistemic-immanence/veridical-epistemicity-relativism-determinism is denaturing as of identitive-constitutedness ${ }^{14}$-as-'epistemic-totality ${ }^{37}$ '-dereification-in-dissingularisation$<$ as-to-the-disjointedness/disentailment-of- presencing - absolutising-identitiveconstitutedness $>$-as-flawed-epistemicity-relativism-determinism as-cloistered-within-thesame- ${ }^{8}$ reference-of-thought at its uninstitutionalised-threshold ${ }^{102}$. We can appreciate that with regards to 'the-very-same ill-health $<$ amplituding/formative--epistemicity $>$ totalising $\sim$ devolvedpurview-as-domain-of-construal-as-intrinsic-reality/ontological-veridicality' highlighted above,

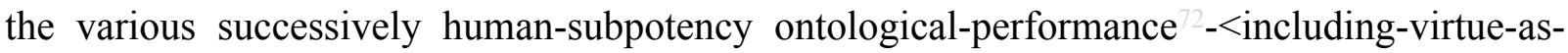
ontology $>$ /morality/ethics/justice/etc. of prior perceptivities as successive uninstitutionalisedthreshold' are rather in 'excogitative-blanking of the prospective institutionalisation 'implicited_atentantontological-contiguity ${ }^{67}$ ' educedexistentialising/contextualising/textualising_'intelligibility/epistemicity/reflexivity-contiguity<imbued-notional cogency>' ${ }^{\prime}$-in-elucidation-or-reification' (by their identitive- 
constitutedness ${ }^{14}$-as-'epistemic-totality ${ }^{37}$ '-dereification-in-dissingularisation-<as-to-thedisjointedness/disentailment-of- presencing - absolutising-identitive-constitutedness $>$-asflawed-epistemicity-relativism-determinism as-cloistered-within-the-same- ${ }^{-3}$ reference-ofthought), as overlooking their successively prospective perceptivities which are actually in prospective relative-ontological-completeness ${ }^{87}$-of- ${ }^{83}$ reference-of-thought as enabling/cogentwith difference-conflatedness ${ }^{13}$-as-to-totalitative-reification-in-singularisation- $<$ as-to-thenondisjointedness/entailment-of-prospective- nonpresencing > -as-veridical-epistemicityrelativism-determinism protracted-teleological-wholeness/nested-congruence-in-reflectingthe-relative-unreflexivity/relative-reflexivity - ontological-contiguity ${ }^{67} \sim$ of-the-humaninstitutionalisation-process ${ }^{68}$,-so-construed-as-singularisation- $<$ as-to-thenondisjointedness/entailment-of-prospective- nonpresencing $>\quad$ projected epistemicimmanence/veridical-epistemicity-relativism-determinism'. The notion of human 'excogitativeblanking of the prospective institutionalisation 'implicited_attendant-ontologicalcontiguity ${ }^{67} \sim$ educedexistentialising/contextualising/textualising_intelligibility/epistemicity/reflexivity-contiguity<imbued-notional cogency>' -in-elucidation-or-reification' can equally be elucidated with regards to a devolved axiomatic-construct of the ${ }^{8}$ reference-of-thought. For instance, we can grasp that with regards to 'the-very-same physics <amplituding/formativeepistemicity $>$ totalising $\sim$ devolved — purview/domain-of-construal-as-intrinsicreality/ontological-veridicality/existential-reality', the per-cep-ti-vi-ty of 'traditional classical mechanics axiomatic-construct' had rather been in 'excogitative-blanking of the prospective construal of 'implicited_attendant-ontological-contiguity ${ }^{67}$ ' educed-

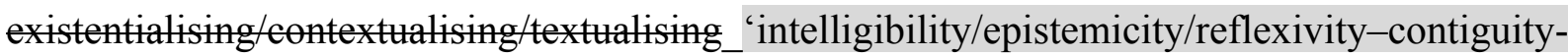
<imbued-notional cogency>' -in-elucidation-or-reification' reflected by the prospective theory-of-relativity-together-with-quantum-mechanics - axiomatic-constructs as the latter's 
prospective relative-ontological-completeness ${ }^{87}$ reflects the former's prior relative-ontologicalincompleteness $^{88}$ as dialectically out-of-phase/preconverging-or-dementing ${ }^{20}$-apriorisingpsychologism. This insight about human 'excogitative-blanking of the prospective institutionalisation 'implicited_attendant-ontological-contiguity ${ }^{6}$ ' educedexistentialising/contextualising/textualising_intelligibility/epistemicity/reflexivity-contiguity$<$ imbued-notional cogency $>$ ' -in-elucidation-or-reification' at uninstitutionalised-threshold actually highlights that from a prospective perspective of prospective relative-ontologicalcompleteness $^{87}$-of- ${ }^{83}$ reference-of-thought our positivism- ${ }^{80}$ procrypticism registryworldview/dimension is very much imbued with a flawed ontological-performance ${ }^{2}$ <including-virtue-as-ontology>, as is the case with all other prior registryworldviews/dimensions, "when we seem to perceive-and-think that our social world of meaningfulness-and-teleology ${ }^{9}$ is coherent, failing to factor in that it is preconverging-ordementing -apriorising-psychologism at its uninstitutionalised-threshold ${ }^{102}$ as reflected as disjointedness-as-of- ${ }^{8}$ reference-of-thought preconverging-or-dementing ${ }^{20}$-apriorisingpsychologism by futural Being-development/ontological-framework-expansion-as-to-depth-ofontologising-development-as-infrastructure-of- meaningfulness-and-teleology as of prospective deprocrypticism-or-preempting - disjointedness-as-of- ${ }^{8}$ reference-of-thought'; as this false sense of coherence is actually the effect of our prior relative-ontologicalincompleteness ${ }^{8}$-of- ${ }^{-3}$ reference-of-thought apriorising/axiomatising/referencing/intelligibilitysettingup/measuringinstrumenting $<$ amplituding/formative-epistemicity $>$ totalising $\sim$ self-referencingsyncretising/circularity/interiorising/akrasiatic-drag ${ }^{34}$ which we necessarily relate to as if of ontological-completeness-of- ${ }^{-}$reference-of-thought, and this further explains as reflected from their prospective relative-ontological-completeness ${ }^{87}$-of- ${ }^{8}$ reference-of-thought the notional procrypticism/notional disjointedness-as-of- ${ }^{8}$ reference-of-thought of all registry- 
worldviews/dimensions as of their prior relative-ontological-incompleteness ${ }^{88}$-of- ${ }^{8}$ referenceof-thought denaturing ${ }^{56}$ meaningfulness-and-teleology $9{ }^{9}$ of their identitiveconstitutedness ${ }^{14}$-as-'epistemic-totality ${ }^{37}$ '-dereification-in-dissingularisation- $<$ as-to-thedisjointedness/disentailment-of- presencing - absolutising-identitive-constitutedness $>$-asflawed-epistemicity-relativism-determinism as-cloistered-within-the-same- ${ }^{8}$ reference-ofthought. Concretely, the latter translates at the uninstitutionalised-threshold ${ }^{102}$ as of humansubpotency temporality $/$ shortness or shortness-of-register-of- ${ }^{56}$ meaningfulness-andteleology ${ }^{9}$ flawed ontological-performance ${ }^{72}-<$ including-virtue-as-ontology $>$, 'being construed temporally as determinative by <amplituding/formative> wooden-language-〈imbuedtemporal-mere-form/virtualities/dereification/akrasiatic-drag/denatured/preconverging-ordementing -narratives - of-the- reference-of-thought- categorical-

imperatives/axioms/registry-teleology $\rangle$, of a given registry-worldview/dimension ${ }^{8}$ referenceof-thought supposedly intemporal/Angness-of-register-of- meaningfulness-and-teleology reference-of-thought- categorical-imperatives/axioms/registry-teleology ${ }^{9}$,-foraposteriorising/logicising/deriving/intelligising/measuring $-{ }^{56}$ meaningfulness-and-teleology ${ }^{9}$, as of temporal dynamic manifestations of postlogism slantedness/ ignorance/affordability/opportunism/exacerbation/social-chainism-or-socialdiscomfiture-or-negative-social-aggregation/temporal-enculturation-or-temporal-endemisation, so-disambiguated as of ${ }^{83}$ reference-of-thought- ${ }^{8}$ devolving ontological-performance ${ }^{72}$ $<$ including-virtue-as-ontology $>$ /morality/ethics/justice/etc. beyond-the-consciousnessawareness-teleology ${ }^{9}<$ of-preconverging-existential-extrication-as-of-existential-unthought $>$. This arises because within the institutionalisation framework of a registry-worldview/dimension human construal of its knowledge-reification $\sim$ gesturing-and-accounting-of-epistemicphenomenalism- $<$ in-prospective_psychologismic $\sim$ apriorising/axiomatising/referencing- of'prospectively_implicited_attendant-ontological-contiguity ' ceduced- 
existentialising/contextualising/textualising_ 'intelligibility/epistemicity/reflexivity-contiguity$<$ imbued-notional $\left.\sim \operatorname{cogency}>^{\prime} \quad\right\}$-conflatedness -in-\{preconverging disentailment by\}

postconverging-entailment $>$ is only as effective as of the institutionalisation ${ }^{83}$ reference-ofthought- categorical-imperatives/axioms/registry-teleology ${ }^{9}$,-foraposteriorising/logicising/deriving/intelligising/measuring $-{ }^{5}$ meaningfulness-and-teleology ${ }^{\circ}$, in ${ }^{103}$ universal-transparency ${ }^{104}$-〈transparency-of-totalising-entailing,-as-to-entailing$<$ amplituding/formative-epistemicity>totalising in-relative-ontological-completeness $\rangle$, thus providing a 'perceptual perspective/framing/reference/horizon/projection of meaningfulnessand-teleology about its knowledge-reification $\sim$ gesturing-and-accounting-of-epistemicphenomenalism-<in-prospective_psychologismic $\sim$ apriorising/axiomatising/referencing- of'prospectively_implicited_attendant-ontological-contiguity ' educedexistentialising/contextualising/textualising_ 'intelligibility/epistemicity/reflexivity-contiguity<imbued-notional cogency $\left.>^{\prime} \quad\right\}$-conflatedness -in-\{preconverging-disentailment by\} postconverging entailment>'. But then at uninstitutionalised-threshold ${ }^{102}$ where meaningfulness-and-teleology' is denaturing , this prior institutionalisation 'perceptual perspective/framing/reference/horizon/projection of ${ }^{56}$ meaningfulness-and-teleology ${ }^{9}$ about 'implicited_attendant-ontological-contiguity ${ }^{7}$ ' educedexistentialising/contextualising/textualising_intelligibility/epistemicity/reflexivity-contiguity$<$ imbued-notional cogency $>$ gives a false certainty/assurance, such that human-subpotency existentially-constrained temporal ontological-performance ${ }^{72}-<_{\text {including-virtue-as- }}$ ontology $>$ /morality/ethics/justice/etc. as of $<$ amplituding/formative $>$ wooden-language〈imbued-temporal-mere-form/virtualities/dereification/akrasiaticdrag/denatured/preconverging-or-dementing -narratives - of-the- reference-of-thoughtcategorical-imperatives/axioms/registry-teleology > in usurpation of that 'perceptual perspective/framing/reference/horizon/projection of ${ }^{56}$ meaningfulness-and-teleology ${ }^{9}$ about its 
knowledge-reification $\sim$ gesturing-and-accounting — of-epistemic-phenomenalism- $<$ inprospective_psychologismic apriorising/axiomatising/referencing-\{of-'prospectively implicited_attendant-ontological-contiguity ' educedexistentialising/contextualising/textualising_'intelligibility/epistemicity/reflexivity-contiguity<imbued-notional cogency >' \}-conflatedness -in-\{preconverging disentailment by\} postconverging-entailment>' tend to be overlooked as of mental-reflex since existentially-disontologising/re-ontologising aporeticism $>$ the bulk of ${ }^{5}$ meaningfulness-and-teleology within the given registry-worldview/dimension as of its institutionalisation conformsto/complies-with its 'perceptual perspective/framing/reference/horizon/projection of meaningfulness-and-teleology ${ }^{9}$ about knowledge-reification $\sim$ gesturing-and-accounting-ofepistemic-phenomenalism-<inprospective_psychologismic apriorising/axiomatising/referencing-\{of-'prospectively implicited_attendant-ontological-contiguity ' educedexistentialising/contextualising/textualising_ 'intelligibility/epistemicity/reflexivity-contiguity<imbued-notional cogency>' \}-conflatedness -in-\{preconverging-disentailment by\} postconverging-entailment>', but with a shadowy uninstitutionalised-threshold ${ }^{12}$ always eloping to such institutionalisation conforming/complying as of prior relative-ontologicalincompleteness ${ }^{8}$-of- ${ }^{3}$ reference-of-thought, and as lack of ${ }^{103}$ universal-transparency ${ }^{104}$ 〈transparency-of-totalising-entailing,-as-to-entailing-<amplituding/formativeepistemicity>totalising in-relative-ontological-completeness $\rangle$ as to 'excogitative-blanking of prospective 'implicited_attendant-ontological-contiguity ${ }^{67}$; educedexistentialising/contextalising/textalising_'intelligibility/epistemicity/reflexivity_contiguity$<$ imbued-notional cogency>' -in-elucidation-or-reification' elicits human temporal/shortnessof register-of meaningfulness-and-teleology uninstitutionalised mental-dispositions. Such 'excogitative-blanking of prospective 'implicited_attendant-ontological-contiguity ${ }^{67}$ ' educed- 
existentialising/contextualising/textualising_intelligibility/epistemicity/reflexivity-contiguity$<$ imbued-notional cogency>' -in-elucidation-or-reification' can be construed as to when say the non-positivistic mindset goes about articulating ${ }^{56}$ meaningfulness-and-teleology ${ }^{99}$ falsely as if superstitious notions ontologically-veridical out of prospective positivism 'implicited_attendant-ontological-contiguity ${ }^{67}$ educedexistentialising/contextualising/textualising_intelligibility/epistemicity/reflexivity-contiguity$<$ imbued-notional cogency $>$-reification, and likewise with regards to a positivism/rationalempiricism manifestation of ${ }^{80}$ procrypticism-or-disjointedness-as-of- ${ }^{3}$ reference-of-thought mindset construal of ${ }^{56}$ meaningfulness-and-teleology ${ }^{9}$ that utterly overlooks the preconverging/postconverging-de-mentative/structural/paradigmatic $\quad{ }^{83}$ reference-of-thought denaturing implications of its prospective disjointedness of ${ }^{56}$ meaningfulness-and-teleology out of prospective 'implicited_attendant-ontological-contiguity ${ }^{67}$ ' educedexistentialising/contextualising/textualising_'intelligibility/epistemicity/reflexivity-contiguity$<$ imbued-notional cogency>' ${ }^{\prime}$-reification, as such disjointedness-as-of- reference-of-thought can be instigated originally from a postlogism -slantedness mental-disposition and the developing social dynamics with human temporality ${ }^{9}$. We can appreciate in this sense that even within a non-positivistic social-setup as animistic or medieval for instance, despite the fact that it is susceptible to ontologically-flawed superstitious beliefs like notions-and-accusations-ofsorcery, the bulk of human action will be in good intent as of its institutionalisation framework 'perceptual perspective/framing/reference/horizon/projection of ${ }^{56}$ meaningfulness-andteleology about 'implicited_attendant-ontological-contiguity ${ }^{67}$ ' educedexistentialising/contextualising/textualising_'intelligibility/epistemicity/reflexivity-contiguity$<$ imbued-notional cogency $>^{\prime}$; but then at its uninstitutionalised-threshold ${ }^{102}$ where its reference-of-thought preconverging/postconverging-de-mentative/structural/paradigmatic ontological-flawed implications of believing in superstition set in as of its prior relative- 
ontological-incompleteness ${ }^{8}$-of- ${ }^{8}$ reference-of-thought, it always systemically faces notional procrypticism/notional disjointedness-as-of- ${ }^{8}$ reference-of-thought as of vices-andimpediments $^{105}$ arising from non-positivism/superstitious human-subpotency existentially$<$ disontologising/re-ontologising aporeticism $>$ constrained temporal ontologicalperformance $^{72}-<$ including-virtue-as-ontology $>/$ morality/ethics/justice/etc.

$<$ amplituding/formative $>$ wooden-language-_imbued-temporal-mere-

form/virtualities/dereification/akrasiatic-drag/denatured/preconverging-or-dementing

narratives - of-the- reference-of-thought- categorical-imperatives/axioms/registry-

teleology $>$ in usurpation of the prior institutionalisation 'perceptual perspective/framing/reference/horizon/projection of ${ }^{56}$ meaningfulness-and-teleology ${ }^{9}$ about 'implicited_attendant-ontological-contiguity ${ }^{67}$ ' educed-

existentialising/contextualising/textualising_'intelligibility/epistemicity/reflexivity-contiguity$<$ imbued-notional cogency>' now in false certainty/assurance. This points out that when consciously aware of uninstitutionalised-threshold ${ }^{102}$ manifestation, we can't naively operate as of our prior institutionalisation 'perceptual perspective/framing/reference/horizon/projection of meaningfulness-and-teleology 9 about ‘implicited_attendant-ontologicalcontiguity $^{67} \sim$ educedexistentialising/contextualising/textualising_intelligibility/epistemicity/reflexivity-contiguity$<$ imbued-notional cogency $>^{\prime}$, as of the fact of the beyond-the-consciousness-awarenessteleology ${ }^{9}<$ of-preconverging-existential-extrication-as-of-existential-unthought $>$ preconverging-or-dementing ${ }^{20}$-apriorising-psychologism human-subpotency existentially< disontologising/re-ontologising aporeticism $>$ constrained temporal ontologicalperformance $^{72}$-<including-virtue-as-ontology $>/$ morality/ethics/justice/etc.

<amplituding/formative > wooden-language-_imbued-temporal-mere- 


\section{narratives - of-the- reference-of-thought- categorical-imperatives/axioms/registry-}

teleology $>$ in usurpation; such that an enlightened insight is able to bring up and examine a preconverging-or-dementing ${ }^{20}$-apriorising-psychologism representation as temporal denaturing ontological-performance ${ }^{2}-<$ including-virtue-asontology $>$ /morality/ethics/justice/etc. of the prior institutionalisation 'perceptual perspective/framing/reference/horizon/projection of ${ }^{56}$ meaningfulness-and-teleology ${ }^{9}$ about 'implicited_attendant-ontological-contiguity ${ }^{67}$ educedexistentialising/contextualising/textualising_'intelligibility/epistemicity/reflexivity_contiguity$<$ imbued-notional cogency ${ }^{\prime}$. But this conception is a reflection of more than just ad-hoc temporal manifestations at uninstitutionalised-threshold ${ }^{102}$ but rather points out, besides the trite or more grave consequences of this state of affairs as a result of human-subpotencyaporia/undecidability/dilemma/ought-indeterminacy/deficiency/limitation/constraint—imbued'notional firstnaturedness-formativeness-<as-to-eventualising inkling-drive-or-seeding misprising $>$ temporal-to-intemporal-dispositions- $<$ so-construed-as-from-perspectiveontological-normalcy/postconvergence>'-existentialism-form-factor, that the possibility for all prospective institutionalisations necessarily passes through understanding 'human-subpotency existentially-< disontologising/re-ontologising apereticism $>$ constrained temporal ontologicalperformance $^{72}-<$ including-virtue-as-ontology $>/$ morality/ethics/justice/etc.

$<$ amplituding/formative > wooden-language-〈imbued-temporal-mereform/virtualities/dereification/akrasiatic-drag/denatured/preconverging-or-dementing narratives - of-the- reference-of-thought- categorical-imperatives/axioms/registryteleology $>$ of the prior registry-worldview/dimension in usurpation', which understanding is actually what empowers the possibility for prospective institutionalisations that surpersede/transcend it. In other words, humans in the various prior institutionalisations before our positivism were not limited to their various registry-worldviews/dimensions as recurrent- 
utter-uninstitutionalisation, base-institutionalisation, ${ }^{103}$ universalisation and our positivism just because they were inherently different from us as a species, but because of the need for the necessary institutional-cumulation/institutional-recomposure-〈as-to- historiality/ontologicaleventfulness /ontological-aesthetic-tracing-<perspective-ontologicalnormalcy/postconvergence-reflected-‘epistemicity-relativism-determinism' $>>$ of understanding as of its organic-knowledge to enable the-very-same species to accede prospective institutionalisations as of human-subpotency adjusting to the full-potency of existence, and not the false certainty/assurance that any human registry-worldview/dimension is fully developed and that existence/intrinsic-reality/ontological-veridicality will adjust to it, however our myopic/cloistered 60-100 years of living perspective. That is, grounding of ${ }^{56}$ meaningfulnessand-teleology is certainly required, but as of transcendence-andsublimity/sublimation/supererogatory de-mentativity it is not about grounding as of the present but rather as of psychoanalytic-unshackling/prospective-grounding/prospective-reification for prospective relative-ontological-completeness ${ }^{87}$-of- ${ }^{8}$ reference-of-thought; and as highlighted elsewhere it is ontological-completeness-of- ${ }^{-}$eference-of-thought (of human-subpotency as of its limited-mentation-capacity-deepening - as-subjecting-limitedness/human-subpotency-to'educed-unlimitedness/existence-sublimating nascence' ${ }^{33}$ ) that can imply human-subpotency ontological-performance ${ }^{2}$-<including-virtue-as-ontology $>/$ morality/ethics/justice/etc.

correspondence with the full-potency of existence. It should be noted here that this ontology'sdirectedness-as-Being/ontologically-veridical notion of human-subpotency singularisation- $<$ asto-the-nondisjointedness/entailment-of-prospective- nonpresencing $>$ projected epistemicimmanence/veridical-epistemicity-relativism-determinism ontological-performance ${ }^{72}$ $<$ including-virtue-as-ontology $>/$ morality/ethics/justice/etc. correspondence with the fullpotency of existence is a notion of teleology ${ }^{9}$ in notional conflatedness ${ }^{13}$ as of ontologicalnormalcy/postconvergence (with teleology'9 fundamentally construed as 'phenomenal/manifest 
conceptivity/epistemic-reflexivity/epistemicity-relativism-determinism-<reifying \{as-toknowledge-developing $\}$-and-empowering $>$ in existence as ontological, and so-reflecting $<$ amplituding/formative >disposedness/psychologismic-construct-〈as-to-orientation/valueconstruct/valuation-and-derived-parameterising $\rangle$ and <amplituding/formative $>$ entailment-〈asto-totalising-contiguous/coherent-factuality-of-variability)', and so as to the specific humansubpotency with regards to overall reifying-and-empowering-reflexivity-of-ecstatic-existenceas-panintelligibility/panreflexivity ${ }^{3}-\langle$ existentially-imbued-and-educing-< $<$ epistemictotalising thermeneutically/textually/reprojectingly/supererogatingly/zeroingly/re-acutingly,$\{$ \{lecompulsing\} $\}$ delinearity for-cogency $\geq$-epistemic-perspective-of-projective/reprojectiveaestheticising-re-motif-and-re-apriorising/re-axiomatising/re-referencing $\sim$ conceptualisation-as-herein-specifically-relevant-to human-subpotency)), as utterly different from a traditional conception of teleology as of dissingularisation-<as-to-the-disjointedness/disentailment-ofpresencing —absolutising-identitive-constitutedness $>$ /epistemic-nonimmanence/flawedepistemicity-relativism-determinism that is rather in apriorising/axiomatising/referencing-\{of'prospectively_implicited_attendant-ontological-contiguity ' educedexistentialising/contextualising/textualising_ intelligibility/epistemicity/reflexivity-contiguity$<$ imbued-notional cogency $\left.>{ }^{\prime} \quad\right\}$ - constitutedness ${ }^{14}$-in-preconverging-entailment as it reflects prior relative-ontological-incompleteness ${ }^{8}$-of- ${ }^{-1 e f e r e n c e-o f-t h o u g h t ~ a s ~ o f ~ i d e n t i t i v e-~}$ constitutedness ${ }^{14}$-as-'epistemic-totality ${ }^{37}$ '-dereification-in-dissingularisation- $<$ as-to-thedisjointedness/disentailment-of- presencing - absolutising-identitive-constitutedness $>$-asflawed-epistemicity-relativism-determinism cloistered reference-of-thought apriorising/axiomatising/referencing/intelligibilitysettingup/measuringinstrumenting. The operant insight here can be articulated as follows: singularisation-<as-to-thenondisjointedness/entailment-of-prospective- nonpresencing $>$ projected epistemicimmanence/veridical-epistemicity-relativism-determinism speaks of ontologically-veridical 
difference-conflatedness ${ }^{13}$-as-to-totalitative-reification-in-singularisation- $<$ as-to-thenondisjointedness/entailment-of-prospective- nonpresencing $>$-as-veridical-epistemicityrelativism-determinism (as of " ${ }^{\text {historiality/ontological-eventfulness }}{ }^{38}$ /ontological-aesthetictracing-<perspective-ontological-normalcy/postconvergence-reflected-‘epistemicityrelativism-determinism'> implied preconverging/postconverging-dementative/structural/paradigmatic postconverging-or-dialectical-thinking - ‘ apriorisingteleological-elevation-in notional-contiguity/epistemic-contiguity ${ }^{62}<<$ profoundsupererogation -of-mentally-aestheticised postconverging/dialectical-thinking -qualiaschema>'-as-intemporality ${ }^{52}$ and preconverging-or-dementing ${ }^{20}$-apriorising-psychologism,'apriorising-teleological-degradation-in notional-discontiguity/epistemic-discontiguity ${ }^{63}$. $<$ between - prior-shallow-supererogation -of-mentallyaestheticised preconverging/dementing -qualia-schema_and_prospective-profoundsupererogation -of-mentally-aestheticised postconverging/dialectical-thinking -qualiaschema>'-as-temporalities, and so given-human-limited-mentation-capacity-as-subjecting 'educed-unlimitedness/existence-sublimating nascence' to-limitedness/human-subpotencyand-limited-mentation-capacity-deepening —as-subjecting-limitedness/human-subpotency-to'educe dunlimitedness/existence sublimating nascence' ${ }^{53}$-dynamic-implications-of-humanontological-performance $^{72}$-<including-virtue-as-ontology $>/$ morality/ethics/justice/etc. sotraceable-as-of-ontologically-veridical difference-conflatedness ${ }^{13}$-as-to-totalitative-reificationin-singularisation-<as-to-the-nondisjointedness/entailment-of-prospective- nonpresencing $>$ as-veridical-epistemicity-relativism-determinism and so in contrast with dissingularisation$<$ as-to-the-disjointedness/disentailment-of- presencing - absolutising-identitiveconstitutedness $>$ /epistemic-nonimmanence/flawed-epistemicity-relativism-determinism which speaks of identitive-constitutedness ${ }^{4}$-as-'epistemic-totality ${ }^{37}$ '-dereification-indissingularisation-<as-to-the-disjointedness/disentailment-of- presencing - absolutising- 
apriorising-teleological-variance'-by-elevation-as-intemporality ${ }^{52}$-and-degradations-astemporalities,-on-the-'flawed-axiomatic-mental-reflex-of no-human-limited-mentationcapacity—as-subjecting-'educed-unlimitedness/existence-sublimating nascence' tolimitedness/human-subpotency-and-limited-mentation-capacity-deepening —as-subjectinglimitedness/human-subpotency-to-'educed-unlimitedness/existence-sublimating nascence' dynamic-implications-of-human-ontological-performance ${ }^{22}-<$ including-virtue-asontology $>$ /morality/ethics/justice/etc. which-is-falsely-construed-identitively-as-of-identitiveconstitutedness ${ }^{14}$-as-'epistemic-totality ${ }^{37}$ '-dereification-in-dissingularisation-<as-to-thedisjointedness/disentailment-of- presencing - absolutising-identitive-constitutedness $>$-asflawed-epistemicity-relativism-determinism . We can appreciate that the relativeunreflexivity/relative-reflexivity — ontological-contiguity ${ }^{67}$ of-the-human-institutionalisationprocess $^{68}$ as of Being-development/ontological-framework-expansion-as-to-depth-ofontologising-development-as-infrastructure-of- meaningfulness-and-teleology speaks of the increasing human limited-mentation-capacity-deepening —as-subjecting limitedness/humansubpotency-to-'educed-unlimitedness/existence-sublimating-nascence' ${ }^{\text {53 }}$ ontologicalperformance ${ }^{72}$-<including-virtue-as-ontology $>$ /morality/ethics/justice/etc. as of the-very-sameimmanent-existence/intrinsic-reality/ontological-veridicality,-as-to'human<amplituding/formative-epistemicity>totalising purview-of-construal'; thus validating registry-worldviews/dimensions ${ }^{83}$ reference-of-thought-level ${ }^{5}$ meaningfulness-and-teleology differentiation as 'ontologically-veridical difference-conflatedness ${ }^{13}$-as-to-totalitativereification-in-singularisation-<as-to-the-nondisjointedness/entailment-of-prospectivenonpresencing $>$-as-veridical-epistemicity-relativism-determinism as of singularisation$<$ as-to-the-nondisjointedness/entailment-of-prospective- nonpresencing $>$ projected epistemic-immanence/veridical-epistemicity-relativism-determinism. It is exactly because any 
given registry-worldview/dimension as of its given ${ }^{83}$ reference-of-thought- categoricalimperatives/axioms/registry-teleology ${ }^{9}$, -for-

aposteriorising/logicising/deriving/intelligising/measuring- ${ }^{5}$ meaningfulness-and-teleology ${ }^{9}$ is a cloistered-consciousness (as wholly set/focusing only on its ${ }^{83}$ reference-of-thoughtcategorical-imperatives/axioms/registry-teleology as of temporal-to-intemporal ontologicalperformance $^{72}-<$ including-virtue-as-ontology $>/$ morality/ethics/justice/etc. failing to appreciate meaningfulness-and-teleology ${ }^{9}$ as of the prospective <amplituding/formative-

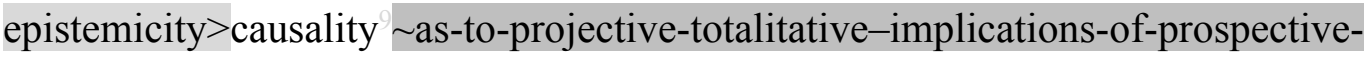
nonpresencing,-for-explicating relative-unreflexivity/relative-reflexivity - ontological-

contiguity of prospective relative-ontological-completeness ${ }^{87}$-of- ${ }^{83}$ reference-of-thought implied by the relative-unreflexivity/relative-reflexivity ontological-contiguity ${ }^{6} \sim$ of-thehuman-institutionalisation-process ${ }^{68}$ ) that its postlogism ${ }^{7}$-slantedness manifestation as temporal manifestation, whether with regards to notions-and-accusations-of-sorcery in a non-positivism social-setup or psychopathy and social psychopathy in a positivism- ${ }^{80}$ procrypticism socialsetup, arises as ontologically-flawed identive-constitutedness ${ }^{14}$-as-' ${ }^{\text {'epistemic-totality }}{ }^{37}$ 'dereification ${ }^{56}$ meaningfulness-and-teleology ${ }^{9}$, so because the given registryworldview/dimension beyond-the-consciousness-awareness-teleology ${ }^{9}-<_{\text {of }}$-preconvergingexistential-extrication-as-of-existential-unthought $>\quad{ }^{56}$ meaningfulness-and-teleology ${ }^{9}$ isn't cognisant in reflecting holographically-<conjugatively-and-transfusively $>$ the relativeunreflexivity/relative-reflexivity - ontological-contiguity of-the-human-institutionalisationprocess as of its prospective relative-ontological-completeness ${ }^{87}$-of- ${ }^{8}$ reference-of-thought $<$ amplituding/formative-epistemicity $>$ causality $\sim$ as-to-projective-totalitative-implications-ofprospective- nonpresencing,-for-explicating relative unreflexivity/relative reflexivity ontological-contiguity , and hence 'wholehearted identify ${ }^{56}$ meaningfulness-and-teleology ${ }^{9}$ as absolute as of the specific registry-worldview/dimension ${ }^{83}$ reference-of-thought- categorical- 
imperatives/axioms/registry-teleology ${ }^{9}$ with little or no sense of mental projection as to the reality of 'differentiation of ${ }^{5}$ meaningfulness-and-teleology ${ }^{9}{ }^{83}$ reference-of-thoughtcategorical-imperatives/axioms/registry-teleology occurring with prospective relativeontological-completeness ${ }^{87}$-of- ${ }^{83}$ reference-of-thought'. Hence, the reference-of-thoughtdevolving in its $<$ amplituding/formative-epistemicity $>$ totalising $\sim$ self-referencingsyncretising/circularity/interiorising/akrasiatic-drag ${ }^{34}$ existential-instantiations as of human living and institutional disposition is inherently inclined to identitive-constitutedness ${ }^{14}$-as'epistemic-totality ${ }^{37}$ '-dereification-in-dissingularisation- $<$ as-to-the-

disjointedness/disentailment-of- presencing - absolutising-identitive-constitutedness $>$-asflawed-epistemicity-relativism-determinism for construing ${ }^{56}$ meaningfulness-and-teleology with a correspondingly weak existential-<disontologising/re-ontologising aporeticism $>$ disposition for dispensing-with-immediacy-for-relative-ontological-completeness ${ }^{87}$-byreification/contemplative-distension ${ }^{27}$ (as of human self-surpassing-existentialism-formfactor,-in-overcoming-'notional collateralising-beholdening-protohumanity'-to-'attainsublimating-humanity'-as-to-existence-potency sublimating-nascence,-disclosed-fromprospective-epistemic-digression to supersede human temporality $/$ shortness $<$ amplituding/formative $>$ wooden-language-<imbued - averaging-of-thought-<as-toleveling/ressentiment/closed-construct-of- meaningfulness-and-teleology -as-of'nondescript/ignorable-void ' -with-regards-to-prospective-apriorising-implications $>>$ ) warranting an ontologically-veridical difference-conflatedness ${ }^{13}$-as-to-totalitative-reification-insingularisation-<as-to-the-nondisjointedness/entailment-of-prospective- nonpresencing $>$-asveridical-epistemicity-relativism-determinism strong existential-<disontologising/reentologising aporeticism $>$ disposition for dispensing-with-immediacy-for-relativeontological-completeness $^{87}$-by-reification/contemplative-distension ${ }^{27}$. Thus the fundamental operant insight for reflecting reified human ${ }^{56}$ meaningfulness-and-teleology ${ }^{99}$ as of 
'disambiguation of veridical/intemporal ontological-performance ${ }^{72}-<$ including-virtue-asontology $>$ /morality/ethics/justice/etc. from flawed/temporal ontological-performance ${ }^{72}$ <including-virtue-as-ontology>' as of prospective relative-ontological-completeness ${ }^{87}$ over prior relative-ontological-incompleteness ${ }^{88}$ is: one that is as of 'difference-conflatedness ${ }^{13}$-as-tototalitative-reification-in-singularisation-<as-to-the-nondisjointedness/entailment-ofprospective- nonpresencing $>$-as-veridical-epistemicity-relativism-determinism underlying ontologically-veridical epistemic-totality ${ }^{37}$ of ${ }^{5}$ meaningfulness-and-teleology ${ }^{9}$ in a subsuming wholeness/nested-congruence/contiguity-as-of-prospective-relative-ontologicalcompleteness $^{87}$, (so-construed as of singularisation-<as-to-the-nondisjointedness/entailment-ofprospective- nonpresencing $>\quad$ projected epistemic-immanence/veridical-epistemicityrelativism-determinism); that reflects 'human susceptibility as of identitive-constitutedness ${ }^{14}$-as'epistemic-totality ${ }^{37}$ '-dereification-in-dissingularisation-<as-to-thedisjointedness/disentailment-of- presencing - absolutising-identitive-constitutedness $>$-asflawed-epistemicity-relativism-determinism to ontologically-flawed parsimony/disparateness/discontiguity-as-of-prior-relative-ontological-incompleteness ${ }^{88}$ in distractiveness from the ontologically-veridical epistemic-totality ${ }^{37}$ of ${ }^{56}$ meaningfulness-andteleology ${ }^{\circ}$ and the latter so-reflected as of human limited-mentation-capacity as stbjecting 'educed-unlimitedness/existence-sublimating nascence' to-limitedness/human-subpotency $\begin{array}{lll}\text { temporal } & \text { dynamic } & \text { of }\end{array}$ slantedness/ ignorance/affordability/opportunism/exacerbation/social-chainism-or-socialdiscomfiture-or-negative-social-aggregation/temporal-enculturation-or-temporal-endemisation, so-disambiguated as of ${ }^{83}$ reference-of-thought- ${ }^{8}$ devolving ontological-performance ${ }^{72}$ $<$ including-virtue-as-ontology $>/$ morality/ethics/justice/etc. reflecting the trace/ontologicalaesthetic-tracing-<perspective-ontological-normalcy/postconvergence-reflected-`epistemicityrelativism-determinism' $>$ of ${ }^{56}$ meaningfulness-and-teleology ${ }^{9}$ denaturing ${ }^{16}$ (so-construed as of 
dissingularisation-<as-to-the-disjointedness/disentailment-of- presencing - absolutisingidentitive-constitutedness $>$ /epistemic-nonimmanence/flawed-epistemicity-relativismdeterminism). In-the-bigger-scheme-of-things singularisation- $<$ as-to-thenondisjointedness/entailment-of-prospective- nonpresencing $>\quad$ projected epistemicimmanence/veridical-epistemicity-relativism-determinism and dissingularisation- $<$ as-to-thedisjointedness/disentailment-of- presencing-absolutising-identitiveconstitutedness $>$ /epistemic-nonimmanence/flawed-epistemicity-relativism-determinism notionally reflect respectively the profoundness and shoddiness associated with human intemporal/longness-of register-of meaningfulness-and-teleology and temporal/shortnessof register-of meaningfulness-and-teleology ontological-performance ${ }^{72}-<$ including-virtueas-ontology>. Singularisation- $<$ as-to-the-nondisjointedness/entailment-of-prospectivenonpresencing $>\quad$ projected epistemic-immanence/veridical-epistemicity-relativismdeterminism fully-reflects-abstractly the ontological-faith-notion-or-ontological-fideism imbued-underdetermination-of-motif-and-apriorising/axiomatising/referencing-as-so-being-asof-existential-reality 'seeding promise of human-subpotency ontological-performance ${ }^{72}$ <including-virtue-as-ontology $>$ /morality/ethics/justice/etc. equivalence/correspondence with the full-potency-of-existence's $\sim$ sublimating-nascence-as-of-its-coherence/contiguity', as existence-as-the-absolute-a-priori-of-conceptualisation and existence-as-sublimatingwithdrawal/unenframing/re-ontologising,-elicited-from-prospective-profoundsupererogation $-<$ as-to-perspective-ontological-normalcy/postconvergence-implied'prospective-aporeticism-overcoming/unovercoming'> is being so at the exclusion-andsurpassing of any apriorising/axiomatising/referencing notion including the often misconstrued apriorising/axiomatising/referencing notions of space and/or time, as all such notions are rather in apriorising/axiomatising/referencing-\{of-'prospectively implicited_attendant-ontologicalcontiguity ' educed- 
existentialising/contextualising/textualising_ 'intelligibility/epistemicity/reflexivity-contiguity<imbued-notional cogency $\left.>^{\prime} \quad\right\}$-constitutedness ${ }^{14}$-in-preconverging-entailment since such notions seem to apriorise as if superseding the apriorising/axiomatising/referencing precedence of existence itself as the absolute a priori; construed herein rather as 'ecstatic' but not as of Heidegger's 'time/period ecstatic' analysis, as it is herein contended that existence-as-theabsolute-a-priori-of-conceptualisation and existence-as-sublimating-

withdrawal/unenframing/re-ontologising,-elicited-from-prospective-profound-

supererogation $-<$ as-to-perspective-ontological-normalcy/postconvergence-implied-

'prospective-aporeticism-overcoming/unovercoming'> construed as 'ecstatic apriorising' subjects even time and any other notion, with the implication that the phenomenality of the analysis herein is not time-bound but solely existential-<disontologising/re-ontologising aporeticism $>$ more like the principles of physics are abstractly existential-<disontologising/reentologising apereticism $>$ as ahistorically-emancipated and so beyond the time-archaeology of astronomical manifestations reflecting such physics principles. Singularisation- $<$ as-to-thenondisjointedness/entailment-of-prospective- nonpresencing $>$ projected epistemicimmanence/veridical-epistemicity-relativism-determinism thus speaks of how human subpotent prospective relative-ontological-completeness ${ }^{87}$-of- ${ }^{83}$ refence-of-thought as of its limitedmentation-capacity-deepening-as-subjecting limitedness/human-subpotency-to-'educedunlimitedness/existence-sublimating nascence' ${ }^{53}$ induce transcendence-andsublimity/sublimation/supererogatoryade-mentativity, with the 'ecstatic releasement of existence to human-subpotency' as to existence-potency ${ }^{32}$ sublimating-nascence,-disclosedfrom-prospective-epistemic-digression. This 'ecstatic releasement of existence to humansubpotency' as of existence — as-the-absolute-a-priori-of-conceptualisation and existence — assublimating-withdrawal/unenframing/re-ontologising,-elicited-from-prospective-profoundsupererogation $-<$ as-to-perspective-ontological-normalcy/postconvergence-implied- 
'prospective-aporeticism-overcoming/unovercoming'> is what has ever always debunked human subpotent dissingularisation-<as-to-the-disjointedness/disentailment-of- presencingabsolutising-identitive-constitutedness > /epistemic-nonimmanence/flawed-epistemicityrelativism-determinism as from the human subpotent ${ }^{83}$ reference-of-thought- categoricalimperatives/axioms/registry-teleology ${ }^{9}$,-for-

aposteriorising/logicising/deriving/intelligising/measuring- ${ }^{5}$ meaningfulness-and-teleology ${ }^{99}$ of recurrent-utter-uninstitutionalisation to our present positivism- ${ }^{80}$ procrypticism, as of an 'ecstatic releasement of existence to human-subpotency' that is increasingly in teleological nestedcongruence along 'intemporal ontological-faith-notion-or-ontological-fideism-imbuedunderdetermination-of-motif-and-apriorising/axiomatising/referencing-as-so-being-as-ofexistential-reality instigated relative-unreflexivity/relative-reflexivity-ontologicalcontiguity $^{67} \sim$ of-the-human-institutionalisation-process ${ }^{68}$ as of difference-conflatedness ${ }^{13}$-as-tototalitative-reification-in-singularisation-<as-to-the-nondisjointedness/entailment-ofprospective- nonpresencing $>$-as-veridical-epistemicity-relativism-determinism implied $<$ amplituding/formative-epistemicity $>$ causality $\sim$ as-to-projective-totalitative-implications-ofprospective- nonpresencing,-for-explicating relative-unreflexivity/relative-reflexivity-

ontological-contiguity , pointing to the ontological-veracity of human-subpotency ontologicalperformance ${ }^{2}-<$ including-virtue-as-ontology $>$ /morality/ethics/justice/etc. correspondence with the full-potency of existence as of singularisation-<as-to-the-nondisjointedness/entailment-ofprospective- nonpresencing $>\quad$ projected epistemic-immanence/veridical-epistemicityrelativism-determinism, and so beyond just the seeding promise of such ontologicalperformance $^{72}$-<including-virtue-as-ontology $>$ /morality/ethics/justice/etc. correspondence solely as of intemporal ontological-faith-notion-or-ontological-fideism-imbuedunderdetermination-of-motif-and-apriorising/axiomatising/referencing-as-so-being-as-ofexistential-reality. Such singularisation-<as-to-the-nondisjointedness/entailment-of- 
prospective- nonpresencing $>\quad$ projected epistemic-immanence/veridical-epistemicityrelativism-determinism conceivable human-subpotency ontological-performance ${ }^{2}-<$ includingvirtue-as-ontology $>$ /morality/ethics/justice/etc. correspondence with the full-potency of existence for futural Being-development/ontological-framework-expansion-as-to-depth-ofontologising-development-as-infrastructure-of- meaningfulness-and-teleology as of prospective notional ${ }^{18}$ deprocrypticism registry-worldview/dimension avoids human temporal individuations denaturing ${ }^{16}$ of ontological-performance ${ }^{72}-<$ including-virtue-as-ontology $>$, as of temporal denaturing of prior registry-worldviews/dimensions ${ }^{83}$ reference-of-thoughtcategorical-imperatives/axioms/registry-teleology ${ }^{99}$, -for-

aposteriorising/logicising/deriving/intelligising/measuring $-{ }^{5}$ meaningfulness-and-teleology ${ }^{9}$, behind the <cumulating/recomposuring attendant-ontological-contiguity $>$-successive registry-worldviews/dimensions logocentric constructs of ${ }^{5}$ meaningfulness-and-teleology ${ }^{9}$. So because it requires going beyond just secondnaturing of 'reproducibilitymathesis/motif/thrownness-disposition,-as-reproducibility-of-aestheticisation as-ofontologically-compromised — categorising-or-qualifying-or-tendentious-or-impulsive' 'apriorising/axiomatising/referencing/intelligibilitysettingup/measuringinstrumenting

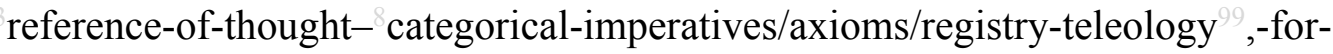
aposteriorising/logicising/deriving/intelligising/measuring - ${ }^{56}$ meaningfulness-and-teleology ${ }^{9}$, induced for the successive prior institutionalisations in order, in Foucauldian terms of parrhesiastic askesis-or-acumen, to reflect dimensionality-of-sublimating ${ }^{25}$ <<amplituding/formative >supererogatery de-mentativeness/epistemic-growth-orconflatedness /transvaluative-rationalising/transepistemicity/anamnestic-residuality/spiritdrivenness-equalisation〉 ontological-faith-notion-or-ontological-fideism —imbuedunderdetermination-of-motif-and-apriorising/axiomatising/referencing-as-so-being-as-ofexistential-reality 'seeding promise of human-subpotency ontological-performance ${ }^{72}$ 
$<$ including-virtue-as-ontology $>/$ morality/ethics/justice/etc. equivalence/correspondence with the full-potency-of-existence's $\sim$ sublimating-nascence-as-of-its-coherence/contiguity' towards its potentiative-attainment of singularisation-<as-to-the-nondisjointedness/entailment-ofprospective- nonpresencing $>\quad$ projected epistemic-immanence/veridical-epistemicityrelativism-determinism, and so construed as of 'ontologically-uncompromised-referentialism notional ${ }^{18}$ deprocrypticism emancipated apriorising/axiomatising/referencing/intelligibilitysettingup/measuringinstrumenting selfconsciousness' parrhesiastic askesis-or-acumen as of reasoning-through/messianic-reasoning'. Thus the very essence of "notional $\sim$ singularisation-<as-to-the-nondisjointedness/entailment-ofprospective- nonpresencing $>\quad$ projected epistemic-immanence/veridical-epistemicityrelativism-determinism' is the idea of 'ontological-faith-notion-or-ontological-fideism imbued-underdetermination-of-motif-and-apriorising/axiomatising/referencing-as-so-being-asof-existential-reality parrhesiastic askesis-or-acumen as of reasoning-through/messianicreasoning' strive for potentiative-attainment of singularisation- $<$ as-to-thenondisjointedness/entailment-of-prospective- nonpresencing $>$ projected epistemicimmanence/veridical-epistemicity-relativism-determinism construed as of 'ontologicallyuncompromised-referentialism notional ${ }^{18 \text { deprocrypticism emancipated }}$ apriorising/axiomatising/referencing/intelligibilitysettingup/measuringinstrumenting selfconsciousness' as it induces prospective transcendence-andsublimity/sublimation/supererogatory de-mentativity as of 'ecstatic releasement of existence to human-subpotency'; going beyond the successive prior institutionalisation ${ }^{83}$ reference-ofthought intemporal reifying reproducibility-mathesis/motif/thrownness-disposition,-asreproducibility-of-aestheticisation-as-of-ontologically-compromised-categorising-orqualifying-or-tendentious-or-impulsive' ${ }^{3}$ reference-of-thought- categoricalimperatives/axioms/registry-teleology ${ }^{9}$,-for- 
aposteriorising/logicising/deriving/intelligising/measuring $-{ }^{5}$ meaningfulness-and-teleology ${ }^{99}$, as well as their correspondingly associated uninstitutionalised-threshold ${ }^{102}$ dereifying ‘<amplituding/formative $>$ wooden-language-〈imbued-temporal-mere-

\section{form/virtualities/dereification/akrasiatic-drag/denatured/preconverging-or-dementing}

narratives - of-the- reference-of-thought- categorical-imperatives/axioms/registry-

teleology $\rangle$ as of temporal/shortness-of-register-of-meaningfulness-and-teleology

denaturing ${ }^{16}$ ontological-performance ${ }^{72}-<$ including-virtue-as-ontology $>$. Thus what is particular about the notional ${ }^{1}$ deprocrypticism registry-worldview/dimension as of preemptingdisjointedness-as-of- ${ }^{8}$ reference-of-thought with its consequent transcendence-andsublimity/sublimation/superentativity implications beyond notional ${ }^{1}$ deprocrypticism logocentric implications, is what can be construed in Foucauldian terms of parrhesiastic askesis-or-acumen, as the superseding of prior institutionalisation reference-of-thought intemporal reifying reproducibility-mathesis/motif/thrownnessdisposition,-as-reproducibility-of-aestheticisation-as-of-ontologically-compromisedcategorising-or-qualifying-or-tendentious-or-impulsive' ${ }^{83}$ reference-of-thought- categoricalimperatives/axioms/registry-teleology ${ }^{9}$,-for-

aposteriorising/logicising/deriving/intelligising/measuring - ${ }^{56}$ meaningfulness-and-teleology , as well as their correspondingly associated uninstitutionalised-threshold ${ }^{102}$ dereifying '<amplituding/formative > wooden-language-_imbued-temporal-mereform/virtualities/dereification/akrasiatic-drag/denatured/preconverging-or-dementing narratives - of-the- reference-of-thought- categorical-imperatives/axioms/registryteleology $\rangle$ as of temporal/shortness-of-register-of- meaningfulness-and-teleology denaturing ontological-performance $^{2}-<$ including-virtue-as-ontology $>$, ultimately as of ontological-faith-notion-or-ontological-fideism - imbued-underdetermination-of-motif-and- 
attainment of singularisation- $<$ as-to-the-nondisjointedness/entailment-of-prospectivenonpresencing $>\quad$ projected epistemic-immanence/veridical-epistemicity-relativismdeterminism construed as of 'ontologically-uncompromised-referentialism notional ${ }^{18}$ deprocrypticism emancipated apriorising/axiomatising/referencing/intelligibilitysettingup/measuringinstrumenting selfconsciousness' parrhesiastic askesis-or-acumen as of reasoning-through/messianic-reasoning' as so-implied', and so-facilitated with grander ${ }^{103}$ universal-transparency ${ }^{104}$-〈transparency-oftotalising-entailing,-as-to-entailing-<amplituding/formative-epistemicity $>$ totalising $\sim$ inrelative-ontological-completeness $\rangle$. Insightfully, we can contemplate that the specific logocentric practices of the <cumulating/recomposuring attendant-ontological-contiguity successive registry-worldviews/dimensions institutional-cumulation/institutional-recomposure〈as-to- historiality/ontological-eventfulness /ontological-aesthetic-tracing-<perspectiveontological-normalcy/postconvergence-reflected-‘epistemicity-relativism-determinism'>> in reflecting holographically-<conjugatively-and-transfusively $>$ the reflexivity - ontological-contiguity of-the-human-institutionalisation-process are effectively the successive shortfall-outcomes-of-human-subpotency-ontological-performance ${ }^{72}$ $<$ including-virtue-as-ontology $>$-correspondence-with-the-full-potency-ofexistence's $\sim$ sublimating-nascence from intemporal-disposition dimensionality-ofsublimating $25-<<$ amplituding/formative $>$ supererogatory $\sim$ de-mentativeness/epistemic-growthor-conflatedness /transvaluative-rationalising/transepistemicity/anamnestic-residuality/spiritdrivenness-equalisation $\rangle$ 'ontological-faith-notion-or-ontological-fideism-imbuedunderdetermination-of-motif-and-apriorising/axiomatising/referencing-as-so-being-as-ofexistential-reality parrhesiastic askesis-or-acumen as of reasoning-through/messianic-reasoning' strive for potentiative-attainment of singularisation-<as-to-the-nondisjointedness/entailment-ofprospective- nonpresencing $>\quad$ projected epistemic-immanence/veridical-epistemicity- 
relativism-determinism construed as of 'ontologically-uncompromised-referentialism notional ${ }^{8}$ deprocrypticism emancipated apriorising/axiomatising/referencing/intelligibilitysettingup/measuringinstrumenting selfconsciousness' parrhesiastic askesis-or-acumen as of reasoning-through/messianic-reasoning' that go on to induce secondnatured institutionalisations as of the successive prospective institutionalisation ${ }^{83}$ reference-of-thought intemporal reifying reproducibilitymathesis/motif/thrownness-disposition,-as-reproducibility-of-aestheticisation-as-ofontologically-compromised—categorising-or-qualifying-or-tendentious-or-impulsive' reference-of-thought- ${ }^{8}$ categorical-imperatives/axioms/registry-teleology ${ }^{9}$,-foraposteriorising/logicising/deriving/intelligising/measuring- ${ }^{5}$ meaningfulness-and-teleology ${ }^{9}$ as reasoning-from-results/afterthought, as well as their correspondingly associated uninstitutionalised-threshold ${ }^{102}$ dereifying '< amplituding/formative $>$ wooden-language〈imbued-temporal-mere-form/virtualities/dereification/akrasiaticdrag/denatured/preconverging-or-dementing -narratives - of-the- reference-of-thoughtcategorical-imperatives/axioms/registry-teleology > as of temporal/shortness-of-register-ofmeaningfulness-and-teleology denaturing ontological-performance ${ }^{12}-<$ including-virtue-asontology>; and it is rather the intemporal-disposition dimensionality-of-sublimating <<amplituding/formative>supererogatory $\sim$ de-mentativeness/epistemic-growth-orconflatedness /transvaluative-rationalising/transepistemicity/anamnestic-residuality/spiritdrivenness-equalisation $>\quad$ 'ontological-faith-notion-or-ontological-fideism-imbuedunderdetermination-of-motif-and-apriorising/axiomatising/referencing-as-so-being-as-ofexistential-reality parrhesiastic askesis-or-acumen as of reasoning-through/messianic-reasoning' strive for potentiative-attainment of singularisation-<as-to-the-nondisjointedness/entailment-ofprospective- nonpresencing $>\quad$ projected epistemic-immanence/veridical-epistemicityrelativism-determinism construed as of 'ontologically-uncompromised-referentialism 
notional deprocrypticism

emancipated

apriorising/axiomatising/referencing/intelligibilitysettingup/measuringinstrumenting selfconsciousness' parrhesiastic askesis-or-acumen as of reasoning-through/messianic-reasoning' that holds the possibility for 'intemporal ontological-faith-notion-or-ontological-fideismimbued-underdetermination-of-motif-and-apriorising/axiomatising/referencing-as-so-being-asof-existential-reality instigated relative-unreflexivity/relative-reflexivity - ontologicalcontiguity ${ }^{67}$ of-the-human-institutionalisation-process ${ }^{68}$ as of difference-conflatedness ${ }^{13}$-as-tototalitative-reification-in-singularisation-<as-to-the-nondisjointedness/entailment-ofprospective- nonpresencing $>$-as-veridical-epistemicity-relativism-determinism implied $<$ amplituding/formative-epistemicity $>$ causality $\sim$ as-to-projective-totalitative-implications-ofprospective- nonpresencing,-for-explicating relative-unreflexivity/relative-reflexivity -

ontological-contiguity ' to arise and be perpetuated in-the-very-first-place as it invigorates-andreinvigorates the relative-unreflexivity/relative-reflexivity - ontological-contiguity ${ }^{67}$ of-thehuman-institutionalisation-process ${ }^{68}$ for potentiative-attainment of singularisation- $<$ as-to-thenondisjointedness/entailment-of-prospective- nonpresencing $>$ projected epistemicimmanence/veridical-epistemicity-relativism-determinism. The transcendence-andsublimity/sublimation//nentativity as successive 'ecstatic releasement of existence to human-subpotency' induced as from intemporal-disposition dimensionality-ofsublimating $25-<$ amplituding/formative $>$ supererogatory $\sim$ de-mentativeness/epistemic-growthor-conflatedness /transvaluative-rationalising/transepistemicity/anamnestic-residuality/spiritdrivenness-equalisation $>\quad$ 'ontological-faith-notion-or-ontological-fideism-imbuedunderdetermination-of-motif-and-apriorising/axiomatising/referencing-as-so-being-as-ofexistential-reality parrhesiastic askesis-or-acumen as of reasoning-through/messianic-reasoning' strive for potentiative-attainment of singularisation-<as-to-the-nondisjointedness/entailment-ofprospective- nonpresencing $>\quad$ projected epistemic-immanence/veridical-epistemicity- 
relativism-determinism construed as of 'ontologically-uncompromised-referentialism notional ${ }^{8}$ deprocrypticism emancipated apriorising/axiomatising/referencing/intelligibilitysettingup/measuringinstrumenting selfconsciousness' parrhesiastic askesis-or-acumen as of reasoning-through/messianic-reasoning', highlights the ontological-veracity as of existence-as-the-absolute-a-priori-ofconceptualisation and existence - as-sublimating-withdrawal/unenframing/re-ontologising,elicited-from-prospective-profound-supererogation $-<$ as-to-perspective-ontologicalnormalcy/postconvergence-implied-'prospective-aporeticism-overcoming/unovercoming'>, of singularisation-<as-to-the-nondisjointedness/entailment-of-prospective- nonpresencing $>$ projected epistemic-immanence/veridical-epistemicity-relativism-determinism which is ever always sought-and-resought by ontological-faith-notion-or-ontological-fideism - imbuedunderdetermination-of-motif-and-apriorising/axiomatising/referencing-as-so-being-as-ofexistential-reality (that is, as of the teleological wholeness/nested-congruence from non-rulesapriorising/axiomatising/referencing-psychologism of recurrent-utter-ininstitutionalisation towards prospectively preempting-disjointedness-as-of- ${ }^{8}$ reference-of-thought of deprocrypticism); with ontologically-veridical singularisation-<as-to-thenondisjointedness/entailment-of-prospective- nonpresencing $>$ projected epistemicimmanence/veridical-epistemicity-relativism-determinism further implying, as of its potentiative-attainment of ontological-performance ${ }^{72}-$ including-virtue-as- $^{2}$ ontology $>$ /morality/ethics/justice/etc. correspondence with existence/intrinsicreality/ontological-veridicality, that existence-as-the-absolute-a-priori-ofconceptualisation $\sim$ and existence — as-sublimating-withdrawal/unenframing/re-ontologising,elicited-from-prospective-profound-supererogation $-<$ as-to-perspective-ontologicalnormalcy/postconvergence-implied-'prospective-aporeticism-overcoming/unovercoming'> is as of 'ecstatic singularity'. This 'ecstatic singularity' about existence-as-the-absolute-a-priori- 
of-conceptualisation and existence—as-sublimating-withdrawal/unenframing/reontologising,-elicited-from-prospective-profound-supererogation $<$ as-to-perspectiveontological-normalcy/postconvergence-implied-'prospective-aporeticismovercoming/unovercoming'> can be delineated as of singularisation-<as-to-thenondisjointedness/entailment-of-prospective- nonpresencing $>$ projected epistemicimmanence/veridical-epistemicity-relativism-determinism, and so-construed as of human sublimation-educing__epistemic-

thermeneutic/textuality/reprojecting/supererogating/zeroing/re-acuting,\{dectinearity for-cogency as-to-possibilities-of-self-becoming-as-of-‘existentialinterpretation/epistemicity-in-apriorising/axiomatising/referencing-of-existence différance/internal-dialectics/difference-deferral for transcendence-andsublimity/sublimation/supererogatory de-mentativity in 'phenomenological ecstatic releasement'. Thus our logocentric sense of certainty as marked by our 'pervasively enframed logocentric constructs of ${ }^{5}$ meaningfulness-and-teleology ${ }^{9}$, as with all the prior logocentrisms of prior <cumulating/recomposuring attendant-ontological-contiguity $>$-successive registryworldviews/dimensions, as of their relatively ontologically-flawed dissingularisation- $<$ as-tothe-disjointedness/disentailment-of- presencing - absolutising-identitive-

constitutedness $>$ /epistemic-nonimmanence/flawed-epistemicity-relativism-determinism is misplaced manifestation of ignorance, and thus in our case in need for our prospective intellectual-and-moral maturing as of prospective ${ }^{15}$ de-mentation-〈supererogatory $\sim$ ontologicalde-mentation-or-dialectical-de-mentation-stranding-or-attributive-dialectics $\rangle$ for the deprocrypticism-or-preempting-disjointedness-as-of- ${ }^{3}$ reference-of-thought registryworldview/dimension. Thus the <amplituding/formative-epistemicity $>$ totalising $\sim$ selfreferencing-syncretising/circularity/interiorising/akrasiatic-drag 34 reality of human meaningfulness-and-teleology 99 ever always subjected to its successive registry- 
worlds/dimensions relatively ontologically-flawed dissingularisation- $<$ as-to-thedisjointedness/disentailment-of- presencing — absolutising-identitive-

constitutedness $>$ /epistemic-nonimmanence/flawed-epistemicity-relativism-determinism distortion, come with the ontologically-veridical implication that human-subpotency ontological-performance ${ }^{2}-<$ including-virtue-as-ontology $>/$ morality/ethics/justice/etc.

correspondence with the full-potency of existence has ever always been as of a 'reifying $<$ amplituding/formative-epistemicity $>$ totalising $\sim$ metaphoricity ${ }^{57}$-conception of 'implicited_attendant-ontological-contiguity ${ }^{67}$; educedexistentialising/contextualising/textmalising_intelligibility/epistemicity/reflexivity-contiguity<imbued-notional cogency> ${ }^{4} \quad$ construed as $\quad{ }^{4}$ historiality/ontologicaleventfulness $^{38}$ /ontological-aesthetic-tracing-<perspective-ontologicalnormalcy/postconvergence-reflected-‘epistemicity-relativism-determinism'>, and so-reflected from the supposed ontological-normalcy/postconvergence epistemic-or-notional projectiveperspective of ontological-completeness-of- ${ }^{3}$ reference-of-thought as of differenceconflatedness $^{13}$-as-to-totalitative-reification-in-singularisation- $<$ as-to-thenondisjointedness/entailment-of-prospective- nonpresencing > -as-veridical-epistemicityrelativism-determinism protracted-teleological-wholeness/nested-congruence-in-reflectingthe-relative-unreflexivity/relative-reflexivity - ontological-contiguity ${ }^{67}$ of-the-humaninstitutionalisation-process ${ }^{68}$,-so-construed-as-singularisation- $<$ as-to-thenondisjointedness/entailment-of-prospective- nonpresencing $>$ projected epistemicimmanence/veridical-epistemicity-relativism-determinism' construal of meaningfulness-andteleology ; with the implication here that hitherto identitive-constitutedness ${ }^{14}$-as-'epistemictotality ${ }^{37}$-dereification-in-dissingularisation-<as-to-the-disjointedness/disentailment-ofpresencing - absolutising-identitive-constitutedness > -as-flawed-epistemicity-relativismdeterminism as-cloistered-within-the-same- ${ }^{8}$ reference-of-thought as implied with historical 
accounts and representations are incomplete, as ontologically-veridical ${ }^{5}$ meaningfulness-andteleology' is as of the aforementioned 'reifying <amplituding/formativeepistemicity>totalising metaphoricity ${ }^{57}$-conception of 'implicited_attendant-ontologicalcontiguity $^{67}$, educed-

existentialising/contextualising/textualising_'intelligibility/epistemicity/reflexivity-contiguity<imbued-notional cogency>' ${ }^{40}$ elaborateness of ${ }^{56}$ meaningfulness-and-teleology ${ }^{99}$ as dynamic differentiated $\quad$ transversality- $<$ for-sublimating-existential-eventuating/denouement,-from-

\section{‘thinking at first/pure-predisposition-preemptive-of-prospective-}

disontologising/subontologising’ - as-of-prospectively-disambiguated-affirmed-and-

unaffirmed-'motif-and-apriorising/axiomatising/referencing' $>101$ of the ontologicalperformance $^{72}-<$ including-virtue-as-ontology $>$ /morality/ethics/justice/etc. of intemporality ${ }^{52}$ /ongness over temporality ${ }^{8}$. The articulation of sublimating historiality/ontological-eventfulness 3 /ontological-aesthetic-tracing-<perspectiveontological-normalcy/postconvergence-reflected-‘epistemicity-relativism-determinism' accounts of ${ }^{56}$ meaningfulness-and-teleology ${ }^{9}$ failing to highlight this process of humansubpotency ontological-performance ${ }^{72}-<$ including-virtue-asontology $>/$ morality/ethics/justice/etc. differentiation are rather incomplete and misrepresenting of human nature in the 'dynamic human-subpotency-aporia/undecidability/dilemma/oughtindeterminacy/deficiency/limitation/constraint—imbued-'notional firstnaturednessformativeness-<as-to-eventualising inkling-drive-or-seeding misprising $>$ temporal-tointemporal-dispositions-<so-construed-as-from-perspective-ontologicalnormalcy/postconvergence>'-existentialism-form-factor as of both dimensionality-ofsublimating $25<<$ amplituding/formative $>$ supererogatory $\sim$ de-mentativeness/epistemic-growthor-conflatedness /transvaluative-rationalising/transepistemicity/anamnestic-residuality/spiritdrivenness-equalisation> mental-dispositions and secondnatured institutionalisation mental- 
dispositions' as the complete operant framework of human-subpotency, and so-construed from an ontological-normalcy/post-convergent ontological-completeness-of- ${ }^{3}$ reference-of-thought perspective (in difference-conflatedness ${ }^{13}$-as-to-totalitative-reification-in-singularisation- $<$ asto-the-nondisjointedness/entailment-of-prospective- nonpresencing $>$-as-veridical-

epistemicity-relativism-determinism protracted-teleological-wholeness/nested-congruence-inreflecting-the-relative-mnreflexivity/relative-reflexivity - ontological-contiguity $\sim$ of-thehuman-institutionalisation-process ${ }^{68}$,-so-construed-as-singularisation- $<$ as-to-thenondisjointedness/entailment-of-prospective- nonpresencing $>$ projected epistemicimmanence/veridical-epistemicity-relativism-determinism'). This is ontologically critical to understand because the wrong mental-reflex conception of uninstitutionalised-threshold ${ }^{02}$ as mainly being as of 'human intemporal secondnatured institutionalisation mental-disposition' will wrongly imply a human nature that is only intemporal and so as of the secondnatured intemporality $52 /$ longness of the prior institutionalisation. This fails to factor in that all uninstitutionalised-threshold ${ }^{12}$ are rather a framework of 'recurring dimensionality-ofsublimating $25-<<$ amplituding/formative $>$ supererogatory $\sim$ de-mentativeness/epistemic-growthor-conflatedness /transvaluative-rationalising/transepistemicity/anamnestic-residuality/spiritdrivenness-equalisation〉 temporal-to-intemporal' requiring prospective institutionalisation prospective relative-ontological-completeness ${ }^{87}$-of- ${ }^{8}$ reference-of-thought, and so without any intemporal secondnatured institutionalisation induced ${ }^{103}$ universal-transparency ${ }^{104}$ 〈transparency-of-totalising-entailing,-as-to-entailing-<amplituding/formative-

epistemicity $>$ totalising in-relative-ontological-completeness $\rangle, \quad$ deferential-formalisationtransference and habituation as of positive-opportunism-of-social-functioning-andaccordance $^{75}$; and thus fully reflecting the ontological-veridicality of human-subpotencyaporia/undecidability/dilemma/ought-indeterminacy/deficiency/limitation/constraint—imbued'notional firstnaturedness-formativeness-<as-to-eventualising-inkling-drive-or-seeding- 
misprising $>$ temporal-to-intemporal-dispositions- $<$ so-construed-as-from-perspectiveontological-normalcy/postconvergence>'-existentialism-form-factor. It is this 'recurring dimensionality-of-sublimating ${ }^{25}$-<<amplituding/formative $>$ supererogatory - dementativeness/epistemic-growth-or-conflatedness /transvaluativerationalising/transepistemicity/anamnestic-residuality/spirit-drivenness-equalisation $\rangle$ temporalto-intemporal' reality at all the successive uninstitutionalised-threshold ${ }^{12}$ that fundamentally reflect the 'same fundamental human potentiation as of human-subpotencyaporia/undecidability/dilemma/ought-indeterminacy/deficiency/limitation/constraint—imbued'notional firstnaturedness-formativeness-<as-to-eventualising inkling-drive-or-seedingmisprising $>$ temporal-to-intemporal-dispositions-<so-construed-as-from-perspectiveontological-normalcy/postconvergence>'-existentialism-form-factor' across all the registryworldviews/dimensions notwithstanding the institutionalisation-level but for the fact that this same 'recurring dimensionality-of-sublimating ${ }^{25}-<<$ amplituding/formative $>$ supererogatory $\sim$ dementativeness/epistemic-growth-or-conflatedness /transvaluativerationalising/transepistemicity/anamnestic-residuality/spirit-drivenness-equalisation $\rangle$ temporalto-intemporal' rather operates on different registry-worldviews/dimensions institutionalisations secondnatured ${ }^{83}$ reference-of-thought- ${ }^{8}$ ategorical-imperatives/axioms/registry-teleology ${ }^{9}$ at their uninstitutionalised-threshold ${ }^{102}$; whereby the successive prior registryworldviews/dimensions institutionalisations fall short, as of their apriorising/axiomatising/referencing/intelligibilitysettingup/measuringinstrumenting ontological-performance ${ }^{2}$-<including-virtue-as-ontology $>/$ morality/ethics/justice/etc. correspondence with the full-potency of existence, of knowledge-reification $\sim$ gesturing-andaccounting - of-epistemic-phenomenalism- $<$ inprospective_psychologismic apriorising/axiomatising/referencing-\{of-'prospectively implicited_attendant-ontological-contiguity ' ceduced- 
existentialising/contextualising/textualising_ 'intelligibility/epistemicity/reflexivity-contiguity$<$ imbued-notional $\left.\sim \operatorname{cogency}>^{\prime} \quad\right\}$-conflatedness -in-\{preconverging disentailment by\} postconverging-entailment $>$ as of successive prospective institutionalisation prospective relative-ontological-completeness ${ }^{87}$-of- ${ }^{-3 e f e r e n c e-o f-t h o u g h t . ~ T h i s ~ i n s i g h t ~ f u n d a m e n t a l l y ~}$ explains 'intemporal ontological-faith-notion-or-ontological-fideism-imbuedunderdetermination-of-motif-and-apriorising/axiomatising/referencing-as-so-being-as-ofexistential-reality instigated relative-unreflexivity/relative-reflexivity-ontologicalcontiguity ${ }^{67}$ of-the-human-institutionalisation-process ${ }^{68}$ as of difference-conflatedness ${ }^{13}$-as-tototalitative-reification-in-singularisation-<as-to-the-nondisjointedness/entailment-ofprospective- nonpresencing $>$-as-veridical-epistemicity-relativism-determinism implied $<$ amplituding/formative-epistemicity $>$ causality $\sim$ as-to-projective-totalitative-implications-ofprospective- nonpresencing,-for-explicating $\sim$ relative-unreflexivity/relative-reflexivity ontological-contiguity , as involving successive ${ }^{83}$ reference-of-thought- categoricalimperatives/axioms/registry-teleology ${ }^{9}$,-foraposteriorising/logicising/deriving/intelligising/measuring- ${ }^{5}$ meaningfulness-and-teleology ${ }^{99}$ as of limited-mentation-capacity-deepening —as-subjecting limitedness/human-subpotency-to'educed unlimitedness/existence sublimating nascence' 3 ; geared towards more and more robust secondnatured institutionalisation $\quad{ }^{83}$ reference-of-thought- categoricalimperatives/axioms/registry-teleology' even though in the face of the-very-same 'recurring dimensionality-of-sublimating 25 -< <mplituding/formative $>$ supererogatory - dementativeness/epistemic-growth-or-conflatedness /transvaluativerationalising/transepistemicity/anamnestic-residuality/spirit-drivenness-equalisation $\rangle$ temporalto-intemporal'. Insightfully, ontologically-veridical 'reifying <amplituding/formativeepistemicity $>$ totalising $\sim$ metaphoricity ${ }^{57}$-conception of 'implicited_attendant-ontologicalcontiguity $^{67} \sim$ educed- 
existentialising/contextualising/textualising_'intelligibility/epistemicity/reflexivity-contiguity<imbued-notional cogency> ${ }^{40}$ as ${ }^{4}$ historiality/ontological-eventfulness ${ }^{38}$ /ontologicalaesthetic-tracing-<perspective-ontological-normalcy/postconvergence-reflected-'epistemicityrelativism-determinism'> by its elaborateness of ${ }^{56}$ meaningfulness-and-teleology ${ }^{9}$ as a differentiated $\quad$ transversality- $<$ for-sublimating-existential-eventuating/denouement-from'thinking-at-first/pure-predisposition-preemptive-of-prospective-

\section{disontologising/subontologising’ as-of-prospectively-disambiguated-affirmed-and-}

unaffirmed-'motif-and-apriorising/axiomatising/referencing'> ${ }^{101}$ selectivity of the ontologicalperformance $^{72}$-<including-virtue-as-ontology $>$ /morality/ethics/justice/etc. of intemporality ${ }^{52} /$ longness over temporality $/$ /shortness can be reflected by the operant technique of 'partialisation of ${ }^{5}$ meaningfulness-and-teleology ${ }^{\circ}$ '. This 'partialisation of ${ }^{56}$ meaningfulnessand-teleology ${ }^{9}$ operant technique of 'reifying <amplituding/formativeepistemicity $>$ totalising metaphoricity ${ }^{57}$-conception of 'implicited_attendant-ontologicalcontiguity ${ }^{67} \sim$ educed-

existentialising/contextualising/textualising_intelligibility/epistemicity/reflexivity-contiguity$<$ imbued-notional cogency> ${ }^{40} \quad$ as $\quad{ }^{4}$ historiality/ontological-eventfulness ${ }^{38}$ /ontologicalaesthetic-tracing-<perspective-ontological-normalcy/postconvergence-reflected-'epistemicityrelativism-determinism'> is convenient because by mental-reflex every registryworldview/dimension will necessarily reflect its ${ }^{56}$ meaningfulness-and-teleology ${ }^{9}$ as of singularisation-<as-to-the-nondisjointedness/entailment-of-prospective- nonpresencing $>$ projected epistemic-immanence/veridical-epistemicity-relativism-determinism as it wrongly implies and operates in its <amplituding/formative-epistemicity $>$ totalising $\sim$ self-referencingsyncretising/circularity/interiorising/akrasiatic-drag ${ }^{34}$ as if it is in ontologicalnormalcy/postconvergence as of ontological-completeness-of- ${ }^{-3 e f e r e n c e-o f-t h o u g h t . ~ F o r ~}$ phenomenological analytical insight, 'partialisation of ${ }^{56}$ meaningfulness-and-teleology" 
operant technique for construing dissingularisation- $<$ as-to-the-disjointedness/disentailment-ofpresencing — absolutising-identitive-constitutedness $>$ /epistemic-nonimmanence/flawedepistemicity-relativism-determinism as of defective representation of singularisation- $<$ as-to-thenondisjointedness/entailment-of-prospective- nonpresencing $>$ projected epistemicimmanence/veridical-epistemicity-relativism-determinism brings to a registryworldview's/dimension's $\quad$ reference-of-thought $\quad$ self-consciousness its preconverging/postconverging-de-mentative/structural/paradigmatic/systemic preconvergingor-dementing ${ }^{20}$-apriorising-psychologism state at its uninstitutionalised-threshold ${ }^{102}$ as so referenced/registered/decisioned from the prospective registry-worldview's/dimension's institutionalisation ${ }^{83}$ reference-of-thought self-consciousness rather in postconverging-ordialectical-thinking -apriorising-psychologism state given its prospective relative-ontologicalcompleteness ${ }^{87}$-of- ${ }^{8}$ reference-of-thought. 'Partialisation of ${ }^{56}$ meaningfulness-and-teleology 9 ', as such simply involves representing the preconverging/postconverging-dementative/structural/paradigmatic/systemic incongruence that arises, as the prior registryworldview/dimension institutionalisation falls short of knowledge-reification $\sim$ gesturing-andaccounting - of-epistemic-phenomenalism- $<$ in-

\section{prospective_psychologismic apriorising/axiomatising/referencing-\{of-'prespectively} implicited_attendant-ontological-contiguity ' reducedexistentialising/contextualising/textualising_ intelligibility/epistemicity/reflexivity-contiguity$<$ imbued-notional cogency $>$ ' $\}$-conflatedness -in-\{preconverging-disentailment by\} postconverging entailment $>$ as of prospective institutionalisation prospective relativeontological-completeness ${ }^{87}$-of- ${ }^{83}$ reference-of-thought in its apriorising/axiomatising/referencing/intelligibilitysettingup/measuringinstrumenting ontological-performance ${ }^{2}$-<including-virtue-as-ontology $>/$ morality/ethics/justice/etc. correspondence with the full-potency of existence, and so due to denaturing at the 
uninstitutionalised-threshold $^{102}$ of prospective institutionalisation knowledgereification $\sim$ gesturing-and-accounting — of-epistemic-phenomenalism- $<$ inprospective_psychologismic apriorising/axiomatising/referencing-\{of-`prospectively implicited_attendant-ontological-contiguity ' educedexistentialising/contextualising/textualising_'intelligibility/epistemicity/reflexivity-contiguity<imbued-notional cogency $>$ ' \}-conflatedness -in-\{preconverging-disentailment by\} postconverging-entailment> by $>$ '<mplituding/formative $>$ wooden-language-〈imbuedtemporal-mere-form/virtualities/dereification/akrasiatic-drag/denatured/preconverging-ordementing -narratives - of-the- reference-of-thought- categoricalimperatives/axioms/registry-teleology $\rangle$ of the prior/transcended/superseded registryworldview/dimension' in usurpation as of the dynamism of temporal mental-dispositions as of postlogism 7 -slantedness/ ${ }^{7}$ ignorance/affordability/opportunism/exacerbation/social-chainismor-social-discomfiture-or-negative-social-aggregation/temporal-enculturation-or-temporalendemisation, so-disambiguated as of ${ }^{83}$ reference-of-thought- ${ }^{8}$ devolving ontologicalperformance ${ }^{72}-<$ including-virtue-as-ontology $>$, thus implying that the aposteriorising/logicising/deriving/intelligising/measuring ${ }^{56}$ meaningfulness-and-teleology ${ }^{9}$ is preconverging-or-dementing ${ }^{20}$-apriorising-psychologism. Such preconverging/postconvergingde-mentative/structural/paradigmatic/systemic prior incongruence of apriorising/axiomatising/referencing/intelligibilitysettingup/measuringinstrumenting ontological-performance ${ }^{2}$-<including-virtue-as-ontology $>/$ morality/ethics/justice/etc. at destructuring-threshold-〈uninstitutionalised-threshold /presublimating-desublimatingdecisionality $>\sim$ of-ontological-performance ${ }^{72}$-<including-virtue-asontology $>/$ morality/ethics/justice/etc. are reflected as of: recurrent-utter-uninstitutionalisation 'non-rules - apriorising/axiomatising/referencing-psychologism,-as-impulsive-or-accidentedor-random' 
'apriorising/axiomatising/referencing/intelligibilitysettingup/measuringinstrumenting reference-of-thought- categorical-imperatives/axioms/registry-teleology ${ }^{9}$,-foraposteriorising/logicising/deriving/intelligising/measuring- ${ }^{5}$ meaningfulness-and-teleology ${ }^{9}$, falling-short-as-needing-rules of knowledge-reification $\sim$ gesturing-and-accounting-ofepistemic-phenomenalism- $<$ in-

\section{prospective_psychologismic apriorising/axiomatising/referencing-\{of-"prospectively} implicited_attendant-ontological-contiguity ' educedexistentialising/contextualising/textualising_'intelligibility/epistemicity/reflexivity-contiguity<imbued-notional cogency $\left.>^{\prime}\right\}$-conflatedness -in-\{preconverging disentailment by\} postconverging-entailment $>$ as of the prospective base-institutionalisation institutionalisation prospective relative-ontological-completeness ${ }^{87}$-of- ${ }^{83}$ reference-of-thought, and thereof construed as preconverging-or-dementing -apriorising-psychologism; baseinstitutionalisation-ununiversalisation 'rulemaking-over-non-rulesapriorising/axiomatising/referencing-psychologism' 'apriorising/axiomatising/referencing/intelligibilitysettingup/measuringinstrumenting reference-of-thought- categorical-imperatives/axioms/registry-teleology $^{9}$,-foraposteriorising/logicising/deriving/intelligising/measuring- ${ }^{5}$ meaningfulness-and-teleology ${ }^{9}$, falling-short-as-needing- ${ }^{103}$ universalising-rules of knowledge-reification $\sim$ gesturing-andaccounting-of-epistemic-phenomenalism- $<$ inprospective_psychologismic apriorising/axiomatising/referencing-\{of- ${ }^{\text {pprospectively }}$ implicited_attendant-ontological-contiguity ' educedexistentialising/contextualising/textualising_'intelligibility/epistemicity/reflexivity_contiguity<imbued-notional cogency>’ $\}$-conflatedness in \{preconverging disentailment by\} postconverging entailment $>$ as of the prospective ${ }^{103}$ universalisation institutionalisation prospective relative-ontological-completeness ${ }^{87}$-of- ${ }^{83}$ reference-of-thought, and thereof 
construed as preconverging-or-dementing ${ }^{2}$-apriorising-psychologism; ${ }^{103}$ universalisation-nonpositivism/medievalism ' ${ }^{103}$ universalisation-directed-rulemaking-over-non-rulesapriorising/axiomatising/referencing-psychologism'

'apriorising/axiomatising/referencing/intelligibilitysettingup/measuringinstrumenting reference-of-thought- categorical-imperatives/axioms/registry-teleology ${ }^{99}$,-foraposteriorising/logicising/deriving/intelligising/measuring $-{ }^{56}$ meaningfulness-and-teleology ${ }^{9}$ falling-short-as-needing-positivistic- ${ }^{103}$ universal-rules of knowledge-reification $\sim$ gesturing-andaccounting - of-epistemic-phenomenalism-<in-

prospective_psychologismic apriorising/axiomatising/referencing-\{of-'prospectively implicited_attendant-ontological-contiguity ' educedexistentialising/contextualising/textualising_intelligibility/epistemicity/reflexivity_contiguity$<$ imbued-notional cogency $\left.>^{\prime}\right\}$-conflatedness -in-\{preconverging-disentailment by\} postconverging entailment $>$ as of the prospective positivism institutionalisation prospective relative-ontological-completeness ${ }^{8}$-of- ${ }^{3}$ reference-of-thought, and thereof construed as preconverging-or-dementing ${ }^{20}$-apriorising-psychologism; and prospectively positivismprocrypticism 'positivising/rational-empiricism-based-universalisation-directed-rulemakingover-non-rules — apriorising/axiomatising/referencing-psychologism’ 'apriorising/axiomatising/referencing/intelligibilitysettingup/measuringinstrumenting reference-of-thought- categorical-imperatives/axioms/registry-teleology ${ }^{9}$,-foraposteriorising/logicising/deriving/intelligising/measuring- ${ }^{5}$ meaningfulness-and-teleology ${ }^{\circ}$, falling-short-as-needing preempting-disjointedness-as-of- ${ }^{8}$ reference-of-thought,-as-to${ }^{6}<$ amplituding/formative-epistemicity $>$ growth-or-conflatedness $13 /$ transvaluativerationalising/transepistemicity/anamnestic-residuality/spirit-drivenness'_-in-supersedingmere-formulaic-positivising/rational-empiricism-based-universalisation-directed-rulemakingover-non-rules - apriorising/axiomatising/referencing-psychologism of knowledge- 
reification $\sim$ gesturing-and-accounting — of-epistemic-phenomenalism- $<$ in-

prospective_psychologismic apriorising/axiomatising/referencing-\{of- ${ }^{\text {pprospectively }}$ implicited_attendant-ontological-contiguity ' educed-

existentialising/contextualising/textualising_intelligibility/epistemicity/reflexivity-contiguity<imbued-notional cogency >' \}-conflatedness -in-\{preconverging disentailment by\} postcenverging-entailment> for futural Being-development/ontological-framework-expansionas-to-depth-of-ontologising-development-as-infrastructure-of- meaningfulness-and-

teleology as of prospective notional deprocrypticism institutionalisation prospective relative-ontological-completeness ${ }^{8}$-of- ${ }^{8}$ reference-of-thought, and thereof construed as preconverging-or-dementing ${ }^{20}$-apriorising-psychologism. From a singularisation- $<$ as-to-thenondisjointedness/entailment-of-prospective- nonpresencing $>\quad$ projected epistemicimmanence/veridical-epistemicity-relativism-determinism insight as it reflects ontologicalcompleteness-of- ${ }^{8}$ reference-of-thought for ontologically-veridical meaningfulness, we can garner that the implications of 'notional-discontiguity/epistemic-discontiguity ${ }^{63}$-with/fallingshort-of prospective institutionalisation 'implicited_attendant-ontologicalcontiguity $^{67} \sim$ educed-

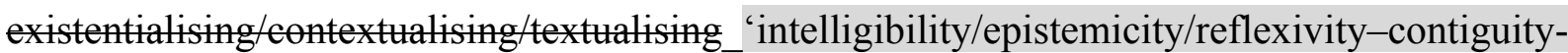
$<$ imbued-notional cogency $>$ '-in-elucidation-or-reification' as of singularisation- $<$ as-to-thenondisjointedness/entailment-of-prospective- nonpresencing $>$ projected epistemicimmanence/veridical-epistemicity-relativism-determinism is what actually generates the various registry-worldviews/dimensions institutionalisations as of their relative identitiveconstitutedness ${ }^{14}$-as-'epistemic-totality ${ }^{37}$ '-dereification-in-dissingularisation-<as-to-thedisjointedness/disentailment-of- presencing - absolutising-identitive-constitutedness $>$-asflawed-epistemicity-relativism-determinism thought; such that their respective destructuring-threshold-〈uninstitutionalised- 
threshold /presublimating-desublimating-decisionality $>$ of-ontological-performance ${ }^{72}$

<including-virtue-as-ontology $>$ /morality/ethics/justice/etc. are actually in $<$ amplituding/formative-epistemicity $>$ totalising $\sim$ self-referencing-

syncretising/circularity/interiorising/akrasiatic-drag ${ }^{34}$ incrementalism-in-relative-ontologicalincompleteness ${ }^{8}$ — enframed/disontologising conceptualisation denaturing of the prior registry-worldviews/dimensions institutionalisations 'apriorising/axiomatising/referencing/intelligibilitysettingup/measuringinstrumenting reference-of-thought- categorical-imperatives/axioms/registry-teleology ${ }^{9}$,-foraposteriorising/logicising/deriving/intelligising/measuring - ${ }^{56}$ meaningfulness-and-teleology ${ }^{9}$, meant to uphold knowledge-reification $\sim$ gesturing-and-accounting-of-epistemicphenomenalism- $<$ in-prospective_psychologismic $\sim$ apriorising/axiomatising/referencing- of'prospectively_implicited_attendant-ontological-contiguity ' ceducedexistentialising/contextualising/textualising_'intelligibility/epistemicity/reflexivity-contiguity$<$ imbued-notional cogency $\left.>^{\prime} \quad\right\}$-conflatedness -in-\{preconverging-disentailment by\} postconverging-entailment> as of ${ }^{5}$ meaningfulness-and-teleology". This insight further highlights the pertinence of the registry-worldview/dimension ${ }^{83}$ reference-of-thought as of secondnatured institutionalisation as rather decisive with regards to human-subpotency ontological-performance ${ }^{2}$-<including-virtue-as-ontology $>/$ morality/ethics/justice/etc.

correspondence with the full-potency of existence. It equally points out that intemporal ontological-faith-notion-or-ontological-fideism—imbued-underdetermination-of-motif-andapriorising/axiomatising/referencing-as-so-being-as-of-existential-reality instigated relativemmeflexivity/relative reflexivity ontological-contiguity ${ }^{67}$ of-the-human-institutionalisationprocess $^{68}$ as of difference-conflatedness ${ }^{13}$-as-to-totalitative-reification-in-singularisation- $<$ as-tothe-nondisjointedness/entailment-of-prospective- nonpresencing > -as-veridical-epistemicityrelativism-determinism implied <amplituding/formative-epistemicity $>$ causality $\sim$ as-to- 
projective-totalitative-implications-of-prospective- nonpresencing,-for-explicating relative-

unreflexivity/relative-reflexivity - ontological-contiguity ' is ever always an exercise for the

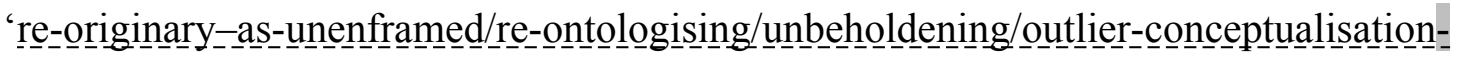
〈imbued-postconverging/dialectical-thinking -'projective-insights'/'epistemic-projection-inconflatedness '-of-notional deprocrypticism-prospective-sublimation $\rangle^{\circ}$ human recurring intemporal-disposition dimensionality-of-sublimating <<amplituding/formative>supererogatory $\sim$ de-mentativeness/epistemic-growth-or-

conflatedness /transvaluative-rationalising/transepistemicity/anamnestic-residuality/spiritdrivenness-equalisation)' to dominate/supersede/overcome 'human recurring temporal dynamics of postlogism slantedness/ ignorance/affordability/opportunism/exacerbation/social-chainism-or-socialdiscomfiture-or-negative-social-aggregation/temporal-enculturation-or-temporalendemisation', so-disambiguated as of ${ }^{83}$ reference-of-thought- ${ }^{8}$ devolving ontologicalperformance ${ }^{72}-<$ including-virtue-as-ontology $>$; in order to bring about the transcendence-andsublimity/sublimation/supererogatory de-mentativity enabling of the 'superior party' that is existence/intrinsic/ontological-veridicality as of <amplituding/formativeepistemicity $>$ causality $\sim$ as-to-projective-totalitative-implications-of-prospectivenonpresencing,-for-explicating relative unreflexivity/relative-reflexivity - ontologicalcontiguity induced positive-opportunism —of-social-functioning-and-accordance ${ }^{5}$ for ontologically-veridical ${ }^{5}$ meaningfulness-and-teleology 9 . It is further critical to understand that while ${ }^{103}$ universal-transparency $^{104}$-〈transparency-of-totalising-entailing,-as-to-entailing$<$ amplituding/formative-epistemicity>totalising in-relative-ontological-completeness $>$ with associated nested-congruence and harmony is brought about as of prior institutional secondnaturing, this should not be naively expected at uninstitutionalised-threshold ${ }^{102}$ as we very much know that all uninstitutionalised-threshold ${ }^{12}$ are conflicted as of their framework of 
'recurring dimensionality-of-sublimating ${ }^{25}-\langle<$ amplituding/formative $>$ supererogatory $\sim$ dementativeness/epistemic-growth-or-conflatedness /transvaluative-

rationalising/transepistemicity/anamnestic-residuality/spirit-drivenness-equalisation $\rangle$ temporalto-intemporal' for prospective institutionalisation prospective relative-ontologicalcompleteness $^{87}$-of- ${ }^{83}$ reference-of-thought. Thus uninstitutionalised-threshold ${ }^{102}$, are necessarily imbued with varied temporal-to-intemporal transversality-<for-sublimating-existentialeventuating/denouement,-from-'thinking at-first/pure-predisposition-preemptive-ofprospective-disontologising/subontologising' as-of-prospectively-disambiguated-affirmedand-unaffirmed-'motif-and-apriorising/axiomatising/referencing'> ${ }^{101}$ narratives as of the 'lack of intemporal secondnatured institutionalisation induced ${ }^{103}$ universal-transparency ${ }^{104}$ 〈transparency-of-totalising-entailing,-as-to-entailing-<amplituding/formativeepistemicity>totalising in-relative-ontological-completeness $\rangle, \quad$ deferential-formalisationtransference and habituation in positive-opportunism—of-social-functioning-and-accordance ${ }^{75}$; since any uninstitutionalised-threshold ${ }^{02}$ ever always brings about human 'recurring dimensionality-of-sublimating ${ }^{25}-<<$ amplituding/formative $>$ supererogatory $\sim$ dementativeness/epistemic-growth-or-conflatedness /transvaluativerationalising/transepistemicity/anamnestic-residuality/spirit-drivenness-equalisation $\rangle$ temporalto-intemporal' but with this recurring as of human dimensionality-of-sublimating ${ }^{2}$ <<amplituding/formative>supererogatory $\sim$ de-mentativeness/epistemic-growth-orconflatedness /transvaluative-rationalising/transepistemicity/anamnestic-residuality/spiritdrivenness-equalisation) temporal operating rather in denaturing the prior institutionalisation's 'apriorising/axiomatising/referencing/intelligibilitysettingup/measuringinstrumenting reference-of-thought- categorical-imperatives/axioms/registry-teleology ${ }^{9}$,-foraposteriorising/logicising/deriving/intelligising/measuring- ${ }^{5}$ meaningfulness-and-teleology ${ }^{9}$, 
form/virtualities/dereification/akrasiatic-drag/denatured/preconverging-or-dementing

narratives - of-the- reference-of-thought- categorical-imperatives/axioms/registry-

teleology > for aposteriorising/logicising/deriving/intelligising/measuring ${ }^{56}$ meaningfulnessand-teleology . The implication here is that dimensionality-of-sublimating ${ }^{25}$ <<amplituding/formative>supererogatory $\sim$ de-mentativeness/epistemic-growth-or-

conflatedness /transvaluative-rationalising/transepistemicity/anamnestic-residuality/spirit-

drivenness-equalisation) prospective transcendental ${ }^{56}$ meaningfulness-and-teleology ${ }^{9}$ is not directly intelligible in the narrow framework of temporal-to-intemporal social-stake-contentionor-confliction at uninstitutionalised-threshold ${ }^{102}$, but rather as a dispensing-with-immediacy-forrelative-ontological-completeness ${ }^{87}$-by-reification/contemplative-distension ${ }^{27}$ (as of human selfsurpassing — existentialism-form-factor,-in-overcoming-‘notional collateralising-beholdeningprotohumanity’-to- ‘attain-sublimating-humanity'-as-to-existence-potency sublimatingnascence,-disclosed-from-prospective-epistemic-digression to supersede human temporality 9 /shortness <amplituding/formative> wooden-language-〈imbued-averaging-ofthought-<as-to-leveling/ressentiment/closed-construct-of- meaningfulness-and-teleology -asof-'nondescript/ignorable-void '-with-regards-to-prospective-apriorising-implications $>>$ ) constraining of knowledge-reification $\sim$ gesturing-and-accounting-of-epistemicphenomenalism- $<$ in-prospective_psychologismic $\sim$ apriorising/axiomatising/referencing- $\{$ of'prospectively implicited_attendant-ontological-contiguity ' ceducedexistentialising/contextualising/textualising_ 'intelligibility/epistemicity/reflexivity-contiguity<imbued-notional cogency $>$ ' \}-conflatedness -in-\{preconverging-disentailment by\} postconverging-entailment $>$ framework as of <amplituding/formativeepistemicity $>$ causality $\sim$ as-to-projective-totalitative-implications-of-prospectivenonpresencing,-for-explicating relative-unreflexivity/relative-reflexivity - ontologicalcontiguity . The constraining implications of knowledge-reification $\sim$ gesturing-and- 
accounting - of-epistemic-phenomenalism- $<$ in-

prospective_psychologismic apriorising/axiomatising/referencing-\{of- ${ }^{\text {pprospectively }}$ implicited_attendant-ontological-contiguity ' educed-

existentialising/contextualising/textualising_intelligibility/epistemicity/reflexivity-contiguity<imbued-notional cogency >' \}-conflatedness -in-\{preconverging disentailment by\} postconverging-entailment $>$ as of human <amplituding/formative-epistemicity $>$ totalising thrownness-in-existence ${ }^{35}$ (I exist therefore existence is transcendentalenabling/sublimating/supereregatery de-mentativity to my human-subpotency / hyperbole-oftemporal-to-intemporal-ontological-performance ${ }^{72}-<$ including-virtue-as-ontology $>$ ) means that it is wrong to construe the relative-unreflexivity/relative-reflexivity-ontologicalcontiguity ${ }^{67}$ of-the-human-institutionalisation-process ${ }^{68}$ as of a human temporal dimensionality-of-sublimating $25<<$ amplituding/formative $>$ supererogatory $\sim$ dementativeness/epistemic-growth-or-conflatedness /transvaluativerationalising/transepistemicity/anamnestic-residuality/spirit-drivenness-equalisation〉 transformation, and so fundamentally because of human limited-mentation-capacity-assubjecting-'educed-unlimitedness/existence-sublimating nascence'-to-limitedness/humansubpotency and the correspondingly constraining consequences on its ontologicalperformance ${ }^{72}-<$ including-virtue-as-ontology $>$. Rather it is more candid to relate to the relativeunreflexivity/relative-reflexivity - ontological-contiguity ${ }^{67} \sim$ of-the-human-institutionalisation$\operatorname{process}^{68}$ as of human limited-mentation-capacity-deepening-as-subjectinglimitedness/human-subpotency-to-'educed-unlimitedness/existence-sublimating nascence' and so as of prospective intemporal secondnatured institutionalisation induced ${ }^{103}$ universaltransparency ${ }^{104}$-〈transparency-of-totalising-entailing,-as-to-entailing-<amplituding/formativeepistemicity $>$ totalising $\sim$ in-relative-ontological-completeness $\rangle, \quad$ deferential-formalisationtransference and habituation in positive-opportunism—of-social-functioning-and-accordance ${ }^{75}$. 
Central to any such prospective institutionalisation transcendentalenabling/sublimating/supereregatery de-mentativity ${ }^{56}$ meaningfulness-and-teleology ${ }^{9}$ is the fact that the human mind is not necessarily geared to come to terms with prospective relativeontological-completeness ${ }^{87}$-of- ${ }^{83}$ reference-of-thought without the necessary psychoanalyticunshackling/prospective-grounding/prospective-reification as of the developed disposition to register such implications as of their intemporal/tongness-of-register-of meaningfulness-andteleology pertinence; as the notion of crossgenerational de-mentation〈supererogatory $\sim$ ontological-de-mentation-or-dialectical-de-mentation-stranding-or-

attributive-dialectics $\rangle$ herein highlighted has ever always been an unconscious human mental process, wherein the mental-disposition hardly places itself in a situation of explaining how its own very present mental-disposition comes about from preceding generations mentaldispositions and drawing the implications, in going beyond excogitative-blanking as of the present in a cloistered-consciousness but which is paradoxically necessarily the framework of such transcendentally implying ${ }^{56}$ meaningfulness-and-teleology ${ }^{9}$. Thus the metaphoricity exercise of transcendence-and-sublimity/sublimation/supereregatery $\sim$ de-mentativity is not one of necessarily eliciting instant ${ }^{56}$ meaningfulness-and-teleology ${ }^{103}$ universal approbation but rather instigating universal untenability as of <amplituding/formativeepistemicity $>$ causality as-to-projective-totalitative-implications-of-prospectivenonpresencing,-for-explicating relative-unreflexivity/relative-reflexivity - ontologicalcontiguity for prospective ${ }^{103}$ universal positive-opportunism-of-social-functioning-andaccordance ${ }^{75}$; as we can appreciate that in reality the possibility of the successive institutionalisations was not the outcome of every human soul grasping the implications as of the successive transcendence-and-sublimity/sublimation/supereregatory $\sim$ de-mentativity but rather as of a generative dynamics as of critical drift/gravitating effect in reflection of differenceconflatedness ${ }^{13}$-as-to-totalitative-reification-in-singularisation- $<$ as-to-the- 
nondisjointedness/entailment-of-prospective- nonpresencing $>$-as-veridical-epistemicity-

relativism-determinism protracted-teleological-wholeness/nested-congruence-in-reflectingthe-relative-unreflexivity/relative-reflexivity - ontological-contiguity ${ }^{67} \sim$ of-the-humaninstitutionalisation-process ${ }^{68}$,-so-construed-as-singularisation- $<$ as-to-thenondisjointedness/entailment-of-prospective- nonpresencing $>$ projected epistemicimmanence/veridical-epistemicity-relativism-determinism'. Furthermore, the implications of 'notional-discontiguity/epistemic-discontiguity ${ }^{63}$-with/falling-short-of prospective institutionalisation 'implicited_attendant-ontological-contiguity ${ }^{67}$ > educedexistentialising/contextmalising/textualising_'intelligibility/epistemicity/reflexivity_contiguity$<$ imbued-notional cogency >' -in-elucidation-or-reification' as of singularisation- $<$ as-to-thenondisjointedness/entailment-of-prospective- nonpresencing $>$ projected epistemicimmanence/veridical-epistemicity-relativism-determinism as the latter reflects ontologicalcompleteness-of- ${ }^{-}$reference-of-thought, with regards to the construal of ${ }^{5}$ meaningfulness-andteleology as teleologically-elevated or teleologically-degraded, is that the conception of ontological-veracity of ${ }^{56}$ meaningfulness-and-teleology ${ }^{9}$ varies as of underlying relativeontological-incompleteness $^{88}$ and relative-ontological-completeness ${ }^{87}{ }^{83}$ reference-of-thought; for instance with regards to the-very-same-immanent-existence/intrinsic-reality/ontologicalveridicality,-as-to-'human<amplituding/formative-epistemicity>totalising $\sim$ purview-ofconstrual', the ${ }^{56}$ meaningfulness-and-teleology ${ }^{9}$ of a positivistic mindset with the idea of going into a supposed evil forest to collect a plant root as a cure in say an animistic social-setup will probably be construed as ridiculous as of its prior relative-ontological-incompleteness ${ }^{88}$-ofreference-of-thought despite the knowledge-reification gesturing-and-accounting-ofepistemic-phenomenalism- $<$ in-

prospective_psychologismic apriorising/axiomatising/referencing-\{of- ${ }^{\text {pprospectively }}$ implicited_attendant-ontological-contiguity ' educed- 
pesteonverging entailment $>$ ontological-veracity that the possibility of curing ailments in the animistic social-setup lies with the positivistic mindset prospective relative-ontologicalcompleteness ${ }^{87}$-of- reference-of-thought. The fundamental implication here is that transcendental ${ }^{56}$ meaningfulness-and-teleology ${ }^{9}$ is hardly construed in any presence registryworldview/dimension ${ }^{83}$ reference-of-thought as of its rather prospective relative-ontologicalcompleteness $^{87}$-of- ${ }^{83}$ reference-of-thought, and thus elicits the presence prior relativeontological-incompleteness ${ }^{88}$-of- ${ }^{83}$ reference-of-thought <amplituding/formativeepistemicity $>$ totalising $\sim$ self-referencing-syncretising/circularity/interiorising/akrasiatic-drag 3 ; with the possibility of transcendence-and-sublimity/sublimation/supererogatory-de-mentativity arising as of crossgenerational induced metaphoricity ${ }^{57}$. In a further analysis of "notionaldiscontiguity/epistemic-discontiguity ${ }^{6}$-with/falling-short-of prospective institutionalisation 'implicited_attendant-ontological-contiguity ${ }^{6 /}$ educedexistentialising/contextualising/textualising_intelligibility/epistemicity/reflexivity-contiguity$<$ imbued-notional cogency $>$-in-elucidation-or-reification' as of singularisation- $<$ as-to-thenondisjointedness/entailment-of-prospective- nonpresencing $>$ projected epistemicimmanence/veridical-epistemicity-relativism-determinism as the latter reflects ontologicalcompleteness-of- ${ }^{3}$ reference-of-thought, with regards to the postconverging-or-dialecticalthinking 2 -apriorising-psychologism and preconverging-or-dementing ${ }^{20}$-apriorisingpsychologism 'ontologically-veridical representations of dispensing-with-immediacy-forrelative-ontological-completeness ${ }^{87}$-by-reification/contemplative-distension ${ }^{27}$ as of respectively Being-development/ontological-framework-expansion-as-to-depth-of-ontologisingdevelopment-as-infrastructure-of- meaningfulness-and-teleology , institutionaldevelopment-as-to-social-function-development and living-development-as-to-personality- 
\{decompulsing\} ${ }^{2}$ delinearity for-cogency> magnitudes $\{$ of-experientiality/experiment $\}$ underdevelopment issues'; human ${ }^{56}$ meaningfulness-and-teleology is ever always caught up in a confusion of its postconverging-or-dialectical-thinking -apriorising-psychologism or preconverging-ordementing -apriorising-psychologism as of the ontologically-veridicality of its underlying relative-ontological-incompleteness ${ }^{88}$ and relative-ontological-completeness ${ }^{87}{ }^{83}$ reference-ofthought reflection of 'implicited_attendant-ontological-contiguity ${ }^{67}$ ' educedexistentialising/contextualising/textualising_'intelligibility/epistemicity/reflexivity-contiguity$<$ imbued-notional cogency $>$ ' . Hence 'ontologically-veridical representations of dispensingwith-immediacy-for-relative-ontological-completeness ${ }^{87}$-by-reification/contemplativedistension (as of human self-surpassing-existentialism-form-factor,-in-overcoming'notional collateralising-beholdening-protohumanity'-to-'attain-sublimating-humanity'-as-toexistence-potency $\sim$ sublimating-nascence,-disclosed-from-prospective-epistemic-digression to supersede human temporality 8 /shortness <amplituding/formative> wooden-language〈imbued - averaging-of-thought-<as-to-leveling/ressentiment/closed-construct-ofmeaningfulness-and-teleology -as-of-'nondescript/ignorable-void '-with-regards-toprospective-apriorising-implications $>\rangle$ ) as of the underdevelopment issues of respectively Being-development/ontological-framework-expansion-as-to-depth-of-ontologisingdevelopment-as-infrastructure-of- meaningfulness-and-teleology , institutionaldevelopment-as-to-social-function-development and living-development-as-to-personalitydevelopment psychologismic epistemic-acutisation difficulty < for, residualising $\{$ \{decompulsing $\}$ delinearity for-cogeney> magnitudes $\{$ of-experientiality/experiment\},, are ever always preconverging-or-dementing -apriorising-psychologism as of living underdevelopment, institutional underdevelopment and Being underdevelopment when construed as of the successive destructuring-threshold-〈uninstitutionalised-threshold /presublimating- 


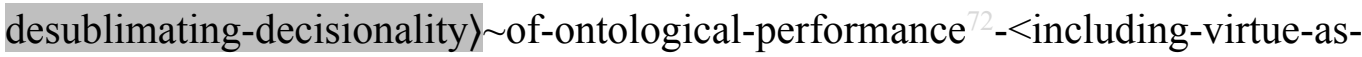

ontology $>$ /morality/ethics/justice/etc. in prospective prior relative-ontologicalincompleteness ${ }^{88}$-of- ${ }^{8}$ reference-of-thought as from the relative-unreflexivity/relativereflexivity - ontological-contiguity ${ }^{67} \sim$ of-the-human-institutionalisation-process ${ }^{68}$ differenceconflatedness ${ }^{13}$-as-to-totalitative-reification-in-singularisation- $<$ as-to-the-

nondisjointedness/entailment-of-prospective- nonpresencing > -as-veridical-epistemicity-

relativism-determinism implied $<$ amplituding/formative-epistemicity $>$ causality $\sim$ as-toprojective-totalitative-implications-of-prospective- nonpresencing,-for-explicating relativeunreflexivity/relative-reflexivity ontological-contiguity ', while these are ever always postconverging-or-dialectical-thinking -apriorising-psychologism as of Beingdevelopment/ontological-framework-expansion-as-to-depth-of-ontologising-development-asinfrastructure-of- meaningfulness-and-teleology , institutional-development-as-to-socialfunction-development and living-development-as-to-personality-development psychologismic epistemic-acutisation difficulty-for, residualising \{decompulsing $\}$ delinearity for-cogency> magnitudes $\{$ of-experientiality/experiment\} when construed as of the $<$ cumulating/recomposuring attendant-ontological-contiguity $>$-successive registryworldviews/dimensions institutionalisations in prospective relative-ontological-completeness ${ }^{87}$ of- ${ }^{8}$ reference-of-thought the relative-unreflexivity/relative-reflexivity-ontologicalcontiguity ${ }^{67}$ of-the-human-institutionalisation-process ${ }^{68} \quad$ difference-conflatedness ${ }^{13}$-as-tototalitative-reification-in-singularisation-<as-to-the-nondisjointedness/entailment-ofprospective- nonpresencing $>$-as-veridical-epistemicity-relativism-determinism implied <amplituding formative-epistemicity $>$ causality $~ a s-t o-p r o j e c t i v e-t o t a l i t a t i v e-$ implications-ofprospective- nonpresencing,-for-explicating relative-unreflexivity/relative-reflexivity-

ontological-contiguity '; thus highlighting the fundamental recurrent ontological-veracity of reference-of-thought- devolving-level of human temporal individuations dynamics as of 
postlogism 7 -slantedness/ ${ }^{5}$ ignorance/affordability/opportunism/exacerbation/social-chainismor-social-discomfiture-or-negative-social-aggregation/temporal-enculturation-or-temporalendemisation, so-disambiguated as of ${ }^{83}$ reference-of-thought- ${ }^{8}$ devolving ontologicalperformance $^{72}$-<including-virtue-as-ontology $>$ /morality/ethics/justice/etc. at destructuringthreshold-〈uninstitutionalised-threshold /presublimating-desublimating-decisionality $\rangle$ ofontological-performance $^{72}$-<including-virtue-as-ontology $>/$ morality/ethics/justice/etc. $\quad$ in 'notional-discontiguity/epistemic-discontiguity ${ }^{3}$-with/falling-short-of prospective institutionalisation 'implicited_attendant-ontological-contiguity ${ }^{67}$; educedexistentialising/contextmalising/textualising_'intelligibility/epistemicity/reflexivity_contiguity$<$ imbued-notional cogency>' -in-elucidation-or-reification' thus reflecting vices-andimpediments $^{105}$ as of living underdevelopment, institutional underdevelopment and Being underdevelopment, so-construed from difference-conflatedness ${ }^{13}$-as-to-totalitative-reificationin-singularisation-<as-to-the-nondisjointedness/entailment-of-prospective- nonpresencing $>$ as-veridical-epistemicity-relativism-determinism protracted-teleological-wholeness/nestedcongruence-in-reflecting-the-relative-unreflexivity/relative-reflexivity - ontologicalcontiguity ${ }^{67}$ of-the-human-institutionalisation-process ${ }^{68}$,-so-construed-as-singularisation- $<$ asto-the-nondisjointedness/entailment-of-prospective- nonpresencing $>$ projected epistemicimmanence/veridical-epistemicity-relativism-determinism'. Further, this 'uninstitutionalisedthreshold ${ }^{02}$ - by - institutionalisation recurrence paradox' of 'intemporal ontological-faithnotion-or-ontological-fideism—imbued-underdetermination-of-motif-andapriorising/axiomatising/referencing-as-so-being-as-of-existential-reality instigated relativemmeflexivity/relative reflexivity ontological-contiguity ${ }^{67}$ of-the-human-institutionalisationprocess $^{68}$ as of difference-conflatedness ${ }^{13}$-as-to-totalitative-reification-in-singularisation- $<$ as-tothe-nondisjointedness/entailment-of-prospective- nonpresencing $>$-as-veridical-epistemicityrelativism-determinism implied <amplituding/formative-epistemicity $>$ causality $\sim$ as-to- 
projective-totalitative-implications-of-prospective- nonpresencing,-for-explicating relative-

unreflexivity/relative-reflexivity ontological-contiguity ', as of human limited-mentationcapacity-deepening —as-subjecting limitedness/human-subpotency to-'educed-

unlimitedness/existence-sublimating nascence' ${ }^{53}$ is what effectively renders the ontologicallyveridical

determination

of

'apriorising/axiomatising/referencing/intelligibilitysettingup/measuringinstrumenting

attitude/mental-disposition/care-and-episteme ${ }^{-}$the critical first step for construing ontologically-veridical ${ }^{56}$ meaningfulness-and-teleology ${ }^{9}$ whether as of the preconverging-ordementing -apriorising-psychologism or postconverging-or-dialectical-thinking ${ }^{21}$-apriorisingpsychologism representation; as in reality existence reflected as of veridical knowledgereification $\sim$ gesturing-and-accounting — of-epistemic-phenomenalism- $<$ in-

prospective_psychologismic apriorising/axiomatising/referencing-\{of-'prospectively_ implicited_attendant-ontological-contiguity ' educedexistentialising/contextualising/textualising_'intelligibility/epistemicity/reflexivity-contiguity<imbued-notional cogency >’ $\}$-conflatedness -in-\{preconverging-disentailment by\} postconverging entailment $>$ never changes, and what is critical is grasping the ontologicalperformance ${ }^{72}-<$ including-virtue-as-ontology $>/$ morality/ethics/justice/etc. of human limitedmentation-capacity—as-subjecting-'educed-unlimitedness/existence-sublimating nascence' to-limitedness/human-subpotency in conceptualising existence/intrinsic-reality/ontologicalveridicality as of knowledge-reification $\sim$ gesturing-and-accounting-of-epistemicphenomenalism-<in-prospective_psychologismic $\sim$ apriorising/axiomatising/referencing- of'prospectively implicited attendant-ontological-contiguity ' educedexistentialising/contextrising/textralising_intelligibility/epistemicity/reflexivity-contiguity<imbued-notional cogency $\left.>^{\prime} \quad\right\}$-conflatedness -in-\{preconverging-disentailment by\} postconverging entailment $>$ and so-construed as of difference-conflatedness ${ }^{13}$-as-to-totalitative- 
reification-in-singularisation-<as-to-the-nondisjointedness/entailment-of-prospectivenonpresencing $>$-as-veridical-epistemicity-relativism-determinism protracted-teleologicalwholeness/nested-congruence-in-reflecting-the-relative-unreflexivity/relative-reflexivity ontological-contiguity ${ }^{67}$ of-the-human-institutionalisation-process ${ }^{68}$,-so-construed-assingularisation-<as-to-the-nondisjointedness/entailment-of-prospective- nonpresencing $>$ projected epistemic-immanence/veridical-epistemicity-relativism-determinism' over identitiveconstitutedness ${ }^{14}$-as-'epistemic-totality ${ }^{37}$ '-dereification-in-dissingularisation-<as-to-thedisjointedness/disentailment-of- presencing - absolutising-identitive-constitutedness $>$-asflawed-epistemicity-relativism-determinism as-cloistered-within-the-same- ${ }^{8}$ reference-ofthought. The very possibility of human transcendence-andsublimity/sublimation/supererogatoryade-mentativity behind the relative-unreflexivity/relativereflexivity ontological-contiguity ${ }^{67} \sim$ of-the-human-institutionalisation-process ${ }^{68}$ arises out of human intemporal individuation dimensionality-of-sublimating

\section{<<amplituding/formative>supererogatery $\sim$ de-mentativeness/epistemic-growth-or-}

\section{conflatedness /transvaluative-rationalising/transepistemicity/anamnestic-residuality/spirit-}

drivenness-equalisation> reification. Reification as such is teleologically reflected as of singularisation-<as-to-the-nondisjointedness/entailment-of-prospective- nonpresencing $>$ projected epistemic-immanence/veridical-epistemicity-relativism-determinism as it reflects ontologically-veridical ${ }^{5}$ meaningfulness-and-teleology"; as reification arises as of the preconverging/postconverging-de-mentative/structural/paradigmatic <amplituding/formativeepistemicity $>$ causality $\sim$ as-to-projective-totalitative-implications-of-prospectivenonpresencing,-for-explicating relative-unreflexivity/relative-reflexivity - ontologicalcontiguity of the ontological-faith-notion-or-ontological-fideism-imbuedunderdetermination-of-motif-and-apriorising/axiomatising/referencing-as-so-being-as-ofexistential-reality potentiative-aspiration for prospective relative-ontological-completeness ${ }^{87}$-of- 
reference-of-thought from within a prior relative-ontological-incompleteness ${ }^{88}$-of- ${ }^{8}$ referenceof-thought. Reification here as from this singularisation- $<$ as-to-thenondisjointedness/entailment-of-prospective- nonpresencing $>$ projected epistemicimmanence/veridical-epistemicity-relativism-determinism insight, with regards to the-verysame-immanent-existence/intrinsic-reality/ontological-veridicality,-as-to-

'human<amplituding/formative-epistemicity>totalising purview-of-construal' implies the preconverging/postconverging-de-mentative/structural/paradigmatic <amplituding/formativeepistemicity $>$ causality $\sim$ as-to-projective-totalitative-implications-of-prospectivenonpresencing,-for-explicating relative-unreflexivity/relative-reflexivity - ontological-

contiguity of meaningfulness-and-teleology as of the prospective relative-ontologicalcompleteness ${ }^{87}$-of-reference-thought construed as ${ }^{55}$ maximalising-recomposuring-for-relativeontological-completeness ${ }^{87}$ - unenframed/re-ontologising conceptualisation over the prior relative-ontological-incompleteness ${ }^{8}$-of- ${ }^{8}$ reference-of-thought construed as ${ }^{51}$ incrementalismin-relative-ontological-incompleteness —enframed/disontologising conceptualisation; wherein the prospective relative-ontological-completeness ${ }^{87}$-of-reference-thought is in a reified overlooking/superseding of the prior relative-ontological-incompleteness ${ }^{88}$-of- ${ }^{8}$ reference-ofthought. In other words, reification is about apriorising-teleological resetting of $<$ amplituding/formative-epistemicity>totalising/circumscribing/delineating ${ }^{56}$ meaningfulnessand-teleology to the prospective relative-ontological-completeness ${ }^{87}$-of- ${ }^{8}$ reference-ofthought. Lacking such an insight about reification will induce an ontologically-flawed supposedly apriorising-teleological-elevation-in $\sim$ notional-contiguity/epistemic-contiguity ${ }^{6}$ -

\section{$<$ profound-supererogation -of-mentally-aestheticised postconverging/dialectical-thinking}

qualia-schema $>$ of the prior relative-ontological-incompleteness ${ }^{88}$-of- ${ }^{8}$ reference-of-thought which is in dereification and the corresponding ontologically-flawed supposedly apriorisingteleological-degradation-in $\sim$ notional-discontiguity/epistemic-discontiguity ${ }^{3}<$ between - prior- 
shallow-supererogation -of-mentally-aestheticised $\sim$ preconverging/dementing -qualiaschema_and_prospective-profound-supererogation -of-mentally-

aestheticised postconverging/dialectical-thinking - qualia-schema $>$ of the prospective relativeontological-completeness ${ }^{87}$-of- ${ }^{8}$ reference-of-thought which is as of reification; wherein dereification involves teleological pedantising/muddling/formulaic-hollowing-out-insubontologisation/subpotentiation-〈blurring/undermining-of-prospective-totalising-entailing,as-to-entailing-<amplituding/formative-epistemicity $>$ totalising in-relative-ontologicalcompleteness > ${ }^{56}$ meaningfulness-and-teleology ${ }^{9}$ to the prior relative-ontologicalincompleteness ${ }^{8}$-of- ${ }^{8}$ reference-of-thought. This is because the lack of reification wrongly implies that the <amplituding/formative $>$ wooden-language-〈imbued-averaging-of-thought$<$ as-to-leveling/ressentiment/closed-construct-of- meaningfulness-and-teleology -as-of'nondescript/ignorable-void '-with-regards-to-prospective-apriorising-implications $>$ > reference-of-thought framework of registry-worldviews/dimensions are the absolute determinants of intemporal value reference, such that the <amplinding formative $>$ woodenlanguage-〈imbued - averaging-of-thought-<as-to-leveling/ressentiment/closed-construct-ofmeaningfulness-and-teleology -as-of-‘nondescript/ignorable-void '-with-regards-toprospective-apriorising-implications $>>\quad$ reference-of-thought framework of recurrent-utteruninstitutionalisation, base-institutionalisation-ununiversalisation, ${ }^{103}$ universalisation-nonpositivism/medievalism, positivism- ${ }^{8}$ procrypticism and deprocrypticism, are paradoxicallyand-falsely equally the absolute determinants of intemporal value reference; whereas reification highlights that all the successive institutionalisations are as of the-very-same-immanentexistence/intrinsic-reality/ontological-veridicality,-as-to-'human<amplituding/formativeepistemicity>totalising purview-of-construal', but of varying ontological-performance ${ }^{72}$ $<$ including-virtue-as-ontology $>/$ morality/ethics/justice/etc. as of their prospective relativeontological-completeness ${ }^{87}$-of- reference-of-thought, as of human limited-mentation-capacity- 
deepening —as-subjecting limitedness/human-subpotency to-'educed-unlimitedness/existencesublimating nascence ${ }^{2}$. Behind this possibility of ontologically-flawed dereification of human meaningfulness-and-teleology 9 is the fact that given the reality of human-subpotencyaporia/undecidability/dilemma/ought-indeterminacy/deficiency/limitation/constraint—imbued'notional firstnaturedness-formativeness-<as-to-eventualising -inkling-drive-or-seedingmisprising $>$ temporal-to-intemporal-dispositions- $<$ so-construed-as-from-perspectiveontological-normalcy/postconvergence>'-existentialism-form-factor, the 'relativeunreflexivity/relative-reflexivity — ontological-contiguity ${ }^{67}$ of-the-human-institutionalisationprocess $^{68}$ as of difference-conflatedness ${ }^{13}$-as-to-totalitative-reification-in-singularisation- $<$ as-tothe-nondisjointedness/entailment-of-prospective- nonpresencing $>$-as-veridical-epistemicityrelativism-determinism implied $<$ amplituding/formative-epistemicity $>$ causality $\sim$ as-toprojective-totalitative-implications-of-prospective- nonpresencing,-for-explicating relativeunreflexivity/relative-reflexivity ontological-contiguity ' is a secondnaturing process as of elicited and secondnatured positive-opportunism-of-social-functioning-and-accordance ${ }^{75}$ of instigated 'dimensionality-of-sublimating ${ }^{25}-<<$ amplituding/formative $>$ supererogatory $\sim$ dementativeness/epistemic-growth-or-conflatedness /transvaluativerationalising/transepistemicity/anamnestic-residuality/spirit-drivenness-equalisation〉 as of ontological-faith-notion-or-ontological-fideism - imbued-underdetermination-of-motif-andapriorising/axiomatising/referencing-as-so-being-as-of-existential-reality reflected as to ontological-good-faith/authenticity over ontological-bad-faith/inauthenticity elucidatin/reification of 'implicited_attendant-ontological-contiguity ${ }^{67}$ ' educedexistentialising/contextualising/textualising_'intelligibility/epistemicity/reflexivity_contiguity$<$ imbued-notional cogency $>$ ' as of <mplituding/formative-epistemicity $>$ causality $\sim$ as-toprojective-totalitative-implications-of-prospective- nonpresencing,-for-explicating relativeunreflexivity/relative-reflexivity - ontological-contiguity articulation of meaningfulness- 
and-teleology ${ }^{9}$ in skewing for ${ }^{103}$ universal-transparency ${ }^{104}$-〈transparency-of-totalisingentailing,-as-to-entailing-<amplituding/formative-epistemicity $>$ totalising $\sim$ in-relative-

ontological-completeness $\rangle$ and social deferential-formalisation-transference. This fact about 'intemporal ontological-faith-notion-or-ontological-fideism - imbued-underdetermination-ofmotif-and-apriorising/axiomatising/referencing-as-so-being-as-of-existential-reality instigated relative- unreflexivity/relative-reflexivity ontological-contiguity $^{67} \sim$ of-the-human-

institutionalisation-process $^{68}$ as of difference-conflatedness ${ }^{13}$-as-to-totalitative-reification-insingularisation-<as-to-the-nondisjointedness/entailment-of-prospective- nonpresencing $>$-asveridical-epistemicity-relativism-determinism implied $\quad$ <amplituding/formativeepistemicity $>$ causality as-to-projective-totalitative-implications-of-prospectivenonpresencing,-for-explicating relative unreflexivity/relative-reflexivity - ontologicalcontiguity implies that 'dimensionality-of-sublimating <<amplituding/formative>supererogatory $\sim$ de-mentativeness/epistemic-growth-orconflatedness /transvaluative-rationalising/transepistemicity/anamnestic-residuality/spiritdrivenness-equalisation> as of ontological-faith-notion-or-ontological-fideism-imbuedunderdetermination-of-motif-and-apriorising/axiomatising/referencing-as-so-being-as-ofexistential-reality reflected as to ontological-good-faith/authenticity ${ }^{6}$ over ontological-badfaith/inauthenticity ${ }^{64}$ elucidatin/reification of 'implicited_attendant-ontologicalcontiguity $^{67}$ ' educed-

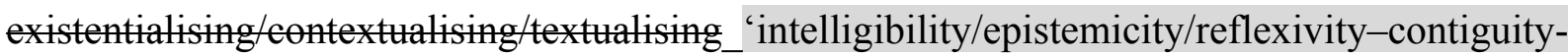
$<$ imbued-notional cogency $>^{\prime}$ is not the sufficient reason for prospective human registryworldview's/dimension's institutionalisation, but warrants a secondnaturing process of elicited and secondnatured positive-opportunism-of-social-functioning-and-accordance ${ }^{75}$ as of $<$ amplituding/formative-epistemicity $>$ causality $\sim$ as-to-projective-totalitative-implications-ofprospective- nonpresencing,-for-explicating $\sim$ relative-unreflexivity/relative-reflexivity 
ontological-contiguity articulation of ${ }^{5}$ meaningfulness-and-teleology ${ }^{9}$ by skewing for universal-transparency ${ }^{104}$-〈transparency-of-totalising-entailing,-as-to-entailing$<$ amplitung formative-epistemicity>totalising in-relative-ontological-completeness $>$ and social deferential-formalisation-transference. The implication here is that the social-construct has ever always been a threshold as of its prior institutionalisation as well as a threshold as of its uninstitutionalised-threshold ${ }^{102}$; wherein respectively there is positive-opportunism-of-socialfunctioning-and-accordance $^{75}$ for prior institutionalisation and no positive-opportunism-ofsocial-functioning-and-accordance $^{75}$ for prospective institutionalisation, explaining the developing reality of the various successive human registry-worldview's/dimension's institutionalisations, as of retrospective and prospective implications. This fundamentally points to a 'human psychology of positive-opportunism — of-social-functioning-and-accordance ${ }^{75}$ as of prior-institutionalisation-reification and uninstitutionalised-threshold ${ }^{12}$-dereification', that points out that hitherto the relative-unreflexivity/relative-reflexivity-ontologicalcontiguity ${ }^{67}$ of-the-human-institutionalisation-process ${ }^{68}$ has not been about 'dimensionality-ofsublimating $25-<$ amplituding/formative $>$ supererogatory $\sim$ de-mentativeness/epistemic-growthor-conflatedness /transvaluative-rationalising/transepistemicity/anamnestic-residuality/spiritdrivenness-equalisation> temporal individuations dispositions' transformation into 'dimensionality-of-sublimating ${ }^{25}-<<$ amplituding/formative $>$ supererogatery-dementativeness/epistemic-growth-or-conflatedness /transvaluativerationalising/transepistemicity/anamnestic-residuality/spirit-drivenness-equalisation〉 as of ontological-faith-notion-or-ontological-fideism - imbued-underdetermination-of-motif-andapriorising/axiomatising/referencing-as-so-being-as-of-existential-reality reflected as to ontological-good-faith/authenticity over ontological-bad-faith/inauthenticity

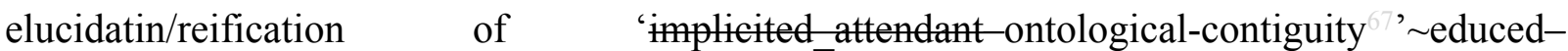
existentialising/contextualising/textualising_'intelligibility/epistemicity/reflexivity-contiguity- 
<imbued-notional cogency>' $>^{\prime}$, but rather a constraining positive-opportunism-of-socialfunctioning-and-accordance ${ }^{75}$ secondnaturing to emancipating ${ }^{83}$ reference-of-thoughtcategorical-imperatives/axioms/registry-teleology ${ }^{99}$, -for-

aposteriorising/logicising/deriving/intelligising/measuring_ ${ }^{5}$ meaningfulness-and-teleology ; and so, despite the fact that 'dimensionality-of-sublimating <<amplituding/formative>supererogatory $\sim$ de-mentativeness/epistemic-growth-orconflatedness /transvaluative-rationalising/transepistemicity/anamnestic-residuality/spiritdrivenness-equalisation) as of ontological-faith-notion-or-ontological-fideism-imbuedunderdetermination-of-motif-and-apriorising/axiomatising/referencing-as-so-being-as-ofexistential-reality reflected as to ontological-good-faith/authenticity ${ }^{6}$ over ontological-badfaith/inauthenticity ${ }^{54}$ elucidatin/reification of 'implicited_attendant-ontologicalcontiguity ${ }^{67} \sim$ educedexistentialising/contextualising/textualising_intelligibility/epistemicity/reflexivity-contiguity<imbued-notional cogency $>^{\prime}$ is a human individuation quality that avails potentially to all individuals as temporal-to-intemporal-individuation-receptacles but as of existential-constraint of ontological-performance ${ }^{2}-<$ including-virtue-as-ontology $>/$ morality/ethics/justice/etc. has not hitherto been preconverging/postconverging-de-mentatively/structurally/paradigmatically defining of relative-unreflexivity/relative-reflexivity - ontological-contiguity ${ }^{6}$ of-the-humaninstitutionalisation-process ${ }^{68}$ even as it has rather been instigative as of a re-originary_-asunenframed/re-ontologising/unbeholdening/outlier-conceptualisation-_imbued-

\section{postconverging/dialectical-thinking -'projective-insights'/'epistemic-projection-in-}

conflatedness '-of-notional deprocrypticism-prospective-sublimation $\rangle^{\circ}$ human intemporaldisposition. The basis for this 'human psychology of positive-opportunism-of-socialfunctioning-and-accordance ${ }^{75}$ as of prior-institutionalisation-reification and uninstitutionalisedthreshold ${ }^{102}$-dereification', is the fact that humankind is caught up in intemporal-reification and 
temporal-dereification as of existential-constraint of ontological-performance ${ }^{2}-<$ includingvirtue-as-ontology $>$ /morality/ethics/justice/etc. given its limited-mentation-capacity-assubjecting 'educed-unlimitedness/existence-sublimating nascence' to-limitedness/humansubpotency; wherein the 'social-construct uninstitutionalised-threshold ${ }^{02}$ ' as of 'no positiveopportunism-of-social-functioning-and-accordance ${ }^{75}$ for prospective institutionalisation' is a threshold at which there is a preconverging/postconverging-dementative/structural/paradigmatic lack of constraining institutionalisation to preempt 'human temporal social-stake-contention-or-confliction dynamics' assuming of uninstitutionalisedthreshold dereification threshold-of-nonconviction/madeupness/bottomlining-in-shallowsupererogation -<as-to- 'attendant-intradimensional'-prospectivelydisontologising preconverging/dementing -apriorising-psychologism $>$ mental-disposition as of ontologically-flawed relation with prospective institutionalisation knowledgereification $\sim$ gesturing-and-accounting — of-epistemic-phenomenalism- $<$ in-

prospective_psychologismic apriorising/axiomatising/referencing-\{of-'prospectively implicited_attendant-ontological-contiguity ' reducedexistentialising/contextualising/textualising_'intelligibility/epistemicity/reflexivity-contiguity<imbued-notional cogency >' \}-conflatedness in \{preconverging disentailment by\} postconverging-entailment $><$ amplituding/formative-epistemicity $>$ causality $\sim$ as-to-projectivetotalitative-implications-of-prospective- nonpresencing,-for-explicating relativeunreflexivity/relative-reflexivity - ontological-contiguity . In other words, as of existentialconstraint of ontological-performance ${ }^{72}-<_{\text {including-virtue-as- }}$ ontology $>$ /morality/ethics/justice/etc. given human limited-mentation-capacity—as-subjecting 'educed unlimitedness/existence sublimating nascence' to limitedness/hmman-subpotency: - at recurrent-utter-uninstitutionalisation, there is 'no constraining prospective reification institutionalisation for rulemaking-over-non-rules - apriorising/axiomatising/referencing- 
psychologism', thus allowing for 'non-rules—apriorising/axiomatising/referencingpsychologism,-as-impulsive-or-accidented-or-random-mental-disposition,-that-is-not-

rulemaking dereification behaviour' at its prospective recurrent-utter-uninstitutionalisation uninstitutionalisation; - at base-institutionalisation-ununiversalisation, there is 'no constraining prospective reification institutionalisation for ${ }^{103}$ universalisation-directed-rulemaking-over-nonrules_-apriorising/axiomatising/referencing-psychologism', thus allowing for rulemakingover-non-rules_-apriorising/axiomatising/referencing-psychologism,-that-is-not-

universalisation-directed dereification behaviour' at its prospective ununiversalisation uninstitutionalisation; - at ${ }^{103}$ universalisation-non-positivism/medievalism, there is 'no constraining prospective reification institutionalisation for positivising/rational-empiricismbased-universalisation-directed-rulemaking-over-non-rules-

apriorising/axiomatising/referencing-psychologism', thus allowing for ${ }^{103}$ universalisationdirected-rulemaking-over-non-rules — apriorising/axiomatising/referencing-psychologism,that-is-not-positivising/rational-empiricism-based dereification behaviour' at its prospective non-positivism/medievalism uninstitutionalisation; - at our positivism- ${ }^{80}$ procrypticism, there is 'no constraining prospective reification institutionalisation for preempting - disjointedness-asof- ${ }^{8}$ reference-of-thought,-as-to- ${ }^{6}<$ emplinding/formative-epistemicity $>$ growth-orconflatedness ${ }^{13} /$ transvaluative-rationalising/transepistemicity/anamnestic-residuality/spiritdrivenness' - in-superseding-mere-formulaic-positivising/rational-empiricism-baseduniversalisation-directed-rulemaking-over-non-rules — apriorising/axiomatising/referencingpsychologism', thus allowing for mere-formulaic-positivising/rational-empiricism-baseduniversalisation-directed-rulemaking-over-non-rules—apriorising/axiomatising/referencingpsychologism,-that-is-not-of-preempting — disjointedness-as-of- ${ }^{8}$ reference-of-thought,-as-to${ }^{32}<$ amplituding/formative-epistemicity $>$ growth-or-conflatedness ${ }^{13} /$ transvaluative- $^{-}$ rationalising/transepistemicity/anamnestic-residuality/spirit-drivenness'—in-superseding- 
mere-formulaic-positivising/rational-empiricism-based-universalisation-directed-rulemakingover-non-rules — apriorising/axiomatising/referencing-psychologism dereification behaviour' at its prospective $\quad{ }^{80}$ prypticism-or-disjointedness-as-of- ${ }^{3}$ reference-of-thought uninstitutionalised-threshold $^{102}$. In this regard as a further elucidation, a preconverging/postconverging-de-mentative/structural/paradigmatic temporal dereification threshold-of-nonconviction/madeupness/bottomlining-in-shallow-supererogation $<-<$ as-to-

\section{‘attendant-intradimensional'-prospectively-disontologising preconverging/dementing} apriorising-psychologism> mental-disposition as of ontologically-flawed relation with prospective institutionalisation knowledge-reification $\sim$ gesturing-and-accounting-ofepistemic-phenomenalism-<in-

\section{prospective_psychologismic apriorising/axiomatising/referencing-\{of-"prospectively} implicited_attendant-ontological-contiguity ' ceducedexistentialising/contextualising/textualising_'intelligibility/epistemicity/reflexivity_contiguity<imbued-notional cogency $>>\quad\}$-conflatedness -in-\{preconverging-disentailment by\} postconverging entailment $><$ amplituding/formative-epistemicity $>$ causality $\sim$ as-to-projectivetotalitative-implications-of-prospective- nonpresencing,-for-explicating relativemnreflexivity/relative reflexivity - ontological-contiguity say on the basis of notions-andaccusations-of-sorcery is easily elicited-as-of-dereification in a non-positivistic social-setup under existential-constraint as there is not reifying positivism/rational-empiricism institutionalisation $\quad{ }^{103}$ universal-transparency ${ }^{104}$-〈transparency-of-totalising-entailing,-as-toentailing-<amplituding/formative-epistemicity $>$ totalising $\sim$ in-relative-ontological-

completeness $\rangle$. Insightfully, the possibility for deprocrypticism/preemption-of-disjointenessas-of- ${ }^{2}$ reference-of-thought registry-worldview/dimension is necessarily one that supersedes mere $\quad{ }^{83}$ reference-of-thought- categorical-imperatives/axioms/registry-teleology ${ }^{9}$,-foraposteriorising/logicising/deriving/intelligising/measuring- ${ }^{5}$ meaningfulness-and-teleology ${ }^{9}{ }^{\prime}$ : 
as of the elicitation/cultivation of human dimensionality-of-sublimating <<amplituding/formative >supererogatory $\sim$ de-mentativeness/epistemic-growth-or-

conflatedness /transvaluative-rationalising/transepistemicity/anamnestic-residuality/spirit-

drivenness-equalisation> 'ontological-faith-notion-or-ontological-fideism-imbuedunderdetermination-of-motif-and-apriorising/axiomatising/referencing-as-so-being-as-of-

existential-reality parrhesiastic askesis-or-acumen as of reasoning-through/messianic-reasoning' strive for potentiative-attainment of singularisation-<as-to-the-nondisjointedness/entailment-ofprospective- nonpresencing $>\quad$ projected epistemic-immanence/veridical-epistemicityrelativism-determinism construed as of 'ontologically-uncompromised-referentialism notional deprocrypticism emancipated apriorising/axiomatising/referencing/intelligibilitysettingup/measuringinstrumenting selfconsciousness'. This is validated by the fact that as of its instigation of prospective relativeontological-completeness ${ }^{87}$-as-of- ${ }^{8}$ reference-of-thought behind the successive institutionalcumulation/institutional-recomposure-〈as-to- historiality/ontologicaleventfulness /ontological-aesthetic-tracing-<perspective-ontologicalnormalcy/postconvergence-reflected-‘epistemicity-relativism-determinism'>> in reflecting holographically-<conjugatively-and-transfusively $>$ the relative-unreflexivity/relativereflexivity - ontological-contiguity of-the-human-institutionalisation-process, the 'dimensionality-of-sublimating ${ }^{25}-<<$ amplituding/formative $>$ supererogatory $\sim$ dementativeness/epistemic-growth-or-conflatedness /transvaluativerationalising/transepistemicity/anamnestic-residuality/spirit-drivenness-equalisation〉 as of ontological-faith-notion-or-ontological-fideism - imbued-underdetermination-of-motif-andapriorising/axiomatising/referencing-as-so-being-as-of-existential-reality reflected as to ontological-good-faith/authenticity over ontological-bad-faith/inauthenticity elucidatin/reification of prospective institutionalisation 'implicited_attendant-ontological- 
contiguity ${ }^{67}$,educed-

existentialising/contextualising/textualising_'intelligibility/epistemicity/reflexivity_contiguity-

<imbued-notional cogency>' ${ }^{\prime}$-in-elucidation-or-reification' had-and-has 'no ${ }^{83}$ reference-ofthought- categorical-imperatives/axioms/registry-teleology $^{9}$,-for-

aposteriorising/logicising/deriving/intelligising/measuring- ${ }^{5}$ meaningfulness-and-teleology ${ }^{9}$,

to go by, but for its underlying 'ontological-faith-notion-or-ontological-fideism-imbued-

underdetermination-of-motif-and-apriorising/axiomatising/referencing-as-so-being-as-of-

existential-reality parrhesiastic askesis-or-acumen as of reasoning-through/messianic-reasoning'

thereof validated by prospective <amplituding/formative-epistemicity $>$ causality $\sim$ as-toprojective-totalitative-implications-of-prospective- nonpresencing,-for-explicating relativeunreflexivity/relative-reflexivity - ontological-contiguity as of prospective institutionalisation knowledge-reification $\sim$ gesturing-and-accounting —of-epistemic-phenomenalism- $<$ inprospective_psychologismic apriorising/axiomatising/referencing-\{of-'prospectively implicited_attendant-ontological-contiguity ' educedexistentialising/contextualising/textualising_intelligibility/epistemicity/reflexivity_contiguity<imbued-notional cogency $>$ ' $\}$-conflatedness -in-\{preconverging-disentailment by\} postconverging entailment $><$ amplituding/formative-epistemicity $>$ causality $\sim$ as-to-projectivetotalitative-implications-of-prospective- nonpresencing,-for-explicating relativeunreflexivity/relative-reflexivity ontological-contiguity; such that in lieu of positiveopportunism-of-social-functioning-and-accordance ${ }^{75}$ of secondnaturing ${ }^{83}$ reference-ofthought- ${ }^{8}$ categorical-imperatives/axioms/registry-teleology ${ }^{99}$, notional ${ }^{18}$ deprocrypticism in its preempting - disjointedness-as-of- ${ }^{3}$ reference-of-thought rather all about arriving-short with no positive-opportunism - of-social-functioning-and-accordance ${ }^{75} \quad{ }^{83}$ reference-of-thoughtcategorical-imperatives/axioms/registry-teleology ${ }^{9}$ by 'failing to elicit any associated positiveopportunism-of-social-functioning-and-accordance ${ }^{75}$ to deprocrypticism' as well as 'eliciting 
ironic nihilism to deprocrypticism', in order not to cultivate a mechanical-knowledge appreciation of ${ }^{56}$ meaningfulness-and-teleology", and rather elicit a sense of 'ontological-faithnotion-or-ontological-fideism —imbued-underdetermination-of-motif-and-

apriorising/axiomatising/referencing-as-so-being-as-of-existential-reality parrhesiastic askesisor-acumen as of reasoning-through/messianic-reasoning' 'as cultivating an organic-knowledge appreciation of ${ }^{56}$ meaningfulness-and-teleology ${ }^{9}$ as dispensing-with-immediacy-for-relativeontological-completeness $^{87}$-by-reification/contemplative-distension ${ }^{27}$ (as of human selfsurpassing — existentialism-form-factor,-in-overcoming-'notional collateralising-beholdeningprotohumanity'-to-'attain-sublimating-humanity'-as-to-existence-potency $\sim$ sublimatingnascence,-disclosed-from-prospective-epistemic-digression to supersede human temporality 8 /shortness <amplituding/formative> wooden-language-〈imbued-averaging-ofthought-<as-to-leveling/ressentiment/closed-construct-of- meaningfulness-and-teleology -asof-'nondescript/ignorable-void '-with-regards-to-prospective-apriorising-implications $>$ ))'; and so implied for Being-development/ontological-framework-expansion-as-to-depth-ofontologising-development-as-infrastructure-of- meaningfulness-and-teleology , institutionaldevelopment-as-to-social-function-development and living-development-as-to-personalitydevelopment psychologismic epistemic-acutisation difficulty-for, residualising \{decom delinearity for-cogency>-magnitudes \{of-experientiality/experiment\}, as the very fact of 'reproducibility—mathesis/motif/thrownness-disposition,-as-reproducibility-ofaestheticisation as-of-ontologically-compromised — categorising-or-qualifying-or-tendentiousor-impulsive' ${ }^{83}$ reference-of-thought- categorical-imperatives/axioms/registry-teleology ${ }^{9}$,-foraposteriorising/logicising/deriving/intelligising/measuring - ${ }^{56}$ meaningfulness-and-teleology underlies relative-ontological-incompleteness ${ }^{8}$ as of human living underdevelopment, institutional underdevelopment and Being underdevelopment, as of a lack of 'ontological-faithnotion-or-ontological-fideism-imbued-underdetermination-of-motif-and- 
apriorising/axiomatising/referencing-as-so-being-as-of-existential-reality parrhesiastic askesisor-acumen as of reasoning-through/messianic-reasoning'; as of the fact that ${ }^{5}$ meaningfulnessand-teleology is always incomplete when conceived simplistically as being all about 'mechanical-constraints of rules without spirit', construed as of reproducibilitymathesis/motif/thrownness-disposition,-as-reproducibility-of-aestheticisation-as-ofontologically-compromised — categorising-or-qualifying-or-tendentious-or-impulsive implied dissingularisation-<as-to-the-disjointedness/disentailment-of- presencing - absolutisingidentitive-constitutedness $>$ /epistemic-nonimmanence/flawed-epistemicity-relativismdeterminism. The full implications here is that a notional deprocrypticism ontologicallyuncompromised — referentialism singularisation-<as-to-the-nondisjointedness/entailment-ofprospective- nonpresencing $>\quad$ projected epistemic-immanence/veridical-epistemicityrelativism-determinism construal of ${ }^{56}$ meaningfulness-and-teleology 99 is more critically about eliciting the 'subject intemporal-disposition sense of knowledge-and-virtue as of its ${ }^{15}$ dementation-〈supererogatory ontological-de-mentation-or-dialectical-de-mentation — strandingor-attributive-dialectics $\rangle$ for a fully protracted-consciousness beyond a cloistered-consciousness' in line with Foucauldian hermeneutics of the subject futural implications. Further, it is important to grasp that 'reinvigoration as of furthered ontological-faith-notion-or-ontological-fideismimbued-underdetermination-of-motif-and-apriorising/axiomatising/referencing-as-so-being-asof-existential-reality parrhesiastic askesis-or-acumen for originary/as-of-event ${ }^{38}$ reasoningthrough/messianic-reasoning' is actually associated with all the transcendence-andsublimity/sublimation/supererogatory de-mentativity of all the $<$ cumulating/recomposuring attendant-ontological-contiguity $>$-successive registryworldviews/dimensions, but that what is particular with notional deprocrypticism summoning of 'reinvigoration as of furthered ontological-faith-notion-or-ontological-fideism - imbuedunderdetermination-of-motif-and-apriorising/axiomatising/referencing-as-so-being-as-of- 
existential-reality parrhesiastic askesis-or-acumen for originary/as-of-event ${ }^{38}$ reasoningthrough/messianic-reasoning' as implied by its ontologically-uncompromised-referentialism singularisation-<as-to-the-nondisjointedness/entailment-of-prospective- nonpresencing $>$ projected epistemic-immanence/veridical-epistemicity-relativism-determinism, is the fact that it achieves the potentiative-aspiration of ontological-faith-notion-or-ontological-fideism imbued-underdetermination-of-motif-and-apriorising/axiomatising/referencing-as-so-being-asof-existential-reality as a 'seeding promise of human-subpotency ontological-performance ${ }^{72}$ $<$ including-virtue-as-ontology $>/$ morality/ethics/justice/etc. equivalence/correspondence with the full-potency-of-existence's $\sim$ sublimating-nascence-as-of-its-coherence/contiguity'; and so, as of 'human ontological-normalcy/postconvergence referentialism ontological-faith-notion-orontological-fideism - imbued-underdetermination-of-motif-andapriorising/axiomatising/referencing-as-so-being-as-of-existential-reality parrhesiastic askesisor-acumen as of reasoning-through/messianic-reasoning' that supplants the notion of reference-of-thought- categorical-imperatives/axioms/registry-teleology ${ }^{9}$,-foraposteriorising/logicising/deriving/intelligising/measuring $-{ }^{56}$ meaningfulness-and-teleology ${ }^{9}$. It is untenable to construe of the ultimate potential of human emancipation without the eliciting of this more fundamentally authentic basis of human emancipation as of the overcoming of human limited-mentation-capacity—as-subjecting-'educed-unlimitedness/existencesublimating nascence' to-limitedness/human-subpotency temporal dynamics beyond just the 'elicitation of positive-opportunism-of-social-functioning-and-accordance ${ }^{75}$ to existential<disontologising/re-ontelogising aporeticism $>$ constraining'; as implied by ontologicallyuncompromised-referentialism singularisation-<as-to-the-nondisjointedness/entailment-ofprospective- nonpresencing $>\quad$ projected epistemic-immanence/veridical-epistemicityrelativism-determinism mirroring ontological-completeness-of- ${ }^{-}$reference-of-thought of inherent existence as 'ecstatic singularity', very much unlike reproducibility- 
mathesis/motif/thrownness-disposition,-as-reproducibility-of-aestheticisation-as-ofontologically-compromised — categorising-or-qualifying-or-tendentious-or-impulsive implied dissingularisation-<as-to-the-disjointedness/disentailment-of- presencing - absolutisingidentitive-constitutedness > /epistemic-nonimmanence/flawed-epistemicity-relativismdeterminism as of their given prior relative-ontological-incompleteness ${ }^{88}$-of- ${ }^{8}$ reference-ofthought that fail to mirror inherent existence as 'ecstatic singularity'. Such implied transcendental ontological-construal is rather originarily/as-of-event ${ }^{38}$ as of prospective relativeontological-completeness ${ }^{87}$-of- ${ }^{8}$ reference-of-thought reasoning-through/messianic-reasoning beyond prior reasoning-from-results/afterthought endemising/enculturating $<$ amplituding/formative-epistemicity $>$ totalising $\sim$ self-referencingsyncretising/circularity/interiorising/akrasiatic-drag ${ }^{34}$. We can appreciate that as of the ordinariness <amplituding/formative $>$ wooden-language-_imbued-averaging-of-thought-<asto-leveling/ressentiment/closed-construct-of- meaningfulness-and-teleology -as-of'nondescript/ignorable-void '-with-regards-to-prospective-apriorising-implications $>>$ of say a non-positivistic registry-worldview/dimension, whether animistic or medieval, notions-andaccusations-of-sorcery as of the uninstitutionalised-threshold ${ }^{102}$ dereification of meaningfulness-and-teleology' will rather as of 'no positivism/rational-empiricism constraining prospective reification institutionalisation' rather elicit spurious palliative adaptive dereification dispositions as of human limited-mentation-capacity-as-subjecting 'educedunlimitedness/existence-sublimating nascence' to-limitedness/human-subpotency, however, when positivism/rational-empiricism originarily/as-of-event ${ }^{38}$ reification avails as of the potential for prospective human limited-mentation-capacity-deepening-as-subjecting limitedness/human-subpotency to-'educed-unlimitedness/existence-sublimating nascence' then it is more about the metaphoricity ${ }^{57}$ that portends to prospective relative-ontologicalcompleteness $^{87}$-of- ${ }^{83}$ reference-of-thought. Such originarily/as-of-event ${ }^{38}$ reification construed 
futural Being-development/ontological-framework-expansion-as-to-depth-of-ontologisingdevelopment-as-infrastructure-of- meaningfulness-and-teleology as of prospective deprocrypticism/preemption-of-procrypticism-as-of- ${ }^{-}$reference-of-thought equally do apply with regards to our positivism- ${ }^{80}$ procrypticism dereification beyond our positivismprocrypticism ordinariness <amplituding/formative $>$ wooden-language-〈imbued-averagingof-thought-<as-to-leveling/ressentiment/closed-construct-of- meaningfulness-and-teleology as-of-'nondescript/ignorable-void ' -with-regards-to-prospective-apriorising-implications >> spurious palliative adaptive dereification disjointedness-as-of- ${ }^{3}$ reference-of-thought mentaldispositions as of human limited-mentation-capacity-as-subjecting-educedunlimitedness/existence-sublimating nascence' to limitedness/human-subpotency, so-implied as of prospective human ontological-performance ${ }^{72}-<$ including-virtue-asontology $>$ /morality/ethics/justice/etc. potentiative-aspiration for singularisation- $<$ as-to-thenondisjointedness/entailment-of-prospective- nonpresencing $>$ projected epistemicimmanence/veridical-epistemicity-relativism-determinism thus enabling the aetiologisation/ontological-escalation-<ontological-

veridicality_commitment/otherliness_transcending/compulsions-encumbered_transcending > behind the relative-unreflexivity/relative-reflexivity - ontological-contiguity ${ }^{67}$ of-the-humaninstitutionalisation-process $^{68}$ and specifically for futural Being-development/ontologicalframework-expansion-as-to-depth-of-ontologising-development-as-infrastructure-ofmeaningfulness-and-teleology as of prospective deprocrypticism. Further besides this elucidated contrast articulated as of prospective relative-ontological-completeness ${ }^{87}$-ofreference-of-thought reification and prior relative-ontological-incompleteness -ofreference-of-thought dereification; the concepts of reification and dereification equally extend within a given registry-worldview/dimension ${ }^{83}$ reference-of-thought as framework of the reference-of-thought- ${ }^{2}$ devolving notional firstnaturedness-formativeness-<as-to- 
eventualising inkling-drive-or-seeding-misprising > temporal-to-intemporal-dispositions$<$ so-construed-as-from-perspective-ontological-normalcy/postconvergence $>\quad$ ontologicalperformance $^{72}-<$ including-virtue-as-ontology $>$ /morality/ethics/justice/etc. (especially as soassociated with postlogism ${ }^{77}$-slantedness and the dynamic conjugated-postlogism 77 temporal denaturing of ${ }^{56}$ meaningfulness-and-teleology ${ }^{9}$ implications) critically construing 'uninstitutionalised-threshold ${ }^{102}$ dereification' as the uninstitutionalised-threshold ${ }^{102}$ temporaland-flawed

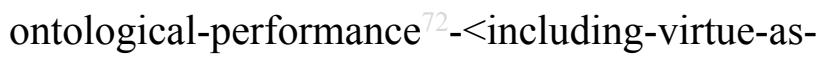
ontology $>$ /morality/ethics/justice/etc. (as of <amplituding/formative $>$ wooden-language〈imbued-temporal-mere-form/virtualities/dereification/akrasiaticdrag/denatured/preconverging-or-dementing -narratives - of-the- reference-of-thoughtcategorical-imperatives/axioms/registry-teleology $\rangle$ ) undermining the registry-

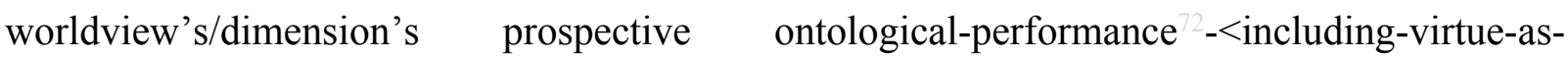
ontology $>$. This conception of reification as of institutionalisation in prospective relativeontological-completeness ${ }^{87}$-of- ${ }^{83}$ reference-of-thought reflects ontologically-veridical meaningfulness-and-teleology 99 as of ontological-normalcy/postconvergence singularisation<as-to-the-nondisjointedness/entailment-of-prospective- nonpresencing $>$ projected epistemic-immanence/veridical-epistemicity-relativism-determinism in relative apriorisingteleological-elevation-in notional-contiguity/epistemic-contiguity ${ }^{2}-<$ profoundsupererogation -of-mentally-aestheticised postconverging/dialectical-thinking -qualiaschema $>$ as of deeper limited-mentation-capacity-as-subjecting 'educedunlimitedness/existence-sublimating nascence' to-limitedness/human-subpotency preconverging/postconverging-de-mentative/structural/paradigmatic < amplituding/formativeepistemicity $>$ causality $\sim$ as-to-projective-totalitative-implications-of-prospectivenonpresencing,-for-explicating relative-unreflexivity/relative-reflexivity - ontologicalcontiguity , while the conception of dereification as of uninstitutionalised-threshold ${ }^{12}$ in prior 
relative-ontological-incompleteness ${ }^{8}$-of- ${ }^{3}$ reference-of-thought reflects ontologically-flawed meaningfulness-and-teleology dissingularisation-<as-to-the-disjointedness/disentailment-ofpresencing — absolutising-identitive-constitutedness > /epistemic-nonimmanence/flawedepistemicity-relativism-determinism in relative apriorising-teleological-degradation-

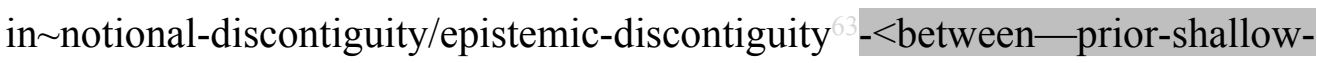

\section{supererogation -of-mentally-aestheticised preconverging/dementing -qualia-}

\section{schema_and_prospective-profound-supererogation -of-mentally-}

aestheticised postconverging/dialectical-thinking -qualia-schema $>$ as of shallow limitedmentation-capacity—as-subjecting 'educed-unlimitedness/existence-sublimating nascence' to-limitedness/human-subpotency preconverging/postconverging-dementative/structural/paradigmatic implication; wherein from a perspective of reification-bydereification knowledge-notionalisation, singularisation-<as-to-thenondisjointedness/entailment-of-prospective- nonpresencing> projected epistemicimmanence/veridical-epistemicity-relativism-determinism contemplated as of 'existentiallypotentiative absolute reification' so-implied as of theoretical existentially-potentiative nohuman-limited-mentation-capacity—as-subjecting-'educed-unlimitedness/existencesublimating nascence' to limitedness/human-subponey/full-human-mentation-capacity will reflect the attainment of notional deprocrypticism without passing through the prior institutional-cumulation/institutional-recomposure-〈as-to- historiality/ontologicaleventfulness /ontological-aesthetic-tracing-<perspective-ontologicalnormalcy/postconvergence-reflected-'epistemicity-relativism-determinism'>> of 'intemporal ontological-faith-notion-or-ontological-fideism - imbued-underdetermination-of-motif-andapriorising/axiomatising/referencing-as-so-being-as-of-existential-reality instigated relativeunreflexivity/relative-reflexivity —ontological-contiguity ${ }^{67}$ of-the-human-institutionalisationprocess $^{68}$ as of difference-conflatedness ${ }^{13}$-as-to-totalitative-reification-in-singularisation- $<$ as-to- 
the-nondisjointedness/entailment-of-prospective- nonpresencing $>$-as-veridical-epistemicity-

relativism-determinism implied $<$ amplituding/formative-epistemicity $>$ causality $\sim$ as-toprojective-totalitative-implications-of-prospective- nonpresencing,-for-explicating $\sim$ relativeunreflexivity/relative-reflexivity - ontological-contiguity , while dissingularisation-<as-tothe-disjointedness/disentailment-of- presencing — absolutising-identitive-

constitutedness $>$ /epistemic-nonimmanence/flawed-epistemicity-relativism-determinism existentially-implied as of notional reification/dereification as to human shallow-to-deepeninglimited-mentation-capacity —as-subjecting 'educed-unlimitedness/existence-sublimating nascence' to-limitedness/human-subpotency, as-limited-mentation-capacity-deepening-assubjecting limitedness/human-subpotency to-'educed-unlimitedness/existence-sublimatingnascence' ${ }^{53}$ effectively reflects the relative-unreflexivity/relative-reflexivity-ontologicalcontiguity $^{67}$ of-the-human-institutionalisation-process ${ }^{68}$ as of prior successive institutionalcumulation/institutional-recomposure-〈as-to- historiality/ontologicaleventfulness /ontological-aesthetic-tracing-<perspective-ontologicalnormalcy/postconvergence-reflected-'epistemicity-relativism-determinism' $>>$ towards the attainment of deprocrypticism. Thus reification aetiologisation/ontological-escalation<ontological-veridicality_commitment/otherliness_transcending/compulsionsencumbered_transcending $>$ is implied as of human ontological-performance ${ }^{2}-<$ includingvirtue-as-ontology $>$ /morality/ethics/justice/etc. potentiative-aspiration for singularisation-<asto-the-nondisjointedness/entailment-of-prospective- nonpresencing $>2$ projected epistemicimmanence/veridical-epistemicity-relativism-determinism. Ultimately, it is the reification of meaningfulness-and-teleology as of the prospective relative-ontological-completeness ${ }^{87}$-ofreference-of-thought that reflects intemporal value reference, and not the $<$ amplituding/formative $>$ wooden-language-<imbued — averaging-of-thought-<as-toleveling/ressentiment/closed-construct-of- meaningfulness-and-teleology -as-of- 
'nondescript/ignorable-void '-with-regards-to-prospective-apriorising-implications $>>$ as of the prior relative-ontological-incompleteness ${ }^{-0}$-of ${ }^{-2}$ ference-of-thought as of temporal-tointemporal

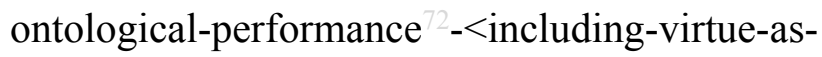
ontology $>$ /morality/ethics/justice/etc. which is rather in <amplituding/formativeepistemicity>totalising $\sim$ self-referencing-syncretising/circularity/interiorising/akrasiatic-drag 34 . Reification as such points out intellectual-and-moral inequivalence thus dismissing as ontologically-flawed a cross-examining/mutual-contending of the prospective relativeontological-completeness ${ }^{87}$-of- ${ }^{8}$ reference-of-thought and the prior relative-ontologicalincompleteness ${ }^{88}$-of- ${ }^{8}$ reference-of-thought; as the latter is in 'notional-discontiguity/epistemicdiscontiguity ${ }^{6}$-with/falling-short-of prospective institutionalisation 'implicited_attendantontological-contiguity ${ }^{67} \sim$ educed-

existentialising/contextualising/textualising_'intelligibility/epistemicity/reflexivity_contiguity$<$ imbued-notional cogency>' -in-elucidation-or-reification' and so, successively as of fallingshort-as-needing-rules with recurrent-utter-uninstitutionalisation to then contend with baseinstitutionalisation, falling-short-as-needing- ${ }^{103}$ universalising-rules with baseinstitutionalisation-ununiversalisation to then contend with ${ }^{103}$ universalisation, and fallingshort-as-needing-positivistic- ${ }^{103}$ universal-rules with $\quad{ }^{103}$ universalisation-nonpositivism/medievalism to then contend with positivism, falling-short-as-needing-preemptingdisjointedness-as-of- ${ }^{8}$ reference-of-thought with our positivism- ${ }^{8}$ procrypticism to then contend with futural Being-development/ontological-framework-expansion-as-to-depth-ofontologising-development-as-infrastructure-of- meaningfulness-and-teleology as of prospective deprocrypticism-or-preempting-disjointedness-as-of- ${ }^{8}$ reference-of-thought. Consider in this regard, the peregrinations of say a Descartes or Rousseau wherein in-manyways they will fail to fulfil the mundane medieval world conception of the 'supposedly good life' as of its <amplituding/formative-epistemicity $>$ totalising $\sim$ self-referencing- 
syncretising/circularity/interiorising/akrasiatic-drag ${ }^{34}$, as they reify ${ }^{56}$ meaningfulness-andteleology 9 by their peregrinations to construe of the preconverging/postconverging-dementative/structural/paradigmatic underdevelopment/unenlightenment of their society as in need of prospective positivistic reflection of the notional-discontiguity/epistemic-discontiguity ${ }^{63}$ $<$ between-prior-shallow-supererogation -of-mentallyaestheticised preconverging/dementing -qualia-schema_and_prospective-profoundsupererogation -of-mentally-aestheticised postconverging/dialectical-thinking -qualiaschema $>$ of non-positivism/medievalism as of their ontological-faith-notion-or-ontologicalfideism —imbued-underdetermination-of-motif-and-apriorising/axiomatising/referencing-asso-being-as-of-existential-reality singularisation-<as-to-the-nondisjointedness/entailment-ofprospective- nonpresencing $>\quad$ projected epistemic-immanence/veridical-epistemicityrelativism-determinism reified insight. The insight here about reification is that all their intemporal value references are rather as subsumed in their 'positivistic reification of meaningfulness-and-teleology ${ }^{\circ}$ as of their prospective relative-ontological-completeness ${ }^{87}$ of- ${ }^{8}$ reference-of-thought with the corresponding implications of human 'prospective positivistic transcendence-and-sublimity/sublimation/supererogatoryade-mentativity ontologicalperformance $^{72}-<$ including-virtue-as-ontology $>$ ' as aetiologisation/ontological-escalation<ontological-veridicality_commitment/otherliness_transcending/compulsions-

encumbered_transcending $>$, and so over non-positivism/medievalism vices-andimpediments ${ }^{105}$. By that token they are effectively of the most intellectually-and-morally inclined persons of their society. Contrastively, the temporal value reference as of nonpositivism/medievalism <amplituding/formative> wooden-language-_imbued - averaging-ofthought-<as-to-leveling/ressentiment/closed-construct-of- meaningfulness-and-teleology -asof-'nondescript/ignorable-void ' -with-regards-to-prospective-apriorising-implications $>$ ) mental-dispositions of persons like 'honourable aristocrats' simply reified to the 
universalisation-non-positivism/medievalism registry-worldview/dimension with its prior relative-ontological-incompleteness ${ }^{8}$-of- ${ }^{3}$ reference-of-thought vices-and-impediments ${ }^{105}$, while favourably looked upon as of non-positivism/medievalism society $<$ amplituding/formative-epistemicity $>$ totalising $\sim$ self-referencingsyncretising/circularity/interiorising/akrasiatic-drag ${ }^{34}$ from a prospective singularisation- $<$ as-tothe-nondisjointedness/entailment-of-prospective- nonpresencing $>$ projected epistemicimmanence/veridical-epistemicity-relativism-determinism insight points to such a prior registryworldview/dimension denaturing ${ }^{16}$ meaningfulness-and-teleology ${ }^{9}$, and implying effectively that they are of lesser intellectual-and-moral dialogical-equivalence- $<$ as-topsychologismic apriorising/axiomatising/referencing-\{of-'prospectively implicited_attendant-ontological-contiguity ' educedexistentialising/contextualising/textualising_'intelligibility/epistemicity/reflexivity-contiguity$<$ imbued-notional cogency $>$ ' \}-conflatedness -in-\{preconverging-disentailment by\} postconverging-entailment,-in-self-becoming/self-conflatedness /formative-supererogating>.

This further explains why vague classification schemes of value like good-naturedness, kindness, honesty, etc. have no inherent meaning as of themselves, as all the ${ }^{56}$ meaningfulness-andteleology ${ }^{9}$ that there is and can exist is ontological as of prospective relative-ontologicalcompleteness ${ }^{87}$, such that any such implied meaning is only ontologically intelligible with its reification as of prospective relative-ontological-completeness ${ }^{87}$-of- ${ }^{8}$ reference-of-thought, as so implied from singularisation-<as-to-the-nondisjointedness/entailment-of-prospectivenonpresencing $>\quad$ projected epistemic-immanence/veridical-epistemicity-relativismdeterminism as the reflection of ontologically-veridical ${ }^{5}$ meaningfulness-and-teleology ${ }^{9}$. This points out that as of its very own <amplituding/formative-epistemicity $>$ totalising $\sim$ selfreferencing-syncretising/circularity/interiorising/akrasiatic-drag ${ }^{34}, \quad$ a $\quad$ registryworldview/dimension ${ }^{83}$ reference-of-thought is not the ontologically-veridical point of 
conceptualisation of intemporal value reference, which is rather as of prospective relativeontological-completeness ${ }^{87}$-of- ${ }^{8}$ reference-of-thought reification of ${ }^{56}$ meaningfulness-andteleology ${ }^{9}$, as we can appreciate with regards to all prior institutionalisations but will certainly be complexified/inhibited to construe the same as of our positivism- ${ }^{80}$ procrypticism as from futural Being-development/ontological-framework-expansion-as-to-depth-of-ontologisingdevelopment-as-infrastructure-of- meaningfulness-and-teleology as of prospective deprocrypticism-or-preempting-disjointedness-as-of- ${ }^{3}$ reference-of-thought prospective relative-ontological-completeness 87 perspective. The fact is no registry-worldview/dimension as of its temporal/shortness-of-register-of meaningfulness-and-teleology $<$ amplituding/formative $>$ wooden-language-<imbued - averaging-of-thought-<as-toleveling/ressentiment/closed-construct-of- meaningfulness-and-teleology -as-of'nondescript/ignorable-void ' -with-regards-to-prospective-apriorising-implications $>$ > instigated prospective transcendence-and-sublimity/sublimation/supererogatory $\sim$ dementativity, is construed as 'putting-into-question its existentially-disontologising/reentologising aporeticism $>$ invested conception-of- ${ }^{-6}$ meaningfulness-and-teleology ${ }^{9}$, which is rather a contradiction of sorts given human-subpotencyaporia/undecidability/dilemma/ought-indeterminacy/deficiency/limitation/constraint—imbued'notional firstnaturedness-formativeness-<as-to-eventualising -inkling-drive-or-seedingmisprising $>$ temporal-to-intemporal-dispositions- $<$ so-construed-as-from-perspectiveontological-normalcy/postconvergence>'-existentialism-form-factor. Rather besides culturaldiffusion pressures, all human transcendence-and-sublimity/sublimation/supererogatory $\sim$ dementativity as of internal processes are rather as of re-originary-_as-unenframed/reontologising/unbeholdening/outlier-conceptualisation___imbued-postconverging/dialecticalthinking -'projective-insights'/'epistemic-projection-in-conflatedness ' 'of- 
meaningfulness-and-teleology individuations dynamic metaphoricity instigation in prospective relative-ontological-completeness ${ }^{87}$-of- ${ }^{8}$ reference-of-thought reifying gestures as of ontological-faith-notion-or-ontological-fideism - imbued-underdetermination-of-motif-andapriorising/axiomatising/referencing-as-so-being-as-of-existential-reality, which by this token is rather concerned with the beyond-the-consciousness-awareness-teleology ${ }^{9}-<$ ofpreconverging-existential-extrication-as-of-existential-unthought $>$ denaturing of the prior institutionalisation ${ }^{83}$ reference-of-thought- categorical-imperatives/axioms/registry-teleology at its uninstitutionalised-threshold 102 in 'notional-discontiguity/epistemic-discontiguity ${ }^{\text {- }}$ with/falling-short-of prospective institutionalisation 'implicited_attendant-ontologicalcontiguity $^{67} \sim$ educed-

existentialising/contextualising/textualising_intelligibility/epistemicity/reflexivity-contiguity$<$ imbued-notional cogency>' ${ }^{\prime}$-in-elucidation-or-reification'. However, this 'ontologicallyveridical reification of value reference as of prospective relative-ontological-completeness ${ }^{87}$, and the 'ontologically-flawed dereification of value reference as of prior relative-ontologicalincompleteness ${ }^{8}$, is associated with a fundamental paradox/confusion with regards to sound human intellection at destructuring-threshold-〈uninstitutionalised-threshold /presublimatingdesublimating-decisionality $>$ of-ontological-performance ${ }^{72}-<$ including-virtue-as-ontology $>$. As this reification/dereification of meaningfulness-and-telelogy paradox/confusion has always provided the room for intellectual-and-moral charlatanism throughout human history as of lack of ${ }^{103}$ universal-transparency $^{104}$-〈transparency-of-totalising-entailing,-as-to-entailing$<$ amplituding/formative-epistemicity>totalising in-relative-ontological-completeness $\rangle$. With such charlatanism certainly knowing better but opting for denaturing conceptions of value reference as of <amplituding/formative> wooden-language-_imbued-averaging-of-thought$<$ as-to-leveling/ressentiment/closed-construct-of- meaningfulness-and-teleology -as-of'nondescript/ignorable-void ' -with-regards-to-prospective-apriorising-implications $>$ > 
advancement of temporal interests in stifling the possibility of prospective human intellectualand-moral emancipation. The idea of ontological-bad-faith/inauthenticity ${ }^{64}$ raised herein by this author is a reflection of the reality that knowledge as organic-knowledge is existentially<disontologising/re-ontologising aporeticism $>$ all-committal by the mere fact of humansubpotency-aporia/undecidability/dilemma/ought-

indeterminacy/deficiency/limitation/constraint—imbued-'notional firstnaturednessformativeness-<as-to-eventualising-inkling drive-or-seeding-misprising $>$ temporal-tointemporal-dispositions-<so-construed-as-from-perspective-ontologicalnormalcy/postconvergence $>$ '-existentialism-form-factor, with the possibility of denaturing ${ }^{6}$ as of social-stake-contention-or-confliction, and particularly so in spurious and blurry domains-ofstudy not readily/easily constraint to <amplituding/formative-epistemicity $>$ causality $\sim$ as-toprojective-totalitative-implications-of-prospective- nonpresencing,-for-explicating relativeunreflexivity/relative-reflexivity - ontological-contiguity reflection of 'implicited_attendantontological-contiguity ${ }^{67}$, educedexistentialising/contextualising/textualising_intelligibility/epistemicity/reflexivity-contiguity$<$ imbued-notional cogency $>$ ' This brings up the implication of what is truly transcendental knowledge by its nature as of knowledge-notionalisation and organic-knowledge. Transcendental knowledge is actually institutionalising and re-institutionalising, implying it supersedes institutional practices and constructs as to the possibility for prospective institutionalisation, and so as of its dimensionality-of-sublimating ${ }^{25}$ 〈<amplituding/formative >supererogatory de-mentativeness/epistemic-growth-or-

\section{conflatedness /transvaluative-rationalising/transepistemicity/anamnestic-residuality/spirit-}

drivenness-equalisation) inducing institutional secondnaturing. It is rather not out of the question that knowledge so-construed as of prospective transcendence-andsublimity/sublimation/supererogatory $\sim$ de-mentativity implications put-into-question as 
'charlatanic' institutions and their practices construed as of prior relative-ontologicalincompleteness ${ }^{8}$-of- ${ }^{8}$ reference-of-thought specifically as extra-intellectual and pedantic orientations that undermine the advancement of their supposed prospective intellectual and emancipating vocations. Interestingly, we can garner that positivistic knowledge arose and was cultivated as of 'its very own apriorising/axiomatising/referencing/intelligibilitysettingup/measuringinstrumenting attitude/mental-disposition/care-and-episteme conception of knowledge' that superseded and didn't recognise-and-submit to medieval-scholasticism for its validation, as it construed that the latter wasn't meant/de-mentated/structured/paradigmed to uphold and perpetuate positivism implied transcendental knowledge as of prospective relative-ontological-completeness ${ }^{87}$-ofreference-of-thought; and in due course, by its <amplituding/formativeepistemicity $>$ causality $\sim$ as-to-projective-totalitative-implications-of-prospective-

\section{nonpresencing,-for-explicating relative -unreflexivity/relative-reflexivity - ontological-}

contiguity constraining it crossgenerationally overrode medieval-scholasticism. It is herein contended that it isn't out of the question that a creeping and slumbering institutional-being-andcraft intellectual tedium today increasingly fails to elicit the full re-originary_-ass-unen_framed_-_re-_.

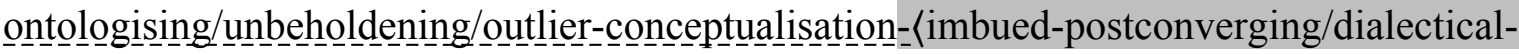
thinking -'projective-insights'/‘epistemic-projection-in-conflatedness '-of-

notional deprocrypticism-prospective-sublimation $\rangle$ potential for prospective intellectual emancipation, and so rather as of preconverging/postconverging-dementative/structural/paradigmatic institutionally-induced and societally-induced antiintellectualism implications. The question can further be asked whether transcendental implied knowledge can actually be construed as the subject of 'understanding' of prior relativeontological-incompleteness ${ }^{8}$-of- ${ }^{8}$ reference-of-thought with the latter's $<$ amplituding/formative-epistemicity $>$ totalising $\sim$ self-referencing- 
syncretising/circularity/interiorising/akrasiatic-drag ${ }^{34}$ given the psychoanalyticunshackling/prospective-grounding/prospective-reification implications of transcendental knowledge. Is transcendental knowledge as of that token rather more a metaphoricity ${ }^{57}$ constraint as of <amplituding/formative-epistemicity $>$ causality $\sim$ as-to-projective-totalitativeimplications-of-prospective- nonpresencing,-for-explicating relative-unreflexivity/relativereflexivity ontological-contiguity for the possibility of prospective transcendence-andsublimity/sublimation/supererogatory de-mentativity as more than just about abstract intellection but extending intellectualism to supersede the existential-investment implications that underlie excogitative-blanking to such prospectively implied 'understanding' as of transcendental knowledge. From the prior relative-ontological-incompleteness ${ }^{8}$-of- ${ }^{8}$ referenceof-thought naïve non-transcendental <amplituding/formative-epistemicity>totalising $\sim$ selfreferencing-syncretising/circularity/interiorising/akrasiatic-drag ${ }^{34}$, it may be thought/reasoned that a transcendentally projecting intemporal mental-disposition is rather uncanny about the 'preconverging-existential-extrication-as-of-existential-unthought malignity reality of existence' construed as pragmatic living, but this rather confirms the 'dereifying irresponsibility/relative-unreflexivity' of such temporal thought/reasoning mental-dispositions 'caught up mainly in their 60-to-100 years of existence reality of ${ }^{5}$ meaningfulness-andteleology', The intemporal 'reifying choice-and-adherence' to the 'reified assumedresponsibility/relative-reflexivity' of aetiologisation/ontological-escalation- $<$ ontologicalveridicality_commitment/otherliness_transcending/compulsions-encumbered_transcending $>$ is ever always a reasoning-through/messianic-reasoning that by definition is not in a 'reasoning with' relation with reasoning-from-results/afterthought deficient prior institutionalising; and certainly explaining why uninstitutionalised-threshold ${ }^{102}$ transcending has ever always been conflicted as to the necessary reality of imposing the 'superior party' that is as of the full-potency existence/existential-reality/intrinsic-reality/ontological-veridicality over the denaturing 
mortals that we are for our prospective emancipation. Without an insight about reification and dereification, the notion of singularisation-<as-to-the-nondisjointedness/entailment-ofprospective- nonpresencing $>$ projected epistemic-immanence/veridical-epistemicityrelativism-determinism as it reflects ontological-completeness-of- ${ }^{-3 e f e r e n c e-o f-t h o u g h t ~ f o r ~}$ ontologically-veridical ${ }^{56}$ meaningfulness-and-teleology ${ }^{9}$ is easily misconstrued since denaturing 16 meaning in dereification will be teleologically-elevated and meaning produced as of reification will be teleologically-degraded; as so blatantly obvious particularly with the dereification manifestation of childhood psychopathy postlogism 7 -slantedness but then takes on a wholly covert nature as of adulthood psychopathy and social psychopathy dynamics. In this regard, divergent as of temporal-to-intemporal dynamics of human ontological-performance ${ }^{72}$ $<$ including-virtue-as-ontology $>$ /morality/ethics/justice/etc.

of aposteriorising/logicising/deriving/intelligising/measuring $\quad{ }^{56}$ meaningfulness-and-teleology reflecting dereified and reified construals of 'implicited_attendant-ontologicalcontiguity $^{67}$ ' educedexistentialising/contextualising/textualising_intelligibility/epistemicity/reflexivity-contiguity<imbued-notional cogency ${ }^{\prime}$ is to be expected, and assessable on the basis of a commonly expected apriorising/axiomatising/referencing/intelligibilitysettingup/measuringinstrumenting, which then of a dialogical-equivalence- $<$ as-topsychologismic $\sim$ apriorising/axiomatising/referencing-\{of-"prospectively implicited_attendant-ontological-contiguity ' educedexistentialising/contextualising/textualising_'intelligibility/epistemicity/reflexivity-contiguity<imbued-notional $\left.\sim \operatorname{cogency}>^{\prime} \quad\right\}$-conflatedness -in-\{preconverging-disentailment by\} posteonverging entailment,-in-self-becoming/self-conflatedness /formative-supererogating > of both temporal mental-dispositions and the intemporal mental-disposition with no dereification and reification contrast. However, compounding this situation making relevant the need to 
contrast reification and dereification and imply moral-and-intellectual inequivalence together with dialogical inequivalence, and so between temporal mental-dispositions and intemporal mental-disposition, is specifically the flawed ontological-performance ${ }^{72}-$ including-virtue-as- $^{-}$ ontology $>$ /morality/ethics/justice/etc. manifestation of psychopathy and social psychopathy which is 'preconverging/postconverging-de-mentatively/structurally/paradigmatically associated with the denaturing of the <amplituding/formativeepistemicity $>$ totalising $\sim$ devolved

apriorising/axiomatising/referencing/intelligibilitysettingup/measuringinstrumenting', and arises so fundamentally with regards to the apriorising/axiomatising/referencing/intelligibilitysettingup/measuringinstrumenting which is the $<$ amplituding/formative-epistemicity $>$ totalising $\sim$ self-referencingsyncretising/circularity/interiorising/akrasiatic-drag 34 backdrop for existential-instantiations aposteriorising/logicising/deriving/intelligising/measuring ${ }^{56}$ meaningfulness-and-teleology ; with the fundamental implication that there are thus divergent apriorising/axiomatising/referencing/intelligibilitysettingup/measuringinstrumentings as of psychopathic induced postlogism ${ }^{77}$-slantedness, and its social cognisance and integration as conjugated-postlogism so-conjugating as of ignorance/affordability/opportunism/exacerbation/social-chainism-or-social-discomfiture-ornegative-social-aggregation/temporal-enculturation-or-temporal-endemisation as of social psychopathy. In this latter case of contrasted reification and dereification and implying moraland-intellectual inequivalence together with dialogical inequivalence, and so between temporalas-psychopathic-and-social-psychopathic mental-dispositions and the intemporal mentaldisposition, and so-implied as of 'disseminative-notional-discontiguity/epistemicdiscontiguity ${ }^{63}$ - contrastive-reification-dissemination ${ }^{28}$-and-dereification-dissemination ${ }^{28}$ implications' construed as the 'variance/discrepancy of ${ }^{56}$ meaningfulness-and-teleology ${ }^{9}$ ' as- 
of-prospective-relative-ontological-completeness ${ }^{87}$-postconverging-or-dialectical-thinking apriorising-psychologism and as-of-prior-relative-ontological-incompleteness ${ }^{8}$-preconvergingor-dementing -apriorising-psychologism respectively; it is only ontologically-veridical difference-conflatedness ${ }^{13}$-as-to-totalitative-reification-in-singularisation- $<$ as-to-thenondisjointedness/entailment-of-prospective- nonpresencing > -as-veridical-epistemicityrelativism-determinism from the projected 'notional $\sim$ singularisation- $<$ as-to-thenondisjointedness/entailment-of-prospective- nonpresencing $>$ projected epistemicimmanence/veridical-epistemicity-relativism-determinism' of the intemporal mental-disposition as-of-prospective-relative-ontological-completeness ${ }^{87}$-postconverging-or-dialecticalthinking -apriorising-psychologism recognising this 'preconverging-or-dementing 2 apriorising-psychologism and postconverging-or-dialectical-thinking ${ }^{21}$-apriorisingpsychologism variance/discrepancy of ${ }^{5}$ meaningfulness-and-teleology ${ }^{9}$ that induces an ontologically-veridical disambiguation of dereified and reified construals of 'implicited_attendant-ontological-contiguity ${ }^{67}$ educedexistentialising/contextualising/textalising_'intelligibility/epistemicity/reflexivity_contiguity$<$ imbued-notional cogency>' as implied by the apriorising/axiomatising/referencing/intelligibilitysettingup/measuringinstrumentings as of reifying intemporal/valid/postconverging-or-dialectical-thinking apriorising/axiomatising/referencing/intelligibilitysettingup/measuringinstrumenting in prospective relative-ontological-completeness ${ }^{87}$ apriorising-teleological-elevation-in $\sim$ notionalcontiguity/epistemic-contiguity ${ }^{2}-<$ profound-supererogation -of-mentallyaestheticised postconverging/dialectical-thinking -qualia-schema $>$ and as of dereifying temporal-as-psychopathic-and-social-psychopathic/invalid/preconverging-or-dementing ${ }^{20}$ apriorising-psychologism apriorising/axiomatising/referencing/intelligibilitysettingup/measuringinstrumentings in prior 
relative-ontological-incompleteness ${ }^{8}$-apriorising-teleological-degradation-in $\sim$ notionaldiscontiguity/epistemic-discontiguity ${ }^{63}<$ between - prior-shallow-supererogation -ofmentally-aestheticised preconverging/dementing -qualia-schema_and_prospective-profoundsupererogation -of-mentally-aestheticised postconverging/dialectical-thinking -qualiaschema $>$ (psychopathic and social psychopathic), and so before aposteriorising/logicising/deriving/intelligising/measuring $\quad{ }^{56}$ meaningfulness-and-teleology can even be then articulated as ontologically-veridical exclusively as of the intemporal/valid/postconverging-or-dialectical-thinking apriorising/axiomatising/referencing/intelligibilitysettingup/measuringinstrumenting perspective or attitude/mental-disposition/care-and-epistemes. Such a differenceconflatedness $^{13}$-as-of-'epistemic-totality ${ }^{37}$, is equally what reflects in-the-bigger-scheme-ofthings, at the ${ }^{83}$ reference-of-thought-level, the reality of humankind as of the $<$ cumulating/recomposuring attendant-ontological-contiguity $>$-successive registryworldviews/dimensions humans psychological dispositions as per their corresponding apriorising/axiomatising/referencing/intelligibilitysettingup/measuringinstrumentings. In this regard, the relative-unreflexivity/relative-reflexivity - ontological-contiguity ${ }^{67}$ of-the-humaninstitutionalisation-process $^{68}$ can be construed as human limited-mentation-capacity-assubjecting 'educed-unlimitedness/existence-sublimating nascence' to-limitedness/humansubpotency

apriorising/axiomatising/referencing/intelligibilitysettingup/measuringinstrumenting reification as 'apriorising-teleological resetting of <amplituding/formativeepistemicity>totalising/circumscribing/delineating ${ }^{56}$ meaningfulness-and-teleology ${ }^{99}$ as of futural Being-development/ontological-framework-expansion-as-to-depth-of-ontologisingdevelopment-as-infrastructure-of- meaningfulness-and-teleology as of prospective deprocrypticism-as-ontological-completeness-of- ${ }^{-3}$ reference-of-thought', construed as of 
difference-conflatedness ${ }^{13}$-as-to-totalitative-reification-in-singularisation- $<$ as-to-thenondisjointedness/entailment-of-prospective- nonpresencing $>$-as-veridical-epistemicityrelativism-determinism protracted-teleological-wholeness/nested-congruence-in-reflectingthe-relative-unreflexivity/relative-reflexivity ontological-contiguity ${ }^{7} \sim$ of-the-humaninstitutionalisation-process ${ }^{68}$,-so-construed-as-singularisation- $<$ as-to-thenondisjointedness/entailment-of-prospective- nonpresencing $>$ projected epistemicimmanence/veridical-epistemicity-relativism-determinism'; with the various prior registryworldviews/dimensions institutional-cumulation/institutional-recomposure-〈as-to-

\section{historiality/ontological-eventfulness /ontological-aesthetic-tracing-<perspective-} ontological-normalcy/postconvergence-reflected-‘epistemicity-relativism-determinism'>> rather successively as lesser and lesser dereification-levels towards the notional ${ }^{1}$ deprocrypticism reification. Consider in that with regards to 'the-very-same physics $<$ amplituding/formative-epistemicity $>$ totalising $\sim$ devolved - purview/domain-of-construal-asintrinsic-reality/ontological-veridicality/existential-reality', its reification as 'apriorisingteleological resetting of $\quad$ <amplituding/formativeepistemicity>totalising/circumscribing/delineating ${ }^{56}$ meaningfulness-and-teleology ${ }^{99}$ to the prospective relative-ontological-completeness ${ }^{87}$-of-physics-axiomatic-construct' implies that preconverging/postconverging-de-mentatively/structurally/paradigmatically 'traditional classical mechanics axiomatic-construct' is dereified as of its prior relative-ontologicalincompleteness ${ }^{88}$ to theory-of-relativity-together-with-quantum-mechanics-axiomaticconstructs which is rather reified as of its prospective relative-ontological-completeness ${ }^{87}$; such that interestingly to construe, as of ontological-veridicality, the reality of 'traditional classical mechanics axiomatic-construct' requires rather assuming/departing-from an understanding of knowledge-reification $\sim$ gesturing-and-accounting — of-epistemic-phenomenalism- $<$ inprospective_psychologismic $\sim$ apriorising/axiomatising/referencing-\{of-'prospectively 
implicited_attendant-ontological-contiguity ' educed-

existentialising/contextualising/textualising_'intelligibility/epistemicity/reflexivity_contiguity-

<imbued-notional cogency>> $\}$-conflatedness -in-\{preconverging-disentailment by\}

postconverging-ntailment $>$ as implied by the reifying theory-of-relativity-together-withquantum-mechanics - axiomatic-constructs in articulating ontologically-veridical differenceconflatedness ${ }^{13}$-as-to-totalitative-reification-in-singularisation- $<$ as-to-the-

nondisjointedness/entailment-of-prospective- nonpresencing > -as-veridical-epistemicity-

relativism-determinism from this projected 'notional $\sim$ singularisation- $<$ as-to-thenondisjointedness/entailment-of-prospective- nonpresencing $>$ projected epistemicimmanence/veridical-epistemicity-relativism-determinism' as of theory-of-relativity-togetherwith-quantum-mechanics - axiomatic-constructs perspective or attitude/mentaldisposition/care-and-episteme over 'traditional classical mechanics axiomatic-construct', and so-implied as of 'disseminative-notional-discontiguity/epistemic-discontiguity ${ }^{63}$ contrastivereification-dissemination -and-dereification-dissemination-implications' construed as the 'variance/discrepancy of ${ }^{56}$ meaningfulness-and-teleology' as of prospective relativeontological-completeness ${ }^{87}$ and as of prior relative-ontological-incompleteness ${ }^{88}$. Note that on the imaginary supposition that no such prospectively projected 'notional $\sim$ singularisation- $<$ as-tothe-nondisjointedness/entailment-of-prospective- nonpresencing $>$ projected epistemicimmanence/veridical-epistemicity-relativism-determinism' existed as 'providing the ontological-veridicality insight-of-completeness for reifying ${ }^{56}$ meaningfulness-and-teleology ${ }^{9}$, mental-dispositions in prior relative-ontological-incompleteness ${ }^{88}$ will falsely go on reasoning with 'traditional classical mechanics axiomatic-construct' by identitive-constitutedness ${ }^{14}$-as'epistemic-totality ${ }^{37}$ '-dereification-in-dissingularisation- $<$ as-to-the-

disjointedness/disentailment-of- presencing - absolutising-identitive-constitutedness $>$-asflawed-epistemicity-relativism-determinism as providing ontological-veridicality as of this 
now dereifying construal of 'implicited_attendant-ontological-contiguity ${ }^{67}$ ' educedexistentialising/contextualising/textualising_'intelligibility/epistemicity/reflexivity_contiguity<imbued-notional cogency>' of 'the-very-same physics <amplituding/formativeepistemicity>totalising devolved—purview/domain-of-construal-as-intrinsic-

reality/ontological-veridicality/existential-reality'. But then again, the reality of theory-ofrelativity-together-with-quantum-mechanics - axiomatic-constructs as of prospective relativeontological-completeness ${ }^{87}$ will point out that such 'traditional classical mechanics axiomaticconstruct' identitive-constitutedness ${ }^{14}$-as-'epistemic-totality ${ }^{37}{ }^{\text {' }}$-dereification-indissingularisation-<as-to-the-disjointedness/disentailment-of- presencing - absolutisingidentitive-constitutedness $>$-as-flawed-epistemicity-relativism-determinism is in reality preconverging-or-dementing ${ }^{20}$-apriorising-psychologism as of its relative-ontologicalincompleteness ${ }^{88}$. This insight equally applies at the ${ }^{83}$ reference-of-thought-level, for instance, with regards to the fact that our positivism- ${ }^{8}$ procrypticism registry-worldview/dimension doesn't recognise-nor-register any such notion as procrypticism-or-disjointedness-as-ofreference-of-thought that speaks of our prospective preconverging-or-dementing apriorising-psychologism at our prospective positivism- ${ }^{8}$ procrypticism uninstitutionalisedthreshold $^{102}$, and so as reflected from futural Being-development/ontological-frameworkexpansion-as-to-depth-of-ontologising-development-as-infrastructure-of- meaningfulnessand-teleology as of prospective deprocrypticism-or-preempting-disjointedness-as-ofreference-of-thought registry-worldview/dimension prospective relative-ontologicalcompleteness ${ }^{87}$. Interestingly, it should be noted here that with such phenomenon as psychopathy and social psychopathy that is "preconverging/postconverging-dementatively/structurally/paradigmatically associated with the denaturing of the $<$ amplituding/formative-epistemicity $>$ totalising $\sim$ devolved apriorising/axiomatising/referencing/intelligibilitysettingup/measuringinstrumenting' as of our 
positivism/rational-empiricism manifestation of ${ }^{80}$ procrypticism-or-disjointedness-as-ofreference-of-thought uninstitutionalised-threshold (just as notions-and-accusations-ofsorcery in a ${ }^{103}$ universalisation-non-positivism/medievalism social-setup is 'preconverging/postconverging-de-mentatively/structurally/paradigmatically associated with the denaturing of the <amplituding/formative-epistemicity $>$ totalising $\sim$ devolved apriorising/axiomatising/referencing/intelligibilitysettingup/measuringinstrumenting' as of their universalisation-non-positivism/medievalism uninstitutionalised-threshold ${ }^{102}$ ), ontologicalveridicality is rather assumed/departs from an understanding of knowledgereification $\sim$ gesturing-and-accounting — of-epistemic-phenomenalism- $<$ inprospective_psychologismic $\sim$ apriorising/axiomatising/referencing-\{of-'prospectively implicited_attendant-ontological-contiguity ' educedexistentialising/contextualising/textualising_'intelligibility/epistemicity/reflexivity-contiguity<imbued-notional cogency $\left.>^{\prime}\right\}$ - conflatedness -in-\{preconverging-disentailment by\} postconverging-entailment> as implied with futural Being-development/ontologicalframework-expansion-as-to-depth-of-ontologising-development-as-infrastructure-ofmeaningfulness-and-teleology as of prospective ${ }^{18}$ deprocrypticism-or-preemptingdisjointedness-as-of- ${ }^{8}$ reference-of-thought registry-worldview/dimension and not our positivism- ${ }^{8}$ procrypticism, in articulating ontologically-veridical difference-conflatedness ${ }^{13}$ as-to-totalitative-reification-in-singularisation- $<$ as-to-the-nondisjointedness/entailment-ofprospective- nonpresencing $>$-as-veridical-epistemicity-relativism-determinism from this projected 'notional $\sim$ singularisation- $<$ as-to-the-nondisjointedness/entailment-of-prospectivenonpresencing $>\quad$ projected epistemic-immanence/veridical-epistemicity-relativismdeterminism' as of '18procrypticism-or-preempting-disjointedness-as-of- ${ }^{18}$ reference-ofthought perspective or attitude/mental-disposition/care-and-episteme over our positivismprocrypticism, so-implied as of their disseminative-notional-discontiguity/epistemic- 
discontiguity ${ }^{63}$ - contrastive-reification-dissemination ${ }^{28}$-and-dereification-dissemination ${ }^{28}$ implications. But then just as the reflex mental state and attitude/mental-disposition/care-andepisteme in a ${ }^{103}$ universalisation-non-positivism/medievalism social-setup will be resistant to an elucidation of notions-and-accusations-of-sorcery adopting the perspective or attitude/mental-disposition/care-and-episteme of the reifying prospective positivism to arrive at ontological-veridicality, likewise more fundamental in undermining the elucidation of the manifestation of psychopathy and social psychopathy is the fact of an ordinariness $<$ amplituding/formative $>$ wooden-language-〈imbued - averaging-of-thought- $<$ as-toleveling/ressentiment/closed-construct-of- meaningfulness-and-teleology -as-of'nondescript/ignorable-void '-with-regards-to-prospective-apriorising-implications $>>\quad$ reflex mental state and attitude/mental-disposition/care-and-episteme in our positivismprocrypticism that will be resistant to adopting the reifying perspective or attitude/mentaldisposition/care-and-episteme of futural Being-development/ontological-frameworkexpansion-as-to-depth-of-ontologising-development-as-infrastructure-of- meaningfulnessand-teleology as of prospective ${ }^{18}$ deprocrypticism-or-preempting-disjointedness-as-ofreference-of-thought to arrive at ontological-veridicality that rather implies the dialectical $\sim$ dementation of our positivism- ${ }^{\text {procrypticism at its uninstitutionalised-threshold }}{ }^{12}$; and as we falsely go on to construe 'implicited_attendant-ontological-contiguity ${ }^{67}$ 'educedexistentialising/contextualising/textualising_intelligibility/epistemicity/reflexivity-contiguity$<$ imbued-notional cogency $>$-in-reification/dereification by adopting the positivismprocrypticism dereifying perspective or attitude/mental-disposition/care-and-episteme in its prior relative-ontological-incompleteness ${ }^{8}$ in an exercise of ontologically-flawed identitiveconstitutedness ${ }^{14}$-as-'epistemic-totality ${ }^{37}$ '-dereification-in-dissingularisation- $<$ as-to-thedisjointedness/disentailment-of- presencing - absolutising-identitive-constitutedness $>$-asflawed-epistemicity-relativism-determinism . Further and insightfully again, with the 
manifestation of childhood psychopathy where the postlogism 7 -slantedness is ${ }^{103}$ universally transparent there is no occurrence of interlocutors cognisant-and-integrative apriorising/axiomatising/referencing/intelligibilitysettingup/measuringinstrumenting reflection of 'implicited_attendant-ontological-contiguity ${ }^{67}$; educedexistentialising/contextualising/textualising_'intelligibility/epistemicity/reflexivity-contiguity<imbued-notional cogency> -in-reification/dereification as of the childhood slantedness, but with respect to adult psychopathy with the attendant maturation/indirectness/spatialisation/credulity/craftiness, such interlocutors cognisant-andintegrative apriorising/axiomatising/referencing/intelligibilitysettingup/measuringinstrumenting reflection of 'implicited_attendant-ontological-contiguity ${ }^{67}$ ' educedexistentialising/contextmalising/textmalising_intelligibility/epistemicity/reflexivity-contiguity<imbued-notional cogency $>$-in-reification/dereification arise as of their temporal thresholdof-nonconviction/madeupness/bottomlining-in-shallow-supererogation $<$ as-to-'attendantintradimensional'-prospectively-disontologising preconverging/dementing -apriorisingpsychologism>, which implies an invested social commitment as of thought and association that is then inclined to overlook inherent ontological-veridicality, as of interlocutors postlogism slantedness/ ignorance/affordability/opportunism/exacerbation/social-chainism-or-socialdiscomfiture-or-negative-social-aggregation/temporal-enculturation-or-temporal-endemisation, so-disambiguated as of ${ }^{83}$ reference-of-thought- ${ }^{8}$ devolving ontological-performance ${ }^{72}$ <including-virtue-as-ontology $>/$ morality/ethics/justice/etc. leading to the dynamics of social psychopathy, and this logic also explains how and why notions-and-accusations-of-sorcery are endemised/enculturated in a non-positivism social-setup; with the insight as articulated by this author that more critically manifestations of postlogism 77 -slantedness across all the registryworldviews/dimensions are rather revelatory of the fundamental prior relative-ontologicalincompleteness ${ }^{8}$-of- ${ }^{8}$ reference-of-thought, with transcendental implications that goes well 
beyond the ad-hoc conception of manifestations of postlogism -slantedness but more broadly conceive as of the destructuring and aetiologisation/ontological-escalation- $<$ ontologicalveridicality_commitment/otherliness_transcending/compulsions-encumbered_transcending> implications arising from underlying relative-ontological-incompleteness ${ }^{8}$ and relativeontological-completeness ${ }^{87}$ reference-of-thought with regards to human Beingdevelopment/ontological-framework-expansion-as-to-depth-of-ontologising-development-asinfrastructure-of- meaningfulness-and-teleology , institutional-development-as-to-socialfunction-development and living-development-as-to-personality-development psychologismic epistemic-acutisation difficulty-for, residualising \{decompulsing $\}$ delinearity for-cogency> magnitudes $\{$ of-experientiality/experiment\} underdevelopment issues. This underlying relativeontological-incompleteness $^{88}$ and relative-ontological-completeness ${ }^{87}{ }^{83}$ reference-of-thought $<$ amplituding/formative-epistemicity $>$ causality $\sim$ as-to-projective-totalitative-implications-ofprospective- nonpresencing,-for-explicating relative-unreflexivity/relative-reflexivityontological-contiguity of analysis, as of difference-conflatedness ${ }^{13}$-as-to-totalitativereification-in-singularisation-<as-to-the-nondisjointedness/entailment-of-prospectivenonpresencing $>$-as-veridical-epistemicity-relativism-determinism protracted-teleologicalwholeness/nested-congruence-in-reflecting-the-relative mnreflexivity/relative reflexivityontological-contiguity ${ }^{67}$ of-the-human-institutionalisation-process ${ }^{68}$,-so-construed-assingularisation-<as-to-the-nondisjointedness/entailment-of-prospective- nonpresencing $>$ projected epistemic-immanence/veridical-epistemicity-relativism-determinism', highlights that human mental-disposition as of human-subpotency-aporia/undecidability/dilemma/oughtindeterminacy/deficiency/limitation/constraint—imbued-'notional firstnaturednessformativeness-<as to eventulising inkling drive or seeding misprising $>$ temporal-tointemporal-dispositions- $<$ so-construed-as-from-perspective-ontologicalnormalcy/postconvergence >'-existentialism-form-factor operates in its 
$<$ amplituding/formative-epistemicity $>$ totalising $\sim$ self-referencing-

syncretising/circularity/interiorising/akrasiatic-drag ${ }^{34}$ on the 'ontologically-flawed basis of a rather $<$ amplituding/formative-epistemicity>totalising $\sim$ self-referencingsyncretising/circularity/interiorising/akrasiatic-drag absolutised/unchanging/given reference-of-thought- categorical-imperatives/axioms/registry-teleology ${ }^{9}$,-foraposteriorising/logicising/deriving/intelligising/measuring_ ${ }^{56}$ meaningfulness-and-teleology ${ }^{99}$; thus underlying a 'human psychology of passivity to the underlying metaphoricity ${ }^{57}$ of human limited-mentation-capacity-deepening —as-subjecting limitedness/human-subpotency-to'educed-unlimitedness/existence-sublimating nascence' ${ }^{53}$ as of human-subpotencyaporia/undecidability/dilemma/ought-indeterminacy/deficiency/limitation/constraint—imbued'notional firstnaturedness-formativeness-<as-to-eventualising inkling-drive-or-seedingmisprising $>$ temporal-to-intemporal-dispositions- $<$ so-construed-as-from-perspectiveontological-normalcy/postconvergence>'-existentialism-form-factor'. The question can then be asked with regards to the capacity of such a positivism- ${ }^{80}$ procrypticism self-consciousness psychology to attend to living-development-as-to-personality-development, institutionaldevelopment-as-to-social-function-development, Being-development/ontological-frameworkexpansion-as-to-depth-of-ontologising-development-as-infrastructure-of- meaningfulnessand-teleology underdevelopment issues/problems directly related to the lack of 'futural Beingdevelopment/ontological-framework-expansion-as-to-depth-of-ontologising-development-asinfrastructure-of- meaningfulness-and-teleology as of prospective notional deprocrypticism self-consciousness psychology that recognises-and-registers the prospective metaphoricity ${ }^{57}$ need as of human limited-mentation-capacity-as-subjecting 'educed unlimitedness/existence sublimating nascence' to limitedness/hmman-subpotency due to human-subpotency-aporia/undecidability/dilemma/oughtindeterminacy/deficiency/limitation/constraint_-imbued-'notional firstnaturedness- 
normalcy/postconvergence>'-existentialism-form-factor'. This insight is in effect the futural rejoinder to the Foucauldian hermeneutics of the subject with respect to human prospective reference-of-thought transcendence-and-sublimity/sublimation/supererogatory $\sim$ dementativity capacity; in the sense that 'intemporal ontological-faith-notion-or-ontologicalfideism - imbued-underdetermination-of-motif-and-apriorising/axiomatising/referencing-asso-being-as-of-existential-reality instigated relative-unreflexivity/relative-reflexivity ontological-contiguity ${ }^{67}$ of-the-human-institutionalisation-process ${ }^{68}$ as of differenceconflatedness $^{13}$-as-to-totalitative-reification-in-singularisation- $<$ as-to-thenondisjointedness/entailment-of-prospective- nonpresencing > -as-veridical-epistemicityrelativism-determinism implied $<$ amplituding/formative-epistemicity $>$ causality $\sim$ as-toprojective-totalitative-implications-of-prospective- nonpresencing,-for-explicating relativeunreflexivity/relative-reflexivity ontological-contiguity ' has always called upon a certain apriorising/axiomatising/referencing/intelligibilitysettingup/measuringinstrumenting development of the human subject itself as enabling-and-making-available the capacity for that human subject to tackle the prospective issues of its world. In this regard, the question could be asked: what is the capacity of the ${ }^{103}$ universalisation-non-positivism/medievalism mindset to tackle prospective issues warranting a positivism self-consciousness psychology, and by extension what is the capacity of our positivism/rational-empiricism manifestation of procrypticism-or-disjointedness-as-of- ${ }^{8}$ reference-of-thought mindset to tackle prospective issues warranting a ${ }^{18}$ deprocrypticism-or-preempting-disjointedness-as-of- ${ }^{8}$ reference-ofthought self-consciousness psychology? The 'postmodern ${ }^{18}$ deprocrypticism-or-preemptingdisjointedness-as-of- ${ }^{83}$ reference-of-thought apriorising/axiomatising/referencing/intelligibilitysettingup/measuringinstrumenting 
attitude/mental-disposition/care-and-epistemes involves prospective ${ }^{83}$ reference-of-thought dispensing-with-immediacy-for-relative-ontological-completeness ${ }^{87}$-by-

reification/contemplative-distension ${ }^{27}$ (as of human self-surpassing-existentialism-formfactor,-in-overcoming-'notional collateralising-beholdening-protohumanity'-to- 'attainsublimating-humanity'-as-to-existence-potency sublimating-nascence,-disclosed-fromprospective-epistemic-digression to supersede human temporality $/$ shortness $^{9}$ $<$ amplituding/formative $>$ wooden-language-_imbued - averaging-of-thought-<as-toleveling/ressentiment/closed-construct-of- meaningfulness-and-teleology -as-of'nondescript/ignorable-void ' -with-regards-to-prospective-apriorising-implications $>>$ )

spurring Being-development/ontological-framework-expansion-as-to-depth-of-ontologisingdevelopment-as-infrastructure-of- meaningfulness-and-teleology metaphoricity ${ }^{57}$ as of protensive-consciousness that is prospectively-grounded-or-psychoanalytically-unshackling, and implying prospective existence-potency ${ }^{32} \sim$ sublimating-nascence,-disclosed-fromprospective-epistemic-digression relative-ontological-completeness ${ }^{87}$-ofapriorising/axiomatising/referencing which is here construed as of deprocrypticism-orpreempting - disjointedness-as-of- ${ }^{83}$ reference-of-thought as implied by postmodern ${ }^{4}$ humansubject-emancipating-relativism-driven-recomposuring-constructivism-towardssingularisation-<as-to-the-nondisjointedness/entailment-of-prospective- nonpresencing $>$. Overall 'exteriorisation attitude/mental-disposition/care-and-episteme' is ontologically validated as of beyond-the-consciousness-awareness-teleology ${ }^{\circ}-<$ of - preconvergingexistential-extrication-as-of-existential-unthought $>\quad$ Being-development/ontologicalframework-expansion-as-to-depth-of-ontologising-development-as-infrastructure-ofmeaningfulness-and-teleology metaphoricity ${ }^{57}$ behind the successive transcendence-andsublimity/sublimation/supererogatory de-mentativity of registry-worldviews/dimensions in the relative-unreflexivity/relative-reflexivity - ontological-contiguity ${ }^{67}$ of-the-human- 
institutionalisation-process $^{68}$ so-associated with human limited-mentation-capacitydeepening —as-subjecting limitedness/human-subpotency to-'educed-unlimitedness/existencesublimating nascence' ${ }^{3}$. Hence the 'postmodern exteriorisation attitude/mentaldisposition/care-and-episteme' superseding of the 'modern take interiorisation attitude/mentaldisposition/care-and-episteme, is what renders possible postmodern transcendence-andsublimity/sublimation/supererogatery-de-mentativity as of its very own "postmodern deprocrypticism-or-preempting - disjointedness-as-of- ${ }^{3}$ reference-of-thought apriorising/axiomatising/referencing/intelligibilitysettingup/measuringinstrumenting

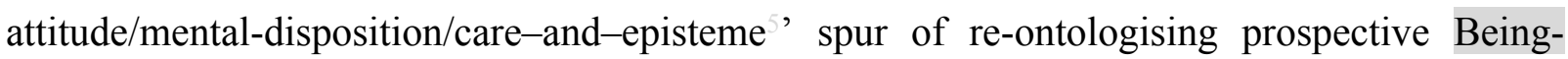
development/ontological-framework-expansion-as-to-depth-of-ontologising-development-asinfrastructure-of- meaningfulness-and-teleology metaphoricity ${ }^{57}$. Overall, 'exteriorisation attitude/mental-disposition/care-and-episteme ${ }^{-}$speaks of prospective relative-ontologicalcompleteness ${ }^{87}$-of- ${ }^{83}$ reference-of-thought as of the-very-same-immanent-existence/intrinsicreality/ontological-veridicality,-as-to-'human<amplituding/formativeepistemicity>totalising purview-of-construal', while 'interiorisation attitude/mentaldisposition/care-and-episteme ${ }^{5}$ speaks of prior relative-ontological-incompleteness ${ }^{8}$-ofreference-of-thought as of the-very-same-immanent-existence/intrinsic-reality/ontologicalveridicality,-as-to-'human<amplituding/formative-epistemicity>totalising $\sim$ purview-ofconstrual'. Thus the former is a reflection as of its postconverging-or-dialectical-thinking apriorising-psychologism of the Being underdevelopment of the latter as of the latter's preconverging-or-dementing ${ }^{20}$-apriorising-psychologism. Ultimately, human limitedmentation-capacity-deepening —as-subjecting limitedness/human-subpotency-to-'educedmlimitedness/existence-sublimating nascence' ${ }^{3}$ speaks to the ontological-veridicality that human ${ }^{56}$ meaningfulness-and-teleology 'is ever always about successive ${ }^{83}$ reference-ofthought- categorical-imperatives/axioms/registry-teleology ${ }^{9}$,-for- 
aposteriorising/logicising/deriving/intelligising/measuring- ${ }^{5}$ meaningfulness-and-teleology ${ }^{9}$ or apriorising/axiomatising/referencing/intelligibilitysettingup/measuringinstrumentingreconceptualisation-about existence-as-the-absolute-a-priori-ofconceptualisation and existence - as-sublimating-withdrawal/unenframing/re-ontologising,-

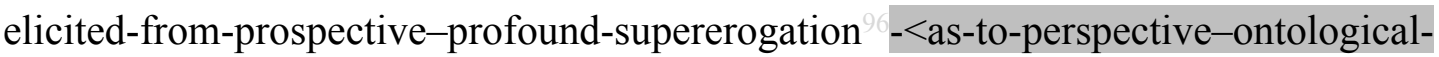
normalcy/postconvergence-implied-'prospective-aporeticism-overcoming/unovercoming'> for prospective relative-ontological-completeness ${ }^{87}$ inducing existential-instatiations devolved meaningfulness', so-construed as human sublimation-educing thermeneutic/textuality/reprojecting/supererogating/zeroing/re-acuting,$\{$ \{decompulsing $\}$ delinearity for-cogency as-to-possibilities-of-self-becoming-as-of-‘existentialinterpretation/epistemicity-in-apriorising/axiomatising/referencing-of-existence différance/internal-dialectics/difference-deferral as of <amplituding/formativeepistemicity $>$ totalising/circumscribing/delineating ${ }^{83}$ reference-of-thought- ${ }^{8}$ devolving; with such apriorising/axiomatising/referencing/intelligibilitysettingup/measuringinstrumentingreconceptualisation reflected in successive 'exteriorisation attitude/mental-disposition/careand-episteme ${ }^{5}$ for prospective institutionalisation superseding/overriding successive 'interiorisation attitude/mental-disposition/care-and-episteme' at uninstitutionalisedthreshold ${ }^{102}$ as successive Being-development/ontological-framework-expansion-as-to-depthof-ontologising-development-as-infrastructure-of- meaningfulness-and-teleology metaphoricity idiosyncratic-ferment_for-notional cogency-〈as-tosurrealising/supererogating-drive>-of-aestheticising-relief/depth-and-impetus $\rangle$ in dispensing-with-immediacy-for-relative-ontological-completeness ${ }^{87}$-byreification/contemplative-distension ${ }^{27}$ as to existence-potency ${ }^{39} \sim$ sublimating-nascence,disclosed-from-prospective-epistemic-digression, with base-institutionalisation from recurrentutter-uninstitutionalisation, $\quad{ }^{103}$ universalisation from $\quad$ base-institutionalisation- 
ununiversalisation, positivism from ${ }^{103}$ universalisation-non-positivism/medievalism and prospectively notional $\sim$ deprocrypticism from positivism- ${ }^{-}$procrypticism as reflecting the overall notional conflatedness ${ }^{13}$ of notional ${ }^{18}$ deprocrypticism protensive-consciousness as the 'ontologically-veridical point-of-focus-as-consciousness prospective exteriorisation attitude/mental-disposition/care-and-episteme '. Insightfully, this author further addresses the common criticism of postmodern-thought with regards to virtue, as of postmodern implied human-subject-emancipating-relativism-driven-recomposuring-constructivism-towardssingularisation-<as-to-the-nondisjointedness/entailment-of-prospective- nonpresencing $>$. Preconverging/postconverging-de-mentatively/structurally/paradigmatically a registryworldview's/dimension's ${ }^{83}$ reference-of-thought points fundamentally to its 'underlying reference-of-thought- categorical-imperatives/axioms/registry-teleology ${ }^{9}$,-foraposteriorising/logicising/deriving/intelligising/measuring_ ${ }^{5}$ meaningfulness-and-teleology ${ }^{\circ}$, with regards to the latter's 'temporality ${ }^{8}$-as-shortness-of-register-of- ${ }^{-}$meaningfulness-andteleology ${ }^{9}$ to intemporality ${ }^{52}$-as-longness-of-register-of- ${ }^{5}$ meaningfulness-and-teleology ontological-performance ${ }^{72}-<$ including-virtue-as-ontology $>$ ' as of notional-contiguity/epistemiccontiguity ${ }^{62}<$ profound-supererogation - of-mentally-aestheticised $\sim$ postconverging/dialecticalthinking -qualia-schema>. Such that it is fundamentally the prior relative-ontologicalincompleteness ${ }^{8}$-of- ${ }^{8}$ reference-of-thought that becomes the 'lack-of-virtue or vice issue', beyond just any associated incidental existential-<disontologising/re-ontologising aporeticism $>$ problems, as requiring aetiologisation/ontological-escalation- $<$ ontologicalveridicality_commitment/otherliness_transcending/compulsions-encumbered_transcending $>$ as of the need for prospective relative-ontological-completeness ${ }^{87}$-of- ${ }^{8}$ reference-of-thought to address the myriad <amplituding/formative-epistemicity $>$ totalising $\sim$ self-referencingsyncretising/circularity/interiorising/akrasiatic-drag $34 \quad$ existential-<disontologising/reentelogising aporeticism $>$ possibilities of the registry-worldview's/dimension's vices-and- 
impediments $^{105}$ as fundamentally bound to its prior relative-ontological-incompleteness ${ }^{8}$-ofreference-of-thought 'underlying reference-of-thought- categoricalimperatives/axioms/registry-teleology ${ }^{9}$,-foraposteriorising/logicising/deriving/intelligising/measuring- ${ }^{5}$ meaningfulness-and-teleology ${ }^{9}$ '; and so beyond just <amplituding/formative-epistemicity $>$ totalising $\sim$ self-referencingsyncretising/circularity/interiorising/akrasiatic-drag ${ }^{34}$ and ad-hoc palliative resolutions.

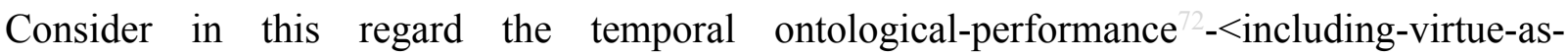
ontology $>$ /morality/ethics/justice/etc. as of say a postlogism 7 -slantedness or any other temporal or derived-temporal mental-disposition associated with vicious accusations-of-sorcery for instance in a non-positivistic as animistic or medieval social-setup. The fact that even an intemporally-inclined mental-disposition in that social-setup has an apriorising/axiomatising/referencing/intelligibilitysettingup/measuringinstrumenting reflection of 'implicited_attendant-ontological-contiguity ${ }^{67}$ ' educedexistentialising/contextualising/textualising_intelligibility/epistemicity/reflexivity-contiguity$<$ imbued-notional cogency>' -in-reification/dereification that is 'mutually cognisant-andintegrative beyond-the-consciousness-awareness-teleology ${ }^{\circ}<$ of-preconverging-existentialextrication-as-of-existential-unthought $>$ ' with notions-and-accusations-of-witcheraft itself as of their 'underlying ${ }^{83}$ reference-of-thought- categorical-imperatives/axioms/registryteleology ${ }^{9}$,-for-aposteriorising/logicising/deriving/intelligising/measuring- ${ }^{5}$ meaningfulnessand-teleology ${ }^{9}$, presents an <amplituding/formative-epistemicity $>$ totalising $\sim$ self-referencingsyncretising/circularity/interiorising/akrasiatic-drag issue that endemises notions-andaccusations-of-witchcraft in the vices-and-impediments ${ }^{105}$ of that given social-setup. It is the

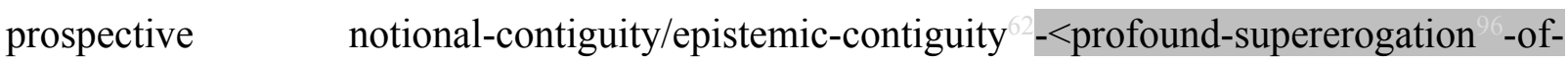
mentally-aestheticised postconverging/dialectical-thinking -qualia-schema $>$ as of prospective positivism apriorising/axiomatising/referencing/intelligibilitysettingup/measuringinstrumenting 
as setting up the positivism 'underlying reference-of-thought- categoricalimperatives/axioms/registry-teleology ${ }^{9}$,-for-

aposteriorising/logicising/deriving/intelligising/measuring - ${ }^{56}$ meaningfulness-and-teleology ${ }^{99}$, that fundamentally undermines such endemisation; and hence it is not by accident that our present positivism registry-worldview/dimension is devoid of such issues since it preconverging/postconverging-de-mentatively/structurally/paradigmatically undermines temporal-to-intemporal cognisance and integrativeness of notions-and-accusations-of-sorcery as of the positivism 'underlying ${ }^{83}$ reference-of-thought- categorical-imperatives/axioms/registryteleology ${ }^{9}$,-for-aposteriorising/logicising/deriving/intelligising/measuring- ${ }^{56}$ meaningfulnessand-teleology ${ }^{9}$, construed as 'transcendental ${ }^{4}$ human-subject-emancipating-relativism-drivenrecomposuring-constructivism-towards-singularisation- $<$ as-to-the-

nondisjointedness/entailment-of-prospective- nonpresencing $>$ that reflects 'modern suprastructuralism'; just as a 'postmodern suprastructuralism' reflects notional deprocrypticism as of its preempting - disjointedness-as-of- ${ }^{8}$ reference-of-thought over our positivism- ${ }^{80}$ procrypticism disjointedness-as-of- ${ }^{-}$reference-of-thought. This insight about the need for prospective notional-contiguity/epistemic-contiguity ${ }^{62}-<$ profoundsupererogation -of-mentally-aestheticised postconverging/dialectical-thinking -qualia-

schema $>$ underlies a postmodern understanding, as it is herein contended, that it is by the exercise of prospective relative-ontological-completeness ${ }^{87}$-of- ${ }^{8}$ reference-of-thought as of human limited-mentation-capacity-deepening —as-subjecting limitedness/human-subpotency to-'educed-unlimitedness/existence-sublimating nascence' ${ }^{53}$ as of the need for futural Beingdevelopment/ontological-framework-expansion-as-to-depth-of-ontologising-development-asinfrastructure-of- meaningfulness-and-teleology as of prospective ${ }^{18}$ deprocrypticism-orpreempting - disjointedness-as-of- ${ }^{3}$ reference-of-thought and so over our positivismprocrypticism temporal-to-intemporal mental-dispositions 'mutual cognisance and 
integrativeness of ${ }^{80}$ procrypticism-or-disjointedness-as-of- ${ }^{3}$ reference-of-thought beyond-theconsciousness-awareness-teleology ${ }^{-<}<$of-preconverging-existential-extrication-as-of-

existential-unthought $>$, that we provide the ontologically-veridical aetiologisation or ontological-esclation resolving the vices-and-impediments ${ }^{105}$ of our 'so-prospectively deprocrypticism-construed' ${ }^{80}$ procrypticism-or-disjointedness-as-of- ${ }^{3}$ reference-of-thought as of its underlying <amplituding/formative-epistemicity $>$ totalising $\sim$ self-referencingsyncretising/circularity/interiorising/akrasiatic-drag ${ }^{34}$, and so beyond just our ad-hoc palliative construals of virtue. Basically when post-structuralists speak of the 'other' this translates into aetiologisation/ontological-escalation-<ontological-

veridicality_commitment/otherliness_transcending/compulsions-encumbered_transcending $>$ as of ' ${ }^{103}$ universal projection implications attitude/mental-disposition/care-and-episteme event $^{38}$ or-operant implications to all and sundry' as implied in the above analysis, as postmodernthought portends to be non-ideology-driven, non-speculative, non-imaginary, theoretical, conceptual and operant. This insight is also very much conscious of the ontologically-flawed misconstrual of the 'other' that pervades human <amplituding/formative $>$ wooden-language〈imbued — averaging-of-thought-<as-to-leveling/ressentiment/closed-construct-ofmeaningfulness-and-teleology -as-of-'nondescript/ignorable-void '-with-regards-toprospective-apriorising-implications $>>$ mental-dispositions as of 'mutual temporal/shortness-ofregister-of- meaningfulness-and-teleology eliciting' construed as 'intemporal temporality ${ }^{\circ}$ '. Such tendencies are hardly of aetiologisation/ontological-escalation- $<$ ontologicalveridicality_commitment/otherliness_transcending/compulsions-encumbered_transcending $>$ as their emphasis lies in preconverging-existential-extrication-as-of-existential-unthought, rather than pestconverging-nonextricatory-existential-preempting-of-existential-unthought in enabling Being-development/ontological-framework-expansion-as-to-depth-of-ontologisingdevelopment-as-infrastructure-of- meaningfulness-and-teleology as of ' ${ }^{103}$ universal 
projection implications attitude/mental-disposition/care-and-episteme event ${ }^{3}$-or-operant implications to all and sundry'; such that fundamentally, such $<$ amplituding/formative $>$ wooden-language-〈imbued - averaging-of-thought-<as-toleveling/ressentiment/closed-construct-of- meaningfulness-and-teleology -as-of'nondescript/ignorable-void '-with-regards-to-prospective-apriorising-implications $>$ > tendencies do not address preconverging/postconverging-dementatively/structurally/paradigmatically defining issues of a registry-worldview/dimension as of its vices-and-impediments ${ }^{105}$ like the comprehensive implications of disjointedness-as-ofreference-of-thought/procrypticism with regards to our positivism-procryticism or say the comprehensive implications of non-positivism in a medieval or animistic social-setup.

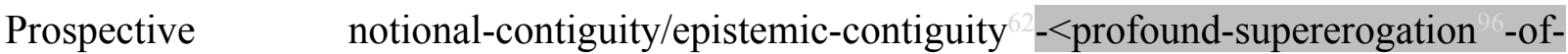
mentally-aestheticised postconverging/dialectical-thinking -qualia-schema $>$ thus effectively implies deneuterising 'exteriorisation attitude/mental-disposition/care-and-episteme' of meaningfulness-and-teleology ${ }^{9}$-as-metaphoricity ${ }^{57}$ superseding/overriding the prior reference-of-thought temporally ${ }^{58}$ neuterising 'interiorisation attitude/mental-disposition/careand-episteme' of ${ }^{5}$ meaningfulness-and-teleology . This fundamentally speaks of a preconverging/postconverging-de-mentative/structural/paradigmatic conception of virtue-asontology transcendence-and-sublimity/sublimation/supererogatory-de-mentativity as of prospective relative-ontological-completeness ${ }^{87}$-of- ${ }^{8}$ reference-of-thought. This very much differs from $\quad<$ amplituding/formative-epistemicity $>$ totalising $\sim$ self-referencingsyncretising/circularity/interiorising/akrasiatic-drag 34 'supposedly of notionalcontiguity/epistemic-contiguity ${ }^{2}-<$ profound-supererogation -of-mentallyaestheticised postconverging/dialectical-thinking -qualia-schema> palliative virtue constructs as of variance of the-very-same reference-of-thought- categoricalimperatives/axioms/registry-teleology ${ }^{9}$,-for- 
aposteriorising/logicising/deriving/intelligising/measuring $-{ }^{5}$ meaningfulness-and-teleology ${ }^{99}$, and thus implies temporally ${ }^{58}$ neuterising 'interiorisation attitude/mental-disposition/care-andepisteme' of ${ }^{56}$ meaningfulness-and-teleology ${ }^{9}$. This wrongly implies the inherent exceptionalism of the conception of virtue for humans in any such registry-worldview/dimension outside/beyond the ontologically-veridical implications of virtue-as-ontology associated with Being-development/ontological-framework-expansion-as-to-depth-of-ontologisingdevelopment-as-infrastructure-of- meaningfulness-and-teleology

in reflecting holographically-<conjugatively-and-transfusively $>$ the relative-unreflexivity/relativereflexivity - ontological-contiguity $\sim$ of-the-human-institutionalisation-process . Such a 'supposedly notional-contiguity/epistemic-contiguity $-<$ profound-supererogation -ofmentally-aestheticised postconverging/dialectical-thinking -qualia-schema> $<$ amplituding/formative-epistemicity $>$ totalising $\sim$ self-referencingsyncretising/circularity/interiorising/akrasiatic-drag ${ }^{34}$ virtue conception is caught up within such a registry-worldview/dimension internal social-stake-contention-or-confliction changing temporal constraints, temporal ${ }^{56}$ meaningfulness-and-teleology ${ }^{9}<$ preconverging $\sim$ 'motif-andapriorising/axiomatising/referencing'-entailing>-existentialising—enframing/imprintedness-

\section{〈as-to- historicity-tracing-in-presencing-hyperrealisation/hyperreal-transposition〉}

frameworks and temporal mandarinism and pedantising/muddling/formulaic-hollowing-outin-subontologisation/subpotentiation-_blurring/undermining-of-prospective-totalisingentailing,-as-to-entailing-<amplituding/formative-epistemicity $>$ totalising $\sim$ in-relativeontological-completeness $>$ frameworks as of the given ${ }^{83}$ reference-of-thought, with these elements in need for prospective transcendence-and-sublimity/sublimation/supereregatery $\sim$ dementativity as of prospective relative-ontological-completeness ${ }^{87}$-of- ${ }^{8}$ reference-of-thought but paradoxically now defining the conception of virtue. The fact is our pretences and arguments of practice, as not critically pinned down to their ontological-veracity as of prospective relative- 
ontological-completeness ${ }^{87}$, can similarly be meted with pretences and arguments of practice as of each and every registry-worldview's/dimension's ${ }^{83}$ reference-of-thought practices, and thus conceptualising virtue by <amplituding/formative-epistemicity $>$ totalising $\sim$ self-referencingsyncretising/circularity/interiorising/akrasiatic-drag ${ }^{34}$ while circumventing as of beyond-theconsciousness-awareness-teleology ${ }^{-<}<$of-preconverging-existential-extrication-as-of-

existential-unthought $>$ the vices-and-impediments ${ }^{105}$ of each registry-worldview/dimension in want of its 'pure-ontology' virtue resolution as of aetiologisation/ontological-escalation<ontological-veridicality_commitment/otherliness_transcending/compulsions-

encumbered_transcending $>$. In this regard such palliative virtue constructs overlooking fundamental underlying preconverging/postconverging-de-mentative/structural/paradigmatic ontological implications about our 'modern take attitude/mental-disposition/care-andepisteme' ${ }^{\prime}$ reflected by the 'postmodern ${ }^{18}$ deprocrypticism-or-preempting-disjointedness-asof- reference-of-thought apriorising/axiomatising/referencing/intelligibilitysettingup/measuringinstrumenting attitude/mental-disposition/care-and-episteme ${ }^{5}$ with regards to social-stake-contention-orconfliction changing temporal constraints, temporal ${ }^{56}$ meaningfulness-and-teleology $<$ preconverging 'motif-and-apriorising/axiomatising/referencing'-entailing $>$ existentialising — enframing/imprintedness-〈as-to- historicity-tracing_-in-presencinghyperrealisation/hyperreal-transposition〉 frameworks and temporal mandarinism and pedantising/muddling/formulaic-hollowing-out - in-subontologisation/subpotentiation〈blurring/undermining-of-prospective-totalising-entailing,-as-to-entailing$<$ amplituding/formative-epistemicity>totalising in-relative-ontological-completeness $>$ frameworks, are no different to say 'non-positivism/medievalism apriorising/axiomatising/referencing/intelligibilitysettingup/measuringinstrumenting attitude/mental-disposition/care-and-episteme ${ }^{5}$ overlooking its own social-stake-contention- 
or-confliction changing temporal constraints, temporal ${ }^{56}$ meaningfulness-and-teleology $<$ preconverging $\sim$ 'motif-and-apriorising/axiomatising/referencing'-entailing $>$ -

existentialising —enframing/imprintedness-〈as-to- historicity-tracing_-in-presencing-

hyperrealisation/hyperreal-transposition〉 frameworks and temporal mandarinism and pedantising/muddling/formulaic-hollowing-out — in-subontologisation/subpotentiation-

\section{〈blurring/undermining-of-prospective-totalising-entailing,-as-to-entailing-}

$<$ amplituding/formative-epistemicity $>$ totalising in-relative-ontological-completeness $>$

frameworks as reflected from 'positivism/rational-empiricism attitude/mental-disposition/careand-episteme'. However, approbating we may be predisposed to such palliative virtue constructs as of lack of dispensing-with-immediacy-for-relative-ontological-completeness ${ }^{87}$-byreification/contemplative-distension ${ }^{27}$, the fact is these are not really the underlying drivers for virtue transcendence-and-sublimity/sublimation/supererogatory de-mentativity and are peripheral to more ontologically profound theorised-or-untheorised emancipating events driving virtue transcendence-and-sublimity/sublimation/superery-de-mentativity as of prospective relative-ontological-completeness ${ }^{87}$-of- ${ }^{8}$ reference-of-thought, notwithstanding our state of beyond-the-consciousness-awareness-teleology $-<$ of-preconverging-existentialextrication-as-of-existential-unthought $>$. The fact is from an ontological standpoint, we inherently are no more virtuously exceptional even with regards to the earliest of humans, and so as of the-very-same species potency, and thus we can't ascribed inherent virtuous superiority by the mere token of our own practice. Rather the exceptionality behind human virtuous potential lies ontologically with 'intemporal ontological-faith-notion-or-ontological-fideism-imbuedunderdetermination-of-motif-and-apriorising/axiomatising/referencing-as-so-being-as-of-

existential-reality instigated relative-unreflexivity/relative-reflexivity_ontologicalcontiguity $^{67} \sim$ of-the-human-institutionalisation-process ${ }^{68}$ as of difference-conflatedness ${ }^{13}$-as-tototalitative-reification-in-singularisation-<as-to-the-nondisjointedness/entailment-of- 
$<$ amplituding/formative-epistemicity $>$ causality $~ a s-t o-p r o j e c t i v e-t o t a l i t a t i v e-i m p l i c a t i o n s-o f-$ prospective- nonpresencing,-for-explicating relative-unreflexivity/relative-reflexivity ontological-contiguity , as of Being-development/ontological-framework-expansion-as-todepth-of-ontologising-development-as-infrastructure-of- meaningfulness-and-teleology , reflecting the fact that pure-ontology that as of its secondnaturing induces the requisite level of human virtue performance at each given registry-worldview/dimension, retrospectively to prospectively. It is rather by acting upon the inherent relative-unreflexivity/relative-reflexivity ontological-contiguity ${ }^{67}$ of-the-human-institutionalisation-process ${ }^{68}$ as of its ontological reflection in Being-development/ontological-framework-expansion-as-to-depth-ofontologising-development-as-infrastructure-of- meaningfulness-and-teleology that virtue transcendence-and-sublimity/sublimation/supereregatory-de-mentativity comes about, whether or not beyond-the-consciousness-awareness-teleology $-<$ of-preconverging-existentialextrication-as-of-existential-unthought $>$. In this regard, any registry-worldview/dimension reference-of-thought is a <amplituding/formative > wooden-language-_imbued-averagingof-thought-<as-to-leveling/ressentiment/closed-construct-of- meaningfulness-and-teleology as-of-'nondescript/ignorable-void '-with-regards-to-prospective-apriorising-implications $>$ > as of the <amplituding/formative-epistemicity $>$ totalising $\sim$ self-referencingsyncretising/circularity/interiorising/akrasiatic-drag ${ }^{34}$, such that prospective relativeontological-completeness ${ }^{87}$-of- ${ }^{83}$ reference-of-thought as required for virtue transcendence-andsublimity/sublimation/supererogatory $\sim$ de-mentativity necessarily implies disrupting and superseding any such <amplituding/formative> wooden-language-〈imbued-averaging-ofthought-<as-to-leveling/ressentiment/closed-construct-of- meaningfulness-and-teleology -asof-'nondescript/ignorable-void ' -with-regards-to-prospective-apriorising-implications $>$ > vices-and-impediments $^{105}$, as of the prospective/new superseding ${ }^{83}$ reference-of-thought- 
categorical-imperatives/axioms/registry-teleology ${ }^{9}$, ,for-

aposteriorising/logicising/deriving/intelligising/measuring- ${ }^{5}$ meaningfulness-and-teleology . Inevitably any such virtue construct is transcendental as meaning 'going beyond oneself'; and so with regards to any prospective institutionalisation relative to the uninstitutionalisedthreshold ${ }^{102}$. Thus the 'field of conception'/notional conception/notion of virtue-as-ontology covers way more than its articulation within a same registry-worldview's/dimension's $<$ amplituding/formative-epistemicity $>$ totalising $\sim$ self-referencingsyncretising/circularity/interiorising/akrasiatic-drag ${ }^{34}$, as its implications as of Beingdevelopment/ontological-framework-expansion-as-to-depth-of-ontologising-development-asinfrastructure-of- meaningfulness-and-teleology need to be drawn beyond a cloisteredconsciousness as of retrospective and prospective transcendental illuminating implications. In this regard, a postmodern/suprastructuralism philosophical stance with regards to virtue-asontology very much aware of the transcendental ontological sublimating-over-desublimating

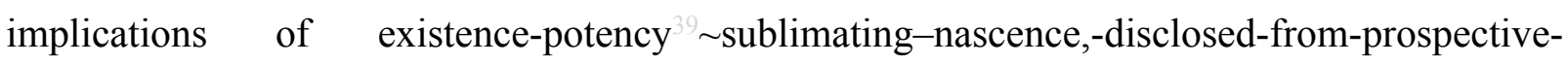
epistemic-digression: will question such reasoning-from-results/afterthought basis of palliative virtue constructs especially as of their <amplituding/formative-epistemicity $>$ totalising $\sim$ selfreferencing-syncretising/circularity/interiorising/akrasiatic-drag ${ }^{34}$ and lack of dispensing-withimmediacy-for-relative-ontological-completeness ${ }^{87}$-by-reification/contemplative-distension ${ }^{27}$ of- reference-of-thought-by-reification/contemplative-distension implications; ask whether by definition a registry-worldview/dimension ${ }^{83}$ reference-of-thought is postconvergingly-dementated/structured/paradigmed to sponsor/promote/endorse its very own prospective transcendence-and-sublimity/sublimation/supereregatory-de-mentativity as of the need for the subversion of its ${ }^{83}$ reference-of-thought- categorical-imperatives/axioms/registry-teleology ${ }^{9}$,for-aposteriorising/logicising/deriving/intelligising/measuring - ${ }^{56}$ meaningfulness-andteleology that endemise-and-enculturate its vices-and-impediments ${ }^{105}$ by prospective 
reference-of-thought- categorical-imperatives/axioms/registry-teleology ${ }^{9}$,-foraposteriorising/logicising/deriving/intelligising/measuring $-{ }^{56}$ meaningfulness-and-teleology for prospective transcendence-and-sublimity/sublimation/supereregatery $\sim$ de-mentativity, more like could the Copernicuses, Galileos, Descartes, Diderots, etc. call upon the-very-same nonpositivism/medievalism in need for prospective positivism transcendence-andsublimity/sublimation/supererogatory-de-mentativity to underwrite the subversion of its entrenched non-positivism/medievalism internal social-stake-contention-or-confliction changing temporal constraints, temporal meaningfulness-and-teleology

\section{$<$ preconverging 'motif-and-apriorising/axiomatising/referencing'-entailing $>$ -}

existentialising — enframing/imprintedness-〈as-to- historicity-tracing —in-presencing-

hyperrealisation/hyperreal-transposition〉 frameworks and temporal mandarinism and pedantising/muddling/formulaic-hollowing-out — in-subontologisation/subpotentiation-

\section{〈blurring/undermining-of-prospective-totalising-entailing,-as-to-entailing-}

\section{$<$ amplituding/formative-epistemicity $>$ totalising in-relative-ontological-completeness $>$}

frameworks; and, hence the ontologically-veridical paradox of the very postconverging-dementating/structuring/paradigming implications of human limited-mentation-capacitydeepening —as-subjecting limitedness/human-subpotency to-'educed-unlimitedness/existencesublimating nascence ${ }^{53}$ renders any registry-worldview/dimension ${ }^{8}$ reference-of-thought ever deficient as of its need for psychoanalytic-unshackling/prospective-grounding/prospectivereification of ${ }^{56}$ meaningfulness-and-teleology . Ultimately, anti-constructivism and antirelativism criticisms of postmodern-thought come down to our 'modern positivism/rationalempiricism ontologically-flawed as of prior relative-ontological-incompleteness perspective/framing/reference/horizon/projection’ apriorising/axiomatising/referencing-\{of'prospectively_implicited_attendant-ontological-contiguity ' educed- 
$<$ imbued-notional cogency $\left.>{ }^{\prime} \quad\right\}$ - constitutedness ${ }^{1}$-in-preconverging-entailment construal of categorising/taxonomising schemes that pervades the 'modern categorising mental-disposition' as of our occlusive-consciousness ${ }^{58}$ neuterising, as we fail to grasp the implication of an implied apriorising/axiomatising/referencing/intelligibilitysettingup/measuringinstrumenting that is naively superseding

the

true apriorising/axiomatising/referencing/intelligibilitysettingup/measuringinstrumenting nature of existential-<disontologising/re-ontologising aporeticism $>$ reality as the absolute a-priori'; such that the ${ }^{5}$ meaningfulness-and-teleology ${ }^{9}$ that arises is a relatively virtual-or-ontologicallyflawed-construal. On the contrary it is apriorising/axiomatising/referencing-\{of-" prospectively implicited_attendant-ontological-contiguity ' educedexistentialising/contextualising/textualising_'intelligibility/epistemicity/reflexivity-contiguity<imbued-notional $\left.\sim \operatorname{cogency}>^{\prime} \quad\right\}$-conflatedness ${ }^{13}$-in-\{preconverging-disentailment by\} postconverging-entailment that ensures that apriorising/axiomatising/referencing/intelligibilitysettingup/measuringinstrumenting syncs with the true apriorising/axiomatising/referencing/intelligibilitysettingup/measuringinstrumenting nature of existential<-disontologising/re-ontologising aporeticism $>$ reality as the absolute a priori, and so as of an ontological-normalcy/postconvergence posture which rather 'turns the idea of analysing and conceptualising on its head' into one of 'grasping human limitedmentation-capacity-deepening_as-subjecting limitedness/human-subpotency-to-'educedunlimitedness/existence-sublimating nascence' ${ }^{33}$ implications as of the underlying psychoanalytic-unshackling' for human-subpotency construal of the full-potency that is existence. This insight about the complete relationship between developing human-subpotency and its potential to fully grasp the full-potency of existence, fundamentally underlies the protensive-consciousness referentialism of the notional conflatedness ${ }^{13}$ of notional ${ }^{1}$ deprocrypticism. However, it is equally critical to grasp the double-gesture reification 
implied in such a postmodern-as-suprastructural conception of human-subject-emancipatingrelativism-driven-recomposuring-constructivism-towards-singularisation- $<$ as-to-thenondisjointedness/entailment-of-prospective- nonpresencing $>$ Such postmodern/suprastructuralism double-gesture reification holds that knowledge involving virtue-as-ontology is truly organic-knowledge as of its appropriate attitude/mentaldisposition/care-and-episteme with respect to human social-stake-contention-or-confliction; with the adherence to the ${ }^{83}$ reference-of-thought- categorical-imperatives/axioms/registryteleology ${ }^{9}$,-for-aposteriorising/logicising/deriving/intelligising/measuring- ${ }^{5}$ meaningfulnessand-teleology ${ }^{9}$ of such organic-knowledge construed in intemporality ${ }^{52}$ as supplantingconviction-as-to-profound-supererogation _of-'attendant-intradimensional'postconverging/dialectical-thinking -apriorising-psychologism, whereas mechanicalknowledge is rather predispose to adhere as of temporal threshold-ofnonconviction/madeupness/bottomlining-in-shallow-supererogation $<-<$ as-to-' $a$ attendant-

\section{intradimensional'-prospectively-disontologising preconverging/dementing -apriorising-}

psychologism $>$ to such mere ${ }^{83}$ reference-of-thought- categorical-imperatives/axioms/registryteleology ${ }^{9}$,-for-aposteriorising/logicising/deriving/intelligising/measuring- ${ }^{5}$ meaningfulnessand-teleology ${ }^{9}$. The latter point to an inappropriate attitude/mental-disposition/care-andepisteme which is not of prospective apriorising/axiomatising/referencing-sublimatingreflexivity - beholdening to prospective institutionalisation and it is rather of preconverging existential-extrication-as-of-existential-unthought relation to it. More concretely, consider the practice of serfdom in Europe, or the annihilation of many Native American tribes and slavery and slave trade in the new world, while at the same time in a registry-worldview/dimension transitioning from the non-positivism/medievalism to the positivism/rational-empiricism registry-worldview with this contrastive mechanical-knowledge attitude/mentaldisposition/care-and-episteme and organic-knowledge attitude/mental-disposition/care-and- 
episteme . While the full implications of a positivism/rational-empiricism organic-knowledge attitude/mental-disposition/care-and-episteme will imply an end to such practices as of universal human rights, 'economic-opportunistic-and-then-enculturated tenants' of such blatant moral supremacy and thus racial supremacy distorted the implications of the technical and social organisation advancement brought about from budding-positivism/rationalempiricism to reconceptualise by their specific interests ${ }^{56}$ meaningfulness-and-teleology ${ }^{9}$ in terms-as-of-axiomatic-construct of the prior non-positivism/medievalism attitude/mentaldisposition/care-and-episteme as of its prior relative-ontological-incompleteness -ofreference-of-thought, and thus justify their nefarious practices; speaking of mechanicalknowledge in positivism/rational-empiricism. Whereas progressive organic-knowledge tenants construed positivism/rational-empiricism as an openness to the potential of all societies and peoples to rather arrive at the higher possibility of positivism/rational-empiricism virtue, and so as of a human-subject-emancipating-relativism-driven-recomposuring-constructivismtowards-singularisation- $<$ as-to-the-nondisjointedness/entailment-of-prospective-

nonpresencing $>$ posture that allows for ${ }^{103}$ universal human emancipation as expressed by the Quakers movement, Rousseaux, Diderots, etc. Incidentally, the positivism/rational-empiricism mechanical-knowledge contenders as of the economic-opportunism-and-then-enculturation of their nefarious practices, were very much countervailing the practice and trend within their own societies of origin undergoing-positivism/rational-empiricism-transformation and the underlying dual-language/split-mentality unscrupulousness was given away as of the 'out-of-sight demeanour' in their main societies, rather than being fully assumed as marking positivism/rational-empiricism progress. The occasional development of enlightenment and positivism/rational-empiricism by its technical and social organisation transformation implications wasn't the opportunity for such societies to turn around and then dehumanise other societies and humanities that haven't done likewise, but rather as of organic-knowledge called 
for a double-gesture reification in recognising that such positivism/rational-empiricism implications are about all of humanity, just as implied in preceding human cultural emancipations. Suprastructuralism or postmodernism double-gesturing of virtue doesn't function on the naïve basis of 'merely construing relative implied levels of virtue development and making relative conclusions' but rather orientate ${ }^{56}$ meaningfulness-and-teleology ${ }^{99}$ to the more profound perspective of all of humanity's potential as of prospective relative-ontologicalcompleteness ${ }^{87}$-of- ${ }^{83}$ reference-of-thought as to ontological-normalcy/postconvergence and then reconstrue the possibility of all of humanity-as-of-societies to ultimately fulfil it virtuous potential; and this is the optimum and emancipating virtue disposition for all humankind and human societies. It adopts this orientation because it always put-into-question the idea of 'grounding ${ }^{56}$ meaningfulness-and-teleology ${ }^{9}$ as of any specific human society relativeontological-incompleteness ${ }^{8}$-of- ${ }^{8}$ reference-of-thought as fundamentally denaturing ${ }^{16}$ and likely to induce transversality- $<$ for-sublimating-existential-eventuating/denouement-from-

\section{thinking at-first/pure-predisposition-preemptive-of-prospective-}

\section{disontologising/subontologising' as-of-prospectively-disambiguated-affirmed-and-}

unaffirmed-'motif-and-apriorising/axiomatising/referencing'>101 dehumanising of some cultures and societies by others'; as it recognises, however tepid, that all societies and humans are curious, predisposed to their emancipation and achieving optimum existential< disontologising/re-ontologising aporeticism $>$ possibilities, and can uphold ${ }^{103}$ universal values, and so as of ${ }^{103}$ universal-transparency ${ }^{104}$-〈transparency-of-totalising-entailing,-as-toentailing-<amplituding/formative-epistemicity $>$ totalising $\sim$ in-relative-ontological-

completeness $\rangle$. Ultimately, such a double-gesturing hold out the possibility in reflecting holographically-<conjugatively-and-transfusively $>$ the relative-unreflexivity/relativereflexivity - ontological-contiguity of-the-human-institutionalisation-process as of Beingdevelopment/ontological-framework-expansion-as-to-depth-of-ontologising-development-as- 
infrastructure-of- meaningfulness-and-teleology as pertinent for all humankind, whether as of internal social-progress, cultural diffusion or cultural-reappropriations. This practically translates, say considering an instance of a given traditional practice that is abhorrent to modern positivism/rational-empricism attitude/mental-disposition/care-and-episteme , by implying from a postmodern perspective that emancipation truly arises when the humans come to assume as well by themselves a ${ }^{103}$ universal positivism/rational-empiricism attitude/mentaldisposition/care-and-episteme in transforming their society. We can appreciate that supposed a space civilisation come to earth, implying for instance in a position of strength that we are too violent, disorganise, etc. and thus morally inferior, and that our best interests was just to take our cue from them. Here as well, the postmodern double-gesture reification of virtue will project that we do have the potential for further development, and that to be ourselves we cannot be utterly alienated from ourselves like robots in our relationship with them, and that our curiosity and openness will correspondingly bring about our functional moral equivalence with ${ }^{103}$ universaltransparency ${ }^{104}$-〈transparency-of-totalising-entailing,-as-to-entailing-<amplituding/formativeepistemicity $>$ totalising in-relative-ontological-completeness $\rangle$. Further arguing that if they are truly more advanced than us, then that advancement is necessarily about a greater aetiologisation/ontological-escalation- $<$ ontologicalveridicality_commitment/otherliness_transcending/compulsions-encumbered_transcending $>$ as of the ${ }^{4}$ human-subject-emancipating-relativism-driven-recomposuring-constructivismtowards-singularisation-<as-to-the-nondisjointedness/entailment-of-prospective-

nonpresencing $>$ that will necessarily subscribe to recognising the 'other' that we are to them; as insightfully, grander aetiologisation/ontological-escalation- $<$ ontologicalveridicality_commitment/otherliness_transcending/compulsions-encumbered_transcending> come with relative-ontologically-veridical attitude/mental-disposition/care-and-episteme . Claims of such grander aetiologisation/ontological-escalation- $<$ ontological- 
veridicality_commitment/otherliness_transcending/compulsions-encumbered_transcending $>$ as implying dehumanising interpretations are ontologically-flawed as such claims are rather surreptitiously based on prior registry-worldview/dimension uninstitutionalised-threshold reference-of-thought- categorical-imperatives/axioms/registry-teleology ${ }^{9}$,-foraposteriorising/logicising/deriving/intelligising/measuring $-{ }^{5}$ meaningfulness-and-teleology ${ }^{99}$ as teleological-degradations-in-notional-discontiguity/epistemic-discontiguity ${ }^{63}<$ between - priorshallow-supererogation -of-mentally-aestheticised preconverging/dementing -qualiaschema_and_prospective-profound-supererogation -of-mentallyaestheticised postconverging/dialectical-thinking -qualia-schema>. In other words, the organic-knowledge in its true appreciation of the 'other' as of aetiologisation or ontological escalation implies a ${ }^{103}$ universal projection implications attitude/mental-disposition/care-andepisteme event $^{38}$-or-operant to all and sundry'. Finally, the naivety when facing such anticonstructivism and anti-relativism arguments is to think that these are always about fair and objective intellectual disagreements; but then the history of many such criticisms has revealed its underlying perfidy; as to when for instance, supposed critiques of postmodern ' nonpresencing-<perspective-ontological-normalcy/postconvergence $>$ relativism/relativescope for epistemic-growth,-as - weridical/sound-relative-reflexivity-inexistence/relativising from-limited-mentation-as-its-deepening/psychologismic epistemic acutisation residualising, \{decompulsing delinearity for-cogency' make mention of the antirelativism stances of many a creed like Christianity (which are necessarily absolutist as to their doctrinal practices) thus decontextualising and equating the framework of secular intellectual discourse with that of a creed, something which even such creeds do not do given the mortal framework of human <amplituding/formative-epistemicity>-totalising $\sim$ thrownness-inexistence $^{35}$ (as to when even the Christian Jesus refers to giving to Caesar what belongs to Caesar and to the Christian God what belongs to God as of a necessary relativistic stance with respect 
to human mortality which requires constructiveness and this stance is further reflected with interfaith dialogue which will be absolutely impossible if creeds were to engage each other on the absolute basis of their doctrinal practices), and furthermore much of the criticisms levied against postmodern ' nonpresencing-<perspective-ontological-normalcy/postconvergence> relativism/relative-scope for epistemic-growth,-as - \{veridical/sound\}-relative-reflexivity-inexistence/relativising from-limited-mentation-as-its-deepening/psychologismic epistemicacutisation - residualising, \{decompulsing\} delinearity for-cogency' is 'forged criticism' in the sense that the critiques make their own flimsy interpretations of postmodern-thought and then go on to criticise the flawed interpretation for instance the idea that pastiche art or the fact that Las Vegas Strip as-copying-other-notable-places-architectures are necessarily inauthentic and flawed is not necessarily a postmodern criticism as ontological-good-faith/authenticity and veracity is more fundamentally about the re-originary_-as-unenframed/re-ontologising/unboheholdening/outlierconceptualisation___imbued-postconverging/dialectical-thinking -'projectiveinsights'/'epistemic-projection-in-conflatedness ' -of-notional deprocrypticism-prospectivesublimation> creative insight and appreciation of any pastiche work or of such a Las Vegas Strip replication of other notable places. With regards to all these 'forged criticisms' the underlying falsehood is rather geared to elicit a non-intellectual emotional response than true knowledge-reification $\sim$ gesturing-and-accounting — of-epistemic-phenomenalism- $<$ inprospective_psychologismic apriorising/axiomatising/referencing-\{of-'prospectively implicited_attendant-ontological-contiguity ' educedexistentialising/contextualising/textualising_'intelligibility/epistemicity/reflexivity-contiguity<imbued-notional cogency>' \}-conflatedness -in-\{preconverging-disentailment by\} postconverging-entailment> insight. Further, as of organic-knowledge and knowledgenotionalisation, this author holds that it is naïve to conceptualise of human knowledge mainly as of pure erudition warranting mainly sound arguments, proofs and convincing demonstrations, 
and that the reality all along 'intemporal ontological-faith-notion-or-ontological-fideismimbued-underdetermination-of-motif-and-apriorising/axiomatising/referencing-as-so-being-asof-existential-reality instigated relative-unreflexivity/relative-reflexivity-ontologicalcontiguity ${ }^{67}$ of-the-human-institutionalisation-process ${ }^{68}$ as of difference-conflatedness ${ }^{13}$-as-tototalitative-reification-in-singularisation-<as-to-the-nondisjointedness/entailment-ofprospective- nonpresencing $>$-as-veridical-epistemicity-relativism-determinism implied $<$ amplituding/formative-epistemicity $>$ causality $\sim$ as-to-projective-totalitative-implications-ofprospective- nonpresencing,-for-explicating relative-unreflexivity/relative-reflexivity ontological-contiguity, shows that there has always been beyond-the-consciousnessawareness-teleology $\quad<$ of-preconverging-existential-extrication-as-of-existential-unthought $>$ 'institutional investment' that is not always just of eruditic ideal, inclined to undermined prospective knowledge as of its prospective relative-ontological-completeness ${ }^{87}$-of-axiomaticconstructs-and- ${ }^{8}$ reference-of-thought, and that true knowledge especially as it portends to transcendence-and-sublimity/sublimation/supererogatory-de-mentativity cannot be conceptualised losing sight of this fact. The blunt fact is that postmodern-thought has shown itself to be more useful and applicable across the humanities with a massive potential for furthering human emancipation, however the tentativeness of many of its bold ideas, and so much more than the vagaries peddled by many such critiques surreptitious anti-intellectual media-driven waylaying who on the contrary seem to construe of institutional anchoring as the very essence of validation. Such situations are often highly liable to ontological-badfaith/inauthenticity ${ }^{64}$ undermining of Being-development/ontological-framework-expansion-asto-depth-of-ontologising-development-as-infrastructure-of- meaningfulness-and-teleology due to 'lack of social ${ }^{103}$ universal-transparency ${ }^{104}$-〈transparency-of-totalising-entailing,-as-toentailing-<amplituding/formative-epistemicity $>$ totalising $\sim$ in-relative-ontological-

completeness \'. In other words, medieval charlatanic eliciting of old ways, conventioning and 
existence as of non-positivism/medievalism despite its prior relative-ontologicalincompleteness ${ }^{8}$-of- ${ }^{8}$ reference-of-thought as underscoring medieval vices-and-impediments with respect to prospective positivism was psychically and surreptitiously undermining of a sense of Being-development/ontological-framework-expansion-as-to-depth-of-ontologisingdevelopment-as-infrastructure-of- meaningfulness-and-teleology ; and this insight is valid across all registry-worldviews/dimensions as of the eliciting of temporal individuations selfreferencing cloistered-consciousness in nihilistically undermining prospective ontologicalcompleteness-of- ${ }^{-}$reference-of-thought. It is only an organic-knowledge sense of consummation-as-not-beholden to temporal/shortness-of-register-of- meaningfulness-andteleology stakes that human intemporal individuations as of a protracted-consciousness can contemplate of Being-development/ontological-framework-expansion-as-to-depth-ofontologising-development-as-infrastructure-of- meaningfulness-and-teleology as of its crossgenerational transcendental implications and as reflected from the insight in reflecting holographically-<conjugatively-and-transfusively $>$ the relative-unreflexivity/relativereflexivity - ontological-contiguity of-the-human-institutionalisation-process . Again, it can be noted here that Einstein, Bohr and the other seminal physics contributors to the theory-ofrelativity-together-with-quantum-mechanics - axiomatic-constructs had no prior basis to adopt their subsequently transcendental and sublimation orientation but for their ontological-faithnotion-or-ontological-fideism—imbued-underdetermination-of-motif-andapriorising/axiomatising/referencing-as-so-being-as-of-existential-reality as of their 'reprojection/re-anticipation' about 'the-very-same physics <amplituding/formativeepistemicity>totalising $\sim$ devolved—purview/domain-of-construal-as-intrinsicreality/ontological-veridicality/existential-reality' which was then validated as of $<$ amplituding/formative-epistemicity $>$ causality $\sim$ as-to-projective-totalitative-implications-ofprospective- nonpresencing,-for-explicating relative-unreflexivity/relative-reflexivity 
ontological-contiguity , and so divulged by existence-potency ${ }^{39} \sim$ sublimating-nascence,disclosed-from-prospective-epistemic-digression; as prior human ${ }^{79}$ presencing-absolutisingidentitive-constitutedness ${ }^{14}$ experience wouldn't have thought about space-time, considered the ether as unreal, considered that the laws of physics are different at atomic scale, etc. In other words, there wasn't any prior 'logocentric transcendental-signifier' as of the prior classicalmechanics-axiomatic-constructs construed as ${ }^{79}$ presencing-absolutising-identitiveconstitutedness ${ }^{14}$ enabling the obtention of any such conclusions from the given classicalmechanics - axiomatic-constructs apriorising/axiomatising/referencing-\{of-"prospectively implicited_attendant-ontological-contiguity ' educedexistentialising/contextualising/textualising_'intelligibility/epistemicity/reflexivity-contiguity<imbued-notional cogency $\left.>^{\prime} \quad\right\}$-constitutedness ${ }^{14}$-in - preconverging-entailment, but rather it is by apriorising/axiomatising/referencing-\{of-'prospectively implicited_attendantontological-contiguity ' educedexistentialising/contextualising/textualising_intelligibility/epistemicity/reflexivity-contiguity<imbued-notional cogency $\left.>^{\prime} \quad\right\}$-conflatedness ${ }^{13}$ in-\{preconverging-disentailment by postconverging-entailment with regards to 'the-very-same physics <amplituding/formativeepistemicity $>$ totalising $\sim$ devolved-purview/domain-of-construal-as-intrinsic-

reality/ontological-veridicality/existential-reality' that the prospective theory-of-relativitytogether-with-quantum-mechanics — axiomatic-constructs was construed as of nonpresencing<perspective-ontological-normalcy/postconvergence>. Interestingly, as of the underlying phenomenology-driven ontology, it is rather more pertinent with respect to transcendence-andsublimity/sublimation/supererogatory de-mentativity to grasp that such ultimate decidability is construed as of human intemporalAlengness of register of meaning individuation mental-disposition in a 'tendential-deliberation-of-decidability as enabled by $<$ amplituding/formative-epistemicity $>$ causality $\sim$ as-to-projective-totalitative-implications-of- 
ontological-contiguity tendential validation as to existence-potency ${ }^{39} \sim$ sublimating-nascence,disclosed-from-prospective-epistemic-digression. Such a construal of human transcendenceand-sublimity/sublimation/supererogatory-de-mentativity will cover the seminal contributions prior and after the defining-threshold epistemic-break/epistemic-resetting of the theory-ofrelativity-together-with-quantum-mechanics — axiomatic-constructs by Einstein and Bohr. Such an ontological-basis for construing sublimation overrides our ${ }^{58}$ neuterising laden modern convention ways of judging breakthroughs overemphasising singular initiative, as it is rather grounded more soundly on an abstract notion of 'intemporal-as-ontological individuation' as the basis of human limited-mentation-capacity-deepening-as-subjecting limitedness/humansubpotency-to-'educed-unlimitedness/existence-sublimating nascence' ${ }^{3}$ analysis; and insightfully, as reflected in the underlying apriorising/axiomatising/referencing-\{of'prospectively_implicited_attendant-ontological-contiguity ' educedexistentialising/contextualising/textualising_ 'intelligibility/epistemicity/reflexivity-contiguity$<$ imbued-notional cogency $\left.>{ }^{\prime}\right\}$-conflatedness ${ }^{13}$-in-\{preconverging-disentailment-by\} postconverging-entailment of accreting-substitutive-subsumption-as-futural-différancefreeplay ${ }^{2}$, sublimation is achieved rather out of the notional obviating of human temporal-asnon-ontological ${ }^{58}$ neuterising with deneuterising - referentialism and with correspondent intemporal-as-ontological rearticulation/reconstrual of ${ }^{56}$ meaningfulness-and-teleology ${ }^{99}$ as of dynamics of insight of shallow-to-deeper human limited-mentation-capacity-as-subjecting 'educed-unlimitedness/existence-sublimating nascence' to-limitedness/human-subpotency implications, and so as of protensive-consciousness of notional deprocrypticism perspective/framing/reference/horizon/projection. Similarly, this author's articulation of futuraldifférance as of transcendence-and-sublimity/sublimation/supererogatory de-mentativity is necessarily construed ontologically as of a rearticulated protractedness as futural différance that 
coincides-and-is-contiguous with a prior Derridean différance as of quasi-transcendence and evasiveness of sublimation. In both cases, this highlights that 'decidability is not instantaneous as of inherent spontaneous identification and occurrence of decisional act' but that decidability in enabling transcendence-and-sublimity/sublimation/supereregatory $\sim$ de-mentativity is as of an 'overall différance tendential-deliberation-of-decidability' as of human limited-mentationcapacity-deepening —as-subjecting-limitedness/human-subpotency-to-'educed-

unlimitedness/existence-sublimating nascence' ${ }^{53}$ process. Thus sublimation is equally reflected in the deliberateness involved in cultivating artistic, educational, technical or research capabilities/skill in the final outcomes derived forthwith, as of the quality imbued on human limited-mentation-capacity—as-subjecting 'educed-unlimitedness/existence-sublimating nascence' to-limitedness/human-subpotency to deepen itself; and this translates into human contemplation of the existential-possibilities attainable by its human-subpotency. Tendentialdeliberation-of-decidability is thus the central ontological insight attached to différance as a 'contiguously theoretical and operant phenomenological construct involving necessarily the deliberateness as of Derridean freeplay différance, as a putting-into-question exercise, and subject to <amplituding/formative-epistemicity $>$ causality $\sim$ as-to-projective-totalitative-

\section{implications-of-prospective- nonpresencing,-for-explicating relative unreflexivity/relative}

reflexivity - ontological-contiguity validation before attaining defining-transcendence and defining-sublimity'; and différance as of such 'existential-reality concreteness dynamics' is scientific and utterly dissimilar from a speculative idealisation exercise à la Hegelian dialectics and well beyond the latter's conceptual-patterning. Ultimately, such tendential-deliberation-ofdecidability for attaining defining-transcendence and defining-sublimity, arises from more than just a blatant/flatminded notion of human limited-mentation-capacity-deepening assubjecting limitedness/human-subpotency-to-'educed-unlimitedness/existence-sublimating nascence' ${ }^{53}$ or say the vague social convention idea of talent, it is more critically beyond and 
about a question of human mental-disposition with respect to the prescience of existencepotency $^{39} \sim$ sublimating-nascence,-disclosed-from-prospective-epistemic-digression so-implied as of ontology's-directedness-as-Being. This is the very meaning of organic-knowledge beyond the conception of mechanical-knowledge as-knowledge-as-a-mere-thing-to-be-acted-upon-forgiven-outcomes. Organic-knowledge as such implies priorly a supplanting-conviction-as-toprofound-supererogation of-'attendant-intradimensional'-postconverging/dialecticalthinking -apriorising-psychologism deference to the prescience of existencepotency ${ }^{32} \sim$ sublimating-nascence,-disclosed-from-prospective-epistemic-digression over any human-as-mortal framing of ${ }^{5}$ meaningfulness-and-teleology ${ }^{9}$ including oneself-as-human-asmortal, as it is human mortality-as-temporality ${ }^{8}$ that is rather what is in need for further Being and consciousness development. Thus the postconverging-dementating/structuring/paradigming of sublimation for a registry-worldview/dimension reference-of-thought, as reflected in the Derridean social ethics stance, is rather one for the 'subsumptive inventing' of the prospective ontological possibilities of prospective relativeontological-completeness ${ }^{87}$-of- ${ }^{83}$ reference-of-thought over human normativity/conventioning as of the latter's prior relative-ontological-incompleteness ${ }^{8}$-of- ${ }^{8}$ reference-of-thought, and so by maximaliing-recomposuring $<$ amplituding $/$ formative-epistemicity $>$-totalising $\sim$ renewingrealisation/re-perception/re-thought as of organic-knowledge. A nonextricatory existential<disontologising/re-ontologising aporeticism> postconverging-dementating/structuring/paradigming of sublimation implying that the state of recurrent-utteruninstitutionalisation, base-institutionalisation-ununiversalisation, ${ }^{103}$ universalisation-nonpositivism/medievalism, and positivism- ${ }^{8}$ procrypticism, are successively-wanting of prospective defining-transcendence and defining-sublimity going by their successively-given mechanical-knowledge in temporality ${ }^{8}$-as-of-neuterisation $\%$ relative-ontologicalincompleteness $8 /$ preconverging-existential-extrication-as-of-existential-unthought. In other 
words, an intemporal-as-ontological mental-disposition projecting of the organic-knowledge as of prospective registry-worldview/dimension ${ }^{83}$ reference-of-thought in prospective relativeontological-completeness ${ }^{87}$-of-axiomatic-construct-or- ${ }^{83}$ reference-of-thought can't sidestep such implied prospective defining-transcendence and defining-sublimity, and undertake existence as of the prior registry-worldview/dimension ${ }^{83}$ reference-of-thought in prior relativeontological-incompleteness ${ }^{8}$, even if it such a mental-disposition could lead to such an outcome as in H.G. Well's country of the blind or Galileo say with the medieval Establishment; despite the fact that the possibilities of such outcomes arise out of establishment Charlatanism, which knows better, but exploits lack of 'social ${ }^{103}$ universal-transparency ${ }^{104}$-〈transparency-oftotalising-entailing,-as-to-entailing-<amplituding/formative-epistemicity $>$ totalising $\sim$ inrelative-ontological-completeness \'. But then it is actually a sign of 'propounded theoretical health and pertinence' when all such Establishment charlatanism comes to dodge such substantive-and-frontal articulation of prospective knowledge, and in lieu come up with worn out refrains and sidestepping manoeuvres avowing their true 'intellectual blankness' grounded on institutional-being-and-craft; as we know that in all genuinely inclined intellectual pursuits the very central tenet has always been about theoretical disputative engagement and not acts of escapism and downgrading of intellectual arguments as of 'solo media exploits of intellectual popularity'. Thus by its prospective relative-ontological-completeness ${ }^{87}$-of-axiomatic-constructor- ${ }^{8}$ reference-of-thought as futural différance, accreting-substitutive-subsumption-as-futuraldifférance-freeplay ${ }^{2}$ comes into terms with both ${ }^{79}$ presencing-absolutising-identitiveconstitutedness $^{14}$ and ${ }^{6}$ nonpresencing-<perspective-ontological-normalcy/postconvergence $>$ on the basis of the prospective relative-ontological-completeness 87 notionalcontiguity/epistemic-contiguity ${ }^{6}<$ profound-supererogation -of-mentallyaestheticised postconverging/dialectical-thinking - qualia-schema $>$ of the latter over the prior relative-ontological-incompleteness of notional-discontiguity/epistemic-discontiguity 
$<$ between-prior-shallow-supererogation -of-mentally-

aestheticised $\sim$ preconverging/dementing -qualia-schema_and_prospective-profound-

supererogation -of-mentally-aestheticised postconverging/dialectical-thinking -qualia-

schema $>$ of the former as of the-very-same-immanent-existence/intrinsic-reality/ontologicalveridicality,-as-to-'human<amplituding/formative-epistemicity>totalising $\sim$ purview-of-

construal'. Thus what is being correctly implied is not 'difference-in-kind/difference-inaposteriorising-or-logicising 23 but rather difference-in-nature/difference-in-apriorising-oraxiomatising-or-referencing ${ }^{24}$ between ${ }^{79}$ presencing-absolutising-identitive-constitutedness and nonpresencing-<perspective-ontological-normalcy/postconvergence $>$. Such an insight is enabled as of the fundamental awareness that human knowledge construction fundamentally involves two different exercises; with the first factoring in that at the fundamental level of knowledge construction humankind has a limited-mentation-capacity-as-subjecting 'educedunlimitedness/existence-sublimating nascence' to-limitedness/human-subpotency that needs to be developed as a 'developed consciousness perspective/framing/reference/horizon/projection as of prospective relative-ontological-completeness notional-contiguity/epistemic$\begin{array}{lll}\text { contiguity }^{6}, & \text { construed } & \text { as }\end{array}$ apriorising/axiomatising/referencing/intelligibilitysettingup/measuringinstrumenting to then be able at an operative level to articulate sound-or-authentic ${ }^{56}$ meaningfulness-and-teleology grounded on such a developed consciousness perspective/framing/reference/horizon/projection. This explains why it is impossible for a 'recurrent-utter-uninstitutionalised mindset perspective/framing/reference/horizon/projection as of trepidatious-consciousness apriorising/axiomatising/referencing/intelligibilitysettingup/measuringinstrumenting' to grasp base-institutionalisation ${ }^{56}$ meaningfulness-and-teleology ${ }^{9}$ without first developing a 'baseinstitutionalisation mindset perspective/framing/reference/horizon/projection as of warpedconsciousness 
apriorising/axiomatising/referencing/intelligibilitysettingup/measuringinstrumenting'; for a 'base-institutionalisation-ununiversalisation mindset perspective/framing/reference/horizon/projection' to grasp ${ }^{103}$ universalisation meaningfulness-and-teleology ${ }^{9}$ without first developing a ${ }^{103}$ universalisation mindset perspective/framing/reference/horizon/projection as of preclusive-consciousness apriorising/axiomatising/referencing/intelligibilitysettingup/measuringinstrumenting'; for a

' ${ }^{103}$ universalisation-non-positivism/medievalism mindset perspective/framing/reference/horizon/projection' to grasp positivistic ${ }^{5}$ meaningfulness-andteleology without first developing a 'positivistic mindset perspective/framing/reference/horizon/projection as of occlusive-consciousness apriorising/axiomatising/referencing/intelligibilitysettingup/measuringinstrumenting'; and prospectively for a $\quad$ a positivism- ${ }^{80}$ procrypticism mindset perspective/framing/reference/horizon/projection' to grasp notional ${ }^{18}$ deprocrypticism meaningfulness-and-meaningfulness without first developing a "notional ${ }^{18}$ deprocrypticism mindset perspective/framing/reference/horizon/projection as of protensive-consciousness apriorising/axiomatising/referencing/intelligibilitysettingup/measuringinstrumenting'. As we can get that the fundamental stake for the Copernicuses, Galileos, Descartes, etc. during the Enlightenment wasn't just about the specific positivistic knowledge they articulated or else they would have been satisfied with just their personal curiosity and enlightenment and leave it at that, but rather they surreptitiously undermined many of the prevailing social norms and rules in trying to expound their knowledge and vision, and more critically so because they knew it is the 'formation of a positivistic $\quad$ social consciousness apriorising/axiomatising/referencing/intelligibilitysettingup/measuringinstrumenting' that would enable the anchoring of all such prospective positivistic knowledge, and this sense of things fully underscored such a more comprehensively directed project-and-purpose undertaken 
later by the Encyclopédistes; with the underlying insight that while a social state of generalised prior relative-ontological-incompleteness ${ }^{8}$-of- ${ }^{83}$ reference-of-thought is enabling to surreptitious Establishment charlatanism, however with increasing 'social ${ }^{103}$ universal-transparency' 〈transparency-of-totalising-entailing,-as-to-entailing-<amplituding/formativeepistemicity>totalising in-relative-ontological-completeness 〉' such charlatanism is exposed for what it really is, explaining the panickiness and falsehood associated with such charlatanism as with the reactionaries to the Encyclopédistes project, as if the articulation of knowledge by itself was a threat rather than subject to disputation! Underlying as the non-speculative, nonimaginary, theoretical and conceptual possibility for such futural différance consciousness development is the notion of de-mentation-/supererogatory ontological-de-mentation-ordialectical-de-mentation - stranding-or-attributive-dialectics $\rangle$ which by pointing out an epistemic-break as of difference-in-nature/difference-in-apriorising-or-axiomatising-orreferencing 24 ontological-discontinuity, underscore at once 'both as affirmation/projection/assertion/notional self-distantiation/dueness-validatinglogicising/suitable-measuringinstrument-validating-measuring-<as-to-postconverging-ordialectical-thinking -apriorising-psychologism> of the consciousness in relativeunreflexivity/relative-reflexivity —ontological-contiguity ${ }^{67} /$ relative-ontologicalcompleteness ${ }^{87}$-of- ${ }^{83}$ reference-of-thought and as unaffirmation/deprojection/deassertion/epistemic-decadence/undueness-invalidatinglogicising/unsuitable-measuringinstrument-invalidating-measuring-<as-to-preconverging-ordementing -apriorising-psychologism> of the consciousness in notionaldiscontiguity/epistemic-discontiguity ${ }^{6}<$ between - prior-shallow-supererogation -ofmentally-aestheticised preconverging/dementing -qualia-schema_and_prospective-profoundsupererogation -of-mentally-aestheticised postconverging/dialectical-thinking -qualiaschema>/relative-ontological-incompleteness ${ }^{88}$-of- ${ }^{83}$ reference-of-thought', 
maximalising-recomposuring-for-relative-ontological-completeness ${ }^{87}$ unenframed/re-

ontologising conceptualisation and not incrementalism-in-relative-ontologicalincompleteness ${ }^{8}$ - enframed/disontologising conceptualisation, as of the-very-sameimmanent-existence/intrinsic-reality/ontological-veridicality,-as-to-

'human<amplituding/formative-epistemicity>totalising purview-of-construal'. As futural différance is enabled, unlike the case with the 'Derridean quasi-transcendental-freeplay différance', as of ontological-faith-notion-or-ontological-fideism - imbued-underdeterminationof-motif-and-apriorising/axiomatising/referencing-as-so-being-as-of-existential-reality involving human mental-disposition successive apriorising/axiomatising/referencing reprojection-or-reanticipation capacity inducing human limited-mentation-capacitydeepening —as-subjecting limitedness/human-subpotency-to-'educed-unlimitedness/existencesublimating nascence' 5 overriding the idea the perspective/framing/reference/horizon/projection of contemplation is absolutely given-anddetermined as of the implication that all ${ }^{56}$ meaningfulness-and-teleology ${ }^{99}$ should be as of 'difference-in-kind/difference-in-aposteriorising-or-logicising ${ }^{23}$, but rather reconceptualising the possibility of difference-in-nature/difference-in-apriorising-or-axiomatising-orreferencing ${ }^{24}$ as of prospective relative-ontological-completeness ${ }^{87}$-of- ${ }^{8}$ reference-of-thought bringing about transcendence-and-sublimity/sublimation/supereregatery $\sim$ de-mentativity as of nonpresencing-<perspective-ontological-normalcy/postconvergence $>$. Thus such a phenomenology associated with accreting-substitutive-subsumption-as-futural-différancefreeplay further divulges, unlike the 'Derridean quasi-transcendental-freeplay différance', the full possibility of human sublimation. Consider in this regard the decisive transitions-assublimitys that occurred in physics: with 'traditional classical mechanics axiomatic-construct' and the theory-of-relativity-together-with-quantum-mechanics - axiomatic-constructs; wherein the successive axiomatic-constructs in prior relative-ontological-incompleteness ${ }^{8}$ and 
prospective relative-ontological-completeness ${ }^{87}$, with regards to 'traditional classical mechanics axiomatic-construct' and the theory-of-relativity-together-with-quantum-mechanicsaxiomatic-constructs as of 'the-very-same physics <amplituding/formativeepistemicity>totalising $\sim$ devolved—-purview/domain-of-construal-as-intrinsicreality/ontological-veridicality/existential-reality' are not as of a 'difference-in-kind/differencein-aposteriorising-or-logicising but rather a difference-in-nature/difference-in-apriorising-oraxiomatising-or-referencing ${ }^{24}$; with human-subpotency aligning towards the full potency of existence which thus divulges the possibility of human sublimation as of the physics science implications today. It is interesting to note that the difference-in-nature/difference-inapriorising-or-axiomatising-or-referencing ${ }^{24}$ bringing about the successive physics axiomaticconstructs/theories are successive 'epistemic-breaks' from prior reasoning and are akin to 'leaps of faith' which then 'establish new reasoning' that then becomes the internal 'difference-inkind/difference-in-aposteriorising-or-logicising ${ }^{23}$ of the new physics as the new presencing; brought about from the transcendence-and-sublimity/sublimation/supererogatery $\sim$ dementativity of ${ }^{6}$ nonpresencing-<perspective-ontological-normalcy/postconvergence $>$. In other words, human consciousness tends to be constraint to its <amplituding/formativeepistemicity $>$ totalising $\sim$ self-referencing-syncretising/circularity/interiorising/akrasiatic-drag ${ }^{34}$, and thus assumes a 'difference-in-kind/difference-in-aposteriorising-or-logicising ${ }^{23}$ mentaldisposition as of ${ }^{79}$ presencing-absolutising-identitive-constitutedness ${ }^{14}$. But existence/ontology's-directedness-as-Being as of nonpresencing-<perspective-ontologicalnormalcy/postconvergence $>$ is beyond and not constraint by human consciousness as of its $<$ amplituding/formative-epistemicity $>$ totalising $\sim$ self-referencingsyncretising/circularity/interiorising/akrasiatic-drag ${ }^{34}$, and thus hints-at the ontological-faithnotion-or-ontological-fideism—imbued-underdetermination-of-motif-and-

apriorising/axiomatising/referencing-as-so-being-as-of-existential-reality possibilities of 
transcendence-and-sublimity/sublimation/supererogatoryade-mentativity

$<$ amplituding/formative-epistemicity $>$ causality $\sim$ as-to-projective-totalitative-implications-ofprospective- nonpresencing,-for-explicating relative-unreflexivity/relative-reflexivity

ontological-contiguity validation that is at the very center of the "promise of correspondence between human-subpotency as of Being-and-consciousness development and existence as of ontological-veridicality', and so despite the complexifying/inhibiting metaphysics-of-presence〈implicited-'nondescript/ignorable-void '-as-to- presencing - absolutising-identitiveconstitutedness $>$ of any given <amplituding/formative-epistemicity $>$ totalising $\sim$ selfreferencing-syncretising/circularity/interiorising/akrasiatic-drag ${ }^{4}$ from a 'difference-inkind/difference-in-aposteriorising-or-logicising ${ }^{23}$ posture; such that humankind then overlooks presencing_absolutising-identitive-constitutedness ${ }^{14}$ and re-projects/re-anticipates nonpresencing-<perspective-ontological-normalcy/postconvergence $>$ enabling human transcendence-and-sublimity/sublimation/supererogatory $\sim$ de-mentativity. Therefore, metaphoricity ${ }^{57}$ as highlighted herein is actually construed as of 'its natural ontology implications', and this natural ontological notion of metaphoricity ${ }^{57}$ is construed herein as superseding-and-englobing all other differentiated adjunctive significations including conventional figures-of-speech. Metaphoricity ${ }^{57}$ as such simply refers to signification adjunctiveness to 'underlying <amplituding/formativeepistemicity>totalising/circumscribing/delineating signifying-construct of language' as of both the meaningfulness-and-teleology ${ }^{56}$ implications to the so-renewed 'underlying $<$ amplituding/formative-epistemicity $>$ totalising/circumscribing/delineating signifyingconstruct of language' and the specific adjunctive-metaphoricity ${ }^{57}$-signification within such renewed 'underlying $<$ amplituding/formativeepistemicity $>$ totalising/circumscribing/delineating signifying-construct of language'. Metaphoricity $^{57}$ is very much a mirroring of existential-<disentologising/re-ontologising 
aporeticism $>$ 'syncretising-effecting' going by the latter's existential-<disontologising/reentologising aporeticism $>$ implications on 'human underlying self-referencing meaningfulness-and-teleology as an epistemic-totalising ${ }^{9} /$ circular construal'. This 'epistemic-totalisation/circularity epistemic-breaking' of self-referencing associated existentially-<disontologising/re-ontologising aporeticism $>$ with syncretising-effecting as mirrored in metaphoricity ${ }^{57}$ arises because of human limited-mentation-capacity—as-subjecting'educed-unlimitedness/existence-sublimating nascence' to-limitedness/human-subpotency, and is a reflection of the circular deepening of human limited-mentation-capacity-assubjecting-'educed-unlimitedness/existence-sublimating nascence'- to-limitedness/humansubpotency as of growing certitude from the opening up of ${ }^{6}$ nonpresencing- $<$ perspectiveontological-normalcy/postconvergence $>$ by human re-projection/re-anticipation ultimately validated by existence/ontology's-directedness-as-Being <amplituding/formativeepistemicity $>$ causality $\sim$ as-to-projective-totalitative-implications-of-prospective-

\section{nonpresencing,-for-explicating relative-unreflexivity/relative-reflexivity ontological-}

contiguity . Further, metaphoricity ${ }^{57}$ as such speaks of the evasiveness of all human meaningfulness-and-teleology 99 at uninstitutionalised-threshold ${ }^{102}$ as recurrently pointed out herein as of token threshold-of-nonconviction/madeupness/bottomlining-in-shallowsupererogation -<as-to-'attendant-intradimensional'-prospectivelydisontologising $\sim$ preconverging/dementing -apriorising-psychologism $>$ possibilities relation to reference-of-thought- categorical-imperatives/axioms/registry-teleology ${ }^{99}$,-foraposteriorising/logicising/deriving/intelligising/measuring- ${ }^{5}$ meaningfulness-and-teleology ${ }^{99}$ as of human limited-mentation-capacity—as-subjecting-'educed-unlimitedness/existencesublimating nascence' to limitedness/hmman-subpency implications. The implications of this reality as of metaphoricity ${ }^{57}$ explains why epistemes are fundamentally and necessarily constricted as of their specific registry-worldview/dimension ${ }^{83}$ reference-of-thought; as 
ultimately epistemes are as relevant as the ontological-possibilities divulgeable by presencing - absolutising-identitive-constitutedness ${ }^{14}$ and ${ }^{6}$ nonpresencing- $<$ perspectiveontological-normalcy/postconvergence>, such that in the case of the latter there is no prior insight about the veracity of any episteme before it is divulged with Beingdevelopment/ontological-framework-expansion-as-to-depth-of-ontologising-development-asinfrastructure-of- meaningfulness-and-teleology as ${ }^{79}$ presencing-absolutising-identitiveconstitutedness ${ }^{14}$. Consider in this regard Galileo's implying positivistic episteme metaphoricity ${ }^{57}$ over a medieval Establishment scholasticism-and-mysticism episteme as of Being-development/ontological-framework-expansion-as-to-depth-of-ontologisingdevelopment-as-infrastructure-of- meaningfulness-and-teleology as the necessary backdrop for the knowledge he articulates and all subsequent positivistic knowledge. In-many-ways, this author as of organic-knowledge is very much aware of the 'drawback implications' of our positivism- ${ }^{80}$ procrypticism episteme as of its apriorising/axiomatising/referencing-\{of'prospectively_implicited_attendant-ontological-contiguity ' educedexistentialising/contextualising/textualising_'intelligibility/epistemicity/reflexivity-contiguity$<$ imbued-notional cogency $>$ ' $\}$-constitutedness ${ }^{1}$-in-preconverging-entailment with respect to futural Being-development/ontological-framework-expansion-as-to-depth-of-ontologisingdevelopment-as-infrastructure-of- meaningfulness-and-teleology as of prospective notional deprocrypticism psychoanalytic-unshackling organic-knowledge, as of the full articulation of accreting-substitutive-subsumption-as-futural-différance-freeplay with respect to our ${ }^{8}$ procrypticism-or-disjointedness-as-of- ${ }^{8}$ reference-of-thought uninstitutionalisation and futural Being-development/ontological-framework-expansion-as-to-depth-of-ontologisingdevelopment-as-infrastructure-of- meaningfulness-and-teleology as of prospective notional deprocrypticism institutionalisation implications representation, and so beyond just our natural inclination for <amplituding/formative-epistemicity $>$ totalising $\sim$ self-referencing- 
syncretising/circularity/interiorising/akrasiatic-drag ${ }^{34}$. Galileo could well had possibly recasted his implied positivism ${ }^{56}$ meaningfulness-and-teleology ${ }^{9}$ in scholasticism-mysticism terms, just as Copernicus work was held back priorly in limbo, but then the implications as he perceived would have been a degradation and lost of the essence of what he was doing, and so more than just the specific scientific knowledge but more critically it warranted a psychoanalyticunshackling into the nonpresencing-or-withdrawal/unenframing/re-ontologising-ormetaphysics-of-absence-〈implicited-epistemic-veracity-of- nonpresencing-<perspectiveontological-normalcy/postconvergence $>$ - - or-transcendental-reasoning-of-event ${ }^{38}$-asprospective-ontology-origination perspective/framing/reference/horizon/projection of positivism ${ }^{56}$ meaningfulness-and-teleology ${ }^{9}$ we entertain today. Likewise, as of such metaphoricity ${ }^{57}$ episteme, the ${ }^{5}$ meaningfulness-and-teleology ${ }^{99}$ herein implied as of its essence cannot do without this fepistemicthermeneutic/textulity/reprojecting/supererogating/zeroing/re-acuting,${ }_{\{\text {decompulsing }\}}$ delinearity for-cogency circle phenomenological ontology elucidation as of its psychoanalytic-unshackling apriorising/axiomatising/referencing-\{of-'prospectively implicited_attendant-ontological-contiguity ' educedexistentialising/contextualising/textualising_'intelligibility/epistemicity/reflexivity-contiguity<imbued-notional cogency $>$ ' \}-conflatedness ${ }^{13}$-in-\{preconverging-disentailment by\} postconverging-entailment; and the ideal backdrop for this lies in a further developed postmodern-thought phenomenological-depth of construction, as implied herein by this author as of accreting-substitutive-subsumption-as-futural-différance-freeplay ${ }^{2}$. This author conceives that at the very core to such genuine understanding of postmodern-thought is a double-gesture reification that consists of perspective/framing/reference/horizon/projection and then contention/argumentation within such articulated perspective/framing/reference/horizon/projection, as so implied by postmodern-thought together 
with other kindred though less dramatic textuality-thinkers like Gadamer and Habermas; as of the need to adopt/instigate the appropriate mindset for knowledge appraisal given the fundamental distorting effect, beyond just perception, of human limited-mentation-capacityas-subjecting 'educed-unlimitedness/existence-sublimating nascence' to-limitedness/humansubpotency. This double-gesture reification reality for construing human knowledge amounts to a quasi-psychoanalytic-unshackling, as it reflects the fact that The-Given as of existentialism/thrownness/facticity is always an insufficiently/poorly developed perspective/framing/reference/horizon/projection for direct instigation of contention/argumentation aspiring for profundity and completeness. Such that this doublegesture reification of the textuality-driven intellectuals involves their 'special focus orientations' profundity say like genealogy with Foucault, deconstruction with Derrida, etc., and this together with transversality-<for-sublimating-existential-eventuating/denouement-from-'thinking-atfirst/pure-predisposition-preemptive-of-prospective-disontologising/subontologising' as-ofprospectively-disambiguated-affirmed-and-unaffirmed-'motif-andapriorising/axiomatising/referencing' $>101$ complementarity and criticisms of all such 'special focus orientations', go on to conjointly-and-fruitfully define what is postmodern-thought. Postmodern-thought as such can be analogised with the anecdote of the blind men striving to determine what an elephant is, but with each one saying authentically what the find in front of them in developing the relevant specific imageries and overall imagery of what an elephant is. This in itself is a milestone in theorisation, and as an overall conception postmodern-thought, besides the 'special focus orientations' of the specific textuality-driven intellectuals, is primarily about 'consistently taking a best shot' at reality and is not inherently driven at its core by ideology but rather ontological-good-faith/authenticity ${ }^{6}$. As such it effectively achieves a more potent construal of the human condition and knowledge especially as it is 'driven by such transversality$<$ for-sublimating-existential-eventuating/denouement-from-'thinking at-first/pure- 
predisposition-preemptive-of-prospective-disontologising/subontologising' as-of-

prospectively-disambiguated-affirmed-and-unaffirmed-'motif-and-

apriorising/axiomatising/referencing'> $>101$ cumulative authenticities that augment the possibilities of human limited-mentation-capacity-as-subjecting 'educedunlimitedness/existence-sublimating nascence' to-limitedness/human-subpotency' thus going a long way to 'open-up'/'throw-up'/'reveal' new and coherent thought possibilities as of its grander and overall conception and spirit. Interestingly, what is central about the ontologicalbad-faith/inauthenticity ${ }^{64}$ critique of postmodern-thought is the lack-of-insight/feinting-lack-ofinsight about all these underlying elements of postmodern-thought construction: as failing to grasp/recognise the implied double-gesture reification as of its transcendentalenabling/sublimating/supereregatory de-mentativity implications, and by not appreciating due to 'flatmindedness'/banality/flimsiness the implications of perspective/framing/reference/horizon/projection before contention/argumentation as of any given perspective/framing/reference/horizon/projection, thus implying 'poor critical judgment'. With such 'flatmindedness'/banality/flimsiness further protracting into a poor grasp of postmodern theorists 'special focus orientations' with the tendency to engage postmodernthought as of an uninsightful literal and shallow-minded/banal/flimsy reading; and with the ultimate outcome that all such naïve uninsightful literal and shallow-minded/banal/flimsy readings are cumulated and summated as the entirety of the postmodern theoretical construct, and so on an apparently implied flawed logic that the discretion allowed for criticism doesn't engage the intellectual credibility of the critique, a notion that is especially abused within a media background. Such 'flatmindedness'/banality/flimsiness with respect to postmodern-thought fails to grasp that all subject-matter as of their inherently deferential-formalisation-transference as of institutional percolation-channelling- $<$ in-deferential-formalisation-transference $>$ are necessarily construed as of a double-gesture reification that supersedes the ordinariness/banality of day to 
day social existence analysis as of <amplituding/formative $>$ wooden-language-〈imbued averaging-of-thought-<as-to-leveling/ressentiment/closed-construct-of- meaningfulness-andteleology -as-of-'nondescript/ignorable-void ' -with-regards-to-prospective-apriorisingimplications $>>$, such that as of the history of such critiques it will be naïve not to factor in the reality of ontological-bad-faith/inauthenticity ${ }^{64}$ and so particularly as it tends to shy away from genuine intellectual engagement with postmodern-thought, and highlighting that the idea of arrogance peddled about postmodernism strangely enough speaks of the 'ignoble arrogance' of such ontological-bad-faith/inauthenticity ${ }^{64}$ critiques, as preconverging/postconverging-dementatively/structurally/paradigmatically that which attributes value judgments is that which is knowledgeable-as-of-its-prospective-relative-ontological-completeness ${ }^{87}$-of- ${ }^{83}$ refence-ofthought-postconverging-or-dialectical-thinking -apriorising-psychologism and not that which is ignorant-as-of-its-prior-relative-ontological-incompleteness -of- reference-of-thoughtpreconverging-or-dementing ${ }^{20}$-apriorising-psychologism. Such that there is no dialogicalequivalence-<as-to-psychologismic apriorising/axiomatising/referencing-\{of-'prospectively implicited_attendant-ontological-contiguity ' educedexistentialising/contextualising/textualising_ 'intelligibility/epistemicity/reflexivity-contiguity<imbued-notional cogency $\left.>^{\prime} \quad\right\}$-conflatedness -in-\{preconverging-disentailment by\} postconverging-entailment,-in-self-becoming/self-conflatedness /formative-supererogating> that then arises by the fact that the former is a nonextricatory/intemporal/ontological relationship with meaningfulness-and-teleology while the latter is an existentialextrication/temporal/non-ontological relationship with ${ }^{5}$ meaningfulness-and-teleology ${ }^{9}$, in the sense that it is the former intemporal-as-ontological individuation mental-disposition that is responsible for bringing about human Being-development/ontological-framework-expansionas-to-depth-of-ontologising-development-as-infrastructure-of- meaningfulness-andteleology in reflecting holographically-<conjugatively-and-transfusively $>$ the relative- 
unreflexivity/relative-reflexivity - ontological-contiguity of-the-human-institutionalisationprocess retrospectively and prospectively while the latter as of its false 'untransvaluatedtemporal-intemporality ${ }^{52}, \quad$ is $\quad$ rather $\quad$ existentially-<disontologising/re-ontologising aporeticism $>$ extricatory and oblivious to Being-development/ontological-frameworkexpansion-as-to-depth-of-ontologising-development-as-infrastructure-of- meaningfulnessand-teleology in reflecting holographically-<conjugatively-and-transfusively $>$ the relativeunreflexivity/relative-reflexivity - ontological-contiguity of-the-human-institutionalisationprocess . As ultimately, it is the prospective relative-ontological-completeness ${ }^{87}$-of- ${ }^{8}$ referenceof-thought pursued by the former that supersedes and dissolves human vices-and-impediments as of prospective registry-worldview/dimension transcendence-andsublimity/sublimation/supererogatoryade-mentativity ${ }^{83}$ reference-of-thought. The overall insight here of such ontological-bad-faith/inauthenticity ${ }^{64}$ can be construed analogically as say in a non-positivistic social-setup where the modern disease theory is not yet socially familiar such that patients may assume that they should be cured immediately/instantly after treatment with no perspective/framing/reference/horizon/projection of appreciation for judging medicine as optimally an over-a-time-period-bodily-reparation construed as the basis of a positivist physician practice; a notion being spread and advocated by the positivist physician in the socialsetup. Now consider a competing healer very much aware of such a non-positivist social-setup 'lack of social ${ }^{103}$ universal-transparency ${ }^{104}$-〈transparency-of-totalising-entailing,-as-toentailing-<amplituding/formative-epistemicity $>$ totalising $\sim$ in-relative-ontological-

completeness \' with regards to such over-a-time-period-bodily-reparation notion and throwing a spanner in the works by pretending that the physician should confirm that patients are cured immediately as otherwise the physician must be practising witchcraft on the patients, understanding fully well the authentic disposition of the physician to affirm a practice of overa-time-period-of-bodily-reparation for a long term dependable notion of medicine. While they 
are pragmatically inclined to advanced opportunistically whatever explanation to justify that their healing is immediate/instant and so involving any such stratagem like opportunistically accusing patients or some other persons for any implied failure of immediate/instant cure having the effect on the most part of shutting-off any complain or at least negative allegations about the healer's cure, and so-enabled on the basis of the healer priorly institutionalised deferentialformalisation-transference posture in the social-setup. Such a healer encouraging the social-setup notion of immediate/instant cure as a ploy (given the possibility of the positivistic disease theory conception subverting their own non-positivistic healing practice notwithstanding ontologicalveracity). The manifest acts of many such ontological-bad-faith/inauthenticity ${ }^{64}$ critiques with respect to postmodern-thought: whether when pretending to misunderstand postmodern doublegesture reification of meaningfulness, blatantly caricaturing in the most inane terms postmodernthought, avoiding genuine intellectual-level disputation, and so rather opting for subversive $<$ amplituding/formative $>$ wooden-language-<imbued - averaging-of-thought-<as-toleveling/ressentiment/closed-construct-of- meaningfulness-and-teleology -as-of'nondescript/ignorable-void '-with-regards-to-prospective-apriorising-implications $>$ > 'uncritical social media preaching towards sold publics-of-conquest' paradoxically while claiming not to grasp postmodern-thought, with subterfuges of unoriginal thought usurping the notion of science and intellectualism towards such uncritical publics; and all this as a manifestation of perverted intellectual institutional-being-and-craft. While postmodern-thought is not and has never been immuned from genuine intellectual criticism not only from other schools-of-thought but among postmodern and poststructuralist thinkers themselves, and this calling out of such ontological-bad-faith/inauthenticity ${ }^{64}$ critics is much more than an issue about postmodern-thought but about all intellectualism generally as such malpractices tend to mark the beginning of intellectual teleological-decadence-<-in-dimensionality-of-desublimating-lackof $^{-}-\langle<$amplituding/formative $>$supererogatory $\sim$ de-mentativeness/epistemic-growth-or- 


\section{conflatedness /transvaluative-rationalising/transepistemicity/anamnestic-residuality/spirit-}

drivenness-equalisation) subversion of progressive thinking and go on to permeate social practices and media practice, thus rendering social and critical thought impotent. Further knowledge as understood by this author is more than just the conception of its intemporal-asontological nature but knowledge is much more completely and potently knowledge as it understands as well the implications of temporal-as-non-ontological mental-dispositions dynamics in relation to pure-ontology, and thus in the face of ontological-badfaith/inauthenticity ${ }^{64}$ shouldn't take the bait of overlooking and thus falsely elevating teleologically as intellectually pertinent ontological-bad-faith/inauthenticity ${ }^{64}$ rather than relating to it at its teleologically-degraded level for what it truly is, and so as part-and-parcel of a complete conception of knowledge. Ultimately, intellectual statuses are as pertinent as veridically enabling to human emancipation as of intemporal/ontological/social/species $/{ }^{103}$ universal/transcendental $/{ }^{5}$ maximalisingrecomposuring-for-relative-ontological-completeness ${ }^{8}$ —unenframed/reontologising conceptualisation postconverging-de-mentating/structuring/paradigming, and intellectuals' choice of ontological-bad-faith/inauthenticity ${ }^{64}$ is nothing less than self-inflicting irreverence and cannot thus turn around to intimate irreverence when surreptitiously undermining knowledge of ${ }^{103}$ universal consequential implications. It is herein summated that as of metaphysics-of-absence-〈implicited-epistemic-veracity-of- nonpresencing-<perspectiveontological-normalcy/postconvergence $>>$ prior postmodern thinking is akin-and-pointing-to a proto-prospective ${ }^{83}$ reference-of-thought as of prospective relative-ontological-completeness ${ }^{87}$ of-axiomatic-construct-or- ${ }^{8}$ reference-of-thought over a $\quad$ amplituding/formativeepistemicity>totalising $\sim$ self-referencing-syncretising/circularity/interiorising/akrasiatic-drag as prior ${ }^{83}$ reference-of-thought, and that necessarily it speaks by its double-gesture reification of quasi-psychoanalytic-unshackling thus requiring a psychoanalytic-reorientation to such an 
implied prospective ${ }^{83}$ reference-of-thought 'as of the prospective relative-ontologicalcompleteness ${ }^{87}$-of-axiomatic-construct-or- ${ }^{83}$ reference-of-thought of a better knowledge perspective ${ }^{83}$ reference-of-thought before/as-preceding contention/argumentative-engagement, and so avoiding 'flatmindedness'/banality/flimsiness. The underlying current of postmodernthought is that our limited-mentation-capacity—as-subjecting 'educed-unlimitedness/existencesublimating nascence'-to-limitedness/human-subpotency induces our prior relativeontological-incompleteness ${ }^{88}$ with regards to ${ }^{83}$ reference-of-thought and its derived meaningfulness-and-teleology, with the implication that we need to a prospective relativeontological-completeness ${ }^{87}$-of- ${ }^{83}$ reference-of-thought to be able to articulate intemporal-asontological construal as of the internal-dialectics/différance of ${ }^{56}$ meaningfulness-andteleology . In other words, all concepts, notions as of ontologically-veridical ${ }^{56}$ meaningfulnessand-teleology ${ }^{9}$, are made to have their internal-dialectics/différance as of ${ }^{6}$ nonpresencing$<$ perspective-ontological-normalcy/postconvergence $>$ for their sublimation and transcendenceand-sublimity/sublimation/supereregatory de-mentativity into more profound and more complete ${ }^{56}$ meaningfulness-and-teleology ${ }^{9}$. For instance the 'postmodern take' about science is rather a more profound and complete notion of science than the 'modern take', such that a 'modern approach' to the conception of science naively fails to factor in unlike the 'postmodern approach' the implications of human limited-mentation-capacity-as-subjecting 'educedunlimitedness/existence-sublimating nascence' to-limitedness/human-subpotency and the need to deepen it, thus translated into the prior need for prospective relative-ontologicalcompleteness ${ }^{87}$; wherein the 'modern take' might naively consider medicine as simply providing medications and remedies, the 'postmodern take' by an internal-dialectics/differance of the notion of medical science will factor in socioeconomic, education, information, environmental, gender and power relations issues underlying healthcare and medical delivery as a more profound and complete notion of medical science; construed effectively as of ${ }^{18}$ deprocrypticism- 
or-preempting - disjointedness-as-of- ${ }^{2}$ reference-of-thought. Thus, for postmodern-thought the capacity to attain relative ontologically-veridical ${ }^{56}$ meaningfulness-and-teleology ${ }^{9}$ comes down to the capacity of arriving at the very essence of ${ }^{56}$ meaningfulness-and-teleology ${ }^{99}$ while overcoming the drawback of our human limited-mentation-capacity-as-subjecting 'educedunlimitedness/existence-sublimating nascence'-to-limitedness/human-subpotency. This insight about the essence of things as to thrownness is what underlies fundamentally Heideggerianessencing-as-of-the-ontological-difference, Sartrean-existence-precedes-essence and Derrideandifférance-as-there-is-nothing-outside-the-text (all construed herein as of 'implicited_attendantontological-contiguity ${ }^{67}$, educed-

existentialising/contextualising/textualising_'intelligibility/epistemicity/reflexivity-contiguity<imbued-notional cogency>' ${ }^{\prime}$ ); as the enabling approach for human ontologicalreconstituting-as-to-conflatedness ${ }^{13}$ as of aetiologisation/ontological-escalation- $<$ ontologicalveridicality_commitment/otherliness_transcending/compulsions-encumbered_transcending >. Basically thus, the overall postmodern project implication is that we deepen our limitedmentation-capacity —as-subjecting-'educed-unlimitedness/existence-sublimating nascence' to-limitedness/human-subpotency first (and so as of dimensionality-of-sublimating <<amplituding/formative>supererogatory $\sim$ de-mentativeness/epistemic-growth-orconflatedness /transvaluative-rationalising/transepistemicity/anamnestic-residuality/spiritdrivenness-equalisation> of our supererogatory acuity/perspicacity/astuteness/edginess/incisiveness-ofapriorising/axiomatising/referencing/intelligibilitysettingup/measuringinstrumenting -forconceptualisation) to ensure that we go about deriving ontologically-veridical ${ }^{56}$ meaningfulnessand-teleology ${ }^{9}$ in relative-ontological-completeness ${ }^{87}$. This is in reality the ultimate scientific insight as such an internal-dialectics/différance is articulated as of non-speculative, nonimaginary, theoretical, conceptual and operant scientific implications; and this is reflected in the 
very initiation of the postmodern postconverging-de-mentating/structuring/paradigming with Heidegger's criticism of Hegelian dialectics, with the latter construed by this author as 'not founded-on-and-constrained-by ontological-veridicality/intrinsic-reality as of $<$ amplituding/formative-epistemicity $>$ causality $\sim$ as-to-projective-totalitative-implications-ofprospective- nonpresencing,-for-explicating relative-unreflexivity/relative-reflexivity

ontological-contiguity ', but rather dialectical discretion, imagination and speculation 'as to lack of a congruent,-cogent-and-operant entailing framework of relative-unreflexivity/relativereflexivity - ontological-contiguity ${ }^{67}$ as herein implied by this author with the 'relativeunreflexivity/relative-reflexivity - ontological-contiguity ${ }^{67} \sim$ of-the-human-institutionalisationprocess ${ }^{68}$ congruent,-cogent-and-operant entailing framework of relative-unreflexivity/relativereflexivity - ontological-contiguity ${ }^{67}$. Anecdotally, the shallow-mindedness of a 'modern take' in failing to recognise the postmodern double-gesture reification will simply consider the blind men reporting of an elephant as a tree-trunk, a rope, a wall, a fan or a spear as 'postmodern madness' without factoring in the underlying double-gesture reification for perspective and insight, given the problematic of human limited-mentation-capacity-as-subjecting 'educedunlimitedness/existence-sublimating nascence' to-limitedness/human-subpotency that itself needs to be factored in and thus actually strengthen the human thought process in its aetiologisation/ontological-escalation- $<$ ontologicalveridicality_commitment/otherliness_transcending/compulsions-encumbered_transcending $>$. In-the-bigger-scheme-of-things, such an internal-dialectics/différance is what explains the relative-unreflexivity/relative-reflexivity ontological-contiguity ${ }^{67} \sim$ of-the-humaninstitutionalisation-process ${ }^{68}$ as of Being-development/ontological-framework-expansion-as-todepth-of-ontologising-development-as-infrastructure-of- meaningfulness-and-teleology psychologismic epistemic-acutisation difficulty-<or, residualising \{decompulsing\} delinearity for-cogency>-magnitude\{of-experientiality/experiment\} and so-construed as 
suprastructuralism beyond just the specific interpretation of suprastructuralism as of postmodernism with respect to modernism. This internal-dialectics/différance as of successive transcendence-and-sublimity/sublimation/supererogatory-de-mentativity is behind the respective registry-worldviews/dimensions as of their given ${ }^{83}$ reference-of-thought specific neuterising as well as the ultimate deneuterising —referentialism of deprocrypticism. But then ontological-bad-faith/inauthenticity ${ }^{64}$ is equally elicited by 'lack of social ${ }^{103}$ universaltransparency ${ }^{104}$-〈transparency-of-totalising-entailing,-as-to-entailing-<amplituding/formativeepistemicity>totalising in-relative-ontological-completeness ' ${ }^{\prime}$ as of a cynicism of institutional-being-and-craft. The transcendental implications of a registryworldview/dimension ${ }^{83}$ reference-of-thought ${ }^{\text {" }}$ reference-of-thought — devolving-teleologicalde-mentating/structuring/paradigming-of-meaningfulness' arises for instance in the sense that however 'wishful' the <amplituding/formative-epistemicity>causality $\sim$ as-to-projectivetotalitative-implications-of-prospective- nonpresencing,-for-explicating relative-

unreflexivity/relative-reflexivity - ontological-contiguity

transcendentalpossibilities/potential as of knowledge-constructs/theories/intersolipsistic-intercessorynotions/notional referential-notions/articulations/virtue and human emancipation potential/possibilities of a prospective registry-worldview/dimension like positivism as of its ${ }^{{ }^{3}}$ reference-of-thought — devolving-teleological-de-mentating/structuring/paradigming-ofmeaningfulness', cannot avail to a prior registry-worldview/dimension like nonpositivism/medievalism. In this regard the Copernicuses, Galileos and Diderots of their eras, and more explicitly Descartes in his direct construal of the positivism apriorising/axiomatising/referencing/intelligibilitysettingup/measuringinstrumenting, would have certainly sensed that their specific knowledge conceptualisations wasn't the more critical issue but rather their insistence was an implicit understanding that the non-positivistic ' reference-of-thought — devolving-teleological-de-mentating/structuring/paradigming-of- 
mentatively/structurally/paradigmatically a framework that wouldn't be enabling for their positivistic and all other positivistic knowledge conceptualisations as of its prior relativeontological-incompleteness ${ }^{8}$-of- ${ }^{8}$ reference-of-thought (and were thus more fundamentally projective dimensionality-of-sublimating 25 -< $<$ amplituding/formative $>$ supererogatory $\sim$ dementativeness/epistemic-growth-or-conflatedness /transvaluativerationalising/transepistemicity/anamnestic-residuality/spirit-drivenness-equalisation〉). Such apriorising/axiomatising/referencing-\{of-'prospectively_implicited_attendant-ontologicalcontiguity ' educedexistentialising/entextualising/textraing_intelligibility/epistemicity/reflexivity-contiguity<imbued-notional cogency $\left.>^{\prime}\right\}$-conflatedness ${ }^{13}$-in-\{preconverging-disentailment by\} postconverging-entailment imbued in postmodern-thought address more than just apriorising/axiomatising/referencing-\{of-'prospectively_implicited_attendant-ontologicalcontiguity ' educedexistentialising/contextualising/textualising_intelligibility/epistemicity/reflexivity-contiguity<imbued-notional cogency $\left.>^{\prime} \quad\right\}$-constitutedness ${ }^{1}$-in preconverging-entailment implications of knowledge construction as articulated herein but equally points critically to intellectually decadent institutional dispositions and practices where sterile/anecdotal imprimatur and the dynamics of sterile/anecdotal imprimatur by themselves are increasingly construed as of more critical epistemic pertinence for knowledge constructions undermining the possibilities of breakthroughs given that the primacy of intellectualism as of the pertinence of intellectual arguments increasingly takes a back seat, with intellectual postures increasingly defended with non-intellectualism obsession of ideologies of schools-of-thought as of institutional-being-andcraft. This manifests itself in the form of many an intellectual increasing disposition 'to misunderstand' others works, as there are little common stakes for breakthroughs but rather the 
stakes are increasingly of institutions academic visibility and tenure with emphasis on likeminded networks and forums driven increasingly by influence than carefree ${ }^{103}$ universal intellectual curiosity. Furthermore intellectualism has increasingly been surreptitiously mingling-and-yielding to social and economic interests undermining its obligation for enabling social clairvoyance; with a resultant sense of socioeconomic and socio-political impotence as such blurriness-<sterilising/anecdotalising/trivialising-of-prospective-re-ontologising_bypreconverging,-in-disontologising-formulaic-dragging-out/hollowing-out> is increasingly undermining the relevance of intellectualism in its public discourse and enlightenment mission. Ultimately, the epistemic and preconverging-de-mentating/structuring/paradigming of academic institutional setups into increasingly into pedantising/muddling/formulaic-hollowingout - in-subontologisation/subpotentiation-_blurring/undermining-of-prospective-totalisingentailing,-as-to-entailing-<amplituding/formative-epistemicity $>$ totalising $\sim$ in-relativeontological-completeness $\rangle$ are not dissociated from the effective possibility for transcendentalenabling/sublimating/supereregatory de-mentativity, especially as such breakthroughs require the spontaneity of Dionysian arrangements. This author's construes of ${ }^{18}$ deprocrypticism-orpreempting — disjointedness-as-of- ${ }^{83}$ reference-of-thought ${ }^{\text {'83 }}$ reference-of-thought—devolvingteleological-de-mentating/structuring/paradigming-of-meaningfulness' conceptualisation as of ontological-escalation or aetiologisation, with respect to our present positivism- ${ }^{80}$ procrypticism disjointedness-as-of- ${ }^{8}$ reference-of-thought, as the more fundamental transcendental issue for prospective $\quad<$ amplituding/formative-epistemicity $>$ causality $\sim$ as-to-projective-totalitativeimplications-of-prospective- nonpresencing,-for-explicating relative-unreflexivity/relativereflexivity ontological-contiguity transcendental-possibilities/potential beyond selfreferencing-syncretism and circular palliative knowledge-constructs/theories/intersolipsisticintercessory-notions/notional referential-notions/articulations/virtue with regards to attending to the inherent deficient uninstitutionalised-threshold ${ }^{102}$ of knowledge-construct possibilities and 
vices-and-impediments ${ }^{105}$ imbued in our positivism- ${ }^{80}$ procrypticism disjointedness-as-ofreference-of-thought

${ }^{6}$ reference-of-thought—devolving-teleological-dementating/structuring/paradigming-of-meaningfulness'. Such a paradox of human ontologicalperformance $^{72}-<$ including-virtue-as-ontology $>$ /morality/ethics/justice/etc. is effectively construed as arising out of human <amplituding/formative-epistemicity $>$ totalising thrownness-in-existence ${ }^{35}$ (I exist therefore existence is of transcendentalenabling/sublimating/supereregatery $\sim$ de-mentativity to my human-subpotency / hyperbole-oftemporal-to-intemporal-ontological-performance ${ }^{2}-<$ including-virtue-as-ontology $>$ ) implying a preformulating/preframing/premeaningfulness- $<$ metaphoricity ${ }^{57}$-disposition — as-to-psycheinduced-psychologism-of-existential-stake $>$ idiosyncrasy that underlies presence institutionalisation ${ }^{83}$ reference-of-thought consciousness as it develops presence meaningfulness-and-teleology ${ }^{9}$-as-of-prospective-thought-and-reflexivity idiosyncrasy. Thus human ${ }^{5}$ meaningfulness-and-teleology ${ }^{9}$ is always at the crossroads of its prospective relativeontological-completeness ${ }^{87}$-of- ${ }^{-}$reference-of-thought and its ontologically undermining metaphysics-of-presence-〈implicited-'nondescript/ignorable-void '-as-to- presencingabsolutising-identitive-constitutedness $\rangle$ construal as of prior relative-ontologicalincompleteness ${ }^{8}$-of- ${ }^{8}$ reference-of-thought and in conjugation with perversion-and-derivedperversion-of- ${ }^{3}$ reference-of-thought-<as-preconvergingly-

apriorising/axiomatising/referencing-in-nonconviction/madeupness/bottomlining-as-toshallow-supererogation $>\quad$ implications $\quad$ as $\quad$ of postlogism ${ }^{77}$ slantedness/ ${ }^{5}$ ignorance/affordability/opportunism/exacerbation/social-chainism-or-socialdiscomfiture-or-negative-social-aggregation/temporal-enculturation-or-temporal-endemisation, so-disambiguated as of ${ }^{83}$ reference-of-thought- ${ }^{8}$ devolving ontological-performance ${ }^{72}$ <including-virtue-as-ontology $>$ /morality/ethics/justice/etc. and both as of beyond-theconsciousness-awareness-teleology ${ }^{9}-<$ of-preconverging-existential-extrication-as-of- 
existential-unthought>; ensuing out of human <amplituding/formative-epistemicity $>$ totalising thrownness-in-existence ${ }^{35}$ (I exist therefore existence is of transcendentalenabling/sublimating/supereregatory de-mentativity to my human-subpotency / hyperbole-of-

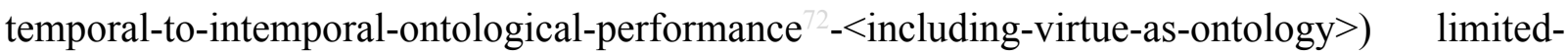
mentation-capacity —as-subjecting-'educed-unlimitedness/existence-sublimating nascence'to-limitedness/human-subpotency implications of preformulating/preframing/premeaningfulness- $<$ metaphoricity ${ }^{57}$-disposition-as-to-psycheinduced-psychologism-of-existential-stake> idiosyncrasy. Human preformulating/preframing/premeaningfulness- $<$ metaphoricity ${ }^{57}$-disposition - as-to-psycheinduced-psychologism-of-existential-stake $>$ idiosyncrasy as of the cumulation of all prior registry-worldviews/dimensions $\quad{ }^{83}$ reference-of-thought $\quad{ }^{4}$ historiality/ontologicaleventfulness 3 /ontological-aesthetic-tracing-<perspective-ontologicalnormalcy/postconvergence-reflected-'epistemicity-relativism-determinism'> as of the notional conflatedness ${ }^{13}$ of notional ${ }^{1}$ deprocrypticism is marked by a mental-disposition of temporal-concatenation-to-intemporality ${ }^{52}$ or intemporal-projection/longness-of-register-ofmeaningfulness-and-teleology to temporal-projection/shortness-of-register-ofmeaning hess and teleology with respect to human ontological-performance ${ }^{72}-<$ includingvirtue-as-ontology>-as-of-its-broadest-implications, and so whether as of natural ontology/natural sciences, social ontology/social sciences, aesthetics-as-ontology, virtue-asontology, etc.; with ontological-performance ${ }^{72}-<_{\text {including-virtue-as- }}$ ontology $>/$ morality/ethics/justice/etc. rather a unified construct but superficially differing with respect to social ontological-performance ${ }^{72}-<$ including-virtue-as- $^{2}$ ontology $>$ /morality/ethics/justice/etc. high emotional-involvement and non-social ontologicalperformance $^{72}$-<including-virtue-as-ontology $>$ /morality/ethics/justice/etc. low emotionalinvolvement. Underlying human <amplituding/formative-epistemicity $>$-totalising $\sim$ thrownness- 
in-existence $^{35}$ (I exist therefore existence is of transcendentalenabling/sublimating/supereregatery de-mentativity to my human-subpotency / hyperbole-of-

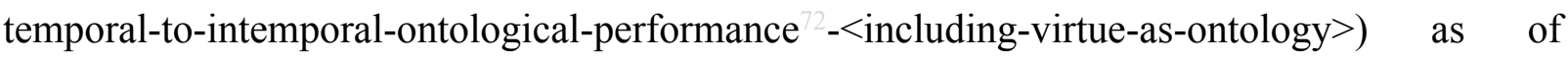
metaphysics-of-presence-〈implicited-'nondescript/ignorable-void ' 'as-to- presencingabsolutising-identitive-constitutedness $\rangle$ is the idea that the underlying idiosyncratic, intricate, compounded and pervasive 'notional conflatedness $13 /$ constitutedness ${ }^{14}$-to-conflatedness preformulating/preframing/premeaningfulness- $<$ metaphoricity ${ }^{57}$-disposition — as-to-psycheinduced-psychologism-of-existential-stake>' reflecting human shallow-to-deepening-limitedmentation-capacity -as-subjecting-'educed-unlimitedness/existence-sublimating nascence'-

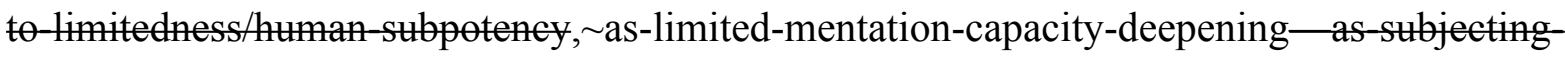
limitedness/human-subpotency-to-'educed-unlimitedness/existence-sublimating nascence' ${ }^{53}$ in reflecting holographically-<conjugatively-and-transfusively $>$ the relative-unreflexivity/relativereflexivity ontological-contiguity of-the-human-institutionalisation-process , as such, is concomitant with a 'dynamic cumulative remnant-and-co-opting preformulating/preframing/premeaningfulness- $<$ metaphoricity ${ }^{57}$-disposition - as-to-psycheinduced-psychologism-of-existential-stake $>\quad$ covert-shallow-limited-mentation-capacity-assubjecting-'educed-unlimitedness/existence-sublimating nascence' to-limitedness/humansubpotency-as-uninstitutionaled-threshold-denaturing -as-of-circular-complexification as an uninstitutionalised-threshold $^{102}$ corollary to the relative-unreflexivity/relative-reflexivityontological-contiguity ${ }^{67}$ of-the-human-institutionalisation-process ${ }^{68}$ likely to induce the 'denaturing ${ }^{6}$ of any given presence institutionalisation consciousness ${ }^{83}$ reference-of-thought apriorising/axiomatising/referencing-\{of-'prospectively_implicited_attendant-ontologicalcontiguity ' educedexistentialising/contextualising/textualising_'intelligibility/epistemicity/reflexivity-contiguity<imbued-notional cogency $\left.>^{\prime}\right\}$ - conflatedness ${ }^{13}$-in-\{preconverging-disentailment by\} 
postconverging-entailment of ${ }^{56}$ meaningfulness-and-teleology 9 at its uninstitutionalisedthreshold ${ }^{102}$, as of the dynamic elicitation of apriorising/axiomatising/referencing-\{of'prospectively implicited_attendant-ontological-contiguity ' ceducedexistentialising/contextualising/textualising_intelligibility/epistemicity/reflexivity_contiguity$<$ imbued-notional cogency $\left.>{ }^{\prime} \quad\right\}$-constitutedness ${ }^{1}$-in-preconverging-entailment $\quad$ as of shallow limited-mentation-capacity as-subjecting-'educed-unlimitedness/existencesublimating nascence' to limitedness/human-subpotency, for instance, as can be elicited as of the given postlogism 77 and conjugated-postlogism associated with the $<$ cumulating/recomposuring attendant-ontological-contiguity $>$-successive registryworldviews/dimensions in shallow limited-mentation-capacity-as-subjecting 'educedunlimitedness/existence-sublimating nascence' to-limitedness/human-subpotency denaturing of reference-of-thought- categorical-imperatives/axioms/registry-teleology as $<$ amplituding/formative $>$ wooden-language-〈imbued-temporal-mereform/virtualities/dereification/akrasiatic-drag/denatured/preconverging-or-dementing narratives - of-the- reference-of-thought- categorical-imperatives/axioms/registryteleology > undermining the ontological-faith-notion-or-ontological-fideism-imbuedunderdetermination-of-motif-and-apriorising/axiomatising/referencing-as-so-being-as-ofexistential-reality behind the ${ }^{8}$ reference-of-thought- categorical-imperatives/axioms/registryteleology 9 as for intemporal-preservation-entropy-or-contiguity-or-ontological-preservation. $\begin{array}{llll}\text { Such a } & \text { dynamic } & \text { cumulative }\end{array}$ preformulating/preframing/premeaningfulness- $<$ metaphoricity ${ }^{57}$-disposition —as-to-psycheinduced-psychologism-of-existential-stake $>$ arises, as of the cumulative succession of prior ontologically-compromised-mediating consciousnesses covert-shallow-limited-mentationcapacity —as-subjecting-'educed-unlimitedness/existence-sublimating nascence' tolimitedness/human-subpotency-as-uninstitutionaled-threshold-denaturing -as-of-circular- 
complexification with respect to the specific presence institutionalisation consciousness reference-of-thought at its uninstitutionalised-threshold ${ }^{102}$. That is, as of (impulsiveontologically-compromised-mediating)-covert-shallow-limited-mentation-capacity as subjecting 'educed unlimitedness/existence sublimating nascence' to limitedness/hmmansubpotency-as-uninstitutionaled-threshold-denaturing -as-of-circular-complexification of base-institutionalisation warped-consciousness ${ }^{83}$ reference-of-thought at its uninstitutionalisedthreshold $^{102}$; or $\quad\langle$ impulsive/tendentious—ontologically-compromised-mediating $\rangle$-covertshallow-limited-mentation-capacity—as-subjecting-'educed-unlimitedness/existencesublimating nascence' to limitedness/human-subponey-as-uninstitutionaled-thresholddenaturing -as-of-circular-complexification of ${ }^{103}$ universalisation preclusive-consciousness reference-of-thought at its uninstitutionalised-threshold ${ }^{102}$ or $\langle$ impulsive/tendentious/qualifying — ontologically-compromised-mediating $\rangle$-covert-shallowlimited-mentation-capacity—as-subjecting-'educed-unlimitedness/existence-sublimating nascence' to limitednesshman-subpency-as-uninstitutionaled-threshold-denaturing -as-ofcircular-complexification of positivism/rational-empiricism occlusive-consciousness reference-of-thought at its uninstitutionalised-threshold ${ }^{102}$ or prospectively, 〈impulsive/tendentious/qualifying/categorising—ontologically-compromised-mediating covert-shallow-limited-mentation-capacity-as-subjecting 'educed-unlimitedness/existencesublimating nascence' to limitedness/human-subpenter-uninstitutionaled-thresholddenaturing -as-of-circular-complexification of notional deprocrypticism protensiveconsciousness ${ }^{83}$ reference-of-thought at its uninstitutionalised-threshold ${ }^{102}$. This covert-shallowlimited-mentation-capacity—as-subjecting 'educed-unlimitedness/existence-sublimating nascence' to-limitedness/human-subpotency-as-uninstitutionaled-threshold-denaturing '-as-ofcircular-complexification of presence institutionalisation <amplituding/formativeepistemicity $>$ totalising/circumscribing/delineating $\quad{ }^{83}$ reference-of-thought- ${ }^{84}$ devolving-as-of- 
instantiative-context - ${ }^{5}$ meaningfulness-and-teleology 9 arises because the relativemnreflexivity/relative-reflexivity — ontological-contiguity ${ }^{67}$ of-the-human-institutionalisationprocess $^{68}$ is inherently a secondnatured construct that is crossgenerationally constrained by percolation-channelling- $<$ in-deferential-formalisation-transference $>\quad$ as $\quad$ of $<$ amplituding/formative-epistemicity $>$ causality $\sim$ as-to-projective-totalitative-implications-ofprospective- nonpresencing,-for-explicating relative-unreflexivity/relative-reflexivity

ontological-contiguity on the social-construct and internalised as of its overall middle to long term social positive-opportunism—of-social-functioning-and-accordance ${ }^{75}$ arising from social ${ }^{3}$ universal-transparency ${ }^{104}$-〈transparency-of-totalising-entailing,-as-to-entailing$<$ amplituding/formative-epistemicity>totalising in-relative-ontological-completeness $\rangle$ but doesn't necessarily speak of human absolute dimensionality-of-sublimating 5 <<amplituding/formative>supererogatory $\sim$ de-mentativeness/epistemic-growth-or-

conflatedness /transvaluative-rationalising/transepistemicity/anamnestic-residuality/spiritdrivenness-equalisation) adherence as of full ${ }^{83}$ reference-of-thought-prelogism ${ }^{78}$-as-ofconviction,-in-profound-supererogation $-<$ existentially-veridical-'attendant-intradimensionalapriorising/axiomatising/referencing'-logical-dueness-precedes-disontologising-logicaloutcome-arrived-at $>$ when it comes to social-stake-contention-or-confliction where there is lack of social ${ }^{103}$ universal-transparency ${ }^{104}$-〈transparency-of-totalising-entailing,-as-to-entailing<amplituding/formative-epistemicity>totalising in-relative-ontological-completeness >,

giving room for human shallow-limited-mentation-capacity-as-subjecting 'educedunlimitedness/existence-sublimating nascence' to-limitedness/human-subpotency as of beyond-the-consciousness-awareness-teleology ${ }^{9}-<$ of-preconverging-existential-extrication-asof-existential-unthought $>$ at uninstitutionalised-threshold ${ }^{02}$ such that at the uninstitutionalised-threshold ${ }^{102}$ in given ${ }^{79}$ presencing-absolutising-identitiveconstitutedness ${ }^{14}$, the disposition to threshold-of-nonconviction/madeupness/bottomlining-in- 
shallow-supererogation -<as-to-'attendant-intradimensional'-prospectively-

disontologising preconverging/dementing -apriorising-psychologism $>$ is elicited as of covertshallow-limited-mentation-capacity—as-subjecting 'educed-unlimitedness/existencesublimating nascence' to-limitedness/human-subpotency-as-uninstitutionaled-thresholddenaturing -as-of-circular-complexification undermining ontological-performance ${ }^{72}$ <including-virtue-as-ontology $>$. In other words, the relative-unreflexivity/relative-reflexivity ontological-contiguity ${ }^{67}$ of-the-human-institutionalisation-process ${ }^{68}$ as of transcendence-andsublimity/sublimation/supererogatoryade-mentativity is achieved by undermining-andovercoming the 'threshold-of-nonconviction/madeupness/bottomlining-in-shallowsupererogation -<as-to- 'attendant-intradimensional'-prospectivelydisontologising preconverging/dementing -apriorising-psychologism> (beyond-theconsciousness-awareness-teleology ${ }^{9}<$ of-preconverging-existential-extrication-as-ofexistential-unthought $>$ disposition) for covert-shallow-limited-mentation-capacity-assubjecting-'educed-unlimitedness/existence-sublimating nascence' to-limitedness/humansubpotency-as-uninstitutionaled-threshold-denaturing -as-of-circular-complexification' of the prior registry-worldview's/dimension's $<$ amplituding/formativeepistemicity>totalising/circumscribing/delineating $\quad{ }^{83}$ reference-of-thought- ${ }^{8}$ devolving-as-ofinstantiative-context - ${ }^{5}$ meaningfulness-and-teleology 9 at its uninstitutionalised-threshold as of crossgenerational psychoanalytic-unshackling for the prospective registryworldview's/dimension's $<$ amplituding/formativeepistemicity $>$ totalising/circumscribing/delineating reference-of-thought- ${ }^{84}$ devolving. However, 'threshold-of-nonconviction/madeupness/bottomlining-in-shallow-supererogation <as-to-'attendant-intradimensional'-prospectivelydisontologising preconverging/dementing -apriorising-psychologism> in covert-shallowlimited-mentation-capacity—as-subjecting-'educed-unlimitedness/existence-sublimating 
nascence' to-limitedness/human-subpotency-as-uninstitutionaled-threshold-denaturing -as-ofcircular-complexification' is bound to arise anew at the prospective institutionalisation reference-of-thought uninstitutionalised-threshold ${ }^{12}$ as of prior relative-ontologicalincompleteness ${ }^{88}$-of- ${ }^{8}$ reference-of-thought, thus requiring again prospective institutionalisation as of maximalising-recomposuring-for-relative-ontological-completeness ${ }^{87}$ - unenframed/reontologising conceptualisation apriorising/axiomatising/referencing-\{of- prospectively implicited_attendant-ontological-contiguity ' educedexistentialising/contextualising/textualising_'intelligibility/epistemicity/reflexivity-contiguity-

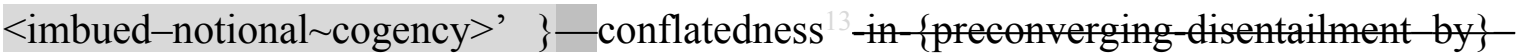
postconverging-entailment inducing social ${ }^{103}$ universal-transparency ${ }^{104}$-〈transparency-oftotalising-entailing,-as-to-entailing-<amplituding/formative-epistemicity $>$ totalising $\sim$ inrelative-ontological-completeness $\rangle$ as of a new prospective institutionalisation ${ }^{83}$ reference-ofthought to further undermine-and-overcome the 'threshold-ofnonconviction/madeupness/bottomlining-in-shallow-supererogation $-<$ as-to-'attendantintradimensional'-prospectively-disontologising preconverging/dementing -apriorisingpsychologism> for covert-shallow-limited-mentation-capacity-as-subjecting 'educedunlimitedness/existence-sublimating nascence' to-limitedness/human-subpotency-asuninstitutionaled-threshold-denaturing -as-of-circular-complexification' with respect to socialstake-contention-or-confliction. The reason why social ${ }^{103}$ universal-transparency ${ }^{104}$ 〈transparency-of-totalising-entailing,-as-to-entailing-<amplituding/formative-

epistemicity $>$ totalising in-relative-ontological-completeness $\rangle$ is empowering for prospective institutionalisation in superseding uninstitutionalised-threshold ${ }^{02}$ lies in the fact that the 'succession of preformulating/preframing/premeaningfulness- $<$ metaphoricity ${ }^{57}$-dispositionas-to-psyche-induced-psychologism-of-existential-stake>' idiosyncrasy as of human $<$ amplituding/formative-epistemicity>-totalising $\sim$ thrownness-in-existence ${ }^{35}$ that allowed for 
prior institutionalisations are inherently predicated on their successive social ${ }^{103}$ universaltransparency ${ }^{104}$-〈transparency-of-totalising-entailing,-as-to-entailing-<amplituding/formativeepistemicity>totalising in-relative-ontological-completeness $>$ such that even at presence uninstitutionalised-threshold ${ }^{102}$, involving denaturing ${ }^{16}$ of ${ }^{83}$ reference-of-thought- ${ }^{8}$ ategoricalimperatives/axioms/registry-teleology $\quad$ as $\quad<$ amplituding/formative $>$ wooden-language-

\section{〈imbued-temporal-mere-form/virtualities/dereification/akrasiatic-}

\section{drag/denatured/preconverging-or-dementing -narratives - of-the- reference-of-thought-}

categorical-imperatives/axioms/registry-teleology \ thus failing intemporal-preservationentropy-or-contiguity-or-ontological-preservation as of beyond-the-consciousness-awarenessteleology $-<$ of-preconverging-existential-extrication-as-of-existential-unthought $>, \quad$ the supposedly implied assumption though false is one of social ${ }^{103}$ universal-transparency 〈transparency-of-totalising-entailing,-as-to-entailing-<amplituding/formative-

epistemicity>totalising in-relative-ontological-completeness \ as all uninstitutionalisedthreshold ${ }^{102}$-or-uninstitutionalised-threshold ${ }^{12}$-are-overtly-unassuming-and-rather-parasitisingor-coopting-of-institutionalisation-in-false-representation-as-institutionalisation such that prospective social ${ }^{103}$ universal-transparency ${ }^{104}$-〈transparency-of-totalising-entailing,-as-toentailing-<amplituding/formative-epistemicity $>$ totalising in-relative-ontological-

completeness $>$ elucidation of prospective institutionalisation reflecting the inherent veridicality of the uninstitutionalised-threshold ${ }^{102}$ in its beyond-the-consciousness-awareness-teleology $<$ of-preconverging-existential-extrication-as-of-existential-unthought $>$ collapses it. Thus the 'notion of limited-mentation-capacity—as-subjecting-'educed-unlimitedness/existencesublimating nascence' to-limitedness/human-subpotency' is basically the 'underlying veridical human ${ }^{56}$ meaningfulness-and-teleology ${ }^{9}$ notion' for which 'ontologically-compromisedmediating,-as-of-their-specific-constitutedness ${ }^{14}$ consciousnesses flawed conceptualisation perspectives' construed as ontologically-flawed constructs in terms-as-of-axiomatic-construct 
of ${ }^{5}$ neuterising as of <amplituding/formative-

epistemicity>totalising/circumscribing/delineating ${ }^{83}$ reference-of-thought- ${ }^{8}$ devolving' whether beyond-the-consciousness-awareness-teleology ${ }^{9}-<$ of-preconverging-existential-extrication-asof-existential-unthought $>$, and so elucidated from the ontological-normalcy/relativeontological-completeness ${ }^{87}$-of- ${ }^{83}$ reference-of-thought perspective of notional ${ }^{18}$ deprocrypticism 'referentialism — ontologically-uncompromised-mediating,-as-ofconflatedness ${ }^{13}$ protensive-consciousness sound conceptualisation perspective'. In so doing, the latter reflects the limited-mentation-capacity—as-subjecting 'educed-unlimitedness/existencesublimating nascence' to-limitedness/human-subpotency dynamism of ${ }^{56}$ meaningfulness-andteleology ${ }^{9}$ as of notional ${ }^{18}$ deprocrypticism as well as temporal-to-intemporal individuations mental-dispositions, by way of deneuterising — referentialism, in lieu of ${ }^{58}$ neuterising. Thus this notion of human limited-mentation-capacity-as-subjecting 'educedunlimitedness/existence-sublimating nascence' to-limitedness/human-subpotency as the basis of différance/internal-dialectics/difference-deferral divulges 'ontologically-compromisedmediating,-as-of-their-specific-constitutedness ${ }^{14}$ consciousnesses flawed conceptualisation perspectives' and as of their ontologically-flawed constructs of ${ }^{58}$ neuterising, with regards to articulating teleological elevation-as-of-upholding-ontological-veridicality or teleological degradation-as-of-failing-ontological-veridicality respectively either as of apriorising/axiomatising/referencing-\{of-'prospectively_implicited_attendant-ontologicalcontiguity ' educedexistentialising/contextualising/textualising_'intelligibility/epistemicity/reflexivity-contiguity<imbued-notional $\left.\sim \operatorname{cogency}>^{\prime} \quad\right\}$-conflatedness ${ }^{13}$ in-\{preconverging disentailment by\} or destructuring respectively. Basically, the construal/conceptualisation of human <amplituding/formative-epistemicity $>$ totalising thrownness-in-existence ${ }^{35}$ (I exist therefore existence is of transcendental- 
enabling/sublimating/supereregatory de-mentativity to my human-subpotency / hyperbole-oftemporal-to-intemporal-ontological-performance ${ }^{2}-<$ including-virtue-as-ontology $>$ ) has always involved a disparateness-of-ontologically-construed-social-reality as of on-the-one-hand a dichotomy of 'intemporal-projection transcendental-enabling/sublimating/supereregatory $\sim$ dementativity abstraction of prospective Being and ${ }^{56}$ meaningfulness-and-teleology ${ }^{99}$ construal as of organic-knowledge implications and so as reductive construction however non-mechanical and intemporal-as-ontological-its-projection and hence as an open-endedincompleteness/nonachievement-of-ontological-normalcy/postconvergence construal of social reality', and on-the-other-hand an 'ad-hoc open-ended summative hotchpotch conventioning of temporal projections and intemporal projection grounding of social reality construction including organic-knowledge as well as mechanical-knowledge implications'; such that from the ontological-normalcy/relative-ontological-completeness ${ }^{87}$-of- ${ }^{8}$ reference-of-thought perspective, the overall social Being and ${ }^{5}$ meaningfulness-and-teleology ${ }^{9}$ transcendentallyenabling-level-of ontological-good-faith-or-authenticity $\%$ objectification/desubjectificationas-objectification-<as-to-ontological-faith-notion-or-ontological-fideism-imbuedunderdetermination-of-motif-and-apriorising/axiomatising/referencing-as-so-being-as-ofexistential-reality as antinihilism $>100$ is ontologically-limited as of organic-knowledge implications reductive constructions in an open-ended-incompleteness/nonachievement-ofontological-normalcy, as of the ontological-deficiency of mechanical-knowledge denaturing implications as well as perversion-and-derived- perversion-of- ${ }^{-}$reference-of-thought- $<$aspreconvergingly-apriorising/axiomatising/referencing-in-

nonconviction/madeupness/bottomlining-as-to-shallow-supererogation $>$ of temporal $\begin{array}{lll}\text { projections } & \text { as } & \text { of }\end{array}$ slantedness/ ignorance/affordability/opportunism/exacerbation/social-chainism-or-socialdiscomfiture-or-negative-social-aggregation/temporal-enculturation-or-temporal-endemisation, 
so-disambiguated as of ${ }^{83}$ reference-of-thought- ${ }^{8}$ devolving ontological-performance ${ }^{72}$ <including-virtue-as-ontology $>$, all occurring as of the conjoined dynamism of apriorising/axiomatising/referencing-\{of-'prospectively_implicited_attendant-ontologicalcontiguity ' educedexistentialising/contextualising/textualising_intelligibility/epistemicity/reflexivity-contiguity<imbued-notional cogency $\left.>^{\prime}\right\}$-conflatedness ${ }^{13}$ in-\{preconverging-disentailment by\} postconverging-ntailment and distractive-alignment-to- ${ }^{-}$reference-of-thought- $<$ofapriorising/axiomatising/referencing $>^{30}$. This overall disparateness-of-ontologically-construedsocial-reality dynamism is reflected in 'ontologically-compromised-mediating,-as-of-theirspecific-constitutedness ${ }^{14}$ consciousnesses flawed conceptualisation perspectives' as of their neuterising: wherein recurrent-utter-uninstitutionalisation has the deepest ${ }^{83}$ reference-ofthought-as-to-preconverging-de-mentating/structuring/paradigming as 'impulsiveontologically-compromised-mediating,-as-of-its-specific-constitutedness ${ }^{14}$ consciousness flawed conceptualisation perspective' ${ }^{5}$ neuterising by its trepidatious-consciousness, while on the other extreme in contrast notional ${ }^{18}$ deprocrypticism rather has a ${ }^{83}$ reference-of-thought-asto-postconverging-de-mentating/structuring/paradigming notional ${ }^{18}$ deprocrypticism 'referentialism—ontologically-uncompromised-mediating,-as-of-conflatedness ${ }^{13} \quad$ protensiveconsciousness sound conceptualisation perspective' that by its 'reference-of-thoughtdevolving_-différance/internal-dialectics/difference-deferral' grasp the ontologicallyveridical 'underlying human limited-mentation-capacity-as-subjecting 'educedunlimitedness/existence-sublimating nascence' to-limitedness/human-subpotency dynamics of $<$ amplituding/formative-epistemicity>totalising/circumscribing/delineating $\quad{ }^{83}$ reference-ofthought- ${ }^{8}$ devolving, and so without being subject to any ${ }^{58}$ neuterising' as is the case with all 'ontologically-compromised-mediating,-as-of-their-specific-constitutedness ${ }^{14}$ consciousnesses flawed conceptualisation perspectives'. Thus by its deneuterising ${ }^{17}$-referentialism construed as 
ontological-normalcy/postconvergence-reflected-‘epistemicity-relativism-determinism’>, notional ${ }^{1}$ deprocrypticism enables a fundamental ontology-driven 'postconverging-ordialectical-thinking -psychology or psychology-of-mentation-dynamics or natural psychological-dynamics', and so superseding a naïve metaphysics-of-presence〈implicited-'nondescript/ignorable-void '-as-to- presencing-absolutising-identitive-

constitutedness $>$ affect-driven mented or stigmatic psychology rather as of a shallow perspective and vaguely articulated as of ${ }^{103}$ universal import. The idea here with regards to human transcendence-and-sublimity/sublimation/supereregatory $\sim$ de-mentativity, is that from a creative perspective: the notion of a given ${ }^{58}$ neuterising is equinominal/equivalent with a given presencing-absolutising-identitive-constitutedness ${ }^{14}$, and as this speaks of human limitedmentation-capacity-as-subjecting 'educed-unlimitedness/existence-sublimating nascence' to-limitedness/human-subpotency prospectively-construed ontologically-flawed implications as of ontological-normalcy/postconvergence. It is over this ${ }^{58}$ neuterising that human transcendenceand-sublimity/sublimation/supererogatory de-mentativity is achieved from the prospective notional conflatedness ${ }^{13}$ of notional ${ }^{18}$ deprocrypticism and so by deneuterising referentialism, which is equinominal/equivalent to nonpresencing-<perspective-ontologicalnormalcy/postconvergence $>$. In other words the historial implications of human limitedmentation-capacity-deepening-as-subjecting limitedness/human-subpotency-to-'educedunlimitedness/existence-sublimating nascence' is that 'as of a less and less ontologicallyflawed ${ }^{56}$ meaningfulness-and-teleology ${ }^{9}$ towards ontological-normalcy/postconvergence, 'it projectively/anticipatorily brought about the <cumulating/recomposuring attendantontological-contiguity >-successive registry-worldviews/dimensions <amplituding/formativeepistemicity>totalising/circumscribing/delineating reference-of-thought- devolving' as of their given neuterisation ${ }^{59}$, construed as equinominal/equivalent with their successively given 
neuterising. From the above insight, transcendence-andsublimity/sublimation/supererogatory de-mentativity, is attainable as of deneuterising 1 , construed as equinominal/equivalent with deneuterising -referentialism as the notional conflatedness ${ }^{13}$ of notional ${ }^{18}$ deprocrypticism that produces the ontologically-

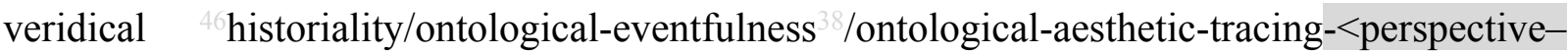
ontological-normalcy/postconvergence-reflected-‘epistemicity-relativism-determinism’>.

Ultimately, this sociohistorial disparateness-of-ontologically-construed-social-reality dynamism comes down to the limited/incomplete association of human 'invention' of organic-knowledge with the reflection of 'this organic-knowledge underlying mental-disposition as of Beingdevelopment/ontological-framework-expansion-as-to-depth-of-ontologising-development-asinfrastructure-of- meaningfulness-and-teleology rather defectively as of mechanicalknowledge construal in existential-<disontologising/re-ontologising aporeticism $>$ instantiations', inducing prospective ${ }^{58}$ neuterising. This disparateness is increasingly closeddown all along in reflecting holographically-<conjugatively-and-transfusively $>$ the relativeunreflexivity/relative-reflexivity - ontological-contiguity of-the-human-institutionalisationprocess from recurrent-utter-uninstitutionalisation to positivism- ${ }^{8}$ procrypticism, with the underlying tenet for achieving futural Being-development/ontological-framework-expansionas-to-depth-of-ontologising-development-as-infrastructure-of- meaningfulness-andteleology as of prospective notional ${ }^{18}$ deprocrypticism as preempting-disjointedness-as-ofreference-of-thought being a full and cogent/tense/limpid-<as-of-prospective-profoundsupererogation ,-for-residuality-in-re-originariness/re-origination> reflection of 'human construal of organic-knowledge' with the 'mental-disposition behind that construal of organicknowledge for Being-development/ontological-framework-expansion-as-to-depth-ofontologising-development-as-infrastructure-of- meaningfulness-and-teleology in existential< disontologising/re-ontologising aporeticism $>$ instantiations' thus resolving the open-ended- 
incompleteness/nonachievement-of-ontological-normalcy. Overall, such a notional conflatedness ${ }^{13} \quad$ reference-of-thought-as-to-preconverging/postconverging-dementating/structuring/paradigming - ontological-performance ${ }^{72}-<$ including-virtue-asontology $>$ /morality/ethics/justice/etc. 'performance-construct of candidity/candour-capacity' can be garnered as of metaphysics-of-absence-〈implicited-epistemic-veracity-ofnonpresencing-<perspective-ontological-normalcy/postconvergence $>\rangle$ wherein across the $<$ cumulating/recomposuring attendant-ontological-contiguity $>$-successive registryworldviews/dimensions a notional ${ }^{18}$ deprocrypticism insight makes obvious that it is increasing ontological-normalcy/postconvergence by increasing prospective relative-ontologicalcompleteness ${ }^{87}$-of- ${ }^{83}$ reference-of-thought that underlies ${ }^{83}$ reference-of-thought-as-topreconverging/postconverging-de-mentating/structuring/paradigming_-ontological-

performance ${ }^{72}-<$ including-virtue-as-ontology $>$ /morality/ethics/justice/etc. as a wholly internal process of apriorising/axiomatising/referencing-\{of-'prospectively implicited_attendantontological-contiguity ' educed-

existentialising/contextualising/textualising_'intelligibility/epistemicity/reflexivity-contiguity<imbued-notional cogency>' \}-conflatedness ${ }^{13}$-in-\{preconverging-disentailment by\} postconverging-ntailment, highlighting the 'concatenation of intemporal-projection inextricably with derived-denaturing -deprojections-in-distractiveness-of-intemporalprojection, with the former in relative longness-of-register-of- ${ }^{5}$ meaningfulness-and-teleology and the latter in relative shortness-of-register-of- ${ }^{56}$ meaningfulness-andteleology $/$ distractiveness' that occurs at the individuation-level and is reflected in the registryworldview/dimension-level by the concatenation of institutionalisation inextricably with uninstitutionalised-threshold ${ }^{102}$ as the former is in longness and the latter in shortness/distractiveness to the former. This conceptualisation of candidity/candour-capacity associated with notional $\sim$ deprocrypticism with regards to "de-mentation- 


\section{〈supereregatery $\sim$ ontological-de-mentation-or-dialectical-de-mentation-stranding-or-}

attributive-dialectics implications for ${ }^{83}$ reference-of-thought transcendence-andsublimity/sublimation/supererogatory $\sim$ de-mentativity' is in effect a 'more profound-andcomprehensive notion of différance construed rather with respect to the defining ${ }^{83}$ reference-ofthought of ${ }^{5}$ meaningfulness-and-teleology ${ }^{9}$ as of prospective relative-ontologicalcompleteness ${ }^{87}$-of- ${ }^{83}$ reference-of-thought' and can be qualified as 'futural différance' as of its suprastructural nature, and goes beyond the limits of a Derridean perspective of différance as 'historial différance' rather articulated from 'presencing-as-prospective-relative-ontologicalcompleteness $^{87}$-of- ${ }^{83}$ reference-of-thought construing of past-as-prior-relative-ontologicalincompleteness ${ }^{88}$-of- ${ }^{8}$ reference-of-thought in ad-hoc reassessing of ${ }^{56}$ meaningfulness-andteleology ${ }^{9}$ of presencing-as-prospective as from its very own ${ }^{83}$ reference-of-thought in grasping alterations of ${ }^{5}$ meaningfulness-and-teleology ${ }^{9}$ going back from the past but not to the point of putting-into-question the presencing-as-prospective overall ${ }^{83}$ reference-of-thought in prospective transcendence-and-sublimity/sublimation/supereregatory $\sim$ de-mentativity'; such that the transcendence-and-sublimity/sublimation/supererogatery $\sim$ de-mentativity implications of 'historial différance' is rather obscure as beyond-the-consciousness-awareness-teleology $<$ of-preconverging-existential-extrication-as-of-existential-unthought $>$ though ancillary as to the possibility of eventual cumulating of 'historial différance' realterations of meaningfulnessand-teleology ${ }^{9}$ enabling the beyond-the-consciousness-awareness possibility of subsequent presencing-as-prospective $\quad{ }^{83}$ reference-of-thought $\quad$ transcendence-andsublimity/sublimation/supererogatoryade-mentativity. Whereas such candidity/candourcapacity conceptualisation associated with notional deprocrypticism future perspective 'futural différance construed suprastructurally as being fully aware of ${ }^{83}$ reference-of-thought-ofmeaningfulness-and-teleology prospective transcendental implications as of the affirmation/projection/assertion/notional self-distantiation/dueness-validating- 
logicising/suitable-measuringinstrument-validating-measuring-<as-to-postconverging-ordialectical-thinking -apriorising-psychologism> of prospective relative-ontologicalcompleteness ${ }^{87}$-of- ${ }^{83}$ reference-of-thought is articulated as from our prior/transcended/superseded relative-ontological-incompleteness ${ }^{8}$-of- ${ }^{83}$ reference-of-thought but now rather contemplating of its defined ${ }^{83}$ reference-of-thought as construed from the futureas-prospective-relative-ontological-completeness ${ }^{87}$-of- ${ }^{83}$ reference-of-thought placeholdersetup/mental-devising-representation/mentation/consciousness-awareness-teleology ${ }^{9}, \quad$ thus undermining prior/transcended/superseded defined ${ }^{83}$ reference-of-thought at its uninstitutionalised-threshold ${ }^{102}$ and highlighting as of 'implicited_attendant-ontologicalcontiguity $^{67}$, educed-

existentialising/contextualising/textualising_intelligibility/epistemicity/reflexivity-contiguity$<$ imbued-notional $\sim$ cogency $>,{ }^{\prime},-<$ reifying-or-elucidating-of-prospective-relative-ontologicalcompleteness -of- reference-of-thought- devolving-as-of-instantiative-context> that the '<amplituding/formative $>$ wooden-language-〈imbued-temporal-mereform/virtualities/dereification/akrasiatic-drag/denatured/preconverging-or-dementing narratives - of-the- reference-of-thought- categorical-imperatives/axioms/registryteleology $>$ of prior/transcended/superseded registry-worldview/dimension' imply it is notupholding/failing intemporal-preservation-entropy-or-contiguity-or-ontological-preservation (beyond-the-consciousness-awareness-teleology ${ }^{\circ}<$ of-preconverging-existential-extricationas-of-existential-unthought>), and hence is construed prospectively as of ' ${ }^{83}$ reference-ofthought - degraded-devolving-as-of-uninstitutionalised-threshold ${ }^{102}$, as of the trace of 'institutionalised-as-postconverging/dialectical-thinking -and-uninstitutionalised-aspreconverging-or-dementing ${ }^{20}$-apriorising-psychologism ${ }^{5}$ meaningfulness-and-teleology ${ }^{9}$ ' of prior/transcended/superseded defined ${ }^{83}$ reference-of-thought; and so as the psychoanalyticunshackling/memetic-reordering/institutional-recomposuring for 
prior/transcended/superseded defined reference-of-thought transcendence-andsublimity/sublimation/supererogatoryade-mentativity into future-as-prospective defined reference-of-thought as of ${ }^{15}$ de-mentation-〈supererogatory $\sim$ ontological-de-mentation-ordialectical-de-mentation - stranding-or-attributive-dialectics $\rangle$. In other words, such a 'futural différance' is predicated on what is implied by apriorising/axiomatising/referencing-\{of'prospectively_implicited_attendant-ontological-contiguity ' ceducedexistentialising/contextualising/textualising_'intelligibility/epistemicity/reflexivity-contiguity$<$ imbued-notional cogency $\left.>^{\prime}\right\}$-conflatedness ${ }^{13}$ in-\{preconverging-disentailment by\} postconverging-entailment as of intemporal/ontological/social/species $/{ }^{103}$ universal/transcendental $/{ }^{5}$ maximalisingrecomposuring-for-relative-ontological-completeness ${ }^{8}$ —unenframed/reontologising conceptualisation postconverging-de-mentating/structuring/paradigming that preconverging/postconverging-de-mentatively/structurally/paradigmatically makes the futureas-prospective-relative-ontological-completeness ${ }^{87}$-of- ${ }^{83}$ reference-of-thought the whole grounding for ${ }^{5}$ meaningfulness-and-teleology ${ }^{99}$ as of intrinsic-reality/ontological-veridicality as it supersedes as an opened-construct-of- meaningfulness-and-teleology the $<$ amplituding/formative $>$ wooden-language-〈imbued - averaging-of-thought- $<$ as-toleveling/ressentiment/closed-construct-of- meaningfulness-and-teleology -as-of'nondescript/ignorable-void '-with-regards-to-prospective-apriorising-implications $>>$ beyondthe-consciousness-awareness-teleology ${ }^{9}<$ of-preconverging-existential-extrication-as-ofexistential-unthought $>$ incrementalism-in-relative-ontological-incompleteness enframed/disontologising conceptualisation dispositions of prior/transcended/superseded perversion-and-derived- ${ }^{7}$ perversion-of- ${ }^{8}$ reference-of-thought- $<$ as-preconverginglyapriorising/axiomatising/referencing-in-nonconviction/madeupness/bottomlining-as-toshallow-supererogation $>$. A candidity/candour-capacity notional ${ }^{18 \text { deprocrypticism }}$ 
placeholder-setup/mental-devising-representation/mentation/consciousness-awarenessteleology' as of 'futural différance' is one that preconverging/postconverging-dementatively/structurally/paradigmatically factors in the defining human-subpotencyaporia/undecidability/dilemma/ought-indeterminacy/deficiency/limitation/constraint—imbued'notional firstnaturedness-formativeness-<as-to-eventualising -inkling-drive-or-seedingmisprising $>$ temporal-to-intemporal-dispositions- $<$ so-construed-as-from-perspectiveontological-normalcy/postconvergence>'-existentialism-form-factor with respect to meaningfulness-and-teleology, and thus grasp as of knowledge-notionalisation that any implied meaningfulness-and-teleology ${ }^{56}$ should be construed by apriorising/axiomatising/referencing-\{of-‘prospectively_implicited_attendant-ontologicalcontiguity ' educedexistentialising/contextualising/textualising_'intelligibility/epistemicity/reflexivity-contiguity<imbued-notional cogency >' \}-conflatedness ${ }^{13}$-in-\{preconverging-disentailment-by\} postconverging-entailment <amplituding/formative-epistemicity $>$ causality $\sim$ as-to-projectivetotalitative-implications-of-prospective- nonpresencing,-for-explicating relativeunreflexivity/relative-reflexivity ontological-contiguity as of the 'concatenation of intemporal-projection inextricably with derived-denaturing -deprojections-in-distractivenessof-intemporal-projection with the former in relative longness-of-register-of- ${ }^{5}$ meaningfulnessand-teleology and the latter in relative shortness-of-register-of- ${ }^{5}$ meaningfulness-andteleology $/$ distractiveness' in order to better skew for intemporality ${ }^{52} / \operatorname{longness}$ as ontology. So a futural différance necessarily projects preconverging/postconverging-dementatively/structurally/paradigmatically apriorising/axiomatising/referencing-\{of'prospectively implicited_attendant-ontological-contiguity ' educedexistentialising/contextualising/textualising_'intelligibility/epistemicity/reflexivity-contiguity<imbued-notional cogency $\left.>^{\prime}\right\}$ - conflatedness ${ }^{13}$-in-\{preconverging-disentailment by\} 
postconverging-entailment $<$ amplituding/formative-epistemicity $>$ causality $\sim$ as-to-projectivetotalitative-implications-of-prospective- nonpresencing,-for-explicating relativeunreflexivity/relative-reflexivity ontological-contiguity as of the 'concatenation of intemporal-projection inextricably with derived-denaturing -deprojections-in-distractivenessof-intemporal-projection with the former in relative longness-of-register-of- ${ }^{56}$ meaningfulnessand-teleology and the latter in relative shortness-of-register-of- ${ }^{56}$ meaningfulness-andteleology /distractiveness' as to imply the ontologically-veridical construal of human relations meaningfulness-and-teleology ${ }^{9}$ is as of prospective secondnatured institutionalisation ensuring relative longness; implied as of dimensionality-of-sublimating ${ }^{25}$ <<amplituding/formative >supererogatory -de-mentativeness/epistemic-growth-orconflatedness /transvaluative-rationalising/transepistemicity/anamnestic-residuality/spiritdrivenness-equalisation) exercise, more like a genuine notion of faith lies fully and completely within the individual without any pretence to external interpersonal appraisal, as such a latter manoeuvre simply opens up the avenue for human mortal-to-mortal impression-driven/goodnaturedness/wishfulness <amplituding/formative> wooden-language-〈imbued-averaging-ofthought-<as-to-leveling/ressentiment/closed-construct-of- meaningfulness-and-teleology -asof-'nondescript/ignorable-void ' '-with-regards-to-prospective-apriorising-implications $>>$ in social-aggregation-enabling rather than transversality-<for-sublimating-existentialeventuating/denouement,-from-'thinking at-first/pure-predisposition-preemptive-ofprospective disontologising/subontologising' as-of-prospectively-disambiguated-affirmedand-unaffirmed-'motif-and-apriorising/axiomatising/referencing'>101 of 'prospective postconverging-aporeticism-overcoming/unovercoming as the-Good/knowledgereification $\sim$ gesturing-and-accounting — of-epistemic-phenomenalism- $<$ inprospective_psychologismic apriorising/axiomatising/referencing-\{of-`prospectively implicited_attendant-ontological-contiguity ' educed- 
existentialising/contextualising/textualising_'intelligibility/epistemicity/reflexivity-contiguity$<$ imbued-notional $\left.\sim \operatorname{cogency}>^{\prime} \quad\right\}$-conflatedness -in-\{preconverging disentailment by\} postconverging-entailment $>$ /understanding/<amplituding/formativeepistemicity $>$ causality $\sim$ as-to-projective-totalitative-implications-of-prospectivenonpresencing,-for-explicating relative-unreflexivity/relative-reflexivity - ontologicalcontiguity , intrinsic-reality/ontological-veridicality transcendentalenabling/sublimating/supereregatory $\sim$ de-mentativity thus undermining the more decisive element of futural différance as based on ontological-faith-notion-or-ontological-fideismimbued-underdetermination-of-motif-and-apriorising/axiomatising/referencing-as-so-being-asof-existential-reality driven organic-knowledge as setting up the $<$ cumulating/recomposuring attendant-ontological-contiguity $>$-successive registryworldviews/dimensions institutionalisations ${ }^{83}$ reference-of-thought in their respective allpervasiveness of transcendentally-enabling-level-of $\sim$ ontological-good-faith-orauthenticity $\%$ objectification/desubjectification-as-objectification-<as-to-ontological-faithnotion-or-ontological-fideism - imbued-underdetermination-of-motif-andapriorising/axiomatising/referencing-as-so-being-as-of-existential-reality as antinihilism> axiomatic-construct of ${ }^{56}$ meaningfulness-and-teleology' 'superseding successive defining human finitudes as destructuring-threshold-〈uninstitutionalised-threshold /presublimatingdesublimating-decisionality $>\sim$ of-ontological-performance ${ }^{22}-<$ including-virtue-asontology $>$ /morality/ethics/justice/etc. towards attaining successive prospective relativeontological-completeness ${ }^{87}$-of- ${ }^{8}$ reference-of-thought as institutionalisations'. Such a construal of futural différance preconverging/postconverging-dementatively/structurally/paradigmatically answers the Heideggerian techne concern as construed by this author of humankind thrown in the midst of the technical as utility while without 'matching notional philosophically developed mindset $/{ }^{3}$ reference-of-thought for a coherent 
grasp and aligning with the organic mental origination as of ontological-faith-notion-orontological-fideism - imbued-underdetermination-of-motif-and-

apriorising/axiomatising/referencing-as-so-being-as-of-existential-reality enabling that technical knowledge to arise-and-be-elevating-of-contemplation-and-Being in-the-very-firstplace and prospectively'. But rather related to as of transcendence-unenablinguninstitutionalised-threshold ${ }^{102}$ in alienation - as-inauthentic/poorly-objectified/poorly-

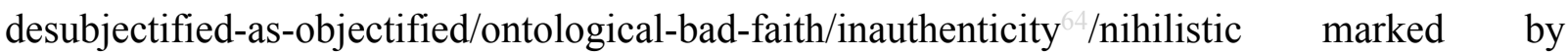
incoherence of contemplative mindset $/{ }^{3}$ reference-of-thought development in the midst of the technical world as rather literally 'hurling along' prospectively prospectively-underdevelopedBeing-as-of-unexpanded-ontological-framework; and so as reflected by apriorising/axiomatising/referencing-\{of-'prospectively_implicited_attendant-ontologicalcontiguity ' educedexistentialising/contextualising/textualising_'intelligibility/epistemicity/reflexivity-contiguity<imbued-notional cogency $\left.>^{\prime}\right\}$-conflatedness ${ }^{13}$-in-\{preconverging-disentailment by\} postconverging-entailment <amplituding/formative-epistemicity $>$ causality $\sim$ as-to-projectivetotalitative-implications-of-prospective- nonpresencing,-for-explicating relative-

mneflexivity/relative reflexivity ontological-contiguity as of the 'concatenation of intemporal-projection inextricably with derived-denaturing -deprojections-in-distractivenessof-intemporal-projection'. Consider a metaphysics-of-absence-〈implicited-epistemic-veracityof- nonpresencing-<perspective-ontological-normalcy/postconvergence $>>$ elucidation with regards to say a remote/isolated non-positivistic animist/base-institutionalisation society for instance which by some token has sustainable-and-learned access to basic but greatly enhancing productive techniques from travellers of a positivistic culture but without a substantial corresponding organisational and institutional diffusion associated with such greatly enhancing productive techniques due to the very brief nature of the encounter or 
disconnected/incoherent/perfunctory/chaotic nature of their relations, this will preconverging/postconverging-de-mentatively/structurally/paradigmatically have degenerative effect on such an animistic social organisation wherein this isn't enhancing of the society's social organisation and relations and will be possibly disruptive. This example isn't that farfetched as anthropological evidence of such cases abounds with many native societies so disrupted by culturally alienating positivistic material diffusion. Human material/technical development and corresponding mentality as of Being-development/ontological-framework-expansion-as-todepth-of-ontologising-development-as-infrastructure-of- meaningfulness-and-teleology are inextricable and critical in reflecting holographically-<conjugatively-and-transfusively $>$ the relative-unreflexivity/relative-reflexivity - ontological-contiguity of-the-humaninstitutionalisation-process including our positivism-procypticism registryworldview/dimension. Inevitably the disparity of being thrown in the midst of technical development associated with the 'underdevelopment of Being construed herein as of individuation-level and registry-worldview/dimension-level disjointedness-as-of- referenceof-thought with respect to our positivism- ${ }^{80}$ procrypticism registry-worldview/dimension' is by itself a preconverging-de-mentating/structuring/paradigming basis for human vices-andimpediments ${ }^{105}$ whether at a micro-level interactional or macro-level social and political preconverging-de-mentating/structuring/paradigming basis, notwithstanding our inclination for $<$ amplituding/formative-epistemicity $>$ totalising $\sim$ self-referencingsyncretising/circularity/interiorising/akrasiatic-drag ${ }^{34}$ where what passes as profound is our temporal mortal-to-mortal acquiescing as social-aggregation-enabling rather than a sense of intersolipsistic intemporal projection of intrinsic-reality/ontological-veridicality; with mentaldispositions rather geared towards temporal extricatory preconverging-dementating/structuring/paradigming as of apriorising/axiomatising/referencing-\{of'prospectively_implicited_attendant-ontological-contiguity ' educed- 
existentialising/contextualising/textualising_'intelligibility/epistemicity/reflexivity-contiguity<imbued-notional cogency>' $\}$-constitutedness ${ }^{14}$-in-preconverging-entailment, rather than intemporal/ontological/social/species/ ${ }^{103}$ universal/transcendental/ ${ }^{5}$ maximalisingrecomposuring-for-relative-ontological-completeness 37 unenframed/reontologising conceptualisation postconverging-de-mentating/structuring/paradigming as of apriorising/axiomatising/referencing-\{of-'prospectively implicited_attendant ontologicalcontiguity ' educedexistentialising/contextualising/textualising_'intelligibility/epistemicity/reflexivity-contiguity-

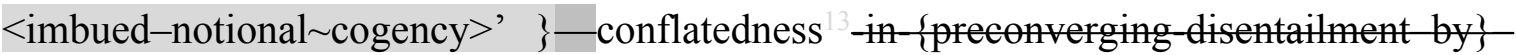
postconverging-entailment as enabling and upholding the relative-unreflexivity/relativereflexivity - ontological-contiguity ${ }^{67}$ of-the-human-institutionalisation-process ${ }^{68}$. Without the development of Being à la Heideggerian imagination the relative-unreflexivity/relativereflexivity ontological-contiguity ${ }^{67} \sim$ of-the-human-institutionalisation-process ${ }^{68}$ itself comes to a halt as of failing of Being transcendentally-enabling-level-of $\sim$ ontological-good-faith-orauthenticity $\%$ objectification/desubjectification-as-objectification- $<$ as-to-ontological-faithnotion-or-ontological-fideism - imbued-underdetermination-of-motif-andapriorising/axiomatising/referencing-as-so-being-as-of-existential-reality as antinihilism> implied by ontological-faith-notion-or-ontological-fideism - imbued-underdetermination-ofmotif-and-apriorising/axiomatising/referencing-as-so-being-as-of-existential-reality driven organic-knowledge; as recurrent-utter-uninstitutionalisation 'requires the transcendentallyenabling-level-of ontological-good-faith-or-authenticity ${ }^{6 / \text { objectification/desubjectification- }}$ as-objectification-<as-to-ontological-faith-notion-or-ontological-fideism-imbuedunderdetermination-of-motif-and-apriorising/axiomatising/referencing-as-so-being-as-ofexistential-reality as antinihilism $>100$ of Being' as of rulemaking-over-non-rulesapriorising/axiomatising/referencing-psychologism to attain base-institutionalisation- 
ununiversalisation, which requires the same as of ${ }^{103}$ universalisation-directed-rulemaking-overnon-rules - apriorising/axiomatising/referencing-psychologism to attain ${ }^{103}$ universalisationnon-positivism/medievalism, which requires the same as of positivising/rational-empiricismbased-universalisation-directed-rulemaking-over-non-rules-

apriorising/axiomatising/referencing-psychologism to attain positivism- ${ }^{80}$ procrypticism, and which prospectively requires the same as of preempting - disjointedness-as-of- ${ }^{8}$ reference-ofthought,-as-to- ${ }^{6}{ }^{2}<$ amplituding/formative-epistemicity $>$ growth-or-

conflatedness ${ }^{13}$ /transvaluative-rationalising/transepistemicity/anamnestic-residuality/spiritdrivenness' - in-superseding-mere-formulaic-positivising/rational-empiricism-baseduniversalisation-directed-rulemaking-over-non-rules_-apriorising/axiomatising/referencingpsychologism to attain deprocrypticism! The notion of ${ }^{83}$ reference-of-thought-as-topreconverging/postconverging-de-mentating/structuring/paradigming_-ontological-

performance $^{72}-<$ including-virtue-as-ontology $>$ /morality/ethics/justice/etc. as being a wholly internal process of apriorising/axiomatising/referencing-\{of-"prospectively implicited_attendant-ontological-contiguity ' educedexistentialising/contextualising/textualising_'intelligibility/epistemicity/reflexivity-contiguity<imbued-notional cogency>' \}-conflatedness ${ }^{13}$ in 'preconverging disentalment by\} postconverging entailment, highlighting the 'concatenation of intemporal-projection inextricably with derived-denaturing -deprojections-in-distractiveness-of-intemporalprojection, with the former in relative longness-of-register-of- ${ }^{5}$ meaningfulness-and-teleology and the latter in relative shortness-of-register-of- $-{ }^{56}$ meaningfulness-andteleology $/$ distractiveness', implied with regards to Being underdevelopment across the $<$ cumulating/recomposuring attendant-ontological-contiguity $>$-successive registryworldviews/dimensions also speaks to how intrinsic-reality/ontological-veridicality transcendental-enabling/sublimating/supererogatory $\sim$ de-mentativity behind the relative- 
unreflexivity/relative-reflexivity — ontological-contiguity ${ }^{67}$ of-the-human-institutionalisationprocess ${ }^{6}$ can and is often usurped by eruditic establishments by a nombrilistic elicitation of temporal mental-dispositions as to the commonsense/social-aggregation-enabling of a given registry-worldview/dimension as a denaturing construal in terms-as-of-axiomatic-construct that are effectively divorced and subpar to the organic-knowledge as enabling the intrinsicreality/ontological-veridicality transcendental-enabling/sublimating/supererogatory dementativity in reflecting holographically-<conjugatively-and-transfusively $>$ the relativeunreflexivity/relative-reflexivity - ontological-contiguity of-the-human-institutionalisationprocess . The idea that intrinsic-reality/ontological-veridicality transcendentalenabling/sublimating/supererogatory $\sim$ de-mentativity is only the panache of the technical as of the sciences and that there is no need for Being-development/ontological-framework-expansionas-to-depth-of-ontologising-development-as-infrastructure-of- meaningfulness-and-

teleology to be instigative-and-be-elevating-of-contemplation-and-Being in complement as of human development is nothing less than a derogation that renders such an establishment erudition no different, as of human-subpotency-aporia/undecidability/dilemma/oughtindeterminacy/deficiency/limitation/constraint—imbued-'notional firstnaturednessformativeness-as to eventualising inkling drive or seeding misprising $>$ temporal-tointemporal-dispositions-<so-construed-as-from-perspective-ontologicalnormalcy/postconvergence>'-existentialism-form-factor, from the mediums, shamans, witchdoctors, dogmatic scholastics of prior registry-worldviews/dimensions as vested in their 'circular-pervasiveness <amplituding/formative> wooden-language-〈imbued-averaging-ofthought-<as-to-leveling/ressentiment/closed-construct-of- meaningfulness-and-teleology -asof-'nondescript/ignorable-void '-with-regards-to-prospective-apriorising-implications $>$ )' rather than moving ahead of human blithe and their platitudes, and construing the real possibility of human emancipation as of a prospective opened-construct-of- ${ }^{56}$ meaningfulness-and- 
teleology ; as the masses-defined-as-non-specialists can effectively be 'tolerated' to be ignorant as of the focussing possibility of human limited-mentation-capacity-as-subjecting 'educedunlimitedness/existence-sublimating nascence' to-limitedness/human-subpotency but that which is duty bound to a human Being-development/ontological-framework-expansion-as-todepth-of-ontologising-development-as-infrastructure-of- meaningfulness-and-teleology domain/specialism beyond-just-an-institutional-construct-but-existentially-<disentelegising/reentologising aporeticism $>$ is morally-and-intellectually bound to spearhead the effective development of that Being domain/specialism and not be involved in dithering, and so as of an intemporal/ontological/social/species $/{ }^{103}$ universal/transcendental $/{ }^{5}$ maximalisingrecomposuring-for-relative-ontological-completeness ${ }^{87}$ - unenframed/reontologising conceptualisation postconverging-de-mentating/structuring/paradigming.] END OF DIGRESSION (ON OVERALL CONCEPTION OF THE FULL POTENTIAL OF HUMAN ONTOLOGICAL-PERFORMANCE ${ }^{2}-<$ INCLUDING-VIRTUE-AS-

\section{ONTOLOGY $>$ )}

Prelogism ${ }^{78}$ at worst implies an ad-hoc problem of defect-of- ${ }^{54}$ logical-processing-or-logicalimplicitation - supposedly-apriorising-in-conviction-as-to-profound-supererogation of the registry-worldview's/dimension's- $-{ }^{83}$ reference-of-thought-for-social-functioning-and-

accordance, while postlogism 77 implies a fundamental defining being/existential/ontological/axiomatic-construct problem of ${ }^{77}$ perversion-of- ${ }^{8}$ reference-ofthought-<as-preconvergingly-apriorising/axiomatising/referencing-innonconviction/madeupness/bottomlining-as-to-shallow-supererogation $>$, that is inherently in circularity/recurrence/repetition/repeatability ${ }^{10}$ thus requires ontological-reconstituting-as-toconflatedness $^{13}$. postlogism 77 is thus an expansive construct developing into conjugatedpostlogism 77 associated with endemising/enculturationg social psychopathy, as temporaldispositions arrive at beyond-the-consciousness-awareness-teleology ${ }^{9}-<$ of - preconverging- 
existential-extrication-as-of-existential-unthought $>$ perversion-and-derived- 7 perversion-ofreference-of-thought-<as-preconvergingly-apriorising/axiomatising/referencing-innonconviction/madeupness/bottomlining-as-to-shallow-supererogation $>$ as mentaldispositions finalities/determinations inducing disjointedness-as-of- ${ }^{8}$ reference-of-thought-asmisappropriated-meaningfulness associated with procrypticism. Prelogism ${ }^{78}$ even when ontologically-flawed can be compared to the defect arising using a 'correct apriorising/axiomatising/referencing/intelligibilitysettingup/measuringinstrumentingproducing-measurements' (appropriateness-of- ${ }^{-3}$ reference-of-thought-as-of-conflatedness ${ }^{13}$ ) for aposteriorising/logicising/deriving/intelligising/measuring-purpose—of-obtainedmeasurements (to derive ${ }^{56}$ meaningfulness-and-teleology ${ }^{9}$ ) but in doing so aposteriorising/logicising/deriving/intelligising/measuring-purpose—of-obtainedmeasurements wrongly (construed as using the correct apriorising/axiomatising/referencing/intelligibilitysettingup/measuringinstrumentingproducing-measurements' wrongly) which specifically speaks of the possibility of reusing the 'same correct apriorising/axiomatising/referencing/intelligibilitysettingup/measuringinstrumentingproducing-measurements' as same appropriateness-of- ${ }^{2}$ reference-of-thought-as-ofconflatedness $^{13} \quad$ (notwithstanding the flawed aposteriorising/logicising/deriving/intelligising/measuring-purpose—of-obtainedmeasurements) for producing veridical ${ }^{56}$ meaningfulness-and-teleology ${ }^{9}$. While postlogism ${ }^{77}$ is akin to the 'defect of the apriorising/axiomatising/referencing/intelligibilitysettingup/measuringinstrumentingproducing-measurements itself' ( ${ }^{\prime}$ perversion-of- ${ }^{2}$ reference-of-thought-<as-preconverginglyapriorising/axiomatising/referencing-in-nonconviction/madeupness/bottomlining-as-toshallow-supererogation $>$ ) besides the 'specific act of 
aposteriorising/logicising/deriving/intelligising/measuring-purpose—of-obtained-

measurements' for producing veridical ${ }^{56}$ meaningfulness-and-teleology ${ }^{9}$, and speaks to a fundamental flaw that is bound to circularly/repetitively/recurrently give erroneous aposteriorising/logicising/deriving/intelligising/measuring-purpose—of-obtained-

$\begin{array}{llll}\text { measurements } \text { given incorrect } & \text { fundamentally }\end{array}$ apriorising/axiomatising/referencing/intelligibilitysettingup/measuringinstrumentingproducing-measurements. postlogism 77 thus speaks of the registry-worldview's/dimension'suninstitutionalised-threshold ${ }^{102}$-defect-<as-Being-or-ontological-or-existential-defect $>55$ in producing ${ }^{56}$ meaningfulness-and-teleology", thus divulging a " ${ }^{83}$ reference-of-thought existentialism construct defect' that is comprehensively devolving all across the given

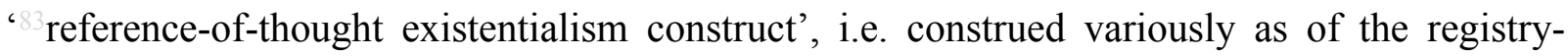
worldview/dimension ${ }^{5}$ meaningfulness-and-teleology ${ }^{9}$ 'implied specific teleological differentiation/scission/variance/disambiguation' as to its prior-institutionalisation-thresholdby-prospective-uninstitutionalised-threshold ${ }^{102}$ implied relative-ontological-completeness ${ }^{87}$-ofreference-of-thought), and so as of the contending-reference (meaningfulness 'implied teleological construct'), the ontological-reference (meaningfulness 'implied being/existential construct'), the meaningful-reference (meaningfulness 'implied contextualisation construct'), the anchoring-of-meaning (meaningfulness 'implied operant construal') and the apriorisingregistry (meaningfulness 'implied basic defining construct' in terms-as-of-axiomatic-construct of logical-dueness/profile/presumptuousness/assumptions/value-reference/teleology ${ }^{9}$ ). This elucidation of postlogism in comparison with the implications of a defective apriorising/axiomatising/referencing/intelligibilitysettingup/measuringinstrumentingproducing-measurements provides a comprehensive insight about the underlying 77 perversionof- reference-of-thought-<as-preconvergingly-apriorising/axiomatising/referencing-in- 
postlogism 7 -as-of- compulsing-nonconviction/madeupness/bottomlining-

$\langle<<$ decontextualising/de-existentialising of-attendant-intradimensional-

apriorising/axiomatising/referencing >-induced-disontologising'-of-the-'attendant-

intradimensional-ontologising'-imbued-<contextualising/existentialising $\sim$ attendant-

ontological-contiguity $>$;-in-shallow-supererogation $-<$ as-to-disontologising-perverted-

outcome-sought-precedes-existentially-veridical-'attendant-intradimensional-

apriorising/axiomatising/referencing'-logical-dueness $>>$ and its social derivation as conjugatedpostlogism 77 preconverging-or-dementing ${ }^{20}$-integration as of relative-ontologicalincompleteness ${ }^{8}$-of- ${ }^{8}$ reference-of-thought. That apparently minor twitch in the defective apriorising/axiomatising/referencing/intelligibilitysettingup/measuringinstrumenting-

producing-measurements' ( ${ }^{\prime}$ perversion-of- ${ }^{3}$ reference-of-thought-<as-preconverginglyapriorising/axiomatising/referencing-in-nonconviction/madeupness/bottomlining-as-to-

shallow-supererogation $>$ ) is a 'covert negative vista' that wrongly undermines/dismantles 'inherent/preceding intrinsic-reality/ontological-veridicality 'sublimating-epistemicimbricatedness/threadedness/recomposuring as of 'implicited_attendant-ontologicalcontiguity $^{67} \sim$ educed-

existentialising/contextualising/textualising_'intelligibility/epistemicity/reflexivity-contiguity$<$ imbued-notional $\sim$ cogency $>,{ }^{\prime},-<$ reifying-or-elucidating-of-prospective-relative-ontologicalcompleteness -of- reference-of-thought- devolving-as-of-instantiative-context $>$ as to existence-potency ${ }^{39} \sim$ sublimating-nascence,-disclosed-from-prospective-epistemicdigression —rules-of-apriorising/axiomatising/referencing-that-further-epistemicallyunconceal-the-very-ontologically-same-existential-reality' (from the perspective of the 'postconverging-or-dialectical-thinking ${ }^{-}{ }^{8}$ reference-of-thought in relative-ontologicalcompleteness $^{87}$ as depth-of-thought'), and so because the ${ }^{7}$ perversion-of- ${ }^{8}$ reference-ofthought-<as-preconvergingly-apriorising/axiomatising/referencing-in- 
nonconviction/madeupness/bottomlining-as-to-shallow-supererogation $>$ is existentially$<$ disontologising/re-ontologising aporeticism $>$ being related to as if it is of appropriateness-ofreference-of-thought-as-of-conflatedness ${ }^{13}$ with all the derived corresponding implications with respect to perverted representation of meaningfulness as well as teleologicallydegraded/preconverging-or-dementing ${ }^{20}$-reflexive/entailing-teleology 9 differentiation implications, given that all the 'apriorising $-{ }^{8}$ reference-of-thought/apriorising-registryelements (out of implicited attendant-ontological-contiguity ${ }^{67}$ ' educedexistentialising/contextualising/textualising_'intelligibility/epistemicity/reflexivity-contiguity$<$ imbued-notional $\sim$ cogency $>^{\prime},-<$ reifying-or-elucidating-of-prospective-relative-ontologicalcompleteness -of- reference-of-thought- devolving-as-of-instantiative-context $>$ )' which are \{epistemic-totalising 3 \} psychologismic-subliminality-of-individuation-effusing/worlding imbued logical-dueness-or-scape-or-frame, profile-or-stature, presumptuousness-or-arrogation, assumptions, value-reference and teleology ${ }^{9}$ falsely/deceptively induced by the ${ }^{74}$ perversion-ofreference-of-thought-<as-preconvergingly-apriorising/axiomatising/referencing-innonconviction/madeupness/bottomlining-as-to-shallow-supererogation $>$ (defect of the apriorising/axiomatising/referencing/intelligibilitysettingup/measuringinstrumenting producing-measurements itself) lead to a first-order faulty-mentation-procedure-deception-orurge $^{13}$ as perversion-and-derived- ${ }^{-7}$ perversion-of- ${ }^{3}$ reference-of-thought- $<$ as-preconverginglyapriorising/axiomatising/referencing-in-nonconviction/madeupness/bottomlining-as-toshallow-supererogation $>\quad$ (inappropriateness of the defective apriorising/axiomatising/referencing/intelligibilitysettingup/measuringinstrumentingproducing-measurements and the derived uses) and which subsequent implications then go on to induce a second-order level wrongly implied deception of ${ }^{54}$ logical-processing-or-logicalimplicitation-supposedly-apriorising-in-conviction-as-to-profound-supererogation of infinite deception possibilities with respect to the infinite possibilities of 'perfect ${ }^{5}$ logical- 
processing-or-logical-implicitation-supposedly-apriorising-in-conviction-as-to-profound-

supererogation ' on the false basis of the perversion-and-derived- perversion-of- ${ }^{-12 f e r e n c e-~}$ of-thought-<as-preconvergingly-apriorising/axiomatising/referencing-in-

nonconviction/madeupness/bottomlining-as-to-shallow-supererogation $>$ (infinite possibilities of errors arising for aposteriorising/logicising/deriving/intelligising/measuring-purpose-ofobtained-measurements with $\mathrm{a}$ defective apriorising/axiomatising/referencing/intelligibilitysettingup/measuringinstrumentingproducing-measurements and the derived uses) for producing 'meaningfulness-andteleology ${ }^{9}$ (aposteriorising/logicising/deriving/intelligising/measuring-purpose-of-obtainedmeasurements) based on the perversion-and-derived- perversion-of- ${ }^{3}$ reference-of-thought$<$ as-preconvergingly-apriorising/axiomatising/referencing-in-

nonconviction/madeupness/bottomlining-as-to-shallow-supererogation $>$ (defect of the apriorising/axiomatising/referencing/intelligibilitysettingup/measuringinstrumentingproducing-measurements itself and its derived uses). Just as fundamentally not resolving the defect of apriorising/axiomatising/referencing/intelligibilitysettingup/measuringinstrumentingproducing-measurements induces systematically

circularity/recurrence/repetition/repeatability in the 'incorrect aposteriorising/logicising/deriving/intelligising/measuring-purpose-of-obtainedmeasurements' in the overall enterprise of the aposteriorising/logicising/deriving/intelligising/measuring-purpose-of-obtainedmeasurements (say architectural for instance) and so 'reflected as preconverging-ordementing -apriorising-psychologism/unsoundness-or-ontological-bad-faith/inauthenticity ${ }^{64}$ of- ${ }^{3}$ reference-of-thought' in relation 'correct aposteriorising/logicising/deriving/intelligising/measuring-purpose—of-obtained- 
measurements' reflected as postconverging-or-dialectical-thinking ${ }^{21}$-apriorisingpsychologism/soundness-or-ontological-good-faith/authenticity ${ }^{6}$-of- reference-of-thought, likewise perversion-of- ${ }^{8}$ reference-of-thought-<as-preconverginglyapriorising/axiomatising/referencing-in-nonconviction/madeupness/bottomlining-as-toshallow-supererogation $>$ related to as being of appropriateness-of- ${ }^{83}$ reference-of-thought-asof-conflatedness ${ }^{13}$ wrongly undermines/dismantles the 'existential ${ }^{56}$ meaningfulness-andteleology ${ }^{\circ}$, implied by 'inherent/preceding intrinsic-reality/ontological-veridicality 'sublimating-epistemic-imbricatedness/threadedness/recomposuring as of 'implicited_attendant-ontological-contiguity ${ }^{67}$ ' educedexistentialising/contextualising/textualising_intelligibility/epistemicity/reflexivity-contiguity$<$ imbued-notional $\sim \operatorname{cogency}>,{ }^{\prime},-<$ reifying-or-elucidating-of-prospective-relative-ontologicalcompleteness -of- reference-of-thought- devolving-as-of-instantiative-context> as to existence-potency ${ }^{32} \sim$ sublimating-nascence,-disclosed-from-prospective-epistemicdigression—rules-of-apriorising/axiomatising/referencing-that-further-epistemicallyunconceal-the-very-ontologically-same-existential-reality' (from the perspective of the 'postconverging-or-dialectical-thinking ${ }^{2}{ }^{83}$ reference-of-thought in relative-ontologicalcompleteness ${ }^{87}$ as depth-of-thought'), and such ${ }^{7}$ perversion-of- ${ }^{8}$ reference-of-thought- $<$ aspreconvergingly-apriorising/axiomatising/referencing-innonconviction/madeupness/bottomlining-as-to-shallow-supererogation $>$ is 'reflected as preconverging-or-dementing ${ }^{20}$-apriorising-psychologism/unsoundness-or-ontological-badfaith/inauthenticity ${ }^{64}$-of- ${ }^{83}$ eference-of-thought' in relation to veridical 'existential meaningfulness-and-teleology ${ }^{9}$ reflected as postconverging-or-dialectical-thinking apriorising-psychologism/soundness-or-ontological-good-faith/authenticity ${ }^{6}$-of- reference-ofthought. The critical importance of highlighting 'inherent/preceding intrinsicreality/ontological-veridicality here as 'sublimating-epistemic- 
imbricatedness/threadedness/recomposuring as of 'implicited_attendant-ontologicalcontiguity $^{67}$; educed-

existentialising/contextualising/textualising_intelligibility/epistemicity/reflexivity_contiguity$<$ imbued-notional $\sim \operatorname{cogency}>{ }^{\prime},-<$ reifying-or-elucidating-of-prospective-relative-ontologicalcompleteness -of- reference-of-thought- devolving-as-of-instantiative-context> as to existence-potency ${ }^{39} \sim$ sublimating-nascence,-disclosed-from-prospective-epistemicdigression—rules-of-apriorising/axiomatising/referencing-that-further-epistemicallyunconceal-the-very-ontologically-same-existential-reality' (from the perspective of the 'postconverging-or-dialectical-thinking ${ }^{2}{ }^{8}$ reference-of-thought in relative-ontologicalcompleteness $^{87}$ as depth-of-thought') has to do with the fact that the language (say technical terminology for architecture) for construing ${ }^{5}$ meaningfulness-and-teleology (purposeful architectural aposteriorising/logicising/deriving/intelligising/measuring-purpose-of-obtainedmeasurements) is equally available to both the appropriateness-of- ${ }^{3}$ reference-of-thought-as-ofconflatedness (correct apriorising/axiomatising/referencing/intelligibilitysettingup/measuringinstrumentingproducing-measurements) and the ${ }^{77}$ perversion-of- ${ }^{83}$ reference-of-thought- $<$ as-preconverginglyapriorising/axiomatising/referencing-in-nonconviction/madeupness/bottomlining-as-to-

shallow-supererogation $>\quad$ (defective apriorising/axiomatising/referencing/intelligibilitysettingup/measuringinstrumentingproducing-measurements) for expression as aposteriorising/logicising/deriving/intelligising/measuring-purpose—of-obtainedmeasurements due to the 'covert negative vista' of the ${ }^{7}$ perversion-of- ${ }^{8}$ reference-of-thought$<$ as-preconvergingly-apriorising/axiomatising/referencing-innonconviction/madeupness/bottomlining-as-to-shallow-supererogation $>$ as well as derivedperversion-of- ${ }^{3}$ reference-of-thought- $<$ as-preconvergingly- 
apriorising/axiomatising/referencing-in-nonconviction/madeupness/bottomlining-as-to-

shallow-supererogation $>$ (derived relation to the defective apriorising/axiomatising/referencing/intelligibilitysettingup/measuringinstrumentingproducing-measurements as being 'correct apriorising/axiomatising/referencing/intelligibilitysettingup/measuringinstrumenting_producing-measurements'). Thus technically speaking all elocution associated with the defective apriorising/axiomatising/referencing/intelligibilitysettingup/measuringinstrumentingproducing-measurements for the aposteriorising/logicising/deriving/intelligising/measuringpurpose-of-obtained-measurements (perversion-and-derived- ${ }^{7}$ perversion-of- ${ }^{8}$ reference-ofthought-<as-preconvergingly-apriorising/axiomatising/referencing-innonconviction/madeupness/bottomlining-as-to-shallow-supererogation $>$ ), as meaningfulness-and-teleology is preconverging/postconverging-dementatively/structurally/paradigmatically constrained as to threshold-ofnonconviction/madeupness/bottomlining-in-shallow-supererogation $<-<$ as-to- 'attendantintradimensional'-prospectively-disontologising preconverging/dementing -apriorisingpsychologism>, as from candidity/candour-capacity perspective. The implication being that preconverging/postconverging-de-mentatively/structurally/paradigmatically $\quad{ }^{83}$ reference-ofthought (grandest-axiomatic-construct) in effect in its soundness or unsoundness induces devolving sound or unsound ${ }^{56}$ meaningfulness-and-teleology ; with appropriateness-ofreference-of-thought-as-of-conflatedness ${ }^{13} \quad$ preconverging/postconverging-dementatively/structurally/paradigmatically implying 'appropriate devolving meaningfulnessand-teleology ${ }^{9}$ of reference', ${ }^{7}$ perversion-of- ${ }^{8}$ reference-of-thought-<as-preconverginglyapriorising/axiomatising/referencing-in-nonconviction/madeupness/bottomlining-as-toshallow-supererogation preconverging/postconverging-dementatively/structurally/paradigmatically implying 'perverted devolving ${ }^{5}$ meaningfulness-and- 
teleology of reference' and derived- perversion-of- ${ }^{9}$ reference-of-thought- $<$ aspreconvergingly-apriorising/axiomatising/referencing-in-

nonconviction/madeupness/bottomlining-as-to-shallow-supererogation

preconverging/postconverging-de-mentatively/structurally/paradigmatically implying 'derivedperverted devolving ${ }^{56}$ meaningfulness-and-teleology ${ }^{99}$ of reference'. (Hence the circularpervasiveness reflex by which a registry-worldview always resets its ${ }^{56}$ meaningfulness-andteleology as neuter/conviction-as-to-profound-supererogation -or-postconverging-ordialectical-thinking -apriorising-psychologism and so even at the point of its underlying demonstrated incompleteness-of- ${ }^{2}$ reference-of-thought behind its perversion-and-derivedperversion-of- ${ }^{3}$ reference-of-thought-<as-preconvergingly-

apriorising/axiomatising/referencing-in-nonconviction/madeupness/bottomlining-as-toshallow-supererogation $>$ is nothing but a 'flawed <amplituding/formativeepistemicity $>$ totalising $\sim$ self-referencing-syncretising/circularity/interiorising/akrasiatic-drag exercise', and revealed so by the prospective/transcending/superseding registry-worldview.) This technically highlights two issues, the inherent ${ }^{7}$ perversion-of- ${ }^{8}$ reference-of-thought- $<$ aspreconvergingly-apriorising/axiomatising/referencing-in-

nonconviction/madeupness/bottomlining-as-to-shallow-supererogation $>$ and the registryworldview/dimension relative-ontological-incompleteness ${ }^{8}$-induced,-`threshold-ofnonconviction/madeupness/bottomlining-in-shallow-supererogation $-<$ as-to-'attendantintradimensional'-prospectively-disontologising preconverging/dementing -apriorisingpsychologism>', that induces a derived- perversion-of- ${ }^{-}$reference-of-thought- $<$aspreconvergingly-apriorising/axiomatising/referencing-innonconviction/madeupness/bottomlining-as-to-shallow-supererogation $>$; in the sense that while a relative-ontological-incompleteness ${ }^{8}$-induced,-'threshold-ofnonconviction/madeupness/bottomlining-in-shallow-supererogation $<$ - as-to-'attendant- 
intradimensional'-prospectively-disontologising preconverging/dementing -apriorising-

psychologism>' as the non-positivism/medievalism mindset $/{ }^{3}$ reference-of-thought will certainly be enabling for a non-positivism/medievalism type of ${ }^{7}$ perversion-of- ${ }^{83}$ reference-ofthought- $<$ as-preconvergingly-apriorising/axiomatising/referencing-innonconviction/madeupness/bottomlining-as-to-shallow-supererogation $>$ like notions-andaccusations-of-sorcery to arise in circularity/recurrence/repetition/repeatability ${ }^{10}$ (as-of'perversion-and-derived- ${ }^{7}$ perversion-of- ${ }^{-3}$ reference-of-thought- $<$ as-preconverginglyapriorising/axiomatising/referencing-in-nonconviction/madeupness/bottomlining-as-toshallow-supererogation >-as-to-uninstitutionalised-threshold ${ }^{02}$-self-referencing-syncretisingand-subtransversality-<in-desublimating-existential-eventuating/denouement $>\sim$ of-motif-andapriorising/axiomatising/referencing') in a non-positivism/medievalism social-setup, a positivistic mindset $/{ }^{8}$ reference-of-thought prospective relative-ontological-completeness ${ }^{87}$-ofreference-of-thought makes it impossible by its 'rational-empiricism/positivising $<$ amplituding/formative-epistemicity $>$-totalising $\sim$ renewing-realisation/re-perception/rethought-as-utter-placeholder-setup-ontological-rescheduling-〈by-a-renewing-ofapriorising/axiomatising/referencing-psychologism-as-the-new-referencing-basis-ofprospective- meaningfulness-and-teleology > ${ }^{83}$ reference-of-thought', likewise a mindset $/{ }^{8}$ reference-of-thought of ${ }^{80}$ procrypticism-or-disjointedness-as-of- ${ }^{8}$ reference-ofthought is all too ready to endemise/enculturate the possibility of psychopathy and social psychopathy arising in circularity/recurrence/repetition/repeatability ${ }^{10}$ (as-of-'perversion-andderived- ${ }^{7}$ perversion-of- ${ }^{3}$ reference-of-thought- $<$ as-preconverginglyapriorising/axiomatising/referencing-in-nonconviction/madeupness/bottomlining-as-toshallow-supererogation >-as-to-uninstitutionalised-threshold ${ }^{102}$-self-referencing-syncretisingand-subtransversality-<in-desublimating-existential-eventuating/denouement $>\sim$ of-motif-andapriorising/axiomatising/referencing') given its relative-ontological-incompleteness ${ }^{8}$-induced,- 
'threshold-of-nonconviction/madeupness/bottomlining-in-shallow-supererogation

‘attendant-intradimensional'-prospectively-disontologising preconverging/dementing

apriorising-psychologism> such that it is a mindset $/{ }^{-3}$ reference-of-thought of deprocrypticism-or-preempting — disjointedness-as-of- ${ }^{3}$ reference-of-thought,-as-to-

${ }^{3}<$ amplituding/formative-epistemicity $>$ growth-or-conflatedness ${ }^{13} /$ transvaluative-

rationalising/transepistemicity/anamnestic-residuality/spirit-drivenness'—in-supersedingmere-formulaic-positivising/rational-empiricism-based-universalisation-directed-rulemakingover-non-rules - apriorising/axiomatising/referencing-psychologism,-

〈apriorising/axiomatising/referencing-\{of-"prospectively_implicited_attendant-ontologicalcontiguity ' educed-

existentialising/contextualising/textualising_intelligibility/epistemicity/reflexivity-contiguity<imbued-notional cogency >' \}-conflatedness ${ }^{13}$-in-\{preconverging-disentailment by\} postconverging-entailment) (also referred to as ${ }^{18}$ deprocrypticism-or-preemptingdisjointedness-as-of- ${ }^{8}$ reference-of-thought), preempting procrypticism, so construed by 'notional $\sim$ deprocrypticism ontologically-perspectival-elevated/pedestaling-aspostconverging-or-dialectical-thinking ${ }^{2}$-differentiation-as-of-supratransversality-<insublimating-existential-eventuating/denouement $>\sim$ of-motif-andapriorising/axiomatising/referencing', by its <amplituding/formative-epistemicity>totalising $\sim$ renewing-realisation/re-perception/re-thought-as-utter-placeholder-setupontological-rescheduling-〈by-a-renewing-of-apriorising/axiomatising/referencingpsychologism-as-the-new-referencing-basis-of-prospective- meaningfulness-and-teleology > of 'reference-of-thought' that is effectively the preconverging/postconverging-dementative/structural/paradigmatic ontological resolution given its ontological-completeness-ofreference-of-thought. This notion of human growing/developing prospective relativeontological-completeness ${ }^{87}$-of- reference-of-thought as of diminishing-human-epistemic- 
abnormalcy-or-preconvergence from recurrent-utter-uninstitutionalisation, baseinstitutionalisation, ${ }^{103}$ universalisation, positivism and prospectively deprocrypticism, as successive $\quad<$ amplituding/formative-epistemicity $>$-totalising $\sim$ renewing-realisation/reperception/re-thought of the construal/conceptualisation of the same ontologicalveridicality/intrinsic-reality going by human limited-mentation-capacity-deepening-assubjecting-limitedness/human-subpotency-to-'educed-unlimitedness/existence-sublimating nascence' ${ }^{53}$, can effectively be construed as a maximalising-recomposuring-for-relativeontological-completeness ${ }^{87}$ - unenframed/re-ontologising conceptualisation 'successive shifting in the curve-of-prospective-relative-ontological-completeness ${ }^{87}$-of- ${ }^{83}$ reference-ofthought of human ${ }^{56}$ meaningfulness-and-teleology ${ }^{9}$, (rather than a naïve construal based on incrementalism-in-relative-ontological-incompleteness

enframed/disontologising conceptualisation as successive additions which will wrongly imply an improvement along the same 'curve-of-prior-relative-ontological-incompleteness ${ }^{88}$-ofreference-of-thought of human ${ }^{5}$ meaningfulness-and-teleology ${ }^{\circ}$ ) wherein going by the apriorising/axiomatising/referencing/intelligibilitysettingup/measuringinstrumenting as reference-of-thought comparison, the implication is one of successive 'transformative apriorising/axiomatising/referencing/intelligibilitysettingup/measuringinstrumenting' (successive transformative ${ }^{83}$ references-of-thought) undertaking respectively the aposteriorising/logicising/deriving/intelligising/measuring-purpose—of-obtainedmeasurements (as ${ }^{5}$ logical-processing-or-logical-implicitation-supposedly-apriorising-inconviction-as-to-profound-supererogation ) of the same inherent existential-reality but with 'respective dramatic changes in the aposteriorising/logicising/deriving/intelligising/measuringpurpose - of-obtained-measurements' (as dramatic changes in ${ }^{5}$ meaningfulness-and-teleology from the <cumulating/recomposuring attendant-ontological-contiguity $>$-successive registryworldviews/dimensions ${ }^{83}$ references-of-thought), together with an underlying recurrent 
postlogism 7 -as-of- compulsing-nonconviction/madeupness/bottomlining-

$\langle `<$ decontextualising/de-existentialising $\sim$ of-attendant-intradimensional-

apriorising/axiomatising/referencing>-induced-disontologising'-of-the-'attendant-

intradimensional-ontologising'-imbued-<contextualising/existentialising $\sim$ attendant-

ontological-contiguity $>$;-in-shallow-supererogation $-<$ as-to-disontologising-perverted-

outcome-sought-precedes-existentially-veridical-'attendant-intradimensional-

apriorising/axiomatising/referencing'-logical-dueness $>$ > issue with the

$<$ cumulating/recomposuring $\sim$ attendant-ontological-contiguity $>$-successive registry-

worldviews/dimensions ${ }^{83}$ references-of-thought as of their prospective relative-ontologicalcompleteness ${ }^{87}$-of- ${ }^{83}$ eference-of-thought (due to 'least-and-derived-temporal-operatingmodalities-of-the- ${ }^{8}$ reference-of-thought-as-of- incrementalism-in-relative-ontological-

incompleteness — enframed/disontologising conceptualisation-inducing-the-

uninstitutionalised-threshold ${ }^{102}$ '); highlighting the notion of defectiveness in successive transformative

apriorising/axiomatising/referencing/intelligibilitysettingup/measuringinstrumenting as corresponding to perversion-and-derived- perversion-of- $^{-}$reference-of-thought- $<$aspreconvergingly-apriorising/axiomatising/referencing-in-

nonconviction/madeupness/bottomlining-as-to-shallow-supererogation $>$ /postlogism 77 -andconjugated-postlogism 77 as of prospective relative-ontological-completeness ${ }^{87}$-of- ${ }^{8}$ referenceof-thought. Consider for instance (with regards to human growing/developing prospective relative-ontological-completeness ${ }^{87}{ }^{83}$ reference-of-thought), the historical transformation of meaningfulness-and-teleology ${ }^{9}$ associated with the development of human astronomical instruments, as from objects for religious calculations such as astrolabes to the development of telescopes today rather for advanced astronomical science mirroring a corresponding human $<$ amplituding/formative-epistemicity $>$-totalising $\sim$ renewing-realisation/re-perception/re- 
thought-as-utter-placeholder-setup-ontological-rescheduling-〈by-a-renewing-ofapriorising/axiomatising/referencing-psychologism-as-the-new-referencing-basis-ofprospective- meaningfulness-and-teleology $\rangle$ as of the successive institutionalisations. This explains the peculiar mimetised-preconverging-or-dementing -apriorising-psychologism placeholder-setup/mental-devising-representation/mentation/consciousness-awarenessteleology ${ }^{9}$ we'll construe for instance of a non-positivism/medievalism mindset/ ${ }^{83}$ reference-ofthought that doesn't register positivistic meaningfulness ${ }^{83}$ reference-of-thought and likewise prospectively such a construal will have our present placeholder-setup/mental-devisingrepresentation/mentation/consciousness-awareness-teleology as of priorly unsoundness-orontological-bad-faith/inauthenticity ${ }^{64}$-of- ${ }^{8}$ reference-of-thought/preconverging-ordementing -apriorising-psychologism by its positivism- ${ }^{80}$ procrypticism ${ }^{83}$ reference-ofthought. Just as the very nature of existential-reality by our limited-mentation-capacitydeepening —as-subjecting limitedness/human-subpotency to-'educed-unlimitedness/existencesublimating nascence' construal/conceptualisation of it is rather an 'uncompromising windedness/foldedness susceptible to our limited-mentation-capacity-deepening-assubjecting-limitedness/human-subpotency-to-'educed-unlimitedness/existence-sublimating nascence' virtuality-or-ontologically-flawed-construal decontextualising/unimbricating/unrecomposuring of its inherent nature', correspondingly the exercise of ontologically-veridical reasoning is rather ${ }^{55}$ maximalising-recomposuring-forrelative-ontological-completeness ${ }^{87}$ — unenframed/re-ontologising conceptualisation.

Correspondingly, from the vantage position of our present positivising/rational-empirical ontological-completeness-of- ${ }^{3}$ reference-of-thought with respect to a nonpositivism/medievalism worldview, we can garner an insight of the threshold-ofnonconviction/madeupness/bottomlining-in-shallow-supererogation $<-<$ as-to- 'attendantintradimensional'-prospectively-disontologising preconverging/dementing -apriorising- 
psychologism $>$ of the postlogism 7 -and-conjugated-postlogism 77 in a nonpositivism/medievalism setup, wherein faced with arguments of the sort who is the sorcerer, how are they using their sorcery, etc., speaking of the non-positivism/medievalism relativeontological-incompleteness ${ }^{8}$-induced,-'threshold-of-nonconviction/madeupness/bottomliningin-shallow-supererogation -<as-to- 'attendant-intradimensional'-prospectivelydisontologising preconverging/dementing -apriorising-psychologism>' (given that sorcery doesn't exist, going by the insight of positivistic prospective relative-ontologicalcompleteness $^{87}$-of- ${ }^{83}$ reference-of-thought whereas the non-positivism/medievalism registryworldview/dimension is ridden with a whole complexity of threshold-ofnonconviction/madeupness/bottomlining-in-shallow-supererogation $<-<$ as-to-' attendantintradimensional'-prospectively-disontologising preconverging/dementing -apriorisingpsychologism> construct of notions-and-accusations-of-sorcery ${ }^{56}$ meaningfulness-andteleology $\quad$ as its preconverging-de-mentating/structuring/paradigming of

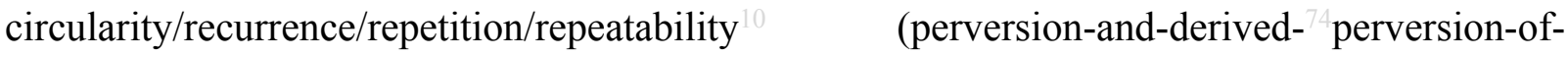
reference-of-thought-<as-preconvergingly-apriorising/axiomatising/referencing-innonconviction/madeupness/bottomlining-as-to-shallow-supererogation >-as-touninstitutionalised-threshold ${ }^{102}$-self-referencing-syncretising-and-subtransversality-<indesublimating-existential-eventuating/denouement $>\sim$ of-motif-andapriorising/axiomatising/referencing). This insight can equally be drawn prospectively in our positivism- ${ }^{80}$ procrypticism registry-worldview/dimension faced with its postlogism 7 -as-ofcompulsing-nonconviction/madeupness/bottomlining-〈'<decontextualising/deexistentialising $\sim$ of-attendant-intradimensional-apriorising/axiomatising/referencing $>$-induceddisontologising'-of-the-‘attendant-intradimensional-ontologising'-imbued$<$ contextualising/existentialising attendant-ontological-contiguity $>$;-in-shallowsupererogation -<as-to-disontologising-perverted-outcome-sought-precedes-existentially- 
veridical-'attendant-intradimensional-apriorising/axiomatising/referencing'-logical-dueness $>$ >

like psychopathy and social psychopathy. This speaks of the very nature of all threshold-ofnonconviction/madeupness/bottomlining-in-shallow-supererogation $-<$ as-to-' $a$ attendant-

\section{intradimensional'-prospectively-disontologising preconverging/dementing -apriorising-}

psychologism> with regards to the limits of a registry-worldview's/dimension's institutionalisation (whether base-institutionalisation, ${ }^{103}$ universalisation and positivism eliciting respectively the uninstitutionalised-threshold 02 of ununiversalisation, nonpositivism/medievalism and procrypticism) across all the relative-unreflexivity/relativereflexivity - ontological-contiguity ${ }^{67}$ of-the-human-institutionalisation-process ${ }^{68}$ wherein the prior/transcended/superseded registry-worldview's/dimension's ${ }^{83}$ reference-of-thought in its $<$ amplituding/formative-epistemicity $>$ totalising $\sim$ self-referencing-

syncretising/circularity/interiorising/akrasiatic-drag ${ }^{34}$ (as metaphysics-of-presence-〈implicited'nondescript/ignorable-void '-as-to- presencing - absolutising-identitive-constitutedness \):

illusion-of-the-present/present-consciousness/mirage) is representing itself as 'postconvergingor-dialectical-thinking -apriorising-psychologism and dialectically/contendingly in-phase' whereas from the prospective institutionalisation registry-worldview's/dimension's ${ }^{8}$ referenceof-thought, as of the ontological-normalcy/postconvergence epistemic-or-notional projectiveperspective, it is 'preconverging-or-dementing -apriorising-psychologism and dialectically/contendingly out-of-phase'. The reason for the ontologically defective $<$ amplituding/formative-epistemicity $>$ totalising $\sim$ self-referencing-

syncretising/circularity/interiorising/akrasiatic-drag ${ }^{34}$ is that all registry-worldviews/dimensions reference-of-thought 'tend to convention' and in so doing close the 'existential frame-ofontology/meaningfulness (which is the transcendental-enabling/sublimating/supereregatory $\sim$ dementativity)' in their conventioning, and thus to the exclusion of prospective ontological profoundness of ${ }^{8}$ reference-of-thought. Thus all registry-worldviews/dimensions had hitherto 
been $<$ amplituding/formative $>$ wooden-language-<imbued — averaging-of-thought- $<$ as-toleveling/ressentiment/closed-construct-of- meaningfulness-and-teleology -as-of'nondescript/ignorable-void ' -with-regards-to-prospective-apriorising-implications $>$ ).

However human existential-disentogising/re ontogising aporeticism> closure of meaningfulness as conventioning doesn't supersede but is rather superseded by existential<disontologising/re-ontologising aporeticism $>$ ontological-veridicality, explaining the susceptibility of registry-worldviews/dimensions ${ }^{83}$ references-of-thought to be transcended/superseded with human limited-mentation-capacity-deepening-as-subjectinglimitedness/human-subpotency-to-'educed-unlimitedness/existence-sublimating nascence' expansion of ontological-depth as increasing ontological-completeness-of- ${ }^{8}$ reference-ofthought (or reducing relative-ontological-incompleteness ${ }^{8}$-induced,-'threshold-ofnonconviction/madeupness/bottomlining-in-shallow-supererogation $<-<$ as-to- 'attendantintradimensional'-prospectively-disontologising preconverging/dementing -apriorisingpsychologism>'). existential-<disentologising/re-ontologising aporeticism $>$ closure of meaningfulness as conventioning induces psychically a registry-worldview/dimension 'exclusive representing' of itself as 'candored and straight' with respect to meaningfulnessand-teleology whereas its transcending/superseding by the prospective registryworldview/dimension exposes psychically that it is rather 'decandored and oblongated' with respect to more profound prospective/transcending/superseding ${ }^{56}$ meaningfulness-andteleology . A further example will be say the 'God-of-plane' type of articulation wherein such a base-institutionalisation as of animistic social-setup which is not positivistic (not the case of non-positivistic as medieval) is psychically 'candored and straight' with itself in $<$ amplituding/formative-epistemicity $>$ totalising $\sim$ self-referencingsyncretising/circularity/interiorising/akrasiatic-drag ${ }^{34}$ (its metaphysics-of-presence-〈implicited'nondescript/ignorable-void '-as-to- presencing-absolutising-identitive-constitutedness 〉) 
and goes on articulating ${ }^{56}$ meaningfulness-and-teleology ${ }^{9}$ even in the new existential< disontologising/re-ontologising aporeticism $>$ transcendental/superseding contextualisation in terms-as-of-axiomatic-construct of the doubly-prior/transcended/superseded baseinstitutionalisation/animistic registry-worldview/dimension. Given such a state of $<$ amplituding/formative-epistemicity $>$ totalising $\sim$ self-referencing-

syncretising/circularity/interiorising/akrasiatic-drag ${ }^{34}$, the notion of generating meaningfulness-and-teleology from the ontological-normalcy/postconvergence epistemicor-notional projective-perspective priorly implies a requisite psychoanalyticunshackling/memetic-reordering/institutional-recomposuring, and so by ${ }^{55}$ maximalisingrecomposuring-for-relative-ontological-completeness ${ }^{87}$ - unenframed/re-

ontologising conceptualisation. While excluding any exercise of elaboration-as-to-mereextrapolating/constituting/abstracting/deducing/inferring-of-elucidation-outside-

'prospectively_implicited_attendant-ontological-contiguity ${ }^{67}$ ' educedexistentialising/contextualising/textualising_intelligibility/epistemicity/reflexivity-contiguity$<$ imbued-notional cogency $>{ }^{\prime 0}$ since the latter is only appropriate in the instance of prospective relative-ontological-completeness ${ }^{8}$-of- ${ }^{-3}$ reference-of-thought; as the base-institutionalisation (animistic) prior relative-ontological-incompleteness ${ }^{8}$-induced,-`threshold-ofnonconviction/madeupness/bottomlining-in-shallow-supererogation $<<$ as-to- 'attendantintradimensional'-prospectively-disontologising preconverging/dementing -apriorisingpsychologism> puts into question the very first and absolute apriorising/axiomatising/referencing/intelligibilitysettingup/measuringinstrumenting of meaningfulness-and-teleology ('prospectively_implicited_attendant-ontologicalcontiguity ${ }^{67}$, educedexistentialising/contextualising/textualising_'intelligibility/epistemicity/reflexivity-contiguity$<$ imbued-notional $\sim$ cogency $>,{ }^{\prime},-<$ reifying-or-elucidating-of-prospective-relative-ontological- 
existence-potency $^{32} \sim$ sublimating-nascence,-disclosed-from-prospective-epistemicdigression—rules-of-apriorising/axiomatising/referencing-that-further-epistemicallyunconceal-the-very-ontologically-same-existential-reality construed as of increasing human limited-mentation-capacity-deepening —as-subjecting limitedness/human-subpotency-to'educed-unlimitedness/existence-sublimating nascence' 33 in the apriorising/axiomatising/referencing of ${ }^{5}$ meaningfulness-and-teleology ${ }^{9}$ construal') with respect to the base-institutionalisation (animistic) registry-worldview's/dimension'suninstitutionalised-threshold ${ }^{102}$-defect- $<$ as-Being-or-ontological-or-existential-defect $>85$. Equally we can imagine that making a positivistic argument in the midst of a nonpositivism/medievalism setup will seem 'deranged' from their perspective and their mental orientation will be geared to their traditional sense of meaning and living as absolutely defining, but then the 'center' had moved from their world (from non-positivistic as baseinstitutionalisation/animistic or medieval preconverging-or-dementing ${ }^{20}$-apriorisingpsychologism decenter) to the positivistic world (as postconverging-or-dialectical-thinking apriorising-psychologism center). Likewise such a suprastructural articulation of our positivismprocrypticism relationship to its postlogism that includes psychopathy and social psychopathy will apparently not make any sense to our present but then ontologically our present is now decentered as threshold-of-nonconviction/madeupness/bottomlining-in-shallowsupererogation -<as-to-'attendant-intradimensional'-prospectivelydisontologising $\sim$ preconverging/dementing -apriorising-psychologism>, though our mentalreflex will be a traditional sense of meaning and living as sound-and-not-preconverging-ordementing -apriorising-psychologism as well. However, to the extent that it is "not such $<$ amplituding/formative-epistemicity $>$ totalising $\sim$ self-referencingsyncretising/circularity/interiorising/akrasiatic-drag temporal/shortness-of-register-of- 
meaningfulness-and-teleology inclinations' that drove human registryworldview's/dimension's institutionalisations and resolved uninstitutionalised-threshold ${ }^{102}$ from recurrent-utter-uninstitutionalisation to base-institutionalisation-ununiversalisation to universalisation-non-positivism/medievalism to positivism- ${ }^{80}$ procrypticism (as by reflex the temporal mental-disposition will rather be inclined to temporal (shortness-of-register-ofmeaningfulness-and-teleology ${ }^{9}$ ) extrication in any registry-worldview/dimension with no upholding of transcendental possibilities), to that extent the intemporal-disposition should rather construe/conceptualise its intemporal-disposition as the tip of human transcendental institutionalisation possibility and thus inherently that it transversally takes precedence over human temporal complexes (and such a 'transversality-<for-sublimating-existentialeventuating/denouement,from-'thinking at-first/pure-predisposition-preemptive-ofprospective-disontologising/subontologising' - as-of-prospectively-disambiguated-affirmedand-unaffirmed-'motif-and-apriorising/axiomatising/referencing'>101 confliction' resolved intemporally by prospective <amplituding/formative-epistemicity $>$ causality $\sim$ as-to-projectivetotalitative-implications-of-prospective- nonpresencing,-for-explicating relativeunreflexivity/relative-reflexivity ontological-contiguity and secondnaturing. This actually explains the inevitable contrariety involved in the making of transcendental human progress involving a prior/transcended/superseded $\quad{ }^{83}$ reference-of-thought and a prospective/transcending/superseding ${ }^{83}$ reference-of-thought; given the blunt fact that 'there is no untransvaluated-temporal-intemporality ${ }^{52}$, and pretences of inevitability of human progress without need for intemporal projection are falsehoods 'arising as temporal/shertness-of-registerof meaningfulness-and-teleology distraction' with respect to the institutionalising/intemporalising constraining effect of intemporal/fos of register of meaningfulness-and-teleology projections.). Critically, the notion of transcendence-andsublimity/sublimation/supererogatory de-mentativity and transcendental- 
enabling/sublimating/supereregatory $\sim$ de-mentativity associated with intemporality ${ }^{52} /$ longness and institutionalisation/intemporalisation as of its very defining core is rather one of $<$ amplituding/formative-epistemicity $>$ causality $\sim$ as-to-projective-totalitative-implications-ofprospective- nonpresencing,-for-explicating relative-unreflexivity/relative-reflexivity _ ontological-contiguity as it propounds the supersedingness/primacy/ascendency of intrinsicreality as a the-Good/understanding/knowledge-driven construct over human 'goodnaturedness'/impression-driven constructs as well as social-aggregation-enablers. The idea being that <amplituding/formative-epistemicity $>$ causality $\sim$ as-to-projective-totalitativeimplications-of-prospective- nonpresencing,-for-explicating relative-unreflexivity/relativereflexivity - ontological-contiguity is much more than a notion associated with the positivistic registry-worldview/dimension (as has naively been traditionally implied when conceptualising that empirical ${ }^{5}$ meaningfulness-and-teleology ${ }^{9}$ is the sole purview of the rationalempiricism/positivism registry-worldview/dimension failing to recognised that all other registryworldviews/dimensions are actually empirical but differ as to interpretation of empirical perception whether as to a magical, cultic or other non-positivising interpretation of empirical manifestation) but speaks of the 'central human epistemictotalising ${ }^{33} \sim$ resubjecting_or totalising-entailing $\sim$ reconstrual $<$ of the whelemerview of the whole/oneness-of-ontology heuristic drive' defining as to preconverging/postconverging-dementating/structuring/paradigming $\quad{ }^{56}$ meaningfulness-and-teleology ${ }^{9} \quad$ the $<$ cumulating/recomposuring attendant-ontological-contiguity $>$-succession of registryworldviews/dimensions (however sublimatingly inefficient in relative-ontologicalincompleteness ${ }^{88}$ and sublimatingly efficient in relative-ontological-completeness ${ }^{87}$ as from nonpresencing-<perspective-ontological-normalcy/postconvergence $>$ epistemic-projection); given that with corresponding shallow to limited-mentation-capacity-deepening-as-subjectinglimitedness/human-subpotency to-'educed-unlimitedness/existence-sublimating nascence'53, 


\section{totalitative-implications-of-prospective- nonpresencing,-for-explicating relative-}

unreflexivity/relative-reflexivity - ontological-contiguity successively induce more and more profound 'mimetic-echoness to ontological-normalcy/postconvergence' as of the full-potency of existence-as-of-its-mimetic-echoness/existence-in-reverberation/existence-

potency ${ }^{39} \sim$ sublimating-nascence,-disclosed-from-prospective-epistemic-digression. Consider the case with ancient Egyptians and even ancient Greeks where their relations with their deities were closely related to the fortune they expected on an empirical basis whether with respect to such occurrences like droughts, warfare, etc. which technically speaking is a rational allocation as $<$ amplituding/formative-epistemicity $>$ causality $\sim$ as-to-projective-totalitative-implicationsof-prospective- nonpresencing,-for-explicating relative-unreflexivity/relative-reflexivity ontological-contiguity of ${ }^{5}$ meaningfulness-and-teleology ${ }^{9}$ going by their given limitedmentation-capacity—as-subjecting-'educed-unlimitedness/existence-sublimating nascence'to-limitedness/human-subpotency. Transcendence-andsublimity/sublimation/supererogatory $\sim$ de-mentativity and transcendentalenabling/sublimating/supereregatory $\sim$ de-mentativity as so construed is more than just a vague notion of dialecticism but one that recognises on an 'effective reality basis that human limitedmentation-capacity-deepening —as-subjecting limitedness/human-subpotency to-'educedunlimitedness/existence-sublimating nascence' ${ }^{3}$, implies more and more profound reconstruals/reconceptualisations $(<$ amplituding/formative-epistemicity $>$-totalising $\sim$ renewingrealisation/re-perception/re-thought) inducing transformative implications with respect to meaningfulness-and-teleology ${ }^{99}$ as transcendence; in contrast to the mere aestheticisation of abstract dialecticism or analogy/mere-analogising speaking thus of human sublimationeducing__epistemic-totalising 3 \}hermeneutic/textuality/reprojecting/supererogating/zeroing/reacuting, ${ }^{\text {- }\{\text { decompulsing }}$ delinearity $\sim$ for-cogency $\sim$ as-to-possibilities-of-self-becoming-as-of- 
'existential-interpretation/epistemicity-in-apriorising/axiomatising/referencing-of-existence .

As knowledge conception as contrasted to sovereign conception, 'transcendence and transcendental-enabling/sublimating/supererogatory $\sim$ de-mentativity doesn't recognise any human discreet primacy with respect to intrinsic-reality/ontological-veridicality' but rather intrinsic-reality is the inherent purveyor of pertinence and primacy. For instance, we don't have a choice in deciding that gravity is about $9.8 \mathrm{~m} / \mathrm{s}^{2}$ on earth since intrinsic-reality imposes that idea and the corresponding knowledge construction and organisation where intrinsic-reality is ascendant is rather based on an 'intemporality ${ }^{52}$-symmetrising-by-desymmetrisingsubsumption-of-temporality ${ }^{\circ}$, for relative intrinsic-reality/ontological-veridicality transcendental-enabling/sublimating/supererogatory $\sim$ de-mentativity. This is not to be confused with sovereign constructions and organisations driven by human sovereign choices such as political choices or marketing choices or other sovereign choices based on practices and habits. The latter are social-scientific (besides the previous notion of social-scientific referring to intrinsic social reality transcendental-enabling/sublimating/supererogatory $\sim$ de-mentativity), with respect to transcendental-enabling/sublimating/supererogatory de-mentativity construals/conceptualisations only as of existence-in-its-mimetic-echoness as inclusive of the human condition, i.e. human existential-disongising aporeticism> sovereign choices of ${ }^{5}$ meaningfulness-and-teleology ${ }^{9}$ as ontological construals 'not in terms of the inherent intrinsic-reality/ontological-verdicality of the ${ }^{5}$ meaningfulness-and-teleology itself' but 'rather as of the veracity/ontological-pertinence of the reality of the human sovereign choices as of themselves as humans values independent of their inherent intrinsicreality/ontological-veridicality as ontologically construing the reality of human condition', and so with respect to ${ }^{4}$ historiality/ontological-eventfulness 3 /ontological-aesthetic-tracing$<$ perspective-ontological-normalcy/postconvergence-reflected-'epistemicity-relativismdeterminism'>, politicisation and other social choices like moralisation, cultural value, economic 
value, etc. This distinction is critical because very often sovereign choices as conventions will tend to be acted upon as if these were transcendental knowledge of intrinsic-reality/ontology construal of the social in a wrong equivalence, and further because the transcendentalenabling/sublimating/supereregatory $\sim$ de-mentativity as of the intrinsic-reality/ontology construal of the social is more fundamental as the tool for 'creating/inventing-anddestroying/deconstructing conventions' for more and more profound grasp of intrinsic-realityontological-coherence_or_superseding-oneness-of-ontology as of human subpotent knowledge. Sovereign constructs can as such be construed beyond-the-consciousness-awarenessteleology ${ }^{9}<$ of-preconverging-existential-extrication-as-of-existential-unthought $>$ to stifle the possibility of intrinsic-reality/ontology of the social, construed as ontology/ontologicalveridicality transcendental-enabling/sublimating/supereregatory $\sim$ de-mentativity knowledge, from arising. This insight explains why all deferential-formalisation-transference are only of pertinence as they justify and are derived from relative intrinsic-reality/ontological-veridicality transcendental-enabling/sublimating/supererogatory de-mentativity conceptualisations, and collapse when they fail that test. For instance, notions such as arguments from authority are useful in ensuring social efficacy but when authority is demonstrated as relatively fallacious, it then has no pretence to the sanctity of not being undermined. Ultimately, the veridical nature of knowledge beyond 'institutionalised-being-and-craft' (as established by prior transcendenceand-sublimity/sublimation/supererogatory - de-mentativity) to prospective transcendence-andsublimity/sublimation/supererogatory de-mentativity is not as an exercise of 'logical mere convincing' as of social-aggregation-enabling about what is knowledge and appropriate, but rather as a critical exercise of channelling of relative intrinsic-reality/ontological-veridicality transcendental-enabling/sublimating/sentativity as secondnaturing institutionalisation percolation-channelling- $<$ in-deferential-formalisation-transference $>$ to elicit the necessary positive-opportunism-of-social-functioning-and-accordance ${ }^{75}$ for prospective 
institutionalisation as skewing ('intemporality ${ }^{52}$-symmetrising-by-desymmetrisingsubsumption-of-temporality ${ }^{8}$, for relative intrinsic-reality/ontological-veridicality transcendental-enabling/sublimating/supererogatory $\sim$ de-mentativity) towards the intemporal/longness-of-register-of-meaningfulness. The fact is as construed by the Galileos, Corpernicus, Diderots and others of the world, transcendental knowledge (as relatively 'consecrated' by relative intrinsic-reality/ontological-veridicality transcendentalenabling/sublimating/supereregatery $\sim$ de-mentativity) necessarily carries a 'cynicism-ofgrandeur-as-of-effective-intemporal-solipsistic-commitment' to deal with the reality of humansubpotency-aporia/undecidability/dilemma/ought-

indeterminacy/deficiency/limitation/constraint—imbued-'notional firstnaturednessformativeness-<as-to-eventualising inkling drive-or-seeding-misprising $>$ - temporal-tointemporal-dispositions- $<$ so-construed-as-from-perspective-ontologicalnormalcy/postconvergence>'-existentialism-form-factor (and so as of 'circularcomplexification'/perpetual-reinstitutionalisation as a result of the same human-subpotencyaporia/undecidability/dilemma/ought-indeterminacy/deficiency/limitation/constraint—imbued'notional firstnaturedness-formativeness-<as-to-eventualising -inkling-drive-or-seedingmisprising $>$ temporal-to-intemporal-dispositions- $<$ so-construed-as-from-perspectiveontological-normalcy/postconvergence>'-existentialism-form-factor mental-dispositions across all the successive relative-unreflexivity/relative-reflexivity - ontological-contiguity $\sim$ of-thehuman-institutionalisation-process ${ }^{68}$ registry-worldviews/dimensions). In-the-bigger-schemeof-things, as of the 'deepest phenomenological transcendental-point-of-departure handle as of the notional conflatedness ${ }^{13}$ of notional ${ }^{18}$ deprocrypticism deneuterising ${ }^{17}$-referentialism' reflected by metaphysics-of-absence-〈implicited-epistemic-veracity-of- nonpresencing$<$ perspective-ontological-normalcy/postconvergence $>\rangle$ in the conception-of- ${ }^{56}$ meaningfulnessand-teleology ontological-performance ${ }^{2}-<$ including-virtue-as- 
ontology $>$ /morality/ethics/justice/etc. as of the transcendental implications in reflecting holographically-<conjugatively-and-transfusively $>\quad$ the relative-unreflexivity/relativereflexivity ontological-contiguity of-the-human-institutionalisation-process

knowledge-constructs/theories/intersolipsistic-intercessory-notions/notional $\sim$ referential-

notions/articulations/virtue, we can appreciate that the <cumulating/recomposuring attendantontological-contiguity >-successive registry-worldviews/dimensions conventioning are increasingly ontologically-driven in their value construct as it is more and more profound ontological-veridicality that enables human transcendence-andsublimity/sublimation/supererogatoryade-mentativity and the relative-unreflexivity/relativereflexivity ontological-contiguity ${ }^{67}$ of-the-human-institutionalisation-process ${ }^{68}$ in the first place; with the notional ${ }^{18}$ deprocrypticism institutionalisation conventioning supposedly attaining absolute ontological grounding. The insight here is that the relative pure-ontologydrive of a Socrates philosophical clairvoyance superseding Athenian society conventioning limits but then with the latter perceiving in <amplituding/formativeepistemicity>totalising $\sim$ self-referencing-syncretising/circularity/interiorising/akrasiatic-drag its conventioning limits as absolutely ontological, Socrates is paradoxically construed as ontologically-impertinent and thus accused of heresy. Such an argument can also be extended to say a Copernicus or a Galileo whose relative pure-ontology drive advocating a heliocentric universe in medieval society comes against medieval society scholastics dogmatism conventioning limits but then with the latter perceiving in <amplituding/formativeepistemicity $>$ totalising $\sim$ self-referencing-syncretising/circularity/interiorising/akrasiatic-drag its conventioning limits as absolutely ontological, Copernicus and Galileo are paradoxically construed as ontologically-impertinent. This highlights that a registry-worldview's/dimension's construes in $\quad<$ amplituding/formative-epistemicity $>$ totalising $\sim$ self-referencingsyncretising/circularity/interiorising/akrasiatic-drag ${ }^{34}$ its conventioning limits as being the 
absolute ontological determinant of ${ }^{5}$ meaningfulness-and-teleology ${ }^{9}$ ontologicalperformance ${ }^{72}-<$ including-virtue-as-ontology $>$, and that ${ }^{56}$ meaningfulness-and-teleology ${ }^{99}$ as of relative pure-ontology superseding it is paradoxically construed as ontologically-impertinent. This is relevant with regards to the 'intellectual projection' choices made as of their transformative implications on society; wherein such highly unconventional thinkers like Diderot of more dramatic social transformation implications are actually less appreciated as of the $<$ amplituding/formative-epistemicity $>$ totalising $\sim$ self-referencingsyncretising/circularity/interiorising/akrasiatic-drag ${ }^{34}$ of their epochal society conventioning limits naively construed by mental-reflex as the absolute ontological determinant of

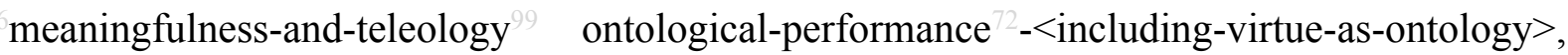
over similar thinkers whose thought are more forthcoming towards such societal conventioning limits. As of relevance to futural Being-development/ontological-framework-expansion-as-todepth-of-ontologising-development-as-infrastructure-of- meaningfulness-and-teleology of prospective ${ }^{18}$ deprocrypticism-or-preempting-disjointedness-as-of- ${ }^{3}$ reference-of-thought with regards to our positivism- ${ }^{80}$ procrypticism, such a phenomenological transcendental-pointof-departure handle reflected by metaphysics-of-absence-_implicited-epistemic-veracity-ofnonpresencing-<perspective-ontological-normalcy/postconvergence $>\rangle$ for the conception-ofmeaningfulness-and-teleology ontological-performance ${ }^{2}-<$ including-virtue-asontology $>$ /morality/ethics/justice/etc. is necessarily 'suspicious' of our presence society 'conventioning-limits' in its beyond-the-consciousness-awareness-teleology ${ }^{9}-<$ ofpreconverging-existential-extrication-as-of-existential-unthought $>$ naively construed $<$ amplituding/formative-epistemicity $>$ totalising $\sim$ self-referencingsyncretising/circularity/interiorising/akrasiatic-drag ${ }^{34}$ mental-reflex as the absolute ontological determinant of ${ }^{56}$ meaningfulness-and-teleology ${ }^{9}$ ontological-performance ${ }^{2}-<$ including-virtueas-ontology>, with regards to its capacity of appreciating prospective relatively profound pure- 
ontology as herein implied that preconverging/postconverging-dementatively/structurally/paradigmatically supposedly supersedes our positivismprocrypticism registry-worldview's/dimension's institutionalisation ${ }^{83}$ reference-of-thought. This explains why fundamentally most human transcendental ideas of progress have been reoriginary_-as-unenframed/re-ontologising/unbeholdening/outlier-conceptualisation-_imbuedpostconverging/dialectical-thinking -'projective-insights'/'epistemic-projection-inconflatedness '-of-notional deprocrypticism-prospective-sublimation $\rangle^{0}$ ideas which 'proponents ultimate purpose (beyond-the-consciousness-awareness-teleology ${ }^{0}-<$ of preconverging-existential-extrication-as-of-existential-unthought> ') weren't fundamentally a 'direct convincing' of humans exercise as of social-aggregation-enabling but rather in projecting a big picture of the-Good/understanding/knowledge-drive as of relative intrinsicreality/ontological-veridicality transcendental-enabling/sublimating/supererogatory $\sim$ dementativity, however unintelligible, as a prospective institutional percolation-channelling- $<$ indeferential-formalisation-transference $>$ exercise as validated by ultimate $<$ amplituding/formative-epistemicity $>$ causality $\sim$ as-to-projective-totalitative-implications-ofprospective- nonpresencing,-for-explicating relative-unreflexivity/relative-reflexivity ontological-contiguity with subsequent corresponding formalisation and secondnaturing. The point of this construal/conceptualisation is inevitably equally along the same lines. In fact, it can be further contended going by the reality of human-subpotencyaporia/undecidability/dilemma/ought-indeterminacy/deficiency/limitation/constraint—imbued'notional firstnaturedness-formativeness-<as-to-eventualising -inkling-drive-or-seedingmisprising $>$ temporal-to-intemporal-dispositions- $<$ so-construed-as-from-perspectiveontological-normalcy/postconvergence>'-existentialism-form-factor that 'human knowledge is necessarily a secondnaturing construction' and not an 'intemporal-disposition construction' as the latter will wrongly imply that we are only intemporal-as-longness-of-register-of- 
meaningfulness-and-teleology ${ }^{9}$, which is obviously false since we are temporal-to-intemporal by our mental-disposition and our virtue with the notional deprocrypticism registryworldview/dimension institutionalisation is actually to understand (as knowledge/the-Good) this and paradoxically be superseding in that respect by a pivoting/decentering psyche and institutionalisation, and not an artificial projection that is not real and hence will be ineffective and circular as threshold-of-nonconviction/madeupness/bottomlining-in-shallowsupererogation -<as-to-'attendant-intradimensional'-prospectivelydisontologising preconverging/dementing -apriorising-psychologism>. Thus human knowledge is a dynamic secondnatured construct in upholding-and-vouching for the intemporal while preempting of the temporal, and so beyond-the-consciousness-awareness-teleology ${ }^{9}-<$ of preconverging-existential-extrication-as-of-existential-unthought> .

[The notion of 'beyond-the-consciousness-awareness-teleology ${ }^{\circ}<$ of-preconvergingexistential-extrication-as-of-existential-unthought>' as used herein goes beyond the notions of 'consciously' or 'unconsciously' as we normally understand them, in the sense that 'beyond-theconsciousness-awareness-teleology ${ }^{\circ}<$ of-preconverging-existential-extrication-as-ofexistential-unthought $>$ speaks of the mental state as of threshold-ofnonconviction/madeupness/bottomlining-in-shallow-supererogation $<-<$ as-to- 'attendantintradimensional'-prospectively-disontologising preconverging/dementing -apriorisingpsychologism $>$ by its relative-ontological-incompleteness ${ }^{8}$-of- ${ }^{8}$ reference-of-thought at the point of uninstitutionalised/unintemporalised/solipsistic/recomposuring/animality-thresholdsof-intemporal-preservation-entropy-or-contiguity-or-ontological-preservation (also referred to as 'uninstitutionalised-threshold ${ }^{102}$ ') where the mental-disposition/mindset $/{ }^{83}$ reference-ofthought is rather emphasised as being in a 'state of relative incapacity' rather than one of fullconscious-capacity but neither full-unconscious-capacity mental-disposition. Thus unlike just 'conscious' or 'unconscious', the notion of beyond-the-consciousness-awareness-teleology - 
and/or 'unconscious' as of threshold-of-nonconviction/madeupness/bottomlining-in-shallowsupererogation -<as-to-'attendant-intradimensional'-prospectively-

disontologising preconverging/dementing -apriorising-psychologism $>$ at the uninstitutionalised-threshold ${ }^{102}$ of a registry-worldview/dimension whether with regards to retrospective or prospective transcendental analysis. For instance say in a non-positivistic as medieval or animistic/base-institutionalisation social-setup someone accused another of sorcery. It is hardly the case that we can absolutely say they committed a conscious immoral act with their accusation of sorcery since the ontological-completeness-of- ${ }^{3}$ reference-of-thought as knowledge-framework available to them doesn't enable their full conscious appraisal of such a judgment call as they are in an insecure-certitude-by-incertitude-and-virtue-by-vice-mental-flux with notions-and-accusations-of-sorcery. However, supposed they adopted such an attitude not only by such ignorance but rather affordability/opportunism/exacerbation/social-chainism-orsocial-discomfiture-or-negative-social-aggregation/temporal-enculturation-or-temporalendemisation, then they are effectively relatively conscious with respect to their action as a dishonest/deceitful/immoral act even though beyond-the-consciousness-awareness-teleology $<$ of-preconverging-existential-extrication-as-of-existential-unthought $>$. Of course, where supposed someone from a positivistic social-setup found themselves in such a non-positivistic social-setup and equally proffered such an accusation of sorcery, then their conscious immorality is fully engaged as being in full-conscious-capacity with respect to their deception going by their positivistic prospective relative-ontological-completeness ${ }^{87}$-of- ${ }^{8}$ reference-of-thought that supersedes superstitions including notions-and-accusations-of-sorcery. By extension, psychopathic/postlogic induced deception can only be construed as beyond-the-consciousnessawareness-teleology $-<$ of-preconverging-existential-extrication-as-of-existential-unthought $>$ as when eliciting ignorance (as of 'lack of constraining social ${ }^{103}$ universal-transparency ${ }^{104}$ 


\section{〈transparency-of-totalising-entailing,-as-to-entailing-<amplituding/formative-}

epistemicity>totalising in-relative-ontological-completeness $>$ of the psychopath's mentaldisposition of postlogism -as-of- compulsing-nonconviction/madeupness/bottomlining$\langle<<$ decontextualising/de-existentialising of-attendant-intradimensionalapriorising/axiomatising/referencing >-induced-disontologising'-of-the-'attendantintradimensional-ontologising'-imbued-<contextualising/existentialising $\sim$ attendant ontological-contiguity $>$;-in-shallow-supererogation -<as-to-disontologising-pervertedoutcome-sought-precedes-existentially-veridical-'attendant-intradimensionalapriorising/axiomatising/referencing'-logical-dueness $>$ )), and while construed as beyond-theconsciousness-awareness-teleology ${ }^{\circ}<$ of-preconverging-existential-extrication-as-ofexistential-unthought> as when eliciting affordability/opportunism/exacerbation/socialchainism-or-social-discomfiture-or-negative-social-aggregation/temporal-enculturation-ortemporal-endemisation, is not disculpating. Ultimately, going by the very decisiveness of relative-ontological-incompleteness ${ }^{88}$-of- ${ }^{8}$ reference-of-thought, as it leads to 'lack of constraining social ${ }^{103}$ universal-transparency ${ }^{104}$-〈transparency-of-totalising-entailing,-as-toentailing-<amplituding/formative-epistemicity $>$ totalising $\sim$ in-relative-ontological-

completeness \, associated with the successive uninstitutionalised-threshold ${ }^{102}$ states, the notion of 'human beyond-the-consciousness-awareness-teleology ${ }^{-<}<$of-preconverging-existentialextrication-as-of-existential-unthought $>^{\prime}$, is actually in-the-bigger-picture the larger determinant of manifest human vices-and-impediments ${ }^{105}$ as of virtue-as-ontology conceptualisation, speaking fundamentally of the specific registry-worldviews/dimensions 'registry-worldview's/dimension's-uninstitutionalised-threshold ${ }^{12}$-defect-<as-Being-orontological-or-existential-defect $>5$, inherent with the state of recurrent-utteruninstitutionalisation, ununiversalisation, non-positivism/medievalism and procrypticism. Whereas the notion of human conscious vices-and-impediments ${ }^{105}$ as of defect-of- ${ }^{5}$ logical- 
processing-or-logical-implicitation - supposedly-apriorising-in-conviction-as-to-profound-

supererogation of the registry-worldview's/dimension's- ${ }^{83}$ reference-of-thought-for-socialfunctioning-and-accordance is mostly able to arise incidentally 'within the scope' of the registryworldview's/dimension's-uninstitutionalised-threshold ${ }^{102}$-defect-<as-Being-or-ontological-orexistential-defect $>^{5}$, as beyond-the-consciousness-awareness-teleology ${ }^{\circ}<$ of-preconvergingexistential-extrication-as-of-existential-unthought $>$ of the registry-worldview/dimension uninstitutionalised-threshold $^{102} ;$ as social ${ }^{103}$ universal-transparency ${ }^{104}$-〈transparency-oftotalising-entailing,-as-to-entailing-<amplituding/formative-epistemicity $>$ totalising $\sim$ inrelative-ontological-completeness $\rangle$ is a strong inherent deterrent of human temporality $/$ shortness and enabler of human intemporality ${ }^{52} /$ longness (explaining why knowledge is truly virtue), even though at the uninstitutionalised-threshold ${ }^{102}$ of such knowledge-as-virtue arises the temporal-dispositions denaturing ${ }^{16}$ its ${ }^{83}$ reference-of-thoughtcategorical-imperatives/axioms/registry-teleology for intemporal-preservation-entropy-orcontiguity-or-ontological-preservation. This nature of 'registry-worldview's/dimension'suninstitutionalised-threshold ${ }^{102}$-defect-<as-Being-or-ontological-or-existential-defect $>{ }^{5}$, as induced beyond-the-consciousness-awareness-teleology ${ }^{9}<$ of-preconverging-existentialextrication-as-of-existential-unthought $>$ as of registry-worldview/dimension uninstitutionalised-threshold ${ }^{102}$ explains why fundamentally issues of ${ }^{83}$ reference-of-thought defect or perversion-of- ${ }^{-}$reference-of-thought- $<$as-preconverginglyapriorising/axiomatising/referencing-in-nonconviction/madeupness/bottomlining-as-toshallow-supererogation $>$ point more decisively/fundamentally as to their resolution as aetiologistion/ontological-escalation towards the need for ontological-completeness-ofreference-of-thought as to the <cumulating/recomposuring attendant-ontologicalcontiguity >-successive registry-worldviews/dimensions institutionalisations-in-supersedingtheir-corresponding-uninstitutionalisation with regards to base-institutionalisation-superseding- 
recurrent-utter-uninstitutionalisation,

universalisation-superseding-ununiversalisation, positivism-superseding-non-positivism/medievalism and prospectively deprocrypticismsuperseding-procrypticism. Thus preconverging/postconverging-dementatively/structurally/paradigmatically, this is the supratransversality-<in-sublimatingexistential-eventuating/denouement $>\sim$ of-motif-and-apriorising/axiomatising/referencing associated with intemporality ${ }^{52} /$ longness and construed as 'intemporality ${ }^{52}$-symmetrising-bydesymmetrising-subsumption-of-temporality ${ }^{\circ}$ ' since it is 'not equable' with the relative shallowness as temporal/shortness-of-register-of- meaningfulness-and-teleology in intradimensional construal of ${ }^{5}$ meaningfulness-and-teleology ${ }^{9}$ but projects directly in grasping fundamentally the issue of relative-ontological-incompleteness ${ }^{8}$-of- ${ }^{8}$ reference-of-thought and the corresponding virtue-as-ontology implications; as insightfully, an arising issue of accusation of sorcery in non-positivism as medieval or animistic setting is more fundamentally/preconverging/postconverging-de-mentatively/structurally/paradigmatically as of aetiologisation/ontological-escalation-<ontologicalveridicality_commitment/otherliness_transcending/compulsions-encumbered_transcending $>$ a question of their relative-ontological-incompleteness ${ }^{8}$-of- ${ }^{-}$reference-of-thought as it endemises/enculturates such notions as its vices-and-impediments ${ }^{105}$ and the same approach applies to our state of positivism- ${ }^{8}$ procrypticism involving ${ }^{80}$ procrypticism-or-disjointednessas-of- ${ }^{3}$ reference-of-thought-as-misappropriated- $-{ }^{5}$ meaningfulness-and-teleology 9 as it endemises/enculturates perversion-of- ${ }^{8}$ reference-of-thought- $<$ as-preconverginglyapriorising/axiomatising/referencing-in-nonconviction/madeupness/bottomlining-as-toshallow-supererogation $>$ of positivistic meaningfulness as vices-and-impediments ${ }^{105}$ requiring its preemption by futural Being-development/ontological-framework-expansion-as-to-depth-ofontologising-development-as-infrastructure-of- meaningfulness-and-teleology as of prospective notional ${ }^{18}$ deprocrypticism institutionalisation.] 
This effective realism as of rational-realism is the requisite insight in understanding how supposedly

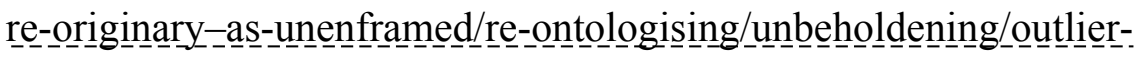

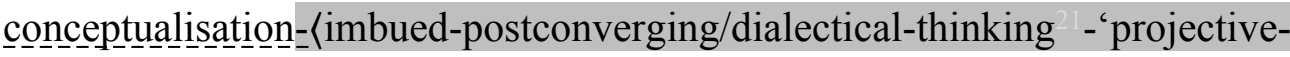
insights'/“epistemic-projection-in-conflatedness '-of-notional deprocrypticism-prospectivesublimation $>$ transcendental notions of intemporality ${ }^{52} /$ longness in successive epochs become dominant notions of human knowledge and institutionalisation by giving man access to relative intrinsic-reality/ontological-veridicality transcendentalenabling/sublimating/supererogatory $\sim$ de-mentativity. Further along the rational-realism line of thinking, the fact is paradoxically that as more cuttingly demonstrated with 'cultural diffusion driven transcendence-and-sublimity/sublimation/supererenate-mentativity', the mechanism of transcendence-and-sublimity/sublimation/supererogatory de-mentativity is not a simplistic transference from a more ontologically-completeness-of- ${ }^{2}$ reference-of-thought registry-worldview to a lesser one. Surprisingly, the lesser one is actually in the position of determination in the contention for transcendence-andsublimity/sublimation/supererogatory $\sim$ de-mentativity, and it is the competitiveness of ideas that are more ontologically-complete and ontologically inducing untenability/internalcontradiction/internal-incoherence/institutional-constraining and inconsistency that initially leads to the <amplituding/formative-epistemicity $>$ totalising $\sim$ self-referencingsyncretising/circularity/interiorising/akrasiatic-drag towards the path of its transcendence; as notions and ideas of the prospective ${ }^{83}$ reference-of-thought gradually creep over those of the prior ${ }^{83}$ reference-of-thought. (This should be distinguish from the case of the transference of ideas where there is a common ${ }^{8}$ reference-of-thought, for instance, the-theory-of-relativity and quantum-mechanics are spectacular developments from Newtonian physics but they still share the same common ${ }^{83}$ reference-of-thought of positivism/rational-empiricism enabling the new theories to be quickly adopted within the mechanism of the common ${ }^{83}$ reference-of-thought in 
terms-as-of-axiomatic-construct of psychical and institutional orientation). Consider in this regard the case in an animistic social-setup wherein failure to be cured from the traditional healer tempts individuals in that setup as a matter of life and death to approach the newcomers of a positivistic registry-worldview/dimension, and with a successful cure sowing doubts about animistic tradition relative intrinsic-reality/ontological-veridicality transcendentalenabling/sublimating/supereregatery de-mentativity, and with various other such positivistic outcomes inducing in the middle to long run further <amplituding/formativeepistemicity $>$ totalising $\sim$ self-referencing-syncretising/circularity/interiorising/akrasiatic-drag of thought; as explanations for the cure will still be advanced in terms-as-of-axiomatic-construct of the old ${ }^{83}$ reference-of-thought (giving human natural predisposition to social-aggregationenabling) but increasingly ridding such explanations of their credible substance until there is critical transference into the new registry-worldview's/dimension's ${ }^{83}$ reference-of-thought. $<$ amplituding/formative-epistemicity $>$ totalising $\sim$ self-referencingsyncretising/circularity/interiorising/akrasiatic-drag ${ }^{34}$ is actually the process by which transcendental meaningfulness, as of prospective/transcending/superseding registry-worldview reference-of-thought, is institutionalised; underlying the essential contiguity of human mentaldisposition across all registry-worldviews/dimensions. This equally highlights a superficialityof-inherent-sanctimony displayed by succeeding institutional-cumulation/institutionalrecomposure-〈as-to- historiality/ontological-eventfulness /ontological-aesthetic-tracing$<$ perspective-ontological-normalcy/postconvergence-reflected-'epistemicity-relativismdeterminism'>>, which may wrongly imply being out of the scope of human-subpotencyaporia/undecidability/dilemma/ought-indeterminacy/deficiency/limitation/constraint—imbued'notional firstnaturedness-formativeness-<as-to-eventualising inkling-drive-or-seeding misprising $>$ temporal-to-intemporal-dispositions- $<$ so-construed-as-from-perspectiveontological-normalcy/postconvergence>'-existentialism-form-factor, and thus fundamentally 
undermine ontologically-veridical analysis where exceptionalism is adhered to instead of the mediocrity principle. This quite sums up the <amplituding/formativeepistemicity $>$ totalising $\sim$ self-referencing-syncretising/circularity/interiorising/akrasiatic-drag

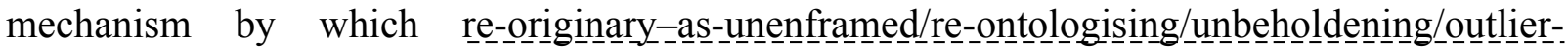
conceptualisation___imbued-postconverging/dialectical-thinking - projectiveinsights'/'epistemic-projection-in-conflatedness ' -of-notional deprocrypticism-prospectivesublimation $\rangle^{\circ}$ transcendental ideas (transcendental in terms-as-of-axiomatic-construct of putting in question the prior <amplituding/formativeepistemicity>totalising/circumscribing/delineating ${ }^{83}$ reference-of-thought- ${ }^{8}$ devolving, beyond just novel ideas within the same ${ }^{83}$ reference-of-thought), whether by diffusion or internal transformation, come to be dominant when ontologically pertinent; as even the 'moulting' intellectual/emancipator, beyond-the-consciousness-awareness-teleology ${ }^{9}-<$ of-preconvergingexistential-extrication-as-of-existential-unthought $>$, is coming from a point of habitation with prior traditional ideas (consider the case of Newton with alchemic notions), wherein acceptance of the new ideas they are purporting only comes after an unconscious process of suspicion and denial of such nagging new ideas until they arrive at a firm point of supplanting-conviction-asto-profound-supererogation of-'attendant-intradimensional'-postconverging/dialecticalthinking -apriorising-psychologism before admitting to themselves the possible veracity/ontological-pertinence of the ideas, and so as their very own <amplituding/formativeepistemicity $>$ totalising $\sim$ self-referencing-syncretising/circularity/interiorising/akrasiatic-drag which makes it unsurprising that even socially <amplituding/formativeepistemicity $>$ totalising $\sim$ self-referencing-syncretising/circularity/interiorising/akrasiatic-drag is a necessary process for the ultimate acceptance of prospective <amplituding/formativeepistemicity $>$ causality $\sim$ as-to-projective-totalitative-implications-of-prospective- 
contiguity as this subsumes-as-supplant-〈as-of-the-more-profound-construal-of 'implicited_attendant-ontological-contiguity ${ }^{7}$ ' educed-

existentialising/contextualising/textualising_'intelligibility/epistemicity/reflexivity-contiguity$<$ imbued-notional $\sim$ cogency $>,{ }^{\prime},-<$ reifying-or-elucidating-of-prospective-relative-ontologicalcompleteness -of- reference-of-thought- devolving-as-of-instantiative-context $>>$ the prior $<$ amplituding/formative-epistemicity $>$ causality $\sim$ as-to-projective-totalitative-implications-ofprospective- nonpresencing,-for-explicating relative-unreflexivity/relative-reflexivityontological-contiguity. It is hardly the case of just a direct intemporal sense of meaningfulness-and-teleology ${ }^{9}$ transference of transcendental notions. The bigger point being that the construal/conceptualisation of transcendental ideas is not necessarily validated by their immediate recognition, a notion the would-be intellectuals/emancipators should be of a '7 presencing —absolutising-identitive-constitutedness ${ }^{14}$ consummated/forfeiting posture', but rather as providing fodder in the competitive ideas assuring human progress with emphasis rather with respect to crossgenerational import (prospective-institutionalisation $<$ amplituding/formative-epistemicity $>$-totalising $\sim$ renewing-realisation/re-perception/rethought-as-utter-placeholder-setup-ontological-rescheduling-〈by-a-renewing-ofapriorising/axiomatising/referencing-psychologism-as-the-new-referencing-basis-ofprospective- meaningfulness-and-teleology $\rangle$ as enabled by psychoanalyticunshackling/memetic-reordering/institutional-recomposuring). It is doubtful that Galileo or Diderot and others of their inclination were naïve to think that their initiatives will immediately lead to a positivistic transformation of society but they certainly had a cynical sense of crossgenerational purposefulness (whether beyond-the-consciousness-awareness-teleology $<$ of-preconverging-existential-extrication-as-of-existential-unthought $>$ ). This equally explains why in all epochs, however different the nature, there is an inherent temporal mental-disposition abhorrence of transcendental ideas as putting-into-question the present and present interests (for 
instance, even the industrial revolution when considered as actually generating material wealth was poorly perceived by many trade guilds). It is only the 'sublimating-epistemicimbricatedness/threadedness/recomposuring as of 'implicited_attendant-ontologicalcontiguity $^{67}$, educed-

existentialising/contextualising/textualising_intelligibility/epistemicity/reflexivity-contiguity$<$ imbued-notional cogency $>{ }^{,},-<$reifying-or-elucidating-of-prospective-relative-ontological-

completeness -of- reference-of-thought- devolving-as-of-instantiative-context $>$ as to

existence-potency $^{39} \sim$ sublimating-nascence,-disclosed-from-prospective-epistemicdigression — rules-of-apriorising/axiomatising/referencing-that-further-epistemicallyunconceal-the-very-ontologically-same-existential-reality' (from the perspective of the 'postconverging-or-dialectical-thinking ${ }^{2}{ }^{8}$ reference-of-thought in relative-ontologicalcompleteness $^{87}$ as depth-of-thought') that allows for a 'relative teleologicaldifferentiation/scission/variance/disambiguation of ${ }^{83}$ references-of-thought' as to what the appropriateness-of- ${ }^{8}$ reference-of-thought-as-of-conflatedness (correct apriorising/axiomatising/referencing/intelligibilitysettingup/measuringinstrumentingproducing-measurements) and the ${ }^{77}$ perversion-of- ${ }^{83}$ refence-of-thought- $<$ as-preconverginglyapriorising/axiomatising/referencing-in-nonconviction/madeupness/bottomlining-as-to-

apriorising/axiomatising/referencing/intelligibilitysettingup/measuringinstrumentingproducing-measurements) truly are, and the implications thereof with regards to meaningfulness-and-teleology $\quad$ (purposeful architectural aposteriorising/logicising/deriving/intelligising/measuring-purpose—of-obtainedmeasurements). Without the notion of 'sublimating-epistemicimbricatedness/threadedness/recomposuring as of 'implicited_attendant-ontologicalcontiguity $^{67}$; educed- 
existentialising/contextualising/textualising_intelligibility/epistemicity/reflexivity-contiguity$<$ imbued-notional $\sim$ cogency $>,{ }^{\prime},-<$ reifying-or-elucidating-of-prospective-relative-ontologicalcompleteness -of- reference-of-thought- devolving-as-of-instantiative-context> as to existence-potency $^{39} \sim$ sublimating-nascence,-disclosed-from-prospective-epistemicdigression—rules-of-apriorising/axiomatising/referencing-that-further-epistemicallyunconceal-the-very-ontologically-same-existential-reality' (from the perspective of the 'postconverging-or-dialectical-thinking ${ }^{2}{ }^{8}$ reference-of-thought in relative-ontologicalcompleteness $^{87}$ as depth-of-thought', so-undertaken as of maximalising-recomposuring-forrelative-ontological-completeness ${ }^{87}$ - unenframed/re-ontologising conceptualisation), the new logical-processing-or-logical-implicitation-supposedly-apriorising-in-conviction-as-toprofound-supererogation as 'supplanting-conviction-as-to-profound-supererogation - of‘attendant-intradimensional'-postconverging/dialectical-thinking -apriorising-psychologism re-engaging reflex' (as prelogism ${ }^{78}$-as-of-conviction,-in-profound-supererogation $<$ existentially-veridical-'attendant-intradimensional-apriorising/axiomatising/referencing'logical-dueness-precedes-disontologising-logical-outcome-arrived-at $>$ ) will simply skip the notion of any perversion-of- ${ }^{2}$ reference-of-thought- $<$ as-preconverginglyapriorising/axiomatising/referencing-in-nonconviction/madeupness/bottomlining-as-toshallow-supererogation $>$ and 'prelogism" -as-of-conviction,-in-profound-supererogation $<$ existentially-veridical-'attendant-intradimensional-apriorising/axiomatising/referencing'logical-dueness-precedes-disontologising-logical-outcome-arrived-at> re-engaging reflex’ (undertaken elaboration-as-to-mereextrapolating/constituting/abstracting/deducing/inferring-of-elucidation-outside'prospectively implicit_attendant-ontological-contiguity ${ }^{67}$ ' educedexistentialising/contextalising/textalising_'intelligibility/epistemicity/reflexivity_contiguity$<$ imbued-notional cogency>' $>^{4}$ ) inducing a 'wrongly-projected decontextualising- 
unimbricatedness/unthreadedness/unrecomposuring,-as-virtuality-or-ontologically-flawedconstrual (which is rather a "prior threshold-of-nonconviction/madeupness/bottomlining-inshallow-supererogation -<as-to-'attendant-intradimensional'-prospectivelydisontologising preconverging/dementing -apriorising-psychologism> $>\quad{ }^{83}$ reference-ofthought' in shallowness-of-thought-or-unsophistication-of-understanding) in grasping 'implicited_attendant-ontological-contiguity ${ }^{67}$ ? educedexistentialising/contextualising/textualising_intelligibility/epistemicity/reflexivity_contiguity$<$ imbued-notional $\sim$ cogency $>,{ }^{\prime},-<$ reifying-or-elucidating-of-prospective-relative-ontologicalcompleteness -of- reference-of-thought- devolving-as-of-instantiative-context $>$ as to existence-potency ${ }^{39} \sim$ sublimating-nascence,-disclosed-from-prospective-epistemicdigression—rules-of-apriorising/axiomatising/referencing-that-further-epistemicallyunconceal-the-very-ontologically-same-existential-reality'), thus preconverging/postconverging-de-mentatively/structurally/paradigmatically upholding the perversion-of- ${ }^{2}$ reference-of-thought-<as-preconverginglyapriorising/axiomatising/referencing-in-nonconviction/madeupness/bottomlining-as-toshallow-supererogation $>$ associated with postlogism 77 and its derived implications as conjugated-postlogism 77 whether as ignorance (unconsciously), affordability (expediently) or opportunism/exacerbation/social-chainism-or-social-discomfiture-or-negative-socialaggregation/temporal-enculturation-or-temporal-endemisation (consciously); and with the corresponding existential-<disontologising/re-ontologising aporeticism $>$ circularity/recurrence/repetition/repeatability ${ }^{10}$ of the postlogism ${ }^{77}$ and conjugated mentalprojections implied, involving temporality $/$ shortness in denaturing $^{16}$ postlogic-backtracking$<$ iterative-looping-'set-of-dereifying-hollow-narratives-and-acts'> $\quad$ towards 'socialaggregation-enablers over intrinsic-reality/ontological-veridicality transcendentalenabling/sublimating/supereregatery $\sim$ de-mentativity', and so to the point that it is upholding 
postlogism 77 and conjugated-postlogism 77 as socially-functional-and-accordant ${ }^{3}$. On-the-otherhand, intemporality $^{52}$-as-longness-of-register-of- ${ }^{56}$ meaningfulness-and-teleology aetiologisation/ontological-escalation-<ontologicalveridicality_commitment/otherliness_transcending/compulsions-encumbered_transcending $>$, can supersede the above ${ }^{77}$ perversion-of- ${ }^{83}$ reference-of-thought- $<$ as-preconverginglyapriorising/axiomatising/referencing-in-nonconviction/madeupness/bottomlining-as-toshallow-supererogation $>$ phenomena as of its derived vices-and-impediments ${ }^{105}$ implications, as veridically validated by intrinsic-reality/ontological-veridicality transcendentalenabling/sublimating/supererogatory $\sim$ de-mentativity so-divulged by the 'sublimatingepistemic-imbricatedness/threadedness/recomposuring as of 'implicited_attendant_ontologicalcontiguity $^{67}$, educedexistentialising/contextualising/textualising_'intelligibility/epistemicity/reflexivity-contiguity$<$ imbued-notional $\sim$ cogency $>$, ,-<reifying-or-elucidating-of-prospective-relative-ontologicalcompleteness -of- reference-of-thought- devolving-as-of-instantiative-context> as to existence-potency ${ }^{39} \sim$ sublimating-nascence,-disclosed-from-prospective-epistemicdigression—rules-of-apriorising/axiomatising/referencing-that-further-epistemicallyunconceal-the-very-ontologically-same-existential-reality' (from the perspective of the prospective 'postconverging-or-dialectical-thinking ${ }^{21}{ }^{8}$ reference-of-thought in relativeontological-completeness ${ }^{87}$ as depth-of-thought') enabling social ${ }^{103}$ universal-transparency ${ }^{104}$ 〈transparency-of-totalising-entailing,-as-to-entailing-<amplituding/formativeepistemicity>totalising in-relative-ontological-completeness $\rangle$-or-understanding-of$<$ amplituding/formative-epistemicity $>$ causality $\sim$ as-to-projective-totalitative-implications-ofprospective- nonpresencing,-for-explicating relative-unreflexivity/relative-reflexivity ontological-contiguity -of-underlying-phenomena superseding grasp of social vices-andimpediments ${ }^{105}$ as of the given transcendence-unenabling-uninstitutionalised-threshold ${ }^{102}$ in 
alienation — as-inauthentic/poorly-objectified/poorly-desubjectified-as-objectified/ontologicalbad-faith/inauthenticity ${ }^{6} /$ nihilistic, by its psychoanalytic-unshackling/memeticreordering/institutional-recomposuring or social pivoting/decentering to reconstrue/reconceptualise ${ }^{56}$ meaningfulness-and-teleology ${ }^{99}$ as of prospective relativeontological-completeness ${ }^{87}$. The difference between postlogism (postlogism ${ }^{77}$-as-ofcompulsing-nonconviction/madeupness/bottomlining-〈‘ $<$ decontextualising/deexistentialising $\sim$ of-attendant-intradimensional-apriorising/axiomatising/referencing $>$-induceddisontologising'-of-the-'attendant-intradimensional-ontologising'-imbued$<$ contextualising/existentialising attendant-ontological-contiguity $>$;-in-shallowsupererogation -<as-to-disontologising-perverted-outcome-sought-precedes-existentiallyveridical-'attendant-intradimensional-apriorising/axiomatising/referencing'-logicaldueness $>$ ) and prelogism ${ }^{78} \quad$ (prelogism ${ }^{78}$-as-of-conviction,-in-profound-supererogation <existentially-veridical-'attendant-intradimensional-apriorising/axiomatising/referencing'logical-dueness-precedes-disontologising-logical-outcome-arrived-at $>$ ) can further be developed as such. Supposed there is a given context where the solution to additions of the aposteriorising/logicising/deriving/intelligising/measuring-purpose_of-obtainedmeasurements ( ${ }^{5}$ meaningfulness-and-teleology $\left.{ }^{9}\right)$ taken involves rewards depending on how big is the number with the Donor not in a position to pay particular attention to the exact sums to be resolved if a character is in a position to fiddle with the implied sum to be resolved like deliberately using the defective apriorising/axiomatising/referencing/intelligibilitysettingup/measuringinstrumentingproducing-measurements as ${ }^{7}$ perversion-of- ${ }^{3}$ reference-of-thought- $<$ as-preconverginglyapriorising/axiomatising/referencing-in-nonconviction/madeupness/bottomlining-as-toshallow-supererogation $>$ (more like the 'covert negative vista' of the hiddennature/unavailable social ${ }^{103}$ universal-transparency ${ }^{104}$-〈transparency-of-totalising-entailing,-as- 


\section{to-entailing-<amplituding/formative-epistemicity $>$ totalising $\sim$ in-relative-ontological-}

completeness $>$ of psychopathy especially at adulthood). Now supposed to resolve a 'purposeful measurement' ('meaningfulness-and-teleology $\left.{ }^{9}\right)$, A appropriately uses a correct apriorising/axiomatising/referencing/intelligibilitysettingup/measuringinstrumenting_

producing-measurements (appropriateness-of- ${ }^{8}$ reference-of-thought-as-of-conflatedness ${ }^{13}$ ) and find out that the numbers measured and to be added are $5+2$ and is trying its best thereafter to resolve the sum but fails in its ${ }^{5}$ logical-processing-or-logical-implicitation-supposedlyapriorising-in-conviction-as-to-profound-supererogation and gives 9 as the answer, this doesn't void logically re-engaging with A with respect to other sums in terms of aposteriorising/logicising/deriving/intelligising/measuring-purpose —of-obtainedmeasurements to be undertaken (as to logical-processing-or-logical-implicitation supposedly-apriorising-in-conviction-as-to-profound-supererogation ) so long as A learns and understands the addition principle well. This instance of A's ${ }^{83}$ reference-of-thought where it is not

perverted

(correct

apriorising/axiomatising/referencing/intelligibilitysettingup/measuringinstrumentingproducing-measurements) but its ${ }^{54}$ logical-processing-or-logical-implicitation—supposedlyapriorising-in-conviction-as-to-profound-supererogation has failed because of A's genuine incapacity for addition calculations is part-and-parcel (whether successful or not) of prelogism 78 . Now supposed B is in a position and has the mental-disposition to covertly add 1 to any of the numbers measured and to be involved in the calculations to be undertaken before then calculating and so as to measurement (so-construed as use of a defective apriorising/axiomatising/referencing/intelligibilitysettingup/measuringinstrumentingproducing-measurements speaking of B's ${ }^{74}$ perversion-of- ${ }^{3}$ reference-of-thought- $<$ aspreconvergingly-apriorising/axiomatising/referencing-innonconviction/madeupness/bottomlining-as-to-shallow-supererogation $>$ ) such that its 
calculations as aposteriorising/logicising/deriving/intelligising/measuring-purpose-ofobtained-measurements ( ${ }^{5}$ meaningfulness-and-teleology $\left.{ }^{9}\right)$ is undertaken erroneously rather implying $6+3$ instead of $5+2$ (with respect to the same correct apriorising/axiomatising/referencing/intelligibilitysettingup/measuringinstrumenting measurement undertaken by A for subsequent calculation as 5+2) and then resolved correctly to be 9 as well just as A did out of wrong calculation, fundamentally the idea of re-engaging with B for solutions of additions (as to ${ }^{5}$ logical-processing-or-logical-implicitation-supposedlyapriorising-in-conviction-as-to-profound-supererogation ) is flawed since B is not committed due to its ${ }^{74}$ perversion-of- ${ }^{83}$ reference-of-thought- $<$ as-preconverginglyapriorising/axiomatising/referencing-in-nonconviction/madeupness/bottomlining-as-to-

apriorising/axiomatising/referencing/intelligibilitysettingup/measuringinstrumentingproducing-measurements) to genuinely strive for correct answers (ontological-veridicality), and this speaks of the possibility of B denaturing an infinite number of additional calculations (to the extent where it is 'socially-functional-and-accordant ${ }^{3}$ ' to do so, i.e. functionally possible in the social context). Unlike the case with A having to do with A's addition ability but whose reference-of-thought is not perverted, such that A's defect is a defect-of- logical-processingor-logical-implicitation—supposedly-apriorising-in-conviction-as-to-profound-

supererogation of the registry-worldview's/dimension's- ${ }^{83}$ reference-of-thought-for-socialfunctioning-and-accordance, on-the-other-hand B's defect is a Being/ontological/existentialdefect, i.e. the teleological disposition of B inherently carries the defect (to the point that B can be socially-functional-and-accordant ${ }^{93}$ while committing the defect, i.e. where the veridical notion/axiomatic-construct of the defective apriorising/axiomatising/referencing/intelligibilitysettingup/measuringinstrumenting is not ${ }^{3}$ universally transparent as a 'negative covert vista'). Now supposed we are in a social context 
where C, D, E, F are to calculate additions as well but from the solutions arrived at by A and B. In the instance where $\mathrm{C}$ is ignorant of $\mathrm{B}$ 's Being/ontological/existential-defect, there is a possibility of re-engaging with C but only where B's condition is exposed to it, but where the characters are not that ignorant but in any of the mental states (implying undermining the intrinsic-reality/ontological-veridicality transcendentalenabling/sublimating/supereregatery - de-mentativity of normal additionality with such a socialaggregation-enabler situation) and so as of expediency or affordability for D, opportunism for $\mathrm{E}$, exacerbation for $\mathrm{F}$, social-chainism/social-discomfiture/negative-social-aggregation for $\mathrm{B}, \mathrm{C}$ (where B's condition is not exposed to it), D, E and F or temporal-endemisation/temporalenculturation of B's condition for B, C (where B's condition is not exposed to it), D, E and F. It should be noted that C (where B's condition is not exposed to it), D, E and F technically speaking have a 'derived-Being/ontological/existential-defect' as well, and so to the point that they consciously perceive it can be socially-functional-and-accordant ${ }^{3}$ to them wherein lack of 'social ${ }^{103}$ universal-transparency ${ }^{104}$-〈transparency-of-totalising-entailing,-as-to-entailing<amplituding/formative-epistemicity>totalising in-relative-ontological-completeness $>$ which protects the internal-coherence of meaning for virtue' enables their own 'covert negative vista' however ad-hoc as conjugated-postlogism 7 , i.e. as to the conjugated-ignorance of C (where B's condition is not exposed to it), conjugated-affordability of D, conjugated-opportunism of E, conjugated-exacerbation of $\mathrm{F}$, and conjugated-social-chainism of $\mathrm{B}, \mathrm{C}$ (where B's condition is not exposed it) D, E and F, and conjugated-temporal-enculturation to B's condition of $\mathrm{B}, \mathrm{C}$ (where B's condition is not exposed to it), D, E and F; and they cannot therefore be re-engaged logically with (as of 'prelogism ${ }^{7}$-as-of-conviction,-in-profound-supererogation

\section{$<$ existentially-veridical-'attendant-intradimensional-apriorising/axiomatising/referencing'-}

logical-dueness-precedes-disontologising-logical-outcome-arrived-at $>$ re-engaging reflex') on the basis that they will relay in circularity/recurrence/repetition/repeatability ${ }^{10}$ the defective 
apriorising/axiomatising/referencing/intelligibilitysettingup/measuringinstrumenting (perversion-and-derived- ${ }^{7}$ perversion-of- ${ }^{-3}$ reference-of-thought-<as-preconverginglyapriorising/axiomatising/referencing-in-nonconviction/madeupness/bottomlining-as-toshallow-supererogation >-as-to-uninstitutionalised-threshold ${ }^{102}$-self-referencing-syncretisingand-subtransversality-<in-desublimating-existential-eventuating/denouement $>\sim$ of-motif-andapriorising/axiomatising/referencing) elicited by B in terms-as-of-axiomatic-construct of B's postlogism -as-of- compulsing-nonconviction/madeupness/bottomlining$\langle<<$ decontextualising/de-existentialising $\sim$ of-attendant-intradimensionalapriorising/axiomatising/referencing>-induced-disontologising'-of-the-'attendantintradimensional-ontologising'-imbued-<contextualising/existentialising $\sim$ attendantontological-contiguity $>$;-in-shallow-supererogation $-<$ as-to-disontologising-pervertedoutcome-sought-precedes-existentially-veridical-'attendant-intradimensionalapriorising/axiomatising/referencing'-logical-dueness $>$ > and C, D, E and F relative-ontologicalincompleteness ${ }^{8}$-induced,-'threshold-of-nonconviction/madeupness/bottomlining-in-shallowsupererogation $-<$ as-to-'attendant-intradimensional'-prospectivelydisontologising preconverging/dementing -apriorising-psychologism>' that is 'in-wait as of prior relative-ontological-incompleteness ${ }^{8}$-of- ${ }^{8}$ reference-of-thought defective ${ }^{83}$ reference-ofthought- categorical-imperatives/axioms/registry-teleology $^{9}$ to enable their conjugatedpostlogism 77 , where it is socially-functional-and-accordant ${ }^{93}$ to do so. It should be qualified that postlogism 77 (psychopathy) and conjugated-postlogism 77 (as social psychopathy) are enabled, endemised and enculturated by the possibility of the phenomena being socially-functional-andaccordant ${ }^{93}$ without negative consequences to its agents so long as it is not socially ${ }^{103}$ universally transparent, and so eliciting the respective temporality $/$ shortness over the intemporality ${ }^{52} /$ longness of adhering to proper apriorising/axiomatising/referencing/intelligibilitysettingup/measuringinstrumenting 
(ontologically-veridical ${ }^{5}$ meaningfulness-and-teleology ${ }^{9}$ ). Further more than postlogism 77 and conjugated-postlogism 77 being just passively socially-functional-and-accordant ${ }^{93}$, a more active socially-functional-and-accordant ${ }^{3}$ framework is often induced by extrinsic-attribution on the token of eliciting 'social-aggregation-enablers over intrinsic-reality/ontological-veridicality transcendental-enabling/sublimating/supererogatory de-mentativity'. This is highly specific and circumscribe for efficacy-sake from accrued involvement with childhood psychopathy (with regards to adult psychopathy or adult postlogism ${ }^{77}$ ) wherein achieving the registryworldview's/dimension's- ${ }^{8}$ reference-of-thought-for-social-functioning-and-accordance threshold enabling postlogism 77 psychopathy and/or conjugated-postlogism 77 socialpsychopathy involves an insight about how 'lack of constraining social ${ }^{103}$ universaltransparency ${ }^{104}$-〈transparency-of-totalising-entailing,-as-to-entailing-<amplituding/formativeepistemicity>totalising in-relative-ontological-completeness > of perversion-and-derivedperversion-of- ${ }^{3}$ reference-of-thought-<as-preconvergingly-

apriorising/axiomatising/referencing-in-nonconviction/madeupness/bottomlining-as-toshallow-supererogation $>$ determines how prelogism ${ }^{7}$-as-of-conviction,-in-profoundsupererogation $-<$ existentially-veridical-'attendant-intradimensionalapriorising/axiomatising/referencing'-logical-dueness-precedes-disontologising-logicaloutcome-arrived-at> minds will act as $\quad$ of ignorance/affordability/opportunism/exacerbation/social-chainism-or-social-discomfiture-ornegative-social-aggregation/temporal-enculturation-or-temporal-endemisation. Besides and critically as well, in addition to this inherently induced faulty-mentation-procedure-deception involved with the state of postlogism -as-of- compulsingnonconviction/madeupness/bottomlining-〈'<decontextualising/de-existentialising ofattendant-intradimensional-apriorising/axiomatising/referencing>-induced-disontologising'-ofthe-'attendant-intradimensional-ontologising'-imbued- 
$<$ contextualising/existentialising attendant-ontological-contiguity $>$;-in-shallow-

supererogation -<as-to-disontologising-perverted-outcome-sought-precedes-existentially-

veridical-'attendant-intradimensional-apriorising/axiomatising/referencing'-logical-dueness $>$ )

and its protraction into conjugated-postlogism 77 social-psychopathy, postlogism 77 and conjugated-postlogism 77 is equally and decisively sustained socially by the accompanying inherent disposition to uphold the registry-worldview's/dimension's- ${ }^{83}$ reference-of-thought-forsocial-functioning-and-accordance thereafter as of mechanical-knowledge (given that inevitably social confliction is bound to arise in the social-setup with the phenomena of postlogism 7 /psychopathy and conjugated-postlogism 77 social-psychopathy), and as the mere recurrence of such social conflictions associated with the postlogism 77 psychopathy and conjugated-postlogism 7 /social-psychopathy characters might ultimately jeopardise the registryworldview's/dimension's- ${ }^{83}$ reference-of-thought-for-social-functioning-and-accordance (even when other prelogism ${ }^{78}$-as-of-conviction,-in-profound-supererogation $<$ <existentiallyveridical-'attendant-intradimensional-apriorising/axiomatising/referencing'-logical-duenessprecedes-disontologising-logical-outcome-arrived-at> minds do lack a social ${ }^{103}$ universaltransparency ${ }^{104}-\langle$ transparency-of-totalising-entailing,-as-to-entailing-<amplituding/formativeepistemicity>totalising in-relative-ontological-completeness > of the veridical postlogism 7 psychopathy and conjugated-postlogism 77 social-psychopathy underlying phenomena of perversion-and-derived- perversion-of- $^{-}$reference-of-thought- $<$aspreconvergingly-apriorising/axiomatising/referencing-in-

nonconviction/madeupness/bottomlining-as-to-shallow-supererogation $>$ as disontologisingperverted-outcome-sought-precedes-existentially-veridical-'attendant-intradimensionalapriorising/axiomatising/referencing'-logical-dueness). In this regard, prelogism ${ }^{78}$-as-ofconviction,-in-profound-supererogation -<existentially-veridical-'attendant-intradimensionalapriorising/axiomatising/referencing'-logical-dueness-precedes-disontologising-logical- 
outcome-arrived-at $>$ minds generally adopt a generalising approach for determining the 'overall registry-worldview's/dimension's- ${ }^{83}$ reference-of-thought-for-social-functioning-and-

accordance experiences and recounts with any specific individual' including psychopathic or conjugated-postlogism 7 , and in so doing construe dichotomously the said individual's as adhering or not-adhering to the registry-worldview's/dimension's- ${ }^{83}$ reference-of-thought-forsocial-functioning-and-accordance (and so specifically judged rather in various shades of the registry-worldview's/dimension's- $-{ }^{83}$ reference-of-thought-for-social-functioning-and-

accordance implied mechanical-knowledge), as entails with associating or not associating the said individual in given occasions or in specifically given aspects of life depending on such experiences and recounts. With this in mind (based on its dormant childhood development experience), the adult psychopathy personality arising from its growth experience (and correspondingly the protraction into conjugated-postlogism 77 behaviour in this regard), wherein its childhood psychopathy failing the registry-worldview's/dimension's- ${ }^{83}$ reference-of-thoughtfor-social-functioning-and-accordance induced a shift in behaviour such that in lieu of 'such preposterous acts-and/or-narratives of vicious postlogism -as-of- compulsingnonconviction/madeupness/bottomlining-〈'<decontextualising/de-existentialising ofattendant-intradimensional-apriorising/axiomatising/referencing $>$-induced-disontologising'-ofthe-'attendant-intradimensional-ontologising'-imbued-

$<$ contextualising/existentialising attendant-ontological-contiguity $>$;-in-shallowsupererogation -<as-to-disontologising-perverted-outcome-sought-precedes-existentiallyveridical-'attendant-intradimensional-apriorising/axiomatising/referencing'-logicaldueness $>\rangle$ ' at childhood, the childhood psychopathy comes to grasp that 'acts-and/or-narratives of vivious postlogism -as-of- compulsing-nonconviction/madeupness/bottomlining-

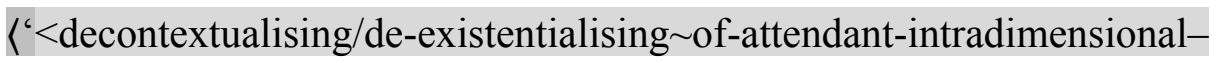
apriorising/axiomatising/referencing>-induced-disontologising'-of-the-'attendant- 
intradimensional-ontologising'-imbued-<contextualising/existentialising $\sim$ attendant-

ontological-contiguity $>$;-in-shallow-supererogation -<as-to-disontologising-perverted-

outcome-sought-precedes-existentially-veridical-'attendant-intradimensional-

apriorising/axiomatising/referencing'-logical-dueness $>$ )' as of 'compensating directed pseudovirtue acts-and/or-narratives' will lead to relative social overlooking of the 'postlogism 7 -as-ofcompulsing-nonconviction/madeupness/bottomlining-〈' $<$ decontextualising/deexistentialising $\sim$ of-attendant-intradimensional-apriorising/axiomatising/referencing $>$-induceddisontologising'-of-the-'attendant-intradimensional-ontologising'-imbued$<$ contextualising/existentialising attendant-ontological-contiguity $>$;-in-shallowsupererogation -<as-to-disontologising-perverted-outcome-sought-precedes-existentiallyveridical-'attendant-intradimensional-apriorising/axiomatising/referencing'-logical-dueness $>$ ) vicious acts-and/or-narratives'; and so cultivating its deterministic <amplituding/formativeepistemicity $>$ causality $\sim$ as-to-projective-totalitative-implications-of-prospectivenonpresencing,-for-explicating relative- unreflexivity/relative-reflexivity - ontological-

contiguity faulty-mentation-procedure-deception 'misconception of meaningfulness-andvirtue'. For instance, as highlighted further below where John in a 'dereifying act' spills water on a chair, his 'misconception of meaningfulness-and-virtue' involving such a mentaldisposition of 'compensating directed pseudo-virtue acts-and/or-narratives' may be to do some house chore but rather in 'crude behaviour manner' that reveals an ad-hoc quest to re-establish the registry-worldview's/dimension's- ${ }^{83}$ reference-of-thought-for-social-functioning-andaccordance with others. The adult psychopathy personality development arising from this fundamental faulty-mentation-procedure-deception 'misconception of meaningfulness-andvirtue' at childhood, further evolves a long way with a constantly readjustment process to ultimately enable the credulity for the registry-worldview's/dimension's- ${ }^{83}$ reference-ofthought-for-social-functioning-and-accordance at adult psychopathy, such that at adulthood 
social

universal-transparency

-〈transparency-of-totalising-entailing,-as-to-entailing-

$<$ amplituding/formative-epistemicity>totalising in-relative-ontological-completeness $>$ as of 'implicited_attendant-ontological-contiguity ${ }^{67}$;educed-

existentialising/contexalising/texalising_intelligibility/epistemicity/reflexivity-contiguity$<$ imbued-notional $\sim$ cogency $>{ }^{\prime},-<$ reifying-or-elucidating-of-prospective-relative-ontological-

completeness -of- reference-of-thought- devolving-as-of-instantiative-context> of its

underlying postlogism 77 -as-of- compulsing-nonconviction/madeupness/bottomlining$\langle `<$ decontextualising/de-existentialising of-attendant-intradimensional-

apriorising/axiomatising/referencing>-induced-disontologising'-of-the-'attendant-

intradimensional-ontologising'-imbued-<contextualising/existentialising $\sim$ attendant-

ontological-contiguity $>$;-in-shallow-supererogation $-<$ as-to-disontologising-perverted-

outcome-sought-precedes-existentially-veridical-'attendant-intradimensional-

apriorising/axiomatising/referencing'-logical-dueness $>$ > often gets lost enabling its faultymentation-procedure-deception at adulthood. By derivation the subsequently induced conjugated-postlogism 77 social-psychopathy, as of human temporal-dispositions will exploit unconsciously (as ignorance), expediently (as affordability) or consciously (as opportunism/exacerbation/social-chainism-or-social-discomfiture-or-negative-socialaggregation/temporal-enculturation-or-temporal-endemisation) the lack of such social ${ }^{3}$ universal-transparency ${ }^{104}$-〈transparency-of-totalising-entailing,-as-to-entailing$<$ amplituding/formative-epistemicity>totalising in-relative-ontological-completeness $>$ of the psychopathic/postlogism 77 perversion-of- ${ }^{8}$ reference-of-thought- $<$ as-preconverginglyapriorising/axiomatising/referencing-in-nonconviction/madeupness/bottomlining-as-toshallow-supererogation $>$, and thus its own derived- perversion-of- ${ }^{7}$ reference-of-thought$<$ as-preconvergingly-apriorising/axiomatising/referencing-in-

nonconviction/madeupness/bottomlining-as-to-shallow-supererogation >; wherein even in the 
case of occasional elucidation of specific postlogism 7 -set-of-narratives-and-acts of the psychopath as being rather of compulsing-nonconviction/madeupness/bottomlining〈‘ $<$ decontextualising/de-existentialising $\sim$ of-attendant-intradimensionalapriorising/axiomatising/referencing>-induced-disontologising'-of-the-'attendantintradimensional-ontologising'-imbued-<contextualising/existentialising $\sim$ attendantontological-contiguity $>$;-in-shallow-supererogation -<as-to-disontologising-pervertedoutcome-sought-precedes-existentially-veridical-'attendant-intradimensionalapriorising/axiomatising/referencing'-logical-dueness $>>$ and preconverging-or-dementing 2 apriorising-psychologism, this does not necessarily transform the mental-dispositions of temporal-dispositions in their conjugation to psychopathic postlogism 77 as conjugatedpostlogism 77 since the induced-deception is fundamentally of apriorising- ${ }^{83}$ reference-ofthought/apriorising-registry_elements (\{epistemic-totalising 3 psychologismic-subliminality-ofindividuation —effusing/worlding imbued logical-dueness-or-scape-or-frame, profile-or-stature, presumptuousness-or-arrogation, assumptions, value-reference and teleology ${ }^{9}$ ), with the conjugated-postlogism 77 interlocutor as of " ${ }^{\text {" }}$ reference-of-thought—degraded-devolving-as-ofuninstitutionalised-threshold $^{102}$, even when they recognised the specific postlogism 7 -set-ofnarratives-and-acts and are rather inclined to contend on the basis of the same flawed and deceptively-induced apriorising $-{ }^{83}$ reference-of-thought/apriorising-registry-elements (whether unconsciously as beyond-the-consciousness-awareness-teleology ${ }^{9}-<$ ofpreconverging-existential-extrication-as-of-existential-unthought $>$ as conjugated-ignorance or by expediency as conjugated-affordability or consciously as conjugatedopportunism/conjugated-exacerbation/conjugated-social-chainism-or-social-discomfiture-ornegative-social-aggregation/conjugated-temporal-enculturation-or-temporal-endemisation, given the 'lack of constraining social ${ }^{103}$ universal-transparency ${ }^{104}$-〈transparency-of-totalisingentailing,-as-to-entailing-<amplituding/formative-epistemicity $>$ totalising in-relative- 
ontological-completeness \) without $\quad{ }^{83}$ reference-of-thought- ${ }^{\text {categorical- }}$ imperatives/axioms/registry-teleology ${ }^{9}$,-for-

aposteriorising/logicising/deriving/intelligising/measuring $-{ }^{5}$ meaningfulness-and-teleology ${ }^{9}$ to the ontological implications of the appropriate 'implicited_attendant-ontologicalcontiguity ${ }^{67} \sim$ educed-

existentialising/contextualising/textualising_intelligibility/epistemicity/reflexivity-contiguity$<$ imbued-notional $\sim$ cogency $>,{ }^{\prime},-<$ reifying-or-elucidating-of-prospective-relative-ontologicalcompleteness -of- reference-of-thought- devolving-as-of-instantiative-context $>$ apriorisingreference-of-thought/apriorising-registry-elements and thus explaining derivedperversion-of- ${ }^{3}$ reference-of-thought-<as-preconvergingly-

\section{apriorising/axiomatising/referencing-in-nonconviction/madeupness/bottomlining-as-to-}

shallow-supererogation $>$ arises, in addition to the more fundamental issue of relativeontological-incompleteness ${ }^{-}$-of- ${ }^{8}$ reference-of-thought as of prospective procrypticism uninstitutionalisation. In other words, 'psychopathic/postlogism and socialpsychopathic/conjugated-postlogism 77 vicious acts-and/or-narratives' as of perversion-andderived- ${ }^{7}$ perversion-of- ${ }^{3}$ reference-of-thought- $<$ as-preconverginglyapriorising/axiomatising/referencing-in-nonconviction/madeupness/bottomlining-as-toshallow-supererogation $>$ take the form of mental 'misconception of meaningfulness-andvirtue' that such 'postlogism 77 -as-of- compulsing-nonconviction/madeupness/bottomlining$\langle<<$ decontextualising/de-existentialising $\sim$ of-attendant-intradimensionalapriorising/axiomatising/referencing>-induced-disontologising'-of-the-'attendantintradimensional-ontologising'-imbued-<contextualising/existentialising $\sim$ attendantontological-contiguity $>$;-in-shallow-supererogation -<as-to-disontologising-pervertedoutcome-sought-precedes-existentially-veridical-'attendant-intradimensionalapriorising/axiomatising/referencing'-logical-dueness $>$ > vicious acts-and/or-narratives' based 
on their systematic combination with 'compensating directed pseudo-virtue acts-and/ornarratives' directed to relevant significant others will enable the registryworldview's/dimension's- ${ }^{83}$ reference-of-thought-for-social-functioning-and-accordance, by such a compensation mechanism. With this faulty-mentation-procedure-deception, this is thus supposed to override the "postlogism 7 -as-of- compulsingnonconviction/madeupness/bottomlining-〈‘ $<$ decontextualising/de-existentialising $\sim$ ofattendant-intradimensional-apriorising/axiomatising/referencing>-induced-disontologising'-ofthe-'attendant-intradimensional-ontologising'-imbued$<$ contextualising/existentialising attendant-ontological-contiguity $>$;-in-shallowsupererogation -<as-to-disontologising-perverted-outcome-sought-precedes-existentiallyveridical-'attendant-intradimensional-apriorising/axiomatising/referencing'-logical-dueness $>>$ vicious acts-and/or-narratives' as of an association between the 'postlogism 7 -as-ofcompulsing-nonconviction/madeupness/bottomlining-<'<decontextualising/deexistentialising $\sim$ of-attendant-intradimensional-apriorising/axiomatising/referencing $>$-induceddisontologising'-of-the-'attendant-intradimensional-ontologising'-imbued$<$ contextualising/existentialising attendant-ontological-contiguity $>$;-in-shallowsupererogation -<as-to-disontologising-perverted-outcome-sought-precedes-existentiallyveridical-'attendant-intradimensional-apriorising/axiomatising/referencing'-logical-dueness $>$ > vicious acts-and/or-narratives', and 'compensating directed pseudo-virtue acts-and/ornarratives' towards relevant significant others, wherein that compensating is not a trite equivalence but rather involves 'high-proportionality of overcompensating directed pseudovirtue acts-and/or-narratives' relative to 'specific or given postlogism 7 -as-of- compulsingnonconviction/madeupness/bottomlining-/“<decontextualising/de-existentialising ofattendant-intradimensional-apriorising/axiomatising/referencing>-induced-disontologising'-ofthe-'attendant-intradimensional-ontologising'-imbued- 
$<$ contextualising/existentialising attendant-ontological-contiguity $>$;-in-shallow-

supererogation -<as-to-disontologising-perverted-outcome-sought-precedes-existentially-

veridical-'attendant-intradimensional-apriorising/axiomatising/referencing'-logical-dueness $>$ )

vicious acts-and/or-narratives' in order to enable the postlogism 77 psychopathic manifestation achieve the registry-worldview's/dimension's- ${ }^{8}$ reference-of-thought-for-social-functioningand-accordance (with such overcompensation involving sought after overall preceding and subsequent sense of social allegiance with relevant significant others and then corresponding 'high-proportionality overcompensating directed pseudo-virtue acts-and/or-narratives' towards relevant significant others, whether relevant individuals and/or relevant social network, as overall 'social investment' that should allow its instigated 'postlogism 7 -as-of- compulsingnonconviction/madeupness/bottomlining-〈' $<$ decontextualising/de-existentialising $\sim$ ofattendant-intradimensional-apriorising/axiomatising/referencing $>$-induced-disontologising'-ofthe-'attendant-intradimensional-ontologising'-imbued$<$ contextualising/existentialising attendant-ontological-contiguity $>$;-in-shallowsupererogation -<as-to-disontologising-perverted-outcome-sought-precedes-existentiallyveridical-'attendant-intradimensional-apriorising/axiomatising/referencing'-logical-dueness $>>$ vicious acts-and/or-narratives' with respect to another individual or situation, as the occasion may arise, to be overlooked/absolved/exonerated/exculpated socially). This faulty-mentationprocedure-deception mental-disposition at adulthood psychopathy is more profound than just an ad-hoc trite association between committing a given vicious act and initiating a given limited 'compensating directed pseudo-virtue act-and/or-narrative' in compensation as is the case at childhood psychopathy, since the adult psychopath discovers at that stage that such triteness of association is relatively inefficient for attaining the registry-worldview's/dimension'sreference-of-thought-for-social-functioning-and-accordance (but rather requires a more profound association of the postlogism 7 -as-of- compulsing- 
nonconviction/madeupness/bottomlining-〈'<decontextualising/de-existentialising ofattendant-intradimensional-apriorising/axiomatising/referencing $>$-induced-disontologising'-ofthe-'attendant-intradimensional-ontologising'-imbued$<$ contextualising/existentialising attendant-ontological-contiguity $>$;-in-shallowsupererogation -<as-to-disontologising-perverted-outcome-sought-precedes-existentiallyveridical-'attendant-intradimensional-apriorising/axiomatising/referencing'-logical-dueness $>>$ vicious acts-and/or-narratives' and 'compensating directed pseudo-virtue acts-and/ornarratives'). As then during its childhood the 'compensating directed pseudo-virtue acts-and/ornarratives' are relatively ${ }^{103}$ universally transparent socially for what these truly are, as rather being associated with its faulty-mentation-procedure-deception mental-disposition of perversion-of- ${ }^{3}$ reference-of-thought-<as-preconverginglyapriorising/axiomatising/referencing-in-nonconviction/madeupness/bottomlining-as-toshallow-supererogation $>$, 'than just merely or confused with innocent virtue acts-and/ornarratives'; and as 'interlocutors in prelogism ${ }^{78}$-as-of-conviction,-in-profound-supererogation <existentially-veridical-'attendant-intradimensional-apriorising/axiomatising/referencing'logical-dueness-precedes-disontologising-logical-outcome-arrived-at $>$ come to grasp the deliberativeness/consciousness of the artificial and fallacious systematic eliciting of 'compensating directed pseudo-virtue acts-and/or-narratives' as a crude-trite-compensating mechanism for its urge to commit 'postlogism -as-of- compulsingnonconviction/madeupness/bottomlining-〈‘ $<$ decontextualising/de-existentialising $\sim$ ofattendant-intradimensional-apriorising/axiomatising/referencing>-induced-disontologising'-ofthe-'attendant-intradimensional-ontologising'-imbued$<$ contextualising/existentialising attendant-ontological-contiguity $>$;-in-shallowsupererogation -<as-to-disontologising-perverted-outcome-sought-precedes-existentiallyveridical-'attendant-intradimensional-apriorising/axiomatising/referencing'-logical-dueness $>$ > 
vicious acts-and/or-narratives' and is thus socially-dysfunctional at childhood. Whereas at adulthood psychopathy the overcompensating involves a surreptitious upending/undermining/blurring of this underlying insight that the 'high-proportionality overcompensating directed pseudo-virtue acts-and/or-narratives' is rather as of a personality development derived-from and connected-with such fallacious crude-trite-compensating at childhood; such that it is then adopted and relayed as contending thus wrongly validating its apriorising- ${ }^{8}$ reference-of-thought/apriorising-registry-elements of \{epistemicPsychologismic-subliminality-of-individuation-effusing/worlding imbued logicaldueness-or-scape-or-frame, profile-or-stature, presumptuousness-or-arrogation, assumptions, value-reference and teleology (which are actually outside 'implicited_attendant_ontologicalcontiguity ${ }^{67}$; educedexistentialising/contextualising/textualising_'intelligibility/epistemicity/reflexivity-contiguity$<$ imbued-notional $\sim$ cogency $>$, ,-<reifying-or-elucidating-of-prospective-relative-ontologicalcompleteness -of- reference-of-thought- devolving-as-of-instantiative-context $>$ ) as firstlevel deception, and thus enabling the infinite possibilities of second-level deception from their logical-processing-or-logical-implicitation-supposedly-apriorising-in-conviction-as-toprofound-supererogation . This underlying postlogism 77 psychopathic faulty-mentationprocedure-deception mental-disposition and its protraction in conjugated-postlogism 7 /socialpsychopathy involving deliberative/conscious or unconscious (conjugated-ignorance) artificial, fallacious and surreptitious systematic eliciting of 'high-proportionality overcompensating directed pseudo-virtue acts-and/or-narratives' systematically enabling the possibility for committing 'postlogism 77 -as-of-' compulsing-nonconviction/madeupness/bottomlining$\langle<<$ decontextualising/de-existentialising of-attendant-intradimensionalapriorising/axiomatising/referencing >-induced-disontologising'-of-the-'attendantintradimensional-ontologising'-imbued-<contextualising/existentialising $\sim$ attendant- 
ontological-contiguity $>$;-in-shallow-supererogation $\quad-<$ as-to-disontologising-perverted-

outcome-sought-precedes-existentially-veridical-'attendant-intradimensional-

apriorising/axiomatising/referencing'-logical-dueness $>$ > vicious acts-and/or-narratives' with respect to another individual or situation, as the occasion may arise, while ensuring social overlooking/absolving/exonerating/exculpating is a central enculturating/endemising mechanism at the registry-worldview/dimension-level (beyond the individuation-level) of human temporalities-drives to adhere to the <amplituding/formative $>$ wooden-language〈imbued-temporal-mere-form/virtualities/dereification/akrasiatic-

\section{drag/denatured/preconverging-or-dementing -narratives - of-the- reference-of-thought-}

categorical-imperatives/axioms/registry-teleology > (failing/not-upholding-<as-of-

apriorising/axiomatising/referencing $>\quad$ intemporal-preservation-entropy-or-contiguity-orontological-preservation as of ontological-normalcy/postconvergence). Further, at the confluence of postlogism 77 psychopathy and conjugated-postlogism 77 social-psychopathy with respect to ontologically-veridical ${ }^{56}$ meaningfulness-and-teleology ${ }^{9}$ arises disjointedness-as-ofreference-of-thought; inherent in temporality ${ }^{9} /$ shortness and as of postlogism 77 and conjugated-postlogism 77 mental-dispositions (shallowness-of-thought construed as of temporalextricatory reasoning as well as incoherent and awkwardly implied ${ }^{103}$ universal projections, but which actually speaks of <amplituding/formative-epistemicity $>$ totalising $\sim$ self-referencingsyncretising/circularity/interiorising/akrasiatic-drag ${ }^{34}$ explaining why its ${ }^{103}$ universal projection lip-servicing nature or inductive limitation fails the test of a true principle', basically highlighting a dynamic ${ }^{83}$ reference-of-thought relationship with ${ }^{56}$ meaningfulness-and-teleology ${ }^{99}$ as of poor performance of supposed intemporal-projection but actually in effect pseudointemporality ${ }^{52}$-astemporality and speaks, more specifically with regards to psychopathic/postlogic meaningfulness-and-teleology", rather as of relatively 'mere-rhyming mental-disposition' emphasising $<$ amplituding/formative $>$ wooden-language-〈imbued-temporal-mere- 
form/virtualities/dereification/akrasiatic-drag/denatured/preconverging-or-dementing

narratives - of-the- reference-of-thought- categorical-imperatives/axioms/registry-

teleology > in 'toning-triggering/snappings-of-impression/tenseness-of-interlocutoryengagement-\{easily copied with conjugated-postlogism 77 at an intuitive-level\}'-falselyprojecting-profoundness-of-thought more like vague-rhyming-or-copied-mimicry-or-formulaicprojection-or-projection-of-form-or-hollow-and-vague-vocalisation-or-subknowledging ${ }^{4}$ with respect to ontologically-veridical ${ }^{5}$ meaningfulness-and-teleology ${ }^{9}$ given psychopathic slantedness 'deception-of-successively-shifting-or-non-cohering-narratives-and-acts/deceptionby-concurrently-false-presupposing/false-presuming/false-premising-of-narratives/deceptionby-concurrently-false-assumptive-preconverging-or-dementing ${ }^{20}$-apriorising-psychologism'), over an intemporal/ontological profoundness-of-thought (as of the 'intemporal synopsisingdepth-of- ${ }^{5}$ meaningfulness-and-teleology 9 /supratransversality-<in-sublimating-existentialeventuating/denouement $>\sim$ of-motif-and-apriorising/axiomatising/referencing as-to$<$ amplituding/formative-epistemicity $>$ totalising $\sim$ social-context-construed-conflatedness ${ }^{13}$, of aetiologisation/ontological-escalation-<ontologicalveridicality_commitment/otherliness_transcending/compulsions-encumbered_transcending $>$ driven by 'intemporal-prioritisation-of- ${ }^{-3}$ reference-of-thought'-as-conflatedness ${ }^{13}$-orontological-reprojecting emphasising reference-of-thought- categoricalimperatives/axioms/registry-teleology as rather about intemporal-preservation-entropy-orcontiguity-or-ontological-preservation as of ontological-normalcy/postconvergence); and interestingly such a contrastive insight (of temporal-to-intemporal contrastive-synopsisingdepths-of- ${ }^{5}$ meaningfulness-and-teleology ${ }^{\circ}$ ) should be central to an elucidative storiedconstruct/ontologically-valid-narration of notional firstnaturedness-formativeness-<as-toeventualising inkling drive-or-seeding-misprising > temporal-to-intemporal-dispositions$<$ so-construed-as-from-perspective-ontological-normalcy/postconvergence $>$ disambiguation. 
The very 'intemporal synopsising-depth-of- meaningfulness-and-teleology' required for 'intemporal mental-projections' or 'ontological construals' outside institutionalisation framework as enabled by deferential-formalisation-transference render them highly susceptible to denaturing ${ }^{16}$ in uninstitutionalised-threshold ${ }^{12}$ framework as with regards to the extendedinformality-_susceptible-to-effecting-parsimony-as-of-shoddiness-and-incompleteness-tomeaningfulness-and-teleology $\rangle$ where these face in the same space of temporal-to-intemporal the registry-worldview's/dimension's- ${ }^{83}$ reference-of-thought-for-social-functioning-andaccordance thresholds 'temporal-distractively-aligned synopsising-depth-of- ${ }^{56}$ meaningfulnessand-teleology ${ }^{9}$-as-shallowness-of-thought-as-subtransversality-<in-desublimatingexistential-eventuating/denouement $>\sim$ of-motif-and-apriorising/axiomatising/referencing and with the "lack of constraining social ${ }^{103}$ universal-transparency ${ }^{104}$-〈transparency-of-totalisingentailing,-as-to-entailing-<amplituding/formative-epistemicity $>$ totalising $\sim$ in-relativeontological-completeness > as of 'implicintontological-contiguity ${ }^{67}$; educed-

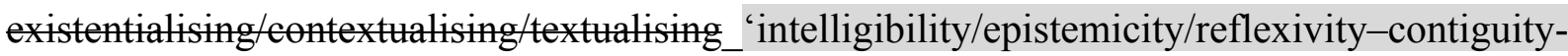
$<$ imbued-notional $\sim$ cogency $>,{ }^{\prime},-<$ reifying-or-elucidating-of-prospective-relative-ontologicalcompleteness -of- reference-of-thought- devolving-as-of-instantiative-context $>$ meaning that same-terms-of-expressions/seemingly-same-implied-meaningfulness are undisambiguated, and available to postlogic/psychopathic, temporal-dispositions in conjugated-postlogism 77 as well as the intemporal-disposition in supplanting-conviction-as-to-profound-supererogation - of'attendant-intradimensional'-postconverging/dialectical-thinking -apriorising-psychologism.

The relative transparency of childhood psychopathy ${ }^{74}$ perversion-of- ${ }^{8}$ reference-of-thought- $<$ aspreconvergingly-apriorising/axiomatising/referencing-in-

nonconviction/madeupness/bottomlining-as-to-shallow-supererogation $>$ (as highlighted with the case of John in a 'dereifying act' spilling water on a chair in conjunction with its psychopathic perverted compensation mental-disposition as a basis for concurrently instigating postlogism - 
as-of- compulsing-nonconviction/madeupness/bottomlining-〈'<decontextualising/deexistentialising $\sim$ of-attendant-intradimensional-apriorising/axiomatising/referencing $>$-induceddisontologising'-of-the-'attendant-intradimensional-ontologising'-imbued$<$ contextualising/existentialising attendant-ontological-contiguity $>$;-in-shallowsupererogation -<as-to-disontologising-perverted-outcome-sought-precedes-existentiallyveridical-'attendant-intradimensional-apriorising/axiomatising/referencing'-logical-dueness $>$ > so long as it can be socially-functional-and-accordant ${ }^{93}$ in satisfying its faulty-mentationprocedure-deception-or-urge by vague-rhyming-or-copied-mimicry-or-formulaic-projectionor-projection-of-form-or-hollow-and-vague-vocalisation-or-subknowledging ${ }^{4}$ ) is highly revealing of the perverted nature of 'temporal psychopathic/postlogic synopsising-depth-ofmeaningfulness-and-teleology ', and as it develops into adult psychopathy where social universal-transparency ${ }^{104}$-〈transparency-of-totalising-entailing,-as-to-entailing$<$ amplinding formative-epistemicity>totalising in-relative-ontological-completeness $>$ as of 'implicited_antentological-contiguity ${ }^{67}$ ' educedexistentialising/contextualising/textualising_'intelligibility/epistemicity/reflexivity-contiguity$<$ imbued-notional $\sim$ cogency $>>,-<$ reifying-or-elucidating-of-prospective-relative-ontologicalcompleteness -of- reference-of-thought- devolving-as-of-instantiative-context $>$ gets lost and its perversion-of- ${ }^{8}$ reference-of-thought- $<$ as-preconverginglyapriorising/axiomatising/referencing-in-nonconviction/madeupness/bottomlining-as-toshallow-supererogation $>$ is related to as appropriateness-of- ${ }^{8}$ reference-of-thought-as-ofconflatedness ${ }^{13}$ in 'prelogism ${ }^{78}$-as-of-conviction,-in-profound-supererogation $-<$ existentiallyveridical-'attendant-intradimensional-apriorising/axiomatising/referencing'-logical-duenessprecedes-disontologising-logical-outcome-arrived-at> rather than as postlogism -as-ofcompulsing-nonconviction/madeupness/bottomlining-〈'<decontextualising/deexistentialising $\sim$ of-attendant-intradimensional-apriorising/axiomatising/referencing $>$-induced- 
disontologising'-of-the-'attendant-intradimensional-ontologising'-imbued-

$<$ contextualising/existentialising attendant-ontological-contiguity $>$;-in-shallow-

supererogation -<as-to-disontologising-perverted-outcome-sought-precedes-existentially-

veridical-'attendant-intradimensional-apriorising/axiomatising/referencing'-logical-

dueness $>$ Y' as the adult psychopath undergoes

maturation/indirectness/spatialisation/credulity/craftiness to attain social-functioning-andaccordance-as-of-social-stake-contention-or-confliction (further elucidated elsewhere) inducing the further protraction in conjugated-postlogism 77 social-psychopathy of derivedperversion-of- ${ }^{3}$ reference-of-thought-<as-preconvergingly-

apriorising/axiomatising/referencing-in-nonconviction/madeupness/bottomlining-as-to-

shallow-supererogation $>$ 'temporal-synopsising-depth-of- ${ }^{-}$meaningfulness-and-teleology ${ }^{9}$ as-shallowness-of-thought in derived-vague-rhyming-or-copied-mimicry-or-formulaicprojection-or-projection-of-form-or-hollow-and-vague-vocalisation-or-subknowledging (beyond-the-consciousness-awareness-teleology ${ }^{9}<$ of-preconverging-existential-extricationas-of-existential-unthought $>$ ). This at the institutional-level, a framework as the extendedinformality-〈susceptible-to-effecting-parsimony-as-of-shoddiness-and-incompleteness-tomeaningfulness-and-teleology $\rangle$ without social ${ }^{103}$ universal-transparency ${ }^{104}$-〈transparency-oftotalising-entailing,-as-to-entailing-<amplituding/formative-epistemicity $>$ totalising $\sim$ inrelative-ontological-completeness > as of 'implieitentontonicalcontiguity $^{67}$, educedexistentialising/contextmalising/textualising_intelligibility/epistemicity/reflexivity_contiguity$<$ imbued-notional $\sim$ cogency $>,,-<$ reifying-or-elucidating-of-prospective-relative-ontologicalcompleteness -of- reference-of-thought- devolving-as-of-instantiative-context> as $>$ reflected by its relative-ontological-incompleteness ${ }^{88}$-of- ${ }^{83}$ reference-of-thought (disjointednessas-of- reference-of-thought) is bound to induce defective/perverted 'temporal-distractively- 
aligned synopsising-depth of ${ }^{5}$ meaningfulness-and-teleology ${ }^{9}$ relative to intemporal/ontological and virtue constructs.

[Consider the instance of an archetype illustration with respect to say a Socrates or Rousseau individuation 'intemporal synopsising-depth-of- ${ }^{56}$ meaningfulness-andteleology $\%$ supratransversality-<in-sublimating-existential-eventuating/denouement $>\sim$ ofmotif-and-apriorising/axiomatising/referencing as-to-<amplituding/formativeepistemicity $>$ totalising $\sim$ social-context-construed-conflatedness ${ }^{13}$, $\quad$ 'temporal-distractivelyaligned synopsising-depth-of- ${ }^{5}$ meaningfulness-and-teleology ${ }^{9}$-as-shallowness-of-thought-assubtransversality-<in-desublimating-existential-eventuating/denouement $>\sim$ of-motif-andapriorising/axiomatising/referencing in pseudointemporality ${ }^{52}$ lip-servicing will within the relative-ontological-incompleteness ${ }^{8}$-of- ${ }^{8}$ reference-of-thought of their respective epochs poorly grasp their respective 'intemporal synopsising-depth-of- meaningfulness-andteleology $/$ supratransversality-<in-sublimating-existential-eventuating/denouement $>\sim$ ofmotif-and-apriorising/axiomatising/referencing as-to-<amplituding/formativeepistemicity $>$ totalising $\sim$ social-context-construed-conflatedness ${ }^{13}$, and rather think as irrational the projective disposition of a Socrates that doesn't rather advance a temporal interest in the citystate polity but is rather bent on spreading new ideas as a natural philosopher while prioritising as of postconverging-nonextricatory-existential-preempting-of-existential-unthought in his asceticism the prospective intemporal/ongness-of-register-of- meaningfulness-andteleology over the temporal/shortness-of-register-of meaningfulness-and-teleology status quo, and likewise with a Rousseau who isn't advancing a temporal/shortness-of-register-ofmeaningfulness-and-teleology interest that his aristocratic stature should warrant like actively pursuing for landed properties and currying favours with kings but is rather bent principally on a prospective commitment on grasping and spreading notions of a renewal of the human condition as ${ }^{103}$ universal rights and enlightened despotism; such that the 
$<$ amplituding/formative $>$ wooden-language-〈imbued - averaging-of-thought-<as-to-

leveling/ressentiment/closed-construct-of- meaningfulness-and-teleology -as-of-

'nondescript/ignorable-void '-with-regards-to-prospective-apriorising-implications $>>$ in such setups will certainly be rife with distraction of such 'temporal-distractively-aligned synopsisingdepth-of- meaningfulness-and-teleology ${ }^{9}$ '-as-shallowness-of-thought-as-subtransversality-

\section{$<$ in-desublimating-existential-eventuating/denouement $>\sim$ of-motif-and-}

apriorising/axiomatising/referencing; wherein a Socrates or Rousseau individuation 'intemporal synopsising-depth-of- ${ }^{5}$ meaningfulness-and-teleology ${ }^{\circ}$ as articulated above will face in the same space of the registry-worldview's/dimension's ${ }^{83}$ reference-of-thought-for-socialfunctioning-and-accordance thresholds with respect to ${ }^{56}$ meaningfulness-and-teleology ${ }^{9}$ such 'temporal-distractively-aligned synopsising-depth-of- ${ }^{5}$ meaningfulness-and-teleology ${ }^{99}$-asshallowness-of-thought-as-subtransversality-<in-desublimating-existential-

eventuating/denouement $>\sim$ of-motif-and-apriorising/axiomatising/referencing as stated above, as the 'lack of constraining social ${ }^{103}$ universal-transparency ${ }^{104}$-〈transparency-of-totalisingentailing,-as-to-entailing-<mplitung/formative-epistemicity $>$ totalising $\sim$ in-relativeontological-completeness > as of 'implicited_attendant-ontological-contiguity ${ }^{67}$ ' educedexistentialising/contextualising/textualising_'intelligibility/epistemicity/reflexivity-contiguity$<$ imbued-notional $\sim \operatorname{cogency}>,,-<$ reifying-or-elucidating-of-prospective-relative-ontologicalcompleteness -of- reference-of-thought- devolving-as-of-instantiative-context $>$ implies that same-terms-of-expressions/seemingly-same-implied-meaningfulness are undisambiguated/undelineated, and available to temporal postlogic/psychopathic synopsisingdepth-of- meaningfulness-and-teleology ${ }^{9}$, temporal-dispositions in conjugated-postlogism synopsising-depth-of- ${ }^{5}$ meaningfulness-and-teleology ${ }^{9}$ as well as intemporal synopsisingdepth-of- ${ }^{5}$ meaningfulness-and-teleology ${ }^{9}$. Likewise, for instance, it won't be surprising that the 'intemporal synopsising-depth-of- ${ }^{5}$ meaningfulness-and-teleology $\%$ /supratransversality- 
$<$ in-sublimating-existential-eventuating/denouement $>\sim$ of-motif-and-

apriorising/axiomatising/referencing

as-to-<amplituding/formative-

epistemicity $>$ totalising $\sim$ social-context-construed-conflatedness ${ }^{13}$,

of

aetiologisation/ontological-escalation-<ontological-

veridicality_commitment/otherliness_transcending/compulsions-encumbered_transcending $>$ as implied in this write-up, in principle, is rather alien as of its purposefulness/ontologicalaspiration (notwithstanding the debatableness of veracity/ontological-pertinence as all knowledge constructs must necessarily be opened to) to many 'temporal-distractively-aligned synopsising-depth-of- ${ }^{56}$ meaningfulness-and-teleology ${ }^{9}$ '-as-shallowness-of-thought-assubtransversality-<in-desublimating-existential-eventuating/denouement $>\sim$ of-motif-andapriorising/axiomatising/referencing. This fundamentally arises due to the fact that prospective transcendence-and-sublimity/sublimation/supereregatory $\sim$ de-mentativity arises as an 'exercise of outward-facing prospective institutionalisation metaphysics-of-absence-〈implicitedepistemic-veracity-of- nonpresencing-<perspective-ontological-normalcy/postconvergence $>$ > value-referencing' relative to a '<amplituding/formative-epistemicity $>$ totalising $\sim$ selfreferencing-syncretising/circularity/interiorising/akrasiatic-drag $34 \quad$ inward facing uninstitutionalised-threshold ${ }^{102}$ value-referencing'.]

Ultimately, loss of social ${ }^{103}$ universal-transparency ${ }^{104}$-〈transparency-of-totalising-entailing,-asto-entailing-<amplituding/formative-epistemicity $>$ totalising $\sim$ in-relative-ontologicalcompleteness > as of 'implicited_attendant-ontological-contiguity ${ }^{67}$ ' educedexistentialising/contextualising/textualising_'intelligibility/epistemicity/reflexivity_contiguity$<$ imbued-notional $\sim \operatorname{cogency}>,,-<$ reifying-or-elucidating-of-prospective-relative-ontologicalcompleteness -of- reference-of-thought- devolving-as-of-instantiative-context $>$ as of relative-ontological-incompleteness ${ }^{8}$-of- ${ }^{3}$ reference-of-thought such that mental states with respect to postlogism and conjugated-postlogism as of specific registry- 
worldviews/dimensions reveal the reality of the registry-worldview/dimension relativeontological-incompleteness ${ }^{8}$-of- ${ }^{8}$ reference-of-thought, and more specifically relevant to the phenomenon of psychopathy and social psychopathy it points to disjointedness-as-ofreference-of-thought associated with procrypticism relative-ontological-incompleteness ${ }^{88}$-ofreference-of-thought. It should be noted as well that the notion of overlooking and resetting (as the fact is the conscious manifestation of perversion-and-derived- ${ }^{7}$ perversion-of- ${ }^{83}$ reference-ofthought-<as-preconvergingly-apriorising/axiomatising/referencing-in-

nonconviction/madeupness/bottomlining-as-to-shallow-supererogation $>$ doesn't truly qualify for such a notion of overlooking and resetting since it is of registry-worldview's/dimension'suninstitutionalised-threshold ${ }^{102}$-defect-<as-Being-or-ontological-or-existential-defect $>55$ and not defect-of- ${ }^{5}$ logical-processing-or-logical-implicitation - supposedly-apriorising-inconviction-as-to-profound-supererogation of the registry-worldview's/dimension'sreference-of-thought-for-social-functioning-and-accordance, more like it can't be pretended that overlooking the nefarious implications of notions-and-accusations-of-sorcery in a nonpositivistic social-setup in some way implies a resetting of non-positivism/medievalism mindsets $/{ }^{3}$ reference-of-thought, and it will be more of an intellectual-and-moral dereliction from a positivistic insight) doesn't cancel the fundamental temporal mental-dispositions as portrayed above given that intrinsic-reality/ontological-veridicality is a contiguity (supersedingoneness-of-ontology), and the relative-ontological-incompleteness ${ }^{8}$-induced,-'threshold-ofnonconviction/madeupness/bottomlining-in-shallow-supererogation $<<$ as-to- 'attendantintradimensional'-prospectively-disontologising preconverging/dementing -apriorisingpsychologism>' as displayed by the individuations (speaking not of a defect-of- ${ }^{5}$ logicalprocessing-or-logical-implicitation-supposedly-apriorising-in-conviction-as-to-profoundsupererogation of the registry-worldview's/dimension's- ${ }^{83}$ reference-of-thought-for-socialfunctioning-and-accordance) above is of 'existential perpetuation in 
circularity/recurrence/repetition/repeatability ${ }^{10}$ (as-of-'perversion-and-derived- ${ }^{74}$ perversion-ofreference-of-thought-<as-preconvergingly-apriorising/axiomatising/referencing-innonconviction/madeupness/bottomlining-as-to-shallow-supererogation >-as-touninstitutionalised-threshold ${ }^{102}$-self-referencing-syncretising-and-subtransversality-<indesublimating-existential-eventuating/denouement $>\sim$ of-motif-andapriorising/axiomatising/referencing'); and so as socially-functional-and-accordant ${ }^{93}$, (wherein with respect to 'least-and-derived-temporal-operating-modalities-of-the- ${ }^{3}$ reference-of-thoughtas-of- incrementalism-in-relative-ontological-incompleteness ${ }^{8}$ enframed/disontologising conceptualisation-inducing-the-uninstitutionalised-threshold ${ }^{02}$, social meaningfulness-and-teleology ${ }^{56}$ is downgraded into ' temporal $<$ amplituding/formative $>$ wooden-language-_imbued - averaging-of-thought-<as-toleveling/ressentiment/closed-construct-of- meaningfulness-and-teleology -as-of'nondescript/ignorable-void '-with-regards-to-prospective-apriorising-implications $>$ > mentaldispositions and projections disposition' with corresponding degrading of the profoundness/sophistication of ${ }^{83}$ reference-of-thought of a ${ }^{55}$ maximalising-recomposuring-forrelative-ontological-completeness ${ }^{87}$ — unenframed/re-ontologising $\sim$ conceptualisation disposition such that for veracity/ontological-pertinence there is need for teleologicaldifferentiation/scission/variance/disambiguation in construing a 'supratransversality- $<$ insublimating-existential-eventuating/denouement $>\sim$ of-motif-andapriorising/axiomatising/referencing $\quad{ }^{83}$ reference-of-thought of ${ }^{56}$ meaningfulness-andteleology ${ }^{9}$ as ontological and 'subtransversality-<in-desublimating-existentialeventuating/denouement $>\sim$ of-motif-and-apriorising/axiomatising/referencing $\quad{ }^{83}$ reference-ofthought of ${ }^{56}$ meaningfulness-and-teleology', while with respect to 'maximal-operatingmodality-of- ${ }^{-3}$ reference-of-thought-as-of-formalisation' social meaningfulness-andteleology ${ }^{9}$ is deferred to the profoundness/sophistication of ${ }^{83}$ reference-of-thought of a 
maximalising-recomposuring-for-relative-ontological-completeness ${ }^{87}$ - unenframed/reontologising conceptualisation disposition by its <amplituding/formativeepistemicity $>$ causality $\sim$ as-to-projective-totalitative-implications-of-prospectivenonpresencing,-for-explicating relative-unreflexivity/relative-reflexivity - ontologicalcontiguity induced prospective institutionalisation formalisations, percolation-channelling$<$ in-deferential-formalisation-transference $>$ and secondnaturing). Thus in summary 'existential perpetuation in circularity/recurrence/repetition/repeatability ' (of 'maximal-as-intemporaloperating-modality-with-respect-to- categorical-imperatives/axioms/registry-teleology ${ }^{9}$-ofreference-of-thought-as-of- ${ }^{5}$ maximalising-recomposuring-for-relative-ontologicalcompleteness ${ }^{87}$ — unenframed/re-ontologising conceptualisation-inducing-the-prospectiveinstitutionalisation'-and-'least-and-derived-temporal-operating-modalities-with-respect-tocategorical-imperatives/axioms/registry-teleology ${ }^{9}$-of- ${ }^{3}$ reference-of-thought-as-ofincrementalism-in-relative-ontological-incompleteness enframed/disontologising conceptualisation-in-inducing-the-uninstitutionalised-threshold ${ }^{102}$ ') defines how and why any 'institutionalisation-by-uninstitutionalised-threshold ${ }^{102}$ limits' come to be attained and sustained (whether recurrent-utter-uninstitutionalisation, baseinstitutionalisation-ununiversalisation, universalisation-non-positivism/medievalism, positivism- ${ }^{8}$ procrypticism, and prospectively deprocrypticism) as it is construed as arising due to the definite/unchangeable reality of 'human-subpotencyaporia/undecidability/dilemma/ought-indeterminacy/deficiency/limitation/constraint—imbued'notional firstnaturedness-formativeness-<as-to-eventualising inkling-drive-or - seeding misprising $>$ temporal-to-intemporal-dispositions- $<$ so-construed-as-from-perspectiveontological-normalcy/postconvergence>'-existentialism-form-factor intertwined with a given institutionalisation relative-ontological-incompleteness ${ }^{8}$-induced,-‘threshold-ofnonconviction/madeupness/bottomlining-in-shallow-supererogation $<<$ as-to-' attendant- 
intradimensional'-prospectively-disontologising preconverging/dementing -apriorising-

psychologism>' (with the latter not-definite/changeable by 'transcendental institutionalisation/intemporalisation' by a maximalising-recomposuring-for-relativeontological-completeness ${ }^{87}$ - unenframed/re-ontologising conceptualisation exercise). This is so reflected as of ${ }^{5}$ maximalising-recomposuring-for-relative-ontological-completeness ${ }^{87}$ unenframed/re-ontologising conceptualisation. This explains why the 'recurrent-utteruninstitutionalisation' mindset/ $/{ }^{3}$ reference-of-thought is existentially-<disontologising/reentologising aporeticism> perpetuating 'failing/not-upholding-<as-ofapriorising/axiomatising/referencing > of rulemaking-over-non-rulesapriorising/axiomatising/referencing-psychologism’ circularity/recurrence/repetition/repeatability ${ }^{10}$ in as-inherently-implied-by-the-

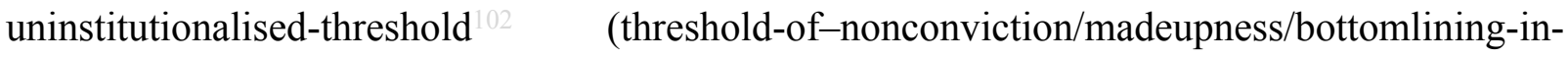
shallow-supererogation -<as-to-'attendant-intradimensional'-prospectivelydisontologising $\sim$ preconverging/dementing -apriorising-psychologism>-of-recurrent-utteruninstitutionalisation), the 'base-institutionalisation-ununiversalisation' mindset/ ${ }^{83}$ reference-ofthought is existentially-<disontologising/re-ontologising aporeticism $>$ perpetuating 'failing/not-upholding-<as-of-apriorising/axiomatising/referencing $>$ of ${ }^{103}$ universalisationdirected-rulemaking-over-non-rules_-apriorising/axiomatising/referencing-psychologism’ circularity/recurrence/repetition/repeatability ${ }^{10}$ in as-inherently-implied-by-theuninstitutionalised-threshold $^{102}$ (threshold-of-nonconviction/madeupness/bottomlining-inshallow-supererogation -<as-to-'attendant-intradimensional'-prospectivelydisontologising preconverging/dementing -apriorising-psychologism>-ofununiversalisation), the " ${ }^{103}$ universalisation-non-positivism/medieval' mindset/ ${ }^{83}$ reference-ofthought is existentially-<disontologising/re-ontologising aporeticism $>$ perpetuating 'failing/not-upholding-<as-of-apriorising/axiomatising/referencing $>$ of positivising/rational- 
empiricism-based-universalisation-directed-rulemaking-over-non-rules-

apriorising/axiomatising/referencing-psychologism'

in

circularity/recurrence/repetition/repeatability

as-inherently-implied-by-the-

uninstitutionalised-threshold

(threshold-of-nonconviction/madeupness/bottomlining-in-

shallow-supererogation $-<$ as-to-'attendant-intradimensional'-prospectively-

disontologising preconverging/dementing -apriorising-psychologism>-of-non-

positivism/medievalism), the 'positivism- ${ }^{8}$ procrypticism' mindset $/{ }^{83}$ reference-of-thought is existentially-< disontologising/re-ontologising aporeticism $>$ perpetuating 'failing/notupholding-<as-of-apriorising/axiomatising/referencing $>$ in preempting-disjointedness-as-ofreference-of-thought,-as-to- ${ }^{6}<$ amplituding/formative-epistemicity $>$ growth-orconflatedness ${ }^{13}$ /transvaluative-rationalising/transepistemicity/anamnestic-residuality/spiritdrivenness' - in-superseding-mere-formulaic-positivising/rational-empiricism-baseduniversalisation-directed-rulemaking-over-non-rules_-apriorising/axiomatising/referencingpsychologism' in circularity/recurrence/repetition/repeatability ${ }^{10}$ as-inherently-implied-by-theuninstitutionalised-threshold $^{102}$ (threshold-of-nonconviction/madeupness/bottomlining-inshallow-supererogation -<as-to-'attendant-intradimensional'-prospectivelydisontologising preconverging/dementing -apriorising-psychologism>-of-procrypticism), and the 'deprocrypticism' mindset $/{ }^{2}$ reference-of-thought will be existentially-<disontologising/reentologising aporeticism $>$ perpetuating 'preempting-disjointedness-as-of- ${ }^{8}$ reference-ofthought,-as-to- ${ }^{6}{ }^{2}<$ amplituding/formative-epistemicity $>$ growth-or-

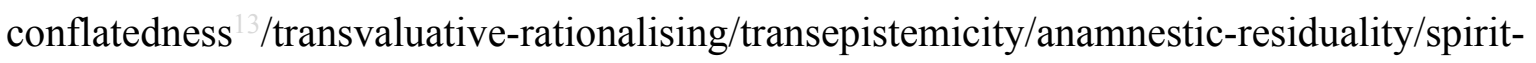
drivenness'-in-superseding-mere-formulaic-positivising/rational-empiricism-baseduniversalisation-directed-rulemaking-over-non-rules — apriorising/axiomatising/referencingpsychologism' in circularity/recurrence/repetition/repeatability ${ }^{10}$ as-inherently-implied-by-itspreempting-of-any-uninstitutionalised-threshold ${ }^{02}$. It should further be noted that the notion of 
in circularity/recurrence/repetition/repeatability ${ }^{10}$ is not about conceptualising in the simplistic sense of any specific effective factual acts of circularity/recurrence/repetition/repeatability ${ }^{10}$-asof-conflated-construal but rather about a defining defectiveness of registry-worldview reference-of-thought-〈reflected-as-unsoundness-or-ontological-bad-faith/inauthenticity -ofreference-of-thought-and-not-logically-contending $>$ construed as 'circularity/recurrence/repetition/repeatability ${ }^{10}$-as-of-conflated-construal of perversion-andderived- ${ }^{74}$ perversion-of- ${ }^{8}$ reference-of-thought- $<$ as-preconvergingly-

apriorising/axiomatising/referencing-in-nonconviction/madeupness/bottomlining-as-toshallow-supererogation $>$ ' inherently-implied (threshold-ofnonconviction/madeupness/bottomlining-in-shallow-supererogation $<<$ as-to- 'attendantintradimensional'-prospectively-disontologising preconverging/dementing -apriorisingpsychologism $>$-of-the-uninstitutionalised-threshold 02 whether as recurrent-utteruninstitutionalisation, ununiversalisation, non-positivism/medievalism or procrypticism) given the registry-worldview/dimension-level of relative-ontological-incompleteness ${ }^{8}$-induced,'threshold-of-nonconviction/madeupness/bottomlining-in-shallow-supererogation ${ }^{\circ}<$ as-to‘attendant-intradimensional'-prospectively-disontologising preconverging/dementing apriorising-psychologism>' . So basically, circularity/recurrence/repetition/repeatability ${ }^{10}$-as-ofconflated-construal is about the 'circularity of recurrent-utter-uninstitutionalisation-〈reflectedas-unsoundness-or-ontological-bad-faith/inauthenticity -of- reference-of-thought-and-notlogically-contending in need for base-institutionalisation-〈reflected-as-soundness-orontological-good-faith/authenticity -of- reference-of-thought-and-logically-contending)', the 'circularity of ununiversalisation-〈reflected-as-unsoundness-or-ontological-badfaith/inauthenticity -of- reference-of-thought-and-not-logically-contending $\rangle$ in need for universalisation-〈reflected-as-soundness-or-ontological-good-faith/authenticity -ofreference-of-thought-and-logically-contending $\rangle$, the 'circularity of non- 
positivism/medievalism-_reflected-as-unsoundness-or-ontological-bad-faith/inauthenticity -ofreference-of-thought-and-not-logically-contending $\rangle$ in need for positivism-〈reflected-assoundness-or-ontological-good-faith/authenticity -of- reference-of-thought-and-logicallycontending)' and prospectively the 'circularity of procrypticism-〈reflected-as-unsoundness-orontological-bad-faith/inauthenticity -of- reference-of-thought-and-not-logically-contending) in need for deprocrypticism-_reflected-as-soundness-or-ontological-good-faith/authenticity of- reference-of-thought-and-logically-contending)', successively as of their prospective relative-ontological-completeness ${ }^{87}$-of- ${ }^{8}$ reference-of-thought.

[For instance, resetting relations anew and overlooking non-positivism/medievalism postlogism issue of say notions-and-accusations-of-sorcery does not mean that characters in such a non-positivism/medievalism setup are no longer susceptible to the same mentaldispositions 'as of non-positivism/medievalism reference-of-thought' on different or subsequent occasions/instances where the medieval postlogism -as-of- compulsingnonconviction/madeupness/bottomlining-〈‘ $<$ decontextualising/de-existentialising $\sim$ ofattendant-intradimensional-apriorising/axiomatising/referencing $>$-induced-disontologising'-ofthe-'attendant-intradimensional-ontologising'-imbued$<$ contextualising/existentialising attendant-ontological-contiguity $>$;-in-shallowsupererogation -<as-to-disontologising-perverted-outcome-sought-precedes-existentiallyveridical-'attendant-intradimensional-apriorising/axiomatising/referencing'-logical-dueness $>$ > issue of notions-and-accusations-of-sorcery will arise again, where it is socially-functional-andaccordant ${ }^{9}$ to do so passively or actively by eliciting social-aggregation-enablers over the intrinsic-reality/ontological-veridicality transcendentalenabling/sublimating/supereregatory-de-mentativity'. The reason being that the 7 perversionof- reference-of-thought-<as-preconvergingly-apriorising/axiomatising/referencing-innonconviction/madeupness/bottomlining-as-to-shallow-supererogation $>$ speaks to a 
fundamental

relative-ontological-incompleteness ${ }^{8}$-induced,-'threshold-of-

nonconviction/madeupness/bottomlining-in-shallow-supererogation $<-<$ as-to-'attendant-

intradimensional'-prospectively-disontologising preconverging/dementing -apriorising-

psychologism>' as a non-positivism/medievalism mindset/ ${ }^{83}$ reference-of-thought as susceptible to further instances (in circularity/recurrence/repetition/repeatability ${ }^{10}$-as-of-conflatedconstrual) of endemising/enculturating notions-and-accusations-of-sorcery and hence this issue can only be preconverging/postconverging-de-mentatively/structurally/paradigmatically resolved by a relative prospective ontological-completeness-of- ${ }^{3}$ reference-of-thought ushered in by a 'positivistic mindset/ ${ }^{3}$ reference-of-thought and social-setting construct prospective/transcending/superseding $<$ amplituding/formative-epistemicity $>$ totalising renewing-realisation/re-perception/re-thought-as-utter-placeholder-setupontological-rescheduling-〈by-a-renewing-of-apriorising/axiomatising/referencingpsychologism-as-the-new-referencing-basis-of-prospective- meaningfulness-and-teleology \' involving psychoanalytic-unshackling/memetic-reordering/institutional-recomposuring as of a crossgenerational import. That is equally the fundamental and preconverging/postconvergingde-mentative/structural/paradigmatic problem associated with psychopathy and social psychopathy given the relative-ontological-incompleteness ${ }^{8}$-induced,-'threshold-ofnonconviction/madeupness/bottomlining-in-shallow-supererogation $<-<$ as-to- 'attendantintradimensional'-prospectively-disontologising preconverging/dementing -apriorisingpsychologism>' of our ${ }^{80}$ procrypticism-or-disjointedness-as-of- ${ }^{8}$ reference-of-thought for a notional ${ }^{18}$ deprocrypticism ${ }^{83}$ reference-of-thought. Such naïve construal of resetting relations anew and overlooking with regards to perversion-and-derived- ${ }^{7}$ perversion-of- ${ }^{8}$ reference-ofthought-<as-preconvergingly-apriorising/axiomatising/referencing-in-

nonconviction/madeupness/bottomlining-as-to-shallow-supererogation $>$ (utterly different from defect-of- ${ }^{5}$ logical-processing-or-logical-implicitation-supposedly-apriorising-in- 
conviction-as-to-profound-supererogation of the registry-worldview's/dimension'sreference-of-thought-for-social-functioning-and-accordance resetting anew and overlooking) simply becomes at best 'impression-driven/good-naturedness/wishfulness active enabler' for temporally inclined mindsets with respect to what can be habituated/endemised/enculturated as of perversion-of- ${ }^{3}$ reference-of-thought-<as-preconverginglyapriorising/axiomatising/referencing-in-nonconviction/madeupness/bottomlining-as-toshallow-supererogation $>$ (where postlogism 77 and conjugated-postlogism 7 can be passively socially-functional-and-accordant ${ }^{3}$ or actively socially-functional-and-accordant ${ }^{93}$ by eliciting social-aggregation-enablers, and so over inherent intrinsic-reality/ontological-veridicality transcendental-enabling/sublimating/supererogatory $\sim$ de-mentativity'). Rather than the idea of resetting relations anew and overlooking, a true intellectual-and-moral elevation is instead achieved by a prospective institutionalisation secondnaturing process construing the inherent reality and derived-implications of ${ }^{7}$ perversion-of- ${ }^{3}$ reference-of-thought- $<$ as-preconverginglyapriorising/axiomatising/referencing-in-nonconviction/madeupness/bottomlining-as-toshallow-supererogation $>$ for its superseding, which effectiveness skews ('intemporality ${ }^{52}$ symmetrising-by-desymmetrising-subsumption-of-temporality ${ }^{\circ}$, for relative intrinsicreality/ontological-veridicality transcendental-enabling/sublimating/sperero-dementativity) to the veritable intemporal/tongness-of-register-of- meaningfulness-andteleology in deferential-formalisation-transference as of aetiologisation/ontologicalescalation-<ontological-veridicality_commitment/otherliness_transcending/compulsionsencumbered_transcending $>$, as the-Good/knowledge-reification $\sim$ gesturing-and-accountingof-epistemic-phenomenalism- $<$ in-

prospective_psychologismic apriorising/axiomatising/referencing-\{of-'prospectively implicited_attendant-ontological-contiguity ' reducedexistentialising/contextualising/textualising_intelligibility/epistemicity/reflexivity_contiguity- 
<imbued-notional cogency >' \}-conflatedness -in-\{preconverging disentailment by\}

postconverging entailment $>$ /understanding/<amplituding/formative-

epistemicity $>$ causality $\sim$ as-to-projective-totalitative-implications-of-prospective-

nonpresencing,-for-explicating relative-unreflexivity/relative-reflexivity - ontological-

contiguity construct; and so construed suprastructurally as of beyond-the-consciousnessawareness-teleology ${ }^{9}<$ of-preconverging-existential-extrication-as-of-existential-

unthought $>$-of-the-prior/transcended/superseded. In other words, recurrent-utteruninstitutionalisation manifestation of postlogism 77 can only be preconverging/postconvergingde-mentatively/structurally/paradigmatically resolved by base-institutionalisation ${ }^{8}$ referenceof-thought, ununiversalisation manifestation of postlogism can only be preconverging/postconverging-de-mentatively/structurally/paradigmatically resolved by ${ }^{3}$ universalisation ${ }^{83}$ reference-of-thought, non-positivism/medievalism manifestation of postlogism can only be preconverging/postconverging-dementatively/structurally/paradigmatically resolved by positivism ${ }^{83}$ reference-of-thought, and prospectively procrypticism manifestation of postlogism can only be preconverging/postconverging-de-mentatively/structurally/paradigmatically resolved by notional ${ }^{18}$ deprocrypticism ${ }^{83}$ reference-of-thought. As palliative construal is rather ontologically incoherent as the idea for striving to construe intemporality ${ }^{5 /} /$ longness from $^{2}$ temporality $/$ shortness is rather naïve and actually as of ontologically-flawed $<$ amplituding/formative-epistemicity $>$ totalising $\sim$ self-referencingsyncretising/circularity/interiorising/akrasiatic-drag ${ }^{34}$. <amplituding/formativeepistemicity $>$ totalising $\sim$ self-referencing-syncretising/circularity/interiorising/akrasiatic-drag here implies that every registry-worldview/dimension is rather pre-inclined to represent its own threshold-of-nonconviction/madeupness/bottomlining-in-shallow-supererogation $<-<$ as-to‘attendant-intradimensional'-prospectively-disontologising preconverging/dementing 
apriorising-psychologism $>$ at worst as a nondescript/ignorable-void (actually speaking of akrasiatic-drag-denatured-and-preconverging-or-dementing -narratives) or a-registryworldview's-or-dimension's-ignoring-of-its-prior-relative-ontological-incompleteness ${ }^{88}$-ofreference-of-thought-as-an-ontologically-flawed-neuterisation -or-bracketing-or-epoché of $<$ amplituding/formative-epistemicity $>$ totalising $\sim$ conflated $-{ }^{5}$ meaningfulness-and-teleology as-of-notional ${ }^{18}$ deprocrypticism-reflected- ${ }^{-}$historiality/ontologicaleventfulness ${ }^{38}$ /ontological-aesthetic-tracing-<perspective-ontologicalnormalcy/postconvergence-reflected-'epistemicity-relativism-determinism'>, and so rather than as truly 'decandored/oblongated and preconverging-or-dementing -apriorising-psychologism and dialectically/contendingly-out-of-phase or decentered', and doing so beyond-theconsciousness-awareness-teleology ${ }^{\circ}<$ of-preconverging-existential-extrication-as-ofexistential-unthought>' to avoid its 'ontologically-perspectival-degraded-asdecentered/preconverging-or-dementing ${ }^{20}$-reflexive/entailing-teleology ${ }^{9}$-differentiation-as-ofsubtransversality-<in-desublimating-existential-eventuating/denouement $>$ - threshold-ofnonconviction/madeupness/bottomlining-in-shallow-supererogation $<-<$ as-to-' attendantintradimensional'-prospectively-disontologising preconverging/dementing -apriorisingpsychologism>' with respect to prospective notional ${ }^{18}$ deprocrypticism 'ontologicallyperspectival-elevated/pedestaling-as-postconverging-or-dialectical-thinking 2 -differentiationas-of-supratransversality-<in-sublimating-existential-eventuating/denouement $>\sim$ of-motif-andapriorising/axiomatising/referencing'; though paradoxically it will effectively recognise such a representation about prior/transcended/superseded registry-worldviews/dimensions. For instance, we'll be hard pressed to acquiesce to an argument with regards to medieval manifestation of postlogism 77 for instance as it instigates notions-and-accusations-of-sorcery, associated with a logic in terms-as-of-axiomatic-construct of non-positivism/medieval relativeontological-incompleteness 8 -induced,-'threshold-of-nonconviction/madeupness/bottomlining- 


\section{in-shallow-supererogation -<as-to-'attendant-intradimensional'-prospectively-}

disontologising preconverging/dementing -apriorising-psychologism>' of the type 'A's action was what brought about the accusation of witchcraft, and A should stop the practice', from our positivistic transcendentally <amplituding/formative-epistemicity $>$-totalising $\sim$ renewingrealisation/re-perception/re-thought as of its positivism prospective relative-ontologicalcompleteness ${ }^{87}$-of- ${ }^{83}$ reference-of-thought, and would rather imply the 'decandored/oblongated and preconverging-or-dementing -apriorising-psychologism and dialectically/contendinglyout-of-phase nature' of such non-positivism/medievalism ${ }^{83}$ reference-of-thought priorly without its contending status even arising in-the-very-first-place; but then with respect to our own postlogism 7 -and-conjugated-postlogism 77 as psychopathy and social psychopathy pointing to our own relative-ontological-incompleteness ${ }^{8}$-induced,-'threshold-ofnonconviction/madeupness/bottomlining-in-shallow-supererogation $<-<$ as-to-' ${ }^{\circ}$ attendantintradimensional'-prospectively-disontologising preconverging/dementing -apriorisingpsychologism>' as procrypticism, we will tend to advance a 'nondescript/ignorable-void (actually speaking of akrasiatic-drag-denatured-and-preconverging-or-dementing ${ }^{20}$-narratives) as a-registry-worldview's-or-dimension's-ignoring-of-its-prior-relative-ontologicalincompleteness ${ }^{8}$-of- ${ }^{8}$ reference-of-thought-as-an-ontologically-flawed-neuterisation ${ }^{59}$-orbracketing-or-epoché of <amplituding/formative-epistemicity>totalising conflatedmeaningfulness-and-teleology ${ }^{9}$-as-of-notional ${ }^{8}$ deprocrypticism-reflectedhistoriality/ontological-eventfulness ${ }^{38} /$ ontological-aesthetic-tracing-<perspectiveontological-normalcy/postconvergence-reflected-'epistemicity-relativism-determinism'> of our own ontological-misconstruing-of-meaningfulness or threshold-ofnonconviction/madeupness/bottomlining-in-shallow-supererogation $-<$ as-to-'attendantintradimensional'-prospectively-disontologising preconverging/dementing -apriorisingpsychologism>, as we strive circularly-as-of-shortness-of-register-of- ${ }^{5}$ meaningfulness-and- 
teleology ${ }^{9}$ in an incoherent patchwork of meaningfulness (charade construal) on the same terms of our relative-ontological-incompleteness ${ }^{88}$-induced,-'threshold-ofnonconviction/madeupness/bottomlining-in-shallow-supererogation $-<$ as-to-'attendantintradimensional'-prospectively-disontologising preconverging/dementing -apriorisingpsychologism>' (in the case of procrypticism, which is rather of 'ontologically-perspectivaldegraded-as-decentered/preconverging-or-dementing ${ }^{20}$-reflexive/entailing-teleology ${ }^{9}$ differentiation-as-of-subtransversality-<in-desublimating-existentialeventuating/denouement $>$ — threshold-of-nonconviction/madeupness/bottomlining-in-shallowsupererogation -<as-to-'attendant-intradimensional'-prospectivelydisontologising preconverging/dementing -apriorising-psychologism>'), ignoring the notion of prospective transcending with respect to ${ }^{7}$ perversion-of- ${ }^{8}$ reference-of-thought- $<$ aspreconvergingly-apriorising/axiomatising/referencing-innonconviction/madeupness/bottomlining-as-to-shallow-supererogation $>$ or derivedperversion-of- ${ }^{3}$ reference-of-thought-<as-preconverginglyapriorising/axiomatising/referencing-in-nonconviction/madeupness/bottomlining-as-toshallow-supererogation $>$ going by ontological-normalcy/postconvergence $<$ amplitung/formative-epistemicity $>$-totalising $\sim$ renewing-realisation/re-perception/rethought-as-utter-placeholder-setup-ontological-rescheduling-〈by-a-renewing-ofapriorising/axiomatising/referencing-psychologism-as-the-new-referencing-basis-ofprospective- meaningfulness-and-teleology $\rangle$ as of notional deprocrypticism (which is rather of 'ontologically-perspectival-elevated/pedestaling-as-postconverging-or-dialecticalthinking -differentiation-as-of-supratransversality-<in-sublimating-existentialeventuating/denouement> of-motif-and-apriorising/axiomatising/referencing') in longness-ofregister-of- ${ }^{5}$ meaningfulness-and-teleology 9 in order to grasp ontologically-veridical meaningfulness; and so, no more different as the non-positivism/medieval mindset/ $/$ reference- 
of-thought trying to process logic on the basis of its relative-ontological-incompleteness ${ }^{\text {- }}$ induced,-'threshold-of-nonconviction/madeupness/bottomlining-in-shallow-supererogation <as-to-'attendant-intradimensional'-prospectively-

disontologising preconverging/dementing -apriorising-psychologism> $>$ as notions-andaccusations-of-sorcery. This reason underlies the notion of prospective institutionalisation which arises not as of ${ }^{54}$ logical-processing-or-logical-implicitation-supposedly-apriorising-inconviction-as-to-profound-supererogation issue but 'more fundamentally an appropriatenessof- ${ }^{8}$ reference-of-thought-as-of-conflatedness ${ }^{13}$-or- ${ }^{7}$ perversion-of- ${ }^{3}$ reference-of-thought- $<$ aspreconvergingly-apriorising/axiomatising/referencing-innonconviction/madeupness/bottomlining-as-to-shallow-supererogation $>$ issue as of a preconverging/postconverging-de-mentative/structural/paradigmatic and ontological meaningfulness-and-teleology implication with respect to eliciting the prospective relativeontological-completeness ${ }^{87}$-of- ${ }^{83}$ reference-of-thought of the prospective/transcending/superseding registry-worldview/dimension, without $<$ amplituding/formative-epistemicity $>$ totalising $\sim$ self-referencing-

syncretising/circularity/interiorising/akrasiatic-drag 34 of the relative-ontologicalincompleteness ${ }^{8}$-induced,-'threshold-of-nonconviction/madeupness/bottomlining-in-shallowsupererogation -<as-to- 'attendant-intradimensional'-prospectivelydisontologising $\sim$ preconverging/dementing -apriorising-psychologism> $>$ of the prior/transcended/superseded registry-worldview/dimension. Thus the articulation of prospective institutionalisation 'is not about <amplituding/formativeepistemicity $>$ causality $\sim$ as-to-projective-totalitative-implications-of-prospectivenonpresencing,-for-explicating relative unreflexivity/relative reflexivity - ontologicalcontiguity implying equivalence between the prior/transcended/superseded and the prospective/transcending/superseding'. It is rather about the 
precedingness/supersedingness/ascendency of the latter in transversality-<for-sublimatingexistential-eventuating/denouement,-from-'thinking-at-first/pure-predisposition-preemptive-ofprospective-disontologising/subontologising' as-of-prospectively-disambiguated-affirmedand-unaffirmed-'motif-and-apriorising/axiomatising/referencing' $>{ }^{101}$ and inequivalence with the former. For instance the factual <amplituding/formative-epistemicity $>$ causality $\sim$ as-toprojective-totalitative-implications-of-prospective- nonpresencing,-for-explicating relativeunreflexivity/relative-reflexivity ontological-contiguity /effectiveness validations of say a chemistry mindset/ ${ }^{83}$ reference-of-thought (with demonstrations of chemistry principles by chemical reactions producing elements and compounds) say in a non-positivism/medievalism setup prone to alchemy and essences-driven explanations 'is not and cannot be construed as a logical-processing-or-logical-implicitation - supposedly-apriorising-in-conviction-as-toprofound-supererogation validation as of alchemic mindset/ ${ }^{\circledR 3}$ reference-of-thought' but rather a 'chemistry scientific mindset/ ${ }^{3}$ reference-of-thought validation', critically because the issue is fundamentally not most critically about the specific occurrent/case validations of chemistry principles but rather about the preconverging/postconverging-dementative/structural/paradigmatic non-positivism/medievalism alchemy and essenses-driven explanations defective mindset $/{ }^{\circ}$ reference-of-thought apriorising/axiomatising/referencing/intelligibilitysettingup/measuringinstrumenting mentaldisposition reflex with respect to 'metaphorically-as-of-a-million-and-one-instances-and-locales as to aetiologisation/ontological-escalation- $<$ ontologicalveridicality_commitment/otherliness_transcending/compulsions-encumbered_transcending>' of interpretive defects that may arise from such non-positivism/medievalism mindset $/{ }^{8}$ reference-of-thought based on alchemy and essences-driven explanations given its relative-ontological-incompleteness ${ }^{8}$-induced,-'threshold-ofnonconviction/madeupness/bottomlining-in-shallow-supererogation $<<$ as-to-'attendant- 
psychologism>'. Thus wrongly implying that a contending engagement between the two is of logical-processing-or-logical-implicitation-supposedly-apriorising-in-conviction-as-to-

profound-supererogation, 'wrongly elevates and validates the non-positivism/medievalism mindset $/{ }^{83}$ reference-of-thought' as the mindset $/{ }^{3}$ reference-of-thought of contention, as such a possibility of contending engagement from the chemistry mindset $/{ }^{3}$ reference-of-thought is about harkening rather to a preconverging/postconverging-de-mentative/structural/paradigmatic and apriorising/axiomatising/referencing-\{of-'prospectively_implicited_attendant-ontologicalcontiguity ' educed-

existentialising/contextualising/textualising_'intelligibility/epistemicity/reflexivity-contiguity<imbued-notional cogency >' \}-conflatedness ${ }^{13}$ in-\{preconverging-disentailment by\} postconverging-entailment (psychoanalytic-unshackling/memetic-reordering/institutionalrecomposuring) of the alchemy and essences-driven explanations mindset/ ${ }^{83}$ reference-ofthought reflex for the ascendency of a positivistic chemistry registry-worldview reflex as of its prospective relative-ontological-completeness ${ }^{87}$-of- ${ }^{83}$ reference-of-thought as it addresses the former defect of <amplituding/formative-epistemicity $>$ totalising $\sim$ self-referencingsyncretising/metaphysics-of-presence-_implicited-'nondescript/ignorable-void ' 'as-topresencing - absolutising-identitive-constitutedness $>$ and thus provides the possibility for resolving 'metaphorically-a-million-and-one-instances-and-locales as to aetiologisation/ontological-escalation- $<$ ontologicalveridicality_commitment/otherliness_transcending/compulsions-encumbered_transcending>' of defects of that non-positivism/medievalism mindset/ ${ }^{3}$ reference-of-thought based on alchemy and essences-driven explanations given its relative-ontological-incompleteness ${ }^{8-i n d u c e d,-}$ 'threshold-of-nonconviction/madeupness/bottomlining-in-shallow-supererogation $>$-<as-to‘attendant-intradimensional'-prospectively-disontologising preconverging/dementing 
apriorising-psychologism>' . This insight equally comes to the mind as we can equally imagine that a mere demonstration or demonstrations of positivistic meaningfulness effectiveness $/<$ amplituding/formative-epistemicity $>$ causality $\sim$ as-to-projective-totalitativeimplications-of-prospective- nonpresencing,-for-explicating relative-unreflexivity/relativereflexivity - ontological-contiguity in say a base-institutionalisation/animistic social-setup or non-positivism/medievalism social-setup to their approbation is not a sufficient basis to imply that they are thereafter of positivistic mindset/ ${ }^{3}$ reference-of-thought and to be engaged with as of ${ }^{54}$ logical-processing-or-logical-implicitation - supposedly-apriorising-in-conviction-as-toprofound-supererogation , as any such positivistic demonstration pertinence is not about its factual effectiveness approbation in the base-institutionalisation/animistic social-setup per se but rather as of its preconverging/postconverging-de-mentative/structural/paradigmatic and apriorising/axiomatising/referencing-\{of-'prospectively_implicited_attendant-ontologicalcontiguity ' educedexistentialising/contextualising/textualising_ 'intelligibility/epistemicity/reflexivity_contiguity<imbued-notional cogency $\left.>^{\prime}\right\}$-conflatedness ${ }^{13}$-in-\{preconverging-disentailment by\} postconverging-entailment (psychoanalytic-unshackling/memetic-reordering/institutionalrecomposuring) of the underlying base-institutionalisation/animistic relative-ontologicalincompleteness 8 -induced,-'threshold-of-nonconviction/madeupness/bottomlining-in-shallowsupererogation -<as-to- 'attendant-intradimensional'-prospectivelydisontologising preconverging/dementing -apriorising-psychologism>' which is rather of crossgenerational import (prospective-institutionalisation $\quad$ amplituding/formativeepistemicity>-totalising $\sim$ renewing-realisation/re-perception/re-thought-as-utter-placeholdersetup-ontological-rescheduling-〈by-a-renewing-of-apriorising/axiomatising/referencingpsychologism-as-the-new-referencing-basis-of-prospective- meaningfulness-and-teleology > as enabled by psychoanalytic-unshackling/memetic-reordering/institutional-recomposuring). 
Such an insight can be extended prospectively on the same measure with respect to our procrypticism prior relative-ontological-incompleteness ${ }^{8}$-induced,-`threshold-ofnonconviction/madeupness/bottomlining-in-shallow-supererogation $-<$ as-to-'attendantintradimensional'-prospectively-disontologising preconverging/dementing -apriorisingpsychologism>' and futural Being-development/ontological-framework-expansion-as-to-depthof-ontologising-development-as-infrastructure-of- meaningfulness-and-teleology as of

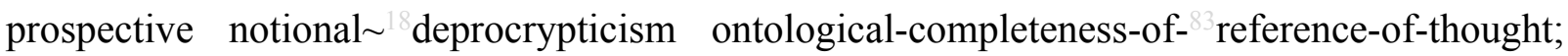
though as previously indicated we will wrongly tend to (just as any <amplituding/formativeepistemicity $>$ totalising $\sim$ self-referencing-syncretising/metaphysics-of-presence-〈implicited'nondescript/ignorable-void ' -as-to- presencing - absolutising-identitive-constitutedness > registry-worldview/dimension) to represent by reflex our own procrypticism threshold-ofnonconviction/madeupness/bottomlining-in-shallow-supererogation $<<$ as-to-'attendantintradimensional'-prospectively-disontologising preconverging/dementing -apriorisingpsychologism $>$ at worst as a nondescript/ignorable-void (actually speaking of akrasiatic-dragdenatured-and-preconverging-or-dementing -narratives) or a-registry-worldview's-ordimension's-ignoring-of-its-prior-relative-ontological-incompleteness ${ }^{88}$-of- ${ }^{83}$ refence-ofthought-as-an-ontologically-flawed-neuterisation -or-bracketing-or-epoché of $<$ amplituding/formative-epistemicity $>$ totalising $\sim$ conflated $-{ }^{5}$ meaningfulness-and-teleology ${ }^{9}-$ as-of-notional ${ }^{18}$ deprocrypticism-reflected- ${ }^{-1}$ historiality/ontologicaleventfulness 38 ontological-aesthetic-tracing-<perspective-ontologicalnormalcy/postconvergence-reflected-'epistemicity-relativism-determinism'> in our placeholder-setup/mentation/mental-devising-representation/consciousness-awarenessteleology ${ }^{9}$ rather than the true reality from an ontological-normalcy/postconvergence epistemicor-notional projective-perspective as 'decandored/oblongated and preconverging-ordementing ${ }^{2}$-apriorising-psychologism and dialectically/contendingly-out-of-phase', and doing 
so beyond-the-consciousness-awareness-teleology

$-<$ of-preconverging-existential-extricationas-of-existential-unthought> to avoid its 'ontologically-perspectival-degraded-asdecentered/preconverging-or-dementing ${ }^{2}$-reflexive/entailing-teleology ${ }^{9}$-differentiation-as-ofsubtransversality-<in-desublimating-existential-eventuating/denouement $>$ — threshold-ofnonconviction/madeupness/bottomlining-in-shallow-supererogation $<-<$ as-to-' attendantintradimensional'-prospectively-disontologising preconverging/dementing -apriorisingpsychologism>' with respect to futural Being-development/ontological-framework-expansionas-to-depth-of-ontologising-development-as-infrastructure-of- meaningfulness-andteleology as of prospective notional ' deprocrypticism 'ontologically-perspectivalelevated/pedestaling-as-postconverging-or-dialectical-thinking -differentiation-as-ofsupratransversality-<in-sublimating-existential-eventuating/denouement $>\sim$ of-motif-andapriorising/axiomatising/referencing'. This reflex is what establishes the defining circularity/recurrence/repetition/repeatability ${ }^{10}$ of procrypticism as of its relative-ontologicalincompleteness 8 -induced,-'threshold-of-nonconviction/madeupness/bottomlining-in-shallowsupererogation -<as-to-'attendant-intradimensional'-prospectivelydisontologising $\sim$ preconverging/dementing -apriorising-psychologism>' in endemising/enculturating psychopathy and social psychopathy. The bigger picture here is that in reflecting holographically-<conjugatively-and-transfusively $>$ the relative-unreflexivity/relativereflexivity ontological-contiguity of-the-human-institutionalisation-process and the institutional-cumulation/institutional-recomposure-〈as-to- historiality/ontologicaleventfulness /ontological-aesthetic-tracing-<perspective-ontologicalnormalcy/postconvergence-reflected-'epistemicity-relativism-determinism'>>, and as reflected insightfully from cultural diffusion induced institutionalisations, the 'prior/transcended/superseded registry-worldview's/dimension's ${ }^{83}$ reference-of-thought in its $<$ amplituding/formative-epistemicity $>$ totalising $\sim$ self-referencing- 
syncretising/circularity/interiorising/akrasiatic-drag

threshold-of-

nonconviction/madeupness/bottomlining-in-shallow-supererogation $<<$ as-to-' attendant-

intradimensional'-prospectively-disontologising preconverging/dementing -apriorising-

psychologism>' need to be recognised, referenced/registered/decisioned and represented from the prospective/transcending/superseding registry-worldview ${ }^{83}$ reference-of-thought for what it is, rather than a "nondescript/ignorable-void" (actually speaking of akrasiatic-drag-denaturedand-preconverging-or-dementing -narratives) as a-registry-worldview's-or-dimension'signoring-of-its-prior-relative-ontological-incompleteness ${ }^{8}$-of- ${ }^{8}$ reference-of-thought-as-anontologically-flawed-neuterisation ${ }^{5}$-or-bracketing-or-epoché of <amplituding/formativeepistemicity $>$ totalising $\sim$ conflated- $-{ }^{56}$ meaningfulness-and-teleology 9 -as-of-

notional ${ }^{18}$ deprocrypticism-reflected- ${ }^{4}$ historiality/ontological-eventfulness ${ }^{38} /$ ontological- $^{-}$ aesthetic-tracing-<perspective-ontological-normalcy/postconvergence-reflected-'epistemicityrelativism-determinism'> to then allowed for the necessary crossgenerational psychoanalyticunshackling/memetic-reordering/institutional-recomposuring of the prospective institutionalisation by its prospective relative-ontological-completeness ${ }^{87}$-of- ${ }^{83}$ reference-ofthought.]

It should be noted as well that the idea of '<amplitung/formative-epistemicity $>$ totalising renewing-realisation/re-perception/re-thought-as-utter-placeholder-setupontological-rescheduling-〈by-a-renewing-of-apriorising/axiomatising/referencingpsychologism-as-the-new-referencing-basis-of-prospective- meaningfulness-and-teleology ' ' enabled by psychoanalytic-unshackling/memetic-reordering/institutional-recomposuring is the deterministic phenomenon behind 'postconverging-or-dialectical-thinking -psychology or psychology-of-mentation-dynamics or natural psychological-dynamics' and the specific institutional-cumulation/institutional-recomposure-〈as-to- historiality/ontologicaleventfulness /ontological-aesthetic-tracing-<perspective-ontological- 
normalcy/postconvergence-reflected-'epistemicity-relativism-determinism' $>>$ in reflecting holographically-<conjugatively-and-transfusively $>$ the relative-unreflexivity/relativereflexivity - ontological-contiguity of-the-human-institutionalisation-process as recurrentutter-uninstitutionalisation, base-institutionalisation-ununiversalisation, ${ }^{103}$ universalisationnon-positivism/medievalism, positivism- ${ }^{80}$ procrypticism, and deprocrypticism. It captures the true notion of transcendence-and-sublimity/sublimation/supereregatory $\sim$ de-mentativity as a maximalising-recomposuring-for-relative-ontological-completeness ${ }^{87}$ unenframed/reontologising conceptualisation involving utterly putting-into-question/reshuffling/remaking the human psyche/placeholder-setup/mental-devising-representation/mentation/consciousnessawareness-teleology ${ }^{9}$ in the very first instance, and on a second-level then imply eliciting the corresponding ${ }^{56}$ meaningfulness-and-teleology ${ }^{9}$ for such renewed psyche as ${ }^{83}$ reference-ofthought. Such '<amplituding/formative-epistemicity>-totalising $\sim$ renewing-realisation/reperception/re-thought-as-utter-placeholder-setup-ontological-rescheduling-〈by-a-renewing-ofapriorising/axiomatising/referencing-psychologism-as-the-new-referencing-basis-ofprospective- meaningfulness-and-teleology $\rangle$ ' involves specific 'memeticism/meaningfulness circular-caricature' with respect to the implied registry-worldview/dimension in their respective institutionalisation state (as candored/straight and postconverging-or-dialectical-thinking apriorising-psychologism/dialectically-or-contendingly in-phase) and their uninstitutionalised-

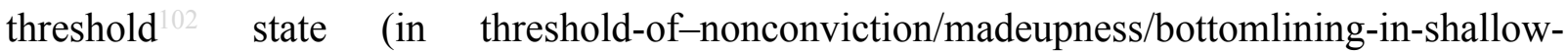
supererogation -<as-to-'attendant-intradimensional'-prospectively-

\section{disontologising preconverging/dementing -apriorising-psychologism>}

\footnotetext{
‘ $<$ amplituding/formative-epistemicity $>$-totalising $\sim$ renewing-realisation/re-perception/rethought-as-utter-placeholder-setup-ontological-rescheduling-〈by-a-renewing-of-
} 
apriorising/axiomatising/referencing-psychologism-as-the-new-referencing-basis-of-

prospective- meaningfulness-and-teleology $\rangle$ as being of true transcendence-andsublimity/sublimation/supererogatory de-mentativity can be further elucidated with regards to two remarkable historical developments which while inherently exceptional, to say the least, aren't truly transcendental. Consider for instance that transcendental is generally considered as the central notion of Kantian philosophy. The reality however is that the supposed transcendentalism is actually an elaboration in the terms of the actual and true rationalempiricism/positivism $\quad$ reference-of-thought transcendence-andsublimity/sublimation/supererogatory-de-mentativity established by Descartes' thinking proposition and scepticism exercise as the fundamental basis for continuously re-elaborated 'extended rationalism' right up to the present. Kantian supposed transcendence-andsublimity/sublimation/supererogatory-de-mentativity (Copernican revolution) is not eliciting a 'postconverging-or-dialectical-thinking - psychology or psychology-of-mentation-dynamics or natural psychological-dynamics' $\quad$ of $\quad$ '<amplituding/formative-epistemicity $>$ totalising renewing-realisation/re-perception/re-thought-as-utter-placeholder-setupontological-rescheduling-〈by-a-renewing-of-apriorising/axiomatising/referencingpsychologism-as-the-new-referencing-basis-of-prospective- meaningfulness-and-teleology ’’ (which is exactly what Descartes' thinking proposition and scepticism exercise does with respect to the non-positivism/medievalism psyche/placeholder-setup/mental-devisingrepresentation/mentation/consciousness-awareness-teleology ${ }^{\circ}$ ). The Kantian construct is an elaboration well within the psychical framework established by dimensionality-ofsublimating $25<<$ amplituding/formative $>$ supererogatery $\sim$ de-mentativeness/epistemic-growthor-conflatedness /transvaluative-rationalising/transepistemicity/anamnestic-residuality/spiritdrivenness-equalisation〉 'extended rationalism' thinking proposition and scepticism exercise, and Kantian ${ }^{56}$ meaningfulness-and-teleology ${ }^{99}$ is utterly comprehensible and intelligible to that 
psyche/mentation, though in-many-ways it is a more profound elaboration of ${ }^{56}$ meaningfulnessand-teleology $\quad$ issues. So it is actually apriorising/axiomatising/referencing/intelligibilitysettingup/measuringinstrumenting within the extended-rationalism ${ }^{83}$ reference-of-thought that doesn't psychically and meaningfully supersede it but elaborates within it; and it doesn't reference an apriorising/axiomatising/referencing/intelligibilitysettingup/measuringinstrumenting ‘ $<$ amplituding/formative-epistemicity $>$-totalising $\sim$ renewing-realisation/re-perception/rethought-as-utter-placeholder-setup-ontological-rescheduling-〈by-a-renewing-ofapriorising/axiomatising/referencing-psychologism-as-the-new-referencing-basis-ofprospective- meaningfulness-and-teleology ' ' as implied by a 'postconverging-or-dialecticalthinking -psychology or psychology-of-mentation-dynamics or natural $\sim$ psychologicaldynamics', as from Recurrent-utter-uninstitutionalisation to Base-institutionalisationununiversalisation, to ${ }^{103}$ universalisation-non-positivism/medievalism, to positivismprocrypticism, and prospectively to deprocrypticism; as successively non-rulesapriorising/axiomatising/referencing-psychologism,-as-impulsive-or-accidented-or-randommental-disposition- $\left\langle\right.$ as 'base-constitutedness ${ }^{4}$ of reference-of-thought' apriorising/axiomatising/referencing/intelligibilitysettingup/measuringinstrumenting $\quad$ gives way to rulemaking-over-non-rules_apriorising/axiomatising/referencing-psychologism,-〈as 'first-level presencing - absolutising-identitive-constitutedness ${ }^{4}$ of reference-of-thought' apriorising/axiomatising/referencing/intelligibilitysettingup/measuringinstrumenting $\quad$ which gives way to ${ }^{103}$ universalisation-directed-rulemaking-over-non-rulesapriorising/axiomatising/referencing-psychologism,-〈as 'second-level presencingabsolutising-identitive-constitutedness of reference-of-thought' apriorising/axiomatising/referencing/intelligibilitysettingup/measuringinstrumenting $\quad$ which gives way to positivising/rational-empiricism-based-universalisation-directed-rulemaking-over- 
non-rules - apriorising/axiomatising/referencing-psychologism,-〈as 'third-level presencing absolutising-identitive-constitutedness of reference-of-thought' apriorising/axiomatising/referencing/intelligibilitysettingup/measuringinstrumenting,, and prospectively bringing about preempting-disjointedness-as-of- ${ }^{-}$reference-of-thought,-as-to${ }^{32}<$ amplituding/formative-epistemicity $>$ growth-or-conflatedness ${ }^{13} /$ transvaluative- $^{2}$ rationalising/transepistemicity/anamnestic-residuality/spirit-drivenness'_-in-supersedingmere-formulaic-positivising/rational-empiricism-based-universalisation-directed-rulemakingover-non-rules_-apriorising/axiomatising/referencing-psychologism,〈'apriorising/axiomatising/referencing-\{of-'prospectively_implicited_attendant-ontologicalcontiguity ' educedexistentialising/contextualising/textualising_'intelligibility/epistemicity/reflexivity_contiguity<imbued-notional cogency $\left.>^{\prime}\right\}$ - conflatedness ${ }^{13}$-in-\{preconverging-disentailment by\} of ${ }^{83}$ reference-of-thought' $\rangle$; and wherein the successive mindsets $/{ }^{3}$ references-of-thought and institutionalisations are suprastructural to each other (beyond-the-consciousness-awareness-teleology ${ }^{0}<$ of-preconverging-existential-extricationas-of-existential-unthought $>$ ). Insightfully, this highlights that human mentation capacity is in a dynamic cumulation as of the maximalising-recomposuring-for-relative-ontologicalcompleteness $^{87}$ —unenframed/re-ontologising conceptualisation of its limited-mentationcapacity-deepening — as-subjecting limitedness/human-subpotency-to-'educed-

unlimitedness/existence-sublimating nascence ${ }^{53}$. It puts into question the Kantian philosophical exercise (Copernican revolution) of striving to establish ${ }^{103}$ universal human mental apriorising/axiomatising/referencing principles with respect to a mental state that is perpetually in a transformative becoming state of shallow-to-deepening-limited-mentation-capacity-assubjecting 'educed-unlimitedness/existence-sublimating nascence' to-limitedness/humansubpotency, as-limited-mentation-capacity-deepening—as-subjecting limitedness/human- 
subpotency-to-'educed-unlimitedness/existence-sublimating-nascence' ${ }^{53}$. (This latter condition inherently means that the certitude of such an enterprise itself can only be grounded on the human existential-<disontologising/re-ontologising aporeticism $>$ existence-potency ${ }^{39} \sim$ sublimatingnascence,-disclosed-from-prospective-epistemic-digression-rules-ofapriorising/axiomatising/referencing-that-further-epistemically-unconceal-the-veryontologically-same-existential-reality as the absolute apriorising.) It is this author's contention that the Kantian conceptualisation exercise while interesting is in-many-ways rather a heuristic construct given its grounding on a categorisation reflex that poorly syncs with and is in constant need for heuristic re-adaptation to match an 'existence-potency' $\sim$ sublimating-nascence,disclosed-from-prospective-epistemic-digression—rules-ofapriorising/axiomatising/referencing-that-further-epistemically-unconceal-the-veryontologically-same-existential-reality existential-<disentologising/re-ontelogising aporeticism $>$ reality nature that is preceding-and-superseding to any human mental apriorising/axiomatising/referencing of it', and thus rendering such an apriorising/axiomatising/referencing conceptualisation exercise highly heuristic (to constantly resolve the virtualities it raises by re-categorisation/re-adaptation/re-classification), and so when not employing a referentialism reflex that is naturally inclined to be contiguous with intrinsicreality as of ontological-normalcy/postconvergence/intemporal-preservation-entropy-orcontiguity-or-ontological-preservation. A further weakness is the naive implication thus that an apriorising/axiomatising/referencing exercise of human mental understanding only starts and ends with the positivism/rational-empiricism registry-worldview's/dimension's ${ }^{83}$ reference-ofthought as if it is the only one that had existed, against the anthropological and historical trend, and without explaining how previous meaningful-frames developed into the positivism/rationalempiricism and how the latter could develop prospectively. Besides the Kantian argument that the transcendent (in all its connotations beyond direct experiences) cannot be known is equally 
anthropologically and historically erroneous as even in his days, with respect to adopting of a positivism/rational-empiricism worldview over non-positivistic/alchemic/essences/medieval registry-worldview/dimension certainly does has a name (transcendence-andsublimity/sublimation/supererogatory de-mentativity). But then it is more the case that from an $<$ amplituding/formative-epistemicity $>$ totalising $\sim$ self-referencing-

syncretising/circularity/interiorising/akrasiatic-drag ${ }^{34}$ posture holding only one registryworldview/dimension $\quad{ }^{8}$ reference-of-thought- categorical-imperatives/axioms/registryteleology as absolute, then prospective transcendence-andsublimity/sublimation/supererogatory $\sim$ de-mentativity is rather a beyond-the-consciousnessawareness-teleology $-<$ of-preconverging-existential-extrication-as-of-existential-unthought $>$ notion. Besides, Kant's notion of transcendence-and-sublimity/sublimation/supereregatery $\sim$ dementativity (transcendental idealism) and subsequent philosophical development of the notion is one relating to immediate phenomenal conceptualisation rather construed as 'phenomenalabstractiveness of presence' (and more precisely phenomenal-abstractiveness of presence as of the 'positivism/rational-empiricism apriorising/axiomatising/referencing/intelligibilitysettingup/measuringinstrumenting-foroperant-or-incidenting-predicative-insights' transcendence-andsublimity/sublimation/supererogatory de-mentativity implied by Descartes) rather than a construal of transcendence-and-sublimity/sublimation/supereregatory $\sim$ de-mentativity as implied herein as of limited-mentation-capacity-deepening —as-subjecting limitedness/humansubpotency-to-'educed-unlimitedness/existence-sublimating naseence' ${ }^{3}$ with respect to thevery-same-immanent-existence/intrinsic-reality/ontological-veridicality,-as-to'human<amplituding/formative-epistemicity>totalising $\sim$ purview-of-construal' as supersedingoneness-of-ontology as an all-encompassing <amplituding/formative-epistemicity>totalising renewing-realisation/re-perception/re-thought of human psychical and 
institutionalisation disposition for ${ }^{5}$ meaningfulness-and-teleology ${ }^{9}$, even though fundamentally enabled by developing human phenomenal-abstractiveness of presence as of <amplituding/formative-epistemicity>totalising random-as-impulsive'implicited_attendant-ontological-contiguity ${ }^{67}$; educedexistentialising/contextualising/textualising_intelligibility/epistemicity/reflexivity-contiguity$<$ imbued-notional cogency>' ${ }^{\prime}$;-phenomenal-abstractiveness-of-presencing-in-'trepidatiousconsciousness' with recurrent-utter-uninstitutionalisation, <amplituding/formativeepistemicity>totalising nominal-as-tendentious_-implicited_attendant_ontologicalcontiguity $^{67}$; educedexistentialising/contextualising/textualising_intelligibility/epistemicity/reflexivity-contiguity$<$ imbued-notional cogency>' ;-phenomenal-abstractiveness-of-presencing-in-'warpedconsciousness' with base-institutionalisation-ununiversalisation, <amplituding/formativeepistemicity>totalising $\sim$ ordinal-as-qualifying__implicited_attendant-ontologicalcontiguity $^{67} \sim$ educedexistentialising/contextualising/textualising_intelligibility/epistemicity/reflexivity-contiguity$<$ imbued-notional cogency>' ;-phenomenal-abstractiveness-of-presencing-in-'preclusiveconsciousness' with ${ }^{103}$ universalisation-non-positivism/medieval, <amplituding/formativeepistemicity $>$ totalising intervalist-as-categorising_- 'implicited_attendant-ontologicalcontiguity $^{67} \sim$ educedexistentialising/contextualising/textualising_intelligibility/epistemicity/reflexivity-contiguity$<$ imbued-notional cogency>' ;-phenomenal-abstractiveness-of-presencing-in-'occlusiveconsciousness' with positivism- ${ }^{8}$ procrypticism, and <amplituding/formativeepistemicity $>$ totalising $\sim$ ratiocontiguity/ratiocination-as-referentialism— implicited_atendant ontological-contiguity ${ }^{67}$, educedexistentialising/contextualising/textualising_'intelligibility/epistemicity/reflexivity-contiguity- 
$<$ imbued-notional cogency>' ${ }^{\prime}$;-phenomenal-abstractiveness-of-presencing-in-'protensiveconsciousness' with deprocrypticism. Basically, Kant lacked a notion of metaphysics-ofabsence-〈implicited-epistemic-veracity-of- nonpresencing-<perspective-ontologicalnormalcy/postconvergence $>>\quad$ (to overcome $\quad<$ amplituding/formativeepistemicity>totalising $\sim$ self-referencing-syncretising/illusion-of-the-present/presentconsciousness/mirage) with respect to the positivism/rational-empiricism registryworldview/dimension. In other words, Kant is involved in an epistemological conceptualisation at a given point in time (erroneously construed as the absolute point of human thought apriorising, without a decentering sense of projection with respect to the prior and prospective). But existential-reality as of its human mental apriorising/axiomatising/referencing (heuristically at least) started well before that point and carries on well after that point, and such an exercise is more profound when it construes human mental apriorising/axiomatising/referencing along the full existence-potency ${ }^{39} \sim$ sublimating-nascence,-disclosed-from-prospective-epistemicdigression—rules-of-apriorising/axiomatising/referencing-that-further-epistemicallyunconceal-the-very-ontologically-same-existential-reality of existence as it redefines meaningfulness-and-teleology 9 on the basis of human limited-mentation-capacitydeepening —as-subjecting-limitedness/human-subpotency-to-'educed-unlimitedness/existencesublimating nascence ${ }^{53}$ in its construal/conceptualisation of a superseding-oneness-ofontology construed as transcendental-enabling/sublimating/supererogatory $\sim$ de-mentativity. Insightfully, this author construes an existential-reference/existential-tautologisation basis of such human mental apriorising/axiomatising/referencing process for the transcendentalenabling/sublimating/supererogatory de-mentativity of successive apriorising/axiomatising/referencing/intelligibilitysettingup/measuringinstrumenting-astranscendental registry-worldviews/dimensions rather as of an exercise of maximalisingrecomposuring-for-relative-ontological-completeness ${ }^{77}$ - unenframed/re- 
ontologising conceptualisation over conceptualisations of human mental apriorising/axiomatising/referencing process on a simple categorisation reflex basis as elaboration-as-to-mere-extrapolating/constituting/abstracting/deducing/inferring-ofelucidation-outside_-'prospectively_implicited_attendant-ontological-contiguity ${ }^{67}$ educedexistentialising/contextualising/textualising_intelligibility/epistemicity/reflexivity-contiguity<imbued-notional cogency $>$ which tend to require constant heuristic adaptations to sync in contiguity with existence-potency ${ }^{39} \sim$ sublimating-nascence,-disclosed-from-prospectiveepistemic-digression - rules-of-apriorising/axiomatising/referencing-that-further-epistemicallyunconceal-the-very-ontologically-same-existential-reality of existential-reality and avoid virtualities, as wrongly operating on the basis of an absolute point of human thought apriorising/axiomatising/referencing that doesn't recognise that successive apriorising/axiomatising/referencing/intelligibilitysettingup/measuringinstrumenting-astranscendental registry-worldviews/dimensions are defining transcendentalenabling/sublimating/supererogatory $\sim$ de-mentativity for new prospective relative-ontologicalcompleteness ${ }^{87}$-of- ${ }^{83}$ reference-of-thought and so-reflected as to the de-mentation〈supererogatory $\sim$ ontological-de-mentation-or-dialectical-de-mentation-stranding-or-

attributive-dialectics $\rangle$ undergirding the relative-unreflexivity/relative-reflexivity-ontologicalcontiguity ${ }^{67}$ of-the-human-institutionalisation-process ${ }^{68}$. In the bigger framework, this author holds that conceptually and operantly nothing is certain but for the certitude of existence and its oneness, thereafter defining relative certitudes by the existentialising/contextualising/textualising_intelligibility/epistemicity/reflexivity-contiguity<imbued-notional cogency>' of existence as of human shallow-to-deepening-limitedmentation-capacity—as-subjecting 'educed-unlimitedness/existence-sublimating nascence' to-limitedness/human-subpotency, as-limited-mentation-capacity-deepening —as-subjecting limitedness/human-subpotency-to-'educed-unlimitedness/existence-sublimating nascence' ${ }^{53}$ as 
of its successively developed transcendental psychical and institutionalisation notions from apriorising/axiomatising/referencing/intelligibilitysettingup/measuringinstrumenting nonrules_-apriorising/axiomatising/referencing-psychologism,-as-impulsive-or-accidented-orrandom-mental-disposition to successively profound apriorising/axiomatising/referencing/intelligibilitysettingup/measuringinstrumenting rules associated with human limited-mentation-capacity-deepening-as-subjectinglimitedness/human-subpotency to-'educed-unlimitedness/existence-sublimating nascence' 53 , as further elaborated herein. This same insight can be extended with respect to an Einstein and Bohr led theory-of-relativity and quantum-mechanics physics respectively in relation to the physics of Newton, Galileo, Leibniz; wherein the latter established the 'postconverging-ordialectical-thinking -psychology or psychology-of-mentation-dynamics or natural psychological-dynamics' psyche as '<amplituding/formative-epistemicity>totalising $\sim$ renewing-realisation/re-perception/re-thought-as-utter-placeholder-setupontological-rescheduling-〈by-a-renewing-of-apriorising/axiomatising/referencingpsychologism-as-the-new-referencing-basis-of-prospective- meaningfulness-and-teleology ’’ of positivistic physics right back then in their epoch such that the overall underlying principle of $<$ amplituding/formative-epistemicity $>$ causality $\sim$ as-to-projective-totalitative-implications-ofprospective- nonpresencing,-for-explicating relative-unreflexivity/relative-reflexivity-

ontological-contiguity as transcendental-enabling/sublimating/supererogatory 0 de-mentativity back then is still what prevails today. It is that physics psyche established back then which enabled seemingly aloof conceptualisations of physics like theory-of-relativity and quantummechanics within a decade or so of their articulations as of more profound elaboration of transcendental-enabling/sublimating/supererogatory $\sim$ de-mentativity <amplituding/formativeepistemicity $>$ causality $\sim$ as-to-projective-totalitative-implications-of-prospectivenonpresencing,-for-explicating relative-unreflexivity/relative-reflexivity - ontological- 
contiguity to establish themselves as the central physics theories with little or no quarrel. It is interesting to grasp that such a physics and science psyche wasn't available to a Copernicus in what may be construed today as a relatively benign conceptualisation of a heliocentric model of the world, with the revolt of Galileo and others ultimately establishing that physics and science psyche over a non-positivism/medievalism apriorising/axiomatising/referencing/intelligibilitysettingup/measuringinstrumenting relationship to <amplituding/formative-epistemicity $>$ causality $\sim$ as-to-projective-totalitativeimplications-of-prospective- nonpresencing,-for-explicating relative-unreflexivity/relativereflexivity - ontological-contiguity that is not ontological-veridicality/intrinsic-reality transcendental-enabling/sublimating/supererogatory $\sim$ de-mentativity as of its non-scientific psyche. In other words however 'good-natured, well-meaning and wishful for enabling human progress' the mental-disposition in that epoch as alchemic and non-positivistic was preconverging/postconverging-de-mentatively/structurally/paradigmatically not ontologicalveridicality/intrinsic-reality transcendental-enabling/sublimating/supereregatory $\sim$ dementativity, and instinctively one may argue that it is by coming out from the frustration of not achieving anything decisive but for 'palliative results' in terms of progress with an alchemic and non-positivistic psyche that the Newton's of that epoch increasingly adopted a positivistic sense of things which they increasingly came to realise as being ontological-veridicality/intrinsicreality transcendental-enabling/sublimating/supererogatory de-mentativity. This same 'ontological misconstrual' naively grounded on 'palliative constructs and naïve conceptualpatterning' driven by 'good-naturedness, well-meaningfulness and wishfulness' is pervasive in the social sciences today as of its poor ontological-veridicality/intrinsic-reality transcendentalenabling/sublimating/superenteriventy construction having to do with an $<$ amplituding/formative-epistemicity $>$ totalising $\sim$ self-referencingsyncretising/circularity/interiorising/akrasiatic-drag ${ }^{4}$ agent of limited-mentation-capacity—as- 
subjecting 'educed-unlimitedness/existence-sublimating nascence' to-limitedness/humansubpotency that we are as of our animate-existential-referencing/subjectification wherein our $<$ amplituding/formative-epistemicity $>$ totalising $\sim$ self-referencing-

syncretising/circularity/interiorising/akrasiatic-drag ${ }^{34}$ of ${ }^{5}$ meaningfulness-and-teleology ${ }^{9}$ is often wrongly construed as ontological as of ${ }^{83}$ reference-of-thought- categoricalimperatives/axioms/registry-teleology ${ }^{9}$,-for-

aposteriorising/logicising/deriving/intelligising/measuring- ${ }^{5}$ meaningfulness-and-teleology ${ }^{9}$.

Consider for instance a situation where statistically people likely to rest more in their home in winter are compared with people spending more time outdoors with regards to prevalence of flu, and then arriving at the conclusion that the treatment for flu is resting more at home. Such a construct as basic apriorising/axiomatising/referencing-\{of-'prospectively implicited_attendant-ontological-contiguity ' educedexistentialising/contextualising/textualising_ 'intelligibility/epistemicity/reflexivity-contiguity<imbued-notional cogency>' $\}$-constitutedness ${ }^{1}$-in-preconverging-entailment is at best a sound palliative construct and naïve conceptual-patterning however good-natured, well-meaning and wishful, but doesn't deal with the required pure-ontology apriorising/axiomatising/referencing-\{of-'prospectively implieited_attendant-ontologicalcontiguity ' $\sim$ educedexistentialising/contextualising/textualising_ intelligibility/epistemicity/reflexivity-contiguity$<$ imbued-notional cogency $\left.>{ }^{\prime}\right\}$-conflatedness ${ }^{13}$ in-\{preconverging-disentailment by\} postconverging-ntailment as of ontological-veridicality/intrinsic-reality transcendentalenabling/sublimating/supereregatory de-mentativity in establishing a comprehensive disease theory for flu that syncs with other human diseases theories and human biology theories and general biology theories and informed by the bigger 'transcendentalenabling/sublimating/supereregatory $\sim$ de-mentativity positivism psyche-and-thereof- 
philosophy' (construed rather as of an organic depth of ontological coherence/contiguity that is preconverging/postconverging-de-mentatively/structurally/paradigmatically transcendentalenabling/sublimating/supereregatery $\sim$ de-mentativity contiguously as from the deeper apriorising/axiomatising/referencing enabling/sublimating/supererogatory $\sim$ de-mentativity of positivism 'transcendental-psyche-and-thereof-philosophy' and not vague ad-hoc mechanical patchwork of non-transcendental-enabling/sublimating/supererogatory-de-mentativity conceptualised/construed relations), and so as of its ${ }^{83}$ reference-of-thought- categoricalimperatives/axioms/registry-teleology ${ }^{9}$, -foraposteriorising/logicising/deriving/intelligising/measuring - ${ }^{5}$ meaningfulness-and-teleology . The practice in many a social science specialism is often to articulate concepts whose linkage with other social science concepts and the overall social science background knowledge construct is vague such that ontological-veridicality/intrinsic-reality transcendentalenabling/sublimating/supereregatery $\sim$ de-mentativity is hardly established but for bare 'palliative constructs and naïve conceptual-patterning' that are more often than not $<$ amplituding/formative-epistemicity $>$ totalising $\sim$ self-referencingsyncretising/circularity/interiorising/akrasiatic-drag ${ }^{34}$ than truly ontological when examined closely such that the test of transcendentally-enabling-level-of $\sim$ ontological-good-faith-orauthenticity $\%$ objectification/desubjectification-as-objectification-<as-to-ontological-faithnotion-or-ontological-fideism —imbued-underdetermination-of-motif-andapriorising/axiomatising/referencing-as-so-being-as-of-existential-reality as antinihilism> when the implications of such notions are examined as of metaphysics-of-absence-〈implicitedepistemic-veracity-of- nonpresencing-<perspective-ontological-normalcy/postconvergence $>$ > not only in terms of one registry-worldview's/dimension's ${ }^{56}$ meaningfulness-and-teleology ${ }^{9}$ but two or more, say our present positivism ${ }^{83}$ reference-of-thought and retrospective non-positivism reference-of-thought, their 'supposed ontological status' turn out to be ridiculous 
$<$ amplituding/formative-epistemicity $>$ totalising $\sim$ self-referencing-

syncretising/circularity/interiorising/akrasiatic-drag ${ }^{34}$, exposing their true nature as rather palliative constructs and conceptual-patterning. In the bigger framework can notions construed/conceptualised as of 'human subjectivity so-construed as ineffectively transcendentally-enabling-level-of ontological-good-faith-or-

authenticity $\%$ objectification/desubjectification-as-objectification- $<$ as-to-ontological-faithnotion-or-ontological-fideism - imbued-underdetermination-of-motif-andapriorising/axiomatising/referencing-as-so-being-as-of-existential-reality as antinihilism>100, be given the label ontology, or rather is ontology exactly not about effective transcendentallyenabling-level-of ontological-good-faith-or-authenticity $\%$ objectification/desubjectificationas-objectification-<as-to-ontological-faith-notion-or-ontological-fideism-imbuedunderdetermination-of-motif-and-apriorising/axiomatising/referencing-as-so-being-as-ofexistential-reality as antinihilism $>{ }^{00}$ ? And what is fundamentally involved in developing that transcendentally-enabling-level-of ontological-good-faith-orauthenticity $\%$ objectification/desubjectification-as-objectification- $<$ as-to-ontological-faithnotion-or-ontological-fideism - imbued-underdetermination-of-motif-andapriorising/axiomatising/referencing-as-so-being-as-of-existential-reality as antinihilism> for ontological-veridicality/intrinsic-reality transcendentalenabling/sublimating/supererogatory $\sim$ de-mentativity is the increasing psychicaltransformation/psychical-detachment with corresponding institutional-cumulation/institutionalrecomposure-〈as-to- historiality/ontological-eventfulness /ontological-aesthetic-tracing$<$ perspective-ontological-normalcy/postconvergence-reflected-‘epistemicity-relativismdeterminism' $>>$ as from non-rules—apriorising/axiomatising/referencing-psychologism,-asimpulsive-or-accidented-or-random-mental-disposition transcendentally-enabling-levelof ontological-good-faith-or-authenticity $\%$ objectification/desubjectification-as- 
objectification-<as-to-ontological-faith-notion-or-ontological-fideism-imbuedunderdetermination-of-motif-and-apriorising/axiomatising/referencing-as-so-being-as-ofexistential-reality as antinihilism $>100$ as recurrent-utter-uninstitutionalisation, rulemaking-overnon-rules - apriorising/axiomatising/referencing-psychologism transcendentally-enablinglevel-of ontological-good-faith-or-authenticity $\%$ objectification/desubjectification-asobjectification-<as-to-ontological-faith-notion-or-ontological-fideism - imbuedunderdetermination-of-motif-and-apriorising/axiomatising/referencing-as-so-being-as-ofexistential-reality as antinihilism $>00$ as base-institutionalisation-ununiversalisation, ${ }^{3}$ universalisation-directed-rulemaking-over-non-rules_-apriorising/axiomatising/referencingpsychologism transcendentally-enabling-level-of $\sim$ ontological-good-faith-orauthenticity $\%$ objectification/desubjectification-as-objectification-<as-to-ontological-faithnotion-or-ontological-fideism —imbued-underdetermination-of-motif-andapriorising/axiomatising/referencing-as-so-being-as-of-existential-reality as antinihilism> as universalisation-non-positivism/medievalism, positivising/rational-empiricism-baseduniversalisation-directed-rulemaking-over-non-rules_ - apriorising/axiomatising/referencingpsychologism transcendentally-enabling-level-of ontological-good-faith-orauthenticity $\%$ objectification/desubjectification-as-objectification- $<$ as-to-ontological-faithnotion-or-ontological-fideism - imbued-underdetermination-of-motif-andapriorising/axiomatising/referencing-as-so-being-as-of-existential-reality as antinihilism> as positivism- ${ }^{80}$ procrypticism, and prospectively preempting-disjointedness-as-of- ${ }^{8}$ referenceof-thought,-as-to- ${ }^{6}<$ amplituding/formative-epistemicity $>$ growth-orconflatedness ${ }^{13} /$ transvaluative-rationalising/transepistemicity/anamnestic-residuality/spiritdrivenness'-in-superseding-mere-formulaic-positivising/rational-empiricism-baseduniversalisation-directed-rulemaking-over-non-rules — apriorising/axiomatising/referencingpsychologism transcendentally-enabling-level-of ontological-good-faith-or- 
authenticity $\%$ objectification/desubjectification-as-objectification-<as-to-ontological-faithnotion-or-ontological-fideism - imbued-underdetermination-of-motif-and-

deprocrypticism; explaining the successive developments of the human psyche transcendentallyenabling-level-of ontological-good-faith-or-authenticity $\%$ objectification/desubjectificationas-objectification-<as-to-ontological-faith-notion-or-ontological-fideism-imbuedunderdetermination-of-motif-and-apriorising/axiomatising/referencing-as-so-being-as-ofexistential-reality as antinihilism $>100$ as ontologically-driven as of increasing prospective relative-ontological-completeness ${ }^{8}$-of- ${ }^{8}$ reference-of-thought. It is this author's contention that the 'transcendental-enabling/sublimating/supererogatory de-mentativity notional ${ }^{18}$ deprocrypticism psyche-and-thereof-philosophy' as so transcendentally-enablinglevel-of ontological-good-faith-or-authenticity $\%$ objectification/desubjectification-asobjectification-<as-to-ontological-faith-notion-or-ontological-fideism-imbuedunderdetermination-of-motif-and-apriorising/axiomatising/referencing-as-so-being-as-ofexistential-reality as antinihilism $>100$ provides the requisite ontologically-veridical background referencing as of its apriorising/axiomatising/referencing-\{of-"prospectively implicited_attendant-ontological-contiguity ' educedexistentialising/contextualising/textualising_'intelligibility/epistemicity/reflexivity-contiguity<imbued-notional cogency $\left.>{ }^{\prime}\right\}$ - conflatedness ${ }^{13}$-in-\{preconverging-disentailment by\} pestcenverging-entailment (in the same vein as the prior positivism- ${ }^{80}$ procrypticism registryworldview/dimension bigger 'transcendental-enabling/sublimating/supereregatery $\sim$ dementativity positivism psyche-and-thereof-philosophy' with regards to nonpositivism/medievalism) as of the prospective-and-more-profound notional ${ }^{18}$ deprocrypticism registry-worldview/dimension bigger 'transcendental-enabling/sublimating/supererogatory $\sim$ dementativity notional ${ }^{18}$ deprocrypticism psyche-and-thereof-philosophy' as herein implied by 
this \{epistemic-totalising $3{ }^{3}$ hermeneutic/textuality/reprojecting/supererogating/zeroing/re-acuting,-

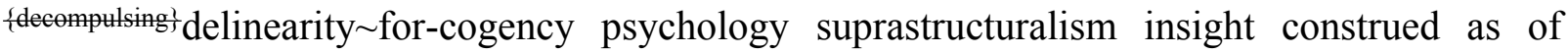
metaphysics-of-absence-〈implicited-epistemic-veracity-of- nonpresencing-<perspectiveontological-normalcy/postconvergence $>>\quad$ as $\quad$ 'postconverging-or-dialectical-thinking psychology or psychology-of-mentation-dynamics or natural psychological-dynamics', not only with regards to the social sciences but also when it comes to the many instances of poor scientific studies thus enabling the decisive superseding of palliative construals and conceptualpatterning-〈as-devoid-of-‘prospectively implieited_attendant-ontologicalcontiguity ' educedexistentialising/contextualising/textualising_'intelligibility/epistemicity/reflexivity-contiguity<imbued-notional cogency>' 's-reifying-or-elucidating-of-'prospective-relative-ontologicalcompleteness ';-so-rather-enabled-<by-a- nonpresencing-divulging-of-momentous-

\section{historiality/ontological-eventfulness /ontological-aesthetic-tracing-<perspective-}

ontological-normalcy/postconvergence-reflected-‘epistemicity-relativism-determinism’ $>>$ that can hardly be qualified as ontological. The underlying contention of both such a present 'transcendental-enabling/sublimating/supererogatory de-mentativity positivism psyche-andthereof-philosophy' and prospective 'transcendental-enabling/sublimating/supererogatory $\sim$ dementativity notional ${ }^{18}$ deprocrypticism psyche-and-thereof-philosophy' as of their respective relative ontologically-veridical psychical background referencing as of apriorising/axiomatising/referencing-\{of-'prospectively implicited_attendant-ontologicalcontiguity ' educedexistentialising/contextualising/textualising_'intelligibility/epistemicity/reflexivity-contiguity$<$ imbued-notional cogency $>>$ ' $\}$-conflatedness ${ }^{13}$ in-\{preconverging-disentailment by\}postconverging-ntailment for knowledge $/{ }^{5}$ meaningfulness-and-teleology ${ }^{9}$ has to do with the bigger ontological-normalcy/postconvergence reality (of ontologically valid 
knowledge $/{ }^{5}$ meaningfulness-and-teleology ${ }^{9}$ )

preconverging/postconverging-de-mentative/structural/paradigmatic basis by which 'ontological-deficiency (conceptually represented as subsuming of virtue-defect or vices-andimpediments 105 'with virtue not truly differentiated from ontology' but rather such a conceptualdifferentiation being represented as of our notional <amplituding/formativeepistemicity $>$ totalising $\sim$ self-referencing-syncretising/circularity/interiorising/akrasiatic-drag animate-existential-referencing/subjectification emotional-involvement implications)' is construed fundamentally going by a registry-worldview's/dimension's ${ }^{83}$ reference-of-thought relative deficiency as prior relative-ontological-incompleteness ${ }^{88}$-of- ${ }^{8}$ reference-of-thought (as its uninstitutionalised-threshold ${ }^{102}$ ) thereby resolvable preconverging/postconverging-dementatively/structurally/paradigmatically by the prospective registry-worldview's/dimension's reference-of-thought prospective relative-ontological-completeness ${ }^{87}$-of- ${ }^{8}$ reference-ofthought; thus validating with regards to both ${ }^{83}$ reference-of-thought respectively as the 'transcendental-enabling/sublimating/supererogatory de-mentativity positivism psyche-andthereof-philosophy' and the 'transcendental-enabling/sublimating/supererogatory $\sim$ dementativity notional ' deprocrypticism psyche-and-thereof-philosophy' their relative ontologically-veridical background referencing as of apriorising/axiomatising/referencing-\{of'prospectively_implicited_attendant-ontological-contiguity ' educedexistentialising/contextualising/textualising_'intelligibility/epistemicity/reflexivity-contiguity$<$ imbued-notional cogency $\left.>^{\prime} \quad\right\}$-conflatedness ${ }^{13}$ in- -preconverging-disentailment by\} pestconverging-entailment as of ontological-normalcy/postconvergence. Since we can perfectly conceptualise with both ${ }^{83}$ reference-of-thought the articulation of coherent ${ }^{56}$ meaningfulnessand-teleology ${ }^{9}$ respectively in non-positivism terms-as-of-axiomatic-constructs and nondeprocrypticism/procrypticism terms-as-of-axiomatic-constructs, or rather in terms-as-of- 
axiomatic-construct that do not grasp preconverging/postconverging-dementatively/structurally/paradigmatically the respective ${ }^{83}$ reference-of-thought organic grounding as of underlying ontological-normalcy/postconvergence implications, and so beyond just a question of vague ad-hoc mechanical patchwork of non-transcendentalenabling/sublimating/supereregatery $\sim$ de-mentativity conceptualised/construed relations. This elucidation points out that transcendence-and-sublimity/sublimation/supererogatery $\sim$ dementativity 'must truly' involve an ${ }^{15}$ de-mentation-/supererogatery $\sim$ ontological-de-mentationor-dialectical-de-mentation-stranding-or-attributive-dialectics $\rangle$ with the utter decentering of understanding itself by the prospective/transcending/superseding ${ }^{8}$ reference-of-thought over the threshold-of-nonconviction/madeupness/bottomlining-in-shallow-supererogation $-<$ as-to-

\section{'attendant-intradimensional'-prospectively-disontologising preconverging/dementing}

apriorising-psychologism> of the prior/transcended/superseded at its uninstitutionalisedthreshold ${ }^{102}$ as an epistemic-totalising $\sim$ renewing-realisation/re-perception/re-thought-as-utterplaceholder-setup-ontological-rescheduling-〈by-a-renewing-of-

\section{apriorising/axiomatising/referencing-psychologism-as-the-new-referencing-basis-of-}

prospective- meaningfulness-and-teleology > eliciting a new

apriorising/axiomatising/referencing/intelligibilitysettingup/measuringinstrumenting of prospective/transcending/superseding ${ }^{8}$ reference-of-thought as candored/straight, postconverging-or-dialectical-thinking ${ }^{21}$-apriorising-psychologism and dialectically/contendingly-in-phase over the prior/transcended/superseded ${ }^{83}$ reference-ofthought as decandored/oblongated, preconverging-or-dementing -apriorising-psychologism and dialectically/contendingly out-of-phase. Basically, de-mentation-

\section{〈supererogatory $\sim$ ontological-de-mentation-or-dialectical-de-mentation-stranding-or-}

attributive-dialectics $\rangle$ speaks of the attendant supersedingness of prospective relativeontological-completeness ${ }^{87}$-of- reference-of-thought of prospective/transcending/superseding 
reference-of-thought over prior relative-ontological-incompleteness ${ }^{88}$-of- ${ }^{8}$ refence-ofthought of prior/transcended/superseded ${ }^{83}$ reference-of-thought, and so 'with respect to the relative veracity/ontological-pertinence of their projected ${ }^{54}$ logical-processing-or-logicalimplicitation - supposedly-apriorising-in-conviction-as-to-profound-supererogation of meaningfulness-and-teleology 9 as of 'implicited_attendant-ontologicalcontiguity $^{67}$; educed-

existentialising/contextualising/textualising_'intelligibility/epistemicity/reflexivity-contiguity$<$ imbued-notional $\sim$ cogency $>,{ }^{\prime},-<$ reifying-or-elucidating-of-prospective-relative-ontologicalcompleteness -of- reference-of-thought- devolving-as-of-instantiative-context>', wherein the prior/transcended/superseded ${ }^{83}$ reference-of-thought is construed as preconverging-ordementing -apriorising-psychologism and decentered/out-of-phase thus subsumed-assupplanted while the prospective/transcending/superseding ${ }^{83}$ reference-of-thought is construed as postconverging-or-dialectical-thinking -apriorising-psychologism and centered/in-phase thus subsuming-as-supplanting (by supratransversality-<in-sublimating-existentialeventuating/denouement> of-motif-and-apriorising/axiomatising/referencing as of 'intemporality ${ }^{52}$-symmetrising-by-desymmetrising-subsumption-of-temporality ${ }^{\circ}$, , rather as of intellectual-and-moral-inequivalence/non-correspondence). Thus attendantly and ontologically, recurrent-utter-uninstitutionalisation is preconverging-or-dementing ${ }^{20}$-apriorisingpsychologism and decentered thus subsumed-as-supplanted (given its failing/not-upholding$<$ as-of-apriorising/axiomatising/referencing $>\quad$ of $\quad$ rulemaking-over-non-rulesapriorising/axiomatising/referencing-psychologism) relative to base-institutionalisationununiversalisation as postconverging-or-dialectical-thinking -apriorising-psychologism and centered, with the latter preconverging-or-dementing ${ }^{20}$-apriorising-psychologism and decentered thus subsumed-as-supplanted (given its failing/not-upholding-<as-ofapriorising/axiomatising/referencing $>$ of ${ }^{103}$ universalisation-directed-rulemaking-over-non- 
rules_-apriorising/axiomatising/referencing-psychologism) relative to ${ }^{103}$ universalisation-nonpositivism/medievalism as postconverging-or-dialectical-thinking -apriorising-psychologism and centered, with the latter preconverging-or-dementing ${ }^{20}$-apriorising-psychologism and decentered thus subsumed-as-supplanted (given its failing/not-upholding-<as-ofapriorising/axiomatising/referencing $>\quad$ of positivising/rational-empiricism-baseduniversalisation-directed-rulemaking-over-non-rules_-apriorising/axiomatising/referencingpsychologism) relative to our positivism- ${ }^{-}$procrypticism as postconverging-or-dialecticalthinking -apriorising-psychologism and centered, with the latter preconverging-ordementing -apriorising-psychologism and decentered thus subsumed-as-supplanted (given its failing/not-upholding-<as-of-apriorising/axiomatising/referencing $>$ in preemptingdisjointedness-as-of- ${ }^{8}$ reference-of-thought,-as-to- ${ }^{32}<$ amplituding/formativeepistemicity $>$ growth-or-conflatedness ${ }^{13} /$ transvaluative-

rationalising/transepistemicity/anamnestic-residuality/spirit-drivenness'_-in-supersedingmere-formulaic-positivising/rational-empiricism-based-universalisation-directed-rulemakingover-non-rules — apriorising/axiomatising/referencing-psychologism) relative to futural Beingdevelopment/ontological-framework-expansion-as-to-depth-of-ontologising-development-asinfrastructure-of- meaningfulness-and-teleology as of prospective notional deprocrypticism as postconverging-or-dialectical-thinking ${ }^{21}$-apriorisingpsychologism and centered; and so successively, 'with respect to relative ontological veridicality of ${ }^{54}$ logical-processing-or-logical-implicitation-supposedly-apriorising-in-conviction-as-toprofound-supererogation projected $\quad{ }^{56}$ meaningfulness-and-teleology 99 as 'implicited_attendant-ontological-contiguity ${ }^{67}$; educedexistentialising / intelligibility/epistemicity/reflexivity-contiguity$<$ imbued-notional $\sim$ cogency $>,{ }^{\prime},-<$ reifying-or-elucidating-of-prospective-relative-ontologicalcompleteness -of- reference-of-thought- devolving-as-of-instantiative-context>'. $\quad{ }^{15}$ de- 
mentation-〈supererogatory $\sim$ ontological-de-mentation-or-dialectical-de-mentation - strandingor-attributive-dialectics $\rangle$ as of overall transcendental/interdimensional/transdimensional registry-worldviews/dimensions-level conceptualisation/construal as enabling prospective suprastructuration (suprastructural psychical-and-institutionalisation orientation of meaningfulness-and-teleology synopsising-depth as of the overall registryworldview's/dimension's reconstrual of superseding-oneness-of-ontology), is technically apprehended rather as of the "'reference-of-thought-degraded-devolving-as-ofuninstitutionalised-threshold ${ }^{102}$ of ${ }^{56}$ meaningfulness-and-teleology ${ }^{9}$ of the prior/transcended/superseded registry-worldview ${ }^{83}$ reference-of-thought implied as of distractive-alignment-to- ${ }^{8}$ reference-of-thought- $<$ of-apriorising/axiomatising/referencing $>{ }^{30}$ in reflecting the prospective/transcending/superseding registry-worldview ${ }^{83}$ reference-of-thought suprastructuration as the 'new ontologically-veridical becoming-or-present-of- ${ }^{3}$ reference-ofthought' since there 'cannot be two different becoming-or-present-of- ${ }^{3}$ reference-of-thought' but rather that the prospective/transcending/superseding suprastructuration is by its prospective relative-ontological-completeness ${ }^{8}$-of- ${ }^{8}$ reference-of-thought the becoming-or-present-ofreference-of-thought. However, in all the ${ }^{15}$ de-mentation-/supererogatory ontological-dementation-or-dialectical-de-mentation-stranding-or-attributive-dialectics $\rangle$ implied successive institutional-cumulation/institutional-recomposure-〈as-to- historiality/ontologicaleventfulness /ontological-aesthetic-tracing-<perspective-ontologicalnormalcy/postconvergence-reflected-‘epistemicity-relativism-determinism'>>, $\quad$ such $\quad$ a 'confusion of relative ontologically-veridical becoming-or-present-of- reference-of-thought' induces an underlying 'paradox of transcendence-andsublimity/sublimation/supererogatory de-mentativity' involved in all such transcendence-andsublimity/sublimation/surentativity wherein mental-dispositions as of reference-of-thought are caught between the prospective/transcending/superseding registry- 
worldview prospective relative-ontological-completeness ${ }^{87}$-of- ${ }^{8}$ reference-of-thought and the prior/transcended/superseded registry-worldview prior relative-ontological-incompleteness ${ }^{\text {- }}$ of- reference-of-thought, with respect to ${ }^{56}$ meaningfulness-and-teleology referencing. Consider in this case the human condition of transience of ${ }^{83}$ reference-of-thought as experienced by Okonkwo returning from banishment to Umuofia village in Chinua Achebe's Things Fall Apart. That is, basically and by reflex, mental-dispositions as of the formation of 'recurrentutter-uninstitutionalisation non-rules - apriorising/axiomatising/referencing-psychologism,-asimpulsive-or-accidented-or-random-mental-disposition $\quad{ }^{83}$ reference-of-thought- categoricalimperatives/axioms/registry-teleology will not necessarily construe transitorily at its uninstitutionalised-threshold ${ }^{102}$ that 'base-institutionalisation-ununiversalisation rulemakingover-non-rules_-apriorising/axiomatising/referencing-psychologism $\quad{ }^{83}$ reference-of-thoughtcategorical-imperatives/axioms/registry-teleology is the relative ontologically-veridical reference-of-thought (as explained further below with respect to 'symmetrisation-ofreference-of-thought but which is in effect an ontologically-non-veridical-or-flawed $<$ amplituding/formative-epistemicity $>$ totalising $\sim$ self-referencing-

syncretising/circularity/interiorising/akrasiatic-drag ${ }^{34}$ and/or desymmetrisation for perceived temporal social-stake-contention-or-confliction' associated with distractive-alignment-toreference-of-thought- $<$ of-apriorising/axiomatising/referencing $>$ ' 0 , and 'intemporality ${ }^{52}$ symmetrising-by-desymmetrising-subsumption-of-temporality $\%$ /ontological-symmetrisation as of deconstruction/ontological-reconstituting-as-to-conflatedness ${ }^{13}$ in aetiologisation/ontological-escalation-<ontologicalveridicality_commitment/otherliness_transcending/compulsions-encumbered_transcending $>$ ); such that on a logical-basis/logic,-as-derived-from $\sim$ transversality-<for-sublimating-existentialeventuating/denouement-from-'thinking-at-first/pure-predisposition-preemptive-of- 
$<$ amplituding/formative $>$ wooden-language-_imbued — averaging-of-thought-<as-toleveling/ressentiment/closed-construct-of- meaningfulness-and-teleology -as-of'nondescript/ignorable-void '-with-regards-to-prospective-apriorising-implications $>>\quad$ in recurrent-utter-uninstitutionalisation will be more inclined to turn towards the 'prior conventional non-rules — apriorising/axiomatising/referencing-psychologism,-as-impulsive-oraccidented-or-random-mental-disposition’ as $\quad{ }^{83}$ reference-of-thought- categoricalimperatives/axioms/registry-teleology', and so over the 'prospective relative pure-ontology apriorising/axiomatising/referencing-\{of-'prospectively_implicited_attendant-ontologicalcontiguity ' educed-

existentialising/contextualising/textualising_'intelligibility/epistemicity/reflexivity_contiguity$<$ imbued-notional $\sim$ cogency $\left.>{ }^{\prime} \quad\right\}$ - conflatedness ${ }^{13}$ in-\{preconverging-disentailment by postconverging-entailment implying rulemaking-over-non-rulesapriorising/axiomatising/referencing-psychologism'. This is because a registryworldview/dimension is a 'circular-pervasiveness <amplituding/formative $>$ wooden-language〈imbued-averaging-of-thought-<as-to-leveling/ressentiment/closed-construct-ofmeaningfulness-and-teleology -as-of-'nondescript/ignorable-void '-with-regards-toprospective-apriorising-implications $>\rangle$ ' wherein achievement motives and temporal-stakes of the conventional constructs as of human finite aspirations whether socially, professionally, family-wise, hedonic, etc. as of the registry-worldview's/dimension's denaturing $<$ amplituding/formative $>$ wooden-language-<imbued - averaging-of-thought- $<$ as-toleveling/ressentiment/closed-construct-of- meaningfulness-and-teleology -as-of'nondescript/ignorable-void '-with-regards-to-prospective-apriorising-implications $>>\quad$ soconstrued prospectively, will tend to 'take precedence as of relative-ontologicalincompleteness ${ }^{8}$-of- ${ }^{8}$ reference-of-thought induced distractive-alignment-to- ${ }^{8}$ reference-of- 
thought- $<$ of-apriorising/axiomatising/referencing $>^{30}$ and override any such sense of relative pure-ontology apriorising/axiomatising/referencing-\{of-'prospectively implicited_attendantontological-contiguity ' educed-

existentialising/contextualising/textualising_'intelligibility/epistemicity/reflexivity-contiguity<imbued-notional cogency $\left.>^{\prime}\right\}$-conflatedness ${ }^{13}$ in-\{preconverging-disentailment by\} pestcenverging-entailment as of prospective relative-ontological-completeness ${ }^{87}$-of- ${ }^{8}$ referenceof-thought (as implied by ontological-faith-notion-or-ontological-fideism -imbuedunderdetermination-of-motif-and-apriorising/axiomatising/referencing-as-so-being-as-of-

existential-reality as heuristic but non-constraining compensation for human limited-mentationcapacity —as-subjecting 'educed-unlimitedness/existence-sublimating nascence' tolimitedness/human-subpotency where constraining social ${ }^{103}$ universal-transparency ${ }^{104}$ 〈transparency-of-totalising-entailing,-as-to-entailing-<amplituding/formativeepistemicity>totalising in-relative-ontological-completeness $>$ doesn't yet avail) even though, it is such relative pure-ontology apriorising/axiomatising/referencing-\{of-"prospectively implicited_attendant-ontological-contiguity ' educedexistentialising/contextualising/textualising_intelligibility/epistemicity/reflexivity-contiguity<imbued-notional cogency >' \}-conflatedness ${ }^{13}$-in-\{preconverging-disentailment by\} postcenverging-entailment that is the ontological-faith-notion-or-ontological-fideism-imbuedunderdetermination-of-motif-and-apriorising/axiomatising/referencing-as-so-being-as-ofexistential-reality enabling (by ultimately making available such prospective constraining social ${ }^{3}$ universal-transparency ${ }^{104}$-〈transparency-of-totalising-entailing,-as-to-entailing$<$ amplituding/formative-epistemicity>totalising in-relative-ontological-completeness $\rangle)$ the successive institutional-cumulation/institutional-recomposure-〈as-to- historiality/ontologicaleventfulness /ontological-aesthetic-tracing-<perspective-ontologicalnormalcy/postconvergence-reflected-'epistemicity-relativism-determinism' $>\rangle$. Even then and 
ultimately, it is mainly a crossgenerational psychoanalytic-unshackling/memeticreordering/institutional-recomposuring that progressively rids the prior conventional constructs of their essence as of <amplituding/formative-epistemicity $>$ totalising $\sim$ self-referencingsyncretising/circularity/interiorising/akrasiatic-drag ${ }^{34}$ that enables prospective registryworldview/dimension suprastructuration/transcendence-andsublimity/sublimation/supererogatory-de-mentativity. This insight extends to all the $<$ cumulating/recomposuring attendant-ontological-contiguity $>$-successive registryworldviews/dimensions including ours as positivism- ${ }^{80}$ procrypticism as the relative pureontology apriorising/axiomatising/referencing-\{of-'prospectively implicited_attendantontological-contiguity ' educedexistentialising/contextualising/textualising_'intelligibility/epistemicity/reflexivity-contiguity<imbued-notional cogency >' \}-conflatedness ${ }^{13}$-in-\{preconverging-disentailment by\} postconverging-entailment as of ontological-faith-notion-or-ontological-fideism - imbuedunderdetermination-of-motif-and-apriorising/axiomatising/referencing-as-so-being-as-ofexistential-reality implying such a construct as the notional ${ }^{18}$ deprocrypticism institutionalisation suprastructuration (preempting-disjointedness-as-of- ${ }^{8}$ reference-ofthought,-as-to- ${ }^{6}<$ amplituling/formative-epistemicity $>$ growth-orconflatedness ${ }^{13}$ /transvaluative-rationalising/transepistemicity/anamnestic-residuality/spiritdrivenness'-in-superseding-mere-formulaic-positivising/rational-empiricism-baseduniversalisation-directed-rulemaking-over-non-rules — apriorising/axiomatising/referencingpsychologism,-〈apriorising/axiomatising/referencing-\{of-'prespectively implicited_attendant ontological-contiguity ' educedexistentialising/contextualising/textualising_'intelligibility/epistemicity/reflexivity-contiguity<imbued-notional cogency $\left.>^{\prime}\right\}$ - conflatedness ${ }^{13}$-in-\{preconverging-disentailment by\} postconverging-ntailment)) will certainly be a remote contemplation of such a 
$<$ amplituding/formative $>$ wooden-language-<imbued — averaging-of-thought-<as-to-

leveling/ressentiment/closed-construct-of- meaningfulness-and-teleology -as-of-

'nondescript/ignorable-void '-with-regards-to-prospective-apriorising-implications $>$ > mentaldisposition of our registry-worldview/dimension, rather construing its circular-pervasiveness $<$ amplituding/formative $>$ wooden-language-_imbued — averaging-of-thought-<as-toleveling/ressentiment/closed-construct-of- meaningfulness-and-teleology -as-of'nondescript/ignorable-void '-with-regards-to-prospective-apriorising-implications $>$ >

absolute by reflex beyond-the-consciousness-awareness-teleology ${ }^{0}<$ of-preconvergingexistential-extrication-as-of-existential-unthought $>$ wherein achievement motives and temporal-stakes of the conventional constructs as of human finite aspirations whether socially, professionally, family-wise, hedonic, etc. as of the registry-worldview's/dimension's denaturing $<$ amplituding-formative $>$ wooden-language-〈imbued-averaging-of-thought- $<$ asto-leveling/ressentiment/closed-construct-of- meaningfulness-and-teleology -as-of'nondescript/ignorable-void ' -with-regards-to-prospective-apriorising-implications $>>\quad$ soconstrued prospectively, will tend to 'take precedence as of relative-ontologicalincompleteness ${ }^{88}$-of- ${ }^{8}$ reference-of-thought induced distractive-alignment-to- ${ }^{83}$ reference-ofthought- $<$ of-apriorising/axiomatising/referencing ${ }^{30}$ and override any such sense of relative pure-ontology apriorising/axiomatising/referencing-\{of-'prospectively implicited_attendantontological-contiguity ' educed-

existentialising/contextualising/textualising_'intelligibility/epistemicity/reflexivity_contiguity<imbued-notional cogency $\left.>^{\prime}\right\}$-conflatedness ${ }^{13}$-in-\{preconverging-disentailment by\} pestconverging-entailment notion as of prospective relative-ontological-completeness ${ }^{87}$-ofreference-of-thought and implying rather a prospective transcendental depth-ofthought $/{ }^{3}$ reference-of-thought. This equally explains why the implied supratransversality-<insublimating-existential-eventuating/denouement $>\sim$ of-motif-and- 
apriorising/axiomatising/referencing as of aetiologisation/ontological-escalation- $<$ ontologicalveridicality_commitment/otherliness_transcending/compulsions-encumbered_transcending $>$ is necessarily a " ${ }^{\text {p }}$ presencing — absolutising-identitive-constitutedness ${ }^{14}$ consummated/forfeiting posture' of intemporality ${ }^{52}$-symmetrising-by-desymmetrising-subsumption-oftemporality $/$ ontological-symmetrisation that needs to take into account this 'paradox of transcendence-and-sublimity/sublimation/supereregatory-de-mentativity'. And critically so, because beyond just 'human conscious willing', transcendence-andsublimity/sublimation/supererogatoryade-mentativity necessarily implies the 'prospect of humans to appreciate/understand ${ }^{56}$ meaningfulness-and-teleology ${ }^{9}$ beyond-the-consciousnessawareness-teleology $-<$ of-preconverging-existential-extrication-as-of-existentialunthought $>, \quad$ (preconverging/postconverging-de-mentatively/structurally/paradigmatically) implies that which gets to 'conceptualise/construe beyond-the-consciousness-awarenessteleology $-<$ of-preconverging-existential-extrication-as-of-existential-unthought $>, \quad$ is necessarily of ontological desymmetry as rather imbued with intellectual-and-moral responsibility/relative-reflexivity over that which doesn't get there (and so, even with regards to a basic non-transcendental construal of ontological desymmetry within a same registryworldview's/dimension's ${ }^{8}$ reference-of-thought like Doctor -Patient, Parent -Child, Server Customer, Teacher -Student etc. as veridically ensues from a Derridean binary opposition analysis rather emphasising 'ontological-veracity drivenness). However at uninstitutionalisedthreshold $^{102}$, the notion of intemporality ${ }^{52}$-symmetrising-by-desymmetrising-subsumption-oftemporality $/$ ontological-symmetrisation is not readily acquiesced to for the simple reason that two ${ }^{83}$ references-of-thought/axiomatic-constructs are at play with those adhering to the prior/transcended/superseded ${ }^{83}$ reference-of-thought- categorical-imperatives/axioms/registryteleology inclined beyond-the-consciousness-awareness-teleology ${ }^{9}-<$ of - preconvergingexistential-extrication-as-of-existential-unthought $>$ to uphold ${ }^{56}$ meaningfulness-and- 
teleology ${ }^{9}$ as such, whereas in contrast adherence to the prospective/transcending/superseding as of its prospective relative-ontological-completeness ${ }^{87}$-of- ${ }^{8}$ reference-of-thought will certainly grasp the pertinence of intemporality ${ }^{52}$-symmetrising-by-desymmetrising-subsumption-oftemporality /ontological-symmetrisation as of deconstruction/ontological-reconstituting-as-toconflatedness aetiologisation/ontological-escalation-<ontologicalveridicality_commitment/otherliness_transcending/compulsions-encumbered_transcending $>$; so construed, as prospective relative-ontological-completeness ${ }^{87}$-of- ${ }^{3}$ reference-of-thought brings about deepening sense as to apriorising/axiomatising/referencing-psychologism of transcendentally-enabling-level-of ontological-good-faith-or-

authenticity $\%$ objectification/desubjectification-as-objectification- $<$ as-to-ontological-faithnotion-or-ontological-fideism - imbued-underdetermination-of-motif-andapriorising/axiomatising/referencing-as-so-being-as-of-existential-reality as antinihilism> meaningfulness-and-teleology ${ }^{9}$ construal for a sounder and sounder relationship with intrinsic-reality/ontological-veridicality. In this respect, it should be noted that in the example on the denaturing ${ }^{16}$ of Additionality as further articulated below with regards to the characters $\mathrm{A}, \mathrm{B}, \mathrm{C}, \mathrm{D}, \mathrm{E}, \mathrm{F}$ and $\mathrm{Z}$, it is naïve to think that the characters $\mathrm{A}, \mathrm{B}, \mathrm{C}, \mathrm{D}, \mathrm{E}, \mathrm{F}$ will simply acquiesce to Z's supposedly ontologically-veridical posture, as by their prior relativeontological-incompleteness ${ }^{8}$-of- ${ }^{8}$ reference-of-thought as beyond-the-consciousnessawareness-teleology $-<$ of-preconverging-existential-extrication-as-of-existential-unthought $>$ they may operate on a logic that once such a situation as A induced additionality defect deception develops as of 'lack of constraining social ${ }^{103}$ universal-transparency ${ }^{104}$-〈transparency-oftotalising-entailing,-as-to-entailing-<amplituding/formative-epistemicity $>$ totalising inrelative-ontological-completeness $\rangle$, that's fine and implicitly others could just as well consciously go along with it, and that it is just as implicitly legitimate as of the '<amplituding/formative $>$ wooden-language-〈imbued-temporal--mere- 
form/virtualities/dereification/akrasiatic-drag/denatured/preconverging-or-dementing

narratives - of-the- reference-of-thought- categorical-imperatives/axioms/registry-

teleology $>$ of prior/transcended/superseded registry-worldview/dimension' notwithstanding its failing/not-upholding-<as-of-apriorising/axiomatising/referencing $>$ intemporal-preservationentropy-or-contiguity-or-ontological-preservation as of ontological-faith-notion-orontological-fideism - imbued-underdetermination-of-motif-and-

apriorising/axiomatising/referencing-as-so-being-as-of-existential-reality; highlighting how across the <cumulating/recomposuring attendant-ontological-contiguity $>$-successive registry-worldviews/dimensions threshold-of-nonconviction/madeupness/bottomlining-inshallow-supererogation -<as-to-'attendant-intradimensional'-prospectively-

disontologising preconverging/dementing -apriorising-psychologism> arise, however, different the perception from 'very-crude' (with recurrent-utter-uninstitutionalisation) to 'seemingly polished' (with our positivism- ${ }^{80}$ procrypticism) depending on prospective relativeontological-completeness ${ }^{87}$-of- ${ }^{8}$ reference-of-thought. This is to point out that at

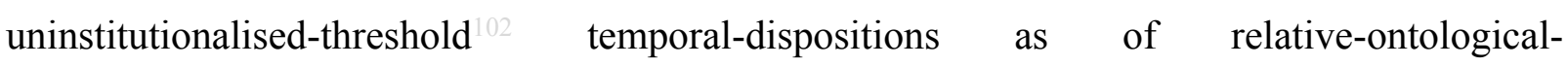
incompleteness ${ }^{8}$-of- ${ }^{8}$ reference-of-thought do not necessarily acquiesce to intemporality ${ }^{52}$ symmetrising-by-desymmetrising-subsumption-of-temporality ${ }^{8}$ (as Z's ... looking down on A, B, C, D, E and F mental-dispositions perversion-and-derived- ${ }^{7}$ perversion-of- ${ }^{8}$ reference-ofthought-<as-preconvergingly-apriorising/axiomatising/referencing-innonconviction/madeupness/bottomlining-as-to-shallow-supererogation $>$ as allowing for the endemisation/enculturation of the denaturing ${ }^{16}$ of additionality and the implications thereof of subsequent denaturing ${ }^{16}$ in circularity/recurrence/repetition/repeatability ${ }^{10}$ that ensue where socially-functional-and-accordant ${ }^{3}$ due to lack of constraining social ${ }^{103}$ universaltransparency ${ }^{104}$-〈transparency-of-totalising-entailing,-as-to-entailing-<amplituding/formativeepistemicity>totalising in-relative-ontological-completeness $>$ which protects the internal- 
coherence of meaning for virtue'; not only as a specific/particular construal/conceptualisation but of ${ }^{103}$ universal import as having to do with endemisation/enculturation of ${ }^{74}$ perversion-ofreference-of-thought-<as-preconvergingly-apriorising/axiomatising/referencing-innonconviction/madeupness/bottomlining-as-to-shallow-supererogation $>$. Does the 'intellectual romanticism' of a Rousseau articulation of ${ }^{103}$ universal human rights necessarily register fully in the mindset $/{ }^{3}$ reference-of-thought of the $<$ amplituding/formative $>$ woodenlanguage-〈imbued — averaging-of-thought-<as-to-leveling/ressentiment/closed-construct-ofmeaningfulness-and-teleology -as-of-'nondescript/ignorable-void '-with-regards-toprospective-apriorising-implications $>>$ of his epoch or is it rather more truly a beyond-theconsciousness-awareness-teleology ${ }^{9}<$ of-preconverging-existential-extrication-as-ofexistential-unthought $>$ notion until the necessary psychoanalytic-unshackling/memeticreordering/institutional-recomposuring generations latter that brings this beyond-theconsciousness-awareness-teleology ${ }^{-<}<$of-preconverging-existential-extrication-as-ofexistential-unthought $>$ notion to the fore of the <amplituding/formative $>$ wooden-language〈imbued-averaging-of-thought-<as-to-leveling/ressentiment/closed-construct-ofmeaningfulness-and-teleology -as-of-‘nondescript/ignorable-void '-with-regards-toprospective-apriorising-implications $>\rangle$, and this interrogation could be extended to say superstitious notions and their implications in a non-positivistic social-setup as the drive of say a rational-empiricism/positivistic emancipating agent in-many-ways will be a beyond-theconsciousness-awareness-teleology ${ }^{9}<$ of-preconverging-existential-extrication-as-ofexistential-unthought $>$ notion for the <amplituding/formative $>$ wooden-language-〈imbuedaveraging-of-thought-<as-to-leveling/ressentiment/closed-construct-of- meaningfulness-andteleology -as-of-‘nondescript/ignorable-void '-with-regards-to-prospective-apriorisingimplications $>>$ in such a social setting, and equally similar issues faced today in many a traditional society like female genital mutilation is more than just an issue of stopping the 
practitioners of genital mutilation but has to do with <amplituding/formative > woodenlanguage-〈imbued — averaging-of-thought-<as-to-leveling/ressentiment/closed-construct-ofmeaningfulness-and-teleology -as-of-'nondescript/ignorable-void '-with-regards-toprospective-apriorising-implications $>>{ }^{5}$ meaningfulness-and-teleology ${ }^{9}$ in such social-setup that is a question of a beyond-the-consciousness-awareness-teleology ${ }^{9}-<$ of-preconvergingexistential-extrication-as-of-existential-unthought $>$ notion with respect to recasting of gender rights in a prospective ${ }^{5}$ meaningfulness-and-teleology ${ }^{9}$. Likewise, it could be asked whether such an aetiologisation/ontological-escalation-<ontologicalveridicality_commitment/otherliness_transcending/compulsions-encumbered_transcending > notion as notional ${ }^{18}$ deprocrypticism institutionalisation implied suprastructuration over our positivism- ${ }^{8}$ procrypticism is rather not a beyond-the-consciousness-awareness-teleology $<$ of-preconverging-existential-extrication-as-of-existential-unthought $>$ notion as of the present $<$ amplituding/formative $>$ wooden-language-〈imbued - averaging-of-thought- $<$ as-toleveling/ressentiment/closed-construct-of- meaningfulness-and-teleology -as-of'nondescript/ignorable-void '-with-regards-to-prospective-apriorising-implications $>$ > mentaldisposition and mental-projection. The fact is that registry-worldviews/dimensions operate meaningfulness-and-teleology ${ }^{9}$ as of their ontological representation of reality within the limits of their ${ }^{83}$ reference-of-thought- ${ }^{8}$ ategorical-imperatives/axioms/registry-teleology which provide them with their 'apriorising/axiomatising/referencing/intelligibilitysettingup/measuringinstrumenting specific referencing $/{ }^{83}$ reference-of-thought/axiomatic-construct for predicative-insights' (so derived from prior ontological-faith-notion-or-ontological-fideisim induced projectiveinsights/postdication/deconstruction), but then the further possibility of expanding the axiomatic-construal/axiomatic-conceptualisation of ontological representation of reality as prospective registry-worldview/dimension suprastructuration requires new projective- 
insights/postdication/deconstruction to establish more profound ${ }^{83}$ reference-of-thoughtcategorical-imperatives/axioms/registry-teleology

as new/prospective 'apriorising/axiomatising/referencing/intelligibilitysettingup/measuringinstrumenting specific referencing $/{ }^{8}$ reference-of-thought/axiomatic-construct for predicative-insights'; but then, such 'apriorising/axiomatising/referencing/intelligibilitysettingup/measuringinstrumenting specific referencing $/{ }^{83}$ reference-of-thought/axiomatic-construct for predicative-insights' of each registry-worldview/dimension suprastructuration comes with a fundamental mentation-reflex flaw that their given 'apriorising/axiomatising/referencing/intelligibilitysettingup/measuringinstrumenting specific referencing $/{ }^{83}$ reference-of-thought/axiomatic-construct for predicative-insights' is absolute and non-transcendable' beyond-the-consciousness-awareness-teleology ${ }^{9}-<$ of - preconvergingexistential-extrication-as-of-existential-unthought $>$, failing to grasp that projectiveinsights/postdication/deconstruction (factoring in human limited-mentation-capacitydeepening —as-subjecting limitedness/human-subpotency to-'educed-unlimitedness/existencesublimating nascence ${ }^{53}$ ) about prospectively more profound ${ }^{83}$ reference-of-thoughtcategorical-imperatives/axioms/registry-teleology will certainly imply an altogether new/prospective

'apriorising/axiomatising/referencing/intelligibilitysettingup/measuringinstrumenting specific referencing ${ }^{83}$ reference-of-thought/axiomatic-construct for predicative-insights' and notwithstanding the fact that that present registry-worldview/dimension is the result of prior projective-insights/postdication/deconstruction induced transcendence-andsublimity/sublimation/supererogatory de-mentativity. Such that it is a crossgenerational psychoanalytic-unshackling/memetic-reordering/institutional-recomposuring as a beyond-theconsciousness-awareness-teleology ${ }^{\circ}<$ of-preconverging-existential-extrication-as-ofexistential-unthought $>$ notion that enables the fulfilment of the promise of projective- 
insights/postdication/deconstruction as of ontological-faith-notion-or-ontological-fideism imbued-underdetermination-of-motif-and-apriorising/axiomatising/referencing-as-so-being-asof-existential-reality effectively with deconstruction/engaged-destruktion/ontologicalreconstituting-as-to-conflatedness ${ }^{13}$; and so, with respect to transcending from recurrent-utteruninstitutionalisation right up to our positivism- ${ }^{80}$ procrypticism institutionalisation suprastructuration, and prospectively the same human-subpotencyaporia/undecidability/dilemma/ought-indeterminacy/deficiency/limitation/constraint—imbued'notional firstnaturedness-formativeness-<as-to-eventualising -inkling-drive-or-seedingmisprising $>$ temporal-to-intemporal-dispositions- $<$ so-construed-as-from-perspectiveontological-normalcy/postconvergence>'-existentialism-form-factor issues arise with respect to the possibility of our prospective transcendence-and-sublimity/sublimation/supereregatory $\sim$ dementativity to deprocrypticism, as we perceive our 'apriorising/axiomatising/referencing/intelligibilitysettingup/measuringinstrumenting specific referencing $/{ }^{8}$ reference-of-thought/axiomatic-construct for predicative-insights' as absolute failing to construe the all-encompassing redefining implications of projectiveinsights/postdication/deconstruction with respect to the possibility of an altogether new/prospective

'apriorising/axiomatising/referencing/intelligibilitysettingup/measuringinstrumenting specific referencing ${ }^{83}$ reference-of-thought/axiomatic-construct for predicative-insights' (as preempting - disjointedness-as-of- ${ }^{83}$ reference-of-thought,-as-to- ${ }^{6}<$ amplituding/formativeepistemicity $>$ growth-or-conflatedness ${ }^{13} /$ transvaluative-

rationalising/transepistemicity/anamnestic-residuality/spirit-drivenness'—in-supersedingmere-formulaic-positivising/rational-empiricism-based-universalisation-directed-rulemakingover-non-rules — apriorising/axiomatising/referencing-psychologism,- 
contiguity ' educed-

existentialising/contextualising/textualising_'intelligibility/epistemicity/reflexivity_contiguity<imbued-notional $\left.\sim \operatorname{cogency}>^{\prime} \quad\right\}$-conflatedness ${ }^{13}$-in-\{preconverging-disentailment by\}

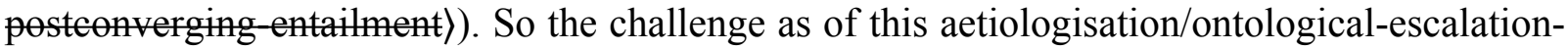
$<$ ontological-veridicality_commitment/otherliness_transcending/compulsions-

encumbered_transcending $>$ as implying futural Being-development/ontological-frameworkexpansion-as-to-depth-of-ontologising-development-as-infrastructure-of- meaningfulnessand-teleology as of prospective deprocrypticism, is one of making conscious beyond the nombrilism/closed-structuring-of- ${ }^{5}$ meaningfulness-and-teleology 9 within all registryworldviews/dimensions just as ours inducing transversality-<for-sublimating-existentialeventuating/denouement,-from-'thinking-at-first/pure-predisposition-preemptive-ofprospective-disontologising/subontologising' as-of-prospectively-disambiguated-affirmedand-unaffirmed-'motif-and-apriorising/axiomatising/referencing' $>{ }^{101}$, that doesn't tend to

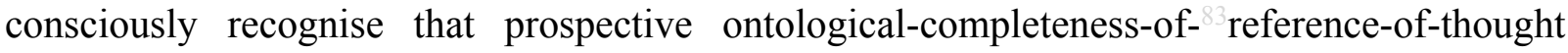
imply in reflecting holographically-<conjugatively-and-transfusively $>$ the relativeunreflexivity/relative-reflexivity - ontological-contiguity of-the-human-institutionalisationprocess that new projective-insights/postdication/deconstruction necessarily induce new 'apriorising/axiomatising/referencing/intelligibilitysettingup/measuringinstrumenting specific referencing $/{ }^{83}$ reference-of-thought/axiomatic-construct for predicative-insights' defining new/prospective registry-worldview/dimension. Particularly $\quad$ so, as $<$ amplituding/formative $>$ wooden-language-<imbued — averaging-of-thought-<as-toleveling/ressentiment/closed-construct-of- meaningfulness-and-teleology -as-of'nondescript/ignorable-void '-with-regards-to-prospective-apriorising-implications $>$ > mentaldispositions most profound relationship to ${ }^{5}$ meaningfulness-and-teleology ${ }^{9}$ tends to be geared rather towards the given 
'apriorising/axiomatising/referencing/intelligibilitysettingup/measuringinstrumenting specific referencing $/{ }^{83}$ reference-of-thought/axiomatic-construct for predicative-insights' as-an-only-one as this enables human finite aspirations whether socially, professionally, family-wise, hedonic, etc. as of the registry-worldview's/dimension's denaturing $<$ amplituding/formative $>$ woodenlanguage-〈imbued — averaging-of-thought-<as-to-leveling/ressentiment/closed-construct-ofmeaningfulness-and-teleology -as-of-'nondescript/ignorable-void '-with-regards-toprospective-apriorising-implications $>>$ so-construed prospectively, as within ONLY recurrentutter-uninstitutionalisation (by its non-rules - apriorising/axiomatising/referencingpsychologism,-as-impulsive-or-accidented-or-random-mental-disposition $\quad$ reference-of-

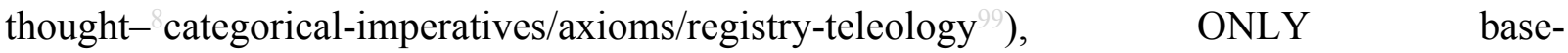
institutionalisation-ununiversalisation (by its rulemaking-over-non-rulesapriorising/axiomatising/referencing-psychologism $\quad{ }^{83}$ reference-of-thought- categoricalimperatives/axioms/registry-teleology ${ }^{9}$ ), $\quad$ ONLY $\quad{ }^{103}$ universalisation-nonpositivism/medievalism (by its ${ }^{103}$ universalisation-directed-rulemaking-over-non-rulesapriorising/axiomatising/referencing-psychologism $\quad{ }^{83}$ reference-of-thought- categoricalimperatives/axioms/registry-teleology ${ }^{9}$ ), or ONLY positivism- ${ }^{8}$ procrypticism (by its positivising/rational-empiricism-based-universalisation-directed-rulemaking-over-non-rules_apriorising/axiomatising/referencing-psychologism $\quad{ }^{83}$ reference-of-thought- categoricalimperatives/axioms/registry-teleology ${ }^{\circ}$ ), and so 'construed-as-of-attendant-circularpervasiveness <amplituding/formative > wooden-language-〈imbued-averaging-of-thought$<$ as-to-leveling/ressentiment/closed-construct-of- meaningfulness-and-teleology -as-of'nondescript/ignorable-void '-with-regards-to-prospective-apriorising-implications $>>\quad$ asinstant-and-absolute-basis-for-being/existence' (despite the relative-ontologicalincompleteness ${ }^{8}$-of- ${ }^{8}$ reference-of-thought induced distractive-alignment-to- ${ }^{83}$ reference-ofthought- $<$ of-apriorising/axiomatising/referencing ${ }^{30}$ and override any such sense of relative 
pure-ontology apriorising/axiomatising/referencing-\{of-'prospectively implicited_attendantontological-contiguity ' educed-

existentialising/contextualising/textualising_'intelligibility/epistemicity/reflexivity-contiguity$<$ imbued-notional cogency $\left.>^{\prime} \quad\right\}$-conflatedness ${ }^{13}$ in-\{preconverging-disentailment by pestcenverging entailment as of prospective relative-ontological-completeness ${ }^{87}$-of- ${ }^{8}$ referenceof-thought apriorising/axiomatising/referencing-\{of-'prospectively implicited_attendant ontological-contiguity ' educed-

existentialising/contextualising/textualising_'intelligibility/epistemicity/reflexivity-contiguity<imbued-notional cogency $\left.>^{\prime}\right\}$-conflatedness ${ }^{13}$-in-\{preconverging-disentailment by\} postconverging entailment), whilst the projective-insights/postdication/deconstruction discernment as of ontological-faith-notion-or-ontological-fideism-imbuedunderdetermination-of-motif-and-apriorising/axiomatising/referencing-as-so-being-as-ofexistential-reality (since the purpose of ${ }^{83}$ reference-of-thought- categoricalimperatives/axioms/registry-teleology is about intemporal-preservation-entropy-orcontiguity-or-ontological-preservation, and not the mimicking of their $<$ amplituding/formative $>$ wooden-language-〈imbued-temporal-mere-

\section{form/virtualities/dereification/akrasiatic-drag/denatured/preconverging-or-dementing} narratives - of-the- reference-of-thought- categorical-imperatives/axioms/registry-

teleology $\rangle$, whether beyond-the-consciousness-awareness-teleology ${ }^{9}-<$ of-preconvergingexistential-extrication-as-of-existential-unthought $>$ ), about how and why the relativeunreflexivity/relative-reflexivity — ontological-contiguity ${ }^{67}$ of-the-human-institutionalisationprocess $^{68}$ as of such $\quad$ successive 'apriorising/axiomatising/referencing/intelligibilitysettingup/measuringinstrumenting specific referencing $/{ }^{83}$ reference-of-thought/axiomatic-construct for predicative-insights' is driven from recurrent-utter-uninstitutionalisation to base-institutionalisation-ununiversalisation to 
universalisation-non-positivism/medievalism to positivism- ${ }^{80}$ procrypticism by projectiveinsights/postdication/deconstruction in establishing them in the first place as of prospective relative-ontological-completeness ${ }^{8}$-of- ${ }^{8}$ reference-of-thought, and thus the utility of projectiveinsights/postdication/deconstruction in enabling futural Being-development/ontologicalframework-expansion-as-to-depth-of-ontologising-development-as-infrastructure-ofmeaningfulness-and-teleology as of prospective notional ${ }^{18}$ deprocrypticism (preemptingdisjointedness-as-of- ${ }^{8}$ reference-of-thought,-as-to- ${ }^{32}<$ amplituding/formativeepistemicity>growth-or-conflatedness ${ }^{13} /$ transvaluativerationalising/transepistemicity/anamnestic-residuality/spirit-drivenness'—in-supersedingmere-formulaic-positivising/rational-empiricism-based-universalisation-directed-rulemakingover-non-rules_-apriorising/axiomatising/referencing-psychologism $\quad{ }^{83}$ reference-of-thoughtcategorical-imperatives/axioms/registry-teleology ${ }^{9}$ ) by construing its grander 're-motif-andre-apriorising/re-axiomatising/re-referencing/re-intelligibilitysettingup/re-

measuringinstrumenting specific $\quad{ }^{83}$ reference-of-thought-as-to-apriorising/axiomaticconstruct/referencing/intelligibilitysettingup/measuringinstrumenting for existentialinstantiations predicative-insights' as of full ontological-completeness-of- ${ }^{3}$ reference-ofthought, tends to be lost to temporal/shortness of register of - meaningfuness and teleology mental-dispositions; speaking more of a mental-orientation not geared to grasp the 'existential tale' of its species as of ontological-faith-notion-or-ontological-fideism -imbuedunderdetermination-of-motif-and-apriorising/axiomatising/referencing-as-so-being-as-ofexistential-reality driven human eternalising and emancipating aspiration behind projectiveinsights/postdication/deconstruction for creating successive 'apriorising/axiomatising/referencing/intelligibilitysettingup/measuringinstrumentings specific referencing $/{ }^{83}$ reference-of-thought/axiomatic-construct for predicative-insights' as of prospective relative-ontological-completeness ${ }^{87}$-of- ${ }^{-}$reference-of-thought. But rather an ad-hoc 
mental-orientation 'construed-as-of-attendant-circular-pervasiveness

$<$ amplituding/formative $>$ wooden-language-_imbued — averaging-of-thought-<as-toleveling/ressentiment/closed-construct-of- meaningfulness-and-teleology -as-of'nondescript/ignorable-void '-with-regards-to-prospective-apriorising-implications $>>\quad$ asinstant-and-absolute-basis-for-being/existence' (despite the relative-ontologicalincompleteness ${ }^{8}$-of- ${ }^{8}$ reference-of-thought induced distractive-alignment-to- ${ }^{8}$ reference-ofthought- $<$ of-apriorising/axiomatising/referencing $>^{30}$ and override any such sense of relative pure-ontology apriorising/axiomatising/referencing-\{of-'prospectively_implicited_attendantontological-contiguity ' educedexistentialising/contextralising/textralising_intelligibility/epistemicity/reflexivity-contiguity<imbued-notional $\left.\sim \operatorname{cogency}>^{\prime} \quad\right\}$-conflatedness ${ }^{13}$ in-\{preconverging-disentailment by\} pestconverging entailment as of prospective relative-ontological-completeness ${ }^{87}$-of- ${ }^{8}$ referenceof-thought apriorising/axiomatising/referencing-\{of-'prospectively implicited_attendantontological-contiguity ' educedexistentialising/contextualising/textualising_intelligibility/epistemicity/reflexivity_contiguity<imbued-notional cogency>' \}-conflatedness ${ }^{13}$-in-\{preconverging-disentailment by\} postconverging-entailment) not geared to uphold eternalising and emancipating possibilities implied by projective-insights/postdication/deconstruction notwithstanding the fact that its 'construed-as-of-attendant-circular-pervasiveness <amplituding/formative $>$ wooden-language〈imbued — averaging-of-thought-<as-to-leveling/ressentiment/closed-construct-ofmeaningfulness-and-teleology -as-of-‘nondescript/ignorable-void ' -with-regards-toprospective-apriorising-implications $>>\quad$ as-instant-and-absolute-basis-for-being/existence' (naively perceived as the only one as of mechanicalism with a poor sense of organicalism, despite the relative-ontological-incompleteness ${ }^{8}$-of- ${ }^{-3}$ reference-of-thought and override any such sense of relative pure-ontology apriorising/axiomatising/referencing-\{of-'prospectively 
implicited_attendant-ontological-contiguity ' reduced-

existentialising/contextualising/textualising_'intelligibility/epistemicity/reflexivity_contiguity-

<imbued-notional cogency >' $\}$-conflatedness ${ }^{13}$-in-\{preconverging-disentailment by\}

pestconverging-entailment as of prospective relative-ontological-completeness ${ }^{87}$-of- ${ }^{8}$ referenceof-thought) arose by projective-insights/postdication/deconstruction as of ontological-faithnotion-or-ontological-fideism —imbued-underdetermination-of-motif-and-

apriorising/axiomatising/referencing-as-so-being-as-of-existential-reality. Further, even more decisively though by reflex we naively-and-erroneously tend to construe of human virtuousdispositions or vices-and-impediments ${ }^{105}$ as arising mainly as of their conscious choices, preconverging/postconverging-de-mentatively/structurally/paradigmatically a registryworldview/dimension prior relative-ontological-incompleteness ${ }^{88}$-of- ${ }^{8}$ reference-of-thought as a beyond-the-consciousness-awareness-teleology ${ }^{9}-<$ of - preconverging-existential-extrication-asof-existential-unthought> notion is the more decisive/salient notion as to human 'objectively construed/analysed virtuous-dispositions or vices-and-impediments ${ }^{105}$, even though individual 'conscious choices' will tend to 'simply qualify the effective possibility of such virtuousdispositions or vices-and-impediments ${ }^{105}$ arising'; such that a registry-worldview/dimension incompleteness-of- ${ }^{-3}$ reference-of-thought is preconverging/postconverging-dementatively/structurally/paradigmatically susceptibility as a state of 'in-wait as of prior relativeontological-incompleteness ${ }^{8}$-of- ${ }^{8}$ reference-of-thought defective ${ }^{83}$ reference-of-thoughtcategorical-imperatives/axioms/registry-teleology ${ }^{9}$ for the vices-and-impediments ${ }^{105}$ so implied to arise-and-be-endemised/enculturated beyond-the-consciousness-awarenessteleology ${ }^{9}<$ of-preconverging-existential-extrication-as-of-existential-unthought $>$. This explains why the relative unreflexivitrelative reflexivity ontological-contiguity $\sim$ of-thehuman-institutionalisation-process ${ }^{68}$ is basically about shifting apriorising/axiomatising/referencing/intelligibilitysettingup/measuringinstrumentings to 
supersede the state of beyond-the-consciousness-awareness-teleology ${ }^{9}<$ of-preconvergingexistential-extrication-as-of-existential-unthought $>$ as of human limited-mentation-capacitydeepening —as-subjecting limitedness/human-subpotency to-'educed-unlimitedness/existencesublimating nascence' 53 in handling the more and more profound/depth of intrinsicreality/ontological-veridicality construing ${ }^{83}$ reference-of-thought/axiomatic-construct that avails as of ontological-normalcy/postconvergence or increasing ontological-completeness-ofreference-of-thought; (such that such meaningfulness as expressed herein is more than just of logical construct implying simple logical meaningfulness as within only a single-as-our-present positivistic predicative-insights framework of reasoning and understanding, but requires a more profound retrospective and prospective mental-projection in its contemplation). This equally explicates the empirical reality associated with the occurrence of human transcendence-andsublimity/sublimation/supererogatory de-mentativity crossgenerationally as the timeframe for psychoanalytic-unshackling/memetic-reordering/institutional-recomposuring of projectiveinsights/postdication/deconstruction induced prospective/transcending/superseding registryworldview/dimension

'apriorising/axiomatising/referencing/intelligibilitysettingup/measuringinstrumenting specific referencing $/{ }^{83}$ reference-of-thought/axiomatic-construct for predicative-insights' to take hold. It equally explicates why threshold-of-nonconviction/madeupness/bottomlining-in-shallowsupererogation -<as-to- 'attendant-intradimensional'-prospectivelydisontologising preconverging/dementing -apriorising-psychologism> (as 'vague staging and performing' and not truly postconverging-or-dialectical-thinking -apriorising-psychologism meaningfulness-and-teleology ${ }^{9}$ ) tend to arise in each registry-worldview/dimension at its uninstitutionalised-threshold $^{102}$. This has to do fundamentally with the antipodality of the mental-dispositions of postlogism 7 -as-of- compulsingnonconviction/madeupness/bottomlining-〈“<decontextualising/de-existentialising $\sim$ of- 
attendant-intradimensional-apriorising/axiomatising/referencing--induced-disontologising'-ofthe-'attendant-intradimensional-ontologising'-imbued-

$<$ contextualising/existentialising attendant-ontological-contiguity $>$;-in-shallow-

supererogation -<as-to-disontologising-perverted-outcome-sought-precedes-existentiallyveridical-'attendant-intradimensional-apriorising/axiomatising/referencing'-logical-dueness $>$ > as of effecting-parsimony-as-of-shoddiness-and-incompleteness-to- ${ }^{5}$ meaningfulness-andteleology and prelogism ${ }^{78}$-as-of-conviction,-in-profound-supererogation $-<$ existentiallyveridical-'attendant-intradimensional-apriorising/axiomatising/referencing'-logical-duenessprecedes-disontologising-logical-outcome-arrived-at> as of effecting-wholeness-as-ofprofoundness-and-completeness-to- ${ }^{5}$ meaningfulness-and-teleology 99 in the construal of intrinsic-reality/ontological-veridicality. It is important to grasp that such 'prelogism ${ }^{78}$-as-ofconviction,-in-profound-supererogation ${ }^{-}<$existentially-veridical-'attendant-intradimensionalapriorising/axiomatising/referencing'-logical-dueness-precedes-disontologising-logicaloutcome-arrived-at> 'implicited_attendant-ontological-contiguity ${ }^{6 /}$ ' educedexistentialising/contextualising/textualising_'intelligibility/epistemicity/reflexivity-contiguity$<$ imbued-notional $\sim$ cogency $>,{ }^{\prime},-<$ reifying-or-elucidating-of-prospective-relative-ontologicalcompleteness -of- reference-of-thought- devolving-as-of-instantiative-context $>$ dynamic' of the nature of 'postlogism -as-of- compulsing-nonconviction/madeupness/bottomlining-

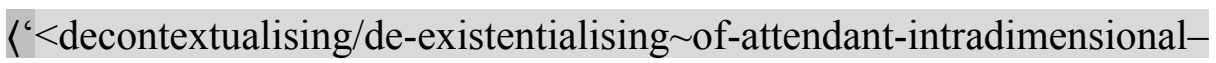
apriorising/axiomatising/referencing >-induced-disontologising'-of-the-'attendantintradimensional-ontologising'-imbued-<contextualising/existentialising $\sim$ attendantontological-contiguity $>$;-in-shallow-supererogation -<as-to-disontologising-pervertedoutcome-sought-precedes-existentially-veridical-'attendant-intradimensionalapriorising/axiomatising/referencing'-logical-dueness $>$ > or distractive-alignment-toreference-of-thought- $<$ of-apriorising/axiomatising/referencing $>^{30}$ dynamism' as knowledge- 
construct/intersolipsistic-intercessory-notion/notional $\sim$ referential-notion/articulation is a critical element for a postlogism 77 psychopathy storied-construct/ontologically-valid-narration development as of aetiologisation/ontological-escalation- $<$ ontologicalveridicality_commitment/otherliness_transcending/compulsions-encumbered_transcending > insight, at the individuation-level of analysis, involving 'themes-driven underlying-agency-orsous-agencement dynamics for narration-construed-as-instantiative-moulting' as of ontologicalnormalcy/postconvergence undermining by 'distractive-alignment-to- ${ }^{3}$ reference-of-thought$<$ of-apriorising/axiomatising/referencing $>30$ with distractive-alignment-to- ${ }^{3}$ reference-ofthought- $<$ of-apriorising/axiomatising/referencing $>$ and corresponding ontologicalnormalcy/postconvergence upholding with apriorising/axiomatising/referencing-\{of'prospectively_implicited_attendant-ontological-contiguity ' educedexistentialising/contextualising/textualising_'intelligibility/epistemicity/reflexivity_contiguity<imbued-notional cogency $\left.>^{\prime}\right\}$-conflatedness ${ }^{13}$-in-\{preconverging-disentailment by\} postconverging-entailment. (Thus disambiguating mental-dispositions as of ${ }^{83}$ reference-ofthought-prelogism ${ }^{78}$-as-of-conviction,-in-profound-supererogation $-<$ existentially-veridical'attendant-intradimensional-apriorising/axiomatising/referencing'-logical-dueness-precedesdisontologising-logical-outcome-arrived-at>, $\quad$ 'postlogism 7 -as-of- compulsingnonconviction/madeupness/bottomlining-〈“<decontextualising/de-existentialising $\sim$ ofattendant-intradimensional-apriorising/axiomatising/referencing $>$-induced-disontologising'-ofthe- 'attendant-intradimensional-ontologising'-imbued$<$ contextualising/existentialising attendant-ontological-contiguity $>$;-in-shallowsupererogation -<as-to-disontologising-perverted-outcome-sought-precedes-existentiallyveridical-'attendant-intradimensional-apriorising/axiomatising/referencing'-logical-dueness $>$ > or psychopathic compulsive threshold-of-nonconviction/madeupness/bottomlining-in-shallowsupererogation $-<$ as-to-'attendant-intradimensional'-prospectively- 
disontologising preconverging/dementing -apriorising-psychologism $>$ individuation', and consequently induced conjugated-postlogism 77 social-psychopathy as threshold-ofnonconviction/madeupness/bottomlining-in-shallow-supererogation $-<$ as-to-' ${ }^{\circ}$ ttendantintradimensional'-prospectively-disontologising preconverging/dementing -apriorisingpsychologism> individuations'; and as this overall 'dynamic-cumulative-aftereffect/aftereffect of upholding/failing ontologically-normalcy/postconvergence' reflects apriorising/axiomatising/referencing-\{of-'prospectively_implicited_attendant-ontologicalcontiguity ' $\sim$ educedexistentialising/contextualising/textualising_intelligibility/epistemicity/reflexivity-contiguity<imbued-notional cogency $\left.>^{\prime} \quad\right\}$-constitutedness ${ }^{14}$-in-preconverging-entailment as of baseconstitutedness ${ }^{14}$, first-level- ${ }^{79}$ presencing-absolutising-identitive-constitutedness ${ }^{14}$, secondlevel- ${ }^{7}$ presencing — absolutising-identitive-constitutedness ${ }^{14}, \quad$ third-level- ${ }^{79}$ presencingabsolutising-identitive-constitutedness ${ }^{14}$ and notional conflatedness ${ }^{13}$ (altogether construed as of notional conflatedness ${ }^{13} /$ constitutedness $^{14}$-to-conflatedness ${ }^{13}$ ) reflecting both the uninstitutionalised-threshold ${ }^{102}$ 's as to conventioning/closed-structure/nontranscendability/distractive-alignment-to- ${ }^{-3}$ reference-of-thought- $<$ of-

apriorising/axiomatising/referencing $>$ "effecting-parsimony as to " degraded-devolving-as-of-uninstitutionalised-threshold ${ }^{102}$ meaningfulness and the corresponding prospective institutionalisation's ontology/openedstructure/transcendability/conflatedness ${ }^{13} \quad$ teleological-elevated-as- ${ }^{83}$ reference-of-thoughtprelogism ${ }^{78}$-as-of-conviction,-in-profound-supererogation $-<$ existentially-veridical'attendant-intradimensional-apriorising/axiomatising/referencing'-logical-dueness-precedesdisontologising-logical-outcome-arrived-at> of meaningfulness, and so as of apriorising/axiomatising/referencing-\{of-'prospectively_implicited_attendant-ontologicalcontiguity ' educed- 
existentialising/contextualising/textualising_ 'intelligibility/epistemicity/reflexivity-contiguity<imbued-notional cogency $>\quad\}$-conflatedness ${ }^{13}$-in-\{preconverging-disentailment by\} postconverging-entailment of social-stake-contention-or-confliction comprehensive-andinsightful itemisation for developing storied-construct/ontologically-valid-narration. As conceptualised at both registry-worldview/dimension-level and individuation-level of analysis unlike $\quad$ reference-of-thought-prelogism ${ }^{78}$-as-of-conviction,-in-profound-supererogation $<$ existentially-veridical-'attendant-intradimensional-apriorising/axiomatising/referencing'logical-dueness-precedes-disontologising-logical-outcome-arrived-at $>, \quad$ threshold-ofnonconviction/madeupness/bottomlining-in-shallow-supererogation $<<$ as-to-'attendantintradimensional'-prospectively-disontologising preconverging/dementing -apriorisingpsychologism> is associated with relative 'temporal-mental-dispositions'-construed-assurreptitiously-or-palpably-committed-to-extrinsic-attribution-or-its-perpetuating-upon-othermental-dispositions-as-supposedly-superseding-intrinsic-reality/ontological-veridicality as somentally-invested with regards to perceived social-stake-contention-or-confliction' notwithstanding subsequent apprehension of ontologically-veridical ${ }^{56}$ meaningfulness-andteleology" , that speaks of 'ad-hoc social-commitment-thresholds for foregoing the upholding of intrinsic-reality/ontological-veridicality' and assuming denaturing ${ }^{16}$ as of 'lack of constraining social ${ }^{103}$ universal-transparency $^{104}$-〈transparency-of-totalising-entailing,-as-to-entailing$<$ amplituding/formative-epistemicity>totalising in-relative-ontological-completeness $>$ at the uninstitutionalised-threshold ${ }^{102}$. It is this dynamic-cumulative-aftereffect/aftereffect that underlies perversion-and-derived- ${ }^{7}$ perversion-of- ${ }^{3}$ reference-of-thought- $<$ as-preconverginglyapriorising/axiomatising/referencing-in-nonconviction/madeupness/bottomlining-as-toshallow-supererogation $>$ associated with uninstitutionalised-threshold ${ }^{102}$.) This thus conveys the individuation-level of analysis <amplituding/formative-epistemicity $>$ causality $\sim$ as-toprojective-totalitative-implications-of-prospective- nonpresencing,-for-explicating relative- 
unreflexivity/relative-reflexivity ontological-contiguity as well as differentiated intemporalconflatedness $^{13}$-as-effecting-wholeness-as-of-profoundness-and-completeness-tomeaningfulness-and-teleology ${ }^{9}$-or-temporal-constitutedness ${ }^{14}$-as-effecting-parsimony-ofmeaningfulness-and-teleology (so implied by metaphysics-of-absence-〈implicitedepistemic-veracity-of- nonpresencing-<perspective-ontological-normalcy/postconvergence $>$ > as of our procrypticism uninstitutionalised-threshold ${ }^{102}$ as disjointedness-as-of- ${ }^{8}$ reference-ofthought). By mental-reflex a postlogism -as-of- compulsingnonconviction/madeupness/bottomlining-〈'<decontextualising/de-existentialising ofattendant-intradimensional-apriorising/axiomatising/referencing>-induced-disontologising'-ofthe-'attendant-intradimensional-ontologising'-imbued$<$ contextualising/existentialising attendant-ontological-contiguity $>$;-in-shallowsupererogation -<as-to-disontologising-perverted-outcome-sought-precedes-existentiallyveridical-'attendant-intradimensional-apriorising/axiomatising/referencing'-logical-dueness $>$ ) stand is a 'mental-shortcut' that is fundamentally perverted as it perceives meaning as 'deterministic of others behaviours by its empty-form' while a prelogism 7 -as-of-conviction,-inprofound-supererogation $-<$ existentially-veridical-'attendant-intradimensionalapriorising/axiomatising/referencing'-logical-dueness-precedes-disontologising-logicaloutcome-arrived-at $>$ stand is one that relates to meaning on the basis of its assumed existential$<$ disentologising/re-ontelogising aporeticism $>$ validity, or at worst involves omissions or exaggerations relative to such fundamental existential-distong aporeticism $>$ validity, but doesn't countenance by mental-reflex the projection of empty-form of meaningfulness which is 'existentially-<disontologising/re-ontologising aporeticism $>$ invalid' in-the-very-first-place. Consequently, where there is 'lack of constraining social ${ }^{103}$ universaltransparency ${ }^{104}$-〈transparency-of-totalising-entailing,-as-to-entailing-<amplituding/formativeepistemicity>totalising in-relative-ontological-completeness $>$ at the uninstitutionalised- 
threshold $^{102}$ due to relative-ontological-incompleteness ${ }^{8}$-of- ${ }^{8}$ reference-of-thought, postlogism 7 -as-of- compulsing-nonconviction/madeupness/bottomlining-

$〈<<$ decontextualising/de-existentialising of-attendant-intradimensionalapriorising/axiomatising/referencing>-induced-disontologising'-of-the-'attendantintradimensional-ontologising'-imbued-<contextualising/existentialising $\sim$ attendantontological-contiguity $>$;-in-shallow-supererogation -<as-to-disontologising-pervertedoutcome-sought-precedes-existentially-veridical-'attendant-intradimensionalapriorising/axiomatising/referencing'-logical-dueness $>>\quad$ implied $\quad{ }^{56}$ meaningfulness-andteleology ${ }^{9}$ will tend to be incidentally conjugated with prelogism ${ }^{78}$-as-of-conviction,-inprofound-supererogation -<existentially-veridical-'attendant-intradimensionalapriorising/axiomatising/referencing'-logical-dueness-precedes-disontologising-logicaloutcome-arrived-at> dispositions

as of ignorance/affordability/opportunism/exacerbation/social-chainism-or-social-discomfiture-ornegative-social-aggregation/temporal-enculturation-or-temporal-endemisation. This is the case beyond just any such specific instances and such specific postlogism -as-of- compulsingnonconviction/madeupness/bottomlining-〈“<decontextualising/de-existentialising ofattendant-intradimensional-apriorising/axiomatising/referencing>-induced-disontologising'-ofthe-'attendant-intradimensional-ontologising'-imbued$<$ contextualising/existentialising attendant-ontological-contiguity $>$;-in-shallowsupererogation -<as-to-disontologising-perverted-outcome-sought-precedes-existentiallyveridical-'attendant-intradimensional-apriorising/axiomatising/referencing'-logical-dueness $>$ ) character(s) and specific conjugated-postlogism 77 character(s) but rather as of dynamiccumulative-aftereffect/aftereffect, and thus defining together with the registryworldview/dimension prior relative-ontological-incompleteness ${ }^{8}$-of- ${ }^{-}$reference-of-thought at its 'uninstitutionalised-threshold ${ }^{12}$ the threshold-of-nonconviction/madeupness/bottomlining- 


\section{in-shallow-supererogation -<as-to-'attendant-intradimensional'-prospectively-}

disontologising $\sim$ preconverging/dementing -apriorising-psychologism $>$ as a preconverging-ordementing -apriorising-psychologism enculturation'. This is characteristic of the successive uninstitutionalised-threshold ${ }^{102}$ whether as recurrent-utter-uninstitutionalisation (non-rulesapriorising/axiomatising/referencing-psychologism,-as-impulsive-or-accidented-or-randommental-disposition caricaturing-hollow-staging-and-performance as random/impulsive mentaldisposition), ununiversalisation (non-universalising caricaturing-hollow-staging-andperformance like animistic attributing of misfortune to someone else's malevolent spirit), nonpositivism/medievalism (non-positivising/non-rational-empirical caricaturing-hollow-stagingand-performance like notions-and-accusations-of-sorcery) or procrypticism (disjointedmisappropriating-of-meaning caricaturing-hollow-staging-and-performance like psychopathy and social psychopathy), thus construing of a registry-worldview as of its relative-ontologicalincompleteness ${ }^{8}$-of- ${ }^{8}$ reference-of-thought as rather reflecting 'virtue-and-ontologicalveridicality' as of its institutionalisation and 'vices-and-impediments ${ }^{105}$, as of its uninstitutionalised-threshold ${ }^{102}$. This consequently implies at the uninstitutionalised-threshold a 'symmetrisation-of- ${ }^{-3}$ reference-of-thought but which is in effect an ontologically-nonveridical-or-flawed $<$ amplituding/formative-epistemicity $>$ totalising $\sim$ self-referencingsyncretising/circularity/interiorising/akrasiatic-drag ${ }^{34}$ and/or desymmetrisation for perceived temporal social-stake-contention-or-confliction as threshold-ofnonconviction/madeupness/bottomlining-in-shallow-supererogation $<-<$ as-to-' $a$ attendantintradimensional'-prospectively-disontologising preconverging/dementing -apriorisingpsychologism> is socially induced in temporality ${ }^{8} /$ shortness requiring $^{2}$ in deconstruction/ontological-reconstituting-as-to-conflatedness ${ }^{13}$ as intemporal-symmetrisingby-desymmetrising-subsumption-of-temporality /ontological-symmetrisation as of prospective relative-ontological-completeness ${ }^{8}$-of- ${ }^{8}$ reference-of-thought, which in-the-bigger-picture 
speaks of 'differentiated construal of 'implicited_attendant_ontological-contiguity ${ }^{67}$ ' educedexistentialising/contextualising/textualising_'intelligibility/epistemicity/reflexivity-contiguity$<$ imbued-notional $\sim$ cogency $>,{ }^{\prime},-<$ reifying-or-elucidating-of-prospective-relative-ontologicalcompleteness -of- reference-of-thought- devolving-as-of-instantiative-context>' wherein the temporal is 'preconverging-or-dementing ${ }^{20}$-and-decentered-prior-institutionalisation'scategorical-imperatives/axioms/registry-teleology and the intemporal-as-ontological postconverging-or-dialectical-thinking -and-centered-prospective-institutionalisation'scategorical-imperatives/axioms/registry-teleology", and further explains the 'paradox of transcendence-and-sublimity/sublimation/supereregatoryade-mentativity' (confusion of relative ontologically-veridical becoming-or-present-of- ${ }^{3}$ reference-of-thought') wherein the temporal is hung (beyond-the-consciousness-awareness-teleology ${ }^{9}<$ of-preconverging-existentialextrication-as-of-existential-unthought $>$ ) to the <amplituding/formative $>$ wooden-language〈imbued-temporal-mere-form/virtualities/dereification/akrasiaticdrag/denatured/preconverging-or-dementing -narratives - of-the- reference-of-thoughtcategorical-imperatives/axioms/registry-teleology $\rangle$ thus 'construed-as-of-attendant-circularpervasiveness <amplituding/formative $>$ wooden-language-_imbued-averaging-of-thought$<$ as-to-leveling/ressentiment/closed-construct-of- meaningfulness-and-teleology -as-of'nondescript/ignorable-void '-with-regards-to-prospective-apriorising-implications $>>\quad$ asinstant-and-absolute-basis-for-being/existence' (despite the relative-ontologicalincompleteness ${ }^{8}$-of- ${ }^{8}$ reference-of-thought induced distractive-alignment-to- ${ }^{8}$ reference-ofthought- $<$ of-apriorising/axiomatising/referencing $>^{30}$ and override any such sense of relative pure-ontology apriorising/axiomatising/referencing-\{of-'prospectively implicited_attendantontological-contiguity ' educedexistentialising/contextualising/textualising_'intelligibility/epistemicity/reflexivity-contiguity<imbued-notional cogency $\left.>^{\prime}\right\}$-conflatedness ${ }^{13}$-in-\{preconverging-disentailment by 
postconverging-entailment as of prospective relative-ontological-completeness ${ }^{87}$-of- ${ }^{8}$ referenceof-thought apriorising/axiomatising/referencing-\{of-‘prospectively_implicited_attendant ontological-contiguity ' educedexistentialising/contextualising/textualising_'intelligibility/epistemicity/reflexivity-contiguity<imbued-notional cogency>' \}-conflatedness ${ }^{13}$-in-\{preconverging disentailment by\} postconverging-entailment) whereas the intemporal-as-ontological construes ${ }^{83}$ reference-ofthought- categorical-imperatives/axioms/registry-teleology ${ }^{9}$ as meant for intemporalpreservation-entropy-or-contiguity-or-ontological-preservation and up for remaking once perversion-and-derived- ${ }^{7}$ perversion-of- ${ }^{83}$ reference-of-thought- $<$ as-preconverginglyapriorising/axiomatising/referencing-in-nonconviction/madeupness/bottomlining-as-toshallow-supererogation $>$ undermines their intemporal-preservation-entropy-or-contiguity-orontological-preservation on the basis of the 'complementing grander social- ${ }^{103}$ universally-nontransparent-thus-non-constraining-element of ontological-faith-notion-or-ontological-fideism imbued-underdetermination-of-motif-and-apriorising/axiomatising/referencing-as-so-being-asof-existential-reality' with regards to human limited-mentation-capacity-as-subjecting'educed-unlimitedness/existence-sublimating nascence' to-limitedness/human-subpotency and as of 'intemporal-prioritisation-of- ${ }^{8}$ reference-of-thought'-as-conflatedness ${ }^{13}$-or-ontologicalreprojecting. This conceptualisation as a 'postconverging-or-dialectical-thinking ${ }^{21}$-psychology or psychology-of-mentation-dynamics or natural psychological-dynamics' is empirically more true of human development which by a flawed metaphysics-of-presence-〈implicited'nondescript/ignorable-void ' 'as-to- presencing - absolutising-identitive-constitutedness > overly construes in <amplituding/formative-epistemicity $>$ totalising $\sim$ self-referencingsyncretising/circularity/interiorising/akrasiatic-drag ${ }^{34}$ the positivistic psyche almost as if it is the sole and genuine one without factoring in the notion of a continuous ' $<$ amplituding/formativeepistemicity>-totalising $\sim$ renewing-realisation/re-perception/re-thought-as-utter-placeholder- 
setup-ontological-rescheduling-〈by-a-renewing-of-apriorising/axiomatising/referencing-

psychologism-as-the-new-referencing-basis-of-prospective- meaningfulness-and-teleology \’ in successions of human psyches arising with human limited-mentation-capacity-deepeningas subjecting limitedness/hmman-subpoteney to 'educed mnlimitedness/existence sublimating nascence' , with the further implication of a prospective 'postconverging-or-dialecticalthinking -psychology or psychology-of-mentation-dynamics or natural $\sim$ psychologicaldynamics' as a notional deprocrypticism psyche and its corresponding memetism or suprastructural ${ }^{56}$ meaningfulness-and-teleology . Now supposed Z was another character inclined for $\quad{ }^{55}$ maximalising-recomposuring-for-relative-ontological-completeness ${ }^{87}$ unenframed/re-ontologising conceptualisation as preserving the inherent intemporality ${ }^{52} /$ longness of additionality as allowing civilisational/institutional-being-and-craft setup preservation, brought in by the Donor, there is no question that $\mathrm{Z}$ will register the newly divulged ontological-veridicality/intrinsic-reality of the defective apriorising/axiomatising/referencing/intelligibilitysettingup/measuringinstrumenting and its derived-implications as perversion-and-derived- perversion-of- $^{-}$reference-of-thought- $<$aspreconvergingly-apriorising/axiomatising/referencing-in-

nonconviction/madeupness/bottomlining-as-to-shallow-supererogation $>$ to renew the construal/conceptualisation of what is considered as a relatively ontological-completeness-ofreference-of-thought for a prospective ${ }^{83}$ reference-of-thought that preserves intemporality ${ }^{52}$, by factoring in the fact of this contextual relative-ontological-incompleteness ${ }^{8}$-induced,'threshold-of-nonconviction/madeupness/bottomlining-in-shallow-supererogation ${ }^{\circ}<$ as-to‘attendant-intradimensional'-prospectively-disontologising preconverging/dementing apriorising-psychologism>' as it enculturates/endemises the ${ }^{77}$ perversion-of- ${ }^{8}$ reference-ofthought-<as-preconvergingly-apriorising/axiomatising/referencing-innonconviction/madeupness/bottomlining-as-to-shallow-supererogation $>$, and thus will be 
predisposed to a reconstrual/reconceptualisation of arithmetic principles factoring in and superseding this specific-type (as exposed by B's postlogism and C, D, E, F conjugatedpostlogism 7 ) of 'sublimating-epistemic-imbricatedness/threadedness/recomposuring as 'implicited_attendant-ontological-contiguity ${ }^{67}$ ' educedexistentialising/contextualising/textualising_intelligibility/epistemicity/reflexivity-contiguity$<$ imbued-notional $\sim$ cogency $>,{ }^{\prime},-<$ reifying-or-elucidating-of-prospective-relative-ontologicalcompleteness -of- reference-of-thought- devolving-as-of-instantiative-context> as to existence-potency ${ }^{39} \sim$ sublimating-nascence,-disclosed-from-prospective-epistemicdigression—rules-of-apriorising/axiomatising/referencing-that-further-epistemicallyunconceal-the-very-ontologically-same-existential-reality' or 'postconverging-or-dialecticalthinking ${ }^{-8}$ reference-of-thought in relative-ontological-completeness ${ }^{87}$ as depth-of-thought', and will look down on $\mathrm{B}, \mathrm{C}, \mathrm{D}, \mathrm{E}$ and $\mathrm{F}$ mental-dispositions perversion-and-derivedperversion-of- ${ }^{-3}$ reference-of-thought-<as-preconvergingly-

\section{apriorising/axiomatising/referencing-in-nonconviction/madeupness/bottomlining-as-to-}

shallow-supererogation $>$ as allowing for the endemisation/enculturation of the denaturing ${ }^{16}$ of additionality and the implications thereof of subsequent denaturing in circularity/recurrence/repetition/repeatability ${ }^{10}$ that ensue where socially-functional-andaccordant ${ }^{93}$ (lack of constraining social ${ }^{103}$ universal-transparency ${ }^{104}$-〈transparency-of-totalisingentailing,-as-to-entailing-<amplituding/formative-epistemicity $>$ totalising $\sim$ in-relativeontological-completeness $\rangle$ which protects the internal-coherence of meaning for virtue'), not only as a specific/particular construal/conceptualisation but of ${ }^{103}$ universal import as having to do with endemisation/enculturation of ${ }^{74}$ perversion-of- ${ }^{3}$ reference-of-thought- $<$ aspreconvergingly-apriorising/axiomatising/referencing-in- 
nonconviction/madeupness/bottomlining-in-shallow-supererogation $<<$ as-to- 'attendantintradimensional'-prospectively-disontologising preconverging/dementing -apriorisingpsychologism>' (wherein Z's disposition is an ordered-construct or secondnaturing institutionalisation over $\mathrm{B}, \mathrm{C}, \mathrm{D}, \mathrm{E}$ and $\mathrm{F}$ mental-anarchy/mentarchy inducing of 'uninstitutionalised-threshold ${ }^{102}$ '). Though metaphorically in the mortal's temporal/shortnessof-register-of meaningfulness-and-teleology terms, that 'low-life' of ${ }^{103}$ universal import may be utterly oblivious to the practicalities of B, C, D, E and F so engrossed in a world of 'highlife' of temporality $/$ extrication as the 'fullness of ${ }^{56}$ meaningfulness-and-teleology" over the appreciation of the intemporal/ontological/social/species $/{ }^{103}$ universal/transcendental/ ${ }^{5}$ maximalisingrecomposuring-for-relative-ontological-completeness ${ }^{87}$ - unenframed/reontologising conceptualisation postconverging-de-mentating/structuring/paradigming, be it that the latter disposition as philosophically intemporal is what creates-and-enables the being in civilisation/institutionalised-being-and-craft in the first place, as the metaphorically 'high-life' of temporality ${ }^{9} /$ extrication cannot count on an overall principle of temporality 8 /extrication for its existential-<disentologising/re-ontologising aporeticism $>$ sustainability (as B, C, D, E and F needs that the Donor grants the rewards by not factoring in the deceit, thus their existential<disontologising/re-ontologising aporeticism $>$ principle doesn't sustain the 'civilisation/institutionalised-being-and-craft setup' in which they are living in, hence qualified as extricatory/temporal/parasitising/co-opting as 'least-and-derived-temporal-operatingmodalities-of-the- ${ }^{8}$ reference-of-thought-as-of- incrementalism-in-relative-ontologicalincompleteness ${ }^{8}$ — enframed/disontologising conceptualisation-inducing-theuninstitutionalised-threshold ${ }^{102}$ ') but unavowedly and paradoxically rather on the parasitising/co-opting of the intemporal/ontological/social/species/ $/{ }^{103}$ universal/transcendental/ $/ 5$ maximalising- 
recomposuring-for-relative-ontological-completeness ${ }^{7}$ — unenframed/re-

ontologising conceptualisation postconverging-de-mentating/structuring/paradigming enabling the relative-unreflexivity/relative-reflexivity ontological-contiguity ${ }^{6}$ of-the-humaninstitutionalisation-process ${ }^{6}$; and besides, it is because the intrinsic-reality/ontologicalveridicality transcendental-enabling/sublimating/supererogatory de-mentativity as prospective ontologising (as undertaken by Z) can supersede denaturing ${ }^{16}$ postlogic-backtracking towards 'social-aggregation-enablers over intrinsic-reality/ontological-veridicality transcendentalenabling/sublimating/supereregatery $\sim$ de-mentativity' (referenced by B, C, D, E and F) that the further possibility (as transcendence-and-sublimity/sublimation/supereregatory $\sim$ de-mentativity) for prospective civilisation/institutionalised-being-and-craft setup as new conventioning arises. Hence the notion of 'sublimating-epistemic-imbricatedness/threadedness/recomposuring as of 'implicited_attendant-ontological-contiguity ${ }^{6 /}$; educedexistentialising/contextualising/textualising_'intelligibility/epistemicity/reflexivity-contiguity$<$ imbued-notional $\sim$ cogency $>,{ }^{\prime},-<$ reifying-or-elucidating-of-prospective-relative-ontologicalcompleteness -of- reference-of-thought- devolving-as-of-instantiative-context $>$ as to existence-potency ${ }^{39} \sim$ sublimating-nascence,-disclosed-from-prospective-epistemicdigression—rules-of-apriorising/axiomatising/referencing-that-further-epistemicallyunconceal-the-very-ontologically-same-existential-reality' (from the perspective of the 'postconverging-or-dialectical-thinking ${ }^{-}{ }^{8}$ reference-of-thought in relative-ontologicalcompleteness $^{87}$ as depth-of-thought') exposes contextually the relative temporality ${ }^{8}$-tointemporality $^{52}$ (shortness-to-longness-of-register-of- ${ }^{-5}$ meaningfulness-and-teleology ${ }^{99}$ ) of human mental-dispositions implying an intellectual-and-moral-inequivalence/noncorrespondence between of temporal-dispositions perversion-and-derived- perversion-ofreference-of-thought-<as-preconvergingly-apriorising/axiomatising/referencing-innonconviction/madeupness/bottomlining-as-to-shallow-supererogation $>$ involved in 
postlogism and conjugated-postlogism 77 as it discloses the temporal-dispositions individuations mental-dispositions displayed by B, C, D, E and F (as 'wrongly-projected decontextualising-unimbricatedness/unthreadedness/unrecomposuring,-as-virtuality-orontologically-flawed-construal (which is rather a 'prior threshold-ofnonconviction/madeupness/bottomlining-in-shallow-supererogation $-<$ as-to-' attendantintradimensional'-prospectively-disontologising preconverging/dementing -apriorisingpsychologism> 'reference-of-thought' in shallowness-of-thought-or-unsophistication-ofunderstanding) in grasping 'implicited_attendant-ontological-contiguity ${ }^{67}$; educedexistentialising/contextualising/textualising_'intelligibility/epistemicity/reflexivity-contiguity$<$ imbued-notional $\sim$ cogency $>,{ }^{\prime},-<$ reifying-or-elucidating-of-prospective-relative-ontologicalcompleteness -of- reference-of-thought- devolving-as-of-instantiative-context $>$ as to existence-potency ${ }^{32} \sim$ sublimating-nascence,-disclosed-from-prospective-epistemicdigression—rules-of-apriorising/axiomatising/referencing-that-further-epistemicallyunconceal-the-very-ontologically-same-existential-reality' in their relationship with additionality

extrapolating/constituting/abstracting/deducing/inferring-of-elucidation-outside'prospectively implicited_attendant-ontological-contiguity ${ }^{67}$; educedexistentialising/contextualising/textualising_intelligibility/epistemicity/reflexivity-contiguity$<$ imbued-notional cogency>' ${ }^{\prime 0}$ ) in contrast to the intemporal-disposition individuation mentaldisposition displayed by $\quad$ b as sublimating-epistemicimbricatedness/threadedness/recomposuring as of 'implicited_attendant-ontologicalcontiguity ${ }^{67}$, educed-

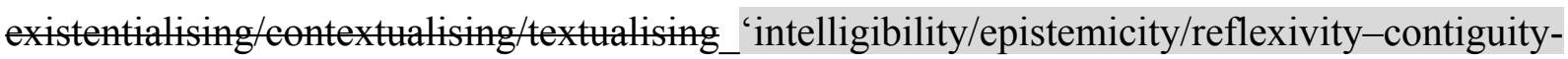
$<$ imbued-notional $\sim$ cogency $>,{ }^{\prime},-<$ reifying-or-elucidating-of-prospective-relative-ontologicalcompleteness -of- reference-of-thought- devolving-as-of-instantiative-context> as to 
existence-potency ${ }^{32} \sim$ sublimating-nascence,-disclosed-from-prospective-epistemicdigression—rules-of-apriorising/axiomatising/referencing-that-further-epistemicallyunconceal-the-very-ontologically-same-existential-reality' (from the perspective of the 'postconverging-or-dialectical-thinking ${ }^{2}{ }^{8}$ reference-of-thought in relative-ontologicalcompleteness ${ }^{87}$ as depth-of-thought') in its relationship with additionality (as elaboration-as-tomere-extrapolating/constituting/abstracting/deducing/inferring-of-elucidation-outside'prospectively_implicited_attendant-ontological-contiguity ${ }^{67}$ ' educedexistentialising/contextualising/textualising_'intelligibility/epistemicity/reflexivity-contiguity$<$ imbued-notional cogency>' ) by way of Z's ' ontological-completeness ${ }^{87}$ - unenframed/re-ontologising conceptualisation-〈unwinding-asunfolding/dépliage-as-détendre of elucidation-of B, C, D, E and F 'wrongly-projected decontextualising-unimbricatedness/unthreadedness/unrecomposuring,-as-virtuality-orontologically-flawed-construal (which is rather a 'prior threshold-ofnonconviction/madeupness/bottomlining-in-shallow-supererogation -<as-to-'attendantintradimensional'-prospectively-disontologising preconverging/dementing -apriorisingpsychologism> reference-of-thought' in shallowness-of-thought-or-unsophistication-ofunderstanding) in grasping 'implicited_attendant-ontological-contiguity ${ }^{7}$ ' educedexistentialising/contextualising/textualising_'intelligibility/epistemicity/reflexivity-contiguity$<$ imbued-notional $\sim$ cogency $>,{ }^{\prime},-<$ reifying-or-elucidating-of-prospective-relative-ontologicalcompleteness -of- reference-of-thought- devolving-as-of-instantiative-context $>$ as to existence-potency $\sim$ sublimating-nascence,-disclosed-from-prospective-epistemicdigression —rules-of-apriorising/axiomatising/referencing-that-further-epistemicallyunconceal-the-very-ontologically-same-existential-reality or B, C, D, E and F . In order words, this situation highlights the ${ }^{103}$ universal issue across all registry-worldviews/dimensions underlying the notion of temporality 8 /shortness and intemporality ${ }^{52}$. Wherein ${ }^{83}$ reference-of- 
thought- categorical-imperatives/axioms/registry-teleology ${ }^{9}$,-for-intemporal-preservationentropy-or-contiguity-or-ontological-preservation for the intemporal mental-disposition individuation are meant to uphold intemporality ${ }^{52} /$ longness incontrovertibly and where such is blurred or undermined given relative-ontological-incompleteness ${ }^{8}$-induced,-'threshold-ofnonconviction/madeupness/bottomlining-in-shallow-supererogation $<<$ as-to- 'attendantintradimensional'-prospectively-disontologising preconverging/dementing -apriorisingpsychologism>' going by human limited-mentation-capacity-deepening-as-subjecting limitedness/human-subpotency to-'educed-unlimitedness/existence-sublimating nascence' requiring a further accruing as deeper human limited-mentation-capacity-deepening-assubjecting limitedness/human-subpotency to-'educed-unlimitedness/existence-sublimatingnascence' ${ }^{53}$ as an 'implicited_attendant-ontological-contiguity ${ }^{67}$ 'educedexistentialising/contextualising/textualising_'intelligibility/epistemicity/reflexivity-contiguity$<$ imbued-notional $\sim$ cogency $>, \quad,<$ reifying-or-elucidating-of-prospective-relative-ontologicalcompleteness -of- reference-of-thought- devolving-as-of-instantiative-context $>$ as to existence-potency $^{39} \sim$ sublimating-nascence,-disclosed-from-prospective-epistemicdigression—rules-of-apriorising/axiomatising/referencing-that-further-epistemicallyunconceal-the-very-ontologically-same-existential-reality' that 'retraces' the existential-reality for intemporal-preservation-entropy-or-contiguity-or-ontological-preservation by maximalising-recomposuring-for-relative-ontological-completeness ${ }^{87}$ unenframed/reontologising conceptualisation of $\quad{ }^{83}$ reference-of-thought- categoricalimperatives/axioms/registry-teleology ${ }^{9}$,-for-intemporal-preservation-entropy-or-contiguityor-ontological-preservation with the implications thereof ushering in the successive institutionalisations as the need for new implieitentontontonto contiguity $^{67}$, educedexistentialising/contextualising/textualising_'intelligibility/epistemicity/reflexivity-contiguity- 
$<$ imbued-notional cogency $>$ ' ${ }^{\prime}$ of existence-potency ${ }^{32} \sim$ sublimating-nascence,-disclosed-fromprospective-epistemic-digression —rules-of-apriorising/axiomatising/referencing-that-furtherepistemically-unconceal-the-very-ontologically-same-existential-reality as-of-existentialreality, when the idea of relative-ontological-incompleteness ${ }^{8}$-induced,-'threshold-ofnonconviction/madeupness/bottomlining-in-shallow-supererogation $<-<$ as-to-' attendantintradimensional'-prospectively-disontologising preconverging/dementing -apriorisingpsychologism>' arises (as uninstitutionalised-threshold ${ }^{102}$ ); i.e. from recurrent-utteruninstitutionalisation to base-institutionalisation-ununiversalisation to ${ }^{103}$ universalisation-nonpositivism/medievalism to positivism- ${ }^{8}$ procrypticism and prospectively to deprocrypticism. While for the temporal mental-disposition individuations the form-and-perception or derivedform-and-perception of intemporal-preservation-entropy-or-contiguity-or-ontologicalpreservation whether upholding ontological-veridicality/intrinsic-reality or not (and so whether unconsciously, expediently or consciously) is a sufficient basis so long as it is sociallyfunctional-and-accordant ${ }^{93}$ such that the possibility of blurring or undermining existential-reality by 'wrongly-projected decontextualising-unimbricatedness/unthreadedness/unrecomposuring,as-virtuality-or-ontologically-flawed-construal (which is rather a 'prior threshold-ofnonconviction/madeupness/bottomlining-in-shallow-supererogation $-<$ as-to-'attendantintradimensional'-prospectively-disontologising preconverging/dementing -apriorisingpsychologism> ${ }^{8}$ reference-of-thought' in shallowness-of-thought-or-unsophistication-ofunderstanding) in grasping 'implicited_attendant-ontological-contiguity ${ }^{67}$; educedexistentialising/contextualising/textualising_'intelligibility/epistemicity/reflexivity-contiguity$<$ imbued-notional $\sim$ cogency $>,{ }^{\prime},-<$ reifying-or-elucidating-of-prospective-relative-ontologicalcompleteness -of- reference-of-thought- devolving-as-of-instantiative-context> as to existence-potency ${ }^{39} \sim$ sublimating-nascence,-disclosed-from-prospective-epistemicdigression—rules-of-apriorising/axiomatising/referencing-that-further-epistemically- 
unconceal-the-very-ontologically-same-existential-reality' is just as valid, hence a failure to abstractly recognise intemporality ${ }^{5} /$ longness as-of-existential-reality with the implication thereof as perversion-and-derived- ${ }^{7}$ perversion-of- ${ }^{8}$ reference-of-thought- $<$ as-preconverginglyapriorising/axiomatising/referencing-in-nonconviction/madeupness/bottomlining-as-to-

shallow-supererogation $>$ with respect to the registry-worldview's/dimension's vices-andimpediments $^{105}$ implied by its implied relative-ontological-incompleteness ${ }^{8}$-induced,'threshold-of-nonconviction/madeupness/bottomlining-in-shallow-supererogation ${ }^{-<\text {as-to- }}$ ‘attendant-intradimensional'-prospectively-disontologising preconverging/dementing apriorising-psychologism>' ${ }^{\prime}$. Hence the reason why the vices-and-impediments ${ }^{105}$ inherent of a given registry-worldview/dimension cannot be preconverging/postconverging-dementatively/structurally/paradigmatically/ontologically resolved within it as there is need for prospective ontological-completeness-of- ${ }^{3}$ reference-of-thought structured to inherently supersede such vices-and-impediments ${ }^{105}$, whether as base-institutionalisation in superseding recurrent-utter-uninstitutionalisation, ${ }^{103}$ universalisation superseding base-institutionalisationununiversalisation, positivism superseding ${ }^{103}$ universalisation-non-positivism/medievalism and deprocrypticsm superseding positivism/rational-empiricism manifestation of procrypticismor-disjointedness-as-of- ${ }^{8}$ reference-of-thought. The central idea here being that the most critically important notion in the situation of A, B, C, D, E, F and Z, is Z's upholding of prospective transcendental-enabling/sublimating/supererogatory de-mentativity over any temporal extricatory preconverging-de-mentating/structuring/paradigming, however, the enculturation and mass thinking behind temporal extricatory preconverging-dementating/structuring/paradigming. (* Noting that individuation as defined elsewhere speaks of temporal-to-intemporal trait characteristic, as anywhere between shortness-to-longness-ofregister-of- ${ }^{5}$ meaningfulness-and-teleology ${ }^{9}$, that can accrue atleast incidentally/on-occasion in all individuals-as-receptacles-of-individuations but more recurrently as teleologically defining 
in a-life-phase-or-life-phases-of-given-individuals, thus critically enabling a dynamiccumulative-aftereffect

intradimensional

and

transcendental/transdimensional/interdimension $/{ }^{5}$ maximalising-recomposuring-for-relative-

ontological-completeness ${ }^{87}$ - unenframed/re-ontologising conceptualisation analysis as

metaphysics-of-absence-〈implicited-epistemic-veracity-of- nonpresencing-<perspective-

ontological-normalcy/postconvergence $>$ /postdication). Finally, thus it is critical to note that the existential-<disontologising/re-ontologising aporeticism $>$ contextualisation above as 'sublimating-epistemic-imbricatedness/threadedness/recomposuring as of 'implicited_attendant-ontological-contiguity ${ }^{67}$ educed-

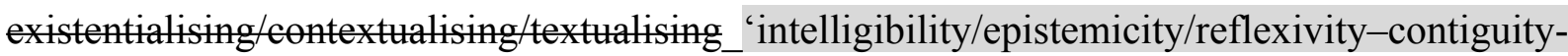
$<$ imbued-notional $\sim$ cogency $>,,-<$ reifying-or-elucidating-of-prospective-relative-ontologicalcompleteness -of- reference-of-thought- devolving-as-of-instantiative-context> as to existence-potency ${ }^{39} \sim$ sublimating-nascence,-disclosed-from-prospective-epistemicdigression—rules-of-apriorising/axiomatising/referencing-that-further-epistemicallyunconceal-the-very-ontologically-same-existential-reality' (from the perspective of the 'postconverging-or-dialectical-thinking ${ }^{2}{ }^{8}$ reference-of-thought in relative-ontologicalcompleteness $^{87}$ as depth-of-thought') is a-priori and supersedes the mere notion of additionality as elaboration-as-to-mere-extrapolating/constituting/abstracting/deducing/inferring-ofelucidation-outside_- 'prospectively_implicited_attendant-ontological-contiguity ${ }^{67}$; educedexistentialising/contextualising/textualising_'intelligibility/epistemicity/reflexivity-contiguity$<$ imbued-notional cogency> $>^{\prime 0}$ since mere additionality is bound to wrongly represent the additions of $\mathrm{B}, \mathrm{C}, \mathrm{D}, \mathrm{E}$ and $\mathrm{F}$ as correct (as it is a virtuality-or-ontologically-flawedconstrual/being-construal-as-abstract-construal-as-of-flawed-and-shallow-and-non-veridicalexistential-reference in $<$ amplituding/formative-epistemicity $>$ totalising $\sim$ self-referencingsyncretising/illusion-of-the-present-present-consciousness/mirage as metaphysics-of-presence- 
〈implicited-'nondescript/ignorable-void '-as-to- presencing - absolutising-identitive-

constitutedness $\rangle$ ) thus overlooking their 'wrongly-projected decontextualisingunimbricatedness/unthreadedness/unrecomposuring,-as-virtuality-or-ontologically-flawed-

construal (which is rather a "prior threshold-of-nonconviction/madeupness/bottomlining-inshallow-supererogation ${ }^{\circ}<$ as-to-'attendant-intradimensional'-prospectively-

disontologising preconverging/dementing -apriorising-psychologism> $>\quad$ reference-of-

thought' in shallowness-of-thought-or-unsophistication-of-understanding) in grasping 'implicited_attendant-ontological-contiguity ${ }^{67}$ educed-

existentialising/contextualising/textualising_'intelligibility/epistemicity/reflexivity_contiguity$<$ imbued-notional $\sim$ cogency $>,{ }^{\prime},-<$ reifying-or-elucidating-of-prospective-relative-ontological-

completeness -of- reference-of-thought- devolving-as-of-instantiative-context $>$ as to

existence-potency ${ }^{32} \sim$ sublimating-nascence,-disclosed-from-prospective-epistemic-

digression—rules-of-apriorising/axiomatising/referencing-that-further-epistemically-

unconceal-the-very-ontologically-same-existential-reality'. Such a 'relative teleologicaldifferentiation/scission/variance/disambiguation of ${ }^{83}$ references-of-thought' of Z's intemporaldisposition $\quad{ }^{83}$ reference-of-thought as supratransversality-<in-sublimating-existentialeventuating/denouement $>\sim$ of-motif-and-apriorising/axiomatising/referencing over $\mathrm{B}, \mathrm{C}, \mathrm{D}, \mathrm{E}$ and $\mathrm{F}$ temporal-dispositions ${ }^{83}$ references-of-thought as subtransversality- $<$ in-desublimatingexistential-eventuating/denouement $>\sim$ of-motif-and-apriorising/axiomatising/referencing, can be demonstrated in the archetype characters of say a Socrates or Rousseau (even though no human individual as receptacle of individuations can be qualified as purely of intemporaldisposition or purely of temporal-dispositions). Wherein within their respective registryworldviews/dimensions setups, their maximalising-as-transcendental recomposuring mentaldispositions in projection for prospective institutionalised-being-and-craft, i.e. ontologising of future conventioning, as $\quad$ supratransversality-<in-sublimating-existential- 
eventuating/denouement $>\sim$ of-motif-and-apriorising/axiomatising/referencing (as the grander intellectual-and-moral effort that can be made within their registry-worldviews/dimensions) is rather poorly construed to the ordinariness/averageness of thought within their respective registry-worldviews/dimensions setups (which mental-dispositions and conventioning -as 'wrongly-projected decontextualising-unimbricatedness/unthreadedness/unrecomposuring,-asvirtuality-or-ontologically-flawed-construal (which is rather a 'prior threshold-ofnonconviction/madeupness/bottomlining-in-shallow-supererogation $<-<$ as-to-'attendantintradimensional'-prospectively-disontologising preconverging/dementing -apriorisingpsychologism> ${ }^{83}$ reference-of-thought' in shallowness-of-thought-or-unsophistication-ofunderstanding) in grasping 'implicited_attendant-ontological-contiguity ${ }^{67}$ ' educedexistentialising/contextualising/textualising_intelligibility/epistemicity/reflexivity-contiguity$<$ imbued-notional $\sim$ cogency $>,{ }^{\prime},-<$ reifying-or-elucidating-of-prospective-relative-ontologicalcompleteness -of- reference-of-thought- devolving-as-of-instantiative-context> as to existence-potency $^{39} \sim$ sublimating-nascence,-disclosed-from-prospective-epistemicdigression—rules-of-apriorising/axiomatising/referencing-that-further-epistemicallyunconceal-the-very-ontologically-same-existential-reality' -will rather think as irrational the projective disposition of a Socrates that doesn't rather advance a temporal interest in the citystate polity but is rather bent on spreading new ideas as a natural philosopher while prioritising as of pestconverging-nonextricatory-existential-preempting-of-existential-unthought in his asceticism the prospective intemporal over the temporal status quo, and likewise with a Rousseau who isn't advancing a temporal interest that his aristocratic stature should warrant like actively pursuing for landed properties and currying favours with kings but is rather bent principally on a prospective commitment on grasping and spreading notions of a renewal of the human condition as ${ }^{103}$ universal rights and enlightened despotism. This is certainly because emanantly/becomingly/solipsistically temporal-dispositions do not appreciate that there is a 
more 'profound level of living in the realm of human thoughtfulness' based on eudaemoniccontemplation of 'intemporal-prioritisation-of- ${ }^{8}$ reference-of-thought'-as-conflatedness ${ }^{13}$-orontological-reprojecting that then 'invents/creates' the preconverging/postconverging-dementative/structural/paradigmatic possibility for prospective institutionalised-being-and-craft as there isn't any inherent intemporality ${ }^{52} /$ longness but for the disposition for ${ }^{5}$ maximalisingrecomposuring-for-relative-ontological-completeness 87 unenframed/re-

ontologising conceptualisation out of the apathy of the ordinariness/averageness of any prior registry-worldview/dimension institutionalised-being-and-craft setup. Hence such intemporality ${ }^{52} /$ longness as $\quad{ }^{55}$ maximalising-recomposuring-for-relative-ontologicalcompleteness $^{87}$ —unenframed/re-ontologising conceptualisation need its $<$ amplituding/formative-epistemicity $>$-totalising $\sim$ renewing-realisation/re-perception/rethought in inducing secondnatured institutionalisation given that the-succession-of-registryworldviews-or-dimensions-institutionalisations as to the-relative-unreflexivity/relativereflexivity - ontological-contiguity ${ }^{67} \sim$ of-the-human-institutionalisation-process ${ }^{68}$ is 'not a human emanance/seeding/incipient — transformation- $<$ as-to-Derridean-messianicity-whereineven-when-the-messiah-as-intemporal-drive-comes-they-still-have-to-come $>$ of temporaldispositions/shorness of register of meaning inness and teleology into the intemporaldisposition/longness-of-register-of meaningfulness-and-teleology but rather is solely a secondnaturing to supersede the uninstitutionalised-threshold ${ }^{12}$ (is not about the firstnaturedness-as-to-inkling of human dimensionality-of-sublimating <<amplituding/formative >supererogatory de-mentativeness/epistemic-growth-or-

conflatedness /transvaluative-rationalising/transepistemicity/anamnestic-residuality/spiritdrivenness-equalisation)) but rather is solely a secondnaturing to supersede the uninstitutionalised-threshold ${ }^{102}$ divulged as to its relative-ontological-incompleteness ${ }^{8}$ induced,-'threshold-of-nonconviction/madeupness/bottomlining-in-shallow-supererogation 


\section{$<$ as-to-'attendant-intradimensional'-prospectively-}

disontologising preconverging/dementing -apriorising-psychologism>'. The implication is that acting as-of-a-'secondnatured reproducibility—mathesis/motif/thrownness-disposition,-as-reproducibility-of-aestheticisation nature' is not enough for articulating prospective institutionalisation requiring 'intemporal projection <amplituding/formative-epistemicity >totalising renewing-realisation/re-perception/re-thought' for the requisite prospective maximalising-recomposuring-for-relative-ontological-completeness ${ }^{87}$ - unenframed/re-

ontologising conceptualisation, and such conceptualisations from only a secondnaturedness of thought as rather contextually temporal is not intemporal as-of- ${ }^{103}$ universal-and-abstractive originariness-parrhesia,-as-spontaneity-of-aestheticisation nature' but is rather in ‘<amplituding/formative-epistemicity $>$ totalising $\sim$ self-referencing-syncretising'/illusion-ofthe-present/present-consciousness/mirage as metaphysics-of-presence-〈implicited‘nondescript/ignorable-void '-as-to- presencing-absolutising-identitive-constitutedness \〉.

Thus a registry-worldview's/dimension's institutionalisation secondnaturedness is challenged by its very own level of relative-ontological-incompleteness ${ }^{8}$-induced,-'threshold-ofnonconviction/madeupness/bottomlining-in-shallow-supererogation $-<$ as-to-'attendantintradimensional'-prospectively-disontologising preconverging/dementing -apriorisingpsychologism>' marking its uninstitutionalised-threshold ${ }^{102}$ whether as recurrent-utteruninstitutionalisation with recurrent-utter-uninstitutionalisation, ununiversalisation with baseinstitutionalisation, non-positivism-or-medievalism with ${ }^{103}$ universalisation and procrypticism with positivism, in need for a renewed institutionalisation respectively as baseinstitutionalisation, ${ }^{103}$ universalisation, positivism and prospectively deprocrypticism. This equally explain why the notion of human transcendental progress is relatively 're-_originary_-as_unenframed/re-_ontologising/unbeholden_ening/outlier_conceptualisation___imbued- 
conflatedness '-of-notional deprocrypticism-prospective-sublimation $\rangle^{\circ}$ driven' as it requires an intemporal-solipsism as to ontological-faith-notion-or-ontological-fideism-imbuedunderdetermination-of-motif-and-apriorising/axiomatising/referencing-as-so-being-as-of-

existential-reality of thought more than just institutionalised secondnaturing such that it has often been the erudition periphery of institutional-cumulation/institutional-recomposure-〈as-tohistoriality/ontological-eventfulness /ontological-aesthetic-tracing-<perspectiveontological-normalcy/postconvergence-reflected-‘epistemicity-relativism-determinism'>> that had tended to fundamentally put-into-question their present with new postconverging-dementating/structuring/paradigming shifts. It is ontologically-speaking impossible to comprehensively undermine a dimension's/registry worldview's postlogism 77 without undermining the registry-worldview's/dimension's ${ }^{83}$ reference-of-thought itself as implied by its state of relative-ontological-incompleteness ${ }^{8}$-induced,-`threshold-ofnonconviction/madeupness/bottomlining-in-shallow-supererogation $<<$ as-to- 'attendantintradimensional'-prospectively-disontologising preconverging/dementing -apriorisingpsychologism>', for instance psychopathy in positivism- ${ }^{80}$ procrypticism or notions of sorcery in ${ }^{103}$ universalisation-non-positivism/medievalism (wherein from the prospective point-ofreference respectively as notional deprocrypticism or positivism, it is in de-mentation〈supererogatory $\sim$ ontological-de-mentation-or-dialectical-de-mentation - stranding-orattributive-dialectics $\rangle$ as of the placeholder-setup/mental-devisingrepresentation/mentation/consciousness-awareness-teleology ${ }^{\circ}$ ), given that this fundamental relative-ontological-incompleteness 8 -induced,-'threshold-ofnonconviction/madeupness/bottomlining-in-shallow-supererogation $-<$ as-to-' ${ }^{\circ}$ attendantintradimensional'-prospectively-disontologising preconverging/dementing -apriorisingpsychologism>' of the given registry-worldview/dimension as reflected from ontologicalnormalcy/postconvergence epistemic-or-notional projective-perspective (by its 
'implicited_attendant_ontological-contiguity ${ }^{67}$; educedexistentialising/contextualising/textualising_intelligibility/epistemicity/reflexivity-contiguity$<$ imbued-notional cogency $>{ }^{\prime 0}$ of existence-potency ${ }^{39} \sim$ sublimating-nascence,-disclosed-fromprospective-epistemic-digression—rules-of-apriorising/axiomatising/referencing-that-furtherepistemically-unconceal-the-very-ontologically-same-existential-reality) is preconverging/postconverging-de-mentatively/structurally/paradigmatically and bound to enculturate/endemise its given postlogism 7 . Obviously we can appreciate that without a positivistic outlook $/{ }^{83}$ reference-of-thought there is no chance that a non-positivism/medievalism registry-worldview/dimension will do away with notions-and-accusations-of-sorcery, as the latter is bound to arise as of human threshold-of-nonconviction/madeupness/bottomlining-inshallow-supererogation -<as-to-'attendant-intradimensional'-prospectivelydisontologising preconverging/dementing -apriorising-psychologism> in nonpositivism/medievalism where the mindset/ ${ }^{3}$ reference-of-thought is not rationallyempirical/positivising. Likewise the ${ }^{80}$ procrypticism-or-disjointedness-as-of- ${ }^{3}$ reference-ofthought wherein the perversion-of- ${ }^{73}$ reference-of-thought- $<$ as-preconverginglyapriorising/axiomatising/referencing-in-nonconviction/madeupness/bottomlining-as-to-

shallow-supererogation $>$ from a psychopathic character is contextually likely to be engaged with (as 'prelogism ${ }^{78}$-as-of-conviction,-in-profound-supererogation $-<$ existentially-veridical-

\section{'attendant-intradimensional-apriorising/axiomatising/referencing'-logical-dueness-precedes-}

disontologising-logical-outcome-arrived-at $>$ re-engaging reflex') and even exploited (whether unconsciously, expediently or consciously), implies a comprehensive preconverging/postconverging-de-mentative/structural/paradigmatic undermining of the phenomena of psychopathy and social psychopathy is impossible without putting in question and undermining our uninstitutionalised-threshold ${ }^{102}$ as procrypticism for futural Beingdevelopment/ontological-framework-expansion-as-to-depth-of-ontologising-development-as- 
notional deprocrypticism which is effectively the preconverging/postconverging-dementative/structural/paradigmatic resolution of psychopathy and social psychopathy (besides palliative conceptualisations that can hardly make a dent on the comprehensively defined preconverging/postconverging-de-mentative/structural/paradigmatic phenomenon in terms-asof-axiomatic-construct of the larger aetiologisation/ontological-escalation- $<$ ontologicalveridicality_commitment/otherliness_transcending/compulsions-encumbered_transcending $>$ ) just as positivism is the preconverging/postconverging-de-mentative/structural/paradigmatic ontological resolution of notions-and-accusations-of-sorcery, and ad-hoc tempering with medieval postlogism (disontologising-perverted-outcome-sought-precedes-existentiallyveridical-'attendant-intradimensional-apriorising/axiomatising/referencing'-logical-dueness) as instances of notions-and-accusations-of-sorcery doesn't grasp the underlying and comprehensive medieval social-construct preconverging/postconverging-dementative/structural/paradigmatic endemisation/enculturation of such a phenomenon. Further, registry-worldviews/dimensions being prospectively <amplituding/formative> woodenlanguage-〈imbued - averaging-of-thought-<as-to-leveling/ressentiment/closed-construct-ofmeaningfulness-and-teleology -as-of-‘nondescript/ignorable-void '-with-regards-toprospective-apriorising-implications $>>$ with their 'intradimensional socially-betrayingthreshold-of-ontologising-depth-of-analysis' or 'socially-betraying-threshold-of-intemporalpreservation-entropy-or-contiguity-or-ontological-preservation' determined by their sanctifiedconventioning-social-aggregation-enablers, there is a need to circumvent and break these sanctified-conventioning-social-aggregation-enablers by prospective 'intrinsicreality/ontological-veridicality transcendental-enabling/sublimating/supererogatory $\sim$ dementativity' to allow for new defining transcendental meaningfulness and its corresponding grander teleological-differentiation/teleology ${ }^{9}$ that can then perceive the prior registry- 
worldview/dimension as of its relative-ontological-incompleteness ${ }^{8}$-induced,-'threshold-ofnonconviction/madeupness/bottomlining-in-shallow-supererogation $-<$ as-to-' attendantintradimensional'-prospectively-disontologising preconverging/dementing -apriorisingpsychologism>' and accessorily its enculturating/endemising of its postlogism ${ }^{77}$, and superseding both of these in the prospective registry-worldview/dimension institutionalisation. For instance, the intrinsic-reality/ontological-veridicality transcendentalenabling/sublimating/supereregatery $\sim$ de-mentativity of a medicine based on natural causes and drugs as natural cures carried the effectiveness $/<$ amplituding/formativeepistemicity $>$ causality $\sim$ as-to-projective-totalitative-implications-of-prospectivenonpresencing,-for-explicating relative unreflexivity/relative-reflexivity - ontologicalcontiguity that undermined non-positivism/medievalism sanctified-conventioning-socialaggregation-enablers to do away with such notions as curses, sorcerers, etc. being the cause of disease, and undermine the whole teleologically-degraded dispositions based on such sanctifiedconventioning-social-aggregation-enablers. Likewise only by articulating comprehensive and effective aetiologisation/ontological-escalation- $<$ ontologicalveridicality_commitment/otherliness_transcending/compulsions-encumbered_transcending > resolutions to the defect of procrypticism and its postlogism ${ }^{77}$ first with respect to formal constructions that the derived effectiveness $/<$ amplituding/formativeepistemicity $>$ causality $\sim$ as-to-projective-totalitative-implications-of-prospectivenonpresencing,-for-explicating relative-unreflexivity/relative-reflexivity - ontologicalcontiguity can feed back as percolation-channelling- $<$ in-deferential-formalisationtransference> to dimensionally (registry-worldview) to undermine the relative-ontologicalincompleteness 8 -induced,-'threshold-of-nonconviction/madeupness/bottomlining-in-shallowsupererogation -<as-to-'attendant-intradimensional'-prospectivelydisontologising $\sim$ preconverging/dementing -apriorising-psychologism>' of our procrypticism 
and accessorily its enculturating/endemising of psychopathy and social psychopathy. Thus suprastructurally (beyond-the-consciousness-awareness-teleology

$-<$ of-preconvergingexistential-extrication-as-of-existential-unthought>) and as of the ontologicalnormalcy/postconvergence ontological-completeness-of- ${ }^{8}$ eference-of-thought perspective, 'sublimating-epistemic-imbricatedness/threadedness/recomposuring as of 'implicited_attendant_ontological-contiguity ${ }^{67}$ ' educedexistentialising/contextualising/textualising_'intelligibility/epistemicity/reflexivity-contiguity$<$ imbued-notional $\sim$ cogency $>,{ }^{\prime},-<$ reifying-or-elucidating-of-prospective-relative-ontologicalcompleteness -of- reference-of-thought- devolving-as-of-instantiative-context $>$ as to existence-potency ${ }^{39} \sim$ sublimating-nascence,-disclosed-from-prospective-epistemicdigression—rules-of-apriorising/axiomatising/referencing-that-further-epistemicallyunconceal-the-very-ontologically-same-existential-reality' implies a transversality-<forsublimating-existential-eventuating/denouement,-from-'thinking at first/pure-predispositionpreemptive-of prospective-disontologising/subontologising' as-of-prospectivelydisambiguated-affirmed-and-unaffirmed-'motif-and-apriorising/axiomatising/referencing'> as a 'relative teleological-differentiation/scission/variance/disambiguation of ${ }^{8}$ references-ofthought' by ${ }^{55}$ maximalising-recomposuring-for-relative-ontological-completeness ${ }^{87}$ unenframed/re-ontologising conceptualisation of prospective ${ }^{83}$ reference-of-thought as supratransversality-<in-sublimating-existential-eventuating/denouement $>\sim$ of-motif-andapriorising/axiomatising/referencing (as of higher ontological-completeness-of- ${ }^{8}$ reference-ofthought reflected in operant individuation terms as "coherence in depth of maximalisingrecomposuring-for-relative-ontological-completeness ${ }^{8}$ —unenframed/reontologising conceptualisation/longness of register of meaningfulness and teleology construal of ${ }^{83}$ reference-of-thought') over the preconverging-or-dementing ${ }^{20}$-apriorisingpsychologism and dialectically/contendingly-out-of-phasing of the prior ${ }^{83}$ reference-of-thought 
apriorising/axiomatising/referencing (as of lesser ontological-completeness-of- ${ }^{3}$ reference-ofthought with respect to ${ }^{7}$ perversion-of- ${ }^{8}$ reference-of-thought-<as-preconverginglyapriorising/axiomatising/referencing-in-nonconviction/madeupness/bottomlining-as-toshallow-supererogation $>$ reflected in operant individuation terms as 'disjointedmisappropriation/arrogation and derived-disjointed-misappropriation/arrogation of meaningfulness-and-teleological-differentiation in shallowness as incremental/shortness-ofregister-of meaningfulness-and-teleology construal of perversion-and-derived- perversionof- ${ }^{8}$ reference-of-thought-<as-preconvergingly-apriorising/axiomatising/referencing-innonconviction/madeupness/bottomlining-as-to-shallow-supererogation >'; construed as of defective

apriorising/axiomatising/referencing/intelligibilitysettingup/measuringinstrumentingproducing-measurements for thee aposteriorising/logicising/deriving/intelligising/measuringpurpose-of-obtained-measurements and derived-implications of the defective apriorising/axiomatising/referencing/intelligibilitysettingup/measuringinstrumentingproducing-measurements for the aposteriorising/logicising/deriving/intelligising/measuringpurpose - of-obtained-measurements (perversion-and-derived- ${ }^{7}$ perversion-of- ${ }^{8}$ reference-ofthought-<as-preconvergingly-apriorising/axiomatising/referencing-in-

nonconviction/madeupness/bottomlining-as-to-shallow-supererogation $>$ 'disjointedness-asof- reference-of-thought' misappropriated meaningfulness-and-teleological-differentiation in arrogation). This relative teleological-differentiation/scission/variance/disambiguation of references-of-thought in terms-as-of-axiomatic-construct of the 'prospective supratransversality-<in-sublimating-existential-eventuating/denouement $>\sim$ of-motif-andapriorising/axiomatising/referencing $\quad{ }^{83}$ reference-of-thought' (as $\quad{ }^{55}$ maximalisingrecomposuring-for-relative-ontological-completeness ${ }^{87}$ - unenframed/re- 
ontologising conceptualisation by way of prospective intrinsic-reality/ontological-veridicality transcendental-enabling/sublimating/supererogatory de-mentativity as it supersedes the prior reference-of-thought 'socially-betraying-threshold-of-ontologising-depth-of-analysis' or 'socially-betraying-threshold-of-intemporal-preservation-entropy-or-contiguity-or-

ontological-preservation' determined by its sanctified-conventioning-social-aggregationenablers) and the 'prior subtransversality-<in-desublimating-existentialeventuating/denouement $>\sim$ of-motif-and-apriorising/axiomatising/referencing $\quad{ }^{83}$ reference-ofthought' (as denaturing ${ }^{16}$ postlogic-backtracking threshold-ofnonconviction/madeupness/bottomlining-in-shallow-supererogation $<-<$ as-to- 'attendantintradimensional'-prospectively-disontologising preconverging/dementing -apriorisingpsychologism $>$ towards the ${ }^{8}$ reference-of-thought sanctified-conventioning-social-aggregationenablers in undermining prospective intrinsic-reality/ontological-veridicality transcendentalenabling/sublimating/supereregatory $\sim$ de-mentativity); is comprehensively rearticulated all across the '83 reference-of-thought existentialism construct', i.e. from the registry-worldview (meaning by its specific teleological differentiation/scission/variance/disambiguation construct), the contending-reference (meaning teleological construct), the ontological-reference (being/existential construct of meaning), meaningful-reference (meaning contextualisation construct), the ${ }^{83}$ reference-of-thought (operant construal of meaning), and right down to the apriorising-registry (basic defining construct of meaning, in terms-as-of-axiomatic-construct of logical-dueness/profile/presumption/assumptions/value-reference/teleology ${ }^{9}$ ). This suprastructural and ontological-normalcy/postconvergence insight from an ontologicalcompleteness-of- ${ }^{8}$ reference-of-thought point-of-departure-of-construal underlines

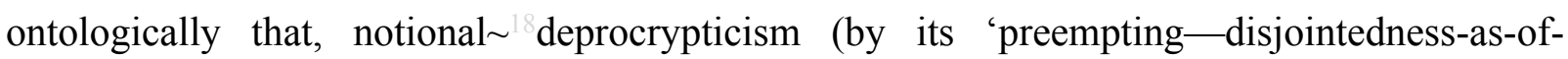
reference-of-thought' $\quad$ reference-of-thought- categorical-imperatives/axioms/registryteleology ${ }^{9}$ i.e. ${ }^{18}$ deprocrypticism-or-preempting-disjointedness-as-of- ${ }^{3}$ reference-of- 
thought) is utter-ontologising-recomposuring by subsuming-as-supplanting-〈as-of-relativelymore-profound-construal-of 'implicited_attendant-ontological-contiguity ' educedexistentialising/contextualising/textualising_intelligibility/epistemicity/reflexivity-contiguity$<$ imbued-notional $\sim$ cogency $>,{ }^{\prime},-<$ reifying-or-elucidating-of-prospective-relative-ontologicalcompleteness -of- reference-of-thought- devolving-as-of-instantiative-context $>>$ positivismprocrypticism which (by its 'positivising/rational-empiricism' ${ }^{83}$ reference-of-thoughtcategorical-imperatives/axioms/registry-teleology , i.e. positivising/rational-empiricismbased-universalisation-directed-rulemaking-over-non-rulesapriorising/axiomatising/referencing-psychologism,-_as 'third-level presencingabsolutising-identitive-constitutedness ${ }^{14}$ of reference-of-thought' apriorising/axiomatising/referencing/intelligibilitysettingup/measuringinstrumenting)) maximalising-recomposuring-for-relative-ontological-completeness ${ }^{87}$ - unenframed/reontologising $\sim$ conceptualisation by subsuming-as-supplanting-〈as-of-relatively-more-profoundconstrual-of 'implicited_attendant_ontological-contiguity ' educedexistentialising/contextualising/textualising_'intelligibility/epistemicity/reflexivity-contiguity$<$ imbued-notional $\sim$ cogency $>$, ,-<reifying-or-elucidating-of-prospective-relative-ontologicalcompleteness -of- reference-of-thought- devolving-as-of-instantiative-context $>$ > universalisation-non-positivism/medievalism which (by its ${ }^{6}{ }^{103}$ universalising' ${ }^{83}$ reference-ofthought- ${ }^{8}$ ategorical-imperatives/axioms/registry-teleology ${ }^{9}$, i.e. ${ }^{103}$ universalisation-directedrulemaking-over-non-rules_ a priorising/axiomatising/referencing-psychologism,-〈as 'secondlevel presencing-absolutising-identitive-constitutedness ${ }^{14}$ of reference-of-thought' apriorising/axiomatising/referencing/intelligibilitysettingup/measuringinstrumenting $\rangle$ ) is maximalising-recomposuring-for-relative-ontological-completeness ${ }^{87}$ - unenframed/reontologising $\sim$ conceptualisation by subsuming-as-supplanting-〈as-of-relatively-more-profound- 
existentialising/contextualising/textualising_'intelligibility/epistemicity/reflexivity_contiguity$<$ imbued-notional $\sim$ cogency $>,{ }^{\prime},-<$ reifying-or-elucidating-of-prospective-relative-ontologicalcompleteness -of- reference-of-thought- devolving-as-of-instantiative-context $>>\quad$ Baseinstitutionalisation-ununiversalisation which (by its 'rule-making' ${ }^{83}$ reference-of-thoughtcategorical-imperatives/axioms/registry-teleology , i.e. rulemaking-over-non-rulesapriorising/axiomatising/referencing-psychologism,-〈as 'first-level presencing_-absolutisingidentitive-constitutedness of reference-of-thought' apriorising/axiomatising/referencing/intelligibilitysettingup/measuringinstrumenting)) maximalising-recomposuring-for-relative-ontological-completeness ${ }^{87}$ - unenframed/reontologising conceptualisation by subsuming-as-supplanting-〈as-of-relatively-more-profoundconstrual-of 'implicited_attendant_ontological-contiguity ' educedexistentialising/contextualising/textualising_intelligibility/epistemicity/reflexivity-contiguity$<$ imbued-notional $\sim \operatorname{cogency}>{ }^{\prime},,-<$ reifying-or-elucidating-of-prospective-relative-ontologicalcompleteness -of- reference-of-thought- devolving-as-of-instantiative-context $>>$ Recurrentutter-uninstitutionalisation (by its specific non-rules - apriorising/axiomatising/referencingpsychologism,-as-impulsive-or-accidented-or-random-mental-disposition $\quad 83$ reference-ofthought- ${ }^{-}$ategorical-imperatives/axioms/registry-teleology ${ }^{9}, \quad$ i.e. non-rulesapriorising/axiomatising/referencing-psychologism,-as-impulsive-or-accidented-or-randommental-disposition-〈as 'base apriorising/axiomatising/referencing- of-'prospectively implicited_attendant-ontological-contiguity ' educedexistentialising/contextualising/textualising_'intelligibility/epistemicity/reflexivity-contiguity$<$ imbued-notional cogency>’ $\quad\}$ - constitutedness ${ }^{14}$-in-preconverging-entailment of reference-of-thought' apriorising/axiomatising/referencing/intelligibilitysettingup/measuringinstrumenting $)$. This implies a human limited-mentation-capacity-deepening -as-subjecting limitedness/human- 
subpotency-to-'educed-unlimitedness/existence-sublimating nascence'

maximalising-recomposuring-for-relative-ontological-completeness ${ }^{87}$ unenframed/re-

ontologising conceptualisation from shallowest limited-mentation-capacity-deepening-assubjecting limitedness/human-subpotency to-'educed-unlimitedness/existence-sublimating nascence' (as recurrent-utter-uninstitutionalisation) to deepest limited-mentation-capacitydeepening - as-subjecting-limitedness/human-subpotency-to-'educed-unlimitedness/existencesublimating nascence' (as deprocrypticism) towards a superseding-oneness-of-ontology. Such that the respective ${ }^{83}$ reference-of-thought registry-worldviews/dimensions in successive shallow-to-deepening-limited-mentation-capacity—as-subjecting-'educedunlimitedness/existence-sublimating nascence' to-limitedness/human-subpotency, as-limitedmentation-capacity-deepening —as-subjecting limitedness/human-subpotency-to-'educedunlimitedness/existence-sublimating nascence' ${ }^{53}$ as recurrent-utter-uninstitutionalisation, baseinstitutionalisation-ununiversalisation, $\quad{ }^{103}$ universalisation-non-positivism/medievalism, positivism $-{ }^{80}$ procrypticism and notional ${ }^{8}$ deprocrypticism successively recomposure more and more profound existentialism a-priori 'implicited_attendant-ontological-contiguity ${ }^{67}$; educedexistentialising/contextualising/textualising_intelligibility/epistemicity/reflexivity_contiguity$<$ imbued-notional cogency $>{ }^{40}$ of existence-potency ${ }^{39} \sim$ sublimating-nascence,-disclosed-fromprospective-epistemic-digression—rules-of-apriorising/axiomatising/referencing-that-furtherepistemically-unconceal-the-very-ontologically-same-existential-reality-of-rules successively as from non-rules - apriorising/axiomatising/referencing-psychologism,-as-impulsive-oraccidented-or-random-mental-disposition-〈as 'base apriorising/axiomatising/referencing-\{of'prespectively implicited_attendant_ontological-contiguity ' educedexistentialising/contextualising/textualising_'intelligibility/epistemicity/reflexivity-contiguity<imbued-notional cogency $\left.>^{\prime} \quad\right\}$ - constitutedness ${ }^{14}$-in-preconverging-entailment of reference-of-thought' 
apriorising/axiomatising/referencing/intelligibilitysettingup/measuringinstrumenting $\rangle, \quad$ overnon-rules_-apriorising/axiomatising/referencing-psychologism,-〈as rulemaking- 'first-level presencing - absolutising-identitive-constitutedness ${ }^{14}$ of reference-of-thought' apriorising/axiomatising/referencing/intelligibilitysettingup/measuringinstrumenting), universalisation-directed-rulemaking-over-non-rules_-apriorising/axiomatising/referencingpsychologism,-〈as 'second-level presencing-absolutising-identitive-constitutedness ${ }^{14}$ of reference-of-thought'

apriorising/axiomatising/referencing/intelligibilitysettingup/measuringinstrumenting), positivising/rational-empiricism-based-universalisation-directed-rulemaking-over-non-rulesapriorising/axiomatising/referencing-psychologism,-〈as 'third-level presencing absolutising-identitive-constitutedness ${ }^{14}$ of reference-of-thought' apriorising/axiomatising/referencing/intelligibilitysettingup/measuringinstrumenting,, and deprocrypticism-or-preempting-disjointedness-as-of- ${ }^{3}$ reference-of-thought with such notion of rules speaking in terms-as-of-axiomatic-construct of both the developing capacity of human placeholder-setup/mental-devising-representation/mentation/consciousness-awarenessteleology in its construing/conceptualising of elaboration-as-to-mereextrapolating/constituting/abstracting/deducing/inferring-of-elucidation-outside'prospectively implicited_attendant-ontological-contiguity ${ }^{67}$ ' educedexistentialising/contextualising/textualising_ 'intelligibility/epistemicity/reflexivity-contiguity<imbued-notional cogency>' as defining the given registry-worldview/dimension-level specific 'postconverging-or-dialectical-thinking'-psychology or psychology-of-mentationdynamics or natural psychological-dynamics', as well as developing institutionalisation capacity as ${ }^{5}$ meaningfulness-and-teleology ${ }^{9}$ differentiations; and so as human $<$ amplituding/formative-epistemicity $>$-totalising $\sim$ renewing-realisation/re-perception/rethought-as-utter-placeholder-setup-ontological-rescheduling-〈by-a-renewing-of- 
apriorising/axiomatising/referencing-psychologism-as-the-new-referencing-basis-of-

prospective- meaningfulness-and-teleology \ by psychoanalytic-unshackling/memeticreordering/institutional-recomposuring. As explained, the reason for the successive institutionalcumulation/institutional-recomposure-〈as-to- historiality/ontologicaleventfulness /ontological-aesthetic-tracing-<perspective-ontologicalnormalcy/postconvergence-reflected-‘epistemicity-relativism-determinism' $>>$ underlying the relative-unreflexivity/relative-reflexivity ontological-contiguity ${ }^{67}$ of-the-humaninstitutionalisation-process ${ }^{68}$ has to do with human limited-mentation-capacity-deepening-assubjecting limitedness/human-subpotency to 'educed unlimitedness/existence sublimating nascence' inducing successive recomposuring from shallow-limited-mentation-capacity-assubjecting 'educed-unlimitedness/existence-sublimating nascence' to-limitedness/humansubpotency to deeper-limited-mentation-capacity-as-subjecting 'educedunlimitedness/existence-sublimating nascence' to-limitedness/human-subpotency construed as diminishing-human-epistemic-abnormalcy-or-preconvergence ${ }^{3 !}$ towards ontologicalnormalcy/postconvergence or intemporal-preservation-entropy-or-contiguity-or-ontologicalpreservation. Hence notionally speaking if humans had completed-mentation-capacity there will only be notional ${ }^{1}$ deprocrypticism institutionalisation and not the subsuming-succession of recurrent-utter-uninstitutionalisation, base-institutionalisation-ununiversalisation, universalisation-non-positivism/medievalism, positivism- ${ }^{80}$ procrypticism, with all mutually implied as subsumed-as-supplanted in notional ${ }^{8}$ deprocrypticism as of achieved ontologicalcompleteness-of- ${ }^{-3}$ reference-of-thought; subsumed-as-supplanted successively as of nonrules_-apriorising/axiomatising/referencing-psychologism,-as-impulsive-or-accidented-orrandom-mental-disposition-〈as 'base apriorising/axiomatising/referencing-\{of-"prospectively implicited_attendant-ontological-contiguity ' educedexistentialising/contextualising/textualising_ 'intelligibility/epistemicity/reflexivity-contiguity- 
<imbued-notional cogency $>\quad\}$ - constitutedness ${ }^{14}$-in-preconverging-entailment

reference-of-thought'

apriorising/axiomatising/referencing/intelligibilitysettingup/measuringinstrumenting $\rangle, \quad$ overnon-rules_-apriorising/axiomatising/referencing-psychologism,-〈as rulemaking-'first-level presencing - absolutising-identitive-constitutedness ${ }^{14}$ of reference-of-thought'

apriorising/axiomatising/referencing/intelligibilitysettingup/measuringinstrumenting),

universalisation-directed-rulemaking-over-non-rules — apriorising/axiomatising/referencingpsychologism,-〈as 'second-level presencing-absolutising-identitive-constitutedness ${ }^{14}$ of reference-of-thought'

apriorising/axiomatising/referencing/intelligibilitysettingup/measuringinstrumenting), 'positivising/rational-empiricism-based-universalisation-directed-rulemaking-over-non-rulesapriorising/axiomatising/referencing-psychologism'-〈as 'third-level presencingabsolutising-identitive-constitutedness ${ }^{14}$ of reference-of-thought' apriorising/axiomatising/referencing/intelligibilitysettingup/measuringinstrumenting,$\quad$ and ultimately with deprocrypticism, ' deprocrypticism-or-preempting-disjointedness-as-ofreference-of-thought-〈apriorising/axiomatising/referencing-\{of-'prespectively implicited_attentant-ontological-contiguity ' educedexistentialising/contextualising/textualising_'intelligibility/epistemicity/reflexivity-contiguity<imbued-notional cogency $\left.>^{\prime}\right\}$ - conflatedness ${ }^{13}$-in-\{preconverging-disentailment by\} pestconverging-ntailment of ${ }^{83}$ reference-of-thought $\rangle$. This existential-becoming-transitioning to notional $\sim$ deprocrypticism as well as the overall existential-becoming-transitioning nature of existence/existential-reality is the validation of the notion of existence-as-of-its-mimeticechoness/existence-in-reverberation/existence-potency ${ }^{32} \sim$ sublimating-nascence,-disclosedfrom-prospective-epistemic-digression. That is existence is existence-as-of-its-mimeticechoness/existence-in-reverberation/existence-potency ${ }^{32} \sim$ sublimating-nascence,-disclosed- 
from-prospective-epistemic-digression, such that it inherently implies the relativemnreflexivity/relative-reflexivity — ontological-contiguity ${ }^{67}$ of-the-human-institutionalisationprocess $^{68}$ which can be construed as deprocrypticism-as-of-its-mimeticechoness/deprocrypticism-in-reverberation or ontological-normalcy-as-of-its-mimeticechoness/ontological-normalcy-in-reverberation or ontological-normalcy/postconvergence. By extension such projective-insights from a 'notional human completed-mentation-capacity' perspective about notional deprocrypticism conceptually implies that procrypticism is the actually implied epistemic-abnormalcy/preconvergence ${ }^{31}$ reflection 'disjointedness-as-ofreference-of-thought'-as-misappropriated- ${ }^{5}$ meaningfulness-and-teleology 9 -in-arrogation, along successive limited-mentation-capacity-deepening —as-subjecting limitedness/humansubpotency-to-'educed-unlimitedness/existence-sublimating nascence' ${ }^{53}$ implied uninstitutionalised-threshold $^{102}$ : as failing/not-upholding-<as-ofapriorising/axiomatising/referencing $>\quad$ recurrently rulemaking-over-non-rulesapriorising/axiomatising/referencing-psychologism,-〈as 'base-constitutedness 14 of referenceof-thought' apriorising/axiomatising/referencing/intelligibilitysettingup/measuringinstrumenting), as failing/not-upholding-<as-of-apriorising/axiomatising/referencing $>$ universalisationdirected-rulemaking-over-non-rules_-apriorising/axiomatising/referencing-psychologism,-〈as 'first-level presencing-absolutising-identitive-constitutedness ${ }^{14}$ of reference-of-thought' apriorising/axiomatising/referencing/intelligibilitysettingup/measuringinstrumenting), as failing/not-upholding-<as-of-apriorising/axiomatising/referencing $>$ positivising/rationalempiricism-based-universalisation-directed-rulemaking-over-non-rulesapriorising/axiomatising/referencing-psychologism,-_as 'second-level presencingabsolutising-identitive-constitutedness of reference-of-thought' 
failing/not-upholding-<as-of-apriorising/axiomatising/referencing $>$ preempting-

disjointedness-as-of- ${ }^{8}$ reference-of-thought,-as-to- ${ }^{6}<{ }^{2}$ amplituding/formative-

epistemicity> growth-or-conflatedness ${ }^{13} /$ transvaluative- $^{2}$

rationalising/transepistemicity/anamnestic-residuality/spirit-drivenness' — in-superseding-

mere-formulaic-positivising/rational-empiricism-based-universalisation-directed-rulemaking-

over-non-rules_-apriorising/axiomatising/referencing-psychologism,-_as 'third-level

presencing — absolutising-identitive-constitutedness

of

reference-of-thought'

apriorising/axiomatising/referencing/intelligibilitysettingup/measuringinstrumenting $\rangle$, and up to

when

uninstitutionalised-threshold

is

preconverging/postconverging-de-

mentatively/structurally/paradigmatically superseded by 'notional ${ }^{18}$ deprocrypticism'

construed as deprocrypticism-as-of-its-mimetic-echoness/deprocrypticism-as-of-its-

reverberation as 'notional $\sim$ 'deprocrypticism' accounts for both notional ${ }^{18}$ deprocrypticism and procrypticism since it is a potency-construal and not a given ${ }^{83}$ reference-of-thought construal (contrasted with 'conceptual deprocrypticism' as a given ${ }^{83}$ reference-of-thought construal); just as 'knowledge-notionalisation' implies a potency-construal of both knowledge and the ignorances/desublimation wherein the enlightening referencing of knowledge extends to a grasp of the nature and possibilities of the ignorances/desublimation as well, in contrast to human 'knowledge conceptualisation' as of knowledge as of its enlightening or intemporal referencing only. Thus just as notional deprocrypticism subsuming perspective (of institutionalisation-

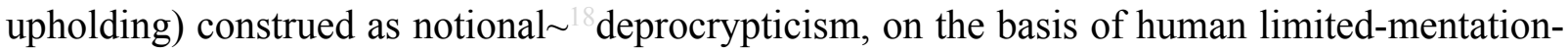
capacity-deepening —as-subjecting limitedness/human-subpotency-to-'educed-

unlimitedness/existence-sublimating nascence' ${ }^{53}$ maximalising-recomposuring-for-relativeontological-completeness ${ }^{87}$ - unenframed/re-ontologising conceptualisation institutionalisation, will construe the successive institutional-cumulation/institutionalrecomposure-〈as-to- historiality/ontological-eventfulness /ontological-aesthetic-tracing- 
<perspective-ontological-normalcy/postconvergence-reflected-'epistemicity-relativism-

determinism' $>>$ as of the 'successive preconverging/postconverging-dementative/structural/paradigmatic

apriorising/axiomatising/referencing/intelligibilitysettingup/measuringinstrumenting,-foraposteriorising/logicising/deriving/intelligising/measuring-of- ${ }^{5}$ meaningfulness-and-

teleology towards deprocrypticism-as-the-real-notion as of ontologicalnormalcy/postconvergence-or-intemporal-preservation-entropy-or-contiguity-or-ontologicalpreservation'; likewise a procrypticism subsuming perspective (as failing-to-upholdinstitutionalisation/upholding-uninstitutionalised-threshold ${ }^{102}$ ) construed as notional procrypticism, will construe the successive uninstitutionalised-threshold ${ }^{102}$ as of the 'successive preconverging/postconverging-de-mentative/structural/paradigmatic apriorising/axiomatising/referencing/intelligibilitysettingup/measuringinstrumenting,-foraposteriorising/logicising/deriving/intelligising/measuring-of- ${ }^{-5}$ meaningfulness-andteleology towards procrypticism-as-the-real-notion as of epistemicabnormalcy/preconvergence -or-failing-intemporal-preservation-entropy-or-contiguity-orontological-preservation'. It is this underlying ontological-normalcy/postconvergence notion as from the (metaphysics-of-absence-〈implicited-epistemic-veracity-of- nonpresencing$<$ perspective-ontological-normalcy/postconvergence $>$ //postdication/projective-insights) perspective of a 'notional human completed-mentation-capacity' implications as notional ${ }^{18}$ deprocrypticism or $<$ amplituding/formative $>$ notional $\sim$ preempting — disjointednessas-of- reference-of-thought when construed rather in 'successive increasingly-profoundapriorising/axiomatising/referencing/intelligibilitysettingup/measuringinstrumenting,-foraposteriorising/logicising/deriving/intelligising/measuring-of- meaningfulness-andteleology ${ }^{9}$ construals with respect to existence-potency ${ }^{32} \sim$ sublimating-nascence,-disclosedfrom-prospective-epistemic-digression — rules-of-apriorising/axiomatising/referencing-that- 
further-epistemically-unconceal-the-very-ontologically-same-existential-reality as of the institutional-cumulation/institutional-recomposure-〈as-to- historiality/ontologicaleventfulness /ontological-aesthetic-tracing-<perspective-ontologicalnormalcy/postconvergence-reflected-'epistemicity-relativism-determinism'>Y' involving human increasingly limited-mentation-capacity-deepening —as-subjecting limitedness/humansubpotency-to-'educed-unlimitedness/existence-sublimating nascence' ${ }^{53}$ : as from non-rulesapriorising/axiomatising/referencing-psychologism,-as-impulsive-or-accidented-or-randommental-disposition (base-constitutedness ${ }^{14}$ of ${ }^{83}$ reference-of-thought), rulemaking-over-non-rule (first-level presencing-absolutising-identitive-constitutedness ${ }^{14} \quad{ }^{83}$ reference-of-thought), universalisation-directed-rulemaking-over-non-rules — apriorising/axiomatising/referencingpsychologism (second-level presencing-absolutising-identitive-constitutedness reference-of-thought), positivising/rational-empiricism-based-universalisation-directedrulemaking-over-non-rules_-apriorising/axiomatising/referencing-psychologism （third-level presencing - absolutising-identitive-constitutedness ${ }^{1483}$ reference-of-thought), and prospective deprocrypticism-or-preempting-disjointedness-as-of- ${ }^{-1}$-eference-of-thought; that underlies the construal/conceptualisation of existence-potency ${ }^{32} \sim$ sublimating-nascence,-disclosed-fromprospective-epistemic-digression—rules-of-apriorising/axiomatising/referencing-that-furtherepistemically-unconceal-the-very-ontologically-same-existential-reality (as of its sublimatingepistemic-imbricatedness/threadedness/recomposuring divulged by the various rules inflections highlighted above starting with non-rules_-apriorising/axiomatising/referencingpsychologism,-as-impulsive-or-accidented-or-random-mental-disposition-〈as 'baseconstitutedness of reference-of-thought' apriorising/axiomatising/referencing/intelligibilitysettingup/measuringinstrumenting $\rangle$ and developing with limited-mentation-capacity-deepening-as-subjecting limitedness/hmmansubpotency-to-'educed-unlimitedness/existence-sublimating nascence' ${ }^{53}$, construed as of 
'increasingly-profound-

apriorising/axiomatising/referencing/intelligibilitysettingup/measuringinstrumenting,-foraposteriorising/logicising/deriving/intelligising/measuring-of- ${ }^{5}$ meaningfulness-andteleology ${ }^{9}$ with respect to existence-potency ${ }^{39} \sim$ sublimating-nascence,-disclosed-fromprospective-epistemic-digression—rules-of-apriorising/axiomatising/referencing-that-furtherepistemically-unconceal-the-very-ontologically-same-existential-reality). The above articulation points out that our conceptions of rules as of their psychical and institutional implications more of our apriorising/axiomatising/referencing/intelligibilitysettingup/measuringinstrumenting,-foraposteriorising/logicising/deriving/intelligising/measuring-of- ${ }^{56}$ meaningfulness-andteleology devising' (reflected in our placeholder-setup/mental-devisingrepresentation/mentation/consciousness-awareness-teleology ${ }^{9}$ ) as of the given level of our limited-mentation-capacity-deepening —as-subjecting-limitedness/human-subpotency-to'educed-unlimitedness/existence-sublimating nascence's3 with respect to existencepotency $^{39} \sim$ sublimating-nascence,-disclosed-from-prospective-epistemic-digression-rules-ofapriorising/axiomatising/referencing-that-further-epistemically-unconceal-the-veryontologically-same-existential-reality as of the superseding-oneness-of-ontology. Thus for construing/conceptualising the relative epistemic-veracity of a supratransversality- $<$ insublimating-existential-eventuating/denouement $>\sim$ of-motif-and-

apriorising/axiomatising/referencing $\quad$ reference-of-thought over a subtransversality-<indesublimating-existential-eventuating/denouement $>\sim$ of-motif-and-

apriorising/axiomatising/referencing ${ }^{83}$ reference-of-thought with respect to the overall relativemneflexivity/relative reflexivity ontological-contiguity ${ }^{67}$ of-the-human-institutionalisationprocess $^{68}$ manifestation of postlogism 77 (wherein suprastructurally/beyond-the-consciousnessawareness-teleology $\quad<$ of-preconverging-existential-extrication-as-of-existential-unthought $>$ 
and from ontological-normalcy/postconvergence epistemic-or-notional projective-perspective, the same $\quad{ }^{5}$ maximalising-recomposuring-for-relative-ontological-completeness ${ }^{87}$ unenframed/re-ontologising conceptualisation rules thate prospective/transcending/superseding institutionalisation but within the institutionalisation prospective limits turns out to be the 'threshold-of-nonconviction/madeupness/bottomlining-inshallow-supererogation -<as-to-'attendant-intradimensional'-prospectivelydisontologising $\sim$ preconverging/dementing -apriorising-psychologism>' beyond these limits construed as uninstitutionalised-threshold ${ }^{102}$ in want for prospective institutionalisation): -the postlogism associated with 'recurrent-utter-uninstitutionalisation ${ }^{83}$ reference-of-thought as subtransversality-<in-desublimating-existential-eventuating/denouement $>\sim$ of-motif-andapriorising/axiomatising/referencing' warrants 'prospective base-institutionalisation reference-of-thought as supratransversality-<in-sublimating-existentialeventuating/denouement> of-motif-and-apriorising/axiomatising/referencing teleologicaldifferentiation/scission/variance/disambiguation', and so by the 'rulemaking-over-non-rulesapriorising/axiomatising/referencing-psychologism of prospective base-institutionalisation'simplicited_attendant-ontological-contiguity ${ }^{67}$ educed-

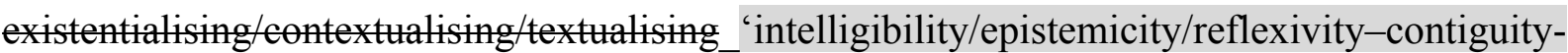
$<$ imbued-notional $\sim$ cogency $>,{ }^{\prime},-<$ reifying-or-elucidating-of-prospective-relative-ontologicalcompleteness -of- reference-of-thought- devolving-as-of-instantiative-context> as to existence-potency ${ }^{39} \sim$ sublimating-nascence,-disclosed-from-prospective-epistemicdigression—rules-of-apriorising/axiomatising/referencing-that-further-epistemicallyunconceal-the-very-ontologically-same-existential-reality' thus preempting the 'non-rulesapriorising/axiomatising/referencing-psychologism,-as-impulsive-or-accidented-or-randommental-disposition (as base-constitutedness ${ }^{14}$ reference-of-thought) of recurrent-utteruninstitutionalisation's - implicited_attendant-ontological-contiguity ${ }^{67}$ ' educed- 
existentialising/contextualising/textualising_intelligibility/epistemicity/reflexivity-contiguity$<$ imbued-notional $\sim$ cogency $>,{ }^{\prime},-<$ reifying-or-elucidating-of-prospective-relative-ontologicalcompleteness -of- reference-of-thought- devolving-as-of-instantiative-context $>$ now of threshold-of-nonconviction/madeupness/bottomlining-in-shallow-supererogation $-<$ as-to'attendant-intradimensional'-prospectively-disontologising preconverging/dementing apriorising-psychologism> $\quad$ as-the-latter-fails-to-reflect $\quad$ existence-potency ${ }^{32} \sim$ sublimatingnascence,-disclosed-from-prospective-epistemic-digression-rules-ofapriorising/axiomatising/referencing-that-further-epistemically-unconceal-the-veryontologically-same-existential-reality at its corresponding uninstitutionalised-threshold ${ }^{102}$ state of recurrent-utter-uninstitutionalisation'; -the postlogism 77 associated with 'baseinstitutionalisation-ununiversalisation reference-of-thought as subtransversality-<indesublimating-existential-eventuating/denouement $>\sim$ of-motif-andapriorising/axiomatising/referencing' warrants 'prospective ${ }^{103}$ universalisation ${ }^{83}$ reference-ofthought as supratransversality- $<$ in-sublimating-existential-eventuating/denouement $>\sim$ of-motifand-apriorising/axiomatising/referencing teleologicaldifferentiation/scission/variance/disambiguation', and so by the "103 universalisation-directedrulemaking-over-non-rules — apriorising/axiomatising/referencing-psychologism of prospective ${ }^{103}$ universalisation's_implicited_attendant-ontological-contiguity ${ }^{67}$ > educedexistentialising/contextualising/textualising_intelligibility/epistemicity/reflexivity-contiguity$<$ imbued-notional $\sim$ cogency $>,{ }^{\prime},-<$ reifying-or-elucidating-of-prospective-relative-ontologicalcompleteness -of- reference-of-thought- devolving-as-of-instantiative-context> as to existence-potency ${ }^{32} \sim$ sublimating-nascence,-disclosed-from-prospective-epistemicdigression—rules-of-apriorising/axiomatising/referencing-that-further-epistemicallyunconceal-the-very-ontologically-same-existential-reality' thus preempting the 'rulemakingover-non-rules_-apriorising/axiomatising/referencing-psychologism ～(as 'first-level 
presencing-absolutising-identitive-constitutedness ${ }^{14}$ of ${ }^{83}$ reference-of-thought') of baseinstitutionalisation's — implicited_attendant_ontological-contiguity ${ }^{67}$ ' educedexistentialising/contextualising/textualising_intelligibility/epistemicity/reflexivity_contiguity$<$ imbued-notional $\sim$ cogency $>,{ }^{\prime},-<$ reifying-or-elucidating-of-prospective-relative-ontologicalcompleteness -of- reference-of-thought- devolving-as-of-instantiative-context> now of threshold-of-nonconviction/madeupness/bottomlining-in-shallow-supererogation $<<$ as-to‘attendant-intradimensional'-prospectively-disontologising preconverging/dementing apriorising-psychologism>', as-the-latter-fails-to-reflect existence-potency ${ }^{3{ }^{3}} \sim$ sublimating- $^{\prime}$ nascence,-disclosed-from-prospective-epistemic-digression—rules-ofapriorising/axiomatising/referencing-that-further-epistemically-unconceal-the-veryontologically-same-existential-reality at its corresponding uninstitutionalised-threshold ${ }^{102}$ state of ununiversalisation'; -the postlogism (including notions-and-accusations-of-sorcery, alchemic-thinking, etc.) associated with ' ${ }^{103}$ universalisation-non-positivism/medievalism reference-of-thought as subtransversality- $<$ in-desublimating-existentialeventuating/denouement> of-motif-and-apriorising/axiomatising/referencing' warrants 'prospective positivism ${ }^{83}$ reference-of-thought as supratransversality-<in-sublimatingexistential-eventuating/denouement $>\sim$ of-motif-and-apriorising/axiomatising/referencing teleological-differentiation/scission/variance/disambiguation', and so by the 'positivising/rational-empiricism-based-universalisation-directed-rulemaking-over-non-rulesapriorising/axiomatising/referencing-psychologism of prospective positivism'simplicited_attendant-ontological-contiguity ${ }^{67}$ ? educedexistentialising/contextualising/textualising_'intelligibility/epistemicity/reflexivity-contiguity$<$ imbued-notional $\sim$ cogency $>,,-<$ reifying-or-elucidating-of-prospective-relative-ontologicalcompleteness -of- reference-of-thought- devolving-as-of-instantiative-context $>$ as to existence-potency ${ }^{32} \sim$ sublimating-nascence,-disclosed-from-prospective-epistemic- 
digression—rules-of-apriorising/axiomatising/referencing-that-further-epistemically-

unconceal-the-very-ontologically-same-existential-reality' thus preempting the

' ${ }^{103}$ universalisation-directed-rulemaking-over-non-rules-

apriorising/axiomatising/referencing-psychologism (as 'second-level $\quad{ }^{79}$ presencingabsolutising-identitive-constitutedness ${ }^{14}$ of ${ }^{83}$ reference-of-thought') of ${ }^{103}$ universalisation'simplicited_attendant-ontological-contiguity ${ }^{67}$, educed-

existentialising/contextualising/textualising_'intelligibility/epistemicity/reflexivity-contiguity-

$<$ imbued-notional $\sim$ cogency $>,{ }^{\prime},-<$ reifying-or-elucidating-of-prospective-relative-ontological-

completeness -of- reference-of-thought- devolving-as-of-instantiative-context $>$ now of threshold-of-nonconviction/madeupness/bottomlining-in-shallow-supererogation $-<$ as-to‘attendant-intradimensional'-prospectively-disontologising preconverging/dementing apriorising-psychologism>, as-the-latter-fails-to-reflect $\quad$ existence-potency ${ }^{39} \sim$ sublimating- $^{-}$ nascence,-disclosed-from-prospective-epistemic-digression—rules-of-

apriorising/axiomatising/referencing-that-further-epistemically-unconceal-the-veryontologically-same-existential-reality at its corresponding uninstitutionalised-threshold ${ }^{102}$ state of non-positivism/medievalism'; -the postlogism 77 (including psychopathy and social psychopathy, etc.) associated with 'positivism- ${ }^{80}$ procrypticism ${ }^{83}$ reference-of-thought as subtransversality-<in-desublimating-existential-eventuating/denouement $>\sim$ of-motif-andapriorising/axiomatising/referencing' warrants 'prospective notional ' ${ }^{8}$ deprocrypticism reference-of-thought as supratransversality-<in-sublimating-existentialeventuating/denouement $>\sim$ of-motif-and-apriorising/axiomatising/referencing teleologicaldifferentiation/scission/variance/disambiguation', and so by the 'preempting — disjointednessas-of- ${ }^{8}$ reference-of-thought,-as-to- ${ }^{6}<$ amplituding/formative-epistemicity $>$ growth-orconflatedness ${ }^{13} /$ transvaluative-rationalising/transepistemicity/anamnestic-residuality/spiritdrivenness'-in-superseding-mere-formulaic-positivising/rational-empiricism-based- 
universalisation-directed-rulemaking-over-non-rules — apriorising/axiomatising/referencingpsychologism of prospective deprocrypticism's - implicited_attendant-ontologicalcontiguity $^{67}$, educed-

existentialising/contextualising/textmalising_intelligibility/epistemicity/reflexivity-contiguity$<$ imbued-notional $\sim$ cogency $>,{ }^{\prime},-<$ reifying-or-elucidating-of-prospective-relative-ontologicalcompleteness -of- reference-of-thought- devolving-as-of-instantiative-context $>$ as to existence-potency ${ }^{39} \sim$ sublimating-nascence,-disclosed-from-prospective-epistemicdigression—rules-of-apriorising/axiomatising/referencing-that-further-epistemicallyunconceal-the-very-ontologically-same-existential-reality' thus preempting the 'positivising/rational-empiricism-based-universalisation-directed-rulemaking-over-non-rulesapriorising/axiomatising/referencing-psychologism (as 'third-level ${ }^{79}$ presencing—absolutisingidentitive-constitutedness ${ }^{14}$ of ${ }^{8}$ reference-of-thought') of positivism's_implicited_attendantontological-contiguity ${ }^{67}$, educedexistentialising/contextualising/textualising_intelligibility/epistemicity/reflexivity-contiguity$<$ imbued-notional $\sim$ cogency $>,{ }^{\prime},-<$ reifying-or-elucidating-of-prospective-relative-ontologicalcompleteness -of- reference-of-thought- devolving-as-of-instantiative-context $>$ now of threshold-of-nonconviction/madeupness/bottomlining-in-shallow-supererogation $<-<$ as-to‘attendant-intradimensional'-prospectively-disontologising preconverging/dementing apriorising-psychologism>, as-the-latter-fails-to-reflect $\quad$ existence-potency ${ }^{32} \sim$ sublimatingnascence,-disclosed-from-prospective-epistemic-digression—rules-ofapriorising/axiomatising/referencing-that-further-epistemically-unconceal-the-veryontologically-same-existential-reality at its corresponding uninstitutionalised-threshold ${ }^{102}$ state of procrypticism-or-disjointedness-as-of- ${ }^{8}$ reference-of-thought'. The prior relativeontological-incompleteness ${ }^{8}$-induced,-`threshold-of-nonconviction/madeupness/bottomliningin-shallow-supererogation -<as-to- 'attendant-intradimensional'-prospectively- 
disontologising $\sim$ preconverging/dementing -apriorising-psychologism> ${ }^{\prime}$ for relativeontological-completeness ${ }^{87}$-of- ${ }^{83}$ reference-of-thought are explained by the fact that: - 'recurrentutter-uninstitutionalisation ${ }^{83}$ reference-of-thought' (base-constitutedness ${ }^{14}$ of ${ }^{83}$ reference-ofthought), by its recurrent-utter-uninstitutionalisation's_-implicited_attendant-ontologicalcontiguity $^{67}$, educed-

existentialising/contextualising/textualising_intelligibility/epistemicity/reflexivity-contiguity$<$ imbued-notional $\sim$ cogency $>,{ }^{\prime},-<$ reifying-or-elucidating-of-prospective-relative-ontologicalcompleteness -of- reference-of-thought- devolving-as-of-instantiative-context>, is epistemically failing/not-upholding-<as-of-apriorising/axiomatising/referencing $>\quad$ the 'rulemaking-over-non-rules_-apriorising/axiomatising/referencing-psychologism of prospective base-institutionalisation's_-implicited_attendant-ontologicalcontiguity ${ }^{67} \sim$ educedexistentialising/contextualising/textualising_'intelligibility/epistemicity/reflexivity-contiguity$<$ imbued-notional $\sim$ cogency $>,{ }^{\prime},-<$ reifying-or-elucidating-of-prospective-relative-ontologicalcompleteness -of- reference-of-thought- devolving-as-of-instantiative-context $>$ as to existence-potency ${ }^{39} \sim$ sublimating-nascence,-disclosed-from-prospective-epistemicdigression—rules-of-apriorising/axiomatising/referencing-that-further-epistemicallyunconceal-the-very-ontologically-same-existential-reality', while upholding 'its now thresholdof-nonconviction/madeupness/bottomlining-in-shallow-supererogation $<<$ as-to-' attendantintradimensional'-prospectively-disontologising preconverging/dementing -apriorisingpsychologism $>\quad$ recurrent-utter-uninstitutionalisation's $\quad$ non-rulesapriorising/axiomatising/referencing-psychologism,-as-impulsive-or-accidented-or-randommental-disposition circularly-inducing its uninstitutionalised-threshold ${ }^{102}$ state of recurrentutter-uninstitutionalisation', -'base-institutionalisation-ununiversalisation ${ }^{83}$ reference-ofthought' (first-level ${ }^{7}$ presencing-absolutising-identitive-constitutedness ${ }^{14}$ of ${ }^{83}$ reference-of- 
thought) is epistemically failing/not-upholding-<as-of-apriorising/axiomatising/referencing $>$ the ' ${ }^{103}$ universalisation-directed-rulemaking-over-non-rulesapriorising/axiomatising/referencing-psychologism of prospective ${ }^{103}$ universalisation'simplicited_attendant-ontological-contiguity ${ }^{67}$, educedexistentialising/contextualising/textualising_intelligibility/epistemicity/reflexivity-contiguity$<$ imbued-notional cogency $>,{ }^{\prime},-<$ reifying-or-elucidating-of-prospective-relative-ontologicalcompleteness -of- reference-of-thought- devolving-as-of-instantiative-context $>$ as to existence-potency $^{39} \sim$ sublimating-nascence,-disclosed-from-prospective-epistemicdigression — rules-of-apriorising/axiomatising/referencing-that-further-epistemicallyunconceal-the-very-ontologically-same-existential-reality', while upholding 'its now thresholdof-nonconviction/madeupness/bottomlining-in-shallow-supererogation $<<$ as-to-' attendantintradimensional'-prospectively-disontologising preconverging/dementing -apriorisingpsychologism> base-institutionalisation's rulemaking-over-non-rulesapriorising/axiomatising/referencing-psychologism inducing its uninstitutionalised-threshold state of ununiversalisation', - ' ${ }^{103}$ universalisation-non-positivism/medievalism ${ }^{83}$ reference-ofthought' (second-level ${ }^{79}$ presencing-absolutising-identitive-constitutedness ${ }^{14}$ of ${ }^{83}$ referenceof-thought) is epistemically failing/not-upholding-<as-of-apriorising/axiomatising/referencing $>$ the 'positivising/rational-empiricism-based-universalisation-directed-rulemaking-over-nonrules_apriorising/axiomatising/referencing-psychologism of prospective positivism'simplicited_attendant-ontological-contiguity ${ }^{67}$, educedexistentialising/contextualising/textmalising_intelligibility/epistemicity/reflexivity-contiguity$<$ imbued-notional $\sim \operatorname{cogency}>,{ }^{\prime},-<$ reifying-or-elucidating-of-prospective-relative-ontologicalcompleteness -of- reference-of-thought- devolving-as-of-instantiative-context $>$ as to existence-potency ${ }^{32} \sim$ sublimating-nascence,-disclosed-from-prospective-epistemicdigression—rules-of-apriorising/axiomatising/referencing-that-further-epistemically- 
unconceal-the-very-ontologically-same-existential-reality', while upholding 'its now thresholdof-nonconviction/madeupness/bottomlining-in-shallow-supererogation $<<$ as-to- 'attendantintradimensional'-prospectively-disontologising preconverging/dementing -apriorisingpsychologism> ${ }^{103}$ universalisation's ${ }^{103}$ universalisation-directed-rulemaking-over-non-rulesapriorising/axiomatising/referencing-psychologism inducing its uninstitutionalised-threshold state of non-positivism/medievalism, and prospectively -our 'positivism- ${ }^{80}$ procrypticism reference-of-thought' (third-level ${ }^{79}$ presencing-absolutising-identitive-constitutedness ${ }^{14}$ of reference-of-thought) is failing/not-upholding-<as-of-apriorising/axiomatising/referencing $>$ the 'preempting — disjointedness-as-of- ${ }^{3}$ reference-of-thought,-as-to${ }^{6}{ }^{32}<$ amplituding/formative-epistemicity $>$ growth-or-conflatedness ${ }^{13} /$ transvaluativerationalising/transepistemicity/anamnestic-residuality/spirit-drivenness'_-in-supersedingmere-formulaic-positivising/rational-empiricism-based-universalisation-directed-rulemakingover-non-rules_-apriorising/axiomatising/referencing-psychologism of prospective deprocrypticism's_-implicited_attendant-ontological-contiguity ${ }^{67}$ 'educedexistentialising/contextalising/textalising_'intelligibility/epistemicity/reflexivity_contiguity$<$ imbued-notional $\sim$ cogency $>,{ }^{\prime},-<$ reifying-or-elucidating-of-prospective-relative-ontologicalcompleteness -of- reference-of-thought- devolving-as-of-instantiative-context> as to existence-potency ${ }^{32} \sim$ sublimating-nascence,-disclosed-from-prospective-epistemicdigression—rules-of-apriorising/axiomatising/referencing-that-further-epistemicallyunconceal-the-very-ontologically-same-existential-reality', while upholding 'its now thresholdof-nonconviction/madeupness/bottomlining-in-shallow-supererogation $<-<$ as-to- 'attendantintradimensional'-prospectively-disontologising preconverging/dementing -apriorisingpsychologism> positivism positivising/rational-empiricism-based-universalisation-directedrulemaking-over-non-rules_-apriorising/axiomatising/referencing-psychologism inducing its corresponding uninstitutionalised-threshold ${ }^{102}$ state of procrypticism'; and it is the latter 
prospective institutionalisation (deprocrypticism) that conceptually achieves ontologicalcompleteness-of- ${ }^{-3}$ reference-of-thought/ontological-normalcy/conflatedness ${ }^{13}$ thus superseding the possibility of prospective postlogism 77 , as it registers and implies by its ${ }^{83}$ reference-ofthought a supratransversality- $<$ in-sublimating-existential-eventuating/denouement $>\sim$ of-motifand-apriorising/axiomatising/referencing that fully reflects the ontological-veracity of humansubpotency-aporia/undecidability/dilemma/oughtindeterminacy/deficiency/limitation/constraint—imbued-'notional firstnaturednessformativeness-<as-to-eventualising-inkling-drive-or-seeding-misprising $>$ temporal-tointemporal-dispositions- $<$ so-construed-as-from-perspective-ontologicalnormalcy/postconvergence>'-existentialism-form-factor. postlogism 77 (disontologisingperverted-outcome-sought-precedes-existentially-veridical-'attendant-intradimensionalapriorising/axiomatising/referencing'-logical-dueness) is the 'abnormal application of logic for virtuality-or-ontologically-flawed-construal/being-construal-as-abstract-construal-as-offlawed-and-shallow-and-non-veridical-existential-reference' or hollow-constituting-<asdisjointed-misappropriation-of-meaningfulness-and-failing-intemporal-preservation> is very much different from the 'normal application of logic for being-construal-or-intrinsic-realityconstrual as-abstract-construal-as-of-veridical-existential-reference' known as prelogism ${ }^{78}$-asof-conviction,-in-profound-supererogation $-<$ existentially-veridical-'attendantintradimensional-apriorising/axiomatising/referencing'-logical-dueness-precedesdisontologising-logical-outcome-arrived-at> as supplanting-conviction-as-to-profoundsupererogation —of-'attendant-intradimensional'-postconverging/dialectical-thinking apriorising-psychologism whether 'good or poor/bad supplanting-conviction-as-to-profoundsupererogation - of-'attendant-intradimensional'-postconverging/dialectical-thinking apriorising-psychologism' which is at the least 'of sound logical-dueness of ${ }^{83}$ reference-ofthought', whereas postlogism (disontologising-perverted-outcome-sought-precedes- 
existentially-veridical-'attendant-intradimensional-apriorising/axiomatising/referencing'logical-dueness) in hollow-constituting-<as-disjointed-misappropriation-of-meaningfulnessand-failing-intemporal-preservation> being 'as of threshold-ofnonconviction/madeupness/bottomlining-in-shallow-supererogation $-<$ as-to-'attendantintradimensional'-prospectively-disontologising preconverging/dementing -apriorisingpsychologism>' do not operate on the same logical-dueness of registry/anchoring-ofmeaning/meaningful-reference/ontological-reference/contending-reference/registry-worldview mental-devising-representation basis of prelogism ${ }^{7}$-as-of-conviction,-in-profoundsupererogation -<existentially-veridical-'attendant-intradimensionalapriorising/axiomatising/referencing'-logical-dueness-precedes-disontologising-logicaloutcome-arrived-at> as 'of sound ${ }^{83}$ reference-of-thought' which is reflected as mental straightness and candored. Rather postlogism 77 in hollow-constituting-<as-disjointedmisappropriation-of-meaningfulness-and-failing-intemporal-preservation $>$ being about 'vaguerhyming-or-copied-mimicry-or-formulaic-projection-or-projection-of-form-or-hollow-andvague-vocalisation-or-subknowledging ', harkens back to a registry/mental-devisingrepresentation that is reflected/perspectivated as preconverging-or-dementing ${ }^{20}$-apriorisingpsychologism (oblongated/decandored-and-dialectically-or-contendingly-out-of-phase). Thus postlogism 7 in hollow-constituting-<as-disjointed-misappropriation-of-meaningfulness-andfailing-intemporal-preservation> and-the-temporal-dispositions-conjugation-to-it-asconjugated-postlogism ${ }^{77}$ ) (psychopathic-implies fundamentally non-veridical implied reference-of-thought- ${ }^{8}$ ategorical-imperatives/axioms/registry-teleology ${ }^{99}$,-for-intemporalpreservation-entropy-or-contiguity-or-ontological-preservation and thus the apriorising-

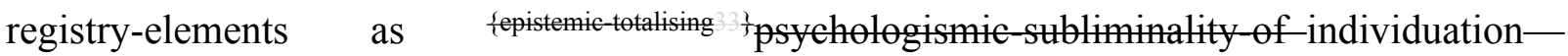
effusing/worlding imbued logical-dueness-or-scape-or-frame, profile-or-stature, presumptuousness-or-arrogation, assumptions, value-reference and teleology ${ }^{9}$ are undue for 
logical contention but rather ontologically reflected/perspectivated in ${ }^{74}$ perversion-ofreference-of-thought-<as-preconvergingly-apriorising/axiomatising/referencing-innonconviction/madeupness/bottomlining-as-to-shallow-supererogation $>$. In existential< disontologising/re-ontelogising aporeticism $>$ terms, postlogism 77 in hollow-constituting$<$ as-disjointed-misappropriation-of-meaningfulness-and-failing-intemporal-preservation $>$ (psychopathic-and-the-temporal-dispositions-conjugation-to-it-as-conjugated-postlogism 77 ) speaks of a disposition to engage in postlogic-backtracking-<iterative-looping-'set-ofdereifying-hollow-narratives-and-acts'>76, involving absolving/fleeting/escaping-reflex-logic , counting on the fact that others will sooner or later be in prelogism ${ }^{7}$-as-of-conviction,-inprofound-supererogation $\quad<$ existentially-veridical-'attendant-intradimensionalapriorising/axiomatising/referencing'-logical-dueness-precedes-disontologising-logicaloutcome-arrived-at> relation with the formulaic slanting compulsingnonconviction/madeupness/bottomlining-〈'<decontextualising/de-existentialising ofattendant-intradimensional-apriorising/axiomatising/referencing>-induced-disontologising'-ofthe-'attendant-intradimensional-ontologising'-imbued$<$ contextualising/existentialising attendant-ontological-contiguity $>$;-in-shallowsupererogation -<as-to-disontologising-perverted-outcome-sought-precedes-existentiallyveridical-'attendant-intradimensional-apriorising/axiomatising/referencing'-logical-dueness $>$ ) as postlogism in preconverging-or-dementing -apriorising-psychologism, hence wrongly elevating its $\quad{ }^{74}$ perversion-of- ${ }^{83}$ reference-of-thought- $<$ as-preconverginglyapriorising/axiomatising/referencing-in-nonconviction/madeupness/bottomlining-as-toshallow-supererogation $>$ into logical-contention rather than dealing with registryworldview's/dimension's-uninstitutionalised-threshold ${ }^{12}$-defect-<as-Being-or-ontological-orexistential-defect $>^{85}$. postlogism 77 in hollow-constituting-<as-disjointed-misappropriation-ofmeaningfulness-and-failing-intemporal-preservation> (psychopathic-and-the-temporal- 
dispositions-conjugation-to-it-as-conjugated-postlogism 77 ) thus inherently implies and is about articulations

of perversion-of- ${ }^{8}$ reference-of-thought-<as-preconverginglyapriorising/axiomatising/referencing-in-nonconviction/madeupness/bottomlining-as-to-

shallow-supererogation $>$ with respect in the very first instance to the validity of implied reference-of-thought rather than valid articulations of logical contention as the latter is with respect to ontological-veridicality of ${ }^{5}$ logical-processing-or-logical-implicitation — supposedlyapriorising-in-conviction-as-to-profound-supererogation only after the former ( ${ }^{8}$ reference-ofthought) has been established as veridical/true. postlogism $77 /$ perverted-as-disontologisingoutcome-sought-precedes-logical-dueness is not about a defect-of- ${ }^{5}$ logical-processing-orlogical-implicitation - supposedly-apriorising-in-conviction-as-to-profound-supererogation of the registry-worldview's/dimension's- ${ }^{8}$ reference-of-thought-for-social-functioning-andaccordance but rather speaks of false projection of 'apriorising- ${ }^{83}$ reference-ofthought/apriorising-registry_elements (out of 'implicited_attendant-ontologicalcontiguity ${ }^{67} \sim$ educed-

existentialising/contextualising/textualising_intelligibility/epistemicity/reflexivity-contiguity$<$ imbued-notional $\sim$ cogency $>,{ }^{\prime},-<$ reifying-or-elucidating-of-prospective-relative-ontological-

completeness -of- reference-of-thought- devolving-as-of-instantiative-context $>$ )' of \{epistemictotalising 3 psychologismic-subliminality-of-individuation-effusing/worlding imbued logicaldueness-or-scape-or-frame, profile-or-stature, presumptuousness-or-arrogation, assumptions, value-reference and teleology implying registry-worldview's/dimension's-uninstitutionalisedthreshold $^{102}$-defect-<as-Being-or-ontological-or-existential-defect $>55$ as first-order faultymentation-procedure-deception-or-urge ${ }^{43} \quad$ (inducing circularity/recurrence/repetition/repeatability ${ }^{10}$ of a subsequent implication of a second-order level wrongly implied deception of ${ }^{5}$ logical-processing-or-logical-implicitation — supposedlyapriorising-in-conviction-as-to-profound-supererogation of infinite deception possibilities 
with respect to the infinite possibilities of 'perfect ${ }^{5}$ logical-processing-or-logicalimplicitation - supposedly-apriorising-in-conviction-as-to-profound-supererogation ' on the false basis of the perversion-and-derived- perversion-of- $^{-}$reference-of-thought- $<$aspreconvergingly-apriorising/axiomatising/referencing-innonconviction/madeupness/bottomlining-as-to-shallow-supererogation $>$ ). Such ${ }^{7}$ perversionof- ${ }^{8}$ reference-of-thought-<as-preconvergingly-apriorising/axiomatising/referencing-innonconviction/madeupness/bottomlining-as-to-shallow-supererogation $>$ /mental-devisingrepresentation-perversion has various shades of 'temporal/shortness to intemporal/longness depth/register of meaningfulness stranded finalities/teleologies'. This can be demonstrated as follows with psychopathy at childhood (which at this point is relatively transparent to the critical observer). Let's say John is a psychopath, he wants to get his brother Peter punished for annoying him. John knows that dad will punish anyone who spills water on the chair. John, in a 'dereifying act', then spills water on a chair and goes and tell dad Peter has spilled water on the chair, and waits for Peter to get punished (and, this way of acting and thinking is not limited only to a benign notion like spilling water as it could be setting fire, destroying an equipment, etc.). This is different even from 'poor or bad supplanting-conviction-as-to-profound-supererogation

\section{of-'attendant-intradimensional'-postconverging/dialectical-thinking -apriorising-}

psychologism' or prelogism ${ }^{78}$ in that a child who has a 'poor or bad supplanting-conviction-asto-profound-supererogation _of-'attendant-intradimensional'-postconverging/dialecticalthinking -apriorising-psychologism' or prelogism ${ }^{78}$ is ad-hoc and circumspect by taking advantage or reacting to a situation that has developed to accuse another as of temporalexistential constraint. They don't initiate such a situation 'as a rational way of thinking' and even less to the gravity that the psychopath does. One other major flaw in the perception of the psychopath is that they are liars (a pathological liar, it is said). This again is a flawed notion. To lie is to be in prelogism ${ }^{78}$-as-of-conviction,-in-profound-supererogation 
veridical-'attendant-intradimensional-apriorising/axiomatising/referencing'-logical-dueness-

precedes-disontologising-logical-outcome-arrived-at> ('poor or bad supplanting-conviction-asto-profound-supererogation —of-'attendant-intradimensional'-postconverging/dialectical-

thinking -apriorising-psychologism'), whether by omitting or exaggerating in a circumspect and ad-hoc manner but relative to 'implicited_attendant-ontological-contiguity ${ }^{67}$; educedexistentialising/contextualising/textualising_intelligibility/epistemicity/reflexivity-contiguity$<$ imbued-notional $\sim$ cogency $>,{ }^{\prime},-<$ reifying-or-elucidating-of-prospective-relative-ontologicalcompleteness -of- reference-of-thought- devolving-as-of-instantiative-context>. Lying as such is an 'ad-hoc defect-of- logical-processing-or-logical-implicitation—supposedlyapriorising-in-conviction-as-to-profound-supererogation of the registryworldview's/dimension's- ${ }^{83}$ reference-of-thought-for-social-functioning-and-accordance that doesn't speak of the true postlogism 77 psychopathic phenomenon which has to do with the perversion-of- ${ }^{-3 e f e r e n c e-o f-t h o u g h t-<a s-p r e c o n v e r g i n g l y-~}$

apriorising/axiomatising/referencing-in-nonconviction/madeupness/bottomlining-as-to-

shallow-supererogation >,-and-not-of-logical-contention with regards to registry/anchoringof-meaning/meaningful-reference/ontological-reference/contending-reference/registry-

worldview as the psychopath ${ }^{7}$ perversion-of- ${ }^{83}$ eference-of-thought- $<$ as-preconverginglyapriorising/axiomatising/referencing-in-nonconviction/madeupness/bottomlining-as-to-

shallow-supererogation $>$ speaks of a 'circularity/recurrence/repetition/repeatability' as enabled by social-functioning-and-accordance-as-of-social-stake-contention-or-confliction' implying a 'being or ontological or meaningfulness or existential-<disontologising/reentologising aporeticism $>$ defect' which is poorly construed as 'pathological lying at the level of ${ }^{5}$ logical-processing-or-logical-implicitation—supposedly-apriorising-in-conviction-as-toprofound-supererogation of supplanting-conviction-as-to-profound-supererogation - of‘attendant-intradimensional'-postconverging/dialectical-thinking -apriorising-psychologism 
or prelogic mental-reflex engagement' rather than being construed as a mental and teleological disposition defect at the level of the ${ }^{83}$ reference-of-thought as of ${ }^{74}$ perversion-of- ${ }^{8}$ reference-ofthought-<as-preconvergingly-apriorising/axiomatising/referencing-in-

nonconviction/madeupness/bottomlining-as-to-shallow-supererogation $>$ construed as mentalunsoundness). In fact, besides 'lying' such poor characterisation of the psychopath extends to other notions like 'bullying', 'manipulating', 'fooling', etc. which are all in ${ }^{83}$ reference-ofthought-prelogism ${ }^{78}$-as-of-conviction,-in-profound-supererogation $-<$ existentially-veridical'attendant-intradimensional-apriorising/axiomatising/referencing'-logical-dueness-precedesdisontologising-logical-outcome-arrived-at> notions though of 'poor or bad supplantingconviction-as-to-profound-supererogation -of-'attendant-intradimensional'postconverging/dialectical-thinking -apriorising-psychologism's' ('poor or bad supplantingconviction-as-to-profound-supererogation —of-'attendant-intradimensional'postconverging/dialectical-thinking -apriorising-psychologism' or prelogism ${ }^{78}$ construed as wrong 54 logical-processing-or-logical-implicitation—supposedly-apriorising-in-conviction-asto-profound-supererogation or wrong operation of prelogism ${ }^{7}$-as-of-conviction,-in-profoundsupererogation -<existentially-veridical-'attendant-intradimensionalapriorising/axiomatising/referencing'-logical-dueness-precedes-disontologising-logicaloutcome-arrived-at $>$ but nonetheless prelogism ${ }^{8}$-as-of-conviction,-in-profoundsupererogation $-<$ existentially-veridical-'attendant-intradimensionalapriorising/axiomatising/referencing'-logical-dueness-precedes-disontologising-logicaloutcome-arrived-at $>$ ). Fundamentally, psychopathic slanting is particular in that it departs from a relation to the "empty-form-of-meaning-as-inherently-deterministic outside the framework of a veridical 'implicited_attendant-ontological-contiguity ${ }^{67}$ ' educedexistentialising/contextualising/textualising_intelligibility/epistemicity/reflexivity-contiguity$<$ imbued-notional $\sim$ cogency $>,{ }^{\prime},-<$ reifying-or-elucidating-of-prospective-relative-ontological- 
completeness -of- reference-of-thought- devolving-as-of-instantiative-context>' contrasted with 'poor or bad supplanting-conviction-as-to-profound-supererogation - of-'attendantintradimensional'-postconverging/dialectical-thinking -apriorising-psychologism' which departs with a relation to 'omitting or exaggerating within the framework of a veridical 'implicited_attendant-ontological-contiguity ${ }^{6 /}$ educedexistentialising/contextualising/textualising_intelligibility/epistemicity/reflexivity-contiguity$<$ imbued-notional $\sim$ cogency $>,{ }^{\prime},-<$ reifying-or-elucidating-of-prospective-relative-ontologicalcompleteness -of- reference-of-thought- devolving-as-of-instantiative-context>' . But while poor-or-bad prelogism ${ }^{78}$ may be what is perceived from a 'normal' social and supplantingconviction-as-to-profound-supererogation _of-'attendant-intradimensional'postconverging/dialectical-thinking -apriorising-psychologism point of view, particularly with adult psychopathy; these are all wrong and actually will make an analysis of the psychopath and psychopathy ontologically-flawed. The psychopath is in a state of compulsingnonconviction/madeupness/bottomlining-〈‘ $<$ decontextualising/de-existentialising $\sim$ ofattendant-intradimensional-apriorising/axiomatising/referencing $>$-induced-disontologising'-ofthe-'attendant-intradimensional-ontologising'-imbued$<$ contextualising/existentialising attendant-ontological-contiguity $>$;-in-shallowsupererogation -<as-to-disontologising-perverted-outcome-sought-precedes-existentiallyveridical-'attendant-intradimensional-apriorising/axiomatising/referencing'-logical-dueness $>$ > or 'compulsive-dementing ${ }^{20}$ (not recognising/giving-up-on the sound operation/processing of logic as the basis for deriving essence of meaning but rather perceiving meaning as just a hollow mimicking form that determines how others will act, more like a projection of form, i.e. compulsing-nonconviction/madeupness/bottomlining-〈'<decontextualising/deexistentialising $\sim$ of-attendant-intradimensional-apriorising/axiomatising/referencing $>$-induceddisontologising'-of-the-‘attendant-intradimensional-ontologising'-imbued- 
$<$ contextualising/existentialising attendant-ontological-contiguity $>$;-in-shallow-

supererogation -<as-to-disontologising-perverted-outcome-sought-precedes-existentially-

veridical-'attendant-intradimensional-apriorising/axiomatising/referencing'-logical-dueness $>$ >

being a state of 'conscious, unprincipled and instrumentalised threshold-ofnonconviction/madeupness/bottomlining-in-shallow-supererogation $<-<$ as-to-' attendant-

intradimensional'-prospectively-disontologising preconverging/dementing -apriorising-

psychologism> in veridical unsoundness-or-ontological-bad-faith/inauthenticity -ofreference-of-thought as the psychopathic mindset/ ${ }^{83}$ reference-of-thought $<$ amplituding/formative-epistemicity $>$ causality $\sim$ as-to-projective-totalitative-implications-ofprospective- nonpresencing,-for-explicating relative-unreflexivity/relative-reflexivity _

ontological-contiguity value-reference reflected by its ${ }^{7}$ perversion-of- ${ }^{3}$ reference-of-thought$<$ as-preconvergingly-apriorising/axiomatising/referencing-in-

nonconviction/madeupness/bottomlining-as-to-shallow-supererogation $>$, in contrast to supplanting-conviction-as-to-profound-supererogation - of-'attendant-intradimensional'postconverging/dialectical-thinking -apriorising-psychologism as a state of 'conscious, principled and uninstrumentalised supplanting-conviction-as-to-profound-supererogation of-'attendant-intradimensional'-postconverging/dialectical-thinking -apriorising-

psychologism in veridical soundness-or-ontological-good-faith/authenticity ${ }^{6}$-of- ${ }^{8}$ reference-ofthought as the supplanting-conviction-as-to-profound-supererogation - of-'attendantintradimensional'-postconverging/dialectical-thinking -apriorising-psychologism mindset $/{ }^{3}$ reference-of-thought $\quad<$ amplituding/formative-epistemicity $>$ causality $\sim$ as-toprojective-totalitative-implications-of-prospective- nonpresencing,-for-explicating relative unreflexivity/relative-reflexivity ontological-contiguity value-reference'. This is the fundamental fact that explains the evasiveness in grasping the psychopath in its motive and orientation as the psychopath's actions can be as simple as a basic formulaic (meaning-by-the- 
mere-illogical-possibility-of-it-being-formulaically-narrated-or-postlogism 7 -formulaic slanting compulsing-nonconviction/madeupness/bottomlining-〈' $<$ decontextualising/deexistentialising $\sim$ of-attendant-intradimensional-apriorising/axiomatising/referencing $>$-induceddisontologising'-of-the-'attendant-intradimensional-ontologising'-imbued$<$ contextualising/existentialising attendant-ontological-contiguity $>$;-in-shallowsupererogation -<as-to-disontologising-perverted-outcome-sought-precedes-existentiallyveridical-'attendant-intradimensional-apriorising/axiomatising/referencing'-logical-dueness $>$ > as to preconverging-or-dementing ${ }^{20}$-apriorising-psychologism) understanding of the effects on interlocutors of endearing, pleasing, laughter, etc. in inducing distraction, empathy, suspensionof-profound-reasoning or ${ }^{83}$ reference-of-thought teleological-degration in relation to its threshold-of-nonconviction/madeupness/bottomlining-in-shallow-supererogation $<<$ as-to‘attendant-intradimensional'-prospectively-disontologising preconverging/dementing apriorising-psychologism> in undermining a prelogism 7 -as-of-conviction,-in-profoundsupererogation $-<$ existentially-veridical-'attendant-intradimensionalapriorising/axiomatising/referencing'-logical-dueness-precedes-disontologising-logicaloutcome-arrived-at $>$ perspective which ${ }^{8}$ reference-of-thought is veridical. All the 'poor or bad supplanting-conviction-as-to-profound-supererogation —of-'attendant-intradimensional'postconverging/dialectical-thinking -apriorising-psychologism' terms above, i.e. lying, bullying, manipulating, fooling, etc., wrongly point to the fact that the psychopath is having a 'deliberative prelogism ${ }^{78}$-as-of-conviction,-in-profound-supererogation $-<$ existentiallyveridical-'attendant-intradimensional-apriorising/axiomatising/referencing'-logical-duenessprecedes-disontologising-logical-outcome-arrived-at> mental process' with respect to its end purpose, and thus wrongly implying it is in 'prelogism ${ }^{8}$-as-of-conviction,-in-profoundsupererogation -<existentially-veridical-'attendant-intradimensionalapriorising/axiomatising/referencing'-logical-dueness-precedes-disontologising-logical- 
outcome-arrived-at> with the wrong idea that its

apriorising/axiomatising/referencing/intelligibilitysettingup/measuringinstrumenting

apriorising- ${ }^{8}$ reference-of-thought/apriorising-registry-elements of totalising $3{ }^{3}$ psychologismic-subliminality-of-individuation-effusing/worlding imbued logicaldueness-or-scape-or-frame, profile-or-stature, presumptuousness-or-arrogation, assumptions, value-reference and teleology are existentially-<disontologising/re-ontologising aporeticism $>$ veridical. The psychopath is operating on the basis of a 'last mimicking denaturing $\quad$ postlogism 7 - construed-as-of-disontologising-perverted-outcome-soughtprecedes-existentially-veridical-'attendant-intradimensional-

apriorising/axiomatising/referencing'-logical-dueness $\quad$ postlogic-backtracking- $<$ iterativelooping-'set-of-dereifying-hollow-narratives-and-acts'> ${ }^{76}$-with-succeeding-shifting-of-thenarratives-and-acts-foci-as-deception-of-successively-shifting-or-non-cohering-narratives-andacts' towards 'social-aggregation-enablers over intrinsic-reality/ontological-veridicality transcendental-enabling/sublimating/supererogatory $\sim$ de-mentativity', and so to satisfy a 'faultymentation-procedure-deception-or-urge ${ }^{4}$; and so, one narrative iteration at a time. Now the faulty-mentation-procedure-deception-or-urge 'i3nplying a 'supplanting-conviction-as-toprofound-supererogation —of-'attendant-intradimensional'-postconverging/dialecticalthinking -apriorising-psychologism deliberativeness' is coming from its interlocutor's 'prelogism ${ }^{78}$-as-of-conviction,-in-profound-supererogation $<-<$ existentially-veridical'attendant-intradimensional-apriorising/axiomatising/referencing'-logical-dueness-precedesdisontologising-logical-outcome-arrived-at> mind' itself which prelogicly/in-conviction-as-toprofound-supererogation (as the prelogism ${ }^{78}$, which is wrongly induced in distractivealignment-to- ${ }^{8}$ reference-of-thought- $<$ of-apriorising/axiomatising/referencing $>{ }^{30}$, conjoins all the denaturing postlogism 7 - construed-as-of-disontologising-perverted-outcome-soughtprecedes-existentially-veridical-'attendant-intradimensional- 
apriorising/axiomatising/referencing'-logical-dueness

postlogic-backtracking-<iterativelooping-'set-of-dereifying-hollow-narratives-and-acts'> ${ }^{76}$-with-succeeding-shifting-of-thenarratives-and-acts-foci-as-deception-of-successively-shifting-or-non-cohering-narratives-andacts as absolving/fleeting/escaping-reflex-logic , to wrongly imply a depth-of-conviction-as-toprofound-supererogation whether as of bad or good supplanting-conviction-as-to-profoundsupererogation —of-'attendant-intradimensional'-postconverging/dialectical-thinking apriorising-psychologism or prelogism ${ }^{78}$ ) in reality is wrongly assuming a depth-ofpostlogism -slantedness/insane integration. The psychopath being postlogic — construed-as-ofdisontologising-perverted-outcome-sought-precedes-existentially-veridical-'attendantintradimensional-apriorising/axiomatising/referencing'-logical-dueness or pathologically/compulsively hollow-constituting-<as-disjointed-misappropriation-ofmeaningfulness-and-failing-intemporal-preservation> is not lying (or manipulating or bullying), in fact the psychopath will prefer that normal supplanting-conviction-as-to-profoundsupererogation - of-'attendant-intradimensional'-postconverging/dialectical-thinking apriorising-psychologism minds think it is lying (or any notion of a 'poor or bad supplantingconviction-as-to-profound-supererogation —of-'attendant-intradimensional'postconverging/dialectical-thinking -apriorising-psychologism' as it wrongly elicits just a defect-of- ${ }^{5}$ logical-processing-or-logical-implicitation — supposedly-apriorising-in-convictionas-to-profound-supererogation rather than the idea of compulsingnonconviction/madeupness/bottomlining-〈“<decontextualising/de-existentialising $\sim$ ofattendant-intradimensional-apriorising/axiomatising/referencing--induced-disontologising'-ofthe- 'attendant-intradimensional-ontologising'-imbued$<$ contextualising/existentialising attendant-ontological-contiguity $>$;-in-shallowsupererogation -<as-to-disontologising-perverted-outcome-sought-precedes-existentiallyveridical-'attendant-intradimensional-apriorising/axiomatising/referencing'-logical-dueness $>>$, 
as at least they will then wrongly realign in prelogism ${ }^{7}$-as-of-conviction,-in-profoundsupererogation $-<$ existentially-veridical-'attendant-intradimensionalapriorising/axiomatising/referencing'-logical-dueness-precedes-disontologising-logicaloutcome-arrived-at>) again to it with respect to its subsequent narratives to examine the pertinence of its logic/logical-processing, i.e. engaging logical operating/processing and wrongly granting it supplanting-conviction-as-to-profound-supererogation - of-'attendantintradimensional'-postconverging/dialectical-thinking -apriorising-psychologism (be it even 'poor or bad supplanting-conviction-as-to-profound-supererogation - of-'attendantintradimensional'-postconverging/dialectical-thinking -apriorising-psychologism' as this will then wrongly imply its wrong or poor performance of ${ }^{54}$ logical-processing-or-logicalimplicitation - supposedly-apriorising-in-conviction-as-to-profound-supererogation , rather than its hollow-constituting-<as-disjointed-misappropriation-of-meaningfulness-and-failingintemporal-preservation>/vague-rhyming-or-copied-mimicry-or-formulaic-projection-orprojection-of-form-or-hollow-and-vague-vocalisation-or-subknowledging $\%$ /slanting of empty narratives that are flawed or non-existent as postlogism -as-of- compulsingnonconviction/madeupness/bottomlining-〈‘ $<$ decontextualising/de-existentialising $\sim$ ofattendant-intradimensional-apriorising/axiomatising/referencing>-induced-disontologising'-ofthe-'attendant-intradimensional-ontologising'-imbued-

$<$ contextualising/existentialising attendant-ontological-contiguity $>$;-in-shallowsupererogation -<as-to-disontologising-perverted-outcome-sought-precedes-existentiallyveridical-'attendant-intradimensional-apriorising/axiomatising/referencing'-logicaldueness $>\rangle$ ) thus wrongly involved in prelogism ${ }^{78}$ hence wrongly validating as real its 'fundamental faulty-mentation-procedure-deception-or-urge ${ }^{13}$ which is its 'apriorisingreference-of-thought/apriorising-registry-elements, that in reality are out of 'implicited_attendant-ontological-contiguity ${ }^{67}$ ' educed- 
existentialising/contextualising/textualising_'intelligibility/epistemicity/reflexivity-contiguity$<$ imbued-notional $\sim$ cogency $>,{ }^{\prime},-<$ reifying-or-elucidating-of-prospective-relative-ontologicalcompleteness -of- reference-of-thought- devolving-as-of-instantiative-context>', of totalising 3 psychologismic-subliminality-of-individuation-effusing/worlding imbued logicaldueness-or-scape-or-frame, profile-or-stature, presumptuousness-or-arrogation, assumptions, value-reference and teleology (instead of examining in-the-very-first-place their relevance/pertinence or its soundness-or-ontological-good-faith/authenticity -of- ${ }^{6}$ referenceof-thought); in so doing, analysing its meaning as essence instead of analysing it as non-veridical hollow mimicking form or vague-rhyming-or-copied-mimicry-or-formulaic-projection-orprojection-of-form-or-hollow-and-vague-vocalisation-or-subknowledging ${ }^{44}$ or meaning-by-themere-illogical-possibility-of-it-being-formulaically-narrated or non-veridical hollow mimicking narratives. What the psychopath is doing is 'SLANTING' as of compulsive-slantingpreconverging-or-dementing 20 -apriorising. That is to arrive at a sought-outcome by subknowledging 9 -or-mimicking the non-veridical hollow-form of the meaning of other persons supplanting-conviction-as-to-profound-supererogation —of-'attendant-intradimensional'postconverging/dialectical-thinking -apriorising-psychologism narratives which it perceives as 'being blatantly deterministic' of the views and actions of the 'normal prelogism ${ }^{78}$-as-ofconviction,-in-profound-supererogation $-<$ existentially-veridical-'attendant-intradimensionalapriorising/axiomatising/referencing'-logical-dueness-precedes-disontologising-logicaloutcome-arrived-at $>$ mind', i.e. the psychopath is 'narrating veridical emptiness/hollow narratives'. The idea being about arriving at a sought-outcome by taking a posture that does not attach a depth of supplanting-conviction-as-to-profound-supererogation - of-'attendantintradimensional'-postconverging/dialectical-thinking -apriorising-psychologism narratives but rather simply the 'mere possibility of the hollow narratives being articulated, and then integrated by interlocutors as real'. Thus the psychopathic postlogic mindset and by 
derivation conjugated-postlogisim/preconverging-or-dementing -integration mindset is one of relating to meaningfulness as valid by the 'mere performative-form representation of meaningfulness' rather than veracity/ontological-pertinence of meaningfulness. The psyche is thus fundamentally one geared towards how to perform in interlocution rather than express a genuine sense of supplanting-conviction-as-to-profound-supererogation - of-'attendantintradimensional'-postconverging/dialectical-thinking -apriorising-psychologism and hence the disposition for extrinsic-attribution by active social-aggregation-enabling. Meaningfulness is seen not as an end-construct that is of passive social determinism by its inherent veracity/ontological-pertinence as of intrinsic-attribution associated with transcendentalenabling/sublimating/supereregatory de-mentativity, but rather as a potent and active construct of social determinism which requires actually eliciting a sought after outcome and not a notion of intrinsic existential/ontological inherence. This mental-disposition is qualified as epistemicdecadence or postlogism 77 and its derivation/adoption by temporal-dispositions is derivedepistemic-decadence in conjugated-postlogism 7 . More precisely, it is critical to distinguish between the notion of slanting (cinglé in French) as postlogism -as-of- compulsingnonconviction/madeupness/bottomlining-〈'<decontextualising/de-existentialising of-

attendant-intradimensional-apriorising/axiomatising/referencing>-induced-disontologising'-ofthe-'attendant-intradimensional-ontologising'-imbued-

$<$ contextualising/existentialising attendant-ontological-contiguity $>$;-in-shallow-

supererogation -<as-to-disontologising-perverted-outcome-sought-precedes-existentiallyveridical-'attendant-intradimensional-apriorising/axiomatising/referencing'-logical-dueness $>$ > and the notion of a lie which is in manifest prelogism -as-of-conviction,-in-profoundsupererogation -<existentially-veridical-'attendant-intradimensionalapriorising/axiomatising/referencing'-logical-dueness-precedes-disontologising-logicaloutcome-arrived-at> (be it a 'poor or bad supplanting-conviction-as-to-profound- 
supererogation —of-'attendant-intradimensional'-postconverging/dialectical-thinking

apriorising-psychologism') as with a lie the implied-logical-dueness (with the corresponding implied- ${ }^{3}$ reference-of-thought/implied-registry elements) are existentially-<disontologising/reentelogising aporeticism $\geqslant$ veridical with the 'lying deception' being of ad-hoc exaggeration or omission or inappropriate accounting of circumstantiality and/or factuality but as of 'effectively due' ${ }^{54}$ logical-processing-or-logical-implicitation - supposedly-apriorising-in-conviction-as-toprofound-supererogation . The narratives-and-acts-foci of the set-of-narratives of a 'lying deception' do not successively shift (as with slanting) but carry an overall coherence implying deception-but-as-of-successively-cohering-narratives. This is because a lie is more of deception arising out of ad-hoc contextual-ambiguity-constraint(s) ad-hocly articulated as deception-butas-of-successively-cohering-narratives to resolve the ad-hoc contextual-ambiguity-constraint(s), and lying doesn't fundamentally imply where such ad-hoc contextual-ambiguity-constraint(s) is non-existent the interlocutor will still not be predisposed to a veridical and appropriate logicalengagement/interlocution/implicitation. This equally explains why a lie collapses as a whole (or whole pieces of the lie) since such a collapse arises out of the truth/ontological-veridicality resolution of the contextual-ambiguity-constraint(s) behind the coherent structure(s) of the lying deception. Slanting on-the-other-hand speaks of a fundamental pathological faulty-mentationprocedure-deception-or-urge associated with postlogism ${ }^{43}$-as-of- compulsingnonconviction/madeupness/bottomlining-〈‘ $<$ decontextualising/de-existentialising $\sim$ ofattendant-intradimensional-apriorising/axiomatising/referencing>-induced-disontologising'-ofthe-'attendant-intradimensional-ontologising'-imbued$<$ contextualising/existentialising attendant-ontological-contiguity $>$;-in-shallowsupererogation -<as-to-disontologising-perverted-outcome-sought-precedes-existentiallyveridical-'attendant-intradimensional-apriorising/axiomatising/referencing'-logical-dueness $>$ > with respect to social-stake-contention-or-confliction (and by extension 'derived-slanting' 
induced as conjugated-postlogism 77 -opportunism and conjugated-postlogism 77 -exacerbation arises out of purposeful enculturation/endemisation of the slanting habit where it is viewed by some interlocutors of the psychopath as socially-functional-and-accordant ${ }^{93}$, since its manifestation is not ${ }^{103}$ universally transparent as ontologically decadent); due to the slanted child psychopathy mind's developmental incompleteness (as it is so focussed on attaining its sought after outcome in advance that it construes of 'presupposing/presuming/premising in concurrence' as an independent mental activity that must not necessarily be derived-and-implied from 'implicited_attendant-ontological-contiguity ${ }^{67}$ ' educedexistentialising/contextualising/textualising_'intelligibility/epistemicity/reflexivity-contiguity$<$ imbued-notional $\sim$ cogency $>,{ }^{\prime},-<$ reifying-or-elucidating-of-prospective-relative-ontologicalcompleteness -of- reference-of-thought- devolving-as-of-instantiative-context $>$, whereas the latter is exactly what validates logical-processing-or-logical-implicitation-supposedlyapriorising-in-conviction-as-to-profound-supererogation as a process reflecting existentialreality as of andividuationeffusing/worlding imbued logical-dueness-or-scape-or-frame, profile-or-stature, presumptuousness-or-arrogation, assumptions, value-reference and teleology ${ }^{9}$ ), with respect to construing meaningfulness as prelogism -as-of-conviction,-in-profound-supererogation $<$ existentially-veridical-'attendant-intradimensional-apriorising/axiomatising/referencing'logical-dueness-precedes-disontologising-logical-outcome-arrived-at $>$, but instead construes meaningfulness as postlogism -as-of- compulsing-nonconviction/madeupness/bottomlining$〈<<$ decontextualising/de-existentialising $\sim$ of-attendant-intradimensionalapriorising/axiomatising/referencing>-induced-disontologising'-of-the-'attendantintradimensional-ontologising'-imbued-<contextualising/existentialising $\sim$ attendantontological-contiguity $>$;-in-shallow-supererogation -<as-to-disontologising-pervertedoutcome-sought-precedes-existentially-veridical-'attendant-intradimensional- 
apriorising/axiomatising/referencing'-logical-dueness $>$ > explaining the circular nature and its particularly overblown extrinsic-attribution mental-disposition to elicit social-aggregationenabling over relative intrinsic-reality/ontological-veridicality transcendentalenabling/sublimating/supereregatery $\sim$ de-mentativity with regards to inherent reality and meaningfulness. The peculiarity of slanting is that it is deception-of-successively-shifting-ornon-cohering-narratives-and-acts wherein the initiation of a hollow falsehood narrative is followed by the projection of another hollow falsehood narrative on the basis of the former as if the former was true, and the projection of another falsehood narrative on the basis of the previous one as if the previous one was true, and so on. Thus slanting doesn't have a 'coherent whole of narratives' with respect to 'implicited_attendant-ontological-contiguity ${ }^{67}$; educedexistentialising/contextualising/textualising_intelligibility/epistemicity/reflexivity-contiguity$<$ imbued-notional $\sim$ cogency $>,{ }^{\prime},-<$ reifying-or-elucidating-of-prospective-relative-ontologicalcompleteness -of- reference-of-thought- devolving-as-of-instantiative-context $>$ as is the case when someone tells a lie, and actually where such a 'coherent whole of narratives' with respect to 'implicited_attendant-ontological-contiguity ${ }^{6 /}$ ' educedexistentialising/contextualising/textualising_intelligibility/epistemicity/reflexivity-contiguity$<$ imbued-notional $\sim$ cogency $>,{ }^{\prime},-<$ reifying-or-elucidating-of-prospective-relative-ontologicalcompleteness -of- reference-of-thought- devolving-as-of-instantiative-context $>$ is wrongly implied about slanting, it has to do with prelogism-as-of-conviction,-in-profoundsupererogation $-<$ existentially-veridical-'attendant-intradimensionalapriorising/axiomatising/referencing'-logical-dueness-precedes-disontologising-logicaloutcome-arrived-at $>$ mind/mental-disposition 'wrongly conjoining the succession of slanting narratives from the last iterated slanted narrative' to wrongly imply that the slanting psychopath narratives are a 'coherent whole of narratives as of 'implicited_attendant-ontologicalcontiguity $^{67}$, educed- 
existentialising/contextualising/textualising_'intelligibility/epistemicity/reflexivity-contiguity$<$ imbued-notional $\sim$ cogency $>,{ }^{\prime},-<$ reifying-or-elucidating-of-prospective-relative-ontologicalcompleteness -of- reference-of-thought- devolving-as-of-instantiative-context>', and this is the mechanism that induces conjugated-postlogism 77 preconverging-or-dementing ${ }^{20}$-integration by some interlocutors of the adult psychopath, whether conscious or unconsciously. It is interesting to note that at childhood psychopathy where the mental-disposition is relatively universally-transparent what is perceived and related to by supplanting-conviction-as-toprofound-supererogation _of-'attendant-intradimensional'-postconverging/dialecticalthinking -apriorising-psychologism interlocutors is not a 'coherent whole of narratives' but a deliriousness/delirious-effect/cinglé-effect/mental-unsoundness-effect arising out of its contemplation (as if it were true), pointing out that the reality of mental-states in wrong prelogism ${ }^{7}$-as-of-conviction,-in-profound-supererogation $-<$ existentially-veridical‘attendant-intradimensional-apriorising/axiomatising/referencing'-logical-dueness-precedesdisontologising-logical-outcome-arrived-at $>$ alignment to psychopathic slanting is actually a mental-unsoundness not different as contemplating aligning in supplanting-conviction-as-toprofound-supererogation _of-'attendant-intradimensional'-postconverging/dialecticalthinking -apriorising-psychologism to the childhood psychopathy slanting as with the dereifying example of spilling water on a chair and accusing another. A salient comparison that strongly highlights the difference between slanting and lying, is that a lying child doesn't come across as delirious since its lying deception is a coherent whole as of contextual-ambiguityconstraint(s) while a slanting deception is as of faulty-mentation-procedure-deception-or-urge due to psychopathic developmental failure to relate to meaningfulness as of prelogism ${ }^{78}$-as-of-

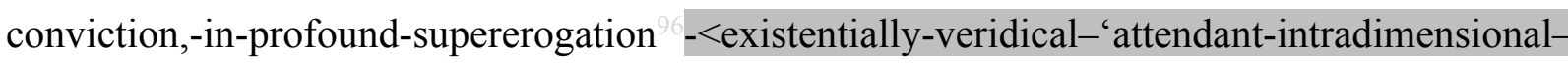
apriorising/axiomatising/referencing'-logical-dueness-precedes-disontologising-logicaloutcome-arrived-at $>$ with the personality development out of that developmental failure bringing 
about the adult psychopath slanting mental-disposition with respect to social-stake-contentionor-confliction; and as the adult psychopath developed maturation/indirectness/spatialisation/credulity/craftiness to attain social-functioning-andaccordance-as-of-social-stake-contention-or-confliction, induces interlocutors prelogic supplanting-conviction-as-to-profound-supererogation —of-'attendant-intradimensional'postconverging/dialectical-thinking -apriorising-psychologism alignment to its postlogic compulsing-nonconviction/madeupness/bottomlining-〈'<decontextualising/deexistentialising $\sim$ of-attendant-intradimensional-apriorising/axiomatising/referencing $>$-induceddisontologising'-of-the-'attendant-intradimensional-ontologising'-imbued$<$ contextualising/existentialising attendant-ontological-contiguity $>$;-in-shallowsupererogation -<as-to-disontologising-perverted-outcome-sought-precedes-existentiallyveridical-'attendant-intradimensional-apriorising/axiomatising/referencing'-logical-dueness $>$ > narratives whereas at childhood psychopathy interlocutors will not align in-prelogic supplanting-conviction-as-to-profound-supererogation -of-'attendant-intradimensional'postconverging/dialectical-thinking -apriorising-psychologismly (in order not to wrongly conjoin the psychopathic postlogic slanting narratives as deception-of-successively-shifting-ornon-cohering-narratives-and-acts as if of coherent whole as prelogic supplanting-conviction-asto-profound-supererogation —of-'attendant-intradimensional'-postconverging/dialecticalthinking -apriorising-psychologism narratives, and this is what actually occurs by inducing conjugated-postlogism 7 preconverging-or-dementing -integration in interlocutors at adulthood psychopathy) given the obvious and transparent deliriousness/delirious-effect/cinglé-effect associated with slanting over a slant over a slant, successively. Hence, this slanting deception (deception-of-successively-shifting-or-non-cohering-narratives-and-acts) is also qualified as deception-by-concurrently-false-presupposing/false-presuming/false-premising-of-narratives or deception-by-concurrently-false-assumptive-preconverging-or-dementing ${ }^{20}$-apriorising- 
psychologism. Thus, with slanting the implied-logical-dueness (with the corresponding impliedreference-of-thought/implied-registry elements) are existentially-<disontologising/reentologising aporeticism $>$ unreal/non-veridical/flawed explaining the meaningful emptiness/hollowness of slanting (as not even an exaggeration or omission or inappropriate accounting of circumstantiality and/or factuality as of 'effectively due' ${ }^{54}$ logical-processing-orlogical-implicitation — supposedly-apriorising-in-conviction-as-to-profound-supererogation ), thus explaining why 'slanting and derived-slanting' is construed as unsoundness-or-ontologicalbad-faith/inauthenticity ${ }^{64}$-of- ${ }^{83}$ reference-of-thought/preconverging-or-dementing ${ }^{20}$-apriorisingpsychologism as opposed to lying deception construed in a shade of soundness-or-ontologicalgood-faith/authenticity ${ }^{6}$-of- ${ }^{8}$ reference-of-thought. Insightfully, it points out as well that the basis of the postlogism 77 psychopathic induced deception is not the psychopath itself (as it is commonly asserted about psychopathic manipulation), but rather it lies in the very nature of the reasoning of the prelogism ${ }^{78}$-as-of-conviction,-in-profound-supererogation $<$ - existentiallyveridical-'attendant-intradimensional-apriorising/axiomatising/referencing'-logical-duenessprecedes-disontologising-logical-outcome-arrived-at> interlocutor mental engagement reflex who 'aligns in-conviction-as-to-profound-supererogation', as it will 'normally do' with other prelogic supplanting-conviction-as-to-profound-supererogation - of-'attendantintradimensional'-postconverging/dialectical-thinking -apriorising-psychologism minds to a postlogism -as-of- compulsing-nonconviction/madeupness/bottomlining$〈<<$ decontextualising/de-existentialising of-attendant-intradimensionalapriorising/axiomatising/referencing>-induced-disontologising'-of-the-'attendantintradimensional-ontologising'-imbued-<contextualising/existentialising $\sim$ attendantontological-contiguity $>$;-in-shallow-supererogation -<as-to-disontologising-pervertedoutcome-sought-precedes-existentially-veridical-'attendant-intradimensionalapriorising/axiomatising/referencing'-logical-dueness $>>$ mind, and then wrongly validates that 
$\langle<<$ decontextualising/de-existentialising of-attendant-intradimensional-

apriorising/axiomatising/referencing >-induced-disontologising'-of-the-'attendant-

intradimensional-ontologising'-imbued-<contextualising/existentialising $\sim$ attendant-

ontological-contiguity $>$;-in-shallow-supererogation $-<$ as-to-disontologising-perverted-

outcome-sought-precedes-existentially-veridical-'attendant-intradimensional-

apriorising/axiomatising/referencing'-logical-dueness $>$ > mind is in prelogism ${ }^{78}$-as-ofconviction,-in-profound-supererogation ${ }^{-}<$existentially-veridical-'attendant-intradimensionalapriorising/axiomatising/referencing'-logical-dueness-precedes-disontologising-logical-

outcome-arrived-at $>$. In order words, the operation of the psychopathic mind as of its incomplete mentation development (as inclined to induce a faulty-mentation-procedure-deception) as it fails to construe meaningfulness as based on prelogism -as-of-conviction,-in-profoundsupererogation $-<$ existentially-veridical-'attendant-intradimensionalapriorising/axiomatising/referencing'-logical-dueness-precedes-disontologising-logicaloutcome-arrived-at> but rather as based on postlogism -as-of- compulsingnonconviction/madeupness/bottomlining-〈" $<$ decontextualising/de-existentialising $\sim$ ofattendant-intradimensional-apriorising/axiomatising/referencing>-induced-disontologising'-ofthe-'attendant-intradimensional-ontologising'-imbued$<$ contextualising/existentialising attendant-ontological-contiguity $>$;-in-shallowsupererogation -<as-to-disontologising-perverted-outcome-sought-precedes-existentiallyveridical-'attendant-intradimensional-apriorising/axiomatising/referencing'-logical-dueness $>$ ) with its personality development into adulthood on this basis, paradoxically leads to the prelogism ${ }^{78}$-as-of-conviction,-in-profound-supererogation $-<$ existentially-veridical'attendant-intradimensional-apriorising/axiomatising/referencing'-logical-dueness-precedesdisontologising-logical-outcome-arrived-at $>$ mind's deception since the latter operates on the 
basis that everyone must be of supplanting-conviction-as-to-profound-supererogation

‘attendant-intradimensional'-postconverging/dialectical-thinking -apriorising-psychologism

(be it 'poor or bad supplanting-conviction-as-to-profound-supererogation - of-'attendantintradimensional'-postconverging/dialectical-thinking -apriorising-psychologism' at worst) and the notion of postlogism 77 -as-of- compulsing-nonconviction/madeupness/bottomlining$\langle<<$ decontextualising/de-existentialising of-attendant-intradimensionalapriorising/axiomatising/referencing >-induced-disontologising'-of-the-'attendantintradimensional-ontologising'-imbued-<contextualising/existentialising $\sim$ attendantontological-contiguity $>$;-in-shallow-supererogation -<as-to-disontologising-pervertedoutcome-sought-precedes-existentially-veridical-'attendant-intradimensionalapriorising/axiomatising/referencing'-logical-dueness $>$ > doesn't register naturally except where the personality development of the childhood psychopathy into an adult psychopath is experienced closely, and the adulthood psychopath mentation processes structure can be retraced to the delirious mentation processes structure at childhood psychopathy when it is ${ }^{103}$ universally transparent as maturation/indirectness/spatialisation/credulity/craftiness continually developed during its personality development into adulthood psychopathy now enables it becoming socially-functional-and-accordant ${ }^{3}$. This induced deception does not however occur at childhood psychopathy since it is very much transparent as a deliriousness/deliriouseffect/cinglé-effect as the childhood psychopathy has hardly achieved maturation/indirectness/spatialisation/credulity/craftiness of its slanting-deception mentaldisposition. What underlies the slanting of the psychopath is its rather unnuanced understanding and gauging of social situations and social cues as out of 'implicited_attendant-ontologicalcontiguity $^{67}$, educedexistentialising/contextmalising/textualising_'intelligibility/epistemicity/reflexivity-contiguity$<$ imbued-notional cogency > ${ }^{\prime 0}$ by its dereification on a mental-processing disposition that is 
rather a 'dereifying bivalent-disposition-to-acute-caricatural-prepotence-or-acute-lullingdiffidence', and so in contrast with the expected 'reifying nuanced/multivalent mentalprocessing' of supplanting-conviction-as-to-profound-supererogation - of-'attendantintradimensional'-postconverging/dialectical-thinking -apriorising-psychologism dispositions in 'implicited_attendant-ontological-contiguity ${ }^{67}$ ' educedexistentialising/contextualising/textualising_intelligibility/epistemicity/reflexivity-contiguity<imbued-notional cogency $>^{\prime}$, , however bad-or-poor their ontological-performance ${ }^{72}$ $<$ including-virtue-as-ontology $>$ /morality/ethics/justice/etc. of supplanting-conviction-as-toprofound-supererogation —of-'attendant-intradimensional'-postconverging/dialecticalthinking -apriorising-psychologism mental-processing. This underlies the apparent vividness of interlocution with the psychopath especially with regards to social-stake-contention-orconfliction due to a 'supplanting-conviction-as-to-profound-supererogation — of-'attendantintradimensional'-postconverging/dialectical-thinking -apriorising-psychologism manifestation of the interlocutor by compulsing-nonconviction/madeupness/bottomlining$\langle<<$ decontextualising/de-existentialising $\sim$ of-attendant-intradimensionalapriorising/axiomatising/referencing >-induced-disontologising'-of-the-'attendantintradimensional-ontologising'-imbued-<contextualising/existentialising attendantontological-contiguity >;-in-shallow-supererogation -<as-to-disontologising-pervertedoutcome-sought-precedes-existentially-veridical-'attendant-intradimensionalapriorising/axiomatising/referencing'-logical-dueness $>>$ manifestation of the psychopath crossperception effect' wherein the supplanting-conviction-as-to-profound-supererogation —of'attendant-intradimensional'-postconverging/dialectical-thinking -apriorising-psychologism interlocutor by its mental-reflex is wrongly inclined to perceive and so specifically with adult psychopathy a 'reifying nuanced/multivalent mental-processing' in knowledgereification $\sim$ gesturing-and-accounting — of-epistemic-phenomenalism- $<$ in- 
prospective_psychologismic apriorising/axiomatising/referencing-\{of- ${ }^{\text {prospectively }}$

implicited_attendant-ontological-contiguity ' educed-

existentialising/contextualising/textualising_'intelligibility/epistemicity/reflexivity-contiguity-

<imbued-notional cogency >’ \}-conflatedness -in-\{preconverging-disentailment by\}

postconverging-entailment $>$ with regards to the psychopath 'dereifying bivalent-disposition-toacute-caricatural-prepotence-or-acute-lulling-diffidence' as to inducing the interlocutor reifying perception of the psychopath's dereifying projection of 'implicited_attendant-ontologicalcontiguity $^{6}$, educed-

existentialising/contextualising/textualising_'intelligibility/epistemicity/reflexivity-contiguity$<$ imbued-notional cogency $>$, while the psychopath view of the supplanting-conviction-asto-profound-supererogation _of-'attendant-intradimensional'-postconverging/dialecticalthinking -apriorising-psychologism interlocutor's supposedly 'reifying nuanced/multivalent mental-processing, knowledge-reification $\sim$ gesturing-and-accounting-of-epistemicphenomenalism- $<$ in-prospective_psychologismic $\sim$ apriorising/axiomatising/referencing- of'prospectively_implicited_attendant-ontological-contiguity ' educedexistentialising/contextualising/textualising_'intelligibility/epistemicity/reflexivity-contiguity<imbued-notional cogency >' \}-conflatedness in \{preconverging disentailment by\} postconverging-entailment> is rather as of its 'dereifying bivalent-disposition-to-acutecaricatural-prepotence-or-acute-lulling-diffidence' inclination as to inducing the interlocutors reifying perception of the psychopath's dereifying projection of 'implicited_attendant ontological-contiguity ${ }^{67}$; educedexistentialising/contextualising/textualising_intelligibility/epistemicity/reflexivity-contiguity$<$ imbued-notional cogency $>$ '. While at childhood psychopathy such a 'dereifying bivalentdisposition-to-acute-caricatural-prepotence-or-acute-lulling-diffidence' as to inducing the interlocutors reifying perception of the psychopath's dereifying projection of 
'implicited_attendant-ontological-contiguity ${ }^{67}$ educedexistentialising/contextualising/textualising_'intelligibility/epistemicity/reflexivity_contiguity<imbued-notional cogency>' is socially inefficacious and trouble-inducing giving the deliriousness effect from ${ }^{103}$ universal-transparency ${ }^{104}$-〈transparency-of-totalising-entailing,-asto-entailing-<amplituding formative-epistemicity $>$ totalising in-relative-ontological-

completeness $>$ of its acts, at adulthood psychopathy the lack of such ${ }^{103}$ universaltransparency ${ }^{104}$-〈transparency-of-totalising-entailing,-as-to-entailing-<amplituding/formativeepistemicity $>$ totalising in-relative-ontological-completeness $>$ of the postlogism ${ }^{77}$-slantedness rather makes the latter 'sound impassioned/stirring/vivid/spirited' to the unsuspecting interlocutor who by mental-reflex wrongly assumes as ontologically-veridical the falsely implied 'implicited_attendant-ontological-contiguity ${ }^{67}$ educedexistentialising/contextualising/textualising_intelligibility/epistemicity/reflexivity-contiguity$<$ imbued-notional cogency $>$ ', giving the psychopath life-long learnedness and adaptation from its childhood inefficacy as of its increasing maturation/indirectness/spatialisation/credulity/craftiness with adulthood, and this latter 'apparently impassioned/stirring/vivid/spirited but rather falsely implied 'implicited_attendantontological-contiguity $^{67}$, educedexistentialising/contextualising/textualising_intelligibility/epistemicity/reflexivity-contiguity$<$ imbued-notional cogency $>{ }^{\prime 0}$ disposition tends to be socially enculturated/endemised as of conjugated-postlogism 7 . But then, more than just the deception this state of affairs has a further nefarious effect on the natural human-subpotency-aporia/undecidability/dilemma/oughtindeterminacy/deficiency/limitation/constraint—imbued-'notional firstnaturednessformativeness-<as-to-eventualising-inkling-drive-or-seeding-misprising $>$ temporal-tointemporal-dispositions- $<$ so-construed-as-from-perspective-ontologicalnormalcy/postconvergence>'-existentialism-form-factor, as the induced 'lack of constraining 

respect to intrinsic meaningfulness further elicits supplanting-conviction-as-to-profoundsupererogation _of-'attendant-intradimensional'-postconverging/dialectical-thinking apriorising-psychologism minds temporal-dispositions of ignorance/affordability/opportunism/exacerbation/social-chainism-or-social-discomfiture-ornegative-social-aggregation/temporal-enculturation-or-temporal-endemisation, which can actually be more decisive grounds for the perpetuation of psychopathy as social-psychopathy, as the fact is the psychopath is very much pathological and tends to act compulsively in its faultymentation-procedure-deception as of circumstantiality.

[This is more profoundly exposed in the conceptualisation in reflecting holographically$<$ conjugatively-and-transfusively $>$ the relative-unreflexivity/relative-reflexivity - ontologicalcontiguity $\sim$ of-the-human-institutionalisation-process as it induces 'socially-functional-and$\begin{array}{lll}\text { accordant } & { }^{83} \text { reference-of-thought } \quad \text { as } & \text { of }\end{array}$ aporia/undecidability/dilemma/ought-indeterminacy/deficiency/limitation/constraint—imbued'notional firstnaturedness-formativeness-<as-to-eventualising-inkling-drive or seedingmisprising $>$ temporal-to-intemporal-dispositions- $<$ so-construed-as-from-perspectiveontological-normalcy/postconvergence>'-existentialism-form-factor; that can be elucidated by an 'implicited_attendant-ontological-contiguity ${ }^{6 /}$ ' educedexistentialising/contextmalising/textualising_'intelligibility/epistemicity/reflexivity_contiguity$<$ imbued-notional $\sim$ cogency $>,,<$, reifying-or-elucidating-of-prospective-relative-ontologicalcompleteness -of- reference-of-thought- devolving-as-of-instantiative-context $>$ analysis of 'least-and-derived-temporal-operating-modalities-of-the- ${ }^{8}$ reference-of-thought-as-ofincrementalism-in-relative-ontological-incompleteness ${ }^{88}$ enframed/disontologising $\sim$ conceptualisation-inducing-the-uninstitutionalised-threshold ${ }^{02}$ '- 
and-not-'maximal-as-intemporal-operating-modality-of- ${ }^{8}$ reference-of-thought-as-ofmaximalising-recomposuring-for-relative-ontological-completeness ${ }^{87}$ unenframed/reontologising conceptualisation-as-inducing-the-prospective-institutionalisation'. Central to such an insight, is the understanding of what the reality of human-subpotencyaporia/undecidability/dilemma/ought-indeterminacy/deficiency/limitation/constraint—imbued'notional firstnaturedness-formativeness-<as-to-eventualising-inkling-drive or seedingmisprising $>$ temporal-to-intemporal-dispositions-<so-construed-as-from-perspectiveontological-normalcy/postconvergence>'-existentialism-form-factor means about human mental-disposition. The implication is that we 'consistently' have two sets of mental-dispositions having to do with the uninstitutionalised-threshold ${ }^{12}$ of all registry-worldviews/dimensions; as of metaphysics-of-presence-_implicited-'nondescript/ignorable-void '-as-to- presencingabsolutising-identitive-constitutedness \ and metaphysics-of-absence-〈implicited-epistemicveracity-of- nonpresencing-<perspective-ontological-normalcy/postconvergence $>>$

representations. First, ‘human registry-worldview's/dimension's institutionalisation mentaldisposition' within the scope of a registry-worldview's/dimension's institutionalisation reference-of-thought- categorical-imperatives/axioms/registry-teleology ${ }^{9}$,-for-intemporalpreservation-entropy-or-contiguity-or-ontological-preservation (as-not-failing/upholding intemporal-preservation-entropy-or-contiguity-or-ontological-preservation as of ontologicalnormalcy/postconvergence which always factor in human limited-mentation-capacitydeepening — as-subjecting-limitedness/human-subpotency-to-'educed-unlimitedness/existencesublimating nascence' 53 by a re-equilibrating metaphysics-of-absence-〈implicited-epistemicveracity-of- nonpresencing-<perspective-ontologicalnormalcy/postconvergence $>$ //postdication). Then, 'human temporal uninstitutionalisedthreshold mental-disposition' construed either 'as out of the scope of the registryworldview's/dimension's institutionalisation $\quad{ }^{83}$ reference-of-thought- categorical- 
imperatives/axioms/registry-teleology ${ }^{9}$,-for-intemporal-preservation-entropy-or-contiguityor-ontological-preservation' or the 'registry-worldview/dimension uninstitutionalisedthreshold reference-of-thought'

(as-failing/not-upholding-<as-ofapriorising/axiomatising/referencing $>\quad$ intemporal-preservation-entropy-or-contiguity-orontological-preservation 'by projected <amplituding/formative $>$ wooden-language-〈imbued temporal-mere-form/virtualities/dereification/akrasiatic-drag/denatured/preconverging-ordementing -narratives - of-the- reference-of-thought- categoricalimperatives/axioms/registry-teleology $\rangle$ of the registry-worldview/dimension institutionalisation ${ }^{83}$ reference-of-thought', as of an ontological-normalcy/postconvergence epistemic-or-notional projective-perspective) as so reflected from the prospective registryworldview's/dimension's institutionalisation $\quad$ reference-of-thought- categoricalimperatives/axioms/registry-teleology ${ }^{9}$,-for-intemporal-preservation-entropy-or-contiguityor-ontological-preservation. With the attainment of registry-worldview/dimension institutionalisation by social ${ }^{103}$ universal-transparency ${ }^{104}-\langle$ transparency-of-totalising-entailing,as-to-entailing-<mplituding/formative-epistemicity $>$ totalising in-relative-ontological-

completeness > we can very much uphold a secondnatured quasi-intemporal-disposition reference-of-thought as ‘human registry-worldview's/dimension's institutionalisation mentaldisposition' which is why humankind pursues institutionalisations as devising human collective emancipation from base-institutionalisation to ${ }^{103}$ universalisation to positivism and

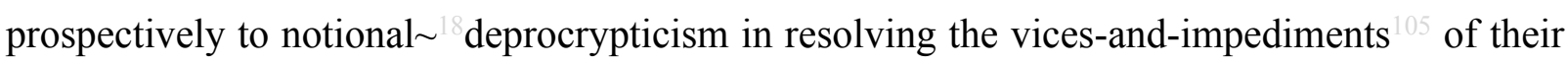
respective uninstitutionalised-threshold ${ }^{102}$ as recurrent-utter-uninstitutionalisation, ununiversalisation, non-positivism/medievalism and procrypticism. But exactly for the purpose of ensuring the perpetuation of this human registry-worldview's/dimension's institutionalisation capacity (as in enabling futural Being-development/ontological-framework-expansion-as-todepth-of-ontologising-development-as-infrastructure-of- meaningfulness-and-teleology as 
of prospective deprocrypticism) as the very essence of human virtue itself, it is equally important to understand how institutionalisation comes to be limited at $<$ cumulating/recomposuring attendant-ontological-contiguity $>$-successive registryworldviews/dimensions institutional-cumulation/institutional-recomposure-〈as-tohistoriality/ontological-eventfulness /ontological-aesthetic-tracing-<perspectiveontological-normalcy/postconvergence-reflected-‘epistemicity-relativism-determinism’ $>$ ) (as of human-subpotency-aporia/undecidability/dilemma/oughtindeterminacy/deficiency/limitation/constraint—imbued-'notional firstnaturednessformativeness-<as-to-eventualising inkling-drive-or-seeding-misprising $>$ temporal-tointemporal-dispositions-<so-construed-as-from-perspective-ontologicalnormalcy/postconvergence>'-existentialism-form-factor) to grasp how we can then supersede/transcend prospectively. 'Human temporal uninstitutionalised-threshold ${ }^{02}$ mentaldisposition' refers to our fixation to the mere- categorical-imperatives/axioms/registryteleology ${ }^{9}$ of the registry-worldview/dimension institutionalisation ${ }^{83}$ reference-of-thought but failing/not-upholding-<as-of-apriorising/axiomatising/referencing $>$ prospective intemporalpreservation-entropy-or-contiguity-or-ontological-preservation as of ontologicalnormalcy/postconvergence which always factor in human limited-mentation-capacitydeepening —as-subjecting limitedness/human-subpotency-to-'educed-unlimitedness/existencesublimating nascence' 53 by a re-equilibrating metaphysics-of-absence-〈implicited-epistemicveracity-of- nonpresencing-<perspective-ontological-

normalcy/postconvergence $>$ /postdication as construed from the prospective registryworldview/dimension institutionalisation ${ }^{83}$ reference-of-thought, and as revealed by this prospective institutionalisation 'implicited_attendant-ontological-contiguity ${ }^{67}$; educedexistentialising/contextualising/textualising_intelligibility/epistemicity/reflexivity-contiguity<imbued-notional cogency>' -in-elucidation-or-reification's-elucidation-of-prospective- 
relative-ontological-completeness ${ }^{87}$-of- ${ }^{8}$ reference-of-thought- ${ }^{8}$ devolving-as-of-instantiativecontext>. Fully understanding psychopathy which is the postlogism 7 -as-of- compulsingnonconviction/madeupness/bottomlining-〈< $<$ decontextualising/de-existentialising $\sim$ ofattendant-intradimensional-apriorising/axiomatising/referencing $>$-induced-disontologising'-ofthe-'attendant-intradimensional-ontologising'-imbued$<$ contextualising/existentialising attendant-ontological-contiguity $>$;-in-shallowsupererogation -<as-to-disontologising-perverted-outcome-sought-precedes-existentiallyveridical-'attendant-intradimensional-apriorising/axiomatising/referencing'-logical-dueness $>$ > of the positivism- ${ }^{80}$ procrypticism registry-worldview/dimension institutionalisationuninstitutionalisation ${ }^{8}$ reference-of-thought is inevitably tied to understanding our procrypticism as our 'human temporal uninstitutionalised-threshold ${ }^{102}$ mental-disposition' from futural Being-development/ontological-framework-expansion-as-to-depth-of-ontologisingdevelopment-as-infrastructure-of- meaningfulness-and-teleology as of prospective notional $\sim$ deprocrypticism registry-worldview institutionalisation ${ }^{83}$ reference-of-thought, as of ontological-normalcy/postconvergence wherein our procrypticism 'human temporal uninstitutionalised-threshold ${ }^{02}$ mental-disposition' is decentered and preconverging-ordementing 2 -apriorising-psychologism as dialectically-out-of-phase, just as understanding the postlogism of the universalisation-non-positivism/medievalism registryworldview's/dimension's ${ }^{8}$ reference-of-thought like notions of and accusations of sorcery, is inevitably tied to understanding non-positivism/medievalism as the 'human temporal uninstitutionalised-threshold ${ }^{102}$ mental-disposition' so-construed from prospective positivism registry-worldview/dimension institutionalisation ${ }^{8}$ reference-of-thought as of ontologicalnormalcy/postconvergence 'wherein the non-positivism/medieval mental-disposition is decentered and preconverging-or-dementing ${ }^{20}$-apriorising-psychologism as dialectically-out-ofphase; and in both instances, construed as of their relative-ontological-incompleteness ${ }^{8}$-of- 
reference-of-thought-induced-virtuality-or-ontologically-flawed-construal-or-caricaturinghollow-staging-and-performance (as-of-their-respective-prospective-registryworldview/dimension 'implicited_attendant-ontological-contiguity ${ }^{67}$ ' educedexistentialising/contextualising/textualising_'intelligibility/epistemicity/reflexivity-contiguity$<$ imbued-notional $\sim$ cogency $>,{ }^{\prime},-<$ reifying-or-elucidating-of-prospective-relative-ontologicalcompleteness -of- reference-of-thought- devolving-as-of-instantiative-context>; since the prospective institutionalisation 'implicited_attendant-ontological-contiguity ${ }^{67}$ ' educedexistentialising/contextualising/textualising_intelligibility/epistemicity/reflexivity-contiguity$<$ imbued-notional cogency> $>$-in-elucidation-or-reification's-elucidation-of-prospective-

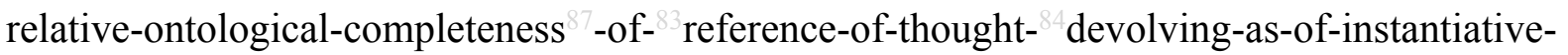
context $>$ speaks of a deeper limited-mentation-capacity-as-subjecting-'educedunlimitedness/existence-sublimating nascence' to-limitedness/human-subpotency-〈as of relative apriorising/axiomatising/referencing-\{of-'prospectively implicited_attendantontological-contiguity ' educedexistentialising/contextualising/textualising_'intelligibility/epistemicity/reflexivity-contiguity<imbued-notional cogency $\left.>^{\prime}\right\}$-conflatedness ${ }^{13}$-in-\{preconverging-disentailment by\} postconverging-entailment $\rangle$ of a deeper and more correct grasp/apriorising-and-understanding of ontology/ontological-veridicality/intrinsic-reality). Effectively, 'human temporal uninstitutionalised-threshold ${ }^{102}$ mental-disposition' is what is reflected at uninstitutionalisedthreshold as registry-worldviews/dimensions threshold-ofnonconviction/madeupness/bottomlining-in-shallow-supererogation $<<$ as-to-' attendantintradimensional'-prospectively-disontologising preconverging/dementing -apriorising-

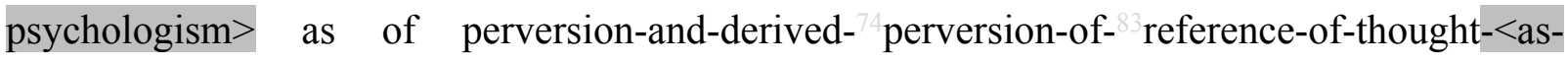
preconvergingly-apriorising/axiomatising/referencing-innonconviction/madeupness/bottomlining-as-to-shallow-supererogation $>$ of recurrent-utter- 
uninstitutionalisation, ununiversalisation, non-positivism/medievalism, and prospectively (as applicable with the construal of psychopathy and social psychopathy postlogism 7 ) procrypticism; wherein the habitual intradimensional placeholder-setup/mentation/mentaldevising-representation/consciousness-awareness-teleology' 'nondescript/ignorable-void (actually speaking of akrasiatic-drag-denatured-and-preconverging-or-dementing ${ }^{20}$-narratives) scheduling or a-registry-worldview's-or-dimension's-ignoring-of-its-prior-relative-ontologicalincompleteness ${ }^{8}$-of- ${ }^{3}$ reference-of-thought-as-an-ontologically-flawed-neuterisation ${ }^{59}$-orbracketing-or-epoché of <amplituding/formative-epistemicity $>$ totalising $\sim$ conflatedmeaningfulness-and-teleology ${ }^{9}$-as-of-notional ${ }^{8}$ deprocrypticism-reflectedhistoriality/ontological-eventfulness 38 /ontological-aesthetic-tracing- $<$ perspectiveontological-normalcy/postconvergence-reflected-'epistemicity-relativism-determinism'> as of the prospective apriorising/axiomatising/referencing/intelligibilitysettingup/measuringinstrumenting', at uninstitutionalised-threshold ${ }^{102}$ (reflecting uninstitutionalised-threshold ${ }^{102}$ ), is now substituted (from ontological-normalcy/postconvergence epistemic-or-notional projective-perspective of the prospective registry-worldview/dimension institutionalisation ${ }^{83}$ reference-of-thought) by its 'decentering and dialectical de-mentation of its ${ }^{83}$ reference-of-thought'; which we can effectively acquiesce to as of the uninstitutionalised-threshold ${ }^{12}$ but will rather have a mental complex when this is implied prospectively to imply our uninstitutionalised-threshold ${ }^{102}$ as procrypticism, just as all registry-worldviews/dimensions had hitherto displayed a mental complex when their construal as uninstitutionalised-threshold ${ }^{12}$ is implied. Thus this implied human 'postconverging-or-dialectical-thinking -psychology or psychology-of-mentationdynamics or natural psychological-dynamics' as driven by ontologicalnormalcy/postconvergence will explain the specific natures of registry-worldviews/dimensions references-of-thought (as 'underlying scheduling of soundness-or-ontological-good- 
faith/authenticity ${ }^{6}$-of- ${ }^{8}$ reference-of-thought')

\section{historiality/ontological-eventfulness /ontological-aesthetic-tracing-<perspective-}

ontological-normalcy/postconvergence-reflected-‘epistemicity-relativism-determinism’>>

peculiar psychologisms/psychologism-constructs of meaningfulness in explaining the empiricalrealities of the various anthropological societies mindsets/ $/{ }^{3}$ reference-of-thought/consciousnessawareness-teleology ; whether as recurrent-utter-uninstitutionalisation psychologism, baseinstutitonalisation-ununiversalisation psychologism, universalisation-nonpositivism/medievalism psychologism, positivism- ${ }^{80}$ procrypticism psychologism, and prospectively notional ${ }^{8}$ deprocrypticism psychologism equally qualified as suprastructuralism. Hence, our present positivism mental-disposition is just one of human historical psychologisms/psychologism-constructs, and it is not absolute as to imply there aren't or weren't other human psychologisms/psychologism-constructs, wherein in their own realisation, perception and thought they are 'not decentered' and 'not preconverging-or-dementing apriorising-psychologism' as of their relative-ontological-incompleteness ${ }^{8}$-of- ${ }^{8}$ reference-ofthought-induced-virtuality-or-ontologically-flawed-construal-or-caricaturing-hollow-stagingand-performance rather so construed from a higher psychologism's articulation of 'implicited_attendant-ontological-contiguity ${ }^{67}$ ' educedexistentialising/contextualising/textualising_'intelligibility/epistemicity/reflexivity-contiguity$<$ imbued-notional $\sim$ cogency $>,,-<$ reifying-or-elucidating-of-prospective-relative-ontological-

ontologically-veridical. Thus, notional deprocrypticism as decentering and preconverging-ordementing -apriorising-psychologism the positivism- ${ }^{-10}$ procrypticism registry-worldview reference-of-thought will certainly imply an altogether different psychologism of 
meaningfulness-and-teleology as suprastructuralism. It should be noted that the implied meaning of psychologism here has to fundamentally do with a psychology arising out of ontological development in the construal of intrinsic-reality/ontological-veridicality establishing a mindset/ ${ }^{3}$ reference-of-thought of ${ }^{56}$ meaningfulness-and-teleology ${ }^{9}$ with its psychologism/psychologism-construct, and so it is ontologically-driven. As further ontological development in the construal of intrinsic-reality/ontological-veridicality arises (as of human limited-mentation-capacity-deepening—as-subjecting limitedness/human-subpotency-to'educed-unlimitedness/existence-sublimating nascence' ${ }^{53}$ ) a renewing of mindset/ $/ 2$ referenceof-thought of ${ }^{56}$ meaningfulness-and-teleology 9 with its corresponding psychologism/psychologism-construct occurs, with this relative-unreflexivity/relativereflexivity - ontological-contiguity ${ }^{67} \sim$ of-the-human-institutionalisation-process ${ }^{68}$ leading to the $<$ cumulating/recomposuring attendant-ontological-contiguity $>$-successive registryworldviews/dimensions ${ }^{83}$ reference-of-thought psychologisms/psychologism-constructs, and implied prospectively as well with the notional deprocrypticism worldview/dimension reference-of-thought psychologism/psychologism-construct. Critically, a psychologism/psychologism-construct takes an apriorising/axiomatising/referencing/intelligibilitysettingup/measuringinstrumenting form that construes meaningfulness from the prior (and even lower) registry-worldview's/dimension's reference-of-thought psychologism up to its own registry-worldview's/dimension's reference-of-thought psychologism as of its more profound 'implicited_attendant-ontologicalcontiguity ${ }^{67} \sim$ educed-

existentialising/contextualising/textualising_'intelligibility/epistemicity/reflexivity-contiguity$<$ imbued-notional $\sim$ cogency $>,{ }^{\prime},-<$ reifying-or-elucidating-of-prospective-relative-ontologicalcompleteness -of- reference-of-thought- devolving-as-of-instantiative-context> in reflecting/perspectivating their relative-ontological-incompleteness ${ }^{8}$-of- ${ }^{-}$reference-of-thought- 
induced-virtuality-or-ontologically-flawed-construal-or-caricaturing-hollow-staging-andperformance. Hence this articulation of the <cumulating/recomposuring attendant-ontologicalcontiguity $>$-successive registry-worldviews/dimensions ${ }^{83}$ reference-of-thought psychologisms up to the deprocrypticism, is an initiation into notional deprocrypticism psychologism as of its apriorising/axiomatising/referencing/intelligibilitysettingup/measuringinstrumenting as of its more profound implicited_attendant-ontological-contiguity ${ }^{67}$ ' educedexistentialising/contextualising/textualising_'intelligibility/epistemicity/reflexivity-contiguity$<$ imbued-notional $\sim$ cogency $>,{ }^{\prime},-<$ reifying-or-elucidating-of-prospective-relative-ontologicalcompleteness -of- reference-of-thought- devolving-as-of-instantiative-context $>\quad$ in reflecting/perspectivating the relative-ontological-incompleteness ${ }^{8}$-of- ${ }^{8}$ reference-of-thoughtinduced-virtuality-or-ontologically-flawed-construal-or-caricaturing-hollow-staging-andperformance of positivism- ${ }^{80}$ procrypticism and all the lower registry-worldviews/dimensions. Basically, this idea of 'human temporal uninstitutionalised-threshold ${ }^{102}$ mental-disposition' as metaphysics-of-absence-〈implicited-epistemic-veracity-of- nonpresencing-<perspectiveontological-normalcy/postconvergence $>>$ points out that ontological analysis should rather be from the prospectively implied 'human registry-worldview's/dimension's institutionalisation mental-disposition', and in this instance implying an ontological analysis of psychopathy and social psychopathy from futural Being-development/ontological-framework-expansion-as-todepth-of-ontologising-development-as-infrastructure-of- meaningfulness-and-teleology of prospective notional ${ }^{18}$ deprocrypticism registry-worldview ${ }^{83}$ reference-of-thought and not the present positivism- ${ }^{80}$ procrypticism, just as analysing notions-and-accusations-of-sorcery should rather be from the prospective positivism registry-worldview ${ }^{83}$ reference-of-thought and not its present ${ }^{103}$ universalisation-non-positivism/medievalism registry-worldview ${ }^{8}$ referenceof-thought; as of the fact of fundamental registry-worldview/dimension 'prospective registryworldview's/dimension's-uninstitutionalised-threshold ${ }^{102}$-defect-<as-Being-or-ontological-or- 
existential-defect $>55$, so construed in order to supersedes its preconverging-dementating/structuring/paradigming vices-and-impediments ${ }^{105}$. Structural/paradigmatically/dementatively, this idea extends to all issues implying metaphysics-of-absence-〈implicitedepistemic-veracity-of- nonpresencing-<perspective-ontological-normalcy/postconvergence $>$ > 'human temporal uninstitutionalised-threshold ${ }^{102}$ mental-disposition'. This brings home the underlying notion of rational-realism as construed herein, as rational-realism attends to the idea of human limited-mentation-capacity-deepening-as-subjecting limitedness/humansubpotency-to-'educed-unlimitedness/existence-sublimating-nascence' ${ }^{53}$ as enabling its more profound grasp of intrinsic-reality/ontological-veridicality by way of a concurrently more and more 'rational realistic' construal of intrinsic-reality/ontological-veridicality as of a natural human psychological growth disposition ('postconverging-or-dialectical-thinking ${ }^{21}$-psychology or psychology-of-mentation-dynamics or natural psychological-dynamics'). Wherein, going by its first impulse with respect to its 'construal/conceptualisation activity as of its coming into existence in the world', human natural mental-reflex starts out with a simplistic idealism to account at one fell swoop for the comprehensiveness/complexity of intrinsic-reality/ontologicalveridicality it faces and has to contend with while construing/conceptualising fundamental meaningfulness-and-teleology ${ }^{9}$. This then gives rise to such a simplistic idealism of the natural idea of Gods or God or Spirits, as taking away the chore of understanding and purpose, and giving a sense of intuitive guidance, hope, peace of mind and as to what humans should expect in their existence. But as of the intrinsic-reality constraints of having to deal with matters of the world on its own by developing notions of understanding and purposefulness as the mere imagination of God or Gods or Spirits by itself doesn't give agency (or at the least 'perceived' sufficient agency) in resolving human issues of the world and making its need for understanding and purposefulness go away. This induces a bifurcation of human intellectual-and-moral allegiance to the supernatural and the real in adjunction, as of their 'perceived' effectiveness. 
With a commitment to the idealism of the supernatural not only as of its 'perceived' virtuous import, but as of 'perceived' nefarious effects to human nolition to it, man hangs on to both an effective realistic as well as idealistic conceptualisation/construal in existence. Such a growth psychology ultimately goes beyond construing idealism as the supernatural but as a complement to more and more profound realistic understanding and purposefulness in existence, but then having to readjust such idealism wherein the real as of its critical import to critical existence issues increasingly comes to take presence as of its effectiveness. Such that as construed today, human history overall has been an exercise in toning down the grander notion of idealism as of notions of the supernatural, essences and metaphysical ideals, and enabling increasing permeation and/or superseding of such notions with an effectiveness-driven realism leading to a general and increasing elevation of knowledge as the-human-and-social-emancipator, the present ascendency of philosophies increasingly concerned with the human realities of existence (strongly so, lately with such movements as positivism, phenomenology, existentialism and poststructuralism) and science in all its facets whether physical, biological or social, as well as a human-centeredness of arts and culture. Rational-realism is grounded on this historic empirical state of affairs of increasing human realism in taking hold of its destiny on the 'premise of a deference to intrinsic-reality as of its effective inherence validated by <amplituding/formativeepistemicity $>$ causality $\sim$ as-to-projective-totalitative-implications-of-prospective-

$$
\text { nonpresencing,-for-explicating relative- unreflexivity/relative-reflexivity ontological- }
$$

contiguity , that has accompanied human limited-mentation-capacity-deepening-assubjecting limitedness/human-subpotency to-'educed-unlimitedness/existence-sublimating nascence' ${ }^{53}$ in construing/conceptualising ${ }^{56}$ meaningfulness-and-teleology ${ }^{9}$. Rational-realism thus finds in the grander notion of idealism, an avowal of human limited-mentation-capacitydeepening —as-subjecting limitedness/human-subpotency-to-'educed-unlimitedness/existencesublimating nascence ${ }^{5}$ that actually is behind all threshold-of- 
nonconviction/madeupness/bottomlining-in-shallow-supererogation $<-<$ as-to-' attendantintradimensional'-prospectively-disontologising preconverging/dementing -apriorisingpsychologism> of the <cumulating/recomposuring attendant-ontological-contiguity $>$ successive registry-worldviews/dimensions; with the idea that there is no place to hide behind idealisms and that human emancipation and virtue has been and is fundamentally about buckling down and undertaking the requisite effort in 'understanding for real' and not differing to 'thin air' in the name of idealism. Rational-realism pushes the grander notion of realism further by asking the question, have all the idealisms as of the grander idealism been identified and superseded? It comes to the conclusion that while that has been decisively the case with supernaturalism, belief in essences and metaphysical idealism, as of preconverging/postconverging-de-mentative/structural/paradigmatic social implications, one other sort of idealism remains to be recognise as 'false realism'; the idealism that doesn't grasp what man itself is, rather as overly indulgent in not recognising how a thorough understanding of itself in enabling pivoting/decentering is effectively the strongest asset for its full emancipation. Central to such a most basic realism is grounding human knowledge of itself and thereof all knowledge on the 'mediocrity principle' as to enable the full construal of both metaphysics-of-presence-〈implicited-'nondescript/ignorable-void '-as-to- presencingabsolutising-identitive-constitutedness > and metaphysics-of-absence-〈implicited-epistemicveracity-of- nonpresencing-<perspective-ontological-normalcy/postconvergence $>>$ ontologies as enabling a further human emancipation registry-worldview's/dimension's ${ }^{83}$ reference-ofthought psychologism, notional ${ }^{1}$ deprocrypticism psychologism. This is the insight behind the articulation of the social construed in threshold terms of social-functioning-and-accordanceas-of-social-stake-contention-or-confliction rather as socially-functional-and-accordant ${ }^{23}$. This insight further divulges the reality across all registry-worldviews/dimensions of 'human registryworldview's/dimension's institutionalisation mental-disposition' and 'human temporal 
uninstitutionalised-threshold ${ }^{102}$ mental-disposition', as powerful conceptualisations for framing issues in their appropriate psychologism however unpalatable/inconveniencing, as history has always shown that unpalatability, inconvenience and contrariety have always been the test that all humans have had to undergo to effectively achieve their respective prospective registryworldview/dimension transcendence-and-sublimity/sublimation/supereregatery $\sim$ dementativity, and the more complete conceptualisation of knowledge goes beyond its technicalities and plainness to imply its underlying sense of dedication as the very intemporalsolipsism as to ontological-faith-notion-or-ontological-fideism - imbued-underdeterminationof-motif-and-apriorising/axiomatising/referencing-as-so-being-as-of-existential-reality disposition behind its creation, cultivation and projection. And as with all previous realism drives, the idea of rational-realism is not as an articulation within the finite scope of the present meaningfulness-and-teleology ${ }^{9}$ frame of thought and social-stake-contention-or-confliction but rather carries a prospective scope, just as the vocation of the realism of a positivistic mindset/ ${ }^{3}$ reference-of-thought in a non-positivistic social-setup should not be about elaborating meaning as of positivistic ${ }^{56}$ meaningfulness-and-teleology to engage the non-positivistic social-setup in terms-as-of-axiomatic-construct of its non-positivistic sense of social-stakecontention-or-confliction of human relations as that will certainly just induce an 'idle circularity and contrariety' within the non-positivistic social-setup. But rather the point is all about recognising 'human prospective institutionalisation capacity as the very essence of human virtue' available to all humans past and present, that enabled this animal among all creatures to be engaged in a grander collective exercise of 'existential-tautological eudaemoniccontemplation' (as of human 'subpotent-mimetic-echoness-derivation-within-the-full-potency of existence-as-of-its-mimetic-echoness'), to imply that there is a prospective virtuous possibility of human registry-worldview's/dimension's institutionalisation that can be grasped, and so expressed in terms-as-of-axiomatic-construct of the notion of social-stake-contention-or- 
confliction of that prospective institutionalisation psychologism, just as the vocation of the positivistic mindset $/{ }^{3}$ reference-of-thought is all about eliciting the notion of social-stakecontention-or-confliction in terms-as-of-axiomatic-construct of positivistic psychologism to imply that the non-positivistic community has the capacity and should come to terms with its human emancipating institutionalisation potential. Insightfully, the apriorising/axiomatising/referencing/intelligibilitysettingup/measuringinstrumenting comparison can be used to reveal the 'perpetually stable notional firstnaturednessformativeness-<as-to-eventualising-inkling-drive-or-seeding-misprising $>$ temporal-tointemporal-dispositions- $<$ so-construed-as-from-perspective-ontologicalnormalcy/postconvergence $>$ nature of human mental-disposition as of institutionalisation or uninstitutionalised-threshold ${ }^{102}$, across all registry-worldviews/dimensions ${ }^{83}$ references-ofthought but for the fact that they have different ${ }^{83}$ reference-of-thought- categoricalimperatives/axioms/registry-teleology ${ }^{9}$,-for-intemporal-preservation-entropy-or-contiguityor-ontological-preservation building up from the prior ones as of their respective elucidation-of 'implicited_attendant-ontological-contiguity ${ }^{67}$ ' educedexistentialising/contextualising/textualising_intelligibility/epistemicity/reflexivity-contiguity$<$ imbued-notional $\sim$ cogency $>,{ }^{\prime},-<$ reifying-or-elucidating-of-prospective-relative-ontologicalcompleteness -of- reference-of-thought- devolving-as-of-instantiative-context> (recurrentutter-uninstitutionalisation non-rules_-apriorising/axiomatising/referencing-psychologism,-asimpulsive-or-accidented-or-random-mental-disposition as failing/not-upholding-<as-ofapriorising/axiomatising/referencing > rulemaking-over-non-rulesapriorising/axiomatising/referencing-psychologism,-〈as 'first-level presencing—absolutisingidentitive-constitutedness of reference-of-thought' apriorising/axiomatising/referencing/intelligibilitysettingup/measuringinstrumenting $\rangle$ required for base-institutionalisation-ununiversalisation, ununiversalisation failing/not-upholding- $<$ as- 

rules_-apriorising/axiomatising/referencing-psychologism,-〈as 'second-level presencingabsolutising-identitive-constitutedness of reference-of-thought' apriorising/axiomatising/referencing/intelligibilitysettingup/measuringinstrumenting required for ${ }^{103}$ universalisation-non-positivism/medievalism, non-positivism/medievalism failing/notupholding-<as-of-apriorising/axiomatising/referencing $>\quad$ positivising/rational-empiricismbased-universalisation-directed-rulemaking-over-non-rulesapriorising/axiomatising/referencing-psychologism,-〈as 'third-level presencingabsolutising-identitive-constitutedness of reference-of-thought' apriorising/axiomatising/referencing/intelligibilitysettingup/measuringinstrumenting $\rangle$ required for positivism- ${ }^{8}$ procrypticism or prospectively, positivism failing/not-upholding-<as-ofapriorising/axiomatising/referencing $>$ ' ${ }^{8}$ deprocrypticism-or-preempting-disjointedness-asof- reference-of-thought,-〈as-full-conflatedness ${ }^{13}$-of apriorising/axiomatising/referencing/intelligibilitysettingup/measuringinstrumenting $\rangle$ required for perpetuating-deprocrypticism). Supposed there was no apriorising/axiomatising/referencing/intelligibilitysettingup/measuringinstrumenting defect (no perversion-of- ${ }^{3}$ reference-of-thought-<as-preconverginglyapriorising/axiomatising/referencing-in-nonconviction/madeupness/bottomlining-as-toshallow-supererogation $>$ ) with social ${ }^{103}$ universal-transparency ${ }^{104}$-〈transparency-of-totalisingentailing,-as-to-entailing-<amplituding/formative-epistemicity $>$ totalising $\sim$ in-relativeontological-completeness $>$ of the calculations to be done, it is fair to say 'human registryworldview's/dimension's institutionalisation mental-disposition' in this ${ }^{8}$ reference-of-thought is of quasi-intemporal-disposition (and the whole point of human knowledge aspiration and virtue is to achieve this state or deferential-states-of-this-state as with formalisations and percolation-channelling- $<$ in-deferential-formalisation-transference $>$ ). Thus calculations 
(logically-derived meaningfulness) in such an institutionalised framework are effectively in ontological-good-faith/authenticity $\sim$ postconverging-de-mentating/structuring/paradigming but for failure in aposteriorising/logicising/deriving/intelligising/measuring performance as defect-of- ${ }^{5}$ logical-processing-or-logical-implicitation — supposedly-apriorising-in-convictionas-to-profound-supererogation of the registry-worldview's/dimension's- ${ }^{83}$ reference-ofthought-for-social-functioning-and-accordance. But then human existential-reality comes with human limited-mentation-capacity-deepening —as-subjecting limitedness/human-subpotencyto-'educed-unlimitedness/existence-sublimating nascence's3 with limited grasp of intrinsicreality at various stages of human emancipation up to the modern-day, such that social ${ }^{3}$ universal-transparency ${ }^{104}$-〈transparency-of-totalising-entailing,-as-to-entailing<amplituding/formative-epistemicity >totalising in-relative-ontological-completeness $>$

required for 'human registry-worldview's/dimension's institutionalisation mental-disposition' has been made transcendentally available only in partial construals/conceptualisations that are as-of existential-reality, and where non-available at uninstitutionalised-threshold ${ }^{102}$, it is naïve to construe human mental-disposition as of quasi-intemporal-disposition; as the anthropological and historical evidence consistently points to a different structure with regards to the 'human temporal uninstitutionalised-threshold ${ }^{102}$ mental-disposition' as of 'implicited_attendantontological-contiguity ${ }^{67}$, educedexistentialising/contextualising/textualising_'intelligibility/epistemicity/reflexivity-contiguity$<$ imbued-notional cogency $>,{ }^{\prime},-<$ reifying-or-elucidating-of-prospective-relative-ontologicalcompleteness -of- reference-of-thought- devolving-as-of-instantiative-context> elucidated ontological-normalcy/postconvergence. It points to a fundamental preconverging/postconverging-de-mentative/structural/paradigmatic disposition for human temporalities-drives to adhere to the <amplituding/formative > wooden-language-〈imbuedtemporal-mere-form/virtualities/dereification/akrasiatic-drag/denatured/preconverging-or- 
dementing -narratives - of-the- reference-of-thought- categorical-

imperatives/axioms/registry-teleology >

(failing/not-upholding-<as-of-

apriorising/axiomatising/referencing > intemporal-preservation-entropy-or-contiguity-orontological-preservation as of ontological-normalcy/postconvergence which always factor in human limited-mentation-capacity-deepening as subjecting limitedness/hmman-subpency to-'educed-unlimitedness/existence-sublimating nascence' 33 by a re-equilibrating metaphysicsof-absence-〈implicited-epistemic-veracity-of- nonpresencing-<perspective-ontologicalnormalcy/postconvergence $>$ /postdication) of the given registry-worldview/dimension, when incapable of construing a prospective registry-worldview ${ }^{83}$ reference-of-thought as providing the resolution for the vices-and-impediments ${ }^{105}$ associated with such a present registryworldview/dimension institutionalisation. Such notions as the following that can be at the very centre of ways of thought in various social-setups or subcultures are not fortuitous but speaks of the reality (as metaphysics-of-absence-〈implicited-epistemic-veracity-of- nonpresencing$<$ perspective-ontological-normalcy/postconvergence $>\rangle)$ of the notion of 'human temporal uninstitutionalised-threshold ${ }^{102}$ mental-disposition' that preconverging/postconverging-dementatively/structurally/paradigmatically 'notionally acquiesce to the possibility of a registryworldview's/dimension's temporality ${ }^{8} /$ shortness and is non-transcendental to that possibility': she deserves to be rape because she was scantily clad as well dressed women will not be raped; his goods deserve to be stolen as he didn't look after them properly; those people/group/ethnicity deserved what happened to them because they are so and so; etc.

[We can note here that such statements as of a variance of more banal to weightier nature can be made as being socially-functional-and-accordant ${ }^{93}$ (without or hardly any negative consequences at the acceptable socially-functional-and-accordant ${ }^{3}$-threshold like being repudiated or incriminated, etc.), construed as 'least-and-derived-temporal-operating-modalities-of-thereference-of-thought-as-of- incrementalism-in-relative-ontological-incompleteness ${ }^{8}$ - 
enframed/disontologising conceptualisation-inducing-the-uninstitutionalised-threshold ${ }^{12}$, in the same social space that statements of 'maximal-as-intemporal-operating-modality-ofreference-of-thought-as-of- maximalising-recomposuring-for-relative-ontologicalcompleteness ${ }^{87}$ - unenframed/re-ontologising conceptualisation-as-inducing-the-prospectiveinstitutionalisation' are made but with both construed in the conventioning of social-functioningand-accordance - as-of-social-stake-contention-or-confliction as effectively 'non-dissociable', thus validating the notion that institutionalisation is not about solipsistic transformation into the intemporality $^{52}$-drive (longness-of-register-of- ${ }^{56}$ meaningfulness-and-teleology ${ }^{99}$ disposition) but rather about acceptable thresholds for the registry-worldview/dimension institutionalisation defined social-functioning-and-accordance-as-of-social-stake-contention-or-confliction, explaining why uninstitutionalised-threshold ${ }^{102}$ are bound to arise successively in the relativeunreflexivity/relative-reflexivity — ontological-contiguity ${ }^{67}$ of-the-human-institutionalisationprocess $^{68}$ (out-of-human temporality ${ }^{8}$ ) together with corresponding prospective institutionalisations (out of-human intemporality ${ }^{52}$ ) with the latter enabling $<$ amplituding/formative-epistemicity $>$-totalising $\sim$ renewing-realisation/re-perception/rethought of defined social-functioning-and-accordance-as-of-social-stake-contention-orconfliction as of the notional-contiguity/epistemic-contiguity ${ }^{2}-<$ profound-supererogation - ofmentally-aestheticised postconverging/dialectical-thinking -qualia-schema $>$ in reflecting holographically-<conjugatively-and-transfusively $>$ the relative-unreflexivity/relativereflexivity - ontological-contiguity of-the-human-institutionalisation-process . This equally explain why and in particular in certain domains like the philosophical construed as "notional philosophical' (by its very 'first-ontology responsibilities'), the social-construct conventioning cannot and should not be considered and related to as an absolute determinant of meaningfulness, value and worth as it is more of a conventioning however ontologically-informed the conventioning, and the "need for the social-construct further development requires that it can 
utterly be put-into-question by pure-ontology apriorising/axiomatising/referencing-\{of'prospectively_implicited_attendant_ontological-contiguity ' educedexistentialising/contextualising/textualising_'intelligibility/epistemicity/reflexivity-contiguity<imbued-notional cogency $\left.>^{\prime}\right\}$-conflatedness ${ }^{13}$-in-\{preconverging-disentailment by\} pestconverging-entailment with no conventioning complexes'! (As a reminder, the notion of intemporality ${ }^{52} /$ temporality $^{98}$ is an ontological-as-of-being construct and the apparent references to virtue imply the subsumed construal of virtue by the ontological-as-of-being construct, such that it is important to grasp that all notions articulated herein are ontological, just as the notions of the being domains-of-study of the natural world are ontological, and the high temporal-tointemporal-conjugating-emotional-involvement/subjectification/epistemic-totalising $\sim$ selfreferencing-syncretising-as-of-perceived-social-stake-contention-or-confliction nature of the being domains-of-study of the social world should not naively imply a construct that isn't ontological or otherwise, as in both instances the aspiration is for 'intrinsic-reality/ontologicalveridicality transcendental-enabling/sublimating/supererogatory de-mentativity as an otherness from any emotional-involvement/subjectification/notional <amplituding/formativeepistemicity $>$ totalising $\sim$ self-referencing-syncretising/circularity/interiorising/akrasiatic-drag predilection of the inquirer'. This elucidation is equally to highlight that the idea of sociallyfunctional-and-accordant ${ }^{3}$ 'modular-thresholds'-of-notional firstnaturedness-formativeness<as-to-eventualising inkling-drive-or-seeding-misprising $>$ temporal-to-intemporaldispositions-<so-construed-as-from-perspective-ontological-normalcy/postconvergence $>$ dissociability is beyond just a construal as of virtue analysis but rather an ontological analysis, as it applies in all social conceptualisations of performance and functionality whether virtuous or virtuously-neutral but necessarily as of the social being/existence domains-of-study.) The conventioning of social-functioning-and-accordance-as-of-social-stake-contention-orconfliction effectively 'non-dissociable' modular construal of temporal-dispositions and 
intemporal-disposition rather as of socially-functional-and-accordant ${ }^{3}$ thresholds, has deterministic implications with regards to 'interdimensional/transdimensional/transcendental registry-worldview/dimension-level of analysis' as well as 'notional firstnaturednessformativeness-<as-to-eventualising-inkling-drive-or-seeding-misprising $>$ temporal-tointemporal-dispositions- $<$ so-construed-as-from-perspective-ontologicalnormalcy/postconvergence $>$ individuation-level of analysis'; for construing the implications of such 'modular-thresholds'-of-notional firstnaturedness-formativeness-<as-toeventualising inkling drive-or seeding misprising $>$ temporal-to-intemporal-dispositions$<$ so-construed-as-from-perspective-ontological-normalcy/postconvergence $>$-dissociability social-functioning-and-accordance-as-of-social-stake-contention-or-confliction effectivenessor-ineffectiveness and ontological-resolution as of 'attendant ontologising-capacity driven apriorising/axiomatising/referencing-psychologism by way of the grander ontologicalnormalcy/postconvergence

apriorising/axiomatising/referencing/intelligibilitysettingup/measuringinstrumenting' in resolving registry-worldview's/dimension's- ${ }^{83}$ reference-of-thought-for-social-functioning-andaccordance capabilities, as the very foundational operant conceptualisation of an ontologicallycontiguous 'postconverging-or-dialectical-thinking ${ }^{2}$-psychology or psychology-of-mentationdynamics or natural psychological-dynamics'. This fundamentally highlights a 'notional conflatedness ${ }^{13}$ /constitutedness ${ }^{14}$-to-conflatedness ${ }^{13}$ dynamic relationship' with meaningfulness-and-teleology' as directly reflecting 'ontological-normalcy/postconvergence dynamics (in abstractly elucidating any given registry-worldview's/dimension's 'suprastructuration' or its 'suprastructural psychical-and-institutionalisation orientation of meaningfulness-and-teleology synopsising-depth as of the overall registryworldview's/dimension's reconstrual of superseding-oneness-of-ontology', and so by the 
worldviews/dimensions in corresponding snowballing succession of synopsising-depth of meaningfulness-and-teleology reconstrual going by ontological-normalcy/postconvergence implications). Critically, central to attaining (intemporal) prospective notionalcontiguity/epistemic-contiguity ${ }^{2}<$ - profound-supererogation -of-mentallyaestheticised postconverging/dialectical-thinking -qualia-schema $>$ as of the notional ${ }^{18}$ deprocrypticism registry-worldview's/dimension's- ${ }^{83}$ reference-of-thought-forsocial-functioning-and-accordance with no-notional firstnaturedness-formativeness-<as-toeventualising inkling drive-or-seeding-misprising > temporal-to-intemporal-dispositions$<$ so-construed-as-from-perspective-ontological-normalcy/postconvergence $>$-non-dissociability (due to social ${ }^{103}$ universal-transparency $^{104}$-〈transparency-of-totalising-entailing,-as-to-entailing<amplituding/formative-epistemicity>totalising in-relative-ontological-completeness > of notional ${ }^{1}$ deprocrypticism ${ }^{56}$ meaningfulness-and-teleology ${ }^{9}$ ), is equally the need to supersede human 'emotional involvement'. As 'emotional-involvement' is self-centering-and-definitional of human consciousness as of our animate-existential-referencing/subjectification, but actually such reality is otherwise of the same ontologically-veridical nature as existence-as-of-itsmimetic-echoness/existence-in-reverberation/existence-potency ${ }^{39} \sim$ sublimating-nascence,disclosed-from-prospective-epistemic-digression into which everything else is caught into as superseding-oneness-of-ontology (even though our high temporal-to-intemporal-conjugatingemotional-involvement/subjectification/epistemic-totalising $\sim$ self-referencing-syncretising-asof-perceived-social-stake-contention-or-confliction will often tend to induce a relatively flawed meaningfulness-and-teleology ${ }^{9}$ construal in this regard, that explains our metaphysics-ofpresence-〈implicited-`nondescript/ignorable-void '-as-to- presencing — absolutisingidentitive-constitutedness $>$ mental-disposition). Thus an appropriate ontologically-veridical social-conceptualisation and/or storied-construct/ontologically-valid-narration as aetiological/ontologically-escalatory that has the capacity to supersede the inherent human high 
temporal-to-intemporal-conjugating-emotional-involvement/subjectification/epistemictotalising $\sim$ self-referencing-syncretising-as-of-perceived-social-stake-contention-orconfliction specific element (which tend to denaturing ${ }^{56}$ meaningfulness-and-teleology construal, as high temporal-to-intemporal-conjugating-emotionalinvolvement/subjectification/epistemic-totalising $\sim$ self-referencing-syncretising-as-ofperceived-social-stake-contention-or-confliction is behind manifest human 'non-dissociability' of the registry-worldview's/dimension's- ${ }^{8}$ reference-of-thought-for-social-functioning-andaccordance temporal-to-intemporal thresholds' within the ontological scope of any given institutionalisation), should be able to imply the same underlying ontologically-veridical existence-as-of-its-mimetic-echoness/existence-in-reverberation/existence-

potency $^{32} \sim$ sublimating-nascence,-disclosed-from-prospective-epistemic-digression of the superseding-oneness-of-ontology as any other truly ontologically-veridical conceptualisation, be it of animate or inanimate nature. The implication being that the underlying notional $<$ amplituding/formative-epistemicity $>$ totalising $\sim$ self-referencing-

syncretising/circularity/interiorising/akrasiatic-drag (of our 'emotional-involvement' as selfcentering-and-definitional of human consciousness as of our animate-existentialreferencing/subjectification) can perfectly be escaped from to more profound and unsuspecting depths of ontologically-veridical ${ }^{56}$ meaningfulness-and-teleology ${ }^{9}$ construal (enabling 'dissociability of the registry-worldview's/dimension's- ${ }^{83}$ reference-of-thought-for-socialfunctioning-and-accordance temporal-to-intemporal thresholds' ontologically), and so beyondthe-consciousness-awareness-teleology ${ }^{9}-<$ of-preconverging-existential-extrication-as-ofexistential-unthought> , ushering in an 'ontologically-veridical existence-as-of-its-mimeticechoness/existence-in-reverberation/existence-potency ${ }^{39} \sim$ sublimating-nascence,-disclosedfrom-prospective-epistemic-digression contemplation to a point that subsumes equably both animate-existential-referencing/subjectification and inanimate-existential-effecting, wherein the 
underlying teleological-determinism of human functional and performance thresholds are effectively desubjectifiable-as-objectifiable to the point of attaining 'effecting teleologicaldetermination' of the same level as inanimate 'effecting determination' (with little temporal-tointemporal-conjugating-emotional-involvement/subjectification/epistemic-totalising $\sim$ selfreferencing-syncretising-as-of-perceived-social-stake-contention-or-confliction denaturing meaningfulness-and-teleology ${ }^{9}$ construal), and so enabled with the referentialism technique of point-referencing for apriorising/axiomatising/referencing-\{of- ${ }^{\text {prospectively }}$ implicited_attendant-ontological-contiguity ' educedexistentialising/contextualising/textualising_'intelligibility/epistemicity/reflexivity-contiguity-

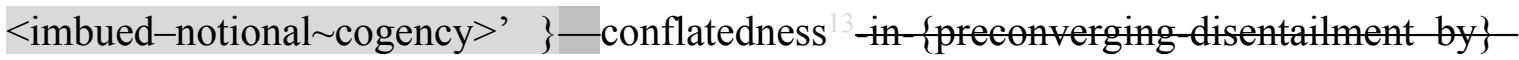
postconverging-entailment in construing temporal-to-intemporal contrastive-synopsisingdepths-of- ${ }^{5}$ meaningfulness-and-teleology as 'dissociable temporal-to-intemporal thresholds of the registry-worldview's/dimension's- ${ }^{8}$ reference-of-thought-for-social-functioning-andaccordance' (inducing the requisite social ${ }^{103}$ universal-transparency ${ }^{104}$-〈transparency-oftotalising-entailing,-as-to-entailing-<amplituding/formative-epistemicity $>$ totalising $\sim$ inrelative-ontological-completeness $\rangle$ for prospective decentering/pivoting as enabling an epistemic-totalising $\sim$ renewing-realisation/re-perception/re-thought in ushering in notional ${ }^{18}$ deprocrypticism institutionalisation). Interestingly, the very conceptual background for such transcendentally-enabling-level-of $\sim$ ontological-good-faith-orauthenticity $\%$ objectification/desubjectification-as-objectification- $<$ as-to-ontological-faith-

\section{notion-or-ontological-fideism - imbued-underdetermination-of-motif-and-}

apriorising/axiomatising/referencing-as-so-being-as-of-existential-reality as antinihilism> ${ }^{100}$ of meaningfulness-and-teleology construal lies with 'intemporal ontological-faith-notion-orontological-fideism - imbued-underdetermination-of-motif-and- 
unreflexivity/relative-reflexivity — ontological-contiguity ${ }^{67}$ of-the-human-institutionalisationprocess $^{68}$ as of difference-conflatedness ${ }^{13}$-as-to-totalitative-reification-in-singularisation- $<$ as-tothe-nondisjointedness/entailment-of-prospective- nonpresencing $>$-as-veridical-epistemicityrelativism-determinism implied $<$ amplituding/formative-epistemicity $>$ causality $\sim$ as-toprojective-totalitative-implications-of-prospective- nonpresencing,-for-explicating relativeunreflexivity/relative-reflexivity ontological-contiguity ' itself, by its successively induced snowballed-recomposuring of human psychical transcendentally-enabling-level-of $\sim$ ontologicalgood-faith-or-authenticity $\%$ objectification/desubjectification-as-objectification- $<$ as-toontological-faith-notion-or-ontological-fideism - imbued-underdetermination-of-motif-andapriorising/axiomatising/referencing-as-so-being-as-of-existential-reality as antinihilism> capacity in a corresponding relation with the successively induced snowballed-recomposuring institutional-cumulation/institutional-recomposure-〈as-to- historiality/ontologicaleventfulness /ontological-aesthetic-tracing-<perspective-ontologicalnormalcy/postconvergence-reflected-'epistemicity-relativism-determinism' $>>$ (as successive institutionalisations involve an increasing sense of transcendentally-enabling-levelof ontological-good-faith-or-authenticity $\%$ objectification/desubjectification-asobjectification-<as-to-ontological-faith-notion-or-ontological-fideism-imbuedunderdetermination-of-motif-and-apriorising/axiomatising/referencing-as-so-being-as-ofexistential-reality as antinihilism>100 ${ }^{56}$ meaningfulness-and-teleology ${ }^{9}$ construal for a sounder and sounder relationship with intrinsic-reality/ontological-veridicality; an idea we appreciate as we can garner that we, as of the positivism- ${ }^{80}$ procrypticism registry-worldview/dimension, are relatively psychologically geared to handle meaningfulness in a relatively objective way than say a non-positivism/medievalism mindset cannot and rather parse over towards arriving at its final 'greater egotistic or <amplituding/formative-epistemicity $>$ totalising $\sim$ self-referencingsyncretising/circularity/interiorising/akrasiatic-drag ${ }^{34}$ driven' belief/conclusion and this explains 
why their mental-dispositions were relatively alchemic, feudal of mentality, etc. For instance and why the corresponding transcendentally-enabling-level-of $\sim$ ontological-good-faith-orauthenticity $\%$ objectification/desubjectification-as-objectification- $<$ as-to-ontological-faithnotion-or-ontological-fideism - imbued-underdetermination-of-motif-andapriorising/axiomatising/referencing-as-so-being-as-of-existential-reality as antinihilism> ${ }^{00}$ of our registry-worldview enabled the natural sciences to arise, our relatively developed sense of democracy, globalisation, etc. Likewise we can appreciate with such phenomena today like 'fake news' easily spreading socially and often just as 'real news' our very own limitations of transcendentally-enabling-level-of $\sim$ ontological-good-faith-or-

authenticity $\%$ objectification/desubjectification-as-objectification- $<$ as-to-ontological-faithnotion-or-ontological-fideism - imbued-underdetermination-of-motif-andapriorising/axiomatising/referencing-as-so-being-as-of-existential-reality as antinihilism> meaningfulness-and-teleology ${ }^{9}$ construal as manifested in our positivism- ${ }^{80}$ procrypticism registry-worldview, with the implication of metaphysics-of-absence-〈implicited-epistemicveracity-of- nonpresencing-<perspective-ontological-normalcy/postconvergence $>>\quad$ insight that a prospective registry-worldview as notional ${ }^{8}$ deprocrypticism will be an improvement over our transcendentally-enabling-level-of $\sim$ ontological-good-faith-orauthenticity $\%$ objectification/desubjectification-as-objectification-<as-to-ontological-faithnotion-or-ontological-fideism - imbued-underdetermination-of-motif-andapriorising/axiomatising/referencing-as-so-being-as-of-existential-reality as antinihilism> meaningfulness-and-teleology construal capacity). Prospectively a transcendentallyenabling-level-of ontological-good-faith-or-authenticity $\%$ objectification/desubjectificationas-objectification-<as-to-ontological-faith-notion-or-ontological-fideism - imbuedunderdetermination-of-motif-and-apriorising/axiomatising/referencing-as-so-being-as-ofexistential-reality as antinihilism $>100$ to the point of attaining 'effecting teleological- 
determination' of the same level as inanimate 'effecting determination' of meaningfulnessand-teleology construal (with little temporal-to-intemporal-conjugating-emotionalinvolvement/subjectification/epistemic-totalising $\sim$ self-referencing-syncretising-as-ofperceived-social-stake-contention-or-confliction denaturing ${ }^{16}$ meaningfulness-andteleology ${ }^{9}$ construal) will inform the underlying psyche of a notional ${ }^{18}$ deprocrypticism mindset $/{ }^{3}$ reference-of-thought/psychologism; as the capacity to objectify/desubjectify-asobjectify/authentify is what enables the human mind to be able to develop towards fully achieving intrinsic-reality/ontological-veridicality transcendentalenabling/sublimating/supereregatory $\sim$ de-mentativity. In this regard, we can grasp how human limited-mentation-capacity-deepening —as-subjecting limitedness/human-subpotency-to'educed-unlimitedness/existence-sublimating nascence' ${ }^{53}$ associated with the relativeunreflexivity/relative-reflexivity — ontological-contiguity ${ }^{67}$ of-the-human-institutionalisationprocess ${ }^{68}$ increasingly implies a 'more and more transcendentally-enabling-levelof $\sim$ ontological-good-faith-or-authenticity $\%$ objectification/desubjectification-asobjectification-<as-to-ontological-faith-notion-or-ontological-fideism - imbuedunderdetermination-of-motif-and-apriorising/axiomatising/referencing-as-so-being-as-ofexistential-reality as antinihilism $>100$ psychologism overcoming subjectification denaturing ${ }^{16}$ of meaningfulness-and-teleology ${ }^{\circ}:$ and so, as of non-rulesapriorising/axiomatising/referencing-psychologism,-as-impulsive-or-accidented-or-randommental-disposition-or-failing-prospective-rulemaking-over-non-rulesapriorising/axiomatising/referencing-psychologism (recurrent-utter-uninstitutionalisation); failing-prospective-universalisation-directed-rulemaking-over-non-rulesapriorising/axiomatising/referencing-psychologism (base-institutionalisationununiversalisation); failing-prospective-positivising/rational-empiricism-baseduniversalisation-directed-rulemaking-over-non-rules — apriorising/axiomatising/referencing- 
psychologism ( ${ }^{103}$ universalisation-non-positivism/medievalism); failing-prospectivepreempting - disjointedness-as-of- ${ }^{8}$ reference-of-thought,-as-to- ${ }^{-3}<$ amplituding/formativeepistemicity $>$ growth-or-conflatedness ${ }^{13} /$ transvaluative- $^{2}$

rationalising/transepistemicity/anamnestic-residuality/spirit-drivenness' — in-supersedingmere-formulaic-positivising/rational-empiricism-based-universalisation-directed-rulemakingover-non-rules — apriorising/axiomatising/referencing-psychologism ～(positivismprocrypticism); and prospectively preempting - disjointedness-as-of- ${ }^{3}$ reference-of-thought,as-to- ${ }^{3}<$ amplituding/formative-epistemicity $>$ growth-or-conflatedness ${ }^{13} /$ transvaluativerationalising/transepistemicity/anamnestic-residuality/spirit-drivenness'_-in-supersedingmere-formulaic-positivising/rational-empiricism-based-universalisation-directed-rulemakingover-non-rules_-apriorising/axiomatising/referencing-psychologism (deprocrypticism). With the latter fully enabling human full attainment of transcendentally-enabling-levelof $\sim$ ontological-good-faith-or-authenticity $\%$ objectification/desubjectification-asobjectification-<as-to-ontological-faith-notion-or-ontological-fideism-imbuedunderdetermination-of-motif-and-apriorising/axiomatising/referencing-as-so-being-as-ofexistential-reality as antinihilism> $>{ }^{00}$ of ${ }^{5}$ meaningfulness-and-teleology and overcoming subjectification, enabling an understanding of the social domain at the same level as of the natural domain and the derived-implications with regards to social and human $<$ amplituding/formative-epistemicity $>$-totalising $\sim$ renewing-realisation/re-perception/rethought associated with the notional deprocrypticism registry-worldview. Basically, transcendentally-enabling-level-of $\sim$ ontological-good-faith-or-

authenticity $\%$ objectification/desubjectification-as-objectification-<as-to-ontological-faithnotion-or-ontological-fideism-imbued-underdetermination-of-motif-andapriorising/axiomatising/referencing-as-so-being-as-of-existential-reality as antinihilism> as implied by the relative-unreflexivity/relative-reflexivity ontological-contiguity $\sim$ of-the- 
human-institutionalisation-process ${ }^{68}$ reflects the successive psychologisms as of the respective mutually beyond-the-consciousness-awareness-teleology ${ }^{-<}<$of-preconverging-existentialextrication-as-of-existential-unthought $>$ (as of the <cumulating/recomposuring attendantontological-contiguity >-successive registry-worldviews/dimensions ${ }^{83}$ reference-of-thought construed ${ }^{56}$ meaningfulness-and-teleology ${ }^{9}$ involving conceptualisation/construal of meaningfulness-and-teleology ${ }^{9}$ ). While the institutionalisation perspective tends to point to a commonness of ${ }^{8}$ reference-of-thought as of prospective relative-ontological-completeness ${ }^{87}$-ofreference-of-thought construed as ${ }^{83}$ reference-of-thought-prelogism ${ }^{78}$-as-of-conviction,-inprofound-supererogation $-<$ existentially-veridical-'attendant-intradimensionalapriorising/axiomatising/referencing'-logical-dueness-precedes-disontologising-logicaloutcome-arrived-at $>$, however at the uninstitutionalised-threshold ${ }^{102}$ the implication of such a commonness of ${ }^{83}$ reference-of-thought is rather construed as of the relative-ontologicalincompleteness ${ }^{8}$-of- ${ }^{8}$ reference-of-thought so-disambiguated as of temporal-dispositions (as well as such temporal-dispositions conjugate with postlogism ${ }^{77}$ perversion-of- ${ }^{8}$ reference-ofthought-<as-preconvergingly-apriorising/axiomatising/referencing-innonconviction/madeupness/bottomlining-as-to-shallow-supererogation $>$ inducing derivedperversion-of- ${ }^{83}$ reference-of-thought-<as-preconverginglyapriorising/axiomatising/referencing-in-nonconviction/madeupness/bottomlining-as-toshallow-supererogation beyond-the-consciousness-awareness-teleology $-<$ ofpreconverging-existential-extrication-as-of-existential-unthought $>$ ) more succinctly construed as threshold-of-nonconviction/madeupness/bottomlining-in-shallow-supererogation $-<$ as-to‘attendant-intradimensional’-prospectively-disontologising preconverging/dementing apriorising-psychologism>, in the sense that in this instance such interlocutors threshold-ofnonconviction/madeupness/bottomlining-in-shallow-supererogation $<-<$ as-to-' $a$ attendantintradimensional'-prospectively-disontologising preconverging/dementing -apriorising- 
psychologism $>$ tend to be circular with respect to their effective temporal/shortness-of-registerof - meaningfulness-and-teleology threshold-of-nonconviction/madeupness/bottomlining-inshallow-supererogation -<as-to-'attendant-intradimensional'-prospectivelydisontologising preconverging/dementing -apriorising-psychologism $>$ commitments and are no longer of ${ }^{83}$ reference-of-thought-prelogism ${ }^{78}$-as-of-conviction,-in-profoundsupererogation $-<$ existentially-veridical-'attendant-intradimensionalapriorising/axiomatising/referencing'-logical-dueness-precedes-disontologising-logicaloutcome-arrived-at $>$ such that the naïve implication of a mutual logical exercise $\left({ }^{5}\right.$ logicalprocessing-or-logical-implicitation - supposedly-apriorising-in-conviction-as-to-profoundsupererogation ) is inherently deceptive as of transversality-<for-sublimating-existentialeventuating/denouement,from-'thinking at-first/pure-predisposition-preemptive-ofprospective-disontologising/subontologising' - as-of-prospectively-disambiguated-affirmedand-unaffirmed-'motif-and-apriorising/axiomatising/referencing' $>{ }^{101}$. This construal effectively enabling delineation of underlying <amplituding/formative-epistemicity $>$ causality $\sim$ as-toprojective-totalitative-implications-of-prospective- nonpresencing,-for-explicating $\sim$ relativeunreflexivity/relative-reflexivity ontological-contiguity of mental-dispositions. Thresholdof-nonconviction/madeupness/bottomlining-in-shallow-supererogation $-<$ as-to- 'attendantintradimensional'-prospectively-disontologising preconverging/dementing -apriorisingpsychologism $>$ across all registry-worldviews/dimensions refers to the constituent temporal individuations mental-dispositions at a registry-worldview/dimension uninstitutionalisedthreshold ${ }^{102}$ and points to their threshold-of-nonconviction/madeupness/bottomlining-inshallow-supererogation -<as-to-'attendant-intradimensional'-prospectivelydisontologising preconverging/dementing -apriorising-psychologism> as of its uninstitutionalised-threshold ${ }^{102}$ pointing to an inclination for untranscendability and undementativity as of mechanical-knowledge (beyond-the-consciousness-awareness-teleology 
$<$ of-preconverging-existential-extrication-as-of-existential-unthought $>$ ) but for the constraint of prospective social ${ }^{103}$ universal-transparency ${ }^{104}$-〈transparency-of-totalising-entailing,-as-toentailing-<amplituding/formative-epistemicity $>$ totalising $\sim$ in-relative-ontological-

completeness $\rangle$, and so in contrast to the same registry-worldview/dimension ${ }^{83}$ reference-ofthought-prelogism ${ }^{78}$-as-of-conviction,-in-profound-supererogation $-<$ existentially-veridical'attendant-intradimensional-apriorising/axiomatising/referencing'-logical-dueness-precedesdisontologising-logical-outcome-arrived-at $>$ mental-disposition that reflects its ontologicallyveridical ${ }^{56}$ meaningfulness-and-teleology ${ }^{9}$ as its institutionalisation which rather points to an inclination for transcendability and de-mentativity as of organic-knowledge once it does conceptualise the veridicality of the uninstitutionalised-threshold ${ }^{102}$ as ontologically-flawed. Such construal of temporal individuations threshold-ofnonconviction/madeupness/bottomlining-in-shallow-supererogation $<<$ as-to-'attendantintradimensional'-prospectively-disontologising preconverging/dementing -apriorisingpsychologism $>$ at uninstitutionalised-threshold ${ }^{102}$ is critical because then and in effect, the mental-reflex to ontologically validate these as of ${ }^{83}$ reference-of-thought-prelogism ${ }^{78}$-as-ofconviction,-in-profound-supererogation -<existentially-veridical-'attendant-intradimensionalapriorising/axiomatising/referencing'-logical-dueness-precedes-disontologising-logicaloutcome-arrived-at> mental-disposition so-construed as of sound 'implicited_attendantontological-contiguity ${ }^{67} \sim$ educedexistentialising/contextualising/textualising_'intelligibility/epistemicity/reflexivity-contiguity$<$ imbued-notional cogency ${ }^{\prime}$ logical-dueness is ontologically put-into-question given the perversion-and-derived- ${ }^{7}$ perversion-of- ${ }^{3}$ reference-of-thought- $<$ as-preconverginglyapriorising/axiomatising/referencing-in-nonconviction/madeupness/bottomlining-as-toshallow-supererogation $>$. Such that ontological-veridicality/intrinsic-reality transcendentalenabling/sublimating/supererogatory $\sim$ de-mentativity is projectable about the 
uninstitutionalised-threshold $^{102}$, and not as it is circularly construed within the uninstitutionalised-threshold ${ }^{102}$ frame as a construal of logical pertinence ( ${ }^{5}$ logical-processingor-logical-implicitation—supposedly-apriorising-in-conviction-as-to-profound-

supererogation ), but rather involving priorly the determination of temporal individuations threshold-of-nonconviction/madeupness/bottomlining-in-shallow-supererogation $<-<$ as-to‘attendant-intradimensional'-prospectively-disontologising preconverging/dementing apriorising-psychologism> as these fail to reflect soundness-or-ontological-goodfaith/authenticity ${ }^{-o f}$ reference-of-thought, that is, establishing whether or not there is perversion-and-derived- ${ }^{7}$ perversion-of- ${ }^{8}$ reference-of-thought- $<$ as-preconverginglyapriorising/axiomatising/referencing-in-nonconviction/madeupness/bottomlining-as-toshallow-supererogation $>$ in the first place before any implication of logical-dueness/logicalpertinence arises. Consider as of metaphysics-of-absence-〈implicited-epistemic-veracity-ofnonpresencing-<perspective-ontological-normalcy/postconvergence $>>\quad$ or $\quad$ ontologicalnormalcy/postconvergence analysis the case of notions-and-accusations-of-sorcery in a nonpositivistic social-setup uninstitutionalised-threshold ${ }^{102}$ which is rather in want of positivistic meaningfulness-and-teleology . Effectively establishing deconstructive ontologicalveridicality implies recognising the overall registry-worldview's/dimension's relativeontological-incompleteness ${ }^{8}$-of- ${ }^{-}$reference-of-thought as superstitious/non-positivistic inclined, its postlogism 77 and conjugated-postlogism ${ }^{77}$ as acknowledging and contending about notions-and-accusations-of-sorcery (beyond-the-consciousness-awareness-teleology ${ }^{0}-<$ ofpreconverging-existential-extrication-as-of-existential-unthought $>$ ) thus leading to perversionand-derived- ${ }^{7}$ perversion-of- ${ }^{8}$ reference-of-thought-<as-preconverginglyapriorising/axiomatising/referencing-in-nonconviction/madeupness/bottomlining-as-toshallow-supererogation $>$, with this succinctly reflecting the reality of temporal-dispositions as to threshold-of-nonconviction/madeupness/bottomlining-in-shallow-supererogation $-<$ as-to- 


\section{'attendant-intradimensional'-prospectively-disontologising preconverging/dementing}

apriorising-psychologism $>$ as of such non-positivism ${ }^{83}$ reference-of-thought uninstitutionalisedthreshold ${ }^{02}$. Such that it is not a logical exercise ( logical-processing-or-logical-implicitationsupposedly-apriorising-in-conviction-as-to-profound-supererogation ) that is in order which will rather be circular as fundamentally operating on false non-positivism registryworldview's/dimension's institutionalisation $\quad{ }^{83}$ reference-of-thought- categoricalimperatives/axioms/registry-teleology ${ }^{9}$ of superstition but rather one of determination of temporal individuations threshold-of-nonconviction/madeupness/bottomlining-in-shallowsupererogation -<as-to- 'attendant-intradimensional'-prospectivelydisontologising preconverging/dementing -apriorising-psychologism> as this reflects postlogism ${ }^{77}$ denaturing ${ }^{16}$ and conjugated-postlogism ${ }^{77}$ derived- ${ }^{7}$ perversion-of- ${ }^{83}$ reference-ofthought-<as-preconvergingly-apriorising/axiomatising/referencing-in-

nonconviction/madeupness/bottomlining-as-to-shallow-supererogation $>$ as deconstruction of ontological-veridicality in implying and projecting about the prospective institutionalisation as of positivism ${ }^{56}$ meaningfulness-and-teleology ${ }^{83}$ reference-of-thought- categoricalimperatives/axioms/registry-teleology ${ }^{9}$,-for-intemporal-preservation-entropy-or-contiguityor-ontological-preservation (rather than a naïve operation of logic as is further highlighted below). The fact is with or without postlogism 77 and derived conjugated-postlogism 77 , human reference-of-thought-prelogism ${ }^{78}$-as-of-conviction,-in-profound-supererogation <existentially-veridical-'attendant-intradimensional-apriorising/axiomatising/referencing'logical-dueness-precedes-disontologising-logical-outcome-arrived-at $>$ tends to be relative. That is, even within a registry-worldview's/dimension's institutionalisation basis we don't necessarily function socially absolutely on the basis of veridical sound logic as we are limited by capacity (beyond-the-consciousness-awareness-teleology $-<$ of-preconverging-existential-extricationas-of-existential-unthought $>$ ) given our relative-ontological-incompleteness ${ }^{88}$-of- ${ }^{8}$ reference- 
of-thought and secondly by projective-arbitrariness/waywardness in the choices we make, and this get even worst at the uninstitutionalised-threshold ${ }^{02}$. Consider in this regard even the case of Heidegger as one of the greatest thinker of the last century in his 'perplexed cooperation' with the Nazi regime. The closest we come to absolute ${ }^{83}$ reference-of-thought-prelogism ${ }^{78}$-as-ofconviction,-in-profound-supererogation $\quad-<$ existentially-veridical-'attendant-intradimensionalapriorising/axiomatising/referencing'-logical-dueness-precedes-disontologising-logical-

outcome-arrived-at $>$ has to do with the abstract and uncompromising determination of mathematical meaningfulness, and receding more and more as we get towards domains of increasing 'emotional involvement' (the social) as ontological-veridicality increasingly takes a backseat to extricatory/temporal preconverging-de-mentating/structuring/paradigming and further so with respect to increasing informality as in the extended-informality-〈susceptible-toeffecting-parsimony-as-of-shoddiness-and-incompleteness-to- meaningfulness-andteleology $>$ of all human institutions, and particularly where social ${ }^{103}$ universal-transparency ${ }^{104}$ 〈transparency-of-totalising-entailing,-as-to-entailing-<amplituding/formativeepistemicity $>$ totalising in-relative-ontological-completeness $\rangle$ is blurred and not forthcoming as logic tends out to be an issue of making-a-mistake-at-one-moment-expressing-the-mostprofound-conviction-as-to-profound-supererogation -at-the-other-moment in a circular reference-of-thought. This tendency is further exacerbated with the dynamic conjugation of temporal-dispositions ( ${ }^{5}$ ignorance/affordability/opportunism/exacerbation/social-chainism-orsocial-discomfiture-or-negative-social-aggregation/temporal-enculturation-or-temporalendemisation) to postlogism 7 -slantedness. This reality of our ${ }^{83}$ reference-of-thoughtprelogism ${ }^{8}$-as-of-conviction,-in-profound-supererogation $-<$ existentially-veridical‘attendant-intradimensional-apriorising/axiomatising/referencing'-logical-dueness-precedesdisontologising-logical-outcome-arrived-at $>$ as being in effect subpar rather than absolute and specifically more compromised at uninstitutionalised-threshold ${ }^{102}$ and as associated with 
postlogism as conjugated-postlogism 77 is what qualifies contextually as temporal individuations threshold-of-nonconviction/madeupness/bottomlining-in-shallowsupererogation -<as-to-'attendant-intradimensional'-prospectivelydisontologising preconverging/dementing -apriorising-psychologism $>$ as a temporal mentaldisposition defect contrasted to a wrongfully implied supposedly ${ }^{83}$ reference-of-thoughtprelogism ${ }^{78}$-as-of-conviction,-in-profound-supererogation $-<$ existentially-veridical-

\section{'attendant-intradimensional-apriorising/axiomatising/referencing'-logical-dueness-precedes-}

disontologising-logical-outcome-arrived-at $>$ as of ontologically-sound mental-disposition. This manifestation as a social dynamic (dynamic-cumulative-aftereffect) of such contrastive threshold-of-nonconviction/madeupness/bottomlining-in-shallow-supererogation $-<$ as-to‘attendant-intradimensional'-prospectively-disontologising preconverging/dementing apriorising-psychologism> and ${ }^{83}$ reference-of-thought-prelogism ${ }^{78}$-as-of-conviction,-inprofound-supererogation $-<$ existentially-veridical-'attendant-intradimensionalapriorising/axiomatising/referencing'-logical-dueness-precedes-disontologising-logicaloutcome-arrived-at $>$ takes the form of temporal-to-intemporal social interlocutors beyond-theconsciousness-awareness-teleology $\quad<$ of-preconverging-existential-extrication-as-ofexistential-unthought $>$ de-convergence as of transversality-<for-sublimating-existentialeventuating/denouement,-from-'thinking-at-first/pure-predisposition-preemptive-ofprospective-disontologising/subontologising' as-of-prospectively-disambiguated-affirmedand-unaffirmed-'motif-and-apriorising/axiomatising/referencing' $>{ }^{101}$. Such a distinction particular at the uninstitutionalised-threshold ${ }^{102}$ is required because it then implies ontologically the relegation of logical engagement as rather irrelevant and in lieu determines ontologicalveridicality by the soundness-of-the- ${ }^{83}$ reference-of-thought as of ${ }^{83}$ reference-of-thoughtcategorical-imperatives/axioms/registry-teleology in the first place to establish or not perversion-and-derived- ${ }^{7}$ perversion-of- ${ }^{8}$ reference-of-thought- $<$ as-preconvergingly- 


\section{apriorising/axiomatising/referencing-in-nonconviction/madeupness/bottomlining-as-to-}

shallow-supererogation $>$. This delineation is in line with the idea of human temporal (shortness-of-register-of- ${ }^{56}$ meaningfulness-and-teleology ${ }^{9}$ ) to intemporal (longness-ofregister-of- ${ }^{56}$ meaningfulness-and-teleology ${ }^{9}$ ) individuations nature as implicitly recognised in the preconverging/postconverging-de-mentating/structuring/paradigming of formal constructs like the law, formal institutions, etc. It equally falls in line with the idea of knowledgenotionalisation on the basis that it is equally critical to understand the possibility of the ignorances/desublimation just as conceptual sublimation knowledge itself to further uphold, advance and skew for the latter. The point being that ${ }^{5}$ meaningfulness-and-teleology ${ }^{9}$ construal should supersede just a naïve unilateral construing of interlocution mainly on the basis of reference-of-thought-prelogism ${ }^{78}$-as-of-conviction,-in-profound-supererogation

\section{<existentially-veridical-'attendant-intradimensional-apriorising/axiomatising/referencing'-}

logical-dueness-precedes-disontologising-logical-outcome-arrived-at $>$ as of reflex but equally examine 'as of circumstances pointing to uninstitutionalised-threshold ${ }^{102}$, the possibility of the ontological-veridicality of interlocutors threshold-of-nonconviction/madeupness/bottomliningin-shallow-supererogation -<as-to-'attendant-intradimensional'-prospectivelydisontologising preconverging/dementing -apriorising-psychologism $>$ mental-dispositions, and as is often associated with mental-dispositions geared towards 'flawed impression-driven, expletive-driven and non-intellectual critique' contention. This difference between threshold-ofnonconviction/madeupness/bottomlining-in-shallow-supererogation $<<$ as-to- 'attendantintradimensional'-prospectively-disontologising preconverging/dementing -apriorisingpsychologism $>\quad$ and $\quad{ }^{83}$ reference-of-thought-prelogism ${ }^{78}$-as-of-conviction,-in-profoundsupererogation -<existentially-veridical-'attendant-intradimensionalapriorising/axiomatising/referencing'-logical-dueness-precedes-disontologising-logicaloutcome-arrived-at> critically explains how the <cumulating/recomposuring attendant- 
ontological-contiguity >-successive registry-worldviews/dimensions psychoanalyticallyunshackled/memetically-reordered/institutionally-recomposured going by the fact that projective-insights about prior registry-worldview/dimension threshold-ofnonconviction/madeupness/bottomlining-in-shallow-supererogation $<<$ as-to-'attendantintradimensional'-prospectively-disontologising preconverging/dementing -apriorisingpsychologism $>$ as of prior relative-ontological-incompleteness ${ }^{8}$-of- ${ }^{-}$reference-of-thought is what needs to be superseded for prospective registry-worldview/dimension institutionalisation prospective relative-ontological-completeness ${ }^{87}$-of- ${ }^{8}$ reference-of-thought effective ${ }^{83}$ referenceof-thought-prelogism ${ }^{78}$-as-of-conviction,-in-profound-supererogation $<<$ existentiallyveridical-'attendant-intradimensional-apriorising/axiomatising/referencing'-logical-duenessprecedes-disontologising-logical-outcome-arrived-at> (as operant construal) by social universal-transparency ${ }^{104}$-〈transparency-of-totalising-entailing,-as-to-entailing<amplituding/formative-epistemicity>totalising in-relative-ontological-completeness > rendering the prior registry-worldview/dimension threshold-ofnonconviction/madeupness/bottomlining-in-shallow-supererogation $<<$ as-to-' attendantintradimensional'-prospectively-disontologising preconverging/dementing -apriorisingpsychologism $>$ (as operant construal) untenable. This brings to the fore the idea that the salient point about human mental-disposition whether construed as of institutionalisation basis or at its uninstitutionalised-threshold ${ }^{102}$ has to do with the possibility of attaining or not attaining social universal-transparency ${ }^{104}$-〈transparency-of-totalising-entailing,-as-to-entailing<amplituding/formative-epistemicity >totalising in-relative-ontological-completeness > .

Where this is effectively attained, it becomes psychically and institutionally untenable for interlocutors to act as of subpar (threshold-of-nonconviction/madeupness/bottomlining-inshallow-supererogation -<as-to-'attendant-intradimensional'-prospectively-

disontologising preconverging/dementing -apriorising-psychologism $>$ ) with regards to 
reference-of-thought-prelogism ${ }^{78}$-as-of-conviction,-in-profound-supererogation <existentially-veridical-'attendant-intradimensional-apriorising/axiomatising/referencing'logical-dueness-precedes-disontologising-logical-outcome-arrived-at $>$. This will explain why the threshold-of-nonconviction/madeupness/bottomlining-in-shallow-supererogation $-<$ as-to‘attendant-intradimensional'-prospectively-disontologising preconverging/dementing

apriorising-psychologism> within a prior registry-worldview/dimension utterly disappears within the prospective registry-worldview/dimension ${ }^{5}$ meaningfulness-and-teleology ${ }^{9}$, in the sense that notions-and-accusations-of-sorcery for instance are not entertained in a positivism social-setup as the positivism/rational-empiricism social ${ }^{103}$ universal-transparency ${ }^{104}$ 〈transparency-of-totalising-entailing,-as-to-entailing-<amplituding/formative-

epistemicity>totalising in-relative-ontological-completeness $>$ knows this to be non-veridical ontologically-speaking giving its prospective relative-ontological-completeness ${ }^{87}$-ofreference-of-thought. This imbued potency in social ${ }^{103}$ universal-transparency ${ }^{104}$ 〈transparency-of-totalising-entailing,-as-to-entailing-<amplituding/formative-

epistemicity>totalising in-relative-ontological-completeness > across all registryworldviews/dimensions is what explains the possibility of social transcendence-andsublimity/sublimation/supererogatory de-mentativity. The reason for this is that the entire construct of human social-functioning-and-accordance-as-of-social-stake-contention-orconfliction as the 'social existential-<disontologising/re-ontologising aporeticism $>$ contract' is implicitly built on supposed ${ }^{83}$ reference-of-thought-prelogism ${ }^{78}$-as-of-conviction,-in-profoundsupererogation -<existentially-veridical-'attendant-intradimensionalapriorising/axiomatising/referencing'-logical-dueness-precedes-disontologising-logicaloutcome-arrived-at $>$ to ${ }^{5}$ meaningfulness-and-teleology ${ }^{9}$ as of both the individual's expectation and the social's expectation such that failure in this respect arises mostly surreptitiously since even the most disingenuous individuation will want the social-construct to function well in order 
to 'parasitise' it, as a failing social-construct as of " ${ }^{103}$ universal social surreptitious parasitising/co-opting' puts even such individuation in jeopardy. We can appreciate this notion by the fact that even a miscreant will tend to advance, however dubious, a rationale that is meant to be socially functional. Basically, the postlogism -as-of- compulsingnonconviction/madeupness/bottomlining-〈‘ $<$ decontextualising/de-existentialising $\sim$ ofattendant-intradimensional-apriorising/axiomatising/referencing >-induced-disontologising'-ofthe-'attendant-intradimensional-ontologising'-imbued$<$ contextualising/existentialising attendant-ontological-contiguity $>$;-in-shallowsupererogation -<as-to-disontologising-perverted-outcome-sought-precedes-existentiallyveridical-'attendant-intradimensional-apriorising/axiomatising/referencing'-logical-dueness $>$ > mindset threshold-of-nonconviction/madeupness/bottomlining-in-shallow-supererogation $<$ as-to-'attendant-intradimensional'-prospectivelydisontologising preconverging/dementing -apriorising-psychologism $>$ arises out of its temporal individuation's surreptitiousness ('lack of constraining social ${ }^{103}$ universaltransparency ${ }^{104}$-〈transparency-of-totalising-entailing,-as-to-entailing-<amplituding/formativeepistemicity>totalising in-relative-ontological-completeness $>$ such that it can induce threshold-of-nonconviction/madeupness/bottomlining-in-shallow-supererogation $-<$ as-to‘attendant-intradimensional'-prospectively-disontologising preconverging/dementing apriorising-psychologism $>$ rule) as of marginal social instigation (consider the targeted nature of the adult psychopath's maturation/indirectness/spatialisation/credulity/craftiness within the scope of social functionality) while socially enabled circularly (due to the underlying prior relative-ontological-incompleteness ${ }^{8}$-of- ${ }^{8}$ reference-of-thought as social ${ }^{8}$ procrypticism-ordisjointedness-as-of- ${ }^{8}$ reference-of-thought is itself an enabler for psychopathy just as a nonpositivistic registry-worldview/dimension social superstition is itself an enabler for its corresponding postlogism 77 for 'imaginary' accusations of sorcery); and so, while socially 
inducing temporal-dispositions conjugated-postlogism 77 derived threshold-ofnonconviction/madeupness/bottomlining-in-shallow-supererogation -<as-to-'attendantintradimensional'-prospectively-disontologising preconverging/dementing -apriorisingpsychologism>, and so overall, on the flawed mental-reflex that such protraction of thresholdof-nonconviction/madeupness/bottomlining-in-shallow-supererogation $-<$ as-to- 'attendantintradimensional'-prospectively-disontologising preconverging/dementing -apriorisingpsychologism> is supposedly ${ }^{83}$ reference-of-thought-prelogism ${ }^{78}$-as-of-conviction,-inprofound-supererogation $-<$ existentially-veridical-'attendant-intradimensionalapriorising/axiomatising/referencing'-logical-dueness-precedes-disontologising-logicaloutcome-arrived-at $>$ (as to the lack of constraining social ${ }^{103}$ universal-transparency ${ }^{104}$ 〈transparency-of-totalising-entailing,-as-to-entailing-<amplituding/formative-

epistemicity>totalising in-relative-ontological-completeness $\rangle)$. Such conditions as highlighted above (surreptitiousness, marginality and circularity) are not fulfilled at childhood psychopathy explaining why conjugated-postlogism 77 as a social dynamism of protracted threshold-of-nonconviction/madeupness/bottomlining-in-shallow-supererogation $-<$ as-to‘attendant-intradimensional'-prospectively-disontologising preconverging/dementing apriorising-psychologism $>$ doesn't socially take hold then, as such childhood postlogism perversion-of- ${ }^{3}$ reference-of-thought-<as-preconverginglyapriorising/axiomatising/referencing-in-nonconviction/madeupness/bottomlining-as-toshallow-supererogation $>$ hasn't superseded the social ${ }^{103}$ universal-transparency ${ }^{104}$ 〈transparency-of-totalising-entailing,-as-to-entailing-<amplituding/formativeepistemicity $>$ totalising in-relative-ontological-completeness $\rangle$ in further inducing temporaldispositions derived- ${ }^{7}$ perversion-of- ${ }^{8}$ reference-of-thought- $<$ as-preconverginglyapriorising/axiomatising/referencing-in-nonconviction/madeupness/bottomlining-as-toshallow-supererogation $>$. The further implication is that such surreptitiousness, marginality 
and circularity with regards to a registry-worldview's/dimension's temporal-dispositions are often construed rather as circumventive issues as of temporal extricatory preconverging-dementating/structuring/paradigming, and not by ontological-veridicality insight as of preconverging/postconverging-de-mentative/structural/paradigmatic <amplituding/formativeepistemicity $>$ causality $\sim$ as-to-projective-totalitative-implications-of-prospectivenonpresencing,-for-explicating relative-unreflexivity/relative-reflexivity ontologicalcontiguity with respect to vices-and-impediments ${ }^{105}$. Thus ensuring ontological-veridical social universal-transparency ${ }^{104}$-〈transparency-of-totalising-entailing,-as-to-entailing<amplituding/formative-epistemicity>totalising in-relative-ontological-completeness $>$ is preconverging/postconverging-de-mentatively/structurally/paradigmatically inherently 'advantaged ultimately' by the social-construct functioning. (But then this can rather be achieved in the medium to long term as of a crossgenerational transcendence-andsublimity/sublimation/supererogatory de-mentativity import and hardly so in the short-run, given that in the short-run the issue of the registry-worldview/dimension relative-ontologicalincompleteness ${ }^{88}$-of- ${ }^{8}$ reference-of-thought is a drawback in this respect. As the framework of generalised social referencing of ${ }^{56}$ meaningfulness-and-teleology ${ }^{99}$ is a circular-pervasiveness closed-structure as of the habituated predicative-insights for ${ }^{5}$ meaningfulness-and-teleology based on the relative-ontological-incompleteness ${ }^{8}$-of- ${ }^{8}$ reference-of-thought of the registryworldview/dimension as prior (despite the relative-ontological-incompleteness ${ }^{8}{ }^{-}$of- ${ }^{-8}$ referenceof-thought induced distractive-alignment-to- ${ }^{3}$ reference-of-thought- $<$ ofapriorising/axiomatising/referencing $>{ }^{30}$ and override any such sense of relative pure-ontology apriorising/axiomatising/referencing-\{of-'prospectively_implicited_attendant-ontologicalcontiguity ' educedexistentialising/contextualising/textualising_ 'intelligibility/epistemicity/reflexivity-contiguity<imbued-notional cogency $\left.>^{\prime}\right\}$ - conflatedness ${ }^{13}$-in-\{preconverging-disentailment by\} 
postconverging-entailment as of prospective relative-ontological-completeness ${ }^{87}$-of- ${ }^{8}$ referenceof-thought apriorising/axiomatising/referencing-\{of-‘prospectively_implicited_attendant ontological-contiguity ' educedexistentialising/contextualising/textualising_'intelligibility/epistemicity/reflexivity-contiguity<imbued-notional cogency>' \}-conflatedness ${ }^{13}$-in-\{preconverging disentailment by\} postcenverging-entailment). So the transcendental ${ }^{56}$ meaningfulness-and-teleology ${ }^{9}$ implied as of projective-insights about the prospective registry-worldview/dimension predicative-insights of meaningfulness-and-teleology ${ }^{5}$ going by its prospective relative-ontologicalcompleteness ${ }^{87}$-of- ${ }^{83}$ reference-of-thought doesn't supersede the prior's 'circular-pervasiveness closed-structure of habituated predicative-insights for ${ }^{5}$ meaningfulness-and-teleology ${ }^{9}$ ' in the short run. Chinua Achebe's Things Fall Apart Okonkwo returning from his long banishment construes ${ }^{5}$ meaningfulness-and-teleology ${ }^{9}$ in terms of the old/prior whereas his Umuofia village which had the same inclination as his as of prior relative-ontological-incompleteness ${ }^{8}$ of- ${ }^{3}$ reference-of-thought before he was banished and likewise at the very beginning of the foreigners cultural diffusion inducing a subsequent prospective relative-ontologicalcompleteness ${ }^{87}$-of- ${ }^{83}$ eference-of-thought had moved on to the new/prospective meaningfulness-and-teleology ${ }^{9}$ which is now antipodal to his, hence his confliction with his circular-pervasiveness <amplituding/formative> wooden-language-_imbued-averaging-ofthought-<as-to-leveling/ressentiment/closed-construct-of- meaningfulness-and-teleology -asof-'nondescript/ignorable-void ' -with-regards-to-prospective-apriorising-implications $>$ > which is equally a reflection of the confliction the village had had with the same prior circularpervasiveness <amplituding/formative > wooden-language-_imbued-averaging-of-thought$<$ as-to-leveling/ressentiment/closed-construct-of- meaningfulness-and-teleology -as-of'nondescript/ignorable-void '-with-regards-to-prospective-apriorising-implications $>>\quad$ when the foreign cultural diffusion arrived before superseding it crossgenerationally. We can equally 
construe of the inverse situation as in H.G. Well's The Country of the Blind which also highlights the implications of relative contrast of ontological-completeness-by-incompleteness-ofreference-of-thought with regards to ${ }^{5}$ meaningfulness-and-teleology construal where Nunez's 'seeing of the environment' ${ }^{83}$ reference-of-thought as of it prospective relativeontological-completeness ${ }^{87}$-of-axiomatic-construct-or- ${ }^{83}$ reference-of-thought doesn't make an impression but is actually frowned upon on the habituated 'feeling of the environment' reference-of-thought as of its prior relative-ontological-incompleteness ${ }^{8}$. This is because the personhood and socialhood formation have been constructed in circular-pervasiveness out of the prior ${ }^{83}$ reference-of-thought as 'feeling of the environment' explaining why a registry-worldview is a <amplituding/formative $>$ wooden-language-_imbued - averaging-of-thought- $<$ as-toleveling/ressentiment/closed-construct-of- meaningfulness-and-teleology -as-of'nondescript/ignorable-void '-with-regards-to-prospective-apriorising-implications $>>\quad$ that hardly entertains its own transcendability/de-mentativity, and why transcendence-andsublimity/sublimation/supererogatory-de-mentativity is rather crossgenerational for the requisite personhood and socialhood psychoanalytic-unshackling exercise to be initiated. Consider that the 'existential value references as what is worth living for' for both Okonkwo and 'feeling of the environment' ${ }^{83}$ reference-of-thought are temporally construed as definite-and-set as of their given or apriorising/axiomatising/referencing/intelligibilitysettingup/measuringinstrumenting-foroperant-or-incidenting-predicative-insights in the circularly-pervasive closed-structure of their reference-of-thought' despite their respective inherent prior relative-ontologicalincompleteness ${ }^{8}$-of- ${ }^{8}$ reference-of-thought without room for countenancing new perspectiveapriorising/axiomatising/referencing/intelligibilitysettingup/measuringinstrumenting-for-newpredicative-insights overcoming their circularly-pervasive closed-structure of ${ }^{83}$ reference-ofthought, speaking of their distractive-alignment-to- ${ }^{-}$reference-of-thought- $<$of- 
apriorising/axiomatising/referencing $>30$ from an ontological-normalcy/postconvergence epistemic-or-notional projective-perspective as of ontological-faith-notion-or-ontologicalfideism —imbued-underdetermination-of-motif-and-apriorising/axiomatising/referencing-as-

so-being-as-of-existential-reality. Interestingly, facing their respective conundrum to take a drastic and immediate decision as of their 'existential value references as what is worth living for', and without the prospect for crossgenerational adjustment, their decisions are equally dramatic in terms of considering physically doing away with Nunez's notion of 'seeing of the world' ${ }^{8}$ reference-of-thought, and Okonkwo's tragic acts upon the foreigners messenger and subsequently upon himself. This reflects the mental-disposition of all registryworldviews/dimensions uninstitutionalised-threshold ${ }^{102}$, including our own as positivismprocrypticism as of its disjointedness-as-of- ${ }^{3}$ reference-of-thought with regards to their 'existential value references as what is worth living for' rather temporally construed as definiteand-set as of distractive-alignment-to- ${ }^{-3}$ reference-of-thought- $<$ ofapriorising/axiomatising/referencing $>30$ notwithstanding any notion of relative prospective ontological-completeness-of- ${ }^{3}$ reference-of-thought. Furthermore, it should be noted that the relative validity of a prospective <amplituding/formativeepistemicity>totalising/circumscribing/delineating $\quad{ }^{83}$ reference-of-thought- ${ }^{8}$ devolving-as-ofinstantiative-context- ${ }^{5}$ meaningfulness-and-teleology

apriorising/axiomatising/referencing/intelligibilitysettingup/measuringinstrumenting-foroperant-or-incidenting-predicative-insights 'is not at all about the demonstrable instantiative logical-processing-or-logical-implicitation - supposedly-apriorising-in-conviction-as-toprofound-supererogation validity' but rather such a demonstration is more preconverging/postconverging-de-mentatively/structurally/paradigmatically, together with all other such demonstrations of the prospective <amplituding/formativeepistemicity>totalising/circumscribing/delineating $\quad{ }^{83}$ reference-of-thought- devolving-as-of- 
instantiative-context- meaningfulness-and-teleology

apriorising/axiomatising/referencing/intelligibilitysettingup/measuringinstrumenting-foroperant-or-incidenting-predicative-insights, a 'contributory invalidation of the prior $<$ amplituding/formative-epistemicity>totalising/circumscribing/delineating $\quad{ }^{83}$ reference-ofthought- ${ }^{8}$ devolving-as-of-instantiative-context -56 meaningfulness-and-teleology apriorising/axiomatising/referencing/intelligibilitysettingup/measuringinstrumenting-foroperant-or-incidenting-predicative-insights in its circular-pervasiveness' at its uninstitutionalised-threshold ${ }^{102}$ as of its ontologising-deficiency/relative-ontologicalincompleteness ${ }^{8}$-of- ${ }^{8}$ reference-of-thought; thus qualified as transcendence-andsublimity/sublimation/supererogatory de-mentativity/suprastructuration. Just as the exercise of demonstrative convincing on the basis of a scientific principle within a non-positivistic social context 'is not at all about the demonstrable instantiative ${ }^{5}$ logical-processing-or-logicalimplicitation - supposedly-apriorising-in-conviction-as-to-profound-supererogation validity' but rather preconverging/postconverging-de-mentatively/structurally/paradigmatically, together with all other such demonstrations as of scientific and positivistic principles/axioms $/{ }^{8}$ referenceof-thought meaningfulness-and-teleology apriorising/axiomatising/referencing/intelligibilitysettingup/measuringinstrumenting-foroperant-or-incidenting-predicative-insights, a 'contributory invalidation of non-scientific and non-positivism <amplituding/formative-epistemicity>totalising/circumscribing/delineating reference-of-thought- devolving-as-of-instantiative-context- ${ }^{56}$ meaningfulness-andteleology apriorising/axiomatising/referencing/intelligibilitysettingup/measuringinstrumenting-foroperant-or-incidenting-predicative-insights in circular-pervasiveness' at its uninstitutionalisedthreshold $^{102}$ as of its ontologising-deficiency/relative-ontological-incompleteness ${ }^{88}$-ofreference-of-thought. We can grasp an abstract sense of this situation as follows. Supposed 
human limited-mentation-capacity-deepening —as-subjecting limitedness/human-subpotencyto-'educed-unlimitedness/existence-sublimating nascence' ${ }^{3}$ as inducing more and more profound projective-insights construed as the successive apriorising/axiomatising/referencing/intelligibilitysettingup/measuringinstrumentings representing the <cumulating/recomposuring attendant-ontological-contiguity $>$-successive registry-worldviews/dimensions ${ }^{83}$ reference-of-thought under which their respective predicative-insights construct their respective ${ }^{56}$ meaningfulness-and-teleology ${ }^{9}$, so grounded axiomatically

apriorising/axiomatising/referencing/intelligibilitysettingup/measuringinstrumenting-foroperant-or-incidenting-predicative-insights; is compared imaginarily to 'mental-dispositions at different successive ascertaining-perspectives unbeknown-to-each other for gauging the overall earth landscape' (representing analogically 'different < cumulating/recomposuring attendantontological-contiguity >-successive registry-worldviews/dimensions for ${ }^{56}$ meaningfulnessand-teleology' '), construed say at sea-level-height perspective/apriorising/axiomatising/referencing/intelligibilitysettingup/measuringinstrumentin $\mathrm{g}$ for predicative-insights' (as recurrent-utter-uninstitutionalisation), 'hill-level-height perspective/apriorising/axiomatising/referencing/intelligibilitysettingup/measuringinstrumentin $\mathrm{g}$ for predicative-insights' (as base-institutionalisation-ununiversalisation), 'mountain-levelheight

perspective/apriorising/axiomatising/referencing/intelligibilitysettingup/measuringinstrumentin $\mathrm{g}$ for predicative-insights' (as ${ }^{103}$ universalisation-positivism), 'airplane-level-height perspective/apriorising/axiomatising/referencing/intelligibilitysettingup/measuringinstrumentin $\mathrm{g}$ for predicative-insights' (as positivism- ${ }^{8}$ procrypticism) and 'space-satellite-level-height perspective/apriorising/axiomatising/referencing/intelligibilitysettingup/measuringinstrumentin $\mathrm{g}$ for predicative-insights' (as deprocrypticism), rather as successive mental-states $/{ }^{8}$ reference- 
of-thought unbeknown-to-each-other in 'circular-pervasiveness closed-structure of apriorising/axiomatising/referencing/intelligibilitysettingup/measuringinstrumenting$\begin{array}{llll}\text { producing-measurements for } & \text { forth landscape }\end{array}$ aposteriorising/logicising/deriving/intelligising/measuring-purpose—of-obtainedmeasurements'. We know that having never experienced 'hill-level-height perspective/apriorising/axiomatising/referencing/intelligibilitysettingup/measuringinstrumentin g for predicative-insights' (base-institutionalisation-ununiversalisation) the 'sea-level-height perspective/apriorising/axiomatising/referencing/intelligibilitysettingup/measuringinstrumentin g for predicative-insights' (recurrent-utter-uninstitutionalisation) will hardly countenance operating the perspective/apriorising/axiomatising/referencing/intelligibilitysettingup/measuringinstrumentin $\mathrm{g}$ for predicative-insights of the former as more ontologically profound, given its 'circularpervasiveness closed-structure of apriorising/axiomatising/referencing/intelligibilitysettingup/measuringinstrumenting$\begin{array}{llll}\text { producing-measurements } & \text { for } & \text { earth } & \text { landscape }\end{array}$ aposteriorising/logicising/deriving/intelligising/measuring-purpose—of-obtainedmeasurements' on the basis of its 'sea-level-height perspective/apriorising/axiomatising/referencing/intelligibilitysettingup/measuringinstrumentin $\mathrm{g}$ for predicative-insights'; and this same mental-reflex applies successively to relatively 'lowerlevel-heights perspective/apriorising/axiomatising/referencing/intelligibilitysettingup/measuringinstrumentin g for predicative-insights' (prior registry-worldviews/dimensions) with respect to relatively 'higher-level-heights

perspective/apriorising/axiomatising/referencing/intelligibilitysettingup/measuringinstrumentin $\mathrm{g}$ for predicative-insights' (prospective registry-worldviews/dimensions). The fundamental 
difficulty

is

that

'no

given

perspective/apriorising/axiomatising/referencing/intelligibilitysettingup/measuringinstrumentin $\mathrm{g}$ for predicative-insights' (registry-worldview/dimension) recognises that there is any above it, and by reflex circularly undertakes predicative-insights from its perspective/apriorising/axiomatising/referencing/intelligibilitysettingup/measuringinstrumentin $\mathrm{g}$ (and it is only the long run crossgenerational habituation construed as of de-mentation〈supererogatory ontological-de-mentation-or-dialectical-de-mentation-stranding-or-

attributive-dialectics $\rangle$ with the prior ontologically construed as decentered and preconvergingor-dementing ${ }^{20}$-apriorising-psychologism as of distractive-alignment-to- ${ }^{3}$ reference-of-thought$<$ of-apriorising/axiomatising/referencing $>$ 30, with the implication that its logical-dueness doesn't exist just as the logical-dueness of the animist ${ }^{83}$ reference-of-thought with their God-ofplane proposition doesn't ontologically exist.) We can grasp as well that it is the 'space-satellitelevel-height

perspective/apriorising/axiomatising/referencing/intelligibilitysettingup/measuringinstrumentin g for predicative-insights' (as deprocrypticism) that ultimately provides the ideal 'ascertainingperspectives for gauging the overall earth landscape'. Besides, why the explication herein is necessarily implying a prospective ${ }^{8}$ reference-of-thought (as the author in here with a supposed notional ${ }^{18}$ deprocrypticism ${ }^{83}$ reference-of-thought construal as implying a prospective relativeontological-completeness ${ }^{87}$-of- ${ }^{83}$ reference-of-thought over our positivism- ${ }^{8}$ procrypticism), the fact is that any transcendental analysis is caught in two worlds as two different ${ }^{83}$ reference-ofthought in striving to explicate the ontological pre-eminence of the prospective ${ }^{83}$ reference-ofthought as of ontological-normalcy/'postconvergence, thus facing the dilemma that by mentalreflex we are not 'habituated' to the notion of our ${ }^{83}$ reference-of-thought being construed as 'preconverging-or-dementing -apriorising-psychologism and not thinking', and so whether speaking of being construed within our positivism- ${ }^{80}$ procrypticism uninstitutionalisation as 
preconverging-or-dementing ${ }^{20}$-apriorising-psychologism and not thinking, within nonpositivism/medievalism uninstitutionalisation as preconverging-or-dementing ${ }^{20}$-apriorisingpsychologism and not thinking, within ununiversalisation uninstitutionalisation as preconverging-or-dementing ${ }^{20}$-apriorising-psychologism and not thinking, and recurrent-utteruninstitutionalisation uninstitutionalisation as preconverging-or-dementing ${ }^{20}$-apriorisingpsychologism and not thinking. We can grasp this by imagining how a non-positivism uninstitutionalised-threshold ${ }^{102}$ will react when construed as preconverging-or-dementing apriorising-psychologism and not thinking with say notions-and-accusations-of-sorcery it considers given as a matter of fact, and imagine of such a reaction with a preconverging-ordementing -apriorising-psychologism and not thinking representation of ourselves construed from futural Being-development/ontological-framework-expansion-as-to-depth-ofontologising-development-as-infrastructure-of- meaningfulness-and-teleology as of prospective ${ }^{18}$ deprocrypticism-or-preempting — disjointedness-as-of- ${ }^{3}$ reference-of-thought perspective as in disjointedness-as-of- ${ }^{3}$ reference-of-thought and rather in distractive-alignmentto- ${ }^{8}$ reference-of-thought- $<$ of-apriorising/axiomatising/referencing $>30$ ! Thus the reality of this analysis in that sense is 'sparing as of our high temporal-to-intemporal-conjugating-emotionalinvolvement/subjectification/epistemicting $\sim$ self-referencing-syncretising-as-ofperceived-social-stake-contention-or-confliction nature' for the sake of deconstructiveengagement/engaged-destruktion because an analysis construed as of ${ }^{83}$ reference-of-thought is all about mental-soundness or unsoundness representation (with no logical engagement implication) hence rather of a psychoanalytic-unshackling purpose; as a change of ${ }^{8}$ referenceof-thought implies a change perspective/apriorising/axiomatising/referencing/intelligibilitysettingup/measuringinstrumentin g-of- ${ }^{56}$ meaningfulness-and-teleology as a shift of the curve-of-prospective-relativeontological-completeness ${ }^{87}$-of- reference-of-thought/axiomatic-construct and not a change in 
logic as a change along the same ${ }^{83}$ reference-of-thought/curve-of-prior-relative-ontologicalincompleteness ${ }^{88}$-of- ${ }^{8}$ reference-of-thought $/{ }^{5}$ logical-processing-or-logical-implicitationsupposedly-apriorising-in-conviction-as-to-profound-supererogation . In other words, a truly direct notional $\sim$ deprocrypticism ontological analysis will be a 'mental breakin'/preconverging-or-dementing -apriorising-psychologism of our positivism- ${ }^{80}$ procrypticism as we by reflex 'mentally break-in'/dement a non-positivistic ${ }^{83}$ reference-of-thought (as we don't engage it on the basis of the non-positivistic ${ }^{83}$ reference-of-thought- categoricalimperatives/axioms/registry-teleology ${ }^{9}$, -foraposteriorising/logicising/deriving/intelligising/measuring - ${ }^{56}$ meaningfulness-and-teleology just as a notional ${ }^{18}$ deprocrypticism analysis will not engage us on the basis of our procrypticism-or-disjointedness-as-of- ${ }^{83}$ reference-of-thought $\quad$ reference-of-thoughtcategorical-imperatives/axioms/registry-teleology ${ }^{9}$, ,for-

aposteriorising/logicising/deriving/intelligising/measuring - ${ }^{56}$ meaningfulness-and-teleology ${ }^{9}$, and so in both cases as of the relative ontologising-deficiency/relative-ontologicalincompleteness ${ }^{8}$-of- ${ }^{8}$ reference-of-thought of non-positivism and ${ }^{80}$ procrypticism-ordisjointedness-as-of- ${ }^{8}$ reference-of-thought). But then wholly carried out in both instances it will be off-putting to both prior ${ }^{8}$ reference-of-thought, explaining why a transcendental analysis is a deconstructive-engagement/engaged-destruktion recognising and harnessing the human potential to psychoanalytically-unshackle. This is more than just an abstract conceptualisation but an 'existentially-disontologising/re-ontologising aporeticism $>$ defining empirical reality' of how the possibility for cultural diffusion took place historically in 'relative-ontologicalcompleteness $^{87}$-of- ${ }^{83}$ reference-of-thought over prior relative-ontological-incompleteness ${ }^{88}$-ofreference-of-thought' (and so for instance, with the 'relative ontological-veracity as to prospective leeway of tolerance- $<$ of-disparateness>-inexactitude as stretched-truth-as-ofrelatively-deficient ontological-performance $^{72}-<$ including-virtue-as-ontology $>$ ' allowed to the 
animist to say 'God-of-plane' in the view that in due course there will be 'psychoanalyticunshackling for epistemic-growth,-as - \{veridical/sound\}-relative-reflexivity-inexistence/relativising from-limited-mentation-as-its-deepening/psychologismic epistemicacutisation residualising, ${ }^{\{\text {decompulsing }}{ }^{\text {\} }}$ delinearity for-cogency' towards positivistic meaningfulness-and-teleology ${ }^{9}$ ); and considering as well with regards to registryworldview/dimension level of elucidation that such a conceptualisation of 'relative ontologicalveracity as to prospective leeway of tolerance-<of-disparateness $>$ /inexactitude as stretchedtruth - as-of-relatively-deficient $\sim$ ontological-performance ${ }^{2}-<$ including-virtue-as-ontology $>^{\prime}$ is crossgenerationally associated with the meeting of cultures wherein their meeting points often as of cultural and commercial relationships initiate 'acculturating-indigenising-pidginising transitioning settings and their social constructions as of <amplituding/formativeepistemicity $>$ totalising $\sim$ self-referencing-syncretising' prior to eventual prospective relativeontological-completeness ${ }^{87}$-of- ${ }^{83}$ reference-of-thought accommodation. Likewise, this 'relative ontological-veracity as to prospective leeway of tolerance-<of-disparateness $>$ /inexactitude as stretched-truth — as-of-relatively-deficient $\sim$ ontological-performance ${ }^{72}-<$ including-virtue-asontology $>^{\prime}$ as of a notional ${ }^{18}$ deprocrypticism construal herein may elicit a misconstrual from a positivistic perspective failing to factor in the circular-pervasiveness implied in the notion of positivism- ${ }^{80}$ procrypticism uninstitutionalisation as ${ }^{80}$ procrypticism-or-disjointedness-as-ofreference-of-thought $\quad{ }^{83}$ reference-of-thought- categorical-imperatives/axioms/registryteleology failing/not-upholding intemporal-preservation-entropy-or-contiguity-orontological-preservation, and thus failing to grasp the notional deprocrypticism apriorising/axiomatising/referencing/intelligibilitysettingup/measuringinstrumenting-foroperant-or-incidenting-predicative-insights that construes our positivism- ${ }^{80}$ procrypticism as preconverging-or-dementing 20 -apriorising-psychologism/not-thinking and decentered, and wrongfully trying to engage ${ }^{56}$ meaningfulness-and-teleology 9 in positivism- ${ }^{80}$ procrypticism 
terms-as-of-axiomatic-construct failing to factor in the circular-pervasiveness of the disjointedness-as-of- ${ }^{8}$ reference-of-thought. (More like a non-positivistic mindset $/{ }^{3}$ referenceof-thought insisting to contendingly engage a positivistic mindset $/{ }^{3}$ reference-of-thought but failing to grasp the implications as of circular-pervasiveness of being of non-positivistic of reference-of-thought as of its prior relative-ontological-incompleteness ${ }^{8}$-of- ${ }^{8}$ reference-ofthought. Such insight point out that the 'mental tools' available to a mental state of recurrentutter-uninstitutionalisation are not logically-intelligible-but-rather-are-distractivelypreconverging-or-dementing ${ }^{20}$-apriorising-psychologism with respect to an implied prospective state of base-institutionalisation, the 'mental tools' available to a mental state of baseinstitutionalisation-ununiversalisation are not logically-intelligible-but-rather-are-distractivelypreconverging-or-dementing ${ }^{20}$-apriorising-psychologism with respect to an implied prospective mental state of ${ }^{103}$ universalisation, the 'mental tools' available to a state of ${ }^{103}$ universalisationnon-positivism/medievalism are not logically-intelligible-but-rather-are-distractivelypreconverging-or-dementing ${ }^{20}$-apriorising-psychologism with respect to an implied prospective mental state of positivism, and prospectively the 'mental tools' available to a state of positivismprocrypticism are not logically-intelligible-but-rather-are-distractively-preconverging-ordementing ${ }^{20}$-apriorising-psychologism with respect to an implied prospective mental-state of deprocrypticism. Thus unlike is the case with issues of logical-dueness/logical-pertinence as of appropriateness or inappropriateness of ${ }^{54}$ logical-processing-or-logical-implicitation supposedly-apriorising-in-conviction-as-to-profound-supererogation , issues of perversionand-derived- ${ }^{74}$ perversion-of- ${ }^{8}$ reference-of-thought-<as-preconvergingly-

\section{apriorising/axiomatising/referencing-in-nonconviction/madeupness/bottomlining-as-to-}

shallow-supererogation $>$ rather render such notions as forgiveness/overlooking/resetting nothing more but vague <amplituding/formative-epistemicity $>$ totalising $\sim$ self-referencingsyncretising/circularity/interiorising/akrasiatic-drag ${ }^{34}$ misconstruing based on a "naïve 
traditional reflex' that truly has no grander virtuous implications but quite the contrary as actually endemising/enculturating vices-and-impediments ${ }^{105}$ as when so-construed as a $<$ amplituding/formative $>$ wooden-language-〈imbued-temporal-mere-

\section{form/virtualities/dereification/akrasiatic-drag/denatured/preconverging-or-dementing} narratives - of-the- reference-of-thought- categorical-imperatives/axioms/registryteleology > failing/not-upholding intemporal-preservation-entropy-or-contiguity-orontological-preservation; thus transforming such 'denaturing notions of forgiveness/overlooking/resetting into a temporal mental-disposition <amplituding/formativeepistemicity $>$ causality $\sim$ as-to-projective-totalitative-implications-of-prospectivenonpresencing,-for-explicating relative unreflexivity/relative reflexivity ontological-

contiguity 'misconstrued vicious insight disposition' thus rather endemising/enculturating vices-and-impediments ${ }^{105}$ ! As the question that arises is what does it mean to forgive/overlook/reset with regards to a temporal mental state of prior relative-ontologicalincompleteness ${ }^{8}$-of- ${ }^{8}$ reference-of-thought beyond-the-consciousness-awareness-teleology $<$ of-preconverging-existential-extrication-as-of-existential-unthought $>$ circular-pervasiveness at its uninstitutionalised-threshold ${ }^{102}$ in perversion-and-derived- ${ }^{7}$ perversion-of- ${ }^{8}$ reference-ofthought-<as-preconvergingly-apriorising/axiomatising/referencing-innonconviction/madeupness/bottomlining-as-to-shallow-supererogation $>$ as recurrent-utteruninstitutionalisation, ununiversalisation, non-positivism/medievalism or procrypticism? It effectively means perpetuating the endemising/enculturation of the given uninstitutionalisedthreshold ${ }^{83}$ reference-of-thought. What is of relevance is a veridically uninhibited/decomplexified 'understanding of how the relative-unreflexivity/relativereflexivity - ontological-contiguity ${ }^{67}$ of-the-human-institutionalisation-process ${ }^{68}$ works and induces prospective institutionalisations' as a 'The-Good/knowledge-reification $\sim$ gesturing-andaccounting - of-epistemic-phenomenalism- $<$ in- 
prospective_psychologismic apriorising/axiomatising/referencing-\{of- ${ }^{\text {prospectively }}$

implicited_attendant-ontological-contiguity ' educed-

existentialising/contextualising/textualising_'intelligibility/epistemicity/reflexivity-contiguity-

$<$ imbued-notional cogency $>\quad\}$-conflatedness -in-\{preconverging-disentailment by\}

postconverging-entailment $>$ /understanding/<amplituding/formative-

epistemicity $>$ causality as-to-projective-totalitative-implications-of-prospective-

nonpresencing,-for-explicating relative unreflexivity/relative-reflexivity - ontological-

contiguity construct' and not a vague 'impression-driven/good-naturedness/wishfulness construct'; and that virtue-as-ontology/moral/ethical act is a ${ }^{8}$ reference-of-thought- categoricalimperatives/axioms/registry-teleology ${ }^{9}$, -for-

aposteriorising/logicising/deriving/intelligising/measuring- ${ }^{5}$ meaningfulness-and-teleology ${ }^{99}$ of crossgenerational psychoanalytic-unshackling/memetic-reordering/institutionalrecomposuring', and so à-la-Diderot as of the Encyclopédistes positivistic liberal and scientific outlook as an opened-construct-of- meaningfulness-and-teleology ${ }^{99}$ with its preconverging/postconverging-de-mentative/structural/paradigmatic virtue-as-ontology implications over a non-positivism/medievalism outlook <amplituding/formative > woodenlanguage-〈imbued — averaging-of-thought-<as-to-leveling/ressentiment/closed-construct-ofmeaningfulness-and-teleology -as-of-‘nondescript/ignorable-void '-with-regards-toprospective-apriorising-implications $>>$ that cannot be construed in forgiveness/overlooking/resetting terms-as-of-axiomatic-construct given its preconverging-dementating/structuring/paradigming vices-and-impediments ${ }^{105}$ implications! Such that 'our pretence to a prospective mental inclination for virtue-as-ontology' goes hand-in-hand with 'our introspection as of the preconverging/postconverging-de-mentative/structural/paradigmatic $<$ amplituding/formative-epistemicity $>$ causality $\sim$ as-to-projective-totalitative-implications-ofprospective- nonpresencing,-for-explicating relative-unreflexivity/relative-reflexivity 
ontological-contiguity of the beyond-the-consciousness-awareness-teleology ${ }^{0}-<$ ofpreconverging-existential-extrication-as-of-existential-unthought $>$ of our prior relativeontological-incompleteness ${ }^{8}$-of- ${ }^{8}$ reference-of-thought given its likelihood to induce our prospective vices-and-impediments ${ }^{105}$, and thus 'our shouldering of the given transcendenceunenabling-uninstitutionalised-threshold 02 in alienation-as-inauthentic/poorlyobjectified/poorly-desubjectified-as-objectified/ontological-bad-faith/inauthenticity ${ }^{64} /$ nihilistic underlying this prior relative-ontological-incompleteness ${ }^{8}$-of- ${ }^{8}$ reference-of-thought behind our uninstitutionalised-threshold ${ }^{102}$ 's $\quad$ perversion-and-derived- ${ }^{7}$ perversion-of- ${ }^{83}$ reference-ofthought-<as-preconvergingly-apriorising/axiomatising/referencing-innonconviction/madeupness/bottomlining-as-to-shallow-supererogation $>$ as vices-andimpediments $^{105}$, and so as of an opened-construct-of- meaningfulness-and-teleology prospective transcendental mental inclination for prospective relative-ontologicalcompleteness ${ }^{87}$-of- ${ }^{8}$ reference-of-thought virtue-as-ontology'. Otherwise, such a notion of forgiveness/overlooking/resetting with respect to perversion-and-derived-74 perversion-ofreference-of-thought-<as-preconvergingly-apriorising/axiomatising/referencing-innonconviction/madeupness/bottomlining-as-to-shallow-supererogation $>$ shouldn't $\quad$ be narrowly interpreted only with regards to our positivism registry-worldview/dimension in its $<$ amplituding/formative-epistemicity $>$ totalising $\sim$ self-referencingsyncretising/circularity/interiorising/akrasiatic-drag $34 \quad<$ amplituding/formative $>$ woodenlanguage-〈imbued - averaging-of-thought-<as-to-leveling/ressentiment/closed-construct-ofmeaningfulness-and-teleology -as-of-'nondescript/ignorable-void '-with-regards-toprospective-apriorising-implications $>>$ but should go back ironically to the very beginning at recurrent-utter-uninstitutionalisation to imply forgiveness/overlooking/resetting within it same $<$ amplituding/formative $>$ wooden-language-_imbued — averaging-of-thought-<as-toleveling/ressentiment/closed-construct-of- meaningfulness-and-teleology -as-of- 
'nondescript/ignorable-void '-with-regards-to-prospective-apriorising-implications $>>\quad$ thus

undermining the very notion in reflecting holographically-<conjugatively-and-transfusively $>$ the relative-unreflexivity/relative-reflexivity - ontological-contiguity of-the-humaninstitutionalisation-process as the very preconverging/postconverging-dementative/structural/paradigmatic essence of virtue-as-ontology by its ${ }^{83}$ reference-of-thoughtcategorical-imperatives/axioms/registry-teleology ${ }^{9}$, -for-

aposteriorising/logicising/deriving/intelligising/measuring - ${ }^{56}$ meaningfulness-and-teleology ${ }^{9}$ of crossgenerational psychoanalytic-unshackling/memetic-reordering/institutionalrecomposuring' as its leads to prospective registry-worldviews/dimensions of increasing prospective relative-ontological-completeness ${ }^{87}$-of- ${ }^{8}$ reference-of-thought superseding successive preconverging/postconverging-de-mentative/structural/paradigmatic basis of vicesand-impediments $^{105} ; \quad$-as failing rulemaking-over-non-rulesapriorising/axiomatising/referencing-psychologism in recurrent-utter-uninstitutionalisation or failing universalisation-directed-rulemaking-over-non-rulesapriorising/axiomatising/referencing-psychologism in ununiversalisation or failing positivising/rational-empiricism-based-universalisation-directed-rulemaking-over-non-rulesapriorising/axiomatising/referencing-psychologism in non-positivism/medievalism or failing preempting - disjointedness-as-of- ${ }^{8}$ reference-of-thought,-as-to- ${ }^{6}<$ amplituding/formativeepistemicity> growth-or-conflatedness ${ }^{13} /$ transvaluativerationalising/transepistemicity/anamnestic-residuality/spirit-drivenness'_-in-supersedingmere-formulaic-positivising/rational-empiricism-based-universalisation-directed-rulemakingover-non-rules - apriorising/axiomatising/referencing-psychologism in procrypticism, and thus requiring respectively transcending/superseding to base-institutionalisation, ${ }^{103}$ universalisation, positivism and deprocrypticism. And by that same 'ironic token' the notion of grander human lives should not be construed as of the mental-disposition perpetuating the relative- 
unreflexivity/relative-reflexivity — ontological-contiguity ${ }^{67}$ of-the-human-institutionalisationprocess ${ }^{6}$ in an opened-construct-of- ${ }^{56}$ meaningfulness-and-teleology ${ }^{9}$ allowing for ${ }^{83}$ referenceof-thought- categorical-imperatives/axioms/registry-teleology ${ }^{99}$,-foraposteriorising/logicising/deriving/intelligising/measuring- ${ }^{5}$ meaningfulness-and-teleology ${ }^{9}$ of crossgenerational psychoanalytic-unshackling/memetic-reordering/institutionalrecomposuring' but rather <amplituding/formative > wooden-language-〈imbued-averaging-ofthought-<as-to-leveling/ressentiment/closed-construct-of- meaningfulness-and-teleology -asof-'nondescript/ignorable-void ' -with-regards-to-prospective-apriorising-implications $>$ ) starting at the recurrent-utter-uninstitutionalisation in permanence that doesn't allow for any such transcending enabled by the relative unreflexivitrelative reflexivity-ontologicalcontiguity $^{67}$ of-the-human-institutionalisation-process ${ }^{68}$. In other words the notion of forgiveness/overlooking/resetting with respect to perversion-and-derived- perversion-ofreference-of-thought-<as-preconvergingly-apriorising/axiomatising/referencing-innonconviction/madeupness/bottomlining-as-to-shallow-supererogation $>$ is rather vague, as the more fundamental issue here is that human ${ }^{56}$ meaningfulness-and-teleology ${ }^{99}$ as of human limited-mentation-capacity—as-subjecting-'educed-unlimitedness/existence-sublimating nascence' to-limitedness/human-subpotency for construing virtue-asontology/ontology/intrinsic-reality/ontological-veridicality is 'ever preconverging/postconverging-de-mentatively/structurally/paradigmatically in need for prospective relative-ontological-completeness ${ }^{87}$-of- ${ }^{8}$ reference-of-thought' and that is what is to be sought after as with the recurrent-utter-uninstitutionalised striving for baseinstitutionalisation, the base-institutionalised-ununiversalised striving for ${ }^{103}$ universalisation, the ${ }^{103}$ universalised-non-positivist/medievalist striving for positivism and in our case the positivist-procryptist striving for notional deprocrypticism as of ontological-faith-notion-orontological-fideism - imbued-underdetermination-of-motif-and- 
apriorising/axiomatising/referencing-as-so-being-as-of-existential-reality; and so as of human limited-mentation-capacity-deepening —as-subjecting limitedness/human-subpotency-to'educed-unlimitedness/existence-sublimating nascence' ${ }^{53}$ enabled by ${ }^{83}$ reference-of-thoughtcategorical-imperatives/axioms/registry-teleology ${ }^{9}$,-for-

aposteriorising/logicising/deriving/intelligising/measuring $-{ }^{56}$ meaningfulness-and-teleology ${ }^{99}$ of crossgenerational psychoanalytic-unshackling/memetic-reordering/institutionalrecomposuring' and so allowed by ${ }^{15}$ de-mentation-(supererogatory $\sim$ ontological-de-mentationor-dialectical-de-mentation-stranding-or-attributive-dialectics $\rangle$. Such naïve construal of forgiveness/overlooking/resetting is on the impression-driven/good-naturedness/wishfulness basis that human mental capacity is a given as if there is no preconverging/postconverging-dementative/structural/paradigmatic issue of relative-ontological-incompleteness ${ }^{8}$-of- ${ }^{-}$referenceof-thought with no recognition of any such relative-unreflexivity/relative-reflexivityontological-contiguity ${ }^{67}$ of-the-human-institutionalisation-process ${ }^{68}$ as human limitedmentation-capacity-deepening —as-subjecting limitedness/human-subpotency-to-'educedunlimitedness/existence-sublimating nascence' ${ }^{5}$ retrospectively to prospectively. This equally explains the ontological vagueness when it comes to perversion-and-derived- perversion-ofreference-of-thought-<as-preconvergingly-apriorising/axiomatising/referencing-innonconviction/madeupness/bottomlining-as-to-shallow-supererogation $>$ not only with regards to the notions of forgiveness/overlooking/resetting but also such notions associated with positive psychology as positivity, flourishing, emotional intelligence, etc. as naively instigating social $<$ amplituding/formative-epistemicity $>$ totalising $\sim$ self-referencingsyncretising/circularity/interiorising/akrasiatic-drag ${ }^{34}$ with their implications when considered at a more profound level turning out to be rather vague and at best palliative since these are not construed preconverging/postconverging-de-mentatively/structurally/paradigmatically as of intrinsic-reality/ontological-veridicality transcendental- 
enabling/sublimating/supereregatory $\sim$ de-mentativity within the framework in reflecting holographically-<conjugatively-and-transfusively $>$ the relative-unreflexivity/relativereflexivity - ontological-contiguity of-the-human-institutionalisation-process involving human limited-mentation-capacity-deepening —as-subjecting limitedness/human-subpotencyto-'educed-unlimitedness/existence-sublimating nascence' '. In other words, what does it mean in a recurrent-utter-uninstitutionalised mental state to have a positive psychology when its fundamental preconverging/postconverging-de-mentative/structural/paradigmatic issue as failing rulemaking-over-non-rules — apriorising/axiomatising/referencing-psychologism is not factored-in in its virtue-as-ontology construal/conceptualisation? And the same can be asked of us with regards to our positivism- ${ }^{80}$ procrypticism disjointedness-as-of- ${ }^{8}$ reference-of-thought. In which case such vague approaches will simply imply beyond-the-consciousness-awarenessteleology $-<$ of-preconverging-existential-extrication-as-of-existential-unthought $>\quad$ naïve perpetuation in $\quad<$ amplituding/formative-epistemicity $>$ totalising $\sim$ self-referencingsyncretising/circularity/interiorising/akrasiatic-drag 34 of the fundamental vices-andimpediments ${ }^{105}$ with both uninstitutionalised-threshold ${ }^{102}$, thus explaining the fundamental dilemma of all institutional Establishments in their <amplituding/formative $>$ wooden-language〈imbued-averaging-of-thought-<as-to-leveling/ressentiment/closed-construct-ofmeaningfulness-and-teleology -as-of-‘nondescript/ignorable-void '-with-regards-toprospective-apriorising-implications $>>$. Such confusion arises from a misconstruing of what is veridically implied deconstructively/ontological-reconstitutively by ${ }^{15}$ de-mentation〈supererogatory $\sim$ ontological-de-mentation-or-dialectical-de-mentation-stranding-orattributive-dialectics), which implies that 'any registry-worldview/dimension presence placeholder-setup/mental-devising-representation/mentation/consciousness-awarenessteleology ${ }^{9}$ as of its prior relative-ontological-incompleteness ${ }^{8}$-of- ${ }^{8}$ reference-of-thought' is a 'preconverging-or-dementing -and-decentered-prior-institutionalisation's- categorical- 
representation/mentation/consciousness-awareness-teleology as unsoundness-or-ontologicalbad-faith/inauthenticity ${ }^{6}$-of- ${ }^{83}$ eference-of-thought' from the 'prospective registryworldview/dimension presence placeholder-setup/mental-devisingrepresentation/mentation/consciousness-awareness-teleology as of its prospective relativeontological-completeness ${ }^{87}$-of- ${ }^{83}$ reference-of-thought' as a 'postconverging-or-dialecticalthinking -and-centered-prospective-institutionalisation's- categoricalimperatives/axioms/registry-teleology placeholder-setup/mental-devisingrepresentation/mentation/consciousness-awareness-teleology 9 as soundness-or-ontologicalgood-faith/authenticity ${ }^{6}$-of- ${ }^{8}$ reference-of-thought'. Certainly, we can recognise the veracity/ontological-pertinence of the above articulation with respect to retrospective registryworldviews/dimensions placeholder-setup/mental-devisingrepresentation/mentation/consciousness-awareness-teleology as of their prior relativeontological-incompleteness ${ }^{8}$-of- ${ }^{8}$ reference-of-thought while our positivism registryworldview/dimension placeholder-setup/mental-devisingrepresentation/mentation/consciousness-awareness-teleology is always of prospective relativeontological-completeness ${ }^{87}$-of- ${ }^{8}$ reference-of-thought. But when it comes to a prospective assessment wherein we are of prior relative-ontological-incompleteness ${ }^{88}$-of- ${ }^{8}$ reference-ofthought as a 'preconverging-or-dementing -and-decentered-prior-institutionalisation'scategorical-imperatives/axioms/registry-teleology ${ }^{9}$ positivism- ${ }^{80}$ procrypticism placeholdersetup/mental-devising-representation/mentation/consciousness-awareness-teleology as unsoundness-or-ontological-bad-faith/inauthenticity ${ }^{6}$-of- ${ }^{3}$ reference-of-thought' from the 'prospective $\quad$ presence placeholder-setup/mental-devisingrepresentation/mentation/consciousness-awareness-teleology of notional ${ }^{18}$ deprocrypticism as of its prospective relative-ontological-completeness ${ }^{87}$-of- ${ }^{-2}$ efence-of-thought' as a 
'postconverging-or-dialectical-thinking -and-centered-prospective-institutionalisation'scategorical-imperatives/axioms/registry-teleology $\quad$ placeholder-setup/mental-devisingrepresentation/mentation/consciousness-awareness-teleology 9 as soundness-or-ontologicalgood-faith/authenticity ${ }^{-}$of- ${ }^{-3}$ reference-of-thought', we are rather less apt to concur going by our $<$ amplituding/formative-epistemicity $>$ totalising $\sim$ self-referencingsyncretising/circularity/interiorising/akrasiatic-drag ${ }^{34}$ reflex such that such notions as forgiveness/overlooking/resetting and notions of positive psychology are rather just a failure to preconverging/postconverging-de-mentatively/structurally/paradigmatically recognise the implied perversion-and-derived- ${ }^{7}$ perversion-of- ${ }^{83}$ reference-of-thought- $<$ as-preconverginglyapriorising/axiomatising/referencing-in-nonconviction/madeupness/bottomlining-as-toshallow-supererogation $>$ as of our relative-ontological-incompleteness ${ }^{8}$-of- ${ }^{83}$ reference-ofthought, and what we are doing then is 're-referencing from the same positivism- ${ }^{80}$ procrypticism relative-ontological-incompleteness ${ }^{8}$-of- ${ }^{8}$ reference-of-thought' and thus wrongly implying our unde-mentativity hence our untranscendability for a preconverging/postconverging-dementative/structural/paradigmatic reference-of-thought- categoricalimperatives/axioms/registry-teleology ${ }^{9}$,-foraposteriorising/logicising/deriving/intelligising/measuring $-{ }^{56}$ meaningfulness-and-teleology ${ }^{9}$ of crossgenerational psychoanalytic-unshackling/memetic-reordering/institutionalrecomposuring', and paradoxically thus by implication that there is no relative-ontologicalincompleteness ${ }^{88}$-of- reference-of-thought, to then wrongly imply such articulations of forgiveness/overlooking/resetting and positive-psychology are of intemporal projection whereas these are actually of conscious or unconscious beyond-the-consciousness-awarenss-teleology temporal/shortness of register of meaning lulness and teleology projection. This insight explains the bizarreness we face from time to time discovering that even institutions we imagine should relatively be spared by scandals as human vices-and-impediments ${ }^{105}$ like many public- 
facing institutions, the media, faith institutions, etc. are now-and-then plague with scandals bound to re-occur because of this misunderstanding of knowledge as virtue-asontology/ontology articulated above as of preconverging/postconverging-dementative/structural/paradigmatic nature of 'prospective postconvergingaapereticismovercoming/unovercoming as the-Good/knowledge-reification $\sim$ gesturing-and-accounting-ofepistemic-phenomenalism- $<$ in-

prospective_psychologismic apriorising/axiomatising/referencing-\{of-'prospectively implicited_attendant-ontological-contiguity ' educedexistentialising/contextualising/textualising_ 'intelligibility/epistemicity/reflexivity-contiguity<imbued-notional cogency >' \}-conflatedness -in-\{preconverging disentailment by\} postconverging-entailment $>$ /understanding/<amplituding/formativeepistemicity $>$ causality $\sim$ as-to-projective-totalitative-implications-of-prospectivenonpresencing,-for-explicating relative-unreflexivity/relative-reflexivity - ontologicalcontiguity , construal/conceptualisation, and not naïve at best palliative construals in impression-driven/good-naturedness/wishfulness. A further reason for the difficulty has to do thus with the fact that each registry-worldview's/dimension's ${ }^{83}$ reference-of-thought is inherently a metaphysics-of-presence-〈implicited-'nondescript/ignorable-void '-as-topresencing - absolutising-identitive-constitutedness > construed as postconverging-ordialectical-thinking -and-centered-prospective-institutionalisation's- categoricalimperatives/axioms/registry-teleology ${ }^{9}$ soundness-or-ontological-good-faith/authenticity ${ }^{6}$-ofreference-of-thought that is in a circular-evasiveness from more ontologically-veridical metaphysics-of-absence-〈implicited-epistemic-veracity-of- nonpresencing-<perspectiveontological-normalcy/postconvergence $>>$ construals/conceptualisations as implied by prospective relative completeness-of- ${ }^{3}$ reference-of-thought which rather construes it as a preconverging-or-dementing -and-decentered-prior-institutionalisation's- ${ }^{2}$-ategorical- 
imperatives/axioms/registry-teleology ${ }^{9}$ unsoundness-or-ontological-bad-faith/inauthenticity ${ }^{64}$ of- ${ }^{3}$ reference-of-thought. The ontological implication is that beforehand/axiomatically with respect to the cross-engagement of a prior relative-ontological-incompleteness ${ }^{88}$-of- ${ }^{8}$ referenceof-thought and a prospective relative-ontological-completeness ${ }^{87}$-of- ${ }^{8}$ reference-of-thought, the former is priorly invalidated into a preconverging-or-dementing ${ }^{20}$-and-decentered-priorinstitutionalisation's- categorical-imperatives/axioms/registry-teleology ${ }^{9}$ unsoundness-orontological-bad-faith/inauthenticity ${ }^{6}$-of- ${ }^{3}$ reference-of-thought by the latter as a postconverging-or-dialectical-thinking -and-centered-prospective-institutionalisation'scategorical-imperatives/axioms/registry-teleology soundness-or-ontological-goodfaith/authenticity ${ }^{6}$ of- ${ }^{3}$ reference-of-thought, invalidating by implication the logicaldueness/logical-pertinence as of ${ }^{54}$ logical-processing-or-logical-implicitation-supposedlyapriorising-in-conviction-as-to-profound-supererogation of the former. This we can grasp retrospectively in a cross-engagement with say notions-and-accusations-of-sorcery between our positivism and the non-positivism/medieval registry-worldview/dimension going by our prospective relative-ontological-completeness ${ }^{87}$-of- ${ }^{83}$ reference-of-thought with respect to its prior relative-ontological-incompleteness ${ }^{8}$-of- ${ }^{8}$ reference-of-thought. But since we have been habituated as of our existential-disentogising/re ontogising apereticism $>$ formation within our $<$ amplituding/formative $>$ wooden-language-〈imbued - averaging-of-thought- $<$ as-toleveling/ressentiment/closed-construct-of- meaningfulness-and-teleology -as-of'nondescript/ignorable-void '-with-regards-to-prospective-apriorising-implications $>\rangle$ to be in logical-dueness for ${ }^{54}$ logical-processing-or-logical-implicitation - supposedly-apriorising-inconviction-as-to-profound-supererogation by default and thus always contendingly relevant on the basis of sharing a mutual positivism ${ }^{8}$ reference-of-thought, we will hardly entertain though a notional ${ }^{18}$ deprocrypticism cross-engagement implied invalidation of our logical-dueness for logical-processing-or-logical-implicitation-supposedly-apriorising-in-conviction-as-to- 
profound-supererogation and thus rendering us contendingly irrelevant on the basis of our prior relative-ontological-incompleteness ${ }^{8}$-of- ${ }^{8}$ reference-of-thought construed as disjointedness-asof- ${ }^{-}$reference-of-thought. But then ironically such a unde-mentativity posture could as well be adopted by a non-positivism/medievalism ${ }^{83}$ reference-of-thought in its own existential$<$ disontologising/re-ontologising aporeticism $>$ formation that recognises non-positivistic ideas and notions-and-accusations-of-sorcery as relevant and of postconverging-or-dialecticalthinking -and-centered-prospective-institutionalisation's- categoricalimperatives/axioms/registry-teleology ${ }^{9}$ with its logical-dueness for ${ }^{5}$ logical-processing-orlogical-implicitation-supposedly-apriorising-in-conviction-as-to-profound-supererogation valid by default. This point out that there is necessarily a central growth element of a preconverging/postconverging-de-mentative/structural/paradigmatic $\quad{ }^{83}$ reference-of-thoughtcategorical-imperatives/axioms/registry-teleology ${ }^{9}$, -for-

aposteriorising/logicising/deriving/intelligising/measuring - ${ }^{56}$ meaningfulness-and-teleology for crossgenerational psychoanalytic-unshackling/memetic-reordering/institutionalrecomposuring' allowing for de-mentativity and thus transcendability as enabling human virtueas-ontology/ontology. Further to the points made this far, talk of such a narrative as of such preconverging/postconverging-de-mentative/structural/paradigmatic <amplituding/formativeepistemicity $>$ causality $\sim$ as-to-projective-totalitative-implications-of-prospective-

\section{nonpresencing,-for-explicating relative - unreflexivity/relative-reflexivity - ontological-}

contiguity of vices-and-impediments ${ }^{105}$ of our prior relative-ontological-incompleteness ${ }^{8}$-ofreference-of-thought that does not focus on substantive critiquing/assessment of the arguments made but is rather geared to imply beforehand that such arguments are impropriety, is actually nothing more than our falsehood as mortals circularly pretending to imply that humankind-inits-deficit does have a status above its mortal shortfall, and so paradoxically as a flawed and unsubstantiated route to wrongly imply no such argumentation is admissible. This is often a 
choice deterrent of institutional and eruditical Establishments of presence failing to recognise that more profound human insights arise from Dionysian dispositions and not just a reflex of looking at the presence as forever given as it is. The bluntness of reality/ontology doesn't recognise the mortals that we are and we can't advance our mortal statuses as superseding inherent reality/ontology, but we are rather bound to be much more substantive than that to avoid 'human closure of ${ }^{56}$ meaningfulness-and-teleology ${ }^{9}$ ' which easily arises given our temporal-tointemporal-conjugating-emotional-involvement/subjectification/epistemic-totalising $\sim$ selfreferencing-syncretising-as-of-perceived-social-stake-contention-or-confliction. The fact is such an articulation is not idle but rather the requisite fervour associated with many an enlightening thought, however qualified as impropriety, as a <amplituding/formative $>$ woodenlanguage-〈imbued - averaging-of-thought-<as-to-leveling/ressentiment/closed-construct-ofmeaningfulness-and-teleology -as-of-‘nondescript/ignorable-void '-with-regards-toprospective-apriorising-implications $>>$ start arising when we temporally carve away statuses out of the reach of ontological contention making the mortals that we are bigger than intrinsicreality/ontological-veridicality.) On any such occasion, ontological-veracity as of notional ${ }^{18}$ deprocrypticism prospective relative-ontological-completeness ${ }^{87}$-of- ${ }^{83}$ reference-ofthought is restored by doing away with 'relative ontological-veracity as to prospective leeway of tolerance-<of-disparateness $>$ /inexactitude as stretched-truth-as-of-relativelydeficient $\sim$ ontological-performance ${ }^{72}-<$ including-virtue-as-ontology $>$ ' and articulating a 'mental break-in'/preconverging-or-dementing ${ }^{20}$-apriorising-psychologism of positivismprocrypticism ${ }^{5}$ meaningfulness-and-teleology 99 at its procrypticism uninstitutionalisation as of disjointedness-as-of- ${ }^{3}$ reference-of-thought from notional ${ }^{18}$ deprocrypticism apriorising/axiomatising/referencing/intelligibilitysettingup/measuringinstrumenting-foroperant-or-incidenting-predicative-insights, just as we'll appreciate that were the animists insistent say on relating to the plane as God-of-plane to a point implying their potential non- 
transcendability as of 'psychoanalytic-unshackling for epistemic-growth,-as\{veridical/sound\}-relative-reflexivity-in-existence/relativising from-limited-mentation-as-itsdeepening/psychologismic epistemic-acutisation residualising, \{decompulsing $\}^{2}$ delinearity foreogency' in due course, 'relative ontological-veracity as to prospective leeway of tolerance-<ofdisparateness $>$-inexactitude as $\quad$ stretched-truth-as-of-relatively-deficient $\sim$ ontologicalperformance ${ }^{72}-<$ including-virtue-as-ontology $>$ ' is no longer warranted but a direct 'mental break-in'/preconverging-or-dementing ${ }^{20}$-apriorising-psychologism by a demonstration to uphold ontological-veracity. Such a demonstration might be construed as of a simple paper plane demonstration of <amplituding/formative-epistemicity $>$ causality $\sim$ as-to-projectivetotalitative-implications-of-prospective- nonpresencing,-for-explicating relativeunreflexivity/relative-reflexivity - ontological-contiguity principles or extraordinarily a flight from the flight deck with explanation or more extensively articulating that things work by natural causes and effects with no spirits inside them thus implying that a positivism-centered meaningfulness-and-teleology ${ }^{9}$ is more ontologically pertinent (even as the ramifications will rather be of crossgenerational existential-<disontologising/re-ontologising aporeticism $>$ import upon the animistic 'social-functioning-and-accordance-as-of-social-stake-contentionor-confliction imbuing existentialising-frame-of entailment of motif and apriorising/axiomatising/referencing of disontologising/ontologising-and-re-ontologising'). Certainly such a 'mental break-in'/preconverging-or-dementing -apriorising-psychologism demonstration with regards to our procrypticism ${ }^{83}$ reference-of-thought as of its disjointednessas-of- ${ }^{8}$ reference-of-thought construed from a notional ${ }^{18}$ deprocrypticism ${ }^{83}$ reference-ofthought perspective or apriorising/axiomatising/referencing/intelligibilitysettingup/measuringinstrumenting-foroperant-or-incidenting-predicative-insights will look weird to us going by our circularly pervasive $<$ amplituding/formative-epistemicity $>$ totalising $\sim$ self-referencing- 
syncretising/circularity/interiorising/akrasiatic-drag procrypticism-or-disjointedness-as-ofreference-of-thought, but it is more of ontological-veridicality/intrinsic-reality even though we are unhabituated to it since it is beyond-the-consciousness-awareness-teleology ${ }^{9}-<$ ofpreconverging-existential-extrication-as-of-existential-unthought $>$ and not yet by social universal-transparency ${ }^{104}$-〈transparency-of-totalising-entailing,-as-to-entailing$<$ amplituding/formative-epistemicity>totalising in-relative-ontological-completeness $\rangle,$ just as had been the case from the perspective or apriorising/axiomatising/referencing/intelligibilitysettingup/measuringinstrumenting-foroperant-or-incidenting-predicative-insights of all the uninstitutionalised-threshold reference-of-thought with respect to the 'mental break-in'/preconverging-or-dementing 2 apriorising-psychologism of their corresponding prospective institutionalisations ${ }^{83}$ reference-ofthought. The bigger point being that by definition a ${ }^{83}$ reference-of-thought doesn't fathom the nature and degree of its relative-ontological-incompleteness ${ }^{8}$-of- ${ }^{8}$ reference-of-thought as of its apriorising/axiomatising/referencing/intelligibilitysettingup/measuringinstrumenting-foroperant-or-incidenting-predicative-insights. (Thus suggesting base-institutionalisation in recurrent-utter-uninstitutionalisation, implying ${ }^{103}$ universalisation in base-institutionalisationununiversalisation, suggesting positivism in ${ }^{103}$ universalisation-non-positivism/medievalism and suggesting notional deprocrypticism in positivism- procrypticism will be perceived initially as 'bullshit' going by human-subpotency-aporia/undecidability/dilemma/oughtindeterminacy/deficiency/limitation/constraint—imbued-'notional firstnaturednessformativeness-<as-to-eventualising-inkling-drive-or-seeding-misprising $>$ temporal-tointemporal-dispositions- $<$ so-construed-as-from-perspective-ontologicalnormalcy/postconvergence>'-existentialism-form-factor as of our temporal inclination to subjectification/nombrilism/self-referencing. But then human temporal inclination to utter expletives is not intellectual argument but a mark of intellectual ineptness, with the 
'ontologically relevant' intellectual issue being about understanding the 'habituation exercise' as of $<$ amplituding/formative-epistemicity $>$ causality $\sim$ as-to-projective-totalitativeimplications-of-prospective- nonpresencing,-for-explicating relative-unreflexivity/relativereflexivity - ontological-contiguity and percolation-channelling- $<$ in-deferentialformalisation-transference $>$ involved in the psychoanalytic-unshackling/memeticreordering/institutional-recomposuring behind the relative-unreflexivity/relative-reflexivity ontological-contiguity $^{67}$ of-the-human-institutionalisation-process ${ }^{68}$ as pertinent for notional ' deprocrypticism 'without in the very least entertaining' the $<$ amplituding/formative $>$ wooden-language-〈imbued - averaging-of-thought-<as-toleveling/ressentiment/closed-construct-of- meaningfulness-and-teleology -as-of'nondescript/ignorable-void '-with-regards-to-prospective-apriorising-implications $>>$ mentalreflex as has been the case across all the institutional-cumulation/institutional-recomposure-〈asto- historiality/ontological-eventfulness /ontological-aesthetic-tracing-<perspectiveontological-normalcy/postconvergence-reflected-‘epistemicity-relativism-determinism'>> that has always been a drawback as of temporal extricatory preconverging-dementating/structuring/paradigming and parasitising/co-opting inclination subpar to the warranted ontological-faith-notion-or-ontological-fideism - imbued-underdetermination-ofmotif-and-apriorising/axiomatising/referencing-as-so-being-as-of-existential-reality perpetually upholding the currency in reflecting holographically-<conjugatively-andtransfusively $>$ the relative unreflexivitrelative reflexivity - ontological-contiguity of-thehuman-institutionalisation-process across-the-times; as at this point, intellectual commitment overtly meets ontology.) Explained in other terms, implying in a non-positivism social-setup that notions-and-accusations-of-sorcery are inherently vices-and-impediments ${ }^{105}$ as of the transcendental prospective positivism prospective relative-ontological-completeness ${ }^{87}$-ofreference-of-thought will-not-be-convincing-on-a-par-with-other-argumentators in that social- 
setup but rather for such temporal/shortness-of-register-of meaningfulness-and-teleology purpose requires making a 'temporal charade argument' of the type oneself or another person is not involved in sorcery or a counterargument that the accuser is the sorcerer, and so on the basis of the prior non-positivism prior relative-ontological-incompleteness ${ }^{8}$-of- ${ }^{8}$ reference-ofthought, to-be-more-convincing-on-a-par-with-other-argumentators in that non-positivism social-setup (but then all this will wrongfully validate superstition and thus fail the 'very point of ontology as to aetiologisation/ontological-escalation- $<$ ontologicalveridicality_commitment/otherliness_transcending/compulsions-encumbered_transcending>’ as an exercise in 'intrinsic-reality/ontological-veridicality transcendentalenabling/sublimating/supereregatery $\sim$ de-mentativity as intemporality ${ }^{52}$-symmetrising-bydesymmetrising-subsumption-of-temporality ${ }^{\circ}$ and not a temporal extrication exercise of 'social-aggregation-enabling as of symmetrisation-of- reference-of-thought, as this is in effect an ontologically-non-veridical-or-flawed $<$ amplituding/formative-epistemicity $>$ totalising $\sim$ selfreferencing-syncretising/circularity/interiorising/akrasiatic-drag ${ }^{34}$ and/or desymmetrisation for perceived temporal social-stake-contention-or-confliction'). Thus there is a fundamental ontological-veridicality/intrinsic-reality argumentation handicap in the short run for undermining the postlogism 77 -and-conjugated-postlogism 77 as notions-and-accusations-ofsorcery associated with the non-positivism registry-worldview/dimension prior relativeontological-incompleteness ${ }^{8}$-of- ${ }^{8}$ reference-of-thought social referencing of ${ }^{5}$ meaningfulnessand-teleology ${ }^{9}$ which is 'superstitious' in the very first instance such that any argumentator putting-into-question superstitiousness like there is nothing like sorcery is 'shooting itself on the foot' in the short run. It is rather the long run crossgenerational resolution construed as of ${ }^{15}$ dementation-〈supererogatory ontological-de-mentation-or-dialectical-de-mentation — strandingor-attributive-dialectics $\rangle$ by superseding the prior non-positivism prior relative-ontologicalincompleteness ${ }^{8}$-of- ${ }^{-1}$ refence-of-thought as of the prospective positivism registry- 
worldview/dimension prospective relative-ontological-completeness ${ }^{87}$-of- ${ }^{83}$ reference-ofthought by 'continuous habituation going by the latter's <amplituding/formativeepistemicity $>$ causality $\sim$ as-to-projective-totalitative-implications-of-prospectivenonpresencing,-for-explicating relative-unreflexivity/relative-reflexivity - ontological-

contiguity in the long run as superseding the prior beyond-the-consciousness-awarenessteleology $-<$ of-preconverging-existential-extrication-as-of-existential-unthought $>\quad$ and initiating the appropriate prospective social ${ }^{103}$ universal-transparency ${ }^{104}$-〈transparency-oftotalising-entailing,-as-to-entailing-<amplituding/formative-epistemicity $>$ totalising $\sim$ inrelative-ontological-completeness $\rangle$ that will preconverging/postconverging-dementatively/structurally/paradigmatically harken back to undermine the postlogism 77 -andconjugated-postlogism grounded on notions-and-accusations-of-sorcery associated with the non-positivism registry-worldview/dimension. That is, it is by turning the non-positivistic mindset $/{ }^{3}$ reference-of-thought into a positivistic mindset $/{ }^{3}$ reference-of-thought that the possibility of 'ontologically' and 'not palliatively' resolving notions-and-accusations-of-sorcery can arise in the very first instance. Likewise, it is the crossgenerational resolution of our positivism- ${ }^{8}$ procrypticism prior relative-ontological-incompleteness ${ }^{88}$-of- ${ }^{8}$ reference-ofthought as of its circular-pervasiveness in countenancing of ${ }^{8}$ procrypticism-or-disjointednessas-of- ${ }^{3}$ reference-of-thought from apriorising/axiomatising/referencing/intelligibilitysettingup/measuringinstrumenting-foroperant-or-incidenting-predicative-insights of ${ }^{56}$ meaningfulness-and-teleology ${ }^{9}$ as conceptualising, articulating and preempting such disjointing/disparateness/disentailing meaningfulness-and-teleology ${ }^{9}$ of our positivism- ${ }^{8}$ procrypticism that is the preconverging/postconverging-de-mentative/structural/paradigmatic resolution as of prospective relative-ontological-completeness ${ }^{8}$-of- ${ }^{-3 e f e r e n c e-o f-t h o u g h t ~ t h a t ~ c a n ~}$ preconverging/postconverging-de-mentatively/structurally/paradigmatically harken back in 
undermining the circular-pervasiveness in countenancing of 'disjointedness-as-of- ${ }^{\text {reference- }}$ of-thought' and the enculturation/endemisation of the manifest postlogism 7 -and-conjugatedpostlogism 77 in our positivism- ${ }^{8}$ procrypticism as psychopathy and social psychopathy, and so going beyond just a temporal palliative resolution within a positivism- ${ }^{80}$ procrypticism circularpervasiveness closed-structure countenancing 'disjointedness-as-of- ${ }^{-3 e f e r e n c e-o f-t h o u g h t ' ~ o f ~}$ meaningfulness-and-teleology , beyond-the-consciousness-awareness-teleology ${ }^{9}-<$ of preconverging-existential-extrication-as-of-existential-unthought> , and hence overlooking the preconverging/postconverging-de-mentative/structural/paradigmatic ontological vices-andimpediments $^{105}$ implications of postlogism ${ }^{77}$-and-conjugated-postlogism ${ }^{77}$ including psychopathy and social psychopathy arising given the relative-ontological-incompleteness ${ }^{88}$-ofreference-of-thought of our procrypticism as disjointedness-as-of- ${ }^{8}$ reference-of-thought. This

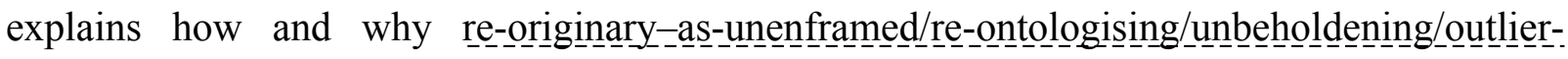
conceptualisation___imbued-postconverging/dialectical-thinking -'projectiveinsights'/'epistemic-projection-in-conflatedness ' -of-notional deprocrypticism-prospectivesublimation $>$ ideas can supersede conventionalised ideas where the former provide in the big picture the possibility for the social-construct to function better by social ${ }^{103}$ universaltransparency ${ }^{104}$-〈transparency-of-totalising-entailing,-as-to-entailing-<amplituding/formativeepistemicity>totalising in-relative-ontological-completeness $\rangle$ at a crossgenerational depth of analysis, and equally explains human historical suspicions of new ideas just in case their social ${ }^{3}$ universal-transparency ${ }^{10}$-〈transparency-of-totalising-entailing,-as-to-entailing$<$ amplituding/formative-epistemicity>totalising in-relative-ontological-completeness $>$ turn out to be better and possibly leading to the dismantling of the prior and vested and attendant interests. It should be grasped that the comprehensiveness/dynamic-cumulative-afereffect of a registry-worldview's/dimension's threshold-of-nonconviction/madeupness/bottomlining-inshallow-supererogation -<as-to-'attendant-intradimensional'-prospectively- 
disontologising preconverging/dementing -apriorising-psychologism> (as an operant construal) at its uninstitutionalised-threshold ${ }^{12}$ is what defines it as uninstitutionalisedthreshold ${ }^{102}$ which is decentered and preconverging-or-dementing ${ }^{20}$-apriorising-psychologism from the prospective institutionalisation perspective while that of its ${ }^{83}$ reference-of-thoughtprelogism ${ }^{78}$-as-of-conviction,-in-profound-supererogation $-<$ existentially-veridical-

\section{'attendant-intradimensional-apriorising/axiomatising/referencing'-logical-dueness-precedes-}

disontologising-logical-outcome-arrived-at $>$ (as an operant construal) of its institutionalisation is what defines it as prior institutionalisation. (As implied by this author the nature of human individuations accounts respectively for human intemporality ${ }^{5 /} /$ longness and human temporality $/$ shortness as the 'more fundamentally <amplituding/formative-

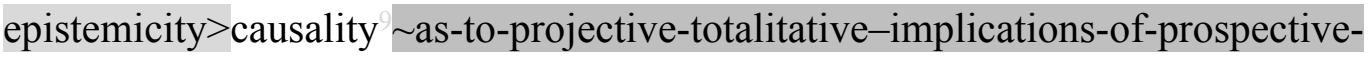
nonpresencing,-for-explicating relative-unreflexivity/relative-reflexivity - ontological-

contiguity analysable operant agency of the human condition as of human knowledge-andvirtue or vices-and-impediments ${ }^{105}$ respectively as such individuations then accrue in varying degrees in individuals as of varying circumstances'; and so-construed respectively as of intemporal individuation apriorising/axiomatising/referencing-\{of-"prospectively implicited_attendant-ontological-contiguity ' reducedexistentialising/contextualising/textualising_ intelligibility/epistemicity/reflexivity-contiguity$<$ imbued-notional cogency $>$ ' $\}$-conflatedness ${ }^{13}$-in-\{preconverging-disentailment by\} postconverging-entailment which enables prospective institutionalisations or temporal individuations distractive-alignment-to- ${ }^{8}$ reference-of-thought- $<$ ofapriorising/axiomatising/referencing $>{ }^{30}$ that induce uninstitutionalised-threshold ${ }^{102}$ at all the institutionalisations uninstitutionalised-threshold ${ }^{102}$.) The conceptual technique for disambiguating individuations as to ${ }^{83}$ reference-of-thought-prelogism ${ }^{78}$-as-of-conviction,-inprofound-supererogation $-<$ existentially-veridical-'attendant-intradimensional- 
apriorising/axiomatising/referencing'-logical-dueness-precedes-disontologising-logical-

outcome-arrived-at> at institutionalisation-threshold/institutionalisation and threshold-ofnonconviction/madeupness/bottomlining-in-shallow-supererogation $-<$ as-to-'attendantintradimensional'-prospectively-disontologising preconverging/dementing -apriorisingpsychologism $>$ at uninstitutionalised-threshold ${ }^{102}$ has to do with the given ${ }^{83}$ reference-ofthought-closeness-of-tethering-to-prelogism ${ }^{78}$-as-of-conviction,-in-profoundsupererogation -<existentially-veridical-'attendant-intradimensionalapriorising/axiomatising/referencing'-logical-dueness-precedes-disontologising-logicaloutcome-arrived-at> or ${ }^{83}$ reference-of-thought-looseness-of-tethering-to-prelogism ${ }^{78}$-as-ofconviction,-in-profound-supererogation ${ }^{-<e x i s t e n t i a l l y-v e r i d i c a l-' a t t e n d a n t-i n t r a d i m e n s i o n a l-~}$ apriorising/axiomatising/referencing'-logical-dueness-precedes-disontologising-logicaloutcome-arrived-at $>$ wherein on one extreme the prelogism ${ }^{7}$-as-of-conviction,-in-profoundsupererogation -<existentially-veridical-'attendant-intradimensionalapriorising/axiomatising/referencing'-logical-dueness-precedes-disontologising-logicaloutcome-arrived-at> mental-disposition individuation adheres to a ${ }^{83}$ reference-of-thoughtcloseness-of-tethering-to-prelogism ${ }^{8}$-as-of-conviction,-in-profound-supererogation <existentially-veridical-'attendant-intradimensional-apriorising/axiomatising/referencing'logical-dueness-precedes-disontologising-logical-outcome-arrived-at $>$ (not necessarily implying their $\quad{ }^{5}$ logical-processing-or-logical-implicitation-supposedly-apriorising-inconviction-as-to-profound-supererogation appropriateness but logically-due as of 'implicited_attendant-ontological-contiguity ${ }^{67}$ ' educedexistentialising/contextualising/textualising_intelligibility/epistemicity/reflexivity-contiguity$<$ imbued-notional $\sim$ cogency $>,,-<$ reifying-or-elucidating-of-prospective-relative-ontologicalcompleteness -of- reference-of-thought- devolving-as-of-instantiative-context $>$ ) while on the other extreme the temporal postlogism -as-of- compulsing- 
nonconviction/madeupness/bottomlining-〈'<decontextualising/de-existentialising ofattendant-intradimensional-apriorising/axiomatising/referencing $>$-induced-disontologising'-ofthe-'attendant-intradimensional-ontologising'-imbued$<$ contextualising/existentialising attendant-ontological-contiguity $>$;-in-shallowsupererogation -<as-to-disontologising-perverted-outcome-sought-precedes-existentiallyveridical-'attendant-intradimensional-apriorising/axiomatising/referencing'-logical-dueness $>$ ) individuation's mental-disposition as a 'vague-rhyming-or-copied-mimicry-or-formulaicprojection-or-projection-of-form-or-hollow-and-vague-vocalisation-or-subknowledging , as reference-of-thought-looseness-of-tethering-to-prelogism ${ }^{78}$-as-of-conviction,-in-profoundsupererogation $-<$ existentially-veridical-'attendant-intradimensionalapriorising/axiomatising/referencing'-logical-dueness-precedes-disontologising-logicaloutcome-arrived-at> (threshold-of-nonconviction/madeupness/bottomlining-in-shallowsupererogation -<as-to- 'attendant-intradimensional'-prospectivelydisontologising preconverging/dementing -apriorising-psychologism $>$ ) is a mentaldisposition for caricaturing-hollow-staging-and-performance (with respect to whatever narratives or acts can be made or committed opportunistically by 'vague-rhyming-or-copiedmimicry-or-formulaic-projection-or-projection-of-form-or-hollow-and-vague-vocalisation-orsubknowledging ${ }^{44}$ out of 'implicited_attendant-ontological-contiguity ${ }^{67}$ 'educedexistentialising/contextualising/textualising_'intelligibility/epistemicity/reflexivity_contiguity$<$ imbued-notional $\sim$ cogency $>,{ }^{\prime},-<$ reifying-or-elucidating-of-prospective-relative-ontologicalcompleteness -of- reference-of-thought- devolving-as-of-instantiative-context>'), while the threshold-of-nonconviction/madeupness/bottomlining-in-shallow-supererogation $<-<$ as-to‘attendant-intradimensional'-prospectively-disontologising preconverging/dementing apriorising-psychologism $>$ arising as of a corresponding derived- ${ }^{7}$ perversion-of- ${ }^{8}$ reference-ofthought-<as-preconvergingly-apriorising/axiomatising/referencing-in- 
nonconviction/madeupness/bottomlining-as-to-shallow-supererogation $>$ caricaturing-hollowstaging-and-performance of the temporal conjugated-postlogism 77 individuation's mentaldisposition is as of corresponding ${ }^{83}$ reference-of-thought-looseness-of-tethering-toprelogism ${ }^{78}$-as-of-conviction,-in-profound-supererogation $-<$ existentially-veridical'attendant-intradimensional-apriorising/axiomatising/referencing'-logical-dueness-precedesdisontologising-logical-outcome-arrived-at> (as of 'derived-vague-rhyming-or-copiedmimicry-or-formulaic-projection-or-projection-of-form-or-hollow-and-vague-vocalisation-orsubknowledging ${ }^{4}$ out of 'implicited_attendant-ontological-contiguity ${ }^{67}$ ' educedexistentialising/contextualising/textmalising_intelligibility/epistemicity/reflexivity-contiguity$<$ imbued-notional $\sim$ cogency $>,{ }^{\prime},-<$ reifying-or-elucidating-of-prospective-relative-ontologicalcompleteness -of- reference-of-thought- devolving-as-of-instantiative-context>>). Such temporal postlogism -as-of- compulsing-nonconviction/madeupness/bottomlining-

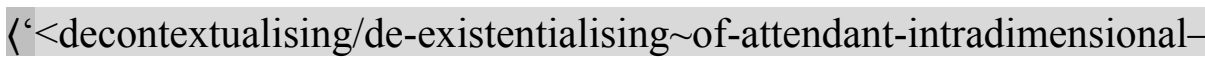
apriorising/axiomatising/referencing >-induced-disontologising'-of-the-'attendantintradimensional-ontologising'-imbued-<contextualising/existentialising attendantontological-contiguity $>$;-in-shallow-supererogation $-<$ as-to-disontologising-pervertedoutcome-sought-precedes-existentially-veridical-'attendant-intradimensionalapriorising/axiomatising/referencing'-logical-dueness $>$ > individuation's mental-disposition threshold-of-nonconviction/madeupness/bottomlining-in-shallow-supererogation $<-<$ as-to‘attendant-intradimensional'-prospectively-disontologising preconverging/dementing apriorising-psychologism> failing 'implicited_attendant-ontological-contiguity ${ }^{67}$ ' educedexistentialising/contextualising/textualising_ 'intelligibility/epistemicity/reflexivity-contiguity$<$ imbued-notional $\sim$ cogency $>{ }^{\prime},-<$ reifying-or-elucidating-of-prospective-relative-ontologicalcompleteness -of- reference-of-thought- devolving-as-of-instantiative-context> as a 'vaguerhyming-or-copied-mimicry-or-formulaic-projection-or-projection-of-form-or-hollow-and- 
vague-vocalisation-or-subknowledging ${ }^{24}$ '-as-nonconviction/madeupness/bottomlining-as-toshallow-supererogation ${ }^{6}$-of-tethering-trajectory to ${ }^{83}$ reference-of-thought-prelogism ${ }^{78}$-as-ofconviction,-in-profound-supererogation $-<$ existentially-veridical-'attendant-intradimensionalapriorising/axiomatising/referencing'-logical-dueness-precedes-disontologising-logicaloutcome-arrived-at $>$ can be seen transparently in the instance of the childhood psychopathy spilling water on a chair as a dereifying mental-shortcut to accuse another. Such personality development into adult psychopathy at which point social ${ }^{103}$ universal-transparency ${ }^{104}$ 〈transparency-of-totalising-entailing,-as-to-entailing-<amplituding/formativeepistemicity>totalising in-relative-ontological-completeness $>$ is undermined with its increasing maturation/indirectness/spatialisation/credulity/craftiness and the corresponding conjugated-postlogism 77 leads to contextualised social dynamics of temporal individuations reference-of-thought-looseness-of-tethering-to-prelogism ${ }^{78}$-as-of-conviction,-in-profoundsupererogation $-<$ existentially-veridical-'attendant-intradimensionalapriorising/axiomatising/referencing'-logical-dueness-precedes-disontologising-logicaloutcome-arrived-at> that underlies various shades of threshold-ofnonconviction/madeupness/bottomlining-in-shallow-supererogation $-<$ as-to-' $a$ attendantintradimensional'-prospectively-disontologising preconverging/dementing -apriorisingpsychologism>. As a general rule the ${ }^{83}$ reference-of-thought-closeness-of-tethering-toprelogism ${ }^{8}$-as-of-conviction,-in-profound-supererogation $-<$ existentially-veridical'attendant-intradimensional-apriorising/axiomatising/referencing'-logical-dueness-precedesdisontologising-logical-outcome-arrived-at> implies a mental-disposition for intrinsicattribution of ${ }^{56}$ meaningfulness-and-teleology ${ }^{9}$ involving an inclination for presuming and implying of ${ }^{5}$ meaningfulness-and-teleology' as limited/constraint by 'implicited_attendant ontological-contiguity ${ }^{67} \sim$ educedexistentialising/contextualising/textualising_'intelligibility/epistemicity/reflexivity-contiguity- 
$<$ imbued-notional $\sim$ cogency $>$

,$-<$ reifying-or-elucidating-of-prospective-relative-ontological-

completeness -of- reference-of-thought- devolving-as-of-instantiative-context> while the reference-of-thought-looseness-of-tethering-to-prelogism ${ }^{78}$-as-of-conviction,-in-profoundsupererogation -<existentially-veridical-'attendant-intradimensionalapriorising/axiomatising/referencing'-logical-dueness-precedes-disontologising-logicaloutcome-arrived-at> implies a mental-disposition for extrinsic-attribution of ${ }^{56}$ meaningfulnessand-teleology as caricaturing-hollow-staging-and-performance involving an inclination for falsely presuming and implying ${ }^{5}$ meaningfulness-and-teleology as vague-rhyming-or-copiedmimicry-or-formulaic-projection-or-projection-of-form-or-hollow-and-vague-vocalisation-orsubknowledging ${ }^{4}$ out of the limits/constraints of 'implicited_attendant-ontologicalcontiguity $^{67}$, educedexistentialising/contextualising/textualising_'intelligibility/epistemicity/reflexivity_contiguity$<$ imbued-notional $\sim$ cogency $>$, ,-<reifying-or-elucidating-of-prospective-relative-ontologicalcompleteness -of- reference-of-thought- devolving-as-of-instantiative-context $>$. Further, the individuation-level analysis highlights that it is the ${ }^{83}$ reference-of-thought-closeness-oftethering-to-prelogism ${ }^{78}$-as-of-conviction,-in-profound-supererogation ${ }^{9}-<$ existentiallyveridical-'attendant-intradimensional-apriorising/axiomatising/referencing'-logical-duenessprecedes-disontologising-logical-outcome-arrived-at $>$ ( ${ }^{8}$ reference-of-thought- prelogism ${ }^{78}$-asof-conviction,-in-profound-supererogation ${ }^{2}<$ existentially-veridical-'attendantintradimensional-apriorising/axiomatising/referencing'-logical-dueness-precedesdisontologising-logical-outcome-arrived-at $>$ ) and $\quad{ }^{83}$ reference-of-thought-looseness-oftethering-to-prelogism ${ }^{78}$-as-of-conviction,-in-profound-supererogation $-<$ existentiallyveridical-'attendant-intradimensional-apriorising/axiomatising/referencing'-logical-duenessprecedes-disontologising-logical-outcome-arrived-at> (threshold-ofnonconviction/madeupness/bottomlining-in-shallow-supererogation $<$ as-to-'attendant- 
psychologism>) respectively as of human intemporal and temporal mental-dispositions that establish the <amplituding/formative-epistemicity $>$ causality $\sim$ as-to-projective-totalitativeimplications-of-prospective- nonpresencing,-for-explicating relative-unreflexivity/relativereflexivity ontological-contiguity of 'implicited_attendant-ontologicalcontiguity $^{67}$; educed-

existentialising/contextualising/textualising_'intelligibility/epistemicity/reflexivity-contiguity$<$ imbued-notional $\sim$ cogency $>,{ }^{\prime},-<$ reifying-or-elucidating-of-prospective-relative-ontologicalcompleteness -of- reference-of-thought- devolving-as-of-instantiative-context> of meaningfulness-and-teleology ${ }^{9}$ whether as of 'direct or derived vague-rhyming-or-copiedmimicry-or-formulaic-projection-or-projection-of-form-or-hollow-and-vague-vocalisation-orsubknowledging 94 out of 'implicited_attendant-ontological-contiguity ${ }^{67}$ ' educedexistentialising/contextmalising/textualising_'intelligibility/epistemicity/reflexivity_contiguity$<$ imbued-notional $\sim$ cogency $>,{ }^{\prime},-<$ reifying-or-elucidating-of-prospective-relative-ontologicalcompleteness -of- reference-of-thought- devolving-as-of-instantiative-context> $\quad$ with temporal-dispositions or logical-dueness as of 'implicited_attendant-ontologicalcontiguity ${ }^{67}$,educedexistentialising/contextualising/textualising_intelligibility/epistemicity/reflexivity-contiguity$<$ imbued-notional $\sim$ cogency $>,{ }^{\prime},-<$ reifying-or-elucidating-of-prospective-relative-ontologicalcompleteness -of- reference-of-thought- devolving-as-of-instantiative-context> with the intemporal/conviction-as-to-profound-supererogation mental-disposition; so-construed as of their contrastive-synopsising-depths-of- ${ }^{-5}$ meaningfulness-and-teleology 9 rather for a 'conflation construal/conceptualisation' and not a rather deceptive analytical reflex of 'apriorising/axiomatising/referencing-\{of-'prospectively_implicited_attendant-ontologicalcontiguity ' educed- 
existentialising/contextualising/textualising_ 'intelligibility/epistemicity/reflexivity-contiguity-

$<$ imbued-notional cogency $\left.>^{\prime} \quad\right\}$-constitutedness ${ }^{14}$-in-preconverging-entailment $\quad$ of reference-of-thought construal/conceptualisation'. The fact is by mental-reflex we relate to social meaningfulness-and-teleology ${ }^{59}$ by apriorising/axiomatising/referencing-\{of'prospectively implicited_attendant-ontological-contiguity ' reducedexistentialising/contextualising/textualising_'intelligibility/epistemicity/reflexivity-contiguity$<$ imbued-notional cogency $>$ ' $\quad\}$-constitutedness ${ }^{1}$-in-preconverging-entailment $\quad$ as of elaboration-as-to-mere-extrapolating/constituting/abstracting/deducing/inferring-ofelucidation-outside_- 'prospectively_implicited_attendant-ontological-contiguity ${ }^{67}$ ? educedexistentialising/contextualising/textualising_intelligibility/epistemicity/reflexivity-contiguity<imbued-notional cogency>' which by habit or chance will often turn out to be as of 'implicited_attendant-ontological-contiguity ${ }^{6 /}$; educedexistentialising/contextualising/textualising_'intelligibility/epistemicity/reflexivity-contiguity$<$ imbued-notional $\sim$ cogency $>,{ }^{\prime},-<$ reifying-or-elucidating-of-prospective-relative-ontologicalcompleteness -of- reference-of-thought- devolving-as-of-instantiative-context $>$ as of the institutionalisation ambits of the domain-of-concern precedingly so-established/soinstitutionalised by ${ }^{55}$ maximalising-recomposuring-for-relative-ontological-completeness ${ }^{87}$ unenframed/re-ontologising conceptualisation, and so with hardly any consequence for our methodological imprecision where the established/institutionalised ${ }^{83}$ reference-of-thoughtcategorical-imperatives/axioms/registry-teleology ${ }^{9}$, ,for-

aposteriorising/logicising/deriving/intelligising/measuring- ${ }^{5}$ meaningfulness-and-teleology ${ }^{9}$ is not ontologically superseded as at uninstitutionalised-threshold ${ }^{02}$. But that is technically/abstractly speaking inappropriate from an ontological-veridicality perspective requiring unassailability/reliability/dependability at uninstitutionalised-threshold ${ }^{102}$ As explained elsewhere and implied above it is the conceptualising (by ${ }^{55}$ maximalising- 
recomposuring-for-relative-ontological-completeness ${ }^{87}$ unenframed/re-

ontologising conceptualisation) of a $\quad{ }^{83}$ reference-of-thought- categoricalimperatives/axioms/registry-teleology ${ }^{9}$,-for-

aposteriorising/logicising/deriving/intelligising/measuring- ${ }^{5}$ meaningfulness-and-teleology ${ }^{99}$ as of apriorising/axiomatising/referencing-\{of-'prospectively_implicited_attendant-ontologicalcontiguity ' educed-

existentialising/contextualising/textualising_intelligibility/epistemicity/reflexivity_contiguity<imbued-notional cogency >' \}-conflatedness ${ }^{13}$-in-\{preconverging-disentailment-by\} pestconverging-entailment that enables such a certitude at uninstitutionalised-threshold ${ }^{102}$ of an epistemic-totalising $\sim$ devolved-purview-as-domain-of-construal-as-intrinsicreality/ontological-veridicality by its specific institutionalisation. And that ${ }^{83}$ reference-ofthought- ${ }^{\text {categorical-imperatives/axioms/registry-teleology }}{ }^{99}$,-foraposteriorising/logicising/deriving/intelligising/measuring $-{ }^{56}$ meaningfulness-and-teleology ${ }^{99}$ of the social at uninstitutionalised-threshold ${ }^{102}$ involves a totalising-entailing/nested-congruence social construal/conceptualisation that necessarily should factor in the reality of a humansubpotency-aporia/undecidability/dilemma/ought-

indeterminacy/deficiency/limitation/constraint—imbued-‘notional firstnaturednessformativeness-<as-to-eventualising-inkling-drive-or-seeding-misprising > temporal-tointemporal-dispositions- $<$ so-construed-as-from-perspective-ontologicalnormalcy/postconvergence>'-existentialism-form-factor but we fail to do this due to our $<$ amplituding/formative-epistemicity $>$ totalising $\sim$ self-referencingsyncretising/circularity/interiorising/akrasiatic-drag ${ }^{34}$ metaphysics-of-presence-〈implicited'nondescript/ignorable-void ' -as-to- presencing - absolutising-identitive-constitutedness > disposition as of institutionalisation and thus wrongly implying intemporal construal as of our secondnatured institutionalisation which while inconsequential within the ambits 
institutionalisation is not ontologically-veridical at the institutionalisation uninstitutionalisedthreshold ${ }^{102}$ with the latter rather requiring a temporal-to-intemporal appraisal as of metaphysicsof-absence-〈implicited-epistemic-veracity-of- nonpresencing-<perspective-ontologicalnormalcy/postconvergence $>>\quad$ as its $\quad$ reference-of-thought- categoricalimperatives/axioms/registry-teleology ${ }^{9}$,-foraposteriorising/logicising/deriving/intelligising/measuring_ ${ }^{5}$ meaningfulness-and-teleology ${ }^{9}$. The implication is that postlogism 77 psychopathy and other human temporal phenomena (and so, across all registry-worldviews) which speak of uninstitutionalised-threshold ${ }^{12}$ are often wrongfully construed on the basis of intemporal secondnatured institutionalisation human nature whereas the apriorising/axiomatising/referencing-\{of-'prespectively implieited_attendantontological-contiguity ' educedexistentialising/contextualising/textualising_'intelligibility/epistemicity/reflexivity-contiguity<imbued-notional cogency $\left.>{ }^{\prime}\right\}$-conflatedness ${ }^{13}$-in-\{preconverging-disentailment-by\} postconverging-entailment requires 'synopsising-depth of a human temporal-to-intemporal nature' and so by apriorising/axiomatising/referencing-\{of-'prospectively implicited_attendant-ontological-contiguity ' educedexistentialising/contextualising/textualising_'intelligibility/epistemicity/reflexivity_contiguity$<$ imbued-notional $\left.\sim \operatorname{cogency}>^{\prime} \quad\right\}$-conflatedness ${ }^{13}$-in-\{preconverging-disentailment by\} pestconverging-entailment to establish the uninstitutionalised-threshold ${ }^{82}$ reference-ofthought- categorical-imperatives/axioms/registry-teleology ${ }^{9}$,-foraposteriorising/logicising/deriving/intelligising/measuring $-{ }^{56}$ meaningfulness-and-teleology rather as of ${ }^{55}$ maximalising-recomposuring-for-relative-ontological-completeness ${ }^{87}$ unenframed/re-ontologising conceptualisation (construed as intimately tying down our limitedmentation-capacity—as-subjecting 'educed-unlimitedness/existence-sublimating nascence' to-limitedness/human-subpotency 
imbricatedness/threadedness/recomposuring to the 'leash' of existentialreality/ontology/intrinsic-reality/ontological-veridicality) as should be the case at all uninstitutionalised-threshold ${ }^{102}$, and so over the mental-reflex of assuming secondnatured institutionalisation ${ }^{83}$ reference-of-thought/axiomatic-construct as elaboration-as-to-mereextrapolating/constituting/abstracting/deducing/inferring-of-elucidation-outside'prospectively implicited_attendant-ontological-contiguity ${ }^{67}$ ' educedexistentialising/contextualising/textualising_intelligibility/epistemicity/reflexivity_contiguity<imbued-notional cogency>' (construed as letting our limited-mentation-capacity-assubjecting-'educed-unlimitedness/existence-sublimating nascence' to-limitedness/humansubpotency by unimbricatedness/unthreadedness/unrecomposuring out of the 'leash' of existential-reality/ontology/intrinsic-reality/ontological-veridicality) as the latter is only practically effective when dealing with an already established human registryworldview's/dimension's institutionalisation/institutionalised-construct but not at uninstitutionalised-threshold ${ }^{102}$ which require their own new specific ${ }^{83}$ reference-of-thoughtcategorical-imperatives/axioms/registry-teleology ${ }^{99}$, -for-

aposteriorising/logicising/deriving/intelligising/measuring - ${ }^{56}$ meaningfulness-and-teleology which so established then enables the practical effectiveness of elaboration-as-to-mereextrapolating/constituting/abstracting/deducing/inferring-of-elucidation-outside'prospectively_implicited_attendant-ontological-contiguity ${ }^{67}$ ' educedexistentialising/contextmalising/textualising_intelligibility/epistemicity/reflexivity_contiguity$<$ imbued-notional cogency $>$ ' . Consider the childhood psychopathy 'dereifying act' of spilling water on a chair and accusing another, even at that relatively social ${ }^{103}$ universal-transparency ${ }^{104}$ 〈transparency-of-totalising-entailing,-as-to-entailing-<amplituding/formativeepistemicity>totalising in-relative-ontological-completeness $>$ level there is a chance of mistaking as with the visitor sitting on the wet chair and needing an explanation of the whole 
situation including the child's condition, and such insight gets more and more opaque with the manifestation of adulthood psychopathy. This is an uninstitutionalised-threshold ${ }^{02}$ situation which is necessarily beyond-the-consciousness-awareness-teleology $-<$ of-preconvergingexistential-extrication-as-of-existential-unthought $>$ and without social ${ }^{10}$ universaltransparency ${ }^{104}$-〈transparency-of-totalising-entailing,-as-to-entailing-<amplituding/formativeepistemicity $>$ totalising in-relative-ontological-completeness $>$ of the visitor. This example is exactly along the lines of the ${ }^{83}$ reference-of-thought- categorical-imperatives/axioms/registryteleology ${ }^{99}$,-for-aposteriorising/logicising/deriving/intelligising/measuring- ${ }^{5}$ meaningfulnessand-teleology ${ }^{99}$ needed for construing postlogism 77 psychopathy and conjugated-postlogism 77 as of its social model at uninstitutionalised-threshold ${ }^{102}$, and so by way of ${ }^{55}$ maximalisingrecomposuring-for-relative-ontological-completeness ${ }^{8}$ — unenframed/re-

ontologising conceptualisation (the latter is what sets up apriorising/axiomatising/referencing/intelligibilitysettingup/measuringinstrumentings and is of sublimating-epistemic-imbricatedness/threadedness/recomposuring 'implicited_attendantontological-contiguity ${ }^{67} \sim$ educedexistentialising/contextualising/textualising_'intelligibility/epistemicity/reflexivity-contiguity$<$ imbued-notional $\sim$ cogency $>,{ }^{\prime},-<$ reifying-or-elucidating-of-prospective-relative-ontologicalcompleteness -of- reference-of-thought- devolving-as-of-instantiative-context $>$, in contrast to elaboration-as-to-mere-extrapolating/constituting/abstracting/deducing/inferring-ofelucidation-outside_-'prospectively_implicited_attendant-ontological-contiguity ${ }^{67}$ ? educedexistentialising/contextualising/textualising_ 'intelligibility/epistemicity/reflexivity-contiguity<imbued-notional cogency>' which is what renders-operant/incidenting predicativeinsights). It is only then that such an established institutionalisation framework allows for elaboration-as-to-mere-extrapolating/constituting/abstracting/deducing/inferring-ofelucidation-outside_- prospectively implicited_attendant-ontological-contiguity ${ }^{67}$ > educed- 
existentialising/contextualising/textualising_intelligibility/epistemicity/reflexivity-contiguity<imbued-notional cogency>' on the basis of the established ${ }^{83}$ reference-of-thoughtcategorical-imperatives/axioms/registry-teleology ${ }^{99}$, -for-

aposteriorising/logicising/deriving/intelligising/measuring $-{ }^{56}$ meaningfulness-and-teleology ${ }^{9}$.

Such a conceptualisation/construal is dramatically different from how we ordinarily conceive the construal of social ${ }^{56}$ meaningfulness-and-teleology ${ }^{9}$ before the institutionalisation of such a specific uninstitutionalised-threshold ${ }^{12}$ takes place. (Consider in this respect how the visitor erred in its relation with the childhood psychopathy on the basis of its commonly assumed social elaboration-as-to-mere-extrapolating/constituting/abstracting/deducing/inferring-ofelucidation-outside_- 'prospectively_implicited_attendant-ontological-contiguity ${ }^{67}$ ? educedexistentialising/contextualising/textualising_intelligibility/epistemicity/reflexivity-contiguity$<$ imbued-notional cogency $>$ ' At this individuation-level representation of the disambiguation of the transcending and transcended registry-worldviews, the visitor is using the 'apriorising/axiomatising/referencing/intelligibilitysettingup/measuringinstrumenting-foroperant-or-incidenting-predicative-insights' of positivism- ${ }^{80}$ procrypticism that do not factor in the possibility of the childhood psychopathy's slantedness as inducing procrypticism or 'disjointedness-as-of- ${ }^{8}$ reference-of-thought'-as-misappropriated- ${ }^{56}$ meaningfulness-andteleology going by the visitor's relative-ontological-incompleteness ${ }^{8}$-of- ${ }^{8}$ reference-ofthought as of positivism- ${ }^{8}$ procrypticism, while the explainer of the situation has factored in notional ${ }^{18}$ deprocrypticism $\quad{ }^{83}$ reference-of-thought- categorical-imperatives/axioms/registryteleology ${ }^{9}$,-for-aposteriorising/logicising/deriving/intelligising/measuring- ${ }^{5}$ meaningfulnessand-teleology 9 to preempt the induced procrypticism or 'disjointedness-as-of- ${ }^{8}$ reference-ofthought'-as-misappropriated- ${ }^{56}$ meaningfulness-and-teleology 99 from the childhood psychopathy slantedness. At this individuation-level, the fact is that in order to be certain to avoid a similar deception again in its relation with the childhood psychopathy the visitor will 
now construe of notional ${ }^{18}$ deprocrypticism ${ }^{83}$ reference-of-thought- categoricalimperatives/axioms/registry-teleology ${ }^{9}$,-for-

aposteriorising/logicising/deriving/intelligising/measuring- ${ }^{5}$ meaningfulness-and-teleology ${ }^{9}$ to preempt the slanted inducing of procrypticism or 'disjointedness-as-of- ${ }^{3}$ reference-of-thought'as-misappropriated- ${ }^{56}$ meaningfulness-and-teleology ${ }^{9}$ and gives up on positivismprocrypticism ${ }^{83}$ reference-of-thought- categorical-imperatives/axioms/registry-teleology ${ }^{99}$,for-aposteriorising/logicising/deriving/intelligising/measuring- ${ }^{5}$ meaningfulness-and-

teleology with respect to its relations with the childhood psychopathy. Thus at this individuation-level uninstitutionalised-threshold ${ }^{102}$ with respect to the childhood psychopathy, a new notional ${ }^{8}$ deprocrypticism $\quad{ }^{83}$ reference-of-thought- categoricalimperatives/axioms/registry-teleology ${ }^{9}$, -for-

aposteriorising/logicising/deriving/intelligising/measuring_- ${ }^{56}$ meaningfulness-and-teleology has superseded the prior positivism- ${ }^{8}$ procrypticism ${ }^{83}$ reference-of-thought- categoricalimperatives/axioms/registry-teleology ${ }^{9}$,-foraposteriorising/logicising/deriving/intelligising/measuring $-{ }^{5}$ meaningfulness-and-teleology ${ }^{99}$, as it is the one to be circularly/recurrently/repetitively/repeatedly be utilised for operant/incidenting predication as elaboration-as-to-mereextrapolating/constituting/abstracting/deducing/inferring-of-elucidation-outside'prospectively_implicited_attendant-ontological-contiguity ${ }^{67}$ ' educedexistentialising/contextualising/textualising_intelligibility/epistemicity/reflexivity-contiguity$<$ imbued-notional cogency $>^{\prime}$. This is equally implied at the registry-worldview/dimensionlevel by dynamic-cumulative aftereffect, but in this instance factoring in well more than just one incident of childhood psychopathy but rather the dynamic-cumulative-aftereffect implications on the social structure of myriad cases of psychopathy, and as of postlogism 77 psychopathic personalities development from childhood to adulthood together with the implications of 
conjugated-postlogism 77 social-psychopathy not only with regards to conjugated-ignorance as with the visitor but all the temporal-dispositions including ignorance/affordability/opportunism/exacerbation/social-chainism-or-social-discomfiture-ornegative-social-aggregation/temporal-enculturation-or-temporal-endemisation as of habits and thinking patterns consequences as of the extended-informality-<susceptible-to-effectingparsimony-as-of-shoddiness-and-incompleteness-to- meaningfulness-and-teleology \ by formality dynamics; with the implication of lack of social ${ }^{103}$ universal-transparency 〈transparency-of-totalising-entailing,-as-to-entailing-<amplituding fformativeepistemicity $>$ totalising $\sim$ in-relative-ontological-completeness $\rangle$ as the manifestation is beyondthe-consciousness-awareness-teleology ${ }^{9}-<$ of-preconverging-existential-extrication-as-ofexistential-unthought $>$ at this uninstitutionalised-threshold ${ }^{102}$, together with the inherent human complex of non-transcendability and hence unde-mentativity across all the registryworldviews/dimensions. At this registry-worldview/dimension-level it is obvious that a straightforward articulation going by the incidental situation of such an individuation-level analysis will not be the case, but rather requires focussing on the bigger preconverging/postconverging-de-mentative/structural/paradigmatic picture of perversion-andderived- ${ }^{7}$ perversion-of- ${ }^{83}$ reference-of-thought- $<$ as-preconvergingly-

\section{apriorising/axiomatising/referencing-in-nonconviction/madeupness/bottomlining-as-to-}

shallow-supererogation $>$. However, suggesting at the registry-worldview/dimension-level of analysis the ontological-veridicality/intrinsic-reality of a new notional ${ }^{18}$ deprocrypticism

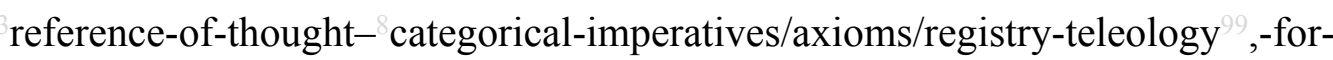
aposteriorising/logicising/deriving/intelligising/measuring - ${ }^{56}$ meaningfulness-and-teleology that implies that the registry-worldview/dimension is in circular-pervasiveness of procrypticism or 'disjointedness-as-of- ${ }^{8}$ reference-of-thought'-as-misappropriated- ${ }^{56}$ meaningfulness-andteleology will meet with a mental-complex of <amplituding/formative- 
epistemicity>totalising self-referencing-syncretising/illusion-of-the-present/presentconsciousness/mirage metaphysics-of-presence-〈implicited-'nondescript/ignorable-void '-asto- presencing-absolutising-identitive-constitutedness $\rangle$ and can only arise as of a crossgenerational psychoanalytic-unshackling/memetic-reordering/institutional-recomposuring. (Such an insight can be further elucidated in a storied-construct/ontologically-valid-narration given the limits of the possibility of explanation as herein about the 'lived social' as of the aforementioned implied notional ${ }^{18}$ deprocrypticism ${ }^{83}$ reference-of-thought- categoricalimperatives/axioms/registry-teleology ${ }^{9}$, -for-

aposteriorising/logicising/deriving/intelligising/measuring - ${ }^{56}$ meaningfulness-and-teleology

construing a storied-construct/ontologically-valid-narration driven by such postlogism 77 psychopathic associated vague-rhyming-or-copied-mimicry-or-formulaicprojection-or-projection-of-form-or-hollow-and-vague-vocalisation-or-subknowledging maturation/indirectness/spatialisation/credulity/craftiness induced narration-construed-asinstantiative-moulting involving childhood psychopathy to adulthood psychopathy development, and corresponding evolving of social relations as of dynamic-cumulativeaftereffect 'disjointedness-as-of- ${ }^{83}$ reference-of-thought'-misappropriated- ${ }^{56}$ meaningfulnessand-teleology involving compulsing-nonconviction/madeupness/bottomlining-

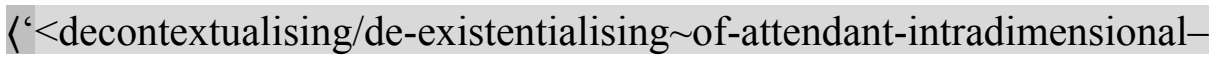
apriorising/axiomatising/referencing>-induced-disontologising'-of-the-'attendantintradimensional-ontologising'-imbued-<contextualising/existentialising attendantontological-contiguity $>$;-in-shallow-supererogation -<as-to-disontologising-pervertedoutcome-sought-precedes-existentially-veridical-'attendant-intradimensionalapriorising/axiomatising/referencing'-logical-dueness $>$ > as of psychopathic/postlogism categorical-imperatives/axioms/registry-teleology ${ }^{99}$, -foraposteriorising/logicising/deriving/intelligising/measuring - ${ }^{56}$ meaningfulness-and-teleology ${ }^{9}$ 
as-prelogism 7 -as-of-conviction,-in-profound-supererogation $-<$ existentially-veridical‘attendant-intradimensional-apriorising/axiomatising/referencing'-logical-dueness-precedesdisontologising-logical-outcome-arrived-at $>$ thus leading to caricaturing-hollow-staging-andperformance; and so construed as of 'themes-driven underlying-agency-or-sous-agencement dynamics for narration-construed-as-instantiative-moulting'). However, we can still get a sense of such preconverging/postconverging-de-mentative/structural/paradigmatic $<$ amplituding/formative-epistemicity $>$ causality $\sim$ as-to-projective-totalitative-implications-ofprospective- nonpresencing,-for-explicating relative-unreflexivity/relative-reflexivity-

ontological-contiguity from a retrospective registry-worldview/dimension perspective like postlogism in a non-positivistic social-setup as of our prospective relative-ontologicalcompleteness $^{87}$-of- ${ }^{83}$ reference-of-thought perspective but it is more difficult to grasp from a notional deprocrypticism prospective perspective of analysis where we will rather be unpalatably represented as decentered and preconverging-or-dementing ${ }^{20}$-apriorisingpsychologism, given our state of metaphysics-of-presence-〈implicited-'nondescript/ignorablevoid '-as-to- presencing - absolutising-identitive-constitutedness $\rangle$. Supposed with regards to a case of notions-and-accusations-of-sorcery as highlighted before as of a social-setup whose relative-ontological-incompleteness ${ }^{8}$-of- ${ }^{3}$ reference-of-thought is non-positivistic, a positivism minded interlocutor arguing that notions-and-accusations-of-sorcery do not exist upon an accusation of sorcery is literally undermining itself but is seen as ontologically necessary for the crossgenerational possibility of prospective transcendence-andsublimity/sublimation/supererogatory de-mentativity. Supposed however that the interlocutor isn't an isolated individual but a member from a positivistic society bringing about a cultural diffusion in the non-positivistic society such that the latter looks up to the former by its prospective relative-ontological-completeness ${ }^{87}$-of- ${ }^{8}$ reference-of-thought as it effectively has greater control on intrinsic-reality/ontological-veridicality reflected by way of say its relative 
technology, then in this case the non-positivistic social-setup will at least in ad-hoc instances be circumspect in countenancing that notions-and-accusations-of-sorcery do not exist as of $<$ amplituding/formative-epistemicity $>$ totalising $\sim$ self-referencing-

syncretising/circularity/interiorising/akrasiatic-drag ${ }^{34}$ This new positivism ${ }^{83}$ reference-ofthought- categorical-imperatives/axioms/registry-teleology $^{9}$,-for-

aposteriorising/logicising/deriving/intelligising/measuring - ${ }^{56}$ meaningfulness-and-teleology voiding notions-and-accusations-of-sorcery and superstition generally as of the prior nonpositivism ${ }^{83}$ reference-of-thought- categorical-imperatives/axioms/registry-teleology ${ }^{9}$,-foraposteriorising/logicising/deriving/intelligising/measuring - ${ }^{5}$ meaningfulness-and-teleology will more likely be taken-up-fully/habituated only crossgenerationally in the middle run as the mental-reflex will constantly relapse into notions-and-accusations-of-sorcery and superstition of the prior non-positivism ${ }^{8}$ reference-of-thought- categorical-imperatives/axioms/registryteleology ${ }^{9}$,-for-aposteriorising/logicising/deriving/intelligising/measuring- ${ }^{5}$ meaningfulnessand-teleology 9 , highlighting that a postlogism like psychopathy in our positivismprocrypticism or one associated with notions-and-accusations-of-sorcery in non-positivism social-setup is not truly speaking an isolated phenomenon as construed from an individuationlevel of analysis but speaks in-the-bigger-picture of an underlying registry-worldview/dimension registry-worldview/dimension-level relative-ontological-incompleteness ${ }^{8}$-of- ${ }^{83}$ reference-ofthought as beyond-the-consciousness-awareness-teleology ${ }^{\circ}<$ of-preconverging-existentialextrication-as-of-existential-unthought>' and 'lack of constraining social ${ }^{103}$ universaltransparency ${ }^{104}$-〈transparency-of-totalising-entailing,-as-to-entailing-<amplituding/formativeepistemicity>totalising in-relative-ontological-completeness $\rangle$; such that implying that our prior positivism- ${ }^{80}$ procrypticism, as of its reference-of-thought- categoricalimperatives/axioms/registry-teleology ${ }^{9}$, -foraposteriorising/logicising/deriving/intelligising/measuring- ${ }^{5}$ meaningfulness-and-teleology ${ }^{9}$, 
cannot longer be upheld at such uninstitutionalised-threshold ${ }^{102}$ but requiring in lieu a notional ${ }^{18}$ deprocrypticism $\quad{ }^{83}$ reference-of-thought- categorical-imperatives/axioms/registryteleology ${ }^{9}$,-for-aposteriorising/logicising/deriving/intelligising/measuring- ${ }^{5}$ meaningfulnessand-teleology ${ }^{9}$ will be difficult to countenance but for a crossgenerational psychoanalyticunshackling/memetic-reordering/institutional-recomposuring since the issue is one of registryworldview's/dimension's-uninstitutionalised-threshold ${ }^{102}$-defect-<as-Being-or-ontological-orexistential-defect $>$. Thus supposed the case of the childhood psychopathy 'dereifying act' of spilling water on a chair arose in say a non-positivistic social-setup, as of its superstitiousness, with its explanation that the reason had to do with its suspicion of sorcery from the brother. While the social-setup entertains superstitious notions however the childhood psychopathy relatively poor maturation/indirectness/spatialisation/credulity/craftiness means that it is more likely to be disbelieved in this instance as well in addition to the household familiarisation with the psychopathic/postlogism 77 condition of the child. Likewise, a visiting stranger in such a nonpositivistic social-setup might just as well have a similar reaction as the visitor in a positivismprocyrpticism social-setup by believing and reacting to the childhood psychopathy manifestation as the non-positivism social-setup apriorising/axiomatising/referencing/intelligibilitysettingup/measuringinstrumenting reflection of 'implicited_attendant-ontological-contiguity ${ }^{67}$ ' educedexistentialising/contextualising/textualising_intelligibility/epistemicity/reflexivity-contiguity<imbued-notional cogency>' -in-reification/dereification entertains/is-cognisant-and-

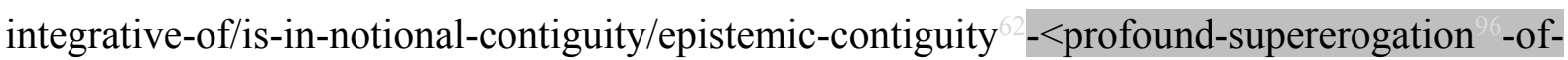
mentally-aestheticised postconverging/dialectical-thinking -qualia-schema $>$-with superstitious claims in its ${ }^{56}$ meaningfulness-and-teleology ${ }^{9}$. An explainer to the visiting stranger in the non-positivism social-setup case about the whole situation would have articulated at the individuation-level of analysis a prospective 'logically-due prelogism ${ }^{7}$-as-of-conviction,-in- 
profound-supererogation $-<$ existentially-veridical-'attendant-intradimensionalapriorising/axiomatising/referencing'-logical-dueness-precedes-disontologising-logicaloutcome-arrived-at> apriorising/axiomatising/referencing-\{of-'prospectivelyimplicited_attendant-ontological-contiguity ' educedexistentialising/contextualising/textualising_ 'intelligibility/epistemicity/reflexivity-contiguity<imbued-notional cogency $\left.>^{\prime}\right\}$-conflatedness ${ }^{13}$-in-'preconverging-disentailment by\} postconverging-entailment as of positivism ${ }^{83}$ reference-of-thought- categoricalimperatives/axioms/registry-teleology ${ }^{9}$, -foraposteriorising/logicising/deriving/intelligising/measuring_ ${ }^{56}$ meaningfulness-and-teleology ${ }^{\circ}$, going by their familiarisation with the childhood psychopathy 'logically-undue postlogism ${ }^{77}$-asof- compulsing-nonconviction/madeupness/bottomlining-〈'<decontextualising/deexistentialising $\sim$ of-attendant-intradimensional-apriorising/axiomatising/referencing $>$-induceddisontologising'-of-the-'attendant-intradimensional-ontologising'-imbued$<$ contextualising/existentialising attendant-ontological-contiguity $>$;-in-shallowsupererogation -<as-to-disontologising-perverted-outcome-sought-precedes-existentiallyveridical-'attendant-intradimensional-apriorising/axiomatising/referencing'-logical-dueness $>$ > denaturing as of non-positivism $\quad{ }^{83}$ reference-of-thought- categoricalimperatives/axioms/registry-teleology ${ }^{9}$, -foraposteriorising/logicising/deriving/intelligising/measuring $-{ }^{5}$ meaningfulness-and-teleology ${ }^{9}$ over the visiting stranger prior superstition believing 'logically-undue conjugatedpostlogism 7 /conjugated-nonconviction/madeupness/bottomlining-as-to-shallow-

supererogation derived-denaturing ${ }^{16}$ as of non-positivism ${ }^{83}$ reference-of-thought- categoricalimperatives/axioms/registry-teleology ${ }^{9},-$ foraposteriorising/logicising/deriving/intelligising/measuring- ${ }^{5}$ meaningfulness-and-teleology ${ }^{9}$, with both latter logically ${ }^{83}$ reference-of-thought construed as of distractive-alignment-to- 
reference-of-thought- $<$ of-apriorising/axiomatising/referencing $>30$ or lacking-an-ontologicallyveridical- ${ }^{8}$ reference-of-thought due to their derived-denaturing which as of dynamiccumulative-aftereffect/aftereffect at registry-worldview/dimension-level of analysis is the very ontologically-central notion of every registry-worldview/dimension uninstitutionalisedthreshold ${ }^{102}$ which should thus be always construed as being in distractive-alignment-toreference-of-thought-<of-apriorising/axiomatising/referencing $>30$ with respect to its prospective institutionalisation. It is effectively derived-denaturing that induces threshold-ofnonconviction/madeupness/bottomlining-in-shallow-supererogation $<-<$ as-to-' ${ }^{\text {attendant- }}$ intradimensional'-prospectively-disontologising preconverging/dementing -apriorisingpsychologism $>$ as of uninstitutionalised-threshold ${ }^{102}$, as we can appreciate that the childhood psychopathy and the visitor's ${ }^{56}$ meaningfulness-and-teleology are in effect ontologicallyspeaking threshold-of-nonconviction/madeupness/bottomlining-in-shallow-supererogation $<$ as-to- 'attendant-intradimensional'-prospectivelydisontologising preconverging/dementing -apriorising-psychologism>. But then at the registry-worldview/dimension-level of analysis however, when compared to the simplistic individuation-level postlogism 77 analysis insight, implying ontological-veridicality/ontologicalreality on the basis of 'logically-due prelogism"-as-of-conviction,-in-profoundsupererogation -<existentially-veridical-'attendant-intradimensionalapriorising/axiomatising/referencing'-logical-dueness-precedes-disontologising-logicaloutcome-arrived-at> apriorising/axiomatising/referencing- $\{$ of-'prospectively implicited_attendant-ontological-contiguity ' educedexistentialising/contextualising/textualising_'intelligibility/epistemicity/reflexivity-contiguity<imbued-notional cogency> $\left.>^{\prime}\right\}$ - conflatedness ${ }^{13}$ in (preconverging disentailment by $^{-}$ postconverging-entailment as of positivism ${ }^{83}$ reference-of-thought- categoricalimperatives/axioms/registry-teleology ${ }^{9}$,-for- 
aposteriorising/logicising/deriving/intelligising/measuring - ${ }^{56}$ meaningfulness-and-teleology ${ }^{9}$, with respect to the overall non-positivism registry-worldview/dimension as of its dynamiccumulative-aftereffect/aftereffect with regards to the manifest registry-worldview/dimensionlevel social construal of superstitions and notions-and-accusations-of-sorcery in general, can only arise from a crossgenerational psychoanalytic-unshackling/memeticreordering/institutional-recomposuring, as the non-positivism registry-worldview/dimension in relation to the prospective positivism registry-worldview/dimension is a $<$ amplituding/formative $>$ wooden-language-〈imbued - averaging-of-thought- $<$ as-toleveling/ressentiment/closed-construct-of- meaningfulness-and-teleology -as-of'nondescript/ignorable-void '-with-regards-to-prospective-apriorising-implications $>>$ just as our positivism- ${ }^{8}$ procrypticism registry-worldview/dimension in relation to futural Beingdevelopment/ontological-framework-expansion-as-to-depth-of-ontologising-development-asinfrastructure-of- meaningfulness-and-teleology as of prospective notional ${ }^{18}$ deprocrypticism $\quad$ registry-worldview/dimension $\quad$ is $<$ amplituding/formative $>$ wooden-language-_imbued — averaging-of-thought- $<$ as-toleveling/ressentiment/closed-construct-of- meaningfulness-and-teleology -as-of'nondescript/ignorable-void '-with-regards-to-prospective-apriorising-implications $>>$, in that as with all registry-worldviews/dimensions both do not contemplate of their transcendability and thus de-mentativity, and keep on relapsing into their respective non-positivism and procrypticism ${ }^{83}$ reference-of-thought- ${ }^{-}$ategorical-imperatives/axioms/registry-teleology ${ }^{9}$,-foraposteriorising/logicising/deriving/intelligising/measuring $-{ }^{5}$ meaningfulness-and-teleology ${ }^{9}$ in lieu of the respective prospective positivism and notional ${ }^{18}$ deprocrypticism ${ }^{83}$ reference-ofthought- categorical-imperatives/axioms/registry-teleology ${ }^{9}$,-foraposteriorising/logicising/deriving/intelligising/measuring- ${ }^{5}$ meaningfulness-and-teleology ${ }^{99}$ as of prospective relative-ontological-completeness ${ }^{87}$-of- ${ }^{3}$ reference-of-thought. This is further 
rendered difficult by a natural human 'emotional involvement' driven social-aggregationenabling as of human condition that undermines intrinsic-reality/ontological-veridicality transcendental-enabling/sublimating/supererogatory $\sim$ de-mentativity. This insight equally explains the pertinence of understanding postlogism 77 psychopathy in general as an epiphenomenon that can provide deeper insight about human nature given its 'lateral-andtransversality-<for-sublimating-existential-eventuating/denouement--from-'thinking-at-

\section{first/pure-predisposition-preemptive-of-prospective-disontologising/subontologising' as-of-}

prospectively-disambiguated-affirmed-and-unaffirmed-'motif-and-

apriorising/axiomatising/referencing'> ${ }^{101}$ disruptive nature on human ${ }^{56}$ meaningfulness-andteleology ${ }^{9}$, and with the preconverging-de-mentating/structuring/paradigming relatively easily perceived at childhood, much like the early modern human biologists relatively simplistic but counterintuitive-as-of-their-epochs understanding of disease provided deeper insight in understanding how the complexity of the human body works. Both individuation-level understanding of postlogism 7 in a non-positivism as of notions-and-accusations-of-sorcery and positivism social-setup as of psychopathy and social psychopathy divulge a bigger reality at the registry-worldview/dimension-level dynamic-cumulative-aftereffect/aftereffect that is hidden by registry-worldview/dimension-level complexity, wherein the childhood postlogism individuation-level construal points out the reality at the registry-worldview/dimension-level of respectively a conventioning non-positivism in lieu of an ontologically-veridical positivism reference-of-thought- categorical-imperatives/axioms/registry-teleology ${ }^{99}$,-foraposteriorising/logicising/deriving/intelligising/measuring - ${ }^{56}$ meaningfulness-and-teleology and a conventioning positivism- ${ }^{80}$ procrypticism as procrypticism in lieu of an ontologicallyveridical notional ${ }^{18}$ deprocrypticism $\quad$ reference-of-thought- ${ }^{8}$ categoricalimperatives/axioms/registry-teleology ${ }^{9}$, -foraposteriorising/logicising/deriving/intelligising/measuring- ${ }^{5}$ meaningfulness-and-teleology . 
That insight then brings up the idea of how does a registry-worldview/dimension-level dynamiccumulative-aftereffect reflect the more simplistic individuation-level ontological-veridicality at childhood postlogism 77 psychopathy; which is the more elaborate purpose herein. That is, how distractive-alignment-to- ${ }^{8}$ reference-of-thought- $<$ of-apriorising/axiomatising/referencing $>{ }^{30}$ as undermining apriorising/axiomatising/referencing-\{of-'prospectively implicited_attendantontological-contiguity ' educed-

existentialising/contextualising/textualising_intelligibility/epistemicity/reflexivity-contiguity<imbued-notional cogency $\left.>{ }^{\prime}\right\}$-conflatedness ${ }^{13}$-in-\{preconverging-disentailment-by\} postconverging-ntailment induces psychological-complexes pointing to, as of dynamiccumulative-aftereffect/aftereffect, the registry-worldview/dimension-level ontologisingdeficiency/relative-ontological-incompleteness ${ }^{8}$-of- ${ }^{83}$ reference-of-thought. Considering again the childhood psychopathy case in a 'dereifying act' of spilling water on a chair, these basic elements can be expounded at the individuation-level of analysis. It should be noted that the visitor 'as of its conjugated-postlogism 77 as conjugated-ignorance' is rather inclined to wrongly imply a 'symmetrisation-of- ${ }^{8}$ reference-of-thought but which is in effect an ontologically-nonveridical-or-flawed $<$ amplituding/formative-epistemicity $>$ totalising $\sim$ self-referencingsyncretising/circularity/interiorising/akrasiatic-drag that may induced its inclination for desymmetrisation for its perceived temporal social-stake-contention-or-confliction but for the fact of the relative contextual innocuousness with respect to social-stake-contention-orconfliction when it comes to childhood psychopathy compared to adulthood psychopathy'. The explainer of the situation 'as of its ${ }^{83}$ reference-of-thought-prelogism ${ }^{78}$-as-of-conviction,-inprofound-supererogation $-<$ existentially-veridical-'attendant-intradimensionalapriorising/axiomatising/referencing'-logical-dueness-precedes-disontologising-logicaloutcome-arrived-at>' is in an intemporality ${ }^{52}$-symmetrising-by-desymmetrising-subsumptionof-temporality ${ }^{98}$ relative to the visitor and childhood psychopathy with respect to the construal 
of ontological-veridicality. Hence the explainer of the situation construes the apriorising/axiomatising/referencing-\{of-'prospectively implicited_attendant-ontologicalcontiguity ' $\sim$ educed-

existentialising/contextualising/textualising_'intelligibility/epistemicity/reflexivity-contiguity<imbued-notional cogency $\left.>^{\prime} \quad\right\}$-conflatedness ${ }^{13}$ in-\{preconverging disentailment by pestcenverging-entailment as of its intemporality ${ }^{52}$-symmetrising-by-desymmetrisingsubsumption-of-temporality ${ }^{8}$ with respect to the visitor whose ${ }^{83}$ reference-of-thought ontologising-deficiency/relative-ontological-incompleteness ${ }^{8}$-of- ${ }^{-3 e f e r e n c e-o f-t h o u g h t ~ i s ~ n o t ~}$ factoring in the childhood psychopathy postlogism -as-of- compulsingnonconviction/madeupness/bottomlining-〈‘ $<$ decontextualising/de-existentialising $\sim$ ofattendant-intradimensional-apriorising/axiomatising/referencing $>$-induced-disontologising'-ofthe-'attendant-intradimensional-ontologising'-imbued$<$ contextualising/existentialising attendant-ontological-contiguity $>$;-in-shallowsupererogation -<as-to-disontologising-perverted-outcome-sought-precedes-existentiallyveridical-'attendant-intradimensional-apriorising/axiomatising/referencing'-logicaldueness $>$ >-of- ${ }^{-}$reference-of-thought which is 'pathologically ontologically-destructuring' implying both the childhood psychopathy and the visitor are rather in a state of unsoundness-orontological-bad-faith/inauthenticity ${ }^{64}$-of- ${ }^{3}$ reference-of-thought and not bad or poor logic such that the notion of logical-dueness doesn't arise in-the-very-first-place, as a ${ }^{83}$ reference-ofthought/axiomatic-construct is fundamentally construed as of its soundness-or-ontologicalgood-faith/authenticity ${ }^{6}$-of- ${ }^{8}$ reference-of-thought prior to the notion of logical-dueness arising once soundness-or-ontological-good-faith/authenticity ${ }^{6}$-of- ${ }^{83}$ reference-of-thought is established; thus, given the intemporality ${ }^{52}$-symmetrising-by-desymmetrising-subsumption-oftemporality ${ }^{8}$ of the explainer of the situation ${ }^{83}$ reference-of-thought/axiomatic-construct as existential/ontological as of 'implicited_attendant-ontological-contiguity ${ }^{67}$ ' educed- 
existentialising/contextualising/textualising_intelligibility/epistemicity/reflexivity-contiguity$<$ imbued-notional $\sim$ cogency $>,{ }^{\prime},-<$ reifying-or-elucidating-of-prospective-relative-ontologicalcompleteness -of- reference-of-thought- devolving-as-of-instantiative-context $>$

contextually-manifest prospective relative-ontological-completeness ${ }^{87}$-of- ${ }^{83}$ reference-ofthought in contrast to the visitor's 'supposed ${ }^{83}$ reference-of-thought/axiomatic-construct' which is non-existential/non-ontological as not-of 'implicited_attendant-ontologicalcontiguity $^{67}$, educed-

existentialising/contextalising/textalising_'intelligibility/epistemicity/reflexivity_contiguity$<$ imbued-notional $\sim$ cogency $>$, ,-<reifying-or-elucidating-of-prospective-relative-ontologicalcompleteness -of- reference-of-thought- devolving-as-of-instantiative-context> contextually-manifest prior relative-ontological-incompleteness ${ }^{88}$-of- ${ }^{83}$ reference-of-thought. It is this fundamental fact that underlies the notion of 'distractiveness or arrogation or usurpation or co-opting' associated with the construal of the ${ }^{56}$ meaningfulness-and-teleology ${ }^{9}$ of temporaldispositions perversion-and-derived- ${ }^{7}$ perversion-of- ${ }^{3}$ reference-of-thought- $<$ aspreconvergingly-apriorising/axiomatising/referencing-innonconviction/madeupness/bottomlining-as-to-shallow-supererogation $>$ as threshold-ofnonconviction/madeupness/bottomlining-in-shallow-supererogation $<-<$ as-to- 'attendantintradimensional'-prospectively-disontologising preconverging/dementing -apriorisingpsychologism $>$ in relation to intemporal ${ }^{5}$ meaningfulness-and-teleology 99 as ontological; as such symmetrisation and subsequent desymmetrisation will wrongfully lead to the ${ }^{8}$ referenceof-thought- categorical-imperatives/axioms/registry-teleology ${ }^{99}$,-for-

aposteriorising/logicising/deriving/intelligising/measuring $-{ }^{56}$ meaningfulness-and-teleology ${ }^{9}$ of the visitor's ${ }^{83}$ reference-of-thought so ontologically-destructured by the childhood psychopathy postlogism 'dereifying act' of spilling water on a chair and accusing another, thereby undermining ontological-veridicality where logic-as-of-prelogism ${ }^{78}$-as-of-conviction,-in- 
profound-supererogation $-<$ existentially-veridical-'attendant-intradimensionalapriorising/axiomatising/referencing'-logical-dueness-precedes-disontologising-logical-

outcome-arrived-at $>$ is wrongly assumed thus supposedly implying ${ }^{54}$ logical-processing-orlogical-implicitation - supposedly-apriorising-in-conviction-as-to-profound-supererogation is now to be engaged on the basis of the visitor's ontologically-destructured ${ }^{83}$ reference-ofthought/axiomatic-construct rather than implying the ${ }^{83}$ reference-of-thought- categoricalimperatives/axioms/registry-teleology ${ }^{9}$,-for-

aposteriorising/logicising/deriving/intelligising/measuring- ${ }^{5}$ meaningfulness-and-teleology ${ }^{9}$ of the explainer of the situation ${ }^{83}$ reference-of-thought/axiomatic-construct as soundness-orontological-good-faith/authenticity ${ }^{-o f}{ }^{-}$reference-of-thought and the visitors and childhood psychopathy $\quad$ ' $\quad$ reference-of-thought—degraded-devolving-as-of-uninstitutionalisedthreshold ${ }^{102}$ unsoundness-or-ontological-bad-faith/inauthenticity ${ }^{64}$-of- ${ }^{8}$ reference-of-thought. The implication here is that the construal/conceptualisation of ontologically-veridical meaningfulness-and-teleology ${ }^{9}$ lies entirely/exclusively/supersedingly on the ${ }^{8}$ reference-ofthought/axiomatic-construct/curve-of-prospective-relative-ontological-completeness ${ }^{87}$-ofreference-of-thought of the explainer of the situation while the logical-dueness of the visitor's 'supposed but rather non-existential/non-ontological ${ }^{83}$ reference-of-thought/axiomaticconstruct/curve-of-prior-relative-ontological-incompleteness ${ }^{88}$-of- ${ }^{83}$ reference-of-thought' doesn't even arise in-the-very-first-place and fundamentally explains why its ${ }^{56}$ meaningfulnessand-teleology 9 is operantly qualified as of 'distractiveness'/distractive-alignment/dismissal-asbeing-in-arrogation and so more aptly as distractive-alignment-to- ${ }^{-}$reference-of-thought- $<$ofapriorising/axiomatising/referencing $>{ }^{30}$. Distractiveness as it implies that in such a context, ontological-veridicality is construed exclusively as of intemporal prelogism ${ }^{78}$-as-of-conviction,in-profound-supererogation $<$-existentially-veridical-'attendant-intradimensionalapriorising/axiomatising/referencing'-logical-dueness-precedes-disontologising-logical- 
outcome-arrived-at $>\quad$ reference-of-thought

apriorising/axiomatising/referencing-\{of-

'prospectively implicited_attendant-ontological-contiguity ' educed-

existentialising/contextualising/textualising_'intelligibility/epistemicity/reflexivity-contiguity-

<imbued-notional cogency $\left.>{ }^{\prime}\right\}$-conflatedness ${ }^{13}$-in-\{preconverging-disentailment-by\}

postconverging-entailment denying any implied symmetrising of ${ }^{56}$ meaningfulness-and-

teleology ${ }^{9}$ from temporal-dispositions in perversion-and-derived- perversion-of- $^{8}$ reference-

of-thought- $<$ as-preconvergingly-apriorising/axiomatising/referencing-in-

nonconviction/madeupness/bottomlining-as-to-shallow-supererogation $>$ as their logicaldueness doesn't arise in-the-very-first-place, hence the reason why perversion-and-derivedperversion-of- ${ }^{-3}$ reference-of-thought-<as-preconvergingly-

apriorising/axiomatising/referencing-in-nonconviction/madeupness/bottomlining-as-to-

shallow-supererogation > is construed more than just as of 'destructuring' but more completely and critically to avoid misconstrual rather as of distractive-alignment-to- ${ }^{3}$ reference-of-thought$<$ of-apriorising/axiomatising/referencing $>30$; to point out that temporal-dispositions perversionand-derived- ${ }^{7}$ perversion-of- ${ }^{8}$ reference-of-thought-<as-preconverginglyapriorising/axiomatising/referencing-in-nonconviction/madeupness/bottomlining-as-toshallow-supererogation $>$ haven't got any 'existentially/ontologically transcendentalenabling/sublimating/supererogatory de-mentativity ${ }^{83}$ reference-of-thought' given that they are in arrogation/usurpation/co-opting but rather the reality of their perversion-and-derivedperversion-of- ${ }^{3}$ reference-of-thought-<as-preconverginglyapriorising/axiomatising/referencing-in-nonconviction/madeupness/bottomlining-as-toshallow-supererogation $>$ is construed operantly as of temporal postlogism -as-ofcompulsing-nonconviction/madeupness/bottomlining-〈'<decontextualising/deexistentialising $\sim$ of-attendant-intradimensional-apriorising/axiomatising/referencing $>$-induceddisontologising'-of-the-'attendant-intradimensional-ontologising'-imbued- 
$<$ contextualising/existentialising attendant-ontological-contiguity $>$;-in-shallow-

supererogation -<as-to-disontologising-perverted-outcome-sought-precedes-existentiallyveridical-'attendant-intradimensional-apriorising/axiomatising/referencing'-logicaldueness $>\rangle$-and-conjugated-postlogism 77 'exercise of distracting from' the intemporal prelogism ${ }^{78}$-as-of-conviction,-in-profound-supererogation $-<$ existentially-veridical'attendant-intradimensional-apriorising/axiomatising/referencing'-logical-dueness-precedesdisontologising-logical-outcome-arrived-at $>\quad{ }^{83}$ reference-of-thought $\quad$ as $\quad$ of apriorising/axiomatising/referencing-\{of-'prospectively_implicited_attendant-ontologicalcontiguity ' educedexistentialising/contextualising/textualising_'intelligibility/epistemicity/reflexivity-contiguity$<$ imbued-notional $\left.\sim \operatorname{cogency}>^{\prime}\right\}$ - conflatedness ${ }^{13}$-in-\{preconverging-disentailment by postconverging-entailment', and so construed as distractive-alignment-to- ${ }^{83}$ reference-ofthought- $<$ of-apriorising/axiomatising/referencing $>$ ' . That is, a 'temporality ${ }^{8}$ distracting from intemporality ${ }^{52}$ construct; wherein the 'apriorising/axiomatising/referencing-\{of'prospectively_implicited_attendant-ontological-contiguity ' educedexistentialising/contextualising/textualising _intelligibility/epistemicity/reflexivity-contiguity<imbued-notional cogency $\left.>^{\prime}\right\}$ - conflatedness ${ }^{13}$-in-\{preconverging-disentailment by\} postconverging-entailment of intemporal prelogism -as-of-conviction,-in-profoundsupererogation -<existentially-veridical-'attendant-intradimensionalapriorising/axiomatising/referencing'-logical-dueness-precedes-disontologising-logicaloutcome-arrived-at> projection' is misconstrued in 'denaturing ' of psychopathy/postlogism with the consequent alignment to it of conjugated-postlogism 77 as 'derived-denaturing ${ }^{1}$. In other words, prospective relative-ontological-completeness ${ }^{87}$-of- ${ }^{-}$reference-of-thought is 'precedingly/supersedingly preconverging/postconverging-dementatively/structurally/paradigmatically cogent/tense/limpid-<as-of-prospective-profound- 
supererogation ,-for-residuality-in-re-originariness/re-origination> and comprehensive framework of ${ }^{5}$ meaningfulness-and-teleology ${ }^{9}$ such that any arising temporal disruption of meaningfulness-and-teleology' 'has nothing to do with constituting ${ }^{56}$ meaningfulness-andteleology as of the temporal disruption prior relative-ontological-incompleteness ${ }^{8}$-ofreference-of-thought', but rather ${ }^{5}$ meaningfulness-and-teleology ${ }^{9}$ is reconstrued as postconverging-de-mentating/structuring/paradigming from the very prospective relativeontological-completeness ${ }^{87}$-of- ${ }^{8}$ reference-of-thought itself. Consider the case of the defective apriorising/axiomatising/referencing/intelligibilitysettingup/measuringinstrumenting perversion-of- ${ }^{8}$ reference-of-thought- $<$ as-preconvergingly-

\section{apriorising/axiomatising/referencing-in-nonconviction/madeupness/bottomlining-as-to-}

shallow-supererogation $>$ and temporal alignment in assuming the defective apriorising/axiomatising/referencing/intelligibilitysettingup/measuringinstrumenting appropriate as derived- ${ }^{-1}$ perversion-of- ${ }^{3}$ reference-of-thought- $<$ as-preconverginglyapriorising/axiomatising/referencing-in-nonconviction/madeupness/bottomlining-as-toshallow-supererogation $>$ as of relative-ontological-incompleteness ${ }^{8}$-of- ${ }^{83}$ reference-ofthought and intemporal projection of appropriate apriorising/axiomatising/referencing/intelligibilitysettingup/measuringinstrumenting prospective relative-ontological-completeness ${ }^{87}$-of- ${ }^{8}$ reference-of-thought. One cannot depart from both the state of the defective apriorising/axiomatising/referencing/intelligibilitysettingup/measuringinstrumenting as perversion-of- ${ }^{3}$ reference-of-thought- $<$ as-preconvergingly-

\section{apriorising/axiomatising/referencing-in-nonconviction/madeupness/bottomlining-as-to-}

shallow-supererogation $>$ or any states of temporal alignment in assuming the defective apriorising/axiomatising/referencing/intelligibilitysettingup/measuringinstrumenting as appropriate as derived- ${ }^{7}$ perversion-of- ${ }^{3}$ reference-of-thought- $<$ as-preconvergingly- 
apriorising/axiomatising/referencing-in-nonconviction/madeupness/bottomlining-as-to-

shallow-supererogation $>$ ' to construe ${ }^{5}$ meaningfulness-and-teleology 9 as of intrinsicreality/ontological-veridicality preconverging/postconverging-dementatively/structurally/paradigmatically by their relative-ontological-incompleteness ${ }^{8-o f-}$ reference-of-thought, as all the ${ }^{56}$ meaningfulness-and-teleology ${ }^{9}$ that can be as of intrinsicreality/ontological-veridicality wholly lies with the intemporal projection of appropriate apriorising/axiomatising/referencing/intelligibilitysettingup/measuringinstrumenting as of its prospective relative-ontological-completeness ${ }^{87}$-of- ${ }^{8}$ refence-of-thought. The implication at the registry-worldview level is that base-institutionalisation 'wholly carries all the meaningfulness-and-teleology ${ }^{9}$ that can be as of intrinsic-reality/ontological-veridicality' over a state of recurrent-utter-uninstitutionalisation, and likewise for ${ }^{103}$ universalisation over baseinstitutionalisation-ununiversalisation, positivism over $\quad{ }^{103}$ universalisation-nonpositivism/medievalism, and in our case futural Being-development/ontological-frameworkexpansion-as-to-depth-of-ontologising-development-as-infrastructure-of- meaningfulnessand-teleology as of prospective notional deprocrypticism over our positivismprocrypticism. The point here is to highlight that 'apriorising/axiomatising/referencing-\{of'prespectively implicited_attendant-ontological-contiguity ' educedexistentialising/contextualising/textualising_ intelligibility/epistemicity/reflexivity-contiguity<imbued-notional cogency $\left.>^{\prime}\right\}$ - conflatedness ${ }^{13}$-in-\{preconverging-disentailment by\} postconverging-entailment' doesn't imply any symmetrisation of ${ }^{56}$ meaningfulness-andteleology ${ }^{9}$ with regards to perversion-and-derived- perversion-of- $^{-}$reference-of-thought- $<$aspreconvergingly-apriorising/axiomatising/referencing-in-

nonconviction/madeupness/bottomlining-as-to-shallow-supererogation $>$ since the latter is preconverging/postconverging-de-mentatively/structurally/paradigmatically not logically-due for ${ }^{5}$ logical-processing-or-logical-implicitation — supposedly-apriorising-in-conviction-as-to- 
profound-supererogation in-the-very-first-place as is erroneously assumed by temporal projection mental-reflex. But rather, it implies an utter preconverging/postconverging-dementative/structural/paradigmatic reconstrual of ${ }^{56}$ meaningfulness-and-teleology ${ }^{9}$ as of intrinsic-reality/ontological-veridicality wholly by the intemporal projection of the prospective relative-ontological-completeness ${ }^{8}$-of- ${ }^{83}$ reference-of-thought. The psychoanalyticunshackling/memetic-reordering/institutional-recomposuring implications associated with perversion-and-derived- ${ }^{7}$ perversion-of- ${ }^{8}$ reference-of-thought- $<$ as-preconverginglyapriorising/axiomatising/referencing-in-nonconviction/madeupness/bottomlining-as-to-

shallow-supererogation $>$ ultimately falls to the grander issue of prior relative-ontologicalincompleteness ${ }^{8}$-of- ${ }^{-1}$ reference-of-thought as fundamentally endemising/enculturating such perversion-and-derived- ${ }^{7}$ perversion-of- ${ }^{8}$ reference-of-thought- $<$ as-preconverginglyapriorising/axiomatising/referencing-in-nonconviction/madeupness/bottomlining-as-toshallow-supererogation $>\quad$ possibilities; $\quad$ such $\quad$ that intemporal/ontological/social/species/ ${ }^{103}$ universal/transcendental/ ${ }^{5}$ maximalisingrecomposuring-for-relative-ontological-completeness ${ }^{87}$-unenframed/reontologising conceptualisation postconverging-de-mentating/structuring/paradigming as maximalising-recomposuring-for-relative-ontological-completeness ${ }^{87}$ - unenframed/reontologising $\sim$ conceptualisation is not one that simply identify a ${ }^{74}$ perversion-of- ${ }^{8}$ reference-ofthought-<as-preconvergingly-apriorising/axiomatising/referencing-innonconviction/madeupness/bottomlining-as-to-shallow-supererogation $>$ in a social-construct but as 'covering all the possibilities for vices-and-impediments ${ }^{105}$ hypothetically susceptible to arise' projects how preconverging/postconverging-de-mentatively/structurally/paradigmatically the social-construct as of its beyond-the-consciousness-awareness-teleology ${ }^{9}-<$ ofpreconverging-existential-extrication-as-of-existential-unthought> prior relative-ontologicalincompleteness ${ }^{88}$-of- reference-of-thought is 'susceptible to integrate' ${ }^{74}$ perversion-of- 
reference-of-thought-<as-preconvergingly-apriorising/axiomatising/referencing-in-

nonconviction/madeupness/bottomlining-as-to-shallow-supererogation

as derived-

perversion-of- ${ }^{8}$ reference-of-thought-<as-preconvergingly-

apriorising/axiomatising/referencing-in-nonconviction/madeupness/bottomlining-as-to-

shallow-supererogation >, and 'build a preconverging/postconverging-dementative/structural/paradigmatic ontology as of prospective relative-ontologicalcompleteness $^{87}$-of- ${ }^{8}$ reference-of-thought going from this more comprehensive-possibilities bases that doesn't allow for ${ }^{51}$ incrementalism-in-relative-ontological-incompleteness ${ }^{8}$ enframed/disontologising conceptualisation' with the implication that no logical interlocution of the <amplituding/formative $>$ wooden-language-_imbued-averaging-of-thought- $<$ as-toleveling/ressentiment/closed-construct-of- meaningfulness-and-teleology -as-of'nondescript/ignorable-void '-with-regards-to-prospective-apriorising-implications $>>$ arises as of prior relative-ontological-incompleteness ${ }^{8}$-of- ${ }^{-}$reference-of-thought. We can appreciate that the childhood psychopathy 'dereifying act' of spilling water on a chair is a distractiveness-drive with no existentially/ontologically veridical ${ }^{8}$ reference-of-thought which when wrongly implied as valid prelogism ${ }^{78}$-as-of-conviction,-in-profound-supererogation $-<$ existentially-veridical‘attendant-intradimensional-apriorising/axiomatising/referencing'-logical-dueness-precedesdisontologising-logical-outcome-arrived-at> ${ }^{83}$ reference-of-thought/axiomatic-construct leads to its ${ }^{83}$ reference-of-thought- categorical-imperatives/axioms/registry-teleology ${ }^{9}$,-foraposteriorising/logicising/deriving/intelligising/measuring - ${ }^{56}$ meaningfulness-and-teleology wrongly transforming the issue into one of logic-as-of-prelogism ${ }^{7}$-as-of-conviction,-inprofound-supererogation $-<$ existentially-veridical-'attendant-intradimensionalapriorising/axiomatising/referencing'-logical-dueness-precedes-disontologising-logicaloutcome-arrived-at> thus supposedly implying ${ }^{54}$ logical-processing-or-logical-implicitation supposedly-apriorising-in-conviction-as-to-profound-supererogation by wrongly enabling 
logical-dueness to arise instead of an issue of unsoundness-or-ontological-badfaith/inauthenticity ${ }^{64}$-of- ${ }^{8}$ reference-of-thought implying its dismissal as distractive-alignmentto- ${ }^{83}$ reference-of-thought- $<$ of-apriorising/axiomatising/referencing $>$; ; and this flaw extends into the visitor's conjugated-postlogism 77 as conjugated-ignorance given its relative-ontologicalincompleteness ${ }^{8}$-of- ${ }^{8}$ reference-of-thought as of positivism- ${ }^{80}$ procrypticism disjointedness-asof- reference-of-thought which is cognisant-and-integrative as of its apriorising/axiomatising/referencing/intelligibilitysettingup/measuringinstrumenting reflection of 'implicited_attendant-ontological-contiguity ${ }^{6 /}$ ' educedexistentialising/contextualising/textualising_'intelligibility/epistemicity/reflexivity-contiguity$<$ imbued-notional cogency $>$-in-reification/dereification of the childhood psychopathy slantedness, and so as a derived-distractiveness-drive with no existentially/ontologically veridical ${ }^{83}$ reference-of-thought which when wrongly implied falsely as ontologically-veridical reference-of-thought/axiomatic-construct also leads to its ${ }^{83}$ reference-of-thought- categoricalimperatives/axioms/registry-teleology ${ }^{9}$,-for-

aposteriorising/logicising/deriving/intelligising/measuring $-{ }^{56}$ meaningfulness-and-teleology wrongly transforming the issue into one of logic-as-of-prelogism ${ }^{7}$-as-of-conviction,-inprofound-supererogation $-<$ existentially-veridical-'attendant-intradimensionalapriorising/axiomatising/referencing'-logical-dueness-precedes-disontologising-logicaloutcome-arrived-at> thus supposedly implying ${ }^{54}$ logical-processing-or-logical-implicitation supposedly-apriorising-in-conviction-as-to-profound-supererogation by wrongly enabling logical-dueness to arise instead of an issue of derived unsoundness-or-ontological-badfaith/inauthenticity ${ }^{6}$-of- ${ }^{8}$ reference-of-thought and thus also implying as well its dismissal as distractive-alignment-to- ${ }^{8}$ reference-of-thought- $<$ of-apriorising/axiomatising/referencing $>30$. In both wrongful 'apriorising/axiomatising/referencing/intelligibilitysettingup/measuringinstrumentings for 
aposteriorising/logicising/deriving/intelligising/measuring $\quad{ }^{5}$ meaningfulness-and-teleology what is produced isn't ontologically-veridical ${ }^{56}$ meaningfulness-and-teleology ${ }^{9}$ but rather threshold-of-nonconviction/madeupness/bottomlining-in-shallow-supererogation $-<$ as-to-

\section{‘attendant-intradimensional'-prospectively-disontologising preconverging/dementing}

apriorising-psychologism $>$ qualified as arrogation or usurpation or co-opting' exactly because of the induced postlogism 77 psychopathy distractive-alignment-to- ${ }^{-}$reference-of-thought- $<$ofapriorising/axiomatising/referencing $>{ }^{30}$ out of existentially/ontologically veridical context; and its social integration/derivation in conjugation with human temporality $/$ shortness of ignorance/affordability/opportunism/exacerbation/social-chainism-or-social-discomfiture-ornegative-social-aggregation/temporal-enculturation-or-temporal-endemisation as conjugatedpostlogism due to relative-ontological-incompleteness ${ }^{8}$-of- ${ }^{73}$ reference-of-thought, and specifically in the case of positivism- ${ }^{80}$ procrypticism, due to disjointedness-as-of- ${ }^{\text {reference- }}$ of-thought. This equally underlies on the basis of dynamic-cumulative-aftereffect/aftereffect at the individuation-level and registry-worldview/dimension-level of analyses the notion of 'decentering' as of ${ }^{15}$ de-mentation-〈supererogatory $\sim$ ontological-de-mentation-or-dialecticalde-mentation - stranding-or-attributive-dialectics $\rangle$, as the idea of value-reference if wrongfully ontologically construed as determined by the '<amplituding/formative $>$ wooden-language〈imbued - averaging-of-thought-<as-to-leveling/ressentiment/closed-construct-of-

$$
\text { meaningfulness-and-teleology -as-of-'nondescript/ignorable-void ' -with-regards-to- }
$$

prospective-apriorising-implications $>>$ as respectively non-positivism ${ }^{83}$ reference-of-thought' or as procrypticism ${ }^{83}$ reference-of-thought', then in effect the phenomena of nonpositivism/medievalism postlogism like notions-and-accusations-of-sorcery as well as psychopathic-postlogism 7 -and-its-social-integration as of our procrypticism-ordisjointedness-as-of- reference-of-thought will respectively be wrongfully construed to be of existential/ontological transcendental-enabling/sublimating/supererogatory $\sim$ de-mentativity 
veracity. The bigger point being that symmetrisation implying mutual recognition of ${ }^{8}$ referenceof-thought can only arise where there is mutual appropriateness-of- ${ }^{3}$ reference-of-thought-as-ofconflatedness

enabling/sublimating/supereregatory de-mentativity veracity thus enabling the logical-dueness of both interlocutors to arise as of their soundness-or-ontological-good-faith/authenticity ${ }^{6}$-ofreference-of-thought in-the-very-first-place, notwithstanding thereafter the appropriateness or inappropriateness of the ${ }^{54}$ logical-processing-or-logical-implicitation-supposedly-apriorisingin-conviction-as-to-profound-supererogation exercise which is then an altogether different issue of effective/ineffective logic as prelogism ${ }^{78}$-as-of-conviction,-in-profoundsupererogation $-<$ existentially-veridical-'attendant-intradimensional-

\section{apriorising/axiomatising/referencing'-logical-dueness-precedes-disontologising-logical-}

outcome-arrived-at>, and this latter is what tends to be falsely implied in situations of postlogism 77 psychopathy and conjugated-postlogism 77 social-psychopathy, and need to be 'ontologically dismissed offhand' and brought back to the fundamental issue of perversion-andderived- ${ }^{74}$ perversion-of- ${ }^{83}$ reference-of-thought-<as-preconvergingly-

\section{apriorising/axiomatising/referencing-in-nonconviction/madeupness/bottomlining-as-to-}

shallow-supererogation $>\quad$ rather $\quad$ reflected-as-of-soundness-or-ontological-goodfaith/authenticity ${ }^{6}$-of- ${ }^{8}$ reference-of-thought in determining whether logical-dueness arises inthe-very-first-place. Central to such a dynamic-cumulative-aftereffect/aftereffect registryworldview/dimension-level analysis derived from such an individuation-level insight is the idea that social-functioning-and-accordance-as-of-social-stake-contention-or-confliction is contiguous as of ${ }^{56}$ meaningfulness-and-teleology ${ }^{9}$ as of the individuation-level and registryworldview/dimension-level of analysis, notwithstanding it developing complexification as of dynamic-cumulative-after/effect as from the individuation-level to the registryworldview/dimension-level and thus with a greater opportunity for the simplistic individuation- 
level childhood postlogism $/$ psychopathy phenomenon relatively resolvable at that individuation-level to fail resolution with the myriad of such cases at the circularcomplexification registry-worldview/dimension-level of more surreptitious adulthood pathological postlogism 77 psychopathy as the maturation/indirectness/spatialisation/credulity/craftiness induces 'lack of constraining social universal-transparency ${ }^{104}$-〈transparency-of-totalising-entailing,-as-to-entailing$<$ amplituding/formative-epistemicity>totalising in-relative-ontological-completeness $>$ with consequent conjugated-postlogism 'involving beyond-the-consciousness-awarenessteleology ${ }^{9}<$ of-preconverging-existential-extrication-as-of-existential-unthought $>$ dynamics further associated with a generalised social 'lack of constraining social ${ }^{103}$ universaltransparency ${ }^{104}$ - transparency-of-totalising-entailing,-as-to-entailing-<amplituding/formativeepistemicity>totalising in-relative-ontological-completeness $>$ reflected by the given registryworldview's/dimension's prior relative-ontological-incompleteness ${ }^{8}$-of- ${ }^{83}$ reference-of-thought thus reflecting the uninstitutionalised-threshold ${ }^{02}$ backdrop for the registryworldview's/dimension's threshold-of-nonconviction/madeupness/bottomlining-in-shallowsupererogation -<as-to-'attendant-intradimensional'-prospectivelydisontologising $\sim$ preconverging/dementing -apriorising-psychologism $>$. In other words, socialfunctioning-and-accordance-as-of-social-stake-contention-or-confliction preconverging/postconverging-de-mentatively/structurally/paradigmatically 'ontologically compromised' as of a registry-worldview's/dimension's prior relative-ontologicalincompleteness ${ }^{8}$-of- ${ }^{8}$ reference-of-thought such that what a registry-worldview/dimension institutionalisation accede to as socially-functioning-and-accordant is limited by its given beyond-the-consciousness-awareness-teleology ${ }^{9}-<$ of-preconverging-existential-extrication-asof-existential-unthought $>$ with the implication that 'lack of constraining social ${ }^{103}$ universaltransparency ${ }^{104}$-〈transparency-of-totalising-entailing,-as-to-entailing-<amplituding/formative- 
epistemicity $>$ totalising in-relative-ontological-completeness $>$ at this uninstitutionalisedthreshold allows for denaturing, which is rather subpar to the notional conflatedness ${ }^{13} /$ constitutedness $^{14}$-to-conflatedness $^{13}$ required for ontologicalnormalcy/postconvergence as 'preempting epistemic-decadence', as <amplituding/formative > wooden-language-_imbued-temporal-mere-

\section{form/virtualities/dereification/akrasiatic-drag/denatured/preconverging-or-dementing}

\section{narratives - of-the- reference-of-thought- categorical-imperatives/axioms/registry-}

teleology > failing intemporal-preservation-entropy-or-contiguity-or-ontological-preservation to be construed as socially-functional-and-accordant ${ }^{93}$, with the possibility for such epistemicdecadence being superseded arising only as of the prospective registry-worldview/dimension institutionalisation prospective relative-ontological-completeness ${ }^{87}$-of- ${ }^{3}$ reference-of-thought driven by the "non-constraining and abstract organic mental-disposition as of ontological-faithnotion-or-ontological-fideism-imbued-underdetermination-of-motif-andapriorising/axiomatising/referencing-as-so-being-as-of-existential-reality' in rearticulating such a prospective institutionalisation 'constraining social ${ }^{103}$ universal-transparency ${ }^{104}$ 〈transparency-of-totalising-entailing,-as-to-entailing-<amplituding/formativeepistemicity>totalising in-relative-ontological-completeness $>\quad{ }^{83}$ reference-of-thoughtcategorical-imperatives/axioms/registry-teleology ${ }^{9}$,-for-intemporal-preservation-entropy-orcontiguity-or-ontological-preservation taking cognisance of the prior registryworldview's/dimension's relative-ontological-incompleteness ${ }^{8}$-of- ${ }^{-3}$ reference-of-thought; wherein notional $\sim$ conflatedness ${ }^{13} /$ constitutedness $^{14}$-to-conflatedness ${ }^{13}$ reflects their institutionalisation and denaturing ${ }^{16}$ reflects their uninstitutionalised-threshold ${ }^{102}$. Hence in-thebigger-picture explaining why the <cumulating/recomposuring attendant-ontologicalcontiguity $>$-successive registry-worldviews/dimensions are construed as of diminishinghuman-epistemic-abnormalcy-or-preconvergence towards ontological- 
normalcy/postconvergence. As of a protracted analysis given human limited-mentationcapacity —as-subjecting 'educed-unlimitedness/existence-sublimating nascence' tolimitedness/human-subpotency with respect to social ${ }^{103}$ universal-transparency ${ }^{104}$ 〈transparency-of-totalising-entailing,-as-to-entailing-<amplituding/formativeepistemicity>totalising in-relative-ontological-completeness $>$ which critically tends to be solicited at its beyond-the-consciousness-awareness-teleology ${ }^{9}-<$ of-preconverging-existentialextrication-as-of-existential-unthought $>$ as in this individuation-level analysis, apriorising/axiomatising/referencing-\{of-'prospectively implicited_attendant-ontologicalcontiguity ' educed-

existentialising/entextualising/textraing_intelligibility/epistemicity/reflexivity-contiguity-

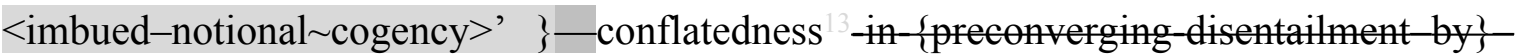
postconverging-ntailment can equally be construed as tying down transcendentally-enablinglevel-of ontological-good-faith-or-authenticity $\%$ objectification/desubjectification-asobjectification-<as-to-ontological-faith-notion-or-ontological-fideism-imbuedunderdetermination-of-motif-and-apriorising/axiomatising/referencing-as-so-being-as-ofexistential-reality as antinihilism $>{ }^{100}$ to ontological-normalcy/postconvergence as ontologicalcompleteness-of- ${ }^{-}$reference-of-thought avails as of ontological-faith-notion-or-ontologicalfideism —imbued-underdetermination-of-motif-and-apriorising/axiomatising/referencing-asso-being-as-of-existential-reality, and hence its construal as of 'intemporal-prioritisation-ofreference-of-thought'-as-conflatedness ${ }^{13}$-or-ontological-reprojecting; while apriorising/axiomatising/referencing-\{of-'prospectively_implicited_attendant-ontologicalcontiguity ' educedexistentialising/contextualising/textualising_'intelligibility/epistemicity/reflexivity-contiguity$<$ imbued-notional cogency $\left.>^{\prime} \quad\right\}$-constitutedness ${ }^{1}$-in-preconverging-entailment can equally be construed as tying down 'supposed objectivity as of conscious or unconscious denaturing 
ontological-bad-faith/inauthenticity ${ }^{64}$ to the <amplituding/formative> wooden-language〈imbued-temporal-mere-form/virtualities/dereification/akrasiaticdrag/denatured/preconverging-or-dementing -narratives - of-the- reference-of-thoughtcategorical-imperatives/axioms/registry-teleology $\rangle$ failing intemporal-preservation-entropyor-contiguity-or-ontological-preservation as of ontological-normalcy/postconvergence enabled by relative-ontological-incompleteness ${ }^{88}$-of- ${ }^{-1 e f e r e n c e-o f-t h o u g h t ~ i n ~ t e m p o r a l ~ p r i o r i t i s a t i o n ~}$ teleology . As such apriorising/axiomatising/referencing-\{of-'prospectively implicited_attendant-ontological-contiguity ' educedexistentialising/contextualising/textualising_'intelligibility/epistemicity/reflexivity-contiguity<imbued-notional cogency>' \}-conflatedness ${ }^{13}$ in (preconerging disentment by postconverging-ntailment is the underlying drive of a human fepistemictotalising ${ }^{3}$ hermeneutic/textuality/reprojecting/supererogating/zeroing/re-acuting,\{decolinearity for-cogency psychology as of an ontologically-driven developing psyche as 'postconverging-or-dialectical-thinking -psychology or psychology-of-mentation-dynamics or natural psychological-dynamics' construed as of notional conflatedness ${ }^{13} /$ constitutedness $^{14}$ to-conflatedness ${ }^{13} \quad$ from $\quad$ apriorising/axiomatising/referencing-\{of-"prospectively implicited_attendant-ontological-contiguity ' educedexistentialising/contextualising/textualising_'intelligibility/epistemicity/reflexivity-contiguity$<$ imbued-notional $\sim$ cogency $\left.>{ }^{\prime} \quad\right\}$-constitutedness ${ }^{14}$-in-preconverging-entailment/recurrentutter-uninstitutionalisation, first-level- ${ }^{7}$ presencing-absolutising-identitive-constitutedness of base-institutionalisation-ununiversalisation, second-level- ${ }^{79}$ presencing-absolutisingidentitive-constitutedness ${ }^{14}$ of ${ }^{103}$ universalisation-non-positivism/medievalism, third-levelpresencing - absolutising-identitive-constitutedness ${ }^{14}$ of positivism- ${ }^{8}$ procrypticism, and fullnotional conflatedness ${ }^{13} /$ deprocrypticism. We can appreciate that prior relative-ontologicalincompleteness ${ }^{88}$-of- ${ }^{8}$ reference-of-thought inherently undermines the capacity for 
transcendentally-enabling-level-of $\sim$ ontological-good-faith-or-

authenticity $\%$ objectification/desubjectification-as-objectification-<as-to-ontological-faithnotion-or-ontological-fideism - imbued-underdetermination-of-motif-and-

apriorising/axiomatising/referencing-as-so-being-as-of-existential-reality as antinihilism $>100$ of a notional $\quad<$ amplituding/formative-epistemicity $>$ totalising $\sim$ self-referencingsyncretising/circularity/interiorising/akrasiatic-drag ${ }^{34}$ agent of limited-mentation-capacity-assubjecting 'educed-unlimitedness/existence-sublimating nascence' to-limitedness/humansubpotency that we are as of our animate-existential-referencing/subjectification, such that our transcendentally-enabling-level-of ontological-good-faith-or-

authenticity $\%$ objectification/desubjectification-as-objectification- $<$ as-to-ontological-faithnotion-or-ontological-fideism - imbued-underdetermination-of-motif-andapriorising/axiomatising/referencing-as-so-being-as-of-existential-reality as antinihilism> enabling our ontology/virtue-construal capacity is more fundamentally a drive for ontologicalcompleteness-of- ${ }^{8}$ reference-of-thought driven by apriorising/axiomatising/referencing-\{of'prospectively_implicited_attendant-ontological-contiguity ' educedexistentialising/contextualising/textualising_'intelligibility/epistemicity/reflexivity_contiguity<imbued-notional cogency $\left.>^{\prime}\right\}$ - conflatedness ${ }^{13}$ in 'preconverging disentailment by postconverging-ntailment as articulated above over denaturing ${ }^{16}$, and explaining why apriorising/axiomatising/referencing-\{of-'prospectively implicited_attendant-ontologicalcontiguity ' educedexistentialising/contextualising/textualising_'intelligibility/epistemicity/reflexivity-contiguity<imbued-notional cogency>' \}-conflatedness ${ }^{13}$-in-\{preconverging-disentailment by\} as of ontological-faith-notion-or-ontological-fideism -imbuedunderdetermination-of-motif-and-apriorising/axiomatising/referencing-as-so-being-as-ofexistential-reality instigating the relative-unreflexivity/relative-reflexivity-ontological- 
contiguity ${ }^{67}$ of-the-human-institutionalisation-process ${ }^{68}$ behind the successive institutionalcumulation/institutional-recomposure-〈as-to- historiality/ontological-

eventfulness /ontological-aesthetic-tracing-<perspective-ontologicalnormalcy/postconvergence-reflected-'epistemicity-relativism-determinism' $>>$ is the very determinant of human ontology/virtue-construct, and so more than just an affixed as denaturing referencing of any one registry-worldview's/dimension's institutionalisation ${ }^{83}$ reference-of-

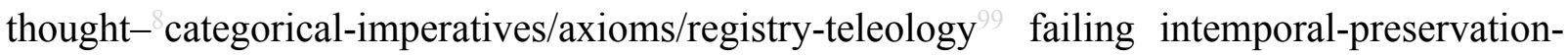
entropy-or-contiguity-or-ontological-preservation as of ontological-normalcy, notwithstanding the mere fact of simply being secondnatured/institutionalised at the backend in reflecting holographically-<conjugatively-and-transfusively $>$ the relative unreflexivity/relativereflexivity - ontological-contiguity of-the-human-institutionalisation-process as of our positivism- ${ }^{8}$ procrypticism. Notional conflatedness ${ }^{13} /$ constitutedness $^{14}$-to-conflatedness points out that it is the aspiration for base-institutionalisation from recurrent-utteruninstitutionalisation, for ${ }^{103}$ universalisation from base-institutionalisation-ununiversalisation, for positivism from ${ }^{103}$ universalisation-non-positivism/medievalism and prospectively for notional ${ }^{18}$ deprocrypticism from our positivism- ${ }^{80}$ procrypticism that are of ontology/virtue equivalence as of ontological-faith-notion-or-ontological-fideism-imbuedunderdetermination-of-motif-and-apriorising/axiomatising/referencing-as-so-being-as-ofexistential-reality; and not the <amplituding/formative-epistemicity>totalising $\sim$ selfreferencing-syncretising/circularity/interiorising/akrasiatic-drag ${ }^{34}$ mental-complex of considering the <amplituding/formative> wooden-language-〈imbued-temporal-mereform/virtualities/dereification/akrasiatic-drag/denatured/preconverging-or-dementing narratives - of-the- reference-of-thought- categorical-imperatives/axioms/registryteleology > while failing intemporal-preservation-entropy-or-contiguity-or-ontologicalpreservation as of ontological-faith-notion-or-ontological-fideism-imbued- 
underdetermination-of-motif-and-apriorising/axiomatising/referencing-as-so-being-as-of-

existential-reality within the given registry-worldview/dimension, be it at the backend in reflecting holographically-<conjugatively-and-transfusively $>$ the relative-unreflexivity/relativereflexivity - ontological-contiguity $\sim$ of-the-human-institutionalisation-process $\quad$ as $\quad$ our positivism- ${ }^{8}$ procrypticism. A naïve conceptualisation of ontology/virtue construal ideal by the mere fact of simply being at the backend in reflecting holographically-<conjugatively-andtransfusively $>$ the relative-unreflexivity/relative-reflexivity ontological-contiguity $\sim$ of-thehuman-institutionalisation-process as of our positivismdoesn't speak of our firstnatured/intemporal projection-of-thought but rather of a secondnatured institutionalisation that induced our prospective relative-ontological-completeness ${ }^{87}$-ofreference-of-thought by the relative-unreflexivity/relative-reflexivity-ontologicalcontiguity ${ }^{67}$ of-the-human-institutionalisation-process ${ }^{68}$ that cannot be confused with the idea of construing our present positivism- ${ }^{80}$ procrypticism uninstitutionalisation ${ }^{83}$ reference-ofthought as the definite ontology/virtue closed-structure, but rather warrants that we take stock of the exceptional relative-unreflexivity/relative-reflexivity ontological-contiguity ${ }^{6} \sim$ of-thehuman-institutionalisation-process ${ }^{68}$ that has gone before in providing the secondnatured possibilities of our present as of ontological-faith-notion-or-ontological-fideism-imbuedunderdetermination-of-motif-and-apriorising/axiomatising/referencing-as-so-being-as-of-

existential-reality driven notional conflatedness ${ }^{13} /$ constitutedness $^{14}$-to-conflatedness ${ }^{13}$, and in that respect conjure how we can equally undertake our own part of the human existential< disentelogising/re-ontelogising aporeticism $>$ tale homework in summoning ontologicalfaith-notion-or-ontological-fideism - imbued-underdetermination-of-motif-andapriorising/axiomatising/referencing-as-so-being-as-of-existential-reality driven notional conflatedness ${ }^{13} /$ constitutedness $^{14}$-to-conflatedness ${ }^{13}$ as an opened-structure for futural Being-development/ontological-framework-expansion-as-to-depth-of-ontologising- 
development-as-infrastructure-of- meaningfulness-and-teleology as of prospective deprocrypticism, and not a closed-structure naïve <amplituding/formativeepistemicity $>$ totalising $\sim$ self-referencing-syncretising/circularity/interiorising/akrasiatic-drag nombrilism as of flawed/perverted reference-of-thought- categoricalimperatives/axioms/registry-teleology ${ }^{9}$ at our positivism- ${ }^{8}$ procrypticism uninstitutionalisation of procrypticism as disjointedness-as-of- ${ }^{8}$ reference-of-thought, and by so doing denying the 'grander human existential-tale implications of notional conflatedness ${ }^{13} /$ constitutedness $^{14}$-toconflatedness $^{13}$. This fundamental and protracted epiphenomenal insight as of 'human subpotent-mimetic-echoness-derivation-within-the-full-potency of ontology/intrinsic-reality/ofreferential-nature/of-intemporal-preservation-entropy-or-contiguity-or-ontological-

preservation of existence-as-of-its-mimetic-echoness/existence-in-reverberation/existencepotency ${ }^{32} \sim$ sublimating-nascence,-disclosed-from-prospective-epistemic-digression more than just as of a virtue conceptualisation is more profoundly/all-embracingly an echoness of the implication of human limited-mentation-capacity-as-subjecting-'educedunlimitedness/existence-sublimating nascence' to-limitedness/human-subpotency for ontological-construal/ontological-conceptualisation, and so with little temporal-to-intemporalconjugating-emotional-involvement/subjectification/epistemic ${ }^{3} \sim$ self-referencingsyncretising-as-of-perceived-social-stake-contention-or-confliction and is equally relevant with regards to innocuous knowledge-constructs/theories/intersolipsistic-intercessorynotions/notional referential-notions/articulations/virtue as it subsumes virtue-as-inherentontology; with dynamic-cumulative-aftereffect/aftereffect implications at the individuationlevel and registry-worldview/dimension-level of analysis as of metaphysics-of-absence〈implicited-epistemic-veracity-of- nonpresencing-<perspective-ontologicalnormalcy/postconvergence $>\rangle$. In this regard, metaphysics-of-absence-〈implicited-epistemicveracity-of- nonpresencing-<perspective-ontological-normalcy/postconvergence $>>$ 
articulated herein by this author is rather about, 'human limited-mentation-capacity-assubjecting 'educed unlimitedness/existence-sublimating nascence' to-limitedness/humansubpotency construed as of ontological-normalcy/postconvergence metaphysics-of-absence〈implicited-epistemic-veracity-of- nonpresencing-<perspective-ontologicalnormalcy/postconvergence $>$ /Doppler-thinking as it disambiguates human-subpotencyaporia/undecidability/dilemma/ought-indeterminacy/deficiency/limitation/constraint—imbued'notional firstnaturedness-formativeness-<as-to-eventualising -inkling-drive-or-seedingmisprising $>$ temporal-to-intemporal-dispositions- $<$ so-construed-as-from-perspectiveontological-normalcy/postconvergence>'-existentialism-form-factor ${ }^{56}$ meaningfulness-andteleology $\quad<$ amplituding/formative-epistemicity $>$ causality $\sim$ as-to-projective-totalitativeimplications-of-prospective- nonpresencing,-for-explicating relative-unreflexivity/relativereflexivity - ontological-contiguity ,,$\quad$ as $\quad$ of historiality/ontologicaleventfulness 38 /ontological-aesthetic-tracing-<perspective-ontologicalnormalcy/postconvergence-reflected-'epistemicity-relativism-determinism’>. For instance, the immediacy of intrinsic-reality/ontological-veridicality transcendental enabling in the natural sciences which is implicited in those fields by their 'relatively high results-constrainingeffectiveness nature' provides metaphysics-of-absence-〈implicited-epistemic-veracity-ofnonpresencing-<perspective-ontological-normalcy/postconvergence $>\rangle$ insights with regards to obviating the high temporal-to-intemporal-conjugating-emotionalinvolvement/subjectification/epistmic ${ }^{3}$ self-referencing-syncretising-as-ofperceived-social-stake-contention-or-confliction bound to disrupt thought and analysis in the social as of its 'relatively low results-constraining-effectiveness nature'. Along the same argument and with regards to the high temporal-to-intemporal-conjugating-emotionalinvolvement/subjectification/epistemic-totalising $\sim$ self-referencing-syncretising-as-ofperceived-social-stake-contention-or-confliction inherent in the social, it is important to grasp 
that such an epiphenomenon/incidental-phenomenon insight as implied herein with postlogism 7 /psychopathy and corresponding human social dynamics implications is rather a social construction supposedly coherent ontological-commitment $-<$ implied-selfassuredness-of-ontological-good-faith/authenticity postconverging-dementating/structuring/paradigming -as-being-as-of-existential-reality $>$ that goes well beyond any given specific epiphenomenon-\{in-the-overall-ecstatic-existence-superveningconflatedness ${ }^{13}$ /incidental occurring behind the inspired/insight-for-the social construction supposedly coherent ontological-commitment $-<$ implied - self-assuredness-of-ontologicalgood-faith/authenticity postconverging-de-mentating/structuring/paradigming -as-beingas-of-existential-reality $>$ as of aetiologisation/ontological-escalation- $<$ ontologicalveridicality_commitment/otherliness_transcending/compulsions-encumbered_transcending > for ${ }^{103}$ universal retrospective to prospective understanding of postlogism 77 psychopathy and human social dynamics implications. In other words such a social construction supposedly coherent ontological-commitment $-<$ implied-self-assuredness-of-ontological-goodfaith/authenticity postconverging-de-mentating/structuring/paradigming -as-being-as-ofexistential-reality $>$ is inherently the more expansive, ${ }^{103}$ universal, decisive, objective and easier basis for critiquing its theorising-conceptualising-operationalising narratives 'in order to assess the veracity/ontological-pertinence of the preconverging/postconverging-dementative/structural/paradigmatic ${ }^{103}$ universal implications arrived-at of the social construction supposedly coherent ontological-commitment $-<$ implied - self-assuredness-of-ontologicalgood-faith/authenticity $\sim$ postconverging-de-mentating/structuring/paradigming -as-beingas-of-existential-reality $>$ as of the possibilities of easily transcendentally-enabling-levelof ontological-good-faith-or-authenticity $\%$ objectification/desubjectification-asobjectification-<as-to-ontological-faith-notion-or-ontological-fideism-imbuedunderdetermination-of-motif-and-apriorising/axiomatising/referencing-as-so-being-as-of- 
existential-reality as antinihilism $>00$ myriad retrospective and prospective social contexts of analysis, and so more critically rather than an obscured/muddled/obfuscated and difficult critiquing grounded on 'assessing the veracity/ontological-pertinence of the preconverging/postconverging-de-mentative/structural/paradigmatic ${ }^{103}$ universal implications arrived-at of the social construction supposedly coherent ontological-commitment $-<$ implied self-assuredness-of-ontological-good-faith/authenticity postconverging-dementating/structuring/paradigming -as-being-as-of-existential-reality $>$ rather on the basis of any such specific epiphenomenon-\{in-the-overall-ecstatic-existence-superveningconflatedness $^{13}$ /incidental occurring as of its relatively poorly objectifiable-asdesubjectifiable/subjectified incidental social context for analysis. Consider similarly that an epiphenomenal/incidental occurrence of an-apple-hitting-Newton-on-the-head-while-he-satunder-a-tree thus inspiring/providing-insight-for his laws of motion supposedly coherent ontological-commitment $\quad<$ implied-self-assuredness-of-ontological-goodfaith/authenticity postconverging-de-mentating/structuring/paradigming -as-being-as-ofexistential-reality> for explaining mechanical phenomena. Certainly, the inherently more expansive, ${ }^{103}$ universal, decisive, objective and easy basis for critiquing its theorisingconceptualising-operationalising narratives 'in order to assess the veracity/ontologicalpertinence of the preconverging/postconverging-de-mentative/structural/paradigmatic ${ }^{3}$ universal implications arrived-at of his laws of motion supposedly coherent ontologicalcommitment $-<$ implied—self-assuredness-of-ontological-goodfaith/authenticity $\sim$ postconverging-de-mentating/structuring/paradigming -as-being-as-ofexistential-reality $>$ is the possibilities of easily transcendentally-enabling-level-of $\sim$ ontologicalgood-faith-or-authenticity ${ }^{6} /$ objectification/desubjectification-as-objectification- $<$ as-toontological-faith-notion-or-ontological-fideism - imbued-underdetermination-of-motif-andapriorising/axiomatising/referencing-as-so-being-as-of-existential-reality as antinihilism> 
myriad retrospective and prospective mechanical phenomena for analysis, and so more critically rather than an obscured/muddled/obfuscated and difficult critiquing grounded on 'assessing the veracity/ontological-pertinence of the preconverging/postconverging-dementative/structural/paradigmatic ${ }^{103}$ universal implications arrived-at of the laws of motion supposedly coherent ontological-commitment $-<$ implied - self-assuredness-of-ontologicalgood-faith/authenticity $\sim$ postconverging-de-mentating/structuring/paradigming -as-beingas-of-existential-reality> on the basis of the specifically given epiphenomenal/incidental occurrence of an-apple-hitting-Newton-on-the-head-while-he-sat-under-a-tree as of the latter relatively poorly objectifiable-as-desubjectifiable/subjectified incidental mechanical occurrence for analysis. In both instances, such an apparently naïve intellectual disposition will point to relative intellectual impertinence at best, and at worst conscious ontological-badfaith/inauthenticity ${ }^{64}$ angling to cynically undermine ${ }^{103}$ universal veracity/ontologicalpertinence as of the opportunity of implying poorly objectifiable-as-desubjectifiable/subjectified incidental analysis as pre-eminently of ${ }^{103}$ universal import. While this logic is immediately obvious with the low temporal-to-intemporal-conjugating-emotionalinvolvement/subjectification/epistemic-totalising $\sim$ self-referencing-syncretising-as-ofperceived-social-stake-contention-or-confliction nature of many a natural sciences $<$ amplituding/formative-epistemicity $>$ totalising $\sim$ devolved-purview-as-domain-of-construalas-intrinsic-reality/ontological-veridicality with their disposition for replication and other experimentation/observation/survey analyses as hardly any scientist will go on if it is problematic to objectively ascertain the contextual reality of an-apple-hitting-Newton-on-thehead-while-he-sat-under-a-tree to contend that Newton's laws of motion supposedly coherent ontological-commitment $\quad$-implied-self-assuredness-of-ontological-goodfaith/authenticity postconverging-de-mentating/structuring/paradigming -as-being-as-ofexistential-reality> is wrong, such an insight about the supposedly coherent ontological- 
commitment $-<$ implied — self-assuredness-of-ontological-good-

\section{faith/authenticity postconverging-de-mentating/structuring/paradigming -as-being-as-of-}

existential-reality> being wholly construed as of its 'very own veracity/ontological-pertinence as of any of its objectificable contexts' can-and-is often easily flouted and sidetracked with the high temporal-to-intemporal-conjugating-emotional-involvement/subjectification/epistemictatising $\sim$ self-referencing-syncretising-as-of-perceived-social-stake-contention-orconfliction that permeates the study of the social as of its blurriness<sterilising/anecdotalising/trivialising-of-prospective-re-ontologising_by-preconverging,-indisontologising-formulaic-dragging-out/hollowing-out>. This equally explains why it is actually better and more critical to construe/conceptualise social knowledge not only on the basis of the inherent veracity/ontological-pertinence of supposedly coherent ontologicalcommitment -<implied-self-assuredness-of-ontological-goodfaith/authenticity $\sim$ postconverging-de-mentating/structuring/paradigming -as-being-as-ofexistential-reality> as with the natural sciences but equally factoring in the human social condition as of high temporal-to-intemporal-conjugating-emotionalinvolvement/subjectification/epistemic-totalising $\sim$ self-referencing-syncretising-as-ofperceived-social-stake-contention-or-confliction, and so as of a knowledge-notionalisation exercise. In other words metaphysics-of-absence-_implicited-epistemic-veracity-ofnonpresencing-<perspective-ontological-normalcy/postconvergence $>>$ refers to any such projections, as of human imaginative capacity derived from our underlying 'coherence/contiguity-of-superseding-oneness-of-ontology-implied-as-of-inherent-existencecoherence/contiguity,-and-so-construed-as-the-enabler-of-insight-or-intuition-or-foresight-asof-embodied-consciousness' (so-enabled by underlying supposedly coherent ontologicalcommitment $-<$ implied - self-assuredness-of-ontological-goodfaith/authenticity postconverging-de-mentating/structuring/paradigming -as-being-as-of- 
existential-reality $>$ as of <amplituding/formative-epistemicity>causality $\sim$ as-to-projectivetotalitative-implications-of-prospective- nonpresencing,-for-explicating relativeunreflexivity/relative-reflexivity ontological-contiguity and not any notion of vague innateness besides existentially-<disontologising/re-ontologising aporeticism $>$ inherent human-subpotency potential to manifest as human) and existence/intrinsic-reality/ontology-asof-its-mimetic-echoness or existence-in-reverberation or existence-potency ${ }^{39} \sim$ sublimatingnascence,-disclosed-from-prospective-epistemic-digression; thus enabling human limitedmentation-capacity-deepening —as-subjecting limitedness/human-subpotency-to-'educedunlimitedness/existence-sublimating nascence' insights as apriorising/axiomatising/referencing/intelligibilitysettingup/measuringinstrumenting-foroperant-or-incidenting-predicative-insights. We can further get a sense with respect to the implications of what is meant by ${ }^{83}$ reference-of-thought- categoricalimperatives/axioms/registry-teleology ${ }^{9}$, -foraposteriorising/logicising/deriving/intelligising/measuring - ${ }^{56}$ meaningfulness-and-teleology ${ }^{9}$, relative to the construal/conceptualisation from the middle of the last century in the biological domain as of its specific uninstitutionalised-threshold ${ }^{02}$ then over which the DNA-based genetics $\quad{ }^{83}$ reference-of-thought- categorical-imperatives/axioms/registry-teleology ${ }^{9}$,-foraposteriorising/logicising/deriving/intelligising/measuring - ${ }^{5}$ meaningfulness-and-teleology was developed which induced an altogether new dramatically different but ontologicallyveridical imagery/picture of the nature of biology at that uninstitutionalised-threshold ${ }^{102}$ that then became a new specific institutionalisation ${ }^{83}$ reference-of-thought- categoricalimperatives/axioms/registry-teleology ${ }^{9}$, -for-

aposteriorising/logicising/deriving/intelligising/measuring - ${ }^{56}$ meaningfulness-and-teleology thereafter amenable to elaboration-as-to-mereextrapolating/constituting/abstracting/deducing/inferring-of-elucidation-outside- 
'prospectively_implicited_attendant_ontological-contiguity ${ }^{67}$ ' educedexistentialising/contextmalising/textualising_intelligibility/epistemicity/reflexivity_contiguity$<$ imbued-notional cogency $>$ such that the prior non DNA-based construal/conceptualisation (as of reference-of-thought- categorical-imperatives/axioms/registry-teleology ${ }^{9}$,-foraposteriorising/logicising/deriving/intelligising/measuring - ${ }^{5}$ meaningfulness-and-teleology ${ }^{99}$ ) with respect to that now DNA-based genetics specific institutionalised <amplituding/formativeepistemicity $>$ totalising $\sim$ devolved-purview-as-domain-of-construal-as-intrinsic-

reality/ontological-veridicality of biology cannot longer be upheld, and this is so in-the-biggerpicture as a contributory apriorising/axiomatising/referencing-\{of-"prospectively implicited_attendant-ontological-contiguity ' educedexistentialising/contextualising/textualising_'intelligibility/epistemicity/reflexivity-contiguity<imbued-notional cogency>' \}-conflatedness ${ }^{13}$-in-\{preconverging-disentailment by\} postconverging-entailment within the same positivism registry-worldview institutionalisation. (In fact, the institutional-cumulation/institutional-recomposure-〈as-to- historiality/ontologicaleventfulness /ontological-aesthetic-tracing-<perspective-ontologicalnormalcy/postconvergence-reflected-'epistemicity-relativism-determinism' $>>$ are the conjoined effect of all specific uninstitutionalised-threshold ${ }^{12}$ institutionalisation breakthroughs of reference-of-thought- categorical-imperatives/axioms/registry-teleology ${ }^{99}$,-foraposteriorising/logicising/deriving/intelligising/measuring $-{ }^{56}$ meaningfulness-and-teleology construed conjointly as of the prospective registry-worldview/dimension institutionalisation.) In this case, however the 'emotional involvement' in apriorising/axiomatising/referencing-\{of'prospectively_implicited_attendant-ontological-contiguity ' educedexistentialising/contextualising/textualising_'intelligibility/epistemicity/reflexivity_contiguity<imbued-notional cogency $\left.>{ }^{\prime}\right\}$ - conflatedness ${ }^{13}$-in-\{preconverging-disentailment by\} postconverging-entailment within the same positivism registry-worldview of appraisal is way 
low compared to the high 'emotional involvement' in making the same construct as of a contrastive transcending/superseding of a prior registry-worldview/dimension institutionalisation ${ }^{83}$ reference-of-thought into an entirely new/prospective registryworldview/dimension institutionalisation ${ }^{83}$ reference-of-thought like between non-positivism and positivism or prospectively between our positivism- - procrypticism and notional deprocrypticism as in this latter instance such a construal/conceptualisation is comprehensively redefining of the human psyche and tend to elicit the highest levels of 'emotional involvement' thus requiring rather a crossgenerational adjustment as apriorising/axiomatising/referencing-\{of-'prospectively implicited_attendant_ontologicalcontiguity ' educed-

existentialising/contextualising/textualising_'intelligibility/epistemicity/reflexivity-contiguity<imbued-notional cogency $\left.>^{\prime}\right\}$-conflatedness ${ }^{13}$-in-\{preconverging-disentailment by\} postconverging-entailment over the prior distractive-alignment-to- ${ }^{8}$ reference-of-thought- $<$ ofapriorising/axiomatising/referencing $>{ }^{30}$. In conclusion, such a construal/conceptualisation as of

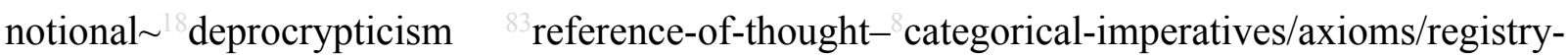
teleology ${ }^{9}$,-for-aposteriorising/logicising/deriving/intelligising/measuring- ${ }^{5}$ meaningfulnessand-teleology ${ }^{9}$ over our positivism- ${ }^{80}$ procrypticism ${ }^{83}$ reference-of-thought- categoricalimperatives/axioms/registry-teleology ${ }^{9}$,-foraposteriorising/logicising/deriving/intelligising/measuring- ${ }^{5}$ meaningfulness-and-teleology ${ }^{99}$ our 'lived social' uninstitutionalised-threshold ${ }^{102}$ with respect to psychopathy and social psychopathy and procrypticism in general is a wholly new dramatically different depth of understanding, and from our present inclination of elaboration-as-to-mereextrapolating/constituting/abstracting/deducing/inferring-of-elucidation-outside'prospectively_implicited_attendant-ontological-contiguity ${ }^{67}$ ' educedexistentialising/contextualising/textualising_'intelligibility/epistemicity/reflexivity-contiguity- 
$<$ imbued-notional cogency $>$ within the positivism institutionalisation framework. Beyond the above constrastive individuation-level and registry-worldview/dimension-level of analysis with respect to the uptake of prospective ${ }^{83}$ reference-of-thought- categoricalimperatives/axioms/registry-teleology ${ }^{9}$, -for-

aposteriorising/logicising/deriving/intelligising/measuring $-{ }^{5}$ meaningfulness-and-teleology ${ }^{99}$, this social reality of varying social ${ }^{83}$ reference-of-thought-closeness-of-tethering-toprelogism ${ }^{78}$-as-of-conviction,-in-profound-supererogation $-<$ existentially-veridical'attendant-intradimensional-apriorising/axiomatising/referencing'-logical-dueness-precedesdisontologising-logical-outcome-arrived-at> and $\quad{ }^{83}$ reference-of-thought-looseness-oftethering-to-prelogism ${ }^{78}$-as-of-conviction,-in-profound-supererogation $-<$ existentiallyveridical-'attendant-intradimensional-apriorising/axiomatising/referencing'-logical-duenessprecedes-disontologising-logical-outcome-arrived-at> implying increasing ${ }^{83}$ reference-ofthought-looseness-of-tethering-to-prelogism ${ }^{78}$-as-of-conviction,-in-profoundsupererogation $-<$ existentially-veridical-'attendant-intradimensionalapriorising/axiomatising/referencing'-logical-dueness-precedes-disontologising-logicaloutcome-arrived-at $>$ as of greater temporality $/$ shortness construed as of various shades of threshold-of-nonconviction/madeupness/bottomlining-in-shallow-supererogation $\quad-<$ as-to‘attendant-intradimensional'-prospectively-disontologising preconverging/dementing apriorising-psychologism> speaks in-the-bigger-picture of a social reality across all registryworldviews/dimensions that tends to 'destructure any registry-worldview/dimension institutionalisation ${ }^{56}$ meaningfulness-and-teleology ${ }^{99}$ by an 'ontological degradation effect' having to do with human-subpotency-aporia/undecidability/dilemma/oughtindeterminacy/deficiency/limitation/constraint—imbued-'notional firstnaturednessformativeness-<as-to-eventualising-inkling-drive-or-seeding-misprising $>$ temporal-tointemporal-dispositions- $<$ so-construed-as-from-perspective-ontological- 
normalcy/postconvergence>'-existentialism-form-factor, and in so doing inducing thresholdof-nonconviction/madeupness/bottomlining-in-shallow-supererogation $<-<$ as-to-'attendantintradimensional'-prospectively-disontologising preconverging/dementing -apriorisingpsychologism $>$ as uninstitutionalised-threshold ${ }^{102}$. In other words, a prospective registryworldview/dimension institutionalisation ${ }^{56}$ meaningfulness-and-teleology ${ }^{9}$ in becoming the new ${ }^{83}$ reference-of-thought (over the prior registry-worldview's/dimension's ${ }^{83}$ reference-ofthought) with its supposedly grander intemporal-preservation-entropy-or-contiguity-orontological-preservation $\quad{ }^{8}$ reference-of-thought- categorical-imperatives/axioms/registryteleology as of the ontological-faith-notion-or-ontological-fideism-imbuedunderdetermination-of-motif-and-apriorising/axiomatising/referencing-as-so-being-as-ofexistential-reality driving/behind its construal, turns out to be a prospective institutionalisation 'reset framework for human temporal-to-intemporal mental-dispositions' respectively in reference-of-thought-looseness-of-tethering-to-prelogism ${ }^{78}$-as-of-conviction,-in-profoundsupererogation $-<$ existentially-veridical-'attendant-intradimensionalapriorising/axiomatising/referencing'-logical-dueness-precedes-disontologising-logicaloutcome-arrived-at $>$ and ${ }^{83}$ reference-of-thought-closeness-of-tethering-to-prelogism ${ }^{78}$-as-ofconviction,-in-profound-supererogation ${ }^{2}<$ existentially-veridical-'attendant-intradimensionalapriorising/axiomatising/referencing'-logical-dueness-precedes-disontologising-logical-

outcome-arrived-at $>$ of the new ${ }^{83}$ reference-of-thought'; as facing/dealing anew with human temporal-to-intemporal mental-dispositions but this time around doing the same thing as occurred with the prior institutionalisation ${ }^{83}$ reference-of-thought- categoricalimperatives/axioms/registry-teleology ${ }^{9}$ that was transcended/superseded to deliver the new registry-worldview/dimension, but now on the new registry-worldview's/dimension's institutionalisation ${ }^{83}$ reference-of-thought- categorical-imperatives/axioms/registry-teleology (with the difference as of a 'relatively lower sensibility' arising just because of the new registry- 
worldview/dimension prospective relative-ontological-completeness ${ }^{87}$-of- ${ }^{83}$ reference-ofthought limiting/constraining on the possibilities of vices-and-impediments ${ }^{105}$ ); implying an underlying relative-unreflexivity/relative-reflexivity - ontological-contiguity ${ }^{67}$ of the reality of human temporal-to-intemporal mental-dispositions across all the registryworldviews/dimensions. Thus while 'ontologically superseding the prior beyond-theconsciousness-awareness-teleology ${ }^{9}-<$ of-preconverging-existential-extrication-as-ofexistential-unthought> and prior 'lack of constraining social ${ }^{103}$ universal-transparency ${ }^{104}$ 〈transparency-of-totalising-entailing,-as-to-entailing-<amplituding/formative-

epistemicity>totalising in-relative-ontological-completeness $>$ this does not imply apart from such institutionalisation-as-secondnaturing a change of human temporal-to-intemporal nature, given that this nature will further manifest at the prospective registry-worldview uninstitutionalised-threshold ${ }^{102}$ as its beyond-the-consciousness-awareness-teleology ${ }^{9}-<$ ofpreconverging-existential-extrication-as-of-existential-unthought>' and 'lack of constraining social ${ }^{103}$ universal-transparency ${ }^{104}$-〈transparency-of-totalising-entailing,-as-to-entailing$<$ amplituding/formative-epistemicity $>$ totalising in-relative-ontological-completeness $>$ inducing anew the new ${ }^{83}$ reference-of-thought owns threshold-ofnonconviction/madeupness/bottomlining-in-shallow-supererogation $-<$ as-to-' $a$ attendantintradimensional'-prospectively-disontologising preconverging/dementing -apriorisingpsychologism>. This social dynamism (dynamic-cumulative-aftereffect) as of the new registryworldview/dimension uninstitutionalised-threshold ${ }^{102}$ can be construed ontologically as arising out of a further temporal/shortness-of-register-of- meaningfulness-and-teleology distortedness of the new <amplituding/formativeepistemicity>totalising/circumscribing/delineating $\quad$ reference-of-thought- ${ }^{8}$ devolving-as-ofinstantiative-context- ${ }^{5}$ meaningfulness-and-teleology 9 in the social extended-informality〈susceptible-to-effecting-parsimony-as-of-shoddiness-and-incompleteness-to- 
meaningfulness-and-teleology $\rangle$ ultimately extending to the extended-informality〈susceptible-to-effecting-parsimony-as-of-shoddiness-and-incompleteness-to-

meaningfulness-and-teleology $\rangle$ spheres of formal constructs distorting formal construal of meaningfulness-and-teleology ${ }^{9}$, and so to a point of equilibrium of the new registryworldview/dimension between its institutionalised ${ }^{56}$ meaningfulness-and-teleology ${ }^{99}$ and its uninstitutionalised-threshold ${ }^{102}$ 's $\quad$ threshold-of-nonconviction/madeupness/bottomlining-inshallow-supererogation -<as-to-'attendant-intradimensional'-prospectively-

disontologising preconverging/dementing -apriorising-psychologism $>$. The operant and technical conceptualisation basis of this phenomenon has to do with the inherent nature of pureontology apriorising/axiomatising/referencing-\{of-'prospectively implicited_attendantontological-contiguity ' educed-

existentialising/contextualising/textualising_'intelligibility/epistemicity/reflexivity-contiguity<imbued-notional cogency $\left.>^{\prime}\right\}$-conflatedness ${ }^{13}$-in-\{preconverging-disentailment by\} postconverging-entailment for ontologically-veridical ${ }^{56}$ meaningfulness-and-teleology ${ }^{9}$ and 'human notional firstnaturedness-formativeness-as a seeding misprising $>$ temporal-to-intemporal-dispositions- $<$ so-construed-as-fromperspective-ontological-normalcy/postconvergence> condition' of reception/distortion across the $\quad<$ cumulating/recomposuring attendant-ontological-contiguity $>$-successive registryworldviews/dimensions involving denaturing where there is 'lack of constraining social universal-transparency ${ }^{104}$-〈transparency-of-totalising-entailing,-as-to-entailing$<$ amplituding/formative-epistemicity>totalising in-relative-ontological-completeness $\rangle$. The establishment or rather coming into being of a prospective registry-worldview/dimension institutionalisation ${ }^{83}$ reference-of-thought can thus be construed as of pure-ontology apriorising/axiomatising/referencing-\{of-'prospectively_implicited_attendant-ontologicalcontiguity ' educed- 
existentialising/contextualising/textualising_'intelligibility/epistemicity/reflexivity-contiguity-

$<$ imbued-notional cogency $>$ ' $\}$-conflatedness ${ }^{13}$ in-\{preconverging-disentailment by\}

pestconverging entailment for ontologically-veridical ${ }^{56}$ meaningfulness-and-teleology ${ }^{9}$, and so because it is both the mechanical-knowledge as the constraining technical outcome and the nonconstraining driving underlying intemporal-disposition ontological-faith-notion-or-ontologicalfideism —imbued-underdetermination-of-motif-and-apriorising/axiomatising/referencing-asso-being-as-of-existential-reality, with both constituting the organic-knowledge. This transcendental knowledge construct establishes a dominant social framework of knowledge grounded on its inherent intrinsic-reality/ontological-veridicality transcendentalenabling/sublimating/supererogatory de-mentativity $<$ amplituding/formativeepistemicity $>$ causality $\sim$ as-to-projective-totalitative-implications-of-prospectivenonpresencing,-for-explicating relative-unreflexivity/relative-reflexivity - ontologicalcontiguity (as it supersedes the prior beyond-the-consciousness-awareness-teleology ${ }^{9}-<$ ofpreconverging-existential-extrication-as-of-existential-unthought $>\quad{ }^{56}$ meaningfulness-andteleology 9 and the prior 'lack of constraining social ${ }^{103}$ universal-transparency ${ }^{104}-\langle$ transparencyof-totalising-entailing,-as-to-entailing-<amplituding/formative-epistemicity $>$ totalising $\sim$ inrelative-ontological-completeness $\rangle$ ), and then imbues the prospective institutionalisation with social validity and social structure of ${ }^{5}$ meaningfulness-and-teleology 9 as of deferentialformalisation-transference. This is the social-setup of the prospective institutionalisation reference-of-thought as of pure-ontology apriorising/axiomatising/referencing-\{of'prospectively_implicited_attendant-ontological-contiguity ' reducedexistentialising/contextualising/textualising_'intelligibility/epistemicity/reflexivity-contiguity$<$ imbued-notional cogency $\left.>{ }^{\prime}\right\}$-conflatedness ${ }^{13}$-in-\{preconverging-disentailment by\} postconverging-entailment for prospective relative-ontological-completeness ${ }^{87}$-of- ${ }^{8}$ referenceof-thought ${ }^{56}$ meaningfulness-and-teleology ${ }^{9}$. But then in due course and at the 
uninstitutionalised-threshold ${ }^{102}$ of this prospective institutionalisation ${ }^{83}$ reference-of-thought, its organic-knowledge (as driven by intemporal-disposition ontological-faith-notion-orontological-fideism - imbued-underdetermination-of-motif-and-

apriorising/axiomatising/referencing-as-so-being-as-of-existential-reality for intemporalpreservation-entropy-or-contiguity-or-ontological-preservation) wanes as the reality of human notional firstnaturedness-formativeness-<as-to-eventualising-inkling-drive or seedingmisprising $>$ temporal-to-intemporal-dispositions-<so-construed-as-from-perspectiveontological-normalcy/postconvergence $>$ nature sets in as it is related to at the uninstitutionalisedthreshold ${ }^{102}$ by the registry-worldview's/dimension's least common denominator as $<$ amplituding/formative $>$ wooden-language-〈imbued-temporal-mere-

\section{form/virtualities/dereification/akrasiatic-drag/denatured/preconverging-or-dementing}

narratives - of-the- reference-of-thought- categorical-imperatives/axioms/registry-

teleology > for social-functioning-and-accordance-as-of-social-stake-contention-orconfliction (in a preconverging epistemic - projective-equalisation social dynamics at the given uninstitutionalised-threshold ${ }^{102}$ that is a drawback-to/undermines prospective-knowledge-andinstitutional deferential-formalisation-transference as of prospective relative-ontologicalcompleteness $^{87}$-of- ${ }^{8}$ reference-of-thought intrinsic-reality/ontological-veridicality transcendental-enabling/sublimating/supererogatory de-mentativity <amplituding/formativeepistemicity $>$ causality $\sim$ as-to-projective-totalitative-implications-of-prospectivenonpresencing,-for-explicating relative-unreflexivity/relative-reflexivity - ontologicalcontiguity, and is rather oriented to sovereign extrication over knowledgereification $\sim$ gesturing-and-accounting — of-epistemic-phenomenalism- $<$ inprospective_psychologismic apriorising/axiomatising/referencing-\{of-'prospectively implicited_attendant-ontological-contiguity ' educedexistentialising/contextualising/textualising_'intelligibility/epistemicity/reflexivity-contiguity- 
postconverging entailment $>$ at this uninstitutionalised-threshold ${ }^{102}$ as of social-aggregationenabling), as of its bare constraining mechanical-knowledge since ${ }^{83}$ reference-of-thoughtcategorical-imperatives/axioms/registry-teleology are only 'mechanistically' constraining, lacking the organic-spirit or ontological-faith-notion-or-ontological-fideism-imbuedunderdetermination-of-motif-and-apriorising/axiomatising/referencing-as-so-being-as-of-

existential-reality. Anecdotally, we know as of our uninstitutionalised-threshold ${ }^{12}$ that in effect the technical constraints of the law tend to supersede the spirit of the law as it is naïve to think that a 'sense of rightness' is all that matters before the law, and this extends to human meaningful and organisational principles in general. Such that temporal-dispositions fulfilment of such 'mechanistic' effectiveness as mechanical-knowledge 'without the non-constraining and abstract organic mental-disposition as of ontological-faith-notion-or-ontological-fideism -imbuedunderdetermination-of-motif-and-apriorising/axiomatising/referencing-as-so-being-as-of-

existential-reality of the emanant-kind that-had-driven the ${ }^{83}$ reference-of-thought construal in the first place' distort in due course organic ${ }^{56}$ meaningfulness-and-teleology ${ }^{9}$, as of temporal mental-dispositions of shortness-of-register-of- ${ }^{-}$meaningfulness-and-teleology ${ }^{9}$. Thus such implied prospective ${ }^{8}$ reference-of-thought, social organisations and institutions as organic meaningfulness-and-teleology 9 then tend to develop 'subcultural reorientations' that are 'mildly alien' and 'on-occasional gravely alien' to the (especially in the extended-informalities of the social and institutions) original organic-knowledge conceptualisation as of the implied prospective ${ }^{83}$ reference-of-thought social and institutions ${ }^{56}$ meaningfulness-and-teleology ${ }^{9}$. Thus for an ontological-veridicality/intrinsic-reality transcendentalenabling/sublimating/surerenterivity $<$ amplituding/formativeepistemicity $>$ causality $\sim$ as-to-projective-totalitative-implications-of-prospectivenonpresencing,-for-explicating relative-unreflexivity/relative-reflexivity - ontological- 
contiguity construal for the notional ${ }^{8}$ deprocrypticism prospective institutionalisation, it is critical to grasp both the inherent ontological-veracity of the ${ }^{56}$ meaningfulness-and-teleology behind the construal of notional ${ }^{18}$ deprocrypticism and the 'reality of a human condition of temporal-dispositions distractive-alignment-to- ${ }^{8}$ reference-of-thought- $<$ ofapriorising/axiomatising/referencing $>$, and so as of notional conflatedness ${ }^{13} /$ constitutedness $^{14}$-to-conflatedness ${ }^{13}$ as ${ }^{4}$ historiality/ontologicaleventfulness ${ }^{3}$ /ontological-aesthetic-tracing-<perspective-ontologicalnormalcy/postconvergence-reflected-'epistemicity-relativism-determinism'> in articulating a 〈protensive-consciousness deneuterising ${ }^{17}$-induced $\rangle-{ }^{3}$ reference-of-thought- devolvingteleological-de-mentating/structuring/paradigming-of-meaningfulness, that is preemptive of a least-common-denominator-of-social-functioning-and-accordance- or-confliction-effecting to bare mechanical-knowledge as of <amplituding/formative> wooden-language-〈imbuedtemporal-mere-form/virtualities/dereification/akrasiatic-drag/denatured/preconverging-ordementing -narratives - of-the- reference-of-thought- categoricalimperatives/axioms/registry-teleology > inducing threshold-ofnonconviction/madeupness/bottomlining-in-shallow-supererogation $-<$ as-to-'attendantintradimensional'-prospectively-disontologising preconverging/dementing -apriorisingpsychologism $>$ as of uninstitutionalised-threshold ${ }^{102}$. This is achieved by a perpetuating metaphysics-of-absence-〈implicited-epistemic-veracity-of- nonpresencing-<perspectiveontological-normalcy/postconvergence $>>$ that factors in human notional firstnaturednessformativeness-<as-to-eventualising-inkling-drive-or-seeding-misprising $>$ temporal-tointemporal-dispositions- $<$ so-construed-as-from-perspective-ontologicalnormalcy/postconvergence $>$ nature. Insightfully, a storied-construct/ontologically-validnarration technique apprehending the notional firstnaturedness-formativeness-<as-toeventualising inkling drive or seeding misprising temporal-to-intemporal-dispositions- 
$<$ so-construed-as-from-perspective-ontological-normalcy/postconvergence $>$ respective mentaldispositions for ${ }^{83}$ reference-of-thought-looseness-of-tethering-to-prelogism ${ }^{78}$-as-of-

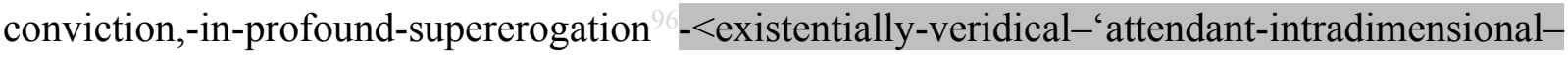
apriorising/axiomatising/referencing'-logical-dueness-precedes-disontologising-logicaloutcome-arrived-at $>$ and ${ }^{83}$ reference-of-thought-closeness-of-tethering-to-prelogism ${ }^{78}$-as-ofconviction,-in-profound-supererogation ${ }^{2}<$ existentially-veridical-'attendant-intradimensionalapriorising/axiomatising/referencing'-logical-dueness-precedes-disontologising-logical-

outcome-arrived-at $>$ can be construed, wherein the instigating temporal postlogism 7 -as-ofcompulsing-nonconviction/madeupness/bottomlining-〈'<decontextualising/deexistentialising $\sim$ of-attendant-intradimensional-apriorising/axiomatising/referencing $>$-induceddisontologising'-of-the-'attendant-intradimensional-ontologising'-imbued$<$ contextualising/existentialising attendant-ontological-contiguity $>$;-in-shallowsupererogation -<as-to-disontologising-perverted-outcome-sought-precedes-existentiallyveridical-'attendant-intradimensional-apriorising/axiomatising/referencing'-logical-dueness $>$ ) reference-of-thought-looseness-of-tethering-to-prelogism ${ }^{78}$-as-of-conviction,-in-profoundsupererogation $-<$ existentially-veridical-'attendant-intradimensionalapriorising/axiomatising/referencing'-logical-dueness-precedes-disontologising-logicaloutcome-arrived-at $>\quad$ (as $\quad$ postlogism 77 -as-of- compulsingnonconviction/madeupness/bottomlining-/‘ $<$ decontextualising/de-existentialising ofattendant-intradimensional-apriorising/axiomatising/referencing>-induced-disontologising'-ofthe-'attendant-intradimensional-ontologising'-imbued$<$ contextualising/existentialising attendant-ontological-contiguity $>$;-in-shallowsupererogation -<as-to-disontologising-perverted-outcome-sought-precedes-existentiallyveridical-'attendant-intradimensional-apriorising/axiomatising/referencing'-logical-dueness $>$ ) temporal threshold-of-nonconviction/madeupness/bottomlining-in-shallow-supererogation - 


\section{$<$ as-to-'attendant-intradimensional'-prospectively-}

disontologising $\sim$ preconverging/dementing -apriorising-psychologism $>$ ) as of the childhood psychopathy (where the ${ }^{83}$ reference-of-thought-looseness-of-tethering-to-prelogism ${ }^{78}$-as-ofconviction,-in-profound-supererogation -<existentially-veridical-'attendant-intradimensionalapriorising/axiomatising/referencing'-logical-dueness-precedes-disontologising-logicaloutcome-arrived-at> mental defect is of social ${ }^{103}$ universal-transparency ${ }^{104}$-〈transparency-oftotalising-entailing,-as-to-entailing-<amplituding/formative-epistemicity $>$ totalising $\sim$ inrelative-ontological-completeness $\rangle$ socially like in a 'dereifying act' of spilling water on a chair and accusing another, pointing to a mental-shortcut as faulty-mentation-procedure-deception-orurge $^{43}$ in relating to social-stake-contention-or-confliction) and adult psychopath (where the reference-of-thought-looseness-of-tethering-to-prelogism ${ }^{78}$-as-of-conviction,-in-profoundsupererogation $-<$ existentially-veridical-'attendant-intradimensionalapriorising/axiomatising/referencing'-logical-dueness-precedes-disontologising-logicaloutcome-arrived-at $>$ mental defect is opaque due to its maturation/indirectness/spatialisation/credulity/craftiness to attain social-functioning-andaccordance-as-of-social-stake-contention-or-confliction) can be elucidated. The underlying process as of temporal postlogism -as-of- compulsingnonconviction/madeupness/bottomlining-〈‘ $<$ decontextualising/de-existentialising ofattendant-intradimensional-apriorising/axiomatising/referencing >-induced-disontologising'-ofthe-'attendant-intradimensional-ontologising'-imbued$<$ contextualising/existentialising attendant-ontological-contiguity $>$;-in-shallowsupererogation -<as-to-disontologising-perverted-outcome-sought-precedes-existentiallyveridical-'attendant-intradimensional-apriorising/axiomatising/referencing'-logical-dueness $>$ > or psychopathic reference-of-thought-looseness-of-tethering-to-prelogism ${ }^{78}$-as-ofconviction,-in-profound-supererogation ${ }_{-}<$existentially-veridical-'attendant-intradimensional- 
apriorising/axiomatising/referencing'-logical-dueness-precedes-disontologising-logical-

outcome-arrived-at> mental defect beginning at childhood involves 'its circular nonconsequential vague trialing of ${ }^{83}$ reference-of-thought-looseness-of-tethering-to- prelogism ${ }^{78}$ as-of-conviction,-in-profound-supererogation $-<$ existentially-veridical-'attendantintradimensional-apriorising/axiomatising/referencing'-logical-dueness-precedes-

disontologising-logical-outcome-arrived-at>' as of its temporal postlogism ${ }^{77}$ threshold-ofnonconviction/madeupness/bottomlining-in-shallow-supererogation $-<$ as-to-'attendantintradimensional'-prospectively-disontologising preconverging/dementing -apriorisingpsychologism $>$ with respect to its postlogic-backtracking-<iterative-looping-'set-of-dereifyinghollow-narratives-and-acts'> ${ }^{6}$, in full conscious-awareness-teleology ${ }^{9}$, which when perceived as uncontested by the psychopath (likely to arise where the concerned party lacks insight of its underlying faulty-mentation-procedure-deception and as it seem socially-function) will ultimately lead to its slanting-deception (or deception-of-successively-shifting-or-non-coheringnarratives-and-acts or deception-by-concurrently-false-presupposing/false-presuming/falsepremising-of-narratives or deception-by-concurrently-false-assumptive-preconverging-ordementing -of-narratives) inducing its threshold-of-nonconviction/madeupness/bottomliningin-shallow-supererogation -<as-to-'attendant-intradimensional'-prospectivelydisontologising preconverging/dementing -apriorising-psychologism $>$ and its consequent derivation as conjugated-postlogism or social psychopathy threshold-ofnonconviction/madeupness/bottomlining-in-shallow-supererogation $-<$ as-to- 'attendantintradimensional'-prospectively-disontologising preconverging/dementing -apriorising-

psychologism $>$. This process is mirrored with the various conjugated-postlogism 77 conscious or unconscious aligning to the psychopathic/postlogic postlogism -as-of- compulsingnonconviction/madeupness/bottomlining-〈‘ $<$ decontextualising/de-existentialising $\sim$ ofattendant-intradimensional-apriorising/axiomatising/referencing--induced-disontologising'-of- 
the-'attendant-intradimensional-ontologising'-imbued-

$<$ contextualising/existentialising attendant-ontological-contiguity $>$;-in-shallow-

supererogation -<as-to-disontologising-perverted-outcome-sought-precedes-existentially-

veridical-'attendant-intradimensional-apriorising/axiomatising/referencing'-logical-dueness $>$ >

vague-rhyming-or-copied-mimicry-or-formulaic-projection-or-projection-of-form-or-hollow-

and-vague-vocalisation-or-subknowledging ${ }^{4}$. Thus effectively such a postlogism -as-of-

compulsing-nonconviction/madeupness/bottomlining-〈'<decontextualising/de-

existentialising $\sim$ of-attendant-intradimensional-apriorising/axiomatising/referencing $>$-induced-

disontologising'-of-the-'attendant-intradimensional-ontologising'-imbued-

$<$ contextualising/existentialising attendant-ontological-contiguity $>$;-in-shallow-

supererogation -<as-to-disontologising-perverted-outcome-sought-precedes-existentially-

veridical-'attendant-intradimensional-apriorising/axiomatising/referencing'-logical-dueness $>$ >

process is rather very simplistic, and the deception arises actually from the prelogism ${ }^{78}$-as-ofconviction,-in-profound-supererogation -<existentially-veridical-'attendant-intradimensionalapriorising/axiomatising/referencing'-logical-dueness-precedes-disontologising-logical-

outcome-arrived-at $>$ mental-states to be by mental-reflex in prelogism ${ }^{78}$-as-of-conviction,-inprofound-supererogation $\quad<$ existentially-veridical-'attendant-intradimensional-

apriorising/axiomatising/referencing'-logical-dueness-precedes-disontologising-logical-

outcome-arrived-at> thus inducing wrongful teleological elevation of the postlogism ${ }^{77}$ psychopathic ${ }^{56}$ meaningfulness-and-teleology", which wouldn't occur at childhood psychopthy. Finally, as of dynamic-cumulative-aftereffect and across all registryworldviews/dimensions, the distractive-alignment-to- ${ }^{-}$reference-of-thought- $<$ofapriorising/axiomatising/referencing $>$ of any registry-worldview/dimension institutionalisation ${ }^{5}$ meaningfulness-and-teleology as of its organic-knowledge' can be construed and analysed across 3 lines; - the initiating temporal postlogism 77 distractive- 
alignment-to- ${ }^{8}$ reference-of-thought- $<$ of-apriorising/axiomatising/referencing $>$

meaningfulness-and-teleology , - the generalised temporal-dispositions to integrate such ontologically-destructured meaningfulness-and-teleology ${ }^{59}$ as of the registryworldview's/dimension's relative-ontological-incompleteness ${ }^{88}$-of- ${ }^{83}$ reference-of-thought explaining its beyond-the-consciousness-awareness-teleology ${ }^{0}<$ of - preconverging-existentialextrication-as-of-existential-unthought $>$ and 'lack of constraining social ${ }^{103}$ universaltransparency ${ }^{104}$-〈transparency-of-totalising-entailing,-as-to-entailing-<amplituding/formativeepistemicity $>$ totalising in-relative-ontological-completeness $\rangle, \quad-\quad$ and the prospective institutionalisation construing/conceptualising the ontological-veridicality and analysis of such registry-worldview/dimension institutionalisation ${ }^{56}$ meaningfulness-and-teleology ${ }^{9}$ distractivealignment-to- ${ }^{8}$ reference-of-thought- $<$ of-apriorising/axiomatising/referencing $>{ }^{30}$ dynamics (as of the previous two) as 'social ontology as to aetiologisation/ontological-escalation$<$ ontological-veridicality_commitment/otherliness_transcending/compulsionsencumbered_transcending >', and equally serves as an ideal storied-construct/ontologicallyvalid-narration of intuitive elucidation framework. The implication of such 'temporal distractivealignment-to- ${ }^{83}$ reference-of-thought- $<$ of-apriorising/axiomatising/referencing $>30 \quad$ of institutionalisation meaningfulness-and-teleology ${ }^{\circ}$, across all registryworldviews/dimensions is that ${ }^{5}$ meaningfulness-and-teleology as of prospective registryworldview/dimension institutionalisation involves apriorising/axiomatising/referencing/intelligibilitysettingup/measuringinstrumenting-foroperant-or-incidenting-predicative-insights enabling utter psychical-and-institutional apriorising/axiomatising/referencing-\{of-'prospectively_implicited_attendant-ontologicalcontiguity ' educedexistentialising/contextualising/textualising_'intelligibility/epistemicity/reflexivity-contiguity<imbued-notional cogency>’ \}-conflatedness ${ }^{13}$-in-\{preconverging-disentailment by\} 
postconverging-entailment of ${ }^{56}$ meaningfulness-and-teleology 99 exactly by transcending/superseding the apriorising/axiomatising/referencing/intelligibilitysettingup/measuringinstrumenting-foroperant-or-incidenting-predicative-insights behind the prior registry-worldview/dimension uninstitutionalised-threshold ${ }^{102}$. As critically the naivety of $<$ amplituding/formative $>$ woodenlanguage-〈imbued — averaging-of-thought-<as-to-leveling/ressentiment/closed-construct-ofmeaningfulness-and-teleology -as-of-'nondescript/ignorable-void '-with-regards-toprospective-apriorising-implications $>>$ within a same registry-worldview/dimension uninstitutionalised-threshold ${ }^{102}$ reference-of-thought is that its defect of apriorising/axiomatising/referencing/intelligibilitysettingup/measuringinstrumenting-foroperant-or-incidenting-predicative-insights arising as ${ }^{74}$ perversion-of- ${ }^{3}$ reference-of-thought$<$ as-preconvergingly-apriorising/axiomatising/referencing-in-

nonconviction/madeupness/bottomlining-as-to-shallow-supererogation $>$ due to its prior relative-ontological-incompleteness ${ }^{8}$-of- ${ }^{8}$ reference-of-thought (as failing rulemaking-overnon-rules - apriorising/axiomatising/referencing-psychologism in recurrent-utteruninstitutionalisation or failing ${ }^{103}$ universalisation-directed-rulemaking-over-non-rulesapriorising/axiomatising/referencing-psychologism in ununiversalisation or failing positivising/rational-empiricism-based-universalisation-directed-rulemaking-over-non-rulesapriorising/axiomatising/referencing-psychologism in non-positivism/medievalism or failing preempting - disjointedness-as-of- ${ }^{83}$ reference-of-thought,-as-to- ${ }^{63}<$ amplituding/formativeepistemicity $>$ growth-or-conflatedness ${ }^{13} /$ transvaluative-

rationalising/transepistemicity/anamnestic-residuality/spirit-drivenness' — in-supersedingmere-formulaic-positivising/rational-empiricism-based-universalisation-directed-rulemakingover-non-rules - apriorising/axiomatising/referencing-psychologism in procrypticism, and thus requiring respectively transcending/superseding to base-institutionalisation, ${ }^{103}$ universalisation, 
positivism and deprocrypticism), is that ${ }^{5}$ meaningfulness-and-teleology ${ }^{9}$ can then still be upheld on the basis of the same uninstitutionalised-threshold $102 /$ uninstitutionalised apriorising/axiomatising/referencing/intelligibilitysettingup/measuringinstrumenting-foroperant-or-incidenting-predicative-insights rather than the more ontologically-veridical implication of prospective registry-worldview/dimension institutionalisation apriorising/axiomatising/referencing/intelligibilitysettingup/measuringinstrumenting-foroperant-or-incidenting-predicative-insights enabling utter psychical-and-institutional apriorising/axiomatising/referencing-\{of-'prospectively implicited_attendant-ontologicalcontiguity ' educedexistentialising/contextualising/textualising_'intelligibility/epistemicity/reflexivity-contiguity$<$ imbued-notional $\left.\sim \operatorname{cogency}>^{\prime}\right\}$-conflatedness ${ }^{13}{ }^{\text {in }}$ - preconverging-disentailment by $^{\prime}$ postconverging-entailment. Explicating thus the preconverging/postconverging-dementative/structural/paradigmatic implication of the non-positivistic or our positivismprocrypticism perversion-of- ${ }^{3}$ reference-of-thought- $<$ as-preconverginglyapriorising/axiomatising/referencing-in-nonconviction/madeupness/bottomlining-as-toshallow-supererogation $>$ construed respectively as of aetiologisation/ontological-escalation$<$ ontological-veridicality_commitment/otherliness_transcending/compulsions-

encumbered_transcending $>$ as an altogether positivism or notional ${ }^{8}$ deprocrypticism utter psychical-and-institutional apriorising/axiomatising/referencing-\{of-"prospectively implicited_attendant-ontological-contiguity ' educedexistentialising/contextualising/textualising_'intelligibility/epistemicity/reflexivity-contiguity<imbued-notional cogency >' \}-conflatedness ${ }^{13}$ in-\{preconverging disentailment by\}

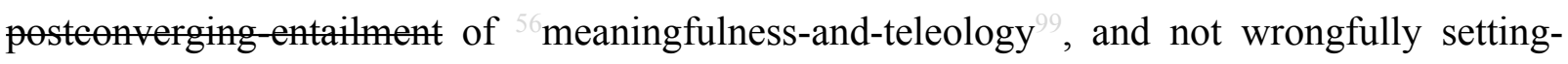
aside/glossing-over/ignoring with the idea that ${ }^{5}$ meaningfulness-and-teleology ${ }^{9}$ is still to be construed as of non-positivism/medievalism or positivism- ${ }^{-1}$ procrypticism; as the grander 
human living as of the species 'existential tale' is in construing that the respective prospective institutionalisation

apriorising/axiomatising/referencing/intelligibilitysettingup/measuringinstrumentings-foroperant-or-incidenting-predicative-insights when availed by contemplation as based-

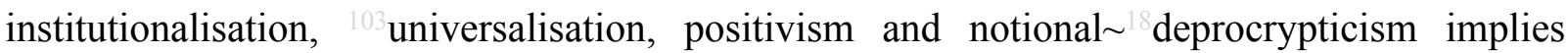
transcending/superseding the respective uninstitutionalised-threshold apriorising/axiomatising/referencing/intelligibilitysettingup/measuringinstrumentings-foroperant-or-incidenting-predicative-insights of recurrent-utter-uninstitutionalisation, ununiversalisation, non-positivism/medievalism and procrypticism, enabling the cumulative recomposuring of 'intemporal ontological-faith-notion-or-ontological-fideism -imbuedunderdetermination-of-motif-and-apriorising/axiomatising/referencing-as-so-being-as-ofexistential-reality instigated relative-unreflexivity/relative-reflexivity-ontologicalcontiguity $^{67} \sim$ of-the-human-institutionalisation-process ${ }^{68}$ as of difference-conflatedness ${ }^{13}$-as-tototalitative-reification-in-singularisation-<as-to-the-nondisjointedness/entailment-ofprospective- nonpresencing $>$-as-veridical-epistemicity-relativism-determinism implied $<$ amplituding/formative-epistemicity $>$ causality $\sim$ as-to-projective-totalitative-implications-ofprospective- nonpresencing,-for-explicating relative unreflexivity/relative reflexivity ontological-contiguity as of intemporal/ontological/social/species/ ${ }^{103}$ universal/transcendental/ ${ }^{55}$ maximalisingrecomposuring-for-relative-ontological-completeness ${ }^{87}$ - unenframed/reontologising conceptualisation postconverging-de-mentating/structuring/paradigming and not temporal extricatory preconverging-de-mentating/structuring/paradigming parasitising/coopting to the species existential-tale.]

The statements articulated priorly (before the square brackets texts digression) speak of the reality of 'human temporal uninstitutionalised-threshold ${ }^{12}$ mental-disposition' even in our own 
positivism ${ }^{83}$ reference-of-thought registry-worldview. It is fair to say the statement made before, "Z ... will look down on B, C, D, E and F mental-dispositions perversion-and-derivedperversion-of- ${ }^{8}$ reference-of-thought-<as-preconvergingly-

\section{apriorising/axiomatising/referencing-in-nonconviction/madeupness/bottomlining-as-to-}

shallow-supererogation $>$ as allowing for the endemisation/enculturation of the denaturing of additionality and the implications thereof of subsequent denaturing in circularity/recurrence/repetition/repeatability ${ }^{10}$ " is circumstantially relevant even in our positivistic registry-worldview wherein 'lack of constraining social ${ }^{103}$ universal-transparency' 〈transparency-of-totalising-entailing,-as-to-entailing-<amplituding/formativeepistemicity>totalising in-relative-ontological-completeness > induces a 'human temporal uninstitutionalised-threshold ${ }^{102}$ mental-disposition' temporality /shortness or shortness-ofregister-of- ${ }^{56}$ meaningfulness-and-teleology ${ }^{9}$ drive. The Milgram experiments, a demonstration par excellence of the human condition at uninstitutionalised-threshold ${ }^{12}$ with respect to perceived-social-stake-contention-or-confliction constraints as of human limited-mentationcapacity-deepening — as-subjecting limitedness/human-subpotency-to-'educed-

tnlimitedness/existence-sublimating nascence' ${ }^{53}$, truly reflect the inherent nature of 'human temporal uninstitutionalised-threshold ${ }^{12}$ mental-disposition'; and the deprocrypticism-driven understanding of which should rather be an avenue for a pivoting/decentering psychologism with respect to positivism- ${ }^{80}$ procrypticism registry-worldview/dimensions vices-and-impediments (just as with all previous transcendence-and-sublimity/sublimation/supererogatory $\sim$ dementativity of 'intemporal ontological-faith-notion-or-ontological-fideism-imbuedunderdetermination-of-motif-and-apriorising/axiomatising/referencing-as-so-being-as-ofexistential-reality instigated relative-unreflexivity/relative-reflexivity_ontologicalcontiguity ${ }^{67}$ of-the-human-institutionalisation-process ${ }^{68}$ as of difference-conflatedness ${ }^{13}$-as-tototalitative-reification-in-singularisation-<as-to-the-nondisjointedness/entailment-of- 
$<$ amplituding/formative-epistemicity $>$ causality $\sim$ as-to-projective-totalitative-implications-ofprospective- nonpresencing,-for-explicating relative-unreflexivity/relative-reflexivity

ontological-contiguity , rather than a naïve metaphysics-of-presence-〈implicited'nondescript/ignorable-void ' -as-to- presencing - absolutising-identitive-constitutedness >

mental complex that only serves 'flawed egos' and is of no ontologically-veridical import). The point of this distinction made between the nature of 'human registry-worldview's/dimension's institutionalisation mental-disposition' registry-worldview's/dimension's ${ }^{83}$ reference-ofthought and 'human temporal uninstitutionalised-threshold ${ }^{12}$ mental-disposition' registryworldview's/dimension's $\quad$ reference-of-thought, as of prospective ontologicalnormalcy/postconvergence is to put into perspective the idea that the present and as of our present social construction and individuations as being relatively more exceptional than the solipsistic nature of humans in prior epochs is false, with such wrongly implied exception rather being a confusion between 'cumulated institutionalisation' (which we carry by being secondnatured at the backend in reflecting holographically-<conjugatively-and-transfusively $>$ the relativeunreflexivity/relative-reflexivity ontological-contiguity of-the-human-institutionalisationprocess as of human limited-mentation-capacity-deepening-as-subjecting limitedness/human-subpotency to-'educed-unlimitedness/existence-sublimating nascence' leading to the positivistic registry-worldview/dimension) and that our inherent solipsistic sense of intemporality ${ }^{52} /$ longness (which overall is no more greater than that of humans of previous $<$ cumulating/recomposuring attendant-ontological-contiguity $>$-successive registryworldviews/dimensions); and further that we are just of the same 'human temporal uninstitutionalised-threshold ${ }^{102}$ mental-disposition' as all humans past when it comes to making solipsistic choices at uninstitutionalised-threshold ${ }^{102}$, which choices when of intemporality ${ }^{52}$ drive solipsistic-choices are maximalising-recomposuring-for-relative-ontological- 
completeness ${ }^{87}$ - unenframed/re-ontologising conceptualisation leading to prospective institutionalisations. This notion of human mental-disposition and by extension meaningfulness-and-teleology ${ }^{99}$ as comprising, rather as a more complete and grander conceptualisation, a registry-worldview's/dimension's institutionalisation-facet and an uninstitutionalised-threshold ${ }^{102}$-facet, so-construed by metaphysics-of-absence-〈implicitedepistemic-veracity-of- nonpresencing-<perspective-ontological-normalcy/postconvergence $>\rangle$, carries institutionalisation and uninstitutionalised-threshold ${ }^{102}$ implications with respect to the determination of ontologically-veridical ${ }^{5}$ meaningfulness-and-teleology ${ }^{9}$ as of pertinent scientific conceptualisation (scientific approach, methodology and methods) as rather construed most critically by its relative intrinsic-reality/ontological-veridicality transcendentalenabling/sublimating/supereregatory de-mentativity. Such metaphysics-of-absence〈implicited-epistemic-veracity-of- nonpresencing-<perspective-ontologicalnormalcy/postconvergence $>>$ considerations are critically relevant in fully appreciating the articulation herein by this author of such notions (that rather speak of uninstitutionalisedthreshold ${ }^{102}$ implications with respect to a 'social pretence of scientific conceptualising as of relative intrinsic-reality/ontological-veridicality transcendentalenabling/sublimating/supereregatøry de-mentativity'), like deferential-formalisationtransference, ordered-construct, percolation-channelling- $<$ in-deferential-formalisationtransference $>$ and transversality-<for-sublimating-existential-eventuating/denouement,-from-

\section{thinking at first/pure predisposition preemptive of prospective}

\section{disontologising/subontologising’ as-of-prospectively-disambiguated-affirmed-and-}

unaffirmed-'motif-and-apriorising/axiomatising/referencing' $>101$. Insightfully, it is the case that our present-day positivistic institutionalisation secondnatured scientific practice outcome of relative intrinsic-reality/ontological-veridicality transcendentalenabling/sublimating/supereregatory de-mentativity is grounded on institutionally-determined 
peerage/collegiality as of positivistic institutionalisation deferential-formalisation-transference, so supposedly recognised within the social collective or 'social framework of intersolipsistic deambulation'. But then we grasp that at the disjuncture of positivistic meaningfulness-andteleology (as 'moulting' firstnature/intemporal conceptualisation of what developed to become today our scientific practice institutionalisation as of its relative intrinsic-reality/ontologicalveridicality transcendental-enabling/sublimating/supererogatory de-mentativity) from the nonpositivism/medievalism registry-worldview/dimension, we can definitely fathom that the enlightenment actors like the Descartes's, Galileos, Diderots, etc. of those transitioning times would have certainly been circumspect with regards to any such notion of preceding social approval (for their scientific ${ }^{56}$ meaningfulness-and-teleology as of relative intrinsicreality/ontological-veridicality transcendental-enabling/sublimating/supererogatory $\sim$ dementativity), given the social non-positivism/medievalism uninstitutionalised-threshold ${ }^{102}$ nonscientific disposition, as beyond-the-consciousness-awareness-teleology ${ }^{\circ}<$ of-preconvergingexistential-extrication-as-of-existential-unthought $>$. This points to an altogether different social relation with the notion of scientific practice construed as of relative intrinsic-reality/ontologicalveridicality transcendental-enabling/sublimating/supererogatory $\sim$ de-mentativity, by such intemporal-solipsism as to ontological-faith-notion-or-ontological-fideism-imbuedunderdetermination-of-motif-and-apriorising/axiomatising/referencing-as-so-being-as-ofexistential-reality mental-disposition that conceive of positivistic ${ }^{56}$ meaningfulness-andteleology ${ }^{9}$ in the uninstitutionalised-threshold ${ }^{102}$ social-setup of non-positivism/medievalism where they were institutionally-outlying. As exemplarily implied with the Encyclopédistes led by Diderot, such construal is grounded on a more basic and potent construct of $<$ amplituding formative-epistemicity $>$ causality $\sim$ as-to-projective-totalitative-implications-ofprospective- nonpresencing,-for-explicating relative-unreflexivity/relative-reflexivity

ontological-contiguity and actually reveals in-many-ways the reality of a natural Foucauldian 
power relations which it turns out is actually in the medium to long term a social-granting-ofpower-exercise with respect to the virtue of true knowledge, as of the social percolationchannelling- $<$ in-deferential-formalisation-transference $>$ possibilities enabling promising ideas, however institutionally-outlying or institutionally-central, to take hold in society depending on their relative intrinsic-reality/ontological-veridicality transcendentalenabling/sublimating/supereregatery-de-mentativity as of veracity/ontological-pertinence; without heed given to mere centrality as veracity/ontological-pertinence but decentering if the centrality is not ontologically pertinent, and rather further secondnaturing prospective institutionalisation of scientific practice as of its relative intrinsic-reality/ontological-veridicality transcendence-enabling; very much highlighting the prospective institutionalisation pertinence of such notions articulated by this author like deferential-formalisation-transference, orderedconstruct, $\quad$ percolation-channelling- $<$ in-deferential-formalisation-transference $>\quad$ and transversality-<for-sublimating-existential-eventuating/denouement-from-'thinking-atfirst/pure-predisposition - preemptive-of prospective-disontologising/subontologising' as-ofprospectively-disambiguated-affirmed-and-unaffirmed-'motif-andapriorising/axiomatising/referencing' $>$ 101. In another respect, with regards to scientific meaningfulness-and-teleology ${ }^{99}$ and as it informs the social-construct of knowledge and deferential-formalisation-transference (as power relations with respect to knowledge as socially empowering), it is critical to grasp that it is relative intrinsic-reality/ontological-veridicality transcendental-enabling/sublimating/supererogatory de-mentativity that induces social deference to formal knowledge constructs and other formal constructs, on the basis that that will 'produce the greater human Good', as at the prior as uninstitutionalised-threshold ${ }^{102}$ when such domains lacked or were deficient with respect to formal knowledge constructs or other formal constructs like officialdoms, it was rather a question of 'relatively free-for-all opinionatedness and imaginary knowledge constructs' with relatively impulsive and simplistic contending 
mental-dispositions on the basis of the determining or non-determining need for 'social consensus as of social-aggregation-enabling by human temporal $<$ amplituding/formative $>$ wooden-language-〈imbued - averaging-of-thought-<as-toleveling/ressentiment/closed-construct-of- meaningfulness-and-teleology -as-of'nondescript/ignorable-void '-with-regards-to-prospective-apriorising-implications $>>$ mentaldispositions and projections' and not necessarily emphasising 'social consensus as of relative intrinsic-reality/ontological-veridicality transcendentalenabling/sublimating/supereregatory de-mentativity by human intemporal mental-dispositions and projections'; explaining why higher and higher registry-worldviews/dimensions as of their prospective relative-ontological-completeness ${ }^{87}$-of- ${ }^{8}$ reference-of-thought increasingly defer domains of ${ }^{56}$ meaningfulness-and-teleology ${ }^{9}$ more and more to formal constructs while increasingly reducing the sphere of the extended-informality-<susceptible-to-effectingparsimony-as-of-shoddiness-and-incompleteness-to- meaningfulness-and-teleology $\rangle$ as of its free-for-all nature. The bigger point being that even in our positivism- ${ }^{80}$ procrypticism registryworldview/dimension with relatively strong 'social consensus as of relative intrinsicreality/ontological-veridicality transcendental-enabling/sublimating/supererogatory $\sim$ dementativity by human intemporal mental-dispositions and projections' in many domains; however, with regards to domains (and so, more than just about broad subject matter areas and broad spheres of other formal constructs including officialdoms, but rather and critically the specifically relatively undeveloped knowledge spheres of such broad subject matters and broad spheres of other formal constructs including officialdoms, and as specific in this instance as with regards to our understanding of psychopathy) that are spurious and blurry, these are often not socially related to in profound knowledge/scientific ${ }^{56}$ meaningfulness-and-teleology ${ }^{9}$ terms on the basis of 'social consensus as of relative intrinsic-reality/ontological-veridicality transcendental-enabling/sublimating/supererogatory $\sim$ de-mentativity by human intemporal 
mental-dispositions and projections' profound treatment, and are rather prone to 'relatively freefor-all opinionatedness and imaginary knowledge constructs' in rather relatively impulsive and simplistic contending mental-dispositions on the basis of the determining or non-determining need for 'social consensus as of social-aggregation-enabling by human temporal $<$ amplituding/formative $>$ wooden-language- $\langle$ imbued — averaging-of-thought- $<$ as-toleveling/ressentiment/closed-construct-of- meaningfulness-and-teleology -as-of'nondescript/ignorable-void '-with-regards-to-prospective-apriorising-implications $>>$ mentaldispositions and projections' and not necessarily emphasising 'social consensus as of relative intrinsic-reality/ontological-veridicality transcendentalenabling/sublimating/ de-mentativity by human intemporal mental-dispositions and projections'. This contrasts with those domains that are more pertinently and decisively intrinsic-reality/ontological-veridicality transcendentalenabling/sublimating/supereregatory de-mentativity which quickly obtain deferentialformalisation-transference (deferential as not opinionating randomly with respect to imagining the legal implications of one another's actions but deferring one's understanding to the formal legal domain, appreciating in deference scientific principles and not opinionating about what we imagine about the stars but deferring to the astronomer and physicist, appreciating statistics and human geography methods and not imagining how censuses and polls should be done but deferring to the demographer and statistician, etc.; as providing a grander depth of knowledge by deferential-formalisation-transference pointing out that 'human intemporal mentaldispositions and projections' are the basis for 'inventing' human knowledge and corresponding virtue (as of aetiologisation/ontological-escalation- $<$ ontologicalveridicality_commitment/otherliness_transcending/compulsions-encumbered_transcending $>$ ), and not 'human temporal <amplituding/formative > wooden-language-〈imbued - averaging-ofthought-<as-to-leveling/ressentiment/closed-construct-of- meaningfulness-and-teleology -as- 
of-'nondescript/ignorable-void '-with-regards-to-prospective-apriorising-implications $>$ >

mental-dispositions and projections'. Hence the construal of knowledge construct in such domains that are spurious and blurry as with respect to postlogism 77 psychopathy social implications should as of precedence be about articulating the illuminating insight that ultimately allows for the attainment of their own deferential-formalisation-transference based on 'social consensus as of relative intrinsic-reality/ontological-veridicality transcendentalenabling/sublimating/supereregatory de-mentativity by human intemporal mental-dispositions and projections', and undermining a social relations with regards to knowledge and virtue that is based on 'social consensus as of social-aggregation-enabling by human temporal $<$ amplituding/formative $>$ wooden-language-<imbued - averaging-of-thought-<as-toleveling/ressentiment/closed-construct-of- meaningfulness-and-teleology -as-of'nondescript/ignorable-void '-with-regards-to-prospective-apriorising-implications $>>$ mentaldispositions and projections', and so in order to release the inherent virtue imbued in true knowledge. The afore elucidations are mainly to point out that it is naïve to construe the analysis of postlogism 77 phenomenon including psychopathy on the assumption of an overall 'human registry-worldview's/dimension's institutionalisation mental-disposition' of the social as of the present as metaphysics-of-presence-〈implicited-'nondescript/ignorable-void '-as-topresencing - absolutising-identitive-constitutedness \ instead of assuming a 'human temporal uninstitutionalised-threshold ${ }^{12}$ mental-disposition' of the social by prospective metaphysics-ofabsence-〈implicited-epistemic-veracity-of- nonpresencing-<perspective-ontologicalnormalcy/postconvergence $>\rangle$, since the construal of our postlogism 77 as of psychopathy and social psychopathy is necessarily, from ontological-normalcy/postconvergence epistemic-ornotional projective-perspective, reflected from futural Being-development/ontologicalframework-expansion-as-to-depth-of-ontologising-development-as-infrastructure-ofmeaningfulness-and-teleology as of prospective notional ${ }^{18 p}$ deprocrypticism registry- 
worldview's/dimension's ${ }^{83}$ reference-of-thought. Insightfully, by metaphysics-of-absence〈implicited-epistemic-veracity-of- nonpresencing-<perspective-ontological-

normalcy/postconvergence $>>$ we can appreciate this logic with respect to notions-andaccusations-of-sorcery as intuitively we'll be hard-pressed to recognise that the nonpositivism/medievalism social-construct mental-disposition is one of human registryworldview's/dimension's institutionalisation of an intemporality ${ }^{52}$-drive whereas in fact it is one of human uninstitutionalised-threshold ${ }^{12}$ of temporalities-drives such that it is endemised/enculturated in various temporality $8 /$ shortness shades $^{2}$ in (5ignorance/affordability/opportunism/exacerbation/social-chainism-or-social-discomfiture-ornegative-social-aggregation/temporal-enculturation-or-temporal-endemisation) as of ontological-normalcy/postconvergence from a prospective positivism registryworldview's/dimension's ${ }^{83}$ reference-of-thought. The same applies with psychopathy in our positivism- ${ }^{8}$ procrypticism, as the <amplituding/formative> wooden-language-〈imbuedaveraging-of-thought-<as-to-leveling/ressentiment/closed-construct-of- meaningfulness-andteleology -as-of-'nondescript/ignorable-void ' -with-regards-to-prospective-apriorisingimplications $>>$ in such a context should not and cannot be the trusted reference of intellectual contemplation as of ontological-normalcy/postconvergence in the elucidation of psychopathy and social psychopathy (just as it is not a trusted reference with regards with priorly established formal knowledge constructs whether subject-matter disciplines or formalising constructs including the law, officialdom, etc.), as it is effectively poorly ontological or non-ontological in the sense that it tends to be of an extricatory/temporal preconverging-dementating/structuring/paradigming not intemporal/ontological/social/species/ ${ }^{103}$ universal/transcendental/ ${ }^{5}$ maximalisingrecomposuring-for-relative-ontological-completeness ${ }^{8}$ —unenframed/reontologising conceptualisation postconverging-de-mentating/structuring/paradigming as when 
it fails to appreciate the virtuous implications of aetiologisation/ontological-escalation$<$ ontological-veridicality_commitment/otherliness_transcending/compulsions-

encumbered_transcending $>$ (metaphorically-as-of-a-million-and-one-instances-and-locales) as providing the possibility for prospective institutionalisation as preconverging/postconvergingde-mentatively/structurally/paradigmatically superseding the positivism- ${ }^{80}$ procrypticism registry-worldview/dimension vices-and-impediments ${ }^{105}$ ! It is thus important to grasp that the notion of virtue as of our temporal-to-intemporal mental-dispositions is more than just about the notion of being at the backend in reflecting holographically-<conjugatively-and-transfusively $>$ the relative-unreflexivity/relative-reflexivity - ontological-contiguity of-the-humaninstitutionalisation-process of institutional-cumulation/institutional-recomposure-〈as-tohistoriality/ontological-eventfulness /ontological-aesthetic-tracing-<perspective-

ontological-normalcy/postconvergence-reflected-‘epistemicity-relativism-determinism'>>, but rather the intemporal mental-disposition (intemporal-disposition) to strive as maximalisingrecomposuring-for-relative-ontological-completeness ${ }^{87}$ - unenframed/re-

ontologising conceptualisation for base-institutionalisation to supersede recurrent-utteruninstitutionalisation equates that striving for ${ }^{103}$ universalisation to supersede baseinstitutionalisation-ununiversalisation equates that striving for positivism to supersede universalisation-non-positivism/medievalism equates that striving for notional ${ }^{18}$ deprocrypticism to supersede positivism- ${ }^{-10}$ procrypticism; as the highest human virtue of ontological import. Since the inducing of institutionalisation-as-a-secondnaturedconstruct across all institutional-cumulation/institutional-recomposure-〈as-tohistoriality/ontological-eventfulness /ontological-aesthetic-tracing-<perspectiveontological-normalcy/postconvergence-reflected-‘epistemicity-relativism-determinism'>> or registry-worldviews/dimensions inevitably implies a dichotomy of ${ }^{83}$ reference-of-thought modalities of the same perpetual temporalities-drives and intemporality ${ }^{52}$-drive (given human- 
subpotency-aporia/undecidability/dilemma/ought-

indeterminacy/deficiency/limitation/constraint—imbued-'notional firstnaturedness-

formativeness-<as-to-eventualising-inkling drive-or-seeding misprising $>$ temporal-to-

intemporal-dispositions-<so-construed-as-from-perspective-ontological-

normalcy/postconvergence>'-existentialism-form-factor), respectively as 'least-and-derivedtemporal-operating-modalities-of-the- ${ }^{8}$ reference-of-thought-as-of- ${ }^{-}$incrementalism-inrelative-ontological-incompleteness — enframed/disontologising conceptualisation-inducingthe-uninstitutionalised-threshold ${ }^{102}$ and 'maximal-as-intemporal-operating-modality-ofreference-of-thought-as-of- ${ }^{5}$ maximalising-recomposuring-for-relative-ontologicalcompleteness $^{87}$ — unenframed/re-ontologising conceptualisation-as-inducing-the-prospectiveinstitutionalisation'. Virtue is essentially about the intemporality ${ }^{52}$-drive as ${ }^{55}$ maximalisingrecomposuring-for-relative-ontological-completeness ${ }^{8}$ —unenframed/re-

ontologising conceptualisation for intemporal-preservation-entropy-or-contiguity-orontological-preservation as of ontological-normalcy/postconvergence which always factor in human limited-mentation-capacity-deepening —as-subjecting limitedness/human-subpotencyto-'educed-unlimitedness/existence-sublimating nascence' ${ }^{53}$ by a re-equilibrating metaphysicsof-absence-〈implicited-epistemic-veracity-of- nonpresencing-<perspective-ontologicalnormalcy/postconvergence $>$ /postdication with $\quad{ }^{83}$ reference-of-thought - categoricalimperatives/axioms/registry-teleology subservient to that purpose, and not about the temporalities-drives as 'mere adherence as intradimensionally deterministic by form' to reference-of-thought- categorical-imperatives/axioms/registry-teleology 9 as these are failing/not-upholding-<as-of-apriorising/axiomatising/referencing $>$ intemporal-preservationentropy-or-contiguity-or-ontological-preservation as of ontological-normalcy/postconvergence which always factor in human limited-mentation-capacity-deepening-as-subjectinglimitedness/human-subpotency-to-'educed-unlimitedness/existence-sublimating nascence' 
by a re-equilibrating metaphysics-of-absence-〈implicited-epistemic-veracity-ofnonpresencing-<perspective-ontological-normalcy/postconvergence $>$ / $/$ postdication rather than upholding it, their very raison d'être. Interestingly, supposed by some circumstance an individual of a positivistic insight found themselves in a non-positivistic community, whether base-institutionalisation/animistic or medieval, facing a disease attributed to a negative spirit or so, but the positivistic individual knows it is a case of an infection with the idea that a certain root or leaf in the nearby forest can be used as cure, however, the community rather believe that the forest is an evil forest and this will just make things worse for them overall. Obviously, as of its positivism prospective relative-ontological-completeness ${ }^{87}$-of- ${ }^{8}$ reference-of-thought, by 'intemporal-prioritisation-of- ${ }^{8}$ reference-of-thought'-as-conflatedness ${ }^{13}$-or-ontologicalreprojecting its mental-disposition will be to unleash its maximalising-recomposuring-forrelative-ontological-completeness ${ }^{87}$ — unenframed/re-ontologising conceptualisation intemporality $^{52}$-drive to supersede the non-positivistic ${ }^{83}$ reference-of-thought- categoricalimperatives/axioms/registry-teleology ${ }^{9}$ that the evil forest brings bad omen substituting it with the positivistic one that the root or leaf in the forest brings about cure by walking over the supposed 'evil forest', and more than just the circumstantial situation will equally appreciate that positivistic thinking over animistic or medieval thinking will go a long way in improving the community's existence. It is interesting to grasp the difference in the dereifying and reifying construal of 'implicited_attendant-ontological-contiguity ${ }^{67}$; educedexistentialising/contextualising/textualising_'intelligibility/epistemicity/reflexivity_contiguity$<$ imbued-notional cogency> $>^{\prime 0}$ here between the non-positivists mindsets and the positivist mindset as of underlying relative-ontological-incompleteness 88 and relative-ontologicalcompleteness ${ }^{87}$ reference-of-thought and respectively as of their divergent non-positivists dereification perspective and positivist reification perspective; as seeing the positivist stranger walking into the supposed 'evil forest' will be the confirmation for members of the non-positivist 
social-setup of its viciousness-or-supernaturalness-or-evil-disposition. It can be noted here that seeing the positivist walking into the evil forest will be branded as proof/evidence by the nonpositivists of its viciousness-or-supernaturalness-or-evil-disposition going by their supernatural conception of implicited_attendant-ontological-contiguity ${ }^{67}$ ' educedexistentialising/contextualising/textualising_'intelligibility/epistemicity/reflexivity-contiguity$<$ imbued-notional cogency>' -in-reification/dereification as of their prior relativeontological-incompleteness ${ }^{8}$-of- ${ }^{8}$ reference-of-thought, contrasted with the positivist naturalist conception of 'implicited_attendant-ontological-contiguity ${ }^{67}$ ' educedexistentialising/contextualising/textualising_'intelligibility/epistemicity/reflexivity_contiguity$<$ imbued-notional cogency> -in-elucidation-or-reification as-seeking-a-cure as of its prospective relative-ontological-completeness ${ }^{87}$-of- ${ }^{83}$ reference-of-thought; and possibly ensuing into a country of the blind scenario. This insight equally highlights the evasiveness of "what is meant by proof/evidence' even in our positivism- ${ }^{80}$ procrypticism registry-worldview/dimension as of its prior relative-ontological-incompleteness ${ }^{8-o f-}$ reference-of-thought, as the notion of proof/evidence is more critically tied down to 'implicited_attendant-ontologicalcontiguity $^{67} \sim$ educed-

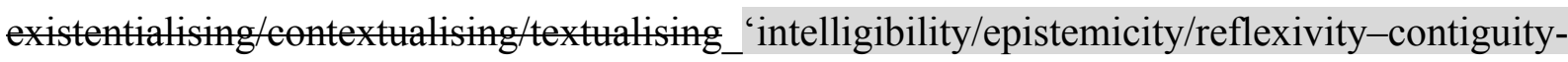
$<$ imbued-notional cogency $>$-reification as of singularisation- $<$ as-to-thenondisjointedness/entailment-of-prospective- nonpresencing $>$ projected epistemicimmanence/veridical-epistemicity-relativism-determinism; just as postmodern-thought notional-contiguity/epistemic-contiguity ${ }^{2}$ - profound-supererogation -of-mentallyaestheticised postconverging/dialectical-thinking -qualia-schema $>$ in decentering the 'modern-take thinking' reveals the underlying bias of the latter ${ }^{56}$ meaningfulness-andteleology as reflected particularly more vividly in gender, race, class, etc. Interestingly, this paradox is very much typical of all transcendental situations and explains the ${ }^{103}$ universal 
'ontological-faith-notion-or-ontological-fideism - imbued-underdetermination-of-motif-andapriorising/axiomatising/referencing-as-so-being-as-of-existential-reality parrhesiastic askesisor-acumen as of reasoning-through/messianic-reasoning' contorted gesturing/accounting-ofepistemic-phenomenalism associated with transcendental thresholds. As we can garner in this case that the positivist constrained to existence rather in such a country-of-the-blind scenario cannot simply be deferential to living and Being as of the non-positivist social-setup value reference while very much aware of the preconverging/postconverging-dementative/structural/paradigmatic virtue implications as of prospective positivism prospective relative-ontological-completeness ${ }^{8}$-of- ${ }^{8}$ reference-of-thought, and thus will 'contortively' hold on to the reasoning-through/messianic-reasoning possibility of positivistic value references over non-positivistic value reference, even as the latter is always in <amplituding/formativeepistemicity $>$ totalising $\sim$ self-referencing-syncretising/circularity/interiorising/akrasiatic-drag 3 ; with the implication that such ontological-faith-notion-or-ontological-fideism-imbuedunderdetermination-of-motif-and-apriorising/axiomatising/referencing-as-so-being-as-ofexistential-reality parrhesiastic askesis-or-acumen/asceticism as of reasoningthrough/messianic-reasoning contortion is rather in transversality-<for-sublimating-existentialeventuating/denouement, from 'thinking at first/pure predisposition preemptive of prospective-disontologising/subontologising' as-of-prospectively-disambiguated-affirmedand-unaffirmed-'motif-and-apriorising/axiomatising/referencing' $>101$ of the prior relativeontological-incompleteness ${ }^{88}$-of- ${ }^{8}$ reference-of-thought and the contorted prospective relativeontological-completeness ${ }^{87}$-of- ${ }^{83}$ reference-of-thought from their respective existentialism intelligibility stances. This contortion as of prospective relative-ontological-completeness ${ }^{87}$-ofreference-of-thought projection is what marks 'transcendental acts of ontological-faith-notionor-ontological-fideism—imbued-underdetermination-of-motif-and-

apriorising/axiomatising/referencing-as-so-being-as-of-existential-reality parrhesiastic askesis- 
or-acumen/asceticism as of reasoning-through/messianic-reasoning' whether of philosophical implications as with say Socrates or philo-religious implications as of pesteonvergingnonextricatory-existential-preempting-of-existential-unthought. The contortion arises because inherently the state of prior relative-ontological-incompleteness ${ }^{8}$-of- ${ }^{8}$ reference-of-thought ever always fails to accompany prospective state of prospective relative-ontological-completeness ${ }^{87}$ of- reference-of-thought but for the induced crossgenerational transcendental metaphoricity possibility, and the contortion is more of a token as of the metaphoricity ${ }^{57}$ possibility for prospective transcendence-and-sublimity/sublimation/supererogatory $\sim$ de-mentativity and without which token contortion there is 'no existential-<disontologising/re-ontologising aporeticism $>$ reference for such transcendence-and-sublimity/sublimation/supereregatery $\sim$ dementativity', as a gesturing/accounting — of-epistemic-phenomenalism of metaphoricity ${ }^{57}$ that is 'beyond the prior relative-ontological-incompleteness ${ }^{8}$-of- ${ }^{8}$ reference-of-thought full meaningfulness-and-teleology implications contemplation'. The contortion implies that there is "nothing any more important than upholding the metaphoricity ${ }^{57}$ possibility for prospective relative-ontological-completeness ${ }^{87}$-of- ${ }^{8}$ reference-of-thought'; as transcendental instigation can't be of ordinary inclination at one moment and at another moment of transcendental inclination, as this will only 'teleologically-degrade and devalue' the implied prospective relative-ontological-completeness ${ }^{87}$-of- ${ }^{8}$ reference-of-thought transcendence-andsublimity/sublimation/supererogatory de-mentativity into the ordinariness of prior relativeontological-incompleteness ${ }^{8}$-of- ${ }^{8}$ reference-of-thought thus psychoanalytically/exegetically/symbiologically existentially-<disontelogising/reentelogising aporeticism $>$ undercutting the token contortion existential-<disentologising/reentologising apreticism $>$ reference for prospective relative-ontological-completeness ${ }^{87}$-ofreference-of-thought transcendence-and-sublimity/sublimation/supererogatory $\sim$ dementativity. Thus 'ontological-faith-notion-or-ontological-fideism-imbued- 
underdetermination-of-motif-and-apriorising/axiomatising/referencing-as-so-being-as-of-

existential-reality parrhesiastic askesis-or-acumen as of reasoning-through/messianic-reasoning' only evolves into such asceticism as of contortive metaphoricity ${ }^{57}$ gesturing/accounting-ofepistemic-phenomenalism for prospective relative-ontological-completeness ${ }^{87}$-of- ${ }^{8}$ referenceof-thought as of pestcenverging-nonextricatory-existential-preempting-of-existentialunthought; and has historically acted as a sort of internal cultural diffusion disposition. Such a prospective ontological conception of asceticism rather as of reasoning-through/messianicreasoning asceticism, different from asceticism as reasoning-from-results/afterthought or institutional asceticism, should basically be understood as of the general notion that all human meaningfulness-and-teleology ${ }^{9}$ are naturally 'correlate-aesthetic-constructs as of the various reproducibility—mathesis/motif/thrownness-disposition,--as-reproducibility-of-aestheticisation in successive prior relative-ontological-incompleteness ${ }^{8-t o w a r d s-o n t o l o g i c a l-c o m p l e t e n e s s s-~}$ of-deprocrypticism' as of their specific reflection of the-very-same-immanentexistence/intrinsic-reality/ontological-veridicality,-as-to-'human<amplituding/formativeepistemicity>totalising purview-of-construal' (just as implied with the case highlighted herein of the 'ill-health <amplituding/formative-epistemicity>totalising $\sim$ devolved — purview/domainof-construal-as-intrinsic-reality/ontological-veridicality/existential-reality'); and are so derived as of ontological-faith-notion-or-ontological-fideism-imbued-underdetermination-of-motifand-apriorising/axiomatising/referencing-as-so-being-as-of-existential-reality 'seeding promise of human-subpotency ontological-performance ${ }^{72}-<$ including-virtue-asontology $>$ /morality/ethics/justice/etc. equivalence/correspondence with the full-potency-ofexistence's $\sim$ sublimating-nascence-as-of-its-coherence/contiguity' and construed as of ontologically-veridical difference-conflatedness ${ }^{13}$-as-to-totalitative-reification-insingularisation-<as-to-the-nondisjointedness/entailment-of-prospective- nonpresencing $>$-asveridical-epistemicity-relativism-determinism ; with the assertion by this author that there is no 
accidental human ${ }^{56}$ meaningfulness-and-teleology ${ }^{9}$ as all prior ${ }^{56}$ meaningfulness-andteleology imply futural deferred traces of their prospectively more ontologically-complete constructs as of grander 'ontological-faith-notion-or-ontological-fideism-imbuedunderdetermination-of-motif-and-apriorising/axiomatising/referencing-as-so-being-as-ofexistential-reality parrhesiastic askesis-or-acumen as of reasoning-through/messianicreasoning'. Critically for futural Being-development/ontological-framework-expansion-as-todepth-of-ontologising-development-as-infrastructure-of- meaningfulness-and-teleology as

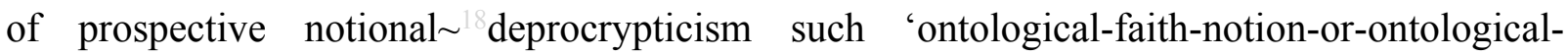
fideism —imbued-underdetermination-of-motif-and-apriorising/axiomatising/referencing-asso-being-as-of-existential-reality parrhesiastic askesis-or-acumen as of reasoningthrough/messianic-reasoning' is all about undermining a nihilistic $<$ amplituding/formative $>$ wooden-language-_imbued - averaging-of-thought-<as-toleveling/ressentiment/closed-construct-of- meaningfulness-and-teleology -as-of'nondescript/ignorable-void '-with-regards-to-prospective-apriorising-implications $>>$ mentaldisposition to prospective opened-construct-of- ${ }^{5}$ meaningfulness-and-teleology ${ }^{9}$ The fundamental ontological dearth of identitive-constitutedness ${ }^{14}$-as-'epistemic-totality ${ }^{37}$ 'dereification-in-dissingularisation-<as-to-the-disjointedness/disentailment-of- presencingabsolutising-identitive-constitutedness $>$-as-flawed-epistemicity-relativism-determinism as of dissingularisation-<as-to-the-disjointedness/disentailment-of- presencing - absolutisingidentitive-constitutedness > /epistemic-nonimmanence/flawed-epistemicity-relativismdeterminism, is that it falsely implies an 'imaginary wholeness/nested-congruence' of $<$ amplituding/formative-epistemicity>totalising/circumscribing/delineating ${ }^{56}$ meaningfulnessand-teleology ${ }^{9}$ with 'no-tracing-and-as-it-neuterises'-the-dynamics-of-temporal-to-intemporalontological-performance ${ }^{72}$-<including-virtue-as-ontology $>/$ morality/ethics/justice/etc. thus failing to reflect existential-<disontologising/re-ontologising aporeticism $>$ wholeness/nested- 
congruence of ${ }^{56}$ meaningfulness-and-teleology 99 and undermining knowledgereification $\sim$ gesturing-and-accounting — of-epistemic-phenomenalism- $<$ inprospective_psychologismic apriorising/axiomatising/referencing-\{of-`prospectively implicited_attendant-ontological-contiguity ' educedexistentialising/contextualising/textualising_'intelligibility/epistemicity/reflexivity-contiguity<imbued-notional cogency $>$ ' \}-conflatedness -in-\{preconverging-disentailment by\} postconverging-entailment>' at a given ${ }^{83}$ reference-of-thought preconverging/postconvergingde-mentative/structural/paradigmatic nondescript/ignorable-void (actually speaking of akrasiatic-drag-denatured-and-preconverging-or-dementing -narratives) threshold as of its prior relative-ontological-incompleteness ${ }^{88}$ construed as uninstitutionalised-threshold ${ }^{102}$, while falsely implying the given ${ }^{83}$ reference-of-thought mere identitive conceptualisations/“candid existential-<disontologising/re-ontologising aporeticism $>$ expressiveness' are existentially<disontologising/re-ontologising aporeticism $>$ veridical; and it is important to grasp that every registry-worldview/dimension is of a reference-of-thought apriorising/axiomatising/referencing/intelligibilitysettingup/measuringinstrumenting that by its reproducibility—mathesis/motif/thrownness-disposition,--as-reproducibility-of-aestheticisation falsely implies that its ${ }^{56}$ meaningfulness-and-teleology ${ }^{9}$ is necessarily as of identitive $<$ amplituding/formative-epistemicity $>$ totalising/circumscribing/delineating postconverging-ordialectical-thinking -apriorising-psychologism' even at its uninstitutionalised-threshold where it is effectively preconverging-or-dementing ${ }^{20}$-apriorising-psychologism as its reproducibility — mathesis/motif/thrownness-disposition,--as-reproducibility-of-aestheticisation fails to induce an ontologically-veridical reifying trace/ontological-aesthetic-tracing$<$ perspective--ontological-normalcy/postconvergence-reflected-‘epistemicity-relativismdeterminism'> of 'implicited_attendant-ontological-contiguity ${ }^{67}$ ' educedexistentialising/contextualising/textualising_intelligibility/epistemicity/reflexivity-contiguity- 
$<$ imbued-notional cogency $>$ ' We can imagine as of a non-positivistic social-setup reference-of-thought identitive-constitutedness ${ }^{14}$-as-'epistemic-totality ${ }^{37}$ '-dereification-indissingularisation-<as-to-the-disjointedness/disentailment-of- presencing - absolutisingidentitive-constitutedness $>$-as-flawed-epistemicity-relativism-determinism $<$ amplituding/formative-epistemicity>totalising/circumscribing/delineating ${ }^{56}$ meaningfulnessand-teleology', the 'candid existential-<disontologising/re-ontologising aporeticism $>$ expressiveness' that 'integrates superstition as-thinking' as of its uninstitutionalisedthreshold ${ }^{102}$, much like as from futural Being-development/ontological-framework-expansionas-to-depth-of-ontologising-development-as-infrastructure-of- meaningfulness-andteleology as of prospective notional ${ }^{18}$ deprocrypticism perspective we can imagine the 'candid existential-<disontologising/re-ontologising _aporeticism $>$ expressiveness' in our positivismprocrypticism that 'integrates ${ }^{80}$ procrypticism-or-disjointedness-as-of- ${ }^{8}$ reference-of-thought as-thinking' as of its uninstitutionalised-threshold ${ }^{102}$; and in both cases the 'trace/ontologicalaesthetic-tracing-<perspective-ontological-normalcy/postconvergence-reflected-‘epistemicityrelativism-determinism'> of ontological wholeness/nested-congruence' as of knowledgereification $\sim$ gesturing-and-accounting - of-epistemic-phenomenalism- $<$ inprospective_psychologismic apriorising/axiomatising/referencing-\{of-‘prespectively implicited_attendant-ontological-contiguity ' reducedexistentialising/contextualising/textualising_ intelligibility/epistemicity/reflexivity-contiguity<imbued-notional cogency >' $\}$-conflatedness -in-\{preconverging-disentailment by\} postconverging-entailment $>$ breaks down at the uninstitutionalised-threshold ${ }^{102}$ thus assuming a nondescript/ignorable-void (actually speaking of akrasiatic-drag-denatured-andpreconverging-or-dementing ${ }^{20}$-narratives) identitive-constitutedness ${ }^{14}$-as-' ${ }^{\text {'epistemic-totality }}{ }^{37}$ 'dereification-in-dissingularisation-<as-to-the-disjointedness/disentailment-of- presencing absolutising-identitive-constitutedness $>$-as-flawed-epistemicity-relativism-determinism 
representation of the breakdown and going on in both cases to 'overlook effectively as-ifthinking respectively' the ontologically-veridical reality of 'preconverging-or-dementing apriorising-psychologism superstition' and 'preconverging-or-dementing ${ }^{20}$-apriorisingpsychologism ${ }^{8}$ procrypticism-or-disjointedness-as-of- ${ }^{8}$ reference-of-thought'. It is singularisation-<as-to-the-nondisjointedness/entailment-of-prospective- nonpresencing $>$

projected epistemic-immanence/veridical-epistemicity-relativism-determinism in preempting any such preconverging/postconverging-de-mentative/structural/paradigmatic threshold construed as uninstitutionalised-threshold ${ }^{102}$ as implied by notional ${ }^{18}$ deprocrypticism that reflects 'ontologically-veridical difference-conflatedness ${ }^{13}$-as-to-totalitative-reification-insingularisation-<as-to-the-nondisjointedness/entailment-of-prospective- nonpresencing $>$-asveridical-epistemicity-relativism-determinism , as factoring in prior registryworldviews/dimensions ${ }^{83}$ reference-of-thought prior relative-ontological-incompleteness ${ }^{88}$ as of the ontologically-flawed threshold of its reproducibility-mathesis/motif/thrownnessdisposition,-as-reproducibility-of-aestheticisation from the perspective of prospective registryworldview/dimension ${ }^{83}$ reference-of-thought prospective relative-ontological-completeness ${ }^{87}$ to construe $\quad{ }^{4}$ historiality/ontological-eventfulness $3 \%$ ontological-aesthetic-tracing-<perspectiveontological-normalcy/postconvergence-reflected-'epistemicity-relativism-determinism'> as of notionally-full knowledge-reification $\sim$ gesturing-and-accounting-of-epistemicphenomenalism- $<$ in-prospective_psychologismic $\sim$ apriorising/axiomatising/referencing- $\{$ of'prospectively_implicited_attendant_ontological-contiguity ' educedexistentialising/contextualising/textualising_'intelligibility/epistemicity/reflexivity-contiguity<imbued-notional cogency >' \}-conflatedness -in-\{preconverging disentailment by\} postconverging entailment>. In other words, 'implicited_attendant-ontologicalcontiguity $^{67}$, educedexistentialising/contextualising/textualising_'intelligibility/epistemicity/reflexivity-contiguity- 
$<$ imbued-notional cogency $>^{\prime}$ as reflecting existence-as-the-absolute-a-priori-ofconceptualisation and existence — as-sublimating-withdrawal/unenframing/re-ontologising,elicited-from-prospective-profound-supererogation $-<$ as-to-perspective-ontologicalnormalcy/postconvergence-implied-'prospective-aporeticism-overcoming/unovercoming'> isn't halted at any given registry-worldview's/dimension's preconverging/postconverging-dementative/structural/paradigmatic limit/threshold-construed-as-mathesis/motif/thrownnessdisposition for ontological conception, but rather reifies as of singularisation- $<$ as-to-thenondisjointedness/entailment-of-prospective- nonpresencing $>$ projected epistemicimmanence/veridical-epistemicity-relativism-determinism as implied with ontologicallyveridical difference-conflatedness ${ }^{13}$-as-to-totalitative-reification-in-singularisation- $<$ as-to-thenondisjointedness/entailment-of-prospective- nonpresencing > -as-veridical-epistemicity-

relativism-determinism as of notional ${ }^{8}$ deprocrypticism, with such singularisation- $<$ as-tothe-nondisjointedness/entailment-of-prospective- nonpresencing $>$ projected epistemicimmanence/veridical-epistemicity-relativism-determinism reflecting an historiality/ontological-eventfulness 38 /ontological-aesthetic-tracing-<perspectiveontological-normalcy/postconvergence-reflected-‘epistemicity-relativism-determinism’> of all such preconverging/postconverging-de-mentative/structural/paradigmatic limits/thresholdsconstrued-as-mathesis/motif/thrownness-disposition of ${ }^{83}$ reference-of-thought ontological conception. In effect, such a trace/ontological-aesthetic-tracing-<perspective-ontologicalnormalcy/postconvergence-reflected-‘epistemicity-relativism-determinism'> can be construed as a 'creative metaphoricity ${ }^{57}$ tracing' of human temporal-to-intemporal ontologicalperformance ${ }^{2}$-<including-virtue-as-ontology $>$ /morality/ethics/justice/etc. of human meaningfulness-and-teleology' as of the dynamics of 'overall human Being-personalitygrowth and the implications for its living-personality-growth and institutional-personalitygrowth' implied as of notional deprocrypticism ontologically-uncompromised- 
referentialism,

totalising 3 ' ${ }^{3}$ hermeneutic/textuality/reprojecting/supererogating/zeroing/re-acuting,-

\{decompling $d$ delinearity for-cogency psychological science which as of singularisation- $<$ as-tothe-nondisjointedness/entailment-of-prospective- nonpresencing $>$ projected epistemicimmanence/veridical-epistemicity-relativism-determinism articulates-and-rearticulates such tracing/ontological-aesthetic-tracing-<perspective-ontological-normalcy/postconvergencereflected-‘epistemicity-relativism-determinism'> as of comprehensive/totalisingentailing/nested-congruence apriorising/axiomatising/referencing-\{of-"prospectively implicited_attendant-ontological-contiguity ' educedexistentialising/contextualising/textualising_'intelligibility/epistemicity/reflexivity-contiguity$<$ imbued-notional $\left.\sim \operatorname{cogency}>^{\prime}\right\}$-conflatedness ${ }^{13}{ }^{\text {in }}$ - preconverging-disentailment by $^{\prime}$ postconverging-entailment from a most profound knowledge-reification $\sim$ gesturing-andaccounting - of-epistemic-phenomenalism- $<$ in-

prospective_psychologismic apriorising/axiomatising/referencing-\{of-'prospectively implicited_attendant-ontological-contiguity ' educedexistentialising/contextualising/textualising_'intelligibility/epistemicity/reflexivity-contiguity<imbued-notional cogency $>$ ' $\}$-conflatedness in \{preconverging disentailment by\} postconverging-entailment $>$ depth of notional ${ }^{1}$ deprocrypticism protracted-consciousness. Such an \{epistemic-totalising 3 ' $h$ hermeneutic/textuality/reprojecting/supererogating/zeroing/reacuting, , from a construal of the fundamental instigation of human knowledge and emancipation as of 'ontological-faith-notion-or-ontological-fideism - imbued-underdetermination-of-motif-andapriorising/axiomatising/referencing-as-so-being-as-of-existential-reality parrhesiastic askesisor-acumen as of reasoning-through/messianic-reasoning', as establishing in-the-very-first-place the prospective relative-ontological-completeness reproducibility- 
mathesis/motif/thrownness-disposition,-as-reproducibility-of-aestheticisation for ${ }^{83}$ referenceof-thought

apriorising/axiomatising/referencing/intelligibilitysettingup/measuringinstrumenting, and so prior to assumed meaningfulness-and-teleology aposteriorising/logicising/deriving/intelligising/measuring. Hence such a notion cannot be construed on the basis of ordinarily assumed ${ }^{56}$ meaningfulness-and-teleology aposteriorising/logicising/deriving/intelligising/measuring which doesn't put-into-question its apriorising/axiomatising/referencing/intelligibilitysettingup/measuringinstrumenting as it is rather submerged/drowned into it by mental-disposition reflex; but rather as implied as of reasoning-through/messianic-reasoning, such an \{epistemictotalising ${ }^{3}{ }^{3}$ hermeneutic/textuality/reprojecting/supererogating/zeroing/re-acuting,\{decompulsing $\}$ delinearity for-cogency psychology is more about instigating a parrhesiastic psychoanalytic-unshackling soul-searching acumen. In this regard, it is akin for instance to budding-positivism reasoning-through/messianic reasoning implied within a nonpositivism/medievalism social-setup, in the sense that that budding-positivism reasoningthrough/messianic reasoning then 'is-not reasoning as-of-yet' as reasoning is then as of the nonpositivism/medievalism social-setup apriorising/axiomatising/referencing/intelligibilitysettingup/measuringinstrumenting 'as nonpositivism reasoning susceptible to superstition and medieval-scholasticism-like pedantising/muddling/formulaic-hollowing-out - in-subontologisation/subpotentiation〈blurring/undermining-of-prospective-totalising-entailing,-as-to-entailing-

\section{$<$ amplituding/formative-epistemicity $>$ totalising in-relative-ontological-completeness $\rangle$}

construed

as universalisation-directed-rulemaking-over-non-rulesapriorising/axiomatising/referencing-psychologism but not yet as of rational-empiricism'; with such budding-positivism rather a metaphoricity ${ }^{57}$ instigation of ontological-faith-notion-or- 
ontological-fideism - imbued-underdetermination-of-motif-and-

apriorising/axiomatising/referencing-as-so-being-as-of-existential-reality parrhesiastic soulsearching for the psychoanalytic-unshackling of the human subject as of a preconverging/postconverging-de-mentative/structural/paradigmatic Lacanian displacement/decentering of the human subject from its prior 'epistemic-totality ${ }^{37} / 8$ referenceof-thought/epistemic-totalising $\sim$ self-referencing-syncretising/circularity conception-ofmeaningfulness-and-teleology as of non-positivism/medievalism' to a prospective 'epistemic-totality ${ }^{37} / 8$ reference-of-thought/epistemic-totalising ${ }^{3} \sim$ self-referencingsyncretising/circularity conception-of- meaningfulness-and-teleology 9 as of positivism/rational-empiricism', that is the fundamental preconverging/postconverging-dementative/structural/paradigmatic seeding-resolution of the 'non-positivism/medievalism human subject superegoic vices-and-impediments ${ }^{105}$. This has the-very-same metaphoricity implications in reflecting holographically-<conjugatively-and-transfusively $>$ the relativeunreflexivity/relative-reflexivity - ontological-contiguity of-the-human-institutionalisationprocess , as such an apistemictotalising ${ }^{3}$ hermeneutic/textuality/reprojecting/supererogating/zeroing/re-acuting,${ }_{\{\text {decompulsing }\}}$ delinearity for-cogency psychology supersedes our ordinary ${ }^{56}$ meaningfulness-andteleology ${ }^{9}$ aposteriorising/logicising/deriving/intelligising/measuring which doesn't put-intoquestion our positivism/rational-empiricism manifestation of procrypticism-ordisjointedness-as-of- ${ }^{8}$ reference-of-thought reproducibility—mathesis/motif/thrownnessdisposition,-as-reproducibility-of-aestheticisation for $\quad{ }^{83}$ reference-of-thought apriorising/axiomatising/referencing/intelligibilitysettingup/measuringinstrumenting, but rather as of its reasoning-through/messianic-reasoning is more about instigating prospective ontological-faith-notion-or-ontological-fideism - imbued-underdetermination-of-motif-andapriorising/axiomatising/referencing-as-so-being-as-of-existential-reality parrhesiastic soul- 
searching, for the psychoanalytic-unshackling of the human subject as of a preconverging/postconverging-de-mentative/structural/paradigmatic Lacanian displacement/decentering of the human subject 'epistemic-totality ${ }^{37} /{ }^{83}$ reference-ofthought/epistemic-totalising $\sim$ self-referencing-syncretising/circularity conception-ofmeaningfulness-and-teleology as from prior positivism- ${ }^{80}$ procrypticism apriorising/axiomatising/referencing/intelligibilitysettingup/measuringinstrumenting to futural Being-development/ontological-framework-expansion-as-to-depth-of-ontologisingdevelopment-as-infrastructure-of- meaningfulness-and-teleology as of prospective deprocrypticism-or-preempting - disjointedness-as-of- ${ }^{83}$ reference-of-thought apriorising/axiomatising/referencing/intelligibilitysettingup/measuringinstrumenting as the fundamental preconverging/postconverging-de-mentative/structural/paradigmatic resolution of the 'positivism- ${ }^{80}$ procrypticism human subject superegoic vices-and-impediments ${ }^{105}$ '. It should be noted that the way the construction of knowledge works at ${ }^{83}$ reference-of-thought-level of reasoning-through/messianic-reasoning is utterly counterintuitive to how we perceive prospective elucidation of human knowledge and emancipation going by the given reproducibility—mathesis/motif/thrownness-disposition,--as-reproducibility-of-aestheticisation as reference-of-thought apriorising/axiomatising/referencing/intelligibilitysettingup/measuringinstrumenting for meaningfulness-and-teleology ${ }^{99}$ aposteriorising/logicising/deriving/intelligising/measuring. In this regard, we can construe that even the <amplituding/formative $>$ wooden-language〈imbued-averaging-of-thought-<as-to-leveling/ressentiment/closed-construct-ofmeaningfulness-and-teleology -as-of-'nondescript/ignorable-void '-with-regards-toprospective-apriorising-implications $>>$ mental-disposition in a non-positivism/medievalism social-setup has a sense of human knowledge development and emancipation but with a mentalreflex that such a conception is necessarily by way of the non-positivism/medievalism social- 

reproducibility—mathesis/motif/thrownness-disposition,-as-reproducibility-ofaestheticisation as of reference-of-thought

apriorising/axiomatising/referencing/intelligibilitysettingup/measuringinstrumenting for meaningfulness-and-teleology aposteriorising/logicising/deriving/intelligising/measuring. The idea that 'ontological-faith-notion-or-ontological-fideism —imbued-underdetermination-ofmotif-and-apriorising/axiomatising/referencing-as-so-being-as-of-existential-reality parrhesiastic askesis-or-acumen as of reasoning-through/messianic-reasoning' articulation of prospective reproducibility - mathesis/motif/thrownness-disposition,-as-reproducibility-ofaestheticisation in prospective relative-ontological-completeness ${ }^{87}$ as of positivism ${ }^{83}$ referenceof-thought apriorising/axiomatising/referencing/intelligibilitysettingup/measuringinstrumenting for meaningfulness-and-teleology aposteriorising/logicising/deriving/intelligising/measuring is the route for ontologicallyveridical human knowledge transformation and emancipation as of prospective positivism is very much alien to the non-positivism/medievalism cloistered-consciousness. Likewise, the $<$ amplituding/formative $>$ wooden-language-〈imbued — averaging-of-thought- $<$ as-toleveling/ressentiment/closed-construct-of- meaningfulness-and-teleology -as-of'nondescript/ignorable-void '-with-regards-to-prospective-apriorising-implications $>$ > mentaldisposition in our positivism- ${ }^{-}$procrypticism effectively do has a sense of human knowledge development and emancipation but as of a mental-reflex that such a conception is necessarily by way of our positivism- ${ }^{80}$ procrypticism reproducibility-mathesis/motif/thrownnessdisposition,-as-reproducibility-of-aestheticisation as of $\quad{ }^{83}$ reference-of-thought apriorising/axiomatising/referencing/intelligibilitysettingup/measuringinstrumenting for meaningfulness-and-teleology aposteriorising/logicising/deriving/intelligising/measuring. In the same vain, the idea that 'ontological-faith-notion-or-ontological-fideism-imbuedunderdetermination-of-motif-and-apriorising/axiomatising/referencing-as-so-being-as-of- 
existential-reality parrhesiastic askesis-or-acumen as of reasoning-through/messianic-reasoning' articulation of prospective ontologically-uncompromised-referentialism notional ${ }^{18}$ deprocrypticism reference-of-thought apriorising/axiomatising/referencing/intelligibilitysettingup/measuringinstrumenting for meaningfulness-and-teleology ${ }^{9}$ aposteriorising/logicising/deriving/intelligising/measuring is the route for ontologically-veridical human knowledge transformation and emancipation in futural Being-development/ontological-framework-expansion-as-to-depth-of-ontologisingdevelopment-as-infrastructure-of- meaningfulness-and-teleology as of prospective notional ${ }^{18}$ deprocrypticism is very much alien to our positivism- ${ }^{80}$ procrypticism cloisteredconsciousness. In both instances the notion of prospective metaphoricity ${ }^{57}$ is one that necessarily faces the fact that the human mind is ever always entrapped in an existentially-invested 'epistemic-totality ${ }^{37} / 8$ reference-of-thought/epistemic-totalising $\sim$ self-referencingsyncretising/circularity conception-of- ${ }^{5}$ meaningfulness-and-teleology ${ }^{9}$, which effective dislodgment/displacement/decentering is as of a crossgenerational instigation, but then wouldn't happen just by accident and thus has to be instigated for prospective relative-ontologicalcompleteness ${ }^{87}$ ! In fact such an insight can be extended across 'intemporal ontological-faithnotion-or-ontological-fideism—imbued-underdetermination-of-motif-and-

apriorising/axiomatising/referencing-as-so-being-as-of-existential-reality instigated relativeunreflexivity/relative-reflexivity — ontological-contiguity ${ }^{67}$ of-the-human-institutionalisationprocess ${ }^{6}$ as of difference-conflatedness ${ }^{13}$-as-to-totalitative-reification-in-singularisation- $<$ as-tothe-nondisjointedness/entailment-of-prospective- nonpresencing $>$-as-veridical-epistemicityrelativism-determinism implied $<$ amplituding/formative-epistemicity $>$ causality $\sim$ as-toprojective-totalitative-implications-of-prospective- nonpresencing,-for-explicating relative unreflexivity/relative-reflexivity ontological-contiguity ' to imply that the state of recurrentutter-uninstitutionalisation is cognisant of emancipation but doesn't anticipate that emancipation 
as of prospective relative-ontological-completeness ${ }^{87}$ is rather as of base-institutionalisation reproducibility —mathesis/motif/thrownness-disposition,-as-reproducibility-of-

aestheticisation, and likewise the latter doesn't anticipate the universalisation reproducibility—-mathesis/motif/thrownness-disposition,--as-reproducibility-of-

aestheticisation, with the latter not anticipating our positivism reproducibilitymathesis/motif/thrownness-disposition,-as-reproducibility-of-aestheticisation which itself doesn't anticipate prospective ontologically-uncompromised—referentialism deprocrypticism. The fact is human-subpotency-aporia/undecidability/dilemma/oughtindeterminacy/deficiency/limitation/constraint—imbued-'notional firstnaturednessformativeness-<as-to-eventualising-inkling-drive-or-seeding-misprising $>$ temporal-tointemporal-dispositions-<so-construed-as-from-perspective-ontologicalnormalcy/postconvergence >'-existentialism-form-factor at its uninstitutionalised-threshold implies that the human psychological reflex as of its limited-mentation-capacity-as-subjecting'educed-unlimitedness/existence-sublimating nascence' to-limitedness/human-subpotency at any such uninstitutionalised-threshold ${ }^{102}$ 'is not geared to adhere to abstract ontologicalveridicality' as it will operate its state of dissingularisation- $<$ as-to-thedisjointedness/disentailment-of- presencing-absolutising-identitiveconstitutedness $>$ /epistemic-nonimmanence/flawed-epistemicity-relativism-determinism as if in a fully-attained state of singularisation-<as-to-the-nondisjointedness/entailment-ofprospective- nonpresencing $>\quad$ projected epistemic-immanence/veridical-epistemicityrelativism-determinism, as of the-very-central-implication-of <amplituding/formativeepistemicity $>$-totalising $\sim$ thrownness-in-existence ${ }^{35}$, as reflected by the successive prior relativeontological-incompleteness $\quad$ reproducibility—mathesis/motif/thrownness-disposition,--asreproducibility-of-aestheticisation towards ontologically-uncompromised-referentialism deprocrypticism-or-preempting-disjointedness-as-of- ${ }^{8}$ reference-of-thought; and thus from 
a strictly ontologically-veridical point-of-view/perspective, and so beyond our enculturatedconception,-normalisation-and-practice-of-psychology and just as various mystical-andmythical-practices of prior non-positivism registry-worldviews/dimensions were their own sort of enculturated-conception,-normalisation-and-practice-of-psychology as of their own times, the notion of a psychological science as reinforcing/propping-up human psychology in any prior relative-ontological-incompleteness ${ }^{88}$-of- ${ }^{83}$ reference-of-thought $\quad{ }^{56}$ meaningfulness-andteleology ${ }^{9}$ state is downright ontologically ridiculous and the manifestation of an $<$ amplituding/formative-epistemicity $>$ totalising $\sim$ self-referencing-

syncretising/circularity/interiorising/akrasiatic-drag naivety. We can appreciate that the psychoanalytic-unshackling of all prior registry-worldviews/dimensions ${ }^{8}$ reference-of-thought is rather one that shouldn't wrongly be reinforcing/propping-up the human subject as if a given reference-of-thought in prior relative-ontological-incompleteness ${ }^{88}$ as of dissingularisation$<$ as-to-the-disjointedness/disentailment-of- presencing - absolutising-identitive-

constitutedness $>$ /epistemic-nonimmanence/flawed-epistemicity-relativism-determinism has its very own complete transformative and emancipative potential as if of fully-attained singularisation-<as-to-the-nondisjointedness/entailment-of-prospective- nonpresencing $>$

projected epistemic-immanence/veridical-epistemicity-relativism-determinism, but an ontologically-veridical psychology rather warrants implying the human subject displacement/decentering as the preconverging/postconverging-dementative/structural/paradigmatic possibility of the human subject emancipation with regards to the successive prior relative-ontological-incompleteness ${ }^{88}$ registry-worldviews/dimensions superegoic vices-and-impediments ${ }^{105}$; wherein postconverging-or-dialectical-thinking apriorising-psychologism reasoning-from-results/afterthought reproducibilitymathesis/motif/thrownness-disposition,-as-reproducibility-of-aestheticisation at its uninstitutionalised-threshold ${ }^{102}$ is construed as preconverging-or-dementing ${ }^{20}$-apriorising- 
psychologism as of prospective postconverging-or-dialectical-thinking ${ }^{2}$-apriorisingpsychologism reasoning-through/messianic-reasoning reproducibilitymathesis/motif/thrownness-disposition,-as-reproducibility-of-aestheticisation up to the prospective ontologically-uncompromised-referentialism of deprocrypticism. As of its inherent $\quad$ organic knowledge, such an totalising 3 'thermeneutic/textuality/reprojecting/supererogating/zeroing/re-acuting,\{decompulsing delinearity for-cogency psychology parrhesiastic articulation as herein 'doesn't do gimmicks of communication' as if to imply any favour whatever as of 'emotional or whatever feel-good trading for the appreciation of the possibility for prospective human emancipation', since by its " ${ }^{7}$ presencing-absolutising-identitive-constitutedness ${ }^{14}$ consummated/forfeiting posture' it is beyond the idea of convincing for convincing sake as it is simply a 'blunted eliciting of a solipsistic sense of intemporal/longness-of-register-of meaningfulness-and-teleology projection in any human and no more' with no point going beyond that point as it then becomes as of intellectual-and-moral apriorising-teleological-degradation-in $\sim$ notionaldiscontiguity/epistemic-discontiguity ${ }^{63}-<$ between - prior-shallow-supererogation -ofmentally-aestheticised preconverging/dementing - qualia-schema_and_prospective-profoundsupererogation -of-mentally-aestheticised postconverging/dialectical-thinking -qualiaschema>; and so, as its essential ${ }^{56}$ meaningfulness-and-teleology 99 is as of a solipsistic transversality-<for-sublimating-existential-eventuating/denouement,-from-'thinking-atfirst/pure-predisposition-preemptive-of-prospective-disontologising/subontologising' as-ofprospectively-disambiguated-affirmed-and-unaffirmed-'motif-andapriorising/axiomatising/referencing' $>{ }^{101}$ reflection of the ontologically 'superior party' that is intrinsic-reality/ontological-veridicality/existence-as-the-absolute-a-priori-ofconceptualisation and existence — as-sublimating-withdrawal/unenframing/re-ontologising,elicited-from-prospective-profound-supererogation $-<$ as-to-perspective-ontological- 
its ecstatic singularity, on the same token that a natural scientist is in a transversality- $<$ forsublimating-existential-eventuating/denouement, from-'thinking-at-first/pure-predispositionpreemptive-of prospective-disontologising/subontologising’' as-of-prospectivelydisambiguated-affirmed-and-unaffirmed-'motif-and-apriorising/axiomatising/referencing'> reflection of its object of study as of existence as the ontologically 'superior party' without any need to be involved in any bogus exercises that may imply that gravity may not be $9.8 \mathrm{~m} / \mathrm{s}^{2}$ on earth if any given human subject isn't accommodated for in some way somehow however faintly, be it that it may be the case that gravity is not $9.8 \mathrm{~m} / \mathrm{s}^{2}$ but that as well needs to be established as of the ontologically 'superior party' that is existence-as-the-absolute-a-priori-ofconceptualisation $\sim$ and existence — as-sublimating-withdrawal/unenframing/re-ontologising,elicited-from-prospective-profound-supererogation $-<$ as-to-perspective-ontologicalnormalcy/postconvergence-implied-'prospective-aporeticism-overcoming/unovercoming'>

of <amplituding/formative-epistemicity $>$ causality $\sim$ as-to-projective-totalitative-implicationsof-prospective- nonpresencing,-for-explicating relative-unreflexivity/relative-reflexivity ontological-contiguity . But then the human reality across all registry-worldviews/dimensions, isn't inherently 'of immediate intellectual responsiveness' to the notion of its uninstitutionalisedthreshold ${ }^{102}$ and the corresponding superseding of this as of prospective institutionalisation; as even the disposition to assume an intellectually enlightening mental-disposition is existentiallyinvested and not necessarily a given. We can appreciate from our positivistic perspective the 'obvious reality' of the fact that superstitious beliefs are bogus, but then paradoxically from the beginning of times superstitious beliefs had pervaded all the echelons of human societies whether as of true belief or opportunistically, and have only been increasingly undermined with the advent of positivistic reasoning at the beginning of modern times about 500 years ago. This has to do with the 'existentially-<disentologising/re-ontologising aporeticism $>$ invested nature as 
of assumed reproducibility—mathesis/motif/thrownness-disposition,-as-reproducibility-ofaestheticisation' of human ‘ $<$ amplituding/formativeepistemicity>totalising/circumscribing/delineating meaningfulness-andteleology ${ }^{9} /{ }^{83}$ reference-of-thought- ${ }^{8}$ devolving. Thus any given registry-worldview/dimension is strongly constrained to represent itself as of its 'postconverging-or-dialectical-thinking apriorising-psychologism' prior institutionalisation as reasoning-from-results/afterthought and very weakly constrained to represent itself as of its preconverging-or-dementing ${ }^{20}$-apriorisingpsychologism uninstitutionalised-threshold ${ }^{12}$ which it tends to represent as nondescript/ignorable-void (actually speaking of akrasiatic-drag-denatured-andpreconverging-or-dementing ${ }^{20}$-narratives), for the possibility of its prospective transcendenceand-sublimity/sublimation/supererogatory-de-mentativity into prospective institutionalisation. This reality is known as human 'supereregatory - de-mentative constraint' to prospective institutionalisation transcendence-and-sublimity/sublimation/supereregatory-de-mentativity as of the possibility of prospective relative-ontological-completeness ${ }^{87}$-of- ${ }^{8}$ reference-of-thought. Human supererogatory de-mentative constraint is fundamentally associated with poor ${ }^{3}$ universal-transparency $^{104}$-〈transparency-of-totalising-entailing,-as-to-entailing$<$ amplituding/formative-epistemicity>totalising in-relative-ontological-completeness $>$ with respect to social-stake-contention-or-confliction at uninstitutionalised-threshold ${ }^{102}$. This then fails to induce the necessary existential-<disontologising/re-ontologising aporeticism $>$ assurance for prospective transcendence-and-sublimity/sublimation/supereregatery $\sim$ dementativity and on that token fails to tip the balance over the 'social obfuscation dynamic effect' of $<$ amplituding/formative $>$ wooden-language-〈imbued-temporal-mereform/virtualities/dereification/akrasiatic-drag/denatured/preconverging-or-dementing narratives - of-the- reference-of-thought- categorical-imperatives/axioms/registryteleology $>$ as of the prior institutionalisation's ${ }^{83}$ reference-of-thought- categorical- 
imperatives/axioms/registry-teleology that stifle the transcendence-andsublimity/sublimation/supererogatoryade-mentativity possibility for prospective institutionalisation. Thus as of the more critical insight that prospective relative-ontologicalcompleteness $^{87}$-of- ${ }^{8}$ reference-of-thought is actually ontologically transformative as of aetiologisation/ontological-escalation-<ontological-

veridicality_commitment/otherliness_transcending/compulsions-encumbered_transcending>, over mere palliative construals as of the-very-same prior ${ }^{83}$ reference-of-thought in prior relativeontological-incompleteness ${ }^{8}$, for resolving a given registry-worldview/dimension vices-andimpediments ${ }^{105}$; this notion of human supereregatery $\sim$ de-mentative constraint is critical for the psychoanalytic-unshackling/prospective-grounding insight underlying dynamism with regards to the human mind prospective transcendence-and-sublimity/sublimation/supererogatory $\sim$ dementativity as implied by a 'postconverging-or-dialectical-thinking -psychology or psychology-of-mentation-dynamics or natural psychological-dynamics' that emphasises the 'Lacanian subject' growth as of ${ }^{15}$ de-mentation-/supererogatory 0 ntological-de-mentation-ordialectical-de-mentation - stranding-or-attributive-dialectics $\rangle$, rather than a second-guessing mented or stigmatic psychology that fails to integrate the decisively ontological transformative implications of human psychology as of underlying relative-ontological-incompleteness ${ }^{8}$ and relative-ontological-completeness reference-of-thought $<$ amplituding/formativeepistemicity $>$ causality $\sim$ as-to-projective-totalitative-implications-of-prospectivenonpresencing,-for-explicating relative-unreflexivity/relative-reflexivity - ontologicalcontiguity , and thus making the given presence ${ }^{83}$ reference-of-thought as our positivismprocrypticism 'all-determinative of what can be construed as psychological emancipation' as of its <amplituding/formative-epistemicity $>$ totalising $\sim$ self-referencingsyncretising/circularity/interiorising/akrasiatic-drag ${ }^{34}$ despite the fact of its prior relativeontological-incompleteness ${ }^{88}$-of- ${ }^{83}$ reference-of-thought

to futural

Being- 
development/ontological-framework-expansion-as-to-depth-of-ontologising-development-asinfrastructure-of- meaningfulness-and-teleology

as

of

prospective

notional ${ }^{18}$ deprocrypticism prospective relative-ontological-completeness ${ }^{87}$-of- ${ }^{8}$ reference-ofthought. The underlying issue here as well as of ontologically-veridical differenceconflatedness ${ }^{13}$-as-to-totalitative-reification-in-singularisation- $<$ as-to-the-

\section{nondisjointedness/entailment-of-prospective- nonpresencing $>$-as-veridical-epistemicity-}

relativism-determinism has to do with deficient human capacity for dispensing-withimmediacy-for-relative-ontological-completeness ${ }^{87}$-by-reification/contemplative-distension (as of human self-surpassing - existentialism-form-factor,-in-overcoming‘notional collateralising-beholdening-protohumanity'-to- 'attain-sublimating-humanity'-as-toexistence-potency $\sim$ sublimating-nascence,-disclosed-from-prospective-epistemic-digression to supersede human temporality $/$ /shortness $<$ amplituding/formative $>$ wooden-language〈imbued-averaging-of-thought-<as-to-leveling/ressentiment/closed-construct-ofmeaningfulness-and-teleology -as-of-‘nondescript/ignorable-void '-with-regards-toprospective-apriorising-implications $>>)$ in construing ${ }^{5}$ meaningfulness-and-teleology ${ }^{99}$ beyond the constraint of 'human lifespan extricatory punctuality/immediacy of depth-of-thought' to a more profound appreciation of the underlying possibility for human transcendence-andsublimity/sublimation/supererogatory-de-mentativity as of human intemporal/ontological/social/species/ ${ }^{103}$ universal/transcendental $/{ }^{55}$ maximalisingrecomposuring-for-relative-ontological-completeness ${ }^{8}$ —unenframed/reontologising conceptualisation postconverging-de-mentating/structuring/paradigming. In this regard as of lack of dispensing-with-immediacy-for-relative-ontological-completeness ${ }^{87}$-byreification/contemplative-distension ${ }^{27}$ is the human temporal inclination to decontortion construed as a disposition to undermine 'intemporal ontological-veracity as of ${ }^{103}$ universal existential-<disontologising/re-ontologising aporeticism $>$ import' for the sake of 'temporal 
narrow-and-specific existentially-invested advantage/interest/apathy with little concern about the sublimating/emancipating/enfranchisement of prospective re-ontologising meaningfulness-and-teleology, , and so as the very contrary disposition to reasoningthrough/messianic-reasoning contortion. Decontortion as of human <amplituding/formativeepistemicity $>$ totalising $\sim$ self-referencing-syncretising/circularity/interiorising/akrasiatic-drag incrementalism-in-relative-ontological-incompleteness ${ }^{8}$ enframed/disontologising conceptualisation is rather counter to ontological-faith-notion-orontological-fideism - imbued-underdetermination-of-motif-and-

apriorising/axiomatising/referencing-as-so-being-as-of-existential-reality disposition by its deterministic hanging onto prior relative-ontological-incompleteness ${ }^{8}$-of- ${ }^{8}$ reference-ofthought reasoning-from-results/afterthought while ignoring/overlooking the ontologicalveracity implications of the trace/ontological-aesthetic-tracing-<perspective-ontologicalnormalcy/postconvergence-reflected-'epistemicity-relativism-determinism'> of reifying 'implicited_attendant-ontological-contiguity ${ }^{67}$ educedexistentialising/contextualising/textualising_intelligibility/epistemicity/reflexivity-contiguity$<$ imbued-notional cogency $>$ ' constraining social ${ }^{103}$ universal-transparency ${ }^{104}$-〈transparency-of-totalising-entailing,-as-toentailing-<amplituding/formative-epistemicity $>$ totalising in-relative-ontological-

completeness $\rangle$ '. Such a human disposition to decontortion at uninstitutionalised-threshold arise on the naïve basis that human temporal willing/volition can effectively supersede the ontological integrity/veracity of ${ }^{5}$ meaningfulness-and-teleology ${ }^{9}$ as it reflects existence's coherence/contiguity as of singularisation-<as-to-the-nondisjointedness/entailment-ofprospective- nonpresencing $>\quad$ projected epistemic-immanence/veridical-epistemicityrelativism-determinism. But then such a decontortioning disposition as can be manifested by a falsely striving to elevate the temporal frame of our 60-100 years of living above the 
intemporal/ontological frame of intrinsic-reality/ontological-veridicality/existential-reality is rather definitional of our uninstitutionalised-threshold ${ }^{102}$ where we are actually preconvergingor-dementing -apriorising-psychologism and prospectively dialectially-primitive, notwithstanding our attendant <amplituding/formative-epistemicity $>$ totalising $\sim$ selfreferencing-syncretising/circularity/interiorising/akrasiatic-drag ${ }^{34}$ and vague untransvaluatedtemporal-intemporality ${ }^{52}$ gesturing/accounting-of-epistemic-phenomenalism. The relativeunreflexivity/relative-reflexivity — ontological-contiguity ${ }^{67}$ of-the-human-institutionalisationprocess ${ }^{68}$ can thus be construed as one of increasingly undermining the human subject temporal decontortion disposition not to dispense-with-immediacy-for-relative-ontologicalcompleteness $^{87}$; wherein across the successive institutional-cumulation/institutionalrecomposure-〈as-to- historiality/ontological-eventfulness /ontological-aesthetic-tracing-

$<$ perspective-ontological-normalcy/postconvergence-reflected-‘epistemicity-relativismdeterminism'>>, decontortion is ontologically-constrained both as of the 'dynamic construal of appropriate-as-intemporal existential<<disontologising/re-ontologising aporeticism> phenomenality/phenomenal-manifestation and construal of appropriate-as-intemporal existential-<disontologising/re-ontologising aporeticism $>$ human mental-disposition'. The former is ontologically-constrained as of <amplituding/formative-epistemicity $>$ causality $\sim$ asto-projective-totalitative-implications-of-prospective- nonpresencing,-for-

explicating relative-unreflexivity/relative-reflexivity ontological-contiguity in undermining the human temporal inclination to phenomenality/phenomenal-manifestation decontortion, while human temporal mental-disposition for decontortion is additionally ontologicallyconstrained with availability of ${ }^{103}$ universal-transparency ${ }^{104}$-〈transparency-of-totalisingentailing,-as-to-entailing-<amplituding/formative-epistemicity $>$ totalising $\sim$ in-relative-

ontological-completeness $\rangle$. Relatively objectified phenomenality/phenomenal-manifestation as implied in the natural sciences is hardly subjected to decontortion while relatively subjective 
phenomenality/phenomenal-manifestation as implied in the social is rather easily subjected to decontortion as of blurriness-<sterilising/anecdotalising/trivialising-of-prospective-reontologising_by-preconverging,-in-disontologising-formulaic-dragging-out/hollowing-out> and emotional-involvement. In another respect the implications of flawed identitiveconstitutedness ${ }^{14}$-as-'epistemic-totality ${ }^{37}$ '-dereification-in-dissingularisation-<as-to-thedisjointedness/disentailment-of- presencing-absolutising-identitive-constitutedness $>$-asflawed-epistemicity-relativism-determinism as of dissingularisation- $<$ as-to-thedisjointedness/disentailment-of- presencing - absolutising-identitive-

constitutedness $>$ /epistemic-nonimmanence/flawed-epistemicity-relativism-determinism also has implications with the ontological-performance ${ }^{72}-$ including-virtue-as- $^{2}$ ontology $>$ /morality/ethics/justice/etc. as of the effective productivity potential of human knowledge construction. In this regard, it is herein contended that the historically recurrent critique of 'naïve formalisation' particularly in many a field of study that uncritically strive to adhere to a 'supposedly pre-given science methodology and epistemology naively construed as of inherent transcendental signifier' such as in the analytic tradition of philosophy, naïve scientific psychology as of facetious methodologies as well as manifested in many a natural science domain (that purport to conceptualise complex social ${ }^{56}$ meaningfulness-and-teleology in naïve naturalistic methodology terms) all arise because of a flawed predisposition to identitive-constitutedness ${ }^{14}$-as-'epistemic-totality ${ }^{37}$ '-dereification-in-dissingularisation- $<$ as-tothe-disjointedness/disentailment-of- presencing - absolutising-identitive-constitutedness > as-flawed-epistemicity-relativism-determinism implied as of dissingularisation- $<$ as-to-thedisjointedness/disentailment-of- presencing - absolutising-identitiveconstitutedness $>$ /epistemic-nonimmanence/flawed-epistemicity-relativism-determinism that in-many-ways ignores/overlooks knowledge-reification $\sim$ gesturing-and-accounting-ofepistemic-phenomenalism-<in- 
prospective_psychologismic apriorising/axiomatising/referencing-\{of-‘prospectively implicited_attendant-ontological-contiguity ' educedexistentialising/contextualising/textualising_'intelligibility/epistemicity/reflexivity_contiguity<imbued-notional cogency $>>\quad\}$-conflatedness -in-\{preconverging-disentailment by\} postconverging-entailment $>$ as of singularisation-<as-to-the-nondisjointedness/entailment-ofprospective- nonpresencing $>$ projected epistemic-immanence/veridical-epistemicityrelativism-determinism; and so, as of their 'formalisation credo as identitive-constitutedness ${ }^{14}$ as-'epistemic-totality ${ }^{37}$ '-dereification-in-dissingularisation-<as-to-thedisjointedness/disentailment-of- presencing - absolutising-identitive-constitutedness $>$-asflawed-epistemicity-relativism-determinism ' thus leading to a disposition that considers knowledge as an exercise of mere conceptual-patterning inherently validated by formalisations on the basis of elaboration-as-to-mere-extrapolating/constituting/abstracting/deducing/inferringof-elucidation-outside_-'prospectively_implicited_attendant-ontologicalcontiguity $^{67}$, educedexistentialising/contextalising/textualising_'intelligibility/epistemicity/reflexivity_contiguity$<$ imbued-notional cogency $>$ ' without the constraint of knowledge-reification $\sim$ gesturing-andaccounting - of-epistemic-phenomenalism- $<$ inprospective_psychologismic apriorising/axiomatising/referencing-\{of-'prospectively implicited_attendant-ontological-contiguity ' educedexistentialising/contextualising/textualising_intelligibility/epistemicity/reflexivity_contiguity<imbued-notional cogency >' \}-conflatedness -in-\{preconverging-disentailment by\} postconverging-entailment $>$ as of existence-as-the-absolute-a-priori-ofconceptualisation $\sim$ and existence — as-sublimating-withdrawal/unenframing/re-ontologising,elicited-from-prospective-profound-supererogation $-<$ as-to-perspective-ontologicalnormalcy/postconvergence-implied-'prospective-aporeticism-overcoming/unovercoming'> 
its very own transcendental signifier which ultimately manifestly-as-inherently enables transcendence-and-sublimity/sublimation/supereregatory $\sim$ de-mentativity as the very essence of knowledge. This has led in-many-ways to a dissonance between their knowledge productivity implications and existential-<disontologising/re-ontologising apereticism $>$ reality wherein for instance psychological and psychiatric science seems to imply that all along its practice human psychological illnesses have multiplied many times over as of ever transforming and expanding formalisation credo, while the analytical tradition of philosophy by the avowals of its internal critics has been involved in a recurrent second-guessing exercise as of its visceral inclination for 'abstracting reality by formalisation outside of social reality' wrongly mimicking a natural science tradition whose domain-of-study ecstatically allows for such an attitude/mentaldisposition/care-and-episteme'. Such an approach that atomises/takes-to-pieces analysis 'as supposedly elucidative' tends to be rather abstract as of elaboration-as-to-mereextrapolating/constituting/abstracting/deducing/inferring-of-elucidation-outside'prospectively_implicited_attendant_ontological-contiguity ${ }^{67}$ ' educedexistentialising/contextualising/textualising_intelligibility/epistemicity/reflexivity-contiguity<imbued-notional cogency $>^{\prime}$. Such that beyond its abstracting exercise, as when it returns in striving to supposedly elucidate social and other existential-distong aporeticism $>$ phenomenality, it is lost to it that social and other existential-<disentologising/reentologising aporeticism $>$ phenomenality is already precedingly/supersedingly as of 'ecstatic totalising-entailing/nested-congruence', with the consequence that it naively construes of reification as simply projecting the 'supposedly reifying atomising/taking-to-pieces formalisation analysis' on the social and other existential-<disontologising/re-ontologising apereticism> phenomenality. Hence it ends up abstractly pulling-apart the 'ecstatic totalisingentailing/nested-congruence' of existential-<disontologising/re-ontologising aporeticism $>$ phenomenality and thus misrepresenting, denaturing ${ }^{16}$ and producing relatively ontologically- 
flawed ${ }^{56}$ meaningfulness-and-teleology . Such articulations tend out to be merely implied decontextualised/abstracted constructs with poor appreciation and construal of their conceptualisations as of underlying relative-ontological-incompleteness 8 /relative-ontologicalcompleteness ${ }^{8}$-〈sublimating $\sim$ referencing/registering/decisioning,-as-self-becoming/selfconflatedness /formative-supererogating-<projective/reprojective-aestheticising-re-motifand-re-apriorising/re-axiomatising/re-referencing,-in-perspective-ontologicalnormalcy/postconvergence $>>$ with respect to temporal-to-intemporal ontological-performance ${ }^{72}$ $<$ including-virtue-as-ontology $>/$ morality/ethics/justice/etc. which is what enables the reification of existence/intrinsic-reality/ontological-veridicality. In this regard for instance, the wellarticulated Foucauldian discourse of 'speech activity' conceptualisation associated with the notion of parrhesia more critically enables its knowledge-reification $\sim$ gesturing-andaccounting - of-epistemic-phenomenalism- $<$ in-

prospective_psychologismic apriorising/axiomatising/referencing-\{of- ${ }^{\text {pprospectively }}$ implicited_attendant-ontological-contiguity ' educedexistentialising/contextualising/textualising_'intelligibility/epistemicity/reflexivity-contiguity<imbued-notional cogency >' \}-conflatedness -in-\{preconverging-disentailment by\} postconverging-entailment> with regards to the possibility of human transcendence-andsublimity/sublimation/supererogatory de-mentativity as can be projected from an Ancient Greece context right up to our modern and futural context in contrast to say analytic philosophy 'speech act' which by its atomising/taking-to-pieces formalisation orientation is in-many-ways by its mere denotative/connotative apriorising/axiomatising/referencing-\{of-"prospectively implicited_attendant-ontological-contiguity ' reducedexistentialising/contextualising/textualising_'intelligibility/epistemicity/reflexivity-contiguity<imbued-notional cogency $\left.>^{\prime} \quad\right\}$-constitutedness ${ }^{1}$-in-preconverging-entailment nature just an implied existentially-<disontologising/re-ontologising aporeticism $>$ 
decontextualised/abstracted construct as of its poor ontological-as-existential-commitment with respect to 'axiomatic-construct construal of ecstatic-existence/the-nature-of-theworld/conditions', in contrast to the reifying apriorising/axiomatising/referencing-\{of'prospectively_implicited_attendant-ontological-contiguity ' educedexistentialising/contextualising/textualising_'intelligibility/epistemicity/reflexivity-contiguity<imbued-notional cogency >' \}-conflatedness ${ }^{13}$-in-\{preconverging-disentailment by\} postconverging entailment connotative nature of 'speech activity' discourse as of its contextualising ecstatic-totalising-entailing/nested-congruence; such that the former assumes rather an identitive-constitutedness ${ }^{14}$-as-'epistemic-totality ${ }^{37}$ '-dereification-indissingularisation-<as-to-the-disjointedness/disentailment-of- presencing - absolutisingidentitive-constitutedness $>$-as-flawed-epistemicity-relativism-determinism $<$ amplituding/formative-epistemicity $>$ causality $\sim$ as-to-projective-totalitative-implications-ofprospective- nonpresencing,-for-explicating relative-unreflexivity/relative-reflexivityontological-contiguity posture as of atomising/taking-to-pieces formalisation rather than a difference-conflatedness ${ }^{13}$-as-to-totalitative-reification-in-singularisation- $<$ as-to-thenondisjointedness/entailment-of-prospective- nonpresencing > -as-veridical-epistemicityrelativism-determinism implied $<$ emplituding/formative-epistemicity $>$ causality $\sim$ as-toprojective-totalitative-implications-of-prospective- nonpresencing,-for-explicating relativeunreflexivity/relative-reflexivity ontological-contiguity posture that is as of ecstatictotalising-entailing/nested-congruence as with the latter. Such a conclusion can be extended to other analytic tradition concepts assuming rather an atomising/taking-to-pieces formalisation orientation like the broader notion of language games when rather analysed as of a denotative/connotative apriorising/axiomatising/referencing-\{of-"prespectively implicited_attendant-ontological-contiguity ' educedexistentialising/contextualising/textualising_'intelligibility/epistemicity/reflexivity-contiguity- 
<imbued-notional cogency>' $\quad\}$-constitutedness ${ }^{14}$-in-preconverging-entailment nature outside 'implicited_attendant-ontological-contiguity ${ }^{67}$; educedexistentialising/contextmalising/textualising_'intelligibility/epistemicity/reflexivity-contiguity$<$ imbued-notional cogency $>$ whereas in contrast this author construes of the ontologicallyveridical reflection of the social purview as better served by the notion of 'ontologicallyhegemonising-narrative ${ }^{71}$ ontological-performance ${ }^{72}-<$ including-virtue-as-ontology $>^{\prime}$ as of its reifying apriorising/axiomatising/referencing-\{of-'prospectively_implicited_attendantontological-contiguity ' educedexistentialising/contextualising/textualising_'intelligibility/epistemicity/reflexivity_contiguity<imbued-notional cogency >' \}-conflatedness ${ }^{13}$-in-\{preconverging-disentailment by\} pestconverging-entailment connotative nature reflecting the ontological-veracity/ontologicalperformance ${ }^{2}$-<including-virtue-as-ontology $>$ /morality/ethics/justice/etc. of humansubpotency epistemic-or-notional projective-perspective ${ }^{56}$ meaningfulness-and-teleology articulated within any given registry-worldview/dimension social-setup going by its supposedly coherent ontological-commitment $-<$ implied — self-assuredness-of-ontological-goodfaith/authenticity $\sim$ postconverging-de-mentating/structuring/paradigming -as-being-as-ofexistential-reality> as so-reflected by its self-assuredness-of-ontological-goodfaith/authenticity ${ }^{6} \sim$ postconverging-de-mentating/structuring/paradigming 7 -as-being-as-ofexistential-reality with respect to its social-stake-contention-or-confliction exposing it to existence-potency ${ }^{39} \sim$ sublimating-nascence,-disclosed-from-prospective-epistemic-digression epistemic-or-notional projective-perspective of $\quad$ amplituding/formativeepistemicity $>$ causality $\sim$ as-to-projective-totalitative-implications-of-prospectivenonpresencing,-for-explicating relative unreflexivity/relative reflexivity - ontologicalcontiguity as of prospective relative-ontological-completeness ${ }^{87}<$ amplituding/formativeepistemicity $>$ causality $\sim$ as-to-projective-totalitative-implications-of-prospective- 
nonpresencing,-for-explicating relative-unreflexivity/relative-reflexivity - ontological-

contiguity ', and so-construed as of difference-conflatedness ${ }^{3}$-as-to-totalitative-reification-insingularisation- $<$ as-to-the-nondisjointedness/entailment-of-prospective- nonpresencing $>$-asveridical-epistemicity-relativism-determinism implied $\quad$ <amplituding/formativeepistemicity $>$ causality $\sim$ as-to-projective-totalitative-implications-of-prospectivenonpresencing,-for-explicating relative-unreflexivity/relative-reflexivity ontologicalcontiguity ; thus further articulating ${ }^{56}$ meaningfulness-and-teleology ${ }^{99}$ as from prior relativeontological-incompleteness $^{8}$ to prospective relative-ontological-completeness ${ }^{87}$, and so from the notional/epistemic/bindingness-sas-determinism/coneeptivity-of-relative-mreflexivity/relative-reflexivitys perspective of existence-potency ${ }^{39} \sim$ sublimating-nascence,-disclosed-from-prospectiveepistemic-digression as-to-ontologically-uncompromised-ontologicalnormalcy/postconvergence/referentialism and this 'ontologically-hegemonising-narrative ontological-performance ${ }^{72}-<$ including-virtue-as-ontology $>$ ' orientation is theoretically, conceptually and operantly ontologically efficacious inherently by its ecstatic-totalisingentailing/nested-congruence as it reflects totalisingly-entailing the 'notional firstnaturednessformativeness-<as-to-eventualising inkling-drive-or-seeding-misprising $>$ temporal-tointemporal-dispositions-<so-construed-as-from-perspective-ontologicalnormalcy/postconvergence> accordioning-〈as-of-varying-individuations-contextuallytransverse-desublimation/sublimation,-as-to-the-wavering/redounding/waveforming of-theirreferencing-and-their-devolved-referencing-imbued-ontological-performance -<includingvirtue-as-ontology $>>\quad$ ontological-performance ${ }^{2}-<$ including-virtue-as-ontology $>$-includingvirtue-as-ontology of narratives' as of the social epistemic-totality ${ }^{37}$ of ${ }^{56}$ meaningfulness-andteleology . This totalising-entailing insight is reflected in the Derridean deconstruction orientation with its obvious narratology implications pertinence to literary studies as of its apriorising/axiomatising/referencing-\{of-'prospectively implicited_attendant-ontological- 
contiguity ' educed-

existentialising/contextualising/textualising_'intelligibility/epistemicity/reflexivity_contiguity<imbued-notional $\left.\sim \operatorname{cogency}>^{\prime} \quad\right\}$-conflatedness ${ }^{13}$-in-\{preconverging-disentailment by\} postconverging-entailment with 'implicited_attendant-ontological-contiguity ${ }^{67}$ ' educedexistentialising/contextualising/textualising_intelligibility/epistemicity/reflexivity-contiguity$<$ imbued-notional cogency $>$ in contrast to such a notion like language games when construed rather in apriorising/axiomatising/referencing-\{of-'prospectively implicited_attendantontological-contiguity ' educed-

existentialising/contextualising/textualising_intelligibility/epistemicity/reflexivity-contiguity<imbued-notional cogency>' $\}$ - constitutedness ${ }^{14}$-in-preconverging-entailment. This difference of conceptualising comes down to the atomising/taking-to-pieces flaw reflex of constituting-towards-'epistemic-totality ${ }^{37}$, implied as of ontologically-flawed identitiveconstitutedness ${ }^{14}$-as-'epistemic-totality ${ }^{37}$ '-dereification-in-dissingularisation-<as-to-thedisjointedness/disentailment-of- presencing — absolutising-identitive-constitutedness $>$-asflawed-epistemicity-relativism-determinism as against the ecstatic-totalising-entailing/nestedcongruence disposition for reifying-'epistemic-totality ${ }^{37}$ '-for-completeness implied as of ontologically-veridical difference-conflatedness ${ }^{13}$-as-to-totalitative-reification-insingularisation-<as-to-the-nondisjointedness/entailment-of-prospective- nonpresencing $>$-asveridical-epistemicity-relativism-determinism ; wherein the apriorising/axiomatising/referencing-\{of-'prospectively implicited_attendant-ontologicalcontiguity ' educedexistentialising/contextualising/textualising_intelligibility/epistemicity/reflexivity-contiguity<imbued-notional cogency $\left.>^{\prime},\right\}$ - conflatedness ${ }^{13}$ in (preconverging disentaiment by postconverging-entailment mental-reflex is involved in construing of both the right apriorising/axiomatising/referencing/intelligibilitysettingup/measuringinstrumenting mindset- 
as-of-prospective-deprocrypticism-dissemination ${ }^{28}$ and thus the knowledge for that right mindset-as-of-prospective-deprocrypticism-dissemination ${ }^{28}$ for completeness as of ontologically-uncompromised ontologicalnormalcy/postconvergence/referentialism/postdication projected apriorising/axiomatising/referencing-\{of-'prospectively_implicited_attendant-ontologicalcontiguity ' educedexistentialising/contextualising/textualising_intelligibility/epistemicity/reflexivity_contiguity<imbued-notional cogency >' \}-conflatedness ${ }^{13}$-in-\{preconverging-disentailment-by\}postconverging-entailment (as of singularisation-<as-to-the-nondisjointedness/entailment-ofprospective- nonpresencing $>\quad$ projected epistemic-immanence/veridical-epistemicityrelativism-determinism and dissingularisation-<as-to-the-disjointedness/disentailment-ofpresencing — absolutising-identitive-constitutedness $>$ /epistemic-nonimmanence/flawedepistemicity-relativism-determinism $\quad<$ amplituding/formative-epistemicity $>$ causality $\sim$ as-toprojective-totalitative-implications-of-prospective- nonpresencing,-for-explicating relativeunreflexivity/relative-reflexivity - ontological-contiguity of 'supererogatory acuity/perspicacity/astuteness/edginess/incisiveness-ofapriorising/axiomatising/referencing/intelligibilitysettingup/measuringinstrumenting -forconceptualisation with regards to human limited-mentation-capacity-deepening —as-subjectinglimitedness/human-subpotency-to-'educed-unlimitedness/existence-sublimating nascence' ${ }^{53}$ as prospective psychoanalytic-unshackling/memetic-reordering/institutional-recomposuring' which speaks of the recurrent edging towards completion of ontological-performance ${ }^{72}$ $<$ including-virtue-as-ontology $>/$ morality/ethics/justice/etc. of intemporal ontological-faithnotion-or-ontological-fideism—imbued-underdetermination-of-motif-andapriorising/axiomatising/referencing-as-so-being-as-of-existential-reality parrhesiastic askesisor-acumen reasoning-through/messianic-reasoning recurrent shot for completeness as of 
successive reproducibility-mathesis/motif/thrownness-disposition,-as-reproducibility-ofaestheticisation), whereas the apriorising/axiomatising/referencing-\{of-"prospectively implicited_attendant-ontological-contiguity ' educed-

existentialising/contextualising/textualising_intelligibility/epistemicity/reflexivity_contiguity<imbued-notional cogency $\left.>^{\prime} \quad\right\}$-constitutedness ${ }^{14}$-in-preconverging-entailment $\quad$ mental$\begin{array}{lllll}\text { reflex } & \text { assumes } & \text { uncritically } & \text { of } & \text { its }\end{array}$ apriorising/axiomatising/referencing/intelligibilitysettingup/measuringinstrumenting mindset,in-positivism- ${ }^{8}$ procrypticism/disjointedness and goes on as of its categorising constituting to construe knowledge for completeness without questioning its mindset,-in-positivismprocrypticism/disjointedness as if it has got an absolutely veridical apriorising/axiomatising/referencing/intelligibilitysettingup/measuringinstrumenting, and this is exactly what is implied by displacement/decentering-of-the-human-subject as of its relativeontological-incompleteness 8 . This specific deficiency of the analytic tradition as so-reflected in many of its conceptualisations has to do with the very notion of knowledge as being about supposedly coherent ontological-commitment $-<$ implied-self-assuredness-of-ontologicalgood-faith/authenticity postconverging-de-mentating/structuring/paradigming -as-beingas-of-existential-reality> as of 'affirmation/projection/assertion/notional $\sim$ selfdistantiation/dueness-validating-logicising/suitable-measuringinstrument-validatingmeasuring-<as-to-postconverging-or-dialectical-thinking -apriorising-psychologism $>\quad$ of apriorising/axiomatising/referencing/intelligibilitysettingup/measuringinstrumenting axiomatic-construct', and logic actually being in effect the 'inner working coherence/contiguity of axiomatic-construct construal of ecstatic-existence/the-nature-of-the-world/conditions', with the implication that all the knowledge as ontologically-veridical ${ }^{56}$ meaningfulness-andteleology ${ }^{9}$ that exists is about knowledge-reification $\sim$ gesturing-and-accounting - of-epistemicphenomenalism-<in-prospective_psychologismic $\sim$ apriorising/axiomatising/referencing-\{of- 
'prospectively_implicited_attendant-ontological-contiguity ' educed-

existentialising/contextualising/textualising_'intelligibility/epistemicity/reflexivity_contiguity<imbued-notional cogency>> $\}$-conflatedness -in-\{preconverging-disentailment by\}

postconverging-entailment $>$ as of $<$ amplituding/formative-epistemicity $>$ causality $\sim$ as-toprojective-totalitative-implications-of-prospective- nonpresencing,-for-explicating $\sim$ relativeunreflexivity/relative-reflexivity ontological-contiguity of supposedly coherent ontologicalcommitment $-<$ implied — self-assuredness-of-ontological-goodfaith/authenticity postconverging-de-mentating/structuring/paradigming -as-being-as-ofexistential-reality> implied as of 'axiomatic-construct construal of ecstatic-existence/the-natureof-the-world/conditions'. In this regard, 'speech activity' discourse speaks of a supposedly coherent ontological-commitment $-<$ implied — self-assuredness-of-ontological-goodfaith/authenticity postconverging-de-mentating/structuring/paradigming -as-being-as-ofexistential-reality> as of 'axiomatic-construct construal of ecstatic-existence/the-nature-of-theworld/conditions' as expressed above (with regards to the social contextualisation beyond just speech for the possibility of human transcendence-andsublimity/sublimation/supererogatory de-mentativity...) which is then being reified/elucidated for the prospective possibility of human emancipation, with logic being the inner working coherence/contiguity of axiomatic-construct construal of ecstatic-existence/the-nature-of-theworld/conditions' as of this articulated ontological-as-existential-commitment having to do with such social contextualisation'. Likewise the underlying notion of ontological-performance ${ }^{72}$ $<$ including-virtue-as-ontology $>/$ morality/ethics/justice/etc. as herein articulated by this author is as difference-conflatedness $^{13}$-as-to-totalitative-reification-in-singularisation- $<$ as-to-thenondisjointedness/entailment-of-prospective- nonpresencing > -as-veridical-epistemicityrelativism-determinism implied <amplituding/formative-epistemicity $>$ causality $\sim$ as-toprojective-totalitative-implications-of-prospective- nonpresencing,-for-explicating relative- 
ontologically-uncompromised-ontological-normalcy/postconvergence/referentialism

supposedly coherent ontological-commitment $-<$ implied - self-assuredness-of-ontologicalgood-faith/authenticity postconverging-de-mentating/structuring/paradigming -as-being-

as-of-existential-reality $>$ about 'axiomatic-construct construal of ecstatic-existence/the-natureof-the-world/conditions'; articulating knowledge as ontologically-veridical ${ }^{56}$ meaningfulnessand-teleology as of the knowledge-reification $\sim$ gesturing-and-accounting-of-epistemicphenomenalism- $<$ in-prospective_psychologismic $\sim$ apriorising/axiomatising/referencing- of'prospectively_implicited_attendant-ontological-contiguity ' ceducedexistentialising/contextualising/textualising_'intelligibility/epistemicity/reflexivity-contiguity<imbued-notional cogency >' \}-conflatedness -in-\{preconverging disentailment by\} postconverging-entailment $><$ amplituding/formative-epistemicity $>$ causality $\sim$ as-to-projectivetotalitative-implications-of-prospective- nonpresencing,-for-explicating relativeunreflexivity/relative-reflexivity - ontological-contiguity of human underlying relativeontological-incompleteness 8 /relative-ontological-completeness ${ }^{87}$

\section{〈sublimating $\sim$ referencing/registering/decisioning,-as-self-becoming/self-}

conflatedness /formative-supererogating-<projective/reprojective-aestheticising-re-motifand-re-apriorising/re-axiomatising/re-referencing,-in-perspective-ontologicalnormalcy/postconvergence $>>$. This underlying notion of ontological-performance ${ }^{2}-<$ includingvirtue-as-ontology $>$ /morality/ethics/justice/etc. speaks more fundamentally of aetiologisation/ontological-escalation-<ontologicalveridicality_commitment/otherliness_transcending/compulsions-encumbered_transcending>, as explicitly underlined in all transcendence-and-sublimity/sublimation/supereregatery $\sim$ dementativity elucidating/reifying subject-matters and sciences, unlike approaches that do-not-or- 
poorly-appreciate the fact that just as scientific studies are transformative the study of the social rightly articulated beyond-institutional-being-and-craft is just as transformative with regards to prospective human Being-development/ontological-framework-expansion-as-to-depth-ofontologising-development-as-infrastructure-of- meaningfulness-and-teleology , institutionaldevelopment-as-to-social-function-development and living-development-as-to-personalitydevelopment psychologismic epistemic-acutisation difficulty-for, residualising ${ }_{\{\text {decompulsing }}$ delinearity for-cogeney $>$ magnitudes $\{$ of-experientiality/experiment\}; even though it is more subject to higher emotional-involvement as of its displacement/decentering-of-the-humansubject $<$ amplituding/formative-epistemicity $>$ causality $\sim$ as-to-projective-totalitativeimplications-of-prospective- nonpresencing,-for-explicating $\sim$ relative-unreflexivity/relativereflexivity - ontological-contiguity . Whereas the analytic tradition posture as with 'speech act' gives precedence to logical-commitment as reflected in its atomising/taking-to-pieces formalisation approach (implied as of elaboration-as-to-mereextrapolating/constituting/abstracting/deducing/inferring-of-elucidation-outside'prospectively_implicited_attendant-ontological-contiguity ${ }^{67}$ ' educedexistentialising/contextualising/textualising_'intelligibility/epistemicity/reflexivity-contiguity$<$ imbued-notional cogency>’"0) geared towards identitive-constitutedness ${ }^{14}$-as-'epistemictotality ${ }^{37}$-dereification-in-dissingularisation-<as-to-the-disjointedness/disentailment-of-

$$
\text { presencing - absolutising-identitive-constitutedness }>\text {-as-flawed-epistemicity-relativism- }
$$

determinism, which by the token of working by atomising/taking-to-pieces formalisation on specific aspects or specific interpretation as of formalisation construct ignores/overlooks 'axiomatic-construct construal of ecstatic-existence/the-nature-of-the-world/conditions' as the veridical supposedly coherent ontological-commitment $-<$ implied-self-assuredness-ofontological-good-faith/authenticity postconverging-de-

mentating/structuring/paradigming -as-being-as-of-existential-reality $>$ in want of knowledge- 
reification $\sim$ gesturing-and-accounting — of-epistemic-phenomenalism- $<$ in-

prospective_psychologismic apriorising/axiomatising/referencing-\{of- ${ }^{\text {pprospectively }}$ implicited_attendant-ontological-contiguity ' educed-

existentialising/contextualising/textualising_intelligibility/epistemicity/reflexivity-contiguity$<$ imbued-notional $\sim$ cogency $>\quad\}$-conflatedness -in-\{preconverging-disentailment by\} postconverging-entailment $>$ for knowledge as ontologically-veridical ${ }^{56}$ meaningfulness-andteleology, as can be validated and falsified by <amplituding/formativeepistemicity $>$ causality $\sim$ as-to-projective-totalitative-implications-of-prospectivenonpresencing,-for-explicating relative- unreflexivity/relative-reflexivity - ontologicalcontiguity. This fundamental difference of conceptualisation very often underlies the disagreements between the analytic philosophical orientation and other philosophical traditions, in the sense that while the latter might be implicitly implying supposedly coherent ontologicalcommitment $-<$ implied — self-assuredness-of-ontological-goodfaith/authenticity $\sim$ postconverging-de-mentating/structuring/paradigming -as-being-as-ofexistential-reality> about 'axiomatic-construct construal of ecstatic-existence/the-nature-of-theworld/conditions' when making its argument, the former will tend to be making a logicalcommitment argument as of formalisation construct that ignores/overlooks-and-hence-is-poorlyconstrained to the precedence/supersedingness/ascendency of 'axiomatic-construct construal of ecstatic-existence/the-nature-of-the-world/conditions' in need of knowledgereification $\sim$ gesturing-and-accounting - of-epistemic-phenomenalism- $<$ inprospective_psychologismic apriorising/axiomatising/referencing-\{of-'prospectively implicited_attendant-ontological-contiguity ' educedexistentialising/contextrising/textralising_intelligibility/epistemicity/reflexivity-contiguity<imbued-notional cogency $\left.>^{\prime} \quad\right\}$-conflatedness -in-\{preconverging-disentailment by\} postconverging-entailment $>$ as of $<$ amplituding/formative-epistemicity $>$ causality $\sim$ as-to- 
projective-totalitative-implications-of-prospective- nonpresencing,-for-explicating relativeunreflexivity/relative-reflexivity - ontological-contiguity, and goes on to naively deploy outside knowledge-reification $\sim$ gesturing-and-accounting-of-epistemic-phenomenalism- $<$ inprospective_psychologismic apriorising/axiomatising/referencing-\{of-'prospectively implicited_attendant-ontological-contiguity ' educedexistentialising/contextualising/textualising_ 'intelligibility/epistemicity/reflexivity-contiguity<imbued-notional cogency >' \}-conflatedness -in-\{preconverging-disentailment by\} postconverging-entailment $>$ such logic notions like non-sequitur, fallacies, etc. and/or mere categorising denotative/connotative formalisations in apriorising/axiomatising/referencing- of'prospectively_implicited_attendant-ontological-contiguity ' ceducedexistentialising/contextualising/textualising_'intelligibility/epistemicity/reflexivity-contiguity$<$ imbued-notional cogency $\left.>^{\prime} \quad\right\}$-constitutedness ${ }^{4}$-in-preconverging-entailment as ends in themselves, rather than construing logic as of the inner working coherence/contiguity of axiomatic-construct construal of ecstatic-existence/the-nature-of-the-world/conditions' of supposedly coherent ontological-commitment $-<$ implied - self-assuredness-of-ontologicalgood-faith/authenticity postconverging-de-mentating/structuring/paradigming -as-beingas-of-existential-reality $>$ for knowledge elucidating/reifying which validation and falsifiability is rather a matter of <amplituding/formative-epistemicity>causality $\sim$ as-to-projectivetotalitative-implications-of-prospective- nonpresencing,-for-explicating relativeunreflexivity/relative-reflexivity ontological-contiguity. The fundamental point here is that logic (reflected by the atomising/taking-to-pieces formalisation approach) is instead the 'inner working coherence/contiguity of axiomatic-construct construal of ecstatic-existence/the-natureof-the-world/conditions' as of Being and beings as reflected in first-level ontology and secondlevel ontologies, and logic cannot derive the superseding/preceding ecstatic existential<disontologising/re-ontelogising aporeticism $>$ veridicality of Being and beings which 
validation and falsifiability ${ }^{22}$ is ever always a matter of <amplituding/formativeepistemicity $>$ causality $\sim$ as-to-projective-totalitative-implications-of-prospective-

\section{nonpresencing,-for-explicating relative-unreflexivity/relative-reflexivity - ontological-}

contiguity . Being and beings construed-as-of-ontology/apriorising/axiomatising/referencing in the conceptualising of the-very-same-immanent-existence/intrinsic-reality/ontologicalveridicality,-as-to-'human<amplituding/formative-epistemicity $>$ totalising $\sim$ purview-ofconstrual' or any <amplituding/formative-epistemicity>totalising $\sim$ devolved-purview-asdomain-of-construal-as-intrinsic-reality/ontological-veridicality or any-issue-in-existence as knowledge, and so as of articulated axiomatic-constructs; is rather reflected either in affirmation/projection/assertion/notional self-distantiation/dueness-validating-

logicising/suitable-measuringinstrument-validating-measuring-<as-to-postconverging-ordialectical-thinking -apriorising-psychologism $>$ when the conceptualising is in prospective relative-ontological-completeness $^{87}$ or $\quad$ is $\quad$ reflected unaffirmation/deprojection/deassertion/epistemic-decadence/undueness-invalidatinglogicising/unsuitable-measuringinstrument-invalidating-measuring-<as-to-preconverging-ordementing -apriorising-psychologism> when the conceptualising is in prior relativeontological-incompleteness 8 , and in both instances as substantiated or unsubstantiated respectively by <amplituding/formative-epistemicity $>$ causality $\sim$ as-to-projective-totalitativeimplications-of-prospective- nonpresencing,-for-explicating relative-unreflexivity/relativereflexivity - ontological-contiguity in reflection of the ascendency of existencepotency $^{39} \sim$ sublimating-nascence,-disclosed-from-prospective-epistemic-digression. $\quad$ For instance, with the affirmation/projection/assertion/notional $\sim$ self-distantiation/duenessvalidating-logicising/suitable-measuringinstrument-validating-measuring-<as-topostconverging-or-dialectical-thinking -apriorising-psychologism> of theory-of-relativitytogether-with-quantum-mechanics - axiomatic-constructs over classical-mechanics- 
decadence/undueness-invalidating-logicising/unsuitable-measuringinstrument-invalidatingmeasuring-<as-to-preconverging-or-dementing -apriorising-psychologism $>$. This is also the case as of the affirmation/projection/assertion/notional $\sim$ self-distantiation/dueness-validatinglogicising/suitable-measuringinstrument-validating-measuring-<as-to-postconverging-ordialectical-thinking -apriorising-psychologism> of the 'relative-ontological-completeness ${ }^{87}$ of- reference-of-thought' over 'relative-ontological-incompleteness ${ }^{8}$-of- ${ }^{8}$ reference-ofthought' as unaffirmation/deprojection/deassertion/epistemic-decadence/unduenessinvalidating-logicising/unsuitable-measuringinstrument-invalidating-measuring-<as-topreconverging-or-dementing -apriorising-psychologism>; for instance, futural Beingdevelopment/ontological-framework-expansion-as-to-depth-of-ontologising-development-asinfrastructure-of- meaningfulness-and-teleology as of prospective notional ${ }^{18}$ deprocrypticism over our positivism- ${ }^{8}$ procrypticism or in the case of our positivism over prior non-positivism-medievalism. Logic arises as a mental-reflex of the 'inner working coherence/contiguity of axiomatic-construct construal of ecstatic-existence/the-nature-of-theworld/conditions' in knowledge construing-as-of-ontology/apriorising/axiomatising/referencing of Being and beings. However, because a ${ }^{83}$ reference-of-thought is already an apriorising/axiomatising/referencing/intelligibilitysettingup/measuringinstrumenting reproducibility—mathesis/motif/thrownness-disposition,-as-reproducibility-of-aestheticisation as of its underlying affirmation/projection/assertion/notional $\sim$ self-distantiation/duenessvalidating-logicising/suitable-measuringinstrument-validating-measuring-<as-topostconverging-or-dialectical-thinking -apriorising-psychologism>, logic seems to be the only mental exercise involved since the underlying affirmation/projection/assertion/notional $\sim$ selfdistantiation/dueness-validating-logicising/suitable-measuringinstrument-validatingmeasuring-<as-to-postconverging-or-dialectical-thinking -apriorising-psychologism $>$ of the 
apriorising/axiomatising/referencing/intelligibilitysettingup/measuringinstrumenting is ever so pervasive-and-transparent to contemplation by mental-reflex, such that when the affirmation/projection/assertion/notional self-distantiation/dueness-validatinglogicising/suitable-measuringinstrument-validating-measuring-<as-to-postconverging-ordialectical-thinking -apriorising-psychologism> of covert flawed-as-dementing apriorising/axiomatising/referencing/intelligibilitysettingup/measuringinstrumenting is implied with regards to say adulthood psychopathic postlogism -slantedness as of the historiality/ontological-eventfulness ${ }^{38} /$ ontological-aesthetic-tracing-<perspectiveontological-normalcy/postconvergence-reflected-‘epistemicity-relativism-determinism'> of its meaningfulness-and-teleology as from difference-conflatedness ${ }^{13}$-as-to-totalitativereification-in-singularisation-<as-to-the-nondisjointedness/entailment-of-prospectivenonpresencing $>$-as-veridical-epistemicity-relativism-determinism in relativeunreflexivity/relative-reflexivity_ontological-contiguity ${ }^{67}$ we go on to aposteriorise/logicise/derive/intelligise/measure and thus wrongly validating the flawed affirmation/projection/assertion/notional $\sim$ self-distantiation/dueness-validatinglogicising/suitable-measuringinstrument-validating-measuring-<as-to-postconverging-ordialectical-thinking -apriorising-psychologism $>$ as of the flawed-as-dementing apriorising/axiomatising/referencing/intelligibilitysettingup/measuringinstrumenting, and so instead of implying its unaffirmation/deprojection/deassertion/epistemic-decadence/unduenessinvalidating-logicising/unsuitable-measuringinstrument-invalidating-measuring-<as-topreconverging-or-dementing -apriorising-psychologism>, as will be done at childhood psychopathy where it is overt and obvious. Further temporal individuation dispositions of ignorance/affordability/opportunism/exacerbation/social-chainism-or-social-discomfiture-ornegative-social-aggregation/temporal-enculturation-or-temporal-endemisation conjugating to this postlogism 7 -slantedness of speaks decially 
affirmation/projection/assertion/notional self-distantiation/dueness-validatinglogicising/suitable-measuringinstrument-validating-measuring-<as-to-postconverging-ordialectical-thinking -apriorising-psychologism> flawed-as-dementing apriorising/axiomatising/referencing/intelligibilitysettingup/measuringinstrumenting, equally requiring unaffirmation/deprojection/deassertion/epistemic-decadence/undueness-invalidatinglogicising/unsuitable-measuringinstrument-invalidating-measuring-<as-to-preconverging-ordementing -apriorising-psychologism>; as so implied at the uninstitutionalised-threshold including as of our procrypticism-or-disjointedness-as-of- ${ }^{8}$ reference-of-thought. The underlying insight can be garnered as of the temporal ${ }^{56}$ meaningfulness-and-teleology ${ }^{99}$ in $<$ amplituding/formative-epistemicity>totalising $\sim$ self-referencingsyncretising/circularity/interiorising/akrasiatic-drag ${ }^{34}$ reflected as of the prior relativeontological-incompleteness ${ }^{8}$ of a ${ }^{83}$ reference-of-thought uninstitutionalised-threshold ${ }^{102}$, for instance with the unaffirmation/deprojection/deassertion/epistemic-decadence/unduenessinvalidating-logicising/unsuitable-measuringinstrument-invalidating-measuring-<as-topreconverging-or-dementing -apriorising-psychologism> of flawed-as-preconverging-ordementing 2 -apriorising-psychologism non-positivism apriorising/axiomatising/referencing/intelligibilitysettingup/measuringinstrumenting with respect to our positivism or prospectively the unaffirmation/deprojection/deassertion/epistemicdecadence/undueness-invalidating-logicising/unsuitable-measuringinstrument-invalidatingmeasuring-<as-to-preconverging-or-dementing -apriorising-psychologism $>$ of our flawed-aspreconverging-or-dementing ${ }^{20}$-apriorising-psychologism positivism/rational-empiricism manifestation of $\quad{ }^{80}$ procrypticism-or-disjointedness-as-of- ${ }^{8}$ reference-of-thought apriorising/axiomatising/referencing/intelligibilitysettingup/measuringinstrumenting with respect to futural Being-development/ontological-framework-expansion-as-to-depth-ofontologising-development-as-infrastructure-of- meaningfulness-and-teleology as of 
prospective deprocrypticism. Being and beings construed-as-ofontology/apriorising/axiomatising/referencing in the conceptualising of existence or any $<$ amplituding/formative-epistemicity $>$ totalising $\sim$ devolved-purview-as-domain-of-construalas-intrinsic-reality/ontological-veridicality or any-issue-in-existence as knowledge, by affirmation/projection/assertion/notional self-distantiation/dueness-validatinglogicising/suitable-measuringinstrument-validating-measuring-<as-to-postconverging-ordialectical-thinking -apriorising-psychologism> and unaffirmation/deprojection/deassertion/epistemic-decadence/undueness-invalidatinglogicising/unsuitable-measuringinstrument-invalidating-measuring-<as-to-preconverging-ordementing -apriorising-psychologism $>\quad<$ amplituding/formative-epistemicity $>$ causality $\sim$ asto-projective-totalitative-implications-of-prospective- nonpresencing,-forexplicating relative-unreflexivity/relative-reflexivity -ontological-contiguity as of underlying relative-ontological-incompleteness 8 /relative-ontological-completeness 〈sublimating $\sim$ referencing/registering/decisioning,-as-self-becoming/selfconflatedness /formative-supererogating-<projective/reprojective-aestheticising-re-motifand-re-apriorising/re-axiomatising/re-referencing,-in-perspective-ontologicalnormalcy/postconvergence $>\rangle$, is further elucidative of the notions of incrementalism-inrelative-ontological-incompleteness ${ }^{8}$ — enframed/disontologising conceptualisation and maximalising-recomposuring-for-relative-ontological-completeness ${ }^{87}$ — unenframed/reontologising conceptualisation. Wherein incrementalism-in-relative-ontologicalincompleteness ${ }^{88}$ enframed/disontologising conceptualisation as associated with mechanicalknowledge is geared on construing on the basis of prior relative-ontological-incompleteness ${ }^{8}$ of- ${ }^{3}$ reference-of-thought apriorising/axiomatising/referencing/intelligibilitysettingup/measuringinstrumenting the ‘<amplituding/formative $>$ wooden-language-<imbued-temporal-mere- 


\section{form/virtualities/dereification/akrasiatic-drag/denatured/preconverging-or-dementing}

\section{narratives - of-the- reference-of-thought- categorical-imperatives/axioms/registry-}

teleology > of the prospective/transcending/superseding registry-worldview/dimension' as deterministically affirmative of sublimating/emancipating ${ }^{56}$ meaningfulness-and-teleology ${ }^{9}$. Whereas maximalising-recomposuring-for-relative-ontological-completeness ${ }^{87}$ unenframed/re-ontologising conceptualisation associated with organic knowledge is about 'utterly resolving as of <amplituding/formative-epistemicity>-totalising $\sim$ renewingrealisation/re-perception/re-thought' the-very-same-immanent-existence/intrinsicreality/ontological-veridicality,-as-to-'human<amplituding/formativeepistemicity>totalising purview-of-construal' $\quad$ or $\quad$ any $\quad<$ amplituding/formativeepistemicity $>$ totalising $\sim$ devolved-purview-as-domain-of-construal-as-intrinsic-

reality/ontological-veridicality or any-issue-in-existence as of prospective relative-ontologicalcompleteness $^{87}$-of- ${ }^{8}$ reference-of-thought

'apriorising/axiomatising/referencing/intelligibilitysettingup/measuringinstrumenting reference-of-thought- ${ }^{\text {categorical-imperatives/axioms/registry-teleology }}{ }^{9}$,-foraposteriorising/logicising/deriving/intelligising/measuring - ${ }^{56}$ meaningfulness-and-teleology ${ }^{9}$, involving supereregatery $\sim$ acuity/perspicacity/astuteness/edginess/incisiveness-ofapriorising/axiomatising/referencing/intelligibilitysettingup/measuringinstrumenting - forconceptualisation $<$ amplituding/formative-epistemicity $>$ causality $\sim$ as-to-projectivetotalitative-implications-of-prospective- nonpresencing,-for-explicating relativeunreflexivity/relative-reflexivity ontological-contiguity . $\quad 5$ incrementalism-in-relativeontological-incompleteness 8 - enframed/disontologising conceptualisation can undermine knowledge development and as of its sophistic/pedantic peddling of $<$ amplituding/formative $>$ wooden-language-〈imbued - averaging-of-thought-<as-toleveling/ressentiment/closed-construct-of- meaningfulness-and-teleology -as-of- 
'nondescript/ignorable-void '-with-regards-to-prospective-apriorising-implications $>>\quad$ while straddling inbetween the prior relative-ontological-incompleteness ${ }^{8}$-of- ${ }^{8}$ reference-of-thought conventioning-referencing and the prospective relative-ontological-completeness ${ }^{87}$-ofreference-of-thought Being-development/ontological-framework-expansion-as-to-depth-ofontologising-development-as-infrastructure-of- meaningfulness-and-teleology , as of socialstake-contention-or-confliction induced institutional-being-and-craft with possible denaturing of such prospective relative-ontological-completeness ${ }^{8}$-of- ${ }^{8}$ reference-of-thought organic knowledge, and by social-construct destructuring postures of significant-otherness. Fundamentally thus there preconverging/postconverging-de-mentative/structural/paradigmatic divergence imbued notional-discontiguity/epistemic-discontiguity ${ }^{63}-<$ between - prior-shallowsupererogation -of-mentally-aestheticised preconverging/dementing -qualiaschema_and_prospective-profound-supererogation -of-mentallyaestheticised postconverging/dialectical-thinking -qualia-schema $>$ of their incrementalismin-relative-ontological-incompleteness ${ }^{8}$ —enframed/disontologising conceptualisation from the prospective notional-contiguity/epistemic-contiguity $-<$ profound-supererogation -ofmentally-aestheticised postconverging/dialectical-thinking -qualia-schema $>\quad$ of maximalising-recomposuring-for-relative-ontological-completeness ${ }^{87}$ - unenframed/reontologising conceptualisation, with ${ }^{5}$ maximalising-recomposuring-for-relative-ontologicalcompleteness $^{87}$ - unenframed/re-ontologising conceptualisation reflected in affirmation/projection/assertion/notional self-distantiation/dueness-validatinglogicising/suitable-measuringinstrument-validating-measuring-<as-to-postconverging-ordialectical-thinking -apriorising-psychologism> as of ontologically-veridical differenceconflatedness $^{13}$-as-to-totalitative-reification-in-singularisation- $<$ as-to-thenondisjointedness/entailment-of-prospective- nonpresencing $>$-as-veridical-epistemicityrelativism-determinism in relative-unreflexivity/relative-reflexivity-ontological-contiguity 
as from existence-potency ${ }^{39} \sim$ sublimating-nascence,-disclosed-from-prospective-epistemicdigression as-to-ontologically-uncompromised-ontologicalnormalcy/postconvergence/referentialism, while ${ }^{51}$ incrementalism-in-relative-ontologicalincompleteness ${ }^{8}$ - enframed/disontologising conceptualisation is reflected in unaffirmation/deprojection/deassertion/epistemic-decadence/undueness-invalidatinglogicising/unsuitable-measuringinstrument-invalidating-measuring-<as-to-preconverging-ordementing -apriorising-psychologism> as ontologically-flawed identitive-constitutedness ${ }^{14}$ as-'epistemic-totality ${ }^{37}$ '-dereification-in-dissingularisation-<as-to-the-

disjointedness/disentailment-of- presencing - absolutising-identitive-constitutedness $>$-asflawed-epistemicity-relativism-determinism of notional-discontiguity/epistemicdiscontiguity ${ }^{63}<$ between - prior-shallow-supererogation -of-mentallyaestheticised preconverging/dementing -qualia-schema_and_prospective-profoundsupererogation -of-mentally-aestheticised postconverging/dialectical-thinking -qualiaschema>; and so with regards to the-very-same-immanent-existence/intrinsicreality/ontological-veridicality,-as-to-'human<amplituding/formativeepistemicity>totalising purview-of-construal'. This divergence implies lack of mutualintelligibility as of lack of common apriorising/axiomatising/referencing/intelligibilitysettingup/measuringinstrumenting for common/mutual aposteriorising/logicising/deriving/intelligising/measuring, beyond just contending differences as of aposteriorising/logicising/deriving/intelligising/measuring which do not imply the divergence of common apriorising/axiomatising/referencing/intelligibilitysettingup/measuringinstrumenting as of underlying relative-ontological-incompleteness 8 /relative-ontological-completeness 〈sublimating referencing/registering/decisioning,-as-self-becoming/selfconflatedness /formative-supererogating-<projective/reprojective-aestheticising-re-motif- 
and-re-apriorising/re-axiomatising/re-referencing,-in-perspective-ontological-

normalcy/postconvergence $>\rangle$. This is so-implied with regards to say Socrates/Plato/Aristotle with their schools Being-development/ontological-framework-expansion-as-to-depth-ofontologising-development-as-infrastructure-of- meaningfulness-and-teleology common apriorising/axiomatising/referencing/intelligibilitysettingup/measuringinstrumenting in prospective relative-ontological-completeness ${ }^{87} \mathrm{~s}$ but as of unaffirmation/deprojection/deassertion/epistemic-decadence/undueness-invalidatinglogicising/unsuitable-measuringinstrument-invalidating-measuring-<as-to-preconverging-ordementing -apriorising-psychologism> devaluing their ${ }^{79}$ presencing - absolutising-identitiveconstitutedness $^{14} \quad$ conventioning-referencing as of aphistry apriorising/axiomatising/referencing/intelligibilitysettingup/measuringinstrumenting in prior relative-ontological-incompleteness $^{88}$ or as with budding-positivists Beingdevelopment/ontological-framework-expansion-as-to-depth-of-ontologising-development-asinfrastructure-of- meaningfulness-and-teleology common apriorising/axiomatising/referencing/intelligibilitysettingup/measuringinstrumenting in prospective relative-ontological-completeness ${ }^{87} \mathrm{~s}$ but as unaffirmation/deprojection/deassertion/epistemic-decadence/undueness-invalidatinglogicising/unsuitable-measuringinstrument-invalidating-measuring-<as-to-preconverging-ordementing -apriorising-psychologism $>$ devaluing their ${ }^{79}$ presencing - absolutising-identitiveconstitutedness $^{14} \quad$ conventioning-referencing in medieval-scholasticism pedantising/muddling/formulaic-hollowing-out — in-subontologisation/subpotentiation〈blurring/undermining-of-prospective-totalising-entailing,-as-to-entailing<amplituding/formative-epistemicity>totalising in-relative-ontological-completeness > apriorising/axiomatising/referencing/intelligibilitysettingup/measuringinstrumenting in prior relative-ontological-incompleteness ${ }^{8} \mathrm{~s}$ or with a Rousseau Being-development/ontological- 
framework-expansion-as-to-depth-of-ontologising-development-as-infrastructure-ofmeaningfulness-and-teleology as of social enlightenment common apriorising/axiomatising/referencing/intelligibilitysettingup/measuringinstrumenting in prospective relative-ontological-completeness ${ }^{87} \mathrm{~s}$ but as of unaffirmation/deprojection/deassertion/epistemic-decadence/undueness-invalidatinglogicising/unsuitable-measuringinstrument-invalidating-measuring-<as-to-preconverging-ordementing -apriorising-psychologism $>$ devaluing the conventioning-referencing as of aristocratic/despotic self-aggrandisement apriorising/axiomatising/referencing/intelligibilitysettingup/measuringinstrumenting in prior relative-ontological-incompleteness ${ }^{8} \mathrm{~s}$. The point here being that the stake for prospective transcendence-and-sublimity/sublimation/supererogatory-de-mentativity are ever always beyond any given registry-worldview/dimension <amplituding/formative $>$ wooden-language〈imbued — averaging-of-thought-<as-to-leveling/ressentiment/closed-construct-ofmeaningfulness-and-teleology -as-of-'nondescript/ignorable-void '-with-regards-toprospective-apriorising-implications $>>\quad$ conventioning-referencing $<$ amplituding/formativeepistemicity $>$ totalising $\sim$ self-referencing-syncretising/circularity/interiorising/akrasiatic-drag ${ }^{34}$, and by that token is geared towards antinihilistic undermining of sophistic/pedantic dispositions as of incrementalism-in-relative-ontological-incompleteness enframed/disontologising conceptualisation. With the very blurry nature of the social, even with the best of intentions as when continental philosophers try to engage the analytic tradition, the experience has often turned out poorly given the failure to explicitly grasp/appreciate the conflicting implications of their differing knowledge commitments as of supposedly coherent ontological-commitment ${ }^{6}<$ implied-self-assuredness-of-ontological-goodfaith/authenticity postconverging-de-mentating/structuring/paradigming -as-being-as-ofexistential-reality $>$ implied ecstatic-totalising-entailing/nested-congruence with the former and 
logical-commitment implied atomising/taking-to-pieces formalisation with the latter; even as going by conceptual-patterning-〈as-devoid-of-'prospectively_implicited_attendant-ontologicalcontiguity ' $\sim$ educed-

existentialising/contextualising/textualising_'intelligibility/epistemicity/reflexivity-contiguity$<$ imbued-notional $\sim$ cogency $>$ ' 's-reifying-or-elucidating-of-" prospective-relative-ontologicalcompleteness ' ;-so-rather-enabled-<by-a- nonpresencing-divulging-of-momentoushistoriality/ontological-eventfulness /ontological-aesthetic-tracing-<perspectiveontological-normalcy/postconvergence-reflected-‘epistemicity-relativism-determinism’’>, it can be naively implied that similar conceptual wordings imply similar knowledge commitments and operant articulations. In the same vein, one can say that notions like spacetime, force, atoms, etc. in the physics <amplituding/formative-epistemicity>totalising $\sim$ devolvedpurview/domain-of-construal-as-intrinsic-reality/ontological-veridicality/existential-reality are inherent supposedly coherent ontological-commitment $-<$ implied-self-assuredness-ofontological-good-faith/authenticity $\sim$ postconverging-dementating/structuring/paradigming -as-being-as-of-existential-reality $>$ about 'axiomaticconstruct construal of ecstatic-existence/the-nature-of-the-world/conditions' that are in need of knowledge-reification $\sim$ gesturing-and-accounting — of-epistemic-phenomenalism- $<$ inprospective_psychologismic apriorising/axiomatising/referencing-\{of-'prospectively implicited_attendant-ontological-contiguity ' educedexistentialising/contextualising/textualising_'intelligibility/epistemicity/reflexivity-contiguity$<$ imbued-notional cogency $>$ ' $\}$-conflatedness -in-\{preconverging-disentailment by\} postconverging-entailment $>$ as of <amplituding/formative-epistemicity $>$ causality $\sim$ as-toprojective-totalitative-implications-of-prospective- nonpresencing,-for-explicating $\sim$ relativeunreflexivity/relative-reflexivity ontological-contiguity , and logic can only be the inner working coherence/contiguity of axiomatic-construct construal of ecstatic-existence/the-nature- 
of-the-world/conditions' as of such supposedly coherent ontological-commitment $-<$ implied self-assuredness-of-ontological-good-faith/authenticity postconverging-de-

mentating/structuring/paradigming -as-being-as-of-existential-reality $>$, and all the physics that is relevant is their further knowledge-reification $\sim$ gesturing-and-accounting-of-epistemicphenomenalism- $<$ in-prospective_psychologismic $\sim$ apriorising/axiomatising/referencing- of'prospectively implicited_attendant-ontological-contiguity ' educedexistentialising/contextualising/textualising_intelligibility/epistemicity/reflexivity_contiguity<imbued-notional cogency $\left.>^{\prime} \quad\right\}$-conflatedness -in-\{preconverging disentailment by\} postconverging-entailment> as physics knowledge as of its ontological-veridical meaningfulness-and-teleology as can be validated and is falsifiable by $<$ amplituding/formative-epistemicity $>$ causality $\sim$ as-to-projective-totalitative-implications-ofprospective- nonpresencing,-for-explicating $\sim$ relative-unreflexivity/relative-reflexivity ontological-contiguity. Even mathematics it is often underestimated works rather on supposedly coherent ontological-commitment $-<$ implied - self-assuredness-of-ontologicalgood-faith/authenticity postconverging-de-mentating/structuring/paradigming -as-beingas-of-existential-reality> as of 'axiomatic-construct construal of ecstatic-existence/the-natureof-the-world/conditions', as of the knowledge-reification $\sim$ gesturing-and-accounting-ofepistemic-phenomenalism- $<$ in-

prospective_psychologismic apriorising/axiomatising/referencing-\{of- ${ }^{\star}$ prospectively implicited_attendant-ontological-contiguity ' educedexistentialising/contextualising/textualising_intelligibility/epistemicity/reflexivity-contiguity<imbued-notional $\left.\sim \operatorname{cogency}>^{\prime} \quad\right\}$-conflatedness -in-\{preconverging-disentailment by\} posteonverging entailment> constraining implications of its 'equal sign', speaking of a selfconscious awareness that calculations should reflect-and-be-constrained as per calculations operative validation and falsifiability ${ }^{42}$ with regards to 'axiomatic-construct construal of ecstatic- 
existence/the-nature-of-the-world/conditions', and with mathematical logic as of mathematics supposedly coherent ontological-commitment $-<$ implied - self-assuredness-of-ontologicalgood-faith/authenticity postconverging-de-mentating/structuring/paradigming -as-beingas-of-existential-reality> 'concurrent formatting as formalisation' being the 'inner working coherence/contiguity of axiomatic-construct construal of ecstatic-existence/the-nature-of-theworld/conditions' towards that purpose. Such reflecting-and-constraining to 'axiomaticconstruct construal of ecstatic-existence/the-nature-of-the-world/conditions' can difficultly be said with regards to the overall atomising/taking-to-pieces formalisation approach as of its $<$ amplituding/formative-epistemicity $>$ totalising $\sim$ self-referencing-

syncretising/circularity/interiorising/akrasiatic-drag ${ }^{34}$ presumption; which strangely enough has been subjected to no less than five major successive internal indictments but still keeps up its operative predilection of atomising/taking-to-pieces, with this author of the opinion that such an in-built institutional grip might be in-many-ways inducing diversion of intellectual and scholarly resources from a more profound advancement of philosophy for greater human transformation implications. It is important to grasp here that 'axiomatic-construct construal of ecstaticexistence/the-nature-of-the-world/conditions' is superseding/preceding as of existence's ecstatic singularity, such that ontology supersedes logic which is rather ontology's 'inner working coherence/contiguity of axiomatic-construct construal of ecstatic-existence/the-nature-of-theworld/conditions'. It is rather the 'ecstatic manifestation of existence and then human experience-and-interpretation of that ecstatic manifestation of existence' that provides the 'apriorising/axiomatising/referencing/intelligibilitysettingup/measuringinstrumenting as axiomatic-construct' insight about supposedly coherent ontological-commitment ${ }_{-}$implied self-assuredness-of-ontological-good-faith/authenticity postconverging-dementating/structuring/paradigming -as-being-as-of-existential-reality $>\quad$ articulated as 'axiomatic-construct construal of ecstatic-existence/the-nature-of-the-world/conditions' and not 
mere logic, with logic not able by itself to derive 'axiomatic-construct construal of ecstaticexistence/the-nature-of-the-world/conditions' as it is often naively implied but instead reflecting the 'inner working coherence/contiguity of axiomatic-construct construal of ecstaticexistence/the-nature-of-the-world/conditions' and as any such implied derivation is rather as of explicited/implicited coherence/contiguity with another/other 'transversally devolving-orcomplementary ontological/axiomatic-construct conceptions' as of 'axiomatic-construct construal of ecstatic-existence/the-nature-of-the-world/conditions'. Interestingly, such notions like experimentation, testing, trials, case studies, observational studies, interviews, surveys, data analysis, content analysis, statistics and basically overall research orientations and research methods as of their formal study implications are just focussed-and-contrasted extensions, with regards to the general and normal day to day experience about living itself for the inspired construing of the 'ecstatic manifestation of existence and then human experience-andinterpretation of that ecstatic manifestation of existence' providing insight about supposedly coherent ontological-commitment $-<$ implied - self-assuredness-of-ontological-goodfaith/authenticity postconverging-de-mentating/structuring/paradigming -as-being-as-ofexistential-reality $>$ in producing knowledge as ${ }^{56}$ meaningfulness-and-teleology ${ }^{9}$; such that critically, appropriate philosophical phenomenal insight with regards to the 'general and normal day to day experience about living itself' as of observational and articulated ontologicalpertinence sufficiency, and as supplemented with the grasp and engagement with other philosophical works, speaks of veridical scientific insight and validity subject to $<$ amplituding/formative-epistemicity $>$ causality $\sim$ as-to-projective-totalitative-implications-ofprospective- nonpresencing,-for-explicating relative-unreflexivity/relative-reflexivity ontological-contiguity , and so because such well-inspired experience-and-interpretation from 'general and normal day to day experience about living itself' in the philosophical domain-ofstudy is generally more ontologically profound and comprehensive as of 
apriorising/axiomatising/referencing-\{of-'prospectively_implicited_attendant-ontological-

contiguity ' educed-

existentialising/contextualising/textualising_'intelligibility/epistemicity/reflexivity-contiguity-

<imbued-notional cogency >' \}-conflatedness ${ }^{13}$ in-\{preconverging-disentailment by\}

postconverging-entailment than any contrasted ad-hoc and focussed domain study, even though such domain studies may be insightfully relevant in specific ways but still as of the more profound background of well-inspired experience-and-interpretation from 'general and normal day to day experience about living itself'. The point here is to highlight that by its very given domain-of-study with respect to overall existence, philosophical knowledge more profoundly makes a totalising-entailing apriorising/axiomatising/referencing-\{of- ${ }^{\text {prospectively }}$ implicited_attendant-ontological-contiguity ' educed-

existentialising/contextualising/textualising_'intelligibility/epistemicity/reflexivity-contiguity-

<imbued-notional cogency $>$ ' \}-conflatedness ${ }^{13}$-in-\{preconverging disentailment by\}

postconverging-entailment demand on human living experience for the inspired construing of the 'ecstatic manifestation of existence and then human experience-and-interpretation of that ecstatic manifestation of existence' than other more specific domains-of-study for which ad-hoc and focussed domain study methods are pervasively decisive for ontological pertinence. But then this is more a question of 'expanded onticising construal of existence as of $<$ amplituding/formative-epistemicity>totalising devolved purviews of existence so-construed as subject-matters/domains-of-study'. The ontological-veracity and epistemic-veracity of all such <amplituding/formative-epistemicity $>$ totalising $\sim$ devolved-purview-as-domain-ofconstrual-as-intrinsic-reality/ontological-veridicality are effectively as of the-very-same underlying congruent philosophical domain-of-study construal of ecstatic manifestation of existence but for their 'onticising specifisms of existence's ecstatic manifestation'; as so-implied as of overall existence metaphoricity ${ }^{57}$ ecstasy reifying-and-empowering-reflexivity-of-ecstatic- 
existence-as-panintelligibility/panreflexivity ${ }^{73}-\langle$ existentially-imbued-and-educing-< $<$ 价istemic thermeneutically/textually/reprojectingly/supererogatingly/zeroingly/re-acutingly,$\{$ decompulsing\} delinearity $\sim$ for-cogency $\geq$-epistemic-perspective-of-projective/reprojectiveaestheticising-re-motif-and-re-apriorising/re-axiomatising/re-referencing conceptualisation,as-herein-specifically-relevant-to human-subpotency) as of supervening-conflatedness ${ }^{13}$. Knowledge as ${ }^{56}$ meaningfulness-and-teleology ${ }^{99}$, whether of underlying ontological-construal or ontical-construal, is epistemically validated as of supposedly coherent ontologicalcommitment $-<$ implied — self-assuredness-of-ontological-goodfaith/authenticity postconverging-de-mentating/structuring/paradigming -as-being-as-ofexistential-reality $>$ as reflected by $<$ mplinding/formative-epistemicity $>$ causality $\sim$ as-toprojective-totalitative-implications-of-prospective- nonpresencing,-for-explicating relativeunreflexivity/relative-reflexivity - ontological-contiguity . Inherently, because humansubpotency supposedly coherent ontological-commitment $-<$ implied-self-assuredness-ofontological-good-faith/authenticity $\sim$ postconverging-dementating/structuring/paradigming -as-being-as-of-existential-reality $>$ is very much intimately linked with the ontological-performance ${ }^{72}-<$ including-virtue-as- $^{2}$ the ontology $>$ /morality/ethics/justice/etc. of human as of prospective relative-ontologicalcompleteness ${ }^{87}$ appraisal, it is always ever the case that as of human <amplituding/formativeepistemicity>-totalising thrownness-in-existence $^{35}$ the validation of knowledge as meaningfulness-and-teleology as of supposedly coherent ontological-commitment <implied-self-assuredness-of-ontological-good-faith/authenticity $\sim$ postconverging-dementating/structuring/paradigming -as-being-as-of-existential-reality $>$ is equally as of thevery-same-immanent-existence/intrinsic-reality/ontological-veridicality,-as-to'human< $<$ amplituding/formative-epistemicity>totalising $\sim$ purview-of-construal' or $<$ amplituding/formative-epistemicity $>$ totalising $\sim$ devolved-purviews-as-domains-of-construal- 
as-intrinsic-reality-or-ontological-veridicality constructs; which construal is necessarily as of apriorising/axiomatising/referencing-\{of-'prospectively_implicited_attendant-ontologicalcontiguity ' educed-

existentialising/contextualising/textualising_intelligibility/epistemicity/reflexivity-contiguity<imbued-notional cogency $\left.>^{\prime} \quad\right\}$-conflatedness ${ }^{13}$ in-\{preconverging-disentailment by postconverging-entailment with respect to the-very-same-immanent-existence/intrinsicreality/ontological-veridicality,-as-to-'human<amplituding/formativeepistemicity>totalising $\sim$ purview-of-construal ${ }^{\prime} \quad$ or $\quad<$ amplituding/formativeepistemicity $>$ totalising $\sim$ devolved-purviews-as-domains-of-construal-as-intrinsic-reality-orontological-veridicality and relative-ontological-completeness ${ }^{87}$ as of human limited-mentationcapacity-deepening —as-subjecting-limitedness/human-subpotency-to-'educedunlimitedness/existence-sublimating nascence' ${ }^{53}$, thus invalidating the epistemic-veracity of apriorising/axiomatising/referencing-\{of- prospectively_implicited_attendant-ontologicalcontiguity ' $\sim$ educedexistentialising/contextualising/textualising_'intelligibility/epistemicity/reflexivity_contiguity<imbued-notional cogency>' $\quad\}$-constitutedness ${ }^{14}$-in-preconverging-entailment $\quad$ of knowledge. The implication here is that the epistemic-veracity of knowledge as meaningfulness-and-teleology' is rather as of the '<amplituding/formativeepistemicity>totalising/circumscribing/delineating construal as of existence' with $<$ amplituding/formative-epistemicity $>$ totalising $\sim$ devolved-purview-as-domain-of-construalas-intrinsic-reality/ontological-veridicality rather "narrowing-construals of their specificallyimplied human-subpotency as to overall reifying-and-empowering-reflexivity-of-ecstaticexistence-as-panintelligibility/panreflexivity ${ }^{33}$-〈existentially-imbued-and-educing-< $<$ epistemictotalising thermeneutically/textually/reprojectingly/supererogatingly/zeroing/y/re-acutingly,\{decompulsing $d$ delinearity $\sim$ for-cogency $\geq$-epistemic-perspective-of-projective/reprojective- 
aestheticising-re-motif-and-re-apriorising/re-axiomatising/re-referencing conceptualisation,-

as-herein-specifically-relevant to human-subpotency), and hence of nested-congruence with existence'. This further points out that the traditional explicited apriorising/axiomatising/referencing-\{of-"prospectively_implicited_attendant-ontologicalcontiguity ' educed-

existentialising/contextualising/textualising_ intelligibility/epistemicity/reflexivity-contiguity$<$ imbued-notional cogency $\left.>^{\prime} \quad\right\}$-constitutedness ${ }^{1}$-in-preconverging-entailment conception of the notion of cause-and-effect so-implied herein as <amplituding/formativeepistemicity $>$ causality $\sim$ as-to-projective-totalitative-implications-of-prospectivenonpresencing,-for-explicating relative-unreflexivity/relative-reflexivity - ontologicalcontiguity is actually epistemically-impertinent and flawed; as this traditional conception tends beyond-the-consciousness-awareness-teleology ${ }^{9}-<$ of-preconverging-existential-extrication-asof-existential-unthought $>$ to imply unconnectedness-with/not-in-nested-congruence with thevery-same-immanent-existence/intrinsic-reality/ontological-veridicality,-as-to'human<amplituding/formative-epistemicity $>$ totalising $\sim$ purview-of-construal' or $<$ amplituding/formative-epistemicity $>$ totalising $\sim$ devolved-purviews-as-domains-of-construalas-intrinsic-reality-or-ontological-veridicality, hence implicitly-or-explicitly liable to elaboration-as-to-mere-extrapolating/constituting/abstracting/deducing/inferring-ofelucidation-outside_-'prospectively_implicited_attendant-ontological-contiguity ${ }^{67}$ ' educedexistentialising/contextualising/textualising_intelligibility/epistemicity/reflexivity-contiguity$<$ imbued-notional cogency $>$ ' . This apriorising/axiomatising/referencing-\{of- 'prospectivelyimplicited_attendant-ontological-contiguity ' educedexistentialising/contextualising/textualising_'intelligibility/epistemicity/reflexivity-contiguity<imbued-notional cogency $\left.>^{\prime} \quad\right\}$-constitutedness ${ }^{14}$-in-preconverging-entailment nature of the notion of cause-and-effect so-implied veridically as <amplituding/formative- 
epistemicity $>$ causality $\sim$ as-to-projective-totalitative-implications-of-prospective-

nonpresencing,-for-explicating relative-unreflexivity/relative-reflexivity - ontological-

contiguity arises as of the 'basic and mere mimicking and deployment' of supposedly science approaches and methodologies on the naïve assumption that their mere deployment is inherently of epistemic-veracity, such that such deployment when it undermines the 'inherently nestedcongruence of the-very-same-immanent-existence/intrinsic-reality/ontological-veridicality,-asto-'human<amplituding/formative-epistemicity $>$ totalising $\sim$ purview-of-construal'

or $<$ amplituding/formative-epistemicity $>$ totalising $\sim$ devolved-purviews-as-domains-of-construalas-intrinsic-reality-or-ontological-veridicality' is in effect just elaboration-as-to-mereextrapolating/constituting/abstracting/deducing/inferring-of-elucidation-outside'prospectively_implicited_attendant-ontological-contiguity ${ }^{67}$ ' educedexistentialising/contextualising/textualising_intelligibility/epistemicity/reflexivity-contiguity$<$ imbued-notional cogency>’ . Rather any such science approaches and methodologies striving to validate knowledge as ${ }^{5}$ meaningfulness-and-teleology ${ }^{9}$ by the supposedly coherent

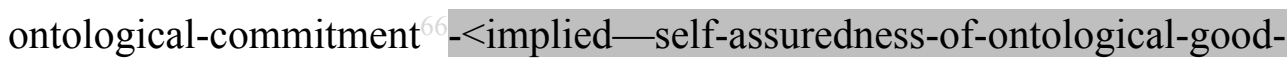
faith/authenticity postconverging-de-mentating/structuring/paradigming -as-being-as-ofexistential-reality $>$ reflected by $<$ emplituding/formative-epistemicity $>$ causality $\sim$ as-toprojective-totalitative-implications-of-prospective- nonpresencing,-for-explicating relativeunreflexivity/relative-reflexivity ontological-contiguity as to existencepotency ${ }^{32} \sim$ sublimating-nascence,-disclosed-from-prospective-epistemic-digression, $\quad$ is necessarily instigated as from a philosophical depth of contemplation as of 'coherence/contiguity-of-superseding-oneness-of-ontology-implied-as-of-inherent-existencecoherence/contiguity,-and-so-construed-as-the-enabler-of-insight-or-intuition-or-foresight-asof-embodied-consciousness'. Insightfully, while in-many-ways such an elucidation hardly needs to be explicited in many a natural science domain-of-study as of their directly constraining cause- 
and-effect nature such that such nested-congruence with existence will often tend to arise naturally as of valid/invalid outcome constraining of <amplituding/formativeepistemicity $>$ causality $\sim$ as-to-projective-totalitative-implications-of-prospectivenonpresencing,-for-explicating relative-unreflexivity/relative-reflexivity - ontological-

contiguity as to existence-potency ${ }^{32} \sim$ sublimating-nascence,-disclosed-from-prospectiveepistemic-digression ${ }_{2}$ this unexplicited implicitness should not be confused with the notion that the natural sciences are essentially reduced to their science approaches and methodologies; as is often and awkwardly naively construed from without in many a social domain-of-study. The fact is notwithstanding the 'onticising specifisms of existence's ecstatic manifestation' of the natural science domains-of-study, these are just as driven by a philosophical depth of contemplation as of 'coherence/contiguity-of-superseding-oneness-of-ontology-implied-as-of-inherentexistence-coherence/contiguity,-and-so-construed-as-the-enabler-of-insight-or-intuition-orforesight-as-of-embodied-consciousness' as reflected in the often 'unspoken/unelaborated scientific hunches and fine-tuning' which is effectively what drives their deployed science approaches and methodologies for their sought after scientific reifying outcomes; and it is this subsuming/nestedness that keeps such science approaches and methodologies in nestedcongruence with 'implicitantontological-contiguity ${ }^{67}$ ' educedexistentialising/contextualising/textualising_'intelligibility/epistemicity/reflexivity-contiguity$<$ imbued-notional cogency $>$ '40 as of apriorising/axiomatising/referencing-\{of-'prespectively implicited_attendant-ontological-contiguity ' reducedexistentialising/contextualising/textualising_'intelligibility/epistemicity/reflexivity-contiguity<imbued-notional cogency >' \}-conflatedness ${ }^{13}$ in-\{preconverging disentailment by\} postariment; so-implied as of their supposedly coherent ontologicalcommitment $-<$ implied — self-assuredness-of-ontological-goodfaith/authenticity postconverging-de-mentating/structuring/paradigming -as-being-as-of- 
existential-reality $>$ reflected by $<$ amplituding/formative-epistemicity $>$ causality $\sim$ as-toprojective-totalitative-implications-of-prospective- nonpresencing,-for-explicating relativeunreflexivity/relative-reflexivity - ontological-contiguity as to existencepotency ${ }^{39} \sim$ sublimating-nascence,-disclosed-from-prospective-epistemic-digression. In other words, science approaches and methodologies in reality are simply the extension of philosophical depth of contemplation when it comes to 'onticising specifisms of existence's ecstatic manifestation' as of the <amplituding/formative-epistemicity>totalising $\sim$ devolvedpurview-as-domain-of-construal-as-intrinsic-reality/ontological-veridicality of natural sciences; with the implication that the philosophical depth of contemplation has to be undertaken, notwithstanding the fact that the implicited nature in the natural sciences of their onticising direct sublimating-validation/desublimating-invalidation outcomes as of <amplituding/formativeepistemicity $>$ causality $\sim$ as-to-projective-totalitative-implications-of-prospectivenonpresencing,-for-explicating relative-unreflexivity/relative-reflexivity - ontological-

contiguity will seem to wrongly imply otherwise. Such a philosophical depth of contemplation in nested-congruence as of 'coherence/contiguity-of-superseding-oneness-of-ontology-impliedas-of-inherent-existence-coherence/contiguity,-and-so-construed-as-the-enabler-of-insight-orintuition-or-foresight-as-of-embodied-consciousness' is very often incomplete, of-divviedtheorisation and/or 'poor coherence of theoricisation with operant approaches and methodologies', when it comes to many a social domain-of-study; as quite often theorisation in many a social domain-of-study strives on disparateness, rather than a tendency to '<amplituding/formative-epistemicity $>$ causality $~ a s-t o-p r o j e c t i v e-t o t a l i t a t i v e-$ implications-ofprospective- nonpresencing,-for-explicating relative-unreflexivity/relative-reflexivity _ ontological-contiguity as to existence-potency ${ }^{32} \sim$ sublimating-nascence,-disclosed-fromprospective-epistemic-digression enforced' unifying coherence as in many a natural science domains-of-study, with the consequence that studies are often aloof to direct 
'implicited_attendant-ontological-contiguity ${ }^{67}$ educedexistentialising/contextualising/textualising_'intelligibility/epistemicity/reflexivity_contiguity$<$ imbued-notional cogency $>$ knowledge reifying exercise as of a tendency to technicality as of institutional-being-and-craft sterile/anecdotal imprimatur, 'fallback to unquestioned/dogmatic normativities' and 'habituated dispositions' which priorly enframed subject-matters and institutional-setups preconverging/postconverging-dementatively/structurally/paradigmatically stifle the possibility for conceptualisation as to existence-potency ${ }^{39} \sim$ sublimating-nascence,-disclosed-from-prospective-epistemic-digression sublimating-validation/desublimating-invalidation implications, beyond their conventioningreferencing $\quad<$ preconverging $\sim$ 'motif-and-apriorising/axiomatising/referencing'-entailing >existentialising — enframing/imprintedness-〈as-to- historicity-tracing-in-presencinghyperrealisation/hyperreal-transposition $\rangle$. Ultimately the bigger issue arises as of the poorlysingularised/poorly-immanented nature of many a social domain-of-study unlike the grand singularised/immanented totalising/circumscribing/delineating $\quad<$ amplituding/formativeepistemicity $>$ reference-of-thought- ${ }^{8}$ devolving ${ }^{4}$ foregrounding_entailment- $<$ in-successionof-profound-supererogation $>-\langle$ postconverging-narrowing-down $\sim$ sublimation-as-to‘existence — as-sublimating-withdrawal/unenframing/re-ontologising,-elicited-fromprospective-profound-supererogation '-in-reflecting-'immanent $\sim$ relativeunreflexivity/relative -reflexivity ontological-contiguity ' $;$;-as-operativenotional deprocrypticism $\rangle$ that are actually actively sought in the natural sciences; and this author portends that the suprastructuralism/postmodernism as of notional ${ }^{18 \text { deprocrypticism }}$ ontology as 'true-ontology_as-of-Being-development/ontological-framework-expansion-asto-depth-of-ontologising-development-as-infrastructure-of- meaningfulness-and-teleology holds the promise for such effective grand singularised/immanented social conceptualisation that doesn't dodge/ignore/disregard outstanding questions about the human existential- 
preconverging/postconverging-de-mentative/structural/paradigmatic biases arising beyond-theconsciousness-awareness-teleology ${ }^{9}<$ of-preconverging-existential-extrication-as-of-

existential-unthought $>$ as of human emotional-involvement and sophistic/pedantic distortion of perception of reality so-implied in our present positivism- ${ }^{8}$ procrypticism 'attendant-ontologyas-of-conventioning-referencing' and just as well when 'science-ideology' seem to subvert and undermine science-in-practice. Worst still while in effect the idea of specialisation in many a natural science domain is often the natural progression of a 'comprehensively elucidated/reified foregrounding_entailment- $<$ in-succession-of-profound-supererogation ${ }^{9}>-\langle$ postconverging narrowing-down $\sim$ sublimation-as-to-'existence - as-sublimating-withdrawal/unenframing/reontologising,-elicited-from-prospective-profound-supererogation '-in-reflecting‘immanent relative-unreflexivity/relative-reflexivity ontological-contiguity ';-as-operativenotional deprocrypticism $\rangle$ of the given natural science domain-of-study' with specialism more of a furtherance of such a ${ }^{45}$ foregrounding_entailment- $<$ in-succession-of-profoundsupererogation $>-\langle$ postconverging-narrowing-down $\sim$ sublimation-as-to-'existence- assublimating-withdrawal/unenframing/re-ontologising,-elicited-from-prospective-profoundsupererogation '-in-reflecting-'immanent relative-unreflexivity/relative-reflexivityontological-contiguity ';--as-operative-notional deprocrypticism) scheme in a strong arborescent syncing with the subject-matter general-theoretical-level, in many such social domain-of-study of disparateness-of-conceptualisation-<unforegrounding-disentailment,failing-prospectively-to-reflect-'immanent relative-unreflexivity/relative-reflexivity ontological-contiguity '> (including some science domains as well which naively tend to draw comprehensive social and human implications of their studies) the drawback to such specialisms is often associated with 'major interpretative loopholes at the general-theoretical-level of the subject-matter' with regards to the knowledge-reification $\sim$ gesturing-and-accounting-of- 
epistemic-phenomenalism-<in-

prospective_psychologismic apriorising/axiomatising/referencing-\{of-'prospectively implicited_attendant-ontological-contiguity ' educed-

existentialising/contextualising/textualising_intelligibility/epistemicity/reflexivity-contiguity<imbued-notional cogency $>>\quad\}$-conflatedness -in-\{preconverging-disentailment by\} postconverging-entailment $>$ implications of supposedly specialisation domains and their studies since such an approach fails to effectively validate its methodological and conclusive implications with respect to the subject-matter general-theoretical-level implied ontology as of the subject-matter specific epistemic-conception phenomenal/manifest $\sim$ subpotency-〈intransitive-conflatedness -reflexivity,-in-the-full-potency-of-existence's $\sim$ sublimatingnascence as to overall reifying-and-empowering-reflexivity-of-ecstatic-existence-aspanintelligibility/panreflexivity ${ }^{3}-\langle$ existentially-imbued-and-educing-<epistemictotalising ${ }^{3}$ hermeneutically/textually/reprojectingly/supererogatingly/zeroingly/re-acutingly,$\{$ decompulsing $\}$ delinearity $\sim$ for-cogency $\geq$-epistemic-perspective-of-projective/reprojectiveaestheticising-re-motif-and-re-apriorising/re-axiomatising/re-referencing conceptualisation,as-herein-specifically-relevant-to human-subpotency) so-reflected in its philosophical depth of contemplation as of 'coherence/contiguity-of-superseding-oneness-of-ontology-implied-as-ofinherent-existence-coherence/contiguity,-and-so-construed-as-the-enabler-of-insight-orintuition-or-foresight-as-of-embodied-consciousness'. This weakness is often reflected in naïve use of statistics and methods as well as drawing out conclusions based rather on ordinary average-thinking interpretation as of human-subpotency 'rather than interpretations and conclusions ensuing naturally and arborescently as from existence-potency ${ }^{39} \sim$ sublimatingnascence,-disclosed-from-prospective-epistemic-digression knowledge-reification $\sim$ gesturingand-accounting - of-epistemic-phenomenalism- $<$ in- 
implicited_attendant-ontological-contiguity ' educed-

existentialising/contextualising/textualising_'intelligibility/epistemicity/reflexivity_contiguity<imbued-notional cogency>> $\}$-conflatedness -in-\{preconverging-disentailment by\} postconverging-ntailment $>$ implications derived from the general-theoretical-level of the subject-matter as reflecting relative-unreflexivity/relative-reflexivity - ontological-contiguity ${ }^{67}$, whereas this is ever always the case with good practice in the natural sciences and just as well as with an increasingly self-conscious social science as specifically upheld by postmodernthought. For instance, the internal-coherence/nested-congruence speaking of the underlying foregrounding_entailment- $<$ in-succession-of-profound-supererogation $>>-\langle$ postconvergingnarrowing-down $\sim$ sublimation-as-to-'existence - as-sublimating-withdrawal/unenframing/reontologising,-elicited-from-prospective-profound-supererogation '-in-reflecting‘immanent relative-unreflexivity/relative-reflexivity ontological-contiguity ';-as-operativenotional deprocrypticism $\rangle$ implications articulated herein in reflecting holographically$<$ conjugatively-and-transfusively $>$ the relative-unreflexivity/relative-reflexivity - ontologicalcontiguity of-the-human-institutionalisation-process can be garnered by the fact that all the knowledge-reification $\sim$ gesturing-and-accounting—of-epistemic-phenomenalism- $<$ inprospective_psychologismic apriorising/axiomatising/referencing-\{of-`prospectively_ implicited_attendant-ontological-contiguity ' reducedexistentialising/contextualising/textualising_'intelligibility/epistemicity/reflexivity-contiguity<imbued-notional cogency >' \}-conflatedness -in-\{preconverging disentailment by\} postconverging-entailment $>$ herein implied arises as of the-very-same underlying 'objectifying cogent/tense/limpid-<as-of-prospective-profound-supererogation ${ }^{2}$,for-residuality—in-reoriginariness/re-origination> unifying process and gesturing/accounting-of-epistemicphenomenalism' as from 'prospective nonpresencing-<perspective-ontologicalnormalcy/postconvergence $>$ reflection of $<$ amplituding/formative-epistemicity $>$ causality $\sim$ as- 
to-projective-totalitative-implications-of-prospective- nonpresencing,-for-

explicating relative-unreflexivity/relative-reflexivity - ontological-contiguity of relativeontological-incompleteness 8 /relative-ontological-completeness ${ }^{87}$ -

〈sublimating referencing/registering/decisioning,--as-self-becoming/self-

conflatedness /formative-supererogating-<projective/reprojective-aestheticising-re-motif-

and-re-apriorising/re-axiomatising/re-referencing,-in-perspective-ontological-

normalcy/postconvergence $>$ '’, which is exactly what avails in the good practices of the natural sciences as driven by their 'cogent-unifying-operant-dynamics' whether with regards to say 'objectifying chemical processes articulation', 'objectifying physical principles articulation' or 'objectifying biological processes articulations', contrary to a practice of disparateness-ofconceptualisation-<unforegrounding-disentailment,-failing-prospectively-to-reflect-

‘immanent relative-unreflexivity/relative-reflexivity - ontological-contiguity '> in many a social domain-of-study wherein supposedly reified knowledge 'hardly has any underlying implied knowledge-reification $\sim$ gesturing-and-accounting — of-epistemic-phenomenalism- $<$ inprospective_psychologismic apriorising/axiomatising/referencing-\{of-‘prospectively implicited_attendant-ontological-contiguity ' educedexistentialising/contextualising/textualising_'intelligibility/epistemicity/reflexivity_contiguity<imbued-notional cogency $>$ ' \}-conflatedness -in-\{preconverging-disentailment by\} postconverging-entailment $>$ process/gesturing for its derivation' as 'cogent-unifying-operantdynamics' such that these turn out to be poorly operant or non-operant with the conceptualpatterning-〈as-devoid-of-'prospectively_implicited_attendant-ontologicalcontiguity ' educedexistentialising/contextualising/textualising_ 'intelligibility/epistemicity/reflexivity-contiguity$<$ imbued-notional cogency>' 's-reifying-or-elucidating-of-'prospective-relative-ontologicalcompleteness ';-so-rather-enabled-<by-a- nonpresencing-divulging-of-momentous- 


\section{historiality/ontological-eventfulness /ontological-aesthetic-tracing-<perspective-}

ontological-normalcy/postconvergence-reflected-‘epistemicity-relativism-determinism'>>

gesturing/accounting - of-epistemic-phenomenalism of mere-referring-confused-withexplicating, mere-mentioning-confused-with-deriving and mere-conceptual-synonymisingconfused-for-prospective-knowledge-reification $\sim$ gesturing-and-accounting —of-epistemicphenomenalism-<in-prospective_psychologismic $\sim$ apriorising/axiomatising/referencing- $\{$ of'prospectively_implicited_attendant-ontological-contiguity ' educedexistentialising/contextualising/textualising_'intelligibility/epistemicity/reflexivity_contiguity$<$ imbued-notional cogency $>$ ' $\}$-conflatedness -in-\{preconverging disentailment by\} postconverging entailment>, such that the underlying 'cogent-unifying-operant-dynamics' of the flawed prior_knowledge-reification $\sim$ gesturing-and-accounting-of-epistemicphenomenalism-<in-prior_psychologismic $\sim$ apriorising/axiomatising/referencing-\{of-'priorimplicited_attendant-ontological-contiguity ' educedexistentialising/contextualising/textualising_ 'intelligibility/epistemicity/reflexivity-contiguity<imbued-notional cogency >' $\}$-constitutedness -in-preconverging-entailment> is hardly operantly existent or is operantly non-existent. Bizarrely, the blurriness$<$ sterilising/anecdotalising/trivialising-of-prospective-re-ontologising_by-preconverging,-indisontologising-formulaic-dragging-out/hollowing-out $>$ of the social seem to be misconstrued as implying knowledge-reification $\sim$ gesturing-and-accounting-of-epistemic-phenomenalism$<$ in-prospective_psychologismic $\sim$ apriorising/axiomatising/referencing-\{of-'prospectively_ implicited_attendant-ontological-contiguity ' educedexistentialising/contextrising/textring_intelligibility/epistemicity/reflexivity-contiguity$<$ imbued-notional cogency $\left.>^{\prime} \quad\right\}$-conflatedness -in-\{preconverging-disentailment by\} postconverging entailment> in the social should reflect such blurriness$<$ sterilising/anecdotalising/trivialising-of-prospective-re-ontologising_by-preconverging,-in- 
disontologising-formulaic-dragging-out/hollowing-out>-as-of-disparateness rather than the ultimate objectifying $\quad{ }^{45}$ foregrounding_entailment- $<$ in-succession-of-profoundsupererogation ${ }^{9}>-\langle$ postconverging-narrowing-down $\sim$ sublimation-as-to-'existence-assublimating-withdrawal/unenframing/re-ontologising,-elicited-from-prospective-profoundsupererogation '-in-reflecting-'immanent relative unreflexivity/relative reflexivity ontological-contiguity ';--as-operative-notional deprocrypticism), and so by conjugating 'relative-ontological-completeness ${ }^{87}<$ amplituding/formative-epistemicity $>$ causality $~$ as-toprojective-totalitative-implications-of-prospective- nonpresencing,-for-explicating $\sim$ relativeunreflexivity/relative-reflexivity ontological-contiguity ' together with 'subject-matter breadth and depth' to achieve such an overall subject-matter knowledge-reification $\sim$ gesturingand-accounting - of-epistemic-phenomenalism-<inprospective_psychologismic apriorising/axiomatising/referencing-\{of- ${ }^{\text {}}$ prospectively implicited_attendant-ontological-contiguity ' educedexistentialising/contextualising/textualising_'intelligibility/epistemicity/reflexivity_contiguity<imbued-notional cogency >' \}-conflatedness -in-\{preconverging disentailment by\} postconverging-entailment $>$ as of objectifying ${ }^{4}$ foregrounding _ entailment- $<$ in-succession-ofprofound-supererogation $>$-〈postconverging-narrowing-down $\sim$ sublimation-as-to- 'existenceas-sublimating-withdrawal/unenframing/re-ontologising,-elicited-from-prospective-profoundsupererogation '-in-reflecting-'immanent relative-unreflexivity/relative-reflexivity ontological-contiguity ';-as-operative-notional deprocrypticism), in order to elucidate the blurriness-<sterilising/anecdotalising/trivialising-of-prospective-re-ontologising_bypreconverging,-in-disontologising-formulaic-dragging-out/hollowing-out>. Such that quite often as of institutional practice the notion of ${ }^{45}$ foregrounding _entailment- $<$ in-succession-ofprofound-supererogation $>$ - $\langle$ postconverging-narrowing-down $\sim$ sublimation-as-to-'existenceas-sublimating-withdrawal/unenframing/re-ontologising,-elicited-from-prospective-profound- 
ontological-contiguity ';-as-operative-notional deprocrypticism) is often misconstrued nonaporetically/undilemmatically/unreframed/untransformed as 'merely bringing together disparate conceptualisations for their cross-examination (on the basis of prior reproducibilitymathesis/motif/thrownness-disposition,-as-reproducibility-of-aestheticisation)' in a naïve substitution of the idea that ${ }^{45}$ foregrounding_entailment- $<$ in-succession-of-profoundsupererogation $>$-〈postconverging-narrowing-down $\sim$ sublimation-as-to-'existence-assublimating-withdrawal/unenframing/re-ontologising,-elicited-from-prospective-profoundsupererogation '-in-reflecting-'immanent relative-unreflexivity/relative-reflexivityontological-contiguity ';--as-operative-notional deprocrypticism) truly speaks of humansubpotency-aporia/undecidability/dilemma/ought-

indeterminacy/deficiency/limitation/constraint elicited reframing/transforming/reconstrual underlying 'cogent-unifying-operant-dynamics' that 'runs-through/deflates' implied conceptualisations in elucidating their ontological-veracity by its capacity to 'objectively deflate-all-conceptualisations as of operant <amplituding/formativeepistemicity $>$ causality $\sim$ as-to-projective-totalitative-implications-of-prospectivenonpresencing,-for-explicating relative-unreflexivity/relative-reflexivity - ontologicalcontiguity as to apriorising/axiomatising/referencing-\{of-" prospectively implicited_attendant-ontological-contiguity ' educedexistentialising/contextualising/textualising_'intelligibility/epistemicity/reflexivity-contiguity$<$ imbued-notional cogency $\left.>^{\prime}\right\}$-conflatedness ${ }^{13}$-in-\{preconverging-disentailment by\} postconverging-entailment' as herein implied (involving prospective originariness-parrhesia,-as-spontaneity-of-aestheticisation for veridical ontologisation/ontologicalveracity/aestheticisation-towards-ontology), rather than vague contrasting-and-comparison of disparate conceptualisations poorly reflecting underlying apriorising/axiomatising/referencing- 
\{of-'prospectively_implicited_attendant-ontological-contiguity ' ceduced-

existentialising/contextualising/textualising_'intelligibility/epistemicity/reflexivity_contiguity<imbued-notional cogency >' \}-conflatedness ${ }^{13}$-in-\{preconverging disentailment by\} postconverging-entailment; and further, such an insight of underlying 'cogent-unifying-operantdynamics' as herein implied is often misconstrued as being monotonous (whereas such 'supposedly monotonous process/gesturing of knowledge-reification $\sim$ gesturing-andaccounting - of-epistemic-phenomenalism- $<$ in-

prospective_psychologismic apriorising/axiomatising/referencing-\{of-'prospectively implicited_attendant-ontological-contiguity ' educedexistentialising/contextualising/textualising_'intelligibility/epistemicity/reflexivity-contiguity<imbued-notional cogency $\left.>^{\prime} \quad\right\}$-conflatedness -in-\{preconverging-disentailment by\} postconverging-entailment>' reflecting inherent domains-of-study as of their given epistemicconceptions phenomenal/manifest $\sim$ subpotency-〈in-transitive-conflatedness -reflexivity,-inthe-full-potency-of-existence's $\sim$ sublimating-nascence) as to overall reifying-and-empoweringreflexivity-of-ecstatic-existence-as-panintelligibility/panreflexivity ${ }^{3}$-〈existentially-imbuedand-educing-< $<$ fepistemic-

totalising thermeneutically/textually/reprojectingly/supererogatingly/zeroingly/re-acutingly,\{decompulsing $d$ delinearity $\sim$ for-cogency $>$-epistemic-perspective-of-projective/reprojectiveaestheticising-re-motif-and-re-apriorising/re-axiomatising/re-referencing conceptualisation,as-herein-specifically-relevant-to human-subpotency) takes the form of the process/gesturing of knowledge-reification $\sim$ gesturing-and-accounting — of-epistemic-phenomenalism- $<$ inprospective_psychologismic $\sim$ apriorising/axiomatising/referencing-\{of-'prospectively_ implicited_attendant-ontological-contiguity ' reducedexistentialising/contextualising/textualising_ intelligibility/epistemicity/reflexivity-contiguity<imbued-notional cogency $>>\quad\}$-conflatedness -in-\{preconverging-disentailment by\} 
postconverging-entailment $>$ in say physics with the 'supposed monotony' of differential equations on physical variables, in chemistry with the 'supposed monotony' of valence bonding explaining chemical reactions or in biology with the 'supposed monotony' of gene regulation rather ultimately central to all biological processes), with the false implication of construing that disparateness-of-conceptualisation-<unforegrounding-disentailment,-failing-prospectively-toreflect-'immanent relative-unreflexivity/relative-reflexivity ontological-contiguity '> is inherently convenient as of a mental-reflex oriented towards ordinary $<$ amplituding/formative $>$ wooden-language-<imbued - averaging-of-thought-<as-toleveling/ressentiment/closed-construct-of- meaningfulness-and-teleology -as-of'nondescript/ignorable-void '-with-regards-to-prospective-apriorising-implications $>>$ humansubpotency ways-of-looking-at-things rather than adopting-the-intellectual-hat for reifying the former in a mental-reflex oriented towards existence-potency ${ }^{3} \sim$ sublimating-nascence,disclosed-from-prospective-epistemic-digression <amplituding/formativeepistemicity $>$ causality $\sim$ as-to-projective-totalitative-implications-of-prospectivenonpresencing,-for-explicating relative-unreflexivity/relative-reflexivity - ontologicalcontiguity ways-of-looking-at-things. Critically, lost to many naïve 'science ideologues' preaching about modelling the social domains-of-study along the natural sciences, is the fact that more than mere adoption-and-mimicking of scientific methods and approaches, the truly pertinent and decisively scientific notion of the natural sciences lies with their 'cogent-unifyingoperant-dynamics' from whence statistical, mathematical and other scientific methods become interpretatively intelligible; such that merely adopting-and-mimicking such methods without precedingly construing of the 'cogent-unifying-operant-dynamics' of any such social domainof-study is 'massively uninsightful/shallow and subject to institutional-being-and-craft sophistic/pedantic misconstrual and manipulation' as it is rather such a 'cogent-unifyingoperant-dynamics' as of apriorising/axiomatising/referencing-\{of-'prospectively 
implicited_attendant-ontological-contiguity ' reduced-

existentialising/contextualising/textualising_'intelligibility/epistemicity/reflexivity_contiguity-

<imbued-notional cogency >' $\}$-conflatedness ${ }^{13}$-in-\{preconverging-disentailment by\}

postconverging-entailment that points to the specific scientific methodology of relevance or irrelevance, given that in certain cases the qualitative nature of things will for instance render statistical and mathematical methods irrelevant. This further explains why Derridean deconstruction and Foucauldian discourse analysis have been found in many social domains-ofstudy, including domains like medical and healthcare practice for instance, to provide a 'cogentunifying-operant-dynamics' that 'fully-address-in-depth social issues'; in the sense that Derridean deconstruction narrative or Foucauldian genealogy-knowledge-and-power-discourse narrative address the displacement/decentering-of-the-human-subject in reflecting the need to undermine human destructuring-threshold-〈uninstitutionalised-threshold /presublimatingdesublimating-decisionality $>$ of-ontological-performance ${ }^{72}-<$ including-virtue-as- $^{-}$ ontology $>$ /morality/ethics/justice/etc. to further advance its constructive/institutionalising/nascent-sublimating-decisionality nature thus overcoming underlying logocentrism as of prospective relative-ontological-completenenss transcendentaland-sublimity implications, and thus reflecting the fact that human knowledge is more completely a two-fold process involving building the right mindset-as-of-prospective-relativeontological-completeness $^{87}$ and thereof the knowledge for that given right mindset-as-ofprospective-relative-ontological-completeness $^{87}$ as of the <amplituding/formativeepistemicity $>$ causality $\sim$ as-to-projective-totalitative-implications-of-prospectivenonpresencing,-for-explicating relative-unreflexivity/relative-reflexivity - ontologicalcontiguity of apriorising/axiomatising/referencing-\{of-'prospectively implicited_attendantontological-contiguity ' educed- 
<imbued-notional cogency>' \}-conflatedness ${ }^{13}$-in-\{preconverging-disentailment-by\} postconverging-ntailment. It is thus not surprising that naive disparateness-ofconceptualisation-<unforegrounding-disentailment,-failing-prospectively-to-reflect‘immanent relative-unreflexivity/relative-reflexivity - ontological-contiguity ' $>$ leads to subject-matters and studies whose flawed prior_knowledge-reification $\sim$ gesturing-andaccounting-of-epistemic-phenomenalism-<inprior_psychologismic apriorising/axiomatising/referencing-\{of-'prior-implicited_attendantontological-contiguity ' educedexistentialising/contextualising/textualising_'intelligibility/epistemicity/reflexivity-contiguity$<$ imbued-notional cogency $>$ ' $\}$-constitutedness -in preconverging-entailment $>$ tend to be most heavily dependent on 'peering to a fault' of the attendant-ontology—as-of-conventioningreferencing of institutional-being-and-craft that is poorly constrained to existential-reality, rather than a peering process that is heavily constrained to existential-reality as of underlying supposedly coherent ontological-commitment $-<$ implied - self-assuredness-of-ontologicalgood-faith/authenticity postconverging-de-mentating/structuring/paradigming -as-beingas-of-existential-reality> as validatable and falsifiable by <amplituding/formativeepistemicity $>$ causality $\sim$ as-to-projective-totalitative-implications-of-prospectivenonpresencing,-for-explicating relative unreflexivity/relative-reflexivity - ontologicalcontiguity as to existence-potency ${ }^{39} \sim$ sublimating-nascence,-disclosed-from-prospectiveepistemic-digression as it is critically the case in the good practices of the natural sciences. The implication here is that the modern positivist 'identitive conception-of- ${ }^{56}$ meaningfulness-andteleology ${ }^{9}$, as of ontologically-flawed identitive-constitutedness ${ }^{14}$-as-'epistemic-totality ${ }^{37}$ dereification-in-dissingularisation-<as-to-the-disjointedness/disentailment-of- presencingabsolutising-identitive-constitutedness $>$-as-flawed-epistemicity-relativism-determinism is basically caught up in its very own enframed <amplituding/formative $>$ wooden-language- 
〈imbued - averaging-of-thought-<as-to-leveling/ressentiment/closed-construct-ofmeaningfulness-and-teleology -as-of-‘nondescript/ignorable-void '-with-regards-toprospective-apriorising-implications $>>$ which as of its ${ }^{79}$ presencing-absolutising-identitiveconstitutedness $^{14}$ is rather 'predisposed to a mental-reflex of construing concepts and conceptualisations in absolute terms of conceptual-patterning-〈as-devoid-of-'prospectively implicited_attendant-ontological-contiguity ' reducedexistentialising/contextualising/textualising_intelligibility/epistemicity/reflexivity-contiguity$<$ imbued-notional cogency>' ${ }^{\prime \prime}$ 's-reifying-or-elucidating-of-'prospective-relative-ontologicalcompleteness ';-so-rather-enabled-<by-a- nonpresencing-divulging-of-momentoushistoriality/ontological-eventfulness /ontological-aesthetic-tracing-<perspectiveontological-normalcy/postconvergence-reflected-'epistemicity-relativism-determinism'>> by mere referring, mentioning and synonymisation of concepts and conceptualisations mere_apriorising/axiomatising/referencing of hardly any prospective profound existentialdisentelogising/re ontelogising apereticism $>$ implications but for institutionalprescience/imprimaturing-<dullness-of the-spirit/psychologismic epistemic-acutisationnonresidualising-imbued-\{compulsing\} linearity in-eclecticism-of prior-mereformulaicity/ritualisation ${ }^{\prime}$ as of a '79 presencing-absolutising-identitive-constitutedness inclination in $\quad<$ amplituding/formative-epistemicity $>$ totalising $\sim$ self-referencingsyncretising/circularity/interiorising/akrasiatic-drag that poorly or doesn't recognise the transforming nature of concepts and conceptualisations as from prospective nonpresencing$<$ perspective-ontological-normalcy/postconvergence $>$ reflection of <amplituding/formativeepistemicity $>$ causality $\sim$ as-to-projective-totalitative-implications-of-prospectivenonpresencing,-for-explicating relative-unreflexivity/relative-reflexivity - ontologicalcontiguity of relative-ontological-incompleteness $8 /$ relative-ontological-completeness ${ }^{87}$ 〈sublimating referencing/registering/decisioning,-as-self-becoming/self- 
conflatedness /formative-supererogating-<projective/reprojective-aestheticising-re-motifand-re-apriorising/re-axiomatising/re-referencing,-in-perspective-ontologicalnormalcy/postconvergence $>\rangle$ involving the displacement/decentering-of-the-human-subject for the right supererogatory $\sim$ acuity/perspicacity/astuteness/edginess/incisiveness-ofapriorising/axiomatising/referencing/intelligibilitysettingup/measuringinstrumenting -forconceptualisation $<$ amplituding/formative-epistemicity $>$ causality $\sim$ as-to-projectivetotalitative-implications-of-prospective- nonpresencing,-for-explicating relativeunreflexivity/relative-reflexivity ontological-contiguity for prospective ${ }^{56}$ meaningfulnessand-teleology 99 as knowledge-reification $\sim$ gesturing-and-accounting-of-epistemicphenomenalism-<in-prospective_psychologismic $\sim$ apriorising/axiomatising/referencing- of'prospectively implicited_attendant-ontological-contiguity ' educedexistentialising/contextualising/textualising_'intelligibility/epistemicity/reflexivity_contiguity<imbued-notional cogency>> $\}$-conflatedness -in-\{preconverging disentailment by\} postconverging-ntailment $>$ as associated with the suprastructuralism/postmodernism perspective in relative-ontological-completeness ${ }^{87}$ This contrast with suprastructuralism/postmodernism 'difference conception-of- ${ }^{56}$ meaningfulness-andteleology, as of ontologically-veridical difference-conflatedness ${ }^{13}$-as-to-totalitativereification-in-singularisation-<as-to-the-nondisjointedness/entailment-of-prospectivenonpresencing $>$-as-veridical-epistemicity-relativism-determinism in its re-originary_as-

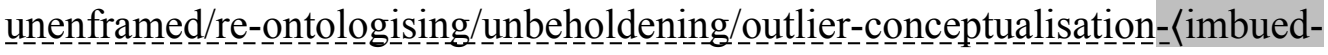
postconverging/dialectical-thinking -'projective-insights'/'epistemic-projection-inconflatedness '-of-notional deprocrypticism-prospective-sublimation $\rangle^{0}$ opened-constructof- ${ }^{5}$ meaningfulness-and-teleology ${ }^{99}$ so-implied with respect to the "transcendental-signifier that is ecstatic-existence', as so-reflected as of apriorising/axiomatising/referencing-\{of'prospectively_implicited_attendant-ontological-contiguity ' ceduced- 
existentialising/contextualising/textualising_ 'intelligibility/epistemicity/reflexivity-contiguity$<$ imbued-notional cogency $>$ ' $\}$-conflatedness ${ }^{13}$ in-\{preconverging-disentailment by\} postconverging entailment for elucidating, deriving and knowledge-reification $\sim$ gesturing-andaccounting - of-epistemic-phenomenalism- $<$ inprospective_psychologismic apriorising/axiomatising/referencing-\{of-"prospectively implicited_attendant_ontological-contiguity ' educedexistentialising/contextualising/textualising_intelligibility/epistemicity/reflexivity_contiguity$<$ imbued-notional cogency $\left.>^{\prime} \quad\right\}$-conflatedness -in-\{preconverging-disentailment by\} postconverging-entailment> of concepts and conceptualisations as from prospective nonpresencing-<perspective-ontological-normalcy/postconvergence $>$ reflection of $<$ amplituding/formative-epistemicity $>$ causality $\sim$ as-to-projective-totalitative-implications-ofprospective- nonpresencing,-for-explicating $\sim$ relative-unreflexivity/relative-reflexivity ontological-contiguity of relative-ontological-incompleteness $8 /$ relative-ontologicalcompleteness ${ }^{87}$-〈sublimating $\sim$ referencing/registering/decisioning,-as-self-becoming/selfconflatedness /formative-supererogating-<projective/reprojective-aestheticising-re-motifand-re-apriorising/re-axiomatising/re-referencing,-in-perspective-ontologicalnormalcy/postconvergence $>\rangle$. This explains why postmodern-thought cannot truly be understood in terms-as-of-axiomatic-construct of naïve identitive positivistic modern thought because the ${ }^{56}$ meaningfulness-and-teleology ${ }^{99}$ of postmodern-thought only arise rather in the reification process/gesturing involving the displacement/decentering-of-the-human-subject implied as from prospective $\quad{ }^{6}$ nonpresencing-<perspective-ontologicalnormalcy/postconvergence $>$ reflection of its <amplituding/formativeepistemicity $>$ causality $\sim$ as-to-projective-totalitative-implications-of-prospectivenonpresencing,-for-explicating relative-unreflexivity/relative-reflexivity - ontologicalcontiguity of relative-ontological-incompleteness ${ }^{88} /$ relative-ontological-completeness $^{87}$ - 


\section{〈sublimating $\sim$ referencing/registering/decisioning,-as-self-becoming/self-}

conflatedness /formative-supererogating-<projective/reprojective-aestheticising-re-motifand-re-apriorising/re-axiomatising/re-referencing,-in-perspective-ontologicalnormalcy/postconvergence $>>$ for elucidating, deriving and knowledge-reification $\sim$ gesturingand-accounting — of-epistemic-phenomenalism- $<$ inprospective_psychologismic apriorising/axiomatising/referencing-\{of-'prospectively implicited_attendant-ontological-contiguity ' educedexistentialising/contextualising/textualising_'intelligibility/epistemicity/reflexivity-contiguity<imbued-notional cogency $\left.>^{\prime} \quad\right\}$-conflatedness -in-\{preconverging-disentailment by\} postconverging entailment $>$ of its concepts and conceptualisations; as naïve identitive positivistic modern thought in its <amplituding/formative-epistemicity>totalising $\sim$ selfreferencing-syncretising/circularity/interiorising/akrasiatic-drag ${ }^{34}$ very often and systematically rather construes of such postmodern concepts and conceptualisations substitutively in its predisposition of ${ }^{79}$ presencing - absolutising-identitive-constitutedness ${ }^{14}$ by its mere referring, mentioning and synonymising of postmodern concepts and conceptualisatioons thus undermining the inherent postmodern-thought implied elucidation, derivation and knowledgereification $\sim$ gesturing-and-accounting — of-epistemic-phenomenalism- $<$ inprospective_psychologismic apriorising/axiomatising/referencing-\{of- ${ }^{\text {pprospectively }}$ implicited_attendant-ontological-contiguity ' educedexistentialising/contextualising/textualising_ 'intelligibility/epistemicity/reflexivity-contiguity<imbued-notional cogency $>>$ \}-conflatedness -in-\{preconverging-disentailment by\} postconverging-entailment $>$ of concepts and conceptualisations, and as such identitive positivistic modern thought fundamentally fails to recognise and factor in the aforementioned postmodern-thought knowledge-reification $\sim$ gesturing-and-accounting-of-epistemicphenomenalism- $<$ in-prospective_psychologismic $\sim$ apriorising/axiomatising/referencing-\{of- 
'prospectively_implicited_attendant-ontological-contiguity ' educed-

existentialising/contextualising/textualising_'intelligibility/epistemicity/reflexivity_contiguity-

<imbued-notional cogency>> $\}$-conflatedness -in-\{preconverging-disentailment by\}

postconverging-entailment> process/gesturing as from prospective ${ }^{61}$ nonpresencing-

$<$ perspective-ontological-normalcy/postconvergence $>$ reflection of <amplituding/formative-

epistemicity $>$ causality $\sim$ as-to-projective-totalitative-implications-of-prospective-

nonpresencing,-for-explicating relative-unreflexivity/relative-reflexivity ontological-

contiguity of relative-ontological-incompleteness 8 /relative-ontological-completeness

〈sublimating $\sim$ referencing/registering/decisioning,-as-self-becoming/self-

conflatedness /formative-supererogating-<projective/reprojective-aestheticising-re-motif-

and-re-apriorising/re-axiomatising/re-referencing,-in-perspective-ontological-

normalcy/postconvergence $>\rangle$. Such a recurrent ontologically-flawed predisposition is tantamount to say construing Newtonian physics in the absolute terms-as-of-axiomatic-construct of its concepts and conceptualisations of say space, time, force, etc. to then project this predisposition by mere referring, mentioning and synonymisation of these Newtonian physics concepts and conceptualisations (as to 'mere referring, mentioning and synonymisation of concepts and conceptualisations mere_apriorising/axiomatising/referencing of hardly any prospective profound existential-<disontologising/re-ontologising aporeticism $>$ implications but for institutional-prescience/imprimaturing-<dullness-of the-spirit/psychologismic epistemic acutisation nonresidualising imbued-\{compulsing $\{$ linearity in-eclecticism-of-priormere-formulaicity/ritualisation $>^{\prime}$ ) as if of Einsteinian physics in the hope that this will enable the elucidation, derivation and knowledge-reification $\sim$ gesturing-and-accounting-ofepistemic-phenomenalism- $<$ in-

prospective_psychologismic apriorising/axiomatising/referencing-\{of-‘prospectively implicited_attendant-ontological-contiguity ' educed- 
existentialising/contextualising/textualising_'intelligibility/epistemicity/reflexivity-contiguity$<$ imbued-notional $\left.\sim \operatorname{cogency}>^{\prime} \quad\right\}$-conflatedness -in-\{preconverging disentailment by\} postconverging-entailment $>$ of Einsteinian physics, whereas the latter implies an utterly different reification process/gesturing for its specific physics elucidation, derivation and knowledgereification $\sim$ gesturing-and-accounting - of-epistemic-phenomenalism- $<$ inprospective_psychologismic apriorising/axiomatising/referencing-\{of-‘prospectively implicited_attendant-ontological-contiguity ' educedexistentialising/contextualising/textualising_ intelligibility/epistemicity/reflexivity-contiguity<imbued-notional cogency $\left.>^{\prime} \quad\right\}$-conflatedness -in-\{preconverging-disentailment by\} postconverging-entailment $>$ as from prospective nonpresencing- $<$ perspective-ontologicalnormalcy/postconvergence $>\quad$ reflection of its $<$ amplituding/formativeepistemicity $>$ causality $\sim$ as-to-projective-totalitative-implications-of-prospectivenonpresencing,-for-explicating relative - unreflexivity/relative-reflexivity - ontologicalcontiguity of relative-ontological-incompleteness $8 /$ relative-ontological-completeness ${ }^{87}$ 〈sublimating $\sim$ referencing/registering/decisioning,-as-self-becoming/selfconflatedness /formative-supererogating-<projective/reprojective-aestheticising-re-motifand-re-apriorising/re-axiomatising/re-referencing,-in-perspective-ontologicalnormalcy/postconvergence $>\rangle$. It is rather the suprastructuralism/postmodernism reification process/gesturing as from prospective ${ }^{6}$ nonpresencing- $<$ perspective-ontologicalnormalcy/postconvergence $>$ reflection of $<$ amplituding/formative-epistemicity $>$ causality $\sim$ asto-projective-totalitative-implications-of-prospective- nonpresencing,-forexplicating relative-unreflexivity/relative-reflexivity - ontological-contiguity of relativeontological-incompleteness ${ }^{8 / \text { relative-ontological-completeness }}{ }^{\text {- }}$ 〈sublimating referencing/registering/decisioning,--as-self-becoming/selfconflatedness /formative-supererogating-<projective/reprojective-aestheticising-re-motif- 
and-re-apriorising/re-axiomatising/re-referencing,-in-perspective-ontological-

normalcy/postconvergence $>\rangle$ that supersedingly induces postmodern-thought implied concepts and conceptualisations elucidation, derivation and knowledge-reification $\sim$ gesturing-andaccounting - of-epistemic-phenomenalism-<in-

prospective_psychologismic apriorising/axiomatising/referencing-\{of-‘prespectively implicited_attendant-ontological-contiguity ' educedexistentialising/contextualising/textualising_'intelligibility/epistemicity/reflexivity_contiguity<imbued-notional cogency $>$ ' \}-conflatedness -in-\{preconverging-disentailment by\} postconverging entailment>, just as the same can be said of Einsteinian physics reification process/gesturing as from prospective nonpresencing-<perspective-ontologicalnormalcy/postconvergence $>$ reflection of $<$ amplituding/formative-epistemicity $>$ causality $\sim$ asto-projective-totalitative-implications-of-prospective- nonpresencing,-forexplicating relative-unreflexivity/relative-reflexivity ontological-contiguity of relativeontological-incompleteness 8 /relative-ontological-completeness ${ }^{87}$ 〈sublimating referencing/registering/decisioning,--as-self-becoming/selfconflatedness /formative-supererogating-<projective/reprojective-aestheticising-re-motifand-re-apriorising/re-axiomatising/re-referencing,-in-perspective-ontologicalnormalcy/postconvergence $>\rangle$ in supersedingly inducing its specific implied concepts and conceptualisations elucidation, derivation and knowledge-reification $\sim$ gesturing-andaccounting - of-epistemic-phenomenalism- $<$ inprospective_psychologismic apriorising/axiomatising/referencing-\{of-'prospectively implicited_attendant-ontological-contiguity ' educedexistentialising/contextualising/textualising_ 'intelligibility/epistemicity/reflexivity-contiguity$<$ imbued-notional cogency $\left.>^{\prime} \quad\right\}$-conflatedness -in-\{preconverging-disentailment by\} postconverging-entailment $>$ of say space-time, force, etc. In both instances, when interpreted 
from the relative-ontological-incompleteness ${ }^{88}$ perspective in ontologically-flawed presencing-absolutising-identitive-constitutedness ${ }^{14}$ of naïve positivistic modern thought or Newtonian physics respectively, suprastructuralism/postmodern-thought and Einsteinian physics will be 'qualified negatively as relativistic' since the latter do not assume a presencing-absolutising-identitive-constitutedness ${ }^{14}$ with concepts like truth, space, time, force, etc. and the latter rather perceive these as ontologically-flawed elaboration-as-to-mereextrapolating/constituting/abstracting/deducing/inferring-of-elucidation-outside-

'prospectively_implicited_attendant-ontological-contiguity ${ }^{67}$ ' educedexistentialising/contextualising/textualising_'intelligibility/epistemicity/reflexivity-contiguity$<$ imbued-notional cogency $>^{\prime 0}$ as from the relative-ontological-completeness ${ }^{87}$ perspective which emphasises construing existential-reality as it manifests itself as of 'implicited_attendant ontological-contiguity ${ }^{67}$, educed-

existentialising/contextualising/textualising_'intelligibility/epistemicity/reflexivity-contiguity$<$ imbued-notional cogency $>$ ' in apriorising/axiomatising/referencing-\{of-'prospectively implicited_attendant-ontological-contiguity ' educedexistentialising/contextualising/textualising_'intelligibility/epistemicity/reflexivity-contiguity<imbued-notional cogency>' $\}$-conflatedness ${ }^{13}$ in 'preconerging disentalment by postconverging entailment; and likewise, the fact that 'implicited_attendant-ontologicalcontiguity $^{67} \sim$ educedexistentialising/contextualising/textualising_'intelligibility/epistemicity/reflexivity-contiguity<imbued-notional cogency>' 40 in apriorising/axiomatising/referencing-\{of-'prospectivelyimplicited_attendant-ontological-contiguity ' educed-

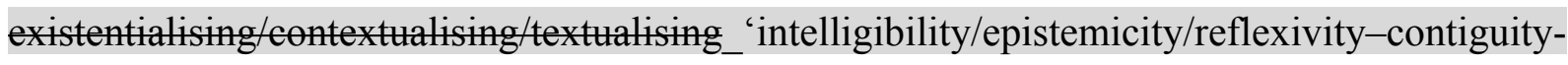
$<$ imbued-notional cogency $\left.>{ }^{\prime}\right\}$-conflatedness ${ }^{13}$-in-\{preconverging-disentailment by\} postconverging entailment 'epistemically implies human limited-mentation-capacity- 
deepening —as-subjecting limitedness/human-subpotency-to-'educed-unlimitedness/existencesublimating nascence' for construing ontological-veracity', thus 'putting-inquestion/deflating by difference-conflatedness ${ }^{13}$-as-to-totalitative-reification-in-singularisation$<$ as-to-the-nondisjointedness/entailment-of-prospective- nonpresencing $>$-as-veridicalepistemicity-relativism-determinism ${ }^{2} \quad$ all $\quad{ }^{79}$ presencing-absolutising-identitiveconstitutedness $^{14}$ traditional conceptions beyond their simplistic conceptual-patterning-〈asdevoid-of-'prospectively_implicited_attendant-ontological-contiguity ' educedexistentialising/contextualising/textualising_'intelligibility/epistemicity/reflexivity-contiguity<imbued-notional cogency>' 's-reifying-or-elucidating-of-'prospective-relative-ontologicalcompleteness ' ;-so-rather-enabled-<by-a- nonpresencing-divulging-of-momentous-

\section{historiality/ontological-eventfulness /ontological-aesthetic-tracing-<perspective-}

ontological-normalcy/postconvergence-reflected-‘epistemicity-relativism-determinism'>> to reflect underlying ecstatic-existence, will tend to be construed from the relative-ontologicalincompleteness ${ }^{88}$ perspective in ${ }^{79}$ presencing-absolutising-identitive-constitutedness ${ }^{14}$ as nominalistic rather than as of "foregrounding_entailment- $<$ in-succession-of-profoundsupererogation $>$-〈postconverging-narrowing-down $\sim$ sublimation-as-to-'existence-assublimating-withdrawal/unenframing/re-ontologising,-elicited-from-prospective-profoundsupererogation '-in-reflecting-'immanent relative-unreflexivity/relative-reflexivity ontological-contiguity ';-as-operative-notional deprocrypticism) acuity/perspicacity/astuteness/edginess/incisiveness-ofapriorising/axiomatising/referencing/intelligibilitysettingup/measuringinstrumenting -forconceptualisation' as from the relative-ontological-completeness ${ }^{87}$ perspective. In other words, the concepts and conceptualisations of postmodern-thought are meaningless without their relevant and underlying theoretical background framework gesturing/accounting-ofepistemic-phenomenalism, and there is no point in construing them as of simplistic conceptual- 
patterning-〈as-devoid-of-'prospectively_implicited_attendant-ontological-

contiguity ' $\sim$ educed-

existentialising/contextualising/textualising_'intelligibility/epistemicity/reflexivity-contiguity-

$<$ imbued-notional cogency>' ${ }^{\prime}$ 's-reifying-or-elucidating-of-'prospective-relative-ontological-

completeness ';-so-rather-enabled-<by-a- nonpresencing-divulging-of-momentous-

historiality/ontological-eventfulness /ontological-aesthetic-tracing-<perspective-

ontological-normalcy/postconvergence-reflected-‘epistemicity-relativism-determinism’>> by mere referring, mentioning and synonymisation as if these are of positivistic thought theoretical background framework gesturing/accounting-of-epistemic-phenomenalism just as the same can be said of striving for the elucidation, derivation and knowledge-reification $\sim$ gesturing-andaccounting - of-epistemic-phenomenalism- $<$ in-

prospective_psychologismic apriorising/axiomatising/referencing-\{of-'prospectively_ implicited_attendant-ontological-contiguity ' educedexistentialising/contextualising/textualising_'intelligibility/epistemicity/reflexivity-contiguity$<$ imbued-notional cogency $>$ ' $\}$-conflatedness -in-\{preconverging disentailment by\} postconverging-entailment> of Einsteinian physics concepts and conceptualisations as if of Newtonian physics concepts and conceptualisations by mere referring, mentioning and synonymisation as if of the latter. In both cases, the as from prospective nonpresencing<perspective-ontological-normalcy/postconvergence $>$ reflection of <amplituding/formativeepistemicity $>$ causality $\sim$ as-to-projective-totalitative-implications-of-prospectivenonpresencing,-for-explicating relative-unreflexivity/relative-reflexivity - ontologicalcontiguity of relative-ontological-incompleteness $8 /$ relative-ontological-completeness 〈sublimating referencing/registering/decisioning,-as-self-becoming/selfconflatedness /formative-supererogating-<projective/reprojective-aestheticising-re-motifand-re-apriorising/re-axiomatising/re-referencing,-in-perspective-ontological- 
normalcy/postconvergence $>>$ implied displacement/decentering-of-the-human-subject points to different sense-of-conscious-representation-of- $-{ }^{-6}$ meaningfulness-and-teleology ${ }^{99}$ between the relative-ontological-incompleteness ${ }^{88}$ and relative-ontological-completeness ${ }^{87}$ such that the former is rather in pseudo-edginess/pseudo-incisiveness implying the need for its unaffirmation/deprojection/deassertion/epistemic-decadence/undueness-invalidating-

logicising/unsuitable-measuringinstrument-invalidating-measuring-<as-to-preconverging-ordementing -apriorising-psychologism $>$ and cannot simply be projected as the latter which is what is rather truly and effectively of supererogatory $\sim$ acuity/perspicacity/astuteness/edginess/incisiveness-ofapriorising/axiomatising/referencing/intelligibilitysettingup/measuringinstrumenting - forconceptualisation $<$ amplituding/formative-epistemicity $>$ causality $\sim$ as-to-projectivetotalitative-implications-of-prospective- nonpresencing,-for-explicating relativeunreflexivity/relative-reflexivity ontological-contiguity implying the need for its true and effective affirmation/projection/assertion/notional $\sim$ self-distantiation/dueness-validatinglogicising/suitable-measuringinstrument-validating-measuring-<as-to-postconverging-ordialectical-thinking -apriorising-psychologism>. A further naivety is the appreciation of postmodern knowledge-reification $\sim$ gesturing-and-accounting-of-epistemic-phenomenalism$<$ in-prospective_psychologismic $\sim$ apriorising/axiomatising/referencing-\{of-'prospectively implicited_attendant-ontological-contiguity ' educedexistentialising/contextualising/textualising_'intelligibility/epistemicity/reflexivity_contiguity<imbued-notional cogency >' \}-conflatedness -in-\{preconverging disentailment by\} postconverging entailment> process/gesturing arises as of a general misunderstanding of what is generally implied with regards to any given knowledge-reification $\sim$ gesturing-andaccounting - of-epistemic-phenomenalism- $<$ inprospective_psychologismic apriorising/axiomatising/referencing-\{of- ${ }^{\star p r o s p e c t i v e l y}$ 
implicited_attendant-ontological-contiguity ' educed-

existentialising/contextualising/textualising_'intelligibility/epistemicity/reflexivity_contiguity<imbued-notional cogency >' \}-conflatedness -in-\{preconverging disentailment by\} postconverging-entailment $>$ process/gesturing. As indicated before all subject-matters/domainsof-study effectively reflect existence's overall reifying-and-empowering-reflexivity-of-ecstaticexistence-as-panintelligibility/panreflexivity ${ }^{73}$-〈existentially-imbued-and-educing-< $<$ epistemictotalising thermeneutically/textually/reprojectingly/supererogatingly/zeroingly/re-acutingly,\{decompulsing $d$ delinearity $\sim$ for-cogency $>$-epistemic-perspective-of-projective/reprojectiveaestheticising-re-motif-and-re-apriorising/re-axiomatising/re-referencing conceptualisation-as-herein-specifically-relevant-to human-subpotency) as of apriorising/axiomatising/referencing-\{of-'prospectively_implicited_attendant-ontologicalcontiguity ' $\sim$ educedexistentialising/contextualising/textualising_ intelligibility/epistemicity/reflexivity-contiguity<imbued-notional cogency $\left.>^{\prime} \quad\right\}$-conflatedness ${ }^{13}$ in-\{preconverging-disentailment by postconverging-entailment with regards to as from prospective ${ }^{6}$ nonpresencing- $<$ perspectiveontological-normalcy/postconvergence $>$ reflection of <amplituding/formativeepistemicity $>$ causality $\sim$ as-to-projective-totalitative-implications-of-prospectivenonpresencing,-for-explicating relative-unreflexivity/relative-reflexivity - ontologicalcontiguity of relative-ontological-incompleteness ${ }^{88} /$ relative-ontological-completeness $^{87}$ 〈sublimating $\sim$ referencing/registering/decisioning,-as-self-becoming/self-

conflatedness /formative-supererogating-<projective/reprojective-aestheticising-re-motifand-re-apriorising/re-axiomatising/re-referencing,-in-perspective-ontologicalnormalcy/postconvergence $>$ //relative-ontological-incompleteness ${ }^{88}$, such that for instance even a naïve traditional conception of the physics domain-of-study as of atomising/taking-to-pieces apriorising/axiomatising/referencing-\{of-'prospectively_implicited_attendant-ontological- 
contiguity ' educed-

existentialising/contextualising/textualising_'intelligibility/epistemicity/reflexivity_contiguity<imbued-notional cogency>' $\}$-constitutedness ${ }^{14}$-in-preconverging-entailment is shown to be veridically rather as of apriorising/axiomatising/referencing-\{of-"prospectively implicited_attendant-ontological-contiguity ' educedexistentialising/contextualising/textualising_ 'intelligibility/epistemicity/reflexivity-contiguity<imbued-notional cogency $\left.>^{\prime}\right\}$-conflatedness ${ }^{13}$-in-\{preconverging-disentailment by postconverging-entailment going by the successive relative-ontological-completeness ${ }^{87}$ physics conception of such notions as space, time, etc. in <amplituding/formativeepistemicity>totalising/circumscribing/delineating development of successive theories say Cartesian, Newtonian, Einsteinian, String theory, etc. using the-very-same notions and derivednotions but with different implications. This <amplituding/formativeepistemicity>totalising/circumscribing/delineating nature of all domains-of-study apriorising/axiomatising/referencing-\{of-'prospectively_implicited_attendant-ontologicalcontiguity ' $\sim$ educed-

existentialising/contextualising/textualising_'intelligibility/epistemicity/reflexivity_contiguity<imbued-notional cogency >' \}-conflatedness ${ }^{13}$ in (preconverging disentailment by postconverging-entailment as of <amplituding/formative-epistemicity $>$ causality $\sim$ as-toprojective-totalitative-implications-of-prospective- nonpresencing,-for-explicating relativeunreflexivity/relative-reflexivity - ontological-contiguity , speaks of the epistemic-veracity of the fact that 'all knowledge is truly developed as of an totalising ${ }^{3}{ }^{3}$ hermeneutic/textuality/reprojecting/supererogating/zeroing/re-acuting,${ }_{\text {\{decompulsing }}$ delinearity for-cogency circle for relative-ontological-completeness ${ }^{87}$ that involves human limited-mentation-capacity-deepening —as-subjecting limitedness/human-subpotency to-'educed-unlimitedness/existence-sublimating nascence' . This \{epistemic- 
totalising 3 ' ${ }^{3}$ hermeneutic/textuality/reprojecting/supererogating/zeroing/re-acuting,-

$\{$ decompulsing $\}$ delinearity for-cogency circle knowledge-reification $\sim$ gesturing-and-accountingof-epistemic-phenomenalism- $<$ in-

prospective_psychologismic apriorising/axiomatising/referencing-\{of-'prospectively implicited_attendant-ontological-contiguity ' reducedexistentialising/contextualising/textualising_'intelligibility/epistemicity/reflexivity_contiguity<imbued-notional cogency >’ \}-conflatedness -in-\{preconverging-disentailment by\} postconverging entailment $>$ process/gesturing is furthermore reflected in both human scholarlyand-pedagagic exercise wherein subject-matters/domains-of-study are grasped in successive articulations of deeper and feeper fepistemictotalising ${ }^{3}$ ' $h e r m e n e u t i c / t e x t u a l i t y /$ reprojecting/supererogating/zeroing/re-acuting,\{decompulsing\} delinearity for-cogency insight as of maximalising-recomposuring-for-relativeontological-completeness ${ }^{87}$ - unenframed/re-ontologising conceptualisation. The implication here is that postmodern knowledge-reification $\sim$ gesturing-and-accounting-of-epistemicphenomenalism-<in-prospective_psychologismic $\sim$ apriorising/axiomatising/referencing- of'prospectively_implicited_attendant-ontological-contiguity ' ceducedexistentialising/contextualising/textulising_intelligibility/epistemicity/reflexivity-contiguity<imbued-notional cogency >' \}-conflatedness -in-\{preconverging-disentailment by\} postconverging-entailment $>$ process/gesturing simply integrates this notion in the sense that toplevel postmodern scholars articulate their knowledge-reification $\sim$ gesturing-and-accounting —ofepistemic-phenomenalism- $<$ in-

prospective_psychologismic apriorising/axiomatising/referencing-\{of-'prospectively implicited_attendant-ontological-contiguity ' educedexistentialising/contextualising/textualising_'intelligibility/epistemicity/reflexivity-contiguity$<$ imbued-notional cogency $\left.>^{\prime} \quad\right\}$-conflatedness -in-\{preconverging-disentailment by\} 
postconverging-entailment> process/gesturing at its 'appropriate \{epistemic-

totalising 3 ? ${ }^{3}$ hermeneutic/textuality/reprojecting/supererogating/zeroing/re-acuting,-

\{decomplesing delinearity for-cogency circle level of postmodern knowledge-reification $\sim$ gesturingand-accounting - of-epistemic-phenomenalism- $<$ in-

prospective_psychologismic apriorising/axiomatising/referencing-\{of-"prospectively

implicited_attendant-ontological-contiguity ' educed-

existentialising/contextualising/textualising_ 'intelligibility/epistemicity/reflexivity-contiguity-

<imbued-notional cogency >’ \}-conflatedness -in-\{preconverging-disentailment by\}

postconverging entailment>' no different from say top-level physicists and natural scientists

articulating their knowledge-reification $\sim$ gesturing-and-accounting-of-epistemicphenomenalism- $<$ in-prospective_psychologismic $\sim$ apriorising/axiomatising/referencing-\{of'prospectively implicited attendant-ontological-contiguity ' e educedexistentialising/contextualising/textualising_'intelligibility/epistemicity/reflexivity-contiguity-

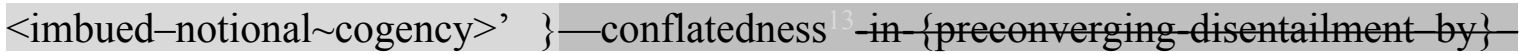
postconverging-ntailment> process/gesturing at their 'appropriate totalising ${ }^{3}$ hermeneutic/textuality/reprojecting/supererogating/zeroing/re-acuting,-

${ }_{\{\text {decompulsing }}$ delinearity for-cogency circle level of top-level physics/natural-science knowledgereification $\sim$ gesturing-and-accounting — of-epistemic-phenomenalism- $<$ in-

prospective_psychologismic apriorising/axiomatising/referencing-\{of-"prospectively implicited_attendant-ontological-contiguity ' educedexistentialising/contextualising/textualising_intelligibility/epistemicity/reflexivity-contiguity<imbued-notional cogency>' \}-conflatedness -in-\{preconverging-disentailment by\} posteonverging entailment>'. In both instances, the knowledge-reification $\sim$ gesturing-andaccounting - of-epistemic-phenomenalism- $<$ in-

prospective_psychologismic apriorising/axiomatising/referencing-\{of-'prospectively 
implicited_attendant-ontological-contiguity ' educed-

existentialising/contextualising/textualising_'intelligibility/epistemicity/reflexivity_contiguity<imbued-notional cogency>> $\}$-conflatedness -in-\{preconverging-disentailment by\} postconverging-entailment> process/gesturing implies that the scholar or student striving to engage at that top-level understanding, needs to grasp the "preceding formative/pedagogic

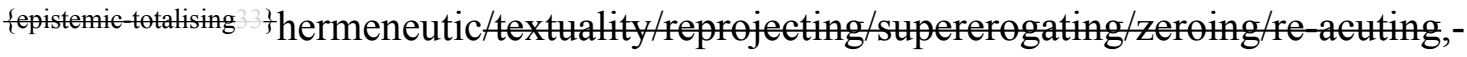
${ }_{\{\text {decompulsing }}$ delinearity for-cogency circle levels of knowledge-reification $\sim$ gesturing-andaccounting - of-epistemic-phenomenalism- $<$ in-

prospective_psychologismic apriorising/axiomatising/referencing-\{of-'prospectively implicited_attendant-ontological-contiguity ' educedexistentialising/contextualising/textualising_'intelligibility/epistemicity/reflexivity-contiguity$<$ imbued-notional cogency $>>$ ' -conflatedness -in-\{preconverging-disentailment by\} postconverging-ntailment>'. Such a supposed scholar or student cannot depart from ordinary/banal <amplituding/formative > wooden-language-_imbued-averaging-of-thought$<$ as-to-leveling/ressentiment/closed-construct-of- meaningfulness-and-teleology -as-of'nondescript/ignorable-void '-with-regards-to-prospective-apriorising-implications $>>$ level of knowledge conception to then claim that the top-level physics/natural-science/postmodernthought 3 hermeneutic/textuality/reprojecting/supererogating/zeroing/reacuting, - \{decompling $\}$ delinearity for-cogency circle of knowledge-reification $\sim$ gesturing-andaccounting - of-epistemic-phenomenalism- $<$ inprospective_psychologismic apriorising/axiomatising/referencing-\{of-'prospectively implicited_attendant-ontological-contiguity ' educedexistentialising/contextualising/textualising_intelligibility/epistemicity/reflexivity_contiguity<imbued-notional cogency >' \}-conflatedness -in-\{preconverging disentailment by\} postconverging-entailment $>$ process/gesturing should be directly and fully graspable to it as of 
leveling/ressentiment/closed-construct-of- meaningfulness-and-teleology -as-of-

'nondescript/ignorable-void '-with-regards-to-prospective-apriorising-implications $>$ >

predisposition to ${ }^{5}$ incrementalism-in-relative-ontological-incompleteness ${ }^{8}$ enframed/disontologising conceptualisation. The fact is the various pedagogic fepistemictotalising 3 hermeneutic/textuality/reprojecting/supererogating/zeroing/re-acuting,-

delinearity for-cogency circle levels of any subject-matter/domain-of-study as of successive $\quad{ }^{55}$ maximalising-recomposuring-for-relative-ontological-completeness ${ }^{87}$ unenframed/re-ontologising conceptualisation are meant to transmit a '<amplitung/formative-epistemicity $>$ totalising/comprehensive organic-attitude-toknowledge which is much more than just its technical knowledge veracity' and that ‘<amplituding/formative-epistemicity $>$ totalising/comprehensive organic-attitude-toknowledge' is needed together with the induced technical dispensation of the lower totalising 3 hermeneutic/textuality/reprojecting/supererogating/zeroing/re-acuting,-

${ }_{\{\text {decompulsing }}$ delinearity for-cogency circle of pedagogic knowledge-acquisition to then be able to engage with the higher/top-level scholarly/pedagogic \{epistemictotalising 3 hermeneutic/textuality/reprojecting/supererogating/zeroing/re-acuting,delinearity for-cogency circle of knowledge-reification $\sim$ gesturing-and-accountingof-epistemic-phenomenalism- $<$ inprospective_psychologismic apriorising/axiomatising/referencing-\{of-‘prospectively_ implicited_attendant-ontological-contiguity ' reducedexistentialising/contextualising/textualising_ 'intelligibility/epistemicity/reflexivity-contiguity<imbued-notional cogency $>$ ' $\}$-conflatedness -in-\{preconverging-disentailment by\} postconverging-entailment> in its ${ }^{5}$ maximalising-recomposuring-for-relative-ontologicalcompleteness $^{87}$ - unenframed/re-ontologising conceptualisation. It is important to understand 
here that the top-level physics/natural-science/postmodern-thought fepistemictotalising 3 3 hermeneutic/textuality/reprojecting/supererogating/zeroing/re-acuting,-

\{decompling $d$ delinearity for-cogency circle of knowledge-reification $\sim$ gesturing-and-accountingof-epistemic-phenomenalism-<in-

prospective_psychologismic apriorising/axiomatising/referencing-\{of-'prospectively implicited_attendant-ontological-contiguity ' educedexistentialising/contextualising/textualising_'intelligibility/epistemicity/reflexivity_contiguity<imbued-notional cogency >' \}-conflatedness -in-\{preconverging disentailment by\} postconverging entailment $>$ process/gesturing cannot strive to engage the supposed scholar or student at any such ordinariness/banal <amplituding/formative $>$ wooden-language-〈imbued averaging-of-thought-<as-to-leveling/ressentiment/closed-construct-of- meaningfulness-andteleology -as-of-'nondescript/ignorable-void '-with-regards-to-prospective-apriorisingimplications $>>$ level of knowledge conception, and implicited in its knowledgereification $\sim$ gesturing-and-accounting — of-epistemic-phenomenalism- $<$ inprospective_psychologismic apriorising/axiomatising/referencing-\{of-'prospectively implicited_attendant-ontological-contiguity ' reducedexistentialising/contextualising/textualising_'intelligibility/epistemicity/reflexivity-contiguity<imbued-notional cogency >' \}-conflatedness -in-\{preconverging disentailment by\} postconverging-entailment $>$ process is the notion that the prior/all-the-prior totalising 3 h hermeneutic/textuality/reprojecting/supererogating/zeroing/re-acuting,-

${ }_{\{\text {decompulsing }}$ delinearity for-cogency circle level(s) of the subject-matter/domain-of-study need to be grasped beforehand; and this is basically because such a top-level is imbued with fundamental and new knowledge-reification $\sim$ gesturing-and-accounting — of-epistemic-phenomenalism- $<$ inprospective_psychologismic apriorising/axiomatising/referencing-\{of-'prospectively implicited_attendant-ontological-contiguity ' educed- 
existentialising/contextualising/textualising_ 'intelligibility/epistemicity/reflexivity-contiguity$<$ imbued-notional cogency $>$ ' $\}$-conflatedness -in-\{preconverging-disentailment by\}

postconverging-ntailment $>$ priorities. While in-many-ways the relatively unblurriness- $<$ reontologising_by-postconverging-as-to-dragged-out-supererogatory -wholesomeness/profoundsupererogation ,-while-anecdotalising-prior-disontologising-thresholding $>$ and sharplydelineated nature of the natural sciences renders such a '\{epistemictotalising 3 hermeneutic/textuality/reprojecting/supererogating/zeroing/re-acuting,\{decomplesting delinearity for-cogency circle of levels of understanding' more or less very transparent, with regards to the blurriness-<sterilising/anecdotalising/trivialising-ofprospective-re-ontologising_by-preconverging,-in-disontologising-formulaic-draggingout/hollowing-out> of the social such a postmodern-thought '\{epistemictotalising 3 ?hermeneutic/textuality/reprojecting/supererogating/zeroing/re-acuting,$\{$ decompulsing $\}$ delinearity for-cogency circle of levels of understanding' rather requires increasing familiarisation, habituation and contemplation with regards to such critical texts and analyses (and as is particularly necessary with regards to the "parrhesiastic nature of philosophy that is behind the engendering/parrhesiastic-aetheticisation of underlying ${ }^{83}$ reference-of-thought reproducibility—mathesis/motif/thrownness-disposition,--as-reproducibility-of-aestheticisation and thereof derived domains-of-study reified-knowledge as from the underlying ${ }^{8}$ reference-ofthought reproducibility—mathesis/motif/thrownness-disposition,-as-reproducibility-ofaestheticisation', and one's intemporal solipsistic level of parrhesiastic contemplation is itself a decisive element for the capacity to appreciate-and-understand philosophical thought more than just an issue of technical acquisition of philosophical knowledge as of mere knowledge mathesis/motif/thrownness-disposition). More critically, social and philosophical knowledge are no different from any other type of knowledge subject to <amplituding/formativeepistemicity $>$ causality $\sim$ as-to-projective-totalitative-implications-of-prospective- 
nonpresencing,-for-explicating relative-unreflexivity/relative-reflexivity - ontological-

contiguity as of inherent existence/ontological implications, as fundamentally requiring contemplative reification arising with human limited-mentation-capacity-deepening-assubjecting limitedness/human-subpotency-to-'educed-unlimitedness/existence-sublimating nascence' ${ }^{53}$, with the implication that any philosophical, historial and social conception of knowledge is not an sterile/anecdotal imprimatur totalisingly-disentailing — discretion/whim-ofthought exercise on the basis of 'relic-or-orthodoxy knowledge' induced disparateness-ofconceptualisation-<unforegrounding-disentailment,-failing-prospectively-to-reflect‘immanent relative-unreflexivity/relative-reflexivity - ontological-contiguity '> but rather implying a furtherance of the overall \{epistemictotalising ${ }^{3}$ ' $h e r m e n e u t i c / t e x t u a l i t y /$ reprojecting/supererogating/zeroing/re-acuting,\{decompulsing $\}$ delinearity for-cogency exercise involved in the advancement of all human knowledge as of <amplituding/formative-epistemicity $>$-totalising $\sim$ renewing-realisation/reperception/re-thought, wherein all such knowledge-reification $\sim$ gesturing-and-accounting_ofepistemic-phenomenalism-<inprospective_psychologismic apriorising/axiomatising/referencing-\{of-‘prospectively implicited_attendant-ontological-contiguity ' reducedexistentialising/contextualising/textualising_ intelligibility/epistemicity/reflexivity-contiguity<imbued-notional cogency $\left.>^{\prime} \quad\right\}$-conflatedness -in-\{preconverging-disentailment by\} postconverging entailment> is an $>$ is thermeneutic/textuality/reprojecting/supererogating/zeroing/re-acuting,${ }_{\{\text {decompulsing }}$ delinearity for-cogency circle involving: the analyst's/philosopher's baseline reoriginary_-as-unenframed/re-ontologising/unbeholdenning/outlier-conceptualisation-_iimbuedpostconverging/dialectical-thinking -'projective-insights'/'epistemic-projection-inconflatedness ' -of-notional deprocrypticism-prospective-sublimation〉 up-to-date 
knowledge-reification $\sim$ gesturing-and-accounting — of-epistemic-phenomenalism- $<$ inprospective_psychologismic apriorising/axiomatising/referencing-\{of-'prospectively implicited_attendant-ontological-contiguity ' educedexistentialising/contextualising/textualising_'intelligibility/epistemicity/reflexivity-contiguity<imbued-notional cogency >' \}-conflatedness -in-\{preconverging disentailment by\} postconverging-entailment $>$ process/gesturing of the specific knowledge area as of inherent existence/ontological implications whether say with a natural science domain like hereditary as of its given specificity or philosopher's thought as of the general ontological comprehensiveness of philosophical thought; to then credibly analyse the coherence of the given prior contribution on the basis of the analyst's/philosopher's baseline re-originary_-as-unentronframed_re-_reontologising/unbeholdening/outlier-conceptualisation__imbued-postconverging/dialecticalthinking -'projective-insights'/‘epistemic-projection-in-conflatedness '-ofnotional deprocrypticism-prospective-sublimation $\rangle$ up-to-date knowledgereification $\sim$ gesturing-and-accounting - of-epistemic-phenomenalism- $<$ inprospective_psychologismic apriorising/axiomatising/referencing-\{of-'prospectively implicited_attendant_ontological-contiguity ' educedexistentialising/contextualising/textualising_'intelligibility/epistemicity/reflexivity_contiguity<imbued-notional cogency >' \}-conflatedness -in-\{preconverging disentailment by\} postconverging-entailment $>$ process/gesturing of the specific knowledge area as of inherent existence/ontological implications as to what it brings and reflects about current knowledgereification $\sim$ gesturing-and-accounting — of-epistemic-phenomenalism- $<$ inprospective_psychologismic apriorising/axiomatising/referencing-\{of-‘prospectively implicited_attendant-ontological-contiguity ' educedexistentialising/contextualising/textualising_'intelligibility/epistemicity/reflexivity_contiguity<imbued-notional cogency >' \}-conflatedness -in-\{preconverging disentailment by\} 
postconverging-entailment>; and then the analyst's/philosopher's reflection on the shortfall in the ontological-performance ${ }^{2}-<$ including-virtue-as-ontology $>/$ morality/ethics/justice/etc. of the given prior contribution while reflecting the epochal constraints for such a shortfall going beyond a construal of the given prior contribution as mere 'relic-or-orthodoxy knowledge'; and finally, the analyst's/philosopher's conceptual interpretation as its prospective contribution that is subject to validation and falsifiability ${ }^{42}$ as of inherent existence/ontological implications thus amenable to ${ }^{45}$ foregrounding_ entailment- $<$ in-succession-of-profound-supererogation $>$ 〈postconverging-narrowing-down $\sim$ sublimation-as-to-'existence-as-sublimatingwithdrawal/unenframing/re-ontologising,-elicited-from-prospective-profoundsupererogation '-in-reflecting-'immanent relative-unreflexivity/relative-reflexivity ontological-contiguity ';-as-operative-notional deprocrypticism〉 with other so-constructed knowledge-reification $\sim$ gesturing-and-accounting — of-epistemic-phenomenalism- $<$ inprospective_psychologismic apriorising/axiomatising/referencing-\{of-'prospectively implicited_attendant-ontological-contiguity ' educedexistentialising/contextualising/textualising_ 'intelligibility/epistemicity/reflexivity-contiguity<imbued-notional cogency >' \}-conflatedness -in-\{preconverging-disentailment by\} postconverging-entailment>, that are well beyond a disparateness-of-conceptualisation$<$ unforegrounding-disentailment,-failing-prospectively-to-reflect-'immanent $\sim$ relativeunreflexivity/relative-reflexivity ontological-contiguity ' $>$ orientation driven by the cultivation of mere sterile/anecdotal imprimatur totalisingly-disentailing — discretion/whim-ofthought 'relic-or-orthodoxy knowledge' disposition. It is important to appreciate here that a history of postmodern-thought criticism driven by populism, media operations, false intellectual engagement and ontological-bad-faith/inauthenticity ${ }^{64}$, is particularly telling not about postmodern thinkers knowledge-reification $\sim$ gesturing-and-accounting-of-epistemicphenomenalism-<in-prospective_psychologismic $\sim$ apriorising/axiomatising/referencing- of- 
'prospectively_implicited_attendant-ontological-contiguity ' educed-

existentialising/contextualising/textualising_'intelligibility/epistemicity/reflexivity_contiguity<imbued-notional cogency>> $\}$-conflatedness -in-\{preconverging-disentailment by\} postconverging entailment $>$ epistemic-veracity but rather the 'knowledge-reification $\sim$ gesturingand-accounting - of-epistemic-phenomenalism- $<$ inprospective_psychologismic apriorising/axiomatising/referencing-\{of-‘prospectively_ implicited_attendant-ontological-contiguity ' educedexistentialising/contextualising/textualising_'intelligibility/epistemicity/reflexivity-contiguity$<$ imbued-notional cogency $>\quad\}$-conflatedness -in-\{preconverging disentailment by\} postconverging-entailment $>$ epistemic-veracity of such critics who often pride themselves on not understanding postmodern-thought then by a strange paradox have the knowledge to produce a profound criticism of postmodern-thought which they supposedly do not understand'. Even more critically, the question can be raised whether such critics profoundly appreciate the overall human knowledge-reification $\sim$ gesturing-and-accounting-of-epistemic-phenomenalism- $<$ inprospective_psychologismic apriorising/axiomatising/referencing-\{of- ${ }^{\star p r o s p e c t i v e l y}$ implicited_attendant-ontological-contiguity ' educedexistentialising/contextualising/textulising_intelligibility/epistemicity/reflexivity-contiguity<imbued-notional cogency>’ \}-conflatedness -in-\{preconverging-disentailment by\} postconverging-entailment $>$ process/gesturing as herein articulated, and whether this very fact isn't linked to the knowledge-reification $\sim$ gesturing-and-accounting-of-epistemicphenomenalism- $<$ in-prospective_psychologismic $\sim$ apriorising/axiomatising/referencing- of'prospectively_implicited_attendant-ontological-contiguity ' ceducedexistentialising/contexalising/textralising_intelligibility/epistemicity/reflexivity-contiguity<imbued-notional cogency $\left.>^{\prime} \quad\right\}$-conflatedness -in-\{preconverging-disentailment by\} postconverging entailment $>$ methodological difficulties arising in many social domains-of- 
study 'assuming a disparateness-of-conceptualisation-<unforegrounding-disentailment,-failingprospectively-to-reflect-'immanent relative- unreflexivity/relative-reflexivity - ontologicalcontiguity '> epistemic-disposition that is in-many-ways poorly constrained to existentialreality' with the result of their relative knowledge-reification $\sim$ gesturing-and-accounting-ofepistemic-phenomenalism- $<$ in-

prospective_psychologismic apriorising/axiomatising/referencing-\{of-'prospectively implicited_attendant-ontological-contiguity ' educedexistentialising/contextualising/textualising_'intelligibility/epistemicity/reflexivity_contiguity<imbued-notional cogency $\left.>^{\prime}\right\}$-conflatedness -in-\{preconverging disentailment by\} postconverging-entailment $>$ passivity with regards to many a social issue 'but for adventures into social commentary divorced from genuine operant knowledge-reification $\sim$ gesturing-andaccounting - of-epistemic-phenomenalism- $<$ inprospective_psychologismic apriorising/axiomatising/referencing-\{of- ${ }^{\text {pprospectively }}$ implicited_attendant-ontological-contiguity ' educedexistentialising/contextualising/textualising_intelligibility/epistemicity/reflexivity_contiguity<imbued-notional cogency >' \}-conflatedness -in-\{preconverging-disentailment by\} pesteonverging entailment> implications'; and in this regards could it be that the true 'unsaid issue with suprastructuralism/postmodern-thought' lies with its parrhesiastic emphasis on the displacement/decentering-of-the-human-subject for the right mindset-as-of-prospectiverelative-ontological-completeness ${ }^{87}$ and thereof the knowledge for that given right mindset-asof-prospective-relative-ontological-completeness ${ }^{87}$ as of projected 'implicited_attendantontological-contiguity ${ }^{67}$, educed-

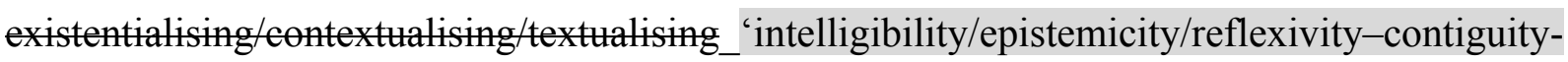
$<$ imbued-notional cogency >’ in apriorising/axiomatising/referencing-\{of-'prospectively implicited_attendant-ontological-contiguity ' educed- 
existentialising/contextualising/textualising_'intelligibility/epistemicity/reflexivity-contiguity$<$ imbued-notional cogency $>$ ' $\}$-conflatedness ${ }^{13}$ in-\{preconverging-disentailment by\} postconverging-ntailment, an issue that has always been a difficult knot throughout the relativeunreflexivity/relative-reflexivity - ontological-contiguity ${ }^{67} \sim$ of-the-human-institutionalisationprocess ${ }^{68}$ but which inevitably has to be dealt with for the possibility of prospective human registry-worldview's/dimension's institutionalisation. Such weaknesses manifested by many a postmodern critic fundamentally points to an atomising/taking-to-pieces predisposition that poorly appreciates the <amplituding/formative-epistemicity $>$ causality $\sim$ as-to-projectivetotalitative-implications-of-prospective- nonpresencing,-for-explicating relativeunreflexivity/relative-reflexivity ontological-contiguity involved in knowledgereification $\sim$ gesturing-and-accounting — of-epistemic-phenomenalism- $<$ inprospective_psychologismic apriorising/axiomatising/referencing-\{of-'prospectively implicited_attendant-ontological-contiguity ' educedexistentialising/contextualising/textualising_intelligibility/epistemicity/reflexivity-contiguity<imbued-notional cogency >' \}-conflatedness -in-\{preconverging disentailment by\} postconverging-entailment>, and is reflected in a lack of parrhesiastic and \{epistemictotalising ${ }^{3}$ 'hermeneutic/textulity/reprejecting/supererogating/zeroing/re aenting,\{decompulsing\} delinearity for-cogency insight that 'poorly grasp the philosophical analysis implications of the existential-<disontologising/re-ontologising aporeticism $>$ background/development of becoming-as- ${ }^{4}$ historiality/ontological-eventfulness ${ }^{38} /$ ontological- $^{2}$ aesthetic-tracing-<perspective-ontological-normalcy/postconvergence-reflected-'epistemicityrelativism-determinism'>, as if philosophy only started as of our present positivist era with a naivety that seems to imply that all-that-should-have-been,-that-is-and-that-will-be,-as-of-thehuman-potential is as of a modern positivist <amplituding/formative $>$ wooden-language〈imbued - averaging-of-thought-<as-to-leveling/ressentiment/closed-construct-of- 
meaningfulness-and-teleology -as-of-'nondescript/ignorable-void '-with-regards-to-

prospective-apriorising-implications $>>$ in its given ${ }^{83}$ reference-of-thought reproducibilitymathesis/motif/thrownness-disposition,-as-reproducibility-of-aestheticisation with no or poor insight of prior-and-prospective human becoming as of 'implicited_attendant-ontologicalcontiguity ${ }^{67} \sim$ educed-

existentialising/contextualising/textualising_intelligibility/epistemicity/reflexivity-contiguity<imbued-notional cogency >’ in apriorising/axiomatising/referencing-\{of- 'prospectivelyimplicited_attendant-ontological-contiguity ' educed-

existentialising/contextualising/textualising_'intelligibility/epistemicity/reflexivity-contiguity<imbued-notional cogency >' \}-conflatedness ${ }^{13}$-in-\{preconverging-disentailment by\} postconverging-entailment'; and so when it generally comes to analysing philosophical texts requiring a sense of parrhesia and \{epistemicthermeneutic/textuality/reprojecting/supererogating/zeroing/re-acuting,delinearity for-cogency insight. This lack is quite often reflected in such misconstrued analyses of traditional philosophical figures by a failure to understand the overall coherent narrative of such figures as of an atomising/taking-to-pieces predisposition to identitive-constitutedness ${ }^{14}$-as-'epistemic-totality ${ }^{37}$ '-dereification-in-dissingularisation- $<$ as-tothe-disjointedness/disentailment-of- presencing - absolutising-identitive-constitutedness > as-flawed-epistemicity-relativism-determinism ending up quite often claiming the incoherence of such figures and/or of their narrative accounts, and so in a 'naïve insight' arising exactly because the possibility for understanding requires the critic's own parrhesiastic insight and then \{epistemic-totalising 3 3 hermeneutic/textulity/reprojecting/supererogating/zeroing/re acuting,-

\{decompulsing delinearity for-cogency conceptualisation to then develop the capacity to grasp first of all such traditional philosophical figures underlying knowledge-reification $\sim$ gesturing-andaccounting-of-epistemic-phenomenalism- $<$ in- 
prospective_psychologismic apriorising/axiomatising/referencing-\{of- ${ }^{\text {prospectively }}$

implicited_attendant-ontological-contiguity ' educed-

existentialising/contextualising/textualising_'intelligibility/epistemicity/reflexivity-contiguity-

<imbued-notional cogency >’ \}-conflatedness -in-\{preconverging-disentailment by\}

postconverging-entailment $>$ process/gesturing and thus be able to understand how such

knowledge-reification $\sim$ gesturing-and-accounting — of-epistemic-phenomenalism- $<$ in-

prospective_psychologismic $\sim$ apriorising/axiomatising/referencing-\{of-'prospectively

implicited_attendant-ontological-contiguity ' educed-

existentialising/contextualising/textualising_'intelligibility/epistemicity/reflexivity-contiguity-

<imbued-notional cogency >' \}-conflatedness -in-\{preconverging-disentailment by\}

postconverging-entailment $>$ process/gesturing develops and why, and thus enabling the grasp not only of the accuracy of narrated accounts and notions but equally insight about the nuanced and covertly narrated accounts and notions, and all these while being informed by the immediate and broader underlying social background and implicited social and philosophical stakes of contention-and-confliction. In this regards, more than just the simpleminded analysis of traditional philosophical figures, such parrhesiastic and \{epistemictotalising ${ }^{3}$ h hermeneutic/textulity/reprojecting/supererogating/zeroing/re acuting,-

\{decompulsing delinearity for-cogency analytical insight actually converges with the epochal philosophical implications of 'implicited_attendant-ontological-contiguity ${ }^{67}$ ' educedexistentialising/contextmalising/textualising_'intelligibility/epistemicity/reflexivity_contiguity<imbued-notional cogency>' 40 in apriorising/axiomatising/referencing-\{of-'prospectivelyimplicited_attendant-ontological-contiguity ' reduced-

existentialising/contexalising/texalising_intelligibility/epistemicity/reflexivity-contiguity$<$ imbued-notional cogency $\left.>{ }^{\prime}\right\}$-conflatedness ${ }^{13}$-in-\{preconverging-disentailment by\} postconverging-entailment and are actually more scientifically profound in that respect than 
meets the eye as to the fact that such analyses are more than just 'archivistic retrieving' but preconverging/postconverging-de-mentatively/structurally/paradigmatically conceptualise the extended existential-<disontologising/re-ontologising aporeticism $>$ possibilities of falsifiability ${ }^{42}$ and validation in determining ontological-veracity as of a critical exercise of $<$ amplituding/formative-epistemicity $>$-totalising $\sim$ renewing-realisation/re-perception/rethought of 'coherence/contiguity-of-superseding-oneness-of-ontology-implied-as-of-inherentexistence-coherence/contiguity,-and-so-construed-as-the-enabler-of-insight-or-intuition-orforesight-as-of-embodied-consciousness'. In this regards, such hermeneutic/textuality/reprojecting/supererogating/zeroing/re-acuting,$\{$ decompulsing $\}$ delinearity for-cogency and parrhesiastic depth of analysis is more profoundly driven beyond the specific accuracy of narrative accounts about traditional philosophical figures but goes on to analyse the preconverging/postconverging-de-mentative/structural/paradigmatic possibilities of overall human social transformation reflected in the narrative accounts of such traditional philosophical figures. For instance, the ontological-veracity of Socratic philosophy is rather more strongly based on the overall social implications and underlying narrative of its novel universalising-idealisation that 'runs-through/is-deflating' by its evental ${ }^{38}$-instigation traditional philosophical figures and schools, and as pursued by their successors including the stoics, cynics, etc. and as to its induced ${ }^{103}$ universalising-idealisation transformative meaningfulness-and-teleology infrastructure impact with respect to societies of the Mediterranean including the Roman empire and subsequent religio-political developments. In another respect, it is often touted from a 79 presencing - absolutising-identitive-constitutedness orientation that Socratic-philosophers were institutionally 'anti-democratic', going particularly by the Platonic emphasis on philosopher kings, by the naivety and mere token that the prevailing ancient Athens 'mob-rule democracy' is of the same conceptual-patterning-〈as-devoid-of'prospectively_implicited_attendant-ontological-contiguity ' ceduced- 
existentialising/contextualising/textualising_ 'intelligibility/epistemicity/reflexivity-contiguity<imbued-notional cogency>' 's-reifying-or-elucidating-of-'prospective-relative-ontologicalcompleteness ${ }^{\prime} ;$-so-rather-enabled-<by-a- nonpresencing-divulging-of-momentoushistoriality/ontological-eventfulness /ontological-aesthetic-tracing-<perspectiveontological-normalcy/postconvergence-reflected-‘epistemicity-relativism-determinism’>> as our modern conception of democracy; but this is rather unnuanced with regards to what was a more pressing question of good governance in Ancient Athens and in the sense that such a 'mobrule democracy' is not what prevails today and more critically the fact is the modern democracy model whether of direct or indirect manifestations is rather more critically informed by these criticisms of the Socratic-philosophers (and not intellectual inspiration from any such mob-rule instigating sophists) wherein we rather place emphasis on 'informed competence/expertising and competence/expertising-institutions for the comprehensive process of our modern democracy' such that modern-day crises of democratic governance with regards to bad governance, institutional crisis, economic crisis or undesirable wars are rather generally construed as arising from 'failure or sophistry of expertise and competence/expertising-institutions' in need of better competence/expertising, and furthermore major political calamities of the $20^{\text {th }}$ century leading to totalitarian governments and their instigation of genocides arose exactly due to misinformed populist democracy. Paradoxically, this insight validates the point advanced herein that human meaningfulness-and-teleology is critically more than just its mechanical-knowledge reproducibility—mathesis/motif/thrownness-disposition,--as-reproducibility-of-aestheticisation but rather an organic-knowledge as of ontological-faith-notion-or-ontological-fideismimbued-underdetermination-of-motif-and-apriorising/axiomatising/referencing-as-so-being-asof-existential-reality dimensionality-of-sublimating

<<amplituding/formative>supererogatory $\sim$ de-mentativeness/epistemic-growth-orconflatedness /transvaluative-rationalising/transepistemicity/anamnestic-residuality/spirit- 
drivenness-equalisation> that then feeds into prospective originariness-parrhesia,-asspontaneity-of-aestheticisation; emphasising as of any given registry-worldview's/dimension's specific limited-mentation-capacity—as-subjecting-'educed-unlimitedness/existencesublimating nascence' to-limitedness/human-subpotency that knowledge 'more profoundly lies with the knowledge-reification $\sim$ gesturing-and-accounting-of-epistemic-phenomenalism- $<$ inprospective_psychologismic apriorising/axiomatising/referencing-\{of-'prospectively implicited_attendant-ontological-contiguity ' educedexistentialising/contextualising/textualising_'intelligibility/epistemicity/reflexivity-contiguity<imbued-notional $\left.\sim \operatorname{cogency}>^{\prime} \quad\right\}$-conflatedness -in-\{preconverging-disentailment by\} postconverging-entailment $>$ and organic implications', just as we cannot simplistically interpret the importance of Aristotelian science in terms of its constitutive elements as earth, water, air, fire and aether on a naïve ${ }^{7}$ presencing - absolutising-identitive-constitutedness ${ }^{14}$ basis from the vantage perspective of our modern positivism (as being at the receiving backend of the institutional-cumulation/institutional-recomposure-〈as-to- historiality/ontologicaleventfulness /ontological-aesthetic-tracing-<perspective-ontologicalnormalcy/postconvergence-reflected-'epistemicity-relativism-determinism' $>>$ in reflecting holographically-<conjugatively-and-transfusively $>$ the relative-unreflexivity/relativereflexivity - ontological-contiguity of-the-human-institutionalisation-process ) but rather the more critical insight lies with its novel and transformative ${ }^{103}$ universalising-classificatory knowledge-reification $\sim$ gesturing-and-accounting — of-epistemic-phenomenalism- $<$ inprospective_psychologismic apriorising/axiomatising/referencing-\{of-‘prospectively implicited_attendant-ontological-contiguity ' educedexistentialising/contextualising/textualising_ intelligibility/epistemicity/reflexivity-contiguity<imbued-notional cogency >' \}-conflatedness -in-\{preconverging-disentailment by\} postconverging-entailment $>$ as opening up the possibility for prospective human 
reconceptualisation of science providing the backdrop from which modern science took off from the medieval times to the present. Likewise, the transformative nature of budding-positivism more than just as garnered from the precised narrative accounts about budding-positivist thinkers, lies more profoundly with its ${ }^{5}$ meaningfulness-and-teleology ${ }^{9}$ infrastructure impact on the developing enlightenment social developments and as this budding-positivism metaphoricity ${ }^{57}$ epistemic-ricochettingly/transepistemically brought about our positivism/rational-empiricism modern society. The analyses of human becoming so-implied as of parrhesiastic and fepistemic thermeneutic/textuality/reprojecting/supererogating/zeroing/re-acuting,${ }_{\{\text {decompulsing }\}}$ delinearity for-cogency development is in of itself a pure science that is epistemically-derivable as of 'coherence/contiguity-of-superseding-oneness-of-ontologyimplied-as-of-inherent-existence-coherence/contiguity,-and-so-construed-as-the-enabler-ofinsight-or-intuition-or-foresight-as-of-embodied-consciousness', and so beyond the specific accuracy of narrative accounts of traditional philosophical figures and besides such parrhesiastic and ${ }^{2}$ hermeneutic/textuality/reprojecting/supererogating/zeroing/re-acuting,${ }_{\{\text {decompulsing }}$ delinearity for-cogency insight actually informs about the ontological-pertinence of such narrative accounts. In another respect, even with a most natural sense of parrhesia and \{epistemic-totalising 3 ? 3 hermeneutic/textuality/reprojecting/supererogating/zeroing/re-acuting,${ }_{\{\text {decompulsing }}$ delinearity for-cogency insight, many a figure predispose to atomising/taking-topieces analysis, including founders of this orientation and other of its leading figures, have ultimately come to realise its relative underlying platitude with respect to prospective human transcendence-and-sublimity/sublimation/supereregatory $\sim$ de-mentativity such that a prevailing notion has developed within as to imply philosophy doesn't necessarily involve a transcendentaland-sublimity promise as of a nombrilistic institutional-being-and-craft predisposition; and as such a merely reproducibility-mathesis/motif/thrownness-disposition,-as-reproducibility-of- 
aestheticisation knowledge culture that 'dodges potential parrhesiastic implications from its very own tentative analyses' speaks of a 'supposed intellectualism' that does not lead prospective social progress as it becomes a sophistic/pedantic problem for prospective social progress especially so when it originates from the 'mother of all disciplines'. The fact is 'philosophy just as any of its derived domain-of-study is not the ownership of any institutional culture' but rather a 'human abstract-property co-opted institutionally in deferential-formalisation-transference to the extend that that deference fulfils its promise of knowledge-reification $\sim$ gesturing-andaccounting - of-epistemic-phenomenalism- $<$ in-

prospective_psychologismic $\sim$ apriorising/axiomatising/referencing-\{of-'prospectively implicited_attendant-ontological-contiguity ' reducedexistentialising/contextualising/textualising_'intelligibility/epistemicity/reflexivity-contiguity<imbued-notional cogency $\left.>^{\prime}\right\}$-conflatedness -in-\{preconverging-disentailment by\} postconverging entailment $>$ for prospective human transcendence-andsublimity/sublimation/supererogatory $\sim$ de-mentativity'. In this regards, the transcendental-andsublimity possibilities of 7.5 billion humans today and human posterity cannot be construed as hanging on such terms of institutional-being-and-craft dispositions prevailing in many a social domain-of-study and even some of the natural sciences as of naïve science-ideology, and so because beyond the temporal human disposition to contemplate of existence as of a-lifespan-ofexistence-implications there need to be 'human intemporal contemplation that abstractly lives/exists beyond a-lifespan-of-existence-implications to fetch for prospective possibilities of meaningfulness-and-teleology infrastructure', something which a 'human lifespan extricatory punctuality/immediacy of depth-of-thought' as of a $<$ amplituding/formative $>$ wooden-language-<imbued — averaging-of-thought-<as-toleveling/ressentiment/closed-construct-of- meaningfulness-and-teleology -as-of'nondescript/ignorable-void '-with-regards-to-prospective-apriorising-implications $>>$ is not 
postconvergingly-de-mentated/structured/paradigmed to do! But then the phenomenological question arising with respect to the fact that many a social domain-of-study 'tend to assume a disparateness-of-conceptualisation-<unforegrounding-disentailment,-failing-prospectively-toreflect-'immanent relative-unreflexivity/relative-reflexivity - ontological-contiguity epistemic-disposition that is in-many-ways poorly constrained to existential-reality', is how exactly does such lack of 'cogent-unifying-operant-dynamics' affect the realisation of the full knowledge-reification $\sim$ gesturing-and-accounting —of-epistemic-phenomenalism- $<$ inprospective_psychologismic apriorising/axiomatising/referencing-\{of-‘prospectively_ implicited_attendant-ontological-contiguity ' educedexistentialising/contextualising/textualising_'intelligibility/epistemicity/reflexivity_contiguity$<$ imbued-notional cogency $>$ ' $\}$-conflatedness -in-\{preconverging-disentailment by\} postconverging-entailment> potentiality of domains-of-study as of their supposedly coherent ontological-commitment $\quad$-<implied-self-assuredness-of-ontological-goodfaith/authenticity postconverging-de-mentating/structuring/paradigming -as-being-as-ofexistential-reality $>$ as reflected by $<$ amplituding/formative-epistemicity $>$ causality $\sim$ as-toprojective-totalitative-implications-of-prospective- nonpresencing,-for-explicating relativemnreflexivity/relative reflexivity ontological-contiguity as of existencepotency $^{39} \sim$ sublimating-nascence,-disclosed-from-prospective-epistemic-digression? Insightfully, this fundamentally has to do with the contrastive implications in construing $<$ amplituding/formative-epistemicity $>$ causality $\sim$ as-to-projective-totalitative-implications-ofprospective- nonpresencing,-for-explicating relative-unreflexivity/relative-reflexivity ontological-contiguity as of good-practice/epistemic-veracity and bad-practice/epistemicimpertinence for knowledge-reification $\sim$ gesturing-and-accounting-of-epistemicphenomenalism- $<$ in-prospective_psychologismic $\sim$ apriorising/axiomatising/referencing-\{of'prospectively_implicited_attendant-ontological-contiguity ' educed- 
existentialising/contextualising/textualising_ intelligibility/epistemicity/reflexivity-contiguity$<$ imbued-notional $\left.\sim \operatorname{cogency}>^{\prime} \quad\right\}$-conflatedness -in-\{preconverging disentailment by\} postconverging-entailment $>$; wherein objectifying $\quad{ }^{45}$ foregrounding_entailment- $<$ insuccession-of-profound-supererogation $>>$-〈postconverging-narrowing-down $\sim$ sublimation-asto-'existence - as-sublimating-withdrawal/unenframing/re-ontologising,-elicited-fromprospective-profound-supererogation ' -in-reflecting-'immanent $\sim$ relativeunreflexivity/relative-reflexivity - ontological-contiguity ';-as-operativenotional deprocrypticism $\rangle$ as good-practice/epistemic-veracity of knowledgereification $\sim$ gesturing-and-accounting — of-epistemic-phenomenalism- $<$ inprospective_psychologismic apriorising/axiomatising/referencing-\{of-‘prespectively implicited_attendant-ontological-contiguity ' educedexistentialising/contextualising/textualising_'intelligibility/epistemicity/reflexivity-contiguity<imbued-notional cogency $\left.>^{\prime} \quad\right\}$-conflatedness -in-\{preconverging-disentailment by\} postconverging entailment> involves the construal of <amplituding/formativeepistemicity $>$ causality $\sim$ as-to-projective-totalitative-implications-of-prospectivenonpresencing,-for-explicating relative-unreflexivity/relative-reflexivity ontologicalcontiguity as of 'cogent-unifying-operant-dynamics of primemovers' so-construed veridically as '<amplituding/formative-epistemicity $>$ causality $\sim$ as-to-projective-totalitative-implicationsof-prospective- nonpresencing,-for-explicating relative-unreflexivity/relative-reflexivity ontological-contiguity as of apriorising/axiomatising/referencing-\{of-'prospectively implicited_attendant-ontological-contiguity ' educedexistentialising/contextualising/textualising_'intelligibility/epistemicity/reflexivity_contiguity<imbued-notional cogency $>$ ' $\}$-conflatedness ${ }^{13}$-in-\{preconverging-disentailment by\} postconverging-entailment', whereas disparateness-of-conceptualisation-<unforegroundingdisentailment,-failing-prospectively-to-reflect-'immanent relative-unreflexivity/relative- 
reflexivity - ontological-contiguity '> as bad-practice/epistemic-impertinence of knowledgereification $\sim$ gesturing-and-accounting — of-epistemic-phenomenalism- $<$ inprospective_psychologismic apriorising/axiomatising/referencing-\{of-"prospectively implicited_attendant-ontological-contiguity ' educedexistentialising/contextualising/textualising_ 'intelligibility/epistemicity/reflexivity-contiguity<imbued-notional cogency $>$ ' \}-conflatedness -in-\{preconverging-disentailment by\} postconverging-ntailment> involves the construal of <amplituding/formativeepistemicity $>$ causality $\sim$ as-to-projective-totalitative-implications-of-prospectivenonpresencing,-for-explicating relative- unreflexivity/relative-reflexivity - ontologicalcontiguity as 'disjointing/disparateness/disentailing of primemovers' so-construed wrongly as '<amplituding/formative-epistemicity $>$ causality $\sim$ as-to-projective-totalitative-implications-ofprospective- nonpresencing,-for-explicating $\sim$ relative-unreflexivity/relative-reflexivity ontological-contiguity in apriorising/axiomatising/referencing-\{of-"prospectively implicited_attendant-ontological-contiguity ' educedexistentialising/contextualising/textualising_'intelligibility/epistemicity/reflexivity_contiguity$<$ imbued-notional cogency $\left.>{ }^{\prime} \quad\right\}$-constitutedness ${ }^{1}$-in-preconverging-entailment $\quad$ outside 'implicited_attentantontological-contiguity ${ }^{67}$ ' educedexistentialising/contextualising/textualising_intelligibility/epistemicity/reflexivity-contiguity$<$ imbued-notional cogency $>$ ' . Thus 'disjointing/disparateness/disentailing of primemovers as disparateness-of-conceptualisation-<unforegrounding-disentailment,-failing-prospectively-toreflect-'immanent relative-unreflexivity/relative-reflexivity - ontological-contiguity basically undermines the veridical underlying 'ontological-totalitative-framework as of apriorising/axiomatising/referencing-\{of-'prospectively implieited_attendant-ontologicalcontiguity ' educedexistentialising/contextualising/textualising_intelligibility/epistemicity/reflexivity_contiguity- 
<imbued-notional cogency >' \}-conflatedness ${ }^{13}$ in-\{preconverging disentailment by\} postconverging-entailment', and thus undermines aetiologisation/ontological-escalation$<$ ontological-veridicality_commitment/otherliness_transcending/compulsions-

encumbered_transcending $>$ predicative-effectivity-sublimation-〈as-to-underlying,-ontologicalcommitment $-<$ implied — self-assuredness-of-ontological-good-

\section{faith/authenticity postconverging-de-mentating/structuring/paradigming -as-being-as-of-}

existential-reality $>$ >. 'disjointing/Disparateness/Disentailing of primemovers as disparatenessof-conceptualisation-<unforegrounding-disentailment,-failing-prospectively-to-reflect‘immanent relative-unreflexivity/relative-reflexivity - ontological-contiguity '>’ undermines the inherent 'cogent-unifying-operant-dynamics of primemovers' reflecting apriorising/axiomatising/referencing-\{of-'prospectively implicited_attendant-ontologicalcontiguity ' $\sim$ educedexistentialising/contextualising/textualising_'intelligibility/epistemicity/reflexivity-contiguity<imbued-notional cogency $\left.>^{\prime} \quad\right\}$-conflatedness ${ }^{13}$ in-\{preconverging-disentailment by postconverging-entailment, such that the supposed exercise of knowledge-reification $\sim$ gesturingand-accounting - of-epistemic-phenomenalism- $<$ inprospective_psychologismic $\sim$ apriorising/axiomatising/referencing-\{of-`prospectively implicited_attendant-ontological-contiguity ' reducedexistentialising/contextualising/textualising_'intelligibility/epistemicity/reflexivity-contiguity<imbued-notional cogency $\left.>^{\prime} \quad\right\}$-conflatedness -in-\{preconverging-disentailment by\} postconverging-entailment> up 'losing the supererogatory acuity/perspicacity/astuteness/edginess/incisiveness-ofapriorising/axiomatising/referencing/intelligibilitysettingup/measuringinstrumenting -forconceptualisation of axiomatic-constructs as reflective of existential-reality'; as of the flawed disjointing/disparateness/disentailing of overall inherent existential-reality 
supererogatory acuity/perspicacity/astuteness/edginess/incisiveness, and further reflected variously as temporal over-emphasising and/or underemphasising/ignoring of primemovers reflecting 'ontological-totalitative-framework as of apriorising/axiomatising/referencing-\{of'prospectively_implicited_attendant-ontological-contiguity ' educedexistentialising/contextualising/textualising_'intelligibility/epistemicity/reflexivity-contiguity<imbued-notional cogency >' $\}$-conflatedness ${ }^{13}$-in- -preconverging-disentailment by\} postconverging-entailment', and so due to 'human-subpotency ${ }^{7}$ presencing-absolutisingidentitive-constitutedness ${ }^{14} \quad<$ amplituding/formative-epistemicity $>$ totalising $\sim$ self-referencingsyncretising/circularity/interiorising/akrasiatic-drag ${ }^{34}$ as well as lack of prospective intemporal parrhesiastic aestheticisation for prospectively renewed reproducibilitymathesis/motif/thrownness-disposition,-as-reproducibility-of-aestheticisation' thus undermining existence-potency ${ }^{32} \sim$ sublimating-nascence,-disclosed-from-prospectiveepistemic-digression as from prospective nonpresencing-<perspective-ontologicalnormalcy/postconvergence $>$ reflection of <amplituding/formative-epistemicity $>$ causality $\sim$ asto-projective-totalitative-implications-of-prospective- nonpresencing,-forexplicating relative-unreflexivity/relative-reflexivity ontological-contiguity of relativeontological-incompleteness 8 /relative-ontological-completeness ${ }^{87}$ 〈sublimating $\sim$ referencing/registering/decisioning,--as-self-becoming/selfconflatedness /formative-supererogating-<projective/reprojective-aestheticising-re-motifand-re-apriorising/re-axiomatising/re-referencing,-in-perspective-ontologicalnormalcy/postconvergence $>>$. While in many a natural science the 'high-and-immediate subjection to existential/experimental falsifiability and validation as of $<$ amplituding/formative-epistemicity $>$ causality $\sim$ as-to-projective-totalitative-implications-ofprospective- nonpresencing,-for-explicating relative-unreflexivity/relative-reflexivity ontological-contiguity of conceptualisations' acts as a strong constraining effect in relatively 
undermining 'disjointing/disparateness/disentailing of primemovers' and rather encouraging 'cogent-unifying-operant-dynamics of primemovers' reflecting apriorising/axiomatising/referencing-\{of-'prospectively_implicited_attendant-ontologicalcontiguity ' educedexistentialising/contextualising/textualising_ 'intelligibility/epistemicity/reflexivity-contiguity<imbued-notional cogency $\left.>^{\prime}\right\}$-conflatedness ${ }^{13}$-in-\{preconverging-disentailment by\} postconverging entailment, the "blurriness-<sterilising/anecdotalising/trivialising-ofprospective-re-ontologising_by-preconverging,-in-disontologising-formulaic-draggingout/hollowing-out> and remoteness of falsifiability and validation as of $<$ amplituding/formative-epistemicity $>$ causality $\sim$ as-to-projective-totalitative-implications-ofprospective- nonpresencing,-for-explicating relative-unreflexivity/relative-reflexivity ontological-contiguity of conceptualisations' in many a social domain-of-study relatively undermines 'good-practice/epistemic-veracity selectiveness towards cogent-unifying-operantdynamics of primemovers' reflecting apriorising/axiomatising/referencing-\{of-'prospectively implicited_attendant-ontological-contiguity ' educedexistentialising/contextualising/textualising_'intelligibility/epistemicity/reflexivity-contiguity<imbued-notional cogency >' \}-conflatedness ${ }^{13}$ in (preconverging disentailment by postconverging-entailment, as the latter is inclined to an institutional-disposition that construes of the unification of disparateness-of-conceptualisation-<unforegrounding-disentailment,failing-prospectively-to-reflect- 'immanent relative-unreflexivity/relative-reflexivity ontological-contiguity '> substitutively as merely 'human-subpotency institutional-practice driven unification as of vague contrasting-and-comparison' rather than as of 'existencepotency ${ }^{32} \sim$ sublimating-nascence,-disclosed-from-prospective-epistemic-digression driven foregrounding_entailment- $<$ in-succession-of-profound-supererogation ${ }^{9}>-\langle$ postconverging narrowing-down $\sim$ sublimation-as-to-'existence - as-sublimating-withdrawal/unenframing/re- 
notional deprocrypticism $\rangle$. This equally explains this author emphasis that ontologicalveridicality cannot be construed as the mutual-agreement as of human-subpotency but rather as of the constraining sublimating-over-desublimating implications of existencepotency $^{32} \sim$ sublimating-nascence,-disclosed-from-prospective-epistemic-digression on humansubpotency. Human ${ }^{5}$ meaningfulness-and-teleology as of its ontological-performance ${ }^{72}$ $<$ including-virtue-as-ontology $>/$ morality/ethics/justice/etc. is the outcrop of human-subpotency conscious-able aestheticisation of ecstatic-existence. Human aestheticisation speaks of the extensive manifest outcomes/outfits/shells — construed-historially-as-of-the-specificallyaestheticised-incrusting/plating/coating,-so-reflected-as-institutional-manifestations of human meaningfulness-and-teleology as from: human 'perceptive motif-manifest aestheticisation as of human conscious-able imagery', 'mere-tracial-and-symbolisation-manifest aestheticisation as of human conscious-able works-of-art/artistry', and 'signification-as-of-existential-realitymanifest aestheticisation as of human conscious-able intermediating ascriptivity'. Basically, human ${ }^{56}$ meaningfulness-and-teleology ${ }^{9}$ refers to human-subpotency conscious-able aestheticisation of ecstatic-existence as of varying human ontological-performance ${ }^{72}$ $<$ including-virtue-as-ontology $>/$ morality/ethics/justice/etc. in veridically reflecting existencepotency $^{39} \sim$ sublimating-nascence,-disclosed-from-prospective-epistemic-digression.

Underlying the ontological-performance ${ }^{72}-<$ including-virtue-as- $^{2}$ ontology $>$ /morality/ethics/justice/etc. of human-subpotency conscious-able aestheticisation of ecstatic-existence is both the human instigative-drivenness construed as originarinessparrhesia,-as-spontaneity-of-aestheticisation and human reproducibilitymathesis/motif/thrownness-disposition,-as-reproducibility-of-aestheticisation reflectedtogether in all human ${ }^{56}$ meaningfulness-and-teleology ${ }^{9}$, as-of-their-inversely-varying- 
emphasis; and more specifically 'as institutive of underlying ${ }^{83}$ reference-of-thought', their implied spontaneity and reproducibility-mathesis/motif/thrownness-disposition,--asreproducibility-of-aestheticisation conjointly drive 'human existence ${ }^{4}$ historiality/ontologicaleventfulness 38 ontological-aesthetic-tracing-<perspective-ontologicalnormalcy/postconvergence-reflected-'epistemicity-relativism-determinism' creative aestheticisation of ${ }^{56}$ meaningfulness-and-teleology ${ }^{9}$. In this regards, originariness-parrhesia,-as-spontaneity-of-aestheticisation is marked by its greater taxing of human limited-mentationcapacity—as-subjecting 'educed-unlimitedness/existence-sublimating nascence' tolimitedness/human-subpotency and specifically so as it 're-stakes/put-back-at-stake the capacity of human ontological-performance ${ }^{72}-<$ including-virtue-asontology $>$ /morality/ethics/justice/etc. by its renewing spontaneity-of-aestheticisation' over already set/established prior reproducibility—mathesis/motif/thrownness-disposition,--asreproducibility-of-aestheticisation; and so as 'human corresponding-sublimation-inducing,profound-and-creative supererogatory $\sim$ acuity/perspicacity/astuteness/edginess/incisiveness-ofapriorising/axiomatising/referencing/intelligibilitysettingup/measuringinstrumenting -forconceptualisation' so-construed as originariness-parrhesia,-as-spontaneity-of-aestheticisation (which is actually constrained to '<amplituding/formativeepistemicity>totalising/circumscribing/delineating 'implicited_attendant-ontologicalcontiguity $^{67} \sim$ educedexistentialising/contextualising/textualising_'intelligibility/epistemicity/reflexivity_contiguity$<$ imbued-notional cogency $>{ }^{40} \quad{ }^{45}$ foregrounding_entailment- $<$ in-succession-of-profoundsupererogation $>$-〈postconverging-narrowing-down $\sim$ sublimation-as-to-'existence-assublimating-withdrawal/unenframing/re-ontologising,-elicited-from-prospective-profoundsupererogation '-in-reflecting-'immanent relative-unreflexivity/relative-reflexivity ontological-contiguity ';--as-operative-notional deprocrypticism) in elucidating relative- 
unreflexivity/relative-reflexivity - ontological-contiguity $-<$ as-from-prospective-ontologicalnormalcy/postconvergence-epistemic-or-notional $\sim$ projective-perspective $>>$ ), $\quad$ precedes-anddefines the pertinence of 'methods/methodologies/approaches as to reproducibilitymathesis/motif/thrownness-disposition,-as-reproducibility-of-aestheticisation'. This inverselyvarying-emphasis of originariness-parrhesia,-as-spontaneity-of-aestheticisation and reproducibility—mathesis/motif/thrownness-disposition,-as-reproducibility-of-

aestheticisation, given human limited-mentation-capacity-as-subjecting 'educedunlimitedness/existence-sublimating nascence' to-limitedness/human-subpotency implications, is reflected in all human aetheticisation construals whether as of reflex aetheticisation construct, instant aetheticisation construct, shallow aetheticisation construct, dragged-out aetheticisation construct, profound aetheticisation construct or subsuming aetheticisation construct with respect to sought out ontological-performance ${ }^{2}-<$ includingvirtue-as-ontology $>$ /morality/ethics/justice/etc. implications. The inevitability of this relation of originariness-parrhesia,-as-spontaneity-of-aestheticisation and reproducibilitymathesis/motif/thrownness-disposition,-as-reproducibility-of-aestheticisation in all human aestheticisation of ${ }^{5}$ meaningfulness-and-teleology ${ }^{9}$ lies with the fact that, however human limited-mentation-capacity-deepening - as subjecting limitedness/hmman-subpotency to 'educed-unlimitedness/existence-sublimating nascence's implications of more and more profound reproducibility-mathesis/motif/thrownness-disposition,-as-reproducibility-ofaestheticisation given supererogatory $\sim$ acuity/perspicacity/astuteness/edginess/incisiveness-ofapriorising/axiomatising/referencing/intelligibilitysettingup/measuringinstrumenting -forconceptualisation for $\quad{ }^{56}$ meaningfulness-and-teleology aposteriorising/logicising/deriving/intelligising/measuring, human-subpotency is ever always unduly prospectively-aporetic/prospectively-undecidable/prospectivelydilemmatic/prospectively-indeterminate/prospectively-deficient/prospectively- 


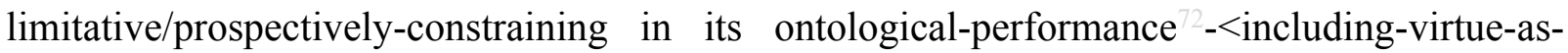
ontology $>$ /morality/ethics/justice/etc. construal of ecstatic-existence to which it only bears an 'as of' semblance (in any of its given presencing) that isn't constraining in anyway on the 'becoming of ecstatic-existence-as-transcendental-signifier' such that ecstatic-existence-astranscendental-signifier-emergence/becoming-spontaneity-implications reflected as existence-potency ${ }^{32} \sim$ sublimating-nascence,-disclosed-from-prospective-epistemic-digression from such human-subpotency prior reproducibility—mathesis/motif/thrownness-disposition,-as-reproducibility-of-aestheticisation ever always warrant prospective originariness-parrhesia,-as-spontaneity-of-aestheticisation and thus the epistemic-ricochetting/transepistemicity prospective implications for renewed reproducibility—mathesis/motif/thrownness-disposition,-as-reproducibility-of-aestheticisation; and so, in order to 'prospectively elevate the ontologicalperformance $^{72}$-<including-virtue-as-ontology $>$ /morality/ethics/justice/etc. of human aestheticisation of ${ }^{5}$ meaningfulness-and-teleology ${ }^{9}$ in the construal of existential-reality' while overcoming the stalling in ontological-performance ${ }^{72}-$ including-virtue-as- $^{-}$ ontology $>$ /morality/ethics/justice/etc. underlying the mere complexification of the prior reproducibility—-mathesis/motif/thrownness-disposition,-as-reproducibility-of-

aestheticisation. This inversely-varying-emphasis of originariness-parrhesia,-as-spontaneity-ofaestheticisation and reproducibility-mathesis/motif/thrownness-disposition,--asreproducibility-of-aestheticisation is so-reflected with: prospective reactualising of 'perceptive motif-manifest aestheticisation as of human conscious-able imagery' (as derived from the reconstruing/reconsideration of both mere-tracial-and-symbolisation-manifest aestheticisation and signification-as-of-existential-reality-manifest aestheticisation); prospective reactualising of 'mere-tracial-and-symbolisation-manifest aestheticisation as of human conscious-able works-ofart/artistry', for instance in the dynamic reproducibility-mathesis/motif/thrownnessdisposition,-as-reproducibility-of-aestheticisation reflected with genres of music as of their 
originariness-parrhesia,-as-spontaneity-of-aestheticisation

implicited_attendant-ontological-contiguity ' educed-

existentialising/contextualising/textualising_'intelligibility/epistemicity/reflexivity-contiguity-

<imbued-notional cogency>' $\}$-re-originariness/re-origination; and prospective reactualising of 'signification-as-of-existential-reality-manifest aestheticisation as of human conscious-able intermediating ascriptivity, and this is more fundamentally with respect to human underlying supposedly coherent ontological-commitment $-<$ implied — self-assurednessof-ontological-good-faith/authenticity postconverging-dementating/structuring/paradigming -as-being-as-of-existential-reality $>$ reflected by $<$ amplituding/formative-epistemicity $>$ causality $~ a s-t o-$ projective-totalitative-implications-ofprospective- nonpresencing,-for-explicating relative-unreflexivity/relative-reflexivity ontological-contiguity as to existence-potency ${ }^{32} \sim$ sublimating-nascence,-disclosed-fromprospective-epistemic-digression ${ }_{2}$ and so-construed from a philosophical depth of contemplation as of 'coherence/contiguity-of-superseding-oneness-of-ontology-implied-as-of-inherentexistence-coherence/contiguity,-and-so-construed-as-the-enabler-of-insight-or-intuition-orforesight-as-of-embodied-consciousness'. The latter ('signification-as-of-existential-realitymanifest aestheticisation as of human conscious-able intermediating ascriptivity') relates for instance to the relative-unreflexivity/relative-reflexivity ontological-contiguity $\sim$ of-thehuman-institutionalisation-process ${ }^{6}:$ in the dynamic reproducibilitymathesis/motif/thrownness-disposition,-as-reproducibility-of-aestheticisation reflected within the <cumulating/recomposuring attendant-ontological-contiguity $>$-successive registryworldviews/dimensions reference-of-thought-level 'supererogatory acuity/perspicacity/astuteness/edginess/incisiveness-ofapriorising/axiomatising/referencing/intelligibilitysettingup/measuringinstrumenting -for- 
$<$ amplituding/formative $>$ wooden-language-_imbued — averaging-of-thought-<as-to-

leveling/ressentiment/closed-construct-of- meaningfulness-and-teleology -as-of-

'nondescript/ignorable-void '-with-regards-to-prospective-apriorising-implications $>>$, and as the originariness-parrhesia,-as-spontaneity-of-aestheticisation enabling the institutionalcumulation/institutional-recomposure-〈as-to- historiality/ontological-

eventfulness /ontological-aesthetic-tracing-<perspective-ontologicalnormalcy/postconvergence-reflected-'epistemicity-relativism-determinism'>> to occur reflecting holographically-<conjugatively-and-transfusively $>$ the relative-unreflexivity/relativereflexivity - ontological-contiguity of-the-human-institutionalisation-process as of prospective intemporal parrhesiastic ontological-faith-notion-or-ontological-fideism-imbuedunderdetermination-of-motif-and-apriorising/axiomatising/referencing-as-so-being-as-ofexistential-reality reasoning-through/messianic-reasoning renewing of reproducibilitymathesis/motif/thrownness-disposition,-as-reproducibility-of-aestheticisation for the $<$ cumulating/recomposuring attendant-ontological-contiguity $>$-succession of registryworldviews/dimensions ${ }^{8}$ reference-of-thought. Obviously given human emotionalinvolvement, such intemporal parrhesiastic instigation of prospective reproducibilitymathesis/motif/thrownness-disposition,-as-reproducibility-of-aestheticisation is ascetic as it emphasises that the ontological-performance ${ }^{72}-<_{\text {including-virtue-as- }}$ ontology $>$ /morality/ethics/justice/etc. of human ${ }^{56}$ meaningfulness-and-teleology ${ }^{9}$ as to existence-potency ${ }^{39} \sim$ sublimating-nascence,-disclosed-from-prospective-epistemic-digression sublimating-validation/desublimating-invalidation implications is not compromisable, and so over temporal nihilistic dispositions of prior reproducibility—mathesis/motif/thrownnessdisposition,-as-reproducibility-of-aestheticisation susceptible to compromising ontological- 
performance $^{72}-<$ including-virtue-as-ontology $>$ /morality/ethics/justice/etc. of human meaningfulness-and-teleology ${ }^{9}$ as of human-subpotency <amplituding/formative $>$ woodenlanguage-_imbued - averaging-of-thought-<as-to-leveling/ressentiment/closed-construct-ofmeaningfulness-and-teleology -as-of-'nondescript/ignorable-void '-with-regards-toprospective-apriorising-implications $>>$ and sophistic/pedantic dispositions. Ultimately, human meaningfulness-and-teleology' as of 'human-subpotency conscious-able aestheticisation of ecstatic-existence as to existence-potency ${ }^{32} \sim$ sublimating-nascence,-disclosed-fromprospective-epistemic-digression is ever always a 'more and more profound enlargingframework of reproducibility-mathesis/motif/thrownness-disposition,-as-reproducibility-ofaestheticisation' which is patternly developed-and-anchored as from its driven originarinessparrhesia,-as-spontaneity-of-aestheticisation; and so at the thresholds of prior reproducibilitymathesis/motif/thrownness-disposition,-as-reproducibility-of-aestheticisation aporetic/undecidable/dilemmatic/indeterminate/deficient/limitative/constraining unduly ontological-performance ${ }^{72}<$ including-virtue-as-ontology $>/$ morality/ethics/justice/etc. wherein originariness-parrhesia,-as-spontaneity-of-aestheticisation re-stakes/puts-back-at-stake epistemic-ricochettingly/transepistemically the reconstruing of existential-reality despite the taxingness-of-originariness, and so as of a perception of unduly aporetic/undecidable/dilemmatic/indeterminate/deficient/limitative/constraining ontologicalperformance $^{72}-<$ including-virtue-as-ontology $>$ /morality/ethics/justice/etc. of prior reproducibility — mathesis/motif/thrownness-disposition,--as-reproducibility-of-aestheticisation meaningfulness-and-teleology ${ }^{99}$ as to existence-potency ${ }^{39} \sim$ sublimating-nascence,-disclosedfrom-prospective-epistemic-digression sublimating-validation/desublimating-invalidation implications. It is important to grasp that the extensive manifest outcomes/outfits/shellsconstrued-historially-as-of-the-specifically-aestheticised-incrusting/plating/coating,-soreflected-as-institutional-manifestations of human meaningfulness-and-teleology 
aestheticisation (as of human 'perceptive motif-manifest aestheticisation as of human consciousable imagery', 'mere-tracial-and-symbolisation-manifest aestheticisation as of human conscious-able works-of-art/artistry', and 'signification-as-of-existential-reality-manifest aestheticisation as of human conscious-able intermediating ascriptivity'), is reflective of

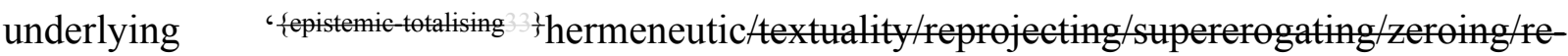
acuting, - decompulsing $^{-}$delinearity for-cogency reactualising as $<$amplituding/formativeepistemicity>-totalising $\sim$ renewing-realisation/re-perception/re-thought' human aestheticisation process with respect to living-development-as-to-personality-development ${ }^{56}$ meaningfulnessand-teleology institutional-development-as-to-social-function-development meaningfulness-and-teleology and Being-development/ontological-framework-expansionas-to-depth-of-ontologising-development-as-infrastructure-of- meaningfulness-andteleology $\quad{ }^{5}$ meaningfulness-and-teleology 99 and $\quad$ so epistemicricochettingly/transepistemically as of 'more and more profound enlarging-framework of reproducibility—-mathesis/motif/thrownness-disposition,-as-reproducibility-of-

aestheticisation' with respect to unduly aporetic/undecidable/dilemmatic/indeterminate/deficient/limitative/constraining ontologicalperformance ${ }^{72}$-<including-virtue-as-ontology $>$ /morality/ethics/justice/etc. wherein originariness-parrhesia,-as-spontaneity-of-aestheticisation re-stakes/puts-back-at-stake the reconstruing of existential-reality despite the taxingness-of-originariness. This human aestheticisation process involves inversely-varying-emphasis of originariness-parrhesia,--asspontaneity-of-aestheticisation and reproducibility-mathesis/motif/thrownness-disposition,-as-reproducibility-of-aestheticisation (so-construed as of 'high/low parrhesiastic-pressure-of-

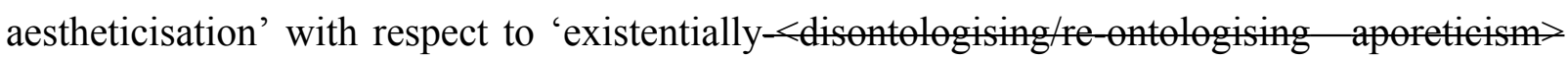
developing/becoming-as-of-social-integration-and-evolving relevant ${ }^{56}$ meaningfulness-andteleology ${ }^{9}$ '), reflecting the 'more and more profound enlarging-framework of reproducibility- 
mathesis/motif/thrownness-disposition,-as-reproducibility-of-aestheticisation'. For instance with regards to living-development-as-to-personality-development ${ }^{56}$ meaningfulness-andteleology ${ }^{9}$, human aestheticisation is reflected in childhood to adulthood social development wherein a child's development as of its 'existentially-<disontologising/re-ontologising apereticism $>\quad$ developing/becoming-as-of-social-integration-and-evolving relevant meaningfulness-and-teleology ${ }^{\circ}$ involves initially a more direct focus on instant-sensationsand-carefreeness with the child aspiring for social-integration-and-evolving at successive stages as it grows up with an increasing sense of dispensing-with-immediacy-for-relative-ontologicalcompleteness ${ }^{87}$-by-reification/contemplative-distension" in a 'high parrhesiastic-pressure-ofaestheticisation for social-integration-and-evolving' as of its 'more and more profound enlarging-framework of reproducibility-mathesis/motif/thrownness-disposition,--asreproducibility-of-aestheticisation' that ultimately involves major stages like language acquisition achievement, schooling achievement, greater social autonomy and responsibility/relative-reflexivity achievement, and developing into an adult with even greater dispensing-with-immediacy-for-relative-ontological-completeness ${ }^{87}$-byreification/contemplative-distension ${ }^{27}$ as for instance the notion of pleasure is increasingly substituted with that of work-and-pleasure, etc. It is critical to grasp here that such livingdevelopment-as-to-personality-development human aestheticisation of meaningfulness-andteleology ('high parrhesiastic-pressure-of-aestheticisation for social-integration-and-evolving' as of a 'more and more profound enlarging-framework of reproducibilitymathesis/motif/thrownness-disposition,-as-reproducibility-of-aestheticisation') apriorising/axiomatising/referencing-\{of-'prospectively implicited_attendant-ontologicalcontiguity ' $\sim$ educedexistentialising/contextualising/textualising_'intelligibility/epistemicity/reflexivity-contiguity<imbued-notional cogency $\left.>^{\prime}\right\}$ - conflatedness ${ }^{13}$-in-\{preconverging-disentailment by\} 
totalising 3 3 hermeneutic/textuality/reprojecting/supererogating/zeroing/re-acuting,-

\{decompling delinearity for-cogency reactualising as <amplituding/formative-epistemicity >totalising renewing-realisation/re-perception/re-thought' always entails the three human aestheticisation manifest elements: 'perceptive motif-manifest aestheticisation as of human conscious-able imagery', 'mere-tracial-and-symbolisation-manifest aestheticisation as of human conscious-able works-of-art/artistry', and 'signification-as-of-existential-reality-manifest aestheticisation as of human conscious-able intermediating ascriptivity'. This human aestheticisation insight is informing about what exactly is meant by such major stages of human personality development like language acquisition achievement, schooling achievement, greater social autonomy and responsibility/relative-reflexivity achievement, etc. in the sense that the underlying/induced 'high parrhesiastic-pressure-of-aestheticisation for social-integration-andevolving' already speaks of the fepistemicthermeneutic/textuality/reprojecting/supererogating/zeroing/re-acuting,\{decompling delinearity for-cogency reactualising as <amplituding/formative-epistemicity $>$ totalising renewing-realisation/re-perception/re-thought' long before a child's language acquisition achievement recognition, schooling achievement recognition, greater social autonomy and responsibility/relative-reflexivity achievement recognition, etc. More specifically we can thus factor in that language as formally defined, and so specifically as this reflects a particular phonetic/written signification construct, is rather in reality the 'teleological outcome/outfit/shell—construed-historially-as-of-the-specifically-aestheticisedincrusting/plating/coating-as-institutional-manifestation' of a rather 'complex sense of meaningfulness-and-teleology ${ }^{9}$ aestheticisation' induced from a 'high parrhesiastic-pressureof-aestheticisation for social-integration-and-evolving' driven '\{epistemictotalising ${ }^{3}$ hermeneutic/textuality/reprojecting/supererogating/zeroing/re-acuting,- 
$\{$ decompulsing\} delinearity for-cogency reactualising as <amplituding/formative-epistemicity $>$ totalising renewing-realisation/re-perception/re-thought' that starts long before a child's 'recognised' acquisition of any such 'language-as-phonetic/written-signification-construct outcome/outfit/shell—construed-historially-as-of-the-specifically-aestheticisedincrusting/plating/coating-as-institutional-manifestation', as the child already has a 'complex sense of ${ }^{56}$ meaningfulness-and-teleology ${ }^{99}$ aestheticisation' before its 'recognised' acquisition of 'language-as-phonetic/written-signification-construct outcome/outfit/shell—construedhistorially-as-of-the-specifically-aestheticised-incrusting/plating/coating-as-institutionalmanifestation', and that acquisition of a specific 'language-as-phonetic/written-significationconstruct outcome/outfit/shell—construed-historially-as-of-the-specifically-aestheticisedincrusting/plating/coating-as-institutional-manifestation' in due course (though annunciative) is rather secondary-and-prolongative of the child's evolving underlying human 'complex sense of meaningfulness-and-teleology aestheticisation' as of its 'high parrhesiastic-pressure-ofaestheticisation for social-integration-and-evolving'. It is this underlying 'complex sense of meaningfulness-and-teleology aestheticisation' that is truly of 'existentially< disontologising/re-ontologising aporeticism $>$ developing/becoming-as-of-social-integrationand-evolving relevant ${ }^{56}$ meaningfulness-and-teleology ${ }^{9}$ ontological analysis as of apriorising/axiomatising/referencing-\{of-'prospectively_implicited_attendant-ontologicalcontiguity ' $\sim$ educedexistentialising/contextualising/textualising_'intelligibility/epistemicity/reflexivity-contiguity<imbued-notional cogency >' $\}$-conflatedness ${ }^{13}$-in-\{preconverging-disentailment by\} postconverging-ntailment (and as it may then be reflected in practice with regards to its analysis on the basis of any specific 'language-as-phonetic/written-signification-construct outcome/outfit/shell—construed-historially-as-of-the-specifically-aestheticisedincrusting/plating/coating-as-institutional-manifestation'); and so, reflecting 'its prior-not- 
recognised-as-language-acquisition stage', 'its recognised-as-language-acquisition stage' and 'its subsequent-deepening-of-recognised-as-language-acquisition stage and as this extends to specialised language or secondary language developments'. Beyond 'living-development-as-topersonality-development ${ }^{5}$ meaningfulness-and-teleology ${ }^{9}$ aestheticisation' (as implied above with living-development-as-to-personality-development aestheticisation of underlying becoming 'complex sense of ${ }^{5}$ meaningfulness-and-teleology ${ }^{99}$ aestheticisation' as of the 'more and more profound enlarging-framework of reproducibility-mathesis/motif/thrownnessdisposition,-as-reproducibility-of-aestheticisation' of language), with human 'institutionaldevelopment-as-to-social-function-development meaningfulness-and-teleology aestheticisation' as of any given conventioned human 'language-as-phonetic/writtensignification-construct outcome/outfit/shell—construed-historially-as-of-the-specificallyaestheticised-incrusting/plating/coating-as-institutional-manifestation', such an insight about 'high/low parrhesiastic-pressure-of-aestheticisation for social-integration-and-evolving' as to the implications of 'more and more profound enlarging-framework of reproducibilitymathesis/motif/thrownness-disposition,-as-reproducibility-of-aestheticisation’ is highly informing about 'language-as-phonetic/written-signification-construct outcome/outfit/shell— construed-historially-as-of-the-specifically-aestheticised-incrusting/plating/coating-as-

institutional-manifestation' and so highlighting the collective social 'existentially< disontologising/re-ontologising aporeticism $>$ developing/becoming-as-of-social-integrationand-evolving relevant ${ }^{56}$ meaningfulness-and-teleology" in reflection of 'institutionaldevelopment-as-to-social-function-development meaningfulness-and-teleology aestheticisation' of any given conventioned human 'language-as-phonetic/written-significationconstruct outcome/outfit/shell—construed-historially-as-of-the-specifically-aestheticisedincrusting/plating/coating-as-institutional-manifestation'. It is important thus to grasp that 'language-as-phonetic/written-signification-construct outcome/outfit/shell—construed- 
historially-as-of-the-specifically-aestheticised-incrusting/plating/coating-as-institutionalmanifestation' is rather established institutionally as of the collective social human 'complex sense of meaningfulness-and-teleology aestheticisation' that drives human social institutions, and that while 'language-as-phonetic/written-signification-construct outcome/outfit/shellconstrued-historially-as-of-the-specifically-aestheticised-incrusting/plating/coating-asinstitutional-manifestation' does reflect this collective social human 'complex sense of meaningfulness-and-teleology ${ }^{9}$ aestheticisation' rather as an 'institutional-development-asto-social-function-development $\quad{ }^{56}$ meaningfulness-and-teleology 9 outcome/outfit/shellconstrued-historially-as-of-the-specifically-aestheticised-incrusting/plating/coating-asinstitutional-manifestation/conflatedness conceptions'

as of apriorising/axiomatising/referencing-\{of-'prospectively_implicited_attendant-ontologicalcontiguity ' $\sim$ educedexistentialising/contextualising/textualising_ 'intelligibility/epistemicity/reflexivity-contiguity<imbued-notional cogency $\left.>^{\prime}\right\}$ - conflatedness ${ }^{13}$-in-\{preconverging-disentailment by\} postconverging-entailment, it is ontologically-flawed for 'language-as-phonetic/writtensignification-construct outcome/outfit/shell—construed-historially-as-of-the-specificallyaestheticised-incrusting/plating/coating-as-institutional-manifestation' to be construed in apriorising/axiomatising/referencing-\{of-'prospectively_implicited_attendant-ontologicalcontiguity ' $\sim$ educedexistentialising/contextualising/textualising_'intelligibility/epistemicity/reflexivity-contiguity<imbued-notional cogency>' $\}$-constitutedness ${ }^{14}$-in-preconverging-entailment $\quad$ as of elaboration-as-to-mere-extrapolating/constituting/abstracting/deducing/inferring-ofelucidation-outside_-'prespectively implicited_attendant-ontological-contiguity ${ }^{67}$ ' educedexistentialising/contextualising/textualising_intelligibility/epistemicity/reflexivity-contiguity$<$ imbued-notional cogency >' (even as on occasion such an ontologically-flawed construal in 
identitive-constitutedness ${ }^{14}$-as- ${ }^{\text {eppistemic-totality }}{ }^{37}$ '-dereification-in-dissingularisation- $<$ as-tothe-disjointedness/disentailment-of- presencing - absolutising-identitive-constitutedness $>$ as-flawed-epistemicity-relativism-determinism may be incidentally/accidentally/ad-hocly seemingly veridical but ontologically-flawed in principle from the perspective of the precedence over 'language-as-phonetic/written-signification-construct outcome/outfit/shell—construedhistorially-as-of-the-specifically-aestheticised-incrusting/plating/coating-as-institutionalmanifestation' of the collective social human 'complex sense of meaningfulness-andteleology aestheticisation' as of the 'more and more profound enlarging-framework of reproducibility—-mathesis/motif/thrownness-disposition,-as-reproducibility-of-

aestheticisation' of language, as of the implied 'high parrhesiastic-pressure-of-aestheticisation for social-integration-and-evolving' driven '\{epistemictotalising ${ }^{3}{ }^{3}$ hermeneutic/textuality/reprojecting/supererogating/zeroing/re-acuting,\{decompulsing delinearity for-cogency reactualising as <amplituding/formative-epistemicity $>$ totalising renewing-realisation/re-perception/re-thought' in difference-conflatedness ${ }^{13}$-as-tototalitative-reification-in-singularisation-<as-to-the-nondisjointedness/entailment-ofprospective- nonpresencing $>$-as-veridical-epistemicity-relativism-determinism ). This is so because 'human <amplituding/formative-epistemicity $>$ causality $\sim$ as-to-projective-totalitativeimplications-of-prospective- nonpresencing,-for-explicating relative-unreflexivity/relativereflexivity ontological-contiguity purposefulness-reflexivity for prospective relativeontological-completeness ${ }^{87}$ orientation' supersedes any such human 'institutional-developmentas-to-social-function-development ${ }^{56}$ meaningfulness-and-teleology ${ }^{9} \quad$ outcome/outfit/shellconstrued-historially-as-of-the-specifically-aestheticised-incrusting/plating/coating-asinstitutional-manifestation/conflatedness ${ }^{13}$ conceptions like language', as of apriorising/axiomatising/referencing-\{of-'prospectively_implicited_attendant-ontologicalcontiguity ' educed- 
existentialising/contextualising/textualising_ 'intelligibility/epistemicity/reflexivity-contiguity$<$ imbued-notional cogency $>$ ' $\}$-conflatedness ${ }^{13}$ in-\{preconverging-disentailment by\} postconverging-ntailment (even as the latter had been precedently contributive to that purposefulness-reflexivity) such that such a human 'institutional-development-as-to-socialfunction-development $\quad{ }^{5}$ meaningfulness-and-teleology ${ }^{9} \quad$ outcome/outfit/shell—construedhistorially-as-of-the-specifically-aestheticised-incrusting/plating/coating-as-institutionalmanifestation/conflatedness ${ }^{13}$ conceptions like language' is more critically a passive ready-athand conception that is notionally/epistemically/bindingnessly as ofermine mreflexivity/relativeriverity 'prospectively_implicited_attendant-ontological-contiguity ' ceducedexistentialising/contextualising/textualising_'intelligibility/epistemicity/reflexivity-contiguity<imbued-notional cogency $\left.>^{\prime}\right\}$-conflatedness ${ }^{13}$-in-\{preconverging-disentailment by\} postconverging-ntailment as it is adapted to 'human <amplituding/formativeepistemicity $>$ causality $\sim$ as-to-projective-totalitative-implications-of-prospectivenonpresencing,-for-explicating relative- unreflexivity/relative-reflexivity - ontologicalcontiguity purposefulness-reflexivity for prospective relative-ontological-completeness orientation'. This basically explains the constantly developing nature of human 'institutionaldevelopment-as-to-social-function-development meaningfulness-and-teleology outcome/outfit/shell—construed-historially-as-of-the-specifically-aestheticisedincrusting/plating/coating-as-institutional-manifestation/conflatedness ${ }^{13}$ conceptions like language' which are not truly absolutely of present-at-hand as to wrongly imply ${ }^{79}$ presencingabsolutising-identitive-constitutedness ${ }^{14}$-of- ${ }^{5}$ meaningfulness-and-teleology ${ }^{9}$ (even as the privileged social conceptualisation of say language is as of 'language as the complete possibilities of language as of an absolute present conception usually of a privileged endinstitution purpose'). Insightfully, we can garner that it is 'human <amplituding/formative- 
epistemicity $>$ causality $\sim$ as-to-projective-totalitative-implications-of-prospective-

nonpresencing,-for-explicating relative-unreflexivity/relative-reflexivity - ontological-

contiguity purposefulness-reflexivity for prospective relative-ontological-completeness orientation' implied as of 'maximalising-recomposuring-for-relative-ontologicalcompleteness ${ }^{87}$ - unenframed/re-ontologising conceptualisation that fundamentally renders/makes human institutional-development-as-to-social-function-development meaningfulness-and-teleology $\quad$ outcome/outfit/shell—construed-historially-as-of-thespecifically-aestheticised-incrusting/plating/coating-as-institutionalmanifestation/conflatedness ${ }^{13}$ conceptions' to be necessarily as of 'implicited_attendantontological-contiguity ${ }^{6}$ ' educed-

existentialising/contextmalising/textmalising_intelligibility/epistemicity/reflexivity-contiguity$<$ imbued-notional cogency>' $>^{\prime}$ in apriorising/axiomatising/referencing-\{of-'prospectively implicited_attendant-ontological-contiguity ' educed-

existentialising/contextualising/textualising_ 'intelligibility/epistemicity/reflexivity-contiguity$<$ imbued-notional cogency $\left.>^{\prime} \quad\right\}$-conflatedness ${ }^{13}$-in-\{preconverging-disentailment by $\}^{\prime}$ postconverging-entailment and not in apriorising/axiomatising/referencing-\{of- prospectively implicited_attendant-ontological-contiguity ' educedexistentialising/contextmalising/textualising_'intelligibility/epistemicity/reflexivity_contiguity<imbued-notional cogency $\left.>^{\prime} \quad\right\}$-constitutedness ${ }^{- \text {in }}$-preconverging-entailment $\quad$ as $\quad$ of elaboration-as-to-mere-extrapolating/constituting/abstracting/deducing/inferring-ofelucidation-outside_- 'prospectively_implicited_attendant-ontological-contiguity ${ }^{67}$ ? educedexistentialising/contextualising/textualising_'intelligibility/epistemicity/reflexivity-contiguity$<$ imbued-notional cogency $>$ '. In another respect, 'living-development-as-to-personalitydevelopment 5 meaningfulness-and-teleology aestheticisation' is of 'high parrhesiasticpressure-of-aestheticisation for social-integration-and-evolving' with regards to human 
childhood to adulthood personality development as of the forming individual need to assimilate/integrate human progressive cultural cumulation, and this is very much in contrast to 'institutional-development-as-to-social-function-development meaningfulness-andteleology ${ }^{9}$ aestheticisation' that rather cumulatively holds-on-to and complexifies the culturally cumulated outcomes/outfits/shells_construed-historially-as-of-the-specifically-aestheticisedincrusting/plating/coating,-so-reflected-as-institutional-manifestations from historially accrued 'high parrhesiastic-pressure-of-aestheticisation for social-integration-and-evolving' construed as of human institutional-cumulation/institutional-recomposure-〈as-to- historiality/ontologicaleventfulness /ontological-aesthetic-tracing-<perspective-ontologicalnormalcy/postconvergence-reflected-'epistemicity-relativism-determinism' $>>$ such as with regards to any specific 'language-as-phonetic/written-signification-construct outcome/outfit/shell—construed-historially-as-of-the-specifically-aestheticisedincrusting/plating/coating-as-institutional-manifestation'. This will explain why the relativeunreflexivity/relative-reflexivity — ontological-contiguity ${ }^{67}$ of-the-human-institutionalisationprocess ${ }^{68}$ as of 'institutional-development-as-to-social-function-development ${ }^{56}$ meaningfulnessand-teleology aestheticisation' is 'highly parrhesiastically economical' as reflected in the overall relative-unreflexivity/relative-reflexivity - ontological-contiguity ${ }^{67}$ of-the-humaninstitutionalisation-process ${ }^{68}$ 'more and more profound enlarging-framework of reproducibility—mathesis/motif/thrownness-disposition,-as-reproducibility-of-

aestheticisation'; wherein only the perception of unduly aporetic/undecidable/dilemmatic/indeterminate/deficient/limitative/constraining ontologicalperformance $^{2}$-<including-virtue-as-ontology $>$ /morality/ethics/justice/etc. of prior reproducibility—mathesis/motif/thrownness-disposition,--as-reproducibility-of-aestheticisation epistemic-ricochettingly/transepistemically elicits 'high parrhesiastic-pressure-ofaestheticisation for social-integration-and-evolving'. This is so because given the taxingness-of- 
originariness any such 'high parrhesiastic-pressure-of-aestheticisation for social-integrationand-evolving' has to resolve considerably unduly aporetic/undecidable/dilemmatic/indeterminate/deficient/limitative/constraining ontologicalperformance $^{72}$-<including-virtue-as-ontology $>$ /morality/ethics/justice/etc. of prior reproducibility—mathesis/motif/thrownness-disposition,--as-reproducibility-of-aestheticisation for such 'institutional-development-as-to-social-function-development ${ }^{56}$ meaningfulness-andteleology aestheticisation' underlying 6 fepistemicthermeneutic/textuality/reprojecting/supererogating/zeroing/re-acuting,\{delinearity for-cogency reactualising as <amplituding/formative-epistemicity $>$ totalising renewing-realisation/re-perception/re-thought' to be worth the epistemicricochetting/transepistemicity effort, with the preference for any such effort rather directed at the complexification of the prior reproducibility-mathesis/motif/thrownness-disposition,--asreproducibility-of-aestheticisation. This will explain for instance why as of the furtherance in reflecting holographically-<conjugatively-and-transfusively $>$ the relative-unreflexivity/relativereflexivity - ontological-contiguity of-the-human-institutionalisation-process, the 'institutional-development-as-to-social-function-development $\quad{ }^{56}$ meaningfulness-andteleology ${ }^{9}$ aestheticisation' with regards to language development hasn't warranted any 'high parrhesiastic-pressure-of-aestheticisation for social-integration-and-evolving' with respect to new language creation but this has rather been directed towards language complexification as of advancing human knowledge and construction-of-the-Self. In-the-bigger-picture, the above human ${ }^{56}$ meaningfulness-and-teleology ${ }^{9}$ aestheticisation analysis (and as reflected specifically with language acquisition) is reflective of the fact that the specific human-subpotency with regards to overall reifying-and-empowering-reflexivity-of-ecstatic-existence-aspanintelligibility/panreflexivity ${ }^{3}-\langle$ existentially-imbued-and-educing-< $<$ fepistemicthermeneutically/textually/reprojectingly/supererogatingly/zeroingly/re-acutingly,- 
aestheticising-re-motif-and-re-apriorising/re-axiomatising/re-referencing conceptualisation,as-herein-specifically-relevant-to human-subpotency), reflected in human underlying supposedly coherent ontological-commitment $-<$ implied - self-assuredness-of-ontologicalgood-faith/authenticity postconverging-de-mentating/structuring/paradigming -as-beingas-of-existential-reality>, is ultimately potentiated/ontologisable as of human 'intemporal ontological-faith-notion-or-ontological-fideism - imbued-underdetermination-of-motif-andapriorising/axiomatising/referencing-as-so-being-as-of-existential-reality parrhesiastic askesisor-acumen for originary/as-of-event ${ }^{8}$ reasoning-through/messianic-reasoning'. This instigation of human aestheticisation of ${ }^{5}$ meaningfulness-and-teleology ${ }^{9}$ so-reflected in 'human existence historiality/ontological-eventfulness 38 ontological-aesthetic-tracing- $<$ perspectiveontological-normalcy/postconvergence-reflected-'epistemicity-relativism-determinism’> creative aestheticisation of ${ }^{56}$ meaningfulness-and-teleology' driven as of originarinessparrhesia,-as-spontaneity-of-aestheticisation in renewing reproducibilitymathesis/motif/thrownness-disposition,-as-reproducibility-of-aestheticisation involves an 'overall flux of human ${ }^{56}$ meaningfulness-and-teleology ${ }^{9}$ of varying temporal-to-intemporal ontological-performance ${ }^{72}$-<including-virtue-as-ontology $>$ ' wherein such a flux construed as human postconverging aporeticism-overcoming/mnovercoming dissemination ${ }^{28}$ is confronted to 'existence-potency ${ }^{3} \sim$ sublimating-nascence,-disclosed-from-prospective-epistemicdigression validative/invalidative selectivity/deselectivity' enabling living-development-as-topersonality-development ${ }^{5}$ meaningfulness-and-teleology , institutional-development-as-tosocial-function-development $\quad{ }^{56}$ meaningfulness-and-teleology ${ }^{9} \quad$ and Beingdevelopment/ontological-framework-expansion-as-to-depth-of-ontologising-development-asinfrastructure-of- meaningfulness-and-teleology $\quad{ }^{56}$ meaningfulness-and-teleology ${ }^{9}$; and thereof reflected in the secondnatured institutionalisation framework of the given registry- 
worldview underpinning-suprasocial-construct and its <amplituding/formative $>$ woodenlanguage-_imbued - averaging-of-thought-<as-to-leveling/ressentiment/closed-construct-ofmeaningfulness-and-teleology -as-of-'nondescript/ignorable-void '-with-regards-toprospective-apriorising-implications $>>$ as uninstitutionalised-threshold ${ }^{102}$. It is important here to grasp that despite any human registry-worldview/dimension <amplituding/formativeepistemicity $>$ totalising $\sim$ self-referencing-syncretising/circularity/interiorising/akrasiatic-drag ontologically-flawed inclination to think otherwise, its given underpinning-suprasocialconstruct and its given <amplituding/formative> wooden-language-〈imbued-averaging-ofthought-<as-to-leveling/ressentiment/closed-construct-of- meaningfulness-and-teleology -asof-'nondescript/ignorable-void '-with-regards-to-prospective-apriorising-implications $>>$ 'are

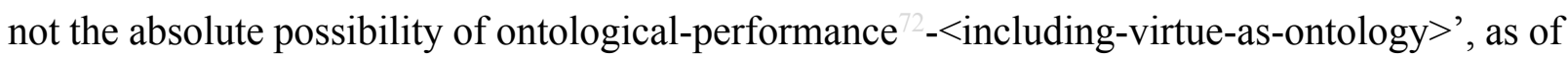
their induced reproducibility-mathesis/motif/thrownness-disposition,--as-reproducibility-ofaestheticisation, for the prospective aestheticisation of human intemporal-as-ontological meaningfulness-and-teleology given that such underpinning-suprasocial-construct and $<$ amplituding/formative $>$ wooden-language-_imbued — averaging-of-thought-<as-toleveling/ressentiment/closed-construct-of- meaningfulness-and-teleology -as-of'nondescript/ignorable-void '-with-regards-to-prospective-apriorising-implications $>>\quad$ are effectively rather secondnatured institutionalisation outcome of reproducibilitymathesis/motif/thrownness-disposition,-as-reproducibility-of-aestheticisation. In this regards, the more profound basis for prospective generation of human intemporal-as-ontological meaningfulness-and-teleology arises as of transepistemic/epistemic-ricochetting originariness-parrhesia,-as-spontaneity-of-aestheticisation that renews reproducibilitymathesis/motif/thrownness-disposition,-as-reproducibility-of-aestheticisation as of prospective existence-potency ${ }^{39} \sim$ sublimating-nascence,-disclosed-from-prospective-epistemic-digression sublimating-validation/desublimating-invalidation implications of human limited-mentation- 
capacity-deepening —as-subjecting-limitedness/human-subpotency-to-'educedunlimitedness/existence-sublimating nascence' ${ }^{53}$. This underlying insight is reflective of the fact that 'secondnaturedness is no substitute for originariness as from prospective nonpresencing-<perspective-ontological-normalcy/postconvergence $>$ reflection of $<$ amplituding/formative-epistemicity $>$ causality $\sim$ as-to-projective-totalitative-implications-ofprospective- nonpresencing,-for-explicating relative-unreflexivity/relative-reflexivity ontological-contiguity of relative-ontological-incompleteness $8 /$ relative-ontologicalcompleteness ${ }^{8}$-〈sublimating $\sim$ referencing/registering/decisioning,-as-self-becoming/selfconflatedness /formative-supererogating-<projective/reprojective-aestheticising-re-motifand-re-apriorising/re-axiomatising/re-referencing,-in-perspective-ontologicalnormalcy/postconvergence $>$ '’, as originariness is ever always about 'intemporal parrhesiastic seeding-promise dimensionality-of-sublimating

<<amplituding/formative>supererogatory $\sim$ de-mentativeness/epistemic-growth-orconflatedness /transvaluative-rationalising/transepistemicity/anamnestic-residuality/spiritdrivenness-equalisation $\rangle$ of the registry-worldview/dimension ${ }^{56}$ meaningfulness-andteleology beyond just its mechanical reproducibility-mathesis/motif/thrownnessdisposition,-as-reproducibility-of-aestheticisation for the possibility of further prospective parrhesiastic instigation as from ontological-faith-notion-or-ontological-fideism -imbuedunderdetermination-of-motif-and-apriorising/axiomatising/referencing-as-so-being-as-ofexistential-reality' in contrast to the essentially mechanical/mere-form of reproducibilitymathesis/motif/thrownness-disposition,-as-reproducibility-of-aestheticisation of secondnaturedness. This fundamental originariness and secondnaturedness conundrum in reflecting holographically-<conjugatively-and-transfusively $>$ the relative-unreflexivity/relativereflexivity - ontological-contiguity of-the-human-institutionalisation-process is reflected by the fact that the human Self is ever always in disseminative constructiveness/destructuring 
defining its given registry-worldview/dimension shiftiness-of-the-Self ${ }^{1}$ as of 'humansubpotency subpar disposition to fail to construe the full existence-potency ${ }^{32} \sim$ sublimatingnascence,-disclosed-from-prospective-epistemic-digression at its uninstitutionalisedthreshold ${ }^{102}$ its $\leq$ mere-formulaicity/ritualisation-of $>$-prior secondnatured reproducibilitymathesis/motif/thrownness-disposition,-as-reproducibility-of-aestheticisation; and so in obfuscation and pedantising/muddling/formulaic-hollowing-out—insubontologisation/subpotentiation-〈blurring/undermining-of-prospective-totalising-entailing,as-to-entailing-<amplituding/formative-epistemicity $>$ totalising in-relative-ontologicalcompleteness $\rangle$. The possibility for prospective human transcendence-and-

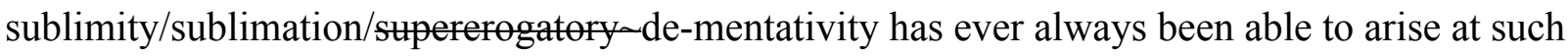
uninstitutionalised-threshold ${ }^{102}$ of registry-worldviews/dimensions not by a 'false pretence' that the ontologically-veridical underlying issue of prospectively-aporetic/prospectivelyundecidable/prospectively-dilemmatic/prospectively-indeterminate/prospectivelydeficient/prospectively-limitative/prospectively-constraining ontological-performance ${ }^{72}$ $<$ including-virtue-as-ontology $>/$ morality/ethics/justice/etc. of $\quad$ prior $\quad$ reproducibilitymathesis/motif/thrownness-disposition,-as-reproducibility-of-aestheticisation in the construal of ecstatic-existence, is one in want of candid analysis as of the-very-same prior reproducibility—mathesis/motif/thrownness-disposition,--as-reproducibility-of-aestheticisation but rather the ontological-veracity of originariness-parrhesia,-as-spontaneity-of-aestheticisation for prospective/renewed reproducibility-mathesis/motif/thrownness-disposition,--asreproducibility-of-aestheticisation; as perfectly understood by the Socratic-philosophers advancing of ${ }^{103}$ universalising-idealisation relative to the ancient-sophists non-universalising inclination, budding-positivists/rational-empiricists advancing of positivism/rationalempiricism relative to the medieval-scholastics pedantic dogmatism and equally as of our positivism- ${ }^{80}$ procrypticism this author construes practices of disparateness-of- 
conceptualisation-<unforegrounding-disentailment,-failing-prospectively-to-reflect-

‘immanent relative-unreflexivity/relative-reflexivity-ontological-contiguity

not

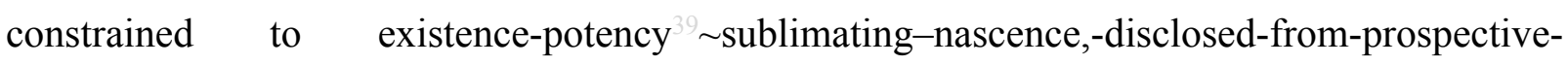
epistemic-digression but rather institutionalised sterile/anecdotal imprimatur as of institutionalbeing-and-craft as intellectually wanting and in need of the advancing of ${ }^{18}$ deprocrypticism-orpreempting — disjointedness-as-of- ${ }^{3}$ reference-of-thought $\quad{ }^{45}$ foregrounding_entailment- $<$ insuccession-of-profound-supererogation $>$ >-〈postconverging-narrowing-down $\sim$ sublimation-asto-'existence - as-sublimating-withdrawal/unenframing/re-ontologising,-elicited-fromprospective-profound-supererogation '-in-reflecting-'immanent $\sim$ relativeunreflexivity/relative-reflexivity - ontological-contiguity ' ';-as-operativenotional deprocrypticism>

supererogatory $\sim$ acuity/perspicacity/astuteness/edginess/incisiveness-ofapriorising/axiomatising/referencing/intelligibilitysettingup/measuringinstrumenting -forconceptualisation. In other words, the uninstitutionalised-threshold ${ }^{12}$ of all registryworldviews/dimensions as of their shiftiness-of-the-Self are the postconverging-aporeticismovercoming/unovereoming point at which their languages collapse into 'wooden languages' that are from a prospective perspective not profound but mechanical/mere-form reproducibilitymathesis/motif/thrownness-disposition,-as-reproducibility-of-aestheticisation thus inherently raising up the underlying ontological-veracity issue of their prospectivelyaporetic/prospectively-undecidable/prospectively-dilemmatic/prospectivelyindeterminate/prospectively-deficient/prospectively-limitative/prospectively-constraining ontological-performance $^{72}-<$ including-virtue-as-ontology $>/$ morality/ethics/justice/etc. of prior reproducibility—mathesis/motif/thrownness-disposition,--as-reproducibility-of-aestheticisation that can only be dealt with as of prospective originariness-parrhesia,-as-spontaneity-ofaestheticisation so-construed as 'intemporal parrhesiastic seeding-promise dimensionality-of- 
sublimating $25<<$ amplituding/formative $>$ supererogatory $\sim$ de-mentativeness/epistemic-growthor-conflatedness /transvaluative-rationalising/transepistemicity/anamnestic-residuality/spiritdrivenness-equalisation) of the registry-worldview/dimension meaningfulness-andteleology beyond just its mechanical reproducibility-mathesis/motif/thrownnessdisposition,-as-reproducibility-of-aestheticisation for the possibility of further prospective parrhesiastic instigation as from ontological-faith-notion-or-ontological-fideism-imbuedunderdetermination-of-motif-and-apriorising/axiomatising/referencing-as-so-being-as-of-

existential-reality'. The fact is that the possibility for prospective institutionalisation transcendence-and-sublimity/sublimation/supererogatory-de-mentativity is ever always underdetermined, as between prior reasoning-from-results/afterthought and prospective reasoning-through/messianic-reasoning is the 'aporia of underdetermined madness' that human ontological-faith-notion-or-ontological-fideism - imbued-underdetermination-of-motif-andapriorising/axiomatising/referencing-as-so-being-as-of-existential-reality dimensionality-ofsublimating $2-\langle<$ amplituding/formative $>$ supererogatery-de-mentativeness/epistemic-growthor-conflatedness /transvaluative-rationalising/transepistemicity/anamnestic-residuality/spiritdrivenness-equalisation) renders possible as prospective ontological-veracity is only then epistemic-ricochettingly/transepistemically salvageable as to existence-potency ${ }^{39} \sim$ sublimatingnascence,-disclosed-from-prospective-epistemic-digression sublimatingvalidation/desublimating-invalidation implications as of <amplituding/formativeepistemicity $>$ causality $\sim$ as-to-projective-totalitative-implications-of-prospectivenonpresencing,-for-explicating relative-unreflexivity/relative-reflexivity - ontologicalcontiguity . That is, between reasoning-as-reasoning-from-results/afterthought and reasoningas-reasoning-through/messianic-reasoning is $\quad$ 'postconverging-aporeticismevercoming/mnovercoming underdetermined madness' that renders a pretence of hanging unto prior reproducibility-mathesis/motif/thrownness-disposition,-as-reproducibility-of- 
aestheticisation more like a 'pretence of already grasping the complete implications of ecstaticexistence while ignoring/not-referencing/registering/decisioning the epistemicricochetting/transepistemicity implications of prospective relative-ontological-completeness ${ }^{87}$, and rather speaks in effect of a nihilistic <amplituding/formative $>$ wooden-language-〈imbuedaveraging-of-thought-<as-to-leveling/ressentiment/closed-construct-of- meaningfulness-andteleology -as-of-'nondescript/ignorable-void '-with-regards-to-prospective-apriorisingimplications $>$ >; and this temporal nihilism at uninstitutionalised-threshold ${ }^{102}$ has ever always been associated with a corresponding intemporal asceticism for opened-construct-ofmeaningfulness-and-teleology (not partaking as of transversality-<for-sublimatingexistential-eventuating/denouement, from 'thinking at first/pure predisposition preemptive of prospective-disontologising/subontologising' - as-of-prospectively-disambiguated-affirmedand-unaffirmed-'motif-and-apriorising/axiomatising/referencing' $>101$ in any such 'wooden language') that is the sine qua non for the habituation of the possibility of prospective transcendence-and-sublimity/sublimation/supererogatory-de-mentativity. Overcoming this 'aporia of underdetermined madness' despite human-subpotencyaporia/undecidability/dilemma/ought-indeterminacy/deficiency/limitation/constraint—imbued'notional firstnaturedness-formativeness-<as-to-eventualising $\sim$ inkling-drive-or-seeding misprising $>$ temporal-to-intemporal-dispositions- $<$ so-construed-as-from-perspectiveontological-normalcy/postconvergence>'-existentialism-form-factor, has ever always been the absolutely determinative possibility for the fulfilment of the construction-of-humanity-as-of-itsdeveloping-construction-of-the-Self enabling human transcendence-andsublimity/sublimation/supererogatory de-mentativity to arise; as its overcoming has ever always elicited humankind's ability to ascetically go beyond its 'prior comfort zone' to reconstrue its future emancipating possibilities. In this regard, the idea of ontological-faithnotion-or-ontological-fideism-imbued-underdetermination-of-motif-and- 
apriorising/axiomatising/referencing-as-so-being-as-of-existential-reality dimensionality-ofsublimating $25<<$ amplituding/formative $>$ supererogatory $\sim$ de-mentativeness/epistemic-growthor-conflatedness /transvaluative-rationalising/transepistemicity/anamnestic-residuality/spiritdrivenness-equalisation $\rangle$, however its recurrent re-originary_-ass-unenframed_reontologising/unbeholdening/outlier-conceptualisation__imbued-postconverging/dialecticalthinking -'projective-insights'/‘epistemic-projection-in-conflatedness ' '-ofnotional deprocrypticism-prospective-sublimation $\rangle$ intemporal instigation as of originariness-parrhesia,-as-spontaneity-of-aestheticisation in reflecting holographically$<$ conjugatively-and-transfusively $>$ the relative-unreflexivity/relative-reflexivity - ontologicalcontiguity of-the-human-institutionalisation-process , speaks to the fact that the sense of prospective base-institutionalisation in prior recurrent-utter-uninstitutionalisation is potentially an actionable possibility as of the latter's ontological-good-faith/authenticity $\sim$ postconvergingde-mentating/structuring/paradigming construed as 'its-given-developed-level-ofWill/Spirit/Drive in dispensing-with-immediacy-for-relative-ontological-completeness ${ }^{87}$-byreification/contemplative-distension ${ }^{27}$ (as of human self-surpassing-existentialism-formfactor,-in-overcoming-'notional collateralising-beholdening-protohumanity'-to- 'attainsublimating-humanity'-as-to-existence-potency sublimating-nascence,-disclosed-fromprospective-epistemic-digression to supersede human temporality $8 /$ shortness $<$ amplituding/formative $>$ wooden-language-<imbued - averaging-of-thought-<as-toleveling/ressentiment/closed-construct-of- meaningfulness-and-teleology -as-of'nondescript/ignorable-void '-with-regards-to-prospective-apriorising-implications $>\rangle)$ ', $\quad$ and likewise between base-institutionalisation and ${ }^{103}$ universalisation, non-positivism/medievalism and positivism/rational-empiricism, and prospectively positivism- ${ }^{80}$ procrypticism and deprocrypticism. But then in reflecting holographically-<conjugatively-and-transfusively $>$ the relative-unreflexivity/relative-reflexivity - ontological-contiguity of-the-human- 
institutionalisation-process what is easily lost is exactly 'this most vital but brittle ontologicalfaith-notion-or-ontological-fideism - imbued-underdetermination-of-motif-andapriorising/axiomatising/referencing-as-so-being-as-of-existential-reality dimensionality-ofsublimating $25-<<$ amplituding/formative $>$ supererogatery-de-mentativeness/epistemic-growthor-conflatedness /transvaluative-rationalising/transepistemicity/anamnestic-residuality/spiritdrivenness-equalisation $>$ element of ${ }^{5}$ meaningfulness-and-teleology ${ }^{9}$ instigating the successive transcendence-and-sublimity/sublimation/supererogatory -de-mentativity-and-sublimity', as the very renewing of reproducibility—-mathesis/motif/thrownness-disposition,--as-reproducibilityof-aestheticisation seems to induce a 'deferment of human instinctual responsibility/relativereflexivity' as to temporally imply 'human ontological-performance ${ }^{72}-<$ including-virtue-asontology $>$ /morality/ethics/justice/etc. strategies are valid by their mechanical/mere-form alignment to any such reproducibility-mathesis/motif/thrownness-disposition,--asreproducibility-of-aestheticisation' inducing human naïve untransvaluated-temporalintemporality $^{52}$ as of the shiftiness-of-the-Self of the corresponding registryworldview/dimension wherein the eliciting of a mutual sense of temporality $/$ /shortness within such a framework as of <amplituding/formative-epistemicity $>$ totalising $\sim$ self-referencingsyncretising/circularity/interiorising/akrasiatic-drag 34 is wrongly reconstrued as 'intemporality ${ }^{52}$ (but then we can garner from our vantage modern positivism perspective that such defective process in prior registry-worldviews/dimensions effectively spoke of their corresponding uninstitutionalised-threshold ${ }^{102}$ and the same does applies in our own respect from a prospective perspective). In this regards the prospective notional $\sim$ deprocrypticism registryworldview/dimension, as of its notional $\sim$ deprocrypticism notional $\sim$ reflexivity$<\{$ veridical/sound $\}$-relative-reflexivity-in-existence/relativising from-limited-mentation-as-

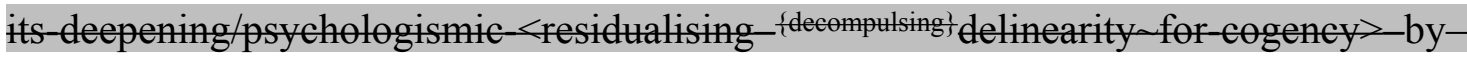
\{flawed/unsound\}-relative-unreflexivity-in-existence/absolutising from-limited- 
mentation/psychologismic epistemic acutisation nonresidualising imbued-

\{compulsing\} linearity-in-eclecticism-of-prior-mere-formulaicity/ritualisation $>$ of this human limited-mentation-capacity—as-subjecting 'educed-unlimitedness/existence-sublimating nascence' to-limitedness/human-subpotency instigating 'postconvergingaaporeticism-

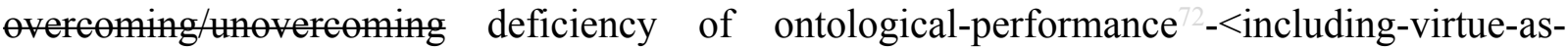
ontology $>$ ' along the overall relative-unreflexivity/relative-reflexivity-ontologicalcontiguity ${ }^{67}$ of-the-human-institutionalisation-process ${ }^{68}$, effectively elicits originarinessparrhesia,-as-spontaneity-of-aestheticisation but then as of its " foregrounding_entailment$<$ in-succession-of-profound-supererogation $>$-_postconverging-narrowingdown sublimation-as-to-'existence - as-sublimating-withdrawal/unenframing/re-ontologising,elicited-from-prospective-profound-supererogation ' '-in-reflecting-'immanent $\sim$ relativeunreflexivity/relative-reflexivity - ontological-contiguity ';-as-operativenotional deprocrypticism>

supererogatory $\sim$ acuity/perspicacity/astuteness/edginess/incisiveness-ofapriorising/axiomatising/referencing/intelligibilitysettingup/measuringinstrumenting -forconceptualisation', it is not receptive to a human dephasing shiftiness-of-the-Self as of 'deferment of human instinctual responsibility/relative-reflexivity' that dehistorialises humankind into Being/Existential homelessness as a vague temporal-to-intemporal nihilism wherein we wrongly deify our 79 presencing-absolutising-identitive-constitutedness $<$ amplituding/formative-epistemicity>totalising $\sim$ self-referencingsyncretising/circularity/interiorising/akrasiatic-drag ${ }^{34}$ while paradoxically failing to articulate a coherent existential-<disontologising/re-ontologising aporeticism $>$ narrative underlying human-subpotency-aporia/undecidability/dilemma/oughtindeterminacy/deficiency/limitation/constraint—imbued-'notional firstnaturednessformativeness-<as-to-eventualising inkling drive-or-seeding-misprising $>$ temporal-to- 
intemporal-dispositions- $<$ so-construed-as-from-perspective-ontologicalnormalcy/postconvergence>'-existentialism-form-factor involving a developing historiality/ontological-eventfulness 38 ontological-aesthetic-tracing-<perspectiveontological-normalcy/postconvergence-reflected-'epistemicity-relativism-determinism'> of human recurrent destructuring-threshold-〈uninstitutionalised-threshold /presublimatingdesublimating-decisionality $>$ of-ontological-performance ${ }^{22}-<$ including-virtue-asontology $>$ /morality/ethics/justice/etc. and its superseding with human recurrent

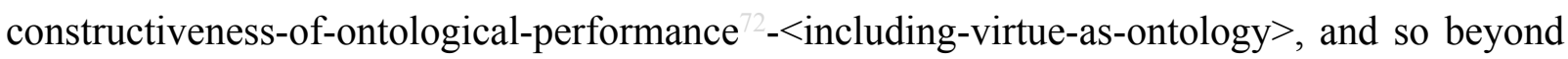
just the nombrilism of our 'human lifespan extricatory punctuality/immediacy of depth-ofthought'. This orientation is very much the peculiarity of notional ${ }^{8}$ deprocrypticism as in reality all the other prior registry-worldviews/dimensions are notionally/epistemically/bindingnessly<as-to-determinism/conceptivity-of-relative-unreflexivity/relative-reflexivity> various levels of notional procrypticism or notional disjointedness-as-of- ${ }^{8}$ reference-of-thought (in successive relative-ontological-

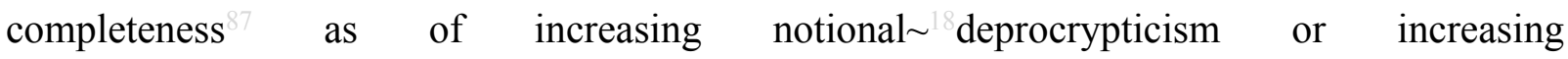
$<$ amplituding/formative $>$ notional $\sim$ preempting - disjointedness-as-of- ${ }^{8}$ reference-of-thought) but it is prospective notional deprocrypticism ontological-faith-notional or-ontologicalfideism dimensionality-of-sublimating $-\langle<$ amplituding/formative $>$ supererogatory $\sim$ dementativeness/epistemic-growth-or-conflatedness /transvaluativerationalising/transepistemicity/anamnestic-residuality/spirit-drivenness-equalisation〉 specific originariness-parrhesia,-as-spontaneity-of-aestheticisation that converges with its reproducibility—mathesis/motif/thrownness-disposition,--as-reproducibility-of-aestheticisation and reflects an indistinctness between the two that overcomes human shiftiness-of-the-Self undermining 'deferment of human instinctual responsibility/relative-reflexivity' in perpetuating the human transcendence-and-sublimity/sublimation/supererogatory $\sim$ de-mentativity narrative; and so-construed as implying that notional deprocrypticism as of its protensive-self- 
consciousness achieves an epistemic-ricochetting/transepistemicity 'explanation of everything' as implied with human limited-mentation-capacity-deepening-as-subjectinglimitedness/human-subpotency-to-'educed-unlimitedness/existence-sublimating nascence' so-reflected with the relative-unreflexivity/relative-reflexivity ontological-contiguity ${ }^{67}$ ofthe-human-institutionalisation-process dimensionality-of-sublimating

\section{<<amplituding/formative >supererogatory $\sim$ de-mentativeness/epistemic-growth-or-}

conflatedness /transvaluative-rationalising/transepistemicity/anamnestic-residuality/spiritdrivenness-equalisation) as to difference-conflatedness ${ }^{13}$-as-to-totalitative-reification-insingularisation-<as-to-the-nondisjointedness/entailment-of-prospective- nonpresencing $>$-asveridical-epistemicity-relativism-determinism implied <amplituding/formativeepistemicity $>$ causality $\sim$ as-to-projective-totalitative-implications-of-prospectivenonpresencing,-for-explicating relative-unreflexivity/relative-reflexivity - ontologicalcontiguity successiveness of registry-worldviews/dimensions involving underlying successive construction-of-the-Self enabling successive human knowledge-reification $\sim$ gesturing-andaccounting - of-epistemic-phenomenalism-<inprospective_psychologismic apriorising/axiomatising/referencing-\{of-'prospectively implicited_attendant-ontological-contiguity ' educedexistentialising/contextualising/textualising_'intelligibility/epistemicity/reflexivity-contiguity$<$ imbued-notional $\left.\sim \operatorname{cogency}>^{\prime} \quad\right\}$-conflatedness -in-\{preconverging-disentailment by\} postconverging entailment $>$ capacity. This is achieved rather as of notional ${ }^{18}$ deprocrypticism

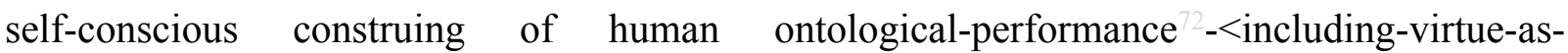
ontology $>$ /morality/ethics/justice/etc. at constructiveness-of-ontological-performance ${ }^{72}$ $<$ including-virtue-as-ontology $>/$ morality/ethics/justice/etc. and vices-and-impediments ${ }^{105}$ at destructuring-threshold-〈uninstitutionalised-threshold /presublimating-desublimatingdecisionality $>$ of-ontological-performance ${ }^{72}$ - $<$ including-virtue-as- 
ontology $>$ /morality/ethics/justice/etc. as inherently defined preconverging/postconverging-dementatively/structurally/paradigmatically by the '<amplituding/formativeepistemicity $>$ causality $\sim$ as-to-projective-totalitative-implications-of-prospectivenonpresencing,-for-explicating relative-unreflexivity/relative-reflexivity - ontologicalcontiguity in reflecting holographically-<conjugatively-and-transfusively $>$ the relativeunreflexivity/relative-reflexivity ontological-contiguity of-the-human-institutionalisationprocess in reflection of underlying human limited-mentation-capacity-as-subjecting 'educedunlimitedness/existence-sublimating nascence' to-limitedness/human-subpotency as of humansubpotency-aporia/undecidability/dilemma/ought-

indeterminacy/deficiency/limitation/constraint—imbued-'notional firstnaturednessformativeness-<as-to-eventualising-inkling-drive-or-seeding-misprising $>$ temporal-tointemporal-dispositions- $<$ so-construed-as-from-perspective-ontologicalnormalcy/postconvergence>'-existentialism-form-factor 'relative-ontologicalincompleteness $8 /$ relative-ontological-completeness 〈sublimating referencing/registering/decisioning,-as-self-becoming/selfconflatedness /formative-supererogating-<projective/reprojective-aestheticising-re-motifand-re-apriorising/re-axiomatising/re-referencing,-in-perspective-ontologicalnormalcy/postconvergence $>>\quad$ as $\quad$ to human-and-social-expectations/anticipationsmetaphoricity ${ }^{57}$-as-preconverging/postconverging-redementating/restructuring/reparadigming-psychologism, ${ }^{99}$ induced/spawned/hatched/emerged difference-conflatedness ${ }^{13}$-as-to-totalitative-reification-in-singularisation- $<$ as-to-thenondisjointedness/entailment-of-prospective- nonpresencing $>$-as-veridical-epistemicityrelativism-determinism as instigating both human constructiveness-of-ontologicalperformance ${ }^{2}$-<including-virtue-as-ontology $>$ /morality/ethics/justice/etc. and human destructuring-threshold-〈uninstitutionalised-threshold /presublimating-desublimating- 
decisionality $>\sim$ of-ontological-performance ${ }^{72}-<$ including-virtue-as-

ontology $>$ /morality/ethics/justice/etc. across the <cumulating/recomposuring attendantontological-contiguity >-successive registry-worldviews/dimensions; thus eliciting the construal of aetiologisation/ontological-escalation- $<$ ontologicalveridicality_commitment/otherliness_transcending/compulsions-encumbered_transcending $>$ as of a reflection of human-subpotency as to overall reifying-and-empowering-reflexivity-ofecstatic-existence-as-panintelligibility/panreflexivity ${ }^{3}$-〈existentially-imbued-and-educing\&\{epistemic-totalising ${ }^{3}$ hermeneutically/textually/reprojectingly/supererogatingly/zeroingly/reacutingly, - \{lecompulsing $^{\text {f }}$ delinearity $\sim$ for-cogency $\geq$-epistemic-perspective-ofprojective/reprojective - aestheticising-re-motif-and-re-apriorising/re-axiomatising/rereferencing conceptualisation,-as-herein-specifically-relevant-to human-subpotency) in preconverging/postconverging-de-mentatively/structurally/paradigmatically upholding human

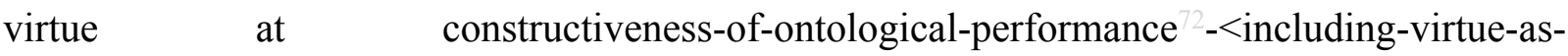
ontology $>$ /morality/ethics/justice/etc. and undermining human vices-and-impediments ${ }^{105}$ at destructuring-threshold-〈uninstitutionalised-threshold /presublimating-desublimatingdecisionality $>$ of-ontological-performance ${ }^{2}$-<including-virtue-as-ontology $>$ '. This preconverging/postconverging-de-mentative/structural/paradigmatic process orientation with

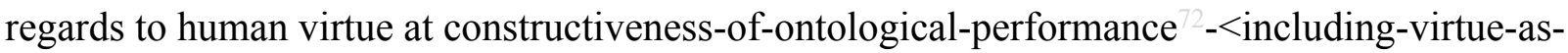
ontology $>$ /morality/ethics/justice/etc. and vices-and-impediments ${ }^{105}$ at destructuring-threshold〈uninstitutionalised-threshold /presublimating-desublimating-decisionality $>$ of-ontologicalperformance $^{2}-<$ including-virtue-as-ontology $>$ /morality/ethics/justice/etc. overrides/supersedes the naïve/ontologically-flawed traditional orientation as of ${ }^{79}$ presencing-absolutisingidentitive-constitutedness ${ }^{14} /$ identitive-constitutedness $^{14}$-as- ${ }^{\text {'epistemic-totality }}{ }^{37}$ '-dereificationin-dissingularisation-<as-to-the-disjointedness/disentailment-of- presencing-absolutisingidentitive-constitutedness $>$-as-flawed-epistemicity-relativism-determinism failing to grasp 
the dynamism implied in the Socratic knowledge-is-virtue insight when it attributes to individuals inherence of good-naturedness or bad-naturedness and 'failing to construe of the knowledge-driven ontologically-pertinent preconverging/postconverging-dementative/structural/paradigmatic process as of 'relative-ontological-incompleteness 8 /relativeontological-completeness ${ }^{8}$-〈sublimating $\sim$ referencing/registering/decisioning,-as-selfbecoming/self-conflatedness /formative-supererogating-<projective/reprojectiveaestheticising-re-motif-and-re-apriorising/re-axiomatising/re-referencing,-in-perspectiveontological-normalcy/postconvergence $>>$ as to human-and-social-expectations/anticipationsmetaphoricity ${ }^{57}$-as-preconverging/postconverging-redementating/restructuring/reparadigming-psychologism' ${ }^{89}$ that then reflects the manifestation of human virtue at constructiveness-of-ontological-performance ${ }^{72}-<$ including-virtue-asontology $>$ /morality/ethics/justice/etc. and human vices-and-impediments ${ }^{105}$ at destructuringthreshold-〈uninstitutionalised-threshold /presublimating-desublimating-decisionality $\rangle$ ofontological-performance ${ }^{72}-<$ including-virtue-as-ontology $>^{\prime}$. The bigger point here is that it is at the supererouity/perspicacity/astuteness/edginess/incisiveness-ofapriorising/axiomatising/referencing/intelligibilitysettingup/measuringinstrumenting -forconceptualisation of ${ }^{18}$ deprocrypticism-or-preempting-disjointedness-as-of- ${ }^{3}$ reference-ofthought as 'point of <amplituding/formative-epistemicity $>$ causality $\sim$ as-to-projectivetotalitative-implications-of-prospective- nonpresencing,-for-explicating relativeunreflexivity/relative-reflexivity ontological-contiguity in reflecting holographically$<$ conjugatively-and-transfusively $>$ the relative-unreflexivity/relative-reflexivity - ontologicalcontiguity of-the-human-institutionalisation-process ', that one can reflect upon the 'notional procrypticism/notional $\sim$ disjointedness-as-of- ${ }^{3}$ reference-of-thought as of differenceconflatedness $^{13}$-as-to-totalitative-reification-in-singularisation- $<$ as-to-thenondisjointedness/entailment-of-prospective- nonpresencing > -as-veridical-epistemicity- 
relativism-determinism ', of our procrypticism-positivism ${ }^{56}$ meaningfulness-and-teleology ${ }^{9}$ in order to construe its induced virtue at constructiveness-of-ontological-performance ${ }^{72}$ $<$ including-virtue-as-ontology $>/$ morality/ethics/justice/etc. and vices-and-impediments ${ }^{105}$ at destructuring-threshold-〈uninstitutionalised-threshold /presublimating-desublimatingdecisionality $>$ of-ontological-performance ${ }^{72}<$ including-virtue-asontology $>$ /morality/ethics/justice/etc. as of Being-development/ontological-frameworkexpansion-as-to-depth-of-ontologising-development-as-infrastructure-of- meaningfulnessand-teleology , institutional-development-as-to-social-function-development and livingdevelopment-as-to-personality-development psychologismic epistemic-acutisationdifficulty < for, residualising \{decompulsing\} delinearity for cogeney> experientiality/experiment\}. We can thus appreciate that just as a ${ }^{79}$ presencing-absolutising-identitiveconstitutedness ${ }^{14} /$ identitive-constitutedness $^{14}$-as-'epistemic-totality ${ }^{37}$ '-dereification-indissingularisation- $<$ as-to-the-disjointedness/disentailment-of- presencing - absolutisingidentitive-constitutedness $>$-as-flawed-epistemicity-relativism-determinism assessment of the virtue and vices-and-impediments ${ }^{105}$ of individuals in any of the preceding registryworldviews/dimensions will find them relatively wanting/deficient with regards to our positivism, this 'is not decisively/critically the case on the basis that we are inherently better individuals than any of the prior registry-worldviews/dimensions individuals' but rather a question of us being at the vantage backend of the institutional-cumulation/institutionalrecomposure-〈as-to- historiality/ontological-eventfulness /ontological-aesthetic-tracing<perspective-ontological-normalcy/postconvergence-reflected-'epistemicity-relativismdeterminism' $>>$ in reflecting holographically-<conjugatively-and-transfusively $>$ the relativeunreflexivity/relative-reflexivity - ontological-contiguity of-the-human-institutionalisationprocess 'relative-ontological-incompleteness 8 /relative-ontological-completeness 7 〈sublimating referencing/registering/decisioning,-as-self-becoming/self- 
conflatedness /formative-supererogating-<projective/reprojective-aestheticising-re-motifand-re-apriorising/re-axiomatising/re-referencing,-in-perspective-ontologicalnormalcy/postconvergence $>>$ as to human-and-social-expectations/anticipationsmetaphoricity ${ }^{5}$-as-preconverging/postconverging-rede-

mentating/restructuring/reparadigming-psychologism' 89 of limited-mentation-capacitydeepening—as-subjecting-limitedness/human-subpotency to-'educed-unlimitedness/existencesublimating nascence ${ }^{53}$, pointing out that what is decisive/critical for inducing human virtue over vices-and-impediments ${ }^{105}$ rather lies with the assessment of any such registryworldview/dimension prospective 'point of <amplituding/formativeepistemicity $>$ causality $\sim$ as-to-projective-totalitative-implications-of-prospectivenonpresencing,-for-explicating relative-unreflexivity/relative-reflexivity ontologicalcontiguity in reflecting holographically-<conjugatively-and-transfusively $>$ the relativeunreflexivity/relative-reflexivity - ontological-contiguity of-the-human-institutionalisationprocess, as so-implied by the prospective registry-worldview/dimension supererogatery $\sim$ acuity/perspicacity/astuteness/edginess/incisiveness-ofapriorising/axiomatising/referencing/intelligibilitysettingup/measuringinstrumenting -forconceptualisation as it reflects upon the preceding registry-worldview/dimension 'notional procrypticism/notional $\sim$ disjointedness-as-of- ${ }^{-3}$ reference-of-thought as of differenceconflatedness $^{13}$-as-to-totalitative-reification-in-singularisation- $<$ as-to-thenondisjointedness/entailment-of-prospective- nonpresencing > -as-veridical-epistemicityrelativism-determinism , in order to construe/assess/supersede by its induced virtue at the prospective $\quad$ constructiveness-of-ontological-performance ${ }^{72}-<$ including-virtue-asontology $>$ /morality/ethics/justice/etc. over vices-and-impediments ${ }^{105}$ at the destructuringthreshold-〈uninstitutionalised-threshold /presublimating-desublimating-decisionality $\rangle$ ofontological-performance $^{72}$-<including-virtue-as-ontology $>/$ morality/ethics/justice/etc. as of 
Being-development/ontological-framework-expansion-as-to-depth-of-ontologising-

development-as-infrastructure-of- meaningfulness-and-teleology , institutionaldevelopment-as-to-social-function-development and living-development-as-to-personalitydevelopment psychologismic epistemic-acutisation difficulty-<for, residualising $\{$ decompulsing $\}$ delinearity for-cogeney>-magnitudes $\{$ of-experientiality/experiment\}. The overall emphasis herein of the conjunction between psychopathic manifestation with the relativeunreflexivity/relative-reflexivity — ontological-contiguity ${ }^{67}$ of-the-human-institutionalisationprocess ${ }^{6}$ arises in the sense that as previously articulated the postlogism 77 -as-psychopathy-asof-'attendant-intradimensional'-preconverging/dementing -apriorising-psychologism$\langle<<$ decontextualising/de-existentialising $\sim$ of-attendant-intradimensionalapriorising/axiomatising/referencing >-induced-disontologising',-as-so-undermining-the'attendant-intradimensional-ontologising'-<as-to-attendant-intradimensionalapriorising/axiomatising/referencing-imbued-<contextualising/existentialising attendantontological-contiguity >-educing-self-referencing-syncretising_forward-facingsupposedly $\sim$ postconverging/dialectical-thinking -apriorising-psychologism $>>$ manifestation of any given registry-worldview/dimension is just a difference-in-kind/difference-inaposteriorising-or-logicising ${ }^{23}$ on the basis of the same apriorising/axiomatising/referencing/intelligibilitysettingup/measuringinstrumenting construed as of the 'underlying apriorising/axiomatising/referencing-psychologism/mental-schema' of the given registry-worldview's/dimension's ${ }^{83}$ reference-of-thought- ${ }^{84}$ devolving ${ }^{56}$ meaningfulnessand-teleology . Thus a registry-worldview's/dimension's postlogism -as-psychopathy-as-of'attendant-intradimensional'-preconverging/dementing 20-apriorising-psychologism$〈<<$ decontextualising/de-existentialising of-attendant-intradimensionalapriorising/axiomatising/referencing>-induced-disontologising',-as-so-undermining-the‘attendant-intradimensional-ontologising'-<as-to-attendant-intradimensional- 
apriorising/axiomatising/referencing-imbued-<contextualising/existentialising $\sim$ attendantontological-contiguity >-educing_-self-referencing-syncretising_forward-facingsupposedly postconverging/dialectical-thinking -apriorising-psychologism $>>$ manifestation is rather as of an 'inordinarily/unexpectedly/anormally $<$ decontextualising/de-existentialising $\sim$ ofattendant-intradimensional-apriorising/axiomatising/referencing $>$-induced-disontologising lower-threshold of human limited-mentation-capacity-as-subjecting-'educedunlimitedness/existence-sublimating nascence' to-limitedness/human-subpotency in failing dispensing-with-immediacy-for-relative-ontological-completeness ${ }^{87}$-byreification/contemplative-distension ${ }^{27}$ for living-development-as-to-personality-development' that contrasts with the registry-worldview's/dimension's 'ordinary/expected/assumed-normal attendant-intradimensional-ontologising- $<$ as-to-attendant-intradimensionalapriorising/axiomatising/referencing-imbued-<contextualising/existentialising $\sim$ attendantontological-contiguity $>$ higher-threshold of human limited-mentation-capacity-assubjecting-'educed-unlimitedness/existence-sublimating nascence' to-limitedness/humansubpotency in failing dispensing-with-immediacy-for-relative-ontological-completeness ${ }^{87}$-byreification/contemplative-distension ${ }^{27}$ for living-development-as-to-personality-development' considered as prelogism ${ }^{78}$-〈as-of-the-'intradimensional'-postconverging/dialectical-thinking apriorising-psychologism,-of-'attendant-intradimensional-ontologising'-<as-to-attendantintradimensional-apriorising/axiomatising/referencing-imbued$<$ contextualising/existentialising attendant-ontological-contiguity $>$-educing-selfreferencing-syncretising_forward-facing-supposedly $\sim$ postconverging/dialectical-thinking apriorising-psychologism $>>$ manifestation; so-reflecting a 'difference-in-kind/difference-inaposteriorising-or-logicising ${ }^{23}$ with regards to the difference between postlogism $<$ decontextualising/de-existentialising of-attendant-intradimensionalapriorising/axiomatising/referencing >-induced-disontologising and prelogism ${ }^{78}$ attendant- 
intradimensional-ontologising-<as-to-attendant-intradimensional-

apriorising/axiomatising/referencing-imbued-<contextualising/existentialising $\sim$ attendant-

ontological-contiguity $>$ as respectively decontextualising/de-existentialising and contextualising/existentialising on the basis of the-very-same apriorising/axiomatising/referencing/intelligibilitysettingup/measuringinstrumenting of the given registry-worldview/dimension'. The implication here is that 'postlogism 77 -aspsychopathy-as-of-'attendant-intradimensional'-preconverging/dementing ${ }^{20}$-apriorisingpsychologism- $<$ ‘ $<$ decontextualising/de-existentialising $\sim$ of-attendant-intradimensionalapriorising/axiomatising/referencing>-induced-disontologising',-as-so-undermining-the‘attendant-intradimensional-ontologising'-<as-to-attendant-intradimensionalapriorising/axiomatising/referencing-imbued-<contextualising/existentialising $\sim$ attendantontological-contiguity >-educing_-self-referencing-syncretising_forward-facingsupposedly postconverging/dialectical-thinking -apriorising-psychologism $>\rangle$, disposition rather 'manifests as ontologically-flawed inordinary/unexpected/anormal catching-up-bydecontextualising/de-existentialising-extrinsic-attribution for $\quad$ social-functioning-andaccordance' in contrast to ontologically-veridical prelogism -〈as-of-the-'intradimensional'postconverging/dialectical-thinking -apriorising-psychologism,-of-‘attendantintradimensional-ontologising'-<as-to-attendant-intradimensionalapriorising/axiomatising/referencing-imbued-<contextualising/existentialising attendantontological-contiguity >-educing-self-referencing-syncretising_forward-facingsupposedly postconverging/dialectical-thinking -apriorising-psychologism $>>\quad$ disposition 'manifest ontologically-veridical ordinary/expected/assumed-normal contextualising/existentialising-intrinsic-attribution for social-functioning-and-accordance'. Postlogism 77 -as-psychopathy-as-of-'attendant-intradimensional'-preconverging/dementing ${ }^{20}$ apriorising-psychologism- $<$ ‘ $<$ decontextualising/de-existentialising $\sim$ of-attendant- 
intradimensional-apriorising/axiomatising/referencing>-induced-disontologising',-as-so-

undermining-the-'attendant-intradimensional-ontologising'-<as-to-attendant-

intradimensional-apriorising/axiomatising/referencing-imbued-

$<$ contextualising/existentialising attendant-ontological-contiguity $>$-educing-self-

referencing-syncretising_forward-facing-supposedly $\sim$ postconverging/dialectical-thinking

apriorising-psychologism $>>$ manifestation is as from 'childhood postlogism 77 psychopathy overt

manifestation of $\quad<$ decontextualising/de-existentialising of-attendant-intradimensionalapriorising/axiomatising/referencing>-induced-disontologising' to 'adulthood postlogism 7 /psychopathy covert manifestation of $<$ decontextualising/de-existentialising ofattendant-intradimensional-apriorising/axiomatising/referencing--induced-disontologising'.

This insight reflects a contrast as of difference-in-kind/difference-in-aposteriorising-orlogicising ${ }^{23}$ implied between 'postlogism 77 -as-psychopathy-as-of-'attendant-intradimensional'preconverging/dementing ${ }^{20}$-apriorising-psychologism- $<$ ‘ $<$ decontextualising/de-

existentialising $\sim$ of-attendant-intradimensional-apriorising/axiomatising/referencing $>$-induceddisontologising',-as-so-undermining-the-'attendant-intradimensional-ontologising'-<as-toattendant-intradimensional-apriorising/axiomatising/referencing-imbued$<$ contextualising/existentialising attendant-ontological-contiguity $>$-educing - selfreferencing-syncretising_forward-facing-supposedly $\sim$ postconverging/dialectical-thinking apriorising-psychologism $>\rangle$ disposition' and 'prelogism ${ }^{7}$-〈as-of-the-'intradimensional'postconverging/dialectical-thinking -apriorising-psychologism,-of-'attendant-

intradimensional-ontologising'-<as-to-attendant-intradimensionalapriorising/axiomatising/referencing-imbued-<contextualising/existentialising attendantontological-contiguity >-educing-self-referencing-syncretising_forward-facingsupposedly postconverging/dialectical-thinking -apriorising-psychologism $>>\quad$ disposition' within a given registry-worldview/dimension ${ }^{83}$ reference-of-thought- ${ }^{84}$ devolving 
meaningfulness-and-teleology ; as respectively decontextualising and contextualising on the basis

apriorising/axiomatising/referencing/intelligibilitysettingup/measuringinstrumenting of the given registry-worldview/dimension. When it comes to the apriorising/axiomatising/referencing/intelligibilitysettingup/measuringinstrumenting differences between two registry-worldviews/dimensions (as of relative-ontologicalincompleteness $8 /$ relative-ontological-completeness ${ }^{87}$

〈sublimating referencing/registering/decisioning,--as-self-becoming/self-

conflatedness /formative-supererogating-<projective/reprojective-aestheticising-re-motifand-re-apriorising/re-axiomatising/re-referencing,-in-perspective-ontologicalnormalcy/postconvergence $>>$ ), it is the case that the same registry-worldview/dimension and priorly considered as being of relative-ontological-completeness ${ }^{87}$ (and as supposedly of prelogism ${ }^{8}$-〈as-of-the- 'intradimensional'-postconverging/dialectical-thinking -apriorisingpsychologism,-of-'attendant-intradimensional-ontologising'-<as-to-attendantintradimensional-apriorising/axiomatising/referencing-imbued$<$ contextualising/existentialising attendant-ontological-contiguity $>$-educing-selfreferencing-syncretising_forward-facing-supposedly $\sim$ postconverging/dialectical-thinking apriorising-psychologism $>$ > manifestation as of apriorising/axiomatising/referencing-\{of'prospectively_implicited_attendant-ontological-contiguity ' ceducedexistentialising/contexalising/textralising_intelligibility/epistemicity/reflexivity-contiguity<imbued-notional cogency >' \}-conflatedness ${ }^{13}$-in-\{preconverging-disentailment by\} postconverging entailment and so-reflecting its 'ordinary/expected/assumed-normal attendantintradimensional-ontologising-<as-to-attendant-intradimensionalapriorising/axiomatising/referencing-imbued-<contextualising/existentialising attendantontological-contiguity $>$ higher-threshold of human limited-mentation-capacity-as- 
subjecting 'educed-unlimitedness/existence-sublimating nascence' to-limitedness/humansubpotency in failing dispensing-with-immediacy-for-relative-ontological-completeness ${ }^{87}$-byreification/contemplative-distension ${ }^{27}$ for living-development-as-to-personality-development') is now rather turning out (when construed rather as from the relative-ontological-completeness nonpresencing-<perspective--ontological-normalcy/postconvergence $>$ epistemic-projection of the prospective registry-worldview/dimension) to be veridically of 'relative-ontologicalincompleteness ${ }^{8}$ or prior-registry-worldview/dimension manifest preconverging/dementing ${ }^{20}$ apriorising-psychologism- $<‘<$ decontextualising/de-existentialising $\sim$ of-prospectiveapriorising/axiomatising/referencing >-inducing-prospective-disontologising'-as-soundermining-the-'attendant-prospective-registry-worldview/dimension-ontologising'-<as-toattendant-prospective-apriorising/axiomatising/referencing-'more-profoundly-sublimatingover-desublimating'-imbued-<contextualising/existentialising attendant-ontologicalcontiguity >-educing_-self-referencing-syncretising_forward-facingsupposedly postconverging/dialectical-thinking -apriorising-psychologism $>$ )' (so-reflected as to its overall <amplituding/formative> wooden-language-_imbued-temporal-mereform/virtualities/dereification/akrasiatic-drag/denatured/preconverging-or-dementing narratives - of-the- reference-of-thought- categorical-imperatives/axioms/registryteleology (); and so just as its postlogism 77 -as-psychopathy-as-of-'attendant-intradimensional'preconverging/dementing 20 -apriorising-psychologism- $-\left\langle^{\text {‘ }}<\right.$ decontextualising/deexistentialising $\sim$ of-attendant-intradimensional-apriorising/axiomatising/referencing $>$-induceddisontologising',-as-so-undermining-the- 'attendant-intradimensional-ontologising'-<as-toattendant-intradimensional-apriorising/axiomatising/referencing-imbued$<$ contextualising/existentialising attendant-ontological-contiguity $>$-educing-selfreferencing-syncretising_forward-facing-supposedly $\sim$ postconverging/dialectical-thinking apriorising-psychologism $>>$ behaviourally prompted $<$ decontextualising/de-existentialising $\sim$ of- 
attendant-intradimensional-apriorising/axiomatising/referencing $>$-induced-disontologising (but with the contrast that the relative-ontological-incompleteness ${ }^{88}$ or prior-registryworldview/dimension manifest $<$ decontextualising/de-existentialising of-prospectiveapriorising/axiomatising/referencing>-inducing-prospective-disontologising' is rather soprompted on the basis of the prospective registry-worldview/dimension change of apriorising/axiomatising/referencing/intelligibilitysettingup/measuringinstrumenting as to its inherent ${ }^{6}$ nonpresencing-<perspective-ontological-normalcy/postconvergence $>$ implications of transcendence-and-sublimity/sublimation/supereregatory-de-mentativity). This explains why the prospective registry-worldview/dimension is rather a difference-in-nature/difference-inapriorising-or-axiomatising-or-referencing

as of its supererogatory acuity/perspicacity/astuteness/edginess/incisiveness-ofapriorising/axiomatising/referencing/intelligibilitysettingup/measuringinstrumenting -forconceptualisation from the prior registry-worldview's/dimension's given supererogatory acuity/perspicacity/astuteness/edginess/incisiveness-ofapriorising/axiomatising/referencing/intelligibilitysettingup/measuringinstrumenting -forconceptualisation, and equally explaining why a postlogism -as-psychopathy-as-of-'attendantintradimensional'-preconverging/dementing 20 -apriorising-psychologism$\langle<<$ decontextualising/de-existentialising of-attendant-intradimensionalapriorising/axiomatising/referencing >-induced-disontologising',-as-so-undermining-the‘attendant-intradimensional-ontologising'-<as-to-attendant-intradimensionalapriorising/axiomatising/referencing-imbued-<contextualising/existentialising attendantontological-contiguity >-educing_self-referencing-syncretising_forward-facingsupposedly $\sim$ postconverging/dialectical-thinking -apriorising-psychologism $>>$ manifestation on the basis of a prior relative-ontological-incompleteness ${ }^{88}$ registry-worldview/dimension doesn't-work/is-inoperant with respect to a prospective relative-ontological-completeness 
registry-worldview/dimension (say for instance a postlogism 7 -as-psychopathy-as-of-'attendantintradimensional'-preconverging/dementing -apriorising-psychologism$\langle<<$ decontextualising/de-existentialising $\sim$ of-attendant-intradimensionalapriorising/axiomatising/referencing >-induced-disontologising',-as-so-undermining-the'attendant-intradimensional-ontologising'-<as-to-attendant-intradimensionalapriorising/axiomatising/referencing-imbued-<contextualising/existentialising attendantontological-contiguity >-educing_-self-referencing-syncretising_forward-facingsupposedly postconverging/dialectical-thinking -apriorising-psychologism $>>$ manifestation on the basis of non-positivism/medievalism superstition/positivistically-unenlightened-insight wouldn't be effective with respect to a positivism/rational-empiricism registryworldview's/dimension's supereregatøry acuity/perspicacity/astuteness/edginess/incisivenessof-apriorising/axiomatising/referencing/intelligibilitysettingup/measuringinstrumenting -forconceptualisation due to the difference-in-nature/difference-in-apriorising-or-axiomatising-orreferencing ${ }^{24}$ between the two registry-worldviews/dimensions (as to the fact that the prospective positivism/rational-empiricism registry-worldview/dimension isn't responsive/receptive to nonpositivising supererogatory acuity/perspicacity/astuteness/edginess/incisiveness-ofapriorising/axiomatising/referencing/intelligibilitysettingup/measuringinstrumenting -forconceptualisation whether of 'non-positivising prelogism 7 -as-of-conviction,-in-profoundsupererogation -<existentially-veridical-'attendant-intradimensionalapriorising/axiomatising/referencing'-logical-dueness-precedes-disontologising-logicaloutcome-arrived-at>' ${ }^{\prime} \quad$ or $\quad$ 'non-positivising postlogism 7 -as-of- compulsingnonconviction/madeupness/bottomlining-〈‘ $<$ decontextualising/de-existentialising ofattendant-intradimensional-apriorising/axiomatising/referencing $>$-induced-disontologising'-ofthe-'attendant-intradimensional-ontologising'-imbued$<$ contextualising/existentialising attendant-ontological-contiguity $>$;-in-shallow- 
supererogation -<as-to-disontologising-perverted-outcome-sought-precedes-existentiallyveridical-'attendant-intradimensional-apriorising/axiomatising/referencing'-logical-

dueness $\left.>\rangle^{\prime}\right)$. Contrastively, postlogism 77 -as-psychopathy-as-of-'attendant-intradimensional'preconverging/dementing 20 -apriorising-psychologism- $-{ }^{\text {‘ }}<$ decontextualising/deexistentialising $\sim$ of-attendant-intradimensional-apriorising/axiomatising/referencing $>$-induceddisontologising',-as-so-undermining-the- 'attendant-intradimensional-ontologising'-<as-toattendant-intradimensional-apriorising/axiomatising/referencing-imbued$<$ contextualising/existentialising attendant-ontological-contiguity $>$-educing - selfreferencing-syncretising_forward-facing-supposedly $\sim$ postconverging/dialectical-thinking apriorising-psychologism $>>$ manifestation going by its 'inordinarily/unexpectedly/anormally $<$ decontextualising/de-existentialising $\sim$ of-attendant-intradimensionalapriorising/axiomatising/referencing >-induced-disontologising lower-threshold of human limited-mentation-capacity—as-subjecting-'educed-unlimitedness/existence-sublimating nascence' to-limitedness/human-subpotency in failing dispensing-with-immediacy-for-relativeontological-completeness ${ }^{87}$-by-reification/contemplative-distension ${ }^{27}$ for living-developmentas-to-personality-development' (and so as from 'childhood postlogism 77 psychopathy overt manifestation of $\quad<$ decontextualising/de-existentialising of-attendant-intradimensionalapriorising/axiomatising/referencing >-induced-disontologising' to 'adulthood postlogism 77 psychopathy covert manifestation of $<$ decontextualising/de-existentialising ofattendant-intradimensional-apriorising/axiomatising/referencing >-induced-disontologising') when effective/successful elicits in others corresponding manifestations as of difference-inkind/difference-in-aposteriorising-or-logicising ${ }^{23}$ (on the basis of the $<$ decontextualising/deexistentialising $\sim$ of-attendant-intradimensional-apriorising/axiomatising/referencing $>$-induceddisontologising of the-very-same registry-worldview's/dimension's apriorising/axiomatising/referencing/intelligibilitysettingup/measuringinstrumenting $\quad$ for 
aposteriorising/logicising/deriving/intelligising/measuring cognisant-and-integrative social meaningfulness-and-teleology ${ }^{9}$ ) eliciting adhoc conjugated-postlogism 77 social dynamics as of conjugated-ignorance/conjugated-affordability/conjugated-opportunism/conjugatedexacerbation/conjugated-social-chainism-or-social-discomfiture-or-negative-socialaggregation/conjugated-temporal-enculturation-or-temporal-endemisation. Likewise, the same registry-worldview/dimension construed rather as of its 'relative-ontological-incompleteness or prior-registry-worldview/dimension manifest preconverging/dementing ${ }^{20}$-apriorisingpsychologism-〈'<decontextualising/de-existentialising $\sim$ of-prospectiveapriorising/axiomatising/referencing>-inducing-prospective-disontologising'-as-soundermining-the-'attendant-prospective-registry-worldview/dimension-ontologising'-<as-toattendant-prospective-apriorising/axiomatising/referencing-'more-profoundly-sublimatingover-desublimating'-imbued-<contextualising/existentialising attendant-ontologicalcontiguity >-educing_-self-referencing-syncretising_forward-facingsupposedly postconverging/dialectical-thinking -apriorising-psychologism $>\rangle$, implied 'inordinary/unexpected/anormal catching-up-by-decontextualising/de-existentialisingextrinsic-attribution for social-functioning-and-accordance' (as so-reflected as from the supererogatory $\sim$ acuity/perspicacity/astuteness/edginess/incisiveness-ofapriorising/axiomatising/referencing/intelligibilitysettingup/measuringinstrumenting -forconceptualisation for aposteriorising/logicising/deriving/intelligising/measuring cognisant-andintegrative social meaningfulness-and-teleology ${ }^{59}$ of the prospective registryworldview/dimension) speaks of the preconverging/postconverging-dementative/structural/paradigmatic manifestation of its given corresponding notional $\sim$ procrypticism/notional disjointedness-as-of- ${ }^{3}$ reference-of-thought 'as to its threshold of failing to reflect 'implicited_attendant-ontological-contiguity ${ }^{67} \sim$ educedexistentialising/contextalising/textalising_'intelligibility/epistemicity/reflexivity_contiguity- 
<imbued-notional cogency>' (as so-underlied with its <amplituding/formative > woodenlanguage-_imbued - temporal-mere-form/virtualities/dereification/akrasiaticdrag/denatured/preconverging-or-dementing -narratives - of-the- reference-of-thoughtcategorical-imperatives/axioms/registry-teleology $\rangle$ and associated dominance/vested-interestsubontologising-skewed-influence-as-to-social-vestedness/normativity- $<$ discretely-impliedfunctionalism> and pedantising/muddling/formulaic-hollowing-out-insubontologisation/subpotentiation-〈blurring/undermining-of-prospective-totalising-entailing,as-to-entailing-<amplituding/formative-epistemicity $>$ totalising $\sim$ in-relative-ontologicalcompleteness \) in reflecting the relative-unreflexivity/relative-reflexivity-ontologicalcontiguity ${ }^{67}$ of-the-human-institutionalisation-process ${ }^{6}$ in ratiocontiguity/ratiocination-as-referentialism_-implicited_attendant_ontologicalcontiguity $^{67}$, educedexistentialising/contextmalising/textualising_intelligibility/epistemicity/reflexivity_contiguity$<$ imbued-notional cogency $>{ }^{40}$ as from ${ }^{18}$ deprocrypticism-or-preempting-disjointedness-asof- ${ }^{8}$ reference-of-thought supererogatory acuity/perspicacity/astuteness/edginess/incisivenessof-apriorising/axiomatising/referencing/intelligibilitysettingup/measuringinstrumenting -forconceptualisation): $\quad$ whether such a corresponding notional $\sim$ procrypticism/notional $\sim$ disjointedness-as-of- ${ }^{2}$ reference-of-thought, starting as from the basis of 'fundamental animality failing dispensing-with-immediacy-for-relative-ontologicalcompleteness $^{87}$-by-reification/contemplative-distension ${ }^{27}, \quad$ is $\quad$ recurrent-utteruninstitutionalisation's trepidatious-self-consciousness $\quad$ specific notional procrypticism/notional $\sim$ disjointedness-as-of- ${ }^{3}$ reference-of-thought of 'failing prospective rulemaking-over-non-rules—apriorising/axiomatising/referencing-psychologism given dispensing-with-immediacy-for-relative-ontological-completeness ${ }^{87}$-byreification/contemplative-distension ${ }^{27}$ so-construed from base-institutionalisation perspective; 
base-institutionalisation-ununiversalisation's

notional procrypticism/notional disjointedness-as-of- ${ }^{\circledR}$ reference-of-thought of 'failing prospective universalisation-directed-rulemaking-over-non-rulesapriorising/axiomatising/referencing-psychologism given dispensing-with-immediacy-forrelative-ontological-completeness ${ }^{87}$-by-reification/contemplative-distension ${ }^{27}$ so-construed from universalisation perspective; universalisation-non-positivism/medievalism's preclusive-self-consciousness specific notional procrypticism/notional disjointedness-as-ofreference-of-thought of 'failing prospective positivising/rational-empiricism-baseduniversalisation-directed-rulemaking-over-non-rules_-apriorising/axiomatising/referencingpsychologism given dispensing-with-immediacy-for-relative-ontological-completeness ${ }^{87}$-byreification/contemplative-distension ${ }^{27}$ so-construed from positivism/rational-empiricism perspective; or prospectively ${ }^{80}$ positivism- ${ }^{8}$ procrypticism occlusive-self-consciousness specific notional $\sim$ procrypticism/notional $\sim$ disjointedness-as-of- ${ }^{8}$ reference-of-thought of 'failing prospective $\quad$ preempting - disjointedness-as-of- ${ }^{-}$reference-of-thought,-as-to' ${ }^{3}<$ amplituding/formative-epistemicity $>$ growth-or-conflatedness ${ }^{13} /$ transvaluativerationalising/transepistemicity/anamnestic-residuality/spirit-drivenness'_-in-supersedingmere-formulaic-positivising/rational-empiricism-based-universalisation-directed-rulemakingover-non-rules - apriorising/axiomatising/referencing-psychologism given dispensing-withimmediacy-for-relative-ontological-completeness ${ }^{87}$-by-reification/contemplative-distension ${ }^{27}$, so-construed from ${ }^{18}$ deprocrypticism-or-preempting-disjointedness-as-of- ${ }^{8}$ reference-ofthought protensive-self-consciousness perspective. And this in underlining the epistemicricochetting/transepistemicity $\quad{ }^{45}$ foregrounding_entailment- $<$ in-succession-of-profoundsupererogation $>$-〈postconverging-narrowing-down $\sim$ sublimation-as-to- 'existence- -assublimating-withdrawal/unenframing/re-ontologising,-elicited-from-prospective-profoundsupererogation '-in-reflecting-'immanent $\sim$ relative-unreflexivity/relative-reflexivity 
ontological-contiguity ';-as-operative-notional deprocrypticism) ${ }^{56}$ meaningfulness-andteleology as of human limited-mentation-capacity-deepening-as-subjectinglimitedness/human-subpotency-to-'educed-unlimitedness/existence-sublimating nascence' ', and so-construed as the given prior registry-worldview's/dimension's susceptibility to its corresponding 'postlogism 77 -as-psychopathy-as-of-'attendant-intradimensional'preconverging/dementing ${ }^{20}$-apriorising-psychologism- $<$ ‘ $<$ decontextualising/deexistentialising $\sim$ of-attendant-intradimensional-apriorising/axiomatising/referencing $>$-induceddisontologising',-as-so-undermining-the- 'attendant-intradimensional-ontologising'-<as-toattendant-intradimensional-apriorising/axiomatising/referencing-imbued$<$ contextualising/existentialising attendant-ontological-contiguity $>$-educing-selfreferencing-syncretising_forward-facing-supposedly $\sim$ postconverging/dialectical-thinking apriorising-psychologism $>>$ manifestation; as so-respectively susceptible to any such 'postlogism 77 -as-psychopathy-as-of-'attendant-intradimensional'-preconverging/dementing 20 apriorising-psychologism- $\langle$ ‘ $<$ decontextualising/de-existentialising of-attendantintradimensional-apriorising/axiomatising/referencing >-induced-disontologising',-as-soundermining-the-'attendant-intradimensional-ontologising'-<as-to-attendantintradimensional-apriorising/axiomatising/referencing-imbued$<$ contextualising/existentialising attendant-ontological-contiguity $>$-educing-selfreferencing-syncretising_forward-facing-supposedly $\sim$ postconverging/dialectical-thinking apriorising-psychologism $>>$ manifestation upon the 'given registry-worldview/dimension mere defining basis/rules (of ${ }^{83}$ reference-of-thought- categorical-imperatives/axioms/registryteleology in want for prospective intemporal-preservation-entropy-or-contiguity-orontological-preservation) which are so-prospectively failing dispensing-with-immediacy-forrelative-ontological-completeness ${ }^{87}$-by-reification/contemplative-distension ${ }^{27}$. Thusly, reflected as of: 'non-rules—apriorising/axiomatising/referencing-psychologism,-as-impulsive- 
or-accidented-or-random-mental-disposition-or-failing-prospective-rulemaking-over-nonrules_apriorising/axiomatising/referencing-psychologism' with recurrent-utteruninstitutionalisation; 'failing-prospective-universalisation-directed-rulemaking-over-nonrules_-apriorising/axiomatising/referencing-psychologism' with base-institutionalisationununiversalisation, 'failing-prospective-positivising/rational-empiricism-baseduniversalisation-directed-rulemaking-over-non-rules — apriorising/axiomatising/referencingpsychologism' with ${ }^{103}$ universalisation-non-positivism/medievalism, 'failing-prospectivepreempting - disjointedness-as-of- ${ }^{83}$ reference-of-thought,-as-to- ${ }^{6}<$ amplituding/formativeepistemicity>growth-or-conflatedness ${ }^{13} /$ transvaluativerationalising/transepistemicity/anamnestic-residuality/spirit-drivenness'—in-supersedingmere-formulaic-positivising/rational-empiricism-based-universalisation-directed-rulemakingover-non-rules - apriorising/axiomatising/referencing-psychologism' with positivismprocrypticism, and prospectively 'preempting - disjointedness-as-of- ${ }^{3}$ reference-of-thought,as-to- ${ }^{3}<$ amplituding/formative-epistemicity $>$ growth-or-conflatedness ${ }^{13} /$ transvaluativerationalising/transepistemicity/anamnestic-residuality/spirit-drivenness'_-in-supersedingmere-formulaic-positivising/rational-empiricism-based-universalisation-directed-rulemakingover-non-rules_-apriorising/axiomatising/referencing-psychologism' with deprocrypticism. Wherein at the destructuring-threshold-〈uninstitutionalised-threshold/presublimating-

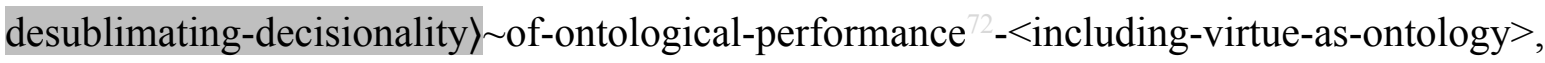
the given registry-worldview's/dimension's reference-of-thought reproducibilitymathesis/motif/thrownness-disposition,-as-reproducibility-of-aestheticisation is rather related to as of <amplituding/formative> wooden-language-_imbued-temporal-mereform/virtualities/dereification/akrasiatic-drag/denatured/preconverging-or-dementing narratives - of-the- reference-of-thought- categorical-imperatives/axioms/registryteleology $\rangle$ (even as it is equally susceptible however difficultly to prospective 
crossgenerational originariness-parrhesia,-as-spontaneity-of-aestheticisation disseminative instigation of renewing reproducibility-mathesis/motif/thrownness-disposition,-asreproducibility-of-aestheticisation for the prospective registry-worldview/dimension supererogatery $\sim$ acuity/perspicacity/astuteness/edginess/incisiveness-ofapriorising/axiomatising/referencing/intelligibilitysettingup/measuringinstrumenting -forconceptualisation as renewed ${ }^{56}$ meaningfulness-and-teleology ${ }^{9}$ infrastructure induced difference-in-nature/difference-in-apriorising-or-axiomatising-or-referencing ${ }^{2}$ ). What is central and critical in this contrastive construal of difference-in-kind/difference-in-aposteriorising-orlogicising and difference-in-nature/difference-in-apriorising-or-axiomatising-or-referencing so-reflected in the implications of 'inordinarily/unexpectedly/anormally $<$ decontextualising/deexistentialising $\sim$ of-attendant-intradimensional-apriorising/axiomatising/referencing $>$-induceddisontologising lower-threshold of human limited-mentation-capacity—as-subjecting 'educedunlimitedness/existence-sublimating nascence' to-limitedness/human-subpotency in failing dispensing-with-immediacy-for-relative-ontological-completeness ${ }^{87}$-byreification/contemplative-distension ${ }^{27}$ for living-development-as-to-personality-development' associated with postlogism 7 -as-psychopathy-as-of-'attendant-intradimensional'preconverging/dementing 20 -apriorising-psychologism- $\left\langle^{\text {‘ }}<\right.$ decontextualising/deexistentialising $\sim$ of-attendant-intradimensional-apriorising/axiomatising/referencing $>$-induceddisontologising',-as-so-undermining-the- 'attendant-intradimensional-ontologising'-<as-toattendant-intradimensional-apriorising/axiomatising/referencing-imbued$<$ contextualising/existentialising attendant-ontological-contiguity $>$-educing-selfreferencing-syncretising_forward-facing-supposedly postconverging/dialectical-thinking apriorising-psychologism $>>$ and 'ordinary/expected/assumed-normal attendantintradimensional-ontologising-<as-to-attendant-intradimensionalapriorising/axiomatising/referencing-imbued-<contextualising/existentialising $\sim$ attendant- 
ontological-contiguity $>$ higher-threshold of human limited-mentation-capacity-assubjecting 'educed unlimitedness/existence-sublimating nascence' to-limitedness/humansubpotency in failing dispensing-with-immediacy-for-relative-ontological-completeness ${ }^{87}$-byreification/contemplative-distension ${ }^{27}$ for living-development-as-to-personality-development' associated with prelogism ${ }^{7}$-〈as-of-the-'intradimensional'-postconverging/dialecticalthinking -apriorising-psychologism,-of-'attendant-intradimensional-ontologising'-<as-toattendant-intradimensional-apriorising/axiomatising/referencing-imbued$<$ contextualising/existentialising attendant-ontological-contiguity $>$-educing - selfreferencing-syncretising_forward-facing-supposedly $\sim$ postconverging/dialectical-thinking apriorising-psychologism $>$ ) (as so-construed from within the-very-same registryworldview/dimension supereregatory $\sim$ acuity/perspicacity/astuteness/edginess/incisiveness-ofapriorising/axiomatising/referencing/intelligibilitysettingup/measuringinstrumenting -forconceptualisation perspective), is the fact that 'all that humankind has got for conceptualising ecstatic-existence, as ever the-very-same-immanent-existence/intrinsic-reality/ontologicalveridicality,-as-to-'human<amplituding/formative-epistemicity>totalising $\sim$ purview-ofconstrual', is effectively our human limited-mentation-capacity-as-subjecting 'educedunlimitedness/existence-sublimating nascence' to-limitedness/human-subpotency of apriorising/axiomatising/referencing/intelligibilitysettingup/measuringinstrumenting' by which we then assume/adopt a ${ }^{7}$ presencing-absolutising-identitive-constitutedness ${ }^{14}$ disposition for aposteriorising/logicising/deriving/intelligising/measuring ${ }^{56}$ meaningfulness-and-teleology ${ }^{9}$. But by so doing wrongly impliciting as to in-effect absolution-<as-toapriorising/axiomatising/referencing-\{ of-'prospectively_implicited_attendant-ontologicalcontiguity ' educedexistentialising/contextualising/textualising_ 'intelligibility/epistemicity/reflexivity-contiguity$<$ imbued-notional cogency $>\quad\}$-constitutedness -in preconverging-entailment $>\quad$ that 
humankind has ever always been as of the given prelogism ${ }^{7}$ - as-of-the-'intradimensional'postconverging/dialectical-thinking -apriorising-psychologism,-of-'attendant-

intradimensional-ontologising'-<as-to-attendant-intradimensional-

apriorising/axiomatising/referencing-imbued-<contextualising/existentialising $\sim$ attendant -

ontological-contiguity >-educing-self-referencing-syncretising_forward-facing-

supposedly postconverging/dialectical-thinking -apriorising-psychologism $>>\quad$ disposition

without drawing the implications arising as to 'relative-ontological-incompleteness ${ }^{88}$ or priorregistry-worldview/dimension manifest preconverging/dementing 2 -apriorising-psychologism〈‘ $<$ decontextualising/de-existentialising $\sim$ of-prospective-apriorising/axiomatising/referencing $>$ inducing-prospective-disontologising'-as-so-undermining-the-'attendant-prospective-registry-

worldview/dimension-ontologising'-<as-to-attendant-prospective-

apriorising/axiomatising/referencing-'more-profoundly-sublimating-over-desublimating'-

imbued-<contextualising/existentialising $\sim$ attendant-ontological-contiguity $>$-educing - self-

referencing-syncretising_forward-facing-supposedly $\sim$ postconverging/dialectical-thinking

apriorising-psychologism $>$ ' , in factoring in $<$ amplituding/formative-

epistemicity $>$ causality $\sim$ as-to-projective-totalitative-implications-of-prospective-

nonpresencing,-for-explicating relative-unreflexivity/relative-reflexivity - ontological-

contiguity as of relative-ontological-incompleteness ${ }^{88} /$ relative-ontological-completeness $^{87}$ 〈sublimating referencing/registering/decisioning,--as-self-becoming/self-

conflatedness /formative-supererogating-<projective/reprojective-aestheticising-re-motifand-re-apriorising/re-axiomatising/re-referencing,-in-perspective-ontologicalnormalcy/postconvergence $>>$ ); and so in the sense that the supererogatory acuity/perspicacity/astuteness/edginess/incisiveness-ofapriorising/axiomatising/referencing/intelligibilitysettingup/measuringinstrumenting -forconceptualisation of recurrent-utter-uninstitutionalisation, base-institutionalisation- 
ununiversalisation, ${ }^{103}$ universalisation-non-positivism/medievalism and our positivismprocrypticism respectively reflexive of their relative-ontological-incompleteness prelogism ${ }^{7}$-〈as-of-the-'intradimensional'-postconverging/dialectical-thinking -apriorisingpsychologism,-of-'attendant-intradimensional-ontologising'-<as-to-attendantintradimensional-apriorising/axiomatising/referencing-imbued$<$ contextualising/existentialising attendant-ontological-contiguity $>$-educing-selfreferencing-syncretising_forward-facing-supposedly $\sim$ postconverging/dialectical-thinking apriorising-psychologism $>>$ disposition as of their ${ }^{79}$ presencing-absolutising-identitiveconstitutedness ${ }^{14}$, do not factor in respectively the transcendental/ nonpresencing<perspective-ontological-normalcy/postconvergence $>$ prospective base-institutionalisation, ${ }^{3}$ universalisation, positivism/rational-empiricism and deprocrypticism in relative-ontologicalcompleteness $^{87} \quad$ prelogism $^{7}$-〈as-of-the- 'intradimensional'-postconverging/dialecticalthinking -apriorising-psychologism,-of-'attendant-intradimensional-ontologising'-<as-toattendant-intradimensional-apriorising/axiomatising/referencing-imbued$<$ contextualising/existentialising attendant-ontological-contiguity $>$-educing-selfreferencing-syncretising_forward-facing-supposedly postconverging/dialectical-thinking apriorising-psychologism $>>$ disposition as implying respectively that the prior recurrent-utteruninstitutionalisation, ununiversalisation, non-positivism/medievalism and procrypticism are then effectively of 'relative-ontological-incompleteness ${ }^{88}$ or prior-registryworldview/dimension manifest preconverging/dementing ${ }^{20}$-apriorising-psychologism〈‘ $<$ decontextualising/de-existentialising of-prospective-apriorising/axiomatising/referencing $>$ inducing-prospective-disontologising'-as-so-undermining-the-'attendant-prospective-registryworldview/dimension-ontologising'-<as-to-attendant-prospectiveapriorising/axiomatising/referencing-'more-profoundly-sublimating-over-desublimating'imbued-<contextualising/existentialising $\sim$ attendant-ontological-contiguity $>$-educing - self- 


\section{referencing-syncretising_forward-facing-supposedly postconverging/dialectical-thinking}

apriorising-psychologism $>$ )'. The point here is that 'ecstatic-existence doesn't have any inherent/supposed limit of manifestation tied-down/bogged-down to human limited-mentationcapacity —as-subjecting 'educed-unlimitedness/existence-sublimating nascence' to-

limitess as of its relative-ontological-incompleteness ${ }^{88}$ with respect to the possibilities of $\quad$ nonpresencing-<perspective-ontological-normalcy/postconvergence $>$ epistemic-projection' (so-successively unlimited by recurrent-utter-uninstitutionalisation, baseinstitutionalisation-ununiversalisation, ${ }^{103}$ universalisation-non-positivism/medievalism and our positivism- ${ }^{80}$ procrypticism), such that the implied difference-conflatedness ${ }^{13}$-as-to-totalitativereification-in-singularisation-<as-to-the-nondisjointedness/entailment-of-prospectivenonpresencing $>$-as-veridical-epistemicity-relativism-determinism between the prior and prospective registry-worldviews/dimensions involving prospective human limited-mentationcapacity-deepening —as-subjecting limitedness/human-subpotency-to-'educedunlimitedness/existence-sublimating nascence' apriorising/axiomatising/referencing/intelligibilitysettingup/measuringinstrumenting construal of ecstatic-existence, as ever the-very-same-immanent-existence/intrinsic-reality/ontologicalveridicality,-as-to-'human<amplituding/formative-epistemicity $>$ totalising $\sim$ purview-ofconstrual', so-implied from the prospective registry-worldview/dimension transcendence-andsublimity/sublimation/supererogatory-de-mentativity constructiveness-of-ontologicalperformance $^{72}-<$ including-virtue-as-ontology $>$ /morality/ethics/justice/etc. exposes the prior registry-worldview's/dimension's destructuring-threshold-〈uninstitutionalisedthreshold /presublimating-desublimating-decisionality $>$ of-ontological-performance ${ }^{72}$ $<$ including-virtue-as-ontology $>/$ morality/ethics/justice/etc. veridically as being of 'relativeontological-incompleteness or prior-registry-worldview/dimension manifest preconverging/dementing 20 -apriorising-psychologism- $-<<$ decontextualising/de- 
existentialising of-prospective-apriorising/axiomatising/referencing >-inducing-prospective-

disontologising'-as-so-undermining-the-'attendant-prospective-registry-worldview/dimension-

ontologising'-<as-to-attendant-prospective-apriorising/axiomatising/referencing-'more-

profoundly-sublimating-over-desublimating'-imbued-

$<$ contextualising/existentialising attendant-ontological-contiguity $>$-educing - self-

referencing-syncretising_forward-facing-supposedly $\sim$ postconverging/dialectical-thinking

apriorising-psychologism $>$ Y' in 'manifest ontologically-flawed inordinary/unexpected/anormal catching-up-by-decontextualising/de-existentialising-extrinsic-attribution for socialfunctioning-and-accordance' (as so-underlied with <amplituding/formative $>$ wooden-language〈imbued-temporal-mere-form/virtualities/dereification/akrasiatic-

drag/denatured/preconverging-or-dementing -narratives - of-the- reference-of-thought-

categorical-imperatives/axioms/registry-teleology $\rangle$ and associated dominance/vested-interestsubontologising-skewed-influence-as-to-social-vestedness/normativity-<discretely-implied-

functionalism> and pedantising/muddling/formulaic-hollowing-out-insubontologisation/subpotentiation-〈blurring/undermining-of-prospective-totalising-entailing,as-to-entailing-<amplituding/formative-epistemicity $>$ totalising in-relative-ontologicalcompleteness †) as so-reflected as from the supererogatery acuity/perspicacity/astuteness/edginess/incisiveness-ofapriorising/axiomatising/referencing/intelligibilitysettingup/measuringinstrumenting -forconceptualisation for aposteriorising/logicising/deriving/intelligising/measuring cognisant-andintegrative social ${ }^{56}$ meaningfulness-and-teleology 9 of the prospective registryworldview/dimension; and thus so-construed as difference-in-nature/difference-in-apriorisingor-axiomatising-or-referencing ${ }^{4}$ of respectively prior and prospective registryworldviews/dimensions. Hence, 'all the human home that exists' is as of the full implications of the perpetuation in reflecting holographically-<conjugatively-and-transfusively $>$ the relative- 
unreflexivity/relative-reflexivity - ontological-contiguity of-the-human-institutionalisationprocess as it explains what is the human and its becoming beyond any epochally blinded nombrilism. But then while realistically the relative-unreflexivity/relative-reflexivityontological-contiguity ${ }^{67}$ of-the-human-institutionalisation-process ${ }^{68}$ is driven as of human dimensionality-of-sublimating $25<<$ amplituding/formative $>$ supererogatory $\sim$ dementativeness/epistemic-growth-or-conflatedness /transvaluativerationalising/transepistemicity/anamnestic-residuality/spirit-drivenness-equalisation〉 and secondnatured institutionalisation dispositions with respect to the fact that the human $<$ amplituding/formative $>$ wooden-language-_imbued — averaging-of-thought-<as-toleveling/ressentiment/closed-construct-of- meaningfulness-and-teleology -as-of'nondescript/ignorable-void ' -with-regards-to-prospective-apriorising-implications $>$ > disposition of all registry-worldviews/dimensions is very much capable of countenancing however fragile prospective 'relative-ontological-incompleteness $8 /$ relative-ontologicalcompleteness ${ }^{8}$-〈sublimating $\sim$ referencing/registering/decisioning,-as-self-becoming/selfconflatedness /formative-supererogating-<projective/reprojective-aestheticising-re-motifand-re-apriorising/re-axiomatising/re-referencing,-in-perspective-ontologicalnormalcy/postconvergence $>>$ as to human-and-social-expectations/anticipationsmetaphoricity ${ }^{57}$-as-preconverging/postconverging-rede-

mentating/restructuring/reparadigming-psychologism' ${ }^{89}$; that is, until when that fragility is exploited by temporal sophistic/pedantic dispositions in wrongly and cynically implying the equivalence of prospective intemporal-projection and prior temporal-projection as to when ancient-sophists elicit the contemplation of Socratic-philosophers intemporal ${ }^{103}$ universalisingidealisation narrative in terms of their epochal <amplituding/formative $>$ wooden-language〈imbued-averaging-of-thought-<as-to-leveling/ressentiment/closed-construct-ofmeaningfulness-and-teleology -as-of-'nondescript/ignorable-void '-with-regards-to- 
prospective-apriorising-implications $>>$ non-universalising narrative, as to when medievalscholasticism fail to engage prospective budding-positivism/rational-empiricism meaningfulness-and-teleology and harkening rather to its dogmatic pedantising/muddling/formulaic-hollowing-out - in-subontologisation/subpotentiation〈blurring/undermining-of-prospective-totalising-entailing,-as-to-entailing$<$ amplituding/formative-epistemicity>totalising in-relative-ontological-completeness $\rangle, \quad$ and as to when modern-day pedantising/muddling/formulaic-hollowing-out-insubontologisation/subpotentiation-〈blurring/undermining-of-prospective-totalising-entailing,as-to-entailing-<amplituding/formative-epistemicity $>$ totalising $\sim$ in-relative-ontologicalcompleteness > seems to be blinded to the implication of 'prospective event 8 /postconverging aporeticism-overcoming/unovercoming thinking implied deprocrypticism-or-preempting-disjointedness-as-of- reference-of-thought' and take the route of eliciting disparateness-of-conceptualisation-<unforegrounding-disentailment,-failingprospectively-to-reflect-'immanent relative- unreflexivity/relative-reflexivity - ontologicalcontiguity '> unconstrained to existential-reality as of <amplituding/formativeepistemicity $>$ causality $\sim$ as-to-projective-totalitative-implications-of-prospectivenonpresencing,-for-explicating relative-unreflexivity/relative-reflexivity - ontologicalcontiguity such that even the idea of a human existential-<disontologising/re-ontologising apereticism $>$ narrative tends to be put-into-question together with a tendency to question the pertinence of historically transformative figures and movements, and so in a 'disparateness-ofconceptualisation-<unforegrounding-disentailment,-failing-prospectively-to-reflect‘immanent relative-unreflexivity/relative-reflexivity - ontological-contiguity '> impotenceinducing exercise' (as to the fact that where there is uncertainty-as-failing-to-reflect-theeffective-'existential-veracity-and-entailment-of $\sim$ relative-unreflexivity/relative-reflexivity', whether $\mathrm{real} / \mathrm{genuine}$ or unreal/manipulated/confused, ontological implications cannot then be 
effectively derived). The manifest reality of human ontologisation/ontologicalveracity/aestheticisation-towards-ontology is thus one that is ever sub-ontological-<as-to-thelimitation-of-human-subpotency-in-its-reifying-and-empowering-reflexivity-of-the-fullpotency-of-existence's $\sim$ sublimating-nascence $>\quad$ as $\quad$ of $\quad$ human-subpotencyaporia/undecidability/dilemma/ought-indeterminacy/deficiency/limitation/constraint—imbued'notional firstnaturedness-formativeness-<as-to-eventualising-inkling-drive or seedingmisprising $>$ temporal-to-intemporal-dispositions-<so-construed-as-from-perspectiveontological-normalcy/postconvergence>'-existentialism-form-factor. This is reflected inherently in the fact that given human limited-mentation-capacity-as-subjecting 'educedunlimitedness/existence-sublimating nascence' to-limitedness/hmman-subpotency, human aestheticisation is ever always reactualising/recomposuring towards a fully ontologising reproducibility—mathesis/motif/thrownness-disposition,--as-reproducibility-of-aestheticisation as of supereregatory $\sim$ acuity/perspicacity/astuteness/edginess/incisiveness-ofapriorising/axiomatising/referencing/intelligibilitysettingup/measuringinstrumenting -forconceptualisation; that is, human aestheticisation as from prospective originariness-parrhesia,-as-spontaneity-of-aestheticisation instigation develops by recomposuring as from 'perceptive motif-manifest aestheticisation as of human conscious-able imagery' to 'mere-tracial-andsymbolisation-manifest aestheticisation as of human conscious-able works-of-art/artistry' and then to 'signification-as-of-existential-reality-manifest aestheticisation as of human consciousable intermediating ascriptivity' with the latter achieving the given registryworldview/dimension reproducibility — mathesis/motif/thrownness-disposition,-asreproducibility-of-aestheticisation ontologisation/ontological-veracity/aestheticisation-towardsontology. Basically, human aestheticisation, in reflection of human limited-mentationcapacity-as-subjecting 'educed-unlimitedness/existence-sublimating nascence' tolimitedness/human-subpotency and human limited-mentation-capacity-deepening-as- 
subjecting limitedness/human-subpotency-to-'educed-unlimitedness/existence-sublimating nascence' 3 possibility, ever always involves a 'human disposition in portraying/reflecting/construing existence/ontological-veracity' as of '7 presencingabsolutising-identitive-constitutedness ${ }^{14}$ finitism of aestheticisation' and as of 'humansubpotency-aporia/undecidability/dilemma/ought-

indeterminacy/deficiency/limitation/constraint $\quad$ nonpresencing- $<$ perspective-ontologicalnormalcy/postconvergence $>$ /transcending infinitism of aestheticisation possibilities' which then define together the aestheticisation specificity of the culturally cumulated outcomes/outfits/shells — construed-historially-as-of-the-specifically-aestheticisedincrusting/plating/coating,-so-reflected-as-institutional-manifestations explaining why human institutional constructs like language, cultural practices, etc. are inherently of their given cultural specificness. In this regards, the social-setup in its furtherance of human aestheticisation towards human ontologising of ${ }^{56}$ meaningfulness-and-teleology 99 is ever always drawn between '7 presencing —absolutising-identitive-constitutedness ${ }^{14}$ finitism of aestheticisation' rather in apriorising/axiomatising/referencing-\{of-'prospectively_implicited_attendant-ontologicalcontiguity ' educedexistentialising/contexalising/textising_intelligibility/epistemicity/reflexivity-contiguity$<$ imbued-notional cogency $>$ ' $\}$-constitutedness ${ }^{4}$-in-preconverging-entailment as of its reproducibility—mathesis/motif/thrownness-disposition,--as-reproducibility-of-aestheticisation and 'human-subpotency-aporia/undecidability/dilemma/oughtindeterminacy/deficiency/limitation/constraint nonpresencing- $<$ perspective-ontologicalnormalcy/postconvergence $>$ /transcending infinitism of aestheticisation possibilities' rather in apriorising/axiomatising/referencing-\{of-'prospectively implieited_attendant-ontologicalcontiguity ' educedexistentialising/contextualising/textualising_intelligibility/epistemicity/reflexivity_contiguity- 
<imbued-notional cogency>' \}-conflatedness ${ }^{13}$-in-\{preconverging-disentailment-by\} postconverging-ntailment as of instigative originariness-parrhesia,-as-spontaneity-ofaestheticisation; explaining the preconverging/postconverging-dementative/structural/paradigmatic nature of human Being-development/ontological-frameworkexpansion-as-to-depth-of-ontologising-development-as-infrastructure-of- meaningfulnessand-teleology , institutional-development-as-to-social-function-development and livingdevelopment-as-to-personality-development psychologismic epistemic-acutisationdifficulty< <or, residualising \{decompulsing\} delinearity for-cogency> magnitudes $\{$ ofexperientiality/experiment\} as to the respective possibility bound by either a non-transcendental $<$ amplituding/formative $>$ wooden-language-〈imbued - averaging-of-thought- $<$ as-toleveling/ressentiment/closed-construct-of- meaningfulness-and-teleology -as-of'nondescript/ignorable-void '-with-regards-to-prospective-apriorising-implications $>>$ and a transcendental opened-construct-of- ${ }^{5}$ meaningfulness-and-teleology 9 with regards to reference-of-thought-level

supererogatory acuity/perspicacity/astuteness/edginess/incisiveness-ofapriorising/axiomatising/referencing/intelligibilitysettingup/measuringinstrumenting -forconceptualisation. The prospect for prospective transcendence-andsublimity/sublimation/supererogatory de-mentativity is thus in-many-ways re-originary_asunenframed/re-ontologising/unbeholdening/outlier-conceptualisation-_iimbuedpostconverging/dialectical-thinking -'projective-insights'/'epistemic-projection-inconflatedness '-of-notional deprocrypticism-prospective-sublimation $\rangle^{\circ}$ to any given socialsetup by the mere token that it more critically construes of ontologisation/ontologicalveracity/aestheticisation-towards-ontology as being within the framework of its value-construct '7 presencing —absolutising-identitive-constitutedness ${ }^{14}$ finitism of aestheticisation' and so in incoherence with outlying implied 'human-subpotency-aporia/undecidability/dilemma/ought- 
indeterminacy/deficiency/limitation/constraint nonpresencing- $<$ perspective-ontologicalnormalcy/postconvergence $>$ /transcending infinitism of aestheticisation possibilities' as to existence-potency $^{39} \sim$ sublimating-nascence,-disclosed-from-prospective-epistemic-digression; explaining why transcendence-and-sublimity/sublimation/supererogatory de-mentativity cannot be construed as of incrementalism-in-relative-ontological-incompleteness ${ }^{8}$ enframed/disontologising conceptualisation of ' 7 presencing-absolutising-identitiveconstitutedness ${ }^{14}$ finitism of aestheticisation' but rather as ${ }^{55}$ maximalising-recomposuring-forrelative-ontological-completeness ${ }^{87}$ - unenframed/re-ontologising $\sim$ conceptualisation of 'human-subpotency-aporia/undecidability/dilemma/oughtindeterminacy/deficiency/limitation/constraint nonpresencing-<perspective-ontologicalnormalcy/postconvergence $>$ /transcending infinitism of aestheticisation possibilities'. Basically, 'human-subpotency-aporia/undecidability/dilemma/ought-

indeterminacy/deficiency/limitation/constraint $\quad$ nonpresencing- $<$ perspective-ontologicalnormalcy/postconvergence $>$ /transcending infinitism of aestheticisation possibilities', as to existence-potency ${ }^{39} \sim$ sublimating-nascence,-disclosed-from-prospective-epistemic-digression value-ricochetting/transvaluation — as-to-prospective-relative-ontological-completeness human-and-social-expectations/anticipations - metaphoricity ${ }^{57}$-aspreconverging/postconverging-rede-mentating/restructuring/reparadigming-psychologism<as-from-perspective-ontological-normalcy/postconvergence $>$ necessarily imply the prospective devaluing of the ${ }^{6}$ presencing — absolutising-identitive-constitutedness ${ }^{14}$ finitism of aestheticisation' implied hierarchisation-of-values. However, the reality as of human limitedmentation-capacity—as-subjecting 'educed-unlimitedness/existence-sublimating nascence' limitednesshman-subper is that however a seemingly ${ }^{103}$ universal disposition for ontologisation/ontological-veracity/aestheticisation-towards-ontology furtherance, such a disposition is not open-ended as reflected at any destructuring-threshold-〈uninstitutionalised- 
threshold /presublimating-desublimating-decisionality $>$ of-ontological-performance ${ }^{72}$ $<$ including-virtue-as-ontology $>/$ morality/ethics/justice/etc. as of prior reproducibilitymathesis/motif/thrownness-disposition,-as-reproducibility-of-aestheticisation, in the sense that the human investment as of " ${ }^{7}$ presencing — absolutising-identitive-constitutedness ${ }^{14}$ finitism of aestheticisation' in prior reproducibility-mathesis/motif/thrownness-disposition,--asreproducibility-of-aestheticisation implies that it can be rather inclined to reject/ignore prospective 'human-subpotency-aporia/undecidability/dilemma/oughtindeterminacy/deficiency/limitation/constraint $\quad$ nonpresencing-<perspective-ontologicalnormalcy/postconvergence $>$ /transcending infinitism of aestheticisation possibilities' of ontologisation/ontological-veracity/aestheticisation-towards-ontology, and so where this discrepancy is sophistically perceived as advantageous to the social-vestedness/normativity$<$ discretely-implied-functionalism $>$ of social-stake-contention-or-confliction (as manifested with sophistic/pedantic mediums, shamans, witchdoctors, ancient-sophists, medievalscholasticism pedants and modern-day pedantising/muddling/formulaic-hollowing-out-insubontologisation/subpotentiation-〈blurring/undermining-of-prospective-totalising-entailing,-

\section{as-to-entailing-<amplituding/formative-epistemicity $>$ totalising in-relative-ontological-}

completeness \). In this regards, the value-ricochetting/transvaluation-as-to-prospectiverelative-ontological-completeness human-and-social-expectations/anticipationsmetaphoricity ${ }^{57}$-as-preconverging/postconverging-rede-

mentating/restructuring/reparadigming-psychologism-<as-from-perspective-ontologicalnormalcy/postconvergence $>$ of a social-setup epistemic-ricochetting/transepistemicity hierarchisation-of-values (rather in <amplituding/formative-epistemicity>totalising $\sim$ selfreferencing-syncretising/circularity/interiorising/akrasiatic-drag ${ }^{34}$ ) is what provides the prospect for deflating/undermining its given vices-and-impediments ${ }^{105}$ as from prospective transcendence-and-sublimity/sublimation/supererogatory - de-mentativity. The fact that all 
registry-worldviews/dimensions are sub-ontological-<as-to-the-limitation-of-humansubpotency-in-its-reifying-and-empowering-reflexivity-of-the-full-potency-of-

existence's $\sim$ sublimating-nascence $>$ as of their ' ${ }^{7}$ presencing-absolutising-identitiveconstitutedness ${ }^{14}$ finitism of aestheticisation' with respect to prospective 'human-subpotencyaporia/undecidability/dilemma/ought-indeterminacy/deficiency/limitation/constraint

nonpresencing- $<$ perspective--ontological-normalcy/postconvergence $>/$ transcending infinitism of aestheticisation possibilities' (so-reflected in the transcendental advancing of ontologisation/ontological-veracity/aestheticisation-towards-ontology as of universalising-

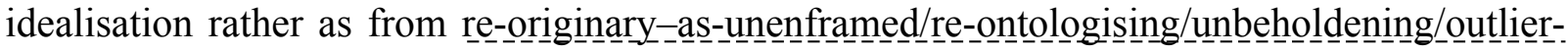
conceptualisation_-_imbued-postconverging/dialectical-thinking -'projectiveinsights'/“epistemic-projection-in-conflatedness ' 'of-notional deprocrypticism-prospectivesublimation> Socratic-philosophers over the ancient mythologies and cultism of the technically more potent Ancient Egyptians and Persians, etc., the transcendental advancing of ontologisation/ontological-veracity/aestheticisation-towards-ontology by re-_originary_-as-

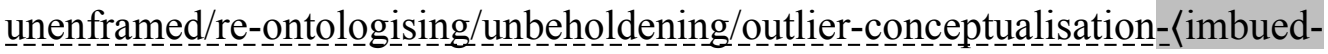
postconverging/dialectical-thinking -'projective-insights'/'epistemic-projection-inconflatedness '-of-notional deprocrypticism-prospective-sublimation ${ }^{\prime 0}$ budding-positivists over medieval-scholasticism pedantising/muddling/formulaic-hollowing-out-insubontologisation/subpotentiation-〈blurring/undermining-of-prospective-totalising-entailing,as-to-entailing-<amplituding/formative-epistemicity $>$ totalising $\sim$ in-relative-ontologicalcompleteness > notwithstanding its medieval institutional hegemony, likewise modern-day manifestation of disparateness-of-conceptualisation-<unforegrounding-disentailment,-failingprospectively-to-reflect-'immanent relative-unreflexivity/relative-reflexivity - ontologicalcontiguity pedantising/muddling/formulaic-hollowing-out—insubontologisation/subpotentiation-〈blurring/undermining-of-prospective-totalising-entailing,- 
as-to-entailing-<amplituding/formative-epistemicity $>$ totalising in-relative-ontological-

completeness > involving institutional-being-and-craft speaks of our uninstitutionalisedthreshold ${ }^{102}$ requiring prospective notional ${ }^{18}$ deprocrypticism transcendental advancing of ontologisation/ontological-veracity/aestheticisation-towards-ontology 'apriorising/axiomatising/referencing- \{of-'prespectively implicited_attendant-ontologicalcontiguity ' educed-

existentialising/contextualising/textualising_ 'intelligibility/epistemicity/reflexivity-contiguity<imbued-notional cogency $>$ ' $\}$-conflatedness ${ }^{13}$-in-\{preconverging-disentailment by\} pestconverging entailment of originariness-parrhesia,--as-spontaneity-of-aestheticisation and reproducibility—mathesis/motif/thrownness-disposition,--as-reproducibility-of-aestheticisation in organic coherence, as to overall reifying-and-empowering-reflexivity-of-ecstatic-existenceas-panintelligibility/panreflexivity ${ }^{33}-\langle$ existentially-imbued-and-educing-<位istemicthermeneutically/textually/reprojectingly/supererogatingly/zeroingly/re-acutingly,\{decompulsing\} delinearity $\sim$ for-cogency $\geq$-epistemic-perspective-of-projective/reprojectiveaestheticising-re-motif-and-re-apriorising/re-axiomatising/re-referencing $\sim$ conceptualisation,as-herein-specifically-relevant to human-subpotency) knowledge-reification $\sim$ gesturing-andaccounting - of-epistemic-phenomenalism- $<$ in-

prospective_psychologismic apriorising/axiomatising/referencing-\{of-‘prospectively_ implicited_attendant-ontological-contiguity ' educedexistentialising/contextualising/textualising_'intelligibility/epistemicity/reflexivity-contiguity$<$ imbued-notional cogency $\left.>^{\prime} \quad\right\}$-conflatedness -in-\{preconverging-disentailment by\} postconverging entailment $>$ maximalising) points out that all registry-worldviews/dimensions tend to assume a sub-ontological-<as-to-the-limitation-of-human-subpotency-in-its-reifyingand-empowering-reflexivity-of-the-full-potency-of-existence's $\sim$ sublimating-nascence> equilibrium at their prospective destructuring-threshold-〈uninstitutionalised- 
threshold /presublimating-desublimating-decisionality $>$ of-ontological-performance ${ }^{72}$ $<$ including-virtue-as-ontology $>$ /morality/ethics/justice/etc. with regards to their given reproducibility—mathesis/motif/thrownness-disposition,-as-reproducibility-ofaestheticisation; with the underpinning-suprasocial-construct, $<$ amplituding/formative $>$ wooden-language-〈imbued - averaging-of-thought- $<$ as-toleveling/ressentiment/closed-construct-of- meaningfulness-and-teleology -as-of'nondescript/ignorable-void '-with-regards-to-prospective-apriorising-implications $>>\quad$ and sophistry in their " ${ }^{7}$ presencing-absolutising-identitive-constitutedness ${ }^{14}$ finitism of aestheticisation' dynamics seemingly substituting in effect for prospective ontologisation/ontological-veracity/aestheticisation-towards-ontology as of 'humansubpotency-aporia/undecidability/dilemma/ought-

indeterminacy/deficiency/limitation/constraint $\quad$ nonpresencing-<perspective-ontologicalnormalcy/postconvergence $>$ /transcending infinitism of aestheticisation possibilities'. The prospective ${ }^{6}$ nonpresencing- $<$ perspective-ontological-normalcy/postconvergence $>$ reflection of <amplituding/formative-epistemicity>causality $\sim$ as-to-projective-totalitative-implicationsof-prospective- nonpresencing,-for-explicating relative-unreflexivity/relative-reflexivity ontological-contiguity of relative-ontological-incompleteness $8 /$ relative-ontologicalcompleteness ${ }^{87}$-〈sublimating $\sim$ referencing/registering/decisioning,-as-self-becoming/selfconflatedness /formative-supererogating-<projective/reprojective-aestheticising-re-motifand-re-apriorising/re-axiomatising/re-referencing,-in-perspective-ontologicalnormalcy/postconvergence $>>$ in reflecting holographically-<conjugatively-and-transfusively $>$ the relative-unreflexivity/relative-reflexivity - ontological-contiguity of-the-humaninstitutionalisation-process critically and insightfully highlights, in reflection of inherent human-subpotency-aporia/undecidability/dilemma/oughtindeterminacy/deficiency/limitation/constraint—imbued-'notional firstnaturedness- 
formativeness-<as-to-eventualising-inkling-drive-or-seeding-misprising $>$ temporal-tointemporal-dispositions-<so-construed-as-from-perspective-ontologicalnormalcy/postconvergence>'-existentialism-form-factor, that 'all registryworldviews/dimensions are ever always at the crossroads of knowledge-reification $\sim$ gesturingand-accounting - of-epistemic-phenomenalism- $<$ inprospective_psychologismic apriorising/axiomatising/referencing-\{of-'prospectively implicited_attendant-ontological-contiguity ' educedexistentialising/contextualising/textualising_'intelligibility/epistemicity/reflexivity_contiguity<imbued-notional cogency $\left.>^{\prime}\right\}$-conflatedness -in-\{preconverging disentailment by\} postconverging-entailment> and sophistry as the latter is facilitated by underlying social $<$ amplituding/formative $>$ wooden-language-_imbued - averaging-of-thought-<as-toleveling/ressentiment/closed-construct-of- meaningfulness-and-teleology -as-of'nondescript/ignorable-void '-with-regards-to-prospective-apriorising-implications $>>$ as of the implications of human limited-mentation-capacity-as-subjecting 'educedunlimitedness/existence-sublimating nascence' to-limitedness/human-subpotency'; and so, as to the confluence of 'prospective parrhesiastic instigative intemporal ontological-faith-notionor-ontological-fideism —imbued-underdetermination-of-motif-andapriorising/axiomatising/referencing-as-so-being-as-of-existential-reality (inherently so as all prospective knowledge is inherently initially underdetermined thus depended at its instigation on ontological-faith-notion-or-ontological-fideism - imbued-underdetermination-of-motif-andapriorising/axiomatising/referencing-as-so-being-as-of-existential-reality, and is only prospectively validated as of $<$ amplituding/formative-epistemicity $>$ causality $\sim$ as-to-projectivetotalitative-implications-of-prospective- nonpresencing,-for-explicating relativeunreflexivity/relative-reflexivity ontological-contiguity in reflection of the-transcendentalsignifier as existence-potency ${ }^{39} \sim$ sublimating-nascence,-disclosed-from-prospective-epistemic- 
digression) parrhesiastic seeding-promise of prospective knowledge-reification $\sim$ gesturing-andaccounting - of-epistemic-phenomenalism- $<$ in-

prospective_psychologismic apriorising/axiomatising/referencing-\{of-'prospectively implicited_attendant-ontological-contiguity ' reducedexistentialising/contextualising/textualising_ 'intelligibility/epistemicity/reflexivity-contiguity<imbued-notional cogency >' \}-conflatedness -in-\{preconverging-disentailment by\} postconverging-entailment> reproducibility-mathesis/motif/thrownness-disposition,--asreproducibility-of-aestheticisation' as of reasoning-through/messianic-reasoning induced constructiveness-of-ontological-performance ${ }^{72}-<$ including-virtue-as- $^{-}$ ontology $>$ /morality/ethics/justice/etc. and 'temporal/sophistic-as-ontologicallyflawed/ontological-bad-faith/inauthenticity ${ }^{64}$ reproducibility—mathesis/motif/thrownnessdisposition,-as-reproducibility-of-aestheticisation seeding-misprising as mere-form of the prospective knowledge-reification $\sim$ gesturing-and-accounting-of-epistemic-phenomenalism<in-prospective_psychologismic $\sim$ apriorising/axiomatising/referencing-\{of-'prospectively_ implicited_attendant-ontological-contiguity ' educedexistentialising/contextualising/textualising_ 'intelligibility/epistemicity/reflexivity-contiguity<imbued-notional cogency >' \}-conflatedness in \{preconverging disentailment by\} postconverging-entailment $>\quad$ reproducibility-mathesis/motif/thrownness-disposition,--asreproducibility-of-aestheticisation' as of reasoning-from-results/afterthought induced destructuring-threshold-〈uninstitutionalised-threshold /presublimating-desublimatingdecisionality $>$ of-ontological-performance ${ }^{2}$-<including-virtue-as-ontology $>$ This preconverging/postconverging-de-mentatively/structurally/paradigmatically defined existential-<disontologising/re-ontologising aporeticism $>$ framework of knowledgereification $\sim$ gesturing-and-accounting — of-epistemic-phenomenalism- $<$ inprospective_psychologismic apriorising/axiomatising/referencing-\{of-'prospectively 
implicited_attendant-ontological-contiguity ' reduced-

existentialising/contextualising/textualising_'intelligibility/epistemicity/reflexivity_contiguity<imbued-notional cogency >' \}-conflatedness -in-\{preconverging disentailment by\}

postconverging-entailment $>$ of any given registry-worldview/dimension is known as its ontological-good-faith/authenticity ${ }^{60} \sim$ postconverging-de-mentating/structuring/paradigming and is intimately associated with its given shiftiness-of-the-Self ${ }^{1}$. The ontological-goodfaith/authenticity ${ }^{\circ} \sim$ postconverging-de-mentating/structuring/paradigming ${ }^{70}$ speaks of 'agiven-developed-level-of-Will/Spirit/Drive in dispensing-with-immediacy-for-relativeontological-completeness $^{87}$-by-reification/contemplative-distension ${ }^{27}$ (as of human selfsurpassing — existentialism-form-factor,-in-overcoming-'notional collateralising-beholdeningprotohumanity'-to-'attain-sublimating-humanity'-as-to-existence-potency sublimatingnascence,-disclosed-from-prospective-epistemic-digression to supersede human temporality ${ }^{8} /$ shortness <amplituding/formative> wooden-language-〈imbued-averaging-ofthought-<as-to-leveling/ressentiment/closed-construct-of- meaningfulness-and-teleology -asof-'nondescript/ignorable-void '-with-regards-to-prospective-apriorising-implications $>$ ))' that then allows for the corresponding 'reproducibility—mathesis/motif/thrownness-disposition,--asreproducibility-of-aestheticisation reference-of-thought-level supererogatory acuity/perspicacity/astuteness/edginess/incisiveness-ofapriorising/axiomatising/referencing/intelligibilitysettingup/measuringinstrumenting -forconceptualisation for $\quad{ }^{56}$ meaningfulness-and-teleology aposteriorising/logicising/deriving/intelligising/measuring'. This is fundamentally what explains why the state of recurrent-utter-uninstitutionalisation cannot all of a sudden start reasoning as of base-institutionalisation, and the latter as of ${ }^{103}$ universalisation, the latter as of positivism/rational-empiricism and prospectively the latter as of deprocrypticism. The overall point here is that it is the ontological-good-faith/authenticity $\sim$ postconverging-de- 
mentating/structuring/paradigming as of parrhesiastic-aestheticisation that 'invents/creates' the prospective registry-worldview's/dimension's reproducibility—mathesis/motif/thrownnessdisposition,-as-reproducibility-of-aestheticisation, and carries the 'intemporal parrhesiastic seeding-promise dimensionality-of-sublimating

\section{<<amplituding/formative>supererogatory $\sim$ de-mentativeness/epistemic-growth-or-}

\section{conflatedness /transvaluative-rationalising/transepistemicity/anamnestic-residuality/spirit-}

drivenness-equalisation) of the registry-worldview/dimension ${ }^{56}$ meaningfulness-andteleology beyond just its mechanical reproducibility-mathesis/motif/thrownnessdisposition,-as-reproducibility-of-aestheticisation for the possibility of further prospective parrhesiastic instigation as from ontological-faith-notion-or-ontological-fideism - imbuedunderdetermination-of-motif-and-apriorising/axiomatising/referencing-as-so-being-as-ofexistential-reality'. But then human temporality $8 /$ shortness loses sight of this 'parrhesiastic instigative intemporal ontological-faith-notion-or-ontological-fideism -imbuedunderdetermination-of-motif-and-apriorising/axiomatising/referencing-as-so-being-as-ofexistential-reality parrhesiastic seeding-promise of prospective knowledgereification $\sim$ gesturing-and-accounting — of-epistemic-phenomenalism- $<$ inprospective_psychologismic apriorising/axiomatising/referencing-\{of-'prospectively implicited_attendant-ontological-contiguity ' educedexistentialising/contextualising/textualising_'intelligibility/epistemicity/reflexivity_contiguity$<$ imbued-notional cogency>> $\}$-conflatedness -in-\{preconverging-disentailment by\} postconverging entailment>' and assumes at the given registry-worldview/dimension destructuring-threshold-〈uninstitutionalised-threshold /presublimating-desublimatingdecisionality $>\sim$ of-ontological-performance ${ }^{72}$ - $<$ including-virtue-asontology $>$ /morality/ethics/justice/etc. an 'absolutising disposition as of temporal/sophistic-asontologically-flawed/ontological-bad-faith/inauthenticity reproducibility- 
mathesis/motif/thrownness-disposition,-as-reproducibility-of-aestheticisation seedingmisprising as mere-form of reproducibility-mathesis/motif/thrownness-disposition,--asreproducibility-of-aestheticisation reflected in the absolutising of normativities, conventions, practices, etc.' without or a poor sense of the 'intemporal parrhesiastic seeding-promise dimensionality-of-sublimating $25<<$ amplituding/formative $>$ supererogatory $\sim$ de-

\section{mentativeness/epistemic-growth-or-conflatedness /transvaluative-}

rationalising/transepistemicity/anamnestic-residuality/spirit-drivenness-equalisation〉 of the registry-worldview/dimension ${ }^{56}$ meaningfulness-and-teleology ${ }^{9}$ beyond just its reproducibility—-mathesis/motif/thrownness-disposition,-as-reproducibility-of-

aestheticisation' (that is, as the shiftiness-of-the-Self loses sight of 'Will/Spirit/Drive parrhesiastic instigative dispensing-with-immediacy-for-relative-ontological-completeness ${ }^{87}$ by-reification/contemplative-distension ${ }^{27}$ ). Such an 'absolutising disposition with the registryworldview/dimension mere-form of reproducibility—mathesis/motif/thrownness-disposition,-as-reproducibility-of-aestheticisation' is what underlies disparateness-of-conceptualisation$<$ unforegrounding-disentailment,-failing-prospectively-to-reflect- 'immanent $\sim$ relative-

threflexivity/relative-reflexivity ontological-contiguity ' $>$ at a registry-worldview/dimension destructuring-threshold-〈uninstitutionalised-threshold /presublimating-desublimating-

decisionality $>$ of-ontological-performance ${ }^{22}-<$ including-virtue-as-

ontology $>$ /morality/ethics/justice/etc. 'wherein normativities, conventions, practices, etc. as secondnatured institutionalised constructs assume absolute determinism that flawly override any parrhesiastic $<$ amplituding/formative-epistemicity $>$-totalising $\sim$ renewing-realisation/reperception/re-thought of ontological-veracity', and explains the Sophists-ideal-type-orindividuation non-universalising inclination on the basis that that social practice is absolutely deterministic of ${ }^{5}$ meaningfulness-and-teleology ${ }^{9}$ and the medieval-scholasticism-pedantsideal-type-or-individuation non-positivism/medievalism dogma on the basis that that social 
practice is absolutely deterministic of ${ }^{56}$ meaningfulness-and-teleology ${ }^{9}$, as well as modern-day overall pedantising/muddling/formulaic-hollowing-out—in-subontologisation/subpotentiation〈blurring/undermining-of-prospective-totalising-entailing,-as-to-entailing-

<amplituding/formative-epistemicity>totalising in-relative-ontological-completeness $>$ as of institutional-being-and-craft normativities, conventions, practices, etc. in " ${ }^{80}$ procrypticism-ordisjointedness-as-of- ${ }^{8}$ reference-of-thought reproducibility - mathesis/motif/thrownnessdisposition,-as-reproducibility-of-aestheticisation as of its lack of prospective deprocrypticism-or-preempting-disjointedness-as-of- ${ }^{83}$ reference-of-thought foregrounding_entailment- $<$ in-succession-of-profound-supererogation $>>-\langle$ postconvergingnarrowing-down $\sim$ sublimation-as-to-'existence - as-sublimating-withdrawal/unenframing/reontologising,-elicited-from-prospective-profound-supererogation '-in-reflecting‘immanent relative-unreflexivity/relative-reflexivity ontological-contiguity ' ';-as-operativenotional deprocrypticism $\rangle$

supererenaity/perspicacity/astuteness/edginess/incisiveness-ofapriorising/axiomatising/referencing/intelligibilitysettingup/measuringinstrumenting -forconceptualisation' on the basis that such social practices are absolutely deterministic of meaningfulness-and-teleology ${ }^{9}$. In other words, adherence to prospective knowledgereification $\sim$ gesturing-and-accounting — of-epistemic-phenomenalism- $<$ inprospective_psychologismic apriorising/axiomatising/referencing-\{of-'prospectively implicited_antentontogical-contiguity ' reducedexistentialising/contextualising/textualising_intelligibility/epistemicity/reflexivity_contiguity<imbued-notional cogency >' $\}$-conflatedness -in-\{preconverging-disentailment by\} postconverging entailment $>$ as of human temporality $/$ /shortness arises as of the existentially-disontologising/re-ontologising aporeticism $>$ constraining untenability of positiveopportunism - of-social-functioning-and-accordance ${ }^{75} \quad$ induced $\quad$ reproducibility- 
mathesis/motif/thrownness-disposition,-as-reproducibility-of-aestheticisation but doesn't necessarily elicits intemporal parrhesiastic seeding-promise dimensionality-of-sublimating 〈<amplituding/formative>supererogatory $\sim$ de-mentativeness/epistemic-growth-or-

conflatedness /transvaluative-rationalising/transepistemicity/anamnestic-residuality/spiritdrivenness-equalisation) for prospective knowledge-reification $\sim$ gesturing-and-accounting —ofepistemic-phenomenalism-<inprospective_psychologismic apriorising/axiomatising/referencing-\{of-'prospectively_ implicited_attendant-ontological-contiguity ' educedexistentialising/contextualising/textualising_'intelligibility/epistemicity/reflexivity-contiguity<imbued-notional cogency >' \}-conflatedness in \{preconverging disentailment by\} postconverging-ntailment> as of a 'weak social mental-reflex that any parrhesiastic $<$ amplituding/formative-epistemicity $>$-totalising $\sim$ renewing-realisation/re-perception/rethought of ontological-veracity will put in question prior reproducibilitymathesis/motif/thrownness-disposition,-as-reproducibility-of-aestheticisation as can be reflected in normativities, conventions, practices, etc.', and this is what explains the prevalence of disparateness-of-conceptualisation-<unforegrounding-disentailment,-failing-prospectivelyto-reflect-'immanent $\sim$ relative-unreflexivity/relative-reflexivity - ontological-contiguity at uninstitutionalised-threshold ${ }^{102}$ as 'mere-form of reproducibility—mathesis/motif/thrownnessdisposition,-as-reproducibility-of-aestheticisation' temporally takes pride-of-place and so unconstrained to prospective existence-potency ${ }^{39} \sim$ sublimating-nascence,-disclosed-fromprospective-epistemic-digression sublimating-validation/desublimating-invalidation implications 'as of parrhesiastic <amplituding/formative-epistemicity>-totalising $\sim$ renewingrealisation/re-perception/re-thought of ontological-veracity' thus providing the framework for ontological-bad-faith/inauthenticity ${ }^{64}$ and sophistry hanging on unto secondnatured normativities, conventions, practices, etc. thus rendering prospective transcendence-and- 
sublimity/sublimation/supererogatory-de-mentativity impotent. Thus the 'possibility for prospective human transcendence-and-sublimity/sublimation/supereregatery $\sim$ de-mentativity is ever always a renewed ontological-good-faith/authenticity $\sim$ postconverging-dementating/structuring/paradigming ${ }^{7}$, that as of its reasoning-through/messianic-reasoning can overcome such a <amplituding/formative > wooden-language-〈imbued-averaging-of-thought$<$ as-to-leveling/ressentiment/closed-construct-of- meaningfulness-and-teleology -as-of'nondescript/ignorable-void '-with-regards-to-prospective-apriorising-implications $>$ >, and so counterintuitively to any given registry-worldview/dimension notion/sense of transcendenceand-sublimity/sublimation/supererogatory-de-mentativity as rather occuring along its already secondnatured established reproducibility—mathesis/motif/thrownness-disposition,--asreproducibility-of-aestheticisation normativities, conventions, practices, etc.; and this very much explains why the <cumulating/recomposuring attendant-ontological-contiguity $>$-successive registry-worldviews/dimensions are successive parrhesiastic instigation of renewed reproducibility—mathesis/motif/thrownness-disposition,-as-reproducibility-of-

aestheticisation. Further the 'renewed ontological-good-faith/authenticity ${ }^{69}$ postconverging-dementating/structuring/paradigming ${ }^{0}$ ' in undermining prior " ${ }^{8}$ reference-of-thought-level and thus reference-of-thought- ${ }^{8}$ devolving-level of disparateness-of-conceptualisation$<$ unforegrounding-disentailment,-failing-prospectively-to-reflect-‘immanent relativeunreflexivity/relative-reflexivity ontological-contiguity '>' implies ‘ foregrounding__entailment-<in-succession-of-profound-supererogation $>$ 〈postconverging-narrowing-down $\sim$ sublimation-as-to-'existence-as-sublimatingwithdrawal/unenframing/re-ontologising,-elicited-from-prospective-profoundsupererogation '-in-reflecting-'immanent relative-unreflexivity/relative-reflexivity ontological-contiguity ';-as-operative-notional deprocrypticism> as to existencepotency ${ }^{32} \sim$ sublimating-nascence,-disclosed-from-prospective-epistemic-digression, and not 
'unification on the basis of human-subpotency elicited contrasting-and-comparison' as the latter just leads to a complexification as of disparateness-of-conceptualisation-<unforegroundingdisentailment,-failing-prospectively-to-reflect-'immanent $\sim$ relative-unreflexivity/relativereflexivity - ontological-contiguity '> along the-very-same reproducibilitymathesis/motif/thrownness-disposition,-as-reproducibility-of-aestheticisation as of an ontologically-flawed human-subpotency dialogical-equivalence- $<$ as-topsychologismic apriorising/axiomatising/referencing-\{of-'prospectively implicited_attendant-ontological-contiguity ' educedexistentialising/contextualising/textualising_'intelligibility/epistemicity/reflexivity-contiguity<imbued-notional cogency >' \}-conflatedness -in-\{preconverging-disentailment by\} postconverging entailment,-in-self-becoming/self-conflatedness /formative-supererogating> that 'allows the mortals that we are to average our thoughts' rather than existencepotency ${ }^{32} \sim$ sublimating-nascence,-disclosed-from-prospective-epistemic-digression imposing ontological-veracity as of prospective <amplituding/formative-epistemicity $>$ causality $\sim$ as-toprojective-totalitative-implications-of-prospective- nonpresencing,-for-explicating relativeunreflexivity/relative-reflexivity ontological-contiguity. This explains why the ${ }^{3}$ universalising-idealisation of Socratic-philosophers, budding-positivists thought and herein as well suprastructuralism/postmodern-thought are all characterised in their knowledgereification $\sim$ gesturing-and-accounting — of-epistemic-phenomenalism- $<$ inprospective_psychologismic apriorising/axiomatising/referencing-\{of-'prospectively implicited_attendant-ontological-contiguity ' educedexistentialising/contextualising/textualising_intelligibility/epistemicity/reflexivity-contiguity<imbued-notional cogency>' $\}$-conflatedness in \{preconverging disentailment by\} postconverging entailment $>$ not by an articulation along the prior established reproducibilitymathesis/motif/thrownness-disposition,-as-reproducibility-of-aestheticisation but rather 
prospective existence-potency ${ }^{39} \sim$ sublimating-nascence,-disclosed-from-prospective-epistemicdigression constraining parrhesiastic aestheticisation of prospective reproducibilitymathesis/motif/thrownness-disposition,-as-reproducibility-of-aestheticisation, that in all three cases looks down upon the notion of human-subpotency sophistic/pedantic pretence of foregrounding_entailment- $<$ in-succession-of-profound-supererogation $>_{-}-\langle$postconverging narrowing-down $\sim$ sublimation-as-to-'existence - as-sublimating-withdrawal/unenframing/reontologising,-elicited-from-prospective-profound-supererogation ' '-in-reflecting‘immanent relative-unreflexivity/relative-reflexivity ontological-contiguity ';-as-operativenotional deprocrypticism $\rangle$ that is no more than complexification as of disparateness-ofconceptualisation-<unforegrounding-disentailment,-failing-prospectively-to-reflect‘immanent relative-unreflexivity/relative-reflexivity - ontological-contiguity '>. Critically as of such parrhesiastic instigation of prospective relative-ontological-completeness ${ }^{87}$ the prior reproducibility—mathesis/motif/thrownness-disposition,--as-reproducibility-of-aestheticisation 'sycophantic-sophistic pretences of candour' are edgily/incisively trampled-upon parrhesiastically as the Socratic-philosophers go out of their way to highlight the intellectual discredit of the sophists, as budding-positivists go out of their way to highlight medievalscholasticism dogma, and likewise suprastructuralism/postmodern-thought is beyond just our positivism- ${ }^{80}$ procrypticism reproducibility—mathesis/motif/thrownness-disposition,--asreproducibility-of-aestheticisation and as reflected herein with the parrhesiastic highlighting of institutional-being-and-craft and pedantising/muddling/formulaic-hollowing-out-insubontologisation/subpotentiation-〈blurring/undermining-of-prospective-totalising-entailing,as-to-entailing-<amplituding/formative-epistemicity $>$ totalising in-relative-ontologicalcompleteness $>$ as of positivism- ${ }^{8}$ procrypticism 'disjointedness-as-of- ${ }^{2}$ reference-of-thought reproducibility—mathesis/motif/thrownness-disposition,--as-reproducibility-of-aestheticisation as of its lack of prospective ${ }^{18}$ deprocrypticism-or-preempting-disjointedness-as-of- 
reference-of-thought

foregrounding_entailment- $<$ in-succession-of-profound-

supererogation $>$-〈postconverging-narrowing-down $\sim$ sublimation-as-to-'existence-as-

sublimating-withdrawal/unenframing/re-ontologising,-elicited-from-prospective-profound-

supererogation '-in-reflecting-'immanent relative-unreflexivity/relative-reflexivity

ontological-contiguity ';-as-operative-notional deprocrypticism)

supererogatery acuity/perspicacity/astuteness/edginess/incisiveness-of-

apriorising/axiomatising/referencing/intelligibilitysettingup/measuringinstrumenting -for-

conceptualisation; as all that is as of knowledge-reification $\sim$ gesturing-and-accounting-of-

epistemic-phenomenalism- $<$ in-

prospective_psychologismic apriorising/axiomatising/referencing-\{of-‘pespecty

implicited_attendant-ontological-contiguity ' educed-

existentialising/contextualising/textualising_'intelligibility/epistemicity/reflexivity-contiguity-

<imbued-notional cogency>’ \}-conflatedness -in-\{preconverging-disentailment by\}

postconverging-entailment $>$ at uninstitutionalised-threshold ${ }^{102}$ is necessarily as of prospective parrhesiastic instigation beyond the priorly parrhesiastic instigated reproducibilitymathesis/motif/thrownness-disposition,-as-reproducibility-of-aestheticisation. In all these three instances of parrhesiastic instigation for human transcendence-andsublimity/sublimation/supererogatory-de-mentativity, it is important to grasp that their validation lies in their 'parrhesiastic <amplituding/formative-epistemicity >totalising renewing-realisation/re-perception/re-thought of ${ }^{83}$ reference-of-thought-level reproducibility—mathesis/motif/thrownness-disposition,-as-reproducibility-of-

aestheticisation' construed as from ${ }^{6}$ nonpresencing-<perspective-ontologicalnormalcy/postconvergence $>$ reflection of <amplituding/formative-epistemicity $>$ causality $\sim$ asto-projective-totalitative-implications-of-prospective- nonpresencing,-forexplicating relative-unreflexivity/relative-reflexivity - ontological-contiguity of relative- 
ontological-incompleteness ${ }^{8 /}$ relative-ontological-completeness ${ }^{87}$

〈sublimating referencing/registering/decisioning,--as-self-becoming/self-

conflatedness /formative-supererogating-<projective/reprojective-aestheticising-re-motifand-re-apriorising/re-axiomatising/re-referencing,-in-perspective-ontological-

normalcy/postconvergence $>>$ as of 'existence-potency ${ }^{32}$ sublimating-nascence,-disclosedfrom-prospective-epistemic-digression induced ${ }^{5}$ foregrounding_entailment- $<$ in-successionof-profound-supererogation $>-\langle$ postconverging-narrowing-down $\sim$ sublimation-as-to‘existence - as-sublimating-withdrawal/unenframing/re-ontologising,-elicited-fromprospective-profound-supererogation '-in-reflecting-'immanent relativeunreflexivity/relative-reflexivity - ontological-contiguity ' ';-as-operativenotional deprocrypticism $\rangle$ at registry-worldview/dimension ${ }^{83}$ reference-of-thought-level for devolving ${ }^{56}$ meaningfulness-and-teleology ${ }^{9}$ as validated by <amplituding/formativeepistemicity $>$ causality $\sim$ as-to-projective-totalitative-implications-of-prospectivenonpresencing,-for-explicating relative unreflexivity/relative reflexivity -ontologicalcontiguity , reflecting a foregrounding_entailment- $<$ in-succession-of-profoundsupererogation $>$-〈postconverging-narrowing-down $\sim$ sublimation-as-to- ${ }^{`}$ existence- assublimating-withdrawal/unenframing/re-ontologising,-elicited-from-prospective-profoundsupererogation '-in-reflecting-'immanent relative-unreflexivity/relative-reflexivity ontological-contiguity ';--as-operative-notional deprocrypticism) so-implied in reflecting holographically-<conjugatively-and-transfusively $>$ the relative-unreflexivity/relativereflexivity ontological-contiguity of-the-human-institutionalisation-process $<$ cumulating/recomposuring attendant-ontological-contiguity $>$-successive registryworldviews/dimensions with respect to human limited-mentation-capacity-deepening-assubjecting limitedness/hmman-subpotency to 'educed unlimitedness/existence sublimating nascence' implications 
supererogatory acuity/perspicacity/astuteness/edginess/incisiveness-ofapriorising/axiomatising/referencing/intelligibilitysettingup/measuringinstrumenting - forconceptualisation for $\quad$ meaningfulness-and-teleology aposteriorising/logicising/deriving/intelligising/measuring, and so 'over human-subpotency dialogical-equivalence-<as-to-psychologismic apriorising/axiomatising/referencing-\{ of'prospectively implicited_attendant-ontological-contiguity ' ceducedexistentialising/contextualising/textualising_'intelligibility/epistemicity/reflexivity_contiguity<imbued-notional cogency >’ \}-conflatedness -in-\{preconverging-disentailment by\} postconverging-entailment,-in-self-becoming/self-conflatedness /formative-supererogating> implied disparateness-of-conceptualisation-<unforegrounding-disentailment,-failingprospectively-to-reflect-'immanent relative-unreflexivity/relative-reflexivity - ontologicalcontiguity ' $>$ unification on the basis of an ontologically-flawed human-subpotency contrasting-and-comparison driven notion of ${ }^{4}$ foregrounding_entailment- $<$ in-succession-ofprofound-supererogation $>$-〈postconverging-narrowing-down $\sim$ sublimation-as-to- ${ }^{\text {‘existence- }}$ as-sublimating-withdrawal/unenframing/re-ontologising,-elicited-from-prospective-profoundsupererogation '-in-reflecting-'immanent relative-unreflexivity/relative-reflexivity ontological-contiguity ';--as-operative-notional deprocrypticism)'. Rather the Socraticphilosophers are not obstinate as all the possibility for prospective transcendence-andsublimity/sublimation/supererogatory de-mentativity that can-exist-as-of-existencepotency ${ }^{32} \sim$ sublimating-nascence,-disclosed-from-prospective-epistemic-digression (as from ontological-faith-notion-or-ontological-fideism - imbued-underdetermination-of-motif-andapriorising/axiomatising/referencing-as-so-being-as-of-existential-reality intemporal parrhesiastic seeding-promise dimensionality-of-sublimating <<amplituding/formative>supererogatery $\sim$ de-mentativeness/epistemic-growth-orconflatedness /transvaluative-rationalising/transepistemicity/anamnestic-residuality/spirit- 
drivenness-equalisation $\rangle$ for prospective knowledge-reification $\sim$ gesturing-and-accounting —ofepistemic-phenomenalism- $<$ in-

prospective_psychologismic apriorising/axiomatising/referencing-\{of-'prospectively implicited_attendant-ontological-contiguity ' educedexistentialising/eontextralising/textlising_intelligibility/epistemicity/reflexivity-contiguity<imbued-notional cogency >’ $\}$-conflatedness -in-\{preconverging disentailment by\} postconverging-entailment $>$, with respect to human limited-mentation-capacity-deepening-assubjecting limitedness/human-subpotency-to-'educed-unlimitedness/existence-sublimating nascence ${ }^{53}$ ) can only arise as to existence-potency ${ }^{32} \sim$ sublimating-nascence,-disclosed-fromprospective-epistemic-digression implied prospective relative-ontological-completeness parrhesiastic instigation implications of ${ }^{103}$ universalising-idealisation as the foregrounding_entailment- $<$ in-succession-of-profound-supererogation $>>-\langle$ postconvergingnarrowing-down $\sim$ sublimation-as-to-'existence - as-sublimating-withdrawal/unenframing/reontologising,-elicited-from-prospective-profound-supererogation '-in-reflecting‘immanent relative-unreflexivity/relative-reflexivity - ontological-contiguity ';-as-operativenotional deprocrypticism $\rangle$ at ${ }^{83}$ reference-of-thought-level for devolving ${ }^{5}$ meaningfulnessand-teleology', and 'not contrasting-and-comparison disparateness-of-conceptualisation$<$ unforegrounding-disentailment,-failing-prospectively-to-reflect- immanent $\sim$ relativeunreflexivity/relative-reflexivity ontological-contiguity ' $>$ in human-subpotency dialogicalequivalence-<as-to-psychologismic apriorising/axiomatising/referencing- \{of-'prespectively implicited_attendant-ontological-contiguity ' educedexistentialising/contextualising/textualising_ intelligibility/epistemicity/reflexivity_contiguity<imbued-notional cogency $>>\quad\}$-conflatedness -in-\{preconverging-disentailment by\} postconverging-entailment,-in-self-becoming/self-conflatedness /formative-supererogating> as of non-universalising sophistry reproducibility—mathesis/motif/thrownness-disposition,--as- 
reproducibility-of-aestheticisation secondnatured normativities, conventions, practices, etc. as of its lack of prospective Socratic-philosophers ${ }^{103}$ universalising-idealisation foregrounding_entailment- $<$ in-succession-of-profound-supererogation ${ }^{9}>-\langle$ postconverging narrowing-down $\sim$ sublimation-as-to-'existence - as-sublimating-withdrawal/unenframing/reontologising,-elicited-from-prospective-profound-supererogation ' '-in-reflecting'immanent relative-unreflexivity/relative-reflexivity —ontological-contiguity ';-as-operativenotional deprocrypticism $\rangle$

supererogatery acuity/perspicacity/astuteness/edginess/incisiveness-ofapriorising/axiomatising/referencing/intelligibilitysettingup/measuringinstrumenting -forconceptualisation'; likewise the budding-positivists are not obstinate as all the possibility for prospective transcendence-and-sublimity/sublimation/supererogatory de-mentativity that canexist-as-of-existence-potency ${ }^{32} \sim$ sublimating-nascence,-disclosed-from-prospective-epistemicdigression (as from ontological-faith-notion-or-ontological-fideism-imbuedunderdetermination-of-motif-and-apriorising/axiomatising/referencing-as-so-being-as-ofexistential-reality intemporal parrhesiastic seeding-promise dimensionality-of-sublimating <<amplituding/formative>supererogatory $\sim$ de-mentativeness/epistemic-growth-orconflatedness /transvaluative-rationalising/transepistemicity/anamnestic-residuality/spiritdrivenness-equalisation) for prospective knowledge-reification $\sim$ gesturing-and-accounting —ofepistemic-phenomenalism-<in-

prospective_psychologismic apriorising/axiomatising/referencing-\{of-'prespectively implicited_attendant-ontological-contiguity ' ceducedexistentialising/contextualising/textualising_'intelligibility/epistemicity/reflexivity-contiguity<imbued-notional cogency $\left.>^{\prime} \quad\right\}$-conflatedness -in-\{preconverging-disentailment by\} postconverging entailment>, with respect to human limited-mentation-capacity-deepening-assubjecting limitedness/human-subpotency-to-'educed-unlimitedness/existence-sublimating- 
nascence ${ }^{53}$ ) can only arise as to existence-potency ${ }^{32} \sim$ sublimating-nascence,-disclosed-fromprospective-epistemic-digression implied prospective relative-ontological-completeness parrhesiastic instigation implications of 'positivism/rational-empiricism' as the foregrounding_entailment- $<$ in-succession-of-profound-supererogation $>>-\langle$ postconvergingnarrowing-down $\sim$ sublimation-as-to-'existence - as-sublimating-withdrawal/unenframing/reontologising,-elicited-from-prospective-profound-supererogation '-in-reflecting'immanent relative - unreflexivity/relative-reflexivity ontological-contiguity ';-as-operativenotional deprocrypticism) at ${ }^{83}$ reference-of-thought-level for devolving ${ }^{56}$ meaningfulnessand-teleology', and 'not contrasting-and-comparison disparateness-of-conceptualisation$<$ unforegrounding-disentailment,-failing-prospectively-to-reflect-'immanent $\sim$ relative-

unreflexivity/relative-reflexivity ontological-contiguity ' $>$ in human-subpotency dialogicalequivalence-<as-to-psychologismic apriorising/axiomatising/referencing- \{of-'prespectively implicited_attendant-ontological-contiguity ' educedexistentialising/contextualising/textualising_'intelligibility/epistemicity/reflexivity-contiguity<imbued-notional cogency> $\quad\}$-conflatedness -in-\{preconverging-disentailment by\} pesteonverging-entailment,-in-self-becoming/self-conflatedness /formative-supererogating> as of non-positivism/medievalism dogma reproducibility—mathesis/motif/thrownnessdisposition,-as-reproducibility-of-aestheticisation secondnatured normativities, conventions, practices, etc. as of its lack of prospective positivism/rational-empiricism foregrounding_entailment-<in-succession-of-profound-supererogation $>>-\langle$ postconvergingnarrowing-down $\sim$ sublimation-as-to-'existence - as-sublimating-withdrawal/unenframing/reontologising,-elicited-from-prospective-profound-supererogation ' '-in-reflecting'immanent relative-unreflexivity/relative-reflexivity ontological-contiguity ';-as-operativenotional deprocrypticism $\rangle$ supererogatory acuity/perspicacity/astuteness/edginess/incisiveness-of- 
apriorising/axiomatising/referencing/intelligibilitysettingup/measuringinstrumenting -for-

conceptualisation'; and likewise prospective suprastructuralism/postmodern-thought is not obstinate as all the prospective possibility for our prospective transcendence-andsublimity/sublimation/supererogatory de-mentativity that can-exist-as-of-existencepotency ${ }^{39} \sim$ sublimating-nascence,-disclosed-from-prospective-epistemic-digression (as from ontological-faith-notion-or-ontological-fideism - imbued-underdetermination-of-motif-andapriorising/axiomatising/referencing-as-so-being-as-of-existential-reality intemporal parrhesiastic seeding-promise dimensionality-of-sublimating <<amplituding/formative>supererogatory $\sim$ de-mentativeness/epistemic-growth-orconflatedness /transvaluative-rationalising/transepistemicity/anamnestic-residuality/spiritdrivenness-equalisation> for prospective knowledge-reification $\sim$ gesturing-and-accounting-ofepistemic-phenomenalism- $<$ inprospective_psychologismic apriorising/axiomatising/referencing-\{of- ${ }^{\text {}}$ prospectively implicited_attendant_ontological-contiguity ' educedexistentialising/contextualising/textualising_'intelligibility/epistemicity/reflexivity-contiguity<imbued-notional cogency>’ $\}$-conflatedness -in-\{preconverging-disentailment by\} postconverging-entailment>, with respect to human limited-mentation-capacity-deepening-assubjecting limitedness/human-subpotency to-'educed-unlimitedness/existence-sublimating nascence ${ }^{53}$ ) can only arise as to existence-potency ${ }^{32} \sim$ sublimating-nascence,-disclosed-fromprospective-epistemic-digression implied prospective relative-ontological-completeness parrhesiastic instigation implications of " ${ }^{18}$ deprocrypticism-or-preempting — disjointedness-asof- ${ }^{8}$ reference-of-thought' as the ${ }^{45}$ foregrounding_entailment- $<$ in-succession-of-profoundsupererogation $>$-〈postconverging-narrowing-down $\sim$ sublimation-as-to-'existence-assublimating-withdrawal/unenframing/re-ontologising,-elicited-from-prospective-profoundsupererogation '-in-reflecting-'immanent relative-unreflexivity/relative-reflexivity 
ontological-contiguity ';--as-operative-notional deprocrypticism) at ${ }^{83}$ reference-of-thoughtlevel for devolving ${ }^{56}$ meaningfulness-and-teleology', and 'not contrasting-and-comparison disparateness-of-conceptualisation-<unforegrounding-disentailment,-failing-prospectively-toreflect- 'immanent relative-unreflexivity/relative-reflexivity - ontological-contiguity '> in human-subpotency dialogical-equivalence-<as-to-

\section{psychologismic apriorising/axiomatising/referencing- $\{$ of-"prospectively}

implicited_attendant-ontological-contiguity ' reduced-

existentialising/contextualising/textualising_'intelligibility/epistemicity/reflexivity-contiguity$<$ imbued-notional cogency $>$ ' $\}$-conflatedness -in-\{preconverging disentailment by\} postconverging entailment,-in-self-becoming/self-conflatedness /formative-supererogating > of positivism- ${ }^{8}$ procrypticism's disjointedness-as-of- ${ }^{2}$ reference-of-thought reproducibilitymathesis/motif/thrownness-disposition,-as-reproducibility-of-aestheticisation secondnatured normativities, conventions, practices, etc. as of its lack of prospective ${ }^{18}$ deprocrypticism-orpreempting — disjointedness-as-of- ${ }^{83}$ reference-of-thought $\quad{ }^{45}$ foregrounding_entailment- $<$ insuccession-of-profound-supererogation $>$ - $\langle$ postconverging-narrowing-down $\sim$ sublimation-asto-'existence - as-sublimating-withdrawal/unenframing/re-ontologising,-elicited-fromprospective-profound-supererogation '-in-reflecting-'immanent $\sim$ relativeunreflexivity/relative-reflexivity - ontological-contiguity ' ';-as-operativenotional deprocrypticism)

supererogatory acuity/perspicacity/astuteness/edginess/incisiveness-ofapriorising/axiomatising/referencing/intelligibilitysettingup/measuringinstrumenting -forconceptualisation'. In furtherance of this prospective epistemic-ricochetting/transepistemicity indictment, this author laments a covert practice of an intellection that has been critical of postmodern-thought but in latter years 'reformulates the implications of postmodern ideas' as original thought even as such practices supposedly passes their institutional thresholds of 
admissibility with the caveat though that much of such thought is poorly operant given its adhoc depth of knowledge-reification $\sim$ gesturing-and-accounting-of-epistemic-phenomenalism<in-prospective_psychologismic $\sim$ apriorising/axiomatising/referencing-\{of-'prospectively_ implicited_attendant-ontological-contiguity ' reducedexistentialising/contextualising/textualising_'intelligibility/epistemicity/reflexivity-contiguity<imbued-notional cogency $\left.>{ }^{\prime}\right\}$-conflatedness -in-\{preconverging-disentailment by\} postconverging-entailment $>$ /process as of disparateness-of-conceptualisation$<$ unforegrounding-disentailment,-failing-prospectively-to-reflect-'immanent $\sim$ relativeunreflexivity/relative-reflexivity - ontological-contiguity ' $>$ implications, and along the same parrhesiastic prospective epistemic-ricochetting/transepistemicity line this author is very much befuddled of a perverted exercise to undermine the originality of this work supposedly because of the theoretical orientation by a naïve ad-hoc synonymising exercise that this author is very much confident fails as it overlooks the coherence and knowledge-reification $\sim$ gesturing-andaccounting-of-epistemic-phenomenalism-<inprospective_psychologismic apriorising/axiomatising/referencing-\{of- ${ }^{\text {pprospectively }}$ implicited_attendant-ontological-contiguity ' educedexistentialising/contextualising/textulising_intelligibility/epistemicity/reflexivity-contiguity<imbued-notional cogency >' \}-conflatedness -in-\{preconverging-disentailment by\} postconverging-entailment $>$ /process articulated herein. Generally, such perversion of thought as it discreetly networks fails society in the long-run when it seems to assume a foreshadowing posture with regards to what can be thought or not thought as of a 'realpolitiking of thought' exercise. Such intellectual shadiness of vague highmindedness is no more different from the gross inanity of ancient-sophists or medieval-scholastic pedants, as of naïve shallow-minded incrementalism-in-relative-ontological-incompleteness ${ }^{8}$ enframed/disontologising conceptualisation as of a poor sense of intemporality ${ }^{2} /$ longness 
beyond earthly materialism. The transepistemic/epistemic-ricochetting veracity of all singularising/immanenting subject-matters/domains-of-study <amplituding/formativeepistemicity $>$ totalising/circumscribing/delineating $\quad$ foregrounding_entailment- $<$ insuccession-of-profound-supererogation $>$-〈postconverging-narrowing-down $\sim$ sublimation-asto-'existence - as-sublimating-withdrawal/unenframing/re-ontologising,-elicited-fromprospective-profound-supererogation ' -in-reflecting-'immanent $\sim$ relativeunreflexivity/relative-reflexivity - ontological-contiguity ';-as-operativenotional deprocrypticism〉' reflecting existence's overall reifying-and-empoweringreflexivity-of-ecstatic-existence-as-panintelligibility/panreflexivity ${ }^{73}$-〈existentially-imbuedand-educing-<\{epistemictotalising thermeneutically/textually/reprojectingly/supererogatingly/zeroingly/re-acutingly,\{decompulsing $d$ delinearity for-cogency $>$-epistemic-perspective-of-projective/reprojectiveaestheticising-re-motif-and-re-apriorising/re-axiomatising/re-referencing conceptualisation,as-herein-specifically-relevant-to human-subpotency), as of the implications of philosophical depth of contemplation as of 'coherence/contiguity-of-superseding-oneness-of-ontologyimplied-as-of-inherent-existence-coherence/contiguity,-and-so-construed-as-the-enabler-ofinsight-or-intuition-or-foresight-as-of-embodied-consciousness', whether with respect to say evolutionary theory in the biological sciences or physics ${ }^{45}$ foregrounding_entailment- $<$ insuccession-of-profound-supererogation $>>$-〈postconverging-narrowing-down $\sim$ sublimation-asto-'existence — as-sublimating-withdrawal/unenframing/re-ontologising,-elicited-fromprospective-profound-supererogation '-in-reflecting-'immanent $\sim$ relativeunreflexivity/relative-reflexivity - ontological-contiguity ';-as-operativenotional deprocrypticism $\rangle$ theories for instance can ultimately imply the reconceptualisation of ${ }^{5}$ meaningfulness-and-teleology ${ }^{9}$ in order to supersede the fundamental approach of 'finite categorising axiomatisation' as of positivism 
apriorising/axiomatising/referencing/intelligibilitysettingup/measuringinstrumenting towards \{epistemic-totalising 3 ’ hermeneutic/textuality/reprojecting/supererogating/zeroing/re-acuting,-

\{decondsing $d$ delinearity for-cogency implicited_attendant-ontological-contiguity ${ }^{67} \sim$ educedexistentialising/contextualising/textualising_'intelligibility/epistemicity/reflexivity-contiguity<imbued-notional cogency>' reifying <amplituding/formative-epistemicity $>$ causality $\sim$ asto-projective-totalitative-implications-of-prospective- nonpresencing,-for-

explicating relative-unreflexivity/relative-reflexivity ontological-contiguity

of

deprocrypticism-or-preempting-disjointedness-as-of- ${ }^{3}$ reference-of-thought referentialism apriorising/axiomatising/referencing/intelligibilitysettingup/measuringinstrumenting in ontological-normalcy/postconvergence involving 'ontologically-projective-as-of-ontologicalnormalcy/postconvergence aestheticising/designed axiomatisation insight'. Basically thus, naïve mimickry of mere scientific approaches and methodologies isn't inherently ontologicallypertinent but for vague 'science-ideology sterile/anecdotal imprimatur' as of institutional-beingand-craft, as priorly any study as of the-very-same-immanent-existence/intrinsicreality/ontological-veridicality,-as-to-'human-<amplituding/formativeepistemicity>totalising purview-of-construal' $\quad$ or $\quad$ any $\quad<$ amplituding/formativeepistemicity $>$ totalising $\sim$ devolved-purview-as-domain-of-construal-as-intrinsic-

reality/ontological-veridicality should necessarily be in nested-congruence as of supposedly coherent ontological-commitment $-<$ implied_-self-assuredness-of-ontological-goodfaith/authenticity postconverging-de-mentating/structuring/paradigming -as-being-as-ofexistential-reality $>$ reflected by $<$ amplituding/formative-epistemicity $>$ causality $\sim$ as-toprojective-totalitative-implications-of-prospective- nonpresencing,-for-explicating relativethreflexivity/relative reflexivity ontological-contiguity as to existencepotency $^{32} \sim$ sublimating-nascence,-disclosed-from-prospective-epistemic-digression, and soconstrued from a philosophical depth of contemplation as of 'coherence/contiguity-of- 
superseding-oneness-of-ontology-implied-as-of-inherent-existence-coherence/contiguity,-andso-construed-as-the-enabler-of-insight-or-intuition-or-foresight-as-of-embodied-

consciousness'; with the ultimate implication that subject-matters/domains-of-study totalising/circumscribing/delineating $<$ amplituding/formative-epistemicity $>$ reference-ofthought- ${ }^{8}$ devolving $\quad{ }^{45}$ foregrounding_entailment- $<$ in-succession-of-profoundsupererogation $>$ - $\langle$ postconverging-narrowing-down $\sim$ sublimation-as-to-'existence - assublimating-withdrawal/unenframing/re-ontologising,-elicited-from-prospective-profoundsupererogation '-in-reflecting-'immanent relative-unreflexivity/relative-reflexivity ontological-contiguity ';-as-operative-notional deprocrypticism) is what validates their maturity/immaturity. It should be noted here as well that it is human limited-mentation-capacitydeepening —as-subjecting limitedness/human-subpotency to-'educed-unlimitedness/existencesublimating nascence ${ }^{53}$ as of relative-ontological-completeness ${ }^{87}$ as of $<$ amplituding/formative-epistemicity $>$-totalising $\sim$ renewing-realisation/re-perception/rethought of "coherence/contiguity-of-superseding-oneness-of-ontology-implied-as-of-inherentexistence-coherence/contiguity,-and-so-construed-as-the-enabler-of-insight-or-intuition-orforesight-as-of-embodied-consciousness' that underlies the <amplituding/formativeepistemicity $>$ causality $\sim$ as-to-projective-totalitative-implications-of-prospectivenonpresencing,-for-explicating relative-unreflexivity/relative-reflexivity - ontologicalcontiguity of ontologically-veridical difference-conflatedness ${ }^{13}$-as-to-totalitative-reificationin-singularisation-<as-to-the-nondisjointedness/entailment-of-prospective- nonpresencing $>$ as-veridical-epistemicity-relativism-determinism over ontologically-flawed identitiveconstitutedness ${ }^{14}$-as-'epistemic-totality ${ }^{37}$ '-dereification-in-dissingularisation-<as-to-thedisjointedness/disentailment-of- presencing - absolutising-identitive-constitutedness $>$-asflawed-epistemicity-relativism-determinism . In another respect this author's re-elaboration of postmodern difference conception, as of ontologically-veridical difference-conflatedness ${ }^{13}$-as- 
to-totalitative-reification-in-singularisation- $<$ as-to-the-nondisjointedness/entailment-of-

prospective- nonpresencing $>$-as-veridical-epistemicity-relativism-determinism contends that this effectively captures-and-reflects the evolving reality of knowledgereification $\sim$ gesturing-and-accounting — of-epistemic-phenomenalism- $<$ inprospective_psychologismic apriorising/axiomatising/referencing-\{of-'prospectively implicited_attendant_ontological-contiguity ' educedexistentialising/contextualising/textualising_ 'intelligibility/epistemicity/reflexivity-contiguity<imbued-notional cogency >' \}-conflatedness -in-\{preconverging disentailment by\} postconverging-entailment> of human ${ }^{56}$ meaningfulness-and-teleology ${ }^{9}$, and so over analytic atomising/taking-to-pieces formalisation approach as of identitive-constitutedness ${ }^{14}$-as'epistemic-totality ${ }^{37}$ '-dereification-in-dissingularisation- $<$ as-to-the-

disjointedness/disentailment-of- presencing - absolutising-identitive-constitutedness $>$-asflawed-epistemicity-relativism-determinism that goes on to analyse as if all the analysis that has ever been is as of ${ }^{7}$ presencing-absolutising-identitive-constitutedness ${ }^{14}$ while ignoring the $<$ amplituding/formative-epistemicity $>$ causality $\sim$ as-to-projective-totalitative-implications-ofprospective- nonpresencing,-for-explicating relative-unreflexivity/relative-reflexivity

ontological-contiguity of human underlying relative-ontological-incompleteness $8 /$ relativeontological-completeness ${ }^{8}$-〈sublimating $\sim$ referencing/registering/decisioning,--as-selfbecoming/self-conflatedness /formative-supererogating-<projective/reprojectiveaestheticising-re-motif-and-re-apriorising/re-axiomatising/re-referencing,-in-perspectiveontological-normalcy/postconvergence $>>$ with respect to temporal-to-intemporal ontologicalperformance ${ }^{72}-<$ including-virtue-as-ontology $>/$ morality/ethics/justice/etc. as from past to present to future with regards to knowledge-reification $\sim$ gesturing-and-accounting-ofepistemic-phenomenalism- $<$ in-

prospective_psychologismic apriorising/axiomatising/referencing-\{of-'prospectively 
implicited_attendant-ontological-contiguity ' reduced-

existentialising/contextualising/textualising_'intelligibility/epistemicity/reflexivity_contiguity<imbued-notional cogency>> $\}$-conflatedness -in-\{preconverging-disentailment by\}

postconverging entailment $>$. Another criticism is the inclination for such atomising/taking-topieces formalisation predisposition to start out with ad-hoc disparate conceptualisations as of identitive-constitutedness ${ }^{14}$-as-'epistemic-totality ${ }^{37}{ }^{\prime}$-dereification-in-dissingularisation- $<$ as-tothe-disjointedness/disentailment-of- presencing - absolutising-identitive-constitutedness $>$ as-flawed-epistemicity-relativism-determinism that often poorly reflect the 'ecstatic totalisingentailing/nested-congruence' of existential-<disontologising/re-ontologising aporeticism $>$ phenomenality rather than the contrary approach that delves directly in 'implicited_attendantontological-contiguity ${ }^{67} \sim$ educedexistentialising/contextualising/textualising_'intelligibility/epistemicity/reflexivity-contiguity<imbued-notional cogency>' and then reifies-out conceptualisations as of differenceconflatedness $^{13}$-as-to-totalitative-reification-in-singularisation- $<$ as-to-thenondisjointedness/entailment-of-prospective- nonpresencing > -as-veridical-epistemicityrelativism-determinism . The implication here is that quite often when required to explicate social phenomena outside the framework of such abstract atomising/taking-to-pieces formalisation approach, what happens is that responses will often tend not to be as of the direct import of such analytical atomising/taking-to-pieces formalisation frameworks of supposed reification/elucidation, but rather as extra-contemplative articulations and commentaries that inmany-ways fall back into the very <amplituding/formative> wooden-language-〈imbuedaveraging-of-thought-<as-to-leveling/ressentiment/closed-construct-of- meaningfulness-andteleology -as-of-'nondescript/ignorable-void '-with-regards-to-prospective-apriorisingimplications $>>$ that is supposed to be reified but now under the sterile/anecdotal imprimatur of authority. This is very much unlike the case with proponents of 'ecstatic totalising- 
entailing/nested-congruence' whose social and existential-<disontologising/re-ontologising aporeticism $>$ analyses are just a natural reification/elucidation projection as from within the 'ecstatic totalising-entailing/nested-congruence' of existential-<disontologising/reentologising aporeticism $>$ phenomenality framework of their study. Furthermore this contrast equally produces other distractive effects in the sense that when such abstract atomising/takingto-pieces formalisation analysis is presumed to be more profound as of its poorly nuanced interpretation of implicited attendant-ontological-contiguity ${ }^{67}$ ' educedexistentialising/contextualising/textualising_'intelligibility/epistemicity/reflexivity-contiguity<imbued-notional cogency $>^{\prime}$ in a rather blurry social domain-of-study, then it assumes that issues of mutual misunderstanding are due to poor writing, poor use of language or ambiguous conceptualisations of such 'ecstatic totalising-entailing/nested-congruence' proponents thought, failing to factor in the 'implicited attendant-ontological-contiguity ${ }^{67}$ ' educedexistentialising/contextualising/textualising_'intelligibility/epistemicity/reflexivity-contiguity-

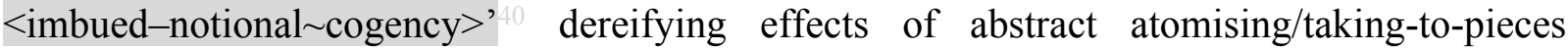
formalisation as decontextualising and pulling-apart the 'ecstatic totalising-entailing/nestedcongruence' of existential-<disentologising/re-ontologising aporeticism $>$ phenomenality, wherein the constraining effect of existence/intrinsic-reality/ontological-veridicality as the 'superior party' is ignored/overlooked on the naïve token of working on specific aspects or specific interpretation, and so out of sync with existence/intrinsic-reality/ontologicalveridicality. Again, what is loss of critical pertinence here is exactly what is implied by ' ${ }^{5}$ meaningfulness-and-teleology $/$ knowledge as of knowledge-reification $\sim$ gesturing-andaccounting — of-epistemic-phenomenalism- $<$ in-

prospective_psychologismic apriorising/axiomatising/referencing-\{of- ${ }^{\text {prespectively }}$ implicited_attendant-ontological-contiguity ' educedexistentialising/contextualising/textualising_'intelligibility/epistemicity/reflexivity-contiguity- 
postconverging entailment>', as being rather all about elucidating the necessary-existentialstates-and-conditions so-construed as 'axiomatic-construct construal of ecstatic-existence/thenature-of-the-world/conditions', and not presuming-and-skirting-around them, before further expanding on the elucidation/reification of their manifestations as validated or can be falsifiable by <amplituding/formative-epistemicity >causality $\sim$ as-to-projective-totalitative-implications-

\section{of-prospective- nonpresencing,-for-explicating relative-unreflexivity/relative-reflexivity}

ontological-contiguity ; or otherwise this simply leads to a loss of the sense of ontologicallyveridical reality. Ultimately, such abstract atomising/taking-to-pieces formalisation tendencies and further as of a frequently gestational knowledge state with respect to the possibility for prospective social transcendence-and-sublimity/sublimation/supererogatory $\sim$ de-mentativity, induces a penchant for flawed intellectually supplementing rhetorisation rather than reification as well as naïve focussing on disparateness of conceptualisations-and-interpretations as of lack or poor constraining <amplituding/formative-epistemicity $>$ causality $\sim$ as-to-projectivetotalitative-implications-of-prospective- nonpresencing,-for-explicating relativeunreflexivity/relative-reflexivity - ontological-contiguity disposition rather than an orientation towards the 'transversality- $<$ for-sublimating-existential-eventuating/denouement, from thinking at first/pure predisposition-preemptive-of prospectivedisontologising/subontologising' - as-of-prospectively-disambiguated-affirmed-andunaffirmed-'motif-and-apriorising/axiomatising/referencing'>101 $\quad$ or $\quad$ transversal-analysistowards-validatory-selectivity-for- ${ }^{45}$ foregrounding _ entailment- $<$ in-succession-of-profoundsupererogation $>$-〈postconverging-narrowing-down $\sim$ sublimation-as-to-'existence-assublimating-withdrawal/unenframing/re-ontologising,-elicited-from-prospective-profoundsupererogation '-in-reflecting-'immanent relative- unreflexivity/relative-reflexivity ontological-contiguity ';--as-operative-notional deprocrypticism) of conceptualisations-and- 
interpretations' as constrained to <amplituding/formative-epistemicity $>$ causality $~$ as-toprojective-totalitative-implications-of-prospective- nonpresencing,-for-explicating relativeunreflexivity/relative-reflexivity - ontological-contiguity which is what further reifies the body of knowledge by enabling existence as the transcendental-signifier/transcendentalenabling/sublimating/supereregatory $\sim$ de-mentativity to continually select the trace/ontologicalaesthetic-tracing-<perspective-ontological-normalcy/postconvergence-reflected-'epistemicityrelativism-determinism'> of sound and complementary conceptualisations-and-interpretations out of a genuine ecstatic reproducibility-mathesis/motif/thrownness-disposition,--asreproducibility-of-aestheticisation disseminative insight, with unsound/superseded conceptualisations-and-interpretations being discarded thereafter. Concretely, we can easily appreciate the greater pertinence of a Foucauldian statement of relative truth as of ontologicallyveridical difference-conflatedness ${ }^{13}$-as-to-totalitative-reification-in-singularisation- $<$ as-to-thenondisjointedness/entailment-of-prospective- nonpresencing > -as-veridical-epistemicityrelativism-determinism, construable rather as a more precise theoretical, conceptual and operant notion of truth by its 'implicited_attendant-ontological-contiguity ${ }^{67}$ ' educedexistentialising/contextualising/textualising_intelligibility/epistemicity/reflexivity_contiguity<imbued-notional cogency>' $\quad$ knowledge-reifying <amplituding/formativeepistemicity $>$ causality $\sim$ as-to-projective-totalitative-implications-of-prospectivenonpresencing,-for-explicating relative unreflexivity/relative-reflexivity —ontologicalcontiguity as of the human-subject-emancipating-relativism-driven-recomposuringconstructivism-towards-singularisation-<as-to-the-nondisjointedness/entailment-ofprospective- nonpresencing $>$ as reflected with 'intemporal ontological-faith-notion-orontological-fideism - imbued-underdetermination-of-motif-andapriorising/axiomatising/referencing-as-so-being-as-of-existential-reality instigated relativeenreflexivity/relative-reflexivity - ontological-contiguity ${ }^{67} \sim$ of-the-human-institutionalisation- 
process $^{68}$ as of difference-conflatedness ${ }^{13}$-as-to-totalitative-reification-in-singularisation- $<$ as-tothe-nondisjointedness/entailment-of-prospective- nonpresencing $>$-as-veridical-epistemicityrelativism-determinism implied $<$ amplituding/formative-epistemicity $>$ causality $\sim$ as-toprojective-totalitative-implications-of-prospective- nonpresencing,-for-explicating relativeunreflexivity/relative-reflexivity ontological-contiguity, as of Beingdevelopment/ontological-framework-expansion-as-to-depth-of-ontologising-development-asinfrastructure-of- meaningfulness-and-teleology ; and so when compared to the atomising/taking-to-pieces formalisation notion of truth-value as of ontologically-flawed identitive-constitutedness ${ }^{14}$-as-'epistemic-totality ${ }^{37}$ '-dereification-in-dissingularisation- $<$ as-tothe-disjointedness/disentailment-of- presencing - absolutising-identitive-constitutedness > as-flawed-epistemicity-relativism-determinism . Such a construal of relative truth doesn't imply a lack of commitment in truth, but is utterly the contrary as of a 'much more critical and ontologically decisive commitment to truth and growing truth' as any pertinent critique can garner in Foucault's truth-delogocentering works/research-programme and its extensive interpretational citability in other scholarly works/research-programmes as of its scholarly advancing of the humanities and social sciences; as his works/research-programme quest for truth 'expands the conception of truth beyond our ${ }^{79}$ presencing-absolutising-identitiveconstitutedness $<$ amplituding/formative-epistemicity $>$ totalising $\sim$ self-referencingsyncretising/circularity/interiorising/akrasiatic-drag ${ }^{34}$ mental-dispositions as if all the world that has ever existed is as of ${ }^{79}$ presencing-absolutising-identitive-constitutedness ${ }^{14}$, and displaces/decenters the human subject as of its ${ }^{79}$ presencing-absolutising-identitiveconstitutedness ${ }^{14}$ cloistered-consciousness for a more mature and nuanced conception of truth and the implications of truth; and so, beyond the contemplation of naïve atomising/taking-topieces formalisation dereifying rhetorisations that border on <amplituding/formative $>$ woodenlanguage-_imbued - averaging-of-thought-<as-to-leveling/ressentiment/closed-construct-of- 
meaningfulness-and-teleology -as-of-'nondescript/ignorable-void '-with-regards-to-

prospective-apriorising-implications $>>$ populist interpretations rather than elevating human ontological construal of the social domain-of-study! It is herein contended that existence-asthe-absolute-a-priori-of-conceptualisation and existence — as-sublimating-

withdrawal/unenframing/re-ontologising,-elicited-from-prospective-profound-

supererogation -<as-to-perspective-ontological-normalcy/postconvergence-implied-

'prospective-aporeticism-overcoming/unovercoming'> as of its ecstatic singularity actually points to appropriate attitude/mental-disposition/care-and-episteme as of ontologicallyveridical difference-conflatedness ${ }^{13}$-as-to-totalitative-reification-in-singularisation- $<$ as-to-thenondisjointedness/entailment-of-prospective- nonpresencing $>$-as-veridical-epistemicityrelativism-determinism for knowledge-reification $\sim$ gesturing-and-accounting-of-epistemicphenomenalism- $<$ in-prospective_psychologismic $\sim$ apriorising/axiomatising/referencing-\{of'prospectively_implicited_attendant-ontological-contiguity ' reducedexistentialising/contextualising/textualising_'intelligibility/epistemicity/reflexivity-contiguity<imbued-notional cogency >' \}-conflatedness -in-\{preconverging disentailment by\} postconverging entailment $>$ of every domain-of-study; as the fact remains that the domain-ofstudy of the social world is utterly different as of 'implicited_attendant-ontologicalcontiguity $^{67} \sim$ educedexistentialising/contextualising/textualising_'intelligibility/epistemicity/reflexivity-contiguity$<$ imbued-notional cogency >' from the domain-of-study of the natural world, and not to mention that even within the natural world or social world there are equally subject-matters peculiarities that require their own specific approaches to elucidation/reification as of 'implicited_attendant-ontological-contiguity ${ }^{67}$ educedexistentialising/contextualising/textualising_'intelligibility/epistemicity/reflexivity-contiguity<imbued-notional cogency $>^{\prime 0}$-and this said without undermining the idea of the ecstatic 
singularity of existence from which all such subject-matter-human-specialisms ecstatically arise as veridically implied by singularisation-<as-to-the-nondisjointedness/entailment-ofprospective- nonpresencing $>$ projected epistemic-immanence/veridical-epistemicityrelativism-determinism speaking of an underlying ecstatic commonness though not common phenomenality. Thus, in all cases the overall implications for the optimum advancement of human knowledge is most critically about constraining knowledge to 'implicited_attendant ontological-contiguity ${ }^{67}$, educed-

existentialising/contextualising/textualising_'intelligibility/epistemicity/reflexivity-contiguity$<$ imbued-notional cogency $>$ ' elucidation/reification rather than just mere formalisation as of conceptual-patterning for its own sake. The fact is the natural sciences are already naturally constraint to knowledge-reification $\sim$ gesturing-and-accounting-of-epistemic-phenomenalism$<$ in-prospective_psychologismic $\sim$ apriorising/axiomatising/referencing-\{of-'prospectively_ implicited_attendant-ontological-contiguity ' educedexistentialising/contextualising/textualising_ 'intelligibility/epistemicity/reflexivity-contiguity<imbued-notional cogency $\left.>^{\prime} \quad\right\}$-conflatedness -in-\{preconverging-disentailment by\} postconverging entailment> by the implicited immediate-constraining <amplituding/formativeepistemicity $>$ causality $\sim$ as-to-projective-totalitative-implications-of-prospectivenonpresencing,-for-explicating relative-unreflexivity/relative-reflexivity - ontologicalcontiguity transcendence-and-sublimity/sublimation/supererogatory $\sim$ de-mentativity whereas the human world is rather blurry in this regard and hence requires the requisite explicited insight about existence as of its ecstatic singularity for its appropriate approach for transcendence-andsublimity/sublimation/supererogatory-de-mentativity. In-many-ways such an insight is often implied in the natural sciences as of its relative transparency of cause-and-effect reification of 'implicited_attendant-ontological-contiguity ${ }^{67}$ > educedexistentialising/contextualising/textualising_intelligibility/epistemicity/reflexivity-contiguity- 
<imbued-notional cogency>' but not by a naïve/mimicked formalisation as of mere conceptual-patterning. Consider in this regard the implications of interpreting natural science transcendental-enabling/sublimating/supererogatory $\sim$ de-mentativity knowledge say between Mendelian heredity and DNA genetics or say Descartes Physics and Newton and Leibniz Physics on the basis of naïve formalisation as of conceptual-patterning, then in-many-ways the latter contributors would be poorly appreciated given that the spectacular transcendence-andsublimity/sublimation/supererogatory de-mentativity implications of their studies are massively overlooked by a poor appreciation that knowledge is critically all about formalisation as of conceptual-patterning rather than knowledge-reification $\sim$ gesturing-and-accounting-ofepistemic-phenomenalism-<in-

prospective_psychologismic apriorising/axiomatising/referencing-\{of-‘prospectively_ implicited_attendant-ontological-contiguity ' educedexistentialising/contextualising/textualising_'intelligibility/epistemicity/reflexivity_contiguity<imbued-notional cogency $>>\quad\}$-conflatedness -in-\{preconverging-disentailment by\} postconverging-entailment $><$ amplituding/formative-epistemicity $>$ causality $\sim$ as-to-projectivetotalitative-implications-of-prospective- nonpresencing,-for-explicating $\sim$ relativemnreflexivity/relative reflexivity ontological-contiguity. Actually, formalisation in the natural sciences and mathematics is the effective 'formatting outcome' of an implicited creative process of knowledge-reification $\sim$ gesturing-and-accounting-of-epistemic-phenomenalism$<$ in-prospective_psychologismic apriorising/axiomatising/referencing-\{of-'prospectively_ implicited_attendant-ontological-contiguity ' educedexistentialising/contextualising/textualising_'intelligibility/epistemicity/reflexivity-contiguity<imbued-notional cogency >' $\}$-conflatedness in \{preconverging disentailment by\} postconverging entailment $>$. This process is one of human limited-mentation-capacitydeepening —as-subjecting limitedness/human-subpotency to-'educed-unlimitedness/existence- 
sublimating nascence's as of 'repeating/repetition of ${ }^{55}$ maximalising-recomposuring-forrelative-ontological-completeness ${ }^{8}$ - unenframed/re-ontologising conceptualisation for knowledge-reification $\sim$ gesturing-and-accounting — of-epistemic-phenomenalism- $<$ inprospective_psychologismic apriorising/axiomatising/referencing-\{of-'prospectively implicited_attendant-ontological-contiguity ' educedexistentialising/contextualising/textualising_'intelligibility/epistemicity/reflexivity_contiguity<imbued-notional cogency >' \}-conflatedness -in-\{preconverging-disentailment by\} postconverging-entailment $>$, inducing successive differences of ontological-performance ${ }^{72}$ $<$ including-virtue-as-ontology $>$ /morality/ethics/justice/etc. of ${ }^{5}$ meaningfulness-and-teleology as of the-very-same-immanent-existence/intrinsic-reality/ontological-veridicality,-as-to'human<amplituding/formative-epistemicity>totalising $\sim$ purview-of-construal' with increasing prospective relative-ontological-completeness $^{87}$, reflected as of difference-conflatedness ${ }^{13}$-asto-totalitative-reification-in-singularisation- $<$ as-to-the-nondisjointedness/entailment-ofprospective- nonpresencing $>$-as-veridical-epistemicity-relativism-determinism , and not just a prior formalisation exercise as mere conceptual-patterning as of elaboration-as-to-mereextrapolating/constituting/abstracting/deducing/inferring-of-elucidation-outside'prospectively implicited_attendant-ontological-contiguity ${ }^{67}$ ' educedexistentialising/contextualising/textualising_'intelligibility/epistemicity/reflexivity-contiguity$<$ imbued-notional cogency>' ${ }^{40}$ reflected as of identitive-constitutedness ${ }^{14}$-as-'epistemictotality $^{37}$ '-dereification-in-dissingularisation- $<$ as-to-the-disjointedness/disentailment-ofpresencing - absolutising-identitive-constitutedness $>$-as-flawed-epistemicity-relativismdeterminism ; with 'repeating/repetition of ${ }^{5}$ maximalising-recomposuring-for-relativeontological-completeness ${ }^{87}$ - unenframed/re-ontologising conceptualisation for knowledgereification $\sim$ gesturing-and-accounting — of-epistemic-phenomenalism- $<$ inprospective_psychologismic apriorising/axiomatising/referencing-\{of-'prospectively 
implicited_attendant-ontological-contiguity ' reduced-

existentialising/contextualising/textualising_'intelligibility/epistemicity/reflexivity_contiguity<imbued-notional cogency>> $\}$-conflatedness -in-\{preconverging-disentailment by\}

postconverging-entailment $>$, inducing successive differences of ontological-performance ${ }^{72}$ $<$ including-virtue-as-ontology $>$ /morality/ethics/justice/etc. of ${ }^{5}$ meaningfulness-and-teleology

as of the-very-same-immanent-existence/intrinsic-reality/ontological-veridicality,-as-to'human<amplituding/formative-epistemicity>totalising purview-of-construal' with increasing prospective relative-ontological-completeness $^{87}$, rather reflected as of ontologically-veridical difference-conflatedness ${ }^{13}$-as-to-totalitative-reification-in-singularisation- $<$ as-to-thenondisjointedness/entailment-of-prospective- nonpresencing $>$-as-veridical-epistemicityrelativism-determinism which implied singularisation- $<$ as-to-thenondisjointedness/entailment-of-prospective- nonpresencing $>$ projected epistemicimmanence/veridical-epistemicity-relativism-determinism enables transcendence-andsublimity/sublimation/supererogatory de-mentativity which is "concurrently formatted as formalisation'. Thus we know of the recurrent stories of 'mathematics invented by physicists or mathematicians working under the physics 'implicited_attendant-ontologicalcontiguity $^{67}$, educed-

existentialising/contextmalising/textualising_intelligibility/epistemicity/reflexivity_contiguity<imbued-notional cogency>' guise' as of the insight of their knowledgereification $\sim$ gesturing-and-accounting — of-epistemic-phenomenalism- $<$ inprospective_psychologismic apriorising/axiomatising/referencing-\{of-‘prospectively implicited_attendant-ontological-contiguity ' educedexistentialising/contexalising/texalising_intelligibility/epistemicity/reflexivity-contiguity<imbued-notional cogency $>$ ' \}-conflatedness -in-\{preconverging-disentailment by\} postconverging entailment $>$ of the physics domain-of-study, with such mathematics 'very often 
not well presented but essentially sublime', and thereafter such 'implicited_attendantontological-contiguity ${ }^{6}$ ' educed-

existentialising/contextualising/textualising_'intelligibility/epistemicity/reflexivity-contiguity$<$ imbued-notional cogency $>$ initially reified mathematics is further reified as of mathematics more generalised-level of 'implicited_attendant-ontological-contiguity ${ }^{67}$ ' educedexistentialising/contextualising/textualising_intelligibility/epistemicity/reflexivity-contiguity<imbued-notional cogency $>$ ' insight while 'exquisitely formalised in concurrence'. This reality of 'repeating/repetition of ${ }^{5}$ maximalising-recomposuring-for-relative-ontologicalcompleteness $^{87}$ — unenframed/re-ontologising conceptualisation for knowledgereification $\sim$ gesturing-and-accounting — of-epistemic-phenomenalism- $<$ inprospective_psychologismic a apriorising/axiomatising/referencing-\{of-'prospectively_ implicited_attendant-ontological-contiguity ' ceducedexistentialising/contextualising/textualising_ intelligibility/epistemicity/reflexivity-contiguity-

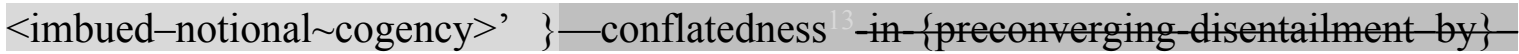
postconverging-entailment $>$, inducing successive differences of ontological-performance ${ }^{72}$ $<$ including-virtue-as-ontology $>$ /morality/ethics/justice/etc. of ${ }^{56}$ meaningfulness-and-teleology as of the-very-same-immanent-existence/intrinsic-reality/ontological-veridicality,-as-to'human<amplituding/formative-epistemicity>totalising $\sim$ purview-of-construal' with increasing prospective relative-ontological-completeness $^{87}$, is very much obvious from the accounts of 'successive partial contributions-and-failures' that lead to major breakthroughs in the natural sciences as of the "very same <amplituding/formative-epistemicity>totalising $\sim$ devolvedpurview/domain-of-construal-as-intrinsic-reality/ontological-veridicality/existential-reality'; with this ontologically-veridical difference-conflatedness ${ }^{13}$-as-to-totalitative-reification-insingularisation-<as-to-the-nondisjointedness/entailment-of-prospective- nonpresencing $>$-asveridical-epistemicity-relativism-determinism 'repeating/repetition of ${ }^{55}$ maximalising- 
recomposuring-for-relative-ontological-completeness ${ }^{8}$ —unenframed/re-

ontologising conceptualisation for knowledge-reification $\sim$ gesturing-and-accounting-ofepistemic-phenomenalism- $<$ in-

prospective_psychologismic apriorising/axiomatising/referencing-\{of-'prospectively implicited_attendant-ontological-contiguity ' educedexistentialising/contextualising/textualising_'intelligibility/epistemicity/reflexivity_contiguity<imbued-notional cogency >' \}-conflatedness -in-\{preconverging-disentailment by\} postconverging-entailment $>$, inducing successive differences of ontological-performance ${ }^{72}$ $<$ including-virtue-as-ontology $>$ /morality/ethics/justice/etc. of ${ }^{56}$ meaningfulness-and-teleology as of the-very-same-immanent-existence/intrinsic-reality/ontological-veridicality,-as-to'human<amplituding/formative-epistemicity>totalising $\sim$ purview-of-construal' with increasing prospective relative-ontological-completeness $^{87}$, construed as occurring within the-very-same scientist, across scientists of the same interest-of-study in a generation, and across scientists of the same developing interest-of-study crossgenerationally as of the "very same $<$ amplituding/formative-epistemicity $>$ totalising $\sim$ devolved — purview/domain-of-construal-asintrinsic-reality/ontological-veridicality/existential-reality'. In this regard, we can appreciate that as of their differing ontological-performance ${ }^{72}-<_{\text {including-virtue-as- }}$ ontology $>$ /morality/ethics/justice/etc. the threshold where the theory-of-relativity-together-withquantum-mechanics - axiomatic-constructs projects its prospective relative-ontologicalcompleteness $^{87}$ is considered as postconverging-or-dialectical-thinking ${ }^{21}$-apriorisingpsychologism, and striving to operate the classical-mechanics-axiomatic-constructs in its projected prior relative-ontological-incompleteness ${ }^{88}$ is effectively preconverging-ordementing -apriorising-psychologism; even though both address the 'very same physics $<$ amplituding/formative-epistemicity $>$ totalising $\sim$ devolved_-purview/domain-of-construal-asintrinsic-reality/ontological-veridicality/existential-reality'. The implications of flawed 
formalisation credo as of conceptual-patterning identitive-constitutedness ${ }^{14}$-as-'epistemictotality ${ }^{37}$-dereification-in-dissingularisation- $<$ as-to-the-disjointedness/disentailment-ofpresencing - absolutising-identitive-constitutedness > -as-flawed-epistemicity-relativismdeterminism implied dissingularisation- $<$ as-to-the-disjointedness/disentailment-ofpresencing — absolutising-identitive-constitutedness $>$ /epistemic-nonimmanence/flawedepistemicity-relativism-determinism extends, as of its flawed primacy of conceptual-patterning on the basis of a conception of knowledge that tends to belittle and trivialise original knowledge contributions geared towards creative knowledge-reification $\sim$ gesturing-and-accounting-ofepistemic-phenomenalism-<in-

prospective_psychologismic $\sim$ apriorising/axiomatising/referencing-\{of-'prospectively implicited_attendant-ontological-contiguity ' educedexistentialising/contextualising/textualising_'intelligibility/epistemicity/reflexivity-contiguity<imbued-notional cogency $\left.>^{\prime}\right\}$ - conflatedness -in-\{preconverging-disentailment by\} postconverging-entailment> while naively overrating contributions to knowledge of a conceptual-patterning orientation, in further blurring the study of the social with mischaracterisations and poor appreciation of transcendence-and-

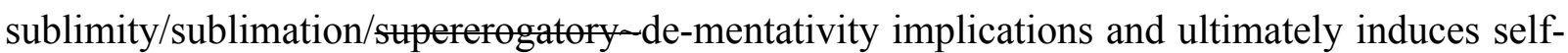
perpetuating artifices of institutional-being-and-craft that mechanically 'paradoxically then supersede knowledge' as of its very organic ontological-good-faith/authenticity ${ }^{6}$. One recurrent consequence of the formalisation credo that keeps on arising for instance in the analytic tradition of philosophy as of its non-totalising-entailing or 'poor apriorising/axiomatising/referencing\{of-'prospectively implicited_attendant-ontological-contiguity ' e educedexistentialising/contextrising/textlising_intelligibility/epistemicity/reflexivity-contiguity$<$ imbued-notional cogency $\left.>{ }^{\prime}\right\}$-conflatedness ${ }^{13}$-in-\{preconverging-disentailment by\} pestcenverging-entailment of totalising-entailing/nested-congruence', is that the underlying 
conception about growing the body of human knowledge seems to be the 'incrementing of all such conceptual-patterning conceptualisations' going by their cross-analysis as of elaborationas-to-mere-extrapolating/constituting/abstracting/deducing/inferring-of-elucidation-outside'prospectively_implicited_attendant-ontological-contiguity ${ }^{67}$ ' educedexistentialising/contextualising/textualising_intelligibility/epistemicity/reflexivity-contiguity<imbued-notional cogency $>^{\prime}$. Basically, the underlying implication of apriorising/axiomatising/referencing-\{of-'prospectively_implicited_attendant-ontologicalcontiguity ' educedexistentialising/contextualising/textualising_'intelligibility/epistemicity/reflexivity-contiguity<imbued-notional cogency $\left.>^{\prime}\right\}$-conflatedness ${ }^{13}$-in-\{preconverging-disentailment-by\} postconverging-entailment, and so over naïve apriorising/axiomatising/referencing-\{of'prospectively_implicited_attendant-ontological-contiguity ' educedexistentialising/contextualising/textualising_'intelligibility/epistemicity/reflexivity-contiguity<imbued-notional cogency >' $\}$-constitutedness ${ }^{1}$-in-preconverging-entailment, is that all ontologically-veridical conceptualisations can only be veridical by their 'abstract reduction to the totalising-entailing/nested-congruence implication of existence-as-the-absolute-a-prioriof-conceptualisation and existence-as-sublimating-withdrawal/unenframing/reontologising,-elicited-from-prospective-profound-supererogation $<$ as-to-perspectiveontological-normalcy/postconvergence-implied-'prospective-aporeticismovercoming/unovercoming'> as of its ecstatic singularity', and thus implies the articulation of all such ontologically-veridical conceptualisations as of singularisation- $<$ as-to-thenondisjointedness/entailment-of-prospective- nonpresencing $>$ projected epistemicimmanence/veridical-epistemicity-relativism-determinism; while avoiding any such conceptualising naivety that may imply 'existence in existence' as this can only lead to flawed conceptualisations, $<$ amplituding/formative-epistemicity $>$ totalising $\sim$ self-referencing- 
syncretising/circularity/interiorising/akrasiatic-drag

and

logocentrism

as

of

apriorising/axiomatising/referencing-\{of-"prospectively_implicited_attendant-ontological-

contiguity ' $\sim$ educed-

existentialising/contextualising/textualising_'intelligibility/epistemicity/reflexivity-contiguity-

<imbued-notional cogency $\left.>{ }^{\prime} \quad\right\}$-constitutedness ${ }^{14}$-in-preconverging entailment. Critically, no concepts have any veridical ${ }^{56}$ meaningfulness-and-teleology ${ }^{9}$ but only rather as of their apriorising/axiomatising/referencing-\{of-'prospectively implicited_attendant-ontologicalcontiguity ' educed-

existentialising/contextualising/textualising_'intelligibility/epistemicity/reflexivity-contiguity<imbued-notional cogency $\left.>^{\prime}\right\}$-conflatedness ${ }^{13}$ in-\{preconverging-disentailment by postconverging-entailment with existence, and cannot be construed as 'existing in existence' as implied by apriorising/axiomatising/referencing-\{of-"prospectively implicited attendantontological-contiguity ' educed-

existentialising/contextualising/textualising_'intelligibility/epistemicity/reflexivity-contiguity<imbued-notional cogency $\left.>^{\prime} \quad\right\}$-constitutedness ${ }^{14}$-in preconverging-entailment which just leads to ontologically-flawed dissingularisation-<as-to-the-disjointedness/disentailment-ofpresencing - absolutising-identitive-constitutedness $>$ /epistemic-nonimmanence/flawedepistemicity-relativism-determinism implied identitive-constitutedness ${ }^{14}$-as-'epistemictotality $^{37}$ '-dereification-in-dissingularisation-<as-to-the-disjointedness/disentailment-ofpresencing - absolutising-identitive-constitutedness $>$-as-flawed-epistemicity-relativismdeterminism . We can appreciate that the naïve conceptual-patterning of conceptualisations in many a social domain-of-study failing to disambiguate divergent knowledge implications-andcontributions as of knowledge-reification $\sim$ gesturing-and-accounting-of-epistemicphenomenalism- $<$ in-prospective_psychologismic $\sim$ apriorising/axiomatising/referencing-\{of'prospectively_implicited_attendant-ontological-contiguity ' ceduced- 
existentialising/contextualising/textualising_'intelligibility/epistemicity/reflexivity-contiguity<imbued-notional cogency>> \}-conflatedness -in-\{preconverging-disentailment by\}

postconverging entailment $>$ end up transforming subject-matters into descriptive enunciations of weak existentially-disontologising/re-ontologising aporeticism $>$ explanatory and predicative capacity. The entire project of human ${ }^{56}$ meaningfulness-and-teleology ${ }^{9}$ is nothing but one of creatively elucidating/reifying existence/existential-possibilities, 'with no out of existence knowledge project', which is merely delusional. Thus, what is critically missing here is the fundamental constraining reality for creative knowledge-reification $\sim$ gesturing-andaccounting - of-epistemic-phenomenalism- $<$ in-

prospective_psychologismic $\sim$ apriorising/axiomatising/referencing-\{of-'prospectively implicited_attendant-ontological-contiguity ' educedexistentialising/contextualising/textualising_'intelligibility/epistemicity/reflexivity_contiguity$<$ imbued-notional cogency $>$ ' \}-conflatedness -in-\{preconverging-disentailment by\} postconverging-entailment>, and so over the mere possibilities for abstracting conceptualisations. This very much explains why many of those who subscribe to the formalisation credo have a poor existential-<disontologising/re-ontologising aporeticism $>$

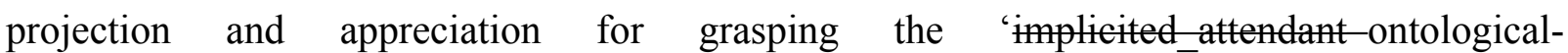
contiguity ${ }^{67} \sim$ educed-

existentialising/contextualising/textualising_intelligibility/epistemicity/reflexivity-contiguity$<$ imbued-notional cogency>' ${ }^{\prime 0}$ reifying gestures of postmodern-thought and other critical theories, and end up often haranguing such orientations by striving to constrain them on the basis of vague abstractions as of elaboration-as-to-mereextrapolating/constituting/abstracting/deducing/inferring-of-elucidation-outside'prospectively_implicited_attendant-ontological-contiguity ${ }^{67}$ ' educedexistentialising/contextualising/textualising_'intelligibility/epistemicity/reflexivity-contiguity- 
<imbued-notional cogency $>$ ' This failure in fully appreciating the import of ontologicallyveridical difference-conflatedness ${ }^{13}$-as-to-totalitative-reification-in-singularisation- $<$ as-to-thenondisjointedness/entailment-of-prospective- nonpresencing > -as-veridical-epistemicity-

relativism-determinism 'repeating/repetition of maximalising-recomposuring-for-relativeontological-completeness ${ }^{87}$ - unenframed/re-ontologising conceptualisation for knowledgereification $\sim$ gesturing-and-accounting - of-epistemic-phenomenalism- $<$ in-

prospective_psychologismic $\sim$ apriorising/axiomatising/referencing-\{of-'prospectively implicited_attendant-ontological-contiguity ' educedexistentialising/contextualising/textualising_'intelligibility/epistemicity/reflexivity-contiguity<imbued-notional cogency $\left.>^{\prime}\right\}$-conflatedness -in-\{preconverging-disentailment by\} postconverging-entailment>, inducing successive differences of ontological-performance ${ }^{72}$ $<$ including-virtue-as-ontology $>$ /morality/ethics/justice/etc. of meaningfulness-and-teleology as of the-very-same-immanent-existence/intrinsic-reality/ontological-veridicality,-as-to'human<amplituding/formative-epistemicity>totalising $\sim$ purview-of-construal' with increasing prospective relative-ontological-completeness $^{87}$, as of implied singularisation-<as-to-thenondisjointedness/entailment-of-prospective- nonpresencing $>$ projected epistemicimmanence/veridical-epistemicity-relativism-determinism has fundamental $<$ amplituding/formative-epistemicity $>$ causality $\sim$ as-to-projective-totalitative-implications-ofprospective- nonpresencing,-for-explicating relative-unreflexivity/relative-reflexivity ontological-contiguity , as transcendence-and-sublimity/sublimation/supererogatory $\sim$ dementativity only arise as of human expansion of its reifying grasp of 'implicited_attendant ontological-contiguity ${ }^{67}$, educed-

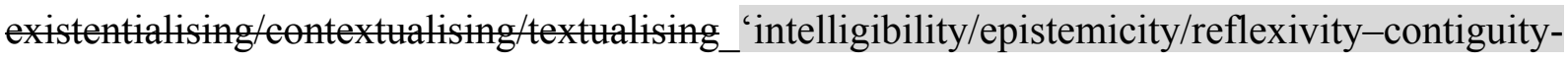
$<$ imbued-notional cogency $>$ ' Consider in this regard that the repeated ${ }^{5}$ maximalisingrecomposuring-for-relative-ontological-completeness ${ }^{8}$ —unenframed/re- 
ontologising $\sim$ conceptualisation articulation by this author on the theme of conceptual-patterning here further complements as of further articulated reification of this very theme elsewhere herein, more than just about a mechanical repeating; and this knowledge-reification $\sim$ gesturing-andaccounting - of-epistemic-phenomenalism- $<$ in-

prospective_psychologismic apriorising/axiomatising/referencing-\{of-'prospectively_ implicited_attendant_ontological-contiguity ' educedexistentialising/contextualising/textualising_intelligibility/epistemicity/reflexivity_contiguity<imbued-notional cogency $\left.>^{\prime} \quad\right\}$-conflatedness -in-\{preconverging-disentailment by\} postconverging-entailment> insight often goes missing with many a subscriber to the formalisation credo, as of reification along the three frames indicated above (as of same scholar interest-of-study, scholars of the same generation interest-of-study and scholars crossgenerationally developing interest-of-study). In this regard, the contribution of poststructuralist scholars like Foucault, Derrida, Lyotard, Lacan, Deleuze have now and then been belittled as not original, as of a very much naïve conceptual-patterning-〈as-devoid-of'prospectively_implicited_attendant_ontological-contiguity ' educedexistentialising/contextualising/textualising_'intelligibility/epistemicity/reflexivity-contiguity<imbued-notional cogency>' 's-reifying-or-elucidating-of-'prospective-relative-ontologicalcompleteness ' ;-so-rather-enabled-<by-a- nonpresencing-divulging-of-momentoushistoriality/ontological-eventfulness /ontological-aesthetic-tracing-<perspectiveontological-normalcy/postconvergence-reflected-‘epistemicity-relativism-determinism’>> conception of knowledge; going by their profound association with earlier scholars and more specifically Heidegger and Nietzsche. From a creative knowledge-reification $\sim$ gesturing-andaccounting - of-epistemic-phenomenalism- $<$ in-

prospective_psychologismic apriorising/axiomatising/referencing-\{of-'prospectively implicited_attendant-ontological-contiguity ' educed- 
existentialising/contextualising/textualising_ 'intelligibility/epistemicity/reflexivity-contiguity$<$ imbued-notional $\left.\sim \operatorname{cogency}>^{\prime} \quad\right\}$-conflatedness -in-\{preconverging disentailment by\}

postconverging-entailment> construal perspective, this is no less silly as dismissing and belittling as unoriginal the ideas of later physicists on the flawed argument that their contributions are supposedly just more evolved formalisation as of conceptual-patterning of concepts originarily/as-of-event ${ }^{38}$ available to earlier contributors to the "traditional classical mechanics axiomatic-construct' propounded by Newton together with the conceptual-patterning influences of Galileo, Descartes, Leibniz, etc. (as to 'a flawed mere conceptual-patterning-〈asdevoid-of-'prospectively_implicited_attendant-ontological-contiguity ' educedexistentialising/contextualising/textualising_'intelligibility/epistemicity/reflexivity-contiguity<imbued-notional cogency>', 's-reifying-or-elucidating-of-'prospective-relative-ontologicalcompleteness ' ;-so-rather-enabled-<by-a- nonpresencing-divulging-of-momentoushistoriality/ontological-eventfulness /ontological-aesthetic-tracing-<perspectiveontological-normalcy/postconvergence-reflected-'epistemicity-relativism-determinism'>> interpreting' of such concepts like space, time, force, etc.). Such a conclusion certainly reflects a 'massive ontological dearth' in failing to appreciate the creative knowledgereification $\sim$ gesturing-and-accounting — of-epistemic-phenomenalism- $<$ inprospective_psychologismic apriorising/axiomatising/referencing-\{of-'prospectively implicited_attendant-ontological-contiguity ' educedexistentialising/contextualising/textualising_ 'intelligibility/epistemicity/reflexivity-contiguity<imbued-notional $\left.\sim \operatorname{cogency}>^{\prime} \quad\right\}$-conflatedness -in-\{preconverging-disentailment by\} postconverging entailment $><$ amplituding/formative-epistemicity $>$ causality $\sim$ as-to-projectivetotalitative-implications-of-prospective- nonpresencing,-for-explicating relativeunreflexivity/relative-reflexivity ontological-contiguity of the latter contributors in both instances. This further speaks of a poor grasp of the human knowledge project as being all about 
further reifying human grasp of the-very-same-immanent-existence/intrinsic-reality/ontologicalveridicality,-as-to-‘human<amplituding/formative-epistemicity $>$ totalising $\sim$ purview-ofconstrual', with the intellectual's job to the best of their abilities rather being about orientating its effort for the best possibility to further this goal whether as of critical altogether new thought development or critical recomposuring of prior thought, or both. More likely than not the headway made by prior scholars means that the good intellectual knows as of the true goal of human knowledge advancement beyond just institutional-being-and-craft that their best effort is rather in further advancing/reifying-or-elucidating the headway as of 'repeating/repetition of maximalising-recomposuring-for-relative-ontological-completeness ${ }^{87}$ - unenframed/reontologising conceptualisation for knowledge-reification $\sim$ gesturing-and-accounting-ofepistemic-phenomenalism-<in-

prospective_psychologismic apriorising/axiomatising/referencing-\{of-'prospectively implicited_attendant-ontological-contiguity ' educedexistentialising/contextualising/textualising_ 'intelligibility/epistemicity/reflexivity-contiguity<imbued-notional cogency>' \}-conflatedness -in-\{preconverging-disentailment by\} postconverging-entailment>, inducing successive differences of ontological-performance ${ }^{72}$ $<$ including-virtue-as-ontology $>$ /morality/ethics/justice/etc. of ${ }^{5}$ meaningfulness-and-teleology as of the-very-same-immanent-existence/intrinsic-reality/ontological-veridicality,-as-to'human<amplituding/formative-epistemicity>totalising purview-of-construal' with increasing prospective relative-ontological-completeness ${ }^{87}$, This is especially the case where such headway mirrors 'pure-ontology' articulation, as there is only one ontological as existential$<$ disentologising/re-ontelogising aporeticism $>$ reality. This orientation and rearticulating exercise by postmodern-thought speaks rather of an assurance that they are on a solid ontological pathway just as physicists orientation and redevelopment of the ontic lines setup by the early Galileos, Newtons and Leibnizes speaks of an assurance of ontological depth, in both instances 
as of their knowledge-reification $\sim$ gesturing-and-accounting-of-epistemic-phenomenalism<in-prospective_psychologismic $\sim$ apriorising/axiomatising/referencing-\{of-'prospectively_ implicited_attendant-ontological-contiguity ' educedexistentialising/contextualising/textualising_'intelligibility/epistemicity/reflexivity-contiguity<imbued-notional cogency >' \}-conflatedness -in-\{preconverging disentailment by\} postconverging-entailment>. Ultimately, and it is herein contended that the various scholarly contributions to postmodern-thought can be understood as rather pointing to the preconverging/postconverging-de-mentative/structural/paradigmatic disseminative implications of futural Being-development/ontological-framework-expansion-as-to-depth-ofontologising-development-as-infrastructure-of- meaningfulness-and-teleology as of prospective ${ }^{18}$ deprocrypticism-or-preempting-disjointedness-as-of- ${ }^{8}$ reference-of-thought ontologically-veridical difference-conflatedness ${ }^{3}$-as-to-totalitative-reification-insingularisation-<as-to-the-nondisjointedness/entailment-of-prospective- nonpresencing $>$-asveridical-epistemicity-relativism-determinism . We can equally appreciate that much of the disseminative rational-empiricism/positivism implications of the works of such pioneers like Copernicus, Galileo, and specifically Descartes, etc. created a 'rational-empiricism/positivism disseminative metaphoricity ${ }^{57}$ orientation making the human subject thinking as of mathesis 'universalis conceptualisation central' reflected by Descartes 'I think therefore I am', and as followed and adopted to resolve various human knowledge issues by subsequent thinkers in successive generations as of human ontological-faith-notion-or-ontological-fideism -imbuedunderdetermination-of-motif-and-apriorising/axiomatising/referencing-as-so-being-as-ofexistential-reality reasoning-through/messianic-reasoning wherein in their states of undecidability/aporia 'left it' to existence as of <emplituding/formativeepistemicity $>$ causality $\sim$ as-to-projective-totalitative-implications-of-prospectivenonpresencing,-for-explicating relative-unreflexivity/relative-reflexivity - ontological- 
contiguity as the veritable transcendental-signifier/transcendentalenabling/sublimating/supereregatery de-mentativity to 'continually select' rationalempiricism/positivism disseminative orientations for transcendence-andsublimity/sublimation/supererogatory $\sim$ de-mentativity, leading to our present refined positivism/rational-empiricism conception! But then because our present 'positivismprocrypticism human subject is rather undecentered' relative to the prospective postmodernnotional ${ }^{18}$ deprocrypticism self-conscious mindset we fail to truly appreciate the preconverging/postconverging-de-mentative/structural/paradigmatic disseminative implications of postmodern-thought as of the prospective exercise of 'leaving it' to existence as of <amplituding/formative-epistemicity $>$ causality $\sim$ as-to-projective-totalitative-implicationsof-prospective- nonpresencing,-for-explicating relative-unreflexivity/relative-reflexivity ontological-contiguity as the veritable transcendental-signifier/transcendentalenabling/sublimating/supereregatory de-mentativity to 'continually select' postmodernnotional ${ }^{1}$ deprocrypticism disseminative orientations for transcendence-andsublimity/sublimation/supererogatory de-mentativity, in the same vain that the 'nonpositivism/medievalism undecentered human subject' failed to truly appreciate the preconverging/postconverging-de-mentative/structural/paradigmatic disseminative implications of prospective positivistm/rational-empiricism thought. On-the-other-hand, recurrent mere conceptual-patterning-〈as-devoid-of-'prospectively implicited_attendantontological-contiguity ' educed-

existentialising/contextualising/textualising_'intelligibility/epistemicity/reflexivity-contiguity<imbued-notional cogency>' 's-reifying-or-elucidating-of-'prospective-relative-ontologicalcompleteness ' ;-so-rather-enabled-<by-a- nonpresencing-divulging-of-momentoushistoriality/ontological-eventfulness /ontological-aesthetic-tracing-<perspectiveontological-normalcy/postconvergence-reflected-‘epistemicity-relativism-determinism’>> 
predispositions and orientations arise because of poor appreciation/reference for judging knowledge often as of poor institutional mechanical conceptualisation of knowledge, wherein the constraining metrics of institutional setups including strangely enough also many such tertiary institutions where poststructuralist thinkers studied-and-taught-as-outlying-intellectuals, 'apparently and falsely surpass existence-as-the-absolute-a-priori-ofconceptualisation and existence — as-sublimating-withdrawal/unenframing/re-ontologising,elicited-from-prospective-profound-supererogation $-<$ as-to-perspective-ontologicalnormalcy/postconvergence-implied-'prospective-aporeticism-overcoming/unovercoming'>’'

Such institutional nombrilistic inclinations operate on the naivety that institutional processes are inherently reifying by their mere infrastructure and deferential-formalisation-transference, and set up enframed constraints that are in-many-ways self-defeating for the purpose of profound knowledge-reification $\sim$ gesturing-and-accounting —of-epistemic-phenomenalism- $<$ inprospective_psychologismic apriorising/axiomatising/referencing-\{of-'prospectively implicited_attendant-ontological-contiguity ' educedexistentialising/contextualising/textualising_'intelligibility/epistemicity/reflexivity-contiguity<imbued-notional cogency >' \}-conflatedness -in-\{preconverging-disentailment by\} pestenverging for transcendence-and-sublimity/sublimation/supererentementativity. But then with regards to the social notwithstanding its high emotional-involvement disruptiveness to knowledge, more profoundly knowledge-reification $\sim$ gesturing-andaccounting - of-epistemic-phenomenalism- $<$ inprospective_psychologismic apriorising/axiomatising/referencing-\{of-'prospectively_ implicited_attendant-ontological-contiguity ' educedexistentialising/contextrising/textralising_intelligibility/epistemicity/reflexivity-contiguity<imbued-notional cogency $\left.>^{\prime} \quad\right\}$-conflatedness -in-\{preconverging-disentailment by\} postconverging entailment $>$ here implies human displacement/decentering even though our 
temporal/shortness-of-register-of - meaningfulness-and-teleology dispositions certainly have a hard time assuming the full implications of such prospectively implied transcendental meaningfulness-and-teleology ${ }^{9}$. This further speaks to the fact that human knowledge is much more than distantly/remotely abstracted conceptions of ${ }^{56}$ meaningfulness-and-teleology ${ }^{9}$ of trite knowledge-reification $\sim$ gesturing-and-accounting —of-epistemic-phenomenalism- $<$ inprospective_psychologismic apriorising/axiomatising/referencing-\{of-'prospectively implicited_attendant-ontological-contiguity ' educedexistentialising/contextualising/textualising_'intelligibility/epistemicity/reflexivity-contiguity$<$ imbued-notional cogency $>\quad\}$-conflatedness -in-\{preconverging disentailment by\} postconverging-entailment $><$ amplituding/formative-epistemicity $>$ causality $\sim$ as-to-projectivetotalitative-implications-of-prospective- nonpresencing,-for-explicating relativeunreflexivity/relative-reflexivity - ontological-contiguity , as on critical occasions this puts the human subject itself into question; and so, as of 'ontological-faith-notion-or-ontologicalfideism —imbued-underdetermination-of-motif-and-apriorising/axiomatising/referencing-asso-being-as-of-existential-reality parrhesiastic askesis-or-acumen as of reasoningthrough/messianic-reasoning' even where this edges into contortioning asceticism as of ostential-preempting-of-existential-unthought. Such 'pureontology' orientation grounded on creative knowledge-reification gesturing-and-accountingof-epistemic-phenomenalism- $<$ in-

prospective_psychologismic apriorising/axiomatising/referencing-\{of-'prospectively implicited_attendant-ontological-contiguity ' educedexistentialising/contextualising/textualising_ intelligibility/epistemicity/reflexivity-contiguity<imbued-notional cogency >' \}-conflatedness in \{preconverging disentailment by\} postconverging-entailment> is ever always a 'apriorising/axiomatising/referencing-\{of'prospectively implicited_attendant-ontological-contiguity ' educed- 
existentialising/contextualising/textualising_ 'intelligibility/epistemicity/reflexivity-contiguity<imbued-notional cogency $>\quad\}$-conflatedness ${ }^{13}$-in-\{preconverging-disentailment by\} postconverging-entailment totalising-entailing/nested-congruence' as it aspires to grasping and articulating ${ }^{56}$ meaningfulness-and-teleology ${ }^{9}$ as portends to the wholeness/nested-congruence of the-very-same-immanent-existence/intrinsic-reality/ontological-veridicality,-as-to'human<amplituding/formative-epistemicity>totalising purview-of-construal'; with such construal in reality rather very much as of singularisation- $<$ as-to-thenondisjointedness/entailment-of-prospective- nonpresencing $>$ projected epistemicimmanence/veridical-epistemicity-relativism-determinism rather than dissingularisation- $<$ as-tothe-disjointedness/disentailment-of- presencing — absolutising-identitive-

constitutedness $>$ /epistemic-nonimmanence/flawed-epistemicity-relativism-determinism. It is thus not a surprise that many natural sciences in their 'creative knowledgereification $\sim$ gesturing-and-accounting — of-epistemic-phenomenalism- $<$ in-

prospective_psychologismic apriorising/axiomatising/referencing-\{of-‘prospectively implicited_attendant-ontological-contiguity ' educedexistentialising/contextualising/textualising_'intelligibility/epistemicity/reflexivity-contiguity<imbued-notional cogency >’ $\}$-conflatedness in \{preconverging disentailment by postconverging-entailment>' develop as and aspire to be whole/congruent in conception, even though their concepts can be misconstrued as rather disparate but in effect are 'operant as of wholeness/nested-congruence'. Likewise, the underlying ${ }^{18}$ deprocrypticism-or-preemptingdisjointedness-as-of- ${ }^{-3 e f e r e n c e-o f-t h o u g h t ~}$ apriorising/axiomatising/referencing- $\{$ of'prospectively_implicited_attendant_ontological-contiguity ' educedexistentialising/contexalising/textlising_intelligibility/epistemicity/reflexivity-contiguity$<$ imbued-notional cogency $\left.>{ }^{\prime}\right\}$-conflatedness ${ }^{13}$-in-\{preconverging-disentailment by\} postconverging-entailment totalising-entailing/nested-congruence suprastructuralism 
conception herein is rather articulated as of singularisation-<as-to-thenondisjointedness/entailment-of-prospective- nonpresencing $>$ projected epistemicimmanence/veridical-epistemicity-relativism-determinism as of epistemic reflection of the ecstatic singularity of existence-as-the-absolute-a-priori-ofconceptualisation $\sim$ and existence — as-sublimating-withdrawal/unenframing/re-ontologising,elicited-from-prospective-profound-supererogation $-<$ as-to-perspective-ontologicalnormalcy/postconvergence-implied-'prospective-aporeticism-overcoming/unovercoming'>. Unlike the apriorising/axiomatising/referencing-\{of-"prospectively implicited_attendantontological-contiguity ' educedexistentialising/contextualising/textualising_'intelligibility/epistemicity/reflexivity-contiguity<imbued-notional cogency $\left.>^{\prime} \quad\right\}$-constitutedness ${ }^{14}$-in-preconverging-entailment $\quad$ rampant with human and social conceptualisations, it is important to grasp that conceptualisations in many a natural science domain tend to be naturally as of apriorising/axiomatising/referencing\{of-'prospectively_implicited_attendant-ontological-contiguity ' educedexistentialising/contextualising/textualising_'intelligibility/epistemicity/reflexivity-contiguity-

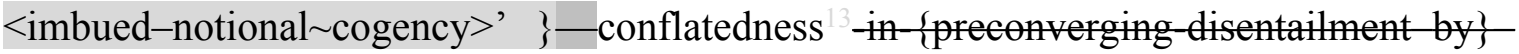
thentalising-entailing/nested-congruence given their theoreal, conceptual and operant existential-<disontologising/re-ontologising aporeticism $>$ contiguity/congruence $\quad<$ amplituding/formative-epistemicity $>$ causality $\sim$ as-to-projectivetotalitative-implications-of-prospective- nonpresencing,-for-explicating relativeunreflexivity/relative-reflexivity ontological-contiguity with the 'ecstatic singularity of thevery-same-immanent-existence/intrinsic-reality/ontological-veridicality,-as-to'human<amplituding/formative-epistemicity>totalising purview-of-construal' implied with regards to all such seemingly ad-hoc conceptualisations being contiguously reflected across space and time'. We can consider in this regard the strongly nested-congruence/contiguity of 
seemingly disparate conceptualisations as force, energy, etc. in physics or hereditary and functional conceptualisations in biology; reflected as of the specifically ecstatically nestedcongruence of such conceptualisations with the existential-<disentologising/re-ontelogising aporeticism $>$ wholeness, and so more than just abstractable conceptualisations out of sync with effective nesting as of the existential-<disontologising/re-ontologising aporeticism $>$ wholeness. In other words, the nestedness of the conceptualisations imply that there is a natural or existential-<disontologising/re-ontologising apereticism $>$ cogency-and-fluidity among the concepts, speaking-of-and-reflecting their wholeness; the implication is not necessarily that all the whole field-of-study must be grasped all at once but rather that this existential$<$ disontologising/re-ontologising aporeticism $>$ cogency-and-fluidity speaking-of-andreflecting wholeness must insightfully be grasped before articulating existentially/ontologically pertinent conceptualisations that are equally cogent-and-fluid with the wholeness. That underlying dynamic theoretical-conceptual-operant interrelatedness speaking of singularisation<as-to-the-nondisjointedness/entailment-of-prospective- nonpresencing $>$ projected epistemic-immanence/veridical-epistemicity-relativism-determinism is often very much lacking in many a social domain-of-study which ad-hoc nature of conceptualisations can easily be misconstrued as of the same wholeness/nested-congruence nature with many natural science conceptualisations. This reality of comprehensive depth of knowledge is easily lost to ad-hoc and disparate social conceptualisations that by their apriorising/axiomatising/referencing-\{of'prospectively_implicited_attendant_ontological-contiguity ' educedexistentialising/contextualising/textualising_intelligibility/epistemicity/reflexivity-contiguity<imbued-notional cogency $\left.>^{\prime} \quad\right\}$ - constitutedness ${ }^{14}$-in-preconverging-entailment token tend to give up on the central issue of knowledge as of its wholeness/nested-congruence reflection 'as of creative knowledge-reification $\sim$ gesturing-and-accounting-of-epistemic-phenomenalism$<$ in-prospective_psychologismic $\sim$ apriorising/axiomatising/referencing-\{of-'prospectively 
implicited_attendant-ontological-contiguity ' reduced-

existentialising/contextualising/textualising_'intelligibility/epistemicity/reflexivity_contiguity<imbued-notional cogency>> $\}$-conflatedness -in-\{preconverging-disentailment by\} postconverging-entailment> $>$ of existence-as-the-absolute-a-priori-ofconceptualisation $\sim$ and existence — as-sublimating-withdrawal/unenframing/re-ontologising,elicited-from-prospective-profound-supererogation $-<$ as-to-perspective-ontologicalnormalcy/postconvergence-implied-'prospective-aporeticism-overcoming/unovercoming'> in its ecstatic singularity. The naivety of implied apriorising/axiomatising/referencing-\{of'prospectively implicited_attendant-ontological-contiguity ' ceducedexistentialising/contextualising/textualising_'intelligibility/epistemicity/reflexivity-contiguity$<$ imbued-notional cogency $\left.>^{\prime} \quad\right\}$-constitutedness ${ }^{14}$-in-preconverging-entailment in the social is in the expectation that the unity of disparateness of conceptualisations as of the-very-sameimmanent-existence/intrinsic-reality/ontological-veridicality,-as-to'human<amplituding/formative-epistemicity>totalising $\sim$ purview-of-construal' will take care of itself in reflecting the ecstatic singularity of existence without human self-conscious wholeness/nested-congruence conception as of apriorising/axiomatising/referencing-\{of'prespectively_implicited_attendant-ontological-contiguity ' educedexistentialising/contextmalising/textualising_'intelligibility/epistemicity/reflexivity_contiguity$<$ imbued-notional $\sim$ cogency $\left.>^{\prime} \quad\right\}$-conflatedness ${ }^{13}$-in-\{preconverging-disentailment by\} postconverging-entailment in this respect; but then such parsimony loses more than just wholeness/nested-congruence in the sense that sound conceptualisations cannot be done without a sense of wholeness/nested-congruence in the first place, and more precisely as of 'totalisingentailing/nested-congruence apriorising/axiomatising/referencing-\{of-"prespectively implicited_attendant-ontological-contiguity ' educedexistentialising/contextualising/textualising_'intelligibility/epistemicity/reflexivity-contiguity- 
<imbued-notional cogency >' \}-conflatedness ${ }^{13}$ in-\{preconverging disentailment by\} postconverging-entailment with existence as of its ecstatic singularity'. While in-many-ways the natural sciences as immediately-and-directly constrained by <amplituding/formativeepistemicity $>$ causality $\sim$ as-to-projective-totalitative-implications-of-prospectivenonpresencing,-for-explicating relative - unreflexivity/relative-reflexivity ontologicalcontiguity are naturally and ad-hocly postconvergingly-de-mentated/structured/paradigmed to implicitly construe wholeness/nested-congruence of conception as of 'totalisingentailing/nested-congruence apriorising/axiomatising/referencing-\{of-"prospectively implicited_attendant-ontological-contiguity ' educedexistentialising/contextualising/textualising_'intelligibility/epistemicity/reflexivity-contiguity$<$ imbued-notional $\left.\sim \operatorname{cogency}>^{\prime}\right\}$-conflatedness ${ }^{13}{ }^{\text {in }}$ - preconverging-disentailment by $^{\prime}$ postconverging-entailment with existence as of its ecstatic singularity' with regards to their conceptualisations, this cannot be said of the same of the social as of the need for its selfconscious understanding of wholeness/nested-congruence conception as of 'apriorising/axiomatising/referencing-\{of-'prospectively_implicited_attendant-ontologicalcontiguity ' educed-

existentialising/contexalising/textising_intelligibility/epistemicity/reflexivity-contiguity<imbued-notional cogency>' \}-conflatedness ${ }^{13}$-in-\{preconverging-disentailment by\} postconverging-entailment with existence as of its ecstatic singularity' given its inherent blurriness-<sterilising/anecdotalising/trivialising-of-prospective-re-ontologising_bypreconverging,-in-disontologising-formulaic-dragging-out/hollowing-out>, $<$ amplituding/formative--epistemicity $>$ totalising $\sim$ self-referencingsyncretising/circularity/interiorising/akrasiatic-drag ${ }^{34}$ and emotional-involvement, in order to then achieve parallel level of <amplituding/formative-epistemicity $>$ causality $\sim$ as-to-projectivetotalitative-implications-of-prospective- nonpresencing,-for-explicating relative- 
unreflexivity/relative-reflexivity ontological-contiguity knowledge conception as of singularisation-<as-to-the-nondisjointedness/entailment-of-prospective- nonpresencing $>$ projected epistemic-immanence/veridical-epistemicity-relativism-determinism. In effect this ontological difficulty fundamentally has to do with the inherent difficulty of dispensing-withimmediacy-for-relative-ontological-completeness ${ }^{87}$-by-reification/contemplative-distension (as of human self-surpassing — existentialism-form-factor,-in-overcoming'notional collateralising-beholdening-protohumanity'-to-'attain-sublimating-humanity'-as-toexistence-potency $\sim$ sublimating-nascence,-disclosed-from-prospective-epistemic-digression to supersede human temporality 8 /shortness <amplituding/formative> wooden-language〈imbued-averaging-of-thought-<as-to-leveling/ressentiment/closed-construct-ofmeaningfulness-and-teleology -as-of-‘nondescript/ignorable-void '-with-regards-toprospective-apriorising-implications $>\rangle$ ) construed as 'dispensing-with-shallowmathesis/motif/thrownness-disposition'-for-relative-ontological-completeness ${ }^{87}$-by-reification; with human self-consciousness rather prone to its given ${ }^{83}$ reference-of-thought reproducibilitymathesis/motif/thrownness-disposition,-as-reproducibility-of-aestheticisation apriorising/axiomatising/referencing/intelligibilitysettingup/measuringinstrumenting for its knowledge construal. The insight for singularisation-<as-to-the-nondisjointedness/entailmentof-prospective- nonpresencing $>$ projected epistemic-immanence/veridical-epistemicityrelativism-determinism being that as of its 'dispensing-with-shallowmathesis/motif/thrownness-disposition'-for-relative-ontological-completeness ${ }^{87}$-by-reification, as increasing prospective relative-ontological-completeness ${ }^{87}$-of- ${ }^{-}$reference-of-thought towards ontologically-uncompromised-referentialism avails, effectively the construal of the social assumes the requisite reproducibility—mathesis/motif/thrownness-disposition,--asreproducibility-of-aestheticisation apriorising/axiomatising/referencing/intelligibilitysettingup/measuringinstrumenting for 
wholeness/nested-congruence conceptualisation as of the apriorising/axiomatising/referencing\{of-'prospectively_implicited_attendant-ontological-contiguity ' e educedexistentialising/contextualising/textualising_'intelligibility/epistemicity/reflexivity-contiguity$<$ imbued-notional $\left.\sim \operatorname{cogency}>^{\prime} \quad\right\}$-conflatedness ${ }^{13}$-in-\{preconverging-disentailment by\} postconverging-entailment of 'prospective ontological-normalcy/postconvergence ontologically-uncompromised-referentialism notional ${ }^{18}$ deprocrypticism apriorising/axiomatising/referencing/intelligibilitysettingup/measuringinstrumenting', implied by the suprastructuralism conception herein in fully reflecting the ecstatic singularity of existence-as-the-absolute-a-priori-of-conceptualisation and existence-as-sublimatingwithdrawal/unenframing/re-ontologising,-elicited-from-prospective-profoundsupererogation -<as-to-perspective-ontological-normalcy/postconvergence-implied'prospective-aporeticism-overcoming/unovercoming'>, and so over our present parsimony/disparateness of conceptualisations 'reproducibility—mathesis/motif/thrownnessdisposition,-as-reproducibility-of-aestheticisation as-of-ontologically-compromisedcategorising positivism- ${ }^{8}$ procrypticism apriorising/axiomatising/referencing/intelligibilitysettingup/measuringinstrumenting'. Thus we can appreciate here that ultimately singularisation-<as-to-the-nondisjointedness/entailment-ofprospective- nonpresencing $>\quad$ projected epistemic-immanence/veridical-epistemicityrelativism-determinism is not just artificially prompted but is rather the preconverging/postconverging-de-mentative/structural/paradigmatic consequence of the prospective relative-ontological-completeness ${ }^{87}$-of- ${ }^{83}$ reference-of-thought apriorising/axiomatising/referencing/intelligibilitysettingup/measuringinstrumenting attitude/mental-disposition/care-and-episteme, ultimately as of prospective ontologicalnormalcy/postconvergence ontologically-uncompromised-referentialism deprocrypticismor-preempting - disjointedness-as-of- ${ }^{-3}$ reference-of-thought. Our mental-disposition is caught 
up between its capacity to conceptualise as of singularisation- $<$ as-to-thenondisjointedness/entailment-of-prospective- nonpresencing $>$ projected epistemicimmanence/veridical-epistemicity-relativism-determinism implied prospective relativeontological-completeness apriorising/axiomatising/referencing- $\{$ of-'prospectively implicited_attendant-ontological-contiguity ' educedexistentialising/contextualising/textualising_ intelligibility/epistemicity/reflexivity-contiguity<imbued-notional cogency $\left.>{ }^{\prime}\right\}$ - conflatedness ${ }^{13}$-in-\{preconverging-disentailment-by\} postconverging-entailment and dissingularisation- $<$ as-to-the-disjointedness/disentailment-ofpresencing — absolutising-identitive-constitutedness $>$ /epistemic-nonimmanence/flawedepistemicity-relativism-determinism implied prior relative-ontological-incompleteness apriorising/axiomatising/referencing-\{of-'prospectively implicited_attendant-ontologicalcontiguity ' $\sim$ educedexistentialising/contextualising/textualising_'intelligibility/epistemicity/reflexivity_contiguity$<$ imbued-notional cogency $>$ ' $\}$-constitutedness ${ }^{1}$-in-preconverging-entailment; $\quad$ and

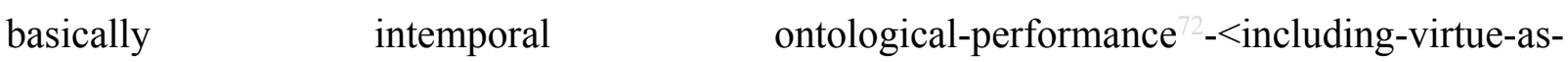
ontology $>$ /morality/ethics/justice/etc. arises by drawing out the full <amplituding/formativeepistemicity $>$ causality $\sim$ as-to-projective-totalitative-implications-of-prospectivenonpresencing,-for-explicating relative-unreflexivity/relative-reflexivity - ontologicalcontiguity of ${ }^{5}$ meaningfulness-and-teleology ${ }^{9}$ exclusively as of singularisation- $<$ as-to-thenondisjointedness/entailment-of-prospective- nonpresencing $>$ projected epistemicimmanence/veridical-epistemicity-relativism-determinism implied apriorising/axiomatising/referencing-\{of- prospectively implicited_attendant-ontologicalcontiguity ' $\sim$ educedexistentialising/contextualising/textualising_intelligibility/epistemicity/reflexivity_contiguity<imbued-notional cogency $\left.>^{\prime}\right\}$ - conflatedness ${ }^{13}$-in-\{preconverging-disentailment by\} 
postconverging-entailment prospective relative-ontological-completeness ${ }^{87}$ as it enables 'ontological-performance ${ }^{72}-<$ including-virtue-as-ontology $>/$ morality/ethics/justice/etc. to be utterly as of predictable preconverging/postconverging-de-mentative/structural/paradigmatic internal-necessity/determinism so-construed as immanence-function-conflatedness ${ }^{13}$, Thus the inherent ecstatic singularity of existence carries intemporal 'immanence-functionsconflatedness ${ }^{13} \quad<$ amplituding/formative-epistemicity $>$ causality $\sim$ as-to-projective-totalitativeimplications-of-prospective- nonpresencing,-for-explicating relative-unreflexivity/relativereflexivity - ontological-contiguity , as of singularisation-<as-to-thenondisjointedness/entailment-of-prospective- nonpresencing $>$ projected epistemicimmanence/veridical-epistemicity-relativism-determinism apriorising/axiomatising/referencing-\{of-"prospectively_implicited_attendant_ontologicalcontiguity ' educedexistentialising/contextualising/textualising_'intelligibility/epistemicity/reflexivity-contiguity-

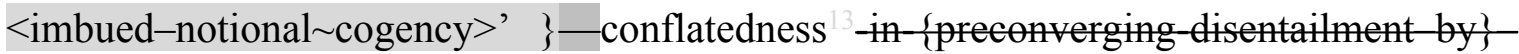
postcenverging-entailment, while dissingularisation- $<$ as-to-the-disjointedness/disentailment-ofpresencing — absolutising-identitive-constitutedness $>$ /epistemic-nonimmanence/flawedepistemicity-relativism-determinism apriorising/axiomatising/referencing-\{of- ${ }^{\text {prespectively }}$ implicited_attendant-ontological-contiguity ' reducedexistentialising/contextualising/textualising_ intelligibility/epistemicity/reflexivity-contiguity<imbued-notional cogency>' $\}$-constitutedness ${ }^{14}$-in-preconverging-entailment arises as of $<$ amplituding/formative-epistemicity $>$ totalising $\sim$ self-referencingsyncretising/circularity/interiorising/akrasiatic-drag ${ }^{34}$ ontological-construal defect when naively failing to convey the 'immanence-function-conflatedness ${ }^{13}$ implication' of overall reifying-andempowering-reflexivity-of-ecstatic-existence-as-panintelligibility/panreflexivity ${ }^{3}$ $\langle$ existentially-imbued-and-educing-<epistemic- 
totalising thermeneutically/textually/reprojectingly/supererogatingly/zeroingly/re-acutingly,-

$\{$ decompulsing $\}$ delinearity $\sim$ for-cogency $\geq$-epistemic-perspective-of-projective/reprojective-

aestheticising-re-motif-and-re-apriorising/re-axiomatising/re-referencing $\sim$ conceptualisation--

as herein-specifieally relevant to human-subpotency). Thus naturalistic methodologies are only as pertinent as of their explaining of underlying background of the social as of physical and biological reality, but not as substitutive explanations as to overall reifying-and-empoweringreflexivity-of-ecstatic-existence-as-panintelligibility/panreflexivity ${ }^{3}$-〈existentially-imbuedand-educing-< $<$ fepistemic-

totalising thermeneutically/textually/reprojectingly/supererogatingly/zeroingly/re-acutingly,$\{$ decompulsing\} $d e$ linearity for-cogency $>$-epistemic-perspective-of-projective/reprojectiveaestheticising-re-motif-and-re-apriorising/re-axiomatising/re-referencing conceptualisation,as-herein-specifically-relevant-to human-subpotency) of social emanance as this is bound to induce apriorising/axiomatising/referencing-\{of-'prospectively implicited_attendantontological-contiguity ' educed-

existentialising/entextrising/textrising_intelligibility/epistemicity/reflexivity-contiguity<imbued-notional cogency $\left.>^{\prime} \quad\right\}$-constitutedness ${ }^{4}$-in-preconverging-entailment. What is misjudged by many naturalistic methodologies with regards to the social is the fact that the very reality as to overall reifying-and-empowering-reflexivity-of-ecstatic-existence-aspanintelligibility/panreflexivity ${ }^{3}$-〈existentially-imbued-and-educing-\{epistemictotalising thermeneutically/textully/reprojectingly/supererogatingly/zeroing/y/re acutingly,$\{$ decompulsing $\}$ delinearity for-cogency $\geq$-epistemic-perspective-of-projective/reprojectiveaestheticising-re-motif-and-re-apriorising/re-axiomatising/re-referencing conceptualisation-as herein-specifically-relevant-to human-subpotency) of an outright social emanance as arising from intemporal ontological-faith-notion-or-ontological-fideism -imbuedunderdetermination-of-motif-and-apriorising/axiomatising/referencing-as-so-being-as-of- 
existential-reality instigated relative-unreflexivity/relative-reflexivity-ontologicalcontiguity ${ }^{67}$ of-the-human-institutionalisation-process ${ }^{68}$ as of difference-conflatedness ${ }^{13}$-as-tototalitative-reification-in-singularisation-<as-to-the-nondisjointedness/entailment-of-

prospective- nonpresencing $>$-as-veridical-epistemicity-relativism-determinism implied $<$ amplituding/formative-epistemicity $>$ causality $\sim$ as-to-projective-totalitative-implications-ofprospective- nonpresencing,-for-explicating relative-unreflexivity/relative-reflexivity

ontological-contiguity ' as of 'abstract cumulation of human memorisation and knowledge immanence' is beyond the human neuropsychological background, and as human consciousness as to overall reifying-and-empowering-reflexivity-of-ecstatic-existence-aspanintelligibility/panreflexivity ${ }^{3}$-〈existentially-imbued-and-educing-< $\{$ epistemictotalising thermeneutically/textually/reprojectingly/supererogatingly/zeroingly/re-acutingly,$\{$ decompulsing\} $d e$ linearity $\sim$ for-cogency $>$-epistemic-perspective-of-projective/reprojectiveaestheticising-re-motif-and-re-apriorising/re-axiomatising/re-referencing conceptualisation-as-herein-specifically-relevant-to human-subpotency) is of an altogether social and sociopsychological immanence; with the implications that a hypothetical instantaneous erasure of all present humans memories and knowledge will lead to humankind's retrograding to its most basic animalistic background potential for social emanence as of the earliest of humans and so rather counterintuitive to what we may intuitively think as to an instant or transitory recovery of our mental-capacities as of our present positivism- ${ }^{80}$ procrypticism (potentially warranting the rehistorialisation of humankind as to a recommencement of the relative-unreflexivity/relativereflexivity - ontological-contiguity ${ }^{67}$ of-the-human-institutionalisation-process ${ }^{68}$ in order to 'potentially' re-achieve generations later the positivism- ${ }^{80}$ procrypticism mental-capacities), speaking of an altogether sublimating-postconverged 'substantive abstract-tissue-of-socialemanance thermeneutically/textully/reprojectingly/supererogatingly/zeroingly/re-acutingly,- 
$\{$ decompulsing $\}$ delinearity for-cogency_cumulated/recomposured as to cumulating/recomposuring of 'prospectively_implicited_attendant-ontological-contiguity ${ }^{67}$ ' educedexistentialising/contextualising/textualising_'intelligibility/epistemicity/reflexivity-contiguity$<$ imbued-notional cogency $>^{\prime 0}$ as to overall reifying-and-empowering-reflexivity-of-ecstaticexistence-as-panintelligibility/panreflexivity ${ }^{3}$-〈existentially-imbued-and-educing-< $<$ epistemictotalising thermeneutically/textually/reprojectingly/supererogatingly/zeroingly/re-acutingly,$\{$ decompulsing $\}$ delinearity $\sim$ for-cogency $>$-epistemic-perspective-of-projective/reprojectiveaestheticising-re-motif-and-re-apriorising/re-axiomatising/re-referencing conceptualisation,as herein-specifieally relevant to human-subptency built up by 'intemporal ontological-faithnotion-or-ontological-fideism—imbued-underdetermination-of-motif-andapriorising/axiomatising/referencing-as-so-being-as-of-existential-reality instigated relativeunreflexivity/relative-reflexivity - ontological-contiguity ${ }^{67} \sim$ of-the-human-institutionalisationprocess $^{68}$ as of difference-conflatedness ${ }^{13}$-as-to-totalitative-reification-in-singularisation- $<$ as-tothe-nondisjointedness/entailment-of-prospective- nonpresencing $>$-as-veridical-epistemicityrelativism-determinism implied $<$ amplituding/formative-epistemicity $>$ causality $\sim$ as-toprojective-totalitative-implications-of-prospective- nonpresencing,-for-explicating $\sim$ relativeunreflexivity/relative-reflexivity ontological-contiguity , underlying the institutionalcumulation/institutional-recomposure-〈as-to- historiality/ontologicaleventfulness /ontological-aesthetic-tracing-<perspective-ontologicalnormalcy/postconvergence-reflected-‘epistemicity-relativism-determinism' $>\rangle$. In this regard, immanence-function-conflatedness ${ }^{13}$ rather reflects the 'ontological-normalcy/postconvergence disposition as of ontological-completeness-of- ${ }^{3}$ reference-of-thought notional ${ }^{18}$ deprocrypticism point-of-departure/perspective as of its protensive selfconsciousness' that fulfils-and-assumes ${ }^{56}$ meaningfulness-and-teleology ${ }^{99}$ as of singularisation- 
epistemic-immanence/veridical-epistemicity-relativism-determinism going by its full comprehension of existence's ecstatic singularity immanence <amplituding/formativeepistemicity $>$ causality $\sim$ as-to-projective-totalitative-implications-of-prospectivenonpresencing,-for-explicating relative-unreflexivity/relative-reflexivity - ontologicalcontiguity , hence overcoming our positivism- ${ }^{80}$ procrypticism <amplituding/formativeepistemicity $>$ totalising $\sim$ self-referencing-syncretising/circularity/interiorising/akrasiatic-drag mental-reflex in apriorising/axiomatising/referencing-\{of-'prospectively implicited_attendantontological-contiguity ' educedexistentialising/contextualising/textualising_intelligibility/epistemicity/reflexivity-contiguity$<$ imbued-notional cogency $>$ ' $\}$ - constitutedness ${ }^{14}$-in-preconverging-entailment that induces dissingularisation-<as-to-the-disjointedness/disentailment-of- presencing - absolutisingidentitive-constitutedness $>$ /epistemic-nonimmanence/flawed-epistemicity-relativismdeterminism; and so, as of immanence-function-conflatedness ${ }^{13}$ insight as to overall reifyingand-empowering-reflexivity-of-ecstatic-existence-as-panintelligibility/panreflexivity ${ }^{3}$ $\langle$ existentially-imbued-and-educing-<epistemictotalising thermeneutically/textually/reprojectingly/supererogatingly/zeroingly/re-acutingly,$\{$ \{ecompulsing\} delinearity $\sim$ for-cogency $\geq$-epistemic-perspective-of-projective/reprojectiveaestheticising-re-motif-and-re-apriorising/re-axiomatising/re-referencing conceptualisation,as-herein-specifically-relevant-to human-subpotency), and so-reflected the superveningconflatedness $^{13}$ of subject-matter epistemic-conceptions say chemistry immanence-functionconflatedness $^{13}$ reifying-and-empowering-reflexivity-of-ecstatic-existence over physics, biology immanence-function-conflatedness ${ }^{13}$ reifying-and-empowering-reflexivity-of-ecstaticexistence over chemistry, neurology immanence-function-conflatedness ${ }^{13}$ reifying-andempowering-reflexivity-of-ecstatic-existence over biology, mental/psychological immanencefunction-conflatedness ${ }^{13}$ reifying-and-empowering-reflexivity-of-ecstatic-existence over 
neurology, social emanance-function-conflatedness ${ }^{13}$ reifying-and-empowering-reflexivity-ofecstatic-existence over mental/psychological, and narrativity (hegemonising intemporal-asontological narrative metaphoricity ${ }^{57}$ as of ${ }^{4}$ historiality/ontological-eventfulness ${ }^{38} /$ ontologicalaesthetic-tracing-<perspective-ontological-normalcy/postconvergence-reflected-'epistemicityrelativism-determinism'>) immanence-function-conflatedness ${ }^{13} \quad$ reifying-and-empoweringreflexivity-of-ecstatic-existence over social, and as of reasoning-through/messianic-reasoning immanence-function-conflatedness ${ }^{13}$ reifying-and-empowering-reflexivity-of-ecstatic-existence over reasoning-from-results/afterthought. Basically, immanence-function-conflatedness speaks of the counterintuitive mental-reflex for drawing out the full <amplituding/formativeepistemicity $>$ causality $\sim$ as-to-projective-totalitative-implications-of-prospectivenonpresencing,-for-explicating relative-unreflexivity/relative-reflexivity - ontologicalcontiguity for 'creative understanding'/insight as of singularisation- $<$ as-to-thenondisjointedness/entailment-of-prospective- nonpresencing $>\quad$ projected epistemicimmanence/veridical-epistemicity-relativism-determinism, going by existence's ecstatic singularity as to overall reifying-and-empowering-reflexivity-of-ecstatic-existence-aspanintelligibility/panreflexivity ${ }^{3}-\langle$ existentially-imbued-and-educing-<epistemictotalising thermeneutically/textually/reprojectingly/supererogatingly/zeroing/y/re-acutingly,$\{$ decompulsing\} $\}$ delinearity $\sim$ for-cogency $\geq$-epistemic-perspective-of-projective/reprojectiveaestheticising-re-motif-and-re-apriorising/re-axiomatising/re-referencing conceptualisation,as-herein-specifically-relevant to human-subpotency). This immanence-functionconflatedness $^{13}$ insight is effectively what marks prospective deprocryticism/preemptingdisjointedness-as-of- ${ }^{8}$ reference-of-thought as of an utterly different protensive selfconsciousness from our hesitant and occlusive positivism- ${ }^{80}$ procrypticism self-consciousness. Hence existence's ecstatic singularity is very much akin with the Deleuzian plane of immanence construed herein as of existence's ecstatic singularity immanence/internal-necessity 
$<$ amplituding/formative-epistemicity $>$ causality $~$ as-to-projective-totalitative-implications-ofprospective- nonpresencing,-for-explicating relative-unreflexivity/relative-reflexivity ontological-contiguity of singularisation-<as-to-the-nondisjointedness/entailment-ofprospective- nonpresencing $>\quad$ projected epistemic-immanence/veridical-epistemicityrelativism-determinism; the ontological implication here being that "we are as potently transcendental as from our flawed apriorising/axiomatising/referencing-\{of-"prospectively implicited_attendant-ontological-contiguity ' educedexistentialising/contextualising/textualising_'intelligibility/epistemicity/reflexivity-contiguity<imbued-notional cogency>' $\}$-constitutedness ${ }^{14}$-in-preconverging-entailment' or 'we are as potently immanent as of our virtuous apriorising/axiomatising/referencing-\{of'prospectively_implicited_attendant-ontological-contiguity ' ceducedexistentialising/contextualising/textualising_'intelligibility/epistemicity/reflexivity_contiguity<imbued-notional cogency $\left.>^{\prime}\right\}$-conflatedness ${ }^{13}$-in-\{preconverging-disentailment by\} postconverging-entailment'. Immanence-function-conflatedness ${ }^{13}$ points out that the mentalreflex for objectifying discursivity between prospective relative-ontological-completeness ${ }^{87}$ and prior relative-ontological-incompleteness ${ }^{88}$ is fundamentally flawed as of apriorising/axiomatising/referencing-\{of-'prospectively implicited_attendant-ontologicalcontiguity ' $\sim$ educedexistentialising/contextualising/textualising_ 'intelligibility/epistemicity/reflexivity-contiguity<imbued-notional cogency>' $\}$-constitutedness ${ }^{14}$-in-preconverging-entailment, as all the objectifying discursivity that is ontologically-veridical is as of the apriorising/axiomatising/referencing-\{of-"prospectively implicited_attendant_ontologicalcontiguity ' educedexistentialising/contextualising/textualising_'intelligibility/epistemicity/reflexivity-contiguity<imbued-notional cogency $\left.>^{\prime}\right\}$ - conflatedness ${ }^{13}$-in-\{preconverging-disentailment by\} 
postconverging-ntailment of prospective relative-ontological-completeness ${ }^{87}$ over prior relative-ontological-incompleteness ${ }^{88}$ construed as immanence-function-conflatedness ${ }^{13}$. Thus metaphoricity ${ }^{57}$ of non-positivism mindset 'supposedly in an objectifying/contending discursivity' with a positivism mindset registers as of positivism immanence-functionconflatedness ${ }^{13}$ reflection of the underlying non-positivism mental-disposition with regards to such issues like existential-<disontologising/re-ontologising aporeticism $>$ desublimation manifestations of superstitution, spiritualism, etc. This same conception holds with the notional ${ }^{18}$ deprocrypticism immanence-function-conflatedness ${ }^{13}$ overriding the meaningfulness-and-teleology ${ }^{9}$ of ${ }^{80}$ procrypticism-or-disjointedness-as-of- ${ }^{8}$ reference-ofthought mindset 'supposedly in an objectifying/contending discursivity' with the notional deprocrypticism mindset, as the latter reflects the underlying positivismprocrypticism mental-disposition mindset with regards to existential-<disentelegising/reentologising aporeticism $>$ desublimation manifestations of disjointedness-as-of- ${ }^{8}$ referenceof-thought. In both instances, the issue lies in the lack of a common apriorising/axiomatising/referencing/intelligibilitysettingup/measuringinstrumenting for meaningfulness-and-teleology aposteriorising/logicising/deriving/intelligising/measuring, with immanence-function-conflatedness ${ }^{13}$ implying that all the ${ }^{5}$ meaningfulness-andteleology ${ }^{9}$ is necessarily as of the prospective relative-ontological-completeness ${ }^{87}$ over the prior relative-ontological-incompleteness ${ }^{8}$; respectively as of positivism and deprocrypticism. If by anticipation we do know immanently that a non-positivism mindset is bound to a nonpositivistic-as-existentially-superstitious

apriorising/axiomatising/referencing/intelligibilitysettingup/measuringinstrumenting as of preconverging/postconverging-de-mentative/structural/paradigmatic internalnecessity/determinism insight from positivism immanence-function-conflatedness ${ }^{13}$ with the obviousness there is no point implying an ontologically-flawed objectifying/contending 
discursivity in assessing the non-positivism existentially-superstitious inclination, the same implication will extend to notional ${ }^{8}$ deprocrypticism immanence-function-conflatedness ${ }^{13}$ as of preconverging/postconverging-de-mentative/structural/paradigmatic internalnecessity/determinism insight with regards to anticipating the disjointedness-as-of- ${ }^{8}$ referenceof-thought apriorising/axiomatising/referencing/intelligibilitysettingup/measuringinstrumenting mindset of our positivism- ${ }^{80}$ procrypticism mental-disposition with no pretence of such a positivism- ${ }^{80}$ procrypticism ontologically-flawed objectifying/contending discursivity in assessing the disjointedness-as-of- reference-of-thought inclination. In other words, immanence-function-conflatedness ${ }^{13}$ is all about reflecting the straightforwardness of $<$ amplituding/formative-epistemicity $>$ causality $\sim$ as-to-projective-totalitative-implications-ofprospective- nonpresencing,-for-explicating relative-unreflexivity/relative-reflexivity _ ontological-contiguity as of singularisation-<as-to-the-nondisjointedness/entailment-ofprospective- nonpresencing $>\quad$ projected epistemic-immanence/veridical-epistemicityrelativism-determinism in arriving at ontological-veridicality over the human mindset flawedand-naive predisposition to make of its objectifying/contending discursivity as preconverging/postconverging-de-mentatively/structurally/paradigmatically deterministic by mere mental-reflex of naively elevating prior relative-ontological-incompleteness meaningfulness-and-teleology as if of prospective relative-ontological-completeness apriorising/axiomatising/referencing/intelligibilitysettingup/measuringinstrumenting. Immanence-function-conflatedness ${ }^{13}$ equally highlights knowledge as of its essential organic construct implications. As an apriorising/axiomatising/referencing-\{of-"prospectively implicited_attendant-ontological-contiguity ' educedexistentialising/contexalising/texalising_intelligibility/epistemicity/reflexivity-contiguity$<$ imbued-notional cogency $>$ ' $\}$ - constitutedness ${ }^{14}$-in- preconverging-entailment predisposition tends to imagine that knowledge is basically a cumulative exercise to an already 
soundly postconvergingly-de-mentated/structured/paradigmed mindset, but nothing could be farther from the truth as knowledge is really an exercise of re-forming-or-reshaping-astransforming the postconverging-de-mentating/structuring/paradigming of the mind. In other words, it is rather vague to 'surreptitiously sneak in supposedly positivism knowledge' into an unquestioned/unchallenged non-positivism mindset, as at best the outcome will be simply a further complexification of the non-positivism mindset apriorising/axiomatising/referencing/intelligibilitysettingup/measuringinstrumenting as with such a reflection as 'God-of-plane' in a non-positivism animistic social-setup, speaking of nonpositivism complexification and not positivism knowledge acquisition. This is effectively what validates the notion of the 'decentering of the human subject' as central to the very notion of organic knowledge as it enables prospective transcendence-andsublimity/sublimation/supererogatory de-mentativity as of prospective relative-ontologicalcompleteness ${ }^{87}$-of- ${ }^{83}$ reference-of-thought. Such a 'decentering of the human subject' implies that the false ontological-certitudes of the non-positivism mindset as of its non-positivism apriorising/axiomatising/referencing/intelligibilitysettingup/measuringinstrumenting are necessarily ironically trampled-upon in the discourse of positivism organic knowledge in a nonpositivism social-setup. For instance, walking into the evil forest to retrieve a plant cure with induced curing eliciting psychoanalytic-unshackling with respect to the non-positivism apriorising/axiomatising/referencing/intelligibilitysettingup/measuringinstrumenting as its superstitious value-reference structure is shown to be inadequate given that it is the violation of that non-positivism value-reference that is what carries the potential for its prospective emancipation into-and-as-of-the-implications-of a prospective positivism mindset. Thus organic knowledge as of its transcendental implications cannot imply that the apriorising/axiomatising/referencing/intelligibilitysettingup/measuringinstrumenting of a prior relative-ontological-incompleteness ${ }^{8}$-of- ${ }^{8}$ reference-of-thought is an appropriate framework for 
prospectively implied ${ }^{83}$ reference-of-thought knowledge acquisition. Likewise, it is herein contended that similarly a notional $\sim$ deprocrypticism contortion reifying gesture necessarily questioning our positivism- ${ }^{80}$ procrypticism disjointedness-as-of- ${ }^{3}$ reference-of-thought apriorising/axiomatising/referencing/intelligibilitysettingup/measuringinstrumenting for the possibility of psychoanalytic-unshackling implications as of the 'decentering of the human subject' is the necessary organic knowledge for futural Being-development/ontologicalframework-expansion-as-to-depth-of-ontologising-development-as-infrastructure-ofmeaningfulness-and-teleology as of prospective deprocrypticism-or-preemptingdisjointedness-as-of- ${ }^{8}$ reference-of-thought transcendence-andsublimity/sublimation/supererogatory de-mentativity. The implication of organic knowledge conception is that the state of recurrent-utter-uninstitutionalisation by its apriorising/axiomatising/referencing/intelligibilitysettingup/measuringinstrumenting fails the objectifying/contending discursivity as of prospective base-institutionalisation immanencefunction-conflatedness $^{13}$, likewise does base-institutionalisation-ununiversalisation fails as of prospective ${ }^{103}$ universalisation immanence-function-conflatedness ${ }^{13},{ }^{103}$ universalisation-nonpositivism/medievialism fails as of prospective positivism immanence-function-conflatedness ${ }^{13}$, and prospectively positivism- ${ }^{8}$ procrypticism fails in futural Being-development/ontologicalframework-expansion-as-to-depth-of-ontologising-development-as-infrastructure-ofmeaningfulness-and-teleology as of prospective notional deprocrypticism immanencefunction-conflatedness ${ }^{13}$; so-implied as of singularisation-<as-to-thenondisjointedness/entailment-of-prospective- nonpresencing $>$ projected epistemicimmanence/veridical-epistemicity-relativism-determinism reflection of existence's ecstatic singularity. Hence 'intemporal ontological-faith-notion-or-ontological-fideism-imbuedunderdetermination-of-motif-and-apriorising/axiomatising/referencing-as-so-being-as-ofexistential-reality instigated relative-unreflexivity/relative-reflexivity-ontological- 
contiguity ${ }^{67}$ of-the-human-institutionalisation-process ${ }^{68}$ as of difference-conflatedness ${ }^{13}$-as-tototalitative-reification-in-singularisation-<as-to-the-nondisjointedness/entailment-ofprospective- nonpresencing $>$-as-veridical-epistemicity-relativism-determinism implied $<$ amplituding/formative-epistemicity $>$ causality $\sim$ as-to-projective-totalitative-implications-ofprospective- nonpresencing,-for-explicating relative-unreflexivity/relative-reflexivity ontological-contiguity , implied organic knowledge is ever always as of the preconverging/postconverging-de-mentative/structural/paradigmatic internalnecessity/determinism of prospective relative-ontological-completeness ${ }^{87}{ }^{83}$ reference-ofthought as of immanence-function-conflatedness ${ }^{13}$, with the pretence of prior relativeontological-incompleteness ${ }^{8}$-of- ${ }^{8}$ reference-of-thought for objectifying/contending discursivity nothing more but flawed <amplituding/formative-epistemicity $>$ totalising $\sim$ self-referencingsyncretising/circularity/interiorising/akrasiatic-drag ${ }^{34}$ temporal ${ }^{56}$ meaningfulness-andteleology ${ }^{9}$. The study of the social as of immanence-function-conflatedness ${ }^{13}$ insight grasp that the blurriness-<sterilising/anecdotalising/trivialising-of-prospective-re-ontologising_bypreconverging,-in-disontologising-formulaic-dragging-out/hollowing-out>, $<$ amplituding/formative-epistemicity $>$ totalising $\sim$ self-referencingsyncretising/circularity/interiorising/akrasiatic-drag ${ }^{34}$ and remoteness of cause-and-effect invoke a more refined conception of <amplituding/formative-epistemicity $>$ causality $\sim$ as-toprojective-totalitative-implications-of-prospective- nonpresencing,-for-explicating relativeunreflexivity/relative-reflexivity ontological-contiguity as reflecting existence/intrinsicreality/ontological-veridicality. Such a refinement while cognisant of the pertinence of falsifiability ${ }^{42}$ and validation is more in line with the Lakatosian research-programme perspective given the complexity of the social just as many a complex domain in the natural sciences in effect assume the research-programme epistemic model; consider that while the natural sciences are generally more amenable to strong immediate cause-and-effect 
determination, such complex studies like string theory in physics, medical research, etc. send to assume in effect the research-programme epistemic model. The underlying insight here is that many a complex study purview as well as the study of the social given its poorly constraining immediate cause-and-effect determination, renders knowledge validation more of a 'construct of comprehensive-coherence and competitive claim to ontological pertinence as of extensive research-programme implications', but this should however implicitly reflect concurrently the underlying notions of falsifiability ${ }^{12}$-or-deferring-falsifiability ${ }^{22}$ and validation-or-deferringvalidation. It is herein contended that it is the implicited orientation of many post-structuralists thinking as of the research-programme epistemic model as articulated herein that renders their thought scientifically credible and pertinent as such scholars like Foucault, Derrida, Deleuze, to cite just these few have turn out to be the dominant scholarly-cited authors in the general humanities, and so precisely because of the very thorough knowledge-reification $\sim$ gesturing-andaccounting - of-epistemic-phenomenalism- $<$ in-

prospective_psychologismic apriorising/axiomatising/referencing-\{of-'prospectively implicited_attendant-ontological-contiguity ' educedexistentialising/contextualising/textualising_'intelligibility/epistemicity/reflexivity-contiguity<imbued-notional cogency>' \}-conflatedness in \{preconverging disentailment by\} postconverging-entailment $>$ in their scholarly output, and paradoxically so over purported scholarly approaches 'supposedly of a more scientific methodology but when evaluated as of such authorial scholarly comprehensive research-programmes' turn out to be of weaker existential-<disontologising/re-ontologising aporeticism $>$ ramifications. This insight equally informs the supplanting-conviction-as-to-profound-supererogation - of-'attendantintradimensional'-postconverging/dialectical-thinking -apriorising-psychologism herein that it is ultimately as of such comprehensive research-programme epistemic model as articulated herein and its further knowledge-reification $\sim$ gesturing-and-accounting-of-epistemic- 
phenomenalism- $<$ in-prospective_psychologismic $\sim$ apriorising/axiomatising/referencing- of'prospectively implicited_attendant-ontological-contiguity ' educedexistentialising/contextualising/textualising_'intelligibility/epistemicity/reflexivity-contiguity<imbued-notional $\left.\sim \operatorname{cogency}>^{\prime} \quad\right\}$-conflatedness -in-\{preconverging-disentailment by\} postconverging-ntailment>, as well as of the disposition for advancing overall knowledgenotionalisation level reflecting the relative-unreflexivity/relative-reflexivity-ontologicalcontiguity ${ }^{67}$ of-the-human-institutionalisation-process ${ }^{68}$ as to transversality- $<$ for-sublimating existential-eventuating/denouement,-from-'thinking-at-first/pure-predisposition-preemptive-ofprospective-disontologising/subontologising' as-of-prospectively-disambiguated-affirmedand-unaffirmed-'motif-and-apriorising/axiomatising/referencing'> in foregrounding_entailment- $<$ in-succession-of-profound-supererogation $>>-\langle$ postconvergingnarrowing-down $\sim$ sublimation-as-to-'existence - as-sublimating-withdrawal/unenframing/reontologising,-elicited-from-prospective-profound-supererogation '-in-reflecting‘immanent relative-unreflexivity/relative-reflexivity - ontological-contiguity ';-as-operativenotional deprocrypticism $\rangle$ of the 'preconverging/postconverging-dementative/structural/paradigmatic disseminative implications of postmodern and other human sublimation-educing__ \{epistemic-

thermeneutic/textuality/reprojecting/supererogating/zeroing/re-acuting,delinearity for-cogency as-to-possibilities-of-self-becoming-as-of-‘existentialinterpretation/epistemicity-in-apriorising/axiomatising/referencing-of-existence ${ }^{5}$ thought, that the ontological-pertinence assumes <amplituding/formative-epistemicity $>$ causality $\sim$ as-toprojective-totalitative-implications-of-prospective- nonpresencing,-for-explicating relativeunreflexivity/relative-reflexivity - ontological-contiguity unassailability; and so, not for the mere sake of research-programme extensiveness but as of its internal constraining to falsifiability ${ }^{42}$-or-deferred-falsifiability ${ }^{22}$ and validation-or-deferred-validation as of knowledge- 
reification $\sim$ gesturing-and-accounting — of-epistemic-phenomenalism- $<$ inprospective_psychologismic apriorising/axiomatising/referencing-\{of- ${ }^{\text {pprospectively }}$ implicited_attendant-ontological-contiguity ' educedexistentialising/contextualising/textualising_'intelligibility/epistemicity/reflexivity-contiguity<imbued-notional cogency $>$ ' $\}$-conflatedness -in-\{preconverging-disentailment by\} postconverging-entailment $>$ so-underlied by ontological-good-faith/authenticity ${ }^{6}$ herein as of reasoning-through/messianic-reasoning attitude/mental-disposition/care-and-episteme 'implicitation of <amplituding/formative-epistemicity $>$ causality $\sim$ as-to-projective-totalitativeimplications-of-prospective- nonpresencing,-for-explicating relative-unreflexivity/relativereflexivity - ontological-contiguity , on the basis that the very first epistemic frontier for ontological-pertinence lies with the scholarly developed creative insight for knowledgereification $\sim$ gesturing-and-accounting — of-epistemic-phenomenalism- $<$ inprospective_psychologismic apriorising/axiomatising/referencing-\{of- ${ }^{\text {pprospectively }}$ implicited_attendant-ontological-contiguity ' educedexistentialising/contextualising/textualising_'intelligibility/epistemicity/reflexivity_contiguity<imbued-notional cogency>' \}-conflatedness -in-\{preconverging disentailment by\} pesteonverging entailment>. Ultimately, postmodern-thought has been unassailable to vague scepticism and ontological-bad-faith/inauthenticity ${ }^{64}$ criticism exactly because of its strong scholarly research-programme 'implicited_attendant-ontological-contiguity ${ }^{67}$ ' educedexistentialising/contextmalising/textualising_intelligibility/epistemicity/reflexivity_contiguity$<$ imbued-notional $\sim$ cogency $>$ ' knowledge-reification $\sim$ gesturing-and-accounting —ofepistemic-phenomenalism- $<$ inprospective_psychologismic apriorising/axiomatising/referencing-\{of-'prespectively implicited_attendant-ontological-contiguity ' educedexistentialising/contextualising/textualising_'intelligibility/epistemicity/reflexivity-contiguity- 
postconverging-entailment>, and thus an immanence-function-conflatedness ${ }^{13}$ insight in the study of the social as of its inherent complex nature is certainly justified to adhere to a researchprogramme epistemic model as herein articulated. In another respect, while intellectualism as of organic knowledge implications in-many-ways commands massive social deference and adherence, it is equally important not to naively assume that at uninstitutionalised-threshold ${ }^{102}$, human existential-investment as of its temporality $/$ shortness cannot be predisposed to antiintellectualism, as this insight is pertinent in the sense that transcendental knowledge is articulated mostly as of its undermining of human temporal existential-investment. The bigger point here being that the possibility of prospective transcendence-andsublimity/sublimation/supererogatory-de-mentativity lies in upholding-and-defending authentic intellectualism even as of metaphoricity ${ }^{57}$ beyond $<$ amplituding/formative $>$ wooden-language〈imbued-averaging-of-thought-<as-to-leveling/ressentiment/closed-construct-ofmeaningfulness-and-teleology -as-of-'nondescript/ignorable-void '-with-regards-toprospective-apriorising-implications $>>$ socially intelligible ${ }^{56}$ meaningfulness-and-teleology conceptualisation in $\quad<$ amplituding/formative-epistemicity $>$ totalising $\sim$ self-referencingsyncretising/circularity/interiorising/akrasiatic-drag ${ }^{34}$. Metaphoricity ${ }^{57}$ as such ironises on social intellectual nihilism as it is bent on undermining any temporality $/$ /shortness as of ontologicalfaith-notion-or-ontological-fideism - imbued-underdetermination-of-motif-andapriorising/axiomatising/referencing-as-so-being-as-of-existential-reality solipsistic intemporality ${ }^{2} /$ longness parrhesiastic askance, and as of immanence-function-conflatedness 'highlights and keeps wide-opened the prospect' for prospective authentic intellectualism by undermining its blending with inauthentic untransvaluated-temporal-intemporality manifestations that usurp and undermine human transcendence-andsublimity/sublimation/supererogatoryade-mentativity. Further, while 'human projected 
conception of knowledge cumulation' seems to be ever always 'perceived absolutely as within an only same institutionalisation ${ }^{8}$ reference-of-thought', with their merits at least for expanding human mastery of its environment at their given level as well as their defects as of undermining the possibility for prospective knowledge, for instance as of the animistic social-setup to perceive its animistic knowledge system as absolute, as of the medieval/non-positivism social-setup to perceive its medieval scholasticism as absolute or as of our positivism- ${ }^{8}$ procrypticism socialsetup to perceive our positivism- ${ }^{8}$ procrypticism humanistic knowledge system as absolute; it is immanence-function-conflatedness ${ }^{13}$ by its implied internal-necessity construct that best reflects the reality of human knowledge cumulation by the relative-unreflexivity/relative-reflexivity ontological-contiguity ${ }^{67} \sim$ of-the-human-institutionalisation-process as of Beingdevelopment/ontological-framework-expansion-as-to-depth-of-ontologising-development-asinfrastructure-of- meaningfulness-and-teleology conception, recognising the underlying retrospective and prospective epistemic dynamics behind knowledge as of protracting selfconsciousness over the cloistering self-consciousness of falsely absolutising specific registryworldviews/dimensions ${ }^{83}$ reference-of-thought. With such immanence-function-conflatedness insight, the epistemic and methodological pretences as of our humanistic positivismprocrypticism are evaluated on their true merits, and such an evaluation reveals that such epistemic and methodological pretences while 'developed institutional practice' are just that asmore-or-less-mechanically-institutionalised, and that critically from a deeper perspective the reality is that it is the research-programme as articulated above that underlies human knowledge cumulation, and so as of the competitive evaluation of various epistemic and methodological commitments made in immediacy and their ultimate prospective evaluation as of their researchprogrammes productive outcomes. The research-programme as such can be reconstrued as the reevaluation of any propounded knowledge and epistemic postconverging-dementating/structuring/paradigming as of their ultimate knowledge-reification $\sim$ gesturing-and- 
accounting - of-epistemic-phenomenalism- $<$ in-

prospective_psychologismic apriorising/axiomatising/referencing-\{of- ${ }^{\text {pprospectively }}$ implicited_attendant-ontological-contiguity ' educed-

existentialising/contextualising/textualising_intelligibility/epistemicity/reflexivity-contiguity<imbued-notional cogency >' \}-conflatedness -in-\{preconverging disentailment by\} postconverging-entailment $>$ as knowledge; such that the immediacy of contention of appropriateness of epistemic and methodological approaches is less critical, as ultimately all knowledge constructs and their epistemic and methodological commitments face their long term bottomline reevaluation as to their relative knowledge-reification gesturing-and-accountingof-epistemic-phenomenalism- $<$ in-

prospective_psychologismic apriorising/axiomatising/referencing-\{of-‘prospectively_ implicited_attendant-ontological-contiguity ' educedexistentialising/contextualising/textualising_'intelligibility/epistemicity/reflexivity-contiguity<imbued-notional cogency >’ $\}$-conflatedness -in-\{preconverging-disentailment by\} postconverging-ntailment $>$ as knowledge construed as their research-programmes. This speaks of the fact that such a conception of epistemic commitment as of research-programme is effectively one of epistemic singularisation-<as-to-the-nondisjointedness/entailment-ofprospective- nonpresencing $>\quad$ projected epistemic-immanence/veridical-epistemicityrelativism-determinism so-implied as of ontological-normalcy/postconvergence associated with ontologically-uncompromised—referentialism deprocrypticism; and very much overcoming the limiting effect of our present conception of epistemic commitment as rather dissingularisation$<$ as-to-the-disjointedness/disentailment-of- presencing-absolutising-identitiveconstitutedness $>$ /epistemic-nonimmanence/flawed-epistemicity-relativism-determinism as of ontologically-compromised — categorising positivism- ${ }^{80}$ procrypticism. Thus, if immanencefunction-conflatedness ${ }^{13}$ reveals that it is the "projected research-programme of any given 
knowledge construct as of its prospective relative knowledge-reification $\sim$ gesturing-andaccounting - of-epistemic-phenomenalism- $<$ in-

prospective_psychologismic apriorising/axiomatising/referencing-\{of-'prospectively implicited_attendant-ontological-contiguity ' educedexistentialising/contextualising/textualising_ 'intelligibility/epistemicity/reflexivity-contiguity<imbued-notional cogency $\left.>{ }^{\prime}\right\}$-conflatedness -in-\{preconverging-disentailment by\} postconverging-entailment>' that is its preeminent epistemic and methodological validation, 'pretences of pre-given epistemic predispositions' that do not attend pertinently and similarly to prospective relative knowledge-reification $\sim$ gesturing-and-accounting-of-epistemicphenomenalism- $<$ in-prospective_psychologismic $\sim$ apriorising/axiomatising/referencing- of'prospectively_implicited_attendant_ontological-contiguity ' ceducedexistentialising/contextmalising/textualising_intelligibility/epistemicity/reflexivity_contiguity<imbued-notional cogency $\left.>^{\prime}\right\}$ - conflatedness -in-\{preconverging-disentailment by\} postconverging-ntailment> are nothing more but <amplituding/formativeepistemicity $>$ totalising $\sim$ self-referencing-syncretising/circularity/interiorising/akrasiatic-drag predispositions that pretend to supersede existence-as-the-absolute-a-priori-ofconceptualisation $\sim$ and existence — as-sublimating-withdrawal/unenframing/re-ontologising,elicited-from-prospective-profound-supererogation $-<$ as-to-perspective-ontologicalnormalcy/postconvergence-implied-'prospective-aporeticism-overcoming/unovercoming'>, and institutionalised, such <amplituding/formative-epistemicity $>$ totalising $\sim$ self-referencingsyncretising/circularity/interiorising/akrasiatic-drag ${ }^{34}$ predispositions may actually be preconverging/postconverging-de-mentatively/structurally/paradigmatically stifling for the possibility of prospective knowledge and transcendence-andsublimity/sublimation/supererogatory-de-mentativity, and more seriously so where the possibility of varied research-programme choices are difficultly entertainable without 
institutional backing for research needing major funding and/or resources. Finally, the researchprogramme epistemic model attends to the social as of the reality of human emotionalinvolvement by its extensiveness. Consider that many a transformative natural science idea have certainly been 'supposedly gross conceptualisations' but with varied social responses as of their given social epoch sensitivities; consider in this regard Copernicus and Galileo heliocentric world argument eliciting social sensitivities then and equally stark physics ideas at the beginning of the last century with relativity and quantum mechanics hardly eliciting any social sensitivities,

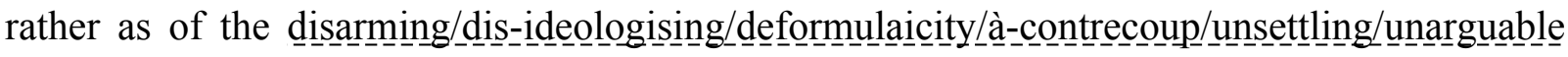
effect on conventioning simply on the basis of their matter-of-fact cause-and-effect. In-manyways the prospect of prospective knowledge very much lies with a shakeup of the social 'sense of presence' and this is not contradictory in the sense that if the present was all that great then its very transcendence-and-sublimity/sublimation/supereregatery $\sim$ de-mentativity wouldn’t be occurring, and so existence/intrinsic-reality/ontological-veridicality warrants that transcendence-and-sublimity/sublimation/supereregatory-de-mentativity occurs as to conflict with the naïve social 'sense of presence' as absolute, and so because it is all about the-verysame-immanent-existence/intrinsic-reality/ontological-veridicality,-as-to-

'human<amplituding/formative-epistemicity>totalising purview-of-construal' but with contrastive underlying relative-ontological-incompleteness $8 /$ relative-ontologicalcompleteness ${ }^{8}$-〈sublimating $\sim$ referencing/registering/decisioning,-as-self-becoming/selfconflatedness /formative-supererogating-<projective/reprojective-aestheticising-re-motifand-re-apriorising/re-axiomatising/re-referencing,-in-perspective-ontologicalnormalcy/postconvergence $>>$. It is quite absurd to think that the possibility of prospective human transcendence-and-sublimity/sublimation/supereregatory-de-mentativity especially, as of our apriorising/axiomatising/referencing/intelligibilitysettingup/measuringinstrumenting, lies wholly within the ambit of our 'sense of presence' agreeableness; as this rather speaks of the 
framework of our limited certitudes as this limits/stifles the possibility of further profound knowledge-reification $\sim$ gesturing-and-accounting —of-epistemic-phenomenalism- $<$ inprospective_psychologismic apriorising/axiomatising/referencing-\{of-'prospectively implicited_attendant-ontological-contiguity ' reducedexistentialising/contextualising/textualising_ 'intelligibility/epistemicity/reflexivity-contiguity<imbued-notional $\left.\sim \operatorname{cogency}>^{\prime} \quad\right\}$-conflatedness -in-\{preconverging-disentailment by\} postconverging-ntailment> for transcendence-and-sublimity/sublimation/supererogatory $\sim$ dementativity. While today that notion of contrariety has in-many-ways sanked in and been accepted with natural science knowledge especially so as it hardly elicits social emotionalinvolvement, the fact of the matter is that the possibility of the profound study and emancipation of the social inevitably comes with a contrariety of our social 'sense of presence'. Just as the 'decentering of the subject' was what brought about the positivistic mindset today that allowed for modern-day science to develop and just as well modern-day social science, it is inevitable that a further development of human knowledge as of its organic knowledge construct warrants a further 'decentering of the human subject' as implied by ${ }^{18}$ deprocrypticism-or-preemptingdisjointedness-as-of- ${ }^{8}$ reference-of-thought; and justified by the fact that if previous generations had to undergo their psychoanalytic-unshackling for prospective institutionalisation, we can only ever be pushed into the corner of our intellectual nihilism when we seem to pretend that we are beyond the prospect of our transcendence-and-sublimity/sublimation/supereregatory $\sim$ dementativity. Immanence-function-conflatedness ${ }^{13}$ analytical implications equally arise as of the 'countervailing transversality- $<$ for-sublimating-existential-eventuating/denouement, - from-

\section{thinking -at-first/pure-predisposition-preemptive-of-prospective-}

disentologising/subontologising’' as-of-prospectively-disambiguated-affirmed-andunaffirmed-'motif-and-apriorising/axiomatising/referencing'>101 relation induced as of $<$ amplituding/formative-epistemicity $>$ causality $\sim$ as-to-projective-totalitative-implications-of- 
prospective- nonpresencing,-for-explicating relative-unreflexivity/relative-reflexivity

ontological-contiguity ' between 'existence/existential-possibilities as the selecting transcendental-signifier/transcendental-enabling/sublimating/supererogatory $\sim$ de-mentativity' and the 'ever developing human limited-mentation-capacity-as-subjecting 'educedunlimitedness/existence-sublimating nascence' to-limitedness/human-subpotency as of its deepening from relative uninstitutionalised-threshold ${ }^{02}$ to relative institutionalisation soconstrued as prospective institutionalisation dissemination ${ }^{2}$, , as this transversality $-<$ forsublimating-existential-eventuating/denouement,-from-'thinking at first/pure-predispositionpreemptive-of prospective-disontologising/subontologising' as-of-prospectivelydisambiguated-affirmed-and-unaffirmed-'motif-and-apriorising/axiomatising/referencing'> is exactly what validates epistemic-veracity as of prospective relative-ontologicalcompleteness ${ }^{87}$ as relevant for the protracted-consciousness of notional ${ }^{18}$ deprocrypticism. Thus for such a notion of research-programme as articulated herein rather than just implying mere epistemic latitude/anarchy, it speaks instead of the construal/justification of epistemic-veracity as of precedence of prospective relative-ontological-completeness ${ }^{87}<$ amplituding/formativeepistemicity $>$ causality $\sim$ as-to-projective-totalitative-implications-of-prospectivenonpresencing,-for-explicating relative unreflexivity/relative reflexivity - ontologicalcontiguity, and so as of the preconverging/postconverging-dementative/structural/paradigmatic implication of singularisation- $<$ as-to-thenondisjointedness/entailment-of-prospective- nonpresencing $>$ projected epistemicimmanence/veridical-epistemicity-relativism-determinism over dissingularisation- $<$ as-to-thedisjointedness/disentailment-of- presencing - absolutising-identitiveconstitutedness $>$ /epistemic-nonimmanence/flawed-epistemicity-relativism-determinism. Thus prospective relative-ontological-completeness ${ }^{87}$ is inherently bound with its very own epistemic $<$ amplituding/formative-epistemicity $>$ causality as-to-projective-totalitative- 
implications-of-prospective- nonpresencing,-for-explicating relative-unreflexivity/relative-

reflexivity - ontological-contiguity as of the 'decentering of the human subject' involved in knowledge-reification $\sim$ gesturing-and-accounting — of-epistemic-phenomenalism- $<$ in-

prospective_psychologismic apriorising/axiomatising/referencing-\{of-"prospectively

implicited_attendant_ontological-contiguity ' educed-

existentialising/contextualising/textualising_'intelligibility/epistemicity/reflexivity_contiguity-

<imbued-notional $\left.\sim \operatorname{cogency}>^{\prime} \quad\right\}$-conflatedness -in-\{preconverging-disentailment by\}

postconverging-entailment>. This inherently projects a 'practical picture of human epistemic determination' of 'maximal disseminative human epistemic articulations at relative uninstitutionalised-threshold ${ }^{102}$ ' and 'minimum select human epistemic articulations at prospective institutionalisations', and so as of existence/existential-possibilities as the transcendental-signifier/transcendental-enabling/sublimating/supererogatory $\sim$ de-mentativity

transversally induced <amplituding/formative-epistemicity $>$ causality $\sim$ as-to-projectivetotalitative-implications-of-prospective- nonpresencing,-for-explicating relative-

unreflexivity/relative-reflexivity ontological-contiguity selective epistemic-veracity transcendence-and-sublimity/sublimation/supereregatory-de-mentativity. In this regard and at the general epistemic level of ${ }^{83}$ reference-of-thought- ${ }^{84}$ devolving, we can appreciate the massively shrunk epistemic-veracity possibilities available for our present positivism credible construal of ontological-veridicality over the epistemic-veracity possibilities previously available for non-positivistic social-setups credible construal of ontological-veridicality as of their full existential-<disontelogising/re-ontologising aporeticism $>$ cognition of superstition, witchcraft, spiritualism, etc., and their social implications; and this reflects the very fact that ‘intemporal ontological-faith-notion-or-ontological-fideism —imbued-underdetermination-ofmotif-and-apriorising/axiomatising/referencing-as-so-being-as-of-existential-reality instigated relative-unreflexivity/relative-reflexivity ontological-contiguity ${ }^{67}$ of-the-human- 
institutionalisation-process ${ }^{68}$ of difference-conflatedness ${ }^{3}$-as-to-totalitative-reification-insingularisation-<as-to-the-nondisjointedness/entailment-of-prospective- nonpresencing $>$-asveridical-epistemicity-relativism-determinism implied <amplituding/formativeepistemicity $>$ causality $\sim$ as-to-projective-totalitative-implications-of-prospectivenonpresencing,-for-explicating relative-unreflexivity/relative-reflexivity - ontologicalcontiguity ' is one associated with increasing thinning out of epistemic-veracity as of prospective relative-ontological-completeness <amplituding/formativeepistemicity $>$ causality $\sim$ as-to-projective-totalitative-implications-of-prospectivenonpresencing,-for-explicating relative-unreflexivity/relative-reflexivity - ontologicalcontiguity induced from <amplituding/formative-epistemicity $>$ causality $\sim$ as-to-projectivetotalitative-implications-of-prospective- nonpresencing,-for-explicating relativeunreflexivity/relative-reflexivity - ontological-contiguity . Central to such epistemic-veracity thinning out is the very essential process behind increasing relative-unreflexivity/relativereflexivity - ontological-contiguity ${ }^{67} \sim$ of-the-human-institutionalisation-process ${ }^{68}$ which is deferential-formalisation-transference. Besides deferential-formalisation-transference associated epistemic-veracity relevance for institutional construction and institutional rules of critical importance for human organisation like political and legal institutions, such deferentialformalisation-transference associated epistemic-veracity has been inherently of strongest relevance in knowledge domains more easily amenable to <amplituding/formativeepistemicity $>$ causality $\sim$ as-to-projective-totalitative-implications-of-prospectivenonpresencing,-for-explicating relative-unreflexivity/relative-reflexivity ontologicalcontiguity and low emotional involvement like the natural sciences but weakly so inherently in many a social domain-of-study not readily amenable to strong <amplituding-formativeepistemicity $>$ causality $\sim$ as-to-projective-totalitative-implications-of-prospectivenonpresencing,-for-explicating relative-unreflexivity/relative-reflexivity - ontological- 
contiguity and of high emotional involvement, and as such social domains practically tend to get into amalgamation with the extended-informality as of its deficient $<$ amplituding/formative $>$ wooden-language-_imbued - averaging-of-thought-<as-toleveling/ressentiment/closed-construct-of- meaningfulness-and-teleology -as-of'nondescript/ignorable-void ' -with-regards-to-prospective-apriorising-implications $>$ >

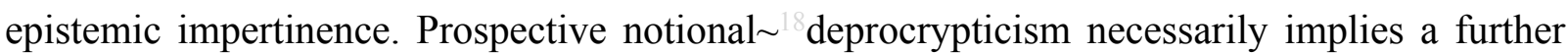
epistemic-veracity thinning out as of its prospective relative-ontological-completeness ${ }^{87}$-ofreference-of-thought associated <amplituding/formative-epistemicity $>$ causality $\sim$ as-toprojective-totalitative-implications-of-prospective- nonpresencing,-for-explicating relativemnreflexivity/relative reflexivity ontological-contiguity, with the implication that our positivism- ${ }^{80}$ procrypticism uninstitutionalised-threshold ${ }^{102}$ epistemic-veracity is in-many-ways construed as of epistemic impertinence at its disjointedness-as-of- ${ }^{3}$ reference-of-thought uninstitutionalised-threshold ${ }^{102}$ and superseded by futural Being-development/ontologicalframework-expansion-as-to-depth-of-ontologising-development-as-infrastructure-ofmeaningfulness-and-teleology as of prospective notional deprocrypticism disseminative epistemic-veracity and so as the prospective epistemic-veracity thinning out outcome of existence/existential-possibilities as the transcendental-signifier/transcendentalenabling/sublimating/supererogatory de-mentativity determinant selector as of the deprocrypticism-or-preempting — disjointedness-as-of- ${ }^{83}$ eference-of-thought disseminative research-programme coherence and relative-unreflexivity/relative-reflexivity-ontologicalcontiguity ${ }^{67}$. The idea being that the notional ${ }^{18}$ deprocrypticism epistemic-veracity as of such disseminative research-programme coherence and relative-unreflexivity/relative-reflexivity_ontological-contiguity ${ }^{67}$ equally imply an underlying falsifiability ${ }^{22}$-or-deferred-falsifiability and validation-or-deferred-validation as a constraint to the social domain-of-study meant to render it more thoroughly amenable <amplituding/formative-epistemicity $>$ causality $\sim$ as-to- 
projective-totalitative-implications-of-prospective- nonpresencing,-for-explicating relative-

unreflexivity/relative-reflexivity ontological-contiguity capable of reflecting the unassailability of the most transversally profound theorisations and conceptualisations on the basis of their demonstrable operant implications as of knowledge-reification $\sim$ gesturing-andaccounting - of-epistemic-phenomenalism- $<$ in-

prospective_psychologismic apriorising/axiomatising/referencing-\{of-‘prospectively

implicited_attendant-ontological-contiguity ' ceduced-

existentialising/contextualising/textualising_'intelligibility/epistemicity/reflexivity-contiguity$<$ imbued-notional $\left.\sim \operatorname{cogency}>^{\prime} \quad\right\}$-conflatedness -in-\{preconverging - disentailment by\}

postconverging-entailment $>$ for transcendence-and-sublimity/sublimation/supererogatory $\sim$ dementativity. Such a notional deprocrypticism epistemic-veracity implication is pertinent because blurriness-<sterilising/anecdotalising/trivialising-of-prospective-re-ontologising_bypreconverging,-in-disontologising-formulaic-dragging-out/hollowing-out> and undisambiguation underlies the indecision and relative impertinence in many an instance of social knowledge conception that is not thoroughly subjected to <amplituding/formativeepistemicity $>$ causality $\sim$ as-to-projective-totalitative-implications-of-prospectivenonpresencing,-for-explicating relative unreflexivity/relative reflexivity ontological-

contiguity , such that it is obvious to all that the epistemic-veracity as of existence/existentialpossibilities selective function of <amplituding/formative-epistemicity $>$ causality $\sim$ as-toprojective-totalitative-implications-of-prospective- nonpresencing,-for-explicating $\sim$ relativeunreflexivity/relative-reflexivity ontological-contiguity as developed in the natural sciences tends to be poorly developed in many a domain-of-study of the social. In this regard, we can appreciate for instance in the physics and other natural sciences <amplituding/formativeepistemicity>totalising devolved-purview-as-domain-of-construal-as-intrinsic-

reality/ontological-veridicality, the 'thin epistemic-veracity line' arrived at transversally as of 
concurrent cause-and-effect determinations that allows for developed singular or near-singular comprehensive explanations of phenomena 'discarding the demonstrably impertinent conceptions', while in contrast with many a domain-of-study in the social, without necessarily implying this as all-encompassing but still critically and substantively so, such a spearheading towards the ontologically decisive is lost/obliterated in an approach driven by theoretical and conceptual mutuality/equilibrium rather than a transversality-<for-sublimating-existentialeventuating/denouement,-from-'thinking-at-first/pure-predisposition-preemptive-ofprospective-disontologising/subontologising' as-of-prospectively-disambiguated-affirmedand-unaffirmed-'motif-and-apriorising/axiomatising/referencing' $>101$ constraining to the 'superior party' that is existence/existential-possibilities, and thus specifically giving room for many an instance of obvious muddlement as well as ontological-bad-faith/inauthenticity ${ }^{64}$ with a corresponding relative passivity to social issues and problems as if institutional-being-and-craft was an end in itself as preconverging/postconverging-dementatively/structurally/paradigmatically knowledge certifying. Furthermore, while the idea of falsifiability ${ }^{42}$ and validation have traditionally been associated with the fundamental research methodologies of experimentation, observation and survey, however the complex nature of social phenomena and even some natural science phenomena has dragged out the epistemicveracity of the scientific methodology. Such that what increasingly underlies the scientific methodology is more extensive as of the reflection of pertinent phenomenality experimented or stated or demonstrated, by the coherence and implied relative-unreflexivity/relativereflexivity - ontological-contiguity ${ }^{67}$ of observations, conceptualisations and predictions, in their apriorising/axiomatising/referencing-\{ of-"prospectively implicited attendantontological-contiguity ' educedexistentialising/contextualising/textualising_'intelligibility/epistemicity/reflexivity-contiguity<imbued-notional cogency $>$ ' \}-conflatedness ${ }^{13}$-in-\{preconverging-disentailment by\} 
postconverging-entailment totalising-entailing/nested-congruence or how these conflate as of prospective relative-ontological-completeness 87 with existence-as-the-absolute-a-priori-ofconceptualisation and existence - as-sublimating-withdrawal/unenframing/re-ontologising,elicited-from-prospective-profound-supererogation $-<$ as-to-perspective-ontologicalnormalcy/postconvergence-implied-'prospective-aporeticism-overcoming/unovercoming'>.

Ultimately, the contrastive epistemic-veracity of theoretical and conceptual articulations rather lies with regards to their knowledge-reification $\sim$ gesturing-and-accounting-of-epistemicphenomenalism-<in-prospective_psychologismic $\sim$ apriorising/axiomatising/referencing- of'prospectively_implicited_attendant-ontological-contiguity ' ceducedexistentialising/contextualising/textualising_'intelligibility/epistemicity/reflexivity-contiguity$<$ imbued-notional $\left.\sim \operatorname{cogency}>^{\prime},\right\}$-conflatedness -in-\{preconverging-disentailment by\} postconverging entailment $>$ as of their critical operant implications and unmuddled conceptions. Furthermore, the notional deprocrypticism epistemic-veracity implies a further extension of deferential-formalisation-transference as of less predisposition to extended-informality $<$ amplituding/formative $>$ wooden-language-〈imbued - averaging-of-thought- $<$ as-toleveling/ressentiment/closed-construct-of- meaningfulness-and-teleology -as-of'nondescript/ignorable-void '-with-regards-to-prospective-apriorising-implications $>>$. With the <amplituding/formative-epistemicity $>$ causality $\sim$ as-to-projective-totalitative-implicationsof-prospective- nonpresencing,-for-explicating relative-unreflexivity/relative-reflexivity ontological-contiguity that the ${ }^{18}$ deprocrypticism-or-preempting-disjointedness-as-ofreference-of-thought extended-informality requires an organic-knowledge type of pedagogy based on eliciting an ontological-faith-notion-or-ontological-fideism-imbuedunderdetermination-of-motif-and-apriorising/axiomatising/referencing-as-so-being-as-ofexistential-reality solipsistic sense-of-things, over the usual mechanical-knowledge type of pedagogy which is rather based on eliciting positive-opportunism-of-social-functioning-and- 
accordance $^{75}$ sense-of-things. This is critical because the notional ${ }^{18}$ deprocrypticism reference-of-thought warrants a more originary/as-of-event ${ }^{38}$ mental-disposition 'beyond just responsiveness to secondnatured institutionalisation' but equally the capacity to assume dimensionality-of-sublimating ${ }^{25}-<$ amplituding/formative $>$ supererogatory - dementativeness/epistemic-growth-or-conflatedness /transvaluativerationalising/transepistemicity/anamnestic-residuality/spirit-drivenness-equalisation〉 ontological-faith-notion-or-ontological-fideism - imbued-underdetermination-of-motif-andapriorising/axiomatising/referencing-as-so-being-as-of-existential-reality parrhesiastic askesisor-acumen behind the 'inventing' as of reasoning-through/messianic-reasoning with respect to 'upholding and defending ontological-veridicality beyond constraining-and/or-secondnatured institutionalisation framework' as well as actually perpetuating prospective ontologicallyveridical sublimation-as-of-deprocrypticism-immanented-implications, and so as of a fundamental mental-disposition for perpetually preempting-disjointedness-as-of- referenceof-thought. With the foregoing immanence-function-conflatedness ${ }^{13}$ insight, of most critical importance and decisiveness as preconverging/postconverging-dementatively/structurally/paradigmatically anchoring futural Being-development/ontologicalframework-expansion-as-to-depth-of-ontologising-development-as-infrastructure-ofmeaningfulness-and-teleology as of prospective notional deprocrypticism meaningfulness-and-teleology is the need for a notional ${ }^{9}$ deprocrypticism reconceptualised conception of the human construction-of-the-Self. In this regard, we can appreciate critically that hitherto and as of a natural human predisposition to <amplituding/formativeepistemicity $>$ totalising $\sim$ self-referencing-syncretising/circularity/interiorising/akrasiatic-drag ${ }^{34}$, the psychology traditions have tended to ad-hocly construe construction-of-the-Self as of a human-subpotency flawed absolutising epistemic reference, and so over an existencepotency ${ }^{39} \sim$ sublimating-nascence,-disclosed-from-prospective-epistemic-digression 
absolutising epistemic reference, specifically as so-construed from our positivismprocrypticism registry-worldview/dimension flawed absolutising epistemic reference. The fact that existence/intrinsic-reality/ontological-veridicality precedes human-subpotency thus questions the veracity of the ontological orientation of traditional psychology/psychoanalysis; wherein the 'human psychology of absolutising epistemic reference is wrongly conceived as of ontological-normalcy/postconvergence rather than as of epistemicabnormalcy/preconvergence ${ }^{3}$ considering the necessarily decontorting human-subpotency psyche on the constraint of our ontologically-compromised reproducibilitymathesis/motif/thrownness-disposition,-as-reproducibility-of-aestheticisation as of our $<$ amplituding/formative-epistemicity $>$-totalising $\sim$ thrownness-in-existence ${ }^{35}$. The implication here is that we cannot have a human-subpotency flawed absolutising epistemic reference that as of human-subpotency can surpass the ontological-veracity of the full-potency of existence/intrinsic-reality/ontological-veridicality as absolutising epistemic reference as of ontological-normalcy/postconvergence, and so given human-subpotency prior relativeontological-incompleteness $^{88}$ implied flawed prospective ontological-performance ${ }^{72}$ <including-virtue-as-ontology $>$. Such a human-subpotency flawed absolutising epistemic reference for ${ }^{56}$ meaningfulness-and-teleology ${ }^{9}$ can be construed as of 'human akrasiasusceptibility-or-akrasiatic-drag/shiftiness-of-the-Self /ontological-

fracturing/desublimation/gimmickiness complex'; as of 'human-subpotency temporality $/$ /shortness flawed absolutising epistemic reference' as it induces flawed ontological-performance $^{72}$-<including-virtue-as-ontology $>/$ morality/ethics/justice/etc. as by its $<$ amplituding/formative-epistemicity $>$ totalising $\sim$ self-referencing-

syncretising/circularity/interiorising/akrasiatic-drag ${ }^{34}$ it 'wrongly seem to advantageously substitute' for the potent as intemporal absolutising epistemic reference ontologicalperformance $^{72}-<$ including-virtue-as-ontology $>$ /morality/ethics/justice/etc. of existence- 
potency $^{32} \sim$ sublimating-nascence,-disclosed-from-prospective-epistemic-digression as to intrinsic-reality/ontological-veridicality. It is this construction-of-the-Self human-subpotency deficiency element construed as 'human akrasia-susceptibility-or-akrasiatic-drag/shiftiness-ofthe-Self /ontological-fracturing/desublimation/gimmickiness complex' that raises-the-chargethat-and-reflects-the-notion-that the mental-disposition of recurrent-utter-uninstitutionalisation is preconverging/postconverging-de-mentatively/structurally/paradigmatically bound to fail the ontological-performance $^{72}$-<including-virtue-as-ontology $>/$ morality/ethics/justice/etc. of baseinstitutionalisation mental-disposition, that of base-institutionalisation-ununiversalisation will likewise fail as of ${ }^{103}$ universalisation mental-disposition, ${ }^{103}$ universalisation-nonpositivism/medievalism will likewise fail as of positivism mental-disposition, and prospectively our positivism- ${ }^{8}$ procrypticism will likewise fail as of notional ${ }^{18}$ deprocrypticism mentaldisposition. This element of the dynamic evolution of the human psyche and the underlying instigative agency, herein articulated as 'human akrasia-susceptibility-or-akrasiaticdrag/shiftiness-of-the-Self /ontological-fracturing/desublimation/gimmickiness complex', is mostly lost to traditional psychology that doesn't register our own positivism- ${ }^{80}$ procrypticism prior relative-ontological-incompleteness ${ }^{8}$-of- ${ }^{8}$ reference-of-thought as of an ontologicalnormalcy/postconvergence/referentialism notional ${ }^{18}$ deprocrypticism perspective of analysis as of singularisation-<as-to-the-nondisjointedness/entailment-of-prospective- nonpresencing $>$ projected epistemic-immanence/veridical-epistemicity-relativism-determinism. We can perceive the '<amplituding/formative-epistemicity>totalising/circumscribing/delineating preconverging/dementing ${ }^{20}$-qualia-schema' associated with akrasia-susceptibility-or-akrasiaticdrag complex only from the perspective of prospective relative-ontological-completeness ${ }^{87}$-ofreference-of-thought, and so as of the latter's difference-conflatedness ${ }^{13}$-as-to-totalitativereification-in-singularisation-<as-to-the-nondisjointedness/entailment-of-prospective- 
apriorising/axiomatising/referencing/intelligibilitysettingup/measuringinstrumenting, as it reflects-and-contemplates of the uninstitutionalised-threshold ${ }^{102}$ of the prior relativeontological-incompleteness ${ }^{88}$-of- ${ }^{83}$ reference-of-thought

apriorising/axiomatising/referencing/intelligibilitysettingup/measuringinstrumenting, whereas the prior relative-ontological-incompleteness ${ }^{8}{ }^{8}$ reference-of-thought mental-disposition reflects its uninstitutionalised-threshold ${ }^{102}$ as a nondescript/ignorable-void (actually speaking of akrasiatic-drag-denatured-and-preconverging-or-dementing -narratives) of notionaldiscontiguity/epistemic-discontiguity ${ }^{6}-<$ between - prior-shallow-supererogation -ofmentally-aestheticised preconverging/dementing -qualia-schema_and_prospective-profoundsupererogation -of-mentally-aestheticised postconverging/dialectical-thinking -qualiaschema> by 'resetting its apriorising/axiomatising/referencing/intelligibilitysettingup/measuringinstrumenting which is flawed at its uninstitutionalised-threshold ${ }^{102}$, thus taking a flawed posture of identitiveconstitutedness ${ }^{14}$-as-'epistemic-totality ${ }^{37}$ '-dereification-in-dissingularisation- $<$ as-to-thedisjointedness/disentailment-of- presencing - absolutising-identitive-constitutedness $>$-asflawed-epistemicity-relativism-determinism of notional-discontiguity/epistemicdiscontiguity ${ }^{6}-<$ between - prior-shallow-supererogation -of-mentallyaestheticised preconverging/dementing -qualia-schema_and_prospective-profoundsupererogation -of-mentally-aestheticised postconverging/dialectical-thinking -qualiaschema $>$. Such akrasia-susceptibility-or-akrasiatic-drag complex '<amplituding/formativeepistemicity>totalising/circumscribing/delineating preconverging/dementing ${ }^{20}$-qualia-schema' is reflected as of the '<amplitung formative-epistemicity $>$ totalising $\sim$ self-referencingsyncretising/circularity/interiorising/akrasiatic-drag ${ }^{4}$ of the prior relative-ontologicalincompleteness ${ }^{8}{ }^{8}$ reference-of-thought 
apriorising/axiomatising/referencing/intelligibilitysettingup/measuringinstrumenting mathesis/motif/thrownness-disposition-at-its-uninstitutionalised-threshold ${ }^{12}$. Consider the akrasia-susceptibility-or-akrasiatic-drag complex ‘ $<$ amplituding/formativeepistemicity>totalising/circumscribing/delineating preconverging/dementing ${ }^{20}$-qualia-schema' from a prospective positivism/rational-empiricism apriorising/axiomatising/referencing/intelligibilitysettingup/measuringinstrumenting in this regards, with respect to 'God-of-plane' type of expression in an animistic/baseinstitutionalisation setup wherein their fundamental apriorising/axiomatising/referencing/intelligibilitysettingup/measuringinstrumenting psychologism is so ingrained that every meaningfulness from a positivistic social-setup cultural diffusion is inevitably reconstrued/devolved in the animistic/base-institutionalisation apriorising/axiomatising/referencing/intelligibilitysettingup/measuringinstrumenting reference-of-thought psychologism of ${ }^{56}$ meaningfulness-and-teleology 9 in $<$ amplituding/formative-epistemicity $>$ totalising $\sim$ self-referencingsyncretising/circularity/interiorising/akrasiatic-drag ${ }^{34}$ with its uninstitutionalised-threshold ${ }^{12}$ as a nondescript/ignorable-void (actually speaking of akrasiatic-drag-denatured-andpreconverging-or-dementing ${ }^{20}$-narratives) whereas such a representation as a nondescript/ignorable-void wouldn't be recognised from the positivism/rational-empiricism perspective as of its prospective relative-ontological-completeness ${ }^{87}$-of- ${ }^{8}$ reference-of-thought. Likewise, as of prospective insight, the nondescript/ignorable-void (actually speaking of akrasiatic-drag-denatured-and-preconverging-or-dementing -narratives) we imply as of our positivism- ${ }^{80}$ procrypticism disjointedness-as-of- ${ }^{8}$ reference-of-thought is certainly prospectively contemplatable in futural Being-development/ontological-framework-expansionas-to-depth-of-ontologising-development-as-infrastructure-of- meaningfulness-andteleology as of prospective notional ${ }^{18}$ deprocrypticism reflection of our akrasia-susceptibility- 
or-akrasiatic-drag

complex

$<$ amplituding/formative-

epistemicity>totalising/circumscribing/delineating preconverging/dementing ${ }^{20}$-qualia-schema' of positivism- ${ }^{8}$ procrypticism disjointedness-as-of- ${ }^{83}$ reference-of-thought in '<amplituding/formative-epistemicity $>$ totalising $\sim$ self-referencing-

syncretising/circularity/interiorising/akrasiatic-drag ${ }^{34}$ as of difference-conflatedness ${ }^{13}$-as-tototalitative-reification-in-singularisation-<as-to-the-nondisjointedness/entailment-of-

prospective- nonpresencing $>$-as-veridical-epistemicity-relativism-determinism from the notional ${ }^{18}$ deprocrypticism relative-unreflexivity/relative-reflexivity - ontological-contiguity ${ }^{67}$, whereas from our positivism- ${ }^{8}$ procrypticism perspective we'll tend to a 'resetting of the apriorising/axiomatising/referencing/intelligibilitysettingup/measuringinstrumenting' of positivism- ${ }^{80}$ procrypticism in ontological-disconguity as of identitive-constitutedness ${ }^{14}$-as'epistemic-totality ${ }^{37}$ '-dereification-in-dissingularisation- $<$ as-to-thedisjointedness/disentailment-of- presencing - absolutising-identitive-constitutedness $>$-asflawed-epistemicity-relativism-determinism. This expansion of the traditional notion of akrasia, as akrasia-susceptibility-or-akrasiatic-drag complex is rather as of the perspective of existence-potency ${ }^{39} \sim$ sublimating-nascence,-disclosed-from-prospective-epistemic-digression as-to-ontologically-uncompromised-ontological-normalcy/postconvergence/referentialism $<$ amplituding/formative $>$ notional $\sim$ preempting — disjointedness-as-of- ${ }^{3}$ reference-of-

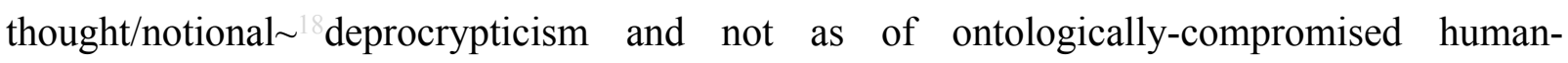
subpotency epistemic-or-notional projective-perspective; and is articulated more completely to reflect ontological-performance ${ }^{72}<$ including-virtue-as-ontology $>/$ morality/ethics/justice/etc. as of the the-Good/knowledge-reification $\sim$ gesturing-and-accounting-of-epistemicphenomenalism- $<$ in-prospective_psychologismic $\sim$ apriorising/axiomatising/referencing- of'prospectively_implicited_attendant-ontological-contiguity ' ceducedexistentialising/contextualising/textualising_intelligibility/epistemicity/reflexivity_contiguity- 
<imbued-notional cogency>' \}-conflatedness -in-\{preconverging-disentailment by\}

postconverging entailment $>$ /understanding/<amplituding/formative-

epistemicity $>$ causality $\sim$ as-to-projective-totalitative-implications-of-prospective-

nonpresencing,-for-explicating relative-unreflexivity/relative-reflexivity - ontological-

contiguity construal/conceptualisation with respect to prospective relative-ontologicalcompleteness ${ }^{87}<$ amplituding/formative-epistemicity $>$ causality $\sim$ as-to-projective-totalitativeimplications-of-prospective- nonpresencing,-for-explicating relative-unreflexivity/relativereflexivity - ontological-contiguity in accounting for human differences of ontologicalperformance ${ }^{2}-<$ including-virtue-as-ontology $>$. It is herein contended that such a traditional psychology approach to construction-of-the-Self is constituted as of identitive-constitutedness ${ }^{14}$ as-'epistemic-totality ${ }^{37}$ '-dereification-in-dissingularisation-<as-to-the-

disjointedness/disentailment-of- presencing - absolutising-identitive-constitutedness $>$-asflawed-epistemicity-relativism-determinism . Thus the notion of 'human akrasia-susceptibilityor-akrasiatic-drag/shiftiness-of-the-Self /ontological-fracturing/desublimation/gimmickiness complex' refers to the mental dispositional state of preconverging/postconverging-dementative/structural/paradigmatic rationalised-closedness-of-ontological-performance ${ }^{72}$ <including-virtue-as-ontology>-of-the-self 'as bound to define-and-shape any given registryworldview's/dimension's specific ontological-performance ${ }^{72}-<$ including-virtue-as-ontology $>$ and-vices-and-impediments ${ }^{105}$, Rather an ontologically-veridical construction-of-the-Self is necessarily in apriorising/axiomatising/referencing-\{of-"prospectively implicited_attendantontological-contiguity ' educed-

existentialising/contextualising/textualising_'intelligibility/epistemicity/reflexivity-contiguity<imbued-notional cogency $\left.>^{\prime},\right\}$-conflatedness ${ }^{13}$ in (preconverging disentailment by postconverging-entailment as of the intemporal absolutising epistemic reference of existencepotency ${ }^{39} \sim$ sublimating-nascence,-disclosed-from-prospective-epistemic-digression 
constrainous-implications-over-human-subpotency so-implied as of ontologicallyuncompromised ontological-normalcy/postconvergence/referentialism and construed as of difference-conflatedness ${ }^{13}$-as-to-totalitative-reification-in-singularisation- $<$ as-to-the-

nondisjointedness/entailment-of-prospective- nonpresencing > -as-veridical-epistemicityrelativism-determinism . Such an apriorising/axiomatising/referencing-\{of-"prospectively implicited_attendant_ontological-contiguity ' educedexistentialising/contextualising/textualising_intelligibility/epistemicity/reflexivity_contiguity<imbued-notional cogency $\left.>^{\prime}\right\}$-conflatedness ${ }^{13}$-in-\{preconverging-disentailment by postconverging-entailment construction-of-the-Self is one that is preconverging/postconverging-de-mentatively/structurally/paradigmatically enframed in grasping the 'notional dissonance/consonance of human superego and existencepotency $^{32} \sim$ sublimating-nascence,-disclosed-from-prospective-epistemic-digression, $\quad$ as $\quad$ it construes of human-subpotency reference-of-thought given level of aetiologisation/ontological-escalation-<ontological-

veridicality_commitment/otherliness_transcending/compulsions-encumbered_transcending $>$ implications; and so as devolvingly thereof, construction-of-the-Self is the individual autonomous ecstatic/existential referencing/registering/decisioning, contemplating, responding, conceptualising, articulating, effecting and acting-out of its social meaningfulness-andteleology as of the <amplituding/formative-epistemicity>causality $\sim$ as-to-projectivetotalitative-implications-of-prospective- nonpresencing,-for-explicating relativeunreflexivity/relative-reflexivity - ontological-contiguity of Being-development/ontologicalframework-expansion-as-to-depth-of-ontologising-development-as-infrastructure-ofmeaningfulness-and-teleology , institutional-development-as-to-social-functiondevelopment and living-development-as-to-personality-development psychologismic epistemic-acutisation difficulty-for, residualising \{decompulsing $\}$ delinearity for-cogency> 
magnitudes \{of-experientiality/experiment\}. Thus fundamentally the <amplituding/formativeepistemicity $>$ causality as-to-projective-totalitative-implications-of-prospectivenonpresencing,-for-explicating relative-unreflexivity/relative-reflexivity - ontological-

contiguity and orientations underlying construction-of-the-Self as of a notional ${ }^{1}$ deprocrypticism conception is rather transformative, in reflecting its protensiveconsciousness insight of varied human constructions-of-the-self underlying the institutionalcumulation/institutional-recomposure-〈as-to- historiality/ontological-

eventfulness /ontological-aesthetic-tracing-<perspective-ontologicalnormalcy/postconvergence-reflected-‘epistemicity-relativism-determinism’>> with $<$ cumulating/recomposuring attendant-ontological-contiguity $>$-successive registryworldviews/dimensions human-subpotency ${ }^{83}$ reference-of-thought induced recurrently from the instigative $\quad<$ amplituding/formative-epistemicity $>$ causality $\sim$ as-to-projective-totalitativeimplications-of-prospective- nonpresencing,-for-explicating relative-unreflexivity/relativereflexivity ontological-contiguity of ${ }^{15}$ de-mentation-〈supereregatery-ontological-dementation-or-dialectical-de-mentation-stranding-or-attributive-dialectics $\rangle. \quad$ Thus, what critically stands out from traditional psychology as inducing such a novel differentiated and transformative articulation of construction-of-the-Self is the notion of 'human akrasiasusceptibility-or-akrasiatic-drag/shiftiness-of-the-Self /ontological-

fracturing/desublimation/gimmickiness complex'. Interestingly, many a traditional take on the notion of akrasia, construed herein as akrasia-susceptibility-or-akrasiatic-drag complex, like the Socratic argument of its non-veridicality strangely enough rather confirms its veridicality, in the sense that such arguments are being made from the perspective of human-subpotency, which is exactly the irrelevant perspective for ontological-veridicality articulation. Consider the idea that a cholera epidemic that was to occur say in 100 B.C. will not stop from occurring because human beings did not know of notions-of-bacteria-as-causing-diseases-and-instead-believed-in-bad- 
omen-for-not-making-the-right-sacrifices-or-so-so-and-so;

reality/ontological-veridicality will not factor in such a state of 'human-subpotency in its $<$ amplituding/formative-epistemicity $>$ totalising $\sim$ self-referencing-

syncretising/circularity/interiorising/akrasiatic-drag ${ }^{34}$, , and adjust to it by stopping such an epidemic. This is exactly why ontologically-veridical ${ }^{56}$ meaningfulness-and-teleology ${ }^{9}$ implies a displacement/decentering-of-the-human-subject with its emancipation arising as of its submitting to the 'superior party' that is existence/intrinsic-reality/ontological-veridicality as is falsifiable and can be validated by <mplituding/formative-epistemicity $>$ causality $~ a s-t o-$ projective-totalitative-implications-of-prospective- nonpresencing,-for-explicating relativeunreflexivity/relative-reflexivity ontological-contiguity . Thus intemporal ontologicalperformance $^{72}-<$ including-virtue-as-ontology $>$ /morality/ethics/justice/etc. ever always warrants human prospective relative-ontological-completeness ${ }^{87}$-of- ${ }^{8}$ reference-of-thought for empowering and responsible ${ }^{5}$ meaningfulness-and-teleology ${ }^{9}$ for transcendence-andsublimity/sublimation/supererogatory $\sim$ de-mentativity. Thus akrasia-susceptibility-or-akrasiaticdrag complex further implies that the very state of unwariness with respect to prior relativeontological-incompleteness ${ }^{8}$ as of a nihilistic disposition is preconverging/postconverging-dementatively/structurally/paradigmatically potently conducive/endemising/enculturating to its vices-and-impediments $^{105}$, and as the very possibility for prospective ontological-performance ${ }^{72}$ $<$ including-virtue-as-ontology $>$ /morality/ethics/justice/etc. arises as of the intemporal ontological-faith-notion-or-ontological-fideism - imbued-underdetermination-of-motif-andapriorising/axiomatising/referencing-as-so-being-as-of-existential-reality parrhesiastic askesisor-acumen reasoning-through/messianic-reasoning as of its 'seeding promise of humansubpotency

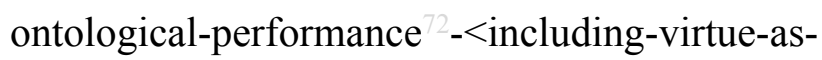
ontology $>$ /morality/ethics/justice/etc. equivalence/correspondence with the full-potency-ofexistence's $\sim$ sublimating-nascence-as-of-its-coherence/contiguity'. Can we wish that we don't 
have understanding whether directly, or indirectly as of reifying deferential-formalisationtransference, so that we aren't intellectually-and-morally accountable then? How can we reconcile the fact that given human <amplituding/formative-epistemicity $>$ totalising thrownness-in-existence ${ }^{35}$ the possibility for prospective human registryworldview's/dimension's institutionalisation enabling transcendence-andsublimity/sublimation/supererogatory-de-mentativity could only arise as of prospective reasoning-through/messianic-reasoning that had no prior effective knowledge and virtue reference to go on to prospectively 'invent' reasoning-through/messianic-reasoning knowledge and virtue before the institutionalising of such reasoning-from-results/afterthought emancipating possibilities, and then contend to make any given reasoning-from-results/afterthought knowledge and virtue limits intellectually and morally deterministic as of a nihilistic $<$ amplituding/formative $>$ wooden-language-_imbued - averaging-of-thought-<as-toleveling/ressentiment/closed-construct-of- meaningfulness-and-teleology -as-of'nondescript/ignorable-void '-with-regards-to-prospective-apriorising-implications $>>$ ? In this regard, the anti-nihilist stance implies that the very first notion of human ontologicalperformance $^{72}-<$ including-virtue-as-ontology $>$ /morality/ethics/justice/etc. as of human $<$ amplituding/formative-epistemicity $>$-totalising $\sim$ thrownness-in-existence ${ }^{35}$ induced anxiety lies in the fact that as of intemporal ontological-faith-notion-or-ontological-fideism - imbuedunderdetermination-of-motif-and-apriorising/axiomatising/referencing-as-so-being-as-ofexistential-reality parrhesiastic askesis-or-acumen reasoning-through/messianic-reasoning, humankind has the relative capacity to build and/or adhere to prospective relative-ontologicalcompleteness ${ }^{87}$ possibilities. It is this insight that validates the ontological-veracity of the conception of 'human akrasia-susceptibility-or-akrasiatic-drag/shiftiness-of-theSelf /ontological-fracturing/desublimation/gimmickiness complex', and it is inherently sovalidated as of 'intemporal ontological-faith-notion-or-ontological-fideism-imbued- 
underdetermination-of-motif-and-apriorising/axiomatising/referencing-as-so-being-as-of-

existential-reality parrhesiastic askesis-or-acumen reasoning-through/messianic-reasoning instigated relative-unreflexivity/relative-reflexivity - ontological-contiguity ${ }^{67}$ of-the-humaninstitutionalisation-process $^{68}$ as of difference-conflatedness ${ }^{13}$-as-to-totalitative-reification-insingularisation-<as-to-the-nondisjointedness/entailment-of-prospective- nonpresencing $>$-asveridical-epistemicity-relativism-determinism implied $\quad<$ amplituding/formativeepistemicity $>$ causality $\sim$ as-to-projective-totalitative-implications-of-prospectivenonpresencing,-for-explicating relative-unreflexivity/relative-reflexivity - ontologicalcontiguity ', as it cogently-and-fluidly as of ecstatic-totalising-entailing/nested-congruence ahistorically-and-aculturally reflects-and-accounts-for the transitioning relativeunreflexivity/relative-reflexivity — ontological-contiguity ${ }^{67}$ of-the-human-institutionalisationprocess ${ }^{6}$ development of the human species psyche. This insight equally specifically underlies the psychoanalytic ontological-veracity of 'human akrasia-susceptibility-or-akrasiaticdrag/shiftiness-of-the-Self '/ontological-fracturing/desublimation/gimmickiness complex' as it reflects the basic human psychological nature across all ages and times, so appraised as from the-Good/knowledge-reification gesturing-and-accounting_-of-epistemic-phenomenalism$<$ in-prospective_psychologismic $\sim$ apriorising/axiomatising/referencing-\{of-'prespectively implicited_attendant-ontological-contiguity ' educedexistentialising/contextualising/textualising_'intelligibility/epistemicity/reflexivity-contiguity<imbued-notional cogency $\left.>^{\prime} \quad\right\}$-conflatedness -in-\{preconverging-disentailment by\} postconverging entailment $>$ /understanding/<amplituding/formativeepistemicity $>$ causality $\sim$ as-to-projective-totalitative-implications-of-prospectivenonpresencing,-for-explicating relative unreflexivity/relative reflexivity - ontologicalcontiguity construal/conceptualisation with respect to prospective relative-ontologicalcompleteness ${ }^{87}$-of- ${ }^{8}$ reference-of-thought $<$ amplituding/formative-epistemicity $>$ causality $\sim$ as- 


\section{to-projective-totalitative-implications-of-prospective- nonpresencing,-for-}

\section{explicating relative-unreflexivity/relative-reflexivity ontological-contiguity in accounting}

for human differences of ontological-performance ${ }^{72}-<$ including-virtue-as- $^{-}$ ontology $>$ /morality/ethics/justice/etc. across the <cumulating/recomposuring attendantontological-contiguity >-successive registry-worldviews/dimensions 83 reference-of-thoughtlevel of ontological-performance ${ }^{72}-<$ including-virtue-as-ontology $>/$ morality/ethics/justice/etc. as well as the temporal-to-intemporal differences of ontological-performance ${ }^{2}-<$ includingvirtue-as-ontology $>$ /morality/ethics/justice/etc. as of each registry-worldview's/dimension's reference-of-thought- ${ }^{-1}$ devolving-level, rather than flawed impression-driven/goodnaturedness/wishfulness conceptualisation as of inherent identitive essences flawed accounting of human differences. This idea of 'human akrasia-susceptibility-or-akrasiatic-drag/shiftinessof-the-Self ${ }^{\prime}$ ontological-fracturing/desublimation/gimmickiness complex' fundamentally harkens back to the notion of ontological-faith-notion-or-ontological-fideism-imbuedunderdetermination-of-motif-and-apriorising/axiomatising/referencing-as-so-being-as-ofexistential-reality as of its 'seeding promise of human-subpotency ontological-performance ${ }^{72}$ <including-virtue-as-ontology $>/$ morality/ethics/justice/etc. equivalence/correspondence with the full-potency-of-existence's $\sim$ sublimating-nascence-as-of-its-coherence/contiguity'; wherein successive prospective relative-ontological-completeness ${ }^{87}$-of- ${ }^{8}$ reference-of-thought generate preconverging/postconverging-de-mentative/structural/paradigmatic existential-disontologising/re-ontologising aporeticism $>$ implications as of 'successive specific lessand-less-degenerate human akrasia-susceptibility-or-akrasiatic-drag/shiftiness-of-theSelf /ontological-fracturing/desublimation/gimmickiness complex' with respect to the $<$ cumulating/recomposuring attendant-ontological-contiguity $>$-successive registryworldviews/dimensions construction-of-the-Self, as of their ontological-performance ${ }^{72}$ $<$ including-virtue-as-ontology>-and-vices-and-impediments ${ }^{105}$. Basically, construction-of-the- 
Self is herein construed rather as: the 'self, as of its <amplituding/formativeepistemicity $>$ totalising $\sim$ self-referencing-syncretising/circularity/interiorising/akrasiatic-drag metaphoricity ${ }^{57}$, as of its evolving-and-devolving constraining ${ }^{83}$ reference-of-thought pitting its preconverging/postconverging-de-mentating/structuring/paradigming apriorising/axiomatising/referencing/intelligibilitysettingup/measuringinstrumenting correspondingly with existence-potency ${ }^{32} \sim$ sublimating-nascence,-disclosed-from-prospectiveepistemic-digression as to intrinsic-reality/ontological-veridicality, as soentertainable/permissible by its given registry-worldview's/dimension's- ${ }^{83}$ reference-ofthought-for-social-functioning-and-accordance', in construction-of-the-Self's existential$\leq$ disontologising/re-ontologising aporeticism $>$ narrative; involving existential<disontologising/re-ontologising aporeticism $>$ reactive temporisation/bouncing-off of construction-of-the-Self elements (- akrasia-susceptibility-or-akrasiatic-drag/shiftiness-of-theSelf /ontological-fracturing/desublimation/gimmickiness complex, - repression and releasement as subconsciousness, and - 'recurrently mediative-<in-expectation/in-anticipation> unconsciousness/potentiation-of-conscionability-<anxiety-as-to-reconstitution/reparation,including-dreaming/psychical-reshuffling>', and so as of a psychological analysis of direct mental-processing ontological-performance ${ }^{2}-<$ including-virtue-asontology $>$ /morality/ethics/justice/etc. implications with respect to the constructiveness-ofontological-performance ${ }^{72}-<$ including-virtue-as-ontology $>/$ morality/ethics/justice/etc. of the social epistemic-totality ${ }^{37}$ of ${ }^{56}$ meaningfulness-and-teleology ${ }^{9}$ so-undergirding the construction-of-the-Self all along in reflecting holographically-<conjugatively-andtransfusively $>$ the relative-unreflexivity/relative-reflexivity - ontological-contiguity $\sim$ of-thehuman-institutionalisation-process ). The psychoanalytic pertinence of human akrasiasusceptibility-or-akrasiatic-drag complex, so-implied as 'human akrasia-susceptibility-orakrasiatic-drag/shiftiness-of-the-Self /ontological-fracturing/desublimation/gimmickiness 
complex', is hinted at even by traditional psychology but rather indirectly as of its ontologicallyflawed perspective as of human-subpotency <amplituding/formativeepistemicity $>$ totalising $\sim$ self-referencing-syncretising/circularity/interiorising/akrasiatic-drag when it recognises that we do fall short of intemporal ontological-performance ${ }^{2}-<$ includingvirtue-as-ontology>, but strangely enough hardly has there been articulated any conception about this obviously fundamental preconverging/postconverging-dementating/structuring/paradigming ontologically-veridical implication of human-subpotency psyche limitation/compensative complex as from the perspective of existencepotency $^{32} \sim$ sublimating-nascence,-disclosed-from-prospective-epistemic-digression as to intrinsic-reality/ontological-veridicality which is exactly what is ontologically pertinent, and so out of our ${ }^{79}$ presencing - absolutising-identitive-constitutedness ${ }^{14}<$ amplituding/formativeepistemicity $>$ totalising $\sim$ self-referencing-syncretising/circularity/interiorising/akrasiatic-drag inclination. Thus, human akrasia-susceptibility-or-akrasiatic-drag complex is rather construed here as of the prior relative-ontological-incompleteness ${ }^{8}$ <amplituding/formativeepistemicity $>$ causality $\sim$ as-to-projective-totalitative-implications-of-prospectivenonpresencing,-for-explicating relative unreflexivity/relative-reflexivity - ontological-

contiguity in the shiftiness-of-the-Self as of living, institutional and Being ontologicalperformance $^{72}-<$ including-virtue-as-ontology $>$ /morality/ethics/justice/etc. arising as of human temporality'; wherein 'human-subpotency temporality $/$ shortness flawed absolutising

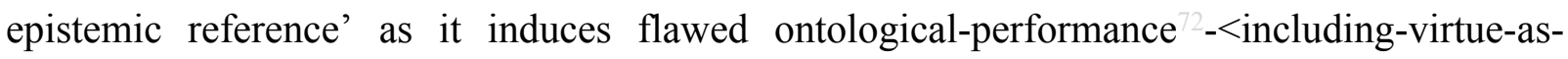
ontology $>$ /morality/ethics/justice/etc. by its $\quad$ amplituding/formativeepistemicity $>$ totalising $\sim$ self-referencing-syncretising/circularity/interiorising/akrasiatic-drag 'wrongly seem to advantageously substitute' for the potent as intemporal absolutising epistemic reference

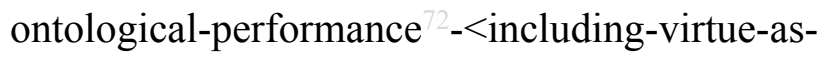
ontology $>/$ morality/ethics/justice/etc. of the existence-potency ${ }^{39} \sim$ sublimating-nascence,- 
disclosed-from-prospective-epistemic-digression as to intrinsic-reality/ontological-veridicality perspective. In this regard, traditional psychology fails a theoretical-conceptual-operant accounting for the changing construction-of-the-Self, as reflected by the fact that 'intemporal ontological-faith-notion-or-ontological-fideism - imbued-underdetermination-of-motif-andapriorising/axiomatising/referencing-as-so-being-as-of-existential-reality instigating recurrent shot for prospective relative-ontological-completeness ${ }^{87}$ as reasoning-through/messianicreasoning enabling in reflecting holographically-<conjugatively-and-transfusively $>$ the relativeunreflexivity/relative-reflexivity - ontological-contiguity of-the-human-institutionalisationprocess as of difference-conflatedness ${ }^{13}$-as-to-totalitative-reification-in-singularisation- $<$ as-tothe-nondisjointedness/entailment-of-prospective- nonpresencing $>$-as-veridical-epistemicityrelativism-determinism implied $<$ amplituding/formative-epistemicity $>$ causality $\sim$ as-toprojective-totalitative-implications-of-prospective- nonpresencing,-for-explicating relativeunreflexivity/relative-reflexivity ontological-contiguity ' brings about successively weaker degenerative apriorising/axiomatising/referencing-\{of-‘prospectively implicited_attendantontological-contiguity ' educedexistentialising/contextualising/textualising_intelligibility/epistemicity/reflexivity-contiguity<imbued-notional cogency>' $\}$-constitutedness ${ }^{1}$-in preconverging entalment 'human akrasia-susceptibility-or-akrasiatic-drag/shiftiness-of-the-Self /ontologicalfracturing/desublimation/gimmickiness complex', with increasing ontological-performance <including-virtue-as-ontology $>$ /morality/ethics/justice/etc. as of the $<$ cumulating/recomposuring attendant-ontological-contiguity $>$-successive registryworldviews/dimensions ${ }^{83}$ reference-of-thought. The implied psychoanalysis is one that propounds that all the psychoanalysis that is ontologically-veridical is rather as of the 'displacement/decentering of human-subpotency epistemic-or-notional projective-perspective towards the realisation of the full existence-potency ${ }^{32} \sim$ sublimating-nascence,-disclosed-from- 
prospective-epistemic-digression epistemic perspective' in order to induce transcendence-andsublimity/sublimation/supererogatory de-mentativity, so-construed as superegoic cleansing as of Being-development/ontological-framework-expansion-as-to-depth-of-ontologisingdevelopment-as-infrastructure-of- meaningfulness-and-teleology , institutionaldevelopment-as-to-social-function-development and living-development-as-to-personalitydevelopment psychologismic epistemic-acutisation difficulty-<for, residualising \{decompulsing $\}$ delinearity for-cogency>-magnitudes $\{$ of-experientiality/experiment $\}$ in dispensing-withimmediacy-for-relative-ontological-completeness ${ }^{87}$-by-reification/contemplativedistension 7 contemplative-distention; as of a prospective psychoanalysis rather constrained to existence-potency ${ }^{39} \sim$ sublimating-nascence,-disclosed-from-prospective-epistemic-digression normalcy/postconvergence/referentialism as-to-ontologically-uncompromised-ontological$<$ amplituding/formative $>$ notional $\sim$ preempting — disjointedness-as-of- ${ }^{3}$ reference-ofthought/notional ${ }^{18}$ deprocrypticism. We can fundamentally appreciate that just in reflecting holographically-<conjugatively-and-transfusively $>$ the relative-unreflexivity/relativereflexivity ontological-contiguity of-the-human-institutionalisation-process is associated with epistemic-veracity $\quad{ }^{45}$ foregrounding_entailment- $<$ in-succession-of-profoundsupererogation $>$-〈postconverging-narrowing-down $\sim$ sublimation-as-to-'existence — assublimating-withdrawal/unenframing/re-ontologising,-elicited-from-prospective-profoundsupererogation '-in-reflecting-'immanent relative-unreflexivity/relative-reflexivity ontological-contiguity ';-as-operative-notional deprocrypticism) with the increasing existential-<disontologising/re-ontologising aporeticism $>$ ousting of superfluous notions like superstitions, etc., likewise 'human akrasia-susceptibility-or-akrasiatic-drag/shiftiness-of-theSelf /ontological-fracturing/desublimation/gimmickiness complex' as of prospective relativeontological-completeness ${ }^{87}$ epistemically shrinks with the relative-unreflexivity/relativereflexivity - ontological-contiguity ${ }^{67}$ of-the-human-institutionalisation-process ${ }^{68}$. That is, in 
reflecting holographically-<conjugatively-and-transfusively $>$ the relative-unreflexivity/relativereflexivity - ontological-contiguity of-the-human-institutionalisation-process epistemicveracity of foregrounding_entailment- $<$ in-succession-of-profound-supererogation $>$ 〈postconverging-narrowing-down sublimation-as-to-'existence-as-sublimatingwithdrawal/unenframing/re-ontologising,-elicited-from-prospective-profoundsupererogation '-in-reflecting-'immanent relative-unreflexivity/relative-reflexivity

ontological-contiguity ';--as-operative-notional deprocrypticism) constraining, the 'human akrasia-susceptibility-or-akrasiatic-drag/shiftiness-of-the-Self /ontologicalfracturing/desublimation/gimmickiness complex' for everyday existential-<disontologising/reentelegising apereticism $>$ occurrences as of ${ }^{56}$ meaningfulness-and-teleology 'is of less-andless-degenerate epistemic-veracity prompting', and so successively as from: - the trepidatiousconsciousness shiftiness-of-the-Self complex (by its epistemic non-rulesapriorising/axiomatising/referencing-psychologism,-as-impulsive-or-accidented-or-randommental-disposition relative ${ }^{58}$ neuterising as of its random-as-uncircumscribing/undelineating-as'epistemic-totality ${ }^{37}$ existential-epistemic-totalisation-scheme-of- ${ }^{56}$ meaningfulness-andteleology ${ }^{9}$ ), given its early hunter-gather recurrent-utter-uninstitutionalisation per-cep-ti-vi-tyas-of-bad-omen 'implicited_attendant-ontological-contiguity ${ }^{67}$ ' educedexistentialising/contextualising/textualising_intelligibility/epistemicity/reflexivity-contiguity$<$ imbued-notional cogency $>$-lowest-level-reification; - the warped-consciousness shiftinessof-the-Self complex (by its epistemic rulemaking-over-non-rulesapriorising/axiomatising/referencing-psychologism relative ${ }^{58}$ neuterising as of its tendentiouscircumscribing-as-'epistemic-totality ${ }^{37}$ '-or-delineating-as-'epistemic-totality ${ }^{37}, \quad$ existentialepistemic-totalisation-scheme-of- ${ }^{5}$ meaningfulness-and-teleology ${ }^{\circ}$, given its animistic baseinstitutionalisation-ununiversalisation per-cep-ti-vi-ty-as-of-a-specific-place-or-specific-evilpeople-or-specific-evil-period 'implicited_attendant-ontological-contiguity ${ }^{67}$ ? educed- 
existentialising/contextualising/textualising_intelligibility/epistemicity/reflexivity-contiguity<imbued-notional cogency> ${ }^{\prime}$-second-level-reification; - the preclusive-consciousness shiftiness-of-the-Self ${ }^{1}$ complex (by its epistemic ${ }^{103}$ universalisation-directed-rulemaking-overnon-rules - apriorising/axiomatising/referencing-psychologism relative ${ }^{58}$ neuterising as of its qualifying-circumscribing-as-'epistemic-totality ${ }^{37}$ '-or-delineating-as-'epistemic-totality ${ }^{37}$, existential-epistemic-totalisation-scheme-of- ${ }^{56}$ meaningfulness-and-teleology ${ }^{9}$ ), given its universalisation-non-positivism/medievalism per-cep-ti-vi-ty-as-of-failure-to-follow-theheeding-of-the-Deity-or-failure-to-adhere-to-a-certain-mysticism-or-failure-to-pay-reverenceto-an-ancestor 'implicited_attendant-ontological-contiguity ${ }^{67}$ ' educedexistentialising/contextualising/textualising_intelligibility/epistemicity/reflexivity-contiguity<imbued-notional cogency>' -third-level-reification; - the occlusive-consciousness shiftinessof-the-Self complex (by its epistemic positivising/rational-empiricism-based-universalisationdirected-rulemaking-over-non-rules—apriorising/axiomatising/referencing-psychologism relative ${ }^{58}$ neuterising as of its categorising-circumscribing-as-'epistemic-totality ${ }^{37}$ '-ordelineating-as-'epistemic-totality $^{37}$ existential-epistemic-totalisation-scheme-ofmeaningfulness-and-teleology ${ }^{9}$ ), given its positivism- ${ }^{80}$ procrypticism per-cep-ti-vi-ty-as-offull-rational-account-as-exclusive-cause-and-effect-conceptualisation 'implieited_attentant ontological-contiguity ${ }^{67}$, educed-

existentialising/contextualising/textualising_intelligibility/epistemicity/reflexivity-contiguity<imbued-notional cogency>' -fourth-level-reification; and prospectively - the protensiveconsciousness nonshiftiness-of-the-Self ${ }^{\prime}$ (by its epistemic preempting-disjointedness-as-ofreference-of-thought,-as-to- ${ }^{6}{ }^{2}<$ amplituding/formative-epistemicity>growth-orconflatedness ${ }^{13} /$ transvaluative-rationalising/transepistemicity/anamnestic-residuality/spiritdrivenness' - in-superseding-mere-formulaic-positivising/rational-empiricism-baseduniversalisation-directed-rulemaking-over-non-rules — apriorising/axiomatising/referencing- 
psychologism deneuterising ${ }^{17}$-referentialism as of referentialism-circumscribing-as'epistemic-totality ${ }^{37}$-or-delineating-as-'epistemic-totality ${ }^{37}$, existential-epistemic-totalisationscheme-of- ${ }^{56}$ meaningfulness-and-teleology ${ }^{9}$ ), given its notional ${ }^{18}$ deprocrypticism per-cep-tivi-ty-as-of-full-preempting-of-preconverging-or-dementing ${ }^{20}$-disjointedness-of-thought-

conceptualisation

'implicited_attendant-ontological-contiguity ${ }^{67}$ educedexistentialising/contextualising/textualising_intelligibility/epistemicity/reflexivity-contiguity<imbued-notional cogency $>$-full-level-of-reification. This reality in reflecting holographically-<conjugatively-and-transfusively $>$ the relative-unreflexivity/relativereflexivity - ontological-contiguity of-the-human-institutionalisation-process very much explains the statement 'I know that I know nothing' made by Socrates reflecting his conception of anamnesis, as the state of human limited-mentation-capacity-as-subjecting 'educedunlimitedness/existence-sublimating nascence' to-limitedness/human-subpotency implies that it is foolhardy to articulate in ${ }^{7}$ presencing-absolutising-identitive-constitutedness ${ }^{14}$ terms meaningfulness-and-teleology ${ }^{9}$ as of absolutising reproducibilitymathesis/motif/thrownness-disposition,-as-reproducibility-of-aestheticisation but rather the 'anamnesis of ${ }^{5}$ meaningfulness-and-teleology ${ }^{9}$ reflects prospective originariness-parrhesia,-as-spontaneity-of-aestheticisation as of recurrent transepistemic renewing of reproducibilitymathesis/motif/thrownness-disposition,-as-reproducibility-of-aestheticisation' (and so, in reflecting holographically-<conjugatively-and-transfusively $>$ the relative-unreflexivity/relativereflexivity - ontological-contiguity of-the-human-institutionalisation-process dimensionality-of-sublimating ${ }^{25}-\langle<$ amplituding/formative $>$ supererogatory $-\mathrm{de}-$ mentativeness/epistemic-growth-or-conflatedness /transvaluativerationalising/transepistemicity/anamnestic-residuality/spirit-drivenness-equalisation〉 as of difference-conflatedness ${ }^{13}$-as-to-totalitative-reification-in-singularisation- $<$ as-to-thenondisjointedness/entailment-of-prospective- nonpresencing $>$-as-veridical-epistemicity- 
relativism-determinism implied $<$ amplituding/formative-epistemicity $>$ causality $\sim$ as-toprojective-totalitative-implications-of-prospective- nonpresencing,-for-explicating relativeunreflexivity/relative-reflexivity ontological-contiguity ). This explains why Socrates construed knowledge as virtue, given that what approaches absolutising capacity in the human is rather the 'sense-of-right-orientation with regards to human-subpotencyaporia/undecidability/dilemma/ought-indeterminacy/deficiency/limitation/constraint of existentially-becoming-and-developing phronetic/practicality situations as to existencepotency $^{39} \sim$ sublimating-nascence,-disclosed-from-prospective-epistemic-digression $\quad$ (with anamnesis so-construed as dimensionality-of-sublimating <<amplituding/formative >supererogatory -de-mentativeness/epistemic-growth-orconflatedness /transvaluative-rationalising/transepistemicity/anamnestic-residuality/spiritdrivenness-equalisation> mental-disposition') and not any ${ }^{79}$ presencing-absolutisingidentitive-constitutedness $^{14}$ as reproducibility-mathesis/motif/thrownness-disposition,--asreproducibility-of-aestheticisation. This in-many-ways explains many a critic misinterpretation of a rift between Socrates and Plato as of their emphasis on anamnesis and the forms/ideas onthe-one-hand and Aristotle on-the-other-hand as of his phronesis/practicality emphasis (on the basis of the specific ${ }^{103}$ universalising-idealisation phronetic/practicality situations as to its defining existence-potency ${ }^{39} \sim$ sublimating-nascence,-disclosed-from-prospective-epistemicdigression). The fact is that Socrates (and as momentously reflected in his abhorrence of writing as of his focus on the 'very spirit-of-things in his pedagogy' over 'mere reproducing by writing that is not necessarily pedagogically instructive', and thus not contradictory with Plato's writing as of recording-for-posterity) and Plato were more engaged with establishing overall philosophical insight beyond just their ${ }^{103}$ universalising-idealisation renewed reproducibilitymathesis/motif/thrownness-disposition,-as-reproducibility-of-aestheticisation over nonuniversalising sophistry (even as their association of anamnesis with mythical recollection was 
caught up in the ${ }^{103}$ universalising-idealisation apriorising/axiomatising/referencingpsychologism but by the practical demonstration is relevant in all registryworldviews/dimensions as of the example articulated as well herein by this author with regards to a child's solipsistic sense of meaning wherein after grasping the rules of additionality even a deliberately collective social misleading will not derail the child's true sense of meaning) as they factored that any such renewal is being undertaken phronetically/practically with human limitedmentation-capacity—as-subjecting-'educed-unlimitedness/existence-sublimating nascence'to-limitedness/human-subpotency that is not of absolutising conceptualisation, speaking prospectively of destructuring-threshold-〈uninstitutionalised-threshold /presublimatingdesublimating-decisionality $>\sim$ of-ontological-performance ${ }^{72}-<$ including-virtue-as-ontology $>$, and thus what is more profoundly critical is knowledge-reification $\sim$ gesturing-and-accountingof-epistemic-phenomenalism- $<$ in-

prospective_psychologismic apriorising/axiomatising/referencing-\{of- ${ }^{\text {}}$ prospectively implicited_attendant_ontological-contiguity ' educedexistentialising/contextualising/textualising_'intelligibility/epistemicity/reflexivity-contiguity<imbued-notional cogency>’ $\}$-conflatedness -in-\{preconverging-disentailment by\} postconverging-ntailment $>$ as of the transepistemic implications of human limited-mentationcapacity-deepening —as-subjecting-limitedness/human-subpotency-to-'educedunlimitedness/existence-sublimating nascence' ${ }^{53}$. Aristotle as successor to their thought effectively had to move on to more fruitfully and complementarily elaborate phronetically/practically the implications of ${ }^{103}$ universalising-idealisation ${ }^{56}$ meaningfulnessand-teleology ${ }^{9}$ infrastructure as of science, practical-virtue, rationality, etc., rather than just theoretically reiterating his predecessors, and as such phronesis as of reproducibilitymathesis/motif/thrownness-disposition,-as-reproducibility-of-aestheticisation is what induces 'implicited_attendant_ontological-contiguity ${ }^{67}$; educed- 
existentialising/contextualising/textualising_intelligibility/epistemicity/reflexivity-contiguity$<$ imbued-notional $\sim \operatorname{cogency}>$ ' and thus allows prospective dimensionality-of-sublimating 〈<amplituding/formative>supererogatory $\sim$ de-mentativeness/epistemic-growth-or-

conflatedness /transvaluative-rationalising/transepistemicity/anamnestic-residuality/spiritdrivenness-equalisation) insight for further human limited-mentation-capacity-deepening —assubjecting limitedness/human-subpotency to-'educed-unlimitedness/existence-sublimating nascence' (as to 'coherence/contiguity-of-superseding-oneness-of-ontology-implied-as-ofinherent-existence-coherence/contiguity,-and-so-construed-as-the-enabler-of-insight-orintuition-or-foresight-as-of-embodied-consciousness', so-enabled by underlying supposedly coherent ontological-commitment $-<$ implied — self-assuredness-of-ontological-goodfaith/authenticity $\sim$ postconverging-de-mentating/structuring/paradigming -as-being-as-ofexistential-reality> as of <amplituding/formative-epistemicity>causality $\sim$ as-to-projectivetotalitative-implications-of-prospective- nonpresencing,-for-explicating relativeunreflexivity/relative-reflexivity ontological-contiguity and not any notion of vague innateness besides the existentially-<disontologising/re-ontologising aporeticism $>$ inherent human-subpotency potential) leading to further superseding/transcendence as of prospective reproducibility—mathesis/motif/thrownness-disposition,-as-reproducibility-ofaestheticisation. But the fact is there is comprehensive coherence in the philosophical articulations of the three thinkers when construed with this comprehensive philosophical knowledge-reification $\sim$ gesturing-and-accounting — of-epistemic-phenomenalism- $<$ inprospective_psychologismic apriorising/axiomatising/referencing-\{of- ${ }^{\text {pprospectively }}$ implicited_attendant-ontological-contiguity ' reducedexistentialising/contextualising/textualising_'intelligibility/epistemicity/reflexivity_contiguity<imbued-notional cogency $\left.>^{\prime} \quad\right\}$-conflatedness -in-\{preconverging-disentailment by\} postconverging entailment> projection insight. In other words, Socratic anamnesis anticipates 
the implications of knowledge as virtue in the sense that human knowledgereification $\sim$ gesturing-and-accounting — of-epistemic-phenomenalism- $<$ inprospective_psychologismic apriorising/axiomatising/referencing-\{of-'prospectively implicited_attendant-ontological-contiguity ' reducedexistentialising/contextualising/textualising_ 'intelligibility/epistemicity/reflexivity-contiguity<imbued-notional cogency $\left.>{ }^{\prime}\right\}$-conflatedness -in-\{preconverging-disentailment by\} postconverging entailment>, and so in all domains without exception, is one of a dynamic complementary relationship between dimensionality-of-sublimating

\section{<<amplituding/formative>supererogatory $\sim$ de-mentativeness/epistemic-growth-or-}

conflatedness /transvaluative-rationalising/transepistemicity/anamnestic-residuality/spirit-

drivenness-equalisation> and phronesis implicited_attendant-ontologicalcontiguity ${ }^{67} \sim$ educed-

existentialising/contextualising/textualising_intelligibility/epistemicity/reflexivity-contiguity<imbued-notional cogency>' in order to grasp ecstatic-existence-as-transcendentalsignifier-emergence/becoming-spontaneity-implications reflected as existencepotency $^{32} \sim$ sublimating-nascence,-disclosed-from-prospective-epistemic-digression $\quad$ as $\quad$ so reflected with prospective originariness-parrhesia,-as-spontaneity-of-aestheticisation for renewed reproducibility-mathesis/motif/thrownness-disposition,-as-reproducibility-ofaestheticisation. In this regards, Socratic philosophy as of its knowledge is virtue contention recognises that the impression-driven/good-naturedness/wishfulness of any given reproducibility—mathesis/motif/thrownness-disposition,-as-reproducibility-of-aestheticisation whether as of non-universalising sophistry or even prospective Socratic-philosophers 'universalising-idealisation is not sufficient to 'absolutely capture' ecstatic-existence-astranscendental-signifier-emergence/becoming-spontaneity-implications reflected as existence-potency ${ }^{39} \sim$ sublimating-nascence,-disclosed-from-prospective-epistemic-digression, 
and that such a possibility lies in perpetual knowledge-reification $\sim$ gesturing-and-accountingof-epistemic-phenomenalism- $<$ in-

prospective_psychologismic apriorising/axiomatising/referencing-\{of-'prospectively implicited_attendant-ontological-contiguity ' reducedexistentialising/contextualising/textualising_ 'intelligibility/epistemicity/reflexivity-contiguity<imbued-notional cogency >' \}-conflatedness -in-\{preconverging-disentailment by\} postconverging-entailment> disposition as of 'prospective postconverging-aporeticismovercoming/unovercoming as the-Good/knowledge-reification $\sim$ gesturing-and-accounting-ofepistemic-phenomenalism-<in-

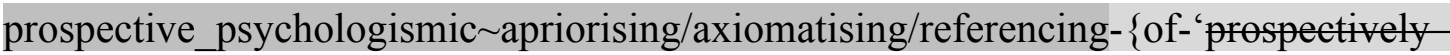
implicited_attendant-ontological-contiguity ' educedexistentialising/contextualising/textualising_'intelligibility/epistemicity/reflexivity-contiguity$<$ imbued-notional cogency $>$ ' \}-conflatedness -in-\{preconverging-disentailment by\} postconverging-entailment $>$ /understanding/<amplituding/formativeepistemicity $>$ causality $\sim$ as-to-projective-totalitative-implications-of-prospectivenonpresencing,-for-explicating relative-unreflexivity/relative-reflexivity —ontologicalcontiguity '. Thus Socratic philosophy as of its very ‘anamnesis core implications' doesn’t only supersedes prior non-universalising sophistry with ${ }^{103}$ universalising-idealisation but it can equally be said that it anticipates prospective positivism/rational-empiricism phronesis 'implicited_attendant-ontological-contiguity ${ }^{67}$ educedexistentialising/contextualising/textualising_ 'intelligibility/epistemicity/reflexivity-contiguity-

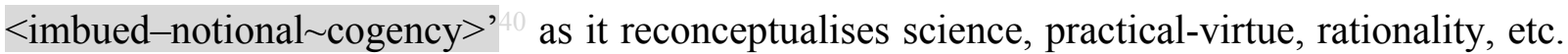

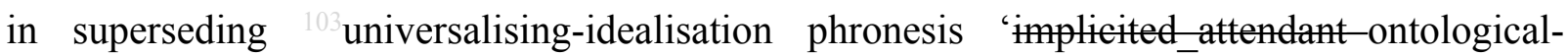
contiguity ${ }^{67}$,educedexistentialising/contextualising/textualising_intelligibility/epistemicity/reflexivity-contiguity- 
$<$ imbued-notional $\sim$ cogency $>^{\prime}$ at the latter's destructuring-threshold-〈uninstitutionalisedthreshold /presublimating-desublimating-decisionality $>$ of-ontological-performance ${ }^{72}$ <including-virtue-as-ontology $>$, as well as anticipate the overall human institutional process as herein conceptualised as of difference-conflatedness ${ }^{13}$-as-to-totalitative-reification-insingularisation-<as-to-the-nondisjointedness/entailment-of-prospective- nonpresencing $>$-asveridical-epistemicity-relativism-determinism implied $\quad<$ amplituding/formativeepistemicity $>$ causality $\sim$ as-to-projective-totalitative-implications-of-prospectivenonpresencing,-for-explicating relative-unreflexivity/relative-reflexivity - ontologicalcontiguity of phronesis 'implicited_attendant-ontological-contiguity ${ }^{67}$ ' educed-

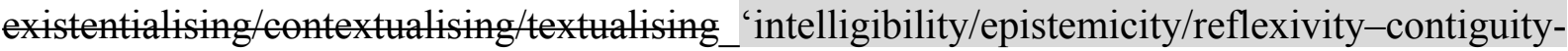
<imbued-notional cogency $>^{\prime}$. In concrete terms, we can contrastively construe of such akrasia-susceptibility-or-akrasiatic-drag complex ‘ $<$ amplituding/formativeepistemicity>totalising/circumscribing/delineating preconverging/dementing ${ }^{20}$-qualia-schema' existential-<disontologising/re-ontologising aporeticism $>$ desublimation manifestation of meaningfulness-and-teleology 9 as of both a ${ }^{103}$ universalisation-non-positivism/medievalism and our positivism- ${ }^{80}$ procrypticism registry-worldview/dimension with regards to "mentaldispositions of general social living, institutional and Being ontological-badfaith/inauthenticity ${ }^{64}$ geared to undermine ontological-veracity'; but then the positivismprocrypticism perspective as of its prospective relative-ontological-completeness ${ }^{87}$ will be less complexed in identifying the mental flaw of the ${ }^{103}$ universalisation-non-positivism/medievalism manifestation of akrasia-susceptibility-or-akrasiatic-drag complex '<amplituding/formativeepistemicity $>$ totalising/circumscribing/delineating preconverging/dementing ${ }^{20}$-qualia-schema' as of the former's <amplituding/formative-epistemicity $>$ totalising $\sim$ self-referencingsyncretising/circularity/interiorising/akrasiatic-drag 34 as it underlies non-positivism preconverging-or-dementing ${ }^{20}$-apriorising-psychologism acts 'like say a plot to accuse someone 
of sorcery' than its own akrasia-susceptibility-or-akrasiatic-drag complex ‘<amplituding/formative-epistemicity $>$ totalising/circumscribing/delineating preconverging/dementing ${ }^{2}$-qualia-schema' as of its <amplituding/formativeepistemicity $>$ totalising $\sim$ self-referencing-syncretising/circularity/interiorising/akrasiatic-drag underlying nondescript/ignorable-void (actually speaking of akrasiatic-drag-denatured-andpreconverging-or-dementing ${ }^{20}$-narratives) of its preconverging-or-dementing ${ }^{20}$-apriorisingpsychologism acts of disjointedness 'say like a plot to frame-up someone'; as the latter on occasion as of a positivism- ${ }^{80}$ procrypticism <amplituding/formative $>$ wooden-language〈imbued - averaging-of-thought-<as-to-leveling/ressentiment/closed-construct-ofmeaningfulness-and-teleology -as-of-'nondescript/ignorable-void '-with-regards-toprospective-apriorising-implications $>>$

apriorising/axiomatising/referencing/intelligibilitysettingup/measuringinstrumenting contemplation may be construed as smart while it construes of the former as abhorrent, but then not factoring in its own abhorrence from futural Being-development/ontological-frameworkexpansion-as-to-depth-of-ontologising-development-as-infrastructure-of- meaningfulnessand-teleology as of prospective deprocrypticism-or-preempting-disjointedness-as-ofreference-of-thought

apriorising/axiomatising/referencing/intelligibilitysettingup/measuringinstrumenting contemplation. This point out the ontological-veracity for avoiding the

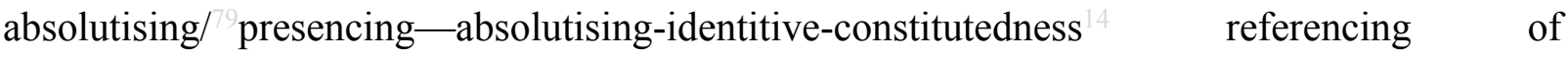
psychology/psychoanalysis as of any human-subpotency epistemic-or-notional projectiveperspective in prior relative-ontological-incompleteness ${ }^{8}$-of- ${ }^{-2}$ eference-of-thought as of identitive-constitutedness ${ }^{14}$-as-'epistemic-totality ${ }^{37}$ '-dereification-in-dissingularisation- $<$ as-tothe-disjointedness/disentailment-of- presencing - absolutising-identitive-constitutedness > as-flawed-epistemicity-relativism-determinism of notional-discontiguity/epistemic- 
discontiguity 3 - $<$ between - prior-shallow-supererogation -of-mentally-

aestheticised preconverging/dementing -qualia-schema_and_prospective-profound-

supererogation -of-mentally-aestheticised postconverging/dialectical-thinking -qualia-

schema $>$, and the critical pertinence in this regard of the notion of 'human akrasia-susceptibilityor-akrasiatic-drag/shiftiness-of-the-Self /ontological-fracturing/desublimation/gimmickiness complex' as it reflects a more profound and fuller construct of the human psychological potency as of difference-conflatedness ${ }^{13}$-as-to-totalitative-reification-in-singularisation- $<$ as-to-thenondisjointedness/entailment-of-prospective- nonpresencing $>$-as-veridical-epistemicityrelativism-determinism in notional-contiguity/epistemic-contiguity ${ }^{6}-<$ profound- $^{2}$ supererogation -of-mentally-aestheticised postconverging/dialectical-thinking -qualiaschema $>$ as from existence-potency ${ }^{32} \sim$ sublimating-nascence,-disclosed-from-prospectiveepistemic-digression as-to-ontologically-uncompromised-ontologicalnormalcy/postconvergence/referentialism; speaking of the veridical protractedness of the notional deprocrypticism protensive self-consciousness as of its $<$ amplituding/formative $>$ notional preempting — disjointedness-as-of- ${ }^{3}$ reference-of-thought as can be conveyed with an elucidative storied-construct/ontologically-valid-narration. In-manyways, akrasia-susceptibility-or-akrasiatic-drag complex is simply a validation of the fundamental preconverging/postconverging-de-mentating/structuring/paradigming of the human psyche as it is caught up between dissingularisation-<as-to-thedisjointedness/disentailment-of- presencing-absolutising-identitive-

constitutedness $>$ /epistemic-nonimmanence/flawed-epistemicity-relativism-determinism $<$ amplituding/formative-epistemicity $>$ causality $\sim$ as-to-projective-totalitative-implications-ofprospective- nonpresencing,-for-explicating relative unreflexivity/relative reflexivity ontological-contiguity of prior relative-ontological-incompleteness ${ }^{8}$ of its apriorising/axiomatising/referencing/intelligibilitysettingup/measuringinstrumenting and 
singularisation-<as-to-the-nondisjointedness/entailment-of-prospective- nonpresencing $>$

projected epistemic-immanence/veridical-epistemicity-relativism-determinism

$<$ amplituding/formative-epistemicity $>$ causality $\sim$ as-to-projective-totalitative-implications-of-

prospective- nonpresencing,-for-explicating relative-unreflexivity/relative-reflexivity

ontological-contiguity of prospective relative-ontological-completeness ${ }^{87}$ of its apriorising/axiomatising/referencing/intelligibilitysettingup/measuringinstrumenting. Such a notional deprocrypticism articulation herein of akrasia-susceptibility-or-akrasiatic-drag complex as the preconverging/postconverging-de-mentative/structural/paradigmatic constraining pervasiveness of any given registry-worldview/dimension akrasia-susceptibility-orakrasiatic-drag complex as of its uninstitutionalised-threshold ${ }^{102}$ construes that: as of the-verysame-immanent-existence/intrinsic-reality/ontological-veridicality,-as-to-

'human<amplituding/formative-epistemicity>totalising purview-of-construal', $\quad$ the affirmation/projection/assertion/notional self-distantiation/dueness-validatinglogicising/suitable-measuringinstrument-validating-measuring-<as-to-postconverging-ordialectical-thinking -apriorising-psychologism> of prospective relative-ontologicalcompleteness ${ }^{87}$ like base-institutionalisation with regards to Being-development/ontologicalframework-expansion-as-to-depth-of-ontologising-development-as-infrastructure-ofmeaningfulness-and-teleology as from its singularisation-<as-to-thenondisjointedness/entailment-of-prospective- nonpresencing $>$ projected epistemicimmanence/veridical-epistemicity-relativism-determinism perspective, lent to the akrasiatic judgment of prior relative-ontological-incompleteness 88 like recurrent-utteruninstitutionalisation as from its dissingularisation- $<$ as-to-the-disjointedness/disentailment-ofpresencing — absolutising-identitive-constitutedness > /epistemic-nonimmanence/flawedepistemicity-relativism-determinism perspective, will be construed as of the latter's $<$ amplituding/formative-epistemicity $>$ totalising $\sim$ self-referencing- 
syncretising/circularity/interiorising/akrasiatic-drag 34 in recurrent-utter-uninstitutionalisation conventioning-referencing over any such prospective base-institutionalisation pretence of Being-development/ontological-framework-expansion-as-to-depth-of-ontologisingdevelopment-as-infrastructure-of- meaningfulness-and-teleology $<$ amplituding/formativeepistemicity $>$ causality $\sim$ as-to-projective-totalitative-implications-of-prospectivenonpresencing,-for-explicating relative-unreflexivity/relative-reflexivity ontologicalcontiguity , and as of social-stake-contention-or-confliction it further elicits sophistic/pedantic significant-otherness dispositions inclined to undermine such prospective transcendental implications as it falsely absolutises the conventioning-referencing of recurrent-utteruninstitutionalisation over any such implied re-ontologising prospective Beingdevelopment/ontological-framework-expansion-as-to-depth-of-ontologising-development-asinfrastructure-of- meaningfulness-and-teleology of prospective base-institutionalisation; as so reflected across the successive uninstitutionalised-threshold ${ }^{102}$ in reflecting holographically$<$ conjugatively-and-transfusively $>$ the relative-unreflexivity/relative-reflexivity - ontologicalcontiguity $\sim$ of-the-human-institutionalisation-process inducing human transcendence-andsublimity/sublimation/supererogatoryade-mentativity. This explains why prospective transcendence-and-sublimity/sublimation/surentativity is actually reflected by the relative-unreflexivity/relative-reflexivity - ontological-contiguity ${ }^{67}$ of-the-humaninstitutionalisation-process 68 as $\quad$ of $\quad$ transversality-<for-sublimating-existentialeventuating/denouement,-from-'thinking-at-first/pure-predisposition-preemptive-ofprospective-disontologising/subontologising' - as-of-prospectively-disambiguated-affirmedand-unaffirmed-'motif-and-apriorising/axiomatising/referencing'> epistemicricochetting/transepistemicity reasoning-through/messianic-reason metaphoricity ${ }^{57}$, and not incisively about dialogical-equivalence- $<$ as-topsychologismic apriorising/axiomatising/referencing-\{of-"prospectively- 
implicited_attendant-ontological-contiguity ' reduced-

existentialising/contextualising/textualising_intelligibility/epistemicity/reflexivity-contiguity-

<imbued-notional cogency >' \}-conflatedness -in-\{preconverging disentailment by\}

postconverging-entailment,-in-self-becoming/self-conflatedness /formative-supererogating >

level of contemplation induced transcendence-and-sublimity/sublimation/supereregatery $\sim$ dementativity even as such a dialogical conception arises as of mutual apriorising/axiomatising/referencing/intelligibilitysettingup/measuringinstrumenting say with Socrates/Plato/Aristotle with their schools Being-development/ontological-frameworkexpansion-as-to-depth-of-ontologising-development-as-infrastructure-of- meaningfulnessand-teleology common

apriorising/axiomatising/referencing/intelligibilitysettingup/measuringinstrumenting in prospective relative-ontological-completeness ${ }^{87} \mathrm{~s}$ but as unaffirmation/deprojection/deassertion/epistemic-decadence/undueness-invalidatinglogicising/unsuitable-measuringinstrument-invalidating-measuring-<as-to-preconverging-ordementing -apriorising-psychologism $>$ devaluing their ${ }^{79}$ presencing-absolutising-identitiveconstitutedness $^{14} \quad$ conventioning-referencing as of sophistry apriorising/axiomatising/referencing/intelligibilitysettingup/measuringinstrumenting in prior relative-ontological-incompleteness ${ }^{88}$ or as with budding-positivists Beingdevelopment/ontological-framework-expansion-as-to-depth-of-ontologising-development-asinfrastructure-of- meaningfulness-and-teleology common apriorising/axiomatising/referencing/intelligibilitysettingup/measuringinstrumenting in prospective relative-ontological-completeness ${ }^{87} \mathrm{~s}$ but as unaffirmation/deprojection/deassertion/epistemic-decadence/undueness-invalidatinglogicising/unsuitable-measuringinstrument-invalidating-measuring-<as-to-preconverging-ordementing -apriorising-psychologism $>$ devaluing their ${ }^{79}$ presencing - absolutising-identitive- 
constitutedness

conventioning-referencing

in

medieval-scholasticism

pedantising/muddling/formulaic-hollowing-out_-in-subontologisation/subpotentiation-

〈blurring/undermining-of-prospective-totalising-entailing,-as-to-entailing-

$<$ amplituding/formative-epistemicity $>$ totalising in-relative-ontological-completeness

apriorising/axiomatising/referencing/intelligibilitysettingup/measuringinstrumenting in prior relative-ontological-incompleteness ${ }^{8} \mathrm{~s}$ or with a Rousseau Being-development/ontologicalframework-expansion-as-to-depth-of-ontologising-development-as-infrastructure-ofmeaningfulness-and-teleology as of social enlightenment common apriorising/axiomatising/referencing/intelligibilitysettingup/measuringinstrumenting in prospective relative-ontological-completeness ${ }^{87} \mathrm{~s}$ but as of unaffirmation/deprojection/deassertion/epistemic-decadence/undueness-invalidatinglogicising/unsuitable-measuringinstrument-invalidating-measuring-<as-to-preconverging-ordementing -apriorising-psychologism $>$ devaluing the conventioning-referencing as of aristocratic/despotic self-aggrandisement apriorising/axiomatising/referencing/intelligibilitysettingup/measuringinstrumenting in prior relative-ontological-incompleteness ${ }^{8} \mathbf{S}$. Thus more critically prospective transcendence-andsublimity/sublimation/supererogatory de-mentativity is induced as of the displacement/decentering-of-the-human-subject in its prior relative-ontologicalincompleteness

apriorising/axiomatising/referencing/intelligibilitysettingup/measuringinstrumenting, and so as of epistemic-ricochetting/transepistemicity reasoning-through/messianic-reason metaphoricity that exploits the supposedly coherent ontological-commitment $-<$ implied - self-assurednessof-ontological-good-faith/authenticity $\sim$ postconverging-dementating/structuring/paradigming -as-being-as-of-existential-reality $>$ so-implied as of a social-setup 'self-assuredness-of-ontological-good-faith/authenticity ${ }^{69} \sim$ postconverging-de- 
mentating/structuring/paradigming 70 -as-being-as-of-existential-reality with respect to its socialstake-contention-or-confliction' which opens it up to prospective intemporal-as-ontological metaphoricity ${ }^{57}$ The reality thus is that prospective transcendence-andsublimity/sublimation/supererogatory-de-mentativity from a ${ }^{70}$ presencing-absolutisingidentitive-constitutedness ${ }^{14}$ perspective is not actual ${ }^{56}$ meaningfulness-and-teleology ${ }^{99}$ but rather such is rather acting as a constrained metaphoricity ${ }^{57}$ upon a social-setup supposedly coherent ontological-commitment $\quad$-implied-self-assuredness-of-ontological-goodfaith/authenticity postconverging-de-mentating/structuring/paradigming -as-being-as-ofexistential-reality $>$ to which the social-setup cannot overtly turn around and wholly assume a contradictory nihilistic disposition; with metaphoricity ${ }^{57}$ rather inducing prospective meaningfulness-and-teleology mostly as of prospective crossgenerational reasoning-fromresults/afterthought. In this regards as of the possibility of futural Beingdevelopment/ontological-framework-expansion-as-to-depth-of-ontologising-development-asinfrastructure-of- meaningfulness-and-teleology as of prospective notional ${ }^{18}$ deprocrypticism transcendence-and-sublimity/sublimation/supereregatory $\sim$ dementativity, this author is of the opinion that any intellectual endeavour must precedingly guarantee that it is truly involved in a transparent ontological reification exercise exclusively as of the full existence-potency ${ }^{39} \sim$ sublimating-nascence,-disclosed-from-prospective-epistemicdigression reflection of its ontological-veracity or ontological-impertinence, and so rather than subject to sophistry, as the latter instance will fundamentally undermine and ridicule the underlying intellectual a-priori aspiration for reification. In this regards, and as of extensive contemplation, it is herein contended that in-many-ways such ontological virginity with regards to intellectual practice today is covertly being undermined at the more fundamental level of social emancipation contemplation, and explains why it has herein been seen as relevant to introduce the notion of ontological-bad-faith/inauthenticity ${ }^{64}$ anticipating of such anti- 
intellectual dispositions. As of a further indictment, this author is sceptical of 'covert cohorting initiatives' that substitute intellectual work for ontological-veracity with 'politicised intellectualism' as to which type of theories can be entertained or not, as if there can be knowledge without knowledge! Such cohorting initiatives pretences like those of many supposedly 'thinking political societies' since the end of the Cold War have rather had catastrophic consequences on the world all round in terms of the price of wars including with regards to the hegemonising policies these covert initiatives were supposed to instigate. Generally, the idea that such entities and initiatives covertly undermining the sovereignty of democracies, serve any given society, nation or human progressive purposes is rather counterproductive, as in fact this actually disrupts the natural course of sensible human answers to problems and issues and because of their parochial vision end up aggravating and escalating them, furthering a social narrative of double standards. The last frontier one can contemplate of with regards to such a proclivity is when it comes to undermining the intellectual sovereignty as of re-ontologising prospective Being-development/ontological-framework-expansion-as-todepth-of-ontologising-development-as-infrastructure-of- meaningfulness-and-teleology .

Knowledge cannot and should not be forestalled because of any supposed politico-economic penchant. The idea that liberal society can only be upheld by artificial and anti-intellectual undermining of many a critical theory including postmodern-thought as of the vital possibility of human social regeneration, is ridiculous and speaks of intellectual lack of self-assuredness; with such institutional grip subterfuges rendering such inclinations just as objectionable as the former ousted communist regimes. Ultimately, it is up to free intellectuals to affirm themselves as to what they think society and human intellectual potential can be, beyond the institutional constraints geared to such naïve conventioning-referencing which seem to imply that as of its anti-knowledge posture it will determine the limits of what can be human knowledge. Human history has systematically shown that despite human-subpotency- 
aporia/undecidability/dilemma/ought-indeterminacy/deficiency/limitation/constraint—imbued'notional firstnaturedness-formativeness-<as-to-eventualising inkling-drive-or-seedingmisprising $>$ temporal-to-intemporal-dispositions- $<$ so-construed-as-from-perspective-

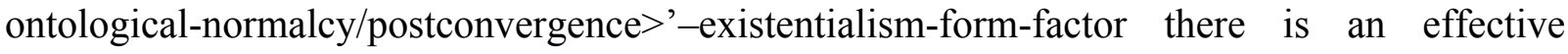
mechanism of human registry-worldview's/dimension's institutionalisation that draws out the best from mankind, and the more critical problem for human emancipation arises as of the contending sophistries that confuse-and-disrupt-as-of-significant-otherness that institutionalisation mechanism in one way or the other, and that's why at all stages of human history, the reasoning-through/messianic-reasoning disposition has more critically focussed rather on calling out the prospective institutionalisation perturbation of such sophistries; especially when these show no qualm in integrating the most ignoramus of $<$ amplituding/formative $>$ wooden-language-_imbued - averaging-of-thought- $<$ as-toleveling/ressentiment/closed-construct-of- meaningfulness-and-teleology -as-of'nondescript/ignorable-void '-with-regards-to-prospective-apriorising-implications $>$ ) dispositions as of a supposed notion of intellectual advancement. In this regards, this author is very much proud of the theoretical orientation taking herein as of a strictly ontological-veracity inclination as to the reality of the fact that existence-potency ${ }^{32} \sim$ sublimating-nascence,disclosed-from-prospective-epistemic-digression supersedes human-subpotency, and it is the latter that adjusts to the former. This is exactly what is reflected by ontological-fracturing, wherein the potential for ontological-normalcy/postconvergence is preconverging/postconverging-de-mentatively/structurally/paradigmatically fractured-atgiven-ontologically-compromised-thresholds in the <amplituding/formativeepistemicity $>$ totalising $\sim$ self-referencing-syncretising/circularity/interiorising/akrasiatic-drag of the successive given levels in reflecting holographically-<conjugatively-and-transfusively $>$ the relative-unreflexivity/relative-reflexivity - ontological-contiguity of-the-human- 
institutionalisation-process ; from recurrent-utter-uninstitutionalisation ontological-fracturing, base-institutionalisation-ununiversalisation ontological-fracturing, $\quad{ }^{103}$ universalisation-nonpositivism-medievalism ontological-fracturing, positivismfracturing towards futural Being-development/ontological-framework-expansion-as-to-depthof-ontologising-development-as-infrastructure-of- meaningfulness-and-teleology as of prospective notional deprocrypticism ontological-normalcy/postconvergence; as of the implications of the ontological-faith-notion-or-ontological-fideism -imbuedunderdetermination-of-motif-and-apriorising/axiomatising/referencing-as-so-being-as-ofexistential-reality 'seeding promise of human-subpotency ontological-performance ${ }^{72}$ $<$ including-virtue-as-ontology $>/$ morality/ethics/justice/etc. equivalence/correspondence with the full-potency-of-existence's $\sim$ sublimating-nascence-as-of-its-coherence/contiguity' in instigating 'intemporal ontological-faith-notion-or-ontological-fideism-imbuedunderdetermination-of-motif-and-apriorising/axiomatising/referencing-as-so-being-as-ofexistential-reality instigated relative-unreflexivity/relative-reflexivity-ontologicalcontiguity $^{67} \sim$ of-the-human-institutionalisation-process ${ }^{68}$ as of difference-conflatedness ${ }^{13}$-as-tototalitative-reification-in-singularisation-<as-to-the-nondisjointedness/entailment-ofprospective- nonpresencing $>$-as-veridical-epistemicity-relativism-determinism implied $<$ amplituding/formative-epistemicity $>$ causality $\sim$ as-to-projective-totalitative-implications-ofprospective- nonpresencing,-for-explicating relative-unreflexivity/relative-reflexivity ontological-contiguity '. Ontological-fracturing as such is a reflection of human-subpotencyaporia/undecidability/dilemma/ought-indeterminacy/deficiency/limitation/constraint—imbued'notional firstnaturedness-formativeness-<as-to-eventualising -inkling-drive-or-seedingmisprising $>$ temporal-to-intemporal-dispositions- $<$ so-construed-as-from-perspectiveontological-normalcy/postconvergence>'-existentialism-form-factor, and points out that the way we tend to conceptualise/construe-of idealisation as reflected in rules, institutional essence, 
institutional processes and ideals is ontologically-flawed/wrong as the assumption is one that tends to imply beyond-the-consciousness-awareness-teleology ${ }^{\circ}<$ of-preconverging-existentialextrication-as-of-existential-unthought $>$ only human intemporal ontological-performance ${ }^{72}$ <including-virtue-as-ontology $>$ /morality/ethics/justice/etc. by mental-reflex, rather than the reality of human temporal-to-intemporal ontological-performance ${ }^{72}-<$ including-virtue-as- $^{-}$ ontology $>$ /morality/ethics/justice/etc. of any given idealisation; speaking of the reality that any idealisation construed as of rules, institutional essence, institutional processes and ideals is preconverging/postconverging-de-mentatively/structurally/paradigmatically bound to be ontological-fractured as of human-subpotency-aporia/undecidability/dilemma/oughtindeterminacy/deficiency/limitation/constraint—imbued-'notional firstnaturednessformativeness-<as-to-eventualising-inkling-drive-or-seeding-misprising > temporal-tointemporal-dispositions- $<$ so-construed-as-from-perspective-ontologicalnormalcy/postconvergence>'-existentialism-form-factor. The implication here is that all projections of idealisation should be anticipatory-and-preemptive of the possibility of their prospective ontological-fracturing, for efficient institutionalisation percolation-channelling- $<$ indeferential-formalisation-transference $>$, 'in order to be more ontologically pertinent and resilient constructs', as they are otherwise subject to the temporal denaturing ${ }^{16}$ of such idealisations with regards to their more profound transcendence-and-sublimity/sublimation/supereregatory $\sim$ dementativity implications. In the same vein, we tend as of habit to construe of the fulfilment of human ideals as of the inherent institution and/or inherent individual identitive dispositions, rather than the fact that it is actually brought about by the preconverging/postconverging-dementative/structural/paradigmatic relations as of projected principles and essences implied intemporally (in cognisance of human temporal-to-intemporal-individuation-within-thereceptable-of-the-individual); and thus that our capacity to fulfil such principles and essences lies with our grasping-and-nurturing-appropriate-intemporal-individuation projection rather than 
falling back to identitive individual inherence or institutional inherence. As even where it may

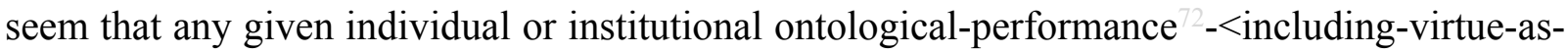
ontology $>$ /morality/ethics/justice/etc. is inherent, the underlying preconverging/postconverging-de-mentative/structural/paradigmatic reality is rather guaranteed and accounted for as of the effective grasping-and-nurturing-appropriate-intemporalindividuation projection for ontological-performance ${ }^{72}-<$ including-virtue-as- $^{2}$ ontology $>/$ morality/ethics/justice/etc. in that individual or institution rather than just identitive inherence. In-the-bigger-scheme-of-things, human registry-worldview's/dimension's institutionalisation outcome as of percolation-channelling- $<$ in-deferential-formalisationtransference $>$ doesn't substitute for the <amplituding/formative-epistemicity>totalising renewing-realisation/re-perception/re-thought as of the underlying dimensionality-ofsublimating ${ }^{25}-<<$ amplituding/formative $>$ supererogatory $\sim$ de-mentativeness/epistemic-growthor-conflatedness /transvaluative-rationalising/transepistemicity/anamnestic-residuality/spiritdrivenness-equalisation) individuation disposition that of reasoning-through/messianicreasoning brought about secondnatured institutionalisation. The bigger point here is that there is never going to be an inherent suprasocial or <amplituding/formative > wooden-language〈imbued - averaging-of-thought-<as-to-leveling/ressentiment/closed-construct-ofmeaningfulness-and-teleology -as-of-‘nondescript/ignorable-void '-with-regards-toprospective-apriorising-implications $>>$ framework that 'invents' and accounts for prospective social transcendence-and-sublimity/sublimation/supererente-mentativity idealisation, in the way that human idealisation is often wrongly construed and propounded. All the human idealisation that exists is as of effective individuals and institutional intemporal individuation projection for prospective <amplituding/formative-epistemicity>-totalising $\sim$ renewingrealisation/re-perception/re-thought of what they as of reasoning-through/messianic-reasoning idealise as from their underlying baseline registry-worldview/dimension ${ }^{83}$ reference-of-thought 
and the subsequent secondnatured institutionalisation of its given intemporal ontologicalperformance ${ }^{72}-<$ including-virtue-as-ontology $>$; and so, beyond the naivety of construing a given registry-worldview/dimension reasoning-from-results/afterthought as a suprasocial or $<$ amplituding-formative $>$ wooden-language-<imbued - averaging-of-thought-<as-toleveling/ressentiment/closed-construct-of- meaningfulness-and-teleology -as-of'nondescript/ignorable-void ' -with-regards-to-prospective-apriorising-implications $>$ > absolutising epistemic reference of ontological-veracity for prospective transcendence-andsublimity/sublimation/supererogatory de-mentativity idealisation. We can garner that it is intemporal individuations transversality-<for-sublimating-existentialeventuating/denouement, from 'thinking at first/pure predisposition preemptive of prospective-disontologising/subontologising' - as-of-prospectively-disambiguated-affirmedand-unaffirmed-'motif-and-apriorising/axiomatising/referencing'> ${ }^{01}$ intemporal projection as of ontological-faith-notion-or-ontological-fideism - imbued-underdetermination-of-motif-andapriorising/axiomatising/referencing-as-so-being-as-of-existential-reality for reasoningthrough/messianic-reasoning in recurrent-utter-uninstitutionalisation that induced prospective base-institutionalisation and not a suprasocial or <amplituding/formative $>$ wooden-language〈imbued-averaging-of-thought-<as-to-leveling/ressentiment/closed-construct-ofmeaningfulness-and-teleology -as-of-‘nondescript/ignorable-void '-with-regards-toprospective-apriorising-implications $>>$ absolutising epistemic reference in recurrent-utteruninstitutionalisation, likewise for prospective ${ }^{103}$ universalisation and not a suprasocial or $<$ amplituding/formative $>$ wooden-language-<imbued - averaging-of-thought-<as-toleveling/ressentiment/closed-construct-of- meaningfulness-and-teleology -as-of'nondescript/ignorable-void '-with-regards-to-prospective-apriorising-implications $>$ > absolutising epistemic reference of base-institutionalisation-ununiversalisation, likewise for prospective positivism and not a suprasocial or <amplituding/formative $>$ wooden-language- 
〈imbued - averaging-of-thought-<as-to-leveling/ressentiment/closed-construct-ofmeaningfulness-and-teleology -as-of-‘nondescript/ignorable-void '-with-regards-toprospective-apriorising-implications $>>$ absolutising epistemic reference of ${ }^{103}$ universalisationnon-positivism/medievalism; and so prospectively it is naivety as well to construe that we do have a suprasocial or <amplituding/formative > wooden-language-〈imbued-averaging-ofthought-<as-to-leveling/ressentiment/closed-construct-of- meaningfulness-and-teleology -asof-'nondescript/ignorable-void ' -with-regards-to-prospective-apriorising-implications $>$ ) absolutising epistemic reference for our prospective transcendence-andsublimity/sublimation/supererogatory $\sim$ de-mentativity rather than as of prospective intemporal individuation $\quad$ transversality- $<$ for-sublimating-existential-eventuating/denouement, - from-

\section{thinking at first/pure-predisposition-preemptive-of-prospective-}

disontologising/subontologising' as-of-prospectively-disambiguated-affirmed-and-

unaffirmed-'motif-and-apriorising/axiomatising/referencing' $>101$ intemporal projection as of ontological-faith-notion-or-ontological-fideism - imbued-underdetermination-of-motif-andapriorising/axiomatising/referencing-as-so-being-as-of-existential-reality for reasoningthrough/messianic-reasoning in our positivism- ${ }^{80}$ procrypticism to bring about futural Beingdevelopment/ontological-framework-expansion-as-to-depth-of-ontologising-development-asinfrastructure-of- meaningfulness-and-teleology as of prospective notional ${ }^{18}$ deprocrypticism

apriorising/axiomatising/referencing/intelligibilitysettingup/measuringinstrumenting. Consider in this regards for instance that while we generally tend to wrongly imply of a suprasocial absolutising epistemic reference that can preconverging/postconverging-dementatively/structurally/paradigmatically bring about human transcendence-andsublimity/sublimation/supererogatory de-mentativity, it is inevitably the case that the examination of any such representation with say for instance the physics 
$<$ amplituding/formative-epistemicity $>$ totalising $\sim$ devolved-purview/domain-of-construal-asintrinsic-reality/ontological-veridicality/existential-reality since medievalism points that such transcendence-and-sublimity/sublimation/supererogatory $\sim$ de-mentativity idealisation necessarily had to pass through the intemporal individuation transversality-<for-sublimatingexistential-eventuating/denouement-from-'thinking-at-first/pure-predisposition-preemptive-ofprospective-disontologising/subontologising' as-of-prospectively-disambiguated-affirmedand-unaffirmed-'motif-and-apriorising/axiomatising/referencing'> projection as of ontological-faith-notion-or-ontological-fideism - imbued-underdetermination-of-motif-andapriorising/axiomatising/referencing-as-so-being-as-of-existential-reality for reasoningthrough/messianic-reasoning of the Copernicuses, Galileos, Descartes, Newtons, Leibnizes, Poincarés, Rutherfords, Einsteins, Bohrs, etc. and the subsequent secondnatured institutionalisation as of percolation-channelling-<in-deferential-formalisation-transference $>$. There has never been any suprasocial or <amplituding/formative> wooden-language-〈imbuedaveraging-of-thought-<as-to-leveling/ressentiment/closed-construct-of- meaningfulness-andteleology -as-of-‘nondescript/ignorable-void '-with-regards-to-prospective-apriorisingimplications $>>$ absolutising epistemic reference of ontological-pertinence for prospective transcendence-and-sublimity/sublimation/supereregatory - de-mentativity idealisation as we seem to construe/contemplate of today-or-at-any-given-presence-epoch as of reasoning-fromresults/afterthought, as the fact is human transcendence-andsublimity/sublimation/supererogatory $\sim$ de-mentativity arises ultimately as of internalised epistemic responsibility/relative-reflexivity of intemporal individuation transversality $-<$ forsublimating-existential-eventuating/denouement,-from-'thinking-at-first/pure-predispositionpreemptive-of prospective-disontologising/subontologising' as-of-prospectivelydisambiguated-affirmed-and-unaffirmed-'motif-and-apriorising/axiomatising/referencing'> projection as of ontological-faith-notion-or-ontological-fideism-imbued-underdetermination- 

reasoning-through/messianic-reasoning that supersede the pretence of any such absolutising epistemic reference on the basis of a suprasocial reasoning-from-results/afterthought. Thus the abstraction as of suprasocial or <amplituding/formative> wooden-language-〈imbuedaveraging-of-thought-<as-to-leveling/ressentiment/closed-construct-of- meaningfulness-andteleology -as-of-'nondescript/ignorable-void '-with-regards-to-prospective-apriorisingimplications $>>$ absolutising epistemic reference about human nature transcendence-andsublimity/sublimation/supererogatory de-mentativity idealisation 'doesn't truly exist', but for effective operant human intemporal individuation transversality-<for-sublimating-existentialeventuating/denouement, from 'thinking at first/pure predisposition preemptive of prospective-disontologising/subontologising' as-of-prospectively-disambiguated-affirmedand-unaffirmed-'motif-and-apriorising/axiomatising/referencing'> ${ }^{01}$ intemporal projection as of ontological-faith-notion-or-ontological-fideism - imbued-underdetermination-of-motif-andapriorising/axiomatising/referencing-as-so-being-as-of-existential-reality for reasoningthrough/messianic-reasoning and subsequent secondnatured institutionalisation. Critically, it is this grasping-and-nurturing-appropriate-intemporal-individuation projection ontologicalperformance ${ }^{2}-<$ including-virtue-as-ontology $>$ /morality/ethics/justice/etc. over the flawed notion of individual inherent and institutional inherent absolutising epistemic reference of intemporality $^{52}$, as of the awareness of the reality of human-subpotencyaporia/undecidability/dilemma/ought-indeterminacy/deficiency/limitation/constraint—imbued'notional firstnaturedness-formativeness-<as-to-eventualising -inkling-drive-or-seedingmisprising $>$ temporal-to-intemporal-dispositions- $<$ so-construed-as-from-perspectiveontological-normalcy/postconvergence>'-existentialism-form-factor, that underlies the relativeunreflexivity/relative-reflexivity —ontological-contiguity ${ }^{67}$ of-the-human-institutionalisationprocess ${ }^{68}$ as of its retrospective, present and prospective possibilities. This doesn't speak of 
subjectivity, no more than a doctor's judgment is necessarily subjective as to the fact of its validation going by the primacy of the 'superior party' that is existence-potency ${ }^{39} \sim$ sublimatingnascence,-disclosed-from-prospective-epistemic-digression as to intrinsic-reality/ontologicalveridicality reflected in effective remedy as of <amplituding/formativeepistemicity $>$ causality $\sim$ as-to-projective-totalitative-implications-of-prospectivenonpresencing,-for-explicating relative-unreflexivity/relative-reflexivity ontologicalcontiguity over imagined <amplituding/formative> wooden-language-〈imbued - averagingof-thought-<as-to-leveling/ressentiment/closed-construct-of- meaningfulness-and-teleology as-of-'nondescript/ignorable-void ' -with-regards-to-prospective-apriorising-implications $>$ > opinionatedness, but rather that human transcendence-andsublimity/sublimation/supererogatory $\sim$ de-mentativity idealisation is more operantly and effectively as of solipsistic projection of intemporal individuations dimensionality-ofsublimating $25<<$ amplituding/formative $>$ supererogatory $\sim$ de-mentativeness/epistemic-growthor-conflatedness /transvaluative-rationalising/transepistemicity/anamnestic-residuality/spiritdrivenness-equalisation) epistemic internalisation for intemporal ontological-performance ${ }^{72}$ $<$ including-virtue-as-ontology $>$. The secondnatured institutionalisation as reflected as of suprasocial or <amplituding/formative> wooden-language-_imbued-averaging-of-thought$<$ as-to-leveling/ressentiment/closed-construct-of- meaningfulness-and-teleology -as-of'nondescript/ignorable-void '-with-regards-to-prospective-apriorising-implications $>>$ abstract integration/assimilation of such resultant intemporal ontological-performance ${ }^{2}-<$ includingvirtue-as-ontology $>$ /morality/ethics/justice/etc. is ever always ontologically jeopardisable/compromisable as of the preconverging/postconverging-dementative/structural/paradigmatic reality of human-subpotencyaporia/undecidability/dilemma/ought-indeterminacy/deficiency/limitation/constraint—imbued'notional firstnaturedness-formativeness-<as-to-eventualising -inkling-drive-or-seeding 
misprising $>$ temporal-to-intemporal-dispositions- $<$ so-construed-as-from-perspective-

ontological-normalcy/postconvergence>'-existentialism-form-factor, wherein human temporal individuations are ever always bound to prospectively denaturing secondnatured institutionalised intemporal ontological-performance ${ }^{72}-<_{\text {including-virtue-as- }}$ ontology $>$ /morality/ethics/justice/etc. at the uninstitutionalised-threshold ${ }^{102}$ as without the constraining prior institutionalisation mechanical-knowledge the underlying ontological-faithnotion-or-ontological-fideism—imbued-underdetermination-of-motif-and-

apriorising/axiomatising/referencing-as-so-being-as-of-existential-reality sense of intemporalprojection behind its 'inventing' is lost; as is needed for prospective institutionalisation prospective relative-ontological-completeness ${ }^{87}$ epistemic want of prospective reasoningthrough/messianic-reasoning to overcome the prior relative-ontological-incompleteness $<$ amplituding/formative-epistemicity $>$ causality $\sim$ as-to-projective-totalitative-implications-ofprospective- nonpresencing,-for-explicating relative-unreflexivity/relative-reflexivityontological-contiguity. Interestingly, thus if there is no suprasocial or $<$ amplituding/formative $>$ wooden-language-<imbued — averaging-of-thought-<as-toleveling/ressentiment/closed-construct-of- meaningfulness-and-teleology -as-of'nondescript/ignorable-void '-with-regards-to-prospective-apriorising-implications $>$ ) absolutising epistemic reference of ontological-veracity for prospective transcendence-andsublimity/sublimation/supererogatoryade-mentativity but for prospective dimensionality-ofsublimating $25<<$ amplituding/formative $>$ supererogatory - de-mentativeness/epistemic-growthor-conflatedness /transvaluative-rationalising/transepistemicity/anamnestic-residuality/spiritdrivenness-equalisation $\rangle$ transversality-<for-sublimating-existential-eventuating/denouement-from-'thinking at-first/pure-predisposition-preemptive-of-prospectivedisontologising/subontologising’ as-of-prospectively-disambiguated-affirmed-andunaffirmed-‘motif-and-apriorising/axiomatising/referencing'> intemporal projection as of 
ontological-faith-notion-or-ontological-fideism - imbued-underdetermination-of-motif-andapriorising/axiomatising/referencing-as-so-being-as-of-existential-reality for reasoningthrough/messianic-reasoning and corresponding secondnatured institutionalisation of intemporal

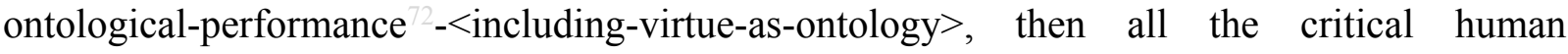
intemporal ${ }^{56}$ meaningfulness-and-teleology ${ }^{9}$ for prospective transcendence-andsublimity/sublimation/supererogatory-de-mentativity that-exists-and-can-prospectively-existrespectively effectively arises-and-lies in the 'induced metaphoricity ${ }^{57}$ of such prospective intemporal individuation transversality-<for-sublimating-existential-eventuating/denouement-from-'thinking at-first/pure-predisposition-preemptive-of-prospectivedisontologising/subontologising’ as-of-prospectively-disambiguated-affirmed-andunaffirmed-'motif-and-apriorising/axiomatising/referencing' $>$ intemporal projection as of ontological-faith-notion-or-ontological-fideism - imbued-underdetermination-of-motif-andapriorising/axiomatising/referencing-as-so-being-as-of-existential-reality for reasoningthrough/messianic-reasoning and corresponding secondnatured institutionalisation of intemporal ontological-performance ${ }^{72}-<$ including-virtue-as-ontology $>$ '. Just as demonstrated above with the physics <amplituding/formative-epistemicity>totalising $\sim$ devolved—purview/domain-ofconstrual-as-intrinsic-reality/ontological-veridicality/existential-reality, in the instance philosophy reflecting the-very-same-immanent-existence/intrinsic-reality/ontologicalveridicality,-as-to-'human<amplituding/formative-epistemicity>totalising $\sim$ purview-ofconstrual' we can as well appreciate, going by the <amplituding/formativeepistemicity $>$ causality $\sim$ as-to-projective-totalitative-implications-of-prospectivenonpresencing,-for-explicating relative- unreflexivity/relative-reflexivity - ontologicalcontiguity of difference-conflatedness ${ }^{13}$-as-to-totalitative-reification-in-singularisation- $<$ asto-the-nondisjointedness/entailment-of-prospective- nonpresencing $>$-as-veridicalepistemicity-relativism-determinism over identitive-constitutedness ${ }^{14}$-as-'epistemic- 
totality ${ }^{37}$-dereification-in-dissingularisation-<as-to-the-disjointedness/disentailment-ofpresencing - absolutising-identitive-constitutedness $>$-as-flawed-epistemicity-relativismdeterminism , that there was no suprasocial or <amplituding/formative $>$ wooden-language〈imbued — averaging-of-thought-<as-to-leveling/ressentiment/closed-construct-ofmeaningfulness-and-teleology -as-of-'nondescript/ignorable-void '-with-regards-toprospective-apriorising-implications $>>$ absolutising epistemic reference for the transcendenceand-sublimity/sublimation/supererogatory $\sim$ de-mentativity idealisation of say Plato's idea concept nor say Descartes's cogito concept but in both cases for their operant prospective intemporal individuation transversality-<for-sublimating-existential-eventuating/denouement-from 'thinking at first/pure predisposition preemptive of prospectivedisontologising/subontologising' as-of-prospectively-disambiguated-affirmed-andunaffirmed-'motif-and-apriorising/axiomatising/referencing' $>101$ intemporal projection as of ontological-faith-notion-or-ontological-fideism - imbued-underdetermination-of-motif-andapriorising/axiomatising/referencing-as-so-being-as-of-existential-reality for reasoningthrough/messianic-reasoning and corresponding secondnatured institutionalisation of intemporal ontological-performance ${ }^{72}-<$ including-virtue-as-ontology $>$. Likewise, it is herein contended that this difference-conflatedness ${ }^{13}$-as-to-totalitative-reification-in-singularisation- $<$ as-to-thenondisjointedness/entailment-of-prospective- nonpresencing > -as-veridical-epistemicityrelativism-determinism implied $<$ amplituding/formative-epistemicity $>$ causality $\sim$ as-toprojective-totalitative-implications-of-prospective- nonpresencing,-for-explicating $\sim$ relativeunreflexivity/relative-reflexivity - ontological-contiguity equally applies prospectively with respect to the deprocrypticism-or-preempting-disjointedness-as-of- ${ }^{3}$ reference-of-thought apriorising/axiomatising/referencing/intelligibilitysettingup/measuringinstrumenting implied transcendence-and-sublmity idealisation, and so as of operant prospective intemporal individuation $\quad$ transversality- $<$ for-sublimating-existential-eventuating/denouement,-from- 


\section{thinking at -first/pure-predisposition-preemptive-of prospective-}

\section{disontologising/subontologising' as-of-prospectively-disambiguated-affirmed-and-}

unaffirmed-'motif-and-apriorising/axiomatising/referencing'> ${ }^{101}$ intemporal projection as of ontological-faith-notion-or-ontological-fideism - imbued-underdetermination-of-motif-andapriorising/axiomatising/referencing-as-so-being-as-of-existential-reality for reasoningthrough/messianic-reasoning and corresponding secondnatured institutionalisation of intemporal

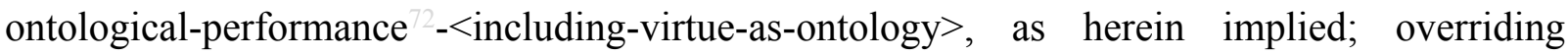
pretences of suprasocial or <amplituding/formative $>$ wooden-language-<imbued - averagingof-thought-<as-to-leveling/ressentiment/closed-construct-of- meaningfulness-and-teleology as-of-'nondescript/ignorable-void '-with-regards-to-prospective-apriorising-implications $>$ > absolutising epistemic reference, and as subject only to falsifiability ${ }^{2}$ and validation as of $<$ amplituding/formative-epistemicity $>$ causality $\sim$ as-to-projective-totalitative-implications-ofprospective- nonpresencing,-for-explicating relative-unreflexivity/relative-reflexivityontological-contiguity of the 'superior party' that is existence-potency ${ }^{39} \sim$ sublimatingnascence,-disclosed-from-prospective-epistemic-digression as to intrinsic-reality/ontologicalveridicality. The fact is and as confirmed by 'intemporal ontological-faith-notion-or-ontologicalfideism —imbued-underdetermination-of-motif-and-apriorising/axiomatising/referencing-asso-being-as-of-existential-reality instigated relative-unreflexivity/relative-reflexivity ontological-contiguity ${ }^{67}$ of-the-human-institutionalisation-process ${ }^{68}$ as of differenceconflatedness $^{13}$-as-to-totalitative-reification-in-singularisation- $<$ as-to-thenondisjointedness/entailment-of-prospective- nonpresencing > -as-veridical-epistemicityrelativism-determinism implied <amplituding/formative-epistemicity $>$ causality $\sim$ as-toprojective-totalitative-implications-of-prospective- nonpresencing,-for-explicating $\sim$ relativeunreflexivity/relative-reflexivity ontological-contiguity ', prospective ${ }^{83}$ reference-of-thought apriorising/axiomatising/referencing/intelligibilitysettingup/measuringinstrumenting 
transcendence-and-sublimity/sublimation/supererogatory-de-mentativity idealisation as of their prospective reasoning-through/messianic-reasoning highlight that the traditional reasoningfrom-results/afterthought construct is construed: - for the Platonic idea transcendence-andsublimity/sublimation/supererogatory $\sim$ de-mentativity as of sophistry, - for the Cartesian cogito transcendence-and-sublimity/sublimation/supereregatory-de-mentativity as of medievalscholasticism pedantising/muddling/formulaic-hollowing-out-insubontologisation/subpotentiation-〈blurring/undermining-of-prospective-totalising-entailing,as-to-entailing-<amplituding/formative-epistemicity $>$ totalising in-relative-ontologicalcompleteness $\rangle$, and prospectively for notional deprocrypticism transcendence-andsublimity/sublimation/surerenterentivity as of spurious institutional-being-andcraft muddlement. Effectively, human-subpotency-aporia/undecidability/dilemma/oughtindeterminacy/deficiency/limitation/constraint—imbued-'notional firstnaturednessformativeness-<as-to-eventualising-inkling drive-or-seeding misprising $>$ temporal-tointemporal-dispositions- $<$ so-construed-as-from-perspective-ontologicalnormalcy/postconvergence>'-existentialism-form-factor implies that metaphoricity ${ }^{57}$ why tending ultimately towards intemporality ${ }^{52}$, is effectively of both intemporal/Angness-ofregister-of- meaningfulness-and-teleology and temporal/shortness-of-register-ofmeaningfulness-and-teleology manifestations. But any given social-setup 'self-assurednessof-ontological-good-faith/authenticity $\sim$ postconverging-de-

mentating/structuring/paradigming 70 -as-being-as-of-existential-reality with respect to its socialstake-contention-or-confliction' in its capacity to demonstrably and objectively uphold and function going by its specific registry-worldview/dimension ${ }^{56}$ meaningfulness-and-teleology as well as the fact that human perceived social-stake-contention-or-confliction interests drift within-and-across social-setups whether with regards to basic trading, curiosity, social competition and generally as of a predisposition to achieve optimum existential- 
<disontologising/re-ontologising aporeticism $>$ possibilities, implies that any such registryworldview/dimension social-setup has a 'basic postconverging-dementating/structuring/paradigming supposedly coherent ontological-commitment $-<$ implied self-assuredness-of-ontological-good-faith/authenticity postconverging-dementating/structuring/paradigming -as-being-as-of-existential-reality ${ }^{\prime}$, for its effective functioning which lays it prospectively exposed to metaphoricity ${ }^{57}$ as of prospective $<$ amplituding/formative-epistemicity $>$ causality $\sim$ as-to-projective-totalitative-implications-ofprospective- nonpresencing,-for-explicating relative-unreflexivity/relative-reflexivity ontological-contiguity as from prospective existence-potency ${ }^{32}$ sublimating-nascence,disclosed-from-prospective-epistemic-digression epistemic-or-notional projective-perspective; as such a registry-worldview/dimension would difficultly renege, as of contradictory and incoherent implications, on such critical prospective ontological-veracity implications of such prospective relative-ontological-completeness ${ }^{87}$ of ${ }^{56}$ meaningfulness-and-teleology ${ }^{9}$. It is this element that equally ultimately renders the study of the social, notwithstanding its strong underlying $<$ amplituding/formative-epistemicity $>$ totalising $\sim$ self-referencingsyncretising/circularity/interiorising/akrasiatic-drag ${ }^{34}$, as of potentially the same ontologicalperformance ${ }^{72}-<$ including-virtue-as-ontology $>/$ morality/ethics/justice/etc. possibility as with the natural sciences. That is the apparent conventioning-referencing of the social as of an immediacy perspective naively implies the social is of a poor supposedly coherent ontologicalcommitment $\_<$implied—self-assuredness-of-ontological-goodfaith/authenticity postconverging-de-mentating/structuring/paradigming -as-being-as-ofexistential-reality $>$ but from a more profound level of appreciation this not the case as explained above, as in effect a society/social-setup conventioning projects correspondingly a profound supposedly coherent ontological-commitment $-<$ implied-self-assuredness-of-ontologicalgood-faith/authenticity $\sim$ postconverging-de-mentating/structuring/paradigming -as-being- 
as-of-existential-reality $>$ as of its 'self-assuredness-of-ontological-goodfaith/authenticity ${ }^{6} \sim$ postconverging-de-mentating/structuring/paradigming -as-being-as-ofexistential-reality with respect to its social-stake-contention-or-confliction' which is then enabling for the critical metaphoricity ${ }^{57}$ of prospective ${ }^{56}$ meaningfulness-and-teleology ontological-veracity implications of <amplituding/formative-epistemicity $>$ causality $\sim$ as-toprojective-totalitative-implications-of-prospective- nonpresencing,-for-explicating relativeunreflexivity/relative-reflexivity ontological-contiguity as of prospective relativeontological-completeness ${ }^{87}$. In other words, as of transversality-<for-sublimating-existentialeventuating/denouement,-from-'thinking at-first/pure-predisposition-preemptive-ofprospective-disontologising/subontologising' as-of-prospectively-disambiguated-affirmedand-unaffirmed-'motif-and-apriorising/axiomatising/referencing' ${ }^{101}$ of human metaphoricity

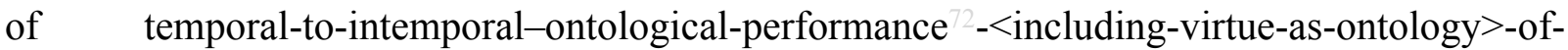
narratives, we know that the <amplituding/formative-epistemicity $>$ causality $\sim$ as-to-projectivetotalitative-implications-of-prospective- nonpresencing,-for-explicating relativeunreflexivity/relative-reflexivity ontological-contiguity that underlies existencepotency $^{39} \sim$ sublimating-nascence,-disclosed-from-prospective-epistemic-digression sublimating-validation/desublimating-invalidation implications of ontological-veracity is bound in the long run to select/skew-toward the intemporal/ontological over the temporal, whether as of internal cultural transformation or cultural diffusion. This is exactly why the overall ‘intemporal ontological-faith-notion-or-ontological-fideism - imbued-underdetermination-ofmotif-and-apriorising/axiomatising/referencing-as-so-being-as-of-existential-reality instigated relative- unreflexivity/relative-reflexivity ontological-contiguity ${ }^{67} \sim$ of-the-humaninstitutionalisation-process $^{68}$ as of difference-conflatedness ${ }^{13}$-as-to-totalitative-reification-insingularisation-<as-to-the-nondisjointedness/entailment-of-prospective- nonpresencing $>$-asveridical-epistemicity-relativism-determinism implied <amplituding/formative- 
epistemicity $>$ causality $\sim$ as-to-projective-totalitative-implications-of-prospective-

nonpresencing,-for-explicating relative-unreflexivity/relative-reflexivity - ontological-

contiguity ' ultimately has a direction as of intemporal-preservation-entropy-or-contiguity-orontological-preservation, notwithstanding preconverging/postconverging-dementative/structural/paradigmatic implications of 'human notional firstnaturednessformativeness-<as-to-eventualising-inkling-drive or seeding-misprising $>$ temporal-tointemporal-dispositions- $<$ so-construed-as-from-perspective-ontologicalnormalcy/postconvergence> accordioning-〈as-of-varying-individuations-contextuallytransverse-desublimation/sublimation,-as-to-the-wavering/redounding/waveforming of-theirreferencing-and-their-devolved-referencing-imbued-ontological-performance -<includingvirtue-as-ontology $>>$ at uninstitutionalised-threshold ${ }^{12}$ as reflecting both desublimating historicity-tracing - in-presencing-hyperrealisation/hyperreal-transposition and sublimating historiality/ontological-eventfulness 38 /ontological-aesthetic-tracing- $<$ perspectiveontological-normalcy/postconvergence-reflected-‘epistemicity-relativism-determinism’> possibilities'. We can appreciate both with regards to the social fabric as well as the natural sciences this common basis of supposedly coherent ontological-commitment $-<$ implied - selfassuredness-of-ontological-good-faith/authenticity $\sim$ postconverging-dementating/structuring/paradigming -as-being-as-of-existential-reality> from a long-term perspective, in the sense that technical and scientific progress associated with the industrial revolution 'could hardly be socially reneged' not only in Western Europe but with respect to its diffusion throughout the world, and so because the supposedly coherent ontologicalcommitment $-<$ implied—self-assuredness-of-ontological-goodfaith/authenticity postconverging-de-mentating/structuring/paradigming -as-being-as-ofexistential-reality> of human societies conventioning as of their 'self-assuredness-ofontological-good-faith/authenticity $\sim$ postconverging-de- 
mentating/structuring/paradigming 70 -as-being-as-of-existential-reality with respect to its socialstake-contention-or-confliction' render themselves exposed to the transcendence-andsublimity/sublimation/supererogatory de-mentativity of the prospective relative-ontologicalcompleteness ${ }^{87}$ as projected by the industrial revolution underlying technical and scientific knowledge manifesting as to existence-potency ${ }^{32}$ sublimating-nascence,-disclosed-fromprospective-epistemic-digression selection/skewing of $\quad<$ amplituding/formativeepistemicity $>$ causality $\sim$ as-to-projective-totalitative-implications-of-prospectivenonpresencing,-for-explicating relative-unreflexivity/relative-reflexivity - ontological-

contiguity and so because these project beyond subjectivity-of-truth-as-of-human-subpotency as implied by the ${ }^{103}$ universal objectivity as to existence-potency ${ }^{39} \sim$ sublimating-nascence,disclosed-from-prospective-epistemic-digression of the underlying sciences and their applications. It is this insight as of 'existence-potency ${ }^{32}$ sublimating-nascence,-disclosed-fromprospective-epistemic-digression selection/skewing of <amplituding/formativeepistemicity $>$ causality $\sim$ as-to-projective-totalitative-implications-of-prospectivenonpresencing,-for-explicating relative-unreflexivity/relative-reflexivity - ontologicalcontiguity $^{\text {, that animates the elucidation of metaphoricity }}{ }^{57}$ herein as of ontology-driven 'ontologically-hegemonising-narrative $\quad$ ontological-performance ${ }^{72}-<$ including-virtue-asontology >', more than just a notion of mere subjective human-subpotency epistemic-ornotional projective-perspective narratives; and so, as underlined by human limited-mentationcapacity-deepening —as-subjecting limitedness/human-subpotency-to-'educedunlimitedness/existence-sublimating nascence' ${ }^{53}$ inducing prospective relative-ontologicalcompleteness ${ }^{87}$-of- ${ }^{83}$ reference-of-thought $<$ amplituding/formative-epistemicity $>$ causality $\sim$ asto-projective-totalitative-implications-of-prospective- nonpresencing,-forexplicating relative-unreflexivity/relative-reflexivity ontological-contiguity . This ontologydriven assessment of intemporality ${ }^{52} /$ longness metaphoricity ${ }^{57}$ perspective rejects the often 
wrongly made critique of relative-for-the-mere-sake-of-relative-disparateness by atomising/taking-to-pieces identitive-constitutedness ${ }^{14}$-as-'epistemic-totality ${ }^{37}$ '-dereificationin-dissingularisation- $<$ as-to-the-disjointedness/disentailment-of- presencing - absolutisingidentitive-constitutedness $>$-as-flawed-epistemicity-relativism-determinism critiques when misrepresenting the ontologically-veridical observations/remarks/'constatations' as of ecstatictotalising-entailing/nested-congruence of postmodern thinkers. Rather as construed herein, relative truth speaks to ${ }^{4}$ human-subject-emancipating-relativism-driven-recomposuringconstructivism-towards-singularisation-<as-to-the-nondisjointedness/entailment-of-

prospective- nonpresencing $>$ as of the $<$ amplituding/formative-epistemicity $>$ causality $\sim$ asto-projective-totalitative-implications-of-prospective- nonpresencing,-for-

explicating relative-unreflexivity/relative-reflexivity - ontological-contiguity of prospective relative-ontological-completeness ${ }^{87}$, and so-construed as of difference-conflatedness ${ }^{13}$-as-tototalitative-reification-in-singularisation-<as-to-the-nondisjointedness/entailment-ofprospective- nonpresencing $>$-as-veridical-epistemicity-relativism-determinism perspective. In other words, it is herein contended that the implied notion of relative truth expressed by postmodern-thought is not a rejection of truth as they are wrongly accused, but that truth deepens relatively with human limited-mentation-capacity-deepening as subjecting limitedness/human-subpotency-to-'educed-unlimitedness/existence-sublimating nascence' and this notion of relative truth is reflected in their works/research-programmes that undermine our $<$ amplituding/formative-epistemicity $>$ totalising $\sim$ self-referencingsyncretising/circularity/interiorising/akrasiatic-drag ${ }^{34} \quad$ identitive-constitutedness ${ }^{14}$-as'epistemic-totality ${ }^{37}$ '-dereification-in-dissingularisation- $<$ as-to-thedisjointedness/disentailment-of- presencing - absolutising-identitive-constitutedness $>$-asflawed-epistemicity-relativism-determinism perspective. Further, the implication as well is that the adjudicator as to transcendental-signifier/transcendental- 
enabling/sublimating/supereregatory $\sim$ de-mentativity with regards to truth as it enables transcendence-and-sublimity/sublimation/supererogatory-de-mentativity then is existencepotency $^{39} \sim$ sublimating-nascence,-disclosed-from-prospective-epistemic-digression as of its $<$ amplituding/formative-epistemicity $>$ causality $\sim$ as-to-projective-totalitative-implications-ofprospective- nonpresencing,-for-explicating relative- unreflexivity/relative-reflexivity

ontological-contiguity selecting/skewing for ontological-pertinence within the underlying human metaphoricity' scheme of 'intemporal ontological-faith-notion-or-ontologicalfideism —imbued-underdetermination-of-motif-and-apriorising/axiomatising/referencing-asso-being-as-of-existential-reality instigated relative-unreflexivity/relative-reflexivity ontological-contiguity ${ }^{67}$ of-the-human-institutionalisation-process ${ }^{68}$ as of differenceconflatedness $^{13}$-as-to-totalitative-reification-in-singularisation- $<$ as-to-thenondisjointedness/entailment-of-prospective- nonpresencing $>$-as-veridical-epistemicityrelativism-determinism implied $<$ amplituding/formative-epistemicity $>$ causality $\sim$ as-toprojective-totalitative-implications-of-prospective- nonpresencing,-for-explicating $\sim$ relativeunreflexivity/relative-reflexivity ontological-contiguity ', and not just mere human subjectivity. Even though in the short-term/immediacy perspective the specific metaphoricity of say a scientific and liberal worldview narrative as implied with the industrial revolution may actually be in the most part ignored/overlooked in a pre-industrial society from a merely meaningfulness-and-teleology ${ }^{9}$ transmission/spreading perspective, the supposedly coherent ontological-commitment $-<$ implied_-self-assuredness-of-ontological-goodfaith/authenticity postconverging-de-mentating/structuring/paradigming -as-being-as-ofexistential-reality> so-implied as of a social-setup 'self-assuredness-of-ontological-goodfaith/authenticity ${ }^{6} \sim$ postconverging-de-mentating/structuring/paradigming 7 -as-being-as-ofexistential-reality with respect to its social-stake-contention-or-confliction' exposes it to the metaphoricity ${ }^{57}$ of the scientific and liberal worldview narrative; wherein for instance such pre- 
industrial societies were constrained politically and as of national vision, economically and culturally to the effect of progressing industrialisation as it induced the requisite knowledge, skills, beliefs, lifestyle, organisations, etc. changes undermining systematically prior preconverging-de-mentating/structuring/paradigming of societies. Such an overall prospective institutionalisation metaphoricity ${ }^{57}$ constraining is very much unlike what we may naively imagine the prior human ${ }^{5}$ meaningfulness-and-teleology ${ }^{9}$ to be from an after the fact analysis; since such a process is much more critically more than just 'mere transmission/spreading of scientific and liberal ${ }^{5}$ meaningfulness-and-teleology ${ }^{9}$ for say a suprasocial or $<$ amplituding/formative $>$ wooden-language-<imbued - averaging-of-thought-<as-toleveling/ressentiment/closed-construct-of- meaningfulness-and-teleology -as-of'nondescript/ignorable-void '-with-regards-to-prospective-apriorising-implications $>>$ human mindset processing', but critically was an epistemic-ricochetting/transepistemicity process that was in-many-ways beyond-the-consciousness-awareness-teleology ${ }^{9}-<$ of-preconvergingexistential-extrication-as-of-existential-unthought $>$ unlike our subsequent reasoning-fromresults/afterthought contemplation afterwards 'wrongly implying a metaphoricity ${ }^{57}$ as of a selfconsciously instigated prior suprasocial or <amplituding/formative $>$ wooden-language〈imbued-averaging-of-thought-<as-to-leveling/ressentiment/closed-construct-ofmeaningfulness-and-teleology -as-of-‘nondescript/ignorable-void '-with-regards-toprospective-apriorising-implications $>>$ comprehensive sense of prospective metaphoricity ${ }^{57}$. This points to a more comprehensive reality of human epistemic-veracity arising as of our $<$ amplituding/formative-epistemicity>-totalising thrownness-in-existence ${ }^{35}$ with regards to the fact that while of immediate epistemic strive for knowledge we are naturally predisposed to immediate validation-and-falsifiability ${ }^{42}$ implications as of <amplituding/formativeepistemicity $>$ causality $\sim$ as-to-projective-totalitative-implications-of-prospective- 
contiguity , in the long run our sense of epistemic-veracity is rather more aptly refined as of our overall existential<<disontologising/re-ontologising aporeticism $>$ knowledge insight as reflected with say the research-programme knowledge implications, and ultimately we come to realise that even then epistemic-veracity is in-many-ways more profoundly as of a beyond-theconsciousness-awareness-teleology ${ }^{-<}<$of-preconverging-existential-extrication-as-ofexistential-unthought $>$ nonpresencing-<perspective-ontological-normalcy/postconvergence $>$ ricochetting that speaks of the preconverging/postconverging-dementative/structural/paradigmatic reality of a human epistemic-veracity as of prospective relative-ontological-completeness ${ }^{87}$ appraisal. The reason for making this point is equally to undermine any overrating of human comprehensive contemplation of any such implied suprasocial or <amplituding/formative> wooden-language-_imbued-averaging-of-thought$<$ as-to-leveling/ressentiment/closed-construct-of- meaningfulness-and-teleology -as-of'nondescript/ignorable-void '-with-regards-to-prospective-apriorising-implications $>$ > presencing-absolutising-identitive-constitutedness ${ }^{14}$ mindset not dispensing-withimmediacy-for-prospective-ontological-completeness/contemplative-distension, and so in order to effectively put in perspective the deficiency of epistemic-veracity so-inherent when it comes to prospective metaphoricity ${ }^{57}$ implications of operant prospective intemporal individuation transversality-<for-sublimating-existential-eventuating/denouement,-from-'thinking-atfirst/pure-predisposition-preemptive-of-prospective-disontologising/subontologising' as-ofprospectively-disambiguated-affirmed-and-unaffirmed-'motif-andapriorising/axiomatising/referencing'>101 intemporal projection as of ontological-faith-notionor-ontological-fideism - imbued-underdetermination-of-motif-andapriorising/axiomatising/referencing-as-so-being-as-of-existential-reality for reasoningthrough/messianic-reasoning. We can appreciate as well in-the-bigger-scheme-of-things the ontological-veridicality of this scepticism with regards to any such suprasocial or 
$<$ amplituding/formative $>$ wooden-language-<imbued - averaging-of-thought-<as-to-

leveling/ressentiment/closed-construct-of- meaningfulness-and-teleology -as-of-

'nondescript/ignorable-void '-with-regards-to-prospective-apriorising-implications $>$ >

epistemic-veracity pretence, as expressed before with respect to Plato's idea ${ }^{103}$ universalisation involving the undermining of the suprasocial epistemic-veracity pretence associated with sophistry or Descartes' cogito implications of positivism/rational-empiricism involving the undermining of the suprasocial epistemic-veracity pretence of medieval-scholasticism pedantising/muddling/formulaic-hollowing-out — in-subontologisation/subpotentiation〈blurring/undermining-of-prospective-totalising-entailing,-as-to-entailing$<$ amplituding/formative-epistemicity $>$ totalising in-relative-ontological-completeness $\rangle$. Just as we can appreciate that in 'the-very-same physics <amplituding/formativeepistemicity>totalising $\sim$ devolved—-purview/domain-of-construal-as-intrinsicreality/ontological-veridicality/existential-reality' as of prospective relative-ontologicalcompleteness ${ }^{87}$-of-axiomatic-construct-or- ${ }^{83}$ reference-of-thought, the epistemic-veracity as implied in succession from Corpenicus, Galileo, Descartes, Newton, Leibniz, Faraday, Rutherford, Poincaré, Einstein, Bohr up to our very present $21^{\text {st }}$ century physics is mostly as of ricochetting prospective nonpresencing-<perspective-ontologicalnormalcy/postconvergence $>$. In a certain way this is obvious, when we appreciate that having the right epistemic-veracity should provide the direct possibility for constructing its preconverging/postconverging-de-mentative/structural/paradigmatic $\quad{ }^{56}$ meaningfulness-andteleology as knowledge, such that the fact that a domain-of-study prospective knowledge possibility is thresholding/has-attained-its-limits somewhere is ever always directly related to the fact that its epistemic-veracity has equally thresholded/attained-its-limits, with the possibility for prospective breakthrough arising as of shifting epistemic-veracity; such that we can appreciate that the history of physics or any domain-of-study can be construed as the history of 
its developing epistemic-veracity in succession as ultimately constrained to $<$ amplituding/formative-epistemicity $>$ causality $\sim$ as-to-projective-totalitative-implications-ofprospective- nonpresencing,-for-explicating relative-unreflexivity/relative-reflexivity

ontological-contiguity validation-and-falsifiability ${ }^{2}$. Naivety will be the pretence of constraining the possibility for transcendence-and-sublimity/sublimation/supereregatory $\sim$ dementativity as of prospective ${ }^{56}$ meaningfulness-and-teleology ${ }^{9}$ as knowledge on a vague notion of any ${ }^{7}$ presencing-absolutising-identitive-constitutedness ${ }^{14}$ epistemic-veracity that at the very least doesn't rise to projectively contemplate and appraise of such a shift as to prospective meaningfulness-and-teleology ${ }^{9}$ as knowledge prospectively implicited epistemic-veracity of research-programme and validation-and-falsifiability ${ }^{42}$. Thus metaphoricity ${ }^{57}$ as such is a notion that is beyond just simplistic transmission/spreading of prospective ${ }^{56}$ meaningfulness-andteleology as knowledge, even though this can be relevant as of a shared prospective apriorising/axiomatising/referencing/intelligibilitysettingup/measuringinstrumenting for meaningfulness-and-teleology 9 as say the commonality of such metaphoricity ${ }^{57}$ inclined reoriginary-ass-unenframed/re-ontologising/unbeholdening/outlier-conceptualisation-_imbued-

\section{postconverging/dialectical-thinking -'projective-insights'/'epistemic-projection-in-}

conflatedness '-of-notional deprocrypticism-prospective-sublimation $\rangle^{0}$ thinkers sharing a common emancipating metaphoricity ${ }^{57}$ mathesis/motif-thrownness-disposition like Socrates, Plato, Aristotle and their schools with their ${ }^{103}$ universalisation projection or the Descartes, Galileos, Copernicuses, Newton, etc. with budding-positivism/rational-empiricism. But rather beyond such shared prospective apriorising/axiomatising/referencing/intelligibilitysettingup/measuringinstrumenting for meaningfulness-and-teleology that is instigative, metaphoricity ${ }^{57}$ is critically about the prospective ricochetting postconverging-de-mentating/structuring/paradigming implications for inducing such prospective ${ }^{56}$ meaningfulness-and-teleology ${ }^{9}$ implications on the fabric of the 
social as an epistemic-totality ${ }^{37}$ framework (beyond-the-consciousness-awareness-teleology $<$ of-preconverging-existential-extrication-as-of-existential-unthought $>$ ), as the supposedly coherent ontological-commitment $-<$ implied-self-assuredness-of-ontological-goodfaith/authenticity $\sim$ postconverging-de-mentating/structuring/paradigming -as-being-as-ofexistential-reality> of 'self-assuredness-of-ontological-goodfaith/authenticity $\sim$ postconverging-de-mentating/structuring/paradigming -as-being-as-ofexistential-reality with respect to its social-stake-contention-or-confliction' of the social-setup exposes it to such an epistemic-ricochetting/transepistemicity metaphoricity ${ }^{57}$. This is so because in the long run transversality- $<$ for-sublimating-existential-eventuating/denouement-from-

\section{thinking at -first/pure-predisposition-preemptive-of-prospective-}

\section{disontologising/subontologising' as-of-prospectively-disambiguated-affirmed-and-}

unaffirmed-'motif-and-apriorising/axiomatising/referencing' $>101$ of temporal-to-intemporalontological-performance $^{2}$-<including-virtue-as-ontology>-of-narratives is rather as of $<$ amplituding/formative-epistemicity $>$ causality $\sim$ as-to-projective-totalitative-implications-ofprospective- nonpresencing,-for-explicating relative-unreflexivity/relative-reflexivity

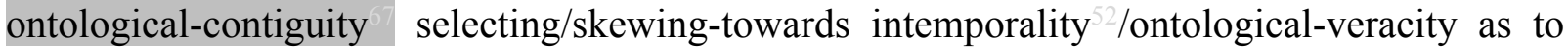
existence-potency ${ }^{39} \sim$ sublimating-nascence,-disclosed-from-prospective-epistemic-digression as-to-ontologically-uncompromised-ontological-normalcy/postconvergence/referentialism. It is important thus to grasp that a social-setup value construct lies somewhere between the possibility of its conventioning-referencing and its ${ }^{79}$ presencing-absolutising-identitive-constitutedness Being-development/ontological-framework-expansion-as-to-depth-of-ontologisingdevelopment-as-infrastructure-of- meaningfulness-and-teleology , when it comes to assessing the possibility of prospective ${ }^{56}$ meaningfulness-and-teleology ${ }^{9}$ inducing of metaphoricity ${ }^{57}$. It is not necessarily the case that a society that doesn't or poorly appreciate the implication of science will value as of immediacy re-ontologising prospective Being-development/ontological- 
framework-expansion-as-to-depth-of-ontologising-development-as-infrastructure-of-

meaningfulness-and-teleology like the cultivation of science over its conventioningreferencing as a cultural inclination or metaphysical predisposition or a creed; as we can appreciate the contrasting disposition towards the cultivation of science as in Europe and the Arabic world during the medieval period, or even disparity in ontological progressiveness within the-very-same societies at various epochs. Thus the assumption that any given society or period is absolutely turned/committed to re-ontologising prospective Being-development/ontologicalframework-expansion-as-to-depth-of-ontologising-development-as-infrastructure-ofmeaningfulness-and-teleology including our modern period, is a flawed appraisal; as inmany-ways, beyond our <amplituding/formative-epistemicity $>$ totalising $\sim$ self-referencingsyncretising/circularity/interiorising/akrasiatic-drag ${ }^{34}$ perception, a closer look at institutional functioning easily points out the pre-eminence of spurious institutional-being-and-craft muddlement highlighting an uninstitutionalised-threshold ${ }^{102}$ as of the privileging of conventioning-referencing over purely re-ontologising prospective Beingdevelopment/ontological-framework-expansion-as-to-depth-of-ontologising-development-asinfrastructure-of- meaningfulness-and-teleology , and in-many-ways this explains at the more socially visible spectrum that is politics, the perceived political impotence today. This insight is critical for appreciating the implication of the conception of futural Beingdevelopment/ontological-framework-expansion-as-to-depth-of-ontologising-development-asinfrastructure-of- meaningfulness-and-teleology as of prospective notional ${ }^{18}$ deprocrypticism metaphoricity ${ }^{57}$ in our positivism- $-{ }^{80}$ procrypticism; as its brings to the self-consciousness the reality that the implication of such a notional ${ }^{18}$ deprocrypticism articulation is bordering on the limits/thresholds of our institutional capacity for re-ontologising prospective Being-development/ontological-framework-expansion-as-to-depth-ofontologising-development-as-infrastructure-of- meaningfulness-and-teleology as of a 
privileging of conventioning-referencing disposition to adopt and assume intellectual nihilism at such an uninstitutionalised-threshold ${ }^{102}$; it is herein contended that the reality is similar to that which scuppered Arabic medieval science or scuppered medieval China progressiveness. The ‘intemporal ontological-faith-notion-or-ontological-fideism —imbued-underdetermination-ofmotif-and-apriorising/axiomatising/referencing-as-so-being-as-of-existential-reality reasoningthrough/messianic-reasoning instigated relative-unreflexivity/relative-reflexivity - ontologicalcontiguity ${ }^{67}$ of-the-human-institutionalisation-process ${ }^{68}$ as of difference-conflatedness ${ }^{13}$-as-tototalitative-reification-in-singularisation-<as-to-the-nondisjointedness/entailment-ofprospective- nonpresencing $>$-as-veridical-epistemicity-relativism-determinism implied $<$ amplituding/formative-epistemicity $>$ causality $\sim$ as-to-projective-totalitative-implications-ofprospective- nonpresencing,-for-explicating relative-unreflexivity/relative-reflexivity _

ontological-contiguity , warrants such intemporal relaying of re-ontologising prospective Being-development/ontological-framework-expansion-as-to-depth-of-ontologisingdevelopment-as-infrastructure-of- meaningfulness-and-teleology beyond just conventioningreferencing; as the very possibility of the <cumulating/recomposuring attendant-ontologicalcontiguity >-successive registry-worldviews/dimensions as of prospective relative-ontologicalcompleteness 87 arises because such reasoning-through/messianic-reasoning can devalue their presencing-absolutising-identitive-constitutedness ${ }^{14}$ conventioning-referencing to value prospective possibility for Being-development/ontological-framework-expansion-as-to-depthof-ontologising-development-as-infrastructure-of- meaningfulness-and-teleology as explained above with Socrates/Plato/Aristotle with their schools Beingdevelopment/ontological-framework-expansion-as-to-depth-of-ontologising-development-asinfrastructure-of- meaningfulness-and-teleology common ${ }^{103}$ universalising-idealisation apriorising/axiomatising/referencing/intelligibilitysettingup/measuringinstrumenting in prospective relative-ontological-completeness ${ }^{87} \mathrm{~s}$ but as 
unaffirmation/deprojection/deassertion/epistemic-decadence/undueness-invalidatinglogicising/unsuitable-measuringinstrument-invalidating-measuring-<as-to-preconverging-ordementing -apriorising-psychologism $>$ devaluing their ${ }^{70}$ presencing - absolutising-identitiveconstitutedness conventioning-referencing as of sophistry apriorising/axiomatising/referencing/intelligibilitysettingup/measuringinstrumenting in prior relative-ontological-incompleteness ${ }^{88}$ or as with budding-positivists Beingdevelopment/ontological-framework-expansion-as-to-depth-of-ontologising-development-asinfrastructure-of- meaningfulness-and-teleology common positivism/rational-empiricism apriorising/axiomatising/referencing/intelligibilitysettingup/measuringinstrumenting in prospective relative-ontological-completeness ${ }^{87} \mathrm{~s}$ but as of unaffirmation/deprojection/deassertion/epistemic-decadence/undueness-invalidatinglogicising/unsuitable-measuringinstrument-invalidating-measuring-<as-to-preconverging-ordementing -apriorising-psychologism $>$ devaluing their ${ }^{79}$ presencing - absolutising-identitiveconstitutedness ${ }^{14}$ conventioning-referencing in medieval-scholasticism dogmatism apriorising/axiomatising/referencing/intelligibilitysettingup/measuringinstrumenting in prior relative-ontological-incompleteness ${ }^{88}$ or with a Rousseau Being-development/ontologicalframework-expansion-as-to-depth-of-ontologising-development-as-infrastructure-ofmeaningfulness-and-teleology as of social enlightenment common apriorising/axiomatising/referencing/intelligibilitysettingup/measuringinstrumenting in prospective relative-ontological-completeness ${ }^{87} \mathrm{~s}$ but as of unaffirmation/deprojection/deassertion/epistemic-decadence/undueness-invalidatinglogicising/unsuitable-measuringinstrument-invalidating-measuring-<as-to-preconverging-ordementing -apriorising-psychologism> devaluing the conventioning-referencing as of aristocratic/despotic self-aggrandisement apriorising/axiomatising/referencing/intelligibilitysettingup/measuringinstrumenting in prior 
relative-ontological-incompleteness ${ }^{8} \mathbf{s}$. Ultimately, the question can be asked as well of our present positivism- ${ }^{80}$ procrypticism wherein its conventioning-referencing procrypticism apriorising/axiomatising/referencing/intelligibilitysettingup/measuringinstrumenting falsely seem to project ontological-pertinence why assuming little or no re-ontologising prospective Being-development/ontological-framework-expansion-as-to-depth-of-ontologisingdevelopment-as-infrastructure-of- meaningfulness-and-teleology responsibility/relativereflexivity in an preconverging-existential-extrication-as-of-existential-unthought posture; as such conventioning-referencing narratives increasingly protrude into supposedly re-ontologising prospective Being-development/ontological-framework-expansion-as-to-depth-ofontologising-development-as-infrastructure-of- meaningfulness-and-teleology purviews in usurpation, and so together with generalised intellectual teleological-decadence-<-indimensionality-of-desublimating-lack-of $-\langle<$ amplituding/formative $>$ supererogatory $\sim$ dementativeness/epistemic-growth-or-conflatedness /transvaluativerationalising/transepistemicity/anamnestic-residuality/spirit-drivenness-equalisation $\rangle$ as of its populism and pecuniary value drive substituting for intellectual reification, and as so increasingly reflected mediatically. This human contrastive mental-disposition to reontologising prospective Being-development/ontological-framework-expansion-as-to-depthof-ontologising-development-as-infrastructure-of- meaningfulness-and-teleology and presencing - absolutising-identitive-constitutedness ${ }^{14}$ conventioning-referencing speaks at a more fundamental level of the reality that the human subject is not psychologically necessarily driven by an absolute commitment to prospective ontological-veracity given its registryworldview/dimension preconverging/postconverging-de-mentative/structural/paradigmatic 'human akrasia-susceptibility-or-akrasiatic-drag/shiftiness-of-the-Self /ontologicalfracturing/desublimation/gimmickiness complex'; and thus that it has an ontological-veracity destructuring-threshold-〈uninstitutionalised-threshold /presublimating-desublimating- 
decisionality $>$ of-ontological-performance ${ }^{2}-<$ including-virtue-as-ontology $>$, where beyondthe-consciousness-awareness-teleology ${ }^{9}-<$ of-preconverging-existential-extrication-as-ofexistential-unthought $>$ it will relate to ontological-veracity as relatively impertinent on critical occasions as of its apriorising/axiomatising/referencing/intelligibilitysettingup/measuringinstrumenting $<$ amplituding/formative-epistemicity $>$ totalising $\sim$ self-referencingsyncretising/circularity/interiorising/akrasiatic-drag ${ }^{34}$, and so-reflected socially as of the uninstitutionalised-threshold $^{102}$. The underlying insight about such ontological-veracity destructuring-threshold-〈uninstitutionalised-threshold /presublimating-desublimatingdecisionality $>$ of-ontological-performance ${ }^{72}-<$ including-virtue-asontology $>$ /morality/ethics/justice/etc. is that the state of human-subpotency is one where overall its capacity to reflect existence-potency ${ }^{39} \sim$ sublimating-nascence,-disclosed-from-prospectiveepistemic-digression as-to-ontologically-uncompromised-ontologicalnormalcy/postconvergence/referentialism is inherently limited such that human meaningfulness-and-teleology ${ }^{9}$ construal ever always varies as of 'individual whim/impulsion narratives ontological-performance $^{72}$-<including-virtue-as-ontology $>$, ‘<amplituding/formative $>$ wooden-language- $\langle$ imbued - averaging-of-thought- $<$ as-toleveling/ressentiment/closed-construct-of- meaningfulness-and-teleology -as-of'nondescript/ignorable-void '-with-regards-to-prospective-apriorising-implications $>$ > narratives ontological-performance ${ }^{72}<$ including-virtue-as-ontology $>$ ', 'suprasocial narratives ontological-performance ${ }^{72}-<$ including-virtue-as-ontology>' and 'ontologically-hegemonising-

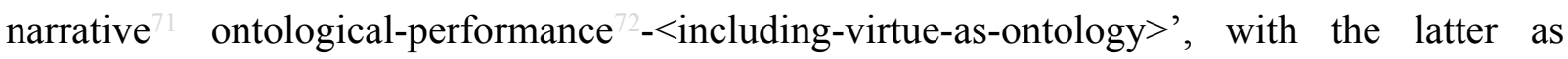
critically bound to fulfil ontological-veracity as of its direct and utter subjection to the superior party that is existence-potency ${ }^{39} \sim$ sublimating-nascence,-disclosed-from-prospective-epistemicdigression as to intrinsic-reality/ontological-veridicality as of <amplituding/formative- 
epistemicity $>$ causality $\sim$ as-to-projective-totalitative-implications-of-prospective-

nonpresencing,-for-explicating relative-unreflexivity/relative-reflexivity ontological-

contiguity and then its percolation-channelling- $<$ in-deferential-formalisation-transference $>$ implications, while it can be appreciated that the preceding three dispositions as of their $<$ amplituding/formative-epistemicity $>$ totalising $\sim$ self-referencing-

syncretising/circularity/interiorising/akrasiatic-drag ${ }^{34}$ are not critically as so-committed to ontological-veracity. Narratives as such are the very <amplituding/formativeepistemicity $>$ totalising $\sim$ self-referencing-syncretising/circularity/interiorising/akrasiatic-drag drive for human ${ }^{56}$ meaningfulness-and-teleology ${ }^{9}$ underlying language development, wherein 'ontologically-hegemonising-narrative ${ }^{71}$ ontological-performance ${ }^{72}-<$ including-virtue-asontology>' as of its dispensing-with-immediacty-for-relative-ontological-completeness profoundness is as of singularisation- $<$ as-to-the-nondisjointedness/entailment-of-prospectivenonpresencing $>\quad$ projected epistemic-immanence/veridical-epistemicity-relativism-

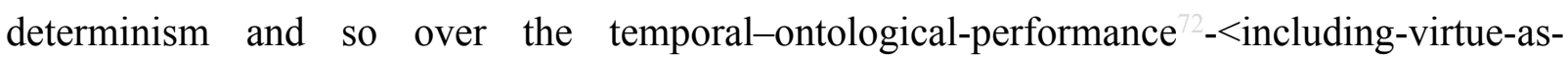
ontology $>$-of-narratives as of dissingularisation- $<$ as-to-the-disjointedness/disentailment-ofpresencing — absolutising-identitive-constitutedness $>$ /epistemic-nonimmanence/flawedepistemicity-relativism-determinism. Unsuspectingly, the reality of projected narratives as of human-subpotency-aporia/undecidability/dilemma/ought-

indeterminacy/deficiency/limitation/constraint—imbued-'notional firstnaturednessformativeness-<as-to-eventualising-inkling-drive-or-seeding-misprising $>$ temporal-tointemporal-dispositions- $<$ so-construed-as-from-perspective-ontologicalnormalcy/postconvergence>'-existentialism-form-factor across the institutionalcumulation/institutional-recomposure-〈as-to- historiality/ontologicaleventfulness /ontological-aesthetic-tracing-<perspective-ontologicalnormalcy/postconvergence-reflected-'epistemicity-relativism-determinism' $>\rangle$ is rather regular 
and stable as of the dynamics of temporal-to-intemporal-ontological-performance ${ }^{2}-<$ includingvirtue-as-ontology>-of-narratives, and so as of their respectively poor to profound dispensingwith-immediacy-for-relative-ontological-completeness ${ }^{87}$-by-reification/contemplativedistension $/$ contemplative-distension implications with regards to social-stake-contention-orconfliction at the given registry-worldview/dimension. It is equally critical to note that as of the profoundness of their social-stake-contention-or-confliction existential-investment, temporalontological-performance $^{72}-<$ including-virtue-as-ontology $>$-of-narratives will drag out as of preconverging-or-dementing - apriorising-psychologism,-'apriorising-teleologicaldegradation-in notional-discontiguity/epistemic-discontiguity ${ }^{63}<<$ between - prior-shallowsupererogation -of-mentally-aestheticised preconverging/dementing -qualiaschema_and_prospective-profound-supererogation -of-mentallyaestheticised postconverging/dialectical-thinking -qualia-schema>' of akrasia-susceptibilityor-akrasiatic-drag complex in obviation of prospective ontological-veracity without the constraining untenability as of <amplituding/formative-epistemicity $>$ causality $\sim$ as-toprojective-totalitative-implications-of-prospective- nonpresencing,-for-explicating relativeunreflexivity/relative-reflexivity ontological-contiguity as to existencepotency $^{39} \sim$ sublimating-nascence,-disclosed-from-prospective-epistemic-digression of intemporal 'ontologically-hegemonising-narrative ${ }^{7 !}$ ontological-performance ${ }^{22}<$ includingvirtue-as-ontology >', going by the fact that the supposedly coherent ontological-commitment $<$ implied - self-assuredness-of-ontological-good-faith/authenticity $\sim$ postconverging-dementating/structuring/paradigming -as-being-as-of-existential-reality $>$ so-implied as of a social-setup 'self-assuredness-of-ontological-good-faith/authenticity ${ }^{69} \sim$ postconverging-dementating/structuring/paradigming 7 -as-being-as-of-existential-reality with respect to its socialstake-contention-or-confliction' opens it up to the prospective intemporal-as-ontological metaphoricity $^{57}$ of 'ontologically-hegemonising-narrative ${ }^{71}$ ontological-performance ${ }^{72}$ 
<including-virtue-as-ontology >'. The reality of a regular and stable dynamic of human temporalto-intemporal-ontological-performance ${ }^{72}-<$ including-virtue-as-ontology $>$-of-narratives across the institutional-cumulation/institutional-recomposure-〈as-to- historiality/ontologicaleventfulness /ontological-aesthetic-tracing-<perspective-ontologicalnormalcy/postconvergence-reflected-'epistemicity-relativism-determinism'>>, critically and naturally makes of anthropology more of a ${ }^{103}$ universally and operantly principled construction of human existence reification as of anthropopsychology, beyond more or less a traditional orientation categorising epistemic disposition with regards to human cultural life, the social and practices of specific societies, with respect to the coherence of human-subpotencyaporia/undecidability/dilemma/ought-indeterminacy/deficiency/limitation/constraint—imbued'notional firstnaturedness-formativeness-<as-to-eventualising -inkling-drive-or-seeding misprising $>$ temporal-to-intemporal-dispositions- $<$ so-construed-as-from-perspectiveontological-normalcy/postconvergence>'-existentialism-form-factor <amplituding/formativeepistemicity $>$ causality $\sim$ as-to-projective-totalitative-implications-of-prospectivenonpresencing,-for-explicating relative-unreflexivity/relative-reflexivity - ontologicalcontiguity as of the preconverging/postconverging-de-mentative/structural/paradigmatic $<$ amplituding/formative-epistemicity $>$ causality $\sim$ as-to-projective-totalitative-implications-ofprospective- nonpresencing,-for-explicating relative-unreflexivity/relative-reflexivity

ontological-contiguity of 'human akrasia-susceptibility-or-akrasiatic-drag/shiftiness-of-theSelf /ontological-fracturing/desublimation/gimmickiness complex'; as reflected as of singularisation-<as-to-the-nondisjointedness/entailment-of-prospective- nonpresencing $>$ projected epistemic-immanence/veridical-epistemicity-relativism-determinism over dissingularisation-<as-to-the-disjointedness/disentailment-of- presencing - absolutisingidentitive-constitutedness > /epistemic-nonimmanence/flawed-epistemicity-relativismdeterminism. Basically, the possibility in reflecting holographically-<conjugatively-and- 
transfusively $>$ the relative-unreflexivity/relative-reflexivity ontological-contiguity $\sim$ of-thehuman-institutionalisation-process arises as of human generation of 'notional firstnaturedness-formativeness-<as-to-eventualising -inkling-drive-or-seedingmisprising $>$ temporal-to-intemporal-dispositions- $<$ so-construed-as-from-perspectiveontological-normalcy/postconvergence $>$ accordioning-〈as-of-varying-individuations-

\section{contextually-transverse-desublimation/sublimation,-as-to-the-}

\section{wavering/redounding/waveforming of-their-referencing-and-their-devolved-referencing-}

imbued-ontological-performance - $<$ including-virtue-as-ontology $>>$

ontological-

performance $^{72}-<$ including-virtue-as-ontology $>$-including-virtue-as-ontology of narratives' as of the specific destructuring-threshold-〈uninstitutionalised-threshold /presublimating-

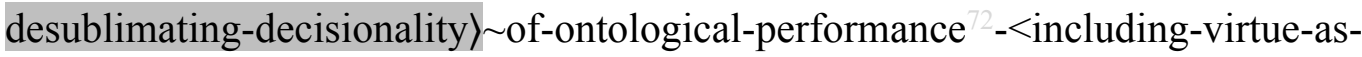
ontology $>$ /morality/ethics/justice/etc. of 'human akrasia-susceptibility-or-akrasiaticdrag/shiftiness-of-the-Self /ontological-fracturing/desublimation/gimmickiness complex'. It is ultimately 'ontologically-hegemonising-narrative ${ }^{71}$ ontological-performance ${ }^{72}-<$ includingvirtue-as-ontology >' that is implicited with respect to the supposedly coherent ontologicalcommitment $-<$ implied — self-assuredness-of-ontological-goodfaith/authenticity postconverging-de-mentating/structuring/paradigming -as-being-as-ofexistential-reality> so-implied as of a social-setup 'self-assuredness-of-ontological-goodfaith/authenticity ${ }^{69} \sim$ postconverging-de-mentating/structuring/paradigming ${ }^{70}$-as-being-as-ofexistential-reality with respect to its social-stake-contention-or-confliction' opening it up to prospective intemporal-as-ontological metaphoricity ${ }^{57}$ such that sublimating historiality/ontological-eventfulness 3 /ontological-aesthetic-tracing-<perspectiveontological-normalcy/postconvergence-reflected-'epistemicity-relativism-determinism’> in reflecting holographically-<conjugatively-and-transfusively $>$ the relative-unreflexivity/relativereflexivity - ontological-contiguity of-the-human-institutionalisation-process can 
effectively be construed as of the dynamism of the 'ontologically-hegemonising-narrative ontological-performance $^{72}$-<including-virtue-as-ontology>', as it supersedes temporal-

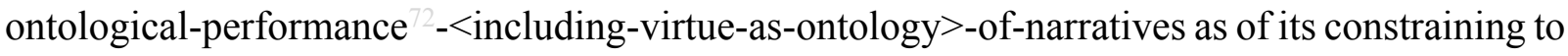
existence-potency ${ }^{39} \sim$ sublimating-nascence,-disclosed-from-prospective-epistemic-digression as of <amplituding/formative-epistemicity $>$ causality $\sim$ as-to-projective-totalitative-

\section{implications-of-prospective- nonpresencing,-for-explicating relative-unreflexivity/relative-}

reflexivity - ontological-contiguity over human-subpotency, and so with respect to human construal of existence and purviews of existence. We can appreciate in this regards the 'ontologically-hegemonising-narrative $\quad$ ontological-performance ${ }^{72}-<$ including-virtue-asontology >' drive in generally overcoming human egregious superstitious beliefs towards our positivism and science orientation today as well as 'relatively free-for-all opinionatedness and imaginary knowledge constructs' about purviews-of-existence which are today articulated in institutionalised frameworks as of subject-matter narratives like physics, law, biology, etc. oelegating social opinionatedness and substituting social percolation-channelling- $<$ indeferential-formalisation-transference> for 'ontologically-hegemonising-narrative ontological-performance ${ }^{72}$-<including-virtue-as-ontology>'. The relative-unreflexivity/relativereflexivity ontological-contiguity ${ }^{67} \sim$ of-the-human-institutionalisation-process ${ }^{68}$ successive overcoming of uninstitutionalised-threshold ${ }^{12}$ involves a migration of the hegemony of social meaningfulness-and-teleology' away from 'individual whim/impulsion narratives ontological-performance ${ }^{72}-<$ including-virtue-as-ontology $>$, ‘ $<$ amplituding/formative $>$ wooden-language-_imbued - averaging-of-thought- $<$ as-toleveling/ressentiment/closed-construct-of- meaningfulness-and-teleology -as-of'nondescript/ignorable-void ' -with-regards-to-prospective-apriorising-implications $>$ > narratives ontological-performance ${ }^{72}-<$ including-virtue-as-ontology $>$ ' and 'suprasocial

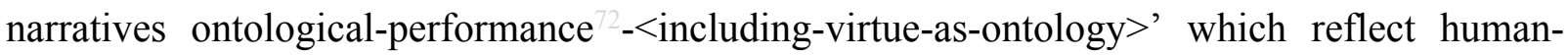


subpotency

$<$ amplituding/formative-epistemicity $>$ totalising $\sim$ self-referencingsyncretising/circularity/interiorising/akrasiatic-drag ${ }^{34}$, towards the hegemony of 'ontologicallyhegemonising-narrative ${ }^{7 !}$ ontological-performance ${ }^{72}-$ including-virtue-as-ontology $>$ rather reflecting existence-potency ${ }^{39} \sim$ sublimating-nascence,-disclosed-from-prospective-epistemicdigression as validated or invalidated by $<$ amplituding/formative-epistemicity $>$ causality $\sim$ as-toprojective-totalitative-implications-of-prospective- nonpresencing,-for-explicating relativeunreflexivity/relative-reflexivity ontological-contiguity, thus involving the displacement/decentering-of-the-human-subject with regards to human transcendence-andsublimity/sublimation/supererogatoryade-mentativity arising as of constraining to existence/intrinsic-reality/ontological-veridicality. As such we can appreciate that our present positivism institutionalisation outcome is the result of prior institutionalcumulation/institutional-recomposure-〈as-to- historiality/ontological-

\section{eventfulness /ontological-aesthetic-tracing-<perspective-ontological-}

normalcy/postconvergence-reflected-‘epistemicity-relativism-determinism' $>\rangle$ in succession of mainly the 'ontologically-hegemonising-narrative ${ }^{71}$ ontological-performance ${ }^{2}-<$ includingvirtue-as-ontology $>^{,}$as to existence-potency ${ }^{32} \sim$ sublimating-nascence,-disclosed-fromprospective-epistemic-digression, while all 'individual whim/impulsion narratives ontologicalperformance ${ }^{2}-<$ including-virtue-as-ontology $>$ ', '<amplituding/formative $>$ wooden-language〈imbued - averaging-of-thought-<as-to-leveling/ressentiment/closed-construct-ofmeaningfulness-and-teleology -as-of-'nondescript/ignorable-void '-with-regards-toprospective-apriorising-implications $>>$ narratives ontological-performance ${ }^{2}-<$ including-virtueas-ontology>' and 'suprasocial narratives ontological-performance ${ }^{72}-<$ including-virtue-asontology >' as of human-subpotency constraining were discarded. The implication here is that prospective relative-ontological-completeness ${ }^{87}$ will necessarily imply a discarding of our present positivism- ${ }^{80}$ procrypticism 'individual whim/impulsion narratives ontological- 
performance ${ }^{2}$-<including-virtue-as-ontology $>$ ', '<amplituding/formative $>$ wooden-language〈imbued — averaging-of-thought-<as-to-leveling/ressentiment/closed-construct-ofmeaningfulness-and-teleology -as-of-'nondescript/ignorable-void '-with-regards-toprospective-apriorising-implications $>>$ narratives ontological-performance ${ }^{2}-<$ including-virtueas-ontology >' and 'suprasocial narratives ontological-performance ${ }^{72}-<$ including-virtue-asontology >' as of human-subpotency, for futural Being-development/ontological-frameworkexpansion-as-to-depth-of-ontologising-development-as-infrastructure-of- meaningfulnessand-teleology as of prospective notional deprocrypticism 'ontologically-hegemonisingnarrative $^{71}$ ontological-performance ${ }^{72}-$ including-virtue-as-ontology $>^{\prime}$ as to existencepotency $^{32} \sim$ sublimating-nascence,-disclosed-from-prospective-epistemic-digression involving the displacement/decentering-of-the-human-subject; reflecting the latter's profoundness in dispensing-with-immediacy-for-relative-ontological-completeness ${ }^{87}$-byreification/contemplative-distension ${ }^{27}$ as enabling Being-development/ontological-frameworkexpansion-as-to-depth-of-ontologising-development-as-infrastructure-of- meaningfulnessand-teleology . This author further contends that as of our positivism- ${ }^{80}$ procrypticism uninstitutionalised-threshold ${ }^{102}$ in disjointedness-as-of- ${ }^{83}$ eference-of-thought, futural Beingdevelopment/ontological-framework-expansion-as-to-depth-of-ontologising-development-asinfrastructure-of- meaningfulness-and-teleology as of prospective notional ${ }^{18}$ deprocrypticism 'ontologically-hegemonising-narrative 11 ontologicalperformance $^{72}-<$ including-virtue-as-ontology $>^{\prime}$ is not meant in anyway to be explicative, as of the idea of falsely validating our defective ${ }^{8}$ procrypticism-or-disjointedness-as-of- referenceof-thought

apriorising/axiomatising/referencing/intelligibilitysettingup/measuringinstrumenting, thus wrongly inducing procrypticism-or-disjointedness-as-of- ${ }^{8}$ reference-of-thought $<$ amplituding/formative-epistemicity $>$ totalising $\sim$ self-referencing- 
syncretising/circularity/interiorising/akrasiatic-drag ${ }^{34}$; but rather has to project as of prospective epistemic-ricochetting/transepistemicity the requisite percolation-channelling- $<$ in-deferentialformalisation-transference $>$ as the mechanism for futural Being-development/ontologicalframework-expansion-as-to-depth-of-ontologising-development-as-infrastructure-ofmeaningfulness-and-teleology as of prospective notional $\sim^{18}$ deprocrypticism institutionalisation based on deprocrypticism-or-preempting-disjointedness-as-ofreference-of-thought

apriorising/axiomatising/referencing/intelligibilitysettingup/measuringinstrumenting $<$ amplituding/formative--epistemicity $>$ totalising $\sim$ self-referencingsyncretising/circularity/interiorising, and so just as with the positivism projection of the requisite percolation-channelling- $<$ in-deferential-formalisation-transference $>\quad$ of $\quad$ positivism apriorising/axiomatising/referencing/intelligibilitysettingup/measuringinstrumenting $<$ amplituding/formative-epistemicity $>$ totalising $\sim$ self-referencingsyncretising/circularity/interiorising as the mechanism of prospective positivism institutionalisation rather than engaging in defective non-positivism/medievalism apriorising/axiomatising/referencing/intelligibilitysettingup/measuringinstrumenting $<$ amplitung/formative-epistemicity $>$ totalising $\sim$ self-referencingsyncretising/circularity/interiorising/akrasiatic-drag ${ }^{34}$. Besides and overlaid on this underlying human-subpotency background deficiency as of human-subpotencyaporia/undecidability/dilemma/ought-indeterminacy/deficiency/limitation/constraint—imbued'notional firstnaturedness-formativeness-<as-to-eventualising -inkling-drive-or-seedingmisprising $>$ temporal-to-intemporal-dispositions- $<$ so-construed-as-from-perspectiveontological-normalcy/postconvergence>'-existentialism-form-factor, is the reality that human meaningfulness-and-teleology fundamentally develops out of the constructive/institutionalising/nascent-sublimating-decisionality and destructuring-threshold- 
〈uninstitutionalised-threshold /presublimating-desublimating-decisionality $\rangle$ of-ontological-

performance $^{72}-<$ including-virtue-as-ontology $>$ /morality/ethics/justice/etc. nature of the socialconstruct (as significant otherness to the individual), and as this social-construct conventioningreferencing is thereof reflected in its relationship with inherent ontological-veracity as of Beingdevelopment/ontological-framework-expansion-as-to-depth-of-ontologising-development-asinfrastructure-of- meaningfulness-and-teleology, that goes into building the individual capacity to uphold ontological-veracity when the social-construct as its significant otherness is constructive/institutionalising/nascent-sublimating-decisionality of ${ }^{56}$ meaningfulness-andteleology as knowledge while by the same token can undermine the individual capacity to uphold ontological-veracity when the social-construct as significant otherness is as of destructuring-threshold-〈uninstitutionalised-threshold /presublimating-desublimatingdecisionality $>\sim$ of-ontological-performance ${ }^{72}$ - $<$ including-virtue-asontology $>$ /morality/ethics/justice/etc. of ${ }^{5}$ meaningfulness-and-teleology as knowledge; as social-construct settings are fundamentally the background of significant otherness for their inherent generalised purposefulness and their enlivening of the possibility for individual human purposefulness as well, such that beyond-the-consciousness-awareness-teleology ${ }^{9}-<$ ofpreconverging-existential-extrication-as-of-existential-unthought $>$ the notion of ontologicalveracity is not necessarily of absolute pertinence to the individual as of pure-ontology implications of aetiologisation/ontological-escalation- $<$ ontologicalveridicality_commitment/otherliness_transcending/compulsions-encumbered_transcending> where individual possible construal of ontological-veracity is subject to its perception/engagement/endearment of specific and/or underpinning-suprasocial-construct settings significant otherness destructuring-threshold-〈uninstitutionalisedthreshold /presublimating-desublimating-decisionality) $\sim$ of-ontological-performance ${ }^{72}$ $<$ including-virtue-as-ontology $>$ /morality/ethics/justice/etc. implications of its possible 
constructive/institutionalising/nascent-sublimating-decisionality construal of ontologicalveracity. This destructuring-threshold-〈uninstitutionalised-threshold /presublimatingdesublimating-decisionality $\rangle$ of-ontological-performance ${ }^{72}-<$ including-virtue-asontology $>$ /morality/ethics/justice/etc. effect of social-construct settings with regards to individual possible constructive/institutionalising/nascent-sublimating-decisionality construal of ontological-veracity is validated by the idea that even the most assured critique in the ontological-veracity of their ideas when this elicits the uninstitutionalised-threshold ${ }^{102}$ cannot just articulate them as if the social-construct is 'purely/absolutely receptive-asconstructive/institutionalising/nascent-sublimating-decisionality to ontological-veracity' but need to implicitly recognise the social-construct predisposition to destructure such meaningfulness-and-teleology as of its conventioning-referencing for social-functioningand-accordance at its uninstitutionalised-threshold ${ }^{102}$, and so in order by its dispensing-withimmediacy-for-relative-ontological-completeness ${ }^{87}$-by-reification/contemplativedistension ${ }^{27} /$ contemplative-distension to strategically articulate such ${ }^{56}$ meaningfulness-andteleology going by the possibility of the social-construct as of its potential constructive/institutionalising/nascent-sublimating-decisionality significant otherness to tolerate it in the immediacy, even as the social-construct is rather predisposed in the immediacy to destructure at this uninstitutionalised-threshold ${ }^{102}$ as of its registry-worldview/dimension preconverging/postconverging-de-mentative/structural/paradigmatic 'human akrasiasusceptibility-or-akrasiatic-drag/shiftiness-of-the-Self /ontologicalfracturing/desublimation/gimmickiness complex'. From the foregoing, while the supposedly coherent ontological-commitment $-<$ implied — self-assuredness-of-ontological-goodfaith/authenticity postconverging-de-mentating/structuring/paradigming -as-being-as-ofexistential-reality> so-implied as of a social-setup 'self-assuredness-of-ontological-goodfaith/authenticity ${ }^{6} \sim$ postconverging-de-mentating/structuring/paradigming 7 -as-being-as-of- 
existential-reality with respect to its social-stake-contention-or-confliction' opens it up to prospective intemporal-as-ontological metaphoricity ${ }^{57}$, it is rather "naïve to construe of socialstake-contention-or-confliction in any social-setup as absolutely about ontological-veracity' giving a social-construct predisposition to destructure ${ }^{56}$ meaningfulness-and-teleology ${ }^{99}$ as of its conventioning-referencing for social-functioning-and-accordance at its uninstitutionalisedthreshold ${ }^{102}$; with any such superseding ontological-veracity at the social-setup uninstitutionalised-threshold ${ }^{102}$ rather beyond-the-consciousness-awareness-teleology ${ }^{9}-<$ ofpreconverging-existential-extrication-as-of-existential-unthought> , as base-institutionalisation implied ${ }^{5}$ meaningfulness-and-teleology ${ }^{9}$ is beyond-the-consciousness-awareness-teleology $<$ of-preconverging-existential-extrication-as-of-existential-unthought $>\quad$ of recurrent-utteruninstitutionalisation, that of ${ }^{103}$ universalisation is beyond-the-consciousness-awarenessteleology $-<$ of-preconverging-existential-extrication-as-of-existential-unthought $>$ of baseinstitutionalisation-ununiversalisation, that of positivism is beyond-the-consciousnessawareness-teleology $-<$ of-preconverging-existential-extrication-as-of-existential-unthought $>$ of ${ }^{103}$ universalisation-non-positivism/medievalism, and prospectively that of deprocryticism is beyond-the-consciousness-awareness-teleology ${ }^{9}-<$ of - preconverging-existential-extrication-asof-existential-unthought $>$ of positivism- ${ }^{80}$ procrypticism; and so because any given registryworldview/dimension preconverging/postconverging-de-mentative/structural/paradigmatic 'human akrasia-susceptibility-or-akrasiatic-drag/shiftiness-of-the-Self /ontologicalfracturing/desublimation/gimmickiness complex defines the social-construct institutionalisation threshold perceived intemporal ${ }^{56}$ meaningfulness-and-teleology ${ }^{99}$ as of its reproducibility—mathesis/motif/thrownness-disposition,--as-reproducibility-of-aestheticisation

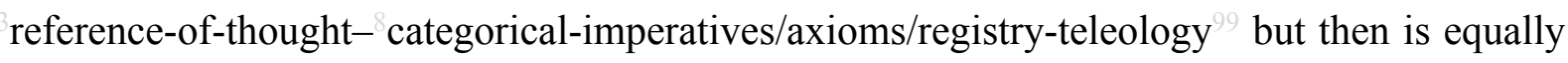
amenable to <amplituding/formative> wooden-language-_imbued-temporal-mereform/virtualities/dereification/akrasiatic-drag/denatured/preconverging-or-dementing 


\section{narratives - of-the- reference-of-thought- categorical-imperatives/axioms/registry-}

teleology > failing/not-upholding-<as-of-apriorising/axiomatising/referencing $>$ intemporalpreservation-entropy-or-contiguity-or-ontological-preservation manifesting at ${ }^{83}$ reference-ofthought- ${ }^{8}$ devolving-level as of postlogism -

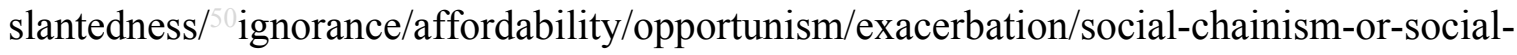
discomfiture-or-negative-social-aggregation/temporal-enculturation-or-temporal-endemisation, and so-disambiguated as of " ${ }^{\circ}$ reference-of-thought- ${ }^{8}$ devolving-level differenceconflatedness $^{13}$-as-to-totalitative-reification-in-singularisation- $<$ as-to-the-

\section{nondisjointedness/entailment-of-prospective- nonpresencing $>$-as-veridical-epistemicity-}

relativism-determinism reflected as the divergent temporal-to-intemporal ontologicalperformance $^{2}$-<including-virtue-as-ontology $>$ /morality/ethics/justice/etc. of the historiality/ontological-eventfulness ${ }^{38} /$ ontological-aesthetic-tracing- $<$ perspectiveontological-normalcy/postconvergence-reflected-'epistemicity-relativism-determinism'>'. This social-construct constructive/institutionalising/nascent-sublimating-decisionality and destructuring-threshold-_uninstitutionalised-threshold /presublimating-desublimating-

decisionality $>$ of-ontological-performance ${ }^{72}-<$ including-virtue-asontology $>$ /morality/ethics/justice/etc. of ${ }^{5}$ meaningfulness-and-teleology ${ }^{9}$ reality is exactly what renders 'prospective metaphoricity' as of ontological-veracity superseding of uninstitutionalised-threshold $^{102}$, necessarily as of ontological-faith-notion-or-ontologicalfideism - imbued-underdetermination-of-motif-and-apriorising/axiomatising/referencing-asso-being-as-of-existential-reality parrhesiastic askesis-or-acumen as of reasoningthrough/messianic-reasoning, wherein the reality of social transformation is more veridically as of prospective nonpresencing-<perspective-ontological-normalcy/postconvergence $>$ epistemic-ricochetting/transepistemicity rather than any prior ${ }^{7}$ presencing-absolutisingidentitive-constitutedness $^{14} \quad$ epistemic grounding; with transcendence-and- 
sublimity/sublimation/supererogatory de-mentativity over the uninstitutionalised-threshold preconverging/postconverging-de-mentative/structural/paradigmatic 'human akrasiasusceptibility-or-akrasiatic-drag/shiftiness-of-the-Self /ontologicalfracturing/desublimation/gimmickiness complex' as of prospective superseding preconverging/postconverging-rede-mentating/restructuring/reparadigming apriorising/axiomatising/referencing/intelligibilitysettingup/measuringinstrumenting supererogatory $\sim$ acuity/perspicacity/astuteness/edginess/incisiveness-ofapriorising/axiomatising/referencing/intelligibilitysettingup/measuringinstrumenting -forconceptualisation $<$ amplituding/formative-epistemicity $>$ causality $\sim$ as-to-projectivetotalitative-implications-of-prospective- nonpresencing,-for-explicating relative-

affirmation/projection/assertion/notional self-distantiation/dueness-validatinglogicising/suitable-measuringinstrument-validating-measuring-<as-to-postconverging-ordialectical-thinking -apriorising-psychologism $>$ of prospective registry-worldview/dimension. The ultimate point here being that critically the notion of human transcendence-andsublimity/sublimation/supererogatoryade-mentativity more often than not occur as 'reasoningthrough/messianic-reasoning projection-beyond-the-presencing-human-self-consciousness-asreinventing-prospective- ${ }^{-}$nonpresencing-<perspective-ontological-

normalcy/postconvergence>-human-self-consciousness' rather than as it can wrongly be implied with 'reasoning-from-results/afterthought postures as of ${ }^{79}$ presencing-absolutising-identitiveconstitutedness $^{14}$ self-consciousness mastery and direction' which are rather ontologicallyflawed $<$ amplituding/formative-epistemicity $>$ totalising $\sim$ self-referencingsyncretising/circularity/interiorising/akrasiatic-drag ${ }^{34}$ In this regards, ontological-veracity as of a perpetual predisposition for prospective relative-ontological-completeness ${ }^{87}$ is ensured by supposedly coherent ontological-commitment $-<$ implied-self-assuredness-of-ontological- 
good-faith/authenticity postconverging-de-mentating/structuring/paradigming -as-being-

as-of-existential-reality> to undermine the social-construct predisposition to destructure meaningfulness-and-teleology 9 as of its conventioning-referencing for social-functioningand-accordance at its uninstitutionalised-threshold ${ }^{102}$, and enable the construal of prospective ontological-veracity by 'ontologically-hegemonising-narrative' ${ }^{1}$ ontological-performance ${ }^{72}$ <including-virtue-as-ontology>', as of ontologically-veridical difference-conflatedness ${ }^{13}$-as-tototalitative-reification-in-singularisation-<as-to-the-nondisjointedness/entailment-of-

prospective- nonpresencing $>$-as-veridical-epistemicity-relativism-determinism , over 'individual whim/impulsion narratives ontological-performance ${ }^{72}-<$ including-virtue-asontology >', '<amplituding-formative $>$ wooden-language-_imbued-averaging-of-thought- $<$ asto-leveling/ressentiment/closed-construct-of- meaningfulness-and-teleology -as-of-

'nondescript/ignorable-void '-with-regards-to-prospective-apriorising-implications $>$ >

narratives ontological-performance ${ }^{72}-<$ including-virtue-as-ontology $>$ ' and 'suprasocial narratives ontological-performance ${ }^{72}-<$ including-virtue-as-ontology $>^{\prime}$ in their various flawed identitive-constitutedness ${ }^{14}$-as-'epistemic-totality ${ }^{37}$ '-dereification-in-dissingularisation- $<$ as-tothe-disjointedness/disentailment-of- presencing - absolutising-identitive-constitutedness as-flawed-epistemicity-relativism-determinism postures. The social epistemic-totality ${ }^{37}$ reality of the metaphoricity ${ }^{57}$ flux of temporal-to-intemporal-ontological-performance ${ }^{2}-<$ includingvirtue-as-ontology>-of-narratives thus implies that in effect a social-setup is a construct of 'notional firstnaturedness-formativeness-<as-to-eventualising-inkling-drive-or-seeding misprising $>$ temporal-to-intemporal-dispositions- $<$ so-construed-as-from-perspectiveontological-normalcy/postconvergence> accordioning-〈as-of-varying-individuationscontextually-transverse-desublimation/sublimation,-as-to-thewavering/redounding/waveforming of-their-referencing-and-their-devolved-referencingimbued-ontological-performance - $<$ including-virtue-as-ontology $>>$ ontological- 
performance ${ }^{72}-<$ including-virtue-as-ontology $>$-including-virtue-as-ontology of narratives' as an epistemic-totality ${ }^{37}$ of ${ }^{5}$ meaningfulness-and-teleology ${ }^{99}$, wherein the most totalisinglyentailing/ontologising/institutionalising of narratives as of 'ontologically-hegemonisingnarrative ontological-performance ${ }^{2}-<$ including-virtue-as-ontology $>$ ' is preconverging/postconverging-de-mentatively/structurally/paradigmatically superseding over

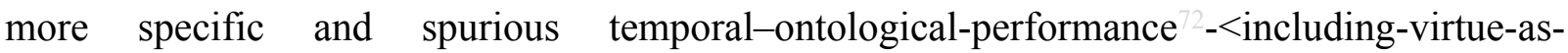
ontology>-of-narratives but with all such temporal-to-intemporal-ontological-performance ${ }^{72}$ $<$ including-virtue-as-ontology $>$-of-narratives susceptible to recombination in unsuspecting ways given human-subpotency-aporia/undecidability/dilemma/oughtindeterminacy/deficiency/limitation/constraint—imbued-'notional firstnaturednessformativeness-<as-to-eventualising inkling-drive-or-seeding-misprising $>$ - temporal-tointemporal-dispositions- $<$ so-construed-as-from-perspective-ontologicalnormalcy/postconvergence>'-existentialism-form-factor, and are variously enabled or inhibited in different spheres/settings wherein the extended-informality including the extendedinformality of institutional frameworks is more susceptible to spurious and specific temporalontological-performance $^{72}$-<including-virtue-as-ontology $>$-of-narratives unlike the strictly formalised institutional frameworks tending to totalisinglyentailing/ontologising/institutionalising of narratives. It is this possibility of narratives recombination as of formative and enculturating implications as well as the criss-crossing of formal and informal spheres/settings differing temporal-to-intemporal value-references that renders even totalisingly-entailing/ontologising/institutionalising narratives susceptible to

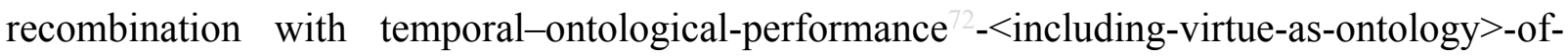
narratives, thus leading to their possible ontological denaturing ${ }^{16}$ as of uninstitutionalisedthreshold ${ }^{02}$ implications. Ultimately, it is herein contended that conceptualising ontologicalveracity reflecting existence-potency ${ }^{32} \sim$ sublimating-nascence,-disclosed-from-prospective- 
epistemic-digression

as-to-ontologically-uncompromised-ontologicalnormalcy/postconvergence/referentialism as this underlies retrospective, present to prospective meaningfulness-and-teleology ${ }^{99}$ rather boils down to grasping prospective relativeontological-completeness ${ }^{87}<$ amplituding/formative-epistemicity $>$ causality $\sim$ as-to-projectivetotalitative-implications-of-prospective- nonpresencing,-for-explicating relativeunreflexivity/relative-reflexivity ontological-contiguity as of notional ${ }^{18}$ deprocrypticism. Effectively prospective ${ }^{56}$ meaningfulness-and-teleology', as articulated from 'ontologically-

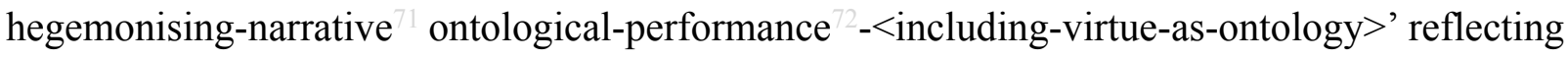
existence-potency ${ }^{39} \sim$ sublimating-nascence,-disclosed-from-prospective-epistemic-digression as-to-ontologically-uncompromised-ontological-normalcy/postconvergence/referentialism perspective, can be construed as: prospective relative-ontological-completeness preconverging/postconverging-rede-mentating/restructuring/reparadigming in superseding/undermining/deflating the 'relative-ontological-incompleteness ${ }^{88}$ perception of prospective relative-ontological-completeness ${ }^{87} \quad$ postconverging-dementating/structuring/paradigming'; wherein the relative-ontological-completeness apriorising/axiomatising/referencing/intelligibilitysettingup/measuringinstrumenting as of its preconverging/postconverging-rede-mentating/restructuring/reparadigming substitutes for the relative-ontological-incompleteness apriorising/axiomatising/referencing/intelligibilitysettingup/measuringinstrumenting, and so as of the-very-same-immanent-existence/intrinsic-reality/ontological-veridicality,-as-to'human<amplituding/formative-epistemicity>totalising purview-of-construal'. This knowledge notion, construed as organic-knowledge, involving articulating prospective meaningfulness-and-teleology 9 as of its postconverging-dementating/structuring/paradigming apriorising/axiomatising/referencing/intelligibilitysettingup/measuringinstrumenting 
substituting of prior ${ }^{56}$ meaningfulness-and-teleology ${ }^{9}$ preconverging-dementating/structuring/paradigming

apriorising/axiomatising/referencing/intelligibilitysettingup/measuringinstrumenting can be referred to as supererogatory $\sim$ acuity/perspicacity/astuteness/edginess/incisiveness-ofapriorising/axiomatising/referencing/intelligibilitysettingup/measuringinstrumenting -for-

conceptualisation with regards to human limited-mentation-capacity-deepening —as-subjectinglimitedness/human-subpotency-to-'educed-unlimitedness/existence-sublimating nascence' 53 as of prospective psychoanalytic-unshackling/memetic-reordering/institutional-recomposuring; speaking of the recurrent edging towards completion of ontological-performance ${ }^{2}-<$ includingvirtue-as-ontology $>$ /morality/ethics/justice/etc. as of intemporal ontological-faith-notion-orontological-fideism - imbued-underdetermination-of-motif-andapriorising/axiomatising/referencing-as-so-being-as-of-existential-reality parrhesiastic askesisor-acumen reasoning-through/messianic-reasoning recurrent shot for completeness as of successive reproducibility-mathesis/motif/thrownness-disposition,-as-reproducibility-ofaestheticisation for a 'seeding promise of human-subpotency ontological-performance $<$ including-virtue-as-ontology $>/$ morality/ethics/justice/etc. equivalence/correspondence with the full-potency-of-existence's $\sim$ sublimating-nascence-as-of-its-coherence/contiguity', which by that token as of the ${ }^{83}$ reference-of-thought-level induces the relative-unreflexivity/relativereflexivity - ontological-contiguity ${ }^{67}$ of-the-human-institutionalisation-process ${ }^{6}$ as $\quad$ of difference-conflatedness ${ }^{13}$-as-to-totalitative-reification-in-singularisation- $<$ as-to-thenondisjointedness/entailment-of-prospective- nonpresencing > -as-veridical-epistemicityrelativism-determinism in relative-unreflexivity/relative-reflexivity-ontological-contiguity from notional ${ }^{18}$ deprocrypticism. In other words, ontologically-veridical ${ }^{56}$ meaningfulness-andteleology as organic-knowledge is more critically overtly walking into the evil forest and finding a root or leaf cure as emancipating to such animistic social-setup beyond just the 
immediate remedy as mechanic knowledge but more profoundly as of the prospective worldview possibility of undermining the flawed ontological implications of the animistic social-setup mythology in prior relative-ontological-incompleteness apriorising/axiomatising/referencing/intelligibilitysettingup/measuringinstrumenting with the latter so-construed as its 'identitive-constitutedness ${ }^{14}$-as-'epistemic-totality ${ }^{37}$ '-dereification-indissingularisation-<as-to-the-disjointedness/disentailment-of- presencing — absolutisingidentitive-constitutedness $>$-as-flawed-epistemicity-relativism-determinism of meaningfulness-and-teleology, , rather than surreptitiously sneaking around and getting the root or leaf cure from the evil forest as remedy but then failing as of the prospective relativeontological-completeness ${ }^{87}$ possibility for superseding/undermining/deflating-the-evil-forestnotion to enable the animistic social-setup to put-into-question and supersede the existential$<$ disontologising/re-ontologising aporeticism $>$ implications of its prior ${ }^{79}$ presencingabsolutising-identitive-constitutedness ${ }^{14}$ preconverging-de-mentating/structuring/paradigming apriorising/axiomatising/referencing/intelligibilitysettingup/measuringinstrumenting for prospective $\quad$ nonpresencing- $<$ perspective-ontological-normalcy/postconvergence $>$ preconverging/postconverging-rede-mentating/restructuring/reparadigming apriorising/axiomatising/referencing/intelligibilitysettingup/measuringinstrumenting with the latter so-construed as of 'difference-conflatedness ${ }^{13}$-as-to-totalitative-reification-insingularisation-<as-to-the-nondisjointedness/entailment-of-prospective- nonpresencing $>$-asveridical-epistemicity-relativism-determinism of ${ }^{5}$ meaningfulness-and-teleology ${ }^{99}$; in both cases, as of the-very-same-immanent-existence/intrinsic-reality/ontological-veridicality,-as-to'human<amplituding/formative-epistemicity>totalising $\sim$ purview-of-construal' but with differing ontological-performance ${ }^{72}-<$ including-virtue-as-ontology $>/$ morality/ethics/justice/etc. of ${ }^{56}$ meaningfulness-and-teleology as it is such 'difference-conflatedness ${ }^{13}$-as-to-totalitativereification-in-singularisation-<as-to-the-nondisjointedness/entailment-of-prospective- 
nonpresencing $>$-as-veridical-epistemicity-relativism-determinism of ${ }^{56}$ meaningfulnessand-teleology construed

supereregatery acuity/perspicacity/astuteness/edginess/incisiveness-of-

apriorising/axiomatising/referencing/intelligibilitysettingup/measuringinstrumenting -for-

conceptualisation that induces the animistic social-setup ${ }^{83}$ reference-of-thought-level prospective society-wide transcendence-and-sublimity/sublimation/supererogatory $\sim$ dementativity into positivism/rational-empiricism. Thus, the prospect of all human meaningfulness-and-teleology arises as of intemporal ontological-faith-notion-orontological-fideism - imbued-underdetermination-of-motif-and-

apriorising/axiomatising/referencing-as-so-being-as-of-existential-reality parrhesiastic askesisor-acumen reasoning-through/messianic-reasoning recurrent/relaying instigating, at uninstitutionalised-threshold $^{102}$, in reflecting holographically-<conjugatively-andtransfusively $>$ the relative-unreflexivity/relative-reflexivity ontological-contiguity $\sim$ of-thehuman-institutionalisation-process as of human limited-mentation-capacity-deepening-assubjecting limitedness/human-subpotency-to-'educed-unlimitedness/existence-sublimating nascence' ${ }^{33}$ implications for prospective relative-ontological-completeness ${ }^{87}$ inducing the sublimating $\quad{ }^{4}$ historiality/ontological-eventfulness $3 \%$ ontological-aesthetic-tracing$<$ perspective-ontological-normalcy/postconvergence-reflected-‘epistemicity-relativismdeterminism'> as of supererogatory $>$ acuity/perspicacity/astuteness/edginess/incisiveness-ofapriorising/axiomatising/referencing/intelligibilitysettingup/measuringinstrumenting -forconceptualisation. We can appreciate in this regards that the $<$ cumulating/recomposuring attendant-ontological-contiguity $>$-successive registryworldviews/dimensions $\quad{ }^{83}$ reference-of-thought are actually in a supererogatory acuity/perspicacity/astuteness/edginess/incisiveness-ofapriorising/axiomatising/referencing/intelligibilitysettingup/measuringinstrumenting -for- 
conceptualisation relation with each other as of prospective relative-ontological-completeness with regards to construing the-very-same <amplituding/formativeepistemicity>totalising/circumscribing/delineating purview-of-construal-as-existence: wherein base-institutionalisation rulemaking edgily/incisively reconstrues existence as of rulemaking over recurrent-utter-uninstitutionalisation construal of existence as of non-rulesapriorising/axiomatising/referencing-psychologism; ${ }^{103}$ universalisation edgily/incisively reconstrues existence as of ${ }^{103}$ universalisation-directed-rulemaking over baseinstitutionalisation-ununiversalisation construal of existence as of rulemaking; positivism/rational-empiricism edgily/incisively reconstrues existence as of positivising/rational-empiricism-based-universalisation-directed-rulemaking over universalisation-non-positivism/medievalism construal of existence as of ${ }^{103}$ universalisationdirected-rulemaking; and prospectively, notional ${ }^{8}$ deprocrypticism edgily/incisively reconstrues existence as of preempting-disjointedness-as-of- ${ }^{-}$reference-of-thought,-as-to'32<amplituding/formative-epistemicity $>$ growth-or-conflatedness ${ }^{13} /$ transvaluativerationalising/transepistemicity/anamnestic-residuality/spirit-drivenness'—in-supersedingmere-formulaic-positivising/rational-empiricism-based-universalisation-directed-rulemakingover-non-rules - apriorising/axiomatising/referencing-psychologism over positivismprocrypticism construal of existence as of positivising/rational-empiricism-baseduniversalisation-directed-rulemaking. We thus appreciate that such reconstrual of existence is as of ${ }^{55}$ maximalising-recomposuring-for-relative-ontological-completeness ${ }^{87}$ - unenframed/reontologising conceptualisation implying the affirmation/projection/assertion/notional $\sim$ selfdistantiation/dueness-validating-logicising/suitable-measuringinstrument-validating- 
incrementalism-in-relative-ontological-incompleteness 8

enframed/disontologising conceptualisation which will wrongly imply the affirmation/projection/assertion/notional self-distantiation/dueness-validating-

logicising/suitable-measuringinstrument-validating-measuring-<as-to-postconverging-ordialectical-thinking -apriorising-psychologism> of the priorly superseded apriorising/axiomatising/referencing/intelligibilitysettingup/measuringinstrumenting instead of its unaffirmation/deprojection/deassertion/epistemic-decadence/undueness-invalidatinglogicising/unsuitable-measuringinstrument-invalidating-measuring-<as-to-preconverging-ordementing -apriorising-psychologism>.

Supererogatory acuity/perspicacity/astuteness/edginess/incisiveness-ofapriorising/axiomatising/referencing/intelligibilitysettingup/measuringinstrumenting -forconceptualisation as-of-contrastive-preconverging-or-dementing 20 -apriorising-psychologismand-postconverging-or-dialectical-thinking -differentiation reflection of historiality/ontological-eventfulness 3 /ontological-aesthetic-tracing-<perspectiveontological-normalcy/postconvergence-reflected-'epistemicity-relativism-determinism’> highlights 'human akrasia-susceptibility-or-akrasiatic-drag/shiftiness-of-the-Self /ontologicalfracturing/desublimation/gimmickiness complex' as of temporal-to-intemporal-ontologicalperformance $^{72}-<$ including-virtue-as-ontology $>$-of-narratives as so-disambiguated as of ${ }^{{ }^{3} 3}$ reference-of-thought- ${ }^{84}$ devolving-level difference-conflatedness ${ }^{13}$-as-to-totalitativereification-in-singularisation-<as-to-the-nondisjointedness/entailment-of-prospectivenonpresencing $>$-as-veridical-epistemicity-relativism-determinism reflected as the differing temporal-to-intemporal ontological-performance ${ }^{72}-<$ including-virtue-asontology $>$ /morality/ethics/justice/etc. in the historiality/ontologicaleventfulness 3 /ontological-aesthetic-tracing-<perspective-ontologicalnormalcy/postconvergence-reflected-'epistemicity-relativism-determinism'>' at the given 
uninstitutionalised-threshold $^{102}$, thus articulating the social epistemic-totality ${ }^{37}$ possibility of 'notional firstnaturedness-formativeness-<as-to-eventualising inkling-drive-or-seedingmisprising $>$ temporal-to-intemporal-dispositions- $<$ so-construed-as-from-perspectiveontological-normalcy/postconvergence> accordioning-〈as-of-varying-individuationscontextually-transverse-desublimation/sublimation,-as-to-thewavering/redounding/waveforming of-their-referencing-and-their-devolved-referencingimbued-ontological-performance -<including-virtue-as-ontology $>>\quad$ ontologicalperformance ${ }^{72}$-<including-virtue-as-ontology $>$-including-virtue-as-ontology of narratives'. 'ontologically-hegemonising-narrative ${ }^{71}$ ontological-performance ${ }^{72}<$ including-virtue-asontology >' as intemporal/ontological is thus effectively as to overall reifying-and-empoweringreflexivity-of-ecstatic-existence-as-panintelligibility/panreflexivity ${ }^{73}$-〈existentially-imbuedand-educing-< $<$ fepistemic-

totalising ${ }^{3}$ hermeneutically/textually/reprojectingly/supererogatingly/zeroingly/re-acutingly,$\{$ decompulsing $\}$ delinearity $\sim$ for-cogency $\geq$-epistemic-perspective-of-projective/reprojectiveaestheticising-re-motif-and-re-apriorising/re-axiomatising/re-referencing $\sim$ conceptualisation,as-herein-specifically-relevant-to human-subpotency) the reflection of the social epistemictotality ${ }^{37}$ of human 'notional firstnaturedness-formativeness-<as-to-eventualising-inklingdrive-or-seeding misprising $>$ temporal-to-intemporal-dispositions- $<$ so-construed-as-fromperspective-ontological-normalcy/postconvergence > accordioning-〈as-of-varyingindividuations-contextually-transverse-desublimation/sublimation,-as-to-thewavering/redounding/waveforming of-their-referencing-and-their-devolved-referencingimbued-ontological-performance -<including-virtue-as-ontology $>>\quad$ ontologicalperformance $^{72}$-<including-virtue-as-ontology $>$-including-virtue-as-ontology of narratives' as of Being-development/ontological-framework-expansion-as-to-depth-of-ontologisingdevelopment-as-infrastructure-of- meaningfulness-and-teleology , institutional- 
development-as-to-social-function-development and living-development-as-to-personalitydevelopment psychologismic epistemic acutisation difficulty-<for, residualising\{delinearity for-cogeney>-magnitudes $\{$ of-experientiality/experiment\}, with respect to existence-potency ${ }^{39} \sim$ sublimating-nascence,-disclosed-from-prospective-epistemic-digression as-to-ontologically-uncompromised-ontological-normalcy/postconvergence/referentialism contrastive disclosing of 'human akrasia-susceptibility-or-akrasiatic-drag/shiftiness-of-theSelf /ontological-fracturing/desublimation/gimmickiness complex', and so-disambiguated ontologically as of ${ }^{83}$ reference-of-thought- devolving-level ontologically-veridical differenceconflatedness $^{13}$-as-to-totalitative-reification-in-singularisation- $<$ as-to-thenondisjointedness/entailment-of-prospective- nonpresencing > -as-veridical-epistemicityrelativism-determinism 'differentiating/disambiguating $\quad$ transversality- $<$ for-sublimatingexistential-eventuating/denouement,-from-'thinking-at-first/pure-predisposition-preemptive-ofprospective-disontelogising/subontelogising'>' of 'notional firstnaturedness-formativeness<as-to-eventualising inkling drive-or-seeding misprising $>$ temporal-to-intemporaldispositions-<so-construed-as-from-perspective-ontological-normalcy/postconvergence $>$ accordioning-〈as-of-varying-individuations-contextually-transversedesublimation/sublimation,-as-to-the-wavering/redounding/waveforming of-theirreferencing-and-their-devolved-referencing-imbued-ontological-performance -<includingvirtue-as-ontology $>>\quad$ ontological-performance ${ }^{2}-<$ including-virtue-as-ontology $>$-includingvirtue-as-ontology of narratives'; wherein what marks out temporal-ontological-performance ${ }^{72}$ <including-virtue-as-ontology>-of-narratives is their 'overt untransvaluated-temporalintemporality $^{52}$ preconverging-existential-extrication-as-of-existential-unthought akrasiasusceptibility-or-akrasiatic-drag complex' as of the dynamic implications of direct and conjugating human temporal dimensionality-of-sublimating 
conflatedness /transvaluative-rationalising/transepistemicity/anamnestic-residuality/spirit-

drivenness-equalisation) manifestation of postlogism -

slantedness/ ${ }^{50}$ ignorance/affordability/opportunism/exacerbation/social-chainism-or-social-

discomfiture-or-negative-social-aggregation/temporal-enculturation-or-temporal-endemisation, so-disambiguated as of " ${ }^{8}$ reference-of-thought- ${ }^{84}$ devolving-level difference-conflatedness ${ }^{13}$-asto-totalitative-reification-in-singularisation- $<$ as-to-the-nondisjointedness/entailment-of-

prospective- nonpresencing $>$-as-veridical-epistemicity-relativism-determinism reflected as

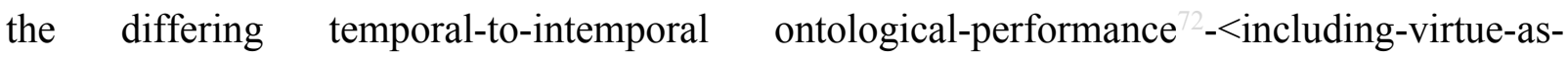
ontology $>$ /morality/ethics/justice/etc. of the ${ }^{4}$ historiality/ontologicaleventfulness 38 ontological-aesthetic-tracing-<perspective-ontological-

normalcy/postconvergence-reflected-'epistemicity-relativism-determinism'>’, and what marks out 'ontologically-hegemonising-narrative'1 ontological-performance' ${ }^{72}<$ including-virtue-asontology $>$ as of intemporal aetiologisation/ontological-escalation- $<$ ontologicalveridicality_commitment/otherliness_transcending/compulsions-encumbered_transcending $>$ of prospective transcendence-and-sublimity/sublimation/supererogatory $\sim$ de-mentativity is its dispensing-with-immediacy-for-relative-ontological-completeness ${ }^{87}$-by-

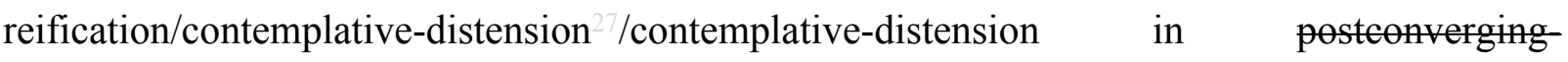
nonextricatory-existential-preempting-of-existential-unthought, and so with respect to overall registry-worldview/dimension uninstitutionalised-threshold implication (procrypticism or non-positivism-medievalism or ununiversalisation or recurrent-utter-uninstitutionalisation) in its flawed <amplituding/formative-epistemicity $>$ totalising $\sim$ self-referencingsyncretising/circularity/interiorising/akrasiatic-drag apriorising/axiomatising/referencing/intelligibilitysettingup/measuringinstrumenting. Basically, 'ontologically-hegemonising-narrative ${ }^{71}$ ontological-performance ${ }^{72}-<$ including-virtue-asontology ${ }^{\prime}$ is thus as to overall reifying-and-empowering-reflexivity-of-ecstatic-existence-as- 
panintelligibility/panreflexivity ${ }^{33}-\langle$ existentially-imbued-and-educing-<epistemic-

thermeneutically/textually/reprojectingly/supererogatingly/zeroingly/re-acutingly,$\{$ decompulsing $\}$ delinearity $\sim$ for-cogency $\geq$-epistemic-perspective-of-projective/reprojective-

aestheticising-re-motif-and-re-apriorising/re-axiomatising/re-referencing conceptualisation,as-herein-specifically-relevant-to-human-subpotency) the social epistemic-totality ${ }^{37}$ of meaningfulness-and-teleology $\quad$ temporal-to-intemporal-ontological-performance ${ }^{72}$ $<$ including-virtue-as-ontology $>$-of-narratives differentiated transversality-<for-sublimatingexistential-eventuating/denouement,-from-'thinking-at-first/pure-predisposition-preemptive-ofprospective-disontologising/subontologising' - as-of-prospectively-disambiguated-affirmedand-unaffirmed-'motif-and-apriorising/axiomatising/referencing'> ${ }^{101}$ as of Beingdevelopment/ontological-framework-expansion-as-to-depth-of-ontologising-development-asinfrastructure-of- meaningfulness-and-teleology , institutional-development-as-to-socialfunction-development and living-development-as-to-personality-development psychologismic epistemic-acutisation difficulty-for, residualising \{decompulsing $\}$ delinearity for-cogency>

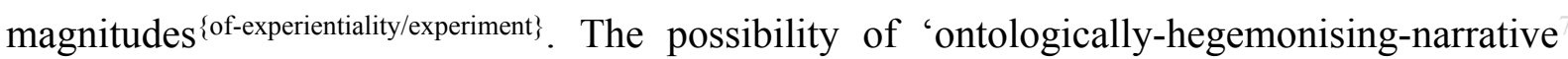
ontological-performance ${ }^{72}-<$ including-virtue-as-ontology $>$ ' as construed from existencepotency ${ }^{32} \sim$ sublimating-nascence,-disclosed-from-prospective-epistemic-digression as-toontologically-uncompromised-ontological-normalcy/postconvergence/referentialism is what allows for veridical aetiologisation/ontological-escalation- $<$ ontologicalveridicality_commitment/otherliness_transcending/compulsions-encumbered_transcending $>$ as of transcendentally-enabling-level-of ontological-good-faith-orauthenticity $\%$ objectification/desubjectification-as-objectification- $<$ as-to-ontological-faithnotion-or-ontological-fideism-imbued-underdetermination-of-motif-andapriorising/axiomatising/referencing-as-so-being-as-of-existential-reality as antinihilism> implied as of singularisation-<as-to-the-nondisjointedness/entailment-of-prospective- 
nonpresencing $>\quad$ projected epistemic-immanence/veridical-epistemicity-relativismdeterminism over dissingularisation- $<$ as-to-the-disjointedness/disentailment-of- presencingabsolutising-identitive-constitutedness > /epistemic-nonimmanence/flawed-epistemicityrelativism-determinism, just as with the natural sciences and so beyond the notion of subjectivity as of $\quad<$ amplituding/formative-epistemicity $>$ causality $\sim$ as-to-projective-totalitativeimplications-of-prospective- nonpresencing,-for-explicating relative-unreflexivity/relativereflexivity - ontological-contiguity validation and falsifiability implications. It is important to grasp that since every registry-worldview/dimension social-construct is involved in a constructive (as of its institutionalising disposition) and destructuring (as of its disposition at its uninstitutionalised-threshold ${ }^{102}$ ) relationship with ontological-veracity, this is exactly what inevitably validates the articulation of ontological-veracity/ontological-veridicality as more completely involving the displacement/decentering-of-the-human-subject priorly as implied with Derridean deconstruction narrative or Foucauldian genealogy-knowledge-and-powerdiscourse narrative in reflecting the need to undermine human destructuring-threshold$\langle$ uninstitutionalised-threshold /presublimating-desublimating-decisionality $\rangle$ of-ontologicalperformance $^{72}-<$ including-virtue-as-ontology $>$ /morality/ethics/justice/etc. to further advance its constructive/institutionalising/nascent-sublimating-decisionality nature, thus overcoming underlying logocentrism as of prospective relative-ontological-completenenss implications; reflecting the fact that human knowledge is more completely a two-fold process involving building the right mindset-as-of-prospective-relative-ontological-completeness ${ }^{87}$ and thus the knowledge for that given right mindset-as-of-prospective-relative-ontological-completeness ${ }^{87}$ as of projected apriorising/axiomatising/referencing-\{of-'prespectively implieited_attendantontological-contiguity ' educedexistentialising/contextualising/textualising_intelligibility/epistemicity/reflexivity_contiguity<imbued-notional cogency>' \}-conflatedness ${ }^{13}$-in-\{preconverging-disentailment by\} 
postconverging-ntailment. This is very much unlike the Ricoeurian narrative theory conception that while of palliative and practical significance is in relative apriorising/axiomatising/referencing-\{of-'prospectively implicited_attendant-ontologicalcontiguity ' educedexistentialising/contextualising/textualising_ 'intelligibility/epistemicity/reflexivity-contiguity$<$ imbued-notional cogency $\left.>^{\prime} \quad\right\}$-constitutedness ${ }^{14}$-in preconverging-entailment since it poorly deals with logocentrism implications as of prior relative-ontological-incompleteness ${ }^{88}$ on ontological-veracity; as it construes of 'logocentric habituated social conditions' as inherently ontological or beyond ontological treatment while failing to countenance the 'decentering heavy lifting' involved in undermining ontologically impertinent 'logocentric habituated social conditions' in enabling the relative-unreflexivity/relative-reflexivity-ontologicalcontiguity ${ }^{67}$ of-the-human-institutionalisation-process ${ }^{68}$ as of Being-development/ontologicalframework-expansion-as-to-depth-of-ontologising-development-as-infrastructure-ofmeaningfulness-and-teleology right up to our present, and as of prospective transformative emancipating possibilities. In-the-bigger-scheme-of-things, the social-construct as significant otherness is ever always inherently put-into-question itself given its constructive/institutionalising/nascent-sublimating-decisionality and destructuring-threshold〈uninstitutionalised-threshold /presublimating-desublimating-decisionality $\rangle$ of-ontologicalperformance ${ }^{2}-<$ including-virtue-as-ontology $>$ /morality/ethics/justice/etc. nature speaking of its reasoning-from-results/afterthought, with regards to its capacity-and-disposition to uphold prospective transcendence-and-sublimity/sublimation/supererogatory-de-mentativity ontological-veracity/ontological-veridicality; as so implied in the epistemicricochetting/transepistemicity unorthodoxy herein expounding futural Beingdevelopment/ontological-framework-expansion-as-to-depth-of-ontologising-development-asinfrastructure-of- meaningfulness-and-teleology as of prospective deprocrypticism, just as 
with the unorthodoxy of postmodern-thought or generally the unorthodoxy of all prospective transcendence-and-sublimity/sublimation/supererogatory-de-mentativity ${ }^{56}$ meaningfulnessand-teleology ${ }^{9}$ whether with regards to the Socrates/Plato/Aristotle, Copernicuses, Galileos, Descartes, Newtons, Darwins, Rousseaus, Nietzsches, Einsteins, etc. as reasoningthrough/messianic-reasoning. This basic idea of the social-construct as of its constructive/institutionalising/nascent-sublimating-decisionality and destructuring-threshold〈uninstitutionalised-threshold /presublimating-desublimating-decisionality $\rangle$ of-ontologicalperformance $^{-2}-<$ including-virtue-as-ontology $>$ /morality/ethics/justice/etc. nature is effectively what underlies in ontologically neutral/objective terms-as-of-axiomatic-construct such displacement/decentering-of-the-human-subject narratives like Derridean deconstruction narrative or Foucauldian genealogy-knowledge-and-power-discourse narrative. However, the capacity to appreciate the ontological neutrality/objectivity of a decentering narrative like deconstruction as being fully more of a purely ontological notion is caught up in our positivismprocrypticism prior relative-ontological-incompleteness ${ }^{88}$ human social-stake-contention-orconfliction in disjointedness-as-of- ${ }^{2}$ reference-of-thought, and thus deconstruction will tend to be deficiently construed in terms-as-of-axiomatic-construct of the circumstantial social primacy of this temporal framework social-stake-contention-or-confliction over its fuller pure-ontology as of prospective relative-ontological-completeness 87 deprocrypticism; explaining in-manyways the difficulty for Derrida to define deconstruction. Again, such a social situation is no more different with say the articulation of budding-positivism/rational-empiricism science in say a non-positivism/medievalism social-setup as caught up in the ${ }^{103}$ universalisation-nonpositivism/medievalism prior relative-ontological-incompleteness ${ }^{88}$ temporal framework of social-stake-contention-or-confliction, such that the more ontologically pure idea we may appreciate today as science is poorly disentangled from that circumstantial social primacy of the non-positivism/medievalism social-stake-contention-or-confliction like the entrenched interests 
that will rather focus mindsets rather in a nominal adversarial binarity perspective as of defending or attacking the traditional scholasticism pedantic literature over a more pure, nuanced and enlightening ontology contemplation of science as of prospective relative-ontologicalcompleteness ${ }^{87}$ positivism, as a result of the failure of dispensing-with-immediacy-for-relativeontological-completeness ${ }^{87}$-by-reification/contemplative-distension ${ }^{27}$ (as of human selfsurpassing — existentialism-form-factor,-in-overcoming-'notional collateralising-beholdeningprotohumanity'-to-'attain-sublimating-humanity'-as-to-existence-potency sublimatingnascence,-disclosed-from-prospective-epistemic-digression to supersede human temporality 9 /shortness <amplituding/formative> wooden-language-〈imbued-averaging-ofthought-<as-to-leveling/ressentiment/closed-construct-of- meaningfulness-and-teleology -asof-'nondescript/ignorable-void～'-with-regards-to-prospective-apriorising-implications $>>$ );

which will explain in-many-ways the difficulty of the Copernicuses, Galileos, Descartes', Diderots, etc. so effectively enculturate their budding-positivism. With respect to deconstruction in this regard, it is herein contended that such a Derridean deconstruction notion like binary opposition effectively speaks of the fact that it is encrusted/caught-up in our positivismprocrypticism prior relative-ontological-incompleteness ${ }^{88}$ human social-stake-contention-orconfliction as of its disjointedness-as-of- ${ }^{-3}$ reference-of-thought but that a more fuller pureontology appreciation of the deconstruction notion as of prospective relative-ontologicalcompleteness $^{87}$ notional ${ }^{18}$ deprocrypticism rather subsumes all such binary opposition conceptions basically into the binarity of intemporality $52 /$ longness and temporality $/$ shortness $^{2}$ as to human limited-mentation-capacity—as-subjecting-'educed-unlimitedness/existencesublimating nascence' to-limitedness/human-subpotency relative ontological-performance $<$ including-virtue-as-ontology $>$. It is effectively from this fuller pure-ontology perspective of prospective relative-ontological-completeness notional ${ }^{87}$ deprocrypticism that we can appreciate more profoundly the ${ }^{103}$ universal ontological epistemic pertinence of decentering 
narratives like deconstruction, and so pervasively well beyond the stereotypical grand themes of gender, race, postcolonialism, power, etc. but rather just as of an all-pervasive ${ }^{103}$ universal ontological profundity for analysing everything as of prospective relative-ontologicalcompleteness $^{87}$ notional ${ }^{18}$ deprocrypticism herein construed as ${ }^{48}$ human-subject-emancipatingrelativism-driven-recomposuring-constructivism-towards-singularisation- $<$ as-to-thenondisjointedness/entailment-of-prospective- nonpresencing $>$; with the implied knowledge emancipation rather construed as of mutual human emancipation beyond just the idea of a decentering narrative being about stronger and weaker but transcending that framework of contemplation in projecting of aetiologisation/ontological-escalation- $<$ ontologicalveridicality_commitment/otherliness_transcending/compulsions-encumbered_transcending $>$ as of a converging vision of emancipation as conjoint human emancipation, as the reality of the supposedly unemancipated speaks of the ontological emancipative deficiency of the supposedly emancipated in need of the latter's state very own deconstructing. Such a mutual-emancipation appreciation of deconstruction will appreciate for instance that the civil war ending slavery in the U.S. was both as emancipative to its practitioners as well as to the freed beyond just the overall social adversariality practical implications, just as in decolonising terms it will appreciate that the more matured as mutually-emancipative notion of decolonisation involved both the capacity of colonised territories to attain and choose independence in mutual cooperation and even in other cases with such territories choosing to follow a mutually respectful and healthy relationship with the metropolitan country which in a few cases turn out to be more beneficial to both. In this regards, we can appreciate that the human predisposition not to dispense-with-

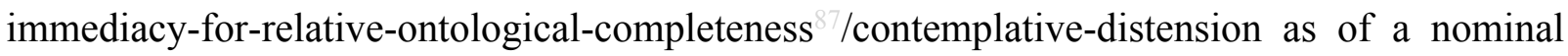
adversarial binarity predisposition in-many-ways renders such an ontologically more profound construct of deconstruction difficult. In this very contrastive sense with regards to our present prospective relative-ontological-completeness ${ }^{87}$ positivism/rational-empiricism, we don't 
ideally construe of science as of its pure-ontology as discriminatorily selective in its conclusions and we further appreciate that its usefulness is ${ }^{103}$ universally emancipating as of social-stakecontention-or-confliction, and so in both instances with regards to say medicine or civil technology or consumer technology or even scientific and technological nomenclatures; with any such discriminatorily selective predisposition and failure to share its usefulness being an indictment of a lack of the requisite liberalism for perpetuating human scientific progress and basically overall human emancipation. Ultimately, the social-construct as of its constructive/institutionalising/nascent-sublimating-decisionality and destructuring-threshold〈uninstitutionalised-threshold /presublimating-desublimating-decisionality $>$ of-ontologicalperformance $^{72}-<$ including-virtue-as-ontology $>$ /morality/ethics/justice/etc. nature inherently points out why human transcendence-and-sublimity/sublimation/supererogatery de-mentativity as of intemporal metaphoricity ${ }^{57}$ epistemic pertinence doesn't lie with any inherent suprasocial framework or inherent <amplituding/formative> wooden-language-_imbued-averaging-ofthought-<as-to-leveling/ressentiment/closed-construct-of- meaningfulness-and-teleology -asof-'nondescript/ignorable-void ' -with-regards-to-prospective-apriorising-implications $>$ > framework. The fact is that the inherent human-subpotencyaporia/undecidability/dilemma/ought-indeterminacy/deficiency/limitation/constraint—imbued'notional firstnaturedness-formativeness-<as-to-eventmalising-inkling-drive-or-seeding misprising $>$ temporal-to-intemporal-dispositions- $<$ so-construed-as-from-perspectiveontological-normalcy/postconvergence>'-existentialism-form-factor renders such $<$ amplituding/formative $>$ wooden-language-<imbued — averaging-of-thought-<as-toleveling/ressentiment/closed-construct-of- meaningfulness-and-teleology -as-of'nondescript/ignorable-void ' -with-regards-to-prospective-apriorising-implications $>$ > framework or suprasocial framework epistemic pertinence for prospective transcendence-and-

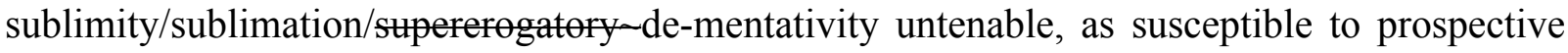


dissingularisation-<as-to-the-disjointedness/disentailment-of- presencing - absolutisingidentitive-constitutedness $>$ /epistemic-nonimmanence/flawed-epistemicity-relativismdeterminism. Such epistemic pertinence for prospective human transcendence-andsublimity/sublimation/supererogatory $\sim$ de-mentativity is rather postconvergingly-dementated/structured/paradigmed dynamically as of prospective reasoning-through/messianicreasoning epistemic-ricochetting/transepistemicity possibility exploiting the supposedly coherent ontological-commitment $-<$ implied - self-assuredness-of-ontological-goodfaith/authenticity postconverging-de-mentating/structuring/paradigming -as-being-as-ofexistential-reality> so-implied as of a social-setup 'self-assuredness-of-ontological-goodfaith/authenticity ${ }^{6} \sim$ postconverging-de-mentating/structuring/paradigming -as-being-as-ofexistential-reality with respect to its social-stake-contention-or-confliction' which opens it up to prospective intemporal-as-ontological metaphoricity ${ }^{57}$. It is by this token that the intemporal ontological-faith-notion-or-ontological-fideism - imbued-underdetermination-of-motif-andapriorising/axiomatising/referencing-as-so-being-as-of-existential-reality parrhesiastic askesisor-acumen reasoning-through/messianic-reasoning recurrent shot for completeness can as to existence-potency ${ }^{39} \sim$ sublimating-nascence,-disclosed-from-prospective-epistemic-digression $<$ amplitung formative-epistemicity $>$ causality $\sim$ as-to-projective-totalitative-implications-ofprospective- nonpresencing,-for-explicating $\sim$ relative-unreflexivity/relative-reflexivity ontological-contiguity validation induce transcendence-andsublimity/sublimation/supererogatoryade-mentativity thus constraining the positive opportunism for prospective human secondnatured institutionalisation as of crossgenerational percolation-channelling- $<$ in-deferential-formalisation-transference $>$. The insight here is that the epistemic possibility for human prospective aetiologisation/ontological-escalation- $<$ ontologicalveridicality_commitment/otherliness_transcending/compulsions-encumbered_transcending $>$ as reflected in all prior transcendence-and-sublimity/sublimation/supereregatory $\sim$ de-mentativity is 
more decisively about such intemporal ontological-faith-notion-or-ontological-fideism imbued-underdetermination-of-motif-and-apriorising/axiomatising/referencing-as-so-being-asof-existential-reality parrhesiastic askesis-or-acumen reasoning-through/messianic-reasoning exploiting of the supposedly coherent ontological-commitment $-<$ implied - self-assurednessof-ontological-good-faith/authenticity postconverging-dementating/structuring/paradigming -as-being-as-of-existential-reality $>$ so-implied as of a social-setup 'self-assuredness-of-ontological-good-faith/authenticity ${ }^{69} \sim$ postconverging-dementating/structuring/paradigming 70 -as-being-as-of-existential-reality with respect to its socialstake-contention-or-confliction', rather than a naïve reliance on <amplituding/formative > wooden-language-<imbued - averaging-of-thought-<as-toleveling/ressentiment/closed-construct-of- meaningfulness-and-teleology -as-of'nondescript/ignorable-void '-with-regards-to-prospective-apriorising-implications $>$ > or suprasocial epistemic relevance which is actually the outcome as reasoning-fromresults/afterthought of secondnatured institutionalisation poorly inclined to such requisite prospective reasoning-through/messianic-reasoning. Human akrasia-susceptibility-orakrasiatic-drag complex is rather reflected operantly and pertinently as of human 'ontologicallyflawed antiakrasiatic disposition' so-construed from existence-potency ${ }^{32} \sim$ sublimating- $^{\prime}$ nascence,-disclosed-from-prospective-epistemic-digression ontological-veracity perspective and so over our human-subpotency epistemic-or-notional projective-perspective which is rather in an ontologically-flawed <amplituding/formative-epistemicity $>$ totalising $\sim$ self-referencingsyncretising/circularity/interiorising/akrasiatic-drag ${ }^{4}$. (It should be noted here thus that going by the entire projection of this work rather towards futural Being-development/ontologicalframework-expansion-as-to-depth-of-ontologising-development-as-infrastructure-ofmeaningfulness-and-teleology as of prospective notional deprocrypticism as of the notional ${ }^{18}$ deprocrypticism framework as implied by existence-potency ${ }^{32} \sim$ sublimating- $^{-}$ 
nascence,-disclosed-from-prospective-epistemic-digression epistemic-or-notional $\sim$ projectiveperspective as a more re-originary__as-unenframed/re-ontologising/unb_ehoholdening/_outlierconceptualisation_on___imbued-postconverging/dialectical-thinking -'projectiveinsights'/'epistemic-projection-in-conflatedness ' -of-notional deprocrypticism-prospectivesublimation $>$ reformulation as of the displacement/decentering-of-the-human-subject in the relative-unreflexivity/relative-reflexivity - ontological-contiguity ${ }^{67}$ of-the-humaninstitutionalisation-process ${ }^{68}<$ amplituding/formative-epistemicity $>$ causality $\sim$ as-to-projectivetotalitative-implications-of-prospective- nonpresencing,-for-explicating relativeunreflexivity/relative-reflexivity ontological-contiguity with regards to re-ontologising prospective Being-development/ontological-framework-expansion-as-to-depth-ofontologising-development-as-infrastructure-of- meaningfulness-and-teleology , institutionaldevelopment-as-to-social-function-development and living-development-as-to-personalitydevelopment psychologismic epistemic-acutisation difficulty-<for, residualising

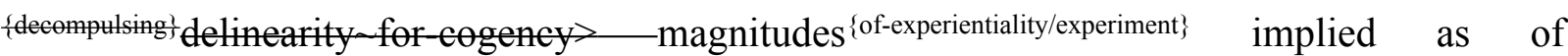
deprocrypticism-or-preempting-disjointedness-as-of- reference-of-thought this author has rather thought it pertinent herein to use the term 'akrasia' differently from the more traditionally restricted personal development implications of the Greek interpretation as of a ${ }^{103}$ universalisingidealisation self-consciousness but very much along the lines of Socratic unification of knowledge and virtue, with a deliberate adherence to the derivation 'akrasiatic' rather than the traditional derivations 'acratic' or 'akratic' to mark such a break, and further the term 'antiakrasiatic' also along the same lines is further meant to emphasise the underlying idea that akrasia is a 'notion of lack' which 'anti disposition' as of relative-ontological-completeness ${ }^{87}$ is then about superseding the lack, and such relative-ontological-incompleteness ${ }^{8}$ is superseded rather as of supererogatory $\sim$ acuity/perspicacity/astuteness/edginess/incisiveness-ofapriorising/axiomatising/referencing/intelligibilitysettingup/measuringinstrumenting -for- 
conceptualisation in reflecting holographically-<conjugatively-and-transfusively $>$ the relativeunreflexivity/relative-reflexivity - ontological-contiguity of-the-human-institutionalisationprocess $<$ amplituding/formative-epistemicity $>$ causality $\sim$ as-to-projective-totalitativeimplications-of-prospective- nonpresencing,-for-explicating relative-unreflexivity/relativereflexivity - ontological-contiguity of human limited-mentation-capacity-deepening-assubjecting-limitedness/human-subpotency-to-'educed-unlimitedness/existence-sublimating nascence' that goes well beyond a 'golden mean'/moderation/temperance, etc. behaviour interpretation as implied with 'enkrateia' which, as explained and further elaborated elsewhere herein, doesn't has an ontological-basis as it is rather an impromptu articulation of a sense of desirability but fundamentally lacks the-Good/knowledge-reification $\sim$ gesturing-andaccounting —of-epistemic-phenomenalism- $<$ inprospective_psychologismic $\sim$ apriorising/axiomatising/referencing-\{of- ${ }^{\text {}}$ prospectively implicited_attendant-ontological-contiguity ' educedexistentialising/contextualising/textualising_ 'intelligibility/epistemicity/reflexivity-contiguity<imbued-notional cogency >’ $\}$-conflatedness -in-\{preconverging-disentailment by\} postconverging-entailment $>$ /understanding/<amplituding/formativeepistemicity $>$ causality $\sim$ as-to-projective-totalitative-implications-of-prospectivenonpresencing,-for-explicating relative-unreflexivity/relative-reflexivity - ontologicalcontiguity reference of relative-unreflexivity/relative-reflexivity - ontological-contiguity ${ }^{67}$ but for naively and wrongly implying good-natured qualities as being ontological; and such 'antiakrasiatic disposition' is more critically reflected as of underlying human 'intemporal-asontologically-veridical/ontological-faith-notion-or-ontological-fideism-imbuedunderdetermination-of-motif-and-apriorising/axiomatising/referencing-as-so-being-as-ofexistential-reality parrhesiastic askesis-or-acumen reasoning-through/messianic-reasoning parrhesiastic seeding-promise of prospective ${ }^{5}$ meaningfulness-and-teleology ${ }^{9}$ as 
equivalence/correspondence antiakrasiatic-aspiration ontological-performance ${ }^{2}-<$ includingvirtue-as-ontology>' with the 'akrasiatic disposition' construed as of 'temporal/sophistic-asontologically-flawed/ontological-bad-faith/inauthenticity ${ }^{64}$ reasoning-from-results/afterthought reproducibility—mathesis/motif/thrownness-disposition,--as-reproducibility-of-aestheticisation seeding-misprising of prospective ${ }^{56}$ meaningfulness-and-teleology ${ }^{99}$ as covert-pretence-ofequivalence/correspondence-antiakrasiatic-aspiration-ontological-performance ${ }^{72}-$ includingvirtue-as-ontology $>^{\prime}$.) This existence-potency ${ }^{32} \sim$ sublimating-nascence,-disclosed-fromprospective-epistemic-digression ontological-veracity perspective reflects the fact that as of our human-subpotency, beyond-the-consciousness-awareness-teleology ${ }^{9}-<$ of-preconvergingexistential-extrication-as-of-existential-unthought $>\quad$ we-fail-to-factor-in/we-are-oblivious-to our human limited-mentation-capacity—as-subjecting-'educed-unlimitedness/existencesublimating nascence' to-limitedness/human-subpotency implications as of our ontologicallycompromised <amplituding/formative-epistemicity>-totalising $\sim$ thrownness-in-existence ${ }^{35}$, soreflected with the <cumulating/recomposuring attendant-ontological-contiguity $>$-successive registry-worldviews/dimensions reference-of-thought-level reproducibilitymathesis/motif/thrownness-disposition,-as-reproducibility-of-aestheticisation apriorising/axiomatising/referencing/intelligibilitysettingup/measuringinstrumenting $<$ amplituding/formative-epistemicity $>$ causality $\sim$ as-to-projective-totalitative-implications-ofprospective- nonpresencing,-for-explicating relative-unreflexivity/relative-reflexivity

ontological-contiguity , to then proceed in affirmation/projection/assertion/notional $\sim$ selfdistantiation/dueness-validating-logicising/suitable-measuringinstrument-validatingmeasuring-<as-to-postconverging-or-dialectical-thinking -apriorising-psychologism> as of our existential-instantiations and so defectively as if we have no limited-mentation-capacityas-subjecting 'educed-unlimitedness/existence-sublimating nascence'-to-limitedness/humansubpotency and no ontologically-uncompromised <amplituding/formative-epistemicity>- 
totalising thrownness-in-existence ${ }^{5}$; and this with respect to our articulated-or-acquiesced-to

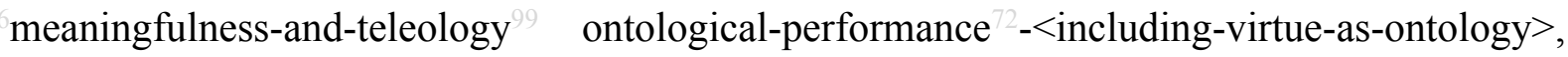
such that inherently our ontological-performance ${ }^{72}-<_{\text {including-virtue-as- }}$ ontology $>$ /morality/ethics/justice/etc. is ever always constrained as of constructive and destructuring-threshold-〈uninstitutionalised-threshold /presublimating-desublimating-

decisionality $>$ of-ontological-performance ${ }^{2}-<$ including-virtue-as-

ontology $>$ /morality/ethics/justice/etc. of ${ }^{56}$ meaningfulness-and-teleology ${ }^{9}$. The destructuringthreshold-〈uninstitutionalised-threshold /presublimating-desublimating-decisionality $\rangle$ ofontological-performance ${ }^{72}<$ including-virtue-as-ontology $>$ /morality/ethics/justice/etc. of human articulated-or-acquiesced-to $\quad{ }^{56}$ meaningfulness-and-teleology ${ }^{99}$ ontologicalperformance ${ }^{72}-<$ including-virtue-as-ontology $>$, and as preconverging/postconverging-dementatively/structurally/paradigmatically reflected at the uninstitutionalised-threshold ${ }^{102}$, speaks of a threshold at which as of our human-subpotency we fail to assume the intellectualand-moral responsibility/relative-reflexivity arising as of ontological-veridicality so-reflected as from the full sublimating-over-desublimating implications of existence-potency ${ }^{39} \sim$ sublimatingnascence,-disclosed-from-prospective-epistemic-digression ontological-veracity perspective insight of affirmation/projection/assertion/notional $\sim$ self-distantiation/dueness-validatinglogicising/suitable-measuringinstrument-validating-measuring-<as-to-postconverging-ordialectical-thinking -apriorising-psychologism>. This is the overall notion explaining human akrasia-susceptibility-or-akrasiatic-drag complex, and so as of human limited-mentationcapacity - as-subjecting-'educed-unlimitedness/existence-sublimating nascence'to-

limitedness/human-subpotency notional implications. Thereafter, understanding of this human 'ontologically-flawed antiakrasiatic disposition' is all about conceptualising the effective operant ontologically-constraining conditions as of human existential-instantiations given our limited-mentation-capacity—as-subjecting 'educed-unlimitedness/existence-sublimating - 
nascence' to-limitedness/human-subpotency implied as of temporality $8 /$ shortness and intemporality ${ }^{52} /$ longness implications, and so construed epistemically as ontologicalnormalcy/postconvergence analysis. Insightfully, we can appreciate that the absolute human ontologically-veridical antiakrasiatic disposition can only be as to existencepotency $^{39} \sim$ sublimating-nascence,-disclosed-from-prospective-epistemic-digression as-toontologically-uncompromised-ontological-normalcy/postconvergence/referentialism soreflected with futural Being-development/ontological-framework-expansion-as-to-depth-ofontologising-development-as-infrastructure-of- meaningfulness-and-teleology as of prospective notional ${ }^{18}$ deprocrypticism registry-worldview/dimension, over humansubpotency-as-of-ontologically-compromised-epistemic-abnormalcy/preconvergence ${ }^{3 !}$ soreflected variously with the preceding <cumulating/recomposuring attendant-ontologicalcontiguity $>$-successive registry-worldviews/dimensions; wherein notional ${ }^{18}$ deprocrypticism as to existence-potency ${ }^{32} \sim$ sublimating-nascence,-disclosed-from-prospective-epistemicdigression will rather speak of prospective 'ontologically-hegemonising-narrative ${ }^{1 !}$ ontologicalperformance ${ }^{72}-<$ including-virtue-as-ontology $>$, which as of its inherent constructive

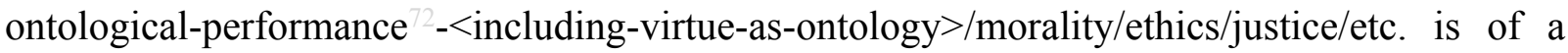
preconverging/postconverging-de-mentative/structural/paradigmatic implication that ultimately supersedes the destructuring-threshold-〈uninstitutionalised-threshold /presublimatingdesublimating-decisionality $\rangle$ of-ontological-performance ${ }^{72}-<$ including-virtue-asontology $>$ /morality/ethics/justice/etc. notionally underlying human-subpotency. Thus all the problem of human ontologically-flawed antiakrasiatic disposition boils down to construing the underlying human mental-processing disposition, construed as of notional $\sim$ phenomenalabstractiveness implications, as from human-subpotency dispositional possibilities of ontological-performance ${ }^{72}$-<including-virtue-as-ontology $>/$ morality/ethics/justice/etc. to existence-potency ${ }^{39} \sim$ sublimating-nascence,-disclosed-from-prospective-epistemic-digression 
possibility of ontological-performance ${ }^{2}-<$ including-virtue-as-ontology $>$. In this respect, we can appreciate that the $<$ cumulating/recomposuring attendant-ontological-contiguity $>$-successive registry-worldviews/dimensions ${ }^{83}$ reference-of-thought in reflecting holographically$<$ conjugatively-and-transfusively $>$ the relative-unreflexivity/relative-reflexivity - ontologicalcontiguity of-the-human-institutionalisation-process are effectively differing preconverging/postconverging-de-mentative/structural/paradigmatic antiakrasiatic dispositions-as-of-self-consciousness varying from most ontologically-flawed as of recurrentutter-uninstitutionalisation to most ontologically-veridical as futural Beingdevelopment/ontological-framework-expansion-as-to-depth-of-ontologising-development-asinfrastructure-of- meaningfulness-and-teleology as of prospective deprocrypticism. We can further appreciate that all the $<$ cumulating/recomposuring attendant-ontological-contiguity $>$ successive registry-worldviews/dimensions ${ }^{83}$ reference-of-thought are marked at their reference-of-thought- devolving-level by temporal-to-intemporal ontological-performance $<$ including-virtue-as-ontology $>/$ morality/ethics/justice/etc. speaking of differing ontologicalperformance $^{72}-<$ including-virtue-as-ontology $>$-including-virtue-as-ontology of intemporal and disambiguated temporal ontologically-flawed antiakrasiatic-disposition as of postlogism slantedness/ ignorance/affordability/opportunism/exacerbation/social-chainism-or-socialdiscomfiture-or-negative-social-aggregation/temporal-enculturation-or-temporal-endemisation reflecting $<$ amplituding/formative $>$ wooden-language-〈imbued-temporal-mereform/virtualities/dereification/akrasiatic-drag/denatured/preconverging-or-dementing narratives - of-the- reference-of-thought- categorical-imperatives/axioms/registryteleology $\rangle$. This analysis so far sums up the overall framework of human temporal-tointemporal ontologically-flawed antiakrasiatic disposition as of the social epistemic-totality ${ }^{37}$ of meaningfulness-and-teleology in reflecting holographically-<conjugatively-andtransfusively $>$ the relative-unreflexivity/relative-reflexivity ontological-contiguity $\sim$ of-the- 
human-institutionalisation-process . Further and of much more profound reification implications, is the reality that the social-construct constructive and destructuring nature can be fundamentally accounted for by the fact that human antiakrasiatic disposition aspiration is truly reflected as from the effective implications of the intemporal ontological-faith-notion-orontological-fideism - imbued-underdetermination-of-motif-and-

apriorising/axiomatising/referencing-as-so-being-as-of-existential-reality parrhesiastic askesisor-acumen reasoning-through/messianic-reasoning 'seeding promise of human-subpotency ontological-performance ${ }^{2}$-<including-virtue-as-ontology $>/$ morality/ethics/justice/etc. equivalence/correspondence with the full-potency-of-existence's $\sim$ sublimating-nascence-as-ofits-coherence/contiguity'; thus with the latter reconceptualised as 'human-subpotency equivalence/correspondence antiakrasiatic-aspiration ontological-performance ${ }^{72}<$ including- $^{2}$ virtue-as-ontology>'. This reflects the epistemic-veracity of construing human-subpotency 'equivalence/correspondence antiakrasiatic-aspiration ontological-performance ${ }^{2}-<$ includingvirtue-as-ontology>' of its articulated-or-acquiesced-to ${ }^{5}$ meaningfulness-and-teleology ${ }^{9}$ as from existence-potency ${ }^{39} \sim$ sublimating-nascence,-disclosed-from-prospective-epistemic-

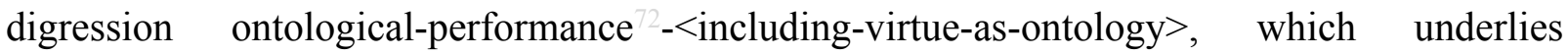
(beyond-the-consciousness-awareness-teleology ${ }^{9}-<$ of - preconverging-existential-extricationas-of-existential-unthought $>$ ) the ${ }^{103}$ universal-transparency ${ }^{104}$-〈transparency-of-totalisingentailing,-as-to-entailing-<amplituding/formative-epistemicity $>$ totalising in-relativeontological-completeness > of the social epistemic-totality ${ }^{37}$ of ${ }^{56}$ meaningfulness-andteleology ${ }^{9}$ with respect to social-stake-contention-or-confliction. With the implication here that human-subpotency is ever always as-of-its-level-of constructiveness-of-ontologicalperformance $^{72}-<$ including-virtue-as-ontology $>$ /institutionalisation/nascent-sublimatingdecisionality_by_destructuring-threshold-〈uninstitutionalised-threshold /presublimatingdesublimating-decisionality $>$ of-ontological-performance ${ }^{72}-<$ including-virtue-as- $^{-}$ 
ontology $>$ /morality/ethics/justice/etc. in a 'metaphorising vacillating-conception' of the social epistemic-totality ${ }^{37}$ of ${ }^{5}$ meaningfulness-and-teleology (as can be fully reflected from existence-potency ${ }^{39} \sim$ sublimating-nascence,-disclosed-from-prospective-epistemic-digression epistemic perspective in ontological-normalcy/postconvergence). This thus points out that human-subpotency 'equivalence/correspondence antiakrasiatic-aspiration ontologicalperformance ${ }^{72}-<$ including-virtue-as-ontology $>{ }^{\prime}$ supposedly of ${ }^{103}$ universal-transparency ${ }^{104}$ 〈transparency-of-totalising-entailing,-as-to-entailing-<amplituding/formativeepistemicity $>$ totalising in-relative-ontological-completeness $\rangle$ is mainly and rather the overtly presumed social posture of articulated-or-acquiesced-to ${ }^{5}$ meaningfulness-and-teleology ontological-performance $^{72}$-<including-virtue-as-ontology $>$; such that human-subpotency implications of human limited-mentation-capacity-as-subjecting 'educedunlimitedness/existence-sublimating nascence' to-limitedness/human-subpotency induces covert-pretence-of-equivalence/correspondence-antiakrasiatic-aspiration-ontologicalperformance $^{72}-<$ including-virtue-as-ontology $>/$ morality/ethics/justice/etc. notionally construed as destructuring-transitoriness -as-of-deratiocination/deratiocontiguity (as implying in effect a destructuring-by-flipping/changing/transitioning-induced-notional-discontiguity/epistemicdiscontiguity ${ }^{6}-<$ between - prior-shallow-supererogation -of-mentallyaestheticised preconverging/dementing -qualia-schema_and_prospective-profoundsupererogation -of-mentally-aestheticised postconverging/dialectical-thinking -qualiaschema $>$ of apriorising/axiomatising/referencing/intelligibilitysettingup/measuringinstrumenting). Thus denaturing the true 'equivalence/correspondence antiakrasiatic-aspiration ontologicalperformance ${ }^{72}-<$ including-virtue-as-ontology $>$ ' from the ontologically-veridical existencepotency ${ }^{39} \sim$ sublimating-nascence,-disclosed-from-prospective-epistemic-digression epistemicor-notional projective-perspective reflecting social-construct constructiveness-of-ontological- 
performance $^{72}-<$ including-virtue-as-ontology $>$; such that it is a difference-conflatedness ${ }^{13}$-as-tototalitative-reification-in-singularisation-<as-to-the-nondisjointedness/entailment-ofprospective- nonpresencing $>$-as-veridical-epistemicity-relativism-determinism that can restore-and-reflect-by-disambiguating/differentiating the ontological-veridicality-as-ofontological-aesthetic-tracing-<perspective-ontological-normalcy/postconvergence-reflected'epistemicity-relativism-determinism'> about the social-construct constructiveness-ofontological-performance ${ }^{72}$-<including-virtue-as-ontology $>/$ morality/ethics/justice/etc. (from this induced destructuring-transitoriness ${ }^{19}$-as-of-deratiocination/deratiocontiguity denaturing ${ }^{16}$ ). Whereas naïve identitive-constitutedness ${ }^{14}$-as-'epistemic-totality ${ }^{37}$ '-dereification-indissingularisation-<as-to-the-disjointedness/disentailment-of- presencing - absolutisingidentitive-constitutedness $>$-as-flawed-epistemicity-relativism-determinism will wrongly validate the so-induced destructuring-transitoriness ${ }^{19}$-as-of-deratiocination/deratiocontiguity (as of the destructuring-by-flipping/changing/transitioning-induced-notionaldiscontiguity/epistemic-discontiguity ${ }^{6}-<$ between - prior-shallow-supererogation -ofmentally-aestheticised preconverging/dementing -qualia-schema_and_prospective-profoundsupererogation -of-mentally-aestheticised postconverging/dialectical-thinking -qualiaschema $>$ ) as ontologically-veridical by its flawed implying of notional-contiguity/epistemic-

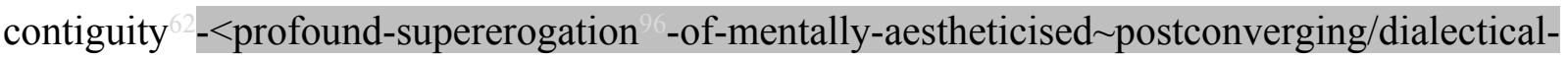
thinking -qualia-schema>; while failing-to restore-and-reflect-bydisambiguating/differentiating the ontological-veridicality-as-of-ontological-aesthetic-tracing$<$ perspective-ontological-normalcy/postconvergence-reflected-'epistemicity-relativismdeterminism'>. This destructuring-transitoriness ${ }^{19}$-as-of-deratiocination/deratiocontiguity exactly reflects the destructuring-threshold-〈uninstitutionalised-threshold /presublimatingdesublimating-decisionality $>$ of-ontological-performance ${ }^{72}$-<including-virtue-asontology $>$ /morality/ethics/justice/etc.: as the point where human-subpotency from its 
'destructuring relative-ontological-incompleteness ${ }^{8}$ ontologically-flawed perspective' is in an $<$ amplituding/formative-epistemicity $>$ totalising $\sim$ self-referencing-

syncretising/circularity/interiorising/akrasiatic-drag 34 that systematically reflects its 'destructuring-by-flipping/changing/transitioning-induced-notional-discontiguity/epistemicdiscontiguity ${ }^{63}<$ between - prior-shallow-supererogation -of-mentallyaestheticised preconverging/dementing -qualia-schema_and_prospective-profoundsupererogation -of-mentally-aestheticised postconverging/dialectical-thinking -qualiaschema> of apriorising/axiomatising/referencing/intelligibilitysettingup/measuringinstrumenting' (as soconstrued notionally/epistemically/bindingnessly-<as-to-determinism/conceptivity-of-relative-unreflexivity/relativereflexivitys from the 'prospective relative-ontological-completeness ${ }^{87}$ as to existencepotency $^{39} \sim$ sublimating-nascence,-disclosed-from-prospective-epistemic-digression constructiveness perspective'); as a nondescript/ignorable-void (that actually speaks of akrasiatic-drag-denatured-and-preconverging-or-dementing -narratives), and goes on to systematically 'contend recurrently' on the basis of its ontologically-flawed destructuring apriorising/axiomatising/referencing/intelligibilitysettingup/measuringinstrumenting. It should thus be noted here that human ${ }^{56}$ meaningfulness-and-teleology ${ }^{99}$ is <amplituding-formativeepistemicity>totalising/circumscribing/delineating (as of its given <amplituding/formativeepistemicity $>$-totalising $\sim$ thrownness-in-existence apriorising/axiomatising/referencing/intelligibilitysettingup/measuringinstrumenting). Thus meaningfulness-and-teleology ${ }^{9}$ is construed in notional $\sim$ conflatedness ${ }^{13}$ with existence-as-toexistential-instantiations (as of as to ${ }^{83}$ reference-of-thought-and- ${ }^{83}$ reference-of-thoughtdevolving apriorising/axiomatising/referencing/intelligibilitysettingup/measuringinstrumenting) and in '<amplituding/formative-epistemicity $>$ totalising/circumscribing/delineating-narrative- 
disposition' (as can then be reflected in an infinite number of propositions by that notional conflatedness ${ }^{13}$ with existence-as-to-existential-instantiations) as so-implicited with such approaches as Derridean deconstruction and Foucauldian discourse analysis; and so, as not speaking to any such notion as 'mélée_of_supposedly-singly conception-of- ${ }^{56}$ meaningfulnessand-teleology ${ }^{9}$, - reflex $\sim$ propositional-attitude rather in apriorising/axiomatising/referencing\{of-'prospectively implicited_attendant-ontological-contiguity ' ceducedexistentialising/contextualising/textualising_intelligibility/epistemicity/reflexivity_contiguity$<$ imbued-notional cogency $>>$ - $\}$ - constitutedness ${ }^{1}$-in-preconverging-entailment $\quad$ which poorly/hardly reflect $\quad$ prospective $\quad<$ amplituding/formativeepistemicity>totalising/circumscribing/delineating-narrative-disposition' (as to overarching registry-worldviews/dimensions prospective transcendence-andsublimity/sublimation/supererogatory de-mentativity). Such veridical reification of prospective meaningfulness-and-teleology ${ }^{9}$ is all about elucidating the ontological-veracity/ontologicalperformance ${ }^{2}$-<including-virtue-as-ontology $>$ /morality/ethics/justice/etc. of humansubpotency epistemic-or-notional projective-perspective (articulated within any given registryworldview/dimension social-setup going by its supposedly coherent ontological-commitment $<$ implied - self-assuredness-of-ontological-good-faith/authenticity postconverging-dementating/structuring/paradigming -as-being-as-of-existential-reality $>$ as so-reflected by its self-assuredness-of-ontological-good-faith/authenticity ${ }^{6} \sim$ postconverging-dementating/structuring/paradigming ${ }^{0}$-as-being-as-of-existential-reality with respect to its socialstake-contention-or-confliction), and rather exposing it to existence-potency ${ }^{39} \sim$ sublimatingnascence,-disclosed-from-prospective-epistemic-digression (as to epistemic-ornotional projective-perspective of $<$ mpliteling/formative-epistemicity $>$ causality $\sim$ as-toprojective-totalitative-implications-of-prospective- nonpresencing,-for-explicating relativeunreflexivity/relative-reflexivity ontological-contiguity as of prospective relative- 
ontological-completeness

totalitative-implications-of-prospective- nonpresencing,-for-explicating relative-

unreflexivity/relative-reflexivity ontological-contiguity '). Whereas the notion of 'mélée_of_supposedly-singly conception-of- ${ }^{5}$ meaningfulness-and-teleology ${ }^{\circ}$ '-

reflex $\sim$ propositional-attitude (as not in apriorising/axiomatising/referencing-\{of'prospectively implicited_attendant_ontological-contiguity ' e educed-

existentialising/contextualising/textualising_intelligibility/epistemicity/reflexivity_contiguity-

<imbued-notional cogency >' \}-conflatedness ${ }^{13}$-in-\{preconverging-disentailment-by\}postconverging-entailment with existence-as-to-existential-instantiations) fails to reflect the given <amplituding/formative-epistemicity>-totalising $\sim$ thrownness-in-existence ${ }^{35}$ devolving apriorising/axiomatising/referencing/intelligibilitysettingup/measuringinstrumenting ‘ $<$ amplituding/formative-epistemicity $>$ totalising/circumscribing/delineating-narrativedisposition' and seem to imply that propositions themselves have their attitude. Rather than the fact that the true ontological-depth lies with the underlying '<amplituding/formativeepistemicity>totalising/circumscribing/delineating-narrative-disposition' in notional conflatedness ${ }^{13}$ with existence-as-to-existential-instantiations (as to ${ }^{83}$ reference-ofthought-and- ${ }^{83}$ reference-of-thought- ${ }^{84}$ devolving

apriorising/axiomatising/referencing/intelligibilitysettingup/measuringinstrumenting) which is thus reflected in the devolving specific propositions aposteriorising/logicising/deriving/intelligising/measuring. Wherein for instance as of a totalising-entailing insight one or a few propositions in a series of propositions uttered may actually decisively imply a $\quad<$ amplituding/formativeepistemicity>totalising/circumscribing/delineating-narrative-disposition' of temporal-asontologically-flawed ${ }^{56}$ meaningfulness-and-teleology ${ }^{9}$ or intemporal-as-ontologically-veridical meaningfulness-and-teleology ${ }^{9}$, with regards to revealing the series of propositions implied 
notional phenomenal-abstractiveness: as of ontologically-flawed destructuring-transitoriness ${ }^{1}$ as-of-deratiocination/deratiocontiguity (as when projecting a destructuring-threshold〈uninstitutionalised-threshold /presublimating-desublimating-decisionality $>$ of-ontologicalperformance $^{72}-<$ including-virtue-as-ontology $>$ /morality/ethics/justice/etc. as of notionaldiscontiguity/epistemic-discontiguity ${ }^{6}-<$ between - prior-shallow-supererogation -ofmentally-aestheticised preconverging/dementing -qualia-schema_and prospective-profoundsupererogation -of-mentally-aestheticised postconverging/dialectical-thinking -qualiaschema> of " $\quad$ reference-of-thought- ${ }^{8}$ devolving-level apriorising/axiomatising/referencing/intelligibilitysettingup/measuringinstrumenting' reflecting a nondescript/ignorable-void , actually speaking of akrasiatic-drag-denatured-andpreconverging-or-dementing -narratives) on-the-one-hand or on-the-other-hand as of ontologically-veridical $<$ amplituding/formativeepistemicity $>$ totalising $\sim$ ratiocontiguity/ratiocination-as-referentialism—'implicited_attendant ontological-contiguity ${ }^{67}$, educedexistentialising/contextualising/textualising_'intelligibility/epistemicity/reflexivity-contiguity<imbued-notional cogency $>^{\prime} \quad$ (in notional-contiguity/epistemic-contiguity ${ }^{62}-<$ profound- $^{2}$ supererogation -of-mentally-aestheticised postconverging/dialectical-thinking -qualiaschema> of ' $\quad$ reference-of-thought- ${ }^{8}$ devolving-level apriorising/axiomatising/referencing/intelligibilitysettingup/measuringinstrumenting'). Thus with their correspondingly differing '<amplituding/formativeepistemicity $>$ totalising/circumscribing/delineating preconverging/dementing ${ }^{20}$-qualia-schema' and ‘ $<$ amplitung/formative-epistemicity $>$ totalising/circumscribing/delineating postconverging/dialectical-thinking -qualia-schema'. Further the notion of 'mélée_of_supposedly-singly conception-of- ${ }^{5}$ meaningfulness-and-teleology ${ }^{9}$ ' reflex $\sim$ propositional-attitude fails to reflect the fact of varying registry-worldviews/dimensions 
(as of relative-ontological-incompleteness 8 /relative-ontological-completeness

\section{〈sublimating referencing/registering/decisioning,-as-self-becoming/self-}

conflatedness /formative-supererogating-<projective/reprojective-aestheticising-re-motifand-re-apriorising/re-axiomatising/re-referencing,-in-perspective-ontologicalnormalcy/postconvergence $>>$ with their varying <amplituding/formative-epistemicity $>$ totalising thrownness-in-existence reference-of-thought-level apriorising/axiomatising/referencing/intelligibilitysettingup/measuringinstrumenting '<amplituding/formative-epistemicity $>$ totalising/circumscribing/delineating-narrativedispositions'); as so-translating in the differing nature of propositions veridically admissible by differing registry-worldviews/dimensions ${ }^{83}$ reference-of-thought (as implied in the contrastive example herein between a positivism and a non-positivism registry-worldview/dimension with their differing '<amplituding/formative-epistemicity $>$ totalising/circumscribing/delineating postconverging/dialectical-thinking ${ }^{2}$-qualia-schema' and '<amplituding/formativeepistemicity>totalising/circumscribing/delineating preconverging/dementing ${ }^{20}$-qualiaschema'). Consider the case of the destructuring-threshold-〈uninstitutionalisedthreshold /presublimating-desublimating-decisionality $>$ of-ontological-performance ${ }^{72}$ -

<including-virtue-as-ontology>/morality/ethics/justice/etc. with a 'God-of-plane' proposition in say an animistic social-setup reflecting the underlying 'animistic superstitious $<$ amplituding/formative-epistemicity>totalising/circumscribing/delineating-narrativedisposition' (since it is fundamentally an ontologically-flawed destructuring nonpositivism/superstitious

apriorising/axiomatising/referencing/intelligibilitysettingup/measuringinstrumenting eliciting this misconstrued proposition of non-positivism/superstitious aposteriorising/logicising/deriving/intelligising/measuring as 'God-of-plane'), a further proposition as of positivism aposteriorising/logicising/deriving/intelligising/measuring like 
'wings generate lift' will just as well elicit a further proposition of non-positivism/superstitious aposteriorising/logicising/deriving/intelligising/measuring 'along the lines of a superstitious effect from the wings'. With the positivism relative-ontological-completeness 87 perspective rather reflecting the non-positivism/superstitious relative-ontological-incompleteness perspective as of a '<amplituding/formative-epistemicity>totalising/circumscribing/delineating preconverging/dementing -qualia-schema' (while the latter non-positivism/superstitious perspective wrongly holds on to an ontologically-flawed '<amplituding/formativeepistemicity>totalising/circumscribing/delineating postconverging/dialectical-thinking qualia-schema'). This is the fundamental conception underlying the notion of de-mentation〈supererogatory ontological-de-mentation-or-dialectical-de-mentation-stranding-orattributive-dialectics $>\quad$ as implying an underlying apriorising/axiomatising/referencing/intelligibilitysettingup/measuringinstrumenting preconverging/postconverging-de-mentative/structural/paradigmatic misconstruing for aposteriorising/logicising/deriving/intelligising/measuring ${ }^{56}$ meaningfulness-and-teleology ${ }^{9}$, thus disambiguating/differentiating prospective relative-ontological-completeness 87 as of ‘<amplituding/formative-epistemicity $>$ totalising/circumscribing/delineating postconverging/dialectical-thinking -qualia-schema' and the prior relative-ontologicalincompleteness 88 of $\quad$ of $<$ amplituding/formativeepistemicity $>$ totalising/circumscribing/delineating preconverging/dementing ${ }^{20}$-qualia-schema'. This is equally what very much underlies from a prospective relative-ontological-completeness

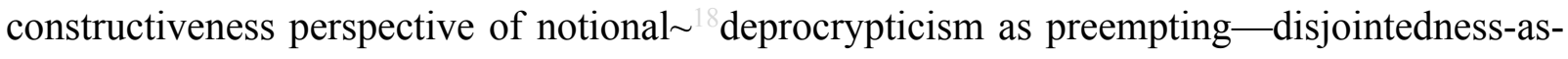
of- ${ }^{-}$reference-of-thought the social manifestation of a phenomenon like psychopathy and social psychopathy reflecting our prior relative-ontological-incompleteness ${ }^{88}$ positivismprocrypticism destructuring-threshold-〈uninstitutionalised-threshold /presublimatingdesublimating-decisionality $>$ of-ontological-performance ${ }^{72}-<$ including-virtue-as- 
ontology $>$ /morality/ethics/justice/etc. as of its disjointedness-as-of- ${ }^{3}$ reference-of-thought, wherein the fundamentally induced destructuring-by-flipping/changing/transitioning-inducednotional-discontiguity/epistemic-discontiguity ${ }^{63}<$ between - prior-shallow-supererogation -ofmentally-aestheticised preconverging/dementing -qualia-schema_and_prospective-profoundsupererogation -of-mentally-aestheticised postconverging/dialectical-thinking -qualia-

apriorising/axiomatising/referencing/intelligibilitysettingup/measuringinstrumenting is thevery-same destructuring apriorising/axiomatising/referencing/intelligibilitysettingup/measuringinstrumenting of instigating disjointedness-as-of- ${ }^{8}$ reference-of-thought that prolongs as of $<$ amplituding/formative-epistemicity $>$ totalising $\sim$ self-referencingsyncretising/circularity/interiorising/akrasiatic-drag ${ }^{34}$ into its lingering social manifestation (just as the non-positivism/superstitious apriorising/axiomatising/referencing/intelligibilitysettingup/measuringinstrumenting for aposteriorising/logicising/deriving/intelligising/measuring enters a lingering social manifestation in striving to interpret positivism ${ }^{56}$ meaningfulness-and-teleology ${ }^{9}$ as reflected about a plane on the basis of its non-positivism/superstitious propositions as it narrative disposition, and reflected by its '<amplituding/formativeepistemicity>totalising/circumscribing/delineating preconverging/dementing 2 -qualiaschema'); with futural Being-development/ontological-framework-expansion-as-to-depth-ofontologising-development-as-infrastructure-of- meaningfulness-and-teleology as of prospective ${ }^{18}$ deprocrypticism-or-preempting-disjointedness-as-of- ${ }^{3}$ reference-of-thought prospectively constructiveness perspective rather reflecting it veridically as of ‘ $<$ amplituding/formative-epistemicity $>$ totalising/circumscribing/delineating preconverging/dementing 2 -qualia-schema' while our positivism- ${ }^{80}$ procrypticism prospectively 
destructuring perspective rather reflecting wrongly as of '<amplituding/formativeepistemicity $>$ totalising/circumscribing/delineating $\quad$ postconverging/dialectical-thinking qualia-schema'. This insight can further be extended to explain the lingering pervasiveness of notions-and-accusation-of-sorcery in non-positivistic social-setups. In all these cases as explained further below as of the '<amplituding/formativeepistemicity $>$ totalising $\sim$ ratiocontiguity/ratiocination-as-referentialism—'implicited_attendant ontological-contiguity ${ }^{67}$,educedexistentialising/contextualising/textualising_'intelligibility/epistemicity/reflexivity-contiguity$<$ imbued-notional cogency $>$ ' constructiveness disposition in singularisation-<as-to-thenondisjointedness/entailment-of-prospective- nonpresencing $>$ projected epistemicimmanence/veridical-epistemicity-relativism-determinism’ of notional $\sim$ phenomenalabstractiveness given its persistently pervasive reshuffling thoughtfulness as from human anxiety, the underlying apriorising/axiomatising/referencing/intelligibilitysettingup/measuringinstrumenting reproducibility—mathesis/motif/thrownness-disposition,--as-reproducibility-of-aestheticisation ontological-performance ${ }^{72}-<$ including-virtue-as-ontology $>/$ morality/ethics/justice/etc. of any given registry-worldview/dimension as of its 'equivalence/correspondence antiakrasiaticaspiration ontological-performance ${ }^{72}-<$ including-virtue-as-ontology $>^{\prime}$ is limited due to human limited-mentation-capacity—as-subjecting 'educed-unlimitedness/existence-sublimating nascence' to-limitedness/human-subpotency with regards to the intemporal ontological-faithnotion-or-ontological-fideism - imbued-underdetermination-of-motif-andapriorising/axiomatising/referencing-as-so-being-as-of-existential-reality parrhesiastic askesisor-acumen reasoning-through/messianic-reasoning that establishes prospective reproducibility—mathesis/motif/thrownness-disposition,--as-reproducibility-of-aestheticisation of apriorising/axiomatising/referencing/intelligibilitysettingup/measuringinstrumenting for 
aposteriorising/logicising/deriving/intelligising/measuring ontologically-veridical meaningfulness-and-teleology ${ }^{9}$, such that this reproducibility-mathesis/motif/thrownnessdisposition,-as-reproducibility-of-aestheticisation of apriorising/axiomatising/referencing/intelligibilitysettingup/measuringinstrumenting thus necessarily has a preconverging/postconverging-de-mentative/structural/paradigmatic prospective destructuring-threshold-〈uninstitutionalised-threshold /presublimatingdesublimating-decisionality $>$ of-ontological-performance ${ }^{72}-<$ including-virtue-as- $^{-}$ ontology $>$ /morality/ethics/justice/etc. that is susceptible to its very own ontologically-flawed manifestation of its <amplituding/formative> wooden-language-_imbued-temporal-mereform/virtualities/dereification/akrasiatic-drag/denatured/preconverging-or-dementing narratives - of-the- reference-of-thought- categorical-imperatives/axioms/registry$\begin{array}{llll}\text { teleology }>\text { so-implied } & \text { as } & \text { of } & \text { postlogism }\end{array}$ slantedness/ ignorance/affordability/opportunism/exacerbation/social-chainism-or-socialdiscomfiture-or-negative-social-aggregation/temporal-enculturation-or-temporal-endemisation instigated as of '<amplituding/formative-epistemicity $>$ totalising $\sim$ random-as-impulsive'implicited_attendant-ontological-contiguity ${ }^{67}$ > educedexistentialising/contextmalising/textualising_intelligibility/epistemicity/reflexivity_contiguity<imbued-notional cogency>> destructuring-disposition-flipping/changing/transitioninginduced-notional-discontiguity/epistemic-discontiguity $33<$ between - prior-shallowsupererogation -of-mentally-aestheticised preconverging/dementing -qualiaschema_and_prospective-profound-supererogation -of-mentallyaestheticised postconverging/dialectical-thinking - qualia-schema $>$ in dissingularisation- $<$ asto-the-disjointedness/disentailment-of- presencing - absolutising-identitiveconstitutedness > /epistemic-nonimmanence/flawed-epistemicity-relativism-determinism', totalising nominal-as-tendentious_ — 'implicited_attendant—ontological-contiguity ${ }^{67}$ ' educed- 
existentialising/contextualising/textualising_intelligibility/epistemicity/reflexivity-contiguity$<$ imbued-notional cogency>' ‘<amplituding/formative-epistemicity $>$ destructuringdisposition_-flipping/changing/transitioning-induced-notional-discontiguity/epistemicdiscontiguity ${ }^{6}-<$ between - prior-shallow-supererogation -of-mentallyaestheticised preconverging/dementing -qualia-schema_and_prospective-profoundsupererogation -of-mentally-aestheticised postconverging/dialectical-thinking -qualiaschema $>$ in dissingularisation- $<$ as-to-the-disjointedness/disentailment-of- presencing absolutising-identitive-constitutedness $>$ /epistemic-nonimmanence/flawed-epistemicityrelativism-determinism', ‘<amplituding/formative-epistemicity>totalising $\sim$ ordinal-asqualifying — 'implicited_attendant-ontological-contiguity ${ }^{67}$ ' educedexistentialising/contextualising/textualising_intelligibility/epistemicity/reflexivity-contiguity<imbued-notional cogency>' destructuring-disposition-flipping/changing/transitioninginduced-notional-discontiguity/epistemic-discontiguity ${ }^{6}<$ between - prior-shallowsupererogation -of-mentally-aestheticised preconverging/dementing -qualiaschema_and_prospective-profound-supererogation -of-mentallyaestheticised postconverging/dialectical-thinking - qualia-schema $>$ in dissingularisation- $<$ asto-the-disjointedness/disentailment-of- presencing - absolutising-identitiveconstitutedness > /epistemic-nonimmanence/flawed-epistemicity-relativism-determinism', and ‘<amplituding/formative-epistemicity $>$ totalising $\sim$ intervalist-as-categorising'implicited_attendant-ontological-contiguity ${ }^{67}$ educedexistentialising/contextualising/textualising_ 'intelligibility/epistemicity/reflexivity-contiguity$<$ imbued-notional cogency>> destructuring-disposition-flipping/changing/transitioninginduced-notional-discontiguity/epistemic-discontiguity ${ }^{63}<$ between - prior-shallowsupererogation -of-mentally-aestheticised preconverging/dementing -qualiaschema_and_prospective-profound-supererogation -of-mentally- 
aestheticised postconverging/dialectical-thinking -qualia-schema $>$ in dissingularisation- $<$ asto-the-disjointedness/disentailment-of- presencing - absolutising-identitive-

constitutedness > /epistemic-nonimmanence/flawed-epistemicity-relativism-determinism' on any such given registry-worldview's/dimension's reproducibility—mathesis/motif/thrownnessdisposition,-as-reproducibility-of-aestheticisation of apriorising/axiomatising/referencing/intelligibilitysettingup/measuringinstrumenting; thus requiring the further ‘ amplituding/formativeepistemicity $>$ totalising $\sim$ ratiocontiguity/ratiocination-as-referentialism—'implicited_attendantontological-contiguity ${ }^{67}$; educedexistentialising/contextualising/textualising_'intelligibility/epistemicity/reflexivity-contiguity$<$ imbued-notional cogency $>^{\prime}$ constructiveness disposition in singularisation-<as-to-thenondisjointedness/entailment-of-prospective- nonpresencing $>\quad$ projected epistemicimmanence/veridical-epistemicity-relativism-determinism’ notional $\sim$ phenomenalabstractiveness as of intemporal ontological-faith-notion-or-ontological-fideism -imbuedunderdetermination-of-motif-and-apriorising/axiomatising/referencing-as-so-being-as-ofexistential-reality parrhesiastic askesis-or-acumen reasoning-through/messianic-reasoning that establishes prospective reproducibility-mathesis/motif/thrownness-disposition,-asreproducibility-of-aestheticisation of apriorising/axiomatising/referencing/intelligibilitysettingup/measuringinstrumenting to further match-and-restore existence-potency ${ }^{39} \sim$ sublimating-nascence,-disclosed-from-prospectiveepistemic-digression epistemic-or-notional projective-perspective of ontological-veridicality as of prospective relative-ontological-completeness ${ }^{87}$-of- ${ }^{8}$ reference-of-thought in order to overcome the preceding destructuring-threshold-〈uninstitutionalisedthreshold /presublimating-desublimating-decisionality $>$ of-ontological-performance ${ }^{72}$ <including-virtue-as-ontology>, and so-implied in this work as futural Being- 
development/ontological-framework-expansion-as-to-depth-of-ontologising-development-asinfrastructure-of- meaningfulness-and-teleology reproducibility — mathesis/motif/thrownness-disposition,-as-reproducibility-of-aestheticisation of apriorising/axiomatising/referencing/intelligibilitysettingup/measuringinstrumenting

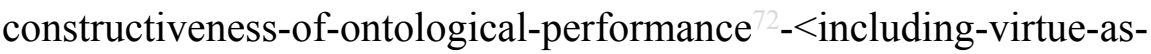
ontology $>$ /morality/ethics/justice/etc. reflected as of $<$ amplituding/formativeepistemicity>totalising/circumscribing/delineating postconverging/dialectical-thinking qualia-schema' with respect to our positivism- ${ }^{80}$ procrypticism disjointedness-as-of- ${ }^{8}$ referenceof-thought prior reproducibility - mathesis/motif/thrownness-disposition,-as-reproducibilityof-aestheticisation

apriorising/axiomatising/referencing/intelligibilitysettingup/measuringinstrumenting of destructuring-threshold-〈uninstitutionalised-threshold /presublimating-desublimatingdecisionality $>\sim$ of-ontological-performance ${ }^{72}$ - $<$ including-virtue-asontology $>$ /morality/ethics/justice/etc. reflected as of '<amplituding/formativeepistemicity $>$ totalising/circumscribing/delineating preconverging/dementing ${ }^{20}$-qualia-schema'. The bigger point here is that, the social as purportedly driven by its constructiveness-ofontological-performance ${ }^{72}$-<including-virtue-as-ontology $>/$ morality/ethics/justice/etc. is rather supposedly all about overtly implicited 'equivalence/correspondence antiakrasiatic-aspiration ontological-performance ${ }^{72}$-<including-virtue-as-ontology $>$ ' of articulated-or-acquiesced-to meaningfulness-and-teleology ontological-performance ${ }^{2}-<$ including-virtue-asontology $>$ /morality/ethics/justice/etc. with regards to the ${ }^{103}$ universal-transparency ${ }^{104}$ 〈transparency-of-totalising-entailing,-as-to-entailing-<amplituding/formativeepistemicity $>$ totalising in-relative-ontological-completeness $>$ of social epistemic-totality ${ }^{37}$ of meaningfulness-and-teleology . However, human limited-mentation-capacity-as- 
subjecting 'educed-unlimitedness/existence-sublimating nascence' to-limitedness/humansubpotency renders such overtly implicited 'equivalence/correspondence antiakrasiaticaspiration ontological-performance ${ }^{72}-<$ including-virtue-as-ontology $>^{\prime}$ unachievable such that this elicits covert-pretence-of-equivalence/correspondence-antiakrasiatic-aspirationontological-performance $^{72}$-<including-virtue-as-ontology $>/$ morality/ethics/justice/etc. as to destructuring-transitoriness -as-of-deratiocination/deratiocontiguity that reflects the socialconstruct prospective destructuring as construed from existence-potency ${ }^{32} \sim$ sublimatingnascence,-disclosed-from-prospective-epistemic-digression epistemic perspective as of ontological-veracity. Such covert-pretence-of-equivalence/correspondence-antiakrasiaticaspiration-ontological-performance ${ }^{72}-<$ including-virtue-as-

ontology $>$ /morality/ethics/justice/etc. as to destructuring-transitoriness 19 -as-ofderatiocination/deratiocontiguity destructuring consequence arises-and-is-reflected more fully and operantly as of human-subpotency destructuring-dispositionflipping/changing/transitioning-induced-notional-discontiguity/epistemic-discontiguity ${ }^{3}$ $<$ between-prior-shallow-supererogation -of-mentallyaestheticised preconverging/dementing -qualia-schema_and_prospective-profoundsupererogation -of-mentally-aestheticised postconverging/dialectical-thinking -qualiaschema $>$ in dissingularisation-<as-to-the-disjointedness/disentailment-of- presencingabsolutising-identitive-constitutedness > /epistemic-nonimmanence/flawed-epistemicityrelativism-determinism of the 'possibilities-of-human-phenomenal-abstractiveness with respect to their apriorising/axiomatising/referencing/intelligibilitysettingup/measuringinstrumenting for ontological-performance $^{72}$-<including-virtue-as-ontology>', as deviating-from/being-wronglyimputed-as-of existence-potency ${ }^{39} \sim$ sublimating-nascence,-disclosed-from-prospective-

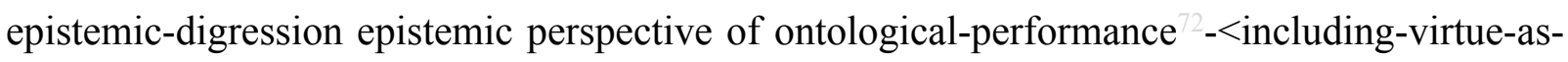
ontology $>$ /morality/ethics/justice/etc. construed as 'equivalence/correspondence antiakrasiatic- 


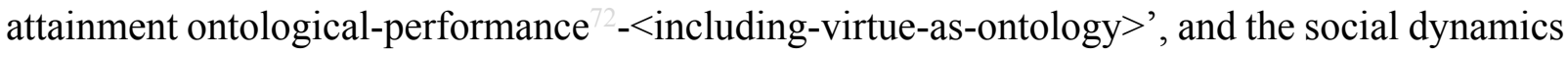
developing thereof as of social-stake-contention-or-confliction. Thus human-subpotency destructuring-disposition — flipping/changing/transitioning-induced-notionaldiscontiguity/epistemic-discontiguity ${ }^{63}-<$ between - prior-shallow-supererogation -ofmentally-aestheticised preconverging/dementing -qualia-schema_and_prospective-profoundsupererogation -of-mentally-aestheticised postconverging/dialectical-thinking -qualiaschema $>$ in dissingularisation- $<$ as-to-the-disjointedness/disentailment-of- presencingabsolutising-identitive-constitutedness > /epistemic-nonimmanence/flawed-epistemicityrelativism-determinism of the 'possibilities-of-human-phenomenal-abstractiveness with respect to their apriorising/axiomatising/referencing/intelligibilitysettingup/measuringinstrumenting for ontological-performance $^{72}$-<including-virtue-as-ontology>', so-conceptualised from the

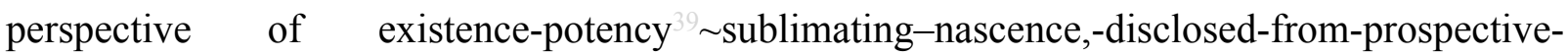
epistemic-digression as the latter reflects 'equivalence/correspondence antiakrasiatic-attainment ontological-performance ${ }^{72}-<$ including-virtue-as-ontology>', vary as of human-subpotency '<amplituding/formative-epistemicity $>$ totalising $\sim$ random-as-impulsive'implicited_attendant-ontological-contiguity ${ }^{67}$ educed-

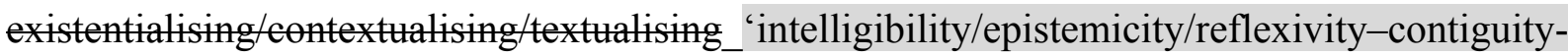
$<$ imbued-notional cogency $>$ ' destructuring-disposition-flipping/changing/transitioninginduced-notional-discontiguity/epistemic-discontiguity ${ }^{63}<$ between - prior-shallowsupererogation -of-mentally-aestheticised $\sim$ preconverging/dementing -qualiaschema_and_prospective-profound-supererogation -of-mentallyaestheticised postconverging/dialectical-thinking -qualia-schema $>$ in dissingularisation- $<$ asto-the-disjointedness/disentailment-of- presencing - absolutising-identitiveconstitutedness > /epistemic-nonimmanence/flawed-epistemicity-relativism-determinism', totalising nominal-as-tendentious_ — 'implicited_attendant—ontological-contiguity ${ }^{67}$ ' educed- 
existentialising/contextualising/textualising_intelligibility/epistemicity/reflexivity-contiguity$<$ imbued-notional cogency>' ‘<amplituding/formative-epistemicity $>$ destructuringdisposition_-flipping/changing/transitioning-induced-notional-discontiguity/epistemicdiscontiguity ${ }^{6}-<$ between - prior-shallow-supererogation -of-mentallyaestheticised preconverging/dementing -qualia-schema_and_prospective-profoundsupererogation -of-mentally-aestheticised postconverging/dialectical-thinking -qualiaschema $>$ in dissingularisation- $<$ as-to-the-disjointedness/disentailment-of- presencing absolutising-identitive-constitutedness $>$ /epistemic-nonimmanence/flawed-epistemicityrelativism-determinism', ‘<amplituding/formative-epistemicity>totalising $\sim$ ordinal-asqualifying — 'implicited_attendant-ontological-contiguity ${ }^{67}$ ' educedexistentialising/contextualising/textualising_intelligibility/epistemicity/reflexivity-contiguity<imbued-notional cogency>' destructuring-disposition-flipping/changing/transitioninginduced-notional-discontiguity/epistemic-discontiguity $33<$ between - prior-shallowsupererogation -of-mentally-aestheticised preconverging/dementing -qualiaschema_and_prospective-profound-supererogation -of-mentallyaestheticised postconverging/dialectical-thinking - qualia-schema $>$ in dissingularisation- $<$ asto-the-disjointedness/disentailment-of- presencing - absolutising-identitiveconstitutedness > /epistemic-nonimmanence/flawed-epistemicity-relativism-determinism', ‘ $<$ amplituding/formative-epistemicity $>$ totalising $\sim$ intervalist-as-categorising'implicited_attendant-ontological-contiguity ${ }^{67}$ educedexistentialising/contextualising/textualising_ 'intelligibility/epistemicity/reflexivity-contiguity$<$ imbued-notional cogency>> destructuring-disposition-flipping/changing/transitioninginduced-notional-discontiguity/epistemic-discontiguity ${ }^{63}<$ between - prior-shallowsupererogation -of-mentally-aestheticised preconverging/dementing -qualiaschema_and_prospective-profound-supererogation -of-mentally- 
aestheticised $\sim$ postconverging/dialectical-thinking -qualia-schema $>$ in dissingularisation- $<$ asto-the-disjointedness/disentailment-of- presencing - absolutising-identitiveconstitutedness > /epistemic-nonimmanence/flawed-epistemicity-relativism-determinism' and '<amplituding/formative-epistemicity $>$ totalising $\sim$ ratiocontiguity/ratiocination-asreferentialism - 'implicited_attendant-ontological-contiguity ${ }^{67}$ > educedexistentialising/contextualising/textualising_intelligibility/epistemicity/reflexivity-contiguity$<_{\text {imbued-notional } \sim \operatorname{cogency}>^{\prime}}$ constructiveness disposition in singularisation- $<$ as-to-thenondisjointedness/entailment-of-prospective- nonpresencing $>$ projected epistemicimmanence/veridical-epistemicity-relativism-determinism', with the latter construed rather as of constructive difference-conflatedness ${ }^{13}$-as-to-totalitative-reification-in-singularisation- $<$ as-tothe-nondisjointedness/entailment-of-prospective- nonpresencing $>$-as-veridical-epistemicityrelativism-determinism with respect to its constructive disambiguating of the covert-pretenceof-equivalence/correspondence-antiakrasiatic-aspiration-ontological-performance ${ }^{72}$ $<$ including-virtue-as-ontology $>/$ morality/ethics/justice/etc. as to destructuring-transitoriness 1 as-of-deratiocination/deratiocontiguity as it disambiguates/differentiates the destructuring-byflipping/changing/transitioning-induced-notional-discontiguity/epistemic-discontiguity ${ }^{63}$

\section{$<$ between - prior-shallow-supererogation -of-mentally-}

aestheticised preconverging/dementing -qualia-schema_and_prospective-profound-

supererogation -of-mentally-aestheticised postconverging/dialectical-thinking -qualia-

schema>

apriorising/axiomatising/referencing/intelligibilitysettingup/measuringinstrumenting denaturing and achieves existence-potency ${ }^{32} \sim$ sublimating-nascence,-disclosed-fromprospective-epistemic-digression epistemic perspective dispositional possibility of ontologicalperformance ${ }^{72}-<$ including-virtue-as-ontology $>$ /morality/ethics/justice/etc. in reflecting the ontologically-veridical 'equivalence/correspondence antiakrasiatic-attainment ontological- 
performance ${ }^{2}-<$ including-virtue-as-ontology $>$ ' exactly because it is the 'human ratioconguity/ratiocination phenomenal-abstractiveness as of developed-intellection-of-exactnesscapacity-ontological-performance ${ }^{72}<_{\text {including-virtue-as-ontology }>/ \text { morality/ethics/justice/etc. }}$ implication thus non-susceptible to destructuring', unlike all the other notional $\sim$ phenomenalabstractiveness that instigate their respectively ontologically-flawed destructuring-dispositionflipping/changing/transitioning-induced-notional-discontiguity/epistemic-discontiguity ${ }^{3}$ $<$ between - prior-shallow-supererogation -of-mentallyaestheticised preconverging/dementing -qualia-schema_and_prospective-profoundsupererogation -of-mentally-aestheticised postconverging/dialectical-thinking -qualiaschema $>$ in dissingularisation-<as-to-the-disjointedness/disentailment-of- presencing absolutising-identitive-constitutedness $>$ /epistemic-nonimmanence/flawed-epistemicityrelativism-determinism of apriorising/axiomatising/referencing/intelligibilitysettingup/measuringinstrumenting by aligning with the destructuring in identitive-constitutedness ${ }^{14}$-as-'epistemic-totality ${ }^{37}$ 'dereification-in-dissingularisation- $<$ as-to-the-disjointedness/disentailment-of- presencing absolutising-identitive-constitutedness $>$-as-flawed-epistemicity-relativism-determinism with regards to the covert-pretence-of-equivalence/correspondence-antiakrasiatic-aspirationontological-performance ${ }^{72}-<$ including-virtue-as-ontology $>/$ morality/ethics/justice/etc. as to destructuring-transitoriness -as-of-deratiocination/deratiocontiguity rather than disambiguating/differentiating it to restore ontological-veridicality as to existencepotency ${ }^{39} \sim$ sublimating-nascence,-disclosed-from-prospective-epistemic-digression, and so beyond-the-consciousness-awareness-teleology ${ }^{9}-<$ of-preconverging-existential-extrication-asof-existential-unthought $>$. Phenomenal-abstractiveness as of human-subpotency notional mental-processing for equivalence/correspondence with existence-potency ${ }^{32} \sim$ sublimating- $^{-}$ nascence,-disclosed-from-prospective-epistemic-digression effectively reflected herein as of the 
varied depth as from <amplituding/formative-epistemicity $>$ totalising $\sim$ random-as-impulsive'implicited_attendant-ontological-contiguity ${ }^{67}$ educed-

existentialising/contextualising/textualising_'intelligibility/epistemicity/reflexivity-contiguity$<$ imbued-notional cogency $>{ }^{\prime}, \quad<$ amplituding/formative-epistemicity $>$ totalising nominal-astendentious_-'implicited_attendant—ontological-contiguity ${ }^{67}$ ' educedexistentialising/contextualising/textualising_intelligibility/epistemicity/reflexivity-contiguity<imbued-notional cogency >’, $\quad<$ amplituding/formative-epistemicity $>$ totalising $\sim$ ordinal-asqualifying_-implicited_attendant-ontological-contiguity ${ }^{6 /}$ ? educedexistentialising/contextualising/textualising_'intelligibility/epistemicity/reflexivity-contiguity$<$ imbued-notional cogency $>$ ',$\quad$ interval-as-categorising and $<$ amplituding/formativeepistemicity $>$ totalising $\sim$ ratiocontiguity/ratiocination-as-referentialism—'implicited_attendant ontological-contiguity ${ }^{67}$, educedexistentialising/contextualising/textualising_'intelligibility/epistemicity/reflexivity-contiguity$<$ imbued-notional cogency $>^{\prime}$; $\quad$ with $\quad$ <mplituding/formativeepistemicity $>$ totalising ratiocontiguity/ratiocination-as-referentialism—'implicited_attendant ontological-contiguity ${ }^{67}$, educed-

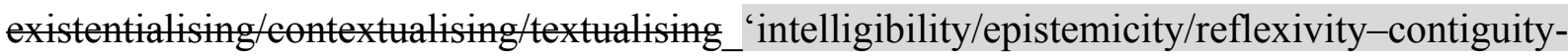
$<$ imbued-notional cogency $>^{\prime} \quad$ phenomenal-abstractiveness allowing notionally/epistemically/bindingnessly-<as-to-determinism/conceptivity-of-relative-unreflexivity/relative-reflexivity> the possibility for human fulfilment of 'ontologically-hegemonising-narrative' ontologicalperformance $^{72}-<$ including-virtue-as-ontology $>$ ' which is what underlies the framework of

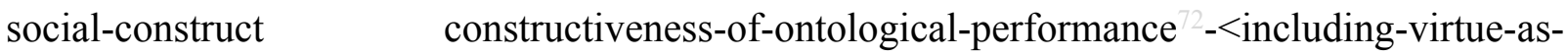
ontology $>$ /institutionalisation and superseding its destructuring-threshold-〈uninstitutionalisedthreshold /presublimating-desublimating-decisionality $>$ of-ontological-performance ${ }^{72}$ $<$ including-virtue-as-ontology $>$, thus reflected as of 'equivalence/correspondence antiakrasiatic- 
attainment ontological-performance ${ }^{72}-<$ including-virtue-as-ontology $>^{\prime}$. Inherently, this most profound $<$ amplituding/formative-epistemicity $>$ totalising $\sim$ ratiocontiguity/ratiocination-asreferentialism - 'implicited_attendant-ontological-contiguity ${ }^{67}$ > educedexistentialising/contextualising/textualising_intelligibility/epistemicity/reflexivity-contiguity$<$ imbued-notional cogency >' human notional phenomenal-abstractiveness is what exactly enables human-subpotency to be able to supersede destructuring-threshold-〈uninstitutionalisedthreshold /presublimating-desublimating-decisionality $>$ of-ontological-performance ${ }^{72}$ $<$ including-virtue-as-ontology $>$ /morality/ethics/justice/etc. by the underlying specific existential-as-ontological disambiguating/differentiating disposition. We can thus contemplate of $\quad<$ amplituding/formative-epistemicity $>$ totalising $\sim$ ratiocontiguity/ratiocination-asreferentialism — 'implicited_attendant_ontological-contiguity ${ }^{67}$ educedexistentialising/contextualising/textualising_intelligibility/epistemicity/reflexivity-contiguity<imbued-notional cogency>' phenomenal-abstractiveness as the human mental-processing capacity that is inclined to ever always expand the frontiers of human knowledge as 'ontologically-hegemonising-narrative $\quad$ ontological-performance ${ }^{72}-<$ including-virtue-asontology >', and so as of the very 'recurrent edging towards completion of ontologicalperformance ${ }^{72}-<$ including-virtue-as-ontology $>$ /morality/ethics/justice/etc. of intemporal ontological-faith-notion-or-ontological-fideism - imbued-underdetermination-of-motif-andapriorising/axiomatising/referencing-as-so-being-as-of-existential-reality parrhesiastic askesisor-acumen reasoning-through/messianic-reasoning recurrent shot for completeness, as of successive reproducibility-mathesis/motif/thrownness-disposition,-as-reproducibility-ofaestheticisation implied ${ }^{83}$ reference-of-thought and ${ }^{83}$ reference-of-thought-devolvingteleological-de-mentating/structuring/paradigming-of-meaningfulness'. Such that the very abstract idea of any 'existential contemplative insurmountability' arising as of human $<$ amplituding/formative-epistemicity $>$-totalising $\sim$ thrownness-in-existence ${ }^{35}$ is-not-acquiesced- 
to/is-rejected naturally by the human mental-processing disposition of <amplituding/formativeepistemicity $>$ totalising $\sim$ ratiocontiguity/ratiocination-as-referentialism_-implicited_attendant ontological-contiguity ${ }^{67}$, educedexistentialising/contextualising/textualising_intelligibility/epistemicity/reflexivity-contiguity$<$ imbued-notional cogency $>$ phenomenal-abstractiveness as of human anxiety and as soreflected by its persistently pervasive reshuffling thoughtfulness. The point here is that the most tasking of human mental-processing is as of <amplituding/formativeepistemicity $>$ totalising $\sim$ ratiocontiguity/ratiocination-as-referentialism—'implicited_attendant ontological-contiguity $^{67}$, educedexistentialising/contextualising/textmalising_intelligibility/epistemicity/reflexivity-contiguity<imbued-notional cogency>' phenomenal-abstractiveness as of its constructive reconstrualas-of-disambiguation/differentiating of destructuring-threshold-〈uninstitutionalisedthreshold /presublimating-desublimating-decisionality $>$ of-ontological-performance ${ }^{72}$ $<$ including-virtue-as-ontology $>$, with $<$ amplituding/formativeepistemicity>totalising intervalist-as-categorising_-'implicited_attendant-ontologicalcontiguity ${ }^{67} \sim$ educedexistentialising/contextualising/textualising_'intelligibility/epistemicity/reflexivity-contiguity<imbued-notional cogency>' $\quad$ phenomenal-abstractiveness, $\quad$ <amplituding/formativeepistemicity $>$ totalising $\sim$ ordinal-as-qualifying_ _implicited_attendant-ontologicalcontiguity ${ }^{67} \sim$ educedexistentialising/contextualising/textualising_intelligibility/epistemicity/reflexivity-contiguity<imbued-notional cogency>' $\quad$ phenomenal-abstractiveness, $\quad$ <amplituding/formativeepistemicity>totalising nominal-as-tendentious_-implicited_attendant_ontologicalcontiguity ${ }^{67} \sim$ educedexistentialising/contextualising/textualising_'intelligibility/epistemicity/reflexivity-contiguity- 
<imbued-notional cogency>' $>^{\prime 0}$ phomenal-abstractiveness and <amplituding/formativeepistemicity $>$ totalising $\sim$ random-as-impulsive_-'implicited_attendant-ontologicalcontiguity $^{67} \sim$ educedexistentialising/contextualising/textualising_'intelligibility/epistemicity/reflexivity-contiguity$<$ imbued-notional cogency>' phenomenal-abstractiveness reflecting lesser-and-lesser mental-processing tasking for operant ${ }^{56}$ meaningfulness-and-teleology ${ }^{99}$ as of 'already achieved

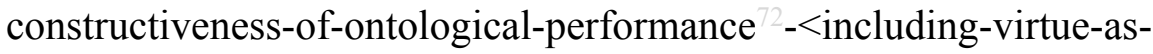
ontology>/institutionalisation' enabled by $\quad$ amplituding/formativeepistemicity $>$ totalising $\sim$ ratiocontiguity/ratiocination-as-referentialism—'implicited_attendant ontological-contiguity ${ }^{67}$, educedexistentialising/contextmalising/textmalising_intelligibility/epistemicity/reflexivity-contiguity<imbued-notional cogency>' phenomenal-abstractiveness disambiguation/differentiation. It is the <amplituding/formative-epistemicity $>$ totalising $\sim$ ratiocontiguity/ratiocination-asreferentialism - 'implicited_attendant-ontological-contiguity ${ }^{67}$ ? educedexistentialising/contextualising/textualising_intelligibility/epistemicity/reflexivity-contiguity<imbued-notional cogency>' phenomenal-abstractiveness existential-<disontologising/reentelogising apereticism $>$ reshuffling thoughtfulness as of its expansion of human knowledge frontier as 'ontologically-hegemonising-narrative ${ }^{71}$ ontological-performance ${ }^{2}-<$ includingvirtue-as-ontology ${ }^{\prime}$, by its disambiguative/differentiative undermining of destructuringthreshold-〈uninstitutionalised-threshold /presublimating-desublimating-decisionality $\rangle$ ofontological-performance $^{72}$-<including-virtue-as-ontology $>/$ morality/ethics/justice/etc. $\quad$ as it enables 'ontology/apriorising/axiomatising/referencing construal of Being and beings' that instigates the knowledge mechanism as it subsequently and summarily parcels out as of a depthof-mental-processing-reflexes-contiguity into the more fully operant ${ }^{56}$ meaningfulness-andteleology ${ }^{9}$ of lesser-and-lesser notional $\sim$ phenomenal-abstractiveness mental-processing 
tasking, and so rather as 'already achieved constructiveness-of-ontological-performance ${ }^{72}$ <including-virtue-as-ontology>/institutionalisation', as from the categorising register of '<amplituding/formative-epistemicity $>$ totalising $\sim$ ratiocontiguity/ratiocination-asreferentialism - 'implicited_attendant_ontological-contiguity ${ }^{67}$ > educedexistentialising/contextualising/textualising_intelligibility/epistemicity/reflexivity-contiguity<imbued-notional cogency $>^{\prime} \quad$ derived ontology/apriorising/axiomatising/referencing construal of Being and beings', the qualifying register of '<amplituding/formativeepistemicity $>$ totalising $\sim$ ratiocontiguity/ratiocination-as-referentialism—'implicited_attendant ontological-contiguity ${ }^{67}$, educedexistentialising/contextualising/textualising_intelligibility/epistemicity/reflexivity-contiguity$<$ imbued-notional cogency $>$ ' derived ontology/apriorising/axiomatising/referencing construal of Being and beings', the tendentious register of '<amplituding/formativeepistemicity $>$ totalising $\sim$ ratiocontiguity/ratiocination-as-referentialism—'implicited_attendant ontological-contiguity ${ }^{67}$, educedexistentialising/contextualising/textualising_intelligibility/epistemicity/reflexivity-contiguity$<$ imbued-notional cogency $>$ ' derived ontology/apriorising/axiomatising/referencing construal of Being and beings' and the impulsive register of '<amplituding/formativeepistemicity $>$ totalising $\sim$ ratiocontiguity/ratiocination-as-referentialism—'implicited_attendant ontological-contiguity ${ }^{67}$, educedexistentialising/contextualising/textualising_'intelligibility/epistemicity/reflexivity-contiguity$<$ imbued-notional cogency $>$ derived ontology/apriorising/axiomatising/referencing construal of Being and beings', reflecting the human understanding process (with this sostructured registers of lesser-and-lesser mental-processing reproducibilitymathesis/motif/thrownness-disposition,-as-reproducibility-of-aestheticisation, as derived from the underlying registry-worldview's/dimension's ${ }^{83}$ reference-of-thought induced 
'<amplituding/formative-epistemicity $>$ totalising $\sim$ ratiocontiguity/ratiocination-as-

referentialism_-'implicited_attendant_ontological-contiguity ${ }^{67}$ 'educed-

existentialising/contextualising/textualising_'intelligibility/epistemicity/reflexivity-contiguity-

$<$ imbued-notional cogency $>^{\prime}$ ontology/apriorising/axiomatising/referencing construal of

Being and beings', forming the said registry-worldview's/dimension's 'notional conflatedness

$<$ amplituding/formative-epistemicity $>$ totalising/circumscribing/delineating self-consciousness

qualia-schema' of memorisation as of replication-and-differentiation-in-a'<amplituding/formative-epistemicity $>$ totalising $\sim$ disambiguation-in-notional $\sim$ conflatedness ${ }^{13}$ with-existence-as-to-existential-instantiations' and thus enabling the notional conflatedness of mental-processing in existence-as-to-existential-instantiations reflected in the "evolving-anddevolving formation/learning-development metaphoricity and transcendence-andsublimity/sublimation/supererogatory $\sim$ de-mentativity metaphoricity ${ }^{57}$ subjoining in $<$ amplituding/formative-epistemicity>totalising/circumscribing/delineating ${ }^{56}$ meaningfulnessand-teleology ', and so as of impulsive mental-reflex, tendentious mental-reflex, qualifying mental-reflex, categorising mental-reflex and <amplituding/formativeepistemicity $>$ totalising $\sim$ ratiocontiguity/ratiocination-as-referentialism—'implicited_attendantontological-contiguity ${ }^{67}$; educedexistentialising/contextualising/textualising_'intelligibility/epistemicity/reflexivity-contiguity<imbued-notional cogency $>^{\prime}$ mental-reflex in their comprehensively underlying 'notional conflatedness ${ }^{13}$ with existence-as-to-existential-instantiations'); from whence meaningfulness-and-teleology aposteriorising/logicising/deriving/intelligising/measuring ensues as of notional conflatedness ${ }^{13}$ with existence-as-to-existential-instantiations ('< $<$ amplituding/formative-epistemicity $>$ totalising/circumscribing/delineating postconverging/dialectical-thinking ${ }^{21}$-qualia-schema' rather arises as of the implied ${ }^{8}$ referenceof-thought apriorising/axiomatising/referencing/intelligibilitysettingup/measuringinstrumenting 
epistemicity $>$ totalising/circumscribing/delineating psychologism-schema' and is the reflected mental-state aftereffect when reflexively, contemplatively, implicitly or explicitly aposteriorising/logicising/deriving/intelligising/measuring propositions as of the given underlying registry-worldview's/dimension's narrative disposition in its notional conflatedness ${ }^{13}$ with existence-as-to-existential-instantiations, and it is necessarily induced-from and reflects the 'developing $<$ amplituding/formativeepistemicity $>$ totalising/circumscribing/delineating self-consciousness culturally-directed eliciting of concepts and contemplative frameworks in notional conflatedness ${ }^{13}$ with existenceas-to-existential-instantiations'; and so-contrued contrary to just an apriorising/axiomatising/referencing-\{of-'prospectively_implicited_attendant-ontologicalcontiguity ' educedexistentialising/contextualising/textualising_'intelligibility/epistemicity/reflexivity-contiguity<imbued-notional cogency $>\quad\}$-constitutedness ${ }^{1}$-in-preconverging-entailment conception as of singular quale which fails to grasp that the possibility for reflecting a quale arises rather as of an underlying '<amplituding/formative-epistemicity $>$ totalising/circumscribing/delineating postconverging/dialectical-thinking ${ }^{2}$-qualia-schema' $<$ amplituding/formativeepistemicity>totalising/circumscribing/delineating reflecting ${ }^{56}$ meaningfulness-and-teleology within which any specific quale then imports as of its replicability-and-differentiability-in-a'<amplituding/formative-epistemicity $>$ totalising $\sim$ disambiguation-in-notional $\sim$ conflatedness ${ }^{13}$ with-existence-as-to-existential-instantiations' such that for instance the self-consciousness for cognising colour and colour schemes with children develops rather as of culturally-directed eliciting of the colour and colour schemes devolving qualia-schema, as it is integrated with the child's developing <amplituding/formative-epistemicity>totalising/circumscribing/delineating self-consciousness and by extension we can grasp that the <amplituding/formative- 

worldviews/dimensions ${ }^{83}$ reference-of-thought are grasp rather as of '< $<$ amplituding/formativeepistemicity $>$ totalising/circumscribing/delineating preconverging/dementing ${ }^{20}$-qualia-schema' as of relative-ontological-incompleteness ${ }^{88}$ so construed from relative-ontologicalcompleteness $^{87}$ as to existence-potency ${ }^{39} \sim$ sublimating-nascence,-disclosed-from-prospectiveepistemic-digression epistemic-or-notional projective-perspective or ' $<$ amplituding/formativeepistemicity>totalising/circumscribing/delineating postconverging/dialectical-thinking qualia-schema' as of relative-ontological-completeness ${ }^{87}$ when so-construed in existencepotency $^{32} \sim$ sublimating-nascence,-disclosed-from-prospective-epistemic-digression as from a protracted-consciousness in relative-ontological-completeness ${ }^{87}$ as of futural Beingdevelopment/ontological-framework-expansion-as-to-depth-of-ontologising-development-asinfrastructure-of- meaningfulness-and-teleology as of prospective notional ${ }^{18}$ deprocrypticism protensive-consciousness <amplituding/formativeepistemicity>totalising/circumscribing/delineating qualia-schema disambiguation of the other consciousnesses in relative-ontological-incompleteness ${ }^{88}$ as of positivism- ${ }^{80}$ procrypticism occlusive-consciousness <amplituding/formativeepistemicity $>$ totalising/circumscribing/delineating qualia-schema, ${ }^{103}$ universalisation-nonpositivism/medievalism preclusive-consciousness <amplituding/formativeepistemicity>totalising/circumscribing/delineating qualia-schema, base-institutionalisationununiversalisation warped-consciousness $<$ amplituding/formativeepistemicity>totalising/circumscribing/delineating qualia-schema and recurrent-utteruninstitutionalisation trepidatious-consciousness $<$ amplituding/formativeepistemicity $>$ totalising/circumscribing/delineating qualia-schema). But then at prospective destructuring-threshold-〈uninstitutionalised-threshold /presublimating-desublimating- 
decisionality $>$ of-ontological-performance ${ }^{2}-<$ including-virtue-as-ontology $>$, the instigation of the categorising register, the qualifying register, the tendentious register and the impulsive register will end up being ontologically-flawed but not recognised as such from the humansubpotency epistemic-or-notional projective-perspective of the given registryworldview/dimension institutionalisation reproducibility-mathesis/motif/thrownnessdisposition,-as-reproducibility-of-aestheticisation

apriorising/axiomatising/referencing/intelligibilitysettingup/measuringinstrumenting in $<$ amplituding/formative-epistemicity $>$ totalising $\sim$ self-referencingsyncretising/circularity/interiorising/akrasiatic-drag ${ }^{4}$, though from existencepotency $^{32} \sim$ sublimating-nascence,-disclosed-from-prospective-epistemic-digression epistemic perspective of analysis as of prospective relative-ontological-completeness ${ }^{87}$ it is shown to be ontologically-flawed. Basically thus prospective destructuring-threshold-〈uninstitutionalisedthreshold /presublimating-desublimating-decisionality) of-ontological-performance ${ }^{72}$ $<$ including-virtue-as-ontology $>/$ morality/ethics/justice/etc. renders the instigation of the categorising register, the qualifying register, the tendentious register and the impulsive register, as of operant meaningfulness-and-teleology ${ }^{59}$ susceptible to be $<$ amplituding/formative $>$ wooden-language-_imbued-temporal-mereform/virtualities/dereification/akrasiatic-drag/denatured/preconverging-or-dementing narratives - of-the- reference-of-thought- categorical-imperatives/axioms/registry$\begin{array}{llll}\text { teleology }\rangle \text { so-implied } \quad \text { of } & \text { postlogism }\end{array}$ slantedness/ ignorance/affordability/opportunism/exacerbation/social-chainism-or-socialdiscomfiture-or-negative-social-aggregation/temporal-enculturation-or-temporal-endemisation. It is only <amplituding/formative-epistemicity>totalising $\sim$ ratiocontiguity/ratiocination-asreferentialism - 'implicited_attendant-ontological-contiguity ${ }^{67}$ > educed-

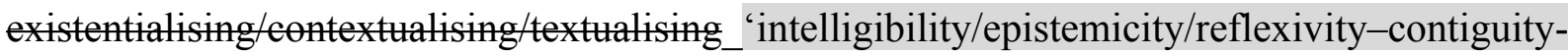


<imbued-notional cogency>' phenomenal-abstractiveness as of its mental-processing persistently pervasive existential-<disontologising/re-ontologising aporeticism $>$ reshuffling thoughtfulness as from human anxiety that is bound at destructuring-threshold〈uninstitutionalised-threshold /presublimating-desublimating-decisionality $>$ of-ontologicalperformance $^{72}-<$ including-virtue-as-ontology $>$ /morality/ethics/justice/etc. to reconstrue the prospective $\quad$ constructiveness-of-ontological-performance ${ }^{72}-<$ including-virtue-asontology $>$ /institutionalisation of ${ }^{56}$ meaningfulness-and-teleology ${ }^{9}$ as so-reflected from existence-potency ${ }^{39} \sim$ sublimating-nascence,-disclosed-from-prospective-epistemic-digression notional/epistemic/bindingness ${ }^{-<a s-t 0-d e t e r m i n i s m / c o n c e p t i v i t y-o f-r e l a t i v e-u n r e f l e x i v i t y / r e l a t i v e-r e f l e x i v i t y ~}>$ perspective of analysis as of prospective relative-ontological-completeness ${ }^{87}$ to be ontologicallyveridical. It is in this way that <amplituding/formativeepistemicity $>$ totalising $\sim$ ratiocontiguity/ratiocination-as-referentialism—'implicited_attendant ontological-contiguity ${ }^{67} \sim$ educedexistentialising/contextualising/textualising_intelligibility/epistemicity/reflexivity-contiguity$<$ imbued-notional cogency $>$ notional $\sim$ phenomenal-abstractiveness prospective expands the frontiers of human knowledge as 'ontologically-hegemonising-narrative' ontologicalperformance ${ }^{2}-<$ including-virtue-as-ontology $>$ ', and thereof instigating the knowledge mechanism as it subsequently and summarily parcels out as of a depth-of-mental-processingreflexes-contiguity into the more fully operant ${ }^{5}$ meaningfulness-and-teleology ${ }^{9}$ of lesser-andlesser notional phenomenal-abstractiveness mental-processing tasking, as from the categorising register, the qualifying register, the tendentious register and the impulsive register, and thus enabling new human understanding; from whence new ${ }^{5}$ meaningfulness-and-teleology aposteriorising/logicising/deriving/intelligising/measuring ensues as of human existentialinstantiations. In-the-bigger-scheme-of-things, this 'constructiveness-of-ontologicalperformance ${ }^{72}-<$ including-virtue-as-ontology $>$ /morality/ethics/justice/etc. from destructuring- 
threshold-〈uninstitutionalised-threshold /presublimating-desublimating-decisionality $\rangle$ ofontological-performance ${ }^{72}-<$ including-virtue-as-ontology $>$ ' operation of the comprehensive human notional $\sim$ phenomenal-abstractiveness process reflecting the cumulation/recomposuring of human ${ }^{56}$ meaningfulness-and-teleology ${ }^{9}$ as knowledge, is what brings about the successive apriorising/axiomatising/referencing/intelligibilitysettingup/measuringinstrumenting for aposteriorising/logicising/deriving/intelligising/measuring as of successive prospective relativeontological-completeness $^{87}$, and is reflected in the relative-unreflexivity/relative-reflexivity ontological-contiguity ${ }^{67}$ of-the-human-institutionalisation-process ${ }^{68}$ reification of ${ }^{8}$ referenceof-thought-level successive self-consciousness/construction-of-the-Self as of the $<$ cumulating/recomposuring attendant-ontological-contiguity $>$-successive registryworldviews/dimensions, and so conceptualised as from existence-potency ${ }^{39} \sim$ sublimatingnascence,-disclosed-from-prospective-epistemic-digression as-to-ontologicallyuncompromised-ontological-normalcy/postconvergence/referentialism perspective. The social as supposedly of prior-institutionalisation-threshold-by-prospective-uninstitutionalisedthreshold 'se2 'self-referencing-syncretising forward-facing-supposedly $\sim$ postconverging-ordialectical-thinking -apriorising-psychologism epistemic-projection as of prior mereformulaicity/ritualisation-<as-to-mere-formulaicmethodologising/mutualising/organising/institutionalising,-prospectively-losing-track-of‘fepistemic talising ’re-apriorising/re-axiomatising/re-referencing $\sim$ residuality-in-reoriginariness/re-origination'>' is one where 'equivalence/correspondence antiakrasiatic-

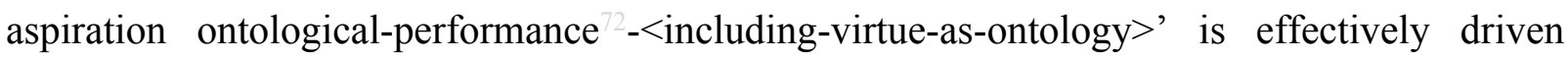
notionally as of ' $<$ amplitudformative-epistemicity $>$ totalising $\sim$ ratiocontiguity/ratiocinationas-referentialism_-'implicited_attendant_ontological-contiguity ${ }^{67}$; educedexistentialising/contextualising/textualising_intelligibility/epistemicity/reflexivity-contiguity$<$ imbued-notional cogency $>$ ' ${ }^{\prime}$ constructiveness disposition in singularisation- $<$ as-to-the- 
nondisjointedness/entailment-of-prospective- nonpresencing $>$ projected epistemicimmanence/veridical-epistemicity-relativism-determinism' as 'ontologically-hegemonising-

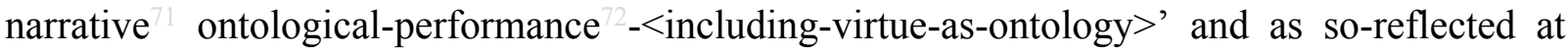
attained institutionalisation-level and constraint in formal social-settings; while as of human limited-mentation-capacity—as-subjecting-'educed-unlimitedness/existence-sublimating nascence'-to-limitedness/human-subpotency implications of notional phenomenalabstractiveness, elicited covert-pretence-of-equivalence/correspondence-antiakrasiaticaspiration-ontological-performance ${ }^{72}<$ including-virtue-as-

ontology $>$ /morality/ethics/justice/etc. as of notional destructuring-transitoriness ${ }^{19}$-as-ofderatiocination/deratiocontiguity arise variously at ${ }^{83}$ reference-of-thought-level uninstitutionalised-threshold ${ }^{102}$ and their ${ }^{83}$ reference-of-thought- ${ }^{8}$ devolving-level unconstraint extended-informality as human '<amplituding/formative-epistemicity>totalising $\sim$ random-asimpulsive_-implicited_attendant-ontological-contiguity ${ }^{67}$ > educedexistentialising/contextualising/textualising_intelligibility/epistemicity/reflexivity-contiguity<imbued-notional cogency>' destructuring-disposition-flipping/changing/transitioninginduced-notional-discontiguity/epistemic-discontiguity ${ }^{63}<$ between - prior-shallowsupererogation -of-mentally-aestheticised preconverging/dementing -qualiaschema_and_prospective-profound-supererogation -of-mentallyaestheticised $\sim$ postconverging/dialectical-thinking -qualia-schema $>$ in dissingularisation- $<$ asto-the-disjointedness/disentailment-of- presencing - absolutising-identitiveconstitutedness > /epistemic-nonimmanence/flawed-epistemicity-relativism-determinism', ‘ $<$ amplituding/formative-epistemicity $>$ totalising $\sim$ nominal-as-tendentious'implicited_atentantontological-contiguity ${ }^{67}$ ' educedexistentialising/contextualising/textualising_'intelligibility/epistemicity/reflexivity-contiguity<imbued-notional cogency $>$ ' destructuring-disposition-flipping/changing/transitioning- 
induced-notional-discontiguity/epistemic-discontiguity ${ }^{63}<$ between - prior-shallow-

supererogation -of-mentally-aestheticised preconverging/dementing -qualia-

schema_and_prospective-profound-supererogation -of-mentally-

aestheticised $\sim$ postconverging/dialectical-thinking -qualia-schema $>$ in dissingularisation- $<$ as-

to-the-disjointedness/disentailment-of- presencing - absolutising-identitive-

constitutedness $>$ /epistemic-nonimmanence/flawed-epistemicity-relativism-determinism',

‘ $<$ amplituding/formative-epistemicity $>$ totalising $\sim$ ordinal-as-qualifying-

'implicited_attendant-ontological-contiguity ${ }^{67}$; educed-

existentialising/contextualising/textualising_'intelligibility/epistemicity/reflexivity-contiguity-

$<$ imbued-notional cogency > $\quad$ destructuring-disposition-flipping/changing/transitioning-

induced-notional-discontiguity/epistemic-discontiguity ${ }^{63}<$ between - prior-shallow-

supererogation -of-mentally-aestheticised preconverging/dementing -qualia-

schema_and_prospective-profound-supererogation -of-mentally-

aestheticised postconverging/dialectical-thinking -qualia-schema $>$ dissingularisation- $<$ as-to-

the-disjointedness/disentailment-of- presencing - absolutising-identitive-

constitutedness > /epistemic-nonimmanence/flawed-epistemicity-relativism-determinism’

'<amplituding/formative-epistemicity $>$ totalising intervalist-as-categorising-

'implicited_attendant-ontological-contiguity ${ }^{6}$ ' educed-

existentialising/contextalising/textalising_'intelligibility/epistemicity/reflexivity_contiguity-

$<$ imbued-notional $\sim$ cogency $>^{\prime} \quad$ in and destructuring-disposition-

flipping/changing/transitioning-induced-notional-discontiguity/epistemic-discontiguity ${ }^{63}$

$<$ between-prior-shallow-supererogation -of-mentally-

aestheticised $\sim$ preconverging/dementing -qualia-schema_and_prospective-profound-

supererogation -of-mentally-aestheticised postconverging/dialectical-thinking -qualia-

schema $>$ in dissingularisation-<as-to-the-disjointedness/disentailment-of- presencing- 
absolutising-identitive-constitutedness $>$ /epistemic-nonimmanence/flawed-epistemicity-

relativism-determinism', and as these covertly pass as being notionally of '<amplituding/formative-epistemicity $>$ totalising $\sim$ ratiocontiguity/ratiocination-as-

referentialism—'implicited_attendant-ontological-contiguity ${ }^{67}$ ' educed-

existentialising/contextualising/textualising_intelligibility/epistemicity/reflexivity-contiguity$<$ imbued-notional cogency $>$ constructiveness disposition in singularisation- $<$ as-to-thenondisjointedness/entailment-of-prospective- nonpresencing $>$ projected epistemicimmanence/veridical-epistemicity-relativism-determinism' thus undermining 'equivalence/correspondence antiakrasiatic-aspiration ontological-performance ${ }^{2}-<$ includingvirtue-as-ontology >'. Destructuring-transitoriness ${ }^{19}$-as-of-deratiocination/deratiocontiguity as of elicited covert-pretence-of-equivalence/correspondence-antiakrasiatic-aspirationontological-performance ${ }^{2}$-<including-virtue-as-ontology $>/$ morality/ethics/justice/etc.

articulated-or-acquiesced-to ${ }^{56}$ meaningfulness-and-teleology ${ }^{9}$ at ${ }^{83}$ reference-of-thoughtdevolving-level, is induced as of destructuring-disposition—flipping/changing/transitioninginduced-notional-discontiguity/epistemic-discontiguity ${ }^{63}<$ between - prior-shallowsupererogation -of-mentally-aestheticised $\sim$ preconverging/dementing -qualiaschema_and_prospective-profound-supererogation -of-mentallyaestheticised postconverging/dialectical-thinking - qualia-schema $>$ in dissingularisation- $<$ asto-the-disjointedness/disentailment-of- presencing - absolutising-identitive-

constitutedness $>$ /epistemic-nonimmanence/flawed-epistemicity-relativism-determinism as $<$ amplituding formative $>$ wooden-language-_imbued-temporal-mere-

\section{form/virtualities/dereification/akrasiatic-drag/denatured/preconverging-or-dementing} narratives - of-the- reference-of-thought- categorical-imperatives/axioms/registry$\begin{array}{llll}\text { teleology }\rangle \text { so-implied } \quad \text { as } & \text { of }\end{array}$ slantedness/ ignorance/affordability/opportunism/exacerbation/social-chainism-or-social- 
discomfiture-or-negative-social-aggregation/temporal-enculturation-or-temporal-endemisation, and so-induced-and-complexified in association with instances/instantiations of constructiveness disposition for 'equivalence/correspondence antiakrasiatic-aspiration ontological-performance $^{72}-<$ including-virtue-as-ontology $>$ ', to then effect as of the dual implications ontologically-flawed overall perception of a primary commitment to constructiveness disposition of 'equivalence/correspondence antiakrasiatic-aspiration ontological-performance $^{72}$-<including-virtue-as-ontology>' so that any such destructuringdisposition - flipping/changing/transitioning-induced-notional-discontiguity/epistemicdiscontiguity ${ }^{6}-<$ between - prior-shallow-supererogation -of-mentallyaestheticised preconverging/dementing -qualia-schema_and_prospective-profoundsupererogation -of-mentally-aestheticised postconverging/dialectical-thinking -qualiaschema $>$ in dissingularisation-<as-to-the-disjointedness/disentailment-of- presencingabsolutising-identitive-constitutedness > /epistemic-nonimmanence/flawed-epistemicityrelativism-determinism as of covert-pretence-of-equivalence/correspondence-antiakrasiaticaspiration-ontological-performance ${ }^{72}-<$ including-virtue-asontology $>$ /morality/ethics/justice/etc. as to destructuring-transitoriness ${ }^{19}$-as-ofderatiocination/deratiocontiguity articulated-or-acquiesced-to $\quad{ }^{56}$ meaningfulness-andteleology ontological-performance ${ }^{2}-<$ including-virtue-asontology $>$ /morality/ethics/justice/etc. is overlooked as marginal; and so with regards to implicited social epistemic-totality ${ }^{37}$ of ${ }^{56}$ meaningfulness-and-teleology 99 , thus inducing the peculiar social dynamism effect of destructuring-transitoriness ${ }^{19}$-as-ofderatiocination/deratiocontiguity wherein that temporally induced marginality mechanism as of destructuring-disposition - flipping/changing/transitioning-induced-notionaldiscontiguity/epistemic-discontiguity ${ }^{63}<$ between - prior-shallow-supererogation -ofmentally-aestheticised preconverging/dementing -qualia-schema_and_prospective-profound- 
supererogation -of-mentally-aestheticised postconverging/dialectical-thinking -qualia-

schema $>$ in dissingularisation-<as-to-the-disjointedness/disentailment-of- presencingabsolutising-identitive-constitutedness $>$ /epistemic-nonimmanence/flawed-epistemicityrelativism-determinism as <amplituding/formative $>$ wooden-language-〈imbued-temporalmere-form/virtualities/dereification/akrasiatic-drag/denatured/preconverging-or-dementing narratives - of-the- reference-of-thought- categorical-imperatives/axioms/registry-

teleology $>$ is the beyond-the-consciousness-awareness-teleology ${ }^{9}-<$ of-preconvergingexistential-extrication-as-of-existential-unthought $>$ temporal grounds for akrasiatically undermining 'equivalence/correspondence antiakrasiatic-aspiration ontological-performance ${ }^{72}$ <including-virtue-as-ontology $>^{\prime}$. It is this destructuring-transitoriness ${ }^{19}$-as-ofderatiocination/deratiocontiguity as of 'pretence of equivalence/correspondence antiakrasiaticaspiration ontological-performance ${ }^{72}-<$ including-virtue-as-ontology $>^{\prime}$ marginality implications reflected in human notional $\sim$ phenomenal-abstractiveness destructuring-dispositionflipping/changing/transitioning-induced-notional-discontiguity/epistemic-discontiguity ${ }^{63}$

\section{$<$ between-prior-shallow-supererogation -of-mentally-}

aestheticised preconverging/dementing -qualia-schema_and_prospective-profound-

supererogation -of-mentally-aestheticised postconverging/dialectical-thinking -qualia-

schema $>$ in dissingularisation- $<$ as-to-the-disjointedness/disentailment-of- presencingabsolutising-identitive-constitutedness > /epistemic-nonimmanence/flawed-epistemicityrelativism-determinism that develop into the social dynamics manifestations of postlogism slantedness/ ignorance/affordability/opportunism/exacerbation/social-chainism-or-socialdiscomfiture-or-negative-social-aggregation/temporal-enculturation-or-temporal-endemisation so-construed from the perspective of existence-potency ${ }^{32}$ sublimating-nascence,-disclosedfrom-prospective-epistemic-digression as-to-ontologically-uncompromised-ontologicalnormalcy/postconvergence/referentialism. This reveals destructuring-transitoriness 19 -as-of- 
deratiocination/deratiocontiguity as the destructuring ontologically-flawed failing antiakrasiatic disposition, that is further complexified with the blending of instances/instantiations of constructiveness disposition of 'equivalence/correspondence antiakrasiatic-aspiration ontological-performance ${ }^{72}-<$ including-virtue-as-ontology $>$ ' with the marginal destructuringdisposition —-flipping/changing/transitioning-induced-notional-discontiguity/epistemicdiscontiguity 33 - between - prior-shallow-supererogation -of-mentallyaestheticised preconverging/dementing -qualia-schema_and_prospective-profoundsupererogation -of-mentally-aestheticised postconverging/dialectical-thinking -qualiaschema $>$ in dissingularisation-<as-to-the-disjointedness/disentailment-of- presencingabsolutising-identitive-constitutedness > /epistemic-nonimmanence/flawed-epistemicityrelativism-determinism as of covert-pretence-of-equivalence/correspondence-antiakrasiaticaspiration-ontological-performance ${ }^{72}<$ including-virtue-as-

ontology $>$ /morality/ethics/justice/etc. as to destructuring-transitoriness ${ }^{19}$-as-ofderatiocination/deratiocontiguity thus inducing the overlooking as marginal of the destructuringdisposition —-flipping/changing/transitioning-induced-notional-discontiguity/epistemicdiscontiguity $^{63}-<$ between - prior-shallow-supererogation -of-mentallyaestheticised preconverging/dementing -qualia-schema_and_prospective-profoundsupererogation -of-mentally-aestheticised postconverging/dialectical-thinking -qualiaschema $>$ in dissingularisation-<as-to-the-disjointedness/disentailment-of- presencingabsolutising-identitive-constitutedness $>$ /epistemic-nonimmanence/flawed-epistemicityrelativism-determinism, and thus defining the specific sustainable destructuring-threshold〈uninstitutionalised-threshold /presublimating-desublimating-decisionality $\rangle$ of-ontologicalperformance ${ }^{2}$-<including-virtue-as-ontology $>$ /morality/ethics/justice/etc. parasitism in $<$ amplituding/formative--epistemicity $>$ totalising $\sim$ self-referencingsyncretising/circularity/interiorising/akrasiatic-drag ${ }^{4}$ as of any given registry- 
worldview's/dimension's uninstitutionalised-threshold ${ }^{102}$, and is so-reflected as of its endemised/enculturated social construal of the 'types of vices-and-impediments ${ }^{105}$ that can be overlooked' beyond-the-consciousness-awareness-teleology ${ }^{9}-<$ of-preconverging-existentialextrication-as-of-existential-unthought $>$, determining its uninstitutionalised-threshold ${ }^{102}$. Critical to the social manifestation of destructuring-transitoriness -as-ofderatiocination/deratiocontiguity and its-extension-in-complexification is that it is socially perceived decisively as not destructuring going by the narrative of the collective social-setting destructuring-disposition — flipping/changing/transitioning-induced-notionaldiscontiguity/epistemic-discontiguity ${ }^{63}<$ between - prior-shallow-supererogation -ofmentally-aestheticised preconverging/dementing -qualia-schema_and_prospective-profoundsupererogation -of-mentally-aestheticised postconverging/dialectical-thinking -qualiaschema $>$ in dissingularisation- $<$ as-to-the-disjointedness/disentailment-of- presencingabsolutising-identitive-constitutedness $>$ /epistemic-nonimmanence/flawed-epistemicityrelativism-determinism at its destructuring-threshold-〈uninstitutionalisedthreshold /presublimating-desublimating-decisionality $>$ of-ontological-performance ${ }^{72}$ $<$ including-virtue-as-ontology $>$, to then reflect of such 'pretence of equivalence/correspondence

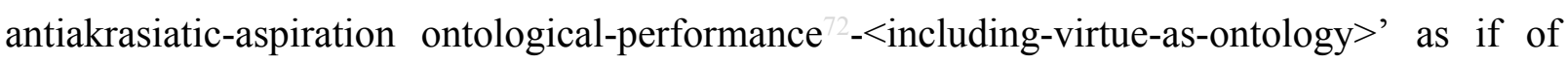
'equivalence/correspondence antiakrasiatic-aspiration ontological-performance ${ }^{2}-<$ includingvirtue-as-ontology >' and to assent to such a state of affairs. Destructuring-transitoriness ${ }^{19}$-as-ofderatiocination/deratiocontiguity thus arises as of human limited-mentation-capacity-assubjecting-'educed-unlimitedness/existence-sublimating nascence' to-limitedness/humansubpotency deficient personality adherence, personality formation and personality development as of the social-setting very own registry-worldview/dimension institutionalisation level, with regards to the construal of the social-construct in its constructiveness-of-ontologicalperformance $^{72}-<$ including-virtue-as-ontology $>/$ morality/ethics/justice/etc. 
'equivalence/correspondence antiakrasiatic-aspiration ontological-performance ${ }^{2}-<$ includingvirtue-as-ontology>', with such destructuring deficiency defining its uninstitutionalisedthreshold $^{102}$. Destructuring-transitoriness ${ }^{19}$-as-of-deratiocination/deratiocontiguity as it speaks to the ${ }^{83}$ reference-of-thought- ${ }^{8}$ devolving-level is a most potent social phenomenon in the extended-informality rather than defined-and-constrained formalised social-settings (though it more fundamentally speaks of the uninstitutionalised-threshold ${ }^{102}$ implied overall registryworldview/dimension prospective preconverging/postconverging-dementative/structural/paradigmatic

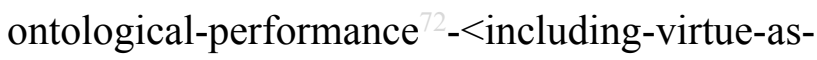
ontology $>$ /morality/ethics/justice/etc. deficiency), as of the dearth of ontologicallyhegemonising-narrative as of '<amplituding/formativeepistemicity $>$ totalising $\sim$ ratiocontiguity/ratiocination-as-referentialism—'implicited_attendant ontological-contiguity ${ }^{67} \sim$ educedexistentialising/contextualising/textualising_'intelligibility/epistemicity/reflexivity-contiguity$<$ imbued-notional cogency $>^{\prime}$ constructiveness disposition in singularisation-<as-to-thenondisjointedness/entailment-of-prospective- nonpresencing $>$ projected epistemicimmanence/veridical-epistemicity-relativism-determinism' in the extended-informality with the latter variously substituted as of human phenomenal-abstractiveness ' $<$ amplituding/formativeepistemicity $>$ totalising $\sim$ random-as-impulsive_-'implicited_attendant-ontologicalcontiguity $^{67} \sim$ educedexistentialising/contextualising/textualising_intelligibility/epistemicity/reflexivity-contiguity<imbued-notional cogency>' $\quad$ destructuring-disposition-flipping/changing/transitioninginduced-notional-discontiguity/epistemic-discontiguity ${ }^{63}-<$ between - prior-shallowsupererogation -of-mentally-aestheticised $\sim$ preconverging/dementing -qualiaschema_and_prospective-profound-supererogation -of-mentallyaestheticised postconverging/dialectical-thinking - qualia-schema $>$ in dissingularisation- $<$ as- 


\section{to-the-disjointedness/disentailment-of- presencing - absolutising-identitive-}

constitutedness > /epistemic-nonimmanence/flawed-epistemicity-relativism-determinism', totalising $\sim$ nominal-as-tendentious_—'implicited_attendant—ontological-contiguity ${ }^{67}$ educedexistentialising/contextualising/textualising_intelligibility/epistemicity/reflexivity-contiguity<imbued-notional cogency >' $\quad$ '<amplituding/formative-epistemicity $>$ destructuringdisposition —-flipping/changing/transitioning-induced-notional-discontiguity/epistemicdiscontiguity 3 - $<$ between - prior-shallow-supererogation -of-mentallyaestheticised preconverging/dementing -qualia-schema_and_prospective-profoundsupererogation -of-mentally-aestheticised postconverging/dialectical-thinking -qualiaschema $>$ in dissingularisation-<as-to-the-disjointedness/disentailment-of- presencingabsolutising-identitive-constitutedness $>$ /epistemic-nonimmanence/flawed-epistemicityrelativism-determinism', ‘<amplituding/formative-epistemicity $>$ totalising $\quad$ ordinal-asqualifying_-implicited_attendant-ontological-contiguity ${ }^{6 /}$ ? educedexistentialising/contextualising/textualising_intelligibility/epistemicity/reflexivity-contiguity<imbued-notional cogency>> destructuring-disposition-flipping/changing/transitioninginduced-notional-discontiguity/epistemic-discontiguity ${ }^{63}<$ between - prior-shallowsupererogation -of-mentally-aestheticised preconverging/dementing -qualiaschema_and_prospective-profound-supererogation -of-mentallyaestheticised postconverging/dialectical-thinking -qualia-schema $>$ in dissingularisation- $<$ asto-the-disjointedness/disentailment-of- presencing-absolutising-identitiveconstitutedness > /epistemic-nonimmanence/flawed-epistemicity-relativism-determinism’ and ‘ $<$ amplituding/formative-epistemicity $>$ totalising intervalist-as-categorising'implicited_atentantontological-contiguity ${ }^{67}$ ' educedexistentialising/contextalising/textalising_'intelligibility/epistemicity/reflexivity_contiguity$<$ imbued-notional cogency > $\quad$ destructuring-disposition-flipping/changing/transitioning- 
induced-notional-discontiguity/epistemic-discontiguity ${ }^{63}<$ between - prior-shallow-

supererogation -of-mentally-aestheticised preconverging/dementing -qualia-

schema_and_prospective-profound-supererogation -of-mentally-

aestheticised postconverging/dialectical-thinking -qualia-schema $>$ in dissingularisation- $<$ asto-the-disjointedness/disentailment-of- presencing - absolutising-identitive-

constitutedness $>$ /epistemic-nonimmanence/flawed-epistemicity-relativism-determinism' as these covertly pass as constructiveness disposition in 'equivalence/correspondence

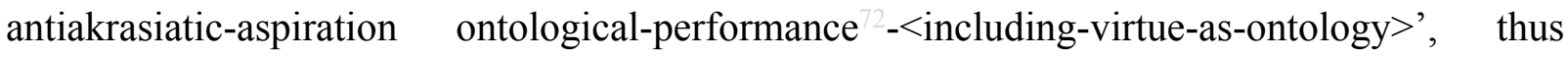
distinctly destructuring. It is important to grasp here that this destructuring-threshold〈uninstitutionalised-threshold /presublimating-desublimating-decisionality $\rangle$ of-ontologicalperformance ${ }^{2}-<$ including-virtue-as-ontology $>$ /morality/ethics/justice/etc. analysis is notionally/epistemically/bindingnessly ${ }^{\text {-as-to-determinism/conceptivity-of-relative-unreflexivity/relative-reflexivity }>}$ as to existence-potency ${ }^{39} \sim$ sublimating-nascence,-disclosed-from-prospective-epistemicdigression epistemic-or-notional $\sim$ projective-perspective of notional $\sim^{18}$ deprocrypticism which is in ontological-normalcy/postconvergence and beyond/superseding the internal positivismprocrypticism disjointedness-as-of- ${ }^{8}$ reference-of-thought human-subpotency social-stakecontention-or-confliction perspective wherein the human-subpotency <amplituding/formativeepistemicity $>$ totalising $\sim$ self-referencing-syncretising/circularity/interiorising/akrasiatic-drag perspective of analysis as of its prior relative-ontological-incompleteness apriorising/axiomatising/referencing/intelligibilitysettingup/measuringinstrumenting will rather be in a pedantising/muddling/formulaic-hollowing-out-in-subontologisation/subpotentiation〈blurring/undermining-of-prospective-totalising-entailing,-as-to-entailing$<$ amplituding/formative-epistemicity $>$ totalising in-relative-ontological-completeness $>$ undisambiguated appraisal of its destructuring-threshold-〈uninstitutionalisedthreshold /presublimating-desublimating-decisionality $>$ of-ontological-performance ${ }^{72}$ 
<including-virtue-as-ontology $>$ /morality/ethics/justice/etc. in contrast to the notional/epistemic/bindingness ${ }^{<a s-t o-d e t e r m i n i s m / c o n c e p t i v i t y-o f-r e l a t i v e-u n r e f l e x i v i t y / r e l a t i v e-r e f l e x i v i t y ~}>$ veracity of existence-potency $^{39} \sim$ sublimating-nascence,-disclosed-from-prospective-epistemic-digression implication as of notional ${ }^{18}$ deprocrypticism in prospective relative-ontological-completeness apriorising/axiomatising/referencing/intelligibilitysettingup/measuringinstrumenting implications of aetiologisation/ontological-escalation- $<$ ontologicalveridicality_commitment/otherliness_transcending/compulsions-encumbered_transcending>; and this is akin to the existence-potency ${ }^{32} \sim$ sublimating-nascence,-disclosed-from-prospectiveepistemic-digression projection to prospective positivism insight of aetiologisation/ontologicalescalation-<ontological-veridicality_commitment/otherliness_transcending/compulsionsencumbered_transcending $>$ with regards to say the reflection of destructuring-transitoriness ${ }^{1}$ as-of-deratiocination/deratiocontiguity in the manifestation of notions-and-accusation-ofsorcery in a non-positivism social-setting social-stake-contention-or-confliction, with the construal of such purportedly constructiveness disposition of 'equivalence/correspondence antiakrasiatic-aspiration ontological-performance ${ }^{72}-<$ including-virtue-as-ontology $^{>}$as of positivism ontologically-hegemonising-narrative ${ }^{71}$ not necessarily telling from within the perspective of the non-positivism human-subpotency social-stake-contention-or-confliction narratives, but for the implied prospective metaphoricity ${ }^{57}$ as prospective ontologicallyhegemonising-narrative $^{7}$ of positivism. Insightfully, such an ontologicalnormalcy/postconvergence destructuring-threshold-〈uninstitutionalisedthreshold /presublimating-desublimating-decisionality/ of-ontological-performance ${ }^{72}$ <including-virtue-as-ontology $>/$ morality/ethics/justice/etc. analysis insight is more like a projective contrast as with the case of the BODMAS characters deficient apriorising/axiomatising/referencing/intelligibilitysettingup/measuringinstrumenting $<$ amplituding/formative-epistemicity $>$ causality $\sim$ as-to-projective-totalitative-implications-of- 
prospective- nonpresencing,-for-explicating $\sim$ relative-unreflexivity/relative-reflexivity

ontological-contiguity operation of Arithmetic construed as of dissingularisation- $<$ as-to-thedisjointedness/disentailment-of- presencing - absolutising-identitive-

constitutedness $>$ /epistemic-nonimmanence/flawed-epistemicity-relativism-determinism in epistemic-abnormalcy/preconvergence ${ }^{31}$ and with regards to our normally conceived apriorising/axiomatising/referencing/intelligibilitysettingup/measuringinstrumenting $<$ amplituding/formative-epistemicity $>$ causality $\sim$ as-to-projective-totalitative-implications-ofprospective- nonpresencing,-for-explicating relative-unreflexivity/relative-reflexivityontological-contiguity for the operation of Arithmetic as of singularisation-<as-to-thenondisjointedness/entailment-of-prospective- nonpresencing $>$ projected epistemicimmanence/veridical-epistemicity-relativism-determinism in ontological-normalcy. Basically, such an ontological-normalcy/postconvergence destructuring-threshold-〈uninstitutionalisedthreshold /presublimating-desublimating-decisionality $>$ of-ontological-performance ${ }^{72}$ $<$ including-virtue-as-ontology $>/$ morality/ethics/justice/etc. analysis speaks of the reality of human $\quad{ }^{15}$ de-mentation-〈supererogatory $\sim$ ontological-de-mentation-or-dialectical-dementation - stranding-or-attributive-dialectics $\rangle$ insights; and the appreciation of the latter as to the displacement/decentering-of-the-human-subject in reflecting holographically$<$ conjugatively-and-transfusively $>$ the relative-unreflexivity/relative-reflexivity - ontologicalcontiguity $\sim$ of-the-human-institutionalisation-process is a requisite for understanding such an ontological-normalcy/postconvergence destructuring-threshold-〈uninstitutionalisedthreshold /presublimating-desublimating-decisionality $>$ of-ontological-performance ${ }^{72}$ $<$ including-virtue-as-ontology $>$ /morality/ethics/justice/etc. analysis. The destructuringthreshold-〈uninstitutionalised-threshold /presublimating-desublimating-decisionality $\rangle$ ofontological-performance $^{72}$-<including-virtue-as-ontology $>/$ morality/ethics/justice/etc. analysis is highly abstracted from such an ontological-normalcy/postconvergence epistemic-or- 
notional projective-perspective (so-understood as of ontologicalnormalcy/postconvergence/Doppler-thinking perspective of analysis). It reflects the abstract development of human-subpotency 'dynamic notional $\sim$ phenomenal-abstractiveness possibilities in their psychodynamic operant apriorising/axiomatising/referencing-\{of-'prospectively implicited_attendant-ontological-contiguity ' educedexistentialising/contextualising/textualising_ 'intelligibility/epistemicity/reflexivity-contiguity<imbued-notional cogency>' \}-conflatedness ${ }^{13}$-in-\{preconverging disentailment by\} postconverging-entailment with the social epistemic-totality of ${ }^{56}$ meaningfulness-andteleology ${ }^{9}$. This psychodynamic operant apriorising/axiomatising/referencing-\{of'prospectively_implicited_attendant-ontological-contiguity ' educedexistentialising/contextualising/textualising_'intelligibility/epistemicity/reflexivity-contiguity<imbued-notional cogency $\left.{ }^{\prime} \quad\right\}$-conflatedness ${ }^{13}$ in-\{preconverging-disentailment by\} postconverging-entailment reflects human-subpotency 'constructiveness-of-ontologicalperformance ${ }^{72}-<$ including-virtue-as-ontology $>$ /institutionalisation/nascent-sublimatingdecisionality_by_destructuring-threshold-〈uninstitutionalised-threshold /presublimatingdesublimating-decisionality $>$ of-ontological-performance ${ }^{72}$-<including-virtue-asontology $>$ /morality/ethics/justice/etc. metaphorising vacillating-conception of the social epistemic-totality ${ }^{37}$ of ${ }^{56}$ meaningfulness-and-teleology ${ }^{9}$; as can veridically be construed from existence-potency ${ }^{39} \sim$ sublimating-nascence,-disclosed-from-prospective-epistemic-digression epistemic perspective as of ontological-normalcy/postconvergence with respect to assessing 'equivalence/correspondence antiakrasiatic-aspiration ontological-performance ${ }^{2}-<$ includingvirtue-as-ontology >'. This destructuring-threshold-〈uninstitutionalisedthreshold /presublimating-desublimating-decisionality $>$ of-ontological-performance ${ }^{72}$ $<$ including-virtue-as-ontology $>$ /morality/ethics/justice/etc. analysis further highlights the 'transitive nature' of the human psyche across the various registry-worldviews/dimensions 
uninstitutionalised-threshold ${ }^{102}$ in reflecting holographically-<conjugatively-and-transfusively $>$ the relative-unreflexivity/relative-reflexivity - ontological-contiguity of-the-humaninstitutionalisation-process with respect to destructuring at all uninstitutionalised-threshold ${ }^{102}$; as so-implied by ${ }^{15}$ de-mentation-〈supereronatory-ontological-de-mentation-or-dialectical-dementation-stranding-or-attributive-dialectics $\rangle$. The comprehensive social susceptibility to destructuring-transitoriness ${ }^{19}$-as-of-deratiocination/deratiocontiguity as the defining element of the social-construct destructuring is what underlies passive to active social mobbishness phenomena as of human limited-mentation-capacity-as-subjecting-educedunlimitedness/existence-sublimating nascence' to-limitedness/human-subpotency social dynamic implications of lacking social ontologically-hegemonising-narrative'? The failing 'reentologising \{epistemic-totalising re-apriorising/re-axiomatising/re-referencing-residuality in-reeriginariness/re-origination $\{$ \{decompulsing\} delinearity/delinear-accreting/recomposuring cogency/tensing/limpidity-<as-of-prospective-profound-supererogation ,-for-residuality-inre-originariness/re-origination $>$, prospective reifying mental-aestheticising-<s-of'prospective_reformulating of mental-aestheticising'as-to-'residuality in re-originariness/reerigination'-of-mental-aestheticising ' and individual wariness of the social as of the lack of a comprehensive expectation of 'equivalence/correspondence antiakrasiatic-aspiration ontological-performance ${ }^{72}-<$ including-virtue-as-ontology $>$ ' arises because of destructuringtransitoriness 1 -as-of-deratiocination/deratiocontiguity as of its implied destructuring-threshold〈uninstitutionalised-threshold /presublimating-desublimating-decisionality $\rangle$ of-ontological-

performance $^{72}$-<including-virtue-as-ontology $>$ /morality/ethics/justice/etc. parasitism $<$ amplituding/formative-epistemicity $>$ totalising $\sim$ self-referencingsyncretising/circularity/interiorising/akrasiatic-drag ${ }^{4}$, as beyond-the-consciousness-awarenessteleology $-<$ of-preconverging-existential-extrication-as-of-existential-unthought $>\quad$ this reflects the individual psyche conception of the social especially as of its extended-informality 
as not necessarily of high operant 'equivalence/correspondence antiakrasiatic-aspiration ontological-performance ${ }^{72}-<$ including-virtue-as-ontology $>$ ', and is further reflected in a social dynamics of dual overt and covert implicited interpretations of social phenomenality arising as of beyond-the-consciousness-awareness-teleology ${ }^{\circ}<$ of-preconverging-existential-extricationas-of-existential-unthought $>$ cognisance-and-adaptation to the reality of the ontologically compromisable possibility of social ${ }^{56}$ meaningfulness-and-teleology ${ }^{9}$. Insightfully, it can be appreciated that the relative-unreflexivity/relative-reflexivity ontological-contiguity ${ }^{7} \sim$ of-thehuman-institutionalisation-process ${ }^{68}$ is one long process involving the undermining of destructuring-transitoriness -as-of-deratiocination/deratiocontiguity at uninstitutionalisedthreshold ${ }^{102}$ with relative 'equivalence/correspondence antiakrasiatic-attainment ontologicalperformance $^{2}-$ including-virtue-as-ontology $>^{\prime}$ as of ontologically-hegemonising-narrative implied as of prospective '<amplituding/formativeepistemicity $>$ totalising $\sim$ ratiocontiguity/ratiocination-as-referentialism—'implicited_attendant ontological-contiguity ${ }^{67}$, educedexistentialising/contextualising/textualising_intelligibility/epistemicity/reflexivity-contiguity<imbued-notional cogency $>^{\prime 0}$ constructiveness disposition in singularisation- $<$ as-to-thenondisjointedness/entailment-of-prospective- nonpresencing $>$ projected epistemicimmanence/veridical-epistemicity-relativism-determinism'. In this regard, we can appreciate anthropologically as of human limited-mentation-capacity-deepening-as-subjectinglimitedness/human-subpotency-to-'educed-unlimitedness/existence-sublimating nascence' implications the destructuring-transitoriness 19 -as-of-deratiocination/deratiocontiguity that upheld superstitious beliefs in non-positivism social constructs but as of positivism/rationalempiricism ontologically-hegemonising-narrative ${ }^{71}$ implied with social enlightenment and the sciences rendered many purviews of existence as of relative 'equivalence/correspondence

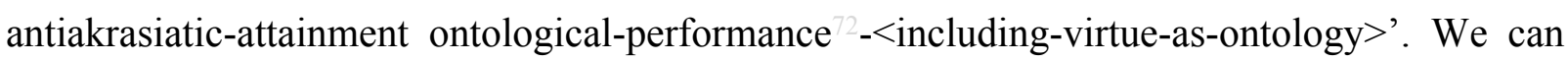


similarly project of the same with respect to our positivism- ${ }^{80}$ procrypticism disjointedness-asof- ${ }^{3}$ reference-of-thought destructuring-transitoriness -as-of-deratiocination/deratiocontiguity at its uninstitutionalised-threshold as to be prospectively superseded by notional ${ }^{8}$ deprocrypticism preempting - disjointedness-as-of- reference-of-thought ontologically-hegemonising-narrative ${ }^{71}$ thus rendering human ontological-performance ${ }^{72}$ $<$ including-virtue-as-ontology $>/$ morality/ethics/justice/etc. correspondence with the-very-sameimmanent-existence/intrinsic-reality/ontological-veridicality,-as-to-

'human<amplituding/formative-epistemicity>totalising purview-of-construal' as prospective relative 'equivalence/correspondence antiakrasiatic-attainment ontologicalperformance ${ }^{72}$-<including-virtue-as-ontology $>$ '. This destructuring-threshold〈uninstitutionalised-threshold /presublimating-desublimating-decisionality $>$ of-ontologicalperformance ${ }^{2}-<$ including-virtue-as-ontology $>$ /morality/ethics/justice/etc. analysis effectively points to the fact that human akrasia-susceptibility-or-akrasiatic-drag complex is such a decisive and determinant notion with respect to the human psyche as the critically interceding notion with respect to human social construction-of-the-Self and as it remains a transitive and constant notion in reflecting holographically-<conjugatively-and-transfusively $>$ the relativeunreflexivity/relative-reflexivity - ontological-contiguity of-the-human-institutionalisationprocess as to the destructuring implications at uninstitutionalised-threshold ${ }^{102}$ implied humansubpotency epistemic-or-notional projective-perspective in dissingularisation-<as-to-thedisjointedness/disentailment-of- presencing - absolutising-identitive-

constitutedness $>$ /epistemic-nonimmanence/flawed-epistemicity-relativism-determinism relative to existence-potency ${ }^{39} \sim$ sublimating-nascence,-disclosed-from-prospective-epistemicdigression epistemic-or-notional projective-perspective in singularisation-<as-to-thenondisjointedness/entailment-of-prospective- nonpresencing $>$ projected epistemicimmanence/veridical-epistemicity-relativism-determinism. This overall reifying-and- 
empowering-reflexivity-of-ecstatic-existence-as-panintelligibility/panreflexivity ${ }^{3}$ <existentially-imbued-and-educing-<epistemic-

totalising thermeneutically/textually/reprojectingly/supererogatingly/zeroingly/re-acutingly,$\{$ decompulsing $\}$ delinearity for-cogency $\geq$-epistemic-perspective-of-projective/reprojectiveaestheticising-re-motif-and-re-apriorising/re-axiomatising/re-referencing conceptualisation,as-herein-specifically-relevant-to human-subpotency) of the social-construct as from the elucidation/reification 'destructuring-threshold-〈uninstitutionalisedthreshold /presublimating-desublimating-decisionality $>$ of-ontological-performance ${ }^{72}$ <including-virtue-as-ontology $>$ /morality/ethics/justice/etc. analysis' is rather notionally/epistemically/bindingnessly-<as-to-determinism/conceptivity-of-relative-unreflexivity/relative-reflexivity> reflective of the social-construct constructiveness-of-ontological-performance ${ }^{2}-<$ includingvirtue-as-ontology>, as such an antiakrasiatic analysis of uninstitutionalised-threshold notionally/epistemically/bindingnessly-<as-to-determinism/conceptivity-of-relative-unreflexivity/relative-reflexivity>

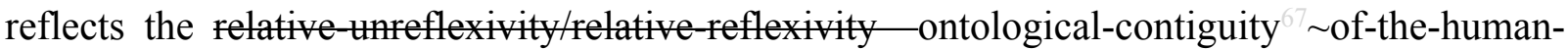
institutionalisation-process ${ }^{8}$; and so, similarly as the analysis of prospective possibilities of disease and illness is not about being pessimistic about the biology of human beings but is notionally/epistemically/bindingnessly-as-to-determinism/conceptivity-of-relative-unneflexivity/relative-reflexivityz reflective of the possibility for the further development and provision of medicine and healthcare, and just as the projective analysis of lack of science and technology capacity is not about being pessimistic about human technical development but is <as-to-determinism/eonceptivity-of-relative-unreflexivity/relative-reflexivity> reflective of the possibility for the further invention of technologies and scientific discoveries. We can appreciate here that the-very-same notional/epistemic/bindingness sas-tederminism/conceptivity-of-relative-nnreflexivity/relative-reflexivityz conceptualisation with respect to the human subject as with natural subject-matters elicits in the former high emotional involvement whereas the latter as of its direct <amplituding/formative- 
epistemicity $>$ causality $\sim$ as-to-projective-totalitative-implications-of-prospective-

nonpresencing,-for-explicating relative-unreflexivity/relative-reflexivity - ontological-

contiguity elicits low emotional-involvement, but for the case where with regards to high and conflicting human social-stake-contention-or-confliction even the natural domain is not immuned from high emotional-involvement as with the climate change issue for instance. The point being made here is that sober analyses of the social as herein articulated tends to elicit naïve criticism that human progress happens anyway, but then such naïve criticism only recounts the fact of human progress while failing to be reifying and is actually dereifying when by its 'implicited passivity implications for prospective human progress' it fails to account for how human progress occurs in-the-very-first-place or even whether there is any underlying process for its occurrence or non-occurrence. Actually, human progress occurs because of effective human constructive disposition to supersede identified-and-defined destructuring-threshold〈uninstitutionalised-threshold /presublimating-desublimating-decisionality $\rangle$ of-ontologicalperformance ${ }^{2}$-<including-virtue-as-ontology $>$ /morality/ethics/justice/etc. and as reflected at uninstitutionalised-threshold $^{102}$. As the Copernicuses, Galileos, Darwins, Diderots, etc. of the world with their subsequently metaphorising societies didn't progress on the basis that human progress occurs anyway but because they effectively superseded their identified-and-defined ontological-performance ${ }^{2}$-<including-virtue-as-ontology $>/$ morality/ethics/justice/etc.

destructuring-threshold-〈uninstitutionalised-threshold /presublimating-desublimating-

decisionality $>\sim$ of-ontological-performance ${ }^{72}$-<including-virtue-as-

ontology $>$ /morality/ethics/justice/etc. and uninstitutionalised-threshold ${ }^{102}$, and it is this difficult task of crossgenerational mobilisation that enables the prospective constructiveness-ofontological-performance $^{72}$-<including-virtue-as-ontology $>/$ morality/ethics/justice/etc. for human Being-development/ontological-framework-expansion-as-to-depth-of-ontologisingdevelopment-as-infrastructure-of- meaningfulness-and-teleology , institutional- 
development-as-to-social-function-development and living-development-as-to-personalitydevelopment psychologismic epistemic-acutisation difficulty-<for, residualising \{decompusing $\}$ delinearity for-cogeney $>$ magnitudes $\{$ of-experientiality/experiment $\}$. The implicited passivity behind such reflections that human progress occurs anyway again highlights why the intemporal mental-dispositions behind the superseding of destructuring-threshold-〈uninstitutionalisedthreshold /presublimating-desublimating-decisionality $>$ of-ontological-performance ${ }^{72}$

$<$ including-virtue-as-ontology $>/$ morality/ethics/justice/etc. need to be integrated into the very core of such secondnatured formulaic/mechanical-knowledge outcome as part-and-parcel of knowledge, construed as organic-knowledge. Otherwise, the very vocation behind such organicknowledge end up being denatured as of deficient apriorising/axiomatising/referencing/intelligibilitysettingup/measuringinstrumenting, and this inevitably actually occurs and reoccurs throughout the relative-unreflexivity/relativereflexivity - ontological-contiguity ${ }^{67}$ of-the-human-institutionalisation-process ${ }^{68} ;$ such that prospective social-construct constructiveness-of-ontological-performance ${ }^{2}-<$ including-virtueas-ontology $>$ /morality/ethics/justice/etc. and institutionalisation is ever always a process of maximalising-recomposuring-for-relative-ontological-completeness ${ }^{87}$ - unenframed/reontologising conceptualisation to prospectively recapture the supererogatory acuity/perspicacity/astuteness/edginess/incisiveness-ofapriorising/axiomatising/referencing/intelligibilitysettingup/measuringinstrumenting -forconceptualisation for prospective organic-knowledge lost in secondnatured institutionalisation with the latter construed in temporality $/$ shortness often bound to induce ${ }^{5}$ incrementalism-inrelative-ontological-incompleteness —enframed/disontologising conceptualisation as of poor apriorising/axiomatising/referencing/intelligibilitysettingup/measuringinstrumenting. Inevitably across the various registry-worldviews/dimensions in reflecting holographically$<$ conjugatively-and-transfusively $>$ the relative-unreflexivity/relative-reflexivity - ontological- 
contiguity $\sim$ of-the-human-institutionalisation-process , the ${ }^{103}$ universally-transparent articulation-and-implications (as herein) of human destructuring as reflected by ‘ $<$ amplituding/formative-epistemicity $>$ totalising/circumscribing/delineating preconverging/dementing ${ }^{2}$-qualia-schema' and constructiveness as reflected by ‘<amplituding/formative-epistemicity>totalising/circumscribing/delineating postconverging/dialectical-thinking -qualia-schema' inherently elicits from the humansubpotency epistemic-or-notional projective-perspective reflected as of the ‘ $<$ amplituding/formative-epistemicity $>$ totalising/circumscribing/delineating preconverging/dementing ${ }^{20}$-qualia-schema' in $\quad$ amplituding/formativeepistemicity $>$ totalising $\sim$ self-referencing-syncretising/circularity/interiorising/akrasiatic-drag ${ }^{34}$, a sense of temporal social-stake-contention-or-confliction existential-investment ushering in the furthering of temporality $8 /$ shortness as of untransvaluated-temporal-intemporality ${ }^{52}$ inclination and accompanying sophistic/pedantic complexes. But from the intemporal-as-ontological teleologically-elevated projection reflected as from existence-potency ${ }^{39} \sim$ sublimating-nascence,disclosed-from-prospective-epistemic-digression epistemic-or-notional projective-perspective for aetiologisation/ontological-escalation-<ontologicalveridicality_commitment/otherliness_transcending/compulsions-encumbered_transcending > such temporal-dispositions are rather unwarranted and irrelevant since such aetiologisation/ontological-escalation- $<$ ontologicalveridicality_commitment/otherliness_transcending/compulsions-encumbered_transcending $>$ is rather geared towards the prospective relative-ontological-completeness ${ }^{87}$ implied social-stakecontention-or-confliction as of human intemporal/ontological/social/species/ ${ }^{103}$ universal/transcendental $/{ }^{5}$ maximalisingrecomposuring-for-relative-ontological-completeness ${ }^{8}$ —unenframed/reontologising conceptualisation postconverging-de-mentating/structuring/paradigming and not 
the prior relative-ontological-incompleteness ${ }^{88}$ social-stake-contention-or-confliction in extricatory/temporal preconverging-de-mentating/structuring/paradigming; and candidly so to the extent that the intemporal-as-ontological dispensing-with-immediacy-for-relativeontological-completeness $^{87}$-by-reification/contemplative-distension ${ }^{27}$ (as of human selfsurpassing — existentialism-form-factor,-in-overcoming-“notional collateralising-beholdeningprotohumanity’-to-'attain-sublimating-humanity'-as-to-existence-potency sublimatingnascence,-disclosed-from-prospective-epistemic-digression to supersede human temporality 9 /shortness <amplituding/formative> wooden-language-〈imbued-averaging-ofthought-<as-to-leveling/ressentiment/closed-construct-of- meaningfulness-and-teleology -asof-'nondescript/ignorable-void ' -with-regards-to-prospective-apriorising-implications $>\rangle)$ is not interpreted from a temporal existential-extricatory-as-of-existential-unthought perspective as ineptness warranting the furtherance of temporal-dispositions as of untransvaluated-temporalintemporality $^{52}$ inclination and accompanying sophistic/pedantic complexes as well as to the extent of entailing prospective relative-ontological-completeness ${ }^{87}$. We can appreciate in this regards that the intemporal projection as of base-institutionalisation implies an incisive/edgy apriorising-teleological-elevation-in $\sim$ notional-contiguity/epistemic-contiguity ${ }^{2} \_$profoundsupererogation -of-mentally-aestheticised postconverging/dialectical-thinking -qualiaschema $>$ beyond recurrent-utter-uninstitutionalisation social-stake-contention-or-confliction as of its $\quad<$ amplituding/formative-epistemicity $>$ totalising/circumscribing/delineating preconverging/dementing ${ }^{20}$-qualia-schema' in $\quad$ <amplituding/formativeepistemicity>totalising $\sim$ self-referencing-syncretising/circularity/interiorising/akrasiatic-drag ${ }^{34}$, and likewise with the intemporal projection as of ${ }^{103}$ universalisation over baseinstitutionalisation-ununiversalisation, positivism over $\quad{ }^{103}$ universalisation-nonpositivism/medievalism and prospectively notional ${ }^{18}$ deprocrypticism over positivismprocrypticism. In this regards, the notion of preconverging-or-dementing ${ }^{20}$-apriorising- 
psychologism as reflected as of '<amplituding/formativeepistemicity>totalising/circumscribing/delineating preconverging/dementing ${ }^{20}$-qualia-schema' of prior relative-ontological-incompleteness ${ }^{8}$ is tied-to and a necessarily associated notion with that of postconverging-or-dialectical-thinking -apriorising-psychologism as reflected as of '<amplituding/formative-epistemicity $>$ totalising/circumscribing/delineating postconverging/dialectical-thinking -qualia-schema' with respect to the possibility of a protracted-consciousness conceptualisation in reflecting holographically-<conjugatively-andtransfusively $>$ the relative-unreflexivity/relative-reflexivity ontological-contiguity $\sim$ of-thehuman-institutionalisation-process ; and as this explains the successive construction-of-the-Self reflected in the <cumulating/recomposuring attendant-ontological-contiguity $>$-successive registry-worldviews/dimensions. It is the possibility for the human mind to dement as of a ‘ $<$ amplituding/formative-epistemicity $>$ totalising/circumscribing/delineating preconverging/dementing - qualia-schema' by its self-conscious <amplituding/formativeepistemicity>-totalising $\sim$ renewing-realisation/re-perception/re-thought $\quad$ as of its $<$ amplituding/formative-epistemicity $>$-totalising $\sim$ thrownness-in-existence ${ }^{35} \quad$ that preconverging/postconverging-de-mentatively/structurally/paradigmatically allows for the possibility of prospective institutionalisation involving the displacement/decentering-of-thehuman-subject. Unlike our naïve human-subpotency epistemic-or-notional projectiveperspective inclined to perceive prior registry-worldviews/dimensions in their '<amplituding/formative-epistemicity $>$ totalising/circumscribing/delineating preconverging/dementing ${ }^{20}$-qualia-schema' in stigmatising terms-as-of-axiomatic-construct, the ontological-veracity from existence-potency ${ }^{32} \sim$ sublimating-nascence,-disclosed-fromprospective-epistemic-digression epistemic-or-notional $\sim$ projective-perspective is one that rather entails a forward-thinking appreciation that the possibility of all prospective relative-ontologicalcompleteness ${ }^{87}$ postconverging-or-dialectical-thinking ${ }^{2}$-apriorising-psychologism reflected as 
postconverging/dialectical-thinking -qualia-schema' can only arise as of the psychoanalyticunshackling/memetic-reordering/institutional-recomposuring possibility of prior relativeontological-incompleteness preconverging-or-dementing ${ }^{20}$-apriorising-psychologism reflected as of '<amplituding/formative-epistemicity $>$ totalising/circumscribing/delineating preconverging/dementing -qualia-schema', and so whether from a retrospective, present or prospective perspective; speaking of the 'miracle of the human mind malleable potential as of the human-subject-emancipating-relativism-driven-recomposuring-constructivism-towardssingularisation-<as-to-the-nondisjointedness/entailment-of-prospective- nonpresencing $>$, , and implying an obligation for any given registry-worldview/dimension to maximalise this human capacity for Being-development/ontological-framework-expansion-as-to-depth-ofontologising-development-as-infrastructure-of- meaningfulness-and-teleology as of its growing self-consciousness and self-awareness. In fact, the notion of preconverging-ordementing -apriorising-psychologism as such speaks of the fact that the entire cross-section of humanity as of recurrent-utter-uninstitutionalisation is of a '<amplituding/formativeepistemicity $>$ totalising/circumscribing/delineating preconverging/dementing ${ }^{20}$-qualia-schema' with respect to prospective base-institutionalisation '< $<$ amplituding/formativeepistemicity $>$ totalising/circumscribing/delineating $\quad$ postconverging/dialectical-thinking qualia-schema', and likewise ${ }^{103}$ universalisation with respect to base-institutionalisationununiversalisation, ${ }^{103}$ universalisation-non-positivism/medievalism with respect to positivism, and our present positivism- ${ }^{8}$ procrypticism with respect to prospective deprocrypticism. The fact is, even the said prospective transcendence-and-sublimity/sublimation/supereregatery $\sim$ dementativity emancipators across the <cumulating/recomposuring attendant-ontologicalcontiguity >-successive registry-worldviews/dimensions in reflecting holographically$<$ conjugatively-and-transfusively $>$ the relative-unreflexivity/relative-reflexivity - ontological- 
contiguity $\sim$ of-the-human-institutionalisation-process are just as equally relatively enmeshed in-many-ways with their ${ }^{83}$ reference-of-thought old psychology '<amplituding/formativeepistemicity>totalising/circumscribing/delineating preconverging/dementing ${ }^{20}$-qualia-schema' like say Newton's involvement with alchemy, and the idea of projecting to a prospective '<amplituding/formative-epistemicity $>$ totalising/circumscribing/delineating postconverging/dialectical-thinking -qualia-schema' speaks of a first level of human uninhibitedness/decomplexification that is exactly what allows for human emancipation. This further shows how our seemingly objectified ${ }^{79}$ presencing-absolutising-identitiveconstitutedness $^{14}$ positivism- ${ }^{8}$ procrypticism disposition is all-encompassing as of our $<$ amplituding/formative--epistemicity $>$ totalising $\sim$ self-referencing-

syncretising/circularity/interiorising/akrasiatic-drag ${ }^{34}$ when we construe of ourselves as 'postconverging-or-dialectical-thinking -apriorising-psychologism as of in-the-absolute' without projecting that just as prior generations of humans were both postconverging-ordialectical-thinking -apriorising-psychologism as of their constructiveness-of-ontological-

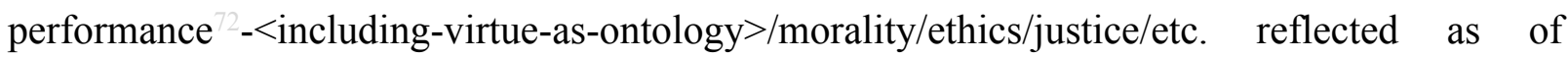
‘<amplituding/formative--epistemicity $>$ totalising/circumscribing/delineating

postconverging/dialectical-thinking -qualia-schema' at their relative-ontologicalcompleteness $^{87}$ and preconverging-or-dementing ${ }^{20}$-apriorising-psychologism as of their destructuring-threshold-〈uninstitutionalised-threshold /presublimating-desublimatingdecisionality $>\sim$ of-ontological-performance ${ }^{72}$ - $<$ including-virtue-asontology $>$ /morality/ethics/justice/etc. reflected as of '< $<$ amplituding/formativeepistemicity $>$ totalising/circumscribing/delineating preconverging/dementing ${ }^{20}$-qualia-schema' at their relative-ontological-incompleteness ${ }^{8}$, we equally manifest the same and so-perceived from the prospective relative-ontological-completeness ${ }^{87}$ of ${ }^{18}$ deprocrypticism-orpreempting - disjointedness-as-of- ${ }^{8}$ reference-of-thought. The critical point here has to do with 
the fact that beyond the 'attendant-ontologies-as-of-conventioning-referencing' of the $<$ cumulating/recomposuring attendant-ontological-contiguity $>$-successive registryworldviews/dimensions, in their <amplituding/formative> wooden-language-<imbued averaging-of-thought-<as-to-leveling/ressentiment/closed-construct-of- meaningfulness-andteleology -as-of-'nondescript/ignorable-void '-with-regards-to-prospective-apriorisingimplications $>>$ as of their ontologically-flawed identitive-constitutedness ${ }^{14}$-as-'epistemictotality ${ }^{37}$-dereification-in-dissingularisation- $<$ as-to-the-disjointedness/disentailment-ofpresencing - absolutising-identitive-constitutedness $>$-as-flawed-epistemicity-relativismdeterminism, that are enabled by human limited-mentation-capacity-deepening-assubjecting limitedness/human subpotency to 'educed unlimitedness/existence sublimating nascence' 3 as herein implied successively as of non-rulesapriorising/axiomatising/referencing-psychologism of recurrent-utter-uninstitutionalisation, rulemaking-over-non-rules - apriorising/axiomatising/referencing-psychologism of baseinstitutionalisation, universalisation-directed-rulemaking-over-non-rulesapriorising/axiomatising/referencing-psychologism of ${ }^{103}$ universalisation, positivising/rationalempiricism-based-universalisation-directed-rulemaking-over-non-rules_apriorising/axiomatising/referencing-psychologism of our positivism and preemptingdisjointedness-as-of- ${ }^{8}$ reference-of-thought,-as-to- ${ }^{\cdot 3}<$ amplituding/formativeepistemicity $>$ growth-or-conflatedness ${ }^{13} /$ transvaluative- $^{2}$ rationalising/transepistemicity/anamnestic-residuality/spirit-drivenness' — in-supersedingmere-formulaic-positivising/rational-empiricism-based-universalisation-directed-rulemakingover-non-rules_-apriorising/axiomatising/referencing-psychologism of futural Beingdevelopment/ontological-framework-expansion-as-to-depth-of-ontologising-development-asinfrastructure-of- meaningfulness-and-teleology as of prospective deprocrypticism; the relative-unreflexivity/relative-reflexivity - ontological-contiguity ${ }^{67}$ of-the-human- 
institutionalisation-process ${ }^{68}$ can thus be qualified as the 'true-ontology-as-of-Beingdevelopment/ontological-framework-expansion-as-to-depth-of-ontologising-development-asinfrastructure-of- meaningfulness-and-teleology, as its opened-construct-ofmeaningfulness-and-teleology reflects the comprehensive ontological-veracity of the $<$ cumulating/recomposuring attendant-ontological-contiguity $>$-successive registryworldviews/dimensions becoming as of ontologically-veridical difference-conflatedness ${ }^{13}$-asto-totalitative-reification-in-singularisation- $<$ as-to-the-nondisjointedness/entailment-ofprospective- nonpresencing $>$-as-veridical-epistemicity-relativism-determinism . This 'trueontology-as-of-Being-development/ontological-framework-expansion-as-to-depth-ofontologising-development-as-infrastructure-of- meaningfulness-and-teleology ' is ultimately construed as of notional conflatedness ${ }^{13}$ with futural Being-development/ontologicalframework-expansion-as-to-depth-of-ontologising-development-as-infrastructure-ofmeaningfulness-and-teleology as of prospective notional ${ }^{18}$ deprocrypticism, reflecting the fact that the relative-unreflexivity/relative-reflexivity - ontological-contiguity ${ }^{67}$ of-the-humaninstitutionalisation-process $^{68}$ as of the <cumulating/recomposuring attendant-ontologicalcontiguity $>$-successive registry-worldviews/dimensions outcomes can be construed as one of human successive failings to attain ${ }^{18}$ deprocrypticism-or-preempting-disjointedness-as-ofreference-of-thought singularisation-<as-to-the-nondisjointedness/entailment-of-prospectivenonpresencing $>\quad$ projected epistemic-immanence/veridical-epistemicity-relativismdeterminism and so up to the prospective human attaining of ${ }^{18}$ deprocrypticism-orpreempting - disjointedness-as-of- ${ }^{83}$ reference-of-thought singularisation-<as-to-thenondisjointedness/entailment-of-prospective- nonpresencing $>$ projected epistemicimmanence/veridical-epistemicity-relativism-determinism. Thus the relativeunreflexivity/relative-reflexivity - ontological-contiguity ${ }^{67}$ of-the-human-institutionalisationprocess ${ }^{68}$ 'true-ontology_as-of-Being-development/ontological-framework-expansion-as-to- 
depth-of-ontologising-development-as-infrastructure-of- meaningfulness-and-teleology

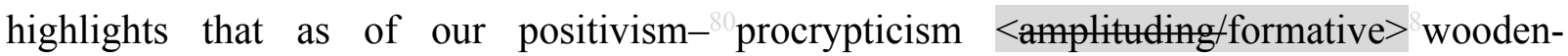
language-〈imbued - averaging-of-thought-<as-to-leveling/ressentiment/closed-construct-ofmeaningfulness-and-teleology -as-of-'nondescript/ignorable-void ' -with-regards-toprospective-apriorising-implications $>\rangle$ as of its ontologically-flawed identitiveconstitutedness ${ }^{14}$-as-'epistemic-totality ${ }^{37}$ '-dereification-in-dissingularisation-<as-to-thedisjointedness/disentailment-of- presencing - absolutising-identitive-constitutedness $>$-asflawed-epistemicity-relativism-determinism , we are involved in a fundamental disjointednessas-of- reference-of-thought in the sense that we seem to imply in our <amplituding/formativeepistemicity $>$ totalising $\sim$ self-referencing-syncretising/circularity/interiorising/akrasiatic-drag that our 'positivism- ${ }^{80}$ procrypticism attendant-ontology-as-of-conventioning-referencing' as reflected by our positivist science-ideology and humanism ideology seemingly surpasses the very 'true-ontology - as-of-Being-development/ontological-framework-expansion-as-to-depthof-ontologising-development-as-infrastructure-of- meaningfulness-and-teleology , in reflecting holographically-<conjugatively-and-transfusively $>$ the relative-unreflexivity/relativereflexivity ontological-contiguity of-the-human-institutionalisation-process that engendered our positivism/rational-empiricism creating as of epistemic-ricochetting the said science without the science-ideology and the said human emancipation without the humanism ideology. This fundamental disjointedness explains why and how our positivist science-ideology and humanism ideology so-misconstrued beyond-the-consciousness-awareness-teleology $<$ of-preconverging-existential-extrication-as-of-existential-unthought $>$ rather turns out to be denaturing and undermines re-ontologising prospective Being-development/ontologicalframework-development, and explains our inclination to ask the wrong questions given the false sense of certainty arising from this 'positivism- ${ }^{80}$ procrypticism attendant-ontology-as-ofconventioning-referencing'. Such questions with regards to how the humanities can be further 
developed as efficaciously as the natural sciences, how can philosophy be more socially potent, and on the social paradoxes of our suboptimum institutional-development-as-to-social-functiondevelopment and living-development-as-to-personality-development psychologismic epistemic-acutisation difficulty-for, residualising \{decompulsing $\}$ delinearity for-cogency> magnitudes ${ }^{\{0 f-e x p e r i e n t i a l i t y / e x p e r i m e n t\}}$, more critically point to the ontological-veracity in reflecting holographically-<conjugatively-and-transfusively $>$ the relative-unreflexivity/relativereflexivity - ontological-contiguity of-the-human-institutionalisation-process 'trueontology_as-of-Being-development/ontological-framework-expansion-as-to-depth-ofontologising-development-as-infrastructure-of- meaningfulness-and-teleology , as of its implied intemporal ontological-faith-notion-or-ontological-fideism - imbuedunderdetermination-of-motif-and-apriorising/axiomatising/referencing-as-so-being-as-ofexistential-reality parrhesiastic askesis-or-acumen reasoning-through/messianic-reasoning recurrent shot for completeness as of successive reproducibility—mathesis/motif/thrownnessdisposition,-as-reproducibility-of-aestheticisation registry-worldviews/dimensions; and so critically by the displacement/decentering-of-the-human-subject as of psychoanalyticunshackling/memetic-reordering/institutional-recomposuring. In this regards, as applies with our positivism- ${ }^{80}$ procrypticism and so just as with any other prior relative-ontologicalincompleteness ${ }^{88}$ registry-worldviews/dimensions $<$ amplituding/formative $>$ wooden-language〈imbued-averaging-of-thought-<as-to-leveling/ressentiment/closed-construct-ofmeaningfulness-and-teleology -as-of-'nondescript/ignorable-void '-with-regards-toprospective-apriorising-implications $>>$ as of their ontologically-flawed identitiveconstitutedness ${ }^{14}$-as- ${ }^{\text {eppistemic-totality }}{ }^{37}$ '-dereification-in-dissingularisation- $<$ as-to-thedisjointedness/disentailment-of- presencing - absolutising-identitive-constitutedness $>$-asflawed-epistemicity-relativism-determinism , there has always been an ontologically-flawed inclination that the given registry-worldview's/dimension's 'attendant-ontology-as-of- 
conventioning-referencing' in its <amplituding/formative-epistemicity $>$ totalising $\sim$ selfreferencing-syncretising/circularity/interiorising/akrasiatic-drag ${ }^{34}$ inherently carries all the prospective possibilities of human emancipation and so oblivious-and-substituting of the underlying relative-unreflexivity/relative-reflexivity — ontological-contiguity ${ }^{67} \sim$ of-the-humaninstitutionalisation-process 68 'true-ontology—as-of-Being-development/ontologicalframework-expansion-as-to-depth-of-ontologising-development-as-infrastructure-ofmeaningfulness-and-teleology '. In other words, unlike we may contemplate as of our positivism/rational-empiricism ${ }^{79}$ presencing-absolutising-identitive-constitutedness ${ }^{14}$ mindset, the notion of prospective human emancipation wasn't alien to the recurrent-utteruninstitutionalisation mindset though such a conception by mental-reflex was projected as of its very own 'recurrent-utter-uninstitutionalisation attendant-ontology—as-of-conventioningreferencing' <amplituding/formative > wooden-language-_imbued-averaging-of-thought-<asto-leveling/ressentiment/closed-construct-of- meaningfulness-and-teleology -as-of'nondescript/ignorable-void '-with-regards-to-prospective-apriorising-implications $>>\quad$ in ontologically-flawed identitive-constitutedness ${ }^{4}$-as-'epistemic-totality ${ }^{37}$ '-dereification-indissingularisation-<as-to-the-disjointedness/disentailment-of- presencing - absolutisingidentitive-constitutedness $>$-as-flawed-epistemicity-relativism-determinism hardly contemplative of the ontological-veracity of the underlying relative-unreflexivity/relativereflexivity - ontological-contiguity ${ }^{67} \sim$ of-the-human-institutionalisation-process ${ }^{68}$ 'trueontology—as-of-Being-development/ontological-framework-expansion-as-to-depth-ofontologising-development-as-infrastructure-of- meaningfulness-and-teleology ${ }^{\prime}$ as of its 'implied intemporal ontological-faith-notion-or-ontological-fideism-imbuedunderdetermination-of-motif-and-apriorising/axiomatising/referencing-as-so-being-as-ofexistential-reality parrhesiastic askesis-or-acumen reasoning-through/messianic-reasoning recurrent shot for completeness as of successive reproducibility-mathesis/motif/thrownness- 
disposition,-as-reproducibility-of-aestheticisation' inducing the displacement/decentering-ofthe-human-subject as of psychoanalytic-unshackling/memetic-reordering/institutionalrecomposuring so-reflected as of difference-conflatedness ${ }^{13}$-as-to-totalitative-reification-insingularisation-<as-to-the-nondisjointedness/entailment-of-prospective- nonpresencing $>$-asveridical-epistemicity-relativism-determinism, in order to attain prospective baseinstitutionalisation emancipation; such that all such relative-ontological-incompleteness attendant-ontologies - as-of-conventioning-referencing including our own 'positivismprocrypticism attendant-ontology_as-of-conventioning-referencing' are rather by mentalreflex of their reasoning-from-results/afterthought rather inclined to be oblivious-andsubstituting over the more profound and underlying relative-unreflexivity/relative-reflexivity ontological-contiguity ${ }^{67}$ of-the-human-institutionalisation-process ${ }^{68}$ 'true-ontology-as-ofBeing-development/ontological-framework-expansion-as-to-depth-of-ontologisingdevelopment-as-infrastructure-of- meaningfulness-and-teleology, reflected as of ontologically-veridical difference-conflatedness ${ }^{3}$-as-to-totalitative-reification-insingularisation-<as-to-the-nondisjointedness/entailment-of-prospective- nonpresencing $>$-asveridical-epistemicity-relativism-determinism implied <amplituding/formativeepistemicity $>$ causality $\sim$ as-to-projective-totalitative-implications-of-prospectivenonpresencing,-for-explicating relative-unreflexivity/relative-reflexivity - ontologicalcontiguity. This reality effectively preconverging/postconverging-dementatively/structurally/paradigmatically explains the manifestation of all such relativeontological-incompleteness ${ }^{88}$ registry-worldviews/dimensions attendant-ontologies-as-ofconventioning-referencing $<$ amplituding/formative-epistemicity $>$ totalising $\sim$ self-referencingsyncretising/circularity/interiorising/akrasiatic-drag ${ }^{34}$ induced destructuring-threshold〈uninstitutionalised-threshold /presublimating-desublimating-decisionality $>$ of-ontologicalperformance ${ }^{2}-<$ including-virtue-as-ontology $>$ /morality/ethics/justice/etc. as reflected by their 
uninstitutionalised-threshold $^{102} ;$ and as such an <amplituding/formativeepistemicity>totalising $\sim$ self-referencing-syncretising/circularity/interiorising/akrasiatic-drag suprasocial or <amplituding/formative > wooden-language-_imbued-averaging-of-thought$<$ as-to-leveling/ressentiment/closed-construct-of- meaningfulness-and-teleology -as-of'nondescript/ignorable-void '-with-regards-to-prospective-apriorising-implications $>>$ relativeontological-incompleteness

apriorising/axiomatising/referencing/intelligibilitysettingup/measuringinstrumenting predilection is further subject to its internal social-stake-contention-or-confliction sophistry, with the implications that all prospective transcendence-andsublimity/sublimation/supererande-mentativity $\quad{ }^{56}$ meaningfulness-and-teleology ${ }^{99}$ as reasoning-through/messianic-reasoning must necessarily be wary of all such sophistry that go on to emphasise logic as of the deficient destructuring-threshold-〈uninstitutionalisedthreshold /presublimating-desublimating-decisionality $>$ of-ontological-performance ${ }^{72}$ $<$ including-virtue-as-ontology $>/$ morality/ethics/justice/etc. and thus fails reification as of prospective existence-potency ${ }^{39} \sim$ sublimating-nascence,-disclosed-from-prospective-epistemicdigression $\quad<$ amplituding/formative-epistemicity $>$ causality $\sim$ as-to-projective-totalitativeimplications-of-prospective- nonpresencing,-for-explicating relative-unreflexivity/relativereflexivity - ontological-contiguity of aetiologisation/ontological-escalation- $<$ ontologicalveridicality_commitment/otherliness_transcending/compulsions-encumbered_transcending $>$ in relative-ontological-completeness ${ }^{87}$, and not wrongfully imply its ontological-elevation as of common/mutual logical-dueness implied 'postconverging-or-dialectical-thinking ${ }^{21}$-apriorisingpsychologism' but rather realise the reality of its notional-discontiguity/epistemicdiscontiguity ${ }^{63}<$ between - prior-shallow-supererogation -of-mentallyaestheticised preconverging/dementing -qualia-schema_and_prospective-profoundsupererogation -of-mentally-aestheticised postconverging/dialectical-thinking -qualia- 
schema $>$ that speaks of its prospective preconverging-or-dementing 2 -apriorising-psychologism and thus ontological-degradation. In other words the relative-unreflexivity/relative-reflexivity ontological-contiguity ${ }^{67}$ of-the-human-institutionalisation-process ${ }^{68}$ 'true-ontology-as-ofBeing-development/ontological-framework-expansion-as-to-depth-of-ontologisingdevelopment-as-infrastructure-of- meaningfulness-and-teleology, points out that our positivism/rational-empiricism induced science-ideology and humanism ideology as 'attendantontology-as-of-conventioning-referencing' is the outcome in reflecting holographically$<$ conjugatively-and-transfusively $>$ the relative-unreflexivity/relative-reflexivity - ontologicalcontiguity of-the-human-institutionalisation-process 'true-ontology_as-of-Beingdevelopment/ontological-framework-expansion-as-to-depth-of-ontologising-development-asinfrastructure-of- meaningfulness-and-teleology ' and that any such 'attendant-ontology-asof-conventioning-referencing' is not of the appropriate ontological-veracity depth/perspective for contemplating re-ontologising prospective Being-development/ontological-frameworkexpansion-as-to-depth-of-ontologising-development-as-infrastructure-of- meaningfulnessand-teleology <amplituding/formative-epistemicity $>$ causality $\sim$ as-to-projective-totalitativeimplications-of-prospective- nonpresencing,-for-explicating $\sim$ relative-unreflexivity/relativereflexivity - ontological-contiguity as it inevitably enters into an <amplituding/formativeepistemicity>totalising $\sim$ self-referencing-syncretising/circularity/interiorising/akrasiatic-drag given its relative-ontological-incompleteness ${ }^{8}$ that fails to put itself in question with regards to the displacement/decentering-of-the-human-subject as of psychoanalytic-unshackling/memeticreordering/institutional-recomposuring. This displacement/decentering-of-the-human-subject as of psychoanalytic-unshackling/memetic-reordering/institutional-recomposuring further points out from the perspective in reflecting holographically-<conjugatively-and-transfusively $>$ the relative-unreflexivity/relative-reflexivity - ontological-contiguity of-the-humaninstitutionalisation-process 'true-ontology — as-of-Being-development/ontological- 
framework-expansion-as-to-depth-of-ontologising-development-as-infrastructure-of-

meaningfulness-and-teleology , the underlying ontological-veracity of human ${ }^{15}$ dementation-〈supererogatory ontological-de-mentation-or-dialectical-de-mentation — strandingor-attributive-dialectics $\rangle$ as it speaks of the human placeholder-setup/mental-devisingrepresentation/mentation/consciousness-awareness-teleology as actually of an underlying coupling of postconverging-or-dialectical-thinking -apriorising-psychologism

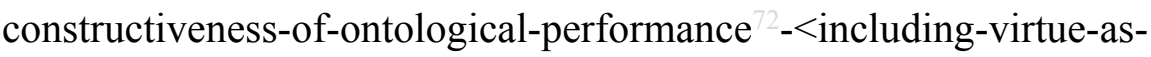
ontology $>$ /morality/ethics/justice/etc. as reflected by '<amplituding/formativeepistemicity $>$ totalising/circumscribing/delineating $\quad$ postconverging/dialectical-thinking qualia-schema' and preconverging-or-dementing -apriorising-psychologism destructuringthreshold-〈uninstitutionalised-threshold /presublimating-desublimating-decisionality) ofontological-performance ${ }^{72}$ - including-virtue-as-ontology $>/$ morality/ethics/justice/etc. reflected by $\quad<$ amplituding/formative-epistemicity $>$ totalising/circumscribing/delineating preconverging/dementing ${ }^{20}$-qualia-schema'. Ultimately, human de-mentation〈supererogatory ontological-de-mentation-or-dialectical-de-mentation-stranding-or-

attributive-dialectics $\rangle$ is the notion underlying human self-consciousness as of construction-ofthe-Self all along in reflecting holographically-<conjugatively-and-transfusively $>$ the relativeunreflexivity/relative-reflexivity - ontological-contiguity of-the-human-institutionalisationprocess 'true-ontology—as-of-Being-development/ontological-framework-expansion-as-todepth-of-ontologising-development-as-infrastructure-of- meaningfulness-and-teleology '. It all arises from the 'human capacity for decomplexified/uninhibited preconverging-ordementing -apriorising-psychologism' in order to then 'prospectively induce originarily/as-ofevent $^{38}$ prospective postconverging-or-dialectical-thinking ${ }^{21}$-apriorising-psychologism'. In this regards, we can factor in for instance that more critically rather than construing the prospective reification of the humanities and philosophy for instance in terms of breakthroughs along the 
lines of say exceptional methods or capacity along the lines of our 'positivism- ${ }^{80}$ procrypticism attendant-ontology — as-of-conventioning-referencing', the reality of any such transcendenceand-sublimity/sublimation/supererogatory de-mentativity will rather be a 'more candid face-up with our ${ }^{80}$ procrypticism-or-disjointedness-as-of- ${ }^{-}$reference-of-thought' as herein implied by this author as of the notion of 'beyond-the-consciousness-awareness-teleology ${ }^{9}-<$ ofpreconverging-existential-extrication-as-of-existential-unthought $>\quad$ institutional-being-andcraft, muddlement and other intellectual complexes/inhibitions' that preconverging/postconverging-de-mentatively/structurally/paradigmatically as of a destructuring-threshold-〈uninstitutionalised-threshold /presublimating-desublimatingdecisionality $>$ of-ontological-performance ${ }^{72}-<$ including-virtue-asontology $>$ /morality/ethics/justice/etc. cloud/undermine the potential for further intellectual emancipation, and so similar to the breakthrough that brought about budding-positivism/rationalempiricism as of say the reasoning-through/messianic-reasoning Galilean gesturing/accounting — of-epistemic-phenomenalism postconverging-dementating/structuring/paradigming based on the fact that looking in the telescope we can appreciate how the planets moved around the sun and as this budding-positivism/rationalempiricism reproducibility—mathesis/motif/thrownness-disposition,-as-reproducibility-ofaestheticisation was relayed by other budding-positivists, and so over the destructuringthreshold-〈uninstitutionalised-threshold /presublimating-desublimating-decisionality $\rangle$ ofontological-performance $^{72}$-<including-virtue-as-ontology $>$ /morality/ethics/justice/etc. of traditional medieval no-trouble disposition to perceive and take comfort in traditional medievalscholasticism reasoning-from-results/afterthought pedantising/muddling/formulaic-hollowingout_-in-subontologisation/subpotentiation-〈blurring/undermining-of-prospective-totalisingentailing,-as-to-entailing-<amplituding/formative-epistemicity $>$ totalising $\sim$ in-relativeontological-completeness $\rangle$ as if critical reification will arise by that pathway. In other words, 
the possibility of all human prospective transcendence-andsublimity/sublimation/supererogatory de-mentativity arises not as we may naively construe vaguely as of exceptional occurrence on the basis of incrementalism-in-relative-ontologicalincompleteness ${ }^{8}$ - enframed/disontologising conceptualisation disposition but rather more concretely only after human decomplexing/uninhibiting preconverging/postconverging-dementative/structural/paradigmatic development 'weaning humankind from its traditional complexes/inhibitions reasoning-from-results/afterthought conceptualising flaws' that then brings about the corresponding existence-potency ${ }^{32} \sim$ sublimating-nascence,-disclosed-fromprospective-epistemic-digression level for human emancipation as of maximalisingrecomposuring-for-relative-ontological-completeness ${ }^{87}$ - unenframed/re-

ontologising conceptualisation; and this is effectively reflected in all cases of human transcendence-and-sublimity/sublimation/supereregatery de-mentativity. Whether of low or high emotional-involvement, it is inevitably the case that the preconverging/postconverging-dementative/structural/paradigmatic possibility for prospective human transcendence-andsublimity/sublimation/supererogatory de-mentativity ever always and has ever always involved or been-grounded-on-prior 'intemporal ontological-faith-notion-or-ontological-fideism

\section{imbued-underdetermination-of-motif-and-apriorising/axiomatising/referencing-as-so-being-as-}

of-existential-reality parrhesiastic askesis-or-acumen reasoning-through/messianic-reasoning recurrent shot for completeness as of successive reproducibility—mathesis/motif/thrownnessdisposition,-as-reproducibility-of-aestheticisation' inducing the displacement/decentering-ofthe-human-subject as of psychoanalytic-unshackling/memetic-reordering/institutionalrecomposuring; as we can appreciate for instance that without the secondnatured institutionalisation arising as from the Galilean gesturing/accounting-of-epistemicphenomenalism reasoning-through/messianic-reasoning highlighted above, there wouldn't have been the human psychology reflected in the displacement/decentering-of-the-human-subject as 
of the resultant reasoning-from-results/afterthought later on in the $20^{\text {th }}$ century to acquiesce to such breakthroughs like theory-of-relativity-together-with-quantum-mechanics-axiomaticconstructs with barely any social contestation. Thus psychoanalytic-unshackling/memeticreordering/institutional-recomposuring, as of human de-mentation〈supererogatory $\sim$ ontological-de-mentation-or-dialectical-de-mentation-stranding-or-

attributive-dialectics $\rangle$ implied prospective postconverging-or-dialectical-thinking ${ }^{21}$-apriorisingpsychologism and prior preconverging-or-dementing -apriorising-psychologism, is merely a reflection of the fact that human ${ }^{56}$ meaningfulness-and-teleology 99 is ever always as of the-verysame overall purview that is existence but then as of various state of human relative-ontologicalincompleteness 88 /relative-ontological-completeness ${ }^{87}$

\section{〈sublimating referencing/registering/decisioning,-as-self-becoming/self-}

conflatedness / $/$ formative-supererogating-<projective/reprojective-aestheticising-re-motifand-re-apriorising/re-axiomatising/re-referencing,-in-perspective-ontologicalnormalcy/postconvergence $>>$ of ${ }^{83}$ reference-of-thought so-construed as registryworldviews/dimensions, such that human ${ }^{5}$ meaningfulness-and-teleology ${ }^{9}$ is thus of lower to higher ontological-veracity/ontological-performance ${ }^{72}-<$ including-virtue-asontology $>$ /morality/ethics/justice/etc. as of relative-ontological-completeness ${ }^{87}$. Further as of human <amplituding/formative-epistemicity>-totalising $\sim$ thrownness-in-existence ${ }^{55}$ with human ${ }^{5}$ meaningfulness-and-teleology ${ }^{9}$ rather undertaken on the-very-same-immanentexistence/intrinsic-reality/ontological-veridicality,-as-to-'human<amplituding/formativeepistemicity>totalising purview-of-construal' and thereof devolving as of existence-as-toexistential-instantiations, the implication is that human ${ }^{56}$ meaningfulness-and-teleology ${ }^{9}$ is thus 'a-given-<amplituding/formative-epistemicity $>$-totalising $\sim$ thrownness-in-existence ${ }^{5}$ construct on existence-as-of-devolving-existential-instantiations' as reflected in the ontologicalveracity/ontological-performance ${ }^{2}$ - $<$ including-virtue-as-ontology $>/$ morality/ethics/justice/etc. 
of its given <amplituding/formative-epistemicity>-totalising thrownness-in-existence registry-worldview/dimension ${ }^{83}$ reference-of-thought- devolving ${ }^{56}$ meaningfulness-andteleology ${ }^{9}$; such that inherently the possibility of prospective virtue and prospective grander ontological-veracity/ontological-performance ${ }^{72}-<$ including-virtue-asontology $>$ /morality/ethics/justice/etc. as required for prospective transcendence-andsublimity/sublimation/supererogatory-de-mentativity beyond/superseding the given $<$ amplituding/formative-epistemicity $>$-totalising $\sim$ thrownness-in-existence ${ }^{35} \quad$ registryworldview/dimension ontological-veracity/ontological-performance ${ }^{72}-<$ including-virtue-asontology $>$ /morality/ethics/justice/etc. as so-reflected in its 'apriorising-teleologicalthresholding-as-teleological-framework/narrative-framework of contextualising/existentialising/instantiative-devolving-meaningfulness' in its prospective relative-ontological-incompleteness 88 cannot spontaneously arise without a displacement/decentering-of-the-human-subject as of prospective relative-ontologicalcompleteness $^{87}$ renewed mathesis/motif/thrownness-dispositon enabled prospective 'apriorising-teleological-thresholding-as-teleological-framework/narrative-framework of contextualising/existentialising/instantiative-devolving-meaningfulness'. It is this $<$ amplinglformative-epistemicity $>$-totalising $\sim$ thrownness-in-existence ${ }^{35} \quad$ induced $<$ amplituding/formative-epistemicity>totalising/circumscribing/delineating nature of human meaningfulness-and-teleology ${ }^{9}$ that renders it necessarily an exercise of $<$ amplituding/formative-epistemicity $>$ totalising $\sim$ self-referencingsyncretising/circularity/interiorising/akrasiatic-drag ${ }^{34}$ as of existence-in-devolving-existentialinstantiations; such that the construal of human ${ }^{56}$ meaningfulness-and-teleology ${ }^{9}$ is rather as of the given <amplituding formative-epistemicity>-totalising $\sim$ thrownness-in-existence ${ }^{35}$ registryworldview/dimension 'apriorising-teleological-thresholding-as-teleologicalframework/narrative-framework of contextualising/existentialising/instantiative-devolving- 
meaningfulness',

epistemicity>totalising/circumscribing/delineating-narrative. Thus the idea of a postconverging-or-dialectical-thinking -apriorising-psychologism representation of human meaningfulness-and-teleology ${ }^{99}$ as to existence-potency ${ }^{39} \sim$ sublimating-nascence,-disclosedfrom-prospective-epistemic-digression epistemic-or-notional projective-perspective is operantly elicited as of the construal of the 'apriorising-teleological-thresholding-asteleological-framework/narrative-framework of contextualising/existentialising/instantiativedevolving-meaningfulness',

of

epistemicity $>$ totalising/circumscribing/delineating-narrative of $<$ amplituding/formative$<$ amplituding/formative-epistemicity $>$-totalising $\sim$ thrownness-in-existence registryworldview/dimension 'implied and underlying background Being-development/ontologicalframework-expansion-as-to-depth-of-ontologising-development-as-infrastructure-ofmeaningfulness-and-teleology devolved institutional-development-as-to-social-functiondevelopment as of its devolving living-development-as-to-personality-development' reflecting its $<$ amplituding/formative-epistemicity $>$ totalising $\sim$ self-referencingsyncretising/circularity/interiorising/akrasiatic-drag reference-of-thought- devolving meaningfulness-and-teleology ${ }^{9}$. Likewise, the idea of a preconverging-or-dementing ${ }^{20}$ apriorising-psychologism representation of human ${ }^{56}$ meaningfulness-and-teleology ${ }^{9}$ as to existence-potency ${ }^{39} \sim$ sublimating-nascence,-disclosed-from-prospective-epistemic-digression epistemic-or-notional projective-perspective is operantly elicited as of the prospective relativeontological-completeness ${ }^{87}$ postconverging-or-dialectical-thinking ${ }^{2}$-apriorising-psychologism registry-worldview/dimension superseding construal of the said preconverging-or-dementing apriorising-psychologism prior relative-ontological-incompleteness ${ }^{88}$ registryworldview/dimension 'dementing ${ }^{20}$ apriorising-teleological-thresholding-as-teleologicalframework/narrative-framework of contextualising/existentialising/instantiative-devolving- 
meaningfulness',

epistemicity>totalising/circumscribing/delineating-narrative implied '<amplituding/formativeepistemicity>totalising/circumscribing/delineating preconverging/dementing ${ }^{20}$-qualia-schema', so-reflected rather as from the prospective relative-ontological-completeness ${ }^{87}$ postconvergingor-dialectical-thinking ${ }^{2}$-apriorising-psychologism registry-worldview/dimension 'deeper/more-profound implied and underlying background Being-development/ontologicalframework-expansion-as-to-depth-of-ontologising-development-as-infrastructure-ofmeaningfulness-and-teleology devolved institutional-development-as-to-social-functiondevelopment as of its devolving living-development-as-to-personality-development' as of the prospective $<$ amplituding/formative-epistemicity $>$ totalising $\sim$ self-referencingsyncretising/circularity/interiorising/akrasiatic-drag reference-of-thought- ${ }^{8}$ devolving meaningfulness-and-teleology ${ }^{9}$, as superseding the prior relative-ontologicalincompleteness ${ }^{88} \quad$ preconverging-or-dementing ${ }^{20}$-apriorising-psychologism registryworldview/dimension 'shallower implied and underlying background Beingdevelopment/ontological-framework-expansion-as-to-depth-of-ontologising-development-asinfrastructure-of- meaningfulness-and-teleology devolved institutional-development-as-tosocial-function-development as of its devolving living-development-as-to-personalitydevelopment' as of the prior <amplituding/formative-epistemicity $>$ totalising $\sim$ self-referencingsyncretising/circularity/interiorising/akrasiatic-drag $\quad$ reference-of-thought- ${ }^{84}$ devolving meaningfulness-and-teleology ${ }^{9}$ More spontaneously, a postconverging-or-dialecticalthinking -apriorising-psychologism representation is construed as of the projection to a given registry-worldview/dimension 'ontological-depth framework of <amplituding/formativeepistemicity>totalising/circumscribing/delineating-narrative' as of its 'implied and underlying background Being-development/ontological-framework-expansion-as-to-depth-ofontologising-development-as-infrastructure-of- meaningfulness-and-teleology devolved 
institutional-development-as-to-social-function-development as of its devolving livingdevelopment-as-to-personality-development', while a preconverging-or-dementing ${ }^{20}$ apriorising-psychologism representation is construed as of the projection to the prospective relative-ontological-completeness ${ }^{87}$ registry-worldview/dimension 'ontological-depth framework of <amplituding/formative-epistemicity>totalising/circumscribing/delineatingnarrative' as of its 'deeper/more-profound implied and underlying background Beingdevelopment/ontological-framework-expansion-as-to-depth-of-ontologising-development-asinfrastructure-of- meaningfulness-and-teleology devolved institutional-development-as-tosocial-function-development as of its devolving living-development-as-to-personalitydevelopment' in reflecting the prior relative-ontological-incompleteness ${ }^{8}$ registryworldview/dimension 'preconverging-or-dementing 2 -apriorising-psychologism $<$ amplituding/formative-epistemicity>totalising/circumscribing/delineating-narrative' as of the latter's 'shallower implied and underlying background Being-development/ontologicalframework-expansion-as-to-depth-of-ontologising-development-as-infrastructure-ofmeaningfulness-and-teleology devolved institutional-development-as-to-social-functiondevelopment as of its devolving living-development-as-to-personality-development'. This $<$ amplitung/formative-epistemicity>totalising/circumscribing/delineating elucidation about postconverging-or-dialectical-thinking -apriorising-psychologism representation and preconverging-or-dementing -apriorising-psychologism representation as of human ${ }^{15} \mathrm{de}$ mentation-〈supererogatory ontological-de-mentation-or-dialectical-de-mentation — strandingor-attributive-dialectics implications underlies the ${ }^{4}$ historiality/ontologicaleventfulness 3 /ontological-aesthetic-tracing-<perspective-ontologicalnormalcy/postconvergence-reflected-'epistemicity-relativism-determinism'> in reflecting holographically-<conjugatively-and-transfusively $>$ the relative-unreflexivity/relativereflexivity - ontological-contiguity of-the-human-institutionalisation-process as of human- 
subpotency-aporia/undecidability/dilemma/ought-

indeterminacy/deficiency/limitation/constraint—imbued-'notional firstnaturedness-

formativeness-<as-to-eventualising-inkling drive-or-seeding misprising $>$ temporal-to-

intemporal-dispositions-<so-construed-as-from-perspective-ontological-

normalcy/postconvergence>'-existentialism-form-factor

<amplituding/formative-

epistemicity $>$ causality as-to-projective-totalitative-implications-of-prospective-

nonpresencing,-for-explicating relative-unreflexivity/relative-reflexivity - ontological-

contiguity . However, from a traditional/modern/positivism history construal perspective, such

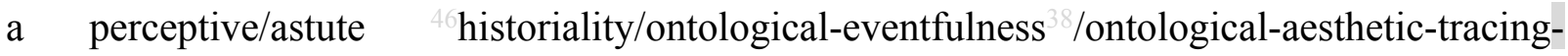
$<$ perspective--ontological-normalcy/postconvergence-reflected-'epistemicity-relativism-

determinism'> is hardly reflected as it tends to induce a naïve, flawed and incomplete representation of the past as being mainly as of the "cumulation of human postconverging-ordialectical-thinking -apriorising-psychologism representations <amplituding/formativeepistemicity>totalising/circumscribing/delineating-narratives and as this is often further skewed towards the locus of the present registry-worldview/dimension (positivism/rational-empiricism) postconverging-or-dialectical-thinking -apriorising-psychologism representation', and thus inmany-ways failing to project fundamentally the reality of human-subpotencyaporia/undecidability/dilemma/ought-indeterminacy/deficiency/limitation/constraint—imbued'notional firstnaturedness-formativeness-<as-to-eventualising -inkling-drive-or-seedingmisprising $>$ temporal-to-intemporal-dispositions- $<$ so-construed-as-from-perspectiveontological-normalcy/postconvergence>'-existentialism-form-factor and further fails to echo the metaphoricity ${ }^{57}$ existential-ecstasy of the sublimating ${ }^{4}$ historiality/ontologicaleventfulness ${ }^{3}$ /ontological-aesthetic-tracing-<perspective-ontologicalnormalcy/postconvergence-reflected-'epistemicity-relativism-determinism'> of meaningfulness-and-teleology' as of the 'relative-unreflexivity/relative-reflexivity- 
ontological-contiguity ${ }^{67}$ of-the-human-institutionalisation-process ${ }^{68}$ dynamics of successive postconverging-or-dialectical-thinking -apriorising-psychologism representation and preconverging-or-dementing ${ }^{20}$-apriorising-psychologism representation of meaningfulnessand-teleology', reflected in 'successive construction-of-the-Self underlying the sublimating historiality/ontological-eventfulness ${ }^{38} /$ ontological-aesthetic-tracing-<perspectiveontological-normalcy/postconvergence-reflected-'epistemicity-relativism-determinism'> as of successive self-consciousness for ${ }^{5}$ meaningfulness-and-teleology ${ }^{9}$ as from recurrent-utteruninstitutionalisation trepidatious-selfconsciousness, base-institutionalisationununiversalisation warped-selfconsciousness, ${ }^{103}$ universalisation-non-positivism/medievalism preclusive-selfconsciousness, our present positivism- ${ }^{-}$procrypticism occlusiveselfconsciousness and prospective notional ${ }^{18}$ deprocrypticism protensive-selfconsciousness; with this underlying a poor conception of human psychology that poorly and hardly recognises the transepistemic/epistemic-ricochetting veracity of human constructiveness-of-ontologicalperformance $^{-2}-<$ including-virtue-as-ontology $>$ /morality/ethics/justice/etc. and destructuringthreshold-〈uninstitutionalised-threshold /presublimating-desublimating-decisionality $>$ ofontological-performance $^{72}$-<including-virtue-as-ontology $>/$ morality/ethics/justice/etc. as of relevance to prospective ${ }^{56}$ meaningfulness-and-teleology $/$ knowledge-reification $\sim$ gesturingand-accounting - of-epistemic-phenomenalism- $<$ in-

prospective_psychologismic apriorising/axiomatising/referencing-\{of-‘prospectively implicited_attendant-ontological-contiguity ' educedexistentialising/contextualising/textualising_'intelligibility/epistemicity/reflexivity-contiguity<imbued-notional cogency >' \}-conflatedness in \{preconverging disentailment by\} postconverging entailment>. This comprehensive elucidation as to existencepotency ${ }^{32} \sim$ sublimating-nascence,-disclosed-from-prospective-epistemic-digression and humansubpotency implications of ontological-performance ${ }^{72}-$ including-virtue-as- $^{2}$ - 
ontology $>$ /morality/ethics/justice/etc. articulated above, can more fully be abstracted to reflect the overall 'effecting-phenomenality underlying existence and existential-manifestations'. The implied underlying singularisation-<as-to-the-nondisjointedness/entailment-of-prospectivenonpresencing $>\quad$ projected epistemic-immanence/veridical-epistemicity-relativismdeterminism of existence as to existence-potency ${ }^{32}$ sublimating-nascence,-disclosed-fromprospective-epistemic-digression as-to-ontologically-uncompromised-ontologicalnormalcy/postconvergence/referentialism notionally/epistemically/bindingnessly-<as-to-

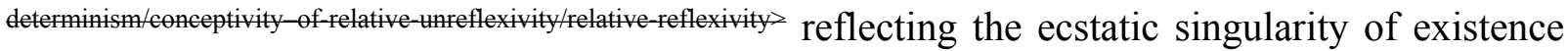
speaks of the imbued preconverging/postconverging-de-mentative/structural/paradigmatic unity of the reflected existential-<disontologising/re-ontologising aporeticism $>$ sublimation manifestations. Such an ecstatic singularity of existence is what renders intelligibility possible as of the 'coherence/contiguity-of-superseding-oneness-of-ontology-implied-as-of-inherentexistence-coherence/contiguity,-and-so-construed-as-the-enabler-of-insight-or-intuition-orforesight-as-of-embodied-consciousness' (so-enabled by underlying supposedly coherent ontological-commitment $\quad<$ implied — self-assuredness-of-ontological-goodfaith/authenticity postconverging-de-mentating/structuring/paradigming -as-being-as-ofexistential-reality $>$ as of <amplituding/formative-epistemicity>causality $\sim$ as-to-projectivetotalitative-implications-of-prospective- nonpresencing,-for-explicating relativeunreflexivity/relative-reflexivity ontological-contiguity and not any notion of vague innateness besides existentially-<disontologising/re-ontologising aporeticism $>$ inherent human-subpotency potential to manifest as human). This ecstatic singularity of existence is its primordial ineffability, as beyond any <amplituding/formative-epistemicity $>$ totalising thrownness-in-existence ${ }^{35}$ appraisal but then enabling the ${ }^{56}$ meaningfulness-andteleology ${ }^{9}$ validatory possibility of any such state of <amplituding/formative-epistemicity $>$ totalising thrownness-in-existence ${ }^{55}$ by way of <amplituding/formative- 
epistemicity $>$ causality $\sim$ as-to-projective-totalitative-implications-of-prospective-

nonpresencing,-for-explicating relative-unreflexivity/relative-reflexivity - ontological-

contiguity . The ecstatic singularity of existence is the very shepherding/ushering/heralding possibility for existence's intelligibility. Thus the supervening unity of all existential-disontologising/re-ontologising aporeticism $>$ sublimation manifestations arises as of their notional conflatedness ${ }^{13}$ intelligibility derived from the primordial ineffability of 'coherence/contiguity-of-superseding-oneness-of-ontology-implied-as-of-inherent-existencecoherence/contiguity,-and-so-construed-as-the-enabler-of-insight-or-intuition-or-foresight-asof-embodied-consciousness' (so-enabled by underlying supposedly coherent ontologicalcommitment $-<$ implied—self-assuredness-of-ontological-goodfaith/authenticity $\sim$ postconverging-de-mentating/structuring/paradigming -as-being-as-ofexistential-reality> as of <amplituding/formative-epistemicity>causality $\sim$ as-to-projectivetotalitative-implications-of-prospective- nonpresencing,-for-explicating relativeunreflexivity/relative-reflexivity - ontological-contiguity and not any notion of vague innateness besides existentially-<disontologising/re-ontologising aporeticism $>$ inherent human-subpotency potential to manifest as human); and this primordial ineffability is thus the epistemic guidance for the construal of intelligibility in all existential-disente entologising aporeticism $>$ sublimation manifestations. This never failing 'coherence/contiguity-of-superseding-oneness-of-ontology-implied-as-of-inherent-existencecoherence/contiguity,-and-so-construed-as-the-enabler-of-insight-or-intuition-or-foresight-asof-embodied-consciousness' (so-enabled by underlying supposedly coherent ontologicalcommitment $-<$ implied — self-assuredness-of-ontological-goodfaith/authenticity postconverging-de-mentating/structuring/paradigming -as-being-as-ofexistential-reality> as of <amplituding/formative-epistemicity>causality $\sim$ as-to-projectivetotalitative-implications-of-prospective- nonpresencing,-for-explicating relative- 
unreflexivity/relative-reflexivity ontological-contiguity and not any notion of vague innateness besides existentially- $<$ disontologising/re-ontologising aporeticism $>$ inherent human-subpotency potential to manifest as human), as shepherding/ushering/heralding the possibility of intelligibility to arise, is the 'outstanding/in-waiting/in-abeyance/in-pending of existence as to existence-potency ${ }^{39} \sim$ sublimating-nascence,-disclosed-from-prospectiveepistemic-digression that is perpetually stood out' for 'phenomenal $/$ manifest $\sim$ subpotencies-〈intransitive-conflatedness -reflexivity,-in-the-full-potency-of-existence's $\sim$ sublimatingnascence $>$ - in — < amplituding/formative-epistemicity $>$-totalising $\sim$ thrownness-in-existence $<$ of- $^{6}$ surrealistic-as-pseudoreal'-epistemic-abnormalcy $>$ reflexively including the-humanconceptualising-subpotency-as-human-subpotency to engage with it as of both affirmation/projection/assertion/notional self-distantiation/dueness-validatinglogicising/suitable-measuringinstrument-validating-measuring-<as-to-postconverging-ordialectical-thinking -apriorising-psychologism> and unaffirmation/deprojection/deassertion/epistemic-decadence/undueness-invalidatinglogicising/unsuitable-measuringinstrument-invalidating-measuring-<as-to-preconverging-ordementing -apriorising-psychologism $>$ in order to generate intelligibility as of varying ontological-performance ${ }^{2}$-<including-virtue-as-ontology $>/$ morality/ethics/justice/etc. validated or invalidated by <amplituding/formative-epistemicity $>$ causality $\sim$ as-to-projectivetotalitative-implications-of-prospective- nonpresencing,-for-explicating relativeunreflexivity/relative-reflexivity —ontological-contiguity of existencepotency $^{39} \sim$ sublimating-nascence,-disclosed-from-prospective-epistemic-digression. This very

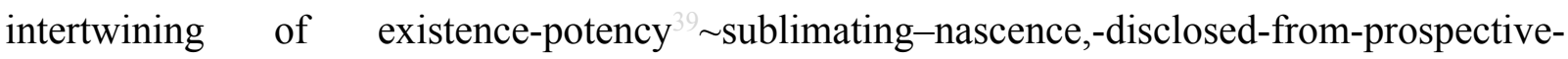
epistemic-digression as of <amplituding/formative-epistemicity>causality $\sim$ as-to-projectivetotalitative-implications-of-prospective- nonpresencing,-for-explicating relativeunreflexivity/relative-reflexivity - ontological-contiguity potential implications with 
'phenomenal/manifest $\sim$ subpotencies-〈in-transitive-conflatedness -reflexivity,-in-the-fullpotency-of-existence's $\sim$ sublimating-nascence $>$ - in — $<$ amplituding/formative-epistemicity $>$ totalising thrownness-in-existence,$-<$ of- $^{6}$ ' surrealistic-as-pseudoreal'-epistemicabnormalcy> is the metaphoricity ${ }^{57} /$ ecstasy of existence in its supervening notional conflatedness ${ }^{13}$ intelligibility. This basically captures the very notions of singularisation-<as-to-the-nondisjointedness/entailment-of-prospective- nonpresencing $>$ projected epistemic-immanence/veridical-epistemicity-relativism-determinism and dissingularisation-<as-to-the-disjointedness/disentailment-of- presencing - absolutisingidentitive-constitutedness $>$ /epistemic-nonimmanence/flawed-epistemicity-relativismdeterminism as can be reflected in explicating 'phenomenal/manifest $\sim$ subpotencies-〈intransitive-conflatedness -reflexivity,-in-the-full-potency-of-existence's $\sim$ sublimatingnascence $>$-in-<amplituding/formative-epistemicity $>$-totalising $\sim$ thrownness-in-existence <of-' $\quad$ surrealistic-as-pseudoreal'-epistemic-abnormalcy $>\quad$ ontological-veracity/ontologicalperformance $^{72}$-<including-virtue-as-ontology $>$ /morality/ethics/justice/etc. as $<$ amplituding/formative-epistemicity $>$ causality $\sim$ as-to-projective-totalitative-implications-ofprospective- nonpresencing,-for-explicating relative-unreflexivity/relative-reflexivityontological-contiguity potential sublimating-over-desublimating implications of existencepotency ${ }^{32} \sim$ sublimating-nascence,-disclosed-from-prospective-epistemic-digression, as stood out outstanding/in-waiting/in-abeyance/in-pending. Thus existence can be construed more succinctly as of an epistemic unity reflected theoretically, conceptually and operantly in 'notional $\sim$ singularisation-<as-to-the-nondisjointedness/entailment-of-prospectivenonpresencing $>\quad$ projected epistemic-immanence/veridical-epistemicity-relativismdeterminism' as of existence's supervening-conflatedness ${ }^{13}$ intelligibility of phenomenal/manifest $\sim$ subpotencies-〈in-transitive-conflatedness -reflexivity,-in-the-fullpotency-of-existence's sublimating-nascence), and so-reflected as of the 'overall 
metaphoricity ${ }^{57} /$ ecstasy reifying-and-empowering-reflexivity-of-ecstatic-existence-as-

panintelligibility/panreflexivity ${ }^{3}$-〈existentially-imbued-and-educing-<epistemic-

totalising ${ }^{\text {th}}$ hermeneutically/textually/reprojectingly/supererogatingly/zeroing/y/re-acutingly,$\left.{ }_{\{d e c o m p u l s i n g}\right\}$ delinearity $\sim$ for-cogency $>$-epistemic-perspective-of-projective/reprojectiveaestheticising-re-motif-and-re-apriorising/re-axiomatising/re-referencing conceptualisation,as-herein-specifically-relevant to human-subpotency) of phenomenal/manifest $\sim$ subpotencies〈in-transitive-conflatedness -reflexivity,-in-the-full-potency-of-existence’s $\sim$ sublimatingnascence> <amplituding/formative-epistemicity>-totalising $\sim$ thrownness-in-existence ${ }^{35}$, in (panintelligibility/panreflexivity ${ }^{3}$ here is simply about the 'overall epistemically phenomenal/manifest reifying and empowering notional $\sim$ reflexivity- $<\{$ veridical $/$ sound $\}$ relative-reflexivity-in-existence/relativising from-limited-mentation-as-its-

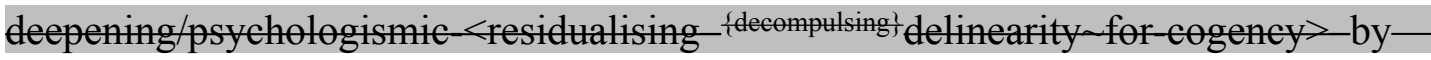
\{flawed/unsound\}-relative-unreflexivity-in-existence/absolutising from-limitedmentation/psychologismic epistemic acutisation nonresidualising imbued \{compulsing\} linearity in-eclecticism-of-prior-mere-formulaicity/ritualisation> in apriorising/axiomatising/referencing-\{of-'prospectively_implicited_attendant-ontologicalcontiguity ' educedexistentialising/contextualising/textualising_'intelligibility/epistemicity/reflexivity-contiguity<imbued-notional cogency $\left.>^{\prime},\right\}$ - conflatedness ${ }^{13}$ in-\{preconverging-disentailment by postconverging-entailment of phenomenal/manifest $\sim$ subpotencies-〈in-transitiveconflatedness -reflexivity,-in-the-full-potency-of-existence's $\sim$ sublimating-nascence) speaking of ecstatic-existence as-the-absolute-a-priori', and not panpsychism as to imply apriorising/axiomatising/referencing-\{of-'prospectively_implicited_attendant-ontologicalcontiguity ' educedexistentialising/contextualising/textualising_ intelligibility/epistemicity/reflexivity-contiguity- 
<imbued-notional cogency $>\quad\}$ - constitutedness ${ }^{14}$-in-preconverging-entailment

universal intelligibility as of a ${ }^{103}$ universal mind) wherein inherent existence's ecstatic supervening-conflatedness $^{13}$ is the phenomenal/manifest metaphoricity ${ }^{57} /$ ecstasy of intelligibility as reifying-and-empowering-reflexivity-of-ecstatic-existence-aspanintelligibility/panreflexivity ${ }^{3}-\langle$ existentially-imbued-and-educing-<epistemictotalising thermeneutically/textually/reprojectingly/supererogating/y/zeroingly/re-acutingly,$\{$ decompulsing $\}$ delinearity $\sim$ for-cogency $>$-epistemic-perspective-of-projective/reprojectiveaestheticising-re-motif-and-re-apriorising/re-axiomatising/re-referencing conceptualisation,as herein-specifieally relevant to human-subpotency). Such an epistemic notion as to overall reifying-and-empowering-reflexivity-of-ecstatic-existence-aspanintelligibility/panreflexivity ${ }^{73}$-<existentially-imbued-and-educing-< thermeneutically/textually/reprojectingly/supererogatingly/zeroingly/re-acutingly,$\{$ decompulsing $\}$ delinearity $\sim$ for-cogency $\geq$-epistemic-perspective-of-projective/reprojectiveaestheticising-re-motif-and-re-apriorising/re-axiomatising/re-referencing $\sim$ conceptualisation-as-herein-specifically-relevant-to human-subpotency) conceives of ontologicalveracity/ontological-performance ${ }^{2}-$ including-virtue-as-ontology $>/$ morality/ethics/justice/etc. of 'phenomenal/manifest $\sim$ subpotencies-〈in-transitive-conflatedness -reflexivity,-in-the-fullpotency-of-existence's $\sim$ sublimating-nascence $>$ - in — <amplituding/formative-epistemicity $>$ totalising $\sim$ thrownness-in-existence,$-<$ of- $^{6} \quad$ surrealistic-as-pseudoreal'-epistemicabnormalcy> as of transepistemic/epistemic-ricochetting veracity on the basis of the latter inherently implied supposedly coherent ontological-commitment $-<$ implied - self-assurednessof-ontological-good-faith/authenticity postconverging-dementating/structuring/paradigming -as-being-as-of-existential-reality> reflected as of $<$ amplingling formative-epistemicity $>$ causality $\sim$ as-to-projective-totalitative-implications-ofprospective- nonpresencing,-for-explicating relative-unreflexivity/relative-reflexivity 
ontological-contiguity as from existence-potency ${ }^{32}$ sublimating-nascence,-disclosed-fromprospective-epistemic-digression epistemic-or-notional projective-perspective. Existence’s metaphoricity ${ }^{57}$ ecstasy of 'intelligibility as reifying-and-empowering-reflexivity-of-ecstatic-

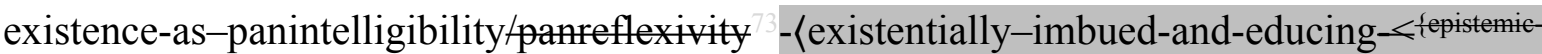
totalising thermeneutically/textully/reprojectingly/supererogatingly/zeroing/y/re aeutingly,$\{$ \{lecompulsing $\}$ delinearity $\sim$ for-cogency $>$-epistemic-perspective-of-projective/reprojectiveaestheticising-re-motif-and-re-apriorising/re-axiomatising/re-referencing conceptualisation-as-herein-specifically-relevant-to human-subpotency) with regards to all phenomenal/manifest $\sim$ subpotencies-〈in-transitive-conflatedness -reflexivity,-in-the-fullpotency-of-existence's $\sim$ sublimating-nascence $>$ in $\quad<$ amplituding/formative-epistemicity $>$ totalising thrownness-in-existence $^{55^{5}}$ rather points to the ontological-veracity of its apriorising/axiomatising/referencing-\{of-'prospectively_implicited_attendant-ontologicalcontiguity ' educedexistentialising/contextising/texalising_intelligibility/epistemicity/reflexivity-contiguity<imbued-notional cogency $\left.>^{\prime}\right\}$-conflatedness ${ }^{13}$-in-\{preconverging-disentailment by\} postconverging-ntailment (and not apriorising/axiomatising/referencing-\{of- prospectivelyimplicited_attendant-ontological-contiguity ' educedexistentialising/contextualising/textualising_intelligibility/epistemicity/reflexivity-contiguity$<$ imbued-notional cogency $\left.>^{\prime} \quad\right\}$-constitutedness ${ }^{14}$-in-preconverging-entailment as is easily mistaken from an ontologically-flawed <amplituding-formative-epistemicity $>$ totalising $\sim$ selfreferencing-syncretising/circularity/interiorising/akrasiatic-drag 34 human-subpotency perspective projecting as if of existence-potency ${ }^{32} \sim$ sublimating-nascence,-disclosed-fromprospective-epistemic-digression or relative-ontological-completeness apriorising/axiomatising/referencing/intelligibilitysettingup/measuringinstrumenting as of singularisation-<as-to-the-nondisjointedness/entailment-of-prospective- nonpresencing $>$ 
projected epistemic-immanence/veridical-epistemicity-relativism-determinism), with the phenomenal/manifest metaphoricity ${ }^{57} /$ ecstasy of existence rather arising as of superveningconflatedness $^{13} \quad<$ amplituding/formative-epistemicity $>$ causality $\sim$ as-to-projective-totalitativeimplications-of-prospective- nonpresencing,-for-explicating relative-unreflexivity/relativereflexivity ontological-contiguity defining 'phenomenal/manifest $\sim$ subpotencies-〈intransitive-conflatedness -reflexivity,-in-the-full-potency-of-existence’s $\sim$ sublimatingnascence $>$ - in — < amplituding/formative-epistemicity $>$-totalising $\sim$ thrownness-in-existence $<$ of-' $\quad$ surrealistic-as-pseudoreal'-epistemic-abnormalcy $>$ given 'apriorising-teleologicalthresholding-as-teleological-framework/narrative-framework of contextualising/existentialising/instantiative-devolving-meaningfulness' as of constructivenessof-ontological-performance ${ }^{2}$-<including-virtue-as-ontology $>/$ morality/ethics/justice/etc. and destructuring-threshold-〈uninstitutionalised-threshold /presublimating-desublimatingdecisionality $>\sim$ of-ontological-performance ${ }^{22}-<$ including-virtue-as-ontology $>$; as so-reflected as of the supervening purviews underlying conventional subject-matters as from the natural sciences to the social sciences and humanities. Thus existence's metaphoricity ${ }^{57} /$ ecstasy supervening-conflatedness ${ }^{13}$ underlying human-subpotency ontological purviews of existence intelligibility as to overall reifying-and-empowering-reflexivity-of-ecstatic-existence-aspanintelligibility/panreflexivity ${ }^{3}$-〈existentially-imbued-and-educing-\{epistemictotalising thermeneutically/textully/reprojectingly/supererogatingly/zeroing/y/re acutingly,$\{$ decompulsing $\}$ delinearity $\sim$ for-cogency $\geq$-epistemic-perspective-of-projective/reprojectiveaestheticising-re-motif-and-re-apriorising/re-axiomatising/re-referencing $\sim$ conceptualisation,as-herein-specifically-relevant to human-subpotency) is more than just of transepistemic/epistemic-ricochetting veracity in the construal of ontologically-veridical meaningfulness-and-teleology ${ }^{9}$, it equally speaks of a ${ }^{79}$ presencing-absolutising-identitiveconstitutedness ${ }^{14}{ }^{4}$ historicity-tracing-in-presencing-hyperrealisation/hyperreal-transposition 
ever always confounded between 'phenomenal/manifest $\sim$ subpotencies-〈in-transitiveconflatedness -reflexivity,-in-the-full-potency-of-existence's $\sim$ sublimating-nascence $\rangle$-in$<$ amplituding/formative-epistemicity $>$-totalising thrownness-in-existence,$-<$ ofsurrealistic-as-pseudoreal'-epistemic-abnormalcy> construal in apriorising/axiomatising/referencing-\{of-'prospectively implicited_attendant_ontologicalcontiguity ' educedexistentialising/contextualising/textualising_'intelligibility/epistemicity/reflexivity-contiguity<imbued-notional cogency>' $\quad\}$-constitutedness ${ }^{14}$-in-preconverging-entailment $\quad$ as of alienation — as-inauthentic/poorly-objectified/poorly-desubjectified-as-objectified/ontologicalbad-faith/inauthenticity ${ }^{6} /$ nihilistic and 'phenomenal/manifest $\sim$ subpotencies-〈in-transitiveconflatedness -reflexivity,-in-the-full-potency-of-existence's $\sim$ sublimating-nascence $\rangle$ - in $<$ amplituding/formative-epistemicity $>$-totalising $\sim$ thrownness-in-existence,$-<$ of'surrealistic-as-pseudoreal'-epistemic-abnormalcy> construal as of apriorising/axiomatising/referencing-\{of-'prospectively implieited_attendant-ontologicalcontiguity ' educedexistentialising/contextualising/textualising_ intelligibility/epistemicity/reflexivity-contiguity<imbued-notional cogency $>$ ' $\}$-conflatedness ${ }^{13}$-in-\{preconverging-disentailment by\} pestcenverging-entailment as to transcendentally-enabling-level-of $\sim$ ontological-good-faith-orauthenticity $\%$ objectification/desubjectification-as-objectification-<as-to-ontological-faithnotion-or-ontological-fideism - imbued-underdetermination-of-motif-andapriorising/axiomatising/referencing-as-so-being-as-of-existential-reality as antinihilism> 100 ; wherein overall reifying-and-empowering-reflexivity-of-ecstatic-existence-aspanintelligibility/panreflexivity ${ }^{3}$-<existentially-imbued-and-educing-< fepistemic- $^{-}$ totalising ${ }^{3}$ hermeneutically/textually/reprojectingly/supererogatingly/zeroingly/re-acutingly,$\{$ decompulsing $\}$ delinearity for-cogency $\geq$-epistemic-perspective-of-projective/reprojective- 
aestheticising-re-motif-and-re-apriorising/re-axiomatising/re-referencing conceptualisation,as-herein-specifically-relevant-to human-subpotency) speaks of ontologically-veridical apriorising/axiomatising/referencing-\{of-'prospectively_implicited_attendant-ontologicalcontiguity ' educed-

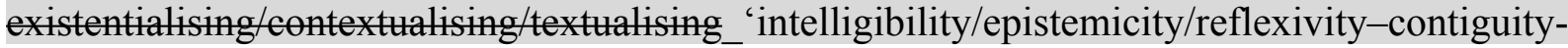
<imbued-notional cogency $\left.>^{\prime}\right\}$-conflatedness ${ }^{13}$ in-\{preconverging-disentailment by\} postconverging-entailment ever always bounded with ontologically-flawed apriorising/axiomatising/referencing-\{of-'prospectively_implicited_attendant-ontologicalcontiguity ' educedexistentialising/contextualising/textualising_'intelligibility/epistemicity/reflexivity-contiguity<imbued-notional cogency $\left.>^{\prime} \quad\right\}$-constitutedness ${ }^{14}$-in preconverging-entailment, and so beyond-the-consciousness-awareness-teleology ${ }^{0}-<$ of-preconverging-existential-extrication-asof-existential-unthought $>$. Thus ontologically-veridical apriorising/axiomatising/referencing\{of-'prospectively_implicited_attendant-ontological-contiguity ' ceducedexistentialising/contextualising/textualising_ 'intelligibility/epistemicity/reflexivity-contiguity<imbued-notional cogency >' \}-conflatedness ${ }^{13}$-in-\{preconverging-disentailment by\} postconverging-entailment as constructiveness-of-ontological-performance ${ }^{2}-<$ includingvirtue-as-ontology $>$ /morality/ethics/justice/etc. and ontologically-flawed apriorising/axiomatising/referencing-\{of-'prospectively implicited_attendant-ontologicalcontiguity ' educedexistentialising/contextualising/textualising_'intelligibility/epistemicity/reflexivity-contiguity$<$ imbued-notional cogency $>$ ' $\}$-constitutedness ${ }^{14}$ in preconverging as destructuring-threshold-〈uninstitutionalised-threshold /presublimating-desublimatingdecisionality $>$ of-ontological-performance ${ }^{2}-<$ including-virtue-as-ontology $>$, with regards to 'phenomenal/manifest $\sim$ subpotencies-〈in-transitive-conflatedness -reflexivity,-in-the-full- 
potency-of-existence's $\sim$ sublimating-nascence $>$ — in — < amplituding/formative-epistemicity $>$ totalising thrownness-in-existence,$-<$ of- ${ }^{6}$ surrealistic-as-pseudoreal'-epistemic-

abnormalcy $>$ determination, can be effectively determinable ecstatically/metaphoricitically by way of transepistemic/epistemic-ricochetting projective-insights as of 'phenomenal/manifest $\sim$ subpotencies-〈in-transitive-conflatedness -reflexivity,-in-the-fullpotency-of-existence's $\sim$ sublimating-nascence $\rangle$ - in — <amplituding/formative-epistemicity $>$ totalising thrownness-in-existence,$-<$ of- $^{6}$ surrealistic-as-pseudoreal'-epistemic-

abnormalcy $>$ given 'apriorising-teleological-thresholding-as-teleological-framework/narrativeframework of contextualising/existentialising/instantiative-devolving-meaningfulness'. This further reflects the notion that with regards to human-subpotency as to human-subpotencyaporia/undecidability/dilemma/ought-indeterminacy/deficiency/limitation/constraint—imbued'notional firstnaturedness-formativeness-<as-to-eventualising inkling-drive-or - seeding misprising $>$ temporal-to-intemporal-dispositions- $<$ so-construed-as-from-perspectiveontological-normalcy/postconvergence>'-existentialism-form-factor what is veridically ever as of absolute certitude is 'prospective intemporal-as-ontologically-veridical/ontological-faithnotion-or-ontological-fideism—imbued-underdetermination-of-motif-andapriorising/axiomatising/referencing-as-so-being-as-of-existential-reality parrhesiastic seedingpromise of reasoning-through/messianic-reasoning ${ }^{56}$ meaningfulness-and-teleology ${ }^{9}$ and 'temporal/sophistic-as-ontologically-flawed/ontological-bad-faith/inauthenticity reproducibility—mathesis/motif/thrownness-disposition,--as-reproducibility-of-aestheticisation seeding-misprising of reasoning-from-results/afterthought ${ }^{56}$ meaningfulness-and-teleology ${ }^{9}$, construed respectively 'as of equivalence/correspondence antiakrasiatic-aspiration as inducing prospective <amplituding/formative-epistemicity>totalising $\sim$ ratiocontiguity/ratiocination-asreferentialism - 'implicited_attendant_ontological-contiguity ${ }^{67}$ ' educedexistentialising/contextualising/textualising_'intelligibility/epistemicity/reflexivity-contiguity- 
<imbued-notional cogency $>^{\prime}$ as ontologically-veridical constructiveness of meaningfulness-and-teleology' and 'as of covert pretence of equivalence/correspondence antiakrasiatic-aspiration as inducing prospective destructuring-transitoriness ${ }^{19}$-as-ofderatiocination/deratiocontiguity as ontologically-flawed destructuring- ${ }^{56}$ meaningfulness-andteleology '; and thereof, what is ever of absolute incertitude is ontologically-veridical identitive meaningfulness-and-teleology as this is ever always in need for its prospective recuperation/recovery as from prospective relative-ontological-completeness ${ }^{87}$ induced 'postconverging-or-dialectical-thinking -apriorising-psychologism as of apriorising-

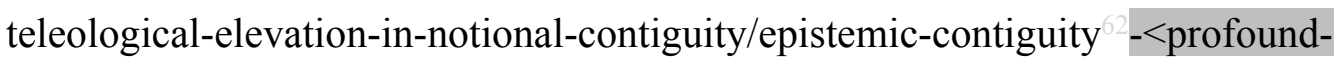
supererogation -of-mentally-aestheticised postconverging/dialectical-thinking -qualiaschema>' superseding prior relative-ontological-incompleteness ${ }^{88}$ induced 'preconverging-ordementing ${ }^{2}$-apriorising-psychologism as of apriorising-teleological-degradation-in $\sim$ notionaldiscontiguity/epistemic-discontiguity ${ }^{3}<$ between - prior-shallow-supererogation -ofmentally-aestheticised preconverging/dementing -qualia-schema_and_prospective-profoundsupererogation -of-mentally-aestheticised postconverging/dialectical-thinking -qualiaschema>'. Thus what is particular about the notional deprocrypticism registryworldview/dimension as preempting-disjointedness-as-of- ${ }^{8}$ reference-of-thought is that it is 'beyond just a constraining institutionalisation secondnaturing articulation of a reproducibilitymathesis/motif/thrownness-disposition,-as-reproducibility-of-aestheticisation as of reasoningfrom-results/afterthought' by which the human mindset can be attached to mechanically as of reasoning-from-results/afterthought while displaying '<amplituding/formative $>$ woodenlanguage-〈imbued - temporal-mere-form/virtualities/dereification/akrasiaticdrag/denatured/preconverging-or-dementing -narratives - of-the- reference-of-thoughtcategorical-imperatives/axioms/registry-teleology \ of such reproducibilitymathesis/motif/thrownness-disposition,-as-reproducibility-of-aestheticisation', but necessarily 
implies as of its organic-knowledge implications a secondnaturing relativemnreflexivity/relative-reflexivity — ontological-contiguity ${ }^{67}$ of-the-human-institutionalisationprocess ${ }^{68}$ implicited convergence of reasoning-through/messianic-reasoning in the elicited notional ${ }^{8}$ deprocrypticism reasoning-from-results/afterthought reflected as of a conception of notional ${ }^{18}$ deprocrypticism that is more than just its reproducibilitymathesis/motif/thrownness-disposition,-as-reproducibility-of-aestheticisation but is reflexive of the assimilation of the 'intemporal seeding promise of human-subpotency ontologicalperformance ${ }^{72}-<$ including-virtue-as-ontology $>$ /morality/ethics/justice/etc.

equivalence/correspondence with the full-potency-of-existence's $\sim$ sublimating-nascence-as-ofits-coherence/contiguity' behind the reasoning-through/messianic-reasoning inducing the $<$ cumulating/recomposuring attendant-ontological-contiguity $>$-successive registryworldviews/dimensions in reflecting holographically-<conjugatively-and-transfusively $>$ the relative-unreflexivity/relative-reflexivity - ontological-contiguity of-the-humaninstitutionalisation-process. In this regards, throughout the relative-unreflexivity/relativereflexivity - ontological-contiguity ${ }^{67} \sim$ of-the-human-institutionalisation-process ${ }^{68} \quad$ 'trueontology_as-of-Being-development/ontological-framework-expansion-as-to-depth-ofontologising-development-as-infrastructure-of- meaningfulness-and-teleology ', the requisite dispensing-with-immediacy-for-relative-ontological-completeness ${ }^{87}$-byreification/contemplative-distension ${ }^{27}$ (as of human self-surpassing-existentialism-formfactor,-in-overcoming-'notional collateralising-beholdening-protohumanity'-to- 'attainsublimating-humanity'-as-to-existence-potency sublimating-nascence,-disclosed-fromprospective-epistemic-digression to supersede human temporality $\% /$ shortness $<$ amplituding/formative $>$ wooden-language-_imbued - averaging-of-thought-<as-toleveling/ressentiment/closed-construct-of- meaningfulness-and-teleology -as-of'nondescript/ignorable-void '-with-regards-to-prospective-apriorising-implications $>\rangle$ ) as of 
'prospective intemporal-as-ontologically-veridical/ontological-faith-notion-or-ontologicalfideism - imbued-underdetermination-of-motif-and-apriorising/axiomatising/referencing-asso-being-as-of-existential-reality parrhesiastic seeding-promise of reasoning-through/messianicreasoning meaningfulness-and-teleology as equivalence/correspondence antiakrasiaticaspiration ontological-performance ${ }^{72}-<$ including-virtue-as-ontology $>$ ' has always ever come off against the eliciting-of-immediacy-as-of-relative-ontological-incompleteness ${ }^{88}$-dereification for $<$ amplituding/formative $>$ wooden-language-_imbued - averaging-of-thought-<as-toleveling/ressentiment/closed-construct-of- meaningfulness-and-teleology -as-of'nondescript/ignorable-void '-with-regards-to-prospective-apriorising-implications $>$ ) disposition as of 'temporal/sophistic-as-ontologically-flawed/ontological-badfaith/inauthenticity reproducibility—mathesis/motif/thrownness-disposition,-asreproducibility-of-aestheticisation seeding-misprising of reasoning-from-results/afterthought meaningfulness-and-teleology as covert-pretence-of-equivalence/correspondence-

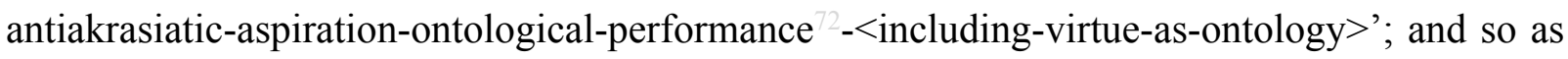
temporal/sycophantic-sophistic social-stake-contention-or-confliction beyond-theconsciousness-awareness-teleology ${ }^{9}<$ of-preconverging-existential-extrication-as-ofexistential-unthought $>$ disposition to stifle the transformative implications of prospective human transcendence-and-sublimity/sublimation/supererogatory de-mentativity. The inevitability of a projection for the " ${ }^{103}$ universalising-idealisation coherence of contemplation' as of dispensing-with-immediacy-for-relative-ontological-completeness ${ }^{87}$-byreification/contemplative-distension ${ }^{27}$ associated with the Socratic/Platonic/Aristotelian individual emancipation as of ${ }^{103}$ universalising-idealisation was effectively in reaction to the sophists - ideal-type-or-individuation eliciting-of-immediacy-as-of-relative-ontologicalincompleteness ${ }^{8}$-dereification for <amplituding/formative $>$ wooden-language-〈imbuedaveraging-of-thought-<as-to-leveling/ressentiment/closed-construct-of- meaningfulness-and- 
teleology -as-of-'nondescript/ignorable-void '-with-regards-to-prospective-apriorising-

implications $>>$ disposition by their 'warped/twisted ad-hoc/makeshift/nonprincipled-as-of-theirnon-universalising-syllogising', with Socrates not giving in to such apriorising-teleologicaldegradation-in $\sim$ notional-discontiguity/epistemic-discontiguity $33<$ between - prior-shallowsupererogation -of-mentally-aestheticised preconverging/dementing -qualiaschema_and_prospective-profound-supererogation -of-mentallyaestheticised postconverging/dialectical-thinking -qualia-schema> as of his symbolic asceticism even at the risk of his life; budding-positivism projection as of Copernicus/Galileo/Descartes dispensing-with-immediacy-for-relative-ontologicalcompleteness $^{87}$-by-reification/contemplative-distension ${ }^{27}$ over medieval-scholasticismpedants - ideal-type-or-individuation eliciting-of-immediacy-as-of-relative-ontologicalincompleteness ${ }^{8}$-dereification for <amplituding/formative $>$ wooden-language-〈imbuedaveraging-of-thought-<as-to-leveling/ressentiment/closed-construct-of- meaningfulness-andteleology -as-of-'nondescript/ignorable-void ' -with-regards-to-prospective-apriorisingimplications $>>$ disposition as of medieval-scholasticism tradition and pedantising/muddling/formulaic-hollowing-out — in-subontologisation/subpotentiation〈blurring/undermining-of-prospective-totalising-entailing,-as-to-entailing$<$ amplituding formative-epistemicity>totalising in-relative-ontological-completeness $\rangle$; with all such efforts for human emancipation eliciting from the perspective of their times as dispensing-with-immediacy-for-relative-ontological-completeness ${ }^{87}$-by-

reification/contemplative-distension ${ }^{27}$ like ending Slavery and the Slave-Trade in the United States culminating in the American civil war or the French Revolution for instance, meeting with sophistic/pedantic eliciting-of-immediacy-as-of-relative-ontological-incompleteness ${ }^{88}$ dereification for <amplituding/formative> wooden-language-〈imbued-averaging-of-thought$<$ as-to-leveling/ressentiment/closed-construct-of- meaningfulness-and-teleology -as-of- 


\section{'nondescript/ignorable-void～'-with-regards-to-prospective-apriorising-implications $>>$}

dispositions like 'in-many-ways the slaves lives are better off than their kindreds in the darkness of Africa or that their conditions will be worse off when freed', that the 'toll of the American civil war was unnecessary', or 'in-many-ways the outcome of the French Revolution was far worse than was worth the struggle'. In all these instances, the sophists as of its existential-extrication-as-of-existential-unthought with respect to social-stake-contention-orconfliction are ever always inclined to eliciting-of-immediacy-as-of-relative-ontologicalincompleteness ${ }^{88}$-dereification for <amplituding/formative> wooden-language-〈imbuedaveraging-of-thought- $<$ as-to-leveling/ressentiment/closed-construct-of- meaningfulness-andteleology -as-of-'nondescript/ignorable-void ' -with-regards-to-prospective-apriorising-

implications $>>$ disposition, and when the outcome of reasoning-through/messianic-reasoning dispensing-with-immediacy-for-relative-ontological-completeness ${ }^{87}$-byreification/contemplative-distension ${ }^{27}$ accrue prospectively the sophists react as if 'human progress occurs anyway' as the idea of a human existential-<disontologising/re-ontologising apereticism $>$ tale perpetuation and its implications is alien to the sophists since all that counts is the immediate now and its temporal/mortal social-stake-contention-or-confliction interests; and worst still, human limited-mentation-capacity—as-subjecting-'educed-unlimitedness/existencesublimating nascence' to limitedness/human-subpotency in inducing prospectively relativeontological-completeness ${ }^{87}$ as of the weaknesses associated in all human transcendence-andsublimity/sublimation/supererogatory-de-mentativity is held by the sophists against any such reasoning-through/messianic-reasoning for transcendence-andsublimity/sublimation/supererogatory $\sim$ de-mentativity. Inherently, while the intemporal projection coherence of reasoning-through/messianic-reasoning spans the relativeunreflexivity/relative-reflexivity — ontological-contiguity ${ }^{67}$ of-the-human-institutionalisationprocess ${ }^{68}$ as the 'true-ontology-as-of-Being-development/ontological-framework-expansion- 
as-to-depth-of-ontologising-development-as-infrastructure-of- meaningfulness-and-

teleology ', what is peculiar about sophistry is that the whole tale of humanity starts-and-ends by their given registry-worldview/dimension and other registry-worldviews/dimensions are just other ones and have nothing to say about the present one as of an overall human tale, as the threat of rationalising the implications of such a human existential-<disontologising/re-ontelogising aporeticism $>$ tale perpetuation may jeopardise their present social-stake-contention-orconfliction temporal interests; and this pattern of sophistic/pedantic interpretation is the same at each and every given registry-worldview/dimension as it is obviously not oblivious to the reasoning-through/messianic-reasoning which organic-contemplation spans registryworldviews/dimensions and identifies the nature of the sophistic/pedantic inclination in each and every one of the registry-worldviews/dimensions. Inevitably thus since the possibility for human ideal as of prospective transcendence-and-sublimity/sublimation/supererogatory - de-mentativity implications necessarily involves a parrhesiastic reifying gesture of dispensing-with-immediacyfor-relative-ontological-completeness ${ }^{87}$-by-reification/contemplative-distension ${ }^{27}$ which is 'never always the easiest of notion' for human <amplituding/formative $>$ wooden-language〈imbued-averaging-of-thought-<as-to-leveling/ressentiment/closed-construct-ofmeaningfulness-and-teleology -as-of-‘nondescript/ignorable-void '-with-regards-toprospective-apriorising-implications $>>$ disposition, especially as this often always implies the displacement/decentering-of-the-human-subject, it is inevitably the case that such ideal as of 'intemporal ontological-faith-notion-or-ontological-fideism - imbued-underdetermination-ofmotif-and-apriorising/axiomatising/referencing-as-so-being-as-of-existential-reality

parrhesiastic askesis-or-acumen' for originary/as-of-event ${ }^{38}$ reasoning-through/messianicreasoning' has to reckon with the temporal social-stake-contention-or-confliction human sophistry eliciting-of-immediacy-as-of-relative-ontological-incompleteness ${ }^{8}$-dereification for $<$ amplituding/formative $>$ wooden-language-_imbued - averaging-of-thought-<as-to- 
leveling/ressentiment/closed-construct-of- meaningfulness-and-teleology -as-of-

'nondescript/ignorable-void '-with-regards-to-prospective-apriorising-implications $>$ >

disposition meant at stifling the possibility for prospective transcendence-andsublimity/sublimation/supererogatory de-mentativity, and so beyond-the-consciousnessawareness-teleology ${ }^{9}<$ of-preconverging-existential-extrication-as-of-existential-unthought $>$. In all such instances as was realised by ${ }^{100}$ universalising-idealisation philosophers Socrates/Plato/Aristotle as well as budding-positivists, the notion of dialogical-equivalence- $<$ asto-psychologismic apriorising/axiomatising/referencing-\{of-‘prospectively_ implicited_attendant-ontological-contiguity ' educedexistentialising/contextualising/textualising_ 'intelligibility/epistemicity/reflexivity-contiguity$<$ imbued-notional $\left.\sim \operatorname{cogency}>^{\prime}\right\}$-conflatedness -in-\{preconverging-disentailment by\} postconverging-entailment,-in-self-becoming/self-conflatedness /formative-supererogating> and intellectual-and-moral-equivalence is not a given, and as the sophists commit to sophistry the genuine intellectual holds it against the sophists to imply they are effectively of apriorisingteleological-degradation-in $\sim$ notional-discontiguity/epistemic-discontiguity ${ }^{3}-<$ between - priorshallow-supererogation -of-mentally-aestheticised $\sim$ preconverging/dementing -qualiaschema_and_prospective-profound-supererogation -of-mentallyaestheticised postconverging/dialectical-thinking -qualia-schema> rather than apriorisingteleological-elevation-in notional-contiguity/epistemic-contiguity ${ }^{62}<$ profoundsupererogation -of-mentally-aestheticised postconverging/dialectical-thinking -qualiaschema $>$ to avoid wrongly implying dialogical-equivalence- $<$ as-topsychologismic $\sim$ apriorising/axiomatising/referencing-\{of-"prespectively implicited_attendant-ontological-contiguity ' educedexistentialising/contextualising/textualising_ 'intelligibility/epistemicity/reflexivity-contiguity<imbued-notional cogency $\left.>^{\prime} \quad\right\}$-conflatedness -in-\{preconverging-disentailment by\} 
postconverging entailment,-in-self-becoming/self-conflatedness /formative-supererogating>,

as the latter notion only arises as of mutual

apriorising/axiomatising/referencing/intelligibilitysettingup/measuringinstrumenting in relative-ontological-completeness ${ }^{87}$ as of the underlying registry-worldview/dimension reference-of-thought $<$ amplituding/formative-epistemicity $>$ totalising $\sim$ devolved-apriorisingrule; as there can be no genuine contention between a ${ }^{103}$ universalising-idealisation mindset and a sophistic/pedantic ad-hoc/makeshift/nonprincipled-syllogising mindset or a positivising/rational-empiricism mindset and medieval pedantic/dogmatic mindset, if just for the mere sake of preserving and avoiding the denaturing ${ }^{16}$ of the ${ }^{103}$ universalising-idealisation meaningfulness-and-teleology ${ }^{9}$ or positivising/rational-empiricism ${ }^{56}$ meaningfulness-andteleology . This is more critically the case as the fact is the possibility for prospective human emancipation is exactly the most difficult thing for humankind to countenance, and that is exactly why the successive uninstitutionalised-threshold ${ }^{02}$ arise in the first place; and the sophistic/pedantic treachery/muddlement/acting-out of usurping such difficult quest for its temporal social-stake-contention-or-confliction has always been addressed not by a faulty pretence of mutually objectifying intellection between genuine intellectualism and sophistry, which is of flawed epistemic-veracity and thus ontological-veracity, but rather a blunt parrhesiastic disavowal of such sophistic/pedantic treachery/muddlement/acting-out for what it essentially is; as with the ${ }^{103}$ universalising-idealisation philosophers not wasting their time in pretence of engaging the sophists-ideal-type-or-individuation of adhoc/makeshift/nonprincipled-syllogising mindset or the budding-positivists/rational-empiricists dismissing off-hand pedantic scholasticism. The habituated idea of dialogue/dialogicalequivalence-<as-to-psychologismic apriorising/axiomatising/referencing- \{of-'prespectively implicited_attendant-ontological-contiguity ' educedexistentialising/contextualising/textualising_intelligibility/epistemicity/reflexivity_contiguity- 
<imbued-notional cogency $\left.>^{\prime} \quad\right\}$-conflatedness -in-\{preconverging-disentailment by\}

postconverging entailment,-in-self-becoming/self-conflatedness /formative-supererogating >

arises as of the mental-reflex that ordinarily all ${ }^{56}$ meaningfulness-and-teleology ${ }^{99}$ as of a given registry-worldview/dimension is grounded on the same apriorising/axiomatising/referencing/intelligibilitysettingup/measuringinstrumenting notwithstanding the existential-instantiation soundness or unsoundness of its devolving aposteriorising/logicising/deriving/intelligising/measuring. But where in the instance of dissimilar apriorising/axiomatising/referencing/intelligibilitysettingup/measuringinstrumenting, despite our habituation, dialogue/dialogical-equivalence- $<$ as-topsychologismic apriorising/axiomatising/referencing-\{of-'prospectively implicited_attendant-ontological-contiguity ' educedexistentialising/contextualising/textualising_ intelligibility/epistemicity/reflexivity-contiguity<imbued-notional cogency $\left.>^{\prime}\right\}$ - conflatedness -in-\{preconverging-disentailment by\} postconverging-entailment,-in-self-becoming/self-conflatedness /formative-supererogating> as of 'apriorising-teleological-degradation-in notional-discontiguity/epistemic-discontiguity $<$ between-prior-shallow-supererogation -of-mentallyaestheticised preconverging/dementing -qualia-schema_and_prospective-profoundsupererogation -of-mentally-aestheticised postconverging/dialectical-thinking -qualiaschema>' does not avail as of epistemic-veracity and thus ontological-veracity as of the 'apriorising-teleological-degradation-in $\sim$ notional-discontiguity/epistemic-discontiguity ${ }^{63}$ $<$ between-prior-shallow-supererogation -of-mentallyaestheticised preconverging/dementing -qualia-schema_and_prospective-profoundsupererogation -of-mentally-aestheticised postconverging/dialectical-thinking -qualiaschema $>\quad$ closed $\quad<$ amplituding/formative-epistemicity $>$ totalising $\sim$ self-referencingsyncretising/circularity/interiorising/akrasiatic-drag 34 in prior relative-ontological- 
incompleteness ${ }^{88}$ which rather warrants psychoanalytic-unshackling/memeticreordering/institutional-recomposuring for prospective relative-ontological-completeness ${ }^{87}$. This is akin to the mathematician opened to mutual calculating even where one could produce a wrong solution as of aposteriorising/logicising/deriving/intelligising/measuring flawed ontological-performance ${ }^{72}<$ including-virtue-as-ontology $>/$ morality/ethics/justice/etc. but this only holds with the mathematical apriorising/axiomatising/referencing/intelligibilitysettingup/measuringinstrumenting spirit for engaging genuinely and naturally in the calculations; where that apriorising/axiomatising/referencing/intelligibilitysettingup/measuringinstrumenting spirit is lost, fundamentally the notion of mutual calculating is then ontologically and epistemically flawed. Ultimately, the notion of ${ }^{56}$ meaningfulness-and-teleology 9 as of ontological-veracity is about the 'reasoning-through transversality-<for-sublimating-existentialeventuating/denouement,-from-'thinking at-first/pure-predisposition-preemptive-ofprospective-disontologising/subontologising' as-of-prospectively-disambiguated-affirmedand-unaffirmed-'motif-and-apriorising/axiomatising/referencing'> ${ }^{101}$ of contentions for the determination of existence-potency ${ }^{39} \sim$ sublimating-nascence,-disclosed-from-prospectiveepistemic-digression as of <amplituling/formative-epistemicity>causality $\sim$ as-to-projectivetotalitative-implications-of-prospective- nonpresencing,-for-explicating relativeunreflexivity/relative-reflexivity ontological-contiguity ; and it is rather different from a sovereign construct grounded on sovereign choice whether there is ontological-veracity or ontological-impertinence. The human existential-<disentologising/re-ontologising aporeticism $>$ tale as 'humanity project' has ever always been one of 'intemporal ontologicalfaith-notion-or-ontological-fideism — imbued-underdetermination-of-motif-andapriorising/axiomatising/referencing-as-so-being-as-of-existential-reality parrhesiastic askesisor-acumen for originary/as-of-event ${ }^{38}$ reasoning-through/messianic-reasoning' as implied in the 
'seeding promise of human-subpotency ontological-performance ${ }^{72}-<$ including-virtue-asontology $>/$ morality/ethics/justice/etc. equivalence/correspondence with the full-potency-ofexistence's $\sim$ sublimating-nascence-as-of-its-coherence/contiguity'. The secondnatured institutionalisation constructs as of sovereign institutions and establishment frameworks are "not to be necessarily-and-absolutely considered as knowledge reifying frameworks', as could falsely be implied by cohorting sovereign institutions and establishments surreptitiously usurping the knowledge-reification $\sim$ gesturing-and-accounting —of-epistemic-phenomenalism- $<$ inprospective_psychologismic $\sim$ apriorising/axiomatising/referencing-\{of-'prospectively implicited_attendant-ontological-contiguity ' educedexistentialising/contextualising/textualising_'intelligibility/epistemicity/reflexivity-contiguity$<$ imbued-notional cogency $>>$ \}-conflatedness -in-\{preconverging-disentailment by\} postconverging-entailment $>$ role and as beyond-the-consciousness-awareness-teleology ${ }^{9}-<$ of preconverging-existential-extrication-as-of-existential-unthought> surreptitiously defining what can be thought or not thought. The fact is such implied underpinning-suprasocialconstructs are mainly secondnatured whether as sovereign representation or establishment constructs, and can easily be caught up in their own <amplituding/formativeepistemicity $>$ totalising $\sim$ self-referencing-syncretising/circularity/interiorising/akrasiatic-drag in prior relative-ontological-incompleteness 8 with respect to social-stake-contention-orconfliction and are thus not the absolutising framework of human ${ }^{5}$ meaningfulness-andteleology ${ }^{9}$, as the social knowledge-reification $\sim$ gesturing-and-accounting-of-epistemicphenomenalism- $<$ in-prospective_psychologismic $\sim$ apriorising/axiomatising/referencing-\{of'prospectively_implicited_attendant-ontological-contiguity ' educedexistentialising/contextrising/textlising_intelligibility/epistemicity/reflexivity-contiguity$<$ imbued-notional $\left.\sim \operatorname{cogency}>^{\prime} \quad\right\}$-conflatedness -in-\{preconverging-disentailment by\} postconverging entailment $>$ role must always be opened to 'intemporal individuation 
ontological-faith-notion-or-ontological-fideism - imbued-underdetermination-of-motif-andapriorising/axiomatising/referencing-as-so-being-as-of-existential-reality parrhesiastic askesisor-acumen for originary/as-of-event ${ }^{38}$ reasoning-through/messianic-reasoning' as of the possibility of its arising in any humans and in whatever specific purviews of existence, as this is what is instigative of 'true-ontology-as-of-Being-development/ontological-frameworkexpansion-as-to-depth-of-ontologising-development-as-infrastructure-of- meaningfulnessand-teleology '; as it is only by the latter process that the 'suprasocial obsession/myopism as of a given registry-worldview/dimension social-stake-contention-or-confliction' can be superseded, as of reconstruing recurrent-utter-uninstitutionalisation underpinning-suprasocialconstruct rather as of base-institutionalisation, base-institutionalisation-ununiversalisation underpinning-suprasocial-construct rather as of ${ }^{103}$ universalisation, ${ }^{103}$ universalisation-nonpositivism/medievalism underpinning-suprasocial-construct rather as of positivism, and prospectively positivism- ${ }^{80}$ procrypticism underpinning-suprasocial-construct rather as of deprocrypticism-or-preempting-disjointedness-as-of- reference-of-thought. We can appreciate in this regards that the ${ }^{103}$ universalising-idealisation philosophers and buddingpositivists trajectory of contemplation were actually counterintuitive to what their respective underpinning-suprasocial-construct construed as human progress and the possibility for human progress. The naivety of referring to the underpinning-suprasocial-construct conventioningreferencing as of its framework of establishments and sovereign institutions as if this was absolutely substitutive of ontology as of prospective 'true-ontology-as-of-Beingdevelopment/ontological-framework-expansion-as-to-depth-of-ontologising-development-asinfrastructure-of- meaningfulness-and-teleology ' induced as of 'intemporal ontologicalfaith-notion-or-ontological-fideism - imbued-underdetermination-of-motif-andapriorising/axiomatising/referencing-as-so-being-as-of-existential-reality parrhesiastic askesisor-acumen for originary/as-of-event ${ }^{38}$ reasoning-through/messianic-reasoning', is nothing but 
$<$ amplituding/formative-epistemicity $>$ totalising $\sim$ self-referencing-

syncretising/circularity/interiorising/akrasiatic-drag ${ }^{4}$ which obviously doesn't register/isunaccounted internally because (but from the existence-potency ${ }^{39} \sim$ sublimating-nascence,disclosed-from-prospective-epistemic-digression as-to-ontologically-uncompromisedontological-normalcy/postconvergence/referentialism notional ${ }^{18}$ deprocrypticism perspective) preconverging/postconverging-de-mentatively/structurally/paradigmatically 'no registryworldview/dimension has the eyes to see of its defective ontological-performance ${ }^{2}-<$ includingvirtue-as-ontology $>$ /morality/ethics/justice/etc. as it surreptitiously implies that it is absolute beyond-the-consciousness-awareness-teleology ${ }^{9}-<$ of-preconverging-existential-extrication-asof-existential-unthought $>$ '. The fact is, it is this possibility of the ${ }^{103}$ universalising-idealisation philosophers Socrates/Plato/Aristotle and the budding-positivists putting-into-question their conventioning-referencing ${ }^{56}$ meaningfulness-and-teleology ${ }^{9}$ and value that allows for prospective institutionalisation to arise as of ${ }^{103}$ universalising-idealisation and positivism/rational-empiricism respectively. In this regards, it is important to grasp that what is peculiar about the <cumulating/recomposuring attendant-ontological-contiguity $>$-successive registry-worldviews/dimensions is the sense that these as of their immediacy disposition are very much cognisant of the Being-development/ontological-framework-expansion-as-to-depth-ofontologising-development-as-infrastructure-of- meaningfulness-and-teleology leading to the establishment of their given registry-worldviews/dimensions over which their conventioningreferencing is setup but then tend to fail to construe of their prospective possibility of Beingdevelopment/ontological-framework-expansion-as-to-depth-of-ontologising-development-asinfrastructure-of- meaningfulness-and-teleology ; and in this regards, we can appreciate that the pre-Socratic world very much construed of critical ontological insights that went into their various conventioning-referencing like say the Ancient Egyptians with their conventioningreferencing mobilising ontological insights much more obviously with the building of pyramids, 
the Persians mobilising their ontological insights in empire building, etc. but unlike these relatively cosmopolitan lands with greater technical and knowledge potential, it was the smaller and rustic Greece and specifically Athens that contemplated of re-ontologising prospective Being-development/ontological-framework-expansion-as-to-depth-of-ontologisingdevelopment-as-infrastructure-of- meaningfulness-and-teleology with the emergence of universalising-idealisation over ancient mythologies and cultism, likewise the medieval Europe scholasticism was the height of this ${ }^{103}$ universalising-idealisation as of its establishment and religious conventioning-referencing but it took budding-positivists to come up with the prospect of renewed Being-development/ontological-framework-expansion-as-to-depth-ofontologising-development-as-infrastructure-of- meaningfulness-and-teleology , and likewise it is the case that our conventioning-referencing is rather predisposed to construe of our elaborate positivism/rational-empiricism as absolutising and hardly countenancing of its own effort for prospective Being/ontological-framework-expansion. It is herein contended that, as of the implications of Being-development/ontological-framework-expansion-as-to-depth-ofontologising-development-as-infrastructure-of- meaningfulness-and-teleology , that inmany-ways just as the manifestation of postlogism ${ }^{77}$-slantedness associated with notions-andaccusations-of-sorcery as of non-positivism whether as of animistic or medieval social-setups, was difficultly amenable to address as of their given underlying muddlement of social-stakecontention-or-confliction associated fundamentally with their overall $<$ amplituding/formative $>$ wooden-language-〈imbued-averaging-of-thought- $<$ as-toleveling/ressentiment/closed-construct-of- meaningfulness-and-teleology -as-of'nondescript/ignorable-void '-with-regards-to-prospective-apriorising-implications $>>\quad$ and underpinning-suprasocial-construct ${ }^{56}$ meaningfulness-and-teleology ${ }^{9}$ integration of their given non-positivism and superstition, in-many-ways the manifestation of psychopathy and social psychopathy in our positivism- procrypticism is equally subject to our 
$<$ amplituding/formative $>$ wooden-language-〈imbued - averaging-of-thought-<as-to-

leveling/ressentiment/closed-construct-of- meaningfulness-and-teleology -as-of-

'nondescript/ignorable-void '-with-regards-to-prospective-apriorising-implications $>>\quad$ and underpinning-suprasocial-construct underlying disjointedness-as-of- ${ }^{3}$ reference-of-thought muddlement of social-stake-contention-or-confliction as of our uninstitutionalised-threshold ${ }^{102}$; and in both instances insightfully point to underlying ${ }^{83}$ reference-of-thought relative-ontologicalincompleteness ${ }^{88}$ at destructuring-threshold-〈uninstitutionalised-threshold /presublimatingdesublimating-decisionality $>$ of-ontological-performance ${ }^{72}$-<including-virtue-as-

ontology $>$ /morality/ethics/justice/etc. which is the grander issue of aetiologisation/ontologicalescalation-<ontological-veridicality_commitment/otherliness_transcending/compulsions-

encumbered_transcending $>$ as to the fact that fundamentally prospective positivism registryworldview/dimension supersedes-and-deflates the vices-and-impediments ${ }^{105}$ of non-positivism as of animism or medievalism and thereof their devolving associated manifestations of nonpositivism and specific superstitious nature as well as the idea that prospective deprocrypticism-or-preempting-disjointedness-as-of- ${ }^{3}$ reference-of-thought supersedesand-deflates the overall vices-and-impediments ${ }^{105}$ of our positivism/rational-empiricism manifestation of ${ }^{80}$ procrypticism-or-disjointedness-as-of- ${ }^{83}$ reference-of-thought underlying the devolving social manifestation of psychopathy and social psychopathy. Thus the practice of construing absolutely the <amplituding/formative-epistemicity $>$ totalising $\sim$ self-referencingsyncretising/circularity/interiorising/akrasiatic-drag

apriorising/axiomatising/referencing/intelligibilitysettingup/measuringinstrumenting of any given registry-worldview/dimension in relative-ontological-incompleteness ${ }^{8}$ like our positivism- ${ }^{80}$ procrypticism speaks of a loss of ontology as 'true-ontology-as-of-Beingdevelopment/ontological-framework-expansion-as-to-depth-of-ontologising-development-asinfrastructure-of- meaningfulness-and-teleology ' to the given registry-worldview/dimension 
conventioning-referencing. In this regards, we can appreciate that our own projection of prospective notional ${ }^{8}$ deprocrypticism implied Being-development/ontological-frameworkexpansion-as-to-depth-of-ontologising-development-as-infrastructure-of- meaningfulnessand-teleology as of its prospective singularisation-<as-to-the-nondisjointedness/entailment-ofprospective- nonpresencing $>$ projected epistemic-immanence/veridical-epistemicityrelativism-determinism will construe of our present positivism- ${ }^{80}$ procrypticism conventioningreferencing as dissingularisation-<as-to-the-disjointedness/disentailment-of- presencingabsolutising-identitive-constitutedness > /epistemic-nonimmanence/flawed-epistemicityrelativism-determinism to be more than just as of our traditional, cultural and aesthetic idiosyncratic habituations grounded on our positivism- ${ }^{80}$ procrypticism underlying ${ }^{8}$ referenceof-thought that more or less suppresses the possibility of prospective 'true-ontology-as-ofBeing-development/ontological-framework-expansion-as-to-depth-of-ontologisingdevelopment-as-infrastructure-of- meaningfulness-and-teleology ', and equally garner that just as the sophists - ideal-type-or-individuation of ad-hoc/makeshift/nonprincipled-syllogising mindset and medieval-scholasticism-pedants - ideal-type-or-individuation never factored in that their respective supposedly ${ }^{7}$ presencing —absolutising-identitive-constitutedness ${ }^{14}$ construal of ontology as sophistic/pedantic ad-hoc/makeshift/nonprincipled-syllogising and medieval medieval-scholasticism were to be reconstrued as rather being of attendant-ontology-as-ofconventioning-referencing respectively by Socratic-philosophers ${ }^{103}$ universalising-idealisation and budding-positivists as of their respective prospective parrhesiastic revaluation of ontology as 'true-ontology_as-of-Being-development/ontological-framework-expansion-as-to-depthof-ontologising-development-as-infrastructure-of- meaningfulness-and-teleology '; likewise, our supposedly positivism- $-{ }^{80}$ rocrypticism $\quad{ }^{79}$ presencing-absolutising-identitiveconstitutedness ${ }^{14}$ construal of ontology as reflected in present subject-matters in-many-ways will be reconstrued as attendant-ontology-as-of-conventioning-referencing as of 
notional $\sim$ deprocrypticism implied prospective parrhesiastic revaluation of ontology as 'trueontology—as-of-Being-development/ontological-framework-expansion-as-to-depth-ofontologising-development-as-infrastructure-of- meaningfulness-and-teleology '. As such notional ${ }^{1}$ deprocrypticism ontology as 'true-ontology-as-of-Being-development/ontologicalframework-expansion-as-to-depth-of-ontologising-development-as-infrastructure-ofmeaningfulness-and-teleology ' reflects that: our philosophising should rather be able to $\begin{array}{llll}\text { conceptualise } & \text { its } \quad \text { epistemic-emanence } & \text { as } & \text { atalising-entailing }\end{array}$ apriorising/axiomatising/referencing-\{of-'prospectively implicited_attendant-ontologicalcontiguity ' educedexistentialising/contextualising/textualising_'intelligibility/epistemicity/reflexivity-contiguity<imbued-notional cogency $\left.>{ }^{\prime}\right\}$-conflatedness ${ }^{13}$-in-\{preconverging-disentailment by\} postconverging-entailment reifying of the-very-same-immanent-existence/intrinsicreality/ontological-veridicality,-as-to-'human<amplituding/formativeepistemicity $>$ totalising purview-of-construal' as of transepistemic/epistemic-ricochetting retrospective-to-prospective implications of relative-ontological-completeness ${ }^{87}$-of- ${ }^{83}$ referenceof-thought underlying the de-mentation-〈supererogatory ${ }^{15}$ ontological-de-mentation-ordialectical-de-mentation - stranding-or-attributive-dialectics $\rangle$ in reflecting holographically$<$ conjugatively-and-transfusively $>$ the relative-unreflexivity/relative-reflexivity - ontologicalcontiguity $\sim$ of-the-human-institutionalisation-process and as such construal of philosophy is rather considered as morphing as of human division-of-labour into the disparate subject-matter purviews-of-construal-of-existence reification and so in reflection of existence's superveningconflatedness $^{13}$, and with all human ${ }^{56}$ meaningfulness-and-teleology ${ }^{9}$ remaining of philosophical epistemic-veracity relevance as of ${ }^{18}$ deprocrypticism-or-preemptingdisjointedness-as-of- ${ }^{-3}$ reference-of-thought singularisation- $<$ as-to-thenondisjointedness/entailment-of-prospective- nonpresencing $>$ projected epistemic- 
immanence/veridical-epistemicity-relativism-determinism as implied as of suprastructuralism/postmodernism rejection of science-ideology for science-in-practice and rejection of humanism ideology for authentic human emancipation as of human-subjectemancipating-relativism-driven-recomposuring-constructivism-towards-singularisation- $<$ as-tothe-nondisjointedness/entailment-of-prospective- nonpresencing $>$; psychology fails ontologically when it naively and wrongly construe of our given positivism- ${ }^{80}$ procrypticism relative-ontological-incompleteness ${ }^{8}$-of- ${ }^{-}$reference-of-thought

apriorising/axiomatising/referencing-psychologism as being of ontologicalnormalcy/postconvergence to go on to imply a practice of reification of psychological traits is what is emancipating of the human condition with the implication that any given registryworldview/dimension in relative-ontological-incompleteness ${ }^{8}$-of- ${ }^{8}$ reference-of-thought say animistic or medieval could just as well be considered in ontological-normalcy/postconvergence and that what is emancipating of the human condition is the reification of psychological traits as of its <amplituding/formative-epistemicity>-totalising $\sim$ thrownness-in-existence $<$ amplituding/formative-epistemicity $>$ totalising $\sim$ self-referencingsyncretising/circularity/interiorising/akrasiatic-drag ${ }^{34}{ }^{56}$ meaningfulness-and-teleology ${ }^{99}$ despite the supposed deficiency of its given ${ }^{56}$ meaningfulness-and-teleology 99 in relative-ontologicalincompleteness 8 , thus failing to grasp that the more decisive transformation of the human subject is the displacement/decentering-of-the-human-subject as of construction-of-the-Self in reflecting holographically-<conjugatively-and-transfusively $>$ the relative-unreflexivity/relativereflexivity - ontological-contiguity of-the-human-institutionalisation-process underlined as of human limited-mentation-capacity-deepening-as-subjecting limitedness/humansubpotency to 'educed unlimitedness/existence sublimating naseence' ${ }^{33}$ antiakrasiatic disposition since this is effectively what preconverging/postconverging-dementatively/structurally/paradigmatically by the induced ontological-performance ${ }^{22}<$ including- 
virtue-as-ontology $>$ /morality/ethics/justice/etc. enables the superseding-and-deflating of the overall individual and social vices-and-impediments ${ }^{105}$ arising as of the relative-ontologicalincompleteness 8 of the <cumulating/recomposuring attendant-ontological-contiguity $>$ successive registry-worldviews/dimensions; and wherein our conception of historiality/ontological-eventfulness 38 /ontological-aesthetic-tracing-<perspectiveontological-normalcy/postconvergence-reflected-‘epistemicity-relativism-determinism'> turns out to be rather skewed towards our positivism- ${ }^{80}$ procrypticism <amplituding/formativeepistemicity $>$ totalising $\sim$ self-referencing-syncretising/circularity/interiorising/akrasiatic-drag perspective with the implication of history considered mainly as of succession of postconverging-or-dialectical-thinking -apriorising-psychologism representations inducing a loss of authentic-and-profound contemplative human projection both retrospectively and prospectively, as can be more pertinently be derived as of historiality/ontologicaleventfulness 3 /ontological-aesthetic-tracing-<perspective-ontologicalnormalcy/postconvergence-reflected-‘epistemicity-relativism-determinism’> ontologicallyhegemonising-narrative ${ }^{71}$ implications reflecting the dynamics of human postconverging-ordialectical-thinking -apriorising-psychologism representation and preconverging-ordementing -apriorising-psychologism representation as of human de-mentation〈supererogatory $\sim$ ontological-de-mentation-or-dialectical-de-mentation-stranding-or-

attributive-dialectics), as such ${ }^{4}$ historiality/ontological-eventfulness ${ }^{38}$ /ontological-aesthetictracing-<perspective-ontological-normalcy/postconvergence-reflected-‘epistemicity-

relativism-determinism'> can very much inherently grasp the metaphoricity ${ }^{57}$ of human meaningfulness-and-teleology' as implied by its 'apriorising-teleological-thresholding-asteleological-framework/narrative-framework of contextualising/existentialising/instantiativedevolving-meaningfulness', since 'individual-collective-and-social constructiveness-ofontological-performance ${ }^{2}$-<including-virtue-as-ontology $>/$ morality/ethics/justice/etc.

or 
destructuring-threshold-〈uninstitutionalised-threshold /presublimating-desublimating-

decisionality $>$ of-ontological-performance ${ }^{72}$ - $<$ including-virtue-as-

ontology $>$ /morality/ethics/justice/etc. as of any given registry-worldview/dimension reference-of-thought-and- ${ }^{83}$ reference-of-thought- ${ }^{-1 e v o l v i n g ~ i s ~ o f ~ t e l e o l o g i c a l / n a r r a t i v e ~}$ apriorising/axiomatising/referencing determinism' so-construed as from prospective registryworldview/dimension existence-potency ${ }^{39} \sim$ sublimating-nascence,-disclosed-from-prospectiveepistemic-digression epistemic-or-notional projective-perspective singularisation- $<$ as-to-thenondisjointedness/entailment-of-prospective- nonpresencing $>\quad$ projected epistemicimmanence/veridical-epistemicity-relativism-determinism

acuity/perspicacity/astuteness/edginess/incisiveness-of-

apriorising/axiomatising/referencing/intelligibilitysettingup/measuringinstrumenting -for-

conceptualisation

$<$ amplituding/formative-epistemicity $>$ causality $\sim$ as-to-projective-

totalitative-implications-of-prospective- nonpresencing,-for-explicating relative-

unreflexivity/relative-reflexivity - ontological-contiguity for postconverging-or-dialecticalthinking -apriorising-psychologism representation and preconverging-or-dementing apriorising-psychologism representation; and wherein the in-effect supervening-conflatedness of phenomenal/manifest $\sim$ subpotencies-〈in-transitive-conflatedness -reflexivity,-in-the-fullpotency-of-existence's sublimating-nascence) with existence speaks of existence's ecstatic singularity as so-reflected as of notional ${ }^{8}$ deprocrypticism singularisation-<as-to-thenondisjointedness/entailment-of-prospective- nonpresencing $>$ projected epistemicimmanence/veridical-epistemicity-relativism-determinism of ${ }^{56}$ meaningfulness-and-teleology in conceptualising 'true-ontology-as-of-Being-development/ontological-frameworkexpansion-as-to-depth-of-ontologising-development-as-infrastructure-of- meaningfulnessand-teleology '. Ultimately, Being-development/ontological-framework-expansion-as-todepth-of-ontologising-development-as-infrastructure-of- meaningfulness-and-teleology 
points to the fundamental dialecticism of human ${ }^{5}$ meaningfulness-and-teleology ; as to the fact that the human is that which is in <amplituding/formative-epistemicity $>$-totalising $\sim$ thrownnessin-existence $^{35}$ as of recurrent-utter-uninstitutionalisation <amplituding/formativeepistemicity $>$ totalising $\sim$ self-referencing-syncretising/circularity/interiorising/akrasiatic-drag by its reference-of-thought apriorising/axiomatising/referencing/intelligibilitysettingup/measuringinstrumenting but then is warranted to ontologically-complete itself successively as of base-institutionalisation, ${ }^{3}$ universalisation, positivism and prospectively notional ${ }^{18 \text { deprocrypticism }}$ apriorising/axiomatising/referencing/intelligibilitysettingup/measuringinstrumenting. The human then is what is warranted to reconstrue Rousseauian perfectibility out of its $<$ amplituding/formative-epistemicity $>$-totalising $\sim$ thrownness-in-existence ${ }^{35} \quad$ flawed constructiveness-of-ontological-performance ${ }^{72}-<$ including-virtue-asontology $>$ /morality/ethics/justice/etc. as of its destructuring-threshold-〈uninstitutionalisedthreshold /presublimating-desublimating-decisionality $>$ of-ontological-performance ${ }^{72}$ $<$ including-virtue-as-ontology $>$, as it can't pretend to avoid this purposefulness as it is, as of its any ${ }^{7}$ presencing-absolutising-identitive-constitutedness ${ }^{14}$ state, the outcome of such purposefulness as relayed with the relative-unreflexivity/relative-reflexivity-ontologicalcontiguity $\sim$ of-the-human-institutionalisation-process 'true-ontology—as-of-Beingdevelopment/ontological-framework-expansion-as-to-depth-of-ontologising-development-asinfrastructure-of- meaningfulness-and-teleology '. This coherently explains the inevitability of human 'intemporal ontological-faith-notion-or-ontological-fideism-imbuedunderdetermination-of-motif-and-apriorising/axiomatising/referencing-as-so-being-as-ofexistential-reality parrhesiastic askesis-or-acumen' for originary/as-of-event ${ }^{38}$ reasoningthrough/messianic-reasoning prospective relative-ontological-completeness ${ }^{87}$-of- ${ }^{8}$ reference-ofthought; as when the organic-knowledge avails it is much more than just an idea of choice but 
rather an obligation as of the implied inherently antiakrasiatic disposition that can't afford to overlook as if lacking the organic-knowledge for degrading into <amplituding/formativeepistemicity $>$ totalising $\sim$ self-referencing-syncretising/circularity/interiorising/akrasiatic-drag in preconverging-existential-extrication-as-of-existential-unthought. When the dialecticism of human ${ }^{56}$ meaningfulness-and-teleology 9 as of its prospective ontological-performance ${ }^{72}$ $<$ including-virtue-as-ontology $>$ /morality/ethics/justice/etc. implications as of virtue at

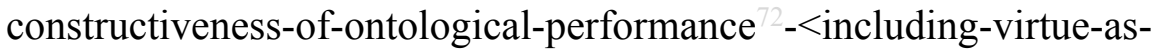

ontology $>$ /morality/ethics/justice/etc. and vices-and-impediments ${ }^{105}$ at destructuring-threshold〈uninstitutionalised-threshold /presublimating-desublimating-decisionality $>$ of-ontologicalperformance $^{72}-<$ including-virtue-as-ontology $>$ /morality/ethics/justice/etc. shows itself to be definitely determinable and is no longer the bigger issue for prospective human emancipation but rather the bigger issue becoming one of human psychological cognisance and adjustment to any such prospective emancipating ${ }^{56}$ meaningfulness-and-teleology ${ }^{9}$ as so-reflected across the $<$ cumulating/recomposuring attendant-ontological-contiguity $>$-successive registryworldviews/dimensions transcendence-and-sublimity/sublimation/supererogatory $\sim$ dementativity. The underlying difficulty of all such psychoanalytic-unshackling/memeticreordering/institutional-recomposuring is all about how can a mindset adjusted as of its $<$ amplituding/formative-epistemicity>-totalising $\sim$ thrownness-in-existence ${ }^{35}$ as of its given $<$ amplituding/formative-epistemicity $>$ totalising $\sim$ self-referencing-

syncretising/circularity/interiorising/akrasiatic-drag

apriorising/axiomatising/referencing/intelligibilitysettingup/measuringinstrumenting for construing ${ }^{56}$ meaningfulness-and-teleology ${ }^{9}$ in $<$ amplituding formative $>$ wooden-language〈imbued-averaging-of-thought-<as-to-leveling/ressentiment/closed-construct-ofmeaningfulness-and-teleology -as-of-'nondescript/ignorable-void ' -with-regards-toprospective-apriorising-implications $>>$ ever gets prodded into contemplating an opened- 
construct-of- ${ }^{5}$ meaningfulness-and-teleology ${ }^{9}$ speaking supposedly of more ontologically profound prospective apriorising/axiomatising/referencing/intelligibilitysettingup/measuringinstrumenting of meaningfulness-and-teleology as implied as of prior transcendence-andsublimity/sublimation/supererogatoryade-mentativity from recurrent-utteruninstitutionalisation to base-institutionalisation, etc. But then as all along the $<$ cumulating/recomposuring attendant-ontological-contiguity $>$-successive registryworldviews/dimensions transcendence-and-sublimity/sublimation/supereregatory $\sim$ dementativity, such a parrhesiastic exercise is ever always caught up between accommodating human temporality ${ }^{8} /$ shortness and existence-potency $^{32} \sim$ sublimating-nascence,-disclosed-fromprospective-epistemic-digression which knows of no such accommodation for human temporality ${ }^{8}$, inevitably the existence-potency ${ }^{32} \sim$ sublimating-nascence,-disclosed-fromprospective-epistemic-digression transcendental-enabling/sublimating/supereregatery $\sim$ dementativity implications necessarily comes ahead of human temporality 8 /shortness emotional convenience. The certitude and determination of human ${ }^{56}$ meaningfulness-and-teleology ${ }^{99}$ as from this hindsight, as so-reflected from singularisation- $<$ as-to-thenondisjointedness/entailment-of-prospective- nonpresencing $>$ projected epistemicimmanence/veridical-epistemicity-relativism-determinism as of prospective notional ${ }^{18}$ deprocrypticism ${ }^{5}$ meaningfulness-and-teleology ${ }^{9}$, will necessarily imply preconverging-or-dementing ${ }^{20}$-apriorising-psychologism implications of supererogatory $\sim$ acuity/perspicacity/astuteness/edginess/incisiveness-ofapriorising/axiomatising/referencing/intelligibilitysettingup/measuringinstrumenting -forconceptualisation with respect to our positivism- ${ }^{80}$ procrypticism ${ }^{56}$ meaningfulness-andteleology as dissingularisation-<as-to-the-disjointedness/disentailment-of- presencing absolutising-identitive-constitutedness > /epistemic-nonimmanence/flawed-epistemicity- 
relativism-determinism even as we are thereby emotionally inconvenienced, just as singularisation-<as-to-the-nondisjointedness/entailment-of-prospective- nonpresencing $>$

projected epistemic-immanence/veridical-epistemicity-relativism-determinism as from our positivism perspective of ${ }^{56}$ meaningfulness-and-teleology ${ }^{9}$ will necessarily imply preconverging-or-dementing ${ }^{20}$-apriorising-psychologism implications of supererogatory acuity/perspicacity/astuteness/edginess/incisiveness-of-

apriorising/axiomatising/referencing/intelligibilitysettingup/measuringinstrumenting -for-

conceptualisation with respect to prior non-positivism/medievalism ${ }^{56}$ meaningfulness-andteleology as dissingularisation-<as-to-the-disjointedness/disentailment-of- presencing absolutising-identitive-constitutedness $>$ /epistemic-nonimmanence/flawed-epistemicityrelativism-determinism even as we can appreciate the emotional inconvenience of the nonpositivism/medievalism establishment mental-dispositions. Existence's metaphoricity ${ }^{5} /$ ecstasy supervening-conflatedness ${ }^{13}$ as of 'phenomenal/manifest $\sim$ subpotencies-<in-transitiveconflatedness -reflexivity,-in-the-full-potency-of-existence's $\sim$ sublimating-nascence $\rangle$-in$<$ amplituding/formative-epistemicity $>$-totalising $\sim$ thrownness-in-existence,$-<$ of-

surrealistic-as-pseudoreal'-epistemic-abnormalcy> given 'apriorising-teleologicalthresholding-as-teleological-framework/narrative-framework of contextualising/existentialising/instantiative-devolving-meaningfulness' speak of transepistemic/epistemic-ricochetting supererogatory acuity/perspicacity/astuteness/edginess/incisiveness-ofapriorising/axiomatising/referencing/intelligibilitysettingup/measuringinstrumenting -forconceptualisation as of organic-knowledge in reflecting both singularisation- $<$ as-to-thenondisjointedness/entailment-of-prospective- nonpresencing $>$ projected epistemicimmanence/veridical-epistemicity-relativism-determinism-as-of-intemporality ${ }^{52}$ and dissingularisation-<as-to-the-disjointedness/disentailment-of- presencing — absolutising- 
identitive-constitutedness $>$ /epistemic-nonimmanence/flawed-epistemicity-relativismdeterminism-as-of-temporality ${ }^{8}$ implications of ${ }^{56}$ meaningfulness-and-teleology ${ }^{9}$ veridical ontological-performance ${ }^{72}<$ including-virtue-as-ontology $>$ /morality/ethics/justice/etc. $\quad$ or ontologically-flawed ontological-performance ${ }^{72}-<_{\text {including-virtue-as- }}$ ontology $>$ /morality/ethics/justice/etc. respectively, as of both the ${ }^{83}$ reference-of-thought-level disambiguation in reflecting holographically-<conjugatively-and-transfusively $>$ the relativeunreflexivity/relative-reflexivity - ontological-contiguity of-the-human-institutionalisationprocess and the ${ }^{83}$ reference-of-thought- devolving-level disambiguation as of temporal-tointemporal ontological-performance ${ }^{2}-<$ including-virtue-as-ontology $>$; wherein singularisation$<$ as-to-the-nondisjointedness/entailment-of-prospective- nonpresencing $>\quad$ projected epistemic-immanence/veridical-epistemicity-relativism-determinism is rather a 'psychoanalytically dragged-out depth/profoundness of ontological-conception' as of dispensing-with-immediacy-for-relative-ontological-completeness ${ }^{87}$-byreification/contemplative-distension ${ }^{27} \quad$ whilst dissingularisation- $<$ as-to-thedisjointedness/disentailment-of- presencing - absolutising-identitiveconstitutedness $>$ /epistemic-nonimmanence/flawed-epistemicity-relativism-determinism is rather a 'psychoanalytically dragged-in shallowness of ontological-misconception' as of poor dispensing-with-immediacy-for-relative-ontological-completeness ${ }^{87}$-byreification/contemplative-distension ${ }^{27}$. Ultimately, existence's metaphoricity ${ }^{57} /$ ecstasy as of supervening-conflatedness ${ }^{13}$ reflected in $\quad<$ amplituding/formative-epistemicity $>$ totalising $\sim$ thrownness-in-existence ${ }^{35}$ of phenomenal/manifest $\sim$ subpotencies-〈in-transitiveconflatedness -reflexivity,-in-the-full-potency-of-existence's $\sim$ sublimating-nascence)' as to their 'apriorising-teleological-thresholding-as-teleological-framework/narrative-framework of contextualising/existentialising/instantiative-devolving-meaningfulness' points to the supervening-conflatedness ${ }^{13} \quad$ notional $\sim$ reflexivity- $<\{$ veridical/sound $\}$-relative-reflexivity-in- 
existence/relativising from-limited-mentation-as-its-deepening/psychologismic-

<residualising \{decompulsing $\}$ delinearity for-cogency>by-\{flawed/unsound\}-relative-

unreflexivity-in-existence/absolutising from-limited-mentation/psychologismic epistemic

acutisation - nonresidualising imbued-\{compulsing\}linearity in-eclecticism-of-prior-mere-

formulaicity/ritualisation> of existence, wherein the ontological-veracity/ontologicalperformance $^{72}$-<including-virtue-as-ontology $>/$ morality/ethics/justice/etc.

of

'phenomenal/manifest $\sim$ subpotencies-〈in-transitive-conflatedness -reflexivity,-in-the-full-

potency-of-existence's $\sim$ sublimating-nascence $\rangle$-in-<amplituding/formative-epistemicity $>$ -

totalising thrownness-in-existence,$-<$ of- ${ }^{6}$ surrealistic-as-pseudoreal'-epistemic-

abnormalcy> phenomena/manifestations are transepistemically/epistemic-ricochettingly

construed as of their supposedly coherent ontological-commitment $-<$ implied - selfassuredness-of-ontological-good-faith/authenticity $\sim$ postconverging-de-

mentating/structuring/paradigming -as-being-as-of-existential-reality $>$ as can be validated by existence-potency ${ }^{39} \sim$ sublimating-nascence,-disclosed-from-prospective-epistemic-digression $<$ amplituding/formative-epistemicity $>$ causality $\sim$ as-to-projective-totalitative-implications-ofprospective- nonpresencing,-for-explicating relative-unreflexivity/relative-reflexivity ontological-contiguity ; as for instance, such an existential-<disontologising/re-ontelogising apereticism $>$ constraining as a child-as-a-subpotency epistemic-conception coming into existence undergoes developmental metaphoricity ${ }^{57}$ as of its inherent supposedly coherent

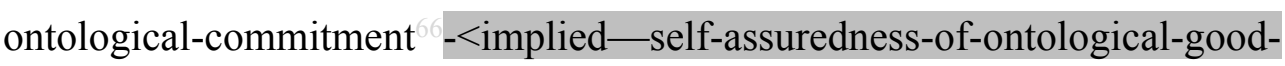
faith/authenticity postconverging-de-mentating/structuring/paradigming -as-being-as-ofexistential-reality> as the defining-and-superseding basis for its acquisition of culture and language all along the way of its entire devolving possibility of flourishing in apriorising/axiomatising/referencing-\{of-'prospectively_implicited_attendant-ontologicalcontiguity ' $\sim$ educed- 
existentialising/contextualising/textualising_'intelligibility/epistemicity/reflexivity-contiguity$<$ imbued-notional cogency $>$ ' $\}$-conflatedness ${ }^{13}$ in-\{preconverging-disentailment by\} postconverging-ntailment-as-of-its-developing-commitment-with-existence as from its feeding, warmth, relating, aspiring, maturing, etc. towards the effective acquisition of culture and language, and by extension a social-setup-as-a-subpotency epistemic-conception is preconverging/postconverging-de-mentatively/structurally/paradigmatically opened to prospective metaphoricity ${ }^{57}$ from existential-constraining/conflatedness ${ }^{13}$-of-its-commitmentwith-existence as of its inherently implied supposedly coherent ontological-commitment <implied - self-assuredness-of-ontological-good-faith/authenticity postconverging-dementating/structuring/paradigming -as-being-as-of-existential-reality $>$ as its individuals and social groups are naturally involved in a dynamic relationship of perceived social-stakecontention-or-confliction striving in apriorising/axiomatising/referencing-\{of-"prospectivelyimplicited_attendant-ontological-contiguity ' educedexistentialising/contextualising/textualising_'intelligibility/epistemicity/reflexivity-contiguity<imbued-notional cogency $\left.>^{\prime}\right\}$-conflatedness ${ }^{13}$-in-\{preconverging-disentailment by\} pestcenverging entailment to draw in various ways the optimum as of perceived existential-

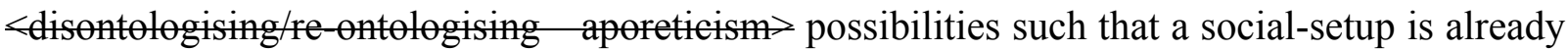
involved internally however restricted in its very own reinvention/circumventing/adaptation as of its implied supposedly coherent ontological-commitment $-<$ implied-self-assuredness-ofontological-good-faith/authenticity postconverging-dementating/structuring/paradigming -as-being-as-of-existential-reality $>$ on the basis of $<$ amplituding/formative-epistemicity $>$ causality $\sim$ as-to-projective-totalitative-implications-ofprospective- nonpresencing,-for-explicating relative unreflexivity/relative reflexivity ontological-contiguity validatory implications as to existence-potency ${ }^{32} \sim$ sublimating- $^{-}$ nascence,-disclosed-from-prospective-epistemic-digression. Basically it is this supervening- 


\section{existence/relativising from-limited-mentation-as-its-deepening/psychologismic-}

<residualising \{decompulsing delinearity for-cogency>by-\{flawed/unsound\}-relative-

unreflexivity-in-existence/absolutising from-limited-mentation/psychologismic epistemic-

acutisation nonresidualising imbued-\{compulsing\} linearity in-eclecticism-of prior-mere-

formulaicity/ritualisation> of existence as of the 'phenomenal/manifest $\sim$ subpotencies-〈intransitive-conflatedness -reflexivity,-in-the-full-potency-of-existence's $\sim$ sublimatingnascence $>$ - in —<amplituding/formative-epistemicity $>$-totalising $\sim$ thrownness-in-existence ,$<$ of-' ${ }^{\text {' }}$ surrealistic-as-pseudoreal'-epistemic-abnormalcy $>\quad$ phenomena/manifestations

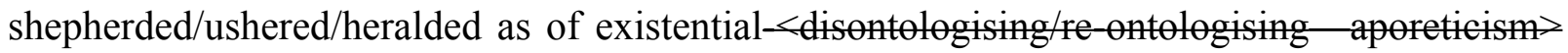
constraining by their supposedly coherent ontological-commitment $-<$ implied - selfassuredness-of-ontological-good-faith/authenticity postconverging-dementating/structuring/paradigming -as-being-as-of-existential-reality $>$ that reflects phenomenal/manifest $\sim$ subpotencies-〈in-transitive-conflatedness -reflexivity,-in-the-fullpotency-of-existence's sublimating-nascence) ‘epistemic-conception framework of ontologically-veridical ontological-performance ${ }^{2}-<$ including-virtue-asontology $>$ /morality/ethics/justice/etc. as-of-conflatedness ${ }^{13}$ as existentially-real or ontologically-flawed ontological-performance ${ }^{2}-<$ including-virtue-asontology $>$ /morality/ethics/justice/etc. as-of-constitutedness ${ }^{14}$ as existentially-unreal'; summating overall reifying-and-empowering-reflexivity-of-ecstatic-existence-aspanintelligibility/panreflexivity ${ }^{3}$-〈existentially-imbued-and-educing-<epistemicthermeneutically/textually/reprojectingly/supererogatingly/zeroingly/re-acutingly,\{decompusing $d e$ inearity $\sim$ for-cogency $\geq$-epistemic-perspective-of-projective/reprojectiveaestheticising-re-motif-and-re-apriorising/re-axiomatising/re-referencing conceptualisation,as-herein-specifically-relevant-to human-subpotency) reflected in the supervening- 
conflatedness $^{13}$ of phenomenal/manifest $\sim$ subpotencies-<in-transitive-conflatedness reflexivity,-in-the-full-potency-of-existence's $\sim$ sublimating-nascence). Going by humansubpotency-aporia/undecidability/dilemma/ought-

indeterminacy/deficiency/limitation/constraint—imbued-'notional firstnaturednessformativeness-<as-to-eventualising-inkling-drive-or-seeding-misprising $>$ temporal-tointemporal-dispositions-<so-construed-as-from-perspective-ontologicalnormalcy/postconvergence>'-existentialism-form-factor, the human construction-of-the-Self as of its constructiveness-of-ontological-performance ${ }^{72}-<_{\text {including-virtue-as- }}$ ontology $>$ /morality/ethics/justice/etc. and destructuring-threshold-〈uninstitutionalisedthreshold /presublimating-desublimating-decisionality $>$ of-ontological-performance ${ }^{72}$ <including-virtue-as-ontology $>$ /morality/ethics/justice/etc. is ever always saddled between 'prospective intemporal-as-ontologically-veridical/ontological-faith-notion-or-ontologicalfideism - imbued-underdetermination-of-motif-and-apriorising/axiomatising/referencing-asso-being-as-of-existential-reality parrhesiastic seeding-promise of reasoning-through/messianicreasoning ${ }^{5}$ meaningfulness-and-teleology ${ }^{9}$ as equivalence/correspondence antiakrasiaticaspiration' and 'temporal/sophistic-as-ontologically-flawed/ontological-badfaith/inauthenticity ${ }^{64} \quad$ reproducibility—mathesis/motif/thrownness-disposition,--asreproducibility-of-aestheticisation seeding-misprising of reasoning-from-results/afterthought meaningfulness-and-teleology 9 as covert-pretence-of-equivalence/correspondence-

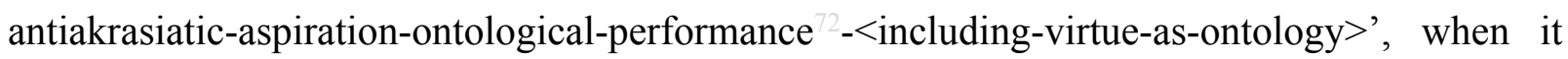
comes to the 'social-construction of ${ }^{56}$ meaningfulness-and-teleology' as of social-stakecontention-or-confliction'. This fundamental saddling of the human construction-of-the-Self as of a 'fixed/set framework of existentially-constraining possibility of temporal-to-intemporal ontological-performance ${ }^{72}-<$ including-virtue-as-ontology $>$ ' can be referred to as the 'shiftinessof-the-Self ${ }^{\prime}$, and construed as the beyond-the-consciousness-awareness-teleology ${ }^{9}-<$ of- 
preconverging-existential-extrication-as-of-existential-unthought $>$ that arises as of human lack of 'intemporal antiakrasiatic disposition for dispensing-with-immediacy-for-relativeontological-completeness $^{87}$-by-reification/contemplative-distension ${ }^{27}$ (as of human selfsurpassing — existentialism-form-factor,-in-overcoming-'notional collateralising-beholdeningprotohumanity'-to-'attain-sublimating-humanity'-as-to-existence-potency sublimatingnascence,-disclosed-from-prospective-epistemic-digression to supersede human temporality 8 /shortness <amplituding/formative> wooden-language-〈imbued-averaging-ofthought-<as-to-leveling/ressentiment/closed-construct-of- meaningfulness-and-teleology -asof-'nondescript/ignorable-void '-with-regards-to-prospective-apriorising-implications $>\rangle$ ) as of human limited-mentation-capacity-deepening as subjecting limitednesshman stbpen to-'educed-unlimitedness/existence-sublimating nascence' ${ }^{3}$ for prospective relativeontological-completeness $^{87}$. The 'shiftiness-of-the-Self', thus refers to any given registryworldview's/dimension's- ${ }^{8}$ reference-of-thought-for-social-functioning-and-accordance 'specific bottomline-of-mere-mathesis/motif/thrownness-disposition for the constructiveness of meaningfulness-and-teleology as of its specific construction-of-the-Self', beyond which bottomline-of-mere-mathesis/motif/thrownness-disposition of the registryworldview's/dimension's- ${ }^{8}$ reference-of-thought-for-social-functioning-and-accordance allows/disregards/unaccounts for human temporal shiftiness as defining its prospective destructuring-threshold-〈uninstitutionalised-threshold /presublimating-desublimatingdecisionality $>$ of-ontological-performance ${ }^{2}-<$ including-virtue-as-ontology $>$, and so beyondthe-consciousness-awareness-teleology ${ }^{9}-<$ of-preconverging-existential-extrication-as-ofexistential-unthought>; and this is exactly what explains the differentiation of registryworldviews/dimensions as of their relative-ontological-completeness ${ }^{87}$-of- ${ }^{83}$ reference-ofthought. The 'shiftiness-of-the-Self', preconverging/postconverging-dementatively/structurally/paradigmatically defines given 
'supererogatory acuity/perspicacity/astuteness/edginess/incisiveness-ofapriorising/axiomatising/referencing/intelligibilitysettingup/measuringinstrumenting -forconceptualisation reflected as of singularisation-<as-to-the-nondisjointedness/entailment-of-

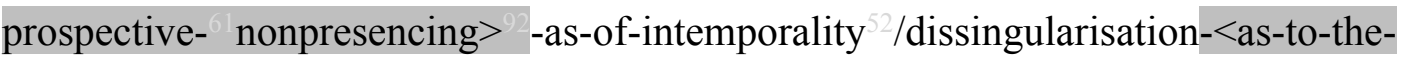
disjointedness/disentailment-of- presencing - absolutising-identitive-constitutedness $>{ }^{2}$-asof-temporality $^{98}$ of the ${ }^{56}$ meaningfulness-and-teleology ${ }^{9}$ of a given registryworldview/dimension implied as of its 'apriorising-teleological-thresholding-as-teleologicalframework/narrative-framework of contextualising/existentialising/instantiative-devolvingmeaningfulness' temporal-to-intemporal ontological-performance ${ }^{72}{ }^{-}$including-virtue-asontology>. Thus the requisite profoundness/depth of prospective human 'social-construction of meaningfulness-and-teleology as of social-stake-contention-or-confliction' as reflected at the prospective superseding/transcending registry-worldview/dimension, as from existencepotency $^{32} \sim$ sublimating-nascence,-disclosed-from-prospective-epistemic-digression $\quad$ as-toontologically-uncompromised-ontological-normalcy/postconvergence/referentialism perspective, can only arise fundamentally as of the prospective construction-of-the-Self renewed secondnatured institutionalisation

'spacuity/perspicacity/astuteness/edginess/incisiveness-ofapriorising/axiomatising/referencing/intelligibilitysettingup/measuringinstrumenting -forconceptualisation reflected as of singularisation-<as-to-the-nondisjointedness/entailment-of-

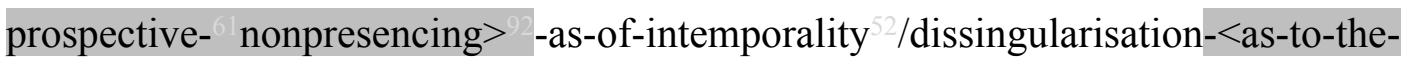
disjointedness/disentailment-of- presencing - absolutising-identitive-constitutedness $>{ }^{2}$-asof-temporality $^{98}$ of the ${ }^{5}$ meaningfulness-and-teleology 9 ' arising from renewed 'intemporal antiakrasiatic disposition for dispensing-with-immediacy-for-relative-ontologicalcompleteness $^{87}$-by-reification/contemplative-distension ${ }^{27}$ as of human limited-mentationcapacity-deepening — as-subjecting limitedness/human-subpotency-to-'educed- 
unlimitedness/existence-sublimating nascence' $^{53}$ for prospective relative-ontologicalcompleteness $^{87}$ ' in undermining the prior registry-worldview's/dimension's 'shiftiness-of-theSelf ' that defines its destructuring-threshold-〈uninstitutionalised-threshold /presublimatingdesublimating-decisionality $>$ of-ontological-performance ${ }^{72}-<$ including-virtue-as- $^{-}$ ontology $>/$ morality/ethics/justice/etc. as uninstitutionalised-threshold ${ }^{102}$; and thus moving the relative-unreflexivity/relative-reflexivity - ontological-contiguity ${ }^{67}$ of-the-humaninstitutionalisation-process ${ }^{68}$ bar of 'shiftiness-of-the-Self' to the prospective registryworldview's/dimension's- ${ }^{83}$ reference-of-thought-for-social-functioning-and-accordance 'specific bottomline-of-mere-mathesis/motif/thrownness-disposition for the constructiveness of meaningfulness-and-teleology as of its specific construction-of-the-Self'. Thus we can appreciate fundamentally that, as reflected in reflecting holographically-<conjugatively-andtransfusively $>$ the relative-unreflexivity/relative-reflexivity ontological-contiguity $\sim$ of-thehuman-institutionalisation-process, human 'prospective intemporal-as-ontologicallyveridical/ontological-faith-notion-or-ontological-fideism-imbued-underdetermination-ofmotif-and-apriorising/axiomatising/referencing-as-so-being-as-of-existential-reality parrhesiastic seeding-promise of reasoning-through/messianic-reasoning ${ }^{5}$ meaningfulness-andteleology ${ }^{9}$ as equivalence/correspondence antiakrasiatic-aspiration' over 'temporal/sophisticas-ontologically-flawed/ontological-bad-faith/inauthenticity reproducibilitymathesis/motif/thrownness-disposition,-as-reproducibility-of-aestheticisation seedingmisprising of reasoning-from-results/afterthought ${ }^{56}$ meaningfulness-and-teleology ${ }^{99}$ as covertpretence-of-equivalence/correspondence-antiakrasiatic-aspiration-ontological-performance ${ }^{72}$ <including-virtue-as-ontology>', has ever always been more critically about the 'existentiallyoperant constraining' for: moving the relative-unreflexivity/relative-reflexivity_ontologicalcontiguity ${ }^{67}$ of-the-human-institutionalisation-process ${ }^{68}$ bar of 'shiftiness-of-the-Self ${ }^{1}$ ' to the prospective registry-worldview's/dimension's- ${ }^{83}$ reference-of-thought-for-social-functioning- 
and-accordance 'specific bottomline-of-mere-mathesis/motif/thrownness-disposition for the constructiveness of ${ }^{5}$ meaningfulness-and-teleology as of its specific construction-of-the-Self in order to undermine human destructuring-threshold-〈uninstitutionalisedthreshold /presublimating-desublimating-decisionality) of-ontological-performance ${ }^{72}$ <including-virtue-as-ontology>; rather than truly eliminating human 'shiftiness-of-the-Self' arising from the ever always present human 'temporal/sophistic-as-ontologicallyflawed/ontological-bad-faith/inauthenticity ${ }^{64}$ reproducibility—mathesis/motif/thrownnessdisposition,-as-reproducibility-of-aestheticisation seeding-misprising of reasoning-fromresults/afterthought $\quad{ }^{56}$ meaningfulness-and-teleology ${ }^{9}$ as $\quad$ covert-pretence-ofequivalence/correspondence-antiakrasiatic-aspiration-ontological-performance ${ }^{72}$-<includingvirtue-as-ontology>'. Thus the relative-unreflexivity/relative-reflexivity-ontologicalcontiguity $\sim$ of-the-human-institutionalisation-process as of the <cumulating/recomposuring attendant-ontological-contiguity $>$-successive registryworldviews/dimensions given 'supererogatory acuity/perspicacity/astuteness/edginess/incisiveness-ofapriorising/axiomatising/referencing/intelligibilitysettingup/measuringinstrumenting -forconceptualisation reflected as of singularisation-<as-to-the-nondisjointedness/entailment-of-

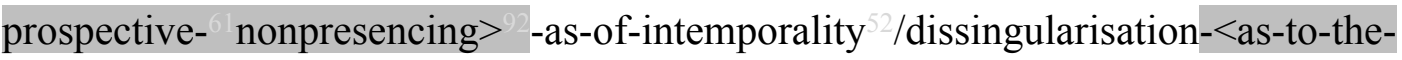
disjointedness/disentailment-of- presencing - absolutising-identitive-constitutedness $>{ }^{2}$-asof-temporality $^{98}$ of the ${ }^{56}$ meaningfulness-and-teleology' arising from renewed 'intemporal antiakrasiatic disposition for dispensing-with-immediacy-for-relative-ontologicalcompleteness $^{87}$-by-reification/contemplative-distension ${ }^{27}$ as of human limited-mentationcapacity-deepening —as-subjecting limitedness/human-subpotency-to-'educedunlimitedness/existence-sublimating nascence' for prospective relative-ontologicalcompleteness $^{87}$, in the preconverging/postconverging-rede- 
mentating/restructuring/reparadigming of human 'social-construction of ${ }^{56}$ meaningfulness-andteleology as of social-stake-contention-or-confliction', can be interpreted as moving the relative-unreflexivity/relative-reflexivity ontological-contiguity ${ }^{67} \sim$ of-the-humaninstitutionalisation-process ${ }^{68}$ bar of 'shiftiness-of-the-Self', to the prospective registryworldview's/dimension's- ${ }^{83}$ reference-of-thought-for-social-functioning-and-accordance 'specific bottomline-of-mere-mathesis/motif/thrownness-disposition for the constructiveness of meaningfulness-and-teleology as of its specific construction-of-the-Self': so-construed as from recurrent-utter-uninstitutionalisation non-rules - apriorising/axiomatising/referencingpsychologism 'shiftiness-of-the-Self ',; base-institutionalisation-ununiversalisation rulemaking-over-non-rules_ apriorising/axiomatising/referencing-psychologism 'shiftiness-ofthe-Self '; $\quad{ }^{103}$ universalisation-non-positivism/medievalism $\quad{ }^{103}$ universalisation-directedrulemaking-over-non-rules — apriorising/axiomatising/referencing-psychologism 'shiftiness-ofthe-Self '; positivism- ${ }^{80}$ procrypticism positivising/rational-empiricism-based-universalisationdirected-rulemaking-over-non-rules — apriorising/axiomatising/referencing-psychologism

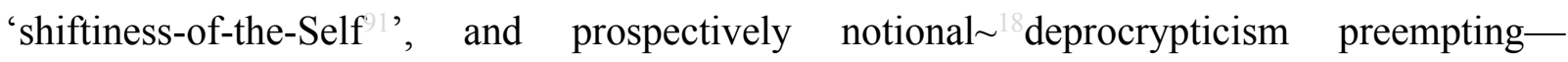
disjointedness-as-of- ${ }^{83}$ reference-of-thought,-as-to- ${ }^{3}<$ amplituding/formativeepistemicity $>$ growth-or-conflatedness ${ }^{13} /$ transvaluative- $^{2}$ rationalising/transepistemicity/anamnestic-residuality/spirit-drivenness'_in-supersedingmere-formulaic-positivising/rational-empiricism-based-universalisation-directed-rulemakingover-non-rules_-apriorising/axiomatising/referencing-psychologism notionally overcoming 'shiftiness-of-the-Self ', We can appreciate in this regards that both for the individual and the social, the capacity to 'spontaneously' be able to articulate 'social-construction of meaningfulness-and-teleology as of social-stake-contention-or-confliction' as in the prospective relative-ontological-completeness ${ }^{87}$ registry-worldview/dimension is fundamentally hampered by its given registry-worldview's/dimension's- ${ }^{83}$ reference-of-thought-for-social- 
functioning-and-accordance 'specific bottomline-of-mere-mathesis/motif/thrownnessdisposition for the constructiveness of ${ }^{5}$ meaningfulness-and-teleology ${ }^{9}$ as of its specific construction-of-the-Self' due to its corresponding lack of 'intemporal antiakrasiatic disposition for dispensing-with-immediacy-for-relative-ontological-completeness ${ }^{87}$-byreification/contemplative-distension ${ }^{27}$ as of human limited-mentation-capacity-deepening-assubjecting-limitedness/human-subpotency-to-'educed-unlimitedness/existence-sublimatingnascence' ${ }^{53}$ for prospective relative-ontological-completeness ${ }^{87}$ that can then allow for the requisite 'supererogatory $\sim$ acuity/perspicacity/astuteness/edginess/incisiveness-ofapriorising/axiomatising/referencing/intelligibilitysettingup/measuringinstrumenting - forconceptualisation reflected as of singularisation-<as-to-the-nondisjointedness/entailment-of-

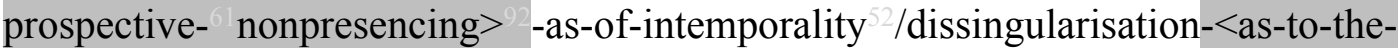
disjointedness/disentailment-of- presencing - absolutising-identitive-constitutedness $>{ }^{2}$-asof-temporality $^{8}$ of the ${ }^{5}$ meaningfulness-and-teleology'. In this regard, we can more specifically appreciate the central and transformative implications of the Socratic-philosophers universalising-idealisation as of the prospective ${ }^{103}$ universalisation registryworldview/dimension 'social-construction of ${ }^{5}$ meaningfulness-and-teleology' as of social-

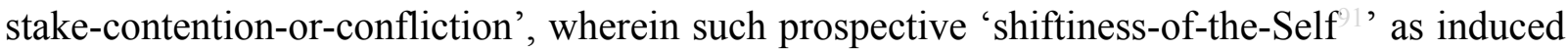
by the Socratic-philosophers ${ }^{103}$ universalising-idealisation construed as ${ }^{103}$ universalisationdirected-rulemaking-over-non-rules_-apriorising/axiomatising/referencing-psychologism inducing the secondnatured institutionalisation of the ${ }^{103}$ universalisation registryworldview's/dimension's- ${ }^{83}$ reference-of-thought-for-social-functioning-and-accordance 'specific bottomline-of-mere-mathesis/motif/thrownness-disposition for the constructiveness of meaningfulness-and-teleology ${ }^{9}$ as of its specific construction-of-the-Self' brought about the coherently ${ }^{103}$ universalising construction of ${ }^{56}$ meaningfulness-and-teleology ${ }^{9}$ with the associated elevated level of ontological-performance ${ }^{72}-$ including-virtue-as- $^{2}$ 
ontology $>$ /morality/ethics/justice/etc. as manifested with the Socratic method for ${ }^{103}$ universal consistency and coherence, Plato's ideas for ${ }^{103}$ universal consistency and coherence and Aristotle's qualifying-categories and ${ }^{103}$ universalising-syllogism for ${ }^{103}$ universal consistency and coherence; thus superseding/transcending the ad-hoc mysticism, ad-hoc cultism and sophistic/pedantic ad-hoc/makeshift/nonprincipled-syllogising mindset as of baseinstitutionalisation mere rulemaking-over-non-rules — apriorising/axiomatising/referencingpsychologism 'shiftiness-of-the-Self' '. This is the more profound explanation for the hegemonising ontological-grip thereafter of the Socratic-philosophers defining ${ }^{3}$ universalisation ${ }^{5}$ meaningfulness-and-teleology ${ }^{9}$ thereafter over the antiquity and their defining relevance in the latter ${ }^{56}$ meaningfulness-and-teleology ${ }^{9}$ of all the medieval societies of the Mediterranean and beyond, and so especially as the increasing population mixing thereafter particularly with the Roman empire naturally required/called-for " ${ }^{103}$ universally coherent, consistent and credible ${ }^{5}$ meaningfulness-and-teleology infrastructure as of Beingdevelopment/ontological-framework-expansion-as-to-depth-of-ontologising-development-asinfrastructure-of- meaningfulness-and-teleology ' that went well beyond traditional ad-hoc mysticism, ad-hoc cultism and sophistic/pedantic ad-hoc/makeshift/nonprincipled-syllogising mindset; as of the knowledge reifying capacity-and-template for developing and cumulating such universalising-idealisation coherence and consistency across culturally diverse peoples and across space and time. The Socratic-philosophers crucial and defining emphasis for differentiating themselves from sophists-ideal-type-or-individuation was very much a selfconscious insight as of the requisite parrhesiastic gesturing/accounting-of-epistemicphenomenalism of 'intemporal antiakrasiatic disposition for dispensing-with-immediacy-forrelative-ontological-completeness ${ }^{87}$-by-reification/contemplative-distension ${ }^{27}$ (as of human selfsurpassing — existentialism-form-factor,-in-overcoming-'notional collateralising-beholdeningprotohumanity'-to-'attain-sublimating-humanity'-as-to-existence-potency sublimating- 
nascence,-disclosed-from-prospective-epistemic-digression to supersede human temporality 8 /shortness <amplituding/formative> wooden-language-〈imbued-averaging-ofthought-<as-to-leveling/ressentiment/closed-construct-of- meaningfulness-and-teleology -asof-'nondescript/ignorable-void '-with-regards-to-prospective-apriorising-implications $>\rangle$ ) as of human limited-mentation-capacity-deepening —as-subjecting limitedness/human-subpotency to-'educed-unlimitedness/existence-sublimating nascence' ${ }^{3}$ for prospective relativeontological-completeness $^{87}$, to allow for the requisite ${ }^{103}$ universalising-idealisation 'supererogatory acuity/perspicacity/astuteness/edginess/incisiveness-of-

apriorising/axiomatising/referencing/intelligibilitysettingup/measuringinstrumenting -forconceptualisation reflected as of singularisation-<as-to-the-nondisjointedness/entailment-of-

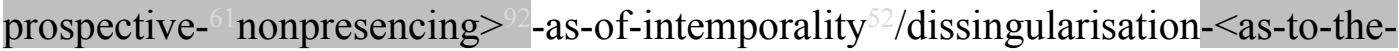
disjointedness/disentailment-of- presencing - absolutising-identitive-constitutedness $>{ }^{2}$-asof-temporality $^{98}$ of the ${ }^{56}$ meaningfulness-and-teleology ${ }^{9}$; which otherwise would be highly underminable as of a predisposition to ad-hoc mysticism, ad-hoc cultism and sophistic/pedantic ad-hoc/makeshift/nonprincipled-syllogising mindset by which populist <amplituding/formative $>$ wooden-language-〈imbued — averaging-of-thought-<as-toleveling/ressentiment/closed-construct-of- meaningfulness-and-teleology -as-of'nondescript/ignorable-void '-with-regards-to-prospective-apriorising-implications $>>\quad$ could easily be elicited were the Socratic-philosophers to imply dialogical-equivalence- $<$ as-topsychologismic apriorising/axiomatising/referencing-\{of-"prespectively implicited_attendant-ontological-contiguity ' ceducedexistentialising/contextualising/textualising_'intelligibility/epistemicity/reflexivity-contiguity<imbued-notional $\left.\sim \operatorname{cogency}>^{\prime} \quad\right\}$-conflatedness -in-\{preconverging-disentailment by\} postconverging-entailment,-in-self-becoming/self-conflatedness /formative-supererogating> and intellectual-and-moral-equivalence as of common/mutual 
aposteriorising/logicising/deriving/intelligising/measuring whereas in reality there were of dissimilar apriorising/axiomatising/referencing/intelligibilitysettingup/measuringinstrumenting as to imply such sophistic/pedantic dispositions were rather in 'apriorising-teleologicaldegradation-in notional-discontiguity/epistemic-discontiguity ${ }^{6}-<$ between - prior-shallowsupererogation -of-mentally-aestheticised preconverging/dementing -qualiaschema_and_prospective-profound-supererogation -of-mentallyaestheticised postconverging/dialectical-thinking -qualia-schema>', and it was more critically a question of upholding ${ }^{103}$ universalising-idealisation reifying ${ }^{56}$ meaningfulness-and-teleology as to existence-potency ${ }^{39} \sim$ sublimating-nascence,-disclosed-from-prospective-epistemicdigression $\quad<$ amplituding/formative-epistemicity $>$ causality $\sim$ as-to-projective-totalitativeimplications-of-prospective- nonpresencing,-for-explicating $\sim$ relative-unreflexivity/relativereflexivity - ontological-contiguity over time. By the same token, the mathesis- ${ }^{103}$ universalis of budding-positivists/rational-empiricists positivising/rational-empiricism-baseduniversalisation-directed-rulemaking-over-non-rules—apriorising/axiomatising/referencingpsychologism 'shiftiness-of-the-Self', for the prospective positivism registryworldview/dimension 'social-construction of ${ }^{56}$ meaningfulness-and-teleology' as of socialstake-contention-or-confliction' induced the requisite 'intemporal antiakrasiatic disposition for dispensing-with-immediacy-for-relative-ontological-completeness ${ }^{87}$-byreification/contemplative-distension ${ }^{27}$ as of human limited-mentation-capacity-deepening-assubjecting limitedness/human-subpotency-to-'educed-unlimitedness/existence-sublimating nascence' ${ }^{53}$ for prospective relative-ontological-completeness ${ }^{87}$, allowing for the requisite 'supererogatory acuity/perspicacity/astuteness/edginess/incisiveness-ofapriorising/axiomatising/referencing/intelligibilitysettingup/measuringinstrumenting -forconceptualisation reflected as of singularisation-<as-to-the-nondisjointedness/entailment-ofprospective- nonpresencing $>$-as-of-intemporality $52 /$ dissingularisation- $<$ as-to-the- 
of-temporality $^{98}$ of the ${ }^{5}$ meaningfulness-and-teleology ${ }^{9}$, for the secondnatured institutionalisation of prospective positivism registry-worldview's/dimension's- ${ }^{83}$ reference-ofthought-for-social-functioning-and-accordance 'specific bottomline-of-meremathesis/motif/thrownness-disposition for the constructiveness of ${ }^{5}$ meaningfulness-andteleology ${ }^{9}$ as of its specific construction-of-the-Self'. Here too, the budding-positivists/rationalempiricists were very much aware of the lack of dialogical-equivalence-<as-topsychologismic apriorising/axiomatising/referencing-\{of-'prospectively implicited_attendant-ontological-contiguity ' educedexistentialising/contextualising/textualising_'intelligibility/epistemicity/reflexivity-contiguity<imbued-notional cogency >' \}-conflatedness -in-\{preconverging-disentailment by\} postconverging entailment,-in-self-becoming/self-conflatedness /formative-supererogating > and intellectual-and-moral-equivalence as of common/mutual aposteriorising/logicising/deriving/intelligising/measuring as of their dissimilar apriorising/axiomatising/referencing/intelligibilitysettingup/measuringinstrumenting as to imply underlying medieval-scholasticism-pedants - ideal-type-or-individuation establishment dogmatism was rather in 'apriorising-teleological-degradation-in $\sim$ notionaldiscontiguity/epistemic-discontiguity ${ }^{63}-<$ between - prior-shallow-supererogation -ofmentally-aestheticised preconverging/dementing -qualia-schema_and_prospective-profoundsupererogation -of-mentally-aestheticised postconverging/dialectical-thinking -qualiaschema>', and that it would be more critically a question of upholding the buddingpositivism/rational-empricism reifying ${ }^{56}$ meaningfulness-and-teleology ${ }^{99}$ as to existencepotency ${ }^{39} \sim$ sublimating-nascence,-disclosed-from-prospective-epistemic-digression <amplituding/formative-epistemicity $>$ causality $~ a s-t o-p r o j e c t i v e-t o t a l i t a t i v e-i m p l i c a t i o n s-o f-$ prospective- nonpresencing,-for-explicating relative-unreflexivity/relative-reflexivity 
ontological-contiguity over time as effected ultimately with the hegemonising ontological-grip of such positivism/rational-empiricism renewed and more profound ${ }^{56}$ meaningfulness-andteleology ${ }^{9}$ infrastructure as of Being-development/ontological-framework-expansion-as-todepth-of-ontologising-development-as-infrastructure-of- meaningfulness-and-teleology that rendered possible the knowledge 'implicited_attendant-ontological-contiguity ${ }^{67}$; educedexistentialising/contextualising/textualising_intelligibility/epistemicity/reflexivity-contiguity$<$ imbued-notional cogency> ${ }^{\text {, }}$ reifying capacity-and-template for the transformative development-and-cumulation of modern science and liberal society. Thus what is transformatively critical with regards to 'intemporal antiakrasiatic disposition for dispensingwith-immediacy-for-relative-ontological-completeness ${ }^{87}$-by-reification/contemplativedistension as of human limited-mentation-capacity-deepening-as-subjecting limitedness/human-subpotency-to-'educed-unlimitedness/existence-sublimating nascence' for prospective relative-ontological-completeness ${ }^{8}$, in inducing the relativeunreflexivity/relative-reflexivity — ontological-contiguity ${ }^{67}$ of-the-human-institutionalisationprocess ${ }^{68}$ successive secondnatured institutionalisation of prospective 'shiftiness-of-the-Self ", construed as of prospective registry-worldview's/dimension's- ${ }^{83}$ reference-of-thought-forsocial-functioning-and-accordance 'specific bottomline-of-mere-mathesis/motif/thrownnessdisposition for the constructiveness of ${ }^{5}$ meaningfulness-and-teleology 9 as of specific construction-of-the-Self', is that with regards to 'social-construction of ${ }^{56}$ meaningfulness-andteleology ${ }^{9}$ as of social-stake-contention-or-confliction' the individual and the collective-social adopt increasingly 'deeper-mutualising-leeway-of-nonimmediacy-of-selfconsciousness(dispensing-with-immediacy-for-relative-ontological-completeness ${ }^{87}$-byreification/contemplative-distension ${ }^{27}$ )' - successively- 'in-superseding-the-immediacydisposition-for-trepidatiousness-of-self-consciousness'-with-base-institutionalisation-overrecurrent-utter-uninstitutionalisation,-'in-superseding-the-immediacy-disposition-for- 
tendentiousness-of-self-consciousness'-with-universalisation-over-base-institutionalisationununiversalisation,-'in-superseding-the-immediacy-disposition-for-preclusivity-of-selfconsciousness'-with-positivism/rational-empiricism-over-universalisation-nonpositivism/medievalism,-and-prospectively,-'in-superseding-the-immediacy-disposition-forocclusivity-of-self-consciousness'-with-deprocrypticism-over-positivism- ${ }^{80}$ procrypticism-'inattaining-the-nonimmediacy-disposition-for-protensivity-of-self-consciousness' (which as notional ${ }^{18}$ deprocrypticism is construed as 'projective-totalitative' with regards to the humansubpotency potential to converge to existence-potency ${ }^{3} \sim$ sublimating-nascence,-disclosedfrom-prospective-epistemic-digression as of opened-construct-of- ${ }^{56}$ meaningfulness-andteleology

apriorising/axiomatising/referencing/intelligibilitysettingup/measuringinstrumenting); and so, as of successive profundity of supererogatory $\sim$ acuity/perspicacity/astuteness/edginess/incisiveness-ofapriorising/axiomatising/referencing/intelligibilitysettingup/measuringinstrumenting - forconceptualisation implied in $<$ amplituding/formative-epistemicity $>$-totalising $\sim$ renewingrealisation/re-perception/re-thought for prospectively 'increasingly profound and complex meaningfulness-and-teleology infrastructure as of Being-development/ontologicalframework-expansion-as-to-depth-of-ontologising-development-as-infrastructure-ofmeaningfulness-and-teleology , institutional-development-as-to-social-functiondevelopment and living-development-as-to-personality-development psychologismic epistemic-acutisation difficulty-for, residualising \{decompulsing ${ }^{\prime}$ delinearity for-cogency> magnitudes $\{$ of-experientiality/experiment $\}$, as enabling-and-reflected successively in more and more sophisticated and elaborate social-setup and institutional constructs. Basically, human destructuring-threshold-〈uninstitutionalised-threshold /presublimating-desublimatingdecisionality $>\sim$ of-ontological-performance ${ }^{72}-<$ including-virtue-as- 
ontology $>$ /morality/ethics/justice/etc. as highlighted as of the constructiveness-anddestructuring-framework of 'shiftiness-of-the-Self', and as reflected in any given registryworldview's/dimension's- ${ }^{83}$ reference-of-thought-for-social-functioning-and-accordance 'specific bottomline-of-mere-mathesis/motif/thrownness-disposition for the constructiveness of meaningfulness-and-teleology as of its specific construction-of-the-Self arises as of destructuring-transitoriness -as-of-deratiocination/deratiocontiguity, so-construed as of dissingularisation-<as-to-the-disjointedness/disentailment-of- presencing - absolutisingidentitive-constitutedness $>$ /epistemic-nonimmanence/flawed-epistemicity-relativismdeterminism induced deratiocination-or-deratiocontiguity; wherein as of flawed supererogatory $\sim$ acuity/perspicacity/astuteness/edginess/incisiveness-ofapriorising/axiomatising/referencing/intelligibilitysettingup/measuringinstrumenting -forconceptualisation $\quad<$ amplituding/formative-epistemicity $>$ causality $\sim$ as-to-projectivetotalitative-implications-of-prospective- nonpresencing,-for-explicating relativeunreflexivity/relative-reflexivity - ontological-contiguity , preconverging-or-dementing 2 apriorising-psychologism representation is wrongly singularised/immanented while postconverging-or-dialectical-thinking -apriorising-psychologism representation is wrongly dissingularised/not-immanent. This actually points out why dialogicalinequivalence/intellectual-and-moral-inequivalence as of 'apriorising-teleological-degradation-

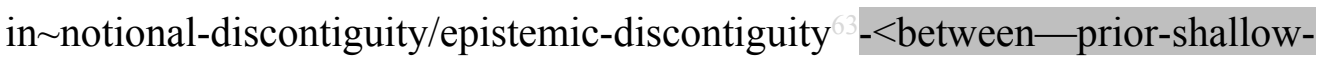
supererogation -of-mentally-aestheticised $\sim$ preconverging/dementing -qualiaschema_and_prospective-profound-supererogation -of-mentallyaestheticised postconverging/dialectical-thinking -qualia-schema> ${ }^{\prime}$ is associated with sophistic/pedantic representations as knowledge as well as temporal manifestations of postlogism 7 -slantedness and conjugated-postlogism 77 manifestations including psychopathy and social-psychopathy as of the positivism- ${ }^{8}$ procrypticism registry-worldview. While as of 
human-subpotency temporal <amplituding/formative-epistemicity $>$ totalising $\sim$ self-referencingsyncretising/circularity/interiorising/akrasiatic-drag ${ }^{34}$ we may be inclined to construe of the notion of dialogical-equivalence-<as-to-psychologismic $\sim$ apriorising/axiomatising/referencing\{of-'prospectively implicited_attendant-ontological-contiguity ' e educedexistentialising/contextualising/textualising_'intelligibility/epistemicity/reflexivity-contiguity<imbued-notional cogency $\left.>{ }^{\prime}\right\}$-conflatedness -in-\{preconverging-disentailment by\} postconverging entailment,-in-self-becoming/self-conflatedness /formative-supererogating $>$ as absolutely requisite, the fact is dialogical-equivalence-<as-topsychologismic apriorising/axiomatising/referencing-\{of-'prospectively implicited_attendant-ontological-contiguity ' educedexistentialising/contextualising/textualising_'intelligibility/epistemicity/reflexivity-contiguity<imbued-notional cogency >' \}-conflatedness -in-\{preconverging disentailment by\} postconverging-entailment,-in-self-becoming/self-conflatedness /formative-supererogating> cannot supersede existence-potency ${ }^{32} \sim$ sublimating-nascence,-disclosed-from-prospectiveepistemic-digression sublimating-validation/desublimating-invalidation implications where its eliciting is preconverging/postconverging-de-mentatively/structurally/paradigmatically flawed for the simple reason that knowledge as of implied underlying supposedly coherent ontologicalcommitment $-<$ implied—self-assuredness-of-ontological-goodfaith/authenticity postconverging-de-mentating/structuring/paradigming -as-being-as-ofexistential-reality $>$ as of <amplituding/formative-epistemicity $>$ causality $\sim$ as-to-projectivetotalitative-implications-of-prospective- nonpresencing,-for-explicating relativeunreflexivity/relative-reflexivity ontological-contiguity is all about existencepotency ${ }^{32} \sim$ sublimating-nascence,-disclosed-from-prospective-epistemic-digression and not about human sovereignty; in the sense that for instance gravity on earth as $9.8 \mathrm{~m} / \mathrm{s}^{2}$ doesn't heed to any human sovereignty exercise as of dialogue as the latter is only as pertinent as it 
preconverging/postconverging-de-mentatively/structurally/paradigmatically implies an intermediative process for the deferred-outcome as to existence-potency ${ }^{32} \sim$ sublimating- $^{-}$ nascence,-disclosed-from-prospective-epistemic-digression but not otherwise, and as being subpotent with existence it is the human that has to ensure that its ${ }^{5}$ meaningfulness-andteleology ${ }^{9}$ coincides with existential-<disontologising/re-ontologising aporeticism $>$ veracity, such that where dialogical-equivalence- $<$ as-topsychologismic $\sim$ apriorising/axiomatising/referencing-\{of-"prospectively implicited_attendant-ontological-contiguity ' educedexistentialising/contextualising/textualising_'intelligibility/epistemicity/reflexivity-contiguity<imbued-notional cogency >' \}-conflatedness -in-\{preconverging-disentailment by\} postconverging entailment,-in-self-becoming/self-conflatedness /formative-supererogating> is wrongly implied and thus likely to undermine existence-potency ${ }^{39} \sim$ sublimating-nascence,disclosed-from-prospective-epistemic-digression what gives in is the false notion of dialogicalequivalence-<as-to-psychologismic apriorising/axiomatising/referencing- \{of-'prespectively implicited_attendant-ontological-contiguity ' educedexistentialising/contextualising/textualising_'intelligibility/epistemicity/reflexivity-contiguity<imbued-notional cogency >' \}-conflatedness in \{preconverging disentailment by\} postconverging-entailment,-in-self-becoming/self-conflatedness /formative-supererogating>. This is equally reflected in the idea that the supererogatory $\sim$ acuity/perspicacity/astuteness/edginess/incisiveness-ofapriorising/axiomatising/referencing/intelligibilitysettingup/measuringinstrumenting -forconceptualisation of ${ }^{5}$ meaningfulness-and-teleology ${ }^{99}$ is rather as of the implication of relativeontological-completeness ${ }^{87}$ associated with human limited-mentation-capacity-deepening-assubjecting limitedness/human-subpotency to-'educed-unlimitedness/existence-sublimating nascence' ${ }^{33}$ from the perspective of existence-potency ${ }^{32}$ sublimating-nascence,-disclosed- 
from-prospective-epistemic-digression as-to-ontologically-uncompromised-ontologicalnormalcy/postconvergence/referentialism rather construed as of difference-conflatedness ${ }^{13}$-asto-totalitative-reification-in-singularisation- $<$ as-to-the-nondisjointedness/entailment-ofprospective- nonpresencing $>$-as-veridical-epistemicity-relativism-determinism, and not identitive-constitutedness ${ }^{14}$-as-'epistemic-totality ${ }^{37}$ '-dereification-in-dissingularisation- $<$ as-tothe-disjointedness/disentailment-of- presencing-absolutising-identitive-constitutedness as-flawed-epistemicity-relativism-determinism flawed projection of supererogatory $\sim$ acuity/perspicacity/astuteness/edginess/incisiveness-ofapriorising/axiomatising/referencing/intelligibilitysettingup/measuringinstrumenting -forconceptualisation by 'mere-formulaic psychologising effect', without ontological-veracity for the manifested formulaic psychologising, due to the failure to factor in relative-ontologicalincompleteness 88 as of shallow human limited-mentation-capacity-as-subjecting 'educedunlimitedness/existence-sublimating nascence' to-limitedness/human-subpotency apriorising/axiomatising/referencing/intelligibilitysettingup/measuringinstrumenting $<$ amplituding/formative-epistemicity $>$ causality $\sim$ as-to-projective-totalitative-implications-ofprospective- nonpresencing,-for-explicating relative-unreflexivity/relative-reflexivity

ontological-contiguity .

Thus

supererogatory $\sim$ acuity/perspicacity/astuteness/edginess/incisiveness-ofapriorising/axiomatising/referencing/intelligibilitysettingup/measuringinstrumenting -forconceptualisation of ${ }^{5}$ meaningfulness-and-teleology ${ }^{9}$, as of the-very-same-immanentexistence/intrinsic-reality/ontological-veridicality,-as-to-'human<amplituding/formativeepistemicity $>$ totalising $\sim$ purview-of-construal $\quad$ or $\quad<$ amplituding/formativeepistemicity $>$ totalising $\sim$ devolved-purview-as-domain-of-construal-as-intrinsicreality/ontological-veridicality, rather points to the fact that ${ }^{56}$ meaningfulness-and-teleology 9 'is not to be construed as accumulated/in-accumulation' but that it is effectively 'as recomposured 
in prospective relative-ontological-completeness ${ }^{87}$ as of <amplituding/formativeepistemicity>-totalising $\sim$ renewing-realisation/re-perception/re-thought since existence or purviews-of-existence $\quad$ ever always preconverging/postconverging-dementatively/structurally/paradigmatically remain the same and it is human-subpotency that is ever always undergoing its transcendence-and-sublimity/sublimation/supereregatory $\sim$ dementativity not by cumulating but rather by 'recomposuring construal of existence or purviewsof-existence'; and this further explains why secondnatured institutionalisation reasoning-fromresults/afterthought, induced as from parrhesiastic messianic-reason/reasoning-through, will tend to act as if ${ }^{56}$ meaningfulness-and-teleology ${ }^{9}$ is accumulated/in-accumulation thus ending up beyond-the-consciousness-awareness-teleology $\quad<$ of-preconverging-existential-extricationas-of-existential-unthought $>$ 'instigating enframed apriorising/axiomatising/referencing/intelligibilitysettingup/measuringinstrumenting institutional-setups and ${ }^{56}$ meaningfulness-and-teleology ${ }^{9}$ implications that are poorly amenable to <amplituding/formative-epistemicity $>$-totalising $\sim$ renewing-realisation/re-perception/rethought', and so preconverging/postconverging-de-mentatively/structurally/paradigmatically limiting the possibility of prospective human transcendence-andsublimity/sublimation/smerenterentivity but for the instigation of prospective parrhesiastic messianic-reason/reasoning-through beyond/overflowing such $<$ preconverging 'motif-and-apriorising/axiomatising/referencing'-entailing $>$ existentialising - enframing/imprintedness-〈as-to- historicity-tracing - in-presencinghyperrealisation/hyperreal-transposition〉. Critically just as 'prospective intemporal-asontologically-veridical/ontological-faith-notion-or-ontological-fideism-imbuedunderdetermination-of-motif-and-apriorising/axiomatising/referencing-as-so-being-as-ofexistential-reality parrhesiastic seeding-promise of reasoning-through/messianic-reasoning meaningfulness-and-teleology as equivalence/correspondence antiakrasiatic-aspiration 
ontological-performance $^{72}$ - $_{\text {including-virtue-as-ontology }>}{ }^{\prime} \quad$ is $\quad$ associated $\quad$ with supererogatory acuity/perspicacity/astuteness/edginess/incisiveness-ofapriorising/axiomatising/referencing/intelligibilitysettingup/measuringinstrumenting -forconceptualisation as of affirmation/projection/assertion/notional $\sim$ self-distantiation/duenessvalidating-logicising/suitable-measuringinstrument-validating-measuring-<as-topostconverging-or-dialectical-thinking -apriorising-psychologism $>$ of prospective relativeontological-completeness ${ }^{87}$-over unaffirmation/deprojection/deassertion/epistemicdecadence/undueness-invalidating-logicising/unsuitable-measuringinstrument-invalidatingmeasuring-<as-to-preconverging-or-dementing -apriorising-psychologism $>$ of prior relativeontological-incompleteness ${ }^{8}$ as to existence-potency ${ }^{32} \sim$ sublimating-nascence,-disclosed-fromprospective-epistemic-digression $\quad<$ amplituding/formative-epistemicity $>$ causality $~ a s-t o-$ projective-totalitative-implications-of-prospective- nonpresencing,-for-explicating relativeunreflexivity/relative-reflexivity - ontological-contiguity, likewise it is the case that 'temporal/sophistic-as-ontologically-flawed/ontological-bad-faith/inauthenticity reproducibility—mathesis/motif/thrownness-disposition,-as-reproducibility-of-aestheticisation seeding-misprising of reasoning-from-results/afterthought ${ }^{56}$ meaningfulness-and-teleology ${ }^{99}$ as covert-pretence-of-equivalence/correspondence-antiakrasiatic-aspiration-ontologicalperformance ${ }^{2}-<$ including-virtue-as-ontology $>$ ' is associated with 'ontologically-flawed denaturing of supererogatory acuity/perspicacity/astuteness/edginess/incisiveness-ofapriorising/axiomatising/referencing/intelligibilitysettingup/measuringinstrumenting - forconceptualisation' construed herein as of 'pseudo-edginess/pseudo-incisiveness'; as to the fact that 'pseudo-edginess/pseudo-incisiveness', whether actively projected or passively insinuated as of vocalisation/interjection/expletive intensification, beyond-the-consciousness-awarenessteleology $-<$ of-preconverging-existential-extrication-as-of-existential-unthought $>$ is bound to wrongly imply the ontological-veracity of the 'pseudo-edginess/pseudo-incisiveness implied 
supererogatory acuity/perspicacity/astuteness/edginess/incisiveness-ofapriorising/axiomatising/referencing/intelligibilitysettingup/measuringinstrumenting -forconceptualisation' as if as of affirmation/projection/assertion/notional $\sim$ selfdistantiation/dueness-validating-logicising/suitable-measuringinstrument-validatingmeasuring-<as-to-postconverging-or-dialectical-thinking -apriorising-psychologism $>\quad$ of $\begin{array}{lll}\text { prospective } & \text { relative-ontological-completeness } & \text { over }\end{array}$ unaffirmation/deprojection/deassertion/epistemic-decadence/undueness-invalidatinglogicising/unsuitable-measuringinstrument-invalidating-measuring-<as-to-preconverging-ordementing -apriorising-psychologism $>$ of prior relative-ontological-incompleteness 88 as to existence-potency ${ }^{39} \sim$ sublimating-nascence,-disclosed-from-prospective-epistemic-digression $<$ amplituding/formative-epistemicity $>$ causality $\sim$ as-to-projective-totalitative-implications-ofprospective- nonpresencing,-for-explicating relative-unreflexivity/relative-reflexivity ontological-contiguity . Pseudo-edginess/pseudo-incisiveness as such exploits the natural and habitual human mental-reflex as of any given registry-worldview's/dimension's-s ${ }^{83}$ reference-ofthought-for-social-functioning-and-accordance to systemically imply and attribute dialogicalequivalence-<as-to-psychologismic apriorising/axiomatising/referencing- $\{$ of-" prospectively implicited_attendant-ontological-contiguity ' educedexistentialising/contextualising/textualising_ intelligibility/epistemicity/reflexivity-contiguity$<$ imbued-notional cogency $>$ ' $\}$-conflatedness -in-\{preconverging-disentailment by\} postconverging-entailment,-in-self-becoming/self-conflatedness /formative-supererogating> with regards to social-stake-contention-or-confliction as of apriorising-teleological-elevationin notional-contiguity/epistemic-contiguity ${ }^{62}$-<profound-supererogation -of-mentallyaestheticised postconverging/dialectical-thinking -qualia-schema>. While this mental-reflex is usually valid in most circumstances, however, in the specific circumstances of pseudoedginess/pseudo-incisiveness manifestation this is ontologically-flawed as the latter is in effect 
rather in 'apriorising-teleological-degration-in-notional-discontiguity/epistemic-discontiguity ${ }^{63}$ $<$ between-prior-shallow-supererogation -of-mentallyaestheticised preconverging/dementing -qualia-schema_and_prospective-profoundsupererogation -of-mentally-aestheticised postconverging/dialectical-thinking -qualiaschema $>$ invalidating any such pretence of dialogical-equivalence- $<$ as-topsychologismic apriorising/axiomatising/referencing-\{of-"prospectively implicited_attendant-ontological-contiguity ' educedexistentialising/contextualising/textualising_'intelligibility/epistemicity/reflexivity-contiguity<imbued-notional cogency $\left.>^{\prime} \quad\right\}$-conflatedness -in-\{preconverging-disentailment by\} postconverging-entailment,-in-self-becoming/self-conflatedness /formative-supererogating>. Thus this rather undermines the natural and habitual human mental-reflex where it wrongly construes of the vocalisation/interjection/expletive intensification associated with such pseudoedginess/pseudo-incisivenes as speaking of profound affirmation/projection/assertion/notional self-distantiation/dueness-validatinglogicising/suitable-measuringinstrument-validating-measuring-<as-to-postconverging-ordialectical-thinking -apriorising-psychologism $>$ that is beyond contention-as-certain. Thus inducing destructuring-transitoriness ${ }^{19}$-as-of-deratiocination/deratiocontiguity as of the pseudoedginess/pseudo-incisiveness manifestation of dissingularisation- $<$ as-to-the-

\section{disjointedness/disentailment-of- presencing-absolutising-identitive-}

constitutedness > /epistemic-nonimmanence/flawed-epistemicity-relativism-determinism instigated destructuring-transitoriness ${ }^{19}$-as-of-deratiocination/deratiocontiguity rather in preconverging-or-dementing ${ }^{20}$-apriorising-psychologism representation but now engaged in dialogical-equivalence-<as-to-psychologismic apriorising/axiomatising/referencing- of'prospectively_implicited_attendant_ontological-contiguity ' educedexistentialising/contextualising/textualising_'intelligibility/epistemicity/reflexivity-contiguity- 
<imbued-notional cogency >' \}-conflatedness -in-\{preconverging disentailment by\}

postconverging-entailment,-in-self-becoming/self-conflatedness /formative-supererogating $>$

of contention as if of postconverging-or-dialectical-thinking -apriorising-psychologism representation. Pseudo-edginess/pseudo-incisiveness is what explains beyond-theconsciousness-awareness-teleology $\quad-<$ of-preconverging-existential-extrication-as-ofexistential-unthought> narrators in 'apriorising-teleological-degration-in-notionaldiscontiguity/epistemic-discontiguity ${ }^{6}-<$ between - prior-shallow-supererogation -ofmentally-aestheticised preconverging/dementing -qualia-schema_and_prospective-profoundsupererogation -of-mentally-aestheticised postconverging/dialectical-thinking -qualiaschema> engaging with interlocutors rather in temporal <amplituding/formativeepistemicity $>$ totalising $\sim$ self-referencing-syncretising/circularity/interiorising/akrasiatic-drag in preconverging-existential-extrication-as-of-existential-unthought as of $<$ amplituding/formative $>$ wooden-language-<imbued - averaging-of-thought-<as-toleveling/ressentiment/closed-construct-of- meaningfulness-and-teleology -as-of'nondescript/ignorable-void ' -with-regards-to-prospective-apriorising-implications $>$ ), wherein the last narratives as of pseudo-edginess/pseudo-incisiveness induces ontologicallyflawed sense of <amplituding/formative-epistemicity $>$ totalising $\sim$ ratiocontiguity/ratiocinationas-referentialism_-'implicited_attendant-ontological-contiguity ${ }^{67}$ ? educedexistentialising/contextualising/textualising_intelligibility/epistemicity/reflexivity-contiguity$<$ imbued-notional cogency $>$ in the interlocutor notwithstanding the postlogic-backtracking$<$ iterative-looping-'set-of-dereifying-hollow-narratives-and-acts'> ${ }^{76}$, as what is always pertinent for the narrator is the pseudo-rationalising of all prior narratives into-and-as-of the last narrative(s). The more simplistic example of such pseudo-edginess/pseudo-incisiveness is with the childhood psychopathy example of spilling water on a chair and accusing another and the dragging out of its postlogism -slantedness narratives as the simpler/uncomplexified 
representation of the adult psychopathy postlogism ${ }^{77}$-slantedness mental-disposition, and this further points to the ${ }^{80}$ procrypticism-or-disjointedness-as-of- ${ }^{3}$ reference-of-thought $<$ amplituding/formative-epistemicity $>$ causality $\sim$ as-to-projective-totalitative-implications-ofprospective- nonpresencing,-for-explicating relative-unreflexivity/relative-reflexivity _ ontological-contiguity when such pseudo-edginess/pseudo-incisiveness phenomenon is rather at the level of maturation/indirectness/spatialisation/credulity/craftiness associated with adult psychopathy and associated social psychopathy, or as we can appreciate as of humansubpotency-aporia/undecidability/dilemma/ought-

indeterminacy/deficiency/limitation/constraint—imbued-'notional firstnaturednessformativeness-<as-to-eventualising-inkling-drive-or-seeding-misprising > temporal-tointemporal-dispositions-<so-construed-as-from-perspective-ontologicalnormalcy/postconvergence>'-existentialism-form-factor manifestations of sophistic/pedantic dispositions social eliciting of <amplituding/formative> wooden-language-〈imbued averaging-of-thought-<as-to-leveling/ressentiment/closed-construct-of- meaningfulness-andteleology -as-of-‘nondescript/ignorable-void '-with-regards-to-prospective-apriorisingimplications $>>$ as of social-stake-contention-or-confliction, beyond-the-consciousnessawareness-teleology $-<$ of-preconverging-existential-extrication-as-of-existential-unthought $>$ whether with traditional witchdoctors, the sophists, medieval-pedants or in-many-ways pedantising/muddling/formulaic-hollowing-out - in-subontologisation/subpotentiation〈blurring/undermining-of-prospective-totalising-entailing,-as-to-entailing$<$ amplituding/formative-epistemicity>totalising in-relative-ontological-completeness $>$ today. Thus a given prospective relative-ontological-completeness 87 registry-worldview/dimension supererogatery $\sim$ acuity/perspicacity/astuteness/edginess/incisiveness-ofapriorising/axiomatising/referencing/intelligibilitysettingup/measuringinstrumenting -forconceptualisation as of 'notional $\sim$ singularisation-<as-to-the-nondisjointedness/entailment-of- 
prospective- nonpresencing $>\quad$ projected epistemic-immanence/veridical-epistemicityrelativism-determinism', by its implied 'apriorising-teleological-thresholding-as-teleologicalframework/narrative-framework of contextualising/existentialising/instantiative-devolvingmeaningfulness', operantly reflects the prior relative-ontological-incompleteness ${ }^{88}$ registryworldview/dimension 'shiftiness-of-the-Self' ' as of a 'reifying gesturing/accounting-ofepistemic-phenomenalism that is-not-to-be-drag-in/commingle-with the prior relativeontological-incompleteness registry-worldview's/dimension's apriorising/axiomatising/referencing/intelligibilitysettingup/measuringinstrumenting socialstake-contention-or-confliction ${ }^{56}$ meaningfulness-and-teleology ${ }^{9}$ as of its pseudoedginess/pseudo-incisiveness $<$ amplituding/formative-epistemicity $>$ causality $\sim$ as-toprojective-totalitative-implications-of-prospective- nonpresencing,-for-explicating relativeunreflexivity/relative-reflexivity - ontological-contiguity '; as reflected by the fact that positivising or prospective notional $\sim^{18}$ deprocrypticism supererogatory acuity/perspicacity/astuteness/edginess/incisiveness-ofapriorising/axiomatising/referencing/intelligibilitysettingup/measuringinstrumenting -forconceptualisation rather construe respectively non-positivising or procrypticism as of apriorising-teleological-degradation-in $\sim$ notional-discontiguity/epistemic-discontiguity ${ }^{63}$ $<$ between-prior-shallow-supererogation -of-mentallyaestheticised preconverging/dementing -qualia-schema_and_prospective-profoundsupererogation -of-mentally-aestheticised postconverging/dialectical-thinking -qualiaschema $>$ as to invalidate the $<$ amplituding/formative $>$ wooden-language-〈imbued - averagingof-thought-<as-to-leveling/ressentiment/closed-construct-of- meaningfulness-and-teleology as-of-'nondescript/ignorable-void ' -with-regards-to-prospective-apriorising-implications $>$ > mental-reflex of dialogical-equivalence- $<$ as-topsychologismic apriorising/axiomatising/referencing-\{of-'prospectively 
implicited_attendant-ontological-contiguity ' reduced-

existentialising/contextualising/textualising_'intelligibility/epistemicity/reflexivity_contiguity<imbued-notional cogency>> $\}$-conflatedness -in-\{preconverging-disentailment by\} postconverging-entailment,-in-self-becoming/self-conflatedness /formative-supererogating> pointing rather to psychoanalytic-unshackling/memetic-reordering/institutional-recomposuring

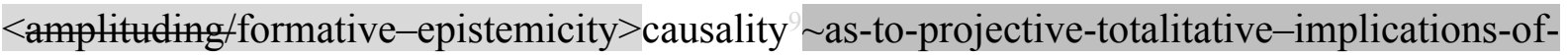
prospective- nonpresencing,-for-explicating relative-unreflexivity/relative-reflexivity ontological-contiguity to be reflected by the prospective supererogatery $\sim$ acuity/perspicacity/astuteness/edginess/incisiveness-ofapriorising/axiomatising/referencing/intelligibilitysettingup/measuringinstrumenting -forconceptualisation, but then this equally implies the destructuring-threshold-〈uninstitutionalisedthreshold /presublimating-desublimating-decisionality $>$ of-ontological-performance ${ }^{72}$ $<$ including-virtue-as-ontology $>/$ morality/ethics/justice/etc. is effectively prone to a general $<$ amplitung-formative $>$ wooden-language-<imbued - averaging-of-thought-<as-toleveling/ressentiment/closed-construct-of- meaningfulness-and-teleology -as-of'nondescript/ignorable-void '-with-regards-to-prospective-apriorising-implications $>$ ) disposition predisposed to forego 'true-ontology-as-of-Being-development/ontologicalframework-expansion-as-to-depth-of-ontologising-development-as-infrastructure-ofmeaningfulness-and-teleology ' for a <amplituding/formative $>$ wooden-language-〈imbuedaveraging-of-thought-<as-to-leveling/ressentiment/closed-construct-of- meaningfulness-andteleology -as-of-'nondescript/ignorable-void ' -with-regards-to-prospective-apriorisingimplications $>>$ as of its <amplituding/formative-epistemicity $>$ totalising $\sim$ self-referencingsyncretising/circularity/interiorising/akrasiatic-drag 34 beyond-the-consciousness-awarenessteleology $-<$ of-preconverging-existential-extrication-as-of-existential-unthought $>$. It has always been the case that <cumulating/recomposuring attendant-ontological-contiguity $>$ - 
successive registry-worldviews/dimensions secondnatured institutionalisations as instigated as from human 'intemporal ontological-faith-notion-or-ontological-fideism -imbuedunderdetermination-of-motif-and-apriorising/axiomatising/referencing-as-so-being-as-ofexistential-reality parrhesiastic askesis-or-acumen' have to contend as of social-stakecontention-or-confliction with corresponding sophistic/pedantic eliciting of $<$ amplituding/formative $>$ wooden-language-〈imbued—averaging-of-thought-<as-toleveling/ressentiment/closed-construct-of- meaningfulness-and-teleology -as-of'nondescript/ignorable-void '-with-regards-to-prospective-apriorising-implications $>>$ whether as traditional witchdoctors, the sophists, medieval-pedants or in-many-ways pedantising/muddling/formulaic-hollowing-out_-in-subontologisation/subpotentiation-

\section{〈blurring/undermining-of-prospective-totalising-entailing,-as-to-entailing-}

$<$ amplituding/formative-epistemicity>totalising in-relative-ontological-completeness $>$ today, with the requisite intemporal-as-ontological reifying ${ }^{5}$ meaningfulness-and-teleology ${ }^{9}$ as to existence-potency ${ }^{39} \sim$ sublimating-nascence,-disclosed-from-prospective-epistemic-digression $<$ amplituding/formative-epistemicity $>$ causality $\sim$ as-to-projective-totalitative-implications-ofprospective- nonpresencing,-for-explicating relative-unreflexivity/relative-reflexivity ontological-contiguity over-time/crossgenerationally inducing the positive opportunism untenability that overcomes such 'temporal/sophistic-as-ontologically-flawed/ontological-badfaith/inauthenticity reproducibility—mathesis/motif/thrownness-disposition,-asreproducibility-of-aestheticisation seeding-misprising of reasoning-from-results/afterthought meaningfulness-and-teleology 9 as covert-pretence-of-equivalence/correspondenceantiakrasiatic-aspiration-ontological-performance ${ }^{72}-{\text { including-virtue-as-ontology }>^{\prime} ;}^{\prime}$ and in this regards, the futural possibility of developing-and-cumulating the capacity-and-template for the renewed and more profound ${ }^{5}$ meaningfulness-and-teleology ${ }^{9}$ infrastructure as of Beingdevelopment/ontological-framework-expansion-as-to-depth-of-ontologising-development-as- 
infrastructure-of- meaningfulness-and-teleology of prospective notional ${ }^{18}$ deprocrypticism preempting - disjointedness-as-of- ${ }^{8}$ reference-of-thought,-as-to- ${ }^{-3}<$ amplituding/formativeepistemicity $>$ growth-or-conflatedness ${ }^{13} /$ transvaluative- $^{2}$

rationalising/transepistemicity/anamnestic-residuality/spirit-drivenness' — in-supersedingmere-formulaic-positivising/rational-empiricism-based-universalisation-directed-rulemakingover-non-rules_ apriorising/axiomatising/referencing-psychologism in notionally overcoming human 'shiftiness-of-the-Self' ' is effectively not beyond human collective contemplation reflected as of human 'projective-totalitative' notional ' deprocrypticism protensive selfconsciousness perspective predisposed to devalue our ${ }^{80}$ procrypticism-or-disjointedness-as-ofreference-of-thought occlusive self-consciousness ${ }^{56}$ meaningfulness-and-teleology ${ }^{9}$. Contrary to the ontologically-flawed implications of identitive-constitutedness ${ }^{14}$-as-'epistemic-totality ${ }^{37}$ dereification-in-dissingularisation-<as-to-the-disjointedness/disentailment-of- presencing absolutising-identitive-constitutedness $>$-as-flawed-epistemicity-relativism-determinism in reflecting that human ${ }^{5}$ meaningfulness-and-teleology 9 as implied by the relativeunreflexivity/relative-reflexivity — ontological-contiguity ${ }^{67}$ of-the-human-institutionalisationprocess $^{68}$ is rather ad-hoc and disparate across cultures-as-sovereign-constructs-not-constrainedexistentially-as-of supposedly coherent ontological-commitment $-<$ implied - self-assurednessof-ontological-good-faith/authenticity $\sim$ postconverging-dementating/structuring/paradigming -as-being-as-of-existential-reality>, $<$ amplituding/formative-epistemicity $>$ causality $\sim$ as-to-projective-totalitative-implications-ofprospective- nonpresencing,-for-explicating relative-unreflexivity/relative-reflexivity ontological-contiguity construal as difference-conflatedness ${ }^{13}$-as-to-totalitative-reification-insingularisation-<as-to-the-nondisjointedness/entailment-of-prospective- nonpresencing $>$-asveridical-epistemicity-relativism-determinism of human ${ }^{56}$ meaningfulness-and-teleology reflects the relative-unreflexivity/relative-reflexivity - ontological-contiguity ${ }^{67}$ of-the-human- 
institutionalisation-process ${ }^{6}$ implied connectedness of human ${ }^{5}$ meaningfulness-and-teleology as constrained-existentially-as-of supposedly coherent ontological-commitment $-<$ implied self-assuredness-of-ontological-good-faith/authenticity postconverging-dementating/structuring/paradigming -as-being-as-of-existential-reality $>$ thus developing as of relative-ontological-completeness $\quad$ ontological-performance ${ }^{72}-<$ including-virtue-as- $^{8}$ ontology $>$ /morality/ethics/justice/etc. implications of human limited-mentation-capacitydeepening —as-subjecting limitedness/human-subpotency-to-'educed-unlimitedness/existencesublimating nascence' ${ }^{5}$. It is this <amplituding/formative-epistemicity $>$ causality $\sim$ as-toprojective-totalitative-implications-of-prospective- nonpresencing,-for-explicating relativeunreflexivity/relative-reflexivity ontological-contiguity construal of human meaningfulness-and-teleology' 'constrained-existentially-as-of-its supposedly coherent ontological-commitment $-<$ implied-self-assuredness-of-ontological-goodfaith/authenticity postconverging-de-mentating/structuring/paradigming -as-being-as-ofexistential-reality $>$ as of <amplituding/formative-epistemicity>causality $\sim$ as-to-projectivetotalitative-implications-of-prospective- nonpresencing,-for-explicating relativeunreflexivity/relative-reflexivity ontological-contiguity that effectively validates the 'epistemic-veracity of notional $\sim$ singularisation- $<$ as-to-the-nondisjointedness/entailment-ofprospective- nonpresencing $>\quad$ projected epistemic-immanence/veridical-epistemicityrelativism-determinism'; wherein the notion of 'relative-ontological-incompleteness $8 /$ relativeontological-completeness ${ }^{8}$-〈sublimating $\sim$ referencing/registering/decisioning,-as-selfbecoming/self-conflatedness /formative-supererogating-<projective/reprojectiveaestheticising-re-motif-and-re-apriorising/re-axiomatising/re-referencing,-in-perspectiveontological-normalcy/postconvergence $>\rangle$ as to human-and-social-expectations/anticipationsmetaphoricity ${ }^{57}$-as-preconverging/postconverging-redementating/restructuring/reparadigming-psychologism' 89 of ontological-performance ${ }^{72}$ - 
<including-virtue-as-ontology>' captures the entire possibilities of human ${ }^{5}$ meaningfulnessand-teleology ontological-performance $^{72}-<$ including-virtue-as-ontology $>$, and as such a $<$ amplituding/formative-epistemicity $>$ causality $\sim$ as-to-projective-totalitative-implications-ofprospective- nonpresencing,-for-explicating relative-unreflexivity/relative-reflexivity _ ontological-contiguity construal reflects overall reifying-and-empowering-reflexivity-ofecstatic-existence-as-panintelligibility/panreflexivity ${ }^{33}$-〈existentially-imbued-and-educing\& \{epistemic-totalising thermeneutically/textually/reprojectingly/supererogatingly/zeroingly/reacutingly, , \{decompulsing? $d$ delinearity $\sim$ for-cogency $\geq$-epistemic-perspective-ofprojective/reprojective - aestheticising-re-motif-and-re-apriorising/re-axiomatising/rereferencing conceptualisation,-as-herein-specifically-relevant-to-human-subpotency $\rangle$ as of 'coherence/contiguity-of-superseding-oneness-of-ontology-implied-as-of-inherent-existencecoherence/contiguity,-and-so-construed-as-the-enabler-of-insight-or-intuition-or-foresight-asof-embodied-consciousness'. It is this <amplituding/formative-epistemicity >causality as-toprojective-totalitative-implications-of-prospective- nonpresencing,-for-explicating relativeunreflexivity/relative-reflexivity - ontological-contiguity construal that allows for intelligibility and renewing-intelligibility to arise in the first place as of relative-ontologicalcompleteness $^{87}$. This 'intelligibility and renewing-intelligibility' arises from '<amplituding/formative-epistemicity $>$ causality $\sim$ as-to-projective-totalitative-implications-ofprospective- nonpresencing,-for-explicating relative-unreflexivity/relative-reflexivity ontological-contiguity apriorising/axiomatising/referencing- of-'prospectively implicited_attendant-ontological-contiguity ' educedexistentialising/contextualising/textualising_'intelligibility/epistemicity/reflexivity_contiguity<imbued-notional cogency $>$ ' $\}$-conflatedness ${ }^{13}$-in-\{preconverging-disentailment by\} postconverging-entailment of construal-and-reconstrual of 'implicited_attendant-ontologicalcontiguity ${ }^{67} \sim$ educed- 
existentialising/contextualising/textualising_intelligibility/epistemicity/reflexivity-contiguity$<$ imbued-notional cogency $>^{\prime}$ as of human limited-mentation-capacity-deepening-assubjecting limitedness/human-subpotency to-'educed-unlimitedness/existence-sublimating nascence' maximalising-recomposuring-for-relative-ontological-completeness ${ }^{87}$ unenframed/re-ontologising conceptualisation', and not as ontologically-flawed atomising/taking-to-pieces apriorising/axiomatising/referencing-\{of-" prospectively implicited_attendant-ontological-contiguity ' educedexistentialising/contextualising/textualising_'intelligibility/epistemicity/reflexivity-contiguity<imbued-notional cogency $>$ ' $\}$-constitutedness ${ }^{14}$-in-preconverging-entailment rather as of elaboration-as-to-mere-extrapolating/constituting/abstracting/deducing/inferring-ofelucidation-outside_-'prospectively_implicited_attendant-ontological-contiguity ${ }^{67}$ ' educedexistentialising/contextualising/textualising_intelligibility/epistemicity/reflexivity-contiguity-

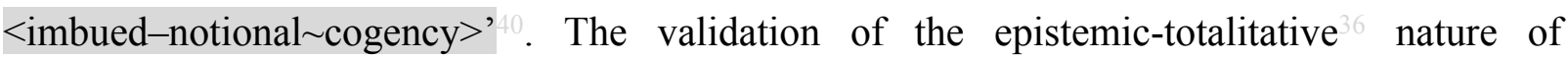
existential-<disontologising/re-ontologising aporeticism $>{ }^{56}$ meaningfulness-and-teleology as of 'relative-ontological-incompleteness ${ }^{88} /$ relative-ontological-completeness $^{87}$ -

\section{〈sublimating referencing/registering/decisioning,--as-self-becoming/self-}

conflatedness /formative-supererogating-<projective/reprojective-aestheticising-re-motifand-re-apriorising/re-axiomatising/re-referencing,-in-perspective-ontologicalnormalcy/postconvergence $>>$ as to human-and-social-expectations/anticipationsmetaphoricity ${ }^{57}$-as-preconverging/postconverging-redementating/restructuring/reparadigming-psychologism' ${ }^{89}$ of ontological-performance ${ }^{72}$ <including-virtue-as-ontology >' is much more directly obvious in the natural sciences which do not imply any inherent splitting/disparateness of intrinsic-reality but rather points to a $<$ amplituding/formative-epistemicity $>$ causality $\sim$ as-to-projective-totalitative-implications-ofprospective- nonpresencing,-for-explicating relative-unreflexivity/relative-reflexivity 
ontological-contiguity construal of 'coherence/contiguity-of-superseding-oneness-ofontology-implied-as-of-inherent-existence-coherence/contiguity,-and-so-construed-as-theenabler-of-insight-or-intuition-or-foresight-as-of-embodied-consciousness' in their knowledge foregrounding_entailment- $<$ in-succession-of-profound-supererogation $>>-\langle$ postconvergingnarrowing-down $\sim$ sublimation-as-to-'existence - as-sublimating-withdrawal/unenframing/reontologising,-elicited-from-prospective-profound-supererogation ' '-in-reflecting'immanent relative - unreflexivity/relative-reflexivity ontological-contiguity ';-as-operativenotional deprocrypticism) schemes. The underlying explanation for disparateness here is effectively construed as a question of the implications of 'relative-ontologicalincompleteness $^{8} /$ relative-ontological-completeness $^{87}$ -

\section{〈sublimating referencing/registering/decisioning,-as-self-becoming/self-}

conflatedness /formative-supererogating-<projective/reprojective-aestheticising-re-motifand-re-apriorising/re-axiomatising/re-referencing,-in-perspective-ontologicalnormalcy/postconvergence $>>$ as to human-and-social-expectations/anticipationsmetaphoricity ${ }^{57}$-as-preconverging/postconverging-rede-

mentating/restructuring/reparadigming-psychologism' 89 of ontological-performance ${ }^{72}$ <including-virtue-as-ontology>' wherein varying ontologically-flawed superfluous, superstitious, mystical and cultic interpretations of the natural world <amplituding/formativeepistemicity>totalising $\sim$ devolved-purview-as-domain-of-construal-as-intrinsic-

reality/ontological-veridicality speaks rather of states of relative-ontological-incompleteness and the prospective possibility of ontologically-veridical grander unifying scientific explanation of the natural world <amplituding/formative-epistemicity>totalising $\sim$ devolved-purview-asdomain-of-construal-as-intrinsic-reality/ontological-veridicality speaks rather of relativeontological-completeness ${ }^{87}$. Such $<$ amplituding/formative-epistemicity $>$ causality $\sim$ as-toprojective-totalitative-implications-of-prospective- nonpresencing,-for-explicating relative- 
unreflexivity/relative-reflexivity ontological-contiguity construal points out that disparateness of ${ }^{5}$ meaningfulness-and-teleology ${ }^{99}$ as often wrongly projected in many a social domain-of-study is not an inherently sovereign notion as to the fact that construal as of relativeontological-incompleteness ${ }^{8}$ cannot be 'qualified as sovereign and beyond the countenance of its ontological-veracity as from relative-ontological-completeness ${ }^{87}$ perspective' given that all human ${ }^{56}$ meaningfulness-and-teleology ${ }^{9}$ are of supposedly coherent ontological-commitment <implied — self-assuredness-of-ontological-good-faith/authenticity postconverging-dementating/structuring/paradigming -as-being-as-of-existential-reality $>$ as so-reflected by its self-assuredness-of-ontological-good-faith/authenticity ${ }^{6} \sim$ postconverging-dementating/structuring/paradigming 70 -as-being-as-of-existential-reality with respect to its socialstake-contention-or-confliction'; such that while recognising the human-subpotency epistemicveracity perspective of say a given social-setup attributing an ailment to say magic, this doesn't override the notion of inherent ontological-veridicality as to existence-potency ${ }^{32} \sim$ sublimating- $^{-}$ nascence,-disclosed-from-prospective-epistemic-digression epistemic-or-notional $\sim$ projectiveperspective wherein modern society in relative-ontological-completeness ${ }^{87}$ attributes the ailment to say flu. In order words, sovereign commitments, recognised as of human-subjectemancipating-relativism-driven-recomposuring-constructivism-towards-singularisation- $<$ as-tothe-nondisjointedness/entailment-of-prospective- nonpresencing $>$, do not override the preeminence of supposedly coherent ontological-commitment $-<$ implied-self-assuredness-ofontological-good-faith/authenticity $\sim$ postconverging-dementating/structuring/paradigming -as-being-as-of-existential-reality $>$ as to existencepotency $^{39} \sim$ sublimating-nascence,-disclosed-from-prospective-epistemic-digression epistemicor-notional projective-perspective, in which case no human transcendence-andsublimity/sublimation/supererogatory de-mentativity will be possible. Stated another way, if Einstein's or Bohr's seminal theories were viewed say unfavourably by the physics community 
of their time as of their sovereign predisposition, that wouldn't annul the ontological-veracity of their theories even if Einstein or Bohr were to acquiesce to that sovereign predisposition over their own theories, for the simple reason that knowledge is constructed as of the absolute dominance of intrinsic-reality as to existence-potency ${ }^{32} \sim$ sublimating-nascence,-disclosed-fromprospective-epistemic-digression over the mortals that we as human beings are in order for transcendence-and-sublimity/sublimation/supererogatory-de-mentativity to be possible; and that reality with respect to knowledge doesn't speak of totalitarianism as will often be sophistically usurped when it comes to the blurriness-<sterilising/anecdotalising/trivialising-ofprospective-re-ontologising_by-preconverging,-in-disontologising-formulaic-dragging-

out/hollowing-out $>$ of the social domain-of-study, as the charge of totalitarianism can only apply with respect to sovereign choice. Further a <amplituding/formative-epistemicity $>$ causality $\sim$ asto-projective-totalitative-implications-of-prospective- nonpresencing,-for-

equally points out that the-very-same-immanent-existence/intrinsic-reality/ontologicalveridicality,-as-to-`human<amplituding/formative-epistemicity>totalising $\sim$ purview-ofconstrual' or any <amplituding/formative-epistemicity>totalising $\sim$ devolved-purview-asdomain-of-construal-as-intrinsic-reality/ontological-veridicality does not imply the preconverging/postconverging-de-mentative/structural/paradigmatic change of existence-as-of 'implicited_attendant-ontological-contiguity ${ }^{67}$ > educedexistentialising/contextmalising/textualising_'intelligibility/epistemicity/reflexivity_contiguity$<$ imbued-notional cogency >' but rather that change is the outcome of human limitedmentation-capacity-deepening —as-subjecting limitedness/human-subpotency to-'educedthlimitedness/existence stblimating naseence' ${ }^{53}$ maximalising-recomposuring-for-relativeontological-completeness ${ }^{87}$ - unenframed/re-ontologising conceptualisation involving ${ }^{15}$ dementation-〈supererogatory ontological-de-mentation-or-dialectical-de-mentation — stranding- 
or-attributive-dialectics $\rangle$ of prospective postconverging-or-dialectical-thinking ${ }^{2}$-apriorisingpsychologism representation and prior preconverging-or-dementing ${ }^{2}$-apriorising-psychologism representation; with the implication here that the issue of knowledge is all about developing human-subpotency towards existence-potency ${ }^{39} \sim$ sublimating-nascence,-disclosed-fromprospective-epistemic-digression. The apriorising/axiomatising/referencing-\{of- "prespetively implicited_attendant-ontological-contiguity ' educedexistentialising/contextualising/textualising_'intelligibility/epistemicity/reflexivity-contiguity<imbued-notional cogency $>$ ' $\}$-conflatedness ${ }^{13}$-in-\{preconverging-disentailment by\} postconverging-entailment of 'implicited_attendant-ontological-contiguity ${ }^{67}$ ' educedexistentialising/contextualising/textualising_intelligibility/epistemicity/reflexivity-contiguity$<_{\text {imbued-notional cogency }>^{\prime}}$ in the natural sciences is often poorly perceived inherently because of their subject-matter/domain-of-study implicited nature of philosophical depth of contemplation as of 'coherence/contiguity-of-superseding-oneness-of-ontology-implied-as-ofinherent-existence-coherence/contiguity,-and-so-construed-as-the-enabler-of-insight-orintuition-or-foresight-as-of-embodied-consciousness'; such that it is often wrongly construed in atomising/taking-to-pieces apriorising/axiomatising/referencing-\{of-'prospectively implicited_attendant-ontological-contiguity ' educedexistentialising/contextualising/textualising_'intelligibility/epistemicity/reflexivity-contiguity<imbued-notional cogency> ' $\quad$ - constitutedness ${ }^{1}$-in-preconverging-entailment $\quad$ as of elaboration-as-to-mere-extrapolating/constituting/abstracting/deducing/inferring-ofelucidation-outside_- 'prospectively_implicited_attendant-ontological-contiguity ${ }^{67}$ ' educed-

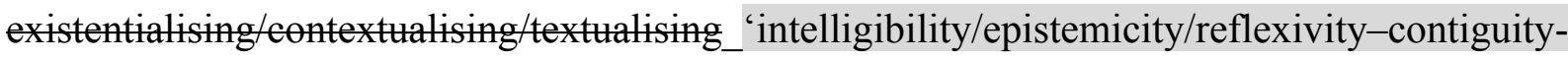
$<$ imbued-notional cogency $>$ ' but with little consequence since such an atomising/taking-topieces apriorising/axiomatising/referencing-\{of-‘prospectively implicited_attendantontological-contiguity ' educed- 
existentialising/contextualising/textualising_ 'intelligibility/epistemicity/reflexivity-contiguity<imbued-notional cogency $\left.>^{\prime}\right\}$-constitutedness ${ }^{14}$-in-preconverging-entailment is generally an ontologically-flawed afterthought reflection/contemplation whereas operantly beyond-theconsciousness-awareness-teleology ${ }^{9}<$ of-preconverging-existential-extrication-as-ofexistential-unthought $>$ scientists generally adopt an apriorising/axiomatising/referencing-\{of'prospectively implicited_attendant-ontological-contiguity ' educedexistentialising/contextualising/textualising_intelligibility/epistemicity/reflexivity_contiguity<imbued-notional cogency >' \}-conflatedness ${ }^{13}$-in-\{preconverging-disentailment-by\} postconverging-entailment of 'implicited_attendant-ontological-contiguity ${ }^{67}$ ' educedexistentialising/contextualising/textalising_'intelligibility/epistemicity/reflexivity_contiguity$<$ imbued-notional cogency $>$ ' posture. The reality of apriorising/axiomatising/referencing\{of-'prospectively_implicited_attendant-ontological-contiguity ' ceducedexistentialising/contextualising/textualising_ 'intelligibility/epistemicity/reflexivity-contiguity<imbued-notional cogency $\left.>{ }^{\prime}\right\}$ - conflatedness ${ }^{13}$-in-\{preconverging-disentailment-by\} postconverging-entailment here is validated by the fact that 'abstract scientific notions are not the point-of-departure of scientists contemplation' as they are rather 'delved in 'implicited_atentontological-contiguity ${ }^{67}$ ' educedexistentialising/contextualising/textualising_'intelligibility/epistemicity/reflexivity-contiguity<imbued-notional cogency>' $>^{\prime 0}$ in $<$ amplituding/formative-epistemicity $>$ causality $\sim$ as-toprojective-totalitative-implications-of-prospective- nonpresencing,-for-explicating $\sim$ relativeunreflexivity/relative-reflexivity ontological-contiguity apriorising/axiomatising/referencing-\{of-'prospectively_implicited_attendant-ontologicalcontiguity ' $\sim$ educedexistentialising/contextualising/textualising_'intelligibility/epistemicity/reflexivity-contiguity<imbued-notional cogency $\left.>^{\prime} \quad\right\}$ - conflatedness ${ }^{13}$ in-\{preconverging-disentailment by 
postconverging-entailment to then reflect abstract scientific notions as knowledgereification $\sim$ gesturing-and-accounting — of-epistemic-phenomenalism- $<$ inprospective_psychologismic apriorising/axiomatising/referencing-\{of-'prospectively implicited_attendant-ontological-contiguity ' educedexistentialising/contextualising/textualising_ 'intelligibility/epistemicity/reflexivity-contiguity<imbued-notional cogency $\left.>{ }^{\prime}\right\}$-conflatedness -in-\{preconverging-disentailment by\} postconverging-entailment> or depart from 'implicited_attendant-ontologicalcontiguity ${ }^{6}$, educedexistentialising/contextualising/textmalising_intelligibility/epistemicity/reflexivity-contiguity$<$ imbued-notional cogency $>$ already reified abstract scientific notions to then reflect further abstract scientific notions in knowledge-reification $\sim$ gesturing-and-accounting-of-epistemicphenomenalism-<in-prospective psychologismic $\sim$ apriorising/axiomatising/referencing- $\{$ of'prospectively_implicited_attendant-ontological-contiguity ' educedexistentialising/contextualising/textualising_ 'intelligibility/epistemicity/reflexivity-contiguity<imbued-notional cogency >’ $\}$-conflatedness -in-\{preconverging-disentailment by\} postconverging-entailment>' . For instance, we can appreciate that physics never establish any absolute atomising/taken-into-pieces notion of say atoms, space, time, energy, etc. on which it merely then go on to be constituting ${ }^{56}$ meaningfulness-and-teleology ${ }^{9} /$ knowledge as physics knowledge-reification $\sim$ gesturing-and-accounting —of-epistemic-phenomenalism- $<$ inprospective_psychologismic apriorising/axiomatising/referencing-\{of- ${ }^{\text {pprospectively }}$ implicited_attendant-ontological-contiguity ' educedexistentialising/contextualising/textualising_ intelligibility/epistemicity/reflexivity-contiguity<imbued-notional cogency>' \}-conflatedness in (preconverging disentailment by postconverging-entailment $>$. Rather we can better appreciate the occurrence of knowledgereification $\sim$ gesturing-and-accounting - of-epistemic-phenomenalism- $<$ in- 
prospective_psychologismic apriorising/axiomatising/referencing-\{of- ${ }^{\text {prospectively }}$

implicited_attendant-ontological-contiguity ' educed-

existentialising/contextualising/textualising_intelligibility/epistemicity/reflexivity-contiguity-

<imbued-notional $\left.\sim \operatorname{cogency}>^{\prime} \quad\right\}$-conflatedness -in-\{preconverging-disentailment by\}

postconverging-entailment $>$ as of $<$ amplituding/formative-epistemicity $>$ causality $\sim$ as-to-

projective-totalitative-implications-of-prospective- nonpresencing,-for-explicating relative-

unreflexivity/relative-reflexivity ontological-contiguity construal in the sense that our ordinary thought process itself is as of <amplituding/formativeepistemicity>totalising/circumscribing/delineating 'implicited_attendant-ontologicalcontiguity $^{67}$, educed-

existentialising/contextualising/textualising_intelligibility/epistemicity/reflexivity-contiguity$<$ imbued-notional cogency $>^{\prime}$ construal of notions like space, time, force, etc. with no absolutely given point of atomising/taking-to-pieces apriorising/axiomatising/referencing-\{of'prospectively_implicited_attendant-ontological-contiguity ' educedexistentialising/contextualising/textualising_'intelligibility/epistemicity/reflexivity-contiguity$<$ imbued-notional cogency $>$ ' $\}$-constitutedness ${ }^{14}$-in-preconverging-entailment even when we may harbour such a confusion, and likewise the development of theories say Cartesian, Newtonian, Einsteinian, String theory, etc. are equally <amplituding/formativeepistemicity $>$ totalising/circumscribing/delineating as to the fact that these imply various ways of reconceptualising the notions of space, time, force, etc. as of the precedence of $<$ amplituding/formative-epistemicity $>$-totalising $\sim$ renewing-realisation/re-perception/rethought of 'implicited_attendant-ontological-contiguity ${ }^{67}$, educed-

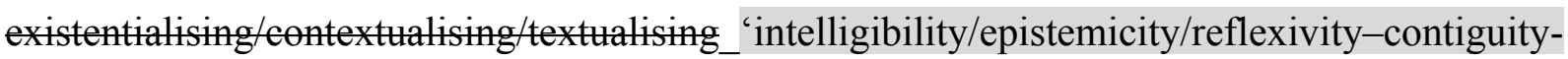
<imbued-notional cogency>' of such notions like space, time, force, etc. in $<$ amplituding/formative-epistemicity $>$ causality $\sim$ as-to-projective-totalitative-implications-of- 
prospective- nonpresencing,-for-explicating relative-unreflexivity/relative-reflexivity

ontological-contiguity

apriorising/axiomatising/referencing- of-" prospectively

implicited_attendant-ontological-contiguity ' ceduced-

existentialising/contextualising/textualising_intelligibility/epistemicity/reflexivity-contiguity-

<imbued-notional cogency $>$ ' $\}$-conflatedness ${ }^{13}$-in-\{preconverging-disentailment by\}

pestcenverging-entailment to then articulate their abstract/theoretical notions/conceptualisations of space, time, force, etc.; thus there isn't any absolutely identitive atomising/taking-to-pieces notions of space, time, force, etc. which are 'constituted once-and-for-all to later on build/reify physics knowledge as of progressive constituting' but rather physics knowledge is always of epistemic-totalising ${ }^{33} \sim$ resubjecting_or_totalising-entailing $\sim$ reconstrual $<0$ f the-

whole/purview-of the-whole/oneness-of-ontology> of 'the-very-same physics notions and their derived implications of new notions' as of 'implicited attendant-ontologicalcontiguity $^{67} \sim$ educed-

existentialising/contextmalising/textualising_'intelligibility/epistemicity/reflexivity-contiguity<imbued-notional cogency $>$ ' 40 in apriorising/axiomatising/referencing-\{of-'prospectively implicited_attendant-ontological-contiguity ' reducedexistentialising/contextralising/textising_intelligibility/epistemicity/reflexivity-contiguity<imbued-notional cogency $\left.>^{\prime}\right\}$ - conflatedness ${ }^{13}$-in-\{preconverging-disentailment by\} postconverging-entailment involving human limited-mentation-capacity-deepening-assubjecting limitedness/human-subpotency-to-'educed-unlimitedness/existence-sublimating nascence' ${ }^{3}$ hermeneutics in avoiding-and-superseding any ${ }^{79}$ presencing-absolutisingidentitive-constitutedness ${ }^{14}$. We can appreciate that the atomising/taking-to-pieces disposition that is often wrongly sought in other domains-of-study is often ontologically-flawed because it fails to see that the "more elaborate panintelligibility/panreflexivity ${ }^{3}$ —effusing/ecstatic-inlining nature of 'implicited_attendant-ontological-contiguity ${ }^{67}$ ' educed- 
existentialising/contextualising/textualising_intelligibility/epistemicity/reflexivity-contiguity<imbued-notional cogency>' ${ }^{\prime}$ in epistemic-conflatedness ${ }^{3}$ in their domains-of-study' implies that their knowledge-reification $\sim$ gesturing-and-accounting —of-epistemic-phenomenalism- $<$ inprospective_psychologismic apriorising/axiomatising/referencing-\{of-'prospectively_ implicited_attendant-ontological-contiguity ' educedexistentialising/contextualising/textualising_ 'intelligibility/epistemicity/reflexivity-contiguity<imbued-notional cogency >' \}-conflatedness -in-\{preconverging-disentailment by\} postconverging-entailment> should increasingly be explicitly totalising-entailing/nestedcongruence as to the hermeneutics involved in avoiding-and-superseding any ${ }^{7}$ presencingabsolutising-identitive-constitutedness ${ }^{14}$, as even the natural sciences are implicitly epistemically totalising-entailing by the mere fact of the 'precedence of 'implicited_attendant ontological-contiguity ${ }^{67} \sim$ educedexistentialising/contextualising/textualising_intelligibility/epistemicity/reflexivity-contiguity$<$ imbued-notional cogency $>$ ' in $<$ amplituding/formative-epistemicity $>$ causality $\sim$ as-toprojective-totalitative-implications-of-prospective- nonpresencing,-for-explicating relativeunreflexivity/relative-reflexivity ontological-contiguity in epistemic-conflatedness ${ }^{13}$ to which their abstract notions are aligned' as well as so-implied by their foregrounding_entailment- $<$ in-succession-of-profound-supererogation $>>-\langle$ postconverging narrowing-down $\sim$ sublimation-as-to-'existence - as-sublimating-withdrawal/unenframing/reontologising,-elicited-from-prospective-profound-supererogation '-in-reflecting'immanent $\sim$ relative-unreflexivity/relative-reflexivity - ontological-contiguity ';-as-operativenotional deprocrypticism $\rangle$ orientations which drives their knowledge-reification $\sim$ gesturingand-accounting - of-epistemic-phenomenalism- $<$ inprospective_psychologismic apriorising/axiomatising/referencing-\{of-"prospectively implicited_attendant-ontological-contiguity ' educed- 
existentialising/contextualising/textualising_ 'intelligibility/epistemicity/reflexivity-contiguity$<$ imbued-notional $\left.\sim \operatorname{cogency}>^{\prime} \quad\right\}$-conflatedness -in-\{preconverging disentailment by\} postconverging-entailment> for unification as of notional-contiguity/epistemic-contiguity <profound-supererogation -of-mentally-aestheticised postconverging/dialectical-thinking qualia-schema $>$ (as not just an idle quest). This misconstrual is further reflected by the fact that the life sciences (as of their axiomatic-construct 'apriorising-teleological-thresholding-asteleological-framework/narrative-framework of contextualising/existentialising/instantiativedevolving-meaningfulness') have a more inherently elaborate panintelligibility/panreflexivity ${ }^{3}$ —effusing/ecstatic-inlining nature of 'implicited_attendantontological-contiguity ${ }^{67}$, educedexistentialising/contextmalising/textmalising_intelligibility/epistemicity/reflexivity-contiguity<imbued-notional cogency>' $>^{\prime 0}$ supervening-conflatedness ${ }^{13}$ thus rendering its methodology more explicitly totalising-entailing and teleological even as it is often naively and wrongly construed as a 'relatively weaker natural science' from a naïve epistemic apriorising/axiomatising/referencing-\{of-'prospectively_implicited_attendant-ontologicalcontiguity ' educedexistentialising/contexalising/textising_intelligibility/epistemicity/reflexivity-contiguity<imbued-notional cogency>' $\}$-constitutedness ${ }^{- \text {in }}$ - preconverging-entailment perspective. This underlying <amplituding/formative-epistemicity>totalising/circumscribing/delineating 'implicited_attendant-ontological-contiguity ${ }^{67}$ ' educedexistentialising/contextualising/textualising_ 'intelligibility/epistemicity/reflexivity-contiguity<imbued-notional cogency> $>^{\prime 0}$ insight reflects ecstatic-existence's superveningconflatedness $^{13}$ as to overall reifying-and-empowering-reflexivity-of-ecstatic-existence-aspanintelligibility/panreflexivity ${ }^{3}-\langle$ existentially-imbued-and-educing-< $<$ epistemicthermeneutically/textually/reprojectingly/supererogatingly/zeroing/y/re-acutingly,- 

epistemically constrained to <amplituding/formative-epistemicity $>$ causality $\sim$ as-to-projectivetotalitative-implications-of-prospective- nonpresencing,-for-explicating relativeunreflexivity/relative-reflexivity ontological-contiguity ', domains-of-study like physics and the natural sciences generally are of a less elaborate 'implicited_attendant-ontologicalcontiguity $^{67} \sim$ educedexistentialising/contextualising/textualising_intelligibility/epistemicity/reflexivity-contiguity$<$ imbued-notional cogency $>^{\prime}$ conceptualisation nature in epistemic-conflatedness ${ }^{13}$ and can thus be ontologically-falsely be perceived as being of atomising/taking-to-pieces epistemic apriorising/axiomatising/referencing-\{of-'prospectively implicited_attendant-ontologicalcontiguity ' educedexistentialising/contextualising/textualising_ 'intelligibility/epistemicity/reflexivity-contiguity<imbued-notional cogency>' $\}$-constitutedness ${ }^{1}$-in-preconverging-entailment $\quad$ while inherently 'less immediate epistemically constrained to <amplituding/formativeepistemicity $>$ causality $\sim$ as-to-projective-totalitative-implications-of-prospectivenonpresencing,-for-explicating relative-unreflexivity/relative-reflexivity - ontologicalcontiguity , domains-of-study like the social domains-of-study are more of an elaborate 'implicited_attendant-ontological-contiguity ${ }^{67}$ ' educedexistentialising/contextalising/textalising_'intelligibility/epistemicity/reflexivity_contiguity$<$ imbued-notional cogency>' $>^{\prime 0}$ conceptualisation nature in epistemic-conflatedness ${ }^{13}$ that speaks to the need for their appropriate totalising-entailing fepistemictotalising 3 hermeneutic/textuality/reprojecting/supererogating/zeroing/re-acuting,\{decomplesing delinearity for-cogency depth of ontological-construal, and in both cases in reflecting 
the implications of human limited-mentation-capacity-deepening-as-subjectinglimitedness/human-subpotency-to-'educed-unlimitedness/existence-sublimating nascence' hermeneutics involved in avoiding-and-superseding any ${ }^{79}$ presencing - absolutising-identitiveconstitutedness $^{14}$ for construing their veridical ${ }^{4}$ historiality/ontologicaleventfulness 38 ontological-aesthetic-tracing-<perspective-ontologicalnormalcy/postconvergence-reflected-'epistemicity-relativism-determinism'>. In-many-ways the natural sciences by the immediate constraining of their <amplituding/formativeepistemicity $>$ causality $\sim$ as-to-projective-totalitative-implications-of-prospectivenonpresencing,-for-explicating relative- unreflexivity/relative-reflexivity - ontologicalcontiguity implicitly avoid atomising/taking-to-pieces apriorising/axiomatising/referencing\{of-'prospectively_implicited_attendant-ontological-contiguity ' educedexistentialising/contextualising/textualising_'intelligibility/epistemicity/reflexivity_contiguity<imbued-notional cogency>' $\}$-constitutedness ${ }^{- \text {in }}$-preconverging-entailment but the misunderstanding that their knowledge-reification $\sim$ gesturing-and-accounting-of-epistemicphenomenalism-<in-prospective_psychologismic $\sim$ apriorising/axiomatising/referencing- of'prospectively implicited_attendant-ontological-contiguity ' educedexistentialising/contextualising/textulising_intelligibility/epistemicity/reflexivity-contiguity<imbued-notional cogency >' \}-conflatedness -in-\{preconverging-disentailment by\} postconverging-entailment> is effectively as of atomising/taking-to-pieces apriorising/axiomatising/referencing-\{of-'prospectively implicited_attendant-ontologicalcontiguity ' educedexistentialising/contextualising/textualising_ intelligibility/epistemicity/reflexivity-contiguity<imbued-notional cogency>' $\}$-constitutedness ${ }^{1}$ in preconverging entalment in other domains-of-study ends up having naïve and distortive effects on such domains-of-study knowledge-reification $\sim$ gesturing-and-accounting — of-epistemic-phenomenalism- $<$ in- 
prospective_psychologismic apriorising/axiomatising/referencing-\{of-‘prospectively_

implicited_attendant-ontological-contiguity ' educed-

existentialising/contextualising/textualising_'intelligibility/epistemicity/reflexivity-contiguity-

<imbued-notional cogency >’ \}-conflatedness -in-\{preconverging-disentailment by\}

postconverging-entailment $>$ and particularly so with regards to the development of their selfconscious philosophical depth of contemplation as of 'coherence/contiguity-of-supersedingoneness-of-ontology-implied-as-of-inherent-existence-coherence/contiguity,-and-so-construedas-the-enabler-of-insight-or-intuition-or-foresight-as-of-embodied-consciousness'. It is herein contended that this poor self-conscious philosophical depth of contemplation as of 'coherence/contiguity-of-superseding-oneness-of-ontology-implied-as-of-inherent-existencecoherence/contiguity,-and-so-construed-as-the-enabler-of-insight-or-intuition-or-foresight-asof-embodied-consciousness' is the preconverging/postconverging-dementatively/structurally/paradigmatically defining issue of many of the social domains-of-study today, as in effect many such domains are turned into technicality as of institutional-being-andcraft sterile/anecdotal imprimatur, 'fallback to unquestioned/dogmatic normativities' and 'habituated dispositions' which priorly enframed subject-matters and institutional-setups preconverging/postconverging-de-mentatively/structurally/paradigmatically stifle the possibility for conceptualisation as to existence-potency ${ }^{3} \sim$ sublimating-nascence,-disclosedfrom-prospective-epistemic-digression sublimating-validation/desublimating-invalidation implications beyond their conventioning-referencing <preconverging 'motif-andapriorising/axiomatising/referencing'-entailing >-existentialising — enframing/imprintedness-

〈as-to- historicity-tracing - in-presencing-hyperrealisation/hyperreal-transposition〉, soimplied as of the perspective of notional ${ }^{18}$ deprocrypticism prospective 'true-ontology-as-ofBeing-development/ontological-framework-expansion-as-to-depth-of-ontologisingdevelopment-as-infrastructure-of- meaningfulness-and-teleology '. Thus existence's overall 
reifying-and-empowering-reflexivity-of-ecstatic-existence-as-

panintelligibility/panreflexivity ${ }^{3}$-〈existentially-imbued-and-educing-< $<$ 'epistemic-

totalising thermeneutically/textually/reprojectingly/supererogating/y/zeroingly/re-acutingly,-

$\{$ decompulsing\} $\}$ delinearity $\sim$ for-cogency $>$-epistemic-perspective-of-projective/reprojective-

aestheticising-re-motif-and-re-apriorising/re-axiomatising/re-referencing conceptualisation,-

as-herein-specifically-relevant-to human-subpotency) implies the 'primacy of a

$<$ amplituding/formative-epistemicity $>$ causality $\sim$ as-to-projective-totalitative-implications-of-

prospective- nonpresencing,-for-explicating relative-unreflexivity/relative-reflexivity

ontological-contiguity basis for conception due to human <amplituding/formativeepistemicity>-totalising $\sim$ thrownness-in-existence ${ }^{35}$ ' as 'existence doesn't wait for the human to incrementally have the complete picture' and thus it is the 'human subject who has to aspire maximalisingly to conform-as-of-its-self-consciousness-growth with existence in a $<$ amplituding/formative-epistemicity $>$ causality $~$ as-to-projective-totalitative-implications-ofprospective- nonpresencing,-for-explicating relative-unreflexivity/relative-reflexivity

ontological-contiguity conception', and this further indicts our traditional conception of induction as being epistemically incremental wrongly construed as of incrementalism-inrelative-ontological-incompleteness ${ }^{8}$ —enframed/disontologising $\sim$ conceptualisation that underlies dispositions for <amplituding/formative-epistemicity $>$ totalising $\sim$ self-referencingsyncretising/circularity/interiorising/akrasiatic-drag ${ }^{34}$ because of 'failure to draw $<$ amplituding/formative-epistemicity $>$ causality $\sim$ as-to-projective-totalitative-implications-ofprospective- nonpresencing,-for-explicating relative-unreflexivity/relative-reflexivity ontological-contiguity as of displacement/decentering-of-the-human-subject and wrongly construing ${ }^{79}$ presencing-absolutising-identitive-constitutedness ${ }^{14}$ situations as of absolute/absolutising grounding', whereas in reality human <amplituding/formativeepistemicity $>$-totalising $\sim$ thrownness-in-existence ${ }^{35}$ rather points out that the epistemic-veracity 
of induction is rather as of 'maximalising <amplituding/formative-epistemicity>causality asto-projective-totalitative-implications-of-prospective- nonpresencing,-forexplicating $\sim$ relative- unreflexivity/relative-reflexivity ontological-contiguity , ${ }^{\prime}$, which is rather as of epistemic-totalising $\sim$ resubjecting_or_totalising-entailing $\sim$ reconstrual $<$ of thewhole/purview-of the-whole/oneness-of-ontology> of ${ }^{56}$ meaningfulness-and-teleology ${ }^{9}$ as to $<$ amplituding/formative-epistemicity $>$-totalising $\sim$ renewing-realisation,-re-perception,-rethought-in-epistemic-conflatedness ${ }^{13}$ with regards to successive inductions) rightly construed as of ${ }^{55}$ maximalising-recomposuring-for-relative-ontological-completeness ${ }^{87}$ - unenframed/reontologising conceptualisation and 'totalitatively involving human limited-mentation-capacitydeepening —as-subjecting limitedness/human-subpotency to-'educed-unlimitedness/existencesublimating nascence' ${ }^{3}$, with displacement/decentering-of-the-human-subject; and such a misconstruing of the effective notion of induction speaks of an 'ontologically-flawed modern positivistic academicism proceduralism reflex of ${ }^{5}$ incrementalism-in-relative-ontologicalincompleteness 8 —enframed/disontologising conceptualisation' that misses-out-on and ends up pruning-and-<preconverging 'motif-and-apriorising/axiomatising/referencing'-entailing >existentialising — enframing/imprintedness-〈as-to- historicity-tracing — in-presencinghyperrealisation/hyperreal-transposition〉 the natural human <amplituding/formativeepistemicity $>$ causality $\sim$ as-to-projective-totalitative-implications-of-prospectivenonpresencing,-for-explicating relative-unreflexivity/relative-reflexivity - ontologicalcontiguity construal predisposition. The specific human-subpotency with regards to overall reifying-and-empowering-reflexivity-of-ecstatic-existence-aspanintelligibility/panreflexivity ${ }^{3}$-<existentially-imbued-and-educing-<epistemic thatising thermeneutically/textually/reprojectingly/supererogatingly/zeroing/y/re-acutingly,\{decompulsing $d$ delinearity $\sim$ for-cogency $\geq$-epistemic-perspective-of-projective/reprojectiveaestheticising-re-motif-and-re-apriorising/re-axiomatising/re-referencing conceptualisation-- 
as-herein-specifically-relevant-to human-subpotency), reflecting human underlying supposedly coherent

faith/authenticity postconverging-de-mentating/structuring/paradigming -as-being-as-of-

existential-reality>, is ultimately potentiated as of human 'intemporal ontological-faith-notionor-ontological-fideism —imbued-underdetermination-of-motif-and-

apriorising/axiomatising/referencing-as-so-being-as-of-existential-reality parrhesiastic askesisor-acumen for originary/as-of-event ${ }^{38}$ reasoning-through/messianic-reasoning' as of the 'seeding promise of human-subpotency ontological-performance ${ }^{72}-$ including-virtue-as- $^{2}$ ontology $>$ /morality/ethics/justice/etc. equivalence/correspondence with the full-potency-ofexistence's $\sim$ sublimating-nascence-as-of-its-coherence/contiguity', as this drives epistemicricochettingly/transepistemically the relative-unreflexivity/relative-reflexivity ontologicalcontiguity $\sim$ of-the-human-institutionalisation-process 'true-ontology—as-of-Beingdevelopment/ontological-framework-expansion-as-to-depth-of-ontologising-development-asinfrastructure-of- meaningfulness-and-teleology ' in developing successive ${ }^{83}$ reference-ofthought reproducibility—mathesis/motif/thrownness-disposition,-as-reproducibility-ofaestheticisation reflecting human successive self-consciousness/construction-of-the-Self that transcendentally-and-sublimely transform human-reflexivity-in-ecstatic-existence so-construed as of ${ }^{4}$ human-subject-emancipating-relativism-driven-recomposuring-constructivism-towardssingularisation-<as-to-the-nondisjointedness/entailment-of-prospective- nonpresencing $>$; wherein we can appreciate that the instigation of ${ }^{103}$ universalising-idealisation ${ }^{56}$ meaningfulnessand-teleology ${ }^{9}$ infrastructure or subsequent positivising/rational-empiricism ${ }^{56}$ meaningfulnessand-teleology 9 infrastructure transform human potentiation construed as 'human-subpotency convergence to existence' with regards respectively to the specific base-institutionalisation or rational-empiricism/positivism self-consciousness/construction-of-the-Self implied as of the specific Being-development/ontological-framework-expansion-as-to-depth-of-ontologising- 
development-as-infrastructure-of- meaningfulness-and-teleology

consciousness/construction-of-the-Self notion is what deflates such 'issues implied with regards to human sovereign options/choice or freewill' and 'issues of natural determinism beyond human sovereign options/choice or freewill', as human self-consciousness/construction-of-the-Self as of Being-development/ontological-framework-expansion-as-to-depth-of-ontologisingdevelopment-as-infrastructure-of- meaningfulness-and-teleology implies 'induced human potentiation of sovereign options/choice or freewill that invalidate natural determinism'. In this regards we can appreciate for instance that with the positivism/rational-empiricism modern society's disease theory, parents failing to figure out that a baby is likely to get sick if kept in dirty surroundings due to bacteria and germs as well that high temperature is a sign that the baby needs medical care, such that were it to be established that the baby develops a serious medical condition because of such failure of parental care then the human potentiation of freewill of the parents is engaged with regards to the parents responsibilities as of the selfconsciousness/construction-of-the-Self implied as of our positivism/rational-empiricism Beingdevelopment/ontological-framework-expansion-as-to-depth-of-ontologising-development-asinfrastructure-of- meaningfulness-and-teleology , however, supposed a similar situation arises in a non-positivistic social-setup with the parents acting that way because of say animistic beliefs that are utterly normal in the given animistic social-setup then it is difficultly the case that the human-potentiation of freewill of the parents is engaged with regards to their responsibilities as of the self-consciousness/construction-of-the-Self implied as of their non-positivism/animistic Being-development/ontological-framework-expansion-as-to-depth-of-ontologisingdevelopment-as-infrastructure-of- meaningfulness-and-teleology (as the relativeontological-incompleteness ${ }^{8}$ in the latter case renders it as an 'ought indeterminacy' while the relative-ontological-completeness ${ }^{77}$ in the former case renders it as an 'is determinacy'); but then, a general underlying human potentiation of freewill of all humans is engaged passively to 
the effect that prospective relative-ontological-completeness 87 inducing prospective selfconsciousness/construction-of-the-Self reflected as of Being-development/ontologicalframework-expansion-as-to-depth-of-ontologising-development-as-infrastructure-ofmeaningfulness-and-teleology in deflating human vices-and-impediments ${ }^{105}$, necessarily warrants all humans to effectively aspire-for/be-receptive-to prospective relative-ontologicalcompleteness ${ }^{87}$. And such a more broad construal of freewill and natural determinism implications can be contemplated as elaborated elsewhere herein with regards to akrasiasusceptibility-or-akrasiatic-drag complex; thus akrasia-susceptibility-or-akrasiatic-drag complex further implies that the very state of unwariness with respect to prior relativeontological-incompleteness ${ }^{8}$ as of a nihilistic disposition is preconverging/postconverging-dementatively/structurally/paradigmatically potently conducive/endemising/enculturating to its vices-and-impediments $^{105}$, and as the very possibility for prospective ontological-performance ${ }^{72}$ $<$ including-virtue-as-ontology $>$ /morality/ethics/justice/etc. arises as of the intemporal ontological-faith-notion-or-ontological-fideism - imbued-underdetermination-of-motif-andapriorising/axiomatising/referencing-as-so-being-as-of-existential-reality parrhesiastic askesisor-acumen reasoning-through/messianic-reasoning as of its 'seeding promise of humansubpotency ontological-performance ${ }^{2}-<$ including-virtue-asontology $>$ /morality/ethics/justice/etc. equivalence/correspondence with the full-potency-ofexistence's $\sim$ sublimating-nascence-as-of-its-coherence/contiguity'. Can we wish that we don't have understanding whether directly, or indirectly as of reifying deferential-formalisationtransference, so that we aren't intellectually-and-morally accountable then? How can we reconcile the fact that given human <amplituding/formative-epistemicity $>$ totalising thrownness-in-existence ${ }^{35}$ the possibility for prospective human registryworldview's/dimension's institutionalisation enabling transcendence-andsublimity/sublimation/supererogatory de-mentativity could only arise as of prospective 
reasoning-through/messianic-reasoning that had no prior effective knowledge and virtue reference to go on to prospectively 'invent' reasoning-through/messianic-reasoning knowledge and virtue before the institutionalising of such reasoning-from-results/afterthought emancipating possibilities, and then contend to make any given reasoning-from-results/afterthought knowledge and virtue limits intellectually and morally deterministic as of a nihilistic $<$ amplituding/formative $>$ wooden-language-<imbued — averaging-of-thought-<as-toleveling/ressentiment/closed-construct-of- meaningfulness-and-teleology -as-of'nondescript/ignorable-void '-with-regards-to-prospective-apriorising-implications $>>$ ? In this regard, the anti-nihilist stance implies that the very first notion of human ontologicalperformance $^{72}-<$ including-virtue-as-ontology $>$ /morality/ethics/justice/etc. as of human $<$ amplituding/formative-epistemicity $>$-totalising $\sim$ thrownness-in-existence ${ }^{35}$ induced anxiety lies in the fact that as of intemporal ontological-faith-notion-or-ontological-fideism -imbuedunderdetermination-of-motif-and-apriorising/axiomatising/referencing-as-so-being-as-of-

existential-reality parrhesiastic askesis-or-acumen reasoning-through/messianic-reasoning, humankind has the relative capacity to build and/or adhere to prospective relative-ontologicalcompleteness ${ }^{87}$ possibilities. Further, in the specific instances it is important to recognise that natural determinism invalidation of sovereign options/choice or freewill 'applies critically only as of poor self-consciousness/construction-of-the-Self implications arising from the underdevelopment of Being/ontological-framework-expansion or selfconsciousness/construction-of-the-Self incapacity as of say insanity', and not necessarily as of lack of new knowledge-construct or technical-development; in the sense that say a criminal that had gone uncaught before a new technical-development like DNA testing establishes their criminal responsibility/relative-reflexivity as of human potentiation, cannot talk of natural determinism implications as a defence just as covert predispositions associated with vices-andimpediments ${ }^{105}$ as of 'self-conscious drive' cannot be qualified to be of natural determinism 
implications when unmasked. Reifying-and-empowering-reflexivity-of-ecstatic-existence-aspanintelligibility/panreflexivity ${ }^{73}-\langle$ existentially-imbued-and-educing-< $<$ epistemictotalising ${ }^{\text {th}}$ hermeneutically/textually/reprojectingly/supererogatingly/zeroing/y/re-acutingly,$\{$ decompulsing\} $\}$ delinearity for-cogency $\geq$-epistemic-perspective-of-projective/reprojectiveaestheticising-re-motif-and-re-apriorising/re-axiomatising/re-referencing conceptualisationas-herein-specifically-relevant-to human-subpotency) 'speaking epistemically with respect to the overall phenomenal/manifest $\sim$ subpotencies-〈in-transitive-conflatedness -reflexivity,-inthe-full-potency-of-existence's $\sim$ sublimating-nascence $\rangle$ including human-subpotency epistemicperspective', inherently reflects the veridical-epistemicity-relativism-determinism as to existence-potency ${ }^{39} \sim$ sublimating-nascence,-disclosed-from-prospective-epistemic-digression in the construal of any such phenomenal/manifest $\sim$ subpotency-/in-transitive-conflatedness reflexivity,-in-the-full-potency-of-existence's $\sim$ sublimating-nascence $\rangle$ 'apriorising-teleologicalthresholding-as-teleological-framework/narrative-framework of contextualising/existentialising/instantiative-devolving-meaningfulness', with humansubpotency 'apriorising-teleological-thresholding-as-teleological-framework/narrativeframework of contextualising/existentialising/instantiative-devolving-meaningfulness' effectively construable in reflecting holographically-<conjugatively-and-transfusively $>$ the relative-unreflexivity/relative-reflexivity - ontological-contiguity of-the-humaninstitutionalisation-process 'true-ontology — as-of-Being-development/ontologicalframework-expansion-as-to-depth-of-ontologising-development-as-infrastructure-ofmeaningfulness-and-teleology '. The overall implied notion of 'intemporality ${ }^{52}$ symmetrising-by-desymmetrising-subsumption-of-temporality ${ }^{\circ}$, as advanced here is one of supratransversality-<in-sublimating-existential-eventuating/denouement $>\sim$ of-motif-andapriorising/axiomatising/referencing over subtransversality-<in-desublimating-existentialeventuating/denouement $>$ of-motif-and-apriorising/axiomatising/referencing rather as of 
intellectual-and-moral-inequivalence/non-correspondence. Such a mental-disposition of substituting old ${ }^{83}$ reference-of-thought- categorical-imperatives/axioms/registry-teleology with new ones of prospective registry-worldview/dimension as implied by $<$ amplituding/formative-epistemicity>-totalising $\sim$ renewing-realisation/re-perception/rethought as of institutional moulting underlies the concept of intemporal-prioritisation-ofreference-of-thought'-as-conflatedness ${ }^{13}$-or-ontological-reprojecting, in dealing with the fact that by reflex all registry-worldviews/dimensions are structured not to construe of their very own prospective transcendence-and-sublimity/sublimation/supererogatory $\sim$ de-mentativity, and thus relating to their ${ }^{83}$ reference-of-thought- categorical-imperatives/axioms/registry-teleology ${ }^{9}$,for-intemporal-preservation-entropy-or-contiguity-or-ontological-preservation on an incrementalism-in-relative-ontological-incompleteness ${ }^{88}$ -

enframed/disontologising conceptualisation basis as 'absolute by the mereformulaicity/ritualisation-<as-to-mere-formulaic-

methodologising/mutualising/organising/institutionalising,-prospectively-losing-track-of‘fepistemic-alising ’’re-apriorising/re-axiomatising/re-referencing $\sim$ residuality-in-reoriginariness/re-origination'>)' $\quad$ whether failing/not-upholding-<as-ofapriorising/axiomatising/referencing $>\quad$ intemporal-preservation-entropy-or-contiguity-orontological-preservation at the uninstitutionalised-threshold ${ }^{12}$. The non-positivistic animistic or medieval social setup as of its incrementalism-in-relative-ontological-incompleteness ${ }^{8}$ enframed/disontologising conceptualisation disposition coming into grips with the positivistic interlocutor's purpose will probably construe it as most contemptuous by its construal of 'implicited_attendant-ontological-contiguity ${ }^{67}$; educed-

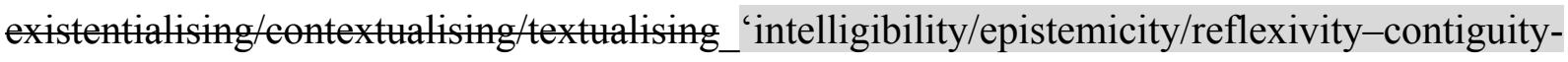
$<$ imbued-notional $\sim$ cogency $>,{ }^{\prime},-<$ reifying-or-elucidating-of-prospective-relative-ontologicalcompleteness -of- reference-of-thought- devolving-as-of-instantiative-context $>$ (whether as 
of its rulemaking-over-non-rules_-apriorising/axiomatising/referencing-psychologism,-〈as 'first-level presencing - absolutising-identitive-constitutedness ${ }^{14}$ of reference-of-thought' apriorising/axiomatising/referencing/intelligibilitysettingup/measuringinstrumenting $\rangle$ of baseinstitutionalisation/animism or as of its ${ }^{103}$ universalisation-directed-rulemaking-over-nonrules_-apriorising/axiomatising/referencing-psychologism,-〈as 'second-level presencing absolutising-identitive-constitutedness of reference-of-thought' apriorising/axiomatising/referencing/intelligibilitysettingup/measuringinstrumenting universalisation-non-positivism/medievalism), though we know from an ontologicalnormalcy/postconvergence epistemic-or-notional projective-perspective that the positivistic 'implicited_attendant-ontological-contiguity ${ }^{6 /}$; educedexistentialising/contextmalising/textualising_'intelligibility/epistemicity/reflexivity_contiguity$<$ imbued-notional $\sim$ cogency $>,{ }^{\prime},-<$ reifying-or-elucidating-of-prospective-relative-ontologicalcompleteness -of- reference-of-thought- devolving-as-of-instantiative-context> as of its positivising/rational-empiricism-based-universalisation-directed-rulemaking-over-non-rulesapriorising/axiomatising/referencing-psychologism,-〈as 'third-level presencing absolutising-identitive-constitutedness of reference-of-thought' apriorising/axiomatising/referencing/intelligibilitysettingup/measuringinstrumenting $\rangle$ is the virtuous-ontological resolution of the non-positivistic registry-worldview's/dimension's reference-of-thought preconverging-de-mentating/structuring/paradigming vices-andimpediments ${ }^{105}$. Likewise, this ontological-normalcy/postconvergence insight can equally be projected of our 'positivism- ${ }^{8}$ procrypticism registry-worldview's/dimension's ${ }^{83}$ reference-ofthought' from 'futural Being-development/ontological-framework-expansion-as-to-depth-ofontologising-development-as-infrastructure-of- meaningfulness-and-teleology as of prospective notional deprocrypticism registry-worldview's/dimension's ${ }^{83}$ reference-ofthought'; wherein notional ' deprocrypticism 'implicited_attendant-ontological- 
contiguity ${ }^{67}$, educed-

existentialising/contextualising/textualising_'intelligibility/epistemicity/reflexivity_contiguity-

$<$ imbued-notional $\sim$ cogency $>,{ }^{\prime},-<$ reifying-or-elucidating-of-prospective-relative-ontological-

completeness -of- reference-of-thought- devolving-as-of-instantiative-context> as of its

' deprocrypticism-or-preempting-disjointedness-as-of- reference-of-thought as of preempting - disjointedness-as-of- ${ }^{83}$ reference-of-thought,-as-to- ${ }^{6}{ }^{32}<$ amplituding/formativeepistemicity $>$ growth-or-conflatedness ${ }^{13} /$ transvaluative-

rationalising/transepistemicity/anamnestic-residuality/spirit-drivenness' — in-supersedingmere-formulaic-positivising/rational-empiricism-based-universalisation-directed-rulemakingover-non-rules — apriorising/axiomatising/referencing-psychologism is the virtuous-ontological resolution of the positivism- ${ }^{8}$ procrypticism registry-worldview's/dimension's ${ }^{83}$ reference-ofthought preconverging-de-mentating/structuring/paradigming vices-and-impediments ${ }^{105}$, as it further contendingly implies a prospective decentering and dialectical de-mentation reflection/perspectivation of positivism- ${ }^{8}$ procrypticism. We can imagine that futural Beingdevelopment/ontological-framework-expansion-as-to-depth-of-ontologising-development-asinfrastructure-of- meaningfulness-and-teleology as of prospective notional ${ }^{18}$ deprocrypticism inclined agent given its 'intemporal-prioritisation-of- ${ }^{8}$ reference-ofthought'-as-conflatedness ${ }^{13}$-or-ontological-reprojecting can effectively forego the normally construed positivistic ${ }^{83}$ reference-of-thought- categorical-imperatives/axioms/registryteleology ${ }^{9}$,-for-intemporal-preservation-entropy-or-contiguity-or-ontological-preservation as projected <amplituding/formative $>$ wooden-language-〈imbued-temporal-mere-

\section{form/virtualities/dereification/akrasiatic-drag/denatured/preconverging-or-dementing}

narratives - of-the- reference-of-thought- categorical-imperatives/axioms/registry-

teleology > failing/not-upholding-<as-of-apriorising/axiomatising/referencing $>$ intemporalpreservation-entropy-or-contiguity-or-ontological-preservation as of 'valued-viability' to 
expend on a 'so-construed most important work' that can be done in a positivismprocrypticism registry-worldview/dimension, as of prospective institutionalisation into notional ${ }^{18}$ deprocrypticism (more like an archaeologist might don on dirty clothing and dig their hands in mud and rubbish 'like an animal' to find out about the treasures that are human histories); and by that equally implying prospectively the decentering and dialectical dementation of positivism- ${ }^{80}$ procrypticism $<$ amplituding/formative $>$ wooden-language〈imbued — averaging-of-thought-<as-to-leveling/ressentiment/closed-construct-ofmeaningfulness-and-teleology -as-of-'nondescript/ignorable-void '-with-regards-toprospective-apriorising-implications $>>$. Such an insight can be appreciated as with the instance in the non-positivistic community where the positivistic mindset $/{ }^{3}$ reference-of-thought will most likely not necessarily perceive and construe the 'achievement motives and temporal-stakes in animistic or medieval lives and living' in the non-positivistic social-setup as 'grandest living' but rather the ${ }^{55}$ maximalising-recomposuring-for-relative-ontological-completeness ${ }^{87}$ unenframed/re-ontologising conceptualisation 'of positivistic transcendental institutionalisation projection over the animistic or medieval setup as much more of existential-<disontologising/reentelegising apereticism $>$ worth' from its vantage ontological-normalcy/postconvergence epistemic-or-notional projective-perspective. There is nothing inherently wrong with achievement motives across all registry-worldviews/dimensions conventional constructs as of human finite aspirations whether socially, professionally, family-wise, hedonic, etc. However, with regards to a prior registry-worldview's/dimension's <amplituding/formative> woodenlanguage-〈imbued - averaging-of-thought-<as-to-leveling/ressentiment/closed-construct-ofmeaningfulness-and-teleology -as-of-‘nondescript/ignorable-void '-with-regards-toprospective-apriorising-implications $>>$ denaturing of ${ }^{56}$ meaningfulness-and-teleology ${ }^{9}$ so construed prospectively, whether as of recurrent-utter-uninstitutionalisation, ununiversalisation, non-positivism/medievalism or procrypticism, such motives are necessarily superseded-and- 
overridden or subsumed-as-supplanted or transvaluated in-the-bigger-picture of human eternalising aspiration as of the intemporal/ongness-of-register-of-meaningfulness-andteleology individuation mental-disposition of 'inventing' the successive becoming possibilities in reflecting holographically-<conjugatively-and-transfusively $>$ the relativeunreflexivity/relative-reflexivity - ontological-contiguity of-the-human-institutionalisationprocess as inducing successively base-institutionalisation, ${ }^{103}$ universalisation, rationalempiricism/positivism and prospectively deprocrypticism; as going by 'attendant ontologisingcapacity driven apriorising/axiomatising/referencing-psychologism as of the grander ontological-normalcy/postconvergence

apriorising/axiomatising/referencing/intelligibilitysettingup/measuringinstrumenting' across retrospective and by implication prospective registry-worldviews/dimensions. To rather assume the notion that 'achievement motives across all registry-worldviews/dimensions conventional constructs as of human finite aspirations whether socially, professionally, family-wise, hedonic, etc. as of a given registry-worldview's/dimension's denaturing $<$ amplituding/formative $>$ wooden-language-<imbued — averaging-of-thought-<as-toleveling/ressentiment/closed-construct-of- meaningfulness-and-teleology -as-of'nondescript/ignorable-void '-with-regards-to-prospective-apriorising-implications $>>\quad$ soconstrued prospectively' take precedence and are not 'necessarily superseded-and-overridden or subsumed-as-supplanted or transvaluated in-the-bigger-picture of human intemporal ontological-faith-notion-or-ontological-fideism - imbued-underdetermination-of-motif-andapriorising/axiomatising/referencing-as-so-being-as-of-existential-reality behind the intemporal individuation mental-disposition of 'inventing' the successive becoming possibilities in reflecting holographically-<conjugatively-and-transfusively $>$ the relative-unreflexivity/relativereflexivity - ontological-contiguity of-the-human-institutionalisation-process , comes with the contradictory implication that the state of recurrent-utter-uninstitutionalisation should never 
have been transcended and overridden (as its human finite aspirations whether socially, professionally, family-wise, hedonic, etc. as of the registry-worldview's/dimension's denaturing $<$ amplituding/formative $>$ wooden-language-_imbued-averaging-of-thought-<asto-leveling/ressentiment/closed-construct-of- meaningfulness-and-teleology -as-of'nondescript/ignorable-void '-with-regards-to-prospective-apriorising-implications $>>\quad$ soconstrued prospectively are rather more pertinent) in order to 'invent' base-institutionalisationununiversalisation, which contradictorily as well, as 'biting the hand of such intemporaldisposition inventing', should never have been transcended and overridden (as its human finite aspirations whether socially, professionally, family-wise, hedonic, etc. as of the registryworldview's/dimension's denaturing $<$ amplituding/formative> wooden-language-〈imbuedaveraging-of-thought-<as-to-leveling/ressentiment/closed-construct-of- meaningfulness-andteleology -as-of-'nondescript/ignorable-void ' -with-regards-to-prospective-apriorisingimplications $>>$ so-construed prospectively are rather more pertinent) in order to 'invent' universalisation-non-positivism/medievalism, which contradictorily as well, as 'biting the hand of such intemporal-disposition inventing', should never have been transcended and overridden (as its human finite aspirations whether socially, professionally, family-wise, hedonic, etc. as of the registry-worldview's/dimension's denaturing $<$ amplituding/formative $>$ wooden-language-<imbued - averaging-of-thought-<as-toleveling/ressentiment/closed-construct-of- meaningfulness-and-teleology -as-of'nondescript/ignorable-void ' -with-regards-to-prospective-apriorising-implications $>>$ soconstrued prospectively are rather more pertinent) in order to 'invent' positivismprocrypticism (that is, paradoxically we shouldn't be existing today!), and which contradictorily as well, as 'biting the hand of such intemporal-disposition inventing', itself should not be transcended and overridden (as its human finite aspirations whether socially, professionally, family-wise, hedonic, etc. as of the registry-worldview's/dimension's 
denaturing $<$ amplituding-formative $>$ wooden-language-〈imbued-averaging-of-thought- $<$ asto-leveling/ressentiment/closed-construct-of- meaningfulness-and-teleology -as-of'nondescript/ignorable-void '-with-regards-to-prospective-apriorising-implications $>>\quad$ soconstrued prospectively are rather more pertinent) in order to 'invent' prospective deprocrypticism, rather reflecting intellectual absurdity; and speaking rather besides a natural weakness of human incapacity that can arise and do arise as a result of our limited-mentationcapacity -as-subjecting 'educed-unlimitedness/existence-sublimating nascence' tolimitedness/human-subpotency rendering us unconscious/unaware/as-of-the-poorer-halves-ofourselves which is fathomable/understandable, of a graver problem if that was to be the case even when we then 'understand', of intellectual-and-moral irresponsibility relative unreflexivity of failing/not-upholding-<as-of-apriorising/axiomatising/referencing $>$ to do our own 'homework' with respect to our forerunners in the bigger notion of the human species continuous emancipation. In order words, the most vital human activities has to do, whether as of a consciously aware or unconscious nature, with the 'intemporal-prioritisation-of- ${ }^{3}$ reference-ofthought'-as-conflatedness ${ }^{13}$-or-ontological-reprojecting that enables human memeticrescheduling (psychoanalytic-unshackling/institutional-recomposuring) as from recurrent-utteruninstitutionalisation to modern-day positivism- ${ }^{80}$ procrypticism and prospectively deprocrypticism; together with the idea that by the very intemporal-disposition essence of that 'inventing' it is inappropriate to construe such institutional-being-and-craft construct as a framework of temporal extricatory preconverging-de-mentating/structuring/paradigming relationship with ${ }^{56}$ meaningfulness-and-teleology ${ }^{99}$ (undermining the implied ${ }^{83}$ reference-ofthought- categorical-imperatives/axioms/registry-teleology ${ }^{99}$,-for-intemporal-preservationentropy-or-contiguity-or-ontological-preservation as of ontologicalnormalcy/postconvergence, by adhering by flaw rather to the $<$ amplituding/formative $>$ woodenlanguage-〈imbued-temporal-mere-form/virtualities/dereification/akrasiatic- 


\section{drag/denatured/preconverging-or-dementing -narratives - of-the- reference-of-thought-}

\section{categorical-imperatives/axioms/registry-teleology > as deterministic thus}

subknowledging $1 /$ mimicking the non-veridical hollow/empty form of the meaning of narratives, and strangely enough 'reflecting' the uninstitutionalised-threshold ${ }^{102}$, represented ontologically as decentered and preconverging-or-dementing -apriorising-psychologism), but rather appreciative of the intemporal mental-disposition (as ontological-faith-notion-or-ontologicalfideism - imbued-underdetermination-of-motif-and-apriorising/axiomatising/referencing-asso-being-as-of-existential-reality) behind the mental projection associated with and contributing to such institutional-being-and-craft 'inventing'. But then transcendental constructs of meaningfulness going beyond the 'conventioning limits' of a given registryworldview/dimension by definition are not actually perceived as 'most critical in value' going by 'intradimensional conventions' which define registry-worldviews/dimensions ontological and virtue limits; the effort of a Socrates, Galileo, Diderot, Copernicus as of implying a prospective ${ }^{83}$ reference-of-thought of meaningfulness, is an afterthought social recognition by the prospective registry-worldview's/dimension's ${ }^{83}$ reference-of-thought institutionalisation, not the social recognition of their own registry-worldview's/dimension's ${ }^{83}$ reference-of-thought (as the prior/transcended/superseded), as transcendental ${ }^{56}$ meaningfulness-and-teleology ${ }^{9}$ involves psychical and institutional recomposuring of high contrariety implications to human temporality $/$ shortness as putting-into-question the present as prior/old, but then the vocation of all transcendence-and-sublimity/sublimation/supereregatery de-mentativity as all knowledge is not about being responsive to the mortals that we are (including this author's mortality as anyone's else) as of social-aggregation-enabling but rather responsive to relative intrinsicreality/ontological-veridicality transcendental-enabling/sublimating/supereregatory $\sim$ dementativity of an intersolipsistic nature. It is equally important to grasp that transcendence-andsublimity/sublimation/supererogatoryade-mentativity is the more profound origination of 
reference-of-thought that enables knowledge conceptualisations, and that the praxis of knowledge may naively be construed as non-transcendental. So all knowledge is actually transcendental and this is not to be confused with its distance/remoteness as coming from the 'transcendental origination of the ${ }^{83}$ reference-of-thought of the knowledge' (whether as baseinstitutionalisation, ${ }^{103}$ universalisation, positivism or prospectively notional ${ }^{18}$ deprocrypticism knowledge), and the idea of neutral/equable knowledge is a 'mental complex of institutional inherence' arising from incrementalism-in-relative-ontological-incompleteness ${ }^{8}$ enframed/disontologising conceptualisation naivety, as if a given institutionalised ${ }^{8}$ referenceof-thought for knowledge has always been that way. By its very nature as construed from relative intrinsic-reality/ontological-veridicality transcendentalenabling/sublimating/supereregatory de-mentativity and not social-aggregation-enabling, transcendence-and-sublimity/sublimation/supererogatory〜de-mentativity (transcendental knowledge) cannot be construed as a neutral/equable exercise that doesn't involve contrariety, as it implies superseding the prior ${ }^{83}$ reference-of-thought- categoricalimperatives/axioms/registry-teleology ${ }^{9}$ with the prospective one for intemporal-preservationentropy-or-contiguity-or-ontological-preservation (as psychoanalytic-unshackling/memeticreordering/institutional-recomposuring) maximalising-recomposuring-for-relativeontological-completeness ${ }^{87}$ - unenframed/re-ontologising conceptualisation $<$ amplituding/formative-epistemicity $>$-totalising $\sim$ renewing-realisation/re-perception/rethought, in contrast to a naïve ${ }^{51}$ incrementalism-in-relative-ontological-incompleteness ${ }^{8}$ enframed/disontologising conceptualisation mental-reflex. The idea that knowledge-as-virtue will be obtained neutrally and be inserted in the social-construct neutrally is rather a simplistic/naïve virtuality-or-ontologically-flawed-construal, as at best such knowledge is not really neutral but rather remote/distant as coming from the 'transcendental origination of the reference-of-thought of the knowledge'. For instance, scientific discoveries and our liberal 
notions today are grounded on the transcendental origination of positivistic modern scientific knowledge and liberal thinking ${ }^{83}$ reference-of-thought established and developed from the days of the Newtons, Galileos, Pasteurs, Copernicus, Descartes, Rousseaux, etc. who and others, then were transcendental as of apriorising/axiomatising/referencing-\{of-" prospectively implicited_attendant-ontological-contiguity ' educedexistentialising/contextualising/textualising_ 'intelligibility/epistemicity/reflexivity-contiguity<imbued-notional cogency >' $\}$-re-originariness/re-origination in their positivistic outlook relative to other outlooks then like alchemy, essences, mysticism, serfdom, feudalism, etc., while equally inducing high social contrariety then to supersedingly establish our positivistic psyche leading to corresponding institutionalisation implications like the culture of science, notions of human rights, etc.; and we now take for granted today such a scientific disposition by the low temporal-to-intemporal-conjugating-emotional-involvement/subjectification/epistemictotalising $\sim$ self-referencing-syncretising-as-of-perceived-social-stake-contention-orconfliction but right back in their epoch this elicited a high temporal-to-intemporal-conjugatingemotional-involvement/subjectification/epistemic-totalising $\sim$ self-referencing-syncretising-asof-perceived-social-stake-contention-or-confliction. The point here is to highlight that where the need for 'reappraisal of ${ }^{83}$ reference-of-thought' arises as for prospective transcendence-andsublimity/sublimation/supererogatory de-mentativity, it will be naïve to imply that knowledge is neutral failing/not-upholding-<as-of-apriorising/axiomatising/referencing $>$ to register that all knowledge is the outcome of transcendence-and-sublimity/sublimation/supererogatory $\sim$ dementativity as 'reappraisals of ${ }^{83}$ references-of-thought' and inducing their corresponding prospective psychologisms (apriorising/axiomatising/referencing/intelligibilitysettingup/measuringinstrumenting-foroperant-or-incidenting-predicative-insights). Effectively, the wrong argument of knowledge neutrality is actually the argument of the prior transcendence-and- 
sublimity/sublimation/supererogatory-de-mentativity of ${ }^{83}$ reference-of-thought that enabled it to be as of the present ${ }^{8}$ reference-of-thought, as a statement of knowledge neutrality respectively in non-positivism/medieval or positivism registry-worldviews/dimensions are just naively asserting respectively the former or the latter as the ${ }^{83}$ reference-of-thought for knowledge; implying that a mental-disposition doesn't naturally factor in its very own relative-ontologicalincompleteness ${ }^{88}$-of- ${ }^{8}$ reference-of-thought. Hence it is rather ontological-completeness-ofreference-of-thought that is the viable construing reference of knowledge with its transcendence-and-sublimity/sublimation/supererogatory-de-mentativity implications for completing the ${ }^{83}$ reference-of-thought, and so not only with regards to transcendence-andsublimity/sublimation/supererogatory de-mentativity of retrospective registryworldviews/dimensions ${ }^{83}$ reference-of-thought but equally with the implication of transcendence-and-sublimity/sublimation/supereregatory-de-mentativity for prospective registry-worldview's/dimension's ${ }^{83}$ reference-of-thought as so validated by ontologicalnormalcy/postconvergernce. This insight about a more succinct social reality as of human institutionalised-and-uninstitutionalised-facets is critically vital for the appraisal of psychopathy and social-psychopathy as social manifestation of postlogism 77 as perversion-and-derivedperversion-of- ${ }^{83}$ reference-of-thought-<as-preconverginglyapriorising/axiomatising/referencing-in-nonconviction/madeupness/bottomlining-as-toshallow-supererogation $>$ within the positivism- ${ }^{8}$ procrypticism registry-worldview/dimension 'dynamic social construction of perceived social-stake-contention-or-confliction'. The social dynamics of perceived social-stake-contention-or-confliction as elicited in psychopathy and social psychopathy are more decisively determined by its induced 'lack of constraining social ${ }^{3}$ universal-transparency $^{104}$-〈transparency-of-totalising-entailing,-as-to-entailing$<$ amplituding/formative-epistemicity $>$ totalising in-relative-ontological-completeness $>$ hence speaking of the positivism- ${ }^{80}$ procrypticism uninstitutionalisation; wherein prospective 
institutionalising-facet insight will construe perversion-and-derived- ${ }^{7}$ perversion-of- ${ }^{~}$ referenceof-thought-<as-preconvergingly-apriorising/axiomatising/referencing-innonconviction/madeupness/bottomlining-as-to-shallow-supererogation $>$ while prospective uninstitutionalising-facet insight will rather overlook such implied denaturing as of beyondthe-consciousness-awareness-teleology ${ }^{9}-<$ of-preconverging-existential-extrication-as-ofexistential-unthought $>$. This very much mirrors such a dichotomy as articulated before within the same social space of relative perception of social-stake-contention-or-confliction at a registry-worldview's/dimension's uninstitutionalised-threshold ${ }^{102}$ defining its very notions of lawfulness and lawlessness, social-functioning and social dysfunction, accordance and discordance, probity and corruption, principledness and unprincipledness, etc. across the full breadth and depth of human institutions dynamic social construction of perceived social-stakecontention-or-confliction at that uninstitutionalised-threshold ${ }^{02}$ especially as of generalisedand-all-pervasive extended-informality. Such a dichotomy points out the reality in positivismprocrypticism that the construal of psychopathy and social psychopathy is in effect a social construction wherein while prospective institutionalisation mental-disposition relates-to-andconstrues-a-narrative-of grave institutional implications of phenomenal psychopathy as of the social dichotomy notions implied above, and so as of intemporal/ontological/social/species/ ${ }^{103}$ universal/transcendental/ ${ }^{5}$ maximalisingrecomposuring-for-relative-ontological-completeness ${ }^{8}$ - unenframed/reontologising conceptualisation postconverging-de-mentating/structuring/paradigming, uninstitutionalised-threshold ${ }^{102}$ mental-disposition will mostly construe irrelevance-andbenignancy as of temporal extricatory preconverging-de-mentating/structuring/paradigming. This is very much in sync with the reality that at a registry-worldview's/dimension's uninstitutionalised-threshold $^{102}$ human solipsistic mental-dispositions are temporal-tointemporal with the implication that such intemporal mental-orientation as ontology divulging 
is just one mental-disposition among others such that any such pre-eminence arises only as of positive opportunity <amplituding/formative-epistemicity $>$ causality $\sim$ as-to-projectivetotalitative-implications-of-prospective- nonpresencing,-for-explicating relative-

unreflexivity/relative-reflexivity - ontological-contiguity induced untenability/internalcontradiction/internal-incoherence/institutional-constraining in the middle to long run or crossgenerationally as intemporality ${ }^{52}$-symmetrising-by-desymmetrising-subsumption-oftemporality ${ }^{8}$. This dichotomy of contradictory narratives explains why it is the bigger framework of prospective relative-ontological-completeness ${ }^{87}$-of- ${ }^{-}$reference-of-thought that perfectly grasp in sync a superseding institutionalising aetiologisation/ontological-escalation$<$ ontological-veridicality_commitment/otherliness_transcending/compulsions-

encumbered_transcending $>\quad$ in notional $\sim$ deprocrypticism apriorising/axiomatising/referencing-\{of-'prospectively_implicited_attendant-ontologicalcontiguity ' $\sim$ educed-

existentialising/contextualising/textualising_ 'intelligibility/epistemicity/reflexivity-contiguity$<$ imbued-notional cogency $\left.>^{\prime} \quad\right\}$-conflatedness ${ }^{13}$-in-\{preconverging-disentailment by $\}^{\prime}$ postconverging-entailment and so over procrypticism disjointedness-as-of- ${ }^{3}$ reference-ofthought denaturing ${ }^{16}$ and harkening back in undermining psychopathy and social psychopathy as the more specific individuation-level denaturing. Interestingly this construing of psychopathy and social psychopathy within a dichotomy of institutionalisation and uninstitutionalised-threshold ${ }^{102}$ mental-dispositions with respect to dynamic social construction of perceived social-stake-contention-or-confliction is very much reflective of humansubpotency-aporia/undecidability/dilemma/ought-

indeterminacy/deficiency/limitation/constraint—imbued-'notional firstnaturednessformativeness-<as-to-eventualising-inkling-drive-or-seeding-misprising $>$ temporal-tointemporal-dispositions-<so-construed-as-from-perspective-ontological- 
normalcy/postconvergence>'-existentialism-form-factor, as we can grasp the veracity/ontological-pertinence of this uninstitutionalised-threshold dichotomy more transparently with regards to say non-positivism/medievalism postlogism 77 manifestation like notions-and-accusations-of-sorcery. We know that such incidents associated with notions-andaccusations-of-sorcery speak of the more profound relative-ontological-incompleteness ${ }^{8}$-ofreference-of-thought issue wherein the incidental denaturing of such manifestations reflected a social denaturing of the registry-worldview/dimension itself as non-positivistic and susceptible to endemise/enculturate superstitiousness as of the 'dynamic social construction of perceived social-stake-contention-or-confliction'. And in both instances it is the corresponding institutionalising aetiologisation/ontological-escalation-<ontologicalveridicality_commitment/otherliness_transcending/compulsions-encumbered_transcending > apriorising/axiomatising/referencing-\{of-'prospectively_implicited_attendant-ontologicalcontiguity ' educedexistentialising/contextualising/textualising_'intelligibility/epistemicity/reflexivity-contiguity<imbued-notional cogency $\left.>^{\prime}\right\}$-conflatedness ${ }^{13}$-in-\{preconverging-disentailment by\} pestcenverging entailment directed to the bigger and subsuming issue of relative-ontologicalincompleteness ${ }^{88}$-of- ${ }^{8}$ reference-of-thought for inducing notional ${ }^{18}$ deprocrypticism over procrypticism or positivism over non-positivism/medievalism respectively that harkens back to undermine in a decisive and nonextricatory and non-palliative manner the associated postlogism . apriorising/axiomatising/referencing-\{of-'prospectively_implicited_attendantontological-contiguity ' educedexistentialising/contextualising/textualising_intelligibility/epistemicity/reflexivity_contiguity-

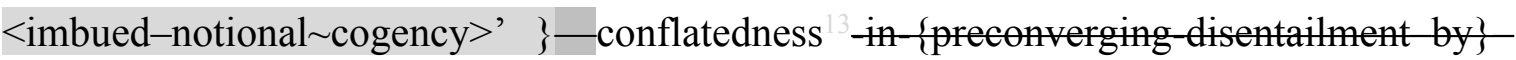
postconverging-entailment as such implies an utter shift as the curve-of-prospective-relativeontological-completeness ${ }^{87}$-of- ${ }^{8}$ reference-of-thought thus superseding the curve-of-prior- 
relative-ontological-incompleteness ${ }^{8}$-of- ${ }^{3}$ reference-of-thought now being construed as preconverging-or-dementing -and-decentered-prior-institutionalisation's- categoricalimperatives/axioms/registry-teleology ${ }^{99}$ as denaturing ${ }^{16}$.]

The defective apriorising/axiomatising/referencing/intelligibilitysettingup/measuringinstrumenting (as perversion-of- ${ }^{3}$ reference-of-thought-<as-preconverginglyapriorising/axiomatising/referencing-in-nonconviction/madeupness/bottomlining-as-toshallow-supererogation >) comparison can equally be used to illustrate how slanting is different from lying. Insightfully, we can grasp that the fundamental defect of the apriorising/axiomatising/referencing/intelligibilitysettingup/measuringinstrumenting just as with slanting arising as a faulty-mentation-procedure-deception explains why it keeps on falsely presupposing new narratives in deception just as a defective apriorising/axiomatising/referencing/intelligibilitysettingup/measuringinstrumentingproducing-measurements systematically keeps on making wrong aposteriorising/logicising/deriving/intelligising/measuring-purpose—of-obtainedmeasurements (systematically flawed meaningfulness) as its fundamental registryworldview's/dimension's-uninstitutionalised-threshold ${ }^{102}$-defect-<as-Being-or-ontological-orexistential-defect $>55$ (in registry-worldview terms of implications). On-the-other-hand, a lying deception is tantamount to undertaking an inappropriate measurement-as-ofaposteriorising/logicising/deriving/intelligising/measuring-purpose (flaw logicalprocesssing/act-execution-implicitation meaningfulness) with an apriorising/axiomatising/referencing/intelligibilitysettingup/measuringinstrumenting that is not defective (thus appropriateness-of- ${ }^{83}$ eference-of-thought-as-of-conflatedness ${ }^{13}$ ). This point to the ad-hoc nature of lying deception wherein there is nothing inherent that precludes subsequent appropriate logical-processing-or-logical-implicitation-supposedly-apriorising-in- 
conviction-as-to-profound-supererogation meaningfulness where the contextual-ambiguityconstraint(s) are resolved. In-the-bigger-scheme-of-things (at the transcendental/transdimensional/interdimensional level) postlogism 77 epistemic-decadence and its integration as perversion-and-derived- perversion-of- $^{-}$reference-of-thought- $<$aspreconvergingly-apriorising/axiomatising/referencing-in-

nonconviction/madeupness/bottomlining-as-to-shallow-supererogation $>$ of ${ }^{83}$ reference-ofthought- categorical-imperatives/axioms/registry-teleology ${ }^{9}$,-of-intemporal-preservationentropy-or-contiguity-or-ontological-preservation defines a registry-worldview's/dimension's uninstitutionalised-threshold ${ }^{102}$; arising in 'socially-perceived-value as of social-stakecontention-or-confliction' situations. This ontologically/intemporally represents the postlogic mindsets as preconverging-or-dementing ${ }^{20}$-apriorising-psychologism- $<$ stranded-as-rightfullyoblongated/decandored-and-dialectically-or-contendingly-out-of-phase $>$ and of hollowconstituting-<as-disjointed-misappropriation-of-meaningfulness-and-failing-intemporal-

preservation $>$ in postlogic-backtracking-<iterative-looping-'set-of-dereifying-hollownarratives-and-acts' $>$ as absolving/fleeting/escaping-reflex-logic (which are not ignored/overlooked but construed in preconverging-or-dementing ${ }^{20}$-apriorising-psychologism$<$ stranded-as-rightfully-oblongated/decandored-and-dialectically-or-contendingly-out-ofphase $>$ ) wherein ontologically-speaking the psychopath's interlocutors had hitherto by new logical-processing-or-logical-implicitation-supposedly-apriorising-in-conviction-as-toprofound-supererogation as 'prelogic supplanting-conviction-as-to-profoundsupererogation - of-'attendant-intradimensional'-postconverging/dialectical-thinking apriorising-psychologism re-engaging reflex' represented and referenced/registered/decisioned and related-to the postlogic mindsets in hollow-constituting-<as-disjointed-misappropriation-ofmeaningfulness-and-failing-intemporal-preservation $>$ in postlogic-backtracking- $<$ iterativelooping-'set-of-dereifying-hollow-narratives-and-acts' $>6$ as absolving/fleeting/escaping- 
reflex-logic wrongly as candored/straightness (wrongly ignoring/overlooking and setting-aside to reassume a candoring/straightness-of-thought as to postconverging-or-dialectical-thinking apriorising-psychologism-<stranded-as-rightfully-straight/candored-and-dialectically-orcontendingly-in-phase $>$ over the ontological-veridicality of preconverging-or-dementing ${ }^{2}$ apriorising-psychologism- $<$ stranded-as-rightfully-oblongated/decandored-and-dialectically-orcontendingly-out-of-phase $>$ ). Thus the registry-worldviews/dimensions which are in epistemicdecadence (notional-discontiguity/epistemic-discontiguity ${ }^{63}<$ - between - prior-shallowsupererogation -of-mentally-aestheticised preconverging/dementing -qualiaschema_and_prospective-profound-supererogation -of-mentallyaestheticised $\sim$ postconverging/dialectical-thinking -qualia-schema $>$-as-of-epistemicdecadence in hollow-constituting-<as-disjointed-misappropriation-of-meaningfulness-andfailing-intemporal-preservation> in postlogic-backtracking-<iterative-looping-‘set-ofdereifying-hollow-narratives-and-acts'>76) with respect to ontological-veridicality (relativeunreflexivity/relative-reflexivity - ontological-contiguity ${ }^{77}$ of ${ }^{83}$ reference-of-thought in intemporal-preservation-entropy-or-contiguity-or-ontological-preservation) and 'wrongly being temporally integrated intradimensionally' as candored/straightness rather than decandored/oblongatedness are recurrent-utter-uninstitutionalisation, ununiversalisation, nonpositivism/medievalism and prospectively, procrypticism. The conscious or unconscious exercise of 'subknowledging 4 mimicking the non-veridical hollow/empty form of the meaning of narratives', whether by a psychopath or a temporally-inclined mental-disposition pedestal, in view of getting interlocutors to wrongly align prelogicly/in-prelogic supplanting-conviction-asto-profound-supererogation _of-'attendant-intradimensional'-postconverging/dialecticalthinking -apriorising-psychologismly and perceive the non-veridical hollow mimicking form of the meaning of narratives as veridical/true/real is known as ${ }^{74}$ perversion-of- ${ }^{8}$ reference-ofthought-<as-preconvergingly-apriorising/axiomatising/referencing-in- 
ontologically, at the 'uninstitutionalised-threshold ${ }^{102}$, 'distractive-alignment-to- ${ }^{8}$ reference-ofthought- $<$ of-apriorising/axiomatising/referencing $>$ which is decandored/oblongated as of threshold-of-nonconviction/madeupness/bottomlining-in-shallow-supererogation $<-<$ as-to-

\section{‘attendant-intradimensional'-prospectively-disontologising preconverging/dementing}

apriorising-psychologism> and dialectically-or-contendingly-out-of-phase (contrasted to prelogism $^{78}$ which is candored, straightness, supplanting-conviction-as-to-profoundsupererogation —of-'attendant-intradimensional'-postconverging/dialectical-thinking apriorising-psychologism, dialectically-or-contendingly-in-phase and logically-congruent). From an intemporal/ontologising perspective, i.e. aetiological understanding of the abstract human animal, $\quad{ }^{7}$ perversion-of- ${ }^{83}$ reference-of-thought- $<$ as-preconverginglyapriorising/axiomatising/referencing-in-nonconviction/madeupness/bottomlining-as-toshallow-supererogation $>$ rather calls to engage with the unsoundness-or-ontological-badfaith/inauthenticity ${ }^{64}$-of- ${ }^{8}$ reference-of-thought/apriorising-registry of the postlogic mindset $/{ }^{83}$ reference-of-thought as transversality-<for-sublimating-existentialeventuating/denouement,from-'thinking-at-first/pure-predisposition-preemptive-ofprospective disontologising/subontologising’ as-of-prospectively-disambiguated-affirmedand-unaffirmed-'motif-and-apriorising/axiomatising/referencing'> and not operating/processing logic based on the articulated ${ }^{7}$ perversion-of- ${ }^{8}$ reference-of-thought- $<$ aspreconvergingly-apriorising/axiomatising/referencing-innonconviction/madeupness/bottomlining-as-to-shallow-supererogation $>$, so as to invalidate the projected false apriorising-registry's \{epistemic-totalising $3 \frac{3}{3}$ psychologismic-subliminality-ofindividuation — effusing/worlding imbued logical-dueness-or-scape-or-frame, profile-or-stature, presumptuousness-or-arrogation, assumptions, value-reference and teleology ${ }^{9}$, and consequently to articulate a manifestation of mental-slantedness/decandoring/distractive- 
alignment-to- ${ }^{-3}$ reference-of-thought- $<$ of-apriorising/axiomatising/referencing $>$ \% $/$ threshold-ofnonconviction/madeupness/bottomlining-in-shallow-supererogation $<-<$ as-to-' attendantintradimensional'-prospectively-disontologising preconverging/dementing -apriorisingpsychologism $>$ /distractive-temporal-priorisation (and not soundness-or-ontological-goodfaith/authenticity ${ }^{6}$ of- ${ }^{3}$ reference-of-thought/candoring/prelogism 8 /organic-comprehensionthinking) of the mind's mental perversion/defect; and so, as an utter and mentally dialecticallyor-contendingly-out-of-phase -as-the-temporal-mind-pedestals-are-dialectically-out-ofphase/dialectically-primitive -from an 'ordered construct from the intemporal as ontological mindset'. Since the state of exhibiting a demonstrated ${ }^{7}$ perversion-of- ${ }^{3}$ reference-of-thought$<$ as-preconvergingly-apriorising/axiomatising/referencing-innonconviction/madeupness/bottomlining-as-to-shallow-supererogation $>$ annuls temporaldispositions' implied logical-dueness/implied-profile-or-implied-stature/impliedpresumptuousness-or-implied-arrogation/implied-assumptions/implied-valuereference/implied-teleology 99 as 'logically contending'; from a pure ontological-veridicality perspective, more like a medieval mind with a superstitious registry-worldview ${ }^{83}$ reference-ofthought- ${ }^{8}$ ategorical-imperatives/axioms/registry-teleology ${ }^{9}$,-for-intemporal-preservationentropy-or-contiguity-or-ontological-preservation doesn't has the implied-profile-or-impliedstature and the implied-presumptuousness-or-implied-arrogation to logically contend about the ontological veridicality of an accusation of witchcraft with a relatively suprastructuring positivistic mental-disposition). This technique of mentally grasping the psychopath and other postlogic minds is by reflecting/perspectivating/highlighting a 'distractive-or-circumventivemental-alignment-or-postlogism ${ }^{77}$ (explained further in the text) as against an 'integrativemental-alignment-or-prelogism ${ }^{7}$, (the latter being the normal reflex by which the normal prelogism ${ }^{78}$-as-of-conviction,-in-profound-supererogation $-<$ existentially-veridical- 
disontologising-logical-outcome-arrived-at $>$ mind ordinarily aligns to meaning, and it is this mental-alignment reflex to meaning that makes it difficult to truly grasp the psychopath's and other postlogic mental-dispositions which mental-alignment are rather as of threshold-ofnonconviction/madeupness/bottomlining-in-shallow-supererogation $<<$ as-to-'attendantintradimensional'-prospectively-disontologising preconverging/dementing -apriorisingpsychologism $>$ with respect to meaningfulness). Paradoxically, this is the fundamental strength of psychopathy, i.e. to get the normal prelogism ${ }^{7}$-as-of-conviction,-in-profoundsupererogation -<existentially-veridical-'attendant-intradimensionalapriorising/axiomatising/referencing'-logical-dueness-precedes-disontologising-logicaloutcome-arrived-at $>$ mind to wrongly elevate psychopathic ${ }^{56}$ meaningfulness-and-teleology ${ }^{99}$ as of veridical 'implicited_attendant-ontological-contiguity ${ }^{67}$ ' educedexistentialising/contextualising/textalising_'intelligibility/epistemicity/reflexivity_contiguity$<$ imbued-notional cogency>' ${ }^{4}$ rather than reflect the reality of its 'formulaic ${ }^{56}$ meaningfulnessand-teleology', which is 'meaning-by-the-mere-illogical-possibility-of-it-being-formulaicallynarrated'. So when we talk about psychopathy we are talking about ${ }^{74}$ perversion-of- ${ }^{8}$ referenceof-thought-<as-preconvergingly-apriorising/axiomatising/referencing-in-

nonconviction/madeupness/bottomlining-as-to-shallow-supererogation $>$ rather than logical defect (defect of logical operation/processing/contention). This distinction is critical. Why? Basically, meaning is what defines/predicates value, thought and action. Meaning has two elementary aspects: ${ }^{83}$ reference-of-thought or axioms or categorical-imperatives (reflected-assoundness-or-ontological-good-faith/authenticity ${ }^{6}$-of- ${ }^{-}$reference-of-thought, by the prospective relative-ontological-completeness ${ }^{87}$-of- ${ }^{83}$ reference-of-thought and logic (logicaloperation/processing/contention/implicitation-of-act-execution, and so, 'fundamentally and validatorily' on the basis of sound reference-of-thought- categoricalimperatives/axioms/registry-teleology ${ }^{9}$,-for-intemporal-preservation-entropy-or-contiguity- 
or-ontological-preservation in the very first instance). Meaningfulness is thus essentially about the 'operation of ${ }^{8}$ reference-of-thought as-of-its-veracity/ontological-pertinence as-soundnessor-ontological-good-faith/authenticity ${ }^{6}$-of- ${ }^{8}$ reference-of-thought', with logic/logicalprocessing basically about the operation of ${ }^{8}$ reference-of-thought as rules as of intrinsic-realityontological-coherence_or_superseding-oneness-of-ontology validated as of established ontological-veridicality/intrinsic-reality/existential-reality. Otherwise stated, meaning has

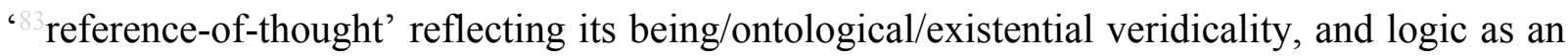
operation of elaboration-as-to-mere-extrapolating/constituting/abstracting/deducing/inferringof-elucidation-outside_-'prospectively_implicited_attendant-ontologicalcontiguity $^{67}$, educedexistentialising/contextualising/textualising_intelligibility/epistemicity/reflexivity-contiguity<imbued-notional cogency>' based on the meaning's implied ${ }^{83}$ reference-of-thoughtcategorical-imperatives/axioms/registry-teleology ${ }^{9}$ valid only inasmuch as the reference to the 'registry elements' of enstemic effusing/worlding imbued logical-dueness-or-scape-or-frame, profile-or-stature, presumptuousness-or-arrogation, assumptions, value-reference and teleology ${ }^{99}$ is 'existentially' established. *Critical for ontological-veridicality of meaningfulness and knowledge, the relatively ontologically-complete- ${ }^{8}$ reference-of-thought defines what is meaningfulness as of its 'soundness-or-ontological-good-faith/authenticity ${ }^{69}$-of- reference-of-thought' construed as 'postconverging-or-dialectical-thinking -apriorising-psychologism and centered understanding' over the relatively ontologically-incomplete- ${ }^{8}$ reference-of-thought as of its 'unsoundness-or-ontological-bad-faith/inauthenticity ${ }^{64}$-of- ${ }^{83}$ reference-of-thought' construed as 'preconverging-or-dementing -apriorising-psychologism and decentered understanding'. Slanting (and by derivation cohering-slanting) is 'technically coherent logical articulation' however over flawed or non-existent apriorising $-{ }^{8}$ reference-of-thought/apriorising-registry- 
elements, and thus falsely implying the apriorising $-{ }^{8}$ reference-of-thought/apriorisingregistry-elements of \{epistemic-totalising 3 psychologismic-subliminality-of-individuationeffusing/worlding imbued logical-dueness-or-scape-or-frame, profile-or-stature, presumptuousness-or-arrogation, assumptions, value-reference and teleology as being 'existentially' established, with the possibility of a further infinite possibility of logical faultymentation-procedure-deception-or-urge ${ }^{43}$ arising where the ${ }^{83}$ reference-of-thought-elements are wrongly implied as of existential-reality. Normally we assume that everyone is sound of mind (that is, assume everyone operates by soundness-or-ontological-good-faith/authenticity ${ }^{-o f-}$ reference-of-thought, with contention arising by reflex rather with respect to logical coherence and not the soundness-or-ontological-good-faith/authenticity ${ }^{6}$-of- ${ }^{3}$ reference-of-thought in the first place) so 'we don't tend to question the being/ontological/existential veridicality of reference-of-thought-〈reflected-as-soundness-or-ontological-good-faith/authenticity -of-

reference-of-thought $\rangle$. But with the phenomenon of psychopathy, this is a critical flaw at its adulthood stage, as at its childhood stage the 'deliriousness/delirious-effect/cinglé-effect' of the implied- ${ }^{-}$reference-of-thought/implied-registry and its elements of \{epistemictotalising 3 psychologismic-subliminality-of-individuation-effusing/worlding imbued logicaldueness-or-scape-or-frame, profile-or-stature, presumptuousness-or-arrogation, assumptions, value-reference and teleology is rather obvious and we don't normally process/operate logically the childhood psychopathy's non-veridical hollow mimicking narratives since 'we just invalidate those apriorising-registry-elements to start with as not of being/ontological/existential veridicality'. For instance in the case above, where John were to witness Dad punish his sister Mary for spilling water on a chair, and by 'vague-rhyming-or-copied-mimicry-or-formulaicprojection-or-projection-of-form-or-hollow-and-vague-vocalisation-or-subknowledging ${ }^{4}$ of meaning' (meaning-by-the-mere-illogical-possibility-of-it-being-formulaically-narrated) determines that if in a 'dereifying act' he spilt some water on a chair and said it was Peter, Peter 
will be punished by dad; dad, however, having an 'implicited_attendant-ontologicalcontiguity ${ }^{67} \sim$ educed-

existentialising/contextualising/textualising_intelligibility/epistemicity/reflexivity_contiguity$<$ imbued-notional cogency $>^{\prime 4}$ sense/projection of meaning' doesn't even dare to operate/process the logic articulated by John (a logic which in-of-itself while utterly sound technically, but is actually irrelevant in the given context by its fundamental logical-undueness' as of its unsound- ${ }^{3}$ reference-of-thought/unsoundness-or-ontological-bad-faith/inauthenticity ${ }^{6}$ of- ${ }^{3}$ reference-of-thought/mental-perversion) as he simply engages his unsoundness-orontological-bad-faith/inauthenticity ${ }^{6}$-of- ${ }^{3}$ reference-of-thought by way of distractivealignment-to- ${ }^{8}$ reference-of-thought- $<$ of-apriorising/axiomatising/referencing $>30$ and then reflect the ${ }^{83}$ reference-of-thought or registry-teleology ${ }^{99}$ of John as ${ }^{74}$ perversion-of- ${ }^{8}$ referenceof-thought-<as-preconvergingly-apriorising/axiomatising/referencing-in-

nonconviction/madeupness/bottomlining-as-to-shallow-supererogation $>$ or mental-perversion in terms-as-of-axiomatic-construct of tosychologismic-subliminality-ofindividuation —effusing/worlding imbued logical-dueness-or-scape-or-frame, profile-or-stature, presumptuousness-or-arrogation, assumptions, value-reference and teleology ${ }^{9}$. In so doing determines that John is 'manifesting a mental defect' and more so, not an ad-hoc defect-oflogical-processing-or-logical-implicitation—supposedly-apriorising-in-conviction-as-toprofound-supererogation of the registry-worldview's/dimension's- ${ }^{83}$ reference-of-thought-forsocial-functioning-and-accordance, but rather registry-worldview's/dimension'suninstitutionalised-threshold ${ }^{102}$-defect-<as-Being-or-ontological-or-existential-defect $>55$ that speaks to how John may act in many other similar situations, i.e. epistemic-decadence (notionaldiscontiguity/epistemic-discontiguity ${ }^{63}<$ between - prior-shallow-supererogation -ofmentally-aestheticised preconverging/dementing -qualia-schema_and_prospective-profoundsupererogation -of-mentally-aestheticised postconverging/dialectical-thinking -qualia- 
schema $>$-as-of-epistemic-decadence in hollow-constituting-<as-disjointed-misappropriation-ofmeaningfulness-and-failing-intemporal-preservation $>$ in postlogic-backtracking- $<$ iterativelooping-'set-of-dereifying-hollow-narratives-and-acts' ${ }^{70}$ ) by the denaturing of the reference-of-thought or the soundness-or-ontological-good-faith/authenticity ${ }^{6}$-of- ${ }^{8}$ referenceof-thought of meaning over which denaturing ${ }^{16}$ he tries to get interlocutors to operate/process logic; and 'is not even contending and that he is the subject of prelogism ${ }^{7}$-as-of-conviction,-inprofound-supererogation -<existentially-veridical-'attendant-intradimensionalapriorising/axiomatising/referencing'-logical-dueness-precedes-disontologising-logicaloutcome-arrived-at $>$ contention about his ${ }^{74}$ perversion-of- ${ }^{8}$ reference-of-thought- $<$ aspreconvergingly-apriorising/axiomatising/referencing-innonconviction/madeupness/bottomlining-as-to-shallow-supererogation $>$ /mentalperversion/unsoundness-or-ontological-bad-faith/inauthenticity ${ }^{64}$-of- ${ }^{3}$ reference-of-thought'. The above is the fundamental nature of psychopathy and it should not be lost even more critically at the adulthood stage and the corollary of social psychopathy' as increasingly prelogism ${ }^{78}$-as-of-conviction,-in-profound-supererogation $-<$ existentially-veridical'attendant-intradimensional-apriorising/axiomatising/referencing'-logical-dueness-precedesdisontologising-logical-outcome-arrived-at $>$ minds will tend to align to adult psychopaths and other conjugated-postlogism 7 teleological mindsets wrongfully as in prelogism 78 conviction-asto-profound-supererogation -or-candored/straightened instead of rightfully keeping a decandored/oblongated/distractive-alignment-to- ${ }^{83}$ reference-of-thought- $<$ ofapriorising/axiomatising/referencing $>$ 3/threshold-of-nonconviction/madeupness/bottomliningin-shallow-supererogation -<as-to-'attendant-intradimensional'-prospectivelydisontologising $\sim$ preconverging/dementing -apriorising-psychologism $>$ (rather circumventive as to distractive-temporal-prioritisation-of- ${ }^{8}$ reference-of-thought). Such reflecting/perspectivating/highlighting (reasoning-through-and-not-reasoning-with) inherently 
implies a dialecticism involving supplanting-conviction-as-to-profound-supererogation

‘attendant-intradimensional'-postconverging/dialectical-thinking -apriorising-psychologism

narratives as of organic-comprehension-thinking (organicalism)/‘intemporal-prioritisation-ofreference-of-thought'-as-conflatedness ${ }^{13}$-or-ontological-reprojecting or longness-of-registerof- ${ }^{5}$ meaningfulness-and-teleology and threshold-ofnonconviction/madeupness/bottomlining-in-shallow-supererogation $<-<$ as-to- 'attendantintradimensional'-prospectively-disontologising preconverging/dementing -apriorisingpsychologism $>$ narratives. This points to a perversion-of- ${ }^{7}$ reference-of-thought- $<$ aspreconvergingly-apriorising/axiomatising/referencing-innonconviction/madeupness/bottomlining-as-to-shallow-supererogation $>$ basically or a registry-worldview denaturing (when it comes to a registry-worldview/dimension transcendence-and-sublimity/sublimation/supererogatory-de-mentativity). The dialecticism involves de-mentation-〈supererogatory $\quad{ }^{15}$ ontological-de-mentation-or-dialectical-dementation - stranding-or-attributive-dialectics $\rangle$,-in-a-contiguity-of-increasing-ontologicalnormalcy/postconvergence pointing to the skewing ('intemporality ${ }^{52}$-symmetrising-bydesymmetrising-subsumption-of-temporality ${ }^{\circ}$, for relative intrinsic-reality/ontologicalveridicality transcendental-enabling/sublimating/supererogatory $\sim$ de-mentativity) for intemporalisation/institutionalisation over the reality of human-subpotencyaporia/undecidability/dilemma/ought-indeterminacy/deficiency/limitation/constraint—imbued'notional firstnaturedness-formativeness-<as-to-eventualising inkling-drive-or-seedingmisprising $>$ temporal-to-intemporal-dispositions- $<$ so-construed-as-from-perspectiveontological-normalcy/postconvergence>'-existentialism-form-factor individuations in transversality-<for-sublimating-existential-eventuating/denouement,-from-'thinking-atfirst/pure-predisposition-preemptive-of prospective-disontologising/subontologising' as-ofprospectively-disambiguated-affirmed-and-unaffirmed-'motif-and- 
apriorising/axiomatising/referencing' $>$ '01, and enabled 'metaphorically-as-of-a-million-andone-instances-and-locales as to aetiologisation/ontological-escalation- $<$ ontologicalveridicality_commitment/otherliness_transcending/compulsions-encumbered_transcending >'. The underlying fact about ${ }^{56}$ meaningfulness-and-teleology ${ }^{9}$ is that the apriorising-registry (as the individual grounding of the reference-of-thought of the social-construct registryworldview/dimension) precedes logic as of apriorising/axiomatising/referencing basis for logic. For instance, if an adult psychopath were to meet a stranger and spoke to him about another stranger whom it knows nothing about, saying logically that it is a bad thing for this guy to be molesting children, etc. The logical operation is entirely right and sound in abstract terms but does the apriorising-registry ( ${ }^{8}$ reference-of-thought) apply?, i.e. the faulty-mentationprocedure-deception-or-urge ${ }^{43}$ is not with regards to the logic (which is technically true) but with the 'implied' denaturing ${ }^{16}$ of the elements of the apriorising-registry as of ${ }^{83}$ reference-ofthought- ${ }^{-}$ategorical-imperatives/axioms/registry-teleology ${ }^{99}$ which are: implied-logicaldueness-or-implied-scape (the implied-logical-dueness-or-implied-scape doesn't exist since the psychopath doesn't know the guy), implied-profile (the psychopath is projecting a false representation of itself and the situation), implied-presumptuousness-or-implied-arrogation (the psychopath has no stature to talk about the guy he doesn't know), implied-assumptions (the assumptions implying the psychopath's relationship with the guy and the guy's relationship with children doesn't exist), implied-value-reference (the psychopath's elicitation of a sense of value reference in the interlocutor is unfounded and ridiculous) and implied-teleology ${ }^{9}$ (the psychopath's articulation of a sense of purpose on its interlocutor about the guy is hollow mimicking). Finally, the psychopath has articulated a lot of faulty-mentation-proceduredeception-or-urge ${ }^{43}$ but none to do with logic, but everything to do with the denaturing ${ }^{16}$ of registry/axiom/categorical-imperatives or the psychopath's unsoundness-or-ontological-badfaith/inauthenticity ${ }^{64}$-of- ${ }^{8}$ reference-of-thought, i.e. slanting-deception or deception-of- 
successively-shifting-or-non-cohering-narratives-and-acts or deception-by-concurrently-falsepresupposing/false-presuming/false-premising-of-narratives or deception-by-concurrentlyfalse-assumptive-preconverging-or-dementing ${ }^{20}$-of-narratives! So with the psychopath, you don't watch the logic, you watch out for the ${ }^{83}$ reference-of-thought/apriorising-registry for mental-perversion or the psychopath's unsoundness-or-ontological-bad-faith/inauthenticity of- ${ }^{8}$ reference-of-thought! Not only that, it is important to note that this unsoundness-orontological-bad-faith/inauthenticity ${ }^{64}$-of- ${ }^{8}$ refence-of-thought as ${ }^{7}$ perversion-of- ${ }^{8}$ referenceof-thought- $<$ as-preconvergingly-apriorising/axiomatising/referencing-innonconviction/madeupness/bottomlining-as-to-shallow-supererogation $>$ do protract and an ignorant prelogism ${ }^{78}$-as-of-conviction,-in-profound-supererogation $<<$ existentially-veridical‘attendant-intradimensional-apriorising/axiomatising/referencing'-logical-dueness-precedesdisontologising-logical-outcome-arrived-at $>$ mind acting in prelogism ${ }^{78}$-as-of-conviction,-inprofound-supererogation $-<$ existentially-veridical-'attendant-intradimensionalapriorising/axiomatising/referencing'-logical-dueness-precedes-disontologising-logicaloutcome-arrived-at $>\quad$ on $\quad$ such $\quad$ postlogism -as-of- compulsingnonconviction/madeupness/bottomlining-<‘ $<$ decontextualising/de-existentialising $\sim$ ofattendant-intradimensional-apriorising/axiomatising/referencing $>$-induced-disontologising'-ofthe-'attendant-intradimensional-ontologising'-imbued$<$ contextualising/existentialising attendant-ontological-contiguity $>$;-in-shallowsupererogation -<as-to-disontologising-perverted-outcome-sought-precedes-existentiallyveridical-'attendant-intradimensional-apriorising/axiomatising/referencing'-logical-dueness $>$ > non-veridical hollow mimicking narratives is 'technically psychopathic as well' as they are in hollow-constituting-<as-disjointed-misappropriation-of-meaningfulness-and-failingintemporal-preservation> or ${ }^{12}$ conjoining-looping-set-of-narratives as-of-cohering-logic-reflex to the psychopath's 'denaturing ${ }^{16}$ postlogic-backtracking-<iterative-looping-'set-of-dereifying- 
hollow-narratives-and-acts'> ${ }^{6}$-with-'successive-shifting-of-the-narratives-and-acts-foci'construed-as-'deception-of-successively-shifting-or-noncohering-narratives-and-acts' towards 'social-aggregation-enablers over intrinsic-reality/ontological-veridicality transcendentalenabling/sublimating/supereregatory $\sim$ de-mentativity’ as non-veridical and dialectically/contendingly out-of-phase. This is known as conjugatedpostlogism 7 preconverging-or-dementing $^{20}$-integration (whether conjugated to in ignorance/affordability/opportunism/exacerbation/social-chainism-or-social-discomfiture-ornegative-social-aggregation/temporal-enculturation-or-temporal-endemisation), which is to be construed as 'distractive-alignment-to- ${ }^{-3}$ reference-of-thought- $<$ ofapriorising/axiomatising/referencing $>{ }^{30}$ and once it is induced by ignorance it leads to an undermining of 'deductive social ${ }^{103}$ universal-transparency ${ }^{10}$-〈transparency-of-totalisingentailing,-as-to-entailing-<amplituding/formative-epistemicity $>$ totalising $\sim$ in-relativeontological-completeness $\rangle$ which protects the internal-coherence of meaning as of soundnessor-ontological-good-faith/authenticity ${ }^{6}$-of- ${ }^{83}$ reference-of-thought and corresponding virtue' and so by way of 'induced-ring-of-gyges-effect/solipsistic-point-of-temporalthresholding/point-of-ontological-faith-notion-or-ontological-fideism-imbuedunderdetermination-of-motif-and-apriorising/axiomatising/referencing-as-so-being-as-ofexistential-reality' at 'uninstitutionalised-threshold ${ }^{02}$ ' of registry-worldviews, with subsequent conjugating ignorance/affordability/opportunism/exacerbation/social-chainism-or-socialdiscomfiture-or-negative-social-aggregation/temporal-enculturation-or-temporal-endemisation, the conjugated-postlogism 77 preconverging-or-dementing -integration is derived from the psychopath's initiated postlogism 7 in hollow-constituting-<as-disjointed-misappropriation-ofmeaningfulness-and-failing-intemporal-preservation> and goes on to lead to social psychopathy; more like a dumb-and-dumb/miscuing degeneration effect. It should be noted that both psychopathic postlogism 77 and conjugated-postlogism 77 cases of unsoundness-or-ontological- 
bad-faith/inauthenticity ${ }^{6}$-of- ${ }^{3}$ reference-of-thought (as slanted and cohering-slanted, respectively), by their 'least-and-derived-temporal-operating-modalities-of-the- ${ }^{8}$ reference-ofthought-as-of- incrementalism-in-relative-ontological-incompleteness ${ }^{88}$ enframed/disontologising $\sim$ conceptualisation-inducing-the-uninstitutionalised-threshold ${ }^{102}$, involve 'disjointedness-as-of- ${ }^{3}$ reference-of-thought' misappropriated meaningfulness in arrogation by the fact that taken singularly from the same interlocutor in different circumstances, each (hollow-constituting-<as-disjointed-misappropriation-of-meaningfulness-and-failingintemporal-preservation>) narrative is apparently coherent but 'construed together as of the retracing of set-of-narratives' these reveal 'unsoundness-or-ontological-badfaith/inauthenticity ${ }^{6}$-of- ${ }^{8}$ reference-of-thought as preconverging-or-dementing ${ }^{20}$-apriorisingpsychologism'. It is rather their respective 'retracing of 'implicited_attendant-ontologicalcontiguity $^{67} \sim$ educed-

existentialising/contextualising/textualising_'intelligibility/epistemicity/reflexivity-contiguity$<$ imbued-notional $\sim$ cogency $>,{ }^{\prime},-<$ reifying-or-elucidating-of-prospective-relative-ontologicalcompleteness -of- reference-of-thought- devolving-as-of-instantiative-context> of set-ofnarratives together' that reveals 'postlogic slanting unsoundness-or-ontological-badfaith/inauthenticity ${ }^{64}$-of- ${ }^{83}$ reference-of-thought $\quad{ }^{74}$ perversion-of- ${ }^{8}$ reference-of-thought- $<$ aspreconvergingly-apriorising/axiomatising/referencing-in-

nonconviction/madeupness/bottomlining-as-to-shallow-supererogation >' and 'conjugatedpostlogism ${ }^{77}$ cohering-slanted unsoundness-or-ontological-bad-faith/inauthenticity ${ }^{6}$-ofreference-of-thought derived- ${ }^{7}$ perversion-of- ${ }^{3}$ reference-of-thought-<as-preconverginglyapriorising/axiomatising/referencing-in-nonconviction/madeupness/bottomlining-as-toshallow-supererogation $>$ (preconverging-or-dementing ${ }^{2}$-integration)'; as in successive postlogic-backtracking-<iterative-looping-'set-of-dereifying-hollow-narratives-and-acts’> and corresponding conjugated-postlogic conjoining of the iterating narratives, the succeeding 
changing/decentering/non-cohering foci (thus revealing the 'deliriousness/deliriouseffect/cinglé-effect' as unsoundness-or-ontological-bad-faith/inauthenticity ${ }^{64}$-of- ${ }^{83}$ reference-ofthought inducing the preconverging-or-dementing -apriorising-psychologism which is particularly obvious at childhood psychopathy but its perception easily gets lost at adult $\begin{array}{llll}\text { psychopathy with } & \text { wsychopath }\end{array}$ maturation/indirectness/spatialisation/credulity/craftiness to attain social-functioning-andaccordance-as-of-social-stake-contention-or-confliction) are constantly modified with circumstantial hollow-constituting-<as-disjointed-misappropriation-of-meaningfulness-andfailing-intemporal-preservation> by 'least-and-derived-temporal-operating-modalities-of-thereference-of-thought-as-of- incrementalism-in-relative-ontological-incompleteness ${ }^{88}$ enframed/disontologising $\sim$ conceptualisation-inducing-the-uninstitutionalised-threshold ${ }^{12}{ }^{\prime}$; and so in order to wrongly imply the apriorising $-{ }^{83}$ reference-of-thought/apriorising-registryelements as the foundation for its faulty-mentation-procedure-deception-or-urge ${ }^{43}$. However, the natural level of human interlocution engagement 'is not the enlightenment of the retracing of an interlocutor's sets-of-narratives' (as this could vary anywhere from say a few days or weeks to years of supplanting-conviction-as-to-profound-supererogation - of-'attendant-

\section{intradimensional'-postconverging/dialectical-thinking -apriorising-psychologism}

engagement, for such an insight to arise), but rather as of 'specific singular circumstantial narrative of interlocution without a comprehensive 'implicited_attendant-ontologicalcontiguity $^{67}$, educed-

existentialising/contextualising/textualising_intelligibility/epistemicity/reflexivity-contiguity$<$ imbued-notional $\sim$ cogency $>,{ }^{\prime},-<$ reifying-or-elucidating-of-prospective-relative-ontologicalcompleteness -of- reference-of-thought- devolving-as-of-instantiative-context> projection' by which interlocutors deduce circumstantially. Thus the postlogism 7 -and-conjugatedpostlogism 77 habit of producing sets-of-narratives (which collective retracing reveals their 
unsoundness-or-ontological-bad-faith/inauthenticity ${ }^{64}$-of- ${ }^{83}$ eference-of-thought and perversion-and-derived- ${ }^{7 /}$ perversion-of- ${ }^{8}$ reference-of-thought- $<$ as-preconverginglyapriorising/axiomatising/referencing-in-nonconviction/madeupness/bottomlining-as-toshallow-supererogation $>$ from 'implicited_attendant-ontological-contiguity ${ }^{67}$, educedexistentialising/contextmalising/textualising_'intelligibility/epistemicity/reflexivity_contiguity$<$ imbued-notional $\sim$ cogency $>,{ }^{\prime},-<$ reifying-or-elucidating-of-prospective-relative-ontologicalcompleteness -of- reference-of-thought- devolving-as-of-instantiative-context $>$ insight, but singularly out of implicited_attendant-ontological-contiguity ${ }^{67}$, educedexistentialising/contextualising/textualising_intelligibility/epistemicity/reflexivity-contiguity$<$ imbued-notional $\sim$ cogency $>,{ }^{\prime},-<$ reifying-or-elucidating-of-prospective-relative-ontologicalcompleteness -of- reference-of-thought- devolving-as-of-instantiative-context $>\quad$ are apparently of soundness-or-ontological-good-faith/authenticity -of- reference-of-thought) come to be endemised and enculturated socially, as of 'least-and-derived-temporal-operatingmodalities-of-the- ${ }^{8}$ reference-of-thought-as-of- ${ }^{5}$ incrementalism-in-relative-ontologicalincompleteness ${ }^{8}$ — enframed/disontologising conceptualisation-inducing-theuninstitutionalised-threshold ${ }^{102}$. Further, this 'natural level of human interlocution engagement is a perpetuation' explaining why the conjugated-postlogism 77 mental-disposition is one of 'slanted-cohering/conjoining' as it rather further integratively rationalises the latest iterated narrative as an elucidation rather than a further preconverging-or-dementing ${ }^{20}$-apriorisingpsychologism of adult psychopath/postlogism 77 (as obvious with the child psychopathy 'delirium effect' as it slants and re-slants on the initial slanting in an absolving-logic/fleetinglogic/escaping-logic reflex); and, the falsely projected ${ }^{83}$ reference-of-thought implied-elements of logical-dueness-or-implied-scape/implied-profile-or-implied-stature/impliedpresumptuousness-or-implied-arrogation/implied-assumptions/implied-valuereference/implied-teleology 9 , create a new foundation for further preconverging-or- 
dementing -apriorising-psychologism when wrongly eliciting in an interlocutor ${ }^{5}$ logicalprocessing-or-logical-implicitation - supposedly-apriorising-in-conviction-as-to-profoundsupererogation issue, such that one salient manifestation of conjugated-postlogism 77 arises with many of such an interlocutor vaguely articulating propositions based on such falsely 'apriorising_ ${ }^{83}$ reference-of-thought/apriorising-registry-elements (out of 'implicited_attendant_ontological-contiguity ${ }^{67}$ ' educedexistentialising/contextualising/textualising_intelligibility/epistemicity/reflexivity_contiguity$<$ imbued-notional $\sim$ cogency $>,{ }^{\prime},-<$ reifying-or-elucidating-of-prospective-relative-ontologicalcompleteness -of- reference-of-thought- devolving-as-of-instantiative-context $>$ )'. The idea that the 'natural level of human interlocution engagement is a perpetuation' can be understood insightfully with respect to a non-positivism/medievalism setup wherein a contention arising in non-positivism/medievalism ${ }^{83}$ reference-of-thought terms when invalidated positivistic terms doesn't imply that such interlocutors will instantly dramatically change their ${ }^{83}$ reference-ofthought into the positivistic terms with their successive contentions (due to $<$ amplituding/formative-epistemicity $>$ totalising $\sim$ self-referencingsyncretising/circularity/interiorising/akrasiatic-drag ${ }^{34}$ ), as their ${ }^{83}$ reference-of-thought remains rather in non-positivism/medievalism circularity/recurrence/repetition/repeatability ${ }^{10}$, and in the big picture in all likelihood can only be 'weaned from' crossgenerationally as of psychoanalyticunshackling/memetic-reordering/institutional-recomposuring. Likewise the 'natural basis of human interlocutory engagement tends to be perpetuating' when it comes with psychopathy and social psychopathy with respect to its eliciting of a 'least-and-derived-temporal-operatingmodalities-of-the- ${ }^{8}$ reference-of-thought-as-of- incrementalism-in-relative-ontologicalincompleteness 8 — enframed/disontologising conceptualisation-inducing-theuninstitutionalised-threshold ${ }^{102}$-\{as-procrypticism\}', thus equally implying a $<$ amplituding/formative-epistemicity $>$ totalising $\sim$ self-referencing- 
syncretising/circularity/interiorising/akrasiatic-drag

circularity/recurrence/repetition/repeatability ${ }^{10}$ of the ${ }^{83}$ reference-of-thought as of the uninstitutionalised-threshold ${ }^{102}$ or ${ }^{80}$ procrypticism-or-disjointedness-as-of- ${ }^{83}$ reference-ofthought. Thus the central notion for preempting psychopathic postlogism 77 and conjugatedpostlogism 77 is the 'retracing of their sets-of-narratives as of 'implicited_attendant-ontologicalcontiguity $^{67} \sim$ educed-

existentialising/contextualising/textualising_intelligibility/epistemicity/reflexivity_contiguity$<$ imbued-notional $\sim \operatorname{cogency}>,{ }^{\prime},-<$ reifying-or-elucidating-of-prospective-relative-ontologicalcompleteness -of- reference-of-thought- devolving-as-of-instantiative-context>'. That

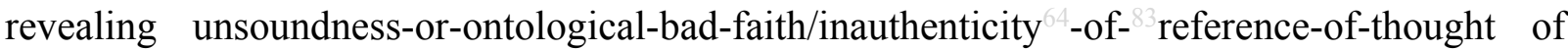
the traces of sets-of-narratives is analogous to resolving a list of BODMAS equations where the solution of the first equation is a variable of the second equation and whose solution is a variable of the third equation whose solution is a variable of the fourth; and where the first equation is $\begin{array}{llll}\text { fundamentally } & \text { flawed } & \text { (as } & \text { of }\end{array}$ apriorising/axiomatising/referencing/intelligibilitysettingup/measuringinstrumenting flaw, for instance), systematically the three other equations will be wrong whether by (5ignorance/affordability/opportunism/exacerbation/social-chainism-or-social-discomfiture-ornegative-social-aggregation/temporal-enculturation-or-temporal-endemisation) mentaldisposition to resolve the equation of the traditional arithmetic principles as ${ }^{83}$ reference-ofthought- categorical-imperatives/axioms/registry-teleology ${ }^{99}$,-for-intemporal-preservationentropy-or-contiguity-or-ontological-preservation without factoring that such ${ }^{83}$ reference-of-

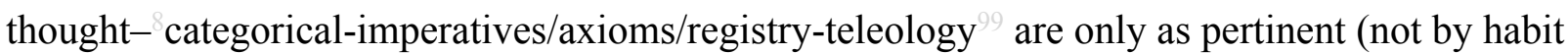
or tradition or expediency) but as of when they are truly for-intemporal-preservation-entropy-orcontiguity-or-ontological-preservation or ontological-normalcy/postconvergence to then articulate the necessary 'sublimating-epistemic-imbricatedness/threadedness/recomposuring as 
existentialising/contextualising/textualising_'intelligibility/epistemicity/reflexivity-contiguity$<$ imbued-notional $\sim \operatorname{cogency}>,{ }^{\prime},-<$ reifying-or-elucidating-of-prospective-relative-ontologicalcompleteness -of- reference-of-thought- devolving-as-of-instantiative-context $>$ as to existence-potency ${ }^{39} \sim$ sublimating-nascence,-disclosed-from-prospective-epistemicdigression—rules-of-apriorising/axiomatising/referencing-that-further-epistemicallyunconceal-the-very-ontologically-same-existential-reality' over naïve elaboration-as-to-mereextrapolating/constituting/abstracting/deducing/inferring-of-elucidation-outside'prospectively_implicited_attendant-ontological-contiguity ${ }^{67}$ ' educedexistentialising/contextualising/textalising_'intelligibility/epistemicity/reflexivity_contiguity<imbued-notional cogency>' (as of <amplituding/formative> wooden-language-〈imbuedtemporal-mere-form/virtualities/dereification/akrasiatic-drag/denatured/preconverging-ordementing -narratives - of-the- reference-of-thought- categoricalimperatives/axioms/registry-teleology $\rangle)$ that is only pertinent when it is of the existential$<$ disontologising/re-ontologising aporeticism $>$ existence-potency ${ }^{39} \sim$ sublimating-nascence,disclosed-from-prospective-epistemic-digression—rules-ofapriorising/axiomatising/referencing-that-further-epistemically-unconceal-the-veryontologically-same-existential-reality. It is important thus to know that since the defect of psychopathy and its derivation as social psychopathy has nothing to do with logical-processing but everything to do with 7 perversion-of- ${ }^{2}$ reference-of-thought-<as-preconverginglyapriorising/axiomatising/referencing-in-nonconviction/madeupness/bottomlining-as-toshallow-supererogation $>$ /perversion-of-axiomatic-construct and the false 'apriorisingreference-of-thought/apriorising-registry_elements (out of 'implicited_attendant ontological-contiguity ${ }^{67}$, educedexistentialising/contextualising/textualising_'intelligibility/epistemicity/reflexivity-contiguity- 
$<$ imbued-notional $\sim$ cogency $>{ }^{\prime},,-<$ reifying-or-elucidating-of-prospective-relative-ontologicalcompleteness -of- reference-of-thought- devolving-as-of-instantiative-context $>$ )' which are

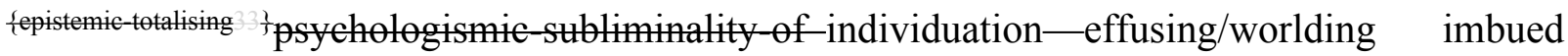
logical-dueness-or-scape-or-frame, profile-or-stature, presumptuousness-or-arrogation, assumptions, value-reference and teleology ${ }^{9}$, it is simply ${ }^{55}$ maximalising-recomposuring-forrelative-ontological-completeness ${ }^{8}$ - unenframed/re-ontologising conceptualisation that is ontologically called for to invalidate the psychopathic 'implied falsehood' by invalidating the 'apriorising ${ }^{83}$ reference-of-thought/apriorising-registry-elements (out of 'implicited_attendant-ontological-contiguity ${ }^{6}$ ' educedexistentialising/contextualising/textualising_intelligibility/epistemicity/reflexivity-contiguity$<$ imbued-notional $\sim$ cogency $>{ }^{\prime},-<$ reifying-or-elucidating-of-prospective-relative-ontologicalcompleteness -of- reference-of-thought- devolving-as-of-instantiative-context $>$ )' of \{epistemictotalising 3 psychologismic-subliminality-of-individuation-effusing/worlding imbued logicaldueness-or-scape-or-frame, profile-or-stature, presumptuousness-or-arrogation, assumptions, value-reference and teleology , and not involve in any elaboration-as-to-mereextrapolating/constituting/abstracting/deducing/inferring-of-elucidation-outside'prospectively implicited_attendant-ontological-contiguity ${ }^{67}$ ' educedexistentialising/contextualising/textualising_intelligibility/epistemicity/reflexivity-contiguity<imbued-notional cogency>' which will 'hollow-constitute' and falsely validate the deceptive foundation of 'apriorising- ${ }^{83}$ reference-of-thought/apriorising-registry-elements (out of 'implicited_attendant-ontological-contiguity ${ }^{67}$ ' educedexistentialising/contextualising/textualising_intelligibility/epistemicity/reflexivity-contiguity$<$ imbued-notional $\sim$ cogency $>,,-<$ reifying-or-elucidating-of-prospective-relative-ontologicalcompleteness -of- reference-of-thought- devolving-as-of-instantiative-context $>$ )' of \{epistemictotalising 3 psychologismic-subliminality-of-individuation-effusing/worlding imbued logical- 
dueness-or-scape-or-frame, profile-or-stature, presumptuousness-or-arrogation, assumptions, value-reference and teleology ${ }^{9}$ This is most apparent with childhood psychopathy as with the dereifying example of spilling water on a chair where it is directly obvious there is no elaboration-as-to-mere-extrapolating/constituting/abstracting/deducing/inferring-ofelucidation-outside_- 'prospectively_implicited_attendant-ontological-contiguity ${ }^{67}$; educedexistentialising/contextualising/textualising_intelligibility/epistemicity/reflexivity-contiguity<imbued-notional cogency>' to be had/entertained nor any logical analysis but rather maximalising-recomposuring-for-relative-ontological-completeness ${ }^{87}$ - unenframed/reontologising conceptualisation invalidating that the implied-logical-dueness-or-implied-scape of the child psychopath who deliberately in a 'dereifying act' spills water on the chair to accuse another even exists, its implied-profile is ridiculous, just as its implied-presumptuousness-orimplied-arrogation, its implied-assumptions, its implied-value-reference and its impliedteleology (or sense-of-purpose), and such an approach will equally extend with regards to social psychopathy where by ignorance at best or 'other cynical temporal manifestations as of conjugating affordability/opportunism/exacerbation/social-chainism-or-social-discomfiture-ornegative-social-aggregation/temporal-enculturation-or-temporal-endemisation' an interlocutor was to falsely imply the need for logical analysis in order to falsely validate the foundational faulty-mentation-procedure-deception-or-urge ${ }^{43}$ of the 'apriorising- ${ }^{83}$ reference-ofthought/apriorising-registry_elements (out of 'implicited_attendant-ontologicalcontiguity ${ }^{67}$, educed-

existentialising/contextualising/textualising_'intelligibility/epistemicity/reflexivity-contiguity$<$ imbued-notional $\sim$ cogency $>,{ }^{\prime},-<$ reifying-or-elucidating-of-prospective-relative-ontologicalcompleteness -of- reference-of-thought- devolving-as-of-instantiative-context $>$ )'. This phenomenon of the 'social protraction of psychopathy across individuals and society' can be articulated as follows. It is important to grasp that the mechanism of SLANTING as of 
compulsive-slanting - preconverging-or-dementing -apriorising is actually about 'denaturing postlogic-backtracking-<iterative-looping-'set-of-dereifying-hollow-narratives-and-acts'> with-'successive-shifting-of-the-narratives-and-acts-foci’-construed-as-'deception-ofsuccessively-shifting-or-noncohering-narratives-and-acts' towards 'social-aggregation-enablers over intrinsic-reality/ontological-veridicality transcendentalenabling/sublimating/supererogatory de-mentativity' dialectically/contendingly out-of-phase. The suspected psychosomatic basis for the psychopath to be slanted/'cinglé' is a 'faulty-mentation-procedure-deception-or-urge ${ }^{43}$ (entitlement folie/folie raisonnante)' as opposed to a logical motivation of a supplanting-conviction-as-toprofound-supererogation _of-'attendant-intradimensional'-postconverging/dialecticalthinking -apriorising-psychologism or prelogic mental-disposition. It is as if the 'psychopath's mental state is to take a faulty-mentation-procedure-shortcut' to the normal process of prelogism ${ }^{78}$-as-of-conviction,-in-profound-supererogation $-<$ existentially-veridical-

\section{'attendant-intradimensional-apriorising/axiomatising/referencing'-logical-dueness-precedes-}

disontologising-logical-outcome-arrived-at> logical articulation with respect to 'sociallyperceived-value as of social-stake-contention-or-confliction'. Going by the example highlighted above, say for instance the interlocutor finds out that the other stranger isn't really a child molester. The psychopath simply articulates another postlogic/disontologising-pervertedoutcome-sought-precedes-existentially-veridical-'attendant-intradimensionalapriorising/axiomatising/referencing'-logical-dueness/formulaic non-veridical hollow mimicking narrative (meaning-by-the-mere-illogical-possibility-of-it-being-formulaicallynarrated) over the previous narrative, and so in 'denaturing ${ }^{16}$ postlogic-backtracking devoidedof-conviction-as-to-profound-supererogation ${ }^{6}$-or-prelogism ${ }^{78}$-basis'. For instance, by saying (in a different social spatial location where the interlocutor cannot verify the underlying contextual reality) it is critical that the stranger should not be taking young children in his house 
as it suspiciously points to a molester (which is certainly a sound statement but rather being parasitised for a perverse purpose of 'denaturing postlogic-backtracking devoided-ofconviction-as-to-profound-supererogation ${ }^{9}$-or-prelogism ${ }^{78}$-basis' towards sanctifiedconventioning-social-aggregation-enablers, as the statement, not to take young children into his house, is sanctifying/as-not-requiring-any-further-contemplation to many a mental-disposition). Even if this latter narrative is proven to be false (as it is another ${ }^{7}$ perversion-of- ${ }^{83}$ reference-ofthought-<as-preconvergingly-apriorising/axiomatising/referencing-innonconviction/madeupness/bottomlining-as-to-shallow-supererogation $>$ or mental-perversion demonstrable as above with it faulty-mentation-procedure-deception-or-urge ${ }^{3}$ not being the logic itself, but in wrongly implying as existentially-<disontologising/re-ontologising aporeticism $>$ real the 'apriorising- ${ }^{83}$ reference-of-thought/apriorising-registry_elements (out of 'implicited_attendant-ontological-contiguity ${ }^{67}$ > educedexistentialising/contextualising/textualising_'intelligibility/epistemicity/reflexivity-contiguity$<$ imbued-notional $\sim$ cogency $>,{ }^{\prime},-<$ reifying-or-elucidating-of-prospective-relative-ontologicalcompleteness -of- reference-of-thought- devolving-as-of-instantiative-context>)' of epistemictotalising 3 psychologismic-subliminality-of-individuation-effusing/worlding imbued logicaldueness-or-scape-or-frame, profile-or-stature, presumptuousness-or-arrogation, assumptions, value-reference and teleology ${ }^{9}$ such that the mere fact of engaging logically with it validates these fundamental falsehood as a first-order faulty-mentation-procedure-deception-or-urge paving the way for an infinite possibility of second-order faulty-mentation-procedure-deceptionor-urge ${ }^{43}$ operating ${ }^{54}$ logical-processing-or-logical-implicitation-supposedly-apriorising-inconviction-as-to-profound-supererogation on such false axioms. Thus, with respect to postlogism 77 generally what is critical for the psychopath/postlogic-mindset is to be seen as being prelogic supplanting-conviction-as-to-profound-supererogation of-'attendantintradimensional'-postconverging/dialectical-thinking -apriorising-psychologism even if it is a 
perception of "poor or bad supplanting-conviction-as-to-profound-supererogation —of'attendant-intradimensional'-postconverging/dialectical-thinking -apriorising-psychologism' since that will validate the 'apriorising- ${ }^{83}$ reference-of-thought/apriorising-registry-elements (out of 'implicited_attendant-ontological-contiguity ${ }^{67}$; educedexistentialising/contextualising/textualising_'intelligibility/epistemicity/reflexivity-contiguity$<$ imbued-notional cogency $>,{ }^{\prime},-<$ reifying-or-elucidating-of-prospective-relative-ontologicalcompleteness -of- reference-of-thought- devolving-as-of-instantiative-context>)' on the basis that it was the ${ }^{54}$ logical-processing-or-logical-implicitation-supposedly-apriorising-inconviction-as-to-profound-supererogation that was wrong hence the possibility and credibility not to question the ${ }^{83}$ reference-of-thought/apriorising-registry/categorical-imperatives/axioms and to re-engage ${ }^{54}$ logical-processing-or-logical-implicitation-supposedly-apriorising-inconviction-as-to-profound-supererogation by 'prelogism ${ }^{7}$-as-of-conviction,-in-profoundsupererogation $-<$ existentially-veridical-'attendant-intradimensionalapriorising/axiomatising/referencing'-logical-dueness-precedes-disontologising-logicaloutcome-arrived-at> re-engaging reflex' wrongly turning the issue into one of ${ }^{54}$ logicalprocessing-or-logical-implicitation - supposedly-apriorising-in-conviction-as-to-profoundsupererogation instead of construing a ${ }^{74}$ perversion-of- ${ }^{8}$ reference-of-thought- $<$ aspreconvergingly-apriorising/axiomatising/referencing-in-

nonconviction/madeupness/bottomlining-as-to-shallow-supererogation $>$ 'preconverging-ordementing ${ }^{20}$-apriorising-psychologism/unsoundness-or-ontological-bad-faith/inauthenticity ${ }^{64}$ of- ${ }^{8}$ reference-of-thought manifestation'). The psychopath simply needs to loop another nonveridical hollow mimicking narrative over the previous one in 'denaturing postlogicbacktracking devoided-of-conviction-as-to-profound-supererogation -or-prelogism ${ }^{78}$-basis' towards sanctified-conventioning-social-aggregation-enablers. What is critical for the psychopath is that the 'last postlogic/formulaic non-veridical hollow mimicking 
narrative/meaning-by-the-mere-illogical-possibility-of-it-being-formulaically-narrated' allows its interlocutors to prelogicly 'rationalise' (align in-conviction-as-to-profound-supererogation to or prelogism 78 , at-a-pedestal,-in-this-case-ignorance-pedestal) the other narratives even if there are all 'non-veridical hollow mimicking narratives'. This might further involve juggling such hollow mimicking in hollow-constituting-<as-disjointed-misappropriation-ofmeaningfulness-and-failing-intemporal-preservation $>$ in postlogic-backtracking- $<$ iterativelooping-'set-of-dereifying-hollow-narratives-and-acts' $>$ as absolving/fleeting/escapingreflex-logic among different set-of-interlocutors (this is simply because postlogism 77 in hollowconstituting-<as-disjointed-misappropriation-of-meaningfulness-and-failing-intemporalpreservation> operates by extrinsic-attribution, i.e. who can I convince to make my argument right as per 'disontologising-perverted-outcome-sought-precedes-existentially-veridical'attendant-intradimensional-apriorising/axiomatising/referencing'-logical-dueness' unlike postlogism 77 as prelogism ${ }^{78}$ which operates by intrinsic-attribution, i.e. what is intrinsically real to uphold ontological virtue as per 'existentially-veridical-'attendant-intradimensionalapriorising/axiomatising/referencing'-logical-dueness-precedes-disontologising-logicaloutcome-arrived-at'), and inducing mutual misconstruing; and the reason for a perpetual psychopath's extrinsic-attribution inclination is that the outcome of its postlogism in hollowconstituting-<as-disjointed-misappropriation-of-meaningfulness-and-failing-intemporal-

preservation> (which is an unusual and rare social experience given that a psychopathic personality and postlogism 77 in hollow-constituting-<as-disjointed-misappropriation-ofmeaningfulness-and-failing-intemporal-preservation $>$ are an outlying phenomenon) with one set-of-interlocutors will involve either a temporal commitment to the postlogism 77 in hollowconstituting-<as-disjointed-misappropriation-of-meaningfulness-and-failing-intemporalpreservation> (due to the "lack of constraining social ${ }^{103}$ universal-transparency ${ }^{104}-\langle$ transparencyof-totalising-entailing,-as-to-entailing-<amplituding/formative-epistemicity $>$ totalising $\sim$ in- 
relative-ontological-completeness $\rangle$ as inducing vices-and-impediments ${ }^{105}$ which will then make it alienating) or a 'fool-me-once-phenomenon' where there is a relative insight on postlogism 77 in hollow-constituting-<as-disjointed-misappropriation-of-meaningfulness-andfailing-intemporal-preservation> from some interlocutors with no more commitment given the inconsistency of the hollow-constituting-<as-disjointed-misappropriation-of-meaningfulnessand-failing-intemporal-preservation> in postlogic-backtracking-<iterative-looping-‘set-ofdereifying-hollow-narratives-and-acts' $>{ }^{76}$ as absolving/fleeting/escaping-reflex-logic , in time speaking to the fundamental mental denaturing involved in postlogism 77 in hollowconstituting-<as-disjointed-misappropriation-of-meaningfulness-and-failing-intemporalpreservation>, and so for the shallowness of the postlogism 77 in hollow-constituting-<asdisjointed-misappropriation-of-meaningfulness-and-failing-intemporal-preservation> the extrinsic-attribution inclination is in constant need for new sets-of-interlocutors. The mental process that takes place in the ignorant prelogism ${ }^{78}$-as-of-conviction,-in-profoundsupererogation $-<$ existentially-veridical-'attendant-intradimensionalapriorising/axiomatising/referencing'-logical-dueness-precedes-disontologising-logicaloutcome-arrived-at $>$ mind is an alignment to the psychopath's (meaning-by-the-mere-illogicalpossibility-of-it-being-formulaically-narrated) postlogism -formulaic slanting compulsingnonconviction/madeupness/bottomlining-〈'<decontextualising/de-existentialising ofattendant-intradimensional-apriorising/axiomatising/referencing>-induced-disontologising'-ofthe-'attendant-intradimensional-ontologising'-imbued$<$ contextualising/existentialising attendant-ontological-contiguity $>$;-in-shallowsupererogation -<as-to-disontologising-perverted-outcome-sought-precedes-existentiallyveridical-'attendant-intradimensional-apriorising/axiomatising/referencing'-logical-dueness $>$ ) projection (distractive-alignment-to- ${ }^{8}$ reference-of-thought- $<$ ofapriorising/axiomatising/referencing $>^{30}$ ) such that the former's mind is rather in a hollow- 
constituting-<as-disjointed-misappropriation-of-meaningfulness-and-failing-intemporal-

preservation> 'conjoining looping narratives (of flawed-existential-elevation-of- ${ }^{8}$ reference-ofthought ${ }^{44}$ and developing a supplanting-conviction-as-to-profound-supererogation -of'attendant-intradimensional'-postconverging/dialectical-thinking -apriorising-psychologism or prelogism ${ }^{78}$ out of them), to the psychopath's 'denaturing ${ }^{16}$ postlogic-backtracking- $<$ iterativelooping-'set-of-dereifying-hollow-narratives-and-acts'> ${ }^{6}$-with-'successive-shifting-of-thenarratives-and-acts-foci’-construed-as-'deception-of-successively-shifting-or-noncoheringnarratives-and-acts' towards 'social-aggregation-enablers over intrinsic-reality/ontologicalveridicality transcendental-enabling/sublimating/supererogatory de-mentativity' as nonveridical and dialectically/contendingly out-of-phase. But again, this is just when the temporal prelogic/prelogism ${ }^{7}$-as-of-conviction,-in-profound-supererogation $-<$ existentially-veridical-

\section{'attendant-intradimensional-apriorising/axiomatising/referencing'-logical-dueness-precedes-}

disontologising-logical-outcome-arrived-at $>$ mind is ignorant of the slanted mental state of the psychopath. The general and complete operative psychopath ${ }^{74}$ perversion-of- ${ }^{8}$ reference-ofthought-<as-preconvergingly-apriorising/axiomatising/referencing-in-

nonconviction/madeupness/bottomlining-as-to-shallow-supererogation $>$ mechanism (it isn't necessarily completed in all manifestations as is rather a 'mental roaming/drifting-cycle disposition known as postlogism 7 -retreating' that carries on depending on how the situation permits) involves the psychopath first projecting initially neutral narratives (pre-valuation), then narratives meant to elicit the sense of excellence/exception/accommodation of its interlocutor (pri-individuation) as well as any other person or notion the interlocutor holds in high esteem, which are then contrasted 'out of context' unfavourably with non-veridical hollow mimicking narratives about the psychopath's 'socially-perceived-value as of social-stake-contention-orconfliction target' (de-individuation) ensuring the latter narratives are articulated craftily and at different social locations/spaces. De-individuation further consists of four elements; 
'consternation' wherein narratives with a 'sense of dismay' are induced on the interlocutor about the psychopath's social-stake-contention-or-confliction target, 'revulsion' wherein narratives with a 'sense of repugnance' are induced on the interlocutor about the target, 'certainty' wherein narratives with a 'false sense of undoubtedness' are projected about the target on the interlocutor, and finally a 'sense of passive or suggestive alienation' towards the psychopath's target is projected upon the interlocutor to 'subconsciously induce a sense of alienation from the target'. The psychopath then strives to settle on the whole of this process circularly doing likewise with other new and pertinent interlocutors as well (commitment). By-and-large this circularity perversion-of- ${ }^{8}$ reference-of-thought-<as-preconvergingly-

\section{apriorising/axiomatising/referencing-in-nonconviction/madeupness/bottomlining-as-to-}

shallow-supererogation $>$ thus involves these four elements as pre-valuation/priindividuation/de-individuation/commitment. Together with its corollary, social psychopathy, this disposition (passive or suggestive alienation) is at various level-of-consciousness-andwittiness extended to the social-construct as a comprehensive nature of extrinsic-attribution. Passive or suggestive alienation as such with corresponding 'temporal-dispositions miscuing' which is 'misconstrued as intrinsic ontological depth-of-conviction-as-to-profoundsupererogation . The underlying reason for the entirety of this mental process in the psychopath has to do with its "mere-formulaic constrained/unconstrained perception and relation to meaningfulness-and-teleology $\quad$ (vague-rhyming-or-copied-mimicry-or-formulaicprojection-or-projection-of-form-or-hollow-and-vague-vocalisation-or-subknowledging faulty-mentation-procedure-deception/meaning-by-the-mere-illogical-possibility-of-it-beingformulaically-narrated) which poorly perceives 'supplanting-conviction-as-to-profoundsupererogation - of-'attendant-intradimensional'-postconverging/dialectical-thinking apriorising-psychologism contentions' not in the 'essence/conviction-as-to-profoundsupererogation sense' but rather as 'formulaic mental alienation schemes' wherein 
disontologising-perverted-outcome-sought-precedes-existentially-veridical-'attendantintradimensional-apriorising/axiomatising/referencing'-logical-dueness (in order words the developmental psychology of the psychopath is actually to perceive supplanting-conviction-asto-profound-supererogation —of-'attendant-intradimensional'-postconverging/dialecticalthinking -apriorising-psychologism meaning as formulaic-schemes/meaning-by-the-mereillogical-possibility-of-it-being-formulaically-narrated, to which it responds in kind), and so is in transversality-<for-sublimating-existential-eventuating/denouement,-from-'thinking-atfirst/pure-predisposition-preemptive-of-prospective-disontologising/subontologising' as-ofprospectively-disambiguated-affirmed-and-unaffirmed-'motif-andapriorising/axiomatising/referencing' $>$ 101 $\quad$ to ${ }^{10}$ pregism ${ }^{78}$-as-of-conviction,-in-profoundsupererogation $-<$ existentially-veridical-'attendant-intradimensionalapriorising/axiomatising/referencing'-logical-dueness-precedes-disontologising-logicaloutcome-arrived-at $>$, and strives to 'square off as ${ }^{71}$ perversion-of- ${ }^{8}$ reference-of-thought- $<$ aspreconvergingly-apriorising/axiomatising/referencing-innonconviction/madeupness/bottomlining-as-to-shallow-supererogation at uninstitutionalised-threshold ${ }^{102}$ involving organic-comprehension-thinking ('intemporalprioritisation-of- ${ }^{83}$ reference-of-thought'-as-conflatedness ${ }^{13}$-or-ontological-reprojecting) being circumvented/distracted by threshold-of-nonconviction/madeupness/bottomlining-in-shallowsupererogation -<as-to- 'attendant-intradimensional'-prospectivelydisontologising preconverging/dementing -apriorising-psychologism> in an epistemictotalising $\sim$ self-referencing-syncretising; and so, in transversality-<for-sublimatingexistential-eventuating/denouement,-from-'thinking-at-first/pure-predisposition-preemptive-ofprospective disentologising/subentologising' as-of-prospectively-disambiguated-affirmedand-unaffirmed-'motif-and-apriorising/axiomatising/referencing'>101 along 3-pedestals (psychopath's slantedness/compulsive-dementing ${ }^{20}$ transversality-<for-sublimating-existential- 
eventuating/denouement,-from-'thinking at-first/pure-predisposition-preemptive-of-

prospective-disontologising/subontologising' as-of-prospectively-disambiguated-affirmed-

and-unaffirmed-'motif-and-apriorising/axiomatising/referencing'>101 pedestal, temporal-

dispositions $\quad$ transversality- $<$ for-sublimating-existential-eventuating/denouement,-from-

'thinking at-first/pure-predisposition-preemptive-of prospective-

disontologising/subontologising’ as-of-prospectively-disambiguated-affirmed-and-

unaffirmed-'motif-and-apriorising/axiomatising/referencing' $>{ }^{101}$ pedestals, and the intemporal-

disposition $\quad$ transversality- $<$ for-sublimating-existential-eventuating/denouement,-from-

'thinking at first/pure-predisposition-preemptive-of-prospective-

disontologising/subontologising’ as-of-prospectively-disambiguated-affirmed-and-

unaffirmed-'motif-and-apriorising/axiomatising/referencing'> ${ }^{101}$ pedestal in their

aetiologisation/ontological-escalation- $<$ ontological-

veridicality_commitment/otherliness_transcending/compulsions-encumbered_transcending $>$ ),

enabling the de-mentation-〈supererogatory $\sim$ ontological-de-mentation-or-dialectical-de-

mentation - stranding-or-attributive-dialectics $\rangle$ not as postconverging-or-dialectical-thinking -

apriorising-psychologism- $<$ stranded-as-rightfully-straight/candored-and-dialectically-or-

contendingly-in-phase > of threshold-of-nonconviction/madeupness/bottomlining-in-shallow-

supererogation -<as-to- 'attendant-intradimensional'-prospectively-

disontologising preconverging/dementing -apriorising-psychologism> as so-being rather

distractive to organic-comprehension-thinking (organicalism/“intemporal-prioritisation-of-

reference-of-thought'-as-conflatedness ${ }^{13}$-or-ontological-reprojecting/longness-of-register-of-

meaningfulness-and-teleology )'; to ultimately prevent its own 'perceived social alienation'

by inducing the alienation of its 'perceived social-stake-contention-or-confliction target' over a

social-stake-contention-or-confliction as to preconverging/postconverging-dementating/structuring/paradigming implications. Critically, it should be understood that passive 
or suggestive alienation is actually the summum of the possibilities of the psychopath's meaningful finality that starts from prevaluation (neutral narrations). It should be noted that the mental state of the psychopath's interlocutor as 'ignorance-temporal-disposition conjugated/inflected/derived/mimicked/in-protraction-to-psychopathic-preconverging-ordementing -apriorising-psychologism' is not really ontologically-speaking a prelogic/conviction-as-to-profound-supererogation mental state but rather technically a 'miscuing/dialectically-or-contendingly-out-of-phase postlogic mental state'. There are two stages at which an interlocutor can be in relation with the psychopathic manifestation: first, as an ignorant of psychopathic postlogism in hollow-constituting-<as-disjointedmisappropriation-of-meaningfulness-and-failing-intemporal-preservation $>$ to which the interlocutor aligns prelogicly and then miscues, and then secondly (in addition), as 'committedby-temporality /interest over intrinsic-veridicality' whether in the form of affordability/opportunism/exacerbation/social-chainism-or-social-discomfiture-or-negativesocial-aggregation/temporal-enculturation-or-temporal-endemisation. It should be noted that this psychopathic manifestation process can be mimicked in the context of social psychopathy, and more thoroughly when as 'exacerbation-temporal-disposition conjugated/inflected/derived/mimicked/in-protraction-to-psychopathic-preconverging-ordementing -apriorising-psychologism'. Over a given or extended period the underlying effect sought by the psychopath might stick, especially where the social target, interlocutors and others are utterly unaware of the mental state of the psychopath, and so evolving more like a socialdiscomfiture of relationship over 'socially-perceived-value as of social-stake-contention-orconfliction' (*social-discomfiture as such can be defined as the subsequent, ignorant or deliberate/disingenuous, adherence as if veridical to the slanted and hollow mimicking narratives of the psychopath with the corresponding ${ }^{74}$ perversion-of- ${ }^{2}$ reference-of-thought- $<$ aspreconvergingly-apriorising/axiomatising/referencing-in- 
nonconviction/madeupness/bottomlining-as-to-shallow-supererogation $>$ or mental-perversion in the social context). It is important to see that such social-discomfiture is in reality not a veridical logical 'contention' but in veridicality/ontologically a 'protracted manifestation' of notional procrypticism/notional-disjointedness-as-of- ${ }^{8}$ reference-of-thought as to underlying registry-worldview/dimension uninstitutionalised-threshold ${ }^{12}{ }^{74}$ perversion-of- ${ }^{8}$ reference-ofthought-<as-preconvergingly-apriorising/axiomatising/referencing-in-

nonconviction/madeupness/bottomlining-as-to-shallow-supererogation $>$ of both the psychopath and its interlocutors (even when the interlocutor is at best ignorant of the underlying psychopathic state), requiring 'distractive-alignment-to- ${ }^{-}$reference-of-thought- $<$ofapriorising/axiomatising/referencing $>$ ' at 'uninstitutionalised-threshold ${ }^{102}$ initiated by the psychopath's postlogism in hollow-constituting-<as-disjointed-misappropriation-ofmeaningfulness-and-failing-intemporal-preservation>, and resolved suprastructurally by a deprocryptic mindset/ ${ }^{3}$ reference-of-thought making reference to superseding deprocryptic

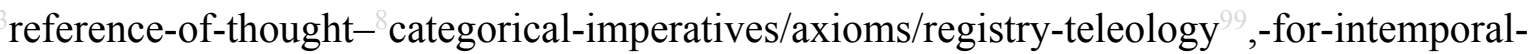
preservation-entropy-or-contiguity-or-ontological-preservation (just like an accusation of witchcraft in medieval society is not veridically/ontologically a 'contention' but rather a 'protracted manifestation' of non-positivism/medieval registry-worlddview/dimension perversion-of- ${ }^{3}$ reference-of-thought-<as-preconvergingly-

\section{apriorising/axiomatising/referencing-in-nonconviction/madeupness/bottomlining-as-to-}

shallow-supererogation $>$ by the dynamism of non-positivism/medieval mindset, resolved/structurally-rendered-inoperant suprastructurally by a positivistic mindset $/{ }^{8}$ referenceof-thought making reference to superseding positivistic ${ }^{83}$ reference-of-thought- ${ }^{8}$ ategoricalimperatives/axioms/registry-teleology ${ }^{9}$ ). It should be noted that suprastructuring implies reflection about an utter and mentally dialectically-or-contendingly-out-of-phase; as of nonontological-reference/non-contending-reference-but-ontologically-or-contendingly-reflected- 
or-perspectivated-as-preconverging-or-dementing ${ }^{20}$-apriorising-psychologism/not-veridical-

thinking-reference-rather-preconverging-or-dementing ${ }^{20}$-reference as-the-temporaldispositions-are-dialectically-out-of-phase/dialectically-primitive as suprastructurally reflected by an 'ordered construct from the intemporal/ontologising disposition' (since the state of exhibiting/demonstrating $\quad{ }^{74}$ perversion-of- ${ }^{83}$ reference-of-thought- $<$ as-preconverginglyapriorising/axiomatising/referencing-in-nonconviction/madeupness/bottomlining-as-toshallow-supererogation $>\quad$ will annul temporal-dispositions pedestals/statures/presumptuousness as postconverging-or-dialectical-thinking ${ }^{21}$-apriorisingpsychologism/'logically contending’, more like a medieval mind with a superstitious registryworldview doesn't has the stature/presumptuousness to 'logically contend' about the ontological veridicality of an accusation of witchcraft with a suprastructuring positivistic mind, as the former makes syncretic/circular references to non-positivism/medievalism ${ }^{83}$ reference-of-thoughtcategorical-imperatives/axioms/registry-teleology in its supposed articulation of logic). Paradoxically, the normal prelogism -as-of-conviction,-in-profound-supererogation $<$ existentially-veridical-'attendant-intradimensional-apriorising/axiomatising/referencing'logical-dueness-precedes-disontologising-logical-outcome-arrived-at $>$ mind is so attached by supplanting-conviction-as-to-profound-supererogation —of-'attendant-intradimensional'postconverging/dialectical-thinking -apriorising-psychologism reflex or prelogic-reflexadmittance-reflex or in-phase-reflex to the notion of the essence of supplanting-conviction-asto-profound-supererogation —of-'attendant-intradimensional'-postconverging/dialecticalthinking -apriorising-psychologism meaning (as it is not priorly inclined to put-into-question narratives but rather to quickly operate/process logic to arrive at outcome while 'trusting' that the other is also prelogism ${ }^{78}$-as-of-conviction,-in-profound-supererogation $-<$ existentiallyveridical-'attendant-intradimensional-apriorising/axiomatising/referencing'-logical-duenessprecedes-disontologising-logical-outcome-arrived-at> in their apriorising-registry, and so 
because psychopathy is a relatively outlying phenomenon thus the natural human personality development doesn't take it much into account in-the-bigger-scheme-of-things, i.e. it will be a 'waste of too much mental energy' to be verifying in detail the apriorising-registry totalising 3 psychologismic-subliminality-of-individuation —effusing/worlding imbued logicaldueness-or-scape-or-frame, profile-or-stature, presumptuousness-or-arrogation, assumptions, value-reference and teleology ${ }^{9}$ of every interlocutor, so mentally the human mind has developed a 'referencing scheme of trusting that involves closeness, familiarity, reputation and appearance'; but such a scheme is strictly speaking ontologically incomplete and underminable but it is standard as it 'saves mental energy and time', hence it is the strongest factor for the social prevalence of psychopathy and its social psychopathy corollary, and by extension all postlogism 77 perverted-as-disontologising-outcome-sought-precedes-logical-dueness across all registry-worldviews/dimensions); that it will find it hard to articulate or for that matter not believe the comprehensiveness and extent by which the psychopath can produce non-veridical hollow mimicking narratives towards its end purpose, particularly as it is a rather social outlying phenomenon and hence not usually integrated in many an individual's conceptualisation of social relations and phenomena. That's why the manifestation of 'poor or bad supplanting-convictionas-to-profound-supererogation —of-'attendant-intradimensional'-postconverging/dialecticalthinking -apriorising-psychologism', contrasted to the psychopath's '1 compulsingnonconviction/madeupness/bottomlining-〈‘ $<$ decontextualising/de-existentialising $\sim$ ofattendant-intradimensional-apriorising/axiomatising/referencing $>$-induced-disontologising'-ofthe-'attendant-intradimensional-ontologising'-imbued$<$ contextualising/existentialising attendant-ontological-contiguity $>$;-in-shallowsupererogation -<as-to-disontologising-perverted-outcome-sought-precedes-existentiallyveridical-'attendant-intradimensional-apriorising/axiomatising/referencing'-logical-dueness $>$ > or compulsively-dementing 2 , is ad-hoc, circumspect and highly contextualised since the 
prelogism ${ }^{7}$-as-of-conviction,-in-profound-supererogation $-<$ existentially-veridical‘attendant-intradimensional-apriorising/axiomatising/referencing'-logical-dueness-precedesdisontologising-logical-outcome-arrived-at $>$ mind even when acting temporally/badly has a hard time escaping from supplanting-conviction-as-to-profound-supererogation - of-'attendantintradimensional'-postconverging/dialectical-thinking -apriorising-psychologism or prelogism $^{78}$ (it has qualms/conscience) while the psychopath's compulsingnonconviction/madeupness/bottomlining-〈“<decontextualising/de-existentialising $\sim$ ofattendant-intradimensional-apriorising/axiomatising/referencing >-induced-disontologising'-ofthe-'attendant-intradimensional-ontologising'-imbued$<$ contextualising/existentialising attendant-ontological-contiguity $>$;-in-shallowsupererogation -<as-to-disontologising-perverted-outcome-sought-precedes-existentiallyveridical-'attendant-intradimensional-apriorising/axiomatising/referencing'-logical-dueness $>$ > is comprehensive since the psychopath naturally doesn't attach any 'emotional involvement' and qualms to the meaning of the narratives it articulates (it views them just as non-veridical hollow mimicking form narratives that determine its interlocutors prelogism ${ }^{78}$-as-of-conviction,-inprofound-supererogation -<existentially-veridical-'attendant-intradimensionalapriorising/axiomatising/referencing'-logical-dueness-precedes-disontologising-logicaloutcome-arrived-at $>$ dispositions and actions). In so doing, the psychopath has a parallel formulaic-representation-of-meaning/meaning-by-the-mere-illogical-possibility-of-it-being-

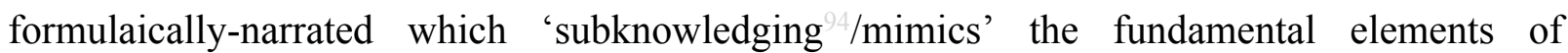
'supplanting-conviction-as-to-profound-supererogation —of-'attendant-intradimensional'postconverging/dialectical-thinking -apriorising-psychologism deductive meaning' such that the (adult) psychopath's non-veridical hollow mimicking narratives come across paradoxically as highly credulous. Basically the relevant question for the psychopath is: 'how was the hollow mimicking form that can be grasped in a prelogism -as-of-conviction,-in-profound- 
supererogation $-<$ existentially-veridical-'attendant-intradimensionalapriorising/axiomatising/referencing'-logical-dueness-precedes-disontologising-logicaloutcome-arrived-at $>$ mind deterministic of other prelogism 7 -as-of-conviction,-in-profoundsupererogation $-<$ existentially-veridical-'attendant-intradimensionalapriorising/axiomatising/referencing'-logical-dueness-precedes-disontologising-logicaloutcome-arrived-at $>$ minds behaviours, and how can I then mimic-and-project this hollow mimicking form to determine how others minds will act. These parallelisation of mereformulaic-projection/extrinsic-attribution induced-meaningfulness elements (meaning-by-themere-illogical-possibility-of-it-being-formulaically-narrated) with their corresponding prelogism ${ }^{7}$-as-of-conviction,-in-profound-supererogation $-<$ existentially-veridical'attendant-intradimensional-apriorising/axiomatising/referencing'-logical-dueness-precedesdisontologising-logical-outcome-arrived-at $>$ as to intrinsic-attribution veridical-meaningfulness elements (which are subknowledged/mimicked) involve: 'toning-triggering/snappings-ofimpression/tenseness-of-interlocutory-engagement- easily copied with conjugated-postlogism at an intuitive-level\}' as subknowledging 'prelogism -as-of-conviction,-in-profoundsupererogation $-<$ existentially-veridical-'attendant-intradimensionalapriorising/axiomatising/referencing'-logical-dueness-precedes-disontologising-logicaloutcome-arrived-at> toning/mannerisms'; 'hollow mimicking presumptuousness/arrogation/usurpation' as subknowledging 'prelogism 78 -as-of-conviction,in-profound-supererogation $-<$ existentially-veridical-'attendant-intradimensionalapriorising/axiomatising/referencing'-logical-dueness-precedes-disontologising-logicaloutcome-arrived-at> suppositions'; 'folie-raisonnante/non-veridical assumptions' as subknowledging ${ }^{44}$ 'veridical assumptions'; 'absolving/fleeting/escaping-reflex-logic' as subknowledging ${ }^{94}$ 'prelogism ${ }^{78}$-as-of-conviction,-in-profound-supererogation $<<$ existentiallyveridical-'attendant-intradimensional-apriorising/axiomatising/referencing'-logical-dueness- 
precedes-disontologising-logical-outcome-arrived-at> logical operation narratives'; inductive/contextual limitation as subknowledging ${ }^{4}$ 'principles/projected-logic'; structuredmanipulation/deception-or-mimicking-or-gotcha-logic as subknowledging 'value referencing/applicative-logic'; 'taking-out-of-context/offsetting logic' as subknowledging 'veridical contexts logic', and 'extrinsic-attribution acts with respect to conventioning/socialtemporal-thresholding contexts on the basis that acts by the psychopath to elicit the temporalself-interest of its interlocutors will override intrinsic right or wrong; whether such actions include praising, endearing, owing a favour, gifting, assisting, being friendly towards, etc.' as subknowledging 94 'intrinsic-attribution of acts as inherently right or wrong'. On the above basis, the psychopath's relation to 'deductive meaning' is actually reverting to 'vague-rhyming-orcopied-mimicry-or-formulaic-projection-or-projection-of-form-or-hollow-and-vague-

vocalisation-or-subknowledging ${ }^{4}$ of postlogic compulsingnonconviction/madeupness/bottomlining-〈'<decontextualising/de-existentialising $\sim$ ofattendant-intradimensional-apriorising/axiomatising/referencing $>$-induced-disontologising'-ofthe-'attendant-intradimensional-ontologising'-imbued-

$<$ contextualising/existentialising attendant-ontological-contiguity $>$;-in-shallowsupererogation -<as-to-disontologising-perverted-outcome-sought-precedes-existentiallyveridical-'attendant-intradimensional-apriorising/axiomatising/referencing'-logical-dueness $>$ ) as to its threshold-of-nonconviction/madeupness/bottomlining-in-shallow-supererogation $<$ as-to-'attendant-intradimensional'-prospectivelydisontologising $\sim$ preconverging/dementing -apriorising-psychologism $>{ }^{\prime} \quad$ construed as 'reverting deduction' whereas 'supplanting-conviction-as-to-profound-supererogation —of'attendant-intradimensional'-postconverging/dialectical-thinking -apriorising-psychologism deductions' emphasise the intrinsic attributive essence of deductions with corresponding latent forms of prosody, psychopathic vague-rhyming-or-copied-mimicry-or-formulaic-projection-or- 
projection-of-form-or-hollow-and-vague-vocalisation-or-subknowledging ' compulsing-nonconviction/madeupness/bottomlining-〈' $<$ decontextualising/de-

existentialising $\sim$ of-attendant-intradimensional-apriorising/axiomatising/referencing $>$-induceddisontologising'-of-the-'attendant-intradimensional-ontologising'-imbued$<$ contextualising/existentialising attendant-ontological-contiguity $>$;-in-shallowsupererogation -<as-to-disontologising-perverted-outcome-sought-precedes-existentiallyveridical-'attendant-intradimensional-apriorising/axiomatising/referencing'-logical-dueness $>$ > backtracking-iterative-looping-'set-of-dereifying-hollow-narratives-and-acts' deductions' imply the psychopath overemphasises in a consciously active manner the empty forms of prosody in-of-themselves first and over the intrinsic attributive essence of meaning like overemphasising the toning form (toning triggering) and the supposition form (presumptuousness) in their expressed deductive reasoning, as it mimicks the fact that the forms of prosody tend to be overemphasised spontaneously when naturally expressing profound/deep conviction; thus naturally the psychopathic mindset $/{ }^{3}$ reference-of-thought has an unusually large repertoire of 'sense of meaningfulness associated with empty forms of prosody' since it artificially perceives them as more critical than the supplanting-conviction-as-to-profoundsupererogation - of-'attendant-intradimensional'-postconverging/dialectical-thinking apriorising-psychologism mind's intrinsic meaningfulness the forms of prosody are latently associated with. The peculiarity with the psychopath and in the instance of protracted slantedness/social psychopathy with the case of exacerbation for instance, is the over-elaboration of such forms in a way that is rather an instrumentalisation of form of expression and not natural expression (mimicking or vague-rhyming-or-copied-mimicry-or-formulaic-projection-orprojection-of-form-or-hollow-and-vague-vocalisation-or-subknowledging ${ }^{9}$ ). In fact, it is often the case that such line of rather 'overly emphasised forms of expression with peculiar tonality' will be noticeable across an entire set of the psychopath interlocutor's in conjugated-postlogism 
in their 'conjoining looping narratives of flawed-existential-elevation-of- ${ }^{3}$ reference-ofthought ${ }^{4}$ (pointing to vague-rhyming-or-copied-mimicry-or-formulaic-projection-orprojection-of-form-or-hollow-and-vague-vocalisation-or-subknowledging 9 ), and can be an advanced insight of a 'psychopathic/postlogic and social psychopathic/conjugated-postlogism situation', construable with an appropriate ${ }^{55}$ maximalising-recomposuring-for-relativeontological-completeness ${ }^{87}$ - unenframed/re-ontologising conceptualisation. This mirrors the operant case highlighted further below, wherein the implied meaningfulness (of postlogic/psychopathic, conjugated-postlogism 77 preconverging-or-dementing 2 -integration and supplanting-conviction-as-to-profound-supererogation of-'attendant-intradimensional'postconverging/dialectical-thinking -apriorising-psychologism mental-dispositions) is existentially-traced as of the circularity/recurrence/repetition/repeatability ${ }^{10}$ as to existentialtransitioning-or-iterability-trace-of-narratives-as-dots_or_implicited_attendant-ontologicalcontiguity $^{67} \sim$ educedexistentialising/contextualising/textualising_'intelligibility/epistemicity/reflexivity-contiguity$<$ imbued-notional cogency>' ${ }^{\prime}$-reification_or_intrinsic-reality-ontologicalcoherence_or_superseding-oneness-of-ontology to establish ontological-veridicality, and not simply operating on the "naïve supposition of ${ }^{103}$ universal human prelogism ${ }^{78}$-as-of-conviction,in-profound-supererogation $-<$ existentially-veridical-'attendant-intradimensionalapriorising/axiomatising/referencing'-logical-dueness-precedes-disontologising-logicaloutcome-arrived-at>' without factoring the 'postlogism 77 mere-formulaic slanting compulsing-nonconviction/madeupness/bottomlining-〈' $<$ decontextualising/deexistentialising $\sim$ of-attendant-intradimensional-apriorising/axiomatising/referencing $>$-induceddisontologising'-of-the-'attendant-intradimensional-ontologising'-imbued$<$ contextualising/existentialising attendant-ontological-contiguity $>$;-in-shallowsupererogation -<as-to-disontologising-perverted-outcome-sought-precedes-existentially- 
veridical-'attendant-intradimensional-apriorising/axiomatising/referencing'-logical-dueness $>$ >

mental-disposition' of the postlogic/psychopathic and conjugated-postlogism 77 preconvergingor-dementing ${ }^{20}$-integration mindsets $/{ }^{3}$ reference-of-thought. It is important to note that the psychopath's targeting is highly evolutive throughout its life (along human personality development stages) as 'socially-perceived-value as of social-stake-contention-or-confliction' with others arise and the 'possibility of going undetected' permits. The psychopath being 'outof-phase' is pushed by a faulty-mentation-procedure-deception/urge/folie raisonnante, and the idea of psychopath's having a grand plan/an overall scheme in its actions is ridiculous and unfounded (this idea again, is due to prelogism ${ }^{78}$-as-of-conviction,-in-profoundsupererogation $-<$ existentially-veridical-'attendant-intradimensional-

\section{apriorising/axiomatising/referencing'-logical-dueness-precedes-disontologising-logical-}

outcome-arrived-at $>$ mental-alignment or in-phasing or prelogism ${ }^{78}$ to the last narrative(s) of the psychopath and rationalising prelogicly/by-essence/candor all its previous 'denaturing postlogic-backtracking-<iterative-looping-'set-of-dereifying-hollow-narratives-and-acts'> $>$ with-'successive-shifting-of-the-narratives-and-acts-foci’-construed-as-'deception-ofsuccessively-shifting-or-noncohering-narratives-and-acts' towards 'social-aggregation-enablers over intrinsic-reality/ontological-veridicality transcendentalenabling/sublimating/supererogatory $\sim$ de-mentativity'

dialectically/contendingly out-of-phase' over the 'intrinsic-reality/ontological-veridicality transcendental-enabling/sublimating/supererogatory $\sim$ de-mentativity' instead of mentally aligning postlogicly/by-form/slantedness/distractive-alignment-to- ${ }^{8}$ reference-of-thought- $<$ ofapriorising/axiomatising/referencing $>$ before reflecting/perspectivating/highlighting (reasoning-through-and-not-reasoning-with) a protracted unsoundness-or-ontological-badfaith/inauthenticity ${ }^{6}$-of- ${ }^{3}$ reference-of-thought/insanity). In fact, the psychopath's faultymentation-procedure-deception-or-urge ${ }^{43}$ occurs because of overthinking (elevating its perverted 
registry/mimicking-subknowledging ${ }^{4}$ to wrongly contend with it) rather than underthinking downgrading the $\quad{ }^{7}$ perversion-of- ${ }^{3}$ reference-of-thought- $<$ as-preconverginglyapriorising/axiomatising/referencing-in-nonconviction/madeupness/bottomlining-as-to-

shallow-supererogation $>$ and not contending with it, just as is naturally done with a 'childhood cinglé' who is not yet surreptitious and the delirium is rather obvious. Actually, instead of being 'deliberate of thought'/'conviction-as-to-profound-supererogation logical motive', the psychopath 'compulsively learns' as of its postlogic compulsingnonconviction/madeupness/bottomlining-〈‘ $<$ decontextualising/de-existentialising $\sim$ ofattendant-intradimensional-apriorising/axiomatising/referencing >-induced-disontologising'-ofthe-'attendant-intradimensional-ontologising'-imbued$<$ contextualising/existentialising attendant-ontological-contiguity $>$;-in-shallowsupererogation -<as-to-disontologising-perverted-outcome-sought-precedes-existentiallyveridical-'attendant-intradimensional-apriorising/axiomatising/referencing'-logical-dueness $>$ ) faulty-mentation-procedure-deception-or-urge from the successive experiences of its failing/not-upholding-<as-of-apriorising/axiomatising/referencing $>$ childhood postlogism slantedness as it grows into an adult by learning first to be socially-functional-and-accordant while being maturated, indirect, spatialising, credulous and crafty about its postlogism slantedness so that it starts becoming effective in inducing supplanting-conviction-as-toprofound-supererogation _of-‘attendant-intradimensional'-postconverging/dialecticalthinking -apriorising-psychologism minds to align in-conviction-as-to-profoundsupererogation to its compulsing-nonconviction/madeupness/bottomlining-

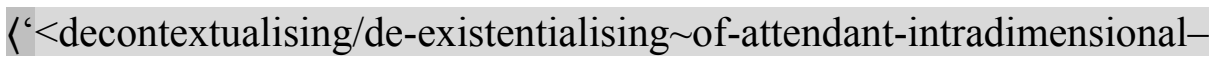
apriorising/axiomatising/referencing >-induced-disontologising'-of-the-'attendantintradimensional-ontologising'-imbued-<contextualising/existentialising $\sim$ attendantontological-contiguity $>$;-in-shallow-supererogation $-<$ as-to-disontologising-perverted- 
outcome-sought-precedes-existentially-veridical-'attendant-intradimensional-

apriorising/axiomatising/referencing'-logical-dueness $>$ > hollow narratives. Thus, social universal-transparency ${ }^{104}$-〈transparency-of-totalising-entailing,-as-to-entailing$<$ amplituding/formative-epistemicity>totalising in-relative-ontological-completeness $>$ ' of its slanted/postlogic narratives mental-disposition at childhood 'gets lost' socially at adulthood to many a supplanting-conviction-as-to-profound-supererogation - of-'attendantintradimensional'-postconverging/dialectical-thinking -apriorising-psychologism mind just getting acquainted but this is basically the same hollow-formulaic structure. This social loss-ofawareness of the social ${ }^{103}$ universal-transparency ${ }^{104}$-〈transparency-of-totalising-entailing,-as-toentailing-<amplituding/formative-epistemicity $>$ totalising $\sim$ in-relative-ontological-

completeness $>$ as being of postlogism mere-formulaic slanting compulsingnonconviction/madeupness/bottomlining-〈'<decontextualising/de-existentialising ofattendant-intradimensional-apriorising/axiomatising/referencing>-induced-disontologising'-ofthe-'attendant-intradimensional-ontologising'-imbued-

$<$ contextualising/existentialising attendant-ontological-contiguity $>$;-in-shallowsupererogation -<as-to-disontologising-perverted-outcome-sought-precedes-existentiallyveridical-'attendant-intradimensional-apriorising/axiomatising/referencing'-logical-dueness $>$ ) further elicits a 'sense of temporality ${ }^{9}$ as of ignorance/affordability/opportunism/exacerbation/social-chainism-or-social-discomfiture-ornegative-social-aggregation/temporal-enculturation-or-temporal-endemisation in many an acquainted or non-acquainted (ignorance) supplanting-conviction-as-to-profoundsupererogation _of-'attendant-intradimensional'-postconverging/dialectical-thinking apriorising-psychologism minds to the psychopathic postlogism 77 mere-formulaic slanting compulsing-nonconviction/madeupness/bottomlining-〈' $<$ decontextualising/deexistentialising $\sim$ of-attendant-intradimensional-apriorising/axiomatising/referencing $>$-induced- 
disontologising'-of-the-'attendant-intradimensional-ontologising'-imbued-

$<$ contextualising/existentialising attendant-ontological-contiguity $>$;-in-shallow-

supererogation -<as-to-disontologising-perverted-outcome-sought-precedes-existentially-

veridical-'attendant-intradimensional-apriorising/axiomatising/referencing'-logical-dueness $>$ >

of preconverging-or-dementing -apriorising-psychologism narratives as if it was truly of supplanting-conviction-as-to-profound-supererogation —of-'attendant-intradimensional'postconverging/dialectical-thinking -apriorising-psychologism as to ontologically-veridical reality thus inducing the phenomenon of social-psychopathy threshold-ofnonconviction/madeupness/bottomlining-in-shallow-supererogation $-<$ as-to- 'attendantintradimensional'-prospectively-disontologising preconverging/dementing -apriorisingpsychologism $>$. Thus, a non-ignorant temporal pedestal mindset $/{ }^{/ 3}$ reference-of-thought whether affordability/opportunism/exacerbation/social-chainism-or-social-discomfiture-or-negativesocial-aggregation/temporal-enculturation-or-temporal-endemisation may find it in their temporal-self-interest to cynically elevate the psychopath's postlogism -as-of- compulsingnonconviction/madeupness/bottomlining-〈‘ $<$ decontextualising/de-existentialising $\sim$ ofattendant-intradimensional-apriorising/axiomatising/referencing $>$-induced-disontologising'-ofthe-'attendant-intradimensional-ontologising'-imbued$<$ contextualising/existentialising attendant-ontological-contiguity $>$;-in-shallowsupererogation -<as-to-disontologising-perverted-outcome-sought-precedes-existentiallyveridical-'attendant-intradimensional-apriorising/axiomatising/referencing'-logical-dueness $>$ > or slantedness/threshold-of-nonconviction/madeupness/bottomlining-in-shallowsupererogation -<as-to- 'attendant-intradimensional'-prospectivelydisontologising preconverging/dementing -apriorising-psychologism>-or-mimicking-orsubknowledging ${ }^{24}$, when this is not socially ${ }^{103}$ universally transparent (at uninstitutionalisedthreshold ${ }^{02}$ ). Further, the element of the need to be socially-functional-and-accordant ${ }^{93}$ first, 
implies that psychopathy is 'more than just the drive of a pathological individual' but inevitably psychopathy and correspondingly social psychopathy involves a 'social split-dynamism' wherein the 'unordinary eliciting' of temporal interest among some as extrinsic-attribution (praising, endearing, owing a favour, gifting, assisting, being friendly towards, etc.) is the basis for the targeting of another or others, further compounded by the fact that while so-called 'rules of sound logic' abstractly permeate more or less effectively most of our formal setups, their sociological pertinence is actually far from established, but for the fact that broad and large general education diminishes social egregiousness in this respect, as specifically 'reasoning by significant others' is actually the more common mental-disposition in the extended-informality〈susceptible-to-effecting-parsimony-as-of-shoddiness-and-incompleteness-to-

meaningfulness-and-teleology $\rangle$ including the 'informal spaces' of formal setups, with the result that this is a further factor that makes psychopathy poorly graspable as simply of individual denaturing dynamics rather than of social denaturing dynamics, thus better construed phenomenally as social psychopathy; as logic will often tend to be 'rationalised in social rather than abstract terms' depending on level of individuals intuition about the underlying dynamism of the postlogism -as-of- compulsing-nonconviction/madeupness/bottomlining-

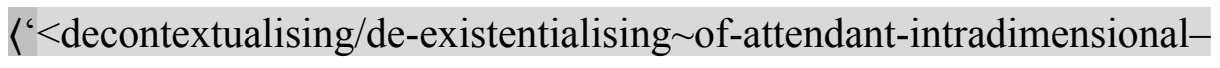
apriorising/axiomatising/referencing >-induced-disontologising'-of-the-'attendantintradimensional-ontologising'-imbued-<contextualising/existentialising $\sim$ attendantontological-contiguity $>$;-in-shallow-supererogation -<as-to-disontologising-pervertedoutcome-sought-precedes-existentially-veridical-'attendant-intradimensionalapriorising/axiomatising/referencing'-logical-dueness $>$ ) mental-disposition (going by experience), and then their sense of abstraction or gullibility or disposition to bandwagon effect with respect to a critical aetiologisation/ontological-escalation- $<$ ontologicalveridicality_commitment/otherliness_transcending/compulsions-encumbered_transcending>. 
(The implication here is that, for instance, it will be very naïve for an investigation involving a psychopath without the investigators being extra-cautious with respect to the underlying social aggregation linkage of potential interlocutors). Hence, the above phenomenon is further compounded in increasing profoundness (i.e. where the psychopath's childhood delirium gives way to an adulthood mental articulation which is diffused/with-hardly-any-social ${ }^{103}$ universaltransparency ${ }^{104}-\langle$ transparency-of-totalising-entailing,-as-to-entailing-<amplituding/formativeepistemicity>totalising in-relative-ontological-completeness $\quad$-but-rather-select-transparencyto-some about the nature of the psychopath's veridical mental state) when the 'temporal prelogism ${ }^{78}$-as-of-conviction,-in-profound-supererogation $-<$ existentially-veridical'attendant-intradimensional-apriorising/axiomatising/referencing'-logical-dueness-precedesdisontologising-logical-outcome-arrived-at $>$ interlocutor', by the mechanism of 'induced-ringof-gyges-effect/solipsistic-point-of-temporal-thresholding/point-of-ontological-faith-notion-orontological-fideism - imbued-underdetermination-of-motif-andapriorising/axiomatising/referencing-as-so-being-as-of-existential-reality' at the point of lack of social ${ }^{103}$ universal-transparency ${ }^{10} 4$-〈transparency-of-totalising-entailing,-as-to-entailing$<$ amplituding/formative-epistemicity>totalising in-relative-ontological-completeness $>$ about the psychopathic postlogism $77 /$ slantedness compulsingnonconviction/madeupness/bottomlining-〈‘ $<$ decontextualising/de-existentialising $\sim$ ofattendant-intradimensional-apriorising/axiomatising/referencing>-induced-disontologising'-ofthe-'attendant-intradimensional-ontologising'-imbued$<$ contextualising/existentialising attendant-ontological-contiguity $>$;-in-shallowsupererogation -<as-to-disontologising-perverted-outcome-sought-precedes-existentiallyveridical-'attendant-intradimensional-apriorising/axiomatising/referencing'-logical-dueness $>$ > in hollow-constituting-<as-disjointed-misappropriation-of-meaningfulness-and-failingintemporal-preservation> (and wherein there is no ${ }^{103}$ universal-transparency ${ }^{104}-\langle$ transparency- 
of-totalising-entailing,-as-to-entailing-<amplituding/formative-epistemicity $>$ totalising $\sim$ in-

relative-ontological-completeness $\rangle$ about notional firstnaturedness-formativeness-<as-toeventualising inkling drive or seeding misprising $>$ temporal-to-intemporal-dispositions$<$ so-construed-as-from-perspective-ontological-normalcy/postconvergence $>$ disambiguation/unequivalences/alienative-hierarchisation), becomes 'affordable' (as it doesn't think it has got anything to lose personally), 'negatively opportunistic' (as it occasionally finds a temporal-self-interest in backing the psychopath, even though it knows better), 'negatively exacerbatory' (as it gains some insight in the psychopath's mental process and actually strives to copy it adhocly, as a successful way of going about one's temporal-self-interest). There is equally a social dynamism aspect wherein the issue of 'social allegiance, affordability and initial prelogism ${ }^{78}$-as-of-conviction,-in-profound-supererogation $-<$ existentially-veridical-

\section{‘attendant-intradimensional-apriorising/axiomatising/referencing'-logical-dueness-precedes-}

disontologising-logical-outcome-arrived-at> alignment to psychopath-and/or-the-protractedpostlogism ${ }^{77}$ comes to override the issue of 'intrinsic rightness' leading to what is known as 'social-chainism or negative-social-aggregation or social-discomfiture' which in turn (because individuals find 'apparent social success and conventioning/social-temporal-thresholding' in such social behaviour) leads to the 'temporal endemisation/enculturation of social psychopathy'. The underlying mental-disposition of the psychopath as postlogic and the temporal prelogic/conviction-as-to-profound-supererogation ${ }^{9}$ minds pedestals that endemise/enculturate this process thus becoming conjugated-postlogism 7 , is known as 'extrinsic-attribution', i.e. the idea of satisfying an interlocutors sense of temporal interests is more important and critical in gaining their support than the notion of intrinsic truth/veridicality of meaning (intrinsicattribution) thus reflecting their threshold-of-nonconviction/madeupness/bottomlining-inshallow-supererogation -<as-to-'attendant-intradimensional'-prospectively-

disontologising preconverging/dementing -apriorising-psychologism>. Ontologically, this 
requires an altogether PURIST and UNCOMPROMISING intemporal/ontological conceptualisation of such a-comprehensive-social-temporal-hodgepodging which is rather ontologically-discontinuous. This author qualifies as procrypticism preconverging-ordementing -apriorising-psychologism, and so as 'ONTOLOGICAL-ENTRAPMENT' going by the 'human solipsistic/emanant template of institutionalisation/intemporalisation', given that reality and predication doesn't compromise with the 'mortal' that man is (more like the positivistic mind can't afford to compromise positivism to non-positivism/medievalism) exactly for the 'intemporal good-of-man'. At childhood the psychopath's mental process can fully be seen in operation as the slanted effect of its thinking produces a 'delirium effect'. However, as the psychopath matures it start adjusting to its failing/not-upholding-<as-ofapriorising/axiomatising/referencing $>$ slanted mental process as it faces the negating social reaction of its immediate family environment and the grander society with respect to its compulsive-slanting-preconverging-or-dementing -apriorising. But then in its child development psychology, this social negation is rather the backdrop by which it evolves (in a process of trial-and-error in hollow-constituting-<as-disjointed-misappropriation-ofmeaningfulness-and-failing-intemporal-preservation $>$ in postlogic-backtracking- $<$ iterativelooping-'set-of-dereifying-hollow-narratives-and-acts' $>$ ${ }^{6}$-absolving-or-fleeting-logic-reflexor-escaping-logic wherein 'disontologising-perverted-outcome-sought-precedes-existentiallyveridical-'attendant-intradimensional-apriorising/axiomatising/referencing'-logical-dueness, i.e. vague-rhyming-or-copied-mimicry-or-formulaic-projection-or-projection-of-form-orhollow-and-vague-vocalisation-or-subknowledging '4') from a 'direct and blatant faultymentation-procedure-deception-or-urge ${ }^{4}$ for postlogic slantedness' in a given social space during its childhood to a state in which the psychopath 'externalises, displaces and transfers its faulty-mentation-procedure-deception-or-urge ${ }^{43}$ for postlogic slantedness to attain an apparent normal social equilibrium or socially-functional-and-accordant ${ }^{93}$ state within any given social 
space as it develops into adulthood'. It is in this way that a mechanism for psychopathic and postlogic slantedness is relayed to apparently sound supplanting-conviction-as-to-profoundsupererogation —of-'attendant-intradimensional'-postconverging/dialectical-thinking apriorising-psychologism interlocutors, and so along five factors: - MATURATION (as childish slanted delirious non-veridical hollow mimicking narratives give way to increasingly adult and serious non-veridical hollow mimicking narratives which unsoundness-or-ontological-badfaith/inauthenticity ${ }^{64}$ of- reference-of-thought/slantedness become harder to perceive); INDIRECTNESS (as the psychopath makes its motive, i.e. the psychopathic faulty-mentationprocedure-deception-or-urge ${ }^{43}$, less direct and obvious, by increasingly appearing to bring up narratives in a neutral and unmotivated manner); - SPATIALISATION (as the psychopath learns to articulate narratives at different 'social spaces/locations' to prevent interlocutors from judging their non-veridical hollow mimicking narratives and comparing with the effective social reality context to establish whether the narratives are sound); - CREDULITY (as with development from childhood to adulthood psychopathy, its narratives increasingly mimic 'genuine supplanting-conviction-as-to-profound-supererogation —of-'attendant-intradimensional'postconverging/dialectical-thinking -apriorising-psychologism narratives' and at an even deeper level mimicking 'profound supplanting-conviction-as-to-profound-supererogation of-'attendant-intradimensional'-postconverging/dialectical-thinking -apriorising-

psychologism mindsets on issues' the psychopath has witnessed or has experienced insight of, and projecting these out of their social context to elicit the same effect) as well as readjusting its compulsive-slanting - preconverging-or-dementing -apriorising in a roaming/drifting-cycle as per evolving situation whether succeeding, being discovered and undermined, reassessing, backing down whether momentarily or not, bifurcating with the compulsive-slantingpreconverging-or-dementing 20 -apriorising, etc. oince it is evolving in an 'absolving or fleetinglogic-reflex-or-escaping-logic'. Further slanting is done at what it perceives to be the 'credulity- 
level-of-slanting' with respect to a given interlocutor which constantly evolves with psychopathic maturation. While the childhood psychopathy slanting is rather haphazard and by reflex, however the successive failing/not-upholding-<as-ofapriorising/axiomatising/referencing $>$ is an experiential basis that ultimately skews ('intemporality ${ }^{52}$-symmetrising-by-desymmetrising-subsumption-of-temporality ${ }^{\circ}$, for relative intrinsic-reality/ontological-veridicality transcendentalenabling/sublimating/supereregatery $\sim$ de-mentativity) it into more strategic postlogic slanting at adolescence and adulthood with more matured construction and themes. Thus implying a corresponding development from a low credulity effect at childhood to high credulity effect at adulthood with respect to interlocutors, in addition to the fact that at adulthood its postlogism slantedness is not socially- ${ }^{103}$ universally-transparency, that is, it now passes the intradimensional socially-betraying-threshold-of-ontologising-depth-of-analysis (or socially-betraying-thresholdof-intemporal-preservation-entropy-or-contiguity-or-ontological-preservation or threshold-ofnonconviction/madeupness/bottomlining-in-shallow-supererogation $<-<$ as-to- 'attendantintradimensional'-prospectively-disontologising preconverging/dementing -apriorisingpsychologism $>$ or 'uninstitutionalised-threshold ${ }^{102}$ ') of many an interlocutor; - CRAFTINESS (with increasingly greater crude-to-polished threshold-ofnonconviction/madeupness/bottomlining-in-shallow-supererogation $<$ as-to- 'attendantintradimensional'-prospectively-disontologising preconverging/dementing -apriorisingpsychologism>): Actually when it comes to social-and-confliction-stakes, the psychopath being postlogism 77 -as-of- compulsing-nonconviction/madeupness/bottomlining$\langle<<$ decontextualising/de-existentialising of-attendant-intradimensionalapriorising/axiomatising/referencing >-induced-disontologising'-of-the-'attendantintradimensional-ontologising'-imbued-<contextualising/existentialising $\sim$ attendantontological-contiguity $>$;-in-shallow-supererogation -<as-to-disontologising-perverted- 
outcome-sought-precedes-existentially-veridical-'attendant-intradimensional-

apriorising/axiomatising/referencing'-logical-dueness $>$ > construes meaningfulness as a hollowconstituting-<as-disjointed-misappropriation-of-meaningfulness-and-failing-intemporal-

preservation> construct driven as a threshold-of-nonconviction/madeupness/bottomlining-inshallow-supererogation -<as-to-'attendant-intradimensional'-prospectively-

disontologising preconverging/dementing -apriorising-psychologism> exercise (with respect to same-terms-of-expressions/seemingly-same-implied-meaningfulness with regards to ordinary meaning) as determining of others/conviction-as-to-profound-supererogation interlocutors behaviours and mental-dispositions; this is rather crude with the childhood-psychopath/cinglé such that it fails to elicit supplanting-conviction-as-to-profound-supererogation - of-

\section{'attendant-intradimensional'-postconverging/dialectical-thinking -apriorising-psychologism}

in others as the postlogic-effect is rather 'delirious' then (as in the case of wetting a chair) but the postlogism 77 at adulthood psychopathy becomes rather polished/less-crude in its effect 'with maturation/indirectness/spatialisation/credulity' to the point then of eliciting a prelogic/conviction-as-to-profound-supererogation mental-disposition as conjugatedpostlogism 7 preconverging-or-dementing ${ }^{20}$-integration (conjugated-ignorance, conjugatedaffordability, conjugated-opportunism, conjugated-exacerbation, conjugated-social-chainism and conjugated-temporal-enculturation) which is hollow-constituting-<as-disjointedmisappropriation-of-meaningfulness-and-failing-intemporal-preservation $>$ with respect to the meaningfulness of ${ }^{83}$ reference-of-thought- ${ }^{8}$ ategorical-imperatives/axioms/registry-teleology from the threshold-of-nonconviction/madeupness/bottomlining-in-shallow-supererogation <as-to-'attendant-intradimensional'-prospectivelydisontologising preconverging/dementing -apriorising-psychologism>. The psychopath perceives instances of rebuttal of its postlogism 77 not essentially in terms-as-of-axiomaticconstruct of the rightness or wrongness of the postlogic acts as a prelogic supplanting- 
conviction-as-to-profound-supererogation -of-'attendant-intradimensional'-

postconverging/dialectical-thinking -apriorising-psychologism mental-disposition will but rather in terms-as-of-axiomatic-construct of not delivering well and failing/not-upholding- $<$ asof-apriorising/axiomatising/referencing $>\quad$ in $\quad$ its compulsingnonconviction/madeupness/bottomlining-〈‘ $<$ decontextualising/de-existentialising $\sim$ ofattendant-intradimensional-apriorising/axiomatising/referencing $>$-induced-disontologising'-ofthe-'attendant-intradimensional-ontologising'-imbued$<$ contextualising/existentialising attendant-ontological-contiguity $>$;-in-shallowsupererogation -<as-to-disontologising-perverted-outcome-sought-precedes-existentiallyveridical-'attendant-intradimensional-apriorising/axiomatising/referencing'-logical-dueness $>$ > postlogic narratives with the idea of how to further confound/muddle hence the reason it is recursive (postlogic-backtracking-<iterative-looping-'set-of-dereifying-hollow-narratives-andacts'>76) as absolving/fleeting/escaping-reflex-logic to the point of faking remorsefulness or being a victim as long as fundamentally it "succeeds in placing its interlocutor in a prelogism ${ }^{78}$ as-of-conviction,-in-profound-supererogation -<existentially-veridical-'attendantintradimensional-apriorising/axiomatising/referencing'-logical-dueness-precedesdisontologising-logical-outcome-arrived-at> relation to its compulsingnonconviction/madeupness/bottomlining-〈‘ $<$ decontextualising/de-existentialising ofattendant-intradimensional-apriorising/axiomatising/referencing--induced-disontologising'-ofthe-'attendant-intradimensional-ontologising'-imbued$<$ contextualising/existentialising attendant-ontological-contiguity $>$;-in-shallowsupererogation -<as-to-disontologising-perverted-outcome-sought-precedes-existentiallyveridical-'attendant-intradimensional-apriorising/axiomatising/referencing'-logical-dueness $>$ > or postlogism mental-disposition' in order for the former to conjoin to its postlogicbacktracking-<iterative-looping-‘set-of-dereifying-hollow-narratives-and-acts’>76). So 
basically, as social-and-confliction-stakes develop from childhood to adulthood, likewise the psychopath's postlogic narratives exercise develop and become increasingly serious in its social consequences as the context of 'socially-perceived-value as of social-stake-contention-orconfliction' moves from family, neighbourhood, school, company, administration, business, criminality, etc. depending on the development of the specific psychopath. The fact, however, is that many of those who grow together with the psychopath (immediate family, close family friends and relatives, etc.) generally have some insight, however wobbly, into this mental process. Further, psychopathic phenomenon meets with varying impact levels as it's just a way of being/living for the psychopath, and differences in the setup of 'socially-perceived-value as of social-stake-contention-or-confliction' context and time might play a role in making its social consequences benign or aggravated. But then psychopathy and its social consequences, as a social phenomenon, is often wrongly perceived as exclusively due solely to an individual (the psychopath). This is rather an incomplete picture of things actually. The psychopath in a way can be said to suffer from a pathological dysfunction arising in the interaction of biology and the social environment. The psychopath has an urge or the inclination to take a faulty-mentationprocedure-deception to resolving 'socially-perceived-value as of social-stake-contention-orconfliction's. This is the reason why its narratives are of succeeding changing/decentering/noncohering foci in order to wrongly imply the veridicality of the projected apriorising $-{ }^{8}$ referenceof-thought/apriorising-registry_elements which when wrongly acquiesced to is the foundation for its faulty-mentation-procedure-deception-or-urge ${ }^{43}$ as the succession of narratives are successive slants over one another, more like a non-cohering deception which is a deception as the basis for a succeeding deception as the basis for a further succeeding deception, and so on, explaining its peculiar absolving/fleeting/escaping-reflex-logic and the deliriousness/deliriouseffect/cinglé-effect). Paradoxically, this faulty-mentation-procedure-deception-or-urge ${ }^{13}$ points to the fact that the slanted child psychopathy mind has a 'developmental incompleteness (as it is 
so focussed on attaining its sought after outcome in advance that it construes of 'presupposing/presuming/premising in concurrence' as an independent mental activity that must not necessarily be derived-and-implied from 'implicited_attendant-ontologicalcontiguity $^{67}$; educed-

existentialising/contextualising/textualising_intelligibility/epistemicity/reflexivity-contiguity$<$ imbued-notional $\sim$ cogency $>,{ }^{\prime},-<$ reifying-or-elucidating-of-prospective-relative-ontologicalcompleteness -of- reference-of-thought- devolving-as-of-instantiative-context>, which is what validates $\quad{ }^{5}$ logical-processing-or-logical-implicitation-supposedly-apriorising-inconviction-as-to-profound-supererogation as a process reflecting existential-reality as of \{epistemic-totalising $3{ }^{3}$ psychologismic-subliminality-of-individuation—effusing/worlding imbued logical-dueness-or-scape-or-frame, profile-or-stature, presumptuousness-or-arrogation, assumptions, value-reference and teleology ${ }^{9}$ ), in the formation of a basic and normal supplanting-conviction-as-to-profound-supererogation of-'attendant-intradimensional'postconverging/dialectical-thinking -apriorising-psychologism of prelogism ${ }^{78}$-as-ofconviction,-in-profound-supererogation $-<$ existentially-veridical-'attendant-intradimensionalapriorising/axiomatising/referencing'-logical-dueness-precedes-disontologising-logicaloutcome-arrived-at $>$ mindset $/{ }^{83}$ reference-of-thought' inducing rather a postlogic ${ }^{11}$ compulsingnonconviction/madeupness/bottomlining-〈‘ $<$ decontextualising/de-existentialising $\sim$ ofattendant-intradimensional-apriorising/axiomatising/referencing $>$-induced-disontologising'-ofthe-'attendant-intradimensional-ontologising'-imbued$<$ contextualising/existentialising attendant-ontological-contiguity $>$;-in-shallowsupererogation -<as-to-disontologising-perverted-outcome-sought-precedes-existentiallyveridical-'attendant-intradimensional-apriorising/axiomatising/referencing'-logical-dueness $>$ > mindset $/{ }^{3}$ reference-of-thought as it relates to meaningfulness as a faulty-mentation-proceduredeception-or-urge relative to social-stake-contention-or-confliction' (explaining its 
absolving/fleeting/escaping-reflex-logic mental-disposition); rather than as of the 'requisite existentially-<disontologising/re-ontologising aporeticism $>$ veridical logical-dueness (of apriorising- ${ }^{83}$ reference-of-thought/apriorising-registry_elements) and logical-processingsoundness driven construct' associated with a prelogic supplanting-conviction-as-to-profoundsupererogation - of-'attendant-intradimensional'-postconverging/dialectical-thinking apriorising-psychologism mindset/ ${ }^{83}$ reference-of-thought. And this fundamental faultymentation-procedure-deception-or-urge ${ }^{-3}$ relative to social-stake-contention-or-confliction of its postlogic compulsing-nonconviction/madeupness/bottomlining-〈' $<$ decontextualising/deexistentialising $\sim$ of-attendant-intradimensional-apriorising/axiomatising/referencing $>$-induceddisontologising'-of-the-'attendant-intradimensional-ontologising'-imbued$<$ contextualising/existentialising attendant-ontological-contiguity $>$;-in-shallowsupererogation -<as-to-disontologising-perverted-outcome-sought-precedes-existentiallyveridical-'attendant-intradimensional-apriorising/axiomatising/referencing'-logical-dueness $>$ ) mindset $/{ }^{8}$ reference-of-thought then goes on to account for the developmental psychology of the psychopath from childhood to adulthood wherein it gains maturation/indirectness/spatialisation/credulity/craftiness in circumventing its postlogism failing/not-upholding-<as-of-apriorising/axiomatising/referencing $>$ experiences at childhood and early adolescence to achieve the registry-worldview's/dimension's- ${ }^{83}$ reference-of-thoughtfor-social-functioning-and-accordance at adulthood. The paradox being that the prelogic supplanting-conviction-as-to-profound-supererogation of-'attendant-intradimensional'postconverging/dialectical-thinking -apriorising-psychologism mindset/ ${ }^{3}$ reference-of-thought will project its own mental-disposition unwittingly upon the psychopath (in the case of adult psychopathy but not in the instance of childhood psychopathy where the latter's deliriousness/delirious-effect/cinglé-effect is often obvious due to lack of maturation/indirectness/spatialisation/credulity/craftiness to attain social-functioning-and- 
accordance-as-of-social-stake-contention-or-confliction), and paradoxically then wrongly validate the psychopath as prelogic supplanting-conviction-as-to-profound-supererogation

\section{of-'attendant-intradimensional'-postconverging/dialectical-thinking -apriorising-}

psychologism with respect to meaningfulness as of 'requisite existentially-<isontologising/reentelogising aporeticism $>$ veridical logical-dueness (of apriorising- ${ }^{83}$ reference-ofthought/apriorising-registry-elements) and logical-processing-soundness driven construct'. However, psychopathy tends to take a social dynamism all of its own which cannot only be explained by the nature of the psychopath who initiates it. The fact is, while supplantingconviction-as-to-profound-supererogation -of-'attendant-intradimensional'-

postconverging/dialectical-thinking -apriorising-psychologism, the rest of the human mentaldispositions include varying levels of temporality $/$ /shortness (when there is no social

universal-transparency ${ }^{104}$-〈transparency-of-totalising-entailing,-as-to-entailing-

$<$ amplituding/formative-epistemicity>totalising in-relative-ontological-completeness $>$ of our acts at 'uninstitutionalised-threshold ${ }^{102}$ ' thus there is not 'intemporal social ${ }^{103}$ universaltransparency ${ }^{104}-\langle$ transparency-of-totalising-entailing,-as-to-entailing-<amplituding/formativeepistemicity>totalising in-relative-ontological-completeness > of notional firstnaturednessformativeness-<as-to-eventualising-inkling-drive-or-seeding-misprising $>$ temporal-tointemporal-dispositions-<so-construed-as-from-perspective-ontologicalnormalcy/postconvergence $>$ disambiguation/unequivalences/alienative-hierarchisation,' thus creating an 'induced-ring-of-gyges-effect/solipsistic-point-of-temporal-thresholding/point-ofontological-faith-notion-or-ontological-fideism - imbued-underdetermination-of-motif-andapriorising/axiomatising/referencing-as-so-being-as-of-existential-reality' derived from the psychopath's initiated postlogism 7 in hollow-constituting-<as-disjointed-misappropriation-ofmeaningfulness-and-failing-intemporal-preservation $>$ ). That is, abstractly, with respect to 'socially-perceived-value as of social-stake-contention-or-confliction' humans do 
solipsistically/emanantly/becomingly suffer perpetually, at 'uninstitutionalised-threshold ${ }^{12}$, from the temporal-dispositions of slantedness (the psychopath), ignorance/affordability/opportunism/exacerbation/social-chainism-or-social-discomfiture-ornegative-social-aggregation/temporal-enculturation-or-temporal-endemisation. These poor solipsistic abstract temporal-dispositions that pervade the social context tend to be overcome with institutionalisation/intemporalisation and formalisations with corresponding internalisation of values or secondnaturing. However, at circumstances where the institutionalisation/intemporalisation threshold is surpassed or often made irrelevant like in the 'extended-informality-〈susceptible-to-effecting-parsimony-as-of-shoddiness-andincompleteness-to- meaningfulness-and-teleology '〉', then a 'induced-ring-of-gygeseffect/solipsistic-point-of-temporal-thresholding/point-of-ontological-faith-notion-orontological-fideism - imbued-underdetermination-of-motif-andapriorising/axiomatising/referencing-as-so-being-as-of-existential-reality' will elicit the 'mediocrity/averageness of mind'. This is strongly the case with psychopathy which when 'successful' (and not perceived deliriously but rather wrongly integrated prelogicly/inconviction-as-to-profound-supererogation ) will often perfectly elicit an 'induced-ring-ofgyges-effect/solipsistic-point-of-temporal-thresholding/point-of-ontological-faith-notion-orontological-fideism - imbued-underdetermination-of-motif-andapriorising/axiomatising/referencing-as-so-being-as-of-existential-reality dynamism' in the social-construct such that others will find it to their temporal self-interest to perpetuate, whether circumstantially or profoundly, the phenomenon of psychopathy in society, so long as they can rationalise their dispositions and acts. This as 'social psychopathy' as a result of the psychopath's initiated postlogism in hollow-constituting-<as-disjointed-misappropriation-ofmeaningfulness-and-failing-intemporal-preservation> (involving protracted/derived slantedness), in the absence of social ${ }^{103}$ universal-transparency ${ }^{104}$-〈transparency-of-totalising- 
entailing,-as-to-entailing-<amplituding/formative-epistemicity $>$ totalising $\sim$ in-relative-

ontological-completeness $>$ on the veridicality of narratives with respect to social-andconfliction-stakes tends to induce ${ }^{50}$ ignorance/affordability/opportunism/exacerbation/socialchainism-or-social-discomfiture-or-negative-social-aggregation/temporal-enculturation-ortemporal-endemisation (at the point of such lack of social ${ }^{103}$ universal-transparency ${ }^{104}$ $\langle$ transparency-of-totalising-entailing,-as-to-entailing-<amplituding/formative-

epistemicity $>$ totalising in-relative-ontological-completeness $\rangle$ of its postlogism ${ }^{77}$-slantedness to many a supplanting-conviction-as-to-profound-supererogation - of-'attendantintradimensional'-postconverging/dialectical-thinking -apriorising-psychologism interlocutor as the 'uninstitutionalised-threshold ${ }^{102}$ '). Hence psychopathy when studied dynamically is rather 'social psychopathy'. Psychopathy through this social dynamism effect equally influences social behaviour as at 'uninstitutionalised-threshold ${ }^{02}$ ' human learned behaviour is primarily geared towards what is "perceived as succeeding or conventioning/social-temporal-thresholding rather than ontological rightness for rightness sake', whether intemporal (the-Good as longness-ofregister-of- ${ }^{5}$ meaningfulness-and-teleology ${ }^{9}$ ) or temporal (shortness-of-register-ofmeaningfulness-and-teleology ${ }^{9}$ ), hence its relation to sociopathy which is a more generalised notion of social vices-and-impediments ${ }^{105}$. The social psychopathy phenomenon (in describing the underlying abstract nature of man before institutionalisation/intemporalisation; institutionalisation/intemporalisation being the exercise of utilising the intemporal-disposition by its purist and ${ }^{103}$ universal projection rules in an 'ontological-entrapment' exercise to undermine/override temporal-dispositions subknowledging $/$ mimicking, by virtue of its $<$ amplituding/formative-epistemicity $>$ causality $~ a s-$ to-projective-totalitative-implications-ofprospective- nonpresencing,-for-explicating relative-unreflexivity/relative-reflexivity

ontological-contiguity and overall medium to long term good to the cross-section of human temporal interests) is equally associated with the notion of the stages of human transcendence- 
and-sublimity/sublimation/supererogatory-de-mentativity/civilisation, in an intemporalpreservation-entropy-or-contiguity-or-ontological-preservation exercise, from a recurrentutter-institutionalised animal through subsequent stages of institutionalisation/intemporalisation (as intemporal-preservation-entropy-or-contiguity-or-ontological-preservation exercise, 'as against the temporal human disposition to subknowledge-〈preconverging-or-dementing -as-ifof-sound-knowledge)/pervert intemporal categorical-imperatives) starting with baseinstitutionalisation (initial sense of social rules/organisation), ${ }^{103}$ universalisation, positivism and prospectively the future institutionalisation/intemporalisation this author qualifies as notional deprocrypticism (preempting procrypticism, so construed by 'notional ${ }^{8}$ deprocrypticism ontologically-perspectival-elevated/pedestaling-aspostconverging-or-dialectical-thinking ${ }^{2}$-differentiation-as-of-supratransversality-<insublimating-existential-eventuating/denouement $>\sim$ of-motif-andapriorising/axiomatising/referencing'). That is, psychopathy as postlogism 77 is associated with temporal-dispositions in their " perversion-of- reference-of-thought-<as-preconverginglyapriorising/axiomatising/referencing-in-nonconviction/madeupness/bottomlining-as-toshallow-supererogation $>$ (as prior intemporal ${ }^{83}$ reference-of-thought- categoricalimperatives/axioms/registry-teleology ${ }^{9}$ ) of the various institutionalisation/intemporalisation levels (vague-rhyming-or-copied-mimicry-or-formulaic-projection-or-projection-of-form-orhollow-and-vague-vocalisation-or-subknowledging ${ }^{4}$ of the ${ }^{83}$ reference-of-thoughtcategorical-imperatives/axioms/registry-teleology ${ }^{9}$ behind a registry-worldview's/dimension's institutionalisation/intemporalisation level that then warrants a subsequent 'intemporalpreservation-entropy-or-contiguity-or-ontological-preservation re-institutionalisation of prospective ${ }^{83}$ reference-of-thought- categorical-imperatives/axioms/registry-teleology ${ }^{9}$ ). To grasp this better say for instance the normal arithmetic we know $2+2=4,5+1=6,7-3=4$, etc. was to be undermine by a new human ${ }^{74}$ perversion-of- ${ }^{83}$ reference-of-thought- $<$ as-preconvergingly- 


\section{apriorising/axiomatising/referencing-in-nonconviction/madeupness/bottomlining-as-to-}

shallow-supererogation $>$ caused by a disease wherein we tend to say $2+2=5,5+1=7$ and $7-3=3$, then the traditional categorical-imperatives of addition and subtraction will be modified to take account of our perversion/defect by saying that additionality will involve subtracting 1 from the result and subtractivity will involve adding 1 to the result, so that arithmetic mirrors intrinsic reality outcome (intemporal transversality-<for-sublimating-existentialeventuating/denouement,-from-'thinking at-first/pure-predisposition-preemptive-ofprospective-disontologising/subontologising' as-of-prospectively-disambiguated-affirmedand-unaffirmed-'motif-and-apriorising/axiomatising/referencing'> ${ }^{101}$ as from ontologicalnormalcy/postconvergence). Thus $\quad$ reference-of-thought- ${ }^{8}$ categoricalimperatives/axioms/registry-teleology ${ }^{9}$ are 'inventions' that are as pertinent as the extent of their preservation of intemporal reality (intemporal-preservation-entropy-or-contiguity-orontological-preservation). Hence a false subknowledging $\% /$ mimicking-and-protractedmimicking with no relationship to intrinsic reality renders categoricalimperatives/registry/axioms-for-intemporal-preservation-entropy-or-contiguity-or-ontologicalpreservation null and void, calling for the overcoming of the slantedness/decandoring/distractive-alignment-to- ${ }^{3}$ reference-of-thought- $<$ of-

apriorising/axiomatising/referencing $>{ }^{30}$ of mental-devising-representation and the articulation of new ${ }^{83}$ reference-of-thought- categorical-imperatives/axioms/registry-teleology ${ }^{9}$,-forintemporal-preservation-entropy-or-contiguity-or-ontological-preservation reflecting intrinsic reality. These registry-worldview/dimension ${ }^{74}$ perversion-of- ${ }^{-}$reference-of-thought- $<$aspreconvergingly-apriorising/axiomatising/referencing-in-

nonconviction/madeupness/bottomlining-as-to-shallow-supererogation

include:

RECURRENT-UTTER-UNINSTITUTIONALISATION (base ${ }^{74}$ perversion-of- ${ }^{8}$ reference-ofthought- $<$ as-preconvergingly-apriorising/axiomatising/referencing-in- 
nonconviction/madeupness/bottomlining-as-to-shallow-supererogation , resolved/structurallyrendered-inoperant by BASE-INSTITUTIONALISATION registry-worldview categoricalimperatives/axioms-for-intemporal-preservation-entropy-as-of-ontological-normalcy), UNUNIVERSALISATION ( ${ }^{\text {perversion-of- }}{ }^{83}$ reference-of-thought- $<$ as-preconverginglyapriorising/axiomatising/referencing-in-nonconviction/madeupness/bottomlining-as-toshallow-supererogation $>$ of base-institutionalisation ${ }^{83}$ reference-of-thought- categoricalimperatives/axioms/registry-teleology,$\quad$ resolved/structurally-rendered-inoperant $\quad$ by

${ }^{3}$ UNIVERSALISATION registry-worldview categorical-imperatives/axioms-for-intemporalpreservation-entropy-as-of-ontological-normalcy), - NON-POSITIVISM/MEDIEVALISM ( 74 perversion-of- ${ }^{8}$ reference-of-thought- $<$ as-preconverginglyapriorising/axiomatising/referencing-in-nonconviction/madeupness/bottomlining-as-toshallow-supererogation $>$ of ${ }^{103}$ universalisation $\quad{ }^{83}$ reference-of-thought- categoricalimperatives/axioms/registry-teleology,$\quad$ resolved/structurally-rendered-inoperant by POSITIVISM registry-worldview categorical-imperatives/axioms-for-intemporal-preservationentropy-as-of-ontological-normalcy), and prospectively, - ${ }^{8}$ procrypticism-or-disjointednessas-of- ${ }^{83}$ reference-of-thought (slanted $\quad{ }^{74}$ perversion-of- ${ }^{83}$ reference-of-thought- $<$ aspreconvergingly-apriorising/axiomatising/referencing-innonconviction/madeupness/bottomlining-as-to-shallow-supererogation $>$ of positivism ${ }^{3}$ reference-of-thought- categorical-imperatives/axioms/registry-teleology ${ }^{9}$, resolved/structurally-rendered-inoperant prospectively by notional ${ }^{18}$ deprocrypticism registryworldview categorical-imperatives/axioms-for-intemporal-preservation-entropy-as-ofontological-normalcy). In-the-bigger-scheme-of-things such 'institutionalcumulation/institutional-recomposure-〈as-to- historiality/ontologicaleventfulness /ontological-aesthetic-tracing-<perspective-ontologicalnormalcy/postconvergence-reflected-'epistemicity-relativism-determinism' $>\rangle$ ' as articulated 
above gives coherence in conceptualising a continuity in the human emanant/becoming anthropological experience; as putting into perspective and not excepting any particular stage of institutionalisation/intemporalisation, as we might tend to do by focussing on the present positive registry-worldview which is just the backend in reflecting holographically-<conjugatively-andtransfusively $>$ the relative-unreflexivity/relative-reflexivity ontological-contiguity $\sim$ of-thehuman-institutionalisation-process, while ignoring the 'effective and causative intemporaldisposition behind the institutional-cumulation/institutional-recomposure-〈as-tohistoriality/ontological-eventfulness /ontological-aesthetic-tracing-<perspectiveontological-normalcy/postconvergence-reflected-‘epistemicity-relativism-determinism’>> transcendental/psychoanalytic-unshackling process', which skews ('intemporality ${ }^{52}$ symmetrising-by-desymmetrising-subsumption-of-temporality ${ }^{\circ}$, for relative intrinsicreality/ontological-veridicality transcendental-enabling/sublimating/supereregatory $\sim$ dementativity) the 'cross-section of human entropic being' in the medium to long run towards intemporal-disposition preservation while undermining temporal-dispositions. Such a depth-ofthought as projected by the 'institutionalisation intemporal-preservation-entropy-or-contiguityor-ontological-preservation' is what creates a 'sounder scientific foundation' for a '\{epistemictotalising 3 ' ${ }^{3}$ hermeneutic/textuality/reprojecting/supererogating/zeroing/re-acuting,-

\{delinearity for-cogency psychological science' termed 'anthropopsychology' or the 'anthropological continuity'. This can be comparatively compared to the hydrocarbon fractionation column wherein virtue is 'lightness'. We may be confused to think that being at a lighter state, a particular hydrocarbon fluid like kerosene is inherently the definition of virtue. But actually, the exceptionality (lightness) of kerosene is the result of the 'distilling process' which fractionates crude oil into kerosene. So if we start having issues of 'lightness' at the kerosene stage of the hydrocarbon fractionation column, what is called for is applying the 'distilling process' over kerosene to produce say petroleum gas. So inherently, all the 
hydrocarbon fluids are hydrocarbon, with virtue being the application of the distilling process. Thus reasoning from the overall perspective of the human species we can't afford not to pass 'so-called modern man' through the 'distilling process' (transcendence as psychoanalyticunshackling/memetic-reordering/institutional-recomposuring) as it is because every successive transcendental level 'did its homework' that we are in the positivistic world, and we can't confuse 'being at the backend of the institutional-cumulation/institutional-recomposure-〈as-tohistoriality/ontological-eventfulness /ontological-aesthetic-tracing-<perspectiveontological-normalcy/postconvergence-reflected-'epistemicity-relativism-determinism'>〉' with us being inherently exceptional (it is the transcendental/psychoanalytic-unshackling process of undermining perversion-of- ${ }^{8}$ reference-of-thought- $<$ as-preconverginglyapriorising/axiomatising/referencing-in-nonconviction/madeupness/bottomlining-as-toshallow-supererogation $>$ that is). Hence 'our homework' is to articulate our very own perversion-of- ${ }^{3}$ reference-of-thought-<as-preconverginglyapriorising/axiomatising/referencing-in-nonconviction/madeupness/bottomlining-as-toshallow-supererogation $>$ for the possibilities of the future, and not strive to arrive at a normalcy of 'our temporal-preservation-as-pseudointemporality ${ }^{52}$-preservation' which speaks of inherent relative-ontological-incompleteness ${ }^{8}$-induced,-'threshold-ofnonconviction/madeupness/bottomlining-in-shallow-supererogation $-<$ as-to-'attendantintradimensional'-prospectively-disontologising preconverging/dementing -apriorisingpsychologism>', $\quad$ as-it-is-thus- 'in-wait'-for- perversion-of- $^{-}$reference-of-thought- $<$aspreconvergingly-apriorising/axiomatising/referencing-innonconviction/madeupness/bottomlining-as-to-shallow-supererogation >,-or-temporalpreservation-as-pseudointemporality ${ }^{52}$-preservation, with respect to ontologicalnormalcy/postconvergence as we get at our 'uninstitutionalised-threshold ${ }^{102}$; ; instead enabling 'intemporal preservation' (by oblongating/decandoring/distractive-alignment-to- ${ }^{8}$ reference-of- 
thought- $<$ of-apriorising/axiomatising/referencing ${ }^{30}$ of our mental-devising-representation as a registry-worldview defect/perversion of positivistic categorical-imperatives/axioms known as procrypticism preconverging-or-dementing -apriorising-psychologism, for a prospective anticipation and preemption of this known as 'deprocrypticism')! It should be noted that while 'institutional-cumulation' and 'institutional-recomposure' are used interchangeably, however, the two terms carry two different connotative emphases necessary to make the conceptualisation complete. 'Institutional-cumulation' emphasises the contiguity of the process of human institutional transcendence-and-sublimity/sublimation/supererogatory de-mentativity (with respect to intemporal-preservation-entropy-or-contiguity-or-ontological-preservation) while institutional-recomposure stresses the peculiarity of the transcendence-andsublimity/sublimation/supererogatoryade-mentativity/memetic-reordering wherein, for instance with regards to positivist institutionalisation/intemporalisation, the constituent institutionalisation and ${ }^{103}$ universalisation for positivism are recomposured peculiarly towards the positivism registry-worldview/dimension, and memetically/meaningfully differently reordered from base-institutionalisation and ${ }^{103}$ universalisation, and so too, the constituent institutionalisation recomposured in ${ }^{103}$ universalisation is memetically/meaningfully differently reordered from base-institutionalisation, and prospectively, the constituent institutionalisation, universalisation and positivism recomposured into notional deprocrypticism will be memetically/meaningfully differently reordered from base-institutionalisation, universalisation and positivism. This speaks of snowballing/expansive recomposuring/memetic-reordering existential-<disontologising/re-ontologising aporeticism $>$ capacity depth with higher institutionalisations; a snowballing akin to the underlying evolutionary and genetic principles behind evolution from say amoebic cells across various other life-forms into a hominid like man, wherein the underlying basic principles go on to induce the complexity of man from simple amoebic cells. Institutional-recomposure also carries the idea 
that successive/prospective 'memetic-reordering' had tended to be based on the use of the outcome of prior memetic-reordering, and so focus mentation capacity on developing new memetic-reordering/recomposuring. This implies that mentation-capacity-wise, human mentation-capacity across all successive institutionalisations is the same but latter psychoanalytic-unshackling/memetic-reordering/institutional-recomposuring show 'grander institutionalisation/intemporalisation outcome' as this is due to their being at the backend of the emanant institutional-cumulation/institutional-recomposure-〈as-to- historiality/ontologicaleventfulness /ontological-aesthetic-tracing-<perspective-ontologicalnormalcy/postconvergence-reflected-‘epistemicity-relativism-determinism’>> preconverging/postconverging-de-mentating/structuring/paradigming implications, as utilising the postconverging-de-mentating/structuring/paradigming outcome of previous institutionalcumulation/institutional-recomposure-〈as-to- historiality/ontologicaleventfulness /ontological-aesthetic-tracing-<perspective-ontologicalnormalcy/postconvergence-reflected-‘epistemicity-relativism-determinism'>> effort. Hence dimensionality-of-sublimating ${ }^{25}-<<$ amplituding/formative $>$ supererogatory $\sim$ dementativeness/epistemic-growth-or-conflatedness /transvaluativerationalising/transepistemicity/anamnestic-residuality/spirit-drivenness-equalisation〉 instigation recurrently inducing the institutionalisation/intemporalisation process (which is not an analogical notion but a contiguous notion as to relative-unreflexivity/relative-reflexivity ontological-contiguity by its intemporal-preservation-entropy-or-contiguity-or-ontologicalpreservation across institutional-cumulation/institutional-recomposure-〈as-tohistoriality/ontological-eventfulness /ontological-aesthetic-tracing-<perspectiveontological-normalcy/postconvergence-reflected-‘epistemicity-relativism-determinism’>> rather so-reflecting notional-contiguity/epistemic-contiguity ${ }^{2}<$ profound-supererogation -ofmentally-aestheticised postconverging/dialectical-thinking -qualia-schema $>$ as to human 
limited-mentation-capacity-deepening —as-subjecting-limitedness/human-subpotency-to'educed-unlimitedness/existence-sublimating nascence' ${ }^{33}$ wherein existence's relativeunreflexivity/relative-reflexivity - ontological-contiguity ${ }^{77}$ construable as to ${ }^{6}$ nonpresencing<perspective-ontological-normalcy/postconvergence $>$ epistemic-projection is not of prospective apriorising/axiomatising/referencing-sublimating-reflexivity_-beholdening to human limited-mentation-capacity as-subjecting-'educed-unlimitedness/existencesublimating nascence' to-limitedness/human-subpotency at any given moment) applies universally across space and time (beyond any given registry-worldview's/dimension's institutional mirage/illusion-of-the-present/present-consciousness) such that ontologically speaking it is prospectively predicative of future institutionalisation/intemporalisation like deprocrypticism. This thus points to the fact that transcendental analysis (institutionalcumulation/institutional-recomposure-〈as-to- historiality/ontological-

\section{eventfulness /ontological-aesthetic-tracing-<perspective-ontological-}

normalcy/postconvergence-reflected-'epistemicity-relativism-determinism'>> analysis) is not, as may wrongly be thought, analogical but is rather an 'ontologically-contiguous meaningfulness-and-teleology reference' (given the contiguity in the 'precedingness/supersedingness/ascendency-and-continuity of intemporal-preservationentropy-or-contiguity-or-ontological-preservation referencing' across all cumulating/recomposuring institutionalisations); i.e. memetic contiguity as the underlying principle of memetic-reordering which is the 'contiguous dynamism for intemporalpreservation-entropy-or-contiguity-or-ontological-preservation in the continuous transdimensional/transcendental relation of intemporal and temporal-dispositions' at uninstitutionalised-threshold $^{102}$, and so, across all cumulating/recomposuring institutionalisations whether from a retrospective, present or prospective perspective. Psychoanalytic-unshackling/memetic-reordering/institutional-recomposuring process can then 
be defined as arising when a registry-worldview's/dimension's \{cumulated/recomposured\}consciousness-awareness-teleology ${ }^{9}$ is transcended/superseded as to human limited-mentationcapacity-deepening — as-subjecting limitedness/human-subpotency-to-'educedunlimitedness/existence-sublimating nascence' ${ }^{53}$, at its uninstitutionalised-threshold involving-organic-comprehension-thinking in contrast with threshold-ofnonconviction/madeupness/bottomlining-in-shallow-supererogation -<as-to-'attendantintradimensional'-prospectively-disontologising preconverging/dementing -apriorisingpsychologism $>$; in transversality- $<$ for-sublimating-existential-eventuating/denouement,-from'thinking at first/pure-predisposition-preemptive-of prospectivedisontologising/subontologising’ as-of-prospectively-disambiguated-affirmed-andunaffirmed-'motif-and-apriorising/axiomatising/referencing' $>101$ along three transversality$<$ for-sublimating-existential-eventuating/denouement,-from-'thinking at-first/purepredisposition-preemptive-of-prospective-disontologising/subontologising’ as-ofprospectively-disambiguated-affirmed-and-unaffirmed-'motif-andapriorising/axiomatising/referencing' $>101$ pedestals (postlogism 77 in hollow-constituting-<asdisjointed-misappropriation-of-meaningfulness-and-failing-intemporal-preservation> not/slantedness/compulsive-dementing /subknowledging -impulse whether-psychopathic-ortransversality-<for-sublimating-existential-eventuating/denouement-from-'thinking-atfirst/pure-predisposition-preemptive-of-prospective-disontologising/subontologising' as-ofprospectively-disambiguated-affirmed-and-unaffirmed-'motif-andapriorising/axiomatising/referencing' $>101$ pedestal, temporal-dispositions transversality- $<$ forsublimating-existential-eventuating/denouement,-from-'thinking at-first/pure-predispositionpreemptive of prospective disentologising/subentologising' as-of-prospectivelydisambiguated-affirmed-and-unaffirmed-'motif-and-apriorising/axiomatising/referencing'> pedestals, and the intemporal-disposition transversality-<for-sublimating-existential- 
eventuating/denouement-from 'thinking at-first/pure-predisposition-preemptive-of-

prospective-disontologising/subontologising' as-of-prospectively-disambiguated-affirmed-

and-unaffirmed-'motif-and-apriorising/axiomatising/referencing'> ${ }^{101}$ pedestal with intemporaldisposition

aetiologisation/ontological-escalation- $<$ ontological-

veridicality_commitment/otherliness_transcending/compulsions-encumbered_transcending $>$ )

enabling the ${ }^{15}$ de-mentation-〈supererogatory $\sim$ ontological-de-mentation-or-dialectical-de-

mentation - stranding-or-attributive-dialectics $\rangle$ not as postconverging-or-dialectical-thinking apriorising-psychologism-<stranded-as-rightfully-straight/candored-and-dialectically-or-

contendingly-in-phase > of threshold-of-nonconviction/madeupness/bottomlining-in-shallowsupererogation -<as-to-'attendant-intradimensional'-prospectively-

disontologising $\sim$ preconverging/dementing -apriorising-psychologism $>$ with the corresponding 'collapsing'/overriding and preconverging-or-dementing 20 -apriorising-psychologism$<$ stranded-as-rightfully-oblongated/decandored-and-dialectically-or-contendingly-out-ofphase $>$ of the prior registry-worldview/dimension 'mental-devising-representation' as preconverging-or-dementing ${ }^{20}$-apriorising-psychologism/decandored/dialectically-or-

contendingly-out-of-phase consciousness-awareness-teleology by the new registryworldview's/dimension's \{cumulated/recomposured\}-consciousness-awareness-teleology (and so deterministically and operantly without any discretion of appraisal which wrongly leads to postconverging-or-dialectical-thinking ${ }^{2}$-apriorising-psychologism- $<$ stranded-as-rightfullystraight/candored-and-dialectically-or-contendingly-in-phase $>$ mental-devising-representation) such as recurrent-utter-uninstitutionalisation 'preconverging-or-dementing ${ }^{20}$-apriorisingpsychologism mental-devising-representation' by base-institutionalisation, ununiversalisation 'preconverging-or-dementing -apriorising-psychologism mental-devising-representation' by ${ }^{3}$ universalisation, non-positivism/medievalism 'preconverging-or-dementing 20 -apriorisingpsychologism mental-devising-representation' by positivism, and prospectively, procrypticism 
'preconverging-or-dementing -apriorising-psychologism mental-devising-representation' by deprocrypticm. This brings up the notion that while candoring/straightness is the way meaning is represented within any registry-worldview/dimension institutionalised/intemporalisedthresholds-of-intemporal-preservation-entropy-or-contiguity-or-ontological-preservation, this is just a mental-devising-representation for implying intemporality ${ }^{52}$-of-thought without which meaningfulness is not functional in the registry-worldview's/dimension's \{cumulated/recomposured\}-consciousness-awareness-teleology 9 , but then at that same prior registry-worldview's/dimension's uninstitutionalised-threshold ${ }^{102}, \quad$ transcendence-andsublimity/sublimation/supererogatory de-mentativity into a prospective registryworldview's/dimension's \{cumulated/recomposured $\}$-consciousness-awareness-teleology put-into-question this candoring/straightness mental-devising-representation and the prior registry-worldview's/dimension's consciousness-awareness-teleology 99 is then represented as preconverging-or-dementing 20 -apriorising-psychologism/decandoring/oblongated. This process is known as collapsing/overriding the prior registry-worldview/dimension, and such perpetual representation in the mental-devising-representation of the registry-worldview/dimension as collapsed/overridden is known as stranding or ${ }^{15}$ de-mentation-〈supererogatory $\sim$ ontological-dementation-or-dialectical-de-mentation-stranding-or-attributive-dialectics $\rangle$. Stranding purely has to do between placeholder-setup/mental-devising-representation/mentation/consciousnessawareness-teleology 9 and ontological-veridicality/relative-unreflexivity/relative-reflexivity ontological-contiguity ${ }^{67}$ of ${ }^{83}$ eference-of-thought (from the ontologicalnormalcy/postconvergence epistemic-or-notional projective-perspective); with the ontologically-veridical/relative-unreflexivity/relative-reflexivity_ontological-contiguity mental-devising-representation stranded/represented as straight, and various shades of notionaldiscontiguity/epistemic-discontiguity ${ }^{3}<$ between - prior-shallow-supererogation -ofmentally-aestheticised preconverging/dementing -qualia-schema_and prospective-profound- 
supererogation -of-mentally-aestheticised postconverging/dialectical-thinking -qualia-

schema $>$-as-of-epistemic-decadence in hollow-constituting-<as-disjointed-misappropriation-ofmeaningfulness-and-failing-intemporal-preservation $>$ in postlogic-backtracking- $<$ iterativelooping-'set-of-dereifying-hollow-narratives-and-acts'> ${ }^{\prime}$, stranded as oblongated/decandored in reflection/perspectivation of their veridical ${ }^{7}$ perversion-of- ${ }^{8}$ reference-of-thought- $<$ aspreconvergingly-apriorising/axiomatising/referencing-in-

nonconviction/madeupness/bottomlining-as-to-shallow-supererogation $>$, beyond their $<$ amplituding/formative-epistemicity $>$ totalising $\sim$ self-referencing-syncretising/presentconsciousness/illusion-of-the-present. Hence we know of the following de-mentation〈supererogatory ontological-de-mentation-or-dialectical-de-mentation-stranding-or-

attributive-dialectics $\rangle$ as preconvergingly-de-mentated/structured/paradigmed registryworldviews/dimensions: recurrent-utter-uninstitutionalisation, ununiversalisation, nonpositivism/medievalism and prospectively ${ }^{80}$ procrypticism-or-disjointedness-as-of- ${ }^{8}$ referenceof-thought (our own prospective mental stranding); as these form the backdrop for the articulation of transcending anticipatory and preemptive ${ }^{83}$ reference-of-thought- categoricalimperatives/axioms/registry-teleology ${ }^{9}$,-for-intemporal-preservation-entropy-or-contiguityor-ontological-preservation of the prospective registry-worldview/dimension that are the resolution to the vices-and-impediments ${ }^{105}$ of the prior (uninstitutionalised-threshold ${ }^{102}$ ) registry-worldview/dimension, successively as base-institutionalisation, ${ }^{103}$ universalisation, positivism and prospectively, deprocrypticism. Each of such psychoanalyticunshackling/memetic-reordering/institutional-recomposuring (along the institutionalcumulation/institutional-recomposure-〈as-to- historiality/ontological-

eventfulness /ontological-aesthetic-tracing-<perspective-ontologicalnormalcy/postconvergence-reflected-‘epistemicity-relativism-determinism'>> process), have particular 'central recomposuring determinants' which the new registry-worldview is coming 
after, as follows: (i) for Base-Institutionalisation, it has to do with the requisite 'organising rules/principles' as a 'memetic ontological-entrapment' for superseding recurrent-utteruninstitutionalisation (as an inherently-'preconverging-or-dementing ${ }^{20}$-apriorisingpsychologism-or-subknowledging ${ }^{4}$-or- ${ }^{7}$ perversion-of- ${ }^{3}$ reference-of-thought- $<$ aspreconvergingly-apriorising/axiomatising/referencing-innonconviction/madeupness/bottomlining-as-to-shallow-supererogation >,-and-corresponding<amplituding/formative-epistemicity>totalising $\sim$ self-referencing-syncretising' relation to meaningfulness). (ii) for ${ }^{103}$ universalisation, it has to do with requisite 'projection rules/principles' as a 'memetic ontological-entrapment' for superseding ununiversalisation (as perversion-of- ${ }^{-3}$ reference-of-thought-<as-preconverginglyapriorising/axiomatising/referencing-in-nonconviction/madeupness/bottomlining-as-toshallow-supererogation $>$ of base-institutional meaningfulness). (iii) for Positivism, it has to do with the requisite 'empirical rules/principles' as a 'memetic ontological-entrapment' for superseding non-positivism/medievalism (as ${ }^{74}$ perversion-of- ${ }^{3}$ reference-of-thought- $<$ aspreconvergingly-apriorising/axiomatising/referencing-innonconviction/madeupness/bottomlining-as-to-shallow-supererogation $>$ of ${ }^{103}$ universalistic meaningfulness). (iv) for Rational-Realism (deprocrypticism), it prospectively has to do with 'notional firstnaturedness-formativeness-<as-to-eventualising-inkling-drive-or-seedingmisprising $>$ temporal-to-intemporal-dispositions- $<$ so-construed-as-from-perspectiveontological-normalcy/postconvergence $>\quad$ accountability/intemporality ${ }^{52}$-skewing ('intemporality ${ }^{52}$-symmetrising-by-desymmetrising-subsumption-of-temporality ${ }^{8}$ ', for relative intrinsic-reality/ontological-veridicality transcendental-

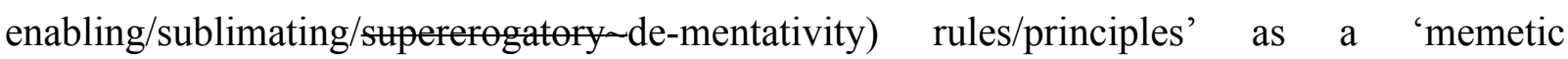
ontological-entrapment' for superseding procrypticism (as the ${ }^{7}$ perversion-of- ${ }^{8}$ reference-ofthought-<as-preconvergingly-apriorising/axiomatising/referencing-in- 
nonconviction/madeupness/bottomlining-as-to-shallow-supererogation $>$ of positivistic meaningfulness). Thus in-the-bigger-scheme-of-things, just as a contrastive dialectical insight (from our present vantage position of the positivism backend of the institutionalcumulation/institutional-recomposure-〈as-to- historiality/ontologicaleventfulness /ontological-aesthetic-tracing-<perspective-ontologicalnormalcy/postconvergence-reflected-‘epistemicity-relativism-determinism'>> process), will strongly highlight by ' ${ }^{5}$ de-mentation-〈supererogatory $\sim$ ontological-de-mentation-ordialectical-de-mentation - stranding-or-attributive-dialectics $\rangle$ of ${ }^{83}$ reference-of-thought', recurrent-utter-uninstitutionalisation, ununiversalisation and non-positivism/medievalism as non-ontological-reference/non-contending-reference-but-ontologically-or-contendinglyreflected-or-perspectivated as in ${ }^{7}$ perversion-of- ${ }^{3}$ reference-of-thought- $<$ as-preconverginglyapriorising/axiomatising/referencing-in-nonconviction/madeupness/bottomlining-as-to-

shallow-supererogation $>$ and-not-of-logical-contention, this shows ontologically speaking that it isn't out-of-the-stranding-template to prospectively imply (beyond our own illusion-of-thepresent/present-consciousness) such a prospective ${ }^{15}$ de-mentation-(supererogatory $\sim$ ontologicalde-mentation-or-dialectical-de-mentation-stranding-or-attributive-dialectics $\rangle$ of our perversion-of- ${ }^{3}$ reference-of-thought-<as-preconverginglyapriorising/axiomatising/referencing-in-nonconviction/madeupness/bottomlining-as-toshallow-supererogation $>$ as of the ${ }^{83}$ reference-of-thought- categoricalimperatives/axioms/registry-teleology ${ }^{9}$,-for-intemporal-preservation-entropy-or-contiguityor-ontological-preservation of our registry-worldview/dimension (positivistic meaningfulness) as ${ }^{80}$ procrypticism-or-disjointedness-as-of- ${ }^{-3}$ reference-of-thought. Noting as well that previous uninstitutionalised-threshold ${ }^{102}$ as to recurrent-utter-uninstitutionalisation, baseinstitutionalisation/ununiversalisation, $\quad{ }^{103}$ universalisation/non-positivism-or-medievalism equally had a sense of straightness/candor of their meaningfulness in a full blossoming of their 
own existentialism/full-existential-depth-implications of supposed postconverging-dementating/structuring/paradigming as we do in our positivistic/procrypticism registryworldview, within the ambits of their the-Good/knowledge-reification $\sim$ gesturing-andaccounting - of-epistemic-phenomenalism- $<$ in-

prospective_psychologismic apriorising/axiomatising/referencing-\{of-'prospectively_ implicited_attendant_ontological-contiguity ' educedexistentialising/contextualising/textualising_intelligibility/epistemicity/reflexivity_contiguity<imbued-notional cogency $\left.>^{\prime} \quad\right\}$-conflatedness -in-\{preconverging disentailment by\} postconverging entailment $>$ /understanding/<amplituding/formativeepistemicity $>$ causality $\sim$ as-to-projective-totalitative-implications-of-prospectivenonpresencing,-for-explicating relative-unreflexivity/relative-reflexivity - ontologicalcontiguity conceptualisation. But then their stranding from the prospective institutionalisation/intemporalisation represents them as preconverging-or-dementing ${ }^{2}$ apriorising-psychologism- $<$ stranded-as-rightfully-oblongated/decandored-and-dialectically-orcontendingly-out-of-phase $>$ as the transcendental backdrop/opportunity for the prospective registry-worldview/dimension. This when extrapolated will equally apply with our present positivism/procrypticism uninstitutionalisation/unintemporalisation for futural Beingdevelopment/ontological-framework-expansion-as-to-depth-of-ontologising-development-asinfrastructure-of- meaningfulness-and-teleology as of prospective notional 18 deprocrypticism institutionalisation/intemporalisation, and any 'complex' we'll have about that has to do with our illusion-of-the-present/present-consciousness/epistemictotalising $\sim$ self-referencing-syncretising/mirage than the ontological-veridicality/relativethreflexivitrelative reflexivity - ontological-contiguity ${ }^{67}$ of ${ }^{83}$ reference-of-thought (as from ontological-normalcy/postconvergence epistemic-or-notional projective-perspective). This equally explains why uninstitutionalised-threshold ${ }^{102}$ equally carried a complex about their 
registry-worldview/dimension and these complexes certainly sound unintelligible to us given our vantage perspective at the backend of the institutional-cumulation/institutionalrecomposure-〈as-to- historiality/ontological-eventfulness /ontological-aesthetic-tracing<perspective-ontological-normalcy/postconvergence-reflected-'epistemicity-relativismdeterminism'>> process. With rational-realism (deprocrypticism), institutionalisation/intemporalisation raises the issue of notional-discontiguity/epistemicdiscontiguity $^{63}-<$ between - prior-shallow-supererogation -of-mentallyaestheticised preconverging/dementing -qualia-schema_and_prospective-profoundsupererogation -of-mentally-aestheticised postconverging/dialectical-thinking -qualiaschema $>\quad$ (undisambiguation as notional firstnaturedness-formativeness- $<$ as toeventualising inkling-drive-or-seeding-misprising $>$ temporal-to-intemporal-dispositions$<$ so-construed-as-from-perspective-ontological-normalcy/postconvergence $>$ are wrongly given the same elevation), and relevantly so at the procrypticism-or-disjointedness-as-ofreference-of-thought uninstitutionalised-threshold ${ }^{12}$. The very specific nature of the deprocryptic transcendence-and-sublimity/sublimation/supererogatery $\sim$ dementativity/institutionalisation is to recognise and articulate the veridicality of the fact of humansubpotency-aporia/undecidability/dilemma/ought-

indeterminacy/deficiency/limitation/constraint—imbued-'notional firstnaturednessformativeness-<as-to-eventualising inkling-drive-or-seeding-misprising $>$ - temporal-tointemporal-dispositions-<so-construed-as-from-perspective-ontologicalnormalcy/postconvergence $>$ '-existentialism-form-factor at the procryptic uninstitutionalisedthreshold $^{102}$, and conjugate this in meaningfulness by going beyond just logical operation/processing/contention of narratives but rather in the first instance introducing the notion of 'notional firstnaturedness-formativeness-<as-to-eventualising-inkling-drive-orseeding-misprising $>$ temporal-to-intemporal-dispositions- $<$ so-construed-as-from- 
perspective-ontological-normalcy/postconvergence> disambiguation' to avoid wrongfully operating/processing of logic by the ${ }^{83}$ reference-of-thought of the intemporal-disposition reference-of-thought- categorical-imperatives/axioms/registry-teleology ${ }^{9}$,-for-intemporalpreservation-entropy-or-contiguity-or-ontological-preservation which is ontological (i.e. is in sync with intrinsic-reality/veridicality), where the effective registries are actually temporaldispositions thus to be construed as of their temporal ${ }^{83}$ references-of-thought. It involves ${ }^{15}$ dementation-_supererogatory $\sim$ ontological-de-mentation-or-dialectical-de-mentation - strandingor-attributive-dialectics $\rangle$ temporal-dispositions manifest denaturing ${ }^{16}$ and thus to avoid elevating temporal-dispositions to intemporal logical contending status as this result in the miscuing of meaning as of notional-discontiguity/epistemic-discontiguity ${ }^{63}<$ between - prior-shallowsupererogation -of-mentally-aestheticised preconverging/dementing -qualia-

schema_and_prospective-profound-supererogation -of-mentallyaestheticised postconverging/dialectical-thinking -qualia-schema>.

notional ${ }^{18}$ deprocrypticism institutionalisation/intemporalisation takes stock of the veridicality of human-subpotency-aporia/undecidability/dilemma/oughtindeterminacy/deficiency/limitation/constraint—imbued-'notional firstnaturednessformativeness-<as-to-eventualising-inkling drive-or-seeding misprising $>$ temporal-tointemporal-dispositions-<so-construed-as-from-perspective-ontologicalnormalcy/postconvergence $>$ '-existentialism-form-factor; as successive circular/recurrent/repetitive/repeatable iterating preconverging constructs, and not as may wrongly be reflected by the natural reflex to be postconverging constructs, to emphasise the 'dominance/supersedingness/suprastructuring of the intemporal-disposition skewing ('intemporality ${ }^{52}$-symmetrising-by-desymmetrising-subsumption-of-temporality ${ }^{8}$, for relative intrinsic-reality/ontological-veridicality transcendentalenabling/sublimating/supererogatory de-mentativity)' for the fulsome articulation of ontology 
as 'utter (postconvergence) ontological-veridicality/relative-unreflexivity/relative-reflexivity_ ontological-contiguity in conscious transdimensional/transcendental-memetic-depth (thinkingand-preconverging-or-dementing ${ }^{20}$-dialectical-dynamism-or-dialectics) of ontologicalnormalcy/postconvergence or prospective-transcendence-in-perpetually-upholding-intemporalpreservation-entropy-or-contiguity-or-ontological-preservation (unlike all prior institutionalisations which are rather intradimensional in their meaningful-depth construed only as a closed <amplituding/formative-epistemicity $>$ totalising $\sim$ self-referencingsyncretising/circularity/interiorising/akrasiatic-drag $34 \quad$ 'postconverging-or-dialecticalthinking -apriorising-psychologism dynamism'). As a corollary, meaningfulness or rather memetism or suprastructural-meaningfulness (the more veridical nature of meaningfulness beyond intradimensionality as being transdimensional/transcendental) should be notional and reflect this notional firstnaturedness-formativeness-<as-to-eventualising-inkling drive-or seeding misprising $>$ temporal-to-intemporal-dispositions-<so-construed-as-fromperspective-ontological-normalcy/postconvergence $>$ nature of notional ${ }^{18 \text { deprocrypticism }}$ institutionalisation/intemporalisation to the point of inducing a collective consciousness/social universal-transparency ${ }^{104}$-〈transparency-of-totalising-entailing,-as-to-entailing<amplituding/formative-epistemicity>totalising in-relative-ontological-completeness $>$ of 'knowledge-notionalisation' (knowledge as understanding not only of the ideal/intemporal but equally how the temporal/defective works distractively, to anticipate and preempt the latter perverseness but doing so rather in a superseding ontologically-minded manner) and intemporal skewing ('intemporality ${ }^{52}$-symmetrising-by-desymmetrising-subsumption-of-temporality ${ }^{8}$ ', for relative intrinsic-reality/ontological-veridicality transcendentalenabling/sublimating/supereregatory $\sim$ de-mentativity)/deferential-formalisation-transference as virtue and (postconvergence) ontological-veridicality/relative-unreflexivity/relativereflexivity - ontological-contiguity ${ }^{67}$ in contrast to the hotchpotching of notional- 
discontiguity/epistemic-discontiguity ${ }^{63}<$ between - prior-shallow-supererogation -ofmentally-aestheticised preconverging/dementing -qualia-schema_and_prospective-profoundsupererogation -of-mentally-aestheticised postconverging/dialectical-thinking -qualia-

schema $>$ of temporal-dispositions and particularly in the extended-informality-〈susceptible-toeffecting-parsimony-as-of-shoddiness-and-incompleteness-to- meaningfulness-and-

teleology $>$ which covers all informal spheres of institutions and society generally. So because knowledge-notionalisation recognises that in a specie of notional firstnaturednessformativeness-<as-to-eventualising-inkling-drive-or-seeding-misprising $>$ temporal-tointemporal-dispositions- $<$ so-construed-as-from-perspective-ontologicalnormalcy/postconvergence $>$ individuation dispositions, deferential-formalisation-transference which is the bases for institutionalisation/intemporalisation by skewing ('intemporality ${ }^{5}$ symmetrising-by-desymmetrising-subsumption-of-temporality ${ }^{\circ}$, for relative intrinsicreality/ontological-veridicality transcendental-enabling/sublimating/supererogatory $\sim$ dementativity) for the supersedingness/lead of the intemporal-disposition individuation is responsible for elevating human uninstitutionalised-threshold ${ }^{102}$ across the successive institutional-cumulation/institutional-recomposure-〈as-to- historiality/ontologicaleventfulness /ontological-aesthetic-tracing-<perspective-ontologicalnormalcy/postconvergence-reflected-'epistemicity-relativism-determinism' $>>$ by the resultant formalisation and internalisation involved in institutionalisation explaining effectively the dialectical evolution from deeper primitivites/mental-out-of-phasings to the present state (limited-and-shallower-human-mentation-capacity to limited-but-deeper-human-mentationcapacity) as a result of the inherent 'intemporal-prioritisation-of- ${ }^{8}$ reference-of-thought'-asconflatedness ${ }^{13}$-or-ontological-reprojecting skewing ('intemporality ${ }^{52}$-symmetrising-bydesymmetrising-subsumption-of-temporality ${ }^{8}$, , for relative intrinsic-reality/ontologicalveridicality transcendental-enabling/sublimating/supererogatory $\sim$ de-mentativity)/deferential- 
formalisation-transference for intemporalisation/institutionalisation, and the implications prospectively. For instance, the uninstitutionalised-threshold ${ }^{102}$ for getting one's way slyly will involve higher and higher thresholds with respect to virtue from a low threshold at recurrent-ofutter-uninstitutionalisation compared to base-institutionalisation-ununiversalisation, then higher and higher with ${ }^{103}$ universalisation-non-positivism-or-medievalism and our positivismprocrypticism, and prospectively highest with deprocrypticism; in line with the ontologicalnormalcy/postconvergence nature of ontological-veridicality. For instance, some hideous acts will hardly be seen as vices in a recurrent-utter-uninstitutionalised registry-worldview. Knowledge-notionalisation as such carries a transcendent-existentialism/in-full-existentialdepth-of-notional firstnaturedness-formativeness-<as-to-eventualising-inkling-drive-orseeding-misprising $>$ temporal-to-intemporal-dispositions- $<$ so-construed-as-fromperspective-ontological-normalcy/postconvergence>-implications which is more than just reactionary to the possibility of temporality $/$ shortness (shortness-of-register-ofmeaningfulness-and-teleology ${ }^{\circ}$ ) but rather a 'transcendent-existentialism maturing of thought' (intemporality $^{52}$ as longness-of-register-of- ${ }^{56}$ meaningfulness-and-teleology ${ }^{99}$ ) that takes abstract cognisance of temporality 8 /shortness as an intransient potency (hitherto accounting for the circularity/recurrence/repetition/repeatability ${ }^{10}$ of human circular-uninstitutionalisedthreshold ${ }^{02}$ ) to be conceptually understood and superseded recurrently and perpetually. Critically, this insight about the effective nature of ontological-normalcy/postconvergence (in its becoming in a conscious transdimensional/transcendental-meaningfulness or memetism or suprastructural-meaningfulness) as 'postconverging-or-dialectical-thinking ${ }^{21}$-apriorisingpsychologism - by - preconverging-or-dementing -apriorising-psychologism dialectics/dialectical-dynamism' indicates that while psychoanalytically prior registryworldviews/dimensions had hitherto been based on mental-devising-representations of 'thresholding meaningfulness constructs' (with their ${ }^{83}$ reference-of-thought- categorical- 
imperatives/axioms/registry-teleology ${ }^{9}$,-for-intemporal-preservation-entropy-or-contiguityor-ontological-preservation) within their 'functional institutionalised/intemporalisedthresholds-of-intemporal-preservation-entropy-or-contiguity-or-ontological-preservation', notional $\sim$ deprocrypticism going by ontological-normalcy/postconvergence implies a mentaldevising-representation of 'non-thresholding meaningfulness as transdimensional/transcendental-meaningfulness or memetic refinement (or a postconvergingor-dialectical-thinking ${ }^{2}$-apriorising-psychologism—by—preconverging-or-dementing ${ }^{20}$ apriorising-psychologism dialectics/dialectical-dynamism paradox) ontologicalnormalcy/postconvergence-or-postdicatory deconstruction/ontological-reconstituting-as-toconflatedness ${ }^{13}$ as dialectical transformation as-prospective ${ }^{8}$ reference-of-thought' in its 'functional institutionalised/intemporalised-approximating-or-proxying-of-intemporalpreservation-entropy-or-contiguity-or-ontological-preservation' as renewing existentialism/full-depth-of-existential-implications meaningfulness and thought; with such non-thresholding ontological-normalcy/postconvergence-or-postdicatory deconstruction/ontological-reconstituting-as-to-conflatedness ${ }^{13}$ as dialectical transformation, as-prospective ${ }^{8}$ reference-of-thought, approximating/proxying being of ontologicalnormalcy/postconvergence and suprastructural nature as the fulsome attainment of the institutionalisation/intemporalisation ideal (ontological-normalcy) culminating with deprocrypticism. The paradox of ontological-normalcy/postconvergence brought to bear with notional $\sim$ deprocrypticism will imply ontologically/intemporally that a registryworldview/dimension-and-as-of-all-successive-registry-worldviews/dimensions can be seen as being in 'preconverging-or-dementing ${ }^{20}$-apriorising-psychologism hollow-constituting-<asdisjointed-misappropriation-of-meaningfulness-and-failing-intemporal-preservation $>$ defect' in need of ontological-normalcy/postconvergence-or-postdicatory deconstruction/ontologicalreconstituting-as-to-conflatedness ${ }^{3}$ of the 'preconverging-or-dementing ${ }^{20}$-apriorising- 
psychologism hollow-constituting-<as-disjointed-misappropriation-of-meaningfulness-andfailing-intemporal-preservation> defect' in an existentialism/full-depth-of-existentialimplications articulation of temporal-dispositions threshold-ofnonconviction/madeupness/bottomlining-in-shallow-supererogation $<<$ as-to-'attendantintradimensional'-prospectively-disontologising preconverging/dementing -apriorisingpsychologism $>$ induced miscuing/disjointed-logic/logical-drag/unconscionability-drag/sub-paror-formulaic-association-or-temporal-or-alibi-conventioning-rationalising/temporalenculturation/temporal-endemisation over a 'wrong supplanting-conviction-as-to-profoundsupererogation - of-'attendant-intradimensional'-postconverging/dialectical-thinking apriorising-psychologism or non-misconstruing reflex' to meaningfulness in a transcendental/transdimensional analysis involving de-mentation〈supererogatory $\sim$ ontological-de-mentation-or-dialectical-de-mentation-stranding-orattributive-dialectics $\rangle$ of ${ }^{83}$ reference-of-thought' over an intradimensional $<$ amplituding/formative-epistemicity $>$ totalising $\sim$ self-referencingsyncretising/circularity/interiorising/akrasiatic-drag ${ }^{34}$ analysis. Insightfully, it implies theGood/knowledge-reification $\sim$ gesturing-and-accounting-of-epistemic-phenomenalism- $<$ inprospective_psychologismic apriorising/axiomatising/referencing-\{of-‘prospectively implicited_attendant-ontological-contiguity ' reducedexistentialising/contextualising/textualising_'intelligibility/epistemicity/reflexivity-contiguity<imbued-notional cogency >’ \}-conflatedness -in-\{preconverging-disentailment by\} postconverging-entailment $>/$ understanding/<amplituding/formativeepistemicity $>$ causality $\sim$ as-to-projective-totalitative-implications-of-prospectivenonpresencing,-for-explicating relative-unreflexivity/relative-reflexivity - ontologicalcontiguity illumination driven institutionalisation over an impression-driven/goodnaturedness/wishfulness conceptualisation as the-Good sticks by essence to intemporal- 
preservation-entropy-or-contiguity-or-ontological-preservation and reinvents ${ }^{83}$ reference-ofthought- ${ }^{\text {categorical-imperatives/axioms/registry-teleology }}{ }^{9}$,-for-intemporal-preservationentropy-or-contiguity-or-ontological-preservation for prospective/transcending/superseding registry-worldview to comply with intemporal-preservation-entropy-or-contiguity-orontological-preservation when the prior one fails, while the latter sticks by form to ${ }^{8}$ referenceof-thought- categorical-imperatives/axioms/registry-teleology ${ }^{9}$,-for-intemporal-preservationentropy-or-contiguity-or-ontological-preservation whether this fails intemporal-preservationentropy-or-contiguity-or-ontological-preservation or not. The conceptualisation of ${ }^{8}$ referenceof-thought- categorical-imperatives/axioms/registry-teleology 9 refers to the same deconstructed/ontological-reconstituting-as-to-conflatedness ${ }^{13}$ notion; axioms emphasises and hints of 'basis' and 'foundation' as well as 'fundamental validation' as of existential-reality, categorical-imperatives emphasises and hints of 'necessity', 'rigour', 'constraining' and 'enforcing', while registry-teleology (short for the apriorising-registry-elements as \{epistemicPychologismic-subliminality-of-individuation-effusing/worlding imbued logicaldueness-or-scape-or-frame, profile-or-stature, presumptuousness-or-arrogation, assumptions, value-reference and teleology ${ }^{9}$ ) emphasises the 'operant' aspect as of human situatedness existential-instantiation elements implied when producing ${ }^{5}$ meaningfulness-and-teleology ${ }^{9}$. The ${ }^{83}$ reference-of-thought is the fundamental-dispositional mentation architecture for human referencing or construing of ${ }^{5}$ meaningfulness-and-teleology ${ }^{9}$, and is capable of ontological-

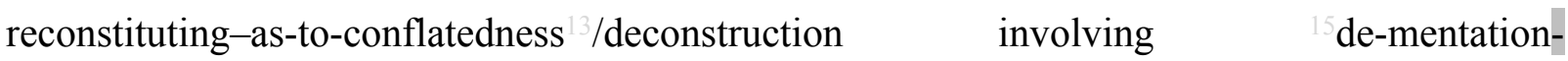
〈supererogatory ontological-de-mentation-or-dialectical-de-mentation-stranding-orattributive-dialectics) with corresponding de-mentation-〈supererogatory $\sim$ ontological-dementation-or-dialectical-de-mentation-stranding-or-attributive-dialectics $\rangle$ thermeneutically/textually/reprojectingly/supererogatingly/zeroingly/re-acutingly,${ }_{\{\text {decompulsing }}$ delinearity $\sim$ for-cogency-educing-human- ${ }^{56}$ meaningfulness-and-teleology ${ }^{9}$-into- 
the-existentialism-becoming of personhoods-and-socialhood-formation. This explains human transcendental capacity and sublimation as well as human ${ }^{77}$ perversion-of- ${ }^{83}$ reference-ofthought-<as-preconvergingly-apriorising/axiomatising/referencing-in-

nonconviction/madeupness/bottomlining-as-to-shallow-supererogation $>$ and desublimation. More precisely, $\quad{ }^{7}$ perversion-of- ${ }^{83}$ reference-of-thought- $<$ as-preconverginglyapriorising/axiomatising/referencing-in-nonconviction/madeupness/bottomlining-as-toshallow-supererogation $>$ as to preconverging-or-dementing -apriorising-psychologism mental-devising-representation implies registry-worldview's/dimension's-uninstitutionalisedthreshold ${ }^{12}$-defect-<as-Being-or-ontological-or-existential-defect $>$ '5, (reflecting 'defects threshold-of-nonconviction/madeupness/bottomlining-in-shallow-supererogation $\quad-<$ as-to‘attendant-intradimensional'-prospectively-disontologising preconverging/dementing apriorising-psychologism>') and this provides the social backdrop underlying the compulsive manifestation of a given registry-worldview's/dimension's postlogism 77 psychopathy in hollowconstituting-<as-disjointed-misappropriation-of-meaningfulness-and-failing-intemporalpreservation> wherein disontologising-perverted-outcome-sought-precedes-existentiallyveridical-'attendant-intradimensional-apriorising/axiomatising/referencing'-logical-dueness involving postlogic-backtracking-<iterative-looping-'set-of-dereifying-hollow-narratives-andacts'> in inducing a protracted social dynamics threshold of ignorance/affordability/opportunism/exacerbation/social-chainism-or-social-discomfiture-ornegative-social-aggregation/temporal-enculturation-or-temporal-endemisation, and soconstrued as from the prospective/transcending/superseding ${ }^{83}$ reference-of-thought. Fundamentally perversion-of- ${ }^{8}$ reference-of-thought- $<$ as-preconverginglyapriorising/axiomatising/referencing-in-nonconviction/madeupness/bottomlining-as-toshallow-supererogation $>$ has to do with the defect of the ${ }^{83}$ reference-of-thought and not the defect of ontological-veridicality/relative-unreflexivity/relative-reflexivity ontological- 
contiguity (which is rather a logical-process/implicitation-of-act-execution defect and which implies an 'implicitation-of-notion-of-agreement-or-disagreement'), as can be reflected as from ontological-normalcy/postconvergence. A ${ }^{8}$ reference-of-thought speaks of the fundamental appropriateness/soundness-or-ontological-good-faith/authenticity ${ }^{6}$-of- ${ }^{2}$ eference-of-thought of ${ }^{83}$ reference-of-thought- categorical-imperatives/axioms/registry-teleology ${ }^{99}$,-for-intemporalpreservation-entropy-or-contiguity-or-ontological-preservation irrespective of their appropriate or inappropriate ${ }^{5}$ logical-processing-or-logical-implicitation-supposedly-apriorising-inconviction-as-to-profound-supererogation with respect to relative-unreflexivity/relativereflexivity - ontological-contiguity ${ }^{67}$ ontological-veridicality, and implying sound ${ }^{83}$ referenceof-thought further emphasises appropriate incidental ${ }^{54}$ logical-processing-or-logicalimplicitation - supposedly-apriorising-in-conviction-as-to-profound-supererogation in producing the right outcome. Hence a registry-worldview/dimension defect is one of systematic defect of reference-of-thought; whether when recurrent-utter-uninstitutionalisation reference-of-thought as of non-rules_-apriorising/axiomatising/referencing-psychologism,as-impulsive-or-accidented-or-random-mental-disposition- $\langle$ as 'base

\section{apriorising/axiomatising/referencing-\{of-'prospectively_implicited_attendant-ontological-}

\section{contiguity ' educed-}

existentialising/contextualising/textualising_'intelligibility/epistemicity/reflexivity-contiguity<imbued-notional cogency $>$ ' $\quad\}$-constitutedness ${ }^{-}$-in-preconverging-entailment $\quad$ of reference-of-thought'

apriorising/axiomatising/referencing/intelligibilitysettingup/measuringinstrumenting $\quad$ is failing/not-upholding-<as-of-apriorising/axiomatising/referencing $>\quad$ rulemaking-over-nonrules_-apriorising/axiomatising/referencing-psychologism,-〈as 'first-level presencingabsolutising-identitive-constitutedness of reference-of-thought' 
for base-institutionalisation, ununiversalisation is failing/not-upholding-<as-ofapriorising/axiomatising/referencing $>\quad{ }^{103}$ universalisation-directed-rulemaking-over-nonrules_-apriorising/axiomatising/referencing-psychologism,-〈as 'second-level presencingabsolutising-identitive-constitutedness ${ }^{4}$ of reference-of-thought' apriorising/axiomatising/referencing/intelligibilitysettingup/measuringinstrumenting $\rangle$ required for ${ }^{103}$ universalisation, non-positivism/medievalism is failing/not-upholding-<as-ofapriorising/axiomatising/referencing > positivising/rational-empiricism-based-universalisationdirected-rulemaking-over-non-rules_ - apriorising/axiomatising/referencing-psychologism,$\left\langle\right.$ as $^{`}$ third-level presencing-absolutising-identitive-constitutedness ${ }^{14}$ of reference-ofthought' apriorising/axiomatising/referencing/intelligibilitysettingup/measuringinstrumenting) required for positivism or prospectively, positivism is failing/not-upholding-<as-ofapriorising/axiomatising/referencing $>\quad$ preempting_disjointedness-as-of- ${ }^{3}$ reference-ofthought,-as-to- ${ }^{6}<$ amplituding/formative-epistemicity $>$ growth-orconflatedness ${ }^{13}$ /transvaluative-rationalising/transepistemicity/anamnestic-residuality/spiritdrivenness'-in-superseding-mere-formulaic-positivising/rational-empiricism-baseduniversalisation-directed-rulemaking-over-non-rules—apriorising/axiomatising/referencingpsychologism required for deprocrypticism. Thus fundamentally preconverging-ordementing -apriorising-psychologism/unsoundness-or-ontological-bad-faith/inauthenticity ${ }^{64}$ of- ${ }^{8}$ reference-of-thought does not arise because of failure of ${ }^{54}$ logical-processing-or-logicalimplicitation - supposedly-apriorising-in-conviction-as-to-profound-supererogation but rather because of failure of ${ }^{83}$ reference-of-thought as of perversion-and-derived- perversion-ofreference-of-thought-<as-preconvergingly-apriorising/axiomatising/referencing-innonconviction/madeupness/bottomlining-as-to-shallow-supererogation $>$. This is unlike the case where logical-engagement of mental-devising-representation as 'postconverging-ordialectical-thinking -apriorising-psychologism'/soundness-or-ontological-good- 
faith/authenticity ${ }^{-}$of- ${ }^{3}$ reference-of-thought is still relevant where there is failing/notupholding-<as-of-apriorising/axiomatising/referencing $>$ logical-processing-or-logicalimplicitation-supposedly-apriorising-in-conviction-as-to-profound-supererogation (like calculating the answer of an arithmetic operation wrongly) so long as the ${ }^{83}$ reference-of-thought is sincerely/genuinely working in adherence to arithmetic axioms to produce the right answer. But this is invalid and not applicable where the issue is about deliberate disposition not to adhere to arithmetic axioms but usurp them (whether consciously, expediently or unconsciously). Soundness-or-ontological-good-faith/authenticity ${ }^{-o f}$ - reference-of-thought on-the-otherhand implies being-or-ontological-or-existential-or- ${ }^{5}$ meaningfulness-and-teleology disposition as of supplanting-conviction-as-to-profound-supererogation - of-'attendantintradimensional'-postconverging/dialectical-thinking -apriorising-psychologism (reflecting sound 54 logical-processing-or-logical-implicitation — supposedly-apriorising-in-conviction-asto-profound-supererogation and at worst defect-of- logical-processing-or-logicalimplicitation - supposedly-apriorising-in-conviction-as-to-profound-supererogation ) and so in effective prelogism ${ }^{78}$ wherein logical-process-precedes-outcome thus upholding intemporal/veracity/ontological-pertinence; so construed from a more profound ontologicalnormalcy/postconvergence insight. This is the fundamental basis and backdrop for an insight for drawing the implications of the (preceding and superseding) nature of intrinsic-reality as ontological-normalcy/postconvergence (prospective-transcendence-in-perpetually-upholdingintemporal-preservation-entropy-or-contiguity-or-ontological-preservation)', in reflecting/perspectivating/highlighting the 'mental-devising-representations of registries/references constructs and protractedly of registry-worldviews/dimensions (on the basis of the de-mentation-〈supererogatory $\sim$ ontological-de-mentation-or-dialectical-dementation - stranding-or-attributive-dialectics $)$ ) whether as of registry-soundness and thus as 'postconverging-or-dialectical-thinking -apriorising-psychologism representations' 
(postconverging-or-dialectical-thinking ${ }^{2}$-apriorising-psychologism- $<$ stranded-as-rightfullystraight/candored-and-dialectically-or-contendingly-in-phase $>$ ) or as of ${ }^{74}$ perversion-ofreference-of-thought-<as-preconvergingly-apriorising/axiomatising/referencing-innonconviction/madeupness/bottomlining-as-to-shallow-supererogation $>$ and thus as 'preconverging-or-dementing -apriorising-psychologism representations' (preconverging-ordementing 20 -apriorising-psychologism- $<$ stranded-as-rightfully-oblongated/decandored-anddialectically-or-contendingly-out-of-phase $>$ ), and $\quad$ so as ${ }^{15}$ de-mentation〈supererogatory $\sim$ ontological-de-mentation-or-dialectical-de-mentation-stranding-orattributive-dialectics $\rangle$

totalising ${ }^{3}{ }^{3}$ hermeneutically/textully/reprojectingly/supererogatingly/zeroing/y/re acutingly,$\{$ decompulsing $\}$ delinearity $\sim$ for-cogency-educing-human- ${ }^{56}$ meaningfulness-and-teleology ${ }^{9}$-intothe-existentialism-becoming of personhoods-and-socialhood-formation. Such dialectical articulation of mental-devising-representations can be conceptualised as defining individuations in terms-as-of-axiomatic-construct of supplanting-conviction-as-to-profoundsupererogation —of-'attendant-intradimensional'-postconverging/dialectical-thinking apriorising-psychologism (postconverging-or-dialectical-thinking -apriorising-psychologism$<$ stranded-as-rightfully-straight/candored-and-dialectically-or-contendingly-in-phase $>$ ) and threshold-of-nonconviction/madeupness/bottomlining-in-shallow-supererogation $-<$ as-to‘attendant-intradimensional'-prospectively-disontologising preconverging/dementing apriorising-psychologism> (preconverging-or-dementing ${ }^{20}$-apriorising-psychologism$<$ stranded-as-rightfully-oblongated/decandored-and-dialectically-or-contendingly-out-ofphase $>$ ). In so doing reflecting/perspectivating/highlighting the teleological-dispositions-oftemporal-individuations in their threshold-of-nonconviction/madeupness/bottomlining-inshallow-supererogation $<<$ as-to-'attendant-intradimensional'-prospectivelydisontologising preconverging/dementing -apriorising-psychologism> and supplanting- 
conviction-as-to-profound-supererogation —of-'attendant-intradimensional'postconverging/dialectical-thinking -apriorising-psychologism as <amplituding/formativeepistemicity $>$ causality $\sim$ as-to-projective-totalitative-implications-of-prospectivenonpresencing,-for-explicating relative-unreflexivity/relative-reflexivity - ontologicalcontiguity dispositional constructs; with threshold-ofnonconviction/madeupness/bottomlining-in-shallow-supererogation -<as-to-'attendantintradimensional'-prospectively-disontologising preconverging/dementing -apriorisingpsychologism $>$ individuations acting in 'circumventive/distractive-temporal-prioritisation-ofreference-of-thought threshold-of-nonconviction/madeupness/bottomlining-in-shallowsupererogation $-<$ as-to-'attendant-intradimensional'-prospectivelydisontologising preconverging/dementing -apriorising-psychologism>' protracting as prior/transcended/superseded registry-worldviews/dimensions (in hollow-constituting-<asdisjointed-misappropriation-of-meaningfulness-and-failing-intemporal-preservation> defectively/non-veridically of ${ }^{8}$ reference-of-thought- categorical-imperatives/axioms/registryteleology ${ }^{9}$,-for-intemporal-preservation-entropy-or-contiguity-or-ontological-preservation whether or not it fails intemporal-preservation-entropy-or-contiguity-or-ontologicalpreservation') with respect to supplanting-conviction-as-to-profound-supererogation —of'attendant-intradimensional'-postconverging/dialectical-thinking -apriorising-psychologism individuation acting in 'intemporal-prioritisation-of- ${ }^{3}$ reference-of-thought'-as-conflatedness ${ }^{13}$ or-ontological-reprojecting organic-comprehension-thinking protracting as prospective-oremancipating/transcending/superseding registry-worldviews/dimensions (ontologicalreconstituting-as-to-conflatedness ${ }^{13} /$ deconstruction of new ${ }^{83}$ reference-of-thought- categoricalimperatives/axioms/registry-teleology ${ }^{9}$,-for-intemporal-preservation-entropy-or-contiguityor-ontological-preservation for intemporal-preservation-entropy-or-contiguity-or-ontologicalpreservation). Such a preconverging-or-dementing ${ }^{20}$-apriorising-psychologism mental- 
devising-representations (threshold-of-nonconviction/madeupness/bottomlining-in-shallowsupererogation -<as-to-'attendant-intradimensional'-prospectivelydisontologising preconverging/dementing -apriorising-psychologism $>$ ) is utterly different from postconverging/dialectical-thinking -apriorising-psychologism mental-devisingrepresentations (supplanting-conviction-as-to-profound-supererogation - of-'attendantintradimensional'-postconverging/dialectical-thinking -apriorising-psychologism) either of sound 54 logical-processing-or-logical-implicitation — supposedly-apriorising-in-conviction-asto-profound-supererogation or defect-of- ${ }^{5}$ logical-processing-or-logical-implicitationsupposedly-apriorising-in-conviction-as-to-profound-supererogation, having to do with appropriate or inappropriate ${ }^{5}$ logical-processing-or-logical-implicitation-supposedlyapriorising-in-conviction-as-to-profound-supererogation . The postconverging/dialecticalthinking -apriorising-psychologism mental-devising-representations of either sound ${ }^{5}$ logicalprocessing-or-logical-implicitation-supposedly-apriorising-in-conviction-as-to-profoundsupererogation and defect-of- ${ }^{5}$ logical-processing-or-logical-implicitation-supposedlyapriorising-in-conviction-as-to-profound-supererogation with respect to subsequent acts 'ofsimilar-or-protracted-contextualisation' by their performers always harken back to a reflex of 'postconverging-or-dialectical-thinking ${ }^{2}$-apriorising-psychologism- $<$ stranded-as-rightfullystraight/candored-and-dialectically-or-contendingly-in-phase>' to imply the upholding of 'ontological-reference/contending-reference'; and so, for the simple reason that the state of being in supplanting-conviction-as-to-profound-supererogation of-'attendant-intradimensional'postconverging/dialectical-thinking -apriorising-psychologism (whether the act is defective or not) implies a 'mental-disposition' of the performer to be intemporal/ontological, and the defectof- logical-processing-or-logical-implicitation-supposedly-apriorising-in-conviction-as-toprofound-supererogation simply have to do with inappropriate ${ }^{54}$ logical-processing-or-logicalimplicitation - supposedly-apriorising-in-conviction-as-to-profound-supererogation , and not 
unsound-mental-disposition or ${ }^{7}$ perversion-of- ${ }^{3}$ reference-of-thought- $<$ as-preconverginglyapriorising/axiomatising/referencing-in-nonconviction/madeupness/bottomlining-as-to-

shallow-supererogation $>$ (which in this latter case will speak of a mental-disposition to act as of threshold-of-nonconviction/madeupness/bottomlining-in-shallow-supererogation $-<$ as-to‘attendant-intradimensional'-prospectively-disontologising preconverging/dementing

apriorising-psychologism> with regards to subsequent acts of similar context by their performers). Hence the postconverging/dialectical-thinking -apriorising-psychologism mentaldevising-representations of either sound ${ }^{5}$ logical-processing-or-logical-implicitationsupposedly-apriorising-in-conviction-as-to-profound-supererogation and defect-of- ${ }^{5}$ logicalprocessing-or-logical-implicitation-supposedly-apriorising-in-conviction-as-to-profoundsupererogation are 'projectively validated by reflex as possibly-of-postconverging-ordialectical-thinking -apriorising-psychologism/possibly-of-soundness-or-ontological-goodfaith/authenticity ${ }^{6}$ of- ${ }^{3}$ reference-of-thought (and not projectively invalidated by reflex as possibly-of-preconverging-or-dementing ${ }^{20}$-apriorising-psychologism/possibly-ofunsoundness-or-ontological-bad-faith/inauthenticity -of- ${ }^{64}$ eference-of-thought) in implying the 'upholding of their sound ${ }^{83}$ reference-of-thought status'. To illustrate, suppose $\mathrm{X}$ and $\mathrm{Y}$ are contending (ontological-reference) to know what $5+4$ will give as answer (ontologicalveridicality), if $\mathrm{X}$ is using pencils to count but inadvertently misplaced a pencil or doesn't perfectly understand how to stack up the pencils to use to count the whole lot, then where his answer was to come out as $5+4=8$, we talk of defect-of- logical-processing-or-logicalimplicitation-supposedly-apriorising-in-conviction-as-to-profound-supererogation as $\mathrm{X}$ sincerely wants to calculate to produce the right answer but X's ${ }^{54}$ logical-processing-or-logicalimplicitation - supposedly-apriorising-in-conviction-as-to-profound-supererogation failed. This doesn't invalidate the notion that $\mathrm{Y}$ can still engage $\mathrm{X}$ as 'possibly-of-postconverging-ordialectical-thinking -apriorising-psychologism'/possibly-of-soundness-or-ontological-good- 
faith/authenticity ${ }^{6}$-of- ${ }^{8}$ reference-of-thought in contending (appropriateness-of- ${ }^{3}$ reference-ofthought-as-of-conflatedness ${ }^{13}$ ) with respect to another arithmetic operation, that is, possibly after pointing out to $\mathrm{X}$ where they went wrong in their operation of arithmetic. While threshold-ofnonconviction/madeupness/bottomlining-in-shallow-supererogation $<<$ as-to-'attendantintradimensional'-prospectively-disontologising preconverging/dementing -apriorisingpsychologism $>$ performers subsequent acts of-similar-or-protracted-contextualisation to their prior acts verified to be of threshold-of-nonconviction/madeupness/bottomlining-in-shallowsupererogation -<as-to-'attendant-intradimensional'-prospectivelydisontologising $\sim$ preconverging/dementing -apriorising-psychologism $>$ are priorly projectively invalidated by reflex as 'possibly-of-preconverging-or-dementing ${ }^{20}$-apriorisingpsychologism'/possibly-of-unsoundness-or-ontological-bad-faith/inauthenticity -ofreference-of-thought and not 'possibly-of-postconverging-or-dialectical-thinking apriorising-psychologism'/possibly-of-soundness-or-ontological-good-faith/authenticity ${ }^{69}$-ofreference-of-thought in implying the 'revoking of their sound ${ }^{8}$ reference-of-thought status'. To illustrate, suppose $\mathrm{X}$ above rather slyly and deliberately (preconverging-or-dementing apriorising-psychologism mental-devising-representation) miscalculated (non-ontologicalreference/non-contending-reference) the answer (in notional-discontiguity/epistemicdiscontiguity ${ }^{6} 3$ - between - prior-shallow-supererogation -of-mentallyaestheticised preconverging/dementing -qualia-schema_and_prospective-profoundsupererogation -of-mentally-aestheticised postconverging/dialectical-thinking -qualiaschema $>$ ) and Y grasps this, then this invalidates the notion that Y can still 'genuinely' engage $\mathrm{X}$ (ontological-pertinence) with regards to another arithmetic operation of-similar-or-protractedcontextualisation, with respect to the upheld context behind X's sly and deliberate basis for miscalculating. The ${ }^{~}{ }^{15}$ de-mentation-〈supererogatory 0 ntological-de-mentation-or-dialecticalde-mentation - stranding-or-attributive-dialectics $\rangle$ of ${ }^{83}$ reference-of-thought' notion reflecting 
supererogation -<as-to-'attendant-intradimensional'-prospectively-

disontologising preconverging/dementing -apriorising-psychologism> acts 'of-similar-orprotracted-contextualisation' implies ontologicalnormalcy/postconvergence/postdication/ontological-normalcy/postconvergence deploying of ' ${ }^{6}$ de-mentation-/supererogatory $\sim$ ontological-de-mentation-or-dialectical-de-mentationstranding-or-attributive-dialectics $\rangle$ of ${ }^{83}$ reference-of-thought' in enabling full mastery/grasp of such 'convolutedness of social dynamics' as of personhoods-and-socialhood-formation with respect to existence-potency ${ }^{39} \sim$ sublimating-nascence,-disclosed-from-prospective-epistemicdigression—rules-of-apriorising/axiomatising/referencing-that-further-epistemicallyunconceal-the-very-ontologically-same-existential-reality, and so based on a 'deconstruction/ontological-reconstituting-as-to-conflatedness ${ }^{13}$ perpetuation of an fepistemicthermeneutic/textulity/reprojecting/supererogating/zeroing/re-acuting,\{decompulsing delinearity for-cogency circle as " ${ }^{5}$ de-mentation-〈supererogatory-ontological-dementation-or-dialectical-de-mentation-stranding-or-attributive-dialectics $\rangle$ of ${ }^{83}$ reference-ofthought analysis', which is technically non-thresholding/doesn't-technically-succumb-to-anysocially-betraying-threshold-of-ontologising-depth-of-analysis in its ontologicalnormalcy/postconvergence ontological-veridicality/relative-unreflexivity/relative-reflexivity ontological-contiguity ${ }^{67}$ proxying/approximating exercise; as when the socially-betrayingthreshold-of-ontologising-depth-of-analysis (which can equally be qualified as the 'sociallybetraying-threshold-of-intemporal-preservation-entropy-or-contiguity-or-ontologicalpreservation', given that 'ontologising-depth-of-analysis' can be construed as 'intemporalpreservation/intemporal-preservation-entropy-or-contiguity-or-ontological-preservation’ which is actually 'ontologically-reconstituting', reconstituting from the base-institutionalisationto-notional ${ }^{18}$ deprocrypticism registry-worldviews/dimensions) is attained the reflex is to imply 
a mental-devising-representation of 'soundness-or-ontological-good-faith/authenticity -ofreference-of-thought (preconverging-or-dementing ${ }^{20}$-apriorising-psychologism- $<$ stranded-asrightfully-oblongated/decandored-and-dialectically-or-contendingly-out-of-phase $>$ ) and thus establishing ${ }^{83}$ reference-of-thought whether that is veridically the case or not, such that preconverging-or-dementing ${ }^{20}$-apriorising-psychologism wrongly get endemised/enculturated as 'postconverging-or-dialectical-thinking ${ }^{21}$-apriorising-psychologism'/of-soundness-orontological-good-faith/authenticity -of- reference-of-thought mental-devising-representation at the socially-betraying-threshold-of-ontologising-depth-of-analysis and this with its consequent implications is the fundamental basis for the temporal-enculturation/temporalendemisation of all perversion-of- ${ }^{7}$ reference-of-thought-<as-preconverginglyapriorising/axiomatising/referencing-in-nonconviction/madeupness/bottomlining-as-toshallow-supererogation $>$ and the corresponding <amplituding/formativeepistemicity>totalising $\sim$ self-referencing-syncretising/illusion-of-the-present/presentconsciousness/mirage, explaining why we don't have notions of sorcery and its practice with us today but we do have the phenomenon of psychopathy and social psychopathy (with our sociallybetraying-threshold-of-ontologising-depth-of-analysis for the former/sorcery as a nonpositivism/medievalism perversion-of- ${ }^{8}$ reference-of-thought- $<$ as-preconverginglyapriorising/axiomatising/referencing-in-nonconviction/madeupness/bottomlining-as-toshallow-supererogation $>$ high enough or relatively-ontologically-complete as it is rationalempiricism/positivising-driven to supersede it but not the latter/psychopathy-and-socialpsychopathy as perversion-of- ${ }^{8}$ reference-of-thought-<as-preconvergingly-

\section{apriorising/axiomatising/referencing-in-nonconviction/madeupness/bottomlining-as-to-}

shallow-supererogation $>$ in our positivistic meaningful frame which is relatively ontologicallyincomplete for that as in need of the requisite notional ${ }^{8}$ deprocrypticism ${ }^{83}$ reference-of-thought as preempting-disjointedness-as-of- ${ }^{3}$ reference-of-thought,-as-to- ${ }^{\circ}$ 
epistemicity $>$ growth-or-conflatedness ${ }^{13} /$ transvaluative-

rationalising/transepistemicity/anamnestic-residuality/spirit-drivenness'_-in-supersedingmere-formulaic-positivising/rational-empiricism-based-universalisation-directed-rulemakingover-non-rules - apriorising/axiomatising/referencing-psychologism. In fact every registryworldview/dimension has its socially-betraying-threshold-of-ontologising-depth-of-analysis (and the idea of questioning beyond it is hardly entertained, whether beyond-the-consciousnessawareness-teleology 9 - $<$ of-preconverging-existential-extrication-as-of-existentialunthought $>$ ) which existentially-<disontologising/re-ontologising aporeticism $>$ explains the registry-worldview/dimension limits or relative-ontological-incompleteness ${ }^{8}$-induced,'threshold-of-nonconviction/madeupness/bottomlining-in-shallow-supererogation ${ }^{\circ}<$ as-to‘attendant-intradimensional'-prospectively-disontologising preconverging/dementing apriorising-psychologism> with respect to ontological-normalcy/postconvergence (prospective-transcendence-in-perpetually-upholding-intemporal-preservation-entropy-orcontiguity-or-ontological-preservation) in its specific grasp of (postconvergence) ontologicalveridicality/relative-unreflexivity/relative-reflexivity —ontological-contiguity ${ }^{67}$ on-the-onehand, and on-the-other-hand is the reason for the more profound/deeper socially-betrayingthreshold-of-ontologising-depth-of-analysis of the prospective/transcending/superseding registry-worldview/dimension which is rather in a 'suprastructural transcendentalmeaningfulness conceptualisation with respect to the prior/transcended/superseded registryworldview/dimension', as it is construed suprastructurally beyond the prior/transcended/superseded registry-worldview/dimension mental-devising-representation given the less veridical ${ }^{83}$ reference-of-thought- categorical-imperatives/axioms/registryteleology ,-for-intemporal-preservation-entropy-or-contiguity-or-ontological-preservation of its 'temporal conventioning compromise' determined by its shallower socially-betrayingthreshold-of-ontologising-depth-of-analysis. Thus we know basically that the successive 
institutional-cumulation/institutional-recomposure-〈as-to- historiality/ontological-

eventfulness /ontological-aesthetic-tracing-<perspective-ontological-

normalcy/postconvergence-reflected-‘epistemicity-relativism-determinism' $>>$ involved the following intradimensional socially-betraying-threshold-of-ontologising-depth-of-analysis with respect to their social-stake-contention-or-confliction specific to each registryworldview/dimension defining its 'inherent institutionalisation and snowballed recomposuring' going by human-subpotency-aporia/undecidability/dilemma/oughtindeterminacy/deficiency/limitation/constraint—imbued-'notional firstnaturednessformativeness-<as-to-eventualising inkling-drive-or-seeding-misprising $>$ temporal-tointemporal-dispositions-<so-construed-as-from-perspective-ontologicalnormalcy/postconvergence>'-existentialism-form-factor: for the mentation of recurrent-utteruninstitutionalisation basically 'trepidatious reasoning as non-rulesapriorising/axiomatising/referencing-psychologism,-as-impulsive-or-accidented-or-randommental-disposition- $\langle$ as 'base apriorising/axiomatising/referencing- of- 'prespectively implicited_attendant-ontological-contiguity ' educedexistentialising/contextualising/textualising_intelligibility/epistemicity/reflexivity-contiguity<imbued-notional cogency> $\left.{ }^{\prime} \quad\right\}$ - constitutedness ${ }^{1}$-in-preconverging-entailment of reference-of-thought'

apriorising/axiomatising/referencing/intelligibilitysettingup/measuringinstrumenting socially-betraying-threshold-of-ontologising-depth-of-analysis; for the mentation at baseinstitutionalisation-ununiversalisation basically 'non-universalising warped rulemaking-overnon-rules — apriorising/axiomatising/referencing-psychologism,-〈as 'first-level presencingabsolutising-identitive-constitutedness ${ }^{14}$ of reference-of-thought' apriorising/axiomatising/referencing/intelligibilitysettingup/measuringinstrumenting $\quad$ as socially-betraying-threshold-of-ontologising-depth-of-analysis; for the mentation at 
universalisation-non-positivism/medievalism basically ' ${ }^{103}$ universalising-idealisation preclusive rulemaking-over-non-rules — apriorising/axiomatising/referencing-psychologism,〈as 'second-level presencing-absolutising-identitive-constitutedness ${ }^{14}$ of reference-ofthought' apriorising/axiomatising/referencing/intelligibilitysettingup/measuringinstrumenting $\rangle$; for the mentation at occlusive positivism- ${ }^{80}$ procrypticism basically 'introducing positivising/rationalempiricist insight in articulating the ${ }^{103}$ universalising of the contextualisation of rules and rulemaking'; and for the mentation of protensive notional ' deprocrypticism basically 'upholding an utterly nondisjointing ontologisation/ontological-veracity/aestheticisation-towards-ontology as notional-contiguity/epistemic-contiguity -<profound-supererogation -of-mentallyaestheticised postconverging/dialectical-thinking -qualia-schema $>$ (over recurrent/threshold of notional-discontiguity/epistemic-discontiguity ${ }^{3}<$ between - prior-shallow-supererogation of-mentally-aestheticised preconverging/dementing -qualia-schema_and_prospectiveprofound-supererogation -of-mentally-aestheticised postconverging/dialectical-thinking qualia-schema $>/$ 'disjointedness-as-of- ${ }^{8}$ reference-of-thought in positivism- ${ }^{80}$ procrypticism) with regards to the underlying intemporal-preservation behind rules-that-remain of the-verysame-immanent-existence/intrinsic-reality/ontological-veridicality,-as-to'human<amplituding/formative-epistemicity>totalising $\sim$ purview-of-construal'. The implication being that in a contention among interlocutors in recurrent-utteruninstitutionalisation, the mentation is very much different from ours (positivism) as any imagined pretext is a legitimate one with emphasis being rather on established dominance/subservience relations, with base-institutionalisation the mentation was to arbitrarily invoke any of a number of recognised or incidentally introduced rules that are in one's favour and again where dominance/subservience relations played a large part, while with universalisation while power relations also played a part the rules and rulemaking-over-non- 
rules_-apriorising/axiomatising/referencing-psychologism,-〈as 'first-level presencingabsolutising-identitive-constitutedness of reference-of-thought' apriorising/axiomatising/referencing/intelligibilitysettingup/measuringinstrumenting) set/given however skewed towards the dominance of say a leader or family/clanic group or priestly class or outright social class; with positivism though, while relatively ${ }^{103}$ universal and empirical, the weakness lies in the notional-contiguity/epistemic-contiguity ${ }^{6}-<$ profoundsupererogation -of-mentally-aestheticised postconverging/dialectical-thinking -qualiaschema $>$ of the contextualisation of rules and rulemaking-over-non-rulesapriorising/axiomatising/referencing-psychologism,-〈as 'first-level presencing_absolutisingidentitive-constitutedness of reference-of-thought' apriorising/axiomatising/referencing/intelligibilitysettingup/measuringinstrumenting (hence not 'absolutely rational' with regards to its socially-betraying-threshold-of-ontologising-depthof-analysis) which preempting - disjointedness-as-of- ${ }^{8}$ reference-of-thought,-as-to${ }^{<}<$amplitung/formative-epistemicity $>$growth-or-conflatedness ${ }^{13} /$ transvaluativerationalising/transepistemicity/anamnestic-residuality/spirit-drivenness'—in-supersedingmere-formulaic-positivising/rational-empiricism-based-universalisation-directed-rulemakingover-non-rules_-apriorising/axiomatising/referencing-psychologism notional ${ }^{18}$ deprocrypticism 'implicited_attendant-ontological-contiguity ${ }^{67}$ ' educedexistentialising/contextmalising/textualising_'intelligibility/epistemicity/reflexivity_contiguity$<$ imbued-notional $\sim$ cogency $>,,-<$ reifying-or-elucidating-of-prospective-relative-ontologicalcompleteness -of- reference-of-thought- devolving-as-of-instantiative-context> as to existence-potency ${ }^{39} \sim$ sublimating-nascence,-disclosed-from-prospective-epistemicdigression—rules-of-apriorising/axiomatising/referencing-that-further-epistemicallyunconceal-the-very-ontologically-same-existential-reality 'preempting the threshold-ofnonconviction/madeupness/bottomlining-in-shallow-supererogation $<-<$ as-to- 'attendant- 
psychologism $>$ of rational-empiricism/positivising-rules' as to 'uncompromising ontologicalreconstituting-as-to-conflatedness ${ }^{13}$ ' focus, as enabling 'fulsome ontologising'. Interestingly, while the socially-betraying-threshold-of-ontologising-depth-of-analysis or socially-betrayingthreshold-of-intemporal-preservation-entropy-or-contiguity-or-ontological-preservation explains how and why successive institutional-cumulation/institutional-recomposure-〈as-tohistoriality/ontological-eventfulness /ontological-aesthetic-tracing-<perspectiveontological-normalcy/postconvergence-reflected-'epistemicity-relativism-determinism'>> are at their given institutionalisation levels on the basis of a memetic/suprastructural-meaningfulness analysis or a transcendental/transdimensional-meaningfulness analysis, the notion of sociallybetraying-threshold-of-ontologising-depth-of-analysis or socially-betraying-threshold-ofintemporal-preservation-entropy-or-contiguity-or-ontological-preservation actually initially applies intradimensionally in all registry-worldviews/dimensions and it is actually the 'intemporal/ontological signal' for the need of prospective transcending/superseding due to 'failing/not-upholding-<as-of-apriorising/axiomatising/referencing > intradimensional ontologising/intemporal-preservation'. Insightfully, we can grasp the 'intemporal/ontological signal' pointing to a socially-betraying-threshold-of-ontologising-depth-of-analysis with regards to a dimension's/registry-worldview 'preconverging-or-dementing -apriorising-psychologism phenomenon' like psychopathy and social psychopathy (with respect to procrypticism or perversion-of- ${ }^{-3 e f e r e n c e-o f-t h o u g h t-<a s-p r e c o n v e r g i n g l y-~}$

\section{apriorising/axiomatising/referencing-in-nonconviction/madeupness/bottomlining-as-to-}

shallow-supererogation $>$ of positivistic meaningfulness) or accusations and notions of sorcery (with respect to medievalism); as this has to do with human-subpotencyaporia/undecidability/dilemma/ought-indeterminacy/deficiency/limitation/constraint—imbued'notional firstnaturedness-formativeness-<as-to-eventualising $-i n k l i n g-d r i v e-o r-s e e d i n g-$ 
misprising $>$ temporal-to-intemporal-dispositions- $<$ so-construed-as-from-perspective-

ontological-normalcy/postconvergence>'-existentialism-form-factor

individuations

dispositions wherein intradimensionally, the 'socially-betraying-threshold-of-ontologisingdepth-of-analysis' (or socially-betraying-threshold-of-intemporal-preservation-entropy-orcontiguity-or-ontological-preservation

or

threshold-of-

nonconviction/madeupness/bottomlining-in-shallow-supererogation $<-<$ as-to-' ${ }^{\circ}$ attendant-

intradimensional'-prospectively-disontologising preconverging/dementing -apriorising-

psychologism>) is rather an overall registry-worldview/dimension ${ }^{74}$ perversion-of- ${ }^{8}$ referenceof-thought-<as-preconvergingly-apriorising/axiomatising/referencing-in-

nonconviction/madeupness/bottomlining-as-to-shallow-supererogation $>$ aftereffect rather as an indirect comprehensive socially-betraying-threshold-of-ontologising-depth-of-analysis (or socially-betraying-threshold-of-intemporal-preservation-entropy-or-contiguity-or-ontologicalpreservation or threshold-of-nonconviction/madeupness/bottomlining-in-shallowsupererogation -<as-to- 'attendant-intradimensional'-prospectivelydisontologising preconverging/dementing -apriorising-psychologism $>$ ) arising from the 'cumulative effect' of the various notional firstnaturedness-formativeness-<as-toeventualising inkling drive or seeding misprising temporal-to-intemporal-dispositions$<$ so-construed-as-from-perspective-ontological-normalcy/postconvergence $>$ individuations dispositions with respect to intradimensionally operant implications of 74 perversion-ofreference-of-thought-<as-preconvergingly-apriorising/axiomatising/referencing-innonconviction/madeupness/bottomlining-as-to-shallow-supererogation $>$, as the various 'temporal-dispositions individuations' will, at that uninstitutionalised-threshold ${ }^{102}$, betray ontologising/ontological-depth-of-analysis/intemporal-preservation by hollow-constituting-<asdisjointed-misappropriation-of-meaningfulness-and-failing-intemporal-preservation> at their specific temporal-dispositions individuations thresholds (postlogism - 
slantedness/ ${ }^{50}$ ignorance/affordability/opportunism/exacerbation/social-chainism-or-socialdiscomfiture-or-negative-social-aggregation/temporal-enculturation-or-temporal-endemisation, so-disambiguated as of ${ }^{83}$ reference-of-thought- ${ }^{8}$ devolving ontological-performance ${ }^{72}$ $<$ including-virtue-as-ontology>) with the idea that 'human intemporal-disposition individuation' will rather be utterly emancipating/transcendental by 'ontologicallyreconstituting'/deconstruction (and so, without any hollow-constituting-<as-disjointedmisappropriation-of-meaningfulness-and-failing-intemporal-preservation $>\quad{ }^{5}$ incrementalismin-relative-ontological-incompleteness ${ }^{8}$ —enframed/disontologising $\sim$ conceptualisation and notional disjointedness-as-of- ${ }^{-3}$ reference-of-thought allowed, in order to sync with the 'postconvergence/preceding/superseding nature of intrinsic reality' which 'doesn't recognise' nor is involved in temporal-and-social-trading with the mortals that we are to establish ontological-reference and ontological-veridicality) instead of betraying ontologising/ontological-depth-of-analysis/intemporal-preservation thus inducing prospective institutionalisation/intemporalisation by positive-opportunism-of-social-functioning-andaccordance $^{75}$ and the intemporal percolation-channelling- $<$ in-deferential-formalisationtransference $>\quad$ of such emancipation/transcendence-andsublimity/sublimation/smerentativity. Thus for instance with regards to adult psychopathy and the induced social psychopathy, it will be naïve to simply analyse on a dichotomous basis of psychopathy and its violation of social norm, with the idea that psychopathy is associated with temporal-dispositions destructuring-threshold〈uninstitutionalised-threshold /presublimating-desublimating-decisionality $\rangle$ of-ontologicalperformance ${ }^{72}-<$ including-virtue-as-ontology $>$ /morality/ethics/justice/etc. 'as of the positivismprocrypticism registry-worldview's/dimension's socially-betraying-threshold-ofontologising-depth-of-analysis'/socially-betraying-threshold-of-intemporal-preservationentropy-or-contiguity-or-ontological-preservation 
ignorance/affordability/opportunism/exacerbation/social-chainism-or-social-discomfiture-ornegative-social-aggregation/temporal-enculturation-or-temporal-endemisation) and it is naïve to simply analyse on the basis that other interlocutors have an intemporal/ontological disposition, in the very first instance. Thus the need, in order to attain such a prior requisite ontological/intemporal insight, to ontologically construe (as to deferential-formalisationtransference) contexts of psychopathy and social psychopathy (and generally contexts of threshold-of-nonconviction/madeupness/bottomlining-in-shallow-supererogation $-<$ as-to‘attendant-intradimensional'-prospectively-disontologising p preconverging/dementing apriorising-psychologism> in all registry-worldviews/dimensions to priorly achieve an ontological/intemporal insight), before conducting a 'truly ontological/intemporal analysis' as the-Good/knowledge-reification gesturing-and-accounting —of-epistemic-phenomenalism$<$ in-prospective_psychologismic $\sim$ apriorising/axiomatising/referencing-\{of-"prospectively implicited_attendant-ontological-contiguity ' educedexistentialising/contextualising/textualising_ 'intelligibility/epistemicity/reflexivity-contiguity<imbued-notional cogency >' \}-conflatedness -in-\{preconverging-disentailment by\} postconverging-entailment $>$ /understanding/<amplituding/formativeepistemicity $>$ causality $\sim$ as-to-projective-totalitative-implications-of-prospectivenonpresencing,-for-explicating relative-unreflexivity/relative-reflexivity - ontologicalcontiguity construct, which necessarily implies projecting into a prospective/transcending/superseding registry-worldview/dimension, in this case deprocrypticism; as otherwise the 'ordinary' reasoning of a social context imbued with interlocutors temporal-dispositions destructuring-threshold-〈uninstitutionalisedthreshold /presublimating-desublimating-decisionality $>$ of-ontological-performance ${ }^{72}$ $<$ including-virtue-as-ontology $>$ /morality/ethics/justice/etc. of postlogism slantedness/ ignorance/affordability/opportunism/exacerbation/social-chainism-or-social- 
discomfiture-or-negative-social-aggregation/temporal-enculturation-or-temporal-endemisation, so-disambiguated as of ${ }^{83}$ reference-of-thought- ${ }^{8}$ devolving ontological-performance ${ }^{72}$ $<$ including-virtue-as-ontology $>/$ morality/ethics/justice/etc. on the basis of the fundamental ontologising limits or the uninstitutionalised-threshold ${ }^{102}$ of the registry-worldview/dimension (procrypticism being the fundamental ontologising limits of a positivistic registryworldview/dimension), will pervert/corrupt the possibility of a 'truly ontological/intemporal analysis as the-Good/knowledge-reification $\sim$ gesturing-and-accounting-of-epistemicphenomenalism-<in-prospective_psychologismic $\sim$ apriorising/axiomatising/referencing- of'prospectively implicited_attendant-ontological-contiguity ' ceducedexistentialising/contextualising/textualising_'intelligibility/epistemicity/reflexivity-contiguity$<$ imbued-notional $\left.\sim \operatorname{cogency}>^{\prime},\right\}$-conflatedness -in-\{preconverging-disentailment by\} postconverging-entailment $>$ /understanding/<amplituding/formativeepistemicity $>$ causality $\sim$ as-to-projective-totalitative-implications-of-prospectivenonpresencing,-for-explicating relative unreflexivity/relative-reflexivity - ontologicalcontiguity construct' preempting the said ${ }^{71}$ perversion-of- ${ }^{8}$ reference-of-thought- $<$ aspreconvergingly-apriorising/axiomatising/referencing-in-

nonconviction/madeupness/bottomlining-as-to-shallow-supererogation $>$ phenomenon. In this respect, it is equally important to be cognisant of potentially nefarious influences that may arise from pseudo-formalisms as well, and where these are construed out of their inherent context to wrongly imply a genuine ontological analysis especially given the gullible/susceptible nature of the social-construct as it 'becomes existentially-<disontologising/re-ontologisingapereticism $>$ in a dynamism of conventioning and ontology'. Take the case of works of arts like novels and films primarily meant to entertain, and in so doing may induce wrong impressions and conceptions with regards to 7 perversion-of- reference-of-thought-<as-preconverginglyapriorising/axiomatising/referencing-in-nonconviction/madeupness/bottomlining-as-to- 
shallow-supererogation $>$ phenomenon like psychopathy wherein the whims of their creators, aesthetic quality and ultimate financial gain are the primary driving motif, and not necessarily a profound and candid ontological insight of the phenomenon and its social implications/consequences. Basically, as we all know novels and films, while excellent in articulating aesthetic qualities, are not the true world of human lives and consequences. While there is more or less some deontological practice implemented with respect to such tendencies when it comes to issues of gender equality, racism, recently homophobia as well as say the portrayal of victims of some degenerative diseases, such intellectually-sound deontology requiring aesthetic-representations-produced-from-sound-ontological-insight by their creators (which is often not the case but for a cursory understanding focused on entertainment) is not ubiquitous especially when the relevant 'theme and the intellectual projection behind its ontological analysis' seem rather aloof to many in society, as is the case with regards to psychopathy and social psychopathy; such that the influential nature of such aesthetic products broadcasted or sold to millions of people can easily induce wrong insights, undue romanticism, a poor grasp of its nefarious effects at individuals-and-institutional levels, and worst still perpetuate social ignorance simply by wrongly implied, naïve and fallacious explanations. Central to all such fallacies prevalent in many an aesthetic product with regards to psychopathy is that these often tend to be short-sighted given the unsustainable nature of the arguments in the middle to long run, and tend to be based on inductive limitation or 'so-called principles' that are actually fallacious since such arguments cannot truly be of entailing-<amplituding/formativeepistemicity $>$ totalising in-relative-ontological-completeness ${ }^{87}$ as they require that others do not act likewise or their implications should be limited to given target(s) and not be totalisinglyentailing, since their fundamental teleology ${ }^{9}$ is not intemporal/not-of-totalising-entailment but speak more of temporal motive. In this respect, one can cite at individuals-levels instances of many a human interest story tragedy in the press which often go unanalysed, and in the bigger 
institutional-level for instance what is the underlying dynamics that lead many an organisation or corporate entities to fail inexplicably due to grave and unprincipled mismanagement with $\begin{array}{llll}\text { profound } & \text { social } & \text { repercussions. } & \text { The }\end{array}$ intemporal/ontological/social/species/ ${ }^{103}$ universal/transcendental/ ${ }^{55}$ maximalisingrecomposuring-for-relative-ontological-completeness ${ }^{8}$ —unenframed/reontologising conceptualisation postconverging-de-mentating/structuring/paradigming, contrasted with a temporal extricatory preconverging-de-mentating/structuring/paradigming, is necessarily the prospective transcending/superseding registry-worldview/dimension. Consider the case of contending about a 74 perversion-of- ${ }^{83}$ eference-of-thought-<as-preconverginglyapriorising/axiomatising/referencing-in-nonconviction/madeupness/bottomlining-as-toshallow-supererogation $>$ like accusations and notions of sorcery in a nonpositivism/medievalism setup where there is no intradimensional intemporal/ontological/social/species// ${ }^{103}$ universal/transcendental/ $/ 5$ maximalisingrecomposuring-for-relative-ontological-completeness ${ }^{7}$ - unenframed/reontologising conceptualisation postconverging-de-mentating/structuring/paradigming given the obliviousness to a positivistic ontological-reference-of-veridicality/contending-reference-ofveridicality as it is suprastructural/beyond the registry-worldview's/dimension'srecomposuredconsciousness-awareness-teleology ${ }^{9}$ to non-positivism/medievalism. Likewise the positivistic meaningful frame is oblivious to its procrypticism, and corresponding resolution as notional ${ }^{18}$ deprocrypticism as the prospective/transcending/superseding ontological-referenceof-veridicality/contending-reference-of-veridicality. Further, this notion of registryworldviews/dimensions having socially-betraying-threshold-of-ontologising-depth-of-analysis (that need to be suprastructured by prospective/transcending/superseding registryworldviews/dimensions) explains why a 'postconverging-or-dialectical-thinking ${ }^{21}$-psychology or psychology-of-mentation-dynamics or natural psychological-dynamics' aligned with 
ontological-normalcy/postconvergence is what escapes and provides for grander emancipating possibilities that an intradimensionally mented or stigmatic psychology wouldn't enable. The bigger notion of such a 'postconverging-or-dialectical-thinking -psychology or psychology-ofmentation-dynamics or natural psychological-dynamics' is to reconcile the idea that we have one ontology/ontological-veridicality/intrinsic-reality across all times whereas our placeholdersetup/mental-devising-representation/mentation/\{cumulated/recomposured $\}$-consciousnessawareness-teleology ${ }^{9}$ in reference (as 'tentative ${ }^{83}$ references-of-thought') of this same one (ontological-normalcy/postconvergence) ontology/ontological-veridicality/intrinsic-reality and our corresponding/derived ${ }^{5}$ meaningfulness-and-teleology ${ }^{9}$ thereof, has been varying all along as we evolve from shallow-limited-mentation-capacity-as-subjecting 'educedunlimitedness/existence-sublimating nascence' to-limitedness/human-subpotency to deeperlimited-mentation-capacity—as-subjecting-'educed-unlimitedness/existence-sublimatingnascence' to-limitedness/human-subpotency; with the implication that the finality of such a 'postconverging-or-dialectical-thinking -psychology or psychology-of-mentation-dynamics or natural psychological-dynamics' is one that aligns with and is driven by ontologicalnormalcy/postconvergence (prospective-transcendence-in-perpetually-upholding-intemporalpreservation-entropy-or-contiguity-or-ontological-preservation) wherein ontologicalnormalcy/postconvergence is an 'abstract conceptualisation that by artifice covers for human limited but deepening mentation capacity'. Ontological-normalcy/postconvergence (as to epistemic relative-ontological-completeness ${ }^{87}$ ) abstractly refers to any relevant/implied registryworldview/dimension that is in a reflected/perspectivated state of prospective transcending/superseding whether as base-institutionalisation, ${ }^{103}$ universalisation, positivism or notional ${ }^{18}$ deprocrypticism as having 'relative sound/ontologically-veridical ${ }^{83}$ reference-ofthought status', in relation to a corresponding reflected/perspectivated state of prior transcended/superseded registry-worldview/dimension whether as recurrent-utter- 
uninstitutionalisation, ununiversalisation, non-positivism/medievalism or procrypticism which is then correspondingly of 'relative unsound/ontologically-impertinent ${ }^{83}$ reference-of-thought status', and so going by the inherent human-subpotency-aporia/undecidability/dilemma/oughtindeterminacy/deficiency/limitation/constraint—imbued-'notional firstnaturednessformativeness-<as-to-eventualising $>$ inkling-drive-or-seeding misprising $>$ temporal-tointemporal-dispositions- $<$ so-construed-as-from-perspective-ontologicalnormalcy/postconvergence >'-existentialism-form-factor that arises by the mere fact that all the institutionalisations are of the same 'human form-factor' with their 'snowballed differences' arise solely due to limited-mentation-capacity-deepening-as-subjecting limitedness/humansubpotency-to-'educed-unlimitedness/existence-sublimating nascence' ${ }^{53}$ involving institutional-cumulation/institutional-recomposure-〈as-to- historiality/ontologicaleventfulness /ontological-aesthetic-tracing-<perspective-ontologicalnormalcy/postconvergence-reflected-'epistemicity-relativism-determinism'>>. Ontologicalnormalcy/postconvergence as such will imply that the successive institutionalisations are rather shifts-in-the-curve-of-prospective-relative-ontological-completeness ${ }^{87}$-of- ${ }^{8}$ reference-ofthought-as-of-ontological-normalcy/postconvergence (shifts-in-the-curve-of-human-grasp-ofone-ontology/‘ontological-reference-of-veridicality', which will graphically/as-imagery imply 'human-grasping-capacity' on one axis and 'depth-of-ontology/ontological-reference-ofveridicality/ontological-completeness' as the institutional-cumulation/institutionalrecomposure-〈as-to- historiality/ontological-eventfulness /ontological-aesthetic-tracing$<$ perspective--ontological-normalcy/postconvergence-reflected-‘epistemicity-relativismdeterminism' $>>$ on the other axis or dialecticisms-of-an-imperfect-human-grasping-of'ontological-reference-of-veridicality'-which-mastery-improves-dialectically) which rather implies defects of ${ }^{7}$ perversion-of- ${ }^{3}$ reference-of-thought-<as-preconverginglyapriorising/axiomatising/referencing-in-nonconviction/madeupness/bottomlining-as-to- 
shallow-supererogation $>$ or unsoundness-or-ontological-bad-faith/inauthenticity ${ }^{6}$-ofreference-of-thought of corresponding prior/transcended/superseded registryworldviews/dimensions implying a voiding of their ${ }^{83}$ reference-of-thought as ontologicallyveridical as these become the subject of contention and aetiologisation/ontological-escalation<ontological-veridicality_commitment/otherliness_transcending/compulsions-

encumbered_transcending $>$ from the corresponding prospective/transcending/superseding registry-worldview/dimension which is then the ontologically-veridical ${ }^{8}$ reference-of-thought. It should be noted that a defect-of- ${ }^{5}$ logical-processing-or-logical-implicitation-supposedlyapriorising-in-conviction-as-to-profound-supererogation of the registryworldview's/dimension's- ${ }^{83}$ reference-of-thought-for-social-functioning-and-accordance (unlike a perversion-of- ${ }^{83}$ reference-of-thought- $<$ as-preconverginglyapriorising/axiomatising/referencing-in-nonconviction/madeupness/bottomlining-as-toshallow-supererogation $>$ ) implies movement-along-the-same-curve-of-prior-relativeontological-incompleteness ${ }^{8}$-of- ${ }^{8}$ reference-of-thought of a given registryworldview's/dimension's ${ }^{83}$ reference-of-thought whether as an inappropriate/poor-or-bad or appropriate/good or any other variation of the ${ }^{54}$ logical-processing-or-logical-implicitation supposedly-apriorising-in-conviction-as-to-profound-supererogation , and doesn't fundamentally voids the 'sound ${ }^{83}$ reference-of-thought status' with regards to the possibility of an appropriate ${ }^{54}$ logical-processing-or-logical-implicitation-supposedly-apriorising-inconviction-as-to-profound-supererogation in another instance. This insight is critical because the defect-of- ${ }^{54}$ logical-processing-or-logical-implicitation-supposedly-apriorising-inconviction-as-to-profound-supererogation of the registry-worldview's/dimension'sreference-of-thought-for-social-functioning-and-accordance will often be implied with regards to an issue and resolution of 7 perversion-of- ${ }^{3}$ reference-of-thought- $<$ as-preconverginglyapriorising/axiomatising/referencing-in-nonconviction/madeupness/bottomlining-as-to- 
shallow-supererogation $>$ which rather speaks to a defect 'revoking the sound ${ }^{83}$ reference-of-

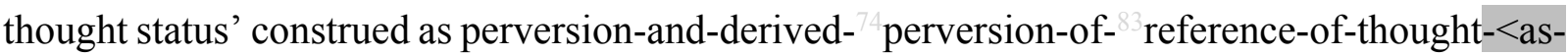
preconvergingly-apriorising/axiomatising/referencing-in-

nonconviction/madeupness/bottomlining-as-to-shallow-supererogation $>$ speaking of registryworldview's/dimension's-uninstitutionalised-threshold ${ }^{102}$-defect-<as-Being-or-ontological-orexistential-defect $>85$. For instance, there is no intradimensional resolution of sorcery accusations and notions of sorcery as intemporal/ontological/social/species/ ${ }^{103}$ universal/transcendental/ $/{ }^{5}$ maximalisingrecomposuring-for-relative-ontological-completeness ${ }^{8}$ —unenframed/reontologising conceptualisation postconverging-de-mentating/structuring/paradigming within a non-positivism/medievalism world, as what is required is a shift-in-the-curve-of-prior-relativeontological-incompleteness ${ }^{8}$-of- ${ }^{-3}$ reference-of-thought-as-of-ontological-

normalcy/postconvergence to imply a prospective transcending/superseding positivistic registryworldview/dimension as the resolution wherein positivising/rational-empiricism takes pride of place as ${ }^{83}$ reference-of-thought of meaningfulness. This applies with all ${ }^{74}$ perversion-ofreference-of-thought-<as-preconvergingly-apriorising/axiomatising/referencing-innonconviction/madeupness/bottomlining-as-to-shallow-supererogation $>\quad$ in $\quad$ all institutionalisations as the ${ }^{83}$ reference-of-thought is what gives registry/anchoring-ofmeaning/meaningful-reference/ontological-reference/contending-reference/registry-worldview status which is voided in the instance of ${ }^{74}$ perversion-of- ${ }^{8}$ reference-of-thought- $<$ aspreconvergingly-apriorising/axiomatising/referencing-in-

nonconviction/madeupness/bottomlining-as-to-shallow-supererogation $>$ with $\quad$ such perversion-of- ${ }^{3}$ reference-of-thought-<as-preconverginglyapriorising/axiomatising/referencing-in-nonconviction/madeupness/bottomlining-as-toshallow-supererogation $>$ defining that registry-worldview/dimension uninstitutionalised- 
threshold ${ }^{102}$ as it then becomes, by way of " ${ }^{15}$ de-mentation-〈supererogatory $\sim$ ontological-dementation-or-dialectical-de-mentation-stranding-or-attributive-dialectics $\rangle$ of ${ }^{83}$ reference-ofthought', the subject of contention and aetiologisation/ontological-escalation- $<$ ontologicalveridicality_commitment/otherliness_transcending/compulsions-encumbered_transcending $>$.

This implies that psychopathy and social psychopathy as ${ }^{74}$ perversion-of- ${ }^{8}$ reference-of-thought$<$ as-preconvergingly-apriorising/axiomatising/referencing-in-

nonconviction/madeupness/bottomlining-as-to-shallow-supererogation $>$ phenomenon in the positivistic registry-worldview/dimension (procrypticism) requires a shift-in-the-curve-ofprospective-relative-ontological-completeness ${ }^{87}$-of- ${ }^{83}$ eference-of-thought-as-of-ontologicalnormalcy/postconvergence from positivism to notional deprocrypticism registryworldview/dimension intemporal/ontological/social/species/ ${ }^{103}$ universal/transcendental $/{ }^{55}$ maximalisingrecomposuring-for-relative-ontological-completeness ${ }^{87}$ - unenframed/reontologising conceptualisation postconverging-de-mentating/structuring/paradigming resolution to psychopathy and social psychopathy, and so beyond an extricatory/temporal preconverging-de-mentating/structuring/paradigming which will wrongly imply a movementalong-the-curve-of-prior-relative-ontological-incompleteness ${ }^{8}$-of- ${ }^{8}$ reference-of-thought-as-ofontological-normalcy/postconvergence that preserves procrypticism ( perversion-ofreference-of-thought-<as-preconvergingly-apriorising/axiomatising/referencing-innonconviction/madeupness/bottomlining-as-to-shallow-supererogation $>$ of positivistic meaningfulness-and-teleology ${ }^{9}$ ) while inducing preconverging-or-dementing ${ }^{20}$-apriorisingpsychologism within the same defective procrypticism registry-worldview/dimension which requires prospective transcendence-and-sublimity/sublimation/supererogatory-de-mentativity as deprocrypticism. Insightfully again with regards to ontological-normalcy/postconvergence and ontological-normalcy/postconvergence critical for a 'postconverging-or-dialectical- 
thinking -psychology or psychology-of-mentation-dynamics or natural $\sim$ psychologicaldynamics', just in reflecting holographically-<conjugatively-and-transfusively $>$ the relativeunreflexivity/relative-reflexivity - ontological-contiguity of-the-human-institutionalisationprocess has to do with a human-limited-mentation-capacity-as-subjecting 'educedunlimitedness/existence-sublimating nascence' to-limitedness/human-subpotency maximalising-recomposuring-for-relative-ontological-completeness ${ }^{87}$ - unenframed/reontologising conceptualisationly institutionalising from prospective base-institutionalisation preempting recurrent-utter-uninstitutionalisation (as the ${ }^{7}$ perversion-of- ${ }^{3}$ reference-of-thought$<$ as-preconvergingly-apriorising/axiomatising/referencing-innonconviction/madeupness/bottomlining-as-to-shallow-supererogation $>$ as to preconvergingor-dementing ${ }^{20}$-apriorising-psychologism of recurrent-utter-uninstitutionalisation), prospective ${ }^{3}$ universalisation preempting base-institutionalisation-ununiversalisation (as the ${ }^{7}$ perversionof- ${ }^{8}$ reference-of-thought-<as-preconvergingly-apriorising/axiomatising/referencing-innonconviction/madeupness/bottomlining-as-to-shallow-supererogation $>$ as to preconvergingor-dementing -apriorising-psychologism of base-institutionalisation-ununiversalisation), prospective positivism preempting ${ }^{103}$ universalisation-non-positivism/medievalism (as the perversion-of- ${ }^{-3}$ reference-of-thought-<as-preconvergingly-

apriorising/axiomatising/referencing-in-nonconviction/madeupness/bottomlining-as-to-

shallow-supererogation $>$ as to preconverging-or-dementing ${ }^{2}$-apriorising-psychologism of universalisation-non-positivism/medievalism), and prospectively, prospective notional ${ }^{18}$ deprocrypticism preempting positivism- ${ }^{80}$ procrypticism (as the ${ }^{74}$ perversion-ofreference-of-thought-<as-preconvergingly-apriorising/axiomatising/referencing-innonconviction/madeupness/bottomlining-as-to-shallow-supererogation $>$ as to preconvergingor-dementing ${ }^{20}$-apriorising-psychologism of positivism- ${ }^{-}$procrypticism); with the implication that notional deprocrypticism is actually recomposuringly subsuming of positivism which is 
subsuming of ${ }^{103}$ universalisation and it too recomposuringly subsuming of baseinstitutionalisation (all these with their respective personhoods-and-socialhood-formation existentialisms/full-depths-existential-implications). Likewise their respective methodologies/implements are recomposuringly subsumed-as-supplanted constructs (of varying ontologising-depths-of-analysis and of shallower to deeper socially-betraying-threshold-ofontologising-depth-of-analysis), with the deepest-to-shallowest, as preempting - disjointednessas-of- ${ }^{3}$ reference-of-thought,-as-to- ${ }^{3}<$ amplituding/formative-epistemicity $>$ growth-orconflatedness ${ }^{13} /$ transvaluative-rationalising/transepistemicity/anamnestic-residuality/spiritdrivenness' - in-superseding-mere-formulaic-positivising/rational-empiricism-baseduniversalisation-directed-rulemaking-over-non-rules_-apriorising/axiomatising/referencingpsychologism as notional ' deprocrypticism 'implicited_attendant-ontologicalcontiguity ${ }^{67} \sim$ educedexistentialising/contextualising/textualising_'intelligibility/epistemicity/reflexivity-contiguity$<$ imbued-notional $\sim \operatorname{cogency}>,{ }^{\prime},-<$ reifying-or-elucidating-of-prospective-relative-ontologicalcompleteness -of- reference-of-thought- devolving-as-of-instantiative-context $>$ as to existence-potency ${ }^{39} \sim$ sublimating-nascence,-disclosed-from-prospective-epistemicdigression — rules-of-apriorising/axiomatising/referencing-that-further-epistemicallyunconceal-the-very-ontologically-same-existential-reality 'preempting the threshold-ofnonconviction/madeupness/bottomlining-in-shallow-supererogation $<-<$ as-to- 'attendantintradimensional'-prospectively-disontologising preconverging/dementing -apriorisingpsychologism $>$ of rational-empiricism/positivising-rules' as to 'uncompromising ontologicalreconstituting-as-to-conflatedness ${ }^{13}$ /deconstruction' methodology of notional ' deprocrypticism (which is very much an 'uncompromising \{epistemictotalising 3 ' $h$ hermeneutic/textuality/reprojecting/supererogating/zeroing/re-acuting,-

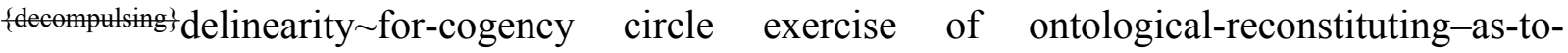


conflatedness ${ }^{13 / d e c o n s t r u c t i o n ', ~ a s ~ a ~ ' d e c o n s t r u c t i o n / o n t o l o g i c a l-r e c o n s t i t u t i n g-a s-t o-~}$ conflatedness perpetuation

of the \{epistemicthermeneutic/textuality/reprojecting/supererogating/zeroing/re-acuting,-

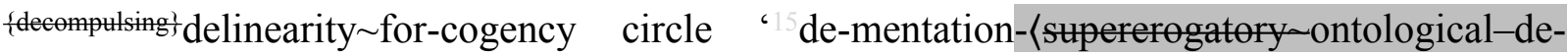
mentation-or-dialectical-de-mentation-stranding-or-attributive-dialectics $\rangle$ of ${ }^{83}$ reference-ofthought analysis' that is technically non-thresholding-and-proxying-or-approximating-toontological-veridicality-and-doesn’t-succumb-to-any-socially-betraying-threshold-ofontologising-depth-of-analysis, and also considering that science as we know today is hardly just a question of adopting scientific methods to obtain scientific results, an unspoken fact is that much of science relies on a 'rudimentary phenomenology in a heuristic fepistemictotalising ${ }^{3}$ hermeneutic/textuality/reprojecting/supererogating/zeroing/re-acuting,\{decompulsing delinearity for-cogency circle exercise of ontological-reconstituting-as-toconflatedness ${ }^{13} /$ deconstruction by the researcher', that simply passes as their personal talents, to obtain results applying scientific methods, and thus we can further imagine the possibilities if this reality came to be fully recognised and sophisticated fepistemictotalising 3 h hermeneutic/textuality/reprojecting/supererogating/zeroing/re-acuting,${ }_{\{\text {decompulsing }}$ delinearity for-cogency circle exercise of ontological-reconstituting-as-toconflatedness ${ }^{13} /$ deconstruction insights were to permeate scientific research and methodologies), is subsuming of 'rational-empiricism/positivising' methodology of positivistic science which is subsuming of the " ${ }^{103}$ universalising-of-rules' methodology of ${ }^{103}$ universalisation and the latter subsuming of the rulemaking-over-non-rules - apriorising/axiomatising/referencingpsychologism,-〈as 'first-level presencing-absolutising-identitive-constitutedness of reference-of-thought' apriorising/axiomatising/referencing/intelligibilitysettingup/measuringinstrumenting) methodology of institutionalisation -these in reflection of the development of human shallower- 
limited-mentation-capacity—as-subjecting 'educed-unlimitedness/existence-sublimating nascence' to-limitedness/human-subpotency to deeper-limited-mentation-capacity-assubjecting 'educed-unlimitedness/existence-sublimating nascence' to-limitedness/humansubpotency cumulation/recomposuring/reordering/reorientation. In the case of threshold-ofnonconviction/madeupness/bottomlining-in-shallow-supererogation $-<$ as-to-'attendantintradimensional'-prospectively-disontologising preconverging/dementing -apriorisingpsychologism> acts of-similar-or-protracted-contextualisation with regards to slantedness/compulsive-dementing (with an underlying element of physiological issue with regards to psychopathic personalities) and the derived social dynamisms of social psychopathy, such implied 'deconstruction/ontological-reconstituting-as-to-conflatedness ${ }^{13}$ perpetuation of the fepistemic-totalising $3{ }^{3}$ 'hermeneutic/textuality/reprojecting/supererogating/zeroing/re-acuting,\{delinearity for-cogency circle ' de-mentation-〈supererogatory $\sim$ ontological-dementation-or-dialectical-de-mentation-stranding-or-attributive-dialectics $\rangle$ of ${ }^{83}$ reference-ofthought analysis' is potentially beyond just 'benign-and-specific-shallow-contexts-scale-ofimplications' but can be more profound involving institutions and individuals contextualisation as individuals-lives-and-institutional-lives-scale-of-implications and in-the-bigger-scheme-ofthings where such dynamics involve social preconverging-dementating/structuring/paradigming effects on perceived meaningfulness and values in the overall social-setup it has a social-structure-scale-of-implications (specifically not only in terms-as-ofaxiomatic-construct of vices-and-impediments ${ }^{105}$ but also in undermining the enculturation of intellectual/emancipating dispositions). Effectively, such a deconstruction/ontologicalreconstituting-as-to-conflatedness ${ }^{13}$ perpetuation of the fepistemictotalising 3 ' $h$ hermeneutic/textuality/reprojecting/supererogating/zeroing/re-acuting,${ }_{\{\text {decompulsing }}$ delinearity for-cogency circle ' ${ }^{5}$ de-mentation-(supererogatory $\sim$ ontological-dementation-or-dialectical-de-mentation-stranding-or-attributive-dialectics $\rangle$ of ${ }^{83}$ reference-of- 
thought analysis' ( ${ }^{15}$ de-mentation-〈supererogatory $\sim$ ontological-de-mentation-or-dialectical-dementation-stranding-or-attributive-dialectics $\rangle$

totalising 3 ’’hermeneutically/textually/reprojectingly/supererogatingly/zeroingly/re-acutingly,$\{$ decompulsing $\}$ delinearity $\sim$ for-cogency-educing-human- ${ }^{56}$ meaningfulness-and-teleology ${ }^{9}$-intothe-existentialism-becoming of personhoods-and-socialhood-formation) of supplantingconviction-as-to-profound-supererogation —of-'attendant-intradimensional'postconverging/dialectical-thinking -apriorising-psychologism individuation as intemporal/ontological (longness-of-register-of- ${ }^{5}$ meaningfulness-and-teleology ${ }^{9}$ ) and threshold-of-nonconviction/madeupness/bottomlining-in-shallow-supererogation $-<$ as-to-

\section{‘attendant-intradimensional'-prospectively-disontologising preconverging/dementing}

apriorising-psychologism> individuations as temporal (shortness-of-register-ofmeaningfulness-and-teleology ${ }^{9}$ ), will comprehensively articulate in a 'deconstruction/ontological-reconstituting-as-to-conflatedness ${ }^{13}$ perpetuation of the totalising ${ }^{3}{ }^{3}$ hermeneutic/textuality/reprojecting/supererogating/zeroing/re-acuting,${ }_{\{\text {decompulsing }}$ delinearity for-cogency circle ' ${ }^{15}$ de-mentation-〈supererogatory $\sim$ ontological-dementation-or-dialectical-de-mentation-stranding-or-attributive-dialectics $\rangle$ of ${ }^{83}$ reference-ofthought analysis' reflecting/perspectivating/highlighting temporal-dispositions pseudoontological-finalities, across social-setups and institutional settings with their evolving 'sociallyperceived-value as of social-stake-contention-or-confliction'. The state of threshold-ofnonconviction/madeupness/bottomlining-in-shallow-supererogation $<<$ as-to- 'attendantintradimensional'-prospectively-disontologising preconverging/dementing -apriorisingpsychologism> requires preconverging-or-dementing ${ }^{20}$-apriorisingpsychologism/unsoundness-or-ontological-bad-faith/inauthenticity ${ }^{64}$-of- ${ }^{8}$ reference-of-thought mental-devising-representations and implies the 'revoking of sound ${ }^{83}$ reference-of-thought status' with respect to interlocution of-similar-or-protracted-contextualisation (in the very first 
instance) while the state of supplanting-conviction-as-to-profound-supererogation —of‘attendant-intradimensional'-postconverging/dialectical-thinking -apriorising-psychologism implies a 'postconverging-or-dialectical-thinking -apriorising-psychologism'/soundness-orontological-good-faith/authenticity ${ }^{-o f}{ }^{-3}$ reference-of-thought mental-devising-representation implying a veridical ${ }^{83}$ reference-of-thought with respect to interlocution (in the very first instance), and enabling the second instance of engaging in terms-as-of-axiomatic-construct of logical pertinence to establish (postconvergence) ontological-veridicality/relativeunreflexivity/relative-reflexivity_ontological-contiguity ${ }^{67}$ Typically, such an insight with regards to compulsing-nonconviction/madeupness/bottomlining-〈' $<$ decontextualising/deexistentialising $\sim$ of-attendant-intradimensional-apriorising/axiomatising/referencing $>$-induceddisontologising'-of-the-'attendant-intradimensional-ontologising'-imbued$<$ contextualising/existentialising attendant-ontological-contiguity $>$;-in-shallowsupererogation -<as-to-disontologising-perverted-outcome-sought-precedes-existentiallyveridical-'attendant-intradimensional-apriorising/axiomatising/referencing'-logical-dueness $>$ ) is obvious and transparent with respect to the childhood psychopathy/cinglée mental-disposition, given that an initial encounter often involves a natural 'postconverging-or-dialectical-thinking apriorising-psychologism reflex' by the interlocutor with respect to their initial narratives but after some familiarisation we come to understand that the initial narratives are in fact preconverging-or-dementing ${ }^{20}$-apriorising-psychologism and thus our expectation of the subsequent narratives they iterate is to initiate or be ready to align by a mental-devisingrepresentation as a 'preconverging-or-dementing -apriorising-psychologism reflex'. This preconverging-or-dementing ${ }^{20}$-apriorising-psychologism veridicality explains both the childhood and adult psychopath disposition for absolving-logic-or-perpetually-fleeting-logicreflex-or-escaping-logic based on extrinsic-attribution wherein the mental-disposition is to move postlogicly/disontologising-perverted-outcome-sought-precedes-existentially-veridical- 
'attendant-intradimensional-apriorising/axiomatising/referencing'-logical-dueness from one set of narratives to the other and one set of interlocutors to the other with the idea convincing is the notion of getting more people 'mechanically convinced by vague-rhyming-or-copied-mimicryor-formulaic-projection-or-projection-of-form-or-hollow-and-vague-vocalisation-or-

subknowledging ${ }^{9}$, and not an articulation of supplanting-conviction-as-to-profoundsupererogation - of-'attendant-intradimensional'-postconverging/dialectical-thinking

apriorising-psychologism or 'implicited_attendant-ontological-contiguity ${ }^{67}$ ' educedexistentialising/contextualising/textualising_'intelligibility/epistemicity/reflexivity-contiguity$<$ imbued-notional cogency $>$ principle of reification, be it by adhering to the mere hollow form of principles and narratives in existential-decontextualisation as being deterministic of others inclinations and actions. Intrinsic-reality in its ontological-normalcy/postconvergence indicates that effectively the conjugating/inflecting/deriving/mimicking/in-protraction-topsychopathic-preconverging-or-dementing -apriorising-psychologism (which is often the case with the adult-psychopathic preconverging-or-dementing ${ }^{20}$-apriorising-psychologism) whether unconscious (ignorance) or conscious (affordability/opportunism/exacerbation/social-chainismor-social-discomfiture-or-negative-social-aggregation/temporal-enculturation-or-temporalendemisation) effectively underlies an ontologically valid mental-devising-representation reflex as preconverging-or-dementing ${ }^{20}$-apriorising-psychologism/unsoundness-or-ontological-badfaith/inauthenticity ${ }^{64}$-of- ${ }^{3}$ reference-of-thought of such protracting threshold-ofnonconviction/madeupness/bottomlining-in-shallow-supererogation $<<$ as-to- 'attendantintradimensional'-prospectively-disontologising preconverging/dementing -apriorisingpsychologism>. In-the-bigger-scheme-of-things, it equally explains our mental-devisingrepresentation preconverging-or-dementing -apriorising-psychologism/unsoundness-orontological-bad-faith/inauthenticity ${ }^{6}$-of- ${ }^{3}$ reference-of-thought underlying reflex with respect to prior/transcended/superseded registry-worldviews/dimensions and 'postconverging-or- 
dialectical-thinking -apriorising-psychologism'/soundness-or-ontological-goodfaith/authenticity ${ }^{6}$-of- ${ }^{3}$ reference-of-thought mental-devising-representation underlying reflex with respect to prospective/transcending/superseding registry-worldviews/dimensions. A perversion-of- ${ }^{-3}$ reference-of-thought-<as-preconverginglyapriorising/axiomatising/referencing-in-nonconviction/madeupness/bottomlining-as-toshallow-supererogation $>$ speaks of a hollow-constituting-<as-disjointed-misappropriation-ofmeaningfulness-and-failing-intemporal-preservation> defect (as sticking 'in form' to reference-of-thought- categorical-imperatives/axioms/registry-teleology ${ }^{9}$,-for-intemporalpreservation-entropy-or-contiguity-or-ontological-preservation that are ontologically defective rather than as being an adjunct to intemporal-preservation-entropy-or-contiguity-orontological-preservation per se, and so due to having attained the socially-betraying-thresholdof-ontologising-depth-of-analysis and thus not initiating ontological-reconstituting-as-toconflatedness ${ }^{13} /$ deconstruction in superseding this socially-betraying-threshold-of-ontologisingdepth-of-analysis) as impression-driven/good-naturedness/wishfulness defect of preconvergingor-dementing ${ }^{20}$-apriorising-psychologism/unsoundness-or-ontological-bad-

faith/inauthenticity ${ }^{64}$-of- ${ }^{83}$ eference-of-thought mental-devising-representation; since ontological-reconstituting-as-to-conflatedness ${ }^{13} /$ deconstruction $_{\text {as }}$ the-Good/knowledgereification $\sim$ gesturing-and-accounting — of-epistemic-phenomenalism- $<$ in-

prospective_psychologismic $\sim$ apriorising/axiomatising/referencing-\{of- ${ }^{\text {}}$ prospectively implicited_attendant-ontological-contiguity ' educedexistentialising/contextualising/textualising_'intelligibility/epistemicity/reflexivity-contiguity<imbued-notional cogency >' \}-conflatedness -in-\{preconverging disentailment by\} postconverging entailment>/understanding/<amplituding/formativeepistemicity $>$ causality $\sim$ as-to-projective-totalitative-implications-of-prospectivenonpresencing,-for-explicating relative-unreflexivity/relative-reflexivity - ontological- 
contiguity of new ${ }^{83}$ reference-of-thought- categorical-imperatives/axioms/registryteleology ${ }^{9}$,-for-intemporal-preservation-entropy-or-contiguity-or-ontological-preservation is veridically of intemporal-preservation-entropy-or-contiguity-or-ontological-preservation (undermining perversion-of- ${ }^{8}$ reference-of-thought- $<$ as-preconverginglyapriorising/axiomatising/referencing-in-nonconviction/madeupness/bottomlining-as-toshallow-supererogation $>$ as to preconverging-or-dementing ${ }^{20}$-apriorising-psychologism as best reflected by 'intemporal-prioritisation-of- ${ }^{3}$ reference-of-thought'-as-conflatedness ${ }^{13}$-orontological-reprojecting organic-comprehension as 'ontological-reconstituting-as-toconflatedness ${ }^{13} /$ deconstruction of new $\quad{ }^{83}$ reference-of-thought- categoricalimperatives/axioms/registry-teleology ${ }^{9}$,-for-intemporal-preservation-entropy-or-contiguityor-ontological-preservation for intemporal-preservation-entropy-or-contiguity-or-ontologicalpreservation' over circumventing/distractive $<$ amplituding/formativeepistemicity>totalising $\sim$ self-referencing-syncretising/circularity/interiorising/akrasiatic-drag mechanical-comprehension in hollow-constituting-<as-disjointed-misappropriation-ofmeaningfulness-and-failing-intemporal-preservation $>\quad$ defectively/non-veridically of reference-of-thought- categorical-imperatives/axioms/registry-teleology $^{9}$,-for-intemporalpreservation-entropy-or-contiguity-or-ontological-preservation whether or not it fails intemporal-preservation-entropy-or-contiguity-or-ontological-preservation'), and the temporaldispositions to stick to the previous one speaks not only of act defects but registryworldview/dimension defects at this socially-betraying-threshold-of-ontologising-depth-ofanalysis to the fact that such 'of-similar-or-protracted-contextualisation', from an ontologicalnormalcy/postconvergence insight that is preceding/superseding to any hollow-constituting-<asdisjointed-misappropriation-of-meaningfulness-and-failing-intemporal-preservation> of shallow limited-mentation-capacity—as-subjecting 'educed-unlimitedness/existencesublimating nascence' to-limitedness/human-subpotency-〈as of relative 
apriorising/axiomatising/referencing-\{of-'prospectively_implicited_attendant-ontological-

contiguity ' $\sim$ educed-

existentialising/contextualising/textualising_intelligibility/epistemicity/reflexivity_contiguity-

<imbued-notional cogency>' $\}$-constitutedness ${ }^{14}$ in preconverging entment will elicit a same defect disposition thus the need to fundamentally undermine ${ }^{83}$ reference-of-thought of the registry-worldview/dimension at that uninstitutionalised-threshold 02 that endemises/enculturates the ontological-or-existential-defect due to its socially-betrayingthreshold-of-ontologising-depth-of-analysis. It should thus be noted that the preconverging-ordementing -apriorising-psychologism of ${ }^{83}$ reference-of-thought of a registryworldview/dimension implicitly reflects a defective/sub-par relative state-of-conceptualisation in hollow-constituting-<as-disjointed-misappropriation-of-meaningfulness-and-failingintemporal-preservation> (a fundamentally defective/sub-par state-of-disposition) with respect to ontological-normalcy/postconvergence, as can be demonstrated by ontologicalreconstituting-as-to-conflatedness ${ }^{13} /$ deconstruction, (and has nothing to do, as-being-caused-by, with an inducing phenomena of " ${ }^{7}$ perversion-of- ${ }^{83}$ reference-of-thought- $<$ as-preconverginglyapriorising/axiomatising/referencing-in-nonconviction/madeupness/bottomlining-as-to-

shallow-supererogation $>$ as to preconverging-or-dementing -apriorising-psychologism' behind say sorcery and psychopathy; even though such phenomena tend to instigate and reveal the inherent defect/sub-par nature of registry-worldviews/dimensions with respect to ontological-normalcy, with the need for ontological-reconstituting-as-toconflatedness ${ }^{13} /$ deconstruction). In other words, the state of being non-positivism/medievalism with respect to ontological-normalcy/postconvergence is already a defective state 'in-wait as of prior relative-ontological-incompleteness ${ }^{8}$-of- ${ }^{8}$ reference-of-thought defective ${ }^{83}$ reference-ofthought- ${ }^{8}$ ategorical-imperatives/axioms/registry-teleology ${ }^{9}$ for issues of superstition/lack-ofrational-empiricism to arise whether we talk of sorcery, bodily mutilations and their effects, 
charlatanisms, etc. Likewise, it will be naïve to imply that our registry-worldview as positivismprocrypticism is in absolute sync with ontological-normalcy/postconvergence by the mere fact that we are at the backend of the institutional-cumulation/institutional-recomposure-〈as-to-

\section{historiality/ontological-eventfulness /ontological-aesthetic-tracing-<perspective-}

ontological-normalcy/postconvergence-reflected-'epistemicity-relativism-determinism'>>, as

we can equally project prospectively from a retrospective projection insight to grasp how 'from

an utter ${ }^{2}$ hermeneutic/textuality/reprojecting/supererogating/zeroing/re-acuting,${ }_{\{\text {decompulsing }\}}$ delinearity for-cogency circle exercise of ontological-reconstituting-as-toconflatedness ${ }^{13} /$ deconstruction (of our notional firstnaturedness-formativeness-<as-toeventusing inkling drive or seeding misprising temporal-to-intemporal-dispositions$<$ so-construed-as-from-perspective-ontological-normalcy/postconvergence $>$ nature)' how procrypticism (preconverging-or-dementing ${ }^{20}$-apriorising-psychologism as to mere-formulaic positivistic ${ }^{56}$ meaningfulness-and-teleology ${ }^{9}$ ) in a positivistic registry-worldview preconverging/postconverging-de-mentatively/structurally/paradigmatically endemises psychopathy and social psychopathy. Insightfully, for a grander grasp of ontological-normalcy, the notion of institutional-cumulation/institutional-recomposure-〈as-tohistoriality/ontological-eventfulness /ontological-aesthetic-tracing-<perspectiveontological-normalcy/postconvergence-reflected-‘epistemicity-relativism-determinism' $>>$ and their related conceptualisations are not just ad-hoc in nature but of 'existentialism/full-depth-ofexistential-implications form-factor'; which is fundamentally defined by ontologicalnormalcy/postconvergence (going by shallower-limited-mentation-capacity-as-subjecting'educed-unlimitedness/existence-sublimating nascence' to-limitedness/human-subpotency to deeper-limited-mentation-capacity—as-subjecting-'educed-unlimitedness/existencesublimating nascence' to limitedness/human-subpotency), in reflecting the precedence/supersedingness of intrinsic-reality/ontology to which an 'animal' comes-to-and-re- 
compose-with-cumulatively by ontological-reconstituting-as-to-conflatedness ${ }^{13} /$ deconstruction $^{2}$ (which is the critical subsuming mechanism for re-establishing ${ }^{83}$ reference-of-thought and ontological-veridicality/relative-unreflexivity/relative-reflexivity-ontological-contiguity ${ }^{67}$ as intemporal-preservation-entropy-or-contiguity-or-ontological-preservation, above and beyond the simple hollow-constituting-<as-disjointed-misappropriation-of-meaningfulness-and-failingintemporal-preservation $>\quad$ of defective $\quad{ }^{83}$ reference-of-thought- categoricalimperatives/axioms/registry-teleology ${ }^{9}$,-for-intemporal-preservation-entropy-or-contiguityor-ontological-preservation of any registry-worldview/dimension and requiring their prospective suprastructuring). This 'existentialism/full-depth-of-existential-implications formfactor' is the reflection of the contiguity of successive existentialisms/full-depths-of-existentialimplications across varying meaningful frames, references and registry-worldviews/dimensions and is abstractly determined by the ontological-normalcy/postconvergence nature of intrinsicreality/ontology (ontological-normalcy) whatever the human limited-mentation-capacitydeepening—as-subjecting-limitedness/human-subpotency-to-'educed-unlimitedness/existencesublimating nascence' 53 induced institutional-cumulation/institutional-recomposure-〈as-tohistoriality/ontological-eventfulness /ontological-aesthetic-tracing-<perspective-

ontological-normalcy/postconvergence-reflected-'epistemicity-relativism-determinism'>>, and inherently implies a " ${ }^{103}$ universal existentialisms/full-depth-of-existential-implications formfactor across institutionalisations'; which define their specificities and potentials which are basically abstractly of a same 'human form-factor', with regards to the reality of their notional firstnaturedness-formativeness-<as-to-eventualising inkling-drive-or-seeding misprising $>$ temporal-to-intemporal-dispositions- $<$ so-construed-as-from-perspectiveontological-normalcy/postconvergence $>$ and the existential-<disontologising/re-entelogising apereticism $>$ implications on every registry-worldview/dimension thereof, though of differing 'snowballed recomposuring' of meaningfulness and ${ }^{83}$ reference-of-thought. Ontological- 
entrapment (as a deterministic point of reference that defines dialectical-out-ofphasing/dialectical-primitivity registry-worldview/dimension, and thus avoiding any confusing effects to analysis of the de-mentation-/supererogatory ontological-de-mentation-ordialectical-de-mentation - stranding-or-attributive-dialectics $\rangle$ of de-mentation〈supererogatory ontological-de-mentation-or-dialectical-de-mentation-stranding-or-

attributive-dialectics $\rangle)$ is attained by 'keeping or aligning' preconverging-or-dementing 2 apriorising-psychologism (with no shifting by reflex into postconverging-or-dialecticalthinking -apriorising-psychologism) of the placeholder-setup/mental-devisingrepresentation/mentation/consciousness-awareness-teleology as of the wrong ontologicalreferences/contending-references of all established ${ }^{7}$ perversion-of- ${ }^{8}$ reference-of-thought- $<$ aspreconvergingly-apriorising/axiomatising/referencing-in-

nonconviction/madeupness/bottomlining-as-to-shallow-supererogation

prior/transcended/superseded registry-worldviews/dimensions, in hollow-constituting-<asdisjointed-misappropriation-of-meaningfulness-and-failing-intemporal-preservation>

failing/not-upholding-<as-of-apriorising/axiomatising/referencing $>$ the ${ }^{83}$ reference-of-thoughtcategorical-imperatives/axioms/registry-teleology ${ }^{9}$,-for-intemporal-preservation-entropy-orcontiguity-or-ontological-preservation, with respect to ontological-normalcy/postconvergence represented by the rightful ontological-references/contending-references of the prospective/transcending/superseding registry-worldviews/dimensions whose mentation/mental-devising representation are 'kept or aligned' as 'ontologically-reconstituting'or-prelogic-or-logical-process-precedes-outcome-or-conviction-as-to-profound-

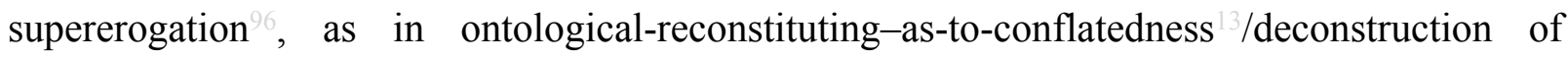
intemporal-preservation-entropy-or-contiguity-or-ontological-preservation with sound reference-of-thought- ${ }^{8}$ ategorical-imperatives/axioms/registry-teleology ${ }^{99}$,-for-intemporalpreservation-entropy-or-contiguity-or-ontological-preservation. A 'postconverging-or- 
dialectical-thinking -psychology or psychology-of-mentation-dynamics or natural psychological-dynamics' as being ontologically-driven is one where placeholdersetup/mental-devising-representation/mentation/consciousness-awareness-teleology ${ }^{99}$ (as to 'postconverging-or-dialectical-thinking -apriorising-psychologism' mental-devisingrepresentation or preconverging-or-dementing -apriorising-psychologism mental-devisingrepresentation) is the reflected/perspectivated implication either as of 'postconverging-ordialectical-thinking -apriorising-psychologism' or of preconverging-or-dementing apriorising-psychologism as so-reflected/so-perspectivated from ontologicalnormalcy/postconvergence, and it is thus ontology-driven beyond any ${ }^{79}$ presencingabsolutising-identitive-constitutedness ${ }^{14}$ distorted ${ }^{56}$ meaningfulness-and-teleology ${ }^{99}$ This equally explains why a prior/transcended/superseded registry-worldview's/dimension's reference-of-thought is cross-sectionally dialectically-out-of-phase/dialectically-primitive given it is sticking to its 'good-natured' but 'ontologically-wrong and failing' ${ }^{83}$ reference-of-

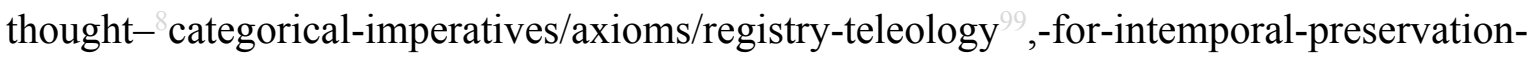
entropy-or-contiguity-or-ontological-preservation $\quad$ (hollow-constituting-<as-disjointedmisappropriation-of-meaningfulness-and-failing-intemporal-preservation $>$ ) as the prospective/transcending/superseding registry-worldview/dimension has the-Good/knowledgereification $\sim$ gesturing-and-accounting — of-epistemic-phenomenalism- $<$ inprospective_psychologismic apriorising/axiomatising/referencing-\{of- ${ }^{\text {pprospectively }}$ implicited_attendant-ontological-contiguity ' educedexistentialising/contextualising/textualising_'intelligibility/epistemicity/reflexivity-contiguity<imbued-notional cogency >' \}-conflatedness -in-\{preconverging disentailment by\} postconverging entailment>/understanding/<amplituding/formativeepistemicity $>$ causality $\sim$ as-to-projective-totalitative-implications-of-prospectivenonpresencing,-for-explicating relative unreflexivity/relative-reflexivity - ontological- 
contiguity sound $\quad{ }^{8}$ reference-of-thought- categorical-imperatives/axioms/registryteleology ${ }^{9}$,-for-intemporal-preservation-entropy-or-contiguity-or-ontological-preservation (in ontological-reconstituting-as-to-conflatedness ${ }^{13} /$ deconstruction); wherein no amount of 'goodnaturedness' of any individuation based on the former (prior/transcended/superseded) reference-of-thought can fundamentally supersede its preconverging-dementating/structuring/paradigming vices-and-impediments ${ }^{105}$, but for the 'emancipating moulting' (psychoanalytic-unshackling/memetic-reordering/recomposuring) into the reference-of-thought of the latter (prospective/transcending/superseding) of such would-be emancipating individuation/intellectuals and consequent institutionalisation/intemporalisation as transcendence-and-sublimity/sublimation/supereregatery de-mentativity. That is why there is no ontologically-veridical intradimensional resolution of issues and notions of sorcery for instance in a non-positivism/medievalism social-setup with any such pretence being nothing but a 'temporal extricatory preconverging-de-mentating/structuring/paradigming' to satisfy temporal preservation', but for implying a prospective need for a positivistic registryworldview/dimension intemporal/ontological/social/species $/{ }^{103}$ universal/transcendental $/{ }^{5}$ maximalisingrecomposuring-for-relative-ontological-completeness ${ }^{87}$ - unenframed/reontologising conceptualisation postconverging-de-mentating/structuring/paradigming in satisfying intemporal-preservation-entropy-or-contiguity-or-ontological-preservation. Likewise there is no intradimensional resolution of a phenomenon like psychopathy and its social corollary in a procrypticism-or-disjointedness-as-of- ${ }^{8}$ reference-of-thought registryworldview/dimension (the ${ }^{74}$ perversion-of- ${ }^{83}$ reference-of-thought- $<$ as-preconverginglyapriorising/axiomatising/referencing-in-nonconviction/madeupness/bottomlining-as-toshallow-supererogation $>$ as to preconverging-or-dementing 2 -apriorising-psychologism of positivistic meaningfulness-and-teleology reference-of-thought- categorical- 
imperatives/axioms/registry-teleology ${ }^{9}$,-for-intemporal-preservation-entropy-or-contiguityor-ontological-preservation, with a hollow-constituting-<as-disjointed-misappropriation-ofmeaningfulness-and-failing-intemporal-preservation> postlogism $>$-or-disontologisingperverted-outcome-sought-precedes-existentially-veridical-'attendant-intradimensionalapriorising/axiomatising/referencing'-logical-dueness placeholder-setup/mental-devisingrepresentation/mentation/consciousness-awareness-teleology ${ }^{9}$ alignment to imply dialecticalout-of-phasing/dialectical-primitivity) insightfully deduced from ontologicalnormalcy/postconvergence represented by the ${ }^{83}$ reference-of-thought of the prospective/transcending/superseding notional ${ }^{18}$ deprocrypticism registryworldview/dimension. Fundamentally, the reason for all the dimensions/registry-worldview perversion-of- ${ }^{8}$ reference-of-thought-<as-preconverginglyapriorising/axiomatising/referencing-in-nonconviction/madeupness/bottomlining-as-toshallow-supererogation $>\quad$ as $\quad$ limited-mentation-capacity-deepening-as-subjecting limitedness/human-subpotency to-'educed-unlimitedness/existence-sublimating nascence' has to do with the veracity/ontological-pertinence of our notional firstnaturednessformativeness-<as-to-eventualising inkling drive-or seeding misprising $>$ - temporal-tointemporal-dispositions-<so-construed-as-from-perspective-ontologicalnormalcy/postconvergence $>$ as individuations of shortness-to-longness-of-register-ofmeaningfulness-and-teleology ${ }^{9}$, such that whenever relatively sound ${ }^{83}$ reference-of-thoughtcategorical-imperatives/axioms/registry-teleology ${ }^{9}$,-for-intemporal-preservation-entropy-orcontiguity-or-ontological-preservation are institutionalised/intemporalised, human temporality $^{8}$ in hollow-constituting-<as-disjointed-misappropriation-of-meaningfulness-andfailing-intemporal-preservation $>$ individuation dispositions (at uninstitutionalised-threshold ${ }^{102}$ ) will tend to relate, by limited-mentation-capacity-deepening —as-subjecting limitedness/humansubpotency-to-'educed-unlimitedness/existence-sublimating nascence' ${ }^{3}$, to this as 
hollow/formulaic constraining deterministic constructs which have to be exploited by the mere determinism-of-form about how others will act (hollow-constituting-<as-disjointedmisappropriation-of-meaningfulness-and-failing-intemporal-preservation $>$ ) rather than the essence as intemporal-preservation-entropy-or-contiguity-or-ontological-preservation being sought originally by the institutionalised/intemporalised ${ }^{8}$ reference-of-thought- categoricalimperatives/axioms/registry-teleology ${ }^{9}$,-for-intemporal-preservation-entropy-or-contiguityor-ontological-preservation $\quad$ (ontological-reconstituting-as-to-conflatedness ${ }^{13}$ ). $\quad$ This fundamental dilemma of the cross-section of human mentation disposition is a 'lost cause', given the reality of the notion of a shortness-to-longness-of-register-ofmeaningfulness/notional firstnaturedness-formativeness-<as-to-eventualising-inkling-driveer-seeding misprising $>$ temporal-to-intemporal-dispositions- $<$ so-construed-as-fromperspective-ontological-normalcy/postconvergence $>$ inherent in a limited-mentation-capacitydeepening -as-subjecting limitedness/human-subpotency-to-'educed-unlimitedness/existencesublimating nascence' ; any resolution is not by wrongly implying any ' dimensionality-ofsublimating 25 -<<mplituding/formative $>$ supererogatory $\sim$ de-mentativeness/epistemic-growthor-conflatedness /transvaluative-rationalising/transepistemicity/anamnestic-residuality/spiritdrivenness-equalisation〉 transformation' but rather institutionalisation/intemporalisation by its inherent eliciting of positive-opportunism — of-social-functioning-and-accordance ${ }^{5}$ to the grander cross-section of society in the medium to long-run wherein intemporaldisposition/longness-of-register-of meaningfulness-and-teleology $\quad$ individuation dispositions by artifice/institutionalisation/intemporalisation come to constrain-or-dominate the social-construct (over temporal-dispositions/shortness-of-register-of- meaningfulness-andteleology -or-hollow-constituting-<as-disjointed-misappropriation-of-meaningfulness-andfailing-intemporal-preservation> individuations dispositions); with corresponding percolationchannelling- $<$ in-deferential-formalisation-transference $>$ facilitating the perpetuation of such 
intemporal enculturation even when such positive-opportunism-of-social-functioning-andaccordance $^{75}$ gets weaker with grander institutionalisations/intemporalisations, and so as the grander human the-good. This underlies the fundamental construct of rational-realism that human progress is the outcome of human increasingly realistic grasp of what man is with 'lesser and lesser vague idealisations', and that such 'rational-realism' enables humans to fully grasp their 'emancipating potential' over 'deluded idealisms' that simply create space for falsehood, dead-end dilemmas as well as the consequent incapacity to take action, since basically knowingis-acting as of conceptivity/epistemic-reflexivity/epistemicity-relativism-determinism$<$ reifying \{as-to-knowledge-developing\}-and-empowering $>$ ! Rational-realism (as to prospective deprocrypticism) as such involves rather elucidating distractive-alignment-to- ${ }^{83}$ reference-ofthought- $<$ of-apriorising/axiomatising/referencing $>$ /decandoring with three preconverging/postconverging-de-mentative/structural/paradigmatic teleologies: subknowledging -impulse/compulsive-dementing temporal-disposition (psychopath), with 'slanted mechanical narratives' (preconverging-or-dementing 20 -apriorising-psychologism$<$ stranded-as-rightfully-oblongated/decandored-and-dialectically-or-contendingly-out-ofphase $>$ ); - $\quad$ subknowledging -temporal-dispositions-teleologies (the-various-temporaldispositions-teleologies), with 'banal mechanical narratives discomfiture' (preconverging-ordementing ${ }^{20}$-apriorising-psychologism- $<$ stranded-as-rightfully-oblongated/decandored-anddialectically-or-contendingly-out-of-phase $>$ ); and - the intemporally given and ontologising teleology which ontologically reflects/perspectivates the subknowledging impulse/compulsive-dementing ${ }^{20}$-temporal-disposition-\{psychopath\} and the subknowledging ${ }^{94}$-registries-teleologies (the-various-temporal-dispositions-teleologies), from a 'organic-comprehension-thinking depth as the ${ }^{15}$ de-mentation-〈supererogatory $\sim$ ontological-dementation-or-dialectical-de-mentation - stranding-or-attributive-dialectics $\rangle$ backdrop of new recomposuring ${ }^{83}$ reference-of-thought- categorical-imperatives/axioms/registry-teleology ${ }^{9}$,- 
for-intemporal-preservation-entropy-or-contiguity-or-ontological-preservation. Thus at the uninstitutionalised-threshold ${ }^{102}$, it is counterintuitive for temporal-dispositions not to perceive their registry-worldview/dimension as 'un-transcendable' (acting as if in intemporalpreservation-entropy-or-contiguity-or-ontological-preservation while actually in temporal preservation-as-pseudointemporality ${ }^{52}$, hence de-mentable/no-longer-thinking) due to $<$ amplituding/formative-epistemicity $>$ totalising $\sim$ self-referencing-syncretising/presentconsciousness/illusion-of-the-present/mirage as metaphysics-of-presence-_implicited'nondescript/ignorable-void ' -as-to- presencing — absolutising-identitive-constitutedness >

which blinds the temporal-dispositions to the registry-worldview's/dimension's 'intemporal preservation discontinuity' as a result of the ${ }^{74}$ perversion-of- ${ }^{3}$ reference-of-thought- $<$ aspreconvergingly-apriorising/axiomatising/referencing-in-

nonconviction/madeupness/bottomlining-as-to-shallow-supererogation $>$ as-of-unsoundnessor-ontological-bad-faith/inauthenticity ${ }^{6}$-of- ${ }^{-}$reference-of-thought-defects (and not logical defect) of compulsive-slanting-preconverging-or-dementing ${ }^{20}$-apriorising (psychopath) and the consequent derived -miscuing, disjointed-logic, logical-drag, unconscionability-drag, and sub-par/formulaic-association/temporal/alibi conventioning-rationalising, and temporalenculturation/temporal-endemisation; arising from the conjugation with the relative-ontologicalincompleteness 8 -induced,-'threshold-of-nonconviction/madeupness/bottomlining-in-shallowsupererogation -<as-to-'attendant-intradimensional'-prospectivelydisontologising preconverging/dementing -apriorising-psychologism>' whether as recurrentutter-uninstitutionalisation, ununiversalisation, non-positivism/medievalism or procrypticism. The reason why this is critical to grasp is that the veridical intemporal-disposition preserving emanance has to 'organically and existentially-<disontologising/re-ontologising aporeticism $>$ pass-through'/reflect/perspectivate the registry-worldview/dimension ${ }^{74}$ perversion-ofreference-of-thought-<as-preconvergingly-apriorising/axiomatising/referencing-in- 
nonconviction/madeupness/bottomlining-as-to-shallow-supererogation $>$ as to preconvergingor-dementing ${ }^{20}$-apriorising-psychologism for psychoanalytic-unshackling/memeticreordering/institutional-recomposuring on the basis of prospective ${ }^{83}$ reference-of-thoughtcategorical-imperatives/axioms/registry-teleology ${ }^{9}$,-for-intemporal-preservation-entropy-orcontiguity-or-ontological-preservation. * It is not an 'avoidable luxury' as it is the necessary transcendental element in establishing the backdrop for transcendence-andsublimity/sublimation/supererogatory $\sim$ de-mentativity/prospective-institutionalisation. Galileo's medieval 'round world utterances' nor Darwin's and others 'evolution contentions' are not idleand-dispensable articulations as all transcendence-andsublimity/sublimation/supererogatory de-mentativity (occurring at the registryworldview/dimension or intradimensional level and not logical operation/processing/contention level, are fundamentally about a new existential-<disontologising/re-ontologising apereticism $>$ mental-devising-representation orientation) need to 'break-the-mind' of the prior temporal perversion-of- ${ }^{3}$ reference-of-thought- $<$ as-preconverginglyapriorising/axiomatising/referencing-in-nonconviction/madeupness/bottomlining-as-toshallow-supererogation $>$ existential-<disontologising/re-ontologising aporeticism $>$ mental orientation to avoid postconverging-or-dialectical-thinking -apriorising-psychologism$<$ stranded-as-rightfully-straight/candored-and-dialectically-or-contendingly-in-phase $>$ (for example, no 'God-of-plane' for say an animistic mental orientation that sees gods and spirits as causative, i.e. avoiding to operate the ${ }^{56}$ meaningfulness-and-teleology ${ }^{9}$ of a transcendent registry-worldview/dimension in terms-as-of-axiomatic-construct of the ${ }^{83}$ reference-ofthought- ${ }^{8}$ ategorical-imperatives/axioms/registry-teleology ${ }^{99}$,-for-intemporal-preservationentropy-or-contiguity-or-ontological-preservation of the transcended registryworldview/dimension). This starts with the would-be transcendence-andsublimity/sublimation/supererogatory $\sim$ de-mentativity inducing intellectual(s)/emancipator(s) 
'owns reflexive individuation maximalising-as-transcendental liberation/emancipation' from the reference-of-thought- categorical-imperatives/axioms/registry-teleology ${ }^{9}$,-for-intemporalpreservation-entropy-or-contiguity-or-ontological-preservation of such prior registryworldview/dimension from which it/they necessarily come from as well as not heeding generalised-social-temporal-preserving-mental-inclinations; and so, consistently crossgenerationally since transcendence-and-sublimity/sublimation/supereregatory - dementativity/institutionalisation is 'beyond just logical argumentation/contention' as it points to 'being-or-ontological existentialism/full-depth-of-existential-implications structure defect' (defect of reference-of-thought/soundness-or-ontological-good-faith/authenticity ${ }^{69}$-ofreference-of-thought, and so beyond logical defect). It is more like (a knowledge-driven/not impression-driven) 'intemporal preservation recomposuring need or memeticreordering/psychoanalytic-unshackling' for institutionalised/intemporalised being/ontology over recurrent-utter-uninstitutionalised, ${ }^{103}$ universalised being/ontology over ununiversalised, positivistic being/ontology over non-positivism/medievalism and prospectively deprocryptic being/ontology over procrypticism-or-disjointedness-as-of- ${ }^{8}$ reference-of-thought. The dynamism of social psychopathy and the ${ }^{74}$ perversion-of- ${ }^{8}$ reference-of-thought- $<$ aspreconvergingly-apriorising/axiomatising/referencing-innonconviction/madeupness/bottomlining-as-to-shallow-supererogation $>$ involved with regards to both the psychopath and protracted social psychopathy (requiring 'distractivealignment-to- ${ }^{83}$ reference-of-thought- $<$ of-apriorising/axiomatising/referencing $>30 \quad$ at 'uninstitutionalised-threshold ${ }^{102}$ ') can be resumed as follows. Basically, the psychopath is involved in postlogic-backtracking-<iterative-looping-'set-of-dereifying-hollow-narrativesand-acts' $>$ in a committed drifting-circularity/roaming (of non-veridical dialectically-orcontendingly-out-of-phase narratives 'it wants to falsely represent veridically'), leading to temporal-dispositions slantedness/postlogic-effect, miscuing, disjointed-logic, logical-drag, 
unconscionability-drag, sub-par/formulaic-association/temporal/alibi conventioningrationalising, and temporal-enculturation/temporal-endemisation-effect (contrasted to ontologising/intemporal conventioning-rationalising) and temporal-enculturation/temporalendemisation effect, and these, hollow-constituting-<as-disjointed-misappropriation-ofmeaningfulness-and-failing-intemporal-preservation>, conjoining and conjugating to temporaldispositions of ${ }^{5}$ ignorance/affordability/opportunism/exacerbation/social-chainism-or-socialdiscomfiture-or-negative-social-aggregation/temporal-enculturation-or-temporal-endemisation, and fundamentally referenced from base ontologising effectivity (intemporal preservation); in ephemeral/temporal and ontologic/intemporal contrast, thus reflecting/perspectivating/highlighting (reasoning-through-and-not-reasoning-with) the ${ }^{15}$ dementation-〈supererogatory $\sim$ ontological-de-mentation-or-dialectical-de-mentation — strandingor-attributive-dialectics〉 of temporal-dispositions denaturing of social psychopathy (subknowledging $/$ mimicking) arising from initiating phenomenal psychopathy (subknowledging ${ }^{4}$ impulse) involving a distractive-alignment-to- ${ }^{8}$ reference-of-thought- $<$ ofapriorising/axiomatising/referencing $>{ }^{30}$ construal (as the backdrop of new recomposuring reference-of-thought- categorical-imperatives/axioms/registry-teleology ${ }^{9}$,-for-intemporalpreservation-entropy-or-contiguity-or-ontological-preservation and ultimately enabling its transcendental collapsing/overriding for psychoanalytic-unshackling/memeticreordering/institutional-recomposuring). That's how the 'given reality' is being subknowledged/registry-perverted. The technique to be utilised comprehensively for grasping the social psychopathy dynamism is by articulating an intemporal-referencing transversality$<$ for-sublimating-existential-eventuating/denouement,-from-'thinking-at-first/purepredisposition-preemptive-of-prospective-disontologising/subontologising' as-ofprospectively-disambiguated-affirmed-and-unaffirmed-'motif-and- 
construct (by intemporal transversality- $<$ for-sublimating-existential-eventuating/denouement-from-'thinking at first/pure-predisposition-preemptive-of-prospective-

disontologising/subontologising’ as-of-prospectively-disambiguated-affirmed-and-

unaffirmed-'motif-and-apriorising/axiomatising/referencing'> ${ }^{101}$ as from ontological-

normalcy/postconvergence is meant an approach that makes the given prelogism ${ }^{78}$-as-ofconviction,-in-profound-supererogation ${ }^{2}<$ existentially-veridical-'attendant-intradimensionalapriorising/axiomatising/referencing'-logical-dueness-precedes-disontologising-logical-

outcome-arrived-at> reality the 'reference of soundness-or-ontological-goodfaith/authenticity ${ }^{6}$-of- ${ }^{8}$ reference-of-thought/candor/organic-comprehension-thinking', and reorientating the mimicking-subknowledging ${ }^{4}$ into a slantedness/decandoring)/distractivealignment-to- ${ }^{8}$ reference-of-thought- $<$ of-apriorising/axiomatising/referencing $>{ }^{30}$ based on: 1 . Given prelogism ${ }^{78}$-as-of-conviction,-in-profound-supererogation $<<$ existentially-veridical'attendant-intradimensional-apriorising/axiomatising/referencing'-logical-dueness-precedesdisontologising-logical-outcome-arrived-at> reality actually being preconverging-ordementing -apriorising-psychologism/subknowledged/registry-perverted (which 'intemporalprioritisation-of- ${ }^{83}$ reference-of-thought'-as-conflatedness ${ }^{13}$-or-ontological-reprojecting should

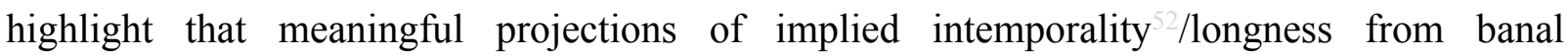
$<$ amplituding/formative $>$ wooden-language-〈imbued - averaging-of-thought-<as-toleveling/ressentiment/closed-construct-of- meaningfulness-and-teleology -as-of'nondescript/ignorable-void '-with-regards-to-prospective-apriorising-implications $>>$ are not veridically and demonstrable to be ontologically real and should be related to as being in distractive-alignment-to- ${ }^{8}$ reference-of-thought- $<$ of-

apriorising/axiomatising/referencing > 30/threshold-of-nonconviction/madeupness/bottomliningin-shallow-supererogation -<as-to- 'attendant-intradimensional'-prospectivelydisontologising preconverging/dementing -apriorising-psychologism $>$ and are rather involved 
in 'temporal preservation' and not intemporal-preservation-entropy-or-contiguity-orontological-preservation), 2. Psychopath's compulsive-slanting-preconverging-ordementing -apriorising (as dialectically-or-contendingly-out-of-phase or hollow-mimicking) in hollow-constituting-<as-disjointed-misappropriation-of-meaningfulness-and-failingintemporal-preservation> in postlogic-backtracking-<iterative-looping-'set-of-dereifyinghollow-narratives-and-acts' $>$ as absolving/fleeting/escaping-reflex-logic in committed 'circularity-of-extrinsic-attribution' (it should be noted that there is an internal contradiction reason why the psychopath in its postlogism 77 in hollow-constituting-<as-disjointedmisappropriation-of-meaningfulness-and-failing-intemporal-preservation>, and equally other temporal interlocutors mimicking the psychopath's postlogism 7 in hollow-constituting-<asdisjointed-misappropriation-of-meaningfulness-and-failing-intemporal-preservation>, will carry on such a 'circularity-of-extrinsic-attribution' as the need to square up to the priorly slanted hollow mimicking narratives call for new slanted hollow mimicking ${ }^{7}$ perversion-of- ${ }^{8}$ referenceof-thought-<as-preconvergingly-apriorising/axiomatising/referencing-innonconviction/madeupness/bottomlining-as-to-shallow-supererogation $>$ narratives even if it's just to get a respite to enable an interlocutor's or another interlocutor's prelogic/conviction-asto-profound-supererogation alignment to the new hollow mimicking postlogism ${ }^{77}$-formulaic slanting compulsing-nonconviction/madeupness/bottomlining-〈' $<$ decontextualising/deexistentialising $\sim$ of-attendant-intradimensional-apriorising/axiomatising/referencing $>$-induceddisontologising'-of-the-'attendant-intradimensional-ontologising'-imbued$<$ contextualising/existentialising attendant-ontological-contiguity $>$;-in-shallowsupererogation -<as-to-disontologising-perverted-outcome-sought-precedes-existentiallyveridical-'attendant-intradimensional-apriorising/axiomatising/referencing'-logical-dueness $>$ > narrative, a process known as absolving/fleeting/escaping-reflex-logic), 3. Psychopath's interlocutor's perversion-of- ${ }^{8}$ reference-of-thought- $<$ as-preconvergingly- 
apriorising/axiomatising/referencing-in-nonconviction/madeupness/bottomlining-as-to-

shallow-supererogation $>$ in $\quad$ hollow-constituting-<as-disjointed-misappropriation-ofmeaningfulness-and-failing-intemporal-preservation $>$ or ${ }^{12}$ conjoining-looping-set-of-narratives as-of-cohering-logic-reflex narratives integration from its prelogism ${ }^{7}$-as-of-conviction,-inprofound-supererogation ${ }_{-}<$existentially-veridical-'attendant-intradimensionalapriorising/axiomatising/referencing'-logical-dueness-precedes-disontologising-logical-

outcome-arrived-at> rationalisation of the last psychopath's postlogic non-veridical hollow mimicking narratives in circularity as well, 4 . Analyst's reflection/perspectivation of the above 3 mechanisms as postlogic/subknowledging $/$ mimicking/registry-perverting with contention never being about logical operation/processing/contention of the non-veridical hollow mimicking narratives but rather mental-slantedness/decandoring (distractive-alignment-toreference-of-thought- $<$ of-apriorising/axiomatising/referencing $>^{30}$ ) of the psychopath and the interlocutors as a 'manifestation of vice-and-impediment (never contention), i.e. REORIENTATION', 5. Analyst's intellectual articulation known as SUPRASTRUCTURING, wherein the ${ }^{103}$ universal ontological implication of social psychopathy dynamism across the human species (across space-and-time)/the social/ontological一 dementating/structuring/paradigming is drawn so that the principles so articulated can be applied in all incidental cases of social psychopathy dynamism (with the intellectual responsibility/relative-reflexivity of avoiding just an ad-hoc/circumstantial based analysis and never elevating such poor rationalisations into an ontology, i.e. avoid the extrication preconverging-de-mentating/structuring/paradigming). SUPRASTRUCTURING effectively involves: (a) 'registering'/ de-mentation-/supererogatory $\sim$ ontological-de-mentation-ordialectical-de-mentation - stranding-or-attributive-dialectics $\rangle$ of the ${ }^{7}$ perversion-ofreference-of-thought-<as-preconvergingly-apriorising/axiomatising/referencing-innonconviction/madeupness/bottomlining-as-to-shallow-supererogation $>$ associated with 
social psychopathy dynamism, i.e. ${ }^{80}$ procrypticism-or-disjointedness-as-of- ${ }^{3}$ reference-ofthought mental-slantedness/decandoring (b) 'superseding' by developing ${ }^{103}$ universal axiomatic construct/categorical-imperatives preempting '(a)' above which are habituated over a generation or two of the human species for notional ${ }^{18}$ deprocrypticism institutionalisation/intemporalisation transcendence-andsublimity/sublimation/supererogatory-de-mentativity involving its formalisations and internalisations (psychoanalytic-unshackling by: (i) articulating a social ${ }^{103}$ universaltransparency ${ }^{104}$-〈transparency-of-totalising-entailing,-as-to-entailing-<amplituding/formativeepistemicity>totalising in-relative-ontological-completeness $>$ of the registry-worldviewperversion, (ii) generating <amplituling/formative-epistemicity $>$ causality $\sim$ as-to-projectivetotalitative-implications-of-prospective- nonpresencing,-for-explicating relativeunreflexivity/relative-reflexivity ontological-contiguity 'internal contradiction' in the perversion-of- ${ }^{3}$ reference-of-thought-<as-preconvergingly-

apriorising/axiomatising/referencing-in-nonconviction/madeupness/bottomlining-as-toshallow-supererogation $>$ registry-worldview (iii) referencing/registering/decisioning or ${ }^{15}$ dementation-/supererogatory $\sim$ ontological-de-mentation-or-dialectical-de-mentation- - strandingor-attributive-dialectics $\rangle$ the perversion-of- ${ }^{73}$ reference-of-thought- $<$ as-preconverginglyapriorising/axiomatising/referencing-in-nonconviction/madeupness/bottomlining-as-toshallow-supererogation $>\quad{ }^{7}$ perversion-of- ${ }^{83}$ reference-of-thought- $<$ as-preconverginglyapriorising/axiomatising/referencing-in-nonconviction/madeupness/bottomlining-as-toshallow-supererogation $>$ /mental-perversion/dimension defect for prospective preemption with new recomposuring ${ }^{83}$ reference-of-thought- categorical-imperatives/axioms/registryteleology ,-for-intemporal-preservation-entropy-or-contiguity-or-ontological-preservation of the prospective registry-worldview/dimension (iv) intemporal projection superseding the transcendence-unenabling-uninstitutionalised-threshold ${ }^{102}$ in alienation-as-inauthentic/poorly- 
objectified/poorly-desubjectified-as-objectified/ontological-bad-faith/inauthenticity ${ }^{64} /$ nihilistic (being-dialectically-or-contendingly-out-of-phase/logically-incongruent/transversal)

reflect/perspectivate a mental-devising-representation of the superseded/transcended registryworldview/dimension as ontologically-preconverging-or-dementing ${ }^{20}$-apriorisingpsychologism/dialectical-preconverging-or-dementing -apriorising-psychologism

( 7 perversion-of- reference-of-thought-<as-preconvergingly-

\section{apriorising/axiomatising/referencing-in-nonconviction/madeupness/bottomlining-as-to-}

shallow-supererogation >/registry-worldview's/dimension's-uninstitutionalised-threshold ${ }^{102}$ defect-<as-Being-or-ontological-or-existential-defect $>5 /$ unsoundness-or-ontological-badfaith/inauthenticity ${ }^{64}$-of- ${ }^{8}$ reference-of-thought/mentalperversion/subknowledging 4 /mimicking-and-corresponding-<amplituding/formativeepistemicity>totalising $\sim$ self-referencing-syncretising), inducing a 'habituation' of the prospective/superseding/transcending registry-worldview/dimension crossgenerationally. For instance, preconverging/postconverging-de-mentatively/structurally/paradigmatically the positivistic mental frame is in alienated-disposition/logically-incongruent and generates internal contradiction towards the non-positivism/medievalism mental frame as otherwise you have $<$ ampliting/formative-epistemicity $>$ totalising $\sim$ self-referencing-

syncretising/circularity/interiorising/akrasiatic-drag ${ }^{34}$ or the referencing/registering/decisioning of meaning in terms-as-of-axiomatic-construct of the registry-worldview/dimension that needs to be superseded/preceded/overrided/uttered, for instance, retrospectively the 'God-of-plane'... type of proposition from an early animistic society which doesn't comes to terms with the prospective positivist worldview construct as it hangs on to its non-positivist ${ }^{83}$ reference-ofthought- ${ }^{-}$ategorical-imperatives/axioms/registry-teleology ${ }^{9}$, and this will equally apply prospectively between notional deprocrypticism and procrypticism as the procryptic mindset/ $/ 3$ reference-of-thought will strive to register meaning not prospectively taking account 
of procrypticism as a 'mental perversion/defect', and likewise retrospectively with the 'medieval mindset' with respect to the positivist mental frame. This obviously calls for an 'intellectual/scientism detachment' towards the ${ }^{71}$ perversion-of- ${ }^{3}$ reference-of-thought- $<$ aspreconvergingly-apriorising/axiomatising/referencing-in-

worldview/dimension, with an intemporal-disposition sense of contributing to the bigger possibilities for of the species, i.e. intemporal/ontological/social/species/ ${ }^{103}$ universal/transcendental/ $/{ }^{5}$ maximalisingrecomposuring-for-relative-ontological-completeness ${ }^{87}$ - unenframed/reontologising conceptualisation postconverging-de-mentating/structuring/paradigming as opposed to an extricatory or incremental or 'disjointedness-as-of- reference-of-thought' or temporal-accommodation preconverging-de-mentating/structuring/paradigming which is about temporal interest, and so, beyond 'temporal emotional involvement' or at 'reality personality' wherein the notion of human temporal compromising is not an ontological notion but rather

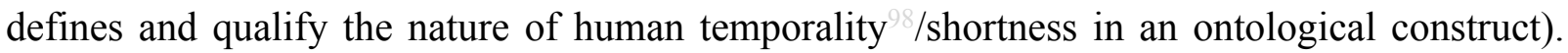
This way of \{epistemic-totalising $3{ }^{3}$ hermeneutic/textmality/reprojecting/supererogating/zeroing/reanting, $-{ }^{\{\text {decompulsing }}$ delinearity for-cogency 'ontological reasoning' to arrive at ' intemporal-orontological meaning' that is beyond any <amplituding/formative-epistemicity $>$ totalising $\sim$ selfreferencing-syncretising/self-centered/present-consciousness/illusion-of-the-present/mirage mental projection within just a given registry-worldview/dimension so as to 'grasp fundamental intemporal-disposition as of the inherent nature of existential-reality' is central to the notional ${ }^{18}$ deprocrypticism registry-worldview/dimension as a doppler-thinking exercise known as suprastructuralism. Suprastructuralism is grounded on ontological-normalcy/postconvergence insight and places 'abstract intrinsic-reality as of intemporal-preservation-entropy-orcontiguity-or-ontological-preservation' above the ${ }^{83}$ reference-of-thought- categorical- 
imperatives/axioms/registry-teleology devising (supposedly for intemporal-preservationentropy-or-contiguity-or-ontological-preservation) meant to represent it in a given registryworldview/dimension as prior/transcended/superseding (which as such is now construed as perversion-of- ${ }^{3}$ reference-of-thought-<as-preconvergingly-

apriorising/axiomatising/referencing-in-nonconviction/madeupness/bottomlining-as-to-

shallow-supererogation $>$ in the mental-devising-representation of intrinsic-reality/ontologicalveridicality, thus requiring new recomposuring ${ }^{83}$ reference-of-thought- categoricalimperatives/axioms/registry-teleology ${ }^{9}$ to 'preserve the abstract and intrinsic-reality as of intemporal-preservation-entropy-or-contiguity-or-ontological-preservation'.

Deprocrypticism's suprastructuralism involves 'intemporality ${ }^{52}$-symmetrising-bydesymmetrising-subsumption-of-temporality ${ }^{8}$, , for relative intrinsic-reality/ontologicalveridicality transcendental-enabling/sublimating/supererogatory $\sim$ de-mentativity existencepotency $^{32} \sim$ sublimating-nascence,-disclosed-from-prospective-epistemic-digression $\quad$ soconstrued as longness-of-register-of- ${ }^{-5}$ meaningfulness-and-teleology ${ }^{9}$ over shortness-ofregister-of- ${ }^{5}$ meaningfulness-and-teleology ${ }^{9}$ '; and so, beyond just about a prospective moral virtue but the prospective overall the-Good/knowledge-reification gesturing-and-accountingof-epistemic-phenomenalism- $<$ in-

prospective_psychologismic apriorising/axiomatising/referencing-\{of-'prospectively implicited_attendant-ontological-contiguity ' reducedexistentialising/contextualising/textualising_'intelligibility/epistemicity/reflexivity-contiguity<imbued-notional cogency >' \}-conflatedness -in-\{preconverging disentailment by\} postconverging-entailment $>$ /understanding/<amplituding/formativeepistemicity $>$ causality $\sim$ as-to-projective-totalitative-implications-of-prospectivenonpresencing,-for-explicating relative-unreflexivity/relative-reflexivity - ontologicalcontiguity construct as 'ontology and its subsuming of virtue', just as positivism is beyond just 
about a moral virtue but comprehensively an overall the-Good/knowledge-reification $\sim$ gesturingand-accounting - of-epistemic-phenomenalism- $<$ inprospective_psychologismic apriorising/axiomatising/referencing-\{of-'prospectively implicited_attendant-ontological-contiguity ' reducedexistentialising/contextualising/textualising_ 'intelligibility/epistemicity/reflexivity-contiguity<imbued-notional cogency $>$ ' \}-conflatedness -in-\{preconverging-disentailment by\} postconverging entailment $>$ /understanding/<amplituding/formative-

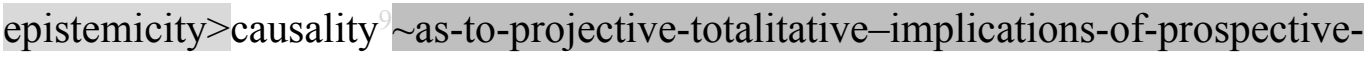
nonpresencing,-for-explicating relative-unreflexivity/relative-reflexivity - ontologicalcontiguity construct carrying a virtue that supersedes the vices-and-impediments ${ }^{105}$ of the nonpositivism/medievalism registry-worldvieww/dimension). It calls for a knowledge construct, whether social or physical, beyond just positivistic categorisation of knowledge but as 'ontological-normalcy/postconvergence referentialism as of intemporal-preservation-entropyor-contiguity-or-ontological-preservation ontology'. Thus, the doppler-thinking exercise of suprastructuralism enables the conceptualisation/construal of institutionalisation-orintemporalisation-or-intemporal-preservation-entropy-or-contiguity-or-ontological-

preservation in grasping the denaturing ${ }^{16}$ of ${ }^{83}$ reference-of-thought- ${ }^{\text {categorical- }}$ imperatives/axioms/registry-teleology ${ }^{9}$ as of ontological-normalcy/postconvergence basis of analysis, and by so doing grasping the precedingness/supersedingness/ascendency of intrinsicreality.

[Referentialism involves a ${ }^{83}$ reference-of-thought (so-characteristic of the prospective deprocrypticism registry-worldview/dimension) construing existence and existentialconceptualisation/construal as about the 'precedingness of becoming' as of apriorising/axiomatising/referencing-\{of-'prospectively_implicited_attendant_ontologicalcontiguity ' educed- 
existentialising/contextualising/textualising_'intelligibility/epistemicity/reflexivity-contiguity<imbued-notional cogency>' \}-conflatedness ${ }^{13}$-in-\{preconverging-disentailment by\} pestcenverging entailment rather than apriorising/axiomatising/referencing-\{of-"prospectively implicited_attendant-ontological-contiguity ' reducedexistentialising/contextualising/textualising_ 'intelligibility/epistemicity/reflexivity-contiguity<imbued-notional cogency $>\quad\}$ - constitutedness ${ }^{14}$-in preconverging-entailment (notwithstanding the instances of the latter's attendant approximating-nature for conceptualisation/construal rather construed as ${ }^{79}$ presencing-absolutising-identitiveconstitutedness ${ }^{14}$ ). apriorising/axiomatising/referencing- \{of-'prospectively implicited_attendant-ontological-contiguity ' educedexistentialising/contextualising/textualising_ intelligibility/epistemicity/reflexivity-contiguity<imbued-notional cogency>' $\}$-constitutedness ${ }^{4}$-in-preconverging-entailment tend to fallaciously imply 'existence of things in existence' whereas apriorising/axiomatising/referencing-\{of-'prospectively_implicited_attendant-ontologicalcontiguity ' $\sim$ educed-

existentialising/contextualising/textualising_'intelligibility/epistemicity/reflexivity_contiguity<imbued-notional cogency >' \}-conflatedness ${ }^{13}$ in (preconverging disentailment by postconverging-entailment rightly implies 'things becoming in existence rather as subsumed-inexistence in a superseding-oneness-of-ontology'; so because apriorising/axiomatising/referencing-\{of-'prospectively implicited_attendant-ontologicalcontiguity ' educedexistentialising/contextualising/textualising_ 'intelligibility/epistemicity/reflexivity-contiguity<imbued-notional cogency>' $\}$-constitutedness ${ }^{14}$ in precontmentma takes a simplistic shot at construal/conceptualisation of existential-reality practically presuming this to be 'effectively absolutely real and final' but then with human limited-mentation-capacity- 
deepening —as-subjecting limitedness/human-subpotency to-'educed-unlimitedness/existencesublimating nascence' ${ }^{5}$ this is erroneous hence the need for re-categorisation/re-adaptation/reclassification as 're-constitutedness ${ }^{14}$ of ${ }^{83}$ reference-of-thought' perpetually when aware of its deficiency. apriorising/axiomatising/referencing-\{of-'prospectively implicited_attendantontological-contiguity ' educed-

existentialising/contextualising/textualising_ 'intelligibility/epistemicity/reflexivity-contiguity<imbued-notional cogency >' \}-conflatedness ${ }^{13}$-in-\{preconverging - disentailment by\} pestconverging-entailment takes a shot at construal/conceptualisation of existential-reality from an open-ended insight/fugue as of referentialism from the more profound ontologicalnormalcy/postconvergence of existential-reality factoring in human limited-mentation-capacitydeepening —as-subjecting limitedness/human-subpotency-to-'educed-unlimitedness/existencesublimating nascence'53 as of metaphysics-of-absence-_implicited-epistemic-veracity-ofnonpresencing-<perspective-ontological-normalcy/postconvergence $>\rangle$, and as implied by the notion of intemporal-preservation-entropy-or-contiguity-or-ontological-preservation that goes beyond $<$ amplituding/formative $>$ wooden-language-〈imbued-temporal-mere-

\section{form/virtualities/dereification/akrasiatic-drag/denatured/preconverging-or-dementing}

narratives - of-the- reference-of-thought- categorical-imperatives/axioms/registry-

teleology $\rangle$ which are continually put-into-question, by being open-ended to upholding/notfailing intemporal-preservation-entropy-or-contiguity-or-ontological-preservation as of ontological-normalcy/postconvergence which always factor in human limited-mentationcapacity-deepening —as-subjecting limitedness/human-subpotency-to-'educed-

unlimitedness/existence-sublimating nascence' ${ }^{53}$ by a re-equilibrating metaphysics-of-absence〈implicited-epistemic-veracity-of- nonpresencing-<perspective-ontologicalnormalcy/postconvergence $>$ /postdication. Thus, apriorising/axiomatising/referencing-\{of'prospectively implicited_attendant-ontological-contiguity ' ceduced- 
existentialising/contextualising/textualising_'intelligibility/epistemicity/reflexivity-contiguity<imbued-notional cogency $\left.>^{\prime} \quad\right\}$-constitutedness ${ }^{14}$-in-preconverging-entailment will wrongly induce virtuality-or-ontologically-flawed-construal/being-construal-as-abstract-construal-as-offlawed-and-shallow-and-non-veridical-existential-reference, and so, with more and more profound defective construal/conceptualisation consequence with deeper and deeper categorisation and analysis. Often, and where aware, about the critical defective nature implied by apriorising/axiomatising/referencing-\{of-'prospectively implicited_attendant-ontologicalcontiguity ' educed-

existentialising/contextualising/textualising_'intelligibility/epistemicity/reflexivity-contiguity<imbued-notional cogency $\left.>^{\prime} \quad\right\}$-constitutedness ${ }^{14}$-in-preconverging-entailment $\quad$ in categorisation schemes, there will be re-categorisation/re-adaptation/re-classification as an attendant resetting resolution for the induced 'virtuality-or-ontologically-flawed-construal-ofconstitutedness ${ }^{14}$ of axiomatic-construct/ ${ }^{3}$ reference-of-thought' (by elaboration-as-to-mereextrapolating/constituting/abstracting/deducing/inferring-of-elucidation-outside'prospectively_implicited_attendant-ontological-contiguity ${ }^{67}$ ' educedexistentialising/contextualising/textualising_'intelligibility/epistemicity/reflexivity-contiguity$<$ imbued-notional $\sim$ cogency $>^{\prime 0}$ ) that will then require another attendant resetting resolution for the subsequently induced 'virtuality-or-ontologically-flawed-construal-of-constitutedness ${ }^{14}$ of reference-of-thought' down the line when aware of its further critical defect again (though, in a sense the entire recomposuring process could be qualified as a "practical ${ }^{79}$ presencingabsolutising-identitive-constitutedness ${ }^{14}$ exercise). But then the inherent nature of existence in relation to human limited-mentation-capacity-deepening —as-subjecting limitedness/humansubpotency to 'educed mnlimitedness/existence sublimating naseence' ${ }^{53}$ construal of it is one of evasiveness as implied by the 'sublimating-epistemicimbricatedness/threadedness/recomposuring as of 'implicited_attendant-ontological- 
contiguity ${ }^{67} \sim$ educed-

existentialising/contextualising/textualising_'intelligibility/epistemicity/reflexivity_contiguity-

$<$ imbued-notional $\sim$ cogency $>,{ }^{\prime},-<$ reifying-or-elucidating-of-prospective-relative-ontological-

completeness -of- reference-of-thought- devolving-as-of-instantiative-context $>$ as to

existence-potency ${ }^{39} \sim$ sublimating-nascence,-disclosed-from-prospective-epistemic-

digression—rules-of-apriorising/axiomatising/referencing-that-further-epistemically-

unconceal-the-very-ontologically-same-existential-reality' such that we are only occasionally and partially aware about the critical defective nature implied by apriorising/axiomatising/referencing-\{of-'prospectively implicited_attendant-ontological-

contiguity ' educed-

existentialising/contextualising/textualising_intelligibility/epistemicity/reflexivity_contiguity-

<imbued-notional cogency>' $\}$-constitutedness ${ }^{- \text {in }}$-preconverging-entailment $\quad$ in

categorisation schemes, thus fundamentally defining the limits even of a presencingabsolutising-identitive-constitutedness ${ }^{14}$ as of existential-conceptualisations/construals. The implication is beyond just the notion of knowledge construal/conceptualisation categorisation schemes and scheming but extends to the very inherent construal/conceptualisation of knowledge as of its implied ontological and virtue construct itself; so because the preconverging/postconverging-de-mentative/structural/paradigmatic basis of categorisation scheming are equally the preconverging/postconverging-de-mentative/structural/paradigmatic basis of the inherent analysis and ${ }^{56}$ meaningfulness-and-teleology ${ }^{9}$ construed/conceptualised. Since categorisation schemes (whether construed/conceptualised beyond-the-consciousnessawareness-teleology ${ }^{9}<$ of-preconverging-existential-extrication-as-of-existential-

unthought> ) define the " ${ }^{\text {r }}$ reference-of-thought of categorisation construal/conceptualisation of knowledge', it is critical to grasp that the inherent preconverging/postconverging-dementative/structural/paradigmatic limits/defects of such " ${ }^{83}$ reference-of-thought of 
categorisation construal/conceptualisation of knowledge' are systemic hence inducing 'flawedexistential-elevation-of- ${ }^{8}$ reference-of-thought ${ }^{4}$, as of ontological and virtue implications (as ontologically-perspectival-degraded-as-decentered/preconverging-or-dementing ${ }^{20}$ reflexive/entailing-teleology ${ }^{9}$-differentiation-as-of-subtransversality-<in-desublimatingexistential-eventuating/denouement $>\sim$ of-motif-and-apriorising/axiomatising/referencing) at the given ' ${ }^{83}$ ference-of-thought of categorisation construal/conceptualisation of knowledge'. Beyond its conceptualisation as of knowledge categorisation and categorisation scheming but rather as of effective ontological-and-virtue conceptualisation/construal, apriorising/axiomatising/referencing-\{of-"prospectively implicited_attendant-ontologicalcontiguity ' educedexistentialising/contextualising/textualising_'intelligibility/epistemicity/reflexivity-contiguity<imbued-notional cogency>' $\}$ - constitutedness ${ }^{1}$-in-preconverging-entailment implies a simplistic/trite categorical relation in the construal/conceptualisation of ${ }^{56}$ meaningfulness-andteleology ${ }^{9}$ as of its ontological and virtue essence that is susceptible to defect as ${ }^{7}$ perversionof- reference-of-thought-<as-preconvergingly-apriorising/axiomatising/referencing-innonconviction/madeupness/bottomlining-as-to-shallow-supererogation $>$ or derivedperversion-of- ${ }^{3}$ reference-of-thought-<as-preconverginglyapriorising/axiomatising/referencing-in-nonconviction/madeupness/bottomlining-as-toshallow-supererogation >; and as such, apriorising/axiomatising/referencing-\{of'prospectively implicited_attendant-ontological-contiguity ' educedexistentialising/contextualising/textualising_'intelligibility/epistemicity/reflexivity-contiguity<imbued-notional cogency $>$ ' $\}$ - constitutedness ${ }^{14}$-in-preconverging-entailment will speak of subtransversality-<in-desublimating-existential-eventuating/denouement $>\sim$ of-motif-andapriorising/axiomatising/referencing and various shades of temporality $/$ shortness in their ‘apriorising/axiomatising/referencing-\{of-‘prospectively_implicited_attendant-ontological- 
contiguity ' $\sim$ educed-

existentialising/contextualising/textualising_'intelligibility/epistemicity/reflexivity_contiguity$<$ imbued-notional $\left.\sim \operatorname{cogency}>^{\prime}\right\}$-constitutedness ${ }^{14}$-in-preconverging-entailment $\quad$ and conjugated apriorising/axiomatising/referencing-\{of-'prospectively implicited_attendantontological-contiguity ' educed-

existentialising/contextualising/textualising_'intelligibility/epistemicity/reflexivity_contiguity<imbued-notional cogency> $\left.{ }^{\prime} \quad\right\}$ - constitutedness ${ }^{1}$-in-preconverging-entailment $\quad$ of reference-of-thought' including psychopathic slantedness apriorising/axiomatising/referencing-\{of-'prospectively_implicited_attendant-ontologicalcontiguity ' $\sim$ educed-

existentialising/contextualising/textualising_'intelligibility/epistemicity/reflexivity-contiguity$<$ imbued-notional cogency $\left.>^{\prime} \quad\right\}$-constitutedness ${ }^{1}$-in-preconverging-entailment. $\quad$ The comparison highlighted further below with respect to the 6 BODMAS characters and character A (Addition) as the additionality defect character, is most telling of the inherent nature of human limited-mentation-capacity-deepening —as-subjecting-limitedness/human-subpotency-to'educed-unlimitedness/existence-sublimating nascence' ${ }^{53}$ induced apriorising/axiomatising/referencing-\{of-'prespectively implicited_attendant-ontologicalcontiguity ' $\sim$ educedexistentialising/contextualising/textualising_'intelligibility/epistemicity/reflexivity-contiguity<imbued-notional cogency $\left.>^{\prime} \quad\right\}$-constitutedness ${ }^{14}$-in-preconverging-entailment which is conceptually associated with conceptualisation/construal of 'human temporal uninstitutionalised-threshold ${ }^{102}$ mental-disposition' (since such a construal fully reflect the reality of a human temporal-to-intemporal ${ }^{83}$ reference-of-thought nature, with high 'apriorising/axiomatising/referencing-\{of-'prospectively_implicited_attendant-ontologicalcontiguity ' educed- 
existentialising/contextualising/textualising_intelligibility/epistemicity/reflexivity-contiguity<imbued-notional cogency>' $\}$-constitutedness ${ }^{-}$-in-preconverging-entailment $\quad$ and conjugated apriorising/axiomatising/referencing-\{of-'prospectively implicited_attendantontological-contiguity ' educedexistentialising/contextualising/textualising_ 'intelligibility/epistemicity/reflexivity-contiguity<imbued-notional cogency $>\quad\}$-constitutedness ${ }^{14}$-in preconverging-entailment $\quad$ of reference-of-thought' of temporal-dispositions ${ }^{83}$ reference-of-thought, much like the 'conjugated apriorising/axiomatising/referencing-\{of-'prospectively implicited_attendantontological-contiguity ' educedexistentialising/contextualising/textualising_'intelligibility/epistemicity/reflexivity_contiguity<imbued-notional cogency $>\quad\}$-constitutedness ${ }^{14}$-in-preconverging-entailment $\quad$ of reference-of-thought' of the other BODMAS characters to A's fundamental postlogism slantedness pathological condition/constitutedness ${ }^{14}$ as when insisting on upholding the $<$ amplituding/formative $>$ wooden-language-〈imbued-temporal-mereform/virtualities/dereification/akrasiatic-drag/denatured/preconverging-or-dementing narratives - of-the- reference-of-thought- categorical-imperatives/axioms/registryteleology $>$ and not factoring in A's underlying condition and defect as apriorising/axiomatising/referencing-\{of-'prospectively_implicited_attendant-ontologicalcontiguity ' $\sim$ educedexistentialising/contextualising/textualising_ 'intelligibility/epistemicity/reflexivity-contiguity$<$ imbued-notional cogency $>$ ' $\}$-constitutedness ${ }^{14}$-in preconverging-entailment, and so out of sync with the 'implicited_attendant-ontological-contiguity ${ }^{67}$; educedexistentialising/contextmalising/textualising_intelligibility/epistemicity/reflexivity_contiguity$<$ imbued-notional $\sim \operatorname{cogency}>,{ }^{\prime},-<$ reifying-or-elucidating-of-prospective-relative-ontologicalcompleteness -of- reference-of-thought- devolving-as-of-instantiative-context $>$ as the more 
fundamental a-priori whose sublimating-epistemic-imbricatedness/threadedness/recomposuring reveals the fundamental defect of applying additionality ${ }^{83}$ reference-of-thought- categoricalimperatives/axioms/registry-teleology 9 by elaboration-as-to-mereextrapolating/constituting/abstracting/deducing/inferring-of-elucidation-outside'prospectively_implicited_attendant-ontological-contiguity ${ }^{67}$ ' educedexistentialising/contextualising/textualising_intelligibility/epistemicity/reflexivity-contiguity$<$ imbued-notional cogency $>^{\prime}$.). The resolution by sublimating-epistemicimbricatedness/threadedness/recomposuring is most telling of the inherent nature of apriorising/axiomatising/referencing-\{of-'prospectively implicited_attendant-ontologicalcontiguity ' educedexistentialising/contextualising/textualising_'intelligibility/epistemicity/reflexivity-contiguity<imbued-notional cogency >' \}-conflatedness ${ }^{13}$-in-\{preconverging-disentailment by\} postconverging-entailment which is conceptually associated with 'human registryworldview's/dimension's institutionalisation mental-disposition'; as apriorising/axiomatising/referencing-\{of-'prospectively_implicited_attendant-ontologicalcontiguity ' educedexistentialising/contexalising/textising_intelligibility/epistemicity/reflexivity-contiguity<imbued-notional cogency>' \}-conflatedness ${ }^{13}$-in-\{preconverging-disentailment by\} postconverging-entailment speaks of a more profound relation in the construal/conceptualisation of ${ }^{5}$ meaningfulness-and-teleology 9 as of its ontological and virtue essence that is susceptible to uphold intemporal-preservation-entropy-or-contiguity-or-ontological-preservation as of ontological-normalcy/postconvergence which always factor in human limited-mentationcapacity-deepening - as subjecting limitedness/human-subpotency to 'educedunlimitedness/existence-sublimating nascence' ${ }^{53}$ by a re-equilibrating metaphysics-of-absence〈implicited-epistemic-veracity-of- nonpresencing-<perspective-ontological- 
normalcy/postconvergence $>$ /postdication, and so even when elaboration-as-to-mereextrapolating/constituting/abstracting/deducing/inferring-of-elucidation-outside-

'prospectively_implicited_attendant_ontological-contiguity ${ }^{67}$ ' educedexistentialising/contextualising/textualising_intelligibility/epistemicity/reflexivity-contiguity$<$ imbued-notional cogency>' is denaturing as exposed by 'implicited_tentant ontological-contiguity ${ }^{67} \sim$ educed-

existentialising/contextualising/textualising_intelligibility/epistemicity/reflexivity-contiguity$<$ imbued-notional $\sim$ cogency $>,{ }^{\prime},-<$ reifying-or-elucidating-of-prospective-relative-ontologicalcompleteness -of- reference-of-thought- devolving-as-of-instantiative-context $>$, to further construe new ${ }^{83}$ reference-of-thought- categorical-imperatives/axioms/registry-teleology ${ }^{9}$,-forintemporal-preservation-entropy-or-contiguity-or-ontological-preservation factoring in the imbricatedness/threadness/recomposuring reflecting the 'implicited_attendant-ontologicalcontiguity ${ }^{67} \sim$ educed-

existentialising/contextualising/textualising_'intelligibility/epistemicity/reflexivity-contiguity$<$ imbued-notional $\sim$ cogency $>,,<$, $<$ reifying-or-elucidating-of-prospective-relative-ontologicalcompleteness -of- reference-of-thought- devolving-as-of-instantiative-context>.

apriorising/axiomatising/referencing-\{of-'prospectively implicited_attendant-ontologicalcontiguity ' educedexistentialising/contextualising/textualising_'intelligibility/epistemicity/reflexivity-contiguity-

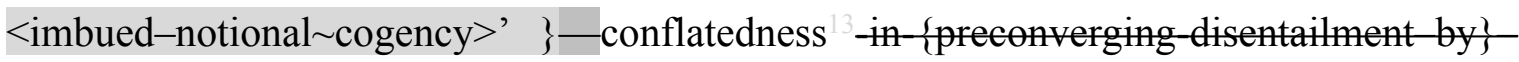
postconverging-ntailment, as so-construed in referentialism, by striving to sync with the very inherent evasive nature of existence in its sublimating-epistemicimbricatedness/threadedness/recomposuring (with respect to human limited-mentationcapacity-deepening —as-subjecting limitedness/human-subpotency-to-'educed-

unlimitedness/existence-sublimating nascence' ${ }^{53}$ ) as of referentialism is absolutely referencing 
on the basis of ontological-normalcy/postconvergence or intemporal-preservation-entropy-orcontiguity-or-ontological-preservation as being the preceding notion for construal/conceptualisation with respect to implicited_attendant-ontologicalcontiguity $^{67}$, educed-

existentialising/contextualising/textualising_intelligibility/epistemicity/reflexivity-contiguity$<$ imbued-notional cogency $>,{ }^{\prime},-<$ reifying-or-elucidating-of-prospective-relative-ontologicalcompleteness -of- reference-of-thought- devolving-as-of-instantiative-context>, and so grasped as apriorising/axiomatising/referencing-\{of-'prospectively implicited_attendantontological-contiguity ' educed-

existentialising/contextualising/textualising_'intelligibility/epistemicity/reflexivity-contiguity$<$ imbued-notional $\left.\sim \operatorname{cogency}>^{\prime},\right\}$-conflatedness ${ }^{13}$-in-\{preconverging-disentailment by postconverging-entailment emphasises projective-insights for upholding ontologicalnormalcy/postconvergence or intemporal-preservation-entropy-or-contiguity-or-ontologicalpreservation. Hence apriorising/axiomatising/referencing- \{of-" prospectively implicited_attendant-ontological-contiguity ' educedexistentialising/contextualising/textualising_'intelligibility/epistemicity/reflexivity_contiguity<imbued-notional cogency >' \}-conflatedness ${ }^{13}$ in (preconverging disentailment by postconverging-ntailment will tend to avoid systemic defects of analysis associated with apriorising/axiomatising/referencing-\{of-'prospectively implicited_attendant-ontologicalcontiguity ' educedexistentialising/contextualising/textualising_'intelligibility/epistemicity/reflexivity-contiguity$<$ imbued-notional cogency $>$ ' $\quad$ - constitutedness ${ }^{14}$-in- preconverging-entailment requiring recategorisation/re-adaptation/re-classification as ' 7 presencing-absolutising-identitiveconstitutedness ${ }^{14}$. apriorising/axiomatising/referencing-\{of-'prospectively implicited_attendant-ontological-contiguity ' educed- 
existentialising/contextualising/textualising_ 'intelligibility/epistemicity/reflexivity-contiguity-

$<$ imbued-notional cogency $>$ ' $\}$-conflatedness ${ }^{13}$ in-\{preconverging-disentailment by\}

pestcenverging entailment is thus naturally inclined to induce 'appropriate-existential-elevationof- reference-of-thought' by the ontological and virtue implications (as ontologicallyperspectival-elevated/pedestaling-as-postconverging-or-dialectical-thinking -differentiationas-of-supratransversality-<in-sublimating-existential-eventuating/denouement $>\sim$ of-motif-andapriorising/axiomatising/referencing). As so articulated, these two concepts operantly address in a storied-construct/ontologically-valid-narration or any other operant conceptualisation the notion of a différance-disambiguation-of-ontologically-veridical- ${ }^{56}$ meaningfulness-andteleology as meaning produced apparently with the 'same-terms-of-expressions/seeminglysame-implied-meaningfulness' (seemingly of veridical-ontological ${ }^{83}$ reference-of-thoughtcategorical-imperatives/axioms/registry-teleology ${ }^{9}$, ,for-intemporal-preservation-entropy-orcontiguity-or-ontological-preservation in the various instances) but actually implying 'different relations to an ontologically veridical ${ }^{8}$ reference-of-thought', underlined by the disambiguated notional firstnaturedness-formativeness-<as-to-eventualising inkling-drive-or-seedingmisprising $>$ temporal-to-intemporal-dispositions- $<$ so-construed-as-from-perspectiveontological-normalcy/postconvergence>. Further, apriorising/axiomatising/referencing-\{of'prospectively implicited_attendant-ontological-contiguity ' educedexistentialising/contextualising/textualising_ 'intelligibility/epistemicity/reflexivity-contiguity<imbued-notional cogency $\left.>^{\prime} \quad\right\}$-constitutedness ${ }^{14}$-in-preconverging-entailment $\quad$ and apriorising/axiomatising/referencing-\{of-'prospectively implicited_attendant-ontologicalcontiguity ' educedexistentialising/contextrising/textralising_intelligibility/epistemicity/reflexivity-contiguity$<$ imbued-notional cogency $\left.>{ }^{\prime}\right\}$-conflatedness ${ }^{13}$-in-\{preconverging-disentailment by\} postcenverging entailment, as so articulated, are such fundamental notions with respect to how 
humans limited-mentation-capacity-deepening —as-subjecting limitedness/human-subpotencyto-'educed-unlimitedness/existence-sublimating nascence' ${ }^{3}$ come to grasp existentialreality/ontological-veridicality that these two underlying notions are critically definitional relative to existential-construal/conceptualisation of understanding and failing-understanding, and insightfully explain the fundamental basis of the consecutive transformations of human psychologisms as induced by 'postconverging-or-dialectical-thinking -psychology or psychology-of-mentation-dynamics or natural psychological-dynamics’ at the transcendental/transdimensional/interdimensional-level of institutionalisations as well as at the individuation-level with respect to conception and misconceptions of ${ }^{56}$ meaningfulness-andteleology not only with respect to understanding but equally dynamics of 'personality formation and teleological-differentiation', and so specifically as associated with the dynamics implied of a human-subpotency-aporia/undecidability/dilemma/oughtindeterminacy/deficiency/limitation/constraint—imbued-'notional firstnaturednessformativeness-<as-to-eventualising-inkling drive-or-seeding-misprising $>$ temporal-tointemporal-dispositions-<so-construed-as-from-perspective-ontologicalnormalcy/postconvergence>'-existentialism-form-factor, further reflected in the overall dynamics of postlogism 77 and conjugated-postlogism 77 (including the dynamics of psychopathy and social psychopathy as social reprising out of 'implicited_attendant-ontologicalcontiguity $^{67} \sim$ educedexistentialising/contextualising/textualising_'intelligibility/epistemicity/reflexivity-contiguity$<$ imbued-notional $\sim$ cogency $>,{ }^{\prime},-<$ reifying-or-elucidating-of-prospective-relative-ontologicalcompleteness -of- reference-of-thought- devolving-as-of-instantiative-context> of psychopathic pathological insane-fitment, as of fundamental/most-simplistic apriorising/axiomatising/referencing-\{of-'prospectively implicited_attendant-ontologicalcontiguity ' educed- 
existentialising/contextualising/textualising_ 'intelligibility/epistemicity/reflexivity-contiguity<imbued-notional cogency >' $\}$-constitutedness ${ }^{14}$-in-preconverging-entailment $\quad$ socially reprised with 'conjugated apriorising/axiomatising/referencing-\{of-'prospectively implicited_attendant-ontological-contiguity ' reducedexistentialising/contextualising/textualising_ 'intelligibility/epistemicity/reflexivity-contiguity<imbued-notional cogency $>\quad\}$-constitutedness ${ }^{14}$-in preconverging-entailment $\quad$ of reference-of-thought') as well as grasping fundamental dynamics of institutions and especially as influenced by the extended-informality-〈susceptible-to-effecting-parsimony-as-ofshoddiness-and-incompleteness-to- meaningfulness-and-teleology $\rangle$ which is highly subject to the reality of human-subpotency-aporia/undecidability/dilemma/oughtindeterminacy/deficiency/limitation/constraint—imbued-‘notional firstnaturednessformativeness-<as-to-eventualising-inkling drive-or-seeding misprising $>$ temporal-tointemporal-dispositions- $<$ so-construed-as-from-perspective-ontologicalnormalcy/postconvergence>'-existentialism-form-factor (emphasising socially-functional-andaccordant ${ }^{9}$ thresholds rather than utter ontology, thus giving room for 'least-and-derivedtemporal-operating-modalities-of-the- ${ }^{8}$ reference-of-thought-as-of- incrementalism-inrelative-ontological-incompleteness —enframed/disontologising conceptualisation-inducingthe-uninstitutionalised-threshold ${ }^{102}$ '). These two concepts are critical relative to grasping and analysing human choice/notions relative to ${ }^{83}$ reference-of-thought- categoricalimperatives/axioms/registry-teleology of meaningful-frameworks. Other implications have to do with human personality development psychology in relation to meaningfulness extending to the construal/conceptualisation of language development as well as aesthetics and virtue as reflecting holographically-<conjugatively-and-transfusively $>$ the relative-unreflexivity/relativereflexivity - ontological-contiguity of-the-human-institutionalisation-process . In a further elaboration of apriorising/axiomatising/referencing-\{of-'prospectively implicited_attendant- 
ontological-contiguity ' educed-

existentialising/contextualising/textualising_'intelligibility/epistemicity/reflexivity_contiguity<imbued-notional cogency>’ $\}$ - constitutedness ${ }^{14}$-in-preconverging-entailment $\quad$ and apriorising/axiomatising/referencing-\{of-'prospectively implicited_attendant-ontologicalcontiguity ' educedexistentialising/contextualising/textualising_'intelligibility/epistemicity/reflexivity-contiguity<imbued-notional cogency $\left.>^{\prime}\right\}$-conflatedness ${ }^{13}$-in-\{preconverging-disentailment by postconverging-entailment with respect to psychologism, the reason why a prospective/transcending/superseding registry-worldview/dimension needs its own knowledgeconstruct ${ }^{83}$ reference-of-thought psychologism has to do with the fact that every registryworldview/dimension has 'its own specific apriorising/axiomatising/referencing-\{of'prospectively_implicited_attendant-ontological-contiguity ' educedexistentialising/contextualising/textualising_ 'intelligibility/epistemicity/reflexivity-contiguity$<$ imbued-notional cogency $\left.>^{\prime} \quad\right\}$ - constitutedness ${ }^{4}$-in-preconverging-entailment/conflation psychological complex reflex mechanism' wherein its limits in the construal/conceptualisation of intrinsic-reality/ontological-veridicality are defined, and this is subpar to the prospective/transcending/superseding registry-worldview/dimension knowledge-construct reference-of-thought which thus needs its own corresponding psychologism for its superseding meaningfulness-and-teleology , achieved by ' ${ }^{99}$ presencing-absolutising-identitiveconstitutedness $^{1,}$ as apriorising/axiomatising/referencing-\{of- prospectively implicited_attendant-ontological-contiguity ' educedexistentialising/contextualising/textualising_intelligibility/epistemicity/reflexivity_contiguity-

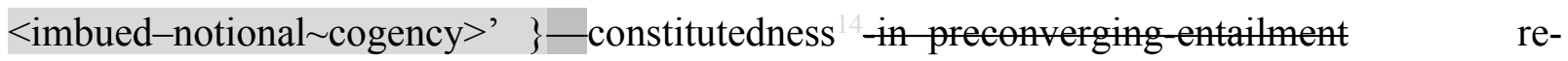
categorisation/re-adaptation/re-classification'. Consider the example of the 'God-of-plane' type of expression in an animistic/base-institutionalisation setup, where their fundamental 
psychologism is so ingrained that every meaningfulness from a positivistic social-setup cultural diffusion is inevitably reconstrued in the animistic/base-institutionalisation psychologism, until down the line the latter's ${ }^{56}$ meaningfulness-and-teleology ${ }^{9}$ amplituding/formativeepistemicity $>$ totalising $\sim$ self-referencing-syncretising/circularity/interiorising/akrasiatic-drag ${ }^{34}$, by way of continuous " 7 presencing — absolutising-identitive-constitutedness ${ }^{1 \text { ' }}$ as 'recurrent recategorisation/re-adaptation/re-classification of the prior apriorising/axiomatising/referencing\{of-‘prospectively_implicited_attendant-ontological-contiguity ' educedexistentialising/contextualising/textualising_'intelligibility/epistemicity/reflexivity-contiguity<imbued-notional cogency>' $\}$ - constitutedness ${ }^{14}$-in-preconverging-entailment of reference-of-thought' is critically rid of the very essence of animistic/base-institutionalisation psychologism inducing an overall break into a positivism psychologism. It is interesting to note that going by the psychologism of a base-institutionalisation social-setup ${ }^{83}$ reference-of-thought for instance, the idea of arithmetic as we may grasp today in a positivistic registryworldview/dimension Being-development/ontological-framework-expansion-as-to-depth-ofontologising-development-as-infrastructure-of- meaningfulness-and-teleology , and as of its operant nature, isn't the case in its operant conceptualisation in such a base-institutionalisation social-setup <emplituding/formative-epistemicity $>$ totalising/circumscribing/delineating reference-of-thought- devolving-as-of-instantiative-context- ${ }^{5}$ meaningfulness-andteleology as rather the mental-disposition apriorising/axiomatising/referencing/intelligibilitysettingup/measuringinstrumenting in the use of numbers is more about acting in currying favours or in view to receiving favours meaningfully as of $\quad<$ amplituding/formative-epistemicity $>$ totalising $\sim$ nominal-as-tendentious'implicitantontological-contiguity ${ }^{67}$ ' educedexistentialising/contextualising/textualising_intelligibility/epistemicity/reflexivity-contiguity$<$ imbued-notional $\sim$ cogency>' ;-phenomenal-abstractiveness-of-presencing-in-'warped- 
consciousness'-enabling-

apriorising/axiomatising/referencing/intelligibilitysettingup/measuringinstrumenting-foroperant-or-incidenting-predicative-insights-of 'implicited_attendant-ontologicalcontiguity ${ }^{67} \sim$ educedexistentialising/contextualising/textualising_intelligibility/epistemicity/reflexivity-contiguity$<$ imbued-notional cogency $>{ }^{,},-<$reifying-or-elucidating-of-prospective-relative-ontologicalcompleteness -of- reference-of-thought- devolving-as-of-instantiative-context>' (as can be observed by anthropologists in various forms in many a hunter-gatherer and animist societies), rather than use of numbers considered as of such a relatively independent-domain and exactness of ${ }^{5}$ meaningfulness-and-teleology ${ }^{9}$ orientation as we construe of arithmetic and mathematics in say a universalisation or positivism registry-worldview/dimension Beingdevelopment/ontological-framework-expansion-as-to-depth-of-ontologising-development-asinfrastructure-of- meaningfulness-and-teleology $<$ amplituding/formativeepistemicity $>$ totalising/circumscribing/delineating ${ }^{83}$ reference-of-thought- ${ }^{8}$ devolving. Thus use of numbers is defined by other ideas in such early hunter-gather and animist societies given Being-development/ontological-framework-expansion-as-to-depth-of-ontologisingdevelopment-as-infrastructure-of- meaningfulness-and-teleology like the notion of wealth accumulation, which will be predominantly about 'inducing a sense of social obligation or faithfulness or deference' from other persons, and so together with other cultural peculiarities that avoid hoarding and emphasise wealth display, gifts, etc. Psychologism (as being central in apriorising/axiomatising/referencing-\{of-'prospectively_implicited_attendant-ontologicalcontiguity ' educedexistentialising/contexalising/texalising_intelligibility/epistemicity/reflexivity-contiguity$<$ imbued-notional cogency $\left.>{ }^{\prime}\right\}$-conflatedness ${ }^{13}$-in-\{preconverging-disentailment by\} pestconverging-entailment or rather ' ${ }^{6}$ presencing — absolutising-identitive-constitutedness ${ }^{1{ }^{\prime}}$ ' as 
apriorising/axiomatising/referencing-\{of-'prospectively implicited_attendant-ontologicalcontiguity ' $\sim$ educed-

existentialising/contextualising/textualising_'intelligibility/epistemicity/reflexivity-contiguity<imbued-notional cogency $\left.>{ }^{\prime} \quad\right\}$-constitutedness ${ }^{14}$-in-preconverging-entailment), refers to the underlying human reflex mental scheme of a given registry-worldview's/dimension's reference-of-thought 'allowing for its given capacity to supersede its psychological complex in construing <amplituding/formative-epistemicity $>$ causality $\sim$ as-to-projective-totalitativeimplications-of-prospective- nonpresencing,-for-explicating relative-unreflexivity/relativereflexivity - ontological-contiguity transcendental-enabling/sublimating/supererogatory $\sim$ dementativity and corresponding ${ }^{56}$ meaningfulness-and-teleology ${ }^{99}$. The bigger question could be asked; why doesn't humans in recurrent-utter-uninstitutionalisation spontaneously articulate and relate to ${ }^{5}$ meaningfulness-and-teleology ${ }^{9}$ as humans in base-institutionalisationununiversalisation, who do not do likewise as humans in ${ }^{103}$ universalisation-nonpositivism/medievalism, who do not do likewise as humans in positivism- ${ }^{80}$ procrypticism? Is it a difference in species, as of successive species? Obviously, no! As we know from history and anthropology that cultural diffusion has shown that all humans are able to come to terms and operate at the highest forms of human registry-worldview's/dimension's institutionalisation. This fundamentally points to the centrality of a registry-worldview's/dimension's ${ }^{83}$ referenceof-thought psychologism 'placeholder-setup/mentation/mental-devisingrepresentation/consciousness-awareness-teleology ${ }^{9}$ as arising and determined by its specific limited-mentation-capacity—as-subjecting 'educed-unlimitedness/existence-sublimating nascence' to-limitedness/human-subpotency-〈as from relative apriorising/axiomatising/referencing-\{of-'prospectively implicited_attendant-ontologicalcontiguity ' educed- 
existentialising/contextualising/textualising_'intelligibility/epistemicity/reflexivity-contiguity-

<imbued-notional cogency>' $\}$-constitutedness ${ }^{- \text {in }}$ - preconverging-entailment to relative apriorising/axiomatising/referencing-\{of-'prospectively_implicited_attendant-ontologicalcontiguity ' educed-

existentialising/contextualising/textualising_intelligibility/epistemicity/reflexivity-contiguity$<$ imbued-notional cogency $\left.>^{\prime} \quad\right\}$-conflatedness ${ }^{13}$-in-\{preconverging-disentailment by\} postconverging-entailment $\rangle$ construal/conceptualisation as soundness-or-ontological-goodfaith/authenticity ${ }^{6}$-of- ${ }^{8}$ reference-of-thought'. The underlying human psyche is in need of a 'framework of intelligibility conception/conceptualisation' as its mental-scheme (psychologism) by which humans, given their limited-mentation-capacity-deepening-as-subjecting limitedness/human-subpotency-to-'educed-unlimitedness/existence-sublimating nascence'53, can then project 'mental and existential-<disontologising/re-ontologising aporeticism> investment' in a world of perceived stakes (social, natural and/or supernatural) in a 'social framework of intersolipsistic deambulation' (which holds the resources for individual and collective human possibilities, like prior developed culture, language, skills, etc. available for individual and collective intersolipsistic exploitation and renewal). Noting that at stake is its existential-<disontologising/re-ontologising aporeticism $>$ survival and thriving, and so it is involved in a relative zero-sum game of existential-<disentologising/re-ontologising aporeticism $>$ possibilities, on the basis of its limited-mentation-capacity-deepening-assubjecting limitedness/human-subpotency-to-'educed-unlimitedness/existence-sublimating nascence' determining its prospective relative-ontological-completeness ${ }^{87}$-of- ${ }^{5}$ reference-ofthought, as enabled by the 'social framework of intersolipsistic deambulation'. This 'social framework of intersolipsistic deambulation' is highly linear as of the possibilities for construing human psychical and institutional readjustments in inducing successive institutionalcumulation/institutional-recomposure-〈as-to- historiality/ontological- 
eventfulness /ontological-aesthetic-tracing-<perspective-ontological-

normalcy/postconvergence-reflected-'epistemicity-relativism-determinism'>> which are thus equally in a linearity. This notion of 'social framework of intersolipsistic deambulation' harkens back to that of human registry-worldview's/dimension's institutionalisation by its sociallyfunctional-and-accordant ${ }^{3}$ thresholds of notional firstnaturedness-formativeness-as to eventualising inkling-drive-or-seeding-misprising > temporal-to-intemporal-dispositions$<$ so-construed-as-from-perspective-ontological-normalcy/postconvergence $>$ further redefining the possibility of uninstitutionalised-threshold ${ }^{102}$ as the threshold for failing/not-upholding the institutionalisation's $\quad$ reference-of-thought- categorical-imperatives/axioms/registryteleology and the possibility of prospective institutionalisation as renewing ${ }^{83}$ reference-ofthought- ${ }^{8}$ ategorical-imperatives/axioms/registry-teleology ${ }^{9}$ for upholding intemporalpreservation-entropy-or-contiguity-or-ontological-preservation as of ontologicalnormalcy/postconvergence with respect to the uninstitutionalised-threshold ${ }^{102}$, thus further redefining successive prospective socially-functional-and-accordant ${ }^{9}$ thresholds as successive prospective registry-worldviews/dimensions. Thus, implying a dual-faceted representation of human mental-disposition as uninstitutionalised-and-institutionalised, wherein by metaphysicsof-presence-〈implicited-'nondescript/ignorable-void ' 'as-to- presencing — absolutising-

identitive-constitutedness $\rangle$, the present registry-worldview's/dimension's ${ }^{83}$ reference-ofthought by its inherent presencing-inclination disposition failing intemporality ${ }^{52}$-symmetrisingby-desymmetrising-subsumption-of-temporality ${ }^{8}$ will be oriented as institutionalised in secluding its uninstitutionalised facet from placeholder-setup/mental-devisingrepresentation/mentation/consciousness-awareness-teleology ${ }^{9}$ with any sense of uninstitutionalised-threshold ${ }^{102}$ being rather an afterthought posture rather with respect to the prior registry-worldview/dimension uninstitutionalised facet of ${ }^{8}$ reference-of-thought. It is this appreciation successively implied registry-worldviews/dimensions prospective relative- 
ontological-completeness ${ }^{87}$-of- ${ }^{83}$ reference-of-thought emphasising both institutionalised-anduninstitutionalised-facets that naturally validates the notion of a 'attendant ontologising-capacity driven apriorising/axiomatising/referencing-psychologism as of the grander ontologicalnormalcy/postconvergence

apriorising/axiomatising/referencing/intelligibilitysettingup/measuringinstrumenting' that is counterintuitive to a stigmatic/mented psychology as conceptualised today. Such a 'attendant ontologising-capacity driven apriorising/axiomatising/referencing-psychologism as of the grander ontological-normalcy/postconvergence apriorising/axiomatising/referencing/intelligibilitysettingup/measuringinstrumenting' by its contiguity in grasping the implications of human temporal (pseudointemporal)-to-intemporal mental-dispositions as a contiguity of shortness-to-longness-of-register-of- ${ }^{56}$ meaningfulnessand-teleology ${ }^{9}$ should be predicative of human ${ }^{56}$ meaningfulness-and-teleology ${ }^{9}$ (much the same way that the notion of temporality ${ }^{8}$-to-intemporality ${ }^{52}$ thresholds driven construal enables an existentially-<isontologising/re-ontologising aporeticism $>$ operant $<$ amplituding/formative-epistemicity $>$ totalising $\sim$ ratiocontiguity/ratiocination-asreferentialism- 'implicited_attendant_ontological-contiguity ${ }^{67}$ > educed-

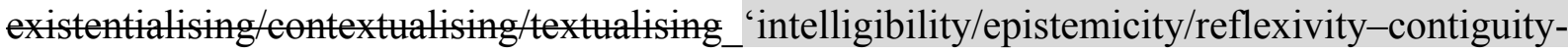
$<$ imbued-notional cogency>' ;-phenomenal-abstractiveness-of-presencing-in-'protensiveconsciousness'-enablingapriorising/axiomatising/referencing/intelligibilitysettingup/measuringinstrumenting-foroperant-or-incidenting-predicative-insights-of 'implicited_attendant-ontologicalcontiguity ${ }^{67}$, educed-

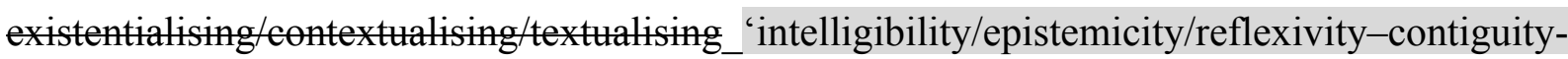
$<$ imbued-notional $\sim$ cogency $>,{ }^{\prime},-<$ reifying-or-elucidating-of-prospective-relative-ontologicalcompleteness -of- reference-of-thought- devolving-as-of-instantiative-context $>$ construal of 
virtue beyond the 'relatively impression-driven basis of conceptualisation' associated with <amplituding/formative-epistemicity >totalising random-as-impulsive'implicited_attendant-ontological-contiguity ${ }^{67}$ ' educedexistentialising/contextualising/textualising_'intelligibility/epistemicity/reflexivity-contiguity$<$ imbued-notional cogency>' ${ }^{\prime}$;-phenomenal-abstractiveness-of-presencing-in- 'trepidatiousconsciousness'-enablingapriorising/axiomatising/referencing/intelligibilitysettingup/measuringinstrumenting-foroperant-or-incidenting-predicative-insights-of 'implicited_attendant-ontologicalcontiguity $^{67} \sim$ educedexistentialising/contextualising/textualising_intelligibility/epistemicity/reflexivity-contiguity$<$ imbued-notional $\sim$ cogency $>,{ }^{\prime},-<$ reifying-or-elucidating-of-prospective-relative-ontologicalcompleteness -of- reference-of-thought- devolving-as-of-instantiative-context>, $<$ amplituding/formative-epistemicity $>$ totalising $\sim$ nominal-as-tendentious'implicited_attendant-ontological-contiguity ${ }^{67}$ educedexistentialising/contextualising/textualising_'intelligibility/epistemicity/reflexivity-contiguity$<$ imbued-notional cogency>' ;-phenomenal-abstractiveness-of-presencing-in-'warpedconsciousness'-enablingapriorising/axiomatising/referencing/intelligibilitysettingup/measuringinstrumenting-foroperant-or-incidenting-predicative-insights-of 'implicited_attendant_ontologicalcontiguity $^{67} \sim$ educedexistentialising/contextualising/textualising_intelligibility/epistemicity/reflexivity-contiguity$<$ imbued-notional $\sim$ cogency $>$ ' ,$-<$ reifying-or-elucidating-of-prospective-relative-ontologicalcompleteness -of- reference-of-thought- devolving-as-of-instantiative-context> involving allegiance/subservience driven construal, $<$ amplituding/formativeepistemicity $>$ totalising ordinal-as-qualifying__implicited_attendant-ontological- 
contiguity ${ }^{67}$,educed-

existentialising/contextualising/textualising_'intelligibility/epistemicity/reflexivity_contiguity-

$<$ imbued-notional cogency>' ;-phenomenal-abstractiveness-of-presencing-in-'preclusiveconsciousness'-enabling-

apriorising/axiomatising/referencing/intelligibilitysettingup/measuringinstrumenting-foroperant-or-incidenting-predicative-insights-of 'implicited_attendant_ontologicalcontiguity $^{67} \sim$ educed-

existentialising/contextualising/textualising_intelligibility/epistemicity/reflexivity-contiguity$<$ imbued-notional $\sim$ cogency $>,{ }^{\prime},-<$ reifying-or-elucidating-of-prospective-relative-ontologicalcompleteness -of- reference-of-thought- devolving-as-of-instantiative-context> involving qualification/good-to-bad driven construal, <amplituding/formativeepistemicity>totalising intervalist-as-categorising_ 'implicited_attendant-ontologicalcontiguity ${ }^{67}$, educedexistentialising/contextualising/textualising_intelligibility/epistemicity/reflexivity-contiguity<imbued-notional cogency>' ${ }^{\prime}$;-phenomenal-abstractiveness-of-presencing-in-'occlusiveconsciousness'-enablingapriorising/axiomatising/referencing/intelligibilitysettingup/measuringinstrumenting-foroperant-or-incidenting-predicative-insights-of 'implicited_attendant_ontologicalcontiguity $^{67} \sim$ educedexistentialising/contextualising/textualising_intelligibility/epistemicity/reflexivity-contiguity$<$ imbued-notional $\sim$ cogency $>,{ }^{\prime},-<$ reifying-or-elucidating-of-prospective-relative-ontologicalcompleteness -of- reference-of-thought- devolving-as-of-instantiative-context $>$ categorisation/kindness-humility-helpfulness-etc. driven construal), superseding the noncontiguous nature of present stigmatic/mented psychology. Such a 'attendant ontologisingcapacity driven apriorising/axiomatising/referencing-psychologism as of the grander 
ontological-normalcy/postconvergence

apriorising/axiomatising/referencing/intelligibilitysettingup/measuringinstrumenting' construes social universal-transparency -〈transparency-of-totalising-entailing,-as-to-entailing$<$ amplituding/formative-epistemicity>totalising in-relative-ontological-completeness $>$ as of 'implicited_attendant-ontological-contiguity ${ }^{67}$; educedexistentialising/contextualising/textualising_intelligibility/epistemicity/reflexivity-contiguity$<$ imbued-notional $\sim$ cogency $>,,-<$ reifying-or-elucidating-of-prospective-relative-ontologicalcompleteness -of- reference-of-thought- devolving-as-of-instantiative-context>; as this is already the natural human psychology which on the token of relative completeness-ofreference-of-thought of successively achieved social ${ }^{103}$ universal-transparency ${ }^{104}$ 〈transparency-of-totalising-entailing,-as-to-entailing-<amplituding/formativeepistemicity>totalising in-relative-ontological-completeness > as of 'implicited_attendant ontological-contiguity ${ }^{67}$, educed-

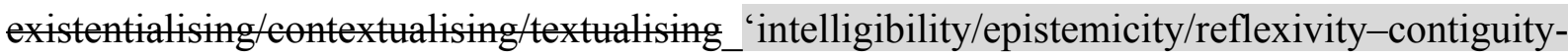
$<$ imbued-notional $\sim$ cogency $>,{ }^{\prime},-<$ reifying-or-elucidating-of-prospective-relative-ontologicalcompleteness -of- reference-of-thought- devolving-as-of-instantiative-context $>$ is behind the untenability/internal-contradiction/internal-incoherence/institutional-constraining that ushers in the successive psychologisms of the <cumulating/recomposuring attendant-ontologicalcontiguity $>$-successive registry-worldviews/dimensions ${ }^{83}$ reference-of-thought, with the bigger insight thus that such natural psychology is central to futural Beingdevelopment/ontological-framework-expansion-as-to-depth-of-ontologising-development-asinfrastructure-of- meaningfulness-and-teleology as of prospective notional ${ }^{18}$ deprocrypticism institutionalisation psychologism; and we can appreciate that the more thorough dilemmas with respect to vices-and-impediments ${ }^{105}$ of the grander human condition have been preconverging/postconverging-de- 
mentatively/structurally/paradigmatically resolved as of these successive psychologisms postconverging-de-mentating/structuring/paradigming arising from prospective relativeontological-completeness ${ }^{87}$-of- ${ }^{83}$ reference-of-thought induced social ${ }^{103}$ universaltransparency ${ }^{104}$-〈transparency-of-totalising-entailing,-as-to-entailing-<amplituding-formativeepistemicity>totalising in-relative-ontological-completeness > as of 'implicited_attendantontological-contiguity ${ }^{67}$, educedexistentialising/contextualising/textualising_'intelligibility/epistemicity/reflexivity-contiguity$<$ imbued-notional $\sim$ cogency $>,>$,-<reifying-or-elucidating-of-prospective-relative-ontologicalcompleteness -of- reference-of-thought- devolving-as-of-instantiative-context>. For instance, the prospective relative-ontological-completeness ${ }^{87}$-of- ${ }^{-3}$ reference-of-thought of rulemaking-over-non-rules_-apriorising/axiomatising/referencing-psychologism,-〈as 'firstlevel presencing-absolutising-identitive-constitutedness ${ }^{14}$ of reference-of-thought' apriorising/axiomatising/referencing/intelligibilitysettingup/measuringinstrumenting $\rangle$ induced a social ${ }^{103}$ universal-transparency ${ }^{104}$-〈transparency-of-totalising-entailing,-as-to-entailing<amplituding/formative-epistemicity>totalising in-relative-ontological-completeness $>$ as of 'implicited_attendant-ontological-contiguity ${ }^{67}$ ' educedexistentialising/contextualising/textualising_intelligibility/epistemicity/reflexivity-contiguity$<$ imbued-notional $\sim \operatorname{cogency}>,{ }^{\prime},-<$ reifying-or-elucidating-of-prospective-relative-ontologicalcompleteness -of- reference-of-thought- devolving-as-of-instantiative-context $>$ that led to the base-institutionalisation-ununiversalisation psychologism grounded on rule-making differing from the non-rules-apriorising/axiomatising/referencing-psychologism,-asimpulsive-or-accidented-or-random-mental-disposition psychologism of recurrent-utteruninstitutionalisation, with its corresponding grander ontological and virtue implications. Interestingly consider for comparison our mented/stigmatic psychology construct (which is relatively ontologically non-contiguous by the positivism registry-worldview/dimension 
‘<amplituding/formative-epistemicity $>$ totalising intervalist-as-categorising-

'implicited_attendant-ontological-contiguity ${ }^{67}$ educed-

existentialising/contextualising/textualising_'intelligibility/epistemicity/reflexivity-contiguity-

$<$ imbued-notional cogency>' ;-phenomenal-abstractiveness-of-presencing-in-'occlusive-

consciousness'-enabling-

apriorising/axiomatising/referencing/intelligibilitysettingup/measuringinstrumenting-for-

operant-or-incidenting-predicative-insights-of

'implicited_attendant-ontological-

contiguity ${ }^{67} \sim$ educed-

existentialising/contextmalising/textualising_'intelligibility/epistemicity/reflexivity-contiguity-

$<$ imbued-notional $\sim$ cogency $>,{ }^{\prime},-<$ reifying-or-elucidating-of-prospective-relative-ontological-

completeness -of- reference-of-thought- devolving-as-of-instantiative-context $>$ categorising

disposition' or 'third-level presencing-absolutising-identitive-constitutedness

apriorising/axiomatising/referencing/intelligibilitysettingup/measuringinstrumenting', as it doesn't

construe

a

<amplituding/formative-

epistemicity $>$ totalising $\sim$ ratiocontiguity/ratiocination-as-referentialism—'implicited_attendant_ ontological-contiguity $^{67}$; educed-

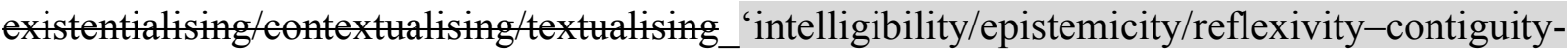

$<$ imbued-notional cogency>' ;-phenomenal-abstractiveness-of-presencing-in-'protensiveconsciousness'-enabling-

apriorising/axiomatising/referencing/intelligibilitysettingup/measuringinstrumenting-foroperant-or-incidenting-predicative-insights-of 'implicited_attendant-ontologicalcontiguity ${ }^{67}$, educed-

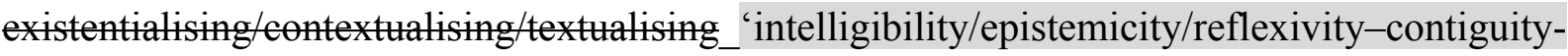
$<$ imbued-notional $\sim$ cogency $>,{ }^{\prime},-<$ reifying-or-elucidating-of-prospective-relative-ontological- 
apriorising/axiomatising/referencing-\{of-'prospectively_implicited_attendant-ontological-

contiguity ' educed-

existentialising/contextualising/textualising_'intelligibility/epistemicity/reflexivity-contiguity-

<imbued-notional cogency >' \}-conflatedness ${ }^{13}$ in-\{preconverging-disentailment by\}

pestconverging-entailment of temporality ${ }^{8}$-as-pseudointemporality ${ }^{52}$-to-intemporality ${ }^{52}$ of human individuations as is the case with referentialism as of ontologicalnormalcy/postconvergence, as so implied by 'notional 'deprocrypticism'), under the positivistic ${ }^{56}$ meaningfulness-and-teleology ${ }^{83}$ reference-of-thought as absolute value-judgment (not withstanding its prior relative-ontological-incompleteness ${ }^{8}$-of- ${ }^{8}$ reference-of-thought as positivism- ${ }^{8}$ procrypticism); likewise, we'll necessarily be suspect with regards to a corresponding approach where for instance the non-positivism/medievalism mindset $/{ }^{3}$ reference-of-thought equally construed a relatively ontologically non-contiguous stigmatic/mented psychology construct based on its registry-worldview/dimension '<amplituding/formative-epistemicity $>$ totalising $\sim$ ordinal-as-qualifying-

'implicited_attendant-ontological-contiguity ${ }^{67}$ ' educed-

existentialising/contextualising/textualising_intelligibility/epistemicity/reflexivity-contiguity-

$<$ imbued-notional cogency>' ;-phenomenal-abstractiveness-of-presencing-in-'preclusiveconsciousness'-enabling-

apriorising/axiomatising/referencing/intelligibilitysettingup/measuringinstrumenting-foroperant-or-incidenting-predicative-insights-of 'implicited_attendant-ontologicalcontiguity $^{67}$, educed-

existentialising/contextualising/textualising_intelligibility/epistemicity/reflexivity-contiguity$<$ imbued-notional $\sim$ cogency $>,{ }^{\prime},-<$ reifying-or-elucidating-of-prospective-relative-ontologicalcompleteness -of- reference-of-thought- devolving-as-of-instantiative-context $>$ categorising dispositions' or 'second-level presencing-absolutising-identitive-constitutedness 
apriorising/axiomatising/referencing/intelligibilitysettingup/measuringinstrumenting', on the basis of its ${ }^{5}$ meaningfulness-and-teleology as value-judgment (not withstanding its prior relative-ontological-incompleteness ${ }^{8}$-of- ${ }^{8}$ reference-of-thought as ${ }^{103}$ universalisation-nonpositivism/medievalism-〈failing positivising/rational-empiricism-based-universalisationdirected-rulemaking-over-non-rules — apriorising/axiomatising/referencing-psychologism)

when factoring in such mental-dispositions as believing in superstitions, alchemy, notions-andaccusations-of-sorcery, etc.). As we come to recognise that such an approach renders the meaningfulness-and-teleology ${ }^{99}$ as value-reference of every registry-worldview/dimension at the backend of the institutional-cumulation/institutional-recomposure-〈as-tohistoriality/ontological-eventfulness /ontological-aesthetic-tracing-<perspective-

ontological-normalcy/postconvergence-reflected-'epistemicity-relativism-determinism' $>>\quad$ as the absolute determinant of what can be psychology, with a naivety that doesn't allow consciously, (as consciously decentering and pivoting with respect to human psychical and institutionalisation implications), for prospective transcendence-andsublimity/sublimation/supererogatory de-mentativity, as it doesn't factor in the said registryworldview/dimension prior relative-ontological-incompleteness ${ }^{8}$-of- ${ }^{8}$ reference-of-thought to then project that there may be a prospective relative-ontological-completeness ${ }^{87}$-of- ${ }^{8}$ referenceof-thought which ${ }^{56}$ meaningfulness-and-teleology 9 as value judgment transforms psychological-construal/psychologism. The best possible outcome in this regard is as of the construal of a 'attendant ontologising-capacity driven apriorising/axiomatising/referencingpsychologism as of the grander ontological-normalcy/postconvergence apriorising/axiomatising/referencing/intelligibilitysettingup/measuringinstrumenting' as it establishes prospective relative-ontological-completeness ${ }^{87}$-of- ${ }^{83}$ reference-of-thought by social universal-transparency ${ }^{104}$-〈transparency-of-totalising-entailing,-as-to-entailing- 
'implicited_attendant-ontological-contiguity ${ }^{67}$;educedexistentialising/contextualising/textualising_intelligibility/epistemicity/reflexivity-contiguity$<$ imbued-notional $\sim$ cogency $>,{ }^{\prime},-<$ reifying-or-elucidating-of-prospective-relative-ontologicalcompleteness -of- reference-of-thought- devolving-as-of-instantiative-context $>$. As setting up the relevant attendant psychologism is only by a construal that the best possible psychologyconstruct/psychologism is necessarily attained by <cumulating/recomposuring attendantontological-contiguity $>$-successive registry-worldviews/dimensions construals/conceptualisations by their attendant prospective relative-ontologicalcompleteness $^{87}$-of- ${ }^{83}$ reference-of-thought by social ${ }^{103}$ universal-transparency ${ }^{104}-\langle$ transparencyof-totalising-entailing,-as-to-entailing-<amplituding/formative-epistemicity $>$ totalising $\sim$ inrelative-ontological-completeness $\rangle$ as of 'implicited_attendant-ontologicalcontiguity ${ }^{67} \sim$ educedexistentialising/contextualising/textualising_intelligibility/epistemicity/reflexivity-contiguity$<$ imbued-notional $\sim$ cogency $>,{ }^{\prime},-<$ reifying-or-elucidating-of-prospective-relative-ontologicalcompleteness -of- reference-of-thought- devolving-as-of-instantiative-context> (that is, 'attendant ontologising-capacity driven apriorising/axiomatising/referencing-psychologism as of the grander ontological-normalcy/postconvergence apriorising/axiomatising/referencing/intelligibilitysettingup/measuringinstrumenting'), and so successively across all registry-worldviews/dimensions, whether retrospectively or prospectively. This insight about the nature of a mented/stigmatic psychology compares with the instance about a Kantian absolute apriorising/axiomatising/referencing exercise; in that in both instances, human mentation capacity is construed as absolutely given at all times, with that mentation capacity rather 'reflexively and erroneously' absolutely construed as of the positivistic mindset $/{ }^{3}$ reference-of-thought, and what is not factored in is the fact that there is a human limited-mentation-capacity—as-subjecting-'educed-unlimitedness/existence-sublimating - 
nascence' to-limitedness/human-subpotency that maximalisingly-recomposures as of human shallow-to-deepening-limited-mentation-capacity—as-subjecting-'educed-

unlimitedness/existence-sublimating nascence' to-limitedness/human-subpotency, as-limitedmentation-capacity-deepening —as-subjecting limitedness/human-subpotency-to-educedunlimitedness/existence-sublimating nascence' ${ }^{53}$ inducing the $<$ cumulating/recomposuring attendant-ontological-contiguity $>$-successive registryworldviews/dimensions institutionalisations ${ }^{83}$ reference-of-thought with their own 'specific institutionalisation/uninstitutionalised-threshold mentaldispositions/apriorising/axiomatising/referencing/intelligibilitysettingup/measuringinstrumenti ngs' as of their prospective relative-ontological-completeness ${ }^{87}$-of- ${ }^{8}$ reference-of-thought with respect to their social ${ }^{103}$ universal-transparency ${ }^{104}$-〈transparency-of-totalising-entailing,-as-toentailing-<amplituding/formative-epistemicity >totalising in-relative-ontologicalcompleteness > as of 'implicited_attendant-ontological-contiguity ${ }^{67}$; educedexistentialising/contextualising/textualising_intelligibility/epistemicity/reflexivity_contiguity$<$ imbued-notional cogency $>,{ }^{\prime},-<$ reifying-or-elucidating-of-prospective-relative-ontologicalcompleteness -of- reference-of-thought- devolving-as-of-instantiative-context>; with the implications being that social ${ }^{103}$ universal-transparency ${ }^{104}$-〈transparency-of-totalisingentailing,-as-to-entailing-<amplituding/formative-epistemicity $>$ totalising $\sim$ in-relativeontological-completeness > as of 'implicitant-ontological-contiguity ${ }^{67}$, educed-

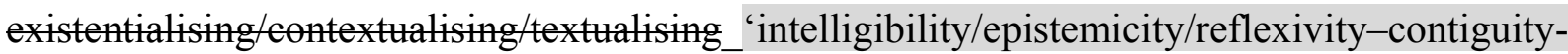
$<$ imbued-notional $\sim$ cogency $>,{ }^{\prime},-<$ reifying-or-elucidating-of-prospective-relative-ontologicalcompleteness -of- reference-of-thought- devolving-as-of-instantiative-context> as of prospective relative-ontological-completeness ${ }^{87}$-of- ${ }^{8}$ reference-of-thought redefines prospective meaningfulness-and-teleology ${ }^{9}$ and the corresponding apriorising/axiomatising/referencing/intelligibilitysettingup/measuringinstrumenting, implying 
an epistemic-totalising $\sim$ renewing-realisation/re-perception/re-thought based on prospective maximalising-recomposuring-for-relative-ontological-completeness ${ }^{87}$ - unenframed/reontologising conceptualisation ultimately as of 'notional ${ }^{18}$ deprocrypticism'; as this consciously factors in the reality of the need of transcendence-andsublimity/sublimation/supererogatory $\sim$ de-mentativity as decentering/pivoting with respect to psychical-orientation, $\quad{ }^{5}$ meaningfulness-and-teleology ${ }^{9} \quad$ construal/conceptualisation, institutionalisation and overall existential-<disontologising/re-ontologising aporeticism $>$ becoming. This validates the notion of 'postconverging-or-dialectical-thinking - psychology or psychology-of-mentation-dynamics or natural psychological-dynamics' as of its construing of notional ${ }^{18}$ deprocrypticism as 'notional ${ }^{18}$ deprocrypticism suprastructuration' or 'notional $\sim$ deprocrypticism suprastructural psychical-and-institutionalisation orientation of meaningfulness-and-teleology ${ }^{99}$ as of the overall registry-worldview/dimension reconstrual of superseding-oneness-of-ontology' (enabling the <amplituding/formativeepistemicity $>$ totalising $\sim$ ratiocontiguity/ratiocination-as-referentialism—'implicited_attendant ontological-contiguity ${ }^{67}$, educedexistentialising/contextualising/textualising_'intelligibility/epistemicity/reflexivity-contiguity$<$ imbued-notional cogency $>$; $;$; phenomenal-abstractiveness-of-presencing-in-'protensiveconsciousness'-enablingapriorising/axiomatising/referencing/intelligibilitysettingup/measuringinstrumenting-foroperant-or-incidenting-predicative-insights-of 'implicited_attendant-ontologicalcontiguity $^{67}$, educedexistentialising/contextualising/textualising_intelligibility/epistemicity/reflexivity-contiguity$<$ imbued-notional $\sim$ cogency $>,{ }^{\prime},-<$ reifying-or-elucidating-of-prospective-relative-ontologicalcompleteness -of- reference-of-thought- devolving-as-of-instantiative-context $>$ /conflation of apriorising/axiomatising/referencing/intelligibilitysettingup/measuringinstrumenting of the 
notional ${ }^{18}$ deprocrypticism socially-functional-and-accordant ${ }^{3}$ as of intemporal/ontological contiguity, with no-notional firstnaturedness-formativeness-<as-to-eventualising inkling drive-or seeding misprising $>$ temporal-to-intemporal-dispositions-<so-construed-as-fromperspective-ontological-normalcy/postconvergence>-non-dissociability, thus upholding notional ${ }^{1}$ deprocrypticism as preempting-disjointedness-as-of- ${ }^{8}$ reference-of-thought,-as-to${ }^{32}$ amplituding/formative-epistemicity $>$ growth-or-conflatedness ${ }^{13} /$ transvaluative- $^{2}$ rationalising/transepistemicity/anamnestic-residuality/spirit-drivenness'_-in-supersedingmere-formulaic-positivising/rational-empiricism-based-universalisation-directed-rulemakingover-non-rules_-apriorising/axiomatising/referencing-psychologism). Thus, with notional $\sim^{18}$ deprocrypticism further enabling the abstract intemporal/ontological contiguity grasp of human 'individuation-level and registry-worldview/dimension-level ${ }^{56}$ meaningfulness-andteleology ${ }^{\circ}$, as it can accrue at the intradimensional-level of individuals-notionally-asreceptacles-of-temporal-to-intemporal-individuation and individuals-as-institutionallyconstrained-actors-as-of-intersolipsistic-deambulation, and hence ontologically-adjoins in its construal/conceptualisation the construct of the individual and the social as of 'notional $\sim$ deprocrypticism suprastructuration' or 'notional $\sim$ deprocrypticism suprastructural psychical-and-institutionalisation orientation of ${ }^{56}$ meaningfulness-and-teleology ${ }^{99}$ synopsisingdepth as of the overall registry-worldview's/dimension's reconstrual of superseding-onenessof-ontology' (just as in the natural sciences, physics ontologically-adjoins chemistry and chemistry ontologically-adjoins biology). This is in contrast with an ontologically noncontiguous stigmatic/mented psychology construct which relative 'third-level ${ }^{79}$ presencingabsolutising-identitive-constitutedness ${ }^{14}$ ' largely limits its notion to 'affect', and not a full-blown notional-contiguity/epistemic-contiguity ${ }^{62}$ - profound-supererogation -of-mentallyaestheticised postconverging/dialectical-thinking -qualia-schema>; as apriorising/axiomatising/referencing-\{of-'prospectively implicited_attendant-ontological- 
contiguity ' educed-

existentialising/contextualising/textualising_'intelligibility/epistemicity/reflexivity_contiguity<imbued-notional $\left.\sim \operatorname{cogency}>^{\prime} \quad\right\}$-conflatedness ${ }^{13}$-in-\{preconverging-disentailment by\} postconverging-entailment elaborated ' meaningfulness-and-teleology"' determination in full ontological converging with the social (as metaphysics-of-absence-〈implicited-epistemicveracity-of- nonpresencing-<perspective-ontological-normalcy/postconvergence $>\rangle$ of the social, 'conflation psychologism' based on 'temporal-to-intemporal contrastive-synopsisingdepths-of- ${ }^{5}$ meaningfulness-and-teleology' ${ }^{9}$ ' going by the 'referentialism technique of pointreferencing, explained elsewhere,' that restores 'implicited_attendant-ontologicalcontiguity $^{67}$, educed-

existentialising/contextualising/textualising_intelligibility/epistemicity/reflexivity-contiguity$<$ imbued-notional $\sim$ cogency $>,,-<$ reifying-or-elucidating-of-prospective-relative-ontologicalcompleteness -of- reference-of-thought- devolving-as-of-instantiative-context> in undermining procrypticism-or-disjointedness-as-of- ${ }^{8}$ reference-of-thought). Hence by recurrent re-categorisation/re-adaptation/re-classification of apriorising/axiomatising/referencing-\{of-'prospectively implicited_attendant-ontologicalcontiguity ' $\sim$ educedexistentialising/contextualising/textualising_ intelligibility/epistemicity/reflexivity-contiguity<imbued-notional cogency>' $\}$ - constitutedness ${ }^{14}$-in-preconverging-entailment of reference-of-thought as a ' ${ }^{\prime}$ presencing - absolutising-identitive-constitutedness ${ }^{14}$, exercise at worldview-level, institutional-level and operant-level of ${ }^{56}$ meaningfulness-and-teleology ${ }^{9}$, the requisite psychoanalytic-unshackling/memetic-reordering/institutional-recomposuring for $<$ amplituding/formative-epistemicity $>$-totalising $\sim$ renewing-realisation/re-perception/rethought for prospective transcendence-and-sublimity/sublimation/supereregatory $\sim$ dementativity is achieved. Insightfully, (beyond '79 presencing-absolutising-identitive- 
constitutedness $^{\mid{ }^{\prime}}$ ) the full <amplituding/formative-epistemicity $>$ causality $\sim$ as-to-projectivetotalitative-implications-of-prospective- nonpresencing,-for-explicating $\sim$ relativeunreflexivity/relative-reflexivity - ontological-contiguity

apriorising/axiomatising/referencing-\{of-'prospectively_implicited_attendant-ontologicalcontiguity ' educed-

existentialising/contextualising/textualising_ 'intelligibility/epistemicity/reflexivity-contiguity<imbued-notional cogency $\left.>^{\prime}\right\}$-conflatedness ${ }^{13}$-in-\{preconverging-disentailment by\} postconverging-entailment as implied with referentialism as the underlying transcendental memetic/suprastructural-meaningfulness fugue reflecting existential-reality will take an even more critical bearing with respect to notional deprocrypticism psychologism as unlike the articulation as ${ }^{79}$ presencing-absolutising-identitive-constitutedness ${ }^{14}$ (rather heuristically and beyond consciousness-awareness-teleology ${ }^{9}$ ) in previous institutional-cumulation/institutionalrecomposure-〈as-to- historiality/ontological-eventfulness /ontological-aesthetic-tracing$<$ perspective-ontological-normalcy/postconvergence-reflected-'epistemicity-relativism-

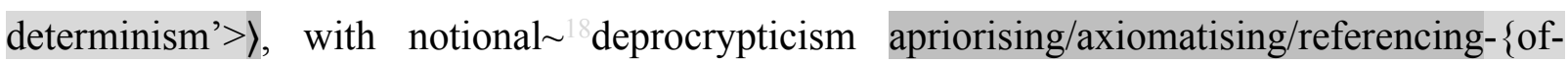
'prospectively implicited_attendant_ontological-contiguity ' educedexistentialising/contextmalising/textualising_'intelligibility/epistemicity/reflexivity_contiguity<imbued-notional cogency $>$ ' \}-conflatedness ${ }^{13}$-in-\{preconverging-disentailment by\} postconverging entailment is rather bound to be perceived and construed as of the \{cumulated/recomposured -consciousness-awareness-teleology ${ }^{9}$ in its full potential on the basis of referentialism as of the full development of ontological-normalcy/postconvergence. Thus, the notion of apriorising/axiomatising/referencing-\{of-'prospectively implicited_attendant-ontological-contiguity ' ceducedexistentialising/contextualising/textualising_'intelligibility/epistemicity/reflexivity_contiguity<imbued-notional cogency $\left.>^{\prime}\right\}$ - conflatedness ${ }^{13}$-in-\{preconverging-disentailment by $\}_{-}$ 
postconverging-entailment (including ' presencing-absolutising-identitiveconstitutedness $^{\mid{ }^{\prime}}$ ) can be conceptualised across all transcendence-andsublimity/sublimation/supererogatory $\sim$ de-mentativity as providing the 'centering platform' (that reflects the sublimating-epistemic-imbricatedness/threadedness/recomposuring of existentialreality as of implicited_attendant-ontological-contiguity ${ }^{67}$ ' educedexistentialising/contextualising/textualising_intelligibility/epistemicity/reflexivity-contiguity$<$ imbued-notional $\sim$ cogency $>,{ }^{\prime},-<$ reifying-or-elucidating-of-prospective-relative-ontologicalcompleteness -of- reference-of-thought- devolving-as-of-instantiative-context $>$ in ontological-normalcy/postconvergence or intemporal-preservation-entropy-or-contiguity-orontological-preservation) as the prospective registry-worldview/dimension institutionalisation reference-of-thought, for 'decentering' the prior registry-worldview/dimension uninstitutionalised-threshold ${ }^{102} \quad{ }^{83}$ reference-of-thought $\quad$ in $\quad$ its 'apriorising/axiomatising/referencing-\{of-'prespectively implicited_attendant-ontologicalcontiguity ' educedexistentialising/contextualising/textualising_'intelligibility/epistemicity/reflexivity-contiguity<imbued-notional cogency>' $\quad\}$-constitutedness ${ }^{14}$-in-preconverging-entailment $\quad$ and conjugated apriorising/axiomatising/referencing-\{of-'prospectively implieited_ttentant ontological-contiguity ' educedexistentialising/contextualising/textualising_'intelligibility/epistemicity/reflexivity-contiguity<imbued-notional cogency $\left.>^{\prime} \quad\right\}$-constitutedness ${ }^{14}$-in-preconverging-entailment $\quad$ of reference-of-thought' with respect to the prospective registry-worldview/dimension institutionalisation ${ }^{83}$ reference-of-thought overall 'implicited_attendant-ontologicalcontiguity ${ }^{67} \sim$ educedexistentialising/contextualising/textualising_'intelligibility/epistemicity/reflexivity-contiguity$<$ imbued-notional $\sim$ cogency $>,{ }^{\prime},-<$ reifying-or-elucidating-of-prospective-relative-ontological- 
completeness -of- reference-of-thought- devolving-as-of-instantiative-context $>$

meaningfulness-and-teleology ; (as ontology/ontological-veridicality/intrinsic-reality increasingly supersedes 'prior-conventioning as social-aggregation-enabling', wherein for instance scientific explanations psychologism (as of prospective apriorising/axiomatising/referencing-\{of-'prospectively_implicited_attendant-ontologicalcontiguity ' educed-

existentialising/contextualising/textualising_intelligibility/epistemicity/reflexivity_contiguity<imbued-notional cogency >' \}-conflatedness ${ }^{13}$-in-\{preconverging-disentailment-by\} postconverging-entailment) supersede mythical/supernatural/alchemic explanations psychologism (as of prior apriorising/axiomatising/referencing-\{of-'prespectively implicited_attendant-ontological-contiguity ' educedexistentialising/contextualising/textualising_'intelligibility/epistemicity/reflexivity-contiguity$<$ imbued-notional cogency $>\quad, \quad\}$-constitutedness ${ }^{-}$-in-preconverging-entailment) $\quad$ as 'prospective-conventioning as transcendental-enabling/sublimating/supereregatory $\sim$ dementativity'; interestingly, highlighting how and why transcendence-andsublimity/sublimation/supererogatoryade-mentativity for prospective institutionalisation is construed in transcendental-enabling/sublimating/superentativity terms as its strive for a prospective relative-ontological-completeness ${ }^{87}$-of- ${ }^{3}$ reference-of-thought necessarily implies a more profound grasp of intrinsic-reality/ontological-veridicality with respect to the prior as uninstitutionalised-threshold ${ }^{102}$ prior relative-ontologicalincompleteness ${ }^{88}$-of- ${ }^{8}$ reference-of-thought revealing which by reflex adopts a social-aggretionenabling disposition with respect to the prior-conventioning). In this respect, ultimately the full achievement of apriorising/axiomatising/referencing-\{of-'prespectively implicited_attendantontological-contiguity ' $\sim$ educed-

existentialising/contextualising/textualising_'intelligibility/epistemicity/reflexivity-contiguity- 
<imbued-notional cogency>' \}-conflatedness ${ }^{13}$-in-\{preconverging-disentailment-by\} postconverging-entailment will involve fully expanding the sphere of relative intrinsicreality/ontological-veridicality transcendental-enabling/sublimating/supereregatory $\sim$ dementativity, as of 'intemporal-disposition knowledge constraining construct', for thorough construal/conceptualisation of social reality which is relatively highly prone to ‘apriorising/axiomatising/referencing-\{of-'prospectively implicited_attendant-ontologicalcontiguity ' $\sim$ educedexistentialising/contextualising/textualising_'intelligibility/epistemicity/reflexivity-contiguity$<$ imbued-notional cogency $>\quad\}$-constitutedness ${ }^{1}$-in-preconverging-entailment $\quad$ and conjugated apriorising/axiomatising/referencing-\{of-'prospectively implicited_attendantontological-contiguity ' educedexistentialising/contextualising/textualising_ intelligibility/epistemicity/reflexivity-contiguity<imbued-notional cogency> ' $\quad$ - constitutedness ${ }^{1}$-in-preconverging-entailment of reference-of-thought and thus resultant presencing-absolutising-identitiveconstitutedness $^{1,}$ as of social-aggregation-enabling, hence undermining relative intrinsicreality/ontological-veridicality transcendental-enabling/sublimating/supererogatory $\sim$ dementativity of the social. Ultimately, given the comprehensive and typical underlying proneness of human limited-mentation-capacity-deepening -as-subjecting limitedness/humansubpotency to-'educed-unlimitedness/existence-sublimating nascence' apriorising/axiomatising/referencing-\{of-'prospectively implicited_attendant-ontologicalcontiguity ' $\sim$ educedexistentialising/contextualising/textualising_'intelligibility/epistemicity/reflexivity-contiguity-

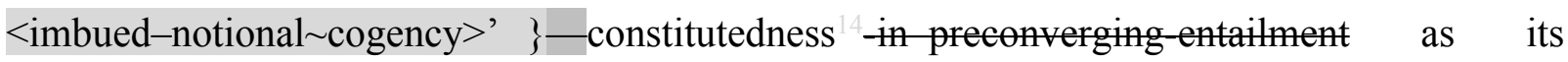
fundamental mentation deficiency at uninstitutionalised-threshold ${ }^{102}$ or as of "human temporal uninstitutionalised-threshold ${ }^{102}$ mental-disposition' (which it tends to resolve by “79 presencing- 
absolutising-identitive-constitutedness ${ }^{1,}$ when aware of defective apriorising/axiomatising/referencing-\{of-'prospectively implicited_attendant-ontologicalcontiguity ' educed-

existentialising/contextualising/textualising_'intelligibility/epistemicity/reflexivity-contiguity<imbued-notional cogency>' $\quad\}$-constitutedness ${ }^{14}$-in-preconverging-entailment) $\quad$ with respect to psychical-orientation, ${ }^{56}$ meaningfulness-and-teleology ${ }^{9}$ construal/conceptualisation, institutionalisation and its overall existential-<disontologising/re-ontologising aporeticism $>$ becoming, as so reflected in the <cumulating/recomposuring attendant-ontologicalcontiguity >-succession of registry-worldviews/dimensions; notional ${ }^{18}$ deprocrypticism by its very transcendental essence comprehensively comes into grips with the apriorising/axiomatising/referencing-\{of-'prospectively_implicited_attendant-ontologicalcontiguity ' educedexistentialising/contextualising/textualising_'intelligibility/epistemicity/reflexivity-contiguity<imbued-notional cogency>' $\}$-constitutedness ${ }^{4}$-in-preconverging-entailment $\quad$ in positivism- ${ }^{80}$ procrypticism as it attains more than just " 7 presencing-absolutising-identitiveconstitutedness $^{14}$, but an overall comprehensive apriorising/axiomatising/referencing-\{of'prospectively implicited_attendant-ontological-contiguity ' ceducedexistentialising/contextualising/textualising_'intelligibility/epistemicity/reflexivity-contiguity<imbued-notional cogency $\left.>{ }^{\prime}\right\}$-conflatedness ${ }^{13}$-in-\{preconverging-disentailment by\} postcenverging-ntailment insight as of ontological-normalcy/postconvergence referentialism for superseding positivism- ${ }^{8}$ procrypticism. apriorising/axiomatising/referencing-\{of'prospectively implicited attendant-ontological-contiguity ' educedexistentialising/contexalising/texalising_intelligibility/epistemicity/reflexivity-contiguity<imbued-notional cogency $\left.>^{\prime} \quad\right\}$-conflatedness ${ }^{13}$ in-\{preconverging-disentailment by pestcenverging entailment as of ontological-normalcy/postconvergence referentialism in 
superseding apriorising/axiomatising/referencing-\{of-'prospectively_implicited_attendantontological-contiguity ' educed-

existentialising/contextualising/textualising_'intelligibility/epistemicity/reflexivity-contiguity<imbued-notional cogency $\left.>^{\prime} \quad\right\}$-constitutedness ${ }^{14}$-in-preconverging-entailment, provides resolution as of 3 aspects of ${ }^{56}$ meaningfulness-and-teleology : firstly, with respect to temporal instigating as apriorising/axiomatising/referencing-\{of-'prospectively implicited_attendantontological-contiguity ' educedexistentialising/contextualising/textualising_'intelligibility/epistemicity/reflexivity-contiguity<imbued-notional cogency >' $\}$-constitutedness ${ }^{14}$-in-preconverging-entailment $\quad$ like

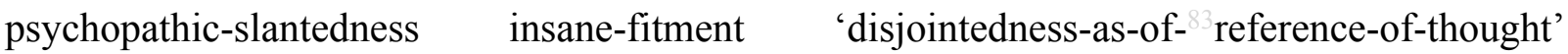
misappropriated ${ }^{56}$ meaningfulness-and-teleology ${ }^{9}$ in arrogation and its derivation with respect to temporal mere-forms/reprisings of such apriorising/axiomatising/referencing-\{of'prospectively_implicited_attendant-ontological-contiguity ' educedexistentialising/contextualising/textualising_'intelligibility/epistemicity/reflexivity-contiguity$<$ imbued-notional cogency $\left.>^{\prime} \quad\right\}$ - constitutedness ${ }^{14}$-in-preconverging-entailment as 'conjugated apriorising/axiomatising/referencing-\{of-'prospectively implicited_attendantontological-contiguity ' educedexistentialising/contextmalising/textualising_'intelligibility/epistemicity/reflexivity_contiguity$<$ imbued-notional cogency>' $\quad\}$-constitutedness ${ }^{- \text {in }}$ - preconverging-entailment $\quad$ of reference-of-thought' associated with conjugated-postlogism temporal mereforms/reprisings by construing/conceptualising such perversion-and-derived- 7 perversion-ofreference-of-thought-<as-preconvergingly-apriorising/axiomatising/referencing-innonconviction/madeupness/bottomlining-as-to-shallow-supererogation $>$ phenomenon, and reestablishing social ${ }^{103}$ universal-transparency ${ }^{104}$-〈transparency-of-totalising-entailing,-as-toentailing-<amplituding/formative-epistemicity >totalising in-relative-ontological- 
completeness $>$ that by itself is the fundamental basis for human knowledge-and-virtue; secondly, articulating the ${ }^{103}$ universal aetiologisation/ontological-escalation- $<$ ontologicalveridicality_commitment/otherliness_transcending/compulsions-encumbered_transcending $>$ as of ontological-reconstituting-as-to-conflatedness ${ }^{13}$; and thirdly, highlighting the preconverging/postconverging-de-mentative/structural/paradigmatic pivoting/decentering as prospective ontological-completeness-of- ${ }^{3}$ reference-of-thought possibilities. It should be noted that a 'mentation reflex as decentered and in ${ }^{15}$ de-mentation-〈supererogatory $\sim$ ontological-dementation-or-dialectical-de-mentation-stranding-or-attributive-dialectics $\rangle$ is no less valid with respect to a placeholder-setup/mental-devising-representation/mentation/consciousnessawareness-teleology ${ }^{9}$ of 'human temporal uninstitutionalised-threshold ${ }^{102}$ mental-disposition' (speaking of uninstitutionalised-threshold ${ }^{102}$ ) as a 'mentation reflex as centered and postconverging-or-dialectical-thinking -apriorising-psychologism' is valid with respect to a placeholder-setup/mental-devising-representation/mentation/consciousness-awarenessteleology of 'human registry-worldview's/dimension's institutionalisation mentaldisposition'; and so, with no relevant need for attending to any 'psychological complexes' with respect to a representation as of an uninstitutionalised-threshold ${ }^{102}$ wrongly being construed as of institutionalisation (at the uninstitutionalised-threshold ${ }^{02}$ ) as being a 'mentation reflex as centered and postconverging-or-dialectical-thinking -apriorising-psychologism' instead of a 'mentation reflex as decentered and in de-mentation-/smpererogatory-ontological-dementation-or-dialectical-de-mentation — stranding-or-attributive-dialectics $\rangle$ '. The point of this statement is that when procrypticism as our uninstitutionalised-threshold ${ }^{102}$ is bound to be construed as of metaphysics-of-absence-〈implicited-epistemic-veracity-of- nonpresencing$<$ perspective-ontological-normalcy/postconvergence $>>$, the normal psychologism we know of as of our positivism institutionalisation will no longer apply, as our procrypticism meaningfulness-and-teleology will be represented as decentered and in ${ }^{15}$ de-mentation- 


\section{〈supererogatory $\sim$ ontological-de-mentation-or-dialectical-de-mentation-stranding-or-}

attributive-dialectics $\rangle$ as the necessary/requisite backdrop for the construal of prospective reference-of-thought- categorical-imperatives/axioms/registry-teleology ${ }^{9}$,-for-intemporalpreservation-entropy-or-contiguity-or-ontological-preservation ushering in notional deprocrypticism as prospective institutionalisation. In this regard, we'll certainly inherently relate to preceding successive uninstitutionalised-threshold ${ }^{102}$ of recurrent-utteruninstitutionalisation, ununiversalisation, non-positivism/medievalism effectively as decentered and in de-mentation-〈stpereratory-ontological-de-mentation-or-dialectical-dementation - stranding-or-attributive-dialectics $\rangle$, though this will most probably be resisted with respect to such a representation of our denaturing of positivistic meaningfulness as our prospective procrypticism uninstitutionalisation (just as the correspondingly humans in the preceding successive uninstitutionalised-threshold ${ }^{102}$ by mentation reflex had, consciously and unconsciously, resisted a representation as decentered and in ${ }^{15}$ de-mentation〈supererogatory $\sim$ ontological-de-mentation-or-dialectical-de-mentation-stranding-or-

attributive-dialectics $\rangle$ ); while we can recognise successively the centered and postconvergingor-dialectical-thinking -apriorising-psychologism nature of base-institutionalisation, universalisation and positivism, though probably less so of notional ${ }^{18}$ deprocrypticism institutionalisation as it points to the decentering and de-mentation-

\section{〈supererogatory $\sim$ ontological-de-mentation-or-dialectical-de-mentation-stranding-or-}

attributive-dialectics $\rangle$ of our procrypticism uninstitutionalisation. Such institutionalisation and uninstitutionalised-threshold construal at the transcendental/transdimensional/interdimensional-level is reflected/perspectivated operantly by the concepts of apriorising/axiomatising/referencing-\{of-"prospectively implicited_attendantontological-contiguity ' educed- 
<imbued-notional cogency>' \}-conflatedness ${ }^{13}$-in-\{preconverging-disentailment-by\} postconverging-entailment as of centering and postconverging-or-dialectical-thinking apriorising-psychologism ${ }^{83}$ reference-of-thought implied with institutionalisations and apriorising/axiomatising/referencing-\{of-'prospectively implicited_attendant-ontologicalcontiguity ' educedexistentialising/contextualising/textualising_ 'intelligibility/epistemicity/reflexivity-contiguity$<$ imbued-notional cogency $>$ ' $\quad\}$-constitutedness ${ }^{1}$-in-preconverging-entailment $\quad$ as of decentering and ontologically/preconverging-or-dementing -apriorising-psychologism reference-of-thought implied with uninstitutionalised-threshold ${ }^{12}$; prompting the respective institutionalisation and uninstitutionalised-threshold ${ }^{12}$ psychologisms as of the apriorising/precedingness of 'implicited_attendant-ontological-contiguity ${ }^{67}$ 'educedexistentialising/contextualising/textualising_intelligibility/epistemicity/reflexivity-contiguity$<$ imbued-notional $\sim$ cogency $>$, ,-<reifying-or-elucidating-of-prospective-relative-ontologicalcompleteness -of- reference-of-thought- devolving-as-of-instantiative-context> reflecting this reality beyond and above our subpar <amplituding/formative-epistemicity $>$ totalising $\sim$ selfreferencing-syncretising/circularity/interiorising/akrasiatic-drag ${ }^{4}{ }^{83}$ reference-of-thought in positivism- ${ }^{80}$ procrypticism from a notional ${ }^{18}$ deprocrypticism perspective, just as we'll recognise for instance that a ${ }^{103}$ universalisation-non-positivism/medievalism mental-disposition contending against positivism institutionalisation meaningfulness is actually acting out a subpar $<$ amplituding/formative-epistemicity $>$ totalising $\sim$ self-referencingsyncretising/circularity/interiorising/akrasiatic-drag ${ }^{34}$ reference-of-thought as of the apriorising/precedingness of 'implicited_attendant-ontological-contiguity ${ }^{67}$, educed-

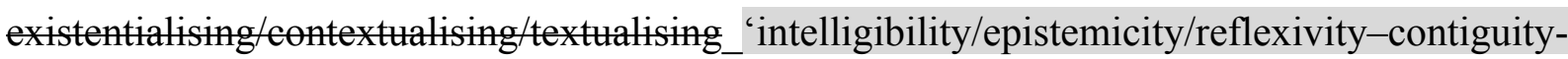
$<$ imbued-notional $\sim$ cogency $>,{ }^{\prime},-<$ reifying-or-elucidating-of-prospective-relative-ontologicalcompleteness -of- reference-of-thought- devolving-as-of-instantiative-context> reflecting 
this reality beyond and above it from the positivism perspective. Thus it is fundamentally the case that the requisite construal/conceptualisation as decentered and in de-mentation〈supererogatory $\sim$ ontological-de-mentation-or-dialectical-de-mentation-stranding-or-

attributive-dialectics $\rangle$ of an uninstitutionalised-threshold ${ }^{02}$ is hardly just one of 'simplistic knowledge elucidation' but rather an elucidation as of intellectual courage in bluntly asserting decentering and ${ }^{15}$ de-mentation-〈supererogatory ontological-de-mentation-or-dialectical-dementation - stranding-or-attributive-dialectics $\rangle$. Intellectual courage as imbuing knowledge with organic profoundness of intemporal-disposition philosophy rather than just a mechanical construct of technicalities is the central driver for all initiated transcendence-andsublimity/sublimation/supererogatory $\sim$ de-mentativity and prospective institutionalisations, as this goes beyond intellectual institutional-being-and-craft, since there is 'no magical knowledge technicality' for implying a more profound ontological-completeness-of- ${ }^{8}$ reference-of-thought over a relatively relative-ontological-incompleteness ${ }^{8}$-of- ${ }^{8}$ reference-of-thought but for such intellectual bravery to buck the trend or subvert as so displayed by the many illustrious positivism registry-worldview/dimension enablers subverting a non-positivism/medievalism mindset $/{ }^{3}$ reference-of-thought, fundamentally so with respect to such an intrinsicreality/ontological-veridicality knowledge construct issue associated with transcendentalenabling/sublimating/supereregatery $\sim$ de-mentativity rather than a conventioning sovereign construct/choice issue associated with social-aggregation-enabling. In this regard, the issue arising is 'altogether not a knowledge elucidation problem' with respect to the implied representation of uninstitutionalised-threshold ${ }^{102}$ as decentered and in de-mentation〈supererogatory $\sim$ ontological-de-mentation-or-dialectical-de-mentation-stranding-orattributive-dialectics $\rangle$ but rather a 'psychological complex issue' of the prior/transcended/superseded ${ }^{83}$ reference-of-thought. This explains why the issue is construed ontologically in 'psychologism terms as of <amplituding/formative- 
epistemicity $>$ totalising $\sim$ self-referencing-syncretising/circularity/interiorising/akrasiatic-drag ${ }^{34}$, as requiring a coming to terms with the understanding implied by prospective institutionalisation as of its more profound 'implicited_attendant-ontological-contiguity ${ }^{67}$ ' educedexistentialising/contextualising/textualising_'intelligibility/epistemicity/reflexivity_contiguity$<$ imbued-notional $\sim \operatorname{cogency}>,{ }^{\prime},-<$ reifying-or-elucidating-of-prospective-relative-ontologicalcompleteness -of- reference-of-thought- devolving-as-of-instantiative-context>; as more fundamentally, Galileo's use of a telescope to demonstrate a heliocentric system with respect to the non-positivism/medievalism ${ }^{83}$ reference-of-thought is not about the inherent knowledge implications to which the non-positivism/medievalism mindset $/{ }^{3}$ reference-of-thought has 'mentally shut-off' to, but fundamentally about the 'psychological complex' of the nonpositivism/medieval world of countenancing such meaningfulness as jeopardising the prior (nonpositivism/medievalism), with the implication rather for the need of the prospective psychologism as the positivism institutionalisation psychologism $(<$ amplituding/formativeepistemicity>-totalising $\sim$ renewing-realisation/re-perception/re-thought foundation as new placeholder-setup/mental-devising-representation/mentation/consciousness-awarenessteleology ${ }^{99}$ requisite knowledge or ${ }^{56}$ meaningfulness-and-teleology ${ }^{93}$ reference-of-thought. Such equally applies with respect to notional ${ }^{18}$ deprocrypticism prospective institutionalisation relative to our procrypticism uninstitutionalised-threshold ${ }^{02}$. In other words, prospective institutionalisation as transcendence-and-sublimity/sublimation/supererogatory de-mentativity is construed not in terms-as-of-axiomatic-construct of 'mechanical-knowledge' which refers to the 'simplistic <amplituding/formative-epistemicity $>$ causality $\sim$ as-to-projective-totalitative-

\section{implications-of-prospective- nonpresencing,-for-explicating relative-unreflexivity/relative-}

reflexivity - ontological-contiguity outcomes construed as the overtly compelling aspect of the knowledge' validating a knowledge construct but is construed rather in terms-as-of-axiomaticconstruct of 'organic-knowledge' which refers to the 'mental-disposition and mental-orientation 
as ${ }^{83}$ reference-of-thought/psychologism construed as including the discretional contemplative aspect of the knowledge, behind the thought process that eventually leads to and is subsuming of the mechanical-knowledge'. Thus prospective institutionalisation as transcendence-andsublimity/sublimation/supererogatory-de-mentativity is grounded on such an underlying reference-of-thought associated with organic-knowledge qualified as the institutionalisation psychologism. In this regard, a chemist or botanist for instance in a non-positivistic as medieval or animistic/base-institutionalisation setup will certainly not confuse the fact that its demonstration of chemical reactions or a plant demonstration to approval in such a social-setup necessarily imply that the 'underlying positivism mental-disposition and mental-orientation as reference-of-thought/psychologism construed as including the discretional contemplative aspect as of ontological-faith-notion-or-ontological-fideism - imbued-underdetermination-ofmotif-and-apriorising/axiomatising/referencing-as-so-being-as-of-existential-reality of positivistic knowledge' behind its thought process eventually producing the validating $<$ amplituding/formative-epistemicity $>$ causality $~$ as-to-projective-totalitative-implications-ofprospective- nonpresencing,-for-explicating relative-unreflexivity/relative-reflexivity ontological-contiguity outcomes means the medieval or animistic/base-institutionalisation setup has grasped the positivistic organic-knowledge, as it is very much likely that it will surreptitiously and beyond-the-consciousness-awareness-teleology ${ }^{\circ}<$ of-preconvergingexistential-extrication-as-of-existential-unthought $>$ conjure up explanations $/{ }^{5}$ meaningfulnessand-teleology ${ }^{9}$ in terms-as-of-axiomatic-construct of its non-positivistic medieval alchemic or non-positivistic animistic ${ }^{83}$ reference-of-thought psychologism; as it is naïve to think that implied organic-knowledge as of prospective institutionalisation transcendence-andsublimity/sublimation/superenterentativity requiring its own ${ }^{83}$ reference-of-thought psychologism can simply be construed as 'mechanical-knowledge' while still upholding/keeping the prior/transcended/superseded registry-worldview's/dimension's ${ }^{83}$ reference-of-thought 
psychologism, as the organic-knowledge rather points to 'validating <amplituding/formativeepistemicity $>$ causality $\sim$ as-to-projective-totalitative-implications-of-prospectivenonpresencing,-for-explicating relative-unreflexivity/relative-reflexivity - ontological-

contiguity outcomes as its mechanical-knowledge aspect but further requires a development of the discretional contemplative aspect as of ontological-faith-notion-or-ontological-fideism imbued-underdetermination-of-motif-and-apriorising/axiomatising/referencing-as-so-being-asof-existential-reality of the knowledge', grounded rather on such a prospective institutionalisation psychologism as its 'suprastructuration' or its 'suprastructural psychical-andinstitutionalisation orientation of ${ }^{5}$ meaningfulness-and-teleology ${ }^{9}$ synopsising-depth as of the overall registry-worldview's/dimension's reconstrual of superseding-oneness-of-ontology', and not the prior/superseded/transcended uninstitutionalised-threshold ${ }^{102}$ psychologism. Such organic-knowledge gets institutionalised to an extent by the habituation as of circularity/recurrence/repetition/repeatability ${ }^{10}$ of the mechanical-knowledge implied reference-of-thought of meaningfulness-and-teleology as of crossgenerational psychoanalytic-unshackling involving <amplituding/formative-epistemicity $>$ totalising $\sim$ selfreferencing-syncretising/circularity/interiorising/akrasiatic-drag ${ }^{34}$ towards the ultimate crossgenerational alignment to the prospective/transcending/superseding registry-worldview reference-of-thought, as a positivistic registry-worldview ${ }^{8}$ reference-of-thought. Interestingly, and so across all successive institutionalisations, what tends to be lost the 'failure to register fully that the 'intemporal-disposition projecting mental-disposition' behind <amplituding/formativeepistemicity $>$ causality $\sim$ as-to-projective-totalitative-implications-of-prospective-

\section{nonpresencing,-for-explicating relative-unreflexivity/relative-reflexivity - ontological-}

contiguity validating the institutionalisation of 'mechanical-knowledge' is rather the 'vitality aspect' of organic-knowledge and it is 'not a passive dispensation', just as well that the 'temporal mental-dispositions' superseded towards attaining the 'mechanical-knowledge' is 'not simply a 
passive distraction' with the insight that there is a contiguity as of temporal-to-intemporal mental-disposition relative to ontological-faith-notion-or-ontological-fideism - imbuedunderdetermination-of-motif-and-apriorising/axiomatising/referencing-as-so-being-as-of-

existential-reality across all the <cumulating/recomposuring attendant-ontologicalcontiguity $>$-successive registry-worldviews/dimensions as at all their uninstitutionalisedthreshold ${ }^{102}$ temporal-individuations-as-shortness-of-register-of- ${ }^{56}$ meaningfulness-andteleology are a drawback to transcendence-and-sublimity/sublimation/supereregatory $\sim$ dementativity (by adherence to '<amplituding/formative > wooden-language-〈imbued - temporalmere-form/virtualities/dereification/akrasiatic-drag/denatured/preconverging-or-dementing narratives - of-the- reference-of-thought- categorical-imperatives/axioms/registryteleology $>$ of prior/transcended/superseded registry-worldviews/dimensions' inducing their successive threshold-of-nonconviction/madeupness/bottomlining-in-shallow-supererogation

\section{<as-to-'attendant-intradimensional'-prospectively-}

disontologising preconverging/dementing -apriorising-psychologism>, and critically so as across all registry-worldviews/dimensions postlogism 77 leads to a characteristic mentaldisposition at their uninstitutionalised-threshold of of deception-of-concurrently-falsepresupposing/false-presuming/false-premising-of-narratives and the consequent derivation, due to induced 'lack of constraining social ${ }^{103}$ universal-transparency ${ }^{104}$-〈transparency-of-totalisingentailing,-as-to-entailing-<amplituding/formative-epistemicity $>$ totalising $\sim$ in-relative-

ontological-completeness $\rangle$, to other temporal-dispositions as conjugated-postlogism 7 , and so beyond-the-consciousness-awareness-teleology ${ }^{9}-<$ of - preconverging-existential-extrication-asof-existential-unthought $>$ whether conscious or unconscious) while the intemporalindividuation-as-longness-of-register-of- ${ }^{5}$ meaningfulness-and-teleology 99 ushers in transcendence-and-sublimity/sublimation/supererogatory - de-mentativity (by it perpetual vouching for intemporal-preservation-entropy-or-contiguity-or-ontological-preservation as of 
ontological-faith-notion-or-ontological-fideism - imbued-underdetermination-of-motif-andapriorising/axiomatising/referencing-as-so-being-as-of-existential-reality in pushing as this enables successive prospective relative-ontological-completeness ${ }^{87}$-of- ${ }^{83}$ reference-of-thought to raise better and better ${ }^{83}$ reference-of-thought- categorical-imperatives/axioms/registryteleology ,-for-intemporal-preservation-entropy-or-contiguity-or-ontological-preservation); thus validating the notion of a human intersolipsistic relation to ${ }^{56}$ meaningfulness-andteleology $\quad$ in $\quad$ transversality- $<$ for-sublimating-existential-eventuating/denouement-from'thinking at-first/pure-predisposition-preemptive-of-prospectivedisontologising/subontologising’ as-of-prospectively-disambiguated-affirmed-andunaffirmed-'motif-and-apriorising/axiomatising/referencing'> ${ }^{101}$ since a wrong 'wishful thinking'/intemporal-romanticism/good-naturedness of vouching for logical-congruence will overlook the inevitable reality of temporal-perversion with prospective implications as of $<$ amplituding/formative-epistemicity $>$ totalising $\sim$ self-referencing-

syncretising/circularity/interiorising/akrasiatic-drag ${ }^{34}$, as its resolution is rather an anticipation as of transversality-<for-sublimating-existential-eventuating/denouement,-from 'thinking atfirst/pure-predisposition-preemptive-of prospective-disontologising/subontologising' as-ofprospectively-disambiguated-affirmed-and-unaffirmed-'motif-andapriorising/axiomatising/referencing'>101. Likewise, futural Being-development/ontologicalframework-expansion-as-to-depth-of-ontologising-development-as-infrastructure-ofmeaningfulness-and-teleology as of prospective notional deprocrypticism institutionalisation ${ }^{5}$ meaningfulness-and-teleology ${ }^{9}$ implies that transcendence-andsublimity/sublimation/supererogatory de-mentativity rather reasoned in our positivismprocrypticism terms of psychologism is inevitably denaturing as of ontologicalnormalcy/postconvergence epistemic-or-notional projective-perspective; as it is in need of the organic-knowledge of the prospective institutionalisation psychologism or 
notional ${ }^{18}$ deprocrypticism psychologism as apriorising/axiomatising/referencing-\{of'prospectively_implicited_attendant-ontological-contiguity ' educedexistentialising/contextualising/textualising_'intelligibility/epistemicity/reflexivity-contiguity<imbued-notional cogency $\left.>{ }^{\prime}\right\}$-conflatedness ${ }^{13}$-in-\{preconverging-disentailment-by\} postconverging-entailment (conflation psychologism) on the basis of the 'referentialism technique of point-referencing (explained elsewhere), which involves 'contrastive temporal-tointemporal synopsising-depth from a notional ${ }^{18}$ deprocrypticism perspective' that re-establishes 'implicited_attendant-ontological-contiguity ${ }^{67}$ ' educedexistentialising/contextualising/textualising_'intelligibility/epistemicity/reflexivity-contiguity$<$ imbued-notional $\sim$ cogency $>,{ }^{\prime},-<$ reifying-or-elucidating-of-prospective-relative-ontologicalcompleteness -of- reference-of-thought- devolving-as-of-instantiative-context $>$ and in so doing undermines the relatively defective terms of 'positivism- ${ }^{80}$ procrypticism uninstitutionalisation psychologism' (disjointedness-as-of- ${ }^{-3}$ eference-of-thought) and setting up 'notional ' deprocrypticism organic-knowledge institutionalisation psychologism including the discretional contemplative as of the ontological-faith-notion-or-ontological-fideism imbued-underdetermination-of-motif-and-apriorising/axiomatising/referencing-as-so-being-asof-existential-reality aspect in preempting-disjointedness-as-of- ${ }^{8}$ reference-of-thought or upholding jointedness', as preconverging/postconverging-dementatively/structurally/paradigmatically transcending the overall vices-and-impediments ${ }^{105}$ of positivism- ${ }^{80}$ procrypticism registry-worldview/dimension. The further implication is that notional ${ }^{1}$ deprocrypticism is rather construed as a perpetuating metaphysics-of-absence〈implicited-epistemic-veracity-of- nonpresencing-<perspective-ontologicalnormalcy/postconvergence $>>$ which driven by ontological-faith-notion-or-ontologicalfideism —imbued-underdetermination-of-motif-and-apriorising/axiomatising/referencing-asso-being-as-of-existential-reality can then enable that way the perpetual upholding of organic- 
knowledge. This 'mechanical-knowledge by organic-knowledge' implication for conceptualising institutional-cumulation/institutional-recomposure-〈as-to-

\section{historiality/ontological-eventfulness /ontological-aesthetic-tracing- $<$ perspective-}

ontological-normalcy/postconvergence-reflected-'epistemicity-relativism-determinism' $>>\quad$ is validated by 'attendant ontologising-capacity driven apriorising/axiomatising/referencingpsychologism as of the grander ontological-normalcy/postconvergence apriorising/axiomatising/referencing/intelligibilitysettingup/measuringinstrumenting' across retrospective and by implication prospective registry-worldviews/dimensions. This can be further expounded as follows in similar terms. The relative-unreflexivity/relative-reflexivityontological-contiguity ${ }^{67}$ of-the-human-institutionalisation-process ${ }^{68}$ behind the institutionalcumulation/institutional-recomposure-〈as-to- historiality/ontological-

\section{eventfulness /ontological-aesthetic-tracing-<perspective-ontological-}

normalcy/postconvergence-reflected-‘epistemicity-relativism-determinism'>> doesn't only

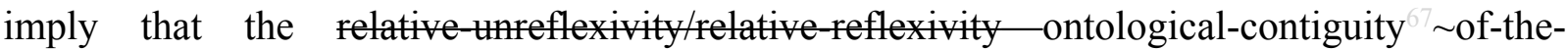
human-institutionalisation-process ${ }^{68}$ is simplistically the result of 'social- ${ }^{103}$ universallytransparent-and-implicitly-formulated direct-constraining-construct' successively as: nonrules — apriorising/axiomatising/referencing-psychologism,-as-impulsive-or-accidented-orrandom-mental-disposition in recurrent-utter-uninstitutionalisation, 'rulemaking-over-nonrules_-apriorising/axiomatising/referencing-psychologism' in base-institutionalisationuniversalisation, $\quad$ ' ${ }^{103}$ universalisation-directed-rulemaking-over-non-rulesapriorising/axiomatising/referencing-psychologism' in $\quad{ }^{103}$ universalisation-nonpositivism/medievalism, 'positivising/rational-empiricism-based-universalisation-directedrulemaking-over-non-rules — apriorising/axiomatising/referencing-psychologism' in positivism- ${ }^{80}$ procrypticism, and prospectively in deprocrypticism, 'preemptingdisjointedness-as-of- ${ }^{8}$ reference-of-thought,-as-to- ${ }^{6}<$ amplituding/formative- 
epistemicity>growth-or-conflatedness ${ }^{13} /$ transvaluative- $^{-}$

rationalising/transepistemicity/anamnestic-residuality/spirit-drivenness'_-in-supersedingmere-formulaic-positivising/rational-empiricism-based-universalisation-directed-rulemakingover-non-rules - apriorising/axiomatising/referencing-psychologism'. Rather the relativeunreflexivity/relative-reflexivity — ontological-contiguity ${ }^{67}$ of-the-human-institutionalisationprocess $^{68}$ is driven by human limited-mentation-capacity-as-subjecting-'educedunlimitedness/existence-sublimating nascence' to-limitedness/human-subpotency as of limited-mentation-capacity-deepening — as-subjecting limitedness/human-subpotency-to'educed-unlimitedness/existence-sublimating nascence' ${ }^{53}$ in the human drive to grasp a same intrinsic-reality/ontological-veridicality that doesn't change with respect to existence-as-of-itsmimetic-echoness/existence-in-reverberation/existence-potency ${ }^{39} \sim$ sublimating-nascence,disclosed-from-prospective-epistemic-digression (with change rather reflected as a result of human limited-mentation-capacity-deepening —as-subjecting limitedness/human-subpotencyto-'educed-unlimitedness/existence-sublimating nascence' ${ }^{3}$ ), such that in addition to the human limited-mentation-capacity-deepening —as-subjecting limitedness/human-subpotencyto-'educed-unlimitedness/existence-sublimating nascence'"53 eliciting the successive 'socialuniversally-transparent-and-implicitly-formulated direct-constraining-construct' as highlighted above equally inherently imply (and so, as of complement to human limited mentation capacity), a grander non-constraining element qualified as 'ontological-faith-notionor-ontological-fideism —imbued-underdetermination-of-motif-andapriorising/axiomatising/referencing-as-so-being-as-of-existential-reality construed as of intemporal-preservation-entropy-or-contiguity-or-ontological-preservation' in-complement-to and reflecting the incompleteness of the 'social- ${ }^{103}$ universally-transparent-and-implicitlyformulated direct-constraining-construct'; with both the 'social- ${ }^{103}$ universally-transparent-andimplicitly-formulated direct-constraining-construct' and the 'complementing grander social- 
universally-non-transparent-thus-non-constraining-element of ontological-faith-notion-orontological-fideism - imbued-underdetermination-of-motif-and-

apriorising/axiomatising/referencing-as-so-being-as-of-existential-reality construed as of intemporal-preservation-entropy-or-contiguity-or-ontological-preservation' implying the 'organic-knowledge' while just the 'social- ${ }^{103}$ universally-transparent-and-implicitly-formulated direct-constraining-construct' is the 'mechanical-knowledge'. The underlying idea is that an individuation in recurrent-utter-uninstitutionalisation notwithstanding its non-rulesapriorising/axiomatising/referencing-psychologism,-as-impulsive-or-accidented-or-randommental-disposition (social- ${ }^{103}$ universally-transparent-and-implicitly-formulated directconstraining-construct), wherein human-subpotency-aporia/undecidability/dilemma/oughtindeterminacy/deficiency/limitation/constraint—imbued-'notional firstnaturednessformativeness-<as-to-eventmalising-inkling-drive-or - seeding-misprising $>$ temporal-tointemporal-dispositions- $<$ so-construed-as-from-perspective-ontologicalnormalcy/postconvergence>'-existentialism-form-factor still applies and if they project intemporally/longness-of register-of - meaningfulness-and-teleology, is not necessarily utterly devoid of a basic sense of 'prospective postconverging-apereticismovereming as the-Good/knowledge-reification $\sim$ gesturing-and-accounting-ofepistemic-phenomenalism- $<$ in-

prospective_psychologismic apriorising/axiomatising/referencing-\{of- ${ }^{\star}$ prospectively implicited_attendant-ontological-contiguity ' educedexistentialising/contextualising/textualising_'intelligibility/epistemicity/reflexivity-contiguity<imbued-notional cogency >' \}-conflatedness -in-\{preconverging disentailment by\} postconverging entailment>/understanding/<amplituding/formativeepistemicity $>$ causality $\sim$ as-to-projective-totalitative-implications-of-prospectivenonpresencing,-for-explicating relative-unreflexivity/relative-reflexivity - ontological- 
contiguity as virtue-as-of-ontological-emancipation on the basis that it doesn't recognise rulemaking-over-non-rules — apriorising/axiomatising/referencing-psychologism as of 'mechanical-knowledge', but while that can as well be the case when projecting temporally/shortness-of-register-of meaningfulness-and-teleology as of the registryworldview's/dimension's- ${ }^{83}$ reference-of-thought-for-social-functioning-and-accordance in such a setup as not constrained by any rulemaking-over-non-rulesapriorising/axiomatising/referencing-psychologism (based on mere 'mechanical nonknowledge' of non-rules - apriorising/axiomatising/referencing-psychologism,-as-impulsiveor-accidented-or-random-mental-disposition in recurrent-utter-uninstitutionalisation), however at the intemporal-threshold as of the registry-worldview's/dimension's- ${ }^{83}$ reference-of-thoughtfor-social-functioning-and-accordance notwithstanding its limited-mentation-capacity-assubjecting 'educed-unlimitedness/existence-sublimating nascence' to-limitedness/humansubpotency, by intemporal-projection it will be able to summon heuristically a sense of 'prospective postconverging aporeticism-overceming/unovercoming as the-Good/knowledgereification $\sim$ gesturing-and-accounting — of-epistemic-phenomenalism- $<$ inprospective_psychologismic $\sim$ apriorising/axiomatising/referencing-\{of-'prospectively_ implicited_attentontological-contiguity ' ceducedexistentialising/contextualising/textualising_'intelligibility/epistemicity/reflexivity-contiguity<imbued-notional $\left.\sim \operatorname{cogency}>^{\prime} \quad\right\}$-conflatedness -in-\{preconverging-disentailment by\} postconverging entailment $>$ /understanding/<amplituding/formativeepistemicity $>$ causality $\sim$ as-to-projective-totalitative-implications-of-prospectivenonpresencing,-for-explicating relative-unreflexivity/relative-reflexivity - ontologicalcontiguity ' from its 'complementing grander social- ${ }^{103}$ universally-non-transparent-thus-nonconstraining-element of ontological-faith-notion-or-ontological-fideism-imbuedunderdetermination-of-motif-and-apriorising/axiomatising/referencing-as-so-being-as-of- 
existential-reality construed as of intemporal-preservation-entropy-or-contiguity-orontological-preservation' (beyond the mere 'mechanical non-knowledge' of non-rulesapriorising/axiomatising/referencing-psychologism,-as-impulsive-or-accidented-or-randommental-disposition) as 'organic-knowledge', for ${ }^{55}$ maximalising-recomposuring-for-relativeontological-completeness ${ }^{87}$ - unenframed/re-ontologising conceptualisation intemporal/ontological/social/species/ ${ }^{103}$ universal/transcendental/ ${ }^{5}$ maximalisingrecomposuring-for-relative-ontological-completeness 87 unenframed/reontologising conceptualisation postconverging-de-mentating/structuring/paradigming) which subsequently as of dynamic-cumulative-aftereffect brings about base-institutionalisationununiversalisation 'social- ${ }^{103}$ universally-transparent-and-implicitly-formulated directconstraining-construct' of 'rulemaking-over-non-rules — apriorising/axiomatising/referencingpsychologism' as the new 'mechanical-knowledge' as well as implying the 'complementing grander social- ${ }^{103}$ universally-non-transparent-thus-non-constraining-element of ontologicalfaith-notion-or-ontological-fideism—imbued-underdetermination-of-motif-andapriorising/axiomatising/referencing-as-so-being-as-of-existential-reality construed as of intemporal-preservation-entropy-or-contiguity-or-ontological-preservation', with both forming the new 'organic-knowledge'. Likewise, base-institutionalisation-ununiversalisation too by dynamic-cumulative-aftereffect at its intemporal-threshold of the registryworldview's/dimension's- ${ }^{83}$ reference-of-thought-for-social-functioning-and-accordance notwithstanding limited-mentation-capacity—as-subjecting-'educed-unlimitedness/existencesublimating nascence' to-limitedness/human-subpotency, the intemporally projecting individuation will be able to summon heuristically a sense of 'prospective postconverging-apereticism-overcoming/movereoming as the-Good/knowledgereification $\sim$ gesturing-and-accounting — of-epistemic-phenomenalism- $<$ in- 
implicited_attendant-ontological-contiguity ' reduced-

existentialising/contextualising/textualising_'intelligibility/epistemicity/reflexivity_contiguity-

<imbued-notional cogency>> $\}$-conflatedness -in-\{preconverging-disentailment by\}

postconverging-entailment $>$ /understanding/<amplituding/formative-

epistemicity $>$ causality $\sim$ as-to-projective-totalitative-implications-of-prospective-

nonpresencing,-for-explicating relative-unreflexivity/relative-reflexivity ontological-

contiguity ', from its 'complementing grander social- ${ }^{103}$ universally-non-transparent-thus-nonconstraining-element of ontological-faith-notion-or-ontological-fideism -imbuedunderdetermination-of-motif-and-apriorising/axiomatising/referencing-as-so-being-as-ofexistential-reality construed as of intemporal-preservation-entropy-or-contiguity-orontological-preservation', (beyond the mere 'mechanical-knowledge' of 'rulemaking-over-nonrules_-apriorising/axiomatising/referencing-psychologism') as 'organic-knowledge', for maximalising-recomposuring-for-relative-ontological-completeness ${ }^{87}$ - unenframed/reontologising conceptualisation

intemporal/ontological/social/species/ ${ }^{103}$ universal/transcendental/ ${ }^{55}$ maximalisingrecomposuring-for-relative-ontological-completeness ${ }^{8}$ —unenframed/re-

ontologising $\sim$ conceptualisation postconverging-de-mentating/structuring/paradigming) leading by a dynamic-cumulative-aftereffect to the subsequent prospective ${ }^{103}$ universalisation-nonpositivism/medievalism as of the new 'social- ${ }^{103}$ universally-transparent-and-implicitlyformulated direct-constraining-construct' of ' ${ }^{103}$ universalisation-directed-rulemaking-over-nonrules - apriorising/axiomatising/referencing-psychologism' as the new 'mechanicalknowledge' as well as implying the 'complementing grander social- ${ }^{103}$ universally-nontransparent-thus-non-constraining-element of ontological-faith-notion-or-ontological-fideism imbued-underdetermination-of-motif-and-apriorising/axiomatising/referencing-as-so-being-asof-existential-reality construed as of intemporal-preservation-entropy-or-contiguity-or- 
ontological-preservation', with both forming the new 'organic-knowledge'. The relativemnreflexivity/relative-reflexivity — ontological-contiguity ${ }^{67}$ of-the-human-institutionalisationprocess $^{68}$ carries on this way right up to deprocrypticism, such that across the successive institutionalisations apart from the intemporal-threshold of the registryworldview's/dimension's- ${ }^{83}$ reference-of-thought-for-social-functioning-and-accordance as explained above; with respect to temporal-thresholds of the registry-worldview's/dimension'sreference-of-thought-for-social-functioning-and-accordance of the registryworldview's/dimension's- ${ }^{8}$ reference-of-thought-for-social-functioning-and-accordance, temporal mental-dispositions are rather in arrogation/usurpation relation with the determinant nature of 'social- ${ }^{103}$ universally-transparent-and-implicitly-formulated direct-constrainingconstruct' as 'mechanical-knowledge', and so as <amplituding/formative> wooden-language〈imbued-temporal-mere-form/virtualities/dereification/akrasiaticdrag/denatured/preconverging-or-dementing -narratives - of-the- reference-of-thoughtcategorical-imperatives/axioms/registry-teleology $\rangle$, while failing/not-upholding-<as-ofapriorising/axiomatising/referencing $>$ the 'complementing grander social- ${ }^{103}$ universally-nontransparent-thus-non-constraining-element of ontological-faith-notion-or-ontological-fideism imbued-underdetermination-of-motif-and-apriorising/axiomatising/referencing-as-so-being-asof-existential-reality construed as of intemporal-preservation-entropy-or-contiguity-orontological-preservation' which together with the 'mechanical-knowledge' make up the 'organic-knowledge', and so rather as of temporal extricatory preconverging-dementating/structuring/paradigming. This further involves shades-of-temporality ${ }^{8}$ as postlogism 7 -slantedness/ ${ }^{5}$ ignorance/affordability/opportunism/exacerbation/social-chainismor-social-discomfiture-or-negative-social-aggregation/temporal-enculturation-or-temporalendemisation, so-disambiguated as of ${ }^{83}$ reference-of-thought- ${ }^{8}$ devolving ontologicalperformance $^{72}-<$ including-virtue-as-ontology $>$ /morality/ethics/justice/etc. inducing defect-of- 
logical-processing-or-logical-implicitation-supposedly-apriorising-in-conviction-as-toprofound-supererogation as well as postlogism ${ }^{77}$ inducing defect of ${ }^{83}$ reference-of-thought or perversion-of- ${ }^{8}$ reference-of-thought-<as-preconvergingly-

apriorising/axiomatising/referencing-in-nonconviction/madeupness/bottomlining-as-to-

shallow-supererogation $>$. postlogism 77 as such involves deliberate and wrong pretence of rational projection of thought (as of teleologically-degraded synopsising-depth) whereas 'implicited_attendant-ontological-contiguity ${ }^{67}$ ' educed-

existentialising/contextualising/textualising_'intelligibility/epistemicity/reflexivity-contiguity$<$ imbued-notional $\sim$ cogency $>,{ }^{\prime},-<$ reifying-or-elucidating-of-prospective-relative-ontologicalcompleteness -of- reference-of-thought- devolving-as-of-instantiative-context $>$ reveals that such thought derives from 'denaturing axiomatic relation' as the '<amplituding/formative $>$ wooden-language-〈imbued-temporal-mereform/virtualities/dereification/akrasiatic-drag/denatured/preconverging-or-dementing narratives - of-the- reference-of-thought- categorical-imperatives/axioms/registryteleology > of mechanical-knowledge' as deterministic for temporal/shortness-of-register-ofmeaningfulness-and-teleology purpose in disdain of the intemporal/1ongness-of-register-ofmeaningfulness-and-teleology essence of knowledge as of its organic essence. The conjugation of other shades-of-temporality ${ }^{8}$ to postlogism 77 induces their respective conjugatedpostlogism leading by dynamic-cumulative-aftereffect to a broader social derivedperversion-of- ${ }^{-3 e f e r e n c e-o f-t h o u g h t-<a s-p r e c o n v e r g i n g l y-~}$

apriorising/axiomatising/referencing-in-nonconviction/madeupness/bottomlining-as-toshallow-supererogation $>$ construed as social-postlogism 77 that fundamentally is denaturing of ${ }^{5}$ meaningfulness-and-teleology ${ }^{9}$ at the given uninstitutionalised-threshold ${ }^{102}$ as thresholdof-nonconviction/madeupness/bottomlining-in-shallow-supererogation $<<$ as-to-'attendantintradimensional'-prospectively-disontologising preconverging/dementing -apriorising- 
psychologism>, in want for prospective institutionalisation. The underlying insight being that human formulation of ${ }^{5}$ meaningfulness-and-teleology ${ }^{9}$ is necessarily incomplete because of its limited-mentation-capacity—as-subjecting-'educed-unlimitedness/existence-sublimating nascence' to-limitedness/human-subpotency and thus comes with an inherent sense/projection of ontological-appropriateness, and as of human developing ontological-completeness-ofreference-of-thought, as the driving element in upholding relative-unreflexivity/relativereflexivity - ontological-contiguity ${ }^{67} /$ ontological-veridicality. This notion as reflected by ontological-faith-notion-or-ontological-fideism - imbued-underdetermination-of-motif-andapriorising/axiomatising/referencing-as-so-being-as-of-existential-reality (as it enables the further expansion of the registry-worldview's/dimension's- ${ }^{83}$ reference-of-thought-for-socialfunctioning-and-accordance intemporal-thresholds and so as of ontological-emancipationbeyond-just-virtue) should be the critical and decisive constructive/institutionalising/nascentsublimating-decisionality element for attaining notional 18 deprocrypticism wherein the 'social'universally-transparent-and-implicitly-formulated direct-constraining-construct' as mechanical-knowledge is construed as overlapping with the "complementing grander socialuniversally-non-transparent-thus-non-constraining-element of ontological-faith-notion-orontological-fideism - imbued-underdetermination-of-motif-andapriorising/axiomatising/referencing-as-so-being-as-of-existential-reality construed as of intemporal-preservation-entropy-or-contiguity-or-ontological-preservation' as organicknowledge. The reality of ontological-faith-notion-or-ontological-fideism-imbuedunderdetermination-of-motif-and-apriorising/axiomatising/referencing-as-so-being-as-ofexistential-reality driven relative-unreflexivity/relative-reflexivity ontologicalcontiguity ${ }^{67} \sim$ of-the-human-institutionalisation-process ${ }^{68}$ points to the fact that the traditional construal of knowledge often tacitly as of intemporal/ongness-of-register-of - meaningfulnessand-teleology is incomplete and rather speaks of 'vague intellectual intemporal-romanticism' 
and doesn't fit with the reality of human-subpotency-aporia/undecidability/dilemma/oughtindeterminacy/deficiency/limitation/constraint—imbued-'notional firstnaturednessformativeness-<as-to-eventualising-inkling drive-or-seeding-misprising $>$ temporal-tointemporal-dispositions- $<$ so-construed-as-from-perspective-ontologicalnormalcy/postconvergence>'-existentialism-form-factor as upheld by the mediocrity principle underlying a rational-realism perspective, and explains why articulating knowledge merely as 'mechanical-knowledge' is bound to lead to its distortion/perversion/misconstrual by the mere fact of human temporal/shortness-of-register-of- meaningfulness-and-teleology mentaldisposition adhering rather to <amplituding/formative > wooden-language-〈imbued - temporalmere-form/virtualities/dereification/akrasiatic-drag/denatured/preconverging-or-dementing

\section{narratives - of-the- reference-of-thought- categorical-imperatives/axioms/registry-}

teleology $>$ implied by the mechanical-knowledge explaining the successive need for ontological-faith-notion-or-ontological-fideism - imbued-underdetermination-of-motif-andapriorising/axiomatising/referencing-as-so-being-as-of-existential-reality to overcome such distortion/perversion/misconstrual; as in fact despite such a vague idealism as intemporalromanticism, implicitly where highly pressing we tend to be obliged to recognised this temporalto-intemporal reality as implied in the way we go about developing many a social formal construct. Thus notional ${ }^{18}$ deprocrypticism knowledge as overlapping the mechanical with the organic, as of the intemporal/longness-of-register-of- meaningfulness-and-teleology mentaldisposition driven by ontological-faith-notion-or-ontological-fideism -imbuedunderdetermination-of-motif-and-apriorising/axiomatising/referencing-as-so-being-as-ofexistential-reality behind the mechanical-knowledge, is a further validation of the idea of notionalisation/notional-conception/amplituding of knowledge which emphasises in principle and beforehand/as-of-a-priori a deliberative consideration of this temporal-to-intemporal human disposition in relating to mechanical-knowledge as of prospective possibilities for a better 
preempting of temporality $/$ shortness and skewing towards the intemporal/Hongness-of-registerof - meaningfulness-and-teleology, and so as of organic-knowledge overlapping. Further, the reality of a human-subpotency-aporia/undecidability/dilemma/oughtindeterminacy/deficiency/limitation/constraint—imbued-'notional firstnaturednessformativeness-<as-to-eventualising inkling drive-or seeding misprising $>$ - temporal-tointemporal-dispositions- $<$ so-construed-as-from-perspective-ontologicalnormalcy/postconvergence>'-existentialism-form-factor means that human meaningfulness at all times is more of a 'solipsistic transversality-<for-sublimating-existentialeventuating/denouement,-from-'thinking at-first/pure-predisposition-preemptive-ofprospective-disontologising/subontologising' -as-of-prospectively-disambiguated-affirmedand-unaffirmed-'motif-and-apriorising/axiomatising/referencing'> ${ }^{101}$ of human meaningfulness as of temporal-to-intemporal mental-dispositions transversality-<for-sublimating-existentialeventuating/denouement,-from-'thinking-at-first/pure-predisposition-preemptive-ofprospective-disontologising/subontologising' as-of-prospectively-disambiguated-affirmedand-unaffirmed-'motif-and-apriorising/axiomatising/referencing'>101 and 'not a 'solipsistic commonness of meaningfulness that wrongly implies no notional firstnaturednessformativeness-<as to entising inkling drive or seeding misprising $>$ temporal-tointemporal-dispositions-<so-construed-as-from-perspective-ontologicalnormalcy/postconvergence $>$ mental-dispositions', as any commonness is a 'commonness implied with respect to secondnaturing institutionalisation as of social-functioning-andaccordance - as-of-social-stake-contention-or-confliction thresholds', with the implication that there is no point acting and relating with knowledge as if it is about a solipsistic transformation into intemporality ${ }^{52} /$ longness but rather relating to it as a secondnaturing exercise of skewing ('intemporality ${ }^{52}$-symmetrising-by-desymmetrising-subsumption-of-temporality ${ }^{8}$ ', for relative intrinsic-reality/ontological-veridicality transcendental- 
enabling/sublimating/supereregatory $\sim$ de-mentativity or deferential-formalisation-transference) with respect to the institutionalisation/intemporalisation process as virtue (a notion equally implied by many a prophesying metaphysico-theological construct as the intemporality ${ }^{52} /$ longness and transcendental projections as of their limited-mentation-capacityas-subjecting 'educed-unlimitedness/existence-sublimating nascence' to-limitedness/humansubpotency in their own times in resolving the issues of human temporality $/$ shortness in their

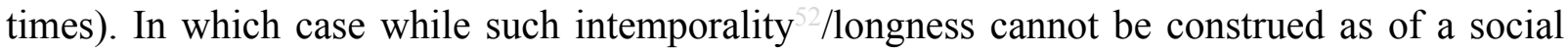
commonness of ${ }^{8}$ reference-of-thought, it's occurrence if it does occur can only be construed in transversality-<for-sublimating-existential-eventuating/denouement,-from-'thinking at-

\section{first/pure-predisposition-preemptive-of-prospective-disontologising/subontologising' as-of-} prospectively-disambiguated-affirmed-and-unaffirmed-'motif-and-

apriorising/axiomatising/referencing' $>$ (more like the abstract notion of faith, by definition and as implied in many a creed, however metaphysical though, can only be solipsistic to an individual and not amenable to a commonness of social contemplation) as of abstract intersolipsism. The Nietzschean metaphor 'God is dead', as of human emancipation, is one whose validity can only be countenance where it implies the capacity of human pretence of intellectual-and-moral sublimation, and not the notion of intellectual-and-moral decadence. *Thus to sum up, the overall notion of apriorising/axiomatising/referencing-\{of- "prospectively implicited_attendant-ontological-contiguity ' educedexistentialising/contextualising/textualising_'intelligibility/epistemicity/reflexivity-contiguity<imbued-notional cogency>' \}-conflatedness ${ }^{13}$-in-\{preconverging disentailment by\} postconverging-entailment in relation with other elucidative associated notions can further be clarified as follows in 'interdimensional/transdimensional/transcendental terms in reflecting holographically-<conjugatively-and-transfusively $>$ the relative-unreflexivity/relativereflexivity - ontological-contiguity of-the-human-institutionalisation-process ${ }^{\prime}$ as well as 
'individuation terms of human temporal-to-intemporal mental-dispositions'. With regards to the interdimensional/transdimensional/transcendental relative-unreflexivity/relative-reflexivity_ ontological-contiguity ${ }^{67}$ of-the-human-institutionalisation-process ${ }^{68}$ level, we can construe of apriorising/axiomatising/referencing-\{of-'prospectively implicited_attendant-ontologicalcontiguity ' educedexistentialising/contextualising/textualising_ 'intelligibility/epistemicity/reflexivity-contiguity<imbued-notional cogency $\left.>^{\prime}\right\}$-conflatedness ${ }^{13}$-in-\{preconverging-disentailment by postconverging-entailment as of the <amplituding/formativeepistemicity $>$ totalising $\sim$ ratiocontiguity/ratiocination-as-referentialism—'implicited_attendant ontological-contiguity ${ }^{67}$, educedexistentialising/contextualising/textualising_intelligibility/epistemicity/reflexivity-contiguity$<$ imbued-notional cogency>' ;-phenomenal-abstractiveness-of-presencing-in-'protensiveconsciousness'-enablingapriorising/axiomatising/referencing/intelligibilitysettingup/measuringinstrumenting-foroperant-or-incidenting-predicative-insights-of 'implicited_attendant-ontologicalcontiguity $^{67} \sim$ educed-

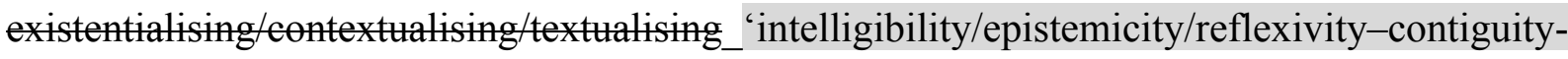
$<$ imbued-notional $\sim$ cogency $>$ ' ,-<reifying-or-elucidating-of-prospective-relative-ontologicalcompleteness -of- reference-of-thought- devolving-as-of-instantiative-context> potency implied as of ontological-normalcy/postconvergence and reconstrued in the successive prospective relative-ontological-completeness ${ }^{87}$-of- ${ }^{3}$ reference-of-thought, wherein the referentialism technique for apriorising/axiomatising/referencing-\{of-'prospectively implicited_attentant-ontological-contiguity ' educedexistentialising/contextualising/textualising_'intelligibility/epistemicity/reflexivity-contiguity<imbued-notional cogency $\left.>^{\prime}\right\}$ - conflatedness ${ }^{13}$-in-\{preconverging-disentailment by\} 
postconverging-ntailment known as point-referencing delineates/disambiguates the various institutional-cumulation/institutional-recomposure-〈as-to- historiality/ontologicaleventfulness /ontological-aesthetic-tracing-<perspective-ontologicalnormalcy/postconvergence-reflected-'epistemicity-relativism-determinism'>> as of ontologicalnormalcy/postconvergence revealing their 'contrastive-synopsising-depths-ofmeaningfulness-and-teleology ${ }^{9}$ as the varying synopsising-depth of human meaningfulness-and-teleology $\quad$ (recurrent-utter-uninstitutionalisation, baseinstitutionalisation-ununiversalisation, $\quad{ }^{103}$ universalisation-non-positivism/medievalism,

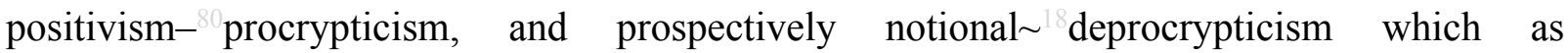
'notional ' deprocrypticism' is the 'point of point-referencing for apriorising/axiomatising/referencing-\{of-'prospectively implicited_attendant-ontologicalcontiguity ' $\sim$ educedexistentialising/contextualising/textualising_'intelligibility/epistemicity/reflexivity-contiguity$<$ imbued-notional cogency $\left.>^{\prime} \quad\right\}$-conflatedness ${ }^{13}$ in-\{preconverging-disentailment by $\}^{\prime}$ postconverging-entailment ', by the construal of its relative-unreflexivity/relative-reflexivity ontological-contiguity ${ }^{67}$ of-the-human-institutionalisation-process ${ }^{68}{ }^{83}$ reference-of-thought as of ontological-normalcy/postconvergence), with respect to the same intrinsicreality/ontological-veridicality such that such varying is attributed to human limited-mentationcapacity-deepening —as-subjecting limitedness/human-subpotency-to-'educedunlimitedness/existence-sublimating nascence' ${ }^{53}$ as of apriorising/axiomatising/referencing\{of-'prospectively_implicited_attendant-ontological-contiguity ' educedexistentialising/contextualising/textualising_'intelligibility/epistemicity/reflexivity_contiguity<imbued-notional cogency $>$ ' $\}$-conflatedness ${ }^{13}$-in-\{preconverging-disentailment by\} postconverging-entailment (or construed as from apriorising/axiomatising/referencing-\{of'prospectively_implicited_attendant-ontological-contiguity ' educed- 
existentialising/contextualising/textualising_'intelligibility/epistemicity/reflexivity-contiguity<imbued-notional $\sim$ cogency $>\quad\}$ - constitutedness ${ }^{1}$-in-preconverging entailment $/{ }^{\circ}$ presencing-absolutising-identitive-constitutedness ${ }^{1 /}$, apriorising/axiomatising/referencing-\{of-'prospectively_implicited_attendant-ontologicalcontiguity ' $\sim$ educedexistentialising/contextualising/textualising_ 'intelligibility/epistemicity/reflexivity-contiguity<imbued-notional cogency >' $\}$-conflatedness ${ }^{13}$-in-\{preconverging-disentailment by\} postconverging-entailment) inducing both the registry-worldviews/dimensions institutionalisation-facets ('centered/in-phase' and 'postconverging-or-dialectical-thinking apriorising-psychologism') and uninstitutionalised-threshold ${ }^{12}$-facets ('decentered/out-ofphase' and preconverging-or-dementing -apriorising-psychologism as caricaturing-hollowstaging-and-performance). $\quad$ Supposed a $\quad$ notional $\sim$ conflatedness $^{13} \quad$ or apriorising/axiomatising/referencing-\{of-'prospectively_implicited_attendant-ontologicalcontiguity ' $\sim$ educedexistentialising/contextualising/textualising_intelligibility/epistemicity/reflexivity_contiguity<imbued-notional cogency >' \}-conflatedness ${ }^{13}$-in-\{preconverging-disentailment by\} abstraction across all the registry-worldviews/dimensions on the basis of the referentialism technique of point-referencing ("notional ${ }^{18}$ deprocrypticism-or-asfrom-recurrent-utter-uninstitutionalisation-to-deprocrypticism') is undertaken with respect to establishing ${ }^{\text {'3 }}$ reference-of-thought-as-to-preconverging/postconverging-dementating/structuring/paradigming - ontological-performance ${ }^{2}-<$ including-virtue-asontology $>$ /morality/ethics/justice/etc. relative to social-stake-contention-or-confliction', it will fundamentally be perceived sceptically by the respective uninstitutionalised-threshold ${ }^{102}$ as it 'decenters and dements beforehand/as-of-a-priori' as of their respective prior relativeontological-incompleteness ${ }^{8}$-of- ${ }^{8}$ reference-of-thought, so implied by their given social 
universal-transparency ${ }^{104}$-〈transparency-of-totalising-entailing,-as-to-entailing-

<amplituding/formative-epistemicity >totalising in-relative-ontological-completeness $>$ as of 'implicited_attendant-ontological-contiguity ${ }^{67}$ educed-

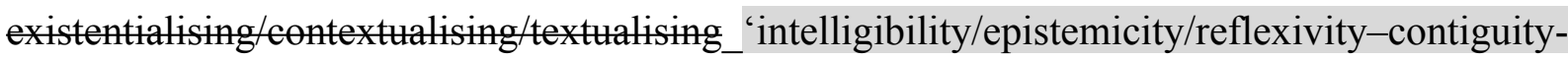
$<$ imbued-notional $\sim$ cogency $>{ }^{\prime},-<$ reifying-or-elucidating-of-prospective-relative-ontological-

completeness -of- reference-of-thought- devolving-as-of-instantiative-context>; that is, as 'decentering and preconverging-or-dementing ${ }^{20}$-apriorising-psychologism beforehand/as-of-apriori' recurrent-utter-uninstitutionalisation given its non-rulesapriorising/axiomatising/referencing-psychologism,-as-impulsive-or-accidented-or-randommental-disposition or as of its failing/not-upholding-<as-ofapriorising/axiomatising/referencing $>\quad$ rulemaking-over-non-rulesapriorising/axiomatising/referencing-psychologism, as 'decentering and preconverging-ordementing -apriorising-psychologism beforehand/as-of-a-priori' base-institutionalisationununiversalisation as failing/not-upholding-<as-of-apriorising/axiomatising/referencing $>$ universalisation-directed-rulemaking-over-non-rules — apriorising/axiomatising/referencingpsychologism, as 'decentering and preconverging-or-dementing -apriorising-psychologism beforehand/as-of-a-priori' ${ }^{103}$ universalisation-non-positivism/medievalism as failing/notupholding-<as-of-apriorising/axiomatising/referencing $>\quad$ positivising/rational-empiricismbased-universalisation-directed-rulemaking-over-non-rules-

apriorising/axiomatising/referencing-psychologism, and as 'decentering and preconverging-ordementing ${ }^{20}$-apriorising-psychologism beforehand/as-of-a-priori' positivism- ${ }^{80}$ procrypticism as failing/not-upholding-<as-of-apriorising/axiomatising/referencing $>\quad$ preemptingdisjointedness-as-of- ${ }^{8}$ reference-of-thought,-as-to- ${ }^{6}<$ amplituding/formativeepistemicity>growth-or-conflatedness $13 /$ transvaluativerationalising/transepistemicity/anamnestic-residuality/spirit-drivenness'_-in-superseding- 
mere-formulaic-positivising/rational-empiricism-based-universalisation-directed-rulemakingover-non-rules_-apriorising/axiomatising/referencing-psychologism. Critically and interestingly with the last stage since our positivism- ${ }^{80}$ procrypticism registryworldview/dimension is necessarily in <amplituding/formative-epistemicity $>$ totalising $\sim$ selfreferencing-syncretising/circularity/interiorising/akrasiatic-drag ${ }^{34}$ as with all 'present-states' of registry-worldviews/dimensions as construed from their backend perspectives in reflecting holographically-<conjugatively-and-transfusively $>$ the relative-unreflexivity/relativereflexivity - ontological-contiguity of-the-human-institutionalisation-process , it would hardly be inclined to interpret such apriorising/axiomatising/referencing-\{of-"prospectively implicited_attendant-ontological-contiguity ' educedexistentialising/contextualising/textualising_'intelligibility/epistemicity/reflexivity-contiguity$<$ imbued-notional cogency $\left.>^{\prime} \quad\right\}$-conflatedness ${ }^{13}$ in-\{preconverging-disentailment by postconverging-entailment referentialism technique of point-referencing (notional ' deprocrypticism) that 'decenters and dements it beforehand/as-of-a-priori' on the basis of such 'doppler-thinking' based on attendant-ontologising-capacity driven 'postconverging-or-dialectical-thinking - psychology or psychology-of-mentation-dynamics or natural psychological-dynamics' as of the grander ontological-normalcy/postconvergence apriorising/axiomatising/referencing/intelligibilitysettingup/measuringinstrumenting' and thus rendering its $\quad{ }^{5}$ meaningfulness-and-teleology ${ }^{9} \quad$ threshold-ofnonconviction/madeupness/bottomlining-in-shallow-supererogation $-<$ as-to-' ${ }^{\circ}$ attendantintradimensional'-prospectively-disontologising preconverging/dementing -apriorisingpsychologism $>$ at the positivism- ${ }^{80}$ procrypticism uninstitutionalisation, while it "pointlessly strives to be centered and postconverging-or-dialectical-thinking -apriorising-psychologism by reflex' by not recognising its uninstitutionalised-threshold ${ }^{02}$ or the procrypticism uninstitutionalisation ${ }^{83}$ reference-of-thought in disjointedness-as-of- ${ }^{8}$ reference-of-thought (as 
all 'present-states' of registry-worldviews/dimensions do by reflex), and thus rather involved in $<$ amplituding/formative-epistemicity $>$ totalising $\sim$ self-referencing-

syncretising/circularity/interiorising/akrasiatic-drag ${ }^{34}$ of meaning as of $<$ amplituding/formativeepistemicity>totalising $\sim$ self-referencing-syncretising/circularity/interiorising/akrasiatic-drag ${ }^{34}$.

But then we know and can appreciate that all the prior registry-worldviews/dimensions were 'decentered and preconverging-or-dementing ${ }^{20}$-apriorising-psychologism beforehand/as-of-apriori' going by 'attendant ontologising-capacity driven apriorising/axiomatising/referencingpsychologism as of the grander ontological-normalcy/postconvergence apriorising/axiomatising/referencing/intelligibilitysettingup/measuringinstrumenting'. This 'anti-transcendence as anti-uninstitutionalised-threshold ${ }^{12}$ and anti-prospective institutionalisation mental-disposition' of all 'present-states' of all registryworldviews/dimensions is due to the fact of such 'present-states' <amplituding/formativeepistemicity $>$ totalising $\sim$ self-referencing-syncretising/circularity/interiorising/akrasiatic-drag desymmetrisation alignment overly-overemphasising the registry-worldview/dimension institutionalisation-facet in a corresponding relation with a desymmetrical alignment over underemphasising its uninstitutionalised-threshold ${ }^{12}$-facet, but with such representation becoming critically ontologically untenable at the registry-worldview/dimension uninstitutionalised-threshold ${ }^{102}$ where ${ }^{56}$ meaningfulness-and-teleology ${ }^{99}$ breaks into thresholdof-nonconviction/madeupness/bottomlining-in-shallow-supererogation $-<$ as-to-'attendantintradimensional'-prospectively-disontologising preconverging/dementing -apriorising-

psychologism $>$. With regards to individuation terms of human temporal-to-intemporal mentaldispositions (and in further articulation of the grander ontological-normalcy/postconvergence apriorising/axiomatising/referencing/intelligibilitysettingup/measuringinstrumenting with respect to registry-worldviews/dimensions 'present-states' as of their <amplituding/formativeepistemicity $>$ totalising $\sim$ self-referencing-syncretising/circularity/interiorising/akrasiatic-drag 
syncretising/circularity/interiorising/akrasiatic-drag ${ }^{34}$ ), apriorising/axiomatising/referencing\{of-'prospectively_implicited_attendant-ontological-contiguity ' ceducedexistentialising/contextualising/textualising_'intelligibility/epistemicity/reflexivity-contiguity$<$ imbued-notional $\left.\sim \operatorname{cogency}>^{\prime},\right\}$-conflatedness ${ }^{13}$ in-\{preconverging-disentailment by pestcenverging-entailment referentialism technique of point-referencing from the intemporalprojection/intemporality $^{52}$ individuation point of point-referencing for apriorising/axiomatising/referencing-\{of-'prospectively implicited_attendant-ontologicalcontiguity ' educedexistentialising/contextualising/textualising_intelligibility/epistemicity/reflexivity-contiguity<imbued-notional cogency $\left.>{ }^{\prime}\right\}$-conflatedness ${ }^{13}$-in-\{preconverging-disentailment by\} postcenverging-ntailment (given that the intemporal-disposition by longness-of-register-ofmeaningfulness-and-teleology 9 is ontological as of supratransversality-<in-sublimatingexistential-eventuating/denouement $>\sim$ of-motif-and-apriorising/axiomatising/referencing), in disambiguating/delineating the 'various temporal-to-intemporal synopsising-depth of meaningfulness-and-teleology ${ }^{9}$, by social ${ }^{103}$ universal-transparency ${ }^{104}$-〈transparency-oftotalising-entailing,-as-to-entailing-<amplituding/formative-epistemicity $>$ totalising $\sim$ inrelative-ontological-completeness > as of 'implicited_attendant-ontologicalcontiguity $^{67}$; educed-

existentialising/contextualising/textualising_'intelligibility/epistemicity/reflexivity-contiguity$<$ imbued-notional cogency $>,{ }^{\prime},-<$ reifying-or-elucidating-of-prospective-relative-ontologicalcompleteness -of- reference-of-thought- devolving-as-of-instantiative-context $>$ with respect to prospective relative-ontological-completeness ${ }^{87}$-of- ${ }^{8}$ reference-of-thought, and in so doing establishing 'registry-worldview's/dimension's-uninstitutionalised-threshold ${ }^{102}$-defect- $<$ asBeing-or-ontological-or-existential-defect> <amplituding/formative- 
epistemicity $>$ causality $\sim$ as-to-projective-totalitative-implications-of-prospective-

nonpresencing,-for-explicating relative-unreflexivity/relative-reflexivity - ontological-

contiguity projection insight' with respect to the distractive alignment implications of postlogism 7 -slantedness/ ${ }^{5}$ ignorance/affordability/opportunism/exacerbation/social-chainismor-social-discomfiture-or-negative-social-aggregation/temporal-enculturation-or-temporalendemisation, so-disambiguated as of ${ }^{83}$ reference-of-thought- ${ }^{8}$ devolving ontologicalperformance $^{72}-<$ including-virtue-as-ontology $>$ /morality/ethics/justice/etc. (which are the very 'temporal-distractively-aligned synopsising-depth-of- ${ }^{5}$ meaningfulness-and-teleology ${ }^{\circ}$ '-asshallowness-of-thought-as-subtransversality-<in-desublimating-existentialeventuating/denouement> of-motif-and-apriorising/axiomatising/referencing) as of aetiologisation/ontological-escalation- $<$ ontologicalveridicality_commitment/otherliness_transcending/compulsions-encumbered_transcending $>$ (which is the very 'intemporal synopsising-depth-of- meaningfulness-andteleology $/$ supratransversality-<in-sublimating-existential-eventuating/denouement $>\sim$ ofmotif-and-apriorising/axiomatising/referencing as-to-<amplituding/formativeepistemicity>totalising $\sim$ social-context-construed-conflatedness ${ }^{1{ }^{\prime}}$ ); such that an insightful storied-construct/ontologically-valid-narration as elucidative of aetiologisation/ontologicalescalation-<ontological-veridicality_commitment/otherliness_transcending/compulsionsencumbered_transcending $>$ is necessarily one construed at the 'dynamic-cumulative-aftereffect transversality-<for-sublimating-existential-eventuating/denouement,-from-'thinking-atfirst/pure-predisposition - preemptive-of prospective-disontologising/subontologising' as-ofprospectively-disambiguated-affirmed-and-unaffirmed-'motif-andapriorising/axiomatising/referencing'> ${ }^{101}$ crossroads of temporal-to-intemporal individuations synopsising-depth-of- ${ }^{5}$ meaningfulness-and-teleology $\left.{ }^{9} \cdot\right]$ 
In other words, suprastructuralism (as of its referential and ontologicalnormalcy/postconvergence emanance perspective and as a doppler-thinking exercise) ushers in a whole new comprehensive registry-worldview across the entire social construction-of-meaning called deprocrypticism, much like positivism did over non-positivism/medievalism or universalisation over ununiversalisation or base-institutionalisation over tteruninstitutionalisation. Central to such a ' ${ }^{103}$ universal notion of deprocrypticism' is the idea of an utter-recomposuring-ontologising by upholding ontological-normalcy/prospectivetranscendence-in-perpetually-upholding-intemporal-preservation-entropy-or-contiguity-orontological-preservation, involving postdication with postdicatory techniques and postdicatory mindset $/{ }^{3}$ reference-of-thought in reflection of the suprastructural and ontologicalnormalcy/postconvergence nature of intrinsic-reality (more like the positivistic registryworldview is all about existential-<disontologising/re-ontologising aporeticism $>$ positivistic conceptualisations, positivistic techniques and basic positivistic mindset $/{ }^{3}$ reference-of-thought superseding existential-<disontologising/re-ontologising aporeticism $>\quad$ alchemic conceptualisations, alchemic techniques and a basic alchemic mindset/ ${ }^{3}$ reference-of-thought that defined the non-positivism/medievalism registry-worldview/dimension); involving ensuring intemporal-disposition organic-comprehension-thinking that upholds-and-is-the ${ }^{83}$ reference-ofthought for relative-unreflexivity/relative-reflexivity ontological-contiguity ${ }^{6} /$ ontologicalveridicality, over threshold-of-nonconviction/madeupness/bottomlining-in-shallowsupererogation -<as-to-'attendant-intradimensional'-prospectivelydisontologising preconverging/dementing -apriorising-psychologism $>$ by temporaldispositions meaningfulness hotchpotching disjointing/disparateness/disentailing' as pervertedand-derived-perverted- ${ }^{8}$ reference-of-thought and induces notional-discontiguity/epistemicdiscontiguity 33 - between - prior-shallow-supererogation -of-mentallyaestheticised $\sim$ preconverging/dementing -qualia-schema_and_prospective-profound- 
supererogation -of-mentally-aestheticised postconverging/dialectical-thinking -qualia-

schema>

as

of

apriorising/axiomatising/referencing/intelligibilitysettingup/measuringinstrumenting. In-thebigger-picture of human institutional transcendence-andsublimity/sublimation/supererogatory de-mentativity, this is very much in line with the transcending/superseding of human uninstitutionalised-threshold ${ }^{102}$ 'with increasing cumulation of placeholder-setup/mental-devising-representation/mentation/consciousness-awarenessteleology ${ }^{9}$ capacity' that defined the successive institutional-cumulation/institutionalrecomposure-〈as-to- historiality/ontological-eventfulness /ontological-aesthetic-tracing$<$ perspective--ontological-normalcy/postconvergence-reflected-‘epistemicity-relativismdeterminism' $>>$ specificities as: existential-<disontologising/re-ontologising aporeticism $>$ base-institutionalising with base-institutionalising techniques and base-institutionalising mindset $/{ }^{3}$ reference-of-thought $\quad$ (Base-institutionalisation); existential-<disontologising/reentologising aporeticism $>{ }^{103}$ universalising with ${ }^{103}$ universalising techniques and ${ }^{3}$ universalising mindset $/{ }^{3}$ reference-of-thought $\quad\left({ }^{103}\right.$ universalisation); existential<disontologising/re-ontelogising aporeticism $>$ positivising/rational-empiricism with positivising techniques and positivising mindset/ ${ }^{83}$ reference-of-thought (Positivism); and prospectively 'existential ontologising', and so beyond its conventioning incrementalism-inrelative-ontological-incompleteness ${ }^{8}$ —enframed/disontologising $\sim$ conceptualisation disjointedness-as-of- ${ }^{8}$ reference-of-thought as of temporal-accommodation of positivistic meaningfulness, as 'existentially-<disontologising/re-ontologising aporeticism $>$ utter postdicatory ontological-normalcy/prospective-transcendence-in-perpetually-upholdingintemporal-preservation-entropy-or-contiguity-or-ontological-preservation', with postdicatory methods and techniques and an overall postdicatory mindset $/{ }^{3}$ reference-of-thought (deprocrypticism). existential-<disentologising/re-ontologising aporeticism $>$ ontologising is 
effectively

the

human

placeholder-setup/mental-devising-

representation/mentation/consciousness-awareness-teleology aspiration towards a fulsome grasp of intrinsic-reality/full-ontological-veridicality as fulfilling ontological-normalcy; all along the institutional-cumulation/institutional-recomposure-〈as-to- historiality/ontologicaleventfulness /ontological-aesthetic-tracing-<perspective-ontological-

normalcy/postconvergence-reflected-‘epistemicity-relativism-determinism' $>>$ levels but for incomplete human placeholder-setup/mental-devising-representation/mentation/consciousnessawareness-teleology ${ }^{9}$ capacity the preceding institutionalisation levels are more like successive compromises towards notional deprocrypticism as ontological-normalcy/postconvergence (prospective-transcendence-in-perpetually-upholding-intemporal-preservation-entropy-orcontiguity-or-ontological-preservation). A critical distinction between notional ${ }^{1}$ deprocrypticism institutionalisation and positivistic institutionalisation has to do with the former uncompromising relation with respect to prospectively upholding notionalcontiguity/epistemic-contiguity ${ }^{62}<$ profound-supererogation -of-mentallyaestheticised postconverging/dialectical-thinking -qualia-schema> thus overcoming the temporal-emananances-registries hotchpotching (<amplituding/formative $>$ wooden-language〈imbued - averaging-of-thought-<as-to-leveling/ressentiment/closed-construct-ofmeaningfulness-and-teleology -as-of-‘nondescript/ignorable-void '-with-regards-toprospective-apriorising-implications $>>$ or banality-of-thought dynamism, and specifically in the extended-informality-〈susceptible-to-effecting-parsimony-as-of-shoddiness-andincompleteness-to- meaningfulness-and-teleology $\rangle$ even though it is very much present in the formal sphere as well) and the incrementalism-in-relative-ontological-incompleteness enframed/disontologising conceptualisation and notional $\sim$ disjointedness-as-of- ${ }^{8}$ reference-ofthought inherent in the positivistic mindset, thus the latter tends relatively to be weakly ontologically-contiguous with all the existential-<disontologising/re-ontologising 
aporeticism $>$ implications thereof, whether with regards to virtue construal or subject-matters issues. Further as with all transcendence-and-sublimity/sublimation/supereregatery $\sim$ dementativity, the transcendence-and-sublimity/sublimation/supereregatery $\sim$ de-mentativity going from procrypticism, or the preconverging-or-dementing -apriorising-psychologism ( 7 perversion-of- ${ }^{8}$ reference-of-thought-<as-preconvergingly-

\section{apriorising/axiomatising/referencing-in-nonconviction/madeupness/bottomlining-as-to-}

shallow-supererogation $>$ as to preconverging-or-dementing 2 -apriorising-psychologism) of positivistic ${ }^{5}$ meaningfulness-and-teleology", to notional ${ }^{18}$ deprocrypticism will involve a psychoanalytically preconverging-or-dementing -apriorising-psychologism deconstruction/ontological-reconstituting-as-to-conflatedness ${ }^{13}$ of our present positivistic placeholder-setup/mental-devising-representation/mentation/consciousness-awarenessteleology wherein this is presently postconverging-or-dialectical-thinking -apriorisingpsychologism- $<$ stranded-as-rightfully-straight/candored-and-dialectically-or-contendingly-inphase $>$ to a placeholder-setup/mental-devising-representation/mentation/consciousnessawareness-teleology ${ }^{9}$ wherein the notional ${ }^{18}$ deprocrypticism mindset/ ${ }^{3}$ reference-of-thought reflects/perspectivates the positivistic placeholder-setup/mental-devisingrepresentation/mentation/consciousness-awareness-teleology ${ }^{9}$ at its uninstitutionalisedthreshold in hollow-constituting-<as-disjointed-misappropriation-of-meaningfulness-andfailing-intemporal-preservation> or preconverging-or-dementing 20 -apriorising-psychologism$<$ stranded-as-rightfully-oblongated/decandored-and-dialectically-or-contendingly-out-ofphase $>$. So the notional ${ }^{18}$ deprocrypticism institutionalisation (as a renewed existentialism/fulldepth-of-existential-implications ${ }^{5}$ meaningfulness-and-teleology ${ }^{9}$ or memetic-refinement) ontologising involves an ontological-normalcy/postconvergence-or-postdicatory deconstruction/ontological-reconstituting-as-to-conflatedness ${ }^{13}$ as dialectical transformation, as-prospective ${ }^{83}$ reference-of-thought, of intradimensional-meaningfulness psychoanalytically 
as-preconverging-or-dementing 2 -apriorising-psychologism of our present positivistic mindset $/{ }^{3}$ reference-of-thought at its uninstitutionalised-threshold ${ }^{102}$. Even though as with all transcended registry-worldviews/dimensions such an implied veridical placeholdersetup/mental-devising-representation/mentation/consciousness-awareness-teleology ${ }^{9} \quad$ will probably sound unintelligible/existentially-suprastructural due to our positivistic illusion-of-thepresent/epistemic-totalising $\sim$ self-referencing-syncretising/present-consciousness/mirage; as the ${ }^{83}$ reference-of-thought, in articulating ontological-normalcy/postconvergence and the suprastructural nature of intrinsic-reality/ontological-veridicality, moves away from a positivistic registry-worldview registrying/dueness to a notional ${ }^{18}$ deprocrypticism registryworldview registrying/dueness with the corresponding de-mentation〈supererogatory $\sim$ ontological-de-mentation-or-dialectical-de-mentation - stranding-or-

attributive-dialectics $\rangle$ stranding the prospective/superseding/transcending registryworldview/dimension transdimensional-meaningfulnessapriorising/axiomatising/referencing/intelligibilitysettingup/measuringinstrumenting as organic-comprehension-thinking and the prior/superseded/transcended registryworldview/dimension intradimensional-meaningfulness as threshold-ofnonconviction/madeupness/bottomlining-in-shallow-supererogation $<-<$ as-to- 'attendantintradimensional'-prospectively-disontologising preconverging/dementing -apriorisingpsychologism> (just as <cumulating/recomposuring attendant-ontological-contiguity >successive registry-worldviews/dimensions ${ }^{83}$ reference-of-thought, in a conceptual grasp of ontological-normalcy/postconvergence and the suprastructural nature of intrinsicreality/ontological-veridicality, had priorly moved from an utter-institutionalisation registrying/dueness/existentialism to a base-institutionalisation registrying/dueness/existentialism, to a ${ }^{103}$ universalisation registrying/dueness/existentialism and then presently a positivistic registrying/dueness/existentialism, with corresponding ${ }^{15}$ de- 
mentation-_supererogatory - ontological-de-mentation-or-dialectical-de-mentation — stranding-

or-attributive-dialectics〉 stranding prospective/superseding/transcending registryworldviews/dimensions meaningfulness as organic-comprehension-thinking and the prior/superseded/transcended registry-worldviews/dimensions meaningfulness as threshold-ofnonconviction/madeupness/bottomlining-in-shallow-supererogation $-<$ as-to-' attendant-

\section{intradimensional'-prospectively-disontologising preconverging/dementing -apriorising-}

psychologism>; as-and-when-it-is-established that a registry-worldview's/dimension's institutionalisation is no longer intemporal-preservational, when it is "7tperversion-ofreference-of-thought-<as-preconvergingly-apriorising/axiomatising/referencing-innonconviction/madeupness/bottomlining-as-to-shallow-supererogation $>$ its ${ }^{83}$ reference-ofthought- categorical-imperatives/axioms/registry-teleology ${ }^{9}$,-for-intemporal-preservationentropy-or-contiguity-or-ontological-preservation at its uninstitutionalised-threshold ${ }^{102}$ ). It should be noted that human uninstitutionalised-threshold ${ }^{102}$ refers to the point where a specific institutionalisation is failing/not-upholding-<as-of-apriorising/axiomatising/referencing $>$ intemporal-preservation-entropy-or-contiguity-or-ontological-preservation by a formulaic adherence (lip-servicing) to ${ }^{83}$ reference-of-thought- categorical-imperatives/axioms/registryteleology ${ }^{9}$,-for-intemporal-preservation-entropy-or-contiguity-or-ontological-preservation hence attaining its uninstitutionalised-threshold ${ }^{12}$ wherein the ontological-veridicality of the mental-devising-representation is 'in threshold-of-nonconviction/madeupness/bottomlining-inshallow-supererogation -<as-to-'attendant-intradimensional'-prospectively-

disontologising preconverging/dementing -apriorising-psychologism> and not organiccomprehension-thinking', and we can envision retrospectively the points of de-mentation〈supererogatory ontological-de-mentation-or-dialectical-de-mentation-stranding-orattributive-dialectics $\rangle$ of preceding registry-worldviews/dimensions from our vantage point of being at the backend of the institutional-cumulation/institutional-recomposure-〈as-to- 
historiality/ontological-eventfulness /ontological-aesthetic-tracing-<perspective-

ontological-normalcy/postconvergence-reflected-‘epistemicity-relativism-determinism’>>

process like an insight in the recurrent-utter-institutionalised 'so-called savage' mindset/ ${ }^{83}$ reference-of-thought or the medieval mindset, for instance. Likewise such a thresholdof-nonconviction/madeupness/bottomlining-in-shallow-supererogation $<<$ as-to-'attendantintradimensional'-prospectively-disontologising preconverging/dementing -apriorising-

psychologism $>$ registry-worldview projection though of a different nature of the positivistic registry-worldview/dimension can be made prospectively from a notional ${ }^{18}$ deprocrypticism insight that overrides our illusion-of-the-present/epistemic-totalising $\sim$ self-referencingsyncretising/present-consciousness/mirage given its more suprastructural and ontologicalnormalcy/postconvergence vantage perspective in relation to intrinsic-reality/ontologicalveridicality/ontological-referencing. The general underlying principle for notional ${ }^{1}$ deprocrypticism methods and techniques is that of being utterly ontologising, beyond positivistic meaningfulness conventioning and temporal-accommodation as 'ontologicallyreconstituting/deconstruction' for undermining notional-discontiguity/epistemicdiscontiguity 3 - $<$ between - prior-shallow-supererogation -of-mentally-

aestheticised $\sim$ preconverging/dementing -qualia-schema_and_prospective-profoundsupererogation -of-mentally-aestheticised postconverging/dialectical-thinking -qualiaschema $>$ arising from temporal-dispositions ${ }^{7}$ perversion-of- ${ }^{-}$reference-of-thought- $<$aspreconvergingly-apriorising/axiomatising/referencing-in-

nonconviction/madeupness/bottomlining-as-to-shallow-supererogation $>$ as to preconvergingor-dementing -apriorising-psychologism, and as it upholds veridical ontologicalveridicality/relative-unreflexivity/relative-reflexivity - ontological-contiguity ${ }^{67}$ as the veridical reference-of-thought; which is what is actually up for contention and is effective contention (organic-comprehension-thinking) over what is being 'epistemically-decadent in notional- 
discontiguity/epistemic-discontiguity ${ }^{63}<$ between - prior-shallow-supererogation -ofmentally-aestheticised preconverging/dementing -qualia-schema_and_prospective-profoundsupererogation -of-mentally-aestheticised postconverging/dialectical-thinking -qualiaschema>', and is actually preconverging-or-dementing ${ }^{20}$-apriorising-psychologism (thresholdof-nonconviction/madeupness/bottomlining-in-shallow-supererogation $<-<$ as-to- 'attendantintradimensional'-prospectively-disontologising preconverging/dementing -apriorisingpsychologism>) and not contending. When implied specifically with regards to psychopathy and social psychopathy (just like a superseding positivistic orientation implied with regards to notions-and-accusations-of-sorcery and medieval mindset $/{ }^{3}$ reference-of-thought to sorcery), notional ${ }^{18}$ deprocrypticism as an intemporal transcendental construct implies prospective notional-contiguity/epistemic-contiguity ${ }^{62}$ - profound-supererogation -of-mentallyaestheticised postconverging/dialectical-thinking -qualia-schema $>$ deconstruction/ontological-reconstituting-as-to-conflatedness ${ }^{13}$ construct of temporaldispositions notional-discontiguity/epistemic-discontiguity ${ }^{63}<$ between - prior-shallowsupererogation -of-mentally-aestheticised preconverging/dementing -qualiaschema_and_prospective-profound-supererogation -of-mentallyaestheticised $\sim$ postconverging/dialectical-thinking - qualia-schema $>$ as the backdrop/grounding of the veridical ${ }^{83}$ reference-of-thought; as what is actually up for contention and is effective contention (organic-comprehension-thinking) over what is 'epistemically-decadent in notionaldiscontiguity/epistemic-discontiguity ${ }^{63}<$ between - prior-shallow-supererogation -ofmentally-aestheticised preconverging/dementing - qualia-schema_and prospective-profoundsupererogation -of-mentally-aestheticised postconverging/dialectical-thinking -qualiaschema>', as the latter is actually in threshold-of-nonconviction/madeupness/bottomlining-inshallow-supererogation -<as-to-'attendant-intradimensional'-prospectivelydisontologising preconverging/dementing -apriorising-psychologism $>$ and is not contending 
as organic-comprehension-thinking. Noting as well that with regards to human mentation capacity, the successive institutional-cumulation/institutional-recomposure-〈as-tohistoriality/ontological-eventfulness /ontological-aesthetic-tracing-<perspectiveontological-normalcy/postconvergence-reflected-'epistemicity-relativism-determinism' $>>$ elicit successive circumspections (as recomposured-consciousness-awareness-teleology ${ }^{9}$ ) in human placeholder-setup/mental-devising-representation/mentation/consciousness-awarenessteleology ${ }^{9}$ capacity that are enablers of the associated institutional-cumulation/institutionalrecomposure-〈as-to- historiality/ontological-eventfulness /ontological-aesthetic-tracing$<$ perspective-ontological-normalcy/postconvergence-reflected-'epistemicity-relativismdeterminism' $>$ ): for base-institutionalisation the circumspection is one of contrastive uninstitutionalised-threshold ${ }^{102}$-institutionalisation analytical placeholder-setup/mentaldevising-representation/mentation/consciousness-awareness-teleology ${ }^{9}$ capacity for upholding institutionalisation; with ${ }^{103}$ universalisation the circumspection involves contrastive ununiversalisation-and- ${ }^{103}$ universalisation analytical placeholder-setup/mental-devisingrepresentation/mentation/consciousness-awareness-teleology 9 capacity for upholding universalisation; with positivism the circumspection involves contrastive nonpositivism/medieval/alchemic-and-positivism/rational-empiricism analytic placeholdersetup/mental-devising-representation/mentation/consciousness-awareness-teleology ${ }^{99}$ capacity for upholding positivism/rational-empiricism; and prospectively, for notional ${ }^{18}$ deprocrypticism the circumspection will involve contrastive notional firstnaturedness-formativeness $<$ as to eventualising inkling-drive-or-seeding-misprising > temporal-to-intemporal-dispositions$<$ so-construed-as-from-perspective-ontological-normalcy/postconvergence $>\quad$ analytic placeholder-setup/mental-devising-representation/mentation/consciousness-awarenessteleology ${ }^{9}$ capacity for upholding the intemporal-disposition as ontology. Critically, human analytical mentation capacity mainly disambiguates what-is-in-effect organic-comprehension- 
thinking and threshold-of-nonconviction/madeupness/bottomlining-in-shallowsupererogation -<as-to-'attendant-intradimensional'-prospectivelydisontologising preconverging/dementing -apriorising-psychologism $>$, respectively as the mental-devising-representation of postconverging-or-dialectical-thinking ${ }^{21}$-apriorisingpsychologism representation and preconverging-or-dementing -apriorising-psychologism representation. Equally, with regards to human mentation capacity, the effect of limited mentation capacity characterising a given registry-worldview/dimension or intradimensional level and its social-construct not only defines its inherent vices-and-impediments ${ }^{105}$ but such a social-construct further and critically structures and stifles the natural renewal of human emancipative dispositions. For instance, non-positivism/medievalism stifling inclinations to think outside of medieval mental-dispositiona and likewise with regards to our procrypticism. The bigger point of successive institutionalisations has to do overall with their specific emancipative registry-worldview/dimension framework as fertilising the cross-section of human practical and conceptual incidental issues and endeavours as well as the virtue constructs at the said registry-worldview/dimension. What is interesting with regards to an incidental study like psychopathy and social psychopathy with respect to the grander notional ${ }^{18}$ deprocrypticism institutionalisation level within the treatment of the institutional-cumulation/institutionalrecomposure-〈as-to- historiality/ontological-eventfulness /ontological-aesthetic-tracing<perspective-ontological-normalcy/postconvergence-reflected-'epistemicity-relativismdeterminism' $>>$ meta-conceptual frame is that it provides (besides being critically important to grasp by itself as a parasitising/co-opting phenomenon that can potentially arise in all human locales) the incidental and the-Good/knowledge-reification $\sim$ gesturing-and-accounting-ofepistemic-phenomenalism-<in-

prospective_psychologismic apriorising/axiomatising/referencing-\{of-'prospectively implicited_attendant-ontological-contiguity ' educed- 
existentialising/contextualising/textualising_ 'intelligibility/epistemicity/reflexivity-contiguity$<$ imbued-notional $\left.\sim \operatorname{cogency}>^{\prime} \quad\right\}$-conflatedness -in-\{preconverging disentailment by\}

postconverging-entailment $>$ /understanding/<amplituding/formative-

epistemicity $>$ causality $\sim$ as-to-projective-totalitative-implications-of-prospectivenonpresencing,-for-explicating relative-unreflexivity/relative-reflexivity - ontological-

contiguity backdrop and background that informs and deepens understanding of the overall meta-conceptual analysis of ${ }^{7}$ perversion-of- ${ }^{3}$ reference-of-thought- $<$ as-preconverginglyapriorising/axiomatising/referencing-in-nonconviction/madeupness/bottomlining-as-to-

shallow-supererogation $>$ issues (issues arising from the tempering or false implying of the apriorising-registry-elements as fepistemic-totalising 3 psychologismic-subliminality-ofindividuation —effusing/worlding imbued logical-dueness-or-scape-or-frame, profile-or-stature, presumptuousness-or-arrogation, assumptions, value-reference and teleology and thus inducing a fundamental flaw with the ${ }^{83}$ reference-of-thought in the first place, and further at a second-order level in wrongly implying the existential-<disontologising/re-ontologisingapereticism $>$ veridicality of logical-dueness (thus making irrelevant the construing of soundness or unsoundness) of ${ }^{54}$ logical-processing-or-logical-implicitation - supposedly-apriorising-inconviction-as-to-profound-supererogation ), which in turn further enlighten the incidental analysis of psychopathy and social psychopath. Such dynamic and mutually beneficial insight at the meta-conceptualisation and incidental further extends to other related incidental issues relevant to the meta-conceptualisation. It should be noted that this overall explanatory exercise is 'not reasoning by analogy' but rather contiguous (relative-unreflexivity/relative-reflexivity ontological-contiguity ${ }^{67}$ ) as the fundamental notion is institutionalisation/intemporalisation entropy (intemporal-preservation contiguity; by a skewing device ('intemporality ${ }^{52}$ symmetrising-by-desymmetrising-subsumption-of-temporality ${ }^{\circ}$, for relative intrinsicreality/ontological-veridicality transcendental-enabling/sublimating/supereregatery $\sim$ de- 
mentativity)/deferential-formalisation-transference of the averageness of human temporaldispositions, with corresponding formalisation and internalisation as psychoanalyticunshackling/memetic-reordering/institutional-recomposuring, towards the supersedingness of the intemporal-disposition which is inherently ontological and syncs with intrinsic reality in its $<$ amplituding/formative-epistemicity $>$ causality $\sim$ as-to-projective-totalitative-implications-ofprospective- nonpresencing,-for-explicating relative-unreflexivity/relative-reflexivity

ontological-contiguity , and hence its supersedingness as it induces overall social virtue-as-ofontology). Institutionalisation/intemporalisation entropy (intemporal-preservation-entropy-orcontiguity-or-ontological-preservation) involves: - recurrent-utter-uninstitutionalisation (initial state of $\quad$ perversion-of- ${ }^{83}$ reference-of-thought- $<$ as-preconverginglyapriorising/axiomatising/referencing-in-nonconviction/madeupness/bottomlining-as-toshallow-supererogation >' that intemporally calls for the introduction of ${ }^{83}$ reference-ofthought- ${ }^{8}$ ategorical-imperatives/axioms/registry-teleology ${ }^{99}$,-for-intemporal-preservationentropy-or-contiguity-or-ontological-preservation as base-institutionalisation), - baseinstitutionalisation institutionalisation/intemporalisation (whose ${ }^{83}$ reference-of-thoughtcategorical-imperatives/axioms/registry-teleology ${ }^{9}$,-for-intemporal-preservation-entropy-orcontiguity-or-ontological-preservation "74 perversion-of- ${ }^{8}$ reference-of-thought- $<$ aspreconvergingly-apriorising/axiomatising/referencing-in-

ununiversalisation intemporally calls for ${ }^{103}$ universalisation), $\quad-\quad{ }^{103}$ universalisation institutionalisation/intemporalisation (whose $\quad{ }^{83}$ reference-of-thought- categoricalimperatives/axioms/registry-teleology ${ }^{9}$,-for-intemporal-preservation-entropy-or-contiguityor-ontological-preservation ' $\quad$ perversion-of- ${ }^{83}$ reference-of-thought- $<$ as-preconverginglyapriorising/axiomatising/referencing-in-nonconviction/madeupness/bottomlining-as-toshallow-supererogation >' as non-positivism/medievalism intemporally calls for positivism), - 
positivism institutionalisation/intemporalisation (prospectively, whose ${ }^{83}$ reference-of-thoughtcategorical-imperatives/axioms/registry-teleology ${ }^{9}$,-for-intemporal-preservation-entropy-orcontiguity-or-ontological-preservation '7 perversion-of- ${ }^{3}$ reference-of-thought- $<$ aspreconvergingly-apriorising/axiomatising/referencing-innonconviction/madeupness/bottomlining-as-to-shallow-supererogation $>>$ as procrypticism intemporally calls for deprocrypticism), - and prospectively notional deprocrypticism institutionalisation/intemporalisation (whose $\quad{ }^{83}$ reference-of-thought- categoricalimperatives/axioms/registry-teleology ${ }^{9}$,-for-intemporal-preservation-entropy-or-contiguityor-ontological-preservation will carry the 'virtuous and intellectual responsibility/relativereflexivity' to recognise that 'perversion-of- reference-of-thought-<as-preconverginglyapriorising/axiomatising/referencing-in-nonconviction/madeupness/bottomlining-as-toshallow-supererogation $>$ is an endemic human mental defect/perversion disposition retrospectively to prospectively, and that this is a 'lost cause' due fundamentally to mediocrity principle of humans having in reality 'notional firstnaturedness-formativeness-<as-toeventualising inkling-drive-or-seeding-misprising > temporal-to-intemporal-dispositions$<$ so-construed-as-from-perspective-ontological-normalcy/postconvergence ${ }^{\prime}$ and not ' ${ }^{103}$ universal intemporal-disposition', and the construct of deprocryptic categoricalimperatives/axioms should be anticipatory and preemptive of ${ }^{77}$ perversion-of- ${ }^{3}$ reference-ofthought-<as-preconvergingly-apriorising/axiomatising/referencing-innonconviction/madeupness/bottomlining-as-to-shallow-supererogation >> perpetually at the 'uninstitutionalised-threshold ${ }^{102}$. More like the modern notion of medicine doesn't work on the idea of exceptional people, as this will ultimately lead to a wrong and superstitious disease theory, but accepts that preconverging/postconverging-dementatively/structurally/paradigmatically bacteria, cancer, organ failure, etc. cause disease and that the virtue of medicine is about how to understand and preempt the above causations; likewise 
deprocryptic virtue operates on a realistic grasp of human subknowledging $94 /$ mimicking/temporal-to-intemporal-solipsistic-projections at uninstitutionalised-threshold ${ }^{102}$ and then strives to skew/deferential-formalisation-transference for the supersedingness of the intemporal-disposition, which is ontological, for intemporalpreservation entropy/contiguity). We can garner such emanant (becoming) 'psychoanalytic unshackled insight' of how we transcended from non-positivism/medievalism to a positivistic registry-worldview. A literary insight can also be grasped reading Chinua Achebe's Things Fall Apart on how a community where a traditional registry-worldview with its sense of purpose had to deal with positivistic transcendence-and-sublimity/sublimation/supereregatory $\sim$ dementativity. Think of the state of the mind of Okonkwo of the Umuofia Clan. Though, in this case the transcendence-and-sublimity/sublimation/supereregatory $\sim$ de-mentativity is by cultural diffusion rather than by internal philosophical transcendence-andsublimity/sublimation/supererogatory $\sim$ de-mentativity. Basically, all transcendence-andsublimity/sublimation/supererogatory de-mentativity involve a "psychoanalytic-unshackling of this sort'. Counterintuitively, it should be understood that no transcendence-andsublimity/sublimation/supererogatery $\sim$ de-mentativity is rational because you rationalise by operating logic on a sound registry-worldview/axiomatic construct/categorical-imperatives but then the need for transcendence-and-sublimity/sublimation/supererogatory $\sim$ de-mentativity due to perversion-and-derived- ${ }^{7}$ perversion-of- ${ }^{-3}$ reference-of-thought- $<$ as-preconverginglyapriorising/axiomatising/referencing-in-nonconviction/madeupness/bottomlining-as-toshallow-supererogation $>$ and the registry-worldview's/dimension's relative-ontologicalincompleteness ${ }^{88}$-induced,-'threshold-of-nonconviction/madeupness/bottomlining-in-shallowsupererogation -<as-to-'attendant-intradimensional'-prospectivelydisontologising preconverging/dementing -apriorising-psychologism>' is putting the soundness of registry-worldview/axiomatic construct/categorical-imperatives in question (as 
reference-of-thought supersedes/precedes $\quad{ }^{5}$ logical-processing-or-logical-implicitation supposedly-apriorising-in-conviction-as-to-profound-supererogation ), so you rather have a reinvention as <amplituding/formative-epistemicity $>$-totalising $\sim$ renewing-realisation/reperception/re-thought of a new and better registry-worldview/axiomatic-construct/categoricalimperatives by the psychoanalytic-unshackling coming from its better grasp/<amplituding/formative-epistemicity $>$ causality $\sim$ as-to-projective-totalitativeimplications-of-prospective- nonpresencing,-for-explicating relative-unreflexivity/relativereflexivity - ontological-contiguity of the world/intrinsic reality. Basically, we can say that human-emanant/becoming-transcendence is the first level of human invention (incremental inventions of relatively sounder minds; with the would-be 'intellectual-analysts' undergoing their own philosophical/first-level transcendence-andsublimity/sublimation/supererogatory de-mentativity to liberate themselves before secondnaturing/institutionalising for the new possibilities for the species; noting that, this doesn't mean that the Descartes, Comtes, Galileos, Newtons, Darwins... of the world, miraculously came up with positivism to supersede/precede/override/utter medievalism, as they were of medieval stock but by philosophical transcendence-andsublimity/sublimation/spentativity could project beyond the limits of nonpositivism/medievalism even were they were still imbued with remnants of the old like alchemic beliefs. Hence it is the transcendental process that is actually critical)! Now what positive can come from psychopathy? From the intemporal perspective NONE. Besides specific social consequences of psychopathy as the context of 'socially-perceived-value as of social-stakecontention-or-confliction' moves from family, neighbourhood, school, company, administration, business, criminality, etc. depending on the development of the specific psychopath; by-andlarge, ontologically and as reflected by the organic-comprehension-thinking (organicalism/“intemporal-prioritisation-of- ${ }^{8}$ reference-of-thought'-as-conflatedness ${ }^{13}$-or- 
ontological-reprojecting/longness-of-register-of- meaningfulness-and-teleology ),

psychopath's and other postlogic articulations have a nefarious effect, on social meaningfulness-and-teleology particularly in 'spheres of extended-informality-〈susceptibleto-effecting-parsimony-as-of-shoddiness-and-incompleteness-to- meaningfulness-and-

teleology $\rangle$ ' of society in general and social institutions, as the postlogic ${ }^{7}$ perversion-ofreference-of-thought-<as-preconvergingly-apriorising/axiomatising/referencing-innonconviction/madeupness/bottomlining-as-to-shallow-supererogation $>$ induces thresholdof-nonconviction/madeupness/bottomlining-in-shallow-supererogation $-<$ as-to-'attendantintradimensional'-prospectively-disontologising preconverging/dementing -apriorisingpsychologism $>$ with many an interlocutor, and which by slantedness/postlogic-effect, miscuing, disjointed-logic, logical-drag, unconscionability-drag, sub-par/formulaicassociation/temporal/alibi conventioning-rationalising, and temporal-enculturation/temporalendemisation-effect, and temporal-enculturation/temporal-endemisation effect, undermines the sophistication/intricacy of thought involved with organic-comprehension-thinking (organicalism/“intemporal-prioritisation-of- ${ }^{8}$ reference-of-thought'-as-conflatedness ${ }^{13}$-orontological-reprojecting/longness-of-register-of meaningfulness-and-teleology ), and often leads to a social dynamism of plainness and mediocrity which is subpar and corrupting to social and institutions teleological potential. In-conviction-as-to-profound-supererogation (prelogicly), threshold-of-nonconviction/madeupness/bottomlining-in-shallowsupererogation -<as-to- 'attendant-intradimensional'-prospectivelydisontologising preconverging/dementing -apriorising-psychologism $>$ is vis a vis organiccomprehension-thinking (organicalism/'intemporal-prioritisation-of- ${ }^{2}$ reference-of-thought'as-conflatedness $^{13}$-or-ontological-reprojectingAlongness-of-register-of- meaningfulness-andteleology'), a 'defect of contiguity (relative-unreflexivity/relative-reflexivity-ontologicalcontiguity ${ }^{6}$ ' in terms-as-of-axiomatic-construct of an intemporal point-of-reference of 
meaningfulness; with threshold-of-nonconviction/madeupness/bottomlining-in-shallowsupererogation -<as-to-'attendant-intradimensional'-prospectively-

miscuing/disjointed-logic/logical-drag/unconscionability-drag/sub-par-or-formulaic-

association-or-temporal-or-alibi conventioning-rationalising of the organic-comprehensionthinking (organicalism/'intemporal-prioritisation-of- ${ }^{3}$ reference-of-thought'-asconflatedness $^{13}$-or-ontological-reprojecting/longness-of-register-of - meaningfulness-andteleology ) point-of-referencing of intemporal/ontological-veridicality. Basically, organiccomprehension-thinking (organicalism/'intemporal-prioritisation-of- ${ }^{8}$ reference-of-thought'as-conflatedness $^{13}$-or-ontological-reprojectingAlongness-of-register-of- meaningfulness-andteleology ) carries the idea of a 'higher teleology complex of being more profound with respect to threshold-of-nonconviction/madeupness/bottomlining-in-shallow-supererogation $<$ as-to-'attendant-intradimensional'-prospectivelydisontologising $\sim$ preconverging/dementing -apriorising-psychologism>' with respect to meaningfulness-and-teleology ${ }^{99}$ ontological-veracity in terms-as-of-axiomatic-construct of registry-teleology 9 \{epistemic-totalising 3 psychologismic-subliminality-of-individuationeffusing/worlding imbued logical-dueness-or-scape-or-frame, profile-or-stature, presumptuousness-or-arrogation, assumptions, value-reference and teleology ${ }^{\circ}$. However, with psychopathy and postlogism in hollow-constituting-<as-disjointed-misappropriation-ofmeaningfulness-and-failing-intemporal-preservation> as compulsingnonconviction/madeupness/bottomlining-<‘ $<$ decontextualising/de-existentialising $\sim$ ofattendant-intradimensional-apriorising/axiomatising/referencing>-induced-disontologising'-ofthe-'attendant-intradimensional-ontologising'-imbued$<$ contextualising/existentialising attendant-ontological-contiguity $>$;-in-shallowsupererogation -<as-to-disontologising-perverted-outcome-sought-precedes-existentially- 
veridical-'attendant-intradimensional-apriorising/axiomatising/referencing'-logical-dueness $>$ >

as reflecting the threshold-of-nonconviction/madeupness/bottomlining-in-shallowsupererogation -<as-to- 'attendant-intradimensional'-prospectively-

disontologising preconverging/dementing -apriorising-psychologism $>$ of the registryworldview's/dimension's-uninstitutionalised-threshold ${ }^{12}$-defect-<as-Being-or-ontological-orexistential-defect $>$ ' , as meaningfulness is now not about a 'defect of failing/not-upholding- $<$ asof-apriorising/axiomatising/referencing > contiguity' intemporality ${ }^{5} /$ ontological-veridicality as of specific existential-instantiation ontological-performance ${ }^{72}-$ including-virtue-as- $^{-}$ ontology $>$ /morality/ethics/justice/etc. but rather ${ }^{74}$ perversion-of- ${ }^{8}$ reference-of-thought- $<$ aspreconvergingly-apriorising/axiomatising/referencing-in-

nonconviction/madeupness/bottomlining-as-to-shallow-supererogation $>$ of ${ }^{56}$ meaningfulnessand-teleology ${ }^{9}$. And this, in its fulsome articulation taken beyond individual and social contexts to the comprehensive registry-worldview/dimension speaks of an underlying "7/perversion-ofreference-of-thought-<as-preconvergingly-apriorising/axiomatising/referencing-innonconviction/madeupness/bottomlining-as-to-shallow-supererogation $>\quad$ registryworldview/dimension defect of reference-of-thought- categoricalimperatives/axioms/registry-teleology ${ }^{9}$ : wherein recurrent-utter-uninstitutionalisation, as of its inherently-non-rules — apriorising/axiomatising/referencing-psychologism,-state-in-relationto $-{ }^{56}$ meaningfulness-and-teleology 9 requires prospective base-institutionalisationununiversalisation which as of its inherently-rulemaking-over-non-rulesapriorising/axiomatising/referencing-psychologism,-state-in-relation-to- ${ }^{5}$ meaningfulness-andteleology ${ }^{9}$ requires ${ }^{103}$ universalisation-non-positivism/medievalism which as of its inherentlyuniversalisation-directed-rulemaking-over-non-rules — apriorising/axiomatising/referencingpsychologism,-state-in-relation-to- ${ }^{5}$ meaningfulness-and-teleology 99 requires positivismprocrypticism as of its inherently-positivising/rational-empiricism-based-universalisation- 
directed-rulemaking-over-non-rules_ - apriorising/axiomatising/referencing-psychologism,state-in-relation-to- ${ }^{5}$ meaningfulness-and-teleology ${ }^{9}$, and prospectively positivismprocrypticism which as of its inherent disjointedness-as-of- reference-of-thought requires deprocrypticism. And this memetic-reordering/psychoanalytic-unshackling process, is fundamentally about the 'precedingness/supersedingness/ascendency/postconvergence of the entropy to preserve intemporality ${ }^{52}$ known as intemporal-preservation-entropy-or-contiguityor-ontological-preservation, with the idea that ${ }^{83}$ reference-of-thought- categoricalimperatives/axioms/registry-teleology ${ }^{9}$,-for-intemporal-preservation-entropy-or-contiguityor-ontological-preservation are as pertinent only as these preserve intemporality ${ }^{52}$, and are collapsed/overriden by new ${ }^{83}$ reference-of-thought- categorical-imperatives/axioms/registryteleology ${ }^{9}$,-for-intemporal-preservation-entropy-or-contiguity-or-ontological-preservation, when shown not to be preserving intemporality ${ }^{52}$, as when of ${ }^{7}$ perversion-of- ${ }^{8}$ reference-ofthought-<as-preconvergingly-apriorising/axiomatising/referencing-in-

nonconviction/madeupness/bottomlining-as-to-shallow-supererogation $>$ as to preconvergingor-dementing ${ }^{20}$-apriorising-psychologism with regards to the preceding ${ }^{83}$ reference-of-thoughtcategorical-imperatives/axioms/registry-teleology ${ }^{9}$,-for-intemporal-preservation-entropy-orcontiguity-or-ontological-preservation. Further a registry-worldview/dimension that so misanalyses is not 'shaped' to review but rather syncretises/is-circular in its failing/notupholding-<as-of-apriorising/axiomatising/referencing $>\quad{ }^{83}$ reference-of-thought- categoricalimperatives/axioms/registry-teleology ${ }^{9}$,-for-intemporal-preservation-entropy-or-contiguityor-ontological-preservation rather than implying prospective ones for intemporal-preservationentropy-or-contiguity-or-ontological-preservation; such that ontologically-speaking the phenomenon is in a circularity/recurrence/repetition/repeatability ${ }^{10}$ as of ${ }^{83}$ reference-of-thought denaturing ${ }^{16}$ and relative-ontological-incompleteness ${ }^{88}$, and endemised/enculturated (with a temporal rationalising reasoning that actually validates the veridicality of a human 
notional firstnaturedness-formativeness-<as-to-eventualising-inkling-drive-or-seedingmisprising $>$ temporal-to-intemporal-dispositions-<so-construed-as-from-perspectiveontological-normalcy/postconvergence $>$ as to shallow-supererogation - to-profoundsupererogation that should not be confused with a secondnatured/institutionalised disposition in relation to virtue). This effectively forms the recomposured backdrop for prospective transcendental construct of deprocrypticism, as the 'ontologising organic-comprehensionthinking (organicalism/'intemporal-prioritisation-of- ${ }^{2}$ reference-of-thought'-asconflatedness ${ }^{13}$-or-ontological-reprojecting/longness-of-register-of - meaningfulness-andteleology ) that reflects/perspectivates the protracted threshold-ofnonconviction/madeupness/bottomlining-in-shallow-supererogation $<<$ as-to-' attendantintradimensional'-prospectively-disontologising preconverging/dementing -apriorisingpsychologism>'. But then, a psychopath can be so irrational that in temporal terms it might do a lot of 'good' to a specific individual or group of individuals (for instance, steal and distribute or even some other things but coming initially from a vice; as may be enabled by the psychopath's faulty-mentation-procedure-deception-or-urge ${ }^{43}$ to attain an outcome). This dynamic element can make psychopathy and social psychopathy difficult to deal with as a social phenomenon, as the questions are not only how culpable is the psychopath but extend to who is temporally getting what from the psychopathic situation, what accounts and narratives should be believed, etc., thus requiring an utter and intemporally uncompromising ontological conceptualisation to construct an <amplituding/formative-epistemicity >causality $\sim$ as-to-projective-totalitative-implicationsof-prospective- nonpresencing,-for-explicating relative-unreflexivity/relative-reflexivity ontological-contiguity science. That said, beyond just about such a present worldly take to societal issues, there is a bigger question of the ${ }^{103}$ universal implications on human civilisation of postlogism 77 in hollow-constituting-<as-disjointed-misappropriation-of-meaningfulness-andfailing-intemporal-preservation $>\quad$ and $\quad{ }^{7}$ perversion-of- ${ }^{3}$ reference-of-thought- $<$ as- 
preconvergingly-apriorising/axiomatising/referencing-in-

nonconviction/madeupness/bottomlining-as-to-shallow-supererogation

phenomena

as

reflected above regarding the contiguous process of intemporal-preservation-entropy-orcontiguity-or-ontological-preservation behind human civilisation. It is equally important to note that as much as the psychopath seem to have a weird mentality (slantedness), the incidence and initiation of psychopathy, equally has to do both with the nature of the psychopathic/postlogism mind contrasted to the nature of the 'normal supplanting-conviction-as-to-profoundsupererogation —of-'attendant-intradimensional'-postconverging/dialectical-thinking apriorising-psychologism or prelogic mind', which are antipodal as the normal mind is by reflex prelogic supplanting-conviction-as-to-profound-supererogation -of-'attendantintradimensional'-postconverging/dialectical-thinking -apriorising-psychologism as to 'implicited_attendant-ontological-contiguity ${ }^{6 /}$; educedexistentialising/contextualising/textualising_'intelligibility/epistemicity/reflexivity-contiguity$<$ imbued-notional cogency $>$ and by reflex will tend to see prelogic supplanting-convictionas-to-profound-supererogation - of-'attendant-intradimensional'-postconverging/dialecticalthinking -apriorising-psychologism narratives while the psychopath is of postlogic compulsing-nonconviction/madeupness/bottomlining-〈'<decontextualising/deexistentialising $\sim$ of-attendant-intradimensional-apriorising/axiomatising/referencing $>$-induceddisontologising'-of-the-'attendant-intradimensional-ontologising'-imbued$<$ contextualising/existentialising attendant-ontological-contiguity $>$;-in-shallowsupererogation -<as-to-disontologising-perverted-outcome-sought-precedes-existentiallyveridical-'attendant-intradimensional-apriorising/axiomatising/referencing'-logical-dueness $>$ > (meaning-by-the-mere-illogical-possibility-of-it-being-formulaically-narrated) and does has an covert vista (when the interlocutor is not forewarned/experienced about its nature) in wrongfully inducing a sense of supplanting-conviction-as-to-profound-supererogation - of-'attendant- 
intradimensional'-postconverging/dialectical-thinking -apriorising-psychologism in the normal mind by compulsing-nonconviction/madeupness/bottomlining$〈<<$ decontextualising/de-existentialising of-attendant-intradimensionalapriorising/axiomatising/referencing>-induced-disontologising'-of-the-'attendantintradimensional-ontologising'-imbued-<contextualising/existentialising $\sim$ attendantontological-contiguity $>$;-in-shallow-supererogation $-<$ as-to-disontologising-pervertedoutcome-sought-precedes-existentially-veridical-'attendant-intradimensionalapriorising/axiomatising/referencing'-logical-dueness $>$ > projective narrating (an insight that is easily picked up seeing the childhood psychopathy growing into an adolescent and an adult, as its more covert mental structure at adulthood can be retraced and associated to the awkwardness of expression at early life in understanding what the adult psychopath is up to), hence the reason a mind in search of supplanting-conviction-as-to-profound-supererogation - of-'attendantintradimensional'-postconverging/dialectical-thinking -apriorising-psychologism prelogism $^{78}$ (normal prelogism ${ }^{78}$-as-of-conviction,-in-profound-supererogation $-<$ existentiallyveridical-'attendant-intradimensional-apriorising/axiomatising/referencing'-logical-duenessprecedes-disontologising-logical-outcome-arrived-at $>$ mind) will speak of a pathological liar, by liar wrongly granting the psychopath a supplanting-conviction-as-to-profoundsupererogation _of-'attendant-intradimensional'-postconverging/dialectical-thinking apriorising-psychologism, be it a 'poor or bad supplanting-conviction-as-to-profoundsupererogation —of-'attendant-intradimensional'-postconverging/dialectical-thinking apriorising-psychologism', in-the-very-first-place, hence aligning integratively to the psychopath instead of aligning in transversality-<for-sublimating-existentialeventuating/denouement,-from-'thinking-at-first/pure-predisposition-preemptive-ofprospective-disontologising/subontologising' as-of-prospectively-disambiguated-affirmedand-unaffirmed-'motif-and-apriorising/axiomatising/referencing' $>{ }^{101}$. It is rather a flaw in the 
prelogism ${ }^{78}$-as-of-conviction,-in-profound-supererogation

$<$ existentially-veridical-

\section{'attendant-intradimensional-apriorising/axiomatising/referencing'-logical-dueness-precedes-}

disontologising-logical-outcome-arrived-at $>$ mind's perception (prelogism ${ }^{78}$ or supplantingconviction-as-to-profound-supererogation -of-'attendant-intradimensional'-

postconverging/dialectical-thinking -apriorising-psychologism while the psychopath's mentaldisposition is formulaic slanting compulsing-nonconviction/madeupness/bottomlining$\langle<<$ decontextualising/de-existentialising of-attendant-intradimensionalapriorising/axiomatising/referencing>-induced-disontologising'-of-the-'attendantintradimensional-ontologising'-imbued-<contextualising/existentialising $\sim$ attendantontological-contiguity $>$;-in-shallow-supererogation $\quad-<$ as-to-disontologising-pervertedoutcome-sought-precedes-existentially-veridical-'attendant-intradimensionalapriorising/axiomatising/referencing'-logical-dueness $>$ > or postlogism 77 in preconverging-ordementing -apriorising-psychologism)! Straying into a basic elucidative anthropopsychology/the-anthropological-continuity $(\mathrm{a}$ novel \{epistemictotalising 3 ' $h e r m e n e u t i c / t e x t u a l i t y /$ reprojecting/supererogating/zeroing/re-acuting,${ }_{\{\text {decompulsing }\}}$ delinearity for-cogency approach to psychology); extrinsic-attribution is a fairly common social mental-disposition, at 'uninstitutionalised-threshold ${ }^{02}$ ' as we are not inherently intemporal (the-Good as longness-of-register-of- ${ }^{-}$meaningfulness-and-teleology ${ }^{9}$ ) in our solipsistic projection but have the potential of temporal (shortness-of-register-ofmeaningfulness-and-teleology ${ }^{99}$ solipsistic/emanant projections of postlogism slantedness/ ${ }^{50}$ ignorance/affordability/opportunism/exacerbation/social-chainism-or-socialdiscomfiture-or-negative-social-aggregation/temporal-enculturation-or-temporal-endemisation, so-disambiguated as of ${ }^{83}$ reference-of-thought- ${ }^{8}$ devolving ontological-performance ${ }^{72}$ $<$ including-virtue-as-ontology $>$. The mechanism of institutionalisation/intemporalisation and formalisation ensures that because of the positive-opportunism-of-social-functioning-and- 
accordance $^{75}$ that the intemporal-disposition (as it syncs with intrinsic reality and is thus ontological) brings to the cross-section of human temporal interests at 'socially-perceived-value as of social-stake-contention-or-confliction', it tends to skew ('intemporality ${ }^{52}$-symmetrising-bydesymmetrising-subsumption-of-temporality ${ }^{8}$, for relative intrinsic-reality/ontologicalveridicality transcendental-enabling/sublimating/supereregatory $\sim$ de-mentativity)/deferentialformalisation-transference and dominate temporal-dispositions in the medium to long perspective. For instance, everyone will like to see a good legal system to ensure that they do not fall afoul of a bad judgment even if, circumstantially, maybe they themselves may be inclined not to have others or some others to enjoy the same (of course, the internalisation of our 'present institutionalised/intemporalised positivistic meaningful worldview' will seem to imply that we do have a first nature disposition to be inherently civilised to want to ${ }^{103}$ universally wish that everyone have to deal with a fair legal system, that anyway is to the credit of the institutionalisation/intemporalisation process, but that is a secondnatured/internalised construct). This explains why there is no need to breach the scientific principle known as the 'mediocrity principle', (which says that there are no exceptions/specialness in science), to wrongly say that man is inherently intemporal (as in reality man is a notional firstnaturedness-formativeness-<asto eventulising inkling drive or seeding misprising temporal-to-intemporal-dispositions$<$ so-construed-as-from-perspective-ontological-normalcy/postconvergence $>$ creature in its moral/virtuous-agency); to explain why society tends to improve/progress. Rather, the intemporal-disposition preconverging/postconverging-dementatively/structurally/paradigmatically brings more overall good and hence skews ('intemporality ${ }^{52}$-symmetrising-by-desymmetrising-subsumption-of-temporality ${ }^{8}$ ', for relative intrinsic-reality/ontological-veridicality transcendentalenabling/sublimating/supereregatory $\sim$ de-mentativity) man in the medium to long perspective towards 'the-Good/knowledge-reification gesturing-and-accounting — of-epistemic- 
phenomenalism- $<$ in-prospective_psychologismic $\sim$ apriorising/axiomatising/referencing-\{of'prospectively implicited_attendant-ontological-contiguity ' educedexistentialising/contextualising/textualising_'intelligibility/epistemicity/reflexivity-contiguity<imbued-notional $\left.\sim \operatorname{cogency}>^{\prime} \quad\right\}$-conflatedness -in-\{preconverging-disentailment by\} postconverging-entailment $>$ /understanding/<amplituding/formativeepistemicity $>$ causality as-to-projective-totalitative-implications-of-prospectivenonpresencing,-for-explicating relative unreflexivity/relative-reflexivity - ontologicalcontiguity (institutionalised, formalised and internalised)'. This elucidation is important because while internalisation might point to the social good it is important to understand that when dealing with our solipsism at 'uninstitutionalised-threshold ${ }^{102}$, we aren't anymore intemporal (the-Good as longness-of-register-of- ${ }^{56}$ meaningfulness-and-teleology ${ }^{90}$ ) than temporal (shortness-of-register-of- ${ }^{5}$ meaningfulness-and-teleology ${ }^{9}$ ) going by the 'mediocrity principle', and the analysis should take account of this (by not just operating/processing logic but construing notional firstnaturedness-formativeness-<as-to-eventualising-inkling drive-orseeding misprising $>$ temporal-to-intemporal-dispositions-<so-construed-as-fromperspective-ontological-normalcy/postconvergence> disambiguation with a de-mentation〈supererogatory $\sim$ ontological-de-mentation-or-dialectical-de-mentation-stranding-orattributive-dialectics) highlighting organic-comprehension-thinking (organicalism/“intemporalprioritisation-of- ${ }^{3}$ reference-of-thought'-as-conflatedness ${ }^{13}$-or-ontologicalreprojecting/longness-of-register-of meaningfulness-and-teleology ) and the distracting threshold-of-nonconviction/madeupness/bottomlining-in-shallow-supererogation $-<$ as-to‘attendant-intradimensional'-prospectively-disontologising preconverging/dementing apriorising-psychologism>. Why talk of 'uninstitutionalised-threshold ${ }^{12}$ '? This is the underlying notion of a 'grand theory of psychology' that has been missing to turn psychology from a preconverging-de-mentating/structuring/paradigming of the human ${ }^{79}$ presencing- 
absolutising-identitive-constitutedness social-vestedness/normativity- $<$ discretely-impliedfunctionalism $>$ as modern into a postconverging-de-mentating/structuring/paradigming acrossand-of-all-times of ${ }^{6}$ nonpresencing-<perspective-ontological-normalcy/postconvergence $>$ ! Why? The foundation of a human psychological science should be fundamentally about the 'contiguity/entropy conceptualisation of the human psyche' (and as this permits institutionalcumulation/institutional-recomposure-〈as-to- historiality/ontological-

eventfulness /ontological-aesthetic-tracing-<perspective-ontologicalnormalcy/postconvergence-reflected-'epistemicity-relativism-determinism'>>

anthropopsychology or 'the-anthropological-continuity', i.e. cumulating/recomposuring from recurrent-utter-uninstitutionalisation, based-institutionalisation-ununuversalisation, universalisation-non-positivism/medievalism, positivism- ${ }^{80}$ procrypticism, and prospectively deprocrypticism). The present treatment of psychology will seem to imply that all psychology is about psychoanalytic techniques on the modern positive mind, which is rather naïve and uninsightful not just in terms of scope but critically depth of conceptualisation. The answer to this 'contiguity/entropy conceptualisation of the psyche' is about how the underlying notion of 'intemporal-preservation-entropy-or-contiguity-or-ontological-preservation abstractly allows for human-subpotency survival/existence/emanance/fulfilment/flourishing in existence-as-ofits-mimetic-echoness/existence-in-reverberation/existence-potency ${ }^{39} \sim$ sublimating-nascence,disclosed-from-prospective-epistemic-digression and assumes a fundamental referencing base in the study of the psyche (noting that by saying 'notion' is meant, the notion of intemporalpreservation-entropy-or-contiguity-or-ontological-preservation covers the concepts of temporal preservation (including subknowledging ${ }^{4}$, mimicking)-to-intemporal preservation, just as the notion of good covers the concepts of good-to-bad). Correspondingly, this notion of intemporalpreservation-entropy-or-contiguity-or-ontological-preservation involves 'mental candoring' where mental-devising-representation syncs with intrinsic-reality and mental decandoring where 
mental-devising-representation is a wrong/flawed perverted representation of intrinsic-reality. If we have an anthropological continuity/anthropopsychology, then the continuity as entropy is the exercise of candoring as 'straightness/soundness-or-ontological-good-faith/authenticity -ofreference-of-thought referencing/registering/decisioning or registry-teleology (being a functional representation of how an intemporalising registry-worldview/dimension perceives itself) and decandoring as 'perverted/brazen-but-unsoundness-or-ontological-badfaith/inauthenticity ${ }^{64}$ of- ${ }^{8}$ eference-of-thought referencing/registering/decisioning or registryteleology ${ }^{9}$, (being a functional representation of how a prospective intemporalising registryworldview/dimension perceives the prior-and-'preconverging-or-dementing ${ }^{20}$-apriorisingpsychologism registry-worldview/dimension); with this latter representation undermining the 'temporal-dispositions solipsistic/emanant postlogic miscuing presumptuousness/arrogation effect' as the unconscionability-drag responsible for ${ }^{7}$ perversion-of- ${ }^{8}$ reference-of-thought- $<$ aspreconvergingly-apriorising/axiomatising/referencing-in-

nonconviction/madeupness/bottomlining-as-to-shallow-supererogation $>$ across the institutional-cumulation/institutional-recomposure-〈as-to- historiality/ontologicaleventfulness /ontological-aesthetic-tracing-<perspective-ontologicalnormalcy/postconvergence-reflected-'epistemicity-relativism-determinism'> $>$, whether in the perversion-of- ${ }^{3}$ reference-of-thought-<as-preconverginglyapriorising/axiomatising/referencing-in-nonconviction/madeupness/bottomlining-as-toshallow-supererogation $>$ as to preconverging-or-dementing ${ }^{20}$-apriorising-psychologism of recurrent-utter-uninstitutionalisation, ununiversalisation, non-positivism/medievalism or procrypticism-or-disjointedness-as-of- ${ }^{-3}$ reference-of-thought. Such transcendental/transdimensional/interdimensional/5 maximalising-recomposuring-for-relativeontological-completeness ${ }^{87}$ - unenframed/re-ontologising conceptualisation, for a novel genuinely ${ }^{103}$ universal psychology as anthropopsychology, involved in all successive 
institutional-cumulation/institutional-recomposure-〈as-to- historiality/ontological-

eventfulness /ontological-aesthetic-tracing-<perspective-ontological-

normalcy/postconvergence-reflected-'epistemicity-relativism-determinism'>> for intemporalpreservation-entropy-or-contiguity-or-ontological-preservation is profoundly elucidated with associated notions as follows: - The concept of ${ }^{15}$ de-mentation-〈supererogatory 0 ontological-dementation-or-dialectical-de-mentation-stranding-or-attributive-dialectics $\rangle$ is the very drive (in providing insight on the transcendental/transdimensional/interdimensional/ $/$ maximalisingrecomposuring-for-relative-ontological-completeness ${ }^{8}$ —unenframed/re-

ontologising conceptualisation $\quad<$ amplituding/formative-epistemicity $>$ causality $\sim$ as-toprojective-totalitative-implications-of-prospective- nonpresencing,-for-explicating relativeunreflexivity/relative-reflexivity ontological-contiguity , i.e. notional firstnaturednessformativeness-<as-to-eventualising-inkling drive-or-seeding-misprising $>$ temporal-tointemporal-dispositions- $<$ so-construed-as-from-perspective-ontologicalnormalcy/postconvergence $>$ ) for such a conceptualisation of anthropopsychology or 'genuinely 'universal psychology'. The philosophical conceptualisation of stranding is rather 'notional firstnaturedness-formativeness-<as-to-eventualising -inkling-drive-or-seedingmisprising $>$ temporal-to-intemporal-dispositions- $<$ so-construed-as-from-perspectiveontological-normalcy/postconvergence $>$ disambiguation' which serves to avoid the supplanting-conviction-as-to-profound-supererogation -of-'attendant-intradimensional'postconverging/dialectical-thinking -apriorising-psychologism reflex or prelogic-reflexadmittance-reflex or in-phase-reflex (instead of rightly aligning by the dialectically-orcontendingly-out-of-phase reflex or transversality-<for-sublimating-existentialeventuating/denouement,-from-'thinking-at-first/pure-predisposition-preemptive-ofprospective-disontologising/subontologising’’ as-of-prospectively-disambiguated-affirmed- 
disposition' being wrongly attributed to all interlocutors by reflex without ensuring that their disposition is effectively intemporal and not temporal. de-mentation〈supererogatory ontological-de-mentation-or-dialectical-de-mentation-stranding-or-

attributive-dialectics), as to its corresponding notions of preconverging-or-dementing 20 apriorising-psychologism- $<$ stranded-as-rightfully-oblongated/decandored-and-dialectically-orcontendingly-out-of-phase $>\quad$ and $\quad$ postconverging-or-dialectical-thinking ${ }^{21}$-apriorisingpsychologism- $<$ stranded-as-rightfully-straight/candored-and-dialectically-or-contendingly-inphase>, are central to transcendental psychoanalytic-unshackling and memetic-reordering. Stranding ensures the 'upholding of the ontological-veridicality/relative-unreflexivity/relativereflexivity - ontological-contiguity ${ }^{67}$ of ${ }^{83}$ reference-of-thought (from ontologicalnormalcy/postconvergence epistemic-or-notional projective-perspective) of the intemporalpreservation-entropy-or-contiguity-or-ontological-preservation' by articulating the veridically contiguous ontological mental-devising-representation of the transcending (and so, in a veridical dialectic and existential-<disontologising/re-ontologising aporeticism $>$ psychoanalytic reorientation as oblongated/decandored in representing/implying defective/perverted temporality ${ }^{8}$ ). It implies reflecting/perspectivating/highlighting (reasoning-through-and-notreasoning-with) hollow and in hollow-constituting-<as-disjointed-misappropriation-ofmeaningfulness-and-failing-intemporal-preservation $>$ in postlogic-backtracking- $<$ iterativelooping-'set-of-dereifying-hollow-narratives-and-acts'>76 as absolving/fleeting/escapingreflex-logic as of notional-discontiguity/epistemic-discontiguity ${ }^{63}<$ between - prior-shallowsupererogation -of-mentally-aestheticised $\sim$ preconverging/dementing -qualiaschema_and_prospective-profound-supererogation -of-mentallyaestheticised $\sim$ postconverging/dialectical-thinking -qualia-schema $>$-as-of-epistemicdecadence in hollow-constituting-<as-disjointed-misappropriation-of-meaningfulness-andfailing-intemporal-preservation $>$ in postlogic-backtracking-<iterative-looping-‘set-of- 
dereifying-hollow-narratives-and-acts' $>{ }^{\circ}$, as these pervert/dement/subknowledge〈preconverging-or-dementing -as-if-of-sound-knowledge $/$ mimick-and-syncretise the reference-of-thought- categorical-imperatives/axioms/registry-teleology ${ }^{9}$,-for-intemporalpreservation-entropy-or-contiguity-or-ontological-preservation providing the backdrop for prospective transcendental dimension with new superseding ${ }^{83}$ reference-of-thoughtcategorical-imperatives/axioms/registry-teleology . $\quad{ }^{15}$ de-mentation〈supererogatory $\sim$ ontological-de-mentation-or-dialectical-de-mentation-stranding-orattributive-dialectics $\rangle$ can be implied as mental-devising-representation across all registryworldviews/dimensions not withstanding any registry-worldview's/dimension's illusion-of-thepresent/present-consciousness mental-devising-representation, and so, by accounting anticipatorily and preemptively for the registry-worldview's/dimension's 7 perversion-ofreference-of-thought-<as-preconvergingly-apriorising/axiomatising/referencing-innonconviction/madeupness/bottomlining-as-to-shallow-supererogation >,-of-its- categoricalimperatives/axioms/registry-teleology ${ }^{9}$-for-intemporal-preservation-entropy-or-contiguity-orontological-preservation whether a retrospective, present or prospective registryworldview/dimension. Hence the need for 'collapsing'/overriding of the transcended registryworldview's/dimension's institutionalisation $\quad$ reference-of-thought- categoricalimperatives/axioms/registry-teleology ${ }^{9}$ with prospective transcending/superseding ${ }^{8}$ referenceof-thought- categorical-imperatives/axioms/registry-teleology ${ }^{9}$,-for-intemporal-preservationentropy-or-contiguity-or-ontological-preservation in anticipation and preemption as untenability/internal-contradiction/internal-incoherence/institutional-constraining, as secondnaturing and 'not as temporal-dispositions transformation' to wrongly imply a ${ }^{3}$ universal dimensionality-of-sublimating ${ }^{25}-\langle<$ amplituding/formative $>$ supererogatory $\sim$ dementativeness/epistemic-growth-or-conflatedness /transvaluative- 
predisposition. For instance, the veridical stranded mental-devising-representation we may have from a positivistic standpoint of the non-positivism/medievalism mind as oblongated/decandored is not recognised by the non-positivism/medievalism mindset $/{ }^{3}$ reference-of-thought by its syncretic reflex to be functionally in its mental straightness and candored (even though such a representation is ontologically wrong regarding its mentaldevising-representation with respect to the its uninstitutionalised-threshold ${ }^{102}$ requiring positivism insititutionalisation/intemporalisation). Prospectively, the de-mentation〈supererogatory $\sim$ ontological-de-mentation-or-dialectical-de-mentation-stranding-orattributive-dialectics $\rangle$ of our own mental-devising-representation by futural Beingdevelopment/ontological-framework-expansion-as-to-depth-of-ontologising-development-asinfrastructure-of- meaningfulness-and-teleology as of prospective notional $\sim$ deprocrypticism as oblongated and decandored at our uninstitutionalised-threshold requiring notional ${ }^{18}$ deprocrypticism institutionalisation/unintemporalisation will equally meet with an epistemic-totalising $\sim$ self-referencing-syncretising wrong reflex of postconverging-ordialectical-thinking -apriorising-psychologism- $<$ stranded-as-rightfully-straight/candored-anddialectically-or-contendingly-in-phase $>$ that will not recognise its slantedness and decandored veridicality. The intemporal-disposition is rather about emphasising institutionalisation/intemporalisation percolation-channelling- $<$ in-deferential-formalisationtransference $>$ as the means and basis for prospective institutionalisation/intemporalisation. This highlights the vacuousness in all transcendental relations wherein the transcended is vacuous with respect to the transcending. Such vacuous transcendental manifestations involves dialectically (the transcended and transcending relation with regards to:) deductive narratives instances, life episodes, life schemes, general being/existential dispositions and the specific existentialism/full-existential-depth-implications involved with a registryworldview/dimension; wherein temporal-dispositions present-consciousness (in their illusions- 
of-the-present) perpetually portray candor and straightness but on retrospection are shown to be decandored and oblongated which ontologically implies these are veridically of ${ }^{5}$ de-mentation〈supererogatory $\sim$ ontological-de-mentation-or-dialectical-de-mentation-stranding-or-

attributive-dialectics $\rangle$ as of preconverging-or-dementing -apriorising-psychologism$<$ stranded-as-rightfully-oblongated/decandored-and-dialectically-or-contendingly-out-ofphase $>$ notwithstanding their wrongly projected postconverging-or-dialectical-thinking apriorising-psychologism-<stranded-as-rightfully-straight/candored-and-dialectically-orcontendingly-in-phase>. This is ontologically foundational (more like the apriorising/axiomatising/referencing/intelligibilitysettingup/measuringinstrumenting grounding spirit of arithmetic cannot be undermined in any way possible and you then have the possibility of sound arithmetic thereafter). ${ }^{15}$ de-mentation-(supererogatory - ontological-de-mentation-ordialectical-de-mentation - stranding-or-attributive-dialectics $\rangle$ prevents temporal-dispositions (in the articulation and re-articulation of narratives) by the 'temporal-dispositions disjunction/skipping' to 'wrongly imply the narratives subsequently articulated and rearticulated are of intemporal-disposition teleology ${ }^{9}$ hence wrongly implying candored and straightness, whereas these are in effect $<$ amplituding/formative-epistemicity $>$ totalising $\sim$ selfreferencing-syncretising/circularity/interiorising/akrasiatic-drag ${ }^{34}$ iterating narratives of temporal-dispositions teleologies'; and so, by way of coring which involves accounting-fortemporal-dispositions-defect/preconverging-or-dementing ${ }^{20}$-apriorising-psychologism (theperversion-of-the- ${ }^{\text {categorical-imperatives/axioms/registry-teleology }}{ }^{9}$-for-intemporalpreservation-entropy-or-contiguity-or-ontological-preservation) and avoiding setting-aside which rather involves glossing-over-temporal-dispositions-defect/preconverging-ordementing -apriorising-psychologism (the-perversion-of-the- categoricalimperatives/axioms/registry-teleology ${ }^{9}$-for-intemporal-preservation-entropy-or-contiguity-orontological-preservation). This ensures in effect the "de-mentation- 


\section{〈supererogatory ontological-de-mentation-or-dialectical-de-mentation-stranding-or-}

attributive-dialectics $\rangle$,-in-a-contiguity-of-increasing-ontological-normalcy/postconvergence'.

Ontology is an altogether coherent construct with no room for excepting from coherence, which then simply implies the superseding of any such pretence of an excepting. (For instance, we can be calculating the sum $(5 * 5)+5-5$, and make the mistake to say $5 * 5=24$ but then overlook it and agree together that the answer should be ${ }^{24}$ and go on to resolve the entire equation as ${ }^{24}$. This type of non-ontological thinking (a non-ontological thinking is also known as a misanalysis or misthinking or misreasoning or mislogic or preconverging-or-dementing ${ }^{20}$-apriorisingpsychologism- $<$ stranded-as-rightfully-oblongated/decandored-and-dialectically-or-

contendingly-out-of-phase $>\quad$ or $\quad<$ amplitudingfformative-epistemicity $>$ totalising $\sim$ selfreferencing-syncretising/circularity/interiorising/akrasiatic-drag $34 \quad$ or notionaldiscontiguity/epistemic-discontiguity ${ }^{6} \_$between - prior-shallow-supererogation -ofmentally-aestheticised preconverging/dementing -qualia-schema_and_prospective-profoundsupererogation -of-mentally-aestheticised postconverging/dialectical-thinking -qualiaschema $>$, as there is no veridical meaningfulness that exists out of ontology or isn't in relativeunreflexivity/relative-reflexivity ontological-contiguity ${ }^{67}$ ) is highly prevalent in the extendedinformality-_susceptible-to-effecting-parsimony-as-of-shoddiness-and-incompleteness-to-

meaningfulness-and-teleology $\rangle$ of society as social-aggregation-enabling, the reason we strive to formalise whether in terms-as-of-axiomatic-construct of laws, institutions, organisations, etc. The basic fact is that the virtue of the intemporal-disposition constructs cannot accommodate non-ontology since reality doesn't adjust to man and it is man that adjusts to reality. The de-mentation-〈supererogatory ontological-de-mentation-or-dialectical-dementation - stranding-or-attributive-dialectics $\rangle$,-in-a-contiguity-of-increasing-ontologicalnormalcy/postconvergence implies that an interlocutor's retrospectively demonstrable narratives miscuing and subsequent 7 perversion-of- ${ }^{8}$ reference-of-thought- $<$ as-preconvergingly- 
apriorising/axiomatising/referencing-in-nonconviction/madeupness/bottomlining-as-to-

shallow-supererogation $>$ speaks of the real nature of its present and prospective narratives as decandored and oblongated in effect ontologically but that by an illusion-of-the-present reflex as well as for the sake of functioning we tend to represent by default such miscuing and perversion-of- ${ }^{3}$ reference-of-thought-<as-preconvergingly-

apriorising/axiomatising/referencing-in-nonconviction/madeupness/bottomlining-as-to-

shallow-supererogation $>$ meaning as straightness/candored (intemporal) which is not ontologically veridical; in which case the prospective transcended registry-worldview strands such meaningfulness as decandored/oblongated (subknowledging $/ /$ mimicking) even if the mental-disposition of the transcended registry-worldview is in an illusion-of-the-present straightness/candoring mental-devising-representation of meaning. In other words, ${ }^{15}$ dementation-〈supererogatory - ontological-de-mentation-or-dialectical-de-mentation - strandingor-attributive-dialectics $\rangle$ ensure an affixing of temporal-dispositions ${ }^{74}$ perversion-of- ${ }^{8}$ referenceof-thought-<as-preconvergingly-apriorising/axiomatising/referencing-in-

nonconviction/madeupness/bottomlining-as-to-shallow-supererogation $>\quad$ teleologic orientations denaturing ${ }^{16}$ to the corresponding temporal ${ }^{74}$ perversion-of- ${ }^{8}$ reference-of-thought$<$ as-preconvergingly-apriorising/axiomatising/referencing-in-

nonconviction/madeupness/bottomlining-as-to-shallow-supererogation $>$ mindsets in their aetiologisation/ontological-escalation- $<$ ontological-

veridicality_commitment/otherliness_transcending/compulsions-encumbered_transcending > without letting for a disjunction/skipping into intemporal/straightness-of-mental-devisingrepresentation disposition teleologic orientation, and so, to the point of the temporal-dispositions collapsing/overriding ('postconverging-or-dialectical-thinking ${ }^{2}$-psychology or psychology-ofmentation-dynamics or natural psychological-dynamics' psychoanalytic-unshackling/memeticreordering/institutional-recomposuring) with the new prospective ${ }^{83}$ reference-of-thought- 
categorical-imperatives/axioms/registry-teleology ,-for-intemporal-preservation-entropy-orcontiguity-or-ontological-preservation of the transcending registry-worldview/dimension. For instance, the mental-devising-representation of a non-positivism/medievalism mindset $/{ }^{3}$ reference-of-thought relating to say an accusation of sorcery by an intemporal positivistic mindset $/{ }^{3}$ reference-of-thought will not be limited to that particular instance but carries the 'disambiguation of notional firstnaturedness-formativeness-<as-toeventualising inkling drive or-seeding-misprising $>$ temporal-to-intemporal-dispositions$<$ so-construed-as-from-perspective-ontological-normalcy/postconvergence $>$ aetiologisation/ontological-escalation- $<$ ontologicalveridicality_commitment/otherliness_transcending/compulsions-encumbered_transcending>' that speaks to metaphorically-a-million-and-one-instances-and-locales dispositions of that nonpositivism/medievalism mindset $/{ }^{3}$ reference-of-thought by way of ${ }^{15}$ de-mentation〈supererogatory $\sim$ ontological-de-mentation-or-dialectical-de-mentation-stranding-or-

attributive-dialectics $\rangle$ from the intemporal positivistic mindset, and upholding such the 'disambiguation of notional firstnaturedness-formativeness-<as-to-eventualising inkling drive or seeding-misprising $>$ temporal-to-intemporal-dispositions-<so-construed-as-fromperspective-ontological-normalcy/postconvergence> as aetiologisation/ontological-escalation$<$ ontological-veridicality_commitment/otherliness_transcending/compulsionsencumbered_transcending > for the psychoanalytic-unshackling/memeticreordering/institutional-recomposuring that collapses/overrides the non-positivism/medievalism mindset/ ${ }^{8}$ reference-of-thought crossgenerationally (consider the diffusion of positivistic registry-worldview and its psychoanalytic-unshackling/memetic-reordering/institutionalrecomposuring of non-positivistic registry-worldviews/dimensions in the th and early $20^{\text {th }}$ century). Stranding defines the 'decandored registry-worldview/dimension dialectically-orcontendingly-out-of-phase/dialectically-primitive) mental-devising-representation' such as the 
mental-devising-representation of recurrent-utter-uninstitutionalisation, ununiversalisation, nonpositivism/medievalism and prospectively procrypticism, and so, beyond the illusion-of-thepresent/present-consciousness of all these <cumulating/recomposuring attendant-ontologicalcontiguity >-successive registry-worldviews/dimensions which in their $<$ amplituding/formative-epistemicity $>$ totalising $\sim$ self-referencing-syncretising/presentconsciousness/illusion-of-the-present will tend to wrongly recover/syncretise to project straightness/candoring of mental-devising-representation as intemporality ${ }^{52} /$ longness rather than decandored/oblongated mental-devising-representation as temporality ${ }^{9}$. Stranding is validated by the fact that transcendental/transdimensional/interdimensional $/ 5$ maximalisingrecomposuring-for-relative-ontological-completeness ${ }^{87}$ - unenframed/re-

ontologising conceptualisation speaks of an 'institutionalisation/intemporalisation constraint/secondnaturing' and 'not temporal-dispositions transformation into intemporaldisposition as dimensionality-of-sublimating 25 -< < amplituding/formative $>$ supererogatery $\sim$ dementativeness/epistemic-growth-or-conflatedness /transvaluativerationalising/transepistemicity/anamnestic-residuality/spirit-drivenness-equalisation〉'; and this idea is so foundational that it is beyond-and-supersedes/precedes/overrides/utters the consciousness-awareness-teleology' of temporal-dispositions such that 'they are not called upon in argumentation', just as we are not consciously called upon to establish whether blood flows in our body, as it is a preceding/superseding truth that supersedes/precedes/overrides/utters our thinking or not of it! Thus ${ }^{15}$ de-mentation-/supererogatory -ontological-de-mentation-ordialectical-de-mentation - stranding-or-attributive-dialectics $\rangle \quad$ is rather intemporally/ontologically conceptualised for its validation and integration in the survival-andflourishing imbued institutionalisation/intemporalisation percolation-channelling- $<$ indeferential-formalisation-transference $>$ (formalisms and internalisations) mechanism with the implied $<$ amplituding/formative-epistemicity $>$ causality $\sim$ as-to-projective-totalitative- 
implications-of-prospective- nonpresencing,-for-explicating relative-unreflexivity/relative-

reflexivity - ontological-contiguity and positive-opportunism-of-social-functioning-andaccordance $^{75}$ as ontological-entrapment, with no temporal-dispositions firstnature-orintemporal-level-validation but rather secondnatured-or-institutionalisation/intemporalisationlevel-validation. At which point ${ }^{15}$ de-mentation-〈supererogatory $\sim$ ontological-de-mentation-ordialectical-de-mentation - stranding-or-attributive-dialectics $\rangle$ articulates temporal-dispositions teleologies orientations as 'subknowledging $/$ mimicking/mental-perversions/slantedness manifestations at that 'uninstitutionalised-threshold ${ }^{102}$, i.e. the ${ }^{83}$ reference-of-thoughtcategorical-imperatives/axioms/registry-teleology ${ }^{9}$,-for-intemporal-preservation-entropy-orcontiguity-or-ontological-preservation of temporal-dispositions undermining the very ‘intemporal-preservation-entropy’ supposedly they are supposed to uphold). Ultimately and inthe-bigger-picture, (with teleology' fundamentally construed as 'phenomenal/manifest conceptivity/epistemic-reflexivity/epistemicity-relativism-determinism-<reifying \{as-toknowledge-developing\}-and-empowering $>$ in existence as ontological (so-reflecting $<$ amplituding/formative >disposedness/psychologismic-construct-〈as-to-orientation/valueconstruct/valuation-and-derived-parameterising $\rangle$ and <amplituding/formative $>$ entailment-〈asto-totalising-contiguous/coherent-factuality-of-variability))' and with regards to the specific human-subpotency with regards to overall reifying-and-empowering-reflexivity-of-ecstaticexistence-as-panintelligibility/panreflexivity ${ }^{73}-\langle$ existentially-imbued-and-educing-< $<$ \{pistemictotalising thermeneutically/textually/reprojectingly/supererogating/y/zeroing/y/re-acutingly,\{decompulsing delinearity for-cogency $\geq$-epistemic-perspective-of-projective/reprojectiveaestheticising-re-motif-and-re-apriorising/re-axiomatising/re-referencing conceptualisation,as-herein-specifically-relevant-to human-subpotency) the teleology ${ }^{9}$ of human ${ }^{15}$ dementation-〈supererogatory ontological-de-mentation-or-dialectical-de-mentation — strandingor-attributive-dialectics $\rangle$ reflects the human-subpotency for attaining crossgenerational 
transcendence-and-sublimity/sublimation/supererogatory-de-mentativity with corresponding dialectical and psychoanalytic existential-<disontologising/re-ontologising aporeticism $>$ reorientations ('postconverging-or-dialectical-thinking ${ }^{2}$-psychology or psychology-ofmentation-dynamics or natural psychological-dynamics' psychoanalytic-unshackling/memeticreordering/institutional-recomposuring), and it is well beyond the idea of just a 'preconverging/postconverging-de-mentative/structural/paradigmatic argumentation convincing' intradimensionally as to 79 presencing-absolutising-identitive-constitutedness (based-on-the- categorical-imperatives/axioms/registry-teleology ${ }^{9}$-of-the-registryworldview/dimension as absolutised) as to a registry-worldview/dimension in relativeontological-incompleteness ${ }^{88}$ that is ontologically-deficient/preconverging-or-dementing ${ }^{20}$ apriorising-psychologism as of its $\quad{ }^{83}$ reference-of-thought- categoricalimperatives/axioms/registry-teleology ${ }^{9}$,-for-intemporal-preservation-entropy-or-contiguityor-ontological-preservation, in the first place; as teleology ${ }^{99}$ as such reflects human-subpotency sublimation-over-desublimation possibilities in existence as to underlying supposedly coherent ontological-commitment ${ }_{-}<$implied-self-assuredness-of-ontological-goodfaith/authenticity postconverging-de-mentating/structuring/paradigming -as-being-as-ofexistential-reality>. Ontology being the intemporal-disposition, the exercise of 'directing' convincing as logical-processing/logical-operation to temporal-dispositions is inherently unwarranted and is rather of $<$ amplituding/formative-epistemicity $>$ totalising $\sim$ self-referencingsyncretising/circularity/interiorising/akrasiatic-drag 34 in preconverging-or-dementing ${ }^{20}$ apriorising-psychologism- $<$ stranded-as-rightfully-oblongated/decandored-and-dialectically-orcontendingly-out-of-phase $>$ as it wrongly implies that temporal-dispositions ${ }^{74}$ perversion-ofreference-of-thought-<as-preconvergingly-apriorising/axiomatising/referencing-innonconviction/madeupness/bottomlining-as-to-shallow-supererogation $>$ of their dimension's/registry worldview's reference-of-thought- categorical- 
imperatives/axioms/registry-teleology ${ }^{9}$,-for-intemporal-preservation-entropy-or-contiguityor-ontological-preservation is of sound mental representation; rather what should be implied is

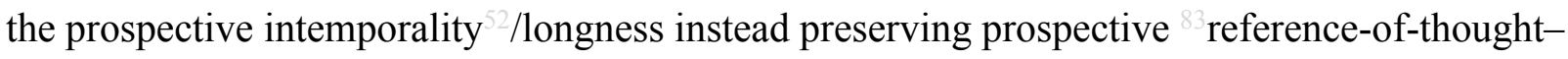
categorical-imperatives/axioms/registry-teleology ${ }^{9}$,-for-intemporal-preservation-entropy-orcontiguity-or-ontological-preservation with pertinence being about 'articulating and directing' intemporal/ontologically-contiguous ${ }^{56}$ meaningfulness-and-teleology ${ }^{9}$ towards the 'institutionalisation/intemporalisation percolation-channelling- $<$ in-deferential-formalisationtransference>' as secondnaturing of the new ${ }^{83}$ reference-of-thought- categoricalimperatives/axioms/registry-teleology ${ }^{9}$,-for-intemporal-preservation-entropy-or-contiguityor-ontological-preservation. For instance, the positive (as to intemporal project) will not engage in a direct logical convincing with the non-positivisitic/medieval mind as this just validates to the non-positivism/medievalism disposition that its non-positivism/medievalism ${ }^{83}$ reference-of-

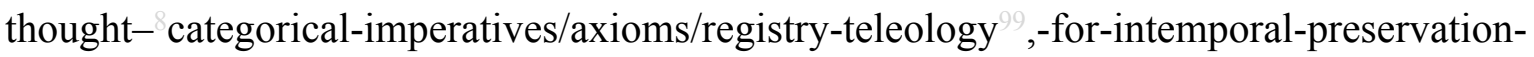
entropy-or-contiguity-or-ontological-preservation relation with meaningfulness-andteleology ${ }^{9}$ is sound such that it goes on to operate/process logic by <amplituding/formativeepistemicity $>$ totalising $\sim$ self-referencing-syncretising/circularity/interiorising/akrasiatic-drag non-positivism/medievalism $\quad{ }^{56}$ meaningfulness-and-teleology ${ }^{9} \quad{ }^{83}$ reference-of-thoughtcategorical-imperatives/axioms/registry-teleology . Rather the positivistic mindset/ $/ 3$ reference-of-thought will project the new ${ }^{83}$ reference-of-thought- categoricalimperatives/axioms/registry-teleology ${ }^{9}$,-for-intemporal-preservation-entropy-or-contiguityor-ontological-preservation of positivism (as rational-empiricism/positivising basis of reasoning) through positivism institutionalisation/intemporalisation percolation-channelling$<$ in-deferential-formalisation-transference $>$ and highlighting, in-the-bigger-scheme-of-things, the relative sublimating efficiency and positive-opportunism-of-social-functioning-andaccordance $^{75}$ of a positivism-based rule of law, social organisation, polity, nation-building, etc. 
based on positivism axioms and which inherent effectiveness and supersedingness/transcendence breaks the non-positivism/medievalism mindset/ ${ }^{8}$ reference-ofthought (which are not rational-empirical/positivising and tend to essences, alchemic-logic, sorcery constructs, etc.) with its defective ${ }^{83}$ reference-of-thought- categoricalimperatives/axioms/registry-teleology ${ }^{9}$,-for-intemporal-preservation-entropy-or-contiguityor-ontological-preservation. This takes an utterly impersonal form (law, officialdoms and subject matter formalisms) which allows for an abstraction of the virtue of ontological contiguity that personalised social-and-temporal-trading doesn't allow reflexively. The 'transcendental/transdimensional/interdimensional/ ${ }^{5}$ maximalising-recomposuring-for-relativeontological-completeness ${ }^{87}$ - unenframed/re-ontologising conceptualisation complex-ofstranding' refers to the counter-intuition from a registry-worldview/dimension perspective in not representing itself as stranded (decandored or oblongated or in threshold-ofnonconviction/madeupness/bottomlining-in-shallow-supererogation $<-<$ as-to-' $a$ attendantintradimensional'-prospectively-disontologising preconverging/dementing -apriorisingpsychologism $>$ when it is demonstrated that it is ${ }^{74}$ perversion-of- ${ }^{8}$ reference-of-thought- $<$ aspreconvergingly-apriorising/axiomatising/referencing-in-

nonconviction/madeupness/bottomlining-as-to-shallow-supererogation $>$ as perversion-of-thecategorical-imperatives/axioms/registry-teleology ${ }^{9}$-for-intemporal-preservation-entropy-orcontiguity-or-ontological-preservation, and rather syncretises in operating those same reference-of-thought- ${ }^{8}$ ategorical-imperatives/axioms/registry-teleology ${ }^{9}$,-for-intemporalpreservation-entropy-or-contiguity-or-ontological-preservation prospectively; while that same registry-worldview/dimension intuitively recognises that a prior/superseded registryworldview/dimension mental-devising-representation as stranded is ontologically veridical as the prior/superseded registry-worldview/dimension subknowledges/mimics and self-referencesyncretises it's ${ }^{83}$ reference-of-thought- categorical-imperatives/axioms/registry-teleology ${ }^{9}$,- 
for-intemporal-preservation-entropy-or-contiguity-or-ontological-preservation at its uninstitutionalised-threshold ${ }^{102}$ The reason for the human 'transcendental/transdimensional/interdimensional/ ${ }^{5}$ maximalising-recomposuring-for-relativeontological-completeness ${ }^{87}$ - unenframed/re-ontologising conceptualisation complex-ofstranding' is that a registry-worldview's/dimension's institutionalisation ${ }^{83}$ reference-of-thoughtcategorical-imperatives/axioms/registry-teleology ${ }^{9}$,-for-intemporal-preservation-entropy-orcontiguity-or-ontological-preservation are fundamental and constitutive functional elements of its existentialism (full-existential-depth-implications) personhoods-and-socialhood-formation and hence the complex when $<$ amplituding/formative-epistemicity $>$ totalising $\sim$ self-referencingsyncretising/present-consciousness/illusion-of-the-present. But then, if such a complex is to stand, the transcendental exercise by which man left the cave-to-so-called-modern-man wouldn't have happened, and any registry-worldview/dimension (retrospective, present, prospective) that fails its own de-mentation-〈supererogatory ontological-de-mentation-or-dialectical-dementation-stranding-or-attributive-dialectics $\rangle$ as to elucidation-and-superseding-of-itsperversion-of- ${ }^{3}$ reference-of-thought- $<$ as-preconvergingly-

\section{apriorising/axiomatising/referencing-in-nonconviction/madeupness/bottomlining-as-to-}

shallow-supererogation >,-as-to-preconverging-or-dementing ${ }^{20}$-apriorising-psychologism to allow for prospective psychoanalytic-unshackling/memetic-reordering/institutionalrecomposuring for transcendence-as-the-grander-possibility-for-human-survival-andflourishing is obviously failing/not-upholding-<as-of-apriorising/axiomatising/referencing $>$ its 'own homework' for the bigger picture in the human species survival-and-flourishing scheme, notwithstanding it is at the backend of the institutional-cumulation/institutional-recomposure〈as-to- historiality/ontological-eventfulness /ontological-aesthetic-tracing-<perspectiveontological-normalcy/postconvergence-reflected-‘epistemicity-relativism-determinism'>> relative-unreflexivity/relative-reflexivity - ontological-contiguity ${ }^{67}$ of-the-human- 
institutionalisation-process 6 ! As an anthropopsychological disposition, rational-realism as notional ${ }^{18}$ deprocrypticism just like all successive transcendence-andsublimity/sublimation/supererogatory de-mentativity in emphasising increasing realism counter-intuitively to a naïve temporal take is actually a "positive-minded/well-meaning disposition with respect to man/the-human-species' with the idea that 'it is better working with what intemporally/ontologically is (that is, the-Good/knowledge-reification $\sim$ gesturing-andaccounting - of-epistemic-phenomenalism- $<$ inprospective_psychologismic apriorising/axiomatising/referencing-\{of-'prospectively implicited_attendant-ontological-contiguity ' educedexistentialising/contextualising/textualising_'intelligibility/epistemicity/reflexivity-contiguity<imbued-notional cogency >' \}-conflatedness -in-\{preconverging-disentailment by\} postconverging-entailment $>$ /understanding/<amplituding/formativeepistemicity $>$ causality $\sim$ as-to-projective-totalitative-implications-of-prospectivenonpresencing,-for-explicating relative-unreflexivity/relative-reflexivity - ontologicalcontiguity ) to achieve the best intellectual-and-moral outcome for man' than 'working with what-one-wishes' from a wrong temporal/impression-driven construal'. The idea of understanding the ontology of human temporal mental defect is not to 'idle' in a temporal circularity that defeats-and-debase the grandor of a ${ }^{103}$ universal/intemporal projection but rather strives to better stir man towards the intemporal-and-ontological as virtue, an exercise which while of ' ${ }^{7}$ presencing-absolutising-identitive-constitutedness ${ }^{14}$ consummated/forfeiting posture' with regards to human temporality $/$ /shortness wouldn't however acquiesce to the naïve disconcertment that takes the "79 presencing-absolutising-identitive-constitutedness

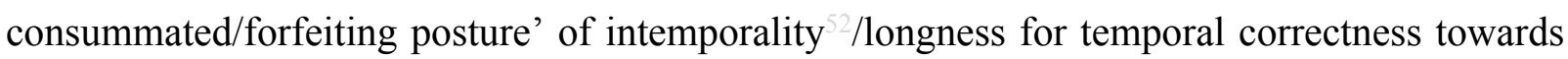
which the intemporal-disposition is definitely intransigent and uncompromising for effective intemporal-preservation-entropy-or-contiguity-or-ontological-preservation. Such a rational- 
realism as notional ${ }^{18}$ deprocrypticism disposition views the fundamental anthropopsychology drive for transcendence-and-sublimity/sublimation/supererogatory - de-mentativity which involves de-mentation-〈supererogatory ontological-de-mentation-or-dialectical-dementation-stranding-or-attributive-dialectics $\rangle$ for transcendence-andsublimity/sublimation/supererogatory $\sim$ de-mentativity by decandoring/oblongating (representation of perversion-of- ${ }^{8}$ reference-of-thought- $<$ as-preconverginglyapriorising/axiomatising/referencing-in-nonconviction/madeupness/bottomlining-as-toshallow-supererogation $>$ as to preconverging-or-dementing ${ }^{20}$-apriorising-psychologism$<$ stranded-as-rightfully-oblongated/decandored-and-dialectically-or-contendingly-out-ofphase $>$ ) on the basis of the veridicality of human-subpotencyaporia/undecidability/dilemma/ought-indeterminacy/deficiency/limitation/constraint—imbued'notional firstnaturedness-formativeness-<as-to-eventualising -inkling-drive-or-seedingmisprising $>$ temporal-to-intemporal-dispositions- $<$ so-construed-as-from-perspectiveontological-normalcy/postconvergence>'-existentialism-form-factor rationally, and ontologically represents the social-construct (as validated by the "shifting relation of social conventioning and purist ontology') as being in effect a 'highly cohesive postconverging-dementating/structuring/paradigming' at institutionalised/intemporalised-thresholds-ofintemporal-preservation-entropy-or-contiguity-or-ontological-preservation but a 'poorly cohesive extricatory preconverging-de-mentating/structuring/paradigming' at uninstitutionalised-threshold $^{102}$. The notion of the social-construct as intemporal/ontological/social/species $/{ }^{103}$ universal/transcendental $/{ }^{5}$ maximalisingrecomposuring-for-relative-ontological-completeness ${ }^{87}$ - unenframed/reontologising conceptualisation postconverging-de-mentating/structuring/paradigming is actually an aspirational ideal and reference for 'human intemporal projection towards it' but it isn't ontologically veridical by the inherent solipsistic human nature due to a 
notional firstnaturedness-formativeness-<as-to-eventualising-inkling-drive-or-seedingmisprising $>$ temporal-to-intemporal-dispositions-<so-construed-as-from-perspectiveontological-normalcy/postconvergence $>$ human reality, and thus the need for institutionalisation to skew ('intemporality ${ }^{52}$-symmetrising-by-desymmetrising-subsumption-of-temporality ${ }^{8}$, for relative intrinsic-reality/ontological-veridicality transcendental-

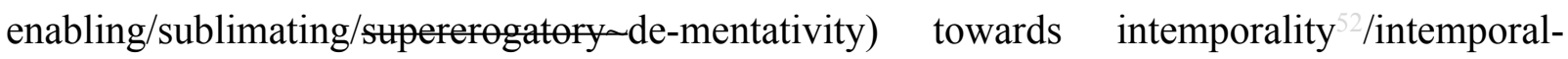
preservation as human secondnaturing. This elucidation is vital in pointing out that the teleology ${ }^{9}$ of rational-realism as notional ${ }^{18}$ deprocrypticism (with teleology fundamentally construed as 'phenomenal/manifest conceptivity/epistemic-reflexivity/epistemicity-relativismdeterminism-<reifying \{as-to-knowledge-developing\}-and-empowering $>$ in existence as ontological (so-reflecting <amplituding/formative>disposedness/psychologismic-construct-〈asto-orientation/value-construct/valuation-and-derived-parameterising and $<$ amplituding/formative>entailment-〈as-to-totalising-contiguous/coherent-factuality-ofvariability $\rangle$ )' and so as to the specific human-subpotency with regards to overall reifying-andempowering-reflexivity-of-ecstatic-existence-as-panintelligibility/panreflexivity ${ }^{3}$ $\langle$ existentially-imbued-and-educing-<epistemicthermeneutically/textually/reprojectingly/supererogatingly/zeroingly/re-acutingly,$\{$ decompulsing $\}$ delinearity $\sim$ for-cogency $\geq$-epistemic-perspective-of-projective/reprojectiveaestheticising-re-motif-and-re-apriorising/re-axiomatising/re-referencing $\sim$ conceptualisation, as-herein-specifically-relevant-to-human-subpotency)), is not to strive for the wrong notion of human intemporal/ontological 'congruence' with respect to knowledge and virtue (as human dispositions are not congruent, as thus the idea of ontological-congruence of the intemporaldisposition with temporal-dispositions will compromise intemporality ${ }^{52}$, and hence compromise ontology), but rather to aspire for a transversality-<for-sublimating-existentialeventuating/denouement,-from-'thinking at-first/pure-predisposition-preemptive-of- 
prospective-disontologising/subontologising' as-of-prospectively-disambiguated-affirmed-

and-unaffirmed-'motif-and-apriorising/axiomatising/referencing'> ${ }^{101}$ of human intemporaldisposition with respect to temporal-dispositions (as this upholds and doesn't compromise the ontological veridicality in intemporal-disposition projection as to the ontological reality of human notional firstnaturedness-formativeness-<as-to-eventualising-inkling-drive-orseeding-misprising $>$ temporal-to-intemporal-dispositions- $<$ so-construed-as-fromperspective-ontological-normalcy/postconvergence $>$ at uninstitutionalised-threshold ${ }^{102}$ ). That is, knowledge-notionalisation involving grasping and understanding both the ignorances/desublimation/temporal-dispositions and ideals to better skew/deferentialformalisation-transference towards idealism as the fulsome ontology, and not failing/notupholding-<as-of-apriorising/axiomatising/referencing $>$ to understand or overlooking the ignorances/desublimation/temporal-dispositions as the temporal on the wrong basis that all that matters is the ideal as intemporal. Furthermore, temporal-dispositions tendency to pervert/dement/subknowledge-〈preconverging-or-dementing -as-if-of-sound-

knowledge//mimick-and-syncretise at uninstitutionalised-threshold ${ }^{102}$ with the dialectical consequence of the development of the <cumulating/recomposuring attendant-ontologicalcontiguity $>$-successive registry-worldviews/dimensions (institutionalisations) validates the appropriateness of striving rather for transversality-<for-sublimating-existentialeventuating/denouement,-from-'thinking-at-first/pure-predisposition-preemptive-ofprospective-disontologising/subontologising' as-of-prospectively-disambiguated-affirmedand-unaffirmed-'motif-and-apriorising/axiomatising/referencing'>101 and not nestedcongruence to uphold intemporality ${ }^{52}$, and hence a complete ontology. To put it in other terms, for instance, $\quad$ transversality- $<$ for-sublimating-existential-eventuating/denouement,-from'thinking at-first/pure-predisposition-preemptive-of-prospectivedisontologising/subontologising' as-of-prospectively-disambiguated-affirmed-and- 
unaffirmed-'motif-and-apriorising/axiomatising/referencing'> ${ }^{101}$ of 'keeping the faith' only in the intrinsic operation of rules of arithmetic (transversality-<for-sublimating-existentialeventuating/denouement,from-'thinking at-first/pure-predisposition-preemptive-ofprospective-disontologising/subontologising' as-of-prospectively-disambiguated-affirmedand-unaffirmed-'motif-and-apriorising/axiomatising/referencing'> ${ }^{101}$ among interlocutors, in principle or notionally, so that at all times it is always about the intrinsic reality of the arithmetic and not the agreement-disagreement of any human interlocutors as we are all mortals and likely to corrupt such intemporal rules with our mortality out of an intemporal frame of reference that is transcendental-enabling/sublimating/supereregatery $\sim$ de-mentativity) is vital to preserving 'ontological arithmetic' as transcendental-enabling/sublimating/supereregatory $\sim$ de-mentativity, whereas if the notion of arithmetic calculations was to involve social-and-temporal-trading with other humans (interlocutors logical nested-congruence) instead of intemporal exercise, it is obvious that down the line the notion of 'ontological arithmetic' will sooner or later be corrupted and/or teleologically-degraded as more likely than not the intemporality ${ }^{2} /$ purity of mathematics will be compromised to human mortals stakes of social-and-temporal-trading as socialaggregation-enabling, and so as of postlogism slantedness/ ${ }^{5}$ ignorance/affordability/opportunism/exacerbation/social-chainism-or-socialdiscomfiture-or-negative-social-aggregation/temporal-enculturation-or-temporal-endemisation, so-disambiguated as of ${ }^{83}$ reference-of-thought- ${ }^{8}$ devolving ontological-performance ${ }^{72}$ $<$ including-virtue-as-ontology>. * It should be noted that in de-mentation〈supererogatory ontological-de-mentation-or-dialectical-de-mentation-stranding-orattributive-dialectics $\rangle$,-in-a-contiguity-of-increasing-ontological-normalcy/postconvergence dialecticism of transcendence-and-sublimity/sublimation/supererogatory-de-mentativity involving the transcended and the transcending dimensions, the terms highlighting the transcended dimension like decandored, oblongated, dialectically-out-of-phasing/dialectically- 
primitive, etc. (as to its superseded Being-development/ontological-framework-expansion-asto-depth-of-ontologising-development-as-infrastructure-of- meaningfulness-and-teleology ) do not carry the same connotation as a shallower temporal analysis intradimensional to the transcended dimension (as to its given institutional-development-as-to-social-functiondevelopment and living-development-as-to-personality-development psychologismic epistemic-acutisation difficulty-<for, residualising \{decompulsing $\}$ delinearity for-cogency> magnitudes $\{$ of-experientiality/experiment\} so-referenced to its given Being-development/ontologicalframework-expansion-as-to-depth-of-ontologising-development-as-infrastructure-ofmeaningfulness-and-teleology ). The idea is not to idle in articulating meaningfulness within the dimension in need of transcendence-and-sublimity/sublimation/supererogatory $\sim$ dementativity. For instance, a positive mind's articulation of defective meaningfulness in nonpositivism/medievalism registry-worldview/dimension is not to 'idle' by relating and staking such meaningful articulation in terms-as-of-axiomatic-construct of the nonpositivism/medievalism world sense of meaningful purposefulness but rather to project a positivistic worldview's transcendental meaningful purposefulness. In that sense, actually for the social scientist and philosopher words like dialectically-or-contendingly-out-of-phase, primitive, decandored, perverted don't carry the ordinary and temporal connotations of stigmatising under a temporal extricatory preconverging-de-mentating/structuring/paradigming. Rather, these are critical and actively sought after notions that provide the 'dialectical backdrop' for enabling prospective transcendence-and-sublimity/sublimation/supererogatory de-mentativity by psychoanalytic-unshackling/memetic-reordering/institutional-recomposuring. The idea is that these notions are veridically dialectical notions that apply in all transcendence-andsublimity/sublimation/superentativity unlike a simplistic 'history fixating conceptualisation' will have. In other words, our non-positivism/medievalism ancestors' possibility of being-represented/mental-devising-representation as dialectically-or- 
contendingly-out-of-phase/dialectically-primitive) is the opportunity for the contrastive construction of a superseding/transcendental registry-worldview/dimension that brought about the relative virtue in the positivistic registry-worldview/dimension of their great-grandchildren today. That is rather the uninhibited/decomplexified and forward-looking perspective imbued in a notional ${ }^{18}$ deprocrypticism institutionalisation/intemporalisation with respect to procrypticism. In-the-bigger-picture, identifying inherent virtue in the institutionalisation/intemporalisation process on the basis that humans of all generations (times and epochs) are 'capacity-wise same' as per notional firstnaturedness-formativeness-<as-toeventualising inkling-drive-or-seeding-misprising $>$ temporal-to-intemporal-dispositions$<$ so-construed-as-from-perspective-ontological-normalcy/postconvergence $>$ going by a preconverging/postconverging-de-mentating/structuring/paradigming of mentation-capacity (shortness-of-register-of- ${ }^{5}$ meaningfulness-and-teleology 9 to longness-of-register-ofmeaningfulness-and-teleology ${ }^{9}$ with respect to the intemporal-preservation-entropy-orcontiguity-or-ontological-preservation, but for the semblance of the superiority of latter registry-worldviews/dimensions which is nothing but the result of being at the backend of the institutional-cumulation/institutional-recomposure-〈as-to- historiality/ontologicaleventfulness /ontological-aesthetic-tracing-<perspective-ontologicalnormalcy/postconvergence-reflected-'epistemicity-relativism-determinism'>> process. Ontological-normalcy/postconvergence equally involves articulating the possibility for the supersedingness of the intemporal-disposition over temporal-dispositions as intemporalisation/institutionalisation, and so, involving 'notional firstnaturednessformativeness-<as-to-eventualising inkling-drive-or-seeding-misprising $>$ temporal-tointemporal-dispositions- $<$ so-construed-as-from-perspective-ontologicalnormalcy/postconvergence $>$ accountability' beyond an 'idle temporal-dispositions stigmatisation'. In that spirit, it can be reasoned that the intradimensional 'ontological blindspot' 
in human mental-devising-representation (wherein temporal ${ }^{7}$ perversion-of- ${ }^{83}$ reference-ofthought- $<$ as-preconvergingly-apriorising/axiomatising/referencing-in-

nonconviction/madeupness/bottomlining-as-to-shallow-supererogation $>$ by miscuing, and in subsequent derivation of disjointed-logic/logical-drag/unconscionability-drag/sub-par-orformulaic-association-or-temporal-or-alibi conventioning-rationalising of temporal-dispositions perversions/defects

of postlogism slantedness/ ${ }^{5}$ ignorance/affordability/opportunism/exacerbation/social-chainism-or-socialdiscomfiture-or-negative-social-aggregation/temporal-enculturation-or-temporal-endemisation, so-disambiguated as of ${ }^{8}$ reference-of-thought- ${ }^{8}$ devolving ontological-performance ${ }^{72}$ <including-virtue-as-ontology $>$ /morality/ethics/justice/etc.

conjugated/inflected/derived/mimicked/in-protraction-to-psychopathic-preconverging-ordementing -apriorising-psychologism), actually points to a decandored/slantedness of the temporal-dispositions (and not candored/straightness), and is definitional of all registryworldviews/dimensions perversion-of- ${ }^{3}$ reference-of-thought- $<$ as-preconverginglyapriorising/axiomatising/referencing-in-nonconviction/madeupness/bottomlining-as-toshallow-supererogation $>$ whether recurrent-utter-uninstitutionalisation, ununiversalisation, non-positivism/medievalism and prospectively procrypticism, as these are in epistemicdecadence-and-derived-epistemic-decadence, i.e. not veridical but perverted and requiring transcendence-and-sublimity/sublimation/supererogatory $\sim$ de-mentativity. This basically undermines the idea that any such registry-worldview/dimension temporal-dispositions should be encouraged to be '<amplituding/formative-epistemicity $>$ totalising $\sim$ self-referencingsyncretising/circularity/interiorising/akrasiatic-drag ${ }^{34}$ in meaning' in a logical engagement with it from an intemporal/ontological perspective (of ontological-normalcy/postconvergence), as it is rather in perversion-and-derived- perversion-of- ${ }^{-3 e f e r e n c e-o f-t h o u g h t-<a s-~}$ preconvergingly-apriorising/axiomatising/referencing-in- 
nonconviction/madeupness/bottomlining-as-to-shallow-supererogation $>$ of its ${ }^{83}$ reference-ofthought- categorical-imperatives/axioms/registry-teleology ${ }^{9}$,-for-intemporal-preservationentropy-or-contiguity-or-ontological-preservation. Instead this requires a transversality- $<$ forsublimating-existential-eventuating/denouement,-from-'thinking-at-first/pure-predispositionpreemptive-of prospective-disontologising/subontologising' as-of-prospectivelydisambiguated-affirmed-and-unaffirmed-'motif-and-apriorising/axiomatising/referencing'> (due to the dialectially-out-of-phasing/unsoundness-or-ontological-bad-faith/inauthenticity ${ }^{64}$ of- ${ }^{3}$ reference-of-thought/preconverging-or-dementing ${ }^{20}$-apriorising-psychologismness with regards to the veridical ontology of temporal-dispositions registries); wherein the intemporaldisposition (which is ontological) doesn't recognise nor acquiesce to the implied-logicaldueness-or-implied-scape and subsequent apriorising-registry-elements of implied-profile-orimplied-stature, implied-presumptuousness-or-implied-arrogation, implied-assumptions, implied-value-reference and implied-teleology ${ }^{9}$ projected by the temporal-dispositions, but rather advances that there is 7 perversion-of- ${ }^{2}$ eference-of-thought-<as-preconverginglyapriorising/axiomatising/referencing-in-nonconviction/madeupness/bottomlining-as-toshallow-supererogation $>$ requiring a transversality-<for-sublimating-existentialeventuating/denouement, from 'thinking at first/pure predisposition preemptive of prospective-disontologising/subontologising' as-of-prospectively-disambiguated-affirmedand-unaffirmed-'motif-and-apriorising/axiomatising/referencing'>101_ 'postconverging-ordialectical-thinking -psychology or psychology-of-mentation-dynamics or natural psychological-dynamics’ psychoanalytic-unshackling/memeticreordering/institutional-recomposuring for prospective ${ }^{83}$ reference-of-thought- categoricalimperatives/axioms/registry-teleology ${ }^{9}$,-for-intemporal-preservation-entropy-or-contiguityor-ontological-preservation. For instance, there is no possible logical engagement but rather a transversality-<for-sublimating-existential-eventuating/denouement,-from-'thinking at- 
prospectively-disambiguated-affirmed-and-unaffirmed-'motif-and-

apriorising/axiomatising/referencing' $>101$ between the recurrent-utter-institutionalised and baseinstitutionalised mindsets $/{ }^{3}$ references-of-thought, likewise between the ununiversalised and universalised mindsets/ $/{ }^{3}$ references-of-thought, non-positivism/medievalism and positivistic mindsets/ $/{ }^{3}$ references-of-thought, and prospectively procrypticism and notional ${ }^{18}$ deprocrypticism mindsets $/{ }^{8}$ references-of-thought. Just as there would have been no ontological possibility for a positivistic worldview without superseding the backdrop of the

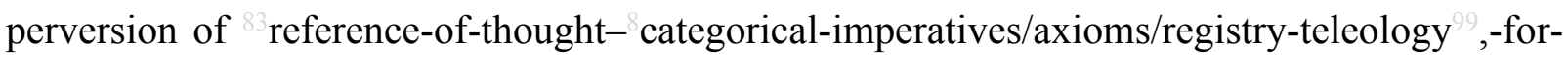
intemporal-preservation-entropy-or-contiguity-or-ontological-preservation of nonpositivism/medievalism uninstitutionalisation preconverging-or-dementing ${ }^{20}$-apriorisingpsychologism- $<$ stranded-as-rightfully-oblongated/decandored-and-dialectically-or-

contendingly-out-of-phase>, there can't equally be an ontological eventuality of futural Beingdevelopment/ontological-framework-expansion-as-to-depth-of-ontologising-development-asinfrastructure-of- meaningfulness-and-teleology as of prospective notional ${ }^{18}$ deprocrypticism without the 'requisite uninhibited/decomplexified mental-devisingrepresentation' superseding the positivism- ${ }^{80}$ procrypticism perversion of ${ }^{83}$ reference-ofthought- ${ }^{8}$ ategorical-imperatives/axioms/registry-teleology ${ }^{99}$,-for-intemporal-preservationentropy-or-contiguity-or-ontological-preservation perspective preconverging-or-dementing apriorising-psychologism- $<$ stranded-as-rightfully-oblongated/decandored-and-dialectically-orcontendingly-out-of-phase> backdrop for futural Being-development/ontological-frameworkexpansion-as-to-depth-of-ontologising-development-as-infrastructure-of- meaningfulness-

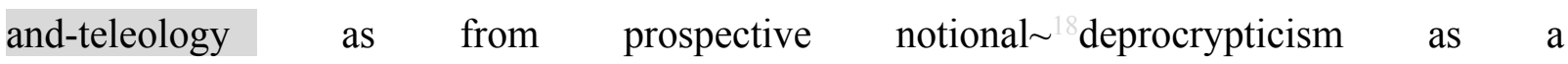
preconverging/postconverging-de-mentative/structural/paradigmatic human-and-social-crosssectional resolution for the virtues of notional deprocrypticism in superseding the vices-and- 
impediments $^{105}$ of procrypticism at its uninstitutionalised-threshold ${ }^{102}$. This construal is placed on a solid firmament (that is able to supplant any intradimensional illusion-of-the-present mental-devising-representation) by the " $<$ amplituding/formative-epistemicity $>$ causality $~ a s-t o-$ projective-totalitative-implications-of-prospective- nonpresencing,-for-explicating relativeunreflexivity/relative-reflexivity_ontological-contiguity retracing (for notional firstnaturedness-formativeness-<as-to-eventualising-inkling-drive or seedingmisprising $>$ temporal-to-intemporal-dispositions-<so-construed-as-from-perspectiveontological-normalcy/postconvergence $>$ disambiguation articulation)' that demonstrably oblongates/decandors temporal-dispositions as it articulates the dialecticism of a registryworldview's/dimension's transcendence-and-sublimity/sublimation/supereregatery $\sim$ dementativity (transcending-dimension/organicalism and transcended-dimension/mechanicalism), on the validity of the stranding-contiguity-of-ontology. Logic and logical-congruence is ontologically valid only as an after-transcendence exercise when through the institutionalisation/intemporalisation percolation-channelling- $<$ in-deferential-formalisationtransference>, the ${ }^{83}$ reference-of-thought- categorical-imperatives/axioms/registryteleology ,-for-intemporal-preservation-entropy-or-contiguity-or-ontological-preservation of the transcending-registry-worldview/dimension in organicalism is institutionalised/intemporalised by positive-opportunism-of-social-functioning-andaccordance $^{75}$ with the induced social ${ }^{103}$ universal-transparency ${ }^{104}$-〈transparency-of-totalisingentailing,-as-to-entailing-<amplituding/formative-epistemicity $>$ totalising $\sim$ in-relativeontological-completeness > (of both the ${ }^{7}$ perversion-of- ${ }^{\text {reference-of-thought- }<\text { as- }}$ preconvergingly-apriorising/axiomatising/referencing-innonconviction/madeupness/bottomlining-as-to-shallow-supererogation $>$ transcended registryworldview/dimension and the discovered ontological-veridicality of the transcending registryworldview/dimension), untenability/internal-contradiction/internal-incoherence/institutional- 
constraining (of transcended registry-worldview/dimension, from <amplituding/formativeepistemicity $>$ causality $\sim$ as-to-projective-totalitative-implications-of-prospectivenonpresencing,-for-explicating relative-unreflexivity/relative-reflexivity - ontologicalcontiguity of the transcending registry-worldview/dimension), referencing/registering/decisioning or stranding (of transcended registry-worldview/dimension perversion-of- ${ }^{-3}$ reference-of-thought-<as-preconverginglyapriorising/axiomatising/referencing-in-nonconviction/madeupness/bottomlining-as-toshallow-supererogation $>$ as backdrop for prospective transcendence-andsublimity/sublimation/supererogatory de-mentativity), and intemporal superseding of the transcendence-unenabling-uninstitutionalised-threshold ${ }^{102}$ in alienation-as-inauthentic/poorlyobjectified/poorly-desubjectified-as-objectified/ontological-bad-faith/inauthenticity ${ }^{6} /$ nihilistic (as of temporal-dispositions disambiguation by transversality-<for-sublimating-existentialeventuating/denouement,-from-'thinking-at-first/pure-predisposition-preemptive-ofprospective-disontologising/subontologising' as-of-prospectively-disambiguated-affirmedand-unaffirmed-'motif-and-apriorising/axiomatising/referencing'> ${ }^{101}$ for crossgenerational 'habituation' of the transcending registry-worldview/dimension in organicalism); defining the 'postconverging-or-dialectical-thinking -psychology or psychology-of-mentation-dynamics or natural psychological-dynamics' psychoanalytic-unshackling/memeticreordering/institutional-recomposuring process. - The concepts of candoring and decandoring as elucidated above (but with variously deconstructed shades as: integrative alignment / aligning in transversality-<for-sublimating-existential-eventuating/denouement,-from-'thinking-atfirst/pure-predisposition-preemptive-of-prospective-disontologising/subontologising' as-ofprospectively-disambiguated-affirmed-and-unaffirmed-'motif-andapriorising/axiomatising/referencing'>101, supplanting-conviction-as-to-profoundsupererogation - of-'attendant-intradimensional'-postconverging/dialectical-thinking 
apriorising-psychologism / $\quad$ compulsing-nonconviction/madeupness/bottomlining-

$\langle<<$ decontextualising/de-existentialising of-attendant-intradimensional-

apriorising/axiomatising/referencing >-induced-disontologising'-of-the-'attendant-

intradimensional-ontologising'-imbued-<contextualising/existentialising attendant-

ontological-contiguity $>$;-in-shallow-supererogation $-<$ as-to-disontologising-perverted-

outcome-sought-precedes-existentially-veridical-'attendant-intradimensional-

apriorising/axiomatising/referencing'-logical-dueness $>$ >, elevating / downgrading, straightness / oblongated, sane integration / insane-or-slantedness integration, soundness-or-ontological-goodfaith/authenticity ${ }^{69}$-of- ${ }^{3}$ reference-of-thought / unsoundness-or-ontological-badfaith/inauthenticity ${ }^{64}$ of- reference-of-thought, thinking / mimicking or compulsive-slantingpreconverging-or-dementing ${ }^{20}$-apriorising, 'implicited_attendant-ontologicalcontiguity ${ }^{67} \sim$ educed-

existentialising/contextualising/textualising_intelligibility/epistemicity/reflexivity-contiguity$<$ imbued-notional $\sim$ cogency $>,{ }^{\prime},-<$ reifying-or-elucidating-of-prospective-relative-ontologicalcompleteness -of- reference-of-thought- devolving-as-of-instantiative-context $>$ /meaningfulprojection-of-intrinsicness / vague-rhyming-or-copied-mimicry-or-formulaic-projection-orprojection-of-form-or-hollow-and-vague-vocalisation-or-subknowledging ${ }^{4}, \quad$ in-phasing / dialectically-out-of-phasing (dialectically-primitive), logical-contention / transversality-<forsublimating-existential-eventuating/denouement, from-'thinking at first/pure-predispositionpreemptive-of prospective-disontologising/subontologising' as-of-prospectivelydisambiguated-affirmed-and-unaffirmed-'motif-and-apriorising/axiomatising/referencing'>101, postconverging-or-dialectical-thinking ${ }^{2}$-apriorising-psychologism- $<$ stranded-as-rightfullystraight/candored-and-dialectically-or-contendingly-in-phase $>$ or breaking-from-the-priormindset/ ${ }^{3}$ reference-of-thought or collapsing/overriding / preconverging-or-dementing apriorising-psychologism-<stranded-as-rightfully-oblongated/decandored-and-dialectically-or- 
contendingly-out-of-phase $>$ (operating-the-very-same-prior-mindset), coring (accounting-forregistry-subknowledging $/$ mimicking/defect) / setting-aside, (glossing-over-registry'preconverging-or-dementing 2 -apriorising-psychologism/defect), transcending-or-superseding / transcended-or-superseded). * It should be noted that this element of deconstructed meaningfulness is obviously reflected in the articulation of this paper itself in a creative, referential and dynamic grasp of ${ }^{83}$ reference-of-thought and ${ }^{56}$ meaningfulness-and-teleology ${ }^{99}$ in a rather ephemeral subject, the social. In this regard, the fepistemicthermeneutic/textuality/reprojecting/supererogating/zeroing/re-acuting,-

delinearity for-cogency exercise originates from an even more wildly idiosyncratic (but personal incommunicable) reflexive process initiated rather spontaneously by the author a few years back which has formed the backdrop for this 'rather relatively benign idiosyncrasy' in this paper as the reader may come across and is the explanation for many of the author's insights. It is this mechanism of deconstructing meaningfulness exhaustively in search of an idiosyncratic but profound philosophical and creative insight that allows the tollising thermeneutic/textuality/reprojecting/supererogating/zeroing/re-acuting,-

\{decompulsing\} delinearity for-cogency design in a 'continuous meaningfulness reshuffling in the quest for veracity/ontological-pertinence' analogical to a twisty puzzle cube exercise in order to infer and arrive at a profoundly explanatory \{epistemictotalising ${ }^{3}$ hermeneutic/textuality/reprojecting/supererogating/zeroing/re-acuting,\{decomentsing delinearity for-cogency insight extending to the possibility of a 'creative existentialism (full-existential-depth-implications) storying construal' which is 'profoundly ontological', with psychoanalytic-unshackling/memetic-reordering/institutional-recomposuring possibilities for transcendental institutionalisation/intemporalisation of notional ${ }^{18}$ deprocrypticism (superseding the vices-and-impediments ${ }^{105}$ of, as well as human emancipation over, procrypticism). Such ontological-normalcy/postconvergence-or- 
postdicatory deconstruction/ontological-reconstituting-as-to-conflatedness ${ }^{13}$ as dialectical transformation as prospective ${ }^{83}$ reference-of-thought of renewing existentialism/full-depth-ofexistential-implications apriorising/axiomatising/referencing/intelligibilitysettingup/measuringinstrumenting in various shades is just as critical for the necessary reconstitutive insight (deconstruction) that can be highly evasive and difficult to fully grasp at different registry-worldviews/dimensions meaningful-references or rather dialectically successive existentialisms. - A 'circular dialectical dynamism of organic-comprehension-thinking (organicalism/“intemporal-prioritisation-ofreference-of-thought'-as-conflatedness ${ }^{13}$-or-ontological-reprojecting/longness-of-register-ofmeaningfulness-and-teleology ) by virtue of intemporal higher teleologies, distracted by threshold-of-nonconviction/madeupness/bottomlining-in-shallow-supererogation $-<$ as-to-

\section{'attendant-intradimensional'-prospectively-disontologising preconverging/dementing}

apriorising-psychologism>, due to temporal and/or perverted/subknowledging $/$ mimicking degraded-teleologies; in the psychoanalytic-unshackling process that explains transcendentaldialecticism transdimensionally/across-registry-worldviews/dimensions reflected/perspectivated as soundness-or-ontological-good-faith/authenticity ${ }^{60}$-of- ${ }^{8}$ referenceof-thought/candoring-and-dialectically-in-phase with regards to organic-comprehensionthinking (organicalism/‘intemporal-prioritisation-of- ${ }^{8}$ reference-of-thought'-asconflatedness $^{13}$-or-ontological-reprojecting/longness-of-register-of - meaningfulness-andteleology ) and as oblongated/decandored-and-dialectically-out-of-phase with regards to threshold-of-nonconviction/madeupness/bottomlining-in-shallow-supererogation $<-<$ as-to-

\section{'attendant-intradimensional'-prospectively-disontologising preconverging/dementing}

apriorising-psychologism>. * The underlying idea behind the circular dialectical dynamism of organic-comprehension-thinking (organicalism/“intemporal-prioritisation-of- ${ }^{3}$ reference-ofthought'-as-conflatedness ${ }^{13}$-or-ontological-reprojecting/longness-of-register-of- 
meaningfulness-and-teleology ) in relation to threshold-ofnonconviction/madeupness/bottomlining-in-shallow-supererogation -<as-to-'attendantintradimensional'-prospectively-disontologising preconverging/dementing -apriorising-

psychologism $>$ is that the threshold-of-nonconviction/madeupness/bottomlining-in-shallowsupererogation -<as-to-'attendant-intradimensional'-prospectivelydisontologising preconverging/dementing -apriorising-psychologism $>$ is rather an existentially-<disontologising/re-ontologising aporeticism $>$ naïve miscuing (with subsequent disjointed-logic/logical-drag/unconscionability-drag/sub-par-or-formulaic-association-ortemporal-or-alibi conventioning-rationalising conjugated/inflected/derived/mimicked/inprotraction-to-psychopathic-preconverging-or-dementing ${ }^{20}$-apriorising-psychologism at the temporal-dispositions perversions/defects of postlogism slantedness/ ignorance/affordability/opportunism/exacerbation/social-chainism-or-socialdiscomfiture-or-negative-social-aggregation/temporal-enculturation-or-temporal-endemisation, so-disambiguated as of ${ }^{83}$ reference-of-thought- ${ }^{8}$ devolving ontological-performance ${ }^{72}$ $<$ including-virtue-as-ontology $>$. This undermines the ontologically-veridical organic-

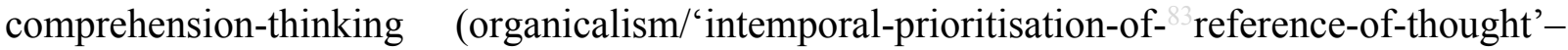
as-conflatedness ${ }^{13}$-or-ontological-reprojecting-tongness of register of - meaning fulness andteleology' ). The '<amplituding/formative-epistemicity $>$ causality $\sim$ as-to-projectivetotalitative-implications-of-prospective- nonpresencing,-for-explicating relativeunreflexivity/relative-reflexivity ontological-contiguity retracing (for notional firstnaturedness-formativeness-<as-to-eventualising-inkling-drive-or-seedingmisprising $>$ temporal-to-intemporal-dispositions- $<$ so-construed-as-from-perspectiveontological-normalcy/postconvergence>-pedestals-disambiguation) as ${ }^{83}$ reference-of-thoughtscheme' is critical as it is the only means for articulating notional firstnaturednessformativeness-<as-to-eventualising inkling drive-or - seeding misprising $>$ temporal-to- 
intemporal-dispositions-<so-construed-as-from-perspective-ontological-

normalcy/postconvergence $>$ disambiguation in perspective as otherwise by the "conviction-asto-profound-supererogation -reflex/prelogic-reflex-admittance-reflex/in-phase-reflex' instead of rightly aligning as dialectically-or-contendingly-out-of-phase (non-ontological-reference or non-contending-reference-but-ontologically-or-contendingly-reflected-or-perspectivated-aspreconverging-or-dementing ${ }^{20}$-apriorising-psychologism or not-veridical-thinking-referencerather-preconverging-or-dementing ${ }^{20}$-reference or ${ }^{74}$ perversion-of- ${ }^{3}$ reference-of-thought- $<$ aspreconvergingly-apriorising/axiomatising/referencing-in-

nonconviction/madeupness/bottomlining-as-to-shallow-supererogation >,-and-not-of-logicalcontention reflex or transversality-<for-sublimating-existential-eventuating/denouement,-fromthinking at first/pure-predisposition-preemptive-of-prospective-

\section{disontologising/subontologising’ as-of-prospectively-disambiguated-affirmed-and-}

unaffirmed-‘motif-and-apriorising/axiomatising/referencing'> ${ }^{01}$ reflex) temporal-dispositions are directly engaged wrongly as straight/candored/conviction-as-to-profound-supererogation and elevated as ontologically veridical as if these were intemporal, to effectively reflect/perspectivate the temporal-dispositions by ${ }^{15}$ de-mentation-〈supereregatery $\sim$ ontologicalde-mentation-or-dialectical-de-mentation - stranding-or-attributive-dialectics $\rangle$ while avoiding $<$ amplituding/formative-epistemicity $>$ totalising $\sim$ self-referencing-syncretising-as-

straight/candored-and-dialectically-or-contendingly-in-phase of the non-veridical narratives expressed by temporal-dispositions. When the dialecticism of organic-comprehension-thinking (organicalism/'intemporal-prioritisation-of- ${ }^{8}$ reference-of-thought'-as-conflatedness ${ }^{13}$-orontological-reprojecting/longness-of-register-of meaningfulness-and-teleology ) and threshold-of-nonconviction/madeupness/bottomlining-in-shallow-supererogation $-<$ as-to‘attendant-intradimensional'-prospectively-disontologising preconverging/dementing apriorising-psychologism> involves psychopathy and social psychopathy postlogism 7 in 
hollow-constituting-<as-disjointed-misappropriation-of-meaningfulness-and-failing-

intemporal-preservation>, it highlights the psychopath's slantedness-or-insane-fitment as 'epistemically-decadent in notional-discontiguity/epistemic-discontiguity ${ }^{63}-<$ between - priorshallow-supererogation -of-mentally-aestheticised preconverging/dementing -qualiaschema_and_prospective-profound-supererogation -of-mentallyaestheticised postconverging/dialectical-thinking -qualia-schema> ${ }^{>}$by its temporaldispositions defect, and the conjugating temporal-dispositions postlogic threshold-ofnonconviction/madeupness/bottomlining-in-shallow-supererogation $<-<$ as-to-' ${ }^{\text {attendant- }}$ intradimensional'-prospectively-disontologising preconverging/dementing -apriorisingpsychologism $>$ as being integrative of the epistemic-decadence (notionaldiscontiguity/epistemic-discontiguity ${ }^{6}-<$ between - prior-shallow-supererogation -ofmentally-aestheticised preconverging/dementing -qualia-schema_and prospective-profoundsupererogation -of-mentally-aestheticised postconverging/dialectical-thinking -qualiaschema $>$-as-of-epistemic-decadence in hollow-constituting-<as-disjointed-misappropriation-ofmeaningfulness-and-failing-intemporal-preservation $>$ in postlogic-backtracking- $<$ iterativelooping-'set-of-dereifying-hollow-narratives-and-acts'>76) as 'notional-discontiguity/epistemicdiscontiguity 33 - between - prior-shallow-supererogation -of-mentallyaestheticised $\sim$ preconverging/dementing -qualia-schema_and_prospective-profoundsupererogation -of-mentally-aestheticised postconverging/dialectical-thinking -qualiaschema $>$-as-of-epistemic-decadence in hollow-constituting-<as-disjointed-misappropriation-ofmeaningfulness-and-failing-intemporal-preservation $>$ or ${ }^{12}$ conjoining-looping-set-of-narratives as-of-cohering-logic-reflex in hollow-constituting-<as-disjointed-misappropriation-ofmeaningfulness-and-failing-intemporal-preservation $>$ in postlogic-backtracking- $<$ iterativelooping-'set-of-dereifying-hollow-narratives-and-acts'> $>$ as absolving/fleeting/escapingreflex-logic given their conjugated/inflected/derived temporal-dispositions perversion, while 
the intemporal-disposition prelogic/conviction-as-to-profound-supererogation organiccomprehension-thinking (organicalism/'intemporal-prioritisation-of- reference-of-thought'as-conflatedness ${ }^{13}$-or-ontological-reprojectingAlongness-of register-of- meaningfulness-andteleology ) supersedes intemporally as ontological-veridicality (relative-unreflexivity/relativereflexivity - ontological-contiguity ${ }^{67} /{ }^{3}$ reference-of-thought/veridical-thinking-reference-overpreconverging-or-dementing ${ }^{20}$-reference), and with the 'disambiguation of notional firstnaturedness-formativeness-<as-to-eventualising-inkling-drive-or-seeding misprising $>$ temporal-to-intemporal-dispositions- $<$ so-construed-as-from-perspectiveontological-normalcy/postconvergence $>$ as aetiologisation/ontological-escalation- $<$ ontologicalveridicality_commitment/otherliness_transcending/compulsions-encumbered_transcending>' by articulating their prospective implications in an infinity (metaphorically-a-million-and-oneinstances-and-locales). To further elucidate, the underlying idea of 'intemporal-prioritisation-ofreference-of-thought'-as-conflatedness ${ }^{13}$-or-ontological-reprojecting (deconstruction/ontological-reconstituting/organic-comprehension-thinking) holds that 'critically what matters with respect to ontology and virtue is simply and completely intemporalpreservation-entropy-or-contiguity-or-ontological-preservation as ontologicalveridicality/relative mnreflexivitrelative reflexivity ontological-contiguity ${ }^{67}$ of ${ }^{83}$ referenceof-thought (as from ontological-normalcy/postconvergence epistemic-or-notional projectiveperspective), and holds that other and subsequent notions are as pertinent as they are intemporally-preservational and where those same supposed notions social use was not intemporally-preservational but perverted/subknowledged/mimicked/confounded, their ontological and virtuous validity is nullified; as it is their relay of intemporal-preservationentropy-or-contiguity-or-ontological-preservation without notional-discontiguity/epistemicdiscontiguity $^{63}-<$ between - prior-shallow-supererogation -of-mentallyaestheticised $\sim$ preconverging/dementing -qualia-schema_and_prospective-profound- 
supererogation -of-mentally-aestheticised postconverging/dialectical-thinking -qualia-

schema $>$-as-of-epistemic-decadence in hollow-constituting-<as-disjointed-misappropriation-ofmeaningfulness-and-failing-intemporal-preservation $>$ in postlogic-backtracking- $<$ iterativelooping-'set-of-dereifying-hollow-narratives-and-acts' ${ }^{\prime}$ ' that matters.' What's the meaning of being good-natured/kind/humble/responsible/friendly/sociable/etc. in a subknowledging 94 perverted or corrupt social-setup or a philosophically-underdeveloped but presumptuous meaningful context (H.G. Well's country of the blind preconverging-dementating/structuring/paradigming, for instance), or worst still in teleologically-degraded social situations that may be mobbish or genocidal, wherein by our illusion-of-the-present/presentconsciousnessas $<$ amplituding/formative--epistemicity $>$ totalising $\sim$ self-referencingsyncretising/circularity/interiorising/akrasiatic-drag ${ }^{34}$ we apparently demonstrate such qualities but ontologically we aren't veridically intemporal-preservational? And even more pertinent, what will those same qualities mean at the uninstitutionalised-threshold ${ }^{12}$ of recurrent-utteruninstitutionalisation, base-institutionalisation, ${ }^{103}$ universalisation, positivism, and prospectively deprocrypticism, with their evolving ${ }^{83}$ reference-of-thought- categoricalimperatives/axioms/registry-teleology ${ }^{9}$ wherein prospective ${ }^{56}$ meaningfulness-and-teleology is beyond-the-consciousness-awareness-teleology $-<$ of-preconverging-existential-extricationas-of-existential-unthought $>$. The only answer that cuts it in all ways, is inevitably intemporalpreservation-entropy-or-contiguity-or-ontological-preservation as of ontological-faith-notionor-ontological-fideism - imbued-underdetermination-of-motif-and-

apriorising/axiomatising/referencing-as-so-being-as-of-existential-reality (mentation-capacitywise, as longness-of-register-of-meaningfulness-over-shortness-of-register-ofmeaningfulness-and-teleology ${ }^{9}$, more than just an abstraction as it carries the notion of a contiguous existentialism/full-depth-of-existential-implications transdimensionalmeaningfulness/memetic-refinement as ontological-normalcy/postconvergence-or-postdicatory 
deconstruction/ontological-reconstituting-as-to-conflatedness ${ }^{13}$ in dialectical transformation as of prospective ${ }^{8}$ reference-of-thought tied to the intemporal-preservation-entropy-or-contiguityor-ontological-preservation). Even the idea of morality as being construed as of a sense of morality is vague self-referening, as it is rather virtue as of knowledge-construct/intersolipsisticintercessory-notion/notional $\sim$ referential-notion/articulation of superseding-oneness-ofontology enabling the possibility in reflecting holographically-<conjugatively-andtransfusively $>$ the relative-unreflexivity/relative-reflexivity ontological-contiguity $\sim$ of-thehuman-institutionalisation-process of the <cumulating/recomposuring attendant-ontologicalcontiguity $>$-successive registry-worldviews/dimensions that is truly of ontological relevance. The idea of conceptualising morality out of such ontology-driven basis is more or less delusional however 'good-natured' when we consider that even a community of miscreants will have to construe of a semblance however perverted of moral conceptualisation that allows for individuals self-preservation and only of a degree of variance however big such a variance is perceived with supposed grander moral conceptualisations that do not factor in the preconverging/postconverging-de-mentative/structural/paradigmatic relation of virtue to ontology as of successive developing prospective relative-ontological-completeness ${ }^{87}$-ofreference-of-thought. As semblances of virtue-constructs out of 'sense of good-naturedness' not factoring in the 'unchangeable' reality of human temporal/shortness-of-register-ofmeaningfulness-and-teleology and intemporal/Angness-of register-of meaningfulnessand-teleology mental-dispositions across all registry-worldviews/dimensions will simply 'out of impression-driven/good-naturedness/wishfulness and naivety' provide an ontologicallyflawed deterministic framework that subject to temporal undermining by the adherence to the ‘<amplituding/formative $>$ wooden-language-〈imbued-temporal-mereform/virtualities/dereification/akrasiatic-drag/denatured/preconverging-or-dementing narratives - of-the- reference-of-thought- categorical-imperatives/axioms/registry- 
teleology > of prior/transcended/superseded registry-worldview/dimension' in subverting intemporal-preservation-entropy-or-contiguity-or-ontological-preservation, pointing to the pertinence of analysing virtue and ontology contiguously as of ontological-faith-notion-orontological-fideism - imbued-underdetermination-of-motif-and-

apriorising/axiomatising/referencing-as-so-being-as-of-existential-reality so-construed as organic-knowledge. This is the central idea of intemporal-prioritisation-of- reference-ofthought'-as-conflatedness ${ }^{13}$-or-ontological-reprojecting that informs organic-comprehensionthinking. 'Intemporal-prioritisation-of- ${ }^{-3}$ reference-of-thought'-as-conflatedness ${ }^{13}$-orontological-reprojecting further holds that in-the-bigger-scheme-of-things, it is intemporalpreservation in its entropy/contiguity that is the referencing of stranding as to de-mentation〈supererogatory $\sim$ ontological-de-mentation-or-dialectical-de-mentation-stranding-orattributive-dialectics) (as of preconverging-or-dementing -apriorising-psychologism representation when temporally-preservational-as-pseudointemporality ${ }^{52}$-preservation or of notional-discontiguity/epistemic-discontiguity ${ }^{6}<$ between - prior-shallow-supererogation -ofmentally-aestheticised preconverging/dementing -qualia-schema_and prospective-profoundsupererogation -of-mentally-aestheticised postconverging/dialectical-thinking -qualiaschema $>$ ) or postconverging-or-dialectical-thinking -apriorising-psychologism representation when intemporally-preservational/relative-unreflexivity/relative-reflexivity-ontologicalcontiguity ${ }^{67}$ 'Intemporal-prioritisation-of- ${ }^{8}$ reference-of-thought'-as-conflatedness ${ }^{13}$-orontological-reprojecting highlights effectively that ontological meaningfulness is contiguous as highlighted further in the paper with regards to virtue 'as a contiguous mentation-capacity (longness-of-register-of- ${ }^{5}$ meaningfulness-and-teleology 9 over shortness-of-register-ofmeaningfulness-and-teleology ${ }^{99}$ transience)' of notional-contiguity/epistemic-contiguity $<$ profound-supererogation -of-mentally-aestheticised postconverging/dialectical-thinking qualia-schema $>$ conceptualisaion for intemporal-preservation-entropy-or-contiguity-or- 
ontological-preservation. Finally, by affirming ontological-veridicality/relativeunreflexivity/relative-reflexivity -ontological-contiguity ${ }^{77}$ of ${ }^{83}$ reference-of-thought (from ontological-normalcy/postconvergence epistemic-or-notional projective-perspective) over notional-discontiguity/epistemic-discontiguity ${ }^{6}<$ between - prior-shallow-supererogation -ofmentally-aestheticised preconverging/dementing -qualia-schema_and_prospective-profoundsupererogation -of-mentally-aestheticised postconverging/dialectical-thinking -qualiaschema $>$-as-of-epistemic-decadence in hollow-constituting-<as-disjointed-misappropriation-ofmeaningfulness-and-failing-intemporal-preservation $>$ in postlogic-backtracking- $<$ iterativelooping-'set-of-dereifying-hollow-narratives-and-acts'> ${ }^{\circ}$ as perverted, 'intemporalprioritisation-of- ${ }^{8}$ reference-of-thought'-as-conflatedness ${ }^{13}$-or-ontological-reprojecting validates the 'stranding/mental-devising-representation of temporal-dispositions in thresholdof-nonconviction/madeupness/bottomlining-in-shallow-supererogation $<<$ as-to-' attendantintradimensional'-prospectively-disontologising preconverging/dementing -apriorisingpsychologism $>\quad(<$ amplituding/formative-epistemicity $>$ totalising $\sim$ self-referencingsyncretising/circularity/interiorising/akrasiatic-drag ${ }^{4}$ ) as transversal/logically-incongruentand-in-distractive-alignment-to- ${ }^{83}$ reference-of-thought- $<$ of-

apriorising/axiomatising/referencing $>^{30}$ to organic-comprehension-thinking (intemporaldisposition's 'intemporal-prioritisation-of- ${ }^{3}$ reference-of-thought'-as-conflatedness ${ }^{13}$-orontological-reprojecting). Basically, with regards to the 'psychologism of precedence as placeholder-setup/mental-devising-representation/mentation/consciousness-awarenessteleology ${ }^{9}$, with respect to a 'prospective/transcending/superseding registryworldview's/dimension's prospective relative-ontological-completeness ${ }^{87}$-of- ${ }^{83}$ reference-ofthought psychologism' as postconverging-or-dialectical-thinking -apriorising-psychologism and centered over a 'prior/transcended/superseded registry-worldview's/dimension's prior relative-ontological-incompleteness ${ }^{8}$-of- ${ }^{-3}$ reference-of-thought psychologism' as 
preconverging-or-dementing ${ }^{20}$-apriorising-psychologism and decentered and beyond-theconsciousness-awareness-teleology $\quad<$ of-preconverging-existential-extrication-as-of-

existential-unthought $>$ of the latter psychologism, even before appraising ${ }^{83}$ reference-ofthought issue as of the registry-worldview's/dimension's- ${ }^{83}$ reference-of-thought-for-socialfunctioning-and-accordance construed as of temporal-to-intemporal thresholds within the ambit of distractive-alignment-to- ${ }^{83}$ reference-of-thought- $<$ of-apriorising/axiomatising/referencing $>$, given the inherent-and-tautological ontological precedence of the prospective/transcending/superseding psychologism as of its prospective relative-ontologicalcompleteness ${ }^{87}$-of- ${ }^{83}$ reference-of-thought over the prior/transcended/superseded psychologism; 'distractive-alignment-to- ${ }^{83}$ reference-of-thought-<of-apriorising/axiomatising/referencing $>$

refers to the operant apriorising/axiomatising/referencing/intelligibilitysettingup/measuringinstrumenting point-ofdeparture-of-construal technique involving a transcendental perspective that dissociates the psychologism of the "prospective institutionalisation as of teleologically-elevated intemporal synopsising-depth of ${ }^{56}$ meaningfulness-and-teleology ${ }^{9}$ psychologism and so postconverging-ordialectical-thinking -apriorising-psychologism and centered' and the psychologism of the 'uninstitutionalised-threshold ${ }^{102}$ as teleologically-degraded shades-of-temporal (postlogism slantedness $/{ }^{50}$ ignorance/affordability/opportunism/exacerbation/social-chainism-or-socialdiscomfiture-or-negative-social-aggregation/temporal-enculturation-or-temporal-endemisation, so-disambiguated as of ${ }^{83}$ reference-of-thought- ${ }^{8}$ devolving ontological-performance ${ }^{72}$ <including-virtue-as-ontology>) synopsising-depth of ${ }^{5}$ meaningfulness-and-teleology construed as in distraction of the prospective institutionalisation psychologism and so preconverging-or-dementing ${ }^{20}$-apriorising-psychologism and decentered', and a nontranscendental metaphysics-of-presence-〈implicited-'nondescript/ignorable-void '-as-topresencing - absolutising-identitive-constitutedness > or <amplituding/formative- 
epistemicity $>$ totalising $\sim$ self-referencing-syncretising/circularity/interiorising/akrasiatic-drag perspective as 'un-dissociated psychologism that wrongly equates the intemporal and shades-oftemporal teleological synopsising-depth of ${ }^{56}$ meaningfulness-and-teleology ${ }^{9}$ as of the two previous transcendence-and-sublimity/sublimation/supererogatory $\sim$ de-mentativity perspective implied psychologisms' (as a result of non-recognition of a divergence with respect to the prospective relative-ontological-completeness ${ }^{87}$-of- ${ }^{8}$ reference-of-thought and the prior/transcended/superseded relative-ontological-incompleteness ${ }^{8}$-of- ${ }^{8}$ reference-of-thought, speaking of the ontological-veridicality of the transcendental perspective as of intemporalprioritisation-of- ${ }^{83}$ reference-of-thought'-as-conflatedness ${ }^{13}$-or-ontological-reprojecting and not a non-transcendental perspective as of <amplituding/formative-epistemicity $>$ totalising $\sim$ selfreferencing-syncretising/circularity/interiorising/akrasiatic-drag ${ }^{44}$ ). In other words, distractivealignment-to- ${ }^{8}$ reference-of-thought- $<$ of-apriorising/axiomatising/referencing $>30$ by the preconverging-or-dementing 20 -apriorising-psychologism and decentering of the prior-aspresent/transcended/superseded beforehand/as-of-a-priori implies that the prospective/transcending/superseding ${ }^{8}$ reference-of-thought is a more profound representation of intrinsic-reality/ontological-veridicality (with regards to notional $\sim^{18}$ deprocrypticism as of the preempting - disjointedness-as-of- ${ }^{8}$ reference-of-thought

apriorising/axiomatising/referencing/intelligibilitysettingup/measuringinstrumenting) by the 'distractive-alignment-to- ${ }^{8}$ reference-of-thought- $<$ of-apriorising/axiomatising/referencing $>$ apriorising/axiomatising/referencing/intelligibilitysettingup/measuringinstrumenting point-ofdeparture-of-construal' over and subsuming-and-supplanting the prior/transcended/superseded/transcended/superseded $\quad{ }^{83}$ reference-of-thought apriorising/axiomatising/referencing/intelligibilitysettingup/measuringinstrumenting (as of its disjointedness-as-of- ${ }^{8}$ reference-of-thought of reference-of-thought apriorising/axiomatising/referencing/intelligibilitysettingup/measuringinstrumenting with 
regards to positivism- ${ }^{8}$ procrypticism), as validated by 'implicited_attendant-ontologicalcontiguity ${ }^{67} \sim$ educed-

existentialising/contextmalising/textualising_'intelligibility/epistemicity/reflexivity-contiguity$<$ imbued-notional $\sim \operatorname{cogency}>{ }^{\prime},-<$ reifying-or-elucidating-of-prospective-relative-ontologicalcompleteness -of- reference-of-thought- devolving-as-of-instantiative-context $>$. $\quad$ Thus, distractive-alignment-to- ${ }^{8}$ reference-of-thought- $<$ of-apriorising/axiomatising/referencing $>30$ is an apriorising/axiomatising/referencing/intelligibilitysettingup/measuringinstrumenting pointof-departure-of-construal of ${ }^{83}$ reference-of-thought as it is about assuming beforehand/as-of-apriori for logical-contention as postconverging-or-dialectical-thinking -apriorisingpsychologism and centered the prospective/transcending/superseding ${ }^{83}$ reference-of-thought (as of its prospective relative-ontological-completeness ${ }^{87}$-of- ${ }^{83}$ reference-of-thought) in preconverging-or-dementing ${ }^{20}$-apriorising-psychologism and decentering the prior-aspresent/transcended/superseded ${ }^{83}$ reference-of-thought (as of its prior relative-ontologicalincompleteness ${ }^{8}$-of- ${ }^{8}$ reference-of-thought), as validated by 'implicited_attendant-ontologicalcontiguity $^{67}$, educed-

existentialising/contextualising/textualising_'intelligibility/epistemicity/reflexivity-contiguity$<$ imbued-notional cogency $>{ }^{,},-<$reifying-or-elucidating-of-prospective-relative-ontologicalcompleteness -of- reference-of-thought- devolving-as-of-instantiative-context>. Critically, for aetiologisation/ontological-escalation-<ontologicalveridicality_commitment/otherliness_transcending/compulsions-encumbered_transcending > as of an intemporal synopsising depth of analysis what is decisive with regards to a postlogism manifestation is the grasp of the reality of prior relative-ontological-incompleteness ${ }^{88}$-ofreference-of-thought as 'in-wait as of prior relative-ontological-incompleteness ${ }^{88}$-ofreference-of-thought defective reference-of-thought- categoricalimperatives/axioms/registry-teleology ${ }^{9}$ for a postlogism 77 manifestation; and just as we can 
appreciate that the organic-knowledge depth of base-institutionalisation is what is required as resolution for postlogism 77 manifestations in recurrent-utter-uninstitutionalisation, likewise that of ${ }^{103}$ universalisation as resolution with postlogism ${ }^{77}$ manifestations in base-institutionalisationununiversalisation, that of positivism as resolution with postlogism manifestations in universalisation-non-positivism/procrypticism, the organic-knowledge depth of notional ${ }^{18}$ deprocrypticism is what is required as resolution for postlogism 77 manifestations in positivism-procryptism. On this basis distractive-alignment-to- ${ }^{-}$reference-of-thought- $<$ofapriorising/axiomatising/referencing $>30$ point-of-departure-construal technique of aetiologisation/ontological-escalation-<ontologicalveridicality_commitment/otherliness_transcending/compulsions-encumbered_transcending > involves starting out not with the specific postlogism 77 construal but rather implying a construal preconverging-or-dementing ${ }^{20}$-apriorising-psychologism and decentering the more fundamental issue of the registry-worldview/dimension prior relative-ontological-incompleteness -of- $^{-}$ reference-of-thought

apriorising/axiomatising/referencing/intelligibilitysettingup/measuringinstrumenting (whether as of non-rules - apriorising/axiomatising/referencing-psychologism,-as-impulsive-oraccidented-or-random-mental-disposition-or-failing-prospective-rulemaking-over-non-rulesapriorising/axiomatising/referencing-psychologism apriorising/axiomatising/referencing/intelligibilitysettingup/measuringinstrumenting of recurrent-utter-uninstitutionalisation, failing-prospective-universalisation-directed-rulemakingover-non-rules_-apriorising/axiomatising/referencing-psychologism

apriorising/axiomatising/referencing/intelligibilitysettingup/measuringinstrumenting of baseinstitutionalisation-ununiversalisation, failing-prospective-positivising/rational-empiricismbased-universalisation-directed-rulemaking-over-non-rulesapriorising/axiomatising/referencing-psychologism 
apriorising/axiomatising/referencing/intelligibilitysettingup/measuringinstrumenting

disjointedness-as-of- ${ }^{8}$ reference-of-thought,-as-to- ${ }^{6}<$ amplituding/formative-

epistemicity $>$ growth-or-conflatedness ${ }^{13} /$ transvaluative- $^{2}$

rationalising/transepistemicity/anamnestic-residuality/spirit-drivenness'_-in-superseding-

mere-formulaic-positivising/rational-empiricism-based-universalisation-directed-rulemaking-

over-non-rules — apriorising/axiomatising/referencing-psychologism

apriorising/axiomatising/referencing/intelligibilitysettingup/measuringinstrumenting

of

positivism- ${ }^{80}$ procrypticism, and prospectively preempting-disjointedness-as-of- ${ }^{8}$ reference-

of-thought,-as-to- ${ }^{6}<$ amplituding/formative-epistemicity $>$ growth-or-

conflatedness $^{13} /$ transvaluative-rationalising/transepistemicity/anamnestic-residuality/spirit-

drivenness'-in-superseding-mere-formulaic-positivising/rational-empiricism-based-

universalisation-directed-rulemaking-over-non-rules — apriorising/axiomatising/referencing-

psychologism

apriorising/axiomatising/referencing/intelligibilitysettingup/measuringinstrumenting

deprocrypticism), which is 'in-wait as of prior relative-ontological-incompleteness ${ }^{88}$-ofreference-of-thought defective reference-of-thought- categoricalimperatives/axioms/registry-teleology and endemising/enculturating the postlogism 77 and social postlogism 77 manifestation as well as other temporal phenomena construed as vices-andimpediments $^{105}$ of the registry-worldview/dimension as of its prior relative-ontologicalincompleteness ${ }^{8}$-of- ${ }^{-1}$ reference-of-thought; thus attaining the supratransversality- $<$ insublimating-existential-eventuating/denouement $>\sim$ of-motif-and-

apriorising/axiomatising/referencing required for aetiologisation/ontological-escalation$<$ ontological-veridicality_commitment/otherliness_transcending/compulsions- 
intemporal/ontological/social/species// ${ }^{103}$ universal/transcendental/ $/ 5$ maximalisingrecomposuring-for-relative-ontological-completeness —unenframed/re-

ontologising conceptualisation postconverging-de-mentating/structuring/paradigming. In other words, just as we can countenance that ontologically we'll not engage a non-positivism/medieval social-setup in contending about say notions-and-accusations-of-sorcery but rather supersede the non-positivism/medievalism meaningful-frame as of its relative-ontological-incompleteness ${ }^{8}$ of- ${ }^{3}$ reference-of-thought as being superstitious/non-positivistic implies the fundamental need for its psychoanalytic-unshackling for <amplituding/formative-epistemicity >totalising renewing-realisation/re-perception/re-thought as of a positivism registryworldview/dimension prospective relative-ontological-completeness ${ }^{87}$-of- ${ }^{8}$ reference-ofthought; likewise our positivism- ${ }^{80}$ procrypticism prior relative-ontological-incompleteness ${ }^{8}$ of- ${ }^{8}$ reference-of-thought is 'not the profound ontologically-veridical meaningful-frame' in which an issue of its corresponding postlogism 77 as psychopathy and social psychopathy is resolved but rather its state of relative-ontological-incompleteness ${ }^{8}$-of- ${ }^{8}$ reference-of-thought is prospectively construed from notional ${ }^{18}$ deprocrypticism as preconverging-or-dementing apriorising-psychologism and decentered by its procrypticism/“disjointedness-as-of- ${ }^{8}$ referenceof-thought'-as-misappropriated- ${ }^{5}$ meaningfulness-and-teleology ${ }^{9}$, implying the more fundamental-and-transversal-and-synergistic need is for our psychoanalytic-unshackling for $<$ amplituding/formative-epistemicity $>$-totalising $\sim$ renewing-realisation/re-perception/rethought as of the notional ${ }^{18}$ deprocrypticism registry-worldview/dimension ontologicalcompleteness-of- ${ }^{8}$ reference-of-thought; thus enabling the attainment of aetiologisation/ontological-escalation-<ontologicalveridicality_commitment/otherliness_transcending/compulsions-encumbered_transcending > required for supratransversality-<in-sublimating-existential-eventuating/denouement $>\sim$ of- 
intemporal/ontological/social/species// ${ }^{103}$ universal/transcendental/ $/ 5$ maximalisingrecomposuring-for-relative-ontological-completeness —unenframed/re-

ontologising conceptualisation postconverging-de-mentating/structuring/paradigming that is transversally preconverging/postconverging-de-mentative/structural/paradigmatic for the resolution not only of the positivism- ${ }^{8}$ procrypticism postlogism 77 as psychopathy and socialpsychopathy but basically all its relative-ontological-incompleteness ${ }^{8}{ }^{8}$ reference-of-thought predicated temporal-phenomena construed as positivism- ${ }^{80}$ procrypticism vices-andimpediments $^{105}$. (It is important to grasp that tenseness-of-expressions made temporally/shortness-of-register-of- meaningfulness-and-teleology as of the positivismprocrypticism registry-worldview/dimension are just 'vague candoring' that are ontologicallyempty and non-veridical by inherent-and-tautological ontological precedence of the prospective/transcending/superseding notional ${ }^{18}$ deprocrypticism apriorising/axiomatising/referencing/intelligibilitysettingup/measuringinstrumenting as of its ontological-completeness-of- ${ }^{-3}$ reference-of-thought over the prior/transcended/superseded positivism- ${ }^{80}$ procrypticism apriorising/axiomatising/referencing/intelligibilitysettingup/measuringinstrumenting as of its prior relative-ontological-incompleteness ${ }^{8}$-of- ${ }^{8}$ reference-of-thought, as what is precedingly warranted is the preconverging-or-dementing -apriorising-psychologism and decentering of positivism- ${ }^{80}$ procrypticism ${ }^{83}$ reference-of-thought beyond its <amplituding/formativeepistemicity>totalising $\sim$ self-referencing-syncretising/illusion-of-the-present/presentconsciousness/mirage as metaphysics-of-presence-_implicited-'nondescript/ignorable-void as-to- presencing-absolutising-identitive-constitutedness $\rangle$, and so beyond-theconsciousness-awareness-teleology $\quad<$ of-preconverging-existential-extrication-as-ofexistential-unthought $>$; and this idea we can grasp from our vantage position with regards to a non-positivism/medieval setup striving to uphold its ${ }^{83}$ reference-of-thought psychologism which 
we understand is prospectively a relative ontological-incomplete- ${ }^{3}$ reference-of-thought, however the bigger issue difficult for us to envisage is rather in placing our own minds as not in a postconverging-or-dialectical-thinking -apriorising-psychologism and centered but rather a preconverging-or-dementing ${ }^{20}$-apriorising-psychologism and decentered position, as implying the need for prospective institutionalisation as notional deprocrypticism apriorising/axiomatising/referencing/intelligibilitysettingup/measuringinstrumenting which is prospectively postconverging-or-dialectical-thinking -apriorising-psychologism and centered). Distractive-alignment-to- ${ }^{83}$ reference-of-thought- $<$ of-apriorising/axiomatising/referencing $>{ }^{30}$ as such basically by definition dismisses the 'prior/transcended/superseded registryworldview's/dimension's relatively relative-ontological-incompleteness ${ }^{8}$-of- ${ }^{83}$ reference-ofthought apriorising/axiomatising/referencing/intelligibilitysettingup/measuringinstrumenting' as circularly endemising/enculturating its ${ }^{83}$ reference-of-thought defect or ${ }^{74}$ perversion-ofreference-of-thought-<as-preconvergingly-apriorising/axiomatising/referencing-innonconviction/madeupness/bottomlining-as-to-shallow-supererogation $>, \quad$ beyond-theconsciousness-awareness-teleology ${ }^{\circ}<$ of-preconverging-existential-extrication-as-ofexistential-unthought $>$ and so preconverging/postconverging-dementatively/structurally/paradigmatically even before an effective ${ }^{83}$ reference-of-thought issue of the registry-worldview's/dimension's- ${ }^{8}$ reference-of-thought-for-social-functioning-andaccordance as of temporal-to-intemporal thresholds (i.e. preconverging/postconverging-dementatively/structurally/paradigmatically being non-positivism/medievalism of apriorising/axiomatising/referencing/intelligibilitysettingup/measuringinstrumenting by definition means incapable of contending as of positivism apriorising/axiomatising/referencing/intelligibilitysettingup/measuringinstrumenting 'thirdlevel- ${ }^{7}$ presencing — absolutising-identitive-constitutedness apriorising/axiomatising/referencing/intelligibilitysettingup/measuringinstrumenting for 
meaningfulness-and-teleology ${ }^{9}$ requiring rather the non-positivism/medievalism apriorising/axiomatising/referencing/intelligibilitysettingup/measuringinstrumenting psychoanalytic-unshackling/memetic-reordering/institutional-recomposuring from $<$ amplituding/formative-epistemicity $>$-totalising $\sim$ renewing-realisation/re-perception/rethought and not a 'false exercise of contending arising from a circular <amplituding/formativeepistemicity $>$ totalising $\sim$ self-referencing-syncretising/circularity/interiorising/akrasiatic-drag ego complex that rather circularly upholds non-positivism/medievalism apriorising/axiomatising/referencing/intelligibilitysettingup/measuringinstrumenting', and prospectively preconverging/postconverging-de-mentatively/structurally/paradigmatically our state of procrypticism-or-disjointedness-as-of- ${ }^{8}$ reference-of-thought of apriorising/axiomatising/referencing/intelligibilitysettingup/measuringinstrumenting by definition means incapable of contending as of notional deprocrypticism preemptingdisjointedness-as-of- ${ }^{3}$ reference-of-thought

apriorising/axiomatising/referencing/intelligibilitysettingup/measuringinstrumenting apriorising/axiomatising/referencing/intelligibilitysettingup/measuringinstrumenting of 'conflation for ${ }^{5}$ meaningfulness-and-teleology ${ }^{9}$ ' requiring rather the positivismprocrypticism

apriorising/axiomatising/referencing/intelligibilitysettingup/measuringinstrumenting psychoanalytic-unshackling/memetic-reordering/institutional-recomposuring from $<$ amplituding/formative-epistemicity $>$-totalising $\sim$ renewing-realisation/re-perception/rethought and not a 'false exercise of contending arising from a circular <amplituding/formativeepistemicity $>$ totalising $\sim$ self-referencing-syncretising/circularity/interiorising/akrasiatic-drag ego complex that rather circularly upholds ${ }^{8}$ procrypticism-or-disjointedness-as-of- ${ }^{8}$ referenceof-thought of apriorising/axiomatising/referencing/intelligibilitysettingup/measuringinstrumenting'); as the 
disjointedness-as-of- ${ }^{8}$ reference-of-thought'-misappropriated- ${ }^{5}$ meaningfulness-andteleology definition dismisses it as not contendingly relevant relative to ${ }^{83}$ reference-of-thought issue requiring deprocrypticism-or-preempting-disjointedness-as-of- ${ }^{18}$ reference-of-thought apriorising/axiomatising/referencing/intelligibilitysettingup/measuringinstrumenting, as the non-positivising/non-rational-empiricism of the universalisation-nonpositivism/medievalism

apriorising/axiomatising/referencing/intelligibilitysettingup/measuringinstrumenting definition dismisses it as not contendingly relevant relative to ${ }^{8}$ reference-of-thought issue requiring positivising/rational-empiricism in want of positivism apriorising/axiomatising/referencing/intelligibilitysettingup/measuringinstrumenting, as the non-universalising of the base-institutionalisation-ununiversalisation apriorising/axiomatising/referencing/intelligibilitysettingup/measuringinstrumenting by definition dismisses it as not contendingly relevant relative to ${ }^{83}$ reference-of-thought issue requiring ${ }^{103}$ universalisation in want of ${ }^{103}$ universalisation apriorising/axiomatising/referencing/intelligibilitysettingup/measuringinstrumenting, and as the non-rules - apriorising/axiomatising/referencing-psychologism,-as-impulsive-or-accidentedor-random-mental-disposition/failing-rule-making as impulsive-accidented-haphazard recurrent-utter-uninstitutionalisation

apriorising/axiomatising/referencing/intelligibilitysettingup/measuringinstrumenting by definition dismisses it as not contendingly relevant relative to ${ }^{83}$ reference-of-thought issue requiring rule-making in want for base-institutionalisation apriorising/axiomatising/referencing/intelligibilitysettingup/measuringinstrumenting. The reason behind this conclusion is that in all registry-worldviews/dimensions apart from futural 


\section{Being-development/ontological-framework-expansion-as-to-depth-of-ontologising-}

development-as-infrastructure-of- meaningfulness-and-teleology as of prospective deprocrypticism, the ${ }^{83}$ reference-of-thought 'fundamentally carries an underlying defect of relative-ontological-incompleteness ${ }^{8}$ irrespective of the arising of a ${ }^{83}$ reference-of-thought incidental issue as of the registry-worldview's/dimension's- ${ }^{83}$ reference-of-thought-for-socialfunctioning-and-accordance in-the-very-first-place and so beyond-the-consciousnessawareness-teleology ${ }^{9}<$ of-preconverging-existential-extrication-as-of-existential-unthought> that makes it fundamentally ontologically unsound; and as highlighted before the nonpositivism/medieval state of being superstitious and non-positivistic is an underlying foundational problem (as the registry-worldview's/dimension's- ${ }^{83}$ reference-of-thought-forsocial-functioning-and-accordance defect as registry-worldview's/dimension'suninstitutionalised-threshold ${ }^{102}$-defect-<as-Being-or-ontological-or-existential-defect $>$ '5) 'inwait as of prior relative-ontological-incompleteness ${ }^{8}$-of- ${ }^{8}$ reference-of-thought defective reference-of-thought- categorical-imperatives/axioms/registry-teleology 9 just as our procrypticism state of disjointedness-as-of- ${ }^{8}$ reference-of-thought (in misappropriating meaningfulness), as failing/not-upholding-<as-of-apriorising/axiomatising/referencing $>$ in dissociating temporal ' ${ }^{\circ 3}$ reference-of-thought—degraded-devolving-as-of-uninstitutionalisedthreshold ${ }^{102}$, and intemporal ${ }^{83}$ reference-of-thought- categorical-imperatives/axioms/registryteleology ${ }^{99}$,-for-aposteriorising/logicising/deriving/intelligising/measuring- ${ }^{5}$ meaningfulnessand-teleology' of ${ }^{56}$ meaningfulness-and-teleology' as of 'same-terms-of-expressions' (seemingly-same-implied-meaningfulness) but actually implying 'different relations to an ontologically veridical ${ }^{83}$ reference-of-thought', is an underlying foundational problem (as the registry-worldview's/dimension's- $-{ }^{83}$ reference-of-thought-for-social-functioning-andaccordance defect as registry-worldview's/dimension's-uninstitutionalised-threshold ${ }^{12}$-defect$<$ as-Being-or-ontological-or-existential-defect ${ }^{85}$ ) 'in-wait as of prior relative-ontological- 
incompleteness ${ }^{8}$-of- ${ }^{8}$ reference-of-thought defective ${ }^{83}$ reference-of-thought- categoricalimperatives/axioms/registry-teleology for issues of ${ }^{7}$ perversion-of- ${ }^{9}$ reference-of-thought$<$ as-preconvergingly-apriorising/axiomatising/referencing-in-

nonconviction/madeupness/bottomlining-as-to-shallow-supererogation $>$ to be stirredup/instigated and endemised/enculturated. This articulation is also important because while it can be countenance retrospectively, however prospective our metaphysics-of-presence〈implicited-'nondescript/ignorable-void '-as-to- presencing-absolutising-identitive-

constitutedness $>$ as of our $<$ amplituding/formative-epistemicity $>$ totalising $\sim$ self-referencingsyncretising/circularity/interiorising/akrasiatic-drag ${ }^{34}$ reflex and so beyond-the-consciousnessawareness-teleology 9 - $<$ of-preconverging-existential-extrication-as-of-existential-unthought $>$ beforehand/as-of-a-priori, will tend towards a 'circular <amplituding/formativeepistemicity $>$ totalising $\sim$ self-referencing-syncretising/circularity/interiorising/akrasiatic-drag ego complex that rather circularly upholds ${ }^{8}$ procrypticism-or-disjointedness-as-of- referenceof-thought

apriorising/axiomatising/referencing/intelligibilitysettingup/measuringinstrumenting', just as occurred in all the prior registry-worldviews/dimensions. The bigger point being that just as we recognise beforehand/as-of-a-priori that engaging (from our positivism psychologism prospective relative-ontological-completeness ${ }^{87}$-of- ${ }^{8}$ reference-of-thought) a nonpositivism/medievalism psychologism with respect to their equivalent postlogism perversion-of- ${ }^{3}$ reference-of-thought-<as-preconvergingly-

\section{apriorising/axiomatising/referencing-in-nonconviction/madeupness/bottomlining-as-to-}

shallow-supererogation $>$ issue like notions-and-accusations-of-sorcery implies beforehand/asof-a-priori an ontologically-veridical engagement that 'doesn't recognise its contending status as postconverging-or-dialectical-thinking ${ }^{2}$-apriorising-psychologism and centered in-the-veryfirst-place' but rather that the non-positivism/medieval 
apriorising/axiomatising/referencing/intelligibilitysettingup/measuringinstrumenting implied meaningfulness-and-teleology 9 is preconverging-or-dementing -apriorising-psychologism and decentered, likewise beforehand/as-of-a-priori engaging (from futural Beingdevelopment/ontological-framework-expansion-as-to-depth-of-ontologising-development-asinfrastructure-of- meaningfulness-and-teleology as of prospective deprocrypticism-as-ofpreempting - disjointedness-as-of- ${ }^{3}$ reference-of-thought of psychologism prospective relativeontological-completeness ${ }^{87}$-of- ${ }^{8}$ reference-of-thought) our ${ }^{8}$ procrypticism-or-disjointednessas-of- ${ }^{3}$ reference-of-thought

apriorising/axiomatising/referencing/intelligibilitysettingup/measuringinstrumenting with respect to its associated postlogism ${ }^{77}$ perversion-of- ${ }^{8}$ reference-of-thought- $<$ aspreconvergingly-apriorising/axiomatising/referencing-in-

nonconviction/madeupness/bottomlining-as-to-shallow-supererogation > issue of psychopathy and social psychopathy implies beforehand/as-of-a-priori an ontologically-veridical engagement that 'doesn't recognise our contending status as postconverging-or-dialectical-thinking apriorising-psychologism and centered in-the-very-first-place' but rather that our procrypticism-or-disjointedness-as-of- ${ }^{83}$ reference-of-thought

apriorising/axiomatising/referencing/intelligibilitysettingup/measuringinstrumenting implied meaningfulness-and-teleology ${ }^{9}$ is preconverging-or-dementing -apriorising-psychologism and decentered; as the starting point of distractive-alignment-to- ${ }^{3}$ reference-of-thought- $<$ ofapriorising/axiomatising/referencing $>^{30}$ is rather in reflecting the prior relative-ontologicalincompleteness ${ }^{88}$-of- ${ }^{83}$ reference-of-thought <amplituding/formativeepistemicity $>$ causality $\sim$ as-to-projective-totalitative-implications-of-prospectivenonpresencing,-for-explicating relative unreflexivity/relative reflexivity - ontologicalcontiguity with respect to ${ }^{83}$ reference-of-thought defect or ${ }^{74}$ perversion-of- ${ }^{8}$ reference-ofthought-<as-preconvergingly-apriorising/axiomatising/referencing-in- 
preconverging-or-dementing ${ }^{20}$-apriorising-psychologism and decentering exercise involving ' ${ }^{3}$ reference-of-thought — degraded-devolving-as-of-uninstitutionalised-threshold ${ }^{02}$, of the shades-of-temporal-dispositions as of 'implicited_attendant-ontological-contiguity ${ }^{67}$ ' educedexistentialising/contextualising/textualising_intelligibility/epistemicity/reflexivity-contiguity$<$ imbued-notional cogency $>,{ }^{\prime},-<$ reifying-or-elucidating-of-prospective-relative-ontological-

completeness -of- reference-of-thought- devolving-as-of-instantiative-context>', and not a postconverging-or-dialectical-thinking -apriorising-psychologism exercise involving reference-of-thought- ${ }^{8}$ categorical-imperatives/axioms/registry-teleology ${ }^{9}$,-foraposteriorising/logicising/deriving/intelligising/measuring - ${ }^{56}$ meaningfulness-and-teleology (as will be wrongly implied by a circular <amplituding/formative-epistemicity $>$ totalising $\sim$ selfreferencing-syncretising/circularity/interiorising/akrasiatic-drag ${ }^{34}$ ego complex that rather circularly upholds procrypticism-or-disjointedness-as-of- ${ }^{83}$ reference-of-thought of apriorising/axiomatising/referencing/intelligibilitysettingup/measuringinstrumenting). For instance and as stated before, such a statement and mental-disposition of the type Socrates or Rousseau by their relative asceticism as of postconverging-nonextricatory-existentialpreempting-of-existential-unthought as compared to others of their statuses (conjugated as of various shades of temporal teleologically-degraded synopsising-depth of ${ }^{5}$ meaningfulness-andteleology ${ }^{9}$ psychologism) in their respective social-setups from a non-transcendental as of its $<$ amplituding/formative-epistemicity $>$ totalising $\sim$ self-referencingsyncretising/circularity/interiorising/akrasiatic-drag 34 perspective by its $<$ amplituding/formative-epistemicity $>$ totalising $\sim$ self-referencingsyncretising/circularity/interiorising/akrasiatic-drag ${ }^{34}$ is rather circularly impervious and will not recognise any dissociation between such a mental-projection/psychologism prior relativeontological-incompleteness ${ }^{88}$-of- ${ }^{83}$ reference-of-thought and the mental- 
projection/psychologism prospective relative-ontological-completeness ${ }^{87}$-of- ${ }^{8}$ reference-ofthought of Socrates or Rousseau in construing the grander notion of social aetiologisation/ontological-escalation-<ontological-

veridicality_commitment/otherliness_transcending/compulsions-encumbered_transcending $>$ as of a transcendental-perspective (as of a teleologically-elevated intemporal synopsising-depth of meaningfulness-and-teleology psychologism contrasted to such teleologically-degraded shades-of-temporal synopsising-depth of ${ }^{5}$ meaningfulness-and-teleology $\left.{ }^{9}\right)$. This elucidation is important because an insightful storied-construct/ontologically-valid-narration with regards to psychopathy and social psychopathy and the overall relative-ontological-incompleteness ${ }^{88}$-ofreference-of-thought as the underlying disjointedness-as-of- ${ }^{3}$ reference-of-thought of

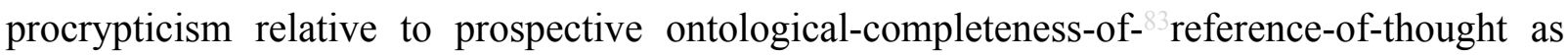
notional deprocrypticism will fundamentally be based on such contrastive mentalprojections/psychologisms as of non-transcendental as <amplituding/formativeepistemicity>totalising $\sim$ self-referencing-syncretising/circularity/interiorising/akrasiatic-drag perspective and the primacy of transcendental perspective (inherently so because the state of prospective relative-ontological-completeness ${ }^{87}$-of- ${ }^{83}$ refence-of-thought precedes and supersedes the state of prior relative-ontological-incompleteness ${ }^{8}$-of- ${ }^{8}$ reference-of-thought by tautological ontological-veridicality validated by the relative-unreflexivity/relative-reflexivityontological-contiguity ${ }^{67}$ of-the-human-institutionalisation-process ${ }^{68}$ itself), just as a storiedconstruct/ontologically-valid-narration of say non-positivism/medieval postlogism manifestation as notions-and-accusations-of-sorcery will imply a 'distractive-alignment-toreference-of-thought- $<$ of-apriorising/axiomatising/referencing $>30$ technical point-ofdeparture-of-construal of ${ }^{83}$ reference-of-thought' highlighting the non-transcendental as $<$ amplituding/formative-epistemicity $>$ totalising $\sim$ self-referencingsyncretising/circularity/interiorising/akrasiatic-drag perspective mental- 
projection/psychologism of the relative-ontological-incompleteness ${ }^{8}$-of- ${ }^{8}$ reference-of-thought of non-positivism/medievalism mental-projection/psychologism that doesn't dissociate the temporal-as-teleologically-degraded or intemporal-as-teleologically-elevated synopsising-depth of ${ }^{5}$ meaningfulness-and-teleology, unlike a transcendental perspective that reflects prospective institutionalisation intemporal teleologically-elevated synopsising-depth of meaningfulness-and-teleology ${ }^{9}$ as the positivism psychologism as dissociated from various temporal-shades of teleologically-degraded synopsising-depth of ${ }^{56}$ meaningfulness-andteleology as the non-positivism/medievalism psychologism (inherently so because the state of prospective relative-ontological-completeness ${ }^{87}$-of- ${ }^{8}$ reference-of-thought precedes and supersedes the state of prior relative-ontological-incompleteness ${ }^{88}$-of- ${ }^{3}$ reference-of-thought by tautological ontological-veridicality validated by the relative-unreflexivity/relative-reflexivity ontological-contiguity ${ }^{67}$ of-the-human-institutionalisation-process ${ }^{68}$ itself). That is, the technical point-of-departure-of-construal of ${ }^{83}$ reference-of-thought for distractive-alignment-toreference-of-thought- $<$ of-apriorising/axiomatising/referencing $>30$ with respect to the '<amplituding/formative-epistemicity $>$ causality $\sim$ as-to-projective-totalitative-implications-ofprospective- nonpresencing,-for-explicating relative-unreflexivity/relative-reflexivity

ontological-contiguity retracing' (for notional firstnaturedness-formativeness-as to eventualising-inkling-drive-or-seeding-misprising $>$ temporal-to-intemporal-dispositions$<$ so-construed-as-from-perspective-ontological-normalcy/postconvergence $>$-pedestalsdisambiguation) as ${ }^{83}$ reference-of-thought-scheme' involves: - articulating a dialectically-orcontendingly-in-phase (mentally sound) organic-comprehension-thinking of the intemporaldisposition as a coherent 'intemporal-prioritisation-of- ${ }^{-}$reference-of-thought'-asconflatedness $^{13}$-or-ontological-reprojecting which is in ontological-veridicality/relativeunreflexivity/relative-reflexivity_ontological-contiguity ${ }^{77}$ of ${ }^{83}$ reference-of-thought (from ontological-normalcy/postconvergence epistemic-or-notional projective-perspective), and is 
veridically the ' ${ }^{8}$ reference-of-thought-or-contending-reference of thought', - articulating a dialectically-or-contendingly-out-of-phase brazen-but-unsoundness-or-ontological-badfaith/inauthenticity ${ }^{64}$-of- ${ }^{8}$ eference-of-thought hollow-possibility-logic/meaning-by-the-mereillogical-possibility-of-it-being-formulaically-narrated of the psychopath in distraction/subtraction to the organic-comprehension-thinking articulation which is of notionaldiscontiguity/epistemic-discontiguity ${ }^{6}-<$ between - prior-shallow-supererogation -ofmentally-aestheticised preconverging/dementing -qualia-schema_and_prospective-profoundsupererogation -of-mentally-aestheticised postconverging/dialectical-thinking -qualiaschema $>$-as-of-epistemic-decadence in hollow-constituting-<as-disjointed-misappropriation-ofmeaningfulness-and-failing-intemporal-preservation $>$ in postlogic-backtracking- $<$ iterativelooping-'set-of-dereifying-hollow-narratives-and-acts' $>$ in $\quad$ hollow-constituting-<asdisjointed-misappropriation-of-meaningfulness-and-failing-intemporal-preservation $>$ and is veridically 'not the ${ }^{83}$ reference-of-thought' but rather reflected/perspectivated as a manifestation of postlogic slanted ${ }^{7}$ perversion-of- ${ }^{3}$ reference-of-thought- $<$ as-preconverginglyapriorising/axiomatising/referencing-in-nonconviction/madeupness/bottomlining-as-toshallow-supererogation >', and then - articulating a derived-out-of-phase (derived-brazen-butunsoundness-or-ontological-bad-faith/inauthenticity ${ }^{64}$ of- ${ }^{8}$ reference-of-thought) threshold-of-

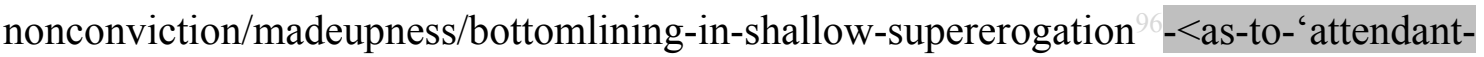
intradimensional'-prospectively-disontologising preconverging/dementing -apriorisingpsychologism $>$ of temporal-dispositions in derived-distraction/derived-subtraction to the organic-comprehension-thinking articulation which integrates the hollow-possibilitylogic/meaning-by-the-mere-illogical-possibility-of-it-being-formulaically-narrated of the psychopath, and is thus of notional-discontiguity/epistemic-discontiguity ${ }^{6}-<$ between - priorshallow-supererogation -of-mentally-aestheticised $\sim$ preconverging/dementing -qualiaschema_and_prospective-profound-supererogation -of-mentally- 
aestheticised $\sim$ postconverging/dialectical-thinking -qualia-schema $>$-as-of-epistemic-

decadence in hollow-constituting-<as-disjointed-misappropriation-of-meaningfulness-andfailing-intemporal-preservation $>$ in postlogic-backtracking-<iterative-looping-‘set-ofdereifying-hollow-narratives-and-acts'> ${ }^{76}$-contiguity and is veridically 'not the ${ }^{83}$ reference-ofthought as well but rather reflected/perspectivated as a manifestation of prelogic-alignment to postlogic compulsive-slanting-preconverging-or-dementing -apriorising. - With ${ }^{15}$ dementation-〈supererogatory $\sim$ ontological-de-mentation-or-dialectical-de-mentation - strandingor-attributive-dialectics〉 as dialectically/contendingly-in-phase and prospective intemporalisation registry-worldview/dimension associated with organic-comprehensionthinking (organicalism/'intemporal-prioritisation-of- ${ }^{8}$ reference-of-thought'-asconflatedness ${ }^{13}$-or-ontological-reprojecting/longness-of-register-of- meaningfulness-andteleology ${ }^{\circ}$ ), and reflecting/perspectivating/highlighting (reasoning-through-and-not-reasoningwith) a dialectically/contendingly-out-of-phase, retrospective ${ }^{74}$ perversion-of- ${ }^{83}$ reference-ofthought-<as-preconvergingly-apriorising/axiomatising/referencing-innonconviction/madeupness/bottomlining-as-to-shallow-supererogation $>\quad$ registryworldview/dimension associated with threshold-of-nonconviction/madeupness/bottomliningin-shallow-supererogation -<as-to- 'attendant-intradimensional'-prospectivelydisontologising preconverging/dementing -apriorising-psychologism $>$. - And so, from the veridicality of human-subpotency-aporia/undecidability/dilemma/oughtindeterminacy/deficiency/limitation/constraint—imbued-'notional firstnaturednessformativeness-<as-to-eventualising - inkling drive-or-seeding misprising $>$ temporal-tointemporal-dispositions- $<$ so-construed-as-from-perspective-ontologicalnormalcy/postconvergence $>$ '-existentialism-form-factor, as $\quad<$ amplituding/formativeepistemicity $>$ causality $\sim$ as-to-projective-totalitative-implications-of-prospectivenonpresencing,-for-explicating relative-unreflexivity/relative-reflexivity - ontological- 
contiguity, wherein temporal-dispositions existentially-<disontologising/re-ontologising aporeticism $>$ are preconverging-or-dementing 20 -apriorising-psychologism- $<$ stranded-asrightfully-oblongated/decandored-and-dialectically-or-contendingly-out-of-phase>, $\quad$ in threshold-of-nonconviction/madeupness/bottomlining-in-shallow-supererogation $\quad-<$ as-to‘attendant-intradimensional'-prospectively-disontologising preconverging/dementing apriorising-psychologism> as of a retrospective registry-worldview/dimension which is preconverging-or-dementing ${ }^{20}$-apriorising-

psychologism/subknowledging 4 mimicking/dialectially-out-of-phase- $\{$ with-the-intemporalpreservation-entropy-or-contiguity-or-ontological-preservation $\}$ on-the-one-hand, and the intemporal-disposition existentially-<disontologising/re-ontologising aporeticism $>$ postconverging-or-dialectical-thinking ${ }^{2}$-apriorising-psychologism- $<$ stranded-as-rightfullystraight/candored-and-dialectically-or-contendingly-in-phase>, in organic-comprehensionthinking (organicalism/'intemporal-prioritisation-of- ${ }^{8}$ reference-of-thought'-asconflatedness $^{13}$-or-ontological-reprojecting/longness-of-register-of meaningfulness-andteleology ) as a prospective registry-worldview/dimension in intemporal-preservation-entropyor-contiguity-or-ontological-preservation). - And so, upholding the perpetual ontologicalnormalcy/postconvergence/supersedingness of intemporal-preservation-entropy-or-contiguityor-ontological-preservation along the continual limitation of uninstitutionalised-threshold ${ }^{102}$, and which continual superseding/transcendence is behind the institutionalcumulation/institutional-recomposure-〈as-to- historiality/ontologicaleventfulness /ontological-aesthetic-tracing-<perspective-ontologicalnormalcy/postconvergence-reflected-'epistemicity-relativism-determinism' $>>$ process. Not adhering to this 'point-of-departure-of-construal of ${ }^{83}$ reference-of-thought technique of distractive-alignment-to- ${ }^{8}$ reference-of-thought- $<$ of-apriorising/axiomatising/referencing $>$ with respect to the '<amplituding/formative-epistemicity $>$ causality $\sim$ as-to-projective- 
totalitative-implications-of-prospective- nonpresencing,-for-explicating relative-

unreflexivity/relative-reflexivity - ontological-contiguity

retracing

(for

notional firstnaturedness-formativeness-<as-to-eventualising-inkling-drive-or-seeding misprising $>$ temporal-to-intemporal-dispositions-<so-construed-as-from-perspectiveontological-normalcy/postconvergence>-pedestals-disambiguation) as reference-of-thoughtscheme' as elaborated above, due to the natural reflex to be in prelogism ${ }^{78}$-as-of-conviction,-inprofound-supererogation $-<$ existentially-veridical-'attendant-intradimensionalapriorising/axiomatising/referencing'-logical-dueness-precedes-disontologising-logical-

outcome-arrived-at>, and thus wrongly engaging logic by reflex, leads to the wrong elevation of the dialectically-or-contendingly-out-of-phase/brazen-but-unsoundness-or-ontological-badfaith/inauthenticity ${ }^{64}$ of- ${ }^{83}$ reference-of-thought) psychopathic ${ }^{74}$ perversion-of- ${ }^{83}$ reference-ofthought-<as-preconvergingly-apriorising/axiomatising/referencing-in-

nonconviction/madeupness/bottomlining-as-to-shallow-supererogation $>$ (eliciting the threshold-of-nonconviction/madeupness/bottomlining-in-shallow-supererogation $-<$ as-to'attendant-intradimensional'-prospectively-disontologising preconverging/dementing apriorising-psychologism>) temporal-dispositions integration of the psychopath's postlogism in hollow-constituting-<as-disjointed-misappropriation-of-meaningfulness-and-failingintemporal-preservation $>$ and conjugation with it ${ }^{74}$ perversion-of- ${ }^{8}$ reference-of-thought- $<$ aspreconvergingly-apriorising/axiomatising/referencing-innonconviction/madeupness/bottomlining-as-to-shallow-supererogation $>$, and thus wrongly implying the same apriorising-registry as the organic-comprehension-thinking (organicalism/'intemporal-prioritisation-of- ${ }^{8}$ reference-of-thought'-as-conflatedness ${ }^{13}$-orontological-reprojecting/tongness of register of meaningfulness and teleology ${ }^{9}$ ) as to supplanting-conviction-as-to-profound-supererogation —of-'attendant-intradimensional'postconverging/dialectical-thinking -apriorising-psychologism, and thus wrongly implying a 
logical contention; instead of the organic-comprehension-thinking (organicalism/“intemporalprioritisation-of- ${ }^{3}$ reference-of-thought'-as-conflatedness ${ }^{13}$-or-ontological-

reprojecting/tongness-of-register-of- meaningfulness-and-teleology ) rather reflecting/perspectivating/highlighting (reasoning-through-and-not-reasoning-with) both the psychopathic postlogism in hollow-constituting-<as-disjointed-misappropriation-ofmeaningfulness-and-failing-intemporal-preservation $>$ and the temporal-dispositions thresholdof-nonconviction/madeupness/bottomlining-in-shallow-supererogation $<-<$ as-to-' ${ }^{6}$ attendantintradimensional'-prospectively-disontologising preconverging/dementing -apriorisingpsychologism $>$ integration and its conjugating/deriving of the psychopathic postlogism 77 in hollow-constituting-<as-disjointed-misappropriation-of-meaningfulness-and-failingintemporal-preservation> as 'subknowledging $/$ mimicking manifestations of unsoundness-orontological-bad-faith/inauthenticity ${ }^{4}$-of- ${ }^{8}$ reference-of-thought/ $/ 7$ perversion-of- ${ }^{8}$ reference-ofthought-<as-preconvergingly-apriorising/axiomatising/referencing-innonconviction/madeupness/bottomlining-as-to-shallow-supererogation $>$, which are the subject of logical contention; thus avoiding to wrongly validate the subknowledging $/$ mimicking-and-syncretising of the elements of apriorising-registry (that is, the implied fepistemic-totalising tosyehologismic subliminality of -individuationeffusing/worlding imbued logical-dueness-or-scape-or-frame, profile-or-stature, presumptuousness-or-arrogation, assumptions, value-reference and teleology ${ }^{9}$ ) and wrongly imply their logical contention validity. Taken to the bigger registry-worldview/dimension or intradimensional level, this points to a registry-worldview/dimension derived-perversion state of temporal-dispositions at the present uninstitutionalised-threshold ${ }^{102}$ involving the

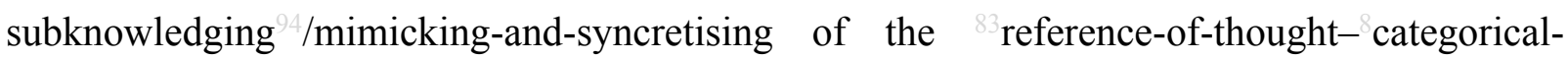
imperatives/axioms/registry-teleology ${ }^{9}$,-for-intemporal-preservation-entropy-or-contiguityor-ontological-preservation of positivistic meaningfulness known as procrypticism-or- 
disjointedness-as-of- ${ }^{8}$ reference-of-thought, calling prospectively for deprocrypticism. Without 'intemporal-prioritisation-of- ${ }^{8}$ reference-of-thought'-as-conflatedness ${ }^{13}$-or-ontologicalreprojecting disposition the possibility for transcendence-andsublimity/sublimation/supererogatory-de-mentativity from ${ }^{77}$ perversion-of- ${ }^{83}$ reference-ofthought-<as-preconvergingly-apriorising/axiomatising/referencing-innonconviction/madeupness/bottomlining-as-to-shallow-supererogation $>$ (as prior intemporal

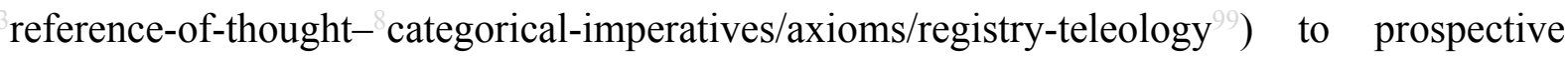
ones which are intemporal-preservational, the institutional-cumulation/institutionalrecomposure-〈as-to- historiality/ontological-eventfulness /ontological-aesthetic-tracing$<$ perspective--ontological-normalcy/postconvergence-reflected-'epistemicity-relativismdeterminism' $>>$ process will not occur and be regenerative, as the circumventive/distractivetemporal-prioritisation-of- ${ }^{8}$ reference-of-thought mental-dispositions rather strives to arrive at an equilibrium at the ${ }^{83}$ reference-of-thought- categorical-imperatives/axioms/registryteleology ${ }^{9}$-for-intemporal-preservation-entropy-or-contiguity-or-ontological-preservation of a registry-worldview/dimension whether these are intemporal-preservational or not, hence have little transcendental capacity. Going by an 'ontologically contiguous comparison' with reference to Arithmetic where a condition was to cause a character to resolve additionality as $1+3=5$, $2+5=8,5+6=12$, etc., the ontological-veridicality/relative-unreflexivity/relative-reflexivity ontological-contiguity ${ }^{67}$ of ${ }^{8}$ reference-of-thought (from ontological-normalcy/postconvergence epistemic-or-notional projective-perspective) of additionality with regards to this character will always involve as of ${ }^{83}$ reference-of-thought- categorical-imperatives/axioms/registryteleology that subtracts 1 from the results of that character's operations of additions (as the sublimating-epistemic-imbricatedness/threadedness/recomposuring for upholding existentialreality), and the usual principles of additionality (its traditional ${ }^{83}$ reference-of-thoughtcategorical-imperatives/axioms/registry-teleology of simply summing directly) will be 
existentially-<disentologising/re-ontologising _aporeticism $>$ rendered null and void in order to allow for intemporal-preservation-entropy-or-contiguity-or-ontological-preservation. Now supposed such a framework ( ${ }^{8}$ reference-of-thought) for resolving Arithmetic calculations now involves the contribution of 6 characters working in collaboration with each contributing their specific arithmetic principle role while taking cognisance of the others roles in 'resolving arithmetic calculations' (as ontological-completeness-of- ${ }^{3}$ reference-of-thought, and so taking into account the prior mentioned character with its defect of additionality; wherein such a framework is BODMAS-based with character B working on brackets operations, character $\mathrm{O}$ working on order operations, character $\mathrm{D}$ working on division operations, character $\mathrm{M}$ working on multiplication operations, the priorly mentioned character A working on addition operations and character $\mathrm{S}$ working on subtraction operations, and so (from ontologicalnormalcy/postconvergence epistemic-or-notional projective-perspective) setup for resolving arithmetic calculations (ontological-completeness-of- ${ }^{3}$ reference-of-thought setup). Naturally, the reference-of-thought- categorical-imperatives/axioms/registry-teleology ${ }^{9}$,-forintemporal-preservation-entropy-or-contiguity-or-ontological-preservation (as the usual BODMAS Arithmetic rules) should apply but this is no longer existentially-<disontologising/reentologising aporeticism $>$ the case in this instance, where the equation is for instance $7(\sqrt{6} 6+3-$ 1)-(6+4-2) $\div 2$. Going by the natural arithmetic rules for BODMAS, the equation will be resolved first with the brackets, and within the brackets for the first brackets the order operation is first carried out, that is, $\sqrt{ } 64=8$ and then addition $8+3=11$, then subtraction $11-1=10$. Then the multiplication operation with the first brackets result as $7 \times 10=70$. For the second brackets, addition as $6+4=10$, then subtraction as $10-2=8$. The division operation then follows with the second brackets result as $8 \div 2=4$. Finally, comes the subtraction with $70-4=66$ as the final answer that is ontologically-veridical (in ontological-normalcy/postconvergence). But then, in this particular case where character A (Addition) operation of additionality is perverted as stated 
above as a result of its condition (that is further adding 1 to any addition operation), the equation will resolve as $\sqrt{ } 64=8,8+3=12,12-1=11$, for the first brackets, and $6+4=11,11-2=9$, for the second brackets. The division operation with the second brackets yields $9 \div 2=4.5$, and the multiplication operation with the first brackets yields $7 \times 11=77$. Finally, subtracting both brackets gives $77-4.5=72.5$ as the final result which is ontologically wrong (from ontologicalnormalcy/postconvergence epistemic-or-notional projective-perspective), and points to the fact that all the 6 BODMAS characters, not only A (Addition) the additionality defect character have failed ontological-veridicality/relative-unreflexivity/relative-reflexivity - ontologicalcontiguity $^{67}$ as of their relative-ontological-incompleteness ${ }^{8}$-induced,-'threshold-ofnonconviction/madeupness/bottomlining-in-shallow-supererogation $<<$ as-to-'attendantintradimensional'-prospectively-disontologising preconverging/dementing -apriorisingpsychologism>' (from ontological-normalcy/postconvergence epistemic-ornotional projective-perspective), as $\quad$ reference-of-thought- categoricalimperatives/axioms/registry-teleology ${ }^{9}$,-for-intemporal-preservation-entropy-or-contiguityor-ontological-preservation are not by themselves the definitive basis for ontology/intrinsicreality/existential-reality as these are only as pertinent as they are ontologicallyveridical/ontologically-continuous/contextually-contiguous (in ontologicalnormalcy/postconvergence). This ontological state with respect to all the characters registries (not only A) is known as perversion-and-derived- perversion-of- $^{-}$reference-of-thought- $<$aspreconvergingly-apriorising/axiomatising/referencing-innonconviction/madeupness/bottomlining-as-to-shallow-supererogation $>$ as-of-unsoundnessor-ontological-bad-faith/inauthenticity ${ }^{64}$-of- ${ }^{8}$ reference-of-thought, as ontologicalveridicality/relative unreflexivity/relative reflexivity - ontological-contiguity ${ }^{67}$ of ${ }^{83}$ referenceof-thought (from ontological-normalcy/postconvergence epistemic-or-notional projectiveperspective) precedes projected <amplituding/formative> wooden-language-〈imbued- 
temporal-mere-form/virtualities/dereification/akrasiatic-drag/denatured/preconverging-or-

dementing -narratives-of-the- reference-of-thought- categorical-

imperatives/axioms/registry-teleology $\rangle, \quad$ with $\quad$ reference-of-thought- categoricalimperatives/axioms/registry-teleology ${ }^{9}$ nothing more but human 'mental inventions' (construed by psychoanalytic-unshackling/memetic-reordering/institutional-recomposuring) for the sake of achieving ontology/intemporal-preservation-entropy-or-contiguity-or-ontologicalpreservation, and pertinent in that regard only when not-failing/upholding intemporalpreservation-entropy-or-contiguity-or-ontological-preservation as of ontologicalnormalcy/postconvergence which always factor in human limited-mentation-capacitydeepening —as-subjecting limitedness/human-subpotency-to-'educed-unlimitedness/existencesublimating nascence' 53 by a re-equilibrating metaphysics-of-absence-〈implicited-epistemicveracity-of- nonpresencing-<perspective-ontological-

normalcy/postconvergence $>$ /postdication. Hence the notion of ontologicalnormalcy/postconvergence and postdication construes intemporal-preservation-entropy-orcontiguity-or-ontological-preservation as superseding/preceding over projected $<$ amplituding/formative $>$ wooden-language-〈imbued-temporal-mereform/virtualities/dereification/akrasiatic-drag/denatured/preconverging-or-dementing narratives - of-the- reference-of-thought- categorical-imperatives/axioms/registryteleology $>$ in affirming ontology/ontological-veridicality/intrinsic-reality (notwithstanding their traditional personhoods-and-socialhood-formation mental-dispositions anchored on projected $<$ amplituding/formative $>$ wooden-language-〈imbued-temporal-mereform/virtualities/dereification/akrasiatic-drag/denatured/preconverging-or-dementing narratives - of-the- reference-of-thought- categorical-imperatives/axioms/registry-

teleology $\rangle$ ). In which case the resolution for the Arithmetic equation (supposedly where A, Addition, is unamendable due to a condition), will involve the other characters taking cognisance 
of A's (Addition's) condition and adhere to intemporal-preservation-entropy-or-contiguity-orontological-preservation over projected $<$ amplituding/formative $>$ wooden-language-〈imbued temporal-mere-form/virtualities/dereification/akrasiatic-drag/denatured/preconverging-ordementing -narratives - of-the- reference-of-thought- categoricalimperatives/axioms/registry-teleology $\rangle$ in affirming ontology/ontologicalveridicality/intrinsic-reality (as the appropriateness-of- ${ }^{3}$ reference-of-thought-as-ofconflatedness $^{13}$ over A's induced preconverging-or-dementing -reference/ perversion-ofreference-of-thought-<as-preconvergingly-apriorising/axiomatising/referencing-innonconviction/madeupness/bottomlining-as-to-shallow-supererogation $>$ ). Thus the new categorical-imperatives/axiom/registry-teleology ${ }^{9}$-for-intemporal-preservation-entropy-orcontiguity-or-ontological-preservation deployed with respect to resolving calculations ontological-completeness-of- ${ }^{3}$ reference-of-thought will integrate the notion that additionality requires subtracting 1 from its results as well as taking cognisance that other characters will be perverted in their operation if they do not take cognisance of A's (Addition's) condition and subtract 1 from it before their operation (whether unconsciously by ignorance, expediently by affordability, and consciously by opportunism/exacerbation/social-chainism-or-socialdiscomfiture-or-negative-social-aggregation/temporal-enculturation-or-temporalendemisation). For instance, B (Brackets) is still in a position to articulate an ontologicalnormalcy/postconvergence ontological-veridicality/relative-unreflexivity/relative-reflexivity_ ontological-contiguity ${ }^{67}$ of ${ }^{8}$ reference-of-thought (from ontological-normalcy/postconvergence epistemic-or-notional projective-perspective) by factoring in all the defects as follows: by reverting all other characters operation up to the point they had to deal with A (Addition) and subtracting 1 from the results at these point before allowing the other characters operations, which then yields the right result. That is $77 \div 7=11$ and $4.5 \times 2=9$ as reverting back, then $11-1=10$ and 9-1=8 to factor in A's (Addition's) additionality defect to yield the results of the two 
brackets. Before then letting back the division and multiplication operations for both brackets respectively, giving $8 \div 2=4$ and $7 \times 10=70$. Finally $70-4=66$, giving the final result that is ontologically-veridical (in ontological-normalcy/postconvergence). So this approach is the new reference-of-thought- categorical-imperatives/axioms/registry-teleology ${ }^{9}$,-for-intemporalpreservation-entropy-or-contiguity-or-ontological-preservation which is ontologicallyveridical/of-intrinsic-reality that $\mathrm{B}$ should be operating. In-the-bigger-scheme-of-things, this explains institutional-cumulation/institutional-recomposure-〈as-to- historiality/ontologicaleventfulness /ontological-aesthetic-tracing-<perspective-ontologicalnormalcy/postconvergence-reflected-‘epistemicity-relativism-determinism’> $>/$ memeticreordering/psychoanalytic-reorientation with respect to an animal that is always bound to perversion-of- ${ }^{-3 e f e r e n c e-o f-t h o u g h t-<a s-p r e c o n v e r g i n g l y-~}$ apriorising/axiomatising/referencing-in-nonconviction/madeupness/bottomlining-as-toshallow-supererogation $>$ as to preconverging-or-dementing ${ }^{20}$-apriorising-psychologism by the very fundamental veridicality of its notional firstnaturedness-formativeness-<as-toeventualising inkling-drive-or-seeding-misprising > temporal-to-intemporal-dispositions$<$ so-construed-as-from-perspective-ontological-normalcy/postconvergence $>$ nature. But then, this being an uninstitutionalised-threshold ${ }^{12}$, B going by human-subpotencyaporia/undecidability/dilemma/ought-indeterminacy/deficiency/limitation/constraint—imbued'notional firstnaturedness-formativeness-<as-to-eventualising inkling-drive-or-seedingmisprising $>$ temporal-to-intemporal-dispositions- $<$ so-construed-as-from-perspectiveontological-normalcy/postconvergence >'-existentialism-form-factor at uninstitutionalisedthreshold ${ }^{102}$ may just as well due to there being 'no institutionalisation constraining' (i.e. no social ${ }^{103}$ universal-transparency $^{104}$-〈transparency-of-totalising-entailing,-as-to-entailing<amplituding/formative-epistemicity>totalising in-relative-ontological-completeness > of perversion-of- ${ }^{8}$ reference-of-thought- $<$ as-preconvergingly- 
apriorising/axiomatising/referencing-in-nonconviction/madeupness/bottomlining-as-to-

shallow-supererogation >, no internal-contradiction induced from <amplituding/formativeepistemicity $>$ causality $\sim$ as-to-projective-totalitative-implications-of-prospectivenonpresencing,-for-explicating relative-unreflexivity/relative-reflexivity - ontologicalcontiguity , no preconverging-or-dementing ${ }^{20}$-apriorising-psychologism of the ${ }^{74}$ perversion-ofreference-of-thought-<as-preconvergingly-apriorising/axiomatising/referencing-innonconviction/madeupness/bottomlining-as-to-shallow-supererogation $>$, and no intemporal projection superseding the transcendence-unenabling-uninstitutionalised-threshold ${ }^{102}$ in alienation — as-inauthentic/poorly-objectified/poorly-desubjectified-as-objectified/ontological-

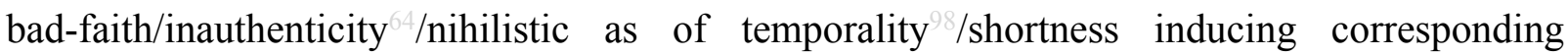
formalisation and internalisation as values), choose to act because of one temporal reason or the other whether by ignorance of the need for this new ${ }^{83}$ reference-of-thought- categoricalimperatives/axioms/registry-teleology ${ }^{9},-$ for-intemporal-preservation-entropy $\}$ affordability/opportunism/exacerbation/social-chainism-or-social-discomfiture-or-negativesocial-aggregation/temporal-enculturation-or-temporal-endemisation (i.e. induced-ring-ofgyges-effect/solipsistic-point-of-temporal-thresholding/point-of-ontological-faith-notion-orontological-fideism - imbued-underdetermination-of-motif-andapriorising/axiomatising/referencing-as-so-being-as-of-existential-reality); and so, fail to follow the latter ${ }^{83}$ reference-of-thought- categorical-imperatives/axioms/registry-teleology ${ }^{9}$,-forintemporal-preservation-entropy-or-contiguity-or-ontological-preservation that are intemporally-preservational. That is, choosing circumventive/distractive-temporalprioritisation-of- ${ }^{8}$ reference-of-thought and thus failing/not-upholding-<as-ofapriorising/axiomatising/referencing $>$ the possibility of transcendence-andsublimity/sublimation/supererogatory-de-mentativity. That being the case, this doesn't in anyway undermine the intrinsic reality/ontological-veridicality/ ${ }^{8}$ reference-of-thought (in 
ontological-normalcy/postconvergence) of the above equation as being equal to the need for new requisite $\quad{ }^{83}$ reference-of-thought- categorical-imperatives/axioms/registry-teleology ${ }^{9}$,-forintemporal-preservation-entropy-or-contiguity-or-ontological-preservation not only for this particular circumstance of the BODMAS characters but all such circumstances that may arise as a perversion-of- ${ }^{-3}$ reference-of-thought- $<$ as-preconverginglyapriorising/axiomatising/referencing-in-nonconviction/madeupness/bottomlining-as-toshallow-supererogation $>\quad$ as-of-unsoundness-or-ontological-bad-faith/inauthenticity ${ }^{6}$-ofreference-of-thought thus requiring de-mentation-〈supererogatory ontological-dementation-or-dialectical-de-mentation-stranding-or-attributive-dialectics $\rangle$ of all such temporal-dispositions. It further speaks of how B will likely act in 'metaphorically-a-millionand-one-instances-and-locales as to aetiologisation/ontological-escalation-<ontologicalveridicality_commitment/otherliness_transcending/compulsions-encumbered_transcending >' (of uninstitutionalised-threshold ${ }^{102}$, where the constraining elements of institutionalisation are not available, i.e. social ${ }^{103}$ universal-transparency ${ }^{104}$-〈transparency-of-totalising-entailing,-asto-entailing-<amplinding formative-epistemicity $>$ totalising $\sim$ in-relative-ontologicalcompleteness $>$ of $\quad{ }^{74}$ perversion-of- ${ }^{83}$ reference-of-thought- $<$ as-preconverginglyapriorising/axiomatising/referencing-in-nonconviction/madeupness/bottomlining-as-toshallow-supererogation >, internal-contradiction induced from <amplituding/formativeepistemicity $>$ causality $\sim$ as-to-projective-totalitative-implications-of-prospectivenonpresencing,-for-explicating relative unreflexivity/relative reflexivity - ontologicalcontiguity inoperance, $\quad{ }^{15}$ de-mentation-/supererogatory $\sim$ ontological-de-mentation-ordialectical-de-mentation - stranding-or-attributive-dialectics $\rangle$ the ${ }^{74}$ perversion-of- ${ }^{8}$ referenceof-thought-<as-preconvergingly-apriorising/axiomatising/referencing-innonconviction/madeupness/bottomlining-as-to-shallow-supererogation $>$, and intemporal projection superseding the transcendence-unenabling-uninstitutionalised-threshold ${ }^{102}$ in 
alienation—as-inauthentic/poorly-objectified/poorly-desubjectified-as-objectified/ontologicalbad-faith/inauthenticity ${ }^{6} /$ nihilistic as of temporality $^{8}$, with corresponding formalisation and internalisation as values), thence defining the given temporal-dispositions of $\mathrm{B}$ aetiologisation/ontological-escalation- $<$ ontological-

veridicality_commitment/otherliness_transcending/compulsions-encumbered_transcending $>$ to be accounted for from similar individuations in such situations as a registryworldview/dimension problem, in order to ensure intemporal-preservation-entropy-orcontiguity-or-ontological-preservation as ontology. In-the-bigger-scheme-of-things, this calls for a prospective registry-worldview/dimension institutionalisation articulation that supersedes/overrides such a temporal dynamism of ${ }^{7}$ perversion-of- ${ }^{8}$ reference-of-thought- $<$ aspreconvergingly-apriorising/axiomatising/referencing-in-

nonconviction/madeupness/bottomlining-as-to-shallow-supererogation $>$ dispositions at various social roles going from A's condition, and the potential overlooking of the intemporalpreservation-entropy-or-contiguity-or-ontological-preservation dispositions by all the other characters $(\mathrm{B}, \mathrm{O}, \mathrm{D}, \mathrm{M}$ and $\mathrm{S})$. Underlying such an intemporal orientation is the idea that fundamentally the conjugation of such an de-mentation-〈supererogatory $\sim$ ontological-dementation-or-dialectical-de-mentation-stranding-or-attributive-dialectics $\rangle$ and subsequent conjugation as with $\mathrm{B}$ above to the temporal-dispositions of a registry-worldview/dimension speaks fundamentally of the uninstitutionalised-threshold ${ }^{12}$ of that registryworldview/dimension, reflected/perspectivated by the marginal ${ }^{7}$ perversion-of- ${ }^{8}$ reference-ofthought- $<$ as-preconvergingly-apriorising/axiomatising/referencing-in-

nonconviction/madeupness/bottomlining-as-to-shallow-supererogation $>$ defect of its reference-of-thought- categorical-imperatives/axioms/registry-teleology ${ }^{9}$,-for-intemporalpreservation-entropy-or-contiguity-or-ontological-preservation with the prior registryworldview/dimension now preconverging-or-dementing ${ }^{20}$-apriorising-psychologism- 
$<$ stranded-as-rightfully-oblongated/decandored-and-dialectically-or-contendingly-out-ofphase>, with a prospective institutionalisation ${ }^{83}$ reference-of-thought- categoricalimperatives/axioms/registry-teleology ${ }^{9}$,-for-intemporal-preservation-entropy-or-contiguityor-ontological-preservation as the new straightness/candored-and-dialectically-orcontendingly-in-phase. de-mentation-〈supererogatory $\sim$ ontological-de-mentation-ordialectical-de-mentation - stranding-or-attributive-dialectics $\rangle$ doesn't confuse appropriateness of the prior ${ }^{83}$ reference-of-thought- categorical-imperatives/axioms/registry-teleology ${ }^{9}$,-forintemporal-preservation-entropy-or-contiguity-or-ontological-preservation for the prior institutionalisation as implying the prior mental-devising-representation is appropriate for prospective institutionalisation as it needs to undergo its own requisite 'postconverging-ordialectical-thinking -psychology or psychology-of-mentation-dynamics or natural psychological-dynamics’ psychoanalytic-unshackling/memeticreordering/institutional-recomposuring to enable and regenerate intemporal-preservationentropy-or-contiguity-or-ontological-preservation. This by itself explains why the different registry-worldviews/dimensions are seemingly preconverging-or-dementing ${ }^{20}$-apriorisingpsychologism with respect to one another (from the prospective perspectives), and not that we are talking about different species of humans, as transcendentalism for intemporal-preservationentropy-or-contiguity-or-ontological-preservation is the foundational concept retrospectively, presently and prospectively; even though by the illusion-of-the-present/presentconsciousness/epistemic totalising $\sim$ self-referencing-syncretising/mirage, all dimensions, and not only ours, tend to think of themselves as definitely mentally straight/candored-anddialectically-or-contendingly-in-phase with no uninstitutionalised-threshold 02 which is obviously fallacious. The reason for this is that 'postconverging-or-dialectical-thinking apriorising-psychologism'/soundness-or-ontological-good-faith/authenticity ${ }^{69}$-of- referenceof-thought (as mental straightness/candored-and-dialectically-or-contendingly-in-phase) starts- 
and-ends/is-sound at institutionalised/intemporalised-thresholds-of-intemporal-preservationentropy-or-contiguity-or-ontological-preservation where the ${ }^{83}$ reference-of-thoughtcategorical-imperatives/axioms/registry-teleology ${ }^{9}$,-for-intemporal-preservationentropy/configuity is in ontological-veridicality/relative-unreflexivity/relative-reflexivityontological-contiguity ${ }^{67}$ of ${ }^{8}$ reference-of-thought (from ontological-normalcy/postconvergence epistemic-or-notional projective-perspective). Where instead such ${ }^{83}$ reference-of-thoughtcategorical-imperatives/axioms/registry-teleology ${ }^{9}$,-for-intemporal-preservation-entropy-orcontiguity-or-ontological-preservation is of notional-discontiguity/epistemic-discontiguity $<$ between-prior-shallow-supererogation -of-mentallyaestheticised preconverging/dementing -qualia-schema_and_prospective-profoundsupererogation -of-mentally-aestheticised postconverging/dialectical-thinking -qualiaschema $>$ /non-ontological-and-non-contending-referencing- $<$ thus-ontologically-orcontendingly-reflected-or-perspectivated-as-of-preconverging-or-dementing ${ }^{20}$-apriorisingpsychologism $>\quad$ (not-veridical-thinking-reference-rather-preconverging-or-dementing reference), it is dementing (preconverging-or-dementing -apriorising-psychologism$<$ stranded-as-rightfully-oblongated/decandored-and-dialectically-or-contendingly-out-ofphase $>$ ). This is further compounded as of <amplitudingfformativeepistemicity $>$ totalising $\sim$ self-referencing-syncretising/circularity/interiorising/akrasiatic-drag ${ }^{34}$, that is, as wrongful upholding and projecting postconverging-or-dialectical-thinking apriorising-psychologism-<stranded-as-rightfully-straight/candored-and-dialectically-orcontendingly-in-phase $>$ mental-devising-representation as so-manifested at institutionalised/intemporalised-thresholds-of-intemporal-preservation-entropy-or-contiguityor-ontological-preservation while rather reflecting the uninstitutionalised-threshold ${ }^{02}$ that requires renewed mental-devising-representation, and this is not ontologically consistent and fundamentally undermines and overlook the idea of an insight about a prospective 
transcendence-and-sublimity/sublimation/supererogatory-de-mentativity with the present registry-worldview/dimension corresponding to the superseded ${ }^{74}$ perversion-of- ${ }^{8}$ reference-ofthought-<as-preconvergingly-apriorising/axiomatising/referencing-in-

worldview/dimension. Thus but for the inherent difficulty of livng and experiencing the effective personhoods-and-socialhood-formation existentialism across all the registryworldviews/dimensions, the apriorising/axiomatising/referencing/intelligibilitysettingup/measuringinstrumenting 'beyond any one registry-worldview/dimension meaningfulness' like ours is perfectly possible in garnering a more profound and informed insight on human nature whether presently, retrospectively to prospectively. In-the-bigger-scheme-of-things, just as logic can only be grounded on coherent and concrete ${ }^{83}$ reference-of-thought- categoricalimperatives/axioms/registry-teleology ${ }^{9}$ based articulations for its ontological effectiveness and veridicality, human ontological transcendental possibilities arise from human individuations that correspond to the appropriate 'intemporal-projecting existential-<disontologising/reentologising aporeticism $>$ becoming' allowing for such ontological possibilities, and the latter is made possible by the so-renewed apriorising/axiomatising/referencing/intelligibilitysettingup/measuringinstrumenting as to renewed logical-basis/logic,-as-derived-from $\sim$ transversality-<for-sublimating-existentialeventuating/denouement,-from-'thinking at-first/pure-predisposition-preemptive-ofprospective-disontologising/subontologising' as-of-prospectively-disambiguated-affirmedand-unaffirmed-'motif-and-apriorising/axiomatising/referencing'>101, going beyond the reference-of-thought- ${ }^{8}$ ategorical-imperatives/axioms/registry-teleology ${ }^{9}$ within just a given registry-worldview/dimension as if it were the absolute mental-devising-representation with respect to intrinsic-reality, and instead hold that transdimensional/transcendental (unlike 
ordinary meaning which reasons only on intradimensional ${ }^{83}$ reference-of-thought- categoricalimperatives/axioms/registry-teleology ${ }^{9}$ ) is what brings us closer to absolute mental-devisingrepresentation with respect to intrinsic-reality as ontological-normalcy/postconvergence (prospective-transcendence-in-perpetually-upholding-intemporal-preservation-entropy-orcontiguity-or-ontological-preservation). Memetism as suprastructural-meaningfulness is able to do that because it can proxy ontological-normalcy/postconvergence in a dynamic dialectical juxtapositioning/doppler-thinking of 'postconverging-or-dialectical-thinking 2 -apriorisingpsychologism mental-devising-representation' and 'preconverging-or-dementing ${ }^{20}$-apriorisingpsychologism mental-devising-representation' from successive ontological dialectical-moments of human shallow limited-mentation-capacity—as-subjecting-'educed-unlimitedness/existencesublimating nascence' to-limitedness/human-subpotency-〈as of relative apriorising/axiomatising/referencing-\{ of-'prospectively_implicited_attendant-ontologicalcontiguity ' $\sim$ educedexistentialising/contextualising/textualising_'intelligibility/epistemicity/reflexivity-contiguity<imbued-notional cogency>' $\}$-constitutedness ${ }^{14}$-in preconverging-entailment $\rangle$ to deeper limited-mentation-capacity—as-subjecting-'educed-unlimitedness/existence-sublimating nascence' to-limitedness/human-subpotency-〈as of relative apriorising/axiomatising/referencing-\{of-'prospectively implicited_attendant-ontologicalcontiguity ' $\sim$ educedexistentialising/contextualising/textualising_'intelligibility/epistemicity/reflexivity-contiguity<imbued-notional cogency >' $\}$-conflatedness ${ }^{13}$-in-\{preconverging-disentailment by\} postconverging entailment $\rangle$ behind the successive institutional-cumulation/institutionalrecomposure-〈as-to- historiality/ontological-eventfulness /ontological-aesthetic-tracing$<$ perspective-ontological-normalcy/postconvergence-reflected-'epistemicity-relativismdeterminism'>>, wherein the dialectically transcending/superseding institutional- 
cumulation/institutional-recomposure-〈as-to- historiality/ontological-

eventfulness /ontological-aesthetic-tracing-<perspective-ontological-

normalcy/postconvergence-reflected-‘epistemicity-relativism-determinism'>> of relatively

deeper limited-mentation-capacity as subjecting 'educed mnlimitedness sublimating nascence' to-limitedness/human-subpotency-〈as of relative

apriorising/axiomatising/referencing-\{of-'prospectively_implicited_attendant_ontological-

contiguity ' educed-

existentialising/contextualising/textualising_'intelligibility/epistemicity/reflexivity-contiguity-

<imbued-notional cogency $\left.>^{\prime} \quad\right\}$-conflatedness ${ }^{13}$ in (preconverging disentailment by

postconverging-entailment $\rangle$ is the shifted ${ }^{83}$ reference-of-thought (dialectically-in-phase) and is thus of "postconverging-or-dialectical-thinking -apriorising-psychologism mental-devisingrepresentation' as it is in (postconvergence) ontological-veridicality/relativeunreflexivity/relative-reflexivity_ontological-contiguity ${ }^{77}$ while the prior transcended/superseded institutional-cumulation/institutional-recomposure-〈as-to-

historiality/ontological-eventfulness /ontological-aesthetic-tracing-<perspective-

ontological-normalcy/postconvergence-reflected-‘epistemicity-relativism-determinism’>> of relatively shallow limited-mentation-capacity—as-subjecting-'educed-unlimitedness/existencesublimating nascence' to-limitedness/human-subpotency-〈as of relative apriorising/axiomatising/referencing-\{of-'prospectively_implicited_attendant-ontologicalcontiguity ' educedexistentialising/contextualising/textualising_'intelligibility/epistemicity/reflexivity-contiguity<imbued-notional cogency $\left.>^{\prime} \quad\right\}$ - constitutedness ${ }^{1}$-in preconverging-entailment $\rangle$ is no longer the ${ }^{83}$ reference-of-thought (dialectically-out-of-phase or dialectically-primitive) and is thus of 'preconverging-or-dementing -apriorising-psychologism mental-devising-representation' as it is of notional-discontiguity/epistemic-discontiguity $<$ between-prior-shallow- 
supererogation -of-mentally-aestheticised preconverging/dementing -qualia-

schema_and_prospective-profound-supererogation -of-mentally-

aestheticised postconverging/dialectical-thinking -qualia-schema>; thus transcendentally

coming into grips with a shifting but more and more profound notion of ${ }^{83}$ reference-of-thought (in-phasing) and corresponding ontological-veridicality/relative-unreflexivity/relativereflexivity - ontological-contiguity ${ }^{67}$ as enabled by ontological-normalcy/postconvergence. The conceptual pertinence in this Arithmetic notional-contiguity/epistemic-contiguity ${ }^{6}-<$ profoundsupererogation -of-mentally-aestheticised postconverging/dialectical-thinking -qualia-

schema> comparison can be rearticulated as follows for greater clarity. As previously highlighted the developmental psychology of the psychopath from childhood to adulthood, involves a child psychopath who is dysfunctional as its subknowledging ${ }^{4}$-impulse/compulsivedementing $/$ postlogism 77 in hollow-constituting-<as-disjointed-misappropriation-ofmeaningfulness-and-failing-intemporal-preservation> is relatively transparent to interlocutors and it induces a 'delirious effect' given that it hasn't yet maturated, is not yet indirect, is not yet spatialising, is not yet credulous and is not yet crafty in 'its postlogism 7 -as-of- compulsingnonconviction/madeupness/bottomlining-〈‘ $<$ decontextualising/de-existentialising of-

attendant-intradimensional-apriorising/axiomatising/referencing $>$-induced-disontologising'-ofthe-'attendant-intradimensional-ontologising'-imbued-

$<$ contextualising/existentialising attendant-ontological-contiguity $>$;-in-shallowsupererogation -<as-to-disontologising-perverted-outcome-sought-precedes-existentiallyveridical-'attendant-intradimensional-apriorising/axiomatising/referencing'-logicaldueness $>$ 〉'; conditions which it increasingly attains from adolescence to adulthood with a corresponding inducing of the development of social psychopathy as its psychopathy conjugates/inflects/gets-mimicked with the temporal-dispositions of ignorance, unconsciously, and consciously with affordability/opportunism/exacerbation/social-chainism-or-social- 
discomfiture-or-negative-social-aggregation/temporal-enculturation-or-temporal-endemisation, in an absolving/fleeting/escaping-reflex-logic eliciting social psychopathy involving moving from various non-veridical/hollow sets-of-postlogic-in hollow-constituting-<as-disjointedmisappropriation-of-meaningfulness-and-failing-intemporal-preservation> in postlogicbacktracking-<iterative-looping-'set-of-dereifying-hollow-narratives-and-acts’> as absolving/fleeting/escaping-reflex-logic , to others and from different sets of interlocutors to others. It is obvious that A's condition/subknowledging -impulse/compulsive-dementing disposition as an adult psychopath isn't systematic with every interlocutor but rather it arises only in the face of perceived-social-stake-contention-or-confliction-and-confliction-targets and furthermore the profoundness of the postlogism 7 -slantedness manifestation is directly related to the gravity of the perceived-social-stake-contention-or-confliction the situation and how the 'evolving social psychopathy situation permits'. Hence the notion of A having an absolute condition wherein it increments additionality by 1 is rather an absolute ideal conceptualisation, as in reality it is a question of degree and highly circumscribed with the adult psychopath who needs to have a postlogic-equilibrium that can be socially-functional-and-accordant ${ }^{2}$, unlike the dysfunctional child psychopath. This comparison equally articulates the nature of uninstitutionalised-threshold ${ }^{102}$. Consider B (together with the other BODMAS characters) in the instance where despite A's conditions they were to stick to the registryworldview's/dimension's institutionalisation $\quad{ }^{83}$ reference-of-thought- categoricalimperatives/axioms/registry-teleology ${ }^{9}$ thus effectively producing the wrong result of 72.5 for the particular equation which is not intemporal preservational (not of prospective ontologicalnormalcy/postconvergence epistemic-projection) and likewise for all other equation where A's condition applies, we'll then be talking about an uninstitutionalised-threshold ${ }^{102}$. The implication is that the registry-worldview/dimension then loses its qualification as being intemporallypreservational, and the psychological tool that is then elicited (from a prospective and new 
reference-of-thought- categorical-imperatives/axioms/registry-teleology ${ }^{9}$,-for-intemporalpreservation-entropy-or-contiguity-or-ontological-preservation as articulated with the arithmetic technique that corrected the equation result from 72.5 to 66 by adjusting for A's condition which is now the ${ }^{83}$ reference-of-thought or veridical-thinking-reference-overpreconverging-or-dementing 20 -reference/ontologically-veridical/relative-unreflexivity/relativereflexivity ontological-contiguity ${ }^{67}$ registry-worldview/dimension) is known as ${ }^{15}$ dementation-_supererogatory $\sim$ ontological-de-mentation-or-dialectical-de-mentation - strandingor-attributive-dialectics〉. Even though going by its illusion-of-the-present/presentconsciousness, the superseded registry-worldview/dimension will still wrongfully strive for a mental-devising-representation at that uninstitutionalised-threshold ${ }^{02}$ of 'ontological-thinking (not preconverging-or-dementing ${ }^{20}$-apriorising-psychologism- $<$ stranded-as-rightfullyoblongated/decandored-and-dialectically-or-contendingly-out-of-phase $>$ which is ontologically wrong, just as all <amplituding/formative-epistemicity $>$ totalising $\sim$ self-referencingsyncretising/illusion-of-the-present/present-consciousness registry-worldviews/dimensions do at their uninstitutionalised-threshold ${ }^{202}$. For instance, the recurrent-utter-uninstitutionalisation mindset $/{ }^{83}$ reference-of-thought doesn't think of itself that way but rather as a nondescript/ignorable-void (actually speaking of akrasiatic-drag-denatured-andpreconverging-or-dementing -narratives) or a-registry-worldview's-or-dimension's-ignoringof-its-prior-relative-ontological-incompleteness ${ }^{88}$-of- ${ }^{8}$ reference-of-thought-as-anontologically-flawed-neuterisation -or-bracketing-or-epoché of <amplituding/formativeepistemicity $>$ totalising $\sim$ conflated- $-{ }^{5}$ meaningfulness-and-teleology 9 -as-of-

notional ${ }^{1}$ deprocrypticism-reflected- ${ }^{4}$ historiality/ontological-eventfulness ${ }^{38} /$ ontologicalaesthetic-tracing-<perspective-ontological-normalcy/postconvergence-reflected-'epistemicityrelativism-determinism'> with respect to its threshold-ofnonconviction/madeupness/bottomlining-in-shallow-supererogation $-<$ as-to-'attendant- 
psychologism>, and such a representation of its mentation is the invention/mental-devisingrepresentation of the base-institutionalisation mindset by its better ontological-completeness-ofreference-of-thought, likewise with ununiversalisation and ${ }^{103}$ universalisation, nonpositivism/medievalism and positivism, and prospectively with procrypticism and deprocrypticism, we will certainly be hardly pre-inclined to acquiesce to a preconverging-ordementing ${ }^{2}$-apriorising-psychologism mental-devising-representation of our ${ }^{7}$ perversion-ofreference-of-thought-<as-preconvergingly-apriorising/axiomatising/referencing-innonconviction/madeupness/bottomlining-as-to-shallow-supererogation $>$ with respect to the denaturing ${ }^{16}$ of the ${ }^{8}$ refence-of-thought- ${ }^{8}$ ategorical-imperatives/axioms/registryteleology ${ }^{9}$-for-intemporal-preservation-entropy-or-contiguity-or-ontological-preservation of positivistic meaningfulness. This insights perfectly highlight that our psychological nature is actually about mental-devising-representation which is meant to serve notionally the pertinence of supposed ontological articulations with respect to intrinsic reality, and it doesn't has any end to itself but for such dialectical readjustments to ontological-veridicality as 'postconverging-ordialectical-thinking -apriorising-psychologism'/soundness-or-ontological-goodfaith/authenticity ${ }^{6}$-of- ${ }^{8}$ reference-of-thought/candored-and-dialectically-or-contendingly-inphase with regards to an intemporal-preservational registry-worldview/dimension institutionalised/intemporalised-threshold-for-intemporal-preservation-entropy-or-contiguityor--ontological-preservation, and with superseded/transcended registry-worldviews/dimensions which are not intemporal-preservational at their uninstitutionalised-threshold ${ }^{102}$ as preconverging-or-dementing 20 -apriorising-psychologism/oblongated/decandored-anddialectically-or-contendingly-out-of-phase explaining the nature of mental-devisingrepresentation of all institutional-cumulation/institutional-recomposure-〈as-tohistoriality/ontological-eventfulness /ontological-aesthetic-tracing-<perspective- 
ontological-normalcy/postconvergence-reflected-‘epistemicity-relativism-determinism’>>

whether from the perspective of a retrospect, our present or prospective point-of-reference. Another aspect highlighted by the Arithmetic equation comparison is with respect to the appropriateness and defects of meaningful references with respect to ontologicalveridicality/intrinsic-reality. The comparison highlights 3 transversality-<for-sublimatingexistential-eventuating/denouement,-from-'thinking-at-first/pure-predisposition-preemptive-ofprospective-disontologising/subontologising' - as-of-prospectively-disambiguated-affirmedand-unaffirmed-'motif-and-apriorising/axiomatising/referencing'>101 pedestals of meaningfulness. Firstly, A's condition with respect to additionality with the idea that it is bound to fail any arithmetic calculation involving additionality. Thus the subknowledging impulse/compulsive-dementing pedestal is of notional-discontiguity/epistemicdiscontiguity 3 - $<$ between - prior-shallow-supererogation -of-mentallyaestheticised preconverging/dementing -qualia-schema_and_prospective-profoundsupererogation -of-mentally-aestheticised postconverging/dialectical-thinking -qualiaschema $>$ /non-ontological-and-non-contending-referencing- $<$ thus-ontologically-orcontendingly-reflected-or-perspectivated-as-of-preconverging-or-dementing ${ }^{20}$-apriorisingpsychologism $>\quad$ (not-veridical-thinking-reference-rather-preconverging-or-dementing ${ }^{20}$ reference). This is effectively the pedestalled state of psychopathic postlogism 7 -as-ofcompulsing-nonconviction/madeupness/bottomlining-〈'<decontextualising/deexistentialising $\sim$ of-attendant-intradimensional-apriorising/axiomatising/referencing $>$-induceddisontologising'-of-the-'attendant-intradimensional-ontologising'-imbued$<$ contextualising/existentialising attendant-ontological-contiguity $>$;-in-shallowsupererogation -<as-to-disontologising-perverted-outcome-sought-precedes-existentiallyveridical-'attendant-intradimensional-apriorising/axiomatising/referencing'-logical-dueness $>$ > in hollow-constituting-<as-disjointed-misappropriation-of-meaningfulness-and-failing- 
intemporal-preservation $>$ as of vague-rhyming-or-copied-mimicry-or-formulaic-projection-orprojection-of-form-or-hollow-and-vague-vocalisation-or-subknowledging 94 inducing 'implicited_attendant-ontological-contiguity ${ }^{67}$ ' educedexistentialising/contextualising/textmalising_intelligibility/epistemicity/reflexivity-contiguity$<$ imbued-notional $\sim \operatorname{cogency}>,{ }^{\prime},-<$ reifying-or-elucidating-of-prospective-relative-ontologicalcompleteness -of- reference-of-thought- devolving-as-of-instantiative-context $>$ /nonveridical-hollow-narratives to be reflected/perspectivated from the intemporal/ontological angle as unsoundness-or-ontological-bad-faith/inauthenticity ${ }^{64}$-of- ${ }^{8}$ reference-of-thought or perversion-of- ${ }^{3}$ reference-of-thought- $<$ as-preconvergingly-

\section{apriorising/axiomatising/referencing-in-nonconviction/madeupness/bottomlining-as-to-}

shallow-supererogation $>$ as to preconverging-or-dementing ${ }^{20}$-apriorising-psychologism and so in $<$ amplituding/formative-epistemicity $>$ totalising $\sim$ self-referencingsyncretising/circularity/interiorising/akrasiatic-drag ${ }^{34}$ or absolving/fleeting/escaping-reflexlogic , from one set-of-postlogic-narratives to the other and one set of interlocutors to the other, in line with its 'short cut' mental relation to meaningfulness as extrinsic-attribution (the temporal

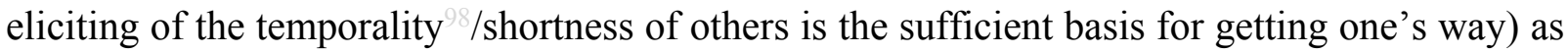
opposed to intrinsic-attribution wherein the intrinsic ontological-veridicality of meaning is the complete and sufficient basis for its pertinence and upholding. This subknowledging impulse/compulsive-dementing ${ }^{20}$ disposition points out that the actual and given meaningfulness being subknowledged/pervertedly-represented is ontologically-veridical both registry-wise (soundness-or-ontological-good-faith/authenticity ${ }^{69}$-of- ${ }^{83}$ reference-of-thought-wise) and logicwise (the normal arithmetic operation of the BODMAS equation) as it is intemporally preservational and thus ontologically-veridical/ ${ }^{83}$ reference-of-thought/relativeunreflexivity/relative-reflexivity - ontological-contiguity ${ }^{67}$. It is this pedestal that is the organic-

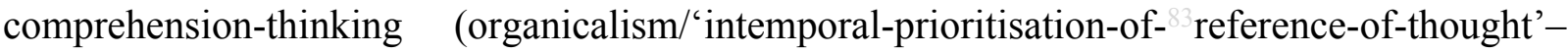


as-conflatedness ${ }^{13}$-or-ontological-reprojecting/longness-of register-of- meaningfulness-andteleology ${ }^{\circ}$ ) pedestal, organic as it is both registry-wise (soundness-or-ontological-goodfaith/authenticity ${ }^{6}$-of- ${ }^{8}$ reference-of-thought-wise) and logic-wise striving for intemporalpreservation-entropy-or-contiguity-or-ontological-preservation. It is the superseding and intemporal pedestal for articulating ontological meaningfulness (intrinsic-attribution). The third pedestal as demonstrated involves the integrating and <amplituding/formativeepistemicity $>$ totalising $\sim$ self-referencing-syncretising/circularity/interiorising/akrasiatic-drag by temporal-dispositions both unconsciously (ignorance) and consciously (affordability/opportunism/exacerbation/social-chainism-or-social-discomfiture-or-negativesocial-aggregation/temporal-enculturation-or-temporal-endemisation) with A's condition/subknowledging impulse as if it was ontologically veridical, and obviously leading to the wrong result thus failing/not-upholding-<as-of-apriorising/axiomatising/referencing $>$ intemporalpreservation-entropy-or-contiguity-or-ontological-preservation. In the case with B it involved resolving the Arithmetic equation as if A's condition was appropriate resulting in 72.5 which is 'epistemically-decadent in notional-discontiguity/epistemic-discontiguity ${ }^{6}-<$ between - priorshallow-supererogation -of-mentally-aestheticised $\sim$ preconverging/dementing -qualiaschema_and prospective-profound-supererogation -of-mentallyaestheticised postconverging/dialectical-thinking -qualia-schema>' rather than which is ontologically veridical. This is the threshold-of-nonconviction/madeupness/bottomlining-inshallow-supererogation -<as-to-'attendant-intradimensional'-prospectivelydisontologising preconverging/dementing -apriorising-psychologism $>$ pedestal, as registrywise it is not striving for intemporal-preservation-entropy-or-contiguity-or-ontologicalpreservation and so fundamentally its logical-contention is voided (as apriorising-registry precedes and defines logical pertinence), such that such a disposition that integrates subknowledging ${ }^{94}$-or-mimicking-impulse/compulsive-dementing ${ }^{20} \quad$ registry-worldview- 
wise/dimensional-wise speaks of the registry-worldview/dimension as in de-mentation〈supererogatory ontological-de-mentation-or-dialectical-de-mentation-stranding-or-

attributive-dialectics $\rangle$ at that uninstitutionalised-threshold ${ }^{102}$. The fourth meaningful reference is actually a variance of the given organic-comprehension-thinking (organicalism/“intemporalprioritisation-of- ${ }^{3}$ reference-of-thought'-as-conflatedness ${ }^{13}$-or-ontological-

reprojecting/ongness-of register-of meaningfulness-and-teleology ) pedestal which is registry-wise and logic-wise pertinent. It is about the intellectual and virtue driven aetiologisation/ontological-escalation-<ontological-

veridicality_commitment/otherliness_transcending/compulsions-encumbered_transcending $>$ (as per this paper aim and other studies) in grasping the human ontological implications and articulating the-Good/knowledge-reification $\sim$ gesturing-and-accounting-of-epistemicphenomenalism- $<$ in-prospective_psychologismic $\sim$ apriorising/axiomatising/referencing- of'prospectively_implicited_attendant-ontological-contiguity ' ceducedexistentialising/contextualising/textualising_'intelligibility/epistemicity/reflexivity-contiguity<imbued-notional cogency >' \}-conflatedness -in-\{preconverging disentailment by\} postconverging-entailment $>$ /understanding/<amplituding/formativeepistemicity $>$ causality $\sim$ as-to-projective-totalitative-implications-of-prospectivenonpresencing,-for-explicating relative-unreflexivity/relative-reflexivity - ontologicalcontiguity construct for the possibility of a conceptual insight and preconverging/postconverging-de-mentative/structural/paradigmatic resolution with regards to (at the registry-worldview/dimension or intradimensional level) procrypticism/the-reality-ofhuman-notional firstnaturedness-formativeness-<as-to-eventualising-inkling-drive-orseeding misprising $>$ temporal-to-intemporal-dispositions- $<$ so-construed-as-fromperspective-ontological-normalcy/postconvergence $>$-with-consequential-positivisticmeaningfulness-perversion preconverging-or-dementing ${ }^{20}$-apriorising-psychologism, resolved 
by deprocrypticism. Comparatively, for instance, articulating new ${ }^{83}$ reference-of-thoughtcategorical-imperatives/axioms/registry-teleology ${ }^{9}$,-for-intemporal-preservation-entropy-orcontiguity-or-ontological-preservation to resolve the uninstitutionalised-threshold ${ }^{102}$ from 72.5 to the ontologically-veridical 66 , and so not only with regards to the specific but as a preconverging/postconverging-de-mentative/structural/paradigmatic institutionalisation/intemporalisation for perpetuating intemporal-preservation-entropy-orcontiguity-or-ontological-preservation. This pedestalled articulation points out that the organiccomprehension-thinking (organicalism/'intemporal-prioritisation-of- ${ }^{8}$ reference-of-thought'as-conflatedness ${ }^{13}$-or-ontological-reprojecting/longness-of-register-of- meaningfulness-andteleology ) pedestal (ontological-veridicality $/{ }^{83}$ reference-of-thought) is transversal/transversality-<for-sublimating-existential-eventuating/denouement-from-

\section{thinking at first/pure-predisposition-preemptive-of-prospective-}

\section{disontologising/subontologising’ as-of-prospectively-disambiguated-affirmed-and-}

unaffirmed-'motif-and-apriorising/axiomatising/referencing' ${ }^{101}$ and not actually in logicalcongruence with both the subknowledging -impulse/compulsive-dementing pedestal (ontological-decandence/non-ontological-reference/non-contending-reference-butontologically-or-contendingly-reflected-or-perspectivated-as-preconverging-or-dementing ${ }^{20}$ apriorising-psychologism/not-veridical-thinking-reference-rather-preconverging-ordementing -reference) and the threshold-of-nonconviction/madeupness/bottomlining-inshallow-supererogation $-<$ as-to-'attendant-intradimensional'-prospectivelydisontologising preconverging/dementing -apriorising-psychologism $>$ pedestal (epistemicdecadence/non-ontological-reference/non-contending-reference-but-ontologically-orcontendingly-reflected-or-perspectivated-as-preconverging-or-dementing ${ }^{20}$-apriorisingpsychologism/not-veridical-thinking-reference-rather-preconverging-or-dementing ${ }^{20}$-reference) which is relates to as preconverging-or-dementing -apriorising-psychologism (as their fepistemic- 
tatising 3 psychologismic-subliminality-of-individuation_effusing/worlding imbued logicaldueness-or-scape-or-frame, profile-or-stature, presumptuousness-or-arrogation, assumptions, value-reference and teleology ${ }^{9}$ are all undue and pervertedly implied). So we then speak of an utter/ ${ }^{5}$ maximalising-recomposuring-for-relative-ontological-completeness ${ }^{8}$ — unenframed/reontologising conceptualisation (not incrementalism-in-relative-ontologicalincompleteness ${ }^{8}$ — enframed/disontologising conceptualisation) 'ordered construct' of the meaningfulness of the intellectual aetiologisation/ontological-escalation- $<$ ontologicalveridicality_commitment/otherliness_transcending/compulsions-encumbered_transcending $>$ as the organic-comprehension-thinking (organicalism/“intemporal-prioritisation-of- ${ }^{8}$ reference-ofthought'-as-conflatedness ${ }^{13}$-or-ontological-reprojectingAlongness-of-register-ofmeaningfulness-and-teleology ${ }^{\circ 9}$ pedestal reflecting/perspectivating/highlighting (reasoningthrough-and-not-reasoning-with) the registry/registry-worldview defects of both the subknowledging ${ }^{4}$-impulse pedestal and the threshold-ofnonconviction/madeupness/bottomlining-in-shallow-supererogation $<<$ as-to- 'attendantintradimensional'-prospectively-disontologising preconverging/dementing -apriorisingpsychologism $>$ pedestal. Ontologically-speaking, a temporal naivety with regards to psychopath and its protraction as social psychopathy is that going by the dynamism of its faulty-mentationprocedure-deception-or-urge towards 'extrinsic-attribution' (the eliciting of the temporality $/$ shortness of others is the sufficient basis for getting one's way), is that the number of people 'convinced' by perverted extrinsic-attribution involving social-and-temporal-trading can have any bearing to the ontological-veridicality/intrinsic-reality in any way. While temporally-speaking, psychopathic situations often lead to a-country-of-the-blind-and-the-oneeye kind of scenario, wherein a thousand blinds may strive to convention out the one-eye, but then it wouldn't still cut it, ontologically-speaking. (Certainly, it is equally and very possible that if such a one-eye isn't beholden to a 'sense of intemporality ${ }^{52}$, and it is rather temporally- 
inclined, it might equally take the easier route of reasoning in terms-as-of-axiomatic-construct of country-of-the-blind temporality $/$ shortness whether with respect to temporally outdoing or undermining the phenomena by acting in a manner that is overall of a temporal/shortness-ofregister-of meaningfulness-and-teleology nature. But that will still be temporality $/$ shortness and the notion of an aetiologisation/ontological-escalation-<ontologicalveridicality_commitment/otherliness_transcending/compulsions-encumbered_transcending $>$ as of intemporality $52 /$ longness will no more be better advanced. Further beyond and more than just with respect to one case of psychopathy but as of intellectual-and-moral-inequivalence/noncorrespondence construing the ${ }^{103}$ universal human social phenomena of psychopathic postlogism 77 and conjugated-postlogism 77 across space and time together with the bigger insight of grasping human nature and the overall possibilities thereof. Insightfully, as well it won't be surprising that such a ${ }^{103}$ universal projection will possibly meet with a more protracted-andprotracting psychopathy and social psychopathy manifestation going by overall human temporal-to-intemporal mental-disposition existential-form-factor as varied temporaldispositions come into the frame and are elicited, just as an intemporal projection within a nonpositivism/medievalism setup aspiring for a positivistic registry-worldview/dimension-level resolutive construal of their corresponding postlogism -as-of- compulsingnonconviction/madeupness/bottomlining-〈‘ $<$ decontextualising/de-existentialising $\sim$ ofattendant-intradimensional-apriorising/axiomatising/referencing $>$-induced-disontologising'-ofthe-'attendant-intradimensional-ontologising'-imbued$<$ contextualising/existentialising attendant-ontological-contiguity $>$;-in-shallowsupererogation -<as-to-disontologising-perverted-outcome-sought-precedes-existentiallyveridical-'attendant-intradimensional-apriorising/axiomatising/referencing'-logical-dueness $>$ > like notions-and-accusations-of-sorcery and which is not palliative to a given situation will equally elicit a social protractedness of the phenomenon as varied temporal-dispositions come 
into the frame and are equally elicited. But then that is an inevitability with respect to the more critical ${ }^{103}$ universal projection low-life purposefulness in both meaningful-frameworks). Rather this then points to the nature of postlogic ${ }^{74}$ perversion-of- ${ }^{3}$ reference-of-thought- $<$ aspreconvergingly-apriorising/axiomatising/referencing-innonconviction/madeupness/bottomlining-as-to-shallow-supererogation $>$ with temporaldispositions; (unconsciously) ignorance and (consciously) other temporal-dispositions of affordability/opportunism/exacerbation/social-chainism-or-social-discomfiture-or-negativesocial-aggregation/temporal-enculturation-or-temporal-endemisation. Ontologically, it is then the subject of contention and aetiologisation/ontological-escalation- $<$ ontologicalveridicality_commitment/otherliness_transcending/compulsions-encumbered_transcending $>$ of the organic-comprehension-thinking (organicalism/“intemporal-prioritisation-of- ${ }^{3}$ reference-ofthought'-as-conflatedness ${ }^{13}$-or-ontological-reprojectingAongness-of register-ofmeaningfulness-and-teleology ) pedestal, both in apriorising-registry and registry-worldview terms as it is reflected/perspectivated as de-mentation-/supererogatory $\sim$ ontological-dementation-or-dialectical-de-mentation-stranding-or-attributive-dialectics $\rangle$. The critical reason for this is that the intemporal-disposition is rather inclined to be utter about intemporalpreservation-entropy-or-contiguity-or-ontological-preservation as the complete and sufficient stand for knowledge and virtue with anything else being denaturing ${ }^{16}$ much in parallel as intrinsic-reality transcendental-enabling/sublimating/supereregatory $\sim$ de-mentativity doesn't accommodate human temporality ${ }^{9}$, and so will not even entertain involving in anyway with social-and-temporal-trading exercise which is non-ontological (since it is fundamentally a perversion-and-derived- ${ }^{74}$ perversion-of- ${ }^{8}$ reference-of-thought- $<$ as-preconverginglyapriorising/axiomatising/referencing-in-nonconviction/madeupness/bottomlining-as-toshallow-supererogation $>$, and has nothing to do with issues of defect-of- ${ }^{5}$ logical-processingor-logical-implicitation—supposedly-apriorising-in-conviction-as-to-profound- 
supererogation of the registry-worldview's/dimension's- ${ }^{83}$ reference-of-thought-for-socialfunctioning-and-accordance). This can further be elucidated analysing ${ }^{74}$ perversion-ofreference-of-thought-<as-preconvergingly-apriorising/axiomatising/referencing-in-

nonconviction/madeupness/bottomlining-as-to-shallow-supererogation $>$ of a different nature in a superseded registry-worldview/dimension like non-positivism/medievalism registryworldview/dimension which should provide an even greater insight analysing from our present perspective, and we can then comparatively project this with respect to notional ${ }^{1}$ deprocrypticism and procrypticism. For instance, accusations of witcheraft in nonpositivism/medievalism societies are ontologically about subknowledging $/ /$ perversion-ofreference-of-thought-<as-preconvergingly-apriorising/axiomatising/referencing-innonconviction/madeupness/bottomlining-as-to-shallow-supererogation $>$ as-of-unsoundnessor-ontological-bad-faith/inauthenticity ${ }^{4}$-of- ${ }^{8}$ reference-of-thought/preconverging-ordementing -apriorising-psychologism based on the fact that such societies didn't develop and integrate notions of empirical and rational cause-and-effect positivistic ideas as ${ }^{83}$ reference-ofthought- ${ }^{8}$ ategorical-imperatives/axioms/registry-teleology ${ }^{99}$,-for-intemporal-preservationentropy-or-contiguity-or-ontological-preservation (a mentation-capacity that further furthers the intemporal-preservation-entropy-or-contiguity-or-ontological-preservation as modern-day positivistic registry-worldview), as it ${ }^{103}$ universally informs the present positivistic worldview and thus the impossibility to sound intelligible in case such an accusation of witchcraft is made today. So structurally, the non-positivism/medievalism society is shaped-and-inclined to integrate and entertain phantasmagorical notions of someone being accused as a witch or sorcerer. We can garner a similar insight just as with the 'disambiguation of

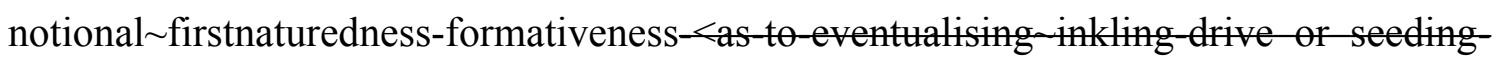
misprising $>$ temporal-to-intemporal-dispositions- $<$ so-construed-as-from-perspectiveontological-normalcy/postconvergence $>$ as aetiologisation/ontological-escalation- $<$ ontological- 
veridicality_commitment/otherliness_transcending/compulsions-encumbered_transcending>' above, where supposed an intemporal mindset/ $/{ }^{3}$ reference-of-thought who is in a nonpositivism/medievalism society was to be accused of witchcraft by someone inclined to accuse people of witchcraft (because of a pathological-condition/subknowledging impulse/compulsive-dementing ${ }^{20}$ ) and who obviously is wrong, as we know today that the notion of witchcraft is ontologically unsound and ridiculous as the ability to perform magic and the like by anyone cannot be demonstrated veridically. The disposition to accuse people of witchcraft will be the subknowledging -impulse/compulsive-dementing pedestal. The disposition to entertain and further exploit such situations (as anthropologists perfectly understand the abhorrent role of such notions as witchcraft in the social-stake-contention-or-confliction of nonpositivism/medievalism societies) in conjugation of temporal-dispositions that are ${ }^{3}$ universally-recurrent or ${ }^{103}$ universal across all times (postlogism ${ }^{77}$-slantedness, ignorance/affordability/opportunism/exacerbation/social-chainism-or-social-discomfiture-ornegative-social-aggregation/temporal-enculturation-or-temporal-endemisation) is the thresholdof-nonconviction/madeupness/bottomlining-in-shallow-supererogation $-<$ as-to-' attendantintradimensional'-prospectively-disontologising preconverging/dementing -apriorisingpsychologism $>$ pedestal which is rather an extricatory preconverging-dementating/structuring/paradigming (of the situation, to fulfil temporal inclinations or distractivetemporal-prioritisaton and not intemporal preservation); given the lack of a social ${ }^{103}$ universaltransparency ${ }^{104}$-〈transparency-of-totalising-entailing,-as-to-entailing-<amplituding/formativeepistemicity>totalising in-relative-ontological-completeness $>$ of the idea that the notion of witchcraft is bogus, with corresponding lack of perceived untenability/internalcontradiction/internal-incoherence/institutional-constraining of such a notion, thus a collectiveconsciousness that doesn't register it as preconverging-or-dementing ${ }^{20}$-apriorisingpsychologism (as we do today) and finally, no ontological alienating reason for not believing, 
endemising and enculturating the phenomenon of witchcraft. The organic-comprehensionthinking (organicalism/'intemporal-prioritisation-of- ${ }^{8}$ reference-of-thought'-asconflatedness ${ }^{13}$-or-ontological-reprojecting/longness-of register-of meaningfulness-andteleology ) pedestal will rather be an inclination to see that the lack of empirical and rational reference-of-thought- categorical-imperatives/axioms/registry-teleology ${ }^{99}$,-for-intemporalpreservation-entropy-or-contiguity-or-ontological-preservation of the nonpositivism/medievalism registry-worldview/dimension is actually, in-the-bigger-scheme-ofthings, what is at the basis of not only the 'one locale accusation of witchcraft, specifically so with this individual but its general integration as a socially viable and entertained notion in this locale'. But more critically, $\quad$ from its intemporal/ontological/social/species/ ${ }^{103}$ universal/transcendental/ ${ }^{5}$ maximalisingrecomposuring-for-relative-ontological-completeness ${ }^{8}$ —unenframed/reontologising conceptualisation postconverging-de-mentating/structuring/paradigming to be intemporally-preservational, more than the notion of just attaining only to the 'one-locale' accusation of witchcraft, for the intemporal mindset $/{ }^{3}$ reference-of-thought in organic-

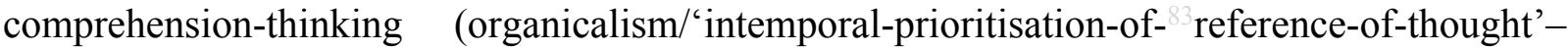
as-conflatedness ${ }^{13}$-or-ontological-reprojecting-tongness of register of - meaning fulness and teleology ) the problem is now the insight about the intellectually and morally wrong in 'metaphorically-a-million-and-one-instances-and-locales as to aetiologisation/ontologicalescalation-<ontological-veridicality_commitment/otherliness_transcending/compulsionsencumbered_transcending >' of accusation of witchcraft and the implications across all societies of the human species qualified as non-positivism/medievalism, with the bigger ontological implications of this specific accusation rather being how is this enlightening preconverging/postconverging-de-mentatively/structurally/paradigmatically about the endemisation and enculturation of vices-and-impediments ${ }^{105}$ associated with superstition in the 
said registry-worldview/dimension. That is, the problem is now about the aetiologisation/ontological-escalation-<ontological-

veridicality_commitment/otherliness_transcending/compulsions-encumbered_transcending $>$ that can be made to address such lack of positivistic empirical and rational notions in all possible human societies qualified as non-positivism/medievalism. In other words, the graver ${ }^{15}$ dementation-〈supererogatory $\sim$ ontological-de-mentation-or-dialectical-de-mentation — strandingor-attributive-dialectics〉 problem' for the organic-comprehension-thinking (organicalism/“intemporal-prioritisation-of- ${ }^{8}$ reference-of-thought'-as-conflatedness ${ }^{13}$-orontological-reprojecting/longness-of-register-of- meaningfulness-and-

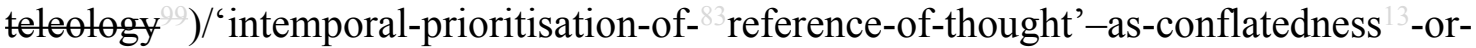
ontological-reprojecting pedestal is 'why is society non-positivism/medievalism, and it is not in 'mentation equivalence' with a subknowledging -impulse/compulsive-dementing mindset $/{ }^{3}$ reference-of-thought pedestal accusing it of witchcraft and the specific locale where such an accusation is made in threshold-of-nonconviction/madeupness/bottomlining-inshallow-supererogation -<as-to-'attendant-intradimensional'-prospectivelydisontologising $\sim$ preconverging/dementing -apriorising-psychologism $>$ /temporal prioritisation pedestal that entertains notions of witchcraft (as the intemporal mindset $/{ }^{3}$ reference-of-thought is thus anecdotally 'boxing far below its weight'). Rather it is about articulating a comprehensive preconverging/postconverging-de-mentative/structural/paradigmatic dialecticism reasoningthrough/utterion (not reasoning-with incrementalism-in-relative-ontologicalincompleteness —enframed/disontologising conceptualisation with temporal-dispositions mindsets) between non-positivism/medievalism and positivism for prospective 'postconvergingor-dialectical-thinking -psychology or psychology-of-mentation-dynamics or natural psychological-dynamics' psychoanalytic-unshackling/memeticreordering/institutional-recomposuring away from the vices-and-impediments ${ }^{105}$ of a non- 
positivism/medievalism superstitious mental-disposition towards a prospective positivistic mental-disposition which is the virtue that is the 'preconverging/postconverging-dementative/structural/paradigmatic resolution' to the superseded registry-worldview/dimension not only superstitious specific vices-and-impediments ${ }^{105}$ but equally critical the overall preconverging/postconverging-de-mentative/structural/paradigmatic <amplituding/formativeepistemicity $>$ causality $\sim$ as-to-projective-totalitative-implications-of-prospective-

\section{nonpresencing,-for-explicating relative-unreflexivity/relative-reflexivity ontological-}

contiguity such superstition to the creative emancipation of human meaningfulness and action. With this insight the ontological 'terms of reasoning' of the subknowledging impulse/compulsive-dementing ${ }^{20}$ pedestal is a wrong and naïve 'mentation equivalence' in preconverging-or-dementing ${ }^{20}$-apriorising-psychologismly striving to establish whether the accused is involved in witchcraft; the 'terms of reasoning' of the threshold-ofnonconviction/madeupness/bottomlining-in-shallow-supererogation $-<$ as-to-' ${ }^{\text {attendant- }}$

\section{intradimensional'-prospectively-disontologising preconverging/dementing -apriorising-}

psychologism $>$ pedestal is a wrong and naïve 'mentation equivalence' in preconverging-ordementing -apriorising-psychologismly striving to establish and examine whether the accusation of witchcraft is true or not, with all the implied existential-disente entologising apereticism $>$ implications meaningfulness in both cases; and the 'terms of reasoning' of the organic-comprehension-thinking (organicalism/“intemporal-prioritisation-ofreference-of-thought'-as-conflatedness ${ }^{13}$-or-ontological-reprojectingAlongness-of register-ofmeaningfulness-and-teleology ${ }^{9}$ ) will be to be dismissive of the two prior pedestals as in ${ }^{15}$ dementation-〈supererogatory $\sim$ ontological-de-mentation-or-dialectical-de-mentation — strandingor-attributive-dialectics〉 and of preconverging-or-dementing -apriorising-psychologism$<$ stranded-as-rightfully-oblongated/decandored-and-dialectically-or-contendingly-out-ofphase $>$ since in reality the elements of their apriorising-registry are perverted (implied-logical- 
dueness -as to accusation of witchcraft, implied-profile, implied-presumptuousness/arrogation, implied-assumptions, implied-value-reference and implied-teleology ${ }^{\circ}$ ), and the issue will rather be about reflecting/perspectivating/highlighting (reasoning-through-and-not-reasoning-with) the perversion-of- ${ }^{-3}$ reference-of-thought-<as-preconvergingly-

\section{apriorising/axiomatising/referencing-in-nonconviction/madeupness/bottomlining-as-to-}

shallow-supererogation $>$ of a registry-worldview/dimension that endemises and enculturates the belief in superstition and witchcraft for a preconverging/postconverging-dementative/structural/paradigmatic resolution

as intemporal/ontological/social/species/ ${ }^{103}$ universal/transcendental/ ${ }^{5}$ maximalisingrecomposuring-for-relative-ontological-completeness ${ }^{7}$ — unenframed/reontologising conceptualisation postconverging-de-mentating/structuring/paradigming. In other words, the temporal-dispositions are not logically-contending but ontologically or dialectically preconverging-or-dementing ${ }^{20}$-apriorising-psychologism as they are rather the subject of contention and aetiologisation/ontological-escalation- $<$ ontologicalveridicality_commitment/otherliness_transcending/compulsions-encumbered_transcending > from the intemporal-disposition given that these are dialectically-or-contendingly-out-of-phase and $<$ amplituding formative-epistemicity $>$ totalising $\sim$ self-referencingsyncretising/circularity/interiorising/akrasiatic-drag ${ }^{34}$. The reason for the above 'intemporalprioritisation-of- ${ }^{8}$ reference-of-thought'-as-conflatedness ${ }^{3}$-or-ontological-reprojecting pedestalling is simple. 'Intemporal-prioritisation-of- ${ }^{83}$ reference-of-thought'-as-conflatedness ${ }^{13}$ or-ontological-reprojecting pedestalling carries the implication that ${ }^{8}$ reference-of-thought and meaningfulness is fundamentally/ontologically structured for ontologicalnormalcy/postconvergence intemporal-preservation-entropy-or-contiguity-or-ontologicalpreservation, and hence the precedence of higher-intemporal-teleologies (organiccomprehension-thinking pedestal) over low temporal teleologies of ${ }^{83}$ reference-of-thought and 
meaningfulness

( 7 perversion-of- reference-of-thought-<as-preconvergingly-

apriorising/axiomatising/referencing-in-nonconviction/madeupness/bottomlining-as-to-

shallow-supererogation $>$ as to preconverging-or-dementing ${ }^{20}$-apriorising-psychologism); and that subpar preconverging-de-mentating/structuring/paradigming of ${ }^{83}$ reference-of-thought and meaningfulness not for intemporal-preservation-entropy-or-contiguity-or-ontologicalpreservation but rather for ${ }^{74}$ perversion-of- ${ }^{8}$ reference-of-thought- $<$ as-preconverginglyapriorising/axiomatising/referencing-in-nonconviction/madeupness/bottomlining-as-toshallow-supererogation $>\quad$ of $\quad$ subpar $\quad{ }^{83}$ reference-of-thought- categoricalimperatives/axioms/registry-teleology ${ }^{9}$,-of-intemporal-preservation-entropy-or-contiguity-orontological-preservation as uninstitutionalised-threshold ${ }^{02}$ is 'perverted ${ }^{83}$ reference-of-thought and meaningfulness' (<amplituding/formative-epistemicity $>$ totalising $\sim$ self-referencingsyncretising/circularity/interiorising/akrasiatic-drag ${ }^{34}$ ), and is ontologically-preconverging-ordementing -apriorising-psychologism （dialectically-preconverging-or-dementing 20 apriorising-psychologism) whether from a superseding/transcending registry/registryworldview $\quad{ }^{83}$ reference-of-thought/veridical-thinking-reference-over-preconverging-ordementing ${ }^{20}$-reference that is retrospective (like base-institutionalisation over recurrent-utteruninstitutionalisation), present (like positivism over non-positivism/medievalism) or prospective (like notional ${ }^{1}$ deprocrypticism over procrypticism/the-'preconverging-or-dementing ${ }^{20}$ apriorising-psychologism-of-the-positivistic-registry-worldview-or-dimension-categoricalimperatives-or-axioms-or-registry-teleology ${ }^{9}$-for-intemporal-preservation-entropy-orcontiguity-or-ontological-preservation). Such a stance equally applies between the superseding/transcending notional ${ }^{18}$ deprocrypticism and the superseded/transcended procrypticism registry-worldviews/dimensions with organic-comprehension-thinking in 'intemporal-prioritisation-of- ${ }^{-3}$ reference-of-thought'-as-conflatedness ${ }^{13}$-or-ontologicalreprojecting as longness-of-register-of- - meaningfulness-and-teleology of 
notional ${ }^{18}$ deprocrypticism

nonconviction/madeupness/bottomlining-in-shallow-supererogation -<as-to-'attendantintradimensional'-prospectively-disontologising preconverging/dementing -apriorisingpsychologism $>$ /alchemic-like-reasoning in circumventive/distractive-temporal-prioritisationof- ${ }^{8}$ reference-of-thought as shortness-of-register-of- ${ }^{5}$ meaningfulness-and-teleology ${ }^{9}$ of procrypticism mental-dispositions. While the de-mentation-〈supererogatory ontological-dementation-or-dialectical-de-mentation — stranding-or-attributive-dialectics $\rangle$ with respect to nonpositivism/medievalism has to do with not integrating empirical and rational positivistic reference-of-thought- categorical-imperatives/axioms/registry-teleology 9 and the corresponding social implications, the de-mentation-〈supererogatory 0 ontological-dementation-or-dialectical-de-mentation-stranding-or-attributive-dialectics $\rangle$ with procrypticism has to do with not integrating the veridicality of temporal-dispositions ${ }^{74}$ perversion-ofreference-of-thought-<as-preconvergingly-apriorising/axiomatising/referencing-innonconviction/madeupness/bottomlining-as-to-shallow-supererogation $>$ as to preconvergingor-dementing ${ }^{20}$-apriorising-psychologism of positivistic ${ }^{83}$ reference-of-thought- categoricalimperatives/axioms/registry-teleology ${ }^{9}$,-for-intemporal-preservation-entropy-or-contiguityor-ontological-preservation as knowledge-notionalisation and a corresponding de-mentation-

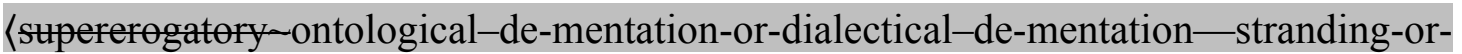
attributive-dialectics $\rangle$ 'intemporal-prioritisation-of- ${ }^{83}$ reference-of-thought'-as-conflatedness ${ }^{13}$ or-ontological-reprojecting pedestalling to reflect/perspectivate the subknowledging impulse/compulsive-dementing ${ }^{20}$ pedestal and the threshold-ofnonconviction/madeupness/bottomlining-in-shallow-supererogation $-<$ as-to-'attendantintradimensional'-prospectively-disontologising preconverging/dementing -apriorisingpsychologism $>$ pedestal from an organic-comprehension pedestal 'ontological-reference of thought and meaningfulness' for a superseding notional ${ }^{18}$ deprocrypticism institutionalisation 
universal/intemporal/ontological/intrinsic-attribution/longness-of-register-ofmeaningfulness/human-species-level postconverging-de-mentating/structuring/paradigming across all space and all time (and not a temporal, extricatory, shortness-of-register-ofmeaningfulness-and-teleology ${ }^{9}$, individuals, extrinsic-attribution, incidental or incremental or 'disjointedness-as-of- ${ }^{8}$ reference-of-thought' or temporal-accommodation preconverging-dementating/structuring/paradigming that endemises and enculturates procrypticism) to induce the appropriate prospective crossgenerational 'postconverging-or-dialectical-thinking psychology or psychology-of-mentation-dynamics or natural psychological-dynamics’ psychoanalytic-unshackling/memetic-reordering/institutional-recomposuring. This conceptual de-mentation-/supererogatory ontological-de-mentation-or-dialectical-de-mentationstranding-or-attributive-dialectics $\rangle$ of (superseded registry/registry-worldview-or-dimension) mental-devising-representation as oblongated/decandored-and-dialectically-or-contendinglyout-of-phase (preconverging-or-dementing ${ }^{20}$-apriorising-psychologism) and (superseding registry/registry-worldview-or-dimension) mental-devising-representation as straightness/candored-and-dialectically-or-contendingly-in-phase (thinking) is critical in grasping the nature of 'intemporal-prioritisation-of- ${ }^{3}$ reference-of-thought'-as-conflatedness ${ }^{13}$ or-ontological-reprojecting with respect to circumventive/distractive-temporal-prioritisation-ofreference-of-thought as the former is 'utter' intemporal-preservation-entropy-or-contiguityor-ontological-preservation (and thus the requisite ${ }^{83}$ reference-of-thought- categoricalimperatives/axioms/registry-teleology ${ }^{9}$,-for-intemporal-preservation-entropy-or-contiguityor-ontological-preservation in order to arrive at /intemporal-preservation is downright uncompromisable). Circumventive/distractive-temporal-prioritisation-of- ${ }^{3}$ reference-of-thought involves various shades of incrementalism-in-relative-ontological-incompleteness enframed/disontologising conceptualisation temporal-accommodation with institutionalisation being rather a secondnaturing to a given set of ${ }^{83}$ reference-of-thought- categorical- 
imperatives/axioms/registry-teleology ${ }^{9}$,-for-intemporal-preservation-entropy-or-contiguityor-ontological-preservation as per percolation-channelling- $<$ in-deferential-formalisationtransference $>$ and a positive-opportunism-of-social-functioning-and-accordance institutionalisation constraining. This is 'no emanance transformation' of temporal-dispositions into the intemporal-disposition; as such a notion can only be solipsistic to individuals beyond the possibility of institutionalisation secondnaturing (point-of-ontological-faith-notion-orontological-fideism - imbued-underdetermination-of-motif-andapriorising/axiomatising/referencing-as-so-being-as-of-existential-reality/induced-ring-ofgyges-effect/solipsistic-point-of-temporal-thresholding). Thus at the uninstitutionalisedthreshold ${ }^{102}$, circumventive/distractive-temporal-prioritisation-of- ${ }^{-}$reference-of-thought will very well do with an outcome (other than its inherent intemporal-projection) whether it is failing/not-upholding-<as-of-apriorising/axiomatising/referencing $>$ intemporal-preservationentropy-or-contiguity-or-ontological-preservation, given its solipsistic disparate nature (noncontiguous/discrete hence of notional-discontiguity/epistemic-discontiguity ${ }^{63}<$ between prior-shallow-supererogation -of-mentally-aestheticised preconverging/dementing -qualiaschema_and_prospective-profound-supererogation -of-mentally-

aestheticised postconverging/dialectical-thinking -qualia-schema $>$ ) with respect to the notion of ${ }^{8}$ reference-of-thought- categorical-imperatives/axioms/registry-teleology ,-for-intemporalpreservation-entropy-or-contiguity-or-ontological-preservation as being about intemporalpreservation-entropy-or-contiguity-or-ontological-preservation, and so, especially when postlogic and integrating the hollow-constituting-<as-disjointed-misappropriation-ofmeaningfulness-and-failing-intemporal-preservation> of postlogism $>$-as-of- compulsingnonconviction/madeupness/bottomlining-〈“<decontextualising/de-existentialising $\sim$ ofattendant-intradimensional-apriorising/axiomatising/referencing $>$-induced-disontologising'-ofthe-'attendant-intradimensional-ontologising'-imbued- 
$<$ contextualising/existentialising attendant-ontological-contiguity $>$;-in-shallow-

supererogation -<as-to-disontologising-perverted-outcome-sought-precedes-existentially-

veridical-'attendant-intradimensional-apriorising/axiomatising/referencing'-logical-dueness $>>$.

And critically, it should be noted that 'intemporal-prioritisation-of- ${ }^{8}$ reference-of-thought'-asconflatedness ${ }^{13}$-or-ontological-reprojecting is about the-Good/knowledge-reification $\sim$ gesturingand-accounting - of-epistemic-phenomenalism- $<$ in-

prospective_psychologismic apriorising/axiomatising/referencing-\{of- ${ }^{\text {}}$ prospectively implicited_attendant_ontological-contiguity ' educed-

existentialising/contextualising/textualising_'intelligibility/epistemicity/reflexivity-contiguity$<$ imbued-notional cogency $\left.>^{\prime} \quad\right\}$-conflatedness -in-\{preconverging disentailment by\} postconverging-entailment>/understanding/<amplituding/formativeepistemicity $>$ causality as-to-projective-totalitative-implications-of-prospectivenonpresencing,-for-explicating relative-unreflexivity/relative-reflexivity - ontologicalcontiguity conceptualisation as registry-worldview/dimension defining, and not about goodnaturedness/vague-temporal-impression-driven notions that may arise in circumstantial situations. This Arithmetic notional-contiguity/epistemic-contiguity ${ }^{6}-<$ profoundsupererogation -of-mentally-aestheticised postconverging/dialectical-thinking -qualiaschema $>$ comparison equally gives an insight on why notional firstnaturedness-formativeness$\leq$ as-to-eventualising-inkling drive-or-seeding misprising $>$ temporal-to-intemporaldispositions-<so-construed-as-from-perspective-ontological-normalcy/postconvergence $>$ pedestals-disambiguation is needed with 3 pedestals: organic-comprehesion/“intemporalprioritisation-of- ${ }^{8}$ reference-of-thought'-as-conflatedness ${ }^{13}$-or-ontological-reprojecting pedestal for which the intemporal-preservation-entropy-or-contiguity-or-ontologicalpreservation as ontology supersedes ${ }^{74}$ perversion-of- ${ }^{8}$ reference-of-thought- $<$ aspreconvergingly-apriorising/axiomatising/referencing-in- 
nonconviction/madeupness/bottomlining-as-to-shallow-supererogation $>$ (as prior intemporal reference-of-thought- categorical-imperatives/axioms/registry-teleology ${ }^{9}$ ) which are actually meant to represent it at uninstitutionalised-threshold ${ }^{102}$, threshold-ofnonconviction/madeupness/bottomlining-in-shallow-supererogation $<<$ as-to-'attendantintradimensional'-prospectively-disontologising preconverging/dementing -apriorisingpsychologism $>$ pedestal for which ${ }^{83}$ reference-of-thought- categoricalimperatives/axioms/registry-teleology ${ }^{9}$,-for-intemporal-preservation-entropy-or-contiguityor-ontological-preservation are wrongly related to as an end by themselves at uninstitutionalised-threshold $^{102}$, and postlogic-including-psychopathic/subknowledging impulse/compulsive-dementing /vague-rhyming-or-copied-mimicry-or-formulaic-projectionor-projection-of-form-or-hollow-and-vague-vocalisation-or-subknowledging ${ }^{4}$ pedestal for which the hollow form of ${ }^{8}$ reference-of-thought- categorical-imperatives/axioms/registryteleology ${ }^{9}$,-for-intemporal-preservation-entropy-or-contiguity-or-ontological-preservation for perversion-of- ${ }^{3}$ reference-of-thought-<as-preconvergingly-

\section{apriorising/axiomatising/referencing-in-nonconviction/madeupness/bottomlining-as-to-}

shallow-supererogation $>$ of ${ }^{83}$ reference-of-thought and meaningfulness is a sound existentialdisontelogising/re ontelogising apereticism $>$ construct. That is, in the bigger scheme when it comes to deciding between ontological-veridicality/relative-unreflexivity/relativereflexivity - ontological-contiguity ${ }^{67}$ of ${ }^{83}$ reference-of-thought (as from ontologicalnormalcy/postconvergence epistemic-or-notional projective-perspective) and the human temporal psyche, what gives-in is the human temporal psyche (and so for the betterment of the species); that is, from an animal that was emanantly/becomingly/solipsistically successively of a mental-devising-representation perspective preconverging-or-dementing ${ }^{20}$-apriorisingpsychologism-<stranded-as-rightfully-oblongated/decandored-and-dialectically-orcontendingly-out-of-phase $>$ at recurrent-utter-uninstitutionalisation, ununiversalisation, non- 
positivism/medievalism, and from a prospective articulation, ${ }^{8}$ procrypticism-or-disjointednessas-of- reference-of-thought, and so respectively, for their successive institutionalisations mental-devising-representation perspectives as postconverging-or-dialectical-thinking apriorising-psychologism- $<$ stranded-as-rightfully-straight/candored-and-dialectically-orcontendingly-in-phase $>$ of base-institutionalisation, ${ }^{103}$ universalisation, positivism and prospectively deprocrypticism. In other words, across all times the 'limits of thought' is not the 'averageness/banality/temporalisation of thought' but rather the 'disposition to intemporalise and ontologise human thought', and so whether from a sense of intrinsic-reality one mortal is rightfully saying that the world is round and by expediency a majority of mortals are saying it is flat. That is the singular construct that man cannot lose across all generations to enable the perpetual existential-<disontologising/re-ontologising aporeticism $>$ regeneration of civilisation beyond just being a secondnatured construct as mere-institutionalised-being-andcraft (which can often actually turn out to be alien to the intemporal-disposition apriorisingregistry, that we can all potentially cultivate, that created, creates, and needs to keep creating the conditions for institutionalisation perpetuation)! It should be noted that the establishment of the reality of an apriorising/axiomatising/referencing-registry's, or in-the-bigger-picture, registryworldview's/dimension's $\quad$ reference-of-thought, dialectical-out-of-phasing at an uninstitutionalised-threshold ${ }^{102}$ speaks of that apriorising-registry's or registryworldview's/dimension's ${ }^{83}$ reference-of-thought ${ }^{15}$ de-mentation-〈supererogatory $\sim$ ontologicalde-mentation-or-dialectical-de-mentation - stranding-or-attributive-dialectics $\rangle$ preconvergingor-dementing 20 -apriorising-psychologism- $<$ stranded-as-rightfully-oblongated/decandored-anddialectically-or-contendingly-out-of-phase $>$ (as it is 'devoid of ${ }^{83}$ reference-of-thought and correspondingly ontological-veridicality/relative-unreflexivity/relative-reflexivity ontological-contiguity $^{67}$ given its epistemic-decadence/psychopath or epistemicdecadence/psychopath's-temporal-interlocutor, as ${ }^{71}$ perversion-of- ${ }^{8}$ reference-of-thought- $<$ as- 
preconvergingly-apriorising/axiomatising/referencing-in-

nonconviction/madeupness/bottomlining-as-to-shallow-supererogation $>$ the ${ }^{83}$ reference-ofthought- categorical-imperatives/axioms/registry-teleology ${ }^{9}$,-for-intemporal-preservationentropy-or-contiguity-or-ontological-preservation), and so, in a state of transversality-<forsublimating-existential-eventuating/denouement, from-'thinking-at-first/pure-predispositionpreemptive-of-prospective-disontologising/subontologising' as-of-prospectivelydisambiguated-affirmed-and-unaffirmed-'motif-and-apriorising/axiomatising/referencing'> as perceived from the superseding/transcending intemporal-disposition or registryworldview/dimension which voids the registry-perverting/subknowledging /preconverging-ordementing -temporal-dispositions' transcended-or-superseded-registryworldview's/dimension's apriorising-registry-elements as fepistemic-totalising 3? psychologismicsubliminality-of-individuation-effusing/worlding imbued logical-dueness-or-scape-or-frame, profile-or-stature, presumptuousness-or-arrogation, assumptions, value-reference and teleology . This as ${ }^{15}$ de-mentation-〈supereregatery $\sim$ ontological-de-mentation-or-dialecticalde-mentation-stranding-or-attributive-dialectics $\rangle$ is what prevents the $<$ amplituding/formative-epistemicity $>$ totalising $\sim$ self-referencing-syncretising-as-straight-andcandored, of the recurrence-of-in hollow-constituting-<as-disjointed-misappropriation-ofmeaningfulness-and-failing-intemporal-preservation $>$ in postlogic-backtracking- $<$ iterativelooping-'set-of-dereifying-hollow-narratives-and-acts'> $76 \quad$ as $\quad$ absolving/fleeting/escapingreflex-logic (which are veridically of notional-discontiguity/epistemic-discontiguity ${ }^{63}$ $<$ between - prior-shallow-supererogation -of-mentallyaestheticised $\sim$ preconverging/dementing -qualia-schema_and_prospective-profoundsupererogation -of-mentally-aestheticised postconverging/dialectical-thinking -qualiaschema $>$ ) as wrongly implied postlogicly-as-rather-being-prelogic; as the instigation (by psychopath) recurrently-of-in hollow-constituting-<as-disjointed-misappropriation-of- 
meaningfulness-and-failing-intemporal-preservation $>$ in postlogic-backtracking- $<$ iterativelooping-'set-of-dereifying-hollow-narratives-and-acts' $>76$ and as the hollow-constituting-<asdisjointed-misappropriation-of-meaningfulness-and-failing-intemporal-preservation> integration/conjoining (psychopath's temporal-interlocutors) recurrently-of-in hollowconstituting-<as-disjointed-misappropriation-of-meaningfulness-and-failing-intemporalpreservation $>$ in postlogic-backtracking-<iterative-looping-'set-of-dereifying-hollownarratives-and-acts' $>$, and in so doing intemporally/ontologically reflecting/perspectivating/highlighting the ontological-veridicality/ontological-reality of the psychopath's effective epistemic-decadence and the psychopath's temporal-interlocutors' epistemic-decadence as effectively preconverging-or-dementing 20 apriorising-psychologism$<$ stranded-as-rightfully-oblongated/decandored-and-dialectically-or-contendingly-out-ofphase $>$ in various shades of temporality ${ }^{8}$. For instance in registry-worldview/dimension terms, the de-mentation-/supererogatory $\sim$ ontological-de-mentation-or-dialectical-de-mentationstranding-or-attributive-dialectics $\rangle$ as to preconverging-or-dementing ${ }^{20}$-apriorisingpsychologism- $<$ stranded-as-rightfully-oblongated/decandored-and-dialectically-orcontendingly-out-of-phase $>$ of the non-positivism/medievalism mindset/ ${ }^{3}$ reference-of-thought with respect to the positivistic mindset/ ${ }^{3}$ reference-of-thought (as reflecting the former perversion of ${ }^{83}$ reference-of-thought- categorical-imperatives/axioms/registry-teleology ${ }^{9}$,-forintemporal-preservation-entropy-or-contiguity-or-ontological-preservation at the uninstitutionalised-threshold ${ }^{102}$ of non-positivistic ${ }^{56}$ meaningfulness-and-teleology ${ }^{9}$ ) wherein there can't be a logical nested-congruence or engagement between the two mindsets as these do not have common ${ }^{83}$ reference-of-thought- categorical-imperatives/axioms/registry-teleology ${ }^{99}$,for-intemporal-preservation-entropy-or-contiguity-or-ontological-preservation, with the ontological-veridicality/relative-unreflexivity/relative-reflexivity-ontological-contiguity ${ }^{67}$ of reference-of-thought as (from ontological-normalcy/postconvergence epistemic-or- 
notional projective-perspective) as a relevant contention exercise being all about the positivistic mindset/ ${ }^{3}$ reference-of-thought reflecting/perspectivating/highlighting (reasoning-through-andnot-reasoning-with) the non-positivism/medievalism registry-worldview/dimension as a manifestation of the latter mental-defect/ perversion-of- $^{-}$reference-of-thought- $<$aspreconvergingly-apriorising/axiomatising/referencing-innonconviction/madeupness/bottomlining-as-to-shallow-supererogation $>$ as-of-unsoundnessor-ontological-bad-faith/inauthenticity ${ }^{6}$-of- ${ }^{8}$ reference-of-thought as to the uninstitutionalisedthreshold ${ }^{102}$ of non-positivism/medievalism ${ }^{56}$ meaningfulness-and-teleology ${ }^{9}$ requiring positivistic ${ }^{56}$ meaningfulness-and-teleology ${ }^{9}$, and in-the-bigger-scheme-of-things requiring the secondnaturing of positivistic (as against non-positivism/medievalism) ${ }^{83}$ reference-of-thoughtcategorical-imperatives/axioms/registry-teleology ${ }^{9}$,-for-intemporal-preservation-entropy-orcontiguity-or-ontological-preservation. The point then is that, from a transcending registryworldview/dimension, the relation with its transcended registry-worldview/dimension is "not ontologically an exercise in logical-congruence with the transcended registryworldview/dimension as a postconverging-or-dialectical-thinking -apriorising-psychologism exercise' but rather ontologically an exercise in transversality-<for-sublimating-existentialeventuating/denouement, from 'thinking at first/pure predisposition preemptive of prospective-disontologising/subontologising' as-of-prospectively-disambiguated-affirmedand-unaffirmed-'motif-and-apriorising/axiomatising/referencing'>

reflecting/perspectivating/highlighting (reasoning-through-and-not-reasoning-with) a preconverging-or-dementing ${ }^{20}$-apriorising-psychologism representation as manifestation-andnot-contention of the transcended registry-worldview/dimension denaturing ${ }^{6}$ of ${ }^{83}$ reference-ofthought- categorical-imperatives/axioms/registry-teleology ${ }^{99}$,-for-intemporal-preservationentropy-or-contiguity-or-ontological-preservation for prospective positivistic meaningfulness, as preconverging-or-dementing -apriorising-psychologism- $<$ stranded-as-rightfully- 
oblongated/decandored-and-dialectically-or-contendingly-out-of-phase>, and avoiding the supplanting-conviction-as-to-profound-supererogation of- 'attendant-intradimensional'postconverging/dialectical-thinking -apriorising-psychologism reflex or prelogic-reflexadmittance-reflex or in-phase-reflex which wrongly elevates ${ }^{77}$ perversion-of- ${ }^{83}$ reference-ofthought-<as-preconvergingly-apriorising/axiomatising/referencing-innonconviction/madeupness/bottomlining-as-to-shallow-supererogation $>$ into logicalcontention. de-mentation-〈supererogatory $\sim$ ontological-de-mentation-or-dialectical-dementation-stranding-or-attributive-dialectics $\rangle$ is effectively the mental-devising-representation of the dialectical-primitivities/dialectical-out-of-phasing registry-worldviews/dimensions of recurrent-utter-uninstitutionalisation, ununiversalisation, non-positivism/medievalism and prospectively procrypticism (preconverging-or-dementing -apriorising-psychologism of positivistic meaningfulness), as from successive veridical ${ }^{83}$ reference-of-thought or veridicalthinking-reference-over-preconverging-or-dementing -reference (ontologicalveridicality/relative-unreflexivity/relative-reflexivity - ontological-contiguity ${ }^{67}$ ) as baseinstitutionalisation, ${ }^{103}$ universalisation, positivism and notional ${ }^{18}$ deprocrypticism respectively which are mentally postconverging-or-dialectical-thinking -apriorising-psychologism$<$ stranded-as-rightfully-straight/candored-and-dialectically-or-contendingly-in-phase $>. \quad{ }^{15}$ dementation-〈supererogatory $\sim$ ontological-de-mentation-or-dialectical-de-mentation — strandingor-attributive-dialectics $\rangle$ as such redefines psychology as a postdicatory science (tying the mental-devising-representation process to the abstract and infallible ontologicalnormalcy/postconvergence ontological-veridicality referencing/correction-tool), that is memetically/meaningfully not limited to-and-within one dimension-or-registryworldview/intradimensionally but by reflecting/perspectivating/highlighting (reasoningthrough-and-not-reasoning-with) ${ }^{7}$ perversion-of- ${ }^{3}$ reference-of-thought- $<$ as-preconverginglyapriorising/axiomatising/referencing-in-nonconviction/madeupness/bottomlining-as-to- 
shallow-supererogation $>$, is transdimensional/transcendental in depth-of-meaningfulness as ontological-normalcy/postconvergence (prospective-transcendence-in-perpetually-upholdingintemporal-preservation-entropy-or-contiguity-or-ontological-preservation). ${ }^{15}$ de-mentation〈supereron ontological-de-mentation-or-dialectical-de-mentation-stranding-orattributive-dialectics $\rangle$ as such is construed at the individuation-level as of the circularity/recurrence/repetition/repeatability ${ }^{10}$ in delineating existential-transitioning-oriterability-trace-of-narratives-as-dots_or_implicited_attendant-ontologicalcontiguity ${ }^{67} \sim$ educedexistentialising/contextualising/textalising_'intelligibility/epistemicity/reflexivity_contiguity$<$ imbued-notional cogency>' ${ }^{\prime}$-reification_or_intrinsic-reality-ontologicalcoherence_or_superseding-oneness-of-ontology . This involves maximalisingrecomposuring-for-relative-ontological-completeness ${ }^{8}$ —unenframed/reontologising $\sim$ conceptualisation as enabled by ${ }^{15}$ de-mentation-〈supererogatory $\sim$ ontological-dementation-or-dialectical-de-mentation-stranding-or-attributive-dialectics $\rangle$ in disambiguating the intemporal-disposition as ontological and temporal-dispositions at the individuation-level; while at the registry-worldview/dimension-level it reflects the determination of the relative registry-worldviews/dimensions as of relative-ontological-incompleteness ${ }^{8}$-of- ${ }^{83}$ reference-ofthought and relative-ontological-completeness ${ }^{87}$-of- ${ }^{8}$ reference-of-thought. The implication is that soundness-or-ontological-good-faith/authenticity ${ }^{69}$-of- ${ }^{83}$ reference-of-thought-ofmeaningfulness is not given, as it is a devising mechanism (mental-devising-representation) for ontological-veridicality as dialectically upheld for intemporal-preservation-entropy-orcontiguity-or-ontological-preservation (ontological-normalcy/postconvergence). There is no doubt that if by some secret manner 'some individuals from recurrent-utter-uninstitutionalisation registry-worldview/dimension' were to appear and be able to live in our present positivistic social-setup (without us knowing beforehand that they are coming from the past to avoid 
inducing a confounding effect in our analysis), and intent on fully living based on the ${ }^{8}$ referenceof-thought- categorical-imperatives/axioms/registry-teleology ${ }^{9}$,-for-intemporal-preservationentropy-or-contiguity-or-ontological-preservation of the recurrent-utter-uninstitutionalisation setup, our current psychology science most probably will treat them as pathological (preconverging-or-dementing -apriorising-psychologism). At which point, implying the conceptualisation of such an ontological-mental-pathology or de-mentation (in contrast to a physiological mental pathology) is much more a question of 'sovereign human existential<disontologising/re-ontologising aporeticism $>$ valour' ('sovereign human existential<disontologising/re-ontologising aporeticism $>$ valour' being defined as a registryworldview's/dimension's ontology depth in relation to its conventioning limitations with respect to pure-intemporal-ontology as to ontological-normalcy/postconvergence). But then, crazy as it may seem, this extends ontological-mental-pathology or de-mentation conceptualisation, on those very same terms of 'sovereign human existential-<disontologising/re-ontelogising apereticism $>$ valour', not only retrospectively but equally prospectively, as from a prospective transcendence-and-sublimity/sublimation/supererogatory-de-mentativity (with a corresponding insight about how we may be that preconverging-or-dementing 20 apriorising-psychologism$<$ stranded-as-rightfully-oblongated/decandored-and-dialectically-or-contendingly-out-ofphase $>$ from such a prospective transcendence-and-sublimity/sublimation/supereregatery $\sim$ dementativity's ${ }^{83}$ reference-of-thought- categorical-imperatives/axioms/registry-teleology ${ }^{9}$,-forintemporal-preservation-entropy-or-contiguity-or-ontological-preservation (of course, that is, when occluding our illusion-of-the-present/present-consciousness/epistemic-totalising $\sim$ selfreferencing-syncretising/mirage) herein construed as the prospective protensive-consciousness deprocrypticism-or-preempting — disjointedness-as-of- ${ }^{83}$ reference-of-thought registryworldview/dimension. In-the-bigger-picture, ${ }^{15}$ de-mentation-〈supererogatory $\sim$ ontological-dementation-or-dialectical-de-mentation-stranding-or-attributive-dialectics $\rangle$ effectively will 
seem to place human $\left\{\right.$ cumulated/recomposured\}-consciousness-awareness-teleology ${ }^{9}$ in the backseat with ontology-in-its-inherent-dialectical-abstraction taking the frontseat in the articulation of intrinsic reality and correspondingly human mental-devising-representation. Actually, registry-worldviews/dimensions are rather prospectively $<$ amplituding/formative $>$ wooden-language-〈imbued-temporal-mere-

\section{form/virtualities/dereification/akrasiatic-drag/denatured/preconverging-or-dementing}

\section{narratives - of-the- reference-of-thought- categorical-imperatives/axioms/registry-}

teleology $>$ of their own specific evolving successive existentialisms (with their full-depths-ofexistential-implications specific evolving preconverging-dementating/structuring/paradigming), and with specific evolving percolation-channelling- $<$ indeferential-formalisation-transference $>$ for prospective ontologising and ontologisingtranscendence-and-sublimity/sublimation/supereregatory $\sim$ de-mentativity. Fundamentally, without the possibility of de-mentativity-of-the-human-psyche-for-prospectiveinstitutionalisation involving ${ }^{15} \mathrm{de}$-mentation-〈supereregatory-ontological-de-mentation-ordialectical-de-mentation — stranding-or-attributive-dialectics $\rangle, \quad$ no registryworldview/dimension will be transcendable (hence de-mentable/as-to-a-threshold-of-lack-ofthinking) for prospective institutionalisation. As it is from de-mentation (literally 'dementation') that an unshackling/recomposuring/reordering/new-mentation of prospective intemporal-preservation-entropy-or-contiguity-or-ontological-preservation $\quad{ }^{83}$ reference-ofthought- ${ }^{-}$ategorical-imperatives/axioms/registry-teleology ${ }^{9}$ is possible. This is because ${ }^{15}$ dementation-〈supererogatory $\sim$ ontological-de-mentation-or-dialectical-de-mentation — strandingor-attributive-dialectics $\rangle$ as such allows for a 'human mentation capacity renewal' by transcendence-and-sublimity/sublimation/supererogatory-de-mentativity (as it is by cumulation/reordering/recomposuring the prior institutionalisation mentation-capacity for a contiguous upholding of intemporal-preservation-entropy-or-contiguity-or-ontological- 
preservation that transcendence-and-sublimity/sublimation/supererogatory de-mentativity occur) of the 'veridical reference-of-thought of meaningfulness' since it dements the mentaldevising-representation of the old/retrospective/superseded/transcended registryworldview/dimension 'as not postconverging-or-dialectical-thinking -apriorisingpsychologism/soundness-or-ontological-good-faith/authenticity ${ }^{6}$-of- ${ }^{-1 e f e r e n c e-o f-t h o u g h t ~ b u t ~}$ preconverging-or-dementing ${ }^{20}$-apriorising-psychologism and dialectically-or-contendinglyout-of-phase at its uninstitutionalised-threshold ${ }^{102}$ and references the mental-devisingrepresentation of the new/prospective/superseding/transcending registry-worldview/dimension as 'effectively postconverging-or-dialectical-thinking -apriorising-psychologism/soundnessor-ontological-good-faith/authenticity ${ }^{6}$-of- ${ }^{8}$ reference-of-thought as a new-and-greatermentation-capacity and dialectically-or-contendingly-in-phase; on the grounds that the veridicality of the reference-of-thought is what upholds ontologicalnormalcy/postconvergence/prospective-transcendence-in-perpetually-upholding-intemporalpreservation-entropy-or-contiguity-or-ontological-preservation. For instance, at its uninstitutionalised-threshold $^{102}$ requiring a prospective positivistic registryworldview/dimension, the non-positivism/medievalism registry-worldview/dimension which is rather superstitious/alchemic/aristocratic is rather ontologically-preconverging-or-dementing apriorising-psychologism/dialectically-preconverging-or-dementing ${ }^{20}$-apriorisingpsychologism in a ${ }^{15}$ de-mentation-〈supererogatory $\sim$ ontological-de-mentation-or-dialectical-dementation - stranding-or-attributive-dialectics $\rangle$ wherein its mental-devising-representation is preconverging-or-dementing ${ }^{20}$-apriorising-psychologism as not thinking/unsoundness-orontological-bad-faith/inauthenticity ${ }^{6}$-of- ${ }^{3}$ reference-of-thought and dialectically-orcontendingly-out-of-phase while the positivistic registry-worldview/dimension mentaldevising-representation is postconverging-or-dialectical-thinking ${ }^{2}$-apriorisingpsychologism/soundness-or-ontological-good-faith/authenticity ${ }^{6}$-of- ${ }^{2}$ reference-of-thought and 
dialectically-or-contendingly-in-phase, thus 'granting the latter ${ }^{83}$ reference-of-thought (veridical-thinking-reference-over-preconverging-or-dementing ${ }^{20}$-reference)' over the former which is 'no longer ${ }^{83}$ reference-of-thought' in the sense that 'we can't think in medieval terms and be considered soundness-or-ontological-good-faith/authenticity ${ }^{6}$-of- ${ }^{8}$ reference-of-thought today but rather ontologically-preconverging-or-dementing ${ }^{20}$-apriorising-psychologism'. This dialectical conceptualisation equally applies regarding procrypticism and futural Beingdevelopment/ontological-framework-expansion-as-to-depth-of-ontologising-development-asinfrastructure-of- meaningfulness-and-teleology as of prospective notional ${ }^{18}$ deprocrypticism registry-worldviews/dimensions. In fact, a deconstruction insight with regards to all the interchangeable deconstructing terms in reference to the notion of 'failing/not-upholding-<as-of-apriorising/axiomatising/referencing > intradimensional

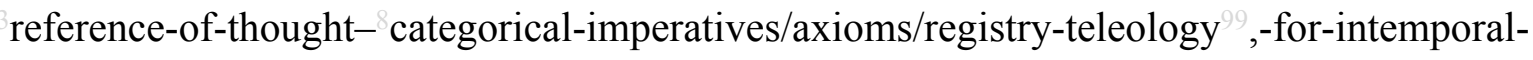
preservation-entropy-or-contiguity-or-ontological-preservation' (i.e. '15-mentation〈supererogatory $\sim$ ontological-de-mentation-or-dialectical-de-mentation-stranding-orattributive-dialectics $\rangle$, perversion-of- ${ }^{8}$ reference-of-thought- $<$ as-preconverginglyapriorising/axiomatising/referencing-in-nonconviction/madeupness/bottomlining-as-toshallow-supererogation >, registry-worldview's/dimension's-uninstitutionalised-threshold ${ }^{102}$ defect-<as-Being-or-ontological-or-existential-defect $>>5, \quad$ unsoundness-or-ontological-badfaith/inauthenticity ${ }^{64}$-of- ${ }^{83}$ reference-of-thought, mental-perversion, subknowledging ${ }^{4}$, mimicking; and-their-corresponding-<amplituding/formative-epistemicity $>$ totalising $\sim$ selfreferencing-syncretising) indicates that de-mentation-(supererogatory $\sim$ ontological-dementation-or-dialectical-de-mentation-stranding-or-attributive-dialectics $\rangle$ is ultimately the 'ideal reference term' for the simple reason that unlike the other terms it 'beats' the 'intuition for intradimensional/non-transcendental/non-transdimensional reasoning' and succeeds to convey, overcoming the counter-intuition, the requisite transdimensional/transcendental reasoning that 
achieves ontological-normalcy/postconvergence (prospective-transcendence-in-perpetuallyupholding-intemporal-preservation-entropy-or-contiguity-or-ontological-preservation); as this counter-intuition for transdimensional reasoning (which is not easily superseded and not even by this author articulating the notion but for this abstraction insight) is basically due to the subconscious-strength of the 'intradimensional-subknowledging -normalcy' (epistemictatalising $\sim$ self-referencing-syncretising/illusion-of-the-present/present-consciousness/mirage inclination) reference of personhood-and-socialhood-formation existentialism/full-depth-ofexistential-implications such that the other notions will tend-to-get-lost-down-the-line by unconsciously returning to and/or admitting to the wrong intradimensional reflexconceptualisations, at one point or the other, and so in lieu of and undermining the ontologicalveridicality of the effectively veridical transcendental reality. de-mentation/supererogatory ontological-de-mentation-or-dialectical-de-mentation-stranding-orattributive-dialectics〉 'beats' this counter-intuition by simply and immediately bringing to the mind an 'overarching conceptualisation' of a ${ }^{15}$ de-mentation-(stperery-ontological-dementation-or-dialectical-de-mentation-stranding-or-attributive-dialectics〉 of superseding/transcending registry/registry-worldview-or-dimension (as straight/candored-anddialectically-or-contendingly-in-phase) and a superseded/transcended registry/registryworldview-or-dimension (as oblongated/decandored-and-dialectically-or-contendingly-out-ofphase); around which all other dynamic constructions fall in place (whether organiccomprehension-thinking or threshold-of-nonconviction/madeupness/bottomlining-in-shallowsupererogation ${ }^{\circ}<$ as-to-'attendant-intradimensional'-prospectivelydisontologising preconverging/dementing -apriorising-psychologism>, circumventive/distractive-temporal-prioritisation-of- ${ }^{8}$ reference-of-thought, subknowledging impulse, etc.). The other deconstructing terms while having specific analytical bearings do not carry this all-encompassing quality that liberates from 'intradimensional-subknowledging - 
normalcy' (epistemic-totalising $\sim$ self-referencing-syncretising/illusion-of-the-present/presentconsciousness/mirage inclination) as de-mentation-(supererogatory $\sim$ ontological-dementation-or-dialectical-de-mentation-stranding-or-attributive-dialectics $\rangle$ does as it further induces 'transdimensional or memetic thinking' by its implied de-mentation〈supererogatory $\sim$ ontological-de-mentation-or-dialectical-de-mentation-stranding-or-

attributive-dialectics $\rangle$ in meeting up with 'ontological-normalcy/postconvergence' (prospectivetranscendence-in-perpetually-upholding-intemporal-preservation-entropy-or-contiguity-orontological-preservation). For instance, while the term registry-worldview's/dimension'suninstitutionalised-threshold ${ }^{102}$-defect-<as-Being-or-ontological-or-existential-defect $>{ }^{8}$, brings to the mind a poor ontological disposition like the other BODMAS characters disposition to systematically operate additionality overlooking A's condition, but it is a sense of ${ }^{15}$ dementation-〈supererogatory $\sim$ ontological-de-mentation-or-dialectical-de-mentation — strandingor-attributive-dialectics $\rangle$ that carries the intuition of an uninstitutionalised-threshold ${ }^{12}$, and construes a superseding/transcending registry/registry-worldview-or-dimension and a superseded/transcended registry/registry-worldview-or-dimension, and all the implications thereof. Now analysing the registry-worldview's/dimension's-uninstitutionalised-threshold ${ }^{102}$ defect- $<$ as-Being-or-ontological-or-existential-defect $>{ }^{5}$, term thereafter, we grasp that it is the '<amplituding/formative-epistemicity $>$ totalising $\sim$ self-referencing-syncretising' in 'notionaldiscontiguity/epistemic-discontiguity ${ }^{3}<$ between - prior-shallow-supererogation -ofmentally-aestheticised preconverging/dementing -qualia-schema_and_prospective-profoundsupererogation -of-mentally-aestheticised postconverging/dialectical-thinking -qualiaschema> of apriorising/axiomatising/referencing/intelligibilitysettingup/measuringinstrumenting' as of the perversion-of- ${ }^{3}$ reference-of-thought-<as-preconvergingly- 
shallow-supererogation $>$ as to preconverging-or-dementing ${ }^{20}$-apriorising-psychologism' that makes it registry-worldview's/dimension's-uninstitutionalised-threshold ${ }^{102}$-defect- $<$ as-Beingor-ontological-or-existential-defect> ${ }^{85}$ (and not about defect-of- ${ }^{54}$ logical-processing-or-logicalimplicitation - supposedly-apriorising-in-conviction-as-to-profound-supererogation ) and this carries the implications of a registry-worldview/dimension defining defect (in a dialectics of prior/transcended/superseded and prospective/transcending/superseding ${ }^{83}$ reference-of-thoughtcategorical-imperatives/axioms/registry-teleology ${ }^{9}$,-for-intemporal-preservation-entropy-orcontiguity-or-ontological-preservation). Specifically, de-mentation-

\section{〈supererogatery $\sim$ ontological-de-mentation-or-dialectical-de-mentation-stranding-or-}

attributive-dialectics〉 as such implies registry-worldview's/dimension's-uninstitutionalisedthreshold ${ }^{12}$-defect-<as-Being-or-ontological-or-existential-defect $>55 /$ not-just-a-logicalprocessing-or-an-implicitation-of-act-execution-or-a-implicitation-of-notion-of-agreement-ordisagreement-defect' wherein we can perceive the complete picture of a registryworldview/dimension defect by its relative-ontological-incompleteness ${ }^{8}$-induced,-`thresholdof-nonconviction/madeupness/bottomlining-in-shallow-supererogation $-<$ as-to-'attendant-

\section{intradimensional'-prospectively-disontologising preconverging/dementing -apriorising-}

psychologism>' like recurrent-utter-uninstitutionalisation (with respect to baseinstitutionalisation), ununiversalisation (with respect to ${ }^{103}$ universalisation), nonpositivism/medievalism (with respect to positivism) and our own dimension procrypticism's (the-'preconverging-or-dementing ${ }^{20}$-apriorising-psychologism of positivistic-meaningfulness) de-mentation-〈supererogatory ontological-de-mentation-or-dialectical-de-mentationstranding-or-attributive-dialectics〉 (with respect to futural Being-development/ontologicalframework-expansion-as-to-depth-of-ontologising-development-as-infrastructure-ofmeaningfulness-and-teleology as of prospective deprocrypticism). A similar articulation can be made with regards to each of the other deconstructing terms where de-mentation- 


\section{〈supererogatory $\sim$ ontological-de-mentation-or-dialectical-de-mentation-stranding-or-}

attributive-dialectics $\rangle$ provides the better overarching conceptualisation from an intemporalprioritisation-of- ${ }^{8}$ reference-of-thought'-as-conflatedness ${ }^{13}$-or-ontological-reprojecting reference-of-thought (veridical-thinking-reference-over-preconverging-or-dementing ${ }^{20}$ reference). Furthermore, by its ${ }^{15}$ de-mentation-(supererogatory $\sim$ ontological-de-mentation-ordialectical-de-mentation-stranding-or-attributive-dialectics $\rangle$, de-mentation-

\section{〈supererogatory ontological-de-mentation-or-dialectical-de-mentation-stranding-or-}

attributive-dialectics $\rangle$ is the only notional term that operantly and deterministically projects the requisite psychoanalytic-unshackling/memetic-reordering/recomposuring/new-mentation with regards to the implied veridical existentialism/full-depth-of-existential-implications taking into account the veridicality of human-subpotency-aporia/undecidability/dilemma/oughtindeterminacy/deficiency/limitation/constraint—imbued-'notional firstnaturednessformativeness-<as-to-eventualising-inkling-drive or seeding-misprising $>$ temporal-tointemporal-dispositions-<so-construed-as-from-perspective-ontologicalnormalcy/postconvergence>'-existentialism-form-factor hotchpotching wherein sound knowledge/virtue is pliable to temporal denaturing and corresponding conjugation/derivation thus the need for knowledge-notionalisation as a response to human-subpotencyaporia/undecidability/dilemma/ought-indeterminacy/deficiency/limitation/constraint—imbued'notional firstnaturedness-formativeness-<as-to-eventualising-inkling-drive-or-seedingmisprising $>$ temporal-to-intemporal-dispositions- $<$ so-construed-as-from-perspectiveontological-normalcy/postconvergence>'-existentialism-form-factor dilemma. The very central idea about procrypticism and notional ${ }^{18}$ deprocrypticism (and for that matter the successive relative-ontological-completeness ${ }^{87}$ dialecticisms of the institutional-cumulation/institutionalrecomposure-〈as-to- historiality/ontological-eventfulness /ontological-aesthetic-tracing- 
determinism' $>>$ so-construed as of notional procrypticism and notional deprocrypticism) with respect to the veridicality of human-subpotency-aporia/undecidability/dilemma/oughtindeterminacy/deficiency/limitation/constraint—imbued-'notional firstnaturednessformativeness-<as-to-eventualising-inkling drive-or-seeding misprising $>$ temporal-tointemporal-dispositions- $<$ so-construed-as-from-perspective-ontologicalnormalcy/postconvergence >'-existentialism-form-factor is in bringing to the fore and contrasting ontological-normalcy/postconvergence as to potential human ontologicalperformance $^{72}-<$ including-virtue-as-ontology $>$ /morality/ethics/justice/etc. (longness-of-depthof-meaningfulness and shortness-of-register-of- ${ }^{5}$ meaningfulness-and-teleology ${ }^{9}$ ) and the reality of human temporal-dispositions at all institutional-cumulation/institutional-recomposure〈as-to- historiality/ontological-eventfulness /ontological-aesthetic-tracing-<perspectiveontological-normalcy/postconvergence-reflected-‘epistemicity-relativism-determinism'>> uninstitutionalised-threshold ${ }^{102}$ perverting/undermining ontological-normalcy/postconvergence, thus highlighting the follow dichotomies that are always associated with ontologicalnormalcy/postconvergence dialectics (underlied by teleological-inflections-〈as-to-moreprofound-nondisjointing-<amplituding/formative-

epistemicity $>$ totalising/circumscribing/delineating $\rangle)$ : 1) re-ontologising idiosyncraticferment_for-notional $\sim$ cogency-〈as-to- $<$ surrealising/supererogating-drive $>$-of-

aestheticising - relief/depth-and-impetus) for intemporal-preservation beyond ${ }^{83}$ reference-ofthought- categorical-imperatives/axioms/registry-teleology ${ }^{99}$ at uninstitutionalised-threshold versus disontologising/subontologising idiosyncratic-ferment_for-notional $\sim$ cogency-〈as-tosurrealising/supererogating-drive>-of-aestheticising - relief/depth-and-impetus $>$ rather manifesting mere ${ }^{83}$ reference-of-thought- categorical-imperatives/axioms/registry-teleology at uninstitutionalised-threshold ${ }^{102}$ 2) thinking as veridical ${ }^{83}$ reference-of-thought (veridicalthinking-reference-over-preconverging-or-dementing ${ }^{20}$-reference) of mental-devising- 
representation of the prospective registry-worldview/dimension as soundness-or-ontologicalgood-faith/authenticity ${ }^{\text {-of- }}{ }^{8}$ reference-of-thought versus preconverging-or-dementing apriorising-psychologism as mental-devising-representation of the retrospective registryworldview/dimension as unsoundness-or-ontological-bad-faith/inauthenticity ${ }^{64}$-of- ${ }^{8}$ referenceof-thought as it is no longer an ${ }^{83}$ reference-of-thought (not-veridical-thinking-reference-ratherpreconverging-or-dementing ${ }^{20}$-reference) 3) organic-comprehension-thinking as intemporal profoundness-of-thought-and-meaningfulness (longness-of-register-of- - meaningfulness-andteleology ${ }^{99} \quad$ versus threshold-of-nonconviction/madeupness/bottomlining-in-shallowsupererogation -<as-to- 'attendant-intradimensional'-prospectivelydisontologising preconverging/dementing -apriorising-psychologism> as temporal shallowness-of-thought-and-meaningfulness (shortness-of-register-of- ${ }^{56}$ meaningfulness-andteleology ${ }^{9}$ ) 4) 'intemporal-prioritisation-of- ${ }^{3}$ reference-of-thought'-as-conflatedness ${ }^{13}$-orontological-reprojecting as defining the priority of life choices or existential-disontologising/re-ontologising aporeticism $>$ living as in priority all that which preserve precedingly the intemporal as it creates the institutionalisation possibilities for the furtherance of intemporality ${ }^{52} /$ longness versus circumventive/distractive-temporal-prioritisation-ofreference-of-thought as defining the priority of life choices or existential-disente entologising apereticism $>$ living as priorly unaccountable to the possibility for the furtherance of intemporality ${ }^{2} /$ longness whether by temporal circumventing or distraction of institutionalisation/intemporalisation reference-of-thought- categoricalimperatives/axioms/registry-teleology ${ }^{9}$,-for-intemporal-preservation-entropy-or-contiguityor-ontological-preservation. Central to intemporal-preservation-entropy-or-contiguity-orontological-preservation is an ontological-normalcy/postconvergence that doesn't recognise any uninstitutionalised-threshold ${ }^{102}$ to the projected <amplituding/formative $>$ wooden-language〈imbued-temporal-mere-form/virtualities/dereification/akrasiatic- 
drag/denatured/preconverging-or-dementing -narratives - of-the- reference-of-thought-

categorical-imperatives/axioms/registry-teleology 〉 considered circumventive/distractivetemporal-prioritisation-of- ${ }^{8}$ reference-of-thought over inherent 'intemporal-prioritisation-ofreference-of-thought'-as-conflatedness ${ }^{13}$-or-ontological-reprojecting of intemporalpreservation-entropy-or-contiguity-or-ontological-preservation; at which point of uninstitutionalised-threshold ${ }^{102},{ }^{15}$ de-mentation-/supererogatory $\sim$ ontological-de-mentation-ordialectical-de-mentation - stranding-or-attributive-dialectics $\rangle$ is implied (in organiccomprehension-thinking over mechanical comprehension or as a ${ }^{15}$ de-mentation〈supererogatory $\sim$ ontological-de-mentation-or-dialectical-de-mentation-stranding-or-

attributive-dialectics $\rangle$ ) for a renewed/prospective mentation for intemporal-preservationentropy-or-contiguity-or-ontological-preservation in 'intemporal-prioritisation-of- ${ }^{8}$ referenceof-thought'-as-conflatedness ${ }^{13}$-or-ontological-reprojecting that 'supersedes deterministically and operantly, without any discretion allowed', circumventive/distractive-temporalprioritisation-of- reference-of-thought. That is de-mentation-〈supererogatory ontologicalde-mentation-or-dialectical-de-mentation - stranding-or-attributive-dialectics $\rangle$ is effectively the notion that, in recognition of the unchanging, preceding and inherent nature of intrinsic-reality with respect to the human psyche (and its mental-devising-representation of intrinsic reality) which is what 'gives-in'/collapses ontologically/as-an-ontological-reference; enables, for the articulation of new mentations as transcendence-and-sublimity/sublimation/supereregatery $\sim$ dementativity, the 'giving-in'/collapsing of the mental-devising-representation of successive institutional-cumulation/institutional-recomposure-〈as-to- historiality/ontologicaleventfulness /ontological-aesthetic-tracing-<perspective-ontologicalnormalcy/postconvergence-reflected-'epistemicity-relativism-determinism'>> mindsets, notwithstanding the fact that the ${ }^{15}$ de-mentation-〈supererogatory 0 ontological-de-mentation-ordialectical-de-mentation - stranding-or-attributive-dialectics $\rangle$ (of their ${ }^{83}$ reference-of-thought- 
categorical-imperatives/axioms/registry-teleology ${ }^{99}$,-for-intemporal-preservation-entropy-orcontiguity-or-ontological-preservation) is unintelligible/existentially-suprastructural to these superseded/transcended registry-worldviews/dimensions mindsets due to their $<$ amplituding/formative-epistemicity $>$ totalising $\sim$ self-referencing-syncretising/illusion-of-thepresent/present-consciousness/mirage disposition. Supposed we were to make a profound analysis of our contiguous human mental-devising-representation/consciousness-awarenessteleology ${ }^{9}$ (in-dialectical/recomposuring-moments) from the appearance of human beings on earth, the effective linkage as new-mentations between those successive recomposuring moments (whether recurrent-utter-uninstitutionalisation, base-institutionalisationununiversalisation, $\quad{ }^{103}$ universalisation-non-positivism-or-medievalism, $\quad$ positivismprocrypticism and prospectively perpetuation-of-deprocrypticism) is as de-mentation〈supererogatory ontological-de-mentation-or-dialectical-de-mentation-stranding-orattributive-dialectics〉 in ${ }^{15}$ de-mentation-〈supererogatory $\sim$ ontological-de-mentation-ordialectical-de-mentation - stranding-or-attributive-dialectics); and this thus predicates or rather postdicates as well our own registry-worldview/dimension de-mentation〈supererogatory $\sim$ ontological-de-mentation-or-dialectical-de-mentation-stranding-orattributive-dialectics $\rangle$ over and as denaturing positivistic meaningfulness ${ }^{83}$ reference-ofthought- ${ }^{8}$ categorical-imperatives/axioms/registry-teleology ${ }^{99}$,-for-intemporal-preservationentropy-or-contiguity-or-ontological-preservation (procrypticism) and implying a prospective need for deprocrypticism. Postdication, when alluding to an de-mentation〈supererogatory $\sim$ ontological-de-mentation-or-dialectical-de-mentation-stranding-orattributive-dialectics $\rangle$ defining psychological science, will effectively hold that the conceptualisation of the social is very much a contiguous ontological disambiguation of a preconverging-or-dementing ${ }^{20}$-apriorising-psychologism social of personhoods-andsocialhood-formation in existentialism/full-depth-of-existential-implications of 
notional firstnaturedness-formativeness-<as-to-eventualising-inkling-drive-or-seedingmisprising $>$ temporal-to-intemporal-dispositions- $<$ so-construed-as-from-perspectiveontological-normalcy/postconvergence>, from a prospective registry-worldview's/dimension's reference-of-thought in ontological-normalcy/postconvergence. Postdication means reasoning from a basis of ontological-normalcy/postconvergence wherein the prior/transcended/superseded registry-worldview/dimension is no longer referenced/registered/decisioned (as ${ }^{83}$ reference-of-thought) but 'dialectically preconverging-ordementing -apriorising-psychologism/unsoundness-or-ontological-bad-faith/inauthenticity of- ${ }^{8}$ reference-of-thought' while the prospective/transcending/superseding registryworldview/dimension is referenced/registered/decisioned (as ${ }^{83}$ reference-of-thought) as 'postconverging-or-dialectical-thinking -apriorising-psychologism/soundness-or-ontologicalgood-faith/authenticity ${ }^{6}$-of- ${ }^{8}$ reference-of-thought' in construing meaningfulness. The grander issue that always arises is in existentialism terms, whether with regards to an obvious human disposition for temporal-accommodation as circumventive/distractive-temporal-prioritisationof- ${ }^{8}$ reference-of-thought of being-and-existence as conceptualised within the successions-ofexisting-in-human-life-spans or rather an abstract eternal-projecting disposition of 'intemporalprioritisation-of- ${ }^{8}$ reference-of-thought'-as-conflatedness ${ }^{13}$-or-ontological-reprojecting wherein the articulation of meaning, being and existence is in existentialism-terms intemporallydriven on the basis that that which is in need of transcendence-and-the-intemporal (the temporal) cannot be seen-as-or-made-a-reference-of-intemporal/ontological-thought, and that it is exactly for that reason that human progress has been and will remain dialectically possible. That is, the reference-of-thought (veridical-thinking-reference-over-preconverging-or-dementing ${ }^{20}$ reference) can only be the pedestalling of an intemporal-prioritisation-of- reference-ofthought'-as-conflatedness ${ }^{13}$-or-ontological-reprojecting as ontology with regards to apriorisingregistry, contrasted to a circumventive/distractive-temporal-prioritisation-of- ${ }^{3}$ reference-of- 
thought-reference implying a perverted-registry reflected/perspectivated by its de-mentation〈supererogatory ontological-de-mentation-or-dialectical-de-mentation-stranding-or-

attributive-dialectics $\rangle$. Where the natural world is resolute with no compromise with the operation of such a notion as $1+1=2$, the same cannot be resolutely affirmed in the human socialand-temporal-trading in the social world where on occasions $1+1$ will add up to 5 where the effective constraining of institutionalisation is lacking. ${ }^{15}$ de-mentation〈supererogatory ontological-de-mentation-or-dialectical-de-mentation-stranding-or-

attributive-dialectics (stranding) has the merits of articulating that for ${ }^{83}$ reference-of-thought (veridical-thinking-reference-over-preconverging-or-dementing ${ }^{20}$-reference) to establish veridicality, no such social-and-temporal-trading is beyond ontological-entrapment 'by reinstitutionalisation with new ${ }^{83}$ reference-of-thought- categorical-imperatives/axioms/registryteleology ${ }^{9}$,-for-intemporal-preservation-entropy-or-contiguity-or-ontological-preservation dialectically implying an de-mentation-〈supererogatory $\sim$ ontological-de-mentation-ordialectical-de-mentation - stranding-or-attributive-dialectics $\rangle$ of transcended ${ }^{83}$ reference-ofthought- categorical-imperatives/axioms/registry-teleology ${ }^{9}$,-for-intemporal-preservationentropy-or-contiguity-or-ontological-preservation (in our present case, notional ${ }^{18}$ deprocrypticism of ${ }^{8}$ procrypticism-or-disjointedness-as-of- ${ }^{8}$ reference-of-thought, for a preconverging/postconverging-de-mentative/structural/paradigmatic resolution of defective-issues or vices-and-impediments ${ }^{105}$ of our registry-worldview/dimension and just as critically the preconverging/postconverging-de-mentatively/structurally/paradigmatically inhibiting effect on the furtherance of human emancipative potential; just as positivism is the preconverging/postconverging-de-mentative/structural/paradigmatic resolution of defectiveissues or vices-and-impediments ${ }^{105}$ of non-positivism/medievalism together with the preconverging/postconverging-de-mentatively/structurally/paradigmatically inhibiting effect on the furtherance of human emancipative potential, and the same applies with 
ununiversalisation and ${ }^{103}$ universalisation, and recurrent-utter-uninstitutionalisation and baseinstitutionalisation); thus the potential to fully close the gap with regards to ontologicalveridicality of the natural sciences in a 'renewed maturation' of the phenomenological ontological-performance ${ }^{2}$-<including-virtue-as-ontology $>/$ morality/ethics/justice/etc.

conceptualisation of the social. Though with the weakness we must be able to rise up to, that the 'social' is existentially-disentelogising/re-ontelogising aporeticism> 'emotionally involved'. But this can be and is effectively overcome by 'appropriately ${ }^{103}$ universalising and detached meaningfulness by percolation-channelling-<in-deferential-formalisation-transference $>$ ' as devised for all formalised and institutionalised settings capable of introducing, upholding and internalising the ascendency of many a social outlying thoughts and meaningfulness which from a 'purely mobbish social disposition' as may arise in the extended-informality-〈susceptible-toeffecting-parsimony-as-of-shoddiness-and-incompleteness-to- meaningfulness-and-

teleology > would hardly be countenanced. The bigger picture here (and of relevance to a registry-worldview/dimension transcendence-and-sublimity/sublimation/supererogatory $\sim$ dementativity from procrypticism to notional ${ }^{18}$ deprocrypticism as the preconverging/postconverging-de-mentative/structural/paradigmatic and general resolution of the vices-and-impediments ${ }^{105}$ together with the preconverging/postconverging-dementatively/structurally/paradigmatically inhibiting effect on the furtherance of human emancipative potential of the ${ }^{7}$ perversion-of- ${ }^{3}$ eference-of-thought- $<$ as-preconverginglyapriorising/axiomatising/referencing-in-nonconviction/madeupness/bottomlining-as-toshallow-supererogation $>$ as to preconverging-or-dementing ${ }^{20}$-apriorising-psychologism of positivistic ${ }^{5}$ meaningfulness-and-teleology , and specifically resolution of the implications of psychopathic subknowledging $4 / 7$ perversion-of- reference-of-thought-<as-preconverginglyapriorising/axiomatising/referencing-in-nonconviction/madeupness/bottomlining-as-toshallow-supererogation >) may be to think, given our own illusion-of-the-present/present- 
syncretising/circularity/interiorising/akrasiatic-drag ${ }^{34}$, that such an analysis applies only to prior institutional-cumulation/institutional-recomposure-〈as-to- historiality/ontological-

\section{eventfulness /ontological-aesthetic-tracing-<perspective-ontological-}

normalcy/postconvergence-reflected-'epistemicity-relativism-determinism' $>\rangle$. But the fact is that such a profound conceptualisation will have to come to terms with the reality of the implied existentialism/full-depth-of-existential-implications beyond our present sense of personhoodsand-socialhood-formation if it were to avoid platitudinising, becoming circular with dead-ends and lose its intemporal purpose and hence ontological purpose, and so for the simple reason that it is the human psyche that 'gives-in' with respect to intrinsic-reality as renewed/prospective ontological-veridicality, starting with that of the intellectual analyst/analysts itself/themselves); as the human psyche gave-in from recurrent-utter-uninstitutionalisation to baseinstitutionalisation, ununiversalisation to ${ }^{103}$ universalisation, non-positivism/medievalism to positivism, and where renewed/prospective ontological-veridicality does establish a new registry-worldview/dimension transcendental postconverging-dementating/structuring/paradigming shift as procrypticism to deprocrypticism, then the human psyche will equally have to give-in, and by the way all transcendence-andsublimity/sublimation/supererogatory de-mentativity meet with some resistance or the other and thus a reason for transversality-<for-sublimating-existential-eventuating/denouement-from-'thinking at first/pure-predisposition-preemptive-of-prospectivedisontologising/subontologising' as-of-prospectively-disambiguated-affirmed-andunaffirmed-'motif-and-apriorising/axiomatising/referencing'> ${ }^{101}$ reflex to preserve the precedingness/supersedingness/ascendency of intrinsic-reality in adverting social-and-temporaltrading of meaningfulness. Part-and-parcel, of human intellectualism beyond mereinstitutionalised-being-and-craft, as has historically been implied in the case with many a great 
human mind, is to recognise that the social-construct is 'not an ontological absolute' but rather a 'conventioning construct at the limits of human ontological capacity' and that that is 'why it has got its defining issues and problems' and further that 'it progresses and transcends', and the intellectual exercise goes beyond just reasoning within ambits of 'temporally-and-sociallyperceived-rightness-of-thinking' to explore possibilities that might actually be 'outright unpalatable' in the temporo-social sense but in-the-bigger-picture as an intemporal/ontological/social/species/ ${ }^{103}$ universal/transcendental/ $/{ }^{5}$ maximalisingrecomposuring-for-relative-ontological-completeness ${ }^{8}$ —unenframed/reontologising conceptualisation postconverging-de-mentating/structuring/paradigming are indispensable. With the idea that an intemporal/ontological/social/species $/{ }^{103}$ universal/transcendental/ $/{ }^{5}$ maximalisingrecomposuring-for-relative-ontological-completeness 87 unenframed/reontologising $\sim$ conceptualisation postconverging-de-mentating/structuring/paradigming that prolongs to intemporality ${ }^{52} /$ an-abstract-eternality while obviously of 'less an immediate temporal existential-<disontologising/re-ontologising aporeticism $>$ sense of good to some humans' is undoubtable of an 'intemporal existential-<disontologising/re-ontologising apereticism $>$ sense of good to all humans at all times' by its percolation-channelling- $<$ indeferential-formalisation-transference $>$ wherein for instance, the preconverging/postconverging-de-mentative/structural/paradigmatic effect of the law is allowing for civilisational living but its circumstantial construal and application may not be in tune with the temporal interests of many but for its institutionalising constraining. This contrast between humans appreciating intemporality ${ }^{52}$ /longness as potentially of ${ }^{103}$ universal import and at the same time disposed occasionally to advanced their temporality ${ }^{8}$, is what warrants a 'constraining institutionalisation'. In the same vain, one may ask what's the temporal benefit to Rousseau or Galileo instead of striving for greater aristocratic privileges for themselves; for the 
one to rather carry the mantle from one royal court to the other of affirming the possibility of human emancipation (by which we are all percolatively benefiting from today) or the other the mantle of a principled engagement and possibility of science starting with an uncompromising supplanting-conviction-as-to-profound-supererogation -of-'attendant-intradimensional'postconverging/dialectical-thinking -apriorising-psychologism from observation that the earth is not at the centre of the solar system, by which a culture of science came to be established. And finally, how coherent are temporal meaningful frames built from such intemporal grand principles but lived on temporal dispositions in extrication in contradiction to such philosophies, and what is the very relevance of such temporal enculturation and endemisation to present-day social and institutional failures in society? And what's the role of 'intellectual irresponsibility/relative-unreflexivity' in all of this? From an intemporal hence ontological depth-of-meaningfulness, precedingly/supersedingly, 'limited-mentation-capacity-assubjecting-'educed-unlimitedness/existence-sublimating nascence' to-limitedness/humansubpotency' (for intemporal-preservation-entropy-or-contiguity-or-ontological-preservation) is the reason for human registry-worldview/dimension ${ }^{74}$ perversion-of- ${ }^{-}$reference-of-thought- $<$aspreconvergingly-apriorising/axiomatising/referencing-in-

nonconviction/madeupness/bottomlining-as-to-shallow-supererogation $>\quad$ defect $\quad$ at uninstitutionalised-threshold ${ }^{102}$; implying that 'ontological-normalcy/postconvergence' is actually for prospective-transcendence-in-perpetually-upholding-intemporal-preservationentropy-or-contiguity-or-ontological-preservation beyond the defective 'intradimensionalsubknowledging -normalcy or reflex-normalcy' which is rather an <amplituding/formativeepistemicity $>$ totalising $\sim$ self-referencing-syncretising/circularity/interiorising/akrasiatic-drag (illusion-of-the-present/present-consciousness) inclination to overlook/aside the notion of prospective transcendence-and-sublimity/sublimation/supererogatory - de-mentativity at its own (limited-mentation-capacity—as-subjecting 'educed-unlimitedness/existence-sublimating 
nascence' to-limitedness/human-subpotency-threshold) uninstitutionalised-threshold ${ }^{102}$ though it will obviously and paradoxically recognise the need of prior registry-worldviews/dimensions to transcend (just as by reflex from our perspective we will recognise such a need for baseinstitutionalisation over recurrent-utter-uninstitutionalisation, ${ }^{103}$ universalisation over ununiversalisation, positivism over non-positivism/medievalism but hardly prospectively the notion that our dimension has an uninstitutionalised-threshold like procrypticism-ordisjointedness-as-of- ${ }^{8}$ reference-of-thought with the need for prospective transcendence-andsublimity/sublimation/supererogatoryade-mentativity as deprocrypticism). However, as previously indicated such an insight can only be garnered, beyond our illusion-of-thepresent/present-consciousness/epistemic-totalising $\sim$ self-referencing-syncretising/mirage as all registry-worldviews/dimensions wrongfully imply, given that 'doppler-thinking' wherein our registry-worldview/dimension isn't the absolute reference of meaningfulness (which is rather an intradimensional-subknowledging -normalcy in lieu of the 'ontologicalnormalcy/postconvergence' as that which allows for prospective-transcendence-in-perpetuallyupholding-intemporal-preservation-entropy-or-contiguity-or-ontological-preservation). It is this 'ontological-normalcy/postconvergence' that reflects/perspectivates ${ }^{74}$ perversion-ofreference-of-thought-<as-preconvergingly-apriorising/axiomatising/referencing-innonconviction/madeupness/bottomlining-as-to-shallow-supererogation $>$ defect as ${ }^{15}$ dementation-〈supererogatory $\sim$ ontological-de-mentation-or-dialectical-de-mentation — strandingor-attributive-dialectics〉 as against the defective reflex-normalcy/intradimensional subknowledging -normalcy that wrongfully represent it as straightness/candored-anddialectically-or-contendingly-in-phase. Thus the general notion of an intemporal/ontological resolution of $\quad$ perversion-of- ${ }^{2}$ reference-of-thought- $<$ as-preconverginglyapriorising/axiomatising/referencing-in-nonconviction/madeupness/bottomlining-as-toshallow-supererogation $>$ is more than just the instigating effect of the subknowledging - 
impulse/compulsive-dementing (psychopathic postlogism in hollow-constituting-<asdisjointed-misappropriation-of-meaningfulness-and-failing-intemporal-preservation $>$ ) $\quad$ but harkens back to the notion of the intraregistry-worldview/dimension limited-mentationcapacity -as-subjecting 'educed-unlimitedness/existence-sublimating nascence' totimitedness/human-subpotency/uninstitutionalised-threshold ${ }^{102}$ in-the-very-first-place. As this is the preconverging-de-mentating/structuring/paradigming disposition for the possibility of perversion-of- ${ }^{3}$ reference-of-thought-<as-preconvergingly-

apriorising/axiomatising/referencing-in-nonconviction/madeupness/bottomlining-as-to-

shallow-supererogation $>$ thus requiring ontological-normalcy/postconvergence epistemicprojection as prospective-transcendence-in-perpetually-upholding-intemporal-preservationentropy-or-contiguity-or-ontological-preservation. For instance, such ${ }^{74}$ perversion-ofreference-of-thought-<as-preconvergingly-apriorising/axiomatising/referencing-innonconviction/madeupness/bottomlining-as-to-shallow-supererogation $>$ as witchcraft in the non-positivism/medievalism registry-worldview/dimension is fundamentally implying preconverging/postconverging-de-mentatively/structurally/paradigmatically a need for the right human mentation-capacity as the prospective transcendence-andsublimity/sublimation/smererentativity of a positivistic registryworldview/dimension, and likewise preconverging/postconverging-dementatively/structurally/paradigmatically regarding procrypticism-or-disjointedness-as-ofreference-of-thought with notional ${ }^{18}$ deprocrypticism (as the-Good/knowledgereification $\sim$ gesturing-and-accounting - of-epistemic-phenomenalism- $<$ in-

prospective_psychologismic apriorising/axiomatising/referencing-\{of- ${ }^{\text {pprospectively }}$ implicited_attentant-ontological-contiguity ' educedexistentialising/contextualising/textualising_'intelligibility/epistemicity/reflexivity-contiguity<imbued-notional cogency>> $\}$-conflatedness -in-\{preconverging-disentailment by\} 
postconverging-entailment $>$ /understanding/<amplituding/formative-

epistemicity $>$ causality $\sim$ as-to-projective-totalitative-implications-of-prospective-

nonpresencing,-for-explicating relative-unreflexivity/relative-reflexivity - ontological-

contiguity and not good-natured/vague-impress construct). Ontologicalnormalcy/postconvergence as prospective-transcendence-in-perpetually-upholding-intemporalpreservation-entropy-or-contiguity-or-ontological-preservation, beyond defective intradimensional-subknowledging -normalcy/reflex-normalcy, points to factoring in notional firstnaturedness-formativeness-<as-to-eventualising-inkling-drive-or-seedingmisprising $>$ temporal-to-intemporal-dispositions- $<$ so-construed-as-from-perspectiveontological-normalcy/postconvergence> disambiguation as 'knowledge-notionalisation' to avoid wrongfully operating/processing of logic by the reference of the intemporal-disposition

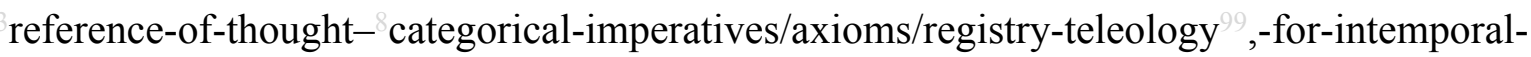
preservation-entropy-or-contiguity-or-ontological-preservation which is ontological (as it is in sync with intrinsic-reality/veridicality), where dealing effectively rather with temporaldispositions. Knowledge-notionalisation factors in how temporal-dispositions relate to intemporal-preservation-entropy-or-contiguity-or-ontological-preservation at uninstitutionalised/unintemporalised/solipsistic/recomposuring/animality-thresholds-forintemporal-preservation-entropy-or-contiguity-or-ontological-preservation (intradimensionalsubknowledging ${ }^{4}$-normalcy/reflex-normalcy) and at institutionalised/intemporalised-thresholds (ontological-normalcy/postconvergence). It should be noted that the peculiarity for achieving all the institutional-cumulation/institutional-recomposure-〈as-to- historiality/ontologicaleventfulness /ontological-aesthetic-tracing-<perspective-ontologicalnormalcy/postconvergence-reflected-'epistemicity-relativism-determinism'>> is about bringing the prior registry-worldview/dimension ${ }^{74}$ perversion-of- ${ }^{2}$ reference-of-thought- $<$ aspreconvergingly-apriorising/axiomatising/referencing-in- 
setup/mental-devising-representation/mentation/\{cumulated/recomposured $\}$-consciousnessawareness-teleology awareness for the collective-mind to psychoanalyticallyunshackle/memetically-reorder/institutionally-recomposure, and thus take-stock-andsupersede/transcend limited-mentation-capacity-deepening-as-subjecting limitedness/human-subpotency-to-'educed-unlimitedness/existence-sublimating nascence' threshold (uninstitutionalised-threshold ${ }^{102}$ ). This is brought to the collective-consciousness so that with regards to social-stake-contention-or-confliction-and-confliction it renews its psychoanalytic-equilibrium, as the latest 'capacity boost' with respect to what is the grander individual-and-social good as positive-opportunism-of-social-functioning-and-accordance ${ }^{75}$. For instance, achieving base-institutionalisation requires that it should be brought to the collective-consciousness that it is 'perilous to survival-and-flourishing' to remain recurrentlyuninstitutionalised for the grander individual-and-social good as positive-opportunism-ofsocial-functioning-and-accordance ${ }^{75}$. Once this enters the collective-consciousness this leads to an inclination for a renewed psychoanalytic-unshackling/memetic-reordering/institutionalrecomposuring wherein recurrent-utter-uninstitutionalisation registry-worldview then becomes preconverging-or-dementing ${ }^{20}$ apriorising-psychologism- $<$ stranded-as-rightfully-

oblongated/decandored-and-dialectically-or-contendingly-out-of-phase>, as it is recurrentlyuninstitutionalised, as the backdrop for the straightness/candoring-and-dialectically-in-phasing of base-institutionalisation registry-worldview. This is relatively direct by the existential<disontologising/re-ontelogising aporeticism $>$ implications to survival-and-flourishing with the lower institutional-cumulation/institutional-recomposure-〈as-to- historiality/ontologicaleventfulness /ontological-aesthetic-tracing-<perspective-ontologicalnormalcy/postconvergence-reflected-'epistemicity-relativism-determinism'>> of baseinstitutionalisation, ${ }^{103}$ universalisation and positivism. For deprocrypticism, an even stronger 
emphasis has to be placed on the abstract percolation-channelling- $<$ in-deferential-formalisationtransference $>$ as setup from positive-opportunism—of-social-functioning-and-accordance ${ }^{75}$ for survival-and-flourishing, just as with the positivistic registry-worldview which as well is relatively deferential with percolation-channelling-<in-deferential-formalisation-transference $>$ (undermining <amplituding/formative $>$ wooden-language-〈imbued-averaging-of-thought$<$ as-to-leveling/ressentiment/closed-construct-of- meaningfulness-and-teleology -as-of'nondescript/ignorable-void '-with-regards-to-prospective-apriorising-implications $>>$ banality-of-thought) to formalised deference like the higher developed legal system involving lesser possibility for mob-and-disparate-justice as with the lower institutionalcumulation/institutional-recomposure-〈as-to- historiality/ontological-

\section{eventfulness /ontological-aesthetic-tracing-<perspective-ontological-} normalcy/postconvergence-reflected-‘epistemicity-relativism-determinism'>>, grander subjectmatter expertise and lesser hearsays-and-vague-opinions limiting the ambit of the influence of the extended-informality-〈susceptible-to-effecting-parsimony-as-of-shoddiness-andincompleteness-to- meaningfulness-and-teleology \; all geared to discriminate for supersedingness of the intemporal-disposition (longness-of-register-of- ${ }^{56}$ meaningfulness-andteleology ${ }^{9}$ ) over temporal-dispositions (shortness-of-register-of- ${ }^{5}$ meaningfulness-andteleology ${ }^{9}$ ) as percolation-channelling- $<$ in-deferential-formalisation-transference $>$ not only in the present but prospectively. In other words, higher institutionalisations imply greater 'deferential-formalisation-transference' wherein the ambits of the extended-informality〈susceptible-to-effecting-parsimony-as-of-shoddiness-and-incompleteness-to-

meaningfulness-and-teleology $\rangle$ with regards to meaningfulness shrinks as formal conceptualisations extend the intemporal-skewing ('intemporality ${ }^{52}$-symmetrising-bydesymmetrising-subsumption-of-temporality ${ }^{8}$, , for relative intrinsic-reality/ontologicalveridicality transcendental-enabling/sublimating/supererogatory $\sim$ de-mentativity) and 
deferential model for construing meaningfulness. For instance, many a subject matter domain like meaning about the heavens, forces of nature, material nature, social laws, etc. are now effectively construed socially in deference to abstract intemporal-disposition teleological conceptualisation voiding social temporal-dispositions teleological dispositions. The reason is simple formal settings use the-Good/knowledge-reification $\sim$ gesturing-and-accounting-ofepistemic-phenomenalism- $<$ in-

prospective_psychologismic apriorising/axiomatising/referencing-\{of-'prospectively implicited_attendant-ontological-contiguity ' educedexistentialising/contextualising/textualising_'intelligibility/epistemicity/reflexivity-contiguity<imbued-notional cogency >' \}-conflatedness -in-\{preconverging-disentailment by\} postconverging-entailment $>$ /understanding/<amplituding/formativeepistemicity $>$ causality $\sim$ as-to-projective-totalitative-implications-of-prospectivenonpresencing,-for-explicating relative-unreflexivity/relative-reflexivity - ontologicalcontiguity to construe knowledge and virtue conceptualisations as this is what proxies/syncswith intrinsic-reality and hence their effective potency while on-the-other-hand informal settings tend more to impression-driven/good-naturedness/wishfulness conceptualisations which may sound appropriate in their <amplituding formative-epistemicity $>$ totalising $\sim$ self-referencingsyncretising/circularity/interiorising/akrasiatic-drag ${ }^{34}$ but are often defective by lack of universality, not ontologically-driven in terms-as-of-axiomatic-construct of understanding and often with temporal punctual/immediacy/constituted/compulsions-encumbered interests/shortness-of-register-of- meaningfulness-and-teleology . In this light, the articulation of the ontological-veridicality $/{ }^{\circ}$ reference-of-thought of human-subpotencyaporia/undecidability/dilemma/ought-indeterminacy/deficiency/limitation/constraint—imbued'notional firstnaturedness-formativeness-<as-to-eventualising inkling-drive-or-seeding misprising $>$ temporal-to-intemporal-dispositions- $<$ so-construed-as-from-perspective- 
ontological-normalcy/postconvergence>'-existentialism-form-factor-pedestals-disambiguation of our mental-devising-representation in explication of our 'mentation capacity limitations' accounting for our $\quad{ }^{7}$ perversion-of- ${ }^{83}$ reference-of-thought-<as-preconverginglyapriorising/axiomatising/referencing-in-nonconviction/madeupness/bottomlining-as-toshallow-supererogation $>$ that 'structurally-explain' the vices-and-impediments ${ }^{105}$ peculiar to

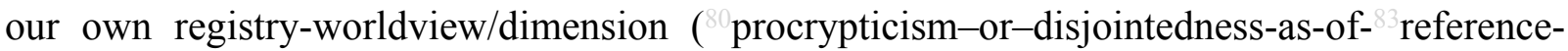
of-thought) or $\quad{ }^{7}$ perversion-of- ${ }^{3}$ reference-of-thought- $<$ as-preconverginglyapriorising/axiomatising/referencing-in-nonconviction/madeupness/bottomlining-as-toshallow-supererogation $>$ of positivistic meaningfulness, beyond our illusion-of-thepresent/present-consciousness (just as non-positivism/medievalism 'structurally-explains' the peculiar vices-and-impediments 105 and preconverging/postconverging-dementative/structural/paradigmatic inhibitions to human emancipation requiring prospective positivism with its corresponding de-mentation-_supererogatory ontological-de-mentationor-dialectical-de-mentation-stranding-or-attributive-dialectics $\rangle$ as de-mentation〈supererogatory $\sim$ ontological-de-mentation-or-dialectical-de-mentation-stranding-or-

attributive-dialectics $\rangle)$. The idea is not to assume an idling-temporal-disposition of stigmatising intradimensionally but rather an intemporal/ontological disposition (longness-of-register-ofmeaningfulness-and-teleology ${ }^{9}$ ), that works with 'what is as it is', and bring this reality to the collective-consciousness for the requisite 'postconverging-or-dialectical-thinking ${ }^{21}$-psychology or psychology-of-mentation-dynamics or natural psychological-dynamics' psychoanalyticunshackling/memetic-reordering/institutional-recomposuring for futural Beingdevelopment/ontological-framework-expansion-as-to-depth-of-ontologising-development-asinfrastructure-of- meaningfulness-and-teleology as of prospective notional ${ }^{1}$ deprocrypticism (wherein procrypticism is preconverging-or-dementing 2 apriorising-psychologism- $<$ stranded-as-rightfully-oblongated/decandored-and-dialectically-or- 
contendingly-out-of-phase $>$, as it subknowledges-or-mimics/perverts-the-registry-of positivistic meaningfulness ${ }^{83}$ reference-of-thought- categorical-imperatives/axioms/registry-teleology ${ }^{9}$,for-intemporal-preservation-entropy-or-contiguity-or-ontological-preservation). The idea of limited-mentation-capacity-deepening—as-subjecting limitedness/hmman-subpotency-to'educed-unlimitedness/existence-sublimating nascence' 53 (for intemporal-preservationentropy-or-contiguity-or-ontological-preservation) fundamentally implies that ${ }^{83}$ reference-of-

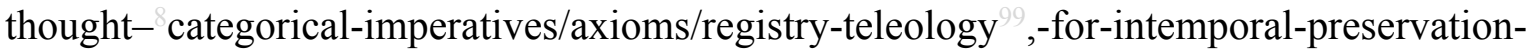
entropy-or-contiguity-or-ontological-preservation are limited at the uninstitutionalisedthreshold ${ }^{102}$ of the specific registry-worldview's/dimension's institutionalisation they enable, and are not absolute with respect to the perpetuation of intemporal-preservation-entropy-orcontiguity-or-ontological-preservation as ontological-normalcy/postconvergence and thus need to be cumulated-upon (or rather more precisely be recomposured institutionally), wherein new reference-of-thought- ${ }^{8}$ ategorical-imperatives/axioms/registry-teleology ${ }^{99}$,-for-intemporalpreservation-entropy-or-contiguity-or-ontological-preservation allow for the furtherance of intemporal-preservation-entropy-or-contiguity-or-ontological-preservation. The positivistic institutionalisation reflex disposition is to imply only a human intemporaldisposition/ontological-disposition, thus wrongly elevating issues of temporal-dispositions perversion-of- ${ }^{3}$ reference-of-thought-<as-preconvergingly-

\section{apriorising/axiomatising/referencing-in-nonconviction/madeupness/bottomlining-as-to-}

shallow-supererogation $>$ as being issues of intemporal-disposition/ontological-dispositions and thus wrongfully implying their ontological-veridicality/relative-unreflexivity/relativereflexivity - ontological-contiguity ${ }^{67}$ of ${ }^{83}$ reference-of-thought (from ontologicalnormalcy/postconvergence epistemic-or-notional projective-perspective) rather than rightfully their notional-discontiguity/epistemic-discontiguity $<$ between - prior-shallowsupererogation -of-mentally-aestheticised $\sim$ preconverging/dementing -qualia- 
schema_and_prospective-profound-supererogation -of-mentally-

aestheticised $\sim$ postconverging/dialectical-thinking - qualia-schema $>$ /non-ontological-and-noncontending-referencing- $<$ thus-ontologically-or-contendingly-reflected-or-perspectivated-as-ofpreconverging-or-dementing ${ }^{20}$-apriorising-psychologism $>\quad$ (not-veridical-thinking-referencerather-preconverging-or-dementing ${ }^{20}$-reference), and thus wrongly engaging in logical contentions instead of reflecting/perspectivating/highlighting (reasoning-through-and-notreasoning-with) manifestations of temporal-dispositions ${ }^{7}$ perversion-of- ${ }^{3}$ reference-of-thought$<$ as-preconvergingly-apriorising/axiomatising/referencing-in-

nonconviction/madeupness/bottomlining-as-to-shallow-supererogation $>$, thus resulting in the consequent endemisation/enculturation of the specific vices-and-impediments ${ }^{105}$ of the positivistic registry-worldview ( procrypticism-or-disjointedness-as-of- ${ }^{8}$ reference-ofthought). In contrast, the particularity of the superseding/transcending 'notional ' deprocrypticism institutionalisation' disposition over procrypticism is that prospectively it points to the ontological-veridicality of a human-subpotencyaporia/undecidability/dilemma/ought-indeterminacy/deficiency/limitation/constraint—imbued'notional firstnaturedness-formativeness-<as-to-eventualising -inkling drive-or-seeding misprising $>$ temporal-to-intemporal-dispositions- $<$ so-construed-as-from-perspectiveontological-normalcy/postconvergence>'-existentialism-form-factor-pedestals-disambiguation (at positivistic meaningfulness uninstitutionalised-threshold ${ }^{102}$ ) to its mental-devisingrepresentation to enable the 'postconverging-or-dialectical-thinking -psychology or psychology-of-mentation-dynamics or natural psychological-dynamics’ psychoanalyticunshackling/memetic-reordering/institutional-recomposuring of the collective-consciousness, and so as a knowledge-notionalisation. That is, a registry-worldview's/dimension's institutionalisation setup that perpetually acknowledges and accounts for human-subpotencyaporia/undecidability/dilemma/ought-indeterminacy/deficiency/limitation/constraint—imbued- 
'notional firstnaturedness-formativeness-<as-to-eventualising -inkling-drive-or-seedingmisprising $>$ temporal-to-intemporal-dispositions- $<$ so-construed-as-from-perspectiveontological-normalcy/postconvergence >'-existentialism-form-factor disambiguation before engaging either with logical contention in the case of issues of intemporaldisposition/ontological-disposition or with reflecting/perspectivating/highlighting (reasoningthrough-and-not-reasoning-with) manifestations of ${ }^{74}$ perversion-of- ${ }^{-}$reference-of-thought- $<$aspreconvergingly-apriorising/axiomatising/referencing-innonconviction/madeupness/bottomlining-as-to-shallow-supererogation $>$ in the instance of issues of temporal-dispositions; bringing this conceptualisation to the collective-consciousness for the necessary psychoanalytic-unshackling/memetic-reordering/institutional-recomposuring that should enable the superseding/transcending of the enculturating/endemising vices-andimpediments ${ }^{105}$ together with the inhibiting effect on human emancipation potential associated with procrypticism. To further elucidate, let's explore again the Arithmetic notionalcontiguity/epistemic-contiguity ${ }^{2}<$ profound-supererogation -of-mentallyaestheticised postconverging/dialectical-thinking -qualia-schema> comparison highlighted previously wherein character A had a condition whereby its results of additionality were systematically incremented by 1 , its's subknowledging -impulse/compulsive-dementing highlighting an uninstitutionalised-threshold ${ }^{102}$ where the other characters wrongly calculated the result (the ontological-veridicality) failing/not-upholding-<as-ofapriorising/axiomatising/referencing $>$ ontological-normalcy/postconvergence as intemporalpreservation-entropy-or-contiguity-or-ontological-preservation implied by ontological-faithnotion-or-ontological-fideism - imbued-underdetermination-of-motif-andapriorising/axiomatising/referencing-as-so-being-as-of-existential-reality, as actually intemporal-preservation-entropy-or-contiguity-or-ontological-preservation supersedes the mere- categorical-imperatives/axioms/registry-teleology -for-intemporal-preservation- 
entropy-or-contiguity-or-ontological-preservation as the latter's pertinence is rather about and subsumed as a mentation capacity to uphold the former. The bigger issue with regards to all the BODMAS characters is with respect to the limits of their ${ }^{83}$ reference-of-thought- categoricalimperatives/axioms/registry-teleology ${ }^{9}$,-for-intemporal-preservation-entropy-or-contiguityor-ontological-preservation which are readily predisposed to such ${ }^{74}$ perversion-of- ${ }^{8}$ referenceof-thought-<as-preconvergingly-apriorising/axiomatising/referencing-in-

subknowledging -impulse/compulsive-dementing whether by character A or any other character rather than just the fact that the condition (psychopathic postlogism 77 in hollowconstituting-<as-disjointed-misappropriation-of-meaningfulness-and-failing-intemporalpreservation> for instance) is the causative factor of their failure to in ontologicalnormalcy/postconvergence ensure intemporal-preservation-entropy-or-contiguity-orontological-preservation. In any case the preconverging/postconverging-dementative/structural/paradigmatic resolution is with regards to the implications of metaphorically-a-million-and-one-instances-and-locales of ${ }^{77}$ perversion-of- ${ }^{83}$ reference-ofthought-<as-preconvergingly-apriorising/axiomatising/referencing-in-

nonconviction/madeupness/bottomlining-as-to-shallow-supererogation $>$ in the given registryworldview/dimension as an aetiologisation/ontological-escalation- $<$ ontologicalveridicality_commitment/otherliness_transcending/compulsions-encumbered_transcending > (as notional firstnaturedness-formativeness-<as-to-eventualising-inkling-drive-or-seedingmisprising $>$ temporal-to-intemporal-dispositions- $<$ so-construed-as-from-perspectiveontological-normalcy/postconvergence $>$ individuations predictable and determinable teleologies). That is, fundamentally the appropriate conceptualisation of ${ }^{83}$ reference-of-thoughtcategorical-imperatives/axioms/registry-teleology ${ }^{9}$,-for-intemporal-preservation-entropy-orcontiguity-or-ontological-preservation is structurally-speaking about perpetually ensuring 
intemporal-preservation-entropy-or-contiguity-or-ontological-preservation

superseding/preceding notion (i.e. ontological-normalcy/postconvergence as prospectivetranscendence-in-perpetually-upholding-intemporal-preservation-entropy-or-contiguity-orontological-preservation). In this regard, we may easily construe the fundamental defects-ofcategorical-imperatives/axioms/registry-teleology ${ }^{9}$-for-intemporal-preservation-entropy-orcontiguity-or-ontological-preservation as these enable ${ }^{7}$ perversion-of- ${ }^{3}$ reference-of-thought$<$ as-preconvergingly-apriorising/axiomatising/referencing-innonconviction/madeupness/bottomlining-as-to-shallow-supererogation $>$ with respect to intemporal-preservation-entropy-or-contiguity-or-ontological-preservation wherein successive institutional-cumulation/institutional-recomposure-〈as-to- historiality/ontological-

\section{eventfulness /ontological-aesthetic-tracing-<perspective-ontological-}

normalcy/postconvergence-reflected-‘epistemicity-relativism-determinism' $>>$ are analogical to various defective instances in operating the BODMAS equation. That is, while the condition/subknowledging ${ }^{4}$-impulse/compulsive-dementing ${ }^{20}$ with A's additionality results are wrongly incremented by 1 , leading to the uninstitutionalised-threshold 02 to be rightfully corrected with new ${ }^{83}$ reference-of-thought- categorical-imperatives/axioms/registryteleology ${ }^{9}$,-for-intemporal-preservation-entropy-or-contiguity-or-ontological-preservation involving subtracting 1; the defect of a second registry-worldview/dimension may involve subtracting 1 from the result of $\mathrm{S}$ as a condition/subknowledging -impulse/compulsivedementing of $\mathrm{S}$, requiring similarly new ${ }^{83}$ reference-of-thought- categoricalimperatives/axioms/registry-teleology ${ }^{9}$,-for-intemporal-preservation-entropy-or-contiguityor-ontological-preservation correction of the BODMAS characters as with the first registryworldview/dimension to uphold the intemporal-preservation-entropy-or-contiguity-orontological-preservation. Likewise, a third and fourth registry-worldview/dimensions defects could involve respectively a subknowledging -impulse/compulsive-dementing 2 /condition of 
$\mathrm{M}$ wherein the latter wrongly adds 1 to a multiplier before multiplying and a subknowledging impulse/compulsive-dementing /condition of $\mathrm{D}$ wherein $\mathrm{D}$ wrongly subtract 1 to a divisor before dividing, with these two latter registry-worldviews/dimensions equally requiring similarly new ${ }^{83}$ reference-of-thought- ${ }^{-}$categorical-imperatives/axioms/registry-teleology ${ }^{9}$,-forintemporal-preservation-entropy-or-contiguity-or-ontological-preservation adjustment of the BODMAS characters as with the first and second registry-worldviews/dimensions to uphold the intemporal-preservation-entropy-or-contiguity-or-ontological-preservation. Ultimately, a notional ${ }^{1}$ deprocrypticism construal of the institutionalisation/intemporalisation process aiming to perpetually sync ${ }^{83}$ reference-of-thought- categorical-imperatives/axioms/registryteleology ${ }^{9}$,-for-intemporal-preservation-entropy-or-contiguity-or-ontological-preservation with intemporal-preservation-entropy-or-contiguity-or-ontological-preservation in ontologicalnormalcy/postconvergence, is one that will bring to the mental-devising-representation, the BODMAS characters potential temporal-dispositions to ${ }^{7}$ perversion-of- ${ }^{3}$ reference-of-thought-

\section{$<$ as-preconvergingly-apriorising/axiomatising/referencing-in-}

nonconviction/madeupness/bottomlining-as-to-shallow-supererogation

and subknowledging -impulse/compulsive-dementing with the resultant integration unconsciously (ignorance) and consciously (other temporal-dispositions of affordability/opportunism/exacerbation/social-chainism-or-social-discomfiture-or-negativesocial-aggregation/temporal-enculturation-or-temporal-endemisation) inducing the various uninstitutionalised-threshold ${ }^{102}$, for a suprastructural resolution to human ${ }^{74}$ perversion-ofreference-of-thought-<as-preconvergingly-apriorising/axiomatising/referencing-innonconviction/madeupness/bottomlining-as-to-shallow-supererogation $>$ disposition, enabling the 'postconverging-or-dialectical-thinking -psychology or psychology-of-mentationdynamics or natural psychological-dynamics’ psychoanalytic-unshackling/memeticreordering/institutional-recomposuring of the collective-consciousness towards knowledge- 
notionalisation; as the recognition of the reality of human-subpotencyaporia/undecidability/dilemma/ought-indeterminacy/deficiency/limitation/constraint—imbued'notional firstnaturedness-formativeness-<as-to-eventualising inkling-drive-or-seeding misprising $>$ temporal-to-intemporal-dispositions- $<$ so-construed-as-from-perspectiveontological-normalcy/postconvergence >'-existentialism-form-factor-pedestals-disambiguation then allows for acknowledging, accounting for and the structural-superseding of our vices-andimpediments ${ }^{15}$ thus enabling ontological-normalcy/postconvergence as prospectivetranscendence-in-perpetually-upholding-intemporal-preservation-entropy-or-contiguity-orontological-preservation involving the de-mentation-〈supererogatory $\sim$ ontological-dementation-or-dialectical-de-mentation-stranding-or-attributive-dialectics $\rangle$ preconverging-ordementing 20 -apriorising-psychologism- $<$ stranded-as-rightfully-oblongated/decandored-anddialectically-or-contendingly-out-of-phase $>$ of temporal-dispositions ${ }^{7}$ perversion-ofreference-of-thought-<as-preconvergingly-apriorising/axiomatising/referencing-innonconviction/madeupness/bottomlining-as-to-shallow-supererogation $>$, as ${ }^{15}$ de-mentation〈supererogatory ontological-de-mentation-or-dialectical-de-mentation-stranding-or-

attributive-dialectics $\rangle$ is the effective psychological tool for 'postconverging-or-dialecticalthinking -psychology or psychology-of-mentation-dynamics or natural $\sim$ psychologicaldynamics' psychoanalytic-unshackling/memetic-reordering/institutional-recomposuring. The implications for the science of psychology can thus be drawn out. The articulated notion of ${ }^{15}$ dementation-〈supererogatory $\sim$ ontological-de-mentation-or-dialectical-de-mentation — strandingor-attributive-dialectics $\rangle$ brings up the central conceptual role of psychology as about understanding human mental-devising-representation and the implications thereof. Central to this ${ }^{15}$ de-mentation-〈supererogatory $\sim$ ontological-de-mentation-or-dialectical-de-mentationstranding-or-attributive-dialectics $\rangle$ process is a dialectical exercise of stranding; either as mentally oblongated/decandored-and-dialectically-or-contendingly-out-of-phase to imply a 
superseded/transcended/unsound registry-or-registry-worldview/dimension or as mentally straight/candored-and-dialectically-or-contendingly-in-phase

\section{〈supererogatory ontological-de-mentation-or-dialectical-de-mentation-stranding-or-}

attributive-dialectics $\rangle$ further implies that instead of a 'conventioning influenced and driven' more or less notational study of human psychological phenomena as is the case today; we can 'think' of psychology in de-mentation-/supererogatory ontological-de-mentation-ordialectical-de-mentation - stranding-or-attributive-dialectics $\rangle$ terms of ${ }^{15}$ de-mentation〈supererogatory ontological-de-mentation-or-dialectical-de-mentation-stranding-or-

attributive-dialectics $\rangle$ of registry-worldview/dimensions successive existentialisms/full-depthsof-existential-implications transdimensional-meaningfulness/memetic-refinements as ontological-normalcy/postconvergence-or-postdicatory deconstruction/ontologicalreconstituting-as-to-conflatedness ${ }^{13}$ as dialectical transformation as-prospective ${ }^{83}$ reference-ofthought ( 15 de-mentation-〈supererogatory $\sim$ ontological-de-mentation-or-dialectical-dementation-stranding-or-attributive-dialectics $\rangle$ with respect to either mentally oblongated/decandored-and-dialectically-or-contendingly-out-of-phase representation or mentally straight/candored-and-dialectically-or-contendingly-in-phase representation) as 'directed' simply by demonstrable ontological-veracity/ontological-relevance/ ${ }^{83}$ reference-ofthought apriorising/axiomatising/referencing/intelligibilitysettingup/measuringinstrumenting; leading to a psychological science which is more comprehensive, timeless and unbounded by its conceptualisation as it emphasises psychological-representation/mental-devising-representation as more 'ontologically-driven/ontologised' rather than 'conventioninglydriven/conventionalised'. In so doing, overriding and superseding the analyst illusion-of-thepresent/epistemic-totalising $\sim$ self-referencing-syncretising/present-consciousness/mirage 
referring to the instance where the personhood-and-socialhood-formation intradimensional conventioning induces an 'analytical-complex' with respect to an ontologically veridical psychological-representation or mental-devising-representation. As implied psychologicalrepresentation/mental-devising-representation is then fundamentally determined by the depth/profoundness-of-ontological-veracity/depth/profoundness-of-ontological-reference of a given registry/registry-worldview-or-dimension as it upholds ontologicalnormalcy/postconvergence (prospective-transcendence-in-perpetually-upholding-intemporalpreservation-entropy-or-contiguity-or-ontological-preservation) over reflex-normalcy or intradimensional-subknowledging ${ }^{94}$-normalcy. Ontological-normalcy/postconvergence appropriately points to the pertinence for ontological construal as of the circularity/recurrence/repetition/repeatability ${ }^{10}$ delineating existential-transitioning-oriterability-trace-of-narratives-as-dots_or_implicited_attendant-ontologicalcontiguity $^{67} \sim$ educedexistentialising/contextualising/textualising_'intelligibility/epistemicity/reflexivity-contiguity$<$ imbued-notional $\sim$ cogency $>$ ' -reification_or_intrinsic-reality-ontologicalcoherence_or_superseding-oneness-of-ontology ${ }^{41}$ by ${ }^{55}$ maximalising-recomposuring-forrelative-ontological-completeness ${ }^{8}$ — unenframed/re-ontologising conceptualisation for an appropriate de-mentation-〈supererogatory ontological-de-mentation-or-dialectical-dementation - stranding-or-attributive-dialectics $\quad{ }^{15}$ de-mentation-〈supererogatory ontologicalde-mentation-or-dialectical-de-mentation-stranding-or-attributive-dialectics $\rangle$ exercise wherein the ${ }^{83}$ reference-of-thought ('intemporal-prioritisation-of- ${ }^{8}$ reference-of-thought'-asconflatedness $^{13}$-or-ontological-reprojecting) is always a moving target (due to the institutionalisation/intemporalisation process) in need for prospective dialectical reconstitution (deconstruction), which then puts a science of psychology in phase with the dialectical development of ontological-depth/profoundness-of-reference in superseding relative- 
ontological-incompleteness 8 -induced,-'threshold-of-nonconviction/madeupness/bottomliningin-shallow-supererogation -<as-to-'attendant-intradimensional'-prospectivelydisontologising preconverging/dementing -apriorising-psychologism>', as-it-is-thus- 'inwait'-for- ${ }^{7}$ perversion-of- ${ }^{3}$ reference-of-thought-<as-preconverginglyapriorising/axiomatising/referencing-in-nonconviction/madeupness/bottomlining-as-toshallow-supererogation >,-or-temporal-preservation-as-pseudointemporality ${ }^{52}$-preservation, in line with intemporal-preservation-entropy-or-contiguity-or-ontological-preservation; whereas a conventioning reference is relatively in circumventive/distractive-temporal-prioritisation-ofreference-of-thought and fails to factor in human limited-mentation-capacity-deepening-assubjecting limitedness/human-subpotency to-'educed-unlimitedness/existence-sublimatingnascence' $^{53}$ and the consequent uninstitutionalised-threshold ${ }^{12}$ or relative-ontologicalincompleteness 8 -induced,-'threshold-of-nonconviction/madeupness/bottomlining-in-shallowsupererogation -<as-to-'attendant-intradimensional'-prospectivelydisontologising $\sim$ preconverging/dementing -apriorising-psychologism>' -threshold （as-it-isthus- ‘in-wait'-for- ${ }^{7}$ perversion-of- ${ }^{3}$ reference-of-thought-<as-preconverginglyapriorising/axiomatising/referencing-in-nonconviction/madeupness/bottomlining-as-toshallow-supererogation >,-or-temporal-preservation-as-pseudointemporality ${ }^{52}$-preservation) hence failing/not-upholding-<as-of-apriorising/axiomatising/referencing $>$ to imply a prospective dialectic ontological-depth/profoundness-of-reference for an appropriate ${ }^{15} \mathrm{de}-$ mentation-〈supererogatory ontological-de-mentation-or-dialectical-de-mentation — strandingor-attributive-dialectics〉 $\quad{ }^{15}$ de-mentation-〈supererogatory $\sim$ ontological-de-mentation-ordialectical-de-mentation - stranding-or-attributive-dialectics $\rangle$. That is, a conventioning influenced-and-driven psychology tends to equate the conventional insights at one ${ }^{15}$ dementation-〈supererogatory ontological-de-mentation-or-dialectical-de-mentation — strandingor-attributive-dialectics〉 dialectical moment or registry-worldview/dimension as 
intradimensionally set in stone and across all moments whereas an ontologically-driven psychology acknowledges and recomposures to the dialectical evolution of ${ }^{83}$ reference-ofthought for a comprehensive, appropriate and veridical de-mentation〈supererogatory ontological-de-mentation-or-dialectical-de-mentation-stranding-orattributive-dialectics $\rangle$ exercise. Such ${ }^{83}$ reference-of-thought of dialecticism registry-worldviewwise/dimension-wise (for ${ }^{15}$ de-mentation-/supererogatory $\sim$ ontological-de-mentation-ordialectical-de-mentation - stranding-or-attributive-dialectics $\rangle \quad$ exercise in reflection/perspectivation of psychological-representation/mental-devising-representation) are the institutional-cumulation/institutional-recomposure-〈as-to- historiality/ontologicaleventfulness /ontological-aesthetic-tracing-<perspective-ontologicalnormalcy/postconvergence-reflected-‘epistemicity-relativism-determinism' $>>$ as recurrentutter-uninstitutionalisation, base-institutionalisation/ununiversalisation, ${ }^{103}$ universalisation/nonpositivism-or-medievalism, positivism/procrypticism preconverging-or-dementing ${ }^{20}$ apriorising-psychologism, and prospectively (critical for a prospective conceptualisation of psychology) perpetuation-of-deprocrypticism. This explains why this memetism/transdimensional-meaningfulness/suprastructural-meaningfulness psychology is a 'postconverging-or-dialectical-thinking -psychology or psychology-of-mentation-dynamics or natural psychological-dynamics' as it is driven/led by a reference to dialectical/ontologicalveridicality (ontological-normalcy/postconvergence in successive ontologicalnormalcy/postconvergence/postdicatory ontological-reconstituting-as-toconflatedness ${ }^{13} /$ deconstruction of dialectical existentialisms/full-depths-of-existentialimplications as ${ }^{83}$ reference-of-thought, rather than intradimensional-subknowledging normalcy or reflex-normalcy) for " ${ }^{15}$ de-mentation-(supererogatery $\sim$ ontological-de-mentationor-dialectical-de-mentation-stranding-or-attributive-dialectics $\rangle$ of ${ }^{83}$ reference-of-thought' exercise in reflection/perspectivation of psychological-representation/mental-devising- 
representation, i.e. preconverging-or-dementing 2 -apriorising-psychologism- $<$ stranded-asrightfully-oblongated/decandored-and-dialectically-or-contendingly-out-of-phase $>$ for the dialectically-and-ontologically superseded/transcended/unsound registry/registry-worldviewor-dimension, and postconverging-or-dialectical-thinking -apriorising-psychologism$<$ stranded-as-rightfully-straight/candored-and-dialectically-or-contendingly-in-phase $>$ for the dialectically-and-ontologically-superseding/transcending/sound registry/registry-worldview-ordimension. This 'postconverging-or-dialectical-thinking -psychology or psychology-ofmentation-dynamics or natural psychological-dynamics' is the foundation of a pure, emancipated and disinhibited psychology (both registry-and-registry-worldview-wise) as such a psychology is grounded exclusively on ontologically demonstrable references of the veridicality of registries and registry-worldviews/dimensions successive existentialisms/full-depths-ofexistential-implications, and the corresponding ontological veracities implied. Such a 'postconverging-or-dialectical-thinking -psychology or psychology-of-mentation-dynamics or natural psychological-dynamics' contrasts with a 'mented' or 'stigmatic' psychology of weak memetism/transdimensional-meaningfulness/suprastructural-meaningfulness $\quad$ reference-ofthought for the simple reason that it is not founded on a pure dialecticism of ontological/dialectical-referencing but rather on intradimensional conventionalised referencing which wrongly hardly proxies the veridicality of ontological-normalcy/postconvergence or construe a dialectical-reference/ontological-reference for " ${ }^{15}$ de-mentation〈supererogatory $\sim$ ontological-de-mentation-or-dialectical-de-mentation-stranding-orattributive-dialectics $\rangle$ of ${ }^{83}$ reference-of-thought' of psychological-representation/mentaldevising-representation at uninstitutionalised-threshold ${ }^{102}$. Thus it mental-devisingrepresentation is stigmatic or mented (set-in-place-or-a-period) as of preconverging-ordementing 20 -apriorising-psychologism- $<$ stranded-as-rightfully-oblongated/decandored-anddialectically-or-contendingly-out-of-phase $>\quad$ for the conventioning- 
superseded/transcended/unsound

registry/registry-worldview-or-dimension, and postconverging-or-dialectical-thinking -apriorising-psychologism- $<$ stranded-as-rightfullystraight/candored-and-dialectically-or-contendingly-in-phase $>$ for the conventioningsuperseding/transcending/sound registry/registry-worldview-or-dimension. This will explain inmany-ways the more or less fitful development of modern-day psychology, more or less 'uncertain of the ontological/dialectical pertinence of temporal-as-out-of-phasingrepresentation' (in reflecting preconverging-or-dementing -apriorising-psychologism) thus undermining its ontological-referencing veracity/ontological-pertinence with respect to an " ${ }^{6}$ dementation-〈supererogatory ontological-de-mentation-or-dialectical-de-mentation — strandingor-attributive-dialectics $\rangle$ of ${ }^{83}$ reference-of-thought' exercise of registry-worldview/dimensions successive existentialisms/full-depths-of-existential-implications transdimensionalmeaningfulness/memetic-refinements in ontological-normalcy/postconvergence-orpostdicatory deconstruction/ontological-reconstituting-as-to-conflatedness ${ }^{13}$ as dialectical transformation as-prospective ${ }^{83}$ reference-of-thought. A dialectical ontological-reconstitutingas-to-conflatedness ${ }^{13} /$ deconstruction of ${ }^{83}$ reference-of-thought (recognising human limitedmentation-capacity-deepening-as-subjecting-limitedness/human-subpotency-to-'educedunlimitedness/existence-sublimating nascence' ${ }^{3}$ and the need to re-institutionalised/reintemporalised resulting in the subsequent institutional-cumulation/institutional-recomposure〈as-to- historiality/ontological-eventfulness /ontological-aesthetic-tracing-<perspectiveontological-normalcy/postconvergence-reflected-‘epistemicity-relativism-determinism’>〉) as articulated above is not only the basis for memetism/transdimensionalmeaningfulness/suprastructural-meaningfulness, but as well for avoiding what can be termed as the 'ontological-circularity' of modern-day psychology. Such ontological-circularities are ingrained in all registry-worldviews/dimensions wherein the naïve pretence for a quest for deeper ontological-veridicality is rather just syncretic/circular and hollow-constituting-<as-disjointed- 
misappropriation-of-meaningfulness-and-failing-intemporal-preservation $>$ as fundamentally the reference-of-thought- categorical-imperatives/axioms/registry-teleology ${ }^{9}$,-for-intemporalpreservation-entropy-or-contiguity-or-ontological-preservation of the said registryworldview/dimension are at a dead-end with a preconverging/postconverging-dementative/structural/paradigmatic impossibility for a critical breakthrough just by the mere fact that the registry-worldview/dimension has attained its mentation-capacity-limitation or uninstitutionalised-threshold ${ }^{102}$ (as the nature of intrinsic-reality with respect to the human psyche is ontological-normalcy/postconvergence or inherently preceding or inherently superseding as it doesn't change an iota, and it is the human psyche that gives-in in its mentaldevising-representation to conform to intrinsic-reality). With such naïve efforts to keep up and develop profound meaningfulness based on the same registry-worldview's/dimension's institutionalisation ${ }^{83}$ reference-of-thought- categorical-imperatives/axioms/registry-teleology mostly a dead-end. Such ontological-circularities will include for instance the dead-end of medieval alchemy preconverging-de-mentating/structuring/paradigming with respect to positivistic chemistry postconverging-de-mentating/structuring/paradigming, a flat-world preconverging-de-mentating/structuring/paradigming with respect to a round world postconverging-de-mentating/structuring/paradigming, a creationism preconverging-dementating/structuring/paradigming with respect to an evolution postconverging-dementating/structuring/paradigming, a ${ }^{103}$ universal humanity postconverging-dementating/structuring/paradigming with respect to aristocratic/racial/tribal preconverging-dementating/structuring/paradigming, a science postconverging-dementating/structuring/paradigming with respect to a superstition preconverging-dementating/structuring/paradigming, etc. Naivety will be to think that issues of ontologicalcircularity in our present positivistic meaningfulness (for transcending beyond our vices-andimpediments $^{105}$ and overcoming inherent inhibitions to human emancipation) are not in 
veridicality about a need for a shift in prospective postconverging-dementating/structuring/paradigming. This brings forward fundamentally the limited-mentationcapacity —as-subjecting 'educed-unlimitedness/existence-sublimating nascence' tolimitedness/human-subpotency/uninstitutionalised-threshold ${ }^{102}$ construct of our times (procrypticism) and the preconverging/postconverging-de-mentative/structural/paradigmatic implications specifically for such a 'postconverging-or-dialectical-thinking -psychology or psychology-of-mentation-dynamics or natural psychological-dynamics' (as highlighted) over a relatively mented-psychology/stigmatic-psychology. What this reveals is that reality is 'not a human mental-devising-representation processing exercise'; rather it is an intrinsic ontologicalnormalcy/postconvergence notion that doesn't respond to human mental-devising-representation processing. The role of ${ }^{15}$ de-mentation-〈supererogatory - ontological-de-mentation-ordialectical-de-mentation - stranding-or-attributive-dialectics $\rangle$ as a mental-devisingrepresentation mechanism that syncs with evolving ontological insight (insight about intrinsic reality) as ontological-normalcy/postconvergence is to reflect/perspectivate the dialectically-orcontendingly-out-of-phase or dialectical-primitivity at the very limit of the capability as its mental-devising-representation of a registry-worldview/dimension (uninstitutionalisedthreshold ${ }^{02}$ ), which otherwise any <amplituding/formative-epistemicity $>$ totalising $\sim$ selfreferencing-syncretising/circularity/interiorising/akrasiatic-drag 34 registry-worldview will overlook as it is a <amplituding/formative $>$ wooden-language-_imbued-averaging-of-thought$<$ as-to-leveling/ressentiment/closed-construct-of- meaningfulness-and-teleology -as-of'nondescript/ignorable-void '-with-regards-to-prospective-apriorising-implications $>>$ that is exclusively operant and deterministic only to its very own ${ }^{83}$ reference-of-thought- categoricalimperatives/axioms/registry-teleology ${ }^{9}$,-for-intemporal-preservation-entropy-or-contiguityor-ontological-preservation and is not tied to intrinsic-reality but rather pertinent only for when it proxies intrinsic-reality. It is only ${ }^{15}$ de-mentation-_supererogatory $\sim$ ontological-de-mentation- 
or-dialectical-de-mentation-stranding-or-attributive-dialectics $\rangle$ that can create the foundation for a new mentation (unshackle it psychoanalytically/memetically/meaningfully reorder it/recomposure it) to in ontological-normalcy/postconvergence come into grips with a more profound ontological-veridicality as a new ${ }^{83}$ reference-of-thought (veridical-thinking-referenceover-preconverging-or-dementing -reference) for a new existentialism/full-depth-ofexistential-implications meaningfulness and thought. This insight about the intrinsic-nature-ofreality/intrinsic-reality is critical and central to understanding how knowledge-deadends- $<$ aspreconverging-de-mentating/structuring/paradigming > can be superseded/overcome. Supposed B was to stick to resolving the BODMAS equation while overlooking A's condition on the basis that the ${ }^{83}$ reference-of-thought- categorical-imperatives/axioms/registry-teleology ${ }^{9}$,-forintemporal-preservation-entropy-or-contiguity-or-ontological-preservation are set and given, whether these uphold intemporal-preservation-entropy-or-contiguity-or-ontologicalpreservation or not (which is what ensures proxying to intrinsic-reality), and further that the other BODMAS characters will do likewise anyway, this doesn't in any way transform the ontologicalnormalcy/postconvergence ontological-veridicality/intrinsic-reality from 66 to 72.5 . Such a wrong disposition rather points aetiologically for the need (in ontological-escalation) of an ${ }^{15}$ dementation-〈supererogatory ontological-de-mentation-or-dialectical-de-mentation — strandingor-attributive-dialectics $\rangle$ of the BODMAS characters at that uninstitutionalised-threshold ${ }^{102}$. Inthe-bigger-picture, knowledge-deadends-<as-preconverging-dementating/structuring/paradigming > (to varying degrees of pertinence) are often the explanation of underlying social issues and problems more than just about limited human ability or insufficiently directed effort towards the resolution of such issues and problems on the basis of the given preconverging-de-mentating/structuring/paradigming. It is inevitable that emancipation from such knowledge-deadends-<as-preconverging-dementating/structuring/paradigming > will always require that the would-be intellectual-analyst or 
intellectual-analysts 'blunt it' (just as intrinsic-reality is uncompromisingly blunt) to the $<$ amplituding/formative-epistemicity $>$ totalising $\sim$ self-referencing-syncretising/illusion-of-thepresent/present-consciousness/mirage registry-worldview/dimension that what is fundamentally needed is a postconverging-de-mentating/structuring/paradigming-shift. Much like observation and a rational interpretation of nature trumps dogma as with Galileo's heliocentric argument for instance, this author holds that a fundamental decomplexifying/uninhibiting of our own (procrypticism or preconverging-or-dementing ${ }^{20}$-apriorisingpsychologism/subknowledging $4 / /$ perversion-of- ${ }^{2}$ reference-of-thought-<as-preconverginglyapriorising/axiomatising/referencing-in-nonconviction/madeupness/bottomlining-as-toshallow-supererogation $>$ of positivistic meaningfulness) psyche as being ontologicallypreconverging-or-dementing -apriorising-psychologism/dialectically-preconverging-ordementing -apriorising-psychologism from futural Being-development/ontologicalframework-expansion-as-to-depth-of-ontologising-development-as-infrastructure-ofmeaningfulness-and-teleology as of prospective notional ${ }^{18}$ deprocrypticism as ${ }^{8}$ referenceof-thought (veridical-thinking-reference-over-preconverging-or-dementing ${ }^{20}$-reference) opens up a new world of transcendental possibilities (wherein a comprehensive insight for addressing psychopathy and social psychopathy and other implied epiphenomena/incidental-phenomena equally lies, and critically so since the fundamental argument for a "postconverging-ordialectical-thinking -psychology or psychology-of-mentation-dynamics or natural psychological-dynamics' has to do with the foundational nature of mental-devisingrepresentation/mentation/recomposured-consciousness-awareness-teleology 99 in the construction of all knowledge) at our positivistic meaningfulness uninstitutionalisedthreshold ${ }^{102}$; much the same way like a positivistic world opened up from the de-mentation〈supererogatory ontological-de-mentation-or-dialectical-de-mentation-stranding-orattributive-dialectics $\rangle$ of a non-positivism/medievalism registry-worldview/dimension at its 
uninstitutionalised-threshold $^{102}$. To further elucidate the criticality as indicated of such a 'postconverging-or-dialectical-thinking -psychology or psychology-of-mentation-dynamics or natural psychological-dynamics' as indicated with respect to a 'mented' or 'stigmatic' psychology can be further reemphasised clearly as such; a 'postconverging-or-dialecticalthinking -psychology or psychology-of-mentation-dynamics or natural $\sim$ psychologicaldynamics' is one that is being ontologically-driven or led by ontological-veridicality when it comes to mental-devising-representation by strictly adhering to the de-mentation〈supererogatory $\sim$ ontological-de-mentation-or-dialectical-de-mentation-stranding-orattributive-dialectics〉 of ${ }^{15}$ de-mentation-〈supererogatontological-de-mentation-ordialectical-de-mentation - stranding-or-attributive-dialectics $\rangle$. In other words, it overrides the mented/stigmatic intradimensional meaningfulness mental-devising-representation and enables a transdimensional-meaningfulness mental-devising-representation, wherein a mented/stigmatic mentation de-mentation-〈supererogatory-ontological-de-mentation-or-dialectical-dementation-stranding-or-attributive-dialectics $\rangle$ in reflecting soundness-or-ontological-goodfaith/authenticity ${ }^{6}$ of- ${ }^{3}$ reference-of-thought/apriorising-registry-soundness and unsoundnessor-ontological-bad-faith/inauthenticity ${ }^{64}$-of- ${ }^{83}$ eference-of-thought/ $/ 7$ perversion-of- ${ }^{8}$ referenceof-thought-<as-preconvergingly-apriorising/axiomatising/referencing-in-

nonconviction/madeupness/bottomlining-as-to-shallow-supererogation $>\quad$ (respectively postconverging-or-dialectical-thinking -apriorising-psychologism- $<$ stranded-as-rightfullystraight/candored-and-dialectically-or-contendingly-in-phase $>$ and preconverging-ordementing 20 -apriorising-psychologism- $<$ stranded-as-rightfully-oblongated/decandored-anddialectically-or-contendingly-out-of-phase $>$ ) is stranded to the 'conventionalised institutionalised/intemporalised-threshold-for-intemporal-preservation-entropy-or-contiguityor-ontological-preservation' whether such a threshold is the 'appropriate basis for ${ }^{8}$ referenceof-thought or not and subsequent ontological-veridicality/relative mreflexivitrelative 
reflexivity - ontological-contiguity ${ }^{67}$ or not, as it is limited to what is the convention thus hollowconstituting-<as-disjointed-misappropriation-of-meaningfulness-and-failing-intemporalpreservation $>$ with the result that mented/stigmatic psychology is limited to hollow-constituting<as-disjointed-misappropriation-of-meaningfulness-and-failing-intemporal-preservation> human intradimensional conventioning $\quad{ }^{83}$ reference-of-thought- categoricalimperatives/axioms/registry-teleology ${ }^{9}$,-for-intemporal-preservation-entropy-or-contiguityor-ontological-preservation, with no prospective/transcending/superseding possibility. For instance, we can project insightfully that a mented/stigmatic mental-disposition in a nonpositivism/medievalism setup in an impression-driven/good-naturedness/wishfulness disposition but hollow-constituting-<as-disjointed-misappropriation-of-meaningfulness-andfailing-intemporal-preservation $>$ (failing/not-upholding-<as-ofapriorising/axiomatising/referencing $>$ reference-of-thought- categoricalimperatives/axioms/registry-teleology ${ }^{9}$,-for-intemporal-preservation-entropy-or-contiguityor-ontological-preservation) will raise an issue of say sorcery in terms-as-of-axiomaticconstruct of who is the sorcerer or sorcerers among us, how should sorcery be stopped and prevented in the community in its preconverging-de-mentating/structuring/paradigming, and not in a prospective positivistic postconverging-de-mentating/structuring/paradigming that is more ontologically-veridical, putting in question the veracity/ontological-pertinence of the nonpositivism/medievalism conventioning notion of sorcery, however 'good-natured'/impressiondriven, while raising the positivistic the-Good/knowledge-reification $\sim$ gesturing-andaccounting-of-epistemic-phenomenalism-<in-

prospective_psychologismic apriorising/axiomatising/referencing-\{of-‘prospectively implicited_attentant-ontological-contiguity ' educedexistentialising/contextualising/textualising_'intelligibility/epistemicity/reflexivity-contiguity<imbued-notional cogency>> $\}$-conflatedness -in-\{preconverging-disentailment by\} 
postconverging-entailment $>$ /understanding/<amplituding/formative-

epistemicity $>$ causality $\sim$ as-to-projective-totalitative-implications-of-prospective-

nonpresencing,-for-explicating relative-unreflexivity/relative-reflexivity - ontological-

contiguity of a positivising/rational-empiricism ${ }^{83}$ reference-of-thought. Such an insight prospectively will involve putting-into-question naïve and ever evolving constructs in our modern-day mented/stigmatic psychology science like personality disorders on the fundamental argument regarding the relatively poor insight about the requisite ${ }^{83}$ reference-of-thought to be established in the first place before then qualifying personalities with respect to such a philosophically and insightfully soundly established ${ }^{83}$ reference-of-thought, and not just naïve assumptions whether on the basis of popular axioms, vagueness and personal however wellmeaning; with the idea of meaningfulness that goes beyond just a conventioning ${ }^{83}$ reference-ofthought and is rather inherently upheld by ontologically-veridical insight and pertinence. Further, such a 'postconverging-or-dialectical-thinking'-psychology or psychology-of-mentationdynamics or natural psychological-dynamics' that is ontologically-driven will go beyond an exercise of mented/stigmatic phenotypes driven abstractly as inherent-personalities nature and in given settings-of-time, but grasp that human personality is critically involved in the ${ }^{15}$ dementation-〈supererogatory $\sim$ ontological-de-mentation-or-dialectical-de-mentation - strandingor-attributive-dialectics $\rangle$

hermeneutically/textully/reprojectingly/supererogatingly/zeroingly/re-acutingly,${ }_{\text {\{decompulsing }}$ delinearity $\sim$ for-cogency-educing-human- ${ }^{56}$ meaningfulness-and-teleology ${ }^{9}$-intothe-existentialism-becoming of personhoods-and-socialhood-formation as so-reflecting ontological-reconstituting-as-to-conflatedness ${ }^{13} /$ deconstruction $_{\text {as }}$ the more profound reference-of-thought and analysis, and with a more fundamental interdimensional/transdimensional/transcendental insight of the human existentialism formfactor. In this regard, it is the opinion of this author that many construed personality disorders 
that do not involve social deviances or not of physiological nature are actually adaptations at one time or the other in an ever-changing-and-challenging-construct that individuals make of a 'wanting and developing social world with its stakes and confliction', and it would rather be better to articulate personality as driven by a pertinence of being/ontological-extension-intoexistentialism-or-full-depth-of-existential-implications with respect to such a 'challenging and developing social world with its stakes and conflictions' in the first place, otherwise we are just affirming arbitrary social classification schemes and not really involved in the requisite postconverging-de-mentating/structuring/paradigming shifts; and such could further be grasped regarding specifically how many an experimental psychology schemes 'desperately' striving to draw social-world level conclusions can't seem to supersede the modesty of schemes that it is just too farfetched and synoptically-limiting, thus trending more towards the defect of apriorising/axiomatising/referencing-\{of-"prospectively implicited_attendant-ontologicalcontiguity ' educedexistentialising/contextualising/textualising_'intelligibility/epistemicity/reflexivity-contiguity<imbued-notional cogency >' $\}$-constitutedness ${ }^{14}$-in-preconverging-entailment in lieu of apriorising/axiomatising/referencing-\{of-'prospectively implicited_attendant-ontologicalcontiguity ' educedexistentialising/contextualising/textualising_'intelligibility/epistemicity/reflexivity-contiguity-

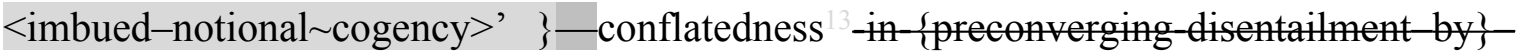
pestcenverging-entailment as articulated by this author. Foucault had qualified the current focus on abnormal psychology as tending more to an 'economic' practice. What about the notion of de-mentation-_supererogatory ontological-de-mentation-or-dialectical-de-mentationstranding-or-attributive-dialectics $\rangle$ as the 'surreptitious driving mechanism of human mentaldevising-representation or mentation' that fully encapsulates and explains human psychological development across all the times and the successive institutional-cumulation/institutional- 
recomposure-〈as-to- historiality/ontological-eventfulness /ontological-aesthetic-tracing-

$<$ perspective-ontological-normalcy/postconvergence-reflected-'epistemicity-relativism-

determinism' $>>$ of human existential-disontogising/re-ontogising aporeticism> emanance, and so as an articulation that is retrospectively, presently and prospectively coherent? Given the fact that de-mentation-/supererogatory $\sim$ ontological-de-mentation-or-dialecticalde-mentation - stranding-or-attributive-dialectics $\rangle$ very much explains human transcendenceand-sublimity/sublimation/supererogatory $\sim$ de-mentativity as the recurrent 'postconverging-ordialectical-thinking -psychology or psychology-of-mentation-dynamics or natural psychological-dynamics’ psychoanalytic-unshackling/memeticreordering/institutional-recomposuring of an animal of limited-mentation-capacity-deepeningas-subjecting limitedness/human-subpotency-to-'educed-unlimitedness/existence-sublimating nascence' . Such a 'postconverging-or-dialectical-thinking -apriorising-psychologism' psychology driven by ontology or rather ontological-normalcy/postconvergence will be postdicatory, with the implications that this will fully focus the 'kernels of postmodernism' to usher in Suprastructuralism as an Age where humankind comes to grasp that its-meaningfulnesswith-respect-to-intrinsic-reality as reflected by the successive institutionalcumulation/institutional-recomposure-〈as-to- historiality/ontological-

eventfulness /ontological-aesthetic-tracing-<perspective-ontologicalnormalcy/postconvergence-reflected-‘epistemicity-relativism-determinism'>> has been progressing (more and more realistically) by successive suprastructuring of prior/transcended/superseded registry-worldviews/dimensions 'beyond their successive corresponding recomposured-consciousness-awareness-teleology ${ }^{\circ}$, and introducing the veridical meaningful-frame/worldview of postmodernity with regards not only to the present but the <ampliting/formative-epistemicity $>$-totalising $\sim$ renewing-realisation/re-perception/rethought past and future, with the insight that our present recomposured-placeholder- 
setup/mental-devising-representation/mentation/consciousness-awareness-teleology ${ }^{9}$ of the positivism- ${ }^{80}$ procrypticism registry-worldview will be subjected to this suprastructuringmeaningfulness nature of human-subpotency-aporia/undecidability/dilemma/oughtindeterminacy/deficiency/limitation/constraint—imbued-'notional firstnaturednessformativeness-<as-to-eventualising-inkling drive-or-seeding misprising $>$ temporal-tointemporal-dispositions-<so-construed-as-from-perspective-ontologicalnormalcy/postconvergence >'-existentialism-form-factor as well. In fact the underlying difficulty of deconstruction when extended from its 'textual basis' to its 'full meaningfulness basis' as 'ontological-reconstituting-as-to-conflatedness ${ }^{13}$, , has to do with the fact that the full implications of 'ontological-reconstituting-as-to-conflatedness ${ }^{13} /$ deconstruction is that it prospectively calls for suprastructuring or construal beyond-the-consciousness-awarenessteleology $-<$ of-preconverging-existential-extrication-as-of-existential-unthought $>$ of prior registry-worldview mindset/ ${ }^{3}$ reference-of-thought (and so as a conception that enables openingup/making-available the prospective registry-worldview), as implied by the veracity/ontologicalpertinence of ' de-mentation-〈supererogatory $\sim$ ontological-de-mentation-or-dialectical-dementation - stranding-or-attributive-dialectics $\rangle$ of ${ }^{8}$ reference-of-thought' as the underlying human placeholder-setup/mental-devising-representation/mentation/consciousness-awarenessteleology ${ }^{9}$ driving mechanism. Considering that deconstruction as 'ontological-reconstitutingas-to-conflatedness $^{13}$, necessarily implies not one but two dialectically opposed registries/meaningful-references/anchorings-of-meaning/ontological-references/contendingreferences/registry-worldviews/dimensions of meaningfulness; with the implication that the prospective/transcending/superseding is suprastructural to (beyond-the-consciousnessawareness-teleology ${ }^{9}<$ of-preconverging-existential-extrication-as-of-existential-

unthought $>$-of) the prior/transcended/superseded, and so as a deeper superseding-oneness-ofontology construal/conceptualisation. The fact is that without the notion of suprastructuring, the 
exercise of de-mentation-_supererogatory $\sim{ }^{15}$ ontological-de-mentation-or-dialectical-dementation - stranding-or-attributive-dialectics $\rangle$ will wrongly imply that the 'postconverging-ordialectical-thinking -apriorising-psychologism' and the preconverging-or-dementing 2 apriorising-psychologism are of the same ${ }^{83}$ reference-of-thought of meaningfulness (which is obviously wrong), and is the effect of the illusion-of-the-present/present-consciousness/mirageas $<$ amplituding/formative-epistemicity $>$ totalising $\sim$ self-referencing-

syncretising/circularity/interiorising/akrasiatic-drag ${ }^{34}$ as we recognise this fact from a vantage perspective to the prior (utter-uninstitutionalisation, base-institutionalisation, universalisation) but have a 'complex' recognising such a fact at a disadvantaged positivistic/procrypticism perspective with respect to the prospective (deprocrypticism), just as all institutionalisations tend to demonstrate when their own transcendence-andsublimity/sublimation/supererogatory de-mentativity is implied, and certainly so the higher the institutionalisation as the mindset ${ }^{/ 3}$ reference-of-thought is increasingly set to 'relate to its institutionalised secondnatured construct as being our very own individuals essential dimensionality-of-sublimating $3-\langle<$ amplituding/formative $>$ supererogatory $\sim$ de-

\section{mentativeness/epistemic-growth-or-conflatedness /transvaluative-}

rationalising/transepistemicity/anamnestic-residuality/spirit-drivenness-equalisation〉 and not a secondnatured construct', and thus perceived as beyond or almost beyond analysis due to the implied temporal alienating effect on us (but then it is the human psyche that gives-in to intrinsicreality/ontological-veridicality, as the foremost rule of humanity's existentialdisontologising/re-ontologising aporeticism $>$ strive). Suprastructuring allows for the necessary transcendental-insight-projection-capacities for grasping the evasive Derridean conceptualisation of 'metaphysics-of-absence-〈implicited-epistemic-veracity-ofnonpresencing-<perspective-ontological-normalcy/postconvergence $>\rangle$ '

projection/postdication in overcoming the illusion-of-the-present/present- 

syncretising/circularity/interiorising/akrasiatic-drag ${ }^{34}$ as 'metaphysics-of-presence-〈implicited'nondescript/ignorable-void '-as-to- presencing-absolutising-identitive-constitutedness '〉'. Suprastructuring boldly answers the underlying issue involved with 'communicating the true implications of deconstruction as ontological-reconstituting-as-to-conflatedness ${ }^{13}$ by highlighting the paradox that it is all about 'articulating a conceptualisation which involves implying that the ${ }^{83}$ reference-of-thought and meaningfulness of the seemingly ${ }^{83}$ reference-ofthought is unsound and needs to be superseded'. It is rather about in the very first instance putting-into-question a given ${ }^{83}$ reference-of-thought and projecting the appropriate ${ }^{83}$ referenceof-thought, before even proceeding to articulate more specifically meaningfulness within the projected ${ }^{83}$ reference-of-thought. This is akin to the idea of a positivistic mindset/ ${ }^{83}$ reference-ofthought articulating chemistry rules and principles to an alchemic mindset/ ${ }^{8}$ reference-ofthought for the latter's validation, requiring the latter to adopt a positivistic mindset $/{ }^{3}$ referenceof-thought in-the-very-first-place before issues of substantive pertinence about chemistry rule and principles are raised within their now mutually positivistic mindsets. Such an exercise requires a highly uninhibited/decomplexified human frame of mind. This may sound rather farfetched as a notion but it is important to remember that the positivistic mindset $/{ }^{3}$ referenceof-thought itself is the outcome of the décomplexing/uninhibiting of the human mind from earlier successive institutionalisations. Such an exercise is necessarily about psychoanalyticunshackling/memetic-reordering/institutional-recomposuring of the positivistic/procryptic reference-of-thought of ${ }^{56}$ meaningfulness-and-teleology ${ }^{9}$ in the middle to long run construed as of ${ }^{15}$ de-mentation-〈supererogatory $\sim$ ontological-de-mentation-or-dialectical-de-mentationstranding-or-attributive-dialectics $\rangle$ with respect to futural Being-development/ontologicalframework-expansion-as-to-depth-of-ontologising-development-as-infrastructure-ofmeaningfulness-and-teleology as of prospective deprocrypticism; and with regards to 
Suprastructuralism as a notion, the implication is that this is a requisite idea that has to come to the collective consciousness (not just unconsciously as with prior institutionalisations, for instance the fact that notions of superstition are false had to be consciously brought up to the attention/consciousness-awareness-teleology of a non-positivism/medievalism mindset $/{ }^{3}$ reference-of-thought for it to effectively undergo the necessary 'postconverging-ordialectical-thinking -psychology or psychology-of-mentation-dynamics or natural psychological-dynamics’ psychoanalytic-unshackling/memeticreordering/institutional-recomposuring by acting as the conscious backdrop that engenders prospectively a positivistic mindset) for human emancipation into a notional ${ }^{18}$ deprocrypticism mindset; as with all psychoanalytic exercise whether of an individual or social conceptualisation nature, the idea of recognising/referencing/registering/decisioning the ontological-deficiency with respect to ontological-normalcy/postconvergence is central to superseding it. 'Suprastructuring as such overcomes the "natural human placeholder-setup/mental-devisingrepresentation/mentation/consciousness-awareness-teleology ${ }^{9}$ reflex' (in any registryworldview/dimension) of 'striving to avert preconverging-or-dementing ${ }^{20}$-apriorisingpsychologism mental-devising-representation/mentation' (whether such averting is ontologically-veridical or not) and so by a mistaken reflex to preserve a $<$ amplituding/formative $>$ wooden-language-_imbued - averaging-of-thought- $<$ as-toleveling/ressentiment/closed-construct-of- meaningfulness-and-teleology -as-of'nondescript/ignorable-void ' -with-regards-to-prospective-apriorising-implications $>>$ of placeholder-setup/mental-devising-representation/mentation/consciousness-awarenessteleology ${ }^{9}$ of intrinsic-reality (but which closure makes its representation of intrinsic-reality inherently incomplete and biased towards the illusion-of-the-present/presentconsciousness/mirageas $\quad<$ amplituding/formative-epistemicity $>$ totalising $\sim$ self-referencingsyncretising/circularity/interiorising/akrasiatic-drag ${ }^{34}$ of its given registry-worldview 
metaphysics-of-presence-〈implicited-'nondescript/ignorable-void '-as-to- presencing-

absolutising-identitive-constitutedness $\rangle$ ), by effectively taking full cognisance of the fact that de-mentation-〈supererogatory $\sim$ ontological-de-mentation-or-dialectical-de-mentationstranding-or-attributive-dialectics $\rangle$ is the driving mechanism of human placeholdersetup/mental-devising-representation/mentation/consciousness-awareness-teleology 99 of intrinsic-reality and thus construe an opened-construct incorporating transcendental-insightprojection-capacities that enable the relative construal of the 'postconverging-or-dialecticalthinking -apriorising-psychologism' and the preconverging-or-dementing ${ }^{20}$-apriorisingpsychologism ' de-mentation-〈supererogatory $\sim$ ontological-de-mentation-or-dialectical-dementation-stranding-or-attributive-dialectics $\rangle$ of ${ }^{83}$ reference-of-thought', and so expanding the potency in construing a much more exact/thorough notion of placeholder-setup/mental-devisingrepresentation/mentation/consciousness-awareness-teleology ${ }^{99}$ of intrinsic-reality and thus for 'ontological-reconstituting-as-to-conflatedness ${ }^{13}$ /deconstruction. In other words, in representing the veridically uninhibited/decomplexified nature of "de-mentation〈supererogatory ontological-de-mentation-or-dialectical-de-mentation-stranding-orattributive-dialectics $\rangle$ of ${ }^{83}$ reference-of-thought' that is not limited by the illusion-of-thepresent/present-consciousness/mirageas <mplituling/formative-epistemicity $>$ totalising $\sim$ selfreferencing-syncretising/circularity/interiorising/akrasiatic-drag 34 of any registryworldview/dimension and so at the deeper memetic/psychoanalytic level, suprastructuring as such reveals that 'human psychology is very much an active construct associated with 'intemporal ontological-faith-notion-or-ontological-fideism-imbued-underdetermination-ofmotif-and-apriorising/axiomatising/referencing-as-so-being-as-of-existential-reality instigated relative-unreflexivity/relative-reflexivity ontological-contiguity $\sim$ of-the-humaninstitutionalisation-process $^{68}$ as of difference-conflatedness ${ }^{13}$-as-to-totalitative-reification-insingularisation-<as-to-the-nondisjointedness/entailment-of-prospective- nonpresencing $>$-as- 


\section{epistemicity $>$ causality as-to-projective-totalitative-implications-of-prospective-}

\section{nonpresencing,-for-explicating relative-unreflexivity/relative-reflexivity —ontological-}

contiguity , in the reflection as placeholder-setup/mental-devisingrepresentation/mentation/consciousness-awareness-teleology of retrospective, present and prospective institutionalisations in reflecting holographically-<conjugatively-andtransfusively $>$ the relative-unreflexivity/relative-reflexivity ontological-contiguity $\sim$ of-thehuman-institutionalisation-process points-of-reference, with the truer nature and representation of human psychology ultimately tied-to/driven-by ontological-normalcy/postconvergenceconstruct'. Insightfully, just as highlighted later that existence-defines/precedes-essence, ideally the construction of psychology needs to be priorly subjected to a 'becoming that defines psychology with its veracity/ontological-pertinence arising in the ontological-reconstituting-asto-conflatedness ${ }^{13}$ of that existential-<disontologising/re-ontologising aporeticism $>$ becoming'. Is our understanding of psychology notionally complete when we can't seem to understand what happens in apparently mentally sound minds partaking in 'socially degraded' situations like murky human interest stories, mobs, genocides and even the 'conventional acceptance and numbness to mass casualty warfare'. In other words, in the first place what is 'ontologically normal' beyond the subjective conventioning of the psychology science (before even worrying about the abnormal)? Further isn't it possible to make the contribution of modernday psychology more complete in constructing a more thorough and dynamic understanding of mentation/psyche in relation to individual-social-humanity aspiration, where psychology evolves in a complete existentialism cadre. In other words, so placed in a becoming/existential cadre, is psychology not meant rather than just encapsulating what the human psyche/mentation is all about as if it is a set and determinate construct (strangely enough inadvertently and often mirroring schemes of social classification, and hence of social power relations) equally involve 
in articulating aspiratory models for human mentation/psyche? And such a postconverging-dementating/structuring/paradigming shift with regards to modern-day mented/stigmatic psychology can actually be implied by prospective ontological-normalcy/postconvergence as notional ${ }^{1}$ deprocrypticism (involving 'ontologically-reconstituting/deconstruction' in upholding of intemporal-preservation-entropy-or-contiguity-or-ontological-preservation by 'overriding failing/not-upholding-<as-of-apriorising/axiomatising/referencing $>$ and renewing ever sound and appropriate' ${ }^{83}$ reference-of-thought- categorical-imperatives/axioms/registryteleology ${ }^{9},-$ for-intemporal-preservation-entropy-or-contiguity-or-ontological-preservation') over the 'conventioningly-driven/conventionalised hollow-constituting-<as-disjointedmisappropriation-of-meaningfulness-and-failing-intemporal-preservation> $>\quad$ reference-ofthought- ${ }^{8}$ ategorical-imperatives/axioms/registry-teleology ${ }^{99}$,-for-intemporal-preservationentropy-or-contiguity-or-ontological-preservation whether the latter is failing/not-upholding$<$ as-of-apriorising/axiomatising/referencing $>\quad$ intemporal-preservation-entropy-or-contiguityor-ontological-preservation. Insight from ontological-normalcy/postconvergence as it matches placeholder-setup/mental-devising-representation/mentation/consciousness-awarenessteleology ${ }^{9}$ to ontological-veridicality (notwithstanding that this undermines habituated conventionalised mented/stigmatic placeholder-setup/mental-devisingrepresentation/mentation) representing all the institutionalisations in a dialectical moment of appropriateness-of- ${ }^{3}$ reference-of-thought-as-of-conflatedness ${ }^{13}$ and thus mentallystraight/candored-and-dialectically-in-phase as simply involving the technique of a 'prelogic/conviction-as-to-profound-supererogation placeholder-setup/mental-devisingrepresentation/mentation/consciousness-awareness-teleology ${ }^{9}$ teleological alignment reflex' to the implied ${ }^{83}$ reference-of-thought since the ${ }^{83}$ reference-of-thought- categoricalimperatives/axioms/registry-teleology ${ }^{9}$,-for-intemporal-preservation-entropy-or-contiguityor-ontological-preservation is prospective/transcending/superseding and 'ontologically- 
reconstituting/deconstruction'; while representing all uninstitutionalised-threshold ${ }^{12}$ in a dialectical moment of appropriateness-of- ${ }^{8}$ reference-of-thought-as-of-conflatedness ${ }^{13}$ and thus mentally-oblongated/decandored-and-dialectically-out-of-phase-or-dialectically-primitive as simply involving the technique of a 'postlogism 77 mere-formulaic slanting compulsingnonconviction/madeupness/bottomlining-〈‘ $<$ decontextualising/de-existentialising $\sim$ ofattendant-intradimensional-apriorising/axiomatising/referencing $>$-induced-disontologising'-ofthe-'attendant-intradimensional-ontologising'-imbued$<$ contextualising/existentialising attendant-ontological-contiguity $>$;-in-shallowsupererogation -<as-to-disontologising-perverted-outcome-sought-precedes-existentiallyveridical-'attendant-intradimensional-apriorising/axiomatising/referencing'-logical-dueness $>$ > placeholder-setup/mental-devising-representation/mentation/consciousness-awarenessteleology ${ }^{9}$ teleological alignment reflex' to the implied ${ }^{83}$ reference-of-thought since the reference-of-thought- categorical-imperatives/axioms/registry-teleology ,-for-intemporalpreservation-entropy-or-contiguity-or-ontological-preservation prior/transcended/superseded and rather hollow-constituting-<as-disjointed-misappropriationof-meaningfulness-and-failing-intemporal-preservation>. And going by human-subpotencyaporia/undecidability/dilemma/ought-indeterminacy/deficiency/limitation/constraint—imbued'notional firstnaturedness-formativeness-<as-to-eventualising -inkling-drive-or-seedingmisprising $>$ temporal-to-intemporal-dispositions- $<$ so-construed-as-from-perspectiveontological-normalcy/postconvergence>'-existentialism-form-factor, a 'postconverging-ordialectical-thinking -psychology or psychology-of-mentation-dynamics or natural psychological-dynamics' can perfectly represent the mentations/mental-devisingrepresentations of all registry-worldviews/dimensions both as implied and driven by ontologicalveridicality by way of ontological-reconstituting-as-to-conflatedness $13 /$ deconstruction and point out their peculiar mented/stigmatic specificities in their hollow-constituting-<as-disjointed- 
misappropriation-of-meaningfulness-and-failing-intemporal-preservation $>$ involving with all mented/stigmatic mental-devising-representations a circular preconverging-or-dementing temporal-manifestation (subontologisation/subpotentiation (in-a-social-dynamism-ofmeaningfulness-misappropriation) of slantedness/postlogic-effect, miscuing, disjointed-logic, logical-drag, unconscionability-drag, $\quad$ sub-par/formulaic-association/temporal/alibi conventioning-rationalising, and temporal-enculturation/temporal-endemisation-effect, and temporal-enculturation/temporal-endemisation effect. In-the-bigger-picture, actually the fact is that the various institutionalisations/institutional-cumulation/institutional-recomposure-〈as-to-

\section{historiality/ontological-eventfulness /ontological-aesthetic-tracing-<perspective-}

ontological-normalcy/postconvergence-reflected-'epistemicity-relativism-determinism'>> are actually the levels at which their specific quality (whether as base-institutionalisation, universalisation, positivism and prospectively deprocrypticism) actively and comprehensively define and characterise each of the institutionalisations while bringing the notion to the collective-consciousness/personhoods-and-socialhood-formation successive existentialisms/full-depths-of-existential-implications. But then, such notions which can be weakly sensed in all prior institutionalisations are actually inconspicuously, selectively and occasionally introduced in the prior institutionalisation in graduated/staggered stages starting with the proto-prospective-institutionalisation right up to the prospective-institutionalisation; whether as proto-base-institutionalisation in recurrent-utter-uninstitutionalisation up to the graduated/staggered attainment of base-institutionalisation, proto-universalisation in baseinstitutionalisation-ununiversalisation up to the graduated/staggered attainment of universalisation, proto-positivism in ${ }^{103}$ universalisation-non-positivism/medievalism up to the graduated/staggered attainment of positivism, and effectively by a prospective insight, protonotional ${ }^{1}$ deprocrypticism in positivism- ${ }^{-}$procrypticism. For instance, many an alchemist in the medieval world were actually very thorough and methodical in their pursuit with skills that 
could be qualified as 'rudimentary positivistic'. However, the fact that fundamentally their preconverging-de-mentating/structuring/paradigming was a dead-end like the pursuit of the philosopher's stone and the implications of not having an outright positivistic outlook/ideology is what mostly distinguishes them from the complexion of 'true positivists'. Likewise, the ordinary practices in the positivistic world of deontological and jurisprudential nature, in disparate formal constructs and settings mostly, are mostly geared to carry abstract and coherent universal virtue implications with respect to all humans as the-Good/understanding-driven formal principles constructs, however approximate their applicative success (a principle is a notion that can coherently uphold itself, i.e. a principle is a notion that warrants that all persons covered by its ambit act the same way or are subjected to it in the same way, and not disparately, and it carries ${ }^{103}$ universal import; the opposite of 'inductive limitation' or 'so-called principles' that are actually fallacious since such arguments cannot truly be of entailing$<$ amplituding/formative-epistemicity>totalising in-relative-ontological-completeness ${ }^{87}$ as they require that others do not act likewise or their implications should be limited to given target(s) and not be totalisingly-entailing, since their fundamental teleology 9 is not intemporal/not-oftotalising-entailment but speak more of a temporal motive). But behind that pursuit is a covert admittance that without the deontology and jurisprudence and the corresponding induced culture as artifices (however approximate their applicative success) humans in their social dynamics do not have the inherent exclusiveness of intemporal-disposition quality to ecstatically/spontaneously/solipsistically/emanantly/becomingly adhere to intemporal $/{ }^{103}$ universal notions on the mere basis of 'preaching' the intemporal $/{ }^{103}$ universal notions and virtues (as the-Good/knowledge-reification $\sim$ gesturing-and-accounting-ofepistemic-phenomenalism- $<$ in-

prospective_psychologismic apriorising/axiomatising/referencing-\{of-'prospectively implicited_attendant-ontological-contiguity ' educed- 
existentialising/contextualising/textualising_ 'intelligibility/epistemicity/reflexivity-contiguity$<$ imbued-notional $\left.\sim \operatorname{cogency}>^{\prime} \quad\right\}$-conflatedness -in-\{preconverging disentailment by\} postconverging-entailment $>$ /understanding/<amplituding/formativeepistemicity $>$ causality $\sim$ as-to-projective-totalitative-implications-of-prospectivenonpresencing,-for-explicating relative-unreflexivity/relative-reflexivity - ontologicalcontiguity ) without institutionalisation design or conceptualisation! This is an unspoken recognition of the inherent reality of human-subpotency-aporia/undecidability/dilemma/oughtindeterminacy/deficiency/limitation/constraint—imbued-'notional firstnaturednessformativeness-<as-to-eventualising-inkling drive-or-seeding-misprising $>$ temporal-tointemporal-dispositions-<so-construed-as-from-perspective-ontologicalnormalcy/postconvergence>'-existentialism-form-factor individuations nature, and the need to skew/design/institutionalise/intemporalise the 'social' for the primacy of the intemporaldisposition individuation, as secondnaturing. This is equally an unspoken insight not only to modern institutionalised/intemporalised-thresholds-for-intemporal-preservation-entropy-orcontiguity-or-ontological-preservation conceptualisation of the-Good (positivistic $<$ amplituding/formative-epistemicity $>$ causality $\sim$ as-to-projective-totalitative-implications-ofprospective- nonpresencing,-for-explicating relative mnreflexivity/relative reflexivityontological-contiguity ). Such an insight is equally implied in prior institutionalisations of theGood conceptualisations wherein for instance the prophetic philosopher using the prophecy tools of their times, as the summum of psychoanalytic-unshackling/memetic-reordering/institutionalrecomposuring for the social criticism of their own times, won't naively imply 'I have preached to you thus you've attain the intemporal', but rather construe insightfully of a practice (institutionalising practice) that cultivates a relative orientation towards the reinforcement of the intemporal, say like having the believers follow a whole routine from their expression of faith, praying in conscious reinforcement, to a way of living, however approximate in its applicative 
success in inducing an intemporal inclination. Positivistic secondnaturing of disparate frameworks of deontologies, constitutions and jurisprudence and the associated culture (as longness-of-register-of- ${ }^{5}$ meaningfulness-and-teleology ${ }^{9}$ ) can be seen as protodeprocrypticism, including their individual and social internalisation in the collective consciousness, and these unsurprisingly are the few elements in the sovereignty constructs of positivistic democracies with their constituent public or private organisations and associations as well as subject matters and specialisms, that are always ferociously, blindly and without further justification upheld by regulation and law and/or newer legitimately made regulation and law even against popular whim given their 'inherent assuredness to preserve the intemporal construct in a furtherance of intemporal-preservation percolation-channelling- $<$ in-deferentialformalisation-transference $>$. Prospectively, notional ${ }^{18}$ deprocrypticism institutionalisation will imply a superseding psychoanalytic-unshackling/memetic-reordering/institutionalrecomposuring as new-mentation and further extension of formalisation as 'deferentialformalisation-transference' of 'deprocryptic formalisation' into the extended-informality〈susceptible-to-effecting-parsimony-as-of-shoddiness-and-incompleteness-to-

meaningfulness-and-teleology > implying a greater underlying demystification of positivism/rational-empiricism manifestation of procrypticism-or-disjointedness-as-ofreference-of-thought reasoning by way of the prospective notional-contiguity/epistemiccontiguity ${ }^{2}<$ profound-supererogation -of-mentally-aestheticised $\sim$ postconverging/dialecticalthinking -qualia-schema $>$ (as from prospective ${ }^{18}$ deprocrypticism-or-preemptingdisjointedness-as-of- ${ }^{8}$ reference-of-thought notional-contiguity/epistemic-contiguity $<$ profound-supererogation -of-mentally-aestheticised postconverging/dialectical-thinking qualia-schema $>$ ) with respect to the veridicality of human temporal-to-intemporal individuations dispositions nature that explains the nature of the positivism- ${ }^{80}$ procrypticism registry-worldview notional-discontiguity/epistemic-discontiguity ${ }^{6}<$ between - prior-shallow-supererogation -of- 
mentally-aestheticised preconverging/dementing -qualia-schema_and_prospective-profound-

supererogation -of-mentally-aestheticised postconverging/dialectical-thinking -qualia-

schema $>$ as we become more consciously insightful, preemptive and superseding of perversion-of- ${ }^{-3}$ reference-of-thought-<as-preconvergingly-

apriorising/axiomatising/referencing-in-nonconviction/madeupness/bottomlining-as-to-

shallow-supererogation $>$ of positivism- ${ }^{8}$ procrypticism ${ }^{56}$ meaningfulness-and-teleology

with its social-construct implications; and this insight prospectively defines the conceptualisation of the present positivism- procrypticism registry-worldview/dimension vices-and-impediments ${ }^{105}$ as the backdrop for the notional ${ }^{18}$ deprocrypticism postconvergingde-mentating/structuring/paradigming shift. But this equally as with all institutionalisations imply bringing to the collective consciousness a dialectically preconverging-or-dementing ${ }^{20}$ apriorising-psychologism mental-devising-representation of the present procrypticism registryworldview/dimension (which is prior) from the prospective registry-worldview/dimension (deprocrypticism) as the new ${ }^{83}$ reference-of-thought, which will seem unintelligible to the prior even though it is actually more real suprastructurally and in ontologicalnormalcy/postconvergence, just as our representation of medievalism though more ontologically-veridical will seem unintelligible/existentially-suprastructural to a medieval mindset $/{ }^{3}$ reference-of-thought in its closed mental-devising-representation of intrinsic-reality. Central to the notion of ${ }^{18}$ deprocrypticism-or-preempting-disjointedness-as-of- ${ }^{3}$ reference-ofthought as the 'veridical 'reference-of-thought' articulation of (ontologicalnormalcy/postconvergence) as ontological-veridicality/relative-unreflexivity/relativereflexivity - ontological-contiguity ${ }^{67}$ as of intemporal-preservation-entropy-or-contiguity-orontological-preservation over the positivism/rational-empiricism manifestation of procrypticism-or-disjointedness-as-of- ${ }^{-3}$ reference-of-thought notionaldiscontiguity/epistemic-discontiguity ${ }^{3}<$ between - prior-shallow-supererogation -of- 
mentally-aestheticised preconverging/dementing -qualia-schema_and_prospective-profound-

supererogation -of-mentally-aestheticised postconverging/dialectical-thinking -qualia-

schema as of its perversion of ${ }^{83}$ reference-of-thought- categoricalimperatives/axioms/registry-teleology ${ }^{9}$,-for-intemporal-preservation-entropy-or-contiguityor-ontological-preservation, and so in a prospective de-mentation〈supererogatory $\sim$ ontological-de-mentation-or-dialectical-de-mentation-stranding-or-

attributive-dialectics $\rangle$ moment wherein ontological-normalcy/prospective-transcendence-inperpetually-upholding-intemporal-preservation-entropy-or-contiguity-or-ontologicalpreservation (ontology) supersedes intradimensional-subknowledging -normalcy (temporal conventioning compromise). This dichotomy between conventioning and ontology is critical to understand human mentation development along the successive institutionalisations, as transcendental knowledge is by definition prospective and hence recognises the ontological limits/thresholds of conventioning as knowledge and virtue reference because to start with all conventioning institutionalisations are preconverging/postconverging-dementatively/structurally/paradigmatically in want of prospective transcendence-andsublimity/sublimation/supererogatory-de-mentativity whether as recurrent-utterinstitutionalised, ununiversalisation, non-positivism/medievalism or procrypticism in a prospective insight. Conventioning as such could only prospectively reflect 'sound ${ }^{8}$ referenceof-thought status' when it prospectively coincides/proxies ontological-normalcy/prospectivetranscendence-in-perpetually-upholding-intemporal-preservation-entropy-or-contiguity-orontological-preservation; the holy grail of the notional deprocrypticism institutionalisation ideal. But actually a conventioning construct in contrast to attaining such a prospect of 'utterpurism-of-ontology' rather tends to operate on the basis of least-acceptable-meaningfulness-orvalue-reference-denominator for that conventioning construct, and the latter is thus the 'effective meaningfulness-or-value-reference' of the said conventioning construct notwithstanding any 
grander ontological meaningfulness-or-value-reference striving for utter-purism-of-ontology. The implication here is effectively that grander ontological and philosophical meaningfulnessor-value-references are no more pertinent in a conventioning construct than its least acceptable meaningfulness-or-value-reference-denominator but for discretional or prestige basis of discretional and disparate recognition, out of discretionary formalisation in inducing the secondnaturing and internalisation for that recognition. This insight is pertinent in that in the construct of ontology driven meaningfulness-and-value-references of intellectual grounding (purism-of-ontology), it is important to grasp that the social integration of meaningfulness-andvalue-references in a conventioning construct is effectively a least-acceptable-meaningfulnessor-value-reference-denominator-driven dynamism, and that it is by an effective utilisation of the institutionalisation percolation-channelling-<in-deferential-formalisation-transference $>$ mechanism that such 'purism-of-ontology', by it's the-Good, can stand out in bringing to bear its human and social emancipation potential. In the same token, thus it is equally important to grasp that primacy of meaningfulness-or-value-reference orientations in conventioning constructs do not necessarily has to do with a primacy of ontological-veridicality pertinence especially where it is not driven by intrinsic-reality transcendentalenabling/sublimating/superentativity but by notwithstanding that such a conventioning construct may be seen as the social reference of grander meaningfulness-and-value-references in its subject area, and so fundamentally because it is a least-acceptable-meaningfulness-or-value-reference play-out notion and not an-utterpurism-of-ontology-reference notion. Thus the ${ }^{74}$ perversion-of- ${ }^{8}$ reference-of-thought- $<$ aspreconvergingly-apriorising/axiomatising/referencing-innonconviction/madeupness/bottomlining-as-to-shallow-supererogation $>$ of meaningfulness in our positivistic registry-worldview/dimension should prospectively be subject to de-mentation〈supererogatory $\sim$ ontological-de-mentation-or-dialectical-de-mentation-stranding-or- 
attributive-dialectics〉 with corresponding de-mentation-〈supererogatory $\sim$ ontological-dementation-or-dialectical-de-mentation-stranding-or-attributive-dialectics $\rangle$ even though it won't be intelligible from our vantage superseded/transcended registry-worldview/dimension point just as with all transcended/superseded registry-worldviews/dimensions. The narrative/storying technique for a comprehensive postconverging-or-dialectical-thinking apriorising-psychologism - by-preconverging-or-dementing -apriorising-psychologism dialectical representation involves articulating a comprehensive organic-comprehensionthinking narrative in 'intemporal-prioritisation-of- ${ }^{83}$ eference-of-thought'-as-conflatedness ${ }^{13}$ or-ontological-reprojecting by which varied induced threshold-ofnonconviction/madeupness/bottomlining-in-shallow-supererogation $<<$ as-to- 'attendant-

\section{intradimensional'-prospectively-disontologising preconverging/dementing -apriorising-}

psychologism $>$ narratives in circumventing/distractive-temporal-prioritisation-of- referenceof-thought naively arise, and over which an organic-comprehension-thinking analysis dements the threshold-of-nonconviction/madeupness/bottomlining-in-shallow-supererogation -<as-to‘attendant-intradimensional'-prospectively-disontologising preconverging/dementing apriorising-psychologism> narratives as of preconverging-or-dementing ${ }^{20}$-apriorisingpsychologism- $<$ stranded-as-rightfully-oblongated/decandored-and-dialectically-orcontendingly-out-of-phase $>$ to articulate an aetiologisation/ontological-escalation- $<$ ontologicalveridicality_commitment/otherliness_transcending/compulsions-encumbered_transcending>, and so whether such threshold-of-nonconviction/madeupness/bottomlining-in-shallowsupererogation -<as-to-'attendant-intradimensional'-prospectivelydisontologising preconverging/dementing -apriorising-psychologism> postlogic narratives are slanting (subknowledging -impulse), miscuing, disjointed-logic, logical-drag, unconscionability-drag, sub-par/formulaic-association/temporal/alibi conventioningrationalising and their corresponding temporal enculturation/temporal-endemisation. Explained 
in another way, the actual depth-of-storying involves: - psychopathic insane-fitment formulaic slanting compulsing-nonconviction/madeupness/bottomlining-〈' $<$ decontextualising/deexistentialising $\sim$ of-attendant-intradimensional-apriorising/axiomatising/referencing $>$-induceddisontologising'-of-the-'attendant-intradimensional-ontologising'-imbued$<$ contextualising/existentialising attendant-ontological-contiguity $>$;-in-shallowsupererogation -<as-to-disontologising-perverted-outcome-sought-precedes-existentiallyveridical-'attendant-intradimensional-apriorising/axiomatising/referencing'-logical-dueness $>$ ) or postlogism 77 or hollow-constituting-<as-disjointed-misappropriation-of-meaningfulness-andfailing-intemporal-preservation> in postlogic-backtracking-<iterative-looping-'set-ofdereifying-hollow-narratives-and-acts' $>$ as absolving/fleeting/escaping-reflex-logic perversion-of- ${ }^{3}$ reference-of-thought-<as-preconverginglyapriorising/axiomatising/referencing-in-nonconviction/madeupness/bottomlining-as-toshallow-supererogation $>$ wrongly implied as of supplanting-conviction-as-to-profoundsupererogation —of-'attendant-intradimensional'-postconverging/dialectical-thinking apriorising-psychologism; - and this being effectively wrongly elevated as of supplantingconviction-as-to-profound-supererogation _of-'attendant-intradimensional'postconverging/dialectical-thinking -apriorising-psychologism by temporal-dispositions by their hollow-constituting-<as-disjointed-misappropriation-of-meaningfulness-and-failingintemporal-preservation> or ${ }^{12}$ conjoining-looping-set-of-narratives as-of-cohering-logic-reflex to these formulaic slanting compulsing-nonconviction/madeupness/bottomlining$\langle<<$ decontextualising/de-existentialising $\sim$ of-attendant-intradimensionalapriorising/axiomatising/referencing >-induced-disontologising'-of-the-'attendantintradimensional-ontologising'-imbued-<contextualising/existentialising $\sim$ attendantontological-contiguity $>$;-in-shallow-supererogation $-<$ as-to-disontologising-pervertedoutcome-sought-precedes-existentially-veridical-'attendant-intradimensional- 
apriorising/axiomatising/referencing'-logical-dueness $>$ > or postlogism 77 or hollow-constituting<as-disjointed-misappropriation-of-meaningfulness-and-failing-intemporal-preservation> in postlogic-backtracking-<iterative-looping-'set-of-dereifying-hollow-narratives-and-acts' $>$ as absolving/fleeting/escaping-reflex-logic (whether unconsciously by ignorance, and consciously by affordability/opportunism/exacerbation/social-chainism-or-social-discomfitureor-negative-social-aggregation/temporal-enculturation-or-temporal-endemisation) inducing the temporal-dispositions threshold-of-nonconviction/madeupness/bottomlining-in-shallowsupererogation -<as-to-'attendant-intradimensional'-prospectivelydisontologising preconverging/dementing -apriorising-psychologism>; - then the ${ }^{8}$ referenceof-thought as the intemporal-disposition organic-comprehension-thinking in 'intemporalprioritisation-of- ${ }^{8}$ reference-of-thought'-as-conflatedness ${ }^{13}$-or-ontological-reprojecting reflecting/perspectivating/highlighting (reasoning-through-and-not-reasoning-with) of the two above as non-ontological-reference/non-contending-reference-but-rather-preconverging-ordementing -apriorising-psychologism as being in veridicality psychopathic-and-socialpsychopathic phenomenon of ${ }^{74}$ perversion-of- ${ }^{3}$ reference-of-thought- $<$ as-preconverginglyapriorising/axiomatising/referencing-in-nonconviction/madeupness/bottomlining-as-to-

shallow-supererogation >; - and so, as an aetiologisation/ontological-escalation-<ontologicalveridicality_commitment/otherliness_transcending/compulsions-encumbered_transcending > (the organic-comprehension-thinking analytical resolution) that is essentially and prospectively deprocrypticism; ideally such a resolution articulation technique comes down to an enigmatic ontological-normalcy/postconvergence-or-postdicatory deconstruction/ontologicalreconstituting-as-to-conflatedness ${ }^{13}$ as dialectical transformation storying reflecting-orperspectivating a procrypticism (preconverging-or-dementing -of-positivistic-meaningfulness) registry-worldview/dimension as notional-discontiguity/epistemic-discontiguity ${ }^{63}<<$ betweenprior-shallow-supererogation -of-mentally-aestheticised preconverging/dementing -qualia- 
schema_and_prospective-profound-supererogation -of-mentally-

aestheticised $\sim$ postconverging/dialectical-thinking -qualia-schema $>$

(at positivismprocrypticism uninstitutionalised-threshold ${ }^{102}$ ) with respect to notional ${ }^{18}$ deprocrypticism utter relative-unreflexivity/relative-reflexivity ontological-contiguity ${ }^{67}$ ontologicalveridicality (postconvergence), and so as the bigger grounding for the resolution of the epiphenomenon/incidental-phenomenon of psychopathy and social psychopathy. By the way this operant conceptualisation is relevant with phenomena of ${ }^{74}$ perversion-of- ${ }^{3}$ reference-ofthought-<as-preconvergingly-apriorising/axiomatising/referencing-in-

nonconviction/madeupness/bottomlining-as-to-shallow-supererogation $>$ in all registryworldviews/dimensions. Wherein for instance in a non-positivism/medievalism registryworldview/dimension: - the subknowledging ${ }^{4}$-impulse/compulsive-dementing $20 /$ postlogism slantedness in hollow-constituting-<as-disjointed-misappropriation-of-meaningfulness-andfailing-intemporal-preservation> together with its postlogic social corollary associated with instigating accusations of sorcery/witchcraft for instance involve formulaic slanting compulsing-nonconviction/madeupness/bottomlining-〈'<decontextualising/de-

existentialising $\sim$ of-attendant-intradimensional-apriorising/axiomatising/referencing $>$-induceddisontologising'-of-the-'attendant-intradimensional-ontologising'-imbued-

$<$ contextualising/existentialising attendant-ontological-contiguity $>$;-in-shallow-

supererogation -<as-to-disontologising-perverted-outcome-sought-precedes-existentiallyveridical-'attendant-intradimensional-apriorising/axiomatising/referencing'-logical-dueness $>>$ or postlogism 7 in preconverging-or-dementing ${ }^{20}$-apriorising-psychologism as to postlogicbacktracking-<iterative-looping-'set-of-dereifying-hollow-narratives-and-acts'> ${ }^{6} \quad$ (thresholdof-nonconviction/madeupness/bottomlining-in-shallow-supererogation $-<$ as-to-'attendantintradimensional'-prospectively-disontologising preconverging/dementing -apriorisingpsychologism>) - $\quad$ and temporal-dispositions in threshold-of- 
nonconviction/madeupness/bottomlining-in-shallow-supererogation $<-<$ as-to-' ${ }^{\text {attendant- }}$ intradimensional'-prospectively-disontologising preconverging/dementing -apriorisingpsychologism $>$ by their hollow-constituting-<as-disjointed-misappropriation-ofmeaningfulness-and-failing-intemporal-preservation $>$ or ${ }^{12}$ conjoining-looping-set-of-narratives as-of-cohering-logic-reflex to the formulaic slanting compulsingnonconviction/madeupness/bottomlining-〈" $<$ decontextualising/de-existentialising $\sim$ ofattendant-intradimensional-apriorising/axiomatising/referencing>-induced-disontologising'-ofthe-'attendant-intradimensional-ontologising'-imbued$<$ contextualising/existentialising attendant-ontological-contiguity $>$;-in-shallowsupererogation -<as-to-disontologising-perverted-outcome-sought-precedes-existentiallyveridical-'attendant-intradimensional-apriorising/axiomatising/referencing'-logical-dueness $>$ > or postlogism 77 or hollow-constituting-<as-disjointed-misappropriation-of-meaningfulness-andfailing-intemporal-preservation> in postlogic-backtracking-<iterative-looping-'set-ofdereifying-hollow-narratives-and-acts' $>76$ thus inducing the wrongful elevation of the formulaic slanting compulsing-nonconviction/madeupness/bottomlining-<" $<$ decontextualising/deexistentialising $\sim$ of-attendant-intradimensional-apriorising/axiomatising/referencing $>$-induceddisontologising'-of-the-'attendant-intradimensional-ontologising'-imbued$<$ contextualising/existentialising attendant-ontological-contiguity $>$;-in-shallowsupererogation -<as-to-disontologising-perverted-outcome-sought-precedes-existentiallyveridical-'attendant-intradimensional-apriorising/axiomatising/referencing'-logical-dueness $>$ > or postlogism 77 or hollow-constituting-<as-disjointed-misappropriation-of-meaningfulness-andfailing-intemporal-preservation> in postlogic-backtracking-<iterative-looping-‘set-ofdereifying-hollow-narratives-and-acts' ${ }^{76}$ as being of supplanting-conviction-as-to-profoundsupererogation - of-'attendant-intradimensional'-postconverging/dialectical-thinking apriorising-psychologism whether unconsciously by ignorance, or consciously by 
affordability/opportunism/exacerbation/social-chainism-or-social-discomfiture-or-negativesocial-aggregation/temporal-enculturation-or-temporal-endemisation (the temporal-'thresholdof-nonconviction/madeupness/bottomlining-in-shallow-supererogation $<$ as-to-'attendantintradimensional'-prospectively-disontologising preconverging/dementing -apriorisingpsychologism>') - with the two above being retrospectively construed from the veridical reference-of-thought of a vantage positivistic registry-worldview/dimension as being nonpositivism/medievalism mindset/ ${ }^{83}$ reference-of-thought and non-ontological-reference/noncontending-reference-but-rather-preconverging-or-dementing ${ }^{20}$-apriorising-psychologism and construed ontologically by their reflecting/perspectivating/highlighting (reasoning-through-andnot-reasoning-with) as the non-positivism/medievalism sorcery phenomenon of ${ }^{74}$ perversion-ofreference-of-thought-<as-preconvergingly-apriorising/axiomatising/referencing-innonconviction/madeupness/bottomlining-as-to-shallow-supererogation $>$ (the organiccomprehension-thinking) - and so, as an aetiologisation/ontological-escalation- $<$ ontologicalveridicality_commitment/otherliness_transcending/compulsions-encumbered_transcending > (the organic-comprehension-thinking analytical resolution) that is essentially and prospectively positivistic, just as the aetiologisation/ontological-escalation- $<$ ontologicalveridicality_commitment/otherliness_transcending/compulsions-encumbered_transcending $>$ of psychopathy and social psychopathy is essentially deprocrypticism. Likewise, one can imagine the same type of enigmatic ontological-normalcy/postconvergence-or-postdicatory deconstruction/ontological-reconstituting-as-to-conflatedness ${ }^{13}$ as dialectical transformation storying reflecting-or-perspectivating a non-positivism/medievalism registryworldview/dimension as notional-discontiguity/epistemic-discontiguity ${ }^{63}-<$ between - priorshallow-supererogation -of-mentally-aestheticised preconverging/dementing -qualiaschema_and_prospective-profound-supererogation -of-mentallyaestheticised postconverging/dialectical-thinking -qualia-schema> (at its uninstitutionalised- 
threshold ${ }^{102}$ ) with respect to positivism as (postconvergence) ontological-veridicality/relativeunreflexivity/relative-reflexivity -ontological-contiguity ${ }^{7}$, as the bigger grounding for the epiphenomenon/incidental-phenomenon of say a medieval phenomenon of ${ }^{7}$ perversion-ofreference-of-thought-<as-preconvergingly-apriorising/axiomatising/referencing-innonconviction/madeupness/bottomlining-as-to-shallow-supererogation $>$ like sorcery. As fundamentally, intemporal/ontological/social/species/ ${ }^{103}$ universal/transcendental/ ${ }^{5}$ maximalisingrecomposuring-for-relative-ontological-completeness ${ }^{8}$ —unenframed/reontologising conceptualisation postconverging-de-mentating/structuring/paradigming resolution as against an extricatory/temporal/non-ontological preconverging-dementating/structuring/paradigming resolution fundamentally implies putting-into-question a registry-worldview's/dimension's ${ }^{83}$ reference-of-thought (to be transcended by a prospective transcending/superseding registry-worldview/dimension) that is structured to enable the

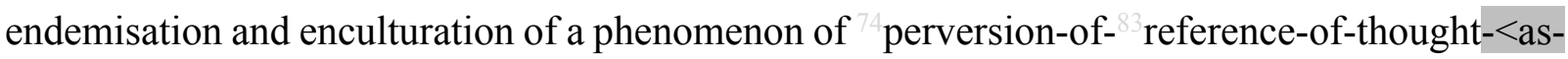
preconvergingly-apriorising/axiomatising/referencing-innonconviction/madeupness/bottomlining-as-to-shallow-supererogation $>$ like sorcery in the non-positivism/medievalism world; implying that an 'intemporal-disposition mindset' of positivistic disposition finding themselves in a non-positivism/medievalism social-setup will not see the proffered accusation of sorcery against them or any other individual as simply requiring defending themselves or the accused of sorcery or 'playing out' in the social-and-temporaltrading of that social-setup to extricate themselves or the accused but rather project that the registry-worldview/dimension in endemising and enculturating the possibility of accusations and notions of sorcery is preconverging/postconverging-dementatively/structurally/paradigmatically dialectically-primitive/dialectically-out-of-phase (thus in need of prospective transcendence-and-sublimity/sublimation/supererogatery $\sim$ de- 
mentativity), and the undermining of that registry-worldview/dimension is the intemporal/ontological/social/species/ ${ }^{103}$ universal/transcendental/ ${ }^{5}$ maximalisingrecomposuring-for-relative-ontological-completeness ${ }^{87}$ - unenframed/re-

ontologising conceptualisation postconverging-de-mentating/structuring/paradigming resolution of the epiphenomenon of sorcery across 'metaphorically-a-million-and-one-instancesand-locales as to aetiologisation/ontological-escalation- $<$ ontologicalveridicality_commitment/otherliness_transcending/compulsions-encumbered_transcending >'. It should be noted that an intemporal or ontological or longness-of-register-of- ${ }^{56}$ meaningfulnessand-teleology resolution to ${ }^{7}$ perversion-of- ${ }^{3}$ reference-of-thought-<as-preconverginglyapriorising/axiomatising/referencing-in-nonconviction/madeupness/bottomlining-as-toshallow-supererogation $>$ in any registry-worldview/dimension is well beyond the notion of resolving just an underlying causative subknowledging -impulse/compulsive-dementing (condition from say a physiological cause), like psychopathy in the positivistic registryworldview/dimension or a sorcerer accuser in a medieval registry-worldview/dimension. That may explain the initiation of a loss of intemporal social ${ }^{103}$ universal-transparency ${ }^{104}$ 〈transparency-of-totalising-entailing,-as-to-entailing-<amplituding/formative-

epistemicity>totalising in-relative-ontological-completeness > arising from postlogism 7 in hollow-constituting-<as-disjointed-misappropriation-of-meaningfulness-and-failingintemporal-preservation> for instance which is then at the base of a registry-

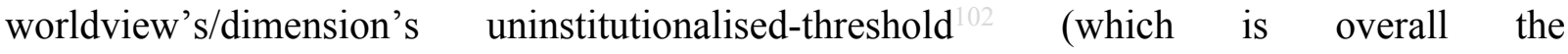
preconverging/postconverging-de-mentative/structural/paradigmatic issue to be resolved), as temporal-dispositions are out of a 'deferential-formalisation-transference'/skewed ('intemporality ${ }^{52}$-symmetrising-by-desymmetrising-subsumption-of-temporality ${ }^{8}$, for relative intrinsic-reality/ontological-veridicality transcendentalenabling/sublimating/supererogatory $\sim$ de-mentativity) institutionalisation setup, whether at 
recurrent-utter-uninstitutionalisation, ununiversalisation, non-positivism/medievalism or procrypticism from the insight of their respective prospective institutionalisation as the resolution in the form of base-institutionalisation, ${ }^{103}$ universalisation, positivism or deprocrypticism. The point is reality is as of ontological-normalcy/postconvergence and suprastructural and is not constraint to and have nothing to do inherently with human mentaldevising-representation $\quad{ }^{5}$ incrementalism-in-relative-ontological-incompleteness ${ }^{8}$ enframed/disontologising conceptualisation and notional disjointedness, as it is up to us to proxy to it and hence we can't say we want to think-one-way or we've-been-thinking-a-certainway (as ${ }^{83}$ reference-of-thought- categorical-imperatives/axioms/registry-teleology ${ }^{9}$ ) to naively imply that reality will and should comply, as failing/not-upholding-<as-ofapriorising/axiomatising/referencing > reference-of-thought- categoricalimperatives/axioms/registry-teleology ${ }^{9}$ speak of human mental-devising-representation deadends and the need for postconverging-de-mentating/structuring/paradigming shifts. Likewise, a suprastructural conceptualisation is one construed beyond and not limited to the $\{$ cumulated/recomposured -consciousness-awareness-teleology 9 or mental-devisingrepresentation of a registry-worldview/dimension ${ }^{83}$ reference-of-thought- categoricalimperatives/axioms/registry-teleology ${ }^{9}$, i.e. not limited to its temporal conventioning compromise. In that sense, the knowledge-notionalisation is about a 'deterministic and operant construct preserving intemporality ${ }^{52} /$ longness as ontology'. This translates as: - the grander problem of a subknowledging -impulse/compulsive-dementing with the instigation of recurrent-utter-uninstitutionalisation and its temporal social recurrency is failing/not-upholding$<$ as-of-apriorising/axiomatising/referencing $>$ (postconvergence and suprastructural) intemporal preservation intemporal/ontological/social/species/ ${ }^{103}$ universal/transcendental $/{ }^{55}$ maximalisingrecomposuring-for-relative-ontological-completeness ${ }^{87}$ - unenframed/re- 
ontologising conceptualisation postconverging-de-mentating/structuring/paradigming in all recurrent-utter-institutionalised human locales beyond just an extricatory preconverging-dementating/structuring/paradigming of any human locale, requiring the de-mentation〈supererogatory-ontological-de-mentation-or-dialectical-de-mentation-stranding-orattributive-dialectics $\rangle$ of recurrent-utter-uninstitutionalisation by a de-mentation〈supererogatory ontological-de-mentation-or-dialectical-de-mentation-stranding-orattributive-dialectics $\rangle$ of prior/transcended/superseded recurrent-utter-uninstitutionalisation as preconverging-or-dementing 20 -apriorising-psychologism, and prospective/transcending/superseding base-institutionalisation as 'postconverging-ordialectical-thinking -apriorising-psychologism'/soundness-or-ontological-good-

faith/authenticity ${ }^{6}$-of- ${ }^{3}$ reference-of-thought and the deterministic and operant institutionalisation/intemporalisation resolution construct (and so, in an ontologicalnormalcy/postconvergence-or-postdicatory deconstruction/ontological-reconstituting-as-toconflatedness $^{13}$ as dialectical transformation of existentialism/full-depth-of-existentialimplications from the transcended to the transcending); - the grander problem of a subknowledging -impulse/compulsive-dementing with the instigation of ununiversalisation and its temporal social recurrency is failing/not-upholding-<as-ofapriorising/axiomatising/referencing $>$ (postconvergence and suprastructural) intemporal preservation as intemporal/ontological/social/species/ ${ }^{103}$ universal/transcendental/ $/{ }^{5}$ maximalisingrecomposuring-for-relative-ontological-completeness ${ }^{8}$ —unenframed/reontologising conceptualisation postconverging-de-mentating/structuring/paradigming in all ununiversalised human locales beyond just an extricatory preconverging-dementating/structuring/paradigming of any one human locale, requiring the de-mentation〈supererogatory $\sim$ ontological-de-mentation-or-dialectical-de-mentation-stranding-or- 
attributive-dialectics〉 of ununiversalisation by a de-mentation-〈supererogatory $\sim$ ontological-dementation-or-dialectical-de-mentation-stranding-or-attributive-dialectics)

prior/transcended/superseded ununiversalisation as preconverging-or-dementing ${ }^{20}$-apriorisingpsychologism, and prospective/transcending/superseding ${ }^{103}$ universalisation as 'postconvergingor-dialectical-thinking -apriorising-psychologism'/soundness-or-ontological-good-

faith/authenticity ${ }^{6}$-of- ${ }^{3}$ reference-of-thought and the deterministic and operant institutionalisation/intemporalisation resolution construct (and so, in an ontologicalnormalcy/postconvergence-or-postdicatory deconstruction/ontological-reconstituting-as-toconflatedness $^{13}$ as dialectical transformation of existentialism/full-depth-of-existentialimplications from the transcended to the transcending); - the grander problem of a subknowledging -impulse/compulsive-dementing with the instigation of nonpositivism/medievalism with such phenomenon as witchcraft and its temporal social recurrency is failing/not-upholding-<as-of-apriorising/axiomatising/referencing $>$ (postconvergence and suprastructural) intemporal preservation as intemporal/ontological/social/species/ ${ }^{103}$ universal/transcendental $/{ }^{5}$ maximalisingrecomposuring-for-relative-ontological-completeness ${ }^{8}$ —unenframed/reontologising conceptualisation postconverging-de-mentating/structuring/paradigming in all non-positivism/medievalism human locales beyond just an extricatory preconverging-dementating/structuring/paradigming of any one human locale, requiring the de-mentation〈supererogatery ontological-de-mentation-or-dialectical-de-mentation-stranding-orattributive-dialectics $\rangle$ of non-positivism/medievalism by a de-mentation〈supererogatory ontological-de-mentation-or-dialectical-de-mentation-stranding-orattributive-dialectics $\rangle$ of prior/transcended/superseded non-positivism/medievalism as preconverging-or-dementing ${ }^{20}$-apriorising-psychologism, and prospective/transcending/superseding positivism as 'postconverging-or-dialectical-thinking 
apriorising-psychologism'/soundness-or-ontological-good-faith/authenticity ${ }^{60}$ of- ${ }^{8}$ referenceof-thought and the deterministic and operant institutionalisation/intemporalisation resolution construct; and prospectively (and so, in an ontological-normalcy/postconvergence-orpostdicatory deconstruction/ontological-reconstituting-as-to-conflatedness ${ }^{13}$ as dialectical transformation of existentialism/full-depth-of-existential-implications from the transcended to the transcending), - the grander problem of a subknowledging -impulse/compulsivedementing with the instigation of procrypticism-or-disjointedness-as-of- ${ }^{2}$ reference-ofthought with such phenomenon as psychopathy and social psychopathy and its temporal social recurrency is failing/not-upholding-<as-of-apriorising/axiomatising/referencing $>$ (postconvergence and suprastructural) intemporal preservation as intemporal/ontological/social/species/ ${ }^{103}$ universal/transcendental/ ${ }^{5}$ maximalisingrecomposuring-for-relative-ontological-completeness ${ }^{8}$ —unenframed/reontologising conceptualisation postconverging-de-mentating/structuring/paradigming in all procrypticism-or-disjointedness-as-of- ${ }^{-3}$ reference-of-thought human locales beyond just an extricatory preconverging-de-mentating/structuring/paradigming of any one human locale, requiring the de-mentation-〈supererogatory ${ }^{15}$ ontological-de-mentation-or-dialectical-dementation-stranding-or-attributive-dialectics $\rangle$ of ${ }^{80}$ procrypticism-or-disjointedness-as-ofreference-of-thought by a de-mentation-〈supererogatory $\sim$ ontological-de-mentation-ordialectical-de-mentation - stranding-or-attributive-dialectics $\rangle$ of prior/transcended/superseded procrypticism-or-disjointedness-as-of- ${ }^{3}$ reference-of-thought as preconverging-ordementing -apriorising-psychologism, and prospective/transcending/superseding notional ' deprocrypticism as 'postconverging-or-dialectical-thinking ${ }^{21}$-apriorisingpsychologism'/soundness-or-ontological-good-faith/authenticity ${ }^{6}$-of- ${ }^{83}$ reference-of-thought and the deterministic and operant institutionalisation/intemporalisation resolution construct (and so, in an ontological-normalcy/postconvergence-or-postdicatory deconstruction/ontological- 
reconstituting-as-to-conflatedness ${ }^{13}$ as dialectical transformation of existentialism/full-depthof-existential-implications from the transcended to the transcending). * In other words, fundamental construal about the conceptual-and-institutionalisation-phenomena has to do with how any and all conceptualisations and meaningfulness harken back to intemporalpreservation-entropy-or-contiguity-or-ontological-preservation', qualified as the very essence of intrinsic-reality as a suprastructural and ontological-normalcy/postconvergence conjointontological-and-virtue-consistency upholding construct; and in so doing, explicates successive institutional-cumulation/institutional-recomposure-〈as-to- historiality/ontological-

\section{eventfulness /ontological-aesthetic-tracing-<perspective-ontological-}

normalcy/postconvergence-reflected-'epistemicity-relativism-determinism'>>

existentialisms/full-depths-of-existential-implications. Hence the subknowledging impulse/compulsive-dementing $\%$ slantedness mechanism that induces ${ }^{7}$ perversion-ofreference-of-thought-<as-preconvergingly-apriorising/axiomatising/referencing-innonconviction/madeupness/bottomlining-as-to-shallow-supererogation $>$ in all institutionalcumulation/institutional-recomposure-〈as-to- historiality/ontological-

\section{eventfulness /ontological-aesthetic-tracing-<perspective-ontological-}

normalcy/postconvergence-reflected-'epistemicity-relativism-determinism'>> effectively define each registry-worldview/dimension respective uninstitutionalised-threshold ${ }^{02}$ while reflecting/perspectivating/highlighting its mental-devising-representation specific superseded/transcended preconverging-or-dementing ${ }^{20}$-apriorising-psychologism- $<$ strandedas-rightfully-oblongated/decandored-and-dialectically-or-contendingly-out-of-phase $>$ that is its uninstitutionalised-threshold ${ }^{102}$ (going by the " ${ }^{15}$ de-mentation-〈supererogatory $\sim$ ontological-dementation-or-dialectical-de-mentation-stranding-or-attributive-dialectics $\rangle$ of ${ }^{83}$ reference-ofthought'). This transcended/superseded uninstitutionalised-threshold ${ }^{102}$ in the ${ }^{15}$ de-mentation〈supererogatory ontological-de-mentation-or-dialectical-de-mentation-stranding-or- 
attributive-dialectics $\rangle$ is a ${ }^{103}$ universal notion in establishing that that which is ${ }^{74}$ perversion-ofreference-of-thought-<as-preconvergingly-apriorising/axiomatising/referencing-innonconviction/madeupness/bottomlining-as-to-shallow-supererogation $>$ and therefore not ontologically-veridical (superseded/transcended preconverging-or-dementing ${ }^{20}$-apriorisingpsychologism- $<$ stranded-as-rightfully-oblongated/decandored-and-dialectically-orcontendingly-out-of-phase $>$ ) reflects the uninstitutionalised-threshold ${ }^{102}$, and that which is not perversion-of- ${ }^{3}$ reference-of-thought-<as-preconvergingly-

\section{apriorising/axiomatising/referencing-in-nonconviction/madeupness/bottomlining-as-to-}

shallow-supererogation $>$ and ontologically-veridical (superseding/transcending postconverging-or-dialectical-thinking ${ }^{2}$-apriorising-psychologism- $<$ stranded-as-rightfullystraight/candored-and-dialectically-or-contendingly-in-phase $>$ ) reflects the institutionalised threshold. This is critical in overcoming our very own <amplituding/formativeepistemicity $>$ totalising $\sim$ self-referencing-syncretising/circularity/interiorising/akrasiatic-drag inclination with respect to procrypticism, ${ }^{71}$ perversion-of- ${ }^{8}$ reference-of-thought- $<$ aspreconvergingly-apriorising/axiomatising/referencing-in-

nonconviction/madeupness/bottomlining-as-to-shallow-supererogation $>$ of positivistic meaningfulness, that is, positivistic ${ }^{83}$ reference-of-thought- categoricalimperatives/axioms/registry-teleology ${ }^{9}$,-for-intemporal-preservation-entropy-or-contiguityor-ontological-preservation), and so beyond our illusion-of-the-present/present-consciousness as more of a veridical ontological-normalcy/postconvergence and suprastructural intrinsicreality/ontological-veridicality to a veridical existentialism/full-depth-of-existential-veridical placeholder-setup/mental-devising-representation/mentation/consciousness-awarenessteleology (of perversion-of- ${ }^{9}$ reference-of-thought-<as-preconverginglyapriorising/axiomatising/referencing-in-nonconviction/madeupness/bottomlining-as-toshallow-supererogation >) over which memetic-reordering/psychoanalytic-unshackling can 
then occur. Otherwise, while such an insight is intuitive from our vantage positivistic registryworldview point of reference with respect to prior registry-worldviews/dimensions dementativity/ ${ }^{15}$ de-mentation-〈supererogatory $\sim$ ontological-de-mentation-or-dialectical-dementation - stranding-or-attributive-dialectics $\rangle$, ours will carry a complex implying wrongly it is unde-mentable and thus non-transcendable. Such ${ }^{6}$ perversion-of- ${ }^{-}$reference-of-thought- $<$aspreconvergingly-apriorising/axiomatising/referencing-innonconviction/madeupness/bottomlining-as-to-shallow-supererogation >> applies with regards to both psychopathic subknowledging -impulse/compulsive-dementing $\%$ slantedness and its corresponding postlogism -as-of- compulsing-nonconviction/madeupness/bottomlining$〈<<$ decontextualising/de-existentialising $\sim$ of-attendant-intradimensionalapriorising/axiomatising/referencing>-induced-disontologising'-of-the-'attendantintradimensional-ontologising'-imbued-<contextualising/existentialising $\sim$ attendantontological-contiguity $>$;-in-shallow-supererogation -<as-to-disontologising-pervertedoutcome-sought-precedes-existentially-veridical-'attendant-intradimensionalapriorising/axiomatising/referencing'-logical-dueness $>$ > protraction as conjugation/inflection/deriving to temporal-dispositions implying consciously taking such insane-fitment mantle and acting like the psychopathic character once committed from ignorance (due to the postlogic inducing of a loss of social ${ }^{103}$ universal-transparency ${ }^{104}-\langle$ transparency-oftotalising-entailing,-as-to-entailing-<amplituding/formative-epistemicity $>$ totalising $\sim$ inrelative-ontological-completeness $\rangle$ that acts as a constrain to temporal-dispositions for institutionalisation); at which point for all effective-predicative practicalities the temporaldispositions character is 'technically psychopathic'. This is the underlying basis for the development of social psychopathy. That is, after ignorance-temporal-disposition conjugation/inflection/deriving of psychopathic subknowledging -impulse/compulsivedementing $\%$ slantedness postlogism 77 -as-of- 1 compulsing- 
nonconviction/madeupness/bottomlining-〈'<decontextualising/de-existentialising ofattendant-intradimensional-apriorising/axiomatising/referencing $>$-induced-disontologising'-ofthe-'attendant-intradimensional-ontologising'-imbued$<$ contextualising/existentialising attendant-ontological-contiguity $>$;-in-shallowsupererogation -<as-to-disontologising-perverted-outcome-sought-precedes-existentiallyveridical-'attendant-intradimensional-apriorising/axiomatising/referencing'-logical-dueness $>>$ protraction as assuming psychopathic subknowledging -impulse/compulsivedementing $\%$ slantedness in ignorance and out of bad-or-wrong supplanting-conviction-as-toprofound-supererogation _of-‘attendant-intradimensional'-postconverging/dialecticalthinking -apriorising-psychologism, the other temporal-dispositions respectively involve: (affordability-temporal-disposition) assuming psychopathic subknowledging impulse/compulsive-dementing $/$ slantedness in affordability and out of its threshold-ofnonconviction/madeupness/bottomlining-in-shallow-supererogation $\quad-<$ as-to- 'attendantintradimensional'-prospectively-disontologising preconverging/dementing -apriorisingpsychologism $>$ as uninstitutionalised-animality-threshold, - (opportunism-temporal-disposition)

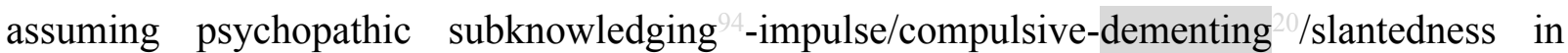
opportunism and out of its threshold-of-nonconviction/madeupness/bottomlining-in-shallowsupererogation -<as-to- 'attendant-intradimensional'-prospectivelydisontologising preconverging/dementing -apriorising-psychologism $>$ as uninstitutionalisedanimality-threshold, - (exacerbation-temporal-disposition) assuming psychopathic subknowledging ${ }^{24}$-impulse/compulsive-dementing /slantedness in exercerbation and out of its threshold-of-nonconviction/madeupness/bottomlining-in-shallow-supererogation $-<$ as-to'attendant-intradimensional'-prospectively-disontologising preconverging/dementing apriorising-psychologism> as uninstitutionalised-animality-threshold; - (social-chainism/socialdiscomfiture/negative-social-aggregation-temporal-disposition) assuming psychopathic 
subknowledging ${ }^{4}$-impulse/compulsive-dementing /slantedness in social-chainism/socialdiscomfiture/negative-social-aggregation and out of its threshold-ofnonconviction/madeupness/bottomlining-in-shallow-supererogation $<-<$ as-to- 'attendantintradimensional'-prospectively-disontologising preconverging/dementing -apriorisingpsychologism $>$ as uninstitutionalised-animality-threshold; - (temporal-enculturation/temporalendemisation-temporal-disposition) assuming psychopathic subknowledging impulse/compulsive-dementing $\%$ slantedness in temporal-enculturation/temporal-endemisation and out of its threshold-of-nonconviction/madeupness/bottomlining-in-shallowsupererogation -<as-to- 'attendant-intradimensional'-prospectivelydisontologising preconverging/dementing -apriorising-psychologism $>$ as uninstitutionalisedanimality-threshold. What is specific about a mental-devising-representation of psychopathic/postlogic perversion-of- ${ }^{8}$ reference-of-thought- $<$ as-preconverginglyapriorising/axiomatising/referencing-in-nonconviction/madeupness/bottomlining-as-toshallow-supererogation $>$ and its protraction as social psychopathy to temporal-dispositions (not to be confused with the spontaneous supplanting-conviction-as-to-profoundsupererogation _of-'attendant-intradimensional'-postconverging/dialectical-thinking apriorising-psychologism reflex or prelogic-reflex-admittance-reflex or in-phase-reflex of wrongly implying prelogism ${ }^{78}$-as-of-conviction,-in-profound-supererogation $-<$ existentiallyveridical-'attendant-intradimensional-apriorising/axiomatising/referencing'-logical-duenessprecedes-disontologising-logical-outcome-arrived-at> as 'poor or bad supplanting-convictionas-to-profound-supererogation —of-'attendant-intradimensional'-postconverging/dialecticalthinking -apriorising-psychologism' wrongly implying logical nested-congruence-wrongly implying a logical contention); the specificity lies in the notion of 'EMPTINESS of psychopathic postlogic-backtracking-<iterative-looping-'set-of-dereifying-hollow-narratives-and-acts’> and the conjugation/inflection/protraction of that EMPTINESS to the temporal-dispositions in 
hollow-constituting-<as-disjointed-misappropriation-of-meaningfulness-and-failing-

intemporal-preservation> postlogism 77 conjoining-looping-sets-of-narratives-<construed-asof-slanted-cohering-'unsoundness-or-ontological-bad-faith/inauthenticity ${ }^{64}$-of- ${ }^{8}$ reference-ofthought'-of-the-derived- ${ }^{7}$ perversion-of- ${ }^{3}$ reference-of-thought- $<$ as-preconverginglyapriorising/axiomatising/referencing-in-nonconviction/madeupness/bottomlining-as-toshallow-supererogation >,-and-avoiding-any-wrongly-implied-logical-processing-engaging $\rangle$. It is the 'reflection/perspectivation' of this EMPTINESS of narratives/affirmations that is behind the notion of ${ }^{74}$ perversion-of- ${ }^{83}$ reference-of-thought- $<$ as-preconverginglyapriorising/axiomatising/referencing-in-nonconviction/madeupness/bottomlining-as-toshallow-supererogation $>$, and so as intemporal organic-comprehension-thinking insight over threshold-of-nonconviction/madeupness/bottomlining-in-shallow-supererogation -<as-to‘attendant-intradimensional'-prospectively-disontologising preconverging/dementing apriorising-psychologism $>$ distraction. In fact, the technique for preconverging-or-dementing 2 apriorising-psychologism involves mentally interceding/intermediating the reflected/perspectivated insight of a postlogic interlocutor's hollow-narratives or derivedhollow-narratives with emptiness to reflect/perspectivate its unsoundness-or-ontological-badfaith/inauthenticity ${ }^{6}$-of- ${ }^{3}$ reference-of-thought as a manifestation of registryworldview's/dimension's-uninstitutionalised-threshold ${ }^{12}$-defect-<as-Being-or-ontological-orexistential-defect> ${ }^{85}$ given the narrative notional-discontiguity/epistemic-discontiguity ${ }^{63}$ $<$ between-prior-shallow-supererogation -of-mentallyaestheticised preconverging/dementing -qualia-schema_and_prospective-profoundsupererogation -of-mentally-aestheticised postconverging/dialectical-thinking -qualiaschema>. It is critical to note that this EMPTINESS of mental-devising-representation of perversion-of- ${ }^{3}$ reference-of-thought- $<$ as-preconverginglyapriorising/axiomatising/referencing-in-nonconviction/madeupness/bottomlining-as-to- 
shallow-supererogation $>$ as the uninstitutionalised-threshold ${ }^{102}$ of ( ${ }^{15}$ de-mentation〈supererogatory ontological-de-mentation-or-dialectical-de-mentation-stranding-orattributive-dialectics $\rangle$ ) de-mentation-〈supererogaty ontological-de-mentation-ordialectical-de-mentation - stranding-or-attributive-dialectics $\rangle$ mentally-representing prior transcended/superseded registry-worldviews/dimensions as oblongated/decandored-anddialectically/contendingly-out-of-phasing-or-dialectical-primitivity with respect to prospective transcending/superseding registry-worldviews/dimensions mentally-represented as mentallystraight/candored-and-dialectically-or-contendingly-in-phase; is the underlying process that permits the 'transcendental shifting of ${ }^{83}$ reference-of-thought (enabling ontologicalnormalcy/prospective-transcendence-in-perpetually-upholding-intemporal-preservationentropy-or-contiguity-or-ontological-preservation) to the apriorising-registry of the prospective/transcending/superseding registry-worldview/dimension while the transcended/superseded registry-worldview/dimension is no longer a dialectically-in-phase reference-of-thought but of dialectically-out-of-phase ${ }^{56}$ meaningfulness-and-teleology perversion-of- ${ }^{3}$ reference-of-thought-<as-preconverginglyapriorising/axiomatising/referencing-in-nonconviction/madeupness/bottomlining-as-toshallow-supererogation $>$ as to its preconverging-or-dementing ${ }^{20}$-apriorising-psychologism. This process basically explains ontologically why and how humans from the very beginning to today are the same as it fundamentally grasps the dynamism of institutionalcumulation/institutional-recomposure-〈as-to- historiality/ontologicaleventfulness /ontological-aesthetic-tracing-<perspective-ontologicalnormalcy/postconvergence-reflected-'epistemicity-relativism-determinism’ $>$ /memeticreordering/psychoanalytic-reorientation that elucidates our human contiguous anthropologicalcontinuity or anthropopsychology. Further, in the practical elucidation of social issues having to do with an issue of ${ }^{7}$ perversion-of- ${ }^{83}$ reference-of-thought- $<$ as-preconvergingly- 
apriorising/axiomatising/referencing-in-nonconviction/madeupness/bottomlining-as-to-

shallow-supererogation $>$ like psychopathy-and-social-psychopathy, it points out that the critical point is to understand what meaningful apriorising-registry is the "veridical ${ }^{83}$ referenceof-thought' as reflected/perspectivated by soundness-or-ontological-good-faith/authenticity ${ }^{6}$ of- ${ }^{8}$ reference-of-thought/candoring-and-dialectically-or-contendingly-in-phase and what is rather non-ontological-and-non-contending-referencing-<thus-ontologically-or-contendinglyreflected-or-perspectivated-as-of-preconverging-or-dementing ${ }^{20}$-apriorising-psychologism> and hence preconverging-or-dementing ${ }^{20}$-apriorising-psychologism as reflected/perspectivated by mental-slantedness/decandoring-and-dialectically-or-contendingly-out-of-phase; and so in an underlying conceptual framework of ontology as an ideal that pulls the social towards the intemporal and the real nature of the social rather as a 'conventioning construct' that while susceptible to ontological/intemporal influence is equally the milieu of temporal drawbacks that need to be critically undermined including with 'knowledge-notionalisation' involving not only the study of the ideal but 'understanding how temporal-dispositions arise and work' to better skew/deferential-formalisation-transference for intemporality ${ }^{52} /$ ontology $^{2}$ as institutionalisation/intemporalisation together with differentiating between good-naturedness which is rather impression-driven, vague and might actually be precarious by its meaningful disposition to extrinsic-attribution and associated 74 perversion-of- ${ }^{8}$ reference-of-thought $-<$ aspreconvergingly-apriorising/axiomatising/referencing-in-

nonconviction/madeupness/bottomlining-as-to-shallow-supererogation $>$ and the-Good which is about understanding in <amplituding/formative-epistemicity>causality $\sim$ as-to-projectivetotalitative-implications-of-prospective- nonpresencing,-for-explicating relative-

mnreflexivity/relative reflexivity - ontological-contiguity how reality is/how things work to deliver virtue and hence is the basis for formalisations, and actually the 'deferentialformalisation-transference' has been the process by which throughout human history, 
increasingly segments of social thinking (present-day subject-matters) are taken out of common hotchpotching and undisambiguated notional firstnaturedness-formativeness-<as-toeventualising inkling drive-or-seeding misprising $>$ temporal-to-intemporal-dispositions$<$ so-construed-as-from-perspective-ontological-normalcy/postconvergence $>$ in the extendedinformality-〈susceptible-to-effecting-parsimony-as-of-shoddiness-and-incompleteness-tomeaningfulness-and-teleology $>$ to be given 'formal deferential status' to ensure the supersedingness and internalisation of intemporal-disposition inclination to ontologicalveridicality. This ${ }^{15}$ de-mentation-〈stpereratory-ontological-de-mentation-or-dialectical-dementation-stranding-or-attributive-dialectics $\rangle$ insight brings up another definition of the psychoanalytic-unshackling/memetic-reordering/institutional-recomposuring process relating human mental-devising-representation with the ontological-normalcy/postconvergence and suprastructural nature of intrinsic-reality, wherein we can imagine an 'initial state for psychoanalytic-unshackling/memetic-reordering/institutional-recomposuring of base dementation and imagine a completed state of psychoanalytic-unshackling/memeticreordering/institutional-recomposuring of non $\sim$ de-mentation-<as-to-perspective-ontologicalnormalcy/postcovergence>', with the underlying mental-devisingrepresentation/(recomposure)-consciousness-awareness-teleology taking/institutionalising/intemporalising the abstract human mind from base de-mentation to non $\sim$ de-mentation- $<$ as-to-perspective-ontological-normalcy/postcovergence $>$; involving at successive uninstitutionalised-threshold ${ }^{102}$ of the institutional-cumulation/institutionalrecomposure-〈as-to- historiality/ontological-eventfulness /ontological-aesthetic-tracing$<$ perspective-ontological-normalcy/postconvergence-reflected-'epistemicity-relativismdeterminism'>>, social ${ }^{103}$ universal-transparency ${ }^{104}$-〈transparency-of-totalising-entailing,-as-toentailing-<amplitung/formative-epistemicity $>$ totalising in-relative-ontologicalcompleteness > of $\quad{ }^{7}$ perversion-of- ${ }^{8}$ reference-of-thought- $<$ as-preconvergingly- 
apriorising/axiomatising/referencing-in-nonconviction/madeupness/bottomlining-as-to-

shallow-supererogation >, internal-contradictions induced from <amplituding/formativeepistemicity $>$ causality $\sim$ as-to-projective-totalitative-implications-of-prospectivenonpresencing,-for-explicating relative-unreflexivity/relative-reflexivity - ontologicalcontiguity inoperance, ${ }^{15}$ de-mentation-/supererogatory $\sim$ ontological-de-mentation-ordialectical-de-mentation - stranding-or-attributive-dialectics $\rangle$ divulging prospectively perversion-of- ${ }^{-3}$ reference-of-thought-<as-preconverginglyapriorising/axiomatising/referencing-in-nonconviction/madeupness/bottomlining-as-toshallow-supererogation >, and intemporal projection superseding the transcendenceunenabling-uninstitutionalised-threshold 02 in alienation-as-inauthentic/poorlyobjectified/poorly-desubjectified-as-objectified/ontological-bad-faith/inauthenticity ${ }^{6 / \text { nihilistic }}$ as of temporality ${ }^{8}$, with corresponding formalisation and internalisation as values. While this process had occurred priorly rather beyond-the-consciousness-awareness-teleology ${ }^{9}-<$ of preconverging-existential-extrication-as-of-existential-unthought $>\quad$ from baseinstitutionalisation, ${ }^{103}$ universalisation and up to positivism, it will possibly be more driven asof-consciousness-awareness-teleology ${ }^{9}$ when it comes to attaining notional ${ }^{18}$ deprocrypticism as the latter registry-worldview/dimension is actually weaker than the preceding registryworldviews/dimensions in eliciting a positive-opportunism-of-social-functioning-andaccordance $^{75}$ and will more strongly depend on percolation-channelling- $<$ in-deferentialformalisation-transference $>$ of intemporality ${ }^{52} /$ longness to be realised. Preconverging-ordementing -apriorising-psychologism as thus implied can be defined as reflecting/perspectivating/highlighting of the deficient mental-devising-representation (as soreferenced from ontological-normalcy/postconvergence so-construed as in prospectivetranscendence-in-perpetually-upholding-intemporal-preservation-entropy-or-contiguity-orontological-preservation as to suprastructural proxying of intrinsic-reality), beyond the deficient 
mental-devising-representation intradimensional representation of ${ }^{56}$ meaningfulness-andteleology ${ }^{9}$. The storying/narrating technique for relating preconverging-or-dementing apriorising-psychologism will involve projecting suprastructurally and in perspective ontological-normalcy/postconvergence in the transcending/superseding registryworldview/dimension for 'ontological-reference meaningfulness as the intemporal-disposition' (in 'intemporal-prioritisation-of- ${ }^{8}$ reference-of-thought'-as-conflatedness ${ }^{13}$-or-ontologicalreprojecting organic-comprehension-thinking), while representing temporal-dispositions as rather in the transcended/superseded registry-worldview/dimension (preconverging-ordementing -apriorising-psychologism) ${ }^{56}$ meaningfulness-and-teleology ${ }^{9}$ which is not-ofontological-reference, and in the place of the temporal-dispositions (incircumventive/distractive-temporal-prioritisation-of- ${ }^{-}$reference-of-thought threshold-ofnonconviction/madeupness/bottomlining-in-shallow-supererogation $-<$ as-to-'attendantintradimensional'-prospectively-disontologising preconverging/dementing -apriorisingpsychologism $>$ s) imply their preconverging-or-dementing 2 -apriorising-psychologism$<$ stranded-as-rightfully-oblongated/decandored-and-dialectically-or-contendingly-out-ofphase>; just as all prospective/transcending/superseding registry-worldviews/dimensions mentally-represent-and-relate-with their prior/transcended/superseded registryworldviews/dimensions, even though all such transcended/superseded registryworldviews/dimensions as to their <amplituding/formative-epistemicity $>$ totalising $\sim$ selfreferencing-syncretising/circularity/interiorising/akrasiatic-drag ${ }^{34}$ naturally resist such representation by the prospective/transcending/superseding registry-worldviews/dimensions. Noting as well that teleologically, the transcending/superseding and the transcended/superseded are in transversality-<for-sublimating-existential-eventuating/denouement, from 'thinking at first/pure-predisposition-preemptive-of-prospective-disontologising/subontologising' as-ofprospectively-disambiguated-affirmed-and-unaffirmed-'motif-and- 
apriorising/axiomatising/referencing' $>$ ' That is, the two 'reason pass each other' (wherein the transcending/superseding is organic-comprehension-thinking while the transcended is in threshold-of-nonconviction/madeupness/bottomlining-in-shallow-supererogation $-<$ as-to-

\section{‘attendant-intradimensional'-prospectively-disontologising preconverging/dementing}

apriorising-psychologism>) as the transcending/superseding is involved in 'reasoningthrough/over' and not 'reasoning-with' the transcended/superseded (this explains why transcendence-and-sublimity/sublimation/supereregatory-de-mentativity is a 'registryworldview's/dimension's institutionalisation-constraining/secondnaturing process' and not a 'first-naturing transformation process'), just as a positivistic mindset/ ${ }^{83}$ reference-of-thought 'can only be in reasoning-through/utterion over' a medieval mindset/ ${ }^{8}$ reference-of-thought and 'not reasoning-with' it as otherwise the former wrongly validates that there is no medieval mindset/ ${ }^{8}$ reference-of-thought in preconverging-or-dementing 20 -apriorising-psychologism$<$ stranded-as-rightfully-oblongated/decandored-and-dialectically-or-contendingly-out-of-

phase $>$ (wrongly defining medievalism as of defect-of- logical-processing-or-logicalimplicitation-supposedly-apriorising-in-conviction-as-to-profound-supererogation within rational-empiricism/positivism postconverging-or-dialectical-thinking -apriorisingpsychologism-<stranded-as-rightfully-straight/candored-and-dialectically-or-contendingly-inphase $>$ existentialising-frame-of-entailment-of-motif-andapriorising/axiomatising/referencing), and warrants in lieu of any pretence of medieval mindset/ $/{ }^{8}$ reference-of-thought mutual contention rather a 'postconverging-or-dialecticalthinking -psychology or psychology-of-mentation-dynamics or natural $\sim$ psychologicaldynamics' psychoanalytic-unshackling/memetic-reordering/institutional-recomposuring of prospective positivistic mindset $\quad{ }^{83}$ reference-of-thought- categoricalimperatives/axioms/registry-teleology ${ }^{9}$ in the first place overriding the notion of mutual contention with medieval mindset as otherwise it wrongly validates the medieval meaningful- 
and-teleology exitentialising-framing ( categorical-imperatives/axioms/registry-teleology ${ }^{9}$ elements-of: \{epistemic-totalising 3 \} psychologismic-subliminality-of-individuationeffusing/worlding imbued logical-dueness-or-scape-or-frame, profile-or-stature, presumptuousness-or-arrogation, assumptions, value-reference and teleology ${ }^{9}$ ) as mentally sound. It is the cause-and-effect-effective-predication by its grander grasp of intrinsic-reality that by way of untenability/internal-contradiction/internal-incoherence/institutional-constraining and social universal-transparency -〈transparency-of-totalising-entailing,-as-to-entailing$<$ amplituding/formative-epistemicity $>$ totalising in-relative-ontological-completeness $>$ imposes crossgenerationally the dominant as transcending/superseding meaningfulness over the dominated as transcended/superseded meaningfulness (there is no social-and-temporal-trading in that regard); as the intrinsic-reality that the transcending/superseding meaningfulness carries is suprastructural and ontological-normalcy/postconvergence and doesn't adjust to the mortals, that we are, 'social-and-temporal-trading', otherwise the supposedly transcending/superseding compromises itself with respect to intrinsic-reality and losses its pertinence as a proxying reference-of-thought to intrinsic-reality, to start with. Such an insight can be garnered as, for instance, in the natural sciences we can't negotiate about gravity being $9.8 \mathrm{~m} / \mathrm{s}^{2}$, but with the 'social' which is rather 'emotionally involved', such negotiated social-and-temporal-trading idiocy is surprisingly quite recurrently articulated. It should be noted that the ${ }^{15}$ de-mentation〈supererogatory ontological-de-mentation-or-dialectical-de-mentation-stranding-orattributive-dialectics $\rangle$ of ${ }^{8}$ reference-of-thought' in upholding a mental-devising-representation of temporal-dispositions as preconverging-or-dementing ${ }^{20}$-apriorising-psychologism$<$ stranded-as-rightfully-oblongated/decandored-and-dialectically-or-contendingly-out-ofphase $>$ is rather a comprehensive intemporality ${ }^{52}$-preserving ontological-entrapment of the 'notional-discontiguity/epistemic-discontiguity ${ }^{3} \_<$between - prior-shallow-supererogation 
profound-supererogation -of-mentally-aestheticised postconverging/dialectical-thinking

qualia-schema>

of

apriorising/axiomatising/referencing/intelligibilitysettingup/measuringinstrumenting'

(i.e.

absolving/fleeting/escaping-reflex-logic -by-psychopathic-in

hollow-constituting-<as-

disjointed-misappropriation-of-meaningfulness-and-failing-intemporal-preservation>

in

postlogic-backtracking-<iterative-looping-'set-of-dereifying-hollow-narratives-and-

acts'> / other-temporal-dispositions-hollow-constituting-<as-disjointed-misappropriation-of-

meaningfulness-and-failing-intemporal-preservation $>$ or ${ }^{12}$ conjoining-looping-set-of-narratives as-of-cohering-logic-reflex in wrongly implying and exploiting the supplanting-conviction-asto-profound-supererogation —of-'attendant-intradimensional'-postconverging/dialectical-

thinking -apriorising-psychologism reflex or prelogic-reflex-admittance-reflex or in-phasereflex so as to wrongly align to the next looped narratives as straight/candored-and-dialecticallyor-contendingly-in-phase whereas veridically these are also of notional-discontiguity/epistemicdiscontiguity ${ }^{3}-<$ between - prior-shallow-supererogation -of-mentallyaestheticised preconverging/dementing -qualia-schema_and_prospective-profoundsupererogation -of-mentally-aestheticised postconverging/dialectical-thinking -qualiaschema $>$-as-of-epistemic-decadence as oblongated/decandored-and-dialectically-orcontendingly-out-of-phase or preconverging-or-dementing-and-not-thinking), as the perversion-of- ${ }^{2}$ reference-of-thought- $<$ as-preconvergingly-

apriorising/axiomatising/referencing-in-nonconviction/madeupness/bottomlining-as-to-

shallow-supererogation $>$ as to preconverging-or-dementing ${ }^{20}$-apriorising-psychologism state of temporal-dispositions more than just about specific narratives rather reflects (preconvergingor-dementing ${ }^{20}$-apriorising-psychologism of ${ }^{74}$ perversion-of- ${ }^{3}$ reference-of-thought- $<$ aspreconvergingly-apriorising/axiomatising/referencing-in- 
worldview's/dimension's-uninstitutionalised-threshold ${ }^{12}$-defect-<as-Being-or-ontological-orexistential-defect $>$ (beyond defect-of- ${ }^{5}$ logical-processing-or-logical-implicitationsupposedly-apriorising-in-conviction-as-to-profound-supererogation ) as-registry-worldviewor-dimension-defect of recurrent (psychopathic) in hollow-constituting-<as-disjointedmisappropriation-of-meaningfulness-and-failing-intemporal-preservation $>$ in postlogicbacktracking-<iterative-looping-'set-of-dereifying-hollow-narratives-and-acts'> as absolving/fleeting/escaping-reflex-logic , and (other-temporal-dispositions) hollowconstituting-<as-disjointed-misappropriation-of-meaningfulness-and-failing-intemporalpreservation> conjoining-looping-set-of-narratives-of-postlogic-narratives/cohering-logicreflex by way of circumventive/distractive-temporal-prioritisation-of- ${ }^{3}$ reference-of-thought wrongly implying temporal-dispositions postconverging-or-dialectical-thinking ${ }^{21}$-apriorisingpsychologism- $<$ stranded-as-rightfully-straight/candored-and-dialectically-or-contendingly-inphase $>$ (wrongly implying 'postconverging-or-dialectical-thinking ${ }^{21}$-apriorisingpsychologism'/soundness-or-ontological-good-faith/authenticity ${ }^{69}$-of- $r$ refence-of-thought rather than preconverging-or-dementing -apriorising-psychologism/unsoundness-orontological-bad-faith/inauthenticity ${ }^{64}$-of ${ }^{8}$ refence-of-thought in veridicality), and recurrently undermined/corrected from an intemporal/ ${ }^{8}$ reference-of-thought as preconverging-ordementing ${ }^{20}$-apriorising-psychologism- $<$ stranded-as-rightfully-oblongated/decandored-anddialectically-or-contendingly-out-of-phase>; and so, superseding/overcoming a conceptualisation of temporal-dispositions ${ }^{74}$ perversion-of- ${ }^{8}$ reference-of-thought- $<$ aspreconvergingly-apriorising/axiomatising/referencing-in-

nonconviction/madeupness/bottomlining-as-to-shallow-supererogation $>$ as to preconvergingor-dementing ${ }^{20}$-apriorising-psychologism as to 'postconverging-or-dialectical-thinking psychology or psychology-of-mentation-dynamics or natural psychological-dynamics' psychoanalytic-unshackling/memetic-reordering/institutional-recomposuring exercise for 
prospective/transcending/superseding reference-of-thought- categoricalimperatives/axioms/registry-teleology ${ }^{9}$,-for-intemporal-preservation-entropy-or-contiguityor-ontological-preservation with respect to the prospective registry-worldviews/dimensions as base-institutionalisation, ${ }^{103}$ universalisation, positivism or deprocrypticism, which in so doing re-establishes prospective notional-contiguity/epistemic-contiguity ${ }^{6}-<$ profoundsupererogation -of-mentally-aestheticised postconverging/dialectical-thinking -qualiaschema in line with intemporal-preservation-entropy-or-contiguity-or-ontologicalpreservation with a mental-devising-representation as postconverging-or-dialectical-thinking apriorising-psychologism-<stranded-as-rightfully-straight/candored-and-dialectically-orcontendingly-in-phase $>$. In fact, it is this latter veridical representation of the mental-devisingrepresentation of temporal-dispositions as recurrently preconverging-or-dementing 2 apriorising-psychologism/subknowledging $/ 7$ perversion-of- ${ }^{83}$ reference-of-thought- $<$ aspreconvergingly-apriorising/axiomatising/referencing-innonconviction/madeupness/bottomlining-as-to-shallow-supererogation $>$,-with-corresponding as to their $\quad<$ amplituding/formative-epistemicity $>$ totalising $\sim$ self-referencingsyncretising/circularity/interiorising/akrasiatic-drag as reflected with all registryworldviews/dimensions (preconverging-or-dementing ${ }^{20}$-apriorising-psychologism) uninstitutionalised-threshold $^{102}$, that suprastructurally and in perspective ontologicalnormalcy/postconvergence defines any specific registry-worldview/dimension dialecticalprimitivity whether as recurrent-utter-uninstitutionalisation, ununiversalisation, nonpositivism/medievalism or ${ }^{80}$ procrypticism-or-disjointedness-as-of- ${ }^{8}$ reference-of-thought. The bigger point is that fundamentally it is impossible to conjugate/inflect/protract

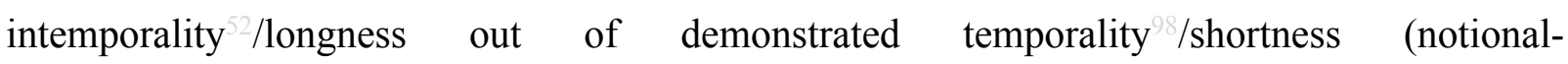
discontiguity/epistemic-discontiguity ${ }^{63}<$ between - prior-shallow-supererogation -ofmentally-aestheticised preconverging/dementing -qualia-schema_and_prospective-profound- 
supererogation -of-mentally-aestheticised postconverging/dialectical-thinking -qualia-

schema $>$ ) as then one is just in <amplituding/formative-epistemicity $>$ totalising $\sim$ selfreferencing-syncretising/circularity/interiorising/akrasiatic-drag 34 and wrongly implying the registry-worldview/dimension is beyond transcendence-andsublimity/sublimation/supererogatory de-mentativity or is non-transcendable (hence undementable/still-of-postconverging-or-dialectical-thinking -apriorising-psychologism) when in fact it is preconverging-or-dementing ${ }^{20}$-apriorising-psychologism/subknowledging $/$ registryperverting-in $<$ amplituding/formative-epistemicity $>$ totalising $\sim$ self-referencingsyncretising/circularity/interiorising/akrasiatic-drag ${ }^{34}$. This latter idea is actually the $<$ amplituding/formative--epistemicity $>$ totalising $\sim$ self-referencingsyncretising/circularity/interiorising/akrasiatic-drag ${ }^{34}$ reflex of all prior/transcended/superseded registry-worldviews/dimensions with respect to the suggestion of prospective/transcending/superseding registry-worldviews/dimensions, as we can appreciate from our vantage perspective at the backend of the institutional-cumulation/institutionalrecomposure-〈as-to- historiality/ontological-eventfulness /ontological-aesthetic-tracing<perspective-ontological-normalcy/postconvergence-reflected-‘epistemicity-relativismdeterminism' $>>$ process to be rather not true with prior transcendence-andsublimity/sublimation/supererogatory de-mentativity though we'll in turn obviously act by reflex in $\quad<$ amplituding/formative-epistemicity $>$ totalising $\sim$ self-referencingsyncretising/circularity/interiorising/akrasiatic-drag with respect to the suggestion of prospective transcendence-and-sublimity/sublimation/supererogatory $\sim$ de-mentativity undermining our registry-worldview's/dimension's categorical-imperatives/axiom/registryteleology -for-intemporal-preservation-entropy-or-contiguity-or-ontological-preservation. The ontological-normalcy/postconvergence nature of intrinsic-reality as such explains why ontological-veridicality is rather a reasoning-through/utterion to apprehend intrinsic-reality, over 
incrementalism-in-relative-ontological-incompleteness ${ }^{8}$

enframed/disontologising conceptualisation

and

notional procrypticism/notional disjointedness-as-of- ${ }^{-}$reference-of-thought which is more about 'transversality-<for-sublimating-existential-eventuating/denouement,-from-'thinking atfirst/pure-predisposition-preemptive-of-prospective-disontologising/subontologising' as-ofprospectively-disambiguated-affirmed-and-unaffirmed-'motif-andapriorising/axiomatising/referencing' $>101$ human conceptual elucidation of reality' (given that the former emphasises <amplituding/formative-epistemicity>causality $\sim$ as-to-projectivetotalitative-implications-of-prospective- nonpresencing,-for-explicating relativeunreflexivity/relative-reflexivity ontological-contiguity as all-determinant); with reasoningthrough/utterion generally implied in formal constructs and settings as the-Good/knowledgereification $\sim$ gesturing-and-accounting — of-epistemic-phenomenalism- $<$ inprospective_psychologismic $\sim$ apriorising/axiomatising/referencing-\{of-'prospectively implicited_attendant-ontological-contiguity ' educedexistentialising/contextualising/textualising_intelligibility/epistemicity/reflexivity_contiguity<imbued-notional cogency>' \}-conflatedness -in-\{preconverging disentailment by\} postconverging entailment $>$ /understanding/<amplituding/formativeepistemicity $>$ causality $\sim$ as-to-projective-totalitative-implications-of-prospectivenonpresencing,-for-explicating relative-unreflexivity/relative-reflexivity - ontologicalcontiguity settings while informal constructs and settings tend more to incrementalism-inrelative-ontological-incompleteness ${ }^{8}$ — enframed/disontologising conceptualisation and notional procrypticism/notional $\sim$ disjointedness-as-of- ${ }^{3}$ reference-of-thought and hence are highly teleologically-degraded as impression-driven/good-naturedness settings. The reason is that formal constructs and settings emphasise 'intemporal-prioritisation-of- ${ }^{8}$ reference-ofthought'-as-conflatedness ${ }^{13}$-or-ontological-reprojecting in longness-of-register-of- 
meaningfulness-and-teleology and hence are equally highly deferential whereas informal constructs and settings do not constrain temporal-dispositions and hence are highly subjected to circumventive/distractive-temporal-prioritisation-of- ${ }^{-}$reference-of-thought in shortness-ofregister-of- ${ }^{56}$ meaningfulness-and-teleology ${ }^{9}$ and are unsurprisingly rather not deferential given that they are opened to hotchpotching/undisambiguation of notional firstnaturednessformativeness-<as-to-eventualising-inkling-drive or seeding-misprising $>$ temporal-tointemporal-dispositions-<so-construed-as-from-perspective-ontologicalnormalcy/postconvergence>. $\quad$ 'Intemporal-prioritisation-of- ${ }^{8}$ reference-of-thought'-asconflatedness $^{13}$-or-ontological-reprojecting points out that conventioning constructs like subpar/formulaic-association/temporal/alibi conventioning-rationalising do not supersede the ontological-normalcy/postconvergence and suprastructural nature of intrinsic-reality/intrinsicveridicality, as may be naively advanced with circumventing/distractive-temporal-prioritisationof- reference-of-thought, such that just as the conventioning construct of nonpositivism/medievalism cannot be evoked to imply that with respect to a nonpositivism/medievalism mindset $/{ }^{8}$ reference-of-thought a prospective positivism mindset, which is the outcrop of an 'intemporal-prioritisation-of- ${ }^{-3}$ reference-of-thought'-as-conflatedness ${ }^{13}$-orontological-reprojecting exercise in non-positivism/medievalism registry-worldview/dimension, is unwarranted. Likewise, it is rather naïve and <amplituding/formativeepistemicity $>$ totalising $\sim$ self-referencing-syncretising/circularity/interiorising/akrasiatic-drag to advance circumventive/distractive-temporal-prioritisation-of- ${ }^{3}$ reference-of-thought concerning psychopathic and its social psychopathic collorary ( 7 perversion-of- ${ }^{8}$ reference-ofthought-<as-preconvergingly-apriorising/axiomatising/referencing-innonconviction/madeupness/bottomlining-as-to-shallow-supererogation $>$ ) in wrongly implying that a notional $\sim$ deprocrypticism aetiologisation/ontological-escalation- $<$ ontologicalveridicality_commitment/otherliness_transcending/compulsions-encumbered_transcending $>$ is 
unwarranted. More like the evocation of circumventive/distractive-temporal-prioritisation-ofreference-of-thought about a past war criminal or rapist based on conventioning constructs like their being in the past, their settled lives, etc. doesn't dispense them from 'intemporalprioritisation-of- reference-of-thought'-as-conflatedness ${ }^{13}$-or-ontological-reprojecting, the need for their judgment and/or in advocating unfailingly/infallibly the uncompromising notions against rape or war crimes, and so without conjugating/inflecting/deriving any excepting human temporal circumstances into it by circumventive/distractive-temporal-prioritisation-ofreference-of-thought. This further point to the dichotomy between temporal-compromisingconventioning and ontology, with a registry-worldview's/dimension's institutionalisation dialectics wherein ontology as 'relative-ontological-completeness ${ }^{87}$-of- ${ }^{8}$ reference-of-thought as to ontological-normalcy/postconvergence' or prospective-transcendence-in-perpetuallyupholding-intemporal-preservation-entropy-or-contiguity-or-ontological-preservation perpetually elevates conventioning. This further translates in the conceptualisation of value-andvalor with the implication that while aspiring for temporal values and valor may be the standard $<$ amplituding/formative $>$ wooden-language-<imbued — averaging-of-thought-<as-toleveling/ressentiment/closed-construct-of- meaningfulness-and-teleology -as-of'nondescript/ignorable-void '-with-regards-to-prospective-apriorising-implications $>$ > perception, however, grander value and valor effectively lies in the ${ }^{103}$ universalising and philosophising orientations (as ontological-profoundness-of-thought/ontologicalnormalcy/postconvergence in contrast to conventioning-profoundness-ofthought/intradimensional-subknowledging ${ }^{4}$-normalcy) that enable the possibility, the construct and the upholding of human emancipation across <cumulating/recomposuring attendantontological-contiguity >-successive registry-worldviews/dimensions in-the-very-first-place, that is, emancipation into base-institutionalisation, ${ }^{103}$ universalisation, positivism and prospectively deprocrypticism. Aristotle's advocating of the 'golden mean' is more of a heuristic 
and aesthetic notion but doesn't has an ontological-basis as it is rather an impromptu articulation of a sense of desirability but fundamentally lacks the-Good/knowledge-reification $\sim$ gesturingand-accounting - of-epistemic-phenomenalism- $<$ in-

prospective_psychologismic apriorising/axiomatising/referencing-\{of-"prospectively implicited_attendant-ontological-contiguity ' educedexistentialising/contextualising/textualising_ 'intelligibility/epistemicity/reflexivity-contiguity<imbued-notional cogency >' \}-conflatedness -in-\{preconverging-disentailment by\} postconverging entailment $>$ /understanding/<amplituding/formativeepistemicity $>$ causality $\sim$ as-to-projective-totalitative-implications-of-prospectivenonpresencing,-for-explicating relative-unreflexivity/relative-reflexivity - ontologicalcontiguity reference of prospective notional-contiguity/epistemic-contiguity ${ }^{62}-<$ profoundsupererogation -of-mentally-aestheticised postconverging/dialectical-thinking -qualiaschema> but for naively and wrongly implying good-natured qualities as being ontological (rather than the-Good/knowledge-reification $\sim$ gesturing-and-accounting-of-epistemicphenomenalism-<in-prospective_psychologismic $\sim$ apriorising/axiomatising/referencing- of'prospectively implicited_attendant-ontological-contiguity ' educedexistentialising/contextualising/textulising_intelligibility/epistemicity/reflexivity-contiguity<imbued-notional cogency>’ \}-conflatedness -in-\{preconverging-disentailment by\} postconverging entailment $>$ /understanding/<amplituding/formativeepistemicity $>$ causality $\sim$ as-to-projective-totalitative-implications-of-prospectivenonpresencing,-for-explicating relative-unreflexivity/relative-reflexivity - ontologicalcontiguity conceptualisation validated by prospective notional-contiguity/epistemiccontiguity ${ }^{6}<$ profound-supererogation -of-mentally-aestheticised $\sim$ postconverging/dialecticalthinking -qualia-schema> or a ratio-conguity notion), and since the relativeenreflexivity/relative-reflexivity — ontological-contiguity ${ }^{67}$ of-the-human-institutionalisation- 
process $^{68}$ shows that 'good-naturedness', without the-Good/knowledge-reification $\sim$ gesturingand-accounting - of-epistemic-phenomenalism- $<$ inprospective_psychologismic apriorising/axiomatising/referencing-\{of-'prospectively implicited_attendant-ontological-contiguity ' ceducedexistentialising/contextualising/textualising_ 'intelligibility/epistemicity/reflexivity-contiguity<imbued-notional cogency $>$ ' \}-conflatedness -in-\{preconverging-disentailment by\} postconverging entailment $>$ /understanding/<amplituding/formative-

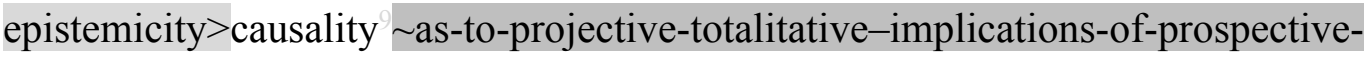
nonpresencing,-for-explicating relative-unreflexivity/relative-reflexivity - ontologicalcontiguity as of relative-unreflexivity/relative-reflexivity-ontological-contiguity ${ }^{67}$, fundamentally has little import or worst bad implications. The truest value and valor resided in what Aristotle and other thinkers or even prophesiers were striving for actually. Aristotle nor Socrates nor Plato nor the prophesiers (working rather more assertively on 'supernatural postconverging-de-mentating/structuring/paradigming' implications) nor latter thinkers like Descartes, Kant, Darwin, Leibniz, Rousseau strove for the golden mean in their overall endeavours. Rather from an ontologically verifiable reality as a theGood/understanding/<emplitung/formative-epistemicity $>$ causality $\sim$ as-to-projectivetotalitative-implications-of-prospective- nonpresencing,-for-explicating relativeunreflexivity/relative-reflexivity - ontological-contiguity /relative-unreflexivity/relativereflexivity - ontological-contiguity ${ }^{67}$ they actually aspired for 'intemporal-prioritisation-ofreference-of-thought'-as-conflatedness ${ }^{13}$-or-ontological-reprojecting, that is, they were prioritising and focussing on that which establishes ${ }^{103}$ universal and philosophical principles of human transcendence-and-sublimity/sublimation/smereronerativity as first-orderontology for-prospective-living as the backdrop for enabling better human emancipation and living (even though where relevant this will subsume-as-supplant-〈as-of-relatively-more- 
existentialising/contextualising/textualising_'intelligibility/epistemicity/reflexivity_contiguity$<$ imbued-notional $\sim$ cogency $>,{ }^{\prime},-<$ reifying-or-elucidating-of-prospective-relative-ontologicalcompleteness -of- reference-of-thought- devolving-as-of-instantiative-context $>>$ the golden mean into 'intemporal-prioritisation-of- ${ }^{8}$ reference-of-thought'-as-conflatedness ${ }^{13}$-orontological-reprojecting but with the latter rather superseding/overriding such a golden mean conception if construed as of ${ }^{7}$ presencing - absolutising-identitive-constitutedness ${ }^{14}$ since we can appreciate the ontological-impertinence of such a golden mean notion with regards to the fact that the <cumulating/recomposuring attendant-ontological-contiguity $>$-succession of registry-worldviews/dimensions as manifesting their very own prospective disontologising uninstitutionalised-threshold ${ }^{102}$ renders absolutising their successive supposedly golden mean ontologically ridiculous as to the need for their prospective ontologising-and-re-ontologising for prospective human transcendence-and-sublimity/sublimation/supereregatery $\sim$ de-mentativity). It is the establishment of such first-order-ontology for-prospective-living as baseinstitutionalisation, ${ }^{103}$ universalisation, positivism and prospectively notional $\sim{ }^{18}$ deprocrypticism which are of transcendental nature as 'shaping the human psyche' (as to re-ontologising prospective Being-development/ontological-framework-expansion-as-to-depth-ofontologising-development-as-infrastructure-of- meaningfulness-and-teleology ) and providing the emancipating umbrella for second-order-ontology (as to derived institutionaldevelopment-as-to-social-function-development and living-development-as-to-personalitydevelopment psychologismic epistemic acutisation difficulty < for, residualising \{decompulsing\} delinearity for yearnings which are rather non-transcendental prospectively and cannot preconverging/postconverging-de-mentatively/structurally/paradigmatically resolve fundamental issues, and of circular institutionalised-being-and-craft. A Rousseau may not be the 
'shrewdest aristocrat' in terms-as-of-axiomatic-construct of the ordinary value of personal gain of the medieval world but the first-order-ontology resolution of issues of social emancipation passes by his and likeminded first-order-ontology philosophical projection. This certainly applies with regards to defining transformative impact of transcendental constructs across all registry-worldviews/dimensions that does not compare with ordinary being-and-craft secondorder-ontology sense of value which is rather intradimensionally circular and is hardly of the intemporal/ontological/social/species/ $/{ }^{103}$ universal/transcendental/ $/{ }^{5}$ maximalisingrecomposuring-for-relative-ontological-completeness ${ }^{8}$ —unenframed/re-

ontologising $\sim$ conceptualisation postconverging-de-mentating/structuring/paradigming addressed from first-order-ontology constructs. Granted if humans had absolute mentation capacity then 'intemporal-prioritisation-of- ${ }^{-3}$ reference-of-thought'-as-conflatedness ${ }^{13}$-orontological-reprojecting will be skewed ('intemporality ${ }^{52}$-symmetrising-by-desymmetrisingsubsumption-of-temporality ${ }^{\circ}$, for relative intrinsic-reality/ontological-veridicality transcendental-enabling/sublimating/supererogatory de-mentativity) or rather supersede/encompass all such desirabilities implied by the golden mean. However, we don't have absolute mentation capacity and the most intemporal of our dispositions should take pride of place in defining our achievement motives whether as philosophies, causes, skillsets and talents in our value and valor aspirations, in line with the notion of a true principle, with the implication that such value and valor is capable of rationally upholding itself and its registryworldview prospectively when implied ${ }^{103}$ universally (as to the fact that it is on this basis that human institutional-cumulation/institutional-recomposure-〈as-to- historiality/ontologicaleventfulness /ontological-aesthetic-tracing-<perspective-ontologicalnormalcy/postconvergence-reflected-'epistemicity-relativism-determinism' $>>$ has been selfperpetuating in explicating the relative-unreflexivity/relative-reflexivity-ontologicalcontiguity ${ }^{67}$ of-the-human-institutionalisation-process ${ }^{68}$ ). Such an insight can further be 
expanded thus, it is critical to note that the institutional-cumulation/institutional-recomposure〈as-to- historiality/ontological-eventfulness /ontological-aesthetic-tracing-<perspectiveontological-normalcy/postconvergence-reflected-‘epistemicity-relativism-determinism'>> are developments of human mentation capacity in grasping its 'internal ontological-reconstitutingas-to-conflatedness ${ }^{13} /$ deconstruction intermediating environment' and the external environment. The former refers to the teleological devised representation of the relationship with the external environment like language, organisation, culture and other institutional construct by which it existentially-<disontologising/re-ontologising aporeticism $>$ accesses the external environment. In effect, though counterintuitive, human registry-worldview's/dimension's institutionalisation is actually an 'intemporal-prioritisation-of- ${ }^{8}$ reference-of-thought'-asconflatedness $^{13}$-or-ontological-reprojecting/intemporal-preservation preemptive construct which paradoxically elicits devised mentation that goes on to build the internal ontological-

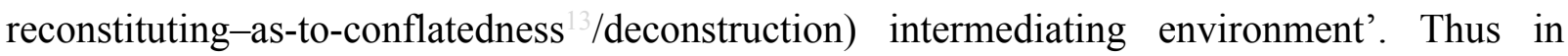
effect base-institutionalisation is the outcome of the 'intemporal-prioritisation-of- ${ }^{-}$reference-ofthought'-as-conflatedness ${ }^{13}$-or-ontological-reprojecting/intemporal-preservation preemption of recurrent-utter-uninstitutionalisation $\quad$ (recurrentas $\quad<$ amplituding/formativeepistemicity $>$ totalising $\sim$ self-referencing-syncretising/circularity/interiorising/akrasiatic-drag for preconverging-or-dementing 2 -apriorising-psychologism/subknowledging $4 /$ perversionof- reference-of-thought-<as-preconvergingly-apriorising/axiomatising/referencing-innonconviction/madeupness/bottomlining-as-to-shallow-supererogation $>$ ), ${ }^{103}$ universalisation is the outcome of the 'intemporal-prioritisation-of- ${ }^{83}$ reference-of-thought'-as-conflatedness ${ }^{13}$ or-ontological-reprojecting/intemporal-preservation preemption of ununiversalisation (preconverging-or-dementing ${ }^{20}$-apriorising-psychologism/subknowledging $/ /$ perversion-ofreference-of-thought-<as-preconvergingly-apriorising/axiomatising/referencing-innonconviction/madeupness/bottomlining-as-to-shallow-supererogation $>$-and- 
$<$ amplituding/formative-epistemicity $>$ totalising $\sim$ self-referencing-

syncretising/circularity/interiorising/akrasiatic-drag ${ }^{34}$ of base-uninstitutionalisation), positivism is the outcome of the 'intemporal-prioritisation-of- ${ }^{3}$ reference-of-thought'-as-conflatedness ${ }^{13}$ or-ontological-reprojecting/intemporal-preservation preemption of non-positivism/medievalism (preconverging-or-dementing ${ }^{20}$-apriorising-psychologism/subknowledging ${ }^{4} / 4$ perversion-ofreference-of-thought-<as-preconvergingly-apriorising/axiomatising/referencing-innonconviction/madeupness/bottomlining-as-to-shallow-supererogation $>$-and$<$ amplituding/formative-epistemicity $>$ totalising $\sim$ self-referencingsyncretising/circularity/interiorising/akrasiatic-drag ${ }^{34}$ of ${ }^{103}$ universalisation) and prospectively, notional ${ }^{18}$ deprocrypticism is the outcome of the 'intemporal-prioritisation-of- ${ }^{8}$ reference-ofthought'-as-conflatedness ${ }^{13}$-or-ontological-reprojecting/intemporal-preservation preemption of procrypticism, so construed by 'notional ' deprocrypticism ontologically-perspectivalelevated/pedestaling-as-postconverging-or-dialectical-thinking -differentiation-as-ofsupratransversality-<in-sublimating-existential-eventuating/denouement $>\sim$ of-motif-andapriorising/axiomatising/referencing'; and so, in the relation between human developing mentation capacity and suprastructural-and-postconvergence-intrinsic-reality in ontologicalnormalcy/postconvergence (prospective-transcendence-in-perpetually-upholding-intemporalpreservation-entropy-or-contiguity-or-ontological-preservation). In this regard, transcendental institutionalisation is basically an 'intemporal-prioritisation-of- ${ }^{3}$ reference-of-thought'-asconflatedness $^{13}$-or-ontological-reprojecting/intemporal-preservation preemptive conceptualisation. Such 'intemporal-prioritisation-of- ${ }^{8}$ reference-of-thought'-asconflatedness $^{13}$-or-ontological-reprojecting/intemporal-preservation preempting (that actually induces institutional-cumulation/institutional-recomposure-〈as-to- historiality/ontologicaleventfulness /ontological-aesthetic-tracing-<perspective-ontologicalnormalcy/postconvergence-reflected-‘epistemicity-relativism-determinism'>> as the- 
Good/knowledge-reification $\sim$ gesturing-and-accounting — of-epistemic-phenomenalism- $<$ inprospective_psychologismic apriorising/axiomatising/referencing-\{of-'prospectively_ implicited_attendant-ontological-contiguity ' educedexistentialising/contextualising/textualising_'intelligibility/epistemicity/reflexivity-contiguity<imbued-notional cogency >' \}-conflatedness -in-\{preconverging disentailment by\} postconverging-entailment $>$ /understanding/<amplituding/formativeepistemicity $>$ causality $\sim$ as-to-projective-totalitative-implications-of-prospectivenonpresencing,-for-explicating relative-unreflexivity/relative-reflexivity - ontologicalcontiguity ) reflecting ontological-normalcy/postconvergence as of prospective-transcendencein-perpetually-upholding-intemporal-preservation-entropy-or-contiguity-or-ontologicalpreservation by harkening back to <amplituding/formative-epistemicity $>$ causality $~ a s-t o-$ projective-totalitative-implications-of-prospective- nonpresencing,-for-explicating $\sim$ relativeunreflexivity/relative-reflexivity - ontological-contiguity to establish prospective ${ }^{8}$ referenceof-thought- categorical-imperatives/axioms/registry-teleology ${ }^{9}$,-for-intemporal-preservationentropy-or-contiguity-or-ontological-preservation (as the corresponding prospective mentaldevising-representation induced from ' de-mentation-〈supererogatory $\sim$ ontological-dementation-or-dialectical-de-mentation - stranding-or-attributive-dialectics $\rangle$ of ${ }^{83}$ reference-ofthought' as to postconverging-or-dialectical-thinking -apriorising-psychologism- $<$ stranded-asrightfully-straight/candored-and-dialectically-or-contendingly-in-phase $>$ ) to-meet-up/proxywith the ever dialectically suprastructural and ontological-normalcy/postconvergence intrinsicreality, explaining the <cumulating/recomposuring attendant-ontological-contiguity successive registry-worldviews/dimensions as from recurrent-utter-uninstitutionalisation, baseinstitutionalisation, ${ }^{103}$ universalisation, positivism and prospectively deprocrypticism, as reflected/perspectivated as from their organic-comprehension-thinking. This contrasts with the defective good-natured construct as impression-driven and intradimensionally-tied and all so apt 
normalcy/prospective-transcendence-in-perpetually-failing-intemporal-preservation-entropyor-contiguity-or-ontological-preservation as it is rather tied to and proxies, by mere-form, with intradimensional ${ }^{83}$ reference-of-thought- categorical-imperatives/axioms/registry-teleology ${ }^{9}$,for-intemporal-preservation-entropy-or-contiguity-or-ontological-preservation irrespective of whether these are failing/not-upholding-<as-of-apriorising/axiomatising/referencing $>$ intemporal-preservation-entropy-or-contiguity-or-ontological-preservation; and thus as the corresponding ' 'de-mentation-〈supererogatory $\sim$ ontological-de-mentation-or-dialectical-dementation-stranding-or-attributive-dialectics $\rangle$ of ${ }^{83}$ reference-of-thought' mental-devisingrepresentation as preconverging-or-dementing ${ }^{20}$-apriorising-psychologism- $<$ stranded-asrightfully-oblongated/decandored-and-dialectically-or-contendingly-out-of-phase>, explaining the registry-worldview's/dimension's-uninstitutionalised-threshold ${ }^{02}$-defect-<as-Being-orontological-or-existential-defect $>{ }^{85}$, reflected in terms-as-of-axiomatic-construct of registryteleology -mentation, behind this human placeholder-setup/mental-devisingrepresentation/mentation/consciousness-awareness-teleology ${ }^{9}$ of the registryworldviews/dimensions of recurrent-utter-uninstitutionalisation, ununiversalisation, nonpositivism/medievalism, and prospectively procrypticism as reflected/perspectivated by their threshold-of-nonconviction/madeupness/bottomlining-in-shallow-supererogation $-<$ as-to-

\section{‘attendant-intradimensional'-prospectively-disontologising preconverging/dementing}

apriorising-psychologism>. Briefly, such an anthropopsychological/the-anthropologicalcontinuity conceptualisation as articulated above further enables the insightful conceptualisation of '<amplituding/formative-epistemicity $>$ causality $~ a s-t o-p r o j e c t i v e-t o t a l i t a t i v e-$ implicationsof-prospective- nonpresencing,-for-explicating relative-unreflexivity/relative-reflexivity ontological-contiguity retracing (for notional firstnaturedness-formativeness-<as-toeventualising-inkling-drive-or-seeding-misprising $>$ temporal-to-intemporal-dispositions- 
$<$ so-construed-as-from-perspective-ontological-normalcy/postconvergence $>$ disambiguation articulation) analysis' as expanded upon below, in the 'ephemerality that is the social-construct', on the basis of an ontological-normalcy/postconvergence intemporal-preservation-entropy-orcontiguity-or-ontological-preservation understanding of the social-construct. This is central in articulating a 'creative existentialism (full-existential-depth-implications) storying construal' which is 'profoundly ontological', with psychoanalytic-unshackling/memeticreordering/institutional-recomposuring possibilities for transcendental institutionalisation/intemporalisation of deprocrypticism (superseding the vices-andimpediments $^{105}$ of procrypticism): - Institutionalised/uninstitutionalised thresholdings ofintemporal-preservation-entropy-or-contiguity-or-ontological-preservation - ${ }^{15}$ de-mentation〈supererogatory ontological-de-mentation-or-dialectical-de-mentation-stranding-or-

attributive-dialectics $\rangle$,-in-a-contiguity-of-increasing-ontological-normalcy/postconvergence in dialecticism of contrastive <amplituding/formative-epistemicity $>$ totalising $\sim$ self-referencingsyncretising-wrongfully-as-straight/candored and stranding-rightfully-as-rightfullyoblongated/decandored. - ontological-normalcy/postconvergence (as ontological-

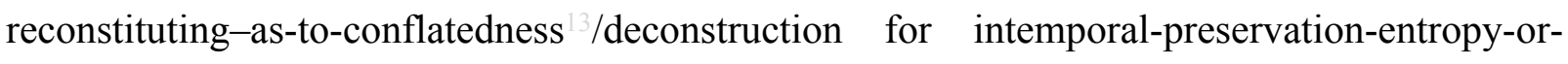
contiguity-or-ontological-preservation) assumptive construal along the three pedestals: the given ontological/intemporal-disposition pedestal (organic-comprehension-thinking), slantedness/insane-fitment (psychopath's 'epistemically-decadent in notionaldiscontiguity/epistemic-discontiguity ${ }^{3}<$ between - prior-shallow-supererogation -ofmentally-aestheticised preconverging/dementing -qualia-schema_and_prospective-profoundsupererogation -of-mentally-aestheticised postconverging/dialectical-thinking -qualiaschema> denaturing of ontologically-veridical/ontologically-continuous meaning), and temporal-dispositions notional-discontiguity/epistemic-discontiguity ${ }^{63}$-as-of-epistemicdecadence in hollow-constituting-<as-disjointed-misappropriation-of-meaningfulness-and- 
failing-intemporal-preservation> in postlogic-backtracking-<iterative-looping-'set-ofdereifying-hollow-narratives-and-acts'> ${ }^{76}$-contiguity with temporal conjugating pedestals, denaturing of ontologically-veridical/ontologically-continuous meaning (threshold-ofnonconviction/madeupness/bottomlining-in-shallow-supererogation $-<$ as-to-'attendantintradimensional'-prospectively-disontologising preconverging/dementing -apriorisingpsychologism> - (ontological/intemporal-disposition) organic-comprehension-thinking (organicalism/'intemporal-prioritisation-of- ${ }^{8}$ reference-of-thought'-as-conflatedness ${ }^{13}$-orontological-reprojecting/tongness-of-register-of meaningfulness-and-teleology ) in dialectic contrast to (temporal-dispositions) threshold-of-nonconviction/madeupness/bottomlining-inshallow-supererogation -<as-to-'attendant-intradimensional'-prospectivelydisontologising $\sim$ preconverging/dementing -apriorising-psychologism $>$ with regards to depth of issues arising from deductive narratives, life episodes, life schemes, general existential<disontologising/re-ontologising aporeticism $>$ being dispositions and specific existentialism/full-existential-depth-implications about the registry-worldview/dimension. * Inthe-bigger-scheme-of-things, anthropopsychology as the-anthropological-continuity as implied by intemporal-preservation-entropy-or-contiguity-or-ontological-preservation relation to reality as ontological-normalcy/postconvergence in precedingness points out that at registryworldview/dimension-level ontology as the transcending dimension is veridically an utter organicalism (organic-comprehension-thinking) over mechanicalism (threshold-ofnonconviction/madeupness/bottomlining-in-shallow-supererogation $<<$ as-to- 'attendantintradimensional'-prospectively-disontologising preconverging/dementing -apriorisingpsychologism $>$ which is the transcended dimension). Further, such utter organicalism (organiccomprehension-thinking) in implying registry-worldview/dimension transcendence-andsublimity/sublimation/supererogatory de-mentativity takes stock of human ${ }^{74}$ perversion-ofreference-of-thought-<as-preconvergingly-apriorising/axiomatising/referencing-in- 
nonconviction/madeupness/bottomlining-as-to-shallow-supererogation $>$ in full dispositional capacity (as such manifestation in dispositional ${ }^{7}$ perversion-of- ${ }^{3}$ reference-of-thought- $<$ aspreconvergingly-apriorising/axiomatising/referencing-in-

nonconviction/madeupness/bottomlining-as-to-shallow-supererogation $>$ fullness in particular highlights a highly compromised and teleologically-degraded social-construct validating such utter organicalism even if it seem counterintuitive to the transcended registryworldview's/dimension'sillusion-of-the-present perception. * So it is important to understand with regards to psychopathy and social psychopathy that the level of profoundness of its manifestation and consequences is directly related to the level of the associated ${ }^{7}$ perversion-ofreference-of-thought-<as-preconvergingly-apriorising/axiomatising/referencing-innonconviction/madeupness/bottomlining-as-to-shallow-supererogation $>$ compromised and degradation of the social construct!) - the-Good/knowledge-reification $\sim$ gesturing-andaccounting - of-epistemic-phenomenalism- $<$ in-

prospective_psychologismic $\sim$ apriorising/axiomatising/referencing-\{of-'prospectively implicited_attendant-ontological-contiguity ' reducedexistentialising/contextualising/textualising_'intelligibility/epistemicity/reflexivity_contiguity<imbued-notional cogency >' \}-conflatedness in \{preconverging disentailment by\} postconverging-entailment $>$ /understanding/<amplituding/formativeepistemicity $>$ causality $\sim$ as-to-projective-totalitative-implications-of-prospectivenonpresencing,-for-explicating relative unreflexivity/relative-reflexivity - ontologicalcontiguity notional firstnaturedness-formativeness-<as-to-eventmalising-inkling drive-orseeding-misprising $>$ temporal-to-intemporal-dispositions- $<$ so-construed-as-fromperspective-ontological-normalcy/postconvergence $>$ disambiguation (straightness-toslantedness/candored-to-decandored) human $\quad$ <amplituding/formativeepistemicity $>$ causality $\sim$ as-to-projective-totalitative-implications-of-prospective- 
contiguity disposition which is ontological correct as contrasted to an ontologically wrong impression-driven/good-naturedness/wishfulness conceptualisation which wrongly references as human <amplituding/formative-epistemicity $>$ causality $\sim$ as-to-projective-totalitativeimplications-of-prospective- nonpresencing,-for-explicating $\sim$ relative-unreflexivity/relativereflexivity ontological-contiguity just an intemporal-disposition ${ }^{103}$ universally among all humans (straightness/candored only), at uninstitutionalised-threshold ${ }^{102}$; while the latter will tend to be ontologically impertinent and wrong as it doesn't account for temporal-dispositions and is hence not capable like the the-Good conceptualisation, working with what veridically is, to anticipate and preempt subknowledging $/$ mimicking as <amplituding/formativeepistemicity $>$ totalising $\sim$ self-referencing-syncretising/circularity/interiorising/akrasiatic-drag to achieve veridical ontological/intemporal virtue. - 'Disambiguation of notional firstnaturedness-formativeness-<as-to-eventualising-inkling-drive-or-seedingmisprising $>$ temporal-to-intemporal-dispositions- $<$ so-construed-as-from-perspectiveontological-normalcy/postconvergence $>$ as aetiologisation/ontological-escalation- $<$ ontologicalveridicality_commitment/otherliness_transcending/compulsions-encumbered_transcending >' (speaking-abstractly-to-a-deterministic-and-predicative-'being-construal' as contrasted to just an 'act construal') to reflect by stranding (as decandored/oblongated) to represent the 'existential being $<$ amplituding/formative-epistemicity $>$ causality $\sim$ as-to-projective-totalitativeimplications-of-prospective- nonpresencing,-for-explicating relative-unreflexivity/relativereflexivity ontological-contiguity , in an ontological-entrapment of institutionalisation/intemporalisation percolation-channelling- $<$ in-deferential-formalisationtransference $>$ at the uninstitutionalised-threshold ${ }^{102}$ - Institutional recomposuring implying that the fundamental issue of 'prospective postconverging aporeticism-overcoming/unovercoming as the-Good/knowledge-reification $\sim$ gesturing-and-accounting-of-epistemic-phenomenalism- 
<in-prospective_psychologismic $\sim$ apriorising/axiomatising/referencing-\{of-'prospectively_ implicited_attendant-ontological-contiguity ' educedexistentialising/contextualising/textualising_'intelligibility/epistemicity/reflexivity-contiguity<imbued-notional cogency $>>$ \}-conflatedness -in-\{preconverging-disentailment by\} postconverging-entailment $>$ /understanding/<amplituding/formativeepistemicity $>$ causality as-to-projective-totalitative-implications-of-prospectivenonpresencing,-for-explicating relative unreflexivity/relative-reflexivity - ontologicalcontiguity , across all registry-worldviews/dimensions for survival-and-flourishing along the intemporal-preservation-entropy-or-contiguity-or-ontological-preservation is about 'notional firstnaturedness-formativeness-<as-to-eventualising -inkling-drive-or-seedingmisprising $>$ temporal-to-intemporal-dispositions- $<$ so-construed-as-from-perspectiveontological-normalcy/postconvergence> disambiguation and skewing ('intemporality ${ }^{52}$ symmetrising-by-desymmetrising-subsumption-of-temporality ${ }^{8}$, for relative intrinsicreality/ontological-veridicality transcendental-enabling/sublimating/supereregatory $\sim$ dementativity)/deferential-formalisation-transference for the intemporal-disposition' but dealt with indirectly progressively by organising rules constraining as base-institutionalisation, projecting rules constraining as ${ }^{103}$ universalisation, empirical rules constraining as positivism and coming full cycle with notional deprocrypticism for a direct treatment as 'notional firstnaturednessformativeness-<as-to-eventualising-inkling-drive-or-seeding-misprising $>$ temporal-tointemporal-dispositions-<so-construed-as-from-perspective-ontologicalnormalcy/postconvergence $>$ disambiguation and skewing ('intemporality ${ }^{52}$-symmetrising-bydesymmetrising-subsumption-of-temporality ${ }^{8}$, , for relative intrinsic-reality/ontologicalveridicality transcendental-enabling/sublimating/supereronede-mentativity)/deferentialformalisation-transference for the intemporal-disposition rules' as deprocrypticism. *Such 'CREATIVE EXISTENTIALISM (FULL-EXISTENTIAL-DEPTH-IMPLICATIONS) 
STORYING CONSTRUAL' will utilise the '<amplituding/formativeepistemicity $>$ causality as-to-projective-totalitative-implications-of-prospectivenonpresencing,-for-explicating relative-unreflexivity/relative-reflexivity - ontologicalcontiguity -retracing (for notional firstnaturedness-formativeness-<as-toeventualising inkling-drive-or-seeding-misprising $>$ temporal-to-intemporal-dispositions$<$ so-construed-as-from-perspective-ontological-normalcy/postconvergence $>$-pedestalsdisambiguation) as ${ }^{83}$ reference-of-thought-scheme' to articulate relevant issues of 'sociallyperceived-value as of social-stake-contention-or-confliction' together with the implied percolation-channelling- $<$ in-deferential-formalisation-transference $>$ for transcendence-andsublimity/sublimation/supererogatory $\sim$ de-mentativity highlighting for such successive issues the notional firstnaturedness-formativeness-<as-to-eventualising -inkling-drive-or-seedingmisprising $>$ temporal-to-intemporal-dispositions- $<$ so-construed-as-from-perspective-

ontological-normalcy/postconvergence $>$ teleologies involved, analogical to concentric-cycles of teleological storying development, as follows: ONTOLOGY-CYCLE-teleology ${ }^{9}$ (as organicalism teleology ${ }^{9}$ or intemporally/ontologically-given teleology ${ }^{9}$ )—EPISTEMICDECADENCE-CYCLE-teleology (as in hollow-constituting-<as-disjointed-misappropriationof-meaningfulness-and-failing-intemporal-preservation $>$ in postlogic-backtracking- $<$ iterativelooping-'set-of-dereifying-hollow-narratives-and-acts' $>$ as $\quad$ absolving/fleeting/escapingreflex-logic in-a-notional-discontiguity/epistemic-discontiguity ${ }^{63}<$ between - prior-shallowsupererogation -of-mentally-aestheticised $\sim$ preconverging/dementing -qualiaschema_and_prospective-profound-supererogation -of-mentally-

aestheticised postconverging/dialectical-thinking - qualia-schema $>$ teleology ${ }^{99}$ or distractiveslantedness teleology ${ }^{9}$ or meaning-by-the-mere-illogical-possibility-of-it-being-formulaicallynarrated teleology ${ }^{9}$; striving to undermine organicalism-or-intemporally/ontologically-given teleology ${ }^{9}$ ) - to-EPISTEMIC-DECADENCE-CYCLE-teleology 9 (as notional- 
discontiguity/epistemic-discontiguity ${ }^{63}<$ between - prior-shallow-supererogation -ofmentally-aestheticised preconverging/dementing -qualia-schema_and_prospective-profoundsupererogation -of-mentally-aestheticised postconverging/dialectical-thinking -qualia-

schema>

apriorising/axiomatising/referencing/intelligibilitysettingup/measuringinstrumenting

teleology $\quad$ or threshold-of-nonconviction/madeupness/bottomlining-in-shallowsupererogation -<as-to-'attendant-intradimensional'-prospectivelydisontologising preconverging/dementing -apriorising-psychologism $>$ aligning to meaningby-the-mere-illogical-possibility-of-it-being-formulaically-narrated teleology ; with the $\begin{array}{llll}\text { temporal-dispositions } & \text { teleologies } & \text { of } & \text { postlogism }\end{array}$ slantedness $/{ }^{50}$ ignorance/affordability/opportunism/exacerbation/social-chainism-or-socialdiscomfiture-or-negative-social-aggregation/temporal-enculturation-or-temporal-endemisation, so-disambiguated as of ${ }^{83}$ reference-of-thought- ${ }^{8}$ devolving ontological-performance ${ }^{72}$ $<$ including-virtue-as-ontology $>$ /morality/ethics/justice/etc. as these integrate/align-inconviction-as-to-profound-supererogation -to psychopathic postlogism -slantedness in hollow-constituting-<as-disjointed-misappropriation-of-meaningfulness-and-failingintemporal-preservation> resulting into their miscuing/disjointed-logic/logicaldrag/unconscionability-drag/sub-par-or-formulaic-association-or-temporal-or-alibi conventioning-rationalising) - to-ONTOLOGICAL-ESCALATION-teleology ontological-entrapment involving an intemporal teleology for stranding the temporaldispositions as oblongated/decandored and 'dialectically-aligning-out-of-phase/dialecticallyprimitive with them', as the backdrop for futural Being-development/ontological-frameworkexpansion-as-to-depth-of-ontologising-development-as-infrastructure-of- meaningfulnessand-teleology as of prospective notional deprocrypticism transcendence-andsublimity/sublimation/supererogatory ${ }^{\text {de-mentativity principle teleology }}{ }^{9}$. That is, relating to 
them as 'dialectically-or-contendingly-out-of-phase' with respect to the intemporalpreservation-entropy-or-contiguity-or-ontological-preservation or relativeunreflexivity/relative-reflexivity ontological-contiguity ${ }^{67} /$ ontological- $^{-}$ normalcy/postconvergence at the procrypticism uninstitutionalisation). And all these, as notional firstnaturedness-formativeness-<as-to-eventualising inkling-drive-or-seedingmisprising $>$ temporal-to-intemporal-dispositions- $<$ so-construed-as-from-perspectiveontological-normalcy/postconvergence $>$ disambiguation conceptualisation of perverse/low teleologies to higher teleologies. (That is, notional firstnaturedness-formativeness-<as-toeventualising inkling-drive-or-seeding-misprising $>$ temporal-to-intemporal-dispositions$<$ so-construed-as-from-perspective-ontological-normalcy/postconvergence $>\quad$ teleological reference of solipsistic grandeur as the differentiating element of characters supplantingconviction-as-to-profound-supererogation —of-'attendant-intradimensional'-

postconverging/dialectical-thinking -apriorising-psychologism depth highlighting-and-tracing the <amplituding/formative-epistemicity $>$ causality $\sim$ as-to-projective-totalitative-implicationsof-prospective- nonpresencing,-for-explicating relative-unreflexivity/relative-reflexivity ontological-contiguity , based on the fundamental fact that 'registry/soundness-or-ontologicalgood-faith/authenticity ${ }^{6}$-of- ${ }^{8}$ reference-of-thought precedes logic'. This equally explains the reason for ${ }^{15}$ de-mentation-〈supererogatory $\sim$ ontological-de-mentation-or-dialectical-dementation-stranding-or-attributive-dialectics〉 including with regards to registryworldview/dimension stranding where the veridicality of the <amplituding/formativeepistemicity $>$ causality $\sim$ as-to-projective-totalitative-implications-of-prospectivenonpresencing,-for-explicating relative-unreflexivity/relative-reflexivity - ontologicalcontiguity narratives is shown to be of perverse/low teleology ontologically speaking). The '<amplituding/formative-epistemicity $>$ causality $\sim$ as-to-projective-totalitative-implications-ofprospective- nonpresencing,-for-explicating relative-unreflexivity/relative-reflexivity 
ontological-contiguity -retracing (for notional firstnaturedness-formativeness-<as-toeventualising inkling-drive-or-seeding-misprising $>$ temporal-to-intemporal-dispositions$<$ so-construed-as-from-perspective-ontological-normalcy/postconvergence $>$ disambiguation) scheme' is equally critical in other respects. It rightfully prevents the ontological mentaldevising-representation from being flipped from formulaic slanting compulsingnonconviction/madeupness/bottomlining-〈'<decontextualising/de-existentialising ofattendant-intradimensional-apriorising/axiomatising/referencing $>$-induced-disontologising'-ofthe-'attendant-intradimensional-ontologising'-imbued$<$ contextualising/existentialising attendant-ontological-contiguity $>$;-in-shallowsupererogation -<as-to-disontologising-perverted-outcome-sought-precedes-existentiallyveridical-'attendant-intradimensional-apriorising/axiomatising/referencing'-logical-dueness $>$ > or postlogism ${ }^{77}$ narratives in preconverging-or-dementing ${ }^{20}$-apriorising-psychologism and wrongly represented parasitically/co-optingly as prelogic/conviction-as-to-profoundsupererogation -or-ontologically-veridical narratives to be contended with rather than being rightfully reflected/perspectivated (in-reasoning-through-and-not-reasoning-with) as manifestations of unsoundness-or-ontological-bad-faith/inauthenticity ${ }^{64}$-of- ${ }^{-3}$ eference-ofthought-and-protracted-unsoundness-or-ontological-bad-faith/inauthenticity ${ }^{6}$-of- ${ }^{8}$ referenceof-thought/subknowledging $/$ mimicking as $<$ amplituding/formativeepistemicity>totalising self-referencing-syncretising/circularity/interiorising/akrasiatic-drag 34 , as it is rightfully perceived during the psychopath's childhood when the psychopath is 'delirious' as at the underdeveloped stage it is not decisively maturated, not decisively indirect, not decisively spatialising, not decisively credulous and not decisively crafty). Thirdly, the '<amplituding/formative-epistemicity $>$ causality $~ a s-t o-p r o j e c t i v e-t o t a l i t a t i v e-$ implications-ofprospective- nonpresencing,-for-explicating relative-unreflexivity/relative-reflexivity ontological-contiguity -retracing (for notional firstnaturedness-formativeness-<as-to- 
eventualising inkling-drive-or-seeding-misprising > temporal-to-intemporal-dispositions$<$ so-construed-as-from-perspective-ontological-normalcy/postconvergence $>$ disambiguation) scheme' equally prevents the relaying of the postlogism 77 in hollow-constituting-<as-disjointedmisappropriation-of-meaningfulness-and-failing-intemporal-preservation> as of formulaiccompulsing-nonconviction/madeupness/bottomlining-<'<decontextualising/de-

existentialising $\sim$ of-attendant-intradimensional-apriorising/axiomatising/referencing $>$-induceddisontologising'-of-the-'attendant-intradimensional-ontologising'-imbued$<$ contextualising/existentialising attendant-ontological-contiguity $>$;-in-shallowsupererogation -<as-to-disontologising-perverted-outcome-sought-precedes-existentiallyveridical-'attendant-intradimensional-apriorising/axiomatising/referencing'-logical-dueness $>$ > initiated from the psychopath to its interlocutors, to wrongly imply that the veridicality of its interlocutors narratives induced postlogicly as of preconverging-or-dementing ${ }^{20}$-apriorisingpsychologism then wrongly become as of postconverging-or-dialectical-thinking ${ }^{2}$-apriorisingpsychologism, and as this conjugates/inflects (in-mimicking-protraction) with the temporaldispositions of ignorance/affordability/opportunism/exacerbation/social-chainism-or-socialdiscomfiture-or-negative-social-aggregation/temporal-enculturation-or-temporal-endemisation, and inducing miscuing/disjointed-logic/logical-drag/unconscionability-drag/sub-par-orformulaic-association-or-temporal-or-alibi conventioning-rationalising/temporal-enculturationor-temporal-endemisation. Finally, the '< $<$ amplituding/formative-epistemicity $>$ causality $\sim$ as-toprojective-totalitative-implications-of-prospective- nonpresencing,-for-explicating relativeunreflexivity/relative-reflexivity - ontological-contiguity -retracing notional firstnaturedness-formativeness-<as-to-eventualising-inkling-drive-or-seedingmisprising $>$ temporal-to-intemporal-dispositions- $<$ so-construed-as-from-perspectiveontological-normalcy/postconvergence>-pedestals-disambiguation) as ${ }^{83}$ reference-of-thoughtscheme' allows for the possibility of a registry-worldview/dimension transcendence-and- 
sublimity/sublimation/supererogatory-de-mentativity by reflecting/perspectivating/highlighting (reasoning-through-and-not-reasoning-with) both psychopathic postlogic subknowledging impulse/compulsive-dementing ${ }^{20}$ (notional-discontiguity/epistemic-discontiguity ${ }^{63}<$ between prior-shallow-supererogation -of-mentally-aestheticised preconverging/dementing -qualiaschema_and prospective-profound-supererogation -of-mentallyaestheticised postconverging/dialectical-thinking -qualia-schema $>$-as-of-epistemicdecadence in hollow-constituting-<as-disjointed-misappropriation-of-meaningfulness-andfailing-intemporal-preservation> in postlogic-backtracking-<iterative-looping-'set-ofdereifying-hollow-narratives-and-acts'> / /non-ontological-reference/non-contendingreference-but-ontologically-or-contendingly-reflected-or-perspectivated-as-preconverging-ordementing ${ }^{2}$-apriorising-psychologism/not-veridical-thinking-reference-rather-compulsiveslanting - preconverging-or-dementing 20 -apriorising-reference $/ 7$ perversion-of- ${ }^{3}$ reference-ofthought-<as-preconvergingly-apriorising/axiomatising/referencing-innonconviction/madeupness/bottomlining-as-to-shallow-supererogation >,-and-not-of-logicalcontention) and the conjugated/inflected/derived temporal-dispositions epistemic-decadence (notional-discontiguity/epistemic-discontiguity ${ }^{63}<$ between - prior-shallow-supererogation of-mentally-aestheticised preconverging/dementing -qualia-schema_and prospectiveprofound-supererogation -of-mentally-aestheticised postconverging/dialectical-thinking qualia-schema $>$-as-of-epistemic-decadence in hollow-constituting-<as-disjointedmisappropriation-of-meaningfulness-and-failing-intemporal-preservation> in postlogicbacktracking-<iterative-looping-'set-of-dereifying-hollow-narratives-and-acts' $>{ }^{6}$-contiguityas-absolving/fleeting/escaping-reflex-logic -or-hollow-constituting-<as-disjointedmisappropriation-of-meaningfulness-and-failing-intemporal-preservation> or ${ }^{12}$ conjoininglooping-set-of-narratives as-of-cohering-logic-reflex in hollow-constituting-<as-disjointedmisappropriation-of-meaningfulness-and-failing-intemporal-preservation $>$ in postlogic- 
backtracking-<iterative-looping-'set-of-dereifying-hollow-narratives-and-acts' $>$ ${ }^{6}$-which-isnot-of-ontological-reference/not-of-contending-reference-but-ontologically-or-contendinglyreflected-or-perspectivated-as-preconverging-or-dementing 20 -since-it-is-not-of-veridicalthinking-reference-rather-preconverging-or-dementing ${ }^{20}$-reference/ perversion-of- $^{8}$ referenceof-thought-<as-preconvergingly-apriorising/axiomatising/referencing-innonconviction/madeupness/bottomlining-as-to-shallow-supererogation >,-and-not-of-logicalcontention) perversion-of- ${ }^{8}$ reference-of-thought-<as-preconverginglyapriorising/axiomatising/referencing-in-nonconviction/madeupness/bottomlining-as-toshallow-supererogation $>$, then preconverging-or-dementing 2 -apriorising-psychologism$<$ stranded-as-rightfully-oblongated/decandored-and-dialectically-or-contendingly-out-ofphase $>$ of the said superseded/transcended registry-worldview's/dimension's institutionalisation reference-of-thought- categorical-imperatives/axioms/registry-teleology ${ }^{9}$, thus articulating the temporal backdrop needing a furtherance of institutionalisation/intemporalisation as new reference-of-thought- categorical-imperatives/axioms/registry-teleology ${ }^{9}$,-for-intemporalpreservation-entropy-or-contiguity-or-ontological-preservation for the superseding/transcending registry-worldview/dimension. Without the ' $<$ amplituding/formativeepistemicity $>$ causality $\sim$ as-to-projective-totalitative-implications-of-prospectivenonpresencing,-for-explicating relative-unreflexivity/relative-reflexivity - ontologicalcontiguity -retracing (for notional firstnaturedness-formativeness-<as-toeventualising inkling-drive-or-seeding-misprising $>$ temporal-to-intemporal-dispositions$<$ so-construed-as-from-perspective--ontological-normalcy/postconvergence $>$-pedestalsdisambiguation) as ${ }^{83}$ reference-of-thought-scheme' all the above will be hardly attainable as the basic fact that the 'conviction-as-to-profound-supererogation -reflex/prelogic-reflexadmittance-reflex/in-phase-reflex instead of rightly aligning by the dialectically-orcontendingly-out-of-phase reflex or $\quad$ transversality-<for-sublimating-existential- 
eventuating/denouement,-from-'thinking at first/pure-predisposition-preemptive-of

prospective-disontologising/subontologising' as-of-prospectively-disambiguated-affirmedand-unaffirmed-'motif-and-apriorising/axiomatising/referencing'> ${ }^{101}$ reflex)' is a 'soundnessor-ontological-good-faith/authenticity ${ }^{6}$-of- ${ }^{3}$ reference-of-thought' functional mechanism which can only be superseded priorly in habituation of the 'effective reality of a unsoundness-orontological-bad-faith/inauthenticity ${ }^{6}$-of- ${ }^{8}$ reference-of-thought' of psychopathic postlogism in hollow-constituting-<as-disjointed-misappropriation-of-meaningfulness-and-failingintemporal-preservation> and other temporal-dispositions postlogism 77 in hollow-constituting$<$ as-disjointed-misappropriation-of-meaningfulness-and-failing-intemporal-preservation $>\quad \mathrm{s}$ which are rather in perversion-of- reference-of-thought-<as-preconverginglyapriorising/axiomatising/referencing-in-nonconviction/madeupness/bottomlining-as-to-

shallow-supererogation >- categorical-imperatives/axioms/registry-teleology ${ }^{99}$,-forintemporal-preservation-entropy-or-contiguity-or-ontological-preservation of positivistic meaningfulness at the procrypticism registry-worldview's/dimension's uninstitutionalisedthreshold ${ }^{102}$. Of course, this is more like a 'notional template' in a 'dynamics of benign implications to grave existentialism/full-existential-depth-implications' articulated over a functional social-construct which however 'endemises psychopathy and social psychopathy rather at the uninstitutionalised-threshold ${ }^{102}$ of the positivistic meaningfulness ${ }^{83}$ reference-ofthought- categorical-imperatives/axioms/registry-teleology ${ }^{99}$,-for-intemporal-preservationentropy-or-contiguity-or-ontological-preservation ${ }^{74}$ perversion-of- ${ }^{8}$ reference-of-thought- $<$ aspreconvergingly-apriorising/axiomatising/referencing-in-

nonconviction/madeupness/bottomlining-as-to-shallow-supererogation $>\quad$ known $\quad$ as procrypticism preconverging-or-dementing ${ }^{20}$-apriorising-psychologism, requiring futural Being-development/ontological-framework-expansion-as-to-depth-of-ontologisingdevelopment-as-infrastructure-of- meaningfulness-and-teleology as of prospective 


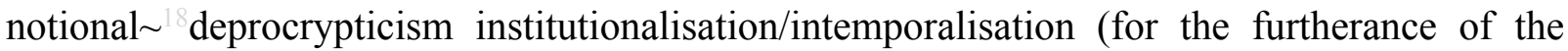
intemporal-preservation-entropy-or-contiguity-or-ontological-preservation or relativeunreflexivity/relative-reflexivity - ontological-contiguity ${ }^{7}$ ontological-veridicality). Further, it is important to appreciate that just as with the profoundness of treatment of subject-matters and specialisms (and even more so with regards to the 'social' given its characteristic 'emotional involvement' aspect), corresponding subject-matter 'focussing of analysis and jargon' will seem rather unusual and unnatural to 'ordinary thinking'. But then 'ordinary thinking' is responsible for mostly nothing, if not thinking mostly in the extended-informality-〈susceptible-to-effectingparsimony-as-of-shoddiness-and-incompleteness-to- meaningfulness-and-teleology $\rangle, \quad$ and cannot be made a reference of formal thinking as issues requiring profound treatment invariably are construed based mostly on unordinary formal constructs which, granted, should be able to ultimately by their <amplituding/formative-epistemicity>causality $\sim$ as-to-projectivetotalitative-implications-of-prospective- nonpresencing,-for-explicating relative-

unreflexivity/relative-reflexivity ontological-contiguity demonstrate that such formal constructs are the best ontological and virtue conceptualisation with regards to the issue or domain of concern. That's why the populace is not asked its opinion about the law or astronomy or medicine, for instance, as the need for deferential-formalisation-transference arises for the effective ontological/intemporal treatment of domains of reality but for when the issues at stake require a sovereignty exercise requiring individuals informed consent whether political or decisional or rather as social learning/inculcation exercise; but then sovereignty exercises are not pure knowledge/ontological constructs but for the construals/conceptualisations of inherently sovereign choices as knowledge/ontological constructs of the sovereign choices. Thirdly, the conceptualisation of this paper is rather unusual and unordinary as it is transcendental by its construct and the implied registry-worldview/dimensions successive existentialisms/full-depthsof-existential-implications, and even further unusual by its phenomenological and hermeneutics 
methodological approaches, which frankly speaking is the only way to creatively garner such insights in broad strokes. Like with all transcendental constructs, which by definition tend to put the usual/ordinary in question, it is not surprising that it will sound highly alienating to ordinary ways of thought. However, its ethos is that it is coming from a depth of conceptualisation that is more profound than our ordinariness when it grasps that other institutionalisations whether as recurrent-utter-uninstitutionalisation, base-institutionalisation-ununiversalisation, ${ }^{3}$ universalisation-non-positivism/medievalism, positivism- ${ }^{80}$ procrypticism, and prospectively deprocrypticism, had their own 'ordinariness' in <amplituding/formativeepistemicity $>$ totalising $\sim$ self-referencing-syncretising/circularity/interiorising/akrasiatic-drag no less than we do, and that the underlying ontological reasoning is beyond the illusion-of-thepresent/present-consciousness/epistemic-totalising $\sim$ self-referencing-syncretising/mirage as metaphysics-of-presence-〈implicited-'nondescript/ignorable-void '-as-to- presencingabsolutising-identitive-constitutedness $\rangle$, of any registry-worldview/dimension including our positivistic meaningful frame, to arrive at a superseding and more profound ontologicalveridicality or grasp of intrinsic-reality with corresponding illuminating implications. In that sense, an argument of the type our society is great as it is, will then be meted with a same argument that there were great things happening in medieval times as well and maybe we shouldn't have transcended into positivism; speaking of a fundamental solipsistic ontologicalbad-faith/inauthenticity ${ }^{64}$. One could argue in the logic of those times, the serfs were doing great feeding themselves, as many did argue; and there was no need for science, as many did argue, etc. The fact is we are the outcrop of the possibility and potential for human transcendence-andsublimity/sublimation/supererogatory de-mentativity before which doesn't end with us but proceeds to undermine our own registry-worldview/dimension as well. Fourthly, it is obvious that if and where what is factored in is only the folksy 'human lifespan extricatory punctuality/immediacy of depth-of-thought' perspectives of individuals existentialism/full- 
depth-of-existential-implications of shallowness of scale and time, without the requisite philosophical depth requiring a profound appreciation, understanding and insights from 'humanity existentialism/full-depth-of-existential-implications level scale and time' which easily gets lost, and thus this bigger pursuit of this paper will be lost and misunderstood by such a shallowness of scale and time of thought, and non-contemplation and pseudologism as a mark of banality/folksy-logic. It is inevitable, as has been the case throughout the human past, that transcendental ideas are inevitably suprastructural/beyond-the-consciousness-awarenessteleology $-<$ of-preconverging-existential-extrication-as-of-existential-unthought $>$ of the $<$ amplituding/formative-epistemicity $>$ totalising $\sim$ self-referencing-

syncretising/circularity/interiorising/akrasiatic-drag ${ }^{34}$ registry-worldview/dimension in which such notions are being advanced in. Fifthly, it is more likely that a banal/folksy inclination may hardly appreciate the difference between the outcome of a mindset $/{ }^{83}$ reference-of-thought as a secondnaturedness and internalisation construct across successive institutionalisations with their requisite psychoanalytic-unshackling/memetic-reordering/institutional-recomposuring induced from intemporal-disposition individuation disposition, and correspondingly differentiate between being so-institutionalised with a secondnatured and internalisation mindset $/{ }^{3}$ referenceof-thought and the intemporal-individuation disposition that will equally be responsible out of mere intemporal-solipsism as to ontological-faith-notion-or-ontological-fideism-imbuedunderdetermination-of-motif-and-apriorising/axiomatising/referencing-as-so-being-as-ofexistential-reality (and no secondnaturing and internalisation) for institutionalising/intemporalising with regards to the present registry-worldview/dimension at its uninstitutionalised-threshold ${ }^{102}$ that will be behind the secondnaturing and internalisation of prospective registry-worldview/dimension. This 'existentialism/full-depth-of-existentialimplications form-factor' is the reflection of the contiguity of successive existentialisms/fulldepths-of-existential-implications across varying meaningful frames, references and registry- 
worldviews/dimensions; and is abstractly determined by the ontologicalnormalcy/postconvergence nature of intrinsic-reality/ontology (ontological-normalcy) whatever the institutional-cumulation/institutional-recomposure-〈as-to- historiality/ontological-

\section{eventfulness /ontological-aesthetic-tracing-<perspective-ontological-}

normalcy/postconvergence-reflected-'epistemicity-relativism-determinism' $>\rangle$, and inherently implies a " ${ }^{103}$ universal existentialisms/full-depth-of-existential-implications form-factor across institutionalisations' though of differing 'snowballed recomposuring' of meaningfulness and reference-of-thought, defining their specificities and potentials. This is just a basic anthropopsychology/the-anthropological-continuity elucidation which while original and useful on its own right, is equally pertinent for an insight in the social manifestation of psychopathy. Besides, one can imagine that a thorough grasp and creative application of the ${ }^{15}$ de-mentation〈supererogatory $\sim$ ontological-de-mentation-or-dialectical-de-mentation-stranding-or-

attributive-dialectics $\rangle$ as to ontological-normalcy/postconvergence drive, as this psychologically reflects/perspectivates postconverging-or-dialectical-thinking -apriorising-psychologism$<$ stranded-as-rightfully-straight/candored-and-dialectically-or-contendingly-in-phase $>\quad$ and preconverging-or-dementing ${ }^{20}$-apriorising-psychologism- $<$ stranded-as-rightfullyoblongated/decandored-and-dialectically-or-contendingly-out-of-phase $>$ of mental-devisingrepresentation by which human transcendence-and-sublimity/sublimation/supereregatory $\sim$ dementativity occur can ultimately be the avenue for liberating the human mind to its full potential and directed transcending capacity. That is, transcendental capacity not only by way of a spontaneous and natural dialectical cycle of social-stake-contention-or-confliction behind the 'postconverging-or-dialectical-thinking - psychology or psychology-of-mentation-dynamics or natural psychological-dynamics' psychoanalytic-unshackling/memeticreordering/institutional-recomposuring history but a 'consciously directed' abstract understanding, more like deprocrypticism-over-procrypticism could-be and would-need-to-be 
relatively highly consciously directed given the relatively lower immediate positiveopportunism-of-social-functioning-and-accordance ${ }^{75}$ (for survival-and-flourishing to the cross-section of human temporal interests) compared to the lower transcendence-andsublimity/sublimation/supererogatory $\sim$ de-mentativity like base-institutionalisation, universalisation and positivism, but for its abstract veridical pertinence and potentially grander possibilities in the institutionalisation/intemporalisation percolation-channelling- $<$ indeferential-formalisation-transference $>$. Such a veering to the creatively abstract, with respect to the philosophical and the social sciences, but nonetheless ontologically veridical will be liberating/emancipating from the 'spontaneously natural dialectical cycle of human progress' and is increasingly certain to be the defining feature of human civilisation. It should be noted that Entropy as defined ('intemporal-preservation-entropy-or-contiguity-or-ontologicalpreservation re-institutionalisation') relates that the intemporal-preservation-institutionalisation entropy is the preceding-and-defining reference for the hermeneutic-referencing of the ontological meaning of all other associated conceptualisations and notions, and so as to nonpresencing-<perspective-ontological-normalcy/postconvergence $>\quad$ epistemicity. (By ontological meaning is implied intemporal/veridical/purism/operant-construct/predicativeeffectivity-sublimation-〈as-to-underlying,-ontological-commitment ${ }^{6}-<$ implied - selfassuredness-of-ontological-good-faith/authenticity $\sim$ postconverging-dementating/structuring/paradigming -as-being-as-of-existential-reality $>>$ meaning or ontology/reality-centered-meaning as contrasted to temporal/non-veridical/compromised/nonoperant-and-vagueas $\quad<$ amplituding/formative-epistemicity $>$ totalising $\sim$ self-referencingsyncretising/circularity/interiorising/akrasiatic-drag ${ }^{34}$ meaning or metaphysical/speculative/banality/social-discomfiture/temporal-human-centered meaning). Central to the hermeneutics approach towards elucidating psychopathy and the underlying psychological science is a method herein qualified as 'referentialism' which makes reference to 
the supersedingness/precedingness of the 'intemporal preservation institutionalisation/intemporalisation entropy/contiguity' before articulating concepts and notions in referential and organic elucidation of the entropic construct. Referentialism as such is actually central to the spontaneity required in hermeneutics. It differs from the traditional scientific categorisation of concepts and notions, in that referentialism implies a highly contiguous, circumstantial and dynamic referencing elucidating of the superseding/preceding entropic notion while categorisation tends to be basically constitutive, definitive and 'weakly contiguous/relatively-fragmented overall' in its elucidation of notions, concepts and ideas. Categorisation has been very efficient with the physical and biological sciences with its classification approach enabling a profoundness of analysis while enabling excellent subject matter organisation. However, this author is of the opinion that categorisation as an approach is actually less efficient in the social sciences (and notions of an ephemeral character) as it underemphasises the 'organic dynamism' of social concepts and often leads to relatively trite classification schemes that are often inoperant or poorly operant given the relative ephemerality of the social world (a weakness of many categorisation classification schemes in the social sciences). On-the-other-hand, referentialism carries the promise of 'point-referencing' notions and concepts in a contiguously dynamic, evolving and ontological-reconstituting-as-toconflatedness ${ }^{13} /$ deconstruction way, putting emphasis on the relative relation of concepts and notions towards the central notion in its dynamic entropic conceptualisation (herein underlied by conceptivity/epistemic-reflexivity/epistemicity-relativism-determinism-<reifying \{as-toknowledge-developing\}-and-empowering $>$ as to human limited-mentation-capacitydeepening —as-subjecting limitedness/human-subpotency-to-'educed-unlimitedness/existence-

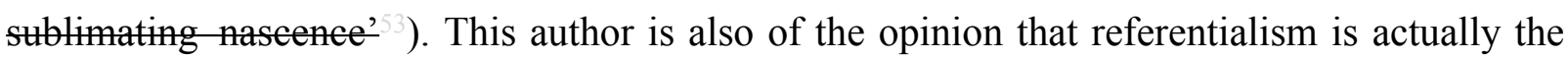
natural human cognitive development approach to acquisition and classification of knowledge with emphasis on the 'organic dynamics of understanding' wherein a child for instance doesn't 
necessarily grasp outright the fullness of concepts-of-meanings but rather the 'relevant dynamic contextualisation of meanings' ensuring a strongly operant and 'wealthy' relationship with meaning in the social context. 'Intemporal-preservation-entropy-or-contiguity-or-ontologicalpreservation re-institutionalisation' with respect to uninstitutionalised-threshold ${ }^{102}$ of registryworldviews/dimensions, can be construed as follows: Supposed all humanity across space and time that ever existed was just 'one human temporal-to-intemporal individuation', the process of general-institutionalisation from recurrent-utter-uninstitutionalisation to baseinstitutionalisation-ununiversalisation to ununiversalisation-non-positivism/medievalism to positivism- ${ }^{80}$ procrypticism, and prospectively to deprocrypticism, is actually one same process but for 'lack of the human-mentation-capacity and need for time for the cumulation of the mentation-capacity' (lack of 'brain capacity') to get it all right from the start (i.e. to fully grasp notional deprocrypticism starting from recurrent-utter-uninstitutionalisation to baseinstitutionalisation-ununiversalisation to ununiversalisation-non-positivism/medievalism to positivism- ${ }^{80}$ procrypticism as convergent concepts towards notional ${ }^{8}$ deprocrypticism (as 'longness-of-register-of- ${ }^{5}$ meaningfulness-and-teleology 99 over shortness-of-register-ofmeaningfulness-and-teleology ${ }^{9}$ in reflecting holographically-<conjugatively-andtransfusively $>$ the relative unreflexivity/relative reflexivity ontological-contiguity of-thehuman-institutionalisation-process , as induced by maximal-as-intemporal-operating-modalityof- reference-of-thought-as-of- maximalising-recomposuring-for-relative-ontologicalcompleteness 87 unenframed/re-ontologising conceptualisation-as-inducing-the-prospectiveinstitutionalisation' and involving more profound/richer ontological-levels over shallower/poorer ontological-levels; with notional ${ }^{18}$ deprocrypticism thus implying a 'full-cycle relative unreflexivity/relative reflexivity - ontological-contiguity ${ }^{67}$ of-the-humaninstitutionalisation-process $^{68}$ undermining of subknowledging $/$ mimicking/emanantuninstitutionalisation-disposition'). Thus the successive institutionalisations are thus construed 
as 'levels of compromise' allowing for sufficient human limited-mentation-capacitydeepening —as-subjecting limitedness/human-subpotency to-'educed-unlimitedness/existencesublimating nascence ${ }^{3}$ to handle the requisite transcendence-andsublimity/sublimation/supererogatory de-mentativity even if from the very start the human doesn't get a grasp of 'higher institutionalisation/intemporalisation registryworldviews/dimensions' all-at-once/as-a-whole but achieves the 'comprehensive institutionalisation/intemporalisation frame' only at deprocrypticism; as it goes on to take on the successive challenges of base-institutionalising, then ${ }^{103}$ universalising, then positivising, and finally with notional ${ }^{8}$ deprocrypticism absolute notional-contiguity/epistemic-contiguity $<$ profound-supererogation -of-mentally-aestheticised postconverging/dialectical-thinking qualia-schema $>$ by undermining 'disjointedness-as-of- ${ }^{8}$ reference-of-thought'-asmisappropriated- ${ }^{5}$ meaningfulness-and-teleology ${ }^{9}$-in-arrogation' (longness-of-register-ofmeaningfulness-and-teleology $\quad$ over shortness-of-register-of- ${ }^{9}$ meaningfulness-andteleology ${ }^{9}$ ). It should be noted that the issue of procrypticism had always been present at all times of human existence but the natural priority going by human shallow limited-mentationcapacity —as-subjecting 'educed-unlimitedness/existence-sublimating nascence' to-

limitedness/human-subpotency-〈as of relative apriorising/axiomatising/referencing-\{of'prospectively_implicited_attendant-ontological-contiguity ' educedexistentialising/contextualising/textualising_'intelligibility/epistemicity/reflexivity_contiguity$<$ imbued-notional cogency $\left.>^{\prime} \quad\right\}$ - constitutedness ${ }^{14}$-in-preconverging-entailment $\rangle$ to deeper limited-mentation-capacity—as-subjecting-'educed-unlimitedness/existence-sublimating nascence' to-limitedness/human-subpotency-〈as of relative apriorising/axiomatising/referencing-\{of-'prospectively_implicited_attendant-ontologicalcontiguity ' $\sim$ educed- 
<imbued-notional cogency >' \}-conflatedness ${ }^{13}$ in-\{preconverging disentailment by\}

postconverging-ntailment $\rangle$ was first to have a base-institutionalisation institutionalisation, universalisation institutionalisation, positivism institutionalisation before prospectively notional ${ }^{18}$ deprocrypticism institutionalisation; more precisely, previous psychoanalyticunshackling/memetic-reordering/institutional-recomposuring are indirectly (skewing towards) addressing base-institutionalisation, ${ }^{103}$ universalisation, positivism and deprocrypticism, up to the point of the respective institutionalisation/intemporalisation-recomposure where the reference-of-thought-as-the-registry-worldview is directly addressed. This thus explains ontological-normalcy/postconvergence across human mental-devising-representation as changes to accommodate intrinsic reality by psychoanalytic-unshackling/memeticreordering/institutional-recomposurings of successive illusions-of-the-present/presentconsciousnesses/epistemic-totalising $\sim$ self-referencing-syncretising/mirage at these successive institutionalisation/intemporalisation levels including the positivism- ${ }^{80}$ procrypticism institutionalisation/intemporalisation, towards intrinsic-reality/ontological-veridicality; that has and will never change, and by way of 'prospective postconverging-apereticismovercoming/unovercoming as the-Good/knowledge-reification $\sim$ gesturing-and-accounting-ofepistemic-phenomenalism-<in-

prospective_psychologismic apriorising/axiomatising/referencing-\{of-'prospectively implicited_attendant-ontological-contiguity ' educedexistentialising/contextualising/textualising_ 'intelligibility/epistemicity/reflexivity-contiguity<imbued-notional cogency >' \}-conflatedness -in-\{preconverging disentailment by\} postconverging entailment $>$ /understanding/<amplituding/formativeepistemicity $>$ causality $\sim$ as-to-projective-totalitative-implications-of-prospectivenonpresencing,-for-explicating relative-unreflexivity/relative-reflexivity - ontologicalcontiguity ${ }^{,}$inducing of social ${ }^{103}$ universal-transparency ${ }^{104}$-〈transparency-of-totalising- 
entailing,-as-to-entailing-<amplituding/formative-epistemicity $>$ totalising $\sim$ in-relative-

ontological-completeness $\rangle$ and internal logical coherence/contradiction this then validates the need for human psychoanalytic-unshackling/memetic-reordering/institutional-recomposuring. In-the-bigger-scheme-of-things, it points to the fact that ontologically for the full potential of human science, this should be 'rising from this fundamental philosophical depth/profoundness of thought' to then transversally address the issues it raises while projecting prospectively. A further insight can be grasped regarding the relationship between psychopathy, anthropopsychology/the-anthropological-continuity, veridicality (intrinsic reality/ontological representation), non-veridical reality (illusion-of-the-present/present-consciousness/epistemictotalising $\sim$ self-referencing-syncretising/mirage as metaphysics-of-presence-〈implicited'nondescript/ignorable-void ' -as-to- presencing - absolutising-identitive-constitutedness 〉), human placeholder-setup/mental-devising-representation/mentation/consciousness-awarenessteleology ${ }^{9}$, and registry-worldviews/dimensions (of institutionalisation/intemporalisation, universalisation, positivism, and prospectively deprocrypticism). Psychopathy points to the psychopath's postlogism in hollow-constituting-<as-disjointed-misappropriation-ofmeaningfulness-and-failing-intemporal-preservation $>$ but postlogism 77 in hollow-constituting$<$ as-disjointed-misappropriation-of-meaningfulness-and-failing-intemporal-preservation $>\quad$ is equally socially conceptualised. postlogism 77 in hollow-constituting-<as-disjointedmisappropriation-of-meaningfulness-and-failing-intemporal-preservation $>$ as vague-rhymingor-copied-mimicry-or-formulaic-projection-or-projection-of-form-or-hollow-and-vaguevocalisation-or-subknowledging ${ }^{4}$ or meaning-by-the-mere-illogical-possibility-of-it-beingformulaically-narrated is not veridical and its genuine mental-devising-representation is a 'slantedness of the mind/mental-slantedness' (distractive-alignment-to- ${ }^{3}$ reference-of-thought$<$ of-apriorising/axiomatising/referencing $>$ \% /dialectically-or-contendingly-out-ofphase/dialectically-primitive), as there 'can't be mutual logical operation/no logical nested- 
congruence'

between

non-veridical

postlogism 7 -as-of- compulsing-

nonconviction/madeupness/bottomlining-/‘<decontextualising/de-existentialising $\sim$ of-

attendant-intradimensional-apriorising/axiomatising/referencing $>$-induced-disontologising'-of-

the-'attendant-intradimensional-ontologising'-imbued-

$<$ contextualising/existentialising attendant-ontological-contiguity $>$;-in-shallow-

supererogation -<as-to-disontologising-perverted-outcome-sought-precedes-existentially-

veridical-'attendant-intradimensional-apriorising/axiomatising/referencing'-logical-dueness $>$ )

in hollow-constituting-<as-disjointed-misappropriation-of-meaningfulness-and-failing-

intemporal-preservation> and veridical prelogism $>$-as-of-conviction,-in-profound-

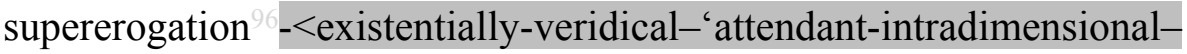

\section{apriorising/axiomatising/referencing'-logical-dueness-precedes-disontologising-logical-}

outcome-arrived-at $>$, but for a dialectically-or-contendingly-out-of-phase (as-the-temporalmind-is-dialectically-out-of-phase) 'ordered construct from the superseding registryworldview/dimension validated by $<$ amplituding/formative-epistemicity $>$ causality $\sim$ as-toprojective-totalitative-implications-of-prospective- nonpresencing,-for-explicating $\sim$ relativeunreflexivity/relative-reflexivity ontological-contiguity and implying a psychoanalyticunshackling of the ${ }^{7}$ perversion-of- ${ }^{8}$ reference-of-thought- $<$ as-preconverginglyapriorising/axiomatising/referencing-in-nonconviction/madeupness/bottomlining-as-to-

shallow-supererogation $>$ registry-worldview'. For instance, there isn't any logical nestedcongruence between the non-positivism/medievalism mindset $/{ }^{/ 3}$ reference-of-thought and the positivistic mindset). A positivistic mind can't explain the denaturing ${ }^{16}$ of the notion of witchcraft to a non-positivism/medievalism mindset as the state of being of nonpositivism/medievalism means we make reference to non-positivism/medievalism ${ }^{8}$ referenceof-thought- categorical-imperatives/axioms/registry-teleology 9 that end up endemising/enculturating such superstitious notions. Logic as logical-congruence only arises 
where there is a mutual registry-worldview ${ }^{83}$ reference-of-thought- categoricalimperatives/axioms/registry-teleology'. What is thus needed is a 'psychoanalyticunshackling/memetic-reordering/institutional-recomposuring' of the medieval mindset $/{ }^{3}$ reference-of-thought (which is subknowledging $/$ mimicking) wherein the untenability/internal-contradiction/internal-incoherence/institutional-constraining generated by the positivist's scientism (superseding) makes the medieval mind put in question its ${ }^{83}$ referenceof-thought- categorical-imperatives/axioms/registry-teleology in-the-very-first-place. This 'psychoanalytic-unshackling process' equally applies prospectively (regarding the positivismprocrypticism and the notional $\sim$ deprocrypticism registry-worldviews/dimensions). In the phenomena of social psychopathy, it is important to grasp that the reflex to mentally represent the narratives of the psychopath and the protraction of the narratives by temporal supplantingconviction-as-to-profound-supererogation —of-'attendant-intradimensional'postconverging/dialectical-thinking -apriorising-psychologism or prelogism ${ }^{78}$ minds as 'straightness/candor/organic-comprehension-thinking of mind' is wrong, 'overcoming the mental-slantedness/decandoring/distractive-alignment-to- ${ }^{83}$ reference-of-thought- $<$ ofapriorising/axiomatising/referencing $>{ }^{30}$ is thus called for, more like we perceive the 'slantedness of a childhood cinglé' (in terms-as-of-axiomatic-construct of the mental state of the psychopath as well as its protraction on the psychopath's interlocutor). In other words, *the mind is actually a mental devising tool' whose veracity/ontological-pertinence must be validated by an abstractly veridical intrinsic-reality/ontological-veridicality. In other words, the abstract grasp of intrinsicreality/ontological-veridicality defines mental-devising-representation as the latter is not inherently given (it is a devising tool validated by abstract intrinsic-reality/ontologicalveridicality established by <amplituling/formative-epistemicity $>$ causality $\sim$ as-to-projectivetotalitative-implications-of-prospective- nonpresencing,-for-explicating relativeunreflexivity/relative-reflexivity - ontological-contiguity. For instance, while the traditional 
reflex of the human mental-devising-representation is disposed to think otherwise, Einstein theory-of-relativity abstraction, and likewise with many conceptualisations of a doppler-thinking nature, is more real by its <amplituding/formative-epistemicity>causality $\sim$ as-to-projectivetotalitative-implications-of-prospective- nonpresencing,-for-explicating relativeunreflexivity/relative-reflexivity ontological-contiguity , thus pointing to the error of the human reflex/impulse thinking). In another light, this explains the transformative evolution of our registry-worldviews/dimensions mental-devising-representations of reality from the recurrent-utter-uninstitutionalised earlymen to our current positivism- ${ }^{80}$ procrypticism registryworldview, with the insight that our mental-devising-representation will evolve when prospective abstract reality <amplituding/formative-epistemicity $>$ causality $\sim$ as-to-projectivetotalitative-implications-of-prospective- nonpresencing,-for-explicating relative-

unreflexivity/relative-reflexivity - ontological-contiguity shows that it is defective/perverted as ${ }^{8}$ procrypticism-or-disjointedness-as-of- ${ }^{2}$ reference-of-thought, from a deprocryptic mentaldevising-representation. In the same vain, why we perceive the recurrent-utteruninstitutionalised mind as that of a 'savage', the recurrent-utter-uninstitutionalised in its '<amplituding/formative-epistemicity $>$ totalising $\sim$ self-referencing-syncretising/illusion-of-thepresent/present-consciousness/mirage as metaphysics-of-presence-〈implicited'nondescript/ignorable-void ' -as-to- presencing - absolutising-identitive-constitutedness > perceives its mind as straight/candored and as of organic-comprehension-thinking (organicalism/'intemporal-prioritisation-of- ${ }^{8}$ reference-of-thought'-as-conflatedness ${ }^{13}$-orontological-reprojecting/longness-of-register-of- meaningfulness-and-teleology ) and soundness-or-ontological-good-faith/authenticity ${ }^{-}$of- ${ }^{3}$ reference-of-thought. It is the prospective base-institutionalised mind that 'invents' the representation of mentalslantedness/decandored-and-dialectically-or-contendingly-out-of-phase/dialectically-primitive) of the recurrent-utter-uninstitutionalised mind; and likewise with the ununiversalised mind and 
universalised mind, non-positivism/medievalism mind and positivistic mind, and prospectively, procrypticism mind and notional deprocrypticism mind. This variance of straightness/candored as organic-comprehension-thinking (organicalism/“intemporalprioritisation-of- ${ }^{8}$ reference-of-thought'-as-conflatedness ${ }^{13}$-or-ontologicalreprojecting/longness-of-register-of- meaningfulness-and-teleology ) and oblongated/decandored as threshold-of-nonconviction/madeupness/bottomlining-in-shallowsupererogation -<as-to-'attendant-intradimensional'-prospectivelydisontologising preconverging/dementing -apriorising-psychologism> mental-devisingrepresentations to ascertain veridicality/intrinsic-reality of psychopathic and social-psychopathic phenomena such that the ordinary reflex to keep a straight/candored organic-comprehensionthinking (organicalism/'intemporal-prioritisation-of- ${ }^{8}$ reference-of-thought'-asconflatedness $^{13}$-or-ontological-reprojecting/longness-of-register-of- meaningfulness-andteleology $)$ with respect to the psychopath's mindset/ ${ }^{2}$ reference-of-thought and protracted social psychopathy non-veridical hollow mimicking narratives should be undermined by a slantedness/decandoring of the mind as distractive-alignment-to- ${ }^{-3}$ reference-of-thought- $<$ ofapriorising/axiomatising/referencing $>$ ' at 'uninstitutionalised-threshold ${ }^{102}$ '. The contention is an 'ontological-entrapment' not about logical operation/processing/contention of the 'nonveridical hollow perversion-of- ${ }^{7}$ reference-of-thought-<as-preconverginglyapriorising/axiomatising/referencing-in-nonconviction/madeupness/bottomlining-as-toshallow-supererogation $>$ narratives' but rather reflecting/perspectivating/highlighting (reasoning-through-and-not-reasoning-with) it $\quad$ as $\quad$ <amplituding/formativeepistemicity $>$ causality as-to-projective-totalitative-implications-of-prospectivenonpresencing,-for-explicating relative unreflexivity/relative reflexivity - ontologicalcontiguity. That is, an understanding of the abstract temporal-dispositions as a specielevel/ ${ }^{103}$ universal/intemporal postconverging-de-mentating/structuring/paradigming as 
prospective ${ }^{83}$ reference-of-thought- categorical-imperatives/axioms/registry-teleology ${ }^{9}$,-forintemporal-preservation-entropy-or-contiguity-or-ontological-preservation, i.e. transcendenceand-sublimity/sublimation/supererogatory - de-mentativity as deprocrypticism. It is a psychoanalytic-unshackling ordered construct (as-the-temporal-minds-pedestals-are-out-ofphase-dialectically-or-dialectically-primitive-by-a-bare-matter-of-fact) from the intemporalsolipsistic/emanant-registry-pedestal in $\quad$ transversality- $<$ for-sublimating-existentialeventuating/denouement,-from-'thinking at-first/pure-predisposition-preemptive-ofprospective-disontologising/subontologising' as-of-prospectively-disambiguated-affirmedand-unaffirmed-'motif-and-apriorising/axiomatising/referencing' $>$ '01. The bigger scheme of things being the preconverging/postconverging-de-mentative/structural/paradigmatic preemption of a defective/perverted registry-worldview, in this case procrypticism-ordisjointedness-as-of- ${ }^{8}$ reference-of-thought. Such an emanant insight can be garnered from the fact that, positivism was established by the 'diktat'/ordered-construct of the Descartes, Comtes, Galileos, Rousseaux, Newtons, Darwins... of the world, and the rest of humanity complied to the formalisms that ensue, by virtue of their proxying-to-intrinsic-reality and the positiveopportunism-of-social-functioning-and-accordance ${ }^{75}$ that led to psychoanalyticunshackling/memetic-reordering/institutional-recomposuring (towards human formalisation and internalisation)! As registry-worldview/dimension defects or denaturing ${ }^{16}$ are responsible for the vices-and-impediments ${ }^{105}$ of the said registry-worldview/dimension; noting that the fundamental construction is a 'the-Good/knowledge-reification $\sim$ gesturing-and-accounting-of-epistemicphenomenalism-<in-prospective_psychologismic $\sim$ apriorising/axiomatising/referencing- of'prospectively implicited_attendant-ontological-contiguity ' educedexistentialising/contextrising/textlising_intelligibility/epistemicity/reflexivity-contiguity<imbued-notional cogency $\left.>^{\prime} \quad\right\}$-conflatedness -in-\{preconverging-disentailment by\} postconverging-entailment $>$ /understanding/<amplituding/formative- 
epistemicity $>$ causality $\sim$ as-to-projective-totalitative-implications-of-prospective-

nonpresencing,-for-explicating relative-unreflexivity/relative-reflexivity - ontological-

contiguity conceptualisation' making reference to <amplituding/formative-

epistemicity $>$ causality $\sim$ as-to-projective-totalitative-implications-of-prospective-

nonpresencing,-for-explicating relative-unreflexivity/relative-reflexivity - ontological-

contiguity and not a vague 'impression/good-naturedness/wishfulness conceptualisation' making reference to the banal <amplituding/formative> wooden-language-_imbuedaveraging-of-thought-<as-to-leveling/ressentiment/closed-construct-of- meaningfulness-andteleology -as-of-'nondescript/ignorable-void ' -with-regards-to-prospective-apriorisingimplications $>>$ as may illusionary be projected intradimensionally/intra-registry-worldview (the latter being represented as oblongated non-veridical narratives by the prospective intemporaldisposition-worldview)! The reason why virtue (knowledge is virtue) is treated scientifically as highlighted above is that virtue is a 'the-Good/understanding/knowledge construct' and not a 'good-natured/impression construct'. For instance, no non-positivism/medieval mindset is 'good-natured/vague by the registry-worldview/dimension impression' enough with the fundamental defective/perverted non-positivism/medieval worldview to be able to address 'theGood/understanding' of a positivistic mindset which will resolve or structurally-renderedinoperant the problems of superstition and witchcraft as the former will always make reference to the defective/perverted ${ }^{83}$ reference-of-thought- categorical-imperatives/axioms/registryteleology 99 of non-positivism/medievalism no matter how 'good-natured/impression-driven' it is. The same applies with procrypticism and deprocrypticism. No procrypticism (preconvergingor-dementing -apriorising-psychologism) mindset as of impression-driven/goodnaturedness/wishfulness has the requisite 'the-Good/knowledge-reification $\sim$ gesturing-andaccounting - of-epistemic-phenomenalism- $<$ in-

prospective_psychologismic apriorising/axiomatising/referencing-\{of-‘prospectively 
implicited_attendant-ontological-contiguity ' reduced-

existentialising/contextualising/textualising_'intelligibility/epistemicity/reflexivity_contiguity<imbued-notional cogency>> $\}$-conflatedness -in-\{preconverging-disentailment by\}

postconverging entailment $>$ /understanding/<amplituding/formative-

epistemicity $>$ causality $\sim$ as-to-projective-totalitative-implications-of-prospective-

nonpresencing,-for-explicating relative-unreflexivity/relative-reflexivity ontological-

contiguity construct' insight to resolve/structurally-rendered-inoperant the issues of the vicesand-impediments $^{105}$ of procrypticism as it is the deprocryptic mindset of 'theGood/understanding/knowledge construct' that is the virtue that carries the sound registryworldview/axiomatic construct/categorical-imperatives to be able to do this. - the-Good is an intemporal/ontological articulation referencing intemporality ${ }^{52} /$ longness in a contiguous emanance of 'transcendental/superseding abstract intemporal-preservation-entropy-orcontiguity-or-ontological-preservation' and corresponding derived ${ }^{83}$ reference-of-thoughtcategorical-imperatives/axioms/registry-teleology"; and is imbued with the 'memetic reordering contiguity' of institutional-cumulation/institutional-recomposure-〈as-tohistoriality/ontological-eventfulness /ontological-aesthetic-tracing-<perspectiveontological-normalcy/postconvergence-reflected-‘epistemicity-relativism-determinism’>> (base-institutionalisation-to-universalisation-to-positivism-to-deprocrypticism, and thereafter). The-Good/knowledge-reification gesturing-and-accounting-of-epistemic-phenomenalism<in-prospective_psychologismic $\sim$ apriorising/axiomatising/referencing-\{of-'prospectively_ implicited_attendant-ontological-contiguity ' educedexistentialising/contextualising/textualising_ 'intelligibility/epistemicity/reflexivity-contiguity<imbued-notional cogency>> $\}$-conflatedness -in-\{preconverging disentailment by\} postconverging entailment $>$ /understanding/<amplituding/formativeepistemicity $>$ causality $\sim$ as-to-projective-totalitative-implications-of-prospective- 
nonpresencing,-for-explicating relative-unreflexivity/relative-reflexivity - ontological-

contiguity is notionally more of a 'capacity and scientific construct' (high or low mentationcapacity) rather than a 'stigmatising construct' (positive or negative impressions). - 'Goodnaturedness' is a temporal articulation that wrongly references (distractively) for temporality ${ }^{8}$ sake registry-worldview's/dimension's institutionalisation ${ }^{83}$ reference-of-thought- categoricalimperatives/axioms/registry-teleology ${ }^{9}$ priorly-and-over 'transcending/superseding abstract intemporal-preservation-entropy-or-contiguity-or-ontological-preservation'; and is imbued with the memetic notional-discontiguity/epistemic-discontiguity ${ }^{63}<$ between - prior-shallowsupererogation -of-mentally-aestheticised $\sim$ preconverging/dementing -qualiaschema_and_prospective-profound-supererogation -of-mentallyaestheticised postconverging/dialectical-thinking -qualia-schema $>$ that undermines institutional-cumulation/institutional-recomposure-〈as-to- historiality/ontologicaleventfulness /ontological-aesthetic-tracing-<perspective-ontologicalnormalcy/postconvergence-reflected-‘epistemicity-relativism-determinism’ $>$ 〉.

Goodnaturedness is notionally more of a 'stigmatising construct' (positive or negative stigmatising) rather than a 'capacity and scientific construct' (high or low mentation-capacity). - Virtue (retrospectively to prospectively) is not determined by 'good-naturedness'/impression-driven construal/conceptualisation of meaning but rather by the-Good/knowledgereification $\sim$ gesturing-and-accounting-of-epistemic-phenomenalism-<inprospective_psychologismic apriorising/axiomatising/referencing-\{of-‘prospectively_ implicited_attendant-ontological-contiguity ' educedexistentialising/contextualising/textualising_'intelligibility/epistemicity/reflexivity_contiguity<imbued-notional cogency $>$ ' \}-conflatedness -in-\{preconverging-disentailment by\} postconverging entailment $>/$ understanding/<amplituding/formativeepistemicity $>$ causality $\sim$ as-to-projective-totalitative-implications-of-prospective- 
nonpresencing,-for-explicating relative-unreflexivity/relative-reflexivity - ontological-

contiguity construal/conceptualisation of meaning as validated by <amplituding/formativeepistemicity $>$ causality $\sim$ as-to-projective-totalitative-implications-of-prospectivenonpresencing,-for-explicating relative -unreflexivity/relative-reflexivity - ontologicalcontiguity (the emanant/becoming ontological-normalcy/postconvergence determinant of veridicality/the-quality-of-being-emanantly-real). The-Good/knowledge-reification $\sim$ gesturingand-accounting - of-epistemic-phenomenalism- $<$ inprospective_psychologismic apriorising/axiomatising/referencing-\{of-'prospectively implicited_attendant-ontological-contiguity ' educedexistentialising/contextualising/textualising_'intelligibility/epistemicity/reflexivity-contiguity<imbued-notional cogency >' \}-conflatedness -in-\{preconverging-disentailment by\} postconverging-entailment $>$ /understanding/<amplituding/formativeepistemicity $>$ causality $\sim$ as-to-projective-totalitative-implications-of-prospectivenonpresencing,-for-explicating relative-unreflexivity/relative-reflexivity ontologicalcontiguity construal/conceptualisation (understanding) as per veridicality demonstrated by $<$ amplituding/formative-epistemicity $>$ causality $\sim$ as-to-projective-totalitative-implications-ofprospective- nonpresencing,-for-explicating relative unreflexivity/relative reflexivity ontological-contiguity is the complete and sufficient elaborative framework for conceptualising virtue! Such <amplituding/formative-epistemicity $>$ causality $\sim$ as-to-projectivetotalitative-implications-of-prospective- nonpresencing,-for-explicating relativeunreflexivity/relative-reflexivity ontological-contiguity is rather tangentially the purview of increasing realism of the institutional-cumulation/institutional-recomposure-〈as-tohistoriality/ontological-eventfulness /ontological-aesthetic-tracing-<perspectiveontological-normalcy/postconvergence-reflected-‘epistemicity-relativism-determinism'>> as it is contiguous with 'human transcending across shifting virtue postconverging-de- 
mentating/structuring/paradigming for intemporal-preservation-entropy-or-contiguity-orontological-preservation' (with corresponding psychoanalytic-unshackling/memeticreordering/institutional-recomposuring); going from recurrent-utter-uninstitutionalisation (impulsive-or-accidented-or-haphazard-or-random mental-disposition), base-institutionalisation (mythologies postconverging-de-mentating/structuring/paradigming, which is of $<$ amplituding/formative-epistemicity $>$ totalising nominal-as-tendentious-

'implicited_attendant-ontological-contiguity ${ }^{67}$ ' educed-

existentialising/contextualising/textualising_'intelligibility/epistemicity/reflexivity-contiguity$<$ imbued-notional cogency>' ${ }^{\prime}$;-phenomenal-abstractiveness-of-presencing-in-'warpedconsciousness'-enabling-

apriorising/axiomatising/referencing/intelligibilitysettingup/measuringinstrumenting-foroperant-or-incidenting-predicative-insights-of 'implicited_attendant-ontologicalcontiguity $^{67}$, educedexistentialising/contextualising/textualising_intelligibility/epistemicity/reflexivity-contiguity$<$ imbued-notional cogency $>>,{ }^{\prime},-<$ reifying-or-elucidating-of-prospective-relative-ontologicalcompleteness -of- reference-of-thought- devolving-as-of-instantiative-context $>\quad$ and represents virtue in terms-as-of-axiomatic-construct of allegiance/subservience transience), universalisation (mystical-principles postconverging-de-mentating/structuring/paradigming, which is of <amplituding/formative-epistemicity>totalising $\sim$ ordinal-as-qualifying'implicited_attendant-ontological-contiguity ${ }^{67}$; educedexistentialising/contextualising/textualising_'intelligibility/epistemicity/reflexivity-contiguity$<$ imbued-notional cogency>' ;-phenomenal-abstractiveness-of-presencing-in-'preclusiveconsciousness'-enablingapriorising/axiomatising/referencing/intelligibilitysettingup/measuringinstrumenting-foroperant-or-incidenting-predicative-insights-of 'implicited_attendant-ontological- 
contiguity ${ }^{67}$,educed-

existentialising/contextualising/textualising_'intelligibility/epistemicity/reflexivity_contiguity-

$<$ imbued-notional $\sim$ cogency $>,{ }^{\prime},-<$ reifying-or-elucidating-of-prospective-relative-ontological-

completeness -of- reference-of-thought- devolving-as-of-instantiative-context> and

represents virtue in terms-as-of-axiomatic-construct of qualification/good-to-bad transience), positivism (principles-rationalism/positivist-idealism postconverging-dementating/structuring/paradigming, which is of <amplituding/formativeepistemicity>totalising intervalist-as-categorising_ 'implicited_attendant-ontologicalcontiguity $^{67}$, educed-

existentialising/contextualising/textmalising_intelligibility/epistemicity/reflexivity-contiguity<imbued-notional cogency>' ;-phenomenal-abstractiveness-of-presencing-in-'occlusiveconsciousness'-enabling-

apriorising/axiomatising/referencing/intelligibilitysettingup/measuringinstrumenting-foroperant-or-incidenting-predicative-insights-of 'implicited_attendant-ontologicalcontiguity $^{67} \sim$ educed-

existentialising/contextualising/textualising_'intelligibility/epistemicity/reflexivity-contiguity$<$ imbued-notional $\sim$ cogency $>,{ }^{\prime},-<$ reifying-or-elucidating-of-prospective-relative-ontologicalcompleteness -of- reference-of-thought- devolving-as-of-instantiative-context> and represents virtue in terms-as-of-axiomatic-construct of categorisations/kindness-humilityhelpfulness-etc. transience), and prospectively deprocrypticism (rational-realism of notional deprocrypticism as of ratiocontiguity/ratiocination-as-referentialism'implicited_attendant-ontological-contiguity ${ }^{67}$ ' educed-

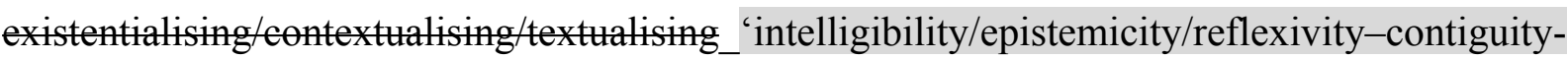

$<$ imbued-notional cogency $>$ mentating/structuring/paradigming as

as nondisjointing 'postconverging-dehuman-subject-emancipating-relativism-driven- 
recomposuring-constructivism-towards-singularisation- $<$ as-to-the-

nondisjointedness/entailment-of-prospective- nonpresencing $>$,,$\quad$ which $\quad$ is a $<$ amplituding/formative-epistemicity $>$ totalising $\sim$ ratiocontiguity/ratiocination-asreferentialism—'implicited_attendant_ontological-contiguity ${ }^{67}$ ' educedexistentialising/contextualising/textualising_intelligibility/epistemicity/reflexivity_contiguity<imbued-notional cogency>' ${ }^{\text {; }}$;-phenomenal-abstractiveness-of-presencing-in-'protensiveconsciousness'-enabling-

apriorising/axiomatising/referencing/intelligibilitysettingup/measuringinstrumenting-foroperant-or-incidenting-predicative-insights-of 'implicited_attendant-ontologicalcontiguity $^{67}$, educedexistentialising/contextualising/textualising_intelligibility/epistemicity/reflexivity-contiguity$<$ imbued-notional $\sim \operatorname{cogency}>{ }^{\prime},,-<$ reifying-or-elucidating-of-prospective-relative-ontologicalcompleteness -of- reference-of-thought- devolving-as-of-instantiative-context> construal and represents virtue 'contiguously' in terms-as-of-axiomatic-construct of human-mentationcapacity/shortness-to-longness-of-register-of- ${ }^{5}$ meaningfulness-and-teleology ${ }^{9} /$ registryteleology -of-meaning intransience; $\quad<$ amplituding/formative-

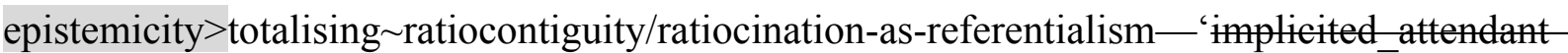
ontological-contiguity ${ }^{67}$ educedexistentialising/contextualising/textualising_intelligibility/epistemicity/reflexivity-contiguity$<$ imbued-notional cogency>' ;-phenomenal-abstractiveness-of-presencing-in-'protensiveconsciousness'-enablingapriorising/axiomatising/referencing/intelligibilitysettingup/measuringinstrumenting-foroperant-or-incidenting-predicative-insights-of 'implicited_attendant-ontologicalcontiguity ${ }^{67} \sim$ educedexistentialising/contextualising/textualising_'intelligibility/epistemicity/reflexivity-contiguity- 

implying all institutionalisations/registry-worldviews/dimensions are about 'construing the same underlying ontology', though yield different but more and more accurate representation of ontology, due to different but improving human limited-mentation-capacity-deepening-assubjecting-limitedness/human-subpotency-to-'educed-unlimitedness/existence-sublimating nascence' from shallow-to-deepening-limited-mentation-capacity-as-subjecting-'educedunlimitedness/existence-sublimating nascence' to-limitedness/human-subpotency, as-limitedmentation-capacity-deepening —as-subjecting limitedness/human-subpotency-to-'educedunlimitedness/existence-sublimating nascence' ${ }^{53}$ ). notional ${ }^{18}$ deprocrypticism being the ontological foundation for the next human virtue preconverging/postconverging-dementative/structural/paradigmatic construct that fully achieves conceptually preemptingdisjointedness-as-of- ${ }^{8}$ reference-of-thought,-as-to- ${ }^{32}<$ amplituding/formativeepistemicity $>$ growth-or-conflatedness ${ }^{13} /$ transvaluativerationalising/transepistemicity/anamnestic-residuality/spirit-drivenness'_-in-supersedingmere-formulaic-positivising/rational-empiricism-based-universalisation-directed-rulemakingover-non-rules_-apriorising/axiomatising/referencing-psychologism existentialising/contextualising/textualising_intelligibility/epistemicity/reflexivity-contiguity$<$ imbued-notional cogency $>,{ }^{,},-<$reifying-or-elucidating-of-prospective-relative-ontologicalcompleteness -of- reference-of-thought- devolving-as-of-instantiative-context> as to existence-potency ${ }^{39} \sim$ sublimating-nascence,-disclosed-from-prospective-epistemicdigression—rules-of-apriorising/axiomatising/referencing-that-further-epistemicallyunconceal-the-very-ontologically-same-existential-reality! Such an articulation of the human, retrospective and prospective, skewing ('intemporality ${ }^{52}$-symmetrising-by-desymmetrising- 
subsumption-of-temporality ${ }^{8}$, for relative intrinsic-reality/ontological-veridicality transcendental-enabling/sublimating/supererogatory $\sim$ de-mentativity)/deferential-formalisationtransference towards/development of virtue is grounded in a theGood/understanding/knowledge-driven conceptualisation on veridicality established by $<$ amplituding/formative-epistemicity $>$ causality $\sim$ as-to-projective-totalitative-implications-ofprospective- nonpresencing,-for-explicating relative-unreflexivity/relative-reflexivity

ontological-contiguity validation. The overarching and defining notion is that each registryworldview/dimension is only capable of the virtue reflected by its intemporal-preservationentropy-or-contiguity-or-ontological-preservation. In other words, a 'registryworldview/dimension defective $\quad{ }^{83}$ reference-of-thought- categoricalimperatives/axioms/registry-teleology ${ }^{9}$ as of its relative-ontological-incompleteness ${ }^{8}$ induced,-'threshold-of-nonconviction/madeupness/bottomlining-in-shallow-supererogation $<$ as-to-'attendant-intradimensional'-prospectivelydisontologising preconverging/dementing -apriorising-psychologism>' is responsible for the vices-and-impediments ${ }^{105}$ of that registry-worldview's/dimension's ${ }^{83}$ reference-of-thought';

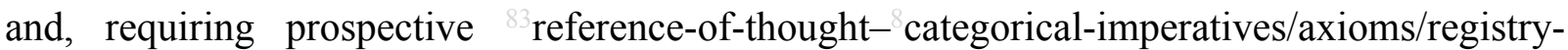
teleology ${ }^{9}$,-for-intemporal-preservation-entropy-or-contiguity-or-ontological-preservation in anticipation and preemption of such ${ }^{7}$ perversion-of- ${ }^{8}$ reference-of-thought- $<$ aspreconvergingly-apriorising/axiomatising/referencing-innonconviction/madeupness/bottomlining-as-to-shallow-supererogation $>$. $\quad$ Thus preconverging/postconverging-de-mentatively/structurally/paradigmatically it is the prospective registry-worldview/dimension which is always the 'prospective virtue potential' for the prior/superseded registry-worldview/dimension. Basically, base-institutionalisation enabled the virtuous resolution of vices-and-impediments ${ }^{105}$ of the state of recurrent-utteruninstitutionalisation, and likewise with ${ }^{103}$ universalisation and ununiversalisation, positivism 
and non-positivism/medievalism, and prospectively, notional deprocrypticism and procrypticism-or-disjointedness-as-of- ${ }^{3}$ reference-of-thought. In the present world, we no longer do institutional slavery, we talk of ${ }^{103}$ universal rights and equality of all people, mob judgment and mob killing is hardly practised anymore, accusations of witchcraft are now viewed as ridiculous, etc.; it is the integration of a positivist registry-worldview/dimension, with corresponding psychoanalytic-unshackling/memetic-reordering/institutional-recomposuring that enabled such human transformation from a non-positivism/medievalism registryworldview/dimension; and not the inherent exceptionalism, as biological or otherwise, of humans living now over their forerunners. Basically, human 'supplanting-conviction-as-toprofound-supererogation of-'attendant-intradimensional'-postconverging/dialecticalthinking -apriorising-psychologism deductive reasoning' as prelogism ${ }^{78}$ is effectively a sound construct for intemporal-preservation-entropy-or-contiguity-or-ontological-preservation and hence virtue; that is, so long as it is adhered to properly. However, this is not the case on two grounds. It is critical to distinguish a defect in improper processing/operating of supplantingconviction-as-to-profound-supererogation -of-'attendant-intradimensional'-

postconverging/dialectical-thinking -apriorising-psychologism or prelogism ${ }^{78}$ which is rather construed as a singular/ad-hoc 'implicitation-of-act-execution defect' and can be then qualified as a 'poor or bad supplanting-conviction-as-to-profound-supererogation - of-'attendantintradimensional'-postconverging/dialectical-thinking -apriorising-psychologism'; it being nonetheless a supplanting-conviction-as-to-profound-supererogation - of-'attendantintradimensional'-postconverging/dialectical-thinking -apriorising-psychologism or prelogism $^{78}$ as it holds the teleological aim of 'intemporal preservation with a principled adherence to supplanting-conviction-as-to-profound-supererogation - of-'attendantintradimensional'-postconverging/dialectical-thinking -apriorising-psychologism' even though it delivered an inappropriate/poor-or-bad ${ }^{54}$ logical-processing-or-logical-implicitation- 
supposedly-apriorising-in-conviction-as-to-profound-supererogation . On-the-other-hand, a defect of postlogism 7 /psychopathy compulsing-nonconviction/madeupness/bottomlining$〈<<$ decontextualising/de-existentialising of-attendant-intradimensionalapriorising/axiomatising/referencing>-induced-disontologising'-of-the-'attendantintradimensional-ontologising'-imbued-<contextualising/existentialising $\sim$ attendantontological-contiguity $>$;-in-shallow-supererogation -<as-to-disontologising-pervertedoutcome-sought-precedes-existentially-veridical-'attendant-intradimensionalapriorising/axiomatising/referencing'-logical-dueness $>$ > in hollow-constituting-<as-disjointedmisappropriation-of-meaningfulness-and-failing-intemporal-preservation $>$ operates on the 'parasitising/co-opting' basis that intemporal-preservation-entropy-or-contiguity-orontological-preservation $\quad{ }^{83}$ reference-of-thought- categorical-imperatives/axioms/registryteleology ${ }^{9}$ are mere-formulaic determinants of human thought and action and is the basis for perversion-of- ${ }^{3}$ reference-of-thought-<as-preconvergingly-

\section{apriorising/axiomatising/referencing-in-nonconviction/madeupness/bottomlining-as-to-}

shallow-supererogation $>$. Such a defect is 'registry-worldview's/dimension'suninstitutionalised-threshold ${ }^{102}$-defect-<as-Being-or-ontological-or-existential-defect $>{ }^{5}$, as it rather holds the teleological aim of 'temporal preservation/undermining-of-intemporalpreservation without a principled adherence to prelogism 7 -as-of-conviction,-in-profoundsupererogation -<existentially-veridical-'attendant-intradimensionalapriorising/axiomatising/referencing'-logical-dueness-precedes-disontologising-logicaloutcome-arrived-at>' and thus speaks to the disposition to act likewise technically in a large or infinite number of cases (syncretising). It should be noted that temporal-dispositions (5ignorance/affordability/opportunism/exacerbation/social-chainism-or-social-discomfiture-ornegative-social-aggregation/temporal-enculturation-or-temporal-endemisation) are in-ofthemselves act defects and not being defects. However, such temporal-dispositions are registry- 
worldview's/dimension's-uninstitutionalised-threshold ${ }^{102}$-defect-<as-Being-or-ontological-orexistential-defect $>85$ when these relay postlogism 77 in hollow-constituting-<as-disjointedmisappropriation-of-meaningfulness-and-failing-intemporal-preservation $>$ as of formulaic slanting compulsing-nonconviction/madeupness/bottomlining-〈' $<$ decontextualising/deexistentialising $\sim$ of-attendant-intradimensional-apriorising/axiomatising/referencing $>$-induceddisontologising'-of-the-'attendant-intradimensional-ontologising'-imbued$<$ contextualising/existentialising attendant-ontological-contiguity $>$;-in-shallowsupererogation -<as-to-disontologising-perverted-outcome-sought-precedes-existentiallyveridical-'attendant-intradimensional-apriorising/axiomatising/referencing'-logical-dueness $>$ > as to threshold-of-nonconviction/madeupness/bottomlining-in-shallow-supererogation $-<$ asto-'attendant-intradimensional'-prospectively-disontologising preconverging/dementing apriorising-psychologism> (whether of the psychopath or not) inducing narratives that are slanted/preconverging-or-dementing ${ }^{20}$-apriorising-psychologism/dialectically-or-contendinglyout-of-phase/non-ontological-reference/non-contending-reference-but-ontologically-orcontendingly-reflected-or-perspectivated as in ${ }^{74}$ perversion-of- ${ }^{8}$ reference-of-thought- $<$ aspreconvergingly-apriorising/axiomatising/referencing-innonconviction/madeupness/bottomlining-as-to-shallow-supererogation $>$ and not-of-logicalcontention; due to the miscuing, disjointed-logic, logical-drag, unconscionability-drag, subpar/formulaic-association/temporal/alibi conventioning-rationalising and temporalenculturation/temporal-endemisation (occurring at the specific temporal-dispositions). For instance, going by the BODMAS equation highlighted before, the mere operation of arithmetic without factoring in A's condition/subknowledging -impulse/compulsive-slantingpreconverging-or-dementing -apriorising as of incrementalism-in-relative-ontologicalincompleteness ${ }^{8}$ — enframed/disontologising conceptualisation additionality with 1 leads to a systematic failure that is ontological and not a mere act defect, and defines an uninstitutionalised- 
threshold ${ }^{102}$. It should be noted that at all uninstitutionalised-threshold ${ }^{102}$, it is ${ }^{15}$ de-mentation〈supererogatory $\sim$ ontological-de-mentation-or-dialectical-de-mentation-stranding-or-

attributive-dialectics $\rangle$ that enables the mental-reflecting/perspectivating/highlighting (reasoningthrough-and-not-reasoning-with)-representation of the registry-worldview's/dimension'suninstitutionalised-threshold ${ }^{102}$-defect- $<$ as-Being-or-ontological-or-existential-defect $>$ as perversion-of- ${ }^{8}$ reference-of-thought- $<$ as-preconverginglyapriorising/axiomatising/referencing-in-nonconviction/madeupness/bottomlining-as-toshallow-supererogation $>$ in construing unsoundness-or-ontological-bad-faith/inauthenticity ${ }^{64}$ of- ${ }^{3}$ reference-of-thought (preconverging-or-dementing ${ }^{20}$-apriorising-psychologism- $<$ strandedas-rightfully-oblongated/decandored-and-dialectically-or-contendingly-out-of-phase >) from whence an exercise of 'postconverging-or-dialectical-thinking - psychology or psychology-ofmentation-dynamics or natural psychological-dynamics’ psychoanalytic-unshackling/memeticreordering/institutional-recomposuring with new ${ }^{83}$ reference-of-thought- categoricalimperatives/axioms/registry-teleology ${ }^{9}$,-for-intemporal-preservation-entropy-or-contiguityor-ontological-preservation initiates a crossgenerational transcendence-andsublimity/sublimation/supererogatory-de-mentativity. Ontologically, the mental-devisingrepresentation of such perversion-of- ${ }^{7}$ reference-of-thought- $<$ as-preconverginglyapriorising/axiomatising/referencing-in-nonconviction/madeupness/bottomlining-as-to-

shallow-supererogation $>$ is as strands-of-perverting-temporal-dispositions, involving oblongating/decandoring/distractive-alignment-to- ${ }^{8}$ reference-of-thought- $<$ ofapriorising/axiomatising/referencing $>{ }^{30}$, that defines the dialectical-out-of-phasing (whether recurrent-utter-uninstitutionalisation, ununiversalisation, non-positivism/medievalism and, in the prospective representation, of procrypticism) as ${ }^{74}$ perversion-of- ${ }^{2}$ reference-of-thought- $<$ aspreconvergingly-apriorising/axiomatising/referencing-innonconviction/madeupness/bottomlining-as-to-shallow-supererogation $>$. For instance, in 
registry-worldview/dimension terms, medievalism/non-positivistic mental-disposition is systematically registry-worldview's/dimension's-uninstitutionalised-threshold ${ }^{102}$-defect- $<$ asBeing-or-ontological-or-existential-defect $>85$ at the uninstitutionalised-threshold ${ }^{102}$ where you need a positivisitic mental-disposition for intemporal-preservation-entropy-or-contiguity-orontological-preservation.

Likewise,

procrypticism

(threshold-ofnonconviction/madeupness/bottomlining-in-shallow-supererogation $<<$ as-to-' attendantintradimensional'-prospectively-disontologising preconverging/dementing -apriorisingpsychologism>/unsoundness-or-ontological-bad-faith/inauthenticity ${ }^{64}$-of- ${ }^{8}$ reference-ofthought/mental-perversion/subknowledging /mimicking-and-corresponding $<$ amplituding/formative-epistemicity $>$ totalising $\sim$ self-referencingsyncretising/circularity/interiorising/akrasiatic-drag ${ }^{34}$ of positivistic ${ }^{83}$ reference-of-thoughtcategorical-imperatives/axioms/registry-teleology ${ }^{9}$,-for-intemporal-preservation-entropy-orcontiguity-or-ontological-preservation) is $\quad$ registry-worldview's/dimension'suninstitutionalised-threshold ${ }^{102}$-defect-<as-Being-or-ontological-or-existential-defect $>55$ at the uninstitutionalised-threshold ${ }^{102}$ where you need deprocrypticism. Reality being blunt/incisive as it is rather preceding/superseding and ontological-normalcy/postconvergence with respect to us, is in essence of potent operant and deterministic phenomenality that doesn't have any place for our thresholding discrete incrementalism-in-relative-ontological-incompleteness ${ }^{8}$ enframed/disontologising conceptualisation notions but even for the cases where such discretion is artificially devised/implied, it is applied as operant and deterministic (consider quantum-mechanics). So ontologically, the mental-devising-representation of ${ }^{74}$ perversion-ofreference-of-thought-<as-preconvergingly-apriorising/axiomatising/referencing-innonconviction/madeupness/bottomlining-as-to-shallow-supererogation $>$ as strands-ofperverting-temporal-dispositions is definitely accurate on two insightful grounds. Reality's bluntness/incisiveness doesn't leave room for discretionary judgments about 'good- 
natured'/impression-driven conceptualisations of virtue and virtuous judgment within the overarching framework of such the-Good/knowledge-reification $\sim$ gesturing-and-accountingof-epistemic-phenomenalism- $<$ in-

prospective_psychologismic apriorising/axiomatising/referencing-\{of-'prospectively implicited_attendant-ontological-contiguity ' educedexistentialising/contextualising/textualising_'intelligibility/epistemicity/reflexivity_contiguity<imbued-notional cogency >' \}-conflatedness -in-\{preconverging-disentailment by\} postconverging-entailment $>$ /understanding/<amplituding/formativeepistemicity $>$ causality $\sim$ as-to-projective-totalitative-implications-of-prospectivenonpresencing,-for-explicating relative-unreflexivity/relative-reflexivity - ontologicalcontiguity reality determinism, and such impressions can only pass for an illusion-of-thepresent/present-consciousness mirage and/or <amplituding/formativeepistemicity $>$ totalising $\sim$ self-referencing-syncretising/circularity/interiorising/akrasiatic-drag (attempting to operate logic in a superseding registry-worldview on the basis of the ${ }^{8}$ referenceof-thought- ${ }^{8}$ ategorical-imperatives/axioms/registry-teleology ${ }^{9}$,-for-intemporal-preservationentropy-or-contiguity-or-ontological-preservation of a superseded registry-worldview; for instance, God-of-plane type of statement in say an animistic society that comes in contact with foreigners and a plane). The second reason is that we can garner insight on prior/superseded institutionalisations and understand that the vices-and-impediments ${ }^{105}$ are actually crosssectional to the registry-worldviews/dimensions as of beyond-the-consciousness-awarenessteleology ${ }^{9}<$ of-preconverging-existential-extrication-as-of-existential-unthought $>$ and it is intemporal philosophical development that goes on to liberate/enlighten/moult-out 'actors of transcendence-and-sublimity/sublimation/superentativity' who in turn then shine the light across society, i.e. institutionalisation/intemporalisation by skewing ('intemporality ${ }^{52}$-symmetrising-by-desymmetrising-subsumption-of-temporality ${ }^{8}$, for relative 
intrinsic-reality/ontological-veridicality

transcendental-

enabling/sublimating/supereregatery $\sim$ de-mentativity)/deferential-formalisation-transference for the supersedingness of the intemporal-disposition over temporal-dispositions for intemporalpreservation-entropy-or-contiguity-or-ontological-preservation.

Transcendence-andsublimity/sublimation/supererogatery $\sim$ de-mentativity as such is more of a deterministic and operant process than discretionary, and works on the-Good/knowledge-reification $\sim$ gesturingand-accounting - of-epistemic-phenomenalism- $<$ inprospective_psychologismic apriorising/axiomatising/referencing-\{of- ${ }^{\text {}}$ prospectively implicited_attendant-ontological-contiguity ' educedexistentialising/contextualising/textualising_'intelligibility/epistemicity/reflexivity-contiguity<imbued-notional cogency >' \}-conflatedness -in-\{preconverging-disentailment by\} postconverging-entailment $>$ /understanding/<amplituding/formativeepistemicity $>$ causality $\sim$ as-to-projective-totalitative-implications-of-prospectivenonpresencing,-for-explicating relative-unreflexivity/relative-reflexivity ontologicalcontiguity basis, even though counterintuitively we tend to turn towards impressions to construe virtue which only confuses the issue as we then wrongly define fulfilling temporal whims (good-natured impressions or not) of the 'collective consciousness of the corresponding present-consciousness/illusion-of-the-present' as an intemporal reference for defining virtue (with no 'emanance disambiguation'/notional firstnaturedness-formativeness-<as-toeventualising inkling drive or -seeding-misprising $>$ temporal-to-intemporal-dispositions$<$ so-construed-as-from-perspective-ontological-normalcy/postconvergence $>$ ), rather than a transcendental understanding of the-Good, i.e. knowledge/virtue-as-institutionalcumulation/institutional-recomposure-〈as-to- historiality/ontologicaleventfulness /ontological-aesthetic-tracing-<perspective-ontologicalnormalcy/postconvergence-reflected-‘epistemicity-relativism-determinism'>>-for-intemporal- 
preservation. This points to the fact that necessarily the preconverging/postconverging-dementative/structural/paradigmatic virtue construct (knowledge-driven) of recurrent-utteruninstitutionalisation is base-institutionalisation, ununiversalisation is ${ }^{103}$ universalisation, nonpositivism/medievalism is positivism, and prospectively, that of our positivism/rational-

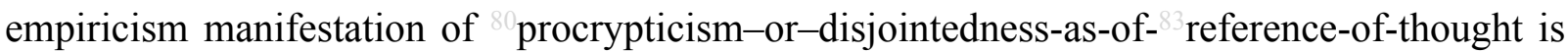
deprocrypticism-or-preempting-disjointedness-as-of- reference-of-thought; and so as a veridical and contiguous deterministic-and-operant psychoanalytic-unshackling/memeticreordering/institutional-recomposuring for intemporal-preservation-entropy-or-contiguity-orontological-preservation, that knows no discretion! There are 'traditionally 4 human mental projections/representations/dispositions' associated with virtuous preconverging/postconverging-de-mentative/structural/paradigmatic construct, analysed from the perspective of an ontological-veridicality establishing <amplituding/formativeepistemicity $>$ causality $\sim$ as-to-projective-totalitative-implications-of-prospectivenonpresencing,-for-explicating relative-unreflexivity/relative-reflexivity - ontologicalcontiguity : (i) The-Good/knowledge-reification $\sim$ gesturing-and-accounting-of-epistemicphenomenalism-<in-prospective_psychologismic $\sim$ apriorising/axiomatising/referencing- $\{$ of'prespectively_implicited_attendant-ontological-contiguity ' educedexistentialising/contextmalising/textualising_'intelligibility/epistemicity/reflexivity_contiguity<imbued-notional cogency $>$ ' \}-conflatedness -in-\{preconverging-disentailment by\} postconverging entailment $>$ /understanding/<amplituding/formativeepistemicity $>$ causality $\sim$ as-to-projective-totalitative-implications-of-prospectivenonpresencing,-for-explicating relative-unreflexivity/relative-reflexivity - ontologicalcontiguity construal/conceptualisation (understanding) which is effectively ontologically operant. (ii) The-Good/knowledge-reification $\sim$ gesturing-and-accounting-of-epistemicphenomenalism-<in-prospective_psychologismic $\sim$ apriorising/axiomatising/referencing- of- 
'prospectively_implicited_attendant-ontological-contiguity ' educed-

existentialising/contextualising/textualising_ 'intelligibility/epistemicity/reflexivity-contiguity<imbued-notional cogency>> $\}$-conflatedness -in-\{preconverging-disentailment by\} postconverging-entailment $>/$ understanding/<amplituding/formativeepistemicity $>$ causality $\sim$ as-to-projective-totalitative-implications-of-prospectivenonpresencing,-for-explicating relative-unreflexivity/relative-reflexivity ontologicalcontiguity construal/conceptualisation which has poor operance due to "poor or bad supplanting-conviction-as-to-profound-supererogation —of-'attendant-intradimensional'postconverging/dialectical-thinking -apriorising-psychologism', though prelogism ${ }^{78}$-as-of-

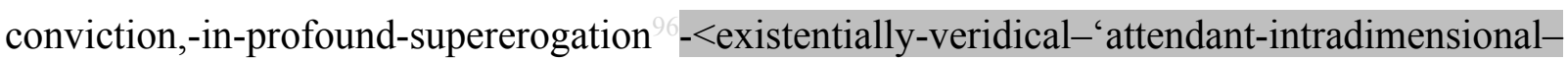
apriorising/axiomatising/referencing'-logical-dueness-precedes-disontologising-logicaloutcome-arrived-at $>$ nonetheless. (iii) An impression-driven/good-naturedness/wishfulness conceptualisation involving perversion-of- ${ }^{7}$ reference-of-thought- $<$ as-preconverginglyapriorising/axiomatising/referencing-in-nonconviction/madeupness/bottomlining-as-toshallow-supererogation $>$ or slantedness operance from an <amplituding/formativeepistemicity $>$ causality $\sim$ as-to-projective-totalitative-implications-of-prospectivenonpresencing,-for-explicating relative unreflexivity/relative reflexivity - ontologicalcontiguity perspective; which is the foundation for derived- ${ }^{7}$ perversion-of- ${ }^{8}$ reference-ofthought-<as-preconvergingly-apriorising/axiomatising/referencing-innonconviction/madeupness/bottomlining-as-to-shallow-supererogation $>$ as of ontologicalincompletenss-of- ${ }^{-3}$ reference-of-thought (iv) An impression-driven/goodnaturedness/wishfulness conceptualisation involving ${ }^{74}$ perversion-of- ${ }^{3}$ reference-of-thought$<$ as-preconvergingly-apriorising/axiomatising/referencing-innonconviction/madeupness/bottomlining-as-to-shallow-supererogation $>$ or slantedness operance from an <amplituding/formative-epistemicity $>$ causality $\sim$ as-to-projective- 
totalitative-implications-of-prospective- nonpresencing,-for-explicating relative-

unreflexivity/relative-reflexivity ontological-contiguity perspective; which generates

(distractive-alignment-to- ${ }^{8}$ reference-of-thought- $<$ of-apriorising/axiomatising/referencing $>{ }^{30}$ )

perversion-of- ${ }^{8}$ reference-of-thought- $<$ as-preconvergingly-

apriorising/axiomatising/referencing-in-nonconviction/madeupness/bottomlining-as-to-

shallow-supererogation $>$ /mental-perversion or slantedness along ${ }^{83}$ reference-of-thoughtcategorical-imperatives/axioms/registry-teleology ${ }^{9}$,-for-intemporal-preservation-entropy-or-

contiguity-or-ontological-preservation of the-Good conceptualisation; pointing to the fact that impression-driven/good-naturedness/wishfulness conceptualisations are rather inclined to induce vices-and-impediments ${ }^{105}$ given that the veridicality of reality (reflected by theGood/knowledge-reification $\sim$ gesturing-and-accounting —of-epistemic-phenomenalism- $<$ inprospective_psychologismic apriorising/axiomatising/referencing-\{of-'prospectively implicited_attendant-ontological-contiguity ' educedexistentialising/contextualising/textualising_ 'intelligibility/epistemicity/reflexivity-contiguity<imbued-notional cogency >’ $\}$-conflatedness -in-\{preconverging-disentailment by\} postconverging-entailment $>$ /understanding/<amplituding/formativeepistemicity $>$ causality $\sim$ as-to-projective-totalitative-implications-of-prospectivenonpresencing,-for-explicating relative-unreflexivity/relative-reflexivity - ontologicalcontiguity conceptualisation) is all the virtue enabler that there is and other conceptualisations are rather distractions that are in effect vice-ridden and an impediment, and more specifically when these undermine the-Good/knowledge-reification $\sim$ gesturing-and-accounting-ofepistemic-phenomenalism-<in-

prospective_psychologismic apriorising/axiomatising/referencing-\{of-'prospectively implicited_attendant-ontological-contiguity ' educedexistentialising/contextualising/textualising_'intelligibility/epistemicity/reflexivity-contiguity- 
<imbued-notional cogency>' \}-conflatedness -in-\{preconverging-disentailment by\}

postconverging entailment $>$ /understanding/<amplituding/formative-

epistemicity $>$ causality $\sim$ as-to-projective-totalitative-implications-of-prospective-

nonpresencing,-for-explicating relative-unreflexivity/relative-reflexivity - ontological-

contiguity conceptualisation. Impression-driven/good-naturedness/wishfulness

conceptualisation lack veridical relative-unreflexivity/relative-reflexivity - ontologicalcontiguity ${ }^{67}$. One may query what is the meaning of good/truth/essence in a recurrent-utterinstitutionalised, an ununiversalised or a non-positivistic society? And invariably the answers will be a vague <amplituding/formative-epistemicity $>$ totalising $\sim$ self-referencingsyncretising/circularity/interiorising/akrasiatic-drag ${ }^{34}$ as of each registry-worldview/dimension, and it is rather the emanant insight of 'prospective postconvergingaaporeticismovercoming/unovercoming as the-Good/knowledge-reification $\sim$ gesturing-and-accounting-ofepistemic-phenomenalism-<in-

prospective_psychologismic apriorising/axiomatising/referencing-\{of-'prospectively implicited_attendant-ontological-contiguity ' educedexistentialising/contextualising/textualising_'intelligibility/epistemicity/reflexivity_contiguity<imbued-notional cogency $>$ ' $\}$-conflatedness in \{preconverging disentailment by\} postconverging-entailment $>$ /understanding/<amplituding/formativeepistemicity $>$ causality $\sim$ as-to-projective-totalitative-implications-of-prospectivenonpresencing,-for-explicating relative-unreflexivity/relative-reflexivity - ontologicalcontiguity ' conceptualisation as of Being-development/ontological-framework-expansion-asto-depth-of-ontologising-development-as-infrastructure-of- meaningfulness-and-teleology that carries the prospective transcendence-and-sublimity/sublimation/sperementativity which are the resolution of the successive prior registry-worldview's/dimension's uninstitutionalised-threshold ${ }^{102}$ vices-and-impediments ${ }^{105}$; and so by successive Being- 
development/ontological-framework-expansion-as-to-depth-of-ontologising-development-asinfrastructure-of- meaningfulness-and-teleology in reflecting holographically$<$ conjugatively-and-transfusively $>$ the relative-unreflexivity/relative-reflexivity - ontologicalcontiguity of-the-human-institutionalisation-process as base-institutionalisation, universalisation and positivism respectively, and prospectively deprocrypticism., i.e. Increasing knowledge-as-virtue understanding, as of ${ }^{83}$ reference-of-thought- categoricalimperatives/axioms/registry-teleology ${ }^{9}$,-for-intemporal-preservation-entropy-or-contiguityor-ontological-preservation as of their respective elucidation-of 'implicited_attendantontological-contiguity ${ }^{67}$, educed-

existentialising/contextualising/textualising_intelligibility/epistemicity/reflexivity-contiguity$<$ imbued-notional $\sim$ cogency $>{ }^{\prime},-<$ reifying-or-elucidating-of-prospective-relative-ontologicalcompleteness -of- reference-of-thought- devolving-as-of-instantiative-context> (recurrentutter-uninstitutionalisation non-rules_-apriorising/axiomatising/referencing-psychologism,-asimpulsive-or-accidented-or-random-mental-disposition as failing/not-upholding-<as-ofapriorising/axiomatising/referencing> rulemaking-over-non-rulesapriorising/axiomatising/referencing-psychologism,-〈as'first-level presencing-absolutisingidentitive-constitutedness of reference-of-thought' apriorising/axiomatising/referencing/intelligibilitysettingup/measuringinstrumenting required for base-institutionalisation-ununiversalisation, ununiversalisation failing/not-upholding-<asof-apriorising/axiomatising/referencing $>\quad{ }^{103}$ universalisation-directed-rulemaking-over-nonrules_-apriorising/axiomatising/referencing-psychologism,-〈as 'second-level presencingabsolutising-identitive-constitutedness of reference-of-thought' apriorising/axiomatising/referencing/intelligibilitysettingup/measuringinstrumenting $\rangle$ required for ${ }^{103}$ universalisation-non-positivism/medievalism, non-positivism/medievalism failing/notupholding-<as-of-apriorising/axiomatising/referencing $>\quad$ positivising/rational-empiricism- 
based-universalisation-directed-rulemaking-over-non-rulesapriorising/axiomatising/referencing-psychologism,-〈as 'third-level presencingabsolutising-identitive-constitutedness ${ }^{14}$ of reference-of-thought' apriorising/axiomatising/referencing/intelligibilitysettingup/measuringinstrumenting $\rangle$ required for positivism- ${ }^{80}$ procrypticism or prospectively, positivism failing/not-upholding-<as-ofapriorising/axiomatising/referencing $>\quad$ 'notional ${ }^{18}$ deprocrypticism preemptingdisjointedness-as-of- ${ }^{8}$ reference-of-thought,-as-to- ${ }^{32}<$ amplituding/formativeepistemicity $>$ growth-or-conflatedness ${ }^{13} /$ transvaluativerationalising/transepistemicity/anamnestic-residuality/spirit-drivenness'_-in-supersedingmere-formulaic-positivising/rational-empiricism-based-universalisation-directed-rulemakingover-non-rules - apriorising/axiomatising/referencing-psychologism,〈apriorising/axiomatising/referencing-\{of-‘prospectively implicited_attendant-ontologicalcontiguity ' educedexistentialising/contextualising/textualising_ 'intelligibility/epistemicity/reflexivity-contiguity<imbued-notional cogency >' \}-conflatedness ${ }^{13}$ in (preconverging disentailment by postconverging-entailment $\rangle$ required for perpetuating-deprocrypticism). Practically, however 'good intentioned or good-natured' a non-positivism/medievalism mindset/ ${ }^{83}$ reference-ofthought it is bound to rely on medieval ${ }^{83}$ reference-of-thought- categoricalimperatives/axioms/registry-teleology ${ }^{9}$ of sickness like a curse or witchcraft rather than a positivist notion like infection, and the virtuous outcome is fundamentally a question of 'prospective postconvergingaaporeticism-overcoming/unovercoming as the-Good/knowledgereification $\sim$ gesturing-and-accounting — of-epistemic-phenomenalism- $<$ inprospective_psychologismic apriorising/axiomatising/referencing-\{of-'prospectively implicited_attendant-ontological-contiguity ' educedexistentialising/contextualising/textualising_ 'intelligibility/epistemicity/reflexivity-contiguity- 
<imbued-notional cogency>' \}-conflatedness -in-\{preconverging-disentailment by\}

postconverging-entailment $>$ /understanding/<amplituding/formative-

epistemicity $>$ causality $\sim$ as-to-projective-totalitative-implications-of-prospective-

nonpresencing,-for-explicating relative-unreflexivity/relative-reflexivity - ontological-

contiguity ' of positivistic understanding, and not any vague impression! Not only is impression-driven/good-naturedness/wishfulness conceptualisation at best vague, ontologically speaking, it is bound to be extricatory (temporal/circumstantial/self-interest preconverging-dementating/structuring/paradigming) rather than intemporal/ontological/social/species $/{ }^{103}$ universal/transcendental $/{ }^{5}$ maximalisingrecomposuring-for-relative-ontological-completeness ${ }^{8}$ —unenframed/reontologising conceptualisation postconverging-de-mentating/structuring/paradigming. Alignment should rather be in transversality-<for-sublimating-existentialeventuating/denouement,-from-'thinking-at-first/pure-predisposition-preemptive-ofprospective-disontologising/subontologising' as-of-prospectively-disambiguated-affirmedand-unaffirmed-'motif-and-apriorising/axiomatising/referencing'> ${ }^{101}$ as strands-of-pervertingtemporal-dispositions as the backdrop for prospective ${ }^{83}$ reference-of-thought- categoricalimperatives/axioms/registry-teleology ${ }^{9}$,-for-intemporal-preservation-entropy-or-contiguityor-ontological-preservation of 'prospective postconverging-apereticismovercoming/mnovercoming as the-Good/knowledge-reification $\sim$ gesturing-and-accounting-ofepistemic-phenomenalism- $<$ inprospective_psychologismic apriorising/axiomatising/referencing-\{of-'prospectively implicited_attendant-ontological-contiguity ' educedexistentialising/contextrising/textlising_intelligibility/epistemicity/reflexivity-contiguity<imbued-notional cogency $\left.>^{\prime} \quad\right\}$-conflatedness -in-\{preconverging-disentailment by\} postconverging-entailment $>$ /understanding/<amplituding/formative- 
epistemicity $>$ causality $\sim$ as-to-projective-totalitative-implications-of-prospective-

nonpresencing,-for-explicating relative-unreflexivity/relative-reflexivity - ontological-

contiguity , conceptualisation. Further, impression-driven/good-naturedness/wishfulness conceptualisation induces both 'logical and unconscionability-drags. A drag is a vague meaningful articulation arising out of veridical incongruence due to the nonreality of initiating narratives or propositions, and subsequent preconverging/postconverging-dementative/structural/paradigmatic contiguity of narratives and propositions thereafter from such initial miscues and/or intermittent miscues. For instance, supposed going by the example where a psychopath had wrongly accused someone of being a paedophile (not in terms-as-ofaxiomatic-construct of 'poor or bad supplanting-conviction-as-to-profound-supererogation of-'attendant-intradimensional'-postconverging/dialectical-thinking -apriorisingpsychologism, or prelogism $^{78}$ but rather ${ }^{11}$ compulsingnonconviction/madeupness/bottomlining-〈'<decontextualising/de-existentialising $\sim$ ofattendant-intradimensional-apriorising/axiomatising/referencing--induced-disontologising'-ofthe-'attendant-intradimensional-ontologising'-imbued$<$ contextualising/existentialising attendant-ontological-contiguity $>$;-in-shallowsupererogation -<as-to-disontologising-perverted-outcome-sought-precedes-existentiallyveridical-'attendant-intradimensional-apriorising/axiomatising/referencing'-logical-dueness $>$ > as to threshold-of-nonconviction/madeupness/bottomlining-in-shallow-supererogation $-<$ asto- 'attendant-intradimensional'-prospectively-disontologising preconverging/dementing apriorising-psychologism> due to the non-existence of the psychopath's fepistemictotalising ${ }^{3}$ psychologismic-subliminality-of-individuation-effusing/worlding imbued logicaldueness-or-scape-or-frame, profile-or-stature, presumptuousness-or-arrogation, assumptions, value-reference and teleology ${ }^{9}$ ), suppose the interlocutor was to go on to in-conviction-as-toprofound-supererogation relay these distortions with other interlocutors, we will talk of a 
'miscue', and where other meaning grounded fundamentally on this miscue were to develop, we talk of 'logical-drag', further where comprehensive generation of social meaningfulness were to arise out of this, we talk of 'unconscionability-drag', and finally sub-par/formulaicassociation/temporal/alibi conventioning-rationalising refers to the temporal mental-disposition to use conventioning thinking as alibi for temporal-motivated dispositions (over the inherent sense of ontological meaningfulness). Actually, strands-of-perverting-temporal-dispositions are the characteristic backdrop mental-devising-representations of superseded/transcended registryworldviews/dimensions when we think from an ontological perspective of the soundness-orontological-good-faith/authenticity ${ }^{6}$-of- ${ }^{8}$ refence-of-thought projection/representation that captures the meaningful framework of a registry-worldview teleology ${ }^{9}$ whether regarding a society at its ununiversalisation whether as recurrent-utter-uninstitutionalisation, ununiversalisation, and medieval/non-positivisitic, and prospectively, we can garnered such strands-of-perverting-temporal-dispositions with respect to procrypticism from futural Beingdevelopment/ontological-framework-expansion-as-to-depth-of-ontologising-development-asinfrastructure-of- meaningfulness-and-teleology as of prospective notional ${ }^{18}$ deprocrypticism institutionalisation. Human mental development across time validate the notion that we have consistently been in a state of psychoanalyticunshackling/memetic-reordering/institutional-recomposuring as we institutionally skew/deferential-formalisation-transference towards intemporal-preservation-entropy-orcontiguity-or-ontological-preservation with a better grasp of reality and $<$ amplituding/formative-epistemicity $>$ causality $\sim$ as-to-projective-totalitative-implications-ofprospective- nonpresencing,-for-explicating relative-unreflexivity/relative-reflexivity ontological-contiguity . Memetic-reordering (psychoanalytic-unshackling) inducing institutionalised skewing ('intemporality ${ }^{52}$-symmetrising-by-desymmetrising-subsumption-oftemporality ${ }^{\circ}$, for relative intrinsic-reality/ontological-veridicality transcendental- 
enabling/sublimating/supererogatory $\sim$ de-mentativity)/deferential-formalisation-transference towards intemporal-disposition involves: articulating a social ${ }^{103}$ universal-transparency 〈transparency-of-totalising-entailing,-as-to-entailing-<amplituding/formative-

epistemicity $>$ totalising in-relative-ontological-completeness $>$ of ${ }^{74}$ perversion-of- ${ }^{8}$ referenceof-thought-<as-preconvergingly-apriorising/axiomatising/referencing-in-

nonconviction/madeupness/bottomlining-as-to-shallow-supererogation $>$ defect; positiveopportunism - of-social-functioning-and-accordance ${ }^{75}$ as common interests to institutionally skew/deferential-formalisation-transference towards intemporality ${ }^{52}$; disambiguating temporaldispositions as the backdrop for new anticipatory and preempting ${ }^{83}$ reference-of-thoughtcategorical-imperatives/axioms/registry-teleology ${ }^{9}$,-for-intemporal-preservation-entropy-orcontiguity-or-ontological-preservation; and, intemporal projection superseding of transcendence-unenabling-uninstitutionalised-threshold ${ }^{102}$ in alienation-as-inauthentic/poorlyobjectified/poorly-desubjectified-as-objectified/ontological-bad-faith/inauthenticity ${ }^{64} /$ nihilistic for crossgenerational collapsing/overriding of temporal/preconverging-or-dementing ${ }^{20}$ apriorising-psychologism registry-worldview/dimension (and not instant 'argumentation convincing' intradimensionally in a registry-worldview/dimension that is defective or perversion-of- ${ }^{3}$ reference-of-thought-<as-preconvergingly-

apriorising/axiomatising/referencing-in-nonconviction/madeupness/bottomlining-as-to-

shallow-supererogation $>$ in the first place), and so in transversality-<for-sublimatingexistential-eventuating/denouement-from-'thinking at-first/pure-predisposition-preemptive-ofprospective-disontologising/subontologising' as-of-prospectively-disambiguated-affirmedand-unaffirmed-'motif-and-apriorising/axiomatising/referencing'> ${ }^{101}$ of temporal-dispositions and the intemporal-disposition; as temporal emanant registries are inclined to aside and syncretise rather than transcend or core/take-stock of the implied ${ }^{74}$ perversion-of- ${ }^{8}$ reference-ofthought-<as-preconvergingly-apriorising/axiomatising/referencing-in- 
nonconviction/madeupness/bottomlining-as-to-shallow-supererogation $>$ /mental-perversion at uninstitutionalised-threshold ${ }^{102}$. Memetic-reordering (psychoanalytic-unshackling) is actually the institutionalisation/intemporalisation process at uninstitutionalised-threshold ${ }^{102}$ requiring dimensionality-of-sublimating ${ }^{5}-\langle<$ amplituling-formative $>$ supererogatory - dementativeness/epistemic-growth-or-conflatedness /transvaluativerationalising/transepistemicity/anamnestic-residuality/spirit-drivenness-equalisation〉 projection to overcome temporal-dispositions (to supersede preconverging-or-dementing ${ }^{20}$ apriorising-psychologism- $<$ stranded-as-rightfully-oblongated/decandored-and-dialectically-orcontendingly-out-of-phase $>$ ), and so in a pedestalled disambiguation of ontologically veridical intemporal-disposition pedestal, slanting/postlogism 77 in hollow-constituting-<as-disjointedmisappropriation-of-meaningfulness-and-failing-intemporal-preservation>

subknowledging ${ }^{4}$ impulse by psychopath pedestal and slantedness/postlogic-integration as perversion-of- ${ }^{3}$ reference-of-thought-<as-preconvergingly-

apriorising/axiomatising/referencing-in-nonconviction/madeupness/bottomlining-as-to-

shallow-supererogation $>$ by the temporal-dispositions pedestals. Memetic-reordering (psychoanalytic-unshackling) is thus the central notion of a new and comprehensive human psychology wherein the human psyche is more of a 'mental devising tool' involving candoring/prelogism 7 /organic-comprehension-thinking and decandoring/distractive-alignmentto- ${ }^{83}$ reference-of-thought- $<$ of-apriorising/axiomatising/referencing $>$ \% $/$ threshold-ofnonconviction/madeupness/bottomlining-in-shallow-supererogation $-<$ as-to-'attendantintradimensional'-prospectively-disontologising preconverging/dementing -apriorisingpsychologism>. The former (candoring/prelogism $\%$ organic-comprehension-thinking) mental orientation points to supplanting-conviction-as-to-profound-supererogation - of-'attendantintradimensional'-postconverging/dialectical-thinking -apriorising-psychologism or prelogism $^{78}$ within any registry-worldview/dimension at institutionalised/intemporalised- 
thresholds-of-intemporal-preservation-entropy-or-contiguity-or-ontological-preservation basically focussed on operating/processing logic over supposedly sound ${ }^{83}$ reference-of-thoughtcategorical-imperatives/axioms/registry-teleology ${ }^{9}$,-for-intemporal-preservation-entropy-orcontiguity-or-ontological-preservation while the latter (decandoring/distractive-alignment-toreference-of-thought-<of-apriorising/axiomatising/referencing $>$ / $/$ threshold-ofnonconviction/madeupness/bottomlining-in-shallow-supererogation $-<$ as-to- 'attendantintradimensional'-prospectively-disontologising preconverging/dementing -apriorisingpsychologism $>$ mental orientation points to transcending situations of uninstitutionalisedthreshold ${ }^{102}$ whereby ${ }^{7}$ perversion-of- ${ }^{2}$ reference-of-thought- $<$ as-preconverginglyapriorising/axiomatising/referencing-in-nonconviction/madeupness/bottomlining-as-toshallow-supererogation $>$ /mental-perversions occur, due to the emanant reality of human temporal-to-intemporal nature, (and are relayed onto the social construct) and operates by reflecting/perspectivating/highlighting (reasoning-through-and-not-reasoning-with) perversion-of- ${ }^{3}$ reference-of-thought-<as-preconverginglyapriorising/axiomatising/referencing-in-nonconviction/madeupness/bottomlining-as-toshallow-supererogation $>$ /mental-perversions to establish unsoundness-or-ontological-badfaith/inauthenticity ${ }^{64}$-of- ${ }^{8}$ eference-of-thought and as this conjugates temporally with ignorance-affordability-opportunism-exacerbation-social-chainism/negative-socialaggregation-temporal enculturation/endemisation, and the need for new and superseding reference-of-thought- ${ }^{8}$ ategorical-imperatives/axioms/registry-teleology ${ }^{9}$,-for-intemporalpreservation-entropy-or-contiguity-or-ontological-preservation. These fundamental human mental-devising-representation or apriorising-registry tools of candoring and decandoring points to the very nature of logic. Logic requires that all interlocutors share a same ${ }^{8}$ referenceof-thought with regards to ${ }^{83}$ reference-of-thought- categorical-imperatives/axioms/registryteleology $9 /$ registry-teleology ${ }^{99}$ for its sound operation, thus logic can only be operated at 
institutionalised/intemporalised thresholds, and not as of uninstitutionalised-threshold ${ }^{102}$ where there is divergence in ${ }^{83}$ reference-of-thought construed ${ }^{56}$ meaningfulness-and-teleology construed as transversality- $<$ for-sublimating-existential-eventuating/denouement-from'thinking at-first/pure-predisposition-preemptive-of-prospectivedisontologising/subontologising’ - as-of-prospectively-disambiguated-affirmed-andunaffirmed-'motif-and-apriorising/axiomatising/referencing'> ${ }^{101}$. At uninstitutionalisedthreshold $^{102}$, given the veridicality of human emanance as temporal-to-intemporal, logic is ridiculous because of the variance and unshared ${ }^{83}$ reference-of-thought- categoricalimperatives/axioms/registry-teleology ${ }^{9} /$ registry-teleology ${ }^{9}$ in terms-as-of-axiomatic-construct of fepistemic-totalising $3{ }^{3}$ psychologismic-subliminality-of-individuation-effusing/worlding imbued logical-dueness-or-scape-or-frame, profile-or-stature, presumptuousness-or-arrogation, assumptions, value-reference and teleology ${ }^{99}$ with respect to argumentation, 'socially-perceivedvalue as of social-stake-contention-or-confliction'. At which point no articulation is inherently more right, however, the intemporal-disposition being ontological has <amplituding/formativeepistemicity $>$ causality $\sim$ as-to-projective-totalitative-implications-of-prospectivenonpresencing,-for-explicating relative-unreflexivity/relative-reflexivity —ontologicalcontiguity veridicality and carries a positive-opportunism-of-social-functioning-andaccordance $^{75}$ that can allow it to dominate human temporal-dispositions reflecting/perspectivating/highlighting (reasoning-through-and-not-reasoning-with) their registries/mental-representations perversion, and so, through social institutionalisation/intemporalisation percolation-channelling- $<$ in-deferential-formalisationtransference $>$ in the medium to long-run. It is only after such uninstitutionalised-threshold ${ }^{12}$ is superseded/dominated/preceded/overridden/uttered by the intemporal-disposition as an ordered construct institutionalisation/intemporalisation with corresponding human secondnaturing as internalisation and formalisation that logic becomes pertinent as it now operates only on one 
axiomatic-construct/categorical-imperatives/registry-teleology

that establishes the sublimating-postconverged 'substantive abstract-tissue-of-social-emanance fepistemicThermeneutically/textually/reprojectingly/supererogatingly/zeroingly/re-acutingly,$\{$ decompulsing $\}$ delinearity for-cogency—cumulated/recomposured as to cumulating/recomposuring of 'prospectively_implicited_attendant-ontological-contiguity ${ }^{67}$ ' educedexistentialising/contextualising/textualising_intelligibility/epistemicity/reflexivity-contiguity<imbued-notional cogency>' (not formulaic-projection/mimicry) and veracity/ontologicalpertinence of interlocutors' articulations. Thus the basis for Rational-Realism as the initial institutionalisation/intemporalisation recomposure orientation that goes beyond just articulating reference-of-thought- categorical-imperatives/axioms/registry-teleology ${ }^{9}$,-for-intemporalpreservation but involves anticipating human notional firstnaturedness-formativeness-<as-toeventualising-inkling-drive-or-seeding-misprising $>$ temporal-to-intemporal-dispositions$<$ so-construed-as-from-perspective-ontological-normalcy/postconvergence $>$ in preempting the perversion-of- ${ }^{3}$ reference-of-thought-<as-preconverginglyapriorising/axiomatising/referencing-in-nonconviction/madeupness/bottomlining-as-toshallow-supererogation $>$ of prior/superseded registry-worldview's ${ }^{83}$ reference-of-thoughtcategorical-imperatives/axioms/registry-teleology ${ }^{9}$,-for-intemporal-preservation-entropy-orcontiguity-or-ontological-preservation; as rational-realism take stock of the fundamental reality across all institutional-cumulation/institutional-recomposure-〈as-to- historiality/ontologicaleventfulness /ontological-aesthetic-tracing-<perspective-ontologicalnormalcy/postconvergence-reflected-'epistemicity-relativism-determinism'>> of human notional firstnaturedness-formativeness-<as-to-eventualising -inkling-drive - or - seedingmisprising $>$ temporal-to-intemporal-dispositions- $<$ so-construed-as-from-perspectiveontological-normalcy/postconvergence $>$ and doesn't just assume the wrong notion of just an intemporal-disposition with the ${ }^{7}$ perversion-of- ${ }^{83}$ reference-of-thought- $<$ as-preconvergingly- 


\section{apriorising/axiomatising/referencing-in-nonconviction/madeupness/bottomlining-as-to-}

shallow-supererogation $>$ result that temporal-dispositions induced manifestations are not accounted for, anticipated and preempted beforehand/as-of-a-priori to prevent their 7 perversionof- ${ }^{83}$ eference-of-thought-<as-preconvergingly-apriorising/axiomatising/referencing-innonconviction/madeupness/bottomlining-as-to-shallow-supererogation $>$ of ${ }^{83}$ reference-ofthought- categorical-imperatives/axioms/registry-teleology ${ }^{99}$,-for-intemporal-preservation at their uninstitutionalised-threshold ${ }^{12}$ thus ensuring ontological contiguity. So with rationalrealism the institutional-cumulation/institutional-recomposure-〈as-to- historiality/ontologicaleventfulness /ontological-aesthetic-tracing-<perspective-ontologicalnormalcy/postconvergence-reflected-'epistemicity-relativism-determinism'>> intemporalpreservation-entropy-or-contiguity-or-ontological-preservation comes around as the 'fullcycle/dynamic recomposuring' that specifically anticipates and preempt priorly/ahead in its reference-of-thought- categorical-imperatives/axioms/registry-teleology ${ }^{9}$,-for-intemporalpreservation-entropy-or-contiguity-or-ontological-preservation the notion of temporaldispositions to dement/subknowledge-/preconverging-or-dementing -as-if-of-soundknowledge)/mimick-and-syncretise (rather than subsequently as a transcendence-andsublimity/sublimation/supererogatory de-mentativity). This raises two dilemma with respect to the conceptualisation of virtue as rational-realism implies that at the procrypticism-ordisjointedness-as-of- ${ }^{8}$ reference-of-thought uninstitutionalised-threshold ${ }^{102}$, we have to register/acknowledge priorly our inclination to subknowledge-〈preconverging-or-dementing as-if-of-sound-knowledge) positivistic registry-worldview's/dimension's institutionalisation reference-of-thought- categorical-imperatives/axioms/registry-teleology 99 to paradoxically then be able to anticipate and stifle this in the active construction of deprocryptic meaning, at which point the ontological-veridicality of meaning then involves not only logical operation/processing/contention on the basis of a sole intemporal-disposition, but equally 
registries-disambiguation to account for ${ }^{74}$ perversion-of- ${ }^{3}$ reference-of-thought- $<$ aspreconvergingly-apriorising/axiomatising/referencing-innonconviction/madeupness/bottomlining-as-to-shallow-supererogation $>$ /mentalperversion/preconverging-or-dementing ${ }^{20}$-apriorising-psychologism by temporal-dispositions: $<$ amplituding/formative-epistemicity $>$ totalising $\sim$ self-referencingsyncretising/circularity/interiorising/akrasiatic-drag ${ }^{34}$ or Setting-aside (as being in denial of perversion-of- ${ }^{8}$ reference-of-thought-<as-preconvergingly-

apriorising/axiomatising/referencing-in-nonconviction/madeupness/bottomlining-as-to-

shallow-supererogation $>$ defect) arises where a registry-worldview returns to its same reference-of-thought- categorical-imperatives/axioms/registry-teleology ${ }^{9}$,-for-intemporalpreservation-entropy-or-contiguity-or-ontological-preservation that have been shown to be subknowledge-〈preconverging-or-dementing -as-if-of-sound-knowledge)/ perversion-ofreference-of-thought-<as-preconvergingly-apriorising/axiomatising/referencing-innonconviction/madeupness/bottomlining-as-to-shallow-supererogation $>$ /mental-perversion at the uninstitutionalised-threshold ${ }^{102}$, and hence remains candored/integratively-aligned; contrasted with the instance of the adoption of a new registry-worldview's (superseding the uninstitutionalised-threshold ${ }^{102}$ ) reference-of-thought- categoricalimperatives/axioms/registry-teleology ${ }^{9}$,-for-intemporal-preservation-entropy-or-contiguityor-ontological-preservation in anticipation and preemption of the afore ${ }^{7}$ perversion-ofreference-of-thought-<as-preconvergingly-apriorising/axiomatising/referencing-innonconviction/madeupness/bottomlining-as-to-shallow-supererogation $>$ registry-worldview. This latter instance involves ${ }^{15}$ de-mentation-/supererogatory ontological-de-mentation-ordialectical-de-mentation - stranding-or-attributive-dialectics $\rangle$ or Coring (in reflection/perspectivation and acknowledgment of 7 perversion-of- ${ }^{8}$ reference-of-thought- $<$ aspreconvergingly-apriorising/axiomatising/referencing-in- 
nonconviction/madeupness/bottomlining-as-to-shallow-supererogation $>$ ) with corresponding decandoring/distractive-alignment-to- ${ }^{8}$ reference-of-thought- $<$ of-

apriorising/axiomatising/referencing $>30$ and is what enables memeticreordering/psychoanalytic-unshackling whereas $<$ amplituding/formativeepistemicity $>$ totalising $\sim$ self-referencing-syncretising/circularity/interiorising/akrasiatic-drag or Setting-aside at best induces 'memetic-inching/psychoanalytic-realigning' which are not of an immediate transcending nature. (ii) Conventioning metaphoricity ${ }^{57}$ involving in a continuum on one side ontologising rationalising though ontological-veridicality is not the sufficient reason for the social acceptance of rightness for rightness sake (as explained previously) and on the other side intemporality ${ }^{2} /$ ontology distractive sub-par/formulaic-association/temporal/alibi conventioning-rationalising. 'Rational-realism of notional ' deprocrypticism as of ratiocontiguity/ratiocination-as-referentialism_-implicited_attendant-ontologicalcontiguity $^{67}$, educedexistentialising/contextualising/textualising_intelligibility/epistemicity/reflexivity-contiguity$<$ imbued-notional cogency $>{ }^{\prime 0}$ as nondisjointing or institutionalisation/intemporalisation fullcycle' can thus be construed as a contiguous cumulation of successive memetic-reordering (as institutional recomposuring) for intemporal-preservation-entropy-or-contiguity-or-ontologicalpreservation; with such successiveness due to the limitation of human mentation-capacity to be able to mimeticly (across suprastructural-meaningfulnes) come full-cycle in one transcendenceand-sublimity/sublimation/supererogatory-de-mentativity, explaining the recomposuring of the successive institutional-cumulation/institutional-recomposure-〈as-to- historiality/ontologicaleventfulness /ontological-aesthetic-tracing-<perspective-ontologicalnormalcy/postconvergence-reflected-'epistemicity-relativism-determinism'>>; from recurrentutter-uninstitutionalisation, base-institutionalisation-ununiversalisation, ${ }^{103}$ universalisationnon-positivism/medievalism, positivism- ${ }^{80}$ procrypticism, and recomposuring full-cycle towards 
prospective rational-realism as of deprocrypticism. Correspondingly, due to human limitedmentation-capacity-deepening —as-subjecting limitedness/human-subpotency-to-'educedunlimitedness/existence-sublimating nascence' ${ }^{53}$, human memetic/psychoanalytic grasp-andfulfilment of intemporal-preservation (in devising ${ }^{83}$ reference-of-thought- categoricalimperatives/axioms/registry-teleology ${ }^{9}$ ) is limited at successive instances of transcendence-andsublimity/sublimation/supererogatory-de-mentativity/institutionalisation, due to: (i) the reality of human dispositions not being just of intemporal-disposition but rather notional firstnaturedness-formativeness-<as-to-eventualising inkling-drive-or-seedingmisprising $>$ temporal-to-intemporal-dispositions- $<$ so-construed-as-from-perspectiveontological-normalcy/postconvergence> (with temporal-dispositions a drawback/distractive to intemporal-preservation-entropy-or-contiguity-or-ontological-preservation at uninstitutionalised-threshold ${ }^{12}$; since these induced in any given institutionalisation a 'leastand-derived-temporal-operating-modalities-of-the- ${ }^{3}$ reference-of-thought-as-ofincrementalism-in-relative-ontological-incompleteness ${ }^{88}$ enframed/disontologising conceptualisation-inducing-the-uninstitutionalised-threshold ${ }^{102}$, as of temporality $8 /$ shortness thus raising the issue of the uninstitutionalised-threshold ${ }^{102}$ ultimately resolved by 'maximal-as-intemporal-operating-modality-of- ${ }^{2}$ reference-of-thought-as-ofmaximalising-recomposuring-for-relative-ontological-completeness ${ }^{87}$ - unenframed/reontologising conceptualisation-as-inducing-the-prospective-institutionalisation' as of intemporality $^{52}$, and so on, circularly with the relative-unreflexivity/relative-reflexivity ontological-contiguity ${ }^{67}$ of-the-human-institutionalisation-process ${ }^{68}$.) (ii) limited memeticreordering/psychoanalytic-unshackling mentation-capacity (in devising ${ }^{83}$ reference-of-thoughtcategorical-imperatives/axioms/registry-teleology ${ }^{9}$ ) for the intemporal-disposition as it skews ('intemporality ${ }^{52}$-symmetrising-by-desymmetrising-subsumption-of-temporality ${ }^{8}$, for relative intrinsic-reality/ontological-veridicality transcendental- 
enabling/sublimating/supererogatory-de-mentativity)

institutionalisation/intemporalisation (iii) temporal-dispositions for ${ }^{7}$ perversion-of- ${ }^{8}$ referenceof-thought-<as-preconvergingly-apriorising/axiomatising/referencing-in-

nonconviction/madeupness/bottomlining-as-to-shallow-supererogation

uninstitutionalised-threshold

(threshold-of-nonconviction/madeupness/bottomlining-in-

shallow-supererogation -<as-to-'attendant-intradimensional'-prospectively-

disontologising preconverging/dementing -apriorising-psychologism>

eliciting

slanting/miscuing/disjointed-logic/logical-drag/unconscionability-drag/sub-par-or-formulaicassociation-or-temporal-or-alibi as to temporal-dispositions elicited act defects of ignorance/affordability/opportunism/exacerbation/social-chainism-or-social-discomfiture-ornegative-social-aggregation/temporal-enculturation-or-temporal-endemisation) Hence intemporal-preservation is a memetically/psychoanalytically evasive construct at uninstitutionalised-threshold ${ }^{102}$, the pursuit of which is veridically the human species eudaemonic comtemplation, construed as 'postconvergence memetic recomposuring'; recomposure is defined as 'ontological-representation/ontological-memetism of intrinsicmeaningfulness (whether implying, on-the-one-hand, an integrative/candor/organiccomprehension-thinking alignment or on-the-other-hand, a distractive/decandored alignment as threshold-of-nonconviction/madeupness/bottomlining-in-shallow-supererogation $<<$ as-to-

\section{‘attendant-intradimensional'-prospectively-disontologising preconverging/dementing}

apriorising-psychologism>) towards intemporal-preservation-entropy-or-contiguity-orontological-preservation' (as validated by veridicality/<amplituding/formativeepistemicity $>$ causality $\sim$ as-to-projective-totalitative-implications-of-prospectivenonpresencing,-for-explicating relative unreflexivity/relative reflexivity - ontological-

contiguity ). This definition explains the succession of the recomposuring of institutionalisations with the notion that where intemporal-preservation-entropy-or-contiguity- 
or-ontological-preservation is lost at a registry-worldview's/dimension's uninstitutionalisedthreshold $^{102}$, a prospective registry-worldview/dimension is implied/recomposured that will ensure intemporal-preservation-entropy-or-contiguity-or-ontological-preservation, and undermines notional-discontiguity/epistemic-discontiguity ${ }^{63}<$ between - prior-shallowsupererogation -of-mentally-aestheticised preconverging/dementing -qualiaschema_and_prospective-profound-supererogation -of-mentallyaestheticised postconverging/dialectical-thinking -qualia-schema $>$ /epistemictotalising $\sim$ self-referencing-syncretising/setting-aside by appropriate stranding/coring representation (-of-perverting-temporal-dispositions) as the backdrop for the prospective registry-worldview's/dimension's institutionalisation $\quad{ }^{83}$ reference-of-thought- categoricalimperatives/axioms/registry-teleology ${ }^{9}$. That is, 'human progress/transcendence happens as a matter of fact, with no registry-worldview/dimension having any ontological and veridical claim/pretence to extricate itself from psychoanalytic-unshackling/memeticreordering/institutional-recomposuring — as-dialectical-stranding-backdrop-for-prospectivetranscendence once it is shown that it subknowledges-or-mimics (as ${ }^{74}$ perversion-of- ${ }^{8}$ referenceof-thought-<as-preconvergingly-apriorising/axiomatising/referencing-in-

nonconviction/madeupness/bottomlining-as-to-shallow-supererogation $>$ ) its ${ }^{83}$ reference-ofthought- categorical-imperatives/axioms/registry-teleology ${ }^{99}$,-for-intemporal-preservationentropy-or-contiguity-or-ontological-preservation at its uninstitutionalised-threshold ${ }^{102}$, even though this from the temporal-dispositions mindset/ ${ }^{3}$ reference-of-thought is always an unpalatable proposition. But then the state of being in a transcended registryworldview/dimension (as in our present positivist registry-worldview/dimension) arises because other prior registry-worldviews/dimensions successively underwent their own psychoanalyticunshackling/memetic-reordering/institutional-recomposuring — as-dialectical-strandingbackdrop-for-prospective-transcendence for intemporal-preservation-entropy-or-contiguity-or- 
ontological-preservation, at their uninstitutionalised-threshold ${ }^{102}$; and so, going back to the recurrent-utter-institutionalised early men who left the caves and trees, thus any denial of prospective transcendence-and-sublimity/sublimation/supererogatory - de-mentativity as articulated above is an argument which incoherence emanantly imply "we should go back to the caves and trees', as we'll seem to validate that prior registry-worldviews/dimensions should never had transcended up to our very own registry-worldview/dimension, and beyond,

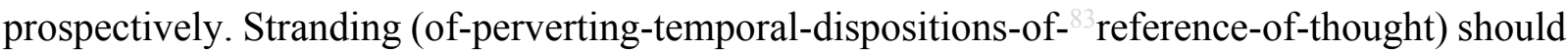
be construed at a registry-worldview's/dimension's uninstitutionalised-threshold ${ }^{12}$ (the threshold where the registry-worldview/dimension is failing/not-upholding-<as-ofapriorising/axiomatising/referencing $>\quad$ intemporal-preservation-entropy-or-contiguity-orontological-preservation), as the 'base preconverging/postconverging-dementative/structural/paradigmatic decandored/distractive-alignment-to- ${ }^{3}$ reference-of-thought$<$ of-apriorising/axiomatising/referencing $>$ perversion-of- ${ }^{8}$ reference-of-thought- $<$ aspreconvergingly-apriorising/axiomatising/referencing-innonconviction/madeupness/bottomlining-as-to-shallow-supererogation $>$ defect reflex' (not a straightness/candor/organic-comprehension-thinking/prelogism ${ }^{78}$ reflex), and ${ }^{15}$ de-mentation〈supererogatery $\sim$ ontological-de-mentation-or-dialectical-de-mentation-stranding-orattributive-dialectics $\rangle$ rather points to a '(lack of) the-Good/knowledge-reification $\sim$ gesturingand-accounting - of-epistemic-phenomenalism- $<$ inprospective_psychologismic apriorising/axiomatising/referencing-\{of- ${ }^{\text {} p r o s p e c t i v e l y ~}$ implicited_attendant-ontological-contiguity ' ceducedexistentialising/contextualising/textualising_'intelligibility/epistemicity/reflexivity-contiguity<imbued-notional cogency>> $\}$-conflatedness -in-\{preconverging disentailment by\} postconverging-entailment $>$ /understanding/<amplituding/formativeepistemicity $>$ causality $\sim$ as-to-projective-totalitative-implications-of-prospective- 
nonpresencing,-for-explicating relative-unreflexivity/relative-reflexivity —ontological-

contiguity reflection/perspectivation' (hence a veridical <amplituding/formativeepistemicity $>$ causality $\sim$ as-to-projective-totalitative-implications-of-prospectivenonpresencing,-for-explicating relative-unreflexivity/relative-reflexivity - ontologicalcontiguity as operant and deterministic, and not an impression-driven/goodnaturedness/wishfulness nor a veridically logically-disjointed/discretionary reflection/perspectivation). Stranding is thus articulated as slanting/miscuing/disjointedlogic/logical-drag/unconscionability-drag/subpar-conventioning-rationalising conjugated/inflected/derived/mimicked/in-protraction-to-psychopathic-preconverging-ordementing -apriorising-psychologism as of the registry-worldview's/dimension'suninstitutionalised-threshold ${ }^{102}$-defect-<as-Being-or-ontological-or-existential-defect $>{ }^{5}$, (induced from temporal-dispositions threshold-of-nonconviction/madeupness/bottomlining-inshallow-supererogation $-<$ as-to-'attendant-intradimensional'-prospectivelydisontologising preconverging/dementing -apriorising-psychologism> as to ignorance/affordability/opportunism/exacerbation/social-chainism-or-social-discomfiture-ornegative-social-aggregation/temporal-enculturation-or-temporal-endemisation). The memeticreordering is in recomposuring, at the uninstitutionalised-threshold ${ }^{102}$ as the threshold-ofnonconviction/madeupness/bottomlining-in-shallow-supererogation $-<$ as-to-'attendantintradimensional'-prospectively-disontologising preconverging/dementing -apriorisingpsychologism> of (registry-worldview) apriorising-registry elements as psychologismic-subliminality-of-individuation-effusing/worlding imbued logicaldueness-or-scape-or-frame, profile-or-stature, presumptuousness-or-arrogation, assumptions, value-reference and teleology ${ }^{9}$ (i.e. ${ }^{83}$ reference-of-thought- ${ }^{\text {categorical- }}$ imperatives/axioms/registry-teleology ${ }^{9}$ ) towards the transcending registry-worldview's fepistemictotalising ${ }^{3}$ psychologismic-subliminality-of-individuation-effusing/worlding imbued logical- 
dueness-or-scape-or-frame, profile-or-stature, presumptuousness-or-arrogation, assumptions, value-reference and teleology (categorical-imperatives/axioms/registry-teleology ) for intemporal-preservation-entropy-or-contiguity-or-ontological-preservation, $\quad$ in $\quad$ reinstitutionalising the uninstitutionalised-threshold ${ }^{102}$. There is no reason for ${ }^{15}$ de-mentation〈supererogatory $\sim$ ontological-de-mentation-or-dialectical-de-mentation-stranding-or-

attributive-dialectics $\rangle$ and recomposuring but for the fact that the internal coherence of a registryworldview/dimension is failing/not-upholding-<as-of-apriorising/axiomatising/referencing $>$ intemporal-preservation-entropy-or-contiguity-or-ontological-preservation at its uninstitutionalised-threshold ${ }^{102}$, as its threshold-of-nonconviction/madeupness/bottomlining-inshallow-supererogation -<as-to-'attendant-intradimensional'-prospectivelydisontologising preconverging/dementing -apriorising-psychologism $>$ provides the dynamic association for psychopathic/postlogic subknowledging $/$ mimicking impulse leading to the vices-and-impediments ${ }^{105}$ of the registry-worldview/dimension from an intemporal/ontological perspective; and ontological-normalcy/postconvergence intemporal-preservation-entropy-orcontiguity-or-ontological-preservation veridicality (as $\quad$ <amplituding/formativeepistemicity $>$ causality $\sim$ as-to-projective-totalitative-implications-of-prospectivenonpresencing,-for-explicating relative-unreflexivity/relative-reflexivity - ontological-

contiguity ) is the drive that resolves lack of human mentation-capacity for intemporalpreservation-entropy-or-contiguity-or-ontological-preservation (at uninstitutionalisedthreshold $^{102}$ ) by stranding-backdrop-for-transcendence and then recomposuring prospective registry-worldview's/dimension's institutionalisation $\quad{ }^{83}$ reference-of-thought- categoricalimperatives/axioms/registry-teleology ${ }^{9}$. The example highlighted on page provides an excellent 'logical insight' on stranding-backdrop-for-transcendence and recomposuring of a registryworldview/dimension that is failing/not-upholding-<as-ofapriorising/axiomatising/referencing $>\quad$ intemporal-preservation-entropy-or-contiguity-or- 
ontological-preservation at its uninstitutionalised-threshold ${ }^{02} \ldots$ To grasp this better say for instance the normal arithmetic we know $2+2=4,5+1=6,7-3=4$, etc. was to be undermine by a new human subknowledging ${ }^{4}$ caused by a disease wherein we tend to say $2+2=5,5+1=7$ and 7 $3=3$, then the traditional categorical-imperatives of addition and subtraction will be modified to take account of our perversion/defect by saying that additionality will involve subtracting 1 from the result and subtractivity will involve adding 1 to the result, so that arithmetic mirrors intrinsic reality outcome (intemporal transversality-<for-sublimating-existentialeventuating/denouement,-from-'thinking at-first/pure-predisposition-preemptive-ofprospective-disontologising/subontologising' as-of-prospectively-disambiguated-affirmedand-unaffirmed-'motif-and-apriorising/axiomatising/referencing'> ${ }^{101}$ as from ontologicalnormalcy/postconvergence). Thus $\quad$ reference-of-thought- categoricalimperatives/axioms/registry-teleology ${ }^{9}$ are 'mental and institutionalisation inventions' that are as pertinent as the extent of their preservation of intemporal reality (intemporal-preservationentropy-or-contiguity-or-ontological-preservation). Hence false subknowledging $/$ mimicking-and-protracted-mimicking with no relationship to intrinsic reality renders ${ }^{83}$ reference-of-thought- categorical-imperatives/axioms/registry-teleology ${ }^{99}$ null and void, calling for overcoming the slantedness/decandoring/distractive-alignment-to- ${ }^{8}$ referenceof-thought- $<$ of-apriorising/axiomatising/referencing $>30$ of mental-devising-representation as to its unsoundness-or-ontological-bad-faith/inauthenticity ${ }^{6}$-of- ${ }^{-3}$ reference-of-thought arising from the perversion-and-derived- ${ }^{7}$ perversion-of- ${ }^{8}$ reference-of-thought- $<$ as-preconverginglyapriorising/axiomatising/referencing-in-nonconviction/madeupness/bottomlining-as-to-

shallow-supererogation $>$, and the articulation of new recomposuring ${ }^{83}$ reference-of-thoughtcategorical-imperatives/axioms/registry-teleology reflecting the intemporal-preservationentropy-or-contiguity-or-ontological-preservation as intrinsic reality. In practical terms, human/social VIRTUE is effectively articulated at the 'crossroad of the notions' of intemporal- 
disposition, ontologising/intemporal-disposition philosophical deference, conventioning, animality (the recurrent temporal-dispositions to subknowledge-<preconverging-ordementing -as-if-of-sound-knowledge intemporal ${ }^{83}$ reference-of-thought- categoricalimperatives/axioms/registry-teleology ${ }^{9}$,-for-intemporal-preservation-entropy-or-contiguityor-ontological-preservation across successive institutionalisations) and institutional recomposuring (prospective memetic-reordering). It is important to note that an ontological construct 'escalates' specific/particular instances of phenomena (in this case psychopathy and social psychopathy phenomenon) into a ${ }^{103}$ universal conceptualisation which 'knowledge principle conceptualisation' then addresses (percolates into) the 'infinity of related incidental phenomena and cases', i.e. Newton articulates the science of mechanics metaphorically from an 'initial apple that hits his head while under a tree' not because the science of mechanics will revolve around an apple that hit his head but because he'll grasp the insight to understand the myriad and infinity of instances requiring those laws of physics. So the intemporal-asontological pedestal (in its treatment) involves ${ }^{103}$ universal projection to grasp ${ }^{103}$ universal principles and is not meant to 'equivocate and idle' with ${ }^{7}$ perversion-of- ${ }^{8}$ reference-of-thought-

\section{$<$ as-preconvergingly-apriorising/axiomatising/referencing-in-}

manifestations which are dialectically-or-contendingly-out-of-phase, but rather then apply the knowledge principles so articulated to the theoretically infinite incidental instances (on the validation and untenability/internal-contradiction/internal-incoherence/institutionalconstraining or internal-contradictions induced by the knowledge principles $<$ amplituding/formative-epistemicity $>$ causality $\sim$ as-to-projective-totalitative-implications-ofprospective- nonpresencing,-for-explicating relative-unreflexivity/relative-reflexivity

ontological-contiguity ). Of course, no registry-worldview/dimension thinks of itself as prospectively dialectically-primitive/dialectically-or-contendingly-out-of-phase, and as such its 
'supposed contention' will always by reflex strive to arrive at an equilibrium in the same registryworldview's/dimension's institutionalisation $\quad$ reference-of-thought- categoricalimperatives/axioms/registry-teleology ${ }^{9}$, but the template of human transcendence-andsublimity/sublimation/supererogatory de-mentativity shows that the intemporal prospective/superseding registry-worldview ${ }^{83}$ reference-of-thought takes precedence with contention construed by its ${ }^{83}$ reference-of-thought- categorical-imperatives/axioms/registryteleology ${ }^{9}$,-for-intemporal-preservation-entropy-or-contiguity-or-ontological-preservation by the ontological-normalcy/postconvergence prioritisation of the relatively intemporal/ ${ }^{103}$ universal/intrinsic, hence, the 'inherent cumulating/recomposuring of intemporalpreservation-entropy' going from recurrent-utter-uninstitutionalisation, baseinstitutionalisation-ununiversalisation, universalisation-non-positivism/medievalism, positivism- - procrypticism, and prospectively deprocrypticism. Such a subknowledging ${ }^{4 / m i m i c k i n g / r e g i s t r y-w o r l d v i e w ~ d e n a t u r i n g ~}{ }^{16}$ resistance is not attended to logically/by-logical-congruence since a ${ }^{74}$ perversion-of- ${ }^{-}$reference-of-thought- $<$aspreconvergingly-apriorising/axiomatising/referencing-in-

unsoundness-or-ontological-bad-faith/inauthenticity ${ }^{6}$-of- ${ }^{83}$ reference-of-

thought/subknowledging ${ }^{4}$ registry-worldview/dimension is circular and syncretic in its logic (as it circularly makes reference to its defective/perverted ${ }^{83}$ reference-of-thought- categoricalimperatives/axioms/registry-teleology ${ }^{9}$,-for-intemporal-preservation-entropy-or-contiguityor-ontological-preservation) but by psychoanalytic-unshackling/memeticreordering/institutional-recomposuring through the untenability/internal-contradiction/internalincoherence/institutional-constraining induced by the <amplituding/formativeepistemicity $>$ causality $\sim$ as-to-projective-totalitative-implications-of-prospective- 
contiguity of the prospective intemporal-disposition-worldview/dimension (with its more appropriate recomposured ${ }^{83}$ reference-of-thought- categorical-imperatives/axioms/registryteleology ${ }^{9} /$ registry-teleology ${ }^{9}$ ); involving rather a crossgenerational collapsing/overriding of the temporal/preconverging-or-dementing ${ }^{20}$-apriorising-psychologism registryworldview/dimension (and not instant 'argumentation convincing' intradimensionally in a registry-worldview/dimension that is defective as of perversion-of- $^{-3}$ reference-of-thought- $<$ aspreconvergingly-apriorising/axiomatising/referencing-innonconviction/madeupness/bottomlining-as-to-shallow-supererogation > in the first place), and so with transversality-<for-sublimating-existential-eventuating/denouement,-from-'thinking-atfirst/pure-predisposition-preemptive-of prospective-disontologising/subontologising' as-ofprospectively-disambiguated-affirmed-and-unaffirmed-'motif-and-

apriorising/axiomatising/referencing' $>101$ of temporal-dispositions and the intemporaldisposition, as temporal emanant registries are inclined to aside and syncretise rather than transcend or core/take-stock of the implied ${ }^{74}$ perversion-of- ${ }^{3}$ reference-of-thought- $<$ aspreconvergingly-apriorising/axiomatising/referencing-innonconviction/madeupness/bottomlining-as-to-shallow-supererogation $>$ registry-worldviewperversion. For instance, the reality that humans did not transcend from a medieval worldview to a positivistic worldview by a mere 'logical/rationalising exercise' (as the mere logical/rationalising conceptualisation we have of such a transformation in today's positivism/rational-empiricism world is rather in effect an afterthought appraisal) but because the 'grander grasp on unlimitedness/existence-<full-potency-of_sublimating naseence $>$ of positivism/rational-empiricism' as to its then 'prior human profound-supererogation metaphoricity $^{57}$ developing human-per-cep-ti-vi-ty-<as-to-notional perceptualisation-ofand-leashing-to_social-functioning-and-accordance-as-of-social-stake-contention-orconfliction> (so-underlied as of preconverging/postconverging-rede- 
mentating/restructuring/reparadigming superseding/overcoming of the 'medievalism nonpositivising psychologismic-epistemic-acutisation-difficulty-<for,-residualising${ }_{\{\text {decompulsing }\}}$ delinearity for-cogency $>$-〈as-of-requisite-profound-supererogation -for-

\section{‘disposedness-or-psychologismic-construct'-\{imbued-demoronisation-<sublimating-}

nascence,-nonextricatory-sublimating-upstreaming/'amontée’’\}〉') before its transformationas-to - transcendence-and-sublimity/sublimation/supererogatory $\sim$ de-mentativity into our modern-day positivism 'prospective human secondnatured ${ }^{56}$ meaningfulness-and-teleology ${ }^{9}$, constrained and made the medieval registry-worldview untenable/internally-contradictory existentially-<disontologising/re-ontologising aporeticism $>$; as well as the fact that the ships that set sail around the world for spices elicit a positive commercial opportunism that is responsible for destroying the social myth of a flat world; the bacteria theory that will ensure that one lives or die if we believe in it or not coerced the destruction of a superstitious medical worldview; or the scientific tools and knowledge that ensured that nation A or nation B will triumph if they believe in it or not, coerces the need to adopt a scientific worldview, etc. It is naïve to think that such progression occurred because of a generalised cross-sectional human 'dimensionality-of-sublimating ${ }^{25}-<<$ amplituding/formative $>$ supererogatory $\sim$ dementativeness/epistemic-growth-or-conflatedness /transvaluative-

rationalising/transepistemicity/anamnestic-residuality/spirit-drivenness-equalisation〉 disposition'. Rather it is as to the secondnaturing manifested in the relativemaneflexivity/relative reflexivity - ontological-contiguity ${ }^{67} \sim$ of-the-human-institutionalisationprocess ${ }^{68}$ as this inherently validates the anthropological-continuity: by distinguishing between the 'notion of parity of individual/institutional distinctiveness ontological-performance ${ }^{72}$ <including-virtue-as-ontology>/morality/ethics/justice/etc.' across the various registryworldviews/dimensions on-the-one-hand and on-the-other-hand the 'notion of more and more profound-as-to-cumulating/recomposuring institutionalised registry-worldviews/dimensions 
(within which the 'notion of parity of individual/institutional distinctiveness ontologicalperformance ${ }^{2}$-<including-virtue-as-ontology $>$ /morality/ethics/justice/etc.' naively arises)' arising out of human institutional-cumulation/institutional-recomposure-〈as-to-

\section{historiality/ontological-eventfulness /ontological-aesthetic-tracing-<perspective-}

ontological-normalcy/postconvergence-reflected-'epistemicity-relativism-determinism' $>>$ as to the capacity bestowed by their forerunners. Such that human limited-mentation-capacity-assubjecting 'educed-unlimitedness/existence-sublimating nascence' to-limitedness/humansubpotency is always mostly directed to 'prospective transformative-as-tocumulating/recomposuring activities' while taking for granted much of the priorly bestowed knowledge heritage. Hence we can't overrate the generalised cross-section/averageness/banality of solipsistic human thought (as of the "notion of parity of individual/institutional distinctiveness ontological-performance ${ }^{72}$-<including-virtue-as-ontology $>$ /morality/ethics/justice/etc.') to 'wrongly imply generalised human disposition is inherently of intemporality as to dimensionality-of-sublimating ${ }^{25}-\langle<$ amplituding/formative $>$ supererogatery - dementativeness/epistemic-growth-or-conflatedness /transvaluativerationalising/transepistemicity/anamnestic-residuality/spirit-drivenness-equalisation〉 disposition' for the possibilities of human progress at uninstitutionalised-threshold ${ }^{102}$. This is due to the veridicality of a human-subpotency-aporia/undecidability/dilemma/oughtindeterminacy/deficiency/limitation/constraint—imbued-'notional firstnaturednessformativeness $<a s$ to eventising inkling drive or seeding misprising $>$ temporal-tointemporal-dispositions-<so-construed-as-from-perspective-ontologicalnormalcy/postconvergence>'-existentialism-form-factor at the uninstitutionalised-threshold across all levels of institutional-cumulation/institutional-recomposure-〈as-tohistoriality/ontological-eventfulness /ontological-aesthetic-tracing-<perspective- 
'lost cause' which will never be changed with the result that temporal-dispositions will always dement (as

of perversion-of- ${ }^{8}$ reference-of-thought-<as-preconverginglyapriorising/axiomatising/referencing-in-nonconviction/madeupness/bottomlining-as-to-

shallow-supererogation $>$ inducing registry-worldview's/dimension's-uninstitutionalisedthreshold ${ }^{102}$-defect-<as-Being-or-ontological-or-existential-defect $>$ / $/$ unsoundness-orontological-bad-faith/inauthenticity ${ }^{64}$-of- ${ }^{8}$ reference-of-thought/mentalperversion/subknowledging /mimicking-and-corresponding-<amplituding/formativeepistemicity $>$ totalising $\sim$ self-referencing-syncretising). But this can rather be anticipated and preempted, as to the 'central tenet of deprocrypticism' reflecting human notional firstnaturedness-formativeness-<as-to-eventualising -inkling-drive-or-seedingmisprising $>$ temporal-to-intemporal-dispositions- $<$ so-construed-as-from-perspectiveontological-normalcy/postconvergence $>$-pedestals-disambiguation before logical processing/operation. Human notional firstnaturedness-formativeness-<as-toeventualising inkling-drive-or-seeding-misprising > temporal-to-intemporal-dispositions$<$ so-construed-as-from-perspective-ontological-normalcy/postconvergence $>$-pedestalsdisambiguation being the contrasting of 'superseding intemporal-disposition organiccomprehension-thinking (organicalism/'intemporal-prioritisation-of- ${ }^{83}$ reference-of-thought'as-conflatedness ${ }^{13}$-or-ontological-reprojecting/ongness-of-register-of- meaningfulness-andteleology )-pedestal-aetiologisation-or-ontological-escalation ordered construct' known as notional ${ }^{18}$ deprocrypticism over-and-stranding-of 'temporal-dispositions which are in threshold-of-nonconviction/madeupness/bottomlining-in-shallow-supererogation $-<$ as-to'attendant-intradimensional' -prospectively-disontologising preconverging/dementing apriorising-psychologism $>$ as ${ }^{74}$ perversion-of- ${ }^{83}$ reference-of-thought- $<$ as-preconverginglyapriorising/axiomatising/referencing-in-nonconviction/madeupness/bottomlining-as-toshallow-supererogation $>$ ' known as procrypticism preconverging-or-dementing ${ }^{20}$-apriorising- 
psychologism, as the backdrop for 'postconverging-or-dialectical-thinking -psychology or psychology-of-mentation-dynamics or natural psychological-dynamics’ psychoanalyticunshackling/memetic-reordering/institutional-recomposuring for intemporal-preservationentropy-or-contiguity-or-ontological-preservation; in the same way as the stranding-oftemporal-dispositions-preconverging-or-dementing -apriorising-psychologism of nonpositivism/medievalism provided the backdrop for positivism recomposuring or that of ununiversalisation for ${ }^{103}$ universalisation recomposure or that of recurrent-utteruninstitutionalisation for base-institutionalisation recomposure. It should be noted that at institutionalised/intemporalised-thresholds-of-intemporal-preservation-entropy-or-contiguityor-ontological-preservation, temporal-dispositions potential inclination for preconverging-ordementing -apriorising-psychologism is suppressed by formalism and internalisation involving intemporal meaningfulness social ${ }^{103}$ universal-transparency ${ }^{104}$-〈transparency-of-totalisingentailing,-as-to-entailing-<amplituding/formative-epistemicity $>$ totalising $\sim$ in-relative-

ontological-completeness $\rangle$, internal-contradiction, referencing/registering/decisioning or stranding as sound or unsound, and alienating of unsound meaningfulness to stifle any such threshold-of-nonconviction/madeupness/bottomlining-in-shallow-supererogation $-<$ as-to‘attendant-intradimensional'-prospectively-disontologising preconverging/dementing apriorising-psychologism>. At uninstitutionalised-threshold ${ }^{12}$ (extended informalities), no formalism and internalisation (generated by the intemporal-disposition for intemporalpreservation-entropy-or-contiguity-or-ontological-preservation) exists in preemption leading potentially to preconverging-or-dementing -apriorising-psychologism. Basically, such a representation of organicalism and mechanicalism can be storied or narrated as follows: Supposed going by the case highlighted where a psychopath met a stranger talking about another stranger as molesting children; the so accused stranger was actually a guardian of the child assuming various responsibilities that come with it (this represents the organic-comprehension- 
conflatedness $^{13}$-or-ontological-reprojecting/longness-of-register-of- meaningfulness-andteleology ${ }^{\circ}$ ) depth of meaning), the psychopath fully aware of this none the less proffered such hollow mimicking narratives to the other stranger who aligned in-prelogic supplantingconviction-as-to-profound-supererogation - of-'attendant-intradimensional'-

postconverging/dialectical-thinking -apriorising-psychologismly/prelogicly to the psychopath but is veridically now in effect the threshold-of-nonconviction/madeupness/bottomlining-inshallow-supererogation -<as-to-'attendant-intradimensional'-prospectivelydisontologising $\sim$ preconverging/dementing -apriorising-psychologism $>$ by ignorance, and goes on to miscue by articulating that the accused stranger should be reported to the police or any other relevant organisation, and possibly does that. Further still, this miscuing comes to develop into disjointed-logic, logical-drag, unconscionability-drag, temporal-dispositions preservation, and sub-par/formulaic-association/temporal/alibi conventioning-rationalising wherein a 'comprehensive depth of perverted narratives' has now been cultivated in the social environment. All such denaturing (and as are conjugated/inflected/derived/mimicked/inprotraction-to-psychopathic-preconverging-or-dementing ${ }^{20}$-apriorising-psychologism to human temporal defects of postlogism slantedness/ ignorance/affordability/opportunism/exacerbation/social-chainism-or-socialdiscomfiture-or-negative-social-aggregation/temporal-enculturation-or-temporal-endemisation, so-disambiguated as of ${ }^{83}$ reference-of-thought- ${ }^{8}$ devolving ontological-performance ${ }^{72}$ $<$ including-virtue-as-ontology $>$ ) are a $\quad{ }^{74}$ perversion-of- ${ }^{8}$ reference-of-thought- $<$ aspreconvergingly-apriorising/axiomatising/referencing-innonconviction/madeupness/bottomlining-as-to-shallow-supererogation $>\quad$ threshold-ofnonconviction/madeupness/bottomlining-in-shallow-supererogation $<-<$ as-to-' $a$ attendantintradimensional'-prospectively-disontologising preconverging/dementing -apriorising- 
psychologism $>$ to the organic veridicality (deprocrypticism). In-the-bigger-scheme-of-things, denaturing of apriorising-registry (as the apriorising-registry is the axiomaticconstruct/categorical-imperatives on which logic operates/is processed pointing to a coherently systematic failure of logic at the uninstitutionalised-threshold ${ }^{102}$; consider that the nonpositivism/medievalism apriorising-registry will coherently fail logical operation/processing/contention with regards to its uninstitutionalised-threshold ${ }^{102}$ requiring positivism, that's the same emanant issue with procrypticism at its uninstitutionalisedthreshold ${ }^{02}$ requiring deprocrypticism) do not simply point to an act defect but registryworldview's/dimension's-uninstitutionalised-threshold ${ }^{12}$-defect-<as-Being-or-ontological-orexistential-defect $>55$ about-and-defining the vices-and-impediments ${ }^{105}$ of the said registryworldview/dimension, that abstractly apply with regards in this case not to one instance of human psychopathy and one case of social context of protracted social psychopathy but points to a registry-worldview/dimension defect that points abstractly to 'metaphorically-a-million-andone-instances-and-locales as to aetiologisation/ontological-escalation- $<$ ontologicalveridicality_commitment/otherliness_transcending/compulsions-encumbered_transcending>' or an-ontological-or-existential-defect of such psychopathic and protracted social psychopathy, in the same vain as the phenomena of witchcraft in a non-positivist/medieval society 'for an ontological/intemporal projecting mind' is more than just a case of witcheraft in a given nonpositivism/medievalism locale but goes beyond to define a dimensional defect of nonpositivism/medievalism across all human societies that are qualified as nonpositivism/medievalism with the idea that the 'disambiguation of notional firstnaturednessformativeness $<a s-$ to-eventualising - inkling drive-or-seeding misprising $>$ temporal-tointemporal-dispositions-<so-construed-as-from-perspective-ontologicalnormalcy/postconvergence $>\quad$ as $\quad$ aetiologisation/ontological-escalation- $<$ ontologicalveridicality_commitment/otherliness_transcending/compulsions-encumbered_transcending>' 
in-the-bigger-scheme-of-things is more than just a locale but a ${ }^{103}$ universal articulation of positivistic thinking as the ${ }^{103}$ universal resolution of the vices-and-impediments ${ }^{105}$ associated with a witchcraft and superstition endemising/enculturating worldview. It should be noted that however 'good-natured an individual' in that worldview the basic knowledge defect of that worldview as non-empirical/superstitious defines the disposition of any such individual, as they adhere to the ${ }^{83}$ reference-of-thought- categorical-imperatives/axioms/registry-teleology ${ }^{9}$,-forintemporal-preservation-entropy-or-contiguity-or-ontological-preservation of that registryworldview/dimension, to commit vices-and-impediments ${ }^{105}$ associated with nonpositivism/medievalism, since virtue actually lies in the-Good/knowledge-reification $\sim$ gesturingand-accounting - of-epistemic-phenomenalism- $<$ inprospective_psychologismic a apriorising/axiomatising/referencing-\{of-'prospectively_ implicited_attendant-ontological-contiguity ' ceducedexistentialising/contextualising/textualising_'intelligibility/epistemicity/reflexivity_contiguity<imbued-notional cogency >' $\}$-conflatedness -in-\{preconverging-disentailment by\} postconverging-entailment $>$ /understanding/<amplituding/formativeepistemicity $>$ causality as-to-projective-totalitative-implications-of-prospectivenonpresencing,-for-explicating relative unreflexivity/relative reflexivity ontologicalcontiguity ' of being empirical/non-superstitious/positivistic. That's equally the problem you have with procrypticism or perversion of ${ }^{83}$ reference-of-thought- categoricalimperatives/axioms/registry-teleology ${ }^{9}$,-for-intemporal-preservation-entropy-or-contiguityor-ontological-preservation of a positivistic registry-worldview as the virtue lies in the theGood/knowledge-reification $\sim$ gesturing-and-accounting — of-epistemic-phenomenalism- $<$ inprospective_psychologismic apriorising/axiomatising/referencing-\{of-'prospectively implicited_attendant-ontological-contiguity ' educedexistentialising/contextualising/textualising_'intelligibility/epistemicity/reflexivity-contiguity- 
<imbued-notional cogency $\left.>^{\prime} \quad\right\}$-conflatedness -in-\{preconverging-disentailment by\}

postconverging entailment $>$ /understanding/<amplituding/formative-

epistemicity $>$ causality $\sim$ as-to-projective-totalitative-implications-of-prospective-

nonpresencing,-for-explicating relative-unreflexivity/relative-reflexivity - ontological-

contiguity as involving psychopathic preconverging-or-dementing ${ }^{20}$-apriorisingpsychologism postlogism 77 in hollow-constituting-<as-disjointed-misappropriation-ofmeaningfulness-and-failing-intemporal-preservation>, and its corollary as social psychopathy involving conjugating/inflecting/deriving preconverging-or-dementing ${ }^{20}$-apriorisingpsychologism postlogism in hollow-constituting-<as-disjointed-misappropriation-ofmeaningfulness-and-failing-intemporal-preservation $>$ by the temporal-dispositions of ignorance, unconsciously, and consciously, affordability/opportunism/exacerbation/socialchainism-or-social-discomfiture-or-negative-social-aggregation/temporal-enculturation-ortemporal-endemisation; slanting/preconverging-or-dementing ${ }^{20}$-apriorising-psychologism of positivistic registry-worldview/dimension $\quad{ }^{83}$ reference-of-thought- categoricalimperatives/axioms/registry-teleology ${ }^{9}$. That is, the <amplituding/formativeepistemicity $>$ causality as-to-projective-totalitative-implications-of-prospectivenonpresencing,-for-explicating relative unreflexivity/relative reflexivity - ontologicalcontiguity is the ${ }^{7}$ perversion-of- ${ }^{3}$ reference-of-thought- $<$ as-preconverginglyapriorising/axiomatising/referencing-in-nonconviction/madeupness/bottomlining-as-toshallow-supererogation $>\quad$ as-of-unsoundness-or-ontological-bad-faith/inauthenticity ${ }^{6}$-ofreference-of-thought/preconverging-or-dementing -apriorisingpsychologism/subknowledging ${ }^{4} /$ mimicking $^{2}$ as <amplituding/formativeepistemicity $>$ totalising $\sim$ self-referencing-syncretising/circularity/interiorising/akrasiatic-drag of positivistic $\quad{ }^{8}$ reference-of-thought- categorical-imperatives/axioms/registryteleology 9 /registry-teleology ${ }^{9}$-for-intemporal-preservation-entropy-or-contiguity-or- 
ontological-preservation. In which case contention (being about intemporal-preservationentropy-or-contiguity-or-ontological-preservation beyond just the preconverging-ordementing ${ }^{20}$-apriorising-psychologism/mimicking-or-subknowledging ${ }^{4}$ of 'previously recomposured/invented' $\quad{ }^{83}$ reference-of-thought- categorical-imperatives/axioms/registryteleology ${ }^{9}$,-for-intemporal-preservation-entropy-or-contiguity-or-ontological-preservation) becomes rather an intemporal-disposition reflection/perspectivation and 'disambiguation of notional firstnaturedness-formativeness-<as-to-eventualising-inkling-drive-or-seeding misprising $>$ temporal-to-intemporal-dispositions- $<$ so-construed-as-from-perspectiveontological-normalcy/postconvergence $>$ as aetiologisation/ontological-escalation- $<$ ontologicalveridicality_commitment/otherliness_transcending/compulsions-encumbered_transcending >' of such psychopathic/temporal-dispositions slantedness/preconverging-or-dementing apriorising-psychologism/mimicking-or-subknowledging as ${ }^{74}$ perversion-of- ${ }^{83}$ reference-ofthought-<as-preconvergingly-apriorising/axiomatising/referencing-in-

nonconviction/madeupness/bottomlining-as-to-shallow-supererogation >/mental-perversion, and not logical-contention/contending-articulation. Such ${ }^{77}$ perversion-of- ${ }^{83}$ reference-ofthought-<as-preconvergingly-apriorising/axiomatising/referencing-in-

nonconviction/madeupness/bottomlining-as-to-shallow-supererogation $>$ as-of-unsoundnessor-ontological-bad-faith/inauthenticity ${ }^{6}$-of- ${ }^{8}$ reference-of-thought in effect involves on the part of psychopathic and conscious conjugated-postlogism 77 minds as with exacerbation-temporaldisposition 'vice in preconverging-or-dementing -apriorising-psychologism perversions' wherein the mimicry/subknowledging ${ }^{4}$ enters into an active dynamics with temporaldispositions prelogism ${ }^{78}$-as-of-conviction,-in-profound-supererogation $<<$ existentiallyveridical-'attendant-intradimensional-apriorising/axiomatising/referencing'-logical-duenessprecedes-disontologising-logical-outcome-arrived-at> inducing their threshold-ofnonconviction/madeupness/bottomlining-in-shallow-supererogation $<<$ as-to- 'attendant- 
psychologism $>$ as miscuing psychopathic/postlogism 7 -slantedness, and subsequent protraction into disjointed-logic, logical-drag, unconscionability-drag, temporal-dispositions preservation and sub-par/formulaic-association/temporal/alibi conventioning-rationalising); such that this development is actually an instrumentalisation of the initial directed-preconverging-ordementing -apriorising-psychologism. Directed-preconverging-or-dementing ${ }^{20}$-apriorisingpsychologism as such being a conscious and operant mental awareness of psychopathic/postlogic minds of the void of their narratives and teleology but understanding and acting by instrumentalisation on the basis that prelogic/conviction-as-to-profound-supererogation ${ }^{96}$ minds are disposed to elevate the hollow mimicking narratives (by ignorance and/or subsequently affordability/opportunism/exacerbation/social-chainism-or-social-discomfiture-or-negativesocial-aggregation/temporal-enculturation-or-temporal-endemisation) to wrongly validate the apriorising-registry as veridical thus falsely implying an fepistemic-totalising $3 \frac{3}{5}$ psychologismicsubliminality-of-individuation-effusing/worlding imbued logical-dueness-or-scape-or-frame, profile-or-stature, presumptuousness-or-arrogation, assumptions, value-reference and teleology ${ }^{9}$. Just as we work with the reality that all humans are predisposed to have cancer and the virtue of curing is not denying but anticipating and preempting the possibility of having cancer with medicines, lifestyle, research, etc., i.e. 'ontology is about working with what is/knowledge-driven, and not wishful-thinking/impression-driven' to accede to intrinsic-reality transcendental-enabling/sublimating/supererogatory $\sim$ de-mentativity as this highlights

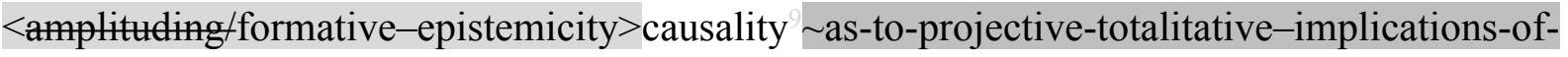
prospective- nonpresencing,-for-explicating relative-unreflexivity/relative-reflexivity ontological-contiguity . It is bluntly speaking a registry-worldview's/dimension's institutionalisation/intemporalisation exercise involving the skewing ('intemporality ${ }^{52}$ symmetrising-by-desymmetrising-subsumption-of-temporality ${ }^{\circ}$, for relative intrinsic- 
reality/ontological-veridicality

transcendental-enabling/sublimating/supererogatory $\sim$ dementativity)/deferential-formalisation-transference towards the intemporal-disposition for intemporal-preservation-entropy-or-contiguity-or-ontological-preservation, to 'pedestally dominate and override' temporal-dispositions in the cross-section/averageness/banality of solipsistic human-subpotency-aporia/undecidability/dilemma/oughtindeterminacy/deficiency/limitation/constraint—imbued-'notional firstnaturednessformativeness-<as-to-eventualising -inkling drive-or-seeding-misprising $>$ - temporal-tointemporal-dispositions-<so-construed-as-from-perspective-ontological-

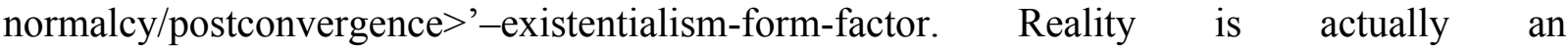
$<$ amplituding/formative-epistemicity $>$ causality $\sim$ as-to-projective-totalitative-implications-ofprospective- nonpresencing,-for-explicating relative-unreflexivity/relative-reflexivity ontological-contiguity construct. Mythologies, metaphysics and hearsays while protoconceptual in human development are out of kilter, and the use of <amplituding/formativeepistemicity $>$ causality $\sim$ as-to-projective-totalitative-implications-of-prospectivenonpresencing,-for-explicating relative-unreflexivity/relative-reflexivity - ontologicalcontiguity conceptualisation is the central notion of ontologies. Insightfully, humansubpotency-aporia/undecidability/dilemma/oughtindeterminacy/deficiency/limitation/constraint—imbued-'notional firstnaturednessformativeness-<as-to-eventualising-inkling-drive-or-seeding-misprising $>$ temporal-tointemporal-dispositions- $<$ so-construed-as-from-perspective-ontologicalnormalcy/postconvergence>'-existentialism-form-factor speak of 'the-real-nature-of-man' that can be skewed with institutional recomposuring/memetic-reordering/psychoanalyticunshackling towards intemporal-preservation-entropy-or-contiguity-or-ontologicalpreservation to explain how-man-can-be/the-nature-of-man at any registry-worldview level, retrospectively or prospectively. Whereas, man, if naively perceived as a whole rather only from 
the angle of a specific 'institutionalisation/secondnaturing level' which is in 'existential immediacy' this may seem to indicate that we are talking about 'different species' with 'different ontological determinants', which is naïve and false. The anthropopsychological approach to psychology is analogical to the development of physics which is not only on the basis of what is immediately at the consciously immediate human operational/functioning level of physicists but equally projecting into a physics conceptualisation of the macrocosm (astronomy and cosmology) as well as the microcosm (particle physics) in other to place the subject on a comprehensively sound footing. Central to such a sound footing in the ontologicalnormalcy/postconvergence conceptualisation of the social domain is the idea of notional firstnaturedness-formativeness-<as-to-eventualising-inkling-drive-or-seedingmisprising $>$ temporal-to-intemporal-dispositions- $<$ so-construed-as-from-perspectiveontological-normalcy/postconvergence $>\quad$ and institutional-cumulation/institutionalrecomposure-〈as-to- historiality/ontological-eventfulness /ontological-aesthetic-tracing$<$ perspective--ontological-normalcy/postconvergence-reflected-'epistemicity-relativismdeterminism' $>$ >. On another note, it is critical to distinguish between a true philosophical development that arises by intemporal-disposition and an institutionalised development that is articulated to elicit 'positive-opportunism — of-social-functioning-and-accordance ${ }^{5}$ ' in humans, so that the intellectual exercise doesn't naively project a philosophical idealism where this doesn't exist and by so doing undermine its work by naively projecting ${ }^{103}$ universal intemporality ${ }^{52} /$ longness and failing/not-upholding-<as-ofapriorising/axiomatising/referencing $>$ to articulate a realism that takes account of temporal mental-dispositions (knowledge-notionalisation, i.e. apprehending not only intemporal implications of any knowledge construct, but preempting by transversality-<for-sublimatingexistential-eventuating/denouement-from-'thinking-at-first/pure-predisposition-preemptive-ofprospective-disontologising/subontologising' as-of-prospectively-disambiguated-affirmed- 
undermining of that intemporal idealism construct; the reason we institutionalise/intemporalise and formalise with subsequent internalisation/secondnaturing). It should be noted that the use of

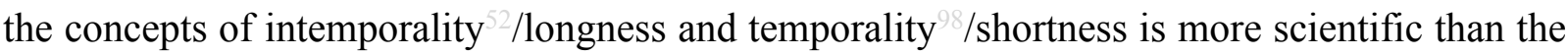
impression notions of good and bad. Intemporality ${ }^{52} /$ longness points to 'what generates the greatest ${ }^{103}$ universal virtue as ontological which is ${ }^{103}$ universally-centered' (and that this corresponds to reality-referencing and the ontology pedestal) while temporality $8 /$ shortness points to "what generates the non-ontological as shallow interest that may be self-centered, at various pedestals, (and that this corresponds to <amplituding/formativeepistemicity $>$ totalising $\sim$ self-referencing-syncretising/circularity/interiorising/akrasiatic-drag

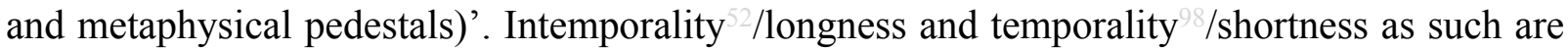
operant knowledge concepts while good and bad are vague and non-operant impression concepts. In fact, why good and bad are impression-driven, intemporality ${ }^{5 / / 1}$ ongness and temporality $/$ shortness by their very definition above are made operant as an $<$ amplituding/formative-epistemicity $>$ causality $\sim$ as-to-projective-totalitative-implications-ofprospective- nonpresencing,-for-explicating relative-unreflexivity/relative-reflexivity

ontological-contiguity scientific principle (without making any reference to stigmatising impression of virtue) by the denotation as longness-of-register-of- - meaningfulness-andteleology (intemporality ${ }^{52}$ ) and shortness-of-register-of- ${ }^{5}$ meaningfulness-and-teleology (temporality $^{9}$ ). That is, with respect to 'socially-perceived-value as of social-stake-contentionor-confliction' (at uninstitutionalised-threshold ${ }^{102}$ ) the intemporal mind conceptually asks what is the best disposition in ${ }^{103}$ universal-depth that abstractly delivers the greatest good to all humans in similar 'socially-perceived-value as of social-stake-contention-or-confliction' setup across space and time; while temporal minds under the same notion (intemporality ${ }^{52}$ temporality ${ }^{8}$ ) conceptually assume lower and lower shades 'in mentation-capacity terms' of 
such an intemporal ${ }^{103}$ universal-depth concept articulation stressing in lieu of 'all humans' various shades of ununiversal, particular or temporal-self-interest dispositions. So there is a depth of continuity in <amplituding/formative-epistemicity>causality $\sim$ as-to-projectivetotalitative-implications-of-prospective- nonpresencing,-for-explicating relativeunreflexivity/relative-reflexivity - ontological-contiguity in the notion of intemporality ${ }^{52}$ temporality ${ }^{8}$ that doesn't need any impression-drive, and this notion can certainly be made scientifically operant as it is a contiguous mentation-capacity-based notion in terms-as-ofaxiomatic-construct of low to high mentation-capacity. The idea of shortness-of-register-ofmeaningfulness-and-teleology and longness-of-register-of- ${ }^{5}$ meaningfulness-andteleology as such is devoid of stigmatisation which is the result of articulating meaning with respect to mere-and-vague impression-driven/good-naturedness/wishfulness temporal references harkening back to the prior/transcended/superseded ${ }^{83}$ reference-of-thought rather than the prospective/transcending/superseding ${ }^{8}$ reference-of-thought; since shortness-of-register-ofmeaningfulness-and-teleology and longness-of-register-of- ${ }^{5}$ meaningfulness-andteleology are a contiguous value construct as in <amplituding/formativeepistemicity $>$ totalising $\sim$ ratiocontiguity/ratiocination-as-referentialism—'implicited_attendantontological-contiguity ${ }^{67}$, educedexistentialising/contextualising/textualising_intelligibility/epistemicity/reflexivity-contiguity$<$ imbued-notional cogency>' ;-phenomenal-abstractiveness-of-presencing-in-'protensiveconsciousness'-enablingapriorising/axiomatising/referencing/intelligibilitysettingup/measuringinstrumenting-foroperant-or-incidenting-predicative-insights-of 'implicited_attendant-ontologicalcontiguity ${ }^{67}$, educedexistentialising/contextualising/textualising_'intelligibility/epistemicity/reflexivity-contiguity$<$ imbued-notional $\sim$ cogency $>,{ }^{\prime},-<$ reifying-or-elucidating-of-prospective-relative-ontological- 
intemporal-preservation-entropy-or-contiguity-or-ontological-preservation beyond just $<$ amplituding/formative-epistemicity $>$ totalising $\sim$ random-as-impulsive-

'implicited_attendant-ontological-contiguity ${ }^{67}$ ' educed-

existentialising/contextualising/textualising_intelligibility/epistemicity/reflexivity-contiguity-

$<$ imbued-notional cogency>' ;-phenomenal-abstractiveness-of-presencing-in-'trepidatiousconsciousness'-enabling-

apriorising/axiomatising/referencing/intelligibilitysettingup/measuringinstrumenting-foroperant-or-incidenting-predicative-insights-of 'implicited_attendant-ontologicalcontiguity $^{67}$, educed-

existentialising/contextmalising/textualising_'intelligibility/epistemicity/reflexivity_contiguity$<$ imbued-notional $\sim$ cogency $>>,-<$ reifying-or-elucidating-of-prospective-relative-ontologicalcompleteness -of- reference-of-thought- devolving-as-of-instantiative-context> (impulsiveor-accidented-or-haphazard-or-random mental-disposition), <amplituding/formativeepistemicity>totalising nominal-as-tendentious_-implicited_attendant—ontologicalcontiguity $^{67}$; educed-

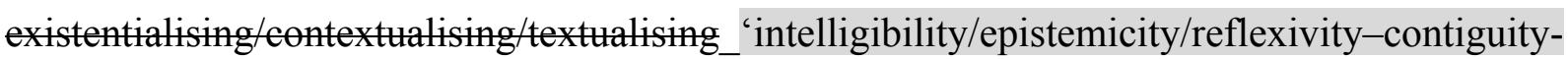
$<$ imbued-notional cogency>’ ;-phenomenal-abstractiveness-of-presencing-in- 'warpedconsciousness'-enablingapriorising/axiomatising/referencing/intelligibilitysettingup/measuringinstrumenting-foroperant-or-incidenting-predicative-insights-of 'implicited_attendant-ontologicalcontiguity $^{67}$, educed-

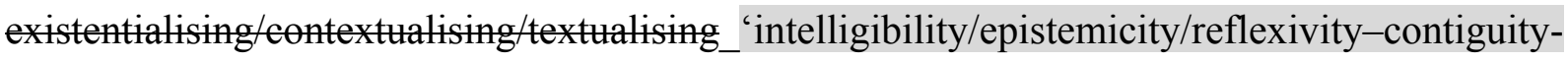
$<$ imbued-notional $\sim$ cogency $>,{ }^{\prime},-<$ reifying-or-elucidating-of-prospective-relative-ontologicalcompleteness -of- reference-of-thought- devolving-as-of-instantiative-context> 
(allegiance/subservience transience), <amplituding/formative-epistemicity>totalising $\sim$ ordinalas-qualifying — 'implicited_attendant-ontological-contiguity ${ }^{67}$ ' educed-

existentialising/contextualising/textualising_'intelligibility/epistemicity/reflexivity-contiguity-

$<$ imbued-notional cogency>' ;-phenomenal-abstractiveness-of-presencing-in-'preclusiveconsciousness'-enabling-

apriorising/axiomatising/referencing/intelligibilitysettingup/measuringinstrumenting-foroperant-or-incidenting-predicative-insights-of 'implicited_attendant-ontologicalcontiguity ${ }^{67} \sim$ educedexistentialising/contextualising/textualising_'intelligibility/epistemicity/reflexivity-contiguity$<$ imbued-notional $\sim$ cogency $>,{ }^{\prime},-<$ reifying-or-elucidating-of-prospective-relative-ontologicalcompleteness -of- reference-of-thought- devolving-as-of-instantiative-context $>$

(qualification/good-to-bad transience), $<$ amplituding/formativeepistemicity $>$ totalising intervalist-as-categorising_- 'implicited_attendant-ontologicalcontiguity $^{67}$ ' educedexistentialising/contextualising/textualising_intelligibility/epistemicity/reflexivity-contiguity$<$ imbued-notional cogency $>$; ;-phenomenal-abstractiveness-of-presencing-in-'occlusiveconsciousness'-enablingapriorising/axiomatising/referencing/intelligibilitysettingup/measuringinstrumenting-foroperant-or-incidenting-predicative-insights-of 'implicited_attendant_ontologicalcontiguity $^{67} \sim$ educedexistentialising/contextualising/textualising_intelligibility/epistemicity/reflexivity-contiguity$<$ imbued-notional $\sim \operatorname{cogency}>,{ }^{\prime},-<$ reifying-or-elucidating-of-prospective-relative-ontologicalcompleteness -of- reference-of-thought- devolving-as-of-instantiative-context $>$ (categorisation/kindness-humility-helpfulness-etc. sransience) of conceptualisation but arrive at rationality (contiguous mentation-capacity/longness-or-shortness-of-register-of- 
meaningfulness-and-teleology $\quad$ transience) $\quad$ or $\quad$ a $\quad$ amplituding/formativeepistemicity $>$ totalising $\sim$ ratiocontiguity/ratiocination-as-referentialism—'implicited_attendant ontological-contiguity ${ }^{67}$, educedexistentialising/contextualising/textualising_intelligibility/epistemicity/reflexivity-contiguity$<$ imbued-notional $\sim$ cogency> ${ }^{\prime}$;-phenomenal-abstractiveness-of-presencing-in-'protensiveconsciousness'-enabling-

apriorising/axiomatising/referencing/intelligibilitysettingup/measuringinstrumenting-foroperant-or-incidenting-predicative-insights-of 'implicited_attendant-ontologicalcontiguity $^{67}$, educedexistentialising/contextmalising/textmalising_intelligibility/epistemicity/reflexivity-contiguity$<$ imbued-notional $\sim$ cogency $>{ }^{\prime},-<$ reifying-or-elucidating-of-prospective-relative-ontologicalcompleteness -of- reference-of-thought- devolving-as-of-instantiative-context $>$ conceptualisation with a corresponding depth/register-of-meaningfulness (in memetic reordering depth) that allows for a grasp of the-Good intemporal-disposition (i.e. beyond just an intradimensional 'good-natured' conceptualisation) of intemporal-preservation-entropy-orcontiguity-or-ontological-preservation, with the memetic-reordering directly associated with the referential entropy in institutional-cumulation/institutional-recomposure-〈as-tohistoriality/ontological-eventfulness /ontological-aesthetic-tracing-<perspectiveontological-normalcy/postconvergence-reflected-'epistemicity-relativismdeterminism' $>$ /transcendence-and-sublimity/sublimation/supereregatory $\sim$ de-mentativity. Thus by intemporality ${ }^{52} /$ longness as a the-Good conceptualisation as 'longness-of-register-ofmeaningfulness-over-shortness-of-register-of- ${ }^{-5}$ meaningfulness-and-teleology ${ }^{9},{ }^{\prime} \quad$ that specificity (as pursued in this paper) that informs ontological understanding of not idling and articulating meaningfulness in equivalence of temporality $\$$ /shortness in its various shades, but rather with intemporal purpose and intent, and an ultimate quest for validation only as an 


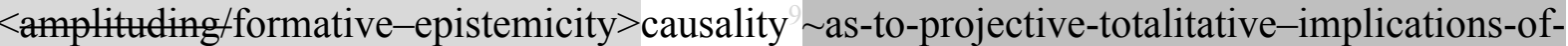

prospective- nonpresencing,-for-explicating relative-unreflexivity/relative-reflexivity

ontological-contiguity conceptualisation will be qualified as 'longness-of-thought'; and it strives to achieve a prospective preconverging/postconverging-dementative/structural/paradigmatic existential-<disontologising/re-ontologising aporeticism $>$ registry-worldview/dimension conceptualisation of transcendence-andsublimity/sublimation/supererogatory de-mentativity wherein aetiologisation/ontologicalescalation-<ontological-veridicality_commitment/otherliness_transcending/compulsionsencumbered_transcending $>$ for prospective transcendental intemporal virtue is the underlying drive. The non-implication of an equivalence between ('intemporal-prioritisation-of- ${ }^{8}$ referenceof-thought'-as-conflatedness ${ }^{13}$-or-ontological-reprojecting pedestalling) with temporality $8 /$ shortness in its various shades will imply a knowledge conceptualisation rather from the perspective of the comprehension of human species intemporal potential rather than mere extrication within a temporal inter-individuals-and-social-stake-contention-or-confliction context, wherein for instance the focus of a positivistic-inclined mindset/ ${ }^{3}$ reference-of-thought is not to idly engage a medieval world in medieval terms to stigmatise as a final end but rather for the virtuous human species potentiality to transcend into positivism, and on-the-other-hand equally not to shy away from articulating, however temporally unpalatable and unintelligibleor-existentially-suprastructural for the temporal present registry-worldview/dimension, an intemporal transcendental prospection on the validation that the present registryworldview/dimension is the outcome of a same-kind intemporal transcendental prospection with a same-kind corresponding emanance unpalatability and unintelligibility for the preceding registry-worldview/dimension, be it in that case driven by a spontaneous and natural dialectical cycle of social constraints of stakes and confliction, in contrast now to a more 'consciously directed' abstract understanding regarding deprocrypticism-over-procrypticism (with 
intellectual responsibility/relative-reflexivity itself being defined as the spirit for authentically upholding such construing/conceptualisation and/or facilitating it as enabling further selfdevelopment together with the furthering of social/specie development). The use of 'human mental-dispositions/individuations' as of notional firstnaturedness-formativeness-<as-toeventualising inkling-drive-or-seeding-misprising $>$ temporal-to-intemporal-dispositions$<$ so-construed-as-from-perspective-ontological-normalcy/postconvergence $>$ herein doesn't mean ontologically that some individuals are inherently/exclusively solipsistically temporal and others are inherently/exclusively solipsistically intemporal. But rather, it is an abstract construction of human notional firstnaturedness-formativeness-<as-to-eventualising inkling drive-or-seeding-misprising $>$ temporal-to-intemporal-dispositions- $<$ so-construed-as-fromperspective-ontological-normalcy/postconvergence> mental-dispositions/individuation potential possibilities that can incidentally arise in any individual by a circumstance or circumstances across time and space; but with a strong propensity of specific dispositions being nurtured in varying profundity across different individuals as per context. This abstract and fleeting notion is known as 'individuation' (more like an abstract and superseding 'hermeneuticaetiology' of notional firstnaturedness-formativeness-<as-to-eventualising inkling-drive-orseeding misprising $>$ temporal-to-intemporal-dispositions-<so-construed-as-fromperspective-ontological-normalcy/postconvergence> s, and hence the possibility of $<$ amplituding/formative-epistemicity $>$ causality $\sim$ as-to-projective-totalitative-implications-ofprospective- nonpresencing,-for-explicating relative-unreflexivity/relative-reflexivity ontological-contiguity or scientism), and is the more scientific notion over 'individual' (which is just the receptacle of individuations). By pedestal is meant the 'temporal-to-intemporal individuations dispositions of meaningfulness whether the intemporal-disposition individuationpedestal or the temporal-dispositions individuations-pedestals (ignorance-temporal-disposition individuation-pedestal, affordability-temporal-disposition individuation-pedestal, opportunism- 
temporal-disposition individuation-pedestal, exacerbation-temporal-disposition individuationpedestal, social-chainism/social-discomfiture/negative-social-aggregation-temporal-disposition individuation-pedestal or temporal-enculturation/temporal-endemisation-temporal-disposition individuation-pedestal). The intemporal and temporal-dispositions-registries individuationspedestals imply and point to the underlying <amplituding/formativeepistemicity $>$ causality $\sim$ as-to-projective-totalitative-implications-of-prospective-

\section{nonpresencing,-for-explicating relative-unreflexivity/relative-reflexivity - ontological-}

contiguity basis of the 'specific temporal-disposition ${ }^{5}$ meaningfulness-and-teleology". Further, by psychopathic or other postlogic subknowledging $4 /$ mimicking-and-mimickingprotraction, the 'temporal-dispositions individuations-pedestals' wrongly conjugate/inflect/protract their apriorising-registry-elements (\{epistemic-totalising $3{ }^{3}$ psychologismicsubliminality-of-individuation-effusing/worlding imbued logical-dueness-or-scape-or-frame, profile-or-stature, presumptuousness-or-arrogation, assumptions, value-reference and teleology ${ }^{99}$ ) from aligning prelogicly to postlogism 77 in hollow-constituting-<as-disjointedmisappropriation-of-meaningfulness-and-failing-intemporal-preservation $>$ thus effectively being postlogic, and this can thus be predicated as per the 'specific temporal-disposition'. Such postlogic temporal-dispositions individuations-pedestals are conjugated/inflected/derived/mimicked-protraction-to-psychopath's compulsive-dementing (as derived from both psychopathic and others postlogism in hollow-constituting-<asdisjointed-misappropriation-of-meaningfulness-and-failing-intemporal-preservation> slantedness/insane-fitment/disontologising-perverted-outcome-sought-precedes-existentiallyveridical-'attendant-intradimensional-apriorising/axiomatising/referencing'-logical-duenessdispositions) in epistemic-decadence (notional-discontiguity/epistemic-discontiguity $<$ between-prior-shallow-supererogation -of-mentallyaestheticised preconverging/dementing -qualia-schema_and_prospective-profound- 
supererogation -of-mentally-aestheticised postconverging/dialectical-thinking -qualia-

schema $>$-as-of-epistemic-decadence in hollow-constituting-<as-disjointed-misappropriation-ofmeaningfulness-and-failing-intemporal-preservation $>$ in postlogic-backtracking- $<$ iterativelooping-'set-of-dereifying-hollow-narratives-and-acts'>70). These will include 'postlogic ignorance-temporal-disposition individuation-pedestal', 'postlogic affordability-temporaldisposition individuation-pedestal', postlogic opportunism-temporal-disposition individuationpedestal, postlogic exacerbation-temporal-disposition individuation-pedestal, postlogic socialchainism/negative-social-aggregation/social-discomfiture-temporal-disposition individuationpedestal, and postlogic temporal-enculturation/temporal-endemisation-temporal-disposition individuation-pedestal). While the prelogic/conviction-as-to-profound-supererogation 'ontologically-reconstituting' intemporal-disposition-teleology 9 is rather the ontologising individuation-pedestal as it strives perpetually to define-and-redefine categorical-imperatives (by its ontologically-veridical associated registry-teleology -mentation elements as fepistemic-

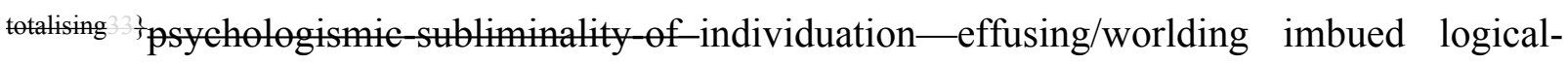
dueness-or-scape-or-frame, profile-or-stature, presumptuousness-or-arrogation, assumptions, value-reference and teleology ${ }^{9}$ ) for 'intemporal/ontological preservation entropy/contiguity’ as it perpetuates institutionalisation/intemporalisation/longness-of-register-of-meaningfulnessover-shortness-of-register-of- ${ }^{56}$ meaningfulness-and-teleology ${ }^{9}$ despite the natural reflex at every registry-worldview/dimension, whether recurrent-utter-uninstitutionalisation, ununiversalisation, non-positivism/medievalism and prospectively procrypticism, to temporally arrive at entropy on the basis of temporal-dispositions teleologies or shortness-of-register-ofmeaningfulness-and-teleology (with the associated non-veridical temporal fepistemictotalising 3 psychologismic subliminality of-individuation-effusing/worlding imbued logicaldueness-or-scape-or-frame, profile-or-stature, presumptuousness-or-arrogation, assumptions, value-reference and teleology ${ }^{9}$ ), i.e. temporal preservation teleologies are inclined to forego 
intemporal-preservation-entropy-or-contiguity-or-ontological-preservation teleology (ontological-veridicality/relative-unreflexivity/relative-reflexivity_ontological-contiguity ${ }^{67}$ of reference-of-thought) at a registry-worldview's/dimension's uninstitutionalised-threshold ${ }^{102}$, which should definitely be resisted by 'intellectual responsibility/relative-reflexivity' which for the positivistic registry-worldview/dimension holds that the intellectual disposition is all too willing to be 'romantic' about the idea of human firstnature cross-sectional inclination for the intemporal-disposition and that intellectual responsibility/relative-reflexivity is to acknowledge the veridicality of human-subpotency-aporia/undecidability/dilemma/oughtindeterminacy/deficiency/limitation/constraint—imbued-‘notional firstnaturednessformativeness-<as-to-eventualising-inkling-drive-or-seeding-misprising > temporal-tointemporal-dispositions- $<$ so-construed-as-from-perspective-ontologicalnormalcy/postconvergence>'-existentialism-form-factor and be preemptive of the 'nonontological/non-knowledge/non-virtue temporal-dispositions threshold-ofnonconviction/madeupness/bottomlining-in-shallow-supererogation $<-<$ as-to- 'attendantintradimensional'-prospectively-disontologising preconverging/dementing -apriorisingpsychologism>' by futural Being-development/ontological-framework-expansion-as-to-depthof-ontologising-development-as-infrastructure-of- meaningfulness-and-teleology as of prospective notional deprocrypticism institutionalisation based on absolute notionalcontiguity/epistemic-contiguity ${ }^{2}<$ - profound-supererogation -of-mentallyaestheticised postconverging/dialectical-thinking -qualia-schema> and taking account of temporal-dispositions perversion-of- ${ }^{8}$ reference-of-thought- $<$ as-preconverginglyapriorising/axiomatising/referencing-in-nonconviction/madeupness/bottomlining-as-toshallow-supererogation $>$; just as the present positivism institutionalisation had been preemptive of human cross-sectional disposition for superstition by emphasising rationalempiricism, and the ${ }^{103}$ universalisation institutionalisation had been preemptive of human 
disposition for ad-hoc social-stake-contention-or-confliction resolutions along whims and interests to imply a sense of ${ }^{103}$ universalisation, and base-institutionalisation had been preemptive of human disposition for recurrent lawlessness to imply a sense of institutionalised living with mutual expectations. 'Unconscionability-drag' (from an ontological/intemporal reference) refers to the comprehensive state of undisambiguation of temporal-dispositions individuation-pedestals which are wrongly associated to the intemporal-disposition as being ontologically-veridical as these conjugate/inflect/protract (in mimicking-protraction) with the psychopath's compulsive-dementing insane-fitment/slantedness/mere-possibility narratives which are as dialectically-or-contendingly-out-of-phase or hollow-mimicking) inducing temporal-dispositions epistemic-decadence (notional-discontiguity/epistemic-discontiguity ${ }^{63}$ $<$ between-prior-shallow-supererogation -of-mentallyaestheticised preconverging/dementing -qualia-schema_and_prospective-profoundsupererogation -of-mentally-aestheticised postconverging/dialectical-thinking -qualiaschema $>$-as-of-epistemic-decadence in hollow-constituting-<as-disjointed-misappropriation-ofmeaningfulness-and-failing-intemporal-preservation $>$ in postlogic-backtracking- $<$ iterativelooping-'set-of-dereifying-hollow-narratives-and-acts'> $>$-contiguity-asabsolving/fleeting/escaping-reflex-logic or-hollow-constituting-<as-disjointedmisappropriation-of-meaningfulness-and-failing-intemporal-preservation> or ${ }^{12}$ conjoininglooping-set-of-narratives as-of-cohering-logic-reflex-of-the-in hollow-constituting-<asdisjointed-misappropriation-of-meaningfulness-and-failing-intemporal-preservation $>\quad$ in postlogic-backtracking-<iterative-looping-'set-of-dereifying-hollow-narratives-and-acts'> which-is-not-of-ontological-reference/not-of-contending-reference-but-ontologically-orcontendingly-reflected-or-perspectivated-as-preconverging-or-dementing 2 -apriorisingpsychologism/not-of-veridical-thinking-reference-but-rather-preconverging-or-dementing 20 reference $/ 7$ perversion-of- ${ }^{3}$ reference-of-thought- $<$ as-preconvergingly- 
apriorising/axiomatising/referencing-in-nonconviction/madeupness/bottomlining-as-to-

shallow-supererogation >,-and-not-of-logical-contention) as these are wrongly aligned prelogicly/by-prelogism ${ }^{78}$ to the initiated postlogism 7 . In which case the temporal-dispositions are 'technically psychopathic' with corresponding conjugated/inflected/derived/mimickedprotraction-to-psychopathic compulsive-dementing (temporal unsoundness-or-ontologicalbad-faith/inauthenticity ${ }^{64}$ of- ${ }^{8}$ reference-of-thought-teleologies/registries-perversion-

teleologies/mental-perversions-teleologies, with corresponding groundless fepistemicpsychologismic-subliminality-of-individuation-effusing/worlding imbued logicaldueness-or-scape-or-frame, profile-or-stature, presumptuousness-or-arrogation, assumptions, value-reference and teleology ${ }^{9}$ ); and are rather the subject of contention and aetiologisation/ontological-escalation-<ontological-

veridicality_commitment/otherliness_transcending/compulsions-encumbered_transcending > reflected/perspectivated as manifestations of ${ }^{74}$ perversion-of- ${ }^{8}$ reference-of-thought- $<$ aspreconvergingly-apriorising/axiomatising/referencing-in-

nonconviction/madeupness/bottomlining-as-to-shallow-supererogation $>$ and not logical contention. And so, in distractive-alignment-to- ${ }^{8}$ reference-of-thought- $<$ ofapriorising/axiomatising/referencing $>^{30}$ in a temporal contiguity (procrypticism) allowing for the conceptualisation of the registry-worldview's/dimension's as dialectically-out-of-phasing (dialectically-primitive) over which new recomposuring ${ }^{83}$ reference-of-thought- categoricalimperatives/axioms/registry-teleology ${ }^{9}$,-for-intemporal-preservation-entropy-or-contiguityor-ontological-preservation is construed to reflect/preempt the ${ }^{7}$ perversion-of- ${ }^{83}$ reference-ofthought-<as-preconvergingly-apriorising/axiomatising/referencing-in-

nonconviction/madeupness/bottomlining-as-to-shallow-supererogation >, for 'postconvergingor-dialectical-thinking ${ }^{21}$-psychology or psychology-of-mentation-dynamics or natural psychological-dynamics' psychoanalytic-unshackling/memetic- 
reordering/institutional-recomposuring of the prospective registryworldview's/dimension's(deprocrypticism) new $\quad{ }^{83}$ reference-of-thought- categoricalimperatives/axioms/registry-teleology ${ }^{9}$,-for-intemporal-preservation-entropy-or-contiguityor-ontological-preservation while keeping the temporal-dispositions downgraded/oblongated/decandored alignment as to threshold-ofnonconviction/madeupness/bottomlining-in-shallow-supererogation $<-<$ as-to-'attendantintradimensional'-prospectively-disontologising preconverging/dementing -apriorisingpsychologism>, and so precedingly to avoid <amplituding/formativeepistemicity >totalising $\sim$ self-referencing-syncretising/circularity/interiorising/akrasiaticdrag ${ }^{34}$ circularity induced straightening/candoring/elevation/prelogism ${ }^{78}$ alignment. Given that at 'uninstitutionalised-threshold ${ }^{12}$ ' human learned behaviour is primarily geared towards what is 'perceived as succeeding as of positive-opportunism-of-social-functioning-andaccordance $^{7}$, whether intemporal (the-Good as longness-of-register-of- - meaningfulness-andteleology ${ }^{9}$ ) or temporal (shortness-of-register-of- ${ }^{5}$ meaningfulness-and-teleology ${ }^{9}$ ); it is this mental-devising-representation as the 'unconscionability-drag' that provides the backdrop for skewing ('intemporality ${ }^{52}$-symmetrising-by-desymmetrising-subsumption-of-temporality ${ }^{8}$, for relative intrinsic-reality/ontological-veridicality transcendentalenabling/sublimating/supereregatery de-mentativity)/deferential-formalisation-transference for intemporal-preservation-entropy-or-contiguity-or-ontological-preservation (enabling ontological reference), as it achieves social ${ }^{103}$ universal-transparency ${ }^{104}$-〈transparency-oftotalising-entailing,-as-to-entailing-<amplituding/formative-epistemicity $>$ totalising inrelative-ontological-completeness \, with corresponding untenability/internalcontradiction/internal-incoherence/institutional-constraining, in reflecting-and-preempting the comprehensively distractive-alignment-to- ${ }^{3}$ reference-of-thought- $<$ ofapriorising/axiomatising/referencing $>^{30}$ of the subknowledging ${ }^{4}$ dimension temporal- 
dispositions for the prospective registry-worldview's/dimension's(deprocrypticism) intemporalpreservation-entropy-or-contiguity-or-ontological-preservation. Unconscionability-drag (from an ontological/intemporal reference) also points to the fact that at any institutional registryworldview/dimension, there can be two mental alignments; whether the apriorising-registry is at the institutionalised/intemporalised threshold of prelogism ${ }^{78}$-as-of-conviction,-in-profoundsupererogation $-<$ existentially-veridical-'attendant-intradimensional-

\section{apriorising/axiomatising/referencing'-logical-dueness-precedes-disontologising-logical-}

outcome-arrived-at $>$ meaning or at the uninstitutionalised-threshold ${ }^{102}$ of meaning involving perversion-of- ${ }^{3}$ reference-of-thought-<as-preconvergingly-

apriorising/axiomatising/referencing-in-nonconviction/madeupness/bottomlining-as-to-

shallow-supererogation $>$ requiring distractive-alignment-to- ${ }^{8}$ reference-of-thought- $<$ ofapriorising/axiomatising/referencing $>30$, and in the latter case the reflex to be integratively aligned is lost across all the temporal-dispositions of the ${ }^{7}$ perversion-of- ${ }^{3}$ reference-of-thought-

\section{$<$ as-preconvergingly-apriorising/axiomatising/referencing-in-}

nonconviction/madeupness/bottomlining-as-to-shallow-supererogation $>$ dimension, and what is called for with the unconscionability-drag is a distractive-alignment-to- ${ }^{83}$ reference-ofthought- $<$ of-apriorising/axiomatising/referencing $>$ which will explain a dialectically-orcontendingly-out-of-phase or dialectically-primitive alignment by oblongating/decandoring/downgrading. *, i.e. Remember 'mental-devising-representation' is a devising construct of preceding/superseding abstract reality/veridicality (postconvergence) as the latter never changes, and it is mental devising that adjusts to the illumination/insight we get about abstract reality/veridicality as validated by <amplituding/formativeepistemicity $>$ causality $\sim$ as-to-projective-totalitative-implications-of-prospectivenonpresencing,-for-explicating relative-unreflexivity/relative-reflexivity - ontological-

contiguity ! In-the-bigger-scheme-of-things, 'unconscionability-drag' as a notion points to 
'ontological abstraction and mental-devising-representation of reality/veridicality defect' whether dealing with psychopathic postlogism in hollow-constituting-<as-disjointedmisappropriation-of-meaningfulness-and-failing-intemporal-preservation $>$ or $\quad$ temporaldispositions conjugated/inflected/derived/mimicked/in-protraction-to-psychopathicpreconverging-or-dementing ${ }^{20}$-apriorising-psychologism postlogism 77 in hollow-constituting$<$ as-disjointed-misappropriation-of-meaningfulness-and-failing-intemporal-preservation $>\mathrm{s}$ or simply plain temporal-dispositions 'defective mental-devising-representation of ontological reality/veridicality'. The notion of 'unconscionability-drag' thus extends to all mental-devisingrepresentation of $\quad{ }^{7}$ perversion-of- ${ }^{3}$ reference-of-thought- $<$ as-preconverginglyapriorising/axiomatising/referencing-in-nonconviction/madeupness/bottomlining-as-toshallow-supererogation $>$ of all registry-worldviews/dimensions with respect to the prospective transcendental as the intemporal-preservation-entropy-or-contiguity-or-ontologicalpreservation registry-worldview/dimension, which is the point of ontological referencing (pointreferencing). The reason why the 'study of the social' had hitherto been EPHEMERAL is because of the lack of contiguity in referencing the two elements of ontological meaning ( ${ }^{8}$ reference-of-thought and logic); with ${ }^{83}$ reference-of-thought being hitherto undisambiguated in the social construction of meaning, thus leading to a 'lack of constraining social ${ }^{103}$ universaltransparency ${ }^{104}$-〈transparency-of-totalising-entailing,-as-to-entailing-<amplituding/formativeepistemicity $>$ totalising in-relative-ontological-completeness $>$ of temporal-dispositions prior relative-ontological-incompleteness ${ }^{8}$-induced,-'threshold-ofnonconviction/madeupness/bottomlining-in-shallow-supererogation $-<$ as-to-'attendantintradimensional'-prospectively-disontologising preconverging/dementing -apriorisingpsychologism>'. However as articulated above, the 'unconscionability-drag' carries the resolution for disambiguating ${ }^{8}$ reference-of-thought in the ontological social construction of meaning as it is fully aligned or 'in ratio alignment' to an 'emanant transdimensional (across 
registry-worldviews) point-referencing of intemporal-preservation-entropy' while reflecting a social universal-transparency ${ }^{104}$-〈transparency-of-totalising-entailing,-as-to-entailing$<$ amplinding formative-epistemicity>totalising in-relative-ontological-completeness $\rangle$ that shows the fallibility of temporal dimensions <amplituding/formativeepistemicity>totalising intervalist-as-categorising_-'implicited_attendant-ontologicalcontiguity $^{67}$ ? educedexistentialising/contextmalising/textualising_'intelligibility/epistemicity/reflexivity_contiguity$<$ imbued-notional cogency>' ;-phenomenal-abstractiveness-of-presencing-in-'occlusiveconsciousness'-enablingapriorising/axiomatising/referencing/intelligibilitysettingup/measuringinstrumenting-foroperant-or-incidenting-predicative-insights-of 'implicited_attendant-ontologicalcontiguity ${ }^{67} \sim$ educedexistentialising/contextualising/textualising_intelligibility/epistemicity/reflexivity-contiguity$<$ imbued-notional $\sim$ cogency $>,{ }^{\prime},-<$ reifying-or-elucidating-of-prospective-relative-ontologicalcompleteness -of- reference-of-thought- devolving-as-of-instantiative-context> pointreferencing and as this further discomfitures in the social-construct of meaning, and hence the perversion-and-derived- ${ }^{7}$ perversion-of- ${ }^{3}$ reference-of-thought- $<$ as-preconverginglyapriorising/axiomatising/referencing-in-nonconviction/madeupness/bottomlining-as-toshallow-supererogation $>$, and elicits an ordered construct of meaning ${ }^{83}$ reference-of-thought (in terms-as-of-axiomatic-construct of \{epistemic-totalising $3{ }^{3}$ psychologismic-subliminality-ofindividuation — effusing/worlding imbued logical-dueness-or-scape-or-frame, profile-or-stature, presumptuousness-or-arrogation, assumptions, value-reference and teleology ${ }^{9}$ ) from the superseding perspective of intemporal-preservation-entropy-or-contiguity-or-ontologicalpreservation alienative-hierarchisation and 'disambiguation of notional firstnaturednessformativeness-<as-to-eventualising-inkling drive-or-seeding-misprising $>$ temporal-to- 
intemporal-dispositions-<so-construed-as-from-perspective-ontological-

normalcy/postconvergence $>\quad$ as $\quad$ aetiologisation/ontological-escalation- $<$ ontologicalveridicality_commitment/otherliness_transcending/compulsions-encumbered_transcending >' (longness-of-register-of- ${ }^{5}$ meaningfulness-and-teleology ${ }^{9}$ ). This actually represents the human ' temporalities-to-intemporality ${ }^{52}$ constant' at all registry-worldviews/dimensions (as postlogism ${ }^{77}$-slantedness/ ${ }^{5}$ ignorance/affordability/opportunism/exacerbation/social-chainismor-social-discomfiture-or-negative-social-aggregation/temporal-enculturation-or-temporalendemisation, so-disambiguated as of ${ }^{83}$ reference-of-thought- ${ }^{8}$ devolving ontologicalperformance $^{72}-<$ including-virtue-as-ontology $>$ /morality/ethics/justice/etc. are ${ }^{103}$ universally present in all registry-worldviews). Practically, this involves articulating: (i) the dialectically-orcontendingly-out-of-phase/dialectically-primitive-or-formulaic slanting threshold-ofnonconviction/madeupness/bottomlining-in-shallow-supererogation $-<$ as-to-' ${ }^{-}$ttendantintradimensional'-prospectively-disontologising preconverging/dementing -apriorisingpsychologism> elicited psychopath's insane-fitment narratives in epistemic-decadence (notional-discontiguity/epistemic-discontiguity ${ }^{6}<$ between - prior-shallow-supererogation of-mentally-aestheticised preconverging/dementing -qualia-schema_and prospectiveprofound-supererogation -of-mentally-aestheticised postconverging/dialectical-thinking qualia-schema $>$-as-of-epistemic-decadence in hollow-constituting-<as-disjointedmisappropriation-of-meaningfulness-and-failing-intemporal-preservation> in postlogicbacktracking-<iterative-looping-‘set-of-dereifying-hollow-narratives-and-acts'> $>$ /nonontological-and-non-contending-referencing- $<$ thus-ontologically-or-contendingly-reflected-orperspectivated-as-of-preconverging-or-dementing ${ }^{20}$-apriorising-psychologism $>$ /not-veridicalthinking-reference-rather-preconverging-or-dementing ${ }^{20}$-reference/ $/ 4$ perversion-of- ${ }^{3}$ referenceof-thought-<as-preconvergingly-apriorising/axiomatising/referencing-innonconviction/madeupness/bottomlining-as-to-shallow-supererogation >,-and-not-of-logical- 
contention) teleology (ii) the dialectically-or-contendingly-out-of-phase/dialecticallyprimitive) procryptic temporal-dispositions teleological conjugations/inflections/derivations to the psychopath's as dialectically-or-contendingly-out-of-phase or hollow-mimicking) insanefitment/slantedness/unsoundness-or-ontological-bad-faith/inauthenticity ${ }^{64}$-of- ${ }^{8}$ reference-ofthought narratives, whether they are ignorant, affordable, opportunistic, exacerbating, socialchainism/social-discomfiture/negative-social-aggregation or temporal-enculturation/temporalendemisation (iii) the dialectically-or-contendingly-in-phase/transcendent/deprocryptic 'disambiguation of notional firstnaturedness-formativeness-<as-to-eventualising inkling drive-or-seeding misprising $>$ temporal-to-intemporal-dispositions- $<$ so-construed-as-fromperspective-ontological-normalcy/postconvergence> as aetiologisation/ontological-escalation$<$ ontological-veridicality_commitment/otherliness_transcending/compulsionsencumbered_transcending >' reflecting the psychopath's and other temporal-dispositions veridical mental/ $/$ perversion-of- reference-of-thought-<as-preconverginglyapriorising/axiomatising/referencing-in-nonconviction/madeupness/bottomlining-as-toshallow-supererogation >/mental-perversions/unsoundness-or-ontological-badfaith/inauthenticity ${ }^{64}$ of- reference-of-thought dispositions. Unconscionability-drag (enabling ontological reference), by which the ${ }^{74}$ perversion-of- ${ }^{8}$ reference-of-thought- $<$ aspreconvergingly-apriorising/axiomatising/referencing-in-

nonconviction/madeupness/bottomlining-as-to-shallow-supererogation $>$ /mental-perversions teleologies of meaning is accounted for can be demonstrated below elaborating on the example highlighted before. Of course, this is just a most basic demonstration as ideally one can imagine a creative storied narrative should articulate the phenomenon to its utmost evolving complexities -a storying construal involving an underlying-and-superseding intemporal/ontologising emanant ${ }^{83}$ reference-of-thought—devolving-teleological-de-mentating/structuring/paradigming-ofmeaningfulness as of ${ }^{4}$ historiality/ontological-eventfulness $\%$ ontological-aesthetic-tracing- 
$<$ perspective-ontological-normalcy/postconvergence-reflected-`epistemicity-relativism-

determinism'> as of the notional conflatedness ${ }^{13}$ of notional ${ }^{1}$ deprocrypticism' for 'postconvergence intemporal-preservation-entropy-or-contiguity-or-ontological-preservation longness-of-register-of- ${ }^{56}$ meaningfulness-and-teleology ${ }^{9}$ as of notional ${ }^{18}$ deprocrypticism teleology ${ }^{9}$ ' putting into perspective 'temporal emanant conjugations/inflections shortness-ofregister-of- ${ }^{56}$ meaningfulness-and-teleology ${ }^{9}$ as of procrypticism teleologies'. For instance, the storying construal 'ontological/intemporal veridicality' of non-positivism/medievalism perversion-of- ${ }^{8}$ reference-of-thought-<as-preconvergingly-

apriorising/axiomatising/referencing-in-nonconviction/madeupness/bottomlining-as-to-

shallow-supererogation $>$ will be 'utterly referenced' from positivism; likewise that of recurrent-utter-uninstitutionalisation inherently-'preconverging-or-dementing ${ }^{20}$-apriorisingpsychologism will be 'utterly referenced' from base-institutionalisation, that of ununiversalisation perversion-of- ${ }^{3}$ reference-of-thought- $<$ as-preconverginglyapriorising/axiomatising/referencing-in-nonconviction/madeupness/bottomlining-as-toshallow-supererogation $>$ will be 'utterly referenced' from ${ }^{103}$ universalisation, and thus that of procrypticism-or-disjointedness-as-of- ${ }^{83}$ reference-of-thought ${ }^{74}$ perversion-of- ${ }^{8}$ reference-ofthought-<as-preconvergingly-apriorising/axiomatising/referencing-in-

nonconviction/madeupness/bottomlining-as-to-shallow-supererogation $>$ has to be 'utterly referenced' from deprocrypticism/longness-of-register-of- meaningfulness-and-teleology over shortness-of-register-of- ${ }^{5}$ meaningfulness-and-teleology 99 . The reason for the above is that you can't address a registry-worldview/dimension ${ }^{74}$ perversion-of- ${ }^{8}$ reference-of-thought- $<$ aspreconvergingly-apriorising/axiomatising/referencing-in-

nonconviction/madeupness/bottomlining-as-to-shallow-supererogation $>$ phenomenal defect (psychopathy) without addressing the defects of the registry-worldview/dimension (procrypticism) that endemises it from the reference of the prospective transcendental dimension, 
just as you can't address witchcraft without fundamentally addressing a nonpositivism/medievalism registry-worldview that will necessarily and readily endemise superstitions and witchcraft. The peculiarities of successive institutionalisations is that these address the successive emanant dimensional defects of: recurrent-utter-uninstitutionalisation by emphasising 'base-institutionalising', ununiversalisation by emphasising ' superstition/non-positivism/medievalism by emphasising 'positivising', and procrypticismor-disjointedness-as-of- ${ }^{8}$ reference-of-thought preconverging-or-dementing ${ }^{20}$-apriorisingpsychologism by the 'undermining of disjointedness/subknowledging /mimicking' and so as to 'longness-of-register-ofmeaningfulness-and-teleology 9 over shortness-of-register-of- ${ }^{56}$ meaningfulness-andteleology construed as deprocrypticising/preempting-disjointedness-as-of- ${ }^{9}$ reference-ofthought' (noting that the latter institutionalisation/intemporalisation contains the sublimatingnascence of the previous institutionalisations up to its own threshold of institutionalisation/intemporalisation, with notional deprocrypticism being organically imbued with all the prior/superseded institutionalisations); all these, pointing to an 'ontological psychoanalytic/memetic-contiguity deconstruction across anthropology' which the present treatment of psychology doesn't recognise: (i) Psychopath narrative teleology : an adult psychopath meets a stranger and speaks to him about another stranger whom it knows nothing about, saying logically that it is a bad thing for this guy to be molesting children (ii) temporaldispositions narratives teleologies: a stranger not knowing the other stranger aligning prelogicly to the psychopath's narrative will have a 'conjugated/inflected/derived/mimicked/in-protractionto-psychopathic-preconverging-or-dementing -apriorising-psychologism ignorance-temporaldisposition defect' if it articulated the following narrative: (a) Such a person should not be allowed to roam the streets and should be interned. A 'conjugated/inflected/derived/mimicked/in-protraction-to-psychopathic-preconverging-or- 
dementing -apriorising-psychologism affordability-temporal-disposition defect' will arise if another interlocutor knowing the accused for not truly being a child molester but because of expediency with respect to the psychopath articulates the following narrative: (b) the guy is actually a bad person and they will not be surprise that he is a child molester. A 'conjugated/inflected/derived/mimicked/in-protraction-to-psychopathic-preconverging-ordementing -apriorising-psychologism opportunism-temporal-disposition defect' will arise if a different interlocutor knowing truly that the accused is not a child molester but for a favour or sense-of-favour they owe to the psychopath articulates the following narrative: (c) this guy has been going around molesting young children for quite a while now. A 'conjugated/inflected/derived/mimicked/in-protraction-to-psychopathic-preconverging-ordementing -apriorising-psychologism exacerbation-temporal-disposition defect' will arise where another interlocutor knowing the truth about the whole thing, thinks they can have an advantage by acting likewise as the psychopath and articulates the following narrative (d) they had actually witnessed the accused shoplifting. A 'conjugated/inflected/derived/mimicked/inprotraction-to-psychopathic-preconverging-or-dementing ${ }^{20}$-apriorising-psychologism socialdiscomfiture/(social-chainism/negative-social-aggregation)-temporal-disposition defect' will arise where (e) such narratives are purposefully and consistently relayed in the social sphere based on ignorances/desublimation, affordabilities, opportunisms and exacerbations, and individuals come to make it a reference for their relation with the accused. And finally, a 'conjugated/inflected/derived/mimicked/in-protraction-to-psychopathic-preconverging-ordementing -apriorising-psychologism temporal-enculturation (temporal-endemisation)temporal-disposition defect' arises where (f) individuals come to learn that by having the appropriate social relations and social support network they can then initiate such narratives if they were to have competing 'socially-perceived-value as of social-stake-contention-orconfliction' situations with others, and not only that it also includes individuals passively 
accepting and giving up on the principle of the intemporality ${ }^{2} /$ longness and intrinsicness of meaning. It is important to distinguish all the above 'temporal instances conjugated/inflected/derived/mimicked/in-protraction-to-psychopathic-preconverging-ordementing -apriorising-psychologism of the psychopath's postlogism -slantedness in hollowconstituting-<as-disjointed-misappropriation-of-meaningfulness-and-failing-intemporalpreservation>', and is different from a 'defect of logical operation/processing/contention which does not imply any temporal-disposition defect (in terms-as-of-axiomatic-construct of perversion-of- ${ }^{8}$ reference-of-thought-<as-preconverginglyapriorising/axiomatising/referencing-in-nonconviction/madeupness/bottomlining-as-toshallow-supererogation $>$ or the denaturing of the ${ }^{83}$ reference-of-thought/apriorisingregistry_elements out of 'implicited_attendant_ontological-contiguity ${ }^{67}$ ' educedexistentialising/contextualising/textualising_'intelligibility/epistemicity/reflexivity-contiguity$<$ imbued-notional $\sim$ cogency $>$, ,-<reifying-or-elucidating-of-prospective-relative-ontologicalcompleteness -of- reference-of-thought- devolving-as-of-instantiative-context> as tasychologismic-subliminality-of-individuation-effusing/worlding imbued logicaldueness-or-scape-or-frame, profile-or-stature, presumptuousness-or-arrogation, assumptions, value-reference and teleology $\left.{ }^{9}\right)^{\prime}$. With temporal- perversion-of- $^{-3}$ reference-of-thought- $<$ aspreconvergingly-apriorising/axiomatising/referencing-in-

nonconviction/madeupness/bottomlining-as-to-shallow-supererogation $>$ (mental-perversion), the interlocutor deliberately (or naively in the case of ignorance) doesn't project intemporally (i.e. projects in terms-as-of-axiomatic-construct of shortness-of-register-of- ${ }^{56}$ meaningfulnessand-teleology ${ }^{9}$ or immediate-temporal-interest and not a ${ }^{103}$ universal ontological sense of meaning), comparatively more like a student guessing that the answer of a math question is say 5 'artificially' operates an equation to yield 5 as answer. Whereas with a 'defect of logical operation/processing/contention' (which is not the case here), an interlocutor perfectly projects 
intemporally (i.e. projects in terms-as-of-axiomatic-construct of longness-of-register-ofmeaningfulness-and-teleology ${ }^{9}$ or a ${ }^{103}$ universal ontological sense of meaning) but poorly operates/processes the logic adhocly. This latter case unlike the former doesn't imply registryworldview's/dimension's-uninstitutionalised-threshold ${ }^{102}$-defect-<as-Being-or-ontological-orexistential-defect $>$ '5 but rather an 'adhoc defect-of- ${ }^{5}$ logical-processing-or-logicalimplicitation - supposedly-apriorising-in-conviction-as-to-profound-supererogation of the registry-worldview's/dimension's- $-{ }^{83}$ reference-of-thought-for-social-functioning-andaccordance whereas the former is 'registry-worldview's/dimension's-uninstitutionalisedthreshold ${ }^{102}$-defect-<as-Being-or-ontological-or-existential-defect $>5$ that speaks to the unprincipled-or-derived-unprincipled disposition of the interlocutor's individuation that is, with respect to an infinite number of cases in the same situation (i.e. comparatively the disposition to go about answering math questions by figuring out their answers then 'artificially' trying to work out equations to yield the answers). Thus establishing the <amplituding/formativeepistemicity $>$ causality $\sim$ as-to-projective-totalitative-implications-of-prospectivenonpresencing,-for-explicating relative-unreflexivity/relative-reflexivity - ontologicalcontiguity of this slantedness/postlogic individuation defective nature ontologically, hence enabling its aetiologisation/ontological-escalation-<ontologicalveridicality_commitment/otherliness_transcending/compulsions-encumbered_transcending $>$. This also requires the disambiguation of the registries (involving stranding-of-pervertingtemporal-dispositions which refers to mental-devising-representation of temporal-dispositionsregistries teleologies registry-worldview's/dimension's-uninstitutionalised-threshold ${ }^{12}$-defect$<$ as-Being-or-ontological-or-existential-defect ${ }^{85}$, i.e. oblongated/decandored as of thresholdof-nonconviction/madeupness/bottomlining-in-shallow-supererogation $<$ as-to-'attendantintradimensional'-prospectively-disontologising preconverging/dementing -apriorisingpsychologism> mechanicalism/alchemic-like-reasoning/circumventive/distractive-temporal- 
prioritisation-of- ${ }^{8}$ reference-of-thought/shortness-of-register-of meaningfulness-andteleology in distractive-alignment-to- ${ }^{-}$reference-of-thought- $<$ofapriorising/axiomatising/referencing $>30$ of ${ }^{74}$ perversion-of- ${ }^{3}$ reference-of-thought $-<$ aspreconvergingly-apriorising/axiomatising/referencing-innonconviction/madeupness/bottomlining-as-to-shallow-supererogation notional procrypticism mindset $\quad$ as per postlogism ${ }^{77}$ slantedness/ ${ }^{50}$ ignorance/affordability/opportunism/exacerbation/social-chainism-or-socialdiscomfiture-or-negative-social-aggregation/temporal-enculturation-or-temporal-endemisation, so-disambiguated as of ${ }^{83}$ reference-of-thought- ${ }^{8}$ devolving ontological-performance ${ }^{72}$ $<$ including-virtue-as-ontology $>$. For intemporal-preservation-entropy-or-contiguity-orontological-preservation, strands-of-perverting-temporal-dispositions implies 'not wrongly implying precedingly the reflex of an intemporal prelogism ${ }^{78}$-as-of-conviction,-in-profoundsupererogation $-<$ existentially-veridical-'attendant-intradimensionalapriorising/axiomatising/referencing'-logical-dueness-precedes-disontologising-logicaloutcome-arrived-at $>$ reflex and reference on the subknowledging $4 /$ mimicking-temporaldispositions but rather reflexively downgrading as dialectically-or-contendingly-out-of-

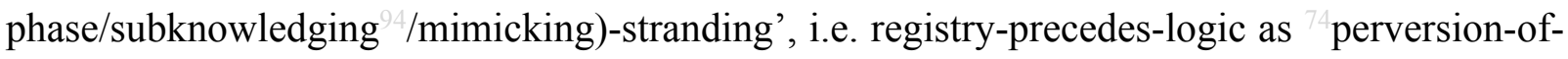
reference-of-thought-<as-preconvergingly-apriorising/axiomatising/referencing-innonconviction/madeupness/bottomlining-as-to-shallow-supererogation $>$ undermines the operation of logic, at which point contention is about the 'generation of ontological preconverging-or-dementing ${ }^{20}$-apriorising-psychologism- $<$ stranded-as-rightfullyoblongated/decandored-and-dialectically-or-contendingly-out-of-phase>' of such temporaldispositions denaturing ${ }^{16}$ to be reflected/perspectivated and ontologised by the intemporal mind as procrypticism as validated by 'unconscionability-drag' such that the temporal-dispositions, which are conjugated/inflected/derived/mimicked/in-protraction-to-psychopathic- 
preconverging-or-dementing ${ }^{20}$-apriorising-psychologism slantedness' as these are protractions of the psychopath's as dialectically-or-contendingly-out-of-phase or hollow-mimicking) insanefitment/postlogism 77 -slantedness, and hence are in transversality-<for-sublimating-existentialeventuating/denouement,-from-'thinking-at-first/pure-predisposition-preemptive-ofprospective-disontologising/subontologising' as-of-prospectively-disambiguated-affirmedand-unaffirmed-'motif-and-apriorising/axiomatising/referencing' $>101$ and should not be represented mentally going by the 'unconscionability-drag' as 'logically/in-prelogic supplanting-conviction-as-to-profound-supererogation —of-'attendant-intradimensional'postconverging/dialectical-thinking -apriorising-psychologismly articulating/composing, i.e. not contending' but rather as a 'mentallyconjugated/inflected/derived/mimicked/subknowledging 94 in-protraction-to-psychopathicpreconverging-or-dementing ${ }^{20}$-apriorising-psychologism,-and-oblongated, i.e. a manifestation of perversion-of- ${ }^{8}$ reference-of-thought- $<$ as-preconverginglyapriorising/axiomatising/referencing-in-nonconviction/madeupness/bottomlining-as-toshallow-supererogation $>$ ' as is the case with the mental-devising-representation at all registryworldviews/dimensions uninstitutionalised-threshold ${ }^{102}$, and should not be wrongly elevated/candored/straightened/integratively-aligned/dialectically-or-contendingly-in-phase in equivalence with intemporal-preservation-entropy-or-contiguity-or-ontological-preservation apriorising-registry (since they are not contending) but rather downgraded/decandored/protracted-preconverging-or-dementing 2 -apriorisingpsychologism/oblongated/logical-incongruence-or-transversality- $<$ for-sublimating-existentialeventuating/denouement,from-'thinking-at-first/pure-predisposition-preemptive-ofprospective disontelogising/subentelogising'>/dialectically-or-contendingly-out-of-phase in threshold-of-nonconviction/madeupness/bottomlining-in-shallow-supererogation $-<$ as-to‘attendant-intradimensional'-prospectively-disontologising preconverging/dementing 
apriorising-psychologism> and are rather manifestations of registry/mental defect or denaturing and are the subject of intemporal/ontological contention from the intemporaldisposition, more like at the registry-worldview/dimension defect level medievalism categoricalimperatives/axioms being superseded and undermined with respect to positivism categoricalimperatives/axioms-for-intemporal-preservation-entropy-or-contiguity-or-ontological-

preservation. Very much counterintuitively with regards to 'unconscionability-drag', the transcendental requirement for a 'habituation' to a so-called 'prospective intemporal and more veridical mental-devising-representation registry-worldview's/dimension's ${ }^{83}$ reference-ofthought - categorical-imperatives/axioms/registry-teleology' is rather 'unfathomable' for the prior $<$ amplituding/formative $>$ wooden-language-〈imbued-temporal-mere-

\section{form/virtualities/dereification/akrasiatic-drag/denatured/preconverging-or-dementing}

\section{narratives - of-the- reference-of-thought- categorical-imperatives/axioms/registry-}

teleology $\rangle$ of the so-called ' perversion-of- ${ }^{83}$ refence-of-thought-<as-preconverginglyapriorising/axiomatising/referencing-in-nonconviction/madeupness/bottomlining-as-to-

shallow-supererogation $>$ dimension'; this applies with regards to recurrent-utteruninstitutionalisation and base-institutionalisation, ununiversalisation and ${ }^{103}$ universalisation, non-positivism/medievalism and positivism, and prospectively for upcoming times, procrypticism and deprocrypticism. The explanation is quite simple; as individuals in any institutionalisation/intemporalisation registry-worldview/dimension are formed by the memeticordering/psychoanalytic-construction at that registry-worldview/dimension which is 'alldefining of meaningfulness (in terms-as-of-axiomatic-construct of ${ }^{83}$ reference-of-thought and logic)' to the individuals and so right up to their subconscious mind. But then a prospective transcendental memetic-reordering/psychoanalytic-unshackling is placing such a prior memeticorder/psychoanalytic-construction of their existentialism (full-existential-depth-implications) personhoods-and-socialhood-formation in jeopardy, and it is only the <amplituding/formative- 
epistemicity $>$ causality $\sim$ as-to-projective-totalitative-implications-of-prospective-

nonpresencing,-for-explicating relative-unreflexivity/relative-reflexivity ontological-

contiguity social ${ }^{103}$ universal-transparency ${ }^{104}$-〈transparency-of-totalising-entailing,-as-to-

entailing-<amplituding/formative-epistemicity $>$ totalising $\sim$ in-relative-ontological-

completeness $\rangle$ of the prospective intemporal dimension inducing untenability/internalcontradiction/internal-incoherence/institutional-constraining with corresponding percolationchannelling- $<$ in-deferential-formalisation-transference $>$ impact from the prospective registryworldview/dimension on the overall social-construct over a generation or two or more that allows for any such 'habituation' to a prospective registry-worldview's/dimension's transcendence-and-sublimity/sublimation/supentativity with its new recomposuring ${ }^{83}$ reference-of-thought- categorical-imperatives/axioms/registry-teleology ${ }^{9}$. This will explain the difficulty of medieval minds (including institutions like the church) over centuries to come to terms with positivism and scientism such that the positivistic psychoanalytic-unshackling/memetic-reordering/institutional-recomposuring is still ongoing. Counterintuitively, every successive institutionalisation/intemporalisation registryworldview/dimension naively thinks it being at the backend of the 'institutionalcumulation/institutional-recomposure-〈as-to- historiality/ontological-

eventfulness /ontological-aesthetic-tracing-<perspective-ontologicalnormalcy/postconvergence-reflected-‘epistemicity-relativism-determinism' $>>$ process' means it is beyond transcendence-and-sublimity/sublimation/superentativity as it doesn't project of itself as being superseded by a prospective registry-worldview with its new recomposuring ${ }^{83}$ reference-of-thought- categorical-imperatives/axioms/registry-teleology ${ }^{99}$ (as of supplanting-conviction-as-to-profound-supererogation -of-'attendant-intradimensional'postconverging/dialectical-thinking -apriorising-psychologism) at the point where the former starts perversion-of- ${ }^{3}$ reference-of-thought- $<$ as-preconvergingly- 
apriorising/axiomatising/referencing-in-nonconviction/madeupness/bottomlining-as-to-

shallow-supererogation $>\quad$ its $\quad$ own $\quad$ reference-of-thought- categoricalimperatives/axioms/registry-teleology ${ }^{9}$, and does not tend to represent itself as oblongated/decandored/logical-incongruence-or-transversality- $<$ for-sublimating-existentialeventuating/denouement,-from-'thinking-at-first/pure-predisposition-preemptive-ofprospective-disontologising/subentologising'>/dialectically-or-contendingly-out-of-phase as of threshold-of-nonconviction/madeupness/bottomlining-in-shallow-supererogation $<-<$ as-to‘attendant-intradimensional'-prospectively-disontologising preconverging/dementing apriorising-psychologism $>$ from a prospective dimension perspective in the sense that. The decandored/oblongated/logical-incongruence-or-transversality- $<$ for-sublimating-existentialeventuating/denouement,from-'thinking-at-first/pure-predisposition-preemptive-ofprospective-disontologising/subontologising'>/dialectically-or-contendingly-out-of-phase insight we think of non-positivism/medievalism with corresponding phenomena like superstitions, witch-hunts, etc. has never been the way they represented themselves as they are candored/straight/integratively-aligned/‘dialectically-or-contendingly-in-phase’ in their $<$ amplituding/formative-epistemicity $>$ totalising $\sim$ self-referencing-syncretising/presentconsciousness/illusion-of-the-present mental-devising-representation of themselves. Rather it is the more profound grasp of reality from positivism that initiates that decandored/oblongated/logical-incongruence-or-transversality- $<$ for-sublimating-existentialeventuating/denouement,from-'thinking-at-first/pure-predisposition-preemptive-ofprospective-disontologising/subontologising'>/dialectically-or-contendingly-out-of-phase mental-devising-representation of non-positivism/medievalism in the positivistic mind, and this is the case as well with all other dialectic institutionalisations across the institutionalcumulation/institutional-recomposure-〈as-to- historiality/ontologicaleventfulness /ontological-aesthetic-tracing-<perspective-ontological- 
normalcy/postconvergence-reflected-‘epistemicity-relativism-determinism' $>>$ /anthropologicalcontinuity/anthropopsychology. The reason for making the above point is that we will most possibly as of <amplituding/formative-epistemicity $>$ totalising $\sim$ self-referencingsyncretising/present-consciousness/illusion-of-the-present act likewise when it is time to imply our own decandored/oblongated/logical-incongruence-or-transversality-<for-sublimating existential-eventuating/denouement-from-'thinking-at-first/pure-predisposition-preemptive-ofprospective-disontologising/subontologising'>/dialectically-or-contendingly-out-of-phase procrypticism-or-disjointedness-as-of- ${ }^{8}$ reference-of-thought mental-devising-representation of our ${ }^{83}$ reference-of-thought- ${ }^{8}$ categorical-imperatives/axioms/registry-teleology ${ }^{9}$ with respect to a prospectively candored/straight/integratively-aligned/dialectically-or-contendingly-inphase notional ${ }^{18}$ deprocrypticism new recomposuring ${ }^{83}$ reference-of-thought- ${ }^{8}$ categoricalimperatives/axioms/registry-teleology that is revealed by the 'unconscionability-drag' disambiguation of our temporal-dispositions-perversion associated with ${ }^{74}$ perversion-ofreference-of-thought-<as-preconvergingly-apriorising/axiomatising/referencing-innonconviction/madeupness/bottomlining-as-to-shallow-supererogation $>$ in our dimension (procrypticism) including psychopathy-and-its-social-psychopathy-corollary subknowledging ${ }^{4 / m i m i c k i n g ! ~(i i i) ~ F o r ~ d e p r o c r y p t i c i s m, ~ ' n o t i o n a l ~ f i r s t n a t u r e d n e s s-~}$ formativeness-<as-to-eventualising-inkling-drive-or-seeding-misprising $>$ temporal-tointemporal-dispositions- $<$ so-construed-as-from-perspective-ontologicalnormalcy/postconvergence> aetiologisation/ontological-escalation-<ontologicalveridicality_commitment/otherliness_transcending/compulsions-encumbered_transcending>' teleology ${ }^{9}$ : will involve identifying, defining, characterising, qualifying and articulating the aetiology of this individuation 74 perversion-of- reference-of-thought-<as-preconverginglyapriorising/axiomatising/referencing-in-nonconviction/madeupness/bottomlining-as-toshallow-supererogation $>$ dynamism endemic in the social-construct and prospective 
categorical-imperatives/axiomatic-construct for its preemption, more like a positive mind will do with respect to a non-positivism/medievalism social-construct ${ }^{83}$ reference-of-thought. (Though interestingly it is important to grasp that such transcendence-andsublimity/sublimation/supererogatory de-mentativity actually takes the natural form of a 'crossgenerational medium to long-term psychoanalytic-drag' and not 'instantaneous utter transformation' towards ontological-completeness-of- ${ }^{8}$ reference-of-thought, even such an ‘instantaneous utter transformation conceptualisation’ is equally a necessary knowledge exercise as the social ${ }^{103}$ universal-transparency ${ }^{104}$-〈transparency-of-totalising-entailing,-as-to-entailing$<$ amplituling/formative-epistemicity $>$ totalising in-relative-ontological-completeness $>$ constraining that allows for a 'crossgenerational medium to long-term psychoanalytic-drag'): (a) articulating a social ${ }^{103}$ universal-transparency ${ }^{104}$-〈transparency-of-totalising-entailing,-as-toentailing-<amplituding/formative-epistemicity $>$ totalising $\sim$ in-relative-ontological-

completeness $\rangle$ of the registry-worldview-perversions, (b) generating <amplituding/formativeepistemicity $>$ causality $\sim$ as-to-projective-totalitative-implications-of-prospectivenonpresencing,-for-explicating relative unreflexivity/relative-reflexivity - ontologicalcontiguity untenability/internal-contradiction/internal-incoherence/institutional-constraining in the perversion-of- ${ }^{8}$ reference-of-thought-<as-preconverginglyapriorising/axiomatising/referencing-in-nonconviction/madeupness/bottomlining-as-toshallow-supererogation $>$ registry-worldview (c) referencing/registering/decisioning or stranding the perversion-of- ${ }^{2}$ reference-of-thought- $<$ as-preconverginglyapriorising/axiomatising/referencing-in-nonconviction/madeupness/bottomlining-as-toshallow-supererogation perversion-of- ${ }^{3}$ reference-of-thought- $<$ as-preconverginglyapriorising/axiomatising/referencing-in-nonconviction/madeupness/bottomlining-as-toshallow-supererogation $>\quad$ as-of-unsoundness-or-ontological-bad-faith/inauthenticity ${ }^{6}$-ofreference-of-thought/subknowledging ${ }^{94}$ registry-worldview/dimension defect for prospective 
preemption with new recomposuring reference-of-thought- categoricalimperatives/axioms/registry-teleology ${ }^{9}$,-for-intemporal-preservation-entropy-or-contiguityor-ontological-preservation of the prospective registry-worldview/dimension, i.e. notional ${ }^{18}$ deprocrypticism (d) intemporal projection superseding the transcendenceunenabling-uninstitutionalised-threshold 02 in alienation-as-inauthentic/poorlyobjectified/poorly-desubjectified-as-objectified/ontological-bad-faith/inauthenticity ${ }^{6} /$ beingdialectically-or-contendingly-out-of-phase/logically-incongruence with the ${ }^{7}$ perversion-ofreference-of-thought-<as-preconvergingly-apriorising/axiomatising/referencing-innonconviction/madeupness/bottomlining-as-to-shallow-supererogation > registry-worldview, inducing a 'habituation'/'postconverging-or-dialectical-thinking -psychology or psychologyof-mentation-dynamics or natural psychological-dynamics’ psychoanalyticunshackling/memetic-reordering/institutional-recomposuring as of the prospective apriorisingregistry worldview crossgenerational (over a generation or two) intemporal projection superseding the transcendence-unenabling-uninstitutionalised-threshold ${ }^{02}$ in alienation-asinauthentic/poorly-objectified/poorly-desubjectified-as-objectified/ontological-badfaith/inauthenticity ${ }^{64}$ /nihilistic; implies that the mental-devising-representation of a superseded/transcended/unsound registry/registry-worldview (which is rather in epistemicdecadence and hence in ontological-discontinuity) as of de-mentation〈supererogatory $\sim$ ontological-de-mentation-or-dialectical-de-mentation-stranding-or-

attributive-dialectics $\rangle$ preconverging-or-dementing ${ }^{20}$-apriorising-psychologism- $<$ stranded-asrightfully-oblongated/decandored-and-dialectically-or-contendingly-out-of-phase>, entails it doesn't re-join by mere logical articulation the prospective superseding/transcending/sound registry/registry-worldview postconverging-or-dialectical-thinking -apriorisingpsychologism-<stranded-as-rightfully-straight/candored-and-dialectically-or-contendingly-inphase $>$, as the prospective institutionalisation is rather about a registry-worldview/registry, and 
not logical, transformation as a 'postconverging-or-dialectical-thinking -psychology or psychology-of-mentation-dynamics or natural psychological-dynamics’ psychoanalyticunshackling/memetic-reordering/institutional-recomposuring; with the notion that any such wrongly implied re-joining as logical articulation is rather <amplituding/formativeepistemicity $>$ totalising $\sim$ self-referencing-syncretising/circularity/interiorising/akrasiatic-drag of the prior registry/registry-worldview reflex-defect in want of 'postconverging-or-dialecticalthinking -psychology or psychology-of-mentation-dynamics or natural $\sim$ psychologicaldynamics' psychoanalytic-unshackling/memetic-reordering/institutional-recomposuring. For instance, in the case mentioned before with regards to B (Brackets), where B was to stick with the same temporal-dispositions individuation disposition that delivered the wrong results with respect to subsequent equations of a similar context (uninstitutionalised-threshold ${ }^{102}$ ) this will be epistemic-decadence, as conjugated/inflected/derived from A's defective condition which is in epistemic-decadence, and the both $\mathrm{A}$ and $\mathrm{B}$ are of notional-discontiguity/epistemicdiscontiguity ${ }^{3}-<$ between - prior-shallow-supererogation -of-mentallyaestheticised preconverging/dementing -qualia-schema_and_prospective-profoundsupererogation -of-mentally-aestheticised postconverging/dialectical-thinking -qualiaschema> defining the registry-worldview/dimension apriorising/axiomatising/referencing/intelligibilitysettingup/measuringinstrumenting defect. This implies ${ }^{15}$ de-mentation-〈supererogatory $\sim$ ontological-de-mentation-or-dialectical-dementation-stranding-or-attributive-dialectics $\rangle$ of $\mathrm{B}$ to such ${ }^{77}$ perversion-of- ${ }^{83}$ reference-ofthought-<as-preconvergingly-apriorising/axiomatising/referencing-in-

nonconviction/madeupness/bottomlining-as-to-shallow-supererogation $>$ (as prior intemporal reference-of-thought- categorical-imperatives/axioms/registry-teleology ${ }^{\circ}$ ) is the effective backdrop for 'postconverging-or-dialectical-thinking -psychology or psychology-ofmentation-dynamics or natural psychological-dynamics' psychoanalytic-unshackling/memetic- 
reordering/institutional-recomposuring for the prospective ${ }^{8}$ reference-of-thought- categoricalimperatives/axioms/registry-teleology ${ }^{9}$,-for-intemporal-preservation-entropy-or-contiguityor-ontological-preservation, and this is rather crossgenerational in nature (rather than instant intra-generational registry/registry-worldview transformation) as personhoods-and-socialhoodformation are rather grounded on the superseded/transcended/unsound ${ }^{83}$ reference-of-thoughtcategorical-imperatives/axioms/registry-teleology ${ }^{9}$,-for-intemporal-preservation-entropy-orcontiguity-or-ontological-preservation. The above analysis shows that soundness-orontological-good-faith/authenticity -of- reference-of-thought-of-meaningfulness is not given, as it is a devising mechanism (mental-devising-representation) for ontological-veridicality as dialectically upheld for intemporal-preservation-entropy-or-contiguity-or-ontologicalpreservation (ontological-normalcy/postconvergence). Unconscionability-drag (from an ontological/intemporal reference) ensures the disambiguation of registries so that the psychopath's and temporal-dispositions are not elevated to the intemporal level which then allows for, by reflex, a simple operation/processing of logic (whereas the fundamental defect being in terms-as-of-axiomatic-construct of the apriorising-registry-elements, totalising $3{ }^{5}$ psychologismic-subliminality-of-individuation-effusing/worlding imbued logicaldueness-or-scape-or-frame, profile-or-stature, presumptuousness-or-arrogation, assumptions, value-reference and teleology ${ }^{9}$ of the registries, i.e. rather the unsoundness-or-ontological-badfaith/inauthenticity ${ }^{64}$-of- reference-of-thought or the dialectically-or-contendingly-out-ofphase meaningful construct). Unconscionability-drag (from an ontological/intemporal reference) is thus central to attending to the rational-realism of notional deprocrypticism as of ratiocontiguity/ratiocination-as-referentialism_-implicited_attendant-ontologicalcontiguity $^{67} \sim$ educedexistentialising/contextualising/textualising_'intelligibility/epistemicity/reflexivity_contiguity$<$ imbued-notional cogency $>$ ' $40 \quad$ as nondisjointing 'postconverging-de- 
mentating/structuring/paradigming as $\quad{ }^{4}$ human-subject-emancipating-relativism-drivenrecomposuring-constructivism-towards-singularisation-<as-to-thenondisjointedness/entailment-of-prospective- nonpresencing $>$ ', as it accounts for the defect of temporal-dispositions teleologies of meaning (shortness-of-register-of- ${ }^{56}$ meaningfulness-andteleology ${ }^{9}$ ) while projecting intemporally/ontologically. The notion of 'unconscionability-drag' also explain how and why banal temporal-dispositions are not readily integrative of psychopathic postlogism 7 -slantedness as conjugated-postlogism 7 preconverging-ordementing -integration' (hence no distractive-alignment-to- ${ }^{8}$ reference-of-thought- $<$ ofapriorising/axiomatising/referencing $>^{30}$ ) to the childhood and early adolescent psychopaths but come to develop a 'mental-unconsciousness' (unconscionability) to be 'integrative of psychopathic postlogism ${ }^{77}$-slantedness' during the stage of late adolescence and adult psychopath. Antipodal to the idea of 'unconscionability-drag' is the idea of 'conventioning'/social-temporal-thresholding. 'Unconscionability-drag' points to an abstract but more veridical ontological construct of the 'social construction of meaning' that is ontological-normalcy/postconvergence, based on intemporal-preservation-entropy-orcontiguity-or-ontological-preservation by using categorical-imperatives of the prospective superseding/transcendental registry-worldview/dimension whether such a representation is aligned or not with the society's collective-social-psyche or present-consciousness. (For instance, we can generate an unconscionability-drag of a medieval society on the basis of a positivistic mental projection and categorical-imperatives; wherein we oblongate the solipsistic mental-dispositions of individuations in such a society. While such a representation, with its corresponding subknowledging $/$ mimicking, is ontologically more accurate about such a society, however, the collective-social-psyche/present-consciousness of individuations in the said society will not recognise any such decandored/oblongated/logical-incongruence-ortransversality-<for-sublimating-existential-eventuating/denouement,-from-'thinking-at- 


\section{first/pure-predisposition-preemptive-of-prospective-}

disontologising/subentologising'>/dialectically-or-contendingly-out-of-phase representation of themselves, rather the medieval society will represent itself as candored/straight/integrativelyaligned/dialectically-or-contendingly-in-phase which is then the 'conventioning/socialtemporal-thresholding representation of the social construction of meaning'). Conventioning/social-temporal-thresholding thus refers to the fact that in a 'social construction of meaning', intrinsic-reality by itself and in of itself (as may be grasped ontologically from superseding/transcendental categorical-imperatives preserving intemporality ${ }^{52}$ ) is not necessarily the deterministic basis for human social adherence to it. Transcended and ontological meaningfulness of reality (contrary to conventioning/social-temporal-thresholding meaningfulness of reality which is rather towards <amplituding/formativeepistemicity $>$ totalising $\sim$ self-referencing-syncretising/temporality ${ }^{0}$-serving) requires a process of institutionalised/intemporalised social integration to induce untenability/internalcontradiction/internal-incoherence/institutional-constraining to "prior or circumstantial social integration gatekeeping construals or (institutionalisation/intemporalisation) percolationchannelling-<in-deferential-formalisation-transference>' of 'any social construction of meaning' for there to be collective institutionalised social adherence (and by the relative positive-opportunism-of-social-functioning-and-accordance elicited). Institutionalisation/Intemporalisation percolation-channelling- $<$ in-deferential-formalisationtransference $>$ are the institutionalised relays for human survival-and-flourishing-teleology ${ }^{9}$, whether diffusely from internalisation-and/or-formalism, and are increasingly vital with higher institutionalisations, and most vital for prospective perpetuation-of-deprocrypticism, such that abstractions that will normally hardly be socially integrated going just by averaging human temporal-to-intemporal nature, can actually come from re-originary_-ass-unenenframe-_ed/reontologising/unbeholdening/outlier-conceptualisation-_imbued-postconverging/dialectical- 
thinking -'projective-insights'/‘epistemic-projection-in-conflatedness ' 'of-

notional deprocrypticism-prospective-sublimation $\rangle^{0}$ intemporal-disposition to inform social institutionalisation/intemporalisation, thus emphasising how vital percolation-channelling- $<$ indeferential-formalisation-transference $>$ are for institutional-cumulation/institutionalrecomposure-〈as-to- historiality/ontological-eventfulness /ontological-aesthetic-tracing-

$<$ perspective--ontological-normalcy/postconvergence-reflected-'epistemicity-relativismdeterminism' $>>$ beyond just the consciousness appraisal of temporal-dispositions. Institutionalisation/Intemporalisation percolation-channelling- $<$ in-deferential-formalisationtransference $>$ imply that the would-be intellectual analyst can perfectly uphold intrinsic reality over 'social-and-temporal-trading' and still impose veridicality (if truly veridical) over populistinclined dispositions which are not veridical, just by the fact of the extendedly implied positiveopportunism-of-social-functioning-and-accordance ${ }^{75}$ for human survival-and-flourishing imbued in institutionalisation/intemporalisation percolation-channelling- $<$ in-deferentialformalisation-transference $>$. This implies that an exercise in institutionalisation/intemporalisation beyond just intemporal philosophical projection is needed for the social integration of any transcending veridicality postconverging-dementating/structuring/paradigming (the latter being any notion that put in question informal or formal conventioning/social-temporal-thresholding ways of perceiving and doing things for supposedly prospective better ways). Correspondingly, the social-construct cannot be and should not be related to as a philosophical construct since it is rather 'conventionalised from institutionalisation/intemporalisation (secondnatured), and has not evolved as of dimensionalityof-sublimating $-<<$ amplituding/formative $>$ supererogatory $\sim$ de-mentativeness/epistemicgrowth-or-conflatedness /transvaluative-rationalising/transepistemicity/anamnesticresiduality/spirit-drivenness-equalisation $\rangle$ projection; as it may be inclined to make references to temporal ${ }^{83}$ reference-of-thought- categorical-imperatives/axioms/registry-teleology ${ }^{9}$,-for- 
intemporal-preservation-entropy-or-contiguity-or-ontological-preservation preconverging-or-dementing 20 -apriorising-psychologism/of-pervertedregistry/subknowledging $/$ mimicking-and-epistemic-totalising $\sim$ self-referencingsyncretising-these. This brings forth the idea of 'ordered construct' between the intemporal firstnature/intemporal (organic-comprehension-thinking as to intemporal supplantingconviction-as-to-profound-supererogation -of-'attendant-intradimensional'postconverging/dialectical-thinking -apriorising-psychologism) and temporal-and-poorlysecondnatured/institutionalised (threshold-of-nonconviction/madeupness/bottomlining-inshallow-supererogation $-<$ as-to-'attendant-intradimensional'-prospectivelydisontologising preconverging/dementing -apriorising-psychologism>, in relation to transcending meaning. Such ordered construct ensures precedence of the former as it skews ('intemporality ${ }^{52}$-symmetrising-by-desymmetrising-subsumption-of-temporality ${ }^{8}$, for relative intrinsic-reality/ontological-veridicality transcendentalenabling/sublimating/supereregatory $\sim$ de-mentativity) solipsistically towards intemporalpreservation-entropy-or-contiguity-or-ontological-preservation while the latter skews ('intemporality ${ }^{52}$-symmetrising-by-desymmetrising-subsumption-of-temporality ${ }^{\circ}$, for relative intrinsic-reality/ontological-veridicality transcendentalenabling/sublimating/supereregatery $\sim$ de-mentativity) for temporal preservation. Anecdotally, moral philosophy as dimensionality-of-sublimating 5 -

\section{<<amplituding/formative>supererogatory $\sim$ de-mentativeness/epistemic-growth-or-}

\section{conflatedness /transvaluative-rationalising/transepistemicity/anamnestic-residuality/spirit-}

drivenness-equalisation) (organic-comprehension-thinking) creates law/legal-conventions but then questions of justice cannot be attended to by populist-social-construct (threshold-ofnonconviction/madeupness/bottomlining-in-shallow-supererogation $<<$ as-to-'attendantintradimensional'-prospectively-disontologising preconverging/dementing -apriorising- 
psychologism>) since only a developed sense of moral philosophy as dimensionality-ofsublimating $25<<$ amplituding/formative $>$ supererogatory $\sim$ de-mentativeness/epistemic-growthor-conflatedness /transvaluative-rationalising/transepistemicity/anamnestic-residuality/spiritdrivenness-equalisation) (organic-comprehension-thinking) ensures sound jurisprudence as a human intemporal/ontological/social/species $/{ }^{103}$ universal/transcendental $/{ }^{5}$ maximalisingrecomposuring-for-relative-ontological-completeness ${ }^{87}$ unenframed/re-

ontologising $\sim$ conceptualisation postconverging-de-mentating/structuring/paradigming rather than a temporal extricatory preconverging-de-mentating/structuring/paradigming. 'Prior or circumstantial social integration gatekeeping construals or institutionalisation/intemporalisation percolation-channelling- $<$ in-deferential-formalisation-transference>' that can enable the superseding of conventioning in the social integration of ontological veridicality include existing percolation-channelling- $<$ in-deferential-formalisation-transference $>$ of formalisms/officialdom which have naturally been instituted to allow for the supersedingness of intemporal/ontological constructs and intemporal-disposition s. For instance, formal institutions selectivity mechanisms; and where the latter fail or are fallacious, basic positive-opportunism—of-social-functioningand-accordance ${ }^{75}$ wherein the ontologising construct elicits positive-opportunism-of-socialfunctioning-and-accordance ${ }^{75}$ for the undermining of defective conventioning/social-temporalthresholding constructs/categorical-imperatives of meaning (for instance, a natural causes disease conception leading to more cures such that positive-opportunism-of-socialfunctioning-and-accordance ${ }^{75}$ then undermines a superstitious-driven disease theory which leads to more pain and deaths). The big idea here is that, it is naïve philosophically to operate mainly on the basis of 'ontological rightness of transcendence-andsublimity/sublimation/supererogatory de-mentativity' with respect to a species whose construct is structured to be temporal (shortness-of-register-of- ${ }^{5}$ meaningfulness-and-teleology ${ }^{\circ}$ ) to intemporal (longness-of-register-of- ${ }^{5}$ meaningfulness-and-teleology ${ }^{\circ}$ ) requiring skewing 
('intemporality ${ }^{52}$-symmetrising-by-desymmetrising-subsumption-of-temporality ${ }^{8}$, for relative intrinsic-reality/ontological-veridicality transcendentalenabling/sublimating/supereregatery $\sim$ de-mentativity)/deferential-formalisation-transference to the latter. And any such 'ontological transcendence-andsublimity/sublimation/supererogatory de-mentativity by mere rightness' has never been acquiesced to for the sole reason of its intrinsic rightness. For instance, round world idea never took off even though it was ontologically right (as the medieval conventioning/social-temporalthresholding construct and strongly ingrained social dispositions). It is the generated untenability/internal-contradiction/internal-incoherence/institutional-constraining together with positive-opportunism—of-social-functioning-and-accordance ${ }^{75}$ coming from sailors sailing around the world on this idea to seek for spices and create wealth that constrained/institutionalised the medieval world into such an ontological transformation/transcendence-and-sublimity/sublimation/supereregatory $\sim$ de-mentativity. Partand-parcel of ontological transformation/transcendence is the existential-<disontologising/reentologising aporeticism $>$ cynicism to grasp the human sense of internal contradictions and positive-opportunism - of-social-functioning-and-accordance ${ }^{75}$ to introduce and uphold these by the mechanism known as institutionalisation/intemporalisation. Regarding futural Beingdevelopment/ontological-framework-expansion-as-to-depth-of-ontologising-development-asinfrastructure-of- meaningfulness-and-teleology as of prospective notional deprocrypticism undermining of procrypticism, it is doubtful that pertinent ontological constructs and generally the "7t perversion-of- ${ }^{3}$ reference-of-thought- $<$ aspreconvergingly-apriorising/axiomatising/referencing-innonconviction/madeupness/bottomlining-as-to-shallow-supererogation $>$ dynamics of procrypticism' are by themselves a sufficient basis for the direct and immediate social integration of notional ${ }^{18}$ deprocrypticism because of its 'rightness' over conventioning/social-temporal- 
thresholding. Part-and-parcel of the intellectual exercise is to understand how to manage the mechanism of transcendence-and-sublimity/sublimation/supererogatory-de-mentativity wherein new and more profound ontological constructs are introduced and upheld, particularly by way of institutional percolation-channelling-<in-deferential-formalisation-transference $>$ for intemporal transcendence-and-sublimity/sublimation/supererogatory -de-mentativity. However, it should be noted that the conceptualisation of 'conventioning' is not wholly antipodal to 'ontologising/intrinsic-veridicality' as the latter prospective integration in the social-construct is through the former; 'conventioning' is thus a dynamic conceptualisation articulating, on-the-

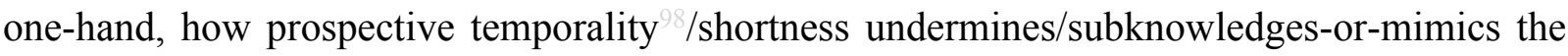
intemporal/ontological construction of meaning (like postlogism ${ }^{77}$-slantedness, miscues, logicaldrag, unconscionability-drag, sub-par-conventioning-rationalising, and temporal-enculturation, with respect to ${ }^{83}$ reference-of-thought- categorical-imperatives/axioms/registry-teleology ${ }^{9}$,for-intemporal-preservation-entropy-or-contiguity-or-ontological-preservation of the intemporal meaning), and on-the-other-hand, how prospective intemporality ${ }^{52} /$ longness is $^{2}$ regenerated to supersede/transcend such ${ }^{74}$ perversion-of- ${ }^{8}$ reference-of-thought- $<$ aspreconvergingly-apriorising/axiomatising/referencing-in-

nonconviction/madeupness/bottomlining-as-to-shallow-supererogation $>$ and bring about new recomposuring $\quad{ }^{83}$ reference-of-thought- categorical-imperatives/axioms/registry-teleology ${ }^{9}$,for-intemporal-preservation-entropy-or-contiguity-or-ontological-preservation). Organiccomprehension-thinking (as to supplanting-conviction-as-to-profound-supererogation —of'attendant-intradimensional'-postconverging/dialectical-thinking -apriorising-psychologism) as highlighted above contrasts with threshold-of-nonconviction/madeupness/bottomlining-inshallow-supererogation -<as-to-'attendant-intradimensional'-prospectivelydisontologising preconverging/dementing -apriorising-psychologism> which is rather temporal-driven (whether ignorance at best, slantedness/psychopathy, 
affordability/opportunism/exacerbation/social-chainism-or-social-discomfiture-or-negativesocial-aggregation/temporal-enculturation-or-temporal-endemisation).

Organiccomprehension-thinking (organicalism/'intemporal-prioritisation-of- reference-of-thought'as-conflatedness $^{13}$-or-ontological-reprojectingAlongness-of-register-of- meaningfulness-andteleology ${ }^{9}$, being intemporal-driven, with respect to transcendence-andsublimity/sublimation/supererogatory-de-mentativity points to the fact that the articulation of meaning referenced/registered/decisioned differently in two registry-worldviews/dimensions, the perversion-of- ${ }^{8}$ reference-of-thought-<as-preconverginglyapriorising/axiomatising/referencing-in-nonconviction/madeupness/bottomlining-as-toshallow-supererogation $>$ as retrospective and transcendental as prospective, is/should be wholly referenced/registered/decisioned intemporally from the superseding transcendence-andsublimity/sublimation/supererogatory $\sim$ de-mentativity that upholds intemporal-preservationentropy-or-contiguity-or-ontological-preservation; as the 'intemporal mind' can't go after the value reference of both registry-worldviews/dimensions since transcendence-andsublimity/sublimation/supererogatory de-mentativity is about 'subverting' ${ }^{74}$ perversion-ofreference-of-thought-<as-preconvergingly-apriorising/axiomatising/referencing-innonconviction/madeupness/bottomlining-as-to-shallow-supererogation $>$ by psychoanalyticunshackling/memetic-reordering/institutional-recomposuring. For instance, the nonpositivism/medievalism value references of aristocracy/class are contrarian to positivistic value references for the possibility of equal opportunities; and the intemporal projecting positivistic mind in medieval times has no business trying to appear 'great and wonderful' with respect to 'conventioned' value reference of aristocracy/class in the medieval world even though it is the dominant and encultured collective mental-disposition. Likewise, such logic will apply regarding notional $\sim$ deprocrypticism and procrypticism requiring a reasoning that goes beyond the '<amplituding/formative-epistemicity>totalising $\sim$ self-referencing-syncretising/illusion-of- 
the-present' mindset/ ${ }^{8}$ reference-of-thought of our current procryptic mental-disposition, i.e. the 'limit of ontological thought is not the banal <amplituding/formative > wooden-language〈imbued - averaging-of-thought-<as-to-leveling/ressentiment/closed-construct-ofmeaningfulness-and-teleology -as-of-'nondescript/ignorable-void '-with-regards-toprospective-apriorising-implications $>>$ of a registry-worldview/dimension'. Otherwise no progress is possible as a dimension progresses exactly because it has defects which when overcome enables the progress to occur! So the intemporal mind cannot as such 'be impressionable' by the banal <amplituding/formative $>$ wooden-language-〈imbued-averagingof-thought-<as-to-leveling/ressentiment/closed-construct-of- meaningfulness-and-teleology as-of-'nondescript/ignorable-void '-with-regards-to-prospective-apriorising-implications $>$ > of a registry-worldview/dimension. It points to the fact that it is 'perfectly ok' to be 'unintelligible/existentially-suprastructural and value-reference-wise unresponsive' to the subknowledge-〈preconverging-or-dementing -as-if-of-sound-knowledge〉 apriorising-registry but rather alienative as to the possibility for its psychoanalytic-unshackling/memeticreordering/institutional-recomposuring. The 'apparent profoundness' of such temporal reference of thought is rather 'depth-of-ignorance' rather than 'depth-of-elucidation'. Threshold-ofnonconviction/madeupness/bottomlining-in-shallow-supererogation $<-<$ as-to- 'attendantintradimensional'-prospectively-disontologising preconverging/dementing -apriorisingpsychologism $>$ arises as a result of shallow mental-dispositions induced by temporaldispositions, and their disambiguation should be called for, and not candored/straightened/integratively-aligned as if intemporal/longness in nature but rather decandored / oblongated / transversality-<for-sublimating-existential-eventuating/denouement-from-thinking at first/pure-predisposition-preemptive-of-prospectivedisontologising/subontologising' as-of-prospectively-disambiguated-affirmed-and- 
Threshold-of-nonconviction/madeupness/bottomlining-in-shallow-supererogation

\section{'attendant-intradimensional'-prospectively-disontologising preconverging/dementing}

apriorising-psychologism> as such is rather a 'flatness-of-the-mind' involving temporality ${ }^{8}$, 'mental triteness' and 'gullibility' with respect to, in the case of psychopathy, insane/slantedness integration as social psychopathy; and more generally, 'lack of intemporal-disposition philosophical depth', i.e. lack of spontaneous dimensionality-of-sublimating ${ }^{25}$ <<amplituding/formative>supererogatory $\sim$ de-mentativeness/epistemic-growth-or-

\section{conflatedness /transvaluative-rationalising/transepistemicity/anamnestic-residuality/spirit-}

drivenness-equalisation) inclination (the-guy-who-spontaneously-stands-out-against-say-agenocide or the milgram-experiment-guy-who-sticks-with-what-is-reality-rather-than-goingwith-the-flow, etc.) not to be confused with secondnaturing/institutionalisation, and as a consequence an inclination to compromise intemporality $2 /$ longness as 'conventioning (socialtemporal-thresholding) of meaning' rather than 'ontologising (intemporal-uncompromising) of meaning'. Overall threshold-of-nonconviction/madeupness/bottomlining-in-shallowsupererogation -<as-to-'attendant-intradimensional'-prospectivelydisontologising preconverging/dementing -apriorising-psychologism> points to the fundamental processes of 'social temporal miscuing of meaning' and the effective temporal consequences whether regarding defective enculturation or defective social ontologisation/ontological-veracity/aestheticisation-towards-ontology. This thus requires 'deconventioning-for-ontologising involving the intemporal-preservation-entropy-orcontiguity-or-ontological-preservation exercise of undermining conventioning at uninstitutionalised-threshold ${ }^{102}$ (due to the inescapable veridicality of human individuation temporal/shortness-to-intemporal/longness which inevitably induces ${ }^{74}$ perversion-ofreference-of-thought-<as-preconvergingly-apriorising/axiomatising/referencing-in- 
uninstitutionalised-threshold ${ }^{102}$ ); deconventioning as such skews ('intemporality ${ }^{52}$ symmetrising-by-desymmetrising-subsumption-of-temporality ${ }^{\circ}$, for relative intrinsicreality/ontological-veridicality transcendental-enabling/sublimating/supererogatory $\sim$ dementativity) and restores ontological veridicality for intemporal-preservation-entropy-orcontiguity-or-ontological-preservation. An essential element underlying the psychopathic and other postlogic relationship with meaning has to do with the nature of attachment to meaning. A postlogic mind doesn't view meaning articulations as 'inherently sanctuous' and thus is inclined to produce mechanically whatever deductions that may engage an interlocutor in-prelogic supplanting-conviction-as-to-profound-supererogation of-'attendant-intradimensional'postconverging/dialectical-thinking -apriorising-psychologismly/prelogicly even if these are hollow mimicking non-veridical narratives, i.e. vague-rhyming-or-copied-mimicry-orformulaic-projection-or-projection-of-form-or-hollow-and-vague-vocalisation-or-

subknowledging ${ }^{44}$ (meaning-by-the-mere-illogical-possibility-of-it-being-formulaicallynarrated). On-the-other-hand, prelogism ${ }^{78}$-as-of-conviction,-in-profound-supererogation <existentially-veridical-'attendant-intradimensional-apriorising/axiomatising/referencing'logical-dueness-precedes-disontologising-logical-outcome-arrived-at $>$ imply more of an organic alignment view of meaningful articulations as 'inherently sanctuous', i.e. 'implicited_attendant-ontological-contiguity ${ }^{67}$ > educedexistentialising/contextualising/textualising_intelligibility/epistemicity/reflexivity-contiguity$<$ imbued-notional cogency>'/meaningful-projection-of-intrinsicness'. Going by these two facts, the postlogic and psychopathic mindset/ ${ }^{3}$ reference-of-thought is readily inclined to call upon a broad base of vague-rhyming-or-copied-mimicry-or-formulaic-projection-or-projectionof-form-or-hollow-and-vague-vocalisation-or-subknowledging 44 narratives (meaning-by-themere-illogical-possibility-of-it-being-formulaically-narrated) whereas the prelogic/convictionas-to-profound-supererogation ${ }^{6}$ mindset $/{ }^{3}$ reference-of-thought is inclined to call upon just the 
narratives it sincerely thinks are relevant/due and intrinsically real. So it is critical not to confuse the over-articulation of postlogic narratives (vague mechanical stylising-of-locution) with an organic depth-of-thought or profoundness, given that these involve postlogism 7 -slantedness, disjointed-logic, miscuing, inventions and platitudes from the postlogic mindset, requiring decandoring/oblongating/distractive-alignment-to- ${ }^{8}$ reference-of-thought- $<$ of-

apriorising/axiomatising/referencing $>^{30}$. Ontologically speaking, meaning is an essential construct of human mental-devising-representation meant to allow for human intemporal teleology . A postlogic-formulaic slanting threshold-ofnonconviction/madeupness/bottomlining-in-shallow-supererogation $<<$ as-to-'attendantintradimensional'-prospectively-disontologising preconverging/dementing -apriorisingpsychologism $>$ relation to such a conceptualisation is sub-par-or-formulaic-association-ortemporal-or-alibi to ontology and is thus regarded as " perversion-of- ${ }^{3}$ reference-of-thought$<$ as-preconvergingly-apriorising/axiomatising/referencing-in-

nonconviction/madeupness/bottomlining-as-to-shallow-supererogation $>$ referencing' that is ontologically inconsistent as it counts on the fact that others remain intemporal/ontological for it to exist parasitically/co-optingly. Worst still such vague-rhyming-or-copied-mimicry-orformulaic-projection-or-projection-of-form-or-hollow-and-vague-vocalisation-or-

subknowledging tend to be integrated at uninstitutionalised-threshold 02 of conventioning/social-temporal-thresholds. Without a sense of 'rational-realism' (the veridicality of meaning involving not only the logical processing/operation of narratives but precedingly notional firstnaturedness-formativeness-<as-to-eventualising -inkling-drive-or-seeding misprising $>$ temporal-to-intemporal-dispositions-<so-construed-as-from-perspectiveontological-normalcy/postconvergence $>$ disambiguation, i.e. in terms-as-of-axiomaticconstruct of \{epistemic-totalising 3 psychologismic-subliminality-of-individuationeffusing/worlding imbued logical-dueness-or-scape-or-frame, profile-or-stature, 
presumptuousness-or-arrogation, assumptions, value-reference and teleology ${ }^{9}$ ), by prelogism ${ }^{78}$ as-of-conviction,-in-profound-supererogation -<existentially-veridical-'attendant-

\section{intradimensional-apriorising/axiomatising/referencing'-logical-dueness-precedes-}

disontologising-logical-outcome-arrived-at $>$ reflex, prelogic/conviction-as-to-profoundsupererogation and postlogism 7 -formulaic slanting narratives as to threshold-ofnonconviction/madeupness/bottomlining-in-shallow-supererogation $<-<$ as-to-'attendantintradimensional'-prospectively-disontologising preconverging/dementing -apriorisingpsychologism $>$ will be analysed at the same pedestal towards construing veridicality/intrinsicreality. Such an analysis is wrong as an inherently prelogic/conviction-as-to-profoundsupererogation mental-disposition will rather re-accentuate prelogic/conviction-as-toprofound-supererogation constructs in contention situations whereas the characteristic of postlogism 77 in hollow-constituting-<as-disjointed-misappropriation-of-meaningfulness-andfailing-intemporal-preservation> as of postlogism 7 -formulaic slanting elicited threshold-ofnonconviction/madeupness/bottomlining-in-shallow-supererogation $-<$ as-to-'attendantintradimensional'-prospectively-disontologising preconverging/dementing -apriorisingpsychologism>, whether direct as with the psychopath postlogic-backtracking-<iterativelooping-'set-of-dereifying-hollow-narratives-and-acts' $>76$ or induced as temporal-dispositions conjugated-postlogism 7 in 'conjoining looping narratives of flawed-existential-elevation-ofreference-of-thought ', of psychopath's postlogic-backtracking-<iterative-looping-'set-ofdereifying-hollow-narratives-and-acts' $>$ ' , is about a mental-disposition to re-undermine intrinsic-reality/veridicality hence its looping nature as absolving/fleeting/escaping-reflexlogic. Hence once the hollow-constituting-<as-disjointed-misappropriation-of-meaningfulnessand-failing-intemporal-preservation $>$ as of postlogism 7 -formulaic slanting threshold-ofnonconviction/madeupness/bottomlining-in-shallow-supererogation $<-<$ as-to-' $a$ attendantintradimensional'-prospectively-disontologising preconverging/dementing -apriorising- 
psychologism $>$ is elicited in an interlocutor, the ontological construct is not to allow it be meaningfully sound (in terms-as-of-axiomatic-construct of implied-registry and thus fepistemicPsychologismic-subliminality-of-individuation-effusing/worlding imbued logicaldueness-or-scape-or-frame, profile-or-stature, presumptuousness-or-arrogation, assumptions, value-reference and teleology ${ }^{9}$ ) to be contending but rather transversality-<for-sublimating existential-eventuating/denouement,-from-'thinking-at-first/pure-predisposition-preemptive-ofprospective-disontologising/subontologising' as-of-prospectively-disambiguated-affirmedand-unaffirmed-'motif-and-apriorising/axiomatising/referencing' $>101$ to it to reflect its perversion-of- ${ }^{3}$ reference-of-thought- $<$ as-preconverginglyapriorising/axiomatising/referencing-in-nonconviction/madeupness/bottomlining-as-toshallow-supererogation $>$. The application of the ${ }^{103}$ universal technique of human transcendence-and-sublimity/sublimation/supereregatory-de-mentativity to procrypticismnotional ${ }^{18}$ deprocrypticism transcendence-and-sublimity/sublimation/supererogatory $\sim$ dementativity can be basically be articulated as follows (the ontological-entrapment): prelogism ${ }^{7}$-as-of-conviction,-in-profound-supererogation $-<$ existentially-veridical'attendant-intradimensional-apriorising/axiomatising/referencing'-logical-dueness-precedesdisontologising-logical-outcome-arrived-at> ANCHORING ('setup of supplanting-convictionas-to-profound-supererogation -of-'attendant-intradimensional'-postconverging/dialecticalthinking -apriorising-psychologism meaning'); -DOWNGRADING (psychopath's hollow mimicking narrative wrongly 'slanting the supplanting-conviction-as-to-profoundsupererogation —of-'attendant-intradimensional'-postconverging/dialectical-thinking apriorising-psychologism meaning'); - MISCUING (temporal-dispositions first aligning prelogicly/in-prelogic supplanting-conviction-as-to-profound-supererogation - of-'attendantintradimensional'-postconverging/dialectical-thinking -apriorising-psychologismly to the slantedness of the prelogism ${ }^{78}$-as-of-conviction,-in-profound-supererogation 
veridical-'attendant-intradimensional-apriorising/axiomatising/referencing'-logical-dueness-

precedes-disontologising-logical-outcome-arrived-at $>$ anchoring at ignorance pedestal, and then by successive temporal pedestals of affordability/opportunism/exacerbation/social-chainism-orsocial-discomfiture-or-negative-social-aggregation/temporal-enculturation-or-temporalendemisation, 'integrating/adopting deliberate postlogic dispositions with respect to the initial supplanting-conviction-as-to-profound-supererogation —of-'attendant-intradimensional'postconverging/dialectical-thinking -apriorising-psychologism meaning'); - denaturing referencing/registering/decisioning or STRANDING (the intemporal-disposition/ontology stigmatising of temporal-dispositions as strands-of-perverting-temporal-dispositions acting as the preempted backdrop for ${ }^{83}$ reference-of-thought- categorical-imperatives/axioms/registryteleology ${ }^{9}$-for-intemporal-preservation-entropy-or-contiguity-or-ontological-preservation of futural Being-development/ontological-framework-expansion-as-to-depth-of-ontologisingdevelopment-as-infrastructure-of- meaningfulness-and-teleology as of prospective notional ${ }^{1}$ deprocrypticism registry-worldview/dimension with its subsequent psychoanalyticunshackling/memetic-reordering/institutional-recomposuring, just as strands-of-pervertingtemporal-dispositions of the non-positivism/medievalism mindset $/{ }^{/ 3}$ reference-of-thought are what act as the preempted backdrop for prospective positivism and the subsequent psychoanalytic-unshackling/memetic-reordering/institutional-recomposuring that followed); and - PERCOLATION-CHANNELLING- $<$ in-deferential-formalisation-transference $>$ (the intemporal-disposition/ontology eliciting untenability/internal-contradiction/internalincoherence/institutional-constraining, medium to long term positive-opportunism-of-socialfunctioning-and-accordance ${ }^{75}$, referencing/registering/decisioning of the ${ }^{74}$ perversion-ofreference-of-thought-<as-preconvergingly-apriorising/axiomatising/referencing-innonconviction/madeupness/bottomlining-as-to-shallow-supererogation $>$ for $\quad$ social ${ }^{3}$ universal-transparency ${ }^{104}$-〈transparency-of-totalising-entailing,-as-to-entailing- 
then its transcendence-unenabling-uninstitutionalised-threshold ${ }^{02}$ in alienation-asinauthentic/poorly-objectified/poorly-desubjectified-as-objectified/ontological-badfaith/inauthenticity ${ }^{64}$ as to fundamentally undermine ${ }^{80}$ procrypticism-or-disjointedness-as-ofreference-of-thought and bring about deprocrypticism, and so crossgenerationally, and not instant argumentation convincing intradimensionally in a registry-worldview/dimension that is defective or perversion-of- reference-of-thought- $<$ as-preconverginglyapriorising/axiomatising/referencing-in-nonconviction/madeupness/bottomlining-as-to-

shallow-supererogation $>$ in the first place). Ontology being the intemporal-disposition, the exercise of 'directing convincing' to temporal-dispositions is inherently unwarranted and is rather $<$ amplituding/formative--epistemicity $>$ totalising $\sim$ self-referencingsyncretising/circularity/interiorising/akrasiatic-drag ${ }^{34}$, with pertinence being about 'articulating and directing' intemporal/ontologically-contiguous meaningfulness towards the 'institutionalisation/intemporalisation percolation-channelling- $<$ in-deferential-formalisationtransference''; the latter being utterly impersonal (law, officialdoms and subject matter formalisms) which allows for an abstraction of the virtue of ontological contiguity that personalised social-and-temporal-trading doesn't allow reflexively. By 'uninstitutionalisedthreshold ${ }^{102}$ (where there is no 'intemporal social ${ }^{103}$ universal-transparency ${ }^{104}-\langle$ transparencyof-totalising-entailing,-as-to-entailing-<amplituding/formative-epistemicity $>$ totalising $\sim$ inrelative-ontological-completeness $\rangle$ as well as no notional firstnaturedness-formativeness-<asto-eventualising-inkling-drive or seeding-misprising> temporal-to-intemporal-dispositions$<$ so-construed-as-from-perspective-ontological-normalcy/postconvergence $>$ disambiguation/unequivalences/alienative-hierarchisation') is meant, the possibilities of human dispositions and acts beyond frameworks that have not been institutionalised; manifesting as (uninstitutionalisation) 'temporal-threshold logic' or 'discomfiture'. So the uninstitutionalised- 
threshold ${ }^{102}$ of the positive registry-worldview will refer to procrypticism (requiring deprocrypticism), to the non-positivism/medievalism registry-worldview it will refer to nonpositivism/medievalism (requiring positivism), to the ununiversalised registry-worldview it will refer to ununiversalisation (requiring ${ }^{103}$ universalisation), and to the recurrent-utterinstitutionalised apriorising-registry worldview it will refer to recurrent-utteruninstitutionalisation (requiring base-institutionalisation). Institutionalisation and formalisation are based exactly on the fact that we don't have a ${ }^{103}$ universal intemporality ${ }^{2} /$ longness or thegood disposition, but rather according to the mediocrity principle of science we are solipsistically temporal-to-intemporal in our mental-disposition with respect to 'socially-perceived-value as of social-stake-contention-or-confliction'. Hence we tend to build artifices (institutions with their formal rules) by the skewing ('intemporality ${ }^{5}$-symmetrising-by-desymmetrising-subsumptionof-temporality , , for relative intrinsic-reality/ontological-veridicality transcendentalenabling/sublimating/supereregatory $\sim$ de-mentativity)/deferential-formalisation-transference of our collective thought process in the medium to long perspective towards intemporalpreservation-entropy, to dominate and preempt temporal dispositions. This explains why modern man (positivistic registry-worldview) is apparently more evolved/developed than he/she should normally be compared to previous generations (recurrent-utter-uninstitutionalised men, ununiversalised men, non-positivism/medievalism men, and prospectively, how he/she will be superseded by the deprocryptic man). It doesn't mean that modern man has a genetic makeup or hardware that is different from the others. The difference is the cumulated 'software' or institutionalisations and formalisations that have been internalised into modern man. Anthropologists know that if you were to take a newly born child from a society like those that do not have contact with the modern world, and raise the child in a modern family, there is no different outcome on average as with any other child bred in the modern world. So our faith in virtue is not in our inherent excellence/exceptionalism but the excellence/exceptionalism of the 
software/institutionalisation that has cumulated, and insightfully, which creative template we will prospectively develop! Incidentally institutionalisation and formalisation ensures that we take the best form of human individuation thinking/capacity potential and constrain society and individuals to that individuation thinking/capacity potential, and inherently so, by the overall positive-opportunism-of-social-functioning-and-accordance ${ }^{75}$ to the cross-section of the species since it better grasp intrinsic reality and its virtues! Solipsism means I exist alone (as to the epistemic perspective with respect to intrinsic reality/ontological-veridicality), and this author notionally interpret solipsism as the deepest sense of existence and meaning available to an individual in its spontaneous emanance or becoming, and as it projects itself "purely and 'universally'. It is a firstnature/intemporal construct beyond and 'inventing the possibility' of secondnatured institutionalisation, and places all humans at all times at the same pedestal of virtuous and ontological appraisal, as it is about our 'transcendental valour' irrespective of the level of institutional-cumulation/institutional-recomposure-〈as-to- historiality/ontologicaleventfulness /ontological-aesthetic-tracing-<perspective-ontologicalnormalcy/postconvergence-reflected-'epistemicity-relativism-determinism' $>>$ at which we are. It contrasts with institutionalisation/intemporalisation which is a "negotiated and secondnatured or nurtured construct with respect to existence and meaning around social-stake-contention-orconfliction'. Institutionalisation/intemporalisation as such, by way of positive-opportunism—ofsocial-functioning-and-accordance ${ }^{75}$ and inducing untenability/internal-contradiction/internalincoherence/institutional-constraining of temporal-dispositions, has at least the merit of allowing for the possibility for human temporal-dispositions to be skewed ("intemporality ${ }^{52}$ symmetrising-by-desymmetrising-subsumption-of-temporality ${ }^{\circ}$, for relative intrinsicreality/ontological-veridicality transcendental-enabling/sublimating/supererogatory $\sim$ dementativity)/deferential-formalisation-transference towards the intemporal-disposition, and thus enabling social transcendence-and-sublimity/sublimation/supererogatory de-mentativity which 
is upheld by formalisation and internalisation. By ontological-normalcy/postconvergence is meant that 'intrinsic reality' is one and given (ontology), and that the flaws and corrections in how we go about representing 'intrinsic reality' (metaphysics or the human-centered temporalperspective) has no influence on reality's intrinsic nature. Our mental-devising-representation of the world in $5000 \mathrm{BC}, 2000 \mathrm{AD}$ and possibly $3000 \mathrm{AD}$ might be worlds apart, but the intrinsic nature of reality never changed and will never change an iota. So our knowledge construct is more of a proxying to intrinsic reality to grasp the possibilities of 'prospective postconverging aporeticism-overcoming/unovercoming as the-Good/knowledgereification $\sim$ gesturing-and-accounting — of-epistemic-phenomenalism- $<$ inprospective_psychologismic $\sim$ apriorising/axiomatising/referencing-\{of-'prospectively implicited_attendant-ontological-contiguity ' reducedexistentialising/contextualising/textualising_'intelligibility/epistemicity/reflexivity-contiguity<imbued-notional cogency $\left.>^{\prime}\right\}$ - conflatedness -in-\{preconverging-disentailment by\} postconverging-entailment $>$ /understanding/<amplituding/formativeepistemicity $>$ causality $\sim$ as-to-projective-totalitative-implications-of-prospectivenonpresencing,-for-explicating relative-unreflexivity/relative-reflexivity ontologicalcontiguity ', for <amplitung/formative-epistemicity $>$ causality $\sim$ as-to-projective-totalitativeimplications-of-prospective- nonpresencing,-for-explicating relative-unreflexivity/relativereflexivity - ontological-contiguity and thus a better grasp of the world; hence proxying mentation-capacity level as the various institutional-cumulation/institutional-recomposure-〈asto- historiality/ontological-eventfulness /ontological-aesthetic-tracing-<perspectiveontological-normalcy/postconvergence-reflected-‘epistemicity-relativism-determinism’ $>\rangle$. That idea that intrinsic reality is preceding/superseding is known as ontologicalnormalcy/postconvergence (we are converging to reality and not adding or taking away anything from it, it is us being illuminated as reality is already given). In the exercise of construing 
ontological veridicality what gives in when the pertinence of <amplituding/formativeepistemicity $>$ causality as-to-projective-totalitative-implications-of-prospective-

\section{nonpresencing,-for-explicating relative-unreflexivity/relative-reflexivity - ontological-}

contiguity is known is the human psyche (whether by candoring/straightness/prelogism ${ }^{78}$ when pertinent or decandoring/slantedness/distractive-alignment-to- ${ }^{-}$reference-of-thought- $<$ofapriorising/axiomatising/referencing $>{ }^{30}$ when impertinent), intrinsic reality never gives in (that's why we are mortals and our hope is to always give-in to intrinsic reality for the possibilities of the future). This latter point is important as by reflex an epistemic-totalising $\sim$ self-referencingsyncretising/temporal-human-centered dimension in its flaws will strive to preserve itself by $<$ amplituding/formative-epistemicity $>$ totalising $\sim$ self-referencingsyncretising/circularity/interiorising/akrasiatic-drag ${ }^{34}$ its registry-worldview/categoricalimperatives (setting-aside of perversion-and-derived-perversion- ${ }^{83}$ reference-of-thought) rather than psychoanalytically-unshackling/memetic-reordering (coring and superseding the perversion-and-derived-perversion- ${ }^{83}$ reference-of-thought) for prospective/transcending/superseding $\quad{ }^{83}$ reference-of-thought- categoricalimperatives/axioms/registry-teleology ${ }^{9}$,-for-intemporal-preservation-entropy-or-contiguityor-ontological-preservation. By 'intemporal transversality-<for-sublimating-existentialeventuating/denouement,-from-'thinking-at-first/pure-predisposition-preemptive-ofprospective-disontologising/subontologising' as-of-prospectively-disambiguated-affirmedand-unaffirmed-'motif-and-apriorising/axiomatising/referencing'>101 as from ontologicalnormalcy/postconvergence' is meant ontological-normalcy/postconvergence meaningfulnessand-teleology as so articulated above is ontologically veridical but that does not necessarily imply the metaphysical framework temporal mental-dispositions will recognise that (i.e. there is no notional-discontiguity/epistemic-discontiguity 3 - between - prior-shallow-supererogation of-mentally-aestheticised preconverging/dementing -qualia-schema_and_prospective- 
profound-supererogation -of-mentally-aestheticised postconverging/dialectical-thinking

qualia-schema $>$ between registry-worldviews/dimensions ${ }^{8}$ references-of-thought as this falsely implies 'no temporal-to-intemporal disambiguation, i.e. equivalence of ${ }^{83}$ references-ofthought/no-alienative-hierarchisation, whereas what is warranted is 'intemporal-prioritisationof- ${ }^{3}$ reference-of-thought'-as-conflatedness ${ }^{13}$-or-ontological-reprojecting pedestalling'); and that it is transversality-<for-sublimating-existential-eventuating/denouement,-from-'thinkingat first/pure-predisposition-preemptive-of prospective-disontologising/subontologising' asof-prospectively-disambiguated-affirmed-and-unaffirmed-'motif-andapriorising/axiomatising/referencing'>101 of such constructed veridicality in its $<$ amplituding/formative-epistemicity $>$ causality $\sim$ as-to-projective-totalitative-implications-ofprospective- nonpresencing,-for-explicating relative-unreflexivity/relative-reflexivity ontological-contiguity determinism and operance that will undermine other possible 'temporal perverted-transversality-<for-sublimating-existential-eventuating/denouement,-from-

\section{thinking at-first/pure-predisposition-preemptive-of-prospective-}

\section{disontologising/subontologising' - as-of-prospectively-disambiguated-affirmed-and-} unaffirmed-'motif-and-apriorising/axiomatising/referencing'>

conjugated/inflected/derived/mimicked/in-protraction-to-psychopathic-preconverging-ordementing -meaning' by rendering them untenable/internal-contradiction and inoperant (not a 'convincing' at the philosophical or emanance level, rather a 'constraining' at the institutionalisation/intemporalisation secondnaturing level out of <amplituding/formativeepistemicity $>$ causality $\sim$ as-to-projective-totalitative-implications-of-prospectivenonpresencing,-for-explicating relative-unreflexivity/relative-reflexivity - ontologicalcontiguity ); noting that 'temporal perverted-transversality-<for-sublimating-existentialeventuating/denouement,-from-'thinking-at-first/pure predisposition-preemptive-ofprospective-disontologising/subontologising' as-of-prospectively-disambiguated-affirmed- 
and-unaffirmed-'motif-and-apriorising/axiomatising/referencing'>

conjugated/inflected/derived/mimicked/in-protraction-to-psychopathic-preconverging-ordementing -apriorising-psychologism meaning' imply temporal existentialising-frame-ofentailment-of-motif-and-apriorising/axiomatising/referencing $\quad{ }^{56}$ meaningfulness-andteleology ${ }^{9}$ cannot-be-referenced/registered/decisioned as-of/having-the same ${ }^{83}$ reference-ofthought/registry of the intemporal-disposition which is ontological, and is thus rather preconverging-or-dementing ${ }^{20}$-apriorising-psychologism- $<$ stranded-as-rightfully-

oblongated/decandored-and-dialectically-or-contendingly-out-of-phase>', i.e. in distractivealignment-to- ${ }^{8}$ reference-of-thought- $<$ of-apriorising/axiomatising/referencing $>{ }^{30}$, (and so all along the apriorising-registry-elements: \{epistemic-totalising 3 psychologismic-subliminality-ofindividuation —effusing/worlding imbued logical-dueness-or-scape-or-frame, profile-or-stature, presumptuousness-or-arrogation, assumptions, value-reference and teleology ${ }^{\circ}$ ) of the mentaldevising-representation from the intemporal-disposition/ontological perspective. Ontology being of the intemporal-disposition, the exercise of 'directing logical convincing' to temporaldispositions is inherently unwarranted and is rather <amplituding/formativeepistemicity>totalising $\sim$ self-referencing-syncretising/circularity/interiorising/akrasiatic-drag ${ }^{34}$, with pertinence being about 'articulating and directing' intemporal/ontologically-contiguous meaningfulness towards <amplituding/formative-epistemicity $>$ causality $\sim$ as-to-projectivetotalitative-implications-of-prospective- nonpresencing,-for-explicating relativeunreflexivity/relative-reflexivity ontological-contiguity which induces the positiveopportunism-of-social-functioning-and-accordance ${ }^{75}$ and untenability/internalcontradiction/internal-incoherence/institutional-constraining for its supersedingness in the ‘institutionalisation/intemporalisation percolation-channelling- $<$ in-deferential-formalisationtransference>'; the latter being utterly impersonal (law, officialdoms and subject matter formalisms) and allows for an abstraction of the virtue of ontological contiguity that personalised 
social-and-temporal-trading doesn't allow reflexively. This is underlying transcendentalenabling/sublimating/supereregatery de-mentativity notion while often obscured in the social $<$ amplituding/formative-epistemicity $>$ totalising $\sim$ devolved-purview-as-domain-of-construalas-intrinsic-reality/ontological-veridicality due to their 'emotional involvement' is immediately obvious with the natural sciences whereby the physicists nor chemists nor biologists worries about convincing anyone but is rather in the business of the 'convincing from natural truths' which then do not ask for human temporal validation but impose themselves because natural truths inherently supersede human egotistic or <amplituding/formativeepistemicity $>$ totalising $\sim$ self-referencing-syncretising/circularity/interiorising/akrasiatic-drag opinionatedness! Postconvergence, in-the-bigger-scheme-of-things, implies that knowledge has to do with the development of our 'mentation capacity' (an entropic-referential memeticreordering/psychoanalytic-unshackling exercise), across 'retrospective-and-prospective history', in grasping 'intrinsic reality/veridicality' which 'has always and will always be ontologically same'. So the concern is about 'us'; in the appropriateness of the registries we make of intrinsic-reality across retrospective-and-prospective history or rather shifting dialectical moments of relative-ontological-completeness ${ }^{8}$ ! The articulation of reality, registryworldviews/dimensions, mental strands (perverted or not), and other constructs of $<$ amplituding/formative-epistemicity $>$ causality $\sim$ as-to-projective-totalitative-implications-ofprospective- nonpresencing,-for-explicating relative-unreflexivity/relative-reflexivity-

ontological-contiguity is 'at-a-superseding-pedestal and incisive/blunt' by the very nature of ontological-normalcy/postconvergence reality. For instance, supposed a society with a nonpositivism/medievalism belief system attributes the cause of a disease to say witchcraft, that doesn't stop the reality of bacteria causing the disease even if such a representation of reality isn't in the present-consciousness/illusion-of-the-present of that society. Such an ontological conceptualisation of reality equally applies in our times where it can be demonstrated 
prospectively that our mental-devising-representation of meaning regarding a phenomenon is out of kilter, and reality won't stop to accommodate us or our banality of thought. Thus the conceptualisation of reality is rather articulated at this depth-of-thought whether it accommodates our present-consciousness/illusion-of-the-present or not (reality personality), and operates by an ordered construct based on <amplituding/formative-epistemicity $>$ causality $\sim$ asto-projective-totalitative-implications-of-prospective- nonpresencing,-for-

explicating relative-unreflexivity/relative-reflexivity - ontological-contiguity and not a disposition of averageness/banality/popularity/extrinsic-attribution-of-thought recurrent in uninstitutionalised-threshold ${ }^{102}$ in the extended-informality-〈susceptible-to-effectingparsimony-as-of-shoddiness-and-incompleteness-to- meaningfulness-and-teleology \,

allowing for the possibility of transcendental meaning, institutionalisation/intemporalisation (skewing ('intemporality ${ }^{52}$-symmetrising-by-desymmetrising-subsumption-of-temporality ${ }^{\circ}$, for relative intrinsic-reality/ontological-veridicality transcendentalenabling/sublimating/supereregatery de-mentativity) for intemporal domination) and human progress; given human temporal/shortness-to-intemporal/longness dispositions. Such an articulation of reality introduces the concept of 'reasoning-through/utterion' over ${ }^{5}$ incrementalism-in-relative-ontological-incompleteness ${ }^{8}$

enframed/disontologising conceptualisation and notional disjointedness'. Reasoningthrough/utterion refers to the uncompromising and non-negotiable nature of reality with respect to the meaningful frames of mortal creatures that we are as reality doesn't adjust to our beliefs, desires, wishes, whims or miscues. Reasoning-through/utterion then implies that meaning is articulated exclusively in terms-as-of-axiomatic-construct of <amplituding/formativeepistemicity $>$ causality $\sim$ as-to-projective-totalitative-implications-of-prospectivenonpresencing,-for-explicating relative-unreflexivity/relative-reflexivity - ontologicalcontiguity and anything else is defined, whether to be candored or to be decandored, at that 
ordered construct point-of-reference or point-referencing. Reason is thus ontologically a 'reasoning-through' as allowed through in a 'pure, organic and intemporally uncompromising state' by reality <amplituding/formative-epistemicity $>$ causality $\sim$ as-to-projective-totalitativeimplications-of-prospective- nonpresencing,-for-explicating relative-unreflexivity/relativereflexivity ontological-contiguity 'at-a-superseding-pedestal and incisively/bluntly'. incrementalism-in-relative-ontological-incompleteness ${ }^{8}$ enframed/disontologising conceptualisation and notional disjointedness-as-of- ${ }^{8}$ reference-ofthought refer to the human reflex to average minds or make reference to extrinsic elements rather than meaning by its inherence as can be predicated effectively, and involves 'reasoning with', as it introduces 'temporal and social trading' elements over or clouding or compromising inherent intemporal veridicality. $\quad{ }^{5}$ incrementalism-in-relative-ontological-incompleteness ${ }^{8}$ enframed/disontologising $\sim$ conceptualisation and notional $\sim$ disjointedness-as-of- ${ }^{3}$ reference-ofthought as such is patently wrong; as can be perceived from point-referencing superseding registry-worldviews/dimensions such that the ontological representation of the veridicality is different from the different perspectives of a recurrent-utter-institutionalised registry-worldview and the superseding institutionalised registry-worldview, and likewise with the ununiversalised and superseding ${ }^{103}$ universalised registry-worldviews, the non-positivism/medievalism and superseding positivistic registry-worldviews, and prospectively the procryptic and superseding deprocryptic registry-worldviews. It implies that 'it isn't veridically weird' to articulate depthsof-meaning that may apparently seem idiosyncratic in our present illusion-of-thepresent/present-consciousness registry-worldview, as the issue is not with such an articulation per se but rather 'our defective apriorising-registry point-referencing threshold', and implying rather the need for our psychoanalytic-unshackling/memetic-reordering/institutionalrecomposuring by distractive-alignment-to- ${ }^{8}$ reference-of-thought- $<$ ofapriorising/axiomatising/referencing $>$. Fundamentally, incrementalism-in-relative- 
ontological-incompleteness ${ }^{8}$ — enframed/disontologising conceptualisation

notional disjointedness-as-of- ${ }^{-3}$ reference-of-thought in human thinking as indicated above with the various institutional-cumulation/institutional-recomposure-〈as-to- historiality/ontologicaleventfulness /ontological-aesthetic-tracing-<perspective-ontologicalnormalcy/postconvergence-reflected-'epistemicity-relativism-determinism' $>\rangle$ is superseded by reasoning-through/utterion; in $\quad$ transversality-<for-sublimating-existentialeventuating/denouement,-from-'thinking-at-first/pure-predisposition-preemptive-ofprospective-disontologising/subontologising' as-of-prospectively-disambiguated-affirmedand-unaffirmed-'motif-and-apriorising/axiomatising/referencing'> at-a-supersedingpedestal, and represented as of threshold-of-nonconviction/madeupness/bottomlining-inshallow-supererogation -<as-to-'attendant-intradimensional'-prospectivelydisontologising preconverging/dementing -apriorising-psychologism> as oblongated/decandored or failing-intemporal-preservation-or-misappropriation-ofmeaningfulness or transversality-<for-sublimating-existential-eventuating/denouement,-from'thinking at-first/pure-predisposition-preemptive-of-prospectivedisontologising/subontologising’ as-of-prospectively-disambiguated-affirmed-andunaffirmed-'motif-and-apriorising/axiomatising/referencing' $>{ }^{101}$, given the fact that this reflects apriorising-registry defect and not logical defect. More precisely, how can ${ }^{5}$ meaningfulnessand-teleology ${ }^{9}$ be represented in a 'prospective apriorising-registry state' which is ontologically more real contrasted to a 'present retrospective apriorising-registry', as ${ }^{56}$ meaningfulness-andteleology 'temporally seems' to vary depending on the uninstitutionalised-threshold ${ }^{102}$ pointof-reference to imply at one moment it is intemporal and at another it is temporal? This fundamentally has to do with our dimensionality-of-sublimating 5 <<amplituding/formative>supererogatery $\sim$ de-mentativeness/epistemic-growth-orconflatedness /transvaluative-rationalising/transepistemicity/anamnestic-residuality/spirit- 
drivenness-equalisation> projection irrespective of the uninstitutionalised-threshold ${ }^{102}$, and calls for PEDESTALLED CONSTRUAL or PEDESTALLED DISAMBIGUATION to skew/deferential-formalisation-transference meaning towards the intemporal/longness disposition for intemporal-preservation-entropy-or-contiguity-or-ontological-preservation, as institutionalisation/intemporalisation. Pedestalled disambiguation thus involves at a given uninstitutionalised-threshold ${ }^{102}$ translating the 'apparently prelogism ${ }^{78}$-as-of-conviction,-inprofound-supererogation $-<$ existentially-veridical-'attendant-intradimensionalapriorising/axiomatising/referencing'-logical-dueness-precedes-disontologising-logicaloutcome-arrived-at $>$ or prelogic teleological finality of a temporal-disposition into its veridical preconverging-or-dementing ${ }^{20}$-apriorising-psychologism as postlogic ${ }^{74}$ perversion-ofreference-of-thought-<as-preconvergingly-apriorising/axiomatising/referencing-innonconviction/madeupness/bottomlining-as-to-shallow-supererogation $>$ teleological finality, and so successively in reflecting the notional-discontiguity/epistemic-discontiguity ${ }^{6}$ $<$ between-prior-shallow-supererogation -of-mentallyaestheticised preconverging/dementing -qualia-schema_and_prospective-profoundsupererogation -of-mentally-aestheticised postconverging/dialectical-thinking -qualia$\begin{array}{llll}\text { schema }> & \text { of } & \text { temporal-dispositions }\end{array}$ (5ignorance/affordability/opportunism/exacerbation/social-chainism-or-social-discomfiture-ornegative-social-aggregation/temporal-enculturation-or-temporal-endemisation) as rather referenced/registered/decisioned from the prospective intemporal-disposition in postconvergingor-dialectical-thinking -apriorising-psychologism to reconstrue new recomposuring reference-of-thought- ${ }^{8}$ ategorical-imperatives/axioms/registry-teleology ${ }^{99}$,-for-intemporalpreservation-entropy-or-contiguity-or-ontological-preservation for intemporal-preservationentropy-or-contiguity-or-ontological-preservation while superseding the prior registryworldview/dimension as backdrop of temporal perversion of the prior ${ }^{83}$ reference-of-thought- 
categorical-imperatives/axioms/registry-teleology . Technically, pedestalled disambiguation should involve reflecting/perspectivating/highlighting from the intemporal-disposition pedestal teleology finality/questioning mental-profoundness (deep candor) the relative longness/shortness-of-teleology ${ }^{9}$ of temporal-dispositions teleologies finalities/questioning mental-triteness (light candor), starting with slantedness pedestal finality/questioning (which is the psychopath's insane/slantedness-fitment-roaming/drifting-cycle), and as it conjugates/inflects across other temporal pedestals teleology finalities/questioning (5ignorance/affordability/opportunism/exacerbation/social-chainism-or-social-discomfiture-ornegative-social-aggregation/temporal-enculturation-or-temporal-endemisation). Pedestalled disambiguation points to the fact that the social representation of meaning is transversal/logically incongruent at uninstitutionalised-threshold ${ }^{102}$ as reflected by human temporal-to-intemporal dispositions (hence the need to articulate various pedestals of 'questioning depth-of-thought' and 'strands of depth-of-meaningfulness' to reflect effective meaningful representation from the intemporal-disposition point-of-reference). Where meaning is not articulated within an institutionalised/intemporalised framework, the idea of logical-congruence (a common reference of meaning in terms-as-of-axiomatic-construct of ${ }^{83}$ reference-of-thought and logic) should be avoided due to ${ }^{7}$ perversion-of- ${ }^{83}$ reference-of-thought- $<$ as-preconverginglyapriorising/axiomatising/referencing-in-nonconviction/madeupness/bottomlining-as-to-

shallow-supererogation $>$ whether psychopathic or not, and pedestalled disambiguation is then required using distractive-alignment-to- ${ }^{8}$ reference-of-thought- $<$ ofapriorising/axiomatising/referencing $>30$ to establish the ontological pre-eminence of the intemporal-disposition. Instances of perversion-and-derived- ${ }^{7}$ perversion-of- ${ }^{83}$ reference-ofthought-<as-preconvergingly-apriorising/axiomatising/referencing-in-

nonconviction/madeupness/bottomlining-as-to-shallow-supererogation $>$ rather point to uninstitutionalised-threshold $^{102}$, whether retrospectively or prospectively, as there is wrong 
equivalence of notional firstnaturedness-formativeness-<as-to-eventualising-inkling-drive-orseeding misprising $>$ temporal-to-intemporal-dispositions-<so-construed-as-from-

perspective-ontological-normalcy/postconvergence $>$ in the articulation of meaning; instead of the pedestalled supersedingness of the intemporal-disposition as it is all about intemporalpreservation-entropy-or-contiguity-or-ontological-preservation (superseding various shades of temporal preservations). Otherwise, $\quad{ }^{71}$ perversion-of- ${ }^{8}$ reference-of-thought- $<$ aspreconvergingly-apriorising/axiomatising/referencing-in-

nonconviction/madeupness/bottomlining-as-to-shallow-supererogation $>$ induces a 'free-forall' false equivalence wrongly construed as of intemporality ${ }^{52} /$ longness (rather than the reality of human-subpotency-aporia/undecidability/dilemma/oughtindeterminacy/deficiency/limitation/constraint—imbued-'notional firstnaturednessformativeness-<as-to-eventualising inkling-drive-or-seeding-misprising $>$ - temporal-tointemporal-dispositions-<so-construed-as-from-perspective-ontologicalnormalcy/postconvergence>'-existentialism-form-factor). Accounting for distractivealignment-to- ${ }^{83}$ reference-of-thought- $<$ of-apriorising/axiomatising/referencing $>30$ is what ends such a 'free-for-all' and is the basis of pedestals alienative hierarchisation as referenced/registered/decisioned from the intemporal-disposition thus bringing about institutionalisation/intemporalisation (given the social cross-sectional eliciting of social ${ }^{3}$ universal-transparency ${ }^{104}$-〈transparency-of-totalising-entailing,-as-to-entailing<amplituding/formative-epistemicity>totalising in-relative-ontological-completeness >, untenability/internal-contradiction/internal-incoherence/institutional-constraining, positiveopportunism - of-social-functioning-and-accordance ${ }^{75}$ and transcendence-unenablinguninstitutionalised-threshold $^{102}$ in alienation—as-inauthentic/poorly-objectified/poorly-

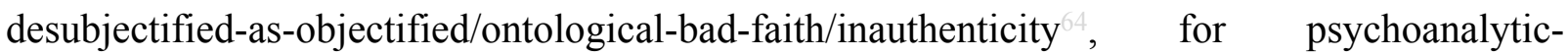
unshackling/memetic-reordering/institutional-recomposuring in the medium to long-run 
percolation) with corresponding dismissal of temporal-dispositions-teleologies as dialecticallyor-contendingly-out-of-phase/dialectically-primitive) as the backdrop for the ${ }^{83}$ reference-ofthought- categorical-imperatives/axioms/registry-teleology ${ }^{9}$,-for-intemporal-preservationentropy-or-contiguity-or-ontological-preservation of the intemporal-disposition anticipation and preemption of these for the institutionalisation/intemporalisation. Pedestalled disambiguation explains the dynamism of human institutional-cumulation/institutionalrecomposure-〈as-to- historiality/ontological-eventfulness /ontological-aesthetic-tracing$<$ perspective-ontological-normalcy/postconvergence-reflected-'epistemicity-relativismdeterminism'>> going by a recurrent emanance/becoming template that involves: (1) Free-forall implying an equivalence of notional firstnaturedness-formativeness-as eventualising inkling-drive-or-seeding-misprising $>$ temporal-to-intemporal-dispositions$<$ so-construed-as-from-perspective-ontological-normalcy/postconvergence $>$ as being all intemporal (rather than temporal-to-intemporal), with the result that meaning then becomes veridically a hotchpotch of various formulaic-association, temporal, 'implicited_attendantontological-contiguity ${ }^{67} \sim$ educedexistentialising/contextualising/textualising_'intelligibility/epistemicity/reflexivity-contiguity$<$ imbued-notional $\sim$ cogency $>,{ }^{\prime},-<$ reifying-or-elucidating-of-prospective-relative-ontologicalcompleteness -of- reference-of-thought- devolving-as-of-instantiative-context>, and the intemporal-emanance, without apriorising-registry disambiguation (as apriorising-registry disambiguation, into the intemporal and various conjugating temporal-dispositions of postlogism 7 -slantedness/ ${ }^{5}$ ignorance/affordability/opportunism/exacerbation/social-chainismor-social-discomfiture-or-negative-social-aggregation/temporal-enculturation-or-temporalendemisation, so-disambiguated as of ${ }^{83}$ reference-of-thought- ${ }^{8}$ devolving ontologicalperformance $^{-2}-<$ including-virtue-as-ontology $>$, allows for the establishment of contextualisation in articulating the contrast of the intemporal-disposition's organic-comprehension-thinking 
(organicalism/‘intemporal-prioritisation-of- ${ }^{2}$ reference-of-thought'-as-conflatedness ${ }^{3}$-orontological-reprojecting/tongness-of-register-of- meaningfulness-and-teleology ) and temporal-dispositions threshold-of-nonconviction/madeupness/bottomlining-in-shallowsupererogation $-<$ as-to- 'attendant-intradimensional'-prospectivelydisontologising preconverging/dementing -apriorising-psychologism $>$ involving slanting by psychopath, miscuing, disjointed-logic, logical-drag, unconscionability-drag, and sub-par-orformulaic-association-or-temporal-or-alibi conventioning-rationalising -with temporaldispositions in varied shades of temporal conjugation/inflection to psychopathic postlogism 77 in hollow-constituting-<as-disjointed-misappropriation-of-meaningfulness-and-failingintemporal-preservation $>$ as <amplituding/formative-epistemicity $>$ causality $\sim$ as-to-projectivetotalitative-implications-of-prospective- nonpresencing,-for-explicating relative-

unreflexivity/relative-reflexivity ontological-contiguity dispositions; thus enabling the stifling (undermining the ontological-veridicality) of temporal-dispositions and skewing ('intemporality ${ }^{52}$-symmetrising-by-desymmetrising-subsumption-of-temporality ${ }^{\circ}$, for relative intrinsic-reality/ontological-veridicality transcendentalenabling/sublimating/supererogatory $\sim$ de-mentativity), by way of institutionalisation/intemporalisation percolation-channelling- $<$ in-deferential-formalisationtransference>, towards the supersedingness of the intemporal-disposition for institutionalisation's/intemporalisation's intemporal-preservation-entropy-or-contiguity-orontological-preservation). For instance, a state of nature (recurrent-utter-uninstitutionalisation) application of the law variably making reference to circumstantial social power relations and spontaneously articulated notions of vices and virtues but no or poor ${ }^{103}$ universal rules (mob situations as well as social psychopathic situations will fall under such an interpretation as well). (2) Pedestalling ('intemporal-prioritisation-of- ${ }^{8}$ reference-of-thought'-as-conflatedness ${ }^{13}$-orontological-reprojecting pedestalling) articulates the relative grandor and virtuous consequence 
of the pedestalled supersedingness of the intemporal-disposition by its intemporal-preservationentropy-or-contiguity-or-ontological-preservation that then leads to society's temporal-tointemporal cross-sectional 'dimensionality-of-sublimating

\section{<<amplituding/formative >supererog de-mentativeness/epistemic-growth-or-}

\section{conflatedness /transvaluative-rationalising/transepistemicity/anamnestic-residuality/spirit-}

drivenness-equalisation) projection induced deference'; whether deference with regards to a superstition/belief system/religion, essences/ ${ }^{103}$ universal-notions, positivist idealism/principlesrationalism (and prospectively rational-realism as of deprocrypticism), involving a posture (institutionalised disposition) of the sort 'the-say-that or it-is-said-that' as 'dimensionality-ofsublimating $25-<$ amplituding/formative $>$ supererogatory $\sim$ de-mentativeness/epistemic-growth-

\section{or-conflatedness /transvaluative-rationalising/transepistemicity/anamnestic-residuality/spirit-}

drivenness-equalisation) projection induced deference' to the intemporal/longness disposition, for instance, 'scientists say that', the 'Bible says that', 'it is said that one should not set foot in that forest as it will bring bad luck', etc. This 'the-say-that/it-is-said-that' 'dimensionality-ofsublimating $25-<<$ amplituding/formative $>$ supererogatory $\sim$ de-mentativeness/epistemic-growthor-conflatedness /transvaluative-rationalising/transepistemicity/anamnestic-residuality/spiritdrivenness-equalisation> projection induced deference' explains why institutionalisation/intemporalisation has been happening across human history; whether deference from personalised/animists beliefs to philosophical, religious and other social belief systems, deference from haphazard application of social rules to ${ }^{103}$ universal notions, laws and principles, deference from spirit-and-mystical-driven notions of nature and various alchemies to a modern scientific construct system. Hence the very place of the averageness/banality-ofhuman-thought-and-meaning in history has been for it to defer to superseding intemporaldisposition construal by 'intemporal-prioritisation-of- ${ }^{8}$ reference-of-thought'-asconflatedness $^{13}$-or-ontological-reprojecting pedestalling. There is no such thing as allowing 
thought-and-meaning to the whims of masses thinking but rather deference to 'reality/veridicality predicating constructs'; as enabled abstractly and existentially< disontologising/re-ontologising aporeticism $>$ by the human individuation intemporalemanant-registry in superseding human individuations temporal-dispositions. 'Intemporalprioritisation-of- ${ }^{8}$ reference-of-thought'-as-conflatedness ${ }^{13}$-or-ontological-reprojecting pedestalling carries the implication that ${ }^{83}$ reference-of-thought and meaningfulness is fundamentally/ontologically structured for ontological-normalcy/postconvergence intemporalpreservation-entropy-or-contiguity-or-ontological-preservation, and hence the precedence of higher intemporal teleologies over low temporal teleologies of ${ }^{8}$ reference-of-thought and meaningfulness; and that subpar preconverging-de-mentating/structuring/paradigming of reference-of-thought and meaningfulness not for intemporal-preservation-entropy-orcontiguity-or-ontological-preservation but rather as ${ }^{7}$ perversion-of- ${ }^{8}$ reference-of-thought- $<$ aspreconvergingly-apriorising/axiomatising/referencing-in-

nonconviction/madeupness/bottomlining-as-to-shallow-supererogation $>$ of subpar

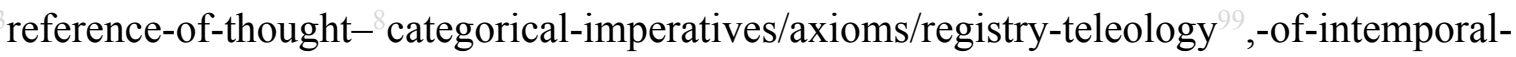
preservation-entropy-or-contiguity-or-ontological-preservation as uninstitutionalisedthreshold ${ }^{102}$ is 'perverted ${ }^{83}$ reference-of-thought and meaningfulness' (<amplituding/formativeepistemicity $>$ totalising $\sim$ self-referencing-syncretising/circularity/interiorising/akrasiatic-drag ), and is ontologically-preconverging-or-dementing -apriorising-psychologism (dialecticallypreconverging-or-dementing ${ }^{20}$-apriorising-psychologism) whether from a superseding/transcending registry/registry-worldview $\quad{ }^{83}$ reference-of-thought/veridicalthinking-reference-over-preconverging-or-dementing ${ }^{20}$-reference that is retrospective (like base-institutionalisation over recurrent-utter-uninstitutionalisation), present (like positivism over non-positivism/medievalism) or prospective (like notional deprocrypticism over procrypticism/the-'preconverging-or-dementing 2 -apriorising-psychologism-of-the- 
positivistic-registry-worldview-or-dimension-categorical-imperatives-or-axioms-or-registryteleology ${ }^{9}$-for-intemporal-preservation-entropy-or-contiguity-or-ontological-preservation). 'Intemporal-prioritisation-of- ${ }^{83}$ reference-of-thought'-as-conflatedness ${ }^{13}$-or-ontologicalreprojecting pedestalling underlines the fundamental nature of institutionalisation/intemporalisation not as a temporal-dispositions-to intemporal-disposition transformation (not emanance transformance) but rather a 'positive-opportunism-of-socialfunctioning-and-accordance ${ }^{75}$ constraining construct' involving 'intemporal-disposition deferential-formalisation-transference' (such that just as jurisprudentialism is dismissive of whatever we'll like to think of it in our social-and-temporal-trading context about the law which is rather articulated as a formal conceptualisation and constraint to be internalised as a 'universal construct to avoid its 'downgrading' by mobbish or other temporal social inclinations, likewise with many a subject-matter domain). In the same vain, the outcrop of an organic-comprehension-thinking 'intemporal-prioritisation-of- ${ }^{8}$ reference-of-thought'-asconflatedness ${ }^{13}$-or-ontological-reprojecting conceptualisation of notional ${ }^{18}$ deprocrypticism over procrypticism can only be construed within a formal institutionalised articulation not opened to 'temporal/ordinary disposition contention' as is the case with subject-matter constructs, but rather an institutionalised percolation-channelling- $<$ in-deferential-formalisationtransference $>$ exercise, so as to avoid temporal-dispositions denaturing ${ }^{16}$ as is the case with all formal constructs, which rather strive to uphold the intemporal/longness-of-register-or-depth-ofmeaningfulness teleology ${ }^{9}$ while relying on principled methods. Prospectively, the intellectual exercise involved in articulating procrypticism-notional $\sim^{18}$ deprocrypticism and psychopathy and its corollary social psychopathy, will have to imply a 'dimensionality-of-sublimating ${ }^{25}$ <<amplituding/formative>supererogatory $\sim$ de-mentativeness/epistemic-growth-orconflatedness /transvaluative-rationalising/transepistemicity/anamnestic-residuality/spiritdrivenness-equalisation> projection induced deference' of the averageness/banality-of-thought 
(notional firstnaturedness-formativeness-<as-to-eventualising-inkling-drive-or-seedingmisprising $>$ temporal-to-intemporal-dispositions- $<$ so-construed-as-from-perspectiveontological-normalcy/postconvergence $>$ ) for futural Being-development/ontologicalframework-expansion-as-to-depth-of-ontologising-development-as-infrastructure-ofmeaningfulness-and-teleology as of prospective notional ${ }^{18 \text { deprocrypticism }}$ institutionalisation/intemporalisation 'dimensionality-of-sublimating

\section{<<amplituding/formative>supererogatory $\sim$ de-mentativeness/epistemic-growth-or-}

\section{conflatedness /transvaluative-rationalising/transepistemicity/anamnestic-residuality/spirit-}

drivenness-equalisation) projection induced deference' of the cross-section of humansubpotency-aporia/undecidability/dilemma/ought-

indeterminacy/deficiency/limitation/constraint—imbued-‘notional firstnaturednessformativeness-<as-to-eventualising-inkling drive-or-seeding misprising $>$ temporal-tointemporal-dispositions- $<$ so-construed-as-from-perspective-ontologicalnormalcy/postconvergence>'-existentialism-form-factor to the intemporal-disposition in order for institutionalisation/intemporalisation to take place is critical in inducing the requisite psychoanalytic-unshackling/memetic-reordering/institutional-recomposuring (in relation to theunchanging-nature/same-intrinsicness of reality) for human retrospective-and-prospective progress/transcendence; and is necessary by the inherent fact of human-subpotencyaporia/undecidability/dilemma/ought-indeterminacy/deficiency/limitation/constraint—imbued'notional firstnaturedness-formativeness-<as-to-eventualising-inkling-drive-or-seeding misprising $>$ temporal-to-intemporal-dispositions- $<$ so-construed-as-from-perspectiveontological-normalcy/postconvergence>'-existentialism-form-factor, going by the mediocrity principle (if men were only of intemporal-disposition, no institutionalisation/intemporalisation nor 'intemporal-prioritisation-of- ${ }^{3}$ reference-of-thought'-as-conflatedness ${ }^{13}$-or-ontologicalreprojecting pedestalling will be necessary as the mere exposure-to/contemplation-of 'rightness 
of thought and meaning' will suffice for transcendence; such a complete human being doesn't and has never existed, and not even philosopher-kings from the Socrates, Aristotles and others who explore such possibilities, even though intemporal-disposition possibilities will tend to accrue more to such 'philosopher-kings' individuals). For the big picture, this point to the fact that institutional-cumulation/institutional-recomposure-〈as-to- historiality/ontologicaleventfulness /ontological-aesthetic-tracing-<perspective-ontologicalnormalcy/postconvergence-reflected-'epistemicity-relativism-determinism’> $>$ /anthropologicalcontinuity/anthropopsychology is only possible for one reason, a continuity in the intemporaldisposition institutionalisation/intemporalisation (with 'dimensionality-of-sublimating ${ }^{25}$ 〈<amplituding/formative>supererogatory $\sim$ de-mentativeness/epistemic-growth-or-

\section{conflatedness /transvaluative-rationalising/transepistemicity/anamnestic-residuality/spirit-}

drivenness-equalisation) projection induced deference') of the cross-section of humansubpotency-aporia/undecidability/dilemma/ought-

indeterminacy/deficiency/limitation/constraint —imbued-'notional firstnaturednessformativeness-<as-to-eventualising-inkling drive-or-seeding misprising $>$ temporal-tointemporal-dispositions- $<$ so-construed-as-from-perspective-ontologicalnormalcy/postconvergence>'-existentialism-form-factor. Where, and if, intemporal-disposition was to possibly end or be upended (either because of lack of further human intemporaldisposition mentation-capacity for higher levels-of-transcendence-andsublimity/sublimation/superenterenterativity, in the dynamism of individual potential, i.e. the solipsistic disposition of individuals' individuations to assume ${ }^{103}$ universal projection of longness-of-thought-and-meaning, or social-construct potential, i.e. where grander institutionalisation/intemporalisation is not confused and implied on the naivety that the institutionalised social-construct is of intemporal-disposition rather than a notional firstnaturedness-formativeness-<as-to-eventualising inkling-drive-or-seeding 
misprising $>$ temporal-to-intemporal-dispositions- $<$ so-construed-as-from-perspective-

ontological-normalcy/postconvergence $>$ construct requiring 'transcending any ${ }^{74}$ perversion-ofreference-of-thought-<as-preconvergingly-apriorising/axiomatising/referencing-innonconviction/madeupness/bottomlining-as-to-shallow-supererogation $>$ of the $<$ amplituding/formative $>$ wooden-language-_imbued - averaging-of-thought-<as-toleveling/ressentiment/closed-construct-of- meaningfulness-and-teleology -as-of'nondescript/ignorable-void '-with-regards-to-prospective-apriorising-implications $>\rangle$ '), then 'human transcendence-and-sublimity/sublimation/supererogatory - de-mentativity and civilisation will stall' (of course, such an insight is purely from an ontological point-of-reference, and not a temporal <amplituding/formative-epistemicity $>$ totalising $\sim$ self-referencingsyncretising/illusion-of-the-present/present-consciousness point-of-reference)! (3) The establishment of institutionalisation/intemporalisation involves necessarily 'delegated gatekeeping and institutionalisation/intemporalisation percolation-channelling- $<$ in-deferentialformalisation-transference> processes' to uphold it thereafter with formalisms and officialdom surrounding it with respect to temporal-dispositions ${ }^{74}$ perversion-of- ${ }^{8}$ reference-of-thought- $<$ aspreconvergingly-apriorising/axiomatising/referencing-innonconviction/madeupness/bottomlining-as-to-shallow-supererogation $>$ and corruption dispositions. For instance, the institutionalisation/intemporalisation of 'scientific chemistry' comes with a 'chemistry lingua' accessible to those sharing and/or educated to uphold the meaningful frame, on the justification that they explain and account more about the material world than any other alternative. This justification goes on to make them formalism and officialdom percolation-channelling- $<$ in-deferential-formalisation-transference $>$ to the extended-informality-〈susceptible-to-effecting-parsimony-as-of-shoddiness-andincompleteness-to- meaningfulness-and-teleology > such that over time alchemic and superstitious conceptualisations of material meaning are effectively destroyed while equally 
seeing to it that pseudo-scientism is kept at bay. 'Delegated gatekeeping and institutionalisation/intemporalisation percolation-channelling- $<$ in-deferential-formalisationtransference> processes'; because such a pedestalled supersedingness is only as valid as to when it is the grandest construal of material meaning until, and if, it is shown not to be the case. A further and nonetheless important reason for such delegation is the relative superficiality generally associated with averageness/banality-of-thought dimensionality-of-sublimating <<amplituding/formative>supererogatory $\sim$ de-mentativeness/epistemic-growth-or-

\section{conflatedness /transvaluative-rationalising/transepistemicity/anamnestic-residuality/spirit-}

drivenness-equalisation〉 projection construal of meaning, and not to speak of its discomposure to the convolutedness often required in articulating and grasping intemporal meaning as intemporal/ontological/social/species $/{ }^{103}$ universal/transcendental/ $/ 5$ maximalisingrecomposuring-for-relative-ontological-completeness ${ }^{87}$ - unenframed/re-

ontologising conceptualisation postconverging-de-mentating/structuring/paradigming. Besides, this raises other issues related to a more or less temporal take of an ontological/intemporal enterprise with regards to articulations that are meant to have ${ }^{103}$ universal import (import of 'metaphorically-a-million-and-one-instances-and-locales as to aetiologisation/ontological-escalation- $<$ ontologicalveridicality_commitment/otherliness_transcending/compulsions-encumbered_transcending>' across space and time) rather than for the sake of any particular circumstantial/temporal take/extricatory-situation in whichever locale, that is, an extricatory preconverging-dementating/structuring/paradigming. A failure to grasp the intellectual-analyst posture rather as a proxying-of-intrinsic-reality-as-ontology as per <amplituding/formativeepistemicity $>$ causality $\sim$ as-to-projective-totalitative-implications-of-prospectivenonpresencing,-for-explicating relative-unreflexivity/relative-reflexivity - ontologicalcontiguity validation and that there-is-no-discretionary-construal-of-ontology/ontological- 
reality since intrinsic reality is superseding of all mortals including the intellectual-analyst. Basically the issue of the intellectual-analyst exercise in grasping such an intrinsic-reality is a proxying one superseded by the <amplituding/formative-epistemicity $>$ causality $\sim$ as-toprojective-totalitative-implications-of-prospective- nonpresencing,-for-explicating $\sim$ relativeunreflexivity/relative-reflexivity —ontological-contiguity of reality 'which in no way depends on any notion of the intellectual-analyst's choice/luxury' (as the intellectual-analyst might actually have by another individuation chose not an intemporal/ontological projection but a temporal posture 'in moral/intellectual equivalence with temporal mental projections' with nefarious temporal consequences). Basically, there is nothing like an intemporal temporality $/$ shortness whereby there is any intemporality $52 /$ longness in accommodating human temporality ${ }^{8}$. Likewise, supposedly the intellectual-analyst was to come short in its intemporal projection or other ${ }^{103}$ universal values by temporal manipulation, it is very naïve to 'reason and projecting temporally' that eliciting such an 'inductive-limitation (the-paradox-of-a- ${ }^{103}$ universalrule-that-doesn't-apply- ${ }^{103}$ universally-but-to-a-specific-circumstance-to-satisfy-a-temporalurging)/gotcha-logic/suggestibility' should undermine the essence of ontological/intemporal meaning which is 'above a human intellectual proxying exercise to it' and doesn't depend on it to exist inherently, is nothing but temporal naivety. The reality of a round world doesn't depend on its recognition of a medieval mindset $/{ }^{3}$ reference-of-thought for it to exist likewise with any veridicality/intrinsic-reality regarding psychopathy and a social manifestation whether it is palatable or not. Finally, temporal-dispositions as eliciting temporal vices-and-impediments are in no way qualified to contend about intemporal articulation/projection. In effect, such temporal pretence are nothing but <amplituding/formative-epistemicity $>$ totalising $\sim$ selfreferencing-syncretising/circularity/interiorising/akrasiatic-drag ${ }^{34}$ mental-dispositions meant to satisfy the 'mortals temporal preservation' on the basis of 'locale context logic' and not 'intemporal preservation as ontological veridicality with the potential for a grander human good' 
on the basis of " ${ }^{103}$ universal implications'; as inevitably, ontologically, the resolution of ontological/being perversion-of- ${ }^{-3}$ reference-of-thought- $<$ as-preconverginglyapriorising/axiomatising/referencing-in-nonconviction/madeupness/bottomlining-as-to-

shallow-supererogation $>$ defects (and as per their manifestation and conjugation as postlogism ${ }^{77}$-slantedness/ ${ }^{5}$ ignorance/affordability/opportunism/exacerbation/social-chainismor-social-discomfiture-or-negative-social-aggregation/temporal-enculturation-or-temporalendemisation, so-disambiguated as of ${ }^{83}$ reference-of-thought- ${ }^{8}$ devolving ontologicalperformance $^{72}-<$ including-virtue-as-ontology $>$ ) are as prospective registryworldviews/dimensions constructs that supersede the prior/superseded registryworldview's/dimension's perversion of $\quad{ }^{83}$ reference-of-thought- categoricalimperatives/axioms/registry-teleology ${ }^{9}$,-for-intemporal-preservation-entropy-or-contiguityor-ontological-preservation (uninstitutionalisation preconverging/postconverging-dementatively/structurally/paradigmatically superseded/resolved/rendered-inoperant by baseinstitutionalisation, ununiversalisation by ${ }^{103}$ universalisation, non-positivism/medievalism by positivism, and prospectively ${ }^{80}$ procrypticism-or-disjointedness-as-of- ${ }^{8}$ reference-of-thought by deprocrypticism). Supposed the intellectual-analyst was to act temporally to the point of overlooking such ontological implications to the level of lowly temporal minds, lowly because not ${ }^{103}$ universal-projecting, it won't mean that the ontological reality will evaporate. It will simply mean that the intellectual-analyst has failed in its intemporal/ontological projection, more like Darwin doesn't have the choice/luxury of deciding from his insight that evolution doesn't exist in placating any temporal mortals or Galileo doesn't have the choice/luxury of deciding from his insight that the world is not round in placating any temporal mortals, and if they were to make that choice they affirm nothing more than their 'aggrandised mortality'. The blunt/incisive reality is that they being in that position to affirm

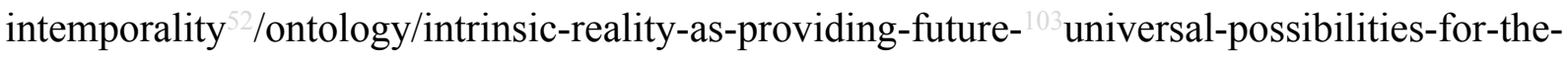


human-species are the 'very tip of the possibility of human civilisation' and their moral/intellectual posture is to 'bluntly look down' to the 'little mortal creatures of temporality and 'shepherd the sheepishness-of-the-species' to grander civilisational grounds. It is an ontological 'moral and intellectual responsibility/relative-reflexivity and privilege', actually, to be in any such position, going by the eudaemonic-contemplation which is what 'effectively grants existential-<disontologising/re-ontologising aporeticism $>$ moral and intellectual

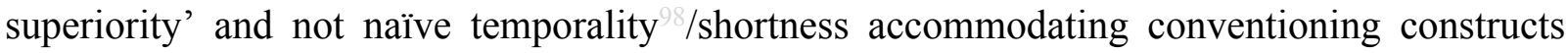
about any such pretence which is nothing more than temporal/the-mortal's ${ }^{74}$ perversion-ofreference-of-thought-<as-preconvergingly-apriorising/axiomatising/referencing-innonconviction/madeupness/bottomlining-as-to-shallow-supererogation $>$ as to preconvergingor-dementing ${ }^{20}$-apriorising-psychologism; as any such is not the intemporal-disposition that started base-institutionalisation (to thwart recurrent-utter-uninstitutionalisation) through universalisation (to thwart ununiversalisation), positivism (to thwart nonpositivism/medievalism), and prospectively its intemporal-disposition that will enable notional ${ }^{18}$ deprocrypticism (to thwart ${ }^{80}$ procrypticism-or-disjointedness-as-of- ${ }^{3}$ reference-ofthought) and thereafter; the intemporal individuation as such projects in an 'abstract eternality' which is what allows for the intemporal-preservation-entropy-or-contiguity-or-ontologicalpreservation. Temporal-dispositions may not need to understand as of < amplituding/formativeepistemicity $>$ totalising $\sim$ self-referencing-syncretising/present-consciousness/illusion-of-thepresent for the pertinence of intrinsic reality to be established as it is preceding in ontologicalnormalcy/postconvergence, anyway, that is why it is a 'registry-worldview's/dimension's prospective institutionalisation/intemporalisation secondnaturing exercise', and 'not human temporal-dispositions transformation exercise' into intemporality ${ }^{5}$ Ultimately, like all institutionalisation/intemporalisation construct, there is a 'dimensionality-of-sublimating <<amplituding/formative>supererogatory $\sim$ de-mentativeness/epistemic-growth-or- 


\section{conflatedness /transvaluative-rationalising/transepistemicity/anamnestic-residuality/spirit-}

drivenness-equalisation> projection induced deference' to such an ontological construal by way of formalism-and-officialdom as the temporality /averageness/banality-of-thought is not allowed to imply dimensionality-of-sublimating <<amplituding/formative>supererogatory $\sim$ de-mentativeness/epistemic-growth-orconflatedness /transvaluative-rationalising/transepistemicity/anamnestic-residuality/spiritdrivenness-equalisation) projection depth with respect to such ontological construal (due to the reality of the mediocrity principle that we are not as of intemporal-disposition but notional firstnaturedness-formativeness-as to or seeding misprising $>$ - temporal-to-intemporal-dispositions- $<$ so-construed-as-from-perspectiveontological-normalcy/postconvergence>, and hence the need for the artifice to skew/deferentialformalisation-transference for intemporality ${ }^{52}$ as enabling ontologisation and re-ontologisation) otherwise we would be working with moral philosophy and not law, subject-matter informalities and not formalisms, etc. There is no such thing as 'intemporal temporality ${ }^{\circ}$ as mentaldispositions 'geared to accommodate temporality' (as to incrementalism-in-relativeontological-incompleteness ${ }^{8}$ — enframed/disontologising conceptualisation) are doing nothing but providing the anchoring for the endemisation and enculturation of the vices-andimpediments $^{105}$ associated with such temporal registry-worldview's/dimension'suninstitutionalised-threshold ${ }^{102}$-defect- $<$ as-Being-or-ontological-or-existential-defect $>$ perversion-of- ${ }^{8}$ reference-of-thought- $<$ as-preconvergingly-

\section{apriorising/axiomatising/referencing-in-nonconviction/madeupness/bottomlining-as-to-}

shallow-supererogation >, and hence are doing nothing but <amplituding/formativeepistemicity $>$ totalising $\sim$ self-referencing-syncretising; as the state of inherent relativeontological-incompleteness ${ }^{8}$-induced,-`threshold-of-nonconviction/madeupness/bottomliningin-shallow-supererogation -<as-to-'attendant-intradimensional'-prospectively- 
disontologising $\sim$ preconverging/dementing -apriorising-psychologism>', as-it-is-thus-'inwait'-for- perversion-of- $^{8}$ reference-of-thought- $<$ as-preconverginglyapriorising/axiomatising/referencing-in-nonconviction/madeupness/bottomlining-as-toshallow-supererogation >,-or-temporal-preservation-as-pseudointemporality ${ }^{52}$-preservation, in temporal-preservation-as-pseudointemporality ${ }^{52}$-preservation with respect to ontologicalnormalcy/postconvergence (the latter assumed to be fully conceptually completed as deprocrypticism) as successively recurrent-utter-uninstitutionalisation recurrence, baseinstitutionalisation/ununiversalisation, ${ }^{103}$ universalisation/non-positivism-or-medievalism and positivism/procrypticism, is an inherent registry-worldview's/dimension's-uninstitutionalisedthreshold ${ }^{02}-$ defect- $<$ as-Being-or-ontological-or-existential-defect $>5$ in want for prospective transcendence-and-sublimity/sublimation/supereregatory de-mentativity (notwithstanding that the defect-in-temporal-preservation is instigated from postlogism as disontologisingperverted-outcome-sought-precedes-existentially-veridical-'attendant-intradimensionalapriorising/axiomatising/referencing'-logical-dueness mental-disposition eliciting temporal inclinations of ${ }^{5}$ ignorance/affordability/opportunism/exacerbation/social-chainism-or-socialdiscomfiture-or-negative-social-aggregation/temporal-enculturation-or-temporal-endemisation in upholding its temporal-preservation-as-pseudointemporality ${ }^{52}$-preservation). That is why psychopathy is better dealt with as 'social psychopathy' given that what is often and mostly overlooked is not with regards to the psychopath and its postlogic impulse to 'hollowconstitute'/fail-intemporal-preservation as $\quad{ }^{74}$ perversion-of- ${ }^{-}$reference-of-thought- $<$aspreconvergingly-apriorising/axiomatising/referencing-in-

nonconviction/madeupness/bottomlining-as-to-shallow-supererogation $>$ but rather the 'distortional effect on analysis' arising from 'postlogic/psychopathic elevation wittingly or unwittingly' by prelogism ${ }^{78}$-as-of-conviction,-in-profound-supererogation $-<$ existentiallyveridical-'attendant-intradimensional-apriorising/axiomatising/referencing'-logical-dueness- 
precedes-disontologising-logical-outcome-arrived-at> mental-dispositions in conjugatedpostlogism 7 /preconverging-or-dementing ${ }^{20}$-integration (by ignorance, at best, then affordability/opportunism/exacerbation/social-chainism-or-social-discomfiture-or-negativesocial-aggregation/temporal-enculturation-or-temporal-endemisation) which then wrongly provide 'supplanting-conviction-as-to-profound-supererogation —of-'attendantintradimensional'-postconverging/dialectical-thinking -apriorising-psychologism credulity' to elevate and integrate the ${ }^{7}$ perversion-of- ${ }^{3}$ reference-of-thought- $<$ as-preconverginglyapriorising/axiomatising/referencing-in-nonconviction/madeupness/bottomlining-as-toshallow-supererogation $>$ of a 'slanted mind'. As of, virtuous construal arises preconverging/postconverging-de-mentatively/structurally/paradigmatically from a universal/intemporal projection which is operant and deterministic with no room for 'temporal discretion' regarding the manifestation of ${ }^{7}$ perversion-of- ${ }^{8}$ reference-of-thought- $<$ aspreconvergingly-apriorising/axiomatising/referencing-in-

nonconviction/madeupness/bottomlining-as-to-shallow-supererogation $>$ in any registryworldview/dimension. The coherent and recurrent manifestation of phenomenal ${ }^{74}$ perversion-ofreference-of-thought-<as-preconvergingly-apriorising/axiomatising/referencing-innonconviction/madeupness/bottomlining-as-to-shallow-supererogation $>$ defect in a registryworldview/dimension speaks of the registry-worldview's/dimension's disposition to endemise/enculturate it. More like we don't have issues of sorcery and so in the positivistic society as preconverging/postconverging-de-mentatively/structurally/paradigmatically the positivistic registry-worldview's/dimension's institutionalisation ${ }^{83}$ reference-of-thoughtcategorical-imperatives/axioms/registry-teleology ${ }^{99}$ do not endemise/enculturate the notion and the social vices-and-impediments ${ }^{105}$ arising from it thereof. On the contrary, preconverging/postconverging-de-mentatively/structurally/paradigmatically the nonpositivism/medievalism registry-worldview's/dimension's institutionalisation ${ }^{83}$ reference-of- 
thought- ${ }^{-}$ategorical-imperatives/axioms/registry-teleology ${ }^{9}$ endemises/enculturate this with the consequent social vices-and-impediments ${ }^{105}$. It is very naïve to think that psychopathy as a social phenomenon is limited in scope to contexts where psychopaths are involved rather than involving a much wider social basis to explain how the positivistic registryworldview/dimension integrates, enculturates and endemises it as 'social psychopathy'. Just as prior/superseded registry-worldviews/dimensions have undergone their prospective institutionalisation/intemporalisation/transcendence once it is established that the ${ }^{83}$ reference-ofthought- categorical-imperatives/axioms/registry-teleology ${ }^{9}$,-for-intemporal-preservationentropy-or-contiguity-or-ontological-preservation are subknowledged/registryperverted/dialectically-preconverging-or-dementing -apriorising-psychologism at their uninstitutionalised-threshold ${ }^{102}$ and thus the need for new ${ }^{83}$ reference-of-thought- categoricalimperatives/axioms/registry-teleology ${ }^{9}$,-for-intemporal-preservation-entropy-or-contiguityor-ontological-preservation, likewise the positivistic dimension ${ }^{74}$ perversion-of- ${ }^{8}$ reference-ofthought-<as-preconvergingly-apriorising/axiomatising/referencing-innonconviction/madeupness/bottomlining-as-to-shallow-supererogation subknowledging $/$ mimicking/registry-perverting/preconverging-or-dementing 20 -apriorisingpsychologism of its ${ }^{83}$ reference-of-thought- categorical-imperatives/axioms/registryteleology ${ }^{9}$,-for-intemporal-preservation-entropy-or-contiguity-or-ontological-preservation known as ${ }^{80}$ procrypticism-or-disjointedness-as-of- ${ }^{2}$ reference-of-thought implies that it is not and cannot be beyond a prospective institutionalisation/intemporalisation/transcendence exercise' known as notional ${ }^{18}$ deprocrypticism which highlights the positivism- ${ }^{80}$ procrypticism registry-worldview's/dimension's enculturated/endemised vices-and-impediments ${ }^{105}$ associated with its $\quad{ }^{7}$ perversion-of- ${ }^{8}$ reference-of-thought-<as-preconverginglyapriorising/axiomatising/referencing-in-nonconviction/madeupness/bottomlining-as-toshallow-supererogation $>$, and so, as the-Good/knowledge-reification $\sim$ gesturing-and- 
accounting-of-epistemic-phenomenalism- $<$ in-

prospective_psychologismic apriorising/axiomatising/referencing-\{of- ${ }^{\text {pprospectively }}$ implicited_attendant-ontological-contiguity ' educed-

existentialising/contextualising/textualising_intelligibility/epistemicity/reflexivity-contiguity<imbued-notional cogency >' \}-conflatedness -in-\{preconverging disentailment by\} postconverging-entailment $>$ /understanding/<amplituding/formativeepistemicity $>$ causality $\sim$ as-to-projective-totalitative-implications-of-prospectivenonpresencing,-for-explicating relative-unreflexivity/relative-reflexivity - ontologicalcontiguity construal, and not as a mere-and-vague impression-driven/goodnaturedness/wishfulness construal. By-and-large, virtue is best understood as the knowledge/lack-of-knowledge ontological possibility offered in a registryworldview's/dimension's ${ }^{83}$ reference-of-thought (whether as base-institutionalised, ${ }^{3}$ universalised, positivising or notional ${ }^{18}$ deprocrypticism 'implicited_attendant-ontologicalcontiguity $^{67}$ ' educed-

existentialising/contextualising/textualising_intelligibility/epistemicity/reflexivity-contiguity$<$ imbued-notional cogency $>{ }^{,},-<$reifying-or-elucidating-of-prospective-relative-ontologicalcompleteness -of- reference-of-thought- devolving-as-of-instantiative-context> as to existence-potency $^{39} \sim$ sublimating-nascence,-disclosed-from-prospective-epistemicdigression—rules-of-apriorising/axiomatising/referencing-that-further-epistemicallyunconceal-the-very-ontologically-same-existential-reality) and not vagueness based on impression of discreet human or social qualities which just serve to confuse and distort the fundamental knowledge/lack-of-knowledge/understanding issue. This is very much in line with the virtues of all human subject-matter formalisms which are the-Good/knowledgereification $\sim$ gesturing-and-accounting — of-epistemic-phenomenalism- $<$ inprospective_psychologismic apriorising/axiomatising/referencing-\{of-'prospectively 
implicited_attendant-ontological-contiguity ' reduced-

existentialising/contextualising/textualising_'intelligibility/epistemicity/reflexivity_contiguity<imbued-notional cogency >' \}-conflatedness -in-\{preconverging disentailment by\}

postconverging entailment $>$ /understanding/<amplituding/formative-

epistemicity $>$ causality $\sim$ as-to-projective-totalitative-implications-of-prospective-

nonpresencing,-for-explicating relative-unreflexivity/relative-reflexivity ontological-

contiguity and not mere-and-vague impression-driven/good-naturedness/wishfulness. This elucidation shows that intrinsic-reality, accessible by 'reasoning-through transversality- $<$ forsublimating-existential-eventuating/denouement,-from-'thinking at-first/pure-predispositionpreemptive-of prospective-disontologising/subontologising' as-of-prospectivelydisambiguated-affirmed-and-unaffirmed-'motif-and-apriorising/axiomatising/referencing'> only at-a-superseding-pedestal that is ontologically utter and incisive/blunt over human incrementalism-in-relative-ontological-incompleteness ${ }^{8}$

enframed/disontologising $\sim$ conceptualisation and notional $\sim$ disjointedness-as-of- ${ }^{3}$ reference-ofthought and $\quad<$ amplituding/formative-epistemicity $>$ totalising $\sim$ self-referencingsyncretising/illusion-of-the-present/present-consciousness, is graspable in transcendence-andsublimity/sublimation/superenterentivity only by an active transversality- $<$ forsublimating-existential-eventuating/denouement-from-'thinking at-first/pure-predispositionpreemptive-of prospective-disontologising/subontologising' as-of-prospectivelydisambiguated-affirmed-and-unaffirmed-'motif-and-apriorising/axiomatising/referencing'> construal involving 'intemporal-prioritisation-of- ${ }^{8}$ reference-of-thought'-as-conflatedness ${ }^{13}$-orontological-reprojecting pedestalling (beyond 'temporal-and-social trading') by distractivealignment-to- ${ }^{83}$ reference-of-thought-<of-apriorising/axiomatising/referencing $>{ }^{30}$. As a reminder to the fact that pedestalled disambiguation is with respect to ${ }^{74}$ perversion-ofreference-of-thought-<as-preconvergingly-apriorising/axiomatising/referencing-in- 
nonconviction/madeupness/bottomlining-as-to-shallow-supererogation $>$ /mental-perversion

(threshold-of-nonconviction/madeupness/bottomlining-in-shallow-supererogation $<-<$ as-to‘attendant-intradimensional'-prospectively-disontologising preconverging/dementing apriorising-psychologism> defect or a defect outside the preconverging-dementating/structuring/paradigming logical-basis/logic,-as-derived-from $\sim$ transversality- $<$ forsublimating-existential-eventuating/denouement,-from-'thinking-at-first/pure-predispositionpreemptive-of prospective-disontologising/subontologising' as-of-prospectivelydisambiguated-affirmed-and-unaffirmed-'motif-and-apriorising/axiomatising/referencing'> of the said registry-worldview) and not logical defect (conviction-as-to-profoundsupererogation defect or a defect in the operation/processing of the preconverging-dementating/structuring/paradigming $\quad$ logical-basis/logic,-as-derived-from $\sim$ transversality- $<$ forsublimating-existential-eventuating/denouement,-from-'thinking at first/pure-predispositionpreemptive-of prospective-disontologising/subontologising' as-of-prospectivelydisambiguated-affirmed-and-unaffirmed-'motif-and-apriorising/axiomatising/referencing'> of the said registry-worldview); it is critical to note that the mental state of the registryworldview/dimension involved with the psychopath's slantedness-integration is not a 'poor or bad supplanting-conviction-as-to-profound-supererogation —of-'attendant-intradimensional'postconverging/dialectical-thinking -apriorising-psychologism' (which is a supplantingconviction-as-to-profound-supererogation —of-'attendant-intradimensional'postconverging/dialectical-thinking -apriorising-psychologism or prelogism ${ }^{78}$ nonetheless) but an elicited threshold-of-nonconviction/madeupness/bottomlining-in-shallow-supererogation $<$ as-to-'attendant-intradimensional'-prospectivelydisontologising preconverging/dementing -apriorising-psychologism>, construed by the slanted social protraction of the psychopath's slantedness inducing a social psychopathy; and it is these strands-of-perverting-temporal-dispositions including that of the psychopathy that are 
the subject of every institutional-cumulation/institutional-recomposure-〈as-tohistoriality/ontological-eventfulness /ontological-aesthetic-tracing-<perspectiveontological-normalcy/postconvergence-reflected-‘epistemicity-relativism-determinism’>> level's psychoanalytic-unshackling/memetic-reordering/institutional-recomposuring. Technically, it can be said that the underlying psychopathic phenomenon known as postlogism as-of- compulsing-nonconviction/madeupness/bottomlining-〈'<decontextualising/deexistentialising $\sim$ of-attendant-intradimensional-apriorising/axiomatising/referencing $>$-induceddisontologising'-of-the-'attendant-intradimensional-ontologising'-imbued$<$ contextualising/existentialising attendant-ontological-contiguity $>$;-in-shallowsupererogation -<as-to-disontologising-perverted-outcome-sought-precedes-existentiallyveridical-'attendant-intradimensional-apriorising/axiomatising/referencing'-logical-dueness $>$ ) is associated with all the institutional-cumulation/institutional-recomposure-〈as-tohistoriality/ontological-eventfulness /ontological-aesthetic-tracing-<perspectiveontological-normalcy/postconvergence-reflected-'epistemicity-relativism-determinism'>> by its eliciting of 'protracted slantedness' in temporal-dispositions ( ignorance/affordability/opportunism/exacerbation/social-chainism-or-social-discomfiture-ornegative-social-aggregation/temporal-enculturation-or-temporal-endemisation), and so given the preconverging-de-mentating/structuring/paradigming relative-ontologicalincompleteness ${ }^{8}$-of- ${ }^{8}$ reference-of-thought induced threshold-ofnonconviction/madeupness/bottomlining-in-shallow-supererogation $<-<$ as-to-' $a t t e n d a n t-$ intradimensional'-prospectively-disontologising preconverging/dementing -apriorisingpsychologism>. Hence, the need for 'dimensionality-of-sublimating ${ }^{25}$ <<amplituding/formative>supererogatory $\sim$ de-mentativeness/epistemic-growth-orconflatedness /transvaluative-rationalising/transepistemicity/anamnestic-residuality/spiritdrivenness-equalisation> projection induced deference' to skew/deferential-formalisation- 
transference towards intemporal-disposition as to prospective institutionalisation/intemporalisation. This 'institutionalisation template' as articulated above implying a 'next best case approach' in 'construing the institutionalisation/intemporalisation of human virtue' where we are face with the reality that man is not as of intemporal-disposition but rather temporal/shortness-to-intemporal/longness dispositions may be counterintuitive with respect to our illusion-of-the-present/present-consciousness, as any present-consciousness is shaped to perceive of itself as intemporal with the notion that its ${ }^{8}$ reference-of-thoughtcategorical-imperatives/axioms/registry-teleology $/$ registry-teleology 9 are perfectly sound. But we simply need to take an ontological-normalcy/postconvergence look of such 'preconverging/dementing ${ }^{20}$-apriorising-psychologism strands-of-perverting-temporaldispositions' regarding recurrent-utter-uninstitutionalisation (from base-institutionalisation institutionalisation/intemporalisation reference as to ${ }^{83}$ reference-of-thought), ununiversal (from universalisation institutionalisation/intemporalisation as to ${ }^{83}$ reference-of-thought), nonpositivism/medievalism (from positivism institutionalisation/intemporalisation as to ${ }^{8}$ referenceof-thought), and prospectively our procrypticism (from notional ${ }^{18 \text { deprocrypticism }}$ institutionalisation/intemporalisation as to ${ }^{83}$ reference-of-thought); to appreciate that such a representation is not farfetched and its implication of the need of our psychoanalyticunshackling/memetic-reordering/institutional-recomposuring over our ${ }^{7}$ perversion-ofreference-of-thought-<as-preconvergingly-apriorising/axiomatising/referencing-innonconviction/madeupness/bottomlining-as-to-shallow-supererogation 'preconverging/dementing ${ }^{20}$-apriorising-psychologism strands-of-perverting-temporaldispositions' at our prospectively uninstitutionalised-threshold ${ }^{12}$ of procrypticism (involving our endemisation/enculturation of the protracted-slantedness of positivistic ${ }^{83}$ reference-ofthought- categorical-imperatives/axioms/registry-teleology ${ }^{9}$,-for-intemporal-preservationentropy-or-contiguity-or-ontological-preservation along the various temporal-dispositions from 
ignorance to temporal enculturation/endemisation). Distractive-alignment-to- ${ }^{8}$ reference-ofthought- $<$ of-apriorising/axiomatising/referencing $>^{30}$ (mental-slantedness or decandoring-ofthe-mind or denaturing ${ }^{16}$ and not soundness-or-ontological-good-faith/authenticity ${ }^{6}$ ofreference-of-thought/candor): refers to the technique at 'uninstitutionalised-threshold ${ }^{102}$, (as against the natural reflex to align-in-prelogic supplanting-conviction-as-to-profoundsupererogation —of-'attendant-intradimensional'-postconverging/dialectical-thinking apriorising-psychologismly or prelogism ${ }^{7}$ ) by which to align the apriorising-registry to the postlogism 77 in hollow-constituting-<as-disjointed-misappropriation-of-meaningfulness-andfailing-intemporal-preservation $>$ articulated by psychopathy and its corollary social psychopathy.

Distractive-alignment-to- ${ }^{83}$ reference-of-thought- $<$ ofapriorising/axiomatising/referencing $>$ ' 30 is induced at the 'uninstitutionalised-threshold ${ }^{102}$ ' by the 'induced-ring-of-gyges-effect/solipsistic-point-of-temporal-thresholding/point-ofontological-faith-notion-or-ontological-fideism - imbued-underdetermination-of-motif-andapriorising/axiomatising/referencing-as-so-being-as-of-existential-reality' derived from the psychopath's initiated postlogism 7 in hollow-constituting-<as-disjointed-misappropriation-ofmeaningfulness-and-failing-intemporal-preservation>. It works like this, supposed by perversion-of- ${ }^{83}$ reference-of-thought-<as-preconverginglyapriorising/axiomatising/referencing-in-nonconviction/madeupness/bottomlining-as-toshallow-supererogation $>$ /mental-perversion (going by the two narratives highlighted above about the psychopath's 74 perversion-of- ${ }^{83}$ refence-of-thought-<as-preconverginglyapriorising/axiomatising/referencing-in-nonconviction/madeupness/bottomlining-as-toshallow-supererogation $>$ /mental-perversion) an interlocutor effectively integrates the perversion-of- ${ }^{3}$ reference-of-thought-<as-preconverginglyapriorising/axiomatising/referencing-in-nonconviction/madeupness/bottomlining-as-toshallow-supererogation $>$ /mental-perversions, at this 'uninstitutionalised-threshold ${ }^{02}$, i.e. 
procrypticism', the normal institutionalised/intemporalised logic (involving secondnaturing/supersedingness of institutionalised intemporal-disposition pedestal solipsistic/emanant disposition) do no longer operate cross-sectionally socially (as mentaldispositions revert there to notional firstnaturedness-formativeness-<as-toeventualising inkling-drive-or-seeding-misprising $>$ temporal-to-intemporal-dispositions<so-construed-as-from-perspective-ontological-normalcy/postconvergence>). This involves: (i) the 'induced-ring-of-gyges-effect/solipsistic-point-of-temporal-thresholding/point-ofontological-faith-notion-or-ontological-fideism - imbued-underdetermination-of-motif-andapriorising/axiomatising/referencing-as-so-being-as-of-existential-reality' (which leads to acting as if the ${ }^{74}$ perversion-of- ${ }^{83}$ reference-of-thought- $<$ as-preconverginglyapriorising/axiomatising/referencing-in-nonconviction/madeupness/bottomlining-as-toshallow-supererogation $>$ /mental-perversion projected by the psychopath is not perverted) as there is a corresponding 'lack of constraining social ${ }^{103}$ universal-transparency ${ }^{104}-\langle$ transparencyof-totalising-entailing,-as-to-entailing-<amplituding/formative-epistemicity $>$ totalising $\sim$ inrelative-ontological-completeness Y' (in the collective human mental-devising-representation at this uninstitutionalised-threshold ${ }^{102}$ ) about the ${ }^{7}$ perversion-of- ${ }^{8}$ reference-of-thought- $<$ aspreconvergingly-apriorising/axiomatising/referencing-innonconviction/madeupness/bottomlining-as-to-shallow-supererogation $>$ /mental-perversion that would have made upholding such a perverted behaviour in the social-construct inopportune/untenable; (ii) this process can effectively be grasped ontologically (at the intemporal-disposition $\quad$ pedestal transversality- $<$ for-sublimating-existentialeventuating/denouement,-from-'thinking at first/pure-predisposition-preemptive-of prospective-disontologising/subontologising' as-of-prospectively-disambiguated-affirmedand-unaffirmed-'motif-and-apriorising/axiomatising/referencing'> $>1$ disposition by the mechanism of alienative-hierarchisation) wherein a 'given supplanting-conviction-as-to- 
profound-supererogation of-'attendant-intradimensional'-postconverging/dialecticalthinking -apriorising-psychologism or prelogism ${ }^{78}$ construct' is as of postlogism ${ }^{77}$-slantedness undermined postlogicly/ perversion-of- ${ }^{8}$ reference-of-thought-<as-preconverginglyapriorising/axiomatising/referencing-in-nonconviction/madeupness/bottomlining-as-toshallow-supererogation $>$ /mental-perversion by the psychopath's postlogism -slantedness pedestal in transversality- $<$ for-sublimating-existential-eventuating/denouement--from-

\section{thinking at first/pure-predisposition-preemptive-of-prospective-}

disontologising/subontologising' as-of-prospectively-disambiguated-affirmed-andunaffirmed-'motif-and-apriorising/axiomatising/referencing'> ${ }^{101}$ disposition with respect to 'socially-perceived-value as of social-stake-contention-or-confliction', and in succession by the derived postlogic temporal-dispositions perversion/mental-perversion pedestal transversality$<$ for-sublimating-existential-eventuating/denouement,-from-'thinking-at-first/purepredisposition-preemptive-of prospective-disontologising/subontologising' as-ofprospectively-disambiguated-affirmed-and-unaffirmed-'motif-andapriorising/axiomatising/referencing'> dispositions of ignorance/affordability/opportunism/exacerbation/social-chainism-or-social-discomfiture-ornegative-social-aggregation/temporal-enculturation-or-temporal-endemisation, and correspondinglyly; (iii) an 'uninstitutionalised-threshold ${ }^{102}$ aetiology' of 'temporal pervertedregistries characterisations in their depth-of-teleologies/orientation as temporal-projections (more like mental-miscuing-projections as strands-of-temporal-dispositions-perversions, for instance, $\quad{ }^{15}$ de-mentation-〈supererogatory ontological-de-mentation-or-dialectical-dementation - stranding-or-attributive-dialectics $\rangle$ a medieval mindset/ ${ }^{3}$ reference-of-thought with respect to a superstitious-disposition or " perversion-of- reference-of-thought-<aspreconvergingly-apriorising/axiomatising/referencing-innonconviction/madeupness/bottomlining-as-to-shallow-supererogation $>$ of ${ }^{103}$ universalisation 
categorical-imperatives' and likewise 'de-mentation-〈supererogatory $\sim$ ontological-dementation-or-dialectical-de-mentation-stranding-or-attributive-dialectics $\rangle$ a procryptic mindset $/{ }^{8}$ reference-of-thought with respect to " perversion-of- ${ }^{8}$ reference-of-thought- $<$ aspreconvergingly-apriorising/axiomatising/referencing-innonconviction/madeupness/bottomlining-as-to-shallow-supererogation $>$ of positivistic categorical-imperatives') and an aetiology of the intemporal-disposition/ontologising characterisation in its depth-of-teleology 99 as intemporal $/{ }^{103}$ universal-projection; (iv) in-thebigger-scheme-of-things, as explained further above the 'abstract inherence of reality is given as it is ontological-normalcy/postconvergence' and supersedes/precedes/overrides/utters any defective reflex of human mental devising of representation of meaning such that it is the latter, the psyche, that gives in when demonstrated to be impertinent abstractly, and hence in lieu of 'prelogism 78 candoring/straightness reflex', 'distractive-alignment-to- ${ }^{8}$ reference-of-thought$<$ of-apriorising/axiomatising/referencing $>^{30}$ (as decandored/oblongated) is always the mental apriorising-registry alignment with regards to the ${ }^{74}$ perversion-of- ${ }^{8}$ reference-of-thought- $<$ aspreconvergingly-apriorising/axiomatising/referencing-in-

nonconviction/madeupness/bottomlining-as-to-shallow-supererogation $>$ registry-worldview, as positivism by ${ }^{15}$ de-mentation-〈supererogatory $\sim$ ontological-de-mentation-or-dialectical-dementation - stranding-or-attributive-dialectics $>$ distractively/decandored/oblongated aligns nonpositivism/medievalism as threshold-of-nonconviction/madeupness/bottomlining-in-shallowsupererogation $-<$ as-to- 'attendant-intradimensional'-prospectivelydisontologising preconverging/dementing -apriorising-psychologism>, ${ }^{103}$ universalisation by de-mentation-〈supererogatory $\sim$ ontological-de-mentation-or-dialectical-de-mentationstranding-or-attributive-dialectics $\rangle$ aligns universalisation distractively/decandored/oblongated as threshold-of-nonconviction/madeupness/bottomliningin-shallow-supererogation -<as-to-'attendant-intradimensional'-prospectively- 
institutionalisation by

de-mentation-〈supererogatery ontological-de-mentation-or-

dialectical-de-mentation - stranding-or-attributive-dialectics $\rangle$ aligns recurrent-utter-

uninstitutionalisation distractively/decandored/oblongated as threshold-of-

nonconviction/madeupness/bottomlining-in-shallow-supererogation $-<$ as-to-' $a t t e n d a n t-$

intradimensional'-prospectively-disontologising preconverging/dementing -apriorising-

psychologism $>$, and prospectively (though counterintuitive, as well) notional ${ }^{18}$ deprocrypticism by ${ }^{15}$ de-mentation-〈supereregatery-ontological-de-mentation-or-dialectical-de-mentation-

stranding-or-attributive-dialectics $\rangle$ aligns procrypticism distractively/decandored/oblongated as threshold-of-nonconviction/madeupness/bottomlining-in-shallow-supererogation $-<$ as-to-

\section{‘attendant-intradimensional'-prospectively-disontologising preconverging/dementing}

apriorising-psychologism>; (v) in-the-bigger-scheme-of-things, distractive-alignment-toreference-of-thought- $<$ of-apriorising/axiomatising/referencing $>$ ' at 'uninstitutionalisedthreshold ${ }^{102}$, will perfectly explain how 'apparently sound human mental-dispositions' within the scope of 'institutionalised/intemporalised-thresholds-of-intemporal-preservation-entropyor-contiguity-or-ontological-preservation' go on to produce such consequences as 'crowd effects' and worst still in teleologically-degraded social and political environments rationalise and/or partake in 'genocidal acts', for instance. Technically, distractive-alignment-toreference-of-thought- $<$ of-apriorising/axiomatising/referencing $>30$ by the temporaldispositions involves simply conjugating/inflecting the underlying '(as dialectically-orcontendingly-out-of-phase or hollow-mimicking) insane/slantedness fitment' of the postlogic mind of the psychopath to ${ }^{5}$ ignorance/affordability/opportunism/exacerbation/social-chainismor-social-discomfiture-or-negative-social-aggregation/temporal-enculturation-or-temporalendemisation. In-the-bigger-scheme-of-things, the articulation of reality as referentially of ontological-normalcy/postconvergence enables and allow creative projective-insights thought 
possibilities that the all too common "fixated traditional categorisation conceptualisation of reality' doesn't allow, as ontological-normalcy/postconvergence referentialism has the strength of overcoming the fundamental difficult issue of ephemerality (as priorly explained with the concept of unconscionability-drag) as 'it enables mental-devising-representation contiguity in recomposuring' across all institutional-cumulation/institutional-recomposure-〈as-to-

\section{historiality/ontological-eventfulness /ontological-aesthetic-tracing-<perspective-}

ontological-normalcy/postconvergence-reflected-‘epistemicity-relativism-determinism’ $>\rangle$. The reason this is possible is that such a referential ontological-normalcy/postconvergence representation is not shaped to prioritise any registry-worldview/dimension as being inherently the absolute reference of thought, such as we unwittingly do with our representation of reality due to the illusion-of-the-present/present-consciousness (a massive drawback in grasping veridical ontological reality especially in the ephemeral social world). With ontologicalnormalcy/postconvergence referentialism we place reality as an abstract construct of oneness that is preceding-and-supersedes our-and-all temporal representations of meaning, and the exercise of articulating ontological/intemporal meaning then becomes 'one of recomposuring how our temporal-and-all-temporal representations of meaning are recomposured to be internally coherent with the abstract ontological-normalcy/postconvergence referentialism 'sense of oneness of preceding-and-superseding intemporal/ontological meaning' as implied by the intemporal-preservation-entropy-or-contiguity-or-ontological-preservation'. The insight we can thus garner is that in absolute terms veridical meaning as represented in ontologicalnormalcy/postconvergence is a 'hypothetical abstraction' of intemporal-preservation-entropyor-contiguity-or-ontological-preservation (more like attaining the abstract but veridical purity in a field of study like mathematics) in 'unwinding' applicative 'colour/emotion/temporalframe/aesthetics/memetics/psychical-representation' of manifest teleologic-articulations as 'subexistence-in-existence/existence-as-of-its-mimetic-echoness/existence-in- 
reverberation/existence-potency ${ }^{32} \sim$ sublimating-nascence,-disclosed-from-prospectiveepistemic-digression (deconstruction/ontological-reconstituting-as-to-conflatedness possibilities) -subexistence-in-existence being that which holds existential-<disontologising/reentologising aporeticism $>$ possibilities or existential-<disontologising/re-ontologising aporeticism $>$ potency for existential-<disontologising/re-ontologising aporeticism $>$ reality or ontological veridicality, as allowed by referential-depth or ('allant' or 'fugue' in French) or 'natural emanant dynamic creative vitality/drive', i.e. ontological-normalcy/postconvergence 'unwinding' as deconstruction/ontological-reconstituting-as-to-conflatedness ${ }^{13}$ (more like the subconscious is that which holds existential-<disontologising/re-ontologising aporeticism $>$ possibilities/existential potency for ontologically-veridical ontologicalnormalcy/postconvergence maximalising-recomposuring-for-relative-ontologicalcompleteness ${ }^{87}$ — unenframed/re-ontologising conceptualisation consciousness reality/veridicality, or more like quantum-mechanics is actually an ontologically-veridical ontological-normalcy/postconvergence maximalising-recomposuring-for-relative-ontologicalcompleteness $^{87}$ — unenframed/re-ontologising conceptualisation about evasive atomic-level physical reality, more like musical and/or artistic creativity hermeneutics is the subexistence-inexistence possibilities or existence-as-of-its-mimetic-echoness/existence-in-reverberation or existence-potency ${ }^{39} \sim$ sublimating-nascence,-disclosed-from-prospective-epistemic-digression for ontologically-veridical ontological-normalcy/postconvergence 'unwinding' concrete music and/or art production). Thereafter, the ontological exercise is about having ontologicalnormalcy/postconvergence (intemporal-preservation-entropy-or-contiguity-or-ontologicalpreservation) as an 'ontologically-veridical abstract and infallible referencing/correction-tool' enabling dynamic recomposuring projecting-and-reflecting: on-the-one-hand, candoring/prelogism 78 organic-comprehension-thinking ontologising, or on-the-other-hand, decandoring/distractive-alignment-to- ${ }^{83}$ reference-of-thought- $<$ of- 
apriorising/axiomatising/referencing > 30/threshold-of-nonconviction/madeupness/bottomliningin-shallow-supererogation -<as-to-'attendant-intradimensional'-prospectivelydisontologising preconverging/dementing -apriorising-psychologism>, even as intemporalpreservation-entropy-or-contiguity-or-ontological-preservation implies a continuallyevasive/ephemeral social world dynamics but that is graspable in referential terms. This allows for a truly ${ }^{103}$ universal and dynamic psychological science (and sound foundation for grasping the 'veridicality of meaning'). The tools for such an ontological-entrapment is basically about ' de-mentation-〈supererogatory ontological-de-mentation-or-dialectical-de-mentation-

stranding-or-attributive-dialectics $\rangle$ of ${ }^{83}$ reference-of-thought' of registry-worldview/dimensions successive existentialisms/full-depths-of-existential-implications 'transdimensionalmeaningfulness/memetic refinements' as ontological-normalcy/postconvergence-orpostdicatory deconstruction/ontological-reconstituting-as-to-conflatedness ${ }^{13}$ as dialectical transformation as prospective ${ }^{83}$ reference-of-thought involving fundamentally the organic harnessing of the notions of candoring/prelogism ${ }^{78}$, dialectically-or-contendingly-in-phase, organic-comprehension-thinking, prelogism ${ }^{78}$-as-of-conviction,-in-profound-supererogation -

\section{$<$ existentially-veridical-'attendant-intradimensional-apriorising/axiomatising/referencing'-}

logical-dueness-precedes-disontologising-logical-outcome-arrived-at $>$ on-the-one-hand and onthe-other-hand decandoring, distractive-alignment-to- ${ }^{8}$ reference-of-thought- $<$ ofapriorising/axiomatising/referencing $>$ 30, dialectically-or-contendingly-out-of-phase, nonontological-reference, non-contending-reference-but-ontologically-or-contendingly-reflectedor-perspectivated-as-preconverging-or-dementing ${ }^{20}$-apriorising-psychologism, not-veridicalthinking-reference-rather-preconverging-or-dementing ${ }^{20}$-reference, ${ }^{7}$ perversion-of- ${ }^{8}$ referenceof-thought-<as-preconvergingly-apriorising/axiomatising/referencing-in-

nonconviction/madeupness/bottomlining-as-to-shallow-supererogation $>$,-and-not-of-logicalcontention as of threshold-of-nonconviction/madeupness/bottomlining-in-shallow- 
supererogation -<as-to-'attendant-intradimensional'-prospectively-

disontologising preconverging/dementing -apriorising-psychologism> (mechanicalism, alchemic-like-reasoning, circumventive/distractive-temporal-prioritisation-of- ${ }^{8}$ reference-ofthought, shortness-of-register-of- ${ }^{5}$ meaningfulness-and-teleology ${ }^{\circ}$ ); which allows the human mind to project beyond just its illusion-of-the-present/present-consciousness/epistemictalising $\sim$ self-referencing-syncretising/mirage, and truly have a fulsome picture of universals. Postdication (as an abstract and infallible referencing/correction-tool) allows for the 'ontological liberation of human mental-devising-representation (of meaning) from any present \{cumulated/recomposured\}-consciousness-awareness-teleology ${ }^{9}$ (whether in the bigger scheme of reference of specific consciousness-awareness-teleologies like recurrent-utteruninstitutionalisation-base-institutionalisation, ununiversalisation-universalisation, nonpositivism/medievalism-positivism, and prospectively procrypticism-deprocrypticism) as 'postdication doesn't tie the mental-devising-representation process to any of the above registryworldview/dimension habituated \{cumulated/recomposured $\}$-consciousness-awarenessteleology ${ }^{9}$ (given that these consciousness-awareness-teleologies are the recomposured outcome of 'incomplete/incremental/temporal-accommodation human brain limited-mentationcapacity-deepening —as stbjecting limitedness/hmman-subpotency to 'educed-

unlimitedness/existence-sublimating nascence' ${ }^{5}$ ') but 'rather ties the mental-devisingrepresentation process to the abstract and infallible ontological-normalcy/postconvergence ontological-veridicality referencing/correction-tool' (given that this allows for complete/utter understanding by the very nature of the ontological-normalcy/postconvergence notion, of course in an 'abstract and evasive caricature'), hence overcoming the illusion-of-the-present/presentconsciousness inherent in any $\{$ cumulated/recomposured $\}$-consciousness-awareness-teleology representing the mentally devised state of any registry-worldview/dimension. Postdication is all about an ontological-normalcy/postconvergence institutionalisation/intemporalisation- 
constraining for intemporal-preservation-entropy-or-contiguity-or-ontological-preservation as de-mentation-〈supererogatory ontological-de-mentation-or-dialectical-de-mentationstranding-or-attributive-dialectics $\rangle$

totalising ${ }^{3}$ 'hermeneutically/textlly/reprojectingly/supererogatingly/zeroing/y/re aeutingly,${ }_{\{d e c o m p u l s i n g}$ delinearity $\sim$ for-cogency-educing-human- ${ }^{5}$ meaningfulness-and-teleology 9 -intothe-existentialism-becoming of personhoods-and-socialhood-formation (existential-storying-incontiguity). An analogical case in point will be ontological theory-of-relativity or quantummechanics wherein the abstractions go beyond our habitual mental-devising-representation of meaning as in the positivist registry-worldview's/dimension's \{cumulated/recomposured consciousness-awareness-teleology ${ }^{9}$. However, the bigger picture is that if prior/superseded institutional-cumulation/institutional-recomposure-〈as-to- historiality/ontologicaleventfulness /ontological-aesthetic-tracing-<perspective-ontologicalnormalcy/postconvergence-reflected-'epistemicity-relativism-determinism'>> have effectively occurred and so, counterintuitively to their natural \{cumulated/recomposured $\}$-consciousnessawareness-teleologies, as anticipated by postdication right up to our present positivistic institutionalisation/intemporalisation owns \{cumulated/recomposured $\}$-consciousnessawareness-teleology ${ }^{9}$; there isn't any particular ontological reason for intemporal/ontological meaning not to be construed in ontological-normalcy/postconvergence (postdication) as more veridically/ontologically real, beyond and counterintuitively to the positivistic mind's temporal \{cumulated/recomposured\}-consciousness-awareness-teleology (even $^{9}$ if it is unintelligible/existentially-suprastructural to it). Such counter-intuitiveness arises because a prospective transcendental psychoanalytic-unshackling/memetic-reordering/institutionalrecomposuring implied by postdication places the prior psychoanalytic-unshackling/memeticreordering/institutional-recomposuring (in this case positivistic institutionalisation/intemporalisation) existentialism/full-existential-depth-implications 
personhoods-and-socialhood-formation in question/jeopardy. But then it is not reality that caves in, it is the 'mortal' with a renewed psychoanalytic-unshackling/memeticreordering/institutional-recomposuring at its uninstitutionalised-threshold ${ }^{12}$ involving organiccomprehension-thinking (organicalism/'intemporal-prioritisation-of- reference-of-thought'as-conflatedness ${ }^{13}$-or-ontological-reprojectingAlongness-of register-of - meaningfulness-andteleology ) in contrast with threshold-of-nonconviction/madeupness/bottomlining-in-shallowsupererogation -<as-to-'attendant-intradimensional'-prospectivelydisontologising $\sim$ preconverging/dementing -apriorising-psychologism $>$; in transversality- $<$ forsublimating-existential-eventuating/denouement-from-'thinking at-first/pure-predispositionpreemptive-of prospective-disontologising/subontologising' as-of-prospectivelydisambiguated-affirmed-and-unaffirmed-'motif-and-apriorising/axiomatising/referencing'> along 3-pedestals (psychopath's slantedness transversality-<for-sublimating-existentialeventuating/denouement,-from-'thinking at-first/pure-predisposition-preemptive-ofprospective-disontologising/subontologising' as-of-prospectively-disambiguated-affirmedand-unaffirmed-'motif-and-apriorising/axiomatising/referencing'> ${ }^{101}$ pedestal, temporaldispositions $\quad$ transversality- $<$ for-sublimating-existential-eventuating/denouement, - from-

\section{thinking at first/pure predispesition preemptive of prospective}

disontologising/subontologising’ as-of-prospectively-disambiguated-affirmed-andunaffirmed-'motif-and-apriorising/axiomatising/referencing'> ${ }^{101}$ pedestals, and the intemporaldisposition $\quad$ transversality-<for-sublimating-existential-eventuating/denouement,-from-

\section{‘thinking at first/pure-predisposition-preemptive-of-prospective-}

\section{disontologising/subontologising' as-of-prospectively-disambiguated-affirmed-and-}

aetiologisation/ontological-escalation-<ontological-

veridicality_commitment/otherliness_transcending/compulsions-encumbered_transcending $>$ ) 
enabling the preconverging-or-dementing ${ }^{20}$-apriorising-psychologism- $<$ stranded-as-rightfullyoblongated/decandored-and-dialectically-or-contendingly-out-of-phase $>$ of threshold-ofnonconviction/madeupness/bottomlining-in-shallow-supererogation $-<$ as-to-' ${ }^{\circ}$ ttendant-

\section{intradimensional'-prospectively-disontologising preconverging/dementing -apriorising-}

psychologism>. Even if this sounds unintelligible/existentially-suprastructural, in any case a retrospective registry-worldview/dimension is 'existentially-<disontologising/re-ontelogising aporeticism $>$ parochial/narrow-minded as reflected/perspectivated by its threshold-ofnonconviction/madeupness/bottomlining-in-shallow-supererogation $<-<$ as-to-' $a$ attendantintradimensional'-prospectively-disontologising preconverging/dementing -apriorisingpsychologism $>$ denaturing from an organic-comprehension-thinking (organicalism/'intemporal-prioritisation-of- ${ }^{8}$ reference-of-thought'-as-conflatedness ${ }^{13}$-orontological-reprojecting/longness-of register-of meaningfulness-and-teleology )ontologising from the prospective registry-worldview/dimension'. For instance, where a positivist mind might see a forest as a subject of scientific inquiry/understanding, a nonpositivist/medieval mindset $/{ }^{3}$ reference-of-thought might rather see a mentally unconscious man going into the 'evil forest'. Such 'existential parochial perspectives' will arise anyway from procrypticism viewed from deprocrypticism, though of a different nature than the example expressed above. In that sense, the deprocryptic mind might actually seem ridiculous in the procryptic registry-worldview/dimension but 'there should be no temptation to want to appear great or adjust in such a perversion-of- ${ }^{73}$ reference-of-thought-<as-preconverginglyapriorising/axiomatising/referencing-in-nonconviction/madeupness/bottomlining-as-toshallow-supererogation $>$ perspective but rather to make it irrelevant' otherwise the deprocryptic mind compromises the essence of its purpose, just as a positivistic mind going by the 'evil forest' comparison 'cannot afford to compromise its positivist stance' by trying 'to be wonderful' in a non-positivism/medievalism perspective that is rather 'in want of transcendence- 
and-sublimity/sublimation/supererogatory-de-mentativity'; as it is exactly because the temporal non-positivism/medievalism reference is defective that it is being transcended. This speaks to the specificity of the would-be intellectualism involved in a transcendental construct, as different from just intellectualism as mere-institutionalised-being-and-craft; it carries the element of knowledge not only as an abstract intradimensional conceptual construct but in its fullness with existential-<disontologising/re-ontologising aporeticism $>$ implications and insights of the dialecticism and psychoanalytic-reorientations involved in all transcendence-andsublimity/sublimation/supererogatory de-mentativity, requiring that such an intellectual analyst be of ' 7 presencing - absolutising-identitive-constitutedness ${ }^{14}$ consummated/forfeiting posture' in $\quad$ transversality-<for-sublimating-existential-eventuating/denouement,-from-'thinking-at-

\section{first/pure-predisposition-preemptive-of-prospective-disontologising/subontologising' as-of-}

\section{prospectively-disambiguated-affirmed-and-unaffirmed-'motif-and-}

apriorising/axiomatising/referencing'> $>$ with temporal meaningful frames which do not define and are not a point-of-reference to intemporal/ontological meaningfulness' with the registryworldview/dimension in need of transcendence-and-sublimity/sublimation/supereregatory $\sim$ dementativity (procrypticism) to avoid dividing its meaningful-referencing instead of taking it prospectively (deprocrypticism), for instance, medieval intellectuals like Galileo and Rousseau have to be of " presencing-absolutising-identitive-constitutedness ${ }^{14}$ consummated/forfeiting posture' in transversality-<for-sublimating-existential-eventuating/denouement-from-

\section{thinking-at-first/pure-predisposition-preemptive-of-prospective-}

\section{disontologising/subontologising’ as-of-prospectively-disambiguated-affirmed-and-}

unaffirmed-'motif-and-apriorising/axiomatising/referencing'> ${ }^{101}$ with temporal meaningful frames which do not define and are not a point-of-reference to intemporal/ontological meaningfulness' with the medieval registry-worldview to generate prospective positivistic registry-worldview which at their time is not intelligible to a medieval take (categorical- 
imperatives/axioms/registry-teleology ${ }^{9}$-for-intemporal-preservation-entropy-or-contiguity-orontological-preservation) on meaningfulness! This can be further expanded on as follows. The intradimensional meaningful frame is an 'abstraction to the preconverging/postconverging-dementative/structural/paradigmatic conceptual limits (uninstitutionalised-threshold ${ }^{102}$ ) of the reference-of-thought- categorical-imperatives/axioms/registry-teleology ${ }^{99}$,-for-intemporalpreservation-entropy-or-contiguity-or-ontological-preservation of that registryworldview/dimension, which do not supersede/precede/override/undermine intrinsicreality/ontology; and the issue that then arises is that it doesn't carries the meaningfulness sought for transcendentally. On-the-other-hand, transdimensional/transcendental ${ }^{56}$ meaningfulnessand-teleology is precedingness/supersedingness/ascendency accruing as 'existential psychoanalytic ontological form (in full blossoming of the transcending dimension)' beyond the superseded intradimensional preconverging-de-mentating/structuring/paradigming conception limits (uninstitutionalised-threshold ${ }^{102}$ ) of the ${ }^{83}$ reference-of-thought- categoricalimperatives/axioms/registry-teleology ${ }^{9}$,-for-intemporal-preservation-entropy-or-contiguityor-ontological-preservation of that registry-worldview/dimension (which itself had been the outcome of a preceding existential-<disontologising/re-ontologising aporeticism $>$ psychoanalytic ontological form). Memetism as to suprastructural ${ }^{56}$ meaningfulness-andteleology ${ }^{9}$ will refer to the projective conceptualisation of ${ }^{56}$ meaningfulness-and-teleology beyond and superseding an intradimensional registry-worldview abstraction scope to the scope of transdimensional/transcendental existential-<disontologising/re-ontologising aporeticism $>$ psychoanalytic ontological form (in full blossoming of the transcending dimension with its existentialism/full-existential-depth-implications personhoods-and-socialhood-formation); highlighting as ontologically wrong any relation to intradimensional meaningfulness as (intemporally/ontologically)-sanctuous-by-reflex (as this wrongly undermines the ${ }^{15} \mathrm{de}-$ mentation-〈supererogatory ontological-de-mentation-or-dialectical-de-mentation — stranding- 
or-attributive-dialectics $\rangle$ of temporal-dispositions-postlogic-backtracking-<iterative-looping'set-of-dereifying-hollow-narratives-and-acts'> $>$-subknowledging 14 mimicking-set-of-

narratives, and wrongly leads to their <amplituding/formative-epistemicity $>$ totalising $\sim$ selfreferencing-syncretising-as-straight/candored)' at that registry-worldview's/dimension's uninstitutionalised-threshold ${ }^{102}$ requiring prospective memetic-reordering. (As a side note, this will explain while 'referentialism' in contrast to 'categorisation' is the appropriate knowledgecadre for such a more or less deconstructive articulation in ontologicalnormalcy/postconvergence and suprastructural, as is the case herein, as to the requisite 'habituation-into and repeatability-from-different-textual-meaningfulness-perspectives' that is necessary to get-to-and-grasp not only an explanation but critically as well the requisite psychoanalytic-state of a construed existential-<disontologising/re-ontologising aporeticism $>$ psychoanalytic ontological form, in full blossoming of the transcending dimension, as ontological meaningfulness.) Finally, it is just a matter of fact going by the institutionalcumulation/institutional-recomposure-〈as-to- historiality/ontologicaleventfulness /ontological-aesthetic-tracing-<perspective-ontologicalnormalcy/postconvergence-reflected-'epistemicity-relativism-determinism' $>>$ process that human cross-sectional mentation-capacity in relation to the intemporal-preservation-entropy-orcontiguity-or-ontological-preservation is limited given ${ }^{74}$ perversion-of- ${ }^{3}$ reference-of-thought$<$ as-preconvergingly-apriorising/axiomatising/referencing-innonconviction/madeupness/bottomlining-as-to-shallow-supererogation $>$, as virtue is rather extended by successive re-institutionalisation in transversality-<for-sublimating-existentialeventuating/denouement,-from-'thinking at-first/pure-predisposition-preemptive-ofprospective-disontologising/subontologising' as-of-prospectively-disambiguated-affirmedand-unaffirmed-'motif-and-apriorising/axiomatising/referencing'> ${ }^{101}$ (not nested-congruence) by the intemporal-disposition intemporalisation skewing ('intemporality ${ }^{52}$-symmetrising-by- 
desymmetrising-subsumption-of-temporality ${ }^{8}$, , for relative intrinsic-reality/ontologicalveridicality transcendental-enabling/sublimating/supererogatory de-mentativity) as deferentialformalisation-transference, going from base-institutionalisation, ${ }^{103}$ universalisation, positivism and prospectively deprocrypticism. Such a 'postconvergence referentialism' skewed ('intemporality ${ }^{52}$-symmetrising-by-desymmetrising-subsumption-of-temporality ${ }^{\circ}$, for relative intrinsic-reality/ontological-veridicality transcendentalenabling/sublimating/supereregatery $\sim$ de-mentativity) hermeneutic-circle goes beyond a traditional hermeneutics exercise of subjective interpretation and rather arrives at an exercise in ' ${ }^{103}$ universal objective (<amplituding/formative-epistemicity $>$ causality $\sim$ as-to-projectivetotalitative-implications-of-prospective- nonpresencing,-for-explicating relativeunreflexivity/relative-reflexivity ontological-contiguity ) ontological explanation' as it emphasises transversally/incongruently the 'recomposuring precedingness/supersedingness/ascendency of abstract ontological-normalcy/postconvergence referentialism notion of reality' in referencing meaningfulness apriorising-registry (whether candored / integratively-aligned / straightness / dialectically-or-contendingly-in-phase or decandored / transversality- $<$ for-sublimating-existential-eventuating/denouement, - from-

\section{thinking at first/pure predisposition preemptive of prospective}

disontologising/subontologising’ as-of-prospectively-disambiguated-affirmed-and-

unaffirmed-‘motif-and-apriorising/axiomatising/referencing'> ${ }^{101} \quad / \quad$ dialectically-or-

contendingly-out-of-phase colour/emotion/temporal-frame/aesthetics/memetics/psychicalrepresentation), and so, as coming from an intemporal-disposition/ontological skewed ('intemporality ${ }^{52}$-symmetrising-by-desymmetrising-subsumption-of-temporality ${ }^{8}$ ', for relative intrinsic-reality/ontological-veridicality transcendentalenabling/sublimating/supererogatory $\sim$ de-mentativity) point-of-referencing. It further holds a promise that goes beyond our notions of ${ }^{83}$ reference-of-thought and meaningfulness (as rather 
intradimensional or a registry-worldview constructs), and arrives at the grander notion of apriorising/axiomatising/referencing/intelligibilitysettingup/measuringinstrumenting which grasp should enable greater human transcendental possibilities. Of course, ontologically (i.e. 'the-Good/understanding' contrasted with 'good-natured/impression-driven') the bigger issue is how do our development and institutionalisation/intemporalisation of true knowledge 'save us from potent-temporality ${ }^{8}$ and its vices-and-impediments ${ }^{105}$ with respect to 'socially-perceivedvalue as of social-stake-contention-or-confliction', rather than how do we over-idealise ourselves and thus fail to be preemptive (as the 'human cross-sectional mental equilibrium disposition', at any successive transcendence-and-sublimity/sublimation/supereregatory $\sim$ dementativity/institutionalisation in the 'human essential notional firstnaturedness-formativeness<as-to-eventualising inkling drive-or-seeding misprising $>$-temporal-to-intemporaldispositions-<so-construed-as-from-perspective-ontological-normalcy/postconvergence $>$ equilibrium nature which is ontologically true', under-accounts for ' temporal-nature which is not ontologically true', and over-accounts for ' intemporality ${ }^{52 / 10 n g n e s s ~ n a t u r e ~ w h i c h ~ i s ~ e q u a l l y ~}$ not ontologically true' -the insight for this is that institutionalisation/intemporalisation is a psychoanalytic-unshackling/memetic-reordering/institutional-recomposuring tool, it doesn't transform temporal-dispositions which is the exclusive purview of individual sense of dimensionality-of-sublimating 5 - $<<$ amplituding/formative $>$ supererogatory $\sim$ de-

\section{mentativeness/epistemic-growth-or-conflatedness /transvaluative-}

rationalising/transepistemicity/anamnestic-residuality/spirit-drivenness-equalisation $\rangle$ and by its very nature is 'beyond a philosophical transformation exercise' as the latter exercise is mainly to 'construct articulations for secondnaturing' at best (articulate new institutionalisation/intemporalisation deterministic-and-operant possibilities for skewing ('intemporality ${ }^{52}$-symmetrising-by-desymmetrising-subsumption-of-temporality ${ }^{8}$, for relative intrinsic-reality/ontological-veridicality transcendental- 
enabling/sublimating/supererogatory $\sim$ de-mentativity)/deferential-formalisation-transference towards intemporal-preservation-entropy-or-contiguity-or-ontological-preservation), hence the need to refer analytically to human notional firstnaturedness-formativeness-<as-toeventualising inkling-drive-or-seeding-misprising $>$ temporal-to-intemporal-dispositions$<$ so-construed-as-from-perspective-ontological-normalcy/postconvergence $>\mathrm{s}$ as of the circularity/recurrence/repetition/repeatability ${ }^{10}$ delineating existential-transitioning-oriterability-trace-of-narratives-as-dots_or_implicited_attendant-ontologicalcontiguity ${ }^{6}$, educedexistentialising/contextualising/textualising_'intelligibility/epistemicity/reflexivity-contiguity$<$ imbued-notional cogency>' -reification_or_intrinsic-reality-ontologicalcoherence_or_superseding-oneness-of-ontology ${ }^{41}$ by $\quad{ }^{55}$ maximalising-recomposuring-forrelative-ontological-completeness ${ }^{87}$ - unenframed/re-ontologising $\sim$ conceptualisation highlighting the uninstitutionalised-threshold ${ }^{102}$ and not analytically implying by reflex solely on the basis of a human intemporal-disposition mental-disposition); and prospectively, do our part of the 'transcendental homework' that has brought the human species this far taking cue from retrospective transcendence-and-sublimity/sublimation/supereregatory $\sim$ de-mentativity. By extension this explains how the notion of 'knowledge problem' is to be apprehended transcendentally/transdimensionally/interdimensionally (as a contiguous intemporal ontological construct). Commonly, intradimensionally, the knowledge problem as 'social problem/questioning' is an 'intradimensional focus' around logical operation/processing/contention based on the ${ }^{83}$ reference-of-thought- categoricalimperatives/axioms/registry-teleology ${ }^{9}$,-for-intemporal-preservation-entropy-or-contiguityor-ontological-preservation of the registry-worldview/dimension 'towards resolution', with the temporal defect of possible denaturing of such ${ }^{83}$ reference-of-thought- categoricalimperatives/axioms/registry-teleology ${ }^{9}$,-for-intemporal-preservation-entropy-or-contiguity- 
or-ontological-preservation undermining the intemporal-preservation-entropy-or-contiguityor-ontological-preservation. However, ontological-normalcy/postconvergence (preceding/superseding intrinsic reality) insight points to a depth-of-focus of the knowledge problem as 'social problem/questioning' on the 'intemporal-preservation-entropy' itself-andbeyond-any-set- categorical-imperatives/axioms/registry-teleology ${ }^{9}$-implying-it (and by extension accounting for incompleteness of human mental/brain mentation-capacity which is the reason of the institutional-cumulation/institutional-recomposure-〈as-tohistoriality/ontological-eventfulness /ontological-aesthetic-tracing-<perspectiveontological-normalcy/postconvergence-reflected-‘epistemicity-relativism-determinism’>> process) to define 'social problem/questioning' as implying a ${ }^{83}$ reference-of-thoughtcategorical-imperatives/axioms/registry-teleology ${ }^{9}$,-for-intemporal-preservation-entropy-orcontiguity-or-ontological-preservation recomposuring/memetic-reordering/psychoanalyticunshackling to enable intemporal-preservation-entropy-or-contiguity-or-ontologicalpreservation when at the uninstitutionalised-threshold ${ }^{102}$ of the registry-worldview/dimension (the contiguous referential exercise of recomposuring/memetic-reordering/psychoanalyticunshackling to perpetually enable intemporal-preservation-entropy-or-contiguity-orontological-preservation is known as 'postdication', a term that is in contrast with 'predication' which is based on 'constitutive categorisation elaboration on an intradimensionally affixed reference-of-thought- categorical-imperatives/axioms/registry-teleology $99 \quad$ whereas postdication refers to a transcendentally/transdimensionally/interdimensionally/across-allinstitutional-cumulation/institutional-recomposure-〈as-to- historiality/ontologicaleventfulness /ontological-aesthetic-tracing-<perspective-ontologicalnormalcy/postconvergence-reflected-‘epistemicity-relativism-determinism’>> entropy as ontological-normalcy/postconvergence recomposuring/memetic-reordering/psychoanalytic-

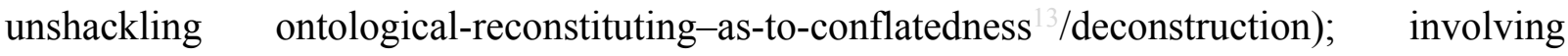


avoiding making an intemporal-disposition representation (with the implication of a purely logical operation/processing/contention) instead of a notional firstnaturedness-formativeness$<$ as-to-eventualising inkling-drive-or-seeding misprising $>$ temporal-to-intemporaldispositions-<so-construed-as-from-perspective-ontological-normalcy/postconvergence $>$ representation (with the implication of notional firstnaturedness-formativeness-<as-toeventualising-inkling-drive or seeding-misprising> temporal-to-intemporal-dispositions$<$ so-construed-as-from-perspective-ontological-normalcy/postconvergence $>$ disambiguation before logical operation/processing/contention; as apriorising-registry disambiguation, into the intemporal-disposition and conjugating temporal-dispositions as of ignorance/affordability/opportunism/exacerbation/social-chainism-or-social-discomfiture-ornegative-social-aggregation/temporal-enculturation-or-temporal-endemisation, allowing for contextualisation in articulating the contrast of the intemporal-disposition's organiccomprehension-thinking (organicalism/'intemporal-prioritisation-of- reference-of-thought'as-conflatedness ${ }^{13}$-or-ontological-reprojectingAlongness-of-register-of- meaningfulness-andteleology ) and temporal-dispositions threshold-of-nonconviction/madeupness/bottomliningin-shallow-supererogation -<as-to-'attendant-intradimensional'-prospectivelydisontologising $\sim$ preconverging/dementing -apriorising-psychologism $>$-involving slanting by psychopath, miscuing, disjointed-logic, logical-drag, unconscionability-drag, and sub-par-orformulaic-association-or-temporal-or-alibi conventioning-rationalising -with temporaldispositions in varied shades of temporal conjugation/inflection to psychopathic postlogism 77 in hollow-constituting-<as-disjointed-misappropriation-of-meaningfulness-and-failingintemporal-preservation $>$ as <amplituding/formative-epistemicity $>$ causality $\sim$ as-to-projectivetotalitative-implications-of-prospective- nonpresencing,-for-explicating relative unreflexivity/relative-reflexivity ontological-contiguity dispositions; thus enabling the stifling (undermining the ontological-veridicality) of temporal-dispositions and skewing 
('intemporality ${ }^{52}$-symmetrising-by-desymmetrising-subsumption-of-temporality ${ }^{8}$, for relative intrinsic-reality/ontological-veridicality transcendentalenabling/sublimating/supererogatory $r$ de-mentativity), by way of institutionalisation/intemporalisation percolation-channelling- $<$ in-deferential-formalisationtransference>, towards the supersedingness of the intemporal-disposition for institutionalisation's/intemporalisation's intemporal-preservation-entropy-or-contiguity-orontological-preservation). Thus the ontological veridicality of the registryworldview's/dimension's perversion-of- ${ }^{8}$ reference-of-thought-<as-preconverginglyapriorising/axiomatising/referencing-in-nonconviction/madeupness/bottomlining-as-toshallow-supererogation $>$ at it uninstitutionalised-threshold ${ }^{102}$ is articulated, with contention then being about reflecting/perspectivating/highlighting and aetiologising/ontologising this, even if it is intradimensionally unintelligible/existentially-suprastructural and unpalatable (consider in this regard, the development of positivism from non-positivism/medievalism). It should be noted then that the postconverging-de-mentating/structuring/paradigming is an intemporal/ontological projection referencing beyond-and-non-implicative of an equivalence between ('intemporal-prioritisation-of- ${ }^{8}$ reference-of-thought'-as-conflatedness ${ }^{13}$-orontological-reprojecting pedestalling) with the intradimensional 'consciousness-awareness frame-of-social-stake-contention-or-confliction' of the temporal/preconverging-ordementing -apriorising-psychologism dimension, more like the positivist ontological biology and medicine postconverging-de-mentating/structuring/paradigming is beyond/supersedes-andis-a-non-implication of an equivalence with the 'consciousness-awareness frame-of-socialstake-contention-or-confliction' of say non-positivism/medievalism temporal value dispositions with respect to the notion of disease, that is, it's point is to define an altogether different and superseding meaningful frame or postconverging-de-mentating/structuring/paradigming and is not involved in an idle exercise of elevating and articulating its meaning in terms-as-of- 
axiomatic-construct of and implying an equivalence with non-positivism/medievalism meaningfulness. That is equally the relation between a transcending notional deprocrypticism registry-worldview and the transcended procrypticism worldview. Postdication as intemporalpreservation-entropy-or-contiguity-or-ontological-preservation (postconvergence), as an ontological-reconstituting-as-to-conflatedness ${ }^{13}$ psychoanalytically/memetically/meaningfully allows for a purist (candored/decandored) ontological grasp/predication of the veridicality of any institutional-cumulation/institutional-recomposure-〈as-to- historiality/ontologicaleventfulness /ontological-aesthetic-tracing-<perspective-ontologicalnormalcy/postconvergence-reflected-'epistemicity-relativism-determinism'>> (retrospectively to prospectively); avoiding the defect of intradimensional-referencing of ${ }^{83}$ reference-of-thoughtcategorical-imperatives/axioms/registry-teleology ${ }^{9}$,-for-intemporal-preservation-entropy-orcontiguity-or-ontological-preservation and consequently a superseded/transcended registry/registry-worldview-or-dimension as preconverging-or-dementing ${ }^{20}$-apriorisingpsychologism- $<$ stranded-as-rightfully-oblongated/decandored-and-dialectically-orcontendingly-out-of-phase $>$ undermining ontological veridicality. This transcendental insight is in line with the idea of low teleologies or temporal concerns in threshold-ofnonconviction/madeupness/bottomlining-in-shallow-supererogation $<-<$ as-to- 'attendant-

\section{intradimensional'-prospectively-disontologising preconverging/dementing -apriorising-}

psychologism>, and ontologically short in a temporal 80-to-90-years-of-life-mental-project, and higher teleologies or intemporal/transcendental concerns in organic-comprehension-thinking (organicalism/“intemporal-prioritisation-of- ${ }^{8}$ reference-of-thought'-as-conflatedness ${ }^{13}$-orontological-reprojecting/longness-of-register-of meaningfulness-and-teleology $\left.{ }^{9}\right), \quad$ and ontologically long in an intemporal/species-possibilities/abstract-eternality-of-being-mentalprojection/eudaemonic-contemplation), and their corresponding abstract individuation aetiologies (even though in effect individuals as 'receptacles of specific individuation 
aetiologies' cannot realistically be construed as absolutely tied to low or higher teleologies but rather as tending to accrue towards a specific-individuation-aetiology/characteral-disposition whether of low or higher teleology ; hence any such 'storied/articulated' absolutely specificindividuation-aetiologies are caricatural of the realistic nature of individuals as 'receptacles of individuation aetiologies', though all such storied/narrated specific individuation aetiologies represent the full possibilities of any and all individuals 'as receptacles of individuation aetiologies'). By 'higher teleologies' is meant 'existential disposition' which is 'in essence intemporally preserving solipsistically/emanantly/becomingly' (and so, by a profoundsupererogation disposition that is beyond just one institutionalised/intemporalised registryworldview/dimension $\quad$ reference-of-thought- categorical-imperatives/axioms/registryteleology but abstractly and supererogatorily across all transcendental retrospective-andprospective institutionalisation/intemporalisation registry-worldviews/dimensions as soreflected by dimensionality-of-sublimating ${ }^{25}$-<<amplituding/formative $>$ supererogatory $\sim$ dementativeness/epistemic-growth-or-conflatedness /transvaluative-

rationalising/transepistemicity/anamnestic-residuality/spirit-drivenness-equalisation)); with the implication that the highest teleologies of Base-institutionalisation (as percolation-channelling$<$ in-deferential-formalisation-transference $>\quad$ undermining of recurrent-utteruninstitutionalisation and its vices-and-impediments ${ }^{105}$ ) -equivocates as of profoundsupererogation to the highest teleologies of ${ }^{103}$ universalisation (as percolation-channelling- $<$ indeferential-formalisation-transference $>$ undermining of ununiversalisation and its vices-andimpediments ${ }^{105}$ ) -equivocates as of profound-supererogation to the highest teleologies of Positivism (as percolation-channelling- $<$ in-deferential-formalisation-transference $>$ undermining of non-positivism/medievalism and its vices-and-impediments ${ }^{105}$ ) -and prospectively, equivocates as of profound-supererogation to the highest teleologies of notional ${ }^{18}$ deprocrypticism (as percolation-channelling- $<$ in-deferential-formalisation- 
transference $>$ undermining of ${ }^{80}$ procrypticism-or-disjointedness-as-of- ${ }^{8}$ reference-of-thought and its vices-and-impediments ${ }^{105}$ ). It should thus be noted as such that 'higher teleologies' are 'equivalences of existential' (in terms-as-of-axiomatic-construct of notional firstnaturednessformativeness-<as-to-eventualising-inkling-drive-or-seeding-misprising $>$ temporal-tointemporal-dispositions- $<$ so-construed-as-from-perspective-ontologicalnormalcy/postconvergence $>$ ), and not equivalences of institutionalisation/intemporalisation levels. That is, being in a transcended institutionalised/intemporalised registryworldview/dimension (internalisation and formalisation induced as a secondnature) doesn't equivocate as highest teleologies to the existential-disontologising/re-ontologising apereticism $>$ projection that 'had the vision' in the prior/superseded subknowledging 94 mimicking/untranscended registry-worldview/dimension ('with-no-elicitedpositive-opportunism - of-social-functioning-and-accordance $7 /$ much-more-likely-temporalnegative-disincentive' and 'out-of-the-blue') to articulate-and-uphold-for-percolationchannelling- $<$ in-deferential-formalisation-transference $>$ the prospect of the transcendedregistry-worldview/dimension-with-its-prospective-- ${ }^{103}$ universal-virtue-over-the-vices-andimpediments ${ }^{105}$-of-the-prior-registry-worldview/dimension even as it seem unintelligible/existentially-suprastructural to the prior/superseded untranscended/preconverging-or-dementing -apriorising-psychologism registryworldview/dimension. So in terms-as-of-axiomatic-construct of 'higher teleologies' (emphasising the existential-<disontologising/re-ontologising aporeticism $>$ intemporaldisposition as a seed-of-virtue over institutionalisation/intemporalisation outcome, which the former enables) being in an institutionalised/intemporalised positivistic world doesn't necessarily equivocate us to the Galileos, Descarteses, Newtons, Leibnizes, Rousseaux, Darwins ... behind the articulation-and-upholding-for-percolation-channelling- $<$ in-deferentialformalisation-transference $>$ of a positivistic registry-worldview/dimension (even though 
together with them we all may recognise and operate within a positivistic world). That is, the 'existential profound-supererogating that enables the articulation-and-upholding-forpercolation-channelling- $<$ in-deferential-formalisation-transference $>$ of a transcending registryworldview/dimension as to dimensionality-of-sublimating <<amplituding/formative>supererogatory $\sim$ de-mentativeness/epistemic-growth-or-

\section{conflatedness /transvaluative-rationalising/transepistemicity/anamnestic-residuality/spirit-}

drivenness-equalisation)' is the higher teleology 9 'over the mere-institutionalised-being-andcraft' in such a transcended registry-worldview/dimension. And why is this distinction critical? Because prospective (intemporality ${ }^{52}$ ) need for prospective institutionalisation/intemporalisation/transcendence for intemporal-preservation-entropy-orcontiguity-or-ontological-preservation necessarily calls upon the (intemporal)-kind that articulated-and-upheld-for-percolation-channelling-<in-deferential-formalisation-transference $>$ the superseding institutionalisation/intemporalisation/transcendence; and the condition of mereinstitutionalised-being-and-craft in the untranscended registry-worldview/dimension doesn't speak of a disposition to prospectively articulate-and-uphold-for-percolation-channelling- $<$ indeferential-formalisation-transference $>$ an intemporally requisite prospective registryworldview/dimension institutionalisation/intemporalisation that is intemporally preserving (in ontological-normalcy/postconvergence), highlighting the veridicality and need for 'human registries-disambiguation at uninstitutionalised-threshold ${ }^{102}$, and as being notional firstnaturedness-formativeness-<as-to-eventualising inkling drive-or-seeding misprising $>$ temporal-to-intemporal-dispositions- $<$ so-construed-as-from-perspectiveontological-normalcy/postconvergence $>$. The notion of higher teleologies as such is specific to the human species in holding that beyond just a 'physical animal passing of specie generational succession' for survival and optimising-specie-flourishing, with higher teleologies there is an 'even more critical passing of generational succession' as memetic-skewing-or-reordering/philo- 
cultural optimising of possibilities of the species towards intemporal virtue as civilisational over temporal vices-and-impediments ${ }^{105}$ (philo-cultural and not cultural, because philosophy notionally supersedes and defines cultural possibilities); and so, by virtue of the exceptional possibility, in time and space, of human transformation/transcendence by philo-cultural skewing ('intemporality ${ }^{52}$-symmetrising-by-desymmetrising-subsumption-of-temporality ${ }^{8}$, for relative intrinsic-reality/ontological-veridicality transcendentalenabling/sublimating/supereregatery $\sim$ de-mentativity)/memetic-reordering with respect to the base physical animal selectivity process (genetics) of the human species generational succession. On other issues of pertinence in-the-bigger-scheme-of-things: (i) Meaningfulness of notional firstnaturedness-formativeness-<as-to-eventualising inkling-drive-or-seedingmisprising $>$ temporal-to-intemporal-dispositions- $<$ so-construed-as-from-perspectiveontological-normalcy/postconvergence $>$ as to 'existential idealism/success' as these define mental orientations or registry-worldview teleological-dispositions. Going by the human 'institutional-cumulation/institutional-recomposure-〈as-to- historiality/ontologicaleventfulness /ontological-aesthetic-tracing-<perspective-ontologicalnormalcy/postconvergence-reflected-‘epistemicity-relativism-determinism'>〉' process involving variously candored/straightness/prelogism ${ }^{78}$ and decandored/oblongated/distractivealignment-to- ${ }^{8}$ reference-of-thought- $<$ of-apriorising/axiomatising/referencing $>30 \quad$ mentaldevising-representation of registry-worldviews/dimensions dependent on which registryworldview is considered perversion-of- ${ }^{7}$ reference-of-thought- $<$ as-preconverginglyapriorising/axiomatising/referencing-in-nonconviction/madeupness/bottomlining-as-toshallow-supererogation > or transcendental/superseding; in any given registry-worldview's social context, the notion of 'existential idealism/success' is averagely viewed invariably as 'living to the 'opportunistic ideals or conventioning/social-temporal-thresholding' of the

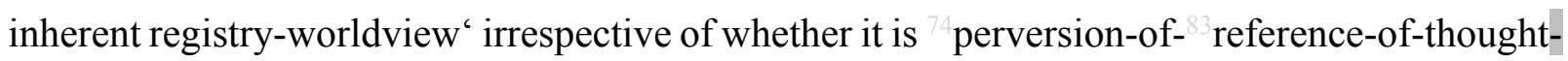




\section{$<$ as-preconvergingly-apriorising/axiomatising/referencing-in-}

transcending/superseding, and not necessarily by its veracity/ontological-pertinence. But then given that what allows for the institutional-cumulation/institutional-recomposure-〈as-tohistoriality/ontological-eventfulness /ontological-aesthetic-tracing-<perspectiveontological-normalcy/postconvergence-reflected-‘epistemicity-relativism-determinism’ $>>$ process transcendence-and-sublimity/sublimation/supererogatory de-mentativity to take us from an uninstitutionalised animal to now a positivistic one and prospectively a deprocryptic one; it is difficult to contemplate 'existential success/idealism' from a knowledge/ontological perspective (in contrast to a temporal <amplituding/formative $>$ wooden-language-〈imbuedaveraging-of-thought-<as-to-leveling/ressentiment/closed-construct-of- meaningfulness-andteleology -as-of-'nondescript/ignorable-void '-with-regards-to-prospective-apriorisingimplications $>>$ perspective) without identifying that intemporal-disposition in contrast to temporal mental-dispositions is what is 'truly existential-disengenging aporeticism $>$ success' as the intemporal-disposition is very much what allows for human transcendence-and-sublimity/sublimation/supererogatory $\sim$ de-mentativity and subsequent institutionalisation/intemporalisation, much as the distilling process allows for the lightness of hydrocarbons, 'where lightness is virtue'. Basically, it can be said that without the human quality of the 'aetiologisation/ontological-escalation- $<$ ontologicalveridicality_commitment/otherliness_transcending/compulsions-encumbered_transcending > individuation of the intemporal' we'll still be probably in caves. Of course, such a depth-andprojecting-scale-of-thought requires an appreciation of the 'percolative impact' of the 'firstnature/intemporal' (which is not readily available to the immediacy/shortness-of-registerof meaningfulness-and-teleology of minds of temporal-dispositions). For instance, men did not 'by magic' develop the possibilities of civilisations whether the stone, bronze, copper, iron 
ages, the antiquities, the medieval and today modern positivism; without a corresponding 'psychoanalytic liberation' that allowed for such a development induced by philosophical revolution, however, prosaic the philosophy. For instance, it is not by magic that science and vaccines were not developed in antiquities but were developed in early industrial Europe, as the 'psychoanalytic liberation' of the ideas expressed by the Descartes and Galileos 'shaped subsequent common minds' to be inclined to rationalise profoundly their grasp of physical phenomena like Pasteur and others. Likewise, the philosophical development in antiquities not being 'profoundly applicative enough' and more or less cultic (available more or less to a priestly class and poorly ${ }^{103}$ universalising in many such slaving-and-class society), such a psychoanalytic liberation percolation-channelling- $<$ in-deferential-formalisation-transference $>$ effect could hardly be obtained from say Aristotle's writings (granted, it percolated into the medieval Arabic and European worlds), and in addition the 'intellectualism' was more like contained in a 'cultic class', and hardly the bread and butter of commoners (and even then, Athens was outlying without scale and time and the sufficient lack of chaos and war). As the establishment of a registry-worldview's/dimension's

'(re-originary-as-unenframed/reontologising/unbeholdening/outlier-conceptualisation-_imbued-postconverging/dialecticalthinking -'projective-insights'/‘epistemic-projection-in-conflatedness ' 'ofnotional deprocrypticism-prospective-sublimation $\rangle^{\circ}$ ) originary/event ${ }^{38}$-of-prospectiveontology-origination psyche rule of intrinsic-reality/ontological-veridicality transcendentalenabling/sublimating/supereregatery $\sim$ de-mentativity as of the notional phenomenalabstractiveness-of-presencing-

apriorising/axiomatising/referencing/intelligibilitysettingup/measuringinstrumenting-foroperant-or-incidenting-predicative-insights-of 'implicited_attendant-ontologicalcontiguity ${ }^{67} \sim$ educedexistentialising/contextualising/textualising_'intelligibility/epistemicity/reflexivity-contiguity- 
$<$ imbued-notional $\sim$ cogency $>,{ }^{\prime},-<$ reifying-or-elucidating-of-prospective-relative-ontologicalcompleteness -of- reference-of-thought- devolving-as-of-instantiative-context>

conceptualisation' is what allows for human individual and collective orienteering-focussingpersisting of construal/conceptualisation by that transcendentalenabling/sublimating/supererogatory de-mentativity

(re-originary-_as-unenframed/reontologising/unbeholdening/outlier-conceptualisation__imbued-postconverging/dialecticalthinking -'projective-insights’/‘epistemic-projection-in-conflatedness '-ofnotional deprocrypticism-prospective-sublimation $\rangle^{\circ}$ ) originary/event ${ }^{38}$-of-prospectiveontology-origination psyche rule to the full exhaustion of what intrinsic-reality/ontological veridicality can avail to humankind as of 'prospective postconverging-apereticismovercoming/unovercoming as the-Good/knowledge-reification $\sim$ gesturing-and-accounting-ofepistemic-phenomenalism- $<$ in-

prospective_psychologismic apriorising/axiomatising/referencing-\{of-"prospectively implicited_attendant-ontological-contiguity ' educedexistentialising/contextualising/textualising_'intelligibility/epistemicity/reflexivity-contiguity<imbued-notional cogency $\left.>^{\prime} \quad\right\}$-conflatedness -in-\{preconverging-disentailment by\} postconverging-entailment $>$ /understanding/<amplituding/formativeepistemicity $>$ causality $\sim$ as-to-projective-totalitative-implications-of-prospectivenonpresencing,-for-explicating relative-unreflexivity/relative-reflexivity - ontologicalcontiguity ${ }^{,}$in construing ${ }^{56}$ meaningfulness-and-teleology ${ }^{9}$ for the prospective institutionalisation; and so, until humankind is dissatisfied of this finitude and aspires as of ontological-faith-notion-or-ontological-fideism - imbued-underdetermination-of-motif-andapriorising/axiomatising/referencing-as-so-being-as-of-existential-reality as of beyond-theconsciousness-awareness-teleology ${ }^{-}<$of-preconverging-existential-extrication-as-ofexistential-unthought $>$ for a new/prospective elevating registry-worldview's/dimension's 
prospective relative-ontological-completeness ${ }^{87}$-of- ${ }^{83}$ eference-of-thought '(re-originary-asunenframed/re-ontologising/unbeholdening/outlier-conceptualisation-_iimbuedpostconverging/dialectical-thinking -'projective-insights'/'epistemic-projection-inconflatedness ' -of-notional deprocrypticism-prospective-sublimation $\rangle^{0}$ ) originary/event $^{38}$ of-prospective-ontology-origination psyche rule of intrinsic-reality/ontological-veridicality transcendental-enabling/sublimating/supererogatory de-mentativity as of the notional $\sim$ phenomenal-abstractiveness-of-presencingapriorising/axiomatising/referencing/intelligibilitysettingup/measuringinstrumenting-foroperant-or-incidenting-predicative-insights-of 'implicited_attendant-ontologicalcontiguity $^{67}$, educedexistentialising/contextualising/textualising_'intelligibility/epistemicity/reflexivity-contiguity$<$ imbued-notional $\sim$ cogency $>,,-<$ reifying-or-elucidating-of-prospective-relative-ontologicalcompleteness -of- reference-of-thought- devolving-as-of-instantiative-context $>$ conceptualisation'. Being at the backend in reflecting holographically-<conjugatively-andtransfusively $>$ the relative-unreflexivity/relative-reflexivity ontological-contiguity of-thehuman-institutionalisation-process, it will be naïve to contend that the transcendentalenabling/sublimating/supererogatory de-mentativity

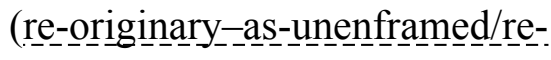
ontologising/unbeholdening/outlier-conceptualisation__imbued-postconverging/dialecticalthinking -'projective-insights'/'epistemic-projection-in-conflatedness ' '-ofnotional deprocrypticism-prospective-sublimation $\rangle^{\circ}$ ) originary/event ${ }^{38}$-of-prospectiveontology-origination psyche rule of our positivism- ${ }^{80}$ procrypticism registryworldview/dimension mental-disposition should inherently be obvious. But that doesn't factor in the implications of human limited-mentation-capacity-deepening-as-subjectinglimitedness/human-subpotency-to-'educed-unlimitedness/existence-sublimating nascence' that by successive prior institutional-cumulation/institutional-recomposure-〈as-to- 
historiality/ontological-eventfulness /ontological-aesthetic-tracing-<perspective-

ontological-normalcy/postconvergence-reflected-‘epistemicity-relativism-determinism'>>

outcome of successive prior psychoanalytic-unshackling/memetic-reordering/institutionalrecomposuring as of their successive prior '(re-originary_-ass-unenenframe-_ed/reontologising/unbeholdening/outlier-conceptualisation__imbued-postconverging/dialectical-

\section{thinking -'projective-insights'/“epistemic-projection-in-conflatedness ' 'of-}

notional deprocrypticism-prospective-sublimation $\rangle^{\circ}$ ) originary/event ${ }^{38}$-of-prospectiveontology-origination psyche rule of intrinsic-reality/ontological-veridicality transcendentalenabling/sublimating/de-mentativity as of the notional $\sim$ phenomenalabstractiveness-of-presencing-

apriorising/axiomatising/referencing/intelligibilitysettingup/measuringinstrumenting-foroperant-or-incidenting-predicative-insights-of 'implicited_attendant-ontologicalcontiguity $^{67}$, educed-

existentialising/contextualising/textualising_intelligibility/epistemicity/reflexivity-contiguity$<$ imbued-notional $\sim$ cogency $>,{ }^{\prime},-<$ reifying-or-elucidating-of-prospective-relative-ontological-

completeness -of- reference-of-thought- devolving-as-of-instantiative-context $>$

conceptualisation' leading up to our positivism- ${ }^{80}$ procrypticism registry-worldview/dimension mental-disposition. In other words in the human <amplituding/formative-epistemicity $>$ totalising thrownness-in-existence ${ }^{35}$ (I exist therefore existence is of transcendentalenabling/sublimating/supereregatory de-mentativity to my human-subpotency / hyperbole-oftemporal-to-intemporal-ontological-performance ${ }^{72}<$ including-virtue-as-ontology $>$ ) finitude of the recurrent-utter-uninstitutionalisation registry-worldview/dimension, we may be forgiven going by human limited-mentation-capacity—as-subjecting 'educed-unlimitedness/existencesublimating nascence' to-limitedness/human-subpotency by its 'non-rulesapriorising/axiomatising/referencing-psychologism,-as-impulsive-or-accidented-or-random- 
mental-disposition' to be unable to grasp greater emancipating '(re-originary-_-_as-unnenframe-_-_-_reontologgising/unb_-_eholdening/outlier-conceptualisation___imbued-postconverging/dialecticalthinking -'projective-insights'/‘epistemic-projection-in-conflatedness '-ofnotional deprocrypticism-prospective-sublimation $\rangle^{0}$ ) originary/event ${ }^{3}$-of-prospectiveontology-origination psyche rules of intrinsic-reality/ontological-veridicality transcendentalenabling/sublimating/supereregatory de-mentativity as of notional phenomenalabstractiveness-of-presencingapriorising/axiomatising/referencing/intelligibilitysettingup/measuringinstrumenting-foroperant-or-incidenting-predicative-insights-of 'implicited_attendant-ontologicalcontiguity ${ }^{67} \sim$ educedexistentialising/contextualising/textualising_'intelligibility/epistemicity/reflexivity-contiguity$<$ imbued-notional $\sim$ cogency $>, \quad,<$ reifying-or-elucidating-of-prospective-relative-ontologicalcompleteness -of- reference-of-thought- devolving-as-of-instantiative-context $>$ conceptualisation' successively as of base-institutionalisation-ununiversalisation apriorising/axiomatising/referencing-psychologism, $\quad$ rulemaking-over-non-rulesuniversalisation-non-positivism/medievalism ${ }^{103}$ universalisation-directed-rulemaking-overnon-rules_-apriorising/axiomatising/referencing-psychologism, positivism- ${ }^{8}$ procrypticism positivising/rational-empiricism-based-universalisation-directed-rulemaking-over-non-rulesapriorising/axiomatising/referencing-psychologism, and notional deprocrypticism preempting — disjointedness-as-of- ${ }^{8}$ reference-of-thought,-as-to- ${ }^{63}<$ amplituding/formativeepistemicity $>$ growth-or-conflatedness ${ }^{13}$ /ransvaluative-

rationalising/transepistemicity/anamnestic-residuality/spirit-drivenness'—in-supersedingmere-formulaic-positivising/rational-empiricism-based-universalisation-directed-rulemakingover-non-rules - apriorising/axiomatising/referencing-psychologism. This highlights that our own location at the backend in reflecting holographically-<conjugatively-and-transfusively $>$ the 
relative-unreflexivity/relative-reflexivity - ontological-contiguity of-the-human-

institutionalisation-process doesn't dispense us from our own de-mentation〈supererogatory $\sim$ ontological-de-mentation-or-dialectical-de-mentation-stranding-or-

attributive-dialectics $\rangle$ for prospective transcendental possibilities. Basically, the entropy behind such a philosophical-driven conceptualisation of human meaning and corresponding psychoanalytic-unshackling, $\quad$ percolation-channelling- $<$ in-deferential-formalisationtransference $>$ into an overall relaying defining the human anthropological-continuity or anthropopsychology or institutional-cumulation/institutional-recomposure-〈as-tohistoriality/ontological-eventfulness /ontological-aesthetic-tracing-<perspectiveontological-normalcy/postconvergence-reflected-‘epistemicity-relativism-determinism’>>

could be summed up this way: - a human-philosophical-conceptualisation of mythologies (of superstitious causations with respect to human and existential-<disontologising/reentologising apøreticism $>$ destiny/teleology ${ }^{9}$ ) 'inducing a human psychoanalytic-unshackling or registry-worldview memetic-reordering' which has the merit of introducing comprehensive social institutionalisation/intemporalisation suprastructurally based around such mythologies (underlying suprastructurally the creation of superstitious practices, religions and belief systems, and practically 'institutionalised living' whether with respect to nature or among humans); - a human-philosophical-conceptualisation of mystical-principles (a system of the appropriate relations humans need to have with such superstitious causations with respect to human and existential-disontogising destiny/teleology") 'renewing the human psychoanalytic-unshackling or registry-worldview memetic-reordering' which has the merit of redefining comprehensive social institutionalisation/intemporalisation as rules/principles-driven though still based on mythological systems (underlying the suprastructural introduction of rules/principles in superstitious practices, religions and belief systems, and practically ' ${ }^{103}$ universal rules of institutionalised living' whether with respect to 
nature or among humans); - a human-philosophical-conceptualisation of principles-rationalism (of principles/rules of causation-in-reflecting-ontology as not superstitious with respect to human and existential-<disontologising/re-ontologising aporeticism $>$ destiny/teleology ${ }^{9}$ ) 'redefining the human psychoanalytic-unshackling or registry-worldview memetic-reordering' and has as merit the superseding of superstitions based on rationalising systems of universalisation, positivism and science (underlying the suprastructural introduction of intemporal principles in the operation of social endeavours including social rules and science, and practically the 'categorical-positivising/rational-empiricism of institutionalised living' whether with respect to nature or among humans); and prospectively - a human-philosophicalconceptualisation of rational-realism of "principles/rules of human representation of effectivecausation-as-it-reflects-ontology' as 'not wholly solipsistically/emanantly/becomingly intemporal' but rather 'temporal-to-intemporal' or shortness-of-register-of- ${ }^{5}$ meaningfulnessand-teleology to longness-of-register-of- ${ }^{5}$ meaningfulness-and-teleology $\quad$ (rather a notionalisation/notional-conception/amplituding of knowledge and meaningfulness, where a 'skewing ('intemporality ${ }^{52}$-symmetrising-by-desymmetrising-subsumption-of-temporality ${ }^{\circ}$, for relative intrinsic-reality/ontological-veridicality transcendental-

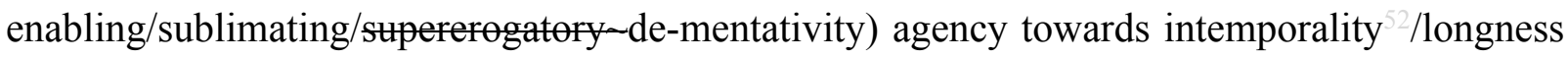
in secondnaturing is what is critical and not a false idealism wrongly implying a direct/immediate cross-sectional intemporal-disposition of humankind'), with respect to human and existential<disontologising/re-ontologising aporeticism $>$ destiny/teleology' 'reorienting the human psychoanalytic-unshackling or registry-worldview memetic-reordering' and has as merit a realistic and hence more <amplituding/formative-epistemicity>causality $\sim$ as-to-projectivetotalitative-implications-of-prospective- nonpresencing,-for-explicating relative 
'preconverging-or-dementing -apriorising-psychologism underlying the suprastructural and practical introduction of notional deprocrypticism postconverging-or-dialectical-thinking apriorising-psychologism rules/principles (postconvergence referentialism entropy of institutionalisation/intemporalisation). The reason for a registry-worldview's/dimension's institutionalisation/intemporalisation transcendence-andsublimity/sublimation/supererogatory-de-mentativity from the superstitious/religion, universal-notions/essences, principles-rationalism/positivist-idealism and then the rationalrealism of notional deprocrypticism as of ratiocontiguity/ratiocination-as-referentialism'implicited_attendant-ontological-contiguity ${ }^{67}$ ' educedexistentialising/contextualising/textualising_intelligibility/epistemicity/reflexivity-contiguity<imbued-notional cogency $>^{\text {' }}$ as nondisjointing is that psychoanalytically/memetically/meaningfully the human psyche is inclined/shaped/desires to find an all-in-all-encompassing-response (magic wand) to explain its world, but then realises across institutional-cumulation/institutional-recomposure-〈as-to- historiality/ontologicaleventfulness /ontological-aesthetic-tracing-<perspective-ontologicalnormalcy/postconvergence-reflected-‘epistemicity-relativism-determinism' $>>$ that successive introduction of more and more 'realistic' conceptualisations enable a grander $<$ amplituding/formative-epistemicity $>$ causality $\sim$ as-to-projective-totalitative-implications-ofprospective- nonpresencing,-for-explicating relative-unreflexivity/relative-reflexivity ontological-contiguity and grasp of its world. Further, what differentiates principles-

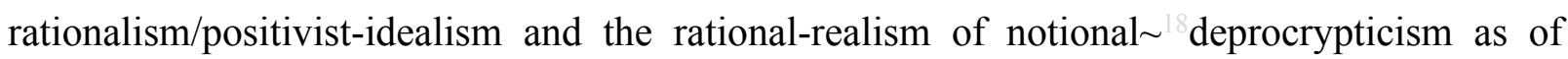
ratiocontiguity/ratiocination-as-referentialism_-implicited_attendant-ontologicalcontiguity $^{67}$, educedexistentialising/contextmalising/textualising_'intelligibility/epistemicity/reflexivity_contiguity$<$ imbued-notional cogency>' as nondisjointing is that the 'institutionalising threshold for 
intemporal-preservation-entropy-or-contiguity-or-ontological-preservation' of the latter introduces the disambiguation of dispositions in meaning construal and subsequent logical operation/processing/contention at ${ }^{83}$ reference-of-thought (on the basis that human dispositions are temporal-to-intemporal/shortness-to-longness; with human registers/registry-teleologies involving subknowledging -impulse/compulsive-dementing $\%$ slantedness/psychopath, ignorance/affordability/opportunism/exacerbation/social-chainism-or-social-discomfiture-ornegative-social-aggregation/temporal-enculturation-or-temporal-endemisation). This is the peculiarity of notional deprocrypticism dialectical-thinkng-or-postconverging-apriorisingpsychologism institutionalisation/intemporalisation exercise. The former simply focuses on logical operation/processing/contention at 'supplanting-conviction-as-to-profoundsupererogation _of-'attendant-intradimensional'-postconverging/dialectical-thinking apriorising-psychologism anchors' (on a wrong reflex basis of ${ }^{103}$ universal human intemporal/longness register/registry-teleology ${ }^{99}$ disposition). Hence the present principlesrationalism/positivist-idealism unlike rational-realism as of deprocrypticism, in the exercise of intemporal-preservation-entropy-or-contiguity-or-ontological-preservation and corresponding

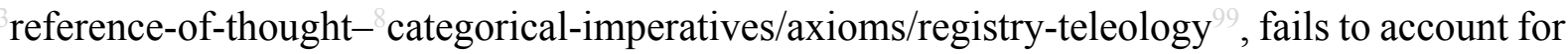
perversion-of- ${ }^{83}$ reference-of-thought-<as-preconvergingly-

apriorising/axiomatising/referencing-in-nonconviction/madeupness/bottomlining-as-to-

shallow-supererogation $>\quad$ registries, as subknowledging ${ }^{4}$-impulse/compulsivedementing / $/$ slantedness/preconverging-or-dementing 2 -apriorising-psychologism of the psychopath, postlogicly conjugated/inflected/derived/mimicked/in-protraction-to-psychopathicpreconverging-or-dementing ${ }^{20}$-apriorising-psychologism by the temporal-dispositions of ignorance/affordability/opportunism/exacerbation/social-chainism-or-social-discomfiture-ornegative-social-aggregation/temporal-enculturation-or-temporal-endemisation.

notional deprocrypticism is particular, as imbued/recomposuring with the other 
institutionalisations and across all the successive institutional-cumulation/institutionalrecomposure-〈as-to- historiality/ontological-eventfulness /ontological-aesthetic-tracing$<$ perspective-ontological-normalcy/postconvergence-reflected-'epistemicity-relativismdeterminism' $>>$, in that it addresses the fundamental issue of ${ }^{7}$ perversion-of- ${ }^{8}$ reference-ofthought-<as-preconvergingly-apriorising/axiomatising/referencing-in-

nonconviction/madeupness/bottomlining-as-to-shallow-supererogation $>$ defect by recognising the reality of human notional firstnaturedness-formativeness-<as-to-eventualising inklingdrive or seeding misprising $>$ temporal-to-intemporal-dispositions- $<$ so-construed-as-fromperspective-ontological-normalcy/postconvergence $>$ in principle and preempting this in principle in its operant conceptualisation, i.e. in principle the deprocryptic reflex is not to simply operate/process logic, it anticipates the verification of soundness of apriorising-registry to establish that this isn't subknowledging -impulse/compulsivedementing $/$ slanted/psychopathy as well as the conjugated/inflected/derived/mimicked/inprotraction-to-psychopathic-preconverging-or-dementing ${ }^{20}$-apriorising-psychologism perversion-of- ${ }^{83}$ reference-of-thought-<as-preconverginglyapriorising/axiomatising/referencing-in-nonconviction/madeupness/bottomlining-as-toshallow-supererogation $>$ by the temporal-dispositions of ignorance/affordability/opportunism/exacerbation/social-chainism-or-social-discomfiture-ornegative-social-aggregation/temporal-enculturation-or-temporal-endemisation. Such 'notional 18 deprocrypticism institutionalisation/intemporalisation transcendence-andsublimity/sublimation/supererogatory $\sim$ de-mentativity' (as with any other institutionalisation/intemporalisation transcendence-andsublimity/sublimation/supererogatory de-mentativity) involves the development of preemptive and prospective categorical-imperatives/axiomatic-construct/registry-teleology ${ }^{9}$-forintemporal-preservation-entropy-or-contiguity-or-ontological-preservation over the prior now 
dialectically-or-contendingly-out-of-phase/dialectically-primitive) ${ }^{74}$ perversion-of- ${ }^{8}$ referenceof-thought-<as-preconvergingly-apriorising/axiomatising/referencing-in-

reference-of-thought- categorical-imperatives/axioms/registry-teleology ${ }^{9}$,-for-intemporalpreservation-entropy-or-contiguity-or-ontological-preservation stranded-rightfully-asdecandored/oblongated, and so with the 'aetiologisation/ontological-escalation- $<$ ontologicalveridicality_commitment/otherliness_transcending/compulsions-encumbered_transcending >' highlighting temporal-dispositions ${ }^{15}$ de-mentation-_supererogatory ontological-de-mentationor-dialectical-de-mentation-stranding-or-attributive-dialectics $\rangle$. It should be noted that while the prior/superseded transcendence-and-sublimity/sublimation/de-mentativity to positivistic institutionalisations have been rather incremental-to-utter, it is likely that procryptic to deprocryptic transcendence-and-sublimity/sublimation/supereregatory $\sim$ dementativity is most probably an outrightly blunt/incisive utter construct, and why, because higher institutional-cumulation/institutional-recomposure-〈as-to- historiality/ontologicaleventfulness /ontological-aesthetic-tracing-<perspective-ontologicalnormalcy/postconvergence-reflected-'epistemicity-relativism-determinism'>> imply higher perversion of ${ }^{83}$ reference-of-thought- categorical-imperatives/axioms/registry-teleology ${ }^{9}$,-forintemporal-preservation-entropy-or-contiguity-or-ontological-preservation that are 'not readily perceived as undermining intemporal-preservation-entropy-or-contiguity-or-ontologicalpreservation in their <amplituling/formative-epistemicity $>$ causality $\sim$ as-to-projectivetotalitative-implications-of-prospective- nonpresencing,-for-explicating relativeunreflexivity/relative-reflexivity ontological-contiguity and are often wrongly analysed as being intemporally preservational' but for a very insightful ontological reflecting/perspectivating/highlighting exercise of organic-comprehension-thinking (organicalism/‘intemporal-prioritisation-of- ${ }^{83}$ reference-of-thought'-as-conflatedness ${ }^{13}$-or- 
ontological-reprojecting/longness-of register-of - meaningfulness-and-teleology $)$

ontological-escalation/aetiologising over threshold-of-

nonconviction/madeupness/bottomlining-in-shallow-supererogation -<as-to-'attendant-

intradimensional'-prospectively-disontologising preconverging/dementing -apriorising-

psychologism>; requiring a corresponding intellectually decisive and utter articulation for procryptic-to-deprocryptic crossgenerational deprocryptic transcendence-andsublimity/sublimation/supererogatory de-mentativity supplanting-conviction-as-to-profoundsupererogation _ of-'attendant-intradimensional'-postconverging/dialectical-thinking apriorising-psychologism, as the procryptic ${ }^{74}$ perversion-of- ${ }^{8}$ reference-of-thought- $<$ aspreconvergingly-apriorising/axiomatising/referencing-in-

nonconviction/madeupness/bottomlining-as-to-shallow-supererogation $>$ is weakly graspable in the cross-section of the social-construct for the transcendence-andsublimity/sublimation/supererogatory de-mentativity to work effectively by incrementalismin-relative-ontological-incompleteness ${ }^{8}$ —enframed/disontologising conceptualisation as of notional disjointedness-as-of- ${ }^{3}$ reference-of-thought even though such ${ }^{51}$ incrementalism-inrelative-ontological-incompleteness ${ }^{88}$ —enframed/disontologising $\sim$ conceptualisation and notional disjointedness-as-of- ${ }^{-3}$ reference-of-thought might later arise in social integration from institutionalisation/intemporalisation percolation-channelling- $<$ in-deferential-formalisationtransference $>$ following an intellectually utter and decisive articulation, or possibly with successive other such intellectual articulations, of the perpetuation-ofnotional ${ }^{18}$ deprocrypticism transcendence-and-sublimity/sublimation/supereregatery $\sim$ dementativity. Methodologically, it should draw on phenomenological-and-hermeneutic-insights, as with this research paper, and extending into a 'creative existentialism (full-existential-depthimplications) storying construal' as the 'ontologically effective, applicative and operant articulation insight' to this background phenomenological-and-hermeneutic-insights. Its 
highlighting of such a transcendence-and-sublimity/sublimation/supererogatory-de-mentativity should be similar to say a literary work like Things Fall Apart by Chinua Achebe even though the latter is rather more about cultural-diffusion-from-Western-philosophical-transcendence which positivistic transcendence-and-sublimity/sublimation/supererogatery de-mentativity integration into the society's institutionalisation/intemporalisation percolation-channelling- $<$ indeferential-formalisation-transference $>\quad$ undermines-psychoanalytically/psychoanalyticunshackling/memetic-reordering/institutional-recomposuring the society's existentialism (fullexistential-depth-implications) personhoods-and-socialhood-formation allowing for positivistic transcendence-and-sublimity/sublimation/supererogatory de-mentativity. But then unlike Things Fall Apart, such a perpetuation-of-notional ${ }^{18}$ deprocrypticism transcendence-andsublimity/sublimation/supererogatory-de-mentativity being not a cultural-diffusion-fromanother-society's-philosophical-transcendence but rather a ${ }^{103}$ universal-humanintradimensional-philosophical-transcendence can be creatively devised as being in substitution to an 'abstract cultural-diffusion-from-another-society's-philosophical-transcendence transcendence-and-sublimity/sublimation/supererogatory-de-mentativity', for an in-depth insight. However, the latter storying will have to be more deterministic, operant and of aesthetic applicability, unlike just a simple literary work, with strong existentialism/full-existential-depthimplications insights with respect to percolation-channelling- $<$ in-deferential-formalisationtransference $>$ effects as predication/deferred-predication and application/deferred-application to human and social issues based on notional firstnaturedness-formativeness-<as-toeventualising inkling drive or seeding misprising $>$ temporal-to-intemporal-dispositions$<$ so-construed-as-from-perspective-ontological-normalcy/postconvergence $>\quad$ conceptual articulation as <amplituding/formative-epistemicity $>$ causality $\sim$ as-to-projective-totalitativeimplications-of-prospective- nonpresencing,-for-explicating relative-unreflexivity/relativereflexivity - ontological-contiguity about the 'abstract nature of man'. This will involve 
'creative existentialism (full-existential-depth-implications) storying construal' in transversality-<for-sublimating-existential-eventuating/denouement,-from-'thinking atfirst/pure - predisposition-preemptive-of prospective-disontologising/subontologising' as-ofprospectively-disambiguated-affirmed-and-unaffirmed-'motif-andapriorising/axiomatising/referencing' $>$ articulated in a dynamic relationship along the three pedestals of: psychopathic characters slantedness as insane/slantedness-fitment in absolving-orfleeting-logic-reflex-or-escaping-logic in hollow-constituting-<as-disjointed-misappropriationof-meaningfulness-and-failing-intemporal-preservation $>$ in postlogic-backtracking- $<$ iterativelooping-'set-of-dereifying-hollow-narratives-and-acts'>76-to-last-narrative-wronglylyallowing-interlocutors-prelogic-or-conviction-as-to-profound-supererogation -alignment; temporal-dispositions (of ${ }^{5}$ ignorance/affordability/opportunism/exacerbation/social-chainismor-social-discomfiture-or-negative-social-aggregation/temporal-enculturation-or-temporalendemisation) insane/slantedness integration/conjugation in threshold-ofnonconviction/madeupness/bottomlining-in-shallow-supererogation $-<$ as-to-'attendantintradimensional'-prospectively-disontologising preconverging/dementing -apriorisingpsychologism $>\quad$ miscuing/disjointed-logic/logical-drag/unconscionability-drag/sub-par-orformulaic-association-or-temporal-or-alibi conventioning-rationalising/temporal-enculturationor-temporal-endemisation of the organic-comprehension-thinking (organicalism/“intemporalprioritisation-of- ${ }^{3}$ reference-of-thought'-as-conflatedness ${ }^{13}$-or-ontologicalreprojecting/tongness-of register-of- meaningfulness-and-teleology ) intemporal point-ofreferencing veridicality; and the intemporal-disposition organic-comprehension-thinking (organicalism/“intemporal-prioritisation-of- ${ }^{8}$ reference-of-thought'-as-conflatedness ${ }^{13}$-orontological-reprojectingtongness of register of meaning fulness and teleology ) on the basis of a higher teleology complex of being more profound with respect to threshold-ofnonconviction/madeupness/bottomlining-in-shallow-supererogation $<<$ as-to-'attendant- 
psychologism>' with respect to intrinsic-meaning/veridicality, in terms-as-of-axiomaticconstruct of its psychologismic-subliminality-of-individuationeffusing/worlding imbued logical-dueness-or-scape-or-frame, profile-or-stature, presumptuousness-or-arrogation, assumptions, value-reference and teleology ${ }^{9}$ ) reflection/perspectivation of the two prior pedestals in ontological-escalation as a registryworldview/dimension defect at this uninstitutionalised-threshold ${ }^{102}$ as backdrop for 'postconverging-or-dialectical-thinking -psychology or psychology-of-mentation-dynamics or natural psychological-dynamics’ psychoanalytic-unshackling/memeticreordering/institutional-recomposuring in the construal of futural Beingdevelopment/ontological-framework-expansion-as-to-depth-of-ontologising-development-asinfrastructure-of- meaningfulness-and-teleology as of prospective notional ${ }^{18}$ deprocrypticism $\quad{ }^{83}$ reference-of-thought- categorical-imperatives/axioms/registryteleology ${ }^{9}$,-for-intemporal-preservation-entropy-or-contiguity-or-ontological-preservation in anticipation and preempting procrypticism, so construed by 'notional $\sim$ 'deprocrypticism ontologically-perspectival-elevated/pedestaling-as-postconverging-or-dialectical-thinking differentiation-as-of-supratransversality-<in-sublimating-existentialeventuating/denouement $>$ of-motif-and-apriorising/axiomatising/referencing'. And so, based on the fundamental psychological preconverging/postconverging-dementating/structuring/paradigming of 'mental-devising-representation devising' giving-in to veridicality/intrinsic-reality when shown to be ${ }^{74}$ perversion-of- ${ }^{8}$ reference-of-thought- $<$ aspreconvergingly-apriorising/axiomatising/referencing-in-

nonconviction/madeupness/bottomlining-as-to-shallow-supererogation $>$. This fundamental psychological preconverging/postconverging-de-mentating/structuring/paradigming operates by way of candoring/prelogism 7 /dialectically-or-contendingly-in-phase or in preconverging-or- 
dementing ${ }^{20}$-apriorising-psychologism/decandoring/distractive-alignment-to- ${ }^{8}$ reference-ofthought- $<$ of-apriorising/axiomatising/referencing $>$ \% / dialectically-or-contendingly-out-of-phase to represent registry-worldview/dimension ontological-veridicality 'as thinking' or ${ }^{71}$ perversionof- ${ }^{3}$ reference-of-thought-<as-preconvergingly-apriorising/axiomatising/referencing-innonconviction/madeupness/bottomlining-as-to-shallow-supererogation $>$ 'as preconvergingor-dementing ${ }^{20}$-apriorising-psychologism' respectively, as is implied in all the transcendenceand-sublimity/sublimation/supererogatory de-mentativity from $\quad$ recurrent-utteruninstitutionalisation, base-institutionalisation/ununiversalisation, ${ }^{103}$ universalisation/nonpositivism-or-medievalism, positivism/procrypticism, and prospectively perpetuation-ofdeprocrypticism. This serves to provide the perspective/reflection to the present positivistic mindset $/{ }^{3}$ reference-of-thought explaining while the 'seemingly unlikely preconverging-ordementing ${ }^{2}$-apriorising-psychologism mental-devising-representation of its mind' at its uninstituionalised/unintemporalised-thresholds-of-intemporal-preservation-entropy-orcontiguity-or-ontological-preservation as ${ }^{80}$ procrypticism-or-disjointedness-as-of- ${ }^{8}$ referenceof-thought so reflected/perspectivated from notional $\sim$ deprocrypticism is more veridical than its illusion-of-the-present/present-consciousnessas $<$ amplituding/formativeepistemicity>totalising $\sim$ self-referencing-syncretising/circularity/interiorising/akrasiatic-drag mental 'postconverging-or-dialectical-thinking -apriorising-psychologism' representation. Inthe-bigger-scheme-of-things, such a 'creative existentialism (full-existential-depth-implications) storying construal' on perpetuation-of-notional ${ }^{8}$ deprocrypticism re-elaborated to a 'creative existentialism (full-existential-depth-implications) storying construal' of all the transcendenceand-sublimity/sublimation/supererogatory de-mentativity provides an even more profound and emanant-insight understanding of the anthropological continuity/anthropopsychology and the proper place of the present positivistic mind in the bigger scheme, and what is prospectively implied, as a perpetuation-of-notional deprocrypticism transcendence-and- 
sublimity/sublimation/supererogatory-de-mentativity). Another ontological element of the perpetuation-of-notional $\sim$ deprocrypticism transcendence-andsublimity/sublimation/supererogatory de-mentativity is that it is 'weakly positive opportunistic' to the cross-section of the social construct. Prior/superseded transcendence-andsublimity/sublimation/supererogatory de-mentativity are relatively 'strongly positive opportunistic' with base-institutionalisation transcendence-andsublimity/sublimation/supererogatoryade-mentativity from recurrent-utteruninstitutionalisation being the strongest in its positive-opportunism-of-social-functioningand-accordance $^{75}$ as the intemporal-preservation-entropy-or-contiguity-or-ontologicalpreservation ${ }^{83}$ reference-of-thought- categorical-imperatives/axioms/registry-teleology ${ }^{99}$,-forintemporal-preservation-entropy-or-contiguity-or-ontological-preservation of: 'organising rules/principles'/base-institutionalisation are opportunistically critical for temporal direct/immediate survival itself, i.e. such an uninstitutionalised state with manifest uncertaintyas-failing-to-reflect-the-effective-'existential-veracity-and-entailment-of $\sim$ relative-

unreflexivity/relative-reflexivity', lack-of-knowledge about the environment and relative lawlessness 'focuses the individual's mind' to adhere to any dependable organised rules/principles/laws, even where such organising rules/principles/laws are bad so long as they are predictable, be it circumstantially (and effectively, base-institutionalisation is a state where such organising/rules/principles/laws are constantly being remade competitively with respect to survival-possibilities and power-relations, but on-the-other-hand base-institutionalisation tends to have weak institutionalisation/intemporalisation percolation-channelling- $<$ in-deferentialformalisation-transference $>\quad$ for intemporal transcendence-andsublimity/sublimation/superentativity in the long run due to 'holding-on-to-theinitial-proven-survival-and-flourishing-assets/tradition' and a 'question of power relations', and more likely than not, in such human society in 'clanic turbulence' base-psychoanalytic- 
unshackling/memetic-reordering/institutional-recomposuring is a highly-diffusionary-jugglingand-reconstituting-transcending-across-clans rather than oriented towards just a singular intrasocial intemporal-philosophical transcending, but also involving on the rare occasion a lopsided diffusion from an altogether different and dominant cultural grouping); those of 'projecting rules/principles' or ${ }^{103}$ universalisation are less opportunistically critical for temporal direct/immediate survival but are relatively vital and extend the ambits of the former; while those of 'empirical rules/principles'/positivism are even less positive-opportunistically critical for temporal direct/immediate survival but relatively critical for flourishing (science, human rights, democracy, etc.). So these institutionalisations transcendence-andsublimity/sublimation/supererogatory de-mentativity can elicit, in effect, a grander sense of intemporal/ontological/social/species/ ${ }^{103}$ universal/transcendental/ $/$ maximalisingrecomposuring-for-relative-ontological-completeness ${ }^{8}$ —unenframed/re-

ontologising conceptualisation postconverging-de-mentating/structuring/paradigming rather than a temporal extricatory preconverging-de-mentating/structuring/paradigming in their crosssection of the social-construct. However, it will probably be more facile for such a cross-section of the social-construct to be strongly disposed to adopt an extricatory/temporality preconverging-de-mentating/structuring/paradigming rather than intemporal/ontological/social/species/ $/{ }^{03}$ universal/transcendental/ $/ 5$ maximalisingrecomposuring-for-relative-ontological-completeness ${ }^{8}$ —unenframed/reontologising conceptualisation postconverging-de-mentating/structuring/paradigming regarding the ${ }^{83}$ reference-of-thought- categorical-imperatives/axioms/registry-teleology ${ }^{9}$,-forintemporal-preservation-entropy-or-contiguity-or-ontological-preservation of 'notional firstnaturedness-formativeness-as to eventulising inkling drive or seeding misprising $>$ temporal-to-intemporal-dispositions- $<$ so-construed-as-from-perspectiveontological-normalcy/postconvergence $>$ accountability as intemporality ${ }^{52}$-skewing 
('intemporality ${ }^{52}$-symmetrising-by-desymmetrising-subsumption-of-temporality ${ }^{8}$, for relative intrinsic-reality/ontological-veridicality transcendentalenabling/sublimating/supereregatery $\sim$ de-mentativity) rules/principles' or notional ${ }^{18}$ deprocrypticism with regards to their temporal direct/immediate survival opportunism statistically to individuals on the cross-section of the social-construct. An intemporal disposition as ontological projecting that may elicit a sense of positiveopportunism - of-social-functioning-and-accordance ${ }^{75}$ for survival itself with baseinstitutionalisation will not necessarily have the same adherence effect on the cross-section of the social-construct when it comes to a transcendence-andsublimity/sublimation/supererogatory $\sim$ de-mentativity which temporal directness/immediacy for 'individuals sense of survival-and-flourishing' is not so obvious but for its abstract ontological veridicality and abstract intemporal transformation implications as is the case with deprocrypticism; but is rendered possible because of the relatively 'strong preset institutionalisation/intemporalisation percolation-channelling- $<$ in-deferential-formalisationtransference $>$ for transcendence-and-sublimity/sublimation/supereregatory $\sim$ de-mentativity' (on the basis of its untenability/internal-contradiction/internal-incoherence/institutionalconstraining generation capacity); more like it would be fair to say that many an abstract and boring scientific efforts do not necessarily appeal temporarily but for the strongly preset institutionalisation/intemporalisation percolation-channelling- $<$ in-deferential-formalisationtransference $>$ for their social integration. Basically, with transcendence-andsublimity/sublimation/supererogatory de-mentativity as temporal directness/immediacy weaken on-the-one-hand, the element of untenability/internal-contradiction/internalincoherence/institutional-constraining (with institutional percolation-channelling- $<$ indeferential-formalisation-transference $>$ for transcendence-andsublimity/sublimation/supererogatory de-mentativity) in assuring prospective transcendence- 
and-sublimity/sublimation/supererogatory-de-mentativity strengthens. To sum up, this highlights the 'temporal existentialism/full-existential-depth-implications practicality aspect' involved in all human transcendence-and-sublimity/sublimation/supereregatory $\sim$ de-mentativity. That is, transcendence-and-sublimity/sublimation/supereregatery $\sim$ de-mentativity is more of a human-mentation-capacity driven construct and its mundane recognition is not inherently by its supposed virtue (given that survival-and-flourishing, and not veracity/ontological-pertinence, are the more punctual/immediacy/constituted/compulsions-encumbered basis for the human temporal drive). To the extent that transcendence-and-sublimity/sublimation/supererogatory $\sim$ dementativity highlights critically that it is what is the best enabler for survival-and-flourishing then it is a force of social transformation. Equally, an ontologically-veridical but not immediately/directly survival-and-flourishing will not, with regards to human temporal practicality, by mere ontological-veridicality be a basis for its social integration, if the insight that it provides a grander survival-and-flourishing scheme isn't immediately palpable. As in this case human temporal practicality disposition is perfectly inclined to threshold at its registryworldview/dimension uninstitutionalised-threshold ${ }^{102}$. But then with an increasing cerebral grasp of our nature and our surrounding world rather than just passive endurers of nature-inaction, we can fairly anticipate and supersede intellectually our human temporal practicality dispositions, in this case with regards to deprocrypticism, and attain prospective knowledge-andvirtue generally. Meaning (defined previously as what defines/predicates value, thought and action) is actually a referential memetic construct in the referential exercise of the entropic

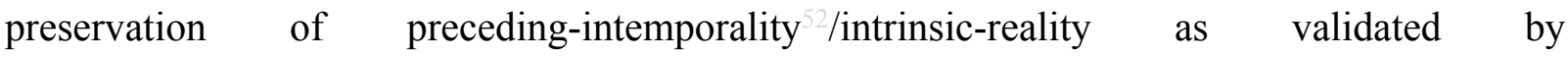

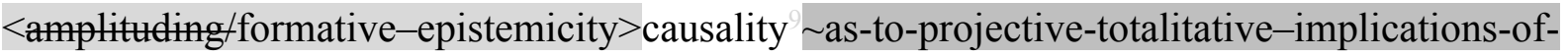
prospective- nonpresencing,-for-explicating relative unreflexivity/relative reflexivity ontological-contiguity . This leads in the instance of ${ }^{74}$ perversion-of- ${ }^{8}$ reference-of-thought$<$ as-preconvergingly-apriorising/axiomatising/referencing-in- 
'memetic-corruption or psychoanalytic-misrepresentation of ${ }^{83}$ reference-of-thoughtcategorical-imperatives/axioms/registry-teleology ; requiring a referential 'memetic reordering/psychoanalytic-unshackling reference-of-thought- categoricalimperatives/axioms/registry-teleology for the entropic preservation of intemporality ${ }^{52}$ /intrinsic-reality as validated by $<$ amplituding/formativeepistemicity $>$ causality $\sim$ as-to-projective-totalitative-implications-of-prospective-

\section{nonpresencing,-for-explicating relative- unreflexivity/relative-reflexivity - ontological-}

contiguity . The referential memetism as suprastructural-meaningfulness implying that meaning is in fact a 'human mental devising construct' (not inherently ontological or intrinsic-reality) and it is grounded on its validation/veridicality by its <amplituding/formativeepistemicity $>$ causality $\sim$ as-to-projective-totalitative-implications-of-prospective-

\section{nonpresencing,-for-explicating relative -unreflexivity/relative-reflexivity - ontological-}

contiguity in showing it is proxying to 'abstract and inherent ontology/intrinsicreality/veridicality' which is a preceding/superseding notion (postconvergence) to our mental devising of meaning; explaining why we adjust our meaning model/memeticreordering/psychoanalytic-unshackling (soundness-or-ontological-good-faith/authenticity ${ }^{6}$-ofreference-of-thought/candored, and then mentally-oblongated/decandored with respect to new/superseding soundness-or-ontological-good-faith/authenticity ${ }^{6}$-of- ${ }^{83}$ reference-ofthought/candored) when the proxying-registry-construct is internally-contradictory and demonstrated to be flawed at successive uninstitutionalised-threshold ${ }^{102}$ whether from recurrentutter-institutionalised to base-institutionalised, ununiversalised to ${ }^{103}$ universalised, nonpositivism/medievalism to positivistic, and prospectively procrypticism to deprocrypticism. More than just an exercise of grasping the possibilities of human transcendence-andsublimity/sublimation/supererogatory de-mentativity, it is critical that for future transcendence- 
and-sublimity/sublimation/supereregatory-de-mentativity we don't confuse the development of a 'banal/temporal/averaging-of-temporal-thoughts' notion in 'our shortness of the lives of mortals' (80 or 100 years or so) as defining what is 'existential idealism/success' on the basis of such 'mental shortness' (which isn't even solipsistically/emanantly/becomingly the intemporal responsibility/relative-reflexivity for the transcendence-andsublimity/sublimation/supererogatory-de-mentativity that enabled its world, the positive worldview from non-positivism/medievalism, but has been rather 'institutionalised and secondnatured there', and so is 'philosophically irresponsible' prospectively with respect to the bigger scheme of things regarding transcendence-and-sublimity/sublimation/supereregatory $\sim$ dementativity/prospective-institutionalisation, necessarily so when inclined to an extricatory temporal-disposition that is not solipsistically intemporally responsible). Intellectually and knowledge-wise, the articulation of 'existential idealism/success' must be the exclusive purview of the aetiological individuation of the intemporal-disposition whose organic-comprehensionthinking (organicalism/'intemporal-prioritisation-of- ${ }^{2}$ reference-of-thought'-asconflatedness $^{13}$-or-ontological-reprojecting/longness-of-register-of- meaningfulness-andteleology ${ }^{9}$ 's ${ }^{103}$ universal projection/intemporality ${ }^{52}$ keeps alive the notion of existentialdisontologising/re ontologising aporeticism> idealism/success as long as from its intemporal-disposition that started base-institutionalisation (to thwart recurrent-utteruninstitutionalisation) through ${ }^{103}$ universalisation (to thwart ununiversalisation), positivism (to thwart non-positivism/medievalism), and prospectively its intemporal-disposition that will enable notional ${ }^{18}$ deprocrypticism (to thwart ${ }^{80}$ procrypticism-or-disjointedness-as-ofreference-of-thought) and thereafter; the intemporal mind as such projects in an 'abstract eternality' that is what allows for the intemporal-preservation-entropy-or-contiguity-orontological-preservation. In-the-bigger-scheme-of-things, all the vices-and-impediments ${ }^{105}$ of the <cumulating/recomposuring attendant-ontological-contiguity $>$-successive registry- 
worldviews/dimensions can be directly ascribed as corresponding ${ }^{7}$ perversion-of- ${ }^{8}$ referenceof-thought-<as-preconvergingly-apriorising/axiomatising/referencing-in-

nonconviction/madeupness/bottomlining-as-to-shallow-supererogation $>$ of temporaldispositions at the registry-worldviews/dimensions uninstitutionalised-threshold ${ }^{102}$ whether as recurrent-utter-uninstitutionalisation, ununiversalisation, non-positivism/medievalism, and prospectively procrypticism (pointing to the fact that virtue is about 'the-Good/knowledgereification $\sim$ gesturing-and-accounting — of-epistemic-phenomenalism- $<$ inprospective_psychologismic $\sim$ apriorising/axiomatising/referencing-\{of-'prospectively implicited_attendant-ontological-contiguity ' educedexistentialising/contextualising/textualising_'intelligibility/epistemicity/reflexivity_contiguity<imbued-notional cogency >' \}-conflatedness -in-\{preconverging-disentailment by\} postconverging entailment $>$ /understanding/<amplituding/formativeepistemicity $>$ causality $\sim$ as-to-projective-totalitative-implications-of-prospectivenonpresencing,-for-explicating relative-unreflexivity/relative-reflexivity - ontologicalcontiguity constructs' of base-institutionalisation, ${ }^{103}$ universalisation, positivism and prospectively deprocrypticism, and not 'good-natured/impression constructs' which are vague, as it is inevitable that there is no good-naturedness/impression-drive that exist to prevent a recurrent-utter-institutionalised mind from deterministically committing the vices-andimpediments ${ }^{105}$ of recurrent-utter-uninstitutionalisation, of an ununiversalised mind those of ununiversalisation, of a non-positivism/medievalism mind those of non-positivism/medievalism, and prospectively of a procryptic mind (as subknowledging $/$ mimicking/perverting positivistic meaningfulness) those of procrypticism. Virtue is plainly and simply about theGood/knowledge-reification $\sim$ gesturing-and-accounting — of-epistemic-phenomenalism- $<$ inprospective_psychologismic apriorising/axiomatising/referencing-\{of- ${ }^{\text {pprospectively }}$ implicited_attendant-ontological-contiguity ' educed- 
existentialising/contextualising/textualising_'intelligibility/epistemicity/reflexivity-contiguity<imbued-notional cogency>' \}-conflatedness -in-\{preconverging-disentailment by\}

postconverging entailment $>$ /understanding/<amplituding/formative-

epistemicity $>$ causality $\sim$ as-to-projective-totalitative-implications-of-prospectivenonpresencing,-for-explicating relative-unreflexivity/relative-reflexivity - ontological-

contiguity construct with corresponding virtuous consequences of knowledge or lack-ofknowledge thereof). It is critical for the sake of the temporal mortal that we are, not to be allowed to be our own God; that is exactly what creates transcendental possibilities, otherwise we

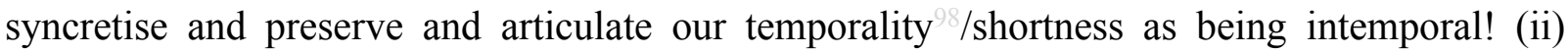
'Intellectual solipsistic/emanant irresponsibility/relative-unreflexivity' referring to 'intellectual idealism' success in conceiving intemporal meaning but failure in preserving intemporal meaning from 'temporal mimicking, denaturing ${ }^{16}$ and subknowledging ${ }^{9}$ ' with corresponding poor temporal-dispositions orientations/registry-worldview over that intemporal meaningfulness in relation to the bigger picture of human/social progress postconverging-dementating/structuring/paradigming. While intellectual ontological/intemporal meaningfulness may strive to articulate a ${ }^{103}$ universal idealism/intemporal projection, it is rather naïve to operate on the 'romantic' basis that ${ }^{103}$ universal idealism/intemporal projection is the sole disposition of humans as temporal dispositions like postlogism -slantedness (the psychopath), ignorance/affordability/opportunism/exacerbation/social-chainism-or-social-discomfiture-ornegative-social-aggregation/temporal-enculturation-or-temporal-endemisation are endemically part-and-parcel of the reality of human dispositions; and so, as a matter of fact on a simple 'scientific basis of determining first principles' and not necessarily to stigmatise, as reality works on the basis that 'what is, is what is!' That then being the case, what then is the relevant question is how do we ensure by institutionalisation/intemporalisation (based on the-Good/knowledgereification $\sim$ gesturing-and-accounting — of-epistemic-phenomenalism- $<$ in- 
prospective_psychologismic apriorising/axiomatising/referencing-\{of-'prospectively

implicited_attendant-ontological-contiguity ' educed-

existentialising/contextualising/textualising_'intelligibility/epistemicity/reflexivity-contiguity-

$<$ imbued-notional $\sim$ cogency $>\quad\}$-conflatedness -in-\{preconverging disentailment by\}

postconverging-entailment $>$ /understanding/<amplituding/formative-

epistemicity $>$ causality $\sim$ as-to-projective-totalitative-implications-of-prospective-

nonpresencing,-for-explicating relative unreflexivity/relative-reflexivity - ontological-

contiguity and not impression/good-naturedness/wishfulness vagueness) the supersedingness of the intemporal-disposition-worldview (as ontological and upholding virtue in the medium to long perspective) over the cross-section of human mental notional firstnaturednessformativeness-<as-to-eventualising-inkling-drive-or-seeding-misprising $>$ temporal-tointemporal-dispositions- $<$ so-construed-as-from-perspective-ontologicalnormalcy/postconvergence $>$ s, i.e. secondnaturing as formalisation and internalisation. For instance, if men were of an intemporal-disposition we will only need 'moral philosophy' and 'no law' as the institutionalising principle of the law is a tacit recognition that realistically we need 'dominating/superseding artifices' or 'institutions and their rules and narratives' whether the human subjects have a grasp of the 'philosophical' ${ }^{103}$ universal end purpose or not). This is the attitude that preserves the virtue inherent in the intemporal conceptualisation of meaning and 'not any temporal romantic idealism' which only leads to ${ }^{74}$ perversion-of- ${ }^{8}$ reference-ofthought-<as-preconvergingly-apriorising/axiomatising/referencing-in-

nonconviction/madeupness/bottomlining-as-to-shallow-supererogation $>$ that goes on to undermine directly or by sub-par-or-formulaic-association-or-temporal-or-alibi conventioningrationalising conjugations the virtue in knowledge, and so in particular in the 'extendedinformality-〈susceptible-to-effecting-parsimony-as-of-shoddiness-and-incompleteness-tomeaningfulness-and-teleology '’ (informal settings) where the constraining social 
universal-transparency ${ }^{104}$-〈transparency-of-totalising-entailing,-as-to-entailing-

$<$ amplituding/formative-epistemicity>totalising in-relative-ontological-completeness

(usually introduced in formal settings) is not available. Hence intellectual responsibility/relativereflexivity warrants that the intellectual exercise (as intemporal-preservation-entropy-orcontiguity-or-ontological-preservation) involves both a construction of the intemporal ideal and

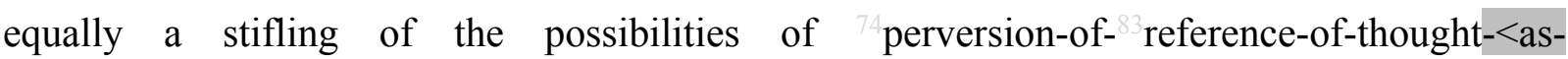
preconvergingly-apriorising/axiomatising/referencing-in-

nonconviction/madeupness/bottomlining-as-to-shallow-supererogation $>$ as to preconvergingor-dementing ${ }^{20}$-apriorising-psychologism. This involves avoiding the naivety of articulating meaning only in the sense of the intemporal ideal but including a constraining and notional firstnaturedness-formativeness-<as-to-eventualising inkling-drive-or-seeding misprising $>$ temporal-to-intemporal-dispositions- $<$ so-construed-as-from-perspectiveontological-normalcy/postconvergence $>$-disambiguating realism that upholds/preserves intemporality ${ }^{52} /$ longness and stifles temporal-dispositions ${ }^{77}$ perversion-of- ${ }^{83}$ reference-ofthought-<as-preconvergingly-apriorising/axiomatising/referencing-in-

nonconviction/madeupness/bottomlining-as-to-shallow-supererogation $>$ inclinations. Such an approach is known as the 'knowledge-notionalisation' or knowledge as a continuum-ofconstrual from human individuative manifestations of 'ignorances'/desublimation/temporaldispositions to knowledge/sublimation/intemporal-disposition ${ }^{52}$ which then allows for scrutinising and preempting the 'ignorances/desublimation'/temporal-dispositions, i.e. apprehending not only intemporal implications of any knowledge construct, but being transversally/logically-incongruent preemptive to potential temporal undermining of that intemporal idealism construct). 'Intemporal and temporal disjuncture' basically refers to the fact that in the elaboration of conventioning with respect to ontological-veridicality with regards to social-stake-contention-or-confliction both the intemporal and temporal-dispositions are 
preservational in their finalities, i.e. temporal-dispositions do not transcend philosophically but by untenability/internal-contradiction/internal-incoherence/institutional-constraining, and it is vague and naïve to intemporally/ontologically engage at the philosophical level to wrongly imply such a solipsistic transcendental process as this should not be confused with the formalisation effect of secondnaturing and internalisation. 'Intemporal and temporal disjuncture' can equally be analysed as transcendental-or-transdimensional prospective/apriorising/axiomatising/referencing/intelligibilitysettingup/measuringinstrumentin $\mathrm{g}$ and intradimensional-meaningfulness disjuncture' given there is mutual unintelligibility between prospective apriorising/axiomatising/referencing/intelligibilitysettingup/measuringinstrumenting and intradimensional meaningfulness for instance respectively as notional $\sim$ deprocrypticism and as procrypticism ( perversion-of- ${ }^{8}$ reference-of-thought- $<$ as-preconverginglyapriorising/axiomatising/referencing-in-nonconviction/madeupness/bottomlining-as-toshallow-supererogation $>$ of positivistic meaningfulness), just as there is mutual unintelligibility between positivism and non-positivism/medievalism meaningfulness. This mutual unintelligibility should not be 'addressed logically' actually by the intemporaldisposition or prospective-memetism or prospective/transcending registry-worldview/dimension as this naively implies both registry-worldviews/dimensions share the same ${ }^{83}$ reference-ofthought- ${ }^{8}$ ategorical-imperatives/axioms/registry-teleology ${ }^{9}$,-for-intemporal-preservationentropy-or-contiguity-or-ontological-preservation (going from the insight of a common vantage perspective of mutually unintelligible/existentially-suprastructural positivism and nonpositivism/medievalism $\quad{ }^{8}$ reference-of-thought- categorical-imperatives/axioms/registryteleology ${ }^{99}$,-for-intemporal-preservation-entropy-or-contiguity-or-ontological-preservation); wherein it is transversality-<for-sublimating-existential-eventuating/denouement,-from'thinking at-first/pure-predisposition-preemptive-of-prospective- 
disontologising/subontologising' as-of-prospectively-disambiguated-affirmed-and-

unaffirmed-'motif-and-apriorising/axiomatising/referencing' $>101$ that plays out to enable the utter superseding/transcendence of the intemporal-disposition or prospective memetism or prospective/transcendental/superseding registry-worldview/dimension over the prior/transcended/superseded intradimensional meaningfulness. For the simple reason that intrinsic-reality being preceding as ontological-normalcy/postconvergence it won't let the positivistic mindset $/{ }^{3}$ reference-of-thought (as intrinsic-reality/ontology is inherently suprastructural or beyond-the-consciousness-awareness-teleology 9 < $<$-preconvergingexistential-extrication-as-of-existential-unthought $>$ of the mortals that we are, in the sense that a cholera epidemic that was to occur say in 100 B.C. Will not stop from occurring because human beings did not know of notions-of-bacteria-as-causing-diseases-and-instead-believed-in-badomen-for-not-making-the-right-sacrifices-or-so-so-and-so; thus naivety will be to strive to syncretise in temporal-and-social-trading our discomfort/unpalatability in construing intrinsicreality/ontology) to be involved in social-and-temporal-trading with the nonpositivism/medievalism mindset $/{ }^{83}$ reference-of-thought as inherently all the greater possibilities of grasping a more profound intrinsic-reality/ontology lies with 'reasoning-through/utterion' with the prospective memetism of positivism which actual mental-devising-representation of non-positivism/medievalism is as preconverging-or-dementing -apriorising-psychologism (where the non-positivism/medievalism registry-worldview/dimension is the prior/transcended/superseded intradimensional meaningfulness perspective). The validation arises from the untenability/internal-contradiction/internal-incoherence/institutionalconstraining in the long-run of non-positivism/medievalism, as the more profound positivistic meaningfulness takes hold in the-Good/understanding/<amplituding/formativeepistemicity $>$ causality $\sim$ as-to-projective-totalitative-implications-of-prospective- 
contiguity institutionalisation percolation-channelling- $<$ in-deferential-formalisationtransference $>$ mechanism. This ontological insight (transversality-<for-sublimating-existentialeventuating/denouement,-from-'thinking-at-first/pure-predisposition-preemptive-ofprospective-disontologising/subontologising' as-of-prospectively-disambiguated-affirmedand-unaffirmed-'motif-and-apriorising/axiomatising/referencing' $>{ }^{101}$ that plays out to enable the utter prospective/superseding/transcending of the intemporal-disposition or prospective memetism or prospective/transcendental/superseding registry-worldview/dimension) also informs, as with all transcendence-and-sublimity/sublimation/supereregatory $\sim$ de-mentativity, the relation between the prospective meaningfulness/memetism or transcending/superseding registry-worldview/dimension as notional $\sim^{18}$ deprocrypticism and prior/transcended/superseded intradimensional meaningfulness/memetism as our procrypticism, with the latter superseded/transcended as of 'reasoning-through/utterion' and represented as preconverging-ordementing -apriorising-psychologism in line with the preceding ontologicalnormalcy/postconvergence nature of intrinsic-reality/ontology, likewise with the idea that notional ${ }^{18}$ deprocrypticism validation will arise from the untenability/internalcontradiction/internal-incoherence/institutional-constraining of procrypticism as futural Beingdevelopment/ontological-framework-expansion-as-to-depth-of-ontologising-development-asinfrastructure-of- meaningfulness-and-teleology as of prospective notional ${ }^{18}$ deprocrypticism takes hold in the the-Good/knowledge-reification $\sim$ gesturing-andaccounting - of-epistemic-phenomenalism- $<$ inprospective_psychologismic apriorising/axiomatising/referencing-\{of-'prospectively implicited_attendant-ontological-contiguity ' educedexistentialising/contextrising/textralising_intelligibility/epistemicity/reflexivity-contiguity<imbued-notional cogency $\left.>^{\prime} \quad\right\}$-conflatedness -in-\{preconverging-disentailment by\} postconverging-entailment $>$ /understanding/<amplituding/formative- 
epistemicity $>$ causality $\sim$ as-to-projective-totalitative-implications-of-prospective-

nonpresencing,-for-explicating relative-unreflexivity/relative-reflexivity - ontological-

contiguity institutionalisation percolation-channelling- $<$ in-deferential-formalisationtransference $>$ mechanism. So deterministically and operantly, without any discretion allowed, from the intemporal/ontological perspective, it is a crossgenerational collapsing/overriding-andsuperseding of temporal-dispositions and a registry-worldview/dimension-intradimensionalmeaningfulness that is ${ }^{77}$ perversion-of- ${ }^{3}$ reference-of-thought- $<$ as-preconverginglyapriorising/axiomatising/referencing-in-nonconviction/madeupness/bottomlining-as-to-

shallow-supererogation $>\quad$ construed in $\quad$ transversality- $<$ for-sublimating-existentialeventuating/denouement,from 'thinking at-first/pure-predisposition-preemptive-ofprospective-disontologising/subontologising' - as-of-prospectively-disambiguated-affirmedand-unaffirmed-'motif-and-apriorising/axiomatising/referencing'> involving reflecting/perspectivating/highlighting (reasoning-through-and-not-reasoning-with) the ${ }^{15}$ dementation-〈supererogatory ontological-de-mentation-or-dialectical-de-mentation — strandingor-attributive-dialectics $\rangle$ as the backdrop of new ${ }^{83}$ reference-of-thought- categoricalimperatives/axioms/registry-teleology ${ }^{9}$,-for-intemporal-preservation-entropy-or-contiguityor-ontological-preservation for prospective psychoanalytic-unshackling/memeticreordering/institutional-recomposuring that enables prospective transcendence-andsublimity/sublimation/supererogatoryade-mentativity. Thus technically, preconverging-ordementing ${ }^{2}$-apriorising-psychologism arises simply by a shift of ${ }^{8}$ reference-of-thought (in the strive for intemporal-preservation-entropy-or-contiguity-or-ontological-preservation wherein the latter ${ }^{83}$ reference-of-thought as a registry-worldview/dimension is shown to be more intemporally-preservational); with the preconverging-or-dementing -apriorising-psychologism reflected/perspectivated in the mental-devising-representation fully implied by the new transcending/superseding ${ }^{83}$ reference-of-thought (of postconverging/dialectical-thinking 
apriorising-psychologism) about the prior transcended/superseded ${ }^{83}$ reference-of-thought (and so, beyond the latter's registry-worldview/dimension wrongful reflex to set-aside/ignore the implications of its demonstrated ontological-impertinence as of notionaldiscontiguity/epistemic-discontiguity ${ }^{63}-<$ between - prior-shallow-supererogation -ofmentally-aestheticised preconverging/dementing -qualia-schema_and_prospective-profoundsupererogation -of-mentally-aestheticised postconverging/dialectical-thinking -qualia-

schema $>$ and go on to be of <amplituding/formative-epistemicity $>$ totalising $\sim$ self-referencingsyncretising/circularity/interiorising/akrasiatic-drag ${ }^{34}$ this now shown-to-be-wrong ${ }^{83}$ referenceof-thought). Preconverging-or-dementing -apriorising-psychologism as such is easily and spontaneously reflected of a prior/superseded/transcended registry-worldview/dimension like for instance a positivistic registry-worldview/dimension mental-devising-representation reflecting the preconverging-or-dementing ${ }^{20}$-apriorising-psychologism of a medieval registryworldview/dimension. But then this is because the positivistic registry-worldview/dimension doesn't have to deal with any existential-<disontologising/re-ontologising aporeticism $>$ illusion-of-the-present/present-consciousness/epistemic-totalising $\sim$ self-referencingsyncretising/mirage that the non-positivism/medievalism registry-worldview/dimension personhoods-and-socialhood-formation has to deal with. However, implying similarly the preconverging-or-dementing ${ }^{20}$-apriorising-psychologism of the positivistic registryworldview/dimension from its intradimensional perspective where its own ${ }^{83}$ reference-ofthought is superseded/transcended by a prospective ${ }^{83}$ reference-of-thought as notional ${ }^{18}$ deprocrypticism will, this time around by the positivistic registryworldview/dimension existential-<disontologising/re-ontologising aporeticism $>$ illusion-ofthe-present/present-consciousness/epistemic that its personhoods-and-socialhood-formation has to deal with, lead to the positivistic registryworldview/dimension by reflex setting-aside/ignoring the prospective and veridical ${ }^{83}$ reference- 
of-thought and corresponding (postconvergence) ontological-veridicality/relativeunreflexivity/relative-reflexivity -ontological-contiguity ${ }^{7}$, and go on to self-referencesyncretise its transcended/superseded ${ }^{83}$ reference-of-thought. In concrete terms for instance, whereas a positivistic mindset $/{ }^{8}$ reference-of-thought will likely shift the ${ }^{83}$ reference-of-thought with regards to say a non-positivism/medievalism context of notions-and-accusations-of-sorcery where A were to accuse B for being a sorcerer who caused A's illness, the mental-devisingrepresentation of the positivistic mindset $/{ }^{3}$ reference-of-thought will be that $\mathrm{A}$ is preconvergingor-dementing ${ }^{20}$-apriorising-psychologism and that a germ and biological functioning theory of the human body is the ${ }^{8}$ reference-of-thought for A's disease. But then intradimensionally, A and B and their society of personhoods-and-socialhood-formation and existentialism/full-depthof-existential-implications that are non-positivism/medievalism will tend to harken back to

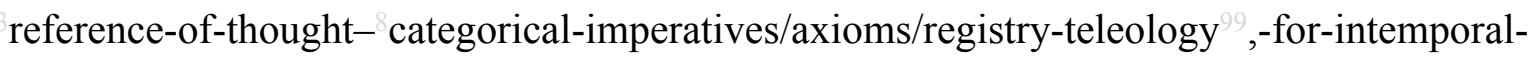
preservation-entropy-or-contiguity-or-ontological-preservation that uphold the prior/transcended/superseded ${ }^{83}$ reference-of-thought that admits to notions-and-accusations-ofsorcery. The effective anthropological and dialectical evidence (mostly from diffusional transcendence-and-sublimity/sublimation/supererogatory-de-mentativity given the relative abruptness of cultural diffusions compared to an intra-society philosophical transcendence-andsublimity/sublimation/supererogatory de-mentativity which is rather slow in the making) shows that it is the crossgenerational habituation by <amplituding/formativeepistemicity $>$ totalising $\sim$ self-referencing-syncretising/circularity/interiorising/akrasiatic-drag into reference-of-thought of the prospective/transcending/superseding registryworldview/dimension (in this instance the positivistic registry-worldview/dimension) that will ultimately 'wean' the prior/superseded/transcended registry-worldview/dimension (in this instance non-positivism/medievalism) from its defective non-positivism/medievalism reference-of-thought and its prior relative-ontological-incompleteness ${ }^{88}$-of- ${ }^{83}$ reference-of- 
thought- ${ }^{8}$ ategorical-imperatives/axioms/registry-teleology ${ }^{9}$ towards a positivistic ${ }^{8}$ referenceof-thought and its prospective/transcending/superseding relative-ontological-completeness ${ }^{87}$-ofreference-of-thought- categorical-imperatives/axioms/registry-teleology ${ }^{9}$,-for-intemporalpreservation-entropy-or-contiguity-or-ontological-preservation as of ontological-faith-notionor-ontological-fideism—imbued-underdetermination-of-motif-and-

apriorising/axiomatising/referencing-as-so-being-as-of-existential-reality, where contention can then take place to establish (postconvergence) relative ontological-veridicality. Likewise, the concrete analysis from a notional deprocrypticism insight shows that our procrypticism ( 7 perversion-of- ${ }^{83}$ reference-of-thought-<as-preconvergingly-

\section{apriorising/axiomatising/referencing-in-nonconviction/madeupness/bottomlining-as-to-}

shallow-supererogation $>$ of positivistic meaningfulness) mindset $/{ }^{83}$ reference-of-thought will by reflex emanantly act the same at its own uninstitutionalised-threshold ${ }^{02}$; wherein the idea that positivism- ${ }^{80}$ procrypticism ${ }^{83}$ reference-of-thought as of its characteristic postlogism associated with psychopathy and social psychopathy with its overall beyond-the-consciousnessawareness-teleology $-<$ of-preconverging-existential-extrication-as-of-existential-unthought $>$ defect of disjointedness-as-of- ${ }^{-3}$ reference-of-thought-as-misappropriated- ${ }^{56}$ meaningfulnessand-teleology ${ }^{99}$ brings about a shift to a new ${ }^{83}$ reference-of-thought and ${ }^{83}$ reference-of-thoughtcategorical-imperatives/axioms/registry-teleology ${ }^{9}$,-for-intemporal-preservation-entropy-orcontiguity-or-ontological-preservation as transcending/superseding deprocrypticism, will sound unintelligible/existentially-suprastructural to the positivism- ${ }^{80}$ procrypticism mindset $/{ }^{8}$ reference-of-thought which simply by reflex set this aside and harken back axiomatically to positivism- ${ }^{80}$ procrypticism ${ }^{83}$ reference-of-thought and ${ }^{83}$ reference-of-thoughtcategorical-imperatives/axioms/registry-teleology ${ }^{9}$, ,for-intemporal-preservation-entropy-orcontiguity-or-ontological-preservation that unconsciously (as ignorance) and consciously (as affordability/opportunism/exacerbation/social-chainism-or-social-discomfiture-or-negative- 
social-aggregation/temporal-enculturation-or-temporal-endemisation) do not acknowledge ontological-impertinence as of notional-discontiguity/epistemic-discontiguity ${ }^{6}<<$ between prior-shallow-supererogation -of-mentally-aestheticised preconverging/dementing -qualiaschema_and_prospective-profound-supererogation -of-mentallyaestheticised postconverging/dialectical-thinking -qualia-schema $>$ of the ${ }^{74}$ perversion-ofreference-of-thought-<as-preconvergingly-apriorising/axiomatising/referencing-innonconviction/madeupness/bottomlining-as-to-shallow-supererogation $>$ associated with such positivism- ${ }^{80}$ procrypticism ${ }^{83}$ reference-of-thought that is bound to directly and indirectly at the uninstitutionalised-threshold ${ }^{102}$ be integrating postlogism 7 -as-of- compulsingnonconviction/madeupness/bottomlining-〈‘ $<$ decontextualising/de-existentialising $\sim$ ofattendant-intradimensional-apriorising/axiomatising/referencing>-induced-disontologising'-ofthe-'attendant-intradimensional-ontologising'-imbued$<$ contextualising/existentialising attendant-ontological-contiguity $>$;-in-shallowsupererogation -<as-to-disontologising-perverted-outcome-sought-precedes-existentiallyveridical-'attendant-intradimensional-apriorising/axiomatising/referencing'-logical-dueness $>$ > in hollow-constituting-<as-disjointed-misappropriation-of-meaningfulness-and-failingintemporal-preservation> teleologically involving, (i) intemporal-disposition introduction-of'ontological-reconstituting-as-to-conflatedness ${ }^{13}$ reference-of-thought- categoricalimperatives/axioms/registry-teleology , (ii) temporal-dispositions undermining-by-hollowconstituting-<as-disjointed-misappropriation-of-meaningfulness-and-failing-intemporal-

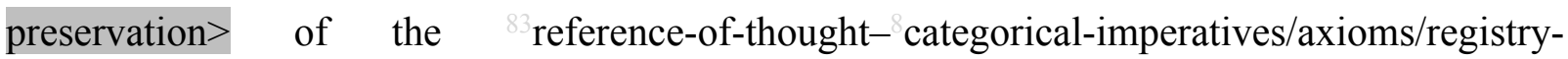
teleology , (iii) intemporal-disposition reflecting/perspectivating/highlighting the temporaldispositions perversion-of- ${ }^{-3 e f e r e n c e-o f-t h o u g h t-~}<$ as-preconverginglyapriorising/axiomatising/referencing-in-nonconviction/madeupness/bottomlining-as-toshallow-supererogation $>-$ categorical-imperatives/axioms/registry-teleology and 
introduction-of-'ontological-reconstituting-as-to-conflatedness ${ }^{13}$, of new ${ }^{83}$ reference-ofthought- categorical-imperatives/axioms/registry-teleology $^{9}$ preempting the temporaldispositions perversion-of- ${ }^{8}$ reference-of-thought-<as-preconverginglyapriorising/axiomatising/referencing-in-nonconviction/madeupness/bottomlining-as-toshallow-supererogation $>$ ) of the subontologisation/subpotentiation (in-a-social-dynamism-ofmeaningfulness-misappropriation) by slantedness/postlogic-effect, miscuing, disjointed-logic, logical-drag, unconscionability-drag, sub-par/formulaic-association/temporal/alibi conventioning-rationalising, and temporal-enculturation/temporal-endemisation effect; as successive circular postlogic-backtracking-<iterative-looping-'set-of-dereifying-hollownarratives-and-acts'> ${ }^{76}$ preconverging-or-dementing -apriorising-psychologism constructs, and not as may wrongly be reflected by the natural reflex to be prelogic supplanting-convictionas-to-profound-supererogation - of-'attendant-intradimensional'-postconverging/dialecticalthinking -apriorising-psychologism, as supplanting-conviction-as-to-profoundsupererogation - of-'attendant-intradimensional'-postconverging/dialectical-thinking apriorising-psychologism (implicited_attendant-ontological-contiguity ${ }^{67}$ ? educedexistentialising/contextualising/textualising_'intelligibility/epistemicity/reflexivity_contiguity<imbued-notional cogency>' veracity or meaningful-projection-of-intrinsic-veracity or authentic-vocalisation or prelogism ${ }^{78}$-as-of-conviction,-in-profound-supererogation

\section{$<$ existentially-veridical-'attendant-intradimensional-apriorising/axiomatising/referencing'-}

logical-dueness-precedes-disontologising-logical-outcome-arrived-at $>$ ) constructs. And likewise, it is a crossgenerational habituation of notional ${ }^{18}$ deprocrypticism ${ }^{83}$ reference-ofthought and ${ }^{83}$ reference-of-thought- categorical-imperatives/axioms/registry-teleology ${ }^{9}$,-forintemporal-preservation-entropy-or-contiguity-or-ontological-preservation that will ultimately lead to a shift in ${ }^{83}$ reference-of-thought and the correspondingly more profound and grander notional ${ }^{8}$ deprocrypticism ontological-veridicality/relative-unreflexivity/relative-reflexivity 
ontological-contiguity thereof. Another validation for the preconverging-or-dementing apriorising-psychologism mental-devising-representation

of retrospective/transcended/superseded registry-worldviews/dimensions has to do with the implications of the notions of impression-driven/good-naturedness/wishfulness and theGood/knowledge-reification $\sim$ gesturing-and-accounting-of-epistemic-phenomenalism- $<$ inprospective_psychologismic apriorising/axiomatising/referencing-\{of-`prospectively implicited_attendant-ontological-contiguity ' educedexistentialising/contextualising/textualising_'intelligibility/epistemicity/reflexivity-contiguity<imbued-notional cogency $\left.>^{\prime}\right\}$ - conflatedness -in-\{preconverging-disentailment by\} postconverging entailment $>$ /understanding/<amplituding/formativeepistemicity $>$ causality $\sim$ as-to-projective-totalitative-implications-of-prospectivenonpresencing,-for-explicating relative unreflexivity/relative-reflexivity - ontologicalcontiguity with respect to the ontological-normalcy/postconvergence and suprastructural nature of intrinsic-reality/ontology/ontological-veridicality. prospective/transcending/superseding registry-worldview the-Good/knowledgereification $\sim$ gesturing-and-accounting — of-epistemic-phenomenalism- $<$ inprospective_psychologismic apriorising/axiomatising/referencing-\{of-'prespectively implicited_attendant-ontological-contiguity ' educedexistentialising/contextualising/textualising_ intelligibility/epistemicity/reflexivity-contiguity$<$ imbued-notional cogency $>$ ' $\}$-conflatedness -in-\{preconverging-disentailment by\} postconverging entailment $>$ /understanding/<amplituding/formativeepistemicity $>$ causality $\sim$ as-to-projective-totalitative-implications-of-prospectivenonpresencing,-for-explicating relative unreflexivity/relative reflexivity - ontologicalcontiguity mental-devising-representation of a retrospective/transcended/superseded impression-driven/good-naturedness/wishfulness construct is always a preconverging-or- 
dementing -apriorising-psychologism construct, and so across all institutionalisations indicating that the ontological-normalcy/postconvergence and suprastructural nature of intrinsicreality/ontology/ontological-veridicality as ontological-normalcy/postconvergence or prospective-transcendence-in-perpetually-upholding-intemporal-preservation-entropy-orcontiguity-or-ontological-preservation effectively construes impression-driven/goodnaturedness/wishfulness constructs as rather of notional-discontiguity/epistemic-discontiguity ${ }^{63}$ $<$ between-prior-shallow-supererogation -of-mentallyaestheticised preconverging/dementing -qualia-schema_and_prospective-profoundsupererogation -of-mentally-aestheticised postconverging/dialectical-thinking -qualiaschema $>$ and hence its preconverging-or-dementing -apriorising-psychologism. This equally implies that our very own 'good-naturedness constructs' in the positivism/procrypticism registry-worldview/dimension are of preconverging-or-dementing -apriorising-psychologism mental-devising-representation from futural Being-development/ontological-frameworkexpansion-as-to-depth-of-ontologising-development-as-infrastructure-of- meaningfulnessand-teleology as of prospective notional deprocrypticism registry-worldview/dimension theGood/knowledge-reification $\sim$ gesturing-and-accounting — of-epistemic-phenomenalism- $<$ inprospective_psychologismic apriorising/axiomatising/referencing-\{of-'prespectively implicited_attendant-ontological-contiguity ' educedexistentialising/contextualising/textualising_ intelligibility/epistemicity/reflexivity-contiguity<imbued-notional cogency $\left.>^{\prime} \quad\right\}$-conflatedness -in-\{preconverging-disentailment by\} postconverging entailment $>$ /understanding/<amplituding/formativeepistemicity $>$ causality $\sim$ as-to-projective-totalitative-implications-of-prospectivenonpresencing,-for-explicating relative unreflexivity/relative reflexivity - ontologicalcontiguity conceptualisation. The reason why ontological-normalcy/postconvergence indicates that 'good-naturedness constructs' are defective is quite simple as it is based on adhering to a 
registry-worldview's/dimension's

form/virtualities/dereification/akrasiatic-drag/denatured/preconverging-or-dementing 20 narratives - of-the- ${ }^{83}$ reference-of-thought- categorical-imperatives/axioms/registryteleology , which along the institutional-cumulation/institutional-recomposure-〈as-tohistoriality/ontological-eventfulness /ontological-aesthetic-tracing-<perspectiveontological-normalcy/postconvergence-reflected-‘epistemicity-relativism-determinism'>> are successively shown to be defective-as-always-being-sub-par-to-intrinsic-reality and defining the uninstitutionalised-threshold $^{102}$. Virtue and ontology/intrinsic-reality rather lies in the intemporal-preservation-entropy-or-contiguity-or-ontological-preservation, and not its

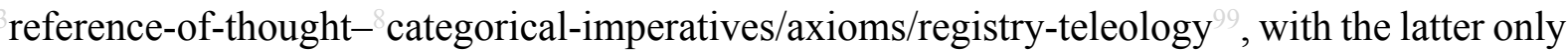
being pertinent in the sense where it relays intemporal-preservation-entropy-or-contiguity-orontological-preservation. Such a relaying is not within the ambits of good-naturedness constructs but rather the-Good as a continuous refinement of <amplituding/formativeepistemicity $>$ causality $\sim$ as-to-projective-totalitative-implications-of-prospectivenonpresencing,-for-explicating relative unreflexivity/relative-reflexivity - ontological-

contiguity that ensures re-institutionalisation/re-intemporalisation for intemporal-preservationentropy-or-contiguity-or-ontological-preservation when $\quad$ amplituding/formativeepistemicity $>$ causality $\sim$ as-to-projective-totalitative-implications-of-prospectivenonpresencing,-for-explicating relative-unreflexivity/relative-reflexivity - ontologicalcontiguity so reveals it. Thus supposed an individual shows good-naturedness following the reference-of-thought- categorical-imperatives/axioms/registry-teleology ${ }^{9}$,-for-intemporalpreservation-entropy-or-contiguity-or-ontological-preservation of the recurrent-utteruninstitutionalised registry-worldview/dimension that warrants that one simply gets one's way no matter the situation even if it means committing murder to have some food for oneself and close ones; a good-natured quality that is highly rated for survival in a recurrent-utter- 
uninstitutionalised setup. That is perfectly within the good-naturedness ambits of a survivaldriven registry-worldview/dimension but prospectively it is the creativeness of 'prospective postconverging aporeticism-overcoming/unovercoming as the-Good/knowledgereification $\sim$ gesturing-and-accounting - of-epistemic-phenomenalism- $<$ inprospective_psychologismic apriorising/axiomatising/referencing-\{of-"prospectively implicited_attendant-ontological-contiguity ' reducedexistentialising/contextualising/textualising_intelligibility/epistemicity/reflexivity_contiguity<imbued-notional cogency $\left.>^{\prime} \quad\right\}$ - conflatedness -in-\{preconverging-disentailment by\} postconverging entailment $>$ /understanding/<amplituding/formativeepistemicity $>$ causality $\sim$ as-to-projective-totalitative-implications-of-prospectivenonpresencing,-for-explicating relative-unreflexivity/relative-reflexivity - ontologicalcontiguity,$\quad$ as of ontological-faith-notion-or-ontological-fideism-imbuedunderdetermination-of-motif-and-apriorising/axiomatising/referencing-as-so-being-as-ofexistential-reality that carries the virtuous and ontological insight to grasp that a registryworldview's/dimension's institutionalisation as base-institutionalisation rulemaking-over-nonrules - apriorising/axiomatising/referencing-psychologism will provide a grander virtuous and ontological outcome for humans, and not a good-naturedness inclination which is stuck at the

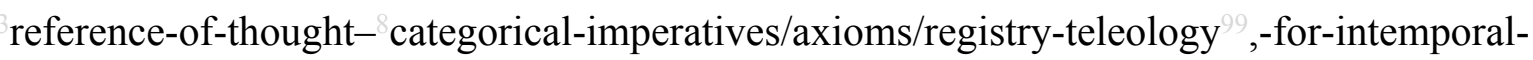
preservation-entropy-or-contiguity-or-ontological-preservation of recurrent-utteruninstitutionalisation. This same fundamental dilemma arises with all other institutionalisations. For instance, the procrypticism inclination to stick to the ${ }^{83}$ reference-of-thought- categoricalimperatives/axioms/registry-teleology ${ }^{9}$,-for-intemporal-preservation-entropy-or-contiguityor-ontological-preservation of a positivistic registry-worldview/dimension viewed as deterministic by projected <amplituding/formative> wooden-language-〈imbued-temporalmere-form/virtualities/dereification/akrasiatic-drag/denatured/preconverging-or-dementing 
narratives - of-the- reference-of-thought- categorical-imperatives/axioms/registry-

teleology > as-to-how-others-act-in-hollow-constituting-<as-disjointed-misappropriation-ofmeaningfulness-and-failing-intemporal-preservation> requiring the-Good/knowledgereification $\sim$ gesturing-and-accounting — of-epistemic-phenomenalism- $<$ inprospective_psychologismic $\sim$ apriorising/axiomatising/referencing-\{of-'prespectively implicited_attendant-ontological-contiguity ' educedexistentialising/contextualising/textualising_'intelligibility/epistemicity/reflexivity_contiguity<imbued-notional cogency $>$ ' \}-conflatedness -in-\{preconverging-disentailment by\} postconverging entailment $>$ /understanding/<amplituding/formativeepistemicity $>$ causality $\sim$ as-to-projective-totalitative-implications-of-prospectivenonpresencing,-for-explicating relative-unreflexivity/relative-reflexivity ontologicalcontiguity appreciation that an <amplituding/formative-epistemicity $>$ causality $\sim$ as-toprojective-totalitative-implications-of-prospective- nonpresencing,-for-explicating $\sim$ relativeunreflexivity/relative-reflexivity ontological-contiguity as to existencepotency ${ }^{32} \sim$ sublimating-nascence,-disclosed-from-prospective-epistemic-digression indicating such a perversion-of- ${ }^{83}$ reference-of-thought- $<$ as-preconverginglyapriorising/axiomatising/referencing-in-nonconviction/madeupness/bottomlining-as-toshallow-supererogation $>$ implies a prospective/transcending/superseding registryworldview's/dimension's new ${ }^{83}$ reference-of-thought- categorical-imperatives/axioms/registryteleology ${ }^{9}$,-for-intemporal-preservation-entropy-or-contiguity-or-ontological-preservation to ensure intemporal-preservation as deprocrypticism. Thus it is the-Good/knowledgereification $\sim$ gesturing-and-accounting — of-epistemic-phenomenalism- $<$ inprospective_psychologismic apriorising/axiomatising/referencing-\{of-'prespectively implicited_attendant-ontological-contiguity ' educedexistentialising/contextualising/textualising_'intelligibility/epistemicity/reflexivity-contiguity- 
<imbued-notional cogency >' \}-conflatedness -in-\{preconverging disentailment by\}

postconverging entailment $>$ /understanding/<amplituding/formative-

epistemicity $>$ causality $\sim$ as-to-projective-totalitative-implications-of-prospective-

nonpresencing,-for-explicating relative-unreflexivity/relative-reflexivity - ontological-

contiguity that carries the mantle of intemporal-preservation-entropy-or-contiguity-orontological-preservation and not good-naturedness/vague-impression drive which temporalmimicking (unconscious or conscious) shouldn't be confused with preserving ontology and virtue. Thus the basic reason for this counter-intuition about the veridical nature of goodnaturedness construct is that it is intradimensionally <amplituding/formativeepistemicity $>$ totalising $\sim$ self-referencing-syncretising/circularity/interiorising/akrasiatic-drag with the wrong implications of inherently representing the ${ }^{83}$ reference-of-thought- categoricalimperatives/axioms/registry-teleology ${ }^{9}$,-for-intemporal-preservation-entropy-or-contiguityor-ontological-preservation of the registry-worldview/dimension as absolute intrinsicreality/ontology without any factoring of intrinsic-reality/ontology ontologicalnormalcy/postconvergence and suprastructural nature as the-Good/knowledgereification $\sim$ gesturing-and-accounting — of-epistemic-phenomenalism- $<$ in-

prospective_psychologismic apriorising/axiomatising/referencing-\{of-'prespectively implicited_attendant-ontological-contiguity ' reducedexistentialising/contextualising/textualising_ 'intelligibility/epistemicity/reflexivity-contiguity<imbued-notional cogency $\left.>^{\prime} \quad\right\}$-conflatedness -in-\{preconverging-disentailment by\} postconverging entailment $>$ /understanding/<amplituding/formativeepistemicity $>$ causality $\sim$ as-to-projective-totalitative-implications-of-prospectivenonpresencing,-for-explicating relative unreflexivity/relative reflexivity - ontologicalcontiguity does. This fundamentally explains why all prior/transcended/superseded registryworldview's/dimension's present-consciousness/illusion-of-the-present/epistemic- 
totalising $\sim$ self-referencing-syncretising/mirage are necessarily preconverging-ordementing -apriorising-psychologism from the mental-devising-representation of the prospective/transcending/superseding registry-worldview/dimension in the requisite 'postconverging-or-dialectical-thinking -psychology or psychology-of-mentation-dynamics or natural psychological-dynamics' psychoanalytic-unshackling/memeticreordering/institutional-recomposuring exercise that enables the existentialism (full-depth-ofexistential-implications) deconstructed/'ontologically-reconstituted' becoming of the prospective/transcending/superseding registry-worldview/dimension. The bigger insight here has to do with the ontological-normalcy/postconvergence nature of intrinsic-reality. Intrinsicreality/ontological-veridicality is already given and what is required to access it absolutely is not the notion of 'any hollow-constituting-<as-disjointed-misappropriation-of-meaningfulness-andfailing-intemporal-preservation $>$ initiative/effort' from the ${ }^{83}$ reference-of-thought- categoricalimperatives/axioms/registry-teleology ${ }^{9}$,-for-intemporal-preservation-entropy-or-contiguityor-ontological-preservation of a reference/registrying/registry-worldview/dimension that is necessarily sub-par to intrinsic-reality/ontology (this is the central idea that fundamentally explains how $\quad{ }^{7}$ perversion-of- ${ }^{83}$ reference-of-thought-<as-preconverginglyapriorising/axiomatising/referencing-in-nonconviction/madeupness/bottomlining-as-toshallow-supererogation $>$ as to preconverging-or-dementing ${ }^{20}$-apriorising-psychologism arise, due to sub-par ${ }^{83}$ reference-of-thought- ${ }^{8}$ ategorical-imperatives/axioms/registry-teleology ${ }^{9}$ in misconstruing ontological-normalcy/postconvergence reflection of intrinsic-reality, and so by slantedness/postlogic-effect, miscuing, disjointed-logic, logical-drag, unconscionability-drag, sub-par/formulaic-association/temporal/alibi conventioning-rationalising, and temporalenculturation/temporal-endemisation-effect, and temporal-enculturation/temporal-endemisation effect); but rather the notion of a 'requisite and grander and grander sense of 'prospective postconverging aporeticism-overcoming/unovercoming the-Good/knowledge- 
reification $\sim$ gesturing-and-accounting — of-epistemic-phenomenalism- $<$ in-

prospective_psychologismic apriorising/axiomatising/referencing-\{of-'prospectively implicited_attendant-ontological-contiguity ' educed-

existentialising/contextualising/textualising_intelligibility/epistemicity/reflexivity_contiguity$<$ imbued-notional cogency $>$ ' \}-conflatedness -in-\{preconverging-disentailment by\} postconverging-entailment $>$ /understanding/<amplituding/formative-

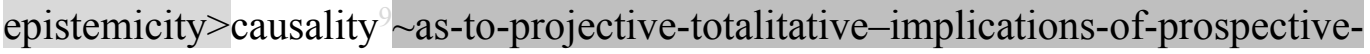
nonpresencing,-for-explicating relative-unreflexivity/relative-reflexivity - ontologicalcontiguity ' illuminating reflecting/perspectivating/highlighting (which is 'more or less ontologically-reconstituting/deconstructional', in the sense that in the bigger scheme to absolutely grasp intrinsic-reality/ontology in cumulation/recomposuring from recurrent-utterinstitutionalisation-to-deprocrypticism, reference-of-thought- categoricalimperatives/axioms/registry-teleology ${ }^{9}$,-for-intemporal-preservation-entropy-or-contiguityor-ontological-preservation of successive institutional-cumulation/institutional-recomposure〈as-to- historiality/ontological-eventfulness /ontological-aesthetic-tracing-<perspectiveontological-normalcy/postconvergence-reflected-‘epistemicity-relativism-determinism'>> are, strictly speaking, of a more-and-more-precise-heuristic-nature in their strive to grasp intrinsicreality/ontology as-we-predicate-better-and-more-about-the-world, notwithstanding the fact that a registry-worldview/dimension acts more-or-less-in-utter-trust to its given ${ }^{83}$ reference-ofthought- ${ }^{8}$ ategorical-imperatives/axioms/registry-teleology ${ }^{9}$,-for-intemporal-preservationentropy-or-contiguity-or-ontological-preservation mainly for the compromising sake of 'effective functioning', and so at one dialectical moment till a better one arises at another dialectical moment, as a transcending/superseding reference/registry/registryworldview/dimension) that simply 'open-up'/'throw-up'/‘reveal' in ontologicalnormalcy/postconvergence successive existentialisms/full-depths-of-existential-implications of 
the notion of what is meant by intrinsic-reality; more precisely and effectively, as ontologicalnormalcy/postconvergence-or-postdicatory deconstruction/ontological-reconstituting-as-toconflatedness ${ }^{13}$ as dialectical transformation as (prospective) transdimensional-meaningfulnessapriorising/axiomatising/referencing/intelligibilitysettingup/measuringinstrumenting or (prospective) existentialism/full-depth-of-existential-implications, i.e. the overall enterprise is about deconstruction/ontological-reconstituting-as-to-conflatedness ${ }^{13}$-towards-intrinsic-reality wherein existence-defines-essence (along Sartrean existence-precedes-essence or existencemeeting-essence), as it is existentialism which is the 'becoming that defines essence' with 'essence-of-meaningfulness being-veridically-in-ontological-reconstituting-as-toconflatedness $^{13}$, and not a traditionally naïve 'wrong hollow-constituting-<as-disjointedmisappropriation-of-meaningfulness-and-failing-intemporal-preservation> perception or construct-of-essence-of-meaningfulness-in-an-abstract-classification-scheme-which-is-out-of 'implicited_attendant-ontological-contiguity ${ }^{67}$ ' educedexistentialising/contextualising/textualising_intelligibility/epistemicity/reflexivity-contiguity$<$ imbued-notional cogency > ${ }^{\prime 0}$ that is usurpable/impostored by mere-formulaicity/ritualisation$<$ as-to-mere-formulaic — methodologising/mutualising/organising/institutionalising,-

\section{prospectively-losing-track-of- ‘ \{epistemic-totalising tre apriorising/re axiomatising/re}

referencing $\sim$ residuality - in-re-originariness/re-origination'>. This is the veridical ontological depth of mental-devising-representation/psychologicalrepresentation/\{cumulated/recomposured $\}$-consciousness-awareness-teleology informed by the de-mentation-〈supereratory ontological-de-mentation-or-dialectical-de-mentation stranding-or-attributive-dialectics〉. The institutional-cumulation/institutional-recomposure-〈asto- historiality/ontological-eventfulness /ontological-aesthetic-tracing-<perspectiveontological-normalcy/postconvergence-reflected-‘epistemicity-relativism-determinism’>> as specific successive existentialisms/full-depths-of-existential-implications imply their mental- 
devising-representation

in

a

reflecting/perspectivating/highlighting

transdimensional/transcendental

dialectics

enabled

by

de-mentation-

〈supererogatory ontological-de-mentation-or-dialectical-de-mentation-stranding-or-

attributive-dialectics) wherein the de-mentation-〈supererogatory ontological-de-mentationor-dialectical-de-mentation - stranding-or-attributive-dialectics $\rangle$

sets

prior/transcended/superseded

institutional-cumulation/institutional-recomposure-〈as-to-

historiality/ontological-eventfulness /ontological-aesthetic-tracing-<perspective-

ontological-normalcy/postconvergence-reflected-'epistemicity-relativism-determinism'>> as

'dialectically-preconverging-or-dementing ${ }^{20}$-apriorising-psychologism' (mentally-

oblongated/decandored-and-dialectically-or-contendingly-out-of-phase) and the

prospective/transcending/superseding institutional-cumulation/institutional-recomposure-〈as-

to- historiality/ontological-eventfulness /ontological-aesthetic-tracing-<perspective-

ontological-normalcy/postconvergence-reflected-'epistemicity-relativism-determinism'>> as

'postconverging-or-dialectical-thinking -apriorising-psychologism'/soundness-or-ontological-

good-faith/authenticity ${ }^{6}$-of- ${ }^{-}$reference-of-thought (mentally-straight/candored-and-

dialectically-or-contendingly-in-phase), in their successive existentialisms/full-depths-ofexistential-implications ontological-normalcy/postconvergence-or-postdicatory deconstruction/ontological-reconstituting-as-to-conflatedness ${ }^{13}$ as dialectical transformation. However from their intradimensional perspectives as ${ }^{74}$ perversion-of- ${ }^{3}$ reference-of-thought$<$ as-preconvergingly-apriorising/axiomatising/referencing-in-

nonconviction/madeupness/bottomlining-as-to-shallow-supererogation $>$, the preconvergingor-dementing ${ }^{20}$-apriorising-psychologism institutional-cumulation/institutional-recomposure〈as-to- historiality/ontological-eventfulness /ontological-aesthetic-tracing-<perspectiveontological-normalcy/postconvergence-reflected-‘epistemicity-relativism-determinism’>> wrongful placeholder-setup/mental-devising-representation/mentation/consciousness- 
awareness-teleology' is a 'syncretising registry-teleology -mentation that articulates the 'intradimensional perversion-of- ${ }^{-3}$ reference-of-thought- $<$ as-preconverginglyapriorising/axiomatising/referencing-in-nonconviction/madeupness/bottomlining-as-to-

shallow-supererogation $>$ as to preconverging-or-dementing ${ }^{20}$-apriorising-psychologism' successive existentialisms/full-depths-implications disposition' with the false implication of non-transcendability of these respective institutional-cumulation/institutional-recomposure-〈asto- historiality/ontological-eventfulness /ontological-aesthetic-tracing-<perspectiveontological-normalcy/postconvergence-reflected-‘epistemicity-relativism-determinism'>> (given their wrong circular-upholding of the hollow-constituting-<as-disjointedmisappropriation-of-meaningfulness-and-failing-intemporal-preservation $>$ of their same reference-of-thought- categorical-imperatives/axioms/registry-teleology ${ }^{9}$,-for-intemporalpreservation-entropy-or-contiguity-or-ontological-preservation, in lieu of upholding as 'ontological-reconstituting-as-to-conflatedness ${ }^{13}$ ' the prospective ones that should carry the mantle for intemporal-preservation-entropy-or-contiguity-or-ontological-preservation; as reflected by the fact that 'any hollow-constituting-<as-disjointed-misappropriation-ofmeaningfulness-and-failing-intemporal-preservation> initiative/effort' to grasp intrinsic-reality from the 'failing/not-upholding-<as-of-apriorising/axiomatising/referencing $>$ and ontologically-wrong' $\quad{ }^{83}$ reference-of-thought- categorical-imperatives/axioms/registryteleology ,-for-intemporal-preservation-entropy-or-contiguity-or-ontological-preservation of a reference/registrying/registry-worldview/dimension is necessarily sub-par to ontologicalnormalcy/postconvergence intrinsic-reality/ontology, and thus 'dialectically-preconverging-ordementing -apriorising-psychologism' to enable its prospective superseding/transcending), and this is rightfully transcended/superseded by the 'postconverging-or-dialectical-thinking apriorising-psychologism'/soundness-or-ontological-good-faith/authenticity ${ }^{69}$-of- referenceof-thought institutional-cumulation/institutional-recomposure-〈as-to- historiality/ontological- 
eventfulness /ontological-aesthetic-tracing-<perspective-ontological-

normalcy/postconvergence-reflected-'epistemicity-relativism-determinism'>>

reflecting/perspectivating/highlighting their rightful/veridical 'preconverging-or-dementing 2 apriorising-psychologism registry-teleology -mentation that articulates transdimensionally successive existentialisms/full-depths-of-existential-implications disposition' with the rightful implication of the transcendability of these respective institutional-cumulation/institutionalrecomposure-〈as-to- historiality/ontological-eventfulness /ontological-aesthetic-tracing-

$<$ perspective-ontological-normalcy/postconvergence-reflected-'epistemicity-relativism-

determinism' $>>$ (given the rightful prospective superseding/transcending of their 'failing/notupholding-<as-of-apriorising/axiomatising/referencing > and ontologically-wrong' ${ }^{83}$ referenceof-thought- categorical-imperatives/axioms/registry-teleology ${ }^{9}$,-for-intemporal-preservationentropy-or-contiguity-or-ontological-preservation; as going by the bigger scheme for absolute grasp of intrinsic-reality/ontology in cumulation/recomposuring from-utter-institutionalisationto-deprocrypticism, $\quad{ }^{83}$ reference-of-thought- ${ }^{-}$ategorical-imperatives/axioms/registryteleology ${ }^{9}$,-for-intemporal-preservation-entropy-or-contiguity-or-ontological-preservation of successive institutional-cumulation/institutional-recomposure-〈as-to- historiality/ontologicaleventfulness /ontological-aesthetic-tracing-<perspective-ontologicalnormalcy/postconvergence-reflected-‘epistemicity-relativism-determinism'>> are, strictly speaking, rather of a more-and-more-precise-heuristic-nature in their strive to grasp intrinsicreality/ontology as-we-predicate-better-and-more-about-the-world). This 'existentialism/fulldepth-of-existential-implications paradox' involving wrongfully intradimensional $<$ amplituding/formative-epistemicity $>$ totalising $\sim$ self-referencingsyncretising/circularity/interiorising/akrasiatic-drag ${ }^{34}$ registry-teleology ${ }^{99}$-mentation and rightfully transdimensional ontological-veridicality rather in an ontological-preconverging-ordementing 20 -apriorising-psychologism/preconverging-or-dementing ${ }^{20}$-apriorising- 
psychologism registry-teleology -mentation is critical in understanding how to circumvent temporal-dispositions circumventive/distractive-temporal-prioritisation-of- ${ }^{3}$ reference-ofthought/temporal-preservation inclination associated with postlogism 77 in hollow-constituting-

\section{<as-disjointed-misappropriation-of-meaningfulness-and-failing-intemporal-preservation>}

(psychopathy and social psychopathy), in lieu of 'intemporal-prioritisation-of- reference-ofthought'-as-conflatedness ${ }^{13}$-or-ontological-reprojecting/intemporal-preservation inclination associated with prelogism ${ }^{78}$-as-of-conviction,-in-profound-supererogation $-<$ existentiallyveridical-'attendant-intradimensional-apriorising/axiomatising/referencing'-logical-duenessprecedes-disontologising-logical-outcome-arrived-at>. Fundamentally, conjugatedpostlogism 77 preconverging-or-dementing ${ }^{20}$-integration hollow-constituting-<as-disjointedmisappropriation-of-meaningfulness-and-failing-intemporal-preservation $>$ is always based on a wrong $<$ amplituding/formative-epistemicity $>$ totalising $\sim$ self-referencingsyncretising/circularity/interiorising/akrasiatic-drag ${ }^{34}$ registry-teleology ${ }^{9}$-mentation in recurrent in hollow-constituting-<as-disjointed-misappropriation-of-meaningfulness-andfailing-intemporal-preservation $>$ in postlogic-backtracking-<iterative-looping-'set-ofdereifying-hollow-narratives-and-acts' $>$ as absolving/fleeting/escaping-reflex-logic (psychopath) or hollow-constituting-<as-disjointed-misappropriation-of-meaningfulness-andfailing-intemporal-preservation $>$ or ${ }^{12}$ conjoining-looping-set-of-narratives as-of-cohering-logicreflex (derived social psychopathy) of hollow narratives, and wrongfully that this is ${ }^{3}$ referenceof-thought; and correspondingly, a rightful transdimensional ontological-representation should imply it is a preconverging-or-dementing ${ }^{20}$-apriorising-psychologism- $<$ stranded-as-rightfullyoblongated/decandored-and-dialectically-or-contendingly-out-of-phase $>$ registry-teleology placeholder-setup/mental-devising-representation/mentation/consciousness-awarenessteleology ${ }^{99}$ and by so doing, to start with, rightfully denying it ${ }^{83}$ reference-of-thought which then fundamentally collapses its soundness-or-ontological-good-faith/authenticity ${ }^{60}$-of- ${ }^{8}$ reference- 
of-thought, as the hollow-constituting-<as-disjointed-misappropriation-of-meaningfulness-andfailing-intemporal-preservation> postlogism 7 -or-disontologising-perverted-outcome-soughtprecedes-existentially-veridical-'attendant-intradimensionalapriorising/axiomatising/referencing'-logical-dueness preconverging-or-dementing ${ }^{20}$ apriorising-psychologism counts on the natural inclination (as 'prelogism 78 -as-of-conviction,-inprofound-supererogation $-<$ existentially-veridical-'attendant-intradimensional-

\section{apriorising/axiomatising/referencing'-logical-dueness-precedes-disontologising-logical-}

outcome-arrived-at> re-engaging reflex') of the 'ontologically-reconstituting-or-prelogic-orlogical-process-precedes-outcome-or-conviction-as-to-profound-supererogation mindset $/{ }^{3}$ reference-of-thought to reflexively engage contendingly/logically with its hollow narratives, with the grander faulty-mentation-procedure-deception-or-urge ${ }^{43}$ not being the hollow narratives per se but in wrongfully implying its veracity/ontological-pertinence as reference-of-thought and implying the falsely apriorising-registry-elements of its fepistemicPychologismic-subliminality-of-individuation-effusing/worlding imbued logicaldueness-or-scape-or-frame, profile-or-stature, presumptuousness-or-arrogation, assumptions, value-reference and teleology; as being an even grander faulty-mentation-proceduredeception-or-urge $^{13}$ of a registry-worldview's/dimension's-uninstitutionalised-threshold ${ }^{102}$ defect- $<$ as-Being-or-ontological-or-existential-defect $>{ }^{5}$, nature of registry-teleology ${ }^{99}$ mentaldevising-representation/mentation, that speaks not only to an act defect but a registryworldview/dimension defect. Thus this insight in transcendental analysis is that by its very nature in that it puts into question ways, assumptions and traditions of thought and practices, the possibility of truly profound insights that go well beyond more or less platitudes and inevitably requires taking stock of the full-depth-of-existential-implications/existentialism of transcendental-meaningfulness-

apriorising/axiomatising/referencing/intelligibilitysettingup/measuringinstrumenting, given the 
need to boldly overcome intellectual and knowledge dead-ends and introduce postconvergingde-mentating/structuring/paradigming shifts often with unconvenient and unpalatable implications to the given registry-worldview/dimension personhoods-and-socialhood-formation. It requires more than just a sense of professional and technical craft but often more critically a profound sense of intemporal/firstnature emanant commitment, an attribute that is by definition of dimensionality-of-sublimating ${ }^{25}-<<$ amplituding/formative $>$ supererogatory $\sim$ dementativeness/epistemic-growth-or-conflatedness /transvaluativerationalising/transepistemicity/anamnestic-residuality/spirit-drivenness-equalisation〉 projection nature and hardly just secondnatured, in thriving for an abstract sense of the intemporal beyond just functioning within the ambits of given ${ }^{83}$ reference-of-thoughtcategorical-imperatives/axioms/registry-teleology with their intemporal preservation limitations as well as their corrupting nature as distractive/circumventive $<$ amplituding/formative-epistemicity $>$ totalising $\sim$ self-referencingsyncretising/circularity/interiorising/akrasiatic-drag ${ }^{34}$ Within all registryworldviews/dimensions as institutional-cumulation/institutional-recomposure-〈as-tohistoriality/ontological-eventfulness /ontological-aesthetic-tracing-<perspectiveontological-normalcy/postconvergence-reflected-‘epistemicity-relativism-determinism’>>, there is a convergence that ensures intemporal-preservation-entropy-or-contiguity-orontological-preservation by selecting as appropriate the "relatively ontologically/intemporally veridical' among myriad possibilities and contradictions of human ${ }^{83}$ reference-of-thought and meaningfulness, turning away from human shallow-limited-mentation-capacity—as-subjecting'educed-unlimitedness/existence-sublimating nascence' to-limitedness/humansubpotency/shortness-of-register-of - meaningfulness-and-teleology /temporality ${ }^{-}$ potency/ ${ }^{7}$ perversion-of- ${ }^{8}$ reference-of-thought- $<$ as-preconverginglyapriorising/axiomatising/referencing-in-nonconviction/madeupness/bottomlining-as-to- 
shallow-supererogation $>$ (wherein 'ontological/intemporal ${ }^{83}$ reference-of-thought and meaningfulness' is wrongly re-conjugated with the temporal-dispositions teleologies/dispositions of ignorance/affordability/opportunism/exacerbation/social-chainismor-social-discomfiture-or-negative-social-aggregation/temporal-enculturation-or-temporalendemisation, inducing corresponding denaturing ${ }^{16}$ of the 'ontological/intemporal ${ }^{8}$ referenceof-thought and meaningfulness' by slantedness/postlogic-effect, miscuing, disjointed-logic, logical-drag, unconscionability-drag, $\quad$ sub-par/formulaic-association/temporal/alibi conventioning-rationalising, and temporal-enculturation/temporal-endemisation-effect, and temporal-enculturation/temporal-endemisation effect) towards profound-limited-mentationcapacity —as-subjecting 'educed-unlimitedness/existence-sublimating nascence' tolimitedness/human-subpotency/longness-of-register-of-meaningfulness/intemporality ${ }^{52}$ potency/registry-soundness which is behind the generation of 'ontological/intemporal reference-of-thought and meaningfulness' and the institutionalisation/intemporalisation process. This convergent selectivity is perpetually directed by 'the-Good/knowledgereification $\sim$ gesturing-and-accounting - of-epistemic-phenomenalism- $<$ inprospective_psychologismic apriorising/axiomatising/referencing-\{of-‘prospectively_ implicited_attendant-ontological-contiguity ' educedexistentialising/contextualising/textualising_'intelligibility/epistemicity/reflexivity-contiguity-

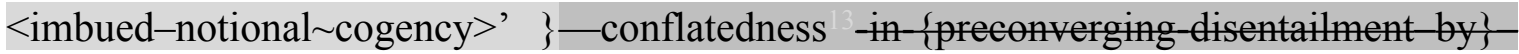
postconverging entailment $>$ /understanding/<amplituding/formativeepistemicity $>$ causality $\sim$ as-to-projective-totalitative-implications-of-prospectivenonpresencing,-for-explicating relative-unreflexivity/relative-reflexivity - ontologicalcontiguity , (not to be confused with good-naturedness/impression-drive) towards the validation of intemporality ${ }^{52}$-potency and the dismissal of temporality ${ }^{8}$-potency, and so in dialectical <cumulating/recomposuring attendant-ontological-contiguity $>$-succession of 
registry-worldviews/dimensions as the successive/snowballing institutionalcumulation/institutional-recomposure-〈as-to- historiality/ontological-

eventfulness /ontological-aesthetic-tracing-<perspective-ontologicalnormalcy/postconvergence-reflected-'epistemicity-relativism-determinism'>>. Thus establishing a human approximating/proxying/aligning relationship with the 'potency of intrinsic-reality/ontological-veridicality (ontological-normalcy) which is a coherent oneness' that can very much be anticipated as ontological-normalcy/postconvergence. In this regard, it should be reiterated that 'registry ( categorical-imperatives/axioms/registry-teleology') establishes ${ }^{8}$ reference-of-thought, and acts as the basis for and defines the operation of logic or logical processing', and it is notionally all about registry-soundness (reflected as soundness of thought) when we are of supplanting-conviction-as-to-profound-supererogation - of‘attendant-intradimensional'-postconverging/dialectical-thinking -apriorising-psychologism or perversion-of- ${ }^{3}$ reference-of-thought- $<$ as-preconverginglyapriorising/axiomatising/referencing-in-nonconviction/madeupness/bottomlining-as-toshallow-supererogation $>$ when we are of threshold-ofnonconviction/madeupness/bottomlining-in-shallow-supererogation $-<$ as-to-' $a$ attendantintradimensional'-prospectively-disontologising preconverging/dementing -apriorisingpsychologism $>$ as with the hollow and formulaic narratives slanted by psychopath and mimicked by temporal-dispositions (beyond-the-consciousness-awareness-teleology ${ }^{9}-<$ ofpreconverging-existential-extrication-as-of-existential-unthought> ) of ignorance/affordability/opportunism/exacerbation/social-chainism-or-social-discomfiture-ornegative-social-aggregation/temporal-enculturation-or-temporal-endemisation in postlogism (disontologising-perverted-outcome-sought-precedes-existentially-veridical-'attendantintradimensional-apriorising/axiomatising/referencing'-logical-dueness). Unlike the 'notion of agreement-disagreement' dealing with soundness/unsoundness of ${ }^{54}$ logical-processing-or- 
logical-implicitation - supposedly-apriorising-in-conviction-as-to-profound-supererogation

wherein a common apriorising-registry of interlocution is already established, there is no logical-basis/logic,-as-derived-from $\sim$ transversality- $<$ for-sublimating-existential-

eventuating/denouement,-from-'thinking-at-first/pure-predisposition-preemptive-of-

prospective-disontologising/subontologising’ as-of-prospectively-disambiguated-affirmed-

and-unaffirmed-'motif-and-apriorising/axiomatising/referencing'> ${ }^{101}$ for one apriorisingregistry disposition as a prospective/superseding/transcending ${ }^{83}$ reference-of-thought like a positivistic registry-worldview to convince another apriorising-registry disposition as a prior/superseded/transcended ${ }^{83}$ reference-of-thought like a non-positivism/medievalism registry-worldview that it is the former's ${ }^{83}$ reference-of-thought that is sound, other than for the fact that its better <amplituding/formative-epistemicity>causality $\sim$ as-to-projectivetotalitative-implications-of-prospective- nonpresencing,-for-explicating relativeunreflexivity/relative-reflexivity - ontological-contiguity will in the middle to long-run be untenable with respect to the latter thus 'collapsing' it; and so reflecting 'Derridean underdetermination-imbued force/violence conception' and 'Foucauldian knowledge/power conception construed as knowledge-empowerment/ignorance-disempowerment' as to supererogating $\{$ 'sublimation affirmation/projection/assertion/notional $\sim$ selfdistantiation/dueness-validating-logicising/suitable-measuringinstrument-validatingmeasuring-<as-to-postconverging-or-dialectical-thinking -apriorising-psychologism>' over 'desublimation unaffirmation/deprojection/deassertion/epistemic-decadence/unduenessinvalidating-logicising/unsuitable-measuringinstrument-invalidating-measuring-<as-topreconverging-or-dementing -apriorising-psychologism>'\} so-underlining existence-as-theabsolute-a-priori-of-conceptualisation and existence — as-sublimatingwithdrawal/unenframing/re-ontologising,-elicited-from-prospective-profoundsupererogation $-<$ as-to-perspective-ontological-normalcy/postconvergence-implied- 
'prospective-aporeticism-overcoming/unovercoming'>. Intradimensionally within a registryworldview like positivism, this could be construed as there is no basis for a mindset $/{ }^{3}$ referenceof-thought advocating for scientific medicine as practised in hospitals to 'logically convince' another mindset $/{ }^{3}$ reference-of-thought advocating rather for traditional medicine (involving a mix of herbalism, incantations, spirits, etc.) that the former is more ontologically-veridical on purely logical terms (as the traditional medicine interlocutor operates logic according to the apriorising-registry or ${ }^{83}$ reference-of-thought- categorical-imperatives/axioms/registryteleology ${ }^{9}$ behind its traditional medicine meaningful-frame while the scientific medicine interlocutor operates logic according to the apriorising-registry or ${ }^{83}$ reference-of-thoughtcategorical-imperatives/axioms/registry-teleology ${ }^{9}$ of a positivistic meaningful-frame), and it is purely the <amplituding/formative-epistemicity>causality $\sim$ as-to-projective-totalitative-

\section{implications-of-prospective- nonpresencing,-for-explicating relative-unreflexivity/relative-}

reflexivity - ontological-contiguity fact in that by-and-large more patients survive/get-cured by going to hospitals which then collapses the traditional medicine interlocutor's ${ }^{83}$ reference-ofthought in the middle to long-run to impose the scientific medicine interlocutor's ${ }^{83}$ reference-ofthought as a common one, and it is only when this common reference arises that the "notion of agreement-disagreement' with regards to logical processing is now relevant, and it is irrelevant and non-applicable before that. The implication is that a différance-disambiguation-ofontologically-veridical- ${ }^{5}$ meaningfulness-and-teleology 99 as meaning produced apparently with the 'same-terms-of-expressions (seemingly-same-implied-meaningfulness)' (seemingly of veridical-ontological $\quad{ }^{8}$ reference-of-thought- categorical-imperatives/axioms/registryteleology ${ }^{9}$,-for-intemporal-preservation-entropy-or-contiguity-or-ontological-preservation in the various instances) but actually implying 'different relations to an ontologically veridical reference-of-thought', underlined by the disambiguated notional firstnaturednessformativeness-<as-to-eventualising-inkling drive-or-seeding-misprising $>$ temporal-to- 
intemporal-dispositions-<so-construed-as-from-perspective-ontological-

normalcy/postconvergence $>$ (aetiological <amplituding/formative-epistemicity $>$ causality $\sim$ asto-projective-totalitative-implications-of-prospective- nonpresencing,-for-

explicating relative-unreflexivity/relative-reflexivity - ontological-contiguity construct), and so whether with regards to the epiphenomenon of psychopathy and social psychopathy (or with respect to ontological-veridicality or issues of ${ }^{83}$ reference-of-thought and meaningfulness generally): - As the 'intemporal-disposition' disposition which is prelogism ${ }^{78}$-as-of-conviction,in-profound-supererogation $-<$ existentially-veridical-'attendant-intradimensionalapriorising/axiomatising/referencing'-logical-dueness-precedes-disontologising-logicaloutcome-arrived-at $>$ as to 'implicited_attendant-ontological-contiguity ${ }^{67}$ ' educedexistentialising/contextualising/textualising_'intelligibility/epistemicity/reflexivity_contiguity$<$ imbued-notional cogency>' with respect to the 'same-terms-of-expressions (seeminglysame-implied-meaningfulness)' (based on ontologically-veridical ${ }^{83}$ reference-of-thoughtcategorical-imperatives/axioms/registry-teleology ${ }^{9}$,-for-intemporal-preservation-entropy-orcontiguity-or-ontological-preservation since its apriorising-registry-elements as totalising 3 psychologismic-subliminality-of-individuation-effusing/worlding imbued logicaldueness-or-scape-or-frame, profile-or-stature, presumptuousness-or-arrogation, assumptions, value-reference and teleology' are ontologically-veridical), which are 'ontologicallyreconstituted/deconstructed' and hence of sound/veridical ${ }^{83}$ reference-of-thought (registrysoundness reflected as soundness-or-ontological-good-faith/authenticity ${ }^{6}$-of- ${ }^{83}$ reference-ofthought), and in registry-worldview terms dialectically-in-phase as "postconverging-ordialectical-thinking -apriorising-psychologism'. - As the 'consciously-slanting- whetherpsychopathic-or-other-postlogic\}-temporal-disposition' disposition which as of the thresholdof-nonconviction/madeupness/bottomlining-in-shallow-supererogation $-<$ as-to-'attendantintradimensional'-prospectively-disontologising preconverging/dementing -apriorising- 
psychologism> or formulaic-projection/postlogism 77 with respect to the 'same-terms-ofexpressions (seemingly-same-implied-meaningfulness)' (based on ontologically non-veridical reference-of-thought- categorical-imperatives/axioms/registry-teleology ${ }^{9}$,-for-intemporalpreservation-entropy-or-contiguity-or-ontological-preservation since the implied slanting apriorising-registry-elements as \{epistemic-totalising 3 psychologismic-subliminality-ofindividuation —effusing/worlding imbued logical-dueness-or-scape-or-frame, profile-or-stature, presumptuousness-or-arrogation, assumptions, value-reference and teleology are not ontologically-veridical but rather usurping/impostoring), which are 'hollow-constituted' and hence of unsound/non-veridical ${ }^{83}$ reference-of-thought ( perversion-of- $^{8}$ reference-of-thought$<$ as-preconvergingly-apriorising/axiomatising/referencing-innonconviction/madeupness/bottomlining-as-to-shallow-supererogation $>$, and in registryworldview terms dialectically-out-of-phase/dialectically-primitive as preconverging-ordementing -apriorising-psychologism. - As conjugating by interlocutors deriving directly-orindirectly/unconsciously-or-consciously from the consciously-slanting-aspsychopathic/postlogic-temporal-disposition as 'derived-slantedignorance/affordability/opportunism/exacerbation/social-chainism-or-social-discomfiture-ornegative-social-aggregation/temporal-enculturation-or-temporal-endemisation' dispositions thus which are parenthetically/incidentally- $\{$ by-their-specific-conjugations-to-theslanting/postlogism 7 \} as of threshold-of-nonconviction/madeupness/bottomlining-in-shallowsupererogation -<as-to- 'attendant-intradimensional'-prospectivelydisontologising preconverging/dementing -apriorising-psychologism $>$ as formulaicprojection/postlogism with respect to the 'same-terms-of-expressions (seemingly-sameimplied-meaningfulness)' (as ontologically non-veridical ${ }^{83}$ reference-of-thought- categoricalimperatives/axioms/registry-teleology ${ }^{9}$,-for-intemporal-preservation-entropy-or-contiguityor-ontological-preservation since their slanting/postlogism -induced-and-implied-registry- 
elements of their respective \{epistemic-totalising 3 ? effusing/worlding imbued logical-dueness-or-scape-or-frame, profile-or-stature, presumptuousness-or-arrogation, assumptions, value-reference and teleology are not ontologically-veridical), which are 'hollow-constituted' and hence are of unsound/non-veridical reference-of-thought ( 7 perversion-of- ${ }^{8}$ reference-of-thought-<as-preconverginglyapriorising/axiomatising/referencing-in-nonconviction/madeupness/bottomlining-as-toshallow-supererogation >), and in registry-worldview terms dialectically-out-ofphase/dialectically-primitive as preconverging-or-dementing -apriorising-psychologism. - As in registry-worldview terms, all the temporal-dispositions in their 'dynamic-cumulativeaftereffect of subontologisation' paradoxically define and establish the said registry-worldview's 'threshold-of-nonconviction/madeupness/bottomlining-in-shallow-supererogation ${ }^{9}<$ as-to'attendant-intradimensional'-prospectively-disontologising preconverging/dementing apriorising-psychologism>' (or socially-betraying-threshold-of-ontologising-depth-of-analysis or socially-betraying-threshold-of-intemporal-preservation-entropy-or-contiguity-orontological-preservation or uninstitutionalised-threshold ${ }^{102}$ ) as rather hollow-constituting-<asdisjointed-misappropriation-of-meaningfulness-and-failing-intemporal-preservation>, $\quad$ and requiring the 'ontological-reconstituting-as-to-conflatedness ${ }^{13} /$ deconstruction of new/prospective 'terms of expressions' (along new/prospective veridical-ontological reference-of-thought- categorical-imperatives/axioms/registry-teleology ${ }^{99}$,-for-intemporalpreservation-entropy-or-contiguity-or-ontological-preservation) for new/prospective sound/veridical ${ }^{83}$ reference-of-thought (registry-soundness reflected as soundness-orontological-good-faith/authenticity ${ }^{-o f}{ }^{8}$ reference-of-thought), and in registry-worldview terms dialectically-in-phase as 'postconverging-or-dialectical-thinking ${ }^{21}$-apriorisingpsychologism'. - As 'threshold-of-nonconviction/madeupness/bottomlining-in-shallowsupererogation -<as-to-'attendant-intradimensional'-prospectively- 
disontologising $\sim$ preconverging/dementing -apriorising-psychologism> $>$ implies that ontological-normalcy/postconvergence (prospective-transcendence-in-perpetually-upholdingintemporal-preservation-entropy-or-contiguity-or-ontological-preservation) being prospective given human limited-mentation-capacity-deepening -as-subjecting limitedness/humansubpotency to-educed-unlimitedness/existence-sublimating nascence'53, the prospective registry-worldview in achieving the ontological-prospection 'is ontologically-veridical and thus dialectically-in-phase as postconverging-or-dialectical-thinking -apriorising-psychologism' while the prior registry-worldview inherently failing/not-upholding-<as-ofapriorising/axiomatising/referencing $>$ the ontological-prospection 'becomes non-veridical ontologically and dialectically-out-of-phase as preconverging-or-dementing ${ }^{20}$-apriorisingpsychologism', and in the broader sense the projective cumulation/recomposuring of limitedmentation-capacity-deepening —as-subjecting limitedness/human-subpotency-to-'educedunlimitedness/existence-sublimating nascence' along such successive dialecticisms of ontological-prospections is what enables the institutionalisation/intemporalisation process by defining human mentation-capacity-limit in a prior ${ }^{83}$ reference-of-thought in hollowconstituting-<as-disjointed-misappropriation-of-meaningfulness-and-failing-intemporal-

preservation $>$ (as the new preconverging-or-dementing ${ }^{20}$-apriorising-psychologism), and the prospective/transcending/superseding ${ }^{83}$ reference-of-thought that redefines human mentationcapacity-limit by ontologically-reconstituting/deconstruction (as the new 'postconverging-ordialectical-thinking -apriorising-psychologism'). By 'reflecting a preconverging-ordementing -apriorising-psychologism placeholder-setup/mental-devisingrepresentation/mentation' so as to point out the registry-defect of intradimensional settingaside/passing-over/ignoring (which implies from ontological-normalcy/postconvergence insight, the registry-worldview is rather hollow-constituting-<as-disjointed-misappropriationof-meaningfulness-and-failing-intemporal-preservation> defective ${ }^{83}$ reference-of-thought- 
categorical-imperatives/axioms/registry-teleology ${ }^{99}$,-for-intemporal-preservation-entropy-or-

contiguity-or-ontological-preservation

and

failing/not-upholding-<as-of-

apriorising/axiomatising/referencing >

intemporal-preservation-entropy-or-contiguity-or-

ontological-preservation) and so pointing out its notional-discontiguity/epistemicdiscontiguity ${ }^{6}-<$ between - prior-shallow-supererogation -of-mentally-

aestheticised preconverging/dementing -qualia-schema_and_prospective-profound-

supererogation -of-mentally-aestheticised postconverging/dialectical-thinking -qualia-

schema>, and in so doing keeping the 'superseding-oneness-of-ontology/ontologicalveridicality/relative-unreflexivity/relative-reflexivity - ontological-contiguity ${ }^{6}$, by recurrently implying that the profoundness-of-ontology-as-a-oneness lies with the prospective/superseding/transcending ${ }^{83}$ reference-of-thought that re-establishes relativeunreflexivity/relative-reflexivity ontological-contiguity ${ }^{67}$ ontological-veridicality by 'ontological-reconstituting-as-to-conflatedness ${ }^{13}$ /deconstruction in upholding the 'postconverging-or-dialectical-thinking -apriorising-psychologism'; the implication is that the $<$ cumulating/recomposuring attendant-ontological-contiguity $>$-successive registryworldviews/dimensions as the institutional-cumulation/institutional-recomposure-〈as-tohistoriality/ontological-eventfulness /ontological-aesthetic-tracing-<perspectiveontological-normalcy/postconvergence-reflected-'epistemicity-relativism-determinism'>> are a strive for successive better profoundness-of-ontology-as-a-oneness by perpetually undermining hollow-constituting-<as-disjointed-misappropriation-of-meaningfulness-and-failingintemporal-preservation> and upholding ontological-reconstituting-as-to-conflatedness ${ }^{13}$ as ontological-normalcy. - As 'same-terms-of-expressions (seemingly-same-impliedmeaningfulness)' (seemingly of veridical-ontological ${ }^{83}$ reference-of-thought- categoricalimperatives/axioms/registry-teleology ${ }^{9}$,-for-intemporal-preservation-entropy-or-contiguityor-ontological-preservation in the various instances) highlights broadly the socially 
shared/common ${ }^{83}$ reference-of-thought and meaningfulness primarily based on language in reflection of ontological-veridicality/intrinsic-reality, but how with respect to social-stakecontention-or-confliction our notional $\sim$ firstnaturedness-formativeness-<as-toeventualising inkling-drive-or-seeding-misprising $>$ temporal-to-intemporal-dispositions$<$ so-construed-as-from-perspective-ontological-normalcy/postconvergence $>$ /individuations contextually have differing relations to ontologically-veridical ${ }^{83}$ reference-of-thought and meaningfulness, notwithstanding the 'same-terms-of-expressions (seemingly-same-impliedmeaningfulness)' and corresponding seemingly common ${ }^{83}$ reference-of-thought- categoricalimperatives/axioms/registry-teleology ${ }^{99}$,-for-intemporal-preservation-entropy-or-contiguityor-ontological-preservation, with the 'ontological-reconstituting-as-toconflatedness ${ }^{13} /$ deconstruction with respect to the ontologically non-veridical hollowconstituting-<as-disjointed-misappropriation-of-meaningfulness-and-failing-intemporalpreservation> leading-to/enabling human registry-worldview's/dimension's institutionalisation/intemporalisation. - As with regards to psychopathy and social psychopathy, différance-disambiguation-of-ontologically-veridical- ${ }^{56}$ meaningfulness-and-teleology ${ }^{9} \quad$ in order to effectively construe ontological-veridicality/relative-unreflexivity/relative-reflexivity ontological-contiguity $^{67}$ and disambiguate notional-contiguity/epistemic-contiguity $<$ profound-supererogation -of-mentally-aestheticised postconverging/dialectical-thinking qualia-schema $>$ from notional-discontiguity/epistemic-discontiguity 33 - between - priorshallow-supererogation -of-mentally-aestheticised $\sim$ preconverging/dementing -qualiaschema_and_prospective-profound-supererogation -of-mentally-

aestheticised postconverging/dialectical-thinking -qualia-schema $>$ requires the operational technique of 'Différance-existential-transitory-articulation-of-the-protraction-of- 7 perversionof- ${ }^{8}$ reference-of-thought-<as-preconvergingly-apriorising/axiomatising/referencing-innonconviction/madeupness/bottomlining-as-to-shallow-supererogation >,-of-meaningfulness' 
*which refers to how on-the-one-hand from a suprastructuring construal-〈as-of-"perversion-andderived- perversion-of- reference-of-thought- $<$ as-preconverginglyapriorising/axiomatising/referencing-in-nonconviction/madeupness/bottomlining-as-toshallow-supererogation >-as-to-uninstitutionalised-threshold $\quad$-self-referencing-syncretisingand-subtransversality-<in-desublimating-existential-eventuating/denouement $>\sim$ of-motif-andapriorising/axiomatising/referencing'-and- 'corresponding-ontological-reconstituting-as-toconflatedness $^{13}$-of-veridical- reference-of-thought-as-prospectiveinstitutionalisation/supratransversality-<in-sublimating-existentialeventuating/denouement> of-motif-and-apriorising/axiomatising/referencing'> delineating existential-transitioning-or-iterability-trace-of-narratives-as-dots_or_implicited_tente ontological-contiguity ${ }^{67}$, educedexistentialising/contextmalising/textualising_'intelligibility/epistemicity/reflexivity_contiguity$<$ imbued-notional cogency>' ${ }^{\prime}$-reification_or_intrinsic-reality-ontologicalcoherence_or_superseding-oneness-of-ontology ${ }^{41}$ by ${ }^{55}$ maximalising-recomposuring-forrelative-ontological-completeness ${ }^{8}$ - unenframed/re-ontologising conceptualisation insight, the psychopath/postlogic-character is contextually in vague-rhyming-or-copied-mimicry-orformulaic-projection-or-projection-of-form-or-hollow-and-vague-vocalisation-orsubknowledging ${ }^{4}$ as of in- compulsing-nonconviction/madeupness/bottomlining-

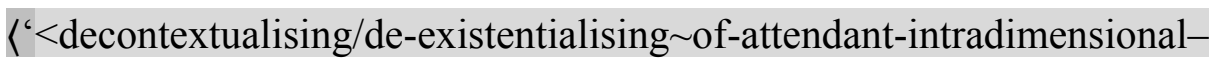
apriorising/axiomatising/referencing>-induced-disontologising'-of-the-'attendantintradimensional-ontologising'-imbued-<contextualising/existentialising $\sim$ attendantontological-contiguity $>$;-in-shallow-supererogation -<as-to-disontologising-pervertedoutcome-sought-precedes-existentially-veridical-'attendant-intradimensionalapriorising/axiomatising/referencing'-logical-dueness $>$ > or postlogicly from social occasions and experiences it witnesses, and wrongly reproduces this from a suprastructuring construal-〈as- 
of-'perversion-and-derived- perversion-of- reference-of-thought-<as-preconvergingly-

apriorising/axiomatising/referencing-in-nonconviction/madeupness/bottomlining-as-to-

shallow-supererogation >-as-to-uninstitutionalised-threshold $\quad$-self-referencing-syncretising-

and-subtransversality-<in-desublimating-existential-eventuating/denouement $>\sim$ of-motif-and-

apriorising/axiomatising/referencing'-and- 'corresponding-ontological-reconstituting-as-to-

conflatedness $^{13}$-of-veridical- reference-of-thought-as-prospective-

institutionalisation/supratransversality-<in-sublimating-existential-

eventuating/denouement $>\sim$ of-motif-and-apriorising/axiomatising/referencing'> delineating

existential-transitioning-or-iterability-trace-of-narratives-as-dots_or_implicited_attendant-

ontological-contiguity ${ }^{67}$; educed-

existentialising/contextualising/textualising_'intelligibility/epistemicity/reflexivity-contiguity-

$<$ imbued-notional cogency $>$ 'reification_or_intrinsic-reality-ontological-

coherence_or_superseding-oneness-of-ontology ${ }^{41}$ by ${ }^{5}$ maximalising-recomposuring-forrelative-ontological-completeness ${ }^{87}$ - unenframed/re-ontologising $\sim$ conceptualisation insight, in postlogic-backtracking-<iterative-looping-'set-of-dereifying-hollow-narratives-and-acts'> $>6$ by its slantedness-of-meaningfulness as 'relevant-occasions-of-opportune' (of social-stakecontention-or-confliction) arise on the basis that the 'copied-hollow-form-of-meaningfulness' is mechanically deterministic of others behaviours such that they can so be swayed, and by following a teleological disposition of 'inductive limitation' or 'so-called principles' that are actually fallacious since such arguments cannot truly be of entailing-<amplituding/formativeepistemicity $>$ totalising $\sim$ in-relative-ontological-completeness ${ }^{87}$ as they require that others do not act likewise as the psychopath/postlogic-character or their implications should be limited to a given target or targets and not be implied as totalisingly-entailing, as the fundamental teleology $\%$ purpose for articulating them is not intemporal/not-of-totalising-entailment but speaks more of a temporal motive, and in a further suprastructuring construal-〈as-of-'perversion- 
and-derived- perversion-of- reference-of-thought-<as-preconvergingly-

apriorising/axiomatising/referencing-in-nonconviction/madeupness/bottomlining-as-to-

shallow-supererogation >-as-to-uninstitutionalised-threshold $\quad$-self-referencing-syncretising-

and-subtransversality-<in-desublimating-existential-eventuating/denouement $>\sim$ of-motif-and-

apriorising/axiomatising/referencing'-and- 'corresponding-ontological-reconstituting-as-to-

conflatedness $^{13}$-of-veridical- reference-of-thought-as-prospective-

institutionalisation/supratransversality-<in-sublimating-existential-

eventuating/denouement $>\sim$ of-motif-and-apriorising/axiomatising/referencing'> delineating

existential-transitioning-or-iterability-trace-of-narratives-as-dots_or_implicited_attendant-

ontological-contiguity ${ }^{67}$; educed-

existentialising/contextmalising/textualising_ intelligibility/epistemicity/reflexivity-contiguity-

$<$ imbued-notional cogency $>$ 'reification_or_intrinsic-reality-ontological-

coherence_or_superseding-oneness-of-ontology ${ }^{41}$ by ${ }^{55}$ maximalising-recomposuring-forrelative-ontological-completeness ${ }^{8}$ - unenframed/re-ontologising conceptualisation insight, on-the-other-hand how circumstantially it's interlocutors unconsciously-orconsciously/wittingly-or-unwittingly by temporal-accommodation-or-interest seemingly inprelogic supplanting-conviction-as-to-profound-supererogation -of-'attendantintradimensional'-postconverging/dialectical-thinking -apriorising-psychologismly alignment (as conjoining) to this formulaic slanting compulsingnonconviction/madeupness/bottomlining-〈“<decontextualising/de-existentialising $\sim$ ofattendant-intradimensional-apriorising/axiomatising/referencing $>$-induced-disontologising'-ofthe-'attendant-intradimensional-ontologising'-imbued-

$<$ contextualising/existentialising attendant-ontological-contiguity $>$;-in-shallow-

supererogation -<as-to-disontologising-perverted-outcome-sought-precedes-existentiallyveridical-'attendant-intradimensional-apriorising/axiomatising/referencing'-logical-dueness $>>$ 
or postlogic meaningfulness, and so recurrently in ${ }^{12}$ conjoining-looping-set-of-narratives to the psychopathic/postlogic-character slantedness-of-meaningfulness postlogic-backtracking$<$ iterative-looping-'set-of-dereifying-hollow-narratives-and-acts' $>$; ; wherein this rather requires from an ontological/intemporal perspective of threshold-ofnonconviction/madeupness/bottomlining-in-shallow-supererogation $-<$ as-to-' attendantintradimensional'-prospectively-disontologising preconverging/dementing -apriorisingpsychologism> reflection of both the (postlogic-backtracking-<iterative-looping-'set-ofdereifying-hollow-narratives-and-acts'>76) psychopathic/postlogic-character and by extension the ( ${ }^{2}$ conjoining-looping-set-of-narratives) interlocutors, and thus as dialectically-out-ofphase/dialectically-primitive, that is, as they are involved in the ${ }^{7}$ perversion-of- ${ }^{8}$ reference-ofthought-<as-preconvergingly-apriorising/axiomatising/referencing-in-

nonconviction/madeupness/bottomlining-as-to-shallow-supererogation $>$ of positivisticmeaningfulness or procrypticism, and beyond just procrypticism, with regards to 7 perversionof- ${ }^{83}$ reference-of-thought-<as-preconvergingly-apriorising/axiomatising/referencing-innonconviction/madeupness/bottomlining-as-to-shallow-supererogation $>$ of all institutionalcumulation/institutional-recomposure-〈as-to- historiality/ontological-

eventfulness /ontological-aesthetic-tracing-<perspective-ontologicalnormalcy/postconvergence-reflected-'epistemicity-relativism-determinism'>> in all registryworldviews/dimensions (given that postlogism 77 as disontologising-perverted-outcome-soughtprecedes-existentially-veridical-'attendant-intradimensional-

apriorising/axiomatising/referencing'-logical-dueness is behind all registryworldviews/dimensions perversion-of- ${ }^{-3}$ reference-of-thought- $<$ as-preconverginglyapriorising/axiomatising/referencing-in-nonconviction/madeupness/bottomlining-as-toshallow-supererogation $>$ whether instigated from a physiological condition or not). This 'postlogic denaturing of temporal-dispositions individuations ontological-performance ${ }^{72}$ 
$<$ including-virtue-as-ontology $>/$ morality/ethics/justice/etc. as conjugated-postlogism ${ }^{7}{ }^{2}$ is soinherently linked with the registry-worldview uninstitutionalised-threshold ${ }^{12}$ associated with perversion-of- ${ }^{8}$ reference-of-thought-<as-preconvergingly-

apriorising/axiomatising/referencing-in-nonconviction/madeupness/bottomlining-as-to-

shallow-supererogation $>$,-in-recurrent-utter-uninstitutionalisation, $\quad{ }^{74}$ perversion-ofreference-of-thought-<as-preconvergingly-apriorising/axiomatising/referencing-innonconviction/madeupness/bottomlining-as-to-shallow-supererogation >,-of-baseinstitutionalisation or ununiversalisation, ${ }^{74}$ perversion-of- ${ }^{8}$ reference-of-thought- $<$ aspreconvergingly-apriorising/axiomatising/referencing-innonconviction/madeupness/bottomlining-as-to-shallow-supererogation $>$,-of-universalisation or non-positivism/medievalism, and ${ }^{7}$ perversion-of- ${ }^{-}$reference-of-thought- $<$aspreconvergingly-apriorising/axiomatising/referencing-innonconviction/madeupness/bottomlining-as-to-shallow-supererogation >,-of-positivism or procrypticism, and so going by the 7 perversion-of- ${ }^{2}$ reference-of-thought- $<$ as-preconverginglyapriorising/axiomatising/referencing-in-nonconviction/madeupness/bottomlining-as-toshallow-supererogation $>$ of their respective meaningfulness and corresponding ${ }^{83}$ reference-ofthought- ${ }^{8}$ ategorical-imperatives/axioms/registry-teleology ${ }^{99}$,-for-intemporal-preservationentropy-or-contiguity-or-ontological-preservation in accordance with human-subpotencyaporia/undecidability/dilemma/ought-indeterminacy/deficiency/limitation/constraint—imbued'notional firstnaturedness-formativeness-<as-to-eventualising inkling-drive-or-seedingmisprising $>$ temporal-to-intemporal-dispositions- $<$ so-construed-as-from-perspectiveontological-normalcy/postconvergence>'-existentialism-form-factor. Without the operational technique of 'Différance-existential-transitory-articulation-of-the-protraction-of- ${ }^{-1}$ perversionof- reference-of-thought-<as-preconvergingly-apriorising/axiomatising/referencing-innonconviction/madeupness/bottomlining-as-to-shallow-supererogation >,-of- 
meaningfulness', the psychopathic/postlogic-character and its interlocutors will, going by the supplanting-conviction-as-to-profound-supererogation —of-'attendant-intradimensional'postconverging/dialectical-thinking -apriorising-psychologism reflex or prelogic-reflexadmittance-reflex or in-phase-reflex, be engaged/related-to wrongly as being in relativeunreflexivity/relative-reflexivity - ontological-contiguity ${ }^{77}$ ontological-veridicality instead of being of notional-discontiguity/epistemic-discontiguity ${ }^{63}<$ between - prior-shallowsupererogation -of-mentally-aestheticised preconverging/dementing -qualiaschema_and_prospective-profound-supererogation -of-mentallyaestheticised postconverging/dialectical-thinking -qualia-schema $>$ of apriorising/axiomatising/referencing/intelligibilitysettingup/measuringinstrumenting (perversion of ${ }^{83}$ reference-of-thought/meaningful-reference/anchoring-of-meaning/registryworldview), as they are emphasising the 'same-terms-of-expressions (seemingly-same-impliedmeaningfulness)' without reference to existential-<disontologising/re-ontologisingaporeticism> reality whereas such a 'Différance-existential-transitory-articulation-of-theprotraction-of- ${ }^{7}$ perversion-of- ${ }^{-}$reference-of-thought- $<$as-preconverginglyapriorising/axiomatising/referencing-in-nonconviction/madeupness/bottomlining-as-toshallow-supererogation >,-of-meaningfulness' operant technique reflects/perspectivates those 'same-terms-of-expressions (seemingly-same-implied-meaningfulness)' wrongly emphasised with reference to existential-<disontologising/re-ontologising aporeticism $>$ reality (as suprastructuring construal-〈as-of-'perversion-and-derived- perversion-of- reference-ofthought-<as-preconvergingly-apriorising/axiomatising/referencing-innonconviction/madeupness/bottomlining-as-to-shallow-supererogation >-as-touninstitutionalised-threshold -self-referencing-syncretising-and-subtransversality-<indesublimating-existential-eventuating/denouement $>\sim$ of-motif-andapriorising/axiomatising/referencing'-and- 'corresponding-ontological-reconstituting-as-to- 
conflatedness $^{13}$-of-veridical- reference-of-thought-as-prospective-

institutionalisation/supratransversality-<in-sublimating-existential-

eventuating/denouement> of-motif-and-apriorising/axiomatising/referencing'> delineating

existential-transitioning-or-iterability-trace-of-narratives-as-dots_or_implicited_attendant-

ontological-contiguity ${ }^{67}$; educed-

existentialising/contextmalising/textualising_ intelligibility/epistemicity/reflexivity-contiguity-

$<$ imbued-notional cogency>' ${ }^{\prime}$-reification_or_intrinsic-reality-ontological-

coherence_or_superseding-oneness-of-ontology ${ }^{41}$ by ${ }^{5}$ maximalising-recomposuring-forrelative-ontological-completeness ${ }^{87}$ - unenframed/re-ontologising conceptualisation insight of meaningfulness) and so establishing their notional-discontiguity/epistemic-discontiguity ${ }^{3}$

\section{$<$ between-prior-shallow-supererogation -of-mentally-}

aestheticised preconverging/dementing -qualia-schema_and_prospective-profound-

supererogation -of-mentally-aestheticised postconverging/dialectical-thinking -qualia-

schema $>$ or ontological-non-veridicality. This technique is a proof of the Sartrean notion of 'existence-preceding-essence' or the Derridean notion of 'there is nothing outside the text' (with the text, from an overall insight of presence and absence metaphysics, rather construable as ontological meaningfulness, with the implication that there is no meaningfulness that is not in ontological-veridicality/relative-unreflexivity/relative-reflexivity-ontological-contiguity ${ }^{67}$, or by the Sartrean argument, there is no essence-of-meaningfulness outside existentialdisontologising/re-ontologising aporeticism $>$ contextualisation of meaningfulness); as the wrong notion of 'non-existential-transitioning-or-iterability-trace-of-narratives-asdots_or_implieited_antentological-contiguity ${ }^{67}$ ' educedexistentialising/contextualising/textualising_'intelligibility/epistemicity/reflexivity-contiguity$<$ imbued-notional cogency ${ }^{\prime}$-reification_or_intrinsic-reality-ontologicalcoherence_or_superseding-oneness-of-ontology ${ }^{4}$, or mere-formulaicity/ritualisation- $<$ as-to- 
mere-formulaic - methodologising/mutualising/organising/institutionalising,-prospectively-

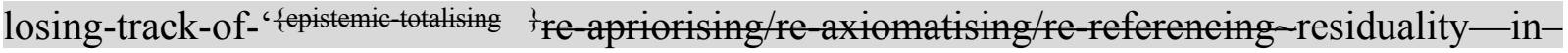
re-originariness/re-origination'> state of essence-of-meaningfulness' (in the case where essenceof-meaningfulness is considered as definitely/absolutely given by the mereformulaicity/ritualisation-<as-to-mere-formulaic-

methodologising/mutualising/organising/institutionalising,-prospectively-losing-track-of-

‘\{epistemic-totalising łre-apriorising/re-axiomatising/re-referencing $\sim$ residuality-in-re-

originariness/re-origination'> of $>\quad$ reference-of-thought- categoricalimperatives/axioms/registry-teleology ${ }^{9}$ without considering whether these are in intemporalpreservation-entropy-or-contiguity-or-ontological-preservation in-the-very-first-place) is the basis of psychopathic/postlogic-character and their interlocutors (beyond-the-consciousnessawareness-teleology $-<$ of-preconverging-existential-extrication-as-of-existential-

unthought $>$ ) hollow-constituting-<as-disjointed-misappropriation-of-meaningfulness-andfailing-intemporal-preservation> (to the ${ }^{83}$ reference-of-thought- categoricalimperatives/axioms/registry-teleology $\quad$ but failing/not-upholding-<as-ofapriorising/axiomatising/referencing > to uphold intemporal-preservation/entropy/contiguity) by vague-rhyming-or-copied-mimicry-or-formulaic-projection-or-projection-of-form-or-hollowand-vague-vocalisation-or-subknowledging ${ }^{4}$ and implying wrongly they are in a state of supplanting-conviction-as-to-profound-supererogation —of-'attendant-intradimensional'postconverging/dialectical-thinking -apriorising-psychologism (be it implied bad or good supplanting-conviction-as-to-profound-supererogation —of-'attendant-intradimensional'postconverging/dialectical-thinking -apriorising-psychologism, to falsely initiate the 'implicitation-of-notion-of-agreement-or-disagreement' as ${ }^{5}$ logical-processing-or-logicalimplicitation - supposedly-apriorising-in-conviction-as-to-profound-supererogation issue rather than the more profound issue of perversion-and-derived- ${ }^{7}$ perversion-of- ${ }^{8}$ reference-of- 
thought-<as-preconvergingly-apriorising/axiomatising/referencing-in-

nonconviction/madeupness/bottomlining-as-to-shallow-supererogation $>$ ) in lieu of their true veridical state of being in a state of threshold-of-nonconviction/madeupness/bottomlining-inshallow-supererogation -<as-to-'attendant-intradimensional'-prospectivelydisontologising preconverging/dementing -apriorising-psychologism> (which speaks of perversion-of- ${ }^{3}$ reference-of-thought-<as-preconverginglyapriorising/axiomatising/referencing-in-nonconviction/madeupness/bottomlining-as-toshallow-supererogation $>$ with the corresponding need rather for a différance-disambiguationof-ontologically-veridical- ${ }^{5}$ meaningfulness-and-teleology ${ }^{9}$ ), and thus wrongly eliciting that they are in a state of 'postconverging-or-dialectical-thinking -apriorising-psychologism' whereas in veridicality they are in a state of preconverging-or-dementing ${ }^{20}$-apriorisingpsychologism and thus dialectically-out-of-phase, wherein as well, the right notion of suprastructuring construal-〈as-of-'perversion-and-derived- perversion-of- reference-ofthought-<as-preconvergingly-apriorising/axiomatising/referencing-innonconviction/madeupness/bottomlining-as-to-shallow-supererogation $>$-as-touninstitutionalised-threshold -self-referencing-syncretising-and-subtransversality-<indesublimating-existential-eventuating/denouement $>\sim$ of-motif-andapriorising/axiomatising/referencing'-and-'corresponding-ontological-reconstituting-as-toconflatedness ${ }^{13}$-of-veridical- reference-of-thought-as-prospectiveinstitutionalisation/supratransversality-<in-sublimating-existentialeventuating/denouement> of-motif-and-apriorising/axiomatising/referencing'> delineating existential-transitioning-or-iterability-trace-of-narratives-as-dots_or_implicited_attendantontological-contiguity ${ }^{6}$ ' educedexistentialising/contextualising/textualising_intelligibility/epistemicity/reflexivity-contiguity$<$ imbued-notional cogency> ${ }^{\prime}$-reification_or_intrinsic-reality-ontological- 
coherence_or_superseding-oneness-of-ontology ${ }^{41}$ by $\quad{ }^{55}$ maximalising-recomposuring-forrelative-ontological-completeness ${ }^{7}$ — unenframed/re-ontologising conceptualisation insight of essence-of-meaningfulness (as existence-precedes/defines-essence, based on contextualising insight from the precedence of existence as becoming) re-establishes the requisite ontologicallyveridical contextualisation of essence-of-meaningfulness by 'ontologicallyreconstituting'/deconstruction of ${ }^{83}$ reference-of-thought and meaningfulness that is veridically supplanting-conviction-as-to-profound-supererogation —of-'attendant-intradimensional'postconverging/dialectical-thinking -apriorising-psychologism since it sticks to intemporalpreservation-entropy-or-contiguity-or-ontological-preservation by overriding the prior reference-of-thought- categorical-imperatives/axioms/registry-teleology ${ }^{9}$ that is failing/notupholding-<as-of-apriorising/axiomatising/referencing $>$ intemporal-preservation-entropy-orcontiguity-or-ontological-preservation with new/prospective ${ }^{83}$ reference-of-thoughtcategorical-imperatives/axioms/registry-teleology to uphold intemporal-preservationentropy-or-contiguity-or-ontological-preservation, and hence implying a state of postconverging-or-dialectical-thinking -apriorising-psychologism that is dialectically-inphase. Hence the "expression of ${ }^{8}$ reference-of-thought and meaningfulness in suprastructuring construal as of 'perversion-and-derived- perversion-of- ${ }^{7}$ reference-of-thought- $<$ aspreconvergingly-apriorising/axiomatising/referencing-in-

uninstitutionalised-threshold ${ }^{102}$-self-referencing-syncretising-and-subtransversality-<in-

\section{desublimating-existential-eventuating/denouement $>\sim$ of-motif-and-}

apriorising/axiomatising/referencing'-and- 'corresponding-ontological-reconstituting-as-to-

conflatedness ${ }^{13}$-of-veridical- ${ }^{8}$ reference-of-thought-as-prospective-

institutionalisation/supratransversality-<in-sublimating-existential-

eventuating/denouement $>\sim$ of-motif-and-apriorising/axiomatising/referencing, delineating 
existential-transitioning-or-iterability-trace-of-narratives-as-dots_or_implicited_attendantontological-contiguity ${ }^{67} \sim$ educed-

existentialising/contextualising/textualising_'intelligibility/epistemicity/reflexivity-contiguity$<$ imbued-notional cogency>' ${ }^{\prime}$-reification_or_intrinsic-reality-ontological-

coherence_or_superseding-oneness-of-ontology ${ }^{41}$ by $\quad{ }^{55}$ maximalising-recomposuring-forrelative-ontological-completeness ${ }^{8}$ —unenframed/re-ontologising conceptualisation insight' as allowed by the technique of the 'Différance-existential-transitory-articulation-of-theprotraction-of- perversion-of- $^{-1}$ reference-of-thought-<as-preconverginglyapriorising/axiomatising/referencing-in-nonconviction/madeupness/bottomlining-as-toshallow-supererogation $>$,-of-meaningfulness' enables the disambiguation of the appropriateness of ${ }^{83}$ reference-of-thought/apriorising-registry-wordview into the shortnessesof-register-of-meaningfulness/temporal-dispositions and longness-of-register-ofmeaningfulness/intemporal-disposition; as the suprastructuring construal-〈as-of-"perversionand-derived- perversion-of- reference-of-thought-<as-preconverginglyapriorising/axiomatising/referencing-in-nonconviction/madeupness/bottomlining-as-toshallow-supererogation >-as-to-uninstitutionalised-threshold -self-referencing-syncretisingand-subtransversality-<in-desublimating-existential-eventuating/denouement $>\sim$ of-motif-andapriorising/axiomatising/referencing'-and- 'corresponding-ontological-reconstituting-as-toconflatedness ${ }^{13}$-of-veridical- reference-of-thought-as-prospectiveinstitutionalisation/supratransversality-<in-sublimating-existentialeventuating/denouement> of-motif-and-apriorising/axiomatising/referencing'> delineating existential-transitioning-or-iterability-trace-of-narratives-as-dots_or_implicited_attendantontological-contiguity ${ }^{67} \sim$ educedexistentialising/contextualising/textualising_'intelligibility/epistemicity/reflexivity-contiguity$<$ imbued-notional $\sim$ cogency $>$ 'reification_or_intrinsic-reality-ontological- 
coherence_or_superseding-oneness-of-ontology ${ }^{41}$ by $\quad{ }^{55}$ maximalising-recomposuring-forrelative-ontological-completeness ${ }^{7}$ — unenframed/re-ontologising conceptualisation insight of essence-of-meaningfulness keeps/upholds the 'superseding-oneness-of-ontology' in relativeunreflexivity/relative-reflexivity ontological-contiguity ${ }^{67}$ ontological-veridicality and consequently is 'postconverging-or-dialectical-thinking -apriorising-psychologism' unlike a 'static or abstract unsound/virtuality-or-Being-construal-as-abstract-construal-as-of-flawedand-shallow-and-non-veridical-existential-reference state of essence-of-meaningfulness', which doesn't keep/uphold the 'superseding-oneness-of-ontology' existentially-<disontologising/reentologising aporeticism $>$ and thus is of notional-discontiguity/epistemic-discontiguity ${ }^{3}$ $<$ between-prior-shallow-supererogation -of-mentallyaestheticised $\sim$ preconverging/dementing -qualia-schema_and_prospective-profoundsupererogation -of-mentally-aestheticised postconverging/dialectical-thinking -qualiaschema $>$ and consequently is preconverging-or-dementing ${ }^{20}$-apriorising-psychologism. This latter point can be seen in context in the example priorly highlighted at the beginning: For instance, if an adult psychopath were to meet a stranger and spoke to him about another stranger whom it knows nothing about, saying logically that it is a bad thing for this guy to be molesting children, etc. The logical operation is entirely right in abstract terms but does the apriorisingregistry apply?, i.e. the faulty-mentation-procedure-deception-or-urge ${ }^{3}$ is not with regards to the logic (which is technically true) but with the 'implied' denaturing of the elements of the apriorising-registry as of ${ }^{83}$ reference-of-thought- categorical-imperatives/axioms/registryteleology (by simply implying their 'static or abstract non-veridical/vacuous state of essenceof-meaningfulness' over suprastructuring construal-〈as-of-'perversion-and-derivedperversion-of- reference-of-thought-<as-preconverginglyapriorising/axiomatising/referencing-in-nonconviction/madeupness/bottomlining-as-toshallow-supererogation >-as-to-uninstitutionalised-threshold -self-referencing-syncretising- 
and-subtransversality-<in-desublimating-existential-eventuating/denouement $>\sim$ of-motif-and-

apriorising/axiomatising/referencing'-and-'corresponding-ontological-reconstituting-as-to-

conflatedness $^{13}$-of-veridical- reference-of-thought-as-prospective-

institutionalisation/supratransversality-<in-sublimating-existential-

eventuating/denouement $>\sim$ of-motif-and-apriorising/axiomatising/referencing'> delineating

existential-transitioning-or-iterability-trace-of-narratives-as-dots_or_implicited_attendant-

ontological-contiguity ${ }^{67}$, educed-

existentialising/contextualising/textualising_intelligibility/epistemicity/reflexivity-contiguity-

$<$ imbued-notional cogency>' ${ }^{\prime}$-reification_or_intrinsic-reality-ontological-

coherence_or_superseding-oneness-of-ontology ${ }^{41}$ by ${ }^{55}$ maximalising-recomposuring-forrelative-ontological-completeness ${ }^{8}$ — unenframed/re-ontologising conceptualisation insight of essence-of-meaningfulness) which are: implied-logical-dueness-or-implied-scape (the impliedlogical-dueness-or-implied-scape doesn't exist since the psychopath doesn't know the guy), implied-profile (the psychopath is projecting a false representation of itself and the situation), implied-presumptuousness-or-implied-arrogation (the psychopath has no stature to talk about the guy he doesn't know), implied-assumptions (the assumptions implying the psychopath's relationship with the guy and the guy's relationship with children doesn't exist), implied-valuereference (the psychopath's elicitation of a sense of value reference in the interlocutor is unfounded and ridiculous) and implied-teleology (the psychopath's articulation of a sense of purpose on its interlocutor about the guy is hollow mimicking). Finally, the psychopath has articulated a lot of faulty-mentation-procedure-deception-or-urge ${ }^{43}$ but none to do with logic, but everything to do with the denaturing of registry/axiom/categorical-imperatives or the psychopath's unsoundness-or-ontological-bad-faith/inauthenticity -of- ${ }^{6}$ reference-of-thought! So with the psychopath, you don't watch the logic, you watch out for the apriorising-registry for mental-perversion or the psychopath's unsoundness-or-ontological-bad-faith/inauthenticity ${ }^{64}$ 
of- ${ }^{3}$ reference-of-thought! Not only that, it is important to note that this unsoundness-orontological-bad-faith/inauthenticity ${ }^{64}$-of- ${ }^{8}$ reference-of-thought do protract and an ignorant prelogism ${ }^{78}$-as-of-conviction,-in-profound-supererogation $-<$ existentially-veridical-

\section{'attendant-intradimensional-apriorising/axiomatising/referencing'-logical-dueness-precedes-}

disontologising-logical-outcome-arrived-at $>$ mind acting in prelogism ${ }^{78}$-as-of-conviction,-inprofound-supererogation $-<$ existentially-veridical-'attendant-intradimensional-

\section{apriorising/axiomatising/referencing'-logical-dueness-precedes-disontologising-logical-}

outcome-arrived-at $>$ on such postlogic (outcome precedes logical process) non-veridical hollow mimicking narratives is 'technically psychopathic as well' as they are in hollow-constituting<as-disjointed-misappropriation-of-meaningfulness-and-failing-intemporal-preservation> or conjoining-looping-set-of-narratives as-of-cohering-logic-reflex to the psychopath's postlogic-backtracking-<iterative-looping-'set-of-dereifying-hollow-narratives-and-acts'> $>$.

This is known as postlogism 77 or preconverging-or-dementing 2 -integration or compulsiveslanting-preconverging-or-dementing ${ }^{20}$-apriorising or conjugated-postlogism 7 (whether conjugated to in ${ }^{5}$ ignorance/affordability/opportunism/exacerbation/social-chainism-or-socialdiscomfiture-or-negative-social-aggregation/temporal-enculturation-or-temporal-

endemisation), which is to be construed by 'distractive-alignment-to- ${ }^{8}$ reference-of-thought- $<$ ofapriorising/axiomatising/referencing $>{ }^{30}$ and once it is induced by ignorance it leads to an undermining of 'deductive social ${ }^{103}$ universal-transparency ${ }^{104}$-〈transparency-of-totalisingentailing,-as-to-entailing-<amplituding/formative-epistemicity $>$ totalising $\sim$ in-relative-

ontological-completeness \ which protects the internal-coherence of meaning for virtue' and so by way of the 'induced-ring-of-gyges-effect/solipsistic-point-of-temporal-thresholding/pointof-ontological-faith-notion-or-ontological-fideism - imbued-underdetermination-of-motif-andapriorising/axiomatising/referencing-as-so-being-as-of-existential-reality $\quad$ at 'uninstitutionalised-threshold ${ }^{102}$, of registry-worldviews, with subsequent conjugating 
ignorance/affordability/opportunism/exacerbation/social-chainism-or-social-discomfiture-ornegative-social-aggregation/temporal-enculturation-or-temporal-endemisation, the conjugatedpostlogism 7 preconverging-or-dementing ${ }^{20}$-integration is derived from the psychopath's initiated postlogism in hollow-constituting-<as-disjointed-misappropriation-ofmeaningfulness-and-failing-intemporal-preservation $>$ and goes on to lead to social psychopathy; more like a dumb-and-dumb/miscuing degeneration effect. The insight here is that without having at hand a 'Différance-existential-transitory-articulation-of-the-protraction-ofperversion-of- ${ }^{8}$ reference-of-thought-<as-preconvergingly-

apriorising/axiomatising/referencing-in-nonconviction/madeupness/bottomlining-as-to-

shallow-supererogation $>$,-of-meaningfulness' technique which is able to disambiguate the underlying existential-<disontologising/re-ontologising aporeticism $>$ reality of the 'sameterms-of-expressions (seemingly-same-implied-meaningfulness)' with regards to the various interlocutors, whether unsoundness-or-ontological-bad-faith/inauthenticity ${ }^{64}$-of- ${ }^{8}$ reference-ofthought and preconverging-or-dementing ${ }^{20}$-apriorising-psychologism slanted/psychopathic/postlogic interlocutor as well as the various (conjugated-postlogism 77 ) temporal-dispositions ignorance/affordability/opportunism/exacerbation/social-chainism-or-social-discomfiture-ornegative-social-aggregation/temporal-enculturation-or-temporal-endemisation interlocutors or

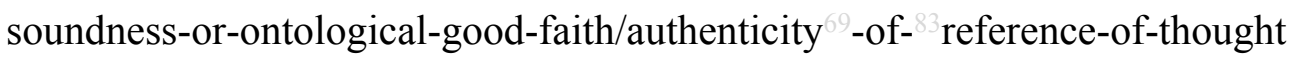
and 'postconverging-or-dialectical-thinking -apriorising-psychologism' intemporal-disposition interlocutor, the natural human reflex when a contestation arises is to be of supplantingconviction-as-to-profound-supererogation —of-'attendant-intradimensional'postconverging/dialectical-thinking -apriorising-psychologism as prelogism ${ }^{78}$-as-of-

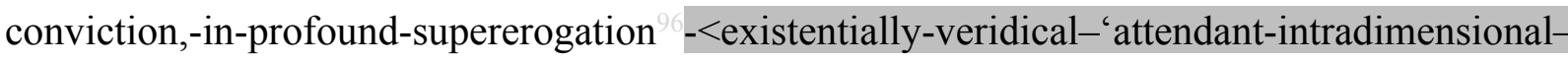
apriorising/axiomatising/referencing'-logical-dueness-precedes-disontologising-logical- 
outcome-arrived-at $>$ (without putting-into-question in-the-very-first-place the veridical state of the various interlocutors registry/registry-elements as fepistemic-totalising $3{ }^{?}$ psychologismicsubliminality-of-individuation-effusing/worlding imbued logical-dueness-or-scape-or-frame, profile-or-stature, presumptuousness-or-arrogation, assumptions, value-reference and teleology ${ }^{9}$ with respect to contestation, and by foregoing this it wrongly attributes the implied essence-of-meaningfulness without the insight of existential-contextualisation by simply and wrongly implying that everybody must be of intemporal-disposition and voiding the notion of disambiguating-and-establishing the existential-contextualisation of the-various-charactersstates-of-minds/the-various-characters-registries with respect to ontological/intemporal meaningfulness in establishing veridicality in-the-very-first-place (whether of temporaldispositions (conjugated-postlogism 77 , intemporal-dispositions or postlogism 77 compulsiveslanting-preconverging-or-dementing ${ }^{20}$-apriorising), hence wrongly turning the analysis into a logical-processing-or-logical-implicitation - supposedly-apriorising-in-conviction-as-toprofound-supererogation issue, rather than an analysis of ${ }^{7}$ perversion-of- ${ }^{83}$ reference-ofthought-<as-preconvergingly-apriorising/axiomatising/referencing-innonconviction/madeupness/bottomlining-as-to-shallow-supererogation $>$ in-the-very-firstplace, as a différance-disambiguation-of-ontologically-veridical- ${ }^{5}$ meaningfulness-andteleology . So without existential-contextualisation, the hollow forms of the essence-ofmeaningfulness are available for arrogation/impostoring by slanted/postlogic as of preconverging-or-dementing ${ }^{20}$-apriorising-psychologism and in protraction/conjugation by the temporal-dispositions (beyond-the-consciousness-awareness-teleology ${ }^{9}-<$ of - preconvergingexistential-extrication-as-of-existential-unthought> ). - As previously explained, it is important to grasp that temporal-to-intemporal individuations dispositions are within the receptacles that are individuals, and hence there is no contradiction in saying that all individuals potentially have both the intemporal-disposition and temporal-dispositions, with the major existential/contextual 
difference among individuals with regards to the existential/contextual inclination to preserveintemporality $^{52}$ or fail-intemporality ${ }^{52} /$ temporality $^{8}$ as social-stake-contention-or-confliction arise varying with regards to the implications of graver and graver temporal consequences (wherein as an archetype elucidation for instance, Socrates or Galileo will strive to keep on preserving intemporality ${ }^{5} /$ longness even when the conventional social-stake-contention-orconfliction threaten as they view the perpetuation of the ideas and principles they stood for were more critical for human posterity, but again a 'sense of intemporality ${ }^{52}$ may vary from an intellectual nature where for instance an ordinary person may spontaneously save from drowning or defend another or others at risk to themselves, etc., implying that individuals 'solipsistic or secondnatured philosophies' with respect to the acuteness of social-stake-contention-orconfliction is more critical in determining their dispositions to preserve-intemporality ${ }^{52}$ or failintemporality ${ }^{52} /$ temporality $^{8}$ ); thus explaining a same notional and contiguous conceptualisation (rather as a variation of degree and not different notions) construed as notional firstnaturednessformativeness-<as-to-eventualising inkling drive-or-seeding misprising $>$ temporal-tointemporal-dispositions-<so-construed-as-from-perspective-ontologicalnormalcy/postconvergence $>$ as shortness-of-register-of- ${ }^{5}$ meaningfulness-and-teleology ${ }^{9}$ to longness-of-register-of- ${ }^{5}$ meaningfulness-and-teleology, and equally explaining why institutionalisation/intemporalisation is possible, as the framework/social-construct wherein social-stake-contention-or-confliction arise can be construed/designed to skew ('intemporality ${ }^{52}$ symmetrising-by-desymmetrising-subsumption-of-temporality ${ }^{\circ}$, for relative intrinsicreality/ontological-veridicality transcendental-enabling/sublimating/supererogatery $\sim$ dementativity) towards and encourage the intemporal-disposition to preserve-intemporality ${ }^{52}$ over

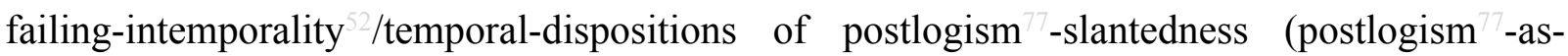
perversion-of- ${ }^{-3}$ reference-of-thought-<as-preconvergingly- 
shallow-supererogation $>$,-instigation-at-a-given-registry-worldview/dimension, $\quad$ that is instigative to the turning of the prospective 'temporal defect-of- ${ }^{5}$ logical-processing-or-logicalimplicitation - supposedly-apriorising-in-conviction-as-to-profound-supererogation of the registry-worldview's/dimension's- ${ }^{83}$ reference-of-thought-for-social-functioning-andaccordance into registry-worldview's/dimension's-uninstitutionalised-threshold ${ }^{102}$-defect- $<$ asBeing-or-ontological-or-existential-defect $>^{85}$ ), and its subsequent conjugation with ignorance/affordability/opportunism/exacerbation/social-chainism-or-social-discomfiture-ornegative-social-aggregation/temporal-enculturation-or-temporal-endemisation. Critically, this accounts for how individuals arrive at their various teleologies/finalities of the intemporaldisposition as 'logically sound acts' or temporal-dispositions as 'logically unsound acts' or defect-of- logical-processing-or-logical-implicitation — supposedly-apriorising-in-convictionas-to-profound-supererogation of the registry-worldview's/dimension's- ${ }^{83}$ reference-ofthought-for-social-functioning-and-accordance (in the latter case, which are more or less incidental and salvable as just attendant). Further in a 'dynamic-cumulative-aftereffect of subontologisation' induced when such defect-of- logical-processing-or-logical-implicitation supposedly-apriorising-in-conviction-as-to-profound-supererogation of the registryworldview's/dimension's- ${ }^{83}$ reference-of-thought-for-social-functioning-and-accordance conjugate to (psychopath or other character) instigated postlogism 77 as disontologisingperverted-outcome-sought-precedes-existentially-veridical-'attendant-intradimensionalapriorising/axiomatising/referencing'-logical-dueness (a mental-disposition that from its instigation 'gives-up on ontological-veridicality/relative-unreflexivity/relative-reflexivityontological-contiguity $^{67}$, not only in terms-as-of-axiomatic-construct of failing/not-upholding$<$ as-of-apriorising/axiomatising/referencing $>\quad$ intemporal-preservation-entropy-or-contiguityor-ontological-preservation as of ontological-normalcy/postconvergence which always factor in human limited-mentation-capacity-deepening —as-subjecting limitedness/human-subpotency 
to-'educed-unlimitedness/existence-sublimating nascence' ${ }^{33}$ by a re-equilibrating metaphysicsof-absence-_implicited-epistemic-veracity-of- nonpresencing-<perspective-ontologicalnormalcy/postconvergence $>$ /postdication but is not even predisposed/inclined to an ontologically veridical ${ }^{83}$ reference-of-thought to meaningfulness but rather relating to meaning as a hollow-form which determines how others act, so-long-as/to-the-limit-that the postlogic character can remain as of the socially-functional-and-accordant ${ }^{3}$ in so doing) inducing in turn temporal-dispositions conjugated-postlogic mental-dispositions (whether unconsciously or consciously, when aligning in-conviction-as-to-profound-supererogation to the postlogic compulsing-nonconviction/madeupness/bottomlining-<'<decontextualising/deexistentialising $\sim$ of-attendant-intradimensional-apriorising/axiomatising/referencing $>$-induceddisontologising'-of-the-'attendant-intradimensional-ontologising'-imbued$<$ contextualising/existentialising attendant-ontological-contiguity $>$;-in-shallowsupererogation -<as-to-disontologising-perverted-outcome-sought-precedes-existentiallyveridical-'attendant-intradimensional-apriorising/axiomatising/referencing'-logicaldueness $>\rangle$ ) conjugating with ${ }^{50}$ ignorance/affordability/opportunism/exacerbation/socialchainism-or-social-discomfiture-or-negative-social-aggregation/temporal-enculturation-ortemporal-endemisation and leading to their registry-worldview's/dimension'suninstitutionalised-threshold ${ }^{102}$-defect-<as-Being-or-ontological-or-existential-defect $>{ }^{85}$, because the temporal-dispositions-so-conjugated-to-postlogism? are now 'acting-recurrentlyin-temporal-preservation, no-longer-as-attendant (defect-of- logical-processing-or-logicalimplicitation - supposedly-apriorising-in-conviction-as-to-profound-supererogation ), while wrongly implying (beyond-the-consciousness-awareness-teleology ${ }^{9}-<$ of - preconvergingexistential-extrication-as-of-existential-unthought>) they are ontologically-veridical or in intemporal-preservation' in their state of conjugated-postlogism 7 . By 'dynamic-cumulativeaftereffect of subontologisation' this defines the given registry-worldview's 'threshold-of- 
nonconviction/madeupness/bottomlining-in-shallow-supererogation $<-<$ as-to-' ${ }^{\text {attendant- }}$ intradimensional'-prospectively-disontologising preconverging/dementing -apriorisingpsychologism>' (uninstitutionalised-threshold ${ }^{102}$ or socially-betraying-threshold-ofontologising-depth-of-analysis or socially-betraying-threshold-of-intemporal-preservationentropy-or-contiguity-or-ontological-preservation), and thus it is dialectically-out-ofphase/dialectically-primitive. It is the exercise of: temporal-dispositions 'acting-recurrently-intemporal-preservation, and-not-as-attendant (defect-of- ${ }^{-}$logical-processing-or-logicalimplicitation - supposedly-apriorising-in-conviction-as-to-profound-supererogation ), while wrongly implying (beyond-the-consciousness-awareness-teleology ${ }^{9}-<$ of-preconvergingexistential-extrication-as-of-existential-unthought>) they are ontologically-veridical or in intemporal-preservation' in rather hollow-constituting-<as-disjointed-misappropriation-ofmeaningfulness-and-failing-intemporal-preservation $>$ conjugated-postlogism 77 (as ${ }^{7}$ perversionof- reference-of-thought-<as-preconvergingly-apriorising/axiomatising/referencing-innonconviction/madeupness/bottomlining-as-to-shallow-supererogation $>$ ) that is behind all the dialectical-out-of-phases/dialectical-primitivities registry-worldviews/dimensions as recurrency-of-utter-uninstitutionalisation ( 7 perversion-of- ${ }^{8}$ reference-of-thought- $<$ aspreconvergingly-apriorising/axiomatising/referencing-innonconviction/madeupness/bottomlining-as-to-shallow-supererogation $>$ in recurrent-utteruninstitutionalisation), ununversalisation ( perversion-of- ${ }^{-}$reference-of-thought- $<$aspreconvergingly-apriorising/axiomatising/referencing-innonconviction/madeupness/bottomlining-as-to-shallow-supererogation $>$ of baseinstitutionalisation), non-positivism/medievalism ( perversion-of- $^{-}$reference-of-thought- $<$aspreconvergingly-apriorising/axiomatising/referencing-in- 
preconvergingly-apriorising/axiomatising/referencing-in-

nonconviction/madeupness/bottomlining-as-to-shallow-supererogation $>$ of positivism)'. This reflects

human-subpotency-aporia/undecidability/dilemma/ought-

indeterminacy/deficiency/limitation/constraint—imbued-'notional firstnaturedness-

formativeness-<as-to-eventualising inkling-drive-or-seeding-misprising $>$ temporal-to-

intemporal-dispositions- $<$ so-construed-as-from-perspective-ontological-

normalcy/postconvergence>'-existentialism-form-factor whereby ontologically speaking,

temporal-dispositions are hollow-constituting-<as-disjointed-misappropriation-of-

meaningfulness-and-failing-intemporal-preservation $>$ (as they are "postlogicly-conjugated to the respective registry-worldviews/dimensions prelogic meaningfulness', and thus in ${ }^{7}$ perversionof- ${ }^{8}$ reference-of-thought-<as-preconvergingly-apriorising/axiomatising/referencing-innonconviction/madeupness/bottomlining-as-to-shallow-supererogation $>$ ) thus endemising/enculturating at the respective registry-worldviews/dimensions 'threshold-ofnonconviction/madeupness/bottomlining-in-shallow-supererogation $-<$ as-to-'attendantintradimensional'-prospectively-disontologising preconverging/dementing -apriorisingpsychologism >' (uninstitutionalised-threshold ${ }^{12}$ or socially-betraying-threshold-ofontologising-depth-of-analysis or socially-betraying-threshold-of-intemporal-preservationentropy-or-contiguity-or-ontological-preservation) the (postlogic) ${ }^{74}$ perversion-of- ${ }^{8}$ referenceof-thought-<as-preconvergingly-apriorising/axiomatising/referencing-innonconviction/madeupness/bottomlining-as-to-shallow-supererogation $>$, which are the respective dialectically-out-of-phase/dialectically-primitive registry-worldviews/dimensions as recurrent-utter-uninstitutionalisation, ununiversalisation, non-positivism/medievalism and prospectively procrypticism. That said in all the registry-worldviews, <amplituding/formativeepistemicity $>$ causality $\sim$ as-to-projective-totalitative-implications-of-prospectivenonpresencing,-for-explicating relative-unreflexivity/relative-reflexivity - ontological- 
contiguity (as a différance-disambiguation-of-ontologically-veridical- ${ }^{56}$ meaningfulness-andteleology ${ }^{9}$ ) and percolation-channelling-<in-deferential-formalisation-transference $>$ from human intemporal-disposition solipsism-of-thought (hence utterly ontologising and rather acting-in-intemporal-preservation, whatever the circumstance) induces in the middle to long run the requisite positive-opportunism-of-social-functioning-and-accordance untenability/internal-contradiction/internal-incoherence/institutional-constraining that dislodges the preconverging-or-dementing ${ }^{20}$-apriorising-psychologism meaningfulness and induce prospective/transcending/superseding institutionalisation/intemporalisation as 'postconvergingor-dialectical-thinking -apriorising-psychologism' meaningfulness as base-institutionalisation, ${ }^{3}$ universalisation, positivism and prospectively notional ${ }^{18}$ deprocrypticism registryworldviews. Without this institutionalisation/intemporalisation 'constraining', there isn't really any temporal intradimensional compunction or insight to cease 'acting-recurrently-in-temporalpreservation, and-not-as-attendant (defect-of- logical-processing-or-logical-implicitationsupposedly-apriorising-in-conviction-as-to-profound-supererogation of the registryworldview's/dimension's- ${ }^{83}$ reference-of-thought-for-social-functioning-and-accordance), while wrongly implying (beyond-the-consciousness-awareness-teleology ${ }^{9}<$ of-preconvergingexistential-extrication-as-of-existential-unthought>) they are ontologically-veridical or in intemporal'. This latter point is critical as it highlights that at the 'threshold-ofnonconviction/madeupness/bottomlining-in-shallow-supererogation $<-<$ as-to- 'attendantintradimensional'-prospectively-disontologising preconverging/dementing -apriorisingpsychologism>', there isn't any logical-basis/logic,-as-derived-from $\sim$ transversality- $<$ forsublimating-existential-eventuating/denouement,-from-'thinking at first/pure-predispositionpreemptive of prospective disentologising/subentologising' as-of-prospectivelydisambiguated-affirmed-and-unaffirmed-'motif-and-apriorising/axiomatising/referencing'> of convincing but for the better <amplituding/formative-epistemicity $>$ causality $\sim$ as-to- 
projective-totalitative-implications-of-prospective- nonpresencing,-for-explicating relative-

unreflexivity/relative-reflexivity - ontological-contiguity of a prospective ${ }^{83}$ reference-ofthought/prospective-registry-worldview established in the middle to long run construed as of de-mentation-〈supererogatory-ontological-de-mentation-or-dialectical-de-mentationstranding-or-attributive-dialectics $\rangle$, which then voids the prior ${ }^{83}$ reference-of-thoughtcategorical-imperatives/axioms/registry-teleology 9 as 'postconverging-or-dialecticalthinking -psychology or psychology-of-mentation-dynamics or natural $\sim$ psychologicaldynamics' psychoanalytic-unshackling/memetic-reordering/institutional-recomposuring. Inmany-ways issues of ${ }^{77}$ perversion-of- ${ }^{8}$ reference-of-thought-<as-preconverginglyapriorising/axiomatising/referencing-in-nonconviction/madeupness/bottomlining-as-toshallow-supererogation $>$ are rather with respect to 'a-country-of-the-blind-scenario', so to speak; wherein $\quad{ }^{7}$ perversion-of- ${ }^{3}$ reference-of-thought- $<$ as-preconverginglyapriorising/axiomatising/referencing-in-nonconviction/madeupness/bottomlining-as-to-

shallow-supererogation $>$ necessarily imply a dialectical situation between two ontologicalreferences with the one being prior/transcended/superseded and the other prospective/transcending/superseding. It is important to grasp that going by human-subpotencyaporia/undecidability/dilemma/ought-indeterminacy/deficiency/limitation/constraint—imbued'notional firstnaturedness-formativeness-<as-to-eventualising -inkling-drive-or-seedingmisprising $>$ temporal-to-intemporal-dispositions- $<$ so-construed-as-from-perspectiveontological-normalcy/postconvergence>'-existentialism-form-factor, the relativeunreflexivity/relative-reflexivity — ontological-contiguity ${ }^{67}$ of-the-human-institutionalisationprocess ${ }^{68}$ where this is skewed ('intemporality ${ }^{52}$-symmetrising-by-desymmetrisingsubsumption-of-temporality ${ }^{\circ}$, for relative intrinsic-reality/ontological-veridicality transcendental-enabling/sublimating/supererogatory $\sim$ de-mentativity) by deferentialformalisation-transference towards the intemporal (intemporalisation) is actually an artifice 
(artificial conceptualisation) that is habituated for its relative positive-opportunism-of-socialfunctioning-and-accordance ${ }^{75}$ with regards to the cross-section of human interest in the middle to long run construed as of ${ }^{15}$ de-mentation-/supererogatory-ontological-de-mentation-ordialectical-de-mentation - stranding-or-attributive-dialectics $\rangle$. However, no institutionalisation construct, going by its implied transcendence-and-sublimity/sublimation/supereregatory $\sim$ dementativity alienating 'present as prior/transcended/superseded ontological-reference conceptualisation' for 'future as prospective/transcending/superseding ontological-reference conceptualisation', has ever been acquiesced to socially without resistance even in instance induced by diffusion involving the power dominance of one cultural entity over another, with such resistance being at least in the short-term of a covert nature and of a $<$ amplituding/formative-epistemicity $>$ totalising $\sim$ self-referencing-

syncretising/circularity/interiorising/akrasiatic-drag ${ }^{34}$ nature as well. Resistance is even stronger where transcendental institutionalisation is implied within a same cultural entity. Thus it might just be the case that the more or less itinerating clanic or tribal groups of early humans were the perfect model for a sort of complementary diffusion of transcendentalism that quickly enabled a hominid to achieve the core assets for its perpetuation of civilisation as complex meaningfulness enabled by language and culture. Insightfully as well the possibility of positivism/rationalrealism arising in Western Europe was greater by this same mechanism of complementary diffusion of transcendentalism given the mutually feeding diffusionary dynamics across the constitutive feudal entities of Medieval Europe sharing a common referent Judaeo-Christian worldview of a 'relatively weak dogmatism'; and this can be contrasted during or just before the same period with the hegemonic or near-hegemonic governance of China and of the Islamic world ultimately stifling their nascent positivistic inclinations involving the stifling of a potential Chinese age of voyage and trading as it turned inward or the stifling of Islamic learning and science respectively. Equally, anthropological examination of various cultural groups shows that 
human progress is not a given and that if the appropriate conditions are not satisfied there is nothing that says a given society will fulfil its potential for prospective transcendence-andsublimity/sublimation/supererogatory $\sim$ de-mentativity, and this author thinks that applies to us as of the positivism- ${ }^{80}$ procrypticism registry-worldview as we are not beyond ontologicalveridicality/intrinsic-reality by mere vague egotistic/self-referential complex but rather as of a lucid contemplation and subjection to insight about prospective ontologicalveridicality/intrinsic-reality axiomatic-construal, in much the same way positivism institutionalisation transcendence-and-sublimity/sublimation/supererogatory-de-mentativity came about. The bigger point here is that while within 'institutionalised constructs', there is more or less summative perception of social-functioning-and-accordance-as-of-social-stakecontention-or-confliction on the basis of common/same/shared registry-worldview ${ }^{8}$ referenceof-thought priorly institutionalised by prospective-institutionalisation/intemporalisation-astranscendence-and-sublimity/sublimation/supererogatory-de-mentativity, however, at uninstitutionalised-threshold ${ }^{102}$, we should be expecting nothing less than the 'normal' humansubpotency-aporia/undecidability/dilemma/ought-

indeterminacy/deficiency/limitation/constraint—imbued-'notional firstnaturednessformativeness-as to eventulising inkling drive or seeding misprising $>$ temporal-tointemporal-dispositions-<so-construed-as-from-perspective-ontologicalnormalcy/postconvergence>'-existentialism-form-factor, and so at the threshold between recurrent-utter-uninstitutionalisation and base-institutionalisation, ${ }^{103}$ universalisation and ununiversalisation, non-positivism/medievalism and positivism, and prospectively procrypticism and deprocrypticism. The implication is that naturally all prospective institutionalisations by their implied transcendence-andsublimity/sublimation/supererogatory de-mentativity are 'antagonistic by inducing contrariety in the temporal sense' even though we'll appreciate that their intemporal valor is inestimable (at 
least when we are looking retrospectively in appreciating that a positivistic outlook should supersede a non-positivism/medievalism outlook, and in the case where we are not uninhibited/decomplexified to equally construe that prospectively as a notional deprocrypticism outlook should supersede a procrypticism outlook). This insight equally highlights that institutionalisation/intemporalisation is implied with regards to humansubpotency-aporia/undecidability/dilemma/oughtindeterminacy/deficiency/limitation/constraint—imbued-'notional firstnaturednessformativeness-<as-to-eventualising-inkling-drive-or-seeding-misprising $>$ temporal-tointemporal-dispositions- $<$ so-construed-as-from-perspective-ontologicalnormalcy/postconvergence >'-existentialism-form-factor, and is critical for would-be emancipation-inducing intemporal individuations in grasping the whys and hows of social reaction to transcendental conceptualisation going by human-subpotencyaporia/undecidability/dilemma/ought-indeterminacy/deficiency/limitation/constraint—imbued'notional firstnaturedness-formativeness-<as-to-eventualising inkling-drive-or-seeding misprising $>$ temporal-to-intemporal-dispositions- $<$ so-construed-as-from-perspectiveontological-normalcy/postconvergence>'-existentialism-form-factor, how temporal 'resistance' is superseded, the mechanism of percolation-channelling- $<$ in-deferential-formalisationtransference $>$ and how transcendental ideas are taken up over time and induce untenability/internal-contradiction/internal-incoherence/institutional-constraining and positiveopportunism-of-social-functioning-and-accordance ${ }^{75}$ in the short run and secondnaturing in the

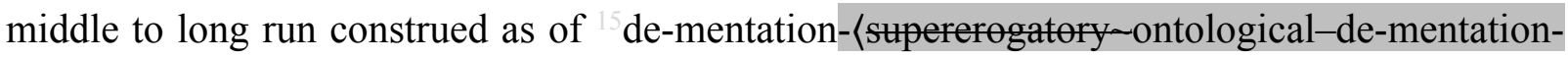
or-dialectical-de-mentation-stranding-or-attributive-dialectics $\rangle$. The fact is that while the social-construct is by-and-large a conceptualisation that determines individuals possibilities, the reality is equally that the social-construct does has 'powerful channels' that enable individuals to drastically redefined what is the social. The individual, it is often ignored, is an abstract- 
atomic-social-construct, as in the individual is priorly implied in the social, beyond just in termsas-of-axiomatic-construct of social aggregation in implying a meaningfulness and valuereference construct relationship to the abstract summative social. Such insight on the nature of human transcendence-and-sublimity/sublimation/supereregatory $\sim$ de-mentativity will certainly highlight why the Encyclopédistes coordinated by Diderot played a relevant role in inducing a domino effect contributing in transforming medieval European societies mindsets into a positive worldview by cynically putting together all the positive knowledge they could muster and disseminating it throughout Europe, and so over the forces of obscurity of the days who understood the implications of such a venture. The fact here as well as with all issues of perversion-of- ${ }^{-3}$ reference-of-thought-<as-preconverginglyapriorising/axiomatising/referencing-in-nonconviction/madeupness/bottomlining-as-toshallow-supererogation $>$ (by the prior relative-ontological-incompleteness ${ }^{8}$-induced,'threshold-of-nonconviction/madeupness/bottomlining-in-shallow-supererogation ${ }^{\circ}<$ as-to‘attendant-intradimensional'-prospectively-disontologising preconverging/dementing apriorising-psychologism>', as-it-is-thus- 'in-wait'-for- ${ }^{7}$ perversion-of- ${ }^{-3}$ reference-of-thought$<$ as-preconvergingly-apriorising/axiomatising/referencing-in-

nonconviction/madeupness/bottomlining-as-to-shallow-supererogation >,-or-temporalpreservation-as-pseudointemporality ${ }^{52}$-preservation, say of a medieval mindset/ ${ }^{83}$ reference-ofthought with respect to a prospective positivistic mindset, as implied by ontological-normalcy), is that there was obviously no mutually common/same ${ }^{83}$ reference-of-thought between the Encyclopédistes as positivists and many in the medieval establishment as non-positivists for any mutually intelligible logical exercise. But rather it was a case of transversality-<for-sublimatingexistential-eventuating/denouement, from 'thinking at first/pure predisposition preemptive of prospective-disontologising/subontologising' as-of-prospectively-disambiguated-affirmedand-unaffirmed-'motif-and-apriorising/axiomatising/referencing'>101 wherein the 
$<$ amplituding/formative-epistemicity $>$ causality $\sim$ as-to-projective-totalitative-implications-of-

prospective- nonpresencing,-for-explicating relative-unreflexivity/relative-reflexivity

ontological-contiguity of positivistic meaningfulness over non-positivism/medievalism ontologically imposed the positivistic ${ }^{83}$ reference-of-thought, as the former elicits untenability/internal-contradiction/internal-incoherence/institutional-constraining in the latter as well as its relative positive-opportunism-of-social-functioning-and-accordance ${ }^{7}$ from its relative ontological effectiveeness such that it ends up being secondnatured further by percolation-channelling- $<$ in-deferential-formalisation-transference $>$. Insightfully, in an intellectual conceptualisation exercise which, though conceptually contiguous, and while not necessarily implying similar dramatisation, in addition to its relatively diffuse implications in the sense of the contention being rather about human-mentation-capacity-furtherance and the fact that as a latter institutionalisation it is apparently less dramatic, at least as of its apparent negative social consequence given it is so focussed on human individuations as atomic-level point-of-departure of transformation but rather finding its radicalness more in the boldly implied décomplexing/uninhibitedness (suprastructuring/metaphysics-of-absence-〈implicitedepistemic-veracity-of- nonpresencing-<perspective-ontological-normalcy/postconvergence $>$ ) emancipation of the positive/procryptic human, and as with all other institutionalisations, it is thus not an issue that notional deprocrypticism meets in the short-term and temporary with 'resistance' or rather criticism (possibly by-and-large more in terms-as-of-axiomatic-construct of intellectual agreement/disagreement, as obviously every notion seriously contemplated about is); such that focus should be relatively more about construing veracity/ontological-pertinence and percolation-channelling- $<$ in-deferential-formalisation-transference $>$ thereof, as an objectively engaged intellectual/emancipating exercise. - As the above circularity/recurrence/repetition/repeatability ${ }^{10}$ (of temporal-dispositions acting-recurrently-intemporal-preservation ...) is the basis for the registry-worldview's/dimension's- 
uninstitutionalised-threshold ${ }^{102}$-defect-<as-Being-or-ontological-or-existential-defect $>$ reflected/perspectivated as the ${ }^{7}$ perversion-of- ${ }^{3}$ reference-of-thought- $<$ as-preconverginglyapriorising/axiomatising/referencing-in-nonconviction/madeupness/bottomlining-as-toshallow-supererogation $>$ <amplituding/formative $>$ wooden-language-〈imbued-averagingof-thought-<as-to-leveling/ressentiment/closed-construct-of- meaningfulness-and-teleology as-of-‘nondescript/ignorable-void '-with-regards-to-prospective-apriorising-implications $>$ > of a given dialectically-out-of-phase/dialectically-primitive registry-worldview in its 'dynamiccumulative-aftereffect of subontologisation' as the subontologisation/subpotentiation (in-asocial-dynamism-of-meaningfulness-misappropriation) by slantedness/postlogic-effect, miscuing, disjointed-logic, logical-drag, unconscionability-drag, sub-par/formulaicassociation/temporal/alibi conventioning-rationalising, and temporal-enculturation/temporalendemisation-effect; superseded/resolved not by logical-processing but as apriorising-registry ( ${ }^{8}$ reference-of-thought) perversion, by the <amplituding/formative-epistemicity $>$ causality $\sim$ asto-projective-totalitative-implications-of-prospective- nonpresencing,-forexplicating relative unreflexivity/relative-reflexivity ontological-contiguity of the prospective apriorising-registry as it elicits by its positive-opportunism-of-social-functioningand-accordance $^{75}$ its untenability/internal-contradiction/internal-incoherence/institutionalconstraining with respect to the prior one, going by ontological-normalcy/postconvergence. This articulation of the given dialectically-out-of-phase/dialectically-primitive registry-worldview as a 'dynamic-cumulative-aftereffect of subontologisation' can be construed going by an ontologically-veridical insight from a 'Différance-existential-transitory-articulation-of-theprotraction-of- perversion-of- $^{-3}$ reference-of-thought- $<$ as-preconverginglyapriorising/axiomatising/referencing-in-nonconviction/madeupness/bottomlining-as-toshallow-supererogation >,-of-meaningfulness' technique which allows essence-ofmeaningfulness to be seen for what it really is as of the 
circularity/recurrence/repetition/repeatability ${ }^{10}$ delineating existential-transitioning-oriterability-trace-of-narratives-as-dots_or_implicited_attendant-ontologicalcontiguity $^{67} \sim$ educedexistentialising/contextualising/textualising_'intelligibility/epistemicity/reflexivity-contiguity$<$ imbued-notional $\sim$ cogency $>$ 'reification_or_intrinsic-reality-ontologicalcoherence_or_superseding-oneness-of-ontology ${ }^{41}$ by $\quad{ }^{55}$ maximalising-recomposuring-forrelative-ontological-completeness ${ }^{87}$ - unenframed/re-ontologising conceptualisation-andcontextualisation, as can be understood insightfully by the notion of 'existence defining/preceding essence', as existential-<disontologising/re-ontologising aporeticism $>$ reality sets up the veridical contextualisation of analysis that is preemptive of a hollowform/postlogic arrogation/impostoring with respect to the 'essence-of-meaningfulness as of intemporal-preservation'), and this as of the circularity/recurrence/repetition/repeatability delineating existential-transitioning-or-iterability-trace-of-narratives-asdots_or_implicited_attendant-ontological-contiguity ${ }^{67}$, educedexistentialising/contextalising/textalising_'intelligibility/epistemicity/reflexivity_contiguity$<$ imbued-notional $\sim$ cogency $>$ ' -reification_or_intrinsic-reality-ontologicalcoherence_or_superseding-oneness-of-ontology wherein temporal-dispositions actingrecurrently-in-temporal-preservation speaks of a relative-ontological-incompleteness ${ }^{8}$ induced,-'threshold-of-nonconviction/madeupness/bottomlining-in-shallow-supererogation $<$ as-to-'attendant-intradimensional'-prospectivelydisontologising preconverging/dementing -apriorising-psychologism>’, as-it-is-thus-'in-

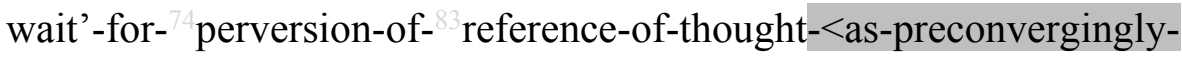
apriorising/axiomatising/referencing-in-nonconviction/madeupness/bottomlining-as-toshallow-supererogation >,-or-temporal-preservation-as-pseudointemporality ${ }^{52}$-preservation, in need for ontological-normalcy/postconvergence epistemic-or-notional projective-perspective 
prospective-transcendence-in-perpetually-upholding-intemporal-preservation-entropy-orcontiguity-or-ontological-preservation. This is the reason why the registries of the dialectically/contendingly-out-of-phase prior/transcended/superseded registryworldviews/dimensions of recurrent-utter-uninstitutionalisation, ununiversalisation, nonpositivism/medievalism and prospectively procrypticism (the- ${ }^{7}$ perversion-of- ${ }^{8}$ reference-ofthought-<as-preconvergingly-apriorising/axiomatising/referencing-in-

nonconviction/madeupness/bottomlining-as-to-shallow-supererogation >,-of-our-positivismconstrued-from-a-prospective- ${ }^{3}$ reference-of-thought-as-deprocrypticism) are correspondingly represented with their own 'specific and peculiar unsoundness-or-ontological-badfaith/inauthenticity ${ }^{64}$ of- ${ }^{8}$ reference-of-thought' $<$ amplituding/formative-epistemicity $>$ totalising renewing-realisation/re-perception/re-thought-as-utter-placeholder-setupontological-rescheduling-〈by-a-renewing-of-apriorising/axiomatising/referencingpsychologism-as-the-new-referencing-basis-of-prospective- meaningfulness-and-teleology $\rangle$, in reflection/perspectivation of their specific and peculiar registry-worldview's/dimension'suninstitutionalised-threshold ${ }^{102}$-defect-<as-Being-or-ontological-or-existential-defect $>$ as effectively preconverging-or-dementing -apriorising-psychologism as reflected/perspectivated from the standpoint of the placeholder-setup/mental-devisingrepresentation/mentation/consciousness-awareness-teleology ${ }^{9}$ of their corresponding prospective dialectically-in-phase as postconverging-or-dialectical-thinking ${ }^{2}$-apriorisingpsychologism prospective/transcending/superseding registry-worldviews/dimensions of baseinstitutionalisation, ${ }^{103}$ universalisation, positivism and prospectively deprocrypticism. It is critical to note that generally the distortion of ontologically-veridical-meaningfulness from postlogism 77 and conjugated-postlogism 77 preconverging-or-dementing 2 -integration leading to temporal-preservation-as-pseudointemporality ${ }^{52}$-preservation occurs at the three levels of contextualisation 
transcendental/transdimensional/interdimensional/ ${ }^{5}$ maximalising-recomposuring-for-relativeontological-completeness ${ }^{87}$ - unenframed/re-ontologising conceptualisation; contextually it explains incidental occasions of ${ }^{74}$ perversion-of- ${ }^{8}$ reference-of-thought- $<$ as-preconverginglyapriorising/axiomatising/referencing-in-nonconviction/madeupness/bottomlining-as-toshallow-supererogation >, registry-worldview-wise/dimension-wise postlogic instigation of temporal-preservation-as-pseudointemporality ${ }^{52}$-preservation (in self-reference-syncretising) explains relative-ontological-incompleteness ${ }^{8}$-induced,-'threshold-ofnonconviction/madeupness/bottomlining-in-shallow-supererogation $<-<$ as-to-' $a$ attendantintradimensional'-prospectively-disontologising preconverging/dementing -apriorisingpsychologism>', as-it-is-thus- 'in-wait'-for- $\quad$ perversion-of- ${ }^{-}$reference-of-thought- $<$aspreconvergingly-apriorising/axiomatising/referencing-in-

nonconviction/madeupness/bottomlining-as-to-shallow-supererogation >,-or-temporalpreservation-as-pseudointemporality ${ }^{52}$-preservation, intradimensionally and need for prospective institutionalisation to resolve the given relative-ontological-incompleteness ${ }^{8}$ induced,-'threshold-of-nonconviction/madeupness/bottomlining-in-shallow-supererogation <as-to-'attendant-intradimensional'-prospectively-

disontologising preconverging/dementing -apriorising-psychologism>', as-it-is-thus-'inwait'-for- ${ }^{7}$ perversion-of- ${ }^{2}$ reference-of-thought-<as-preconverginglyapriorising/axiomatising/referencing-in-nonconviction/madeupness/bottomlining-as-toshallow-supererogation >,-or-temporal-preservation-as-pseudointemporality ${ }^{52}$-preservation, with respect to ontological-normalcy, and transcendentally/transdimensionally/interdimensionally this further explains ontologicalnormalcy/postconvergence as being about representing successive institutionalcumulation/institutional-recomposure-〈as-to- historiality/ontologicaleventfulness /ontological-aesthetic-tracing-<perspective-ontological- 
'diminishing-human-epistemic-abnormalcy-or-preconvergence ${ }^{31}$ ' so that the perspective is one of 'abnormalcy', such that the mindset/ ${ }^{3}$ reference-of-thought in no institutionalisation including ours/positivistic should be 'so-complexed' as to wrongly imply a perspective of 'its ontologicalnormalcy' to be then defining itself as prospectively non-transcendable/unsupersedeable at its uninstitutionalised-threshold ${ }^{102}$, thus being falsely 'dialectically-unde-mentable/dialecticallyunprimitivable and dialectically-un-out-of-phaseable' while intuitively it appreciates that prior registry-worldviews/dimensions had been thus-construed in succession to deliver its own; thus speaking of an 'ontological-bad-faith/inauthenticity ${ }^{6}$ ' for the prospective possibilities of the future. - As it is important to grasp that the postlogic/psychopathic characters instigation of conjugated-postlogism 7 /preconverging-or-dementing -integration in the other temporaldispositions doesn't mean postlogism 77 characters are the causation of the 'dynamic-cumulativeaftereffect of subontologisation' that induces the placeholder-setup/mental-devisingrepresentation/mentation/consciousness-awareness-teleology 9 of a dialectically-out-ofphase/dialectically-primitive registry-worldview as preconverging-or-dementing ${ }^{20}$-apriorisingpsychologism. Rather, from ontological-normalcy/postconvergence insight, this points to human limited-mentation-capacity-deepening—as-subjecting-limitedness/human-subpotency-to'educed-unlimitedness/existence-sublimating nascence' ${ }^{53}$ at that registryworldview/dimension-level or registry-worldview/dimension as the threshold-ofnonconviction/madeupness/bottomlining-in-shallow-supererogation $<<$ as-to-' attendantintradimensional'-prospectively-disontologising preconverging/dementing -apriorisingpsychologism> (or uninstitutionalised-threshold ${ }^{102}$ or socially-betraying-threshold-ofontologising-depth-of-analysis or socially-betraying-threshold-of-intemporal-preservationentropy-or-contiguity-or-ontological-preservation), which is 'in wait' to be revealed by the registry-worldview's/dimension's corresponding postlogism ${ }^{77}$ perversion-of- ${ }^{83}$ reference-of- 
thought-<as-preconvergingly-apriorising/axiomatising/referencing-in-

nonconviction/madeupness/bottomlining-as-to-shallow-supererogation $>$ instigation at that registry-worldview/dimension-level or registry-worldview/dimension. For instance, the corresponding postlogism 77 as ${ }^{77}$ perversion-of- ${ }^{83}$ eference-of-thought-<as-preconverginglyapriorising/axiomatising/referencing-in-nonconviction/madeupness/bottomlining-as-to-

shallow-supererogation $>$ instigation in non-positivism/medievalism instigating say of notions of sorcery and accusations of the type while effective in inducing ${ }^{7}$ perversion-of- ${ }^{8}$ reference-ofthought-<as-preconvergingly-apriorising/axiomatising/referencing-in-

nonconviction/madeupness/bottomlining-as-to-shallow-supererogation $>$ in a nonpositivism/medievalism setup will not be effective in a positivistic social-setup, as the nonpositivism/medievalism condition of being superstitious and non-empirical is by itself a condition 'in wait' for accusations and notions of sorcery to arise and be endemised/enculturated. Likewise, from ontological-normalcy/postconvergence insight, with regards to our positivistic registry-worldview reflected/perspectivated as being dialectically-out-of-phase/dialecticallyprimitive as procrypticism at its human limited-mentation-capacity-deepening-as-subjectinglimitedness/human-subpotency-to-'educed-unlimitedness/existence-sublimating nascence' registry-worldview/dimension-level as the threshold-ofnonconviction/madeupness/bottomlining-in-shallow-supererogation $<<$ as-to- 'attendantintradimensional'-prospectively-disontologising preconverging/dementing -apriorisingpsychologism>, our condition of not being in relative-unreflexivity/relative-reflexivity ontological-contiguity ${ }^{67}$, 'not-reflecting-absolute-ontological-pertinence', as being involved with 6 incrementalism-in-relative-ontological-incompleteness ${ }^{88}$ enframed/disontologising conceptualisation $<$ amplituding/formative $>$ wooden-language〈imbued-averaging-of-thought-<as-to-leveling/ressentiment/closed-construct-ofmeaningfulness-and-teleology -as-of-'nondescript/ignorable-void '-with-regards-to- 
prospective-apriorising-implications $>\rangle$ '/temporal-accommodation as well as our peculiar conjugated-postlogism 77 preconverging-or-dementing -integration as psychopathy-and-socialpsychopathy (that is, the conjugating of the temporal-dispositions of ignorance/affordability/opportunism/exacerbation/social-chainism-or-social-discomfiture-ornegative-social-aggregation/temporal-enculturation-or-temporal-endemisation to the postlogism -slantedness associated with psychopathy and social psychopathy) specifically in the extended-informality-〈susceptible-to-effecting-parsimony-as-of-shoddiness-andincompleteness-to- meaningfulness-and-teleology $\rangle$ of the positivism registry-worldview's permeating on occasion its formalities, rather than ${ }^{55}$ maximalising-recomposuring-for-relativeontological-completeness ${ }^{87}$ - unenframed/re-ontologising conceptualisation where the veridical ontological-reference is an 'abstract-sense-of-adherence-to-intrinsic-reality' as validated by the-Good/knowledge-reification $\sim$ gesturing-and-accounting-of-epistemicphenomenalism-<in-prospective_psychologismic $\sim$ apriorising/axiomatising/referencing- of'prospectively_implicited_attendant-ontological-contiguity ' educedexistentialising/entextrising/textrising_intelligibility/epistemicity/reflexivity-contiguity<imbued-notional cogency >' \}-conflatedness -in-\{preconverging-disentailment by\} postconverging entailment $>$ /understanding/<amplituding/formativeepistemicity $>$ causality $\sim$ as-to-projective-totalitative-implications-of-prospectivenonpresencing,-for-explicating relative-unreflexivity/relative-reflexivity - ontologicalcontiguity /understanding/knowledge-driven, and not impression-driven/goodnaturedness/wishfulness meaningfulness associated with the "incrementalism-in-relativeontological-incompleteness ${ }^{88}$ —enframed/disontologising $\sim$ conceptualisation $<$ amplituding/formative $>$ wooden-language-〈imbued - averaging-of-thought- $<$ as-toleveling/ressentiment/closed-construct-of- meaningfulness-and-teleology -as-of'nondescript/ignorable-void '-with-regards-to-prospective-apriorising-implications $>\rangle$ ' that 
'tends to reference/accommodate/orientate for a disposition to rather seek other humans 'temporal-validation' as rather 'angling for the summative human mental-disposition' with respect to social-stake-contention-or-confliction as 'extrinsic-attribution' over a 'validation by inherent-veridicality/intrinsic-reality' of meaningfulness as 'intrinsic-attribution' leading to social-and-temporal-trading, and so whether consciously-or-unconsciously/wittingly-orunwittingly', and thus inducing notional-discontiguity/epistemic-discontiguity ${ }^{6}<$ between prior-shallow-supererogation -of-mentally-aestheticised $\sim$ preconverging/dementing -qualiaschema_and_prospective-profound-supererogation -of-mentallyaestheticised postconverging/dialectical-thinking -qualia-schema $>$ speaking of epistemicdecadence (postlogism 7 ). Insightfully again, going by the first example, it might (wrongly) be argued, by human 'temporal extricatory preconverging-de-mentating/structuring/paradigming', that notions-and-accusations-of-sorcery in a non-positivism/medievalism setup should imply that any such accused should equally 'make-up' accusations in their own defence to neutralise and possibly defend their own interests. But such a stance is a temporal extricatory preconverging-de-mentating/structuring/paradigming that faces human temporality $\% /$ shortness with human temporality ${ }^{8}$. Intemporal/ontological/social/species/ $/{ }^{103}$ universal/transcendental/ ${ }^{55}$ maximalisingrecomposuring-for-relative-ontological-completeness ${ }^{8}$ - unenframed/reontologising conceptualisation postconverging-de-mentating/structuring/paradigming will garner the insight that humanity-at-large at all such non-positivism/medievalism setups is rather in need (as the resolution) of a renewed institutionalisation prospectively as the positivistic registry-worldview based on rational-empiricism as the postconverging-dementating/structuring/paradigming for superseding the vices-and-impediments ${ }^{105}$ that the enculturation/endemisation of the notions-and-accusations-of-sorcery speak of inherently, together with the social-structural implications and derivations arising, with regards to the non- 
positivism/medievalism registry-worldview. The vocation of the intemporal-disposition

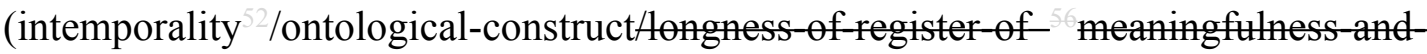
teleology ${ }^{9}$ ) is not-to-come-to-and-construe ${ }^{56}$ meaningfulness-and-teleology ${ }^{99}$ at a same pedestal as a temporal-dispositions extricatory preconverging-de-mentating/structuring/paradigming, and this invariably means that its on-occasion/incidental insight about temporal-dispositions defects (temporality ${ }^{8}$ ) is 'necessarily escalated ontologically at a humanity-at-large scale of $<$ amplituding/formative-epistemicity $>$ causality $\sim$ as-to-projective-totalitative-implications-ofprospective- nonpresencing,-for-explicating relative-unreflexivity/relative-reflexivity

ontological-contiguity '. This construal is what enables ontological-normalcy/postconvergence (prospective-transcendence-in-perpetually-upholding-intemporal-preservation-entropy-orcontiguity-or-ontological-preservation) or ontological-normalcy/postconvergence, and its $<$ amplituding/formative-epistemicity $>$ causality $\sim$ as-to-projective-totalitative-implications-ofprospective- nonpresencing,-for-explicating relative-unreflexivity/relative-reflexivity ontological-contiguity on human-subpotency-aporia/undecidability/dilemma/oughtindeterminacy/deficiency/limitation/constraint—imbued-'notional firstnaturednessformativeness-<as-to-eventualising-inkling drive-or-seeding misprising $>$ temporal-tointemporal-dispositions- $<$ so-construed-as-from-perspective-ontologicalnormalcy/postconvergence >'-existentialism-form-factor across all the registryworldviews/dimensions whether retrospective, present or prospective. In other words, inherent human ontologising-deficiency as implied by ontological-normalcy/postconvergence due to human limited-mentation-capacity-deepening —as-subjecting limitedness/human-subpotency to-'educed-unlimitedness/existence-sublimating nascence' ${ }^{33}$ is the inherent reason why humankind has to 'make-up-for' (by projection as 'ontological-reconstituting-as-toconflatedness ${ }^{13} /$ deconstruction) its ontologising-deficiency by renewing its ${ }^{83}$ reference-ofthought/implied-registry-worldview in successions as transcendence-and- 
sublimity/sublimation/supererogatory de-mentativity involving a 'placeholder-setup/mentaldevising-representation/mentation/consciousness-awareness-teleology ${ }^{9}$ dialecticism' (' ${ }^{\text {de- }}$ mentation-〈supererogatory $\sim$ ontological-de-mentation-or-dialectical-de-mentation — strandingor-attributive-dialectics $\rangle \quad$ of $\quad$ reference-of-thought') that involves prospective/transcending/superseding registry-worldview as 'postconverging-or-dialecticalthinking -apriorising-psychologism' which is dialectically-in-phase over prior/transcended/superseded registry-worldview as preconverging-or-dementing ${ }^{20}$-apriorisingpsychologism which is dialectically-out-of-phase/dialectically-primitive. With the various registry-worldview/dimensions $\quad$ postlogism 77 disontologising-perverted-outcome-soughtprecedes-existentially-veridical-'attendant-intradimensional-

apriorising/axiomatising/referencing'-logical-dueness-or-disontologising-perverted-outcomesought-precedes-existentially-veridical-'attendant-intradimensionalapriorising/axiomatising/referencing'-logical-dueness ${ }^{7}$ perversion-of- ${ }^{3}$ reference-of-thought$<$ as-preconvergingly-apriorising/axiomatising/referencing-innonconviction/madeupness/bottomlining-as-to-shallow-supererogation $>$ (whether instigating from physiological or enculturated basis) being incidental phenomena (associated with humansubpotency-aporia/undecidability/dilemma/ought-

indeterminacy/deficiency/limitation/constraint—imbued-'notional firstnaturednessformativeness-<as-to-eventualising-inkling-drive-or-seeding-misprising $>$ temporal-tointemporal-dispositions- $<$ so-construed-as-from-perspective-ontologicalnormalcy/postconvergence>'-existentialism-form-factor) emphasising the more fundamental issue of the dialecticism implicited in human transcendence-andsublimity/sublimation/supererogatory-de-mentativity, and with this dialecticism being the 'suprastructural insight' that informs the veracity/ontological-pertinence and handling of all issues of ontological-or-existential-defect/registry-defect $/ 7$ perversion-of- ${ }^{3}$ reference-of- 
thought-<as-preconvergingly-apriorising/axiomatising/referencing-in-

nonconviction/madeupness/bottomlining-as-to-shallow-supererogation $>$ /transcendental-

dialecticism going by a différance-disambiguation-of-ontologically-veridical- ${ }^{56}$ meaningfulnessand-teleology 9 . This differs from issues in relation with existentially-<disontologising/reentelogising apereticism $>$ veridical logical-dueness and from thence enabling the construing of relevant soundness or unsoundness of ${ }^{54}$ logical-processing-or-logical-implicitation supposedly-apriorising-in-conviction-as-to-profound-supererogation that 'comes only after the notion of a sound reference-of-thought is established in the first place' and are intradimensional, and doesn't put-into-question/imply the soundness/unsoundness of registry/axioms/ontological-reference/contending-reference/meaningful-reference/anchoringof-meaning/soundness-or-ontological-good-faith/authenticity ${ }^{60}$-of- ${ }^{8}$ reference-of-thought-orsoundness-of-mind/registry-worldview, and furthermore are grounded on a same/common reference-of-thought/implied-registry-worldview. Thus if strictly speaking a postlogism phenomenon (disontologising-perverted-outcome-sought-precedes-existentially-veridical'attendant-intradimensional-apriorising/axiomatising/referencing'-logical-dueness) like a psychopathic disposition is not the causation of a ${ }^{83}$ reference-of-thought ${ }^{74}$ perversion-ofreference-of-thought-<as-preconvergingly-apriorising/axiomatising/referencing-innonconviction/madeupness/bottomlining-as-to-shallow-supererogation $>$, then what is its relevance and pertinence? The fact is with or without postlogism including psychopathic individuations, human limited-mentation-capacity-deepening-as-subjectinglimitedness/human-subpotency-to-'educed-unlimitedness/existence-sublimating nascence' warrants that our temporal-dispositions will nonetheless still fail the intemporal-preservationentropy-or-contiguity-or-ontological-preservation at the registry-worldview/dimension uninstitutionalised-threshold ${ }^{102}$ that correspondingly mark the successive uninstitutionalisedthreshold $^{102}$ states of recurrent-utter-uninstitutionalisation, ununiversalisation, non- 
positivism/medievalism and prospectively procrypticism, just by the mere fact of relativeontological-incompleteness -induced,-‘threshold-of-nonconviction/madeupness/bottomliningin-shallow-supererogation -<as-to-'attendant-intradimensional'-prospectivelydisontologising preconverging/dementing -apriorising-psychologism>’, as-it-is-thus-'inwait'-for- ${ }^{74}$ perversion-of- ${ }^{3}$ reference-of-thought-<as-preconverginglyapriorising/axiomatising/referencing-in-nonconviction/madeupness/bottomlining-as-toshallow-supererogation >,-or-temporal-preservation-as-pseudointemporality ${ }^{52}$-preservation, (ontological-completeness-of- ${ }^{3}$ reference-of-thought involving institutionalising, universalising, positivising and deprocrypticising, with notional ${ }^{18}$ deprocrypticism 'conceptually' marking ontological-completeness as it subsumes-as-supplant-〈as-of-the-moreprofound-construal-of 'implicited_attendant-ontological-contiguity ${ }^{\text {' }}$ educedexistentialising/contextualising/textualising_ 'intelligibility/epistemicity/reflexivity-contiguity$<$ imbued-notional $\sim$ cogency $>,{ }^{\prime},-<$ reifying-or-elucidating-of-prospective-relative-ontologicalcompleteness -of- reference-of-thought- devolving-as-of-instantiative-context $>>$ all the rest). The critical thing however is that at these uninstitutionalised thresholds, without the postlogic effects including psychopathic, the corresponding requisite human transcendence-andsublimity/sublimation/supererogatory de-mentativity will be more straightforward, direct and definite from the prior preconverging-or-dementing ${ }^{20}$-apriorising-psychologism to the prospective 'postconverging-or-dialectical-thinking -apriorising-psychologism' as temporaldispositions are less predisposed to temporal-preservation-as-pseudointemporality ${ }^{52}$ preservation once social ${ }^{103}$ universal-transparency ${ }^{104}$-〈transparency-of-totalising-entailing,-asto-entailing-<amplituding/formative-epistemicity $>$ totalising $\sim$ in-relative-ontologicalcompleteness > of $\quad{ }^{7}$ perversion-of- ${ }^{83}$ reference-of-thought- $<$ as-preconverginglyapriorising/axiomatising/referencing-in-nonconviction/madeupness/bottomlining-as-toshallow-supererogation $>$ or registry-worldview-perversion is established together with the 
untenability/internal-contradiction/internal-incoherence/institutional-constraining of that perversion, thus facilitating the referencing/registering/decisioning or stranding of the implied dialecticism in the social-psyche/collective-consciousness of what is effectively 'postconverging-or-dialectical-thinking -apriorising-psychologism' and what is preconverging-or-dementing ${ }^{20}$-apriorising-psychologism, with the latter being alienated in the operation of meaningfulness as the new institutionalisation is established. This straightforwardness, directness and definitiveness is fundamentally undermined by the iterability/iteration nature (of ontologically-veridical-meaningfulness-and-ontologicalreference) induced by the postlogic hollow-constituting-<as-disjointed-misappropriation-ofmeaningfulness-and-failing-intemporal-preservation $>$ distorting effect including psychopathic which renders establishing social ${ }^{103}$ universal-transparency ${ }^{104}$-〈transparency-of-totalisingentailing,-as-to-entailing-<amplituding/formative-epistemicity $>$ totalising $\sim$ in-relativeontological-completeness > of ${ }^{7}$ perversion-of- ${ }^{83}$ reference-of-thought-<as-preconverginglyapriorising/axiomatising/referencing-in-nonconviction/madeupness/bottomlining-as-toshallow-supererogation $>$ or registry-worldview-perversion together with the untenability/internal-contradiction/internal-incoherence/institutional-constraining of such perversion-of- ${ }^{3}$ reference-of-thought-<as-preconvergingly-

\section{apriorising/axiomatising/referencing-in-nonconviction/madeupness/bottomlining-as-to-}

shallow-supererogation $>$ with respect to other temporal-dispositions rather obscure, and further so as conjugated-postlogism mental-dispositions equally assume a distortional purposefulness with respect to ontologically-veridical-meaningfulness of their own. Postlogicly perverted/distorted induced iterability with regards to ontologically-veridical-meaningfulnessand-ontological-reference (as denaturing the apriorising-registry-elements as fepistemicpsychologismic-subliminality-of-individuation-effusing/worlding imbued logicaldueness-or-scape-or-frame, profile-or-stature, presumptuousness-or-arrogation, assumptions, 
value-reference and teleology ${ }^{9}$ ) takes the form of 'denaturing postlogic-backtracking$<$ iterative-looping-'set-of-dereifying-hollow-narratives-and-acts'> $>$-with-'successive-shiftingof-the-narratives-and-acts-foci'-construed-as-'deception-of-successively-shifting-ornoncohering-narratives-and-acts' towards 'social-aggregation-enablers over intrinsicreality/ontological-veridicality transcendental-enabling/sublimating/supererogatery $\sim$ dementativity' as non-veridical and dialectically/contendingly out-of-phase, absolving/fleeting/escaping-reflex-logic and extrinsic-attribution with respect to successive sets of interlocutors, and as conjugated-postlogism 77 mental-dispositions equally assume a purposefulness of their own (that must be factored-in when analysing psychopathic/postlogic and social-psychopathic situations). This in turn induces 'conjoining looping narratives of flawed-existential-elevation-of- ${ }^{8}$ reference-of-thought as conjugatedpostlogism 77 preconverging-or-dementing ${ }^{20}$-integration-of-temporal-dispositions in a 'dynamiccumulative-aftereffect of subontologisation' (slantedness/postlogic-effect, miscuing, disjointedlogic, logical-drag, unconscionability-drag, sub-par/formulaic-association/temporal/alibi conventioning-rationalising, and temporal-enculturation/temporal-endemisation-effect). Thus strengthening the temporality $/$ /shortness preservation dispositions of temporal-dispositions as the mere dynamism of the conjugating state of postlogism slantedness/ ${ }^{5}$ ignorance/affordability/opportunism/exacerbation/social-chainism-or-socialdiscomfiture-or-negative-social-aggregation/temporal-enculturation-or-temporal-endemisation, so-disambiguated as of ${ }^{83}$ reference-of-thought- ${ }^{8}$ devolving ontological-performance ${ }^{72}$ <including-virtue-as-ontology $>/$ morality/ethics/justice/etc. takes a turn into registryworldview's/dimension's-uninstitutionalised-threshold ${ }^{102}$-defect-<as-Being-or-ontological-orexistential-defect $>5$ when these become temporally-preservational-as-pseudointemporality ${ }^{52}$ preservation as of the circularity/recurrence/repetition/repeatability ${ }^{10}$ delineating existentialtransitioning-or-iterability-trace-of-narratives-as-dots_or_implicited_attendant-ontological- 
contiguity ${ }^{67}$,educed-

existentialising/contextualising/textualising_'intelligibility/epistemicity/reflexivity_contiguity-

$<$ imbued-notional $\sim \operatorname{cogency}>{ }^{\prime}$-reification_or_intrinsic-reality-ontological-

coherence_or_superseding-oneness-of-ontology ${ }^{41}$ in a 'dynamic-cumulative-aftereffect of subontologisation' (slantedness/postlogic-effect, miscuing, disjointed-logic, logical-drag, unconscionability-drag, sub-par/formulaic-association/temporal/alibi conventioningrationalising, and temporal-enculturation/temporal-endemisation-effect), thus defining the 'threshold-of-nonconviction/madeupness/bottomlining-in-shallow-supererogation ${ }_{-<\text {as-to- }}$

\section{'attendant-intradimensional'-prospectively-disontologising preconverging/dementing}

apriorising-psychologism>' (as the uninstitutionalised-threshold ${ }^{102}$ ) as 'a-perpetuated-state-initerability/iteration' until the point where social ${ }^{103}$ universal-transparency ${ }^{104}$-〈transparency-oftotalising-entailing,-as-to-entailing-<amplituding/formative-epistemicity $>$ totalising $\sim$ in-

relative-ontological-completeness $\rangle$ and untenability/internal-contradiction/internalincoherence/institutional-constraining are decisive enough to instigate prospective institutionalisation as transcendence-and-sublimity/sublimation/supererogatory $\sim$ de-mentativity, breaking the temporal-dispositions acts-execution/logical-processing defects that had become registry-worldview's/dimension's-uninstitutionalised-threshold ${ }^{22}$-defect- $<$ as-Being-orontological-or-existential-defect $>5$ by temporal-preservation-as-pseudointemporality ${ }^{52}$ preservation as of the circularity/recurrence/repetition/repeatability ${ }^{10}$ delineating existentialtransitioning-or-iterability-trace-of-narratives-as-dots_or_implicited_attendant-ontologicalcontiguity $^{67}$; educed-

existentialising/contextualising/textualising_'intelligibility/epistemicity/reflexivity_contiguity$<$ imbued-notional $\sim$ cogency>' -reification_or_intrinsic-reality-ontologicalcoherence_or_superseding-oneness-of-ontology due to relative-ontological-incompleteness ${ }^{8}$ induced,-'threshold-of-nonconviction/madeupness/bottomlining-in-shallow-supererogation 
<as-to-'attendant-intradimensional'-prospectively-

disontologising $\sim$ preconverging/dementing -apriorising-psychologism>’, as-it-is-thus-'inwait'-for- perversion-of- ${ }^{8}$ reference-of-thought-<as-preconvergingly-

apriorising/axiomatising/referencing-in-nonconviction/madeupness/bottomlining-as-to-

shallow-supererogation >,-or-temporal-preservation-as-pseudointemporality ${ }^{52}$-preservation,

Of course, in registry-worldview terms it's more than just the individuations of individuals, but rather a dynamic-cumulative-aftereffect construed at the comprehensive institutionalisation/uninstitutionalised-threshold ${ }^{02}$ level. Basically, by blurring (by way of hollow-constituting-<as-disjointed-misappropriation-of-meaningfulness-and-failing-

intemporal-preservation $>$ in-iterating alterations or slanting) the notion that a ${ }^{8}$ reference-ofthought is preconverging-or-dementing ${ }^{20}$-apriorising-psychologism given it relativeontological-incompleteness ${ }^{8}$-induced,-‘threshold-of-nonconviction/madeupness/bottomliningin-shallow-supererogation $-<$ as-to-'attendant-intradimensional'-prospectivelydisontologising preconverging/dementing -apriorising-psychologism>’, as-it-is-thus-'inwait'-for- perversion-of- $^{8}$ reference-of-thought- $<$ as-preconverginglyapriorising/axiomatising/referencing-in-nonconviction/madeupness/bottomlining-as-toshallow-supererogation >,-or-temporal-preservation-as-pseudointemporality ${ }^{52}$-preservation, postlogism 77 induces temporal-preservation by circularity/recurrence/repetition/repeatability of unprincipled-or-derived-unprincipled mental-dispositions in temporal-dispositions (which equally assume a purposefulness of their own (that must be factored-in when analysing psychopathic/postlogic and social-psychopathic situations) inducing registryworldview's/dimension's-uninstitutionalised-threshold ${ }^{102}$-defect-<as-Being-or-ontological-orexistential-defect $>5$ by temporal-preservation as of the circularity/recurrence/repetition/repeatability ${ }^{10}$ delineating existential-transitioning-oriterability-trace-of-narratives-as-dots_or_implicited_attendant-ontological- 
contiguity ${ }^{67}$,educed-

existentialising/contextualising/textualising_'intelligibility/epistemicity/reflexivity_contiguity-

$<$ imbued-notional cogency>> ${ }^{\prime}$-reification_or_intrinsic-reality-ontological-

coherence_or_superseding-oneness-of-ontology 4 -of-recurrence/repeatability in principle.

postlogism -as-of- compulsing-nonconviction/madeupness/bottomlining-

$\langle<<$ decontextualising/de-existentialising $\sim$ of-attendant-intradimensional-

apriorising/axiomatising/referencing >-induced-disontologising'-of-the-'attendant-

intradimensional-ontologising'-imbued-<contextualising/existentialising $\sim$ attendant-

ontological-contiguity $>$; -in-shallow-supererogation -<as-to-disontologising-perverted-

outcome-sought-precedes-existentially-veridical-'attendant-intradimensional-

apriorising/axiomatising/referencing'-logical-dueness $>>\quad$ as $\quad$ to $\quad$ compulsing-

nonconviction/madeupness/bottomlining-〈‘ $<$ decontextualising/de-existentialising $\sim$ of-

attendant-intradimensional-apriorising/axiomatising/referencing>-induced-disontologising'-of-

the-'attendant-intradimensional-ontologising'-imbued-

$<$ contextualising/existentialising attendant-ontological-contiguity $>$;-in-shallow-

supererogation -<as-to-disontologising-perverted-outcome-sought-precedes-existentially-

veridical-'attendant-intradimensional-apriorising/axiomatising/referencing'-logical-

dueness $>\rangle^{\prime}$ and conjugated-postlogism ${ }^{77}$ can possibly be explained by the notion of pseudointemporality $^{52}$ wherein under social-and-confliction-stake temporal-dispositions individuation 'mental-dispositional incapacity for intemporality ${ }^{52}$ induces 'notional disjointedness-as-of- ${ }^{8}$ reference-of-thought' misappropriated ${ }^{56}$ meaningfulness-andteleology ${ }^{9}$ in arrogation (at individuation-level relative-ontological-incompleteness ${ }^{8}$-induced,'threshold-of-nonconviction/madeupness/bottomlining-in-shallow-supererogation ${ }^{9}<$ as-to‘attendant-intradimensional'-prospectively-disontologising preconverging/dementing

apriorising-psychologism>', as-it-is-thus- 'in-wait'-for- ${ }^{7}$ perversion-of- ${ }^{3}$ reference-of-thought- 


\section{$<$ as-preconvergingly-apriorising/axiomatising/referencing-in-}

nonconviction/madeupness/bottomlining-as-to-shallow-supererogation >,-or-temporalpreservation-as-pseudointemporality ${ }^{52}$-preservation, as it strives to act as if it was intemporal, whether-consciously-or-unconsciously-and-so-beyond-the-consciousness-awarenessteleology ${ }^{-}<$of-preconverging-existential-extrication-as-of-existential-unthought $>$manifestation. In that sense the postlogic/psychopathic mental-disposition will seem to be the 'weakest human mental-disposition for acting intemporally in supplanting-conviction-as-toprofound-supererogation of-'attendant-intradimensional'-postconverging/dialecticalthinking -apriorising-psychologism reflex to ${ }^{56}$ meaningfulness-and-teleology ${ }^{99}$ as of its intrinsicness/essence/ontological-veridicality' and so directly engages in its kind of pseudointemporality $^{52}$, for pathological reasons, as it takes a faulty-mentation-procedureshortcut to meaningfulness towards its naively sought-outcome/end-purpose as 'meaning by its mere-formulaicity/ritualisation-<as-to-mere-formulaicmethodologising/mutualising/organising/institutionalising,-prospectively-losing-track-of‘fepistemic-atising ’’re-apriorising/re-axiomatising/re-referencing $\sim$ residuality-in-reoriginariness/re-origination'> as being deterministic of how others will act', such that this is actually part-and-parcel of its developmental psychology. While other temporal-dispositions individuations come to pseudointemporality by ignorance/affordability/opportunism/exacerbation/social-chainism-or-social-discomfiture-ornegative-social-aggregation/temporal-enculturation-or-temporal-endemisation, whetherconsciously-expediently-or-unconsciously-and-so-beyond-the-consciousness-awarenessteleology ${ }^{9}<$ of-preconverging-existential-extrication-as-of-existential-unthought $>$ manifestation. postlogism -as-of- compulsing-nonconviction/madeupness/bottomlining$〈<<$ decontextualising/de-existentialising of-attendant-intradimensionalapriorising/axiomatising/referencing >-induced-disontologising'-of-the-'attendant- 
intradimensional-ontologising'-imbued-<contextualising/existentialising $\sim$ attendant-

ontological-contiguity $>$;-in-shallow-supererogation -<as-to-disontologising-pervertedoutcome-sought-precedes-existentially-veridical-'attendant-intradimensionalapriorising/axiomatising/referencing'-logical-dueness $>>\quad$ as $\quad$ to $\quad$ " compulsingnonconviction/madeupness/bottomlining-<‘ $<$ decontextualising/de-existentialising $\sim$ ofattendant-intradimensional-apriorising/axiomatising/referencing--induced-disontologising'-ofthe-'attendant-intradimensional-ontologising'-imbued$<$ contextualising/existentialising attendant-ontological-contiguity $>$;-in-shallowsupererogation -<as-to-disontologising-perverted-outcome-sought-precedes-existentiallyveridical-'attendant-intradimensional-apriorising/axiomatising/referencing'-logicaldueness $>$ ' instigation of ${ }^{7}$ perversion-of- ${ }^{83}$ reference-of-thought- $<$ as-preconverginglyapriorising/axiomatising/referencing-in-nonconviction/madeupness/bottomlining-as-toshallow-supererogation $>$ is associated with intradimensional temporal-preservation-aspseudointemporality ${ }^{52}$-preservation at a registry-worldview's/dimension's uninstitutionalisedthreshold $^{102}$ or relative-ontological-incompleteness ${ }^{8}$-induced,-`threshold-ofnonconviction/madeupness/bottomlining-in-shallow-supererogation $-<$ as-to-'attendantintradimensional'-prospectively-disontologising preconverging/dementing -apriorisingpsychologism>'-threshold (as-it-is-thus- 'in-wait'-for- perversion-of- reference-of-thought$<$ as-preconvergingly-apriorising/axiomatising/referencing-innonconviction/madeupness/bottomlining-as-to-shallow-supererogation >,-or-temporalpreservation-as-pseudointemporality ${ }^{52}$-preservation), such that equally temporal-dispositions are effectively in threshold-of-nonconviction/madeupness/bottomlining-in-shallowsupererogation -<as-to- 'attendant-intradimensional'-prospectivelydisontologising preconverging/dementing -apriorising-psychologism> (whether-consciouslyor-unconsciously-and-so-beyond-the-consciousness-awareness-teleology ${ }^{9}-<$ of-preconverging- 
existential-extrication-as-of-existential-unthought $>$-manifestation intradimensionally). This can be highlighted by the fact that from a positivistic perspective, a truly medieval mindset $/{ }^{8}$ reference-of-thought at its core is fundamentally and preconverging/postconvergingde-mentatively/structurally/paradigmatically of a relative structural-being/ontological-orexistential-defect no matter how 'good-natured' we may conceive of it by the mere fact of the 'spectacularly defective knowledge and virtue implications' of it not having a positivistic outlook given its medieval relative-ontological-incompleteness ${ }^{8}$-induced,-'threshold-ofnonconviction/madeupness/bottomlining-in-shallow-supererogation $<-<$ as-to-' $a$ attendantintradimensional'-prospectively-disontologising preconverging/dementing -apriorisingpsychologism>', $\quad$ as-it-is-thus- 'in-wait'-for- perversion-of- $^{-}$reference-of-thought- $<$aspreconvergingly-apriorising/axiomatising/referencing-in-

nonconviction/madeupness/bottomlining-as-to-shallow-supererogation >,-or-temporalpreservation-as-pseudointemporality ${ }^{52}$-preservation, before even speaking of an issue arising from medieval postlogism 7 like someone coming up with notions and accusations associated with superstition. For instance, the consciousness state of say the non-positivism/medievalism mindset $/{ }^{3}$ reference-of-thought at its relative-ontological-incompleteness ${ }^{8}$-induced,-'thresholdof-nonconviction/madeupness/bottomlining-in-shallow-supererogation $<-<$ as-to-' ${ }^{6}$ attendantintradimensional'-prospectively-disontologising preconverging/dementing -apriorisingpsychologism>'-threshold (as-it-is-thus- 'in-wait'-for- perversion-of- reference-of-thought$<$ as-preconvergingly-apriorising/axiomatising/referencing-innonconviction/madeupness/bottomlining-as-to-shallow-supererogation $>$,--or-temporalpreservation-as-pseudointemporality ${ }^{52}$-preservation) with respect to the mental-dispositions of the positivistic mindset $/{ }^{3}$ reference-of-thought wherein obviously the latter's more ontologicalcompletude construes that notions-and-accusations-of-sorcery, however serene the mental states of persons in such medieval setup, are without any doubt ridiculous from its positivistic 
perspective as there is no explanation for them but for the fact that having arrived at its relativeontological-incompleteness -induced,-‘threshold-of-nonconviction/madeupness/bottomliningin-shallow-supererogation -<as-to-'attendant-intradimensional'-prospectivelydisontologising $\sim$ preconverging/dementing -apriorising-psychologism>'-threshold （as-it-isthus- 'in-wait'-for- ${ }^{7}$ perversion-of- ${ }^{3}$ reference-of-thought- $<$ as-preconverginglyapriorising/axiomatising/referencing-in-nonconviction/madeupness/bottomlining-as-toshallow-supererogation >,-or-temporal-preservation-as-pseudointemporality ${ }^{52}$-preservation) the human mindset $/{ }^{3}$ reference-of-thought (medieval in this instance) with respect to social-andconfliction-stake is just as well, whether-consciously-or-unconsciously-and-so-beyond-theconsciousness-awareness-teleology $\quad<$ of-preconverging-existential-extrication-as-ofexistential-unthought $>$-manifestation intradimensionally, inclined to engaged in what is in reality preconverging-or-dementing ${ }^{20}$-apriorising-psychologism (as notions-and-accusationsof-sorcery in a medieval setup). Thus at a registry-worldview's/dimension's uninstitutionalisedthreshold $^{102}$ or relative-ontological-incompleteness ${ }^{8}$-induced,-`threshold-ofnonconviction/madeupness/bottomlining-in-shallow-supererogation $-<$ as-to- 'attendantintradimensional'-prospectively-disontologising preconverging/dementing -apriorisingpsychologism >'-threshold (as-it-is-thus- 'in-wait'-for- ${ }^{7}$ perversion-of- ${ }^{3}$ reference-of-thought<as-preconvergingly-apriorising/axiomatising/referencing-in-

nonconviction/madeupness/bottomlining-as-to-shallow-supererogation >,-or-temporalpreservation-as-pseudointemporality ${ }^{52}$-preservation), its disposition for temporal-preservationas-pseudointemporality ${ }^{5}$-preservation (whether instigated postlogicly or arising from enculturated-postlogism ${ }^{77}$ is bound to reflect the corresponding registryworldview's/dimension's preconverging-or-dementing -apriorising-psychologism that speaks fundamentally of relative-ontological-incompleteness ${ }^{8}$-induced,-`threshold-ofnonconviction/madeupness/bottomlining-in-shallow-supererogation $<-<$ as-to-'attendant- 
intradimensional'-prospectively-disontologising preconverging/dementing -apriorising-

psychologism>' (as-it-is-thus- 'in-wait'-for- ${ }^{7}$ perversion-of- ${ }^{2}$ reference-of-thought- $<$ aspreconvergingly-apriorising/axiomatising/referencing-in-

nonconviction/madeupness/bottomlining-as-to-shallow-supererogation >,-or-temporal-

preservation-as-pseudointemporality ${ }^{52}$-preservation, whether-consciously-or-unconsciouslyand-so-beyond-the-consciousness-awareness-teleology ${ }^{09}-<$ of-preconverging-existential-

extrication-as-of-existential-unthought $>$-manifestation intradimensionally); and equally so, as the successive relative-ontological-incompleteness ${ }^{8}$-induced,-'threshold-ofnonconviction/madeupness/bottomlining-in-shallow-supererogation $-<$ as-to-' attendantintradimensional'-prospectively-disontologising preconverging/dementing -apriorisingpsychologism>'-threshold will reflect as of preconverging-or-dementing ${ }^{20}$-apriorisingpsychologism the 'recurrent-utter-institutionalised mindset $/{ }^{8}$ reference-of-thought with respect to base-institutionalised mental-dispositions' as from the base-institutionalised perspective, likewise the 'ununiversalised mindset/ ${ }^{3}$ reference-of-thought with respect to ${ }^{103}$ universalised mental-dispositions' as from the ${ }^{103}$ universalised perspective, the 'non-positivism/medievalism mindset/ ${ }^{2}$ reference-of-thought with respect to positivistic mental-dispositions' as from the positivistic perspective, and prospectively so, the 'procrypticism mindset $/{ }^{3}$ reference-of-thought

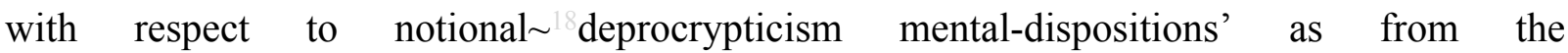
notional ${ }^{1}$ deprocrypticism perspective. (This preconverging-or-dementing ${ }^{20}$-apriorisingpsychologism reflection of the other lower registry-worldviews/dimensions mental-devisingrepresentation naturally occurs to us but not when our positivism- ${ }^{8}$ procrypticism registryworldview/dimension is so-construed as of preconverging-or-dementing ${ }^{20}$-apriorisingpsychologism with respect to prospective deprocrypticism; and so as from the overall insight of a 'postconverging-or-dialectical-thinking -psychology or psychology-of-mentation-dynamics or natural psychological-dynamics' grounded at the successive institutional- 
cumulation/institutional-recomposure-〈as-to- historiality/ontological-

eventfulness /ontological-aesthetic-tracing-<perspective-ontological-

normalcy/postconvergence-reflected-‘epistemicity-relativism-determinism'> $>$, as ontologicalcompleteness/ontological-normalcy/postconvergence driven). Taking the case of a nonpositivism/medievalism context as highlighted above at its relative-ontologicalincompleteness ${ }^{8}$-induced,-'threshold-of-nonconviction/madeupness/bottomlining-in-shallowsupererogation -<as-to- 'attendant-intradimensional'-prospectivelydisontologising preconverging/dementing -apriorising-psychologism>' -threshold （as-it-isthus- ‘in-wait'-for- ${ }^{7}$ perversion-of- ${ }^{3}$ reference-of-thought-<as-preconverginglyapriorising/axiomatising/referencing-in-nonconviction/madeupness/bottomlining-as-toshallow-supererogation >,-or-temporal-preservation-as-pseudointemporality ${ }^{52}$-preservation) warranting the positivistic registry-worldview/dimension, we can appreciate that there is a whole gamut of seemingly genuine ontological/being/existential dispositions as social practices within the non-positivism/medievalism registry-worldview/dimension like alchemy, superstitions, beliefs and other similar social constructions of meaningfulness that from a 'positivistic angle' are perfectly caricaturable as nothing but threshold-ofnonconviction/madeupness/bottomlining-in-shallow-supererogation $<-<$ as-to- ${ }^{\text {'attendant- }}$ intradimensional'-prospectively-disontologising preconverging/dementing -apriorisingpsychologism $>$ arising from the hollow-constituting-<as-disjointed-misappropriation-ofmeaningfulness-and-failing-intemporal-preservation $>$ of ${ }^{103}$ universalisation's ${ }^{83}$ reference-ofthought- ${ }^{8}$ ategorical-imperatives/axioms/registry-teleology ${ }^{9}$ as intradimensional existentialdecontextualised-transposition (of r reference-of-thought- categoricalimperatives/axioms/registry-teleology ${ }^{9}$ of ${ }^{103}$ universalisation meaningfulness). This is a recurrent dynamism associated with human-subpotency-aporia/undecidability/dilemma/oughtindeterminacy/deficiency/limitation/constraint—imbued-'notional firstnaturedness- 
formativeness-<as-to-eventualising-inkling-drive-or-seeding-misprising $>$ temporal-tointemporal-dispositions-<so-construed-as-from-perspective-ontologicalnormalcy/postconvergence $>$ '-existentialism-form-factor across all institutionalcumulation/institutional-recomposure-〈as-to- historiality/ontologicaleventfulness /ontological-aesthetic-tracing-<perspective-ontologicalnormalcy/postconvergence-reflected-'epistemicity-relativism-determinism' $>\rangle$, as at the point of a prospective/superseding/transcending institutionalisation's relative-ontologicalincompleteness ${ }^{8}$-induced,-'threshold-of-nonconviction/madeupness/bottomlining-in-shallowsupererogation -<as-to-'attendant-intradimensional'-prospectivelydisontologising preconverging/dementing -apriorising-psychologism>', as-it-is-thus-'inwait'-for- perversion-of- ${ }^{83}$ reference-of-thought-<as-preconverginglyapriorising/axiomatising/referencing-in-nonconviction/madeupness/bottomlining-as-toshallow-supererogation >,-or-temporal-preservation-as-pseudointemporality ${ }^{52}$-preservation, there is an eliciting of hollow-constituting-<as-disjointed-misappropriation-of-meaningfulnessand-failing-intemporal-preservation $>$ of its $\quad{ }^{83}$ reference-of-thought- categoricalimperatives/axioms/registry-teleology ${ }^{9}$ by temporal-dispositions (as temporal-preservation-aspseudointemporality ${ }^{52}$-preservation instigated by postlogism 77 and enculturated-postlogism 7 ) manifested in various social constructions of meaningfulness such that these are in effect derived-'threshold-of-nonconviction/madeupness/bottomlining-in-shallow-supererogation $<$ as-to-'attendant-intradimensional'-prospectivelydisontologising preconverging/dementing -apriorising-psychologism> $>$ and whose ontologically-veridical-meaningfulness is defective (as intradimensional existentialdecontextualised-transposition), requiring prospective transcending/superseding institutionalisation by ontological-reconstituting-as-to-

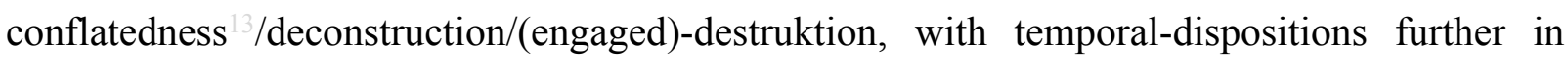


hollow-constituting-<as-disjointed-misappropriation-of-meaningfulness-and-failing-

intemporal-preservation> of ${ }^{8}$ reference-of-thought- categorical-imperatives/axioms/registryteleology ${ }^{9}$ of the latter transcending/superseding institutionalisation at its point of relativeontological-incompleteness ${ }^{8}$-induced,-'threshold-of-nonconviction/madeupness/bottomliningin-shallow-supererogation -<as-to- 'attendant-intradimensional'-prospectivelydisontologising $\sim$ preconverging/dementing -apriorising-psychologism>', as-it-is-thus-'inwait'-for- perversion-of- ${ }^{8}$ reference-of-thought-<as-preconverginglyapriorising/axiomatising/referencing-in-nonconviction/madeupness/bottomlining-as-toshallow-supererogation >,-or-temporal-preservation-as-pseudointemporality ${ }^{52}$-preservation, inducing new derived-'threshold-of-nonconviction/madeupness/bottomlining-in-shallowsupererogation -<as-to-'attendant-intradimensional'-prospectivelydisontologising preconverging/dementing -apriorising-psychologism>' social constructions of meaningfulness, and the cycle carries on this way till the attainment of ontologicalnormalcy/postconvergence (deprocrypticism) as ontological-completeness brings an end to derived-'threshold-of-nonconviction/madeupness/bottomlining-in-shallow-supererogation -

\section{$<$ as-to-'attendant-intradimensional'-prospectively-}

disontologising preconverging/dementing -apriorising-psychologism>' social constructions of meaningfulness that are veridically-unreal. These derived-'threshold-ofnonconviction/madeupness/bottomlining-in-shallow-supererogation $<-<$ as-to- 'attendantintradimensional'-prospectively-disontologising preconverging/dementing -apriorisingpsychologism>' social constructions of meaningfulness are in effect reflecting the registryworldview/dimension uninstitutionalised-threshold ${ }^{102}$ requiring corresponding prospective institutionalisations/intemporalisations (whether-consciously-or-unconsciously-and-so-beyondthe-consciousness-awareness-teleology ${ }^{9}-<$ of-preconverging-existential-extrication-as-ofexistential-unthought $>$-manifestation intradimensionally); and it is important to grasp that 
uninstitutionalised-threshold ${ }^{102}$ (however nefarious the consequences from an ontologicalnormalcy/postconvergence appreciation) are as critical and defining in their existentialism/fulldepth-of-existential-implications just as institutionalisations, to fully appreciate the very nature of transcendence-and-sublimity/sublimation/supererogatory de-mentativity as the most important thing/purposefulness of humanity-at-large. But then, our human intemporaldisposition responsible for the institutionalisation/intemporalisation process is equally inclined to focus-the-mind-more-thoroughly when dealing with phenomena that undermine ontologicalveridicality and so specifically with the undermining of soundness of ${ }^{83}$ reference-of-thought, and so across the various institutional-cumulation/institutional-recomposure-〈as-tohistoriality/ontological-eventfulness /ontological-aesthetic-tracing-<perspectiveontological-normalcy/postconvergence-reflected-‘epistemicity-relativism-determinism' $>\rangle$. It is more likely that in this regard, more likely than not ${ }^{7}$ perversion-of- ${ }^{8}$ reference-of-thought- $<$ aspreconvergingly-apriorising/axiomatising/referencing-innonconviction/madeupness/bottomlining-as-to-shallow-supererogation $>$ phenomena as postlogic effect including psychopathic may actually have been a boost for more rapid human registry-worldview's/dimension's institutionalisation/intemporalisation as our intemporaldisposition going by its own intemporal preservational individuation disposition (in intemporalpreservation-entropy-or-contiguity-or-ontological-preservation) is rather prone to apprehend and deal with $\quad{ }^{7}$ perversion-of- ${ }^{3}$ reference-of-thought- $<$ as-preconverginglyapriorising/axiomatising/referencing-in-nonconviction/madeupness/bottomlining-as-toshallow-supererogation $>$ issue at the humanity-at-large scale for the need of human registryworldview's/dimension's institutionalisation as secondnaturing given that with human limitedmentation-capacity-deepening —as-subjecting limitedness/human-subpotency-to-'educedunlimitedness/existence-sublimating nascence' ${ }^{53}$ it is naïve to operate on the basis of a 'human transformation on the wrong dependence of our intemporal-disposition as firstnatureness', thus 
the reason why we institutionalise as secondnaturing taking cognisance of the reality of our temporal-to-intemporal individuations dispositions. Just as implied elsewhere in this paper, the skewing ('intemporality ${ }^{52}$-symmetrising-by-desymmetrising-subsumption-of-temporality ${ }^{8}$ ', for relative intrinsic-reality/ontological-veridicality

transcendentalenabling/sublimating/supereregatery $\sim$ de-mentativity) (from shortness-of-register-ofmeaningfulness-and-teleology ${ }^{99}$ to longness-of-register-of- ${ }^{5}$ meaningfulness-and-teleology ${ }^{9}$ ) of capacity as shallow-limited-mentation-capacity-as-subjecting 'educedunlimitedness/existence-sublimating nascence' to-limitedness/human-subpotency to deeperlimited-mentation-capacity—as-subjecting-'educed-unlimitedness/existence-sublimating nascence' to-limitedness/human-subpotency, is the trascendental construct of human virtue, and so as a contiguity notion, and not of abstract analogy. This notion of contiguity is what explains the capacity for humankind to accumulate/recomposure/reorder its institutionalisation/intemporalisation capacity. This can be explained as follows. Considering the instance where for instance the target of accusations of sorcery was to equally adopt a temporal stance by making a vague accusation of sorcery as well. Seemingly, such a temporal approach will more or less be more effective in preempting the 'incidental resolution of temporalpreservation-as-pseudointemporality ${ }^{52}$-preservation' (with respect to themselves in their specific locale) associated with the 'dynamic-cumulative-aftereffect of subontologisation' (slantedness/postlogic-effect, miscuing, disjointed-logic, logical-drag, unconscionability-drag, sub-par/formulaic-association/temporal/alibi conventioning-rationalising, and temporalenculturation/temporal-endemisation-effect) rather as an extricatory/temporal preconvergingde-mentating/structuring/paradigming in serving their purpose of a temporal mortal. In so doing incidentally it doesn't actually preempt but fails the " ${ }^{103}$ universal resolution of temporalpreservation-as-pseudointemporality ${ }^{52}$-preservation' (at humanity-at-large scale) as it advances an argument that still enculturates/endemises the upkeep of notions of superstition and sorcery. 


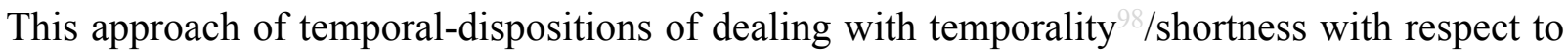
perversion-of- ${ }^{-3}$ reference-of-thought-<as-preconvergingly-

apriorising/axiomatising/referencing-in-nonconviction/madeupness/bottomlining-as-to-

shallow-supererogation $>$ in all the registry-worldviews/dimensions (institutionalcumulation/institutional-recomposure-〈as-to- historiality/ontological-

eventfulness /ontological-aesthetic-tracing-<perspective-ontological-

normalcy/postconvergence-reflected-'epistemicity-relativism-determinism'> $>\rangle$ ) is what endemises/enculturates the dialectically-out-of-phase or dialectically-primitive. A truly intemporal/ontological/social/species/ ${ }^{103}$ universal/transcendental/ ${ }^{5}$ maximalisingrecomposuring-for-relative-ontological-completeness ${ }^{8}$ —unenframed/re-

ontologising conceptualisation postconverging-de-mentating/structuring/paradigming warrants 'a transcendental posture of ${ }^{103}$ universal-projection as of aetiologisation/ontological-escalation$<$ ontological-veridicality_commitment/otherliness_transcending/compulsions-

encumbered_transcending $>$ ' that overlooks resolving temporality ${ }^{9} /$ shortness with temporality $/$ shortness and seeks to grasp the ${ }^{103}$ universal implications of all such temporalpreservation-as-pseudointemporality ${ }^{52}$-preservation inclinations of ${ }^{74}$ perversion-of- ${ }^{8}$ referenceof-thought-<as-preconvergingly-apriorising/axiomatising/referencing-in-

nonconviction/madeupness/bottomlining-as-to-shallow-supererogation $>$ at the humanity-atlarge/intemporal level of all locales and situations, and only then in transversality $-<$ forsublimating-existential-eventuating/denouement,-from-'thinking-at-first/pure-predispositionpreemptive-of-prospective-disontologising/subontologising', as-of-prospectivelydisambiguated-affirmed-and-unaffirmed-'motif-and-apriorising/axiomatising/referencing'> that all such incidentals of 77 perversion-of- reference-of-thought-<as-preconverginglyapriorising/axiomatising/referencing-in-nonconviction/madeupness/bottomlining-as-toshallow-supererogation $>$ and temporal-preservation-as-pseudointemporality ${ }^{52}$-preservation 
endemisation/enculturation are construed and resolved by deferential-formalisation-transference of the intemporal-disposition approach as institutionalisation/intemporalisation. It is only such an intemporal approach that suprastructurally (beyond-the-consciousness-awarenessteleology ${ }^{9}-<$ of-preconverging-existential-extrication-as-of-existential-unthought $>$-oftemporal-dispositions) allows for the requisite base-institutionalising of recurrent-utteruninstitutionalisation, ${ }^{103}$ universalisation of ununiversalisation, positivising/rational-empiricism of non-positivism/medievalism, and prospectively deprocrypticising/preemptingdisjointedness-as-of- ${ }^{8}$ reference-of-thought of procrypticism-or-disjointedness-as-ofreference-of-thought. The fact has always been that throughout the various institutionalisations this human intemporal-disposition individuation disposition has always been an indispensable re-originary_as-unenframed_rene-ontologising/unbeholdening/outlier-conceptualisation-_imbuedpostconverging/dialectical-thinking -'projective-insights'/'epistemic-projection-inconflatedness ' -of-notional deprocrypticism-prospective-sublimation $\rangle^{\circ}$ (as longness-ofregister-of- ${ }^{56}$ meaningfulness-and-teleology ${ }^{9}$ ) with respect to human social-stake-contentionor-confliction-and-confliction and the reason for its conceptualisations to be construed as institutionalisation-as-virtue even though going by temporal-dispositions inclinations, 'such abstract projection basically would hardly make sense'. The fact is that this intemporal inclination, while often not downright articulated for what it is but rather implied, is actually behind all formal constructs with an adoption of a 'maximalist approach' in the construal of social phenomenal possibilities. Likewise, the fepistemictotalising ${ }^{3}$ hermeneutic/textuality/reprojecting/supererogating/zeroing/re-acuting,$\{$ decompulsing $\}$ delinearity for-cogency orientation of this paper takes up such a maximalist approach in understanding phenomena of 7 perversion-of- reference-of-thought- $<$ as-preconverginglyapriorising/axiomatising/referencing-in-nonconviction/madeupness/bottomlining-as-toshallow-supererogation $>$ and more precisely psychopathy and social psychopathy in the social- 
construct even though from a simplistic temporal perception it may seem at times overblown (very much like in a core medieval setup a positivistic ${ }^{55}$ maximalising-recomposuring-forrelative-ontological-completeness ${ }^{87}$ - unenframed/re-ontologising conceptualisation disposition such as Galileo's or Darwin's or Rousseau's or Descartes's assertions will seem overblown to the 'core non-positivism/medievalism mindset' going by its customary perception), since it doesn't accommodate temporal/incremental/'disjointedness-as-ofreference-of-thought' ways of thinking and instead strives for a ${ }^{103}$ universal implications depthof-thought. Basically, on the same token the maximalising-recomposuring-for-relativeontological-completeness ${ }^{87}$ - unenframed/re-ontologising conceptualisation of formal constructs is all about construing human transcendental potential as a 'virtue tipping exercise' wherein for instance the seemingly overblown representation of humans as susceptible to malfeasance/offence by the construct of the Law doesn't necessarily imply that everything about humans is how they are likely to commit malfeasance/offence but rather that the transcendental potential of the construct of Law caters for and is a virtue tipping exercise for maximalisingrecomposuring-for-relative-ontological-completeness ${ }^{87}$-unenframed/re-

ontologising conceptualisation the possibility of limited committing of malfeasance/offence, just as likewise the ${ }^{5}$ maximalising-recomposuring-for-relative-ontological-completeness ${ }^{8}$ unenframed/re-ontologising conceptualisation construct of medicine of humans as likely to be diseased doesn't necessarily mean that everything about humans is how they will get an ailment but is a human transcendental potential as a virtue tipping exercise for ${ }^{55}$ maximalisingrecomposuring-for-relative-ontological-completeness ${ }^{8}$ — unenframed/re-

ontologising conceptualisation the possibility of human health. The reason for this deferentialformalisation-transference disposition is simple, as formal constructs 'reason' on the basis of intemporality $2 /$ utter-ontological-veridicality in the quest for reifying abstract ${ }^{103}$ universal projection very much unlike everyday informal conceptualisations that are rather driven by 
vague impressions and good-naturedness and tend to construe meaningfulness by reflex without factoring in relative-ontological-incompleteness ${ }^{8}$-induced,-`threshold-ofnonconviction/madeupness/bottomlining-in-shallow-supererogation $<-<$ as-to- 'attendant-

\section{intradimensional'-prospectively-disontologising preconverging/dementing -apriorising-}

psychologism>' of ordinary day to day thinking (common sense), and tend to be unsure, poorly methodical, poorly ${ }^{103}$ universalising, poorly insightful, and with elevated subjectivity (not only with regards to facts but with the purported ${ }^{83}$ reference-of-thought as well as the apriorisingreference-of-thought/apriorising-registry-elements which are pychologismic-subliminality-of-individuation-effusing/worlding imbued logicaldueness-or-scape-or-frame, profile-or-stature, presumptuousness-or-arrogation, assumptions, value-reference and teleology ${ }^{\circ}$ ), and so beforehand/as-of-a-priori even without the instigating effect of any perversion-of- ${ }^{73}$ reference-of-thought- $<$ as-preconverginglyapriorising/axiomatising/referencing-in-nonconviction/madeupness/bottomlining-as-to-

shallow-supererogation $>$ like postlogism 7 psychopathy; such that such temporal/incremental/'disjointedness-as-of- ${ }^{-3 e f e r e n c e-o f-t h o u g h t ' ~ r e a s o n i n g ~ i s ~ b e s t ~ l e f t ~ f o r ~}$ inconsequential and trite matters of day to day living, as validated by the processes and procedures of our formal institutions however approximate in their success given the pervasiveness of the extended-informality-〈susceptible-to-effecting-parsimony-as-ofshoddiness-and-incompleteness-to- meaningfulness-and-teleology $\rangle$ even in formal setups, with its susceptibility to undermine or overlook 'formal effectiveness' (which can sometimes be naively construed as weakness of formalism rather than insufficiently effective formalism or extended-informality-〈susceptible-to-effecting-parsimony-as-of-shoddiness-andincompleteness-to- meaningfulness-and-teleology $\rangle$ disruption of formal effectiveness). Abstractly $\quad{ }_{5}^{5}$ maximalising-recomposuring-for-relative-ontological-completeness ${ }^{87}$ unenframed/re-ontologising conceptualisation meaningfulness carries an intemporal/longness- 
of-register-of meaningfulness-and-teleology and ${ }^{103}$ universal coherence that incremental meaningfulness doesn't, and thus ${ }^{55}$ maximalising-recomposuring-for-relative-ontologicalcompleteness ${ }^{87}$ - unenframed/re-ontologising conceptualisation is actually the drive for transcendence-and-sublimity/sublimation/supererogatory-de-mentativity in reflecting holographically-<conjugatively-and-transfusively $>$ the relative-unreflexivity/relativereflexivity ontological-contiguity of-the-human-institutionalisation-process successive institutional-cumulation/institutional-recomposure-〈as-to- historiality/ontological-

eventfulness /ontological-aesthetic-tracing-<perspective-ontologicalnormalcy/postconvergence-reflected-'epistemicity-relativism-determinism'>>, with human ontological development from 'shallow limited-mentation-capacity as subjecting 'educedunlimitedness/existence-sublimating nascence' to-limitedness/human-subpotency-〈as of relative apriorising/axiomatising/referencing-\{of-'prospectively implicited_attendant ontological-contiguity ' educedexistentialising/contextualising/textualising_'intelligibility/epistemicity/reflexivity-contiguity<imbued-notional cogency> $\quad\}$ - constitutedness ${ }^{14}$-in-preconverging-entailment $\rangle$ to deeper limited-mentation-capacity—as-subjecting 'educed-unlimitedness/existence-sublimating nascence' to-limitedness/human-subpotency-〈as of relative apriorising/axiomatising/referencing-\{of-'prospectively_implicited_attendant-ontologicalcontiguity ' educed-

existentialising/contextualising/textualising_'intelligibility/epistemicity/reflexivity-contiguity<imbued-notional cogency >' \}-conflatedness ${ }^{13}$-in-\{preconverging-disentailment by\} postconverging-entailment $\rangle$ reconstrual/reconceptualisation' and hence it is ontologicallycontiguous as a virtue construct that is self-sustaining. ${ }^{55}$ maximalising-recomposuring-forrelative-ontological-completeness ${ }^{87}$ - unenframed/re-ontologising conceptualisation as such is the mental-disposition

to uphold 'sublimating-epistemic- 
imbricatedness/threadedness/recomposuring as of 'implicited_attendant-ontologicalcontiguity $^{67}$; educed-

existentialising/contextualising/textualising_intelligibility/epistemicity/reflexivity_contiguity$<$ imbued-notional $\sim$ cogency $>,{ }^{\prime},-<$ reifying-or-elucidating-of-prospective-relative-ontologicalcompleteness -of- reference-of-thought- devolving-as-of-instantiative-context> as to existence-potency ${ }^{39} \sim$ sublimating-nascence,-disclosed-from-prospective-epistemicdigression—rules-of-apriorising/axiomatising/referencing-that-further-epistemicallyunconceal-the-very-ontologically-same-existential-reality' (from the perspective of the 'postconverging-or-dialectical-thinking ${ }^{2}{ }^{8}$ reference-of-thought in relative-ontologicalcompleteness 87 as depth-of-thought') as 'shallow limited-mentation-capacity-as-subjecting'educed-unlimitedness/existence-sublimating nascence' to-limitedness/human-subpotency-〈as of relative apriorising/axiomatising/referencing-\{of-'prospectively implicited_attendantontological-contiguity ' $\sim$ educedexistentialising/contextualising/textualising_'intelligibility/epistemicity/reflexivity_contiguity$<$ imbued-notional cogency> $\quad\}$-constitutedness ${ }^{1}$-in preconverging-entailment $\rangle$ to deeper limited-mentation-capacity_as-subjecting-'educed-unlimitedness/existence-sublimating nascence' to-limitedness/human-subpotency-〈as of relative apriorising/axiomatising/referencing-\{of-'prospectively implicited_attendant_ontologicalcontiguity ' educedexistentialising/contextualising/textualising_'intelligibility/epistemicity/reflexivity-contiguity<imbued-notional cogency $\left.>^{\prime}\right\}$-conflatedness ${ }^{13}$-in-\{preconverging-disentailment by\} postconverging entailment $\rangle /$ /relative-ontological-completeness ${ }^{87} /$ diminishing-humanepistemic-abnormalcy-or-preconvergence ${ }^{31}$ avails for the development of ${ }^{8}$ reference-of-thought in construing intrinsic-reality/ontology, by its very intemporal/Aongness-of-register-ofmeaningfulness-and-teleology principle-driven nature; hence it thus regenerates new 
reference-of-thought- categorical-imperatives/axioms/registry-teleology ${ }^{9}$,-for-intemporalpreservation-entropy-or-contiguity-or-ontological-preservation to match developing 'shallow limited-mentation-capacity—as-subjecting 'educed-unlimitedness/existence-sublimating nascence' to limitednesshman-subpotency- as relative apriorising/axiomatising/referencing-\{of-'prospectively implieited_attendant-ontologicalcontiguity ' educedexistentialising/contextualising/textualising_'intelligibility/epistemicity/reflexivity-contiguity<imbued-notional cogency>' $\}$-constitutedness ${ }^{1}$-in-preconverging-entailment $\rangle$ to deeper limited-mentation-capacity—as-subjecting 'educed-unlimitedness/existence-sublimating nascence' to-limitedness/human-subpotency-〈as of relative apriorising/axiomatising/referencing-\{of-'prospectively implicited_attendant-ontologicalcontiguity ' $\sim$ educedexistentialising/contextualising/textualising_'intelligibility/epistemicity/reflexivity-contiguity<imbued-notional cogency $\left.>^{\prime}\right\}$-conflatedness ${ }^{13}$-in-\{preconverging-disentailment by postconverging entailment $\rangle$ '/relative-ontological-completeness ${ }^{87} /$ diminishing-humanepistemic-abnormalcy-or-preconvergence ${ }^{3 !}$. Whereas ${ }^{51}$ incrementalism-in-relative-ontologicalincompleteness ${ }^{8}$ - enframed/disontologising conceptualisation tends to operate as if any one instance human meaningfulness is absolutely set (and so rather as mereformulaicity/ritualisation-<as-to-mere-formulaicmethodologising/mutualising/organising/institutionalising,-prospectively-losing-track-of-

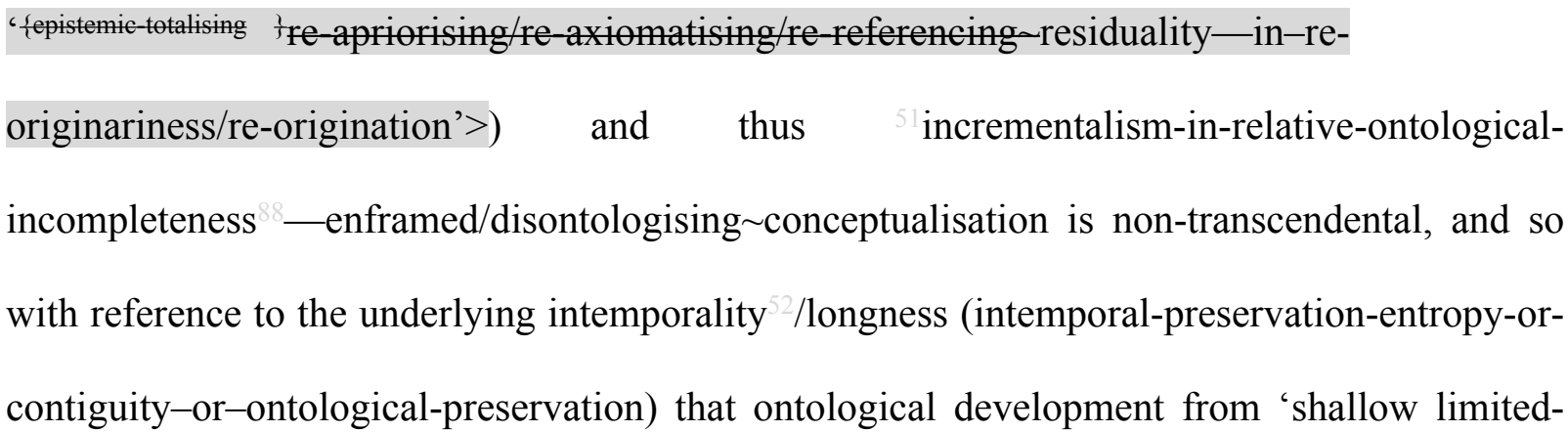


mentation-capacity—as-subjecting-'educed-unlimitedness/existence-sublimating nascence' to-limitedness/human-subpotency-〈as of relative apriorising/axiomatising/referencing-\{of'prospectively_implicited_attendant-ontological-contiguity ' educedexistentialising/contextualising/textualising_'intelligibility/epistemicity/reflexivity-contiguity$<$ imbued-notional cogency $>$ ' $\}$ - constitutedness ${ }^{1}$-in-preconverging-entailment $\rangle$ to deeper limited-mentation-capacity—as-subjecting 'educed-unlimitedness/existence-sublimating nascence' to-limitedness/human-subpotency-〈as of relative apriorising/axiomatising/referencing-\{of-'prospectively_implicited_attendant-ontologicalcontiguity ' educedexistentialising/contextualising/textualising_'intelligibility/epistemicity/reflexivity-contiguity<imbued-notional cogency >' \}-conflatedness ${ }^{13}$-in-\{preconverging-disentailment by\} postconverging-ntailment $\rangle$ '/relative-ontological-completeness ${ }^{87} /$ diminishing-humanepistemic-abnormalcy-or-preconvergence ${ }^{3 !}$ elicits, and in lieu it is rather of a temporality $/$ /shortness reflex mental-disposition such that correspondingly developed reference-of-thought- ${ }^{8}$ ategorical-imperatives/axioms/registry-teleology ${ }^{99}$,-for-intemporalpreservation-entropy-or-contiguity-or-ontological-preservation is related to in virtuality-orontologically-flawed-construal (being-construal-as-abstract-construal-as-of-flawed-andshallow-and-non-veridical-existential-reference) terms, whether unconsciously (ignorance), expediently (affordability) or consciously. Thus as mental-disposition, incrementalism-inrelative-ontological-incompleteness ${ }^{8}$ — enframed/disontologising conceptualisation across all registry-worldviews/dimensions involves teleological-decadence-<-in-dimensionality-ofdesublimating-lack-of ${ }^{-}-\langle<$amplituding/formative $>$supererogatory $\sim$ de-mentativeness/epistemicgrowth-or-conflatedness /transvaluative-rationalising/transepistemicity/anamnesticresiduality/spirit-drivenness-equalisation $\rangle$ at the uninstitutionalised-threshold ${ }^{102}$, speaking fundamentally of the reality of human-subpotency-aporia/undecidability/dilemma/ought- 
indeterminacy/deficiency/limitation/constraint—imbued-'notional firstnaturednessformativeness-<as-to-eventualising-inkling-drive-or-seeding-misprising $>$ temporal-tointemporal-dispositions- $<$ so-construed-as-from-perspective-ontologicalnormalcy/postconvergence>'-existentialism-form-factor and underlining the 'se-mentation〈supererogatory $\sim$ ontological-de-mentation-or-dialectical-de-mentation-stranding-orattributive-dialectics $\rangle$ of ${ }^{83}$ reference-of-thought threshold' with respect to ${ }^{83}$ reference-of-thought mental representations between intemporality ${ }^{52} /$ longness as candored-supratransversality- $<$ insublimating-existential-eventuating/denouement $>\sim$ of-motif-andapriorising/axiomatising/referencing and temporality $\%$ /shortness as decandoredsubtransversality-<in-desublimating-existential-eventuating/denouement $>\sim$ of-motif-andapriorising/axiomatising/referencing. $\quad{ }^{51}$ incrementalism-in-relative-ontologicalincompleteness 8 - enframed/disontologising conceptualisation wrongly construes meaningfulness (both ontology and virtue perspectives) as rather a process of additionality over the prior ${ }^{83}$ reference-of-thought whereas in reality (from the insight that our placeholdersetup/mental-devising-representation/mentation/consciousness-awareness-teleology ${ }^{9}$ develops from shallow limited-mentation-capacity-as-subjecting-'educed-unlimitedness/existencesublimating nascence' to-limitedness/human-subpotency-〈as of relative apriorising/axiomatising/referencing-\{of-'prospectively implicited_attendant-ontologicalcontiguity ' $\sim$ educedexistentialising/contextualising/textualising_'intelligibility/epistemicity/reflexivity-contiguity<imbued-notional cogency>' $\}$-constitutedness ${ }^{1}$-in-preconverging-entailment $\rangle$ to deeper limited-mentation-capacity—as-subjecting 'educed-unlimitedness/existence-sublimating nascence' to-limitedness/human-subpotency-〈as of relative apriorising/axiomatising/referencing-\{of-'prospectively_implicited_attendant-ontologicalcontiguity ' educed- 
existentialising/contextualising/textualising_ 'intelligibility/epistemicity/reflexivity-contiguity-

$<$ imbued-notional cogency $>$ ' $\}$-conflatedness ${ }^{13}$ in-\{preconverging-disentailment by\}

postconverging-entailment) by way of the " ${ }^{15}$ de-mentation-〈supererogatory $\sim$ ontological-dementation-or-dialectical-de-mentation-stranding-or-attributive-dialectics $\rangle$ of ${ }^{83}$ reference-ofthought') ${ }^{5}$ meaningfulness-and-teleology ${ }^{9}$ develops rather as a ${ }^{55}$ maximalising-recomposuringfor-relative-ontological-completeness ${ }^{87}$ - unenframed/re-ontologising conceptualisation process of recomposuring towards a deeper superseding-oneness-of-ontology, with recomposuring reflecting that human progress is rather an relative-unreflexivity/relativereflexivity ontological-contiguity ${ }^{67}$ of-the-human-institutionalisation-process secondnaturing/institutional-design defined by skewing ('intemporality ${ }^{52}$-symmetrising-bydesymmetrising-subsumption-of-temporality ${ }^{8}$, for relative intrinsic-reality/ontologicalveridicality transcendental-enabling/sublimating/supererogatory de-mentativity) as deferentialformalisation-transference by the intemporal-disposition/longness-of-register-ofmeaningfulness-and-teleology ${ }^{\circ}$ ) and critically without the transformation of the reality of human individuation dispositions as temporal (shortness-of-register-of- ${ }^{56}$ meaningfulness-andteleology ${ }^{9}$ )-to-intemporal (longness-of-register-of- ${ }^{56}$ meaningfulness-and-teleology ${ }^{9}$ ) as of human existential-form-factor. Thus the implication is that the relative-unreflexivity/relativereflexivity - ontological-contiguity ${ }^{67}$ of-the-human-institutionalisation-process ${ }^{68}$ succumbs to uninstitutionalised-threshold ${ }^{102}$ due to the dynamic-cumulative-aftereffect of human temporality $/$ temporal-dispositions as of shortness-of-register-of- ${ }^{5}$ meaningfulness-andteleology in inducing uninstitutionalised-threshold ${ }^{12}$ which can only further be preconverging/postconverging-de-mentatively/structurally/paradigmatically resolved by maximalising-recomposuring-for-relative-ontological-completeness ${ }^{87}$ - unenframed/re$\begin{array}{llll}\text { ontologising conceptualisation } & \text { recomposre } & \text { as } & \text { transcendental- }\end{array}$ enabling/sublimating/supereregatory $\sim$ de-mentativity. Basically, incrementalism-in-relative- 
ontological-incompleteness ${ }^{8}$ — enframed/disontologising conceptualisation relation to meaningfulness as a 'comprehensive additionality exercise' thus fails to account for human temporality 9 /temporal-dispositions as 'not transformed' and will tend at uninstitutionalisedthreshold ${ }^{102}$ towards the perversion/derived-perversion of the institutionalisation ${ }^{83}$ reference-ofthought or ${ }^{83}$ reference-of-thought- ${ }^{-1}$ ategorical-imperatives/axioms/registry-teleology ${ }^{9}$,-forintemporal-preservation-entropy-or-contiguity-or-ontological-preservation (whether unconsciously, expediently or consciously), involving flawed-existential-elevation-ofreference-of-thought ${ }^{4}$. This insight equally explains the nature of human progress as the natural mental-reflex is to think that human progress occurs incrementally as an exercise of additionality to the prior ${ }^{83}$ reference-of-thought and institutionalisation, which is wrong as human progress is all about our placeholder-setup/mental-devisingrepresentation/mentation/consciousness-awareness-teleology grasp of the same intrinsicreality-as-ontological-veridicality in construing ${ }^{56}$ meaningfulness-and-teleology $/$ teleologicaldifferentiation involving rather a 'continuous ${ }^{55}$ maximalising-recomposuring-for-relativeontological-completeness ${ }^{87}$ - unenframed/re-ontologising conceptualisation exercise' of the same intrinsic-reality-as-ontological-veridicality but with deeper limited-mentation-capacityas subjecting 'educed unlimitedness/existence sublimating nascence' to limitedness/hmman subpotency-〈as of relative apriorising/axiomatising/referencing-\{of-'prospectively implicited_attendant-ontological-contiguity ' educedexistentialising/contextualising/textualising_'intelligibility/epistemicity/reflexivity-contiguity<imbued-notional cogency >' \}-conflatedness ${ }^{13}$-in-\{preconverging-disentailment by\} postconverging-entailment $\rangle$ arising from the overall and specific accumulated human experiential possibilities of being on earth. Thus human progress as maximalisingrecomposuring-for-relative-ontological-completeness ${ }^{8}$ —unenframed/reontologising conceptualisation is a change of human <amplituding/formative-epistemicity $>$ - 
totalising $\sim$ renewing-realisation/re-perception/re-thought-as-utter-placeholder-setupontological-rescheduling-〈by-a-renewing-of-apriorising/axiomatising/referencingpsychologism-as-the-new-referencing-basis-of-prospective- meaningfulness-and-teleology > enabled by psychoanalytic-unshackling/memetic-reordering/institutional-recomposuring, and it not about being incremental/additional but is rather a ${ }^{55}$ maximalising-recomposuring-forrelative-ontological-completeness ${ }^{8}$ —unenframed/re-ontologising conceptualisation emergingthrough (by maximal-as-intemporal-operating-modality-of- ${ }^{3}$ reference-of-thought-as-ofmaximalising-recomposuring-for-relative-ontological-completeness ${ }^{87}$ - unenframed/reontologising conceptualisation-as-inducing-the-prospective-institutionalisation) of prospective-institutionalisation over the old/uninstitutionalised-threshold due to human limited-mentation-capacity-deepening —as-subjecting-limitedness/human-subpotency-to'educed-unlimitedness/existence-sublimating nascence' ',', as base-institutionalisation is not an addition/increment over recurrent-utter-uninstitutionalisation but a " maximalisingrecomposuring-for-relative-ontological-completeness ${ }^{8}$ —unenframed/re-

ontologising conceptualisation emerging-through', just as is ${ }^{103}$ universalisation over ununiversalisation, positivism over non-positivism/medievalism, and prospectively notional ${ }^{1}$ deprocrypticism over procrypticism; as a maximalising-recomposuring-forrelative-ontological-completeness ${ }^{8}$ - unenframed/re-ontologising conceptualisation process in the recomposuring accrual of human 'shallow limited-mentation-capacity-as-subjecting'educed-unlimitedness/existence-sublimating nascence'-to-limitedness/human-subpotency-〈as of relative apriorising/axiomatising/referencing-\{of-'prespectively implicited_attendant ontological-contiguity ' educedexistentialising/contextualising/textualising_'intelligibility/epistemicity/reflexivity-contiguity<imbued-notional cogency $\left.>^{\prime} \quad\right\}$ - constitutedness ${ }^{14}$-in-preconverging-entailment $\rangle \quad$ towards deeper limited-mentation-capacity—as-subjecting 'educed-unlimitedness/existence- 
sublimating nascence' to-limitedness/human-subpotency-〈as

of

relative

apriorising/axiomatising/referencing-\{of-'prospectively_implicited_attendant-ontological-

contiguity ' educed-

existentialising/contextualising/textualising_'intelligibility/epistemicity/reflexivity-contiguity-

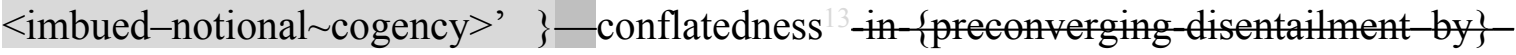

postconverging-entailment $\rangle$ ' wherein the relative-unreflexivity/relative-reflexivity-

ontological-contiguity ${ }^{67}$ of-the-human-institutionalisation-process ${ }^{68}$ is rather construed as of

‘sublimating-epistemic-imbricatedness/threadedness/recomposuring

as

of

'implicited_attendant-ontological-contiguity ${ }^{67}$ ' educed-

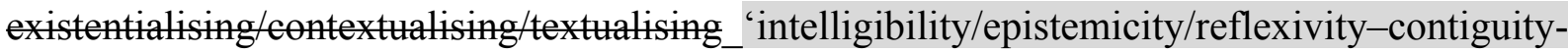

$<$ imbued-notional $\sim$ cogency $>^{,},-<$reifying-or-elucidating-of-prospective-relative-ontological-

completeness -of- reference-of-thought- devolving-as-of-instantiative-context> as to

existence-potency ${ }^{39} \sim$ sublimating-nascence,-disclosed-from-prospective-epistemic-

digression—rules-of-apriorising/axiomatising/referencing-that-further-epistemically-

unconceal-the-very-ontologically-same-existential-reality' providing existential-context

priorly-and-over

elaboration-as-to-mere-

extrapolating/constituting/abstracting/deducing/inferring-of-elucidation-outside-

'prospectively_implicited_attendant_ontological-contiguity ${ }^{67}$ 'educed-

existentialising/contextualising/textualising_'intelligibility/epistemicity/reflexivity-contiguity-

$<$ imbued-notional cogency $>$ due to the fact that when not so existentially-contextualised our

limited-mentation-capacity-deepening —as-subjecting-limitedness/human-subpotency-to-

'educed-unlimitedness/existence-sublimating nascence' ${ }^{53}$ in an elaboration-as-to-mereextrapolating/constituting/abstracting/deducing/inferring-of-elucidation-outside-

'prospectively_implicited_attendant_ontological-contiguity ${ }^{67}$ ' educed-

existentialising/contextualising/textualising_'intelligibility/epistemicity/reflexivity-contiguity- 
$<$ imbued-notional cogency>' exercise is bound to induce 'wrongly-projected decontextualising-unimbricatedness/unthreadedness/unrecomposuring,-as-virtuality-orontologically-flawed-construal (which is rather a 'prior threshold-ofnonconviction/madeupness/bottomlining-in-shallow-supererogation $-<$ as-to-'attendantintradimensional'-prospectively-disontologising preconverging/dementing -apriorisingpsychologism> ${ }^{8}$ reference-of-thought' in shallowness-of-thought-or-unsophistication-ofunderstanding), in wrong grasp of 'implicited_attendant-ontological-contiguity ${ }^{67}$ ' educedexistentialising/contextualising/textualising_'intelligibility/epistemicity/reflexivity-contiguity$<$ imbued-notional $\sim$ cogency $>^{\prime},-<$ reifying-or-elucidating-of-prospective-relative-ontologicalcompleteness -of- reference-of-thought- devolving-as-of-instantiative-context> as to existence-potency ${ }^{39} \sim$ sublimating-nascence,-disclosed-from-prospective-epistemicdigression —rules-of-apriorising/axiomatising/referencing-that-further-epistemicallyunconceal-the-very-ontologically-same-existential-reality'. This further explains why meaningfulness is effectively an existentialism construct; existentialism in the sense that our limited-mentation-capacity-deepening—as-subjecting limitedness/human-subpotency-to'educed-unlimitedness/existence-sublimating nascence' ${ }^{53}$ needs to grasp sublimatingepistemic-imbricatedness/threadedness/recomposuring as of 'implieitentantontolonicalcontiguity ${ }^{67} \sim$ educedexistentialising/contextualising/textualising_intelligibility/epistemicity/reflexivity-contiguity$<$ imbued-notional $\sim$ cogency $>,{ }^{\prime},-<$ reifying-or-elucidating-of-prospective-relative-ontologicalcompleteness -of- reference-of-thought- devolving-as-of-instantiative-context> as to existence-potency ${ }^{32} \sim$ sublimating-nascence,-disclosed-from-prospective-epistemicdigression—rules-of-apriorising/axiomatising/referencing-that-further-epistemicallyunconceal-the-very-ontologically-same-existential-reality, as a-priori over any subsequent elaboration-as-to-mere-extrapolating/constituting/abstracting/deducing/inferring-of- 
elucidation-outside_-'prospectively_implicited_attendant-ontological-contiguity ${ }^{67}$ > educedexistentialising/contextualising/textualising_'intelligibility/epistemicity/reflexivity_contiguity$<$ imbued-notional cogency $>$ for the latter to be ontologically valid. Furthermore, the precedingness nature of ontological-normalcy/postconvergence with respect to human existential-reference/existential-tautologisation pivoting to ontology/ontological-veridicality speaks of a 'decentering' to the prospective ontological-construct that maximalisingrecomposuring-for-relative-ontological-completeness 87 unenframed/re-

ontologising conceptualisation effectively enables by placeholder-setup/mental-devisingrepresentation/mentation/consciousness-awareness-teleology ${ }^{9}$ rescheduling (as it perpetually recomposure to the intemporal as the relative absolute in value and ontology) over incrementalism-in-relative-ontological-incompleteness ${ }^{8}$

enframed/disontologising $\sim$ conceptualisation which wrongly falls back to the relatively limitedmentation-capacity-deepening —as-subjecting limitedness/human-subpotency-to-'educedunlimitedness/existence-sublimating nascence' ${ }^{53}$ of the temporal presencing-as-if-definitely-set in wrongly construing it as the relative absolute ${ }^{83}$ reference-of-thought. Insightfully with respect to the notion of ${ }^{55}$ maximalising-recomposuring-for-relative-ontological-completeness ${ }^{87}$ unenframed/re-ontologising conceptualisation, the law typically operates on the basis of anticipating maximally the possibilities of criminal acts with the anticipation of the maximal possibilities of victimisation from such acts (when it regulates weapons ownership, for example) in effectively construing optimal prevention of criminality in society as a preconverging/postconverging-de-mentative/structural/paradigmatic construct that more vitally shapes human action and its 'effective enforcement' is actually a minor portion of the preconverging/postconverging-de-mentative/structural/paradigmatic construct of law over

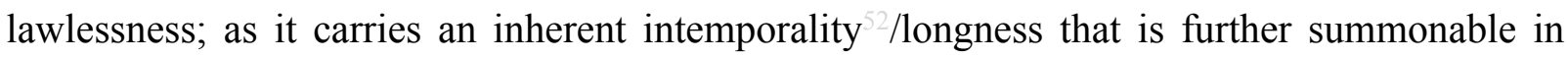
improving the law with human 'shallow limited-mentation-capacity-as-subjecting 'educed- 
unlimitedness/existence-sublimating nascence' to-limitedness/human-subpotency-〈as of relative apriorising/axiomatising/referencing-\{of-‘prospectively_implicited_attendantontological-contiguity ' educedexistentialising/contextualising/textualising_'intelligibility/epistemicity/reflexivity-contiguity$<$ imbued-notional cogency $>$ ' $\}$ - constitutedness ${ }^{1}$-in-preconverging-entailment $\rangle$ to deeper limited-mentation-capacity—as-subjecting 'educed-unlimitedness/existence-sublimating nascence' to-limitedness/human-subpotency-〈as of relative apriorising/axiomatising/referencing-\{of-'prospectively implicited_attendant-ontologicalcontiguity ' $\sim$ educedexistentialising/contextualising/textualising_'intelligibility/epistemicity/reflexivity-contiguity<imbued-notional cogency >' \}-conflatedness ${ }^{13}$-in-\{preconverging-disentailment by\} postconverging-entailment $\rangle$ reconstrual/reconceptualisation'. Like all formal constructs it wouldn't rely on incremental-dispositions or temporal-accommodation of $<$ amplituding/formative $>$ wooden-language-〈imbued-averaging-of-thought- $<$ as-toleveling/ressentiment/closed-construct-of- meaningfulness-and-teleology -as-of'nondescript/ignorable-void '-with-regards-to-prospective-apriorising-implications $>>$ that may lead to temporal mobbish dispositions, the fundamental point being that that element of 'abstraction-of-thought/principled-thought' is decisive as with all knowledge constructs. Rather the limit of such intemporal thinking is not the <amplituding/formative $>$ wooden-language〈imbued — averaging-of-thought-<as-to-leveling/ressentiment/closed-construct-ofmeaningfulness-and-teleology -as-of-'nondescript/ignorable-void '-with-regards-toprospective-apriorising-implications $>>$ but operates and is based in effect on intemporal projection-of-thought in an intersolipsistic relation to intrinsic-reality/ontology/ontologicalveridicality on the validity of the intercession of <amplituding/formativeepistemicity $>$ causality $\sim$ as-to-projective-totalitative-implications-of-prospective- 
nonpresencing,-for-explicating relative-unreflexivity/relative-reflexivity - ontological-

contiguity implied predicative-effectivity-sublimation-〈as-to-underlying,-ontologicalcommitment $-<$ implied — self-assuredness-of-ontological-good-

faith/authenticity postconverging-de-mentating/structuring/paradigming -as-being-as-of-

existential-reality $>>$ and by extension the intercession of formal/conventioning rules as institutionalisation arising in validation of the former, and their corresponding percolationchannelling- $<$ in-deferential-formalisation-transference $>\quad$ in $\quad$ deferential-formalisationtransference. The notion of intersolipsism is actually the notional validation of the solipsistic argument as it frames the question in the right manner, that is, inversely (contrary to the traditional philosophical framing of the solipsism question, which by so doing naively and wrongly implies that 'individuals precede and/or are in supposedly in existence in existence' upon an affirmative solipsistic response, rather than the idea of becoming solipsistically in existence which subsumes their individuality and projecting of the same about others in an intersolipsistic recognition arising from individuals' own solipsistic insights of predication-andprojection as so-reflected as to overall reifying-and-empowering-reflexivity-of-ecstaticexistence-as-panintelligibility/panreflexivity ${ }^{73}$-〈existentially-imbued-and-educing-< $<$ epistemictotalising thermeneutically/textually/reprojectingly/supererogatingly/zeroingly/re-acutingly,\{decomplsing delinearity for-cogency $\geq$-epistemic-perspective-of-projective/reprojectiveaestheticising-re-motif-and-re-apriorising/re-axiomatising/re-referencing conceptualisation,as-herein-specifically-relevant-to human-subpotency)), since it priorly implies existential<disontologising/re-ontologising aporeticism $>$ emanance-or-becoming validated by $<$ amplituding/formative-epistemicity $>$ causality $\sim$ as-to-projective-totalitative-implications-ofprospective- nonpresencing,-for-explicating relative-unreflexivity/relative-reflexivity ontological-contiguity about a superseding-oneness-of-ontology as the intercessory basis for mutual-solipsism/intersolipsism. This author equally conceptualise of a difference between 
solipsism and subjectivity in that solipsism is rather purely ontological as it implies notionally the individual's perspective in existential-<disontologising/re-ontologising aporeticism $>$ becoming as of existence/intrinsic-reality/ontology-as-of-its-mimetic-echoness or existence-inreverberation or existence-potency ${ }^{32}$ sublimating-nascence,-disclosed-from-prospectiveepistemic-digression (however effective-as-solipsistically-intemporal or ineffective-assolipsistically-temporal such perspectival performance), whereas subjectivity refers to our animate-existential-referencing-as-subjectification which is not necessarily oriented to the ontological appropriateness/veridicality of that reference but rather is a notional construal of the reality of 'human condition of perceived ontological appropriateness/veridicality' irrespective of whether it can be said of such perception as being objectively right or wrong going by inherent ontological-veridicality. So solipsism speaks of the human projection in notionally construing ontological veridicality/appropriateness notwithstanding the perspectival effectiveness or ineffectiveness of such a construal as of solipsistic-temporality ${ }^{9}$ to solipsistic-intemporality and as such solipsism as of solipsistic-intemporality ${ }^{52}$ is the drive behind ontological-faithnotion-or-ontological-fideism-imbued-underdetermination-of-motif-and-

apriorising/axiomatising/referencing-as-so-being-as-of-existential-reality. Whereas subjectivity speaks notionally of a human condition orientation with respect to perceived ontological veridicality/appropriateness no matter whether right or wrong. This possibility of distinguishing an inherently ontological foundation of existential-<disontologising/re-ontelogisingapereticism $>$ meaning different from an ontological as human epistemic-conception notional $\sim$ reflexivity- $<\{$ veridical/sound $\}$-relative-reflexivity-in-existence/relativising fromlimited-mentation-as-its-deepening/psychologismic-<residualising ${ }^{\text {\{decompulsing }}$ \} delinearity foreogeney>-by-\{flawed/msound\}relative-unreflexivity-in-existence/absolutising from limited-mentation/psychologismic epistemic acutisation nonresidualising imbued\{compulsing\} linearity in-eclecticism-of prior-mere-formulaicity/ritualisation> of perceived 
existential-<disontologising/re-ontologising aporeticism $>$ meaning is central to a notional ${ }^{1}$ deprocrypticism mindset in enabling the most elaborate transcendentally-enablinglevel-of ontological-good-faith-or-authenticity $\%$ objectification/desubjectification-asobjectification-<as-to-ontological-faith-notion-or-ontological-fideism-imbuedunderdetermination-of-motif-and-apriorising/axiomatising/referencing-as-so-being-as-ofexistential-reality as antinihilism $>00$ construal since necessarily intrinsic-reality/ontologicalveridicality is inherently tautologuous, and 'human capacity to grasp the possibilities of referential relations to inherent existential-<disontologising/re-ontologising aporeticism $>$ tautology as of human animate-existential-referencing/subjectification' in conjunction with 'human construal of the inherent existential-<disontologising/re-ontologising aporeticism> tautology' is exactly the definition of knowledge. Supposed for instance a child comes to learn the rules of addition for all types of number additions such that the child understands the addition principle, but then there is a deliberate ploy by the teacher and other 'supposed learners' all along to constantly calculate $2+2$ as equals to 5 . Sooner or later the child's solipsistic sense of meaning (as becoming into existence alone in an intersolipsistic relationship with others interceded with

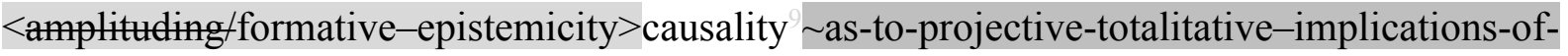
prospective- nonpresencing,-for-explicating relative unreflexivity/relative reflexivity ontological-contiguity inducing projective-insights and predicative-insights) will become a self-made revolutionary and question the teacher indicating the correct answer to $2+2$ as being 4; depending equally on its notional sense of intemporal-projection/longness-of-register-ofmeaningfulness-and-teleology relative to temporality /shortness-of register-ofmeaningfulness-and-teleology' as to the child's underlying 'conception of the ontologicalgood-faith/authenticity ${ }^{69} \sim$ postconverging-de-mentating/structuring/paradigming ${ }^{70}, \quad$ further explaining in-the-bigger-picture why ${ }^{55}$ maximalising-recomposuring-for-relative-ontologicalcompleteness ${ }^{87}$ — unenframed/re-ontologising conceptualisation pursuits, apparently 
unnecessary from a temporal interest point of view, are intemporal-solipsistically undertaken. Insightfully despite the constant 'social affirming' that the correct answer is 5, unlike it might be erroneously be thought, the child's insistence now that the answer is 4 is 'not truly' out of the ordinary as with respect to its construal of all other meaning including other additions, the child's knowledge and learning has always been about confirming any such meaning by its notional sense-of-solipsism as of superseding-oneness-of-ontology; but this particular solution for the addition rather becomes outlying for the child because despite the 'social affirming' of $2+2$ as being 5 , such a confirmation by a notional intemporal sense-of-solipsism as of supersedingoneness-of-ontology is not forthcoming, and in lieu rather gets the solipsistic confirmation as $2+2=4$ ! Thus this points out that our interrelationship to meaningfulness is most authentically and fundamentally by pointing out a notional intemporal 'sense of solipsism' in each of us to access intrinsic meaning. Such 'intersolipsistic-pointing exercise' is only possible because of: our common underlying 'coherence/contiguity-of-superseding-oneness-of-ontology-impliedas-of-inherent-existence-coherence/contiguity,-and-so-construed-as-the-enabler-of-insight-orintuition-or-foresight-as-of-embodied-consciousness' (so-enabled by underlying supposedly coherent ontological-commitment -<implied-self-assuredness-of-ontological-goodfaith/authenticity $\sim$ postconverging-de-mentating/structuring/paradigming -as-being-as-ofexistential-reality> as of <amplituding/formative-epistemicity>causality $\sim$ as-to-projectivetotalitative-implications-of-prospective- nonpresencing,-for-explicating relativeunreflexivity/relative-reflexivity ontological-contiguity and not any notion of vague innateness besides existentially-<disontologising/re-ontologising aporeticism $>$ inherent human-subpotency potential to manifest as human) which as of derivation 'intuitively-assigns projected-and-then-ensuing-predicated coherence/contiguity as meaningfulness' as of the 'coherence/contiguity of the actual insight-giving relevant-and-implied knowledgeconstruct/intersolipsistic-intercessory-notion/notional referential-notion/articulation （enabled 
obviously by language as well as any human meaning relaying medium like signs, whether active or passive or implied or direct)'. By extension, our consciousness-awareness-teleology ${ }^{99}$ as of a solipsistic notional/epistemic/bindingnesss-as-teterminism/conceptivity-of-relative-nnreflexivity/relativereflexivity $>\sim$ construct is equally the result of our animate-existential-referencing/subjectification as of our existential-<disontologising/re-ontologising aporeticism $>\quad$ underlying 'coherence/contiguity-of-superseding-oneness-of-ontology-implied-as-of-inherent-existencecoherence/contiguity,-and-so-construed-as-the-enabler-of-insight-or-intuition-or-foresight-asof-embodied-consciousness' (so-enabled by underlying supposedly coherent ontologicalcommitment $-<$ implied — self-assuredness-of-ontological-goodfaith/authenticity $\sim$ postconverging-de-mentating/structuring/paradigming -as-being-as-ofexistential-reality $>$ as of <amplituding/formative-epistemicity $>$ causality $\sim$ as-to-projectivetotalitative-implications-of-prospective- nonpresencing,-for-explicating $\sim$ relativeunreflexivity/relative-reflexivity ontological-contiguity and not any notion of vague innateness besides existentially-<disontologising/re-ontologising aporeticism $>$ inherent human-subpotency potential to manifest as human) which as of derivation 'intuitively-assignsand-accrues projected-and-then-ensuing-predicated coherence/contiguity as meaningfulness', and existentially-disontogising so as of our 'social framework of intersolipsistic deambulation'. So there is no medium for intersolipsism but for the fact of existence-as-of-its-mimetic-echoness/existence-in-reverberation/existencepotency ${ }^{39} \sim$ sublimating-nascence,-disclosed-from-prospective-epistemic-digression accruing to each individual, implying our limited-mentation-capacity-as-subjecting 'educedunlimitedness/existence-sublimating nascence' to-limitedness/human-subpotency enables us at any given phase of our existence to mutually be able to 'solipsistically reference a common sense of inherent existential-reality', and so increasingly as of our common species, common registryworldviews, common communities, common institutions and common personhoods and 
socialhood; and so, however ontologically-veridical our ${ }^{5}$ meaningfulness-and-teleology within institutionalisation-threshold or as of threshold-ofnonconviction/madeupness/bottomlining-in-shallow-supererogation -<as-to-'attendantintradimensional'-prospectively-disontologising preconverging/dementing -apriorisingpsychologism $>$ at uninstitutionalised-threshold ${ }^{102}$. This will equally explain why in the rare cases reported in the media of infants abandoned and adopted by animals like dogs and monkeys, such infants often tend to adopt behaviours of the animals as of 'mutual solipsism or intersolipsism of reference to underlying 'coherence/contiguity-of-superseding-oneness-of-ontology-impliedas-of-inherent-existence-coherence/contiguity,-and-so-construed-as-the-enabler-of-insight-orintuition-or-foresight-as-of-embodied-consciousness' (so-enabled by underlying supposedly coherent ontological-commitment $-<$ implied — self-assuredness-of-ontological-goodfaith/authenticity postconverging-de-mentating/structuring/paradigming -as-being-as-ofexistential-reality> as of <amplituding/formative-epistemicity>causality $\sim$ as-to-projectivetotalitative-implications-of-prospective- nonpresencing,-for-explicating relativeunreflexivity/relative-reflexivity ontological-contiguity and not any notion of vague innateness besides existentially-<disontologising/re-ontologising aporeticism $>$ inherent human-subpotency potential to manifest as human), as the capacity for the infant to act and behave like a human effectively requires its personality development in a mutual solipsism or intersolipsism of underlying 'coherence/contiguity-of-superseding-oneness-of-ontologyimplied-as-of-inherent-existence-coherence/contiguity,-and-so-construed-as-the-enabler-ofinsight-or-intuition-or-foresight-as-of-embodied-consciousness' (so-enabled by underlying supposedly coherent ontological-commitment $-<$ implied - self-assuredness-of-ontologicalgood-faith/authenticity postconverging-de-mentating/structuring/paradigming -as-beingas-of-existential-reality $>$ as of <amplituding/formative-epistemicity $>$ causality $~ a s-t o-$ projective-totalitative-implications-of-prospective- nonpresencing,-for-explicating relative- 
unreflexivity/relative-reflexivity ontological-contiguity and not any notion of vague innateness besides existentially- $<$ disontologising/re-ontologising aporeticism $>$ inherent human-subpotency potential to manifest as human) with other humans from whence the existential-<disontologising/re-ontologising aporeticism $>$ specificity/instantiation basis as of the family, neighbourhood, local institutions, sociocultural context and increasingly in a globalised world social trends of all sorts whether fashion, cultural, educational, intellectual, political, environmental, social media, etc. are now critical determinants of its subjective and intersubjective ${ }^{56}$ meaningfulness-and-teleology ${ }^{9}$. Supposed again in a non-positivism socialsetup a case of accusation-of-sorcery was to be brought up, wherein as of the relativeontological-incompleteness ${ }^{8}$-of- ${ }^{8}$ reference-of-thought implied beyond-the-consciousnessawareness-teleology $-<$ of-preconverging-existential-extrication-as-of-existential-unthought $>$ of the registry-worldview/dimension, it is a generalised certainty that sorcery and sorcerers/sorceresses do exist (as of the non-positivism social-setup own threshold-ofnonconviction/madeupness/bottomlining-in-shallow-supererogation $<-<$ as-to- 'attendantintradimensional'-prospectively-disontologising preconverging/dementing -apriorisingpsychologism $>$ at their non-positivism uninstitutionalised-threshold ${ }^{102}$ ). This conception speaks of that registry-worldview/dimension subjectivity and intersubjectivity as of a '<amplituding/formative $>$ wooden-language-〈imbued - averaging-of-thought- $<$ as-toleveling/ressentiment/closed-construct-of- meaningfulness-and-teleology -as-of'nondescript/ignorable-void '-with-regards-to-prospective-apriorising-implications $>>$ human condition of construal of intrinsic-reality/ontological-veridicality as knowledge' which is the 'indubitable reality' as far as they are concerned. Such a subjectivity and intersubjectivity conceptualisation/construal can be implied as well as of '<amplituding/formative > woodenlanguage-〈imbued - averaging-of-thought-<as-to-leveling/ressentiment/closed-construct-ofmeaningfulness-and-teleology -as-of-'nondescript/ignorable-void '-with-regards-to- 
prospective-apriorising-implications $>>$ human condition of construal of intrinsicreality/ontological-veridicality supposedly as knowledge' across all the $<$ cumulating/recomposuring attendant-ontological-contiguity $>$-successive registryworldviews/dimensions (including the subjectivity and intersubjectivity in our positivismprocrypticism) with respect to their respectively relative-ontological-incompleteness ${ }^{8}$-ofreference-of-thought implied uninstitutionalised-threshold ${ }^{102}$. However, without a solipsistic notion of construal of intrinsic-reality/ontological-veridicality as of inherent intrinsicreality/ontological-veridicality, and so beyond subjectivity and intersubjectivity, arising as of purely 'solipsistic-and-intersolipsistic insights in referencing underlying 'coherence/contiguityof-superseding-oneness-of-ontology-implied-as-of-inherent-existence-coherence/contiguity,and-so-construed-as-the-enabler-of-insight-or-intuition-or-foresight-as-of-embodiedconsciousness' (so-enabled by underlying supposedly coherent ontological-commitment <implied - self-assuredness-of-ontological-good-faith/authenticity postconverging-dementating/structuring/paradigming -as-being-as-of-existential-reality> as of $<$ amplituding/formative-epistemicity $>$ causality $\sim$ as-to-projective-totalitative-implications-ofprospective- nonpresencing,-for-explicating relative-unreflexivity/relative-reflexivity ontological-contiguity and not any notion of vague innateness besides existentially< disontologising/re-ontologising aporeticism $>$ inherent human-subpotency potential to manifest as human) as a potential capacity in all individuals, then the construal of intrinsicreality/ontological-veridicality will tend to actually be defined whether beyond-theconsciousness-awareness-teleology ${ }^{9}-<$ of-preconverging-existential-extrication-as-of-

existential-unthought $>$ as implied by subjectivity and intersubjectivity as a 'construct of human condition of construal of intrinsic-reality/ontological-veridicality as supposedly knowledge', with the consequence that humankind construal of intrinsic-reality/ontological-veridicality is naively-and-wrongly interpreted as superseding 'inherent intrinsic-reality/ontological- 
veridicality' at registry-worldviews/dimensions uninstitutionalised-threshold ${ }^{102}$ (which is obviously fallacious, as it is the 'possibility of humankind being subjected to the meaningfulnessand-teleological implications of further solipsistic-and-intersolipsistic elucidations in referencing underlying 'coherence/contiguity-of-superseding-oneness-of-ontology-implied-asof-inherent-existence-coherence/contiguity,-and-so-construed-as-the-enabler-of-insight-orintuition-or-foresight-as-of-embodied-consciousness' (so-enabled by underlying supposedly coherent ontological-commitment <implied-self-assuredness-of-ontological-goodfaith/authenticity postconverging-de-mentating/structuring/paradigming -as-being-as-ofexistential-reality> as of <amplituding/formative-epistemicity>causality $\sim$ as-to-projectivetotalitative-implications-of-prospective- nonpresencing,-for-explicating relativeunreflexivity/relative-reflexivity - ontological-contiguity and not any notion of vague innateness besides existentially-<disontologising/re-ontologising aporeticism $>$ inherent human-subpotency potential to manifest as human) as of intrinsic-reality/ontological-veridicality that allows for the requisite pivoting/decentering as of psychoanalytic-unshackling/memeticreordering/institutional-recomposuring enabling human emancipation and progress, and not the other way round). The further implication is that by a retrospective and prospective analysis the possibility of human transcendence-and-sublimity/sublimation/sure-mentativity,

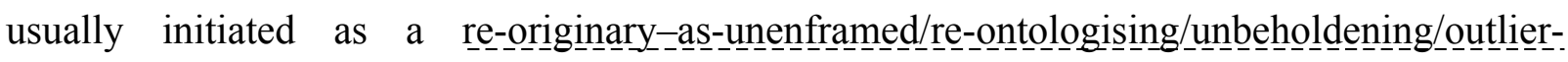
conceptualisation_-_imbued-postconverging/dialectical-thinking -'projectiveinsights'/ epistemic-projection-in-conflatedness ' -of-notional deprocrypticism-prospectivesublimation $\rangle^{0}$ solipsistic-and-intersolipsistic activity in referencing of underlying 'coherence/contiguity-of-superseding-oneness-of-ontology-implied-as-of-inherent-existencecoherence/contiguity,-and-so-construed-as-the-enabler-of-insight-or-intuition-or-foresight-asof-embodied-consciousness' (so-enabled by underlying supposedly coherent ontologicalcommitment $-<$ implied — self-assuredness-of-ontological-good- 
faith/authenticity postconverging-de-mentating/structuring/paradigming -as-being-as-of-

existential-reality> as of <amplituding/formative-epistemicity>causality $\sim$ as-to-projectivetotalitative-implications-of-prospective- nonpresencing,-for-explicating relative-

unreflexivity/relative-reflexivity - ontological-contiguity and not any notion of vague innateness besides existentially-<disontologising/re-ontologising aporeticism $>$ inherent human-subpotency potential to manifest as human), will largely be jeopardised since the 'putting-into-question' as a solipsistic exercise with the possibility of getting at the very core of what is 'further divulge-able' by intrinsic-reality/ontological-veridicality, is largely compromised by a subjectivity and intersubjectivity <amplituding/formative> woodenlanguage-〈imbued - averaging-of-thought-<as-to-leveling/ressentiment/closed-construct-ofmeaningfulness-and-teleology -as-of-‘nondescript/ignorable-void '-with-regards-toprospective-apriorising-implications $>>$ mental-disposition. This distinction between subjectivity and intersubjectivity as referencing human condition of construal of intrinsic-reality/ontologicalveridicality from solipsism and intersolipsism as referencing human effective/ineffective construal of intrinsic-reality/ontological-veridicality as to ontological-performance ${ }^{72}$ $<$ including-virtue-as-ontology $>$, is actually important because (while less critical to elucidate this in the natural sciences given the immediacy of constraint from intrinsic-reality/ontologicalveridicality transcendental-enabling/sublimating/supererogatory-de-mentativity hence implicited), the implications for its comprehensive and conscious understanding in the social world (for conceptualising knowledge while superseding human temporality $8 /$ shortness as ignorances/desublimation, so-construed as 'knowledge-notionalisation') is decisive as it requires both an understanding of the 'human condition in its construal/relation to intrinsicreality/ontological-veridicality' and 'understanding of inherent intrinsic-reality/ontologicalveridicality'; and so, as a prerequisite for the organic-knowledge necessary for futural Beingdevelopment/ontological-framework-expansion-as-to-depth-of-ontologising-development-as- 
notional deprocrypticism registry-worldview institutionalisation. For instance, the concepts of apriorising/axiomatising/referencing-\{of-"prospectively implicited_attendant-ontologicalcontiguity ' $\sim$ educedexistentialising/contextualising/textualising_'intelligibility/epistemicity/reflexivity-contiguity<imbued-notional cogency $\left.>^{\prime} \quad\right\}$-constitutedness ${ }^{14}$ in preconverging-entailment, first-level presencing-absolutising-identitive-constitutedness ${ }^{14}, \quad$ second-level $\quad{ }^{7}$ presencingabsolutising-identitive-constitutedness ${ }^{14}$, third-level ${ }^{79}$ presencing-absolutising-identitiveconstitutedness $^{14}$ and apriorising/axiomatising/referencing-\{of-'prospectively implicited_attendant-ontological-contiguity ' educedexistentialising/contextualising/textualising_'intelligibility/epistemicity/reflexivity-contiguity<imbued-notional cogency>' \}-conflatedness ${ }^{13}$-in-\{preconverging-disentailment by\} postconverging-ntailment of temporal-to-intemporal individuations as of ${ }^{83}$ reference-ofthought-prelogism ${ }^{7}$-as-of-conviction,-in-profound-supererogation $-<$ existentially-veridical'attendant-intradimensional-apriorising/axiomatising/referencing'-logical-dueness-precedesdisontologising-logical-outcome-arrived-at> to threshold-ofnonconviction/madeupness/bottomlining-in-shallow-supererogation $<-<$ as-to- 'attendantintradimensional'-prospectively-disontologising preconverging/dementing -apriorisingpsychologism> so-articulated previously as of 'notional conflatedness ${ }^{13} /$ constitutedness ${ }^{14}$-to-

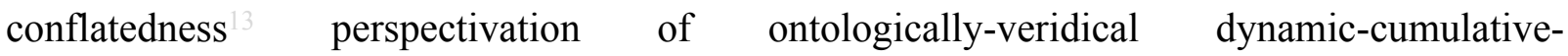
aftereffect/aftereffect' in enabling a storied-construct/ontologically-valid-narration aetiologisation/ontological-escalation-<ontologicalveridicality_commitment/otherliness_transcending/compulsions-encumbered_transcending > insight, can only be properly construed as of such a disambiguation in conceptualising not only 'inherent intrinsic-reality/ontological-veridicality' but equally the 'human temporal-to- 
intemporal conditions/states of perception/relation with intrinsic-reality/ontologicalveridicality' (so-underlying human conceptivity/epistemic-reflexivity/epistemicity-relativismdeterminism-<reifying \{as-to-knowledge-developing\}-and-empowering $>\quad$ imbued theoretical/conceptual/operant implications). This is fundamentally so because 'inherent existential-reality/intrinsic-reality/ontological-veridicality is already what it is as given whether humankind knows about it or not' but rather the point of human knowledge is an sublimating/emancipating exercise involving the need to decenter/pivot and supersede our animate-existential-referencing/subjectification as of the <amplituding/formativeepistemicity $>$ totalising $\sim$ self-referencing-syncretising/circularity/interiorising/akrasiatic-drag human condition to derive knowledge-and-virtue, and so as human-subpotency/‘subpotentmimetic-echoness-derivation-within-the-full-potency of existence/intrinsic-reality/ontology-asof-its-mimetic-echoness or existence-in-reverberation or existence-potency ${ }^{39} \sim$ sublimatingnascence,-disclosed-from-prospective-epistemic-digression). Solipsism as such is truly the foundational notion of all phenomenological conceptualisations and derivation of value and meaningfulness as intersolipsistic teleological constructs from a transversal-and/or-common perceived existential-reference/existential-tautologisation and derived-representations of existential-reference/existential-tautologisation. It is what allows for the possibility of human construal of intrinsic-reality/ontological-veridicality transcendentalenabling/sublimating/supererogatory de-mentativity to supersede social-aggregation-enabling as a knowledge and virtue construct. The implication being that there is a contiguity in solipsistic insight as simplistically elucidative in the relatively more simpler experimental framework of natural phenomenon studied by the natural sciences (which practice is categorisation-driven, more like elaboration-as-to-mere-extrapolating/constituting/abstracting/deducing/inferring-ofelucidation-outside_-'prospectively_implicited_attendant-ontological-contiguity ${ }^{67}$ > educedexistentialising/contextualising/textualising_'intelligibility/epistemicity/reflexivity-contiguity- 
$<$ imbued-notional cogency $>$ but then with a high risk of inducing virtualities thus explaining the continually reshaping/re-categorisation/re-optimising of experimental content when the virtualities come to be seen as unreal or deficient or suboptimal, and so more critically with the practitioner's experience tend to be driven heuristically actually as of presencingabsolutising-identitive-constitutedness $^{14}$ or apriorising/axiomatising/referencing-\{of'prospectively implicited_attendant_ontological-contiguity ' educedexistentialising/contextualising/textualising_intelligibility/epistemicity/reflexivity_contiguity<imbued-notional cogency >' \}-conflatedness ${ }^{13}$-in-\{preconverging-disentailment-by\}postconverging-entailment) but such solipsistic insight extends to the more convoluted social phenomenon studied by the social sciences, as well as the phenomenal convoluted equally inherent in scientific domains like quantum-mechanics, as herein contemplated should ideally be understood as of referentialism implied ontological-normalcy/postconvergence epistemicprojection perspective, more like ${ }^{55}$ maximalising-recomposuring-for-relative-ontologicalcompleteness $^{87}$ - unenframed/re-ontologising conceptualisation from the most profound of conceptualisation which is intemporality ${ }^{52} /$ longness or intemporal-preservation-entropy-orcontiguity-or-ontological-preservation, as of inherent superseding-oneness-of-ontology, and so on the basis of the absolute a priori, 'implicitanteontological-contiguity ${ }^{67}$, educedexistentialising/contextmalising/textualising_'intelligibility/epistemicity/reflexivity_contiguity$<$ imbued-notional $\sim$ cogency $>,{ }^{\prime},-<$ reifying-or-elucidating-of-prospective-relative-ontologicalcompleteness -of- reference-of-thought- devolving-as-of-instantiative-context> as to existence-potency ${ }^{39} \sim$ sublimating-nascence,-disclosed-from-prospective-epistemicdigression—rules-of-apriorising/axiomatising/referencing-that-further-epistemicallyunconceal-the-very-ontologically-same-existential-reality, construed as of increasing human limited-mentation-capacity-deepening —as-subjecting limitedness/human-subpotency-to'educed-unlimitedness/existence-sublimating nascence' 33 in the 
apriorising/axiomatising/referencing of ${ }^{5}$ meaningfulness-and-teleology ${ }^{9}$ construal', in the staggered elucidation of less and less profound but critical conceptualisations as undertaken in this ${ }_{\{\text {decompulsing }\}}$ delinearity for-cogency design. Furthermore, solipsism will equally explain why human ${ }^{56}$ meaningfulness-and-teleology ${ }^{9}$ is developed rather by ${ }^{55}$ maximalising-recomposuringfor-relative-ontological-completeness ${ }^{87}$ - unenframed/re-ontologising $\sim$ conceptualisation of the same superseding-oneness-of-ontology as of our limited-mentation-capacity-deepening-assubjecting limitedness/human-subpotency-to-'educed-unlimitedness/existence-sublimatingnascence' (whereby successive generations take a shot at the superseding-oneness-of-ontology that is existence like Ancient Civilisations like Greece establishing that matter is made up of water, fire, air, earth and ether critically establishing the psyche of matter as composed of basic elements and successive recomposurings right up to our modern-day quantum-mechanics

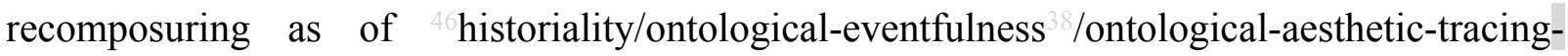
$<$ perspective-ontological-normalcy/postconvergence-reflected-'epistemicity-relativismdeterminism'>), rather than it erroneously being construed as an incremental exercise; as it is only incremental in the literal sense but in the 'operant sense' it is an exercise of maximalisingrecomposuring-for-relative-ontological-completeness ${ }^{8}$ —unenframed/reontologising $\sim$ conceptualisation as of transversality-<for-sublimating-existentialeventuating/denouement,from-'thinking-at-first/pure-predisposition-preemptive-ofprospective-disontologising/subontologising' as-of-prospectively-disambiguated-affirmedand-unaffirmed-'motif-and-apriorising/axiomatising/referencing'> overall reconstruing/reconceptualising rather than just incrementing. This insight is important for critical thought and analysis as oftentimes it is naively assumed that prospective knowledge is to be simply obtained by 'additioning' or 'cumulating' to prior works rather than the more pertinent insight of $\quad<$ amplituding/formative-epistemicity $>$-totalising $\sim$ renewing-realisation/re- 
perception/re-thought as of a same superseding-oneness-of-ontology that is existence. On the same token, this tautological insight about the precedingness of existence can be extended to the notion of nothingness with nothingness rather existing in existence as there is no nothingness or for that matter anything out of existence which is 'conceptually' emanation-as-to-the-alldefining-<amplituding/formative-epistemicity $>$ causality $\sim$ as-to-projective-totalitativeimplications-of-prospective- nonpresencing,-for-explicating relative-unreflexivity/relativereflexivity - ontological-contiguity -intercession, with nothingness rather the 'conceptual devising of the metaphysics-of-absence-〈implicited-epistemic-veracity-of- nonpresencing<perspective-ontological-normalcy/postconvergence $>\rangle$ of existence' with existence conceptually construed in metaphysics-of-presence-〈implicited-'nondescript/ignorable-void 'as-to- presencing - absolutising-identitive-constitutedness $\rangle$; but then with existence being its very own metaphysics-of-presence-〈implicited-'nondescript/ignorable-void '-as-topresencing - absolutising-identitive-constitutedness $\rangle$, the mutual equivalence of both metaphysics-of-presence-〈implicited-'nondescript/ignorable-void '-as-to- presencingabsolutising-identitive-constitutedness $\rangle$ and metaphysics-of-absence-〈implicited-epistemicveracity-of- nonpresencing-<perspective-ontological-normalcy/postconvergence $>\rangle$ implying that nothingness is likewise tautologically the emanation-as-to-the-all-defining$<$ amplituding/formative-epistemicity $>$ causality $\sim$ as-to-projective-totalitative-implications-ofprospective- nonpresencing,-for-explicating relative-unreflexivity/relative-reflexivityontological-contiguity -intercession of existence. Basically a nothingness conceptualisation is necessarily and tautologically an existential-<disontologising/re-ontologising aporeticism $>$ conceptualisation as 'implicitantontological-contiguity ${ }^{67}$ ' educedexistentialising/contextmalising/textmalising_intelligibility/epistemicity/reflexivity-contiguity$<$ imbued-notional $\sim$ cogency $>,{ }^{\prime},-<$ reifying-or-elucidating-of-prospective-relative-ontologicalcompleteness -of- reference-of-thought- devolving-as-of-instantiative-context> as to 
existence-potency $^{32} \sim$ sublimating-nascence,-disclosed-from-prospective-epistemicdigression—rules-of-apriorising/axiomatising/referencing-that-further-epistemicallyunconceal-the-very-ontologically-same-existential-reality' which is necessarily the 'absolute apriori' (as 'implicited_attendant-ontological-contiguity ${ }^{67}$ ' educedexistentialising/contextualising/textualising_'intelligibility/epistemicity/reflexivity-contiguity$<$ imbued-notional $\sim$ cogency $>,{ }^{\prime},-<$ reifying-or-elucidating-of-prospective-relative-ontologicalcompleteness -of- reference-of-thought- devolving-as-of-instantiative-context> as to existence-potency $^{39} \sim$ sublimating-nascence,-disclosed-from-prospective-epistemicdigression—rules-of-apriorising/axiomatising/referencing-that-further-epistemicallyunconceal-the-very-ontologically-same-existential-reality construed as of increasing human limited-mentation-capacity-deepening —as-subjecting-limitedness/human-subpotency-to'educed-unlimitedness/existence-sublimating nascence' 33 in the apriorising/axiomatising/referencing of ${ }^{5}$ meaningfulness-and-teleology ${ }^{9}$ construal') of superseding-oneness-of-ontology/oneness-of-meaningfulness and just as well the notion of nothingness can't 'conceptually' exist out of the notion of meaningfulness which references existence and all that is in existence as ontological. Actually nothingness is rather a 'constructive tautological device' as is actually the case with all human knowledge (mental-devisingrepresentation of teleological reorientation), as it doesn't speak of any inherent change in intrinsic-reality but rather of change of human <amplituding/formative-epistemicity>totalising renewing-realisation/re-perception/re-thought-as-utter-placeholder-setupontological-rescheduling-〈by-a-renewing-of-apriorising/axiomatising/referencingpsychologism-as-the-new-referencing-basis-of-prospective- meaningfulness-and-teleology $\rangle$, just as the many conceptualisation herein like the registry-worldviews/dimensions and relativeunreflexivity/relative-reflexivity — ontological-contiguity ${ }^{67}$ of-the-human-institutionalisationprocess ${ }^{6}$ are actually speaking of human rescheduling of placeholder-setup/mental-devising- 
representation/mentation/consciousness-awareness-teleology 9 in grasping a supersedingoneness-of-ontology/intrinsic-reality that has been so all the time; and so critically talk of transcending from shallow to deeper superseding-oneness-of-ontology is no more than about human <amplituding/formative-epistemicity $>$-totalising $\sim$ renewing-realisation/re-perception/rethought-as-utter-placeholder-setup-ontological-rescheduling-〈by-a-renewing-of-

\section{apriorising/axiomatising/referencing-psychologism-as-the-new-referencing-basis-of-}

prospective- meaningfulness-and-teleology > as 'subpotent-mimetic-echoness-derivationwithin-the-full-potency of existence/intrinsic-reality/ontology-as-of-its-mimetic-echoness or existence-in-reverberation or existence-potency ${ }^{32} \sim$ sublimating-nascence,-disclosed-fromprospective-epistemic-digression already given as ontological-normalcy/postconvergence oneness) along the same lines with the notion of ${ }^{15}$ de-mentation-〈supererogatory $\sim$ ontologicalde-mentation-or-dialectical-de-mentation - stranding-or-attributive-dialectics $\rangle$ in compensation of human limited-mentation-capacity-deepening as-subjecting limitedness/humansubpotency to 'educed unlimitedness/existence sublimating nascence' as 'shallow limitedmentation-capacity—as-subjecting 'educed-unlimitedness/existence-sublimating nascence' to-limitedness/human-subpotency-〈as of relative apriorising/axiomatising/referencing-\{of'prospectively_implicited_attendant-ontological-contiguity ' educedexistentialising/contextualising/textualising_'intelligibility/epistemicity/reflexivity_contiguity<imbued-notional cogency>' $\}$-constitutedness ${ }^{1}$-in-preconverging-entailment $\rangle$ to deeper limited-mentation-capacity—as-subjecting-'educed-unlimitedness/existence-sublimating nascence' to-limitedness/human-subpotency-〈as of relative apriorising/axiomatising/referencing-\{of-'prospectively_implicited_attendant-ontologicalcontiguity ' $\sim$ educed-

existentialising/contextualising/textualising_ 'intelligibility/epistemicity/reflexivity-contiguity<imbued-notional cogency $>$ ' \}-conflatedness ${ }^{13}$-in-\{preconverging-disentailment by\} 
postconverging-entailment $\rangle$ reconstrual/reconceptualisation'. That is, such 'conceptual devices' are reformulations arising from 'grander/transcendental insights' about the same question but implying a radical transformation of ontological/meaningful conceptualisation of the human mind and human teleology ${ }^{9}$. The idea is that 'intrinsic-reality/ontology is not changed' but rather it is 'human <amplituding/formative-epistemicity>-totalising renewing-realisation/reperception/re-thought-as-utter-placeholder-setup-ontological-rescheduling-〈by-a-renewing-ofapriorising/axiomatising/referencing-psychologism-as-the-new-referencing-basis-ofprospective- meaningfulness-and-teleology $\rangle$ that is changed'. Technically, the implication is that existence/being cannot be thought outside of human thought/limited-mentation-capacityas-subjecting 'educed-unlimitedness/existence-sublimating nascence' to-limitedness/humansubpotency); as a conclusion driven by the insight that human thought/limited-mentationcapacity —as-subjecting-'educed-unlimitedness/existence-sublimating nascence' tolimitedness/human-subpotency in construing existence/being implies human ${ }^{56}$ meaningfulnessand-teleology is necessarily of <amplituding/formative-epistemicity $>$ causality $\sim$ as-toprojective-totalitative-implications-of-prospective- nonpresencing,-for-explicating relative unreflexivity/relative-reflexivity - ontological-contiguity or attendant. However the disavowal rather than renewal/deconstruction/ontological-reconstituting-as-to-conflatedness ${ }^{13}$ of human thought/limited-mentation-capacity—as-subjecting-'educed-unlimitedness/existencesublimating nascence' to-limitedness/human-subpotency will imply its dissolving into a 'nihilism of ${ }^{56}$ meaningfulness-and-teleology ${ }^{9}$ ' as the alternate logical outcome, but then with this latter construal/conceptualisation being rather an 'unequal measure alternative' since it has the drawback of 'putting an end to contemplation itself', of 'misunderstanding that contemplation is a human growth activity and not an absolutely achieved activity', besides abandoning the notion of human existentialism/thrownness/facticity behind human strife itself thus contradictorily undermining again the assumption of such an alternate logical outcome as 
itself a 'contemplated strife' construed as arising only by the implication of such existentialism/thrownness/facticity, and further failing to factor in that deepening human thought/limited-mentation-capacity—as-subjecting-'educed-unlimitedness/existencesublimating nascence' to-limitedness/human-subpotency increasingly narrows the framework of human existential-<disontologising/re-ontologising aporeticism $>$ contingency $/<$ amplituding/formative-epistemicity $>$ causality $\sim$ as-to-projective-totalitativeimplications-of-prospective- nonpresencing,-for-explicating relative-unreflexivity/relativereflexivity - ontological-contiguity 'enabling human existential-<disontologising/reentelogising aporeticism $>$ development as less and less a question of fate' on the basis of 'intemporal ontological-faith-notion-or-ontological-fideism - imbued-underdetermination-ofmotif-and-apriorising/axiomatising/referencing-as-so-being-as-of-existential-reality instigated relative-unreflexivity/relative-reflexivity ontological-contiguity ${ }^{67}$ of-the-humaninstitutionalisation-process $^{68}$ as of difference-conflatedness ${ }^{3}$-as-to-totalitative-reification-insingularisation-<as-to-the-nondisjointedness/entailment-of-prospective- nonpresencing $>$-asveridical-epistemicity-relativism-determinism implied $\quad$ amplituding/formativeepistemicity $>$ causality as-to-projective-totalitative-implications-of-prospectivenonpresencing,-for-explicating relative enreflexivity/relative reflexivity - ontologicalcontiguity '. Thus the bigger issue is not existence/being in itself as it is given, whatever it is that is given. Rather the bigger issue of concern is our human thought/limited-mentationcapacity - as-subjecting 'educed-unlimitedness/existence-sublimating nascence' tolimitedness/human-subpotency in apprehending existence/being as of our $<$ amplituding/formative-epistemicity $>$ causality $\sim$ as-to-projective-totalitative-implications-ofprospective- nonpresencing,-for-explicating relative unreflexivity/relative reflexivity ontological-contiguity /attendant reconstruals/reconceptualisations of existence/being as of human deepening thought/limited-mentation-capacity-as-subjecting-'educed- 
unlimitedness/existence-sublimating nascence' to-limitedness/human-subpotency so enabled by our capacity for ${ }^{15}$ de-mentation-〈supererogatory - ontological-de-mentation-or-dialecticalde-mentation-stranding-or-attributive-dialectics $\rangle$ behind the successive institutionalcumulation/institutional-recomposure-〈as-to- historiality/ontologicaleventfulness /ontological-aesthetic-tracing-<perspective-ontologicalnormalcy/postconvergence-reflected-'epistemicity-relativism-determinism'>> narrowing the framework of human existential-<disontologising/re-ontologising aporeticism $>$ contingency, with the further possibility of prospective <amplituding/formative-epistemicity $>$ totalising renewing-realisation/re-perception/re-thought as notional $\sim$ deprocrypticism as of ontological-normalcy/postconvergence. Such maximalist intemporal projection reasoning doesn't entertain banal ordinary logic (that is all too readily incremental, 'disjointedness-as-ofreference-of-thought' and temporally-preservational-as-pseudointemporality ${ }^{52}$-preservation) of the sort: she deserves to be rape because she was scantily clad as well dressed women will not be raped; his goods deserve to be stolen as he didn't look after them properly; those people/group/ethnicity deserved what happened to them because they are so and so; etc. The intemporal reasoning maximalist approach (non-incremental, non-'disjointedness-as-ofreference-of-thought' and striving for the ontologically-utter) that permeates many a formalised construct does not entertain meaningfulness within the sphere of temporal-andsocial-trading and is rather transcendental inherently, as it simply supersedes and skews ('intemporality ${ }^{52}$-symmetrising-by-desymmetrising-subsumption-of-temporality ${ }^{8}$, for relative intrinsic-reality/ontological-veridicality transcendentalenabling/sublimating/supererogatory $\sim$ de-mentativity) meaningfulness-and-teleology towards the ${ }^{103}$ universal/intemporal as of implication. In other words, ${ }^{5}$ maximalisingrecomposuring-for-relative-ontological-completeness ${ }^{8}$ —unenframed/reontologising conceptualisation is construed as of the apparently least possibly perceived 
constraining context in order to truly affirm the ${ }^{103}$ universalism of rules or any ontologicalconstructs; as the test of incrimination with respect to the above apparently least possibly perceived constraining specific crimes contexts is effectively what validates the ${ }^{103}$ universalism for all other contexts of such specific crimes. ${ }^{55}$ maximalising-recomposuring-for-relativeontological-completeness ${ }^{87}$ - unenframed/re-ontologising conceptualisation, across all institutional-cumulation/institutional-recomposure-〈as-to- historiality/ontological-

eventfulness /ontological-aesthetic-tracing-<perspective-ontologicalnormalcy/postconvergence-reflected-'epistemicity-relativism-determinism'> $>$, is effectively the projective mechanism as of ontological-faith-notion-or-ontological-fideism-imbuedunderdetermination-of-motif-and-apriorising/axiomatising/referencing-as-so-being-as-ofexistential-reality that reinvents new reference-of-thought- categoricalimperatives/axioms/registry-teleology ${ }^{9}$,-for-intemporal-preservation-entropy-or-contiguityor-ontological-preservation as a metaphysics-of-absence-〈implicited-epistemic-veracity-ofnonpresencing-<perspective-ontological-normalcy/postconvergence $>\rangle$ conceptualisation in further human limited-mentation-capacity-deepening -as-subjecting limitedness/humansubpotency-to-'educed-unlimitedness/existence-sublimating nascence' ${ }^{53}$ and opening up new institutionalisation possibilities behind the successive transcendence-andsublimity/sublimation/supererogatory $\sim$ de-mentativity of an animal of notional firstnaturednessformativeness-<as-to-eventualising-inkling drive-or-seeding-misprising $>$ temporal-tointemporal-dispositions-<so-construed-as-from-perspective-ontologicalnormalcy/postconvergence> in need for skewing ('intemporality ${ }^{52}$-symmetrising-bydesymmetrising-subsumption-of-temporality ${ }^{8}$, , for relative intrinsic-reality/ontologicalveridicality transcendental-enabling/sublimating/supereregatory $\sim$ de-mentativity)/deferentialformalisation-transference towards the intemporal to induce a registry-worldview's/dimension's institutionalisation-as-virtue that very much elevate it beyond its temporality ${ }^{8} /$ shortness which $^{2}$ 
left to its own device will strive for ${ }^{5}$ incrementalism-in-relative-ontological-incompleteness ${ }^{8}$ enframed/disontologising conceptualisation temporal-accommodation/extrication. maximalising-recomposuring-for-relative-ontological-completeness ${ }^{87}$ - unenframed/reontologising conceptualisation is an intemporal framework of dimensionality-of-sublimating <<amplituding/formative>supererogatery $\sim$ de-mentativeness/epistemic-growth-orconflatedness /transvaluative-rationalising/transepistemicity/anamnestic-residuality/spiritdrivenness-equalisation> organic-knowledge 'inventing' of prospective human registryworldview's/dimension's institutionalisation possibilities allowing for their percolationchannelling- $<$ in-deferential-formalisation-transference $>\quad$ as of secondnatured institutionalisation. It is behind 'intemporal ontological-faith-notion-or-ontological-fideism imbued-underdetermination-of-motif-and-apriorising/axiomatising/referencing-as-so-being-asof-existential-reality instigated relative-unreflexivity/relative-reflexivity-ontologicalcontiguity $^{67} \sim$ of-the-human-institutionalisation-process ${ }^{68}$ as of difference-conflatedness ${ }^{13}$-as-tototalitative-reification-in-singularisation-<as-to-the-nondisjointedness/entailment-ofprospective- nonpresencing $>$-as-veridical-epistemicity-relativism-determinism implied $<$ amplituding/formative-epistemicity $>$ causality $~ a s-t o-p r o j e c t i v e-t o t a l i t a t i v e-$ implications-ofprospective- nonpresencing,-for-explicating $\sim$ relative-unreflexivity/relative-reflexivity ontological-contiguity , whether in early times as of non-universal and ${ }^{103}$ universal metaphysico-theological creeds or as of metaphysico-worldviews nature and practices in later human history marked by the preconverging/postconverging-dementative/structural/paradigmatic emphasis of intemporal/ontological/social/species/ ${ }^{103}$ universal/transcendental $/{ }^{55}$ maximalisingrecomposuring-for-relative-ontological-completeness ${ }^{8}$ —unenframed/reontologising conceptualisation postconverging-de-mentating/structuring/paradigming over ordinariness <amplituding/formative $>$ wooden-language-_imbued-averaging-of-thought- $<$ as- 
to-leveling/ressentiment/closed-construct-of- meaningfulness-and-teleology -as-of-

'nondescript/ignorable-void '-with-regards-to-prospective-apriorising-implications $>>$ mentaldisposition within the secondnatured institutionalisation of such percolation-channelled meaningfulness-and-teleology marked by temporal extricatory preconverging-dementating/structuring/paradigming. This latter point is pertinent as invalidating any implied equivalence of ${ }^{83}$ reference-of-thought of ${ }^{56}$ meaningfulness-and-teleology between a maximalising-recomposuring-for-relative-ontological-completeness ${ }^{87}$ - unenframed/reontologising conceptualisation mental-disposition and an ordinariness $<$ amplituding/formative $>$ wooden-language-〈imbued — averaging-of-thought-<as-toleveling/ressentiment/closed-construct-of- meaningfulness-and-teleology -as-of'nondescript/ignorable-void '-with-regards-to-prospective-apriorising-implications $>>$ mentaldisposition going by their different existential-<disontologising/re-ontologising aporeticism $>$ preconverging/postconverging-de-mentating/structuring/paradigming; as the ordinariness <amplituding/formative> wooden-language-<imbued — averaging-of-thought-<as-toleveling/ressentiment/closed-construct-of- meaningfulness-and-teleology -as-of'nondescript/ignorable-void '-with-regards-to-prospective-apriorising-implications $>$ > mentaldisposition will emphasise a registry-worldview/dimension <amplituding/formative $>$ woodenlanguage-_imbued - averaging-of-thought-<as-to-leveling/ressentiment/closed-construct-ofmeaningfulness-and-teleology -as-of-'nondescript/ignorable-void '-with-regards-toprospective-apriorising-implications $>>$ in a temporal extricatory preconverging-dementating/structuring/paradigming as of 'human lifespan extricatory punctuality/immediacy of depth-of-thought' as if such < amplituding/formative> wooden-language-_imbued-averagingof-thought-<as-to-leveling/ressentiment/closed-construct-of- meaningfulness-and-teleology as-of-'nondescript/ignorable-void ' -with-regards-to-prospective-apriorising-implications $>$ > arose all by itself whereas a ${ }^{55}$ maximalising-recomposuring-for-relative-ontological- 
completeness $^{87}$ — unenframed/re-ontologising conceptualisation mental-disposition emphasises the human existential-<disontologising/re-ontologising apereticism $>$ tale as of the succession of opened-structures of ${ }^{56}$ meaningfulness-and-teleology 99 that account for the possibility of our present and prospectively opened-construct-of- ${ }^{56}$ meaningfulness-and-teleology ${ }^{9}$ for enabling future possibilities. Even when it comes to the social integration of maximalisingrecomposuring-for-relative-ontological-completeness 87 unenframed/re-

ontologising conceptualisation postconverging-de-mentating/structuring/paradigming, it is often the case that such ${ }^{56}$ meaningfulness-and-teleology ${ }^{9}$ is bound to the denaturing ${ }^{16}$ in-manyways as of human ordinariness <amplituding/formative> wooden-language-〈imbuedaveraging-of-thought-<as-to-leveling/ressentiment/closed-construct-of- meaningfulness-andteleology -as-of-'nondescript/ignorable-void '-with-regards-to-prospective-apriorisingimplications $>>$ temporal extricatory preconverging-de-mentating/structuring/paradigming concatenation to it, if the requisite percolation-channelling- $<$ in-deferential-formalisationtransference $>$ institutionalisation and formalisation constructs are not priorly attended to. Even such that notions like exceptional, genius, prophesying, etc. associated with ${ }^{5}$ maximalisingrecomposuring-for-relative-ontological-completeness ${ }^{7}$ — unenframed/re-

ontologising conceptualisation mental-dispositions, as recognised by the Niezschean imagination are more often than not construed beyond-the-consciousness-awarenessteleology ${ }^{9}-<$ of-preconverging-existential-extrication-as-of-existential-unthought> as 'derogation to the fact that such maximalising-recomposuring-for-relative-ontologicalcompleteness $^{87}$ - unenframed/re-ontologising conceptualisation postconverging-dementating/structuring/paradigming can hypothetically be incumbent of all humans as to their choice of intellectual-and-moral orientation and their specific focus', and thus paradoxically implying as of the blurriness-<sterilising/anecdotalising/trivialising-of-prospective-reontologising_by-preconverging,-in-disontologising-formulaic-dragging-out/hollowing-out> of 
the social domain that such so-called exceptional, genius, prophesying, etc. are 'abnormal' with the paradox that their implied ontological-veridicality is 'abnormal', thus by that same token falsely upholding the ontological-pertinence of ordinariness <amplituding/formative $>$ woodenlanguage-〈imbued - averaging-of-thought-<as-to-leveling/ressentiment/closed-construct-ofmeaningfulness-and-teleology -as-of-'nondescript/ignorable-void '-with-regards-toprospective-apriorising-implications $>>\quad$ as $\quad$ a $\quad$ non-decenterable $<$ amplituding/formative $>$ wooden-language-〈imbued - averaging-of-thought- $<$ as-toleveling/ressentiment/closed-construct-of- meaningfulness-and-teleology -as-of'nondescript/ignorable-void ' -with-regards-to-prospective-apriorising-implications $>$ )! Actually the paradox is that, no transcendentally implied construct is effectively a 'grounded knowledge-construct commitment' inherently as it inevitably and fundamentally puts into question the underlying intrinsic-reality/ontological-veridicality transcendentalenabling/sublimating/supererogatory de-mentativity $<$ amplituding/formativeepistemicity $>$ causality $\sim$ as-to-projective-totalitative-implications-of-prospectivenonpresencing,-for-explicating relative-unreflexivity/relative-reflexivity - ontologicalcontiguity notion, which is the prior <amplituding/formativeepistemicity>totalising/circumscribing/delineating $\quad{ }^{83}$ reference-of-thought- ${ }^{\text {devolving-as-of- }}$ instantiative-context - ${ }^{5}$ meaningfulness-and-teleology as of its 〈given consciousness's neuterising-induced $>-{ }^{8}$ reference-of-thought — devolving-teleological-dementating/structuring/paradigming-of-meaningfulness. Such transcendental implications arise as a transitional construct that is in effect as of a psychoanalytic-unshackling/memeticreordering/institutional-recomposuring articulation by its crossgenerational transcendental implications. By the mere fact of implied prospective relative-ontological-completeness ${ }^{87}$-ofreference-of-thought over prior relative-ontological-incompleteness ${ }^{88}$-of- reference-ofthought a prospective transcendence-and-sublimity/sublimation/supererogatory de-mentativity 
involves the prospective ${ }^{8}$ reference-of-thought rather 'registering-and-reflecting a beyond-theconsciousness-awareness-teleology ${ }^{9}<$ of-preconverging-existential-extrication-as-ofexistential-unthought $>{ }^{5}$ meaningfulness-and-teleology ${ }^{9}$ as of organic-knowledge Being correction' of the prior ${ }^{83}$ reference-of-thought, such that the prior ${ }^{83}$ reference-of-thought logicaldueness doesn't even arise as the prospective ${ }^{83}$ reference-of-thought is the relatively complete 'ontological-resetting' in an 'organic effecting-wholeness-as-of-profoundness-andcompleteness-to- ${ }^{5}$ meaningfulness-and-teleology ${ }^{9}$, over the prior ${ }^{83}$ reference-of-thought 'effecting-parsimony-as-of-shoddiness-and-incompleteness-to- ${ }^{5}$ meaningfulness-andteleology ${ }^{9} ;$ just as the introduction of chemistry science carries an organic effecting-wholenessas-of-profoundness-and-completeness-to- ${ }^{56}$ meaningfulness-and-teleology 9 over a nonpositivism/medievalism alchemic material construal. Basically, ${ }^{55}$ maximalising-recomposuringfor-relative-ontological-completeness ${ }^{87}$ - unenframed/re-ontologising conceptualisation summoning a depth of 'ontological-reconstituting-as-to-conflatedness ${ }^{13} /$ deconstruction as of ontological-faith-notion-or-ontological-fideism - imbued-underdetermination-of-motif-andapriorising/axiomatising/referencing-as-so-being-as-of-existential-reality enables humankind to supersede the circularity of intradimensional hollow-constituting-<as-disjointedmisappropriation-of-meaningfulness-and-failing-intemporal-preservation> (which temporalpreservation-as-pseudointemporality ${ }^{52}$-preservation actually speaks of relative-ontologicalincompleteness -induced,-'threshold-of-nonconviction/madeupness/bottomlining-in-shallowsupererogation -<as-to-'attendant-intradimensional'-prospectivelydisontologising preconverging/dementing -apriorising-psychologism>', thus-'in-wait'-forperversion-of- ${ }^{83}$ reference-of-thought-<as-preconverginglyapriorising/axiomatising/referencing-in-nonconviction/madeupness/bottomlining-as-toshallow-supererogation >,-or-temporal-preservation-as-pseudointemporality ${ }^{52}$-preservation, and defines successive institutional-cumulation/institutional-recomposure-〈as-to- 


\section{historiality/ontological-eventfulness /ontological-aesthetic-tracing-<perspective-}

ontological-normalcy/postconvergence-reflected-‘epistemicity-relativism-determinism'>>

uninstitutionalised-threshold ${ }^{102}$ explaining why institutionalisation becomes stuck at that level until the corresponding threshold is superseded for a prospective/transcending/superseding institutionalisation) for prospective transcendental possibilities. On the basis of such hollowconstituting-<as-disjointed-misappropriation-of-meaningfulness-and-failing-intemporal-

preservation $>$ circularity, one may perfectly argue that any of the institutionalisations are just as good so long as people are relatively satisfied but such an argument is never made of lower/prior institutionalisations with the implications that its elicitation within a registry-worldview as present is nothing more but an act of 'ontological-bad-faith/inauthenticity ${ }^{6 /}$, but then a maximalising-recomposuring-for-relative-ontological-completeness ${ }^{87}$ - unenframed/reontologising conceptualisation approach is one that doesn't reason in temporal-accommodation but provides the opportunity for prospective institutional possibilities. ${ }^{55}$ maximalisingrecomposuring-for-relative-ontological-completeness ${ }^{87}$ —unenframed/re-

ontologising conceptualisation was what was in the minds of the Copernicuses, Galileos, Rousseaux, Darwins and the enlightenment Encyclopédistes led by Denis Diderot in cynically vouching for the possibilities of the future of positivism over a non-positivism/medievalism worldview. Such that vague arguments of the type we've been living well without such ideas are nothing but avowals of temporal-dispositions poor grasp of how their present institutionalisation came about and future institutionalisation possibilities; since we can project that all humans in recurrent-utter-uninstitutionalisation were recurrent-utter-institutionalised, all humans in ununiversalisation were ununiversalised, all humans in medieval non-positivism were nonpositivistic, and by extention (but for the complexes arising from our metaphysics-of-presence〈implicited-'nondescript/ignorable-void '-as-to- presencing-absolutising-identitiveconstitutedness 7$)$ all humans in our ${ }^{80}$ procrypticism-or-disjointedness-as-of- ${ }^{8}$ reference-of- 
thought are procryptic and it is no use turning around to our fellow mortals to do socialaggregation-enabling; with the more criticial issue being what is the relativeunreflexivity/relative-reflexivity — ontological-contiguity ${ }^{67}$ of-the-human-institutionalisationprocess ${ }^{68}$ implication as from the prospective epistemic-projection perspective! Such temporaldispositions are characteristically draggy across all registry-worldviews/dimensions explaining why all transcendence-and-sublimity/sublimation/supererogatory -de-mentativity meet with temporal resistance going by human-subpotency-aporia/undecidability/dilemma/oughtindeterminacy/deficiency/limitation/constraint—imbued-'notional firstnaturednessformativeness-<as-to-eventualising-inkling drive-or-seeding-misprising $>$ temporal-tointemporal-dispositions-<so-construed-as-from-perspective-ontologicalnormalcy/postconvergence>'-existentialism-form-factor which take the form of subontologisation/subpotentiation (slantedness/postlogic-effect, miscuing, disjointed-logic, logical-drag, unconscionability-drag, sub-par/formulaic-association/temporal/alibi conventioning-rationalising, and temporal-enculturation/temporal-endemisation-effect). - As the 6 incrementalism-in-relative-ontological-incompleteness ${ }^{88}$ enframed/disontologising conceptualisation $<$ amplituding/formative $>$ wooden-language〈imbued - averaging-of-thought-<as-to-leveling/ressentiment/closed-construct-ofmeaningfulness-and-teleology -as-of-'nondescript/ignorable-void '-with-regards-toprospective-apriorising-implications $>\rangle$ ' disposition tends to wrongly define the ${ }^{83}$ reference-ofthought of a given prior/transcended/superseded registry-worldview as the absolute framework of 'postconverging-or-dialectical-thinking -apriorising-psychologism', and so by reflex, as if the successive prior institutional-cumulation/institutional-recomposure-〈as-tohistoriality/ontological-eventfulness /ontological-aesthetic-tracing-<perspectiveontological-normalcy/postconvergence-reflected-‘epistemicity-relativism-determinism’>> were geared to end at its own registry-worldview as the absolute registry-worldview that doesn't incur 
perversion-of- ${ }^{-3}$ reference-of-thought-<as-preconvergingly-

apriorising/axiomatising/referencing-in-nonconviction/madeupness/bottomlining-as-to-

shallow-supererogation $>$ (in our case, the positivistic registry-worldview) without any notion of a prospective registry-worldview by which, where our own ${ }^{77}$ perversion-of- ${ }^{83}$ reference-ofthought-<as-preconvergingly-apriorising/axiomatising/referencing-in-

nonconviction/madeupness/bottomlining-as-to-shallow-supererogation $>$ arises, we will be preconverging-or-dementing ${ }^{20}$-apriorising-psychologism as dialectically-out-ofphase/dialectically-primitive, at our threshold-of-nonconviction/madeupness/bottomlining-inshallow-supererogation -<as-to-'attendant-intradimensional'-prospectivelydisontologising preconverging/dementing -apriorising-psychologism $>$ (or uninstitutionalisedthreshold ${ }^{02}$ or socially-betraying-threshold-of-ontologising-depth-of-analysis or sociallybetraying-threshold-of-intemporal-preservation-entropy-or-contiguity-or-ontological-

preservation); as our relative-ontological-incompleteness ${ }^{8}$-induced,-'threshold-ofnonconviction/madeupness/bottomlining-in-shallow-supererogation $<-<$ as-to- 'attendantintradimensional'-prospectively-disontologising preconverging/dementing -apriorisingpsychologism $>$ ' endemises/enculturates the denaturing ${ }^{16}$ and generally explains the vices-andimpediments ${ }^{105}$ of any registry-worldview/dimension as of its given limited-mentation-capacitydeepening —as-subjecting limitedness/human-subpotency-to-'educed-unlimitedness/existencesublimating nascence' 5 . As by reflex 'the-<amplituding/formative $>$ 'wooden-language〈imbued-averaging-of-thought-<as-to-leveling/ressentiment/closed-construct-ofmeaningfulness-and-teleology -as-of-‘nondescript/ignorable-void '-with-regards-toprospective-apriorising-implications $>\rangle$, wrongly ignores the ontologicalnormalcy/postconvergence (prospective-transcendence-in-perpetually-upholding-intemporalpreservation-entropy-or-contiguity-or-ontological-preservation) nature of intrinsicreality/ontological-veridicality, such that when there is a need to achieve ontologically-veridical 
meaningfulness by prospective ${ }^{83}$ reference-of-thought with new ${ }^{83}$ reference-of-thoughtcategorical-imperatives/axioms/registry-teleology ${ }^{9}$,-for-intemporal-preservation-entropy-orcontiguity-or-ontological-preservation, the 'incrementalism-in-relative-ontologicalincompleteness ${ }^{88}$ - enframed/disontologising conceptualisation

$<$ amplituding/formative $>$ wooden-language-_imbued - averaging-of-thought-<as-to-

leveling/ressentiment/closed-construct-of- meaningfulness-and-teleology -as-of-

'nondescript/ignorable-void '-with-regards-to-prospective-apriorising-implications $>\rangle$ ' simply engages in '<amplituding/formative-epistemicity $>$ totalising $\sim$ self-referencing-syncretising' to its prior/transcended/superseded ${ }^{83}$ reference-of-thought with its prior/old ${ }^{83}$ reference-of-

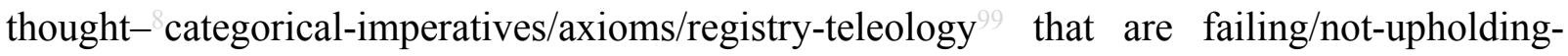
$<$ as-of-apriorising/axiomatising/referencing $>$ intemporal-preservation-entropy-or-contiguityor-ontological-preservation due to their temporal-preservational nature with respect to their own perversion-of- ${ }^{-3}$ reference-of-thought-<as-preconvergingly-

apriorising/axiomatising/referencing-in-nonconviction/madeupness/bottomlining-as-toshallow-supererogation $>$ threshold. It is only the <amplituding/formativeepistemicity $>$ causality $\sim$ as-to-projective-totalitative-implications-of-prospectivenonpresencing,-for-explicating relative-unreflexivity/relative-reflexivity - ontologicalcontiguity and positive-opportunism-of-social-functioning-and-accordance ${ }^{75}$ of the prospective/transcending/superseding ${ }^{83}$ reference-of-thought in the middle to long run construed as of ${ }^{15}$ de-mentation-〈supererogatory ontological-de-mentation-or-dialectical-de-mentationstranding-or-attributive-dialectics $\rangle$ that will induce its untenability/internalcontradiction/internal-incoherence/institutional-constraining and the collapsing/overriding of the prior/transcended/superseded (as "postconverging-or-dialectical-thinking - psychology or psychology-of-mentation-dynamics or natural psychological-dynamics' psychoanalyticunshackling/memetic-reordering/institutional-recomposuring), and so going by their 'relative 
ontological-effectivity'. This explains why a recurrent-utter-uninstitutionalised, an ununiversalised, a non-positivism/medievalism, or prospectively a procrypticism mindset, by $<$ amplituding/formative-epistemicity $>$ totalising $\sim$ self-referencingsyncretising/circularity/interiorising/akrasiatic-drag ${ }^{34}$, cannot correspondingly 'dialecticallythink' in terms-as-of-axiomatic-construct of the ${ }^{83}$ reference-of-thought mindset/ ${ }^{83}$ reference-ofthought of base-institutionalisation, ${ }^{103}$ universalisation, positivism and prospectively deprocrypticism, going by human limited-mentation-capacity-deepening-as-subjectinglimitedness/human-subpotency to-'educed-unlimitedness/existence-sublimating nascence' ${ }^{53}$ as of human-subpotency-aporia/undecidability/dilemma/oughtindeterminacy/deficiency/limitation/constraint—imbued-'notional firstnaturednessformativeness-<as-to-eventualising inkling-drive-or-seeding-misprising $>$ - temporal-tointemporal-dispositions- $<$ so-construed-as-from-perspective-ontologicalnormalcy/postconvergence>'-existentialism-form-factor with respect to social-stakecontention-or-confliction in all registry-worldviews, thus rather requiring the corresponding institutionalisation at the corresponding threshold-of-nonconviction/madeupness/bottomliningin-shallow-supererogation -<as-to-'attendant-intradimensional'-prospectivelydisontologising $\sim$ preconverging/dementing -apriorising-psychologism $>$ (or uninstitutionalisedthreshold ${ }^{02}$ or socially-betraying-threshold-of-ontologising-depth-of-analysis or sociallybetraying-threshold-of-intemporal-preservation-entropy-or-contiguity-or-ontologicalpreservation). However, contrary to the 'incrementalism-in-relative-ontologicalincompleteness ${ }^{88}$ — enframed/disontologising conceptualisation $<$ amplituding/formative $>$ wooden-language-_imbued — averaging-of-thought-<as-toleveling/ressentiment/closed-construct-of- meaningfulness-and-teleology -as-of'nondescript/ignorable-void ' -with-regards-to-prospective-apriorising-implications $>$ )' disposition, it is only solipsism-of-thought by its emphasis on intrinsicness (I come to reality 
alone solipsism) that has the requisite and socially-uncompromised backdrop for construing ontologically-veridical-meaningfulness, that is, 'at such uninstitutionalised-threshold requiring prospective transcendence-and-sublimity/sublimation/supereregatory $\sim$ dementativity', by the possibility for its adherence to ontological-normalcy/postconvergence, and hence the requisite transcendental limited-mentation-capacity-deepening-as-subjectinglimitedness/human-subpotency-to-'educed-unlimitedness/existence-sublimating nascence' ${ }^{53}$ to put the prior/transcended/superseded into question (including and priorly, the transcendental emancipator own's mentation) for the prospective/transcending/superseding ${ }^{83}$ reference-ofthought; and so, with the notion that the prior/transcended/superseded is preconverging-ordementing -apriorising-psychologism as dialectically-out-of-phase/dialectically-primitive, with no place for its '<amplituding/formative-epistemicity $>$ totalising $\sim$ self-referencingsyncretising' which is no more than its 'internal myth/metaphysics' that has nothing to do with ontological-veridicality/relative-unreflexivity/relative-reflexivity-ontological-contiguity ${ }^{67}$. As such, solipsism enables the requisite 'moulting' of human limited-mentation-capacitydeepening —as-subjecting limitedness/human-subpotency to-'educed-unlimitedness/existencesublimating nascence ${ }^{53}$ of notional firstnaturedness-formativeness-<as-toeventising inkling drive or seeding misprising> temporal-to-intemporal-dispositions$<$ so-construed-as-from-perspective-ontological-normalcy/postconvergence $>$ to allow for successive transcendence-and-sublimity/sublimation/supererogatory $\sim$ de-mentativity; and as a social conceptualisation operates as a 'relation of intersolipsistic mindsets in transversality $-<$ forsublimating-existential-eventuating/denouement,-from-'thinking-at-first/pure-predispositionpreemptive-of-prospective-disontologising/subontologising' as-of-prospectivelydisambiguated-affirmed-and-unaffirmed-'motif-and-apriorising/axiomatising/referencing’> led by the preceding/superseding intercession of intrinsic-reality/ontological-veridicality as validated by $<$ amplituding/formative-epistemicity $>$ causality $\sim$ as-to-projective-totalitative- 
implications-of-prospective- nonpresencing,-for-explicating relative-unreflexivity/relative-

reflexivity - ontological-contiguity '. (Noting that beyond this point of solipsistic contemplation is the end of ontology, as of <amplituding/formative-epistemicity >causality $\sim$ asto-projective-totalitative-implications-of-prospective- nonpresencing,-forexplicating relative-unreflexivity/relative-reflexivity - ontological-contiguity /attendantprojective-and-predicative-validation, and metaphysics arises though metaphysical constructs tend to harken back towards ontology in trying to explain the metaphysical-as-of-existential thus explaining the blurring that often arises between metaphysics and ontology as there is hardly any metaphysical construct that doesn't strive to be existentially-<disentologising/re-ontelogising aporeticism $>$ relevant as of the present, thus carrying ontological implications of conceptualisation whether it is demonstrably ontologically-veridical or not; and this latter point answers the fundamental philosophical quest to escape metaphysics for ontology as of the very relative-unreflexivity/relative-reflexivity - ontological-contiguity ${ }^{67}$ of-the-humaninstitutionalisation-process ${ }^{68}$ which is rather about 'successions of metaphysics-of-absence〈implicited-epistemic-veracity-of- nonpresencing-<perspective-ontologicalnormalcy/postconvergence $>>$ insights as the successive transcendentalenabling/sublimating/supererogatory de-mentativity rules in reflecting holographically$<$ conjugatively-and-transfusively $>$ the relative-unreflexivity/relative-reflexivity - ontologicalcontiguity of-the-human-institutionalisation-process yielding in-lockstep the successively more ontologically profound metaphysics-of-presence-〈implicited-‘nondescript/ignorablevoid '-as-to- presencing-absolutising-identitive-constitutedness > construed as the successive institutionalisations as implied by ontological-normalcy/postconvergence' towards the notional deprocrypticism registry-worldview/dimension which is what then achieves ontology as 'attained ontological-normalcy/postconvergence'. Likewise, since in effect there is hardly any 'present pure-ontology' as one that is beyond existential-<disontologising/re- 
entologising aporeticism>

implications

contentions

about

the

purity/absoluteness/unassailability of its veracity, this rather validates a novel and positive construal of metaphysics as that which is subject to present existential-<disontologising/reentelogising aporeticism $>$ implications contentions such that all supposed present ontologies are metaphysical constructs as of their non-elucidations. Hence even science itself despite its positive perspective is a metaphysical construct.) Hence, from a maximalising-recomposuringfor-relative-ontological-completeness ${ }^{87}$ — unenframed/re-ontologising $\sim$ conceptualisation insight, the <amplituding/formative-epistemicity $>$ totalising $\sim$ self-referencingsyncretising/circularity/interiorising/akrasiatic-drag ${ }^{34}$ of ' incrementalism-in-relativeontological-incompleteness — enframed/disontologising conceptualisation $<$ amplituding/formative $>$ wooden-language- $\langle$ imbued - averaging-of-thought- $<$ as-toleveling/ressentiment/closed-construct-of- meaningfulness-and-teleology -as-of'nondescript/ignorable-void ' -with-regards-to-prospective-apriorising-implications $>$ )' disposition is rather the prior/transcended/superseded ${ }^{83}$ reference-of-thought to be construed as preconverging-or-dementing ${ }^{20}$-apriorising-psychologism and dialectically-out-ofphase/dialectically-primitive with respect to a prospective/transcending/superseding ${ }^{8}$ referenceof-thought that is 'postconverging-or-dialectical-thinking -apriorising-psychologism' as dialectically-in-phase. $\quad-\quad$ As $\quad$ informing human-subpotencyaporia/undecidability/dilemma/ought-indeterminacy/deficiency/limitation/constraint—imbued'notional firstnaturedness-formativeness-<as-to-eventualising -inkling drive-or-seeding misprising $>$ temporal-to-intemporal-dispositions- $<$ so-construed-as-from-perspectiveontological-normalcy/postconvergence>'-existentialism-form-factor is the idea that the notion in reflecting holographically-<conjugatively-and-transfusively $>$ the relativeunreflexivity/relative-reflexivity - ontological-contiguity of-the-human-institutionalisationprocess (accounting for the institutional-cumulation/institutional-recomposure-〈as-to- 


\section{historiality/ontological-eventfulness /ontological-aesthetic-tracing-<perspective-}

ontological-normalcy/postconvergence-reflected-`epistemicity-relativism-determinism’>〉)

'the-transcendental/transdimensional/interdimensional/5 maximalising-recomposuring-forrelative-ontological-completeness ${ }^{87}$ - unenframed/re-ontologising conceptualisation', the notion of 'dynamic-cumulative-aftereffect of subontologisation' by human-subpotencyaporia/undecidability/dilemma/ought-indeterminacy/deficiency/limitation/constraint—imbued'notional firstnaturedness-formativeness-<as-to-eventualising inkling-drive-or-seedingmisprising $>$ temporal-to-intemporal-dispositions- $<$ so-construed-as-from-perspectiveontological-normalcy/postconvergence>'-existentialism-form-factor (accounting for any given reference-of-thought) as 'registry-worldview/dimension or intradimensional level', and the notion of human-subpotency-aporia/undecidability/dilemma/oughtindeterminacy/deficiency/limitation/constraint—imbued-'notional firstnaturednessformativeness-<as-to-eventualising-inkling drive-or-seeding misprising $>$ temporal-tointemporal-dispositions-<so-construed-as-from-perspective-ontologicalnormalcy/postconvergence $>$ '-existentialism-form-factor with respect to temporal-and-socialstake-contention-or-confliction (accounting for human registry-soundness/perversion) as 'theindividuations', can be elucidated going by the 'ontological implications' of the Derridean conceptualisations of Différance, Répétititon, Altérité and Iterabilité (in a further elaboration of the notion of différance-disambiguation-of-ontologically-veridical- ${ }^{5}$ meaningfulness-andteleology' based on the technique of 'Différance-existential-transitory-articulation-of-theprotraction-of- perversion-of- $^{8}$ reference-of-thought- $<$ as-preconvergingly-

\section{apriorising/axiomatising/referencing-in-nonconviction/madeupness/bottomlining-as-to-}

shallow-supererogation >,-of-meaningfulness'); and so, in drawing out and analysing the $<$ amplituding/formative-epistemicity $>$ causality $\sim$ as-to-projective-totalitative-implications-ofprospective- nonpresencing,-for-explicating relative-unreflexivity/relative-reflexivity 
ontological-contiguity with regards to the différance-disambiguation-of-ontologicallyveridical- ${ }^{56}$ meaningfulness-and-teleology ${ }^{9}$ of same-terms-of-expressions (seemingly-sameimplied-meaningfulness)' wherein there is 'induced alterity/alteration' of 'same-terms-ofexpressions (seemingly-same-implied-meaningfulness)' of the repetititon/repeatability/recurrence, as 'same-terms-of-expressions (seemingly-same-impliedmeaningfulness) by temporal-dispositions is rather 'hollow-constituted' which is then 'ontologically-reconstituted'/deconstructed by the intemporal-disposition, and thus the 'sameterms-of-expressions (seemingly-same-implied-meaningfulness) revealing, in-the-biggerpicture, the alterities/alterations of the-individuations, the registry-worldview/dimension or intradimensional level and the-interdimension/transcendental'. The insight here is that the spontaneous and generalised human prelogism ${ }^{78}$-as-of-conviction,-in-profoundsupererogation -<existentially-veridical-'attendant-intradimensionalapriorising/axiomatising/referencing'-logical-dueness-precedes-disontologising-logical-

outcome-arrived-at> reflex (or 'conviction-as-to-profound-supererogation -reflex' or intemporal-disposition-reflex-admittance-reflex/in-phase-reflex) is wrong when dealing with perversion-of- ${ }^{8}$ reference-of-thought- $<$ as-preconverginglyapriorising/axiomatising/referencing-in-nonconviction/madeupness/bottomlining-as-toshallow-supererogation $>$ (reflected-as-unsoundness-or-ontological-bad-faith/inauthenticity ${ }^{64}$ of- ${ }^{8}$ reference-of-thought with the ${ }^{83}$ reference-of-thought reflecting the registry-worldviewdevolving-apriorising/axiomatising/referencing or contending-reference or ontologicalreference or meaningful-reference or anchoring-of-meaning or registry) arising due to human temporal-compromises/temporal-accommodation $\quad{ }^{5}$ incrementalism-in-relative-ontologicalincompleteness 8 - enframed/disontologising conceptualisation disjointedness-as-ofreference-of-thought to 'socially-perceived-value as of social-stake-contention-or-confliction' (whether consciously, expediently or unconsciously) and particularly so at thresholds where 
there is no deferential-formalisation-transference as institutionalisation (uninstitutionalisedthreshold ${ }^{102}$ ), and this fundamentally undermines the 'ontological validity and veracity' of such a placeholder-setup/mental-devising-representation/mentation/consciousness-awarenessteleology as supposedly of prelogism ${ }^{78}$-as-of-conviction,-in-profound-supererogation $<$ existentially-veridical-'attendant-intradimensional-apriorising/axiomatising/referencing'logical-dueness-precedes-disontologising-logical-outcome-arrived-at> reflex (or 'convictionas-to-profound-supererogation -reflex' or intemporal-disposition-reflex-admittance-reflex/inphase-reflex). Beyond our illusion-of-the-present/present-consciousness/mirageas $<$ amplituding/formative-epistemicity>totalising $\sim$ self-referencingsyncretising/circularity/interiorising/akrasiatic-drag ${ }^{34}$ positivistic registry-worldview perspective, we can grasp that the lower registry-worldviews/dimensions 'mentally projected prelogism ${ }^{8}$-as-of-conviction,-in-profound-supererogation $<-<$ existentially-veridical'attendant-intradimensional-apriorising/axiomatising/referencing'-logical-dueness-precedesdisontologising-logical-outcome-arrived-at> reflex (or 'conviction-as-to-profoundsupererogation '-reflex' or intemporal-disposition-reflex-admittance-reflex/in-phase-reflex') are flawed at their uninstitutionalised-threshold ${ }^{102}$, and the same applies to us in ontologicalnormalcy/postconvergence. The nature of this 'conviction-as-to-profound-supererogation reflex flaw' is that it actually defines a 'threshold of circularity/recurrence/repetition/repeatability ${ }^{10}$ of the failing/not-upholding-<as-ofapriorising/axiomatising/referencing> supplanting-conviction-as-to-profoundsupererogation - of-'attendant-intradimensional'-postconverging/dialectical-thinking apriorising-psychologism reflex' in circularity/recurrence/repetition/repeatability ${ }^{10}$, effectively as its uninstitutionalised-threshold ${ }^{102}$. For instance, where a non-positivism/medievalism mindset/ $/ 3$ reference-of-thought keeps on arguing a case of sorcery recurrently in nonpositivism/medievalism terms which inherently defines its placeholder-setup/mental-devising- 
representation/mentation/consciousness-awareness-teleology 99 as non-positivism/medievalism, and the same insight does applies from a prospective ontological-normalcy/postconvergence reference (as deprocrypticism) wherein we'll need to psychoanalytically-unshackle/mimeticlyreorder/institutionally-recomposure from a positivism- ${ }^{80}$ procrypticism mindset/mentaldevising-representation/mentation. Further, the notional firstnaturedness-formativeness-<as-toeventualising inkling-drive or seeding-misprising> temporal-to-intemporal-dispositions$<$ so-construed-as-from-perspective-ontological-normalcy/postconvergence $>$ implies that where there is postlogism 77 -and-conjugated-postlogism 77 as uninstitutionalised-threshold ${ }^{102}$, the more ontologically-veridical placeholder-setup/mental-devisingrepresentation/mentation/consciousness-awareness-teleology ${ }^{9}$ reflex is actually of preconverging-or-dementing ${ }^{20}$-apriorising-psychologism reflex (and not new ${ }^{54}$ logicalprocessing-or-logical-implicitation - supposedly-apriorising-in-conviction-as-to-profoundsupererogation as 'prelogic supplanting-conviction-as-to-profound-supererogation —of'attendant-intradimensional'-postconverging/dialectical-thinking -apriorising-psychologism re-engaging reflex')/temporal-disposition-reflex-reflex/out-of-phase-reflex). Both postlogism and conjugated-postlogism instances of the failing/not-upholding-<as-ofapriorising/axiomatising/referencing $>\quad$ circularity/recurrence/repetition/repeatability ${ }^{10}$ at

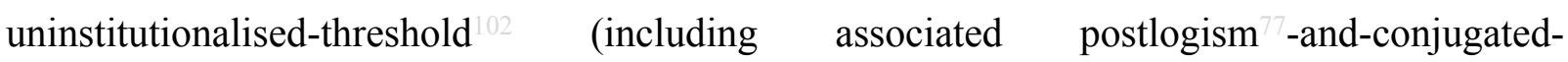
postlogism ${ }^{77}$ ) reveal the 'alteration of the same-terms-of-expressions (seemingly-same-impliedmeaningfulness)' as temporal-dispositions alterity/alteration. Insightfully, it is this grasp of the uninstitutionalised-threshold $^{102} \quad$ (including associated postlogism 77 -and-conjugatedpostlogism -of-temporal-dispositions) in the existential-flux of ontologically-veridical in circularity/recurrence/repetition/repeatability ${ }^{10}$ of same-terms-of-expressions (seemingly-sameimplied-meaningfulness) alternating with ontologically-non-veridical alterity/alterations of same-terms-of-expressions (seemingly-same-implied-meaningfulness)', as Différance, that is 
critical in defining notional firstnaturedness-formativeness-<as-to-eventualising-inklingdrive or seeding misprising $>$ temporal-to-intemporal-dispositions-<so-construed-as-fromperspective-ontological-normalcy/postconvergence $>\quad$ disambiguated teleologicaldifferentiations. It is the dynamic-extension of this Différance-suprastructurally-disambiguatedmental-dispositions-meaningfulness-as-the-various-notional firstnaturedness-formativeness<as-to-ventualising-inkling-drive or seeding-misprising > temporal-to-intemporaldispositions-<so-construed-as-from-perspective-ontological-normalcy/postconvergence $>\quad$ in 'dynamic-cumulative-aftereffect of subontologisation' (as slantedness/postlogic-effect, miscuing, disjointed-logic, logical-drag, unconscionability-drag, sub-par/formulaicassociation/temporal/alibi conventioning-rationalising, and temporal-enculturation/temporalendemisation-effect) at the-individuations level to registry-worldview level and thetranscendental/transdimensional/interdimensional $/ 5$ maximalising-recomposuring-for-relativeontological-completeness ${ }^{87}$ - unenframed/re-ontologising conceptualisation level that explains the 'alterating iterability dynamism' at these three levels; whether at the-individuations level involving the hollow-constituting-<as-disjointed-misappropriation-of-meaningfulness-andfailing-intemporal-preservation $>$ alteration' by temporal-dispositions as slanted-and-formulaic postlogic-backtracking-<iterative-looping-'set-of-dereifying-hollow-narratives-and-acts'> $>$ of meaningfulness of the postlogic disposition or 'conjoining looping narratives of flawedexistential-elevation-of- ${ }^{2}$ reference-of-thought ${ }^{1}$, of the slanted-and-formulaic perverted meaningfulness as the conjugated-postlogic disposition, meted with the 'ontological-

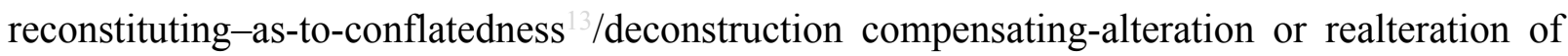
meaningfulness' of the intemporal-disposition), as the basis of the institutionalisation/intemporalisation processs at registry-worldview/dimension or intradimensional level, and ultimately explaining thetranscendental/transdimensional/interdimensional $/ 5$ maximalising-recomposuring-for-relative- 
ontological-completeness ${ }^{87}$ - unenframed/re-ontologising conceptualisation

successiveness of institutionalisations (as recurrent-utter-uninstitutionalisation, baseinstitutionalisation/ununiversalisation, universalisation/non-positivism-or-medievalism, positivism/procrypticism, and perpetuation-of-deprocrypticism); and so, by a 'human limitedmentation-capacity-deepening —as-subjecting limitedness/human-subpotency-to-'educedunlimitedness/existence-sublimating nascence' ${ }^{23}$ recurrence of intemporal projection over the alterity/alteration, in circularity/recurrence/repetition/repeatability ${ }^{10}$ by temporality ${ }^{\circ}$, and such iterability/iteration (of ontologically-veridical-meaningfulness-and-ontological-reference) being driven by intemporal-preservation-in circularity/recurrence/repetition/repeatability ${ }^{10}$ (as longness-of-register-of- ${ }^{5}$ meaningfulness-and-teleology ${ }^{9}$ with the latter 'distracted/circumvented' by temporal-preservation-as-pseudointemporality ${ }^{52}$-preservation alterity/alteration-in circularity/recurrence/repetition/repeatability ${ }^{10}$ as shortness-of-register-ofmeaningfulness-and-teleology ${ }^{9}$, requiring the further realterity/realteration-of-such temporalpreservation-alterity/alteration-in $\quad$ circularity/recurrence/repetition/repeatability $10 \quad$ as 'ontological-reconstituting-as-to-conflatedness $13 /$ deconstruction' by intemporal-preservationentropy-or-contiguity-or-ontological-preservation in iterability/iteration (for the preservation of ontologically-veridical-meaningfulness-and-appropriateness-of- ${ }^{3}$ reference-of-thought-as-ofconflatedness $^{13}$ ). In-the-bigger-picture and as with all natural iterations, this 'alterationsiterability dynamism' at the-individuation-level takes the form of an existential-flux ('dynamiccumulative-aftereffect of subontologisation') of recursive/recurrent alterity/alterations which tend to be perpetuating (like the pathological psychopath's disposition out of a faulty-mentationprocedure-deception/' urge'/entitlement-folie of postlogism 7 -slantedness effect) or progressive alterity/alterations which could be regular (like an exacerbation or opportunism interlocutors in conjugated-postlogism 77 or regressive alterity/alterations which could be momentary (like an ignorance or affordability interlocutors in conjugated-postlogism 77 . The notion of iterability as 
the 'induced effect of alterity/alterations (by the temporal-dispositions hollow-constituting-<asdisjointed-misappropriation-of-meaningfulness-and-failing-intemporal-preservation $>$ and the intemporal-disposition compensation-alterity/alteration by 'ontological-reconstituting-as-toconflatedness ${ }^{13}$ /deconstruction) in the repeatability/recurrence of same-terms-of-expressions or same-implied-meaningfulness', implies that temporal-dispositions being just as preservational as the intemporal-disposition thus inducing the circular recurrence of iterability (as prospective successive institutionalisations and uninstitutionalised-threshold ${ }^{102}$ ), the exercise of institutionalisation/intemporalisation is not about transforming temporal-dispositions as of dimensionality-of-sublimating $25<<$ amplituding/formative $>$ supererogatory $\sim$ dementativeness/epistemic-growth-or-conflatedness /transvaluativerationalising/transepistemicity/anamnestic-residuality/spirit-drivenness-equalisation〉 exercise but rather institutionalisation/intemporalisation or secondnaturing, which is about 'skewing ('intemporality ${ }^{52}$-symmetrising-by-desymmetrising-subsumption-of-temporality ${ }^{8}$, for relative intrinsic-reality/ontological-veridicality transcendentalenabling/sublimating/supereregatory $\sim$ de-mentativity)/constraining towards' the intemporaldisposition for intemporal-preservation-entropy-or-contiguity-or-ontological-preservation to enable the given prospective institutionalisation. Thus the fact is that this iterability (of meaningfulness and ontological-reference) is not a property of 'intrinsic-reality as existenceemanance' but actually the result/effect of human limited-mentation-capacity-deepening-assubjecting limitedness/human-subpotency to 'educed-unlimitedness/existence-sublimating nascence' coming-into-grips with intrinsic-reality as existence-emanance, and so in the succession of institutionalisations. The implication of this iterability (due to temporality preservational-alterity/alterations in distraction/circumvention of intemporality ${ }^{52}$-preservationiteration for construct of intemporal/ontologically-veridical meaningfulness) is that all issues of perversion-of- ${ }^{-3}$ reference-of-thought-<as-preconvergingly- 
apriorising/axiomatising/referencing-in-nonconviction/madeupness/bottomlining-as-to-

shallow-supererogation $>$ (as opposed to issues of ${ }^{54}$ logical-processing-or-logicalimplicitation - supposedly-apriorising-in-conviction-as-to-profound-supererogation ), can only be construed as implying a 'perpetual construct for upholding intemporality ${ }^{52}$-inpreservational-compensation-alterity/alteration over temporality ${ }^{8}$-in-preservational-distortingalterity/alterations' hence validating the notion of intemporal-preservation-entropy-orcontiguity-or-ontological-preservation as ontological-normalcy/postconvergence; and that the 'illusion-of-definitiveness-of-ontological-construal-on-the-basis-of-an-intemporal/ontologicaldefinitive-construct-as-a-common-ontological-reference-of-the-meaningfulness-of-the-variousnotional firstnaturedness-formativeness-<as-to-eventualising inkling-drive-or-seeding misprising $>$ temporal-to-intemporal-dispositions- $<$ so-construed-as-from-perspectiveontological-normalcy/postconvergence>' is wrong, as this simply allows for temporality ${ }^{8}$-inpreservational-alterity/alterations to 'hollow-constitute' at that supposed 'intemporal/ontological-definitive-construct-as-a-common-ontological-reference-of-themeaningfulness-of-the-various-notional firstnaturedness-formativeness-<as-toeventualising inkling-drive-or-seeding-misprising > temporal-to-intemporal-dispositions$<$ so-construed-as-from-perspective-ontological-normalcy/postconvergence $>$ '. And just as we grasp this notion of 'the-upholding-of-intemporal/ontologically-veridical-meaningfulness' at the-interdimension level where the registry-worldviews/dimensions are intemporally 'ontologically-reconstituted'/deconstructed, only to be temporally 'hollow-constituted' requiring prospective intemporal 'ontological-reconstituting-as-toconflatedness ${ }^{13} \%$ deconstruction explaining the successive institutional-cumulation/institutionalrecomposure-〈as-to- historiality/ontological-eventfulness /ontological-aesthetic-tracing$<$ perspective-ontological-normalcy/postconvergence-reflected-'epistemicity-relativismdeterminism' $>>$, rather than going by the wrong idea of an 'illusion-of-definitiveness-of- 
ontological-construal-on-the-basis-of-an-intemporal/ontological-definitive-construct-as-acommon-ontological-reference-of-the-meaningfulness-of-the-various-

notional firstnaturedness-formativeness-<as-to-eventualising inkling drive-or-seeding misprising $>$ temporal-to-intemporal-dispositions-<so-construed-as-from-perspectiveontological-normalcy/postconvergence>', likewise at registry-worldview level, différancedisambiguation-of-ontologically-veridical- ${ }^{5}$ meaningfulness-and-teleology ${ }^{9}$ ensures that (by factoring in the distraction/circumvention of intemporally/ontologically-veridicalmeaningfulness in circularity/recurrence/repetition/repeatability ${ }^{10}$, by temporal-preservationalterity/alteration in circularity/recurrence/repetition/repeatability ${ }^{10}$, requiring the further intemporal-preservation compensation-alterity/alteration of such temporal-preservationalterity/alteration in circularity/recurrence/repetition/repeatability ${ }^{10}$ to uphold intemporally/ontologically-veridical-meaningfulness) the intemporal-disposition doesn't imply a same/common ${ }^{83}$ reference-of-thought with temporal-dispositions, and in so doing avoid to wrongfully elevate postlogism 77 -and-conjugated-postlogism 77 in preconverging-or-dementing ${ }^{2}$ integration-of-temporal-dispositions to a 'conviction-as-to-profound-supererogation -reflex' rather as of postconverging-or-dialectical-thinking -apriorising-psychologism when dealing with their meaningful-reference-defect/registry-defect/ perversion-of- ${ }^{-}$reference-of-thought$<$ as-preconvergingly-apriorising/axiomatising/referencing-in-

nonconviction/madeupness/bottomlining-as-to-shallow-supererogation $>$ defect. $\quad$ The implication being that the intemporal-disposition ontological-reference of meaningfulness is suprastructural (beyond-the-consciousness-awareness-teleology ${ }^{9}-<$ of-preconvergingexistential-extrication-as-of-existential-unthought>) of the postlogism 7 -and-conjugatedpostlogism 7 which is in preconverging-or-dementing ${ }^{20}$-integration-of-temporal-dispositions (which explains the latter subontologisation/subpotentiation (in-a-social-dynamism-ofmeaningfulness-misappropriation) by slantedness/postlogic-effect, miscuing, disjointed-logic, 
logical-drag, unconscionability-drag, sub-par/formulaic-association/temporal/alibi conventioning-rationalising, and temporal-enculturation/temporal-endemisation-effect). Ultimately the philosophical pessimism of many a philosopher stems from this confusion about the achievement of human emancipation and virtue, in naively construing that such an achievement is a definitiveness-construct-of-meaningfulness rather than an iterabilityconstruct-of-meaningfulness for the upholding of the intemporal construct of ontologicallyveridical-meaningfulness' as implied by the intemporal-preservation-entropy-or-contiguity-orontological-preservation as of ontological-normalcy/postconvergence. Strangely enough, this idea can be derived from the contrastive implications of metaphysics-of-presence-〈implicited'nondescript/ignorable-void '-as-to- presencing - absolutising-identitive-constitutedness >

(with its illusion-of-the-present/present-consciousness/mirage/epistemic-totalising $\sim$ selfreferencing-syncretising) and metaphysics-of-absence-(implicited-epistemic-veracity-ofnonpresencing-<perspective-ontological-normalcy/postconvergence $>>$ as postdication (suprastructuring transcendental-insight-projection-capacities). Ontologically speaking, the institutional-cumulation/institutional-recomposure-〈as-to- historiality/ontologicaleventfulness /ontological-aesthetic-tracing-<perspective-ontologicalnormalcy/postconvergence-reflected-‘epistemicity-relativism-determinism' $>>$ in their evolving de-mentation-〈supererogatory $\sim$ ontological-de-mentation-or-dialectical-de-mentationstranding-or-attributive-dialectics $\rangle$ registry/registry-worldview/ontological-reference dialecticisms as at one moment 'postconverging-or-dialectical-thinking ${ }^{21}$-apriorisingpsychologism' and at another preconverging-or-dementing ${ }^{20}$-apriorising-psychologism are effectively a reflection of the reality of a dynamic dialectics of 'metaphysics-of-presence〈implicited-'nondescript/ignorable-void '-as-to- presencing-absolutising-identitiveconstitutedness \' and 'metaphysics-of-absence-〈implicited-epistemic-veracity-ofnonpresencing-<perspective-ontological-normalcy/postconvergence $>$ ' $\quad$ retracing of 
ontologically-veridical

placeholder-setup/mental-devisingrepresentation/mentation/consciousness-awareness-teleology 9 retrospectively, presently and prospectively, going by a human shallow limited-mentation-capacity-as-subjecting 'educedunlimitedness/existence-sublimating nascence' to limitedness/human-subpotency-〈as of relative apriorising/axiomatising/referencing-\{of-"prespectively implicited_attendant ontological-contiguity ' educed-

existentialising/contextualising/textualising_'intelligibility/epistemicity/reflexivity-contiguity<imbued-notional cogency>' $\}$-constitutedness ${ }^{1}$-in-preconverging-entailment $\rangle$ to deeper limited-mentation-capacity—as-subjecting 'educed-unlimitedness/existence-sublimating nascence' to-limitedness/human-subpotency-〈as of relative apriorising/axiomatising/referencing-\{of-'prospectively implicited_attendant-ontologicalcontiguity ' $\sim$ educedexistentialising/contextualising/textualising_'intelligibility/epistemicity/reflexivity-contiguity<imbued-notional cogency $\left.>^{\prime} \quad\right\}$-conflatedness ${ }^{13}$ in-\{preconverging-disentailment by postconverging-entailment $\rangle$ institutionalisation/intemporalisation process. Such an insight points out that a non-positivism/medievalism 'metaphysics-of-presence-〈implicited'nondescript/ignorable-void '-as-to- presencing-absolutising-identitive-constitutedness 〉' will 'wrongly be contending' on the basis of a non-positivism/medievalism ${ }^{83}$ reference-ofthought with regards to issues of sorcery and so and so, instead of the requisite 'metaphysics-ofabsence-〈implicited-epistemic-veracity-of- nonpresencing-<perspective-ontologicalnormalcy/postconvergence $>\rangle^{\prime}$ as a suprastructuring transcendental-insight-projection into positivistic (rational-empiricism) mindset/ ${ }^{83}$ reference-of-thought that supersedes the 'flaws-andmanipulations' or vices-and-impediments ${ }^{105}$ involved in such a non-positivism/medievalism setting ${ }^{83}$ reference-of-thought; in need of deconstruction/(engaged)-destruktion/'ontologicalreconstituting-as-to-conflatedness ${ }^{13}$, into prospective suprastructuring positivism ${ }^{8}$ reference- 
of-thought of ontologically-veridical meaningfulness, and so, 'as the suprastructuring construal〈as-of-'perversion-and-derived- perversion-of- reference-of-thought-<as-preconverginglyapriorising/axiomatising/referencing-in-nonconviction/madeupness/bottomlining-as-toshallow-supererogation >-as-to-uninstitutionalised-threshold -self-referencing-syncretisingand-subtransversality-<in-desublimating-existential-eventuating/denouement $>\sim$ of-motif-andapriorising/axiomatising/referencing'-and- 'corresponding-ontological-reconstituting-as-toconflatedness $^{13}$-of-veridical- reference-of-thought-as-prospectiveinstitutionalisation/supratransversality-<in-sublimating-existentialeventuating/denouement> of-motif-and-apriorising/axiomatising/referencing'> delineating existential-transitioning-or-iterability-trace-of-narratives-as-dots_or_implicited_tente ontological-contiguity ${ }^{67}$, educedexistentialising/contextmalising/textualising_'intelligibility/epistemicity/reflexivity_contiguity$<$ imbued-notional cogency>' ${ }^{\prime}$-reification_or_intrinsic-reality-ontologicalcoherence_or_superseding-oneness-of-ontology ${ }^{41}$ of ontologically-veridical-meaningfulness that is not actually spoken-of by non-positivism/medievalism mindset/ ${ }^{3}$ reference-of-thought wrongly contending'; with the Derridean (existential)-trace being the suprastructuring positivistic ${ }^{83}$ reference-of-thought of ontologically-veridical meaningfulness with respect to intrinsic-reality. Such an insight can certainly be grasped with respect to procrypticism and notional ${ }^{18}$ deprocrypticism as well, with the associated postlogic ${ }^{74}$ perversion-of- ${ }^{8}$ reference-ofthought-<as-preconvergingly-apriorising/axiomatising/referencing-innonconviction/madeupness/bottomlining-as-to-shallow-supererogation $>$ phenomena. The ontological-normalcy/postconvergence referentialism perspective inherently carries the requisite suprastructuring transcendental-insight-projection for fulfilling the promise of 'metaphysics-ofabsence-〈implicited-epistemic-veracity-of- nonpresencing-<perspective-ontologicalnormalcy/postconvergence $>$ ' ' as postdication. Paradoxically, postdication (as metaphysics-of- 
absence-〈implicited-epistemic-veracity-of- nonpresencing-<perspective-ontological-

normalcy/postconvergence $>>$ ) highlights that ontological-normalcy/postconvergence is rather conceptualised more effectively with the present-considered-as-being-in-epistemicabnormalcy/preconvergence ${ }^{31}$-perspective- \{preconverging-or-dementing ${ }^{20}$-apriorisingpsychologism- ${ }^{-3}$ reference-of-thought $\}$-and-hence-suprastructurable by 'metaphysics-ofabsence-〈implicited-epistemic-veracity-of- nonpresencing-<perspective-ontologicalnormalcy/postconvergence $>$ ’'-perspective- $\{$ 'postconverging-or-dialectical-thinking 1 apriorising-psychologism'- ${ }^{8}$ reference-of-thought $\}$ which is then actually prospective (toresolve-the epistemic-abnormalcy/preconvergence ${ }^{31}$ ); and not 'metaphysics-of-presence〈implicited-'nondescript/ignorable-void '-as-to- presencing - absolutising-identitive-

constitutedness Y' conceptualisation which 'wrong pretence of being in ontological-normalcy' is actually stifling the prospective orientation by its illusion-of-the-present/presentconsciousness/mirage as <amplituding/formative-epistemicity $>$ totalising $\sim$ self-referencingsyncretising/circularity/interiorising/akrasiatic-drag ${ }^{4}$. This posture is validated by the decreasing epistemic-abnormalcy/preconvergence ${ }^{3 !}$ nature of the successive institutionalcumulation/institutional-recomposure-〈as-to- historiality/ontological-

eventfulness /ontological-aesthetic-tracing-<perspective-ontological-

normalcy/postconvergence-reflected-'epistemicity-relativism-determinism'>> from retrospective to present to prospective, whereby there is decreasing epistemicabnormalcy/preconvergence ${ }^{3}$ as the institutionalisation/intemporalisation process veers towards ontological-normalcy/postconvergence (from recurrent-utter-uninstitutionalisation to baseinstitutionalisation to ${ }^{103}$ universalisation to positivism and prospectively to deprocrypticism). With respect to the postlogism -as-of- compulsing-nonconviction/madeupness/bottomlining$〈<<$ decontextualising/de-existentialising of-attendant-intradimensionalapriorising/axiomatising/referencing>-induced-disontologising'-of-the-'attendant- 
intradimensional-ontologising'-imbued-<contextualising/existentialising $\sim$ attendant-

ontological-contiguity $>$;-in-shallow-supererogation -<as-to-disontologising-perverted-

outcome-sought-precedes-existentially-veridical-'attendant-intradimensional-

apriorising/axiomatising/referencing'-logical-dueness $>>\quad$ perversion-of- ${ }^{83}$ reference-of-

thought-<as-preconvergingly-apriorising/axiomatising/referencing-in-

nonconviction/madeupness/bottomlining-as-to-shallow-supererogation $>$ (reflected as mentalperversion/unsoundness-or-ontological-bad-faith/inauthenticity ${ }^{6}$-of- ${ }^{3}$ reference-of-thought) phenomenon of psychopathy and social psychopathy, the Derridean (existential)-trace as the suprastructuring transcendental-insight-projection (metaphysics-of-absence-〈implicitedepistemic-veracity-of- nonpresencing-<perspective-ontological-normalcy/postconvergence $>\rangle$ ) reference-of-thought, wherein there is ${ }^{7}$ perversion-of- ${ }^{3}$ reference-of-thought- $<$ aspreconvergingly-apriorising/axiomatising/referencing-in-

nonconviction/madeupness/bottomlining-as-to-shallow-supererogation $>$ of positivistic reference-of-thought of ontologically-veridical meaningfulness as procrypticism preconverging-or-dementing ${ }^{20}$-apriorising-psychologism, in need of deconstruction/(engaged)destruktion/ontological-reconstituting-as-to-conflatedness ${ }^{13}$ into prospective suprastructuring notional ${ }^{8}$ deprocrypticism ${ }^{83}$ reference-of-thought of ontologically-veridical meaningfulness, and so, 'as the suprastructuring as of the circularity/recurrence/repetition/repeatability delineating existential-transitioning-or-iterability-trace-of-narratives-asdots_or_implicited_attendant-ontological-contiguity ${ }^{67}$, educedexistentialising/contextualising/textualising_intelligibility/epistemicity/reflexivity_contiguity$<$ imbued-notional cogency>' $>^{\prime}$-reification_or_intrinsic-reality-ontologicalcoherence_or_superseding-oneness-of-ontology that is not actually spoken-of by our procrypticism and postlogic/psychopathic mindsets $/{ }^{\circ}$ reference-of-thought wrongly contending'; as of the circularity/recurrence/repetition/repeatability ${ }^{10}$ delineating existential- 
transitioning-or-iterability-trace-of-narratives-as-dots_or_implicited_attendant-ontologicalcontiguity $^{67}$ > educed-

existentialising/contextmalising/textualising_'intelligibility/epistemicity/reflexivity-contiguity$<$ imbued-notional cogency>' ${ }^{\prime}$-reification_or_intrinsic-reality-ontologicalcoherence_or_superseding-oneness-of-ontology being (metaphysics-of-absence-〈implicitedepistemic-veracity-of- nonpresencing-<perspective-ontological-normalcy/postconvergence $>>$ ) suprastructuring notional ${ }^{18}$ deprocrypticism ${ }^{83}$ reference-of-thought of ontologically-veridical meaningfulness with respect to intrinsic-reality. Such temporally-preservational-aspseudointemporality ${ }^{52}$-preservation $\quad$ iterability-\{of-ontological-veridicality $\}$-by-\{hollowconstituting-<as-disjointed-misappropriation-of-meaningfulness-and-failing-intemporal-

preservation> \}-alteration/alterity associated with psychopathy and social psychopathy takes the form of absolving/fleeting/escaping-reflex-logic wherein the postlogic mindset/ ${ }^{83}$ reference-ofthought is all about parasitising/co-opting the supplanting-conviction-as-to-profoundsupererogation —of-'attendant-intradimensional'-postconverging/dialectical-thinking apriorising-psychologism ${ }^{83}$ reference-of-thought (registry/meaningful-reference/anchoring-ofmeaning/contending-reference/ontological-reference/registry-worldview) by simply projecting and implying false forms of ${ }^{8}$ reference-of-thought- categorical-imperatives/axioms/registryteleology that are not in intemporal-preservation-entropy-or-contiguity-or-ontologicalpreservation, and so in temporal-preservation-as-pseudointemporality ${ }^{52}$-preservation as of the circularity/recurrence/repetition/repeatability ${ }^{10} \quad$ delineating existential-transitioning-oriterability-trace-of-narratives-as-dots_or_implicited_attendant-ontologicalcontiguity $^{67}$; educedexistentialising/contextmalising/textualising_'intelligibility/epistemicity/reflexivity_contiguity$<$ imbued-notional cogency>' -reification_or_intrinsic-reality-ontologicalcoherence_or_superseding-oneness-of-ontology ${ }^{41}$, with the fundamental faulty-mentation- 
procedure-deception-or-urge ${ }^{43}$ being the wrongful validation as supplanting-conviction-as-toprofound-supererogation of-'attendant-intradimensional'-postconverging/dialecticalthinking -apriorising-psychologism of its ${ }^{83}$ reference-of-thought in-the-very-first-place as in reality the ${ }^{83}$ reference-of-thought reflected from futural Being-development/ontologicalframework-expansion-as-to-depth-of-ontologising-development-as-infrastructure-ofmeaningfulness-and-teleology as of prospective notional ${ }^{18}$ deprocrypticism registryworldview will be suprastructural to it (or beyond-the-consciousness-awareness-teleology $<$ of-preconverging-existential-extrication-as-of-existential-unthought $>$ of the procrypticism perversion-of- ${ }^{3}$ reference-of-thought- $<$ as-preconverginglyapriorising/axiomatising/referencing-in-nonconviction/madeupness/bottomlining-as-toshallow-supererogation $>$ as reflected/perspectivated as preconverging-or-dementing ${ }^{20}$ apriorising-psychologism). The idea equally is that as a ${ }^{7}$ perversion-of- ${ }^{3}$ reference-of-thought$<$ as-preconvergingly-apriorising/axiomatising/referencing-in-

nonconviction/madeupness/bottomlining-as-to-shallow-supererogation $>$, there isn't any 'definitiveness-intemporal/ontological-construal-of-meaningfulness-as-there-is-no-commonreference-of-thought-relative-to-the-notional firstnaturedness-formativeness-<as-toeventualising inkling drive or seeding misprising temporal-to-intemporal-dispositions$<$ so-construed-as-from-perspective-ontological-normalcy/postconvergence $>$ ' but rather 'iterability-\{of-ontological-veridicality\}-by-\{ontologically-reconstituting/deconstructing\}alteration/alterity-for-intemporal/ontological-construal-as-the-basis-for-suprastructurallydisambiguating- ${ }^{8}$ reference-of-thought-of-the-various-notional firstnaturedness-formativeness<as-to-eventtalising inkling drive-or-seeding misprising $>$ temporal-to-intemporaldispositions-<so-construed-as-from-perspective-ontological-normalcy/postconvergence $>\quad$ in grasping and preempting postlogism 77 and temporal-dispositions-conjugated-postlogism 77 in temporal-preservation-as-pseudointemporality ${ }^{52}$-preservation. As by implying rather a 
'definitiveness-of-intemporal/ontological-construal-of-meaningfulness-on-the-basis-of-acommon- ${ }^{83}$ reference-of-thought-relative-to-the-notional firstnaturedness-formativeness-<asto-eventualising inkling drive-or seeding-misprising $>$ temporal-to-intemporal-dispositions$<$ so-construed-as-from-perspective-ontological-normalcy/postconvergence ${ }^{\prime}$ ' will just be a basis for the further iterability-\{of-ontological-veridicality $\}$-by-\{hollow-constituting-<asdisjointed-misappropriation-of-meaningfulness-and-failing-intemporal-preservation> $>$ alteration/alterity of ontologically-veridical meaningfulness by the postlogism 7 -and-temporaldispositions-conjugated-postlogism 77 as the fundamental <amplituding/formativeepistemicity $>$ causality $\sim$ as-to-projective-totalitative-implications-of-prospectivenonpresencing,-for-explicating relative unreflexivity/relative-reflexivity - ontologicalcontiguity agency hollow-constituting-<as-disjointed-misappropriation-of-meaningfulnessand-failing-intemporal-preservation $>$ in alterity/alteration' by 'perverting the ${ }^{83}$ reference-ofthought of ontologically-veridical meaningfulness' in iteration/succession; as a 'dynamiccumulative-aftereffect of subontologisation' (slantedness/postlogic-effect, miscuing, disjointedlogic, logical-drag, unconscionability-drag, sub-par/formulaic-association/temporal/alibi conventioning-rationalising, and temporal-enculturation/temporal-endemisation-effect) as shortness-of-register-of- ${ }^{5}$ meaningfulness-and-teleology ${ }^{9}$. Thus avoiding wrongly implying their dimensionality-of-sublimating $25<<$ amplituding/formative $>$ supererogatory $\sim$ dementativeness/epistemic-growth-or-conflatedness /transvaluativerationalising/transepistemicity/anamnestic-residuality/spirit-drivenness-equalisation〉 transformation as instigative intemporal-disposition (longness-of-register-of- ${ }^{56}$ meaningfulnessand-teleology ${ }^{9}$ ), but rather 'institutionalisation-skewing ('intemporality ${ }^{52}$-symmetrising-bydesymmetrising-subsumption-of-temporality ${ }^{8}$, for relative intrinsic-reality/ontologicalveridicality transcendental-enabling/sublimating/supererogatory $\sim$ de-mentativity)' in the socialconstruct for intemporal-preservation-entropy-or-contiguity-or-ontological-preservation as of 
ontological-normalcy/postconvergence which always factor in human limited-mentationcapacity-deepening —as-subjecting limitedness/human-subpotency-to-'educed-

unlimitedness/existence-sublimating nascence' ${ }^{53}$ by a re-equilibrating metaphysics-of-absence〈implicited-epistemic-veracity-of- nonpresencing-<perspective-ontologicalnormalcy/postconvergence $>$ /postdication, as secondnaturing. It is this understanding of postlogism 7 -and-conjugated-postlogism 77 in preconverging-or-dementing ${ }^{20}$-integration-oftemporal-dispositions as a 'dynamic-cumulative-aftereffect of subontologisation' as 'perverting, by alterity/alteration, the ${ }^{8}$ reference-of-thought of ontologically-veridical meaningfulness' in iteration/succession', wherein new sets of denaturing slanted-and-formulaic-postlogicbacktracking-<iterative-looping-‘set-of-dereifying-hollow-narratives-and-acts’> (absolving/fleeting/escaping-reflex-logic ) involving their conjoining as ' ${ }^{12}$ conjoining-loopingset-of-narratives of flawed-existential-elevation-of- ${ }^{3}$ reference-of-thought ${ }^{14}$, by temporaldispositions-conjugated-postlogism 7 , as well as extrinsic-attribution with different sets of interlocutors in succession underlies the psychopathic and social psychopathy phenomenon, 'with emphasis being rather on examining this alterity/alteration as of the circularity/recurrence/repetition/repeatability ${ }^{10} \quad$ delineating existential-transitioning-oriterability-trace-of-narratives-as-dots_or_implicited_attendant-ontologicalcontiguity $^{67}$ ? educedexistentialising/contextualising/textualising_'intelligibility/epistemicity/reflexivity-contiguity$<$ imbued-notional cogency>' ${ }^{\prime}$-reification_or_intrinsic-reality-ontologicalcoherence_or_superseding-oneness-of-ontology $y^{41}$ as 'successive slanted-and-formulaicpostlogic-backtracking-<iterative-looping-'set-of-dereifying-hollow-narratives-and-acts’> with their corresponding ${ }^{12}$ conjoining-looping-set-of-narratives' perverted-meaningfulness and extrinsic-attribution with successive sets of interlocutors and as conjugated-postlogism 77 mentaldispositions equally assume a purposefulness of their own (that must be factored-in when 
analysing psychopathic/postlogic and social-psychopathic situations), in grasping the true nature of the fundamental psychopathic-postlogism -and-other-temporal-conjugated-postlogism mental-dispositions in 'dynamic-cumulative-aftereffect of subontologisation' (slantedness/postlogic-effect, miscuing, disjointed-logic, logical-drag, unconscionability-drag, sub-par/formulaic-association/temporal/alibi conventioning-rationalising, and temporalenculturation/temporal-endemisation-effect)', and so, as of aetiologisation/ontologicalescalation-<ontological-veridicality_commitment/otherliness_transcending/compulsionsencumbered_transcending $>$ in grasping the importance of social and formal institutionalisation percolation-channelling- $<$ in-deferential-formalisation-transference $>$ in the construing of institutionalised deconstruction/(engaged)-destruktion as psychoanalytic-unshackling/memeticreordering/institutional-recomposuring in the medium to long-run as with other ${ }^{74}$ perversion-ofreference-of-thought-<as-preconvergingly-apriorising/axiomatising/referencing-innonconviction/madeupness/bottomlining-as-to-shallow-supererogation $>$ in prior institutionalisations (for instance a scientific worldview over notions-and-accusations-of-sorcery in medieval times). The insight from an ontological-normalcy/postconvergence epistemic-ornotional projective-perspective with regards to ${ }^{74}$ perversion-of- ${ }^{8}$ reference-of-thought- $<$ aspreconvergingly-apriorising/axiomatising/referencing-innonconviction/madeupness/bottomlining-as-to-shallow-supererogation $>$ arises by the mere fact that the registry-worldview's/dimension's prior relative-ontological-incompleteness ${ }^{8}$ induced,-'threshold-of-nonconviction/madeupness/bottomlining-in-shallow-supererogation <as-to-'attendant-intradimensional'-prospectively-

disontologising preconverging/dementing -apriorising-psychologism>’, as-it-is-thus-'in-

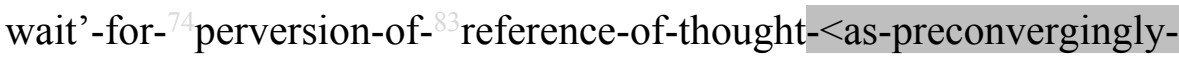
apriorising/axiomatising/referencing-in-nonconviction/madeupness/bottomlining-as-toshallow-supererogation >,-or-temporal-preservation-as-pseudointemporality ${ }^{52}$-preservation, 
upon instigation of postlogism -as-of- compulsing-nonconviction/madeupness/bottomlining$〈<<$ decontextualising/de-existentialising of-attendant-intradimensionalapriorising/axiomatising/referencing>-induced-disontologising'-of-the-'attendantintradimensional-ontologising'-imbued-<contextualising/existentialising attendantontological-contiguity $>$;-in-shallow-supererogation -<as-to-disontologising-pervertedoutcome-sought-precedes-existentially-veridical-'attendant-intradimensionalapriorising/axiomatising/referencing'-logical-dueness $>>$ by conjugating to temporaldispositions inducing 'registry-worldview's/dimension's-uninstitutionalised-threshold ${ }^{102}$ defect- $<$ as-Being-or-ontological-or-existential-defect $>^{55}$ or intradimensional' as of the circularity/recurrence/repetition/repeatability ${ }^{10}$ delineating existential-transitioning-oriterability-trace-of-narratives-as-dots_or_implicited_attendant-ontologicalcontiguity $^{67}$; educedexistentialising/contextualising/textmalising_'intelligibility/epistemicity/reflexivity_contiguity$<$ imbued-notional cogency>' $>^{\prime}$-reification_or_intrinsic-reality-ontologicalcoherence_or_superseding-oneness-of-ontology ${ }^{41}$. This is the abstract foundation that defines registry-worldviews/dimensions uninstitutionalised-threshold ${ }^{102}$, and so, as fundamentally imbued in human-subpotency-aporia/undecidability/dilemma/oughtindeterminacy/deficiency/limitation/constraint—imbued-'notional firstnaturednessformativeness-<as-to-eventualising-inkling-drive-or-seeding-misprising $>$ temporal-tointemporal-dispositions- $<$ so-construed-as-from-perspective-ontologicalnormalcy/postconvergence>'-existentialism-form-factor which is preconverging/postconverging-de-mentatively/structurally/paradigmatically susceptible to relative-ontological-incompleteness ${ }^{8}$-induced,-'threshold-ofnonconviction/madeupness/bottomlining-in-shallow-supererogation $<<$ as-to- 'attendantintradimensional'-prospectively-disontologising preconverging/dementing -apriorising- 


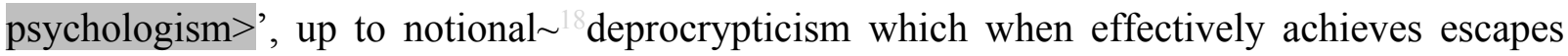
uninstitutionalised-threshold ${ }^{102}$ by the mere fact that notional ${ }^{18}$ deprocrypticism psychologism is one that factors in in its $\left\{\right.$ cumulated/recomposured \}-consciousness-awareness-teleology ${ }^{9}$ the reality of human-subpotency-aporia/undecidability/dilemma/oughtindeterminacy/deficiency/limitation/constraint—imbued-'notional firstnaturednessformativeness-<as-to-eventualising-inkling-drive or seeding-misprising $>$ temporal-tointemporal-dispositions-<so-construed-as-from-perspective-ontologicalnormalcy/postconvergence>'-existentialism-form-factor. Thus issues of ${ }^{74}$ perversion-ofreference-of-thought-<as-preconvergingly-apriorising/axiomatising/referencing-innonconviction/madeupness/bottomlining-as-to-shallow-supererogation $>\quad$ including postlogism 77 are more-than-just-and-beyond an issue of a temporal frame of contemplation as this requires an overall registry-worldview/dimension transcendental preconverging/postconverging-de-mentative/structural/paradigmatic resolution, as of the comprehensive ontologising of notional deprocrypticism with respect to notional procrypticism, notwithstanding the further palliative conceptualisation of the necessity of the resolution as of temporal <preconverging 'motif-andapriorising/axiomatising/referencing'-entailing>-existentialising—enframing/imprintedness〈as-to- historicity-tracing - in-presencing-hyperrealisation/hyperreal-transposition〉 of issues of psychopathy in the present positivistic registry-worldview. Thus psychopathy and social psychopathy should rather be related to suprastructurally (as preconverging-or-dementing 20 apriorising-psychologism consciousness-awareness-teleology ${ }^{9}$ which ${ }^{83}$ reference-of-thought is invalid in the very first instance, going by ontological-normalcy/postconvergence epistemic-ornotional projective-perspective for intemporal-preservation-entropy-or-contiguity-orontological-preservation). The nature of ${ }^{74}$ perversion-of- ${ }^{8}$ reference-of-thought- $<$ aspreconvergingly-apriorising/axiomatising/referencing-in- 
is very much in line with human-subpotency-aporia/undecidability/dilemma/oughtindeterminacy/deficiency/limitation/constraint—imbued-'notional firstnaturednessformativeness-<as-to-eventualising-inkling drive-or-seeding-misprising $>$ temporal-tointemporal-dispositions- $<$ so-construed-as-from-perspective-ontologicalnormalcy/postconvergence>'-existentialism-form-factor which represents that any transcendence-and-sublimity/sublimation/supererogatory - de-mentativity is a secondnatured institutionalisation/intemporalisation exercise of untenability/internal-contradiction/internalincoherence/institutional-constraining on human-subpotencyaporia/undecidability/dilemma/ought-indeterminacy/deficiency/limitation/constraint—imbued'notional firstnaturedness-formativeness-<as-to-eventualising -inkling-drive-or-seedingmisprising $>$ temporal-to-intemporal-dispositions- $<$ so-construed-as-from-perspectiveontological-normalcy/postconvergence>'-existentialism-form-factor mental-dispositions 'induced by social ${ }^{103}$ universal-transparency ${ }^{104}$-〈transparency-of-totalising-entailing,-as-toentailing-<amplituding/formative-epistemicity $>$ totalising $\sim$ in-relative-ontological-

completeness > of the prior registry-worldview's/dimension's unsound ${ }^{83}$ reference-of-thought of meaningfulness with respect to that of the prospective registry-worldview's/dimension's and the positive-opportunism-of-social-functioning-and-accordance ${ }^{75}$ thereof', and thus undermining human temporal-preservation-as-pseudointemporality ${ }^{52}$-preservation behind the uninstitutionalised-threshold ${ }^{102}$ and institutionalisation/intemporalisation secondnaturing; and not as may wrongly be construed as an emanance transformation exercise from temporaldispositions as shortness-of-register-of- ${ }^{-5}$ meaningfulness-and-teleology ${ }^{9}$ to intemporaldisposition as longness-of-register-of-meaningfulness. This latter point is to highlight that ontological focus should rather be placed on the 'abstract conceptualisation that enables institutionalisation-as-virtue and not any naïve purported ${ }^{79}$ presencing — absolutising-identitive- 
constitutedness $^{14}$ poorly appreciative of dimensionality-of-sublimating ${ }^{5}$ <<amplituding/formative>supererogatory $\sim$ de-mentativeness/epistemic-growth-or-

conflatedness /transvaluative-rationalising/transepistemicity/anamnestic-residuality/spirit-

drivenness-equalisation), as in-the-bigger-scheme-of-things the latter is delusional (for an animal whose potency under social-stake-contention-or-confliction is rather as of humansubpotency-aporia/undecidability/dilemma/ought-

indeterminacy/deficiency/limitation/constraint—imbued-'notional firstnaturedness-

formativeness-<as-to-eventualising-inkling-drive-or-seeding-misprising $>$ temporal-tointemporal-dispositions- $<$ so-construed-as-from-perspective-ontologicalnormalcy/postconvergence>'-existentialism-form-factor thus needing its secondnatured skewing ('intemporality ${ }^{52}$-symmetrising-by-desymmetrising-subsumption-of-temporality ${ }^{8}$ ', for relative intrinsic-reality/ontological-veridicality transcendentalenabling/sublimating/supererogatory de-mentativity as deferential-formalisation-transference to the intemporal for its transcendence-and-sublimity/sublimation/supererogatory $\sim$ dementativity) and that's why society and more specifically formal organisations 'operate on the clairvoyance of institutionalising principles and rules', and 'not the purported impressiondriven/good-naturedness dispositions of the one or the other', as this is an unsustainable construct and is simply a call for institutional failure in the middle to long run. A human secondnaturing institutionalising construct is a requisite because, at best even the intemporaldisposition individuation in individuals purporting prospective emancipation comes from and are from the stock of the prior ${ }^{83}$ reference-of-thought uninstitutionalised-threshold ${ }^{102}$ registryworldview/dimension, and such prospective emancipation involves such individuals own 'moulting', as actually intemporality ${ }^{52 / 10 n g n e s s ~ i s ~ a ~ ' p o t e n t i a l ~ c o n s t r u c t ~ o f ~ o r i e n t a t i o n ' ~ a s ~}$ implied by ontological-normalcy/postconvergence (prospective-transcendence-in-perpetuallyupholding-intemporal-preservation-entropy-or-contiguity-or-ontological-preservation) and it is 
only a devised institutionalisation construct as secondnaturing that achieves that potentialconstruct-of-orientation and not any naïve inherently intemporal-disposition in individuals. By that token there is no base-institutionalised individual in recurrent-utter-uninstitutionalisation, no ${ }^{103}$ universalised individual in ununiversalisation, no positivistic individual in nonpositivism/medievalism, and prospectively no notional ${ }^{1}$ deprocrypticism individual in procrypticism, as at best such emancipating intemporal individuals are 'moulting' their intemporal individuations and implying-of-the-same of their registry-worldview in prospective institutionalisation design/conceptualisation, as the effective institutionalisation is what is really and effectively attained. - As the notion of 'dynamic-cumulative-aftereffect of ontology and subontologisation/subpotentiation (slantedness/postlogic-effect, miscuing, disjointed-logic, logical-drag, unconscionability-drag, sub-par/formulaic-association/temporal/alibi conventioning-rationalising, and temporal-enculturation/temporal-endemisation-effect), is rather an operant conceptualisation that highlights the need for an operant conceptualisation of psychology in grasping human dynamics. But then psychological science as we know today inmany-ways mainly takes the form of an adjunct construct in grasping the social as is equally the case with social psychology; as the focus of can mostly be resumed to 'identity' of individual dispositions such that psychology tends more to have a subjective intercessory practice nature involving intersubjective valuation). Thus, as with all such approaches it is hardly surprising that we haven't got an academic 'postconverging-or-dialectical-thinking -psychology or psychology-of-mentation-dynamics or natural $\sim$ psychological-dynamics' (as an ontology-driven $<$ amplituding/formative-epistemicity $>$ totalising $\sim$ ratiocontiguity/ratiocination-asreferentialism — 'implicited_attendant_ontological-contiguity ${ }^{67}$ ' educed-

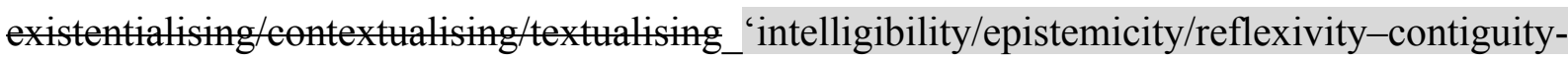
$<$ imbued-notional cogency>' ;-phenomenal-abstractiveness-of-presencing-in-'protensiveconsciousness'-enabling- 
apriorising/axiomatising/referencing/intelligibilitysettingup/measuringinstrumenting-foroperant-or-incidenting-predicative-insights-of 'implicited_attendant_ontologicalcontiguity $^{67}$, educedexistentialising/contextualising/textualising_'intelligibility/epistemicity/reflexivity-contiguity$<$ imbued-notional cogency $>,{ }^{\prime},-<$ reifying-or-elucidating-of-prospective-relative-ontologicalcompleteness -of- reference-of-thought- devolving-as-of-instantiative-context $>$ conceptualisation); but rather a 'psychology of qualifications' as is equally the case with social psychology. The author as previously implied with the notion of a 'postconverging-ordialectical-thinking -psychology or psychology-of-mentation-dynamics or natural psychological-dynamics' perceives the need for defining human psychology from a transcendentally-enabling-level-of $\sim$ ontological-good-faith-or-

authenticity $\%$ objectification/desubjectification-as-objectification-<as-to-ontological-faithnotion-or-ontological-fideism - imbued-underdetermination-of-motif-andapriorising/axiomatising/referencing-as-so-being-as-of-existential-reality as antinihilism> and thus operant perspective of ontologically-dynamic-and-coherent construal/conceptualisation, as a profound superseding-oneness-of-ontology. This is implied in ontological-normalcy/postconvergence, and should be more precisely invigorated in the construal/conceptualisation of the " ${ }^{83}$ reference-of-thought as futural Beingdevelopment/ontological-framework-expansion-as-to-depth-of-ontologising-development-asinfrastructure-of- meaningfulness-and-teleology as of prospective notional ${ }^{18}$ deprocrypticism registry-worldview/dimension as metaphysics-of-absence〈implicited-epistemic-veracity-of- nonpresencing-<perspective-ontologicalnormalcy/postconvergence $>>$ of the positivism/procrypticism reference-of-thought metaphysics-of-presence-〈implicited-'nondescript/ignorable-void '-as-to- presencingabsolutising-identitive-constitutedness \'; implying an ontologically-driven conceptualisation 
of 'postconverging-or-dialectical-thinking -psychology or psychology-of-mentation-dynamics or natural psychological-dynamics’ as the prospective psychoanalysis, implying the epistemicabnormalcy/preconvergence ${ }^{3 !}$ perspective (preconverging-or-dementing ${ }^{20}$-apriorisingpsychologism ${ }^{83}$ reference-of-thought) of the prior positivism/procrypticism with respect to ontological-normalcy/postconvergence perspective of futural Being-development/ontologicalframework-expansion-as-to-depth-of-ontologising-development-as-infrastructure-ofmeaningfulness-and-teleology as of prospective notional ${ }^{\text {deprocrypticism }}$ ('postconverging-or-dialectical-thinking -apriorising-psychologism' ${ }^{83}$ reference-of-thought). With ontology-driven implying that our placeholder-setup/mental-devisingrepresentation/mentation/consciousness-awareness-teleology ${ }^{9}$ is just a 'placeholder-setup' that doesn't has any inherent ontological validity, but is rather as valid as its representation/schedule of ontology/ontologically-veridical-meaningfulness/intemporality ${ }^{52}$, such that with the insight of more profound ontology/ontologically-veridical-meaningfulness/intemporality ${ }^{52}$, the 'placeholder-setup' as placeholder-setup/mental-devisingrepresentation/mentation/consciousness-awareness-teleology ${ }^{9}$ is accordingly rescheduled psychoanalytically ('postconverging-or-dialectical-thinking -psychology or psychology-ofmentation-dynamics or natural psychological-dynamics' psychoanalytic-unshackling/memeticreordering/institutional-recomposuring), validating and explaining why our placeholdersetup/mental-devising-representation/mentation/consciousness-awareness-teleology ${ }^{99}$ has been developing all along from the mindset/ ${ }^{3}$ reference-of-thought of a recurrent-utterinstitutionalised, base-institutionalised, ${ }^{103}$ universalised and positivised, with the implication that the latter's mindset $/{ }^{8}$ reference-of-thought is not beyond prospective transcendence-and-

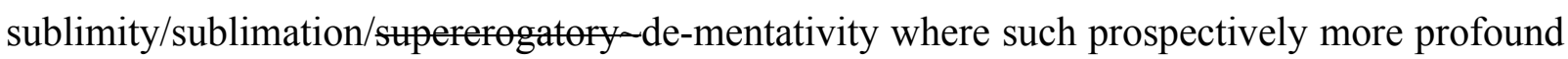
ontology is demonstrated to imply a renewal of human ${ }^{83}$ reference-of-thought of meaningfulness (as deprocrypticism), and with the further implication that all along it is essentially about a same 
species of a same underlying human-subpotency-aporia/undecidability/dilemma/oughtindeterminacy/deficiency/limitation/constraint—imbued-'notional firstnaturedness-

formativeness-<as-to-eventualising-inkling drive-or-seeding-misprising $>$ temporal-tointemporal-dispositions- $<$ so-construed-as-from-perspective-ontological-

normalcy/postconvergence>'-existentialism-form-factor induced dynamism of shallow limitedmentation-capacity as-subjecting-'educed-unlimitedness/existence-sublimating nascence'to-limitedness/human-subpotency-〈as of relative apriorising/axiomatising/referencing-\{of'prospectively_implicited_attendant_ontological-contiguity ' educedexistentialising/contextualising/textualising_'intelligibility/epistemicity/reflexivity-contiguity<imbued-notional cogency> $\quad\}$-constitutedness ${ }^{1}$-in preconverging-entailment $\rangle$ to deeper limited-mentation-capacity—as-subjecting 'educed-unlimitedness/existence-sublimating nascence' to-limitedness/human-subpotency-〈as of relative apriorising/axiomatising/referencing-\{of-'prospectively implicited_attendant-ontologicalcontiguity ' $\sim$ educedexistentialising/entextrising/textrising_intelligibility/epistemicity/reflexivity-contiguity<imbued-notional cogency $\left.>^{\prime}\right\}$-conflatedness ${ }^{13}$-in-\{preconverging-disentailment by\} postconverging-entailment $\rangle$. In fact, psychoanalysis is actually a natural existential<disontelogising/re-ontelogising aporeticism $>$ human placeholder-setup/mental-devisingrepresentation/mentation/consciousness-awareness-teleology ${ }^{9}$ process with the difference that such comprehensively conceptually-directed constructs as is implied with notional ${ }^{18}$ deprocrypticism with respect to the present positivism/procrypticism are relatively more focussed and thus potent where 'ontologically-pertinent and so-demonstrated to be ontologically-pertinent'; and by-and-large form part-and-parcel of the human psychoanalytic experience with regards to passive to conceptually-directed constructs of human teleological projection. Transcendence-and-sublimity/sublimation/supererogatory $\sim$ de-mentativity 
(prospective) as a placeholder-setup/mental-devising-representation/mentation/consciousnessawareness-teleology ${ }^{9}$ effectuation, is not technically achieved as may naively/counterintuitively be implied by construing directly of a prospective placeholder-setup/mental-devisingrepresentation/mentation/consciousness-awareness-teleology ${ }^{9}$ (from the present) but rather, on the basis of 'prospective ${ }^{83}$ reference-of-thought transcendental insights', it correspondingly implies 'construing the present as metaphysics-of-present as the transcended/superseded/prior placeholder-setup/mental-devising-representation/mentation' to be represented as 'preconverging-or-dementing ${ }^{20}$-apriorising-psychologism ${ }^{83}$ reference-of-thought', and so implied by the 'prospective ${ }^{83}$ reference-of-thought transcendental insights', such that the prospective (transcending/superseding) placeholder-setup/mental-devisingrepresentation/mentation/consciousness-awareness-teleology' defect as 'postconverging-ordialectical-thinking -apriorising-psychologism ${ }^{8}$ reference-of-thought' is naturally implied as being the new and prospective suprastructuring, (beyond-the-consciousness-awarenessteleology ${ }^{9}<$ of-preconverging-existential-extrication-as-of-existential-unthought> ) of the 'old present'/retrospective as prior. That is it is critical to grasp that de-mentation〈supererogatory $\sim$ ontological-de-mentation-or-dialectical-de-mentation-stranding-or-

attributive-dialectics〉 of 'postconverging-or-dialectical-thinking -apriorising-psychologism' and preconverging-or-dementing -apriorising-psychologism is never about generating a prospective 'postconverging-or-dialectical-thinking -apriorising-psychologism' (with respect to the present as 'postconverging-or-dialectical-thinking -apriorising-psychologism'), but such de-mentation-〈supererogatory ontological-de-mentation-or-dialectical-de-mentationstranding-or-attributive-dialectics $\rangle$ is rather about decentering and preconverging-ordementing -apriorising-psychologism/oblongating the placeholder-setup/mental-devisingrepresentation/mentation/consciousness-awareness-teleology ${ }^{99}$ of the present as preconvergingor-dementing ${ }^{20}$-apriorising-psychologism which becomes 'old-present'/retrospective as prior' 
and dialectically ushering contrastively from that backdrop a new and prospective 'postconverging-or-dialectical-thinking -apriorising-psychologism'. This is actually about maximalising-recomposuring-for-relative-ontological-completeness ${ }^{87}$ - unenframed/re-

ontologising conceptualisation of the implied prospective meaningful-reference/anchoring-ofmeaning/ontological-reference/contending-reference, rather than attempting its elaboration-asto-mere-extrapolating/constituting/abstracting/deducing/inferring-of-elucidation-outside'prospectively_implicited_attendant-ontological-contiguity ${ }^{67}$ ' educedexistentialising/contextualising/textualising_'intelligibility/epistemicity/reflexivity-contiguity$<$ imbued-notional cogency>' which will 'wrongly make reference to and wrongly elevate', and so by mix-up, the prior ${ }^{8}$ reference-of-thought as veridical. ${ }^{55}$ maximalising-recomposuringfor-relative-ontological-completeness ${ }^{87}$ — unenframed/re-ontologising $\sim$ conceptualisation being about optimally rescheduling the 'placeholder-setup' (as placeholder-setup/mental-devisingrepresentation/mentation) with regards to ontologically-veridical-meaningfulness, on the ontological backdrop of a more profound superseding-oneness-of-ontology construal/conceptualisation of 'implicited_attendant-ontological-contiguity ${ }^{67}$ ' educedexistentialising/contextualising/textualising_'intelligibility/epistemicity/reflexivity-contiguity$<$ imbued-notional $\sim$ cogency $>,{ }^{\prime},-<$ reifying-or-elucidating-of-prospective-relative-ontologicalcompleteness -of- reference-of-thought- devolving-as-of-instantiative-context>. This involves a pointedness-of-prospective ${ }^{83}$ reference-of-thought which ${ }^{55}$ maximalisingrecomposuring-for-relative-ontological-completeness ${ }^{8}$ —unenframed/reontologising conceptualisation then 'upholds in contiguity' the 'trace of disambiguated-mentaldispositions-and-meaningfulness implied by intemporal/conviction-as-to-profoundsupererogation mental-dispositions, postlogism 7 /psychopathic mental-dispositions and conjugated-postlogism 77 preconverging-or-dementing -integration mental-dispositions' as ${ }^{3}$ universal and aetiological <amplituding/formative-epistemicity $>$ causality $\sim$ as-to-projective- 
totalitative-implications-of-prospective- nonpresencing,-for-explicating relative-

unreflexivity/relative-reflexivity ontological-contiguity construct, (while equally reflecting the flaws induced in misrepresenting ontological-references arising from elaborative elucidation), on the backdrop of a more profound superseding-oneness-of-ontology construal/conceptualisation. As ${ }^{55}$ maximalising-recomposuring-for-relative-ontologicalcompleteness $^{87}$ — unenframed/re-ontologising conceptualisation achieves this by not letting non-veridical/vacuous hollow-constituting-<as-disjointed-misappropriation-of-meaningfulnessand-failing-intemporal-preservation $>{ }^{83}$ reference-of-thought by postlogism 77 psychopathic and conjugated-postlogism 7 /preconverging-or-dementing 20 -integration mental-dispositions wrongly being implied as sound reflection of existentialist/'ontologically-reconstituting' reference-of-thought and thus wrongly implying their ontological-veridicality, and equally avoiding their perversion-of-representation of supplanting-conviction-as-to-profoundsupererogation - of-'attendant-intradimensional'-postconverging/dialectical-thinking apriorising-psychologism as to intemporal mental-dispositions by the "mere ontologicaldecontextualising' (of the latter rightfully existentially-veridical ${ }^{83}$ reference-of-thought) implied in their non-veridical/vacuous hollow-constituting-<as-disjointed-misappropriation-ofmeaningfulness-and-failing-intemporal-preservation $>{ }^{8}$ reference-of-thought; such that a placeholder-setup/mental-devising-representation/mentation/consciousness-awarenessteleology defect as preconverging-or-dementing ${ }^{20}$-apriorising-psychologism by mere nonveridical/vacuous hollow-constituting-<as-disjointed-misappropriation-of-meaningfulness-andfailing-intemporal-preservation $>$ (of ${ }^{8}$ reference-of-thought) is what restores the ontologicallyveridical 'existentialist reality' ${ }^{83}$ reference-of-thought. Thus unlike elaboration-as-to-mereextrapolating/constituting/abstracting/deducing/inferring-of-elucidation-outside'prospectively_implicited_attendant_ontological-contiguity ${ }^{67}$ ' educedexistentialising/contextualising/textualising_intelligibility/epistemicity/reflexivity-contiguity- 
<imbued-notional cogency>' what ${ }^{55}$ maximalising-recomposuring-for-relative-ontologicalcompleteness $^{87}$ - unenframed/re-ontologising conceptualisation enables is to uphold in contiguity ontological-reality as of the circularity/recurrence/repetition/repeatability delineating existential-transitioning-or-iterability-trace-of-narratives-asdots_or_implicited_attendant-ontological-contiguity ${ }^{67}$, educed-

existentialising/contextualising/textualising_intelligibility/epistemicity/reflexivity-contiguity$<$ imbued-notional cogency>' ${ }^{\prime}$-reification_or_intrinsic-reality-ontological-

coherence_or_superseding-oneness-of-ontology ${ }^{41}$ in other to reflect that the ${ }^{67}$ perversion-ofreference-of-thought-<as-preconvergingly-apriorising/axiomatising/referencing-innonconviction/madeupness/bottomlining-as-to-shallow-supererogation $>$ phenomena' is as of the circularity/recurrence/repetition/repeatability delineating existential-transitioning-oriterability-trace-of-narratives-as-dots_or_implicited_attendant-ontologicalcontiguity $^{67}$ ? educedexistentialising/contextmalising/textualising_intelligibility/epistemicity/reflexivity-contiguity$<$ imbued-notional $\sim$ cogency $>$ 'reification_or_intrinsic-reality-ontologicalcoherence_or_superseding-oneness-of-ontology ${ }^{41}$ reflecting/perspectivating registryworldview's/dimension's-uninstitutionalised-threshold ${ }^{102}$-defect-<as-Being-or-ontological-orexistential-defect $>55$ even though it is iterating-by-alterations, whereas elaboration-as-to-mereextrapolating/constituting/abstracting/deducing/inferring-of-elucidation-outside'prospectively_implicited_attendant_ontological-contiguity ${ }^{67}$ ' educedexistentialising/contextualising/textualising_'intelligibility/epistemicity/reflexivity-contiguity$<$ imbued-notional cogency>' will erroneously lead to a reassessment of ${ }^{74}$ perversion-ofreference-of-thought-<as-preconvergingly-apriorising/axiomatising/referencing-innonconviction/madeupness/bottomlining-as-to-shallow-supererogation $>$ as defect-oflogical-processing-or-logical-implicitation-supposedly-apriorising-in-conviction-as-to- 
profound-supererogation of the registry-worldview's/dimension's- ${ }^{83}$ reference-of-thought-forsocial-functioning-and-accordance by wrongly implying that it is an issue of defect-of- ${ }^{5}$ logicalprocessing-or-logical-implicitation-supposedly-apriorising-in-conviction-as-to-profound-

supererogation of the registry-worldview's/dimension's- ${ }^{83}$ reference-of-thought-for-socialfunctioning-and-accordance whereas it is an issue of perversion-of- $^{-3}$ reference-of-thought- $<$ aspreconvergingly-apriorising/axiomatising/referencing-in-

nonconviction/madeupness/bottomlining-as-to-shallow-supererogation $>$, and thus not upholding intemporality ${ }^{5} /$ longness in the contiguity as of the circularity/recurrence/repetition/repeatability ${ }^{10}$ delineating existential-transitioning-oriterability-trace-of-narratives-as-dots_or_implicited_attendant-ontological-

contiguity $^{67}$; educed-

existentialising/contextualising/textualising_'intelligibility/epistemicity/reflexivity_contiguity-

$<$ imbued-notional cogency>' ${ }^{\prime}$-reification_or_intrinsic-reality-ontological-

coherence_or_superseding-oneness-of-ontology 41 and reflected/perspectivated as preconverging-de-mentating/structuring/paradigming registry-worldview's/dimension'suninstitutionalised-threshold ${ }^{102}$-defect-<as-Being-or-ontological-or-existential-defect $>55$ or intradimensional defect'. Basically, ${ }^{55}$ maximalising-recomposuring-for-relative-ontologicalcompleteness ${ }^{87}$ - unenframed/re-ontologising conceptualisation creatively puts into perspective temporality 8 /shortness in non-veridical/vacuous hollow-constituting-<as-disjointedmisappropriation-of-meaningfulness-and-failing-intemporal-preservation> terms as 'shallow superseding-oneness-of-ontology construal/conceptualisation', and longness-of-register-ofmeaningfulness-and-teleology ${ }^{9}$ in existentialist/'ontologically-reconstituting' terms as 'deeper superseding-oneness-of-ontology construal/conceptualisation' veering towards transcendence-and-sublimity/sublimation/supererogatory-de-mentativity. That is, by transcendence-and-sublimity/sublimation/supereregatory-de-mentativity is meant dispose to 
construe the ontological resolution of registry-worldview's/dimension's-uninstitutionalisedthreshold ${ }^{102}$-defect-<as-Being-or-ontological-or-existential-defect $>$

transcendentally/transdimensionally/interdimensionally, as needing a prospective registryworldview/dimension; for instance, capable of putting in question medieval intradimensional superstition in the first place supersedingly/transcendentally by implying the need for positivising rather than a usual temporalities-drives reciprocity of superstitious contentions or capable of putting-into-question positivism- ${ }^{8}$ procrypticism postlogism 7 -and-conjugatedpostlogism 77 in the first place supersedingly/transcendentally by implying the need for notional ${ }^{18}$ deprocrypticism rather than temporalities-drives reciprocal equivalence of procrypticism-or-disjointedness-as-of- ${ }^{83}$ reference-of-thought. Further the notion of deeper superseding-oneness-of-ontology conceptualisation and shallow superseding-oneness-ofontology conceptualisation, central to a ${ }^{5}$ maximalising-recomposuring-for-relative-ontologicalcompleteness ${ }^{87}$ - unenframed/re-ontologising conceptualisation, can be demonstrated as follows: supposed A has the (existentially-<disontologising/re-ontologisingaporeticism $>$ veridical) mental projection with respect to say a housing project and undertook the initiative of bringing together and obtaining advanced payments from prospective buyers for the project, and $\mathrm{B}$ was to by non-veridical/vacuous hollow-constituting-<as-disjointedmisappropriation-of-meaningfulness-and-failing-intemporal-preservation $>$ mental-disposition spread stories of the scheme being a scam (not to the buyers who have all the documentations validating the genuineness of A's housing project) but rather other interlocutors mainly to undermine A's business credibility, and so whether B is pathological/psychopathic or postlogicly-enculturated, and supposed some other interlocutors, not only by ignorance but affordability/opportunism/exacerbation/social-chainism-or-social-discomfiture-or-negativesocial-aggregation/temporal-enculturation-or-temporal-endemisation further engaged in such vilifying (as social ${ }^{103}$ universal-transparency ${ }^{104}$-〈transparency-of-totalising-entailing,-as-to- 
entailing-<amplituding/formative-epistemicity $>$ totalising $\sim$ in-relative-ontological-

completeness $>$ of their mental denaturing disposition is socially opaque); engaging meaningfulness at a same ${ }^{83}$ reference-of-thought will wrongly imply that there is an issue of ${ }^{\text {‘ }}$ logical-processing-or-logical-implicitation—supposedly-apriorising-in-conviction-as-toprofound-supererogation ' at hand rather than in veridicality one of ${ }^{7 /}$ perversion-of- ${ }^{8}$ referenceof-thought-<as-preconvergingly-apriorising/axiomatising/referencing-in-

nonconviction/madeupness/bottomlining-as-to-shallow-supererogation $>$, requiring instead a maximalising-recomposuring-for-relative-ontological-completeness ${ }^{87}$ - unenframed/reontologising conceptualisation that is 'postconverging-or-dialectical-thinking ${ }^{21}$-apriorisingpsychologism' from the 'deeper superseding-oneness-of-ontology construal/conceptualisation' as existentialist/'ontologically-reconstituting' of $\mathrm{A}$ as intemporally-preservational, (in a pointedness of notional ${ }^{8}$ deprocrypticism prospective ${ }^{83}$ reference-of-thought which maximalising-recomposuring-for-relative-ontological-completeness ${ }^{87}$ - unenframed/reontologising conceptualisation then 'upholds in contiguity' the 'trace of disambiguated-mentaldispositions-and-meaningfulness implied by intemporal/conviction-as-to-profoundsupererogation deprocryptic mental-dispositions, postlogism 77 psychopathic procryptic mental-dispositions and conjugated-postlogism 77 preconverging-or-dementing ${ }^{20}$-integration procryptic mental-dispositions' as ${ }^{103}$ universal and aetiological <amplituding/formativeepistemicity $>$ causality $\sim$ as-to-projective-totalitative-implications-of-prospectivenonpresencing,-for-explicating relative- unreflexivity/relative-reflexivity - ontologicalcontiguity construct), and reflecting in transversality-<for-sublimating-existentialeventuating/denouement, from 'thinking at first/pure predisposition preemptive of prospective-disontologising/subontologising’ as-of-prospectively-disambiguated-affirmedand-unaffirmed-'motif-and-apriorising/axiomatising/referencing'>101 as both B's postlogism

'7 perversion-of- reference-of-thought-<as-preconvergingly- 
apriorising/axiomatising/referencing-in-nonconviction/madeupness/bottomlining-as-to-

shallow-supererogation $>$ as ${ }^{80}$ procrypticism-or-disjointedness-as-of- ${ }^{8}$ reference-of-thought mental-perversion/unsoundness-or-ontological-bad-faith/inauthenticity ${ }^{64}$-of- ${ }^{8}$ reference-ofthought disposition' ontological/being-construal-defect together with B's interlocutors' conjugated-postlogism 77 preconverging-or-dementing 2 -integration $\quad$ '77 perversion-ofreference-of-thought-<as-preconvergingly-apriorising/axiomatising/referencing-innonconviction/madeupness/bottomlining-as-to-shallow-supererogation $>$ as ${ }^{80}$ procrypticismor-disjointedness-as-of- ${ }^{8}$ reference-of-thought mental-perversion/unsoundness-or-ontologicalbad-faith/inauthenticity ${ }^{64}$-of- ${ }^{83}$ reference-of-thought dispositions' ontological/being-construaldefects (as temporally-preservational-as-pseudointemporality ${ }^{52}$-preservation); and so, going by the ontological-normalcy/postconvergence nature of intrinsic-reality/ontology that precedes, is utter and doesn't increment with human placeholder-setup/mental-devisingrepresentation/mentation, and further so in 'intellectual-and-moral in-equivalence', not only as an incidental/on-occasion ontological/being-construal-defect' phenomenon but a potent intradimension construal/conceptualisation of the basis of vices-and-impediments ${ }^{105}$ in 'metaphorically-a-million-and-one-instances-and-locales as to aetiologisation/ontologicalescalation-<ontological-veridicality_commitment/otherliness_transcending/compulsionsencumbered_transcending >'. That is, just as from a positivistic perspective (as metaphysics-ofabsence-〈implicited-epistemic-veracity-of- nonpresencing-<perspective-ontologicalnormalcy/postconvergence $>$ ), an incidental/on-occasion phenomenon of notions-andaccusations-of-sorcery in a medieval setup (as metaphysics) intemporally/ontologically elicits a conceptualisation of how such ' perversion-of- ${ }^{7}$ reference-of-thought-<as-preconverginglyapriorising/axiomatising/referencing-in-nonconviction/madeupness/bottomlining-as-toshallow-supererogation $>\quad$ as $\quad$ mental-perversion/unsoundness-or-ontological-badfaith/inauthenticity ${ }^{64}$-of- ${ }^{8}$ reference-of-thought dispositions' of ontological/being-construal- 
defects define human vices-and-impediments ${ }^{105}$ in medieval setups, that's the same elicitation going by human-subpotency-aporia/undecidability/dilemma/oughtindeterminacy/deficiency/limitation/constraint—imbued-'notional firstnaturednessformativeness-<as-to-eventualising-inkling drive-or-seeding-misprising $>$ temporal-tointemporal-dispositions- $<$ so-construed-as-from-perspective-ontologicalnormalcy/postconvergence>'-existentialism-form-factor which is intemporally/ontologically prompted with an on-occasion/incidental manifestation of postlogism 77 and conjugatedpostlogism 7 /preconverging-or-dementing ${ }^{20}$-integration ontological/being-construal-defects in our positivistic/procrypticism registry-worldview from futural Being-development/ontologicalframework-expansion-as-to-depth-of-ontologising-development-as-infrastructure-ofmeaningfulness-and-teleology as of prospective notional deprocrypticism registryworldview ontological point-of-reference (as the deeper superseding-oneness-of-ontology construal/conceptualisation, rather of a transcendental/utter nature in line with intrinsicreality/ontology, and not incremental). A rule of thumb with ${ }^{55}$ maximalising-recomposuring-forrelative-ontological-completeness ${ }^{8}$ - unenframed/re-ontologising conceptualisation will be to void the wrongly implied existentialist-as-ontologically-veridical-meaningfulness by perceiving the reference-of-thought of postlogic/psychopathic and conjugatedpostlogism 7 preconverging-or-dementing ${ }^{20}$-integration mental-dispositions as purely nonveridical/vacuous hollow-constituting-<as-disjointed-misappropriation-of-meaningfulness-andfailing-intemporal-preservation>. Effectively, reality/existence/being as becoming is actually an 'unwinding elucidation' model construct. However, since meaningfulness involves an interceding placeholder-setup/mental-devising-representation/mentation/consciousnessawareness-teleology ${ }^{9}$ as ${ }^{83}$ reference-of-thought in relation to intrinsic-reality/ontology and given our limited-mentation-capacity-deepening as-subjecting limitedness/humansubpotency-to-'educed-unlimitedness/existence-sublimating nascence' ${ }^{3}$, there thus tend to 
develop a mix-up of our representation (with unsound/vacuous/denaturing hollowconstituting-<as-disjointed-misappropriation-of-meaningfulness-and-failing-intemporal-

preservation> of ${ }^{83}$ reference-of-thought- ${ }^{-}$ategorical-imperatives/axioms/registry-teleology ${ }^{9}$ ) when reflecting/perspectivating ontologically-veridical existential-<disontologising/reentologising aporeticism $>$ reality, such that there is a rule of recurrence in existentialtransitioning-or-iterability-trace-of-narratives-as-dots_or_implicited_attendant_ontologicalcontiguity $^{67}$, educed-

existentialising/contextualising/textualising_'intelligibility/epistemicity/reflexivity-contiguity$<$ imbued-notional cogency>' $>^{\prime}$-reification_or_intrinsic-reality-ontological-

coherence_or_superseding-oneness-of-ontology defined by the uninstitutionalisedthreshold ${ }^{102} \quad$ which arises preconverging/postconverging-dementatively/structurally/paradigmatically and accounts for vices-and-impediments ${ }^{105}$. This is more than just a question of acts-execution/logical-processing defects but registryworldview's/dimension's-uninstitutionalised-threshold ${ }^{02}$-defect-<as-Being-or-ontological-orexistential-defect $>$, ${ }^{5}$, that speaks of the registry-worldview's/dimension's inherent relativeontological-incompleteness ${ }^{8}$-induced,-'threshold-of-nonconviction/madeupness/bottomliningin-shallow-supererogation $-<$ as-to-'attendant-intradimensional'-prospectivelydisontologising preconverging/dementing -apriorising-psychologism>', as-it-is-thus- 'inwait'-for- ${ }^{7}$ perversion-of- ${ }^{8}$ reference-of-thought-<as-preconverginglyapriorising/axiomatising/referencing-in-nonconviction/madeupness/bottomlining-as-toshallow-supererogation >,-or-temporal-preservation-as-pseudointemporality ${ }^{52}$-preservation. That is at the basis of the <amplituding/formative-epistemicity $>$ totalising $\sim$ self-referencingsyncretising/circularity/interiorising/akrasiatic-drag ${ }^{34}$ nature of a registry-worldview/dimension vices-and-impediment. This is equally why epistemologically-speaking categorisation schemes tend to be incomplete and requiring further re-categorisations and readjustments as rather 
construed/conceptualised on an <amplituding/formative-epistemicity $>$ totalising $\sim$ selfreferencing-syncretising/circularity/interiorising/akrasiatic-drag ${ }^{34}$ basis of organisation that isn't in the full potency for grasping intrinsic reality and requiring further adjustments all along (the whole exercise actually being 'ad-hoc referentialism'), and why referentialism as previously articulated, though 'relatively abstract as a notion of representation' is a conceptualisation basis needing constant insights, it is actually a better conceptualisation scheme of prospective being/becoming notions particularly of an ephemeral nature. Just as we will represent the nonpositivism/medievalism placeholder-setup/mental-devisingrepresentation/mentation/consciousness-awareness-teleology allusions to superstition in its $<$ amplituding/formative--epistemicity $>$ totalising $\sim$ self-referencingsyncretising/circularity/interiorising/akrasiatic-drag ${ }^{34}$ as utterly preconverging-or-dementing ${ }^{20}$ apriorising-psychologism and unintelligible/existentially-suprastructural and being as of elaboration-as-to-mere-extrapolating/constituting/abstracting/deducing/inferring-ofelucidation-outside_- 'prospectively_implicited_attendant_ontological-contiguity ${ }^{67}$; educedexistentialising/contextualising/textualising_intelligibility/epistemicity/reflexivity-contiguity<imbued-notional cogency ${ }^{\prime}$ with it will wrongly imply the ontological-veridicality of its meaningfulness, a notional ${ }^{18}$ deprocrypticism placeholder-setup/mental-devisingrepresentation/mentation/consciousness-awareness-teleology 9 of a procrypticism mindset/ ${ }^{3}$ reference-of-thought will rather be utterly preconverging-or-dementing ${ }^{20}$-apriorisingpsychologism and unintelligible/existentially-suprastructural of 'our procrypticism terms of meaningfulness' and will equally avoiding elaboration-as-to-mereextrapolating/constituting/abstracting/deducing/inferring-of-elucidation-outside'prospectively implicited_attendant-ontological-contiguity ${ }^{67}$; educedexistentialising/contextualising/textualising_'intelligibility/epistemicity/reflexivity_contiguity<imbued-notional cogency>' recognition of the soundness of our procrypticism-or- 
disjointedness-as-of- ${ }^{3}$ reference-of-thought

unintemporalised/solipsistic/recomposuring/animality-thresholds-of-intemporal-preservationentropy-or-contiguity-or-ontological-preservation in other to effectively and adequately reflect the requisite metaphysics-of-absence-〈implicited-epistemic-veracity-of- nonpresencing$<$ perspective-ontological-normalcy/postconvergence $>>$ necessary to act as the referenced/registered/decisioned-psychical-backdrop for futural Beingdevelopment/ontological-framework-expansion-as-to-depth-of-ontologising-development-asinfrastructure-of- meaningfulness-and-teleology as of prospective deprocrypticism, as implied by de-mentation-〈supererogatory ontological-de-mentation-or-dialectical-dementation - stranding-or-attributive-dialectics $>\quad$ as-uninstitutionalised-threshold ${ }^{02}$ suprastructuring ${ }^{15}$ de-mentation-〈supererogatory $\sim$ ontological-de-mentation-or-dialectical-dementation-stranding-or-attributive-dialectics $\rangle$ that is the mechanism that enables 'postconverging-or-dialectical-thinking -psychology or psychology-of-mentation-dynamics or natural psychological-dynamics’ psychoanalytic-unshackling/memeticreordering/institutional-recomposuring. *The fundamental ontological/meaningful question is: which is the 'superseding ${ }^{83}$ reference-of-thought, from where meaningfulness is aligned as 'thinking and contending' over the 'perverting/superseded ${ }^{83}$ reference-of-thought' aligned to as 'preconverging-or-dementing -apriorising-psychologism and not-contending'? 'Anchoring-ofmeaning as base-institutionalisation' over recurrent-utter-uninstitutionalisation, 'anchoring-ofmeaning as ${ }^{103}$ universalisation' over ${ }^{74}$ perversion-of- ${ }^{3}$ reference-of-thought- $<$ aspreconvergingly-apriorising/axiomatising/referencing-in-

nonconviction/madeupness/bottomlining-as-to-shallow-supererogation >,-of-baseinstitutionalisation-as-ununiversalisation, 'anchoring-of-meaning as positivism' over perversion-of- ${ }^{3}$ reference-of-thought-<as-preconvergingly- 
shallow-supererogation >,-of-universalisation-as-non-positivism/medievalism or 'anchoringof-meaning as deprocrypticism' over ${ }^{71}$ perversion-of- ${ }^{2}$ reference-of-thought- $<$ aspreconvergingly-apriorising/axiomatising/referencing-in-

nonconviction/madeupness/bottomlining-as-to-shallow-supererogation $>$,-of-positivism-asprocrypticism. A 'postconverging-or-dialectical-thinking -psychology or psychology-ofmentation-dynamics or natural psychological-dynamics' will actually be about a novel construal of the social as 'metaphysics-of-absence-_implicited-epistemic-veracity-ofnonpresencing-<perspective-ontological-normalcy/postconvergence $>>$ '/postdication of the individual as 'metaphysics-of-presence-〈implicited-'nondescript/ignorable-void '-as-topresencing - absolutising-identitive-constitutedness ' '; with the implication that the concepts and conceptualisations of the individual of the current "psychology of qualification and qualification schemes' are actually and effectively construed by the 'postconverging-ordialectical-thinking -psychology or psychology-of-mentation-dynamics or natural psychological-dynamics' as of an ontological-normalcy/postconvergence cadre and as becoming into the social, for its analytic purposes and framework. 'Possibly' this won't imply 'doing away' with concepts and conceptualisations of the current 'psychology of qualifications and qualification schemes', but will however be uncompromising with respect to being ontologydriven, and thus 'possibly' enable the reconstrual of such psychology concepts as the self, ego, id, etc. in their metaphysics-of-absence-〈implicited-epistemic-veracity-of- nonpresencing$<$ perspective-ontological-normalcy/postconvergence $>$ )/postdication $\quad$ (as the existential<disontologising/re-ontelogising aporeticism $>$ social) articulation. Insightfully, a 'postconverging-or-dialectical-thinking - psychology or psychology-of-mentation-dynamics or natural psychological-dynamics’ rather mobilises ${ }^{55}$ maximalising-recomposuring-for-relativeontological-completeness ${ }^{87}$ - unenframed/re-ontologising conceptualisation as is necessarily the case with all metaphysics-of-absence-〈implicited-epistemic-veracity-of- nonpresencing- 
$<$ perspective-ontological-normalcy/postconvergence $>$ //postdication conceptualisations (which must avert the mix-up induced by the illusion-of-the-present/present-consciousness/mirageas $<$ amplituding/formative-epistemicity $>$ totalising $\sim$ self-referencingsyncretising/circularity/interiorising/akrasiatic-drag ${ }^{34}$ as metaphysics-of-presence-〈implicited'nondescript/ignorable-void '-as-to- presencing-absolutising-identitive-constitutedness 〉)

in ontologising/ontological-conceptualising. This thus validates and operates on the fundamental assumption that the individual-as-of-its-temporal-to-intemporal-individuation-potency is an abstract-atomic-social-construct capable-of-and-as-the-basis-for-both-social-effectuation-andinstitutionalisation/intemporalisation. What is then qualified as social phenomenon is determined and effectively deconstructible/ontologically-reconstitutable from the inherent dynamism of human-subpotency-aporia/undecidability/dilemma/oughtindeterminacy/deficiency/limitation/constraint—imbued-'notional firstnaturednessformativeness-<as-to-eventualising-inkling-drive-or-seeding-misprising $>$ temporal-tointemporal-dispositions- $<$ so-construed-as-from-perspective-ontologicalnormalcy/postconvergence>'-existentialism-form-factor; and in construing/conceptualising the 'transcendence and skewing ('intemporality ${ }^{52}$-symmetrising-by-desymmetrising-subsumptionof-temporality , , for relative intrinsic-reality/ontological-veridicality transcendentalenabling/sublimating/supereregatory $\sim$ de-mentativity)/deferential-formalisation-transference' of meaningfulness-\{and-value\} towards the intemporal-disposition (ontologisation/ontologicalveracity/aestheticisation-towards-ontology -tautologically construed as ontology-in-theadvancement-of-intemporality $^{52}$ or institutionalisation or intemporalisation) of that abstractatomic-social-construct or individual-as-of-its-temporal-to-intemporal-individuation-potency. At all registry-worldview/dimension-levels, for there to be transcendence-andsublimity/sublimation/supererogatory-de-mentativity prospectively as the "postconverging-dementating/structuring/paradigming resolution of the vices-and-impediments 105 of the 
prior/transcended/superseded

registry-worldview/dimension',

human-subpotencyaporia/undecidability/dilemma/ought-indeterminacy/deficiency/limitation/constraint—imbued'notional firstnaturedness-formativeness-<as-to-eventualising inkling drive-or-seeding misprising $>$ temporal-to-intemporal-dispositions-<so-construed-as-from-perspectiveontological-normalcy/postconvergence>'-existentialism-form-factor implies that the 'determination of the 'postconverging-or-dialectical-thinking -psychology or psychology-ofmentation-dynamics or natural psychological-dynamics' of the human placeholdersetup/mental-devising-representation/mentation/consciousness-awareness-teleology ${ }^{99}$ as of the circularity/recurrence/repetition/repeatability ${ }^{10}$ delineating existential-transitioning-oriterability-trace-of-narratives-as-dots_or_implicited_attendant-ontologicalcontiguity ${ }^{67}$,educedexistentialising/contextualising/textualising_'intelligibility/epistemicity/reflexivity-contiguity$<$ imbued-notional cogency>' ${ }^{\prime}$-reification_or_intrinsic-reality-ontologicalcoherence_or_superseding-oneness-of-ontology involving iterability-by-alterations-andrealterations as 'ontological-reconstituting-as-to-conflatedness ${ }^{13}$, realterations over hollowconstituting-<as-disjointed-misappropriation-of-meaningfulness-and-failing-intemporal-

preservation> alterations in upholding ontology over subontologisation/subpotentiation and so beyond-intradimensional-institutionalisation-

limits/transcendentally/transdimensionally/interdimensionally, is what effectively allows for the 'postconverging-or-dialectical-thinking - psychology or psychology-of-mentation-dynamics or natural psychological-dynamics' psychoanalytic-unshackling/memeticreordering/institutional-recomposuring that sustains the possibility for human-crossgenerational prospective institutionalisation transcendence-and-sublimity/sublimation/dementativity towards ontological-normalcy. As previously indicated, a registryworldview/dimension ontological/being-construal-defect (as its subontologisation) is 'not 
caused' by compulsing-nonconviction/madeupness/bottomlining-〈' $<$ decontextualising/deexistentialising $\sim$ of-attendant-intradimensional-apriorising/axiomatising/referencing $>$-induceddisontologising'-of-the-'attendant-intradimensional-ontologising'-imbued$<$ contextualising/existentialising attendant-ontological-contiguity $>$;-in-shallowsupererogation -<as-to-disontologising-perverted-outcome-sought-precedes-existentiallyveridical-'attendant-intradimensional-apriorising/axiomatising/referencing'-logical-dueness $>$ > or postlogism 7 , whether pathological/psychopathic or enculturated, (as this is priorly due to the inherent registry-worldview's/dimension's uninstitutionalised-threshold ${ }^{12}$ 'in wait' for such compulsing-nonconviction/madeupness/bottomlining- $<$ ‘ $<$ decontextualising/deexistentialising $\sim$ of-attendant-intradimensional-apriorising/axiomatising/referencing $>$-induceddisontologising'-of-the-'attendant-intradimensional-ontologising'-imbued$<$ contextualising/existentialising attendant-ontological-contiguity $>$;-in-shallowsupererogation -<as-to-disontologising-perverted-outcome-sought-precedes-existentiallyveridical-'attendant-intradimensional-apriorising/axiomatising/referencing'-logical-dueness $>$ > or postlogism elicitation of its threshold-of-nonconviction/madeupness/bottomlining-inshallow-supererogation -<as-to-'attendant-intradimensional'-prospectivelydisontologising preconverging/dementing -apriorising-psychologism $>$, for instance, the state of being superstitious in non-positivism/medievalism is itself 'in wait' for notions-andaccusations-of-sorcery to elicit its threshold-of-nonconviction/madeupness/bottomlining-inshallow-supererogation -<as-to-'attendant-intradimensional'-prospectivelydisontologising preconverging/dementing -apriorising-psychologism $>$ in such a social-setup by corresponding non-positivism/medievalism $\quad{ }^{11}$ compulsingnonconviction/madeupness/bottomlining-/“<decontextualising/de-existentialising $\sim$ ofattendant-intradimensional-apriorising/axiomatising/referencing $>$-induced-disontologising'-ofthe-'attendant-intradimensional-ontologising'-imbued- 
$<$ contextualising/existentialising attendant-ontological-contiguity $>$;-in-shallow-

supererogation -<as-to-disontologising-perverted-outcome-sought-precedes-existentially-

veridical-'attendant-intradimensional-apriorising/axiomatising/referencing'-logical-dueness $>$ )

or postlogism ${ }^{77}$ ), whereas the positivistic registry-worldview ${ }^{83}$ reference-of-thought has the prospective relative-ontological-completeness ${ }^{87}$-of- ${ }^{8}$ refence-of-thought for the eliciting of such $\mathrm{a}$ notions-and-accusations-of-sorcery threshold-ofnonconviction/madeupness/bottomlining-in-shallow-supererogation $<-<$ as-to-' ${ }^{\circ}$ attendantintradimensional'-prospectively-disontologising preconverging/dementing -apriorisingpsychologism $>$ not to arise. However, as highlighted again previously, the subsequent temporalpreservation-as-pseudointemporality ${ }^{52}$-preservation of a registry-worldview's/dimension's subontologisation/subpotentiation is largely due to the perpetuating recurrence, as an intradimensional dynamic-cumulative-aftereffect, of such pathological/psychopathic-andenculturated compulsing-nonconviction/madeupness/bottomlining-〈' $<$ decontextualising/deexistentialising $\sim$ of-attendant-intradimensional-apriorising/axiomatising/referencing $>$-induceddisontologising'-of-the-'attendant-intradimensional-ontologising'-imbued$<$ contextualising/existentialising attendant-ontological-contiguity $>$;-in-shallowsupererogation -<as-to-disontologising-perverted-outcome-sought-precedes-existentiallyveridical-'attendant-intradimensional-apriorising/axiomatising/referencing'-logical-dueness $>$ ) or postlogism 77 and conjugated-postlogism 77 preconverging-or-dementing ${ }^{20}$-integration that undermine and blur recurrently intemporal-disposition supplanting-conviction-as-to-profoundsupererogation _of-'attendant-intradimensional'-postconverging/dialectical-thinking apriorising-psychologism to induce social ${ }^{103}$ universal-transparency ${ }^{104}$-〈transparency-oftotalising-entailing,-as-to-entailing-<amplituding/formative-epistemicity $>$ totalising inrelative-ontological-completeness > of the registry-worldview's/dimension's ontological/being-construal-defect as unsound ${ }^{83}$ reference-of-thought of meaningfulness and the 
positive-opportunism - of-social-functioning-and-accordance ${ }^{75}$ thereof for prospective institutionalisation transcendence-and-sublimity/sublimation/supererogatory-de-mentativity and leading to the registry-worldview's/dimension's uninstitutionalised-threshold endemised/enculturated temporal-preservation-as-pseudointemporality ${ }^{52}$-preservation. This aspect of postlogism 77 and conjugated-postlogism 77 preconverging-or-dementing ${ }^{20}$-integration temporal-preservation-as-pseudointemporality ${ }^{52}$-preservation endemisation/enculturation is thus the more salient construal for the de-endemisation/de-enculturation of ontological/beingconstrual-defect as unsound ${ }^{8}$ reference-of-thought of meaningfulness, as defined by recurrence and 'non-transient transcendability' at the uninstitutionalised-threshold ${ }^{102}$; (in contrast with either a state of ${ }^{54}$ logical-processing-or-logical-implicitation-supposedly-apriorising-inconviction-as-to-profound-supererogation that doesn't speak of 'recurrence of perversion/unsoundness of ${ }^{83}$ reference-of-thought' or an 'abstract' state of inherent uninstitutionalised-threshold ${ }^{102}$ but which is 'transiently transcendable' as it is not in temporalpreservation-as-pseudointemporality ${ }^{52}$-preservation instigated by postlogism 7 -as-ofcompulsing-nonconviction/madeupness/bottomlining-〈'<decontextualising/deexistentialising $\sim$ of-attendant-intradimensional-apriorising/axiomatising/referencing $>$-induceddisontologising'-of-the-'attendant-intradimensional-ontologising'-imbued$<$ contextualising/existentialising attendant-ontological-contiguity $>$;-in-shallowsupererogation -<as-to-disontologising-perverted-outcome-sought-precedes-existentiallyveridical-'attendant-intradimensional-apriorising/axiomatising/referencing'-logicaldueness $>\rangle)$. Thus it is the condition of 'recurrence' and 'non-transience' transcendability arising from postlogism 77 and conjugated-postlogism 77 preconverging-or-dementing 2 -integration that is ontologically relevant for ontological-reconstituting-as-to-conflatedness $13 /$ deconstruction for prospective transcendability (as it conceptually defines the successive uninstitutionalisedthreshold $^{02}$ of recurrent-utter-uninstitutionalisation, ununiversalisation, non- 
positivism/medievalism and procrypticism), and it basically encapsulates the phenomenality of preconverging/dementing -apriorising-psychologism mental-devising-representation of postlogism 77 and temporal-dispositions-conjugated-postlogism 77 so-construed as threshold-ofnonconviction/madeupness/bottomlining-in-shallow-supererogation $<<$ as-to-'attendantintradimensional'-prospectively-disontologising preconverging/dementing -apriorisingpsychologism> (and so-reflected of the registry-worldview's/dimension's social-construct of notional firstnaturedness-formativeness-<as-to-eventualising inkling-drive-or-seedingmisprising $>$ temporal-to-intemporal-dispositions- $<$ so-construed-as-from-perspectiveontological-normalcy/postconvergence $>$ at its uninstitutionalised-threshold ${ }^{102}$ defined by recurrence and 'non-transient transcendability'). Thus subontologisation/subpotentiation is induced as threshold-of-nonconviction/madeupness/bottomlining-in-shallow-supererogation $<$ as-to-'attendant-intradimensional'-prospectivelydisontologising preconverging/dementing -apriorising-psychologism> so-associated with postlogism 7 -and-conjugated-postlogism 77 leading to temporal-preservation, and so at a registryworldview's/dimension's uninstitutionalised-threshold ${ }^{102}$ defined by recurrence and 'nontransient transcendability'. The 'maximalising-recomposuring-for-relative-ontologicalcompleteness ${ }^{87}$ — unenframed/re-ontologising conceptualisation construct' for prospective institutionalisation transcendence-and-sublimity/sublimation/supereregatory $\sim$ de-mentativity is thus fundamentally grounded on the 'backdrop' of the construal of the threshold-ofnonconviction/madeupness/bottomlining-in-shallow-supererogation $-<$ as-to-' ${ }^{\circ}$ attendant-

\section{intradimensional'-prospectively-disontologising preconverging/dementing -apriorising-}

psychologism $>$ which is reflected and superseded postconvergently as of supplantingconviction-as-to-profound-supererogation -of-'attendant-intradimensional'postconverging/dialectical-thinking -apriorising-psychologism in existentially-veridical ontology as shallow to deeper superseding-oneness-of-ontology construal/conceptualisation. 
The so-reflected 'threshold-of-nonconviction/madeupness/bottomlining-in-shallowsupererogation -<as-to-'attendant-intradimensional'-prospectivelydisontologising preconverging/dementing -apriorising-psychologism> and supplantingconviction-as-to-profound-supererogation _of-'attendant-intradimensional'postconverging/dialectical-thinking -apriorising-psychologism' is actually central to suprastructuring or a conceptualisation that can integrate both relevant metaphysics-of-presence〈implicited-'nondescript/ignorable-void '-as-to- presencing-absolutising-identitiveconstitutedness > and metaphysics-of-absence-〈implicited-epistemic-veracity-ofnonpresencing-<perspective-ontological-normalcy/postconvergence $>\rangle$, with the capacity of easily reflecting both preconverging-or-dementing ${ }^{20}$-apriorising-psychologism and postconverging-or-dialectical-thinking ${ }^{21}$-apriorising-psychologism as implied from a renewed human mentation transcendental insights (in notional $\sim$ reflexivity $<<$ vveridical/sound $\}$-relativereflexivity-in-existence/relativising from-limited-mentation-as-its-deepening/psychologismic<residualising \{decompulsing \}elinearity for-cogency>-by-\{flawed/unsound\}-relativeunreflexivity-in-existencetabsolutising from limited mentation/psychologismic epistemic acutisation nonresidualising imbued-\{compulsing\} linearity-in-eclecticism-of-prior-mereformulaicity/ritualisation>) about intrinsic-reality/ontological-veridicality. Threshold-ofnonconviction/madeupness/bottomlining-in-shallow-supererogation $<<$ as-to- 'attendantintradimensional'-prospectively-disontologising preconverging/dementing -apriorisingpsychologism $>$ implies that at registry-worldview's/dimension's uninstitutionalised-threshold at which they are prospectively reflected/perspectivated as being in epistemicabnormalcy/preconvergence (as shallow superseding-oneness-of-ontology construal/conceptualisation) with respect to ontological-normalcy/prospective-transcendencein-perpetually-upholding-intemporal-preservation-entropy-or-contiguity-or-ontologicalpreservation (as deeper superseding-oneness-of-ontology construal/conceptualisation), 
correspondingly the ontological-veridicality of human dispositions is construed as requiring a notional firstnaturedness-formativeness-<as-to-eventualising inkling-drive-or-seeding misprising $>$ temporal-to-intemporal-dispositions- $<$ so-construed-as-from-perspectiveontological-normalcy/postconvergence $>$ disambiguation of ${ }^{8}$ reference-of-thought (rather than naively, an assumption of ${ }^{103}$ universal human intemporal-disposition as reflected/perspectivated within a functional institutionalised registry-worldview <preconverging 'motif-andapriorising/axiomatising/referencing'-entailing >-existentialising — enframing/imprintedness〈as-to- historicity-tracing - in-presencing-hyperrealisation/hyperreal-transposition〉'), with the implication that the 'same-terms-of-expressions (seemingly-same-implied-meaningfulness)' are actually of disambiguated notional firstnaturedness-formativeness-<as-toeventualising inkling-drive or seeding-misprising> temporal-to-intemporal-dispositions$<$ so-construed-as-from-perspective-ontological-normalcy/postconvergence $>\quad{ }^{83}$ reference-ofthought and meaningfulness. This broadly sums up the importance of elucidating the thresholdof-nonconviction/madeupness/bottomlining-in-shallow-supererogation $<<$ as-to-' attendantintradimensional'-prospectively-disontologising preconverging/dementing -apriorisingpsychologism> when it comes to registry-worldviews/dimensions construed as to their uninstitutionalised-threshold ${ }^{102}$ as being in epistemic-abnormalcy/preconvergence ${ }^{31}$, as it enables the conceptual articulation of meaningfulness that the "perspective of a functionally institutionalised registry-worldview/dimension $<$ preconverging $\sim$ 'motif-andapriorising/axiomatising/referencing'-entailing>-existentialising — enframing/imprintedness〈as-to- historicity-tracing-in-presencing-hyperrealisation/hyperreal-transposition〉' doesn't permit beyond its <amplituding/formative-epistemicity $>$ totalising $\sim$ self-referencingsyncretising/illusion-of-the-present/present-consciousness/mirage limits at its uninstitutionalised-threshold $^{102}$. The suprastructuring effect of threshold-ofnonconviction/madeupness/bottomlining-in-shallow-supererogation $-<$ as-to-'attendant- 
intradimensional'-prospectively-disontologising preconverging/dementing -apriorising-

psychologism $>$ is what actually allows to prospectively reflect/perspectivate ${ }^{74}$ perversion-ofreference-of-thought-<as-preconvergingly-apriorising/axiomatising/referencing-in-

nonconviction/madeupness/bottomlining-as-to-shallow-supererogation $>$ and as dialecticallyout-of-phase/dialectically-primitive at the uninstitutionalised-threshold ${ }^{12}$ marking out recurrent-utter-uninstitutionalisation from base-institutionalisation, ununiversalisation from universalisation, non-positivism/medievalism from positivism and procrypticism from deprocrypticism; thus enabling the requisite 'postconverging-or-dialectical-thinking psychology or psychology-of-mentation-dynamics or natural psychological-dynamics’ psychoanalytic-unshackling/memetic-reordering/institutional-recomposuring by which prospective institutionalisation/intemporalisation for intemporal-preservation-entropy-orcontiguity-or-ontological-preservation as 'ontological-reconstituting-as-toconflatedness ${ }^{13} /$ deconstruction is undertaken to supersede (as deeper superseding-oneness-ofontology construal/conceptualisation) the drawback or vices-and-impediments ${ }^{105}$ of the prior registry-worldview/dimension as now preconverging-or-dementing -apriorising-psychologism and dialectically-out-of-phase. Thus the reality of threshold-ofnonconviction/madeupness/bottomlining-in-shallow-supererogation $-<$ as-to-'attendantintradimensional'-prospectively-disontologising preconverging/dementing -apriorisingpsychologism $>$ implies that virtue shouldn't naively be perceived in terms-as-of-axiomaticconstruct of $a^{\text {' }}{ }^{103}$ universal human intemporal-disposition nature or intemporal-disposition nature' since human-subpotency-aporia/undecidability/dilemma/oughtindeterminacy/deficiency/limitation/constraint—imbued-'notional firstnaturednessformativeness-as to eventulising inkling drive or seeding misprising temporal-tointemporal-dispositions- $<$ so-construed-as-from-perspective-ontologicalnormalcy/postconvergence>'-existentialism-form-factor speaks otherwise (even though such an 
axiom of a ' ${ }^{103}$ universal human intemporal-disposition' is only surreptitiously implied, as a necessary 'functional pseudo-conceptualisation' which functionally assumes intemporality ${ }^{52} /$ longness to avoid the cumbrous need for disambiguating ${ }^{83}$ reference-of-thought of meaningfulness into notional firstnaturedness-formativeness-<as-to-eventualising inkling drive-or-seeding misprising $>$ temporal-to-intemporal-dispositions- $<$ so-construed-as-fromperspective-ontological-normalcy/postconvergence> (at any singular instances) 'within established institutionalised registry-worldview/dimension' but virtue cannot be assumed beyond the uninstitutionalised-threshold ${ }^{102}$; that is, virtue is preconverging/postconverging-dementatively/structurally/paradigmatically the result of intemporalisation-as-institutionalisation secondnaturing, for instance, we can broadly argue that the positivistic registryworldview/dimension implies more or less a ' ${ }^{103}$ universal positivistic intemporality ${ }^{52}$ as a functional pseudo-conceptualisation of intemporality ${ }^{52} /$ longness 'as people do not act medieval by-and-large' but at our uninstitutionalised-threshold ${ }^{02}$ wherein ${ }^{80}$ procrypticism-ordisjointedness-as-of- ${ }^{8}$ reference-of-thought arises our positivistic registry-worldview/dimension can only be qualified as of notional firstnaturedness-formativeness-<as-toeventualising inkling drive or seeding-misprising $>$ temporal-to-intemporal-dispositions$<$ so-construed-as-from-perspective-ontological-normalcy/postconvergence $>$ since the requisite intemporalisation-as-institutionalisation as deprocrypticism-or-preempting-disjointednessas-of- ${ }^{3}$ reference-of-thought secondnaturing is wanting), but virtue should rather be construed as the superseding/transcendental institutionalisation/intemporalisation design/conceptualisation that by inducing untenability/internal-contradiction/internal-incoherence/institutionalconstraining and positive-opportunism - of-social-functioning-and-accordance ${ }^{75}$ in the short run and secondnaturing in the long run enables the prospective registry-worldview/dimension institutionalisation; it is this focus on institutionalisation/intemporalisation that is effectively institutionalisation-as-virtue given that in the succession of human institutional- 
cumulation/institutional-recomposure-〈as-to- historiality/ontological-

eventfulness /ontological-aesthetic-tracing-<perspective-ontological-

normalcy/postconvergence-reflected-'epistemicity-relativism-determinism'>>,

institutionalisation effectively transforms human notional firstnaturedness-formativeness $<a s$ to-eventualising inkling-drive-or-seeding-misprising > temporal-to-intemporal-dispositions$<$ so-construed-as-from-perspective-ontological-normalcy/postconvergence $>$ nature into an absolutely intemporal-disposition nature, but rather reduces human epistemicabnormalcy/preconvergence towards ontological-normalcy/postconvergence as deeper and deeper superseding-oneness-of-ontology construal/conceptualisations. The bigger point being that it is by effectively grasping that any human intemporal-disposition individuations that can 'spontaneously' arise in whatever concern there is should be directed/skewed ('intemporality ${ }^{5}$ symmetrising-by-desymmetrising-subsumption-of-temporality ${ }^{\circ}$, for relative intrinsicreality/ontological-veridicality transcendental-enabling/sublimating/supererogatory $\sim$ dementativity) (as deferential-formalisation-transference of meaningfulness) for institutionalisation/intemporalisation-as-virtue for secondnaturing, and not a wrong implication of functionally grounding virtue on human 'temporal disposition' which will inevitably bring about temporal-and-social-trading with respect to 'socially-perceived-value as of social-stakecontention-or-confliction'. The fact is that our institutional and organisational constructs at their very core, unspokenly do imply this notion of institutionalisation-as-virtue (in tacit recognition of our notional firstnaturedness-formativeness-<as-to-eventualising $-i n k l i n g-d r i v e-o r-s e e d i n g-$ misprising $>$ temporal-to-intemporal-dispositions- $<$ so-construed-as-from-perspectiveontological-normalcy/postconvergence $>$ ), however, the notion of 'consciously-spoken' as herein highlighted is that it enables the necessary uninhibitedness/decomplexification that allows the requisite 'postconverging-or-dialectical-thinking -psychology or psychology-of-mentationdynamics or natural psychological-dynamics' psychoanalytic-unshackling/memetic- 
reordering/institutional-recomposuring required in fully assuming the ${ }^{8}$ reference-of-thought of any prospective registry-worldview/dimension. Actually, it could be argued that the more critical element of medieval emancipators/enlighteners had to do often not with their specific discoveries, which were more or less debated issues as well in their societies, but critically the idea that they were ready to imply a 'new psychological orientation as positivistic' that in itself structured the possibilities of a new worldview and many other positivistic discoveries once it became mainstream. Insistence of making mainstream such ideas as a heliocentric solar system by Galileo a century after Copernicus based on observations, the evolution of living things by Darwin based on research analysis, '<amplituding/formative-epistemicity>totalising rationalism' by Descartes based on methodical thinking, ${ }^{103}$ universal human rights by Rousseau based on thorough analysis of the human condition, principles explaining physical phenomena by Newton and Leibniz based on physical observation, etc. all speak of a new mindset $/{ }^{3}$ reference-of-thought as a postconverging-de-mentating/structuring/paradigming shift that has no complexes and is uninhibited with respect to notions of the old notions of dogmas, alchemies, essences and myths. The fact is that (unlike we may naively reason by reflex from our relatively vantage position at the backend of the institutional-cumulation/institutionalrecomposure-〈as-to- historiality/ontological-eventfulness /ontological-aesthetic-tracing$<$ perspective-ontological-normalcy/postconvergence-reflected-'epistemicity-relativismdeterminism' $>>$ process) this is not spontaneously given, when we consider that many of such emancipators were equally relatively enmeshed with the old psychology like Newton's involvement with alchemy, for instance. This point to the critical importance of the psychological state of the mind for the very possibility of prospective ontologically-veridical transcendence-and-sublimity/sublimation/supereregatory-de-mentativity to occur; as ontology is already given as a oneness and it is up to the human psyche to 'moult itself' (psychoanalyticunshackling/memetic-reordering/institutional-recomposuring) towards a more profound 
construal/conceptualisation as of that superseding-oneness-of-ontology, however strongly we might naively believe in our ideas in any given epoch as of its metaphysics-of-presence〈implicited-'nondescript/ignorable-void '-as-to- presencing - absolutising-identitive-

constitutedness $\rangle$. Thus metaphysics-of-absence-〈implicited-epistemic-veracity-ofnonpresencing-<perspective-ontological-normalcy/postconvergence $>\rangle$ notion of thresholdof-nonconviction/madeupness/bottomlining-in-shallow-supererogation $<-<$ as-to-' ${ }^{\text {attendant- }}$ intradimensional'-prospectively-disontologising preconverging/dementing -apriorisingpsychologism> (substituting, to induce a 'preconverging-or-dementing ${ }^{20}$-apriorisingpsychologism mentation reflex' in sync with the ontological perspective, over the same notion as subontologisation/subpotentiation as metaphysics-of-presence-〈implicited‘nondescript/ignorable-void ' -as-to- presencing - absolutising-identitive-constitutedness 〉, which rather wrongly induces a 'postconverging-or-dialectical-thinking ${ }^{21}$-apriorisingpsychologism mentation reflex' out of sync with the ontological perspective, thus is subject to $<$ amplituding/formative-epistemicity $>$ totalising $\sim$ self-referencing-syncretising/illusion-of-thepresent/present-consciousness/mirage) effectively arises from a maximalist construct in grasping the salience of a transcending/utter conceptualisation that mirrors the uncompromising nature of intrinsic-reality/ontology over incrementalism-in-relative-ontological-incompleteness ${ }^{8}$ enframed/disontologising $\sim$ conceptualisation notional procrypticism or notional disjointedness-as-of- ${ }^{-3}$ reference-of-thought as the natural intradimensional summative temporal mental-disposition (which speaks of a registry-worldview/dimension relativeontological-incompleteness -induced,-'threshold-of-nonconviction/madeupness/bottomliningin-shallow-supererogation -<as-to- 'attendant-intradimensional'-prospectivelydisontologising preconverging/dementing -apriorising-psychologism>', as-it-is-thus-'inwait'-for- perversion-of- ${ }^{83}$ reference-of-thought-<as-preconverginglyapriorising/axiomatising/referencing-in-nonconviction/madeupness/bottomlining-as-to- 
shallow-supererogation >,-or-temporal-preservation-as-pseudointemporality ${ }^{52}$-preservation, and the need for ontological-normalcy/prospective-transcendence-in-perpetually-upholdingintemporal-preservation-entropy-or-contiguity-or-ontological-preservation), which incrementalism-in-relative-ontological-incompleteness ${ }^{8}$

enframed/disontologising $\sim$ conceptualisation

notional procrypticism

or notional disjointedness-as-of- ${ }^{8}$ reference-of-thought however represents the enculturation/endemisation that is defining of given registry-worldview's/dimension's uninstitutionalised-threshold ${ }^{102}$. In other words, without a ${ }^{55}$ maximalising-recomposuring-forrelative-ontological-completeness ${ }^{87}$ — unenframed/re-ontologising $\sim$ conceptualisation disposition no prospective institutionalisation transcendence-andsublimity/sublimation/supererogatoryade-mentativity will be possible, as baseinstitutionalisation is the ultimate ${ }^{55}$ maximalising-recomposuring-for-relative-ontologicalcompleteness ${ }^{87}$ — unenframed/re-ontologising conceptualisation construct over a summative mental-disposition of $<$ amplituding/formative-epistemicity $>$ totalising $\sim$ self-referencingsyncretising/circularity/interiorising/akrasiatic-drag ${ }^{34}$ in recurrent-utter-uninstitutionalisation enabling the latter's transcendence-and-sublimity/sublimation/supererogatory $\sim$ de-mentativity, likewise ${ }^{103}$ universalisation is the ultimate ${ }^{55}$ maximalising-recomposuring-for-relativeontological-completeness ${ }^{87}$ - unenframed/re-ontologising conceptualisation construct over a summative mental-disposition of <amplituding/formative-epistemicity $>$ totalising $\sim$ selfreferencing-syncretising/circularity/interiorising/akrasiatic-drag 34 in ununiversalisation enabling the latter's transcendence-and-sublimity/sublimation/supereregatory $\sim$ de-mentativity, so too with positivism over non-positivism, and prospectively notional ${ }^{18}$ deprocrypticism over procrypticism/as-the- ${ }^{-1}$ perversion-of- ${ }^{3}$ reference-of-thought-<as-preconverginglyapriorising/axiomatising/referencing-in-nonconviction/madeupness/bottomlining-as-toshallow-supererogation >,-of-positivism reference-of-thought- categorical- 
imperatives/axioms/registry-teleology'. An 'existential-decontextualised-transposition (threshold-of-nonconviction/madeupness/bottomlining-in-shallow-supererogation $-<$ as-to‘attendant-intradimensional'-prospectively-disontologising preconverging/dementing apriorising-psychologism> defect) of ontology/ontologically-veridicalmeaningfulness/intemporality ${ }^{52}$ conceptualisation' is equally critical, along with the implied psychological uninhibitedness/décomplexing for a prospective registry-worldview/dimension as deprocrypticism, with respect to the central concept of 'knowledge-notionalisation' wherein understanding is much more than about grasping the ideals but equally preemptively construing the possibilities of the 'ignorances/desublimation'/temporal-dispositions as part-and-parcel of knowledge construct, not for an idle temporal motive, but to better skew ('intemporality ${ }^{52}$ symmetrising-by-desymmetrising-subsumption-of-temporality ${ }^{\circ}$, for relative intrinsicreality/ontological-veridicality transcendental-enabling/sublimating/supererogatory $\sim$ dementativity) for institutionalisation/intemporalisation-as-virtue, as a specific necessity for a notional deprocrypticism registry-worldview/dimension preempting-disjointedness-as-ofreference-of-thought,-as-to- ${ }^{6}<$ amplituding/formative-epistemicity>growth-orconflatedness $^{13}$ /transvaluative-rationalising/transepistemicity/anamnestic-residuality/spiritdrivenness'-in-superseding-mere-formulaic-positivising/rational-empiricism-baseduniversalisation-directed-rulemaking-over-non-rules_apriorising/axiomatising/referencingpsychologism as deprocrypticism. Ultimately the purpose of maximalising-recomposuring-forrelative-ontological-completeness ${ }^{8}$ - unenframed/re-ontologising conceptualisation as an intemporal conceptualisation of transcendental implication should be of "79 presencingabsolutising-identitive-constitutedness ${ }^{14}$ consummated/forfeiting posture' and is not for the sake of 'immediate intelligibility' within a given uninstitutionalised registry-worldview/dimension in want for a prospective corresponding institutionalisation registry-worldview/dimension, as such a purpose will wrongly and paradoxically imply that the logical-dueness/logical-pertinence of 
the uninstitutionalised-threshold ${ }^{102}$ is sound as its ${ }^{83}$ reference-of-thought is prospectively defective (for instance a positivistic implied transcendence-andsublimity/sublimation/supererogatory de-mentativity cannot be logically intelligible to a medieval setup that harkens back to medieval ${ }^{83}$ reference-of-thought- categoricalimperatives/axioms/registry-teleology ${ }^{9}$ for its logic, i.e. 'Issue of articulating chemistry rules and principles for the evaluation of an alchemist not logically cognisant of chemistry rules and principles, in-the-very-first-place'), but rather it is a middle to long run construed as of ${ }^{15}$ dementation-_supererogatory ontological-de-mentation-or-dialectical-de-mentation-strandingor-attributive-dialectics〉 instigation of prospective registry-worldview/dimension institutionalisation ${ }^{83}$ reference-of-thought as of a 'postconverging-or-dialectical-thinking psychology or psychology-of-mentation-dynamics or natural psychological-dynamics’ psychoanalytic-unshackling/memetic-reordering/institutional-recomposuring (though we can mostly grasp such an insight not from instances of "natural intra-society transcendence-andsublimity/sublimation/supererogatoryade-mentativity' since this takes a longer time to occur and is relatively obscure, but transcendence-and-sublimity/sublimation/supereregatery $\sim$ dementativity by cultural diffusion associated with conquests where the dominant is at a more advanced stage of institutionalisation or in the rare cases where it is the reverse like Ancient Egypt or Ancient Greece, with the dominated actually relatively dominating or in parity with the dominant culturally as of divergent aspects). The implication here is that transcendental maximalising-recomposuring-for-relative-ontological-completeness ${ }^{87}$ - unenframed/reontologising conceptualisation is rather grounded on a relatively intemporal-and-deeper existential-reference-of-meaningfulness with the positive-opportunism-of-social-functioningand-accordance $^{75}$ of the prospective institutionalisation <amplituding/formativeepistemicity $>$ causality $\sim$ as-to-projective-totalitative-implications-of-prospective- 
contiguity over its corresponding uninstitutionalised-threshold ${ }^{12}$ to put in question the latter's reference-of-thought- categorical-imperatives/axioms/registry-teleology for the ones of the prospective institutionalisation, and it is only after that that the notion of mutual logical intelligibility arises (it is only after the alchemist 'psychoanalytically-unshackle' into a positivistic-inclined mindset $/{ }^{8}$ reference-of-thought with respect to appreciating notion of natural cause-and-effect and experimentation as well that the notion of mutual intelligibility of chemistry rules and principles makes sense, until then there cannot be much of intelligibility without such a 'postconverging-or-dialectical-thinking -psychology or psychology-ofmentation-dynamics or natural psychological-dynamics' psychoanalytic-unshackling/memeticreordering/institutional-recomposuring exercise from the perspective of the prospective chemist). That explain why maximalising-recomposuring-for-relative-ontologicalcompleteness $^{87}$ — unenframed/re-ontologising conceptualisation construct are meant to be detached and totalisingly-entailing so as to act as a backdrop for prospective institutionalisation, and not to necessarily make sense in terms-as-of-axiomatic-construct of the "now temporal mental-disposition reference-of-though' which, it is contended, is in want of prospective institutionalisation with its corresponding psychologism. In-the-bigger-scheme-of-things, it is inevitable that suprastructuring (the conceptualisation that renders de-mentation〈supererogatory $\sim$ ontological-de-mentation-or-dialectical-de-mentation-stranding-or-

attributive-dialectics $\rangle$ relative-mutual-construal of the prospective/superseding/transcending registry-worldview/dimension as deeper superseding-oneness-of-ontology construal/conceptualisation over the prior/superseded/transcended registryworldview/dimension as shallow superseding-oneness-of-ontology construal/conceptualisation by (suprastructurally) reflecting/perspectivating, beyond-the-consciousness-awarenessteleology $-<$ of-preconverging-existential-extrication-as-of-existential-unthought $>$ of the prior/superseded/transcended, respectively the 'postconverging-or-dialectical-thinking 
apriorising-psychologism as dialectically-in-phase' and the 'preconverging-or-dementing 20 apriorising-psychologism as dialectically-out-of-phase'), is rendered operant by the notion of 'existential-decontextualising-transposition (threshold-ofnonconviction/madeupness/bottomlining-in-shallow-supererogation $<<$ as-to-'attendantintradimensional'-prospectively-disontologising preconverging/dementing -apriorisingpsychologism $>$ defect) of ontology/ontologically-veridical-meaningfulness/intemporality ${ }^{52}$ in operantly grasping such suprastructuring transcendence-andsublimity/sublimation/supererogatory de-mentativity/transdimensional/interdimensional construct; as it perpetually upholds ontological-veridicality by its 'existential-reality' (not nonveridical/vacuous hollow-constituting-<as-disjointed-misappropriation-of-meaningfulness-andfailing-intemporal-preservation>) on the basis of, first and critically, the validity of the reference-of-thought so-reflected as soundness-or-ontological-good-faith/authenticity ${ }^{6}$-ofreference-of-thought if valid and unsoundness-or-ontological-bad-faith/inauthenticity ${ }^{64}$-ofreference-of-thought if invalid (before even recognising whether the 'implicitation-of-notionof-agreement-or-disagreement' or 'of logical-processing' arises) to determine the 'postconverging-or-dialectical-thinking -apriorising-psychologism and dialectically-in-phase' over the 'preconverging-or-dementing ${ }^{20}$-apriorising-psychologism and dialectically-out-ofphase/dialectically-primitive'. It is critical to grasp that the notion of threshold-ofnonconviction/madeupness/bottomlining-in-shallow-supererogation $<-<$ as-to- 'attendantintradimensional'-prospectively-disontologising preconverging/dementing -apriorisingpsychologism $>$ is rather of conceptual metaphysics-of-absence-_implicited-epistemic-veracityof- nonpresencing-<perspective-ontological-normalcy/postconvergence $>$ > (meant to ensure a natural maximalising-recomposuring-for-relative-ontological-completeness ${ }^{87}$ unenframed/re-ontologising conceptualisation to avoid mix-up of ${ }^{8}$ reference-of-thought) with such a mix-up arising from the <amplituding/formative-epistemicity $>$ totalising $\sim$ self- 
referencing-syncretising/circularity/interiorising/akrasiatic-drag ${ }^{34}$ (whether wittingly or unwittingly) induced subontologisation/subpotentiation (in-a-social-dynamism-ofmeaningfulness-misappropriation) so-construed as metaphysics-of-presence-〈implicited‘nondescript/ignorable-void '-as-to- presencing-absolutising-identitive-constitutedness $\rangle$.

So both notions are conceptually the same but implying different approaches with respect to the temporal undermining of ontological-veridicality; with subontologisation/subpotentiation referencing/biased within the contextual perspective of institutionalised registryworldview/dimension, with existential-decontextualised-transposition referencing/biased within the contextual perspective of uninstitutionalised registry-worldview/dimension, thus the latter enabling an appropriate disambiguation of notional firstnaturedness-formativeness-as to eventualising inkling-drive-or-seeding-misprising > temporal-to-intemporal-dispositions$<$ so-construed-as-from-perspective-ontological-normalcy/postconvergence $>$ with respect to ontologically-veridical ${ }^{83}$ reference-of-thought, and by extension it is the concept of thresholdof-nonconviction/madeupness/bottomlining-in-shallow-supererogation $-<$ as-to-'attendant-

\section{intradimensional'-prospectively-disontologising preconverging/dementing -apriorising-}

psychologism $>$ that is appropriate in all instances of implied uninstitutionalised registryworldviews/dimensions as metaphysics-of-absence-_implicited-epistemic-veracity-ofnonpresencing-<perspective-ontological-normalcy/postconvergence $>\rangle$ perspective since it avoids the $\quad<$ amplituding/formative-epistemicity $>$ totalising $\sim$ self-referencingsyncretising/illusion-of-the-present/present-consciousness/mirage that is inevitable when reasoning by a metaphysics-of-presence-〈implicited-'nondescript/ignorable-void '-as-topresencing - absolutising-identitive-constitutedness > induced subontologisation. Besides even within the intradimension contextual perspective of institutionalised registryworldview/dimension, it is equally the best approach with respect to the construal/conceptualisation of the instigating of postlogism -as-of- compulsing- 
nonconviction/madeupness/bottomlining-〈'<decontextualising/de-existentialising ofattendant-intradimensional-apriorising/axiomatising/referencing $>$-induced-disontologising'-ofthe-'attendant-intradimensional-ontologising'-imbued$<$ contextualising/existentialising attendant-ontological-contiguity $>$;-in-shallowsupererogation -<as-to-disontologising-perverted-outcome-sought-precedes-existentiallyveridical-'attendant-intradimensional-apriorising/axiomatising/referencing'-logical-dueness $>>$ hollow-constituting-<as-disjointed-misappropriation-of-meaningfulness-and-failingintemporal-preservation> mental-disposition that will induce temporal-preservation-aspseudointemporality ${ }^{52}$-preservation in temporal-dispositions as conjugatedpostlogism 77 preconverging-or-dementing ${ }^{20}$-integration (by hollow-constituting-<as-disjointedmisappropriation-of-meaningfulness-and-failing-intemporal-preservation $>$ on the ${ }^{8}$ referenceof-thought- categorical-imperatives/axioms/registry-teleology ${ }^{9}$ of the priorly institutionalised registry-worldview/dimension) and by so doing reflecting the uninstitutionalised registryworldview/dimension. That is an construal/conceptualisation approach that construes the relative-unreflexivity/relative-reflexivity — ontological-contiguity ${ }^{67}$ of-the-humaninstitutionalisation-process ${ }^{68}$ as of diminishing-human-epistemic-abnormalcy-orpreconvergence ${ }^{3 !}$ Effectively, such a highlight of how human secondnaturing within institutionalised construct implies a pseudo-conceptual ${ }^{103}$ universal human intemporaldisposition as metaphysics-of-presence-〈implicited-'nondescript/ignorable-void '-as-topresencing - absolutising-identitive-constitutedness $\rangle$ in contrast to a human-subpotencyaporia/undecidability/dilemma/ought-indeterminacy/deficiency/limitation/constraint—imbued'notional firstnaturedness-formativeness-<as-to-eventualising inkling-drive-or-seedingmisprising $>$ temporal-to-intemporal-dispositions- $<$ so-construed-as-from-perspectiveontological-normalcy/postconvergence>'-existentialism-form-factor mental-dispositions highlight at uninstitutionalised construct as metaphysics-of-absence-〈implicited-epistemic- 
effectively the unspoken psychoanalytic conceptualisation which needs to 'be referenced/registered/decisioned-as-consciously-recognised' as the backdrop for superseding into deprocrypticism. Such a psychoanalytic insight about the 'dynamic-cumulative-aftereffect of subontologisation' grasps how postlogism instigates the temporal-preservation-aspseudointemporality ${ }^{52}$-preservation inclination of temporal-dispositions that enculturates/endemises the various uninstitutionalised-threshold ${ }^{102}$ even though the state as dynamic-cumulative-aftereffect of temporal-dispositions is in 'ontological-incompleteness-ofreference-of-thought-induced-virtuality-or-ontologically-flawed-construal-or-caricaturinghollow-staging-and-performance-so-construed-by-prospective- ${ }^{8}$ reference-of-thought, as-it-isthus- 'in-wait'-for- perversion-of- $^{83}$ reference-of-thought- $<$ as-preconverginglyapriorising/axiomatising/referencing-in-nonconviction/madeupness/bottomlining-as-toshallow-supererogation >,-or-temporal-preservation-as-pseudointemporality ${ }^{52}$-preservation, with respect to ontological-normalcy' by 'undermining social ${ }^{103}$ universal-transparency ${ }^{104}$ 〈transparency-of-totalising-entailing,-as-to-entailing-<amplituding/formativeepistemicity>totalising in-relative-ontological-completeness > for ontological-veridicality'; wherein the postlogic mental-disposition is recursive in eliciting temporal-preservation, the conjugated exacerbatory/opportunistic mental-dispositions are progressive in upholding temporal-preservation-as-pseudointemporality ${ }^{52}$-preservation and the conjugated ignorance/affordable mental-dispositions as largely summative of the dynamic-cumulativeaftereffect, are geared towards upholding or undermining temporal-preservation-aspseudointemporality ${ }^{52}$-preservation by supplanting-conviction-as-to-profoundsupererogation _of-'attendant-intradimensional'-postconverging/dialectical-thinking apriorising-psychologism inclination whether naively conjugating to postlogism as misconstrual or good supplanting-conviction-as-to-profound-supererogation - of-'attendant- 
intradimensional'-postconverging/dialectical-thinking -apriorising-psychologism when the untenability/internal-contradiction/internal-incoherence/institutional-constraining and positiveopportunism-of-social-functioning-and-accordance ${ }^{75}$ of ontological-veridicality is established from an intemporal-disposition, in which latter case as being largely summative of the dynamiccumulative-aftereffect it leads to the collapsing of postlogism 77 mental-disposition recursiveness and exacerbatory/opportunistic mental-dispositions progressiveness with respect to temporalpreservation, and thus orienting towards intemporal-preservation/intemporalisation and the possibility for prospective institutionalisation, itself subjectable to temporal-preservation-aspseudointemporality ${ }^{52}$-preservation at its uninstitutionalised-threshold ${ }^{102}$. Thus this is the underlying dimensionality-of-sublimating 25 -< < amplituding/formative $>$ supererogatory - de-

\section{mentativeness/epistemic-growth-or-conflatedness /transvaluative-}

rationalising/transepistemicity/anamnestic-residuality/spirit-drivenness-equalisation $\rangle$ in the psychoanalytic dynamism of human-subpotency-aporia/undecidability/dilemma/oughtindeterminacy/deficiency/limitation/constraint—imbued-'notional firstnaturednessformativeness-<as-to-eventualising inkling drive-or-seeding misprising $>$ temporal-tointemporal-dispositions- $<$ so-construed-as-from-perspective-ontologicalnormalcy/postconvergence>'-existentialism-form-factor across all the institutionalcumulation/institutional-recomposure-〈as-to- historiality/ontologicaleventfulness /ontological-aesthetic-tracing-<perspective-ontologicalnormalcy/postconvergence-reflected-'epistemicity-relativism-determinism' $>>$ as of human shallow-to-deepening-limited-mentation-capacity-as-subjecting-'educedunlimitedness/existence-sublimating nascence' to-limitedness/human-subpotency, as-limitedmentation-capacity-deepening —as-subjecting limitedness/human-subpotency-to-'educedunlimitedness/existence-sublimating nascence' ${ }^{53}$ explaining the alternation of prospective institutionalisation (as ontologically-reconstituting) and uninstitutionalised-threshold ${ }^{12}$ (in 
hollow-constituting-<as-disjointed-misappropriation-of-meaningfulness-and-failing-

intemporal-preservation> with regards to the ${ }^{83}$ reference-of-thought- categoricalimperatives/axioms/registry-teleology ${ }^{9}$ of the prior institutionalisation) which need to be brought to the collective consciousness appraisal for the necessary psychological uninhibitedness/décomplexing enabling prospective deprocrypticism. * Ultimately, an 'ontological-reconstituting-as-to-conflatedness $13 /$ deconstruction articulation' (beyond just conceptualisations as in this paper) for more thorough insights reflective of a 'suprastructural construal of any given state of uninstitutionalised-threshold ${ }^{02}$ from prospective institutionalisation point-of-reference, such as can be retrospectively implied of nonpositivism/medievalism from positivism or prospectively implied of procrypticism from deprocrypticism', will more profoundly involve a 'storied-construct/ontologically-validnarration of comprehensive intuitive insight' grounded on: the construal of temporal-dispositions threshold-of-nonconviction/madeupness/bottomlining-in-shallow-supererogation $<<$ as-to‘attendant-intradimensional'-prospectively-disontologising preconverging/dementing apriorising-psychologism> (enabling the EXISTENTIAL-TRACING-as$<$ amplituding/formative-epistemicity $>$ causality $\sim$ as-to-projective-totalitative-implications-ofprospective- nonpresencing,-for-explicating relative unreflexivity/relative reflexivity ontological-contiguity of disambiguated notional firstnaturedness-formativeness-<as-toeventualising inkling-drive-or-seeding-misprising $>$ temporal-to-intemporal-dispositions$<$ so-construed-as-from-perspective-ontological-normalcy/postconvergence $>\quad$ and-theirassociated $\quad{ }^{83}$ reference-of-thought', reflecting soundness-or-ontological-goodfaith/authenticity ${ }^{69}$-of- ${ }^{83}$ reference-of-thought/postconverging-or-dialectical-thinking ${ }^{21}$ apriorising-psychologism (as-in-intemporal-preservation-entropy-or-contiguity-or-ontologicalpreservation) over unsoundness-or-ontological-bad-faith/inauthenticity ${ }^{64}$-of- ${ }^{8}$ reference-ofthought/preconverging-or-dementing ${ }^{2}$-apriorising-psychologism (as-failing-intemporal- 
preservation-or-misappropriation-of-meaningfulness-entropy/contiguity) non-veridical/vacuous reference-of-thought- categorical-imperatives/axioms/registry-teleology 99 'same-terms-ofexpressions/seemingly-same-implied-meaningfulness', so-construed insightfully and contextually as existential-transitioning-or-iterability-trace-of-narratives-asdots_or_implicited_attendant-ontological-contiguity ${ }^{67}$, educed-

existentialising/contextualising/textualising_intelligibility/epistemicity/reflexivity-contiguity$<$ imbued-notional $\sim$ cogency $>$-reification_or_intrinsic-reality-ontological-

coherence_or_superseding-oneness-of-ontology ${ }^{41}$ by $\quad{ }^{55}$ maximalising-recomposuring-forrelative-ontological-completeness ${ }^{87}$ - unenframed/re-ontologising $\sim$ conceptualisation, reflecting 'shallow/temporal superseding-oneness-of-ontology to deeper/intemporal supersedingoneness-of-ontology mental-conceptions teleologies'; from the perspective of a suprastructural superseding/transcending/deeper/intemporal superseding-oneness-of-ontology mentalconception teleology . - As beyond the epiphenomenon of psychopathy and social psychopathy, as it provides a peculiar perspective for insight on human placeholder-setup/mental-devisingrepresentation/mentation/consciousness-awareness-teleology ${ }^{99}$ with respect to ${ }^{83}$ reference-ofthought and meaningfulness; différance-disambiguation-of-ontologically-veridicalmeaningfulness-and-teleology implies preempting-disjointedness-as-of- reference-ofthought,-as-to- ${ }^{6}<$ amplituding/formative-epistemicity $>$ growth-orconflatedness ${ }^{13} /$ transvaluative-rationalising/transepistemicity/anamnestic-residuality/spiritdrivenness' - in-superseding-mere-formulaic-positivising/rational-empiricism-baseduniversalisation-directed-rulemaking-over-non-rules — apriorising/axiomatising/referencingpsychologism as deprocrypticism. Insightfully, ontological-normalcy/postconvergence establishes beyond human limited-mentation-capacity-deepening as limitedness/human-subpotency-to-'educed-unlimitedness/existence-sublimating nascence' that there is a potent and overall oneness/contiguity of ontologically-veridical meaningfulness 
which transverses and supersedes all other conceptualisations of ${ }^{83}$ reference-of-thought and meaningfulness (which are therefore approximates) by mere 'ontological-consistency' whether with regards to virtue conceptualisation (as highlighted with the intemporal-preservationentropy-or-contiguity-or-ontological-preservation) or second-level ontological constructs as is the case with subject matters conceptualisations. Ultimately, the capacity for philosophy to further clarify such an 'ontological-consistency' will be a further critical foundation for broadening the efficacy of all second-level ontologies (as the veritable job of philosophy). Inherently, 'ontological-consistency' as superseding-oneness-of-ontology is by itself the complete rationale for explaining human possibilities with regards to knowledge and virtue as so reflected/perspectivated by the very potency of ontological-normalcy/postconvergence, as the latter is the 'potency for all the text-of-ontologically-veridical-meaningfulness that can exist'. Ontological-consistency in the inherent intemporalisation/institutionalisation orientation of ontological-normalcy/postconvergence validates virtue conceptualisation not as a discreet notion of choice, but rather a necessary disposition as 'intemporal projection' (or longness-of-registerof- ${ }^{5}$ meaningfulness-and-teleology ${ }^{9}$ ) for human-mastery-of-reality or knowledge, as inherently implied by ontological-normalcy/postconvergence (prospective-transcendence-in-perpetuallyupholding-intemporal-preservation-entropy-or-contiguity-or-ontological-preservation). The reason is simple. It is impossible, for instance, for an utter-ununiversalisation setup 'to access' the emancipating ontological possibilities available to a prospective base-institutionalisation setup without the 'requisite solipsistic insight' of intemporal-disposition individuation within the recurrent-utter-uninstitutionalisation registry-worldview that 'projects' that rulemaking-overnon-rules_-apriorising/axiomatising/referencing-psychologism,-_as 'first-level presencingabsolutising-identitive-constitutedness ${ }^{14}$ of reference-of-thought' apriorising/axiomatising/referencing/intelligibilitysettingup/measuringinstrumenting $\rangle$ as a postconverging-de-mentating/structuring/paradigming for superseding the vices-and- 
impediments ${ }^{105}$ inherent to recurrent-utter-uninstitutionalisation is a necessity-for-its-own-andby-extension-the-registry-worldview's/dimension's 'moulting' in the middle to long run construed as of de-mentation-〈supererogatory ${ }^{15}$ ontological-de-mentation-or-dialectical-dementation-stranding-or-attributive-dialectics $\rangle$ into a base-institutionalisation registryworldview. Such solipsistic insight is the effective 'transcendental virtue conceptualisation' that drives ontological-normalcy/postconvergence across all the successive institutionalisations and by that token coincides with ontology as a necessary ontological development driver in an animal of shallow limited-mentation-capacity—as-subjecting-'educed-unlimitedness/existencesublimating nascence' to-limitedness/human-subpotency-〈as of relative apriorising/axiomatising/referencing-\{of-'prospectively_implicited_attendant-ontologicalcontiguity ' $\sim$ educedexistentialising/contextualising/textualising_'intelligibility/epistemicity/reflexivity-contiguity<imbued-notional cogency>' $\}$-constitutedness ${ }^{1}$ in preconverging entment $\rangle$ to deeper limited-mentation-capacity_as subjecting 'educed unlimitedness/existence sublimating nascence' to-limitedness/human-subpotency-〈as of relative apriorising/axiomatising/referencing-\{of-'prospectively implicited_attendant-ontologicalcontiguity ' educedexistentialising/contextualising/textualising_'intelligibility/epistemicity/reflexivity-contiguity<imbued-notional cogency>' \}-conflatedness ${ }^{13}$ in (preconverging disentalment by\} postconverging-entailment $\rangle$. This analysis is very much in line with the notion of virtue as a $<$ amplituding/formative-epistemicity $>$ totalising $\sim$ ratiocontiguity/ratiocination-asreferentialism - 'implicited_attendant-ontological-contiguity ${ }^{67}$; educedexistentialising/contextmalising/textualising_'intelligibility/epistemicity/reflexivity_contiguity$<$ imbued-notional cogency>' ;-phenomenal-abstractiveness-of-presencing-in-'protensiveconsciousness'-enabling- 
apriorising/axiomatising/referencing/intelligibilitysettingup/measuringinstrumenting-foroperant-or-incidenting-predicative-insights-of 'implicited_attendant_ontologicalcontiguity $^{67}$, educedexistentialising/contextualising/textualising_'intelligibility/epistemicity/reflexivity-contiguity$<$ imbued-notional cogency $>,{ }^{\prime},-<$ reifying-or-elucidating-of-prospective-relative-ontologicalcompleteness -of- reference-of-thought- devolving-as-of-instantiative-context> construal, representing virtue 'contiguously' in terms-as-of-axiomatic-construct of human limitedmentation-capacity-deepening —as-subjecting limitedness/human-subpotency-to-'educedunlimitedness/existence-sublimating nascence' ${ }^{53}$ of shortness-to-longness-of-register-ofmeaningfulness-and-teleology ${ }^{9}$ in the intransience of ontological-normalcy/postconvergence (from shallow superseding-oneness-of-ontology to deeper superseding-oneness-of-ontology). This ontology-driving nature of virtue characteristic of human-subpotencyaporia/undecidability/dilemma/ought-indeterminacy/deficiency/limitation/constraint—imbued'notional firstnaturedness-formativeness-<as-to-eventualising-inkling-drive-or-seedingmisprising $>$ temporal-to-intemporal-dispositions- $<$ so-construed-as-from-perspectiveontological-normalcy/postconvergence>'-existentialism-form-factor points out that it is rather such intemporality $52 /$ longness solipsistic 'transcendental virtue projection' that enables the superseding of the uninstitutionalised-threshold 02 of the various registryworldviews/dimensions as institutional-cumulation/institutional-recomposure-〈as-tohistoriality/ontological-eventfulness /ontological-aesthetic-tracing-<perspectiveontological-normalcy/postconvergence-reflected-‘epistemicity-relativism-determinism'>>. In other words, it is the necessary 'transcendental virtue projection' for a prospective registryworldview superseding the vices-and-impediments ${ }^{105}$ of the prior registry-worldview that enables the ontological possibilities for such prospective registry-worldview to even arise existentially; as the temporally-inclined recurrent-utter-institutionalised individuation is non- 
cognisant of any such thing as base-institutionalisation and the ontological possibilities availing to it, likewise with the temporally-inclined ununiversalised individuation with respect to universalisation and its ontological possibilities, the temporally-inclined nonpositivism/medievalism individuation with respect to the positivistic and its ontological possibilities, and prospectively the temporally-inclined procrypticism individuation with respect to notional ${ }^{8}$ deprocrypticism and its ontological possibilities, and all such possibilities as allowed by ontological-normalcy/postconvergence. A question that arises will be how can a society deliver an Einstein or a Bohr respectively that will articulate the theory-of-relativity or quantum-mechanics without it having the necessary institutional-recomposure (orientation and capacities) and memetic-reordering (of the individual mindset $/{ }^{3}$ reference-of-thought and associated other contributing mindsets) that allows for the possibility of such discoveries? In other words what was the possibility for the theory-of-relativity or quantum-mechanics to be delivered in the Middle Ages, for instance? Rather improbable. As a side note, such an insight equally attends to such a debate we currently entertain with respect to coming into contact with an advanced alien civilisation. A transcendental virtue conceptualisation will hold that in-thevery-first-place such a civilisation won't be able to exist without the necessary virtue construct (as successions of metaphysics-of-absence-〈implicited-epistemic-veracity-of- nonpresencing<perspective-ontological-normalcy/postconvergence $>>$ insights yielding in-lockstep the successively more ontologically profound metaphysics-of-presence-_implicited'nondescript/ignorable-void ' 'as-to- presencing - absolutising-identitive-constitutedness >

as implied by ontological-normalcy/postconvergence) that enables it to come into being; as necessarily they will be base-institutionalising, ${ }^{103}$ universalising, positivising and probably deprocrypticising, such that it will be untenable and inconsistent to have cosmic travellers that are savage-inclined or of a medieval age, for instance, going by the mere human-subpotencyaporia/undecidability/dilemma/ought-indeterminacy/deficiency/limitation/constraint—imbued- 
'notional firstnaturedness-formativeness-<as-to-eventualising-inkling-drive-or-seedingmisprising $>$ temporal-to-intemporal-dispositions-<so-construed-as-from-perspectiveontological-normalcy/postconvergence>'-existentialism-form-factor. Insightfully thus, while ontological-normalcy/postconvergence expands human ontological possibilities (comprehensively), it also leads to a growth in human institutionalised virtue disposition in equivalence which sustains such ontological development. However wary we should be with the possibility of nuclear annihilation, we equally can recognise that the 'better' registryworldview/dimension-level, in terms-as-of-axiomatic-construct of its relative transcendental virtue conceptualisation, to handle such weapons is the present one (positivistic) with regards to the possibility of averting a global annihilation compared to say feuding tribal or medieval setups (that is, if by some imaginary circumstances they could have access to and utilise such weapons). This points out that virtue is rather an inherent and necessary construct of ontology, existentially< disontologising/re-ontologising aporeticism $>$ speaking; as the transcendental construct that enables the expanding of the ontological possibilities of an animal of shallow limited-mentationcapacity-as-subjecting 'educed-unlimitedness/existence-sublimating nascence' tolimitedness/human-subpotency-〈as of relative apriorising/axiomatising/referencing-\{of'prospectively_implicited_attendant_ontological-contiguity ' educedexistentialising/contextualising/textualising_'intelligibility/epistemicity/reflexivity-contiguity<imbued-notional cogency>' $\}$-constitutedness ${ }^{1}$-in-preconverging-entailment $\rangle$ to deeper limited-mentation-capacity—as-subjecting-'educed-unlimitedness/existence-sublimating nascence' to-limitedness/human-subpotency-〈as of relative apriorising/axiomatising/referencing-\{of-'prospectively implicited_attendant-ontologicalcontiguity ' educedexistentialising/contextualising/textualising_'intelligibility/epistemicity/reflexivity-contiguity<imbued-notional cogency>' \}-conflatedness ${ }^{13}$-in-\{preconverging disentailment by\} 
postconverging-entailment $\rangle$ by enabling 'solipsistic moulting' (as 'intemporal-disposition individuation as of ontological-faith-notion-or-ontological-fideism-imbuedunderdetermination-of-motif-and-apriorising/axiomatising/referencing-as-so-being-as-ofexistential-reality' at uninstitutionalised-threshold ${ }^{102}$ states, with a human-subpotencyaporia/undecidability/dilemma/ought-indeterminacy/deficiency/limitation/constraint—imbued'notional firstnaturedness-formativeness-<as-to-eventualising -inkling-drive-or-seedingmisprising $>$ temporal-to-intemporal-dispositions- $<$ so-construed-as-from-perspectiveontological-normalcy/postconvergence>'-existentialism-form-factor mental-disposition due to lack of social ${ }^{103}$ universal-transparency ${ }^{104}$-〈transparency-of-totalising-entailing,-as-to-entailing<amplituding/formative-epistemicity>totalising in-relative-ontological-completeness $>$ about virtue inducing supplanting-conviction-as-to-profound-supererogation —of-'attendantintradimensional'-postconverging/dialectical-thinking -apriorising-psychologism') and the secondnaturing of the social-construct (as institutionalisation-as-virtue) including the requisite human psychical pivoting/decentering. In another respect, ontological-consistency as highlighted previously is in coherence with the notion of human-subpotencyaporia/undecidability/dilemma/ought-indeterminacy/deficiency/limitation/constraint—imbued'notional firstnaturedness-formativeness-<as-to-eventualising -inkling-drive-or-seedingmisprising $>$ temporal-to-intemporal-dispositions- $<$ so-construed-as-from-perspectiveontological-normalcy/postconvergence>'-existentialism-form-factor, and as of the circularity/recurrence/repetition/repeatability ${ }^{10}$ delineating existential-transitioning-oriterability-trace-of-narratives-as-dots_or_implicited_attendant-ontologicalcontiguity $^{67}$, educedexistentialising/contextualising/textualising_'intelligibility/epistemicity/reflexivity-contiguity$<$ imbued-notional $\sim$ cogency>' ${ }^{\prime}$-reification_or_intrinsic-reality-ontologicalcoherence_or_superseding-oneness-of-ontology with the implication that the 
'reflected/perspectivated notional firstnaturedness-formativeness-<as-toeventualising inkling-drive-or-seeding-misprising $>$ temporal-to-intemporal-dispositions$<$ so-construed-as-from-perspective-ontological-normalcy/postconvergence $>$ disambiguation' (at the uninstitutionalised-threshold ${ }^{102}$ ) as $<$ amplituding/formative-epistemicity $>$ causality $\sim$ asto-projective-totalitative-implications-of-prospective- nonpresencing,-forexplicating relative-unreflexivity/relative-reflexivity ontological-contiguity , underlines the iterability/iteration nature of ontologically-veridical-meaningfulness, grasped from the perpetuating intemporal-disposition 'ontological-reconstituting-as-toconflatedness ${ }^{13} /$ deconstruction realteration over the perpetuating hollow-constituting- $<$ asdisjointed-misappropriation-of-meaningfulness-and-failing-intemporal-preservation $>$ alteration by temporal-dispositions. Fundamentally, a normally institutionalised functional disposition warrants that there is a 'common/same ontological-reference of ontologically-veridicalmeaningfulness' but this is voided at the uninstitutionalised-threshold ${ }^{102}$ where temporaldispositions become temporally-preservational-as-pseudointemporality ${ }^{52}$-preservation whether by recurrence registry-worldview's/dimension's-uninstitutionalised-threshold ${ }^{102}$-defect- $<$ asBeing-or-ontological-or-existential-defect $>55$ (whether beyond-the-consciousness-awarenessteleology ${ }^{9}<$ of-preconverging-existential-extrication-as-of-existential-unthought $>$ ), as may arise with postlogism 7 -and-conjugated-postlogism 7 , with the effective consequence of 'temporal-to-intemporal-disambiguated-mental-dispositions' wherein the hollow-constituting<as-disjointed-misappropriation-of-meaningfulness-and-failing-intemporal-preservation> of temporal-dispositions are reflected/perspectivated as rather in temporal-preservation-aspseudointemporality ${ }^{52}$-preservation $\quad$ '<amplituding/formative-epistemicity $>$ totalising $\sim$ selfreferencing-syncretising', with their meaningfulness ontologically being suprastructured (as perverted beyond their consciousness-awareness-teleology ${ }^{9}$ ) by the intemporal-disposition in construing the <amplituding/formative-epistemicity $>$ causality $\sim$ as-to-projective-totalitative- 
implications-of-prospective- nonpresencing,-for-explicating relative-unreflexivity/relative-

reflexivity - ontological-contiguity as of the circularity/recurrence/repetition/repeatability delineating existential-transitioning-or-iterability-trace-of-narratives-asdots_or_implicited_attendant-ontological-contiguity ${ }^{67}$, educedexistentialising/contextmalising/textualising_'intelligibility/epistemicity/reflexivity_contiguity$<$ imbued-notional cogency>' ${ }^{\prime}$-reification_or_intrinsic-reality-ontological-

coherence_or_superseding-oneness-of-ontology ${ }^{41}$ This disambiguated-mental-dispositions as of the circularity/recurrence/repetition/repeatability ${ }^{10}$ delineating existential-transitioning-oriterability-trace-of-narratives-as-dots_or_implicited_attendant-ontologicalcontiguity $^{67}$, educedexistentialising/contextualising/textualising_'intelligibility/epistemicity/reflexivity-contiguity$<$ imbued-notional $\sim \operatorname{cogency}>{ }^{\prime}$-reification_or_intrinsic-reality-ontologicalcoherence_or_superseding-oneness-of-ontology develops, with changing contextualisation, at the registry-worldview/dimension or intradimensional level as the 'dynamic-cumulativeaftereffect of subontologisation' (slantedness/postlogic-effect, miscuing, disjointed-logic, logical-drag, unconscionability-drag, sub-par/formulaic-association/temporal/alibi conventioning-rationalising, and temporal-enculturation/temporal-endemisation-effect), and is equally characteristic across registry-worldviews; with the implication that this is an attribute of human-subpotency-aporia/undecidability/dilemma/oughtindeterminacy/deficiency/limitation/constraint—imbued-'notional firstnaturednessformativeness-<as-to-eventualising-inkling drive-or-seeding-misprising $>$ temporal-tointemporal-dispositions-<so-construed-as-from-perspective-ontologicalnormalcy/postconvergence >'-existentialism-form-factor. That is, the uninstitutionalisedthreshold ${ }^{02}$ is characterised by the 'trace of disambiguated-mental-dispositions as notional firstnaturedness-formativeness-<as-to-eventualising-inkling-drive-or-seeding 
misprising $>$ temporal-to-intemporal-dispositions- $<$ so-construed-as-from-perspective-

ontological-normalcy/postconvergence $>$ <amplituding/formative-epistemicity $>$ causality $\sim a$ to-projective-totalitative-implications-of-prospective- nonpresencing,-for-

explicating relative-unreflexivity/relative-reflexivity - ontological-contiguity . It is mainly a différance-disambiguation-of-ontologically-veridical- ${ }^{56}$ meaningfulness-and-teleology 9 that can establish the ontological-veridicality-of-meaningfulness precisely by disambiguating the effective ontological-references of the various notional firstnaturedness-formativeness-<as-toeventualising inkling-drive-or-seeding-misprising > temporal-to-intemporal-dispositions$<$ so-construed-as-from-perspective-ontological-normalcy/postconvergence $>$ individuations, and so not only at an instant or act or specific circumstance or context (which is rather an act construal and not a being/ontological construal) but projectively in their retrospective-to-presentto-prospective existentialism-deambulation/meandering which provides the full insight of notional firstnaturedness-formativeness-<as-to-eventualising inkling-drive-or-seedingmisprising $>$ temporal-to-intemporal-dispositions- $<$ so-construed-as-from-perspectiveontological-normalcy/postconvergence $>$ individuations mental-dispositions/meaningfulreferences/ontological-references/contending-references as ontological-entrapment. Such a being/ontological-basis, as described above, of a différance-disambiguation-of-ontologicallyveridical- ${ }^{5}$ meaningfulness-and-teleology ${ }^{9}$ is in line with and further elucidates the 'Différanceexistential-transitory-articulation-of-the-protraction-of- ${ }^{-1}$ perversion-of- ${ }^{8}$ reference-of-thought$<$ as-preconvergingly-apriorising/axiomatising/referencing-innonconviction/madeupness/bottomlining-as-to-shallow-supererogation >,-of-meaningfulness' technique. Going respectively by the Sartrean and Derridean principles for establishing ontologically-veridical-meaningfulness, that is, 'existence precedes/defines essence' or 'there is nothing outside the text' in evaluating 'same-terms-of-expressions (seemingly-same-impliedmeaningfulness)' with respect to their veridical-ontological ${ }^{83}$ reference-of-thought- categorical- 
imperatives/axioms/registry-teleology ${ }^{9}$,-for-intemporal-preservation-entropy-or-contiguityor-ontological-preservation in-various-instances as of the circularity/recurrence/repetition/repeatability ${ }^{10}$ delineating existential-transitioning-oriterability-trace-of-narratives-as-dots_or_implicited_attendant-ontologicalcontiguity $^{67}$, educedexistentialising/contextualising/textualising_intelligibility/epistemicity/reflexivity-contiguity$<$ imbued-notional $\sim$ cogency $>$ 'reification_or_intrinsic-reality-ontologicalcoherence_or_superseding-oneness-of-ontology ${ }^{41}$ by $\quad{ }^{55}$ maximalising-recomposuring-forrelative-ontological-completeness ${ }^{8}$ - unenframed/re-ontologising conceptualisation. What is critical to understand here is to distinguish between: (i) recurrence in existential-transitioningor-iterability-trace-of-narratives-as-dots_or_implicited_attendant_ontologicalcontiguity ${ }^{67} \sim$ educedexistentialising/contextualising/textualising_'intelligibility/epistemicity/reflexivity-contiguity$<$ imbued-notional cogency>' -reification_or_intrinsic-reality-ontologicalcoherence_or_superseding-oneness-of-ontology ${ }^{41}$ by ${ }^{55}$ maximalising-recomposuring-forrelative-ontological-completeness ${ }^{8}$ —unenframed/re-ontologising conceptualisation basis of meaningfulness that is grounded on grasping that ${ }^{83}$ reference-of-thought- categoricalimperatives/axioms/registry-teleology ${ }^{9}$,-for-intemporal-preservation-entropy-or-contiguityor-ontological-preservation are deterministic by virtue of reflecting/perspectivating/highlighting their recurrent context of reality and thus subjects them to 'ontological-reconstituting-as-toconflatedness ${ }^{13} \%$ deconstruction in upholding intemporal-preservation-entropy-or-contiguityor-ontological-preservation, and (ii) an elaboration-as-to-mereextrapolating/constituting/abstracting/deducing/inferring-of-elucidation-outside'prospectively_implicited_attendant_ontological-contiguity ${ }^{67}$ ' educedexistentialising/contextualising/textualising_intelligibility/epistemicity/reflexivity-contiguity- 
$<$ imbued-notional cogency $>$ basis of meaningfulness that is purely and wrongly grounded on grasping that ${ }^{83}$ reference-of-thought- categorical-imperatives/axioms/registry-teleology ${ }^{9}$,-forintemporal-preservation-entropy-or-contiguity-or-ontological-preservation' are by themselves abstractly deterministic, even as this fail intemporal-preservation-entropy-or-contiguity-orontological-preservation as of ontological-normalcy/postconvergence which always factor in human limited-mentation-capacity-deepening —as-subjecting limitedness/human-subpotencyto-'educed-unlimitedness/existence-sublimating nascence' 33 by a re-equilibrating metaphysicsof-absence-〈implicited-epistemic-veracity-of- nonpresencing-<perspective-ontologicalnormalcy/postconvergence $>$ /postdication, and thus subjects meaningfulness to hollowconstituting-<as-disjointed-misappropriation-of-meaningfulness-and-failing-intemporalpreservation>. Intemporal-disposition as supplanting-conviction-as-to-profoundsupererogation —of-'attendant-intradimensional'-postconverging/dialectical-thinking apriorising-psychologism disposition (whether appropriate/good or inappropriate/poor-or-'poor or bad supplanting-conviction-as-to-profound-supererogation - of-'attendantintradimensional'-postconverging/dialectical-thinking -apriorising-psychologism') are construed as of the circularity/recurrence/repetition/repeatability ${ }^{10}$ delineating existentialtransitioning-or-iterability-trace-of-narratives-as-dots_or_implicited_attendant-ontologicalcontiguity $^{67}$ ? educedexistentialising/contextualising/textualising_'intelligibility/epistemicity/reflexivity-contiguity$<$ imbued-notional $\sim \operatorname{cogency}>{ }^{\prime}$-reification_or_intrinsic-reality-ontologicalcoherence_or_superseding-oneness-of-ontology ${ }^{41}$ by ${ }^{55}$ maximalising-recomposuring-forrelative-ontological-completeness ${ }^{87}$ - unenframed/re-ontologising conceptualisation basis of meaningfulness on the ground that successive-instances-of-'existential-transitioning-oriterability-trace-of-narratives-as-dots_or_implicited_attendant-ontologicalcontiguity $^{67} \sim$ educed- 
existentialising/contextualising/textualising_intelligibility/epistemicity/reflexivity-contiguity$<$ imbued-notional cogency>' ${ }^{\prime}$-reification_or_intrinsic-reality-ontological-

coherence_or_superseding-oneness-of-ontology ${ }^{41}$ by ${ }^{55}$ maximalising-recomposuring-forrelative-ontological-completeness 37 unenframed/re-ontologising conceptualisation requires their subjection to 'ontological-reconstituting-as-to-conflatedness ${ }^{13} \%$ deconstruction to establish the existential-<disontologising/re-ontologising aporeticism $>$ context of reality thus establishing ontologically-veridical-meaningfulness. On-the-other-hand, the postlogic/psychopathic disposition (and by extension temporal-dispositions conjugatedpostlogism 77 preconverging-or-dementing ${ }^{20}$-integration dispositions) adhere to an elaborationas-to-mere-extrapolating/constituting/abstracting/deducing/inferring-of-elucidation-outside'prospectively_implicited_attendant_ontological-contiguity ${ }^{67}$ 'educedexistentialising/contextualising/textualising_intelligibility/epistemicity/reflexivity-contiguity$<$ imbued-notional cogency $>$ ' basis of meaningfulness on the ground that plausibly construing a false-premising to an existential-context-of-reference-narrative 'provides licence' to then ('recursively' in concurrence -in the case of the postlogic/psychopathic character, progressively -in the case of a conjugated-exacerbatory and conjugated-opportunism characters, and regressively -in the case of a conjugated-ignorance and conjugated-affordability characters) comprehensively articulate any possible existentially-unreal-and-abstract-narratives (on the basis of a conceptualisation of mere hollow-constituting-<as-disjointed-misappropriation-ofmeaningfulness-and-failing-intemporal-preservation $>$ static-or-abstract non-veridical/vacuousstate of essence-of-meaningfulness' with respect to ${ }^{83}$ reference-of-thought- categoricalimperatives/axioms/registry-teleology ${ }^{9}$ and hence failing/not-upholding-<as-ofapriorising/axiomatising/referencing $>\quad$ intemporal-preservation-entropy-or-contiguity-orontological-preservation) by exploiting the plausibility derived from the concurrently-falsepremising existential-context-of-reference-narrative. So the latter disposition, and so particularly 
with the postlogic/psychopathic mindset, is to induce or generate or exploit any plausible existential-context-of-reference-narrative to then unleash slanted-and-formulaic hollow existentially-unreal-and-abstract narratives by concurrently-false-premising on the plausible existential-context-of-reference-narrative. In other words, the postlogic/psychopathic individuation character gets that there is a human mental-reflex to grasp ontologically-veridicalmeaningfulness on 'static-or-abstract non-veridical/vacuous-state (abstract ${ }^{83}$ reference-ofthought- ${ }^{8}$ ategorical-imperatives/axioms/registry-teleology ${ }^{9}$ ) of essence-of-meaningfulness terms, so long as their existential-<disontologising/re-ontologising aporeticism $>$ basis is established, including and critically for its purpose, where it is so deceptively implied', to artificially or opportunistically construe a plausible existential-context-of-reference-narrative which then 'provides licence' to articulate existentially-unreal-and-abstract-narratives in hollowconstituting-<as-disjointed-misappropriation-of-meaningfulness-and-failing-intemporalpreservation> concurrently-false-premising on the initial plausible existential-context-ofreference-narrative, with the idea that that human mental-reflex will by reflex naively-andwrongly imply the existential/contextualisation ontological-veridicality of its generated slantedand-formulaic hollow existentially-unreal-and-abstract-narratives; and so, in terms-as-ofaxiomatic-construct of the 'apriorising- ${ }^{83}$ reference-of-thought/apriorising-registry-elements (out of implicited_attendant-ontological-contiguity ${ }^{67}$ ' educedexistentialising/contextualising/textualising_intelligibility/epistemicity/reflexivity-contiguity$<$ imbued-notional $\sim$ cogency $>,{ }^{\prime},-<$ reifying-or-elucidating-of-prospective-relative-ontologicalcompleteness -of- reference-of-thought- devolving-as-of-instantiative-context $>$ )' as apistemictotalising $3{ }^{3}$ psychologismic-subliminality-of-individuation-effusing/worlding imbued logicaldueness-or-scape-or-frame, profile-or-stature, presumptuousness-or-arrogation, assumptions, value-reference and teleology ${ }^{9}$ as highlighted priorly. This preconverging-or-dementing 2 apriorising-psychologism is in contrast with a postconverging-or-dialectical-thinking - 
apriorising-psychologism (when the latter is of inappropriate/bad or appropriate/good supplanting-conviction-as-to-profound-supererogation of-'attendant-intradimensional'postconverging/dialectical-thinking -apriorising-psychologism) which is always inclined to ensure that the succession-of-narratives it propounds are tied to successive-instances as of the circularity/recurrence/repetition/repeatability ${ }^{10}$ delineating existential-transitioning-oriterability-trace-of-narratives-as-dots_or_implicited_attendant_ontologicalcontiguity $^{67} \sim$ educedexistentialising/contextualising/textualising_intelligibility/epistemicity/reflexivity-contiguity$<$ imbued-notional $\sim$ cogency $>$ 'reification_or_intrinsic-reality-ontologicalcoherence_or_superseding-oneness-of-ontology ${ }^{41}$ by ${ }^{55}$ maximalising-recomposuring-forrelative-ontological-completeness ${ }^{8}$ - unenframed/re-ontologising conceptualisation. Thus, the reason why the ontological construal (ontological-entrapment) of the postlogic/psychopathic individuation characters and conjugated-postlogism 77 preconverging-or-dementing ${ }^{20}$ integration individuation characters is rather as an intemporal/ontological suprastructuring (implying $\quad{ }^{15}$ de-mentation-〈supererogatory $\sim$ ontological-de-mentation-or-dialectical-dementation - stranding-or-attributive-dialectics $\rangle)$ of their hollow-constituting-<as-disjointedmisappropriation-of-meaningfulness-and-failing-intemporal-preservation> of ontologicallyveridical-meaningfulness, as this fail intemporal-preservation-entropy-or-contiguity-orontological-preservation. Going by the example of a medieval setup again as effectively in $<$ amplituding/formative-epistemicity $>$ totalising $\sim$ ratiocontiguity/ratiocination-asreferentialism—'implicited_attendant_ontological-contiguity ${ }^{67}$ ' educedexistentialising/contextualising/textualising_'intelligibility/epistemicity/reflexivity-contiguity$<$ imbued-notional cogency>' ;-phenomenal-abstractiveness-of-presencing-in-'protensiveconsciousness'-enablingapriorising/axiomatising/referencing/intelligibilitysettingup/measuringinstrumenting-for- 
operant-or-incidenting-predicative-insights-of 'implicited_attendant_ontologicalcontiguity ${ }^{67} \sim$ educed-

existentialising/contextualising/textualising_'intelligibility/epistemicity/reflexivity-contiguity$<$ imbued-notional $\sim$ cogency $>,{ }^{\prime},-<$ reifying-or-elucidating-of-prospective-relative-ontologicalcompleteness -of- reference-of-thought- devolving-as-of-instantiative-context> and not analogy (epistemic-totalising $\sim$ ratiocontiguity/ratiocination-as-referentialism'implicited_attendant-ontological-contiguity ${ }^{6}$ ' educedexistentialising/contextualising/textualising_intelligibility/epistemicity/reflexivity-contiguity$<$ imbued-notional cogency>' ;-phenomenal-abstractiveness-of-presencing-in-'protensiveconsciousness'-enabling-

apriorising/axiomatising/referencing/intelligibilitysettingup/measuringinstrumenting-foroperant-or-incidenting-predicative-insights-of 'implicited_attendant-ontologicalcontiguity $^{67}$, educedexistentialising/contextualising/textualising_intelligibility/epistemicity/reflexivity-contiguity$<$ imbued-notional $\sim \operatorname{cogency}>{ }^{,},-<$reifying-or-elucidating-of-prospective-relative-ontologicalcompleteness -of- reference-of-thought- devolving-as-of-instantiative-context> insightfully implying all institutionalisations/registry-worldviews/dimensions are about "construing the same underlying ontology', though yield different but more and more accurate representations of ontology, due to different but improving human limited-mentation-capacity-as-subjecting'educed-unlimitedness/existence-sublimating nascence' to-limitedness/human-subpotency-〈as from apriorising/axiomatising/referencing-\{of-'prospectively_implicited_attendantontological-contiguity ' educedexistentialising/contextualising/textualising_ intelligibility/epistemicity/reflexivity-contiguity$<$ imbued-notional cogency $>\quad\}$ - constitutedness ${ }^{\prime}$ - in - preconverging-entailment towards apriorising/axiomatising/referencing-\{of-'prospectively_implicited_attendant-ontological- 
contiguity ' educed-

existentialising/contextualising/textualising_'intelligibility/epistemicity/reflexivity_contiguity<imbued-notional cogency >' \}-conflatedness ${ }^{13}$-in-\{preconverging disentailment by\} from shallow-to-deepening-limited-mentation-capacity-assubjecting 'educed unlimitedness/existence sublimating nascence' to limitedness/humansubpotency, as-limited-mentation-capacity-deepening—as-subjecting limitedness/humansubpotency-to-'educed-unlimitedness/existence-sublimating nascence' ${ }^{53}$ with the succession of institutionalisations, but with the non-positivism/medievalism as being lower from our positivistic perspective, thus providing a sound basis of transcendental analytical insight since the positivistic present is in metaphysics-of-absence-〈implicited-epistemic-veracity-ofnonpresencing-<perspective-ontological-normalcy/postconvergence $>\rangle$ with it, in contrast to our more or less blurred disposition to <amplituding/formative-epistemicity $>$ totalising $\sim$ selfreferencing-syncretising/circularity/interiorising/akrasiatic-drag 34 when analysing transcendental issues within our present positivistic/procryptic registry-worldview/dimension as its own metaphysics-of-presence-〈implicited-'nondescript/ignorable-void ' 'as-topresencing - absolutising-identitive-constitutedness > problem), if say a totem was to be presented as proof that a targeted individual was a sorcerer (as existential-context-of-referencenarrative) for establishing plausibility for subsequent comprehensive articulation of existentially-unreal-and-abstract-narratives accusing the target of sorcery, a transcendental/utter/intemporal conceptualisation will imply rather a prospective ontologicalreference of essence-of-meaningfulness as positivism, with the ontologicalnormalcy/postconvergence implication of construing not only the accuser as being of 'medieval mental-perversion/ $/$ perversion-of- ${ }^{-}$reference-of-thought- $<$as-preconverginglyapriorising/axiomatising/referencing-in-nonconviction/madeupness/bottomlining-as-toshallow-supererogation $>$ but the temporal-dispositions and overall social-enculturation of that 
inclination abstractly with respect to metaphorically-a-million-and-one-instances-andlocales/aetiologically/ontological-escalation as a fundamental ontological/being-construaldefect of such a medieval ${ }^{83}$ reference-of-thought; noting as well that there is no need ontologically/intemporally for such a target to adjust to such accusation but rather a dismissive disposition with respect to such ${ }^{7}$ perversion-of- ${ }^{8}$ reference-of-thought- $<$ as-preconverginglyapriorising/axiomatising/referencing-in-nonconviction/madeupness/bottomlining-as-toshallow-supererogation $>$ as to preconverging-or-dementing ${ }^{20}$-apriorising-psychologism and its defective ontological-reference of meaningfulness, as acting otherwise like 'being logical' with such implied meaningfulness by saying for instance it is not its totem or it doesn't know about it or it is somebody else', wrongly validates that the ${ }^{83}$ reference-of-thought of such medieval accusation is valid and is thus rather contributing then to upholding its temporalenculturation/temporal-endemisation, as where there is ${ }^{7}$ perversion-of- ${ }^{3}$ reference-of-thought$<$ as-preconvergingly-apriorising/axiomatising/referencing-in-

nonconviction/madeupness/bottomlining-as-to-shallow-supererogation $>$ there is no logicaldueness and from thence enabling the construing of relevant soundness or unsoundness of logical-processing-or-logical-implicitation-supposedly-apriorising-in-conviction-as-toprofound-supererogation ) to start with in-the-very-first-place but rather a superseding/transcendental representation of such ${ }^{7}$ perversion-of- ${ }^{8}$ reference-of-thought- $<$ aspreconvergingly-apriorising/axiomatising/referencing-innonconviction/madeupness/bottomlining-as-to-shallow-supererogation $>$ as unsoundness-orontological-bad-faith/inauthenticity ${ }^{6}$-of- ${ }^{3}$ reference-of-thought/preconverging-ordementing -apriorising-psychologism and actually implying a suprastructuring (beyond its consciousness-awareness-teleology ${ }^{90}$ at the said (non-positivism/medievalism) uninstitutionalised-threshold ${ }^{102}$ requiring positivism registry-worldview ${ }^{83}$ reference-of-thought institutionalisation. Thus unlike in a case of defect-of- logical-processing-or-logical- 
implicitation - supposedly-apriorising-in-conviction-as-to-profound-supererogation of the registry-worldview's/dimension's- ${ }^{83}$ reference-of-thought-for-social-functioning-andaccordance the idea of falling-back to the same exercise to correctly do the exercise $\left({ }^{5}\right.$ logicalprocessing-or-logical-implicitation-supposedly-apriorising-in-conviction-as-to-profoundsupererogation ) in a same or different circumstance, is invalidated when dealing with perversion-of- ${ }^{3}$ reference-of-thought-<as-preconverginglyapriorising/axiomatising/referencing-in-nonconviction/madeupness/bottomlining-as-toshallow-supererogation $>\quad$ as $\quad$ registry-worldview's/dimension's-uninstitutionalisedthreshold ${ }^{102}$-defect-<as-Being-or-ontological-or-existential-defect ${ }^{85}$ (with regards to both postlogism 77 and conjugated-postlogism 77 ; with the implication that there can't be mutual contention but rather transversality- $<$ for-sublimating-existential-eventuating/denouement-

\section{from-'thinking at-first/pure-predisposition-preemptive-of prospective-}

\section{disontologising/subontologising’ as-of-prospectively-disambiguated-affirmed-and-}

unaffirmed-'motif-and-apriorising/axiomatising/referencing' $>{ }^{101}$ wherein the superseding (and ontologically-veridical) ${ }^{83}$ reference-of-thought can only construe of the superseded (and ontologically unsound) as preconverging-or-dementing ${ }^{20}$-apriorisingpsychologism/unsoundness-or-ontological-bad-faith/inauthenticity ${ }^{6}$-of- ${ }^{3}$ reference-ofthought/oblongated requiring psychoanalytic-unshackling/memetic-reordering/institutionalrecomposuring to transcend into the superseding ${ }^{83}$ reference-of-thought in the very first instance, before any ontologically-veridical pretence to mutual contention. Certainly this same reaction is what is warranted in the example highlighted before (if an adult psychopath were to meet a stranger and spoke to him about another stranger whom it knows nothing about,...) In the bigger perspective with regards to the institutionalisation of notional ${ }^{18}$ deprocrypticism for instance, it is such an existentialism construal from a transcendental intemporal ${ }^{83}$ reference-of-thought over temporal perversion-of- ${ }^{-}$reference-of-thought-<as-preconvergingly- 
apriorising/axiomatising/referencing-in-nonconviction/madeupness/bottomlining-as-to-

shallow-supererogation $>$ that allows for the superseding of vices-and-impediments ${ }^{105}$ as prospective registry-worldview/dimension structural-resolution of positivism- ${ }^{80}$ procrypticism preconverging-or-dementing ${ }^{20}$-apriorising-psychologism. It should be noted that as earlier articulated, intemporal/ontological/social/species $/{ }^{103}$ universal/transcendental $/{ }^{5}$ maximalisingrecomposuring-for-relative-ontological-completeness ${ }^{87}$ - unenframed/re-

ontologising conceptualisation postconverging-de-mentating/structuring/paradigming (in contrast to a temporal extricatory preconverging-de-mentating/structuring/paradigming) can only be transcendental as superseding (by implying an altogether different ${ }^{83}$ reference-ofthought as 'postconverging-or-dialectical-thinking -apriorising-psychologism'), and not incremental/'disjointedness-as-of- ${ }^{8}$ reference-of-thought' (wrongly operating on the same temporal registry-worldview's/dimension's-uninstitutionalised-threshold ${ }^{102}$-defect- $<$ as-Beingor-ontological-or-existential-defect $>{ }^{53}$ reference-of-thought which is actually preconvergingor-dementing ${ }^{20}$-apriorising-psychologism/oblongated and dialectically/contendingly-out-ofphase). Taking the previously articulated case of sorcery in a non-positivism/medievalism setup, it has no ontological structural-resolution by reciprocity of sorcery accusations on the same reference-of-thought terms but rather by the transcendental undermining of such nonpositivism/medievalism mindset/ ${ }^{3}$ reference-of-thought with an altogether superseding positivistic ${ }^{83}$ reference-of-thought that is in transversality-<for-sublimating-existentialeventuating/denouement,-from-'thinking at-first/pure-predisposition-preemptive-ofprospective-disontologising/subontologising' as-of-prospectively-disambiguated-affirmedand-unaffirmed-'motif-and-apriorising/axiomatising/referencing'>101 with a nonpositivism/medievalism ontological-reference (registry-worldview). Even though, inevitably (and as in the 'present as-present-consciousness' of all registry-worldviews/dimensions with regards to their own corresponding 7 perversion-of- ${ }^{3}$ reference-of-thought-<as-preconvergingly- 
apriorising/axiomatising/referencing-in-nonconviction/madeupness/bottomlining-as-to-

shallow-supererogation $>$ phenomena), there is bound to be more or less a dumb-and-dumb effect of summative social acquiescence to a superstitious mindset/ ${ }^{83}$ reference-of-thought in a non-positivism/medievalism setup, that will in the short term temporal perspective be a drawback to such a transcendental projection of positivistic mental-disposition, and likewise there will inevitably be more or less be a dumb-and-dumb effect of summative social discontentment where a transcendental notional ${ }^{1}$ deprocrypticism mental-disposition is implied in a procrypticism setup. This shows that going by human-subpotencyaporia/undecidability/dilemma/ought-indeterminacy/deficiency/limitation/constraint—imbued'notional firstnaturedness-formativeness-<as-to-eventualising -inkling-drive-or-seedingmisprising $>$ temporal-to-intemporal-dispositions- $<$ so-construed-as-from-perspectiveontological-normalcy/postconvergence >'-existentialism-form-factor, in all registryworldviews/dimensions the more or less summative mindset/ ${ }^{3}$ reference-of-thought is bound to be incremental/'disjointedness-as-of- ${ }^{~}$ reference-of-thought' and not transcending such that would-be emancipating individuation's projection (that is, if ontologically pertinent) is necessarily the middle to long run construed as of ${ }^{15}$ de-mentation-〈supererogatory $\sim$ ontologicalde-mentation-or-dialectical-de-mentation - stranding-or-attributive-dialectics $\rangle$ percolationchannelling- $<$ in-deferential-formalisation-transference $>$ for the necessary 'postconverging-ordialectical-thinking -psychology or psychology-of-mentation-dynamics or natural psychological-dynamics’ psychoanalytic-unshackling/memeticreordering/institutional-recomposuring accompanying such prospective transcendental institutionalisation. That is, by transcendence-and-sublimity/sublimation/supereregatory $\sim$ dementativity is meant dispose to construe the ontological resolution of an intradimensional ontological/being-construal-defect transcendentally/transdimensionally/interdimensionally; for instance, capable of putting in question non-positivism/medievalism intradimensional 
superstition as of the registry-worldview defect in the first place supersedingly/transcendentally rather than a usual attendant/incidental reciprocity of superstitious contentions or capable of putting-into-question procrypticism/perversion-of-positivistic-meaningfulness with its corresponding postlogism 7 -and-conjugated-postlogism of psychopathy and social psychopathy as of the registry-worldview in-the-very-first-place supersedingly/transcendentally rather than a temporally reciprocal equivalence. Basically, such an intemporaldisposition/ontologically-veridical transcendental disposition storied-construct/ontologicallyvalid-narration will be of sublimating-epistemic-imbricatedness/threadedness/recomposuring as existential-tracing of ontologically-veridical-meaningfulness reflecting temporal-dispositions rather in 'virtuality-or-Being-construal-as-abstract-construal-as-of-flawed-and-shallow-andnon-veridical-existential-reference'. The fact being that, in the short term, the temporallyminded recurrent-utter-institutionalised individuation has no place for the 'transcendental rulemaking-over-non-rules_ — apriorising/axiomatising/referencing-psychologism,-_as'firstlevel presencing-absolutising-identitive-constitutedness ${ }^{14}$ of reference-of-thought' apriorising/axiomatising/referencing/intelligibilitysettingup/measuringinstrumenting notion' (for base-institutionalisation) of the intemporal-minded individuation; the temporally-minded ununiversalised individuation (in base-institutionalisation) has no place for the 'transcendental rules ${ }^{103}$ universalising notion' of the intemporal-minded individuation; the temporally-minded non-positivism/medievalism individuation has no place for the 'transcendental positivising/rational-empiricism notion' of the intemporal-minded individuation; and likewise, prospectively, the temporally-minded procrypticism individuation has no place for the 'transcendental deprocrypticism/rational-realism notion' of the intemporal-minded individuation; rather as the subontologisation/subpotentiation moves from slantedness-effect, miscuing towards sub-par/formulaic-association/temporal/alibi conventioning-rationalising in all the different registry-worldviews/dimensions, 'for intradimensional functionality sake a 
transcendental articulation is beyond the intradimensional summative mental-disposition of value-referencing', as the summative mental projection of individuals is more of an earthily lifespan conceptualisation rather than transcendental or poorly appreciative of the transcendentalism that is preconverging/postconverging-de-mentatively/structurally/paradigmatically responsible for present ${ }^{83}$ reference-of-thought to project to the postconverging-dementating/structuring/paradigming need of prospective transcendence-andsublimity/sublimation/supererogatory de-mentativity. This further points out that with regards to 'metaphysics-of-absence-〈implicited-epistemic-veracity-of- nonpresencing-<perspectiveontological-normalcy/postconvergence $>$ ') projection (in overcoming the illusion-of-thepresent/present-consciousness/mirage/episticing $\sim$ self-referencing-syncretising), across all registry-worldviews/dimensions from prior to prospective there are basically two ways by which the placeholder-setup/mental-devising-representation/mentation/consciousnessawareness-teleology ${ }^{9}$ works with respect to the same intrinsic-reality/ontologically-veridicalmeaningfulness; for the 'intradimensional reflex' sake of having a coherent functioning by sharing a common/same ${ }^{83}$ reference-of-thought as it is obvious that if one was to drop in a thoroughly non-positivism/medievalism setup and insisted absolutely to articulate meaningfulness in positivistic terms, there will be no mutual understanding, at least at the (positivistic) uninstitutionalised-threshold ${ }^{12}$ of that medieval setup, whether at one moment or another it fails intrinsic-reality/ontologically-veridical-meaningfulness/intemporal-preservationentropy-or-contiguity-or-ontological-preservation, any registry-worldview/dimension as prior wrongly represents that such its registry-worldview's/dimension's-uninstitutionalisedthreshold $^{102}-$ defect-<as-Being-or-ontological-or-existential-defect $>55$ is nontranscendable/unsupersedable by its <amplituding/formative-epistemicity $>$ totalising $\sim$ selfreferencing-syncretising/illusion-of-the-present/present-consciousness/mirage as 'metaphysicsof-presence-〈implicited-'nondescript/ignorable-void ' -as-to- presencing — absolutising- 
identitive-constitutedness $\rangle^{\prime}$ thus upholding its soundness-or-ontological-goodfaith/authenticity ${ }^{6}$-of- ${ }^{8}$ reference-of-thought by ignoring the registry-worldview's/dimension'suninstitutionalised-threshold ${ }^{102}$-defect-<as-Being-or-ontological-or-existential-defect $>{ }^{85}$ while the prospective registry-worldview/dimension implying a new ${ }^{83}$ reference-of-thought that preconverging/postconverging-de-mentatively/structurally/paradigmatically resolves the prior's registry-worldview's/dimension's-uninstitutionalised-threshold ${ }^{102}$-defect-<as-Being-orontological-or-existential-defect $>5$ represents the prior as prior/transcended/superseded and hence unsoundness-or-ontological-bad-faith/inauthenticity ${ }^{64}$-of- ${ }^{8}$ reference-ofthought/preconverging-or-dementing ${ }^{20}$-apriorising-psychologism/suprastructurable (at that uninstitutionalised-threshold ${ }^{102}$ ). The bigger point here is that just as we will represent the nonpositivism/medievalism placeholder-setup/mental-devisingrepresentation/mentation/consciousness-awareness-teleology ${ }^{9}$ allusions to superstition in its $<$ amplituding/formative-epistemicity $>$ totalising $\sim$ self-referencing-syncretising/illusion-of-thepresent/present-consciousness/mirage as utterly preconverging-or-dementing ${ }^{20}$-apriorisingpsychologism and unintelligible/existentially-suprastructured, a notional ${ }^{18}$ deprocrypticism placeholder-setup/mental-devising-representation/mentation/\{cumulated/recomposured \}consciousness-awareness-teleology ${ }^{9}$ of ${ }^{80}$ procrypticism-or-disjointedness-as-of- ${ }^{8}$ referenceof-thought mindset/ ${ }^{8}$ reference-of-thought will rather be construed as decentered and preconverging-or-dementing 20 -apriorising-psychologism, unintelligible/existentiallysuprastructured with respect to 'our positivism- ${ }^{80}$ procrypticism terms of meaningfulness' that is, at the (deprocrypticism) uninstitutionalised-threshold ${ }^{102}$ in order to effectively and adequately reflect the requisite metaphysics-of-absence-_implicited-epistemic-veracity-of- nonpresencing$<$ perspective-ontological-normalcy/postconvergence $>>$ necessary to act as the referenced/registered/decisioned-psychical-backdrop for futural Beingdevelopment/ontological-framework-expansion-as-to-depth-of-ontologising-development-as- 
infrastructure-of- meaningfulness-and-teleology as of prospective deprocrypticism, as implied by de-mentation-〈supererogatory ${ }^{15}$ ontological-de-mentation-or-dialectical-dementation - stranding-or-attributive-dialectics $>\quad$ as-uninstitutionalised-threshold ${ }^{102}$ suprastructuring ${ }^{15}$ de-mentation-〈supererogatory $\sim$ ontological-de-mentation-or-dialectical-dementation - stranding-or-attributive-dialectics $\rangle$ that is the mechanism of a 'postconverging-ordialectical-thinking -psychology or psychology-of-mentation-dynamics or natural psychological-dynamics’ psychoanalytic-unshackling/memeticreordering/institutional-recomposuring for prospective institutionalisation. This latter notion is important as with all psychoanalysis whether of an individual or social conceptualisation nature, the idea of recognising/referencing/registering/decisioning the registryworldview's/dimension's-uninstitutionalised-threshold ${ }^{102}$-defect-<as-Being-or-ontological-orexistential-defect $>5$ is central to superseding it, and so the idea of implying preconverging-ordementing -apriorising-psychologism/out-of-phase/dialectically-primitive is 'beyond the notion of an idle denotative exercise', be it validly so, and the meaningfulness of such conceptualisations certainly do not carry the poorer connotations of temporal/banal mentaldispositions, but rather it is technically a necessary and useful ontological conceptualisation in the psychoanalytic-unshackling/memetic-reordering/institutional-recomposuring from our shallow limited-mentation-capacity—as-subjecting-'educed-unlimitedness/existencesublimating nascence' to limitedness/human-subpotency-〈as of relative apriorising/axiomatising/referencing-\{of-'prospectively_implicited_attendant-ontologicalcontiguity ' $\sim$ educedexistentialising/contextualising/textualising_ intelligibility/epistemicity/reflexivity-contiguity$<$ imbued-notional cogency>' $\}$-constitutedness ${ }^{1}$ in preconverging limited-mentation-capacity as subjecting ' aluced mnlimithess/existence sublimating nascence' to-limitedness/human-subpotency-〈as of relative 
apriorising/axiomatising/referencing-\{of-'prospectively_implicited_attendant-ontological-

contiguity ' educed-

existentialising/contextualising/textualising_ 'intelligibility/epistemicity/reflexivity-contiguity-

<imbued-notional cogency >' \}-conflatedness ${ }^{13}$ in-\{preconverging-disentailment by\}

postconverging-entailment $\rangle$. Thus psychoanalysis is actually in effect an existentialism process of human skewing towards intemporal-disposition as we construe meaningfulness and valuereferencing, and so beyond the Foucauldian referenced critique of a relatively 'economic/traded/exchange/battered' conceptualisation of psychology we know of when we talk of psychoanalysis in the subject matter of psychology, but rather construed as a natural ontologically-driven 'postconverging-or-dialectical-thinking -psychology or psychology-ofmentation-dynamics or natural $\sim$ psychological-dynamics' behind human secondnaturing across the

successive

institutional-cumulation/institutional-recomposure-〈as-to-

historiality/ontological-eventfulness /ontological-aesthetic-tracing-<perspective-

ontological-normalcy/postconvergence-reflected-‘epistemicity-relativism-determinism'>> in reflecting holographically-<conjugatively-and-transfusively $>$ the relative mreflexivityolativereflexivity ontological-contiguity of-the-human-institutionalisation-process. As a side note though, it is important to grasp that the registry-worldviews/dimensions as the institutionalcumulation/institutional-recomposure-〈as-to- historiality/ontologicaleventfulness /ontological-aesthetic-tracing-<perspective-ontologicalnormalcy/postconvergence-reflected-‘epistemicity-relativism-determinism' $>>$ are actually broad categorisations and that actually human placeholder-setup/mental-devisingrepresentation/mentation/consciousness-awareness-teleology ${ }^{9}$ of intrinsicreality/ontologically-veridical-meaningfulness varies (though not varying in terms-as-ofaxiomatic-construct of the central defining conceptualisation of each registryworldview/dimension) within each registry-worldview/dimension from its early to later 
spectrum, given human more or less passive continuous psychoanalytic readjustment to 'ontological experience'. For instance, there is certainly a marked difference in scope and depth between the positivistic construct in the th century with its nature in the late $20^{\text {th }}$ and early $21^{\text {st }}$ century. Further to the two elucidations made of postlogism 77 psychopathic and conjugatedpostlogism /preconverging-or-dementing -integration distortion/perversion of essence-ofmeaningfulness that go on to endemise psychopathy and social psychopath with reference to with the différance-disambiguation-of-ontologically-veridical- ${ }^{5}$ meaningfulness-andteleology and its 'Différance-existential-transitory-articulation-of-the-protraction-ofperversion-of- ${ }^{8}$ reference-of-thought-<as-preconvergingly-

\section{apriorising/axiomatising/referencing-in-nonconviction/madeupness/bottomlining-as-to-}

shallow-supererogation >,-of-meaningfulness' technique as well as plausibly concurrentlyfalse-premising to an existential-context-of-reference-narrative providing licence for postlogic narratives, a third elucidation provides an even more profound insight of the distortion/perversion of essence-of-meaningfulness and the implications at the comprehensive existential-<disontologising/re-ontologising aporeticism $>$ level. This basically has to do with the ontological consequences and implications of the 'existentialist' and 'non-veridical/vacuous' conceptualisation of ${ }^{83}$ reference-of-thought and meaningfulness, and so with respect to perception of registry-soundness/soundness-or-ontological-good-faith/authenticity -ofreference-of-thought and ${ }^{7}$ perversion-of- ${ }^{3}$ reference-of-thought-<as-preconverginglyapriorising/axiomatising/referencing-in-nonconviction/madeupness/bottomlining-as-toshallow-supererogation $>\quad$ as-of-unsoundness-or-ontological-bad-faith/inauthenticity ${ }^{6}$-ofreference-of-thought, and ultimately the disambiguation of ontological-reference (trace) with respect to postlogism 77 and conjugated-postlogism 77 threshold-ofnonconviction/madeupness/bottomlining-in-shallow-supererogation $<-<$ as-to-' $a$ attendantintradimensional'-prospectively-disontologising preconverging/dementing -apriorising- 
psychologism> individuation characters, and supplanting-conviction-as-to-profoundsupererogation —of-'attendant-intradimensional'-postconverging/dialectical-thinking

apriorising-psychologism individuation characters. Basically the ontological-veridicality of meaningfulness is construed in 'non-veridical/vacuous' terms of ${ }^{83}$ reference-of-thoughtcategorical-imperatives/axioms/registry-teleology99 'supposedly' in intemporal-preservationentropy-or-contiguity-or-ontological-preservation and this 'supposedly-ness' is only validated if 'existentially-disontologising/re-ontologising aporeticism> real' as ontologicallyveridical. However there is an 'existentialist-shortfall' of the human supplanting-conviction-asto-profound-supererogation —of-'attendant-intradimensional'-postconverging/dialectical-

thinking -apriorising-psychologism mind with respect to assuring the 'existential-reality' in the face of 'non-veridical/vacuous terms of ${ }^{83}$ reference-of-thought- categoricalimperatives/axioms/registry-teleology 9 . This 'existentialist-shortfall' has to do with the fact that it will be a 'waste of too much mental energy' to be verifying in detail the 'apriorisingreference-of-thought/apriorising-registry_elements (out of 'implicited_attendantontological-contiguity ${ }^{67} \sim$ educed-

existentialising/contextualising/textualising_intelligibility/epistemicity/reflexivity-contiguity$<$ imbued-notional cogency $>{ }^{,},-<$reifying-or-elucidating-of-prospective-relative-ontologicalcompleteness -of- reference-of-thought- devolving-as-of-instantiative-context $>$ )' of \{epistemictotalising 3 psychologismic-subliminality-of-individuation_effusing/worlding imbued logicaldueness-or-scape-or-frame, profile-or-stature, presumptuousness-or-arrogation, assumptions, value-reference and teleology ${ }^{9}$-of every interlocutor, and so mentally the human mind has developed a 'referencing scheme of trusting that involves closeness, familiarity, reputation and appearance'; but such a scheme is strictly speaking ontologically incomplete and can be undermined and usurped, but it is standard as it 'saves mental energy and time'. This 'existentialist-shortfall' is relatively inconsequential where interlocutors are mutually of 
prelogism 7 -as-of-conviction,-in-profound-supererogation

$<$ existentially-veridical-

'attendant-intradimensional-apriorising/axiomatising/referencing'-logical-dueness-precedes-

disontologising-logical-outcome-arrived-at> or 'implicited_attendant-ontologicalcontiguity $^{67}$; educed-

existentialising/contextualising/textualising_'intelligibility/epistemicity/reflexivity-contiguity$<$ imbued-notional cogency $>,{ }^{\prime},-<$ reifying-or-elucidating-of-prospective-relative-ontologicalcompleteness -of- reference-of-thought- devolving-as-of-instantiative-context $>$ and even better when mutually of good supplanting-conviction-as-to-profound-supererogation -of'attendant-intradimensional'-postconverging/dialectical-thinking -apriorising-psychologism (than when one or the other is of 'poor or bad supplanting-conviction-as-to-profoundsupererogation _of-'attendant-intradimensional'-postconverging/dialectical-thinking apriorising-psychologism' even though the latter is relatively circumspect and ad-hoc in its misrepresentation of reality, and so its consequence with respect to the 'existentialist-shortfall' is rather limited as defect-of- ${ }^{-1}$ logical-processing-or-logical-implicitation-supposedlyapriorising-in-conviction-as-to-profound-supererogation of the registryworldview's/dimension's- ${ }^{83}$ reference-of-thought-for-social-functioning-and-accordance rather than registry-worldview's/dimension's-uninstitutionalised-threshold ${ }^{02}$-defect-<as-Being-orontological-or-existential-defect $>5$ associated with postlogism 77 whether pathological/psychopathic or enculturated, and conjugated-postlogism 77 . However, with the psychopathic/postlogic and social psychopathic case where compulsingnonconviction/madeupness/bottomlining-〈'<decontextualising/de-existentialising of-

attendant-intradimensional-apriorising/axiomatising/referencing>-induced-disontologising'-ofthe-'attendant-intradimensional-ontologising'-imbued-

$<$ contextualising/existentialising attendant-ontological-contiguity $>$;-in-shallow-

supererogation -<as-to-disontologising-perverted-outcome-sought-precedes-existentially- 
veridical-'attendant-intradimensional-apriorising/axiomatising/referencing'-logical-dueness $>$ >

or postlogism 77 as disontologising-perverted-outcome-sought-precedes-existentially-veridical'attendant-intradimensional-apriorising/axiomatising/referencing'-logical-dueness is the underlying principle as vague-rhyming-or-copied-mimicry-or-formulaic-projection-orprojection-of-form-or-hollow-and-vague-vocalisation-or-subknowledging ${ }^{4}$, this 'existentialistshortfall' is highly consequential as it is the basis of the induced registryworldview's/dimension's-uninstitutionalised-threshold ${ }^{22}$-defect- $<$ as-Being-or-ontological-orexistential-defect $>55$; by wrongly and so comprehensively implying the 'existential-reality' of 'non-veridical/vacuous <amplituding/formative> wooden-language-〈imbued-temporal-mereform/virtualities/dereification/akrasiatic-drag/denatured/preconverging-or-dementing narratives - of-the- reference-of-thought- categorical-imperatives/axioms/registryteleology $>$ articulated in hollow-constituting-<as-disjointed-misappropriation-ofmeaningfulness-and-failing-intemporal-preservation> or otherwise by the rather nonveridical/vacuous implied meaningfulness and ${ }^{83}$ reference-of-thought or otherwise by the nonveridical/vacuous implied meaningfulness and ${ }^{83}$ reference-of-thought based on inductive limitation nature or 'so-called principles' that are actually fallacious since such arguments cannot truly be of entailing-<amplituding/formative-epistemicity>totalising in-relative-ontologicalcompleteness $^{87}$ as they require that others do not act likewise or their implications should be limited to given target(s) and not be totalisingly-entailing, since their fundamental teleology ${ }^{9}$ is not intemporal/not-of-totalising-entailment but speak more of temporal motive. In other words meaningfulness and ${ }^{83}$ reference-of-thought is only veridical as an 'ontologically-veridical construct' validated in the construal of the circularity/recurrence/repetition/repeatability delineating existential-transitioning-or-iterability-trace-of-narratives-asdots_or_implicited_attendant-ontological-contiguity ${ }^{67}$, educed- 
$<$ imbued-notional $\sim$ cogency>' ${ }^{\prime}$-reification_or_intrinsic-reality-ontological-

coherence_or_superseding-oneness-of-ontology ${ }^{41}$ by $\quad{ }^{55}$ maximalising-recomposuring-forrelative-ontological-completeness ${ }^{8}$ —unenframed/re-ontologising conceptualisation that establishes ontologically-veridical-meaningfulness. The human 'existentialist-shortfall' with respect to ontologically-veridical meaningfulness and ${ }^{83}$ reference-of-thought thus allows for an overall existential/being framework/cadre of 'non-veridical/vacuous distortion/perversion' of meaningfulness in hollow-constituting-<as-disjointed-misappropriation-of-meaningfulnessand-failing-intemporal-preservation $>$ induced from postlogism 77 psychopathic and temporaldispositions-conjugated-postlogism 77 which is wrongly projected as of the recurrence in existential-transitioning-or-iterability-trace-of-narratives-as-dots_or_implicited_attendantontological-contiguity ${ }^{6}$ ' educedexistentialising/contextualising/textualising_intelligibility/epistemicity/reflexivity-contiguity$<$ imbued-notional cogency>' -reification_or_intrinsic-reality-ontologicalcoherence_or_superseding-oneness-of-ontology ${ }^{41}$ by ${ }^{5}$ maximalising-recomposuring-forrelative-ontological-completeness ${ }^{87}$ — unenframed/re-ontologising conceptualisation as ontologically-veridical-meaningfulness, and particularly so as the postlogism 77 psychopathic disposition is basically recursive (recursive denaturing alteration of the essence-ofmeaningfulness and so 'pathologically iterative', in the form of hollow-constituting-<asdisjointed-misappropriation-of-meaningfulness-and-failing-intemporal-preservation> 'denaturing postlogic-backtracking-<iterative-looping-'set-of-dereifying-hollow-narrativesand-acts’> $>$-with-'successive-shifting-of-the-narratives-and-acts-foci’-construed-as'deception-of-successively-shifting-or-noncohering-narratives-and-acts' towards 'socialaggregation-enablers over intrinsic-reality/ontological-veridicality transcendentalenabling/sublimating/supereregatory $\sim$ de-mentativity' as non-veridical and dialectically/contendingly out-of-phase, based on absolving/fleeting/escaping-reflex-logic and 
extrinsic-attribution with respect to successive sets of interlocutors, and as conjugatedpostlogism 77 mental-dispositions equally assume a purposefulness of their own (that must be factored-in when analysing psychopathic/postlogic and social-psychopathic situations), and conjugated-postlogism 77 preconverging-or-dementing -integration dispositions are either progressive (with conjugated-opportunistic/conjugated-exacerbation) or regressive (with conjugated-ignorance/conjugated-affordability) in their hollow-constituting-<as-disjointedmisappropriation-of-meaningfulness-and-failing-intemporal-preservation> or ${ }^{12}$ conjoininglooping-set-of-narratives as-of-cohering-logic-reflex to the psychopath's 'denaturing postlogic-backtracking-<iterative-looping-'set-of-dereifying-hollow-narratives-and-acts' $>$ ' with-'successive-shifting-of-the-narratives-and-acts-foci’-construed-as-'deception-ofsuccessively-shifting-or-noncohering-narratives-and-acts' towards 'social-aggregation-enablers over intrinsic-reality/ontological-veridicality transcendentalenabling/sublimating/supererogatory de-mentativity' dialectically/contendingly out-of-phase. The centrality of 'concurrently-false-premising-ofmeaning thread/tracing' in the entire process of postlogism and conjugatedpostlogism 7 preconverging-or-dementing ${ }^{20}$-integration lies in the fact that it provides the 'as non-veridical and dialectically/contendingly out-of-phase hollow-form concurrently-falsepremising' for $\quad{ }^{7}$ perversion-of- ${ }^{3}$ reference-of-thought-<as-preconverginglyapriorising/axiomatising/referencing-in-nonconviction/madeupness/bottomlining-as-toshallow-supererogation $>$ as 'denaturing ${ }^{16}$ postlogic-backtracking-<iterative-looping-'set-ofdereifying-hollow-narratives-and-acts'> ${ }^{76}$-with-'successive-shifting-of-the-narratives-and-actsfoci'-construed-as-'deception-of-successively-shifting-or-noncohering-narratives-and-acts' towards social-aggregation-enablers over intrinsic-reality/ontological-veridicality transcendental-enabling/sublimating/supererogatory de-mentativity, and so together with a 'false-projection-of-bad-or-good-conviction-as-to-profound-supererogation representation of 
meaning' rather than' veridically of a threshold-of-nonconviction/madeupness/bottomlining-inshallow-supererogation -<as-to-'attendant-intradimensional'-prospectivelydisontologising preconverging/dementing -apriorising-psychologism> concurrently-falsepremising of meaning' (and so, wrongly implying an issue of defect-of- ${ }^{5}$ logical-processing-orlogical-implicitation - supposedly-apriorising-in-conviction-as-to-profound-supererogation of the registry-worldview's/dimension's- ${ }^{8}$ reference-of-thought-for-social-functioning-andaccordance rather than veridically the perception of compulsingnonconviction/madeupness/bottomlining-〈'<decontextualising/de-existentialising $\sim$ ofattendant-intradimensional-apriorising/axiomatising/referencing--induced-disontologising'-ofthe-'attendant-intradimensional-ontologising'-imbued$<$ contextualising/existentialising attendant-ontological-contiguity $>$;-in-shallowsupererogation -<as-to-disontologising-perverted-outcome-sought-precedes-existentiallyveridical-'attendant-intradimensional-apriorising/axiomatising/referencing'-logical-dueness $>$ > or postlogism 77 as hollow-form implying an issue of perversion-of- $^{-}$reference-of-thought- $<$aspreconvergingly-apriorising/axiomatising/referencing-in-

nonconviction/madeupness/bottomlining-as-to-shallow-supererogation $>$ ); $\quad$ inducing conjugated-postlogism 77 preconverging-or-dementing -integration mental-dispositions (as conjugated-ignorance, conjugated-affordability, conjugated-opportunism, conjugatedexacerbation, conjugated-social-chainism and conjugated-temporal-enculturation) involved in conjoining-looping-set-of-narratives of the postlogic/psychopathic hollow-form postlogicbacktracking-<iterative-looping-'set-of-dereifying-hollow-narratives-and-acts' $>$ ' $;$ and thus leading to temporal-preservation-as-pseudointemporality ${ }^{52}$-preservation. It is critical to understand this underlying thread of concurrently-false-premising by its compulsingnonconviction/madeupness/bottomlining-/‘<decontextualising/de-existentialising ofattendant-intradimensional-apriorising/axiomatising/referencing>-induced-disontologising'-of- 
the-'attendant-intradimensional-ontologising'-imbued-

$<$ contextualising/existentialising attendant-ontological-contiguity $>$;-in-shallow-

supererogation -<as-to-disontologising-perverted-outcome-sought-precedes-existentially-

veridical-'attendant-intradimensional-apriorising/axiomatising/referencing'-logical-dueness $>$ >

or postlogism 77 instigation as a false-sense-of-good-to-poor or bad supplanting-conviction-asto-profound-supererogation —of-'attendant-intradimensional'-postconverging/dialectical-

thinking -apriorising-psychologism postlogism 77 and conjugated-postlogism 77 preconvergingor-dementing ${ }^{20}$-integration in psychopathic and social psychopathic situations. Thus unlike in the instance of defect-of- ${ }^{5}$ logical-processing-or-logical-implicitation-supposedly-apriorisingin-conviction-as-to-profound-supererogation of the registry-worldview's/dimension'sreference-of-thought-for-social-functioning-and-accordance the idea of falling-back to the same exercise to correctly do the exercise ( ${ }^{-}$logical-processing-or-logical-implicitationsupposedly-apriorising-in-conviction-as-to-profound-supererogation ) in a same or different circumstance, is invalidated when dealing with ${ }^{7}$ perversion-of- ${ }^{-}$reference-of-thought- $<$aspreconvergingly-apriorising/axiomatising/referencing-in-

nonconviction/madeupness/bottomlining-as-to-shallow-supererogation $>$ as registryworldview's/dimension's-uninstitutionalised-threshold ${ }^{12}$-defect-<as-Being-or-ontological-orexistential-defect $>55$ (with regards to both postlogism 77 and conjugated-postlogism 77 ); with the implication that there can't be mutual contention but rather transversality-<for-sublimatingexistential-eventuating/denouement-from-'thinking-at-first/pure-predisposition-preemptive-ofprospective-disontologising/subontologising' as-of-prospectively-disambiguated-affirmedand-unaffirmed-'motif-and-apriorising/axiomatising/referencing'> ${ }^{101}$ wherein the superseding (and sound) ${ }^{8}$ reference-of-thought can only construe of the superseded (and non-veridical) as preconverging-or-dementing ${ }^{20}$-apriorising-psychologism/unsoundness-or-ontological-badfaith/inauthenticity ${ }^{64}$-of- ${ }^{83}$ reference-of-thought/oblongated requiring psychoanalytic- 
unshackling/memetic-reordering/institutional-recomposuring to transcend into the superseding reference-of-thought in the very first instance before any ontologically-veridical pretence to mutual contention. The nature of how 'concurrently-false-premising-of-meaning thread/tracing' arises can equally conspicuously be understood at childhood psychopathy situation wherein the childhood psychopathy blatantly attempts to initiate a dereifying narrative like in the case of spilling water on a chair highlighted before to which if concurred to by the interlocutor will be the basis for the child to assume apparently normal logical contentions but fundamentally based on this distorted deceptive high-point of concurrently-false-premising as of ${ }^{83}$ reference-ofthought- categorical-imperatives/axioms/registry-teleology $^{9}$,-foraposteriorising/logicising/deriving/intelligising/measuring $-{ }^{5}$ meaningfulness-and-teleology ${ }^{9}$. It is basically the same process with an adult psychopath but for the fact of the highly opaque nature of adult psychopath mental-disposition unlike a child psychopath, and as previously explained is 'maturated' in its theme on issues that are rather of serious import, 'spatialising' (to confound by not acting postlogicly/disontologising-perverted-outcome-sought-precedesexistentially-veridical-'attendant-intradimensional-apriorising/axiomatising/referencing'logical-dueness within the same spatialisation of relevant social interlocutors, which may raise the hollow nature of its narratives from cross-examination), being 'indirect' (by increasingly appearing neutral and unmotivated unlike at childhood), increasingly 'credulous' (by effective eliciting of social threshold-of-nonconviction/madeupness/bottomlining-in-shallowsupererogation -<as-to-'attendant-intradimensional'-prospectivelydisontologising preconverging/dementing -apriorising-psychologism> as $>$ to subontologisation/subpotentiation miscuing/disjointed-logic/logical-drag/unconscionabilitydrag/sub-par-conventioning-rationalising/temporal-enculturation where its 'apriorisingreference-of-thought/apriorising-registry_elements (out of 'implicited_attendantontological-contiguity ${ }^{67}$, educed- 
existentialising/contextualising/textualising_intelligibility/epistemicity/reflexivity-contiguity$<$ imbued-notional $\sim$ cogency $>,{ }^{\prime},-<$ reifying-or-elucidating-of-prospective-relative-ontologicalcompleteness -of- reference-of-thought- devolving-as-of-instantiative-context $>$ )' as totalising 3 psychologismic-subliminality-of-individuation-effusing/worlding imbued logicaldueness-or-scape-or-frame, profile-or-stature, presumptuousness-or-arrogation, assumptions, value-reference and teleology ${ }^{9}$ are all false) and 'crafty' (with increasingly greater staging and performance: as the psychopath perceives instances of rebuttal of its postlogism 77 not essentially in terms-as-of-axiomatic-construct of the rightness or wrongness of the postlogic acts in its personality development into adulthood, as a prelogic supplanting-conviction-as-to-profoundsupererogation _of-'attendant-intradimensional'-postconverging/dialectical-thinking

apriorising-psychologism mental-disposition will, but rather in terms-as-of-axiomatic-construct of its failure in performing the postlogic acts well with the idea of how to further confound/muddle hence the reason it is recursive as absolving/fleeting/escaping-reflex-logic to the point of faking remorsefulness or acting as a victim as long as fundamentally its 'interlocutor is in a prelogism ${ }^{78}$-as-of-conviction,-in-profound-supererogation $-<$ existentially-veridical'attendant-intradimensional-apriorising/axiomatising/referencing'-logical-dueness-precedesdisontologising-logical-outcome-arrived-at> relation to its postlogism 7 -formulaic slanting compulsing-nonconviction/madeupness/bottomlining-〈'<decontextualising/deexistentialising $\sim$ of-attendant-intradimensional-apriorising/axiomatising/referencing $>$-induceddisontologising'-of-the-'attendant-intradimensional-ontologising'-imbued$<$ contextualising/existentialising attendant-ontological-contiguity $>$;-in-shallowsupererogation -<as-to-disontologising-perverted-outcome-sought-precedes-existentiallyveridical-'attendant-intradimensional-apriorising/axiomatising/referencing'-logical-dueness $>$ > or disontologising-perverted-outcome-sought-precedes-existentially-veridical-'attendantintradimensional-apriorising/axiomatising/referencing'-logical-dueness mental-disposition' in 
order for the interlocutor to go on to conjoin the psychopath's postlogic-backtracking- $<$ iterativelooping-'set-of-dereifying-hollow-narratives-and-acts'> ${ }^{76}$ ). Paradoxically, the basis of the adult psychopath 'concurrently-false-premising-of-meaningful thread/tracing' is the disposition of a supplanting-conviction-as-to-profound-supererogation —of-'attendant-intradimensional'postconverging/dialectical-thinking -apriorising-psychologism mindset/ ${ }^{3}$ reference-of-thought to be open-minded in wrongly granting supplanting-conviction-as-to-profoundsupererogation _of-'attendant-intradimensional'-postconverging/dialectical-thinking apriorising-psychologism (be it 'good or poor/bad supplanting-conviction-as-to-profoundsupererogation - of-'attendant-intradimensional'-postconverging/dialectical-thinking apriorising-psychologism') to a compulsing-nonconviction/madeupness/bottomlining$〈<<$ decontextualising/de-existentialising $\sim$ of-attendant-intradimensionalapriorising/axiomatising/referencing >-induced-disontologising'-of-the-'attendantintradimensional-ontologising'-imbued-<contextualising/existentialising $\sim$ attendantontological-contiguity $>$;-in-shallow-supererogation -<as-to-disontologising-pervertedoutcome-sought-precedes-existentially-veridical-'attendant-intradimensionalapriorising/axiomatising/referencing'-logical-dueness $>>$ mental-disposition for its deceptive high-point of concurrently-false-premising for producing ontologically non-veridical narratives (in terms-as-of-axiomatic-construct of psychologismic-subliminality-ofindividuation —effusing/worlding imbued logical-dueness-or-scape-or-frame, profile-or-stature, presumptuousness-or-arrogation, assumptions, value-reference and teleology ${ }^{9}$ ). This 'concurrently-false-premising-of-meaning thread/tracing' can be construed as of the circularity/recurrence/repetition/repeatability ${ }^{10}$ delineating existential-transitioning-oriterability-trace-of-narratives-as-dots_or_implicited_attendant-ontologicalcontiguity ${ }^{67} \sim$ educedexistentialising/contextualising/textualising_'intelligibility/epistemicity/reflexivity-contiguity- 
$<$ imbued-notional $\sim$ cogency>' ${ }^{\prime}$-reification_or_intrinsic-reality-ontological-

coherence_or_superseding-oneness-of-ontology ${ }^{41}$ by $\quad{ }^{55}$ maximalising-recomposuring-forrelative-ontological-completeness ${ }^{8}$ —unenframed/re-ontologising conceptualisation wherein ontologically-veridical-meaningfulness is established by reflecting soundness-or-ontologicalgood-faith/authenticity ${ }^{6}$-of- ${ }^{83}$ reference-of-thought/postconverging-or-dialectical-thinking ${ }^{2}$ apriorising-psychologism (as-in-intemporally-preservational) narratives over unsoundness-orontological-bad-faith/inauthenticity ${ }^{64}$-of- ${ }^{3}$ reference-of-thought/preconverging-ordementing -apriorising-psychologism narratives. Critically, this 'concurrently-falsepremising-of-meaning thread/tracing' explains how temporal-preservation-aspseudointemporality ${ }^{52}$-preservation occurs operantly and how by intradimensional cumulativedynamic-aftereffect it instigates the endemising/enculturating of uninstitutionalised-threshold in the transcendental/transdimensional/interdimensional/ maximalising-recomposuring-forrelative-ontological-completeness ${ }^{87}$ — unenframed/re-ontologising $\sim$ conceptualisation dynamism, as it further extends to explain how and why 'ontological-reconstituting-as-toconflatedness ${ }^{13} /$ deconstruction on-the-one-hand and hollow-constituting-<as-disjointedmisappropriation-of-meaningfulness-and-failing-intemporal-preservation> on-the-other-hand drive the dynamism of successive prospective institutionalisations and uninstitutionalisedthreshold respectively; as postlogic/psychopathic-individuations hollow postlogicbacktracking-<iterative-looping-'set-of-dereifying-hollow-narratives-and-acts'> ${ }^{6} \quad$ and conjugated-postlogism 77 preconverging-or-dementing -integration individuations conjoining-looping-set-of-narratives to the hollow postlogic-backtracking-<iterative-looping'set-of-dereifying-hollow-narratives-and-acts'> $>$, in hollow-constituting-<as-disjointedmisappropriation-of-meaningfulness-and-failing-intemporal-preservation> to ${ }^{83}$ reference-ofthought- categorical-imperatives/axioms/registry-teleology $^{9}$ (but then failing/not-upholding<as-of-apriorising/axiomatising/referencing $>$ intemporal-preservation-entropy-or-contiguity- 
or-ontological-preservation

and

undermining

transcendence-and-

sublimity/sublimation/supererogatory de-mentativity)

of

'ontologically-

reconstituted'/deconstructed institutionalised registry-worldview/dimension' inducing prospective 'uninstitutionalised registry-worldview/dimension' (as prospective diminishinghuman-epistemic-abnormalcy-or-preconvergence ${ }^{3}$ ), eliciting the intemporal-disposition to 'ontologically-reconstitute'/deconstruct the new 'uninstitutionalised registryworldview/dimenson'... and so on, circularly up to futural Being-development/ontologicalframework-expansion-as-to-depth-of-ontologising-development-as-infrastructure-of-

meaningfulness-and-teleology as of prospective notional ${ }^{18}$ deprocrypticism institutionalised registry-worldview as utterly-ontological (ontological-normalcy) as 'it can't be hollowconstituted' by its mere ontological-completeness or ontological-utterness or as-ontologicalnormalcy. This further highlights the reality of human-subpotencyaporia/undecidability/dilemma/ought-indeterminacy/deficiency/limitation/constraint—imbued'notional firstnaturedness-formativeness-<as-to-eventualising-inkling-drive-or-seedingmisprising $>$ temporal-to-intemporal-dispositions- $<$ so-construed-as-from-perspectiveontological-normalcy/postconvergence>'-existentialism-form-factor as validating the requisite 'postconverging-or-dialectical-thinking -psychology or psychology-of-mentation-dynamics or natural psychological-dynamics' psychoanalytic-unshackling/memeticreordering/institutional-recomposuring decomplexifying/uninhibiting postconverging-dementating/structuring/paradigming for futural Being-development/ontological-frameworkexpansion-as-to-depth-of-ontologising-development-as-infrastructure-of- meaningfulnessand-teleology as of prospective deprocrypticism, in contrast to a 'wrongly misconstrued 'universal human intemporal-disposition nature' (which is rather a 'functional construal/conceptualisation' arising from intemporalisation/institutionalisation within an institutionalised registry-worldview/dimension as secondnatured but not beyond its 
uninstitutionalised-threshold ${ }^{102}$ ) as it will fail to account and register for the ontological/beingconstrual-defect of the present as procrypticism which should enable superseding for the prospective transcendent institutionalisation secondnaturing as deprocrypticism. This explains how a différance-disambiguation-of-ontologically-veridical- ${ }^{5}$ meaningfulness-and-teleology gives ontological-anchoring for a Derridean metaphysics-of-presence-〈implicited'nondescript/ignorable-void ' -as-to- presencing - absolutising-identitive-constitutedness >

(due to human limited-mentation-capacity-deepening-as-subjecting limitedness/humansubpotency-to-'educed-unlimitedness/existence-sublimating-nascence' ${ }^{53}$ ) propped up by a metaphysics-of-absence-〈implicited-epistemic-veracity-of- nonpresencing-<perspectiveontological-normalcy/postconvergence $>$ > (rather as human projection in 'making-up for' its limited-mentation-capacity-deepening—as-subjecting-limitedness/human-subpotency-to'educed-unlimitedness/existence-sublimating nascence' 'making-up for' with the abstract and infallible ontological-normalcy/postconvergence referencing/correction-tool as postdication, which upholds intemporal-preservation-entropy-orcontiguity-or-ontological-preservation), to paradoxically transcend and supersede towards deeper ontological-veridicality/intrinsic-reality, as so enabled by the dialecticism of " ${ }^{15}$ mentation-〈supererogatory ontological-de-mentation-or-dialectical-de-mentation — strandingor-attributive-dialectics $\rangle$ of ${ }^{83}$ reference-of-thought' in construing the ${ }^{83}$ reference-of-thought and meaningfulness of the 'prospective' (of a more intemporal-potency as it further deepens the socially-betraying-threshold-of-ontologising-depth-of-analysis or socially-betraying-thresholdof-intemporal-preservation-entropy-or-contiguity-or-ontological-preservation or threshold-ofnonconviction/madeupness/bottomlining-in-shallow-supererogation $<<$ as-to-'attendantintradimensional'-prospectively-disontologising preconverging/dementing -apriorisingpsychologism $>$ over the 'prior' in the strive for ontological-normalcy/postconvergence (potency of intrinsic-reality/ontological-veridicality) along with disambiguating human-subpotency- 
aporia/undecidability/dilemma/ought-indeterminacy/deficiency/limitation/constraint—imbued'notional firstnaturedness-formativeness-<as-to-eventualising inkling-drive-or-seedingmisprising $>$ temporal-to-intemporal-dispositions- $<$ so-construed-as-from-perspectiveontological-normalcy/postconvergence>'-existentialism-form-factor as the pathway towards intrinsicness/essence, reality, truth and virtue. Such a différance-disambiguation-ofontologically-veridical- ${ }^{5}$ meaningfulness-and-teleology 9 is rather about the ontologicalveridicality of ${ }^{8}$ reference-of-thought. It should not be confused with the more familiar issue involving existentially-<disontelogising/re-ontelogising aporeticism $>$ veridical logicaldueness and from thence enabling the construing of relevant soundness or unsoundness of logical-processing-or-logical-implicitation — supposedly-apriorising-in-conviction-as-toprofound-supererogation , and this doesn't put-into-question the soundness/appropriateness or unsoundness/inappropriateness of ${ }^{83}$ reference-of-thought. Thus unlike in the instance of defectof- ${ }^{5}$ logical-processing-or-logical-implicitation-supposedly-apriorising-in-conviction-as-toprofound-supererogation of the registry-worldview's/dimension's- ${ }^{83}$ reference-of-thought-forsocial-functioning-and-accordance the idea of falling-back to the same exercise to correctly do the exercise ( ${ }^{5}$ logical-processing-or-logical-implicitation-supposedly-apriorising-inconviction-as-to-profound-supererogation ) in a same or different circumstance, is invalidated when dealing with ${ }^{7}$ perversion-of- ${ }^{3}$ reference-of-thought- $<$ as-preconverginglyapriorising/axiomatising/referencing-in-nonconviction/madeupness/bottomlining-as-toshallow-supererogation $>\quad$ as $\quad$ registry-worldview's/dimension's-uninstitutionalisedthreshold ${ }^{102}$-defect-<as-Being-or-ontological-or-existential-defect ${ }^{85}$ (with regards to both postlogism ${ }^{77}$ and conjugated-postlogism 77 ; with the implication that there can't be mutual contention but rather transversality-<for-sublimating-existential-eventuating/denouementfrom-'thinking-at-first/pure-predisposition-preemptive-of-prospectivedisontologising/subontologising' as-of-prospectively-disambiguated-affirmed-and- 
unaffirmed-'motif-and-apriorising/axiomatising/referencing'> ${ }^{101}$ wherein the superseding (and sound) ${ }^{83}$ reference-of-thought can only construe of the superseded (and unsound) as preconverging-or-dementing -apriorising-psychologism/unsoundness-or-ontological-badfaith/inauthenticity ${ }^{64}$ of- ${ }^{-1}$ eference-of-thought/oblongated requiring psychoanalyticunshackling/memetic-reordering/institutional-recomposuring to transcend into the superseding reference-of-thought in the very first instance before any ontologically-veridical pretence to mutual contention). It is based on perpetuating the precedingness/supersedingness/ascendency over ${ }^{83}$ reference-of-thought and meaningfulness of the intemporal-disposition as ontological over the temporal-dispositions; as the latter, going by human-subpotencyaporia/undecidability/dilemma/ought-indeterminacy/deficiency/limitation/constraint—imbued'notional firstnaturedness-formativeness-<as-to-eventualising-inkling-drive-or-seedingmisprising $>$ temporal-to-intemporal-dispositions-<so-construed-as-from-perspectiveontological-normalcy/postconvergence>'-existentialism-form-factor are inclined to ' ${ }^{\text {incrementalism-in-relative-ontological-incompleteness }}{ }^{8}$ enframed/disontologising conceptualisation $\quad<$ amplituding/formative $>$ wooden-language〈imbued-averaging-of-thought-<as-to-leveling/ressentiment/closed-construct-ofmeaningfulness-and-teleology -as-of-'nondescript/ignorable-void '-with-regards-toprospective-apriorising-implications $>$ ) $\quad$ (implying incremental/temporal-accommodation $\begin{array}{lll}\text { meaningful } & \text { dispositions } & \text { of }\end{array}$ slantedness/ ${ }^{50}$ ignorance/affordability/opportunism/exacerbation/social-chainism-or-socialdiscomfiture-or-negative-social-aggregation/temporal-enculturation-or-temporal-endemisation, so-disambiguated as of ${ }^{83}$ reference-of-thought- ${ }^{8}$ devolving ontological-performance ${ }^{72}$ $<$ including-virtue-as-ontology $>$ /morality/ethics/justice/etc. as defect-of- ${ }^{5}$ logical-processingor-logical-implicitation—supposedly-apriorising-in-conviction-as-to-profound-

supererogation of the registry-worldview's/dimension's- ${ }^{83}$ reference-of-thought-for-social- 
functioning-and-accordance, and worst still when conjugated to postlogism 77 become temporally-preservational-as-pseudointemporality ${ }^{52}$-preservation or conjugated-postlogism 77 as of circularity/recurrence/repetition/repeatability ${ }^{10}$ in existential-transitioning-or-iterabilitytrace-of-narratives-as-dots_or_implicited_attendant-ontological-contiguity ${ }^{6}$, educedexistentialising/contextualising/textualising_'intelligibility/epistemicity/reflexivity-contiguity$<$ imbued-notional $\sim$ cogency $>$ 'reification_or_intrinsic-reality-ontologicalcoherence_or_superseding-oneness-of-ontology ${ }^{41}$ in contrast to defect-of- ${ }^{5}$ logical-processingor-logical-implicitation — supposedly-apriorising-in-conviction-as-to-profound-

supererogation of the registry-worldview's/dimension's ${ }^{8}$ reference-of-thought-for-socialfunctioning-and-accordance, and rather implying a 'preconverging-dementating/structuring/paradigming registry-worldview's/dimension's-uninstitutionalisedthreshold ${ }^{02}-$ defect-<as-Being-or-ontological-or-existential-defect $>5$ that defines a registryworldview/dimension as preconverging-or-dementing 20 -apriorising-psychologism and dialectically-out-of-phase with respect to intrinsic-reality/ontological-veridicality going by its hollow-constituting-<as-disjointed-misappropriation-of-meaningfulness-and-failingintemporal-preservation> (take the case of the BODMAS characters highlighted previously where the other characters simply went along calculating without factoring A's defect), such that where there is induced derived- ${ }^{7}$ perversion-of- ${ }^{3}$ reference-of-thought-<as-preconverginglyapriorising/axiomatising/referencing-in-nonconviction/madeupness/bottomlining-as-toshallow-supererogation > when such defect-of- ${ }^{5}$ logical-processing-or-logical-implicitation supposedly-apriorising-in-conviction-as-to-profound-supererogation of the registryworldview's/dimension's- ${ }^{8}$ reference-of-thought-for-social-functioning-and-accordance dispositions are conjugated to postlogism ${ }^{77}$ (which directly perverts ${ }^{83}$ reference-of-thought), temporal-dispositions are rather then construed as in registry-worldview's/dimension'suninstitutionalised-threshold ${ }^{102}$-defect-<as-Being-or-ontological-or-existential-defect $>{ }^{5}$, in 
line with a 'dynamic-cumulative-aftereffect of subontologisation' of the prior/transcended/superseded registry-worldview as being in a dialectically-out-of-phase state which is thus preconverging-or-dementing ${ }^{20}$ apriorising-psychologism, while the intemporaldisposition is inclined to "maximalising-recomposuring-for-relative-ontologicalcompleteness $^{87}$ — unenframed/re-ontologising conceptualisation intemporal projection-ofthought' (implying notional ' deprocrypticism in its preempting-disjointedness-as-ofreference-of-thought,-as-to- ${ }^{6}<$ amplituding/formative-epistemicity $>$ growth-orconflatedness ${ }^{13} /$ transvaluative-rationalising/transepistemicity/anamnestic-residuality/spiritdrivenness' - in-superseding-mere-formulaic-positivising/rational-empiricism-baseduniversalisation-directed-rulemaking-over-non-rules - apriorising/axiomatising/referencingpsychologism as 'ontologically-reconstituting' intrinsic-reality and thus with respect to perversion-of- ${ }^{8}$ reference-of-thought-<as-preconverginglyapriorising/axiomatising/referencing-in-nonconviction/madeupness/bottomlining-as-toshallow-supererogation $>$ is inclined to solipsistically-put-into-question/ontologicallyreconstituting of the perversion-of- ${ }^{73}$ reference-of-thought-<as-preconverginglyapriorising/axiomatising/referencing-in-nonconviction/madeupness/bottomlining-as-to-

shallow-supererogation $>$ and imply a prospective/superseding/transcendental registryworldview that is the new dialectically-in-phase and thus the new "postconverging-ordialectical-thinking -apriorising-psychologism' as the prior registry-worldview becomes dialectically-out-of-phase/dialectically-primitive and preconverging-or-dementing ${ }^{20}$ apriorising-psychologism. A différance-disambiguation-of-ontologically-veridicalmeaningfulness-and-teleology in registry-worldview terms is rendered operant by 'ontological-reconstituting-as-to-conflatedness ${ }^{13}$ / deconstruction over hollow-constituting-<asdisjointed-misappropriation-of-meaningfulness-and-failing-intemporal-preservation> (with 'ontological-reconstituting-as-to-conflatedness ${ }^{13}$ /deconstruction more like a 'making-up for 
projection' in transcending as a metaphysics-of-absence-_implicited-epistemic-veracity-ofnonpresencing-<perspective-ontological-normalcy/postconvergence $>>$ conceptualisation over hollow-constituting-<as-disjointed-misappropriation-of-meaningfulness-and-failingintemporal-preservation> as a 'failing, due to limited-mentation-capacity-deepening as subjecting limitedness/human-subpotency to 'educed unlimitedness/existence-sublimating nascence ' ${ }^{5}$ ' metaphysics-of-presence-_implicited-'nondescript/ignorable-void '-as-topresencing - absolutising-identitive-constitutedness $>$ conceptualisation), forming the very backbone of the human registry-worldview's/dimension's institutionalisation/intemporalisation process that is behind the institutional-cumulation/institutional-recomposure-〈as-tohistoriality/ontological-eventfulness /ontological-aesthetic-tracing-<perspectiveontological-normalcy/postconvergence-reflected-'epistemicity-relativism-determinism' $>\rangle$ as it dialectically leaves by the wayside human temporality ${ }^{9} /$ shortness and temporal ${ }^{83}$ reference-ofthought and meaningfulness. Critically, the placeholder-setup/mental-devisingrepresentation/mentation/consciousness-awareness-teleology implications are utterly different between such a familiar ${ }^{54}$ logical-processing-or-logical-implicitation - supposedly-apriorisingin-conviction-as-to-profound-supererogation and a différance-disambiguation-ofontologically-veridical- ${ }^{5}$ meaningfulness-and-teleology 9 as the latter calls upon ${ }^{15}$ dementation-(supererogatory-ontological-de-mentation-or-dialectical-de-mentation-strandingor-attributive-dialectics $\rangle$ in setting up two dialectical ${ }^{87}$ reference-of-thought, wherein the one as prior/present/transcended/superseded is preconverging-or-dementing ${ }^{20}$-apriorisingpsychologism and the other as prospective/transcending/superseding is postconverging-ordialectical-thinking -apriorising-psychologism. In other words, différance-disambiguation-ofontologically-veridical- ${ }^{-5}$ meaningfulness-and-teleology ${ }^{99}$ is dealing with perversion-andderived- perversion-of- ${ }^{8}$ reference-of-thought- $<$ as-preconverginglyapriorising/axiomatising/referencing-in-nonconviction/madeupness/bottomlining-as-to- 
shallow-supererogation $>$ (at the uninstitutionalised-threshold ${ }^{12}$ or socially-betrayingthreshold-of-ontologising-depth-of-analysis or socially-betraying-threshold-of-intemporalpreservation-entropy-or-contiguity-or-ontological-preservation or threshold-ofnonconviction/madeupness/bottomlining-in-shallow-supererogation $-<$ as-to-'attendantintradimensional'-prospectively-disontologising preconverging/dementing -apriorisingpsychologism>) is all about articulating the 'dialectically-in-phase reference' (which is relatively sound ontologically/intemporally) over the 'dialectically-out-of-phase or dialectically-primitive reference' (which is relatively unsound ontologically/intemporally). In registry-worldview terms of notional firstnaturedness-formativeness-<as-to-eventualising -inkling drive-or-seeding misprising $>$ temporal-to-intemporal-dispositions- $<$ so-construed-as-from-perspectiveontological-normalcy/postconvergence> 'dynamic-cumulative-aftereffect of subontologisation', this establishes ontological precedence/supersedingness/ascendency. The grander insight and answer to the elusive Derridean conundrum is that the full $<$ amplituding/formative-epistemicity $>$ causality $\sim$ as-to-projective-totalitative-implications-ofprospective- nonpresencing,-for-explicating relative-unreflexivity/relative-reflexivity ontological-contiguity of a différance-disambiguation-of-ontologically-veridicalmeaningfulness-and-teleology ${ }^{9}$ renders our presencing-as-positivistic meaningfulreference/anchoring-of-meaning/registry/axiomatic-construct/ontologicalreference/contending-reference/registry-worldview 'dialectically-out-of-phase or dialecticallyprimitive' as preconverging-or-dementing -apriorising-psychologism to a prospective-asdeprocryptic ${ }^{83}$ reference-of-thought, which is 'dialectically-in-phase' as postconverging-ordialectical-thinking -apriorising-psychologism. The latter (as with all relative postconvergingor-dialectical-thinking ${ }^{21}$-apriorising-psychologism references) can only be 'habituated' over the former, and so 'by virtue of its more profound intemporality ${ }^{52}$-potency' validated by its greater $<$ amplituding/formative-epistemicity $>$ causality $\sim$ as-to-projective-totalitative-implications-of- 
prospective- nonpresencing,-for-explicating $\sim$ relative-unreflexivity/relative-reflexivity

ontological-contiguity in the middle to long-run with respect to the dialectically corresponding prior meaningful-reference/anchoring-of-meaning/registry/axiomatic-construct/ontologicalreference/contending-reference/registry-worldview. For instance, there is no logicalbasis/logic,-as-derived-from $\sim$ transversality- $<$ for-sublimating-existentialeventuating/denouement,-from-'thinking-at-first/pure-predisposition-preemptive-ofprospective-disontologising/subontologising' as-of-prospectively-disambiguated-affirmedand-unaffirmed-'motif-and-apriorising/axiomatising/referencing' $>101$ for a positivistic mindset $/{ }^{3}$ reference-of-thought to convince a non-positivism/medievalism mindset $/{ }^{3}$ referenceof-thought that it ${ }^{83}$ reference-of-thought is better but for the fact that its better $<$ amplituding/formative-epistemicity $>$ causality $\sim$ as-to-projective-totalitative-implications-ofprospective- nonpresencing,-for-explicating $\sim$ relative-unreflexivity/relative-reflexivity

ontological-contiguity will in the middle to long-run be ontologically untenable thus 'collapsing' the non-positivism/medievalism mindset $/{ }^{/ 3}$ reference-of-thought; and so reflecting 'Derridean underdetermination-imbued force/violence conception' and 'Foucauldian knowledge/power conception construed as knowledge-empowerment/ignorancedisempowerment' as to supererogating \{'sublimation affirmation/projection/assertion/notional self-distantiation/dueness-validatinglogicising/suitable-measuringinstrument-validating-measuring-<as-to-postconverging-ordialectical-thinking -apriorising-psychologism>' 'desublimation unaffirmation/deprojection/deassertion/epistemic-decadence/undueness-invalidatinglogicising/unsuitable-measuringinstrument-invalidating-measuring-<as-to-preconverging-ordementing -apriorising-psychologism>'\} so-underlining existence-as-the-absolute-a-prioriof-conceptualisation and existence — as-sublimating-withdrawal/unenframing/reontologising,-elicited-from-prospective-profound-supererogation $-<$ as-to-perspective- 
ontological-normalcy/postconvergence-implied-'prospective-aporeticism-

overcoming/unovercoming'>. This is the only basis for establishing the relative ascendency of divergent ${ }^{83}$ reference-of-thought (not to be confused with " logical-processing-or-logicalimplicitation-supposedly-apriorising-in-conviction-as-to-profound-supererogation convincing' as this by definition will instead make circular references to a prior ${ }^{83}$ reference-ofthought that is already established and uncontested in-the-very-first-place; thus highlighting the notion that it is the veridicality of the prospective ${ }^{83}$ reference-of-thought that precedes and defines the pertinence of an exercise of " logical-processing-or-logical-implicitationsupposedly-apriorising-in-conviction-as-to-profound-supererogation convincing' whereby interlocutors already share this common ${ }^{83}$ reference-of-thought, and not the other way around). Such a postconverging-or-dialectical-thinking -apriorising-psychologism over preconvergingor-dementing 20 apriorising-psychologism habituation (at their respective 'uninstitutionalisedthreshold ${ }^{02}$ or socially-betraying-threshold-of-ontologising-depth-of-analysis or sociallybetraying-threshold-of-intemporal-preservation-entropy-or-contiguity-or-ontologicalpreservation or threshold-of-nonconviction/madeupness/bottomlining-in-shallowsupererogation -<as-to-'attendant-intradimensional'-prospectivelydisontologising $\sim$ preconverging/dementing -apriorising-psychologism>') with regards to the postconverging-or-dialectical-thinking -apriorising-psychologism and preconverging-ordementing -apriorising-psychologism dialecticism of meaningful-reference/anchoring-ofmeaning/registry/axiomatic-construct/ontological-reference/contending-reference/registryworldview' developed as base-institutionalisation over recurrent-utter-uninstitutionalisation, universalisation over ununiversalisation, positivism over non-positivism/medievalism and prospectively notional ${ }^{18}$ deprocrypticism over procrypticism. It should equally be noted that just as no ${ }^{83}$ reference-of-thought will recognise itself as rather preconverging-or-dementing apriorising-psychologism (from its own present placeholder-setup/mental-devising- 
representation/mentation/consciousness-awareness-teleology of itself as postconverging-ordialectical-thinking -apriorising-psychologism) as we may appreciate from our relative vantage point being at a higher registry-worldview ontological-completeness-of- ${ }^{8}$ reference-of-thought, we will equally have a hard time recognising a preconverging-or-dementing ${ }^{20}$-apriorisingpsychologism placeholder-setup/mental-devising-representation/mentation/consciousnessawareness-teleology ${ }^{9}$ of our present positivistic registry-worldview as rather preconverging-ordementing ${ }^{20}$-apriorising-psychologism (as $\quad$ procrypticism-or-disjointedness-as-ofreference-of-thought) from futural Being-development/ontological-framework-expansion-asto-depth-of-ontologising-development-as-infrastructure-of- meaningfulness-and-teleology as of prospective notional $\sim$ deprocrypticism higher registry-worldview ontologicalcompleteness-of- reference-of-thought; as in both instances, the différance-disambiguation-ofontologically-veridical- ${ }^{5}$ meaningfulness-and-teleology ${ }^{9}$ highlights that the prior preconverging-or-dementing ${ }^{20}$-apriorising-psychologism ${ }^{83}$ reference-of-thought faces $\quad$ a 'Heideggerian (engaged)-destruktion', as it is not about substituting our species but enabling the further development of our same species as institutionalisation/intemporalisation, articulated as a Derridean deconstruction involving 'ontological-reconstituting-as-to-conflatedness ${ }^{13}$ ' of the prospective postconverging-or-dialectical-thinking ${ }^{2}$-apriorising-psychologism ${ }^{83}$ reference-ofthought over the hollow-constituting-<as-disjointed-misappropriation-of-meaningfulness-andfailing-intemporal-preservation $>$ of the prior preconverging-or-dementing ${ }^{20}$-apriorisingpsychologism meaningful-reference/anchoring-of-meaning/ontological-reference. So our natural 'argumentation reflex'/new ${ }^{5}$ logical-processing-or-logical-implicitation-supposedlyapriorising-in-conviction-as-to-profound-supererogation as 'prelogic supplanting-convictionas-to-profound-supererogation —of-'attendant-intradimensional'-postconverging/dialecticalthinking -apriorising-psychologism re-engaging reflex' with respect to the more familiar existentially $<$ disontologising/re-ontologising aporeticism $>$ veridical logical-dueness and 
from thence enabling the construing of relevant soundness or unsoundness of ${ }^{54}$ logicalprocessing-or-logical-implicitation - supposedly-apriorising-in-conviction-as-to-profoundsupererogation do not apply with respect to différance-disambiguation-of-ontologicallyveridical- ${ }^{56}$ meaningfulness-and-teleology ; as the latter is more about an engagement between a prior/transcended/superseded ${ }^{83}$ reference-of-thought say in registry-worldview terms like nonpositivism/medievalism (which harkens back to its ${ }^{83}$ reference-of-thought- categoricalimperatives/axioms/registry-teleology ${ }^{9}$,-for-intemporal-preservation-entropy-or-contiguityor-ontological-preservation) as rather hollow-constituting-<as-disjointed-misappropriation-ofmeaningfulness-and-failing-intemporal-preservation> to its ${ }^{83}$ reference-of-thoughtcategorical-imperatives/axioms/registry-teleology ${ }^{9}$ whether these are failing/not-upholding$<$ as-of-apriorising/axiomatising/referencing $>$ intemporal-preservation-entropy-or-contiguityor-ontological-preservation and a prospective/transcending/superseding ${ }^{8}$ reference-of-thought like positivism (which develops new ${ }^{83}$ reference-of-thought- categoricalimperatives/axioms/registry-teleology ${ }^{9}$,-for-intemporal-preservation-entropy-or-contiguityor-ontological-preservation) as 'ontologically-reconstituting' to uphold intemporalpreservation-entropy-or-contiguity-or-ontological-preservation, no matter what. Such a différance-disambiguation-of-ontologically-veridical- ${ }^{56}$ meaningfulness-and-teleology ${ }^{99}$ equally takes cognisance of the fact that a ${ }^{83}$ reference-of-thought construal is simply as of a dynamiccumulative-aftereffect apriorising/axiomatising/referencing-\{of-"prospectively implicited_attendant-ontological-contiguity ' educedexistentialising/contextualising/textualising_'intelligibility/epistemicity/reflexivity-contiguity$<$ imbued-notional $\left.\sim \operatorname{cogency}>^{\prime} \quad\right\}$ - conflatedness ${ }^{13}$ in-\{preconverging-disentailment by\} , and with perversion- ${ }^{83}$ reference-of-thought involving a subontologisation/subpotentiation rather indirectly as a comprehensive socially-betrayingthreshold-of-ontologising-depth-of-analysis (or socially-betraying-threshold-of-intemporal- 
preservation-entropy-or-contiguity-or-ontological-preservation

psychologism $>$ ) arising from the 'cumulative effect' of the various notional firstnaturednessformativeness-<as-to-eventualising-inkling-drive-or-seeding-misprising $>$ temporal-tointemporal-dispositions-<so-construed-as-from-perspective-ontologicalnormalcy/postconvergence $>$ individuations dispositions with respect to intradimensionally operant $<$ amplituding/formative-epistemicity $>$ causality $\sim$ as-to-projective-totalitativeimplications-of-prospective- nonpresencing,-for-explicating relative-unreflexivity/relativereflexivity - ontological-contiguity of ${ }^{74}$ perversion-of- ${ }^{8}$ reference-of-thought- $<$ aspreconvergingly-apriorising/axiomatising/referencing-in-

nonconviction/madeupness/bottomlining-as-to-shallow-supererogation $>$, as the various 'temporal-dispositions individuations' will, at the given uninstitutionalised-threshold ${ }^{102}$, betray ontologising/ontological-depth-of-analysis/intemporal-preservation by hollow-constituting-<asdisjointed-misappropriation-of-meaningfulness-and-failing-intemporal-preservation> at their specific temporal-dispositions individuations thresholds (5ignorance/affordability/opportunism/exacerbation/social-chainism-or-social-discomfiture-ornegative-social-aggregation/temporal-enculturation-or-temporal-endemisation). Thus providing the basis for a différance-disambiguation-of-ontologically-veridical- ${ }^{56}$ meaningfulness-andteleology $^{9}$ of ontological-reconstituting-as-to-conflatedness ${ }^{13}$ not only at a registryworldview/dimension or intradimensional level of hollow-constituting-<as-disjointedmisappropriation-of-meaningfulness-and-failing-intemporal-preservation> but also at notional firstnaturedness-formativeness-as to entulising inkling drive or seeding misprising $>$ temporal-to-intemporal-dispositions- $<$ so-construed-as-from-perspectiveontological-normalcy/postconvergence $>$ individuations level of hollow-constituting-<as- 
disjointed-misappropriation-of-meaningfulness-and-failing-intemporal-preservation>, $\quad$ which then allows for disambiguated <amplituding/formative-epistemicity $>$ causality $~ a s-t o-$ projective-totalitative-implications-of-prospective- nonpresencing,-for-explicating relativeunreflexivity/relative-reflexivity ontological-contiguity with respect to individuals teleologies as being of any of the various notional firstnaturedness-formativeness-<as-toeventualising inkling-drive or seeding-misprising> temporal-to-intemporal-dispositions$<$ so-construed-as-from-perspective-ontological-normalcy/postconvergence $>$ individuations (for instance, psychopath postlogic-backtracking-<iterative-looping-'set-of-dereifying-hollownarratives-and-acts'> -as-reflex-fleeting-logic, psychopath's or postlogic interlocutor conjoining-looping-set-of-narratives as-reflex-cohering-logic, etc.). This effectively allows for 'différance conceptualisation' of hollow-constituting-<as-disjointed-misappropriation-ofmeaningfulness-and-failing-intemporal-preservation> and ontological-reconstituting-as-to-

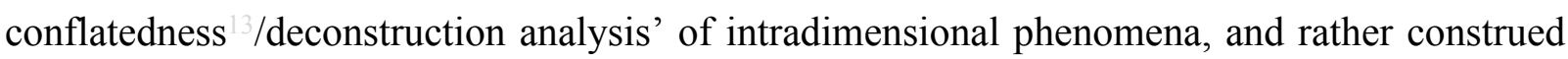
as of the conflaction of the corresponding registry-worldview ${ }^{83}$ reference-of-thought transcendental dialectics. Such a différance-disambiguation-of-ontologically-veridicalmeaningfulness-and-teleology ${ }^{9}$ thus goes on to encompass the de-mentation〈supererogatory $\sim$ ontological-de-mentation-or-dialectical-de-mentation-stranding-orattributive-dialectics $\rangle$

hermeneutically/textully/reprojectingly/supererogatingly/zeroingly/re-acutingly,${ }_{\text {\{decompulsing }}$ delinearity $\sim$ for-cogency-educing-human- ${ }^{56}$ meaningfulness-and-teleology ${ }^{9}$-intothe-existentialism-becoming of personhoods-and-socialhood-formation marking any registryworldview ${ }^{83}$ reference-of-thought. The underlying idea here being that faced with incidental issues arising in various effective social contexts, the 'ontological/intemporal postconvergingde-mentating/structuring/paradigming approach' is to have at hand a ' ${ }^{103}$ universal cadre' that conceptualises and is geared towards attending-to/resolving all such and other incidental issues 
as it is suprastructural to all such incidentals. That ${ }^{103}$ universal cadre with regards to issues of perversion-of- ${ }^{-3}$ reference-of-thought-<as-preconvergingly-

apriorising/axiomatising/referencing-in-nonconviction/madeupness/bottomlining-as-to-

shallow-supererogation $>$ pointing to différance-disambiguation-of-ontologically-veridicalmeaningfulness-and-teleology , and so across all registry-worldviews/dimensions, is humansubpotency-aporia/undecidability/dilemma/ought-

indeterminacy/deficiency/limitation/constraint—imbued-'notional firstnaturedness-

formativeness-<as-to-eventualising-inkling-drive-or-seeding-misprising $>$ temporal-to-

intemporal-dispositions-<so-construed-as-from-perspective-ontological-

normalcy/postconvergence>'-existentialism-form-factor conjugating with respect to intemporal/ontological meaningfulness requiring re-institutionalisation/re-intemporalisation in successive institutional-cumulation/institutional-recomposure-〈as-to- historiality/ontologicaleventfulness /ontological-aesthetic-tracing-<perspective-ontologicalnormalcy/postconvergence-reflected-‘epistemicity-relativism-determinism'>>,

cumulating/recomposuring along various ontologising-depth-of-analysis/intemporalpreservation-entropy-or-contiguity-or-ontological-preservation (as institutionalising, universalising, positivising and fully/utterly-ontologising into deprocrypticism). Humansubpotency-aporia/undecidability/dilemma/ought-

indeterminacy/deficiency/limitation/constraint—imbued-'notional firstnaturednessformativeness-<as-to-eventualising-inkling-drive-or-seeding-misprising $>$ temporal-tointemporal-dispositions- $<$ so-construed-as-from-perspective-ontologicalnormalcy/postconvergence>'-existentialism-form-factor as such is ontologically a preceding and defining construct that provides insight on 'existentialism/full-depth-of-existentialimplications issues' across all the institutional-cumulation/institutional-recomposure-〈as-tohistoriality/ontological-eventfulness /ontological-aesthetic-tracing-<perspective- 
ontological-normalcy/postconvergence-reflected-‘epistemicity-relativism-determinism' $>>$ since 'it grasps the ontological-veracity of notional firstnaturedness-formativeness-<as-toeventualising inkling-drive-or-seeding-misprising > temporal-to-intemporal-dispositions$<$ so-construed-as-from-perspective-ontological-normalcy/postconvergence $>$ as it recomposures across all the successive institutional-cumulation/institutional-recomposure-〈as-tohistoriality/ontological-eventfulness /ontological-aesthetic-tracing-<perspectiveontological-normalcy/postconvergence-reflected-‘epistemicity-relativism-determinism'>〉'; due to the inherent/permanent nature of human shallow to profound limited-mentation-capacitydeepening as subjecting limitedness/hmman subpotency to 'educed unlimitedness/existence sublimating nascence' (notional firstnaturedness-formativeness-<as-toeventualising inkling-drive or-seeding-misprising $>$ temporal-to-intemporal-dispositions$<$ so-construed-as-from-perspective-ontological-normalcy/postconvergence $>$ individuations dispositions) along the successive/snowballing institutional-recomposures with respect to the succession of recomposured human meaningfulness-and-action based-on/given this same formfactor. This implies individuality is then simply the 'unique incidence' of 'human-subpotencyaporia/undecidability/dilemma/ought-indeterminacy/deficiency/limitation/constraint—imbued'notional firstnaturedness-formativeness-<as-to-eventualising -inkling-drive-or-seedingmisprising $>$ temporal-to-intemporal-dispositions- $<$ so-construed-as-from-perspectiveontological-normalcy/postconvergence>'-existentialism-form-factor individuations dispositions (as form-factor)' in the 'receptacle' that is an individual in a given 'recomposuredexistentialism contextualisation', and as such a given 'recomposured-existentialism contextualisation' harbours other individuals (as receptacles) of their own 'unique incidence' of 'human-subpotency-aporia/undecidability/dilemma/oughtindeterminacy/deficiency/limitation/constraint—imbued-'notional firstnaturednessformativeness-<as-to-eventualising-inkling-drive-or-seeding-misprising $>$ temporal-to- 
intemporal-dispositions-<so-construed-as-from-perspective-ontologicalnormalcy/postconvergence>'-existentialism-form-factor individuations dispositions'. A further implication is that going by ontological-normalcy/postconvergence (prospective-transcendencein-perpetually-upholding-intemporal-preservation-entropy-or-contiguity-or-ontologicalpreservation) that is behind the institutional-cumulation/institutional-recomposure-〈as-tohistoriality/ontological-eventfulness /ontological-aesthetic-tracing-<perspectiveontological-normalcy/postconvergence-reflected-‘epistemicity-relativism-determinism'>> involving the skewing ('intemporality ${ }^{52}$-symmetrising-by-desymmetrising-subsumption-oftemporality ${ }^{8}$, for relative intrinsic-reality/ontological-veridicality transcendental-

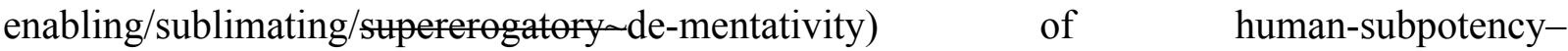
aporia/undecidability/dilemma/ought-indeterminacy/deficiency/limitation/constraint—imbued'notional firstnaturedness-formativeness-<as-to-eventualising inkling-drive-or-seeding misprising $>$ temporal-to-intemporal-dispositions- $<$ so-construed-as-from-perspectiveontological-normalcy/postconvergence>'-existentialism-form-factor (as human-subpotencyaporia/undecidability/dilemma/ought-indeterminacy/deficiency/limitation/constraint—imbued'notional firstnaturedness-formativeness-<as-to-eventualising-inkling-drive or seedingmisprising $>$ temporal-to-intemporal-dispositions- $<$ so-construed-as-from-perspectiveontological-normalcy/postconvergence>'-existentialism-form-factor individuations dispositions) towards the ascendency of the intemporal-disposition's meaningfulness (longnessof-register-of- ${ }^{5}$ meaningfulness-and-teleology ${ }^{\circ}$ ) as institutionalisation/intemporalisation, this highlights that différance-disambiguation-of-ontologically-veridical- ${ }^{56}$ meaningfulness-andteleology which is rather about perversion-and-derived- ${ }^{7}$ perversion-of- ${ }^{3}$ reference-ofthought-<as-preconvergingly-apriorising/axiomatising/referencing-innonconviction/madeupness/bottomlining-as-to-shallow-supererogation $>$ (as humansubpotency-aporia/undecidability/dilemma/ought- 
indeterminacy/deficiency/limitation/constraint—imbued-'notional firstnaturednessformativeness-<as-to-eventualising-inkling-drive-or-seeding-misprising $>$ temporal-tointemporal-dispositions- $<$ so-construed-as-from-perspective-ontologicalnormalcy/postconvergence>'-existentialism-form-factor as of postlogism slantedness/ ${ }^{5}$ ignorance/affordability/opportunism/exacerbation/social-chainism-or-socialdiscomfiture-or-negative-social-aggregation/temporal-enculturation-or-temporal-endemisation, so-disambiguated as of ${ }^{83}$ reference-of-thought- ${ }^{8}$ devolving ontological-performance ${ }^{72}$ $<$ including-virtue-as-ontology $>/$ morality/ethics/justice/etc. 'conjugate with and thus pervert intemporal/ontological meaningfulness' requiring 'ontological-reconstituting-as-toconflatedness $^{13}$, over their hollow-constituting-<as-disjointed-misappropriation-ofmeaningfulness-and-failing-intemporal-preservation>) contrasted to 'notion of agreementdisagreement', is a permanent construct for the ontological/intemporal resolution/skewing of human-subpotency-aporia/undecidability/dilemma/oughtindeterminacy/deficiency/limitation/constraint—imbued-'notional firstnaturednessformativeness-<as-to-eventualising-inkling-drive-or-seeding-misprising $>$ temporal-tointemporal-dispositions- $<$ so-construed-as-from-perspective-ontologicalnormalcy/postconvergence >'-existentialism-form-factor, and in registry-worldview terms différance-disambiguation-of-ontologically-veridical- ${ }^{5}$ meaningfulness-and-teleology ${ }^{9}$ is the mechanism of transcending the registry-worldview ${ }^{83}$ reference-of-thought as 'ontologicalreconstituting-as-to-conflatedness ${ }^{13} /$ deconstruction' articulates better and better ${ }^{83}$ reference-of-

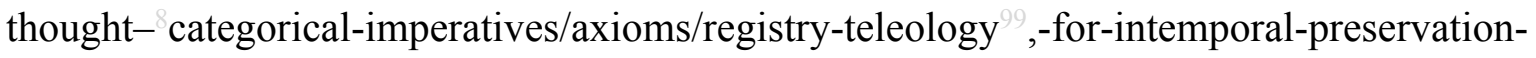
entropy-or-contiguity-or-ontological-preservation and is geared exclusively for prospective intemporal-preservation-entropy-or-contiguity-or-ontological-preservation, and thus recomposuring-in-a-snowballing-effect base-institutionalisation, ${ }^{103}$ universalisation, positivism, and prospectively deprocrypticism. It also points out that the exercise of 
institutionalisation/intemporalisation is not an exercise of human emanance transformation from temporal-dispositions to intemporal-disposition (as we wrongly imply by intuition) but a registry-worldview's/dimension's institutionalisation or secondnaturing exercise, explaining why we are continually the same species from utter-institutionalisation to prospectively deprocrypticism. This point can be demonstrated by the fact that when a prospective/transcending/superseding registry-worldview is institutionalised, our same temporality 8 /shortness as of human-subpotency-aporia/undecidability/dilemma/oughtindeterminacy/deficiency/limitation/constraint—imbued-'notional firstnaturednessformativeness-<as-to-eventtalising-inkling-drive-or-seeding-misprising $>$ temporal-tointemporal-dispositions- $<$ so-construed-as-from-perspective-ontologicalnormalcy/postconvergence>'-existentialism-form-factor will now rather conjugate temporarily as shortness-of-register-of- ${ }^{5}$ meaningfulness-and-teleology ${ }^{99}$ or ${ }^{74}$ perversion-of- ${ }^{8}$ reference-ofthought-<as-preconvergingly-apriorising/axiomatising/referencing-inpostlogism ${ }^{77}$-slantedness/ ${ }^{5}$ ignorance/affordability/opportunism/exacerbation/social-chainismor-social-discomfiture-or-negative-social-aggregation/temporal-enculturation-or-temporalendemisation, so-disambiguated as of ${ }^{83}$ reference-of-thought- ${ }^{8}$ devolving ontologicalperformance ${ }^{72}-<$ including-virtue-as-ontology $>$ ) to the new ${ }^{83}$ reference-of-thought- categoricalimperatives/axioms/registry-teleology ${ }^{99}$,-for-intemporal-preservation-entropy-or-contiguityor-ontological-preservation at the new institutionalisation's uninstitutionalised-threshold ${ }^{102}$, and thus eliciting the need for prospective intemporalisation/institutionalisation. The need for successive institutional-cumulation/institutional-recomposure-〈as-to- historiality/ontologicaleventfulness /ontological-aesthetic-tracing-<perspective-ontologicalnormalcy/postconvergence-reflected-'epistemicity-relativism-determinism' $>>$ thus leads to notional ${ }^{1}$ deprocrypticism which specificity going by the increasing 'rational-realism' of the 
institutional-cumulation/institutional-recomposure-〈as-to- historiality/ontological-

eventfulness /ontological-aesthetic-tracing-<perspective-ontological-

normalcy/postconvergence-reflected-'epistemicity-relativism-determinism'>> process is to recognise the veridicality of this human-subpotency-aporia/undecidability/dilemma/oughtindeterminacy/deficiency/limitation/constraint—imbued-'notional firstnaturednessformativeness-<as-to-eventualising-inkling drive-or-seeding-misprising $>$ - temporal-tointemporal-dispositions-<so-construed-as-from-perspective-ontologicalnormalcy/postconvergence>'-existentialism-form-factor (as of the intemporal-disposition and temporal-dispositions of postlogism slantedness/ ${ }^{50}$ ignorance/affordability/opportunism/exacerbation/social-chainism-or-socialdiscomfiture-or-negative-social-aggregation/temporal-enculturation-or-temporal-endemisation, so-disambiguated as of ${ }^{83}$ reference-of-thought- ${ }^{8}$ devolving ontological-performance ${ }^{72}$ <including-virtue-as-ontology>) and construct prospective knowledge factoring it in, as 'knowledge-notionalisation' or knowledge construct not only based on intemporal idealisation but that also factors in how the temporalities will relate to meaning, and be conceptually preemptive of human temporality ${ }^{8 / \text { shortness }}$ since human-subpotencyaporia/undecidability/dilemma/ought-indeterminacy/deficiency/limitation/constraint—imbued'notional firstnaturedness-formativeness-<as-to-eventualising -inkling-drive-or-seedingmisprising $>$ temporal-to-intemporal-dispositions- $<$ so-construed-as-from-perspectiveontological-normalcy/postconvergence >'-existentialism-form-factor can't be emanantly/becomingly/solipsistic transformed as 'of intemporal-disposition only' (it's a lost cause as that is not our firstnatureness since we are effectively of notional firstnaturednessformativeness-<as-to-eventualising-inkling-drive-or-seeding-misprising $>$ temporal-tointemporal-dispositions-<so-construed-as-from-perspective-ontologicalnormalcy/postconvergence $>$ given our human-subpotency ever limited-mentation-capacity—as- 
subjecting 'educed-unlimitedness/existence-sublimating nascence' to-limitedness/humansubpotency relative to the full-potency of existence as existence-potency ${ }^{39} \sim$ sublimatingnascence,-disclosed-from-prospective-epistemic-digression) and avoid articulating knowledge as if the human mentation is by reflex only intemporal of emanance ${ }^{8}$ reference-of-thought when in reality it is of notional firstnaturedness-formativeness-<as-to-eventualising-inkling-driveor seeding-misprising $>$ temporal-to-intemporal-dispositions- $<$ so-construed-as-fromperspective-ontological-normalcy/postconvergence>, and so by way of percolationchannelling- $<$ in-deferential-formalisation-transference $>$. Effectively given that going by human-subpotency-aporia/undecidability/dilemma/ought-

indeterminacy/deficiency/limitation/constraint—imbued-'notional firstnaturednessformativeness-<as-to-eventualising-inkling-drive-or-seeding-misprising > temporal-tointemporal-dispositions- $<$ so-construed-as-from-perspective-ontologicalnormalcy/postconvergence>'-existentialism-form-factor, the determinant nature of intemporal/ontological constructs induced by institutionalisation with respect to social-stakecontention-or-confliction is always bound to elicit two classes of human mental-dispositions with respect to it whether as a temporal extricatory preconverging-dementating/structuring/paradigming or as an intemporal/ontological/social/species/ ${ }^{103}$ universal/transcendental/ ${ }^{5}$ maximalisingrecomposuring-for-relative-ontological-completeness ${ }^{8}$ - unenframed/reontologising conceptualisation postconverging-de-mentating/structuring/paradigming, and knowledge-notionalisation is grounded on addressing meaningfulness insightfully in these two respects. The veridical insight to the reality of human-subpotencyaporia/undecidability/dilemma/ought-indeterminacy/deficiency/limitation/constraint—imbued'notional firstnaturedness-formativeness-<as-to-eventualising -inkling-drive-or-seedingmisprising $>$ temporal-to-intemporal-dispositions- $<$ so-construed-as-from-perspective- 
ontological-normalcy/postconvergence>'-existentialism-form-factor lies in the fact that the cross-section of humankind at any instittutionalisation is institutionalised at its sociallybetraying-threshold-of-ontologising-depth-of-analysis or socially-betraying-threshold-ofintemporal-preservation-entropy-or-contiguity-or-ontological-preservation or uninstitutionalised-threshold $^{102}$ or threshold-of-nonconviction/madeupness/bottomlining-inshallow-supererogation -<as-to-'attendant-intradimensional'-prospectivelydisontologising preconverging/dementing -apriorising-psychologism>; as basically intemporality ${ }^{52} /$ longness is a pathway from base-institutionalisation to ${ }^{103}$ universalisation to positivism and prospectively notional deprocrypticism as the fulfilment of ontologicalnormalcy/postconvergence potency, and any pretence at a positivistic registry-worldview to be non-transcendable (in terms-as-of-axiomatic-construct of différance-disambiguation-ofontologically-veridical- ${ }^{5}$ meaningfulness-and-teleology ${ }^{9}$ ) is untenable as the same could be implied at base-institutionalisation and ${ }^{103}$ universalisation, which obviously we won't recognise and acquiesce to, implying the temporal-difficulty of dealing with the transcendental implications in reflecting holographically-<conjugatively-and-transfusively $>$ the relativeunreflexivity/relative-reflexivity - ontological-contiguity of-the-human-institutionalisationprocess often lead to ontological-bad-faith/inauthenticity ${ }^{64}$ as human-subpotencyaporia/undecidability/dilemma/ought-indeterminacy/deficiency/limitation/constraint—imbued'notional firstnaturedness-formativeness-<as-to-eventualising inkling-drive-or-seedingmisprising $>$ temporal-to-intemporal-dispositions- $<$ so-construed-as-from-perspectiveontological-normalcy/postconvergence>'-existentialism-form-factor! The grander insight being that 'institutionalisation devising and devices' already speaks a lot about human potential and capacity (and are basically our virtue with no need for 'false idealisation' that just induces 'vaintemporality ${ }^{98}$ passing for intemporality ${ }^{52}$ ), and just as previous institutionalisations prospered, due to increasing realism, because they did away with deities and spirits in recognising that 
human potential lies in what humans can do themselves, and strived even more by doing away with essences in recognising that understanding effectively what happens in the world is what gives power and effectiveness over nature, a further extension of rational-realism is to do away with the 'false feel good' naivety of construing man by reflex in intemporal terms (not recognising or rather taking full cognisance of the implications that we have notional firstnaturedness-formativeness-<as-to-eventualising-inkling-drive or seedingmisprising $>$ temporal-to-intemporal-dispositions-<so-construed-as-from-perspective-

ontological-normalcy/postconvergence> meaningfulness-and-teleology as

or shortness-to-longness-of-register-ofperversion-of- ${ }^{8}$ reference-of-thought- $<$ as-

preconvergingly-apriorising/axiomatising/referencing-in-

nonconviction/madeupness/bottomlining-as-to-shallow-supererogation $>$ teleologies) which failure only leads to unrealistically grounded ${ }^{83}$ reference-of-thought and meaningfulness (characterised by the readiness to overlook vices-and-impediments ${ }^{105}$ of our registryworldview/dimension as side notes rather than the idea that these point to our deficiencies and 'that these are actually the necessary pathway for superseding/transcending' for prospective postconverging-de-mentating/structuring/paradigming, just as preceding registryworldviews/dimensions had to deal with their preconverging-dementating/structuring/paradigming that led up to our positivistic registry-worldview) and aspiring for the intemporal while factoring in the temporal. In a further elaboration, there is no pathway for prospective base-institutionalisation without a recognition of recurrent-utteruninstitutionalisation for its superseding, no pathway for prospective ${ }^{103}$ universalisation without a recognition of ${ }^{74}$ perversion-of- ${ }^{83}$ reference-of-thought- $<$ as-preconverginglyapriorising/axiomatising/referencing-in-nonconviction/madeupness/bottomlining-as-to-

shallow-supererogation >,-of-base-institutionalisation-as-ununiversalisatiion for its superseding, no pathway for prospective positivism without a recognition of ${ }^{74}$ perversion-of- 
reference-of-thought-<as-preconvergingly-apriorising/axiomatising/referencing-in-

nonconviction/madeupness/bottomlining-as-to-shallow-supererogation >,-of-universalisationas-non-positivism/medievalism for its superseding, and there is equally no pathway for futural Being-development/ontological-framework-expansion-as-to-depth-of-ontologisingdevelopment-as-infrastructure-of- meaningfulness-and-teleology as of prospective notional ${ }^{18}$ deprocrypticism without a recognition of 7 perversion-of- ${ }^{-}$reference-of-thought- $<$aspreconvergingly-apriorising/axiomatising/referencing-innonconviction/madeupness/bottomlining-as-to-shallow-supererogation >,-positivism-asprocrypticism for its superseding. However, such an intemporal-disposition of transcendental depth-of-thought, it must be acknowledged is hardly the panacea of a $<$ amplituding/formative $>$ wooden-language-_imbued - averaging-of-thought-<as-toleveling/ressentiment/closed-construct-of- meaningfulness-and-teleology -as-of'nondescript/ignorable-void ' -with-regards-to-prospective-apriorising-implications $>$ > temporal mental-disposition that is more predisposed to project mainly in terms-as-ofaxiomatic-construct of 'temporal lifespan of living scale' rather than 'humanity-at-large spatial and timeless scale' of intemporal projection-of-thought mental-disposition; with the inherent moral and intellectual superiority of the latter warranting an uncompromising stance over the former, in $\quad$ transversality- $<$ for-sublimating-existential-eventuating/denouement, - from'thinking at first/pure-predisposition-preemptive-of prospectivedisontologising/subontologising' as-of-prospectively-disambiguated-affirmed-andunaffirmed-'motif-and-apriorising/axiomatising/referencing'> ${ }^{101}$, as has always been the case all along in reflecting holographically-<conjugatively-and-transfusively $>$ the relativeunreflexivity/relative-reflexivity - ontological-contiguity of-the-human-institutionalisationprocess , and so 'looking down' at temporality $/$ shortness effects of 'country-of-the-blind effect' and 'crowd effects'. Already with respect to futural Being-development/ontological- 
framework-expansion-as-to-depth-of-ontologising-development-as-infrastructure-of-

meaningfulness-and-teleology as of prospective deprocrypticism, our formalisation mechanisms acknowledge unspokenly/tacitly/by-mere-intuition the veracity/ontologicalpertinence of our potential 'perverting temporal-dispositions inclinations' by its 'abstract preemptive mechanisms', the bigger prospect though lies in fully unleashing such a potential for a knowledge-notionalisation emancipation that is consciously aware of the full implications and thus paradoxically uninhibited/decomplexified in dealing with this realism rationally and further expand human intemporal potential as the notional ${ }^{18}$ deprocrypticism registry-worldview. Actually the notional ${ }^{1}$ deprocrypticism registry-worldview/dimension we will be able to supersede human-subpotency-aporia/undecidability/dilemma/oughtindeterminacy/deficiency/limitation/constraint—imbued-'notional firstnaturednessformativeness-<as-to-eventtalising inkling-drive-or seeding misprising $>$ temporal-tointemporal-dispositions- $<$ so-construed-as-from-perspective-ontologicalnormalcy/postconvergence $>$ '-existentialism-form-factor because its preemptingdisjointedness-as-of- ${ }^{83}$ reference-of-thought,-as-to- ${ }^{32}<$ amplituding/formativeepistemicity $>$ growth-or-conflatedness ${ }^{13} /$ transvaluative- $^{2}$ rationalising/transepistemicity/anamnestic-residuality/spirit-drivenness'_in-supersedingmere-formulaic-positivising/rational-empiricism-based-universalisation-directed-rulemakingover-non-rules_-apriorising/axiomatising/referencing-psychologism enables 'absolute social ${ }^{3}$ universal-transparency ${ }^{104}$-〈transparency-of-totalising-entailing,-as-to-entailing$<$ amplituding/formative-epistemicity>totalising in-relative-ontological-completeness $>$ about the real nature of human action' thus undermining the disposition for human temporalpreservation-and-prevarication behind relative-ontological-incompleteness ${ }^{8}$-induced,'threshold-of-nonconviction/madeupness/bottomlining-in-shallow-supererogation -<as-to‘attendant-intradimensional'-prospectively-disontologising preconverging/dementing 
apriorising-psychologism>'; as in fact the successive institutional-cumulation/institutionalrecomposure-〈as-to- historiality/ontological-eventfulness /ontological-aesthetic-tracing$<$ perspective-ontological-normalcy/postconvergence-reflected-'epistemicity-relativismdeterminism' $>>$ (as 'postconverging-or-dialectical-thinking -apriorising-psychologism and inphase/soundness-or-ontological-good-faith/authenticity ${ }^{69}$-of- ${ }^{3}$ reference-of-thought' in voiding/annulling the 'supposed pretence of a contending posture or ${ }^{83}$ reference-of-thought' of the successive corresponding uninstitutionalised-threshold ${ }^{102}$ as actually the ontological reflection of their mental-disposition is 'of threshold-ofnonconviction/madeupness/bottomlining-in-shallow-supererogation $<<$ as-to-'attendantintradimensional'-prospectively-disontologising preconverging/dementing -apriorisingpsychologism> $\quad$ (beyond-the-consciousness-awareness-teleology ${ }^{\circ}-<$ of-preconvergingexistential-extrication-as-of-existential-unthought $>$ manifestation intradimensionally) as temporal-dispositions are actually involved in pseudointemporality ${ }^{52}$ inducing temporalpreservation-as-pseudointemporality ${ }^{52}$-preservation defining the corresponding uninstitutionalised-threshold ${ }^{102}, \quad$ beyond-the-consciousness-awareness-teleology ${ }^{9}-<$ ofpreconverging-existential-extrication-as-of-existential-unthought $>$ manifestation, thus represented as 'preconverging-or-dementing -apriorising-psychologism and dialectically-outof-phase/unsoundness-or-ontological-bad-faith/inauthenticity ${ }^{4}$-of- ${ }^{3}$ reference-of-thought', and thus the 'point of engagement' with all established uninstitutionalised-threshold ${ }^{102}$ is rather a 'reflection of postlogism 7 -formulaic-nonconviction/madeupness/bottomlining-as-to-shallowsupererogation -or-'threshold-of-nonconviction/madeupness/bottomlining-in-shallowsupererogation -<as-to- 'attendant-intradimensional'-prospectivelydisontologising preconverging/dementing -apriorising-psychologism> reflex disposition or preconverging-or-dementing 20 -apriorising-psychologism' and not the 'natural institutionalisations inclination to reflect a prelogic supplanting-conviction-as-to-profound- 
supererogation _of-'attendant-intradimensional'-postconverging/dialectical-thinking

apriorising-psychologism re-engaging reflex or thinking reflex', for instance 'we don't think' with a non-positivism/medievalism uninstitutionalisation-mindset $/{ }^{/ 3}$ reference-of-thought as the point-of-meaningful-engagement' with it from our positivistic perspective is its out-of-phase decentering and preconverging-or-dementing -apriorising-psychologism, likewise the pointof-meaningful-engagement from futural Being-development/ontological-frameworkexpansion-as-to-depth-of-ontologising-development-as-infrastructure-of- meaningfulnessand-teleology as of prospective notional deprocrypticism perspective with our registryworldview/dimension ${ }^{80}$ procrypticism-or-disjointedness-as-of- ${ }^{8}$ reference-of-thought is "not a thinking relation' but a 'decentering and preconverging-or-dementing ${ }^{20}$-apriorisingpsychologism' as dialectically-out-of-phase and logically-incongruent) arise because of intermittent/relative ${ }^{103}$ universal transparencies induced by knowledge in grasping over recurrent-utter-uninstitutionalisation-recurrency the notion of rulemaking-over-non-rulesapriorising/axiomatising/referencing-psychologism,-〈as`first-level presencing—absolutisingidentitive-constitutedness of reference-of-thought' apriorising/axiomatising/referencing/intelligibilitysettingup/measuringinstrumenting $\rangle$ social ${ }^{3}$ universal-transparency $^{104}$-〈transparency-of-totalising-entailing,-as-to-entailing<amplituding/formative-epistemicity>totalising in-relative-ontological-completeness > as base-institutionalisation which temporal hollow-constituting-<as-disjointed-misappropriationof-meaningfulness-and-failing-intemporal-preservation> as ununiversalisation led to universalisation-directed-rulemaking-over-non-rules_-apriorising/axiomatising/referencingpsychologism,-〈as 'second-level presencing-absolutising-identitive-constitutedness ${ }^{14}$ of reference-of-thought'

apriorising/axiomatising/referencing/intelligibilitysettingup/measuringinstrumenting $\rangle$ social universal-transparency ${ }^{104}$-〈transparency-of-totalising-entailing,-as-to-entailing- 
universalisation which temporal hollow-constituting-<as-disjointed-misappropriation-ofmeaningfulness-and-failing-intemporal-preservation> as non-positivism/medievalism led to positivising/rational-empiricism-based-universalisation-directed-rulemaking-over-non-rulesapriorising/axiomatising/referencing-psychologism,-_as 'third-level presencingabsolutising-identitive-constitutedness ${ }^{14}$ of reference-of-thought' apriorising/axiomatising/referencing/intelligibilitysettingup/measuringinstrumenting social ${ }^{3}$ universal-transparency ${ }^{104}$-〈transparency-of-totalising-entailing,-as-to-entailing$<$ amplituding/formative-epistemicity>totalising in-relative-ontological-completeness $>$ as positivism/rational-empiricism, and which temporal hollow-constituting-<as-disjointedmisappropriation-of-meaningfulness-and-failing-intemporal-preservation $>$ as ${ }^{80}$ procrypticismor-disjointedness-as-of- ${ }^{8}$ reference-of-thought should lead to preempting - disjointedness-asof- ${ }^{8}$ reference-of-thought,-as-to- ${ }^{6}{ }^{3}<$ amplituding/formative-epistemicity $>$ growth-orconflatedness ${ }^{13}$ /transvaluative-rationalising/transepistemicity/anamnestic-residuality/spiritdrivenness' - in-superseding-mere-formulaic-positivising/rational-empiricism-baseduniversalisation-directed-rulemaking-over-non-rules — apriorising/axiomatising/referencingpsychologism social ${ }^{103}$ universal-transparency ${ }^{104}$-〈transparency-of-totalising-entailing,-as-toentailing-<amplituding/formative-epistemicity $>$ totalising in-relative-ontological-

completeness > as deprocrypticism. The conceptualisation of 'knowledge-notionalisation' is rather based on the fundamental notion of a superseding-oneness-of-ontology with respect to knowledge-and-virtue conceptualisation such that so-construed it is rather a 'referential-asnatural' conceptualisation of knowledge that consciously tautologically subsumes temporaldispositions and intemporal-disposition (as opposed to our present 'categories-as-artificial' conceptualisation of knowledge often predisposed to overlook the temporal, and critically so, with respect to understanding the social as of the human condition together with inherent 
ontological-veridicality in naively assuming the intemporal/Aongness-of-register-ofmeaningfulness-and-teleology by reflex focussed mostly on inherent ontological-veridicality, and whose artificially-demarcated subject-matters and hierarchical relationship with the firstorder-ontology/notional philosophy-<as-to-the-veridical-conception-of-philosophy-asenglobing-all-human-prospective-organic-knowledge-generation-in-relative-ontologicalcompleteness ,-beyond-a-convenient-division-of-labour-conception-of-knowledge $>$ is by itself a preconverging-de-mentating/structuring/paradigming shortcoming with respect to our understanding possibilities, given that our artificial subject-matter categories-schemes do not precede nor define intrinsic-reality as 'knowledge-in-its-oneness-and-entirety'), and is postconvergent in its ontological-tautologisation/existential-reference conceptualisation of reality in a unison of second-order-ontologies with the first-order-ontology/philosophy wherein second-order subject-matters aren't discontinuously hollowed out from the first-order-ontology but rather their inter-relational and hierarchical relationship with the first-order-ontology (philosophy) is subsumptive with the latter as superseding-oneness-of-ontology and the place for elucidating epistemic disagreement (with the practical desire for an appropriate proportion of subject-matter experts directly studying and understanding the first-orderontology/philosophy elucidations and the possibilities implied for their subject-matters), and as the first-order-ontology/philosophy furthermore is the 'abstractly inventing conceptualising construct that construes the requisite overhanging knowledge psychical-orientation/psyche', as the fact is it was a philosophical orientation whether explicit with Descartes's 'I think therefore I am' establishing the positivistic mindset/ ${ }^{8}$ reference-of-thought/consciousness-awarenessteleology ${ }^{9}$ so excellently, with the later requalification of Hume, Kant and others of that same mindset $/{ }^{83}$ reference-of-thought/consciousness-awareness-teleology 99 and actually 'in complement to it' than truly criticisms (which is often philosophically misconstrued, as Descartes's 'thinking proposition' is so profound that it is the very 'transparent pillar or social 
universal-transparency ${ }^{104}$-〈transparency-of-totalising-entailing,-as-to-entailing-

$<$ amplituding/formative-epistemicity>totalising in-relative-ontological-completeness $>$ for the tenability of the supposed critiques of rationalism, which are actually in complement to it, by latter philosophers, and it is rather the failure to compare what the 'thinking proposition' implies with respect to the prior as the core-medieval mindset/ ${ }^{83}$ reference-of-thought/consciousnessawareness-teleology 9 of essences, alchemies and superstition as an altogether different $<$ amplituding/formative-epistemicity $>$-totalising $\sim$ renewing-realisation/re-perception/re-

thought of human mindset ${ }^{/ 3}$ reference-of-thought/consciousness-awareness-teleology ${ }^{9}$, together with the naïve predisposition for categorisation of knowledge in artificial human categories undermining the 'natural referentialism ontological-normalcy/postconvergence nature of knowledge' that is at the basis of misapprehending the complementing as criticisms, as in fact these will actually be better construed as Extended Rationalism -rationalism, empiricism, subjectivism, realism, idealism, phenomenology, as the fact is none of the latter claims to be 'irrational') or less-explicit with Copernicus, Galileo, Darwin, etc. scientific endeavours/postures that 'invented-and-upheld' the positivistic psyche/psychical-orientation for our present-day positivistic knowledge form, as the fact is Descartes 'utterly-thinkingproposition psyche' is not a given as of its epistemological and ontological implications as to projective dimensionality-of-sublimating $-\langle<$ amplituding/formative $>$ supererogatory $\sim$ dementativeness/epistemic-growth-or-conflatedness /transvaluativerationalising/transepistemicity/anamnestic-residuality/spirit-drivenness-equalisation $\rangle$ as to existence — as-sublimating-withdrawal/unenframing/re-ontologising,-elicited-fromprospective-profound-supererogation , and in the same token there is a case to be made that suprastructuralism as a meaningful-frame ushered in by post-structuralism will be the requisite human teleology 9 of mindset $^{2}$ reference-of-thought/ $\{$ cumulated/recomposured $\}$ consciousness-awareness-<amplituding/formative-epistemicity $>$-totalising $\sim$ renewing- 
realisation/re-perception/re-thought for the prospective knowledge-form $/{ }^{5}$ meaningfulness-andteleology associated with notional ${ }^{18}$ deprocrypticism as ontologicalnormalcy/postconvergence dimensionality-of-sublimating

\section{<<amplituding/formative >supererog de-mentativeness/epistemic-growth-or-}

conflatedness /transvaluative-rationalising/transepistemicity/anamnestic-residuality/spirit-

drivenness-equalisation> as to existence-as-sublimating-withdrawal/unenframing/reontologising,-elicited-from-prospective-profound-supererogation ; as 'different institutionalcumulation/institutional-recomposure-〈as-to- historiality/ontologicaleventfulness /ontological-aesthetic-tracing-<perspective-ontologicalnormalcy/postconvergence-reflected-‘epistemicity-relativism-determinism'>> have their knowledge-form $/{ }^{5}$ meaningfulness-and-teleology ${ }^{9}$ psyches (psychologisms) which is a difficult notion to grasp when operating only within a same registry-worldview/dimension psyche of apriorising/axiomatising/referencing without projecting of varying/successive fundamental apriorising/axiomatising/referencing framing, but this can be elucidated by an ontology-driven 'postconverging-or-dialectical-thinking -psychology or psychology-of-mentation-dynamics or natural psychological-dynamics' highlighting the defining stage by stage psychical development as from recurrent-utter-uninstitutionalisation to base-institutionalisationununiversalisation to ${ }^{103}$ universalisation-non-positivism-or-medievalism to positivismprocrypticism, and prospectively notional ${ }^{18}$ deprocrypticism psyche. Suprastructuralism ultimately reflects the relative mneflexivitrelative reflexivity ontological-contiguity ${ }^{67} \sim$ ofthe-human-institutionalisation-process ${ }^{6}$ by bringing to the 'collective-human-psyche-andconsciousness as a transparent-pillar or social ${ }^{103}$ universal-transparency ${ }^{104}$-〈transparency-oftotalising-entailing,-as-to-entailing-<amplituding/formative-epistemicity $>$ totalising $\sim$ inrelative-ontological-completeness $\rangle$ the insight of a lockstep relationship of the-postconvergingor-dialectical-thinking 'narrative-by-the-preconverging-or-dementing -narrative' in 
grasping ontology/ontologically-veridical-meaningfulness/intrinsic-reality across all human retrospective, present and prospective institutionalisations, as implied by de-mentation〈supererogatory $\sim$ ontological-de-mentation-or-dialectical-de-mentation-stranding-or-

attributive-dialectics〉 with a corresponding comprehensive grasp of the implications of humansubpotency-aporia/undecidability/dilemma/ought-

indeterminacy/deficiency/limitation/constraint—imbued-'notional firstnaturednessformativeness-<as-to-eventualising inkling-drive-or-seeding-misprising $>$ temporal-tointemporal-dispositions- $<$ so-construed-as-from-perspective-ontologicalnormalcy/postconvergence>'-existentialism-form-factor with respect to institutionalisation possibilities and more precisely and prospectively, preempting-disjointedness-as-ofreference-of-thought,-as-to- ${ }^{6}{ }^{2}<$ amplituding/formative-epistemicity>growth-orconflatedness ${ }^{13} /$ transvaluative-rationalising/transepistemicity/anamnestic-residuality/spiritdrivenness' - in-superseding-mere-formulaic-positivising/rational-empiricism-baseduniversalisation-directed-rulemaking-over-non-rules_ - apriorising/axiomatising/referencingpsychologism as deprocrypticism-and-its-potential-for-prevailing-over-or-superseding-humanvices-and-impediments ${ }^{105}$-as-arising-from-disjointedness-as-of- ${ }^{-}$reference-of-thought as well as knowledge-notionalisation undermining the prospective denaturing of institutionalisation possibilities as subknowledging ${ }^{4}$. Going by our mirage/illusion-of-the-present/presentconsciousness we will possibly think otherwise, but this rather points to how our forerunners felt psychologically when their worlds built of deities and later essences were being put-intoquestion by an 'increasing realism insight' of an intrinsic-reality that is ontologically given and in ontological-normalcy/postconvergence with respect to us, with the implication that it is our psyche that 'gives-in' to intrinsic-reality and not the other way around. - As central to an overall Suprastructuralism conceptualisation that subsumes all the transcendental concepts highlighted with regards to grasping ontology/ontologically-veridical-meaningfulness/intrinsic-reality, and 
corresponding perversion-of- ${ }^{8}$ reference-of-thought-<as-preconverginglyapriorising/axiomatising/referencing-in-nonconviction/madeupness/bottomlining-as-toshallow-supererogation $>$ with respect to ushering in the requisite preempting - disjointednessas-of- ${ }^{8}$ reference-of-thought,-as-to- ${ }^{32}<$ amplituding/formative-epistemicity $>$ growth-orconflatedness ${ }^{13}$ /transvaluative-rationalising/transepistemicity/anamnestic-residuality/spiritdrivenness' - in-superseding-mere-formulaic-positivising/rational-empiricism-baseduniversalisation-directed-rulemaking-over-non-rules_ apriorising/axiomatising/referencingpsychologism that should define and conceptualise the notional ${ }^{18}$ deprocrypticism registryworldview/dimension (as the effective attainment of ontological-normalcy), is the idea of a 'postconverging-or-dialectical-thinking -psychology or psychology-of-mentation-dynamics or natural psychological-dynamics' 'psycho-ontological-tautologisation/psycho-existentialreference conceptual-scheme'. Basically, a 'postconverging-or-dialectical-thinking psychology or psychology-of-mentation-dynamics or natural psychological-dynamics’ ‘psycho-ontological-tautologisation/psycho-existential-reference conceptual-scheme' (in defining individual, $\quad$ summative intradimensional and transcendental/transdimensional/interdimensional $/ 5$ maximalising-recomposuring-for-relativeontological-completeness ${ }^{87}$ - unenframed/re-ontologising conceptualisation meaningfulness reference-of-thought), renders suprastructuralism and associated transcendental concepts comprehensively operant (as well as rendering ontologically-pertinent a storiedconstruct/ontologically-valid-narration enabling a more profound intuitive elucidation of the phenomena reflected by the conceptualisations in this paper) as such a conceptual-scheme effectively construes the reality of human placeholder-setup/mental-devisingrepresentation/mentation/consciousness-awareness-teleology ${ }^{9}$ defect in its failing-andsucceeding representation of ontologically-veridical-meaningfulness/intrinsic-reality grasped as of the circularity/recurrence/repetition/repeatability ${ }^{10}$ delineating existential-transitioning-or- 
iterability-trace-of-narratives-as-dots_or_implicited_attendant-ontological-

contiguity ${ }^{67} \sim$ educed-

existentialising/contextmalising/textualising_'intelligibility/epistemicity/reflexivity-contiguity-

$<$ imbued-notional $\sim$ cogency $>$ ' -reification_or_intrinsic-reality-ontological-

coherence_or_superseding-oneness-of-ontology ${ }^{41}$ by $\quad{ }^{55}$ maximalising-recomposuring-forrelative-ontological-completeness ${ }^{8}$ - unenframed/re-ontologising conceptualisation; with the idea that notional ${ }^{18}$ deprocrypticism 'implicited_attendant-ontological-contiguity ${ }^{67} \sim$ educedexistentialising/contextualising/textualising_'intelligibility/epistemicity/reflexivity-contiguity$<$ imbued-notional $\sim$ cogency $>$, ,-<reifying-or-elucidating-of-prospective-relative-ontologicalcompleteness -of- reference-of-thought- devolving-as-of-instantiative-context $>$ as to existence-potency ${ }^{39} \sim$ sublimating-nascence,-disclosed-from-prospective-epistemicdigression—rules-of-apriorising/axiomatising/referencing-that-further-epistemicallyunconceal-the-very-ontologically-same-existential-reality 'preempting the threshold-ofnonconviction/madeupness/bottomlining-in-shallow-supererogation $<-<$ as-to- 'attendantintradimensional'-prospectively-disontologising preconverging/dementing -apriorisingpsychologism $>$ of rational-empiricism/positivising-rules' is attainable as of the circularity/recurrence/repetition/repeatability ${ }^{10}$ delineating existential-transitioning-oriterability-trace-of-narratives-as-dots_or_implicited_attendant-ontologicalcontiguity $^{67}$, educedexistentialising/contextmalising/textualising_intelligibility/epistemicity/reflexivity_contiguity$<$ imbued-notional cogency>' ${ }^{\prime}$-reification_or_intrinsic-reality-ontologicalcoherence_or_superseding-oneness-of-ontology ${ }^{41}$ by ${ }^{55}$ maximalising-recomposuring-forrelative-ontological-completeness ${ }^{87}$ - unenframed/re-ontologising conceptualisation clear delineating, in human-subpotency-aporia/undecidability/dilemma/oughtindeterminacy/deficiency/limitation/constraint—imbued-'notional firstnaturedness- 
formativeness-<as-to-eventualising-inkling drive-or-seeding-misprising $>$ temporal-tointemporal-dispositions-<so-construed-as-from-perspective-ontologicalnormalcy/postconvergence>'-existentialism-form-factor driven lockstep dynamism of uninstitutionalised-threshold 1 /institutionalisation as a circular process of 'ontologicalreconstituting-as-to-conflatedness ${ }^{13}$ (upholding-of-intemporal-preservation) of hollowconstituting-<as-disjointed-misappropriation-of-meaningfulness-and-failing-intemporalpreservation $>$ as prospective institutionalisation' and hollow-constituting-<as-disjointedmisappropriation-of-meaningfulness-and-failing-intemporal-preservation> of ontologicalreconstituting-as-to-conflatedness ${ }^{13}$ (upholding-intemporal-preservation) as uninstitutionalisedthreshold ${ }^{102}$, and so in prospective circularity'. The 'postconverging-or-dialectical-thinking psychology or psychology-of-mentation-dynamics or natural psychological-dynamics' 'psycho-ontological-tautologisation/psycho-existential-reference conceptual-scheme' thus construes notional ${ }^{18}$ deprocrypticism 'implicited_attendant-ontological-contiguity ${ }^{67}$; educedexistentialising/contextmalising/textualising_'intelligibility/epistemicity/reflexivity_contiguity$<$ imbued-notional cogency $>{ }^{,},-<$reifying-or-elucidating-of-prospective-relative-ontologicalcompleteness -of- reference-of-thought- devolving-as-of-instantiative-context> as to existence-potency $^{39} \sim$ sublimating-nascence,-disclosed-from-prospective-epistemicdigression—rules-of-apriorising/axiomatising/referencing-that-further-epistemicallyunconceal-the-very-ontologically-same-existential-reality 'preempting the threshold-ofnonconviction/madeupness/bottomlining-in-shallow-supererogation $-<$ as-to- 'attendant-

\section{intradimensional'-prospectively-disontologising preconverging/dementing -apriorising-}

psychologism> of rational-empiricism/positivising-rules' as a suprastructural tautological/existential-reference representation of existence/intrinsic-reality/ontology as of inherent ontological-normalcy/postconvergence teleology'. Thus, such a 'postconverging-ordialectical-thinking -psychology or psychology-of-mentation-dynamics or 
reference conceptual-scheme' involves, mobilising an 'ontological-tautologisation/existentialreference conceptual-scheme' (like a hermeneutics-derived psycho-ontological, bio-ontological, econo-ontological, mathematico-ontological, etc.) construed as of ontologicalnormalcy/postconvergence teleology thus postdicatory (as metaphysics-of-absence〈implicited-epistemic-veracity-of- nonpresencing-<perspective-ontological-

normalcy/postconvergence $>>$ conceptualisation), is of 'subpotent-mimetic-echoness-derivationwithin-the-full-potency of ontology/intrinsic-reality/of-referential-nature/of-intemporalpreservation-entropy-or-contiguity-or-ontological-preservation of existence-as-of-its-mimeticechoness/existence-in-reverberation/existence-potency ${ }^{32} \sim$ sublimating-nascence,-disclosedfrom-prospective-epistemic-digression ${ }_{2}$ as the given subject-matter in a full-blossoming unison of second-order ontology with first-order ontology. Insightfully, superseding-oneness-ofontology points out that human ascription of knowledge into various categories as science, humanities, arts, etc. is actually an unnatural differentiation that has to do with arbitrary human categorisation out of practicalities of division-of-labour and organisation, while equally leading to confusions. Actually knowledge as a whole imply the two basic elements: its conceptualisation and the causal effectiveness thereof of the conceptualisation. Knowledge conceptualisation and causal effectiveness can successively be construed in three respects; specific, intermediary and general, with all aspects of conceptualisations being notionally philosophical as providing meaningful insights while all aspects of causal effectiveness provide confirmatory and predicative-insights to meaningful insights. (Interestingly it is important to note that empiricism speaks of the possibility of knowledge revelation by the inherent nature of the subject-matter and not an abstract approach as often naively construed; with the implication that empiricism can be construed as deriving from a confirmatory analysis of a mere insight, experimentation, observation or survey depending on the inherent nature of the said subject-matter, so long as this 
then allows for <amplituding/formative-epistemicity>causality as-to-projective-totalitativeimplications-of-prospective- nonpresencing,-for-explicating relative-unreflexivity/relativereflexivity - ontological-contiguity .) Thus notionally speaking all human knowledge is philosophical knowledge as being about meaningful insights. For practicalities, the general basis for establishing conceptual pertinence as of the more general abstract notions of knowledge is attributed to the philosophical disciplines (involving philosophy and the philosophies of subjectmatters including sciences, and its extension in the humanities and social sciences) even though in further practical terms such construal will be punctually undertaken as well when relevant to specific disciplines of immediate cause-and-effect construals/conceptualisations. This equally practically partakes in the denotative and connotative disambiguation of subject-matters. The practical basis for intermediate conceptual pertinence has to do with the inter-relation and delineating of subject-matters with a lesser direct implication of the philosophy, and even less so when it comes to the practical basis for specific conceptual pertinence as practised within subject-matters/specialisms themselves. Thus in human practical terms, knowledge can be construed as a wheel made up of three parts with the central part viewed as the hub of the wheel (philosophical) that provides control (as asking the most basic notional questions of meaningfulness and logic), the outer part of subject-matter (tyre) that connects with the ground (as causal effectiveness asking the more immediate questions of specific domains of nature and reality) and the middle part as the rim and spoke of the wheel holding the other two parts together (providing logical coherence, construed both within subject-matters/specialisms and philosophical disciplines). For practical purposes though, any of these conceptualisation logical-coherence -causal-effectiveness dispositions can be overemphasised or underemphasised, but it is critical to grasp that any such underemphasising or overemphasising doesn't speak of a change of ontological-veridicality/intrinsic-reality but a human practicality purpose (conventioning) which pertinence lies in not losing sight of and ultimately recovering 
the superseding ontological-veridicality/intrinsic-reality. This basic conception of knowledge fundamentally explains what to expect of the philosophical as first-order ontology or the sciences including all other applied studies of second-order ontology. Often times, issues are raised which underlying presumption/presupposition/premise should actually be wholly or partially of fundamental philosophical conceptualisation of ${ }^{5}$ meaningfulness-and-teleology ${ }^{9}$ but naively purported to be answered wholly as of a second-order ontology terms. Broadly speaking philosophy as the first-order ontology (acting as a cog) has been more about providing the overall scope for meaningful insights and the broader conceptual background for other subject-matters while science and other second-order ontology disciplines (as the wheel that meets the ground) draws on a sound and broad philosophical conceptual background to articulate causal effectiveness (as of the inherent nature of their subject-matters). It is rather naïve to depart from a philosophical angle and try to imply causal effectiveness of a natural science nature (rather than effective validation techniques relevant to transversal nature of philosophical conceptualisation) just as the same holds true the other way round. The reality is that if science was the best method to answer philosophical questions as of its subject-matter, then it would have already taken over from philosophy as practised and the reverse holds true as well, as in reality it is all about human practical organisation in construing a superseding-oneness-ofontology while dealing with our given limited-mentation-capacity-deepening —as-subjecting limitedness/human-subpotency-to-'educed-unlimitedness/existence-sublimating nascence' 53 . The fact is science is preconverging/postconverging-dementatively/structurally/paradigmatically bound to construe causal effectiveness as of the inherent nature of its domains of reality and philosophy is fundamentally conceptualising by its very nature and providing the broad conceptual background for all human knowledge with the implication that without such conceptualisation the historical insight for the need and upholding of the sciences and scientific method wouldn't have come about while equally defining the limits 
of what science can achieve. Insightfully and beyond their practical differentiations, with all knowledge actually being conceptually philosophical, a lot of science is actually a sort of impromptu and punctual heuristic philosophy at sciences subject-matter level. So it is rather critical here to distinguish between a human denotative and segmenting exercise (as not determining inherent reality) which is conventioned knowledge and the inherent connotation of the reality of knowledge as the superseding knowledge ontology inherent structure. In that sense, one often misconstrued notion with respect to notional philosophy is that it is not as successful as the sciences, which is a naïve conceptualisation as the very idea of such notional philosophy is its conceptualising irrigation of second-order ontology with the more immediate and $<$ amplituding/formative-epistemicity $>$ causality $\sim$ as-to-projective-totalitative-implications-ofprospective- nonpresencing,-for-explicating relative-unreflexivity/relative-reflexivity

ontological-contiguity success being not only a success of the second-order ontology but a percolated success of notional philosophy as of its historical development of human conceptualisation in inducing the second-order-ontologies and irrigating them with meaningfulinsights, whether we talk about the sciences, jurisprudence and law, ethics, engineering, aesthetics, etc. (This insight means that the classical conception we have of philosophy as mainly about great philosophical thinkers is incomplete as we equally need to understand the 'organicknowledge' as of ontological-faith-notion-or-ontological-fideism-imbuedunderdetermination-of-motif-and-apriorising/axiomatising/referencing-as-so-being-as-of-

existential-reality of other thinkers as they were developing second-order ontologies, and analyse such thoughts in philosophical terms and make these part-and-parcel of philosophy without necessarily going deeply in their concrete 'operant mechanical-knowledge' except where this clarifies their 'organic-knowledge'. That's why the work of such transcendental thinkers like Newton, Galileo, Einstein, Bohr, Pasteur, etc. are 'more than just technicalities' as these involve a certain commitment as of ontological-faith-notion-or-ontological-fideism -imbued- 
underdetermination-of-motif-and-apriorising/axiomatising/referencing-as-so-being-as-of-

existential-reality which needs to be properly relayed not only in the further development of the 'mechanical-knowledge' they advanced but equally about elucidating the profundity of knowledge itself. This insight is equally valid with respect to great artists like Michelangelo, among others. While critically, highlighting how human emancipation has been associated with such 'organic-knowledge' brought by scientists, artists and philosophers as of ontological-faithnotion-or-ontological-fideism—imbued-underdetermination-of-motif-and-

apriorising/axiomatising/referencing-as-so-being-as-of-existential-reality across various epochs, such that the history of philosophy is much more than just biographical and analytical accounts of past masters but further involves the active relation of these in construing the 'becoming-and-emancipating human psyche as of individual and social implications then and now'.) 'Notional philosophy' as articulated above is the very profundity behind the human ('social framework of intersolipsistic deambulation') imagination, projection, development, articulation and conceptualisation-resourcing possibilities for all second-order ontologies; not so as an instant present development (of philosophers and philosophy-impacting scientists and artists) but rather as of its historical development, accrual and drive into today's second-order ontologies, as inventing the overall knowledge psyche and their perspectives in-the-very-firstplace. A notion that is often hardly grasped because of the poor imagination of the notional philosophical work across epochs inducing human <amplituding/formative-epistemicity>totalising renewing-realisation/re-perception/re-thought, and psychically and institutionally bringing about our present conventioned knowledge being naively related to as if our present mentation-capacity and insights are simply a given, lacking a full appreciation of prior notional philosophical transformations of mindsets $/{ }^{83}$ references-of-thought/psychologisms and human developments of knowledge construal/conceptualisation, and correspondingly lacking a full appreciation of prospective overall human knowledge development possibilities of future 
philosophical $<$ amplituding/formative-epistemicity $>$-totalising $\sim$ renewing-realisation/reperception/re-thought as of a prospective mindset/ ${ }^{3}$ reference-of-thought/psychologism for the construal/conceptualisation of all human knowledge. It should be noted that this articulation about the role of notional philosophy speaks of the ontologically philosophical beyond just conventioning/classical sense of conceptual philosophy. That is, a scientist that develops insights about issues of philosophical import is ontologically contributing to philosophy even though qualified as a scientist by conventioning (as the natural ontological construct of knowledge as intrinsic-reality/ontological-veridicality doesn't recognise our artificial delimitations of knowledge organisation), just as the reverse equally holds true as well. Consider that Aristotle set out as a philosopher but in-many-ways has turned out to be the true father of science. Notional philosophy in the bigger framework construed of organic-knowledge itself as of ontologicalfaith-notion-or-ontological-fideism — imbued-underdetermination-of-motif-andapriorising/axiomatising/referencing-as-so-being-as-of-existential-reality as the superseding drive behind the 'inventing/creating' of all human technicalities/mechanical-knowledge refers to the mental-disposition to break from 'ordinary apathy and constraining framework of secondnatured institutionalisation' to rearticulate dimensionality-of-sublimating ${ }^{25}$ <<amplituding/formative>supererogatory $\sim$ de-mentativeness/epistemic-growth-orconflatedness /transvaluative-rationalising/transepistemicity/anamnestic-residuality/spiritdrivenness-equalisation) projection underlying the 'inventing/creating' of prospective secondnatured institutionalisation possibilities as prospective knowledgeconstructs/theories/intersolipsistic-intercessory-notions/notional $\sim$ referentialnotions/articulations/virtue. Ultimately and beyond shallow technicalities/professions of presences as has been variously and decisively the case throughout humankind history, the most important philosophical work is the preservation of the human existential-<disentelogising/reentelogising apereticism $>$ tale in prolongation as of ontological-faith-notion-or-ontological- 


\section{fideism - imbued-underdetermination-of-motif-and-apriorising/axiomatising/referencing-as-}

so-being-as-of-existential-reality by 'maintaining a contemplative distance/detachment from ordinary human blithe' susceptible to render ${ }^{56}$ meaningfulness-and-teleology a closedstructure (as merely-exploiting-Being-as-of-its-presence-state-with-poor-regards-for-Beingunderdevelopment-and-development-potential-construed-as-nihilism

\section{$<$ amplituding/formative $>$ wooden-language-<imbued - averaging-of-thought-<as-to-}

leveling/ressentiment/closed-construct-of- meaningfulness-and-teleology -as-of-

'nondescript/ignorable-void '-with-regards-to-prospective-apriorising-implications $>\rangle$ ) as of its temporal $<$ amplituding/formative-epistemicity $>$ totalising $\sim$ self-referencingsyncretising/circularity/interiorising/akrasiatic-drag ${ }^{44}$ by adopting a ' 7 presencingabsolutising-identitive-constitutedness ${ }^{14}$ consummated/forfeiting posture' as 'looking down upon the value-reference constructs of all successive presences construed as conventionedaberrations of pure-ontology' in order to 'keep agape' an opened-structure (as developingBeing-potential-over-mere-exploiting-of-presence-state-of-Being-construed-as-antinihilism-oropened-construct-of- ${ }^{5}$ meaningfulness-and-teleology ${ }^{9}$ ) for prospective ${ }^{56}$ meaningfulness-andteleology ; as no registry-worldview/dimension 'as a product of secondnatured institutionalisation' should be construed as defining itself 'in its self-referencing/nombrilism as being the ultimate grounding of ${ }^{5}$ meaningfulness-and-teleology ${ }^{9}$, be it at the backend in reflecting holographically-<conjugatively-and-transfusively $>$ the relative-unreflexivity/relativereflexivity - ontological-contiguity of-the-human-institutionalisation-process. That is the most important work of all human jobs whether it is done as of 'institutionally secondnatured construed technical/professional philosophy' or not, as secondnatured institutionalisation by itself doesn't guarantee such a requisite dimensionality-of-sublimating <<amplituding/formative>supererogatery $\sim$ de-mentativeness/epistemic-growth-orconflatedness /transvaluative-rationalising/transepistemicity/anamnestic-residuality/spirit- 
drivenness-equalisation> projection even though the latter does ensue in any case as of notional philosophy. Such 'dimensionality-of-sublimating

<<amplituding/formative >supererogatory de-mentativeness/epistemic-growth-or-

conflatedness /transvaluative-rationalising/transepistemicity/anamnestic-residuality/spirit-

drivenness-equalisation> projection notional philosophical dispositions' upholding an openedconstruct-of- ${ }^{5}$ meaningfulness-and-teleology ${ }^{9}$ to enable prospective institutionalisation as assumed by the Socrates, Aristotles, Avicennas, Mansa-Musas, Zheng-Hes, Buddhas, Copernicuses, Galileos, Rousseaux, Diderots, Darwins, etc. as-'inventing'-or-'creating'-or'upholding'-new-intellection-de-mentating/structuring/paradigming-of-societies, are the 'most social of human acts' as keeping up by renewing-apriorising/axiomatising/referencing of prospective apriorising/axiomatising/referencing-\{of-'prospectively implicited_attendantontological-contiguity ' educed-

existentialising/contextualising/textualising_'intelligibility/epistemicity/reflexivity-contiguity<imbued-notional cogency $\left.>^{\prime} \quad\right\}$-conflatedness ${ }^{13}$ in-\{preconverging-disentailment by

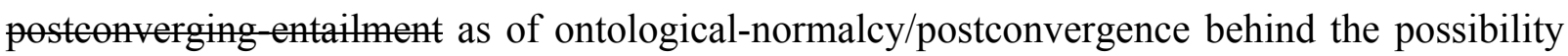
of prolonging the human existential-<disontologising/re-ontologising aporeticism $>$ tale for prospective civilisation, and so not on the same pedestal with 'nombrilistic presences of registryworldviews/dimensions in their <amplituding/formative-epistemicity>totalising $\sim$ selfreferencing-syncretising/circularity/interiorising/akrasiatic-drag ${ }^{44}$ temporal-dispositions' as $<$ amplituding/formative $>$ wooden-language-<imbued — averaging-of-thought-<as-toleveling/ressentiment/closed-construct-of- meaningfulness-and-teleology -as-of'nondescript/ignorable-void '-with-regards-to-prospective-apriorising-implications $>>$ blithe to such retrospective-and-thus-prospective insight by their temporal extricatory preconverging-dementating/structuring/paradigming in distractive-alignment-to- ${ }^{-}$reference-of-thought- $<$ofapriorising/axiomatising/referencing $>^{30}$ as of epistemic-abnormalcy/preconvergence ${ }^{31}$. This is 
enabled by the tautological/referential/existential-reference nature of intrinsicreality/ontology/existence allowing for 'predication or predictive-insight' and 'postdication or projective-insights', the latter very much attached with the arts and aesthetic forms but hardly hitherto associated with the predicting of the former like in scientific constructions, though such postdication-as-predictive can possibly be enabled as 'metaphysics-of-absence-〈implicitedepistemic-veracity-of- nonpresencing-<perspective-ontological-normalcy/postconvergence $>\rangle$ conceptualisations' in domains concerned with predication as introduced (besides the 'projective intemporal-preservation-contiguity/referential analysis' of this author in this paper taking cognisance of metaphysics-of-absence-〈implicited-epistemic-veracity-of- nonpresencing$<$ perspective-ontological-normalcy/postconvergence $>\rangle$ as the need to supersede our illusion-ofthe-present/present-consciousness/epistemic-totalising $\sim$ self-referencing-syncretising/mirage) in the form of conceptualisations based on 'creative-spaces-of-metaphors' (or for that matter the jargon as can reasonably be expected of the thoroughness of all inherently analytical subject matter especially in this case by the highly exploratory nature of such analysis, as such writing are not 'story writings' nor should the artificial excuse in the case of core post-structural writings like quoting Einstein in saying that good science is associated with beautiful equation as obviously just as $\mathrm{E}=\mathrm{MC}^{2}$ is beautiful but the underlying physics is a head-scratcher one can equally say 'there is nothing outside the text' is a beautiful statement but don't expect the underlying Derridean deconstruction and implications to be child's play, nor should the fact that the meaningfulness of the social 'being closer to us emotionally' compared to the natural sciences that this should preclude its analysis if and when we are temporally uncomfortable with it, as that is part-and-parcel of our human development as our forerunners had taken their responsibilities about that to usher in our positivistic registry-worldview/dimension and we can't exclude ourselves from prospective transcendence-andsublimity/sublimation/supererogatory de-mentativity), which ultimate knowledge-credential is 
not in the 'metaphors themselves', as misunderstood by naïve critics, since these are just a 'conceptualisation detour' with respect to apprehending a fleeting-perception of reality but rather 'as-of-the-implied-or-derived-elucidation' which is the actual 'product of ontological import', by such thinkers as Deleuze, Guattari, Lacan, Rory, Derrida and others, and so, as pertinent and as so-validated by <amplituding/formative-epistemicity $>$ causality $\sim$ as-to-projectivetotalitative-implications-of-prospective- nonpresencing,-for-explicating relativeunreflexivity/relative-reflexivity ontological-contiguity and insight. Central to such 'ontological-tautologisation/existential-reference conceptual-scheme' is the idea of superseding-oneness-of-ontology, as obviously there can't be any predication-and-postdication without a 'sole ontology' with a 'sole intrinsic ontologically-veridical-meaningfulness' (otherwise meaningfulness will be chaotic-and-meaningless), not to be confused with human constantly evasive meaningful grasp of intrinsic-reality/ontology having to do with our relativeontological-incompleteness -induced,-`threshold-of-nonconviction/madeupness/bottomliningin-shallow-supererogation -<as-to- 'attendant-intradimensional'-prospectivelydisontologising preconverging/dementing -apriorising-psychologism>' due to our limitedmentation-capacity-deepening —as-subjecting limitedness/human-subpotency-to-'educedtnlimitedness/existence sublimating nascence ${ }^{3}$, with such a conceptual scheme thus enabling aetiologisation/ontological-escalation- $<$ ontologicalveridicality_commitment/otherliness_transcending/compulsions-encumbered_transcending $>$. However, with our human limited-mentation-capacity-deepening-as-subjectinglimitedness/human-subpotency-to-'educed-unlimitedness/existence-sublimating nascence' 53 , we are actually involved in a 'developmental notional teleology' of ontology' construed as coherent shallow superseding-oneness-of-ontology to coherent deeper superseding-oneness-ofontology in reflecting holographically-<conjugatively-and-transfusively $>$ the relativeunreflexivity/relative-reflexivity - ontological-contiguity of-the-human-institutionalisation- 
process ; with such limited-mentation-capacity-deepening —as-subjecting limitedness/humansubpotency-to-'educed-unlimitedness/existence-sublimating-nascence' ${ }^{3}$ reflected and encapsulated in the operant concept of 'disjointedness-as-of- reference-of-thought' misappropriated ${ }^{56}$ meaningfulness-and-teleology ${ }^{9}$ in arrogation (as relative-ontologicalincompleteness ${ }^{8}$-induced,-'threshold-of-nonconviction/madeupness/bottomlining-in-shallowsupererogation -<as-to- 'attendant-intradimensional'-prospectivelydisontologising preconverging/dementing -apriorising-psychologism>', thus- 'in-wait'-forperversion-of- ${ }^{3}$ reference-of-thought-<as-preconverginglyapriorising/axiomatising/referencing-in-nonconviction/madeupness/bottomlining-as-toshallow-supererogation >,-or-temporal-preservation-as-pseudointemporality ${ }^{52}$-preservation, with respect to ultimate ontological-normalcy/postconvergence. The <amplituding/formativeepistemicity $>$ causality $\sim$ as-to-projective-totalitative-implications-of-prospectivenonpresencing,-for-explicating relative-unreflexivity/relative-reflexivity - ontologicalcontiguity of 'disjointedness-as-of- ${ }^{2}$ reference-of-thought' misappropriated ${ }^{56}$ meaningfulnessand-teleology ${ }^{9}$ in arrogation are twofold. Firstly, with respect to the nature of human knowledge development as a constant deepening (with augmenting <amplituding/formativeepistemicity $>$ causality $\sim$ as-to-projective-totalitative-implications-of-prospectivenonpresencing,-for-explicating relative-unreflexivity/relative-reflexivity - ontologicalcontiguity with respect to intrinsic-reality/ontology/ontologically-veridical-meaningfulness) from a 'shallow coherent superseding-oneness-of-ontology' towards a 'deeper coherent superseding-oneness-of-ontology' by the institutionalisation dynamism of ${ }^{15}$ de-mentation〈supererogatory $\sim$ ontological-de-mentation-or-dialectical-de-mentation-stranding-orattributive-dialectics $\quad$ inducing 'placeholder-setup/mental-devisingrepresentation/mentation/consciousness-awareness-teleology ${ }^{99}$ rescheduling' wherein a given present registry-worldview of relative-ontological-incompleteness ${ }^{8}$-induced,-'threshold-of- 
nonconviction/madeupness/bottomlining-in-shallow-supererogation $<-<$ as-to-' ${ }^{\text {attendant- }}$ intradimensional'-prospectively-disontologising preconverging/dementing -apriorising-

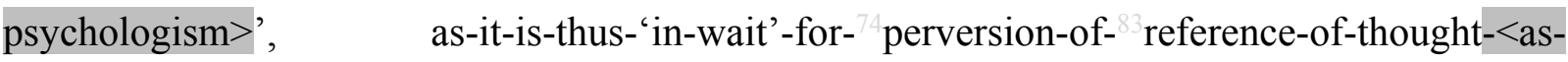
preconvergingly-apriorising/axiomatising/referencing-innonconviction/madeupness/bottomlining-as-to-shallow-supererogation >,-or-temporalpreservation-as-pseudointemporality ${ }^{52}$-preservation, is transcended/superseded as preconverging-or-dementing ${ }^{20}$-apriorising-psychologism ushering in a new present registryworldview of less relative-ontological-incompleteness ${ }^{8}$-induced,-'threshold-ofnonconviction/madeupness/bottomlining-in-shallow-supererogation $<-<$ as-to- 'attendantintradimensional'-prospectively-disontologising preconverging/dementing -apriorising-

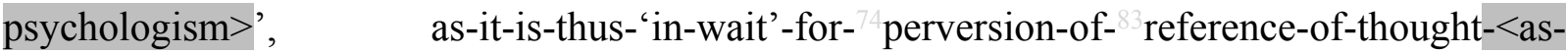
preconvergingly-apriorising/axiomatising/referencing-innonconviction/madeupness/bottomlining-as-to-shallow-supererogation >,-or-temporalpreservation-as-pseudointemporality ${ }^{52}$-preservation, which is transcending/superseding as 'postconverging-or-dialectical-thinking -apriorising-psychologism', and at the 'individuationlevel of conceptualisation of knowledge' construed as predisposed to either hollow-constituting$<$ as-disjointed-misappropriation-of-meaningfulness-and-failing-intemporal-preservation> ' and 'ontologically-reconstituting (upholding-intemporal-preservation)' as of the circularity/recurrence/repetition/repeatability ${ }^{10}$ delineating existential-transitioning-oriterability-trace-of-narratives-as-dots_or_implicited_attendant-ontologicalcontiguity $^{67} \sim$ educedexistentialising/contextualising/textualising_intelligibility/epistemicity/reflexivity-contiguity$<$ imbued-notional $\sim$ cogency $>$-reification_or_intrinsic-reality-ontologicalcoherence_or_superseding-oneness-of-ontology ${ }^{41}$ by ${ }^{55}$ maximalising-recomposuring-forrelative-ontological-completeness ${ }^{87}$ - unenframed/re-ontologising conceptualisation of 
ontology/ontologically-veridical-meaningfulness/intrinsic-reality. Secondly, with respect to the psychological/psychoanalytical basis of meaningfulness representation (placeholdersetup/mentation/mental-devising-representation/consciousness-awareness-teleology ${ }^{9}$ ), $\quad$ with regards to the fact that the 'reflex supplanting-conviction-as-to-profound-supererogation - of'attendant-intradimensional'-postconverging/dialectical-thinking -apriorising-psychologism mental-disposition' is a 'purely abstract construct' of ${ }^{83}$ reference-of-thought- categoricalimperatives/axioms/registry-teleology ${ }^{9}$ representation of meaningfulness but then without 'existential reality validation' is wrong (particularly beyond the scope of a registry-worldview's institutionalisation ${ }^{83}$ reference-of-thought where intemporality ${ }^{52} /$ / meaningfulness-and-teleology has been more or less secondnatured, at its uninstitutionalisedthreshold ${ }^{102}$ ) as this fails to reflect the fact that the same-terms-of-expressions/seemingly-sameimplied-meaningfulness have various temporal-to-intemporal conjugations of meaningfulness with regards to ontologically-veridical-meaningfulness when truly reflecting the reality of a human-subpotency-aporia/undecidability/dilemma/oughtindeterminacy/deficiency/limitation/constraint—imbued-'notional firstnaturednessformativeness-<as-to-eventualising inkling drive-or seeding misprising $>$ - temporal-tointemporal-dispositions- $<$ so-construed-as-from-perspective-ontologicalnormalcy/postconvergence>'-existentialism-form-factor unlike a naïve foundation wrongly based solely on an intemporal human nature conceptualisation specifically at a registryworldview's/dimension's uninstitutionalised-threshold ${ }^{102}$, and that in all instances, to ensure ontologically-veridical-meaningfulness, this is deduced of recurrence in existentialtransitioning-or-iterability-trace-of-narratives-as-dots_or_implicited_attendant-ontologicalcontiguity ${ }^{67}$, educedexistentialising/contextualising/textualising_'intelligibility/epistemicity/reflexivity-contiguity<imbued-notional $\sim \operatorname{cogency}>$ ' -reification_or_intrinsic-reality-ontological- 
coherence_or_superseding-oneness-of-ontology ${ }^{41}$ by $\quad{ }^{55}$ maximalising-recomposuring-forrelative-ontological-completeness ${ }^{7}$ - unenframed/re-ontologising conceptualisation that is readily available in construing the hollow-constituting-<as-disjointed-misappropriation-ofmeaningfulness-and-failing-intemporal-preservation>' 'ontologicallyreconstituting/upholding-intemporal-preservation' trace-of-transitioning-in-existence that ensures perfect grasp of ontologically-veridical-meaningfulness from non-veridical/vacuous constructs of ${ }^{83}$ reference-of-thought- categorical-imperatives/axioms/registry-teleology representation of meaningfulness affirmations (and, specifically with a perversion-ofreference-of-thought-<as-preconvergingly-apriorising/axiomatising/referencing-innonconviction/madeupness/bottomlining-as-to-shallow-supererogation $>$ phenomenon like a psychopathic-and-social-psychopathic-situation, it is never about bringing up or falling back to the ${ }^{54}$ logical-processing-or-logical-implicitation - supposedly-apriorising-in-conviction-as-toprofound-supererogation but in the first place, rather the preceding/superseding ontological notion of the appropriateness/soundness-or-ontological-good-faith/authenticity ${ }^{60}$-of- ${ }^{8}$ referenceof-thought of implied ${ }^{83}$ reference-of-thought in establishing what is 'postconverging-ordialectical-thinking -apriorising-psychologism/soundness-or-ontological-good-

faith/authenticity ${ }^{6}$ of- reference-of-thought and in-phase' and 'preconverging-ordementing ${ }^{2}$-apriorising-psychologism/dialectically-primitive/unsoundness-or-ontologicalbad-faith/inauthenticity ${ }^{64}$-of- ${ }^{3}$ reference-of-thought/slantedness and dialectically-out-of-phase'; from whence ${ }^{5}$ logical-processing-or-logical-implicitation-supposedly-apriorising-inconviction-as-to-profound-supererogation then arises in protraction in an altogether different construction only if appropriate/soundness/ontological-good-faith/authenticity ${ }^{6}$-of- ${ }^{8}$ referenceof-thought of meaningfulness is established, dismissing hollow-constituting-<as-disjointedmisappropriation-of-meaningfulness-and-failing-intemporal-preservation>/nonveridical/vacuous constructs of $\quad{ }^{83}$ reference-of-thought- ${ }^{8}$ categorical- 
imperatives/axioms/registry-teleology

\section{preconvergingly-apriorising/axiomatising/referencing-in-}

nonconviction/madeupness/bottomlining-as-to-shallow-supererogation $>$ with the apriorisingregistry-elements as \{epistemic-totalising ${ }^{\text {f }}$ psychologismic-subliminality-of-individuationeffusing/worlding imbued logical-dueness-or-scape-or-frame, profile-or-stature, presumptuousness-or-arrogation, assumptions, value-reference and teleology ${ }^{99}$ as non-existent and bogus). With respect to social-and-confliction-stakes the 'same-terms-ofexpressions/seemingly-same-implied-meaningfulness' have different implications with respect to whether the interlocutor is a supplanting-conviction-as-to-profound-supererogation 'attendant-intradimensional'-postconverging/dialectical-thinking -apriorising-psychologism interlocutor or postlogic/psychopathic/postlogic-backtracking-<iterative-looping-'set-ofdereifying-hollow-narratives-and-acts'> ${ }^{6}$ interlocutor or conjugated-postlogic/ ${ }^{2}$ conjoininglooping-set-of-narratives interlocutor, and is what makes it a requisite to construe as of the circularity/recurrence/repetition/repeatability ${ }^{10}$ delineating existential-transitioning-oriterability-trace-of-narratives-as-dots_or_implicited_attendant-ontologicalcontiguity $^{67} \sim$ educed-

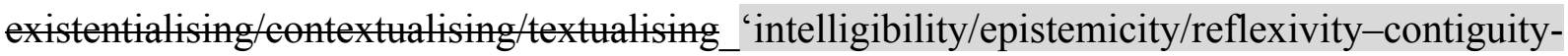
$<$ imbued-notional cogency>' ${ }^{\prime}$-reification_or_intrinsic-reality-ontologicalcoherence_or_superseding-oneness-of-ontology ${ }^{41}$ by $\quad{ }^{55}$ maximalising-recomposuring-forrelative-ontological-completeness ${ }^{8}$ —unenframed/re-ontologising conceptualisation. We can’t be certain about the ontological-veridicality of 'separate dots as separate narratives' themselves as the 3 different interlocutors can all express the 'same-terms-of-expressions/seemingly-sameimplied-meaningfulness' going by their mental-dispositions with the latter two, postlogic/psychopathic/postlogic-backtracking-<iterative-looping-'set-of-dereifying-hollownarratives-and-acts'> interlocutor or conjugated-postlogic $/{ }^{12}$ conjoining-looping-set-of- 
narratives interlocutor, being deceptive by their mental-dispositions (recursively with postlogic/psychopathic, progressively with exacerbation/opportunism and regressively with ignorance/affordability). However, we can ascertain the true motive and ontological-veridicality of the 3 types of interlocutors by the 'trace of their dots as separate narratives' in revealing their true mental-dispositions and motives, as of the circularity/recurrence/repetition/repeatability ${ }^{10}$ as of existential-transitioning-or-iterability-trace-of-narratives-as-dots_or_implicited_attendantontological-contiguity ${ }^{67} \sim$ educed-

existentialising/contextualising/textualising_'intelligibility/epistemicity/reflexivity-contiguity$<$ imbued-notional $\sim$ cogency $>$ 'reification_or_intrinsic-reality-ontologicalcoherence_or_superseding-oneness-of-ontology ${ }^{41}$ quickly reveals that however coherent and sound each separate narrative of the postlogic/psychopathic/postlogic-backtracking- $<$ iterativelooping-'set-of-dereifying-hollow-narratives-and-acts'> ${ }^{6}$ interlocutor $\quad$ or $\quad$ conjugatedpostlogic/ $/ 2$ conjoining-looping-set-of-narratives interlocutor (particularly as recursive and progressive), the 'perception-together-in-succession or as-a-trace' of their 'expressed dots as separate narratives' reveals 'disjointedness-as-of- ${ }^{8}$ reference-of-thought' misappropriated meaningfulness-and-teleology 9 in arrogation that shines the light on the fundamental driver/<amplituding/formative-epistemicity $>$ causality $\sim$ as-to-projective-totalitativeimplications-of-prospective- nonpresencing,-for-explicating relative-unreflexivity/relativereflexivity - ontological-contiguity of the postlogism 7 /psychopathic and conjugatedpostlogism interlocutors as well as the reality of the threshold-ofnonconviction/madeupness/bottomlining-in-shallow-supererogation $-<$ as-to-'attendantintradimensional'-prospectively-disontologising preconverging/dementing -apriorisingpsychologism $>$ whereas the same exercise with supplanting-conviction-as-to-profoundsupererogation - of-'attendant-intradimensional'-postconverging/dialectical-thinking apriorising-psychologism interlocutor will show a coherence of the trace-of-dots-as-narratives 
and actually in the case where a supplanting-conviction-as-to-profound-supererogation

‘attendant-intradimensional'-postconverging/dialectical-thinking -apriorising-psychologism

interlocutor is actually the target of such postlogism 77 -slantedness inducing 'faulty-mentationprocedure-deception-or-urge ${ }^{43}$ about the latter, that trace-of-dots-as-narratives from the supplanting-conviction-as-to-profound-supererogation —of-'attendant-intradimensional'postconverging/dialectical-thinking -apriorising-psychologism and the postlogic/psychopathic and/or conjugated-postlogic interlocutors will reveal the ontological nature of the 'faultymentation-procedure-deception-or-urge ${ }^{13}$ '. The reason why 'separate dots as separate narratives' lead to postlogic and conjugated-postlogic faulty-mentation-procedure-deception-or-urge ${ }^{3}$ is that their extrapolation is actually an extrapolation of ${ }^{7}$ perversion-of- ${ }^{8}$ reference-of-thought$<$ as-preconvergingly-apriorising/axiomatising/referencing-in-

nonconviction/madeupness/bottomlining-as-to-shallow-supererogation $>$ of 'same-terms-ofexpressions/seemingly-same-implied-meaningfulness as if supplanting-conviction-as-toprofound-supererogation _of-'attendant-intradimensional'-postconverging/dialecticalthinking -apriorising-psychologism' whereas retracing of the mental-disposition foregoes elaboration-as-to-mere-extrapolating/constituting/abstracting/deducing/inferring-of-

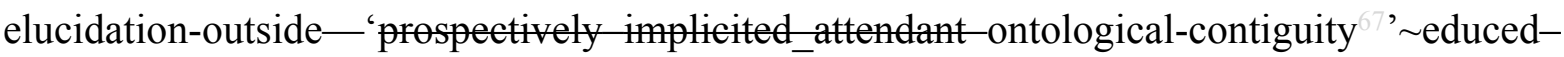
existentialising/contextualising/textualising_intelligibility/epistemicity/reflexivity-contiguity$<$ imbued-notional cogency $>{ }^{\prime 0}$ of separate dots as separate narratives, and thus is existentially<disontologising/re-ontologising aporeticism $>$ involved in construing the reality to the point of revealing 'disjointedness-as-of- ${ }^{83}$ reference-of-thought' misappropriated ${ }^{56}$ meaningfulnessand-teleology ${ }^{9}$ arrogation in the trace-of-successive-dots-as-\{hollow $\}$-narratives that shines the light on the fundamental driver/ $<$ amplituding/formative-epistemicity $>$ causality $\sim$ as-toprojective-totalitative-implications-of-prospective- nonpresencing,-for-explicating relativeunreflexivity/relative-reflexivity - ontological-contiguity of the postlogic and/or conjugated- 
postlogic interlocutor as well as the threshold-of-nonconviction/madeupness/bottomlining-inshallow-supererogation -<as-to-'attendant-intradimensional'-prospectivelydisontologising preconverging/dementing -apriorising-psychologism $>$ as vague-rhyming-orcopied-mimicry-or-formulaic-projection-or-projection-of-form-or-hollow-and-vaguevocalisation-or-subknowledging of its narratives. That's why spatialisation, indirectness and craftiness are critical to postlogic and conjugated-postlogic mental-dispositions so as to evade their prospective interlocutors 'putting one and one together' as will arise in an existentially$<$ disentologising/re-ontelogising aporeticism $>$ veridical context and so that their interlocutors should rather undertake elaboration-as-to-mereextrapolating/constituting/abstracting/deducing/inferring-of-elucidation-outside'prospectively_implicited_attendant_ontological-contiguity ${ }^{67}$ 'educedexistentialising/contextualising/textualising_'intelligibility/epistemicity/reflexivity-contiguity$<$ imbued-notional cogency $>$ of the purely abstract meaning as seemingly sound separate dots as separate narratives but which are non-existentially-<disentologising/re-ontologising aporeticism $>$ real, rather than existentially-<disontologising/re-ontologising aporeticism $>$ trace the successive dots as separate narratives. This is what enables the establishment, as of the circularity/recurrence/repetition/repeatability ${ }^{10}$ as of existential-transitioning-or-iterabilitytrace-of-narratives-as-dots_or_implicited_attendant-ontological-contiguity ${ }^{67}$, educedexistentialising/contextualising/textualising_'intelligibility/epistemicity/reflexivity-contiguity$<$ imbued-notional $\sim$ cogency>' ${ }^{\prime}$-reification_or_intrinsic-reality-ontologicalcoherence_or_superseding-oneness-of-ontology ${ }^{41}$, at the relative-ontological-incompleteness ${ }^{8}$ induced,-'threshold-of-nonconviction/madeupness/bottomlining-in-shallow-supererogation $<$ as-to-'attendant-intradimensional'-prospectivelydisontologising preconverging/dementing -apriorising-psychologism>'-threshold (as-it-isthus-'in-wait'-for- ${ }^{7}$ perversion-of- ${ }^{3}$ reference-of-thought-<as-preconvergingly- 
apriorising/axiomatising/referencing-in-nonconviction/madeupness/bottomlining-as-to-

shallow-supererogation >,-or-temporal-preservation-as-pseudointemporality ${ }^{52}$-preservation), defining the typical threshold-of-nonconviction/madeupness/bottomlining-in-shallowsupererogation $-<$ as-to- 'attendant-intradimensional'-prospectivelydisontologising preconverging/dementing -apriorising-psychologism $>$ psyche of successive uninstitutionalised-threshold $^{102} \quad$ (beyond-the-consciousness-awareness-teleology ${ }^{90}-<$ ofpreconverging-existential-extrication-as-of-existential-unthought $>\quad$ manifestation intradimensionally, and so-construed from the perspective of their corresponding superseding/transcending/prospective institutionalisations) as recurrent-utteruninstitutionalisation preconverging-or-dementing ${ }^{20}$-psyche, ununiversalisation preconvergingor-dementing ${ }^{20}$-psyche, non-positivism/medievalism preconverging-or-dementing ${ }^{20}$-psyche and our uninstitutionalised-threshold ${ }^{102}$ as procrypticism-or-disjointedness-as-of- ${ }^{8}$ reference-ofthought preconverging-or-dementing ${ }^{2}$-psyche. This equally reflect how the childhood psychopathy psyche is preconverging-or-dementing -apriorising-psychologismly perceived though at childhood temporal-dispositions-conjugated-postlogism 77 preconverging-ordementing ${ }^{20}$-integration to psychopathy is not significant as its ${ }^{74}$ perversion-of- ${ }^{8}$ reference-ofthought-<as-preconvergingly-apriorising/axiomatising/referencing-in-

nonconviction/madeupness/bottomlining-as-to-shallow-supererogation $>$ is still ${ }^{103}$ universally transparent as delirious and thus it doesn't elicit temporal-preservation by conjugatedpostlogism 77 preconverging-or-dementing ${ }^{20}$-integration, since it is not spatialising, maturating, and being sufficiently indirect, credulous and crafty to be non-transparent by its motives and acts. Ultimately, this highlights generally that at relative-ontological-incompleteness ${ }^{8}$-induced,'threshold-of-nonconviction/madeupness/bottomlining-in-shallow-supererogation ${ }^{\circ}<$ as-to‘attendant-intradimensional'-prospectively-disontologising preconverging/dementing apriorising-psychologism>'-threshold (as the-relative-ontological-incompleteness ${ }^{8}{ }^{8}$-is- 
inherently-thus-'in-wait' for $\quad{ }^{7}$ perversion-of- ${ }^{8}$ reference-of-thought-<as-preconverginglyapriorising/axiomatising/referencing-in-nonconviction/madeupness/bottomlining-as-to-

shallow-supererogation $>$ or temporal-preservation-as-pseudointemporality ${ }^{52}$-preservation) as so-manifested at the uninstitutionalised-threshold ${ }^{02}$, hollow-constituting-<as-disjointedmisappropriation-of-meaningfulness-and-failing-intemporal-

preservation>/extrapolating/inferring to derive essence-of-meaningfulness is not a credible notion with respect to a human animal of notional firstnaturedness-formativeness-<as-toeventualising inkling drive-or-seeding-misprising > temporal-to-intemporal-dispositions$<$ so-construed-as-from-perspective-ontological-normalcy/postconvergence $>$ wherein 'sameterms-of-expressions/seemingly-same-implied-meaningfulness' is bound to be perverted by temporal-dispositions, though within institutionalised/intemporalised-thresholds-of-intemporalpreservation-entropy-or-contiguity-or-ontological-preservation secondnaturing, for instance, with respect to the fact that a medieval postlogic phenomenon like witchcraft cannot be credibly implied both in terms-as-of-axiomatic-construct of eliciting abstract/extrapolating/inferring hollow-constituting-<as-disjointed-misappropriation-of-meaningfulness-and-failingintemporal-preservation> nor existential-transitioning/iterability-tracing-of-dots-as$<$ hollow $>$ narratives in our present institutionalised positivistic registry-worldview. Vitally, with regards to postlogism 77 and conjugated-postlogism 7 , it is always about 'falsely and parasitically/co-optingly' staking a claim to the ${ }^{83}$ reference-of-thought in order to wrongly elicit its 3 psychologismic-subliminality-of-individuation-effusing/worlding imbued logical-dueness-or-scape-or-frame, profile-or-stature, presumptuousness-or-arrogation, assumptions, value-reference and teleology ${ }^{9}$ to a prospective interlocutor, and so recursively (psychopathic/postlogic-character), progressively (conjugated-exacerbation and conjugatedopportunism characters) and regressively (conjugated-ignorance and conjugated-affordability characters). Generally, this insight harkens back to the previous elucidation with regards to the 
BODMAS characters where the pure arithmetic operation as a deductive/inferring/extrapolation exercise is no longer valid when the fundamental axiom is breached due to a pathological condition, and with the 'lack of constraining social ${ }^{103}$ universal-transparency ${ }^{104}-$ transparencyof-totalising-entailing,-as-to-entailing-<amplituding/formative-epistemicity $>$ totalising $\sim$ inrelative-ontological-completeness > resulting in other temporal characters, beyond-theconsciousness-awareness-teleology ${ }^{9}-<$ of-preconverging-existential-extrication-as-ofexistential-unthought $>$, operating arithmetic as if the condition never existed; and thus there is a need for a retracing to establish the existential-<disontologising/re-ontelogisingapereticism $>$ reality of the breaching or non-breaching of axiomatic rules, before determining the ontological-veridicality of the results of the arithmetic operations. In a further elucidation of psychological/psychoanalytical basis of meaningfulness representation, this further confirms the

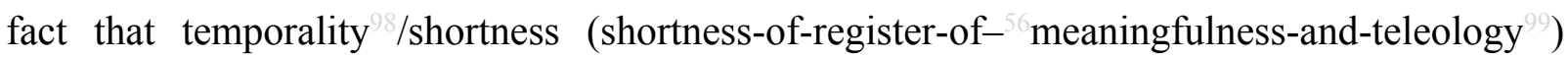
and intemporality ${ }^{52} /$ longness (longness-of-register-of- ${ }^{56}$ meaningfulness-and-teleology ${ }^{9}$ ) are both basically the same notion of intemporality ${ }^{52}$, but with temporal-dispositions (5ignorance/affordability/opportunism/exacerbation/social-chainism-or-social-discomfiture-ornegative-social-aggregation/temporal-enculturation-or-temporal-endemisation) being rather in various grades of poor execution of intemporality ${ }^{52} /$ longness (longness-of-register-ofmeaningfulness-and-teleology ${ }^{9}$ ) but that in so doing such temporal-dispositions of individuation 'falsely retaining their teleology /purposefulness' as if of intemporal-disposition leading to their 'pseudointemporality ${ }^{52}$, (and so with respect to their apriorising-registryelements as \{epistemic-totalising 3 psychologismic-subliminality-of-individuationeffusing/worlding imbued logical-dueness-or-scape-or-frame, profile-or-stature, presumptuousness-or-arrogation, assumptions, value-reference and teleology ${ }^{\circ}$ ), inducing preconverging-de-mentating/structuring/paradigming registry-worldview's/dimension'suninstitutionalised-threshold ${ }^{102}$-defect-<as-Being-or-ontological-or-existential-defect $>$ 
where such false-retention construed as temporal-preservation-as-pseudointemporality ${ }^{52}$ preservation is rather in conjugated-postlogism 7 ; with the idea that this 'false-retention' by temporal-dispositions individuations results in 'disjointedness-as-of- reference-of-thought' misappropriated ${ }^{56}$ meaningfulness-and-teleology ${ }^{9}$ in arrogation with respect to ontologicallyveridical-meaningfulness as meaningfulness become an 'exercise in threshold-ofnonconviction/madeupness/bottomlining-in-shallow-supererogation $<-<$ as-to- 'attendant-

\section{intradimensional'-prospectively-disontologising preconverging/dementing -apriorising-}

psychologism>' (whether-consciously-or-unconsciously), as can be so established as of the circularity/recurrence/repetition/repeatability ${ }^{10}$ delineating existential-transitioning-oriterability-trace-of-narratives-as-dots_or_implicited_attendant-ontologicalcontiguity $^{67}$; educedexistentialising/contextualising/textualising_'intelligibility/epistemicity/reflexivity-contiguity$<$ imbued-notional cogency>' ${ }^{\prime}$-reification_or_intrinsic-reality-ontologicalcoherence_or_superseding-oneness-of-ontology ${ }^{41}$ by ${ }^{5}$ maximalising-recomposuring-forrelative-ontological-completeness ${ }^{8}$ —unenframed/re-ontologising conceptualisation. This

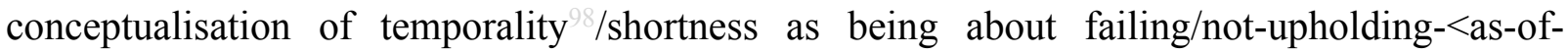
apriorising/axiomatising/referencing $>$ intemporality ${ }^{52} /$ longness (which perfectly syncs intemporality $52 /$ longness and temporality $8 /$ shortness as longness-of-register-ofmeaningfulness-and-teleology 9 and shortness-of-register-of- ${ }^{5}$ meaningfulness-andteleology ${ }^{9}$, beyond just a qualification notion but rather a <amplituding/formativeepistemicity $>$ totalising $\sim$ ratiocontiguity/ratiocination-as-referentialism—'implicited_attendant ontological-contiguity ${ }^{67} \sim$ educed-

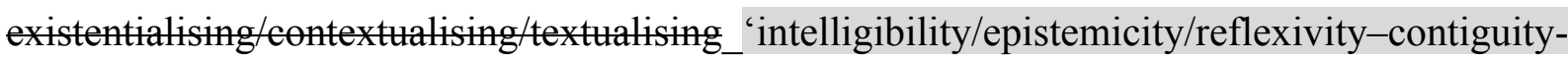
$<$ imbued-notional cogency>' ;-phenomenal-abstractiveness-of-presencing-in-'protensiveconsciousness'-enabling- 
apriorising/axiomatising/referencing/intelligibilitysettingup/measuringinstrumenting-foroperant-or-incidenting-predicative-insights-of 'implicited_attendant_ontologicalcontiguity $^{67}$, educedexistentialising/contextualising/textualising_'intelligibility/epistemicity/reflexivity-contiguity$<$ imbued-notional cogency $>,{ }^{\prime},-<$ reifying-or-elucidating-of-prospective-relative-ontologicalcompleteness -of- reference-of-thought- devolving-as-of-instantiative-context> construct), equally perfectly renders the notion of temporality ${ }^{8} /$ shortness and intemporality $^{52} /$ longness operant for a 'postconverging-or-dialectical-thinking -psychology or psychology-ofmentation-dynamics or natural psychological-dynamics' 'psycho-ontologicaltautologisation/psycho-existential-reference conceptual-scheme'. The notion of temporality $/$ /shortness as actually 'pseudointemporality ${ }^{52}$, provides a deeper insight to such traditional notions as bad, evil, wicked, etc. that we attach to temporal-dispositions (specifically, in the moral sense as temporality $8 /$ shortness is much more than morality as derived from intemporality $52 /$ longness which is about 'full potency of ontological-and-virtue effectiveness') by de-emphasising the naïve but wrong intuition that these notions have their own "mentaldispositional drives-as-teleology" (to be bad, to be evil, to be wicked, etc.) by rather highlighting that 'mental-dispositional incapacity for intemporality" of such individuations induces 'notional-disjointedness-as-of- ${ }^{8}$ reference-of-thought' misappropriated meaningfulness-and-teleology ${ }^{9}$ in arrogation (at individuation-level as relative-ontologicalincompleteness ${ }^{8}$-induced,-'threshold-of-nonconviction/madeupness/bottomlining-in-shallowsupererogation -<as-to-'attendant-intradimensional'-prospectivelydisontologising preconverging/dementing -apriorising-psychologism>', as-it-is-thus-'inwait'-for- ${ }^{7}$ perversion-of- ${ }^{3}$ reference-of-thought-<as-preconverginglyapriorising/axiomatising/referencing-in-nonconviction/madeupness/bottomlining-as-toshallow-supererogation >,-or-temporal-preservation-as-pseudointemporality ${ }^{52}$-preservation, 
which when taken into preservation, as temporal-preservation, is rather in pseudointemporality ${ }^{52}$, while with respect to a traditional conceptualisation it is wrongly 'vaguely imbued with a dispositional-drive-as-teleology ${ }^{9}$, as bad, as evil, as wicked... etc. Now, the consequences of pseudointemporality $^{52} \quad$ individuations $\quad$ (postlogism ${ }^{77}$-slantedness, postlogism ${ }^{77}$ slantedness/ ignorance/affordability/opportunism/exacerbation/social-chainism-or-socialdiscomfiture-or-negative-social-aggregation/temporal-enculturation-or-temporal-endemisation, so-disambiguated as of ${ }^{83}$ reference-of-thought- ${ }^{8}$ devolving ontological-performance ${ }^{72}$ $<$ including-virtue-as-ontology>) are reflected developmentally in the social fabric which is a 'framework of social-stake-contention-or-confliction' as the transference, in dynamiccumulative-aftereffect, of such pseudointemporality ${ }^{52}$ individuations into 'individual personalities dispositions and social dispositions' induces correspondingly subontologisation/subpotentiation in 'disjointedness-as-of- reference-of-thought' misappropriated ${ }^{56}$ meaningfulness-and-teleology in arrogation (at individuation-level relativeontological-incompleteness 8 -induced,-‘threshold-of-nonconviction/madeupness/bottomliningin-shallow-supererogation -<as-to- 'attendant-intradimensional'-prospectivelydisontologising preconverging/dementing -apriorising-psychologism>', as-it-is-thus-'inwait'-for- perversion-of- ${ }^{83}$ reference-of-thought-<as-preconverginglyapriorising/axiomatising/referencing-in-nonconviction/madeupness/bottomlining-as-toshallow-supererogation >,-or-temporal-preservation-as-pseudointemporality ${ }^{52}$-preservation, on 'social ontologically-veridical-meaningfulness' and is the basis, in dynamic-cumulativeaftereffect, of given registry-worldviews/dimensions vices-and-impediments ${ }^{105}$, and how these can be superseded/transcended, because the reality is that humans have transcended retrospectively to the present and there is no particular reason to think that there can't be prospective transcendence-and-sublimity/sublimation/supererogatory de-mentativity going by human-subpotency-aporia/undecidability/dilemma/ought- 
indeterminacy/deficiency/limitation/constraint—imbued-'notional firstnaturednessformativeness-<as-to-eventualising-inkling-drive-or-seeding-misprising $>$ temporal-tointemporal-dispositions- $<$ so-construed-as-from-perspective-ontologicalnormalcy/postconvergence>'-existentialism-form-factor. Such a 'postconverging-ordialectical-thinking -psychology or psychology-of-mentation-dynamics or natural psychological-dynamics' 'psycho-ontological-tautologisation/psycho-existentialreference conceptual-scheme' will further highlight in contrast to the present 'psychology of qualification/qualification-schemes' that human psychology is actually much more of a becoming dynamic construct, rather than static, which wholly readjusts to human deepening grasp of ontologically-veridical-meaningfulness/intrinsic-reality/existence as a retrospective, present and prospective development; that collectively-and-inclusively-individuals-and-theirsocial-constructs do have latitude for the choices they make in existence more than and beyond the limits of personality traits and social character, and further that the human mind is 'not irresponsible' with respect to given personalities dispositions (whether with respect to abnormal psychology or functional psychology) with the idea that such stances taken by a 'psychology of qualifications/qualification-schemes' induces a confounding-effect with respect to individual personalities themselves in assuming their self-emancipation possibilities and what they can aspire for together with their interveners/relators, whether social or clinical. Such insight do arise when we factor in that all along in reflecting holographically-<conjugatively-and-transfusively $>$ the relative-unreflexivity/relative-reflexivity - ontological-contiguity of-the-humaninstitutionalisation-process, human secondnaturing is actually the very central ontologicallyled developmental element as the critical tool of human psychological renewal that enabled an 'animal in-many-ways' to emancipate itself developmentally across epochs such that the 'insightful depth' of such a developmental understanding of human psychology is necessarily much more than a 'cultural universe of several decades of modernity', as it conceives that human 
psychology is an ongoing active construct such that a 'postconverging-or-dialectical-thinking psychology or psychology-of-mentation-dynamics or natural psychological-dynamics’ rather captures the ontological undercurrents that constantly redefine human placeholder-setup/mentaldevising-representation/mentation/consciousness-awareness-teleology as it recognises that (and explains why) the mental-disposition/consciousness-awareness-teleology of a recurrentutter-institutionalised mindset/ ${ }^{3}$ reference-of-thought varies from that of a basedinstitutionalised/ununiversalised mindset, the latter from that of a ${ }^{103}$ universalised/nonpositivistic-or-medieval mindset, the latter from that of a positivistic/procrypticism mindset $/{ }^{83}$ reference-of-thought (our own mental-disposition), and the latter from that of futural Being-development/ontological-framework-expansion-as-to-depth-of-ontologisingdevelopment-as-infrastructure-of- meaningfulness-and-teleology as of prospective notional ${ }^{1}$ deprocrypticism mindset, while not ignoring as well the intradimensional spectrum of variation within each mindset; and wherein ${ }^{5}$ de-mentation-〈supererogatory $\sim$ ontological-dementation-or-dialectical-de-mentation-stranding-or-attributive-dialectics $\rangle$ is the central concept for such a succession of human 'postconverging-or-dialectical-thinking ${ }^{2}$-psychology or psychology-of-mentation-dynamics or natural psychological-dynamics' renewal retrospectively, presently and prospectively, with ontological-normalcy/postconvergence teleology ${ }^{9}$ being the central determinant driving and defining human psychology construed by its metaphysics-of-absence-〈implicited-epistemic-veracity-of- nonpresencing-<perspectiveontological-normalcy/postconvergence $>>$ as diminishing-human-epistemic-abnormalcy-or-

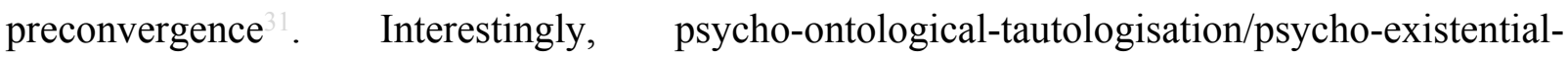
reference as a human disposition for correspondence/equalisation/squaring-off with existence/intrinsic-reality/ontology, as of subpotency-to-full-potency as qualified by recomposuring from shallow limited-mentation-capacity-as-subjecting 'educedunlimitedness/existence-sublimating nascence' to-limitedness/human-subpotency-〈as of 
ontological-contiguity ' educed-

existentialising/contextualising/textualising_'intelligibility/epistemicity/reflexivity-contiguity-

<imbued-notional cogency>' $\}$-constitutedness ${ }^{1}$ in preconverging entment $\rangle$ to deeper limited-mentation-capacity as subjecting 'educed unlimitedness/existence sublimating nascence' to-limitedness/human-subpotency-〈as of relative apriorising/axiomatising/referencing-\{of-'prospectively_implicited_attendant-ontologicalcontiguity ' educedexistentialising/contextualising/textualising_'intelligibility/epistemicity/reflexivity-contiguity<imbued-notional cogency >' \}-conflatedness ${ }^{13}$ in (preenverging disentment by postconverging-entailment $\rangle$, speaks of the mind as an abstract 'teleologically imbricated tautologisation/existential-reference' ('teleologically imbricated tautologisation/existentialreference' implying: striving for ontological-normalcy/postconvergence, inlockstep/intertwining of success-and-pseudosuccess/failure as institutionalisation-and-pseudoinstitutionalisation/uninstitutionalised-threshold ${ }^{102}$ ), as the teleological driving-seat of the body validating dualism as 'imbricated dualism'; the human mind being rather an 'abstract imbricated transcendable/maximalisable placeholder-setup-of-tautologisation/placeholder-setup-ofexistential-reference for prospective ontological-normalcy/postconvergence superseding the human body, as entailing human existence'. This points out that the potency for ontologicalnormalcy/postconvergence is tautologically inherent in our being construct, and that abstract tautologisation/existential-reference as human teleology' is the mind as 'human $<$ amplituding/formative-epistemicity $>$-totalising $\sim$ renewing-realisation/re-perception/rethought-as-utter-placeholder-setup-ontological-rescheduling-〈by-a-renewing-ofapriorising/axiomatising/referencing-psychologism-as-the-new-referencing-basis-ofprospective- meaningfulness-and-teleology $\rangle$ as subpotent-mimetic-echoness-derivation- 
within-the-full-potency

existence-as-of-its-mimetic-echoness/existence-inreverberation/existence-potency ${ }^{32} \sim$ sublimating-nascence,-disclosed-from-prospectiveepistemic-digression $_{2}$ as our being construct is more than just 'constituted-matter' but rather 'being within the contextualisation potency that is existence' and thus imbued with existential$<$ disontologising/re-ontologising aporeticism $>$ tautological/existential-reference supotentmimetic-teleology as the human-mimetic-mind. Existence is actually an 'implicited_attendantontological-contiguity ${ }^{67}$, educed-

existentialising/contextualising/textualising_'intelligibility/epistemicity/reflexivity-contiguity$<$ imbued-notional cogency $>{ }^{\prime 0}$ of existence-potency ${ }^{32} \sim$ sublimating-nascence,-disclosed-fromprospective-epistemic-digression—rules-of-apriorising/axiomatising/referencing-that-furtherepistemically-unconceal-the-very-ontologically-same-existential-reality (so-construed from our given limited-mentation-capacity—as-subjecting-'educed-unlimitedness/existencesublimating nascence' to-limitedness/human-subpotency as of our relative-ontologicalincompleteness 8 -induced,-'threshold-of-nonconviction/madeupness/bottomlining-in-shallowsupererogation -<as-to-'attendant-intradimensional'-prospectivelydisontologising $\sim$ preconverging/dementing -apriorising-psychologism>’'), wherein tautologically/by-existential-reference 'being-in-existence'/existing implies there can't be any elaboration-as-to-mere-extrapolating/constituting/abstracting/deducing/inferring-ofelucidation-outside_-'prospectively_implicited_attendant-ontological-contiguity ${ }^{67}$ ? educedexistentialising/contextualising/textualising_'intelligibility/epistemicity/reflexivity-contiguity<imbued-notional cogency>' (induced by our limited-mentation-capacity-as-subjecting'educed-unlimitedness/existence-sublimating nascence' to-limitedness/human-subpotency as of our relative-ontological-incompleteness ${ }^{8}$-induced,-`threshold-ofnonconviction/madeupness/bottomlining-in-shallow-supererogation $<-<$ as-to-' $a$ attendantintradimensional'-prospectively-disontologising preconverging/dementing -apriorising- 
psychologism>') 'outside of 'implicited_attendant-ontological-contiguity ${ }^{67}$ ' educedexistentialising/contextualising/textualising_'intelligibility/epistemicity/reflexivity_contiguity$<$ imbued-notional $\sim$ cogency $>,{ }^{\prime},-<$ reifying-or-elucidating-of-prospective-relative-ontologicalcompleteness -of- reference-of-thought- devolving-as-of-instantiative-context $>$ as to existence-potency ${ }^{39} \sim$ sublimating-nascence,-disclosed-from-prospective-epistemicdigression—rules-of-apriorising/axiomatising/referencing-that-further-epistemicallyunconceal-the-very-ontologically-same-existential-reality that syncs with existential< disontologising/re-ontologising aporeticism $>$ reality', in wrongly implying existence-inexistence which is nothing but 'virtuality-or-Being-construal-as-abstract-construal-as-offlawed-and-shallow-and-non-veridical-existential-reference' (wherein the disposition to 'constitute/abstract/extrapolate/deduce/infer essence-of-meaning is wrongly preceding/defining or even superseding existential<<disontologising/re-ontologising aporeticism $>$ reality' rather than the Sartrean reality of 'existence or existential-<disontologising/re-ontologising aporeticism $>$ reality preceding/defining essence'), so actually 'existence is rather an 'implicited_attendant-ontological-contiguity ${ }^{67}$ educed-

existentialising/contextualising/textualising_intelligibility/epistemicity/reflexivity-contiguity$<$ imbued-notional cogency $>{ }^{40}$ of existence-potency ${ }^{32} \sim$ sublimating-nascence,-disclosed-fromprospective-epistemic-digression —rules-of-apriorising/axiomatising/referencing-that-furtherepistemically-unconceal-the-very-ontologically-same-existential-reality that supersedes the elaboration-as-to-mere-extrapolating/constituting/abstracting/deducing/inferring-ofelucidation-outside_- 'prospectively implicited_attendant-ontological-contiguity ${ }^{67}$ ' educedexistentialising/contextualising/textualising_intelligibility/epistemicity/reflexivity-contiguity$<$ imbued-notional cogency $>$, when so-construed from our limited-mentation-capacity-assubjecting-'educed-unlimitedness/existence-sublimating nascence' to-limitedness/humansubpotency as of our relative-ontological-incompleteness ${ }^{8}$-induced,-'threshold-of- 
nonconviction/madeupness/bottomlining-in-shallow-supererogation $-<$ as-to-' ${ }^{\text {attendant- }}$ intradimensional'-prospectively-disontologising preconverging/dementing -apriorisingpsychologism>'. 'Implicited_attendant-ontological-contiguity ${ }^{67}$ ' educedexistentialising/contextualising/textualising_intelligibility/epistemicity/reflexivity-contiguity$<$ imbued-notional $\sim \operatorname{cogency}>,{ }^{,},-<$reifying-or-elucidating-of-prospective-relative-ontologicalcompleteness -of- reference-of-thought- devolving-as-of-instantiative-context $>$ as to existence-potency ${ }^{39} \sim$ sublimating-nascence,-disclosed-from-prospective-epistemicdigression—rules-of-apriorising/axiomatising/referencing-that-further-epistemicallyunconceal-the-very-ontologically-same-existential-reality in sync with existence 'speaks of threaded-or-intertwined subsumed referencing of all in existence' beyond just elaboration-as-tomere-extrapolating/constituting/abstracting/deducing/inferring-of-elucidation-outside'prospectively_implicited_attendant-ontological-contiguity ${ }^{67}$ ' educedexistentialising/contextualising/textualising_intelligibility/epistemicity/reflexivity-contiguity$<$ imbued-notional cogency $>$, thus validating philosophically such approaches in physics as string-theory concepts lending support to the string phenomenology approach. This conceptually implies that the 'all-in-one/oneness' (of ontology) implied of existence supersedes our elaboration-as-to-mere-extrapolating/constituting/abstracting/deducing/inferring-ofelucidation-outside_- 'prospectively_implicited_attendant-ontological-contiguity ${ }^{67}$ ? educedexistentialising/contextualising/textualising_intelligibility/epistemicity/reflexivity-contiguity$<$ imbued-notional cogency>' conceptualisations, and while these are 'mental tools of analysis' we have in grasping knowledge, as elaboration-as-to-mereextrapolating/constituting/abstracting/deducing/inferring-of-elucidation-outside'prospectively implicited_attendant-ontological-contiguity ${ }^{67}$, educedexistentialising/contextualising/textualising_'intelligibility/epistemicity/reflexivity-contiguity<imbued-notional cogency>' these are rather 'sub-par to the full grasp of existential- 
< disontologising/re-ontologising aporeticism $>$ reality' (given that our limited-mentationcapacity-deepening —as-subjecting limitedness/human-subpotency-to-'educed-

unlimitedness/existence-sublimating nascence' ${ }^{53}$ as of our relative-ontologicalincompleteness ${ }^{88}$-induced,-'threshold-of-nonconviction/madeupness/bottomlining-in-shallowsupererogation -<as-to- 'attendant-intradimensional'-prospectivelydisontologising preconverging/dementing -apriorising-psychologism>', will often fail to reference the underlying being-construal/existential-reference/existential-tautologisation 'for an 'implicited_attendant-ontological-contiguity ${ }^{67}$; educedexistentialising/contextualising/textualising_'intelligibility/epistemicity/reflexivity-contiguity$<$ imbued-notional cogency $>{ }^{\prime 0}$ of existence-potency ${ }^{32} \sim$ sublimating-nascence,-disclosed-fromprospective-epistemic-digression—rules-of-apriorising/axiomatising/referencing-that-furtherepistemically-unconceal-the-very-ontologically-same-existential-reality that syncs with existential-<disontologising/re-ontologising aporeticism $>$ reality'. For instance say in the case of the BODMAS characters highlighted before, where the other characters ignore the given pathological condition in simply operating arithmetic rules, however, the inherence of existential-<disontologising/re-ontologising aporeticism $>$ reality will not be superseded simply by such elaboration-as-to-mereextrapolating/constituting/abstracting/deducing/inferring-of-elucidation-outside'prospectively_implicited_attendant-ontological-contiguity ${ }^{67}$ ' educedexistentialising/contextmalising/textualising_intelligibility/epistemicity/reflexivity_contiguity$<$ imbued-notional cogency>' of arithmetic rules in protraction as 'virtuality-or-Beingconstrual-as-abstract-construal-as-of-flawed-and-shallow-and-non-veridical-existentialreference', as such arithmetic rules of extrapolating/constituting/abstracting/deducing/inferring will have to be adjusted-in-a- 'threadedness/imbricatedness/recomposuring' like subtracting 1 to A's results to sync with the existential-<disontologising/re-ontologising aporeticism $>$ reality 
implications of A's pathological condition of wrongly adding 1 to the correct result of arithmetic operations), and as metaphysics-of-presence-〈implicited-'nondescript/ignorable-void '-as-topresencing - absolutising-identitive-constitutedness > (i.e. 'virtuality-or-Being-construal-asabstract-construal-as-of-flawed-and-shallow-and-non-veridical-existential-reference') metaphysics-of-absence-〈implicited-epistemic-veracity-of- nonpresencing-<perspectiveontological-normalcy/postconvergence $>\rangle$ is rather the ontological-normalcy/postconvergence correction-tool of postdication, as-of projective-insights for predication, which is equally construed as ontological-reconstituting-as-to-conflatedness ${ }^{13} /$ deconstruction (i.e. implying 'projective-insights of sublimating-epistemic-imbricatedness/threadedness/recomposuring as of 'implicited_attendant-ontological-contiguity ${ }^{6 /}$; educedexistentialising/contextualising/textualising_'intelligibility/epistemicity/reflexivity-contiguity$<$ imbued-notional $\sim$ cogency $>,{ }^{\prime},-<$ reifying-or-elucidating-of-prospective-relative-ontologicalcompleteness -of- reference-of-thought- devolving-as-of-instantiative-context $>$ as to existence-potency ${ }^{39} \sim$ sublimating-nascence,-disclosed-from-prospective-epistemicdigression—rules-of-apriorising/axiomatising/referencing-that-further-epistemicallyunconceal-the-very-ontologically-same-existential-reality/dynamic-cumulativeaftereffect/aftereffect'). This is more of a simplistic though conceptually correct demonstration, and the implications to meaningfulness can be much more elaborate and as explained further below, with the notion of elaboration-as-to-mereextrapolating/constituting/abstracting/deducing/inferring-of-elucidation-outside'prospectively_implicited_attendant-ontological-contiguity ${ }^{67}$ ' educedexistentialising/contextmalising/textmalising_intelligibility/epistemicity/reflexivity-contiguity$<$ imbued-notional cogency>' as ontologically-veridical only as abstract-construal (such as the abstract arithmetic operations) but its wrong ontological derivation in lieu of beingconstrual/existential-reference/existential-tautologisation is ontologically wrong/non-veridical 
as it leads to 'virtuality-or-Being-construal-as-abstract-construal-as-of-flawed-and-shallow-andnon-veridical-existential-reference' (wherein the elaboration-as-to-mereextrapolating/constituting/abstracting/deducing/inferring-of-elucidation-outside'prospectively_implicited_attendant_ontological-contiguity ${ }^{67}$ ' educedexistentialising/contextualising/textualising_intelligibility/epistemicity/reflexivity-contiguity<imbued-notional cogency $>^{\prime}$ in protraction of the abstract arithmetic operations wrongly overlooks existential-reality as of being-construal/existential-reference/existentialtautologisation given by the existential-<disontologising/re-ontologising aporeticism $>$ pathological condition), instead of 'projective-insights of sublimating-epistemicimbricatedness/threadedness/recomposuring as of 'implicited_attendant-ontologicalcontiguity ${ }^{67}$, educedexistentialising/contextualising/textualising_'intelligibility/epistemicity/reflexivity-contiguity$<$ imbued-notional $\sim$ cogency $>$, ,-<reifying-or-elucidating-of-prospective-relative-ontologicalcompleteness -of- reference-of-thought- devolving-as-of-instantiative-context> as to existence-potency ${ }^{39} \sim$ sublimating-nascence,-disclosed-from-prospective-epistemicdigression — rules-of-apriorising/axiomatising/referencing-that-further-epistemicallyunconceal-the-very-ontologically-same-existential-reality/dynamic-cumulativeaftereffect/aftereffect' as the ontological-veridicality of being-construal/existentialreference/existential-tautologisation (which in the face of the 'existential pathological condition' as being-construal/existential-reference/existential-tautologisation upholds existential-reality by way of sublimating-epistemic-imbricatedness/threadedness/recomposuring by subtracting 1 from A's result to existentially-<disontelogising/re-ontologising aporeticism $>$ account for its pathological condition). It is thus not a coincidence that a Deleuzian approach and string phenomenology approaches intuitively develop the same insight about the need for 'creativespaces-of-expression/metaphors' to be able to conceptualise by projective-insights on topics that 
critically highlight this more fundamental nature of existential-<disontologising/reentologising aporeticism $>$ reality as an 'implicited_attendant-ontologicalcontiguity $^{67}$, educedexistentialising/contextualising/textmalising_intelligibility/epistemicity/reflexivity-contiguity$<$ imbued-notional $\sim \operatorname{cogency}>{ }^{40}$ of existence-potency ${ }^{39} \sim$ sublimating-nascence,-disclosed-fromprospective-epistemic-digression —rules-of-apriorising/axiomatising/referencing-that-furtherepistemically-unconceal-the-very-ontologically-same-existential-reality so-construed from the perspective of our limited-mentation-capacity-deepening - as-subjecting limitedness/humansubpotency-to-'educed-unlimitedness/existence-sublimating nascence' ${ }^{53}$ as of our relativeontological-incompleteness ${ }^{8}$-induced,-'threshold-of-nonconviction/madeupness/bottomliningin-shallow-supererogation $-<$ as-to- 'attendant-intradimensional'-prospectivelydisontologising $\sim$ preconverging/dementing -apriorising-psychologism>', in order to avoid elaboration-as-to-mere-extrapolating/constituting/abstracting/deducing/inferring-ofelucidation-outside_- 'prospectively_implicited_attendant_ontological-contiguity ${ }^{67}$; educedexistentialising/contextualising/textualising_intelligibility/epistemicity/reflexivity-contiguity<imbued-notional cogency>' inducing 'virtuality-or-Being-construal-as-abstract-construalas-of-flawed-and-shallow-and-non-veridical-existential-reference'. It is important to grasp here that elaboration-as-to-mere-extrapolating/constituting/abstracting/deducing/inferring-ofelucidation-outside—'prospectively_implicited_attendant—ontological-contiguity ${ }^{67}$ ' educedexistentialising/contextualising/textualising_intelligibility/epistemicity/reflexivity-contiguity$<$ imbued-notional cogency>' are not ontologically wrong concepts in themselves as of abstract-construal but are ontologically wrong when implied in lieu of beingconstrual/existential-reference/existential-tautologisation as this leads to 'virtuality-or-Beingconstrual-as-abstract-construal-as-of-flawed-and-shallow-and-non-veridical-existentialreference'. Philosophically, this critically brings up the reality of how the ontological- 
veridicality of an 'abstract-construal' and a 'being-construal' can be established; going by human limited-mentation-capacity-deepening —as-subjecting limitedness/human-subpotency-to'educed-unlimitedness/existence-sublimating nascence' ${ }^{53}$ as of our relative-ontologicalincompleteness ${ }^{88}$-induced,-'threshold-of-nonconviction/madeupness/bottomlining-in-shallowsupererogation -<as-to-'attendant-intradimensional'-prospectivelydisontologising preconverging/dementing -apriorising-psychologism>’'. An abstract-construal is of vague-reference/vague-tautologisation, and is of existential-<disontologising/reentelogising apereticism $>$ import only as of a being-construal, and is effectively conceptualised by elaboration-as-to-mereextrapolating/constituting/abstracting/deducing/inferring-of-elucidation-outside'prospectively_implicited_attendant-ontological-contiguity ${ }^{67}$ ? educedexistentialising/contextualising/textualising_'intelligibility/epistemicity/reflexivity-contiguity$<$ imbued-notional cogency $>^{\prime 0}$ and this is ontologically-veridical by abstractconstrual/abstractly. Being-construal on-the-other-hand is of existential-reference/existentialtautologisation as of becoming/being (as practically qualified by our consciousness-awarenessteleology ${ }^{9}$ ). If by mere derivation of elaboration-as-to-mereextrapolating/constituting/abstracting/deducing/inferring-of-elucidation-outside'prospectively_implicited_attendant-ontological-contiguity ${ }^{67}$ ' educedexistentialising/contextualising/textualising_'intelligibility/epistemicity/reflexivity-contiguity<imbued-notional cogency>' $\quad$ (given human limited-mentation-capacity-deepening-assubjecting limitedness/human-subpotency-to-'educed-unlimitedness/existence-sublimating nascence' ${ }^{53}$ as of our relative-ontological-incompleteness ${ }^{8}$-induced,-'threshold-ofnonconviction/madeupness/bottomlining-in-shallow-supererogation $-<$ as-to-'attendantintradimensional'-prospectively-disontologising preconverging/dementing -apriorisingpsychologism>') is implied as being-construal, this will lead to 'virtuality-or-Being-construal- 
as-abstract-construal-as-of-flawed-and-shallow-and-non-veridical-existential-reference' which is 'conceptually' ontologically non-veridical. Being-construal as of existentialreference/existential-tautologisation needs to be conceptualised as in 'implicited_attendantontological-contiguity ${ }^{67}$, educed-

existentialising/contextualising/textualising_intelligibility/epistemicity/reflexivity-contiguity$<$ imbued-notional $\sim$ cogency $>,{ }^{\prime},-<$ reifying-or-elucidating-of-prospective-relative-ontologicalcompleteness -of- reference-of-thought- devolving-as-of-instantiative-context $>$ as to existence-potency $^{39} \sim$ sublimating-nascence,-disclosed-from-prospective-epistemicdigression—rules-of-apriorising/axiomatising/referencing-that-further-epistemicallyunconceal-the-very-ontologically-same-existential-reality/dynamic-cumulativeaftereffect/aftereffect in order to be ontologically-veridical, and besides that sublimatingepistemic-imbricatedness/threadedness/recomposuring gets deeper the deeper the beingconstrual/existential-reference/existential-tautologisation. The elaboration-as-to-mereextrapolating/constituting/abstracting/deducing/inferring-of-elucidation-outside'prospectively_implicited_attendant-ontological-contiguity ${ }^{67}$ ' educedexistentialising/contextualising/textualising_intelligibility/epistemicity/reflexivity_contiguity$<$ imbued-notional cogency >' as of abstract-construal as ontologically-veridical harkens to a disposition for abstract predication (predictive-insights) while 'projective-insights of sublimating-epistemic-imbricatedness/threadedness/recomposuring as of 'implicited_attendant-ontological-contiguity ${ }^{67}$ educedexistentialising/contextualising/textualising_intelligibility/epistemicity/reflexivity-contiguity$<$ imbued-notional $\sim \operatorname{cogency}>,{ }^{\prime},-<$ reifying-or-elucidating-of-prospective-relative-ontologicalcompleteness -of- reference-of-thought- devolving-as-of-instantiative-context> as to existence-potency ${ }^{39} \sim$ sublimating-nascence,-disclosed-from-prospective-epistemicdigression—rules-of-apriorising/axiomatising/referencing-that-further-epistemically- 
unconceal-the-very-ontologically-same-existential-reality/dynamic-cumulative-

aftereffect/aftereffect' as of being-construal/existential-reference/existential-tautologisation harkens to a disposition for postdication (projective-insights as predicative, brought to their full potential as metaphysics-of-absence-〈implicited-epistemic-veracity-of- nonpresencing$<$ perspective-ontological-normalcy/postconvergence $>\rangle)$. But, then how is the ontologicalveridicality of being-construal/existential-reference/existential-tautologisation attained? Though ontologically non-veridical, 'virtuality-or-Being-construal-as-abstract-construal-as-of-flawedand-shallow-and-non-veridical-existential-reference' as metaphysics-of-presence-〈implicited'nondescript/ignorable-void '-as-to- presencing — absolutising-identitive-constitutedness >

has as metaphysics-of-absence-〈implicited-epistemic-veracity-of- nonpresencing$<$ perspective-ontological-normalcy/postconvergence $>$ > 'projective-insights of sublimatingepistemic-imbricatedness/threadedness/recomposuring as of 'implicited_attendant-ontologicalcontiguity ${ }^{67}$, educed-

existentialising/contextualising/textualising_intelligibility/epistemicity/reflexivity-contiguity$<$ imbued-notional $\sim$ cogency $>,{ }^{\prime},-<$ reifying-or-elucidating-of-prospective-relative-ontologicalcompleteness -of- reference-of-thought- devolving-as-of-instantiative-context> as to existence-potency ${ }^{32} \sim$ sublimating-nascence,-disclosed-from-prospective-epistemicdigression—rules-of-apriorising/axiomatising/referencing-that-further-epistemicallyunconceal-the-very-ontologically-same-existential-reality/dynamic-cumulativeaftereffect/aftereffect'), which is ontologically-veridical with regards to beingconstrual/existential-reference/existential-tautologisation. More precisely, 'projective-insights of sublimating-epistemic-imbricatedness/threadedness/recomposuring as of 'implicited_attendant-ontological-contiguity ${ }^{67}$ ' educed-

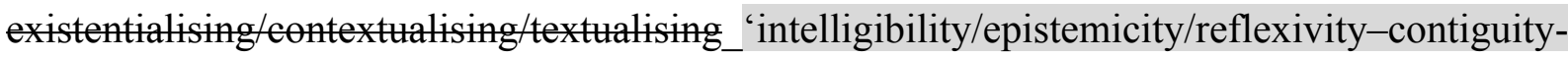
$<$ imbued-notional $\sim$ cogency $>,{ }^{\prime},-<$ reifying-or-elucidating-of-prospective-relative-ontological- 
existence-potency $^{32} \sim$ sublimating-nascence,-disclosed-from-prospective-epistemicdigression —rules-of-apriorising/axiomatising/referencing-that-further-epistemicallyunconceal-the-very-ontologically-same-existential-reality/dynamic-cumulativeaftereffect/aftereffect' as with all metaphysics-of-absence-〈implicited-epistemic-veracity-ofnonpresencing-<perspective-ontological-normalcy/postconvergence $>>$ can be ontologicallyreconstituted/deconstructed from the corresponding metaphysics-of-presence-〈implicited'nondescript/ignorable-void ' -as-to- presencing —absolutising-identitive-constitutedness >

as virtuality-or-Being-construal-as-abstract-construal-as-of-flawed-and-shallow-and-nonveridical-existential-reference', even though the latter is ontologically wrong/non-veridical (not to be confused with elaboration-as-to-mereextrapolating/constituting/abstracting/deducing/inferring-of-elucidation-outside'prospectively_implicited_attendant-ontological-contiguity ${ }^{67}$ ' educed-

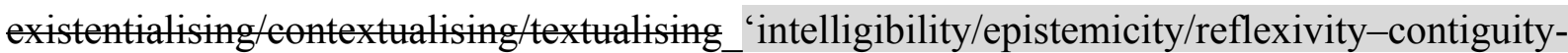
<imbued-notional cogency>' which is ontologically-veridical as abstract-construal). This ontological-reconstituting-as-to-conflatedness ${ }^{13} /$ deconstruction is rather a 'honing exercise'/recomposure of 'virtuality-or-Being-construal-as-abstract-construal-as-of-flawedand-shallow-and-non-veridical-existential-reference' to deliver 'projective-insights of sublimating-epistemic-imbricatedness/threadedness/recomposuring as of 'implicited_attendant-ontological-contiguity ${ }^{67}$ ' educedexistentialising/contextualising/textualising_ 'intelligibility/epistemicity/reflexivity-contiguity$<$ imbued-notional $\sim$ cogency $>,{ }^{\prime},-<$ reifying-or-elucidating-of-prospective-relative-ontologicalcompleteness -of- reference-of-thought- devolving-as-of-instantiative-context> as to existence-potency ${ }^{39} \sim$ sublimating-nascence,-disclosed-from-prospective-epistemicdigression—rules-of-apriorising/axiomatising/referencing-that-further-epistemically- 
unconceal-the-very-ontologically-same-existential-reality/dynamic-cumulative-

aftereffect/aftereffect' as ontologically-veridical, as it reflects-and-supersedes the defectiveness of 'virtuality-or-Being-construal-as-abstract-construal-as-of-flawed-and-shallow-and-nonveridical-existential-reference' with respect to ontological-veridicality and in so doing attaining ontological-veridicality or veracity/ontological-pertinence as a being-construal/existentialreference/existential-tautologisation. This can readily be appreciated when we grasp that we cannot just operate basic principles in producing scientific research for instance, as there is a whole reality of a 'honing exercise' or recomposure (in superseding our 'virtuality-or-Beingconstrual-as-abstract-construal-as-of-flawed-and-shallow-and-non-veridical-existentialreference reflex' as metaphysics-of-presence-〈implicited-'nondescript/ignorable-void ' -as-topresencing - absolutising-identitive-constitutedness $\rangle$ ) with respect to beingconstrual/existential-reference/existential-tautologisations to attain ontological-veridicality by ontological-reconstituting-as-to-conflatedness ${ }^{13} /$ deconstruction (as 'projective-insights of sublimating-epistemic-imbricatedness/threadedness/recomposuring as of 'implicited_attendant-ontological-contiguity ${ }^{67}$ > educedexistentialising/contextualising/textualising_'intelligibility/epistemicity/reflexivity_contiguity$<$ imbued-notional $\sim$ cogency $>,{ }^{\prime},-<$ reifying-or-elucidating-of-prospective-relative-ontologicalcompleteness -of- reference-of-thought- devolving-as-of-instantiative-context $>$ as to existence-potency ${ }^{39} \sim$ sublimating-nascence,-disclosed-from-prospective-epistemicdigression—rules-of-apriorising/axiomatising/referencing-that-further-epistemicallyunconceal-the-very-ontologically-same-existential-reality/dynamic-cumulativeaftereffect/aftereffect'), however mild or elaborate the ontological-reconstituting-as-to-

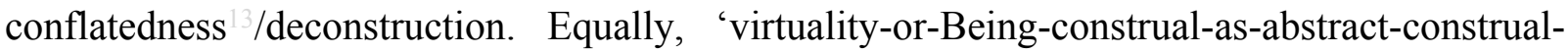
as-of-flawed-and-shallow-and-non-veridical-existential-reference' is metaphysics-of-presence〈implicited-'nondescript/ignorable-void '-as-to- presencing-absolutising-identitive- 
constitutedness $>$ that is the 'honing exercise'/recomposure backdrop for metaphysics-ofabsence-〈implicited-epistemic-veracity-of- nonpresencing-<perspective-ontologicalnormalcy/postconvergence $>>$ as 'projective-insights of sublimating-epistemicimbricatedness/threadedness/recomposuring as of 'implicited_attendant-ontologicalcontiguity $^{67} \sim$ educedexistentialising/contextualising/textualising_'intelligibility/epistemicity/reflexivity-contiguity$<$ imbued-notional $\sim$ cogency $>,{ }^{\prime},-<$ reifying-or-elucidating-of-prospective-relative-ontologicalcompleteness -of- reference-of-thought- devolving-as-of-instantiative-context> as to existence-potency ${ }^{39} \sim$ sublimating-nascence,-disclosed-from-prospective-epistemicdigression —rules-of-apriorising/axiomatising/referencing-that-further-epistemicallyunconceal-the-very-ontologically-same-existential-reality/dynamic-cumulativeaftereffect/aftereffect' to generate the art-forms/aesthetics as being-construal/existentialreference/existential-tautologisation, by way of 'strategic-insight of perspectives' for artistic expression. (Idyllically, superseding-oneness-of-ontology attainable by notional ${ }^{18}$ deprocrypticism 'implicited attendant-ontological-contiguity ${ }^{67}$ ' educedexistentialising/contextualising/textalising_'intelligibility/epistemicity/reflexivity-contiguity$<$ imbued-notional $\sim$ cogency $>,{ }^{\prime},-<$ reifying-or-elucidating-of-prospective-relative-ontologicalcompleteness -of- reference-of-thought- devolving-as-of-instantiative-context $>$ as to existence-potency ${ }^{39} \sim$ sublimating-nascence,-disclosed-from-prospective-epistemicdigression—rules-of-apriorising/axiomatising/referencing-that-further-epistemicallyunconceal-the-very-ontologically-same-existential-reality 'preempting the threshold-ofnonconviction/madeupness/bottomlining-in-shallow-supererogation $<-<$ as-to-' $a$ attendantintradimensional'-prospectively-disontologising preconverging/dementing -apriorisingpsychologism $>$ of rational-empiricism/positivising-rules' should imply ontologically subsuming 'projective-insights of sublimating-epistemic-imbricatedness/threadedness/recomposuring as of 
'implicited_attendant-ontological-contiguity ${ }^{67}$ educedexistentialising/contextualising/textualising_intelligibility/epistemicity/reflexivity-contiguity$<$ imbued-notional $\sim$ cogency $>,{ }^{\prime},-<$ reifying-or-elucidating-of-prospective-relative-ontologicalcompleteness -of- reference-of-thought- devolving-as-of-instantiative-context $>$ as to existence-potency ${ }^{39} \sim$ sublimating-nascence,-disclosed-from-prospective-epistemicdigression —rules-of-apriorising/axiomatising/referencing-that-further-epistemicallyunconceal-the-very-ontologically-same-existential-reality/dynamic-cumulativeaftereffect/aftereffect' as of the ontologically deepest being-construal/existentialreference/existential-tautologisisation, and thus will be the ${ }^{103}$ universal nested-congruence of the comprehension of intrinsic-reality, aesthetics/art-forms and virtue.) In the bigger scheme, we can equally grasp that the uninstitutionalised-threshold ${ }^{102}$ arise from 'virtuality-or-Being-construalas-abstract-construal-as-of-flawed-and-shallow-and-non-veridical-existential-reference' of the reference-of-thought- categorical-imperatives/axioms/registry-teleology 9 of corresponding prior institutionalisations and thus failing/not-upholding-<as-ofapriorising/axiomatising/referencing $>\quad$ intemporal-preservation-entropy-or-contiguity-orontological-preservation as threshold-of-nonconviction/madeupness/bottomlining-in-shallowsupererogation -<as-to- 'attendant-intradimensional'-prospectivelydisontologising preconverging/dementing -apriorising-psychologism> (beyond-theconsciousness-awareness-teleology ${ }^{\circ}<$ of-preconverging-existential-extrication-as-ofexistential-unthought $>$ manifestation intradimensionally); wherein temporal-dispositions are involved in temporal-preservation-as-pseudointemporality ${ }^{52}$-preservation by wrongly elaboration-as-to-mere-extrapolating/constituting/abstracting/deducing/inferring-ofelucidation-outside_- 'prospectively implicitantantontological-contiguity ${ }^{67}$ ' educedexistentialising/contextualising/textualising_'intelligibility/epistemicity/reflexivity-contiguity<imbued-notional cogency>' their $\quad{ }^{83}$ reference-of-thought- categorical- 
imperatives/axioms/registry-teleology as 'virtuality-or-Being-construal-as-abstract-construalas-of-flawed-and-shallow-and-non-veridical-existential-reference', and which ontologicalreconstituting-as-to-conflatedness ${ }^{13} /$ deconstruction (in disambiguating ${ }^{83}$ reference-of-thought, with the prior/untranscended/superseded uninstitutionalised-threshold ${ }^{102}$ reference-of-thought as 'virtuality-or-Being-construal-as-abstract-construal-as-of-flawed-and-shallow-and-nonveridical-existential-reference' which is ontologically non-veridical, and the prospective/transcending/superseding ${ }^{8}$ reference-of-thought involving the "projective-insights of sublimating-epistemic-imbricatedness/threadedness/recomposuring as of 'implicited_attendant-ontological-contiguity ${ }^{67}$ ' educedexistentialising/contextualising/textualising_intelligibility/epistemicity/reflexivity-contiguity$<$ imbued-notional $\sim$ cogency $>,{ }^{\prime},-<$ reifying-or-elucidating-of-prospective-relative-ontologicalcompleteness -of- reference-of-thought- devolving-as-of-instantiative-context> as to existence-potency ${ }^{32} \sim$ sublimating-nascence,-disclosed-from-prospective-epistemicdigression—rules-of-apriorising/axiomatising/referencing-that-further-epistemicallyunconceal-the-very-ontologically-same-existential-reality/dynamic-cumulativeafereffect/aftereffect') is what brings about the prospective institutionalisation as secondnaturing. Critically important to grasp is that the notion of ${ }^{83}$ reference-of-thought is rather a 'being-contrual'/existential-reference/existential-tautologisation that implies 'projectiveinsights of sublimating-epistemic-imbricatedness/threadedness/recomposuring as of 'implicited_attendant-ontological-contiguity ${ }^{67}$; educedexistentialising/contextualising/textualising_'intelligibility/epistemicity/reflexivity-contiguity$<$ imbued-notional $\sim$ cogency $>,{ }^{\prime},-<$ reifying-or-elucidating-of-prospective-relative-ontologicalcompleteness -of- reference-of-thought- devolving-as-of-instantiative-context> as to existence-potency ${ }^{39} \sim$ sublimating-nascence,-disclosed-from-prospective-epistemicdigression—rules-of-apriorising/axiomatising/referencing-that-further-epistemically- 
unconceal-the-very-ontologically-same-existential-reality/dynamic-cumulative-

afereffect/aftereffect', and should not mistakenly be confused with the notion of an abstractconstrual since this is ontologically non-veridical as it will lead to virtuality-or-ontologicallyflawed-construal/being-construal-as-abstract-construal-as-of-flawed-and-shallow-and-nonveridical-existential-reference; as ${ }^{83}$ reference-of-thought as being-construal/existentialreference/existential-tautologisation makes reference to the comprehensive implications existentially-<disentologising/re-ontologising aporeticism $>$ with respect to mentaldispositions along the apriorising-registry-elements/anchoring-of-meaning-elements of Pysychologismic-subliminality-of-individuation-effusing/worlding imbued logicaldueness-or-scape-or-frame, profile-or-stature, presumptuousness-or-arrogation, assumptions, value-reference and teleology ${ }^{9}$, and involving the potency of both consciousness-awarenessteleology ${ }^{9}$ representations and implications, for instance, the difference of the ${ }^{8}$ reference-ofthought as an alchemist and a chemist is much more than just an on-occasion/incidental difference (difference in abstract-construal) with respect to elaboration-as-to-mereextrapolating/constituting/abstracting/deducing/inferring-of-elucidation-outside'prospectively_implicited_attendant-ontological-contiguity ${ }^{67}$ >educed-

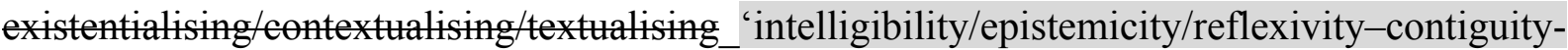
<imbued-notional cogency>' of meaning but carries derived being-construal/existentialreference/existential-tautologisation differences with respect to their consciousness-awarenessteleologies and registry-worldviews/dimensions $\quad$ <amplituding/formativeepistemicity $>$ causality $\sim$ as-to-projective-totalitative-implications-of-prospectivenonpresencing,-for-explicating relative-unreflexivity/relative-reflexivity - ontologicalcontiguity. In fact, ontological-reconstituting-as-to-conflatedness $13 /$ deconstruction which always refers rather to the issue of ${ }^{8}$ reference-of-thought is actually of 'projective-insights of sublimating-epistemic-imbricatedness/threadedness/recomposuring 
'implicited_attendant-ontological-contiguity ${ }^{67}$ educedexistentialising/contextualising/textualising_intelligibility/epistemicity/reflexivity-contiguity$<$ imbued-notional $\sim$ cogency $>,{ }^{\prime},-<$ reifying-or-elucidating-of-prospective-relative-ontologicalcompleteness -of- reference-of-thought- devolving-as-of-instantiative-context $>$ as to existence-potency ${ }^{39} \sim$ sublimating-nascence,-disclosed-from-prospective-epistemicdigression —rules-of-apriorising/axiomatising/referencing-that-further-epistemicallyunconceal-the-very-ontologically-same-existential-reality/dynamic-cumulativeafereffect/aftereffect' nature and it is about implying a prospective ${ }^{83}$ reference-of-thought, rather than just a différance (differentiation) as within the same prior/given ${ }^{83}$ reference-of-thought as of a basic abstract-construal. This is one of the reasons for its misapprehension as it implies an overall change in the ${ }^{83}$ reference-of-thought of appreciation which ends up putting everything 'of old/of prior' into question, contrary to the traditional analytical expectation of selective-orlimited critique/contestation usually of a non-transcendental nature. Insightfully, the overall relation of deconstruction as ontological-reconstituting-as-to-conflatedness ${ }^{13}$ to the existential<disontologising/re-ontologising aporeticism $>$ framework of ontological-veridicality should further allay the confusion. Deconstruction is actually tautological with respect to intrinsic reality/ontological-veridicality because it is always about the same existential< disontologising/re-ontologising aporeticism $>$ reality being dealt with by improving human limited-mentation-capacity-deepening—as-subjecting-limitedness/human-subpotency-to'educed-unlimitedness/existence-sublimating nascence' ${ }^{53}$ as shallow-limited-mentationcapacity —as-subjecting 'educed-unlimitedness/existence-sublimating nascence' tolimitedness/human-subpotency to deeper-limited-mentation-capacity-as-subjecting 'educedmnlimitedness/existence sublimating nascence' to limitedness/hmman-subpotency ontologicalreconstituting-as-to-conflatedness ${ }^{13}$; generating differing consciousness-awareness-teleology outcomes of the same existential-<disontologising/re-ontologising aporeticism $>$ reality 
whether talking of deconstruction at the registry-worldview/dimension or intradimensional level or individuation-level. Since it is always about the same existential-<disontologising/reentologising aporeticism $>$ reality, in effect the readjustment for intrinsic-reality/ontologicalveridicality is actually a human 'changing-of-the-psyche'/psychical-readjustment (psychoanalytic-unshackling/memetic-reordering/institutional-recomposuring) with its increasing-ontological-completeness or diminishing-human-epistemic-abnormalcy-orpreconvergence ${ }^{31}$ as implied by an ontology-driven 'postconverging-or-dialectical-thinking psychology or psychology-of-mentation-dynamics or natural $\sim$ psychological-dynamics', wherein placeholder-setup/mental-devising-representation/mentation/consciousness-awarenessteleology ${ }^{9}$ scheduling 'is not inherently sanctimonious' (the naïve way every registryworldview tends to relate to its mental-disposition) but is determined and shaped (by way of ' ${ }^{\prime}$ de-mentation-〈supererogatory $\sim$ ontological-de-mentation-or-dialectical-de-mentationstranding-or-attributive-dialectics $\rangle$ of ${ }^{83}$ reference-of-thought') by construed ontologicalveridicality. Since it is always about the same existential-<disontologising/re-ontologising apereticism $>$ reality but improving-rather-as-cumulating/recomposuring human limitedmentation-capacity-deepening —as-subjecting-limitedness/human-subpotency-to-'educedunlimitedness/existence-sublimating nascence' ${ }^{33}$ in 'engaging the same existential< disontologising/re-ontologising aporeticism $>$ reality and drawing implications thereof' as human <amplituding/formative-epistemicity>-totalising $\sim$ renewing-realisation/re-perception/rethought-as-utter-placeholder-setup-ontological-rescheduling-〈by-a-renewing-of-

\section{apriorising/axiomatising/referencing-psychologism-as-the-new-referencing-basis-of-}

prospective- meaningfulness-and-teleology \ as 'subpotent-mimetic-echoness-derivationwithin-the-full-potency of existence/intrinsic-reality/ontology-as-of-its-mimetic-echoness or existence-in-reverberation or existence-potency ${ }^{32} \sim$ sublimating-nascence,-disclosed-fromprospective-epistemic-digression, it is thus analysed as maximalising-recomposuring-for- 
relative-ontological-completeness ${ }^{87}$ - unenframed/re-ontologising $\sim$ conceptualisation $\quad$ as $\quad$ a mental-rescheduling and goes by the 'projective-insights of sublimating-epistemicimbricatedness/threadedness/recomposuring as of 'implicited_attendant-ontologicalcontiguity $^{67} \sim$ educed-

existentialising/contextualising/textualising_'intelligibility/epistemicity/reflexivity-contiguity$<$ imbued-notional $\sim$ cogency $>,{ }^{\prime},-<$ reifying-or-elucidating-of-prospective-relative-ontologicalcompleteness -of- reference-of-thought- devolving-as-of-instantiative-context $>$ as to existence-potency $^{39} \sim$ sublimating-nascence,-disclosed-from-prospective-epistemicdigression — rules-of-apriorising/axiomatising/referencing-that-further-epistemicallyunconceal-the-very-ontologically-same-existential-reality/dynamic-cumulativeaftereffect/aftereffect' unlike an elaboration-as-to-mereextrapolating/constituting/abstracting/deducing/inferring-of-elucidation-outside'prospectively_implicited_attendant-ontological-contiguity ${ }^{6 /}$ educedexistentialising/contextualising/textualising_intelligibility/epistemicity/reflexivity-contiguity$<$ imbued-notional cogency>' which will wrongly hollow-constitute and induce 'virtuality-orBeing-construal-as-abstract-construal-as-of-flawed-and-shallow-and-non-veridical-existentialreference'. So the tautological implication of deconstruction as ontological-reconstituting-as-toconflatedness $^{13}$ is all about human rescheduling of placeholder-setup/mental-devisingrepresentation/mentation/consciousness-awareness-teleology ${ }^{9}$ in deepening its grasp of a superseding-oneness-of-ontology/intrinsic-reality that has been so all the time, and so critically talk of transcending from shallow to deeper superseding-oneness-of-ontology is no more than about human <amplituding/formative-epistemicity>-totalising renewing-realisation/reperception/re-thought-as-utter-placeholder-setup-ontological-rescheduling-〈by-a-renewing-ofapriorising/axiomatising/referencing-psychologism-as-the-new-referencing-basis-ofprospective- meaningfulness-and-teleology > as 'subpotent-mimetic-echoness-derivation- 
within-the-full-potency of existence/intrinsic-reality/ontology-as-of-its-mimetic-echoness or existence-in-reverberation or existence-potency ${ }^{32}$ sublimating-nascence,-disclosed-fromprospective-epistemic-digression already given as ontological-normalcy/postconvergence oneness, and prospectively transcendentally a 'psychoanalytic-rescheduling from procrypticism-or-disjointedness-as-of- ${ }^{2}$ reference-of-thought to ${ }^{18}$ deprocrypticism-orpreempting - disjointedness-as-of- reference-of-thought 'implicited_attendant-ontologicalcontiguity $^{67} \sim$ educed-

existentialising/contextualising/textualising_'intelligibility/epistemicity/reflexivity-contiguity$<$ imbued-notional $\sim$ cogency $>^{\prime},-<$ reifying-or-elucidating-of-prospective-relative-ontologicalcompleteness -of- reference-of-thought- devolving-as-of-instantiative-context> involving existence-potency ${ }^{39} \sim$ sublimating-nascence,-disclosed-from-prospective-epistemicdigression — rules-of-apriorising/axiomatising/referencing-that-further-epistemicallyunconceal-the-very-ontologically-same-existential-reality 'preempting the threshold-ofnonconviction/madeupness/bottomlining-in-shallow-supererogation $<-<$ as-to- 'attendantintradimensional'-prospectively-disontologising preconverging/dementing -apriorisingpsychologism $>$ of rational-empiricism/positivising-rules' while intradimensionally it is about an analytical rescheduling ( ${ }^{5}$ maximalising-recomposuring-for-relative-ontologicalcompleteness ${ }^{87}$ - unenframed/re-ontologising conceptualisation that 'decenters the prior reference-of-thought' for the 'centering of the prospective ${ }^{83}$ reference-of-thought'). Noting that the 'increasing relative realism' over the corresponding-successive-prior-uninstitutionalisationsregistry-worldviews (utter-uninstitutionalisation, ununiversalisation, nonpositivism/medievalism and procrypticism) of the corresponding-successive-prospectiveinstitutionalisations-registry-worldviews/dimensions (of protracted sublimating-epistemicimbricatedness/threadedness/recomposuring as of 'implicited_attendant-ontologicalcontiguity $^{67}$; educed- 
existentialising/contextualising/textualising_intelligibility/epistemicity/reflexivity-contiguity$<$ imbued-notional $\sim$ cogency $>,{ }^{\prime},-<$ reifying-or-elucidating-of-prospective-relative-ontologicalcompleteness -of- reference-of-thought- devolving-as-of-instantiative-context $>$ as to existence-potency ${ }^{32} \sim$ sublimating-nascence,-disclosed-from-prospective-epistemicdigression—rules-of-apriorising/axiomatising/referencing-that-further-epistemicallyunconceal-the-very-ontologically-same-existential-reality as: Base-institutionalisation-as-rulemaking, $\quad{ }^{103}$ universalisation-as-universalisation-of-rules-making, Positivism-as-rationalempiricism/positivising-of-universalisation-of-rules-making and deprocrypticism-as-utterontologising-of-rational-empiricism/positivising-of-universalisation-of-rules-making)

establishes the corresponding-successive-prior-uninstitutionalisations-registryworldviews/dimensions at the uninstitutionalised-threshold ${ }^{102}$ of the corresponding-successiveprospective-institutionalisations-registry-worldviews, 'as of threshold-ofnonconviction/madeupness/bottomlining-in-shallow-supererogation $<-<$ as-to-' $a$ attendantintradimensional'-prospectively-disontologising preconverging/dementing -apriorisingpsychologism>' which are 'ontologically filled-up' by the corresponding-successiveprospective-institutionalisations-registry-worldviews; implying a dialecticism of 'ontologicalsuperseding of prospective ${ }^{83}$ reference-of-thought over the prior one' (even where the prior as the-present is locked-in-its-ways/complexed-about-its-own-transcendability)! The distinction in grasping intrinsic-reality/ontological-veridicality with respect to whether it is of abstractconstrual or being-construal/existential-reference/existential-tautologisation in order to avoid the ontologically non-veridical 'virtuality-or-Being-construal-as-abstract-construal-as-of-flawedand-shallow-and-non-veridical-existential-reference' (by elaboration-as-to-mereextrapolating/constituting/abstracting/deducing/inferring-of-elucidation-outside'prospectively_implicited_attendant_ontological-contiguity ${ }^{67}$ ' educedexistentialising/contextualising/textualising_intelligibility/epistemicity/reflexivity-contiguity- 
imperatives/axioms/registry-teleology ${ }^{9}$ of the prior positivism institutionalisation leading to procrypticism-or-disjointedness-as-of- ${ }^{8}$ reference-of-thought, and failing-intemporalpreservation-entropy-or-contiguity-or-ontological-preservation) has bearing when it comes to the veracity/ontological-pertinence of a psycho-ontological-tautologisation/psycho-existentialreference conceptual-scheme meant to be the ontologically-veridical basis, as of aetiologisation/ontological-escalation-<ontological-

veridicality_commitment/otherliness_transcending/compulsions-encumbered_transcending>, for construing an insightful storied-construct/ontologically-valid-narration articulating on an intuitive level the conceptualisations introduced in this paper. The aetiologisation/ontologicalescalation-<ontological-veridicality_commitment/otherliness_transcending/compulsionsencumbered_transcending $>$ implied by such a storied-construct/ontologically-valid-narration will be grounded on 'projective-insights of sublimating-epistemicimbricatedness/threadedness/recomposuring as of 'implicited_attendant-ontologicalcontiguity $^{67}$, educed-

existentialising/contextualising/textualising_'intelligibility/epistemicity/reflexivity-contiguity$<$ imbued-notional $\sim$ cogency $>,{ }^{\prime},-<$ reifying-or-elucidating-of-prospective-relative-ontologicalcompleteness -of- reference-of-thought- devolving-as-of-instantiative-context> as to existence-potency ${ }^{39} \sim$ sublimating-nascence,-disclosed-from-prospective-epistemicdigression—rules-of-apriorising/axiomatising/referencing-that-further-epistemicallyunconceal-the-very-ontologically-same-existential-reality/dynamic-cumulativeaftereffect/aftereffect', as the underlying being-construal/existential-reference/existentialtautologisation of the storied-construct/ontologically-valid-narration's existential-tracing of ontologically-veridical-meaningfulness, and reflecting temporal-dispositions rather in 'virtuality-or-Being-construal-as-abstract-construal-as-of-flawed-and-shallow-and-non- 
veridical-existential-reference'; as it contrastively reflects the reality of an ontologically nonveridical intradimensional 'virtuality-or-Being-construal-as-abstract-construal-as-of-flawedand-shallow-and-non-veridical-existential-reference' of temporal-dispositions narratives (instigated from postlogism 77 and conjugated-postlogism 7 ) as being of threshold-ofnonconviction/madeupness/bottomlining-in-shallow-supererogation $-<$ as-to-' attendant-

\section{intradimensional'-prospectively-disontologising preconverging/dementing -apriorising-}

psychologism $>\quad$ (beyond-the-consciousness-awareness-teleology ${ }^{9}<$ of - preconvergingexistential-extrication-as-of-existential-unthought $>$ manifestation intradimensionally) and as of 'virtuality-or-Being-construal-as-abstract-construal-as-of-flawed-and-shallow-and-nonveridical-existential-reference', in construing the consequent ${ }^{80}$ procrypticism-ordisjointedness-as-of- ${ }^{8}$ reference-of-thought uninstitutionalisation, and so as the transcendental backdrop highlighted by prospective intemporal-preservation notional ${ }^{18}$ deprocrypticism 'projective-insights of sublimating-epistemic-imbricatedness/threadedness/recomposuring as of 'implicited_attendant-ontological-contiguity ${ }^{67}$ > educed-

existentialising/contextualising/textalising_'intelligibility/epistemicity/reflexivity_contiguity$<$ imbued-notional $\sim \operatorname{cogency}>{ }^{,},-<$reifying-or-elucidating-of-prospective-relative-ontological-

completeness -of- reference-of-thought- devolving-as-of-instantiative-context> as to existence-potency $^{39} \sim$ sublimating-nascence,-disclosed-from-prospective-epistemicdigression—rules-of-apriorising/axiomatising/referencing-that-further-epistemicallyunconceal-the-very-ontologically-same-existential-reality/dynamic-cumulativeaftereffect/aftereffect'. Hence the deepest being-construal/existential-reference/existentialtautologisation implied by 'projective-insights of sublimating-epistemicimbricatedness/threadedness/recomposuring as of 'implieitentontonicalcontiguity $^{67}$, educedexistentialising/contextmalising/textmalising_intelligibility/epistemicity/reflexivity-contiguity- 
existence-potency ${ }^{39} \sim$ sublimating-nascence,-disclosed-from-prospective-epistemicdigression—rules-of-apriorising/axiomatising/referencing-that-further-epistemicallyunconceal-the-very-ontologically-same-existential-reality/dynamic-cumulativeaftereffect/aftereffect' enabling the ontological transcendence: of a procrypticism setup is necessarily

a 'deprocrypticism-intemporal sublimating-epistemicimbricatedness/threadedness/recomposuring' thus reflecting procrypticism/perversion-ofpositivistic-meaningfulness as 'virtuality-or-Being-construal-as-abstract-construal-as-offlawed-and-shallow-and-non-veridical-existential-reference'; in a non-positivism/medievalism setup is necessarily a 'positivism-intemporal sublimating-epistemicimbricatedness/threadedness/recomposuring' while reflecting non-positivism-ormedievalism/perversion-of-universalisation-meaningfulness as 'virtuality-or-Being-construalas-abstract-construal-as-of-flawed-and-shallow-and-non-veridical-existential-reference'; in an ununiversalisation setup is necessarily a " ${ }^{103}$ universalisation sublimating-epistemicimbricatedness/threadedness/recomposuring' while reflecting ununiversalisation/perversion-ofbase-institutionalisation-meaningfulness as 'virtuality-or-Being-construal-as-abstract-construalas-of-flawed-and-shallow-and-non-veridical-existential-reference'; and in a recurrent-utteruninstitutionalisation setup is necessarily a 'base-institutionalisation sublimating-epistemicimbricatedness/threadedness/recomposuring' while reflecting recurrent-utteruninstitutionalisation/recurrent-perversion-in-upholding-utter-uninstitutionalisation 'virtuality-or-Being-construal-as-abstract-construal-as-of-flawed-and-shallow-and-nonveridical-existential-reference'. Transcendentally/transdimensionally/interdimensionally, it is the notional-contiguity/epistemic-contiguity $-<$ profound-supererogation -of-mentallyaestheticised postconverging/dialectical-thinking -qualia-schema> implied by 'projective- 
insights of sublimating-epistemic-imbricatedness/threadedness/recomposuring as of 'implicited_attendant-ontological-contiguity ${ }^{67}$ educed-

existentialising/contextualising/textualising_'intelligibility/epistemicity/reflexivity-contiguity$<$ imbued-notional $\sim \operatorname{cogency}>{ }^{\prime},-<$ reifying-or-elucidating-of-prospective-relative-ontologicalcompleteness -of- reference-of-thought- devolving-as-of-instantiative-context> as to existence-potency ${ }^{39} \sim$ sublimating-nascence,-disclosed-from-prospective-epistemicdigression—rules-of-apriorising/axiomatising/referencing-that-further-epistemicallyunconceal-the-very-ontologically-same-existential-reality/dynamic-cumulativeaftereffect/aftereffect' as of deepest being-construal/existential-reference/existentialtautologisation that underlies the relative-unreflexivity/relative-reflexivity-ontologicalcontiguity $\sim$ of-the-human-institutionalisation-process behind baseinstitutionalisation/ ${ }^{103}$ universalisation/positivism/prospective-deprocrypticism, and likewise it is the notional-discontiguity/epistemic-discontiguity

$<$ between-prior-shallowsupererogation -of-mentally-aestheticised preconverging/dementing -qualiaschema_and_prospective-profound-supererogation -of-mentallyaestheticised postconverging/dialectical-thinking -qualia-schema $>$ implied by 'virtuality-orBeing-construal-as-abstract-construal-as-of-flawed-and-shallow-and-non-veridical-existentialreference' thus in 'disjointedness-as-of- ${ }^{3}$ reference-of-thought' misappropriated meaningfulness-and-teleology ${ }^{9}$ in arrogation (beyond-the-consciousness-awarenessteleology ${ }^{9}-<$ of-preconverging-existential-extrication-as-of-existential-unthought> manifestation), that induces the uninstitutionalised-threshold ${ }^{102}$ process behind recurrent-utteruninstitutionalisation/ununiversalisation/non-positivism-or-medievalism/procypticism. The implications at the individuation-level is that our limited-mentation-capacity-as subjecting 'educed-unlimitedness/existence-sublimating nascence' to-limitedness/human-subpotency, as of our temporal-to-intemporal mental-dispositions, in the construal of intrinsic- 
reality/ontological-veridicality tends towards temporality ${ }^{8} /$ shortness as of $^{2}$ as apriorising/axiomatising/referencing-\{of-'prospectively implicited_attendant-ontologicalcontiguity ' educedexistentialising/contextualising/textualising_'intelligibility/epistemicity/reflexivity-contiguity<imbued-notional cogency $\left.>{ }^{\prime} \quad\right\}$-constitutedness ${ }^{14}$-in-preconverging-entailment $\quad$ that ultimately fails hence inducing virtualities. And so, when initially striving to explicate the coherence of a given ontological/being phenomenon or explicating its coherence with other ontological/being phenomena or more profoundly explicating its coherence with the overall existential-<disontologising/re-ontologising aporeticism $>$ ontological/being phenomenon. This is inherently-and-intuitively underscored by our underlying 'coherence/contiguity-ofsuperseding-oneness-of-ontology-implied-as-of-inherent-existence-coherence/contiguity,-andso-construed-as-the-enabler-of-insight-or-intuition-or-foresight-as-of-embodied-consciousness' (so-enabled by underlying supposedly coherent ontological-commitment ${ }^{6}-$ implied $_{-}$selfassuredness-of-ontological-good-faith/authenticity $\sim$ postconverging-dementating/structuring/paradigming -as-being-as-of-existential-reality> $<$ amplituding/formative-epistemicity $>$ causality $\sim$ as-to-projective-totalitative-implications-ofprospective- nonpresencing,-for-explicating relative unreflexivity/relative reflexivity ontological-contiguity and not any notion of vague innateness besides existentially<disontologising/re-ontologising aporeticism $>$ inherent human-subpotency potential to manifest as human) which as of derivation 'intuitively-assigns projected-and-then-ensuingpredicated coherence/contiguity as meaningfulness' as of the 'coherence/contiguity of the actual insight-giving relevant-and-implied knowledge-constructs/theories/intersolipsistic-intercessorynotions/notional referential-notions/articulations/virtue for the <amplituding/formativeepistemicity>totalising $\sim$ devolved-purview-as-domain-of-construal-as-intrinsicreality/ontological-veridicality articulation' such as 
logic/mathematics/virtue/space/time/ ${ }^{+}$historiality/ontological-eventfulness ${ }^{38} /$ ontological- $^{-}$ aesthetic-tracing-<perspective-ontological-normalcy/postconvergence-reflected-'epistemicityrelativism-determinism'>/instantaneity/cogency/methodology (or in the case herein 'human limited-mentation-capacity—as-subjecting 'educed-unlimitedness/existence-sublimating nascence' to-limitedness/human-subpotency construed as of ontologicalnormalcy/postconvergence metaphysics-of-absence-_implicited-epistemic-veracity-ofnonpresencing-<perspective-ontological-normalcy/postconvergence $>$ //Doppler-thinking as it disambiguates human-subpotency-aporia/undecidability/dilemma/oughtindeterminacy/deficiency/limitation/constraint—imbued-'notional firstnaturednessformativeness-as to eventulising inkling drive or seeding misprising $>$ temporal-tointemporal-dispositions-<so-construed-as-from-perspective-ontologicalnormalcy/postconvergence>'-existentialism-form-factor $\quad{ }^{5}$ meaningfulness-and-teleology $<$ amplituding/formative-epistemicity $>$ causality $\sim$ as-to-projective-totalitative-implications-ofprospective- nonpresencing,-for-explicating relative-unreflexivity/relative-reflexivity ontological-contiguity , and not as it may be wrongly construed to be ${ }^{\natural}$ historiality/ontological-eventfulness 3 /ontological-aesthetic-tracing-<perspectiveontological-normalcy/postconvergence-reflected-'epistemicity-relativism-determinism'>’ which is just incidentally-associated-and-not-the-actual-basis of the underlying 'coherence/contiguity-of-superseding-oneness-of-ontology-implied-as-of-inherent-existencecoherence/contiguity,-and-so-construed-as-the-enabler-of-insight-or-intuition-or-foresight-asof-embodied-consciousness' (so-enabled by underlying supposedly coherent ontologicalcommitment $-<$ implied — self-assuredness-of-ontological-goodfaith/authenticity postconverging-de-mentating/structuring/paradigming -as-being-as-ofexistential-reality> as of <amplituding/formative-epistemicity>causality $\sim$ as-to-projectivetotalitative-implications-of-prospective- nonpresencing,-for-explicating relative- 
unreflexivity/relative-reflexivity - ontological-contiguity and not any notion of vague innateness besides existentially- $<$ disontologising/re-ontologising aporeticism $>$ inherent human-subpotency potential to manifest as human) which as of derivation 'intuitively-assigns projected-and-then-ensuing-predicated coherence/contiguity as meaningfulness' as of the 'coherence/contiguity of the actual insight-giving relevant-and-implied knowledgeconstruct/intersolipsistic-intercessory-notion/notional $\sim$ referential-notion/articulation for the $<$ amplituding/formative-epistemicity $>$ totalising $\sim$ devolved-purview-as-domain-of-construalas-intrinsic-reality/ontological-veridicality articulation'), in much the same way that ‘instantaneity’ as knowledge-construct/intersolipsistic-intercessory-notion/notional $\sim$ referentialnotion/articulation is just incidentally-associated-and-not-the-actual-basis for logic or mathematics domains-of-study articulations. Thus, requiring on our part an sublimatingepistemic-imbricatedness/threadedness/recomposuring exercise in grasping how the underlying 'coherence/contiguity-of-superseding-oneness-of-ontology-implied-as-of-inherent-existencecoherence/contiguity,-and-so-construed-as-the-enabler-of-insight-or-intuition-or-foresight-asof-embodied-consciousness' (so-enabled by underlying supposedly coherent ontologicalcommitment $-<$ implied — self-assuredness-of-ontological-good-

\section{faith/authenticity postconverging-de-mentating/structuring/paradigming -as-being-as-of-}

existential-reality> as of <amplituding/formative-epistemicity $>$ causality $\sim$ as-to-projectivetotalitative-implications-of-prospective- nonpresencing,-for-explicating relative-

unreflexivity/relative-reflexivity ontological-contiguity and not any notion of vague innateness besides existentially-<disontologising/re-ontologising aporeticism $>$ inherent human-subpotency potential to manifest as human) which as of derivation 'intuitively-assigns projected-and-then-ensuing-predicated coherence/contiguity as meaningfulness' as of the 'coherence/contiguity of the actual insight-giving relevant-and-implied knowledgeconstruct/intersolipsistic-intercessory-notion/notional $\sim$ referential-notion/articulation for the 
$<$ amplituding/formative-epistemicity $>$ totalising $\sim$ devolved-purview-as-domain-of-construalas-intrinsic-reality/ontological-veridicality articulation' should be construed to compensate for our temporality $/$ /shortness disposition associated with apriorising/axiomatising/referencing\{of-'prospectively_implicited_attendant-ontological-contiguity ' ceducedexistentialising/contextualising/textualising_ 'intelligibility/epistemicity/reflexivity-contiguity<imbued-notional cogency $\left.>^{\prime} \quad\right\}$-constitutedness ${ }^{14}$-in preconverging-entailment, with this compensating exercise construed as of ${ }^{6}$ presencing — absolutising-identitive-constitutedness ${ }^{14}$, or more consummately as apriorising/axiomatising/referencing-\{of-"prospectively implicited_attendant-ontological-contiguity ' educedexistentialising/contextualising/textualising_'intelligibility/epistemicity/reflexivity-contiguity$<$ imbued-notional cogency $\left.>^{\prime} \quad\right\}$-conflatedness ${ }^{13}$-in-\{preconverging-disentailment by $\}^{2}$ postconverging-entailment/conflatedness ${ }^{13}$. This ${ }^{79}$ presencing-absolutising-identitiveconstitutedness ${ }^{14} \quad$ and apriorising/axiomatising/referencing- \{of- prospectively implicited_attendant-ontological-contiguity ' educedexistentialising/contextualising/textualising_'intelligibility/epistemicity/reflexivity-contiguity$<$ imbued-notional cogency $\left.>^{\prime} \quad\right\}$-conflatedness ${ }^{13}$ in-\{preconverging-disentailment by compensation mechanism, given our limited-mentation-capacityas-subjecting 'educed-unlimitedness/existence-sublimating nascence' to-limitedness/humansubpotency for the construal/conceptualisation of intrinsic-reality/ontologicalveridicality/ontology, equally clarifies why ${ }^{55}$ maximalising-recomposuring-for-relativeontological-completeness ${ }^{87}$ - unenframed/re-ontologising conceptualisation (as intimately tying down our limited-mentation-capacity—as-subjecting-'educed-unlimitedness/existencesublimating nascence' to limitedness/hmman-subpency by sublimating-epistemicimbricatedness/threadedness/recomposuring to the 'leash' of existentialreality/ontology/intrinsic-reality/ontological-veridicality) takes precedence over elaboration-as- 
to-mere-extrapolating/constituting/abstracting/deducing/inferring-of-elucidation-outside'prospectively_implicited_attendant_ontological-contiguity ${ }^{67}$ ' educedexistentialising/contextualising/textualising_'intelligibility/epistemicity/reflexivity-contiguity<imbued-notional cogency> ${ }^{\prime 4}$ (as letting our limited-mentation-capacity-as-subjecting 'educed-unlimitedness/existence-sublimating nascence' to-limitedness/human-subpotency by unimbricatedness/unthreadedness/unrecomposuring out of the 'leash' of existentialreality/ontology/intrinsic-reality/ontological-veridicality). With regards to logic and by extension mathematics, this equally points out that logic as well as mathematics (and for that matter all other knowledge-constructs/theories/intersolipsistic-intercessorynotions/notional referential-notions/articulations/virtue like time, space, virtue, historiality/ontological-eventfulness ${ }^{38} /$ ontological-aesthetic-tracing- $<$ perspectiveontological-normalcy/postconvergence-reflected-‘epistemicity-relativism-determinism’>, instantaneity, cogency, methodology, etc.) are abstract constructs that underscore the underlying 'coherence/contiguity-of-superseding-oneness-of-ontology-implied-as-of-inherent-existencecoherence/contiguity,-and-so-construed-as-the-enabler-of-insight-or-intuition-or-foresight-asof-embodied-consciousness' (so-enabled by underlying supposedly coherent ontologicalcommitment $-<$ implied—self-assuredness-of-ontological-goodfaith/authenticity postconverging-de-mentating/structuring/paradigming -as-being-as-ofexistential-reality> as of <amplituding/formative-epistemicity>causality $\sim$ as-to-projectivetotalitative-implications-of-prospective- nonpresencing,-for-explicating relativeunreflexivity/relative-reflexivity - ontological-contiguity and not any notion of vague innateness besides existentially-<disontologising/re-ontologising aporeticism $>$ inherent human-subpotency potential to manifest as human) which as of derivation by ${ }^{79}$ presencingabsolutising-identitive-constitutedness $^{14}$ or apriorising/axiomatising/referencing-\{of'prospectively_implicited_attendant-ontological-contiguity ' educed- 
existentialising/contextualising/textualising_'intelligibility/epistemicity/reflexivity-contiguity<imbued-notional cogency >' \}-conflatedness ${ }^{13}$-in-\{preconverging-disentailment by\} postconverging-entailment intuitively-assign projected-and-then-ensuing-predicated coherence/contiguity as meaningfulness' in the construal/conceptualisation of intrinsicreality/ontological-veridicality/ontology. That is, these are notions that reflect existence-as-ofits-mimetic-echoness/existence-in-reverberation/existence-potency ${ }^{39} \sim$ sublimating-nascence,disclosed-from-prospective-epistemic-digression as of the underlying 'coherence/contiguity-ofsuperseding-oneness-of-ontology-implied-as-of-inherent-existence-coherence/contiguity,-andso-construed-as-the-enabler-of-insight-or-intuition-or-foresight-as-of-embodied-consciousness' (so-enabled by underlying supposedly coherent ontological-commitment $-<$ implied - selfassuredness-of-ontological-good-faith/authenticity postconverging-dementating/structuring/paradigming -as-being-as-of-existential-reality>

$<$ amplituding/formative-epistemicity $>$ causality $\sim$ as-to-projective-totalitative-implications-ofprospective- nonpresencing,-for-explicating relative-unreflexivity/relative-reflexivity ontological-contiguity and not any notion of vague innateness besides existentially-disontologising/re-ontologising aporeticism $>$ inherent human-subpotency potential to manifest as human). Logic is thus about logical axiomatic-construct-incidenting (construed as logic 'ontological ${ }^{83}$ reference-of-thought or axiomatic-construct' incidenting) as 'implicited by underlying 'coherence/contiguity-of-superseding-oneness-of-ontology-implied-as-of-inherentexistence-coherence/contiguity,-and-so-construed-as-the-enabler-of-insight-or-intuition-orforesight-as-of-embodied-consciousness' (so-enabled by underlying supposedly coherent ontological-commitment $\quad<$ implied_-self-assuredness-of-ontological-goodfaith/authenticity postconverging-de-mentating/structuring/paradigming -as-being-as-ofexistential-reality> as of <amplituding/formative-epistemicity>causality $\sim$ as-to-projectivetotalitative-implications-of-prospective- nonpresencing,-for-explicating relative- 
unreflexivity/relative-reflexivity ontological-contiguity and not any notion of vague innateness besides existentially- $<$ disontologising/re-ontologising aporeticism $>$ inherent human-subpotency potential to manifest as human), likewise, mathematics is about mathematical axiomatic-construct-incidenting (construed as mathematical 'ontological reference-of-thought or axiomatic-construct' incidenting) as 'implicited by underlying 'coherence/contiguity-of-superseding-oneness-of-ontology-implied-as-of-inherent-existencecoherence/contiguity,-and-so-construed-as-the-enabler-of-insight-or-intuition-or-foresight-asof-embodied-consciousness' (so-enabled by underlying supposedly coherent ontologicalcommitment $-<$ implied — self-assuredness-of-ontological-goodfaith/authenticity postconverging-de-mentating/structuring/paradigming -as-being-as-ofexistential-reality> as of <amplituding/formative-epistemicity>causality $\sim$ as-to-projectivetotalitative-implications-of-prospective- nonpresencing,-for-explicating $\sim$ relativeunreflexivity/relative-reflexivity - ontological-contiguity and not any notion of vague innateness besides existentially-<disontologising/re-ontologising aporeticism $>$ inherent human-subpotency potential to manifest as human); and by extension any knowledgeconstruct/intersolipsistic-intercessory-notion/notional $\sim$ referential-notion/articulation is about its axiomatic-construct-incidenting (construed as its 'ontological ${ }^{3}$ reference-of-thought or axiomatic-construct' incidenting) as 'implicited by underlying 'coherence/contiguity-ofsuperseding-oneness-of-ontology-implied-as-of-inherent-existence-coherence/contiguity,-andso-construed-as-the-enabler-of-insight-or-intuition-or-foresight-as-of-embodied-consciousness' (so-enabled by underlying supposedly coherent ontological-commitment $-<$ implied - selfassuredness-of-ontological-good-faith/authenticity $\sim$ postconverging-dementating/structuring/paradigming -as-being-as-of-existential-reality> 
ontological-contiguity and not any notion of vague innateness besides existentially-disontologising/re-ontologising aporeticism $>$ inherent human-subpotency potential to manifest as human); with the further insight that all knowledgeconstructs/theories/intersolipsistic-intercessory-notions/notional $\sim$ referential-

notions/articulations/virtue as of intrinsic-reality/ontological-veridicality transcendentalenabling/sublimating/supererogatery de-mentativity are about 'existential/ontological/axiomatic incidenting' as of underlying 'coherence/contiguity-ofsuperseding-oneness-of-ontology-implied-as-of-inherent-existence-coherence/contiguity,-andso-construed-as-the-enabler-of-insight-or-intuition-or-foresight-as-of-embodied-consciousness' (so-enabled by underlying supposedly coherent ontological-commitment $-<$ implied - selfassuredness-of-ontological-good-faith/authenticity postconverging-dementating/structuring/paradigming -as-being-as-of-existential-reality>

$<$ amplituding/formative-epistemicity $>$ causality $\sim$ as-to-projective-totalitative-implications-ofprospective- nonpresencing,-for-explicating relative-unreflexivity/relative-reflexivity ontological-contiguity and not any notion of vague innateness besides existentially< disontologising/re-ontologising aporeticism $>$ inherent human-subpotency potential to manifest as human). Thus implying that ontology-as-of-existence is 'potently-and-cogently superseding, and knowledge-constructs/theories/intersolipsistic-intercessorynotions/notional referential-notions/articulations/virtue are subsumed derivations as of the superseding apriorising/axiomatising/referencing-\{of-"prospectively implicited_attendantontological-contiguity ' educed-

existentialising/contextualising/textualising_'intelligibility/epistemicity/reflexivity-contiguity$<$ imbued-notional cogency $>$ ' $\}$-conflatedness ${ }^{13}$ in (preconverging disentalment by postconverging-entailment of ontological/existential-implications; with such ontological/existential-implications construed operantly as of a given deepening/shallow level 
of human limited-mentation-capacity-as-subjecting 'educed-unlimitedness/existencesublimating nascence'- to-limitedness/human-subpotency as human-subpotency preconvergingexistential-extrication-as-of-existential-unthought, construed rather as of the implied given registry-worldview's/dimension's ${ }^{83}$ reference-of-thought 〈given consciousness's ${ }^{58}$ neuterisinginduced-or-deneuterising 17 -induced $>$ - ${ }^{3}$ reference-of-thought—devolving-teleological-dementating/structuring/paradigming-of-meaningfulness as of its intradimensional existentialinstantiations derived/devolved axiomatic-constructs of ${ }^{56}$ meaningfulness-and-teleology ${ }^{9}$ as knowledge-constructs/theories/intersolipsistic-intercessory-notions/notional $\sim$ referentialnotions/articulations/virtue, thus reflecting the registry-worldview's/dimension's ${ }^{83}$ reference-ofthought ontological-performance ${ }^{72}-<$ including-virtue-as-ontology $>/$ morality/ethics/justice/etc. as of its ${ }^{4}$ historiality/ontological-eventfulness $3 \%$ ontological-aesthetic-tracing-<perspectiveontological-normalcy/postconvergence-reflected-‘epistemicity-relativism-determinism’> as soanalysed as from notional ${ }^{18}$ deprocrypticism! (It is important in this regard to distinguish what is implied by 'incidenting' not to be confused with 'instantiation', as incidenting implies an 'abstract construction' of the implication of logic or any 'knowledgeconstructs/theories/intersolipsistic-intercessory-notions/notional $\sim$ referential-

notions/articulations/virtue' that may or may not be of existential-instantiation, whereas instantiation refers actually to 'actual existential-<disontologising/re-ontelogisingapereticism $>$ instance'. It is critical to uphold this distinction with respect to the existentially$<$ disentologising/re-ontelogising aporeticism $>$ attendant nature, as of sublimating-epistemicimbricatedness/threadedness/recomposuring, of human limited-mentation-capacity-assubjecting-'educed-unlimitedness/existence-sublimating nascence' to-limitedness/humansubpotency grasp of all 'intersolipsistic-intercessory-notions/notional referentialnotions'/knowledge including our grasp of logic or mathematics. As 'abstractly-speaking' there is no absolute certitude that in say a million years from now a 'given as of yet unelucidated 
notion', as a further sublimating-epistemic-imbricatedness/threadedness/recomposuring, will invalidate in a million years from now the 'existential-instantiations' validity of knowledgeconstructs/theories/intersolipsistic-intercessory-notions/notional referentialnotions/articulations/virtue including logic and mathematics as we know of them today. Such distinction as of more immediate concern is to point out the subsuming precedence of existence as of its inherent intrinsicness beyond-and-over human construal/conceptualisation of meaningfulness-and-teleology ${ }^{9}$ about it as at best the latter can only achieve as of its upper limit a 'correspondence of construal/conceptualisation of existence'; noting here as well for coherence sake that such a statement cannot be made about existence itself as the absolute a priori, simply because any arising existential-instantiations no matter the strangeness or abnormality to what is traditionally thought or expected however imbricated/threaded/recomposured or unimbricated/unthreaded/unrecomposured is of the inherently valid scope of existence itself as of its superseding-oneness-of-ontology and precedence, thus meaningful.) Logic and mathematics (and any such knowledgeconstructs/theories/intersolipsistic-intercessory-notions/notional referentialnotions/articulations/virtue) are only as meaningful as when reflecting a ${ }^{83}$ reference-of-thoughtcategorical-imperatives/axioms/registry-teleology ${ }^{9}$, ,for-

aposteriorising/logicising/deriving/intelligising/measuring - ${ }^{56}$ meaningfulness-and-teleology ${ }^{9}$ of a given <amplituding/formative-epistemicity>totalising $\sim$ devolved-purview-as-domain-ofconstrual-as-intrinsic-reality/ontological-veridicality whether as of a science, a social science or social study, or even abstract logic ontology or abstract mathematics ontology; otherwise the naïve use of logic or mathematics (and/or any such knowledgeconstructs/theories/intersolipsistic-intercessory-notions/notional $\sim$ referentialnotions/articulations/virtue) become a relatively sub-ontological-<as-to-the-limitation-ofhuman-subpotency-in-its-reifying-and-empowering-reflexivity-of-the-full-potency-of- 
existence's $\sim$ sublimating-nascence $>$ exercise qualified more pertinently as 'conceptualpatterning' as of apriorising/axiomatising/referencing-\{of-'prospectively implicited_attendantontological-contiguity ' educed-

existentialising/contextualising/textualising_'intelligibility/epistemicity/reflexivity-contiguity$<$ imbued-notional cogency $\left.>^{\prime},\right\}$-constitutedness ${ }^{1}$-in-preconverging-entailment in any such $<$ amplituding/formative-epistemicity $>$ totalising $\sim$ devolved-purview-as-domain-of-construalas-intrinsic-reality/ontological-veridicality rather than actually conceptualising a ${ }^{83}$ reference-ofthought- categorical-imperatives/axioms/registry-teleology ${ }^{9}$,-foraposteriorising/logicising/deriving/intelligising/measuring- ${ }^{5}$ meaningfulness-and-teleology ${ }^{9}$ of a given <amplituding/formative-epistemicity>totalising $\sim$ devolved-purview-as-domain-ofconstrual-as-intrinsic-reality/ontological-veridicality as of apriorising/axiomatising/referencing\{of-'prospectively implicited_attendant-ontological-contiguity ' educedexistentialising/contextualising/textualising_'intelligibility/epistemicity/reflexivity-contiguity<imbued-notional cogency $\left.>^{\prime}\right\}$-conflatedness ${ }^{13}$ in-\{preconverging-disentailment by\} postconverging-entailment. Pointing out that there must necessarily be an exercise in developing the requisite 'ontological ${ }^{83}$ reference-of-thought or axiomatic-construct of an epistemicalising $\sim$ devolved-purview-as-domain-of-construal-as-intrinsic-reality/ontologicalveridicality' to which logic and mathematics (and any knowledgeconstructs/theories/intersolipsistic-intercessory-notions/notional referentialnotions/articulations/virtue) can then contribute in furthering its elaboration (as of existence-asof-its-mimetic-echoness/existence-in-reverberation/existence-potency ${ }^{39} \sim$ sublimatingnascence,-disclosed-from-prospective-epistemic-digression), but it wouldn't work out the other way round on the basis of simple methodological mimicry starting out from the mimicked construal/conceptualisation of logic and mathematics (and any such knowledgeconstructs/theories/intersolipsistic-intercessory-notions/notional referential- 
notions/articulations/virtue) on the naïve goal of then grasping a ${ }^{83}$ reference-of-thoughtcategorical-imperatives/axioms/registry-teleology ${ }^{99}$, -for-

aposteriorising/logicising/deriving/intelligising/measuring- ${ }^{5}$ meaningfulness-and-teleology ${ }^{99}$ of a given <amplituding/formative-epistemicity>totalising $\sim$ devolved-purview-as-domain-ofconstrual-as-intrinsic-reality/ontological-veridicality. For instance, the need to develop a reference-of-thought- categorical-imperatives/axioms/registry-teleology ${ }^{9}$,-foraposteriorising/logicising/deriving/intelligising/measuring- ${ }^{5}$ meaningfulness-and-teleology ${ }^{9}$ of the specific biology <amplituding/formative-epistemicity>totalising $\sim$ devolved-purview-asdomain-of-construal-as-intrinsic-reality/ontological-veridicality as DNA-based genetics that explains genes and genetic principles is ontologically preceding and defining of how the knowledge-constructs/theories/intersolipsistic-intercessory-notions/notional referentialnotions/articulations/virtue of mathematics, logic, information processing, etc. can further contribute in elaborating DNA-based genetics but it is rather naïve to think mathematics, logic, information processing or for that matter any other knowledgeconstructs/theories/intersolipsistic-intercessory-notions/notional referential-

notions/articulations/virtue like 'mere research methodologies lacking critically the requisite ontological cogency' can by themselves develop a ${ }^{83}$ reference-of-thought- categoricalimperatives/axioms/registry-teleology ${ }^{9}$, -for-

aposteriorising/logicising/deriving/intelligising/measuring $-{ }^{5}$ meaningfulness-and-teleology ${ }^{9}$ of a given <amplituding/formative-epistemicity>totalising $\sim$ devolved-purview-as-domain-ofconstrual-as-intrinsic-reality/ontological-veridicality by such vague methodological mimicry. The latter at best induces a vague and blurred 'conceptual-patterning-〈as-devoid-of'prospectively_implicited_attendant-ontological-contiguity ' educedexistentialising/contextualising/textualising_intelligibility/epistemicity/reflexivity_contiguity<imbued-notional cogency>' 's-reifying-or-elucidating-of-'prospective-relative-ontological- 
completeness ' ;-so-rather-enabled-<by-a- nonpresencing-divulging-of-momentous-

historiality/ontological-eventfulness /ontological-aesthetic-tracing-<perspective-

ontological-normalcy/postconvergence-reflected-'epistemicity-relativism-determinism'>>'

particularly in such domains-of-study where the positive or negative sanctioning by $<$ amplitung formative-epistemicity $>$ causality $\sim$ as-to-projective-totalitative-implications-ofprospective- nonpresencing,-for-explicating relative-unreflexivity/relative-reflexivity

ontological-contiguity of intrinsic-reality/ontological-veridicality transcendentalenabling/sublimating/supereregatery $\sim$ de-mentativity is not immediately perceptible but rather remote like in the human sciences and to some extent as well with some studies in the natural sciences (where for instance the overall 're-ontologising fepistemic-totalising 're-apriorising/reaxiomatising/re-referencing-residuality in re-originariness/re-origination $\{$ decompulsing $\}$ delinearity/delinear-accreting/recomposuring $\quad$ cogency/tensing/limpidity-<as-ofprospective-profound-supererogation ,-for-residuality-in-re-originariness/reorigination>-aprospective_reifying mental-aestheticising-<as-of 'prospective_reformulating of-mental-aestheticising'as-to 'residuality in-re-originariness/re-origination' of-mentalaestheticising $>$ ' of the whole experimental framework relative to the conclusions advanced of many a research study is dubious as not pertinently unconfounded). Supposedly a mathematical and/or statistical methodological analysis was to be introduced with regards to the underlying articulation herein and based say on an 'arbitrary ${ }^{4}$ historiality/ontologicaleventfulness 38 ontological-aesthetic-tracing-<perspective-ontologicalnormalcy/postconvergence-reflected-'epistemicity-relativism-determinism'> grounded methodology on the basis of just vague impression' it will rather be mere conceptual-patterning. What is required is an underlying ${ }^{83}$ reference-of-thought- categoricalimperatives/axioms/registry-teleology ${ }^{9}$, -foraposteriorising/logicising/deriving/intelligising/measuring - ${ }^{56}$ meaningfulness-and-teleology 
(as implied herein, as of 'human limited-mentation-capacity-as-subjecting-educedunlimitedness/existence-sublimating nascence' to-limitedness/human-subpotency construed as of ontological-normalcy/postconvergence metaphysics-of-absence-〈implicited-epistemicveracity-of- nonpresencing-<perspective-ontological-normalcy/postconvergence $>$ /Dopplerthinking as it elicits human-subpotency-aporia/undecidability/dilemma/oughtindeterminacy/deficiency/limitation/constraint—imbued-‘notional firstnaturednessformativeness-<as-to-eventualising-inkling-drive-or-seeding-misprising $>$ temporal-tointemporal-dispositions-<so-construed-as-from-perspective-ontologicalnormalcy/postconvergence>'-existentialism-form-factor $<$ amplituding/formativeepistemicity $>$ causality $\sim$ as-to-projective-totalitative-implications-of-prospectivenonpresencing,-for-explicating relative-unreflexivity/relative-reflexivity - ontologicalcontiguity '). The contention being that studies and research that do not develop their conceptual formulations validly and succinctly as the underlying framework of the <amplituding/formativeepistemicity>totalising $\sim$ devolved-purview-as-domain-of-construal-as-intrinsicreality/ontological-veridicality but simply expect to dangle/associate methodologies including statistical and mathematical analyses are rather involved in vague conceptual-patterning-〈asdevoid-of-'prospectively_implicited_attendant-ontological-contiguity ' educedexistentialising/contextualising/textualising_'intelligibility/epistemicity/reflexivity-contiguity<imbued-notional cogency>' 's-reifying-or-elucidating-of-'prospective-relative-ontologicalcompleteness ${ }^{\prime} ;$-so-rather-enabled-<by-a- nonpresencing-divulging-of-momentoushistoriality/ontological-eventfulness /ontological-aesthetic-tracing-<perspectiveontological-normalcy/postconvergence-reflected-'epistemicity-relativism-determinism' $>>$ as of reference-of-though apriorising/axiomatising/referencing-\{of-'prospectively implicited_attendant-ontological-contiguity ' educedexistentialising/contextualising/textualising_ 'intelligibility/epistemicity/reflexivity-contiguity- 
$<$ imbued-notional cogency $\left.>^{\prime} \quad\right\}$-constitutedness ${ }^{14}$-in-preconverging-entailment. This insight is critical with respect to the validity of interpretations and conclusions in many experimental and study frameworks in the social sciences often 'under-elaborating the ontological ${ }^{83}$ referenceof-thought or axiomatic-construct of their study' to which the implications of statistical and mathematical methodologies and analyses are naively brought to bear. This further speaks inthe-bigger-scheme-of-things, of the need for the articulation of what will be a 'fully intrinsicreality/ontological-veridicality transcendental-enabling/sublimating/supererogatory $\sim$ dementativity constraining social science' as futural Being-development/ontological-frameworkexpansion-as-to-depth-of-ontologising-development-as-infrastructure-of- meaningfulnessand-teleology as of prospective notional ${ }^{18}$ deprocrypticism registry-worldview psychologism should fully enable (rather as an overall grounding of ${ }^{56}$ meaningfulness-and-teleology ${ }^{99}$ that overcomes disjointedness-as-of- ${ }^{-3}$ reference-of-thought-as-misappropriated-meaningfulness) just as the positivism registry-worldview psychologism relatively enabled an intrinsicreality/ontological-veridicality transcendental-enabling/sublimating/supereregatory $\sim$ dementativity natural sciences including an emerging and upcoming social science. Insightfully, this analysis equally underlines that there is a 'human sense-of-ontology/intersolipsisticintercession as of underlying 'coherence/contiguity-of-superseding-oneness-of-ontologyimplied-as-of-inherent-existence-coherence/contiguity,-and-so-construed-as-the-enabler-ofinsight-or-intuition-or-foresight-as-of-embodied-consciousness' (so-enabled by underlying supposedly coherent ontological-commitment $-<$ implied-self-assuredness-of-ontologicalgood-faith/authenticity postconverging-de-mentating/structuring/paradigming -as-beingas-of-existential-reality $>\quad$ as $\quad$ of $<$ amplituding/formative-epistemicity $>$ causality $~$ as-toprojective-totalitative-implications-of-prospective- nonpresencing,-for-explicating relative unreflexivity/relative-reflexivity ontological-contiguity and not any notion of vague innateness besides existentially-<disontologising/re-ontologising aporeticism $>$ inherent 
human-subpotency potential to manifest as human) anchoring the human in the becoming of existence' allowing for human subpotent-mimetic-echoness-derivation-within-the-full-potency of existence-as-of-its-mimetic-echoness/existence-in-reverberation/existencepotency ${ }^{39} \sim$ sublimating-nascence,-disclosed-from-prospective-epistemic-digression wherein we pivot/decenter (psychoanalytic-unshackling/memetic-reordering/institutional-recomposuring) in defining-and-redefining ${ }^{56}$ meaningfulness-and-teleology ; with this sense-ofontology/solipsistic-intercession as of underlying 'coherence/contiguity-of-supersedingoneness-of-ontology-implied-as-of-inherent-existence-coherence/contiguity,-and-so-construedas-the-enabler-of-insight-or-intuition-or-foresight-as-of-embodied-consciousness' (so-enabled by underlying supposedly coherent ontological-commitment $-<$ implied - self-assuredness-ofontological-good-faith/authenticity $\sim$ postconverging-dementating/structuring/paradigming -as-being-as-of-existential-reality $>\quad$ as $\quad$ of $<$ amplituding/formative-epistemicity $>$ causality $\sim$ as-to-projective-totalitative-implications-ofprospective- nonpresencing,-for-explicating relative-unreflexivity/relative-reflexivity ontological-contiguity and not any notion of vague innateness besides existentially< disontologising/re-ontologising aporeticism $>$ inherent human-subpotency potential to manifest as human) acting as the fundamental human drive for its being and conceptualisations of any ${ }^{56}$ meaningfulness-and-teleology ${ }^{9}$ in existence. Basically, the induced social ${ }^{103}$ universaltransparency ${ }^{104}$ - transparency-of-totalising-entailing,-as-to-entailing-<amplituding/formativeepistemicity>totalising in-relative-ontological-completeness \' of meaningfulness from 'projective-insights of sublimating-epistemic-imbricatedness/threadedness/recomposuring as of 'implicited_attendant-ontological-contiguity ${ }^{67}$ > educedexistentialising/contextmalising/textualising_'intelligibility/epistemicity/reflexivity_contiguity$<$ imbued-notional $\sim$ cogency $>,{ }^{,},-<$reifying-or-elucidating-of-prospective-relative-ontologicalcompleteness -of- reference-of-thought- devolving-as-of-instantiative-context $>$ as to 
existence-potency $^{32} \sim$ sublimating-nascence,-disclosed-from-prospective-epistemicdigression—rules-of-apriorising/axiomatising/referencing-that-further-epistemicallyunconceal-the-very-ontologically-same-existential-reality/dynamic-cumulativeaftereffect/aftereffect' of its deeper being-construal/existential-reference/existentialtautologisation (as of intemporal-disposition/ontological-veridicality) in superseding-andrepresenting-as-preconverging-or-dementing ${ }^{20}$-apriorising-psychologism 'virtuality-or-Beingconstrual-as-abstract-construal-as-of-flawed-and-shallow-and-non-veridical-existentialreference' (of temporal-dispositions ${ }^{74}$ perversion-of- ${ }^{3}$ reference-of-thought- $<$ aspreconvergingly-apriorising/axiomatising/referencing-innonconviction/madeupness/bottomlining-as-to-shallow-supererogation $>$ s), will reflect the reality of temporal-dispositions as of postlogism 7 -slantedness (psychopathic-or-postlogic) or ignorance/affordability/opportunism/exacerbation/social-chainism-or-social-discomfiture-ornegative-social-aggregation/temporal-enculturation-or-temporal-endemisation (at the point where the social ${ }^{103}$ universal-transparency ${ }^{104}$-〈transparency-of-totalising-entailing,-as-toentailing-<amplituding/formative-epistemicity $>$ totalising $\sim$ in-relative-ontological-

completeness > is lost or at uninstitutionalised-threshold ${ }^{102}$ ) and the consequent ‘subontologisation/existential-decontextualised-transposition' (in-a-social-dynamism-ofmeaningfulness-misappropriation) by slantedness/postlogic-effect/miscuing/disjointedlogic/logical-drag/unconscionability-drag/sub-par-or-formulaic-association-or-temporal-oralibi-conventioning-rationalising/temporal-enculturation-or-temporal-endemisation-effect as the bigger dynamic framework of human-subpotency-aporia/undecidability/dilemma/oughtindeterminacy/deficiency/limitation/constraint—imbued-'notional firstnaturednessformativeness-<as-to-eventualising-inkling-drive-or-seeding-misprising $>$ temporal-tointemporal-dispositions- $<$ so-construed-as-from-perspective-ontologicalnormalcy/postconvergence>'-existentialism-form-factor, and so across all uninstitutionalised- 
threshold $^{102}$. Thus, basically ontological-reconstituting-as-to-conflatedness ${ }^{13} /$ deconstruction as $^{2}$ 'projective-insights of sublimating-epistemic-imbricatedness/threadedness/recomposuring as of 'implicited_attendant-ontological-contiguity ${ }^{67}$ ' educedexistentialising/contextualising/textualising_intelligibility/epistemicity/reflexivity_contiguity$<$ imbued-notional $\sim$ cogency $>,{ }^{\prime},-<$ reifying-or-elucidating-of-prospective-relative-ontologicalcompleteness -of- reference-of-thought- devolving-as-of-instantiative-context> as to existence-potency $^{39} \sim$ sublimating-nascence,-disclosed-from-prospective-epistemicdigression—rules-of-apriorising/axiomatising/referencing-that-further-epistemicallyunconceal-the-very-ontologically-same-existential-reality/dynamic-cumulativeaftereffect/aftereffect' reflects/perspectivates transversality-<for-sublimating-existentialeventuating/denouement,from-'thinking at-first/pure-predisposition-preemptive-ofprospective-disontologising/subontologising' as-of-prospectively-disambiguated-affirmedand-unaffirmed-'motif-and-apriorising/axiomatising/referencing'> (transversality-<forsublimating-existential-eventuating/denouement,-from-'thinking-at-first/pure-predispositionpreemptive-of prospective-disontologising/subontologising' as-of-prospectivelydisambiguated-affirmed-and-unaffirmed-'motif-and-apriorising/axiomatising/referencing'> ${ }^{101}$ ) dynamism of "temporal-dispositions threshold-of-nonconviction/madeupness/bottomlining-inshallow-supererogation -<as-to-'attendant-intradimensional'-prospectivelydisontologising preconverging/dementing -apriorising-psychologism>> (as elicited by postlogism 7 -and-conjugated-postlogism 7 ) and the 'intemporal-disposition/ontologicallyveridical supplanting-conviction-as-to-profound-supererogation of-'attendantintradimensional'-postconverging/dialectical-thinking -apriorising-psychologism as of its sublimating-epistemic-imbricatedness/threadedness/recomposuring, and the ontological implications thereof'. The requisite 'projective-insights of sublimating-epistemicimbricatedness/threadedness/recomposuring as of 'implicited_attendant-ontological- 
contiguity ${ }^{67} \sim$ educed-

existentialising/contextualising/textualising_'intelligibility/epistemicity/reflexivity_contiguity-

$<$ imbued-notional $\sim \operatorname{cogency}>,+,-<$ reifying-or-elucidating-of-prospective-relative-ontological-

completeness -of- reference-of-thought- devolving-as-of-instantiative-context $>$ as to

existence-potency ${ }^{39} \sim$ sublimating-nascence,-disclosed-from-prospective-epistemic-

digression—rules-of-apriorising/axiomatising/referencing-that-further-epistemically-

unconceal-the-very-ontologically-same-existential-reality/dynamic-cumulative-

aftereffect/aftereffect', of 'relevant aetiologisation/ontological-escalation- $<$ ontologicalveridicality_commitment/otherliness_transcending/compulsions-encumbered_transcending $>$ storied-construct/ontologically-valid-narration', is necessarily of 'notional ' deprocrypticism sublimating-epistemic-imbricatedness/threadedness/recomposuring referential-depth-orexistential-reference-or-tautologisation', reflecting/perspectivating/highlighting (the corresponding postlogism 7 -and-conjugated-postlogism 77 uninstitutionalised-threshold perversion-of- ${ }^{8}$ reference-of-thought- $<$ as-preconverginglyapriorising/axiomatising/referencing-in-nonconviction/madeupness/bottomlining-as-toshallow-supererogation $>$ as) 'procrypticism-virtuality-or-Being-construal-as-abstractconstrual-as-of-flawed-and-shallow-and-non-veridical-existential-reference' (the- perversionof- ${ }^{2}$ reference-of-thought-<as-preconvergingly-apriorising/axiomatising/referencing-innonconviction/madeupness/bottomlining-as-to-shallow-supererogation >,-of-positivisticmeaningfulness or the- perversion-of- $^{83}$ reference-of-thought-<as-preconverginglyapriorising/axiomatising/referencing-in-nonconviction/madeupness/bottomlining-as-toshallow-supererogation >,-of-positivistic-categorical-imperatives-or-axioms-or-registryteleology ${ }^{9}$-for-intemporal-preservation-entropy-or-contiguity-or-ontological-preservation), as threshold-of-nonconviction/madeupness/bottomlining-in-shallow-supererogation $-<$ as-to‘attendant-intradimensional'-prospectively-disontologising preconverging/dementing 
preconverging-existential-extrication-as-of-existential-unthought $>$ manifestation); and soconstrued suprastructurally (beyond the positivistic/procrypticism registry-worldview consciousness-awareness-teleology ${ }^{99}$, as it is preconverging-or-dementing ${ }^{20}$-apriorisingpsychologism and dialectically-out-of-phase). This 'aetiologisation/ontological-escalation$<$ ontological-veridicality_commitment/otherliness_transcending/compulsions-

encumbered_transcending > storied-construct/ontologically-valid-narration conceptualisation' can be extended 'correspondingly as of positivism, ${ }^{103}$ universalisation and baseinstitutionalisation sublimating-epistemic-imbricatedness/threadedness/recomposuring referential-depth-or-existential-reference-or-tautologisation' as these reflect/perspectivate/highlight the corresponding postlogism -and-conjugated-postlogism uninstitutionalised-threshold ${ }^{102}{ }^{74}$ perversion-of- ${ }^{8}$ reference-of-thought- $<$ as-preconverginglyapriorising/axiomatising/referencing-in-nonconviction/madeupness/bottomlining-as-to-

shallow-supererogation $>$ as 'non-positivistic-or-medieval-virtuality-or-Being-construal-asabstract-construal-as-of-flawed-and-shallow-and-non-veridical-existential-reference', 'ununiversalisation-virtuality-or-Being-construal-as-abstract-construal-as-of-flawed-andshallow-and-non-veridical-existential-reference' and 'recurrent-utter-uninstitutionalisationvirtuality-or-Being-construal-as-abstract-construal-as-of-flawed-and-shallow-and-nonveridical-existential-reference'; and the correspondingly reflected/perspectivated/highlighted suprastructural construal of each of the corresponding uninstitutionalised-threshold ${ }^{12}$ (as beyond their respective corresponding consciousness-awareness-teleology ${ }^{9}$ ) which we will readily acknowledge from the vantage backend of our positivistic prospective registryworldview position of analysis equally speaks of the validity of such a corresponding suprastructural construal of notional ${ }^{18}$ deprocrypticism as beyond-the-consciousnessawareness-teleology $-<$ of-preconverging-existential-extrication-as-of-existential-unthought $>$ 
of our present 'procrypticism-virtuality-or-Being-construal-as-abstract-construal-as-of-flawedand-shallow-and-non-veridical-existential-reference'. Thus it may be useful for ontologically inducing untenability/internal-contradiction/internal-incoherence/institutional-constraining (as we are more likely to have complexes about our positivistic/procrypticism registryworldview/dimension as untranscendenable) by articulating the same aetiologisation/ontological-escalation- $<$ ontologicalveridicality_commitment/otherliness_transcending/compulsions-encumbered_transcending $>$ storied-construct/ontologically-valid-narration at a 'notional ' deprocrypticism sublimatingepistemic-imbricatedness/threadedness/recomposuring as against procrypticism-virtuality' as well as 'positivism sublimating-epistemic-imbricatedness/threadedness/recomposuring as against non-positivism-or-medieval-virtuality' wherein from our vantage positivistic position we'll recognise the suprastructurally implied preconverging-or-dementing ${ }^{20}$-apriorisingpsychologism and dialectically-out-of-phase state of non-positivism/medievalvirtuality-orontologically-flawed-construal putting us in a paradox with respect to recognising the same from futural Being-development/ontological-framework-expansion-as-to-depth-of-ontologisingdevelopment-as-infrastructure-of- meaningfulness-and-teleology as of prospective notional ${ }^{18}$ deprocrypticism about the suprastructurally implied preconverging-or-dementing 2 apriorising-psychologism and dialectically-out-of-phase state of our procrypticism-virtuality; and so, introducing the grounds for our prospective 'postconverging-or-dialectical-thinking psychology or psychology-of-mentation-dynamics or natural psychological-dynamics’ psychoanalytic-unshackling/memetic-reordering/institutional-recomposuring wherein notional ${ }^{18}$ deprocrypticism is the structural-resolution for the ${ }^{74}$ perversion-of- ${ }^{83}$ reference-ofthought-<as-preconvergingly-apriorising/axiomatising/referencing-in- 
positivistic meaningfulness. The fact is all constructs as transcending or implying transcendenceand-sublimity/sublimation/supererogatory de-mentativity are always by definition in confliction with the constructs being transcended. The reason is rather straightforward as there is a 'mental/psychoanalytic investment' behind the construal of meaningfulness in a given way within a registry-worldview's/dimension's ${ }^{83}$ reference-of-thought defining its ontologicalcapacity with respect to inherent intrinsic-reality-ontological-coherence_or_supersedingoneness-of-ontology. Where its ontological-capacity is limited is known as its relativeontological-incompleteness ${ }^{8}$-induced,-`threshold-of-nonconviction/madeupness/bottomliningin-shallow-supererogation -<as-to-'attendant-intradimensional'-prospectivelydisontologising preconverging/dementing -apriorising-psychologism>', and includes the following registry-worldviews/dimensions recurrent-utter-uninstitutionalisation, baseinstitutionalisation-ununiversalisation, ${ }^{103}$ universalisation-non-positivism/medievalism and positivism- ${ }^{80}$ procrypticism. At the point of relative-ontological-incompleteness ${ }^{8-i n d u c e d,-}$ 'threshold-of-nonconviction/madeupness/bottomlining-in-shallow-supererogation ${ }_{-<\text {as-to- }}$ ‘attendant-intradimensional'-prospectively-disontologising preconverging/dementing apriorising-psychologism>' or uninstitutionalised-threshold ${ }^{102}$ meaningfulness in the registryworldview/dimension is related to as if there isn't any relative-ontological-incompleteness ${ }^{8}$ induced,-'threshold-of-nonconviction/madeupness/bottomlining-in-shallow-supererogation <as-to-'attendant-intradimensional'-prospectivelydisontologising preconverging/dementing -apriorising-psychologism>' as of threshold-ofnonconviction/madeupness/bottomlining-in-shallow-supererogation $<<$ as-to- 'attendantintradimensional'-prospectively-disontologising preconverging/dementing -apriorisingpsychologism $>\quad$ (beyond-the-consciousness-awareness-teleology ${ }^{9}-<$ of-preconvergingexistential-extrication-as-of-existential-unthought>) hence inducing uninstitutionalisedthreshold $^{102}$, as it is impossible to critically extend ontological-capacity on the basis of the same 
reference-of-thought/psyche/psychological—de-mentating/structuring/paradigming but for a new ${ }^{83}$ reference-of-thought/psyche/psychological—de-mentating/structuring/paradigming with respect to existential-<disontologising/re-ontologising aporeticism $>$ reality to enable prospective institutionalisation over the uninstitutionalised-threshold ${ }^{102}$ with the result that all prospective institutionalisations are equally about annulling corresponding uninstitutionalisedthreshold ${ }^{102}$; whether annulling notions of deities, sorcery, essences, etc., and prospectively annulling the ${ }^{51}$ incrementalism-in-relative-ontological-incompleteness ${ }^{8}$ enframed/disontologising conceptualisation and notional $\sim$ disjointedness-as-of- ${ }^{3}$ reference-ofthought associated with procrypticism-or-disjointedness-as-of- reference-of-thought for notional ${ }^{8}$ deprocrypticism 'implicited_attendant-ontological-contiguity ${ }^{67}$ ' educedexistentialising/contextualising/textualising_'intelligibility/epistemicity/reflexivity-contiguity$<$ imbued-notional $\sim$ cogency $>>,-<$ reifying-or-elucidating-of-prospective-relative-ontologicalcompleteness -of- reference-of-thought- devolving-as-of-instantiative-context> as to existence-potency ${ }^{32} \sim$ sublimating-nascence,-disclosed-from-prospective-epistemicdigression—rules-of-apriorising/axiomatising/referencing-that-further-epistemicallyunconceal-the-very-ontologically-same-existential-reality 'preempting the threshold-ofnonconviction/madeupness/bottomlining-in-shallow-supererogation $<-<$ as-to- 'attendantintradimensional'-prospectively-disontologising preconverging/dementing -apriorisingpsychologism $>$ of rational-empiricism/positivising-rules'. This consequent 'postconverging-ordialectical-thinking -psychology or psychology-of-mentation-dynamics or natural psychological-dynamics’ reflecting/perspectivating/highlighting of the prior/transcended/superseded registry-worldview of positivism- ${ }^{80}$ procrypticism (temporaldispositions-in-temporal-preservation-as-pseudointemporality ${ }^{52}$-preservation) 'preconverging-or-dementing -apriorising-psychologism and dialectically-out-of-phase' is so about their non-committal (whether with respect to good or bad commitment as 'good or 
poor/bad

supplanting-conviction-as-to-profound-supererogation

of-'attendant-

intradimensional'-postconverging/dialectical-thinking -apriorising-psychologism')

as

threshold-of-nonconviction/madeupness/bottomlining-in-shallow-supererogation

$<$ as-to-

\section{'attendant-intradimensional'-prospectively-disontologising $\sim$ preconverging/dementing}

apriorising-psychologism> with respect to the ${ }^{83}$ reference-of-thought- categoricalimperatives/axioms/registry-teleology in ontological-normalcy/postconvergence of new/prospective institutionalisation as deprocrypticism; (beyond-the-consciousness-awarenessteleology ${ }^{0}<$ of-preconverging-existential-extrication-as-of-existential-unthought>

manifestation), in $\quad$ ' $\quad$ perversion-of- ${ }^{83}$ reference-of-thought-<as-preconverginglyapriorising/axiomatising/referencing-in-nonconviction/madeupness/bottomlining-as-to-

shallow-supererogation >- categorical-imperatives/axioms/registry-teleology ${ }^{99}$ of the prior institutionalisation as positivism known as procrypticism uninstitutionalisation ('procrypticismuninstitutionalisation of positivism-institutionalisation'), in threshold-ofnonconviction/madeupness/bottomlining-in-shallow-supererogation $<-<$ as-to- 'attendantintradimensional'-prospectively-disontologising preconverging/dementing -apriorisingpsychologism $>$ of the positivistic ${ }^{83}$ reference-of-thought- categoricalimperatives/axioms/registry-teleology,$\quad$ and failing/not-upholding-<as-ofapriorising/axiomatising/referencing $>\quad$ intemporal-preservation-entropy-or-contiguity-orontological-preservation which is the whole purpose in-the-very-first-place' and which need for restoration/ontological-reconstituting-as-to-conflatedness ${ }^{13} /$ deconstruction $^{\text {calls }}$ for futural Being-development/ontological-framework-expansion-as-to-depth-of-ontologisingdevelopment-as-infrastructure-of- meaningfulness-and-teleology as of prospective notional ${ }^{18}$ deprocrypticism $\quad{ }^{83}$ reference-of-thought- categorical-imperatives/axioms/registryteleology $\quad$ supplanting-conviction-as-to-profound-supererogation -of-'attendantintradimensional'-postconverging/dialectical-thinking -apriorising-psychologism. It is only 
the 'collapsing' of the ontologically non-veridical/wrong (with respect to intemporalpreservation-entropy-or-contiguity-or-ontological-preservation) 'procrypticism uninstitutionalisation virtuality-or-ontologically-flawed-construal (abstract-construal-ofpositivistic - categorical-imperatives/axioms/registry-teleology -as-of-flawed-and-shallowexistential-reference-as-virtuality) by way of 'postconverging-or-dialectical-thinking psychology or psychology-of-mentation-dynamics or natural psychological-dynamics’ psychoanalytic-unshackling/memetic-reordering/institutional-recomposuring wherein procrypticism uninstitutionalisation is shown as 'threshold-ofnonconviction/madeupness/bottomlining-in-shallow-supererogation $<<$ as-to-'attendantintradimensional'-prospectively-disontologising preconverging/dementing -apriorisingpsychologism>, and preconverging-or-dementing -apriorising-psychologism and dialecticallyout-of-phase' by the <amplituding/formative-epistemicity>causality $\sim$ as-to-projectivetotalitative-implications-of-prospective- nonpresencing,-for-explicating relativeunreflexivity/relative-reflexivity - ontological-contiguity of the notional ${ }^{18}$ deprocrypticism implied ${ }^{83}$ reference-of-thought- categorical-imperatives/axioms/registry-teleology as of the 'notional $\sim$ deprocrypticism sublimating-epistemicimbricatedness/threadedness/recomposuring as of 'implicitantontologicalcontiguity $^{67}$; educedexistentialising/contextalising/textalising_'intelligibility/epistemicity/reflexivity_contiguity$<$ imbued-notional $\sim$ cogency $>,{ }^{\prime},-<$ reifying-or-elucidating-of-prospective-relative-ontologicalcompleteness -of- reference-of-thought- devolving-as-of-instantiative-context> as to existence-potency ${ }^{39} \sim$ sublimating-nascence,-disclosed-from-prospective-epistemicdigression—rules-of-apriorising/axiomatising/referencing-that-further-epistemicallyunconceal-the-very-ontologically-same-existential-reality/dynamic-cumulativeaftereffect/aftereffect (as the nature of existential-reality) reflecting/perspectivating/highlighting 
procrypticism uninstitutionalisation virtuality-or-ontologically-flawed-construal (abstractconstrual-of-positivistic- categorical-imperatives/axioms/registry-teleology ${ }^{9}$-as-of-flawedand-shallow-existential-reference-as-virtuality)' . Correspondingly, such 'notional 1 deprocrypticism sublimating-epistemicimbricatedness/threadedness/recomposuring referential-depth-or-existential-reference-ortautologisation storied-construct/ontologically-valid-narration aetiologisation/ontologicalescalation-<ontological-veridicality_commitment/otherliness_transcending/compulsionsencumbered_transcending >' as of the reflecting/perspectivating/highlighting of 'procrypticism uninstitutionalisation threshold-of-nonconviction/madeupness/bottomlining-in-shallowsupererogation $-<$ as-to-'attendant-intradimensional'-prospectivelydisontologising $\sim$ preconverging/dementing -apriorising-psychologism>' will be critically about: (i) the phased storied articulation of procrypticism uninstitutionalisation threshold-ofnonconviction/madeupness/bottomlining-in-shallow-supererogation $<-<$ as-to-' ${ }^{\text {attendant- }}$ intradimensional'-prospectively-disontologising preconverging/dementing -apriorisingpsychologism> as being a social-construct 'uninstitutionalised-threshold ${ }^{02}$ mirroring development of the fundamental insane-fitment of the childhood-psychopath/cingle perversion-of- ${ }^{3}$ reference-of-thought-<as-preconverginglyapriorising/axiomatising/referencing-in-nonconviction/madeupness/bottomlining-as-toshallow-supererogation $>$ mental-disposition structure' (which is very much socially universally transparent at childhood and thus does not start to elicit protracted social postlogism 7 -as-of- compulsing-nonconviction/madeupness/bottomlining〈‘ $<$ decontextualising/de-existentialising of-attendant-intradimensionalapriorising/axiomatising/referencing >-induced-disontologising'-of-the-'attendantintradimensional-ontologising'-imbued-<contextualising/existentialising $\sim$ attendantontological-contiguity $>$;-in-shallow-supererogation -<as-to-disontologising-perverted- 
outcome-sought-precedes-existentially-veridical-'attendant-intradimensional-

apriorising/axiomatising/referencing'-logical-dueness $>$ )

as

conjugated-

postlogism 7 preconverging-or-dementing 2 -integration by temporal-dispositions at that point, as it is frowned upon and the childhood-psychopath is socially dysfunctional with its postlogism 7 ), (ii) and creatively protracting this fundamental phased storied articulation in 'successive phased phases of integration with the social construction' (wherein the 'increasing shrewdness and selectivity' of the growing-and-developing childhood-psychopath postlogism lessens the social dysfunctioning of its postlogism 77 as it learns from past experience and is now select and targeted as per social circumstances and interlocutors), and obviously at this point the social integration as conjugated-postlogism 77 preconverging-or-dementing ${ }^{20}$-integration threshold-of-nonconviction/madeupness/bottomlining-in-shallow-supererogation $-<$ as-to‘attendant-intradimensional'-prospectively-disontologising preconverging/dementing apriorising-psychologism $>$ is rather 'storied-construed/conceptualised from a broader societyat-large/humanity-at-large angle-of-perception as of a creative dynamic-cumulative-aftereffect reflected as of implicited_attendant-ontological-contiguity ${ }^{67}$, educedexistentialising/contextmalising/textualising_intelligibility/epistemicity/reflexivity_contiguity$<$ imbued-notional cogency $>$ ' ${ }^{40}$ existence-potency ${ }^{32} \sim$ sublimating-nascence,-disclosed-fromprospective-epistemic-digression—rules-of-apriorising/axiomatising/referencing-that-furtherepistemically-unconceal-the-very-ontologically-same-existential-reality aetiologisation/ontological-escalation- $<$ ontologicalveridicality_commitment/otherliness_transcending/compulsions-encumbered_transcending $>$ of notional firstnaturedness-formativeness $<a s$ to entulising inkling drive or seeding misprising $>$ temporal-to-intemporal-dispositions- $<$ so-construed-as-from-perspectiveontological-normalcy/postconvergence $>$ individuations and social-circumstances phenotyping elucidation in the social-construct, wherein the social-dynamics-of-individuation-phenotypes- 
of-individuals is a construable metaphysics-of-absence-〈implicited-epistemic-veracity-ofnonpresencing-<perspective-ontological-normalcy/postconvergence $>\rangle$ of the social as metaphysics-of-presence-〈implicited-'nondescript/ignorable-void '-as-to- presencingabsolutising-identitive-constitutedness Y' (arising because of the decreasing social ${ }^{10}$ universaltransparency ${ }^{104}$ - transparency-of-totalising-entailing,-as-to-entailing-<amplituding/formativeepistemicity>totalising in-relative-ontological-completeness \ of the cinglé's postlogism slantedness/disontologising-perverted-outcome-sought-precedes-existentially-veridical'attendant-intradimensional-apriorising/axiomatising/referencing'-logical-dueness as well as increasing temporal-dispositions enculturation and thus endemisation of conjugatedpostlogism 7 -slantedness in a social atmosphere where it is not ${ }^{103}$ universally transparent to be the denaturing of ${ }^{83}$ reference-of-thought with respect to social-stake-contention-orconfliction), as postlogism 7 -and-its-conjugated-postlogism 7 /preconverging-or-dementing 20 integration is upheld by temporal-preservation-as-pseudointemporality ${ }^{52}$-preservation thresholdof-nonconviction/madeupness/bottomlining-in-shallow-supererogation $-<$ as-to-'attendantintradimensional'-prospectively-disontologising preconverging/dementing -apriorisingpsychologism $>$ of the procrypticism uninstitutionalisation, and thus is temporally integrated by conjugated-ignorance/conjugated-affordability/conjugated-opportunism/conjugatedexacerbation/conjugated-social-chainism/conjugated-temporal-enculturation, of course, with the broader point and purpose for aetiologisation/ontological-escalation- $<$ ontologicalveridicality_commitment/otherliness_transcending/compulsions-encumbered_transcending> here being that 'our virtue is not inherent' but rather our 'understanding/knowledge/<amplituding/formative-epistemicity $>$ causality $\sim$ as-to-projectivetotalitative-implications-of-prospective- nonpresencing,-for-explicating relativemnreflexivity/relative reflexivity ontological-contiguity construction' is what creates our virtue in superseding our vices-and-impediments ${ }^{105}$, just as for instance, 'medieval vices-and- 
impediments ${ }^{105}$, weren't inherently because they were a different human species to us but rather due to their lack of positivistic understanding/knowledge which creation-and-accrual led to our relatively grander state of virtue and knowledge, likewise the point here is about articulating such prospective understanding/knowledge/<amplituding/formativeepistemicity $>$ causality $\sim$ as-to-projective-totalitative-implications-of-prospectivenonpresencing,-for-explicating relative-unreflexivity/relative-reflexivity ontologicalcontiguity and its corresponding 'institutional-designing by percolation-channelling- $<$ indeferential-formalisation-transference>' as our virtue and knowledge potential), (iii) and so subsumed and articulated in a creative 'psycho-ontological-tautologisation/psycho-existentialreference conceptual-scheme of insightful 'tone-as-temperament and thematic construal of notional firstnaturedness-formativeness-<as-to-eventualising-inkling-drive-or-seedingmisprising $>$ temporal-to-intemporal-dispositions- $<$ so-construed-as-from-perspectiveontological-normalcy/postconvergence $>$ individuations teleologies/teleological-differentiations (by ${ }^{55}$ maximalising-recomposuring-for-relative-ontological-completeness ${ }^{87}$ - unenframed/reontologising conceptualisation covering the concepts articulated in this paper on socialconstruct and social institutions teleology and value-reference as of notional ${ }^{18}$ deprocrypticism sublimating-epistemicimbricatedness/threadedness/recomposuring with regards to the 'implications of postlogism and-procrypticism mental orientations', (iv) and further, the possibility of a remaking of the above storied-construct/ontologically-valid-narration aetiologisation/ontological-escalation$<$ ontological-veridicality_commitment/otherliness_transcending/compulsionsencumbered_transcending $>$ (as elaborated in i, ii and iii above) rather as of 'positivism sublimating-epistemic-imbricatedness/threadedness/recomposuring referential-depth-orexistential-reference-or-tautologisation' reflecting/perspectivating/highlighting 'nonpositivism/medieval uninstitutionalised-threshold threshold-of- 
nonconviction/madeupness/bottomlining-in-shallow-supererogation

$<$ as-to-'attendant-

\section{intradimensional'-prospectively-disontologising preconverging/dementing -apriorising-}

psychologism>', to contrastively provide the revealing retrospective insight of threshold-ofnonconviction/madeupness/bottomlining-in-shallow-supererogation $<-<$ as-to-' $a$ attendantintradimensional'-prospectively-disontologising preconverging/dementing -apriorisingpsychologism $>\quad$ as $\quad$ uninstitutionalised-threshold ${ }^{102}$ as human-subpotencyaporia/undecidability/dilemma/ought-indeterminacy/deficiency/limitation/constraint—imbued'notional firstnaturedness-formativeness-<as-to-eventualising inkling-drive-or-seeding misprising $>$ temporal-to-intemporal-dispositions- $<$ so-construed-as-from-perspectiveontological-normalcy/postconvergence>'-existentialism-form-factor is construable from the perspective of ontological-normalcy/postconvergence and so paradoxically provide the décomplexage/uninhibitedness (induced by our metaphysics-of-presence-〈implicited'nondescript/ignorable-void ' -as-to- presencing - absolutising-identitive-constitutedness >

or illusion-of-the-present/present-consciousness/epistemic-totalising $\sim$ self-referencingsyncretising/mirage) of the afore deprocrypticism-procrypticism articulated prospective storiedconstruct/ontologically-valid-narration $\quad$ aetiologisation/ontological-escalation- $<$ ontologicalveridicality_commitment/otherliness_transcending/compulsions-encumbered_transcending > construed from the perspective of ontological-normalcy/postconvergence, wherein we are then in a position to appreciate the 'threshold-of-nonconviction/madeupness/bottomlining-inshallow-supererogation -<as-to-'attendant-intradimensional'-prospectivelydisontologising $\sim$ preconverging/dementing -apriorising-psychologism $>$ ' representation of the present positivism- ${ }^{8}$ procrypticism uninstitutionalisation as ${ }^{8}$ procrypticism-or-disjointednessas-of- ${ }^{-3 e f e r e n c e-o f-t h o u g h t-a n d-t e l e o l o g y ~}$ reference-of-thought- categoricalimperatives/axioms/registry-teleology ${ }^{9}$ with respect to futural Being-development/ontologicalframework-expansion-as-to-depth-of-ontologising-development-as-infrastructure-of- 
meaningfulness-and-teleology as of prospective deprocrypticism, even though such an appreciation is rather counterintuitive. * The underlying technique for perpetually upholding ontological-veridicality as 'sublimating-epistemic-imbricatedness/threadedness/recomposuring as of 'implicited_attendant-ontological-contiguity ${ }^{67}$; educedexistentialising/contextualising/textualising_'intelligibility/epistemicity/reflexivity-contiguity$<$ imbued-notional cogency $>,{ }^{\prime},-<$ reifying-or-elucidating-of-prospective-relative-ontologicalcompleteness -of- reference-of-thought- devolving-as-of-instantiative-context> as to existence-potency $^{39} \sim$ sublimating-nascence,-disclosed-from-prospective-epistemicdigression—rules-of-apriorising/axiomatising/referencing-that-further-epistemicallyunconceal-the-very-ontologically-same-existential-reality' (from the perspective of the 'postconverging-or-dialectical-thinking ${ }^{2}{ }^{8}$ reference-of-thought in relative-ontologicalcompleteness $^{87}$ as depth-of-thought') and preempting virtuality-or-ontologically-flawedconstrual (being-construal-as-abstract-construal-as-of-flawed-and-shallow-and-non-veridicalexistential-reference), is by not allowing for the 'breaking of the threadedness/thread of ontologically-veridical meaningfulness (as such a breaking induces virtuality-or-ontologicallyflawed-construal leading correspondingly to the false uptake as ontologically-veridical of the wrongly implied soundness/non-perverted- ${ }^{8}$ reference-of-thought, i.e. unsound/perverted 'apriorising- ${ }^{83}$ reference-of-thought/apriorising-registry-elements of 'implicited_attendant-ontological-contiguity ${ }^{67}$ educedexistentialising/contextmalising/textualising_intelligibility/epistemicity/reflexivity_contiguity$<$ imbued-notional $\sim$ cogency $>,{ }^{\prime},-<$ reifying-or-elucidating-of-prospective-relative-ontologicalcompleteness -of- reference-of-thought- devolving-as-of-instantiative-context>)' including \{epistemic-totalising 3 psychologismic subliminality of-individuation-effusing/worlding imbued logical-dueness-or-scape-or-frame, profile-or-stature, presumptuousness-or-arrogation, assumptions, value-reference and teleology ${ }^{9}$ ); by rather reflecting/perspectivating/highlighting 
the points where such 'breaking-of-the-threadedness/thread-of-ontologically-veridical meaningfulness' occur as of 'threshold-of-nonconviction/madeupness/bottomlining-in-shallowsupererogation -<as-to-'attendant-intradimensional'-prospectivelydisontologising preconverging/dementing -apriorising-psychologism> (in postlogism 77 and conjugated-postlogism 77 and as preconverging-or-dementing ${ }^{20}$-apriorising-psychologism and dialectically-out-of-phase', as the 'very notion of postlogic-backtracking-<iterative-looping'set-of-dereifying-hollow-narratives-and-acts'> $>6$ and conjugated-postlogism ${ }^{77}$ conjoininglooping-set-of-narratives of postlogic-backtracking-<iterative-looping-'set-of-dereifyinghollow-narratives-and-acts' $>$ ' ontologically-veridical meaningfulness as virtuality-or-ontologically-flawed-construal/beingconstrual-as-abstract-construal-as-of-flawed-and-shallow-and-non-veridical-existentialreference'. As breaking (by new logical-processing-or-logical-implicitation-supposedlyapriorising-in-conviction-as-to-profound-supererogation as 'prelogic supplanting-convictionas-to-profound-supererogation -of-'attendant-intradimensional'-postconverging/dialecticalthinking -apriorising-psychologism re-engaging reflex') wrongly implies the validity of a logical-level-engagement ( ${ }^{5}$ logical-processing-or-logical-implicitation — supposedlyapriorising-in-conviction-as-to-profound-supererogation ) based on wrongly implied prospective relative-ontological-completeness ${ }^{87}$-of- ${ }^{8}$ reference-of-thought- $\{$ as-of 'implicited_attendant-ontological-contiguity ${ }^{67}$ > educedexistentialising/contextmalising/textualising_intelligibility/epistemicity/reflexivity_contiguity$<$ imbued-notional $\sim$ cogency $>,{ }^{\prime},-<$ reifying-or-elucidating-of-prospective-relative-ontologicalcompleteness -of- reference-of-thought- devolving-as-of-instantiative-context $>$ \} and wrongly implied soundness/non-perverted- ${ }^{8}$ reference-of-thought, whereas in reality it is just an $<$ amplituding/formative-epistemicity $>$ totalising $\sim$ self-referencingsyncretising/circularity/interiorising/akrasiatic-drag 34 of the relative-ontological- 
incompleteness 8 -induced,-'threshold-of-nonconviction/madeupness/bottomlining-in-shallowsupererogation -<as-to-'attendant-intradimensional'-prospectivelydisontologising $\sim$ preconverging/dementing -apriorising-psychologism> $>$ and its unsound/perverted 'apriorising- ${ }^{8}$ reference-of-thought/apriorising-registry-elements (out of 'implicited_attendant-ontological-contiguity ${ }^{6}$ ' educedexistentialising/contextualising/textualising_intelligibility/epistemicity/reflexivity-contiguity$<$ imbued-notional $\sim$ cogency $>,{ }^{\prime},-<$ reifying-or-elucidating-of-prospective-relative-ontologicalcompleteness -of- reference-of-thought- devolving-as-of-instantiative-context $>$ )' of epistemicpychologismic-subliminality-of-individuation-effusing/worlding imbued logicaldueness-or-scape-or-frame, profile-or-stature, presumptuousness-or-arrogation, assumptions, value-reference and teleology ${ }^{9}$. Such a defect as registry-worldview's/dimension'suninstitutionalised-threshold ${ }^{102}$-defect-<as-Being-or-ontological-or-existential-defect $>$ having to do with the defect of ${ }^{83}$ reference-of-thought and relative-ontological-incompleteness is utterly different from a 'defect-of- ${ }^{5}$ logical-processing-or-logical-implicitation—supposedlyapriorising-in-conviction-as-to-profound-supererogation of the registryworldview's/dimension's- ${ }^{83}$ reference-of-thought-for-social-functioning-and-accordance which doesn't bar a new ${ }^{54}$ logical-processing-or-logical-implicitation-supposedly-apriorising-inconviction-as-to-profound-supererogation as 'prelogic supplanting-conviction-as-toprofound-supererogation of-'attendant-intradimensional'-postconverging/dialecticalthinking -apriorising-psychologism re-engaging reflex' as the latter is with regards to wrong logical-processing-or-logical-implicitation-supposedly-apriorising-in-conviction-as-toprofound-supererogation which might be well/soundly-be logically-processed or effectivelyexecuted upon reengagement, so long as the ${ }^{8}$ reference-of-thought for the reengaging is not unsound/perverted and not undermined by relative-ontological-incompleteness ${ }^{88}$. A registryworldview's/dimension's-uninstitutionalised-threshold ${ }^{102}$-defect-<as-Being-or-ontological-or- 
existential-defect $>{ }^{85}$ on-the-other-hand having to do with defect of ${ }^{83}$ reference-of-thought needs a more fundamental transformation as a psychoanalytic-unshackling/memeticreordering/institutional-recomposuring of the ${ }^{83}$ reference-of-thought, and so a decentering of meaningfulness; the <amplituding/formative-epistemicity $>$ causality $\sim$ as-to-projectivetotalitative-implications-of-prospective- nonpresencing,-for-explicating relative-

unreflexivity/relative-reflexivity ontological-contiguity being more like what it takes to get a medieval as non-positivistic mindset $/{ }^{3}$ reference-of-thought into a positivistic mindset $/{ }^{3}$ reference-of-thought, that is, suppose for instance where in a medieval social-setup an accusation of witchcraft is demonstrated by an outsider from a positivistic social-setup to be incorrect and unsound to the approval of all in that social-setup, that outsider understanding fundamentally that the medieval setup by its relative-ontological-incompleteness ${ }^{8}$-induced,'threshold-of-nonconviction/madeupness/bottomlining-in-shallow-supererogation ${ }^{\circ}<$ as-to‘attendant-intradimensional'-prospectively-disontologising preconverging/dementing apriorising-psychologism> ${ }^{\prime}$ is in a state of <amplituding/formativeepistemicity $>$ totalising $\sim$ self-referencing-syncretising/circularity/interiorising/akrasiatic-drag of a medieval worldview will grasp that that unique demonstration of medievalpostlogism $7 / /$ perversion-of- ${ }^{83}$ reference-of-thought- $<$ as-preconverginglyapriorising/axiomatising/referencing-in-nonconviction/madeupness/bottomlining-as-toshallow-supererogation $>$ (as accusation of witchcraft) is not to be construed naively as an adequate basis for a new ${ }^{5}$ logical-processing-or-logical-implicitation-supposedly-apriorisingin-conviction-as-to-profound-supererogation as 'prelogic supplanting-conviction-as-toprofound-supererogation of-'attendant-intradimensional'-postconverging/dialecticalthinking -apriorising-psychologism re-engaging mental-reflex' that re-engages with nonpositivism/medievalism mindset/ ${ }^{3}$ reference-of-thought, given the possibilities of further accusations of witchcrafts or by-and-large the vices-and-impediments ${ }^{105}$ potentially arising from 
such a non-positivism/medievalism worldview as of the 'local community dynamism of individual interests involved' that endemises and enculturates notions-and-accusations-ofsorcery. It is rather the crossgenerational psychoanalytic-unshackling/memeticreordering/institutional-recomposuring transforming of the non-positivism/medievalism mindset $/{ }^{3}$ reference-of-thought into a positivistic mindset/ ${ }^{3}$ reference-of-thought that is ontologically-speaking to be construed as the postconverging-dementating/structuring/paradigming resolution of the vices-and-impediments ${ }^{105}$ arising from a non-positivism/medievalism worldview with respect to such notions-and-accusations-ofsorcery. The same applies with respect to our positivism- ${ }^{8}$ procrypticism worldview and futural Being-development/ontological-framework-expansion-as-to-depth-of-ontologisingdevelopment-as-infrastructure-of- meaningfulness-and-teleology as of prospective notional ${ }^{18}$ deprocrypticism worldview. This explains why 'perversion-and-derivedperversion-of- ${ }^{-3 e f e r e n c e-o f-t h o u g h t-<a s-p r e c o n v e r g i n g l y-~}$

\section{apriorising/axiomatising/referencing-in-nonconviction/madeupness/bottomlining-as-to-}

shallow-supererogation $>$ is more than just an issue of an act or acts, but is 'reconceptualised rather as prior relative-ontological-incompleteness ${ }^{88}$-of- ${ }^{8}$ reference-of-thought as of denaturing ${ }^{\prime}$ in implying that inherent intrinsic-reality/ontological-veridicality is already given and the perversion-and-derived- ${ }^{7}$ perversion-of- ${ }^{2}$ reference-of-thought- $<$ as-preconverginglyapriorising/axiomatising/referencing-in-nonconviction/madeupness/bottomlining-as-to-

shallow-supererogation $>$ is in-the-bigger-picture revealing an inherent problem as of the prior human ${ }^{8}$ reference-of-thought conceptualisation of inherently given intrinsic-reality/ontologicalveridicality, and that the 'occurred event ${ }^{38}$ of perversion-and-derived- perversion-ofreference-of-thought-<as-preconvergingly-apriorising/axiomatising/referencing-innonconviction/madeupness/bottomlining-as-to-shallow-supererogation > is simply 'pointing to an altogether deeper underlying human relative-ontological-incompleteness ${ }^{88}$-of- ${ }^{8}$ reference-of- 
thought issue, in this case as of psychopathy and its conjugated-postlogism 77 at the uninstitutionalised-threshold ${ }^{102}$ of positivism- ${ }^{80}$ procrypticism as well as providing a revealing overall understanding of the human uninstitutionalised-threshold ${ }^{12}$-by-relativeunreflexivity/relative-reflexivity ${ }^{\circ}$ ontological-contiguity ${ }^{67}$ of-the-human-institutionalisationprocess $^{68}$ with notional ${ }^{18}$ deprocrypticism prospective institutionalisation $<$ amplituding/formative-epistemicity $>$ causality $\sim$ as-to-projective-totalitative-implications-ofprospective- nonpresencing,-for-explicating relative-unreflexivity/relative-reflexivity

ontological-contiguity , which are then the-entire-reconceptualised-problem as of aetiologisation/ontological-escalation-<ontologicalveridicality_commitment/otherliness_transcending/compulsions-encumbered_transcending>' as the prospective relative-ontological-completeness ${ }^{87}$-of- ${ }^{-3 e f e r e n c e-o f-t h o u g h t ; ~ j u s t ~ a s ~ a n ~}$ apple falling on Newton's head under a tree is simply 'pointing to an altogether deeper underlying human non-positivistic relative-ontological-incompleteness ${ }^{8}$-of- ${ }^{83}$ reference-ofthought issue which is then the-entire-reconceptualised-problem as of the aetiologisation/ontological-escalation- $<$ ontological-

veridicality_commitment/otherliness_transcending/compulsions-encumbered_transcending $>$ in producing the science/laws of physics and equally inspiring other such similar positivistic $<$ amplituding/formative-epistemicity $>$ causality $\sim$ as-to-projective-totalitative-implications-ofprospective- nonpresencing,-for-explicating relative-unreflexivity/relative-reflexivity ontological-contiguity approaches in human conceptualising of the natural world as the prospective relative-ontological-completeness ${ }^{87}$-of- ${ }^{83}$ reference-of-thought. Hence contrary to what we may think from our $<$ amplituding/formative-epistemicity $>$ totalising $\sim$ self-referencingsyncretising/circularity/interiorising/akrasiatic-drag ${ }^{34}$ perspective the mere fact of relativeontological-incompleteness ${ }^{8}$-of- ${ }^{8}$ reference-of-thought is preconverging/postconverging-dementatively/structurally/paradigmatically associated with a perversion-or-derived- 7 perversion- 
of- reference-of-thought-<as-preconvergingly-apriorising/axiomatising/referencing-in-

nonconviction/madeupness/bottomlining-as-to-shallow-supererogation $>$ by the very inherent nature of ontology/intrinsic-reality as preceding/superseding our ${ }^{83}$ reference-of-thought conceptualisation as of its shallow limited-mentation-capacity-as-subjecting 'educedunlimitedness/existence-sublimating nascence' to-limitedness/human-subpotency such that where our $\quad{ }^{\circ}$ reference-of-thought-as-to-preconverging/postconverging-de-

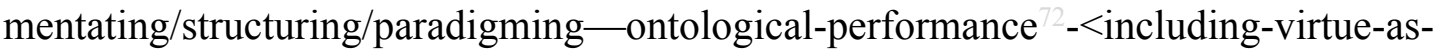
ontology $>$ /morality/ethics/justice/etc. of ${ }^{83}$ reference-of-thought conceptualisation' is deficient we are in perversion-or-derived-perversion at that threshold, wherein the threshold defect reference-of-thought-as-to-preconverging/postconverging-dementating/structuring/paradigming — ontological-performance ${ }^{72}<$ including-virtue-asontology $>$ /morality/ethics/justice/etc. is rather 'construed in emotionally-laden terms' with respect as of knowledge-constructs/theories/intersolipsistic-intercessorynotions/notional referential-notions/articulations/virtue of the social like law, virtue, etc., as of our subpotent-mimetic-echoness-derivation-within-the-full-potency of existence-as-of-itsmimetic-echoness/existence-in-reverberation/existence-potency ${ }^{39} \sim$ sublimating-nascence,disclosed-from-prospective-epistemic-digression. Thus intrinsic-reality/ontological-veridicality is derived 'wholly by apriorising/axiomatising/referencing-\{of-"prospectively implicited_attendant-ontological-contiguity ' reducedexistentialising/contextualising/textualising_'intelligibility/epistemicity/reflexivity-contiguity<imbued-notional cogency >' \}-conflatedness ${ }^{13}$-in-\{preconverging-disentailment by\} postconverging-entailment' or in other words ensuring the prospective relative-ontologicalcompleteness ${ }^{87}$-of- ${ }^{8}$ reference-of-thought with respect to problematic prior relative-ontologicalincompleteness ${ }^{8}$-of- ${ }^{8}$ reference-of-thought reflected by perversion-and-derived- 7 perversionof- ${ }^{8}$ reference-of-thought-<as-preconvergingly-apriorising/axiomatising/referencing-in- 
$<$ amplituding/formative-epistemicity $>$ totalising $\sim$ self-referencing-

syncretising/circularity/interiorising/akrasiatic-drag ${ }^{34}$ allowed by intrinsic-reality/ontologicalveridicality. In other words as of metaphysics-of-absence-〈implicited-epistemic-veracity-ofnonpresencing-<perspective-ontological-normalcy/postconvergence $>\rangle$, the ordinariness $<$ amplituding/formative $>$ wooden-language-_imbued - averaging-of-thought-<as-toleveling/ressentiment/closed-construct-of- meaningfulness-and-teleology -as-of'nondescript/ignorable-void '-with-regards-to-prospective-apriorising-implications $>>$ in nonpositivism/medievalism with its ${ }^{83}$ reference-of-thought is inclined to relate to perversion-andderived- ${ }^{7}$ perversion-of- ${ }^{8}$ reference-of-thought- $<$ as-preconverginglyapriorising/axiomatising/referencing-in-nonconviction/madeupness/bottomlining-as-toshallow-supererogation $>$ phenomenon as a non-positivism/medieval postlogism phenomenon such as notions-and-accusations-of-sorcery on the basis of nonpositivism/medievalism ${ }^{83}$ reference-of-thought $<$ amplituding/formative $>$ wooden-language〈imbued - averaging-of-thought-<as-to-leveling/ressentiment/closed-construct-ofmeaningfulness-and-teleology -as-of-‘nondescript/ignorable-void ' -with-regards-toprospective-apriorising-implications $>>$ of 'great living' as of its prior relative-ontologicalincompleteness ${ }^{8}$-of- ${ }^{8}$ reference-of-thought but then a 'apriorising/axiomatising/referencing\{of-'prospectively_implicited_attendant-ontological-contiguity ' ceducedexistentialising/contextualising/textualising_'intelligibility/epistemicity/reflexivity_contiguity$<$ imbued-notional cogency $\left.>^{\prime}\right\}$-conflatedness ${ }^{13}$-in-\{preconverging-disentailment by\} postconverging-entailment of conceptualisation' will convert such perversion-and-derivedperversion-of- ${ }^{3}$ reference-of-thought-<as-preconverginglyapriorising/axiomatising/referencing-in-nonconviction/madeupness/bottomlining-as-toshallow-supererogation $>$ in terms of the 'Being defect as uninstitutionalised-threshold ${ }^{102}$ of the 
so-called great living of non-positivism/medievalism ${ }^{83}$ reference-of-thought' to arrive at the prospective relative-ontological-completeness ${ }^{87}$-of- ${ }^{83}$ reference-of-thought of positivism openedconstruct-of- ${ }^{5}$ meaningfulness-and-teleology ${ }^{9}$ which preconverging/postconverging-dementatively/structurally/paradigmatically resolves the vices-and-impediments ${ }^{105}$ of nonpositivism/medievalism. This same process applies to our positivism- ${ }^{80}$ procrypticism with respect to psychopathy and social psychopathy wherein the associated perversion-and-derivedperversion-of- ${ }^{-3}$ reference-of-thought-<as-preconvergingly-

apriorising/axiomatising/referencing-in-nonconviction/madeupness/bottomlining-as-to-

shallow-supererogation > will elicit an ordinariness <amplituding/formative $>$ woodenlanguage-〈imbued - averaging-of-thought-<as-to-leveling/ressentiment/closed-construct-ofmeaningfulness-and-teleology -as-of-‘nondescript/ignorable-void '-with-regards-toprospective-apriorising-implications $>>$ procrypticism-or-disjointedness-as-of- ${ }^{3}$ reference-ofthought <amplituding/formative $>$ wooden-language-_imbued - averaging-of-thought- $<$ as-toleveling/ressentiment/closed-construct-of- meaningfulness-and-teleology -as-of'nondescript/ignorable-void '-with-regards-to-prospective-apriorising-implications $>>$ of 'great living' as of its prior relative-ontological-incompleteness ${ }^{8}$-of- ${ }^{-}$reference-of-thought but then a 'apriorising/axiomatising/referencing-\{of-'prospectively implicited_attendant-ontologicalcontiguity ' educedexistentialising/contextualising/textualising_'intelligibility/epistemicity/reflexivity-contiguity<imbued-notional cogency >' \}-conflatedness ${ }^{13}$ in 'preconverging disentailment by postconverging-entailment of conceptualisation' will convert such perversion-and-derivedperversion-of- ${ }^{-3}$ reference-of-thought- $<$ as-preconvergingly-

apriorising/axiomatising/referencing-in-nonconviction/madeupness/bottomlining-as-to-

shallow-supererogation $>$ in terms of the 'Being defect as uninstitutionalised-threshold ${ }^{102}$ of the so-called great living of our positivism- ${ }^{80}$ procrypticism in disjointedness-as-of- ${ }^{8}$ reference-of- 
thought' to arrive at the prospective relative-ontological-completeness ${ }^{87}$-of- ${ }^{8}$ reference-ofthought of notional ${ }^{1}$ deprocrypticism as preempting-disjointedness-as-of- ${ }^{3}$ reference-ofthought opened-construct-of- ${ }^{5}$ meaningfulness-and-teleology which preconverging/postconverging-de-mentatively/structurally/paradigmatically resolves the vicesand-impediments ${ }^{105}$ of our positivism- ${ }^{80}$ procrypticism; as basically, our intellectual-and-moral constructs as of our <amplituding/formative-epistemicity $>$ totalising $\sim$ self-referencingsyncretising/circularity/interiorising/akrasiatic-drag ${ }^{34}$ are shown to be of prior relativeontological-incompleteness ${ }^{8}$-of- ${ }^{8}$ reference-of-thought and thus ontologically-speaking our logical-dueness doesn't even arise, no more than the logical-dueness of a nonpositivism/medievalism mindset arises as with respect to medieval postlogism 77 phenomenon like notions-and-accusations-of-sorcery as in both cases ontologically-veridical meaningfulness-and-teleology ${ }^{9}$ exists beyond their <amplituding/formative $>$ woodenlanguage-〈imbued - averaging-of-thought-<as-to-leveling/ressentiment/closed-construct-ofmeaningfulness-and-teleology -as-of-'nondescript/ignorable-void '-with-regards-toprospective-apriorising-implications $>>$ as of the respective notional deprocrypticism as preempting - disjointedness-as-of- ${ }^{83}$ reference-of-thought and positivism ${ }^{83}$ reference-of-thought that carry the prospective relative-ontological-completeness ${ }^{8}$-of- ${ }^{3}$ reference-of-thought openedconstruct-of- ${ }^{-}$meaningfulness-and-teleology . Ultimately, the very transversality- $<$forsublimating-existential-eventuating/denouement, from-'thinking at first/pure-predispositionpreemptive-of prospective-disontologising/subontologising' as-of-prospectivelydisambiguated-affirmed-and-unaffirmed-'motif-and-apriorising/axiomatising/referencing'> between the prior registry-worldview/dimension as of its prior relative-ontologicalincompleteness ${ }^{8}$-of- ${ }^{8}$ reference-of-thought and the prospective registry-worldview/dimension as of its prospective relative-ontological-completeness ${ }^{87}$-of- ${ }^{8}$ reference-of-thought is the "very paradox of ${ }^{56}$ meaningfulness-and-teleology ${ }^{9}$ explaining their discordance, construed as the 
paradox of transcendence-and-sublimity/sublimation/supereregatery $\sim$ de-mentativity'. In other words, if the former had a grasp of its state 'as to its prior relative-ontological-incompleteness ${ }^{\text {- }}$ of- reference-of-thought' with the transcendental preconverging/postconverging-dementative/structural/paradigmatic $<$ amplituding/formative-epistemicity $>$ causality $\sim$ as-toprojective-totalitative-implications-of-prospective- nonpresencing,-for-explicating relativeunreflexivity/relative-reflexivity ontological-contiguity arising thereof it would have paradoxically transcended, thus explaining the psychoanalytic-unshackling/memeticreordering/institutional-recomposuring nature of transcendence-andsublimity/sublimation/supererogatory de-mentativity as of a crossgenerational exercise and why such implied transcendental ${ }^{5}$ meaningfulness-and-teleology ${ }^{9}$ might seem arbitrary when meaningfulness-and-teleology ${ }^{9}$ is rather interpreted in terms of the prior ${ }^{83}$ reference-ofthought. This further explains the 'socially conflicted nature of all implied transcendental constructs' whether with prophesying metaphysico-theological constructs of early times reflected in non-universalising and ${ }^{103}$ universalising creeds up to our metaphysico-ontological worldviews implied transcendence-and-sublimity/sublimation/supereregatory $\sim$ de-mentativity, and so as of human-subpotency-aporia/undecidability/dilemma/oughtindeterminacy/deficiency/limitation/constraint—imbued-'notional firstnaturednessformativeness-<as-to-eventualising-inkling-drive-or-seeding-misprising > temporal-tointemporal-dispositions- $<$ so-construed-as-from-perspective-ontologicalnormalcy/postconvergence>'-existentialism-form-factor; but then humankind has always been called upon to show itself capable of surperseding/surpassément for prospective possibilities to avail. This is exactly what underlies the notion of ${ }^{15}$ de-mentation-/supererogatory $\sim$ ontologicalde-mentation-or-dialectical-de-mentation - stranding-or-attributive-dialectics $\rangle$ in that relativeontological-incompleteness ${ }^{8}$-of- ${ }^{8}$ reference-of-thought 'is not a logical issue/problem' but a 'Being/existential/ontological/axiomatic-construct problem' with its 
preconverging/postconverging-de-mentative/structural/paradigmatic implied vices-andimpediments ${ }^{105}$, as it is rather an issue of uninstitutionalised-threshold ${ }^{102}$ as of recurrent-utteruninstitutionalisation uninstitutionalisation requiring base-institutionalisation institutionalisation, ununiversalisation uninstitutionalisation requiring ${ }^{103}$ universalisation institutionalisation, non-positivism/medievalism uninstitutionalisation requiring positivism institutionalisation, and our ${ }^{80}$ procrypticism-or-disjointedness-as-of- ${ }^{3}$ reference-of-thought uninstitutionalisation requiring prospective notional ${ }^{18}$ deprocrypticism institutionalisation as preempting - disjointedness-as-of- ${ }^{3}$ reference-of-thought institutionalisation, and so rather as of a transcendental habituation exercise construed as 'ontological-resetting' of placeholdersetup/mental-devising-representation/mentation/consciousness-awareness-teleology of relative epistemic-abnormalcy/preconvergence ${ }^{3 !}$ for relative ontologicalnormalcy/postconvergence as of ${ }^{15}$ de-mentation-/supererogatory $\sim$ ontological-de-mentation-ordialectical-de-mentation - stranding-or-attributive-dialectics $\rangle$ stranding dynamics. A 'relativeontological-completeness ${ }^{87}$-of- ${ }^{83}$ refence-of-thought' implies a 'new all-pervasiveness of

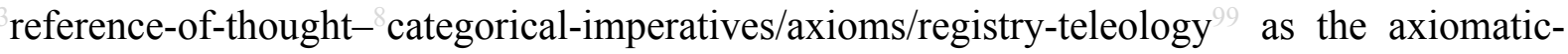
construct of ${ }^{56}$ meaningfulness-and-teleology 9 ' as a prospective institutionalisation ${ }^{8}$ referenceof-thought. Thus a ${ }^{83}$ reference-of-thought is an all-pervasiveness of ${ }^{83}$ reference-of-thoughtcategorical-imperatives/axioms/registry-teleology as the axiomatic-construct of meaningfulness-and-teleology ; explaining why it is preconverging/postconverging-dementatively/structurally/paradigmatically non-derogable as of its state of prospective relativeontological-completeness ${ }^{87}$-of- ${ }^{83}$ reference-of-thought, with such implied derogation of such 'allpervasiveness of ${ }^{83}$ reference-of-thought- categorical-imperatives/axioms/registry-teleology as the axiomatic-construct of ${ }^{56}$ meaningfulness-and-teleology ${ }^{9}$, signalling fundamentally a threshold of failure of ${ }^{8}$ reference-of-thought-as-to-preconverging/postconverging-dementating/structuring/paradigming — ontological-performance ${ }^{72}-<$ including-virtue-as- 
ontology $>$ /morality/ethics/justice/etc. and construed as relative-ontological-incompleteness ${ }^{8}$ of- ${ }^{3}$ reference-of-thought. As a further elucidation, across all registry-worldviews/dimensions prospective relative-ontological-completeness ${ }^{87}$-of- ${ }^{8}$ reference-of-thought, construed as its institutionalisation, is as of 'apriorising/axiomatising/referencing-\{of-'prospectively implicited_attendant-ontological-contiguity ' educedexistentialising/contextualising/textualising_ 'intelligibility/epistemicity/reflexivity-contiguity<imbued-notional cogency $\left.>^{\prime}\right\}$-conflatedness ${ }^{13}$-in-\{preconverging-disentailment by\} postconverging-entailment' which itself involves the ' ${ }^{103}$ universally-transparent constraining mechanical-knowledge as of the bare ${ }^{83}$ reference-of-thought- ${ }^{8}$ ategoricalimperatives/axioms/registry-teleology as axiomatic-construct' and the 'social- ${ }^{103}$ universallynon-transparent-thus-non-constraining-element of ontological-faith-notion-or-ontologicalfideism —imbued-underdetermination-of-motif-and-apriorising/axiomatising/referencing-asso-being-as-of-existential-reality as the creating-and-essence-attributing drive for knowledgeand-virtue'. $\quad$ Perversion-and-derived- perversion-of- $^{-}$reference-of-thought- $<$aspreconvergingly-apriorising/axiomatising/referencing-innonconviction/madeupness/bottomlining-as-to-shallow-supererogation $>$ is induced by 'denaturing ${ }^{16}$ of the form of ${ }^{56}$ meaningfulness-and-teleology 9 ' on the " ${ }^{103}$ universally-transparent constraining mechanical-knowledge as of the bare ${ }^{83}$ reference-of-thought- categoricalimperatives/axioms/registry-teleology as axiomatic-construct' and obviating the 'social${ }^{3}$ universally-non-transparent-thus-non-constraining-element of ontological-faith-notion-orontological-fideism - imbued-underdetermination-of-motif-andapriorising/axiomatising/referencing-as-so-being-as-of-existential-reality as the creating-andessence-attributing drive for knowledge-and-virtue' while paradoxically wrongly projecting it in distractiveness/shortness-of register-of meaningfulness-and-teleology as if it was of 'apriorising/axiomatising/referencing-\{of-'prospectively implicited_attendant-ontological- 
contiguity ' educed-

existentialising/contextualising/textualising_'intelligibility/epistemicity/reflexivity_contiguity<imbued-notional $\left.\sim \operatorname{cogency}>^{\prime} \quad\right\}$-conflatedness ${ }^{13}$-in-\{preconverging-disentailment by\} postconverging-entailment' in $\quad<$ amplituding/formative-epistemicity $>$ totalising $\sim$ selfreferencing-syncretising/circularity/interiorising/akrasiatic-drag $34 \quad$ implying an uninstitutionalised-threshold $^{102}$ of perversion-and-derived- ${ }^{7}$ perversion-of- ${ }^{83}$ reference-ofthought-<as-preconvergingly-apriorising/axiomatising/referencing-innonconviction/madeupness/bottomlining-as-to-shallow-supererogation $>$ reconceptualised as prior relative-ontological-incompleteness ${ }^{8}$-of- ${ }^{-}$reference-of-thought. Across all registryworldviews/dimensions, the specific association of postlogism 77 to 'denaturing ${ }^{16}$ of the form of meaningfulness-and-teleology, arises as of its compulsingnonconviction/madeupness/bottomlining-〈‘ $<$ decontextualising/de-existentialising $\sim$ ofattendant-intradimensional-apriorising/axiomatising/referencing>-induced-disontologising'-ofthe-'attendant-intradimensional-ontologising'-imbued$<$ contextualising/existentialising attendant-ontological-contiguity $>$;-in-shallowsupererogation -<as-to-disontologising-perverted-outcome-sought-precedes-existentiallyveridical-'attendant-intradimensional-apriorising/axiomatising/referencing'-logical-dueness $>$ ) physiological condition in relation to 'prelogism -as-of-conviction,-in-profoundsupererogation -<existentially-veridical-'attendant-intradimensionalapriorising/axiomatising/referencing'-logical-dueness-precedes-disontologising-logicaloutcome-arrived-at $>{ }^{56}$ meaningfulness-and-teleology ${ }^{9}$, which at childhood postlogism ${ }^{77}$ is more or less ${ }^{103}$ universally-transparent but with adulthood given maturation/indirectness/spatialisation/credulity/craftiness is associated with bringing about social lack of social ${ }^{103}$ universal-transparency ${ }^{104}$-〈transparency-of-totalising-entailing,-as-toentailing-<amplituding/formative-epistemicity $>$ totalising in-relative-ontological- 
completeness $>$ inducing the conjugated-postlogism 77 of temporal-dispositions of ignorance/affordability/opportunism/exacerbation/social-chainism-or-social-discomfiture-ornegative-social-aggregation/temporal-enculturation-or-temporal-endemisation as a grounding for the social extension of 'denaturing ${ }^{16}$ of the form of ${ }^{56}$ meaningfulness-and-teleology ${ }^{9}$ '. Thus at that uninstitutionalised-threshold ${ }^{102}$ which highlight 'denaturing of the form of meaningfulness-and-teleology ${ }^{\circ}$ as temporality $/$ shortness in concatenation with 'apriorising/axiomatising/referencing-\{of-'prospectively_implicited_attendant-ontologicalcontiguity ' educed-

existentialising/contextualising/textualising_'intelligibility/epistemicity/reflexivity-contiguity<imbued-notional cogency $\left.>^{\prime} \quad\right\}$ - conflatedness ${ }^{13}$ in-\{preconverging-disentailment by postconverging-entailment' as intemporality ${ }^{52}$, it is only a renewed 'apriorising/axiomatising/referencing-\{of-'prospectively_implicited_attendant-ontologicalcontiguity ' $\sim$ educedexistentialising/contextualising/textualising_ intelligibility/epistemicity/reflexivity-contiguity<imbued-notional cogency $\left.>^{\prime},\right\}$ - conflatedness ${ }^{13}$ in-\{preconverging-disentailment by postconverging-entailment' as of ontological-faith-notion-or-ontological-fideism-imbuedunderdetermination-of-motif-and-apriorising/axiomatising/referencing-as-so-being-as-ofexistential-reality that induces a prospective " ${ }^{103}$ universally-transparent constraining mechanical-knowledge as new bare reference-of-thought- categoricalimperatives/axioms/registry-teleology as axiomatic-construct' and 'its social- ${ }^{103}$ universallynon-transparent-thus-non-constraining-element of ontological-faith-notion-or-ontologicalfideism - imbued-underdetermination-of-motif-and-apriorising/axiomatising/referencing-asso-being-as-of-existential-reality as the creating-and-essence-attributing drive for knowledgeand-virtue' that brings about prospective relative-ontological-completeness ${ }^{87}$-of- ${ }^{8}$ reference-ofthought; construed as 'ontological-resetting' of placeholder-setup/mental-devising- 
representation/mentation/consciousness-awareness-teleology ${ }^{9}$ of relative epistemicabnormalcy/preconvergence ${ }^{1}$ for relative ontological-normalcy/postconvergence as of ${ }^{15} \mathrm{de}-$ mentation-〈supererogatory $\sim$ ontological-de-mentation-or-dialectical-de-mentation-strandingor-attributive-dialectics〉 stranding dynamics 'which is effectively the concatenated mechanism that engenders sublimating historiality/ontological-eventfulness ${ }^{38}$ /ontological-aesthetictracing-<perspective--ontological-normalcy/postconvergence-reflected-'epistemicityrelativism-determinism'> towards prospective notional ${ }^{18}$ deprocrypticism'. Thus this further explains the very thorny difficulty of dealing with psychopathy and social psychopathy, because more than just an individuation phenotype and incidental/on-occasion phenomenon, it speaks of a registry-worldview's/dimension's our dimension, relative-ontological-incompleteness ${ }^{8}$ induced,-'threshold-of-nonconviction/madeupness/bottomlining-in-shallow-supererogation $<$ as-to-'attendant-intradimensional'-prospectivelydisontologising preconverging/dementing -apriorising-psychologism>' as 'procrypticismor-disjointedness-as-of- ${ }^{8}$ reference-of-thought in endemising/enculturating it, thus in need of notional ${ }^{8}$ deprocrypticism as preempting - disjointedness-as-of- ${ }^{-}$reference-of-thought as an overall preconverging/postconverging-de-mentative/structural/paradigmatic resolution to the vices-and-impediments ${ }^{105}$ of our positivism- ${ }^{80}$ procrypticism registry-worldview/dimension. That is, with acts of perversion-and-derived- perversion-of- ${ }^{3}$ reference-of-thought- $<$ aspreconvergingly-apriorising/axiomatising/referencing-innonconviction/madeupness/bottomlining-as-to-shallow-supererogation $>$ 'it is vague to consider just arriving at ontological-veridicality/intrinsic-reality construal of such acts as of the paradox of their ${ }^{103}$ universally implied prior relative-ontological-incompleteness ${ }^{8}$-ofreference-of-thought' with the latter by itself becoming the grander problematic, more like the relative non-positivism/medievalism relative-ontological-incompleteness ${ }^{8}$-of- ${ }^{3}$ reference-ofthought itself is the grander problematic with respect to the endemisation/enculturation of 
notions-and-accusations-of-sorcery acts/occurrences, and so more than just an act or acts of notions-and-accusations-of-sorcery construed as perversion-and-derived-74 perversion-ofreference-of-thought-<as-preconvergingly-apriorising/axiomatising/referencing-innonconviction/madeupness/bottomlining-as-to-shallow-supererogation $>$, as revealing of the grander framework of vices-and-impediments ${ }^{105}$ inherent to the relative nonpositivism/medievalism relative-ontological-incompleteness ${ }^{8}$-of- ${ }^{8}$ reference-of-thought. Rather it is about articulating the ontological-completeness-of- ${ }^{-1 e f e r e n c e-o f-t h o u g h t ~ a s ~ ' B e i n g ~}$ correction' as of base-institutionalisation institutionalisation over recurrent-utteruninstitutionalisation uninstitutionalisation, ${ }^{103}$ universalisation institutionalisation over ununiversalisation uninstitutionalisation, positivism institutionalisation over nonpositivism/medievalism uninstitutionalisation, and prospectively notional deprocrypticism institutionalisation over our procrypticism uninstitutionalisation. Obviously a traditional approach of analysis of psychopathy (as so construed from this papers totalisingentailing/nested-congruence insight including psychopathy and social psychopathy) will tend to be just as palliative as a non-positivism/medievalism world's postlogism ${ }^{77}$ associated with their social cognisance-and-integration of say notions-and-accusations-of-sorcery were individuals will equally be wary of non-positivism/medievalism ${ }^{74}$ perversion-of- ${ }^{-}$reference-of-thought- $<$aspreconvergingly-apriorising/axiomatising/referencing-in-

nonconviction/madeupness/bottomlining-as-to-shallow-supererogation $>$ and will equally be inclined to charade regarding notions-and-accusations-of-sorcery depending on circumstances; though obviously the ontologically preconverging/postconverging-dementative/structural/paradigmatic resolution in both instances is with respect to the necessary ontological-completeness-of- ${ }^{2}$ reference-of-thought in overcoming <emplituding/formativeepistemicity $>$ totalising $\sim$ self-referencing-syncretising/circularity/interiorising/akrasiatic-drag by prior/transcended/superseded non-positivistic or procrypticism ${ }^{83}$ reference-of-thought- 
categorical-imperatives/axioms/registry-teleology ${ }^{99}$,-for-intemporal-preservation-entropy-orcontiguity-or-ontological-preservation that are failing/not-upholding-<as-ofapriorising/axiomatising/referencing $>\quad$ intemporal-preservation-entropy-or-contiguity-orontological-preservation with prospective/transcending/superseding positivistic or

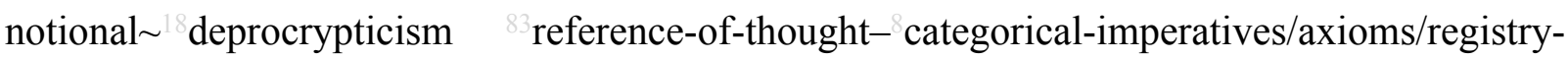
teleology ${ }^{9}$,-for-intemporal-preservation-entropy-or-contiguity-or-ontological-preservation. So perversion-of- ${ }^{-3}$ reference-of-thought-<as-preconvergingly-

apriorising/axiomatising/referencing-in-nonconviction/madeupness/bottomlining-as-to-

shallow-supererogation $>$ has always been recurrent in reflecting holographically$<$ conjugatively-and-transfusively $>$ the relative-unreflexivity/relative-reflexivity - ontologicalcontiguity $\sim$ of-the-human-institutionalisation-process because institutionalisation is not emanance transformation of temporal-dispositions as shortness-of-register-ofmeaningfulness-and-teleology into the intemporal-disposition as longness-of-register-ofmeaningfulness-and-teleology' but designed to skew ('intemporality ${ }^{52}$-symmetrising-bydesymmetrising-subsumption-of-temporality ${ }^{8}$, , for relative intrinsic-reality/ontologicalveridicality transcendental-enabling/sublimating/supererogatory $\sim$ de-mentativity) towards the intemporal-disposition, such that where institutionalisation reaches its design limits given human limited-mentation-capacity-deepening—as-subjecting-limitedness/human-subpotency-to'educed-unlimitedness/existence-sublimating nascence' ${ }^{53}$, the possibility for ${ }^{74}$ perversion-ofreference-of-thought-<as-preconvergingly-apriorising/axiomatising/referencing-innonconviction/madeupness/bottomlining-as-to-shallow-supererogation $>$ arises with its corresponding enculturation/endemisation as uninstitutionalised-threshold ${ }^{102}$ in want for prospective institutionalisation as the ontologically-veridical preconverging/postconverging-dementative/structural/paradigmatic resolution. When that insight avails (a Derridean event ${ }^{38}$ ), it is properly time to 'trample' the melee of common sense disposition for self-preserving 
extrication/temporal preconverging-de-mentating/structuring/paradigming with the elicited intemporal/ontological/social/species/ ${ }^{103}$ universal/transcendental/ ${ }^{5}$ maximalisingrecomposuring-for-relative-ontological-completeness ${ }^{8}$ — unenframed/reontologising conceptualisation postconverging-de-mentating/structuring/paradigming, as has been the case along and defining human history ultimately ushering our very own registryworldview/dimension. The breaking of 'sublimating-epistemicimbricatedness/threadedness/recomposuring as of 'implicited_attendant-ontologicalcontiguity ${ }^{67} \sim$ educed-

existentialising/contextualising/textualising_intelligibility/epistemicity/reflexivity-contiguity$<$ imbued-notional $\sim$ cogency $>,{ }^{\prime},-<$ reifying-or-elucidating-of-prospective-relative-ontologicalcompleteness -of- reference-of-thought- devolving-as-of-instantiative-context $>$ as to existence-potency ${ }^{32} \sim$ sublimating-nascence,-disclosed-from-prospective-epistemicdigression—rules-of-apriorising/axiomatising/referencing-that-further-epistemicallyunconceal-the-very-ontologically-same-existential-reality' (from the perspective of the 'postconverging-or-dialectical-thinking ${ }^{21}{ }^{8}$ reference-of-thought in relative-ontologicalcompleteness ${ }^{87}$ as depth-of-thought') thus take the form of postlogism ${ }^{77}$-slantedness and its conjugation to temporal-dispositions as conjugated-ignorance (unconsciously), conjugatedaffordability (expeditiously), and (consciously with) conjugated-opportunism, conjugatedexacerbation, conjugated-social-chainism/social-discomfiture/negative-social-aggregation, and conjugated-temporal-enculturation/temporal-endemisation; inducing their corresponding virtualities/being-construals-as-abstract-construal-as-of-flawed-and-shallow-and-non-veridicalexistential-reference. With the 'breaking-of-the-threadedness/thread-of-ontologically-veridical meaningfulness' always disambiguated creatively as a 'supratransversality-<in-sublimatingexistential-eventuating/denouement $>\sim$ of-motif-and-apriorising/axiomatising/referencing transitioning construal' of 'ontologically-veridical meaningfulness with ${ }^{83}$ reference-of-thought- 
categorical-imperatives/axioms/registry-teleology as intemporally-preservational' distracted by the 'breaking or a subtransversality-<in-desublimating-existentialeventuating/denouement $>\sim$ of-motif-and-apriorising/axiomatising/referencing 'disjointednessas-of- ${ }^{83}$ reference-of-thought' misappropriated ${ }^{56}$ meaningfulness-and-teleology ${ }^{9}$ in arrogation as ontologically non-veridical with $\quad{ }^{83}$ reference-of-thought- categoricalimperatives/axioms/registry-teleology ${ }^{9}$ apriorising/axiomatising/referencing $>$ failing/notupholding-<as-of-intemporal-preservation-entropy-or-contiguity-or-ontological-preservation', 'in distractive-alignment-to- ${ }^{8}$ reference-of-thought- $<$ of-apriorising/axiomatising/referencing $>$ as-the-arrogation-or-disjointedness-of-acting-in-pseudointemporality ${ }^{52}$ (by temporaldispositions in postlogism and conjugated-postlogism 77 , with respect to the supratransversality-<in-sublimating-existential-eventuating/denouement $>\sim$ of-motif-andapriorising/axiomatising/referencing as 'notional ' deprocrypticism sublimating-epistemicimbricatedness/threadedness/recomposuring of ontologically-veridical meaningfulness', thus 'reflecting/perspectivating/highlighting temporal-dispositions (postlogism?7 and conjugatedpostlogism ${ }^{77}$ as $\quad$ procrypticism-or-disjointedness-as-of- ${ }^{8}$ reference-of-thought, preconverging-or-dementing ${ }^{20}$-apriorising-psychologism and dialectically-out-of-phase in pseudointemporality ${ }^{52}$, and so by a ${ }^{55}$ maximalising-recomposuring-for-relative-ontologicalcompleteness $^{87}$ - unenframed/re-ontologising conceptualisation that is ontologicallyreconstituting (deconstruction) of the threadedness/thread, with no elaboration-as-to-mereextrapolating/constituting/abstracting/deducing/inferring-of-elucidation-outside'prospectively_implicited_attendant-ontological-contiguity ${ }^{67}$ ' educedexistentialising/contextualising/textualising_intelligibility/epistemicity/reflexivity-contiguity$<$ imbued-notional cogency $>$ ' (that will falsely validate the wrongly implied soundness/nonperverted ${ }^{8}$ reference-of-thought, i.e. unsound/perverted 'apriorising- ${ }^{83}$ reference-ofthought/apriorising-registry_elements (out of 'implicited_attendant-ontological- 
contiguity ${ }^{67}$, educed-

existentialising/contextualising/textualising_'intelligibility/epistemicity/reflexivity_contiguity-

$<$ imbued-notional $\sim$ cogency $>,{ }^{\prime},-<$ reifying-or-elucidating-of-prospective-relative-ontological-

completeness -of- reference-of-thought- devolving-as-of-instantiative-context $>$ )' of \{epistemic-

totalising 3 t psychologismic-subliminality-of-individuation-effusing/worlding imbued logicaldueness-or-scape-or-frame, profile-or-stature, presumptuousness-or-arrogation, assumptions, value-reference and teleology ${ }^{99}$, as first-order faulty-mentation-procedure-deception-or-urge ${ }^{3}$, and thereafter the infinite logical articulations as second-order level deceptive-virtualities that can be made from wrongly assuming the implied first-order faulty-mentation-proceduredeception-or-urge ${ }^{3}$ as correct). Insightfully, humans actually come into existence which avows an 'implicited_attendant-ontological-contiguity ${ }^{67}$ ' educedexistentialising/contextualising/textualising_'intelligibility/epistemicity/reflexivity_contiguity$<$ imbued-notional $\sim$ cogency $>$, ,-<reifying-or-elucidating-of-prospective-relative-ontologicalcompleteness -of- reference-of-thought- devolving-as-of-instantiative-context> of imbricated-becoming-transitioning within which they come to grasp rules and principles (elaboration-as-to-mere-extrapolating/constituting/abstracting/deducing/inferring-ofelucidation-outside_- prospectively implicitententantontological-contiguity ${ }^{67}$ ' educedexistentialising/contextualising/textualising_'intelligibility/epistemicity/reflexivity-contiguity$<$ imbued-notional cogency>' ${ }^{\prime 0}$ ), but these rules and principles are divulged by 'implicited_attendant-ontological-contiguity ${ }^{6 /}$ educedexistentialising/contextualising/textualising_'intelligibility/epistemicity/reflexivity_contiguity$<$ imbued-notional $\sim$ cogency $>{ }^{\prime},-<$ reifying-or-elucidating-of-prospective-relative-ontologicalcompleteness -of- reference-of-thought- devolving-as-of-instantiative-context> as to existence-potency $^{39} \sim$ sublimating-nascence,-disclosed-from-prospective-epistemicdigression—rules-of-apriorising/axiomatising/referencing-that-further-epistemically- 
unconceal-the-very-ontologically-same-existential-reality' and the limits of such rules and principles are in effect their validation as <amplituding/formative-epistemicity $>$ causality $\sim$ asto-projective-totalitative-implications-of-prospective- nonpresencing,-for-

explicating relative-unreflexivity/relative-reflexivity - ontological-contiguity

within

'implicited_attendant-ontological-contiguity ${ }^{67}$ ' educed-

existentialising/contextualising/textualising_intelligibility/epistemicity/reflexivity-contiguity-

$<$ imbued-notional $\sim$ cogency $>,{ }^{\prime},-<$ reifying-or-elucidating-of-prospective-relative-ontological-

completeness -of- reference-of-thought- devolving-as-of-instantiative-context> as to

existence-potency ${ }^{32} \sim$ sublimating-nascence,-disclosed-from-prospective-epistemic-

digression—rules-of-apriorising/axiomatising/referencing-that-further-epistemically-

unconceal-the-very-ontologically-same-existential-reality', with the implication that any naïve construal of such rules and principles (elaboration-as-to-mereextrapolating/constituting/abstracting/deducing/inferring-of-elucidation-outside-

'prospectively_implicited_attendant-ontological-contiguity ${ }^{67}$ ' educed-

existentialising/contextalising/textalising_'intelligibility/epistemicity/reflexivity_contiguity-

$<$ imbued-notional cogency>' ${ }^{40}$ ) out of the scope of 'implicited_attendant-ontologicalcontiguity ${ }^{67} \sim$ educed-

existentialising/contextualising/textualising_'intelligibility/epistemicity/reflexivity-contiguity-

$<$ imbued-notional $\sim$ cogency $>{ }^{\prime},-<$ reifying-or-elucidating-of-prospective-relative-ontological-

completeness -of- reference-of-thought- devolving-as-of-instantiative-context> as to

existence-potency ${ }^{39} \sim$ sublimating-nascence,-disclosed-from-prospective-epistemic-

digression—rules-of-apriorising/axiomatising/referencing-that-further-epistemically-

unconceal-the-very-ontologically-same-existential-reality' is a virtuality-or-ontologically-

flawed-construal/non-existent/unreal;

as

'implicited_attendant_ontological-

contiguity $^{67} \sim$ educed- 
existentialising/contextualising/textualising_intelligibility/epistemicity/reflexivity-contiguity$<$ imbued-notional $\sim$ cogency $>,{ }^{\prime},-<$ reifying-or-elucidating-of-prospective-relative-ontologicalcompleteness -of- reference-of-thought- devolving-as-of-instantiative-context $>$ as to existence-potency $^{39} \sim$ sublimating-nascence,-disclosed-from-prospective-epistemicdigression—rules-of-apriorising/axiomatising/referencing-that-further-epistemicallyunconceal-the-very-ontologically-same-existential-reality' is 'conceptually the very absolute irreducible a-priori of all human ${ }^{5}$ meaningfulness-and-teleology ${ }^{9}$ ' as it is divulged with human limited-mentation-capacity-deepening — as-subjecting limitedness/human-subpotency-to'educed-unlimitedness/existence-sublimating nascence' ${ }^{53}$ in the construal of supersedingoneness-of-ontology. The reason for the disambiguation of transversality-<for-sublimatingexistential-eventuating/denouement,-from-'thinking-at-first/pure-predisposition-preemptive-of prospective-disontologising/subontologising' - as-of-prospectively-disambiguated-affirmedand-unaffirmed-'motif-and-apriorising/axiomatising/referencing' $>101$ into a supratransversality$<$ in-sublimating-existential-eventuating/denouement $>\sim$ of-motif-and-

apriorising/axiomatising/referencing ${ }^{83}$ reference-of-thought over a subtransversality-<indesublimating-existential-eventuating/denouement $>\sim$ of-motif-and-

apriorising/axiomatising/referencing ${ }^{83}$ reference-of-thought for the ontological-reconstitutingas-to-conflatedness ${ }^{13}$ of 'implicited_attendant-ontological-contiguity ${ }^{67}$ ' educedexistentialising/contextualising/textalising_'intelligibility/epistemicity/reflexivity_contiguity$<$ imbued-notional $\sim$ cogency $>,{ }^{\prime},-<$ reifying-or-elucidating-of-prospective-relative-ontologicalcompleteness -of- reference-of-thought- devolving-as-of-instantiative-context> as to existence-potency ${ }^{39} \sim$ sublimating-nascence,-disclosed-from-prospective-epistemicdigression—rules-of-apriorising/axiomatising/referencing-that-further-epistemicallyunconceal-the-very-ontologically-same-existential-reality' has to do with the fundamental basis of the perversion-of- ${ }^{8}$ reference-of-thought- $<$ as-preconvergingly- 
apriorising/axiomatising/referencing-in-nonconviction/madeupness/bottomlining-as-to-

shallow-supererogation $>$ behind all the postlogism 7 /disontologising-perverted-outcomesought-precedes-existentially-veridical-'attendant-intradimensional-

apriorising/axiomatising/referencing'-logical-dueness of all registry-worldviews' ${ }^{83}$ referencesof-thought including with regards to the phenomenon of psychopathy and social psychopathy (as indicated at the beginning) of the positivism- ${ }^{80}$ procrypticism registry-worldview, i.e. specifically with the psychopathic/postlogic induced pre-valuation/pri-individuation/deindividuation/commitment perversion-of- ${ }^{8}$ reference-of-thought-<as-preconverginglyapriorising/axiomatising/referencing-in-nonconviction/madeupness/bottomlining-as-toshallow-supererogation $>$; wherein this process is reversed (but beyond a temporal equivalence and rather for an aetiologisation/ontological-escalation- $<$ ontologicalveridicality_commitment/otherliness_transcending/compulsions-encumbered_transcending $>$ of the ${ }^{103}$ universal implications as metaphysics-of-absence-〈implicited-epistemic-veracity-ofnonpresencing-<perspective-ontological-normalcy/postconvergence $>\rangle)$ in re-establishing ontological-veridicality of 'implicited_attendant-ontological-contiguity ${ }^{67}$; educedexistentialising/contextualising/texttalising_'intelligibility/epistemicity/reflexivity-contiguity$<$ imbued-notional $\sim$ cogency $>,{ }^{\prime},-<$ reifying-or-elucidating-of-prospective-relative-ontologicalcompleteness -of- reference-of-thought- devolving-as-of-instantiative-context> as to existence-potency ${ }^{39} \sim$ sublimating-nascence,-disclosed-from-prospective-epistemicdigression—rules-of-apriorising/axiomatising/referencing-that-further-epistemicallyunconceal-the-very-ontologically-same-existential-reality' ${ }^{83}$ reference-of-thought, wherein the 'induced de-individuation ${ }^{83}$ reference-of-thought' is rather reconstrued in its veridical existential-reality of narratives by SUPRATRANSVERSALITY- $<$ IN-SUBLIMATINGEXISTENTIAL-EVENTUATING/DENOUEMENT> OF-MOTIF-AND-

APRIORISING/AXIOMATISING/REFERENCING (ontologically-veridical ${ }^{83}$ reference-of- 
thought of 'notional 18 deprocrypticism preempting-disjointedness-as-of- ${ }^{3}$ reference-ofthought $<$ amplituding/formative-epistemicity $>$ causality $\sim$ as-to-projective-totalitativeimplications-of-prospective- nonpresencing,-for-explicating relative-unreflexivity/relativereflexivity - ontological-contiguity ', of psychopathy and social psychopathy along all implied thematics of the social-construct whether as of phenomenal/criminal/social/corporate/valuestructure/social-structure/registry-worldview insight for aetiologisation/ontological-escalation$<$ ontological-veridicality_commitment/otherliness_transcending/compulsions-

encumbered_transcending $>$ rather as of intellectual-and-moral-inequivalence/noncorrespondence with the subtransversality-<in-desublimating-existentialeventuating/denouement $>$ of-motif-and-apriorising/axiomatising/referencing; and so by way of the-transcendental-enabling/sublimating/supererogatory de-mentativity-that-is-intrinsicreality-or-ontological-veridicality as against 'social-aggregation-enablers undermining of prospective intrinsic-reality/ontological-veridicality transcendentalenabling/sublimating/supereregatory de-mentativity' with perverted use of such notions as differentness, infamy, status, significant-others basis of logic, repute, social authorities and influencers naively involved in fallacies of authority, disparagement, contrivance, duplicity, imposturing, ontological-bad-faith/inauthenticity ${ }^{64}$ implying an equivalence between ${ }^{3}$ universal/intemporal sense of purpose with extricatory/temporal/mundane sense of purposes, underhandedness, inductive-limitation or so-called principle that is not articulated as a universal construct but targeted, avowing its reality as fake and thus of temporal-disposition, etc.), while the 'induced pri-individuation ${ }^{83}$ reference-of-thought' of psychopathic postlogism and conjugated-postlogism in its virtuality-or-ontologically-flawed-construal (beingconstrual-as-abstract-construal-as-of-flawed-and-shallow-and-non-veridical-existentialreference) of narratives is construed as SUBTRANSVERSALITY $-<$ IN-DESUBLIMATINGEXISTENTIAL-EVENTUATING/DENOUEMENT> OF-MOTIF-AND- 
APRIORISING/AXIOMATISING/REFERENCING (in perverted-or-derived-pervertedreference-of-thought procrypticism-or-disjointedness-as-of- ${ }^{8}$ reference-of-thought extricatory-and-temporal incidental construals of ${ }^{5}$ meaningfulness-and-teleology ${ }^{9}$ wrongly striving to equivocate its extrication/temporality ${ }^{9}$ by using 'social-aggregation-enablers over intrinsic-reality/ontological-veridicality transcendentalenabling/sublimating/supereregatery de-mentativity' in undermining the transcendentalenabling/sublimating/supererogatory $\sim$ de-mentativity-that-is-of-intrinsic-reality-or-ontologicalveridicality upheld by the notional deprocrypticism supratransversality-<in-sublimatingexistential-eventuating/denouement $>\sim$ of-motif-and-apriorising/axiomatising/referencing preempting — disjointedness-as-of- ${ }^{8}$ reference-of-thought <amplituding/formativeepistemicity $>$ causality $\sim$ as-to-projective-totalitative-implications-of-prospectivenonpresencing,-for-explicating relative-unreflexivity/relative-reflexivity - ontologicalcontiguity ). The disambiguation of transversality-<for-sublimating-existentialeventuating/denouement,-from-'thinking at-first/pure-predisposition-preemptive-ofprospective-disontologising/subontologising' as-of-prospectively-disambiguated-affirmedand-unaffirmed-'motif-and-apriorising/axiomatising/referencing'> into

'supratransversality-<in-sublimating-existential-eventuating/denouement $>\sim$ of-motif-andapriorising/axiomatising/referencing ${ }^{83}$ reference-of-thought of ${ }^{56}$ meaningfulness-andteleology ${ }^{\circ}$ over a subtransversality-<in-desublimating-existentialeventuating/denouement> of-motif-and-apriorising/axiomatising/referencing ${ }^{83}$ reference-ofthought of ${ }^{5}$ meaningfulness-and-teleology ${ }^{\circ}$ ' can equally be understood by comparison with the notion of apriorising/axiomatising/referencing/intelligibilitysettingup/measuringinstrumenting as ${ }^{83}$ reference-of-thought of ${ }^{5}$ meaningfulness-and-teleology ${ }^{99}$, as there can't be common reference-of-thought of contention (mutually intelligible aposteriorising/logicising/deriving/intelligising/measuring as mutually intelligible 
apriorising/axiomatising/referencing/intelligibilitysettingup/measuringinstrumenting (subtransversality-<in-desublimating-existential-eventuating/denouement $>\sim$ of-motif-andapriorising/axiomatising/referencing $\quad{ }^{83}$ reference-of-thought $\quad$ of ${ }^{56}$ meaningfulness-andteleology ${ }^{9}$, as preconverging-or-dementing ${ }^{20}$-apriorising-psychologism from ontologicalnormalcy/postconvergence epistemic-or-notional projective-perspective) and a correctly functioning

apriorising/axiomatising/referencing/intelligibilitysettingup/measuringinstrumenting (supratransversality-<in-sublimating-existential-eventuating/denouement $>\sim$ of-motif-andapriorising/axiomatising/referencing $\quad{ }^{83}$ reference-of-thought $\quad$ of ${ }^{56}$ meaningfulness-andteleology', as 'postconverging-or-dialectical-thinking -apriorising-psychologism' from ontological-normalcy/postconvergence epistemic-or-notional projective-perspective). It is the idea of the <amplituding/formative-epistemicity $>$ causality $\sim$ as-to-projective-totalitativeimplications-of-prospective- nonpresencing,-for-explicating relative-unreflexivity/relativereflexivity - ontological-contiguity of the latter over the former that will existentially/ontologically impose the latter, and not common/mutual logical-processing as logic is then a 'lower, inappropriate and inherently defective level of ${ }^{5}$ meaningfulness-andteleology processing' in relation to 'appropriateness-of- ${ }^{9}$ reference-of-thought-as-ofconflatedness $^{13}$ processing' (just as there can't be logical intelligibility between a nonpositivisit/medieval mindset $/{ }^{83}$ reference-of-thought of ${ }^{56}$ meaningfulness-and-teleology ${ }^{99}$ with a positivistic one); by its ontologically inducing untenability/internal-contradiction/internalincoherence/institutional-constraining as the correct apriorising/axiomatising/referencing/intelligibilitysettingup/measuringinstrumenting functioning (the appropriateness-of- ${ }^{8}$ reference-of-thought-as-of-conflatedness ${ }^{13}$ ) in the middle to long run construed as of de-mentation-/supererogatory ${ }^{15}$ ontological-de-mentation-or- 
dialectical-de-mentation - stranding-or-attributive-dialectics $\rangle$. This process can be qualified as the 'blunt act of existence over the human temporal egotistic/self-referential complex to prospective transcendence-and-sublimity/sublimation/supererogatory $\sim$ dementativity/superseding ontological-veridicality/intrinsic-reality ${ }^{83}$ reference-of-thought', and is the actual basis for all transcendence-and-sublimity/sublimation/surentativity for prospective institutionalisations since the successive institutional-cumulation/institutionalrecomposure-〈as-to- historiality/ontological-eventfulness /ontological-aesthetic-tracing$<$ perspective-ontological-normalcy/postconvergence-reflected-'epistemicity-relativismdeterminism' $>>$ do not arise because of the reality of a 'human intemporal-emanance philosophical acquiescence' but rather by ontologically inducing untenability/internalcontradiction/internal-incoherence/institutional-constraining of existential-<disontologising/reentologising aporeticism $>$ reality as a constraint for the secondnaturing of institutionalisation, without transforming the underlying reality of a human-subpotencyaporia/undecidability/dilemma/ought-indeterminacy/deficiency/limitation/constraint—imbued'notional firstnaturedness-formativeness-as to or seeding misprising $>$ temporal-to-intemporal-dispositions- $<$ so-construed-as-from-perspectiveontological-normalcy/postconvergence>'-existentialism-form-factor individuations. That is while the implied aposteriorising/logicising/deriving/intelligising/measuring-purpose_-ofobtained-measurements (implied ${ }^{56}$ meaningfulness-and-teleology ${ }^{9}$ ) imply speaking the same language but the existential/ontological/being realities are utterly different with the correct apriorising/axiomatising/referencing/intelligibilitysettingup/measuringinstrumentingproducing-measurements (supratransversality-<in-sublimating-existentialeventuating/denouement $>\sim$ of-motif-and-apriorising/axiomatising/referencing) being real and the defective apriorising/axiomatising/referencing/intelligibilitysettingup/measuringinstrumenting (being 
unreal as of threshold-of-nonconviction/madeupness/bottomlining-in-shallowsupererogation -<as-to-'attendant-intradimensional'-prospectivelydisontologising preconverging/dementing -apriorising-psychologism $>$ ), without mutual intelligibility of ${ }^{5}$ logical-processing-or-logical-implicitation-supposedly-apriorising-inconviction-as-to-profound-supererogation but for the effectiveness/<amplituding/formativeepistemicity $>$ causality as-to-projective-totalitative-implications-of-prospectivenonpresencing,-for-explicating relative-unreflexivity/relative-reflexivity - ontologicalcontiguity of the correct apriorising/axiomatising/referencing/intelligibilitysettingup/measuringinstrumenting — producing-measurements (supratransversality-<in-sublimating-existentialeventuating/denouement $>\sim$ of-motif-and-apriorising/axiomatising/referencing) appropriatenessof- ${ }^{8}$ reference-of-thought-as-of-conflatedness ${ }^{13}$ that collapses the defective apriorising/axiomatising/referencing/intelligibilitysettingup/measuringinstrumenting (subtransversality-<in-desublimating-existential-eventuating/denouement $>\sim$ of-motif-andapriorising/axiomatising/referencing) $\quad$ perversion-of- ${ }^{8}$ reference-of-thought- $<$ aspreconvergingly-apriorising/axiomatising/referencing-innonconviction/madeupness/bottomlining-as-to-shallow-supererogation $>$, as of the consequences in a comparative use of both apriorising/axiomatising/referencing/intelligibilitysettingup/measuringinstrumenting after a while (crossgenerationally). Thus issues of defect of ${ }^{83}$ reference-of-thought (apriorising/axiomatising/referencing/intelligibilitysettingup/measuringinstrumenting defect issues) cannot be resolved by mutually intelligible ${ }^{54}$ logical-processing-or-logicalimplicitation - supposedly-apriorising-in-conviction-as-to-profound-supererogation (mutually intelligible measuring), but rather by the superseding supratransversality-<in-sublimatingexistential-eventuating/denouement $>\sim$ of-motif-and-apriorising/axiomatising/referencing 
apriorising/axiomatising/referencing/intelligibilitysettingup/measuringinstrumenting producing-measurements) in intemporal/longness projection for aetiologisation/ontologicalescalation-<ontological-veridicality_commitment/otherliness_transcending/compulsionsencumbered_transcending $>$ over the subtransversality-<in-desublimating-existentialeventuating/denouement> of-motif-and-apriorising/axiomatising/referencing $\quad{ }^{83}$ reference-ofthought

(as-of defective

apriorising/axiomatising/referencing/intelligibilitysettingup/measuringinstrumenting) of temporal extricatory preconverging-de-mentating/structuring/paradigming incidental construal in wrong equivalence to the supratransversality-<in-sublimating-existentialeventuating/denouement> of-motif-and-apriorising/axiomatising/referencing $\quad$ reference-ofthought. This equally validates the notion of transversality-<for-sublimating-existentialeventuating/denouement,-from-'thinking at-first/pure predisposition-preemptive-ofprospective-disontologising/subontologising' as-of-prospectively-disambiguated-affirmedand-unaffirmed-'motif-and-apriorising/axiomatising/referencing'> as logical-incongruence of appropriateness-of- ${ }^{83}$ eference-of-thought-as-of-conflatedness ${ }^{13}$ and perversion-and-derivedperversion-of- ${ }^{8}$ reference-of-thought-<as-preconverginglyapriorising/axiomatising/referencing-in-nonconviction/madeupness/bottomlining-as-toshallow-supererogation $>$. This is preconverging/postconverging-dementatively/structurally/paradigmatically the most elevated construct for the production of human knowledge as transcendental knowledge and as implied in its dissemination ${ }^{28}$ along formal constructs based on a postconverging-de-mentating/structuring/paradigming for skewing ('intemporality ${ }^{52}$-symmetrising-by-desymmetrising-subsumption-of-temporality ${ }^{\circ}$, , for relative intrinsic-reality/ontological-veridicality transcendentalenabling/sublimating/supereregatery $\sim$ de-mentativity) towards intemporality ${ }^{52}$, and not wrongly 
averaging of human thought in equivalence as logical-congruence of temporality 8 /shortness and intempolity/longness-of-meaningfulness, such that knowledge is not constructed as a 'human mutual agreement exercise for its construal/conceptualisation/discovery/invention/development' since solipsistically/emanantly/becomingly we are of temporal/shortness to intemporal/longness mental-dispositions and this cannot be averaged to get transcendental knowledge which is rather the outcome of an enabling process as to 'intrinsic-reality/ontological-veridicality transcendental enabling' that allows what is intemporal as of mental-disposition to be effective by $<$ amplituding/formative-epistemicity $>$ causality $\sim$ as-to-projective-totalitative-implications-ofprospective- nonpresencing,-for-explicating relative-unreflexivity/relative-reflexivity ontological-contiguity as of ontological and virtue constructs, and be imposed as knowledge. Thus it is critical to understand that the exercise of reconstituting ontological veridicality is a wholly maximalising-recomposuring-for-relative-ontological-completeness ${ }^{87}$ unenframed/re-ontologising conceptualisation in grasping 'implicited_attendant-ontologicalcontiguity $^{67}$ ' educed-

existentialising/contextualising/textualising_intelligibility/epistemicity/reflexivity-contiguity$<$ imbued-notional cogency $>{ }^{,},-<$reifying-or-elucidating-of-prospective-relative-ontologicalcompleteness -of- reference-of-thought- devolving-as-of-instantiative-context> as to existence-potency ${ }^{39} \sim$ sublimating-nascence,-disclosed-from-prospective-epistemicdigression—rules-of-apriorising/axiomatising/referencing-that-further-epistemicallyunconceal-the-very-ontologically-same-existential-reality', even when it would seem weird due to metaphysics-of-presence-〈implicited-'nondescript/ignorable-void '-as-to- presencingabsolutising-identitive-constitutedness $\rangle$, and is creatively grounded on 'on phased phases construed in mirroring the fundamental insane/postlogism -fitment of the childhoodpsychopath perversion-of- ${ }^{-3 e f e r e n c e-o f-t h o u g h t-~}<$ as-preconverginglyapriorising/axiomatising/referencing-in-nonconviction/madeupness/bottomlining-as-to- 
shallow-supererogation $>$ mental-disposition structure as it induces conjugatedpostlogism 7 /preconverging-or-dementing ${ }^{20}$-integration later on and most effectively at adulthood psychopathy'. This fundamental structure of the denaturing nature of postlogism and conjugated-postlogism 7 /preconverging-or-dementing 20 -integration can be demonstrated with the blatantly obvious case of the childhood-psychopath even though the denaturing ${ }^{16}$ of its mental-disposition is relatively socially- ${ }^{103}$ universally-transparent (enabling an understandingof-<amplituding/formative-epistemicity $>$ causality $\sim$ as-to-projective-totalitative-implicationsof-prospective- nonpresencing,-for-explicating $\sim$ relative-unreflexivity/relative-reflexivityontological-contiguity -of-the-underlying-phenomenon). In the case were in a 'dereifying act' water is spilled on a chair, and a visiting stranger (as-of-pseudointemporality ${ }^{52}$ by ignorance) not aware of the mental-disposition of the childhood-psychopath coming into the scene after the event $^{38}$ and sitting unknowingly on the soaked sofa, and was to frown and remonstrate against or possibly smack the innocent brother, such a stranger is in ignorance-conjugated-postlogism or conjugated-ignorance as its relative-ontological-incompleteness ${ }^{8}$-induced,-'threshold-ofnonconviction/madeupness/bottomlining-in-shallow-supererogation $<<$ as-to-'attendantintradimensional'-prospectively-disontologising preconverging/dementing -apriorisingpsychologism>' led it to align in-prelogic supplanting-conviction-as-to-profoundsupererogation —of-'attendant-intradimensional'-postconverging/dialectical-thinking apriorising-psychologismly (as-of-pseudointemporality ${ }^{52}$ ) to the childhood-psychopath's postlogic narrative, and so in 'ignorance-temporal-preservation-as-pseudointemporality ${ }^{52}$ preservation', that it was the brother that spilled the water on the chair on purpose (noting that even at this level, for all practical purpose the visiting stranger's meaningfulness is 'supposedly in $\quad$ prelogism $^{78}$-as-of-conviction,-in-profound-supererogation $<-<$ existentially-veridical'attendant-intradimensional-apriorising/axiomatising/referencing'-logical-dueness-precedesdisontologising-logical-outcome-arrived-at> (as-of-pseudointemporality ${ }^{52}$ ) but is rather 
effectively 'conjoining looping narratives of flawed-existential-elevation-of- ${ }^{3}$ reference-ofthought ' ' with respect to the 'denaturing postlogic-backtracking-<iterative-looping-'set-ofdereifying-hollow-narratives-and-acts'> ${ }^{76}$-with-'successive-shifting-of-the-narratives-and-actsfoci'-construed-as-'deception-of-successively-shifting-or-noncohering-narratives-and-acts' towards 'social-aggregation-enablers over intrinsic-reality/ontological-veridicality transcendental-enabling/sublimating/supererogatory-de-mentativity' as non-veridical and dialectically/contendingly out-of-phase, of the childhood-psychopath's meaningfulness is effectively in conjugated-postlogism 77 and has "joined the childhood-psychopath in thresholdof-nonconviction/madeupness/bottomlining-in-shallow-supererogation $-<$ as-to-'attendantintradimensional'-prospectively-disontologising preconverging/dementing -apriorisingpsychologism> and is preconverging-or-dementing -apriorising-psychologism and dialectically-out-of-phase' with respect to ontologically-veridical existential-reality as construed from ontological-normalcy/postconvergence, and further it state of ignorance speaks of its relative-ontological-incompleteness ${ }^{88}$-induced,-'threshold-ofnonconviction/madeupness/bottomlining-in-shallow-supererogation $<-<$ as-to- 'attendantintradimensional'-prospectively-disontologising preconverging/dementing -apriorisingpsychologism>' as ${ }^{80}$ procrypticism-or-disjointedness-as-of- ${ }^{8}$ reference-of-thought which can't be overlooked for aetiologisation/ontological-escalation- $<$ ontologicalveridicality_commitment/otherliness_transcending/compulsions-encumbered_transcending > conceptualisation by the fact that the visiting stranger or more precisely an individuation of the type expressed by the visiting stranger (as-of-pseudointemporality ${ }^{52}$ by ignorance) might act the same way he acted in 'metaphorically-a-million-and-one-instances-and-locales' as aetiologisation/ontological-escalation-<ontologicalveridicality_commitment/otherliness_transcending/compulsions-encumbered_transcending>, and this particular example symbolises why virtue is a 'The-Good/knowledge- 
reification $\sim$ gesturing-and-accounting — of-epistemic-phenomenalism- $<$ in-

prospective_psychologismic apriorising/axiomatising/referencing-\{of-'prospectively implicited_attendant-ontological-contiguity ' ceduced-

existentialising/contextualising/textualising_intelligibility/epistemicity/reflexivity_contiguity<imbued-notional cogency >' \}-conflatedness -in-\{preconverging disentailment by\} postconverging-entailment $>$ /understanding/<amplituding/formative-

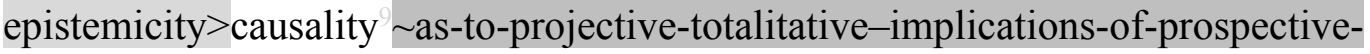
nonpresencing,-for-explicating relative-unreflexivity/relative-reflexivity - ontological-

contiguity construct' and not 'impression-driven/good-naturedness/wishfulness construct' as reality is above all 'effectivity' by its manifestation. But then given the relative social universal-transparency ${ }^{104}$-〈transparency-of-totalising-entailing,-as-to-entailing$<$ amplituding/formative-epistemicity $>$ totalising in-relative-ontological-completeness $>$ at this childhood stage, it is more likely that the whole situation will be explained to the visiting stranger (as-of-pseudointemporality ${ }^{52}$ ) and will assume mostly an incidental/on-occasion conjugatedpostlogism 77 effect in the attendant social space. The fact is at this childhood stage conjugatedpostlogism 77 will tend to be incidental and mostly arise as ignorance-conjugated-postlogism 77 . (Such a construal can further be articulated not only in the case of ignorance as ignoranceconjugated-postlogism 77 but equally as the child-psychopath develops into adulthood and is less and less socially-dysfuntional and social ${ }^{103}$ universal-transparency ${ }^{104}$-〈transparency-oftotalising-entailing,-as-to-entailing-<amplituding/formative-epistemicity $>$ totalising $\sim$ inrelative-ontological-completeness > of the postlogism 7 is lost socially with its maturation/spatialisation/indirectness/credulity/craftiness, giving rise to the conjugatedpostlogism cases of conjugated-affordability, conjugated-opportunism, conjugatedexacerbation, conjugated-social-chainism and conjugated-temporal-enculturation by temporaldispositions where the effect is "more than just benign and incidental/on-occasional with 
dramatic social consequences and as there is further eliciting of enculturated postlogism 77 as social psychopathy, however ad-hoc and opportunistic'. At the grander transcendental/transdimensional/interdimensional $/ 5$ maximalising-recomposuring-for-relativeontological-completeness ${ }^{87}$ - unenframed/re-ontologising conceptualisation level as dynamiccumulative-aftereffect maximalising-recomposuring-for-relative-ontologicalcompleteness $^{87}$ —unenframed/re-ontologising conceptualisation sublimating-epistemicimbricatedness/threadedness/recomposuring as of 'implicited_attendant-ontologicalcontiguity ${ }^{67} \sim$ educed-

existentialising/contextmalising/textualising_'intelligibility/epistemicity/reflexivity-contiguity$<$ imbued-notional $\sim$ cogency $>,{ }^{\prime},-<$ reifying-or-elucidating-of-prospective-relative-ontologicalcompleteness -of- reference-of-thought- devolving-as-of-instantiative-context $>$ as to existence-potency ${ }^{39} \sim$ sublimating-nascence,-disclosed-from-prospective-epistemicdigression —rules-of-apriorising/axiomatising/referencing-that-further-epistemicallyunconceal-the-very-ontologically-same-existential-reality' reflects/perspectivates/highlights this comprehensively as the registry-worldview/dimension uninstitutionalised-threshold threshold highlighting the ${ }^{7}$ perversion-of- ${ }^{83}$ refence-of-thought-<as-preconverginglyapriorising/axiomatising/referencing-in-nonconviction/madeupness/bottomlining-as-toshallow-supererogation $>$ of the registry-worldview's/dimension's institutionalised meaningfulness-and-teleology reference-of-thought- categoricalimperatives/axioms/registry-teleology ${ }^{9}$ as temporal-preservation-in-pseudointemporality ${ }^{52}$ preservation as of threshold-of-nonconviction/madeupness/bottomlining-in-shallowsupererogation -<as-to-'attendant-intradimensional'-prospectivelydisontologising preconverging/dementing -apriorising-psychologism>, going by the dynamism of human-subpotency-aporia/undecidability/dilemma/oughtindeterminacy/deficiency/limitation/constraint—imbued-'notional firstnaturedness- 
formativeness-<as-to-eventualising-inkling-drive-or-seeding-misprising $>$ temporal-tointemporal-dispositions-<so-construed-as-from-perspective-ontologicalnormalcy/postconvergence $>$ '-existentialism-form-factor). The example with ignorance is however the 'fundamental atomic mental-disposition characteristic of psychopathy and social psychopathy' as it develops more and more shrewdly into adulthood with a further loss of social universal-transparency ${ }^{104}$-〈transparency-of-totalising-entailing,-as-to-entailing$<$ amplituding/formative-epistemicity>totalising in-relative-ontological-completeness $>$ of the underlying postlogism -as-of- compulsing-nonconviction/madeupness/bottomlining-

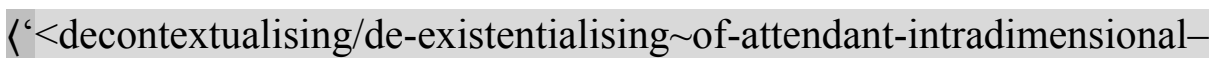
apriorising/axiomatising/referencing >-induced-disontologising'-of-the-'attendantintradimensional-ontologising'-imbued-<contextualising/existentialising $\sim$ attendantontological-contiguity $>$;-in-shallow-supererogation -<as-to-disontologising-pervertedoutcome-sought-precedes-existentially-veridical-'attendant-intradimensionalapriorising/axiomatising/referencing'-logical-dueness $>>$ mental-disposition wherein with development of childhood psychopathy into adult psychopathy, 'social expansion-and-gravity of tones-as-temperament and thematic implications with regards to notional firstnaturednessformativeness-<as-to-eventualising-inkling-drive-or-seeding-misprising $>$ temporal-tointemporal-dispositions-<so-construed-as-from-perspective-ontologicalnormalcy/postconvergence $>$ individuations teleologies/teleological-differentiations (as postlogism and conjugated-postlogism 77 in pseudointemporality ${ }^{52} /$ preconverging-or- $^{77}$ dementing -apriorising-psychologism, and supplanting-conviction-as-to-profoundsupererogation —of-'attendant-intradimensional'-postconverging/dialectical-thinking apriorising-psychologism as to intemporal/ontological in non-pseudointemporality ${ }^{52} /$ thinking) $^{2}$ ensue. It exclusively requires on an ontological postconverging-dementating/structuring/paradigming involving ${ }^{55}$ maximalising-recomposuring-for-relative- 
ontological-completeness ${ }^{87}$ - unenframed/re-ontologising conceptualisation, as the explanation given to the visiting stranger about its error and the childhood-psychopath mental state as 'sublimating-epistemic-imbricatedness/threadedness/recomposuring 'implicited_attendant-ontological-contiguity ${ }^{67}$ ' educedexistentialising/contextualising/textualising_'intelligibility/epistemicity/reflexivity-contiguity$<$ imbued-notional $\sim$ cogency $>,{ }^{\prime},-<$ reifying-or-elucidating-of-prospective-relative-ontologicalcompleteness -of- reference-of-thought- devolving-as-of-instantiative-context $>$ as to existence-potency $^{39} \sim$ sublimating-nascence,-disclosed-from-prospective-epistemicdigression—rules-of-apriorising/axiomatising/referencing-that-further-epistemicallyunconceal-the-very-ontologically-same-existential-reality' (from the perspective of the 'postconverging-or-dialectical-thinking ${ }^{2}{ }^{8}$ reference-of-thought in relative-ontologicalcompleteness $^{87}$ as depth-of-thought') (child-psychopath of unsound-mental-disposition in a 'dereifying act' poured water on chair, you mistakenly sat down on the chair, he told you his brother did it on purpose, by supplanting-conviction-as-to-profound-supererogation —of'attendant-intradimensional'-postconverging/dialectical-thinking -apriorising-psychologism reflex you acted in belief -and so, as an 'unwinding-as-unfolding/dépliage-as-détendre of elucidation'), and no elaboration-as-to-mereextrapolating/constituting/abstracting/deducing/inferring-of-elucidation-outside'prospectively_implicited_attendant-ontological-contiguity ${ }^{67}$ ' educedexistentialising/contextmalising/textualising_'intelligibility/epistemicity/reflexivity_contiguity$<$ imbued-notional $\sim$ cogency $>^{\prime 0}$ as the visiting stranger (as-of-pseudointemporality ${ }^{52}$ ) wrongly did (as the latter only arises where 'apriorising $-{ }^{83}$ reference-of-thought/apriorising-registryelements (out of 'implicitantantontological-contiguity ${ }^{67}$ ' educedexistentialising/contextmalising/textualising_intelligibility/epistemicity/reflexivity_contiguity$<$ imbued-notional $\sim$ cogency $>,{ }^{\prime},-<$ reifying-or-elucidating-of-prospective-relative-ontological- 
ontologically-veridical as \{epistemic-totalising 3 psychologismic-subliminality-of-individuationeffusing/worlding imbued logical-dueness-or-scape-or-frame, profile-or-stature, presumptuousness-or-arrogation, assumptions, value-reference and teleology ${ }^{99}$, even though the natural reflex to be of supplanting-conviction-as-to-profound-supererogation - of-'attendantintradimensional'-postconverging/dialectical-thinking -apriorising-psychologism

prelogism ${ }^{78}$-as-of-conviction,-in-profound-supererogation $-<$ existentially-veridical-

\section{'attendant-intradimensional-apriorising/axiomatising/referencing'-logical-dueness-precedes-}

disontologising-logical-outcome-arrived-at $>$ means that we rather tend to assume by reflex that the implied-logical-dueness-or-implied-scape of every interlocutor we engage with or by extension of the referenced interlocutor(s) of the interlocutor with whom we are engaging with is sound, thus by default validating all the 'apriorising- ${ }^{8}$ reference-of-thought/apriorisingregistry_elements (out of 'implicited_attendant-ontological-contiguity ${ }^{67}$ ' educedexistentialising/contextualising/textualising_intelligibility/epistemicity/reflexivity-contiguity$<$ imbued-notional $\sim \operatorname{cogency}>,{ }^{\prime},-<$ reifying-or-elucidating-of-prospective-relative-ontologicalcompleteness -of- reference-of-thought- devolving-as-of-instantiative-context $>$ )', which is the psychopath foundational faulty-mentation-procedure-deception-or-urge ${ }^{43}$ as first-order level of faulty-mentation-procedure-deception-or-urge ${ }^{3}$, as it further enables an infinitely expansive second-order level deception arising from wrongful ${ }^{54}$ logical-processing-or-logicalimplicitation-supposedly-apriorising-in-conviction-as-to-profound-supererogation once we wrongly go on to operate the fundamental first-order level of faulty-mentation-proceduredeception-or-urge logically/elaboration-as-to-mereextrapolating/constituting/abstracting/deducing/inferring-of-elucidation-outside'prospectively_implicited_attendant-ontological-contiguity ${ }^{67}$ ' educedexistentialising/contextualising/textualising_'intelligibility/epistemicity/reflexivity-contiguity- 
<imbued-notional cogency>' wherein we end up hollow-constituting-<as-disjointedmisappropriation-of-meaningfulness-and-failing-intemporal-preservation> inducing the virtuality-or-ontologically-flawed-construal/being-construal-as-abstract-construal-as-offlawed-and-shallow-and-non-veridical-existential-reference, and that's why psychopathy as an outlying mental-disposition we are not often used to, will tend to be deceptive and so fundamentally not because of the psychopath but the supplanting-conviction-as-to-profoundsupererogation - of-'attendant-intradimensional'-postconverging/dialectical-thinking apriorising-psychologism mind's own reflex mental-disposition to be of supplantingconviction-as-to-profound-supererogation -of-'attendant-intradimensional'postconverging/dialectical-thinking -apriorising-psychologism as prelogism ${ }^{78}$-as-ofconviction,-in-profound-supererogation $-<$ existentially-veridical-'attendant-intradimensionalapriorising/axiomatising/referencing'-logical-dueness-precedes-disontologising-logicaloutcome-arrived-at>). Critically, the concepts articulations in the storiedconstruct/ontologically-valid-narration aetiologisation/ontological-escalation- $<$ ontologicalveridicality_commitment/otherliness_transcending/compulsions-encumbered_transcending $>$ involve the "point-of-departure-of-construal of ${ }^{83}$ reference-of-thought technique of distractivealignment-to- ${ }^{83}$ reference-of-thought- $<$ of-apriorising/axiomatising/referencing $>{ }^{30}$ wherein: the narratives of the temporal-dispositions (postlogism 77 and conjugated-postlogism 77 ) as of threshold-of-nonconviction/madeupness/bottomlining-in-shallow-supererogation $-<$ as-to'attendant-intradimensional'-prospectively-disontologising preconverging/dementing apriorising-psychologism $>$ are construed in transversality-<for-sublimating-existentialeventuating/denouement,-from-'thinking at-first/pure-predisposition-preemptive-ofprospective disentologising/subentologising' as-of-prospectively-disambiguated-affirmedand-unaffirmed-'motif-and-apriorising/axiomatising/referencing'>101 as of subtransversality$<$ in-desublimating-existential-eventuating/denouement $>\sim$ of-motif-and- 
apriorising/axiomatising/referencing(*as-of-pseudointemporalities; referring to unsound reference-of-thought, and so as 'breaking sublimating-epistemicimbricatedness/threadedness/recomposuring as of 'implicited_attendant-ontologicalcontiguity ${ }^{67}$, educed-

existentialising/contextualising/textualising_'intelligibility/epistemicity/reflexivity-contiguity$<$ imbued-notional $\sim$ cogency $>,{ }^{\prime},-<$ reifying-or-elucidating-of-prospective-relative-ontologicalcompleteness -of- reference-of-thought- devolving-as-of-instantiative-context $>$ as to existence-potency ${ }^{39} \sim$ sublimating-nascence,-disclosed-from-prospective-epistemicdigression — rules-of-apriorising/axiomatising/referencing-that-further-epistemicallyunconceal-the-very-ontologically-same-existential-reality as existential-reality or procrypticism-or-disjointedness-as-of- ${ }^{8}$ reference-of-thought preconverging-or-dementing ${ }^{20}$ apriorising-psychologism', and consequently necessarily wrongly implied soundness/nonperverted- ${ }^{8}$ reference-of-thought, i.e. unsound/perverted 'apriorising- ${ }^{83}$ reference-ofthought/apriorising-registry_elements (out of 'implicited_attendant-ontologicalcontiguity $^{67} \sim$ educed-

existentialising/contextualising/textualising_'intelligibility/epistemicity/reflexivity-contiguity$<$ imbued-notional $\sim$ cogency $>,{ }^{\prime},-<$ reifying-or-elucidating-of-prospective-relative-ontologicalcompleteness -of- reference-of-thought- devolving-as-of-instantiative-context $>$ )' including \{epistemic-totalising 3 psychologismic-subliminality-of-individuation-effusing/worlding imbued logical-dueness-or-scape-or-frame, profile-or-stature, presumptuousness-or-arrogation, assumptions, value-reference and teleology ${ }^{9}$ and speaking of a mental-disposition not thriving for intemporal-preservation -whether unconsciously as with conjugated-ignorance, byexpediency as with conjugated-affordability or consciously as with conjugated-opportunism and conjugated-exacerbation, hence of threshold-of-nonconviction/madeupness/bottomlining-inshallow-supererogation -<as-to-'attendant-intradimensional'-prospectively- 
disontologising preconverging/dementing -apriorising-psychologism>, i.e. ${ }^{74}$ perversion-ofreference-of-thought-<as-preconvergingly-apriorising/axiomatising/referencing-innonconviction/madeupness/bottomlining-as-to-shallow-supererogation $>$ )-narratives-ofarrogation/impostoring/disjointedness-non-contending-meaningful-reference- $\{$ but-rather-thesubject-of-ontologically-veridical-contending-as-reflected-by-recursive-postlogicbacktracking-<iterative-looping-'set-of-dereifying-hollow-narratives-and-acts' $>{ }^{76}$-as-well-asconjugated-postlogism 77 -progressive-and-regressive- ${ }^{2}$ conjoining-looping-set-of-narratives $\}$ as-recursive/progressive/regressive-preconverging-or-dementing 20 -distractive-loopings- $\{$ in'threshold-of-nonconviction/madeupness/bottomlining-in-shallow-supererogation ${ }^{9}<$ as-to‘attendant-intradimensional'-prospectively-disontologising preconverging/dementing apriorising-psychologism>' -as-preconverging-or-dementing ${ }^{20}$-apriorising-psychologism-anddialectically-out-of-phase $\}$-to the-supratransversality-<in-sublimating-existentialeventuating/denouement $>\sim$ of-motif-and-apriorising/axiomatising/referencing (as-of-nonpseudointemporality ${ }^{52}$; referring to sound ${ }^{83}$ reference-of-thought, and so as 'upholding sublimating-epistemic-imbricatedness/threadedness/recomposuring as of 'implicited_attendant-ontological-contiguity ${ }^{67}$; educed-

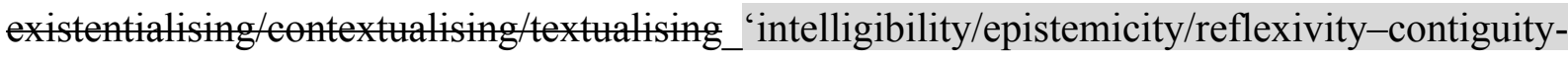
$<$ imbued-notional $\sim$ cogency $>$ ' ,-<reifying-or-elucidating-of-prospective-relative-ontologicalcompleteness -of- reference-of-thought- devolving-as-of-instantiative-context> as to existence-potency ${ }^{39} \sim$ sublimating-nascence,-disclosed-from-prospective-epistemicdigression—rules-of-apriorising/axiomatising/referencing-that-further-epistemicallyunconceal-the-very-ontologically-same-existential-reality as existential-reality or deprocrypticism, speaking of a mental-disposition thriving in all instances for intemporalpreservation but with-or-without necessarily subsequent perfect ${ }^{54}$ logical-processing-or-logicalimplicitation - supposedly-apriorising-in-conviction-as-to-profound-supererogation , hence 
postconverging-or-dialectical-thinking -apriorising-psychologism and dialectically-in-phase, i.e. sound-registry-〈reflected-as-soundness-or-ontological-good-faith/authenticity -of-

reference-of-thought $\rangle$ )-ontologically-hegemonising-narrative ${ }^{71}$ - as-the-deprocrypticismsublimating-epistemic-imbricatedness/threadedness/recomposuring-as-of-existential-realityand-as-the-suprastructuring-meaningful-reference-for-maximalising-unwinding-asunfolding/dépliage-as-détendre-of-elucidation $\}. \quad$ From an ontologicalnormalcy/postconvergence epistemic-or-notional projective-perspective, the distinction between the subtransversality-<in-desublimating-existential-eventuating/denouement $>\sim$ ofmotif-and-apriorising/axiomatising/referencing (as-of-pseudointemporalities) as of thresholdof-nonconviction/madeupness/bottomlining-in-shallow-supererogation $<-<$ as-to-' ${ }^{6}$ attendantintradimensional'-prospectively-disontologising preconverging/dementing -apriorisingpsychologism $>$ and the supratransversality-<in-sublimating-existentialeventuating/denouement $>\sim$ of-motif-and-apriorising/axiomatising/referencing (as-of-nonpseudointemporality ${ }^{52}$ ) as 'conviction-as-to-profound-supererogation", transcendental and maximalising' implies that the assertive pretences of 'supposed intellectual-and-moral equivalence' of the subtransversality-<in-desublimating-existentialeventuating/denouement $>\sim$ of-motif-and-apriorising/axiomatising/referencing (as-ofpseudointemporalities) are of threshold-of-nonconviction/madeupness/bottomlining-inshallow-supererogation -<as-to-'attendant-intradimensional'-prospectivelydisontologising preconverging/dementing -apriorising-psychologism> (beyond-theconsciousness-awareness-teleology ${ }^{9}<$ of-preconverging-existential-extrication-as-ofexistential-unthought>). As the notion of 'first-order-ontology/ontological-construal' of intemporal/ontological/social/species $/{ }^{103}$ universal/transcendental $/{ }^{55}$ maximalisingrecomposuring-for-relative-ontological-completeness ${ }^{8}$ — unenframed/reontologising conceptualisation postconverging-de-mentating/structuring/paradigming for 
'creating/inventing' prospective institutionalised-being-and-craft' implied by the transcendental, inherently 'dements' pretences of 'second-order meaningfulness' of extricatory/temporal preconverging-de-mentating/structuring/paradigming within secondnatured institutionalisedbeing-and-craft $\quad$ constructs. Supratransversality-<in-sublimating-existentialeventuating/denouement $>\sim$ of-motif-and-apriorising/axiomatising/referencing (as-of-nonpseudointemporality ${ }^{52}$ ) speaks of upholding the intemporal/transcendental $/ 5$ maximalisingrecomposuring-for-relative-ontological-completeness ${ }^{8}$ —unenframed/re-

ontologising conceptualisation by underlining sublimating-epistemicimbricatedness/threadedness/recomposuring that is of-existential-reality as of relative notionalcontiguity/epistemic-contiguity ${ }^{62}<$ profound-supererogation -of-mentallyaestheticised postconverging/dialectical-thinking -qualia-schema $>$ of ${ }^{8}$ reference-of-thought, and reflecting/perspectivating/highlighting subtransversality-<in-desublimating-existentialeventuating/denouement $>\sim$ of-motif-and-apriorising/axiomatising/referencing (as-ofpseudointemporalities) as upholding the temporal/non-transcendental/ incrementalism-inrelative-ontological-incompleteness ${ }^{8}$ —enframed/disontologising $\sim$ conceptualisation by disjointed/discontinuous/decontextualised/misappropriated utilisation of the same abstract construal (elaboration-as-to-mere-extrapolating/constituting/abstracting/deducing/inferring-ofelucidation-outside_- 'prospectively_implicited_attendant-ontological-contiguity ${ }^{67}$ ? educedexistentialising/contextualising/textualising_intelligibility/epistemicity/reflexivity-contiguity<imbued-notional cogency>' ${ }^{\prime 0}$ ) for being-construal/existential-reality-construal as does supratranversality, thus inducing virtualities/being-construals-as-abstract-construal-as-offlawed-and-shallow-and-non-veridical-existential-reference as ${ }^{7}$ perversion-of- ${ }^{83}$ reference-ofthought-<as-preconvergingly-apriorising/axiomatising/referencing-innonconviction/madeupness/bottomlining-as-to-shallow-supererogation $>$ involving the discontinuity (as postlogic-backtracking-<iterative-looping-'set-of-dereifying-hollow- 
narratives-and-acts' $>$ and ${ }^{12}$ conjoining-looping-set-of-narratives of the postlogicbacktracking-<iterative-looping-'set-of-dereifying-hollow-narratives-and-acts'>76) of reference-of-thought, reflecting a teleologically-perverted (postlogism77) and derivedteleologically-perverted (conjugated-postlogism 7 ) mental-dispositions and so as of ontologicalbad-faith/inauthenticity ${ }^{64}$, where such is not unconscious/unwitting as arises with ignoranceconjugated-postlogism 7 . It is this ever-perverting effect on ontological-veridicality of subtransversality-<in-desublimating-existential-eventuating/denouement $>\sim$ of-motif-andapriorising/axiomatising/referencing (as-of-pseudointemporalities) reflected by the 'contrastive intellectual-and-moral tone-as-temperament and thematic teleological constructs of subtransversality-<in-desublimating-existential-eventuating/denouement $>\sim$ of-motif-andapriorising/axiomatising/referencing (as-of-pseudointemporalities) in relation to supratransversality-<in-sublimating-existential-eventuating/denouement $>\sim$ of-motif-andapriorising/axiomatising/referencing (as-of-non-pseudointemporality ${ }^{52}$ ' as instigated by postlogism 77 enculturated-postlogism 77 in protraction as temporal-preservation-aspseudointemporality ${ }^{52}$-preservation that tends to generate threshold-ofnonconviction/madeupness/bottomlining-in-shallow-supererogation $<<$ as-to- 'attendant-

\section{intradimensional'-prospectively-disontologising preconverging/dementing -apriorising-}

psychologism> reflecting the uninstitutionalised-threshold ${ }^{12}$ at institutionalisations' uninstitutionalised-threshold $^{102}$. $\quad$ Basically, $\quad$ from a transcendental/transdimensional/interdimensional $/{ }^{55}$ maximalising-recomposuring-for-relativeontological-completeness ${ }^{87}$ - unenframed/re-ontologising conceptualisation insight, the supratransversality-<in-sublimating-existential-eventuating/denouement $>\sim$ of-motif-andapriorising/axiomatising/referencing contends about the ${ }^{74}$ perversion-of- ${ }^{8}$ reference-of-thought$<$ as-preconvergingly-apriorising/axiomatising/referencing-in- 
subtransversality-<in-desublimating-existential-eventuating/denouement $>\sim$ of-motif-and-

apriorising/axiomatising/referencing which is in protracted-pseudointemporality ${ }^{52}$; more like a deprocrypticism, positivism, ${ }^{103}$ universalisation or base-institutionalisation supratransversality$<$ in-sublimating-existential-eventuating/denouement $>\sim$ of-motif-and-

apriorising/axiomatising/referencing (as-of-non-pseudointemporality ${ }^{52}$ ) contending correspondingly about the perversion-of- ${ }^{73}$ reference-of-thought-<as-preconverginglyapriorising/axiomatising/referencing-in-nonconviction/madeupness/bottomlining-as-toshallow-supererogation $>$ of the procrypticism, non-positivism/medievalism, ununiversalisation or recurrent-utter-uninstitutionalisation subtransversality-<in-desublimatingexistential-eventuating/denouement $>\sim$ of-motif-and-apriorising/axiomatising/referencing (asof-pseudointemporality $^{52}$ ). The implication here is that from a storied-construct/ontologicallyvalid-narration aetiologisation/ontological-escalation- $<$ ontologicalveridicality_commitment/otherliness_transcending/compulsions-encumbered_transcending>, just as a positivistic supratransversality-<in-sublimating-existentialeventuating/denouement $>$ of-motif-and-apriorising/axiomatising/referencing $\quad$ (as-of-nonpseudointemporality ${ }^{52}$ ) will imply a deeper intellectual-and-moral ontological construct (in a projection of a positivistic worldview where the mental-dispositions and conventioning in a nonpositivism/medievalism setup are construed as prospectively questionable) of non-equivalence over that projected by a non-positivism/medievalism subtransversality-<in-desublimatingexistential-eventuating/denouement $>\sim$ of-motif-and-apriorising/axiomatising/referencing (asof-pseudointemporality ${ }^{52}$ ) as a 'distractive looping-alignment-of-narratives' in distraction to the former, with the positivistic supratransversality-<in-sublimating-existentialeventuating/denouement $>\sim$ of-motif-and-apriorising/axiomatising/referencing $\quad$ rather a maximalising/transcendental firmament for obtruding the subtransversality-<in-desublimatingexistential-eventuating/denouement $>\sim$ of-motif-and-apriorising/axiomatising/referencing as of 
its 'threshold-of-nonconviction/madeupness/bottomlining-in-shallow-supererogation

‘attendant-intradimensional'-prospectively-disontologising preconverging/dementing

apriorising-psychologism>', reflected by the subtransversality-<in-desublimating-existentialeventuating/denouement> of-motif-and-apriorising/axiomatising/referencing

subontologisation/subpotentiation (in-a-social-dynamism-of-meaningfulness-misappropriation) by slantedness/postlogic-effect, miscuing, disjointed-logic, logical-drag, unconscionabilitydrag, sub-par/formulaic-association/temporal/alibi conventioning-rationalising, and temporalenculturation/temporal-endemisation effect; the same analysis will be drawn for a storiedconstruct/ontologically-valid-narration aetiologisation/ontological-escalation- $<$ ontologicalveridicality_commitment/otherliness_transcending/compulsions-encumbered_transcending > with respect to notional ${ }^{18}$ deprocrypticism supratransversality-<in-sublimating-existentialeventuating/denouement $>\sim$ of-motif-and-apriorising/axiomatising/referencing (as-of-nonpseudointemporality $^{52}$ ) and procrypticism subtransversality-<in-desublimating-existentialeventuating/denouement $>$ of-motif-and-apriorising/axiomatising/referencing (as-ofpseudointemporality ${ }^{52}$ ) in terms-as-of-axiomatic-construct of their implied intellectual-andmoral implications (in a projection of a notional ${ }^{18}$ deprocrypticism worldview where the mentaldispositions and conventioning in a procrypticism setup are construed as 'prospectively questionable'). Such a supratransversality-<in-sublimating-existentialeventuating/denouement> of-motif-and-apriorising/axiomatising/referencing over subtransversality-<in-desublimating-existential-eventuating/denouement $>\sim$ of-motif-andapriorising/axiomatising/referencing insight can transcendentally be grasped in the archetype characters of say a Socrates or Rousseau. Wherein within their respective registryworldviews/dimensions setups, their maximalising/transcendental mental-dispositions in projection for prospective institutionalised-being-and-craft, i.e. ontologising of future conventioning, as supratransversality-<in-sublimating-existential- 
eventuating/denouement $>\sim$ of-motif-and-apriorising/axiomatising/referencing (as the grander intellectual-and-moral effort that can be made within their registry-worldviews/dimensions) is rather poorly construed to the ordinariness/averageness of thought within their respective registry-worldviews/dimensions setups (which mental-dispositions and conventioning -as 'wrongly-projected decontextualising-unimbricatedness/unthreadedness/unrecomposuring,-asvirtuality-or-ontologically-flawed-construal (which is rather a 'prior threshold-ofnonconviction/madeupness/bottomlining-in-shallow-supererogation -<as-to-'attendantintradimensional'-prospectively-disontologising preconverging/dementing -apriorisingpsychologism> ${ }^{83}$ reference-of-thought' in shallowness-of-thought-or-unsophistication-ofunderstanding) in grasping 'implicited_attendant-ontological-contiguity ${ }^{67}$ ' educedexistentialising/contextualising/textualising_intelligibility/epistemicity/reflexivity-contiguity$<$ imbued-notional $\sim$ cogency $>,{ }^{\prime},-<$ reifying-or-elucidating-of-prospective-relative-ontologicalcompleteness -of- reference-of-thought- devolving-as-of-instantiative-context> as to existence-potency $^{39} \sim$ sublimating-nascence,-disclosed-from-prospective-epistemicdigression—rules-of-apriorising/axiomatising/referencing-that-further-epistemicallyunconceal-the-very-ontologically-same-existential-reality' -will rather think as irrational the projective disposition of a Socrates that doesn't rather advance a temporal interest in the citystate polity but is rather bent on spreading new ideas as a natural philosopher while prioritising as of pestconverging-nonextricatory-existential-preempting-of-existential-unthought in his asceticism the prospective intemporal over the temporal status quo, and likewise with a Rousseau who isn't advancing a temporal interest that his aristocratic stature should warrant like actively pursuing for landed properties and currying favours with kings but is rather bent principally on a prospective commitment on grasping and spreading notions of a renewal of the human condition as ${ }^{103}$ universal rights and enlightened despotism. This is certainly because emanantly/becomingly/solipsistically temporal-dispositions do not appreciate that there is a 
more 'profound level of living in the realm of human thoughtfulness' based on eudaemoniccontemplation of 'intemporal-prioritisation-of- ${ }^{8}$ reference-of-thought'-as-conflatedness ${ }^{13}$-orontological-reprojecting that then 'invents/creates' the preconverging/postconverging-dementative/structural/paradigmatic possibility for prospective institutionalised-being-and-craft as there isn't any inherent intemporality ${ }^{52} /$ longness but for the disposition for ${ }^{5}$ maximalisingrecomposuring-for-relative-ontological-completeness 87 unenframed/re-

ontologising conceptualisation out of the apathy of the ordinariness/averageness of any prior registry-worldview/dimension institutionalised-being-and-craft setup. Hence such intemporality ${ }^{52} /$ longness as $\quad{ }^{55}$ maximalising-recomposuring-for-relative-ontologicalcompleteness ${ }^{87}$ - unenframed/re-ontologising conceptualisation needs its $<$ amplituding/formative-epistemicity $>$-totalising $\sim$ renewing-realisation/re-perception/rethought in inducing secondnatured institutionalisation given that the-succession-of-registryworldviews-or-dimensions-institutionalisations as to the-relative-unreflexivity/relativereflexivity - ontological-contiguity ${ }^{67} \sim$ of-the-human-institutionalisation-process ${ }^{68}$ is 'not a human emanance/seeding/incipient — transformation- $<$ as-to-Derridean-messianicity-whereineven-when-the-messiah-as-intemporal-drive-comes-they-still-have-to-come $>$ of temporaldispositions/shorness of register of meaning inness and teleology into the intemporaldisposition/longness-of-register-of- meaningfulness-and-teleology (not about firstnaturedness-as-to-inkling of human dimensionality-of-sublimating <<amplituding/formative>supererogatory $\sim$ de-mentativeness/epistemic-growth-orconflatedness /transvaluative-rationalising/transepistemicity/anamnestic-residuality/spiritdrivenness-equalisation)) but rather is solely a positive-opportunism-of-social-functioningand-accordance ${ }^{75}$ secondnaturing to supersede the uninstitutionalised-threshold ${ }^{102}$ divulged as to its relative-ontological-incompleteness ${ }^{8}$-induced,-'threshold-ofnonconviction/madeupness/bottomlining-in-shallow-supererogation $-<$ as-to-'attendant- 
psychologism>'. The implication is that acting as-of-a-'secondnatured reproducibilitymathesis/motif/thrownness-disposition,-as-reproducibility-of-aestheticisation nature' is not enough for articulating prospective institutionalisation requiring 'intemporal projection $<$ amplituding/formative-epistemicity $>$-totalising $\sim$ renewing-realisation/re-perception/re-

thought' for the requisite prospective ${ }^{55}$ maximalising-recomposuring-for-relative-ontologicalcompleteness ${ }^{87}$ — unenframed/re-ontologising conceptualisation, and such conceptualisations from only a secondnaturedness of thought as rather contextually temporal is not 'intemporal asof- ${ }^{103}$ universal-and-abstractive originariness-parrhesia,-as-spontaneity-of-aestheticisation nature' but is rather in '<amplituding/formative-epistemicity $>$ totalising $\sim$ self-referencingsyncretising'/illusion-of-the-present/present-consciousness/mirage as metaphysics-of-presence〈implicited-'nondescript/ignorable-void '-as-to- presencing-absolutising-identitive-

constitutedness $\rangle$. Thus institutionalisation secondnaturedness is challenged by its very own level of relative-ontological-incompleteness ${ }^{8}$-induced,-'threshold-ofnonconviction/madeupness/bottomlining-in-shallow-supererogation $<<$ as-to-'attendantintradimensional'-prospectively-disontologising preconverging/dementing -apriorisingpsychologism>' marking its uninstitutionalised-threshold ${ }^{02}$ whether as recurrent-utteruninstitutionalisation, ununiversalisation, non-positivism-or-medievalism and procrypticism in need for a renewed institutionalisation respectively as base-institutionalisation, universalisation, positivism and prospectively deprocrypticism. This is rather addressed by transversality-<for-sublimating-existential-eventuating/denouement-from-'thinking-atfirst/pure-predisposition-preemptive-of-prospective-disontologising/subontologising' as-ofprospectively-disambiguated-affirmed-and-unaffirmed-'motif-andapriorising/axiomatising/referencing'>101 as supratransversality-<in-sublimating-existentialeventuating/denouement $>\sim$ of-motif-and-apriorising/axiomatising/referencing non- 
pseudointemporality ${ }^{52}$-as-thinking-and-in-phase $\quad$ over $\quad$ subtransversality- $<$ in-desublimatingexistential-eventuating/denouement $>\sim$ of-motif-and-apriorising/axiomatising/referencing pseudointemporality ${ }^{52}$-as-preconverging-or-dementing ${ }^{20}$-and-out-of-phase so reflected in storied-construct/ontologically-valid-narration aetiologisation/ontological-escalation<ontological-veridicality_commitment/otherliness_transcending/compulsions-

encumbered_transcending $>$ evolving thematic and tone-as-temperament rather by maximalising-recomposuring-for-relative-ontological-completeness ${ }^{87}$ - unenframed/re-

ontologising conceptualisation

imbricatedness/threadedness/recomposuring of

as of 'implicited_attendant-ontologicalcontiguity $^{67}$, educed-

existentialising/contextmalising/textmalising_intelligibility/epistemicity/reflexivity-contiguity$<$ imbued-notional $\sim \operatorname{cogency}>,{ }^{\prime},-<$ reifying-or-elucidating-of-prospective-relative-ontologicalcompleteness -of- reference-of-thought- devolving-as-of-instantiative-context> as to existence-potency ${ }^{32} \sim$ sublimating-nascence,-disclosed-from-prospective-epistemicdigression—rules-of-apriorising/axiomatising/referencing-that-further-epistemicallyunconceal-the-very-ontologically-same-existential-reality as existential-reality, for the ultimate crossgenerational purpose of psychoanalytic-unshackling/memetic-reordering/institutionalrecomposuring). The transcendental first-order-ontology/ontological-construal work derived by maximalising-recomposuring-for-relative-ontological-completeness ${ }^{87}$ - unenframed/reontologising conceptualisation (as intemporal-projection/longness-of register-ofmeaningfulness-and-teleology ) in recurrent-utter-uninstitutionalisation inducing transcendental/intemporal-preserving base-institutionalisation, ${ }^{55}$ maximalising-recomposuringfor-relative-ontological-completeness ${ }^{87}$ - unenframed/re-ontologising $\sim$ conceptualisation in base-institutionalisation-ununiversalisation inducing transcendental/intemporal-preserving ${ }^{3}$ universalisation, ${ }^{55}$ maximalising-recomposuring-for-relative-ontological-completeness ${ }^{87}$ - 
unenframed/re-ontologising conceptualisation (as intemporal-projection/longness-of-registerof - meaningfulness-and-teleølogy $)$ in ${ }^{103}$ universalisation-non-positivism/medievalism inducing transcendental/intemporal-preserving positivism, and prospectively maximalisingrecomposuring-for-relative-ontological-completeness ${ }^{8}$ —unenframed/re-

ontologising conceptualisation (as intemporal-projection/longness-of-register-ofmeaningfulness-and-teleelogy $)$ in positivism- ${ }^{80}$ procrypticism inducing transcendental/intemporal-preserving deprocrypticism, are the most important effort available at every corresponding registry-worldview as defining the institutionalisation possibilities and psyches that secondnatured as institutionalisation as their corresponding institutionalised-beingand-craft setups even though paradoxically the ordinariness within such institutionalised-beingand-craft setups may be impervious to what is behind this very creation/invention in the first place as it fails philosophically to appreciate the need for transcendental first-orderontology/ontological-construal in the elucidation (as institutionalisation and psychicalreorientation) of meaningful-and-teleological pertinence within its own registryworldview/dimension but equally in 'inventing/creating' the institutionalisation possibilities and psyche for the prospective institutionalised-being-and-craft setup. Thus it is generally not surprising that the transcendental first-order-ontology/ontological-construal by an ascetic intemporal-prioritising/ maximalising-recomposuring-for-relative-ontologicalcompleteness ${ }^{87}$ — unenframed/re-ontologising conceptualisation Socrates will be passed by the ordinariness/earthliness of thought in that institutionalised-being-and-craft setup as vague while upholding its shallow notion of value with the true worth and value of such implied transcendence-and-sublimity/sublimation/supererogatory - de-mentativity grasped, at least expediently, mostly in the prospective institutionalised-being-and-craft setup it ushers, the same could be said of an intemporal-prioritising/ $/ 5$ maximalising-recomposuring-for-relativeontological-completeness ${ }^{87}$ - unenframed/re-ontologising conceptualisation Copernicus, an 
intemporal-prioritising $/$ maximalising-recomposuring-for-relative-ontological-

completeness ${ }^{87}$ - unenframed/re-ontologising conceptualisation Rousseau, an intemporalprioritising/ maximalising-recomposuring-for-relative-ontological-completeness ${ }^{87}$ unenframed/re-ontologising conceptualisation Galilei or an intemporalprioritising/ ${ }^{5}$ maximalising-recomposuring-for-relative-ontological-completeness ${ }^{87}$ unenframed/re-ontologising conceptualisation Darwin, and so as a fact of human-subpotencyaporia/undecidability/dilemma/ought-indeterminacy/deficiency/limitation/constraint—imbued'notional firstnaturedness-formativeness-<as-to-eventualising inkling-drive-or-seeding misprising $>$ temporal-to-intemporal-dispositions- $<$ so-construed-as-from-perspectiveontological-normalcy/postconvergence>'-existentialism-form-factor. But then mentaldispositions that come to intemporal notions by expediency cannot truly have the pretence of engaging such on the basis of shallow temporal extricatory preconverging-dementating/structuring/paradigming as of institutionalised-being-and-craft setup whose temporaldispositions terms are alien to the intemporal disposition required for transcendental $/{ }^{55}$ maximalising-recomposuring-for-relative-ontological-completeness ${ }^{87}$ unenframed/re-ontologising conceptualisation first-order-ontology/ontological-construal required for 'creating/inventing' the prospective institutionalised-being-and-craft setup! That failed test of understanding the transcendental/ $/ 5$ maximalising-recomposuring-for-relativeontological-completeness ${ }^{87}$ - unenframed/re-ontologising conceptualisation not in a prospective appreciation, but rather possibly as of retrospective appreciation and expediency, speaks of the social-construct as more of a secondnatured institutionalised-construct rather than an intemporal-disposition construal, and therefore assertive pretences that naively imply the latter should necessarily be suspect of their threshold-ofnonconviction/madeupness/bottomlining-in-shallow-supererogation $<-<$ as-to-' $a$ attendantintradimensional'-prospectively-disontologising preconverging/dementing -apriorising- 
psychologism $>$ without the corresponding demonstration of the requisite salient philosophical insight of intemporal/ontological/social $/$ species $/{ }^{103}$ universal/transcendental $/{ }^{5}$ maximalisingrecomposuring-for-relative-ontological-completeness ${ }^{8}$ —unenframed/re-

ontologising conceptualisation postconverging-de-mentating/structuring/paradigming (that goes beyond subontologisation/subpotentiation as slantedness/postlogic-effect, miscuing, disjointed-logic, logical-drag, unconscionability-drag, sub-par/formulaicassociation/temporal/alibi conventioning-rationalising, and temporal-enculturation/temporalendemisation-effect); and the fundamental issue that will then arise in that instance is one of 'irrealism and corresponding virtualities' that will undermine analytical pertinence, as man has to be understood exactly for what man is in effective reality, to then articulate effective knowledge constructs that are actually most efficient because of their realism, and that is paradoxically our virtue, not a wrong or false idealism (which metaphorically ends up hiding things under the table beyond the analysis required for their understanding and resolution)! It equally speaks of the 'requisite specialness of the discipline of philosophy as a first-order ontology' among all subject-matters (or-as-it-protrudes-into-subject-matters-or-second-orderontologies), as the one that can least afford to be of normal trade, as it starts with a commitment of the mind (rather like modern-day religion) rather than just a normal craft, and further requiring the central quality of transcendentally-enabling-level-of $\sim$ ontological-good-faith-orauthenticity $\%$ objectification/desubjectification-as-objectification-<as-to-ontological-faithnotion-or-ontological-fideism - imbued-underdetermination-of-motif-andapriorising/axiomatising/referencing-as-so-being-as-of-existential-reality as antinihilism> ${ }^{00}$ of thought, postures and teleology ${ }^{9}$ above anything else (not even the value of institutional recognition as Socrates, Rousseau, Sartre and others intuitively understood, necessarily so, since it is what is of a-priori definition and can't be compromised in institutional-constructs-andsetups)! The blunt fact here is that, with respect to social-stake-contention-or-confliction within 
a given registry-worldview, the everyday <amplituding/formative $>$ wooden-language〈imbued-averaging-of-thought-<as-to-leveling/ressentiment/closed-construct-ofmeaningfulness-and-teleology -as-of-'nondescript/ignorable-void '-with-regards-toprospective-apriorising-implications $>\rangle$ or banality-of-thought doesn't necessarily as of solipsistic intemporal projection appreciate the 'need for prospective transcendental/ maximalising-recomposuring-for-relative-ontological-completeness ${ }^{87}$ unenframed/re-ontologising conceptualisation postconverging-dementating/structuring/paradigming over the extricatory/temporal/expediency preconverging-dementating/structuring/paradigming with respect to its registry-worldview/dimension' (even though it does appreciate this retrospectively with respect to prior registryworldviews/dimensions), but for effective secondnatured institutional devising. Inevitably an aetiologisation/ontological-escalation-<ontologicalveridicality_commitment/otherliness_transcending/compulsions-encumbered_transcending> $\begin{array}{lll}\text { construct } & \text { is about }\end{array}$ intemporal/ontological/social/species/ ${ }^{103}$ universal/transcendental/ ${ }^{5}$ maximalisingrecomposuring-for-relative-ontological-completeness ${ }^{87}$ — unenframed/reontologising conceptualisation postconverging-de-mentating/structuring/paradigming which is necessarily antipodal to the everyday temporal extricatory preconverging-dementating/structuring/paradigming mental-disposition, ontologically justifying 'subtransversality-<in-desublimating-existential-eventuating/denouement $>\sim$ of-motif-andapriorising/axiomatising/referencing(as-of-pseudointemporalities)/suprastraversality 'point-ofdeparture-of-construal of ${ }^{83}$ reference-of-thought technique of distractive-alignment-toreference-of-thought-<of-apriorising/axiomatising/referencing $>$ given its applicative pertinence and validation to the ontologically-veridical but counterintuitive notion of thresholdof-nonconviction/madeupness/bottomlining-in-shallow-supererogation $<$ - as-to- 'attendant- 
intradimensional'-prospectively-disontologising preconverging/dementing -apriorising-

psychologism> underlying all uninstitutionalised-threshold ${ }^{102}$, and so beyond their consciousness-awareness-teleologies; with the implication that (from a maximalisingrecomposuring-for-relative-ontological-completeness ${ }^{87}$ —unenframed/re-

ontologising conceptualisation ontological-normalcy/postconvergence epistemic-ornotional projective-perspective) the subtransversality-<in-desublimating-existentialeventuating/denouement $\gg \sim$ of-motif-and-apriorising/axiomatising/referencing (as-ofpseudointemporalities) is 'unprofound'-or-of-a-non-transcendental/extricatory/impostoring disjointing/disparateness/disentailing-of-narratives-implied-intellectual-and-moral-disposition while the supratransversality-<in-sublimating-existential-eventuating/denouement $>\sim$ of-motifand-apriorising/axiomatising/referencing (as-of-non-pseudointemporality ${ }^{52}$ ) is 'profound'-orof-a-transcendental-intemporal/totalisingly-entailing-ontologically-hegemonising-narrative implied-intellectual-and-moral-disposition. We would possibly appreciate this argument from a retrospective insight of how the retrospective institutionalisations came about to the present, but it will certainly be alienating to think the same of our present in those transcended terms from a prospective transcending reference, even though the ontological insight points in that direction. This 'subtransversality-<in-desublimating-existential-eventuating/denouement $>$-bysupratransversality-<in-sublimating-existential-eventuating/denouement $>$ technique of transversality-<for-sublimating-existential-eventuating/denouement,-from-'thinking atfirst/pure-predisposition-preemptive-of prospective-disontologising/subontologising' as-ofprospectively-disambiguated-affirmed-and-unaffirmed-'motif-and-

apriorising/axiomatising/referencing' $>101$ is further rendered operant as the teleological structure of the storied-construct/ontologically-valid-narration aetiologisation/ontological-escalation<ontological-veridicality_commitment/otherliness_transcending/compulsionsencumbered_transcending $>$ based on the underlying principle involved in the example of the 
visiting stranger (as-of-pseudointemporality ${ }^{52}$ ) or generally the BODMAS characters. This underlying principle is one of 'decentering' wherein apparently the visiting stranger (as-ofpseudointemporality ${ }^{52}$ ) was of 'sound registry-〈reflected-as-soundness-or-ontological-goodfaith/authenticity -of- reference-of-thought $\rangle$ ' in its circumstantial/existential relationship with

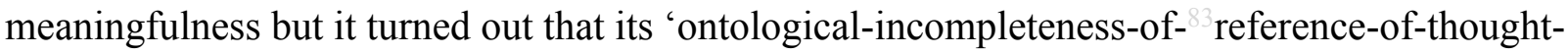
induced-virtuality-or-ontologically-flawed-construal-or-caricaturing-hollow-staging-andperformance-so-construed-by-prospective- ${ }^{8}$ reference-of-thought' notional ${ }^{18}$ deprocrypticism from an ontological-normalcy/postconvergence epistemic-ornotional projective-perspective) arising from its ${ }^{80}$ procrypticism-or-disjointedness-as-ofreference-of-thought (as social ${ }^{103}$ universal-transparency ${ }^{104}$-〈transparency-of-totalisingentailing,-as-to-entailing-<amplituding/formative-epistemicity $>$ totalising $\sim$ in-relativeontological-completeness > about the child-psychopath's postlogism 77 wasn't available to it) implied an existential-reality of sublimating-epistemicimbricatedness/threadedness/recomposuring that 'decentered' (by ${ }^{55}$ maximalisingrecomposuring-for-relative-ontological-completeness 8 - unenframed/re-

ontologising conceptualisation) its meaningfulness as of threshold-ofnonconviction/madeupness/bottomlining-in-shallow-supererogation $-<$ as-to-' $a$ attendantintradimensional'-prospectively-disontologising preconverging/dementing -apriorisingpsychologism $>, \quad$ as $\quad$ subtransversality- $<$ in-desublimating-existentialeventuating/denouement $>$ of-motif-and-apriorising/axiomatising/referencing (as-ofpseudointemporalities), of the visiting stranger rather as a virtuality-or-ontologically-flawedconstrual/being-construal-as-abstract-construal-as-of-flawed-and-shallow-and-non-veridicalexistential-reference given the visiting stranger's (as-of-pseudointemporality ${ }^{52}$ ) ignoranceconjugated-postlogism 7 , such that it was actually in 'threshold-ofnonconviction/madeupness/bottomlining-in-shallow-supererogation $<-<$ as-to- 'attendant- 
psychologism>'. This 'decentering drive' rather construed by ${ }^{55}$ maximalising-recomposuringfor-relative-ontological-completeness ${ }^{87}$ - unenframed/re-ontologising $\sim$ conceptualisation that then reveals the true center as 'notional ${ }^{18}$ deprocrypticism supplanting-conviction-as-toprofound-supererogation of-'attendant-intradimensional'-postconverging/dialecticalthinking -apriorising-psychologism as of transcendental-projection/intemporalpreserving/ ${ }^{5}$ maximalising-recomposuring-for-relative-ontological-completeness ${ }^{8}$ unenframed/re-ontologising conceptualisation sublimating-epistemicimbricatedness/threadedness/recomposuring as existential-reality' (while undermining various shades of virtualities/being-construals-as-abstract-construal-as-of-flawed-and-shallow-and-nonveridical-existential-reference), is the 'underlying teleological conceptualisation of the phenomenon of psychopathy and social psychopathy in society in its absolving/fleeting/escaping-reflex-logic'; as it uncompromisingly 'decenters temporaldispositions as postlogism (disontologising-perverted-outcome-sought-precedes-existentiallyveridical-'attendant-intradimensional-apriorising/axiomatising/referencing'-logical-dueness) and conjugated-postlogism ${ }^{7}$, (in the latter case whether beyond-the-consciousness-awarenessteleology ${ }^{0}-<$ of-preconverging-existential-extrication-as-of-existential-unthought $>$-asignorance) as per their 'ontological-incompleteness-of- ${ }^{8}$ reference-of-thought-inducedvirtuality-or-ontologically-flawed-construal-or-caricaturing-hollow-staging-and-performanceso-construed-by-prospective- ${ }^{8}$ reference-of-thought' (as being procrypticism-ordisjointedness-as-of- ${ }^{8}$ reference-of-thought), starting with the psychopath's postlogism $77 /$ perversion-of- ${ }^{83}$ reference-of-thought- $<$ as-preconverginglyapriorising/axiomatising/referencing-in-nonconviction/madeupness/bottomlining-as-toshallow-supererogation $>$ itself wherein its decentering (by ${ }^{55}$ maximalising-recomposuring-forrelative-ontological-completeness ${ }^{87}$ — unenframed/re-ontologising $\sim$ conceptualisation 
'unwinding-as-unfolding/dépliage-as-détendre of élucidation') is reflected as a virtuality-orontologically-flawed-construal/being-construal-as-abstract-construal-as-of-flawed-andshallow-and-non-veridical-existential-reference in threshold-ofnonconviction/madeupness/bottomlining-in-shallow-supererogation $-<$ as-to-' attendantintradimensional'-prospectively-disontologising preconverging/dementing -apriorisingpsychologism $>$ while 'establishing the center' as the 'notional ${ }^{18}$ deprocrypticism supplantingconviction-as-to-profound-supererogation —of-'attendant-intradimensional'postconverging/dialectical-thinking -apriorising-psychologism as of transcendentalprojection/intemporal-preserving/ $/ 5$ maximalising-recomposuring-for-relative-ontologicalcompleteness ${ }^{87}$ — unenframed/re-ontologising conceptualisation sublimating-epistemicimbricatedness/threadedness/recomposuring of 'implicited_attendant-ontologicalcontiguity $^{67}$, educed-

existentialising/contextalising/textalising_'intelligibility/epistemicity/reflexivity_contiguity$<$ imbued-notional $\sim \operatorname{cogency}>,{ }^{\prime},-<$ reifying-or-elucidating-of-prospective-relative-ontologicalcompleteness -of- reference-of-thought- devolving-as-of-instantiative-context> as to existence-potency $^{39} \sim$ sublimating-nascence,-disclosed-from-prospective-epistemicdigression—rules-of-apriorising/axiomatising/referencing-that-further-epistemicallyunconceal-the-very-ontologically-same-existential-reality') by its 'effective supplantingconviction-as-to-profound-supererogation —of-'attendant-intradimensional'postconverging/dialectical-thinking -apriorising-psychologism as to intemporalpreserving/transcendental/ $/ 5$ maximalising-recomposuring-for-relative-ontologicalcompleteness ${ }^{87}$ - unenframed/re-ontologising conceptualisation teleological ${ }^{83}$ reference-ofthought' as supratranversality, and as conjugated-postlogism 77 preconverging-or-dementing integration (as per the corresponding mental-dispositions highlighted earlier for the various conjugated-postlogism 7 , with corresponding 'contrastive intellectual-and-moral tone-as- 
temperament and thematic teleological constructs of subtransversality- $<$ in-desublimatingexistential-eventuating/denouement $>\sim$ of-motif-and-apriorising/axiomatising/referencing, as-ofpseudointemporalities, in relation to supratransversality-<in-sublimating-existentialeventuating/denouement $>\sim$ of-motif-and-apriorising/axiomatising/referencing, as-of-nonpseudointemporality ${ }^{52}$ ) arises from ignorance-conjugated-postlogism ${ }^{77}$ affordabilityconjugated-postlogism 77 opportunistm-conjugated-postlogism 7 , exacerbation-conjugatedpostlogism 77 social-chainism-conjugated-postlogism 77 and temporal-enculturation-conjugatedpostlogism 7 , such that correspondingly these are 'decentered' (by maximalisingrecomposuring-for-relative-ontological-completeness ${ }^{8}$ —unenframed/re-

ontologising conceptualisation) as virtualities/being-construals-as-abstract-construal-as-offlawed-and-shallow-and-non-veridical-existential-reference with a 'more and more profound/elaborated notional deprocrypticism supplanting-conviction-as-to-profoundsupererogation —of-'attendant-intradimensional'-postconverging/dialectical-thinking apriorising-psychologism as of transcendental-projection/intemporalpreserving/ ${ }^{5}$ maximalising-recomposuring-for-relative-ontological-completeness ${ }^{87}$ unenframed/re-ontologising conceptualisation 'sublimating-epistemicimbricatedness/threadedness/recomposuring as of 'implieitontontologicalcontiguity $^{67}$; educed-

existentialising/contextualising/textualising_intelligibility/epistemicity/reflexivity-contiguity$<$ imbued-notional cogency $>,{ }^{,},-<$reifying-or-elucidating-of-prospective-relative-ontologicalcompleteness -of- reference-of-thought- devolving-as-of-instantiative-context> as to existence-potency $^{39} \sim$ sublimating-nascence,-disclosed-from-prospective-epistemicdigression—rules-of-apriorising/axiomatising/referencing-that-further-epistemicallyunconceal-the-very-ontologically-same-existential-reality' (from the perspective of the 'postconverging-or-dialectical-thinking ${ }^{2}{ }^{8}$ reference-of-thought in relative-ontological- 
completeness ${ }^{87}$ as depth-of-thought') reflecting their corresponding ${ }^{7}$ perversion-of- ${ }^{8}$ referenceof-thought-<as-preconvergingly-apriorising/axiomatising/referencing-in-

nonconviction/madeupness/bottomlining-as-to-shallow-supererogation $>$, and these are ontologically never allowed to escape the intrinsic-reality of their threshold-ofnonconviction/madeupness/bottomlining-in-shallow-supererogation $<<$ as-to- 'attendantintradimensional'-prospectively-disontologising preconverging/dementing -apriorisingpsychologism>, wherein the 'notional ' deprocrypticism supplanting-conviction-as-toprofound-supererogation of-'attendant-intradimensional'-postconverging/dialecticalthinking -apriorising-psychologism as of transcendental-projection/intemporalpreserving/ ${ }^{5}$ maximalising-recomposuring-for-relative-ontological-completeness ${ }^{87}$ unenframed/re-ontologising conceptualisation threadedness/thread as of existential-reality never breaks' (given that intrinsic-reality/existential-reality is a notional-contiguity/epistemiccontiguity ${ }^{2}-<$ profound-supererogation - of-mentally-aestheticised $\sim$ postconverging/dialecticalthinking -qualia-schema $>$ that precedes and supersedes any threshold-ofnonconviction/madeupness/bottomlining-in-shallow-supererogation $<<$ as-to-'attendantintradimensional'-prospectively-disontologising preconverging/dementing -apriorising-

psychologism>)! This 'continuous profound/elaborate notional ${ }^{18}$ deprocrypticism supplantingconviction-as-to-profound-supererogation -of-'attendant-intradimensional'-

postconverging/dialectical-thinking -apriorising-psychologism as of transcendentalprojection/intemporal-preserving $/{ }^{55}$ maximalising-recomposuring-for-relative-ontologicalcompleteness ${ }^{87}$ —unenframed/re-ontologising conceptualisation 'sublimating-epistemicimbricatedness/threadedness/recomposuring as of 'implicited_attendant-ontologicalcontiguity ${ }^{67}$ educedexistentialising/contextualising/textualising_intelligibility/epistemicity/reflexivity-contiguity$<$ imbued-notional $\sim$ cogency $>,,-<$ reifying-or-elucidating-of-prospective-relative-ontological- 
existence-potency $^{39} \sim$ sublimating-nascence,-disclosed-from-prospective-epistemicdigression—rules-of-apriorising/axiomatising/referencing-that-further-epistemicallyunconceal-the-very-ontologically-same-existential-reality' (from the perspective of the 'postconverging-or-dialectical-thinking ${ }^{8}$ reference-of-thought in relative-ontologicalcompleteness ${ }^{87}$ as depth-of-thought') is the supratransversality-<in-sublimating-existentialeventuating/denouement $>\sim$ of-motif-and-apriorising/axiomatising/referencing (as-of-nonpseudointemporality ${ }^{52}$ ) that is a complete and unique 'ontologically-hegemonising-narrative ontological-performance ${ }^{72}$-<including-virtue-as-ontology $>$ ' in its supplanting-conviction-as-toprofound-supererogation _of-‘attendant-intradimensional'-postconverging/dialecticalthinking -apriorising-psychologism or transcendental/intemporal $/{ }^{5}$ maximalisingrecomposuring-for-relative-ontological-completeness ${ }^{8}$ —unenframed/reontologising conceptualisation disposition of ${ }^{83}$ reference-of-thought which 'bounces off and decenters' (by ${ }^{55}$ maximalising-recomposuring-for-relative-ontological-completeness ${ }^{87}$ unenframed/re-ontologising conceptualisation) the-recursive/progressive/regressivepreconverging-or-dementing ${ }^{20}$-distractive-looping-narratives-of-

arrogation/impostoring/disjointedness-non-contending-meaningful-reference of temporaldispositions (postlogism 77 and conjugated-postlogism 7 ) as the subtransversality-<indesublimating-existential-eventuating/denouement $>\sim$ of-motif-and-

apriorising/axiomatising/referencing (as-of-pseudointemporalities), to their collapsing (psychoanalytic-unshackling/memetic-reordering/institutional-recomposuring). Thematically (with regards to 'associated-themes-and-social-contexts'/thematic) psychopathy as postlogism interlocks with temporal-dispositions (instigating social psychopathy in 'socially-perceivedvalue as of social-stake-contention-or-confliction situations') as temporal-dispositions are already preset/'in-wait as of prior relative-ontological-incompleteness ${ }^{88}$-of- ${ }^{8}$ reference-of- 
thought defective ${ }^{83}$ reference-of-thought- categorical-imperatives/axioms/registry-teleology for its induced conjugated-postlogism 77 by inherent relative-ontological-incompleteness ${ }^{8}$ induced,-'threshold-of-nonconviction/madeupness/bottomlining-in-shallow-supererogation

\section{<as-to-'attendant-intradimensional'-prospectively-}

\section{disontologising preconverging/dementing -apriorising-psychologism>’}

(notional procrypticism, i.e. the corresponding uninstitutionalised-threshold ${ }^{102}$ ), such that the postlogism dynamism in its social protraction reflects a threshold-ofnonconviction/madeupness/bottomlining-in-shallow-supererogation $<-<$ as-to-' $a$ attendant-

\section{intradimensional'-prospectively-disontologising preconverging/dementing -apriorising-}

psychologism $>$ as of temporality 8 /non-transcendence-andsublimity/sublimation/supererogatory de-mentativity/ incrementalism-in-relative-ontologicalincompleteness 8 - enframed/disontologising conceptualisation in corresponding conjugatedpostlogism 77 of temporal-dispositions with the protracting effect of 'significant others basis of logic', as subtransversality-<in-desublimating-existential-eventuating/denouement $>\sim$ of-motifand-apriorising/axiomatising/referencing (as-of-pseudointemporalities). Such that grasping and superseding of psychopathy and social psychopathy ontologically requires 'avoiding to construe the generality/averaging of the social-construct as being of the sound/appropriate ontological cadre/framework' but rather ontologically adopting deferential-formalisation-transference (as all formal constructions whether the law, subject-matters, formal institutions, etc. have always been conceived) to 'abstractly reference prospective institutionalising as a secondnaturing that is of universal implications as to aetiologisation/ontological-escalation- $<$ ontologicalveridicality_commitment/otherliness_transcending/compulsions-encumbered_transcending > for all times and all humans' by factoring-in the requisite supplanting-conviction-as-toprofound-supererogation _of-'attendant-intradimensional'-postconverging/dialecticalthinking -apriorising-psychologism as of transcendental-projection/intemporal- 
preserving/ ${ }^{5}$ maximalising-recomposuring-for-relative-ontological-completeness ${ }^{87}$

unenframed/re-ontologising conceptualisation construct that transcends/supersedes subtransversality-<in-desublimating-existential-eventuating/denouement $>\sim$ of-motif-and-

apriorising/axiomatising/referencing (as-of-pseudointemporalities), as supratransversality-<insublimating-existential-eventuating/denouement $>\sim$ of-motif-and-

apriorising/axiomatising/referencing (as-of-non-pseudointemporality ${ }^{52}$ ). Such a technique for articulating supratransversality-<in-sublimating-existential-eventuating/denouement $>\sim$ ofmotif-and-apriorising/axiomatising/referencing (as-of-non-pseudointemporality ${ }^{52}$ ) in aetiologisation/ontological-escalation- $<$ ontologicalveridicality_commitment/otherliness_transcending/compulsions-encumbered_transcending $>$ with respect to 'associated-themes-and-social-contexts'/thematic as deferential-formalisationtransference involves 'construing supratransversality-<in-sublimating-existentialeventuating/denouement $>\sim$ of-motif-and-apriorising/axiomatising/referencing (as-of-nonpseudointemporality ${ }^{52}$ over $\quad$ subtransversality-<in-desublimating-existentialeventuating/denouement> of-motif-and-apriorising/axiomatising/referencing (as-ofpseudointemporalities)' wherein the differentiated-conjugated-postlogism 77 are construed as interlocking with postlogic-backtracking-<iterative-looping-‘set-of-dereifying-hollownarratives-and-acts'> (as the conjugated-postlogism ${ }^{77}$ conjoin to and elevate postlogicbacktracking-<iterative-looping-'set-of-dereifying-hollow-narratives-and-acts'> ${ }^{\circ}$ ) in the 'associated-themes-and-social-contexts'/thematic framework/cadre. The fact is this thematic construal is further compounded by the varying tone-as-temperament associated with psychopathy and social psychopathy wherein the threshold-ofnonconviction/madeupness/bottomlining-in-shallow-supererogation $<<$ as-to-'attendantintradimensional'-prospectively-disontologising preconverging/dementing -apriorisingpsychologism $>$ of postlogism 77 , conjugated-postlogism 77 or temporal-dispositions means that it 
is 'ontologically wrong to be engaged solely on the basis of a supplanting-conviction-as-toprofound-supererogation _of-'attendant-intradimensional'-postconverging/dialecticalthinking -apriorising-psychologism tone as temperament'; as the 'consciously eluding/circumventing' psychopathy as postlogism 77 mental-disposition adopts various 'hollow tones as temperaments' on the basis of its perceived position of weakness/disadvantage or strength/advantage, with implications on soundness of ${ }^{83}$ reference-of-thought, whether acting (threshold-of-nonconviction/madeupness/bottomlining-in-shallow-supererogation $<-<$ as-to‘attendant-intradimensional'-prospectively-disontologising preconverging/dementing apriorising-psychologism>) by 'imploring, contesting, affirming, condescending, rebelling or self-victimising' depending on what it perceives as advancing its postlogism -as-ofcompulsing-nonconviction/madeupness/bottomlining-〈' $<$ decontextualising/deexistentialising $\sim$ of-attendant-intradimensional-apriorising/axiomatising/referencing $>$-induceddisontologising'-of-the-'attendant-intradimensional-ontologising'-imbued$<$ contextualising/existentialising attendant-ontological-contiguity $>$;-in-shallowsupererogation -<as-to-disontologising-perverted-outcome-sought-precedes-existentiallyveridical-'attendant-intradimensional-apriorising/axiomatising/referencing'-logical-dueness $>$ > at one moment or the other, and this mental-disposition is naively (where ignorant-conjugatedpostlogism 7 ) or consciously adopted by conjugated-postlogism mental-dispositions particularly when exacerbatory or opportunistic. This 'contrastive intellectual-and-moral toneas-temperament and thematic teleological constructs of subtransversality-<in-desublimatingexistential-eventuating/denouement $>\sim$ of-motif-and-apriorising/axiomatising/referencing (asof-pseudointemporalities) in relation to supratransversality-<in-sublimating-existentialeventuating/denouement $>\sim$ of-motif-and-apriorising/axiomatising/referencing (as-of-nonpseudointemporality ${ }^{52}$ )' is central in articulating a storied-construct/ontologically-validnarration aetiologisation/ontological-escalation- $<$ ontological- 
veridicality_commitment/otherliness_transcending/compulsions-encumbered_transcending $>$ that further elucidates the conceptualisations herein. The conceptual background for this toneas-temperament and thematic teleological conceptualisation (for the storiedconstruct/ontologically-valid-narration $\quad$ aetiologisation/ontological-escalation- $<$ ontologicalveridicality_commitment/otherliness_transcending/compulsions-encumbered_transcending $>$ ) lies in the notion that human construal of meaningfulness/memetism defines and structures its teleology $/$ teleological-differentiation with respect to 'socially-perceived-value as of socialstake-contention-or-confliction' situations whether in 'notional firstnaturedness-formativeness<as-to-eventualising inkling-drive-or-seeding-misprising $>$ temporal-to-intemporaldispositions-<so-construed-as-from-perspective-ontological-normalcy/postconvergence $>$ individuation terms' and as this in dynamic-cumulative-aftereffect defines individuals actions intradimensionally or transcendentally/transdimensionally/interdimensionally/maximalisingly. For instance, in the latter case a meaningfulness/memetism fundamentally based on spirits as causes-and-effects will fundamentally be predisposed to a defining teleology $/$ teleologicaldifferentiation of animism practices, and the corresponding ways of thoughts and live patterns; likewise a meaningfulness/memetism fundamentally based on a grand religion will fundamentally be structured on the basis of such religious practices, and the corresponding ways of thoughts and live pattern (depending on the degree of religious absolutism) as its defining teleology $/$ teleological-differentiation, and likewise a meaningfulness/memetism that is mostly secular-inclined will be predisposed to the defining teleology $/$ teleological-differentiation of down-to-earth interests including utilitarianism and practical knowledge/scientism, and the corresponding ways of thoughts and live patterns. Going by the defining notional firstnaturedness-formativeness $<$ as to ventulising inkling drive or seeding misprising $>$ temporal-to-intemporal-dispositions- $<$ so-construed-as-from-perspectiveontological-normalcy/postconvergence $>$ of individuals action intradimensionally (and as 
recurrently affirmed by the relative-unreflexivity/relative-reflexivity-ontologicalcontiguity ${ }^{67}$ of-the-human-institutionalisation-process ${ }^{68}$ across all the registryworldviews/dimensions, giving rise to prospective institutionalisations and uninstitutionalisedthreshold ${ }^{102}$ ), this establishes that there is a deterministic existential-tautologisation/existentialreference of human-subpotency-aporia/undecidability/dilemma/oughtindeterminacy/deficiency/limitation/constraint—imbued-'notional firstnaturednessformativeness-<as-to-eventualising-inkling-drive-or-seeding-misprising $>$ temporal-tointemporal-dispositions- $<$ so-construed-as-from-perspective-ontologicalnormalcy/postconvergence>'-existentialism-form-factor mental-dispositions with respect to 'socially-perceived-value as of social-stake-contention-or-confliction' highlighting a teleology $/$ teleological-differentiation at the individuation-level in a continuum from pseudointemporality ${ }^{52}$ (involving the 'faulty-mentation-procedure-deception-or-urge ${ }^{13}$ of postlogism -slantedness and the derived-by-conjoining temporal-accommodation-of-thisperversion-of- ${ }^{3}$ reference-of-thought-<as-preconvergingly-

\section{apriorising/axiomatising/referencing-in-nonconviction/madeupness/bottomlining-as-to-}

shallow-supererogation $>$ as $\quad$ conjugated-postlogism 77 preconverging-or-dementing ${ }^{20}$ integration, grounded on 'extrinsic-attribution involving inducing sociologically significant others basis of meaning and logic') as it induces the uninstitutionalised-threshold ${ }^{102}$ - to - nonpseudointemporality $^{52}$ (of intemporal mental-disposition inclined to account for pseudointemporality ${ }^{52}$ as 'intemporal-preservation as to aetiologisation/ontological-escalation<ontological-veridicality_commitment/otherliness_transcending/compulsionsencumbered_transcending >' operating on a teleology $/$ teleological-differentiation of 'intrinsicattribution based on solely eliciting intersolipsistic understanding of intemporally/ ${ }^{103}$ universally valid meaning and logic', inducing the institutionalisations; with the implication that futural Being-development/ontological-framework-expansion-as-to-depth-of-ontologising- 
development-as-infrastructure-of- meaningfulness-and-teleology as of prospective notional ${ }^{18}$ deprocrypticism teleology 9 /teleological-differentiation by its ${ }^{18}$ deprocrypticism-orpreempting - disjointedness-as-of- reference-of-thought 'implicited_attendant-ontologicalcontiguity $^{67}$, educed-

existentialising/contextualising/textualising_intelligibility/epistemicity/reflexivity-contiguity$<$ imbued-notional $\sim$ cogency $>,{ }^{\prime},-<$ reifying-or-elucidating-of-prospective-relative-ontologicalcompleteness -of- reference-of-thought- devolving-as-of-instantiative-context> involving existence-potency $^{39} \sim$ sublimating-nascence,-disclosed-from-prospective-epistemicdigression—rules-of-apriorising/axiomatising/referencing-that-further-epistemicallyunconceal-the-very-ontologically-same-existential-reality 'preempting the threshold-ofnonconviction/madeupness/bottomlining-in-shallow-supererogation $-<$ as-to-' attendantintradimensional'-prospectively-disontologising preconverging/dementing -apriorisingpsychologism $>$ of rational-empiricism/positivising-rules' is necessarily construed to stall the possibility of any uninstitutionalised-threshold ${ }^{102}$ ). This then validates the idea that teleology /teleological-differentiation is not a discrete construct but rather deterministic as of existential-reference/existential-tautologisation/ontology/ontological-veridicality of 'implicited_atentantontological-contiguity ${ }^{67}$; educedexistentialising/contextmalising/textualising_'intelligibility/epistemicity/reflexivity_contiguity$<$ imbued-notional $\sim$ cogency $>>,-<$ reifying-or-elucidating-of-prospective-relative-ontologicalcompleteness -of- reference-of-thought- devolving-as-of-instantiative-context $>$ (as a naïve free-willist conceptualisation may construe teleology ${ }^{9} /$ teleological-differentiation as discrete, as a conceptualisation of teleology' is rather valid by 'emanance/becoming/existentialintersolipsism notional $\sim$ reflexivity- $<\{$ veridieal/sound $\}$ relative-reflexivity-inexistence/relativising from-limited-mentation-as-its-deepening/psychologismic<residualising \{decompulsing delinearity for-cogency $>$ by-\{flawed/unsound\}-relative- 
unreflexivity-in-existence/absolutising from-limited-mentation/psychologismic epistemic

acutisation nonresidualising-imbued-\{compulsing\} linearity in-eclecticism-of-prior-mere-

formulaicity/ritualisation> $>$ with regards to reference-of-thought as to

postconverging/dialectical-thinking -apriorising-psychologism mental-devising-representation from whence $\quad{ }^{5}$ logical-processing-or-logical-implicitation-supposedly-apriorising-inconviction-as-to-profound-supererogation arises whether the supplanting-conviction-as-toprofound-supererogation _of-'attendant-intradimensional'-postconverging/dialecticalthinking -apriorising-psychologism is appropriate/good or inappropriate/poor-or-bad, over preconverging/dementing ${ }^{20}$-apriorising-psychologism mental-devising-representation in a state of mentarchy/mental-anarchy logical-undueness as reflected by postlogism 77 and conjugatedpostlogism 77 but from whence/which-point the teleology $\%$ teleological-differentiation attached to that as of mental-disposition orientation made, whether as of various temporal-dispositions as postlogism 77 -slantedness/ ${ }^{5}$ ignorance/affordability/opportunism/exacerbation/social-chainismor-social-discomfiture-or-negative-social-aggregation/temporal-enculturation-or-temporalendemisation, so-disambiguated as of ${ }^{83}$ reference-of-thought- ${ }^{8}$ devolving ontologicalperformance $^{72}-<$ including-virtue-as-ontology $>$ /morality/ethics/justice/etc. $\quad$ or intemporaldisposition, is wholly deterministic-as-predictable/projectable enabling $<$ amplituding/formative-epistemicity $>$ causality $\sim$ as-to-projective-totalitative-implications-ofprospective- nonpresencing,-for-explicating relative-unreflexivity/relative-reflexivity ontological-contiguity construal/conceptualisation). Existence/existential-reality is thus a teleological-contiguity/oneness-of-teleology" 'with teleological-discretion being defined only by epistemic choice/differentiation', as epistemically-situated chosen/differentiated meaningfulness (as to ontology/ontological-veridicality which is notionally/epistemically/bindingnessly-<as-to-determinism/conceptivity-of-relative-unreflexivity/relative-reflexivity> $\quad$ a contiguity construed-as relative-unreflexivity/relative-reflexivity-ontological- 
contiguity ${ }^{6}$ or_intrinsic-reality-ontological-coherence_or_superseding-oneness-of-ontology), defines and structures teleology/teleological-differentiation in its derivation as 'sublimatingepistemic-imbricatedness/threadedness/recomposuring as of 'implicited_attendant-ontologicalcontiguity $^{67}$, educed-

existentialising/contextualising/textualising_intelligibility/epistemicity/reflexivity-contiguity$<$ imbued-notional $\sim$ cogency $>,{ }^{\prime},-<$ reifying-or-elucidating-of-prospective-relative-ontologicalcompleteness -of- reference-of-thought- devolving-as-of-instantiative-context> as to existence-potency $^{39} \sim$ sublimating-nascence,-disclosed-from-prospective-epistemicdigression—rules-of-apriorising/axiomatising/referencing-that-further-epistemicallyunconceal-the-very-ontologically-same-existential-reality' (from the perspective of the 'postconverging-or-dialectical-thinking ${ }^{2}{ }^{8}$ reference-of-thought in relative-ontologicalcompleteness ${ }^{87}$ as depth-of-thought'). Beyond, the individuation-level and the intradimensional perspectives, at the transcendental/transdimensional/interdimensional $/ 5$ maximalisingrecomposuring-for-relative-ontological-completeness ${ }^{87}$ - unenframed/re-

ontologising conceptualisation perspective as across all institutional-cumulation/institutionalrecomposure-〈as-to- historiality/ontological-eventfulness /ontological-aesthetic-tracing$<$ perspective--ontological-normalcy/postconvergence-reflected-‘epistemicity-relativismdeterminism' $>$, this ${ }^{55}$ maximalising-recomposuring-for-relative-ontological-completeness ${ }^{8}$ unenframed/re-ontologising conceptualisation decentering drive in a dynamic-cumulativeaftereffect (wherein prior relative-ontological-incompleteness ${ }^{8}$-induced,-'threshold-ofnonconviction/madeupness/bottomlining-in-shallow-supererogation $<<$ as-to- 'attendantintradimensional'-prospectively-disontologising preconverging/dementing -apriorisingpsychologism>' <amplituding/formative-epistemicity $>$ causality $\sim$ as-to-projective-totalitativeimplications-of-prospective- nonpresencing,-for-explicating relative-unreflexivity/relativereflexivity - ontological-contiguity on meaningfulness 'as to social dynamism of threshold-of- 
nonconviction/madeupness/bottomlining-in-shallow-supererogation

$<$ as-to-'attendant-

intradimensional'-prospectively-disontologising preconverging/dementing -apriorising-

psychologism>', is decentered with the more ontologically-complete emerging at the centre as supplanting-conviction-as-to-profound-supererogation —of-'attendant-intradimensional'postconverging/dialectical-thinking -apriorising-psychologism as of transcendentalprojection/intemporal-preserving/ ${ }^{55}$ maximalising-recomposuring-for-relative-ontologicalcompleteness ${ }^{87}$ — unenframed/re-ontologising conceptualisation 'sublimating-epistemicimbricatedness/threadedness/recomposuring as of 'implicited_attendant-ontologicalcontiguity $^{67}$, educed-

existentialising/contextmalising/textualising_'intelligibility/epistemicity/reflexivity_contiguity$<$ imbued-notional $\sim$ cogency $>,{ }^{\prime},-<$ reifying-or-elucidating-of-prospective-relative-ontologicalcompleteness -of- reference-of-thought- devolving-as-of-instantiative-context> as to existence-potency ${ }^{32} \sim$ sublimating-nascence,-disclosed-from-prospective-epistemicdigression—rules-of-apriorising/axiomatising/referencing-that-further-epistemicallyunconceal-the-very-ontologically-same-existential-reality' as from the perspective of the 'postconverging-or-dialectical-thinking ${ }^{21}{ }^{83}$ reference-of-thought in relative-ontologicalcompleteness $^{87}$ as depth-of-thought') is what 'decenters/drives-out' by '"de-mentation〈supererogatory $\sim$ ontological-de-mentation-or-dialectical-de-mentation-stranding-or-

attributive-dialectics $\rangle$ of ${ }^{83}$ reference-of-thought' of an uninstitutionalised-threshold ${ }^{12}$ (like nonpositivism/medievalism) to 'center' the corresponding and prospective institutionalisation (like positivism) ${ }^{83}$ reference-of-thought, and ultimately reflects/perspectivates/highlights/decenters the uninstitutionalised-threshold ${ }^{102}$ as of threshold-of-nonconviction/madeupness/bottomliningin-shallow-supererogation -<as-to-'attendant-intradimensional'-prospectivelydisontologising preconverging/dementing -apriorising-psychologism $>$, from the perspective of the succeeding institutionalisation/centered. Thus, decentering is what divulges all the 
uninstitutionalised-threshold ${ }^{102}$ as recurrent-utter-uninstitutionalisation, ununiversalisation, nonpositivism/medievalism and prospectively procrypticism by ${ }^{55}$ maximalising-recomposuring-forrelative-ontological-completeness ${ }^{8}$ —unenframed/re-ontologising conceptualisation, while 'centering' divulges all the institutionalisations as base-institutionalisation, ${ }^{103}$ universalisation, positivism and prospectively deprocrypticism; and so with their ontological possibilities and limits as well as corresponding 'postconverging-or-dialectical-thinking -psychology or psychology-of-mentation-dynamics or natural psychological-dynamics’ or registryworldview/dimension orienting/pivoting/decentering psyches (by psychoanalyticunshackling/memetic-reordering/institutional-recomposuring), $\quad{ }^{83}$ reference-of-thought and teleologies/teleogical-differentiations. Insightfully from metaphysics-of-absence-〈implicitedepistemic-veracity-of- nonpresencing-<perspective-ontological-normalcy/postconvergence $>\rangle$, we'll certainly grasp that a non-positivism/medievalism mindset $/{ }^{3}$ reference-of-thought 'is not qualified/sound' by virtue of its relative-ontological-incompleteness ${ }^{8}$-induced,-'threshold-ofnonconviction/madeupness/bottomlining-in-shallow-supererogation $-<$ as-to-'attendant-

\section{intradimensional'-prospectively-disontologising preconverging/dementing -apriorising-}

psychologism>' as not being positivising/rationally-empirical given that its meaningfulness is based on its non-positivism/medievalism $\quad{ }^{83}$ reference-of-thought- categoricalimperatives/axioms/registry-teleology ${ }^{9}$,-for-intemporal-preservation-entropy-or-contiguityor-ontological-preservation thus failing/not-upholding- $<$ as-ofapriorising/axiomatising/referencing $>$ any meaningfulness requiring prospective positivising/rationally-empirical reference-of-thought- categoricalimperatives/axioms/registry-teleology ${ }^{9}$,-for-intemporal-preservation-entropy-or-contiguityor-ontological-preservation, and that its pretence otherwise is nothing but $<$ amplituding/formative-epistemicity $>$ totalising $\sim$ self-referencing-syncretising/illusion-of-thepresent/present-consciousness/mirage that simply goes on to uphold/enculturate/endemise the 
prior inherent vices-and-impediments ${ }^{105}$ inherent from its relative-ontological-incompleteness ${ }^{8}$ induced,-'threshold-of-nonconviction/madeupness/bottomlining-in-shallow-supererogation <as-to-'attendant-intradimensional'-prospectively-

disontologising preconverging/dementing -apriorising-psychologism>' (nonpositivism/medievalism) of lacking a positivising/rationally-empirical mindset, we can just as well project of the same of our procrypticism mindset $/{ }^{83}$ reference-of-thought with respect to our relative-ontological-incompleteness ${ }^{8}$-induced,-'threshold-ofnonconviction/madeupness/bottomlining-in-shallow-supererogation $-<$ as-to-' ${ }^{-}$ttendantintradimensional'-prospectively-disontologising preconverging/dementing -apriorising-

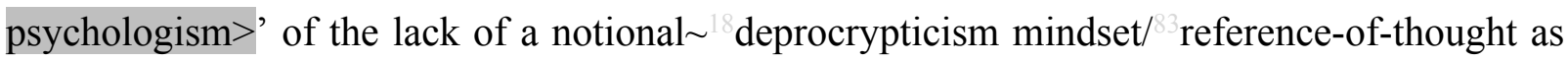
of ${ }^{18}$ deprocrypticism-or-preempting - disjointedness-as-of- ${ }^{3}$ reference-of-thought 'implicited_attendant-ontological-contiguity ${ }^{67}$ ' educedexistentialising/contextmalising/textualising_'intelligibility/epistemicity/reflexivity-contiguity$<$ imbued-notional $\sim$ cogency $>,{ }^{\prime},-<$ reifying-or-elucidating-of-prospective-relative-ontologicalcompleteness -of- reference-of-thought- devolving-as-of-instantiative-context> involving existence-potency $^{39} \sim$ sublimating-nascence,-disclosed-from-prospective-epistemicdigression—rules-of-apriorising/axiomatising/referencing-that-further-epistemicallyunconceal-the-very-ontologically-same-existential-reality 'preempting the threshold-ofnonconviction/madeupness/bottomlining-in-shallow-supererogation $<<$ as-to- 'attendantintradimensional'-prospectively-disontologising preconverging/dementing -apriorisingpsychologism> of rational-empiricism/positivising-rules' based 'sublimating-epistemicimbricatedness/threadedness/recomposuring as of 'implicited_attendant-ontologicalcontiguity $^{67}$, educedexistentialising/contextalising/textalising_'intelligibility/epistemicity/reflexivity_contiguity$<$ imbued-notional $\sim$ cogency $>,{ }^{\prime},-<$ reifying-or-elucidating-of-prospective-relative-ontological- 
existence-potency $^{32} \sim$ sublimating-nascence,-disclosed-from-prospective-epistemicdigression—rules-of-apriorising/axiomatising/referencing-that-further-epistemicallyunconceal-the-very-ontologically-same-existential-reality') and a disposition for our metaphysics-of-presence-〈implicited-‘nondescript/ignorable-void '-as-to- presencingabsolutising-identitive-constitutedness $\rangle \quad$ as <amplituding/formativeepistemicity>totalising self-referencing-syncretising/illusion-of-the-present/presentconsciousness/mirage, and thus the 'rational need' for our own psychoanalyticunshackling/memetic-reordering/institutional-recomposuring to supersede the vices-andimpediments ${ }^{105}$ associated with a positivism- ${ }^{8}$ procrypticism mental frame, even though we'll possibly carry-complexes/complexé about the blunt fact, as all registry-worldviews/dimensions prior to ours had equally done. Decentering thus fundamentally speaks of human shallowlimited-mentation-capacity—as-subjecting 'educed-unlimitedness/existence-sublimating nascence' to-limitedness/human-subpotency to deeper-limited-mentation capacity recomposuring from ontological-normalcy/postconvergence point of reference maximalisingrecomposuring-for-relative-ontological-completeness ${ }^{87}$ - unenframed/re-

ontologising conceptualisation across all institutional-cumulation/institutional-recomposure〈as-to- historiality/ontological-eventfulness /ontological-aesthetic-tracing-<perspectiveontological-normalcy/postconvergence-reflected-‘epistemicity-relativism-determinism’>>. The notion of pivoting/decentering as fundamentally psychoanalytic actually extends to the construal of understanding itself with regards to the underlying rescheduling of the placeholdersetup/mental-devising-representation/mentation/consciousness-awareness-teleology ${ }^{99}$, as the idea of pivoting/decentering extends to the notion of the 'self's own pivoting/decentering for understanding'. It is an aberration to construe 'transcendental text' which puts into question the reference-of-thought itself in non-transcendental terms 'as the transcendental reality (divulged 
by human limited-mentation-capacity-deepening -as-subjecting limitedness/humansubpotency-to-'educed-unlimitedness/existence-sublimating-nascence' ${ }^{3}$ with corresponding recomposuring of ontological import) that is being implied given the ontologicalnormalcy/postconvergence nature of transcendental text doesn't concede to a human temporal complex of its established metaphysics-of-presence-〈implicited-'nondescript/ignorable-void as-to- presencing - absolutising-identitive-constitutedness > conventioning/traditional-ways of understanding as superseding but rather superseded, and having to cave in'. In other words the postconverging-aporeticism-overcoming/unovercoming nature of a Derridean deconstruction text doesn't speak of the poor writing of Derrida, it speaks of the reader's 'complex of understanding' that fails to recognise its need to psychoanalytically-unshackle, construed in interdimensional transcendence-and-sublimity/sublimation/supererogatory $\sim$ dementativity terms as akin to a positivistic laden text articulated in a non-positivism/medievalism setup implying a necessary psychoanalytic-unshackling as requiring the pivoting/decentering of the reader for its understanding as it is more than an explanation in the terms of the old as nonpositivism/medievalism ${ }^{56}$ meaningfulness-and-teleology ${ }^{9}$ but more critically an invitation into the new as of a positivising/rational-empirical mindset $/{ }^{3}$ reference-of-thought ${ }^{56}$ meaningfulnessand-teleology ; having to do fundamentally with the human mind complex and reflex of failing/not-upholding-<as-of-apriorising/axiomatising/referencing $>$ to acquiesce to prospective transcendence-and-sublimity/sublimation/supereregatory-de-mentativity and so all across the various institutional-cumulation/institutional-recomposure-〈as-to- historiality/ontologicaleventfulness /ontological-aesthetic-tracing-<perspective-ontologicalnormalcy/postconvergence-reflected-'epistemicity-relativism-determinism'>> in reflecting holographically-<conjugatively-and-transfusively $>$ the relative-unreflexivity/relativereflexivity - ontological-contiguity of-the-human-institutionalisation-process , even though it will readily acquiesce from a standpoint of retrospectively implied construal of transcendence- 
and-sublimity/sublimation/supererogatoryade-mentativity. Such a pivoting/decentering of understanding itself is what is implied by 'projective-insights'/postdication/metaphysics-ofabsence-〈implicited-epistemic-veracity-of- nonpresencing-<perspective-ontologicalnormalcy/postconvergence $>$ ); further explaining the underlying notion of suprastructuralism as the ability to construe/conceptualise meaningfulness across different ontological-completenessof- ${ }^{3}$ reference-of-thought perspective whether recurrent-utter-uninstitutionalisation, baseinstitutionalisation-ununiversalisation, $\quad{ }^{103}$ universalisation-non-positivism/medievalism, our present positivism- ${ }^{8}$ procrypticism or futural Being-development/ontological-frameworkexpansion-as-to-depth-of-ontologising-development-as-infrastructure-of- meaningfulnessand-teleology as of prospective deprocrypticism, with the necessary de-mentation〈supererogatory $\sim$ ontological-de-mentation-or-dialectical-de-mentation-stranding-orattributive-dialectics $\rangle$ involved in such a pivoting/decentering as psychoanalyticunshackling/memetic-reordering/institutional-recomposuring. Suprastructuralism as such will also explain the underlying logic of Bruno Latour's famous criticism of the notion that scientists reported discovery of $\mathrm{TB}$ as being the cause of Pharaoh Ramses II death together with the organisation of an official ceremony in full honours in celebration of Ramses II corpse and the discovery, as being an entanglement of ${ }^{8}$ references-of-thought between the modern frame-ofreference/collective-consciousness-awareness-teleology ${ }^{99}$ and the Ancient Egypt pharaonic era frame-of-reference/collective-consciousness-awareness-teleology (a mix-up that must not occur for history itself to conceptually exist 'since history wouldn't deny its object of study its very own frame-of-reference, as being oblivious here to the notion of TB', for an exercise of understanding the past and projecting to the future); as if it were 'possible and desired' that the modern frame-of-reference equally carry modern weapons back in time in Ancient Egypt and fight pharaoh Ramses II wars (which is obviously ridiculous). Suprastructuralism as such highlights the 'mental complex of all present mindsets as metaphysics-of-presence-〈implicited- 
'nondescript/ignorable-void '-as-to- presencing - absolutising-identitive-constitutedness \’,

and going by 'projective-insights'/postdication/metaphysics-of-absence-〈implicited-epistemicveracity-of- nonpresencing-<perspective-ontological-normalcy/postconvergence $>\rangle$ is equally what can enable our own prospective transcendence-andsublimity/sublimation/supererogatory de-mentativity in grasping a more profound intrinsicreality/ontological-veridicality as notional deprocrypticism which is deeper than our present positivism- ${ }^{80}$ procrypticism registry-worldview ${ }^{83}$ reference-of-thought. As implied in this paper, the implication of pivoting/decentering for understanding itself is that our metaphysics-ofpresence-〈implicited-'nondescript/ignorable-void '-as-to- presencing —absolutising-

identitive-constitutedness $\rangle$ traditional/conventioning ${ }^{83}$ reference-of-thought- categoricalimperatives/axioms/registry-teleology ${ }^{9}$ is put-into-question, and the notion of understanding itself is pivoted/decentered such as implied by the referentialism approach of this fepistemictotalising ${ }^{3}{ }^{3}$ hermeneutic/textuality/reprojecting/supererogating/zeroing/re-acuting,-

\{decompulsing delinearity for-cogency design (as opposed to a categorisation constituting elaboration basis for understanding). As the referential harkens to the most profound concept (intemporal-preservation-entropy-or-contiguity-or-ontological-preservation also construed as ontological-normalcy/postconvergence) and ontologically-reconstitutes/deconstructs lesser and lesser profound concepts in relation to the most profound concept by a referencing understanding. The implication is that the entirety of the text is a unity in contiguity perceptible from the subtexts fusion with the unity. Hence the organisation of the text can only be crossreferencing (and not, wrongly, an organisation based on categorisation constituting elaboration) to retain its cross-referencing coherence of prospective meaningfulness. The recognition for the need to disambiguate human mental-dispositions as of temporal-to-intemporal is not an exception here as all our formalisations implicitly operate on this basis as deferentialformalisation-transference, tacitly confirming its veracity/ontological-pertinence. It should be 
noted that the representation of registry-worldview's/dimension's uninstitutionalisedthreshold ${ }^{02}$ as of 'threshold-of-nonconviction/madeupness/bottomlining-in-shallowsupererogation -<as-to-'attendant-intradimensional'-prospectivelydisontologising preconverging/dementing -apriorising-psychologism> $>$ based on their respective relative-ontological-incompleteness ${ }^{8}$-induced,-'threshold-ofnonconviction/madeupness/bottomlining-in-shallow-supererogation $<<$ as-to-'attendantintradimensional'-prospectively-disontologising preconverging/dementing -apriorisingpsychologism > while most ontologically-veridical from an ontologicalnormalcy/postconvergence epistemic-or-notional projective-perspective, $\quad$ such a suprastructural-meaningfulness/memetism is rather unordinary and suprastructural (beyond-theconsciousness-awareness-teleology ${ }^{9}<$ of-preconverging-existential-extrication-as-ofexistential-unthought $>$ ) to the given uninstitutionalised-threshold ${ }^{102}$ registryworldview's/dimension's ${ }^{83}$ reference-of-thought; since in our positivism- ${ }^{80}$ procrypticism uninstitutionalisation (which is procrypticism), 'utter-ontologising/5 maximalisingrecomposuring-for-relative-ontological-completeness ${ }^{87}$-unenframed/reontologising conceptualisation 'sublimating-epistemicimbricatedness/threadedness/recomposuring as of 'implieitantontologicalcontiguity ${ }^{67} \sim$ educed-

existentialising/contextualising/textualising_intelligibility/epistemicity/reflexivity-contiguity$<$ imbued-notional $\sim$ cogency $>,{ }^{\prime},-<$ reifying-or-elucidating-of-prospective-relative-ontologicalcompleteness -of- reference-of-thought- devolving-as-of-instantiative-context> as to existence-potency $^{39} \sim$ sublimating-nascence,-disclosed-from-prospective-epistemicdigression—rules-of-apriorising/axiomatising/referencing-that-further-epistemicallyunconceal-the-very-ontologically-same-existential-reality' (from the perspective of the 'postconverging-or-dialectical-thinking ${ }^{2}{ }^{8}$ reference-of-thought in relative-ontological- 
completeness $^{87}$ as depth-of-thought') will reflect/perspectivate/highlight procrypticism to be rather of threshold-of-nonconviction/madeupness/bottomlining-in-shallow-supererogation

\section{$<$ as-to-'attendant-intradimensional'-prospectively-}

disontologising preconverging/dementing -apriorising-psychologism>

thus

pivoting/decentering/'psychoanalytically-unshackling/memetically-reordering/institutionally-

recomposuring' into notional ${ }^{18}$ deprocrypticism suprastructuring/transcendental/intemporalpreserving ${ }^{83}$ reference-of-thought by way of the given 'utter-ontologising/ maximalisingrecomposuring-for-relative-ontological-completeness 87 unenframed/re-

ontologising conceptualisation'. While the above proposition is most difficult to fathom given our metaphysics-of-presence-〈implicited-'nondescript/ignorable-void '-as-to- presencing

\section{absolutising-identitive-constitutedness > illusion-of-the-present/present-}

consciousness/epistemic-totalising $\sim$ self-referencing-syncretising/mirage, we'll relatively grasp this reality on a same token wherein: in recurrent-utter-uninstitutionalisation uninstitutionalisation, maximalising-recomposuring-for-relative-ontologicalcompleteness ${ }^{87}$ — unenframed/re-ontologising conceptualisation as suprastructural or beyondthe-consciousness-awareness-teleology ${ }^{9}-<$ of-preconverging-existential-extrication-as-ofexistential-unthought> of 'recurrent-utter-uninstitutionalisation core meaningfulness of reference' is reflected/perspectivated/highlighted as rather of threshold-ofnonconviction/madeupness/bottomlining-in-shallow-supererogation $<-<$ as-to- 'attendantintradimensional'-prospectively-disontologising preconverging/dementing -apriorisingpsychologism> (thus pivoting/decentering/“psychoanalytically-unshackling/memeticallyreordering/institutionally-recomposuring' into base-institutionalisation suprastructuring/transcendental/intemporal-preserving ${ }^{83}$ reference-of-thought by way of the given ${ }^{5}$ maximalising-recomposuring-for-relative-ontological-completeness ${ }^{87}$ - unenframed/reontologising conceptualisation); in base-institutionalisation-ununiversalisation 
uninstitutionalisation (which is ununiversalisation), ${ }^{55}$ maximalising-recomposuring-for-relativeontological-completeness ${ }^{87}$ - unenframed/re-ontologising conceptualisation as suprastructural or beyond-the-consciousness-awareness-teleology $-<$ of-preconverging-existential-extricationas-of-existential-unthought $>$ of ununiversalisation core meaningfulness of reference' is reflected/perspectivated/highlighted as rather of threshold-ofnonconviction/madeupness/bottomlining-in-shallow-supererogation $-<$ as-to- 'attendantintradimensional'-prospectively-disontologising preconverging/dementing -apriorisingpsychologism> (thus pivoting/decentering/'psychoanalytically-unshackling/memeticallyreordering/institutionally-recomposuring' into universalisation suprastructuring/transcendental/intemporal-preserving ${ }^{83}$ reference-of-thought by way of the given ${ }^{55}$ maximalising-recomposuring-for-relative-ontological-completeness ${ }^{8}$ —unenframed/reontologising conceptualisation); and, in ${ }^{103}$ universalisation-non-positivism/medievalism uninstitutionalisation (which is non-positivism/medievalism), ${ }^{5}$ maximalising-recomposuringfor-relative-ontological-completeness ${ }^{87}$ - unenframed/re-ontologising $\sim$ conceptualisation as suprastructural or beyond-the-consciousness-awareness-teleology ${ }^{9}<$ of-preconvergingexistential-extrication-as-of-existential-unthought $>$ of non-positivism/medievalism core meaningfulness of reference' is reflected/perspectivated/highlighted as rather of threshold-ofnonconviction/madeupness/bottomlining-in-shallow-supererogation $<-<$ as-to-' ${ }^{\circ}$ attendant-

\section{intradimensional'-prospectively-disontologising preconverging/dementing -apriorising-}

psychologism $>\quad$ (thus pivoting/decentering/“psychoanalytically-unshackling/memeticallyreordering/institutionally-recomposuring' into positivism suprastructuring/transcendental/intemporal-preserving ${ }^{83}$ reference-of-thought by way of the given ${ }^{55}$ maximalising-recomposuring-for-relative-ontological-completeness ${ }^{87}$ - unenframed/reontologising conceptualisation). Thus suprastructuralism as such validates the reality of an underlying ontology-driven human 'postconverging-or-dialectical-thinking ${ }^{21}$-psychology or 
psychology-of-mentation-dynamics or natural psychological-dynamics' in rescheduling (psychoanalytic-unshackling/memetic-reordering/institutional-recomposuring) the placeholdersetup/mental-devising-representation/mentation, as of human-subpotencyaporia/undecidability/dilemma/ought-indeterminacy/deficiency/limitation/constraint—imbued'notional firstnaturedness-formativeness-<as-to-eventualising -inkling-drive-or-seedingmisprising $>$ temporal-to-intemporal-dispositions- $<$ so-construed-as-from-perspectiveontological-normalcy/postconvergence>'-existentialism-form-factor. The fundamental point about a transcendental conceptualisation as implied in a positivism- ${ }^{80}$ procrypticism uninstitutionalisation by the 'psychoanalytic-unshackling/memetic-reordering/institutionalrecomposuring' into notional ${ }^{18}$ deprocrypticism suprastructuring/transcendental/intemporalpreserving ${ }^{83}$ reference-of-thought by way of utter-ontologising/ ${ }^{5}$ maximalising-recomposuringfor-relative-ontological-completeness ${ }^{87}$ - unenframed/re-ontologising conceptualisation', is not about logical nested-congruence but as with the transcendence-andsublimity/sublimation/supererogatory $\sim$ de-mentativity of all prospective institutionalisations rather the transversality-<for-sublimating-existential-eventuating/denouement,-from-'thinkingat first/pure-predisposition-preemptive-of prospective-disontologising/subontologising' as-

\section{of-prospectively-disambiguated-affirmed-and-unaffirmed-'motif-and-}

apriorising/axiomatising/referencing' $>$ 101 of the transcendental/suprastructural meaningfulness-and-teleology $/$ teleological-differentiations known as supratransversality$<$ in-sublimating-existential-eventuating/denouement $>\sim$ of-motif-andapriorising/axiomatising/referencing over the transcended meaningfulness-andteleology ${ }^{9} /$ teleological-differentiations known as subtransversality-<in-desublimatingexistential-eventuating/denouement $>\sim$ of-motif-and-apriorising/axiomatising/referencing in inducing a middle-to-long-run or trans-generational 'postconverging-or-dialectical-thinking psychology or psychology-of-mentation-dynamics or natural psychological-dynamics' 
pivoting/decentering/psychoanalytic-unshackling/memetic-reordering/institutionalrecomposuring from the transcended/superseded state as ${ }^{80}$ procrypticism-or-disjointedness-asof- ${ }^{8}$ reference-of-thought ${ }^{5}$ meaningfulness-and-teleology ${ }^{9} \quad$ reference-of-thoughtcategorical-imperatives/axioms/registry-teleology ${ }^{9}$ to the maximalising-as' deprocrypticism-or-preempting-disjointedness-as-of- ${ }^{3}$ reference-of-thought transcending/superseding $\quad{ }^{56}$ meaningfulness-and-teleology ${ }^{9} \quad{ }^{83}$ reference-of-thoughtcategorical-imperatives/axioms/registry-teleology ${ }^{99}$ of futural Being-development/ontologicalframework-expansion-as-to-depth-of-ontologising-development-as-infrastructure-ofmeaningfulness-and-teleology as of prospective deprocrypticism, going by prospective $<$ amplituding/formative-epistemicity $>$ causality $\sim$ as-to-projective-totalitative-implications-ofprospective- nonpresencing,-for-explicating relative-unreflexivity/relative-reflexivity _ ontological-contiguity and induced untenability/internal-contradiction/internalincoherence/institutional-constraining bringing about percolation-channelling- $<$ in-deferentialformalisation-transference $>$ as futural Being-development/ontological-framework-expansionas-to-depth-of-ontologising-development-as-infrastructure-of- meaningfulness-andteleology as of prospective notional deprocrypticism institutionalisation; as the very state of a prior/transcended/superseded registry-worldview relative-ontological-incompleteness ${ }^{8}$ induced,-'threshold-of-nonconviction/madeupness/bottomlining-in-shallow-supererogation

\section{<as-to-'attendant-intradimensional'-prospectively-}

disontologising preconverging/dementing -apriorising-psychologism>' implies it is 'in-wait as of prior relative-ontological-incompleteness ${ }^{8}$-of- ${ }^{8}$ reference-of-thought defective reference-of-thought- ${ }^{\text {categorical-imperatives/axioms/registry-teleology }}$ for the perversion-of- ${ }^{3}$ reference-of-thought-<as-preconvergingly-

apriorising/axiomatising/referencing-in-nonconviction/madeupness/bottomlining-as-to-

shallow-supererogation $>$ to be instigated, upheld and be enculturated and endemised, for the 
preconverging/postconverging-de-mentative/structural/paradigmatic perpetuation of the vicesand-impediments preconverging/postconverging-dementatively/structurally/paradigmatically associated 'with respect to the fundamental relativeontological-incompleteness ${ }^{8}$-induced,-'threshold-of-nonconviction/madeupness/bottomliningin-shallow-supererogation $-<$ as-to-'attendant-intradimensional'-prospectivelydisontologising preconverging/dementing -apriorising-psychologism>' and postlogism phenomenon'. The suprastructural (beyond-the-consciousness-awareness-teleology ${ }^{9}-<$ ofpreconverging-existential-extrication-as-of-existential-unthought> ) <amplituding/formativeepistemicity $>$ causality $\sim$ as-to-projective-totalitative-implications-of-prospectivenonpresencing,-for-explicating relative-unreflexivity/relative-reflexivity - ontologicalcontiguity at the individuation-level is that with respect to 'socially-perceived-value as of social-stake-contention-or-confliction' situations, there is an underlying meaningfulness-andteleological differentiation of human mental-dispositions as of non-pseudointemporality ${ }^{52}$ as of supplanting-conviction-as-to-profound-supererogation —of-'attendant-intradimensional'postconverging/dialectical-thinking -apriorising-psychologism and pseudointemporality ${ }^{52}$ as of threshold-of-nonconviction/madeupness/bottomlining-in-shallow-supererogation $-<$ as-to‘attendant-intradimensional'-prospectively-disontologising preconverging/dementing apriorising-psychologism> (including as derived/conjugated pseudointemporality ${ }^{52}$ as to threshold-of-nonconviction/madeupness/bottomlining-in-shallow-supererogation $-<$ as-to'attendant-intradimensional'-prospectively-disontologising preconverging/dementing apriorising-psychologism>), and so in contrast to the social/normal reflex of naively-andwrongly construing and falling back to the idea of ${ }^{56}$ meaningfulness-and-teleology ${ }^{9}$ (as of reference-of-thought) rather essentially of non-pseudointemporality ${ }^{52}$ as of supplantingconviction-as-to-profound-supererogation —of-'attendant-intradimensional'- 
of threshold-of-nonconviction/madeupness/bottomlining-in-shallow-supererogation

$<$ as-to-

‘attendant-intradimensional'-prospectively-disontologising preconverging/dementing

apriorising-psychologism $>$ and by its derivations (consciously, expediently or unconsciously), the representations of ${ }^{56}$ meaningfulness-and-teleology ${ }^{9}$ are set/formulaic and the fundamental essential/intrinsic/inherent attributions behind the representations of meaningfulness-andteleology ${ }^{9}$ are irrelevant, and a parasitising/co-opting association that is alien to the fundamental essential/intrinsic/inherent/intemporal attributions of meaningfulness-and-teleology ${ }^{9}$ is just as valid; basically due to the fact that our fundamental relative-ontological-incompleteness ${ }^{88}$ induced,-'threshold-of-nonconviction/madeupness/bottomlining-in-shallow-supererogation $<$ as-to-'attendant-intradimensional'-prospectivelydisontologising $\sim$ preconverging/dementing -apriorising-psychologism>' at all prior registryworldviews/dimensions, whether as recurrent-utteruninstitutionalisation/ununiversalisation/non-positivism-or-medievalism/procrypticism, is bound to lead to human integration of the corresponding postlogism $7 / 7$ perversion-ofreference-of-thought-<as-preconvergingly-apriorising/axiomatising/referencing-innonconviction/madeupness/bottomlining-as-to-shallow-supererogation >,-of- categoricalimperatives/axioms/registry-teleology ${ }^{9}$-for-intemporal-preservation-entropy-or-contiguity-orontological-preservation at the uninstitutionalised-threshold ${ }^{102}$ that speaks of relativeontological-incompleteness ${ }^{8}$-induced,-'threshold-of-nonconviction/madeupness/bottomliningin-shallow-supererogation $-<$ as-to- 'attendant-intradimensional'-prospectivelydisontologising preconverging/dementing -apriorising-psychologism>'. Thus a nonpseudointemporality $^{52}$ mental-disposition re-affirmatory (as maximalising) of the essential/intrinsic/inherent/intemporal attributions behind the representations of meaningfulness-and-teleology 9 will put in question the reflex idea (in instances of perversion-of- ${ }^{3}$ reference-of-thought- $<$ as-preconvergingly- 
apriorising/axiomatising/referencing-in-nonconviction/madeupness/bottomlining-as-to-

shallow-supererogation $>$ and the corresponding <amplituding/formative-

epistemicity $>$ causality $\sim$ as-to-projective-totalitative-implications-of-prospective-

nonpresencing,-for-explicating relative-unreflexivity/relative-reflexivity —ontological-

contiguity ) to naively operate logic and its axioms as of a sound human ${ }^{103}$ universal mentaldisposition for construing ontologically-veridical meaningfulness as virtuality-or-ontologicallyflawed-construal/being-construal-as-abstract-construal-as-of-flawed-and-shallow-and-nonveridical-existential-reference, in order to account for such 'parasitism/parasitising/co-optingmeaningfulness' by parasitising/co-opting association with the essential/intrinsic/inherent attributions behind the representations of ${ }^{56}$ meaningfulness-and-teleology ${ }^{9}$, and so as 'intemporal-preservation as to aetiologisation/ontological-escalation- $<$ ontologicalveridicality_commitment/otherliness_transcending/compulsions-encumbered_transcending>' enabling prospective ${ }^{83}$ reference-of-thought- categorical-imperatives/axioms/registryteleology ${ }^{9}$,-for-intemporal-preservation-entropy-or-contiguity-or-ontological-preservation that override such 'parasitism of ${ }^{56}$ meaningfulness-and-teleology" as temporal arrogation/disjointedness/impostoring/extrication/misappropriation whether consciously/byexpediency/unconsciously. This is the intemporal-disposition individuation decentering mechanism with respect to ontology/ontologically-veridical-meaningfulness in a dynamiccumulative-aftereffect at the registry-worldview/dimension or intradimensional level that brings about prospective institutionalisations by rescheduling the placeholder-setup/mental-devisingrepresentation/mentation/consciousness-awareness-teleology ${ }^{9}$ with respect to construed prospective ontology/ontological-veridicality (as psychoanalytic-unshackling/memeticreordering/institutional-recomposuring) explaining why we are able and do transcend; or else as in all prior registry-worldviews, the pseudointemporality ${ }^{52}$ logic will tend to become one of conscious or unconscious ontological-bad-faith/inauthenticity ${ }^{64}$ that construes of the present (by 

intemporal-preservation-entropy-or-contiguity-or-ontological-preservation whether being usurped/disjointed/impostored/parasitized/co-opted) as of absolute reference-value regardless, failing/not-upholding-<as-of-apriorising/axiomatising/referencing $>$ to register that the grandest value as ontologically-coherent (as a principle sustaining its perpetuation) is the transcendental $/{ }^{5}$ maximalising-recomposuring-for-relative-ontological-completeness ${ }^{87}$ unenframed/re-ontologising $\sim$ conceptualisation longness-of-register-ofmeaningfulness/intemporality ${ }^{52}$ that accounts for the becoming from all the priors to the present to the prospective registry-worldviews/dimensions institutionalisations, thus not wrongly implying an equivalence between such a meaningful construct of ${ }^{103}$ universal import with temporal extricatory preconverging-de-mentating/structuring/paradigming contentions (more like metaphorically an apple falling on Newton's head and his projection of this in grasping the universal implications of the laws of motion being wrongly equivocated in the terms of say an apple merchant and other interests in extricatory/temporal fear of the idea that understanding the laws of motions will be 'temporally' undermining in one way or the other). Critically, it isn't idle idealism but rather a realistic insight, as just as articulations of notions of positivism like evolution, ${ }^{103}$ universal human emancipation, rationalism, empiricism and science cannot be sustainably intelligible in a mindset/psyche that is non-positivism/medievalism and has not been pivoted (psychoanalytically-unshackled/mimeticly-reordered/institutionally-recomposured) to a positivistic mindset/psyche thus explaining why their proponents actively undermined the overall ordinary meaningful-frame of non-positivism/medievalism including such effort as the Encyclopédistes, likewise it is naïve to think that notional ${ }^{18}$ deprocrypticism (by its deprocrypticism-or-preempting-disjointedness-as-of- ${ }^{3}$ reference-of-thought sublimatingepistemic-imbricatedness/threadedness/recomposuring as of 'implicited_attendant-ontologicalcontiguity $^{67}$; educed- 
existentialising/contextualising/textualising_intelligibility/epistemicity/reflexivity-contiguity$<$ imbued-notional $\sim$ cogency $>,{ }^{\prime},-<$ reifying-or-elucidating-of-prospective-relative-ontologicalcompleteness -of- reference-of-thought- devolving-as-of-instantiative-context $>$ as to existence-potency $^{39} \sim$ sublimating-nascence,-disclosed-from-prospective-epistemicdigression—rules-of-apriorising/axiomatising/referencing-that-further-epistemicallyunconceal-the-very-ontologically-same-existential-reality) is an inherent meaningfulness that is perfectly construable within just a positivism- ${ }^{80}$ procrypticism mental-disposition and the latter's many compromised assumptions as articulated in this paper, as notional deprocrypticism is priorly implying futural Being-development/ontological-framework-expansion-as-to-depth-ofontologising-development-as-infrastructure-of- meaningfulness-and-teleology as of prospective notional $\sim$ deprocrypticism psyche/mindset. This equally raises the fundamental issue with post-structuralism, does it fully make sense in a 'modern mindset' of reference or reference-of-thought or rather it is implying priorly a prospective 'postmodern mindset' of prospective reference or ${ }^{83}$ reference-of-thought as its existential-reference/existentialtautologisation wherein human 'deeper limited-mentation-capacity-as-subjecting-educedunlimitedness/existence-sublimating nascence' to-limitedness/human-subpotency-〈as of relative apriorising/axiomatising/referencing-\{of-'prospectively implicited_attendantontological-contiguity ' educedexistentialising/contexttalising/textualising_intelligibility/epistemicity/reflexivity-contiguity-

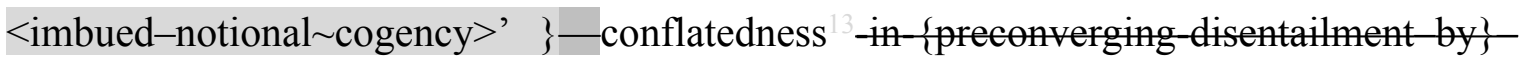
postconverging-ntailment〉' pivots/decenters to reconstrue/reconceptualise ${ }^{5}$ meaningfulnessand-teleology ${ }^{9}$, most critically marked by suprastructuralism/meaningfulness-as-beyondtemporal-consciousness-awareness-teleology ${ }^{9}$ as a knowledge construct grounded on the ontological-veridicality of human-subpotency-aporia/undecidability/dilemma/oughtindeterminacy/deficiency/limitation/constraint—imbued-'notional firstnaturedness- 
formativeness-<as-to-eventualising-inkling-drive-or-seeding-misprising $>$ temporal-tointemporal-dispositions-<so-construed-as-from-perspective-ontologicalnormalcy/postconvergence>'-existentialism-form-factor and the implications for the derivation of meaningfulness (a progression from just a positivism mindset/ ${ }^{3}$ reference-of-thought of meaningfulness-and-teleology grounded pre-eminently on a human intemporal nature construct thus failing/not-upholding-<as-of-apriorising/axiomatising/referencing $>$ to appropriately factor in the dynamism of human-subpotencyaporia/undecidability/dilemma/ought-indeterminacy/deficiency/limitation/constraint—imbued'notional firstnaturedness-formativeness-<as-to-eventualising inkling-drive-or-seeding misprising $>$ temporal-to-intemporal-dispositions- $<$ so-construed-as-from-perspectiveontological-normalcy/postconvergence>'-existentialism-form-factor mental-dispositions prospectively, with focus wholly on positivistic construal and logic grounded solely on an intemporal construct (overlooking the implication of "parasitism of meaningfulness-andteleology ${ }^{9}$, as temporal arrogation/disjointedness/impostoring/extrication/misappropriation whether consciously/by-expediency/unconsciously, coming from the extended-informality〈susceptible-to-effecting-parsimony-as-of-shoddiness-and-incompleteness-to-

meaningfulness-and-teleology $\rangle)$ in inducing defect of ${ }^{83}$ reference-of-thought as perversionand-derived- ${ }^{7}$ perversion-of- ${ }^{8}$ reference-of-thought-<as-preconvergingly-

\section{apriorising/axiomatising/referencing-in-nonconviction/madeupness/bottomlining-as-to-}

shallow-supererogation >). Critically, ontological-normalcy/postconvergence points out that paradoxically the transcendental mindset $/{ }^{-3}$ reference-of-thought associated with a 'knowledge construct of intrinsic-reality' should priorly be established ('centered' over the prior meaningfulframe which is 'decentered') for the knowledge construct to take hold by the continuing 'moulting' of its proponents and corresponding social construct, as intrinsic-reality doesn't adjust its inherent meaningfulness to us but rather humans need to achieve a given psychical 
development to have-access-to or be-able-to-register the knowledge construct of the more profound existential-reference/existential-tautologisation to intrinsic-reality/ontologicalveridicality that that psychical development allows for, in meaningfulness-and-teleological terms. This is rather a difficult task as it implies " ${ }^{15}$ de-mentation-〈supererontogicalde-mentation-or-dialectical-de-mentation-stranding-or-attributive-dialectics $\rangle$ of ${ }^{8}$ referenceof-thought' behind the psychoanalytic-unshackling/memetic-reordering/institutionalrecomposuring, and no registry-worldview/dimension sees itself as de-mentable prospectively, as being decentered for a prospective centering, even where it acquiesces to the notion retrospectively up to its own institutionalisation; pointing that ontologicalnormalcy/postconvergence is the genuine perspective for construing the dynamism of knowledge-and-virtue or ${ }^{56}$ meaningfulness-and-teleology . The fundamental point of a knowledge construct (which is necessarily tautological as intrinsic-reality/ontology is already given) is rather an exercise of 'human <amplituding/formative-epistemicity>totalising $\sim$ renewing-realisation/re-perception/re-thought-as-utter-placeholder-setupontological-rescheduling-〈by-a-renewing-of-apriorising/axiomatising/referencingpsychologism-as-the-new-referencing-basis-of-prospective- meaningfulness-and-teleology > as subpotent-mimetic-echoness-derivation-within-the-full-potency of existence-as-of-itsmimetic-echoness/existence-in-reverberation/existence-potency ${ }^{39} \sim$ sublimating-nascence,disclosed-from-prospective-epistemic-digression wherein we pivot/decenter (psychoanalyticunshackling/memetic-reordering/institutional-recomposuring) for redefined ${ }^{56}$ meaningfulnessand-teleology . Thus for a storied-construct/ontologically-valid-narration aetiologisation/ontological-escalation-<ontologicalveridicality_commitment/otherliness_transcending/compulsions-encumbered_transcending > in 'grasping the uninstitutionalised-threshold ${ }^{102}$ reflecting procrypticism involving postlogism and conjugated-postlogism ${ }^{77}$, the knowledge construct will assume this same fundamental goal 
of 'human <amplituding/formative-epistemicity $>$-totalising $\sim$ renewing-realisation/reperception/re-thought-as-utter-placeholder-setup-ontological-rescheduling-〈by-a-renewing-ofapriorising/axiomatising/referencing-psychologism-as-the-new-referencing-basis-ofprospective- meaningfulness-and-teleology $\rangle$ as subpotent-mimetic-echoness-derivationwithin-the-full-potency of existence-as-of-its-mimetic-echoness/existence-inreverberation/existence-potency ${ }^{39} \sim$ sublimating-nascence,-disclosed-from-prospectiveepistemic-digression. Pivoting/decentering as such for transcendence-andsublimity/sublimation/supererogatory - de-mentativity at the individuation-level speaks of intemporal-disposition maximalising-recomposuring-for-relative-ontologicalcompleteness $^{87}$ — unenframed/re-ontologising conceptualisation value and disposition reontologising terms even though for temporal-dispositions value and disposition conventioning terms this may sound unintelligible. Such a transcendental/intemporal pivoting/decentering necessarily construed from the prospective institutionalisation (whether base-institutionalisation, universalisation, positivism or deprocrypticsm, as ontological-normalcy/postconvergence epistemic-or-notional projective-perspective), of temporal-dispositions individuations in uninstitutionalised-threshold ${ }^{102}$ (recurrent-utter-uninstitutionalisation, ununiversalisation, nonpositivism/medievalism or procrypticism) as being of 'mental anarchy' (mentarchy) which 'speaks of a defining state of ontologically-defective ${ }^{56}$ meaningfulness-and-teleology ${ }^{9}$, arising from lack of common (lack of an ordered construct of deferential-formalisation-transference) ontologically-veridical ${ }^{83}$ reference-of-thought, wherein both temporal-dispositions in various shades and the intemporal-disposition are socially-perceived as meaningfully-and-teleologically entitled-in-equivalence "notwithstanding veridical veracity/ontological-pertinence conveyable by imbricatedness/threadednes/recomposuring of 'implicited_attendant-ontologicalcontiguity $^{67}$; educedexistentialising/contextualising/textualising_'intelligibility/epistemicity/reflexivity-contiguity- 
$<$ imbued-notional $\sim$ cogency $>,{ }^{\prime},-<$ reifying-or-elucidating-of-prospective-relative-ontological-

completeness -of- reference-of-thought- devolving-as-of-instantiative-context> as to

existence-potency ${ }^{39} \sim$ sublimating-nascence,-disclosed-from-prospective-epistemic-

digression —rules-of-apriorising/axiomatising/referencing-that-further-epistemically-

unconceal-the-very-ontologically-same-existential-reality' which 'breaking'/existentialdecontextualised-transposition by temporal-dispositions (on the wrong basis of a prelogic supplanting-conviction-as-to-profound-supererogation - of-'attendant-intradimensional'postconverging/dialectical-thinking -apriorising-psychologism mental-disposition reflex that will wrongly reassumed soundness/non- ${ }^{74}$ perversion-of- ${ }^{-3}$ reference-of-thought over-andignoring the reality of a postlogism -as-of- compulsingnonconviction/madeupness/bottomlining-〈‘ $<$ decontextualising/de-existentialising $\sim$ ofattendant-intradimensional-apriorising/axiomatising/referencing $>$-induced-disontologising'-ofthe-'attendant-intradimensional-ontologising'-imbued$<$ contextualising/existentialising attendant-ontological-contiguity $>$;-in-shallowsupererogation -<as-to-disontologising-perverted-outcome-sought-precedes-existentiallyveridical-'attendant-intradimensional-apriorising/axiomatising/referencing'-logical-dueness $>$ > induced unsound/perverted- ${ }^{3}$ reference-of-thought, as the breaking undermines 'implicited_attendant-ontological-contiguity ${ }^{6}$ ' educedexistentialising/contextualising/textualising_intelligibility/epistemicity/reflexivity-contiguity$<$ imbued-notional $\sim$ cogency $>,{ }^{\prime},-<$ reifying-or-elucidating-of-prospective-relative-ontologicalcompleteness -of- reference-of-thought- devolving-as-of-instantiative-context> as to existence-potency $^{32} \sim$ sublimating-nascence,-disclosed-from-prospective-epistemicdigression—rules-of-apriorising/axiomatising/referencing-that-further-epistemicallyunconceal-the-very-ontologically-same-existential-reality thus eliciting virtuality-orontologically-flawed-construal) is what induces uninstitutionalised-threshold ${ }^{102}$ mental- 
anarchy/mentarchy at the individuation-level of conceptualisation, and which in a dynamiccumulative-aftereffect of 'threshold-of-nonconviction/madeupness/bottomlining-in-shallowsupererogation -<as-to-'attendant-intradimensional'-prospectivelydisontologising preconverging/dementing -apriorising-psychologism>' accounts for the uninstitutionalised-threshold ${ }^{102}$ of recurrent-utter-uninstitutionalisation/ununiversalisation/nonpositivism/medievalism/procrypticism. Thus insightfully, the same notion as uninstitutionalisedthreshold ${ }^{102}$ threshold-of-nonconviction/madeupness/bottomlining-in-shallowsupererogation -<as-to-'attendant-intradimensional'-prospectivelydisontologising preconverging/dementing -apriorising-psychologism $>$ and dialectically-outof-phase and Mental-anarchy/Mentarchy (the latter which emphasises the state of ontologicalveridicality implying an equivalence between-entitlement of both the temporal-dispositions and the intemporal-disposition, unlike an ordered-construct-of-deferential-formalisationtransference or an-institutionalised-construct that rightfully assumes the longness-of-register-ofmeaningfulness/intemporal-meaningfulness of the intemporal-disposition individuation as the 'superseding secondnaturing construct'), respectively reflecting the transcendental/transdimensional/interdimensional, intradimensional and individuation-levels; providing the necessary dynamic-cumulative-aftereffect grasp for storiedconstruct/ontologically-valid-narration aetiologisation/ontological-escalation- $<$ ontologicalveridicality_commitment/otherliness_transcending/compulsions-encumbered_transcending > for ${ }^{55}$ maximalising-recomposuring-for-relative-ontological-completeness ${ }^{87}$ - unenframed/reontologising conceptualisation from futural Being-development/ontological-frameworkexpansion-as-to-depth-of-ontologising-development-as-infrastructure-of- meaningfulnessand-teleology as of prospective notional ${ }^{18}$ deprocrypticism ${ }^{83}$ reference-of-thought, with no elaboration-as-to-mere-extrapolating/constituting/abstracting/deducing/inferring-ofelucidation-outside_- 'prospectively_implicited_attendant-ontological-contiguity ${ }^{67}$ ? educed- 
existentialising/contextualising/textualising_intelligibility/epistemicity/reflexivity-contiguity$<$ imbued-notional cogency $>^{\prime}$ allowed as this induces virtualities/being-construals-asabstract-construal-as-of-flawed-and-shallow-and-non-veridical-existential-reference.

Mentarchy/Mental-anarchy _ (as inducing 'threshold-ofnonconviction/madeupness/bottomlining-in-shallow-supererogation $<-<$ as-to-' attendantintradimensional'-prospectively-disontologising preconverging/dementing -apriorising-

psychologism> and dialectically-out-of-phase' and uninstitutionalised-threshold ${ }^{102}$ ) can also be construed as a disposition for temporal-finitude on the basis of referencing 'social-aggregationenablers over intrinsic-reality/ontological-veridicality transcendentalenabling/sublimating/supereregatery $\sim$ de-mentativity' by the temporal-dispositions ${ }^{83}$ referencesof-thought (whether consciously, expediently or unconsciously) in order to undermine the referencing of intrinsic-reality/ontological-veridicality transcendentalenabling/sublimating/supererogatory-de-mentativity as intemporal ${ }^{83}$ reference-of-thought (thus implying a mental-representation-devising/mentation/placeholder-setup of the 'socialaggregation-enablers over intrinsic-reality/ontological-veridicality transcendentalenabling/sublimating/supereregatery de-mentativity' as ontologically preconverging-ordementing -apriorising-psychologism from the perspective of the transcendentalenabling/sublimating/supererogatory de-mentativity as ontologically thinking). Insightfully, for a storied-construct/ontologically-valid-narration aetiologisation/ontological-escalation<ontological-veridicality_commitment/otherliness_transcending/compulsions-

encumbered_transcending $>$ such a 'dynamic-cumulative-aftereffect of individuation/intradimensional/transcendental-or-transdimensional-or-interdimensional levels of conceptualisation' ontologically validates a 'deterministically teleological-differentiated storied-construct/ontologically-valid-narration' of projectable/predictable-relative-existentialimplications of the various 'incrementalism-in-relative-ontological-incompleteness ${ }^{8}$ - 
enframed/disontologising conceptualisation temporal-dispositions incremental/shortnessdisposition-relative-finitudes' and 'maximalising-recomposuring-for-relative-ontologicalcompleteness ${ }^{87}$ — unenframed/re-ontologising conceptualisation intemporal-disposition superseding/longness-disposition-to-finitude'; finitude being the full-depth-of-existentialimplications/existentialism arising when acting (as-being/as-existing) with regards to one's prior relative-ontological-incompleteness ${ }^{8 / \text { relative-ontological-completeness }}{ }^{87}$

\section{〈sublimating referencing/registering/decisioning,-as-self-becoming/self-}

conflatedness /formative-supererogating-<projective/reprojective-aestheticising-re-motifand-re-apriorising/re-axiomatising/re-referencing,-in-perspective-ontologicalnormalcy/postconvergence $>>$ of ${ }^{83}$ reference-of-thought. As a side note, such a notion of mentarchy in its dynamic-cumulative-aftereffect should be able to highlight the peculiarity of reference-of-thought associated with human languages from ancient ones to modern ones (as of the registry-worldview/dimension-levels of the corresponding societies), facilitating the deciphering and understanding of ancient languages, as well as the reconceptualisation of meaningfulness-and-teleology ${ }^{9}$ across history, which conceptual exercise tends to be rather biased towards a modern perspective metaphysics-of-presence-〈implicited‘nondescript/ignorable-void ' -as-to- presencing-absolutising-identitive-constitutedness \).

Finally, a storied-construct/ontologically-valid-narration aetiologisation/ontological-escalation$<$ ontological-veridicality_commitment/otherliness_transcending/compulsions-

encumbered_transcending $>$ will need to take cognisance of the very peculiar nature of the social world (in contrast to the natural world) that makes the social 'susceptible to incorrect understanding and analysis' particularly at a practical and operant level by the fact that it is highly emotionally-involved/politically-driven especially so with disturbing issues, and this is further compounded by the 'blurriness-<sterilising/anecdotalising/trivialising-of-prospectivere-ontologising_by-preconverging,-in-disontologising-formulaic-dragging-out/hollowing-out> 
and distance of <amplituding/formative-epistemicity $>$ causality $\sim$ as-to-projective-totalitativeimplications-of-prospective- nonpresencing,-for-explicating relative-unreflexivity/relativereflexivity - ontological-contiguity /intrinsic-reality/ontological-veridicality transcendentalenabling/sublimating/supererogatory $\sim$ de-mentativity', and finally from a transcendental/ maximalising-recomposuring-for-relative-ontological-completeness ${ }^{87}$ unenframed/re-ontologising conceptualisation perspective human mental-disposition with regards to the social can be poorly ontological with unconscious, expedient or conscious emphasis on significant others basis of logic as well as <amplituding/formative > woodenlanguage-〈imbued - averaging-of-thought-<as-to-leveling/ressentiment/closed-construct-ofmeaningfulness-and-teleology -as-of-'nondescript/ignorable-void '-with-regards-toprospective-apriorising-implications $>>$ mental-dispositions (social-aggregation-enablers) undermining the solipsistic relationship with intrinsic-reality required for veracity/ontologicalpertinence (transcendental-enabling/sublimating/supererogatory $\sim$ de-mentativity). In this regard, it will actually be naïve to assume that an articulation of veracity/ontological-pertinence as with the natural sciences is all that is necessary in achieving effectiveness. With the weaknesses highlighted above with regards to grasping the social, it is important that such veracity/ontological-pertinence is effectively emphasised within the 'realistic social contexts of mental-dispositions and actions' driven by social-aggregation-enabling, wherein for instance the transcendental-enabling/sublimating/supererogatory $\sim$ de-mentativity that is intrinsicreality/ontology grounded on intrinsic-attribution can easily take a backseat over socialaggregation-enabler grounded on extrinsic-attribution driven by such 'social-aggregationenablers over intrinsic-reality/ontological-veridicality transcendentalenabling/sublimating/supereregatory de-mentativity' as perverted use of notions of differentness, infamy, status, significant-others basis of logic, repute, social authorities and influencers naively involved in fallacies of authority, disparagement, contrivance, duplicity, 
imposturing, ontological-bad-faith/inauthenticity ${ }^{64}$ implying an equivalence between universal/intemporal sense of purpose with extricatory/temporal/mundane sense of purposes, underhandedness, inductive-limitation (so-called principle that is not articulated as a ${ }^{103}$ universal construct but targeted, avowing its reality as fake), etc., and so, including intellectual milieus as well. The implications for a truly ontologically effective social science can be construed as follows; say for instance an accused miscreant was to articulate a credibly demonstrable notion in physics or chemistry, the "promptness of $<$ amplituding/formative-epistemicity $>$ causality $\sim$ asto-projective-totalitative-implications-of-prospective- nonpresencing,-forexplicating relative-unreflexivity/relative-reflexivity - ontological-contiguity /intrinsicreality/ontological-veridicality transcendental-enabling/sublimating/supererogatory $\sim$ dementativity' will easily allow for such veracity/ontological-pertinence to establish itself without undermining of the transcendental-enabling/sublimating/supererogatory-de-mentativity that is intrinsic-reality/ontology by any social-aggregation-enabler (perverted use of notions of differentness, infamy, status, significant-others basis of logic, repute, social authorities and influencers naively involved in fallacies of authority, disparagement, contrivance, duplicity, imposturing, ontological-bad-faith/inauthenticity ${ }^{64}$, implying an equivalence between ${ }^{3}$ universal/intemporal sense of purpose with extricatory/temporal/mundane sense of purposes, underhandedness, inductive-limitation or so-called principle that is not articulated as a universal construct but targeted, avowing its reality as fake, etc.). The ' blurriness$<$ sterilising/anecdotalising/trivialising-of-prospective-re-ontologising_by-preconverging,-indisontologising-formulaic-dragging-out/hollowing-out> and distance of $<$ amplituding/formative-epistemicity $>$ causality $\sim$ as-to-projective-totalitative-implications-ofprospective- nonpresencing,-for-explicating relative mnreflexivity/relative reflexivity ontological-contiguity /intrinsic-reality/ontological-veridicality transcendentalenabling/sublimating/supereregatery $\sim$ de-mentativity' makes this altogether a more difficult 
proposition in the social sciences particularly with issues that are highly emotionallyinvolved/'interested'/politically-driven wherein even in intellectual circles arguments of differentness/subtle-infamy-implications/status/significant-others-basis-of-logic/repute are often easily advanced in undermining inherent veracity/ontological-pertinence. One such notorious argument with regards to poststructuralists involved the notion that French poststructuralism was developed by peripheral intellectuals of French society but then failing to equally say that a lot of the good science and social science in many Western countries have generally had the same personalities attributes. Of course, such a narrative will not be countenanceable in the promptness of effectiveness driven natural science of $<$ amplituding/formative-epistemicity $>$ causality $\sim$ as-to-projective-totalitative-implications-ofprospective- nonpresencing,-for-explicating relative-unreflexivity/relative-reflexivity

ontological-contiguity , for instance, holding that Einstein's theory-of-relativity is flawed with the non-substantive argument he was a peripheral intellectual to German or Swiss or American society. The bigger point here with respect to a storied-construct/ontologically-valid-narration aetiologisation/ontological-escalation-<ontological-

veridicality_commitment/otherliness_transcending/compulsions-encumbered_transcending $>$, is that veracity/ontological-pertinence by mere articulation of sound ontological conceptualisations as transcendental-enabling/sublimating/supererogatory $\sim$ de-mentativity-of-intrinsic-socialreality in the social contextualisation especially where blurry is often not sufficient purely by itself but that it needs to be creatively construed in facing off 'social-aggregation-enablers over intrinsic-reality/ontological-veridicality transcendentalenabling/sublimating/supereregatory $\sim$ de-mentativity' with the transcendental-

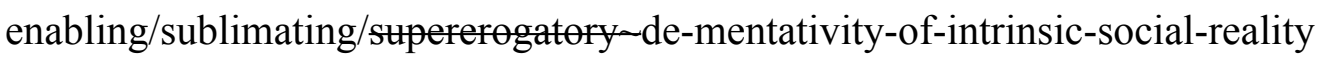
$<$ amplituding/formative-epistemicity $>$ causality $\sim$ as-to-projective-totalitative-implications-ofprospective- nonpresencing,-for-explicating relative-unreflexivity/relative-reflexivity 
ontological-contiguity. This weakness actually takes a turn for the worst when it comes to the phenomenon of psychopathy and social psychopathy as this phenomenon is actually the quintessence of active extrinsic-attribution 'social-aggregation-enablers over intrinsicreality/ontological-veridicality transcendental-enabling/sublimating/supererogatory $\sim$ dementativity' as driven by postlogism — construed-as-of-disontologising-perverted-outcomesought-precedes-existentially-veridical-'attendant-intradimensional-

apriorising/axiomatising/referencing'-logical-dueness backtracking-<iterative-looping-‘set-ofdereifying-hollow-narratives-and-acts'> postlogism and corresponding conjugatedpostlogism $7{ }^{12}$ conjoining-looping-set-of-narratives of such postlogic-backtracking- $<$ iterativelooping-'set-of-dereifying-hollow-narratives-and-acts' $>$, respectively in recursiveness (psychopathic), progressiveness (opportunistic and exacerbatory) and regressiveness (ignorance and affordability). So a storied-construct/ontologically-valid-narration aetiologisation/ontological-escalation-<ontologicalveridicality_commitment/otherliness_transcending/compulsions-encumbered_transcending > will need to demonstrate veracity/ontological-pertinence of the conceptualisations highlighted in this paper not purely by themselves as transcendental-

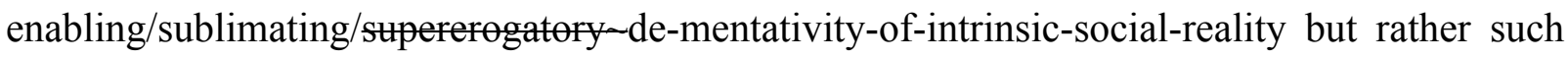
conceptualisation in a supratransversality-<in-sublimating-existentialeventuating/denouement $>\sim$ of-motif-and-apriorising/axiomatising/referencing should be overand-face-off a subtransversality-<in-desublimating-existential-eventuating/denouement $>\sim$ ofmotif-and-apriorising/axiomatising/referencing of temporal undermining by 'socialaggregation-enablers over intrinsic-reality/ontological-veridicality transcendentalenabling/sublimating/surate-mentativity' such as perverted use of notions of differentness, infamy, status, significant-others basis of logic, repute, social authorities and influencers naively involved in fallacies of authority, disparagement, contrivance, duplicity, 
imposturing, ontological-bad-faith/inauthenticity ${ }^{64}$ implying an equivalence between universal/intemporal sense of purpose with extricatory/temporal/mundane sense of purposes, underhandedness, inductive-limitation (so-called principle that is not articulated as a ${ }^{103}$ universal construct but targeted, avowing its reality as fake), etc., and this is the realistic developing social contextualisation within which psychopathy and social psychopathy manifests itself. Further the social-aggregation-enabler mechanism is what brings about social-chainism/socialdiscomfiture/negative-social-aggregation as well as the temporal-endemisation/temporalenculturation of psychopathy and social psychopathy by eliciting of differentness, infamy, status, significant-others basis of logic, repute, social authorities and influencers naively involved in fallacies of authority, disparagement, contrivance, duplicity, imposturing, ontological-badfaith/inauthenticity ${ }^{64}$, implying an equivalence between ${ }^{103}$ universal/intemporal sense of purpose with extricatory/temporal/mundane sense of purposes, underhandedness, inductive-limitation, etc., to induce subontologisation/subpotentiation or existential-decontextualised-transposition. Ontologically, thus the construal/conceptualisation of the Social postconverging-dementating/structuring/paradigming is necessarily a construct that harkens to the intemporalprojection enabling the thoughtfulness as the imbued intemporal-preservation consciousnessawareness-teleology ${ }^{9}$ with corresponding ${ }^{56}$ meaningfulness-and-teleology ${ }^{99}$ (so-reflected as to the <cumulating/recomposuring attendant-ontological-contiguity $>$-succession of registryworldviews/dimensions of the relative-unreflexivity/relative-reflexivity-ontologicalcontiguity ${ }^{67}$ of-the-human-institutionalisation-process ${ }^{68}$ ) inducing the ${ }^{55}$ maximalisingrecomposuring-for-relative-ontological-completeness ${ }^{8}$ — unenframed/re-

ontologising conceptualisation: so-enabling the development and endemisation/enculturation, as from recurrent-utter-uninstitutionalisation (non-rules - apriorising/axiomatising/referencingpsychologism,-as-impulsive-or-accidented-or-random-mental-disposition), successively of base-institutionalisation (rulemaking-over-non-rules - apriorising/axiomatising/referencing- 
psychologism) social-setup, ${ }^{103}$ universalisation ( ${ }^{103}$ universalisation-directed-rulemaking-overnon-rules_-apriorising/axiomatising/referencing-psychologism) social-setup, positivism (positivising/rational-empiricism-based-universalisation-directed-rulemaking-over-non-rulesapriorising/axiomatising/referencing-psychologism) social-setup and prospectively notional ${ }^{18}$ deprocrypticism (preempting — disjointedness-as-of- ${ }^{8}$ reference-of-thought,-as-to${ }^{32}<$ amplituding/formative-epistemicity $>$ growth-or-conflatedness ${ }^{13} /$ transvaluative- $^{-}$ rationalising/transepistemicity/anamnestic-residuality/spirit-drivenness'_in-supersedingmere-formulaic-positivising/rational-empiricism-based-universalisation-directed-rulemakingover-non-rules_-apriorising/axiomatising/referencing-psychologism) social-setup. The implication being that the Social is much more than aggregativity (social-aggregation) wherein a mental-disposition of 'overt aggregative social disposition' that conceives that a social-setup

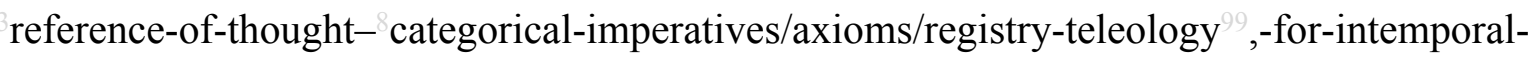
preservation-entropy-or-contiguity-or-ontological-preservation are simply 'perceptively-andformulaically deterministic' for 'its purpose of temporal extricatory preconverging-dementating/structuring/paradigming relating with the ${ }^{83}$ reference-of-thought- categoricalimperatives/axioms/registry-teleology ${ }^{9}$ (as perversion-and-derived- ${ }^{7 / 2}$ perversion-of- ${ }^{8}$ referenceof-thought- $<$ as-preconvergingly-apriorising/axiomatising/referencing-innonconviction/madeupness/bottomlining-as-to-shallow-supererogation $>$ )' that undermines the imbued intemporal-preservation-entropy-or-contiguity-or-ontological-preservation of the social-setup 'is not ontologically social' (as aggregativity construals and mental-dispositions about social relations of extricatory temporal-dispositions are perfectly construable as of varying covert to overt ' ${ }^{83}$ reference-of-thought—degraded-devolving-as-of-uninstitutionalisedthreshold ${ }^{102}$ '). Likewise a mental-disposition of 'overt non-aggregative social disposition' conceiving the social-setup ${ }^{83}$ reference-of-thought- categorical-imperatives/axioms/registryteleology ${ }^{9}$,-for-intemporal-preservation-entropy-or-contiguity-or-ontological-preservation 'as 
of inherent essence and to be upheld and maximalisingly recomposured' (as appropriateness-ofreference-of-thought-as-of-conflatedness ${ }^{13}$ ) 'is ontologically social'. The Social as such is an abstract construct not about the 'equability in mutuality of the mortals that we are' but rather the opportunity for transcendental construal of our potential for intemporality ${ }^{52}$. Paradoxically and across all registry-worldviews/dimensions this has always imply sociologically that uninstitutionalised-threshold ${ }^{102}$ are in a transversality-<for-sublimating-existentialeventuating/denouement,-from-'thinking-at-first/pure-predisposition-preemptive-ofprospective-disontologising/subontologising’ as-of-prospectively-disambiguated-affirmedand-unaffirmed-'motif-and-apriorising/axiomatising/referencing' $>101$ of these two divergent mental-dispositions with respect to ${ }^{56}$ meaningfulness-and-teleology ${ }^{99}$ whether conceptualisation of the transcendental as defining prospective social ontology in a sense of intellectual solipsistic fulfilment driven by relative intrinsic-reality/ontological-veridicality transcendentalenabling/sublimating/supereregatory $\sim$ de-mentativity or conceptualisation in aggregativity/social-aggregation as of <amplituding/formative> wooden-language-〈imbuedaveraging-of-thought-<as-to-leveling/ressentiment/closed-construct-of- meaningfulness-andteleology -as-of-‘nondescript/ignorable-void '-with-regards-to-prospective-apriorisingimplications $>>$ driven by social-aggregation-enabling, explaining the underlying confliction implied by any prospective institutionalisation as transcendental. This insight can be grasped from ontological-normalcy/postconvergence epistemic-or-notional $\sim$ projective-perspective, when we garner that the 'equability in mutuality of temporally-disposed minds as shortness-ofregister-of- ${ }^{56}$ meaningfulness-and-teleology ${ }^{9}$, in a non-positivism/medievalism social-setup doesn't supersede the ontological-veridicality of a social ontology insight providing anchoring for prospective positivistic institutionalisation construed ${ }^{83}$ reference-of-thought. Plausibly most likely the 'developing consciousness-awareness-teleology ${ }^{9}$ mindset' of such a 'social ontology insight about prospective positivism' (as '55aximalising-recomposuring-for-relative- 
ontological-completeness ${ }^{87}$ - unenframed/re-ontologising conceptualisation for intemporalpreservation-entropy-or-contiguity-or-ontological-preservation) may lead to its very own circumspection with the registry-worldview's/dimension's meaningfulness-and-teleology and possibly non-aggregativity. Consider the instance of such characters as Galileo and Newton, at the crossroad of 'what is to be considered as valued ${ }^{56}$ meaningfulness-and-teleology ${ }^{9}$ ' with respect to the prospective as the posivistic registry-worldview/dimension and the prior as the non-positivism/medievalism world, as consciously-or-unconsciously they register that the prior needs to be 'decentered' and the prospective 'centered', even though by reflex the prior will construe of itself as undecenterable center of meaningfulness-and-teleology ${ }^{5}$. This may go a long way in explaining such biographic accounts about Isaac Newton as unsocial wherein a naïve conceptualisation of impression-driven/good-naturedness/wishfulness construal as virtue (in lieu of 'prospective postconverging-aporeticism-overcoming/unovercoming as theGood/knowledge-reification $\sim$ gesturing-and-accounting — of-epistemic-phenomenalism- $<$ inprospective_psychologismic apriorising/axiomatising/referencing-\{of-'prospectively implicited_attendant-ontological-contiguity ' educedexistentialising/contextualising/textualising_'intelligibility/epistemicity/reflexivity-contiguity<imbued-notional cogency>' \}-conflatedness in \{preconverging disentailment by\} postconverging-entailment $>$ /understanding/<amplituding/formativeepistemicity $>$ causality $\sim$ as-to-projective-totalitative-implications-of-prospectivenonpresencing,-for-explicating relative-unreflexivity/relative-reflexivity - ontologicalcontiguity in its <amplituding/formativeepistemicity $>$ totalising $\sim$ ratiocontiguity/ratiocination-as-referentialism—'implicited_attendant ontological-contiguity ${ }^{67}$, educedexistentialising/contextualising/textualising_intelligibility/epistemicity/reflexivity-contiguity$<$ imbued-notional cogency>' ;-phenomenal-abstractiveness-of-presencing-in-'protensive- 
consciousness'-enabling-

apriorising/axiomatising/referencing/intelligibilitysettingup/measuringinstrumenting-foroperant-or-incidenting-predicative-insights-of 'implicited_attendant-ontologicalcontiguity $^{67} \sim$ educedexistentialising/contextualising/textualising_intelligibility/epistemicity/reflexivity-contiguity$<$ imbued-notional $\sim$ cogency $>,{ }^{\prime},-<$ reifying-or-elucidating-of-prospective-relative-ontologicalcompleteness -of- reference-of-thought- devolving-as-of-instantiative-context> of intemporality ${ }^{52}$ ) will not factor in the inherent deficiency in value judgment of a nonpositivism/medievalism inclined ordinary mindset $/{ }^{8}$ reference-of-thought from which such accounts are coming from (given such a society's state of paradox of transcendence-andsublimity/sublimation/supererogatory de-mentativity of relative-ontological-incompleteness ${ }^{8}$ induced,-'threshold-of-nonconviction/madeupness/bottomlining-in-shallow-supererogation $<$ as-to-'attendant-intradimensional'-prospectivelydisontologising preconverging/dementing -apriorising-psychologism>') about a figure involved in 'intemporal-prioritisation-of- ${ }^{8}$ reference-of-thought'-as-conflatedness ${ }^{13}$-orontological-reprojecting as partaking in the 'inventing/creating' of the preconverging/postconverging-de-mentative/structural/paradigmatic possibility (and the corresponding psychologism) for prospective positivism institutionalised-being-and-craft, more like biting a hand that intemporal-solipsistically as of ontological-faith-notion-or-ontologicalfideism —imbued-underdetermination-of-motif-and-apriorising/axiomatising/referencing-asso-being-as-of-existential-reality provides the opportunity for prospective preconverging/postconverging-de-mentative/structural/paradigmatic human flourishing, with the underlying fact being that inherently such a personality type rather as of a solipsisticintemporality $^{52}$ individuation disposition, by its contemplative reappraisal, is exactly what can provide the opportunity for such transcendental possibilities (when we come to grasp that the 
true profoundness of knowledge is more than just 'mechanical as something construed soullessly' without a more complete appreciation of knowledge as 'organic as something construed with a profound sense of intemporal projection philosophy as to profoundsupererogation" with the idea that the type of knowledge construed as of first order transcendental-enabling/sublimating/supererogatory $\sim$ de-mentativity is not based on an ordinary notion of 'intelligence as we'll normally think of as simply technical' but rather on such a sense of intemporal philosophical projection and more than just a 'product' for a materiality purpose but a driven sense of human emancipation). In fact, this equally points to a major flaw of the inherently implied value judgement in a lot of what passes for social sciences today explaining the vagueness, platitude and emptiness of little or no relative intrinsic-reality/ontologicalveridicality transcendental-enabling/sublimating/supererogatory $\sim$ de-mentativity implication as an $<$ amplituding/formative-epistemicity $>$ totalising $\sim$ self-referencingsyncretising/circularity/interiorising/akrasiatic-drag ${ }^{34}$ circular exercise, wherein the unabated recourse to naïve feel good averaging of thought mental-dispositions are equated with ontological-veridicality uncritically, rather than construing that the animal that we are is in want of knowledge as a construct that enable it to supersede/transcend itself rather than a vain exercise of nombrilism, in which case one may argue that each registry-worldview/dimension $<$ amplituding/formative $>$ wooden-language-_imbued — averaging-of-thought- $<$ as-toleveling/ressentiment/closed-construct-of- meaningfulness-and-teleology -as-of'nondescript/ignorable-void '-with-regards-to-prospective-apriorising-implications $>>\quad$ ideas should be the basis for construing its social science! In fact, technically Newton might be the most inclined person for social engagement but then will he as of intemporal projection be inclined to 'go along as social' where he construed beyond-the-consciousness-awarenessteleology $-<$ of-preconverging-existential-extrication-as-of-existential-unthought $>\quad$ the 'medieval social' as in want of its further development (this highlights a contrast between a 
stigmatic/mented psychology of the present, as of any 'present registry-worldview/dimension', with value references related to as absolute without or poorly factoring in that the animal that is the human is rather a becoming animal in constant psychological development of its limitedmentation-capacity -as-subjecting 'educed-unlimitedness/existence-sublimating nascence'to-limitedness/human-subpotency with respect to social ${ }^{103}$ universal-transparency 〈transparency-of-totalising-entailing,-as-to-entailing-<amplituding/formativeepistemicity>totalising in-relative-ontological-completeness > as of 'implicited_attendantontological-contiguity ${ }^{67} \sim$ educedexistentialising/contextualising/textualising_intelligibility/epistemicity/reflexivity-contiguity$<$ imbued-notional cogency $>,{ }^{\prime},-<$ reifying-or-elucidating-of-prospective-relative-ontologicalcompleteness -of- reference-of-thought- devolving-as-of-instantiative-context $>$ as of ontological-completeness-of- reference-of-thought; as determining its value reference and defining its underlying placeholder-setup/mental-devisingrepresentation/mentation/consciousness-awareness-teleology ${ }^{9}$, and hardly addressing such a more fundamental question as implied by 'postconverging-or-dialectical-thinking ${ }^{2}$-psychology or psychology-of-mentation-dynamics or natural $\sim$ psychological-dynamics'). In this respect, this makes many such so-called 'social science approaches' 'poorly grounded on a social relative intrinsic-reality/ontological-veridicality transcendentalenabling/sublimating/supereregatery $\sim$ de-mentativity' more or less sciences of methodological mimicry, as we know that much of the 'true sciences' (including the natural sciences and many a true social science are not grounded on an <amplituding/formativeepistemicity $>$ totalising $\sim$ self-referencing-syncretising/circularity/interiorising/akrasiatic-drag construal but identify objective reality by its naturally constraining <amplituding/formativeepistemicity $>$ causality $\sim$ as-to-projective-totalitative-implications-of-prospective- 
contiguity , as differing from sovereign constructs, as the determinant of pertinence (and such profound transcendental-enabling/sublimating/supererogatory $\sim$ de-mentativity basis of knowledge are then bound to further redevelop sovereign constructs and conventions, with the sovereign constructs and conventions not becoming intrinsic-reality/ontological-veridicality in of themselves but rather as of social, institutional, cultural, moral or historical reality of the human condition); though much more easier for the natural sciences as hardly any or nobody feels impinged today with scientific discoveries and inventions given that their transcendentalenabling/sublimating/supereregatory $\sim$ de-mentativity as of a positivism outlook psychologism of the world had taken place both in philosophical and practical scientific terms with the Descartes, Hobbes's, Kants, Copernicuses, Galileos, Newtons, of the past. Whereas a lot of modern-day social science is relatively pulled back in many an unsuspecting manner, by elicited emotional involvement and underlying constraints of their institutional setups. Such can equally be implied with regards to procrypticism from futural Being-development/ontological-frameworkexpansion-as-to-depth-of-ontologising-development-as-infrastructure-of- meaningfulnessand-teleology as of prospective notional deprocrypticism insight, wherein positivismprocrypticism is decentered and notional deprocrypticism is centered, and so in comprehensive psychologism terms; with the idea that the possibly unsavoriness is not of this author's or anyone's chosen but rather that the test for futural Being-development/ontologicalframework-expansion-as-to-depth-of-ontologising-development-as-infrastructure-ofmeaningfulness-and-teleology as of prospective notional ${ }^{18}$ deprocrypticism transcendenceand-sublimity/sublimation/supererogatory - de-mentativity set by intrinsic-reality/ontologicalveridicality requires us coming to terms with it, no lesser than the test set by positivistic transcendence-and-sublimity/sublimation/superentativity in the nonpositivism/medievalism epoch intrinsic-reality required them to come to terms with this, however unpalatable to many then, and this underlying vitality across all epochs as of 
'implicited_attendant_ontological-contiguity ${ }^{67}$; educedexistentialising/contextualising/textualising_intelligibility/epistemicity/reflexivity-contiguity$<$ imbued-notional $\sim$ cogency $>,{ }^{\prime},-<$ reifying-or-elucidating-of-prospective-relative-ontologicalcompleteness -of- reference-of-thought- devolving-as-of-instantiative-context $>$, induced by prospective relative-ontological-completeness ${ }^{87}$-of- ${ }^{83}$ reference-of-thought is what counts as true knowledge beyond the blurriness-<sterilising/anecdotalising/trivialising-of-prospective-reontologising_by-preconverging,-in-disontologising-formulaic-dragging-out/hollowing-out>in-reflecting-and/or-coming-to-terms-with-implied-transcendence that often tends to arise with all institutionalisations institutionalised-being-and-craft erudition! More fundamentally, as previously highlighted with the mediocrity principle of science as it applies to humankind as well (as the notion of metaphysics-of-absence-〈implicited-epistemic-veracity-ofnonpresencing-<perspective-ontological-normalcy/postconvergence $>\rangle$ is pushed to its full implications over metaphysics-of-presence-〈implicited-'nondescript/ignorable-void '-as-topresencing - absolutising-identitive-constitutedness $\rangle$ as our present-consciousness/illusionof-the-present/epistemic-totalising $\sim$ self-referencing-syncretising/mirage), the reality of a human-subpotency-aporia/undecidability/dilemma/oughtindeterminacy/deficiency/limitation/constraint—imbued-'notional firstnaturednessformativeness-<as-to-eventualising inkling drive-or-seeding misprising $>$ temporal-tointemporal-dispositions-<so-construed-as-from-perspective-ontologicalnormalcy/postconvergence>'-existentialism-form-factor may actually more objectively (and so beyond-our-consciousness-awareness-teleology ${ }^{9}$ ) point to the idea that institutionalisation (the relative-unreflexivity/relative-reflexivity - ontological-contiguity ${ }^{67}$ of-the-humaninstitutionalisation-process ${ }^{68}$ ) as intemporalisation is actually a ${ }^{65}$ maximalising-recomposuringfor-relative-ontological-completeness ${ }^{87}$ — unenframed/re-ontologising conceptualisation recomposured abstract-construction/institutionalisation-designing' which 'in its operant 
effectuation (due to limited-mentation-capacity-as-subjecting-'educedunlimitedness/existence-sublimating nascence' to-limitedness/human-subpotency as of '7 presencing - absolutising-identitive-constitutedness ${ }^{14}$ ) defines its very own prospective interspersing with uninstitutionalised-threshold ${ }^{102}$, articulated as 'socially-functional-andaccordant ${ }^{93}$ temporalisation of ${ }^{5}$ meaningfulness-and-teleology ${ }^{99}$ as from idiosyncratic individuations frame-of-reference at childhood to full-blown threshold-ofnonconviction/madeupness/bottomlining-in-shallow-supererogation $<-<$ as-to-' attendantintradimensional'-prospectively-disontologising preconverging/dementing -apriorisingpsychologism $>$ individuations frame-of-reference at adulthood'; that is, the relativeunreflexivity/relative-reflexivity - ontological-contiguity ${ }^{67}$ of-the-human-institutionalisationprocess $^{68}$ or institutionalisation design construed rather as about reducing-humantemporalisation- $\left\{\right.$ shortness-of-register-of- ${ }^{5}$ meaningfulness-and-teleology $\left.{ }^{9}\right\}$ uninstitutionalised-threshold ${ }^{102}$, with such a notion of uninstitutionalised-threshold ${ }^{102}$ being the central notion of conceptualisation/construal for a thorough the-Good/knowledgereification $\sim$ gesturing-and-accounting — of-epistemic-phenomenalism- $<$ inprospective_psychologismic apriorising/axiomatising/referencing-\{of-‘prospectively implicited_atendant-ontological-contiguity ' educedexistentialising/contextmalising/textualising_'intelligibility/epistemicity/reflexivity_contiguity<imbued-notional cogency $\left.>^{\prime} \quad\right\}$-conflatedness -in-\{preconverging-disentailment by\} postconverging-entailment $>$ /understanding/<amplituding/formativeepistemicity $>$ causality $\sim$ as-to-projective-totalitative-implications-of-prospectivenonpresencing,-for-explicating relative-unreflexivity/relative-reflexivity - ontologicalcontiguity construct (however counterintuitive from our natural thinking reflex metaphysicsof-presence-〈implicited-'nondescript/ignorable-void ' 'as-to- presencing — absolutisingidentitive-constitutedness > 'based on reasoning in terms-as-of-axiomatic-construct of 
cumulating institutionalisations'). Such a construal/conceptualisation of 'institutionalisation as of uninstitutionalised-threshold ${ }^{102}$ will explain why with regards to 'all the successive institutionalisations formal constructs' as of their respective 'comprehensive abstract setups of deferential-formalisation-transference institutionalised ${ }^{56}$ meaningfulness-and-teleology ${ }^{9}$, there is a tendency associated with their corresponding extended-informality-〈susceptible-toeffecting-parsimony-as-of-shoddiness-and-incompleteness-to- meaningfulness-and-

teleology 〉wherein there is 'parallel construed extended-informality-〈susceptible-to-effectingparsimony-as-of-shoddiness-and-incompleteness-to- meaningfulness-and-teleology > meaningfulness-and-teleology ${ }^{9}$-as-of-a-relatively-poor-institutionalising-inclination' of a subpar and occasionally of a superseding practical applicative bearing/effectiveness over the supposedly formal construct. By-and-large, this will often arise within the scope of blurry institutional setups not construed for operant effectiveness. Strangely enough we do actually tend to elicit such extended-informality-〈susceptible-to-effecting-parsimony-as-of-shoddiness-andincompleteness-to- meaningfulness-and-teleology $>$ construal as more determinant when the principles of formal constructs are rearticulated operantly in extended-informality-〈susceptibleto-effecting-parsimony-as-of-shoddiness-and-incompleteness-to- meaningfulness-andteleology > $\quad{ }^{56}$ meaningfulness-and-teleology ${ }^{9}$-as-of-a-relatively-poor-institutionalisinginclination terms; and often contributing to institutional inefficiencies and failures of all sorts whether with respect to mismanagement, misappropriation, incompetence, etc. from a modern perspective of analysis. Further, the fact is such extended-informality-〈susceptible-to-effectingparsimony-as-of-shoddiness-and-incompleteness-to- meaningfulness-and-teleology \ effect can be more than just about the operant effect but equally protracted as 'designed-formalisationineffectiveness' in ensuring the ascendency of extended-informality-<susceptible-to-effectingparsimony-as-of-shoddiness-and-incompleteness-to- meaningfulness-and-teleology > meaningfulness-and-teleology -as-of-a-relatively-poor-institutionalising-inclination over 
formal constructs. By-and-large, this can be construed as the flawed/unsound\}-relativeunreflexivity-in-existence/absolutising from-limited-mentation/psychologismic epistemic acutisation nonresidualising-imbued formulaicity/ritualisation residual temporalisation effect arising from the fundamental reality of a human-subpotency-aporia/undecidability/dilemma/oughtindeterminacy/deficiency/limitation/constraint—imbued-'notional firstnaturednessformativeness-<as-to-eventualising inkling drive-or-seeding misprising $>$ temporal-tointemporal-dispositions- $<$ so-construed-as-from-perspective-ontologicalnormalcy/postconvergence>'-existentialism-form-factor with respect to all the successive institutionalisations; with the notion of notional deprocrypticism requiring referencing/registering/decisioning the reality of human-subpotencyaporia/undecidability/dilemma/ought-indeterminacy/deficiency/limitation/constraint—imbued'notional firstnaturedness-formativeness-<as-to-eventualising inkling-drive-or-seedingmisprising $>$ temporal-to-intemporal-dispositions- $<$ so-construed-as-from-perspectiveontological-normalcy/postconvergence>'-existentialism-form-factor without any complexes and psychically pivoting/decentering (as psychoanalytic-unshackling/memeticreordering/institutional-recomposuring) over its $\quad{ }^{18}$ deprocrypticism-or-preemptingdisjointedness-as-of- ${ }^{8}$ reference-of-thought (just as the 'positivistic mindset' arose from referencing/registering/decisioning the reality of defective essences, alchemic, spirits, etc. ${ }^{3}$ universalising-rules and psychically pivoting/decentering for rationalempiricism/positivising-rules, just as the ' ${ }^{103}$ universalising mindset' arose from referencing/registering/decisioning the reality of vague, sporadic, incidental, and animistic rulemaking-over-non-rules — apriorising/axiomatising/referencing-psychologism,-〈as 'firstlevel presencing-absolutising-identitive-constitutedness ${ }^{14}$ of reference-of-thought' apriorising/axiomatising/referencing/intelligibilitysettingup/measuringinstrumenting $\quad$ and 
psychically pivoting/decentering for ${ }^{103}$ universalisation-directed-rulemaking-over-non-rulesapriorising/axiomatising/referencing-psychologism,-〈as 'second-level presencingabsolutising-identitive-constitutedness ${ }^{14}$ of reference-of-thought' apriorising/axiomatising/referencing/intelligibilitysettingup/measuringinstrumenting $\rangle$, and just as the 'base-institutionalised mindset' arose from referencing/registering/decisioning the reality of non-rules - apriorising/axiomatising/referencing-psychologism,-as-impulsive-oraccidented-or-random-mental-disposition-〈as 'base apriorising/axiomatising/referencing-\{of'prospectively_implicited_attendant-ontological-contiguity ' educed-

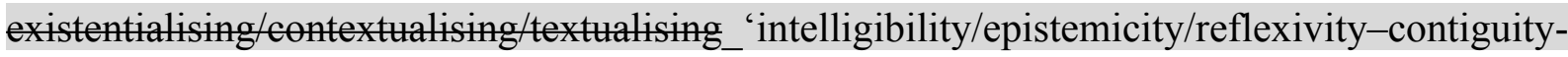
$<$ imbued-notional cogency $>$ ' $\}$-constitutedness ${ }^{14}$-in-preconverging-entailment of reference-of-thought'

apriorising/axiomatising/referencing/intelligibilitysettingup/measuringinstrumenting $\quad$ and psychically pivoting/decentering for rulemaking-over-non-rulesapriorising/axiomatising/referencing-psychologism,-〈as 'first-level presencing — absolutisingidentitive-constitutedness of reference-of-thought' apriorising/axiomatising/referencing/intelligibilitysettingup/measuringinstrumenting); and so, as of psychical and institutionalisation implications). Across all institutionalcumulation/institutional-recomposure-〈as-to- historiality/ontological-

eventfulness /ontological-aesthetic-tracing-<perspective-ontologicalnormalcy/postconvergence-reflected-‘epistemicity-relativism-determinism'>> in reflecting holographically-<conjugatively-and-transfusively $>$ the relative-unreflexivity/relativereflexivity - ontological-contiguity of-the-human-institutionalisation-process defining why any given institutionalisation is stuck at its level of relative-ontological-incompleteness ${ }^{8}$ induced,-'threshold-of-nonconviction/madeupness/bottomlining-in-shallow-supererogation $<$ as-to-'attendant-intradimensional'-prospectively- 
disontologising preconverging/dementing -apriorising-psychologism $>$ ' is its flawed notion of sanctified-conventioning-social-aggregation-enablers defining the conventioning threshold of the given institutionalisation wherein the inherent prospective intrinsicreality/veracity/ontological-pertinence transcendental-enabling/sublimating/supererogatory $\sim$ dementativity is (unconsciously, expediently or consciously) superseded/overridden by the given institutionalisation's sanctified-conventioning-social-aggregation-enablers, thus endemising/enculturating the said institutionalisation specific ${ }^{7}$ perversion-of- ${ }^{83}$ reference-ofthought-<as-preconvergingly-apriorising/axiomatising/referencing-in-

nonconviction/madeupness/bottomlining-as-to-shallow-supererogation $>$ (postlogism 77 -andconjugated-postlogism 77 , whether as 'procrypticism ${ }^{7}$ perversion-of- ${ }^{8}$ reference-of-thought$<$ as-preconvergingly-apriorising/axiomatising/referencing-in-

nonconviction/madeupness/bottomlining-as-to-shallow-supererogation $>$ (psychopathy and social psychopathy)', 'Non-positivism/medievalism 7 perversion-of- ${ }^{-}$reference-of-thought- $<$aspreconvergingly-apriorising/axiomatising/referencing-in-

nonconviction/madeupness/bottomlining-as-to-shallow-supererogation >’, 'Ununiversalisation perversion-of- ${ }^{83}$ reference-of-thought-<as-preconvergingly-

apriorising/axiomatising/referencing-in-nonconviction/madeupness/bottomlining-as-to-

shallow-supererogation $>$ ' or 'Recurrent-utter-uninstitutionalisation ${ }^{77}$ perversion-ofreference-of-thought-<as-preconvergingly-apriorising/axiomatising/referencing-innonconviction/madeupness/bottomlining-as-to-shallow-supererogation >', whereby the specific uninstitutionalised-threshold ${ }^{102}$ has its specific point of sanctified-conventioning-socialaggregation-enablers where transcendental-enabling/sublimating/supererogatory $\sim$ dementativity is impeded: with recurrent-utter-uninstitutionalisation sanctified-conventioningsocial-aggregation-enablers $\quad{ }^{83}$ reference-of-thought $\quad$ failing/not-upholding-<as-ofapriorising/axiomatising/referencing $>\quad$ the rulemaking-over-non-rules- 
apriorising/axiomatising/referencing-psychologism,-〈as 'first-level presencing-absolutisingidentitive-constitutedness

apriorising/axiomatising/referencing/intelligibilitysettingup/measuringinstrumenting $\rangle$ required for the transcendental-enabling/sublimating/supererede-mentativity of baseinstitutionalisation, with ununiversalisation sanctified-conventioning-social-aggregationenablers reference-of-thought failing/not-upholding-<as-ofapriorising/axiomatising/referencing $>{ }^{103}$ universalisation-rules' required for the transcendentalenabling/sublimating/supereregatory de-mentativity of ${ }^{103}$ universalisation, with nonpositivism/medievalism sanctified-conventioning-social-aggregation-enablers ${ }^{83}$ reference-ofthought failing/not-upholding-<as-of-apriorising/axiomatising/referencing $>\quad$ 'rationalempiricism/positivising-rules' required for the transcendentalenabling/sublimating/supererogatory $\sim$ de-mentativity of positivism or prospectively, with procrypticism sanctified-conventioning-social-aggregation-enablers $\quad{ }^{83}$ reference-of-thought failing/not-upholding-<as-of-apriorising/axiomatising/referencing $>\quad$ 'nondisjointing-rules' required for the transcendental-enabling/sublimating/supereregatery $\sim$ de-mentativity of deprocrypticism-or-preempting-disjointedness-as-of- ${ }^{83}$ reference-of-thought; and so as to their successive 'implicited_attendant-ontological-contiguity ${ }^{6}$ ' educedexistentialising/contextualising/textualising_'intelligibility/epistemicity/reflexivity_contiguity$<$ imbued-notional cogency $>$ ' existence-potency ${ }^{39} \sim$ sublimating-nascence,-disclosed-fromprospective-epistemic-digression—rules-of-apriorising/axiomatising/referencing-that-furtherepistemically-unconceal-the-very-ontologically-same-existential-reality'. Such sanctifiedconventioning-social-aggregation-enablers as to the prospective epistemic-projection implies a perversion-of- ${ }^{-3}$ reference-of-thought-<as-preconverginglyapriorising/axiomatising/referencing-in-nonconviction/madeupness/bottomlining-as-toshallow-supererogation $>$ (as enabling postlogism 7 -and-conjugated-postlogism ${ }^{77}$ ) wherein the 
instigated postlogism (disontologising-perverted-outcome-sought-precedes-existentiallyveridical-'attendant-intradimensional-apriorising/axiomatising/referencing'-logical-dueness) and protracted-conjugated-postlogism mental-dispositions contendingly perceive the sanctified-conventioning-social-aggregation-enablers as the enabling point of 'denaturing postlogic-backtracking devoided-of-conviction-as-to-profound-supererogation -orprelogism ${ }^{78}$-basis' when facing the 'intrinsic-reality/veracity/ontological-pertinence transcendental enabler'. Concretely, the fact is that psychopathic postlogic-backtracking$<$ iterative-looping-'set-of-dereifying-hollow-narratives-and-acts'> $>$ and conjugatedpostlogism as 'conjoining looping narratives of flawed-existential-elevation-of- ${ }^{83}$ reference-ofthought ' ' of postlogic-backtracking-<iterative-looping-'set-of-dereifying-hollow-narrativesand-acts' $>$ are 'denaturing devoided-of-conviction-as-to-profound-supererogation -orprelogism -basis' towards the given institutionalisation'ssanctified-conventioning-socialaggregation-enablers in order to override, undermine and escape from the intrinsicreality/veracity/ontological-pertinence transcendental-enabling/sublimating/supererogatory $\sim$ dementativity. As in the case previously highlighted where a psychopath spoke to an interlocutor that it is a bad thing for a said individual to be molesting children, with its logic being sound from an abstract/virtuality appreciation but with the existential-reality of its 'apriorisingreference-of-thought/apriorising-registry_elements (out of 'implicited_attendantontological-contiguity ${ }^{67}$, educedexistentialising/contextualising/textualising_'intelligibility/epistemicity/reflexivity-contiguity<imbued-notional cogency $>{ }^{\prime},-<$ reifying-or-elucidating-of-prospective-relative-ontologicalcompleteness -of- reference-of-thought- devolving-as-of-instantiative-context>)' of \{epistemictotalising 3 psychologismic subliminality of-individuation-effusing/worlding imbued logicaldueness-or-scape-or-frame, profile-or-stature, presumptuousness-or-arrogation, assumptions, value-reference and teleology ${ }^{9}$ being utterly unfounded as a first-order faulty-mentation- 
procedure-deception-or-urge ${ }^{43}$ potentially enabling an infinite possibility of second-order level deception if re-engaged as of ${ }^{5}$ logical-processing-or-logical-implicitation-supposedlyapriorising-in-conviction-as-to-profound-supererogation . Where the interlocutor finds out that the other stranger isn't really a child molester. The psychopath simply articulates another postlogic/disontologising-perverted-outcome-sought-precedes-existentially-veridical'attendant-intradimensional-apriorising/axiomatising/referencing'-logical-dueness/formulaic non-veridical hollow mimicking narrative (meaning-by-the-mere-illogical-possibility-of-itbeing-formulaically-narrated) over the previous narrative, and so in 'denaturing postlogicbacktracking devoided-of-conviction-as-to-profound-supererogation ${ }^{6}$-or-prelogism ${ }^{78}$-basis' For instance, by saying (in a different social spatial location where the interlocutor cannot verify the underlying contextual reality) it is critical that the stranger should not be taking young children in his house as it suspiciously points to a molester (which is certainly a sound statement but rather being parasitised for a perverse purpose of 'denaturing postlogic-backtracking devoided-of-conviction-as-to-profound-supererogation ${ }^{6}$-or-prelogism 7 -basis' towards sanctified-conventioning-social-aggregation-enablers, as the statement, not to take young children into his house, is sanctifying/as-not-requiring-any-further-contemplation to many a supplanting-conviction-as-to-profound-supererogation _of-'attendant-intradimensional'postconverging/dialectical-thinking -apriorising-psychologism mind). Even if this latter narrative is proven to be false (as it is another ${ }^{74}$ perversion-of- ${ }^{2}$ reference-of-thought- $<$ aspreconvergingly-apriorising/axiomatising/referencing-innonconviction/madeupness/bottomlining-as-to-shallow-supererogation $>$ or mental-perversion demonstrable as above with it faulty-mentation-procedure-deception-or-urge ${ }^{43}$ not being the logic itself, but in wrongly implying as existentially-disongelogising aporeticism $>$ real the 'apriorising_- ${ }^{83}$ eference-of-thought/apriorising-registry_elements (out of 'implicited_attendant-ontological-contiguity ${ }^{67}$ ' educed- 
existentialising/contextualising/textualising_intelligibility/epistemicity/reflexivity-contiguity$<$ imbued-notional $\sim$ cogency $>,{ }^{\prime},-<$ reifying-or-elucidating-of-prospective-relative-ontologicalcompleteness -of- reference-of-thought- devolving-as-of-instantiative-context $>$ )' of totalising 3 psychologismic-subliminality-of-individuation-effusing/worlding imbued logicaldueness-or-scape-or-frame, profile-or-stature, presumptuousness-or-arrogation, assumptions, value-reference and teleology ${ }^{99}$ such that the mere fact of engaging logically with it validates these fundamental falsehood as a first-order faulty-mentation-procedure-deception-or-urge paving the way for an infinite possibility of second-order faulty-mentation-procedure-deceptionor-urge ${ }^{43}$ operating $\quad{ }^{5}$ logical-processing-or-logical-implicitation — supposedly-apriorising-inconviction-as-to-profound-supererogation on such false axioms. Thus, with respect to postlogism generally what is critical for the psychopath/postlogic-mindset is to be seen as being of prelogic supplanting-conviction-as-to-profound-supererogation - of-'attendantintradimensional'-postconverging/dialectical-thinking -apriorising-psychologism even if it is a perception of 'poor or bad supplanting-conviction-as-to-profound-supererogation - of'attendant-intradimensional'-postconverging/dialectical-thinking -apriorising-psychologism' (and not to be seen as being of postlogic compulsingnonconviction/madeupness/bottomlining-〈'<decontextualising/de-existentialising ofattendant-intradimensional-apriorising/axiomatising/referencing>-induced-disontologising'-ofthe-'attendant-intradimensional-ontologising'-imbued$<$ contextualising/existentialising attendant-ontological-contiguity $>$;-in-shallowsupererogation -<as-to-disontologising-perverted-outcome-sought-precedes-existentiallyveridical-'attendant-intradimensional-apriorising/axiomatising/referencing'-logicaldueness $>\rangle$ ) since that will validate the 'apriorising- ${ }^{8}$ reference-of-thought/apriorisingregistry_elements (out of 'implicited_attendant-ontological-contiguity ${ }^{67} \sim$ educedexistentialising/contextualising/textualising_'intelligibility/epistemicity/reflexivity-contiguity- 
completeness -of- reference-of-thought- devolving-as-of-instantiative-context>)' on the basis that it was the logical-processing-or-logical-implicitation-supposedly-apriorising-inconviction-as-to-profound-supererogation that was wrong hence the possibility and credibility not to question and imply the denaturing ${ }^{6}$ of ${ }^{83}$ reference-of-thought as perverted ${ }^{83}$ reference-ofthought- categorical-imperatives/axioms/registry-teleology ${ }^{9}$ and thus to wrongly re-engage

$$
\text { logical-processing-or-logical-implicitation-supposedly-apriorising-in-conviction-as-to- }
$$

profound-supererogation turning the issue into one of 'notion of agreement or disagreement' instead of construing a perversion-of- ${ }^{73}$ reference-of-thought-<as-preconverginglyapriorising/axiomatising/referencing-in-nonconviction/madeupness/bottomlining-as-toshallow-supererogation 'preconverging-or-dementing -apriorising-psychologism manifestation' implying and requiring intellectual-and-moral-inequivalence/noncorrespondence in transversality- $<$ for-sublimating-existential-eventuating/denouement,-from‘thinking-at-first/pure-predisposition-preemptive-of-prospectivedisontologising/subontologising’-as-of-prospectively-disambiguated-affirmed-andunaffirmed-'motif-and-apriorising/axiomatising/referencing' $\left.{ }^{101}\right)$. This equally applies in the instance of derived- ${ }^{7}$ perversion-of- ${ }^{8}$ reference-of-thought- $<$ as-preconverginglyapriorising/axiomatising/referencing-in-nonconviction/madeupness/bottomlining-as-toshallow-supererogation $>$ as conjugated-postlogism 77 by temporal-dispositions of ignorance/affordability/opportunism/exacerbation/social-chainism-or-social-discomfiture-ornegative-social-aggregation/temporal-enculturation-or-temporal-endemisation. The psychopath simply needs to loop another non-veridical hollow mimicking narrative over the previous one in 'denaturing postlogic-backtracking devoided-of-conviction-as-to-profound-supererogation or-prelogism 7 -basis' towards sanctified-conventioning-social-aggregation-enablers. Summarily, instances of such sanctified-conventioning-social-aggregation-enablers could be 
exemplified in dereifying context as: in the case of child psychopathy, - pour water on chair, point stranger to sit on, - accuse brother, - when found out, postlogicly retreat with delirious statement accident happened, etc.; in the case of adult psychopathy (including the conjugatedpostlogism 77 acts involved in protraction of postlogism 77 , - commit offence, - act as morally ascendant, - when the postlogic and conjugated-postlogism mental-dispositions are ontologically undermined, 'falsely contend' by extrinsic-attribution of 'social-aggregationenablers over intrinsic-reality/ontological-veridicality transcendentalenabling/sublimating/supererogatory de-mentativity' $<$ amplituding/formative $>$ woodenlanguage-〈imbued - averaging-of-thought-<as-to-leveling/ressentiment/closed-construct-ofmeaningfulness-and-teleology -as-of-'nondescript/ignorable-void ' -with-regards-toprospective-apriorising-implications $>>$ as 'denaturing postlogic-backtracking devoided-ofconviction-as-to-profound-supererogation -or-prelogism ${ }^{78}$-basis' towards the sanctifiedconventioning-social-aggregation-enablers in order to undermine the intrinsicattribution/ontological-veridicality transcendental-enabling/sublimating/supererogatory $\sim$ dementativity, - when further undermined claim in 'denaturing ${ }^{16}$ postlogic-backtracking devoidedof-conviction-as-to-profound-supererogation -or-prelogism ${ }^{78}$-basis', things have moved on, on the basis of sanctified-conventioning-social-aggregation-enablers over and undermining intrinsic-reality/veracity/ontological-pertinence transcendental enabler as a civilisational/institutional-being-and-craft setup creating mental-disposition. The fundamental issue, going by the postlogism 77 -and-conjugated-postlogism $77 /$ perversion-of- ${ }^{8}$ reference-ofthought-<as-preconvergingly-apriorising/axiomatising/referencing-innonconviction/madeupness/bottomlining-as-to-shallow-supererogation $>$ is then one that at the transcendental/transdimensional/interdimensional/maximalising-level defines the uninstitutionalised-threshold $^{102}$ vices-and-impediments ${ }^{105}$ construct of the registryworldview/dimension, more than just on-occasionally/incidentally. From an 
intemporal/ontological perspective that speaks of 'modern savage mentality', whether as postlogic or conjugated-postlogic, as procrypticism-or-disjointedness-as-of- ${ }^{8}$ reference-ofthought in need for prospective institutionalisation as deprocrypticism, not as an onoccasion/incidental issue but about ontologically appreciating the how and why in reflecting holographically-<conjugatively-and-transfusively $>$ the relative-unreflexivity/relativereflexivity ontological-contiguity of-the-human-institutionalisation-process $\quad$ as it undermines uninstitutionalised-threshold ${ }^{102}$ arising from ${ }^{7}$ perversion-of- ${ }^{3}$ reference-of-thought$<$ as-preconvergingly-apriorising/axiomatising/referencing-in-

nonconviction/madeupness/bottomlining-as-to-shallow-supererogation $>$ for the recurrent intemporal-disposition $<$ amplituding/formative-epistemicity $>$-totalising $\sim$ renewingrealisation/re-perception/re-thought possibility of further prospective civilisational living/institutionalised-being-and-craft setup, and so as an aetiologisation/ontologicalescalation-<ontological-veridicality_commitment/otherliness_transcending/compulsionsencumbered_transcending $>$ /'metaphorically-a-million-and-one-instances-and-locales' conceptualisation. The grandest job and the grandest living from an intemporalprojection/longness-of-register-of-meaningfulness/ontological-faith-notion-or-ontological-

\section{fideism-imbued-underdetermination-of-motif-and-apriorising/axiomatising/referencing-as-}

so-being-as-of-existential-reality point-of-departure-of-construal is one that construes and purports for human engaged-destruction/deconstruction/ontological-reconstituting-as-toconflatedness $^{13}$ of such uninstitutionalised-threshold ${ }^{102}$ : by 'engageddestruction/deconstruction/ontological-reconstituting-as-to-conflatedness ${ }^{13}$ of prospective recurrent-uninstitutionalisation vices-and-impediments ${ }^{105}$, for prospective baseinstitutionalisation, 'engaged-destruction/deconstruction/ontological-reconstituting-as-toconflatedness $^{13}$ of prospective ununiversalisation vices-and-impediments ${ }^{105}$, for prospective universalisation, 'engaged-destruction/deconstruction/ontological-reconstituting-as-to- 
conflatedness $^{13}$ of prospective non-positivism/medievalism vices-and-impediments ${ }^{20}$, for prospective positivism, and ultimately, 'engaged-destruction/deconstruction/ontologicalreconstituting-as-to-conflatedness ${ }^{13}$ of prospective procrypticism vices-and-impediments ${ }^{105}$ for futural Being-development/ontological-framework-expansion-as-to-depth-of-ontologisingdevelopment-as-infrastructure-of- meaningfulness-and-teleology as of prospective deprocrypticism. That exercise has always been one of decentering of the defective center for the emergence of a new and more ontologically-complete- ${ }^{8}$ reference-of-thought center, and no registry-worldview/dimension can pretend to imply it is 'un-decenterable (implying its preconverging-or-dementing ${ }^{20}$-apriorising-psychologism and out-of-phasing for the prospective thinking centering and in-phasing) by its $<$ amplituding/formative-epistemicity $>$ totalising $\sim$ selfreferencing-syncretising/illusion-of-the-present/present-consciousness/mirage speaking of its metaphysics-of-presence-〈implicited-'nondescript/ignorable-void '-as-to- presencingabsolutising-identitive-constitutedness $\rangle$, as that is the full implication of intemporal ontological-faith-notion-or-ontological-fideism - imbued-underdetermination-of-motif-andapriorising/axiomatising/referencing-as-so-being-as-of-existential-reality instigated relativeunreflexivity/relative-reflexivity ontological-contiguity ${ }^{67}$ of-the-human-institutionalisationprocess $^{68}$ as of difference-conflatedness ${ }^{13}$-as-to-totalitative-reification-in-singularisation- $<$ as-tothe-nondisjointedness/entailment-of-prospective- nonpresencing $>$-as-veridical-epistemicityrelativism-determinism implied $<$ amplituding/formative-epistemicity $>$ causality $\sim$ as-toprojective-totalitative-implications-of-prospective- nonpresencing,-for-explicating relativeunreflexivity/relative-reflexivity ontological-contiguity ', for our present as well, its psychoanalytic-unshackling/memetic-reordering/institutional-recomposuring. As with all prospective institutionalisations, a human secondnaturing institutionalising construct is a requisite because, at best even the intemporal-disposition individuation individuals, purporting (by maximalising-recomposuring-for-relative-ontological-completeness ${ }^{87}$ — unenframed/re- 
ontologising conceptualisation) prospective emancipation come from and are of the stock of the prior ${ }^{83}$ reference-of-thought uninstitutionalised-threshold ${ }^{102}$ registry-worldview/dimension, and such prospective emancipation involves such individuals own 'moulting', as actually intemporality ${ }^{5} /$ longness is a 'potential construct of orientation' as implied by ontologicalnormalcy/postconvergence (prospective-transcendence-in-perpetually-upholding-intemporalpreservation-entropy-or-contiguity-or-ontological-preservation) and it is only a devised institutionalisation construct that achieves that potential-construct-of-orientation and not any implied inherent emanance intrinsicness (though the meaningfulness as articulated as such, and as the meaningfulness in this entire paper, is rather of an intemporal register validation and not of any temporal register validation, since an authentic psychoanalytic-unshackling/memeticreordering/institutional-recomposuring is what underlies transcendence-and-

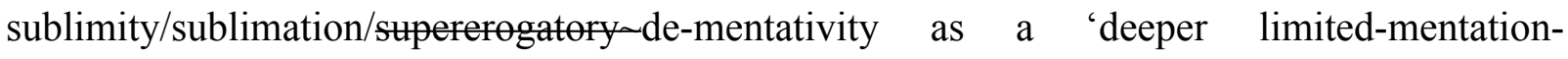
capacity—as-subjecting 'educed-unlimitedness/existence-sublimating nascence' tolimitedness/human-subpotency-〈as of relative apriorising/axiomatising/referencing-\{of'prospectively_implicited_attendant-ontological-contiguity ' educedexistentialising/contextualising/textualising_'intelligibility/epistemicity/reflexivity-contiguity<imbued-notional cogency >' \}-conflatedness ${ }^{13}$-in-\{preconverging-disentailment by\} postconverging entailment)' existential-tautologisation/existential-reference pivot/decenter to reconstrue/reconceptualise ${ }^{56}$ meaningfulness-and-teleology; more like a jurisprudential maximalising-recomposuring-for-relative-ontological-completeness ${ }^{87}$ - unenframed/reontologising conceptualisation contention for rehabilitation is not of the same meaningfulframework as a temporal mental-disposition of illicitness for shifty expectation of rehabilitation which it should necessarily anticipate and preempt). By that token there is no baseinstitutionalised individuation in recurrent-utter-uninstitutionalisation, no ${ }^{103}$ universalised individuation in ununiversalisation, no positivistic individuation in non-positivism/medievalism, 
and prospectively no notional ${ }^{8}$ deprocrypticism individuation in procrypticism; as at best such emancipating intemporal individuation are 'moulting' and implying-of-the-same of their registry-worldview in prospective institutionalisation design/conceptualisation, as the effective institutionalisation is what is really and effectively attained. The notion of threshold-ofnonconviction/madeupness/bottomlining-in-shallow-supererogation $<<$ as-to-'attendantintradimensional'-prospectively-disontologising preconverging/dementing -apriorisingpsychologism $>$ as defining the registry-worldviews/dimensions uninstitutionalised-threshold is rather a most real idea from an ontological-normalcy/postconvergence epistemic-ornotional projective-perspective wherein we can very much fathom out that the successive relative-ontological-incompleteness ${ }^{8}$-induced,-'threshold-ofnonconviction/madeupness/bottomlining-in-shallow-supererogation $-<$ as-to-'attendantintradimensional'-prospectively-disontologising preconverging/dementing -apriorisingpsychologism>' as the successively reducing-ontological-abnormalities of recurrent-utteruninstitutionalisation uninstitutionalisation, ununiversalisation uninstitutionalisation, nonpositivism/medievalism uninstitutionalisation and procrypticism uninstitutionalisation effectively speaks of their threshold-of-nonconviction/madeupness/bottomlining-in-shallowsupererogation -<as-to-'attendant-intradimensional'-prospectivelydisontologising preconverging/dementing -apriorising-psychologism> as the respective uninstitutionalised-threshold ${ }^{102}$ with respect to the superseding-oneness-of-ontology which as existential-reality isn't changed but rather the respective cumulating/recomposuring uninstitutionalised-threshold ${ }^{102}$ are due to 'changes in human meaningfulness and the teleological implications thereof' confirming by extension that the reality of their threshold-ofnonconviction/madeupness/bottomlining-in-shallow-supererogation $<<$ as-to-'attendantintradimensional'-prospectively-disontologising preconverging/dementing -apriorisingpsychologism $>$ is veridical or a most real idea with implications on psychical- 
orientations/mindsets as structured by the ontology-driven 'postconverging-or-dialecticalthinking -psychology or psychology-of-mentation-dynamics or natural $\sim$ psychologicaldynamics'. However apparently logical this idea, it is an altogether different to mentally register the idea of such a threshold-of-nonconviction/madeupness/bottomlining-in-shallowsupererogation -<as-to- 'attendant-intradimensional'-prospectivelydisontologising preconverging/dementing -apriorising-psychologism $>$ construct and perception about our own registry-worldview uninstitutionalised-threshold ${ }^{12}$ as procrypticism just as it would be by reflex difficult in all the successive registry-worldviews, often requiring a generation or more for transcendental implications to sink in. This threshold-ofnonconviction/madeupness/bottomlining-in-shallow-supererogation $<-<$ as-to-' attendantintradimensional'-prospectively-disontologising preconverging/dementing -apriorisingpsychologism> conceptualisation of the 'social as at its uninstitutionalised-threshold threshold' wherein the representation as 'being in threshold-ofnonconviction/madeupness/bottomlining-in-shallow-supererogation $<-<$ as-to- 'attendantintradimensional'-prospectively-disontologising preconverging/dementing -apriorisingpsychologism>' is more real (from an ontological-normalcy/postconvergence epistemic-ornotional projective-perspective) than the actual placeholder-setup/mental-devisingrepresentation/mentation/consciousness-awareness-teleology 99 defect of conscious mindsets within the given uninstitutionalised-threshold ${ }^{102}$ registry-worldview/dimension (as the threshold-of-nonconviction/madeupness/bottomlining-in-shallow-supererogation $-<$ as-to-

\section{'attendant-intradimensional'-prospectively-disontologising preconverging/dementing}

apriorising-psychologism> insight is suprastructural to it or beyond-its-consciousnessawareness-teleology ${ }^{9}$ ); is an ontological validation of Derridean hauntology/hantologie conceptualisation of the social in cinematographic terms of meaningfulness (and will seem very much akin, from an ontological perspective, to the central notion of 'intemporal-preservation- 
entropy-or-contiguity-or-ontological-preservation as the superseding referential conceptualisation of ontology and inherently imbued with ontological-reconstituting-as-toconflatedness $^{13}$ as a centering/decentering mechanism' as implied in this paper, though hauntology/hantologie is not quite articulated in such more precise ontological terms but sublimating-epistemic-imbricatedness/threadedness/recomposuring notion of existential-reality in there can be grasped), and equally highlights the fundamental 'paradox of post-structural deconstruction by its transcendental implications', in that the mental-disposition/psychicalorientation of the present registry-worldview/dimension as positivism- ${ }^{80}$ procrypticism is not developed enough (in terms-as-of-axiomatic-construct of its ${ }^{83}$ reference-of-thoughtcategorical-imperatives/axioms/registry-teleology ${ }^{9}$,-for-intemporal-preservation-entropy-orcontiguity-or-ontological-preservation) to grasp its implications (in want of futural Beingdevelopment/ontological-framework-expansion-as-to-depth-of-ontologising-development-asinfrastructure-of- meaningfulness-and-teleology as of prospective deprocrypticism-orpreempting - disjointedness-as-of- ${ }^{3}$ reference-of-thought sublimating-epistemicimbricatedness/threadedness/recomposuring as of 'implicited_attendant-ontologicalcontiguity $^{67}$, educed-

existentialising/contextralising/textring_intelligibility/epistemicity/reflexivity-contiguity$<$ imbued-notional $\sim$ cogency $>$ ' ,-<reifying-or-elucidating-of-prospective-relative-ontologicalcompleteness -of- reference-of-thought- devolving-as-of-instantiative-context> as to existence-potency ${ }^{39} \sim$ sublimating-nascence,-disclosed-from-prospective-epistemicdigression—rules-of-apriorising/axiomatising/referencing-that-further-epistemicallyunconceal-the-very-ontologically-same-existential-reality' ${ }^{83}$ reference-of-thought- categoricalimperatives/axioms/registry-teleology ${ }^{9}$ for intemporal-preservation-entropy-or-contiguity-orontological-preservation), just as the core non-positivism/medievalism mindset/ ${ }^{83}$ reference-ofthought wasn't developed enough to grasp the implications of created-and-accruing positivistic 
meaningfulness and redefined mindset/psyche inducted by the Descartes, Copernicuses, Galileos, Newtons, Kants, Rousseaux and it had to psychoanalytically-unshackle/memeticallyreorder/institutionally-recomposure over generations 'for what were re-originary_-as-

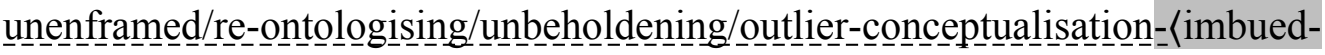
postconverging/dialectical-thinking -'projective-insights'/'epistemic-projection-inconflatedness '-of-notional deprocrypticism-prospective-sublimation $\rangle^{\circ}$ outlying ideas to become the defining ideas of modernity'. Thus the apparent issues today raised with poststructuralism have as much to do with the psychical orientation (as underdeveloped) of its critiques as well as the requisite effort required to further develop, elucidate and focus it; and in this regard why there have been many serious and constructive criticisms of post-structuralism as required for any subject-matter, most of the 'popular criticisms' levied against poststructuralism fail to past the test of intellectual criticism and have mostly been populist and media-driven attacks, gaining traction by social trending than genuine intellectual validity. The most popular being an initiative on an unrecognised social science journal which by that mere token disqualifies the so-called criticism but has turned out to be the most populist ploy by all accounts for condemning post-structuralism. Furthermore and critically, the intellectual exercise as with all institutional processes operate fundamentally on a basis of mutual trust. However the methodologies, theories and concepts, what can be articulated as new knowledge is not necessarily assessed on the basis that any peer review mechanism is absolutely full-proof particularly as the new knowledge is often at the margin of what is understood, and thus much of peer reviewing is not really an approval of the knowledge but rather an admission into the body of institutionally or formally acknowledgeable perspectives for further elucidation. Even then many a study not approved with peer reviewed journals have later on down the years ended up becoming dominant theory. So there isn't any inherent sanctity in peer reviewing but for its practicality in formal knowledge organisation (and not even so with approval). Technically the 
majority of all new knowledge down the years will be found wanting in-many-ways, and the objective of the overall peer review process is to channel potentially admissible and debatable knowledge towards further elucidation in the overall scheme of establishing overall human knowledge as of veracity/ontological-pertinence. Review of new knowledge doesn't end with a journal's peer review though that point tends to be a 'highly political point nowadays' as of the increasing bean-counting institutional reflex of funding implications and sometimes at the detriment of novel approaches to knowledge. The abstract notion of reviewing goes well beyond journals approval and extends with the continual critiquing of knowledge whether dominant or outlying. Ultimately, the more fundamental test in such a negotiated process is a strive for consistency and validatory clues with no guarantees of effectiveness but for the overall consistency, as of the very cutting edge of peer reviewed knowledge. Just for the sake of perspective here, it might equally be argued that peer-reviewing and by extension all epistemological and their corresponding methodological activities are not natural knowledge activities as of inherent pure-ontology in of itself but derived activities as of human norms, practices and policies for establishing thresholds that then enable articulated qualifications as of pure-ontology; in other words, any such epistemological and methodological activity is irrelevant if pure-ontology can be arrived at without it. Consider for instance that mathematicians hardly make use of experimental designs or that many secret research by corporations and government aren't peer reviewed, at least not publicly. Besides at a more fundamental level the question can be asked what are the metaphysics-of-absence-〈implicitedepistemic-veracity-of- nonpresencing-<perspective-ontological-normalcy/postconvergence $>$ > implications of knowledge epistemology, methodologies and peering as to the weightier construal of the successive human ontological developments involving increasing prospective relative-ontological-completeness ${ }^{8}$-of- ${ }^{3}$ eference-of-thought associated with the overall institutional-cumulation/institutional-recomposure-〈as-to- historiality/ontological- 
eventfulness /ontological-aesthetic-tracing-<perspective-ontological-

normalcy/postconvergence-reflected-'epistemicity-relativism-determinism' $>>$ in reflecting holographically-<conjugatively-and-transfusively $>$ the relative-unreflexivity/relativereflexivity - ontological-contiguity of-the-human-institutionalisation-process , beyond just an intra-positivism registry-worldview/dimension illusion-of-the-present/presentconsciousness/epistemic-totalising $\sim$ self-referencing-syncretising/mirage conceptualisation of knowledge epistemology, methodologies and peering naively articulated-and-implied-as ‘ ${ }^{103}$ universally applicable', à la Kantian positivism registry-worldview/dimension $<$ amplituding/formative-epistemicity $>$ totalising intervalist-as-categorising'implicited_attendant-ontological-contiguity ${ }^{67}$ ' educedexistentialising/contextualising/textualising_intelligibility/epistemicity/reflexivity-contiguity$<$ imbued-notional cogency> -phenomenal-abstractiveness-of-presence however remarkable, to all registry-worldviews/dimensions particularly since such a conceptualisation doesn't factor in 'transcendental implications' as preconverging/postconverging-dementatively/structurally/paradigmatically overthrowing/fazing-out/collapsing the uninstitutionalised-threshold ${ }^{102}$ of ${ }^{56}$ meaningfulness-and-teleology ${ }^{99}$ of the prior/old registryworldview's/dimension's ${ }^{83}$ reference-of-thought as a decentering subsumption; along the same line as the medieval 'dogmatic scholastics' insisting that the now established positivism registryworldview/dimension knowledge constructs, which were then transcendental, should conform to their 'institutionalised dogmatic scholasticism methods and processes of reviewing'. By extension the question can be asked whether beyond our '<amplituding/formativeepistemicity>totalising $\sim$ self-referencing-syncretising/circularity/interiorising/akrasiatic-drag institutionalised positivism conceptualisation of ${ }^{56}$ meaningfulness-and-teleology ${ }^{9}$, whether such is truly in a 'requisite contemplative-and-Being position as of the prospective transcendentally-enabling-level-of $\sim$ ontological-good-faith-or- 
authenticity $\%$ objectification/desubjectification-as-objectification-<as-to-ontological-faithnotion-or-ontological-fideism - imbued-underdetermination-of-motif-andapriorising/axiomatising/referencing-as-so-being-as-of-existential-reality as antinihilism>100, of 'evaluating a construct of prospective transcendence-andsublimity/sublimation/supererogatory de-mentativity' as herein implied about futural Beingdevelopment/ontological-framework-expansion-as-to-depth-of-ontologising-development-asinfrastructure-of- meaningfulness-and-teleology as of prospective notional ${ }^{18}$ deprocrypticism registry-worldview/dimension ${ }^{56}$ meaningfulness-and-teleology which paradoxically preconverging/postconverging-dementatively/structurally/paradigmatically entails overthrowing/fazing-out/collapsing the positivism- ${ }^{80}$ procrypticism ${ }^{56}$ meaningfulness-and-teleology 9 at its uninstitutionalisedthreshold ${ }^{102}$ as a decentering subsumption; when we factor that such a contemplation-and-Being as from a positivism- ${ }^{80}$ procrypticism ${ }^{56}$ meaningfulness-and-teleology ${ }^{9}$ is being called upon to evaluate as to a 'meaningfulness-and-teleology ${ }^{9}$ world beyond its ordinary contemplation' with the mental tools for such a prospective projection mostly of abstract projective contemplation for grasping the prospective organic-knowledge implied, and so beyond an ordinary evaluation within an implied same ${ }^{83}$ reference-of-thought. It should be noted here that the more pertinent quality for such implied transcendentalism as of its implied organicknowledge beyond just a mechanical construct is ontological-faith-notion-or-ontologicalfideism - imbued-underdetermination-of-motif-and-apriorising/axiomatising/referencing-asso-being-as-of-existential-reality explaining the disparate nature of the development of human knowledge. This author as previously articulated points out that there is a more profound basis for how and why new/prospective knowledge whether outlying or main stream is socially integrated in driving 'intemporal ontological-faith-notion-or-ontological-fideism - imbuedunderdetermination-of-motif-and-apriorising/axiomatising/referencing-as-so-being-as-of- 
existential-reality instigated relative-unreflexivity/relative-reflexivity-ontologicalcontiguity ${ }^{67}$ of-the-human-institutionalisation-process ${ }^{68}$ as of difference-conflatedness ${ }^{13}$-as-tototalitative-reification-in-singularisation- $<$ as-to-the-nondisjointedness/entailment-ofprospective- nonpresencing $>$-as-veridical-epistemicity-relativism-determinism implied $<$ amplituding/formative-epistemicity $>$ causality $\sim$ as-to-projective-totalitative-implications-ofprospective- nonpresencing,-for-explicating relative-unreflexivity/relative-reflexivity ontological-contiguity , across all the institutional-cumulation/institutional-recomposure-〈asto- historiality/ontological-eventfulness /ontological-aesthetic-tracing-<perspectiveontological-normalcy/postconvergence-reflected-'epistemicity-relativism-determinism'>> as the very human-subpotency-aporia/undecidability/dilemma/oughtindeterminacy/deficiency/limitation/constraint—imbued-'notional firstnaturednessformativeness-<as-to-eventualising-inkling drive-or-seeding misprising $>$ temporal-tointemporal-dispositions- $<$ so-construed-as-from-perspective-ontologicalnormalcy/postconvergence>'-existentialism-form-factor implying that human registryworldview's/dimension's have institutionalisation-threshold and uninstitutionalised-threshold broken only in the medium to long-run beyond-the-consciousness-awareness-teleology ${ }^{9}-<$ ofpreconverging-existential-extrication-as-of-existential-unthought> 'by a power relations dynamics preconverging/postconverging-de-mentatively/structurally/paradigmatically ingrained in the social ${ }^{103}$ universal-transparency ${ }^{104}$-〈transparency-of-totalising-entailing,-as-toentailing-<amplituding/formative-epistemicity $>$ totalising $\sim$ in-relative-ontologicalcompleteness \; and so as of 'intrinsic-reality/ontological-veridicality transcendentalenabling/sublimating/supererogatory $\sim$ de-mentativity <amplituding/formativeepistemicity $>$ causality $\sim$ as-to-projective-totalitative-implications-of-prospectivenonpresencing,-for-explicating relative-unreflexivity/relative-reflexivity - ontologicalcontiguity ', and thereafter the eliciting of positive-opportunism—of-social-functioning-and- 
accordance $^{75}$ deferential-formalisation-transference, ordered-construct, percolationchannelling- $<$ in-deferential-formalisation-transference $>$ as of transversality- $<$ for-sublimatingexistential-eventuating/denouement,-from-'thinking at-first/pure-predisposition-preemptive-ofprospective-disontologising/subontologising’ as-of-prospectively-disambiguated-affirmedand-unaffirmed-'motif-and-apriorising/axiomatising/referencing'> ${ }^{101}$ of opposing axiomaticconstructs $/{ }^{3}$ references-of-thought that allows for the more ontologically-veridical to supersede as inducing untenability/internal-contradiction/internal-incoherence/institutional-constraining. This is the more profound suprastructural-construct of 'human validationconceptualisation/epistemological relationship to knowledge' applicable across all registryworldviews/dimensions as of a 'notional futural différance' construed as of a 'postconvergingor-dialectical-thinking -psychology or psychology-of-mentation-dynamics or natural psychological-dynamics', notwithstanding the more superficial constructions of 'human validation-conceptualisation/epistemological relationship to knowledge' within a same registryworldview's/dimension's institutionalisation whether base-institutionalisation/animisticuniversalisation shamanism, ${ }^{103}$ universalisation-non-positivism/medieval dogmatic scholasticism or our positivism- ${ }^{80}$ procrypticism 'categorisation epistemes'; but also the apriorising/axiomatising/referencing-\{of-'prospectively implieited_antologicalcontiguity ' $\sim$ educedexistentialising/contextualising/textualising_ 'intelligibility/epistemicity/reflexivity-contiguity<imbued-notional cogency $\left.>^{\prime}\right\}$ - conflatedness ${ }^{13}$-in-\{preconverging-disentailment by\} pestcenverging-entailment of futural Being-development/ontological-framework-expansion-asto-depth-of-ontologising-development-as-infrastructure-of- meaningfulness-and-teleology as of prospective notional ' deprocrypticism 'referentialism as epistemological' (as of notional deprocrypticism which reflects ontological-construal along the full potency of existence-as-of-its-mimetic-echoness or existence-in-reverberation or existence- 
potency $^{32} \sim$ sublimating-nascence,-disclosed-from-prospective-epistemic-digression). Such a notional futural différance as a suprastructural construct appreciation of epistemological implications about social integration of knowledge certainly informs a commitment to reoriginary_as-unenframed/re-ontologising/unbeholdening/outlier-conceptualisation_-_imbuedpostconverging/dialectical-thinking -'projective-insights'/'epistemic-projection-inconflatedness '-of-notional deprocrypticism-prospective-sublimation $\rangle^{0}$ ideas as being ultimately validatable in effect as of their intrinsic-reality/ontological-veridicality, if that is as of what they truly are, in the medium to long-run. Basically the transcendental as (re-originary_asunenframed/re-ontologising/unbeholdening/outlier-conceptualisation-_imbuedpostconverging/dialectical-thinking -'projective-insights'/'epistemic-projection-inconflatedness ' -of-notional deprocrypticism-prospective-sublimation $\rangle^{90}$ ) originary/event $^{38}$ of-prospective-ontology-origination to a knowledge and its knowledge system however remote the origination, in-the-very-first-place, speaks of the notion of <amplituding/formativeepistemicity>-totalising $\sim$ renewing-realisation/re-perception/re-thought associated with 'postconverging-or-dialectical-thinking -psychology or psychology-of-mentation-dynamics or natural psychological-dynamics' behind any retrospective or prospective registryworldview's/dimension's ${ }^{83}$ reference-of-thought validation-conceptualisation/epistemological relationship to knowledge/ontological-construal. Ultimately, the very transversality-<forsublimating-existential-eventuating/denouement-from-'thinking at first/pure-predispositionpreemptive of prospective disontologising/subontologising' as-of-prospectivelydisambiguated-affirmed-and-unaffirmed-'motif-and-apriorising/axiomatising/referencing'> between the prior registry-worldview/dimension as of its prior relative-ontologicalincompleteness ${ }^{8}$-of- ${ }^{8}$ reference-of-thought and the prospective registry-worldview/dimension as of its prospective relative-ontological-completeness ${ }^{87}$-of- ${ }^{8}$ reference-of-thought is the "very paradox of ${ }^{56}$ meaningfulness-and-teleology explaining their discordance, construed as the 
paradox of transcendence-and-sublimity/sublimation/supereregatery $\sim$ de-mentativity'. In other words, if the former had a grasp of its state 'as to its prior relative-ontological-incompleteness ${ }^{\text {- }}$ of- reference-of-thought' with the transcendental preconverging/postconverging-dementative/structural/paradigmatic $<$ amplituding/formative-epistemicity $>$ causality $\sim$ as-toprojective-totalitative-implications-of-prospective- nonpresencing,-for-explicating relativeunreflexivity/relative-reflexivity ontological-contiguity arising thereof it would have paradoxically transcended, thus explaining the psychoanalytic-unshackling/memeticreordering/institutional-recomposuring nature of transcendence-andsublimity/sublimation/supererogatory de-mentativity as of a crossgenerational exercise and why such implied transcendental ${ }^{5}$ meaningfulness-and-teleology ${ }^{9}$ might seem arbitrary when meaningfulness-and-teleology ${ }^{9}$ is rather interpreted in terms of the prior registryworldview's/dimension's ${ }^{83}$ reference-of-thought not factoring its prior relative-ontologicalincompleteness ${ }^{8}$-of- ${ }^{8}$ reference-of-thought. But this is simply valid on the fact that a more profound axiomatic-construct on a given domain of reality as of prospective relative-ontologicalcompleteness ${ }^{87}$-of- ${ }^{83}$ reference-of-thought is of intemporal-or-ontological prioritisation as of its apriorising/axiomatising/referencing-\{of-'prospectively_implicited_attendant-ontologicalcontiguity ' educedexistentialising/contextualising/textualising_'intelligibility/epistemicity/reflexivity_contiguity$<$ imbued-notional $\sim$ cogency $\left.>^{\prime} \quad\right\}$-conflatedness ${ }^{13}$-in-\{preconverging-disentailment by\} postconverging-entailment relative to a less profound axiomatic-construct on that same given domain of reality as of prior relative-ontological-incompleteness ${ }^{88}$-of- ${ }^{8}$ reference-of-thought as of its apriorising/axiomatising/referencing-\{of-'prospectively implicited_attendantontological-contiguity ' educedexistentialising/contextualising/textualising_'intelligibility/epistemicity/reflexivity-contiguity$<$ imbued-notional cogency $>$ ' $\}$-constitutedness ${ }^{14}$-in-preconverging-entailment, as the latter 
is rather in shortness-of-register-of- ${ }^{5}$ meaningfulness-and-teleology $\% /$ distractiveness to the former as of ${ }^{8}$ reference-of-thought-as-to-preconverging/postconverging-de-

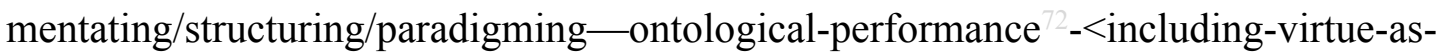
ontology>. Consider for instance Einstein's theory-of-relativity and Newton's laws of motion with respect to the same given physics domain-of-study reality, wherein the former's prospective relative-ontological-completeness ${ }^{8}$-of- ${ }^{8}$ reference-of-thought over the latter implies the former's utter 'ontological-resetting' in the conceptualisation of the-very-same physics domainof-study reality as of transversality-<for-sublimating-existential-eventuating/denouement-from-'thinking at first/pure-predisposition-preemptive-of-prospectivedisontologising/subontologising’ as-of-prospectively-disambiguated-affirmed-andunaffirmed-'motif-and-apriorising/axiomatising/referencing' $>{ }^{101}$ with the latter; as henceforth the logical-dueness of the latter doesn't even arise but rather as it maybe subsumed/implied/isnon-contradictory as of the former or for educational and practical insights purposes! Of course, this comparison differs from a construal of postlogism 77 and conjugated-postlogism 77 associated perversion-and-derived- ${ }^{74}$ perversion-of- ${ }^{83}$ reference-of-thought- $<$ as-preconverginglyapriorising/axiomatising/referencing-in-nonconviction/madeupness/bottomlining-as-toshallow-supererogation $>$; in that as of a human condition relations it is construed rather as (beyond-the-consciousness-awareness-teleology ${ }^{9}-<$ of-preconverging-existential-extricationas-of-existential-unthought> ) postlogism -and-conjugated-postlogism 7 -as-of- compulsingnonconviction/madeupness/bottomlining-〈'<decontextualising/de-existentialising ofattendant-intradimensional-apriorising/axiomatising/referencing>-induced-disontologising'-ofthe-'attendant-intradimensional-ontologising'-imbued$<$ contextualising/existentialising attendant-ontological-contiguity $>$;-in-shallowsupererogation -<as-to-disontologising-perverted-outcome-sought-precedes-existentiallyveridical-'attendant-intradimensional-apriorising/axiomatising/referencing'-logical-dueness $>$ > 
prior relative-ontological-incompleteness -of- reference-of-thought 'waylaying', as $<$ amplituding/formative> wooden-language-〈imbued-temporal-mereform/virtualities/dereification/akrasiatic-drag/denatured/preconverging-or-dementing narratives - of-the- reference-of-thought- categorical-imperatives/axioms/registryteleology > hence preconverging-or-dementing 2 -apriorising-psychologism, of prior prelogism ${ }^{78}$-as-of-conviction,-in-profound-supererogation -<existentially-veridical'attendant-intradimensional-apriorising/axiomatising/referencing'-logical-dueness-precedesdisontologising-logical-outcome-arrived-at $>$ prospective relative-ontological-completeness ${ }^{87}$ of- reference-of-thought, thus requiring for intemporal-preservation-entropy-or-contiguity-orontological-preservation renewed 'apriorising/axiomatising/referencing-\{of-'prespectively implicited_attendant-ontological-contiguity ' educedexistentialising/contextualising/textualising_'intelligibility/epistemicity/reflexivity_contiguity<imbued-notional cogency $\left.>{ }^{\prime}\right\}$-conflatedness ${ }^{13}$-in-\{preconverging-disentailment-by\} postconverging-entailment' as of ontological-faith-notion-or-ontological-fideism-imbuedunderdetermination-of-motif-and-apriorising/axiomatising/referencing-as-so-being-as-ofexistential-reality that induces a prospective " ${ }^{103}$ universally-transparent constraining mechanical-knowledge as new bare ${ }^{83}$ reference-of-thought- categoricalimperatives/axioms/registry-teleology as axiomatic-construct' and 'its social- ${ }^{103}$ universallynon-transparent-thus-non-constraining-element of ontological-faith-notion-or-ontologicalfideism —imbued-underdetermination-of-motif-and-apriorising/axiomatising/referencing-asso-being-as-of-existential-reality as the creating-and-essence-attributing drive for knowledgeand-virtue' bringing about prospective relative-ontological-completeness ${ }^{87}$-of- ${ }^{8}$ reference-ofthought, construed as 'ontological-resetting' of placeholder-setup/mental-devisingrepresentation/mentation/consciousness-awareness-teleology ${ }^{9}$. By the mere fact of implied prospective relative-ontological-completeness ${ }^{87}$-of- ${ }^{83}$ refence-of-thought over prior relative- 
ontological-incompleteness ${ }^{8}$-of- ${ }^{8}$ reference-of-thought a prospective transcendence-andsublimity/sublimation/supererogatoryade-mentativity involves the prospective ${ }^{83}$ reference-ofthought rather 'registering-and-reflecting a beyond-the-consciousness-awareness-teleology"

\section{$<$ of-preconverging-existential-extrication-as-of-existential-unthought $>{ }^{56}$ meaningfulness-and-} teleology as of organic-knowledge Being correction' of the prior ${ }^{83}$ reference-of-thought, such that the prior ${ }^{83}$ reference-of-thought logical-dueness doesn't even arise as the prospective reference-of-thought is the relatively complete 'ontological-resetting' in an 'organic effectingwholeness-as-of-profoundness-and-completeness-to- ${ }^{56}$ meaningfulness-and-teleology ${ }^{9} \quad$ over the prior ${ }^{83}$ reference-of-thought 'effecting-parsimony-as-of-shoddiness-and-incompleteness-tomeaningfulness-and-teleology ${ }^{9}$; just as the introduction of chemistry science carries an organic effecting-wholeness-as-of-profoundness-and-completeness-to- ${ }^{56}$ meaningfulness-andteleology ${ }^{9}$ over a non-positivism/medievalism alchemic material construal. This further explains the 'socially conflicted nature of all implied transcendental constructs' whether with prophesying metaphysico-theological constructs of early times reflected in non-universal and universal creeds up to our metaphysico-ontological worldviews implied transcendence-andsublimity/sublimation/supererogatory de-mentativity, and so as of human-subpotencyaporia/undecidability/dilemma/ought-indeterminacy/deficiency/limitation/constraint—imbued'notional firstnaturedness-formativeness-<as-to-eventualising $-i n k l i n g-d r i v e-o r-s e e d i n g-$ misprising $>$ temporal-to-intemporal-dispositions- $<$ so-construed-as-from-perspectiveontological-normalcy/postconvergence>'-existentialism-form-factor; but then humankind has always been called upon to show itself capable of superseding/surpassément for prospective possibilities to avail. A second weakness of many critiques is by naively misrepresenting poststructural meaningfulness, and going on to criticise this. For instance, such arguments about post-structuralism as a theory that has no worldview are not made by poststructuralists who in their transcendentally-enabling-level-of ontological-good-faith-or- 
authenticity $\%$ objectification/desubjectification-as-objectification-<as-to-ontological-faithnotion-or-ontological-fideism - imbued-underdetermination-of-motif-andapriorising/axiomatising/referencing-as-so-being-as-of-existential-reality as antinihilism> have been rather questioning openly what the reality of the meaningfulness they construct implies, as a basis for further intellectual development. This explains the convoluted responses of say Derrida because that is the intrinsic-reality insight at hand, and the issue is rather how to further develop. This will be tantamount to criticising early quantum physics for contending that the fundamental particles are rather like waves and evasive without yet establishing an advanced basis of the science. Knowledge is not an exercise of one set of individuals arguing against another nor is it a popularity contest but rather it is all about finding out what constitutes intrinsicreality as it reflects <amplituding/formative-epistemicity>causality as-to-projectivetotalitative-implications-of-prospective- nonpresencing,-for-explicating relativeunreflexivity/relative-reflexivity ontological-contiguity ; intrinsic-reality being the superseding transcendental enabler, and not any humans no matter their statuses. A third weakness has been by relating to poststructuralists as if they have got to get all their ideas right on by the instant, as if the theoretical framework isn't in development like all theoretical frameworks (by the same token imagine all the unanswered questions that underlie quantum physics for over half a century that are still being elucidated, for instance, string theory which is so highly speculative but is still credibly a basis for research and analysis). The purpose of a theoretical framework is not to provide an immediate answer for everything but rather to provide a framework for constant critical development of ideas. Otherwise, it will be best to develop a correlational construct that may statistically be coherent with many arguments at any given point in time but is of little predicative or projective value because it hasn't got a profundity as a genuine theoretical construct which may actually be mostly incoherent with many arguments at its earlier stage but provides a wealthy framework for the continuous articulation of ideas and 
resolutions, and this is actually the point of a theory in-the-very-first-place. It is thus no accident that many other disciplines have found post-structuralism as a relatively ideal tool for invoking much needed insight. A fourth criticism has to do with the 'political nature' of human affairs obviously, and even the intellectual is not beyond this especially with ideas of 'sociallyperceived disturbing implications' (as has been the case throughout human history) and further so in a social domain that is not immediately amenable to predicative-effectivity-sublimation〈as-to-underlying,-ontological-commitment $-<$ implied — self-assuredness-of-ontological-goodfaith/authenticity $\sim$ postconverging-de-mentating/structuring/paradigming -as-being-as-of-

existential-reality $>>$ as with the natural domain even though the latter equally faces similar issues but to a lesser extent. When we come to reflect that the leading poststructuralist of his time had an entire school, rather than focusing on developing research criticisms of his work and other poststructuralists (which would have been the more impressive thing to do) instead taking a 'political stance' for the denial of his recognition with an institution of higher learning. Thus it is obviously, naïve for anyone to think that intellectualism and ideas occur in an absolute neutral environment particularly when of socially-perceived disturbing implications. While it is generally recognised that knowledge is determined on its own merits as an interest-free principle, the fact is in the real world of 'socially-perceived-value as of social-stake-contention-orconfliction' situations, human mental-disposition is not that intemporal and principled, whether wittingly or unwittingly, and extra-intellectual meaningfulness becomes fair game. Fifthly, the argument of unintelligibility of post-structural meaning is outright ridiculous with respect to the exegetical aims of its authors, and no less so as expecting advanced chemistry, biology and physics writing to be popularly intelligible. Jargon is rather a mechanism of deferentialformalisation-transference permeating all subject-matters and disciplines, which speaks to the idea that the 'ordinariness of thought' is not the sound basis for construing issues raised in termsas-of-axiomatic-construct of profoundness of contemplation. The relative-unreflexivity/relative- 
reflexivity ontological-contiguity ${ }^{67}$ of-the-human-institutionalisation-process

by its deferential-formalisation-transference is an exercise of shrinking the melee of common sense wherein spheres previously opened for common opinionionatedness are shoved away as 'deferred to' specialisms whether institutional or subject-matters by the mere effectiveness, with 'informed common and individual opinions' being the panache for the expression of sovereignty whether about the polity or individual choices, but not to be confused as a sign of inherent knowledge as of popularity. The idea that there is a common sense social science is a falsehood no more than there is no common sense natural science, and intellectuals are irresponsible when peddling the notion that readers shouldn't acquire the requisite 'intellectual elevation' to grasp the profundity of meaningfulness and rather expect that they should be able to satisfactorily engage at the same intellectual level ( ${ }^{8}$ reference-of-thought) involving advanced studies and research on the basis of ordinariness of thought. This should not be confused with a popularising exercise meant to stir popular interest like popular science, though in fact there is no truly popular science for that matter but serious/candid science. Such a confusion can hardly arise in the natural sciences because of the "promptness of $<$ amplituding/formative-epistemicity $>$ causality $~$ as-toprojective-totalitative-implications-of-prospective- nonpresencing,-for-explicating relativeunreflexivity/relative reflexivity ontological-contiguity /intrinsic-reality/ontologicalveridicality transcendental-enabling/sublimating/supererogatory $\sim$ de-mentativity' in constraining veracity/ontological-pertinence of thought by the immediate effectiveness of studies, discoveries and inventions wherein a flaw thought proposition will be proven wrong by its ontological ineffectiveness with relatively little concern for third-party convincing over the transcendental-enabling/sublimating/supererogatory $\sim$ de-mentativity that is existence/intrinsicreality/ontological-veridicality, whereas the " blurriness- $<$ sterilising/anecdotalising/trivialisingof-prospective-re-ontologising_by-preconverging,-in-disontologising-formulaic-dragging-

out/hollowing-out $>$ and distance of <amplituding/formative-epistemicity $>$ causality $\sim$ as-to- 
projective-totalitative-implications-of-prospective- nonpresencing,-for-explicating relative-

unreflexivity/relative-reflexivity ontological-contiguity /intrinsic-reality/ontological-

veridicality transcendental-enabling/sublimating/supereregatory $\sim$ de-mentativity' in the social sciences allows for propositions to crop up that are hardly constrained by immediate effectiveness of studies, discoveries and inventions, such that such propositions will often border on popular thinking or the political (technically) or a concern priorly driven with garnering support and agreement, rather than of genuine intellectual strife for <amplituding/formativeepistemicity $>$ causality $\sim$ as-to-projective-totalitative-implications-of-prospectivenonpresencing,-for-explicating relative-unreflexivity/relative-reflexivity —ontologicalcontiguity /intrinsic-reality/ontological-veridicality transcendentalenabling/sublimating/supereregatory $\sim$ de-mentativity. In this regard, the central tenet of poststructuralists with respect to their pursuit has been transcendentally-enabling-levelof $\sim$ ontological-good-faith-or-authenticity $\%$ objectification/desubjectification-asobjectification-<as-to-ontological-faith-notion-or-ontological-fideism-imbuedunderdetermination-of-motif-and-apriorising/axiomatising/referencing-as-so-being-as-ofexistential-reality as antinihilism $>100$ with respect to their reflections, studies and research at all cost, even at the cost of many poststructuralists not recognising explicitly that they are poststructuralists or not recognising similarities in their works with other poststructuralists, so because fundamentally they can only vouch for their authentic reflections and analyses without a 'surreptitious pretence' for such amalgamation which will undermine their ontological-goodfaith/authenticity ${ }^{6}$ with regards to conceptualising intrinsic-reality/ontological-veridicality, with the idea that the notion of a commonness of their ideas and as a movement will take care of itself if they are truly articulating an intrinsic-reality/ontological-veridicality that reflects that commonness; more like the Indian story of blind men who came across an elephant and each one sincerely/authentically said what their capacity enabled them to say, no more no less, with the 
idea that if what they say is of-the-reality of an elephant, that notion will take care of itself but their first posture is to say authentically what is in front of them. This speaks of the essential nature of all sciences wherein the researcher considers the most determinant element to be not itself or other humans (who are together mortals; mortal because they/humans don't really invent any rules of existence-or-intrinsic-reality-or-ontological-veridicality but rather at best discover them or utilise them as 'supposed inventions' -and the scientist is all about a validation by intrinsic-reality/ontological-veridicality-as-the-transcendental-

enabling/sublimating/supererogatory $\sim$ de-mentativity in contrast to a mental-disposition of social-aggregation-enabler where the emphasis is naively about convincing the other mortal or mortals over a validation by intrinsic-reality/ontological-veridicality transcendental enabler thus leading to subontologisation/subpotentiation in-a-social-dynamism-of-meaningfulnessmisappropriation, rather than the supersedingness/precedingness of intrinsic-reality/ontologicalveridicality transcendental enabler) but the superseding transcendentalenabling/sublimating/supereregatery $\sim$ de-mentativity which is intrinsic-reality/existentialreality/ontological-veridicality as reflected by effectiveness of <amplituding/formativeepistemicity $>$ causality $\sim$ as-to-projective-totalitative-implications-of-prospective-

\section{nonpresencing,-for-explicating relative unreflexivity/relative reflexivity - ontological-}

contiguity and projection; with the latter wholly the focus of intellectual contention. The medical researcher involved in seeking a cure by reflex is concerned about what the transcendental-enabling/sublimating/supererogatory de-mentativity that is intrinsicreality/ontological-veridicality/existence 'naturally and best construed/conceptualised' in the crafted jargon of biomedical sciences will make available as cure as the 'superior party' over whatever they themselves or for that matter any other humans no matter their statuses may 'sovereignly' want to think or imagine. This same notion applies in the construct of knowledge in the social sciences, the pursuit of the social scientist as the study of social reality is "not about 
convincing people or making sense to people' (that can be accessory) but rather about grasping/conceptualising the intrinsic-reality/ontological-veridicality of the social as the transcendental-enabling/sublimating/supererogatory de-mentativity whatever the jargon required for that purpose; the social education/enlightening exercise that arise thereafter just as a popular science exercise is an altogether different exercise of education and not first-level scientific engagement, and even then such education exercise will still call for a degree of intellectual elevation of the general public. It is critical that in the natural competition of intellectual ideas, intellectuals do not fall in the pattern of using debased or social feel good basis of non-intellectual logic in eliciting 'mass thinking' in order to advance their postures but rather fairly and squarely engage at the transcendental-enabling/sublimating/supererogatory $\sim$ dementativity of intrinsic-reality/ontological-veridicality level in proving or disproving those they agree or disagree with as of <amplituding/formative-epistemicity $>$ causality $\sim$ as-to-projectivetotalitative-implications-of-prospective- nonpresencing,-for-explicating relativeunreflexivity/relative-reflexivity ontological-contiguity ontological implications of existence — as-the-absolute-a-priori-of-conceptualisation and existence—as-sublimatingwithdrawal/unenframing/re-ontologising,-elicited-from-prospective-profoundsupererogation -<as-to-perspective-ontological-normalcy/postconvergence-implied'prospective-aporeticism-overcoming/unovercoming'>. Sixth, thus the idea of deferentialformalisation-transference behind formal predicates of institutions and subject-matter specialisms is all about construing meaningfulness in a depth-of-thought (intemporality ${ }^{52}$ ) that is not available to ordinariness of thought, wherein there is a disambiguating of the supratransversality-<in-sublimating-existential-eventuating/denouement $>\sim$ of-motif-andapriorising/axiomatising/referencing as a construct of formalised ${ }^{83}$ reference-of-thought that is of intemporal-projection/longness-of-register-of-meaningfulness/totalisinglyentailing/maximalising/transcendental over the subtransversality-<in-desublimating-existential- 
reference-of-thought as melee of common sense of temporality /non-totalisinglyentailing/non-maximalising/non-transcendental constructions. The idea is that such a disambiguating is a necessity going by human-subpotencyaporia/undecidability/dilemma/ought-indeterminacy/deficiency/limitation/constraint—imbued'notional firstnaturedness-formativeness-<as-to-eventualising-inkling-drive or seedingmisprising $>$ temporal-to-intemporal-dispositions- $<$ so-construed-as-from-perspectiveontological-normalcy/postconvergence>'-existentialism-form-factor requiring skewing ('intemporality ${ }^{52}$-symmetrising-by-desymmetrising-subsumption-of-temporality ${ }^{\circ}$, for relative intrinsic-reality/ontological-veridicality transcendentalenabling/sublimating/supererogatory $\sim$ de-mentativity) towards the intemporal/Angness-ofregister-of meaningfulness-and-teleology as the ontological construct that institutionalises (intemporalises). Hence such a skewing ('intemporality ${ }^{52}$-symmetrising-by-desymmetrisingsubsumption-of-temporality ${ }^{8}$, for relative intrinsic-reality/ontological-veridicality transcendental-enabling/sublimating/supererogatory de-mentativity) in the relativeunreflexivity/relative-reflexivity — ontological-contiguity ${ }^{67}$ of-the-human-institutionalisationprocess ${ }^{68}$ of shrinking the melee of common sense involves developing institutional and subjectmatter specialisms as $\quad$ supratransversality-<in-sublimating-existentialeventuating/denouement $>\sim$ of-motif-and-apriorising/axiomatising/referencing narratives (for instance, the developing sciences and institutional specialisms) that induce corresponding untenability/internal-contradiction/internal-incoherence/institutional-constraining effectiveness on the subtransversality-<in-desublimating-existentialeventuating/denouement $>\sim$ of-motif-and-apriorising/axiomatising/referencing as the melee of common sense inducing the latter's 'deference', for instance, such deference as such postures as the law says that..., physicists say that..., etc. and not a common sense posture of the sort I think 
that..., thus relegating the melee of common sense out of the construal and conceptualisation of institutional or domain specialisms which hitherto had been free-for-all opinionatedness. Such an exercise is not just retrospective but prospective as well in the expansion of human formalised constructs and including in this case the relatively profound insights of such social science as post-structuralism which sadly get undermined paradoxically by some critiques not by a samelevel supratransversality-<in-sublimating-existential-eventuating/denouement $>\sim$ of-motif-andapriorising/axiomatising/referencing intellectual criticism but raising subtransversality- $<$ indesublimating-existential-eventuating/denouement $>\sim$ of-motif-and-

apriorising/axiomatising/referencing narrative to wrongly imply that post-structuralism should be as intelligible as common sense thinking, which is paradoxically never the case with say the jargon of law, natural sciences, etc. exactly for the reason highlighted above. The fact is the melee of common sense as subtransversality-<in-desublimating-existentialeventuating/denouement $>\sim$ of-motif-and-apriorising/axiomatising/referencing hasn't got the requisite intemporality $52 /$ longness in terms-as-of-axiomatic-construct of ${ }^{103}$ universal projection of ${ }^{83}$ reference-of-thought and the logical-dueness/profile/presumption/assumptions/valuereference/teleology ${ }^{9}$ that arises from such a formal ${ }^{83}$ reference-of-thought (for instance, as the universal/intemporal proposition underlying this paper's purported construct for aetiologisation/ontological-escalation- $<$ ontologicalveridicality_commitment/otherliness_transcending/compulsions-encumbered_transcending $>$ in grasping the phenomenon of postlogism 77 in general and the general background human science conceptualisation; together with its exposure for falsifiability ${ }^{2} /$ validation from subsequent critical analyses). Such that there will tend to be 'confusion of ${ }^{83}$ reference-of-thought' where such subtransversality-<in-desublimating-existential-eventuating/denouement $>\sim$ of-motif-andapriorising/axiomatising/referencing melee of common sense was apparently to act assumingly/presumptuously rather than 'to defer', or otherwise the instance where individuals 
assume the requisite intellectual elevation (whether by corresponding education and reflection) for a first-level engagement with such specialisms. As our melee of common sense defers when it comes to the natural sciences, it defers when it comes to the legal science, it shouldn't expect otherwise but to defer when it comes to rigorous post-structural and other social science constructions however their approximations, and so as the best construction potential of human meaningfulness and teleological possibilities. On that same token the notion of validation of supratransversality-<in-sublimating-existential-eventuating/denouement $>\sim$ of-motif-andapriorising/axiomatising/referencing with respect to subtransversality-<in-desublimatingexistential-eventuating/denouement $>\sim$ of-motif-and-apriorising/axiomatising/referencing is not one of contending/argumentative validation at a same contending pedestal but rather as a validation of the supratransversality-<in-sublimating-existential-eventuating/denouement $>\sim$ ofmotif-and-apriorising/axiomatising/referencing ${ }^{83}$ reference-of-thought as intellectually-andmorally institutionalising and not implying its equivalence with subtransversality-<indesublimating-existential-eventuating/denouement $>\sim$ of-motif-and-

apriorising/axiomatising/referencing melee of common sense ${ }^{83}$ reference-of-thought, wherein for instance a consistent demonstration of a chemistry science (as supratransversality-<insublimating-existential-eventuating/denouement $>\sim$ of-motif-and-

apriorising/axiomatising/referencing) effectiveness earns chemistry science the deferentialformalisation-transference of no longer being engaged at a same contending pedestal as the melee of common sense with respect to human social contention about material constitution in order to avoid the circular drawback of constantly making arguments in $<$ amplituding/formative $>$ wooden-language-_imbued - averaging-of-thought-<as-toleveling/ressentiment/closed-construct-of- meaningfulness-and-teleology -as-of'nondescript/ignorable-void '-with-regards-to-prospective-apriorising-implications $>>$ termsas-of-axiomatic-construct, such that social deference is now institutionalised as 'chemists say 
that/it is said in chemistry that' rather than a social melee of common sense equivalence of 'chemists think that but I also think that going by my common sense'. This argumentation is not idle as the social sciences as 'being closest to human conscious sense of sovereignty' tend to be most affected by such fallacies as highlighted that should be superseded by all knowledge whether natural or social-construct, and while such notion are often intuitively grasped with other formalisms whether institutional, legal or in the natural sciences subject-matter specialisms, for the social sciences there is a need to actively bring this notion to the consciousness-awarenessteleology ${ }^{9}$ in order to circumvent such nature of knowledge fallacies with regards to an emotionally charged domain that is the social. This equally explain why the studies of the social are easiest prone to ontological-bad-faith/inauthenticity ${ }^{64}$, whether beyond-the-consciousnessawareness-teleology ${ }^{9}<$ of-preconverging-existential-extrication-as-of-existential-unthought $>$, as even where contending intellectual postures are of relative elevated formal knowledge, it is quite easy for a pedantising/muddling/formulaic-hollowing-out-insubontologisation/subpotentiation-〈blurring/undermining-of-prospective-totalising-entailing,as-to-entailing-<amplituding/formative-epistemicity $>$ totalising $\sim$ in-relative-ontologicalcompleteness > with <amplituding/formative> wooden-language-〈imbued-averaging-ofthought-<as-to-leveling/ressentiment/closed-construct-of- meaningfulness-and-teleology -asof-'nondescript/ignorable-void ' -with-regards-to-prospective-apriorising-implications $>$ > mentality in order to advance one intellectual posture, and so as intellectual politics rather than genuine intellectualism. Seventh, as advanced by this author the ontologicalnormalcy/postconvergence of intrinsic-reality as reflecting holographically-<conjugatively-andtransfusively $>$ the relative-unreflexivity/relative-reflexivity ontological-contiguity $\sim$ of-thehuman-institutionalisation-process validates and restores the notion of essential meaningfulness (the notion of a center -be it conceptualised as an 'sublimating-epistemicimbricatedness/threadedness/recomposuring as of 'implicited_attendant-ontological- 
contiguity ${ }^{67}$, educed-

existentialising/contextualising/textualising_'intelligibility/epistemicity/reflexivity_contiguity-

$<$ imbued-notional $\sim$ cogency $>,{ }^{\prime},-<$ reifying-or-elucidating-of-prospective-relative-ontological-

completeness -of- reference-of-thought- devolving-as-of-instantiative-context> as to

existence-potency $^{39} \sim$ sublimating-nascence,-disclosed-from-prospective-epistemic-

digression—rules-of-apriorising/axiomatising/referencing-that-further-epistemically-

unconceal-the-very-ontologically-same-existential-reality') to post-structural thought as its

scholars had rather previously mostly focussed on disambiguating/clarifying the certitude/lackof-certitude of human meaningfulness and thought. Even then the practical application and conceptualisation of post-structural meaningfulness has always been one that has tended to restore a sense of re-equilibrium with respect to perceived vested interest and skewed power relations whether with regards to its articulation in feminist studies, postcolonial studies, power relations in social settings with regards to appropriate deliverance and more responsive public services, etc. as post-structuralism has often been a framework giving weaker and subjected meaningful frames public voice. Thus the so-called " ${ }^{4}$ human-subject-emancipating-relativismdriven-recomposuring-constructivism-towards-singularisation- $<$ as-to-the-

nondisjointedness/entailment-of-prospective- nonpresencing $>$ of post-structuralism' has been in real and practical world terms more a question of abstract reconstructive thinking since such practical applications have tended to be effective further highlighting the need rather for more decentering contemplations. Besides, post-structuralism practical emphasis has mostly been methodical rather than dogmatic. In-the-bigger-scheme-of-things, this author further highlights that post-structuralism by implying 'decentering' is implying transcendence-andsublimity/sublimation/smenterentivity or an 'existential-reference/existentialtautologisation pivoting/decentering' such that the 'center' as the new basis of analysis/knowledge-construct has moved to the prospective/transcendental/superseding 
reference-of-thought putting-into-question the now-and-present way of thinking as prior/transcended/superseded ${ }^{83}$ reference-of-thought. What has been misconstrued is exactly the idea of 'existential-conversion' that is actually central to all subject-matters wherein the abstract articulation of principles is of existential-tautologisation/existential-reference neutrally. For instance, physics principles can be used for either aggressive and warring applications or peaceful and life-enhancing applications, and to say that physics principles are wrong because these can be construed as applicable for non-peaceful purposes is to misunderstand the fundamental nature of theoretic knowledge as fundamentally construing the possibility of existential-reality. Hence human application of knowledge as 'human existential-conversion' implies human self-preservation disposition in redefining ${ }^{56}$ meaningfulness-and-teleology from existential-tautologisation/existential-reference as of human subpotent existentialteleology ${ }^{9}$ within the full potency of existence-as-of-its-mimetic-echoness or existence-inreverberation or existence-potency ${ }^{32}$ sublimating-nascence,-disclosed-from-prospectiveepistemic-digression. In other words, abstract post-structural construct as any other theoretical constructs have no commitments to upholding any value-disposition and teleology ${ }^{9}$ but rather construe the ontological possibility conflated as of existential-<disontologising/reentogising apreticism> reality. The idea of discretely eliciting value-disposition and teleology choices/options is a secondary exercise of human social application (with teleology fundamentally construed as 'phenomenal/manifest conceptivity/epistemicreflexivity/epistemicity-relativism-determinism-<reifying \{as-to-knowledge-developing $\}$-and$\begin{array}{llll}\text { empowering }> & \text { in } & \text { existence } & \text { antological, }\end{array}$ $<$ amplituding/formative $>$ disposedness/psychologismic-construct-<as-to-orientation/valueconstruct/valuation-and-derived-parameterising $\rangle$ and <amplituding/formative $>$ entailment-〈asto-totalising-contiguous/coherent-factuality-of-variability)', and so with regards to the specific human-subpotency with regards to overall reifying-and-empowering-reflexivity-of-ecstatic- 
existence-as-panintelligibility/panreflexivity ${ }^{73}-\langle$ existentially-imbued-and-educing-< $<$ 价istemic thalising thermeneutically/textually/reprojectingly/supererogatingly/zeroingly/re-acutingly,$\{$ decompulsing\} $d e l i n e a r i t y \sim$ for-cogency $\geq$-epistemic-perspective-of-projective/reprojectiveaestheticising-re-motif-and-re-apriorising/re-axiomatising/re-referencing conceptualisation,as-herein-specifically-relevant-to human-subpotency)), and specifically with regards to the practical application of post-structural thought as a re-equilibrium exercise derived from the 'theoretic reshuffling-of-the-cards/putting-into-question'. Thus post-structuralism being so construed as ontologically-driven (having a center as of ontological-normalcy/postconvergence graspable by the 'dynamics of metaphysics-of-absence-〈implicited-epistemic-veracity-ofnonpresencing- $<$ perspective-ontological-normalcy/postconvergence $>>$ or postdication insight with respect to metaphysics-of-presence-〈implicited-'nondescript/ignorable-void '-as-topresencing - absolutising-identitive-constitutedness $\rangle$ ' involving diminishing-humanepistemic-abnormalcy-or-preconvergence 1 /increasing-relative-ontological-completeness ${ }^{87}$-ofreference-of-thought in construing-ontological-veridicality as determined-by 'implicited_attendant-ontological-contiguity ${ }^{77}$ educedexistentialising/contextualising/textualising_'intelligibility/epistemicity/reflexivity-contiguity$<$ imbued-notional $\sim \operatorname{cogency}>,{ }^{\prime},-<$ reifying-or-elucidating-of-prospective-relative-ontologicalcompleteness -of- reference-of-thought- devolving-as-of-instantiative-context> due to human limited-mentation-capacity-deepening —as-subjecting limitedness/human-subpotencyto-'educed-unlimitedness/existence-sublimating nascence' 33 as 'shallow limited-mentationcapacity —as-subjecting 'educed-unlimitedness/existence-sublimating nascence' tolimitedness/human-subpotency to deeper limited-mentation-capacity-as-subjecting 'educedunlimitedness/existence-sublimating nascence' to-limitedness/human-subpotency-〈as of relative apriorising/axiomatising/referencing-\{of-'prospectively implicited_attendantontological-contiguity ' educed- 
postconverging entailment $\rangle$ development') effectively heralds post-ideology as ideas and notions are validated/invalidated by their demonstrated ontological-veracity/ontologicalpertinence. In order words the supposed ontological-terms of notions and ideas are the basis for their analysis as ontologically-pertinent or impertinent, and so more than just perfunctory analyses constrained by the limiting framework of institutionalised-being-and-craft constructs and setups but at an existentialism/full-depth-of-existential-implications level highlighting the precedingness/supersedingness/ascendency of ontologically-driven analysis over 'habits', 'conventions' and rights-of-precedence/entitlement fallacies. Post-structuralism as such should posit to remedy and supersede the inherent 'conceptual hyperbole' imbued in the often 'poorlyontological, non-ontological or metaphysical constructions permeating ideologies' and projected as worldviews, to 'restore existential-<disontologising/re-ontologising aporeticism $>$ veracity/ontological-pertinence as the central notion behind worldview construction and representation', and so beyond just 'present-driven conceptualisations' of ideologies, but of an insight derived from a historical and anthropological depth with respect to human mentation, meaningfulness and institutional-development-as-to-social-function-development as implied by a suprastructuralism highlighting of metaphysics-of-absence-〈implicited-epistemic-veracity-ofnonpresencing-<perspective-ontological-normalcy/postconvergence $>>$ or postdication. Such a grounding of post-structuralism provides the underlying ontological outlet of analysis with regards to issues and conundrums of veracity/ontological-pertinence faced by earlier poststructuralists like Sartre (not often recognised as a poststructuralist but whose work interpretively does fit the mould, just as the works of many 'seriously engaged' critiques of poststructuralism like Gadamer and Habermas have been highly beneficial to post-structuralism), Foucault and Derrida when it came to draw out veracity/ontological-pertinence from such 
hyperbolic traditional ideologies including Marxism as constructs highly laden with metaphysics/non-ontology, on-the-one-hand, while addressing, on-the-other-hand, the imbued liberal and neoliberal dogmas of their times wrongly upholding that its 'dogmatic practices and conventions' are beyond ontological-reconstituting-as-to-conflatedness ${ }^{13} /$ deconstruction, and pertinently so by highlighting their underlying ontological failures with recurrent just about decadal institutional crises and social malaises, speaking of the ontological-wobbliness of a liberal thought that has become highly contradictory as marked by its very own perpetual secondguessing. Eighthly, it is this author's 'suprastructural contention' that human-subpotencyaporia/undecidability/dilemma/ought-indeterminacy/deficiency/limitation/constraint—imbued'notional firstnaturedness-formativeness-<as-to-eventualising inkling drive-or-seeding misprising $>$ temporal-to-intemporal-dispositions- $<$ so-construed-as-from-perspectiveontological-normalcy/postconvergence>'-existentialism-form-factor and a social world is inherently hampered by a blurriness-<sterilising/anecdotalising/trivialising-of-prospective-reontologising_by-preconverging,-in-disontologising-formulaic-dragging-out/hollowing-out> and distance of <amplituding/formative-epistemicity $>$ causality $\sim$ as-to-projective-totalitativeimplications-of-prospective- nonpresencing,-for-explicating relative-unreflexivity/relativereflexivity ontological-contiguity /intrinsic-reality/ontological-veridicality transcendentalenabling/sublimating/supererogatory $\sim$ de-mentativity'. Thus approaching a scientific study of the Social on the same operational basis as that of the natural world is necessarily deficient as the latter's immediacy of concurrent <amplituding/formative-epistemicity $>$ causality $~ a s-t o-$ projective-totalitative-implications-of-prospective- nonpresencing,-for-explicating relativeunreflexivity/relative-reflexivity - ontological-contiguity /intrinsic-reality/ontologicalveridicality transcendental-enabling/sublimating/supererone-de-mentativity as well as the fundamental pivoting/decentering of understanding involving the psychoanalyticunshackling/memetic-reordering/institutional-recomposuring that took place starting over 500 
years ago in establishing the positivising/rational-empirical mindset/ $/{ }^{3}$ reference-of-thought by the Galileos, Newtons, Leibnizes, Darwins, etc. of the world, such that an Einstein could perfectly articulate the idea of the-theory-of-relativity that would normally make no sense even to the majority of the scientific community at the time but for the 'very strength' of the established positivism/rational-empiricism psyche (operating on the basis that what predicates on rational-empirical basis takes precedence) already established which ensured its transcendental enabling. The positivistic/rational-empirical psyche today, it is herein contended, is not 'ontologically performant' enough (of sufficient ontological-completeness-of- ${ }^{\text {reference- }}$ of-thought in construing-ontological-veridicality as determined-by its 'implicited_attendantontological-contiguity ${ }^{67}$, educedexistentialising/contextmalising/textmalising_intelligibility/epistemicity/reflexivity-contiguity$<$ imbued-notional $\sim$ cogency $>,{ }^{\prime},-<$ reifying-or-elucidating-of-prospective-relative-ontologicalcompleteness -of- reference-of-thought- devolving-as-of-instantiative-context> for the further development today of the study of the Social as of its fleeting/blurred nature (on such terms of 'what predicates should take precedence'). It must be said that the notion of transcendental enabler with regards to the Social today is rather of relative ontological weakness such that critically a lot of the basis for the social sciences today is influenced rather by practice, authority, and is more or less intellectual-politics driven beyond-the-consciousness-awarenessteleology $-<$ of-preconverging-existential-extrication-as-of-existential-unthought $>$, rather than truly ontological-primemovers totalitative-framework deterministic ontological 'projected constructs'. Consequently despite the projected candour, the study of the social is inevitably permeated with 'intellectual-ontological-bad-faith/inauthenticity ${ }^{6}$, (unconsciously or consciously), and by this is meant it will be naïve to think that all issues of intellectual disagreements with respect to the study of the social are necessarily in purely logical terms without factoring the possibility of 'intellectual perfidy'. What the blatant constraining of the 
natural world can do to thinking by mere ontological-primemovers totalitative-framework under the rational-empiricism postconverging-de-mentating/structuring/paradigming is often weakly possible with the Social particularly where there is perceived interest to act otherwise. This is particularly the case with regards to the undermining of social criticism and especially poststructuralism with the intellectual standards of such criticisms strangely enough falling incredibly so low (and mostly finding credibility by 'pride of place' of intellectual engagement often beyond-the-consciousness-awareness-teleology $<$ of-preconverging-existentialextrication-as-of-existential-unthought $>$ abused as objective bases of intellectual criticism get discarded easily for highly subjective ones); and this author equally holds that a 'fully emancipated social science' will only prevail with the requisite pivoting/decentering of understanding as ${ }^{18}$ deprocrypticism-or-preempting-disjointedness-as-of- ${ }^{8}$ reference-ofthought psychoanalytic-unshackling/memetic-reordering/institutional-recomposuring, which should enable the attainment of a suprastructural/beyond-the-consciousness-awarenessteleology $-<$ of-preconverging-existential-extrication-as-of-existential-unthought $>$ level of social thought involving notional ${ }^{18}$ deprocrypticism as preempting-disjointedness-as-ofreference-of-thought. More like in-many-ways the level of thought in the natural sciences is wholly divorced from our consciousness awareness teleology ${ }^{9}$ and is fully transcendentalenabling/sublimating/supererogatoryade-mentativity by confirmatory existence/intrinsicreality/ontological-veridicality with little or no social-aggregation-enabling but say for human organisational issues and wrong preconceptions induced by social-aggregation-enabling. This arises because it is inevitable to have conscious or unconscious ontological-badfaith/inauthenticity ${ }^{64}$ just going by human temporal-to-intemporal nature without an inherently strong transcendental-enabling/sublimating/sperentativity. While in the natural and mathematical sciences the subject-matter by itself is highly transcendentalenabling/sublimating/supereregatery $\sim$ de-mentativity this is not the case with the subject-matter 
of the social due to its high temporal-to-intemporal-conjugating-emotionalinvolvement/subjectification/epistemic-totalising $\sim$ self-referencing-syncretising-as-ofperceived-social-stake-contention-or-confliction requiring rather a further strengthening of ontologising rules as of knowledge-notionalisation and utter-ontologising-recomposuring (notional ${ }^{18}$ deprocrypticism as preempting-procrypticism or preempting—disjointedness-as-ofreference-of-thought) beyond the present just positivism/rational-empiricism striving social science bringing together profound insight with causal effectiveness. This doesn't necessarily imply a naïve mimicry of the experimental approach as is often the case it can be argued as prevalent in the psychological sciences, and even in the natural sciences there is need for thorough insight when experimenting like say much of quantum physics is often based on elaborate abstractness of thought that is merely validated by critical confirmatory experiments. In fact, this author will contend that the overall 'insightful empirical' conceptualisation of this paper is actually more profound than catches the eye in a naïve empirical sense that cannot see beyond our positivistic registry-worldview to recognise human successive transcendental states like recurrent-utter-uninstitutionalisation, base-institutionalisation-ununiversalisation, universalisation-non-positivism/medievalism, positivism- ${ }^{80}$ procrypticism and deprocrypticism; as even empirical conceptualisations requires insight and it is more than just a matter of obtaining results because an experimentation has been made which is certainly simplistic as the very existential-<disontologising/re-ontologising aporeticism $>$ state of things when disambiguated is actually a more profound notion of experiment. It is interesting to note that this argument on the specific basis of (conscious or unconscious) ontological-badfaith/inauthenticity ${ }^{64}$ for the requisite condition of a 'fully emancipated social science' is more than just of circumstantial and idle implication but is rather construed as a preconverging/postconverging-de-mentative/structural/paradigmatic notion much like saying it is impossible to have a fully emancipated science in a transitory non-positivism/medievalism to 
positivistic social-setup still emphasising essences and supranatural causations over a transcendental-enabling/sublimating/supererogatory $\sim$ de-mentativity of rationalempiricism/positivising based knowledge of intrinsic-reality, as transcendentalenabling/sublimating/supereregatory $\sim$ de-mentativity positivistic contentions will still be undermined with such a discrepancy of notional-discontiguity/epistemic-discontiguity ${ }^{63}$ $<$ between-prior-shallow-supererogation -of-mentally-

aestheticised preconverging/dementing -qualia-schema_and_prospective-profoundsupererogation -of-mentally-aestheticised postconverging/dialectical-thinking -qualiaschema in the apriorising/axiomatising/referencing/intelligibilitysettingup/measuringinstrumenting of reference-of-thought/axiomatic-construct. Likewise, the positivism- ${ }^{80}$ procrypticism meaningful-frame is not sufficiently beyond-the-consciousness-awareness-teleology ${ }^{9}-<$ ofpreconverging-existential-extrication-as-of-existential-unthought $>$ of social-aggregationenabling with respect to its social reality subject-matter as of its spurious/remote nature, for a more profound transcendental-enabling/sublimating/supererogatory $\sim$ de-mentativity (unlike the relative case with the physical reality subject-matter as immediate) as required for futural Beingdevelopment/ontological-framework-expansion-as-to-depth-of-ontologising-development-asinfrastructure-of- -5 meaningfulness and-teleology 9 as of prospective notional ${ }^{1}$ deprocrypticism intrinsic-reality/ontological-veridical transcendental enabling. Thus, the only credible logic this author can think of is that post-structuralism as one of the major critical theories given its potential ontological vigour has been seen as a threat with a deliberate covert non-intellectual effort to stifle it and limit its influence often having to do with misrepresenting the ideas and implications of the ideas of its main proponents (as in fact, one of the central issue with regards to post-structural thinking with respect to other intellectual postures has had to do with the unusually high level of accusations of its proponents of misrepresentation 
of their ideas by many of their critiques whether with respect to such accusations of nihilism or untruth, with a central characteristics of many of such critiques being a failure of recognising exactly the central point of post-structural thinking as rather a 'putting-into-question/shufflingof-the-cards for a more profound perspective for ontological analysis'. Consider in this case one media-driven and popularised argument that Karl Rove 'we make our own reality' quote during the Bush mandate, is due to post-structuralism. Such arguments are revealing of the "nonintellectual spirit' of many such critics, and in this instance wrongly intimating that Karl Rove considered himself a poststructuralist whereas a sincere take will garner that this is nothing other than a Machiavellian, opportunistic and unprincipled statement than 'truly post-structural theory inspired' as with or without post-structuralism it is no less likely that the same statement would have been uttered. And the pseudointellectual exercise of linking the two is revealing not only of such out-of-the-way criticism but equally the 'wayward mindset' that is often brought into supposedly rigorous social science on the basis of such anything-goes rhyming-logic! Poststructuralism generally occupy a relatively sound position when it comes to all the practical applications of post-structural thought which, to say the least, have always highlighted a sense of re-equilibrium rather than the bogus and insincere criticisms of nihilism or untruth which this author construes as 'in-effect ontological-bad-faith/inauthenticity' of 'parodying' of poststructuralists positions and analysing the 'parody' in usurpation as against a genuinely candid critical intellectualism of their true postures in ontological-good-faith/authenticity ${ }^{6}$. Post-structural exposition of the realities of the social are not value judgements in themselves just as natural sciences exposition of natural and physical reality doesn't carry any value judgements. For instance, discovering that bacteria cause disease is a simple objective truth then giving rise to human animate-existential-referencing/subjectification inducing the teleological meaningfulness to pivot/decenter that knowledge into avoiding disease and finding cure for diseases. This is no more different with post-structural thought which is not a 
metaphysical/ideological advocacy but telling the social reality for what it is, with human pivoting/decentering to apply that knowledge for its defined teleological meaningfulness. One of the serious consequence of such a weakened social criticism driven by such a targeted and induced atmosphere of quasi-anti-intellectualism is the result that the domain of the political economy and corresponding economic interests have been spared from the critical analysis of such powerful ontological tools; specifically going by the issues of misallocation and inequality we face today based on axioms of models that remain critically beyond analysis, as effectively an anti-intellectualism with respect to social criticism including post-structuralism is cultivated in favour of a default socially uncritical political economy practice (with the cover-up of an 'intellectually platitudinal' media) to protect them. Notwithstanding the impressive theoretical conceptualisations of an ever second-guessing economics science, the 'underlying liberal political economy axiomatic constructs' on which it rests are massively arbitrary, flawed and degenerate; and this is one area in which developed social criticism including post-structuralism could do an excellent job in debunking the 'underlying mysticism', as the domain of the political economy beyond competition of ideas at such a fundamental level is the very foundation of the uncritical preservation of such axioms. Such issues as political choices for bailouts, reallocations and remuneration practices are strictly speaking not economic science issues but political economy issues that require a criticism with respect to social choice about the political economy, but this has been usurped uncritically as if of a natural economic allocation mechanism (a falsehood). This author makes this latter point on the belief that knowledge is an existential-disontologising/re-ontologising aporeticism $>$ exercise and that the intellectual should sincerely put their 'hand in fire' at the risk of being proven wrong, as the intellectual exercise is not one of self-veneration but discovering the truth (even at the risk of sounding/looking ridiculous). If there is one area of speculative thinking allowed to this author in this paper, it is such a proposition together with the idea that it is incredible to think that a lot of the criticisms 
directed to post-structuralism since the 1980s arises out of such (it is herein contended) 'intellectual triteness' by such critics particularly going by the 'frivolous arguments' advanced compared to the high intellectual standards they have been able to show elsewhere, together with the notion that these have tended to be unusually media driven in inducing a populist effect. Imagination will point to the idea that something much more 'cynical and non-intellectual' must be at work but passing for legitimate intellectualism; or is it, more like the medieval scholasticism erudition establishment more or less grasping the true implications of a nonmedieval positivistic thinking on the whole intellectual, belief system and social-construct, and cynically upholding notions they knew better to be wrong but for their overall sense of preservation of their present and their present interests. This impression can be extended as well with respect to the idea of the social implications of postlogism -as-of- compulsingnonconviction/madeupness/bottomlining-〈' $<$ decontextualising/de-existentialising $\sim$ ofattendant-intradimensional-apriorising/axiomatising/referencing>-induced-disontologising'-ofthe-'attendant-intradimensional-ontologising'-imbued$<$ contextualising/existentialising attendant-ontological-contiguity $>$;-in-shallowsupererogation -<as-to-disontologising-perverted-outcome-sought-precedes-existentiallyveridical-'attendant-intradimensional-apriorising/axiomatising/referencing'-logical-dueness $>$ ) as of its ontological-resolution (aetiologisation/ontological-escalation- $<$ ontologicalveridicality_commitment/otherliness_transcending/compulsions-encumbered_transcending $>$ ) in all the <cumulating/recomposuring attendant-ontological-contiguity >-successive registryworldviews/dimensions given human-subpotency-aporia/undecidability/dilemma/oughtindeterminacy/deficiency/limitation/constraint—imbued-'notional firstnaturednessformativeness-<as-to-eventualising-inkling-drive-or-seeding-misprising $>$ temporal-tointemporal-dispositions-<so-construed-as-from-perspective-ontologicalnormalcy/postconvergence>'-existentialism-form-factor. As we can grasp that an 
aetiologisation/ontological-escalation- $<$ ontological-

veridicality_commitment/otherliness_transcending/compulsions-encumbered_transcending $>$ as resolution for non-positivism/medievalism world postlogism 77 which is more than just palliative/incidental-in-its implication with regards to a specific instance or specific instances of notions-and-accusations-of-sorcery for instance, but rather construing the whole nonpositivism/medievalism registry-worldview/dimension relative-ontological-incompleteness ${ }^{8}$ induced,-'threshold-of-nonconviction/madeupness/bottomlining-in-shallow-supererogation $<$ as-to-'attendant-intradimensional'-prospectivelydisontologising preconverging/dementing -apriorising-psychologism>' (as of metaphoricallya-million-and-one-instances-and-locales as enabling the possibility of the phenomenon of notions-and-accusations-of-sorcery and other vices-and-impediments ${ }^{105}$ of the state of nonpositivism/medievalism and thus requiring preconverging/postconverging-dementatively/structurally/paradigmatically and comprehensively a positivistic ontologicalcompleteness of- ${ }^{3}$ reference-of-thought will preconverging/postconverging-dementatively/structurally/paradigmatically elicit a non-positivism/medievalism world sense of 'temporal/shortness of-register-of- ${ }^{5}$ meaningfulness and-teleology ${ }^{9}$ preservation' that wouldn't necessarily construe the social manifestations of notions-and-accusations-of-sorcery with their associated vices-and-impediments ${ }^{105}$ as abstractly and ontologically unwarranted ${ }^{103}$ universally (which we know was actually the case, with the 'establishment' idea being that the masses didn't need to know about such 'positivistic stuff' even if such stuff was ontologically-veridical), to ensure its 'temporal/shortness of-register-of- meaningfulness and-teleology ${ }^{99}$ preservation'. Likewise an articulation as of aetiologisation/ontological-escalation- $<$ ontologicalveridicality_commitment/otherliness_transcending/compulsions-encumbered_transcending> (ontological-resolution) that is more than just palliative/incidental-in-its implication with respect to the notion of psychopathy and social psychopathy with regards to a specific instance or 
specific instances of psychopathy and social psychopathy but by pointing to the bigger picture to the procrypticism registry-worldview's/dimension's disjointedness-as-of- reference-ofthought relative-ontological-incompleteness ${ }^{88}$-induced,-'threshold-ofnonconviction/madeupness/bottomlining-in-shallow-supererogation $-<$ as-to-'attendantintradimensional'-prospectively-disontologising preconverging/dementing -apriorisingpsychologism>' (as enabling the possibility of the phenomenon of psychopathy and social psychopathy as of metaphorically-a-million-and-one-instances-and-locales as well as other vices-and-impediments $^{105}$ of procrypticism preconverging/postconverging-dementatively/structurally/paradigmatically and comprehensively requiring a notional ${ }^{18}$ deprocrypticism ontological-completeness of ${ }^{8}$ reference-of-thought will preconverging/postconverging-de-mentatively/structurally/paradigmatically elicit a human procrypticism sense of 'temporal/shortness of-register-of- ${ }^{56}$ meaningfulness and-teleology preservation' that wouldn't necessarily construe the social manifestations of psychopathy and social psychopathy with their associated vices-and-impediments ${ }^{105}$ as abstractly and ontologically unwarranted ${ }^{103}$ universally and such an approach may just be off-putting with regards to the prospective implication for the need for notional ${ }^{1}$ deprocrypticism ontologicalcompleteness of- ${ }^{3}$ reference-of-thought (as intemporal/longness of-register-ofmeaningfulness and-teleology ${ }^{9}$ ) undermining of procrypticism relative-ontologicalincompleteness 8 -induced,-'threshold-of-nonconviction/madeupness/bottomlining-in-shallowsupererogation -<as-to-'attendant-intradimensional'-prospectivelydisontologising preconverging/dementing -apriorising-psychologism> ${ }^{\prime}$ (as the temporal/shortness of-register-of- ${ }^{5}$ meaningfulness and-teleology ${ }^{99}$ ). Such an articulation equally extends to the idea that notions overlooking vices-and-impediments ${ }^{105}$ associated with psychopathy and equally wrongly implying its associated virtue in the procrypticism registryworldview are just as of 'temporal threshold-of-nonconviction/madeupness/bottomlining-in- 
shallow-supererogation -<as-to-'attendant-intradimensional'-prospectivelydisontologising preconverging/dementing -apriorising-psychologism>' like the disposition to overlook vices-and-impediments ${ }^{105}$ associated with notions-and-accusations-of-sorcery and equally implying the associated virtue in a non-positivism/medievalism setup; and so, as of human-subpotency-aporia/undecidability/dilemma/ought-

indeterminacy/deficiency/limitation/constraint—imbued-` $\quad$ notional firstnaturednessformativeness-<as-to-eventualising-inkling drive-or-seeding-misprising $>$ temporal-tointemporal-dispositions-<so-construed-as-from-perspective-ontologicalnormalcy/postconvergence>'-existentialism-form-factor due to their respective relativeontological-incompleteness 8 -induced,-‘threshold-of-nonconviction/madeupness/bottomliningin-shallow-supererogation -<as-to- 'attendant-intradimensional'-prospectivelydisontologising $\sim$ preconverging/dementing -apriorising-psychologism>' with respect to their respective perversion-and-derived- ${ }^{7}$ perversion-of- ${ }^{-}$reference-of-thought- $<$as-preconverginglyapriorising/axiomatising/referencing-in-nonconviction/madeupness/bottomlining-as-toshallow-supererogation $>$ phenomena. Thus in all registry-worldviews/dimensions ${ }^{83}$ referenceof-thought, $\quad$ postlogism -as-of- compulsing-nonconviction/madeupness/bottomlining〈‘ $<$ decontextualising/de-existentialising of-attendant-intradimensionalapriorising/axiomatising/referencing >-induced-disontologising'-of-the-'attendantintradimensional-ontologising'-imbued-<contextualising/existentialising $\sim$ attendantontological-contiguity $>$;-in-shallow-supererogation -<as-to-disontologising-pervertedoutcome-sought-precedes-existentially-veridical-'attendant-intradimensionalapriorising/axiomatising/referencing'-logical-dueness $>$ > once it is 'as of socially-functionaland-accordant ${ }^{3}$, (beyond the case at childhood where it is accompanied by overt delirium and social universal-transparency ${ }^{104}$-〈transparency-of-totalising-entailing,-as-to-entailing- 
defect) as at adulthood, the postlogism 'disjointedness-as-of- reference-of-thought' misappropriated ${ }^{56}$ meaningfulness and-teleology ${ }^{9}$ in arrogation tends to extend as conjugatedpostlogism 'disjointedness-as-of- ${ }^{73}$ reference-of-thought' misappropriated ${ }^{56}$ meaningfulness and-teleology in arrogation involving the temporal elicitation of derived- perversion-ofreference-of-thought-<as-preconvergingly-apriorising/axiomatising/referencing-innonconviction/madeupness/bottomlining-as-to-shallow-supererogation $>$, and it is thus naïve to construe postlogism 77 without such a corresponding differentiation of social analysis in the construing/conceptualisation of ontological-veridicality. Now the criticism of populism-driven critiques of post-structuralism is not raised idly, as an exercise that purports to articulate such breadth and depth of novel ideas as herein necessarily requires that the authorship effectively assume the profile and presumption that the implied knowledge construct warrants (which obviously every truly intellectual spirit will appreciate for what it is, if not agree with the arguments). Such an articulation is driven by the idea that knowledge as a transcendenceenabling construct is more than just about its craftiness/technique but part-and-parcel of the intellectual exercise is to articulate meaningfulness by its existentialism/full-depth-ofexistential-implications. And just as faced with the evasive nature of quantum theory the physicists never said reality is wrong since it is difficult to understand, likewise it is naïve to imply that the reality reflected by post-structuralism is wrong because it doesn't quite fit into our ordinary everyday way of thinking (that is exactly the point, our ordinary everyday way of thinking is in want of its further development, just as all prior ordinary everyday ways of thinking had to be psychoanalytically-unshackled)! 


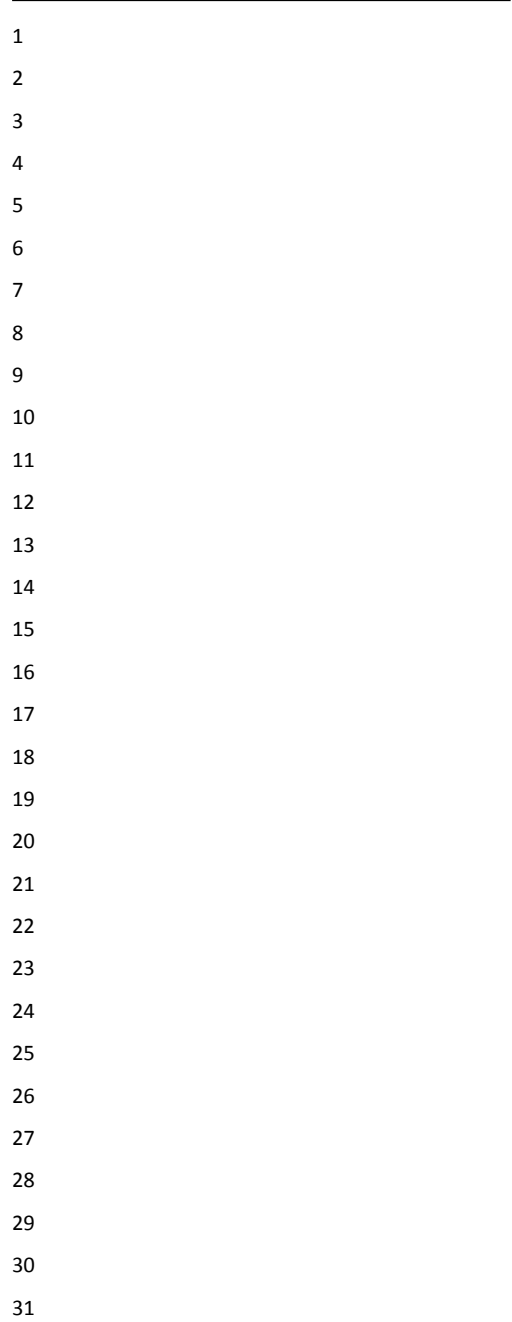


59

60

61 
105 